Class R R 121

Book_...G65

Gopyright 1 No

COPYRIGHT DEPOSTT 







AN ILLUSTRATED

DICTIONARY OF MEDICINE BIOLOGY

AND ALLIED SCIENCES

\author{
G O U L D
}




\section{FOR INDEX OF SPECIAL TABLES AND IMPORTANT DEFINITIONS, CLASSIFYIING LARGE}

NUMBERS OF FACTS. SEE PAGE XVI.

From The Practitioner, London.

"The language of medicine changes so quickly with the advance of knowleds re that for practitioners who wish to keep fairly aloreast of scientific progress a good medical dictionary is not so much a luxury as a necessity of intellectual life. Dr. George M. Gould, who is one of the leading ophthalmic surgeons ix I the United States, and editor of the . Weitical Nezus, has in the work before us presented the profession with the coml letest lexicon of medical terminology that exists in the English language. . . . . Dr. Gould has done for our medical language what Dr. Murray is doing for the mother tongue of English-speaking peoples. It need only ty added that the work is printed in a clear type that bears witness to the careful regard of the author, as an ophthalm ologist, for the reader's eyes, and is 'got up' in a style sufficiently handsome to make it an ornament to the book shelf and strong enough to withstand the wear and tear of daily use." 


\title{
AN ILLUSTRATED DICTIONARY OF MEDICINE BIOLOGY AND ALLIED SCIENCES
}

INCLUDING THE

PRONUNCIATION, ACCENTUATION, DERIVATION, AND DEFINITION OF THE TERMS USED IN

MEDICINE, ANATOMY, SURGERY, OBSTETRICS, GYNECOLOGY, THERAPEUTICS, MATERIA MEDICA, PATHOLOGY, DERMATOLOGY, PEDIATRICS, OPHTHALMOLOGY, OTOLOGY, LARYNGOLOGY, PHYSIOLOGY, NEUROLOGY, HISTOLOGY, TOXICOLOGY, DIETETICS, LEGAL MEDICINE, PSYCHOLOGY, CLIMATOLOGY, ETC., ETC.

AND THE

\section{VARIOUS SCIENCES CLOSELY RELATED TO MEDICINE}

BACTERIOLOGY, PARASITOLOGY, MICROSCOPY, BOTANY, ZOÖLOGY, DENTISTRY, PHARMACY, CHEMISTRY, HYGIENE, ELECTRICITY, VETERINARY MEDICINE, ETC.

BY

GEORGE M. GOULD, A.M., M.D.

AUTHOR OF " THE STUDENT'S MEDICAL DICTIONARY," 30,000 MEDICAL WORDS PRONOUNCED AND DEFINED," "THE MEANING AND THE METHOD OF LIFE"; EDITOR OF "THE PHILADELPHIA MEDICAL JOURNAL"; PRESIDENT, I893-I894, AMERICAN ACADEMY OF MEDICINE

\section{BASED UPON RECENT SCIENTIFIC LITERATURE}

FIFTH EDITION, WITH ADDITIONS ANE CORKECTIONS

\author{
PHILADELPHIA \\ P. BLAKISTON'S SON \& CO.
}

IOI 2 WALNUT STREET 


\section{TWO COPIES RECEIVED, \\ L library of congeanes \\ Ufflou of the \\ APR 2 - 1900 \\ Reglatop of Gopprighte.}

\section{3}

COPYRIGHT, 1894, BY P. BLAKISTON, SON \& CO.

COPYRIGHT, I900, BY P. BLAKISTON'S SON \& CO.

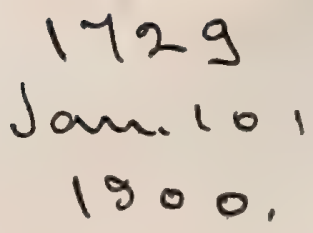




\section{PREFACE.}

IN this work I have conscientiously endeavored to give the greatest possible amount of lexicographic and encyclopedic knowledge within the limits of a single volume, condensed as much as is consistent with clearness, and so arranged as to furnish the student and worker with concise, accurate, and useful definitions.

I have tried to satisfy the following specific desiderata:-

I. The inclusion of the many thousands of new words and terms that have been introduced into medicine during the last few years, marked as they have been by unparalleled scientific activity and progress. To this end an almost countless number of volumes and periodicals have been systematically gleaned by myself and a tireless corps of friends and assistants. Not to have met this important and pressing need would have made this volume a work of mere inexcusable compilation and copying from the many word-books already published, instead of a fresh gathering from the living literature of the day.

2. To give the most compact epitomization of the works of older and authoritative lexicographers, including all such obsolete or obsolescent terms as may be met with in the medical encyclopedias or handbooks likely to be used by a modern student.

3. To include all the more commonly-used terms of biology - a tning highly desirable; $a$. Because of the modern recognition of the great truth that general biologic science is the foundation of genuine and progressive medical science; $b$. Because the best schools of medicine are more and more urging or making obligatory the preliminary biologic course of study; and $c$. Because, so far as I know, no satisfactory lexicon of biology exists in English.

4. Keeping the size and purpose of the book well in view, to give it an encyclopedic character-not only by supplying the usual pronunciation, derivation, and definition of words, but also by showing their logical relations, their bearings, and their practical importance for the worker in literary or clinical medicine. This aim will explain a number of peculiar features, as for instance, the large number of tables, whereby at a glance one may catch the correlations of a single fact with many others, and thus at once classify and crystallize his comprehension of them. It seems deserving of mention that in modern literature there is not to be found as complete and digested a résumé of surgical operations, of bacteriology, of parasitology, of tests, and of many other subjects, as is here furnished.

5. When advisable, to give a pictorial illustration that would tell what words could not make clear. Hence, those who find the work helpful in this respect will thank the publishers for the generous supply of illustrations, a large number being new engravings from original drawings made expressly for this work. Conservatism in this respect, however difficult, has been the rule, because pictures, for example of surgical instruments, are plenteous and to be had for the asking, and because illustrations that are useless, or that do not illustrate, might possibly have made the book superficially more attractive, but would certainly have given ground for just criticism. Besides the large number of original illustrations first presented in this volume, many have been taken or adapted from the well-known and authoritative works of Sappey, Landois, Ziegler, Piersol, Stirling, Woodhead, Holden, Tyson, Fullerton, and others. 
6. As regards orthography, to do what Professor Whitney, in the preface to his great work, The Century Dictionary, says is the duty of the dictionary-maker :-

"The language is struggling toward a more consistent and phonetic spelling, and it is proper in disputed and doubtful cases to cast the influence of the dictionary in favor of this movement, both by its own usage in the body of the text, and at the head of articles by the order of forms, or by the selection of the form under which the word shall be treated."

More than this I have not attempted to do, and not to have done this much would have been distinctly wrong. The lexicographer may not impose or command, but in the interest of true and prudent progress he may suggest and advise. Both spellings are noted of words in dispute, and one is of course at liberty to accept that which he thinks best. Those who prefer to follow the older practice have against them all the best philologists, such authorities as Professor Whitney, Professor Skeat, the editors of the Standard, and of other great Dictionaries. Gradual, careful phonetic progress is a duty we all owe to our profession.

I have usually recommended that in medicine the diphthongs $a$ and $\propto$ be supplanted by $e$; such usage is already well established as regards many words, and the suggestion is in strict harmony with etymology and the spirit of the language. We do not spell such words as gaingrane, ather, aconomy, aternal, ponalty, mediceval, solcecism, primaval, as here written, and the redundant diphthong should not be retained in diarrhoe, hamorrhage, cedema, coliotomy, padiatric, etc. Why is the change right in one instance and wrong in the other?

In the spelling of certain chemic words, the advice of The American Association for the Advancement of Science has, as a rule, been followed, and seems to be in the line of cautious and wise progress. The unanimous acceptance and practice of all these recommendations by the American Medical Editors' Association constitute a gratifying proof of progressiveness and freedom from irrational prejudice.

7. To indicate the best pronunciation of words by the simplest and most easily understood phonetic method. The plan I have used is simple and little liable to mistaking. The syllabification has no significance except to show the pronunciation, and in this the natural English common usage and power of letters are followed. Thus, in all but a few instances, the use of diacritic marks and vexatious signs or symbols is avoided. When a vowel stands alone or at the end of a syllable it has its natural long sound: $a$, as in male; $e$, as in mete; $i$, as in mile; 0 , as in mole; $u$, as in mule; when preceding, or between, consonants, the vowels have their natural short sounds, unless occasionally the use of the diacritic mark gives them the long sound, as $\bar{a} t$ (ate), ōs (ose), itt (ite). In a few instances the sign, $\checkmark$ has been used over $a$, as in marriage, to distinguish the sound from that of $a$, as in harm. When $a$ has the sound of $a h$, it has generally been written $a h$. In such words as cystotomy, acidity, and the like, the pronunciation of the final vowel-sound is indicated by $e$, as being the simplest representation of the common sound not otherwise easily expressed phonetically. When $s$ has the sound of $z$ it is indicated by $z$. The pronunciation of some foreign words has been approximated by devices readily comprehended.

It is impossible to adequately express my deep sense of gratitude to those who have aided me in the preparation and proof-reading of this volume. Dr. C. W. Greene, the experienced philologist, also Dr. IV. A. N. Dorland, Professor Charles S. Dolley, Dr. A. A. Eshner, and Professor Burt G. Wilder, have been most self-sacrificing, and to their scientific zeal, literary experience, and tireless good-will those who find the book useful will be indebted. To Dr. Dolley, the well-known biologist, belongs unstinted praise for the preparation of the definitions of biologic terms, the table of Bacteria, and that of Parasites, as well as for a number of 
original drawings. Intelligence, learning, and never-failing conscientiousness have been given almost every line of the work by Drs. Dorland and Eshner. The same is true of the work of Dr. David Riesman.

It seems almost wrong to mention in a second order the names of Professor S. H. Gage, Professor Henry Leffmann, Dr. A. C. Wood, Dr. Alfred Stengel, Professor A. P. Brubaker, Dr. J. Chalmers Da Costa, Dr. A. H. Cleveland, Mr. Ryland W. Greene, Dr. J. Hendrie Lloyd, Mr. Pierre A. Fish, Dr. D. Bevan, Dr. Emma Billstein, Dr. S. McClintock Hamill, Dr. A. H. Stewart, and others.

Every author well knows, or perhaps regrets that he does not know, the blessing of a publisher and of a printer who take pride in their work above and beyond the question of dollars and cents. Such a publisher and such a printer I have had.

The acceptability of the smaller dictionaries I have offered the profession (something like twenty-five thousand copies having been distributed) leads me to hope that the present more complete work will find a wider range of usefulness.

Philadelphia, Aprit, I894.

\section{PREFACE TO THE THIRD EDITION.}

The rapid exhaustion of the first and second editions of this dictionary permits me to correct a number of typographic and other errors, to modify some definitions, and to add new material throughout the entire extent of the book. I have profited by the kind criticisms of friends and of reviewers, and such suggestions as seemed to me just have been accepted and embodied in the work. In science, and especially in the science of medicine, what was true yesterday may be only half-true to-day, and may even be wholly untrue to-morrow. Old knowledge is constantly undergoing modification, and new knowledge is as constantly appearing, so that it is only by constant changes that a book seeking to reflect the condition and growth of a science can from day to day remain a perfect mirror of its progress.

The most outspoken words of praise in reviews, notices, private letters, etc., as also the exhaustion in so short a time of two large editions, give evidence that the volume has found a certain field of usefulness, and, personally, nothing can be more gratifying than the assurance that one has been of distinct service to his profession and to his fellows.

Philadelphia, September, 1895 .

\section{PREFACE TO THE FIFTH EDITION.}

In the present fifth edition I have endeavored to reduce the remaining inaccuracies to a minimum. I have also added the more important of the new terms in medicine which have come into use since the issue of the fourth edition. The changes in the text number altogether about four hundred.

Philadelphia, March, 1900.

GEORGE M. GOULD. 



\section{ABBREVIATIONS.}

\section{ABBREVIATIONS USED IN GENERAL MEDICINE.}

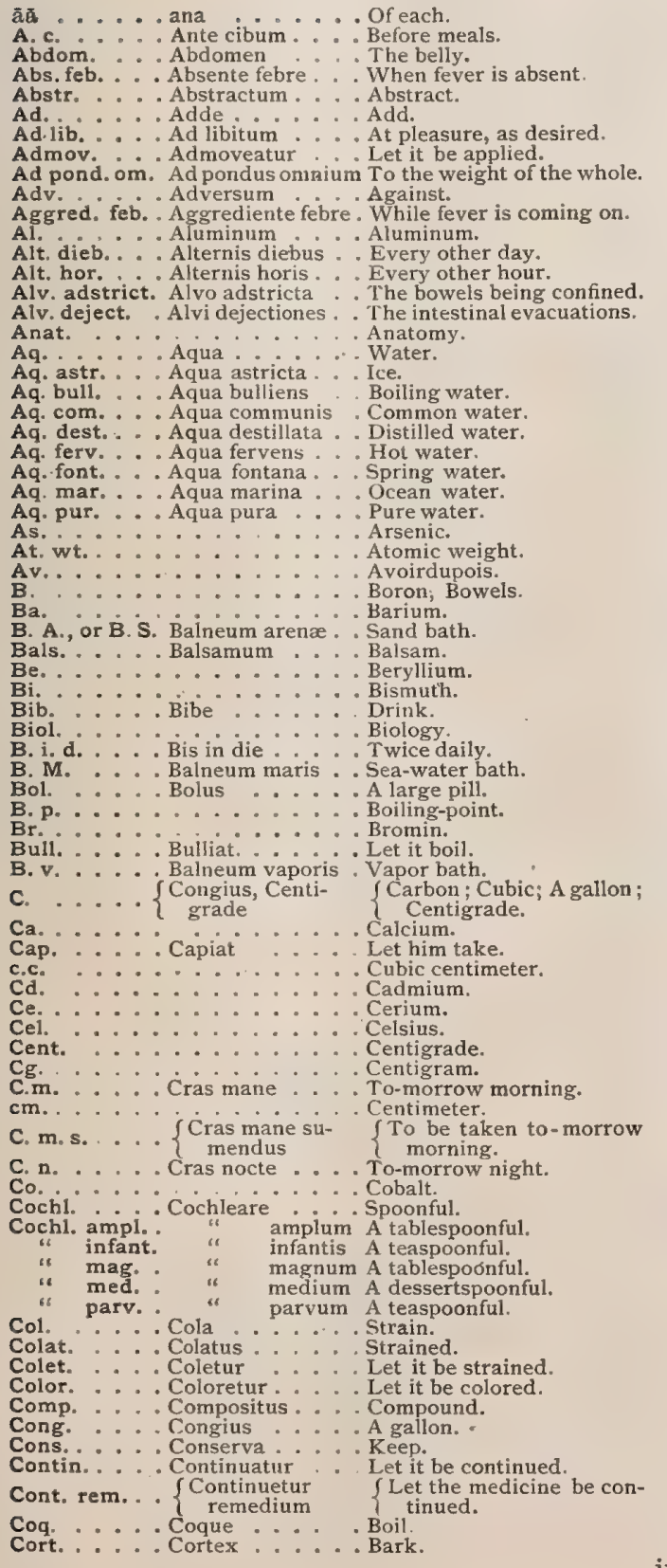

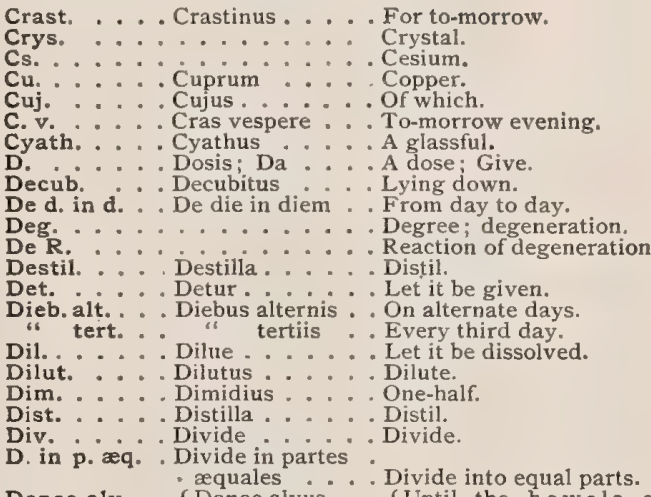
Donec alv.
sol. fuerit, $\quad \begin{gathered}\text { xoquales } \\ \text { Donec alvus } \\ \text { soluta fuerit }\end{gathered} \quad\left\{\begin{array}{l}\text { Divide into equal parts. } \\ \text { opened. }\end{array}\right.$

D. P. . . Directione propria With a proper direction.

Eb. . Erbium

E - j . . . . Elbow-jerk.

Ejusd. Ejusdem ...... Of the same

Elec. : Electuarium : An electuary; Electricity

Emb. . . . Electuarium . . . Embryology.

Erem. . . . . . Enema.

Er. Exhib. : Exhibeatur : Erbium.

Ext. . . Extractum ... Extract.

F. Fahrenheit ; Fluorin

Far. Faradic.

Fe. Ferrum : : Iron.

Feb. dur. : Febre durante : The fever continuing.

F., Ft..... Fac, Fiat .... Make.

Filt. .... Filtra...... Filter.

Fld. .... Fluidus . .... Fluid.

Flor. Flores ....... Flowers.

F. Fiat mistura . Make a mixture

Fol. : Folia ..... Leaves.

F. p. : Fiat potio : : : Make a potion.

F. pil. : Fiat pilula : : Make a pill.

F. s.a.:. Fiat secundum

artem ...... Prepare skilfully.

Galv............ Galvanic.

G1. . . . . . . . Glucinum

Gr. . . . Granum . . . Grain.

Gtt. .... Guttæ .... Drops.

Guttat. . . Guttatim ... By drops.

H. ........... Hydrogen.

Hg. . Hydrargyrum . Mercury.

H1. . Hectoliter.

Hm. . . . . . Hectometer.

Hor decub. Hora decubitus . At bed-time.

H. s. .... Hora somni ... At bed-time.

I. . . . . Iodum . . . . Iodin.

In. .............. Indium.

In d. . . . In die....... Daily.

Inf. . . . Infunde..... Pour in.

Inj. . . . Injectio . . . . An Injection

K. : Kalium : . Potassium.

K.-j. . . . . . . Knee-jerk.

Ki. . . . . . . . Kiloliter.

Km. .................... Kilometer.

L. . . . . . . . . . Liter

Li. . . . . . . Lithium.

Liq. . . . Meridies Misce Liquor.

M. . Meridies; Misce . Noon; Mix. 


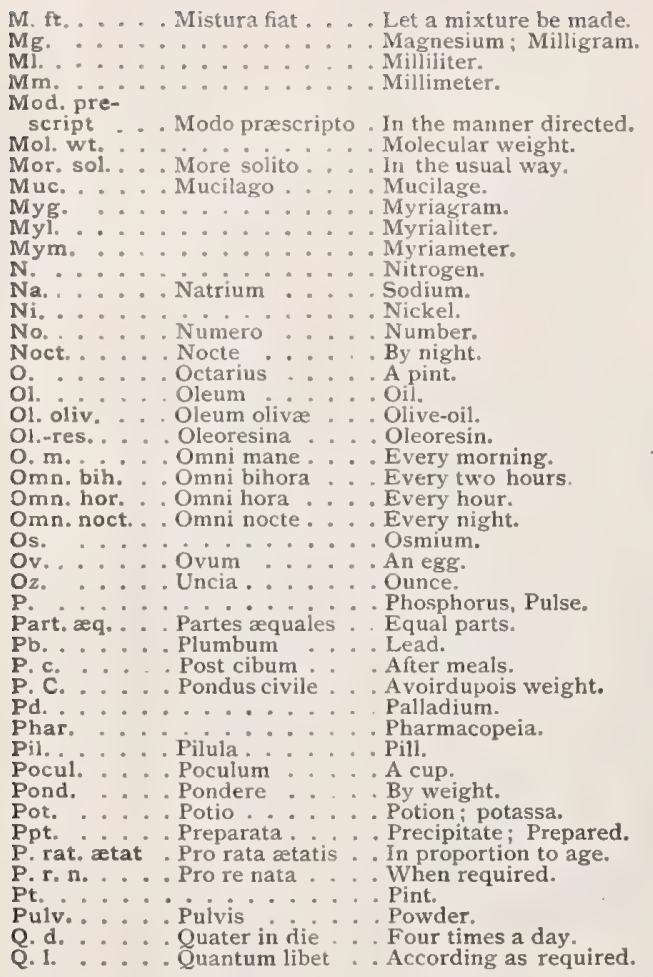

Q. p. .... Quantum placeat . At will.

Q. s. : . . Quantum sufficit. A sufficient quantity.

Q.

Q.v. : Q Quantum vis : Q Auart.

Q. v. . . Quantum vis . . As much as you wish.

H. Recipe Respiration.

Rad. : Radix .... Take.

Rb. D. . . . . Rubidium

R. D........... Reaction of

Rep. . . . Repetatur . . . Ret it be repeated.

S. . . . Semis..... Half; Sulphur.

S...... Signa ..... Label.

S. a. ... Secundum artem . According to art.

Sb...... Stibium ...... Antimony,

Scr. Scrupulum Scruple.

Sig. ..... Signetur... Let it be labeled.

Sig. n. pr. : Signa nomine

proprio..... Label with common name.

Si non val. : Si non valeat . . - If it does not answer

Si op. sit. . Si opus sit .. . If requisite.

Solv. Solve . Dissolve

Sp. or Spir. Spiritus:

Ss. . Semi, semissis: One-half.

St. . . . Stet. . . . Let it stand.

Su. . . . Sumat : . . Let him take.

S. v. .... Spiritus vini ... Alcoholic spirit

S. $v, r, 0$. Spiritus vini rectificatus ... Rectified spirit of wine

S. v. t. ... Spiritus vini tenuis Dilute alcohol, proof-spirit. Syr. .... Syrupus .... Syrup.

T. . . Temperature.

T. d. : Ter in die. . . Three times a day.

Tr., Tinct. . Tinctura .... Tincture.

Ung. ..... Unguentum .... Ointment.

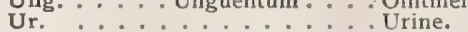

Vesic. : Vésicatorium . A blister.

Vesic. . Vesicatorium . A blister

V.s. b. : Venesectio brachil Bleeding from the arm.

m. ..... Minimum .... Minim.

3..... Drachma .... Dram.

9. ...... Scrupulum ... Scruple.

\$. Uncia ..... Ounce.

\section{ABBREVIATIONS THAT SHOULD ONLY BE USED UNDER HEADINGS, OR WITH A CONTEXT, RENDERING THE MEANING OBVIOUS.-Ewart.}

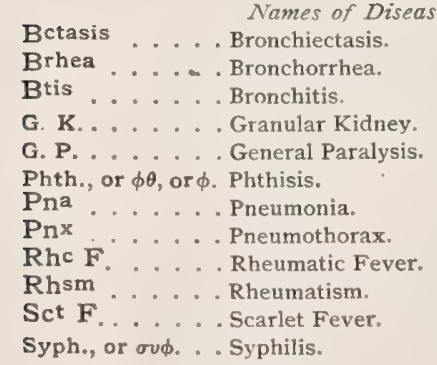

Names of Regions or Organs.

Clavr ..... Clavicular.

I. C. F. . . . Infraclavicular Fossa,

Infraser .... Infrascapular.

Interscr . . . Interscapular.

Mamy .... Mammary.
S. C. F. .... Supraclavicular Fossa.

Sp. C. ..... Spinal Cord.

S. S. F. .... Supraspinous fossa.

V. C. or V. B. . Vocal Bands.

C Names of Signs and Symptoms.

..... Cough.

Cephgia.... Cephalalgia.

Hge ....... Hemorrhage.

Ngia. . .... Neuralgia.

N. S. . ..... Night-sweats.

Spm ...... Sputum.

T....... Tongue.

Vg ..... Vomiting.

Vt ....... Vomit.

In Physical Examination, Etc.

H. C...... Humid Crepitations.

R. S. ...... Respiratory Sound.

V. F....... Vocal Fremitus.

V. S. ..... Voice-sounds.

\section{ABBREVIATIONS USED IN OPHTHALMOLOGY.}

Acc. ...... Accommodation.

Ah. : : : Hyperopic Astigmatism.

Am. ....... Myopic Astigmatism.

As. ...... Astigmatism.

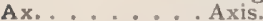

A. D. . . : Base (of prism) down.

B. $1 . \cdots$. : " : "

B. O. . . : * " * " s " s out

cm. . . . Centimeter. Cylinder, Cylindric Lens.

D. Diopter.

E. : : Emmetropia, Emmetropic.

F. ......... Formula

H. : Hyperopia, Hyperopic, Horizontal.
L. E...... Left Eye

M. : : Mvopia, Myopic.

mm........ Millimeter.

O. D. . : : Oculus dexter-Right Eye.

O. S. . Oculus sinister-Left Eye.

P. p. Punctum proximum Near Point.

P. p. .... Punctum proximum, Far Point.

R. E. : Right Eye.

Sph. : . . . Spheric, Spheric Lens

Sym. . . Symmetric

V. Vision, Visual Acuity, Vertical.

,,$+- \ldots$.... Plus, Minus, Equal to.

$\infty$........ Infinity, $20 \mathrm{ft}$. distance

E......... Combined with. 


\section{ABBREVIATIONS USED IN OTOLOGY.}

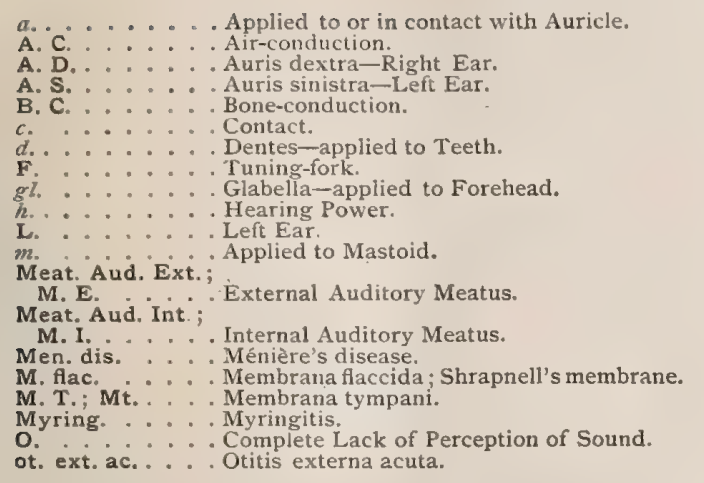
ot. ext. chron. . Otitis externa chronica.
ot. ext. diff. . Otitis externa diffusa.
ot. med. sup. ac. : Otitis media suppurativa acuta ot. med. sup.

chron. ..... Otitis media suppurativa chronica.

Pol. ..... Politzer's.

Pol. Ac. : . - Politzer's Acoumeter.

R. : : : Right Ear

S. : : : : Susurrus-a Whisper.

t. ........ Applied to Temple

Tymp. . . . Tympanum.

$u b . . .$. Ubique - when applied at all points.

v. ....... Voice.

V. ...... Applied to Vertex.

vib. ...... Vibration.

$z . . . .$. Applied to Zygoma

"......... Foot.

. . . Heard, but not Understood

+R. ...... Rinne's Test Positive.

-R. ...... Rinnê's Test Negative.

\section{ABBREVIATIONS USED IN ELECTROTHERAPEUTICS.}

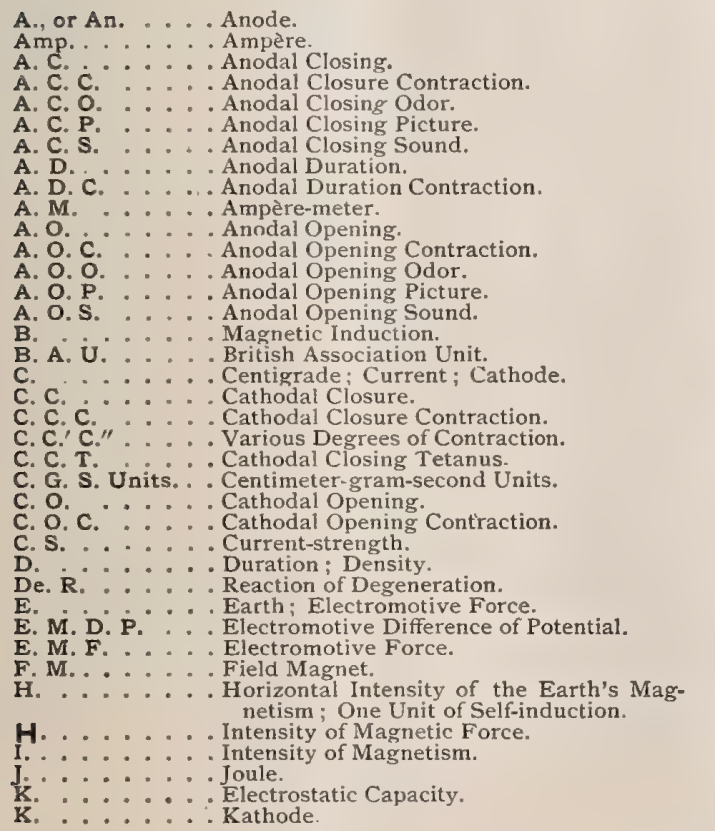

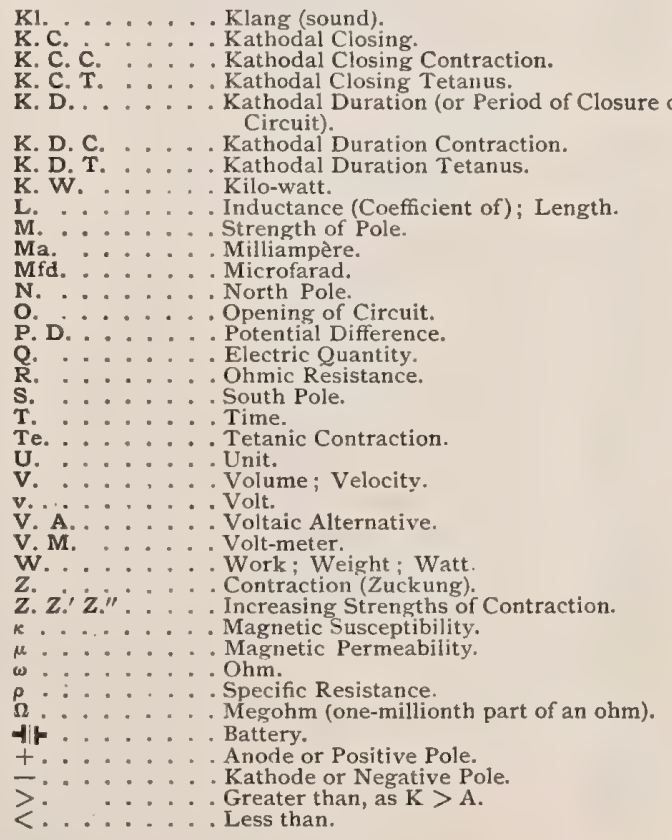

\section{PREFIXES AND SUFFIXES USED IN CHEMISTRY.}

Am- indicates the group $\mathrm{NH}_{2}$.

Azo-, diazo-, and hydrazo- indicate compounds in which nitrogen atoms are linked in various ways.

Di- is applied as a prefix to signify two.

Im- indicates the group NH.

Ket- indicates the molecule $\mathrm{CO}$ in certain structural relations.

Mon- is employed as a prefix to signify one.

Nitro- indicates the group $\mathrm{NO}_{2}$

Pent- is applied as a prefix to signify five.

per- denotes in a rather vague sense an indefinitely large amount of the body to which it is prefixed, or to which it is referred.

Sesqui-indicates the proportion of two to three.

Sub- is emploved in a rather vague sense to indicate deficiency of the body to which it is prefixed.

Tetr- is applied as a prefix to signify four.

Thio- indicates sulphur, especially replacing oxygen.

"rri- (sometimes "ter-") is applied as a prefix to signify three.

-al indicates aldehydic structure.

-an is applied to a class of bodies related to the starch and sugar group.

-ane indicates a saturated hydrocarbon.

-ase indicates an enzyme, or non-organized ferment, e.g., dias-

tase. This termination is at present restricted gener ally to enzymes of vegetable origin, but it should also be
used with animal enzymes-which, however, usually end in "in." It would thus be better to say pepsase and trypsase, rather than pepsin and trypsin.

-ate. A suffix to nouns in chemistry signifying any salt formed by an acid acting on a base ; $e . g$., sulphate, phosphate.

-ic denotes the higher of two valencies assumed by an element, and incidentally in many cases a larger amount of oxy-

gen.
-in is of no precise significance, and is mostly applied to bodies the structure of which is not yet known.

$-y l$, -ene, -enyl, and -ine indicate hydrocarbons. According to the American system of orthography, the only case in which "ine" is used is as a termination for a series of hydrocarbons, beginning with Ethine, $\mathrm{C}_{2} \mathrm{H}_{2}$. English hydrocarbons, beginning with Ethine, $\mathrm{C}_{2} \mathrm{H}_{2}$. English writers and some American chemists use it to signify basic
properties, regarding -in as the proper term for non-basic bodies. They thus distinguish between salicin, which forms no salts with acids, and morphin (which under such system is spelled "morphine"), which does. It must be noted that such methods are not in accordance with the tendency of modern chemic nomenclature, which seeks to express structure, not properties. The organic bases 
or alkaloids are not all of the same type, and when their structure is elucidated systematic names will be found for them. Until then there is no particular gain in indicating them as a group.

-id is similar to "in.

-ol indicates alcoholic structure, $i . e$., presence of the group HO (hydroxyl), e. $g$., alcohol, glycerol, phenol.

- one is applied to bodies related to the starches and sugars. It is, however, not used with this significance in "pep- tone," which word is not formed according to any established system.

-ose indicates a carbohydrate, $e, g$. glucose, although it is also occasionally applied to the results of digestion of proteids, $e, g$, albumose.

-ous denotes the lower of two degrees of valency assumed by an element and incidentally indicates, in many cases. a small amount of oxygen.

The word sulphonic indicates the group $\mathrm{HSO}_{3}$

\section{ABBREVIATIONS USED IN HYGIENE AND SANITARY LAW.}

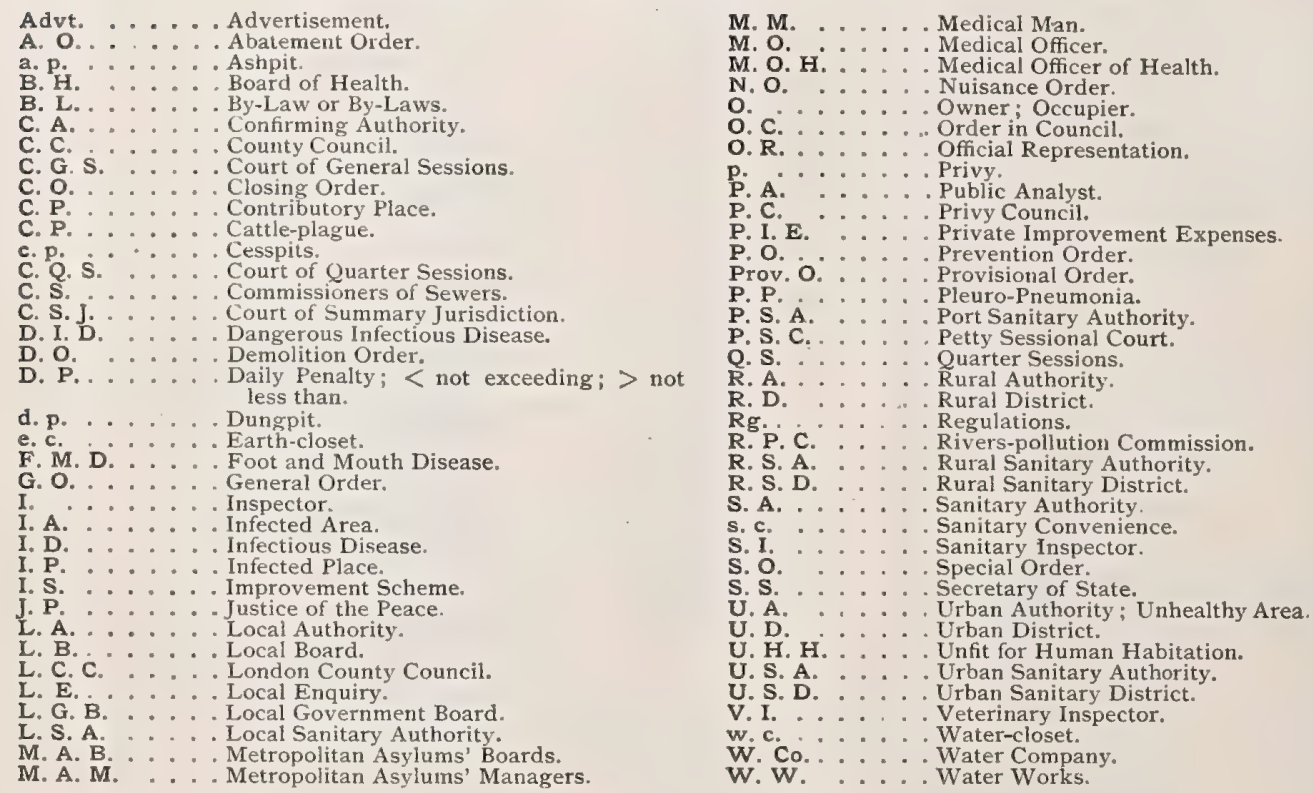

\section{ABBREVIATIONS USED FOR ACTS OF PARLIAMENT.}

A. A. . . . . Alkali Acts, 1863, I874 (Consolidated), I88I. C. B. A. C. Canal Boats Acts, $1877-84$

C. D. (A.) A. . Contagious Diseases (Animal) Act, 1878 .

C. L. H. A. : Common Lodging Houses Act, 185I, etc.

D. C. M. O. . : . Dairy, Cowshed, and Milk Shop Order, I885-6.

F. W. A. . . F Factories and Workshop Act, 1878 . Housing of Working Classes Act, 1890 . 1. D. (N.) A. . Infectious Diseases (Notification) Act, I88g 1. Drevention) Act, 1890. L. C. (C.) A. . L Land Clauses (Consolidation) Acts, 1845 Local Government Act, I888
M. L. M. A. . . Metropolis Local Management Act, 1855 . M. W. C. A. : " Water Companies Act, 1871. P. H. A. . . . Public Health (England) Act, 1875 . P. H. (A.) A. . . " " " (Amendt.) " 1890 P. H. (I.) A. " " " " (Ireland) " 1878 " P. H. (L.) A. . " " " (London) " $189 \mathrm{I}$ P. H. (S.) A. . " " " (Scotland) " 1867 P. H. (W.) A. " " (Water) " 1878 .

P. W. L. A. . . Public Works Loans Act, I879.

R. P. A. . . Rivers Pollution Act, I876.

S. F. D. A. . Sale of Food and Drugs Act, 1875

S. J. A. ...... Summary Jurisdiction Act.

\section{SIGNS ABBREVIATIONS, ETC., USED IN DESCRIPTIVE ZOÖLOGY AND BOTANY.}

o........ Feet.

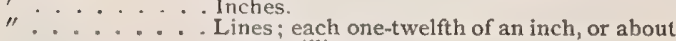
two millimeters.

!...... A mark of affirmation or authentication.

?.... A mark of doubt

Figures or words separated by a short dash indicate the extremes of variation, as 5-Io"l long, few-many flowered; i. $e$ varying from 5 to Io lines in length, and with few to many flowers.

c.c. ....... Cubic centimeter

cm. ...... Centimeter.

mm. ....... Millimeter.

$\mu$....... The Micron, Micromillimeter, or unit of Microscopic Measurement. For convenience of reference, the following table of

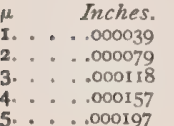

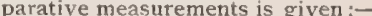

Inches. Inches. $\mu$

6....000236 एकीषण ... 2.5399

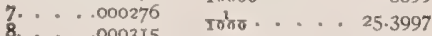

.00035

บก์ส ....253.9972

One Meter . 39.370432 in
$X$..... Used to express magnification, thus $X 1000$ indicates a magnification of 1000 diameters. The improper fraction 1000 indi-

(1) cates the same thing, but is rarely used.

An annual Herb.

.... A biennial Herb.

A perennial Herb.

๖ ....... An Undershrub, deciduous.

b....... An Underthrub, evergreen.

5 ......... A Shrub, deciduous.

$5 \ldots . .$. A Shrub, evergreen

\$ ........ A Tree, deciduous.

$5 \ldots . .$. A Tree, evergreen.

h....... An herbaceous Vine, annual or biennial.

ち ....... A woody Vine, deciduous.

\$ ........ A woody Vine, evergreen.

L ...... A trailing Herb, annual or biennial.

h........ A trailing Herb, perennial.

$m \ldots$...... An aquatic plant.

૪........ Flowers perfect. 
* ....... A male animal, or a plant or flower bearing only stamens or antheridia.

\&........ A female animal or a plant or flower bearing only pistils or archegonia.

C........ A young animal of undetermined sex, thus to, young male, or iyg for young female, but $\bigcirc$ juv (juvenis, young).

$\odot \ldots . . .$. A monocarpic plant.

................ Cotyledons accumbent.

$8 \| \ldots \ldots$ Cotyledons incumbent

....... A plant introduced and naturalized.

....... A plant cultivated for ornament.

..... A plant cultivated for use.

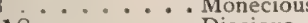

\% ...... Diecious

o $\uparrow \ldots . .$. Polygamus.

Wanting or none.

$\infty \ldots \ldots$ Numerous or indefinite; more than twenty when applied to stamens.

$\sigma \ldots \ldots . .$. The microsecond represents .oor second or the unit of time in experiments or psycho. physic reactions.

Authors' names are abbreviated in the following Manner:-

Ait., Aiton. Bech., Bechstein. Cham., Chamisso. Dum., Duméril, etc.

Nupt, signifies in ornithology, breeding plumage.

hornot, means a bird of the year.

-acex, a suffix used in botany to designate a family, the name chosen being one of the principal genera. Ex., Rosa, Ros acec, Ranunculus, Ranunculacee. Cf, icea, idece, inea, ece.

-ana, preferably used as a suffix to the rame of a species around which others naturally cluster, in the naming of subsections or groups of species: $\varepsilon_{0} g$. the group of species of Helix related to $H$. pomatia may be indicated by the term Pomatiana.

-ensis, a termination given to the names of species only when derived from the name of their habitat; $e . g$., Tania madagascariensis, Daphne chinensis, Dracana brasiliensis.

Eu-, employed as a prefix in forming the names of genera, subgenera, or sections of genera before a Greek derivative.

Excl, gen., exclusit genus.

Excl. sps, exclusit species.

Excl, var, exclusit varietas, when following an onym, indicates that the group has undergone revision, and the name does not cover the original ground to the extent indicated.

-ia, -ius, -ica, -icus, -ina, -inus, -ita, -itus, terminations used in making specific names which are derived from the name of a river or other body of water, a province, a country, or a kingdom; $e$. $g$, arabicus.

-icea, -idea, -inex, suffixes used in botany to designate a family when the name taken ends in Latin $-i x$ or $-i s$ (genitive icis, idis, iscis); e.g., Salicinea from Salix, Berberidece from Berberis, Tamariscinece from Tamarix.

-eae, as a rule, these suffixes, together with $e a$, are employed to designate botanic sub-families, tribes, and sub-tribes; e. g., Rosece from Rosa.

-ida, -ina, the suffixes added to the name of the earliest known or most characteristic genus, to designate zoölogic families or sub-families; $e_{1} \rho$., Strix, strigis, Strigide, Bucerotis, Bucerotida.

-ites, -itis, frequently employed to designate fossil organisms analogous to the living form whose generic name is the radical to which ites is appended. They are rarely used with specific names.

Mutatis char., mutatis characteris, when following a specific name signifies a change in the diagnostic characters of a species.

-astrum, -oidea or -oides, -oidalis, -oideum, -opsis, terminations employed in forming generıc, sub-generic, or specific names after a Greek derivative. Bourguinat suggests that astrum be reserved to be appended to the name of a genus to indicate its typical sub-division. Opsis and oides should be reserved for sub-divisions of a genus which resemble another genus, by adding them to the name of that other genus when it is of Greek origin.

-oides is preferably reserved for specific namies of Greek or barbarous (never Latin) origin.

(a) When the radical of the specific name is the name of a genus which it resembles, $e_{a} g$, Salix myrilloides, Bupleurum ranunculoides, Malva abutiloides, Thuja cupressoides.

(b) When the radical is the name of another species which the new one resembles. Helix carascaloides, a species like $H$. carascalensis.

(c) When the radical of the specific name is a Greek word signifying an animal, organ, part, object, as Potentilla arachnoidea, Prenanthes deltoidea, Jungermannia zoöp. sis, icthyoides, rhomboidale, pterigoideus, paraboloides, dendroideus.

Only one apparent exception to the compounding of Greek and Latin has been consecrated by usage; viz.: ovoides

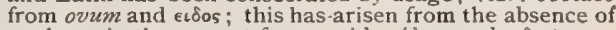

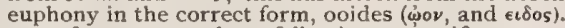

pro-parte, for a part, when following a specific name indicates that since its first application the group has been revised.

Pseudo-, a prefix employed in forming specific names before a Greek derivative.

-pteris, a termination frequently employed in the generic names of ferns, for the purpose of recalling the affinities of the genus.

sp. (I) In zoology, abbreviation of species, written when the specific name is not known or is wanting, or if placed after the name of the authority, as Crania craniolaris, Linne sp., indicates that Linne is only to be credited with the specific name.

(2) In botany, species or specimen.

Sub-, a prefix employed in forming specific names before a Latin derivative. It may also be used in designating a new species before the name of another with which the first was in intimate relation. It is also used in the sense of nearly, less, somewhat, slightly. It has, moreover, a few legitimate Latin compounds which may be used for specific names; $e_{0} g .$, subterraneus, subalpinus-a-um, subcurrens, subcutaneus, subdimidiatus, subjectus, sub. mersus, subrotundus, substratus.

Sub-sp., subspecies.

gen., genus.

var., variety, placed before the name of a plant or animal indicates that it is a hybrid of doubtful origin.

\section{SUNDRY ABBREVIATIONS.}

\author{
Adj. . $\therefore$ Adjective \\ Adv. Adverb. \\ Am. American \\ Arab. Arabic \\ A. S. Anglo-Saxon. \\ Bot. Botany Botanic \\ B. Ph. . . British Pharmacopeia. \\ Celt. Celtic. \\ Ch. . . . Confer, see. Chemistry, Chemic. \\ Colloq. . . Colloquial. Compounded, Compound. \\ Dim. . . Diminutive \\ e. $g$. . . . (Exempligratia), For example. \\ Elec. . . Electricity. \\ Eng. English \\ Etym. : . : Etymology, Etymologic. \\ $f . \ldots . .$. Feminine \\ Geog. . . French. \\ Geol. . . . Geology, Geologic. \\ Geom. . . Geometry, Geometric. \\ Geom. ..... Geometry \\ Ger. Ph. : . . German \\ Gr. Greek. \\ Heb. Hebrew \\ Hind. ...... Hindustani. \\ Ichth. ...... Ichthyology. \\ i. e. . . . . (id est $)$, that is. \\ It. Italian
}

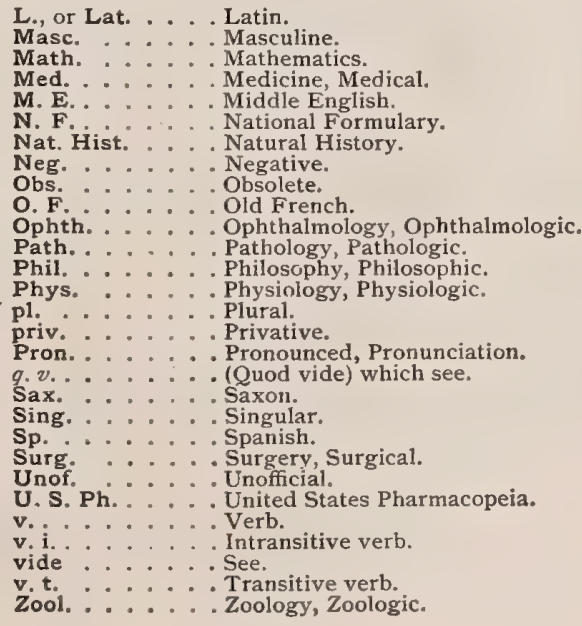

L., or Lat. . . Latin.

Medical

Ophthalmologic.

Pron - a a a a

q. v. . . (Quod vide) which see

Sax. ....". Saxon.

rgery, Surgical.

Unofficial.

J. S. Ph. United States Pharmacopeia.

t. Transitive verb. 


\section{PREFIXES AND SUFFIXES USED IN MEDICAL TERMS.}

\section{PREFIXES.}

A-, an-, called alpha privative (Gr, a, av, or au), the equivalent of our prefix, un-, or in-, denotes an absence or want of the thing or quality expressed by the principal; e. $g$., adynamia, anaërobic, aphasia, apraxia, apyrexia, astigmatism, atony, etc. $a$ is used before consonants, $a n$ before vowels, and, rarely, $a m$ before $b l$ or $b r$. (To be distinguished from ana.)

Ad- (ad), to, at, toward, as, adduction, adhesion. The $d$ is often changed in the compound to correspond ti the next letter, as accretion, appendix.

Al-(Arab.) article the; e.g., alchemy, the secret art; alcohol, the very subtle.

Amphi- (or amph-) ( $\dot{a} \mu \phi i)$, upon both sides, in two ways, as in amphiarthrosis, amphibia, etc.

Ana- $(\alpha \nu \alpha ́)$. Up, through, again; e.g., anabolism, anasarca, anatomy, etc.

Anti- (or ant-) (ávii). Against, opposed to, opposite of ; as antaphrodisiac, antibrachium, antipyretic, antiseptic, etc

Apo-(ámó). Off, away, upon; e. g., aponeurosis, apoplexy, etc.

Auto-(ấtós). Self; as autopepsia, autopsy.

Bary-(Bapiss). Heavy, difficult, as barymezia baryphonia, etc.

Bi-, bin-(bis). Twice, twofold; e. g., bicrespid, bivalent, binocular, binaural.

Bio- (Bios). Life, e.g., bioplasm, biology, biolysis.

Brach- $\left(\beta \rho \alpha \chi^{i \omega \nu}\right)$. Arm, pertaining to the arm; as brachialgia, brachioncus.

Broncho- ( $\beta$ póy os). Pertaining to the trachea; as bronchorrhagia bronchotomy.

Cardi-, cardio- (kapóia). Pertaining to the heart, as cardiogram, cardialgia.

Celio-, cœlio- (koidia). Pertaining to the belly, as celiotomy, celiac.

Chiro- ( $\chi$ cip). The hand. Chiragra, chiropodist.

Co-, con- Together, along with; e, g, coitus, congenital.

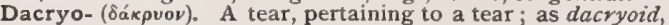
dacryo-cystilis.

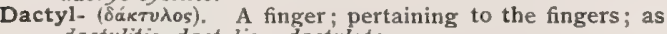
dactylitis, dactylion, dactylate.

Dermo-, dermato- $\left(\delta \varepsilon^{\rho} \mu a\right)$. The skin; pertaining to the skin; g., dermotomy, dermatolysis.

Di- (dís). "Twice, double : as dimorphism, digastric.

Dia-(óá). Through. Examples: diabetes, diagnosis, diaphragm, diarrhea, etc.

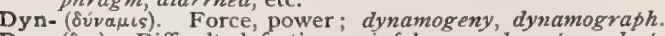

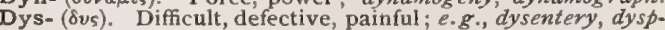
nea, dysuria.

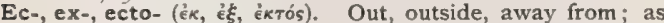
in ecchymoses, ecdemic, eclampsia, exostosis, exanthema, ectropion, ectoderm.

En-, em- $(\dot{\epsilon} \nu, \dot{e} \mu)$. In, within; as in embryo, embolism, endemic, etc.

Endo-, ento- (évтós). Within, internal; e. g., endarteritis, endoscope, entoblast, entoptic.

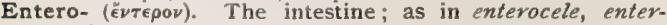
ostomy, etc.

Epi- ('́ní). Upon, over, above; e. g.. epiblast, epicranium, epistaxis, epidemic, etc.

Extra-(Lat.). Outside; e.g., extravasation, extroversion,

Galact-(yáda). Milk: as galactocele, galactozemia, galacturia.

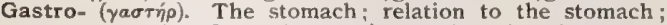
e. g. gastrocele, gastrocnemius, gastroenterostomy, etc.

Genio-(yeveiov). Pertaining to the chin; e. g., geniohyoglos. sus, geniohyoid.

Glosso- $(\gamma \hat{\lambda} \omega \sigma \sigma a)$. Pertaining to the tongue. See glossology, glossoplegia, glossophytia.

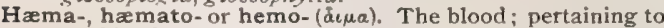
the blood. See hematemesis, hematoma, hemorrhage, etc.

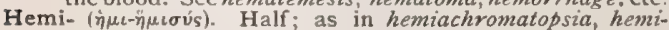
crania, hemiplegia.

Hepat- $(\eta \pi a \rho)$. The liver ; pertaining to the liver. See hepatemphraxis, hepatization, hepatopostema.

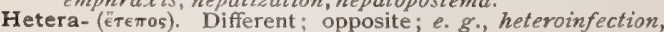
heterologous, heteropathy.

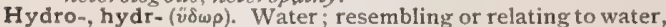
dropsy, etc.; as in hydremia, hydragogue, hydrate, hydrocephalus, etc.

Hyper- (vंmé). Excess; exaggerated abnormality in amount, size, quality, etc. See hyperesthesia, hypermetropia, hyperpyrexia, hyperirophy, and others.

Hypno-(vivos). Sleep. See hypnopathy, hypnotism.

Hypo- (iлó). Diminution as to degree, amount, size, quality, etc. or that located under or beneath. e. o. hyposthenia, hypoblast hypochondriac, hypodematic, hypoglossal.

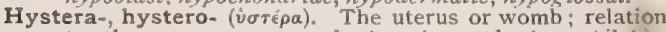

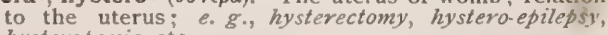
hysteropexia, etc.

Ileo-(flekm). Pertaining to the ileum - e.g., ileo-colitis, ileotyphus.
Ilio- (Iium). Pertaining to the ilium; e.g., ilio femoral, it lumbar.

Im-, in- $(I n)$. Privative, negative; as imperforate, incarcer. ation, insane, incontinence.

In- ( $\epsilon \nu)$. In, within, upon, by ; as incubation, infarction, inflammation, inoculation, etc.

Infra- (Infra). Beneath, below; $e_{0} g$, inframaxillary, infrascapular.

Inter-(Inter). Between. See intercellular, intercostal, inter. trigo, and others.

Intra- (Intra). Within, inside of, as intra-articular, intra uterine.

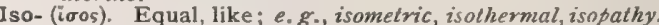

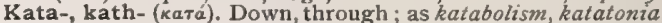
kathode.

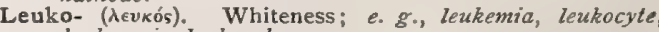
leukomain, leukorrhea.

Lith-, litho- $\left(\lambda_{i} \theta 0 s\right)$. Pertaining to stone, calculus, or lithic acid. See lithemia, lithiasis, lithotripsy, etc

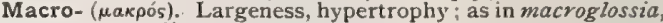
macromelia.

Mal-(Malus). Bad ; as malformation, malpractice, malaria.

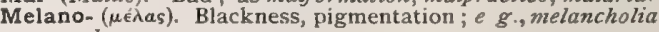
melano-sarcoma.

Meso-( $\mu$ é $\sigma o s)$. The middle ; e.g., mesoblast, mesocolon, etc,

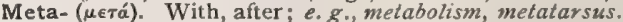

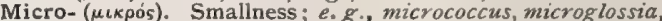

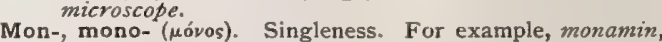
monomania, monorchis.

Morpho- $(\mu \circ \rho \phi \eta)$. Shape, form; e.g., morphography, morphology, morphomelry.

Multi-(multus). Number, many ; e.g., multilocular, multiparous.

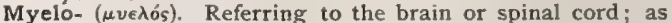
myeloid, myelitis.

Myo- ( $\mu \hat{v} s)$. Pertaining to a muscle or to muscularity. See myocarditis, myoma, myopathy.

Neo-(véos). New, tecent, young; as neogala, neo-membrane, neoplasm.

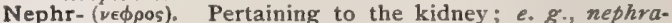
postasis, nephria, nephritis.

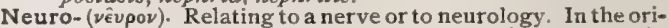
ginal Greek the word meant a cord or tendon,-neurosis, the stringing of the bow. It is now applied only to nerve-structure; as, $e . g_{*}$, neuralgia, neurasthenia, neurilemma, neuroglia.

Ob- $(O b)$. In front of, against, denoting hindrance or obstruction; e. $g$, obstruent, obturator, occlusion, opponens.

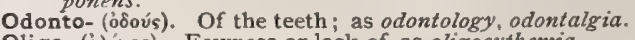

Oligo- (òi(yos). Fewness or lack of, as oligocythemia.

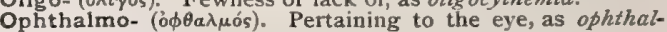
mia, ophthalmoplegia.

Ortho- (optós). Straight, upright, correct. See orthoscope, orthopedia, orthopraxis.

Osteo-(oбreov). Referring to bone. See osteoblast, osteomyelitis, osteoplastic.

Oto- (ovis). Pertaining to the ear, as otorrhea, otophone.

Oxy- (ủ $\left.v^{2}\right)$ ). Denoting the presence of oxygen, or acidity; as oxygen, oxyhemoglobin.

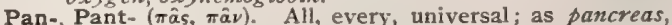
pangenesis, pantomorphic.

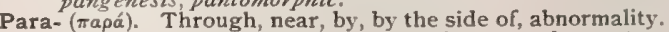
Examples: paracentesis, paresthesia, parenchyma, parotid.

Peri- $(\pi \in p i)$. About, around. See, e. g., pericardium, perimeter, perilymph, periosteum.

Pod- (Toús) Pertaining to the foot, as podalgia podedema.

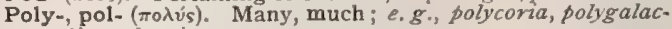
tia, polyuria.

Præ-, pre-(Pre). Before; e. $g$, precordia, prepuce.

Pro- (mpó). Before, down; as in process, procidentia, prolapse, proptosis.

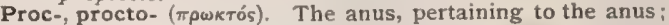
e. g., proctitis, proctoplegia.

Pseudo- ( $\left.\psi \in v \delta \gamma^{\prime}\right)$. False, spurious; as in pseudarthrosis, pseudo. cyesis.

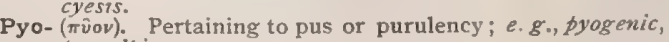

Pyr-, pyro- $(\pi \nu \rho)$. Concerning fire or heat, or inflammation ; e. g. pyrogenous, pyrexia.

Retro- (Retro). Backward, behind; e. g., retroflex, retroversion.

Rhin-, Rhino- (pis). Pertaining to the nose, as rhinoplasty, rhinitis.

Semi-(Semis). Half, partly, almost, as semicapium, semilunar 
Sphyg-( $\sigma \phi v \gamma \mu o$ s). Pertaining to the pulse, as sphygmometer, sphygmolechny.

Sub- $(S u b)$. Beneath, under; and also partialty or deficiency of, as subclavian, subluxation.

Super-(Super). Ahove, upon; exccss of; e.g., supercilium, superfecundation.

\section{SUFFIXES.}

-ago (agere). Gives the idea of activity, presentation, etc.; as lumbago.

-agogue ( $a$ yetv, to bear off, carry away). Signifies an agent stimulating the function of excretion or secretion of the product. Thus, emmenagogue, hydragogue, sialagogue. -agra (âpa, an attack, seizure). Denotes an acute attack of pain in the part, as arthragra, podagra.

-algia (ä $\lambda$ os, pain). Pain in a part, expressed by the chief word; e. g., cephalalgia, gastralgia.

-atresia (átpضoia). Imperforate, as ill proctatresia.

-cele $(\kappa \eta \dot{\lambda} \eta)$. A tumor, hernia, or protrusion. See cystocele, hydrocele, meningocele.

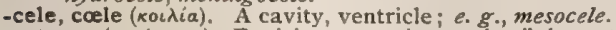

-ectomy (єкте́ $\mu \nu \in \iota \nu)$. Excision, exsection; as in oöphorectomy, nephrectomy, splenectomy.

-emia, (at $\mu a$ blood). Denotes a condition of the blood, or an ingredient in the same, expressed by preceding word; e.g., hydremia, lithemia, pyemia, uremia.

-etin ( $\rho$ '

-fuge (fugare, to expel). Driving out, an expeller, as vermifuge, febrifuge, etc

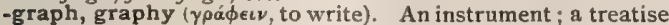
or description; $e . g$., sphygmograph demography.

-ia, often contracted to $-y$, denotes the quality of the root-word as an abstract noun, as akromegalia, akromegaly.

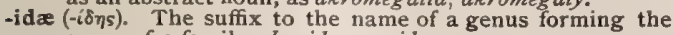
name of a family; bovide, equide.

-igo. A variation of -ago; e.g., prurigo, vertigo.

-is, -sis. Present the abstract idea of activity of the root-word.

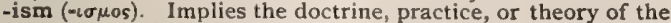
principal word; Darwinism, tribadism.

-ite (-iтns). Of the nature of. In anatomy, denoting a constit. uent part of an organ; as sergite, stemite. In chemistry, any salt of an -ous acid; as sulphite, phosphite.

-itis (-iтs). Originally the feminine ending of Greek substantives and denotes an especial activity of the root-word. By habit and general use it is now limited to inflammatory activity; as gastritis, otitis, etc.

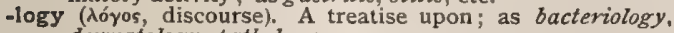
dermatology, pathology.

-lysis ( $\lambda u ́ \sigma \iota s$, a loosening). A separation into constituent parts, or the setting free of some part; as hydrolysis, analysis.

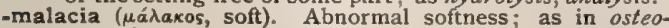
malacia.

-mania ( mavia, madness). The chief word denotes the principal
Supra- (Supra). Above, upon, superior to, as supraorbital, supraspinatus.

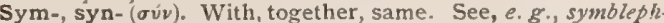
aron, symphysis, synalgia, synchondrosis.

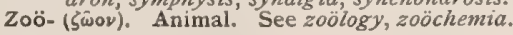

symptom of the mental affection; e. $g$., erotomania, kleptomania, etc.

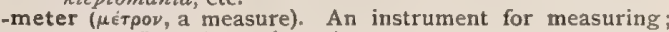
e. $g$., ä̈rometer, urinometer.

-odynia odvinn, excessive pain). The principal word denotes the seat of great pain, as coccygodynia.

-oid (ह่น์os, form). Similar in shape, etc.; as in choroid, cuboid, sphenoid, xiphoid.

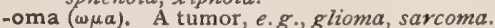

-opia $(\omega \psi)$. Pertaining to the eye or vision; as in amblyopia, myopia, etc

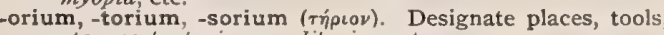
etc.; as tentorium, auditorium, etc

-osis, -osus, derived from Greek words in -ów, and usually denote fulness, redundancy, excess.

-pathy $(\pi \alpha \dot{\theta} 0$ s). A condition of disease, and also a method of cure; as adenopathy, psychopathy, homeopathy, hydropathy.

-phobia ( $\phi \circ \beta_{0}$, fear). Morbid or exaggerated fear or dread, as agoraphobia. photophobia.

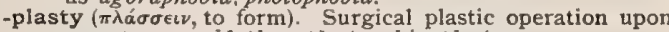
a part; $e . g .$, blepharoplasty, rhinoplasty.

-rhagia ( discharge; e. g., blennorrhagia, metrorrhagia.

-rhaphy ( $\dot{\rho} a \phi \eta \dot{\eta}$, a suture). A stitching or suturing of a part ; as enterorrhaphy, perineorrhaphy.

-rhea ( $\rho \in \varepsilon \in \iota \nu$, to flow). An excessive discharge or excretion; as blennorrhea, diarrhea, leukorrhea.

-scope ( $\sigma \kappa 0 \pi \epsilon i \nu$, to look). An instrument for making an examination; as laryngoscope, microscope.

-scopy ( $\sigma \kappa o \pi \epsilon \epsilon \iota)$. An examination: as ophthalmoscopy.

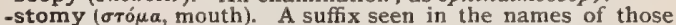
surgical operations in which an artificial opening or passage is formed, as enterostomy.

-tas, -ty. Derived originally from the Greek $-\tau \eta$, denote abstract quality or idea, as immunity, acidity.

-tio, -atio, -tion. A suffix of verbal roots denoting an action or function as taking place-an occurrence. The $n$ was added to the original -tio by Roman and French influence.

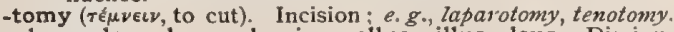
-ulus, -ula, -ulum, -ola, -ion, -ellus, -illus, -leus, Diminutives.

-uria (ovpeetv, to urinate). Abnormalities of the urine or of urination; as albuminuria, polyuria.

\section{DEGREES, DIPLOMAS, AND QUALIFICATIONS.}
A. A. S
Fellow of the American Academy.
A. B. or B. A. Bachelor of Arts.
A. M. . Master of Arts.
C. M. : : : Master in Surgery.
D. D. S. . . Doctor of Dental Surgery
D. P. H. .... Diploma in Public Health
D. S. M. . . Diploma in State Medicine.
D. S. S. . . . Diploma in Sanitary Science.
F. B. S. Ed. - Fellow of the Botanical Society. Fourgh
F. C. S. . . Fellow of the Chemical Society.
F. E. S. . : Fellow of the Entomological Society.
F. F. P. S. G. : Fellow of the Faculty of Physicians and Surgeons of Glasgow. F. K. Q. C. P. I. . Fellow of the King and Queen's College of
F. L. S. ... Fellow of the Linnæean Society.
F. R. C. P. L. Fellow of the Royal College of Physicians of London.
F. R. C. P. Ed. . Fellow of the Royal College of Physicians of Edinburgh.
F. R. C. P. I. . . Fellow of the Royal College of Physicians of Ireland.
F. R. C. S. E. . Fellow of the Royal College of Surgeons
F. R. C. S. Ed. . Fellow of the Royal College of Surgeons of Edinburgh.
F. R. C. S. I. . . Fellow of the Royal College of Surgeons in Ireland.
F. R. S. . . . Fellow of the Royal Society.
F.R. S. E. : - Fellow of the Royal Society of Edinburgh.
F. R, S, L. Fellow of the Royal Society of London
L. A. H. . . . Licentiate of the A pothecaries' Hall,Dublin.
L. A. H. . . . Licentiate of the Apothecaries
L. F. P. S. G. : - Licentiate of the Faculty of Physicians and Surgeons of Glasgow.
L. K. Q. C. P. I. . Licentiate of the King and Queen's College

LL. B. . . . B Bachelor of Laws.

LL. D. . . Doctor of Laws.

L. R. C. P. L. : Licentiate of the Royal College of Physi-

L. R. C. P. Ed. . Licentiate of the Royal College of Physi-

cians of Edinbnrgh.

L. R. C. S. Ed. . . Licentiate of the Royal College of Surgeons of Edinburgh.

L. R. C. S. I. . . Licentiate of the Royal College of Surgeons in Ireland.

L. S. A. . . . Licentiate of the Apothecaries' Society of London.

L. S. S. . . . Licentiate in Sanitary Science.

M. A. . . . Master of Arts.

M. B. . . Bachelor of Medicine.

M. D. Doctor of Medicine.

M. K. Q. C. P. I. Member of the King and Queen's College of Physicians of Ireland.

M. P. S. . . . Member of the Pharmaceutical Society.

M. R. C. C. : Member Royal College of Chemistry.

M. R. C. P. L. - Member of the Royal College of Physicians of London.

M. R. C. P. Ed. . Member of the Royal College of Physicians of Edinburgh.

M. R. C. P. I. . Member of the Royal College of Physicians of Ireland.

M. R. C. S. E. . Member of the Royal College of Surgeons of England.

M. R. C. S. Ed. Member of the Royal College of Surgeons

M. R. C. S. I. . Member of the Royal College of Surgeons in Ireland.

M. R. C. V. S. . Member of the Royal College of Veterinary Surgeons.

M. S. . . . . Master in Surgery.

Ph. B. . . . Bachelor of Philosophy.

Ph. D. : . . Doctor of Philosophy

V. S. . . Veterinary Surgeon. 


\section{INDEX OF TABLES}

\section{AND IMPORTANT DEFINITIONS, WHEREIN LARGE NUMBERS OF FACTS ARE BROUGHT TOGETHER AND CLASSIFIED.}

Abbreviations,

Prefixes and Suffixes,

Acids,

Alcohols,

Aldehyds,

Anesthetics,

Angles,

Arteries (Illustrated),

II

Bacteria (Illustrated), ........... I57

Bandages (Illustrated), . . . . . . . . I88

Baths, . . . . . . . . I95

Batteries, Electrical, used in Medicine, . . . . 198

Bones (Illustrated), . . . . . . . 2I7

Breath Sounds, . . . . . . . . . 235

Canals, ............. 253

Carbohydrates, ........... 26I

Catheters, Sizes of (Illustrated), . . . . . 272

Cereals, ............. 280

Cheese, . . . . . . . . . 285

Condensed Milks, . . . . . . . . 3 I6

Convolutions of Cerebrum (Illustrated), . . . 323

Craniometric Points, . . . . . . . . 337

Diameters, Craniometric and Pelvic, .... 369

Diseases, Eponymic, . . . . . . . . 380

Doses, Gaubins' Table, . . . . . . . . 395

Ducts, . . . . . . . . . . . 398

Electric Units, . . . . . . . . . 413

Elements, Chemic, . . . . . . . . 416

Ethers, . . . . . . . . . . . . . . 444

Exanthemata, . . . . . . . . 450

Fetometry, .............. 465

Fetus, Positions and Presentations of, . . . . . 467

Fevers, . . . . . . . . . 466

Fissures, . . . . . . . . . . 473

Flour, . . . . . . . . . . 479

Foods, .............. . . 482

Foramina, . . . . . . . . . . 483

Ganglia, . . . . . . . . . 502

Glands, . . . . . . . . . 517

Handkerchief Dressings (Illustrated), . . . 540

Hernia (Illustrated), .......... 561

Hydrocarbons, ........... $58 \mathrm{I}$

Insanity, . . . . . . . . . . 615

Knots, Surgical (Illustrated), . . . . . . 645

Koumiss, Analysis of, . . . . . . . . 646

Lamina, . . . . . . . . . . 655

Laws, . . . . . . . . . . . 663

Leukomains, . . . . . . . . . 674

Life, Expectation of, . . . . . . . . . 678

Ligament (Illustrated), . . . . . . . . 679

Lines or Lineæ, . . . . . . . . . . 688

Localization (Illustrated), . . . . . . . 70I

Membrana, . . . . . . . . . . 74I

Metric System,
PAGE

Milk, Analysis of, . . . . . . . 768

Monstrosities, . . . . . . . . . 779

Motor Points (Illustrated), . . . . . . . 784

Mulatto, . . . . . . . . . . 789

Murmurs, . . . . . . . . . 792

Muscles (Illustrated), . . . . . . . . . 795

Nerves (Illustrated), . . . . . . . . 848

Nuclei, . . . . . . . . . . 878

Oils, . . . . . . . . . . . 889

Oleomargarin, Analysis of, ........ 892

Operations, Eponymic, . . . . . . . . . 899

Organotherapy, ........... . 940

Paralyses, ........... . . 973

Parasites (Illustrated), . . . . . . . . . . 978

Pelves (Illustrated), . . . . . . . . . I035

Phthisis, . . . . . . . 1075

Pigments, . . . . . . . . . . . 1085

Planes, . . . . . . . . . . I I IOg

Plates, . . . . . . . . . . . III4

Plexuses, . . . . . . . . . . IIII

Points, . . . . . . . . . . II33

Poisons, . . . . . . . . . . II 36

Position, and Position and Direction, . . . . I I6I

Postures (Illustrated), . . . . . . . . . I167

Pregnancy, . . . . . . . . I I 75

Processes, . . . . . . . . . II 18 I

Ptomains, . . . . . . . . . . 1210

Râles, . . . . . . . . . . . I235

Reflexes, ............. I 245

Regions (Illustrated), . . . . . . . . I248

Resins, . . . . . . . . . 1253

Respiration, . . . . . . . . . I255

Signs and Symptoms of Disease, ...... . 1323

Sinuses (Illustrated), . . . . . . . . 1329

Skin Diseases, ... . . . . . . . I333

Soaps, . . . . . . . . . . . I 333

Spaces, . . . . . . . . . I I343

Spectacle Lenses, Numbering of, . . . . . . . I346

Spinal Cord, Localization in (Illustrated), . . . I 354

Stains, Fluids for Fixing and Hardening, etc., . . 1367

Starches (Illustrated), . . . . . . . . I408

Sugars, ............. I . I430

Sutures (Illustrated), . . . . . . . . . I437

Tests, ............ I . . . . 468

Theories, . . . . . . . . . I I I

Thermometers, Comparison of, . . . . . I513

Treatments, . . . . . . . . . . 1532

Triangles, . . . . . . . . . . . . . . .

Tumors (Illustrated), .......... I555

Urinary Calculi, Analysis of, . . . . . . 1576

Urinary Sediments (Illustrated), . . . . . . 1577

Urine, Colors of the, . . . . . . . . I580

Veins, . . . . . . . . . . 1592

Wave-lengths, and Frequencies of Light, . . . I612

Weights and Measures (Illustrated), ...... 1613 


\section{AN ILLUSTRATED DICTIONARY}

\section{Medicine, Biology, and Allied Sciences.}

A $[\dot{a}, \dot{a} \nu$, or $\dot{a} \mu$, without]. The Greek letter alpha, called alpha privative, equivalent to the prefix $u n$ or in. It denotes absence or want of the thing or quality expressed by the root of the word. $a$ - is used before consonant, and $a n$-before vowel sounds; am-is sometimes used before $-b l$ or $-b e$. Also, the symbol of Anode.

Aa [ává, of each]. An abbreviation, written $\bar{a} \bar{a}$, used in prescriptions to denote repetition of the same quantity for each item.

āāā. Abbreviation for Amalgam.

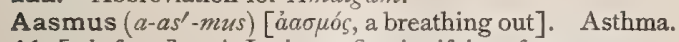

$\mathrm{Ab}[a b$, from $]$. A Latin prefix signifying from.

Abaca $\left(a b^{\prime}-a k-a h\right.$, Sp. pron. $\left.a h-v a h-k a h^{\prime}\right)$. Manilla hemp. See Hemp. Also Musa textilis, the plant which produces it.

Abactinal $\left(a b-a k^{\prime}-t i n-a l\right)$ [ab, away; actinal, the oral surface of a radiate animal]. In biology, aboral. Agassiz's term for the surface of radiates opposite to that having the mouth.

Abactio $\left(a b-a k^{\prime}-s h e-0\right)$ [abigere, to drive away]. An abortion, or labor, artificially induced.

Abactus Venter ( $a b$ - $a k^{\prime}$-tus ven'-ter) [abigeré, to drive out; venter, the belly]. An abortion procured by artificial means.

Abadie's Sign. See Signs and Symptoms, Table of.

Abalienated ( $\left.a b-\bar{a} l^{\prime}-y e n-a-t e d\right)$ [abalienatus, alienated, estranged]. 1. Deranged, or insane. 2. Gangrenous, or so severely injured as to require amputation or extirpation.

Abalienation ( $\left.a b-\bar{a} l-y e n-a^{\prime}-\operatorname{sh} u n\right)$ [abalienatio; $a b$, away; alienare, to transfer]. Decay, especially mental decay, insanity.

Abanet. See Abnet.

Abaptista ( $a h$-bap-tis'-tah). Same as Abaptiston.

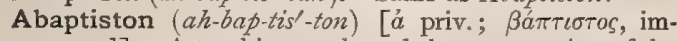
mersed]. A trephine so shaped that penetration of the brain is impossible.

Abarthrosis ( $a b$ - $a r$-thro'-sis) [ab, from; arthrosis, a joint]. Same as Diarthrosis, or Abarticulation.

Abarticular (ab-ar-tik'-u-lar) [ab, from; articulus, joint]. Not connected with or sîtuated near a joint.

Abarticulation ( $a b$ ar-tik-u-la'-shun) [ab, from; articulatio, joint]. I. Same as Diarthrosis, a term more frequently used; sometimes also a synonym of Synarthrosis. 2. A luxation; the dislocation of a joint.

Abasia ( $\left.a h-b \vec{a}^{\prime}-z e-a h\right)$ [á priv.; $\beta a ́ \sigma \iota$, a step]. Motor incoördination in walking. See Astasia.

Abasic $\left(a h-b \bar{a}^{\prime}-s i k\right)$. Pertaining to, or affected with, abasia.

Abatement ( $\left.a-b \bar{a} t^{\prime}-m e n t\right)$ [ $a b$, from; batuere, to strike]. Mitigation or decrease in severity of pain, or of any untoward symptom or condition.
Abattoir (ah-bat-war') [Fr.]. A slaughter-house or establishment for the killing and dressing of animals.

Abaxial $\left(a b-a k^{\prime}-s e-a l\right)$ [ab, from; $a x i s$, an axle]. Not situated in the line of the axis. In botany, indicating that the embryo is not in the axis of the seed.

Abbé Condenser. See Illuminator, Abbé. A. Illuminator. See Illuminator.

Abbé's Apochromatic Lenses. See Apochromatic Lens, A. Catgut Rings, rings composed of eight or ten turns of heavy catgut in the shape of an oval, with inside diameter of two inches, for use in intestinal anastomosis.

Abbreviate, or Abbreviated (ab-bre'-ve-a-ted) [ab, from; breviare, to shorten]. Shortened, cut short.

Abbreviations (ab-bre-ve-a'-shunz). See List of Abbreviations in introductory matter.

Abdomen $\left(a b-d o^{\prime}-m e n\right.$ or $\left.a b^{\prime}-d o-m e n\right)$ [abdere, to hide]. The large inferior cavity of the trunk, extending from the pelvic cavity to the diaphragm, and bounded in front and at the sides by the lower ribs and abdominal muscles, and behind by the vertebral column, the psoas and quadratus lumborum muscles. It is artificially divided into nine regions by two circular lines, the upper parallel with the cartilages of the ninth ribs, the lower with the iliac crests, and by two lines from the cartilages of the eighth rib to the center of Poupart's ligament. The regions thus formed are, above, the right hypochondriac, the epigastric, and the left hypochondriac; secondly, the right lumbar, umbilical, and left lumbar; and below, the right inguinal, the hypogastric and the left inguinal. A., Pendulous, a relaxed condition of the abdominal walls in which they hang down over the pubis.

Abdominal ( $\left.a b \cdot d o m^{\prime}-i n-a l\right)$ [abdere, to hide]. Pertaining to or connected with the abdomen. A. Aneurysm. See Aneurysm. A. Aorta. See Artery. A. Aponeurosis. See Aponeurosis. A. Brain, the solar plexus. A. Compress, a form of local pack, made by forming folds of a coarse linen towel of sufficient breadth to reach from the ensiform cartilage to the pubis; one of the folds is then wrung out of cold water, applied, and the remainder is rolled around the body so as to retain it in position. A. Ganglia. See Ganglia. A. Gestation, See Pregnancy, Extrauterine. A. Hysteria, an hysterical condition simulating peritonitis, in which the abdomen becomes extremely painful to the touch, swollen, and distended with gas, attended with temporary rise of temperature. A. Line, the linea alba. A. Muscles, the internal and external obliques, the transversalis, rectus, pyramidalis, and quadratus lumborum. See Muscles, Table of. A. Pore, a name applied to the openings connecting the peritoneal 
cavity of a few fishes with the urino-genital cloaca, and employed in the outward transportation of the generative products. A. Press. See Prelum Abdo-

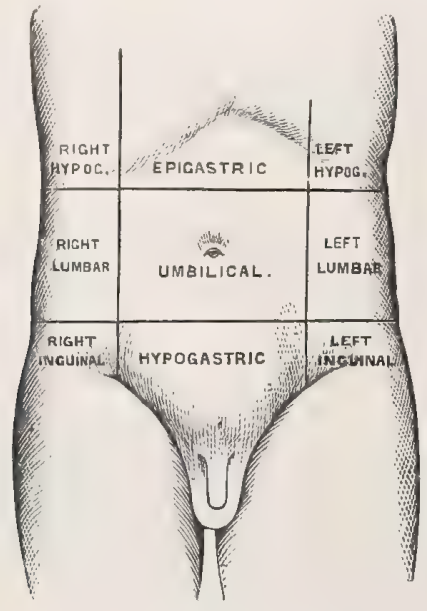

Abdominal Regions,

minale. A. Reflex. See Reflexes, Table of. A. Regions. See Abdomen. A. Respiration, R. carried en chiefly by the diaphragm and abdominal muscles. A. Ribs, transverse ossifications (dermal?) of the abdominal wall of crocodiles and certain other reptiles. A. Ring, External, a triangular opening in the fibers of the aponeurosis of the external oblique muscle transmitting the spermatic cord of the male and the round ligament of the female. A. Ring, Internal, an oval aperture in the fascia transversalis that transmits the spermatic cord of the male and the round ligament of the female. A. Scutella, the broad, belly scales of serpents, so far as the anus. A. Section. See Celiotomy. A. Segments, the more or less evident transverse divisions or somites of the abdomen in arthropods. A. Typhus, Enteric Fever. A. Vertebræ, those vertebræ in fishes, that give off ribs or processes arching the visceral cavity.

Abdomino-anterior ( $\left.a b-d o m^{\prime}-i n-a-a n-t e^{\prime}-r e-o r\right)$. Having the belly forward (used of the fetus in utero).

Abdomino-genital ( $a b$-dom'-in-o-jen'-it-al). Relating to the abdomen and the genitalia. A. Nerve, Inferior, the ilio-inguinal nerve. A. Nerve, Superior, the iliohypogastric nerve.

Abdomino - hysterectomy (ab-dom'-in-o-his-ler-ek'to-me). Removal of the uterus through an abdominal incision.

Abdomino - hysterotomy (ab-dom'-in-o-his-ter-ot'-o$m e$ ). Hysterotomy through an abdominal incision.

Abdomino-posterior ( $a b$-dom'-in-o-poss-te'-re-or). Having the belly toward the mother's back (used of the fetus in utero).

Abdomino-scrotal ( $a b$-dom'-in-o-skro'-tal). Relating to the abdomen and the scrotum. A. Muscle, the cremaster muscle.

Abdomino-thoracic (ab-dom'-in-o-tho-ras'-ik). Relating to the abdomen and thorax.

Abdomino-uterotomy (ab-dom $\left.m^{\prime}-i n-a-u-t e r-o t^{\prime}-o \cdot m e\right)$. See Abdomino-hysterotomy.

Abdomino-vesical ( $\left.a b-d o m^{\prime}-i n-a-v e s^{\prime}-i k-a l\right)$. Relating to the abdomen and the urinary bladder. A. Pouch, a fold of the peritoneum in which are comprised the urachal fossæ.

Abdominoscopy $\left(a b-d o m-i n-a s^{\prime}-k o-p e\right)$ [abdomen; $\sigma \kappa o \pi \varepsilon i v$, to examine]. Examination of the abdomen for diagnostic purposes, by inspection, palpation, measurement, percussion, etc.

Abdominous ( $a b$-dom'-in-us) [abdere, to hide]. Having a large abdomen.

Abduce $(a b$-dús') [ab, away ; ducere, to lead]. To draw away, as by an abductor muscle.

Abducens $\left(a b-d u^{\prime}-\operatorname{sen} z\right)$ [L., "leading away"]. A term applied to certain muscles, or their nerves, that draw the related part from the median line of the body. Also, the sixth pair of nerves supplying the external recti of the eye. A. oculi. See Muscles, Table of.

Abducent $\left(a b-d u^{\prime}\right.$-sent). See Abducens.

Abduct $(a b$-dukt $)$ [ab, from; ducere, to draw]. To draw, or cause to move, away from the median line, whether of the body or of a limb.

Abduction ( $\left.a b-d u k^{\prime}-\operatorname{shun}\right)$ [ $a b$, from; ducere, to lead]. I. The withdrawal of a part from the axis of the body, or of a limb, 2. The recession or separation from each other of the parts of a fractured bone. 3. A. of the Eyes, the power of the external recti, measured by the maximum ability to preserve singleness of the image with prisms placed bases toward the nose. It is commonly from $6^{\circ}$ to $8^{\circ}$. See, also Adduction.

Abductor (ab-duk'-tor). Same as Abducens, q.v. A. Auris. See Muscles, Table of.

Abelmoschus (a-bel-mos'-kus) [Ar., 'habb-el-misk, a grain of musk]. A genus of malvaceous plants. $A$. esculentus furnishes the esculent known as gumbo, or okra. A. moschatus affords Ambrette, $q . v$, or muskseed, formerly used in medicine. Unof.

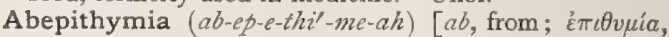
longing]. I. A perverted longing, or desire. 2. $\mathrm{Pa}$ ralysis of the solar plexus (the diaphragm formerly was regarded as the seat of the soul [tivess], and of the desires).

Abernethy's Operation. See Operations, Table of. A. Sarcoma, a form of spindle-celled vascular sarcoma.

Aberrant $(a b$-er'-ant) [ab, from; errare, to wander]. Deviating from the normal or regular type, in appearance, structure, course, etc., e.g., the aberrant duct of the testis or liver, aberrant arteries, etc.

A berration ( $\left.a b-e r-\alpha^{\prime}-\operatorname{sh} u n\right)$ [ $a b$, from; errare, to wander]. Deviation from the normal; mental derangement; fetal malformation; vicarious menstruation; escape of the fluids of the body by any unnatural channel. In optics, any imperfection of focalization or refraction of a lens. A., Chromatic, the dispersion arising from unequal refraction of light of different parts of the spectrum. The violet rays being more refrangible than the red rays, are brought to a focus nearer the lens, and the image is surrounded by a halo of colors. A., Mental, a degree of paranoia that may or may not amount to insanity. A., Spherical, the excess of refraction of the peripheral part of a convex lens over the central area, producing an imperfect focus and a blurred image.

Abesamum (ab-es'-am-um) [L.]. Wheel-grease; fat charged with iron; formerly used as a remedy.

Abevacuation $\left(a b-e-v a k-u-a^{\prime}-\operatorname{sh} u n\right)[a b$, from; evacuation ]. I. A morbid evacuation; an excessive or deficient discharge. 2. The passage of matter from one organ or cavity into another; metastasis.

Abeyance $\left(a b-a^{\prime}\right.$-ans) [O. Fr., for "open-mouthed expectation"]. A suspension of activity, or of function; a state of suspended animation, or action.

Abi $\left(a h^{\prime}-b e\right)$. See Lucuma.

Abiaba (ah-be $\left.a h^{\prime}-b a h\right)$. See Lucuma.

Abicum $\left(a b^{\prime}-i k-u m\right)$ [L.]. The thyroid cartilage. (Obs., or rare.)

Abies $\left(a^{\prime}-b e-\bar{c} z\right)[\mathrm{L}$.$] . A genus of coniferous plants, includ-$ ing the fir, hemlock, and spruce A. balsamea, Silver Fir, Balsam Fir, or Balm of Gilead, a tree of the nat. 
ord. Conifera, from which is derived the Terebinthina Canadensis. A. canadensis, Hemlock Spruce. Bark of the Canadian Fir-tree. Used as an astringent in various local and internal conditions. Yields Pix Canadensis, A. excelsa, Norway Spruce. Yields Pix Burgundica. A. pectinata, the European Silver Fir. Its buds are resinous, balsamic, and sudorific. Unof. A. Preparations, Extractum Abietis Canadensis Liquidum (B. P.). Dose $m \times x v-1 x$. Glycerinum Abietis (B. P.). Dose $\mathbf{3}$ j-ij. Geddes's Fluid-Extract of Hemlock Bark. Dose $\mathrm{m}^{\mathrm{v}-\mathrm{x} \text {. }}$

Abietene $\left(a-b i^{\prime}-e t-e \hat{n} n\right), \mathrm{C}_{7} \mathrm{H}_{16}$. A hydrocarbon, obtained from the Pinus sabiniana, a Californian nut pine. It is an aromatic, volatile liquid, agreeing in composition with normal heptane. It is extensively used as a popular remedy; called, also, Erasene. Unof.

Abietic $\left(a b-i-e t^{\prime}-i k\right)$, Abietinic $\left(a b-i-e t-i n^{\prime}-i k\right)$ [Abies]. Pertaining to the genus $A b i e s$, as Abietic Acid, $\mathrm{C}_{44} \mathrm{H}_{64} \mathrm{O}_{5}$ or $\mathrm{C}_{20} \mathrm{H}_{30} \mathrm{O}_{2}$, discovered by Maly in the resin of Abies excelsa and Larix europea.

Abietin $\left(a-b i^{\prime}-e t-i n\right)$ [Abies]. A resinous principle obtained from the turpentine of various species of pine and fir. A. Anhydrid, $\mathrm{C}_{44} \mathrm{H}_{62} \mathrm{O}_{4}$, the main constituent of Resin, q. v.

Abietis Resina ( $a-b i^{\prime}-e t-i s$ res-i'-nah). The resin of the fir or pine.

Abietite $\left(a b^{\prime}-i-e t-i t\right), \mathrm{C}_{6} \mathrm{H}_{8} \mathrm{O}_{3}$. A sugar resembling mannite, found by Rochleder in the needles of the European Silver Fir, Abies pectinata.

Abiogenesis $\left(a b-i-o-j e n^{\prime}-e s-i s\right)[\dot{a}$ priv,; $\beta \iota b ́ s$, life, and genesis]. The (theoretical) production of living by non-living matter. The older term was Spontaneous Generation. Other synonyms of the word are Generatio aquivoca, Generatio primaria, Archigenesis, Archebiosis, etc. The theory has been supported by Pouchet, Haeckel, Huxley, Bastian, and others. Those opposed to the doctrine are called panspermists or heterogenists. The dispute is one of the most fundamental in biology.

Abiological (ah-bi-o-loj'-ik-al) [áa priv.; $\beta \iota b s$, life; $\lambda 6 \gamma o s$, treatise]. Not pertaining to biology.

Abirritant (ab-ir'-it-ant) [ab, from; irritare, to irritate]. I. Tending to diminish irritation; soothing. 2. Relating to diminished sensitiveness. 3. A remedy or agent that allays irritation.

Abirritation ( $\left.a b-i r-i t-a^{\prime}-s h u n\right)[a b$, from; irritare, to irritate]. Diminished tissue-irritability; atony or asthenia.

Abirritative $(a b$-ir'-it-a-tiv) [ab, from ; irritare, to irritate]. Due to, or characterized by, atony.

Abitus $\left(a b^{\prime}-i t-u s\right)$ [ab, from, away; ire, to go]. In comparative anatomy, any one of the narrow canals leading from a ciliated chamber to the excurrent canal, as in the higher forms of sponges.

Abjoint (ab-joint') [abjungere, to separate]. In biology, to separate by means of a joint or septum.

Abjunction ( $a b$-jung $k^{\prime}$-shun) [see Abjoint]. In biology, the separation by "means of a joint or septum, as of spores from a growing hypha in some fungi.

Ablactation ( $\left.a b-l a k-t a^{\prime}-s h u n\right) \quad[a b$, from; lactare, to give suck]. The end of the suckling period. The weaning of a child.

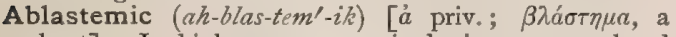
shoot]. In biology, non-germinal; in no way related to germination.

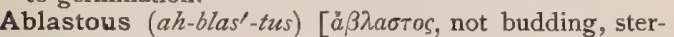
ile]. In biology, producing no germs or buds.

Ablation $\left(a b-l a^{\prime}-\right.$ shun $)$ [ablatio, removal]. Removal of a part of the body, as a tumor, by amputation, excision, etc.

Ablatio retinæ $(a b$-la'-she-o ret-in'-e). Detachment of the retina.

Ablator (ab-la'-tor) [L., "remover"]. A cutting in- strument used in the removal of parts (a name chiefly used in veterinary surgery).

Ablepharia (ah-blef-ar' $e$-ah) [á priv; $\beta \lambda \varepsilon \varphi a \rho o v$, the eyelid]. The condition of the absence of the eyelids.

Ablepharon (ah-blef'-ar-on) [á priv.; $\beta \lambda \varepsilon \phi a p o v$, the eyelid]. Congenital absence of the eyelids.

Ablepharous (ah-blef'-ar-zes) [a priv.; $\beta \lambda \varepsilon \dot{\varepsilon} \phi \rho o v$, the eyelid]. Having no eyelids.

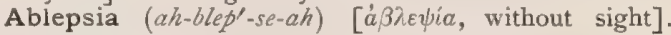
I. Blindness. 2. Dulness of perception.

Ablepsy (ah-blep'-se). See Ablepsia.

Abloom $(a-b l o o m !)$. In biology, the state of being in blossom.

Abluent $\left(a b^{\prime}\right.$-lu-ent $)$ [abluere, to wash away]. Deter gent. That which cleanses or washes away.

Ablution $\left(a b-l u^{\prime}-s h u n\right)$ [abluere, to wash away]. Washing or cleansing the body. Separation of chemical impurities by washing.

Abmortal (ab-mor'-tal) [ab, from; mors, death]. Passing from dead or dying to living muscular fiber (used of electric currents).

Abnerval (ab-ner'-val) [ab, from; nervus, a sinew]. Passing from a nerve (used of electric currents in muscular fiber).

Abnet (ab'-net) [Hebr., a girdle]. A girdle, or girdleshaped bandage.

Abneural $\left(a b-n u^{\prime}-r a l\right)$ [ $a b$, from; veṽpov, nerve]. Pertaining to a part remote from the neural or dorsal aspect; ventral.

Abnormal ( $a b$-nor'-mal) [ab, away from; norma, a law]. Not normal; not conformable. with nature or with the general rule. A. Pigmentation, any excess, deficiency, or uncommon distribution of the natural pig. ment cells in the rete mucosum. Sometimes caused arti. ficially either by mechanical means, such as tattooing, or by the reduction and deposition under the epidermis of metallic salts administered as medicine, such as nitrate of silver.

Abnormalism (ab-nor'-mal-izm) [ab, away from: nor$m a$, a law ]. 1. Abnormality. 2. An abnormal thing or structure.

Abnormality ( $\left.a b-n o r^{\prime}-m a l^{\prime}-i t-e\right)[a b$, away from; norma, a law]. The quality of being abnormal; a deformity or malformation.

Abnormity (ab-norl-mit-e). Same as Abnormality.

Aboiement (ah-bwah-mong') [Fr.]. Barking; the involuntary utterance of barking sounds.

Abolition $\left(a b-0-l i s h^{\prime}-u n\right)$ [abolitio]. Destruction; cessation; suspension, as of a physiological function.

Abomasum $\left(a b-o-m a^{\prime}-s u m\right)$ [ab, away; omasum,paunch]. In biolugy, the reed or proper digestive stomach of ruminating mammals. It is pyriform, lined by smooth mucous membrane, which secretes gastric juice. Also called "fourth," or "true," stomach ; dried, it is called rennet and used for coagulating milk.

Aborad $\left(a b-o^{\prime}-r a d\right)$ [ab, away from; os, mouth]. Away from the mouth; in an aboral situation or direction.

Aboral $\left(a b-o^{\prime}-r a l\right)$ [ab, away from; os, mouth]. Opposite to, or remote from, the mouth.

Aborally $\left(a b-o^{\prime}-r a l-e\right)[a b$, away from; $a s$, mouth]. In an aboral situation, direction, or manner.

Aborigines ( $a b$-or-ij'-in-ez) [ab, from; origo (origin), origin, beginning]. Primitive, autochthonous, native, indigenous.

Abort $(a b$-ort' $)$ [abortare, to miscarry]. I. To miscarry; to expel the fetus before it is viable. 2. To prevent the full development, as of a disease. 3. To come short of full development. 4. An abortion; an aborted fetus.

Aborticide ( $a b$-or'-tis-i $d)$ [abortus, a miscarriage ; cadere, to kill]. I. The killing of the unborn fetus. 
2. The means of killing the fetus. 3. Causing the destruction of a fetus.

Aborticidium (ab-or-lis-ial-e-um) [abortus, a miscarriage; cadere, to kill]. Means of killing a fetus.

Abortient (ab-or'shent) [L. abortiens, miscarrying]. Abortive; abortifacient

Abortifacient (ab-or-te-fa'-shent) [abortus; facere, to make]. I. Causing abortion. 2. A drug or agent inducing the expulsion of the fetus. Ergot, rue, cotton-root, and digitalis, are examples. They act by causing uterine contractions. See Oxytocic and Ecbolic.

Abortion (ab-or'-shun) [abortus, a miscarriage]. The premature expulsion of the ovum before the child is viable, that is, occurring any time before the end of the sixth month. It may be produced by various general diseases, as syphilis, the acute fevers, nephritis, most exhausting diseases; by traumatism, reflex influences, emotional disturbances; by the action of various poisons, as ergot, cantharides, rue, and savin ; by diseased conditions of the uterus and displacements of that organ; or by diseases of the fetus, its membranes, or the placenta. The most important symptoms are hemorrhage and pain, with final expulsion of the uterine contents. In the first two months of pregnancy the ovum is usually expelled entire; later the membranes and placenta are retained after the fetus comes away, and must be removed subsequently. By some authors expulsion of the ovum during the first three months is abortion:" from this time to viability it is termed immature delivery, or miscarriage, and from the period of viability to that of maturity, premature delivery. A., Artificial, that produced intentionally. A., Criminal, when not demanded for therapeutic reasons. A., Embryonic, up to the fourth month. A., External Causes of, those acting from without, as violence, pressure, injections, etc. A., Fetal, taking place subsequent to the fourth month. A., Habitual, repeated A. in successive pregnancies. A., Incomplete, when the membranes or placenta are retained. A., Inevitable, when the embryo or fetus is dead, or when there is an extensive detachment or rupture of the ovum. A., Internal Causes of, those due to abnormal conditions or diseases of the mother. A., Missed, the death of the fetus and not followed within two weeks by its expulsion. A., Ovular, that occurring during the first three weeks after conception. A., Paternal and Maternal Causes of, those due to diseases of the father or of the mother respectively. A., Spontaneous, that not induced by artificial means.

Abortionist ( $a b$-orl-shun-ist) [abortus, a miscarriage]. One who criminally produces abortions; especially one who follows the business of producing abortions.

Abortive (ab-or'-tiv) [abortus, a miscarriage]. Prematurely born; coming to an untimely end; incompletely developed; cutting short the course of a disease; abortifacient. A. Epilepsy. See Epilepsy.

Abortus $(a b$-or'-tus) [L.]. An aborted fetus; the fruit of an abortion.

Aboulia $\left(a h-b o o^{\prime}-l e-a h\right)$. See Abulia.

Aboulomania (ah-boo-lo-ma'-ne-ah). See Abulomania.

$\mathrm{Ab}$ ovo $\left(a b o^{\prime}-v o\right)$ [L.]. In biology, from the egg; from the beginning.

Abrachia ( $\left.a h-b r a^{\prime}-k e-a h\right)$ [á priv.; $\beta \rho \alpha \chi i \omega v$, arm]. The condition of an armless monster. In biology, without anterior limbs

Abrachiocephalia $\left(a h-b r a-k e-0-s e f-a^{\prime}-l e-a h\right)[\dot{a}$ priv.;

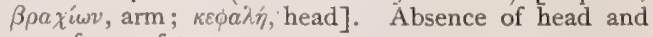
arms from a fetus.

Abrachius $\left(a h-b r a^{\prime}-k e-u s\right)$. A monster without arms. See Abrachia.

Abrade $\left(a-b r a \bar{a} d^{\prime}\right)$ [abradere, to rub off ]. To remove by friction or chafing; to roughen by friction.

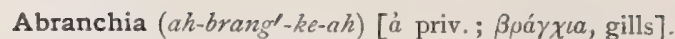
In biology, a name given to several different groups of animals that have no gills.

Abrasio $\left(a b-r a^{\prime}-z e-0\right)$ [L.]. An abrasion. A. corneæ, operative removal of the epithelium of the cornea because of diseased conditions.

Abrasion $\left(a b-r a^{\prime}-z h u n\right)$ [abrasio: $a b$, priv.; radere, to rub]. Excoriation of the cutaneous or mucous surface by mechanical means. In dentistry, the wearing away of the dentine and enamel, or the cutting edges of the teeth, whether by mechanical or chemical means.

Abrasor ( $\left.a b-r a^{\prime}-z o r\right)$ [L. "abrader"]. A surgeon's rasp or xyster; any file or instrument used in the surgical or dental abrasion of a surface; also, a rasp used in pharmacy.

Abric Acid ( $a^{\prime}$-brik as $\left.-i d\right)$. See Acid.

Abrin $\left(a^{\prime}-b r i n\right)$. I. The chemical ferment or poisonous principle of jequirity, erroneously supposed to be due to a specific microbe. See Bacillus of jequirity ophthalmia in Table of Bacteria. 2. A vegetable albuminoid employed in the study of immunity.

Abroma (ah-brol-mah) [á priv.; $\beta \rho \tilde{\omega} \mu o s$, a stink]. A genus of sterculiaceous trees. A. augusta, of S. Asia, affords a milky juice, esteemed in dysmenorrhea. Unof.

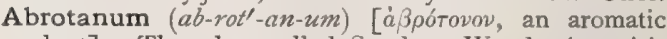
plant]. The plant called Southern Wood, Artemisia abrotanum. See Artemisia.

Abrupt (ab-rupt') [abmuptus, broken off]. In biology, terminating suddenly; truncated.

Abruption (ab-rup'-shun) [abruptio, from $a b$, and rumpere, to break]. I. A rupture or tearing asunder. 2. A transverse fracture.

Abrus $\left(a^{\prime}-b r u s\right)$ [áßpós, pretty]. Jequirity; Indian Licorice. The seeds of $A$. precatorius, or Wild Licorice. Properties are thought to be due to the presence of certain ferments. Non-sterilized infusions applied to the conjunctiva or to any mucous surface induce violent purulent inflammation with growth of false membrane. It is used in producing artificial conjunctivitis. A. Infusum: semina iij, aqua dest. $\bar{\zeta}$ ss. Macerate and add aq. $\overline{3}$ ss. All unofficial. Abri Liquor, strength 12 per cent.; dilute with 3 to 5 times its bulk of water and apply 2 drops daily. Abri Pasta, $I$ in 4 ; used with caution in affections of the skin.

Abscess $\left(a b^{\prime}-s e s\right)$ [abscessus, a departure or separation -of the matter]. A pus-formation within some cavity of the body, the result of localized inflammation. According to location, abscesses are named Dorsal, Iliac, Mammary, Ischio-rectal, Peri-typhlitic, Retro. pharyngeal, Urethral, etc. A., Alveolar, abscess in the gum or alveolus. A., Atheromatous. See Endarteritis, Chronic. A. of Brain, due to local injury, or to suppurative inflammation near or distant, such, especially, as diseases of the ear. The symptoms are those of pressure, impaired function of the part affected, meningitis, headache, optic neuritis, etc. A., Bursal, abscess in the bursæ, the most frequent being in the bursæ patellæ, commonly called Housemaid's Knee. A., Canalicular, mammary abscess that communicates with a milk duct. A., Caseous, one that contains cheesy materials. A., Chronic, or Cold Abscess, one of slow and apparently non-inflammatory development, usually about a bone, joint, or gland. A., Cold. See A., Chronic. A., Congestive, the pus appears at a point distant from where it is formed. A., Constitutional, due to some systemic disorder. A., Critical, occurring at some critical period of an acute disease. A., Embolic, formed in the clot of an embolism. A., Fecal, one developing in the rectum or large intestine. A., Gangrenous, one attended with death of adjacent parts. A., Lacunar, one in the lacunæ of the urethra. A., Metastatic. See Pyemia. A., Miliary. See 
Pyemia. A, Milk, or A., Mammary, one in the female breast. A., Multiple. See Pyemia. A., Ossifluent. See Ossifluent. A., Perforating, one perforating the cornea, the lung, or other containing wall. A., Phlegmonous, an acute A. A., Pointing of, the point where the abscess tends to break through its external confining wall. A., Psoas, one arising from disease of the lumbar, or lower dorsal vertebre, the pus descending in the sheath of the psoas muscle, and usually pointing beneath Poupart's ligament. A., Pyemic. See Pyemia. A., Residual, about the products of some old result of inflammation. A. Root, the root of Polemonium Reptans. Alterative, astringent and expectorant. Dose of fld. ex. 3 ss-ij. Unof. A., Shirt Stud, retro-mammary abscess concurrent with a subintegumentary abscess, the two sacs communicating by means of a sinus. A., Stercoraceous. See Fecal A. A., Symptomatic, one indicative of some other affection. A., Thecal, in the sheaths of tendons. A., Tropical, acute hepatitis terminating in suppuration and abscess formation. A., Tubercular. Same as $A$., Cold.

Abscession $(a b$-sesh'- $u n)$ [abscessio, departure]. I. An abscess ; a critical discharge. 2. Metastasis.

Abscissæ $\left(a b-s i s^{\prime}-s e\right)$ [ab, away; scindere, to cut]. The transverse lines cutting vertical ones at right angles, to show by a diagram the relations of two series of facts, as, $e . g$. , the number of pulse-beats, or the temperature record in given periods of time.

Abscission $\left(a b-s i s h^{\prime}-2 m\right)$ [ $a b$, from; scindere, to cut]. Removal of a part, as the prepuce, or a fractured bone, by cutting. Applied particularly to a surgical operation upon a staphylomatous. cornea, in which the bulging portion is excised, the parts brought together so that the posterior and chief part of the globe forms a "stump" for an artificial eye. In biology, a term applied to that mode of detachment of spores in fungi which consists in the disorganization of the zone connecting the spores with the hypha.

Absconsio (ab-skon'-se-o) [abscondere, to hide]. A sinus or cavity whether normal or pathological.

Absence (of mind) (ab'-sens) [absentia, absence]. Inattention to surroundings; in marked instances it may be a result of central lesions. It is often seen in epileptics and melancholiacs.

Absentia epileptica ( $a b-s e n^{\prime}-s h e-a h$ ep-il-ep'-tik-ah). Brief losses of consciousness occurring in the mild form of epilepsy.

Absinthe $\left(a b^{\prime}-\operatorname{sinth}\right.$ or $\left.a b-\operatorname{sant}\right)$. See Absinthium.

Absinthin (ab-sin'-thin) [absinthium]. A bitter and crystalline principle obtainable from wormwood. See Absinthium.

Absinthism (ab-sinth'-izm). A disease similar to alcoholism, the result of the excessive use of absinthe. It is characterized by general muscular debility and mental disturbances, which may proceed to convulsions, acute mania, general softening of the brain, or general paralysis.

Absinthium (ab-sinth'-e-um) [L.]. Wormwood. The leaves and tops of Artemisia absinthium. Contains a volatile oil and an intensely bitter principle, Absinthin, $\mathrm{C}_{20} \mathrm{H}_{28} \mathrm{O}_{4}$, which is a narcotic poison. A. increases cardiac action, produces tremor and epileptiform convulsions. Dose gr. $\mathrm{xx}-\mathrm{xl}$, in infusion. Used as a stomachic tonic. Absinthe, a French liquor, is an alcoholic solution of the oil exhibited with oils of anise, marjoram, and other aromatic oils.

Absinthol $\left(a b\right.$-sinth'-ol), $\mathrm{C}_{10} \mathrm{H}_{16} \mathrm{O}$. The principal constituent of oil of wormwood; it is isomeric with ordinary camphor.

Absolute Alcohol ( $a b^{\prime}$-so-lüt $\left.a l^{\prime}-k o-h o l\right)$. See Alcohol. Absorb ( $a b$-sor $\left.b^{\prime}\right)$ [ $a b$, from; sorbere, to suck up]. In physiology, to suck up or imbibe, as the imbibition performed by the lacteals in the body.

Absorbent ( $a b$-sor'-bent) [absorbere, to suck in]. In physiology, an organ or part that absorbs, withdraws, or takes up. A term applied to the Lacteals and Lymphatics, q. v. In materia medica, a drug or medicine that produces absorption or exudation of diseased tissue. In surgery, a substance that mechanically takes up excreted matter, as $A$. Cotton, A. Sponge, etc. A. Glands. See Lymphatics. A. System, the lacteals and lymphatics, with their associated glands.

Absorptiometer (ab-sorp-te-om'-et-er) [absorption; meter]. A device for measuring the thickness of the layer of liquid that is taken up between two glass plates by capillary attraction. Used in conjunction with a spectro-photometer, it serves as a hematoscope.

Absorption (ab-sorp'-shun) [absorbere, to suck in]. The permeation or imbibition of one body by another. The process whereby nourishment, medicines, morbid products of tissue metamorphosis, etc., are taken up by the lymphatic and venous systems. In ophthalmology the process by which the lens is disintegrated and carried off after the capsule has been ruptured. A. Lines or Bands, the lines of the spectrum, called Fraunhofer's lines; they are dark lines caused by the arrestation or absorption of the ethereal waves of certain lengths and rapidities, mainly by vapors of the sun's atmosphere. A. of Composition, or External Absorption, the taking up of material by the skin or mucous surfaces. A., Cutaneous, absorption by the skin. A., Disjunctive, the removal of living tissue around a necrosed mass, and its consequent separation from its surroundings. A., Interstitial, the removal by the absorbent system of effete matters. A. Method, to determine whether or not hematuria is due to lesion of the bladder. It is based on the fact that the undenuded. surface of the bladder will not absorb foreign substances. Fifteen grains of potassium iodid are injected into the bladder, and fifteen minutes later the saliva is examined for iodin. If found, it is an indication of an unhealthy state of the bladder. A., Progressive, atrophy of a part due to pressure. A., Pulmonary, the taking up of oxygen, or of vapors (as of ether), by the lungs. A., Venous, absorption by the veins.

Absorptive (ab-sorf'-tiv) [absorbere, to suck in]. Having the power or function of absorbing.

Absorptivity (ab-sorp-tiv'-i-te) [absorbere, to suck in]. The power or quality of being absorbent.

Abstemiouşness (ab-ste'-me-us-nes) [abs, from; temetum, wine]. Abstinence from wine. Temperance or moderation in matters of diet.

Abstention (ab-sten'-shun) [abstentio, retention]. An act of abstinence, or of abstaining ; retention; constipation.

Abstergent (ab-ster'-jent) [abs, from; tergere, to cleanse]. Cleansing, detergent. See Detergent.

Abstersive $\left(a b\right.$-ster'-si $\left.{ }^{\prime}\right)$ [abstersivus]. Abstergent.

Abstinence $\left(a b^{\prime}\right.$-stin-ens) [abs, from; tenere, to hold or keep]. Privation or self-denial in regard to food, .liquors, etc. See Fasting.

Abstract $\left(a b^{\prime}\right.$-strakt) [abstrahere, to draw away; $A b$ stractum; gen., Abstracti: pl., Abstracta]. In pharmacy, a solid preparation in which two parts of the drug are represented by one part of the abstract (which is compounded with milk-sugar). Abstracts are double the strength of fluid extracts. They are permanent, but should be kept in a cool place.

Abstraction (ab-strak'-shun) [abstractio, a drawing away]. Blood-letting. Also, attention to one idea to the exclusion of others. Generalization or classi- 
fication of the qualities common to the individuals of a group. In pharmacy, the process of distillation.

Abstractitious (ab-strak-tish'-us) [abstrahere, to draw away]. Susceptible of being abstracted without change from another substance; derived or derivable by abstraction.

Abstractum (ab-strak'-tum) [pl., Abstracta]. An abstract. See Abstract.

Abstriction ( $a b$-strik'-shun) [ab, from; stringere, to bind]. Spore-formation in lower cryptogams characterized by decided constriction of the walls at the place of division.

Absus $\left(a b^{\prime}\right.$-sus $)$ [L.]. The plant Cassia absus of India and Egypt. Its seeds are locally employed in the treatment of ophthalmia, and are regarded as depurative. Unof

Abterminal ( $a b$-terl-min-al) [ $a b$, from; terminus, end]. Passing from tendinous into muscular tissue (used of electric currents)

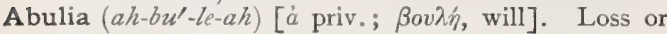
defect of will power

Abulic $\left(a h-b u^{\prime}-l i k\right)$. Characterized by or affected with abulia; of defective will-power.

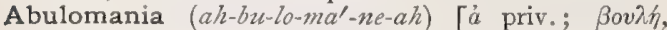
will; $\mu a v i a$, madness]. A disease of the mind characterized by imperfect or lost will-power.

Abumbrella (ab-um-brel'-ah) [ab, from; umbrella, the disc of acalephs]. In biology, a term applied to the surface of the velum, it being turned away from the disc, in medusæ. Opposite of Adumbrella.

Abuta $\left(a h-b 0 o^{\prime}-t a h\right)[\mathrm{L}$.$] . A genus of menispermaceous$ plants. A. amara, affords false pareira brava, and $A$. rufescens is the so-called white pareira brava. Both are S. American. Unof.

Abutilon (a-bu'-til-on) [L.]. A genus of malvaceous plants. A. avicenne, common in the U. S. (velvetleaf Indian mallow); is demulcent, and is a safe remedy for diarrhea. Unof.

Abvacuation $\left(a b-v a k-u-a^{\prime}-s h u n\right)$. Same as Abevacuation, $q . v$.

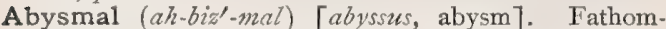
less. Pertaining to great depths in the ocean. See Abyssal.

Abyssal $\left(a / h-b i s^{\prime}-a l\right)[\ddot{a} \beta v \sigma \sigma o s$, without bottom]. In biology, refers to plants and animals inhabiting the depths of the ocean between IOO and IOOO fathoms. A. Theory of Light, an hypothesis assuming the importance of phosphorescence and of luminous organs in fishes and other animals in depths of the ocean where no sunlight penetrates.

Acacia $\left(a h-k a^{\prime}-s h e-a h\right)$ [L.; Gr., ákakía]. I. A large genus of leguminous trees, shrubs, and herbs, many of them Australian or African. Many of the species are medicinal, and some are poisonous. The bark is usually very astringent. Gum arabic is produced by various species, mostly either African or Asiatic. 2. A. anthelmintica. See Mussanin. A. catechu. See Catechr. A. lebbek, $A$. nilotica, $A$. vera, and $A$. verek, are among the species that furnish gum arabic, 3. Gum Arabic. A nearly white transparent gum exuding from Acacia Senegal. Soluble in water. Used in the manufacture of mucilage. Contains Arabin, $\mathrm{C}_{12} \mathrm{H}_{22} \mathrm{O}_{11}$, identical in composition with canesugar. A., Mucilage, acacia 34, water I00 parts; incompatible with alcoholic tinctures. A., Syrup, mucilage 25 , syrup. simp. 75 . Used in various mixtures as a demulcent and to suspend insoluble powders.

Acajou $\left(a k-a-z / h o 0^{\prime}\right)$. See Casherw.

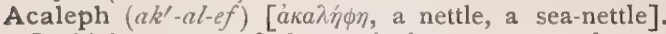
In biology, one of the acalephæ, or sea-nettles; a medusa, a sea-blubber.

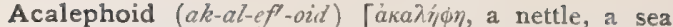
nettle]. Resembling an acaleph.

Acalycal (ah-kal'-ik-al) [ả priv,; $\kappa a ́ \lambda v \xi$, calyx]. In biology, used to describe stamens inserted upon the receptacle, not adherent to the calyx.

Acalycine $\left(a h-k a l^{\prime}-i s-i n\right)$ [á priv. ; $\kappa a ́ \lambda v \xi \xi$, calyx]. In biology, lacking a calyx, acalycinous.

Acalyculate (ah-kal-ik'-u-lat) [a priv, ; calyculus, a calycle]. In biology, having no calycle, or accessory calyx.

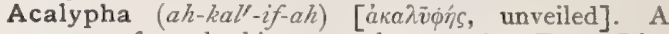
genus of euphorbiaceous plants. A., Ext., Liq. Dose $m \mathrm{x}-3 \mathrm{j}$. A. fruticosa, of India, is useful in dyspepsia and diarrhea, and is tonic and alterant. $A$. hispida has similar uses. $A$. indica, a euphorbiaceous plant, common in India. The leaves are expectorant, emetic, laxative. A. Succus. Dose for an infant $3 \mathrm{j}$. Unof. $A$. virginica, of North America, is diuretic and expectorant.

Acamathesia $\left(a k-a m-a t h-e^{\prime}-z e-a h\right)[a \kappa a \mu a ́ \theta \eta \sigma \iota \varsigma]$. Same as Akatamathesia.

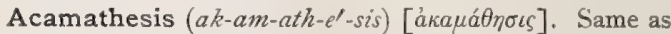
Akatamathesia.

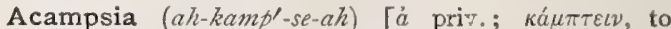
bend]. Inflexibility of a limb.

Acanaceous (ak-an-a'-se-us) [ăkavos, a prickly shrub]. In biology, beset with prickles, as the edges of some leaves.

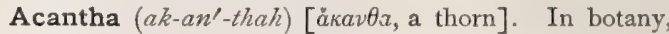
a thorn or prickle; in zoölogy, a spine or fin ray; in anatomy, a vertebral process.

Acanthrsthesia (ak-anth-es-the'-ze-ah). See Akanthesthesia.

Acanthia lectularia (ak-an'-the-ah lek-chu-lat'-re-ah) [L.]. The common bedbug:

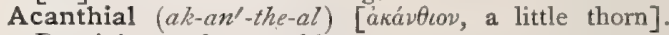
Pertaining to the acanthion.

Acanthichthyosis (ak-anth-ik-the-o'-sis) [ákávflov, a little thorn; ix $\theta$ vs. a fish]. Ichthyosis spinosa, q. v.

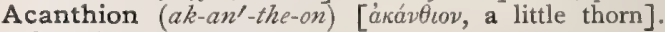
See Cranionetrical Points.

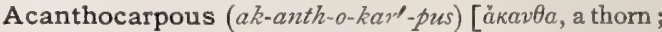
$\kappa \alpha \rho \pi \delta s$, fruit]. In biology, spiny-fruited.

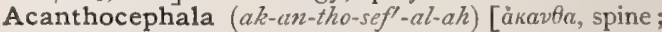
$\kappa \varepsilon \phi a \lambda n^{\prime}$ head]. An order of parasitic worms, characterized by a thorny armature of the head and proboscis. They are generally grouped in one genus, Echinor rhynchys. They infest pigs, birds, and fishes, and in their larval stage live in crustaceans.

Acanthocephalous (ak-anth-o-sef'-al-us) [åkavta, a spine; $\kappa \varepsilon \phi \alpha \lambda \eta$, head]. In biology, spiny-headed.

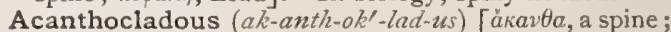
$\kappa \lambda a ́ \delta o \varsigma$, a branch]. In biology, possessing spiny branches.

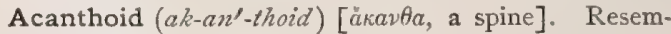
bling a spine, or spicula; spinous.

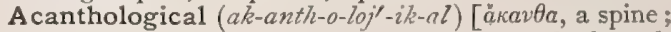
$\lambda{ }^{\prime} \gamma \varepsilon \imath v$, to speak]. In biology, pertaining to the knowledge of spines.

Acantholysis (ak-an-thol'-is-is) [ǎkavfa, prickle; $\lambda \dot{v} \sigma \iota s$, a loosening, a wasting]. Any skin disease in which there is an atrophy of the prickle-layer. A. Bullosa. See Epidermolysis.

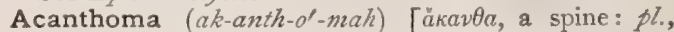
Acantho'mata]. A localized excessive growth in any part of the prickle-cell layer of the skin.

Acanthomastic (ak-anth-o-mas'-tik) [àkavfa, a spine;

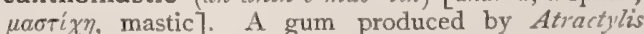
summifera, a plant of the Mediterranean region; valued in the Oriental countries. Unof.

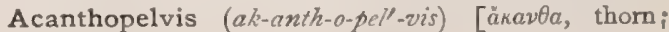
$\pi \varepsilon \lambda_{v \varsigma}$, pelvis]. Same as Acanthopelys. 


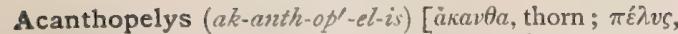
pelvis]. A pelvis that is encroached upon by exostoses. Acanthophorous $\left(a k-a n t h-o f^{\prime}-o r-u s\right)$ [ákavfla, a spine; $\phi \varepsilon \varepsilon_{\ell} \downarrow$, to bear]. In biology, bearing or producing spines or thorns.

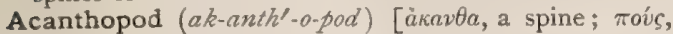
foot]. In biology, an animal with spiny feet, or spine-like claws.

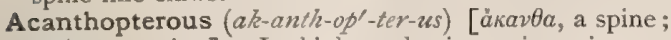
$\pi \tau \varepsilon \rho \rho \nu$, a wing]. In biology, having spiny wings or fins.

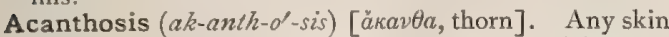
disease marked by abnormalities in the prickle-cell layer. A. Nigricans, a general, pigmentation of the skin, with papillary, mole-like growths; a rare condition.

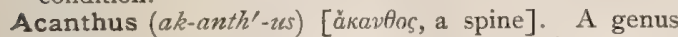
of European herbs. A. mollis and $A$. spinosa were formerly much esteemed as vulnerary, antidysenteric and antihectic remedies; they are demulcent and mucilaginous. Unof.

Acapsular (ah-kap'-su-lar) [ả priv. ; capsula, a small box or capsule]. In biology, destitute of a capsule.

Acardia ( $\left.a h-k a r^{\prime}-d e-a h\right)$ [á priv.; kapdia, heart]. A monstrosity without heart, developed simultaneously with a normal fetus.

Acardiac $\left(a / h-k a \gamma^{\prime}-d e-a k\right)$ [á priv. ; kapdia, heart]. I . Having no heart. 2. A fetus with no heart. See Acardiacus.

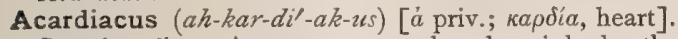
See Acardiac. A synonym, employed mainly by the German writers, for omphalosite. The term was adopted because of the frequent absence of the heart in this condition. A. Acormus. See Asomata. A. Anceps. Same as Paracephalus, $q . v$.

Acardiohemia, or Acardiohæmia (ah-kar-de-o-he'-

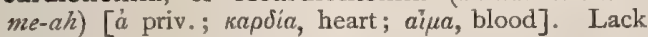
of blood in the heart.

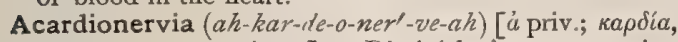
heart; nervus, a sinew]. Diminished nervous action or nerve-stimulus in the heart.

Acardiotrophia (ah-kar-de-o-tro'-fe-ah) [ả priv.; kapdia, heart; $\tau \rho \circ \varphi$, nutrition]. Atrophy of the heart.

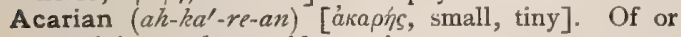
pertaining to the acarids or mites.

Acariasis $\left(a k-a r-i^{\prime}-a s-i s\right)$ [a priv.; $\kappa \varepsilon i \rho \varepsilon v$, to cut]. See Mange.

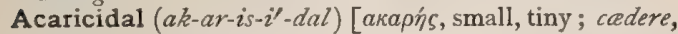
to kill]. Destructive of acarids, or mites.

Acaricide $\left(a k-a r^{\prime}-i s-i d\right)$ [ákróns, small, tiny; cadere, to kill]. An agent that destroys acarids.

Acarid, Acaridan ( $a k^{\prime}-a r-i d, a k$-ar'-id-an) [ákaṕns, small, tiny]. Pertaining to Acarus.

Acarina (ak-ar-i'-nah) [L.]. An order of insects (mites) with stout bodies, having the unjointed abdomen consolidated with the head and thorax, with biting, sucking, or puncturing mouth-organs, breathing mostly by means of tracheæ.

Acarinosis (ak-ar-in-o'-sis) [acarus, a mite]. Any disease, as the itch, produced by a mite, or acarid.

Acarodermatitis (ak-ar-o-der-mat-i'-tis) [acarus, a mite; dermatitis]. Dermatitis dependent upon or caused by acari, or mites.

Acaroid (ak'-ar-oid) [Acarus, a mite]. Mite-like. A. Gum, Botany Bay Gum; Resina lutea. An aromatic resin used in Australia as a remedy for gastric troubles, intestinal catarrhs, diarrheas, etc. Dose grs. viij-xvj, in alcoholic solution. Unof. A. Resin, Black Boy Gum. The resin of various species of Xanthorrhea, q. v. Benzoic acid is prepared from it, and it is said to have the properties of storax, and balsam of Peru.

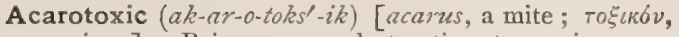
a poison]. Poisonous, or destructive, to acari.

Acarpæ $\left(a-k a r^{\prime}-p \bar{e}\right)$ [ả priv.; $\kappa a \rho \pi o ́ s$, fruit]. A name proposed for a group of skin diseases in which there are no papules, tubercles, or elevated points.

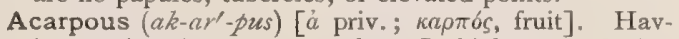
ing no elevations; not nodular. In biology, producing no fruit; sterile, barren.

Acarus $\left(a k^{\prime}-a \gamma-u s\right)$ [ $\dot{a}$ priv. ; $\kappa \varepsilon i p \varepsilon \imath \nu$, to cut (because so small) : pl., Acari]. The mite, or tick, a parasite of man and animals. A. autumnalis the harvest-bug, now called Leptus autumnalis. A. folliculorum. See Steatozoön. A. scabiei. See Scabies.

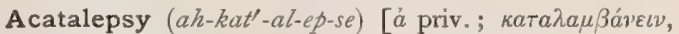
to understand]. I. Uncertainty in diagnosis. 2. Mental impairment; dementia.

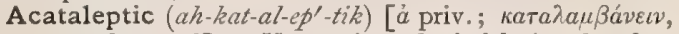
to understand]. Uncertain; doubtful (used of a prognosis or a diagnosis of a disease).

Acatamathesia $\left(a h\right.$-kat-am-ath-e'-ze-ah) $\left[{ }^{\prime}\right.$ priv.;

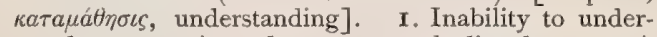
stand conversation, due to mental disorder. 2. A morbid blunting of the perceptions; as in psychical deafness, or psychical blindness.

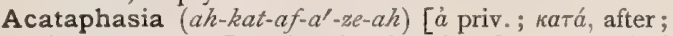
páols, utterance]. A disorder in the syntactical arrangement of uttered speech, due to some central lesion.

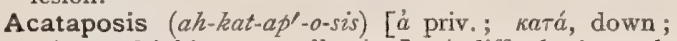
$\pi o ́ \sigma \iota s$, a drinking, a swallowing]. A difficulty in swallowing ; dysphagia.

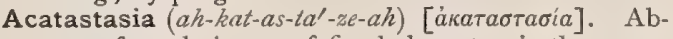
sence of regularity, or of fixed character, in the course of a disease, or in the nature of an excretion.

Acatastatic $\left(a h-k a t-a s_{-}-t^{\prime}-i k\right)$. Marked or characterized by acatastasia; irregular; not of definite type.

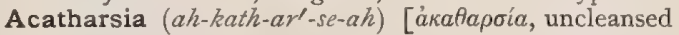
state]. Impurity; foulness; need of purgation, or cleansing.

Acaudal (ah-kaw'-dal) [á priv.; cauda, a tail]. Acaudate, ecaudate, tailless, anurous.

Acaudate (ah-kaw'-dāt). Same as Acaudal.

Acaules (ah-kazv'-léz) [ả priv.; caulis, a stem]. Plants which, as in the case of lichens, algæ, etc., lack a stalk, or have it but very indistinctly developed.

Acaulescence (ah-kazv-les'-ens) [à priv.; caulis, a stalk]. In biology, plants wherein the growth of the main stem is arrested. Also Acaulosia.

Acaulescent (ah-kaw-les'-ent) $\left[{ }^{\prime} a\right.$ priv.; caulis, a stalk]. In botany, stemless.

Acaulosia (ah-kazv-lo'-se-ah) [á priv.; cautis, a stalk]. See Acaulescence.

Accelerans Nerve (ak-sel'-er-ans) [L.]. A nerve from the accelerans center in the medulla to the heart, intermediating acceleration of its rhythm.

Acceleration (ak-sel-er-a'-shun) [acceleratio]. Quickening, as of the pulse, or of the respiratory function. In biology, the term applied to change of structure during growth brought about by the addition of parts, either by " homotopy" or by " heterotopy."

Accelerative Epilepsy (ak-sel'-er-a-tiv ep'-il-ep-se). See Epilepsy.

Accelerator Urinæ $(a k$-sel'-er-a-tor $u$-ri'-nē $)$ [L.]. A muscle of the penis whose function is to expel the last drops in urination, to expel the semen, and to assist erection. The sphincter vaginæ is its analogue in the female. See Muscles, Table of.

Accentuation (ak-sen-tu- $a^{\prime}-\operatorname{shun)}$ [accentuare]. A term applied to the heart sounds, generally the second, when they are louder, because of an increased bloodtension in the vessels, giving rise to a forcible elastic recoil of the latter with abrupt closure of the valves. 
Access $\left(a k^{\prime}-s e s\right)$ [accessus, an approach]. I. An attack of a disease. 2. The return of a fit, or paroxysm. 3. Cohabitation.

Accessiflexor (ak-ses-e-fleks'-or) [accessus and flexor]. An accessory flexor muscle.

Accession (ak-sesh'-un) [accessio; ad, to ; cedere, to go]. The assault, beginning, or onset of a disease, or of a stage of the same; applied especially to a recurrence of periodical disease.

Accessive $\left(a k-s e s^{\prime}-i v\right)$ [accessio]. Marked or characterized by sharp and sudden accessions or paroxysms.

Accessorium (ak-ses-so'-re-um) [L.]. An accessory part ; an adjunct, or appendage.

Accessory (ak'-ses-o-re, or ak-ses'-o-re) [accessorius]. A term applied to certain glands, muscles, ducts, nerves, arteries, etc., that are often inconstant, but always auxiliary in function, course, etc., to the principal. Certain small muscles, as the lumbricales, are regarded as accessory to more important muscles. In biology, something additional; as an accessory bud, fruit, or plume. A. Buds, in botany, buds that are developed by the side of, or above, the normal axillary bud. A. Fruits, in botany, those fruits a considerable portion of whose substance is distinct from the seedvessel and formed of the accrescent and succulent calyx, or torus, or receptacle, bracts, etc. A. Gland of Rosenmüller. See Gland. A. Gland of the Pancreas, Brunner's Glands, q. v. A. of the Parotid, the Socia Parotidis, q. $v$. A. Valves, in zoölogy, small additional valves which occur in certain forms, as the accessory valves placed near the umbones of the genus Pholas among the Mollusca.

Accident (ak'-se-dent) [accedere, to occur]. I. In legal medicine, an event occurring to an individual without his expectation, and without the possibility of his preventing it at the moment. of its occurrence. 2. An intercurrent or complicating symptom or event, not to be looked for in the regular progression of an attack of disease.

Accidental (ak-se-dent'-al) [acridentalis]. 1. Due to, or caused by, an accident. 2. Intercurrent; having no essential connection with other conditions or symptoms. A. Hemorrhage. See Hemorrhage.

Accidentalism (ak-se-dent'-al-ism) [accidentalis]. That theory of medicine that ignores pathology and etiology, and attends only to the symptoms or accidental features of disease.

Accidentalist (ak-se-dent'-ai-ist) [accidentalis]. One who advocates or follows accidentalism.

Accipiter (ak-siph-it-er) [L., a "hawk"]. A facial bandage with tails radiating like the claws of a hawk.

Acclimate (ak-kli'-māt) [ad, to; clima, a climate]. To accustom to a new or untried climate.

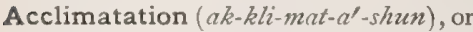

Acclimation (ak-lim-a'-shun). See Acclimatization.

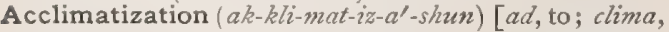
climate]. The process of becoming accustomed to the climate, soil, water, etc., of a country to which a plant, animal, person, or a people has removed.

Acclimatize (ak-kli'-mat-iz) [ad, to; clima, climate]. See Acclimate.

Acclivis (ak-kli'-vis) [L., "sloping"']. The Obliquus internus muscle of the abdomen.

Accommodation (ak-om-o-d $\left.a^{\prime}-s h u n\right)$ [accommodare, to adjust]. Adaptation or adjustment. Adaptation of the fetus to the uterus and birth-canal. A., Absolute, the accommodation of either eye separately. A., Anomalies of, departures from the normal in the action of the mechanism of accommodation. A., Histological, the occurrence of changes in the morphology and function of cells following changed conditions. A., Negative, the eye passive or at rest. A. of the Eye, that function of the ciliary muscle and lens whereby objects at different distances are clearly seen. It depends upon the inherent elasticity of the lens, which when the ciliary muscle of an emmetropic eye is at rest is adapted to the proper focalization of parallel rays of light, or of such rays as proceed from an infinite distance, or from the horizon of the observer. Objects nearer, to be clearly seen, require a greater refracting power on the part of the eye because the rays from such objects are more divergent. This additional refracting power is gained by an increased antero-posterior diameter of

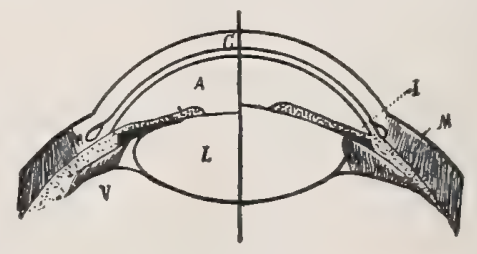

the lens, L, (illustration annexed) brought about by the contraction of the ciliary muscle, $M$, which occasions a loosening of the suspensory ligament and a thickening of the lens by its own elasticity. A., Paralysis of, paralysis of the ciliary muscle. A., Phosphenes, the peripheral light streak seen in the dark after the act of accommodation. A., Range of, the distance between the Punctum proximum, or nearest of distinct vision, and the Punctum remotissimum, or the most distant point. A. Theory, a theory that ascribes the production of myopia to a distention of the posterior portion of the sclera from the increased intra-ocular pressure dependent upon frequently repeated accommodation of the eyes.

Accompaniment (of the Cataract) $\left(a-k u m^{\prime}-p a n-e-m e n t\right)$. An old name for secondary or recurrent capsular cataract; opacity of the capsule following an operation for cataract.

Accouchée ( $a k$-koo-shay) [Fr., $a$, to; couche, a bed]. A woman delivered of a child.

Accouchement (ak-koosk-mong) [ad, to ; couche, bed]. The French term for labor, or delivery of a child. The act of childbirth. A. Forcé, rapid and forcible delivery with the hand during severe hemorrhage.

Accoucheur (ak-koo-shur) [Fr.]. A man-midwife.

Accoucheuse $(a k-k 00-s h u z)$ [Fr.]. A midwife.

Accrementitial (ak-re-men-tis $\left.h^{\prime}-a l\right)$ [accrescere, to increase]. In biology, of or pertaining to the process of accrementition.

Accrementition (ak-re-men-tish'-un) [ad, to; cresiere, to grow]. A growth in which increase takes place by interstitial development from blastema, and also by reproduction of cells by fission. The production or development of a new individual by the separation of a part of the parent; gemmation.

Accrescent (ak-res'-ent) [accrescere, to grow]. In biology, refers to those parts connected with the flower which increase in size after flowering, as frequently occurs with the calyx, involucre, etc.

Accrete (ak-rët) [accretus; accrescere, to increase, grow]. In biology, grown together.

Accretion ( $\left.a k-r c^{\prime}-\operatorname{shun}\right)$ [ad, to ; crescere, to increase]. A term denoting the manner by which crystalline and certain organic forms increase their material substance. Also, the adherence of parts that are normally separate.

Accumbent (ak-um'-bent) [ad, to; cumbere, to lie down]. In biology, lying against a thing. Cotyledons 
are accumbent when the edges of their applied faces lie against the radicle.

Accumulator $\left(a k-u^{\prime}-n n u-l a-t o r\right)$ [accumulare, to heap up]. An apparatus to store electricity.

A. C. E. Mixture. An anesthetic mixture composed of alcohol I part, chloroform 2 parts, ether 3 parts. See Anesthetic.

Acedia $\left(a h-s e^{\prime}-d e-a h\right)$ [ákndia]. A certain form of melancholia.

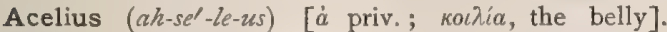
Without a belly; applied to those extremely emaciated.

Acelomatous (ah-sel-o'-mat-us) [à priv.; кoi $\lambda \omega \mu a$, a hollow]. In biology, destitute of a perivisceral cavity or coelum.

Acelomi ( $\left.a h-s e^{\prime}-l o-m i\right)$ [á priv.; $\kappa o \iota \lambda i \alpha$, the belly]. In biology, worms destitute of a perivisceral cavity, as tapeworms.

Acelomous (ah-se'-lo-mus). See Acelomatous.

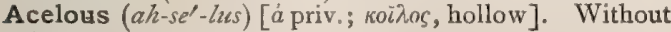
intestines; anenterous.

Acenaphthene (as-en-af'-thèn) [aceticus; naphthalene], $\mathrm{C}_{12} \mathrm{H}_{10^{*}}$ A hydrocarbon that occurs in coal tar, and separates on cooling from the fraction boiling at $260-280^{\circ} \mathrm{C}$. It crystallizes from hot alcohol in long needles melting at $95^{\circ} \mathrm{C}$. and boiling at $277^{\circ} \mathrm{C}$.

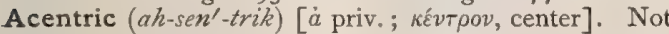
centric ; not originating in, or pertaining to, a nervecenter; peripheric.

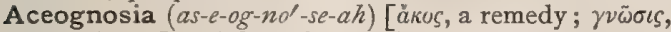
knowledge]. A knowledge of remedies.

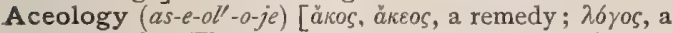
discourse]. Therapeutics; medical and surgical treatment of disease; acology.

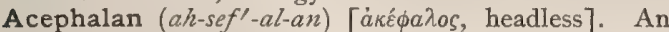
acephal, one of the acephala, or pertaining to such. A lamellibranchiate mollusc.

Acephalemia, or Acephalhemia ( $\left.a h-s e f-a l-e^{\prime}-m e-a h\right)[\dot{a}$ priv.; $\kappa \varepsilon \phi a \lambda \dot{n}$, head; ai $\mu a$, blood]. Deficiency of blood in the head.

Acephalia (ah-sef-a'-le-ah) [ả priv.ı; $\kappa \varepsilon \phi a \lambda \dot{h}$, head]. In teratology, the absence of the head.

Acephalism (ah-sef'-al-izm) [á priv.; $\kappa \varepsilon \phi a \lambda \eta \dot{n}$, head]. See Acephalia.

Acephalobrachia (ah-sef-al-o-bra'-ke-ah) [á priv.; $\kappa \varepsilon \phi a \lambda \dot{n}$, head; $\beta \rho \alpha \chi i \omega \nu$, arm]. In teratology, absence of the head and arms.

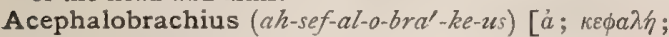
$\beta \rho a \chi i \omega \nu]$. A monster with neither head nor arms.

Acephalocardia (ah-sef-al-o-kar'-de-ah) [á priv.

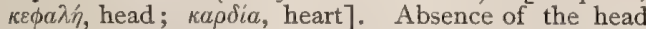
and heart.

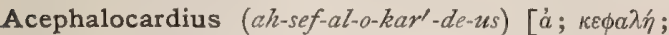
$\kappa a \rho \delta i a]$. A monster with neither head nor heart.

Acephalochiria ( $\left.a h-s e f-a l-o-k i^{\prime}-r e-a h\right)$ [ $\dot{\alpha}$ priv. ; $\kappa \varepsilon \phi a \lambda h$, head; $\chi \varepsilon i \rho$, hand]. Absence of the head and hands.

Acephalochirus (ah-sef'-al-o-ki'-rus) [See Acephalochiria]. A monster with neither head nor hands.

Acephalocyst (ah-sef'-al-o-sist) [á priv.; $\kappa \varepsilon \phi \alpha \lambda \eta \dot{\eta}$, head; кúorı̧, a bladder]. The bladder-worm. A headless, sterile hydatid, found in the liver and other organs. $A$. racemosa, the hydatid mole of the uterus.

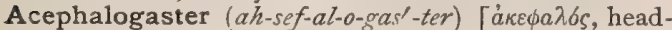

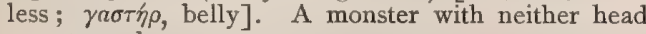
nor stomach.

Acephalogasteria (ah-sef-al-o-gas-te'-re-ah). Absence of the head and stomach. See Acephalovaster.

Acephalophoran (ah-sef-al-off'-o-ran) [á priv.; $\kappa \varepsilon \phi a \lambda \eta$, head; фદ́ $\varepsilon \varepsilon \nu$, to bear]. In biology, a member of DeBlainville's group of molluscs, Acephalophora.

Acephalopodia (ah-sef-al-o-po'-de-ah) [ả priv. ; $\kappa \varepsilon \phi a \lambda \eta ́$, head; $\pi$ oús, foot]. Absence of the head and feet.

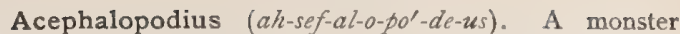
with neither head nor feet. See Acephalopodia.

Acephalorrhachia (ah-sef-al-o-ra'-ke-ah) [ia priv. $\kappa \varepsilon \phi a \lambda \eta$, head; $\rho a ́ \chi \iota s$, spine]. Absence of the head and vertebral column.

Acephalostomia (ah-sef-al-o-r+ol-me-ah) [á priv.; $\kappa \varepsilon \phi \alpha \lambda \dot{\eta}$, head; $\sigma \tau \delta \mu \alpha$, mouth]. Absence of the head, with a mouth-like opening on the superior aspect.

Acephalostomus (ah̀-sef-al-os'-to-mus) [à priv.; $\kappa \varepsilon \phi a \lambda n^{\prime}$; $\sigma \tau 6 \mu a]$. A monster with no head, but with a mouthlike aperture. See Acephalostomia.

Acephalothoracia (ah-sef-al-o-tho-ra'se-ah) [ả priv.; $\kappa \varepsilon \phi \alpha \lambda \dot{r}$, head; $\theta \omega \omega a \xi$, chest]. Absence of the head and thorax.

Acephalothorus (ah-sef-al-o-tho'-rus). A monster without head or thorax. See Acephalothoracia.

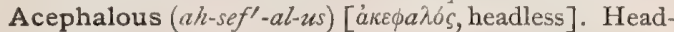
less.

Acephalus (ah-sef'-al-us) [à priv.; $\kappa \varepsilon \phi a \lambda \dot{\eta}$, head $]$. I. A species of omphalositic monsters characterized by complete absence of the head and usually of the upper extremities. It is the commonest condition among the omphalosites. 2. A variety of the above species marked by the highest form of development. The head is absent, but there is at least one superior extremity, and the thorax is generally fairly welldeveloped.

Acer $\left(a^{\prime}-\operatorname{ser}\right)$. A genus of sapindaceous trees and shrubs; the maples. A. saccharinum, the Sugar Maple of North America, affords a large commercial supply of sugar. A. rubrum, the Red Maple, has an astringent inner bark. $A$. pennsylvanicum, Striped Maple, is said to be antemetic and alterative. Unof.

Aceras (as'-er-as) [ả priv.; képas, horn, spur]. A genus of orchids. $A$. anthropophora (green-man, man-orchid) has sudorific leaves, and the bulbs are used as salep. Unof.

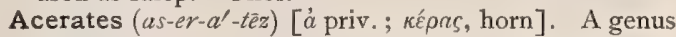
of asclepiadaceous plants, regarded by some as a section of the genus Gomphocarpus. A. decumbens, of New Mexico, is said to cure snake bites. A. longifolia, of the U.S., is diaphoretic. Unof.

Aceratophorous (ah-se-ra-tof'-o-rus) [ả priv. ; Képas, horn; $\phi \varepsilon \rho \varepsilon \iota \nu$, to bear]. In biology, hornless, muley. Cf. Acerous.

Aceratosis (ah-ser-at-o'-sis) [ả priv.; képas, horn]. Deficiency or imperfection of corneous tissue.

Acerb (a-serb') [acerbus, bitter]. Having a bitter, astringent and pungent taste; as certain drugs.

Acerbity $\left(a-\operatorname{ser} b^{\prime}-i t-e\right)$ [acerbitas, sharpness, sourness]. Acidity combined with astringency.

Aceric (as-er'-ik) [acer, a maple tree]. Pertaining to, or found in the maple; as aceric acid.

Aceride $\left(a s^{\prime}-e r-i d\right)$ [ $a \dot{\alpha}$ priv.; cera, wax $]$. An ointment or plaster containing no wax.

Acerose $\left(a s^{\prime}-e r-\bar{o} s\right)$ [acus (acer), chaff]. In botany, chaffy; needle-shaped, as pine needles.

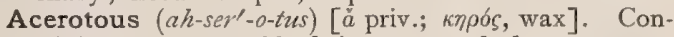
taining no wax; said of ointments and plasters.

Acerous (as'-er-us) [’a priv.; Képas, a horn]. In biology, having undeveloped, minute, or no horns or antennæ; aceratophorous.

Acervate (as-er'-vāt) [acervatus, p.p. of acervare, to heap upon]. In biology, growing in heaps or clusters.

Acervuline (as-er'-vu-lin) [acervulus, a heap]. Agminated, or aggregated; as certain mucous glands.

Acervulus, or Acervulus cerebri (as-er.-vu-lus ser'$e$-bri). Concretionary matter near the base of the pineal gland, consisting of alkaline phosphates and carbonates, with amyloid matter; brain-sand.

Acescence (as-es'-ens) [acescere, to grow sour]. I. The process of becoming sour; the quality of being 
somewhat sour. 2. A disease of wines, whereby they become sour owing to the agency of mycoderma aceti. Acescency (as-es'-en-se). See Acescence.

Acescent $\left(a s-e s^{\prime}-e n t\right)$ [acescere, to become sour]. Somewhat acid or tart; acidulous.

Aceta $\left(a s-e^{\prime}-t a h\right)$. Plural of Acetum, $q \cdot v$.

Acetable (as-et'-a-bl) [acetabulum, a small cup]. An old name for the acetabulum.

Acetabular $\left(a s-e t-a b^{\prime}-u-l a r\right)$ [acetabulum, a small cup]. Pertaining to the acetabulum.

Acetabuliferous (as-et-ab-u-lif'-er-us) [acetabulum, a small cup; ferre, to bear]. Having suckers, as the arms of cuttle-fishes and squids.

Acetabuliform (as-et-ab'-u-le-form) [acetabulum, a small cup; forma, form $]$. Having the form of the acetabulum, or of a shallow cup; cotyloid, or glenoid.

Acetabulum $\left(a s-e t-a b^{\prime}-\imath-l u m\right)$ [L., a small cup or measure]. In biology, any cup-shaped cavity or organ. The articulating cavity of the head of the femur, or the leg of an insect; one of the suckers on the arms of cephalopods, or on the scolex of a tapeworm; the receptacle of certain fungi and lichens.

Acetal (as'-et-al) [acetum, vinegar], $\mathrm{C}_{6} \mathrm{H}_{14} \mathrm{O}_{2}$. Ethidene diethylate, a colorless, mobile liquid, with an ethereal odor, produced by the imperfect oxidation of alcohol under the influence of platinum black. Sparingly soluble in water; boils at $104^{\circ} \mathrm{C}$.; sp. gr. at $20^{\circ}$ is 0.8304 . Its action is that of a soporific. Dose $3 \mathrm{j}$.

Acetaldehyd (as-et-al'-de-hìd). The normal aldehyd; ethaldehyd. See Aldehyd.

Acetals $\left(a s^{\prime}-e t-a l z\right)$ [acetum, vinegar]. Products of the combination of aldehyds with the alcohols at $100^{\circ} \mathrm{C}$

Acetamid (as-et'-am-id), $\mathrm{C}_{2} \mathrm{H}_{5} \mathrm{NO}$. A white crystalline solid produced by distilling ammonium acetate, or by heating ethyl acetate with strong aqueous ammonia. It combines with both acids and metals to form unstable compounds.

Acetanilid (as-et-an'-il-id), $\mathrm{C}_{8} \mathrm{H}_{0} \mathrm{NO}$, A white, crystalline solid. Produced by boiling anilin and glacial acetic acid together for several hours; the crystalline mass is then distilled. It melts at $\mathbf{I} 4^{\circ}$ and boils at $295^{\circ}$. It is soluble in hot water, alcohol and ether. Under the name antifebrin it is prescribed as an antipyretic. Dose gr. iij-xv.

Acetarium (as-et-a'-re-um) [gen., Acetarii: pl., Acetaria]. A pickle or salad. A. Scorbuticum, a pickle containing leaves of scurvy-grass or other anti-scorbutic plants; used in the treatment of scorbutic cases. Unof.

Acetary $\left(a s^{\prime}\right.$-et-a-re) [acetum, vinegar]. An obsolete or rare name for a sour pulpy substance found in pears and some other fruits; often enclosed within a congeries of calculous granules.

Acetate $\left(a s^{\prime}-e t-\bar{a} t\right)$ [acetum, vinegar]. Any salt of acetic acid. A. of Lead, plumbi acetas. See Plumbum.

Acetic (as-el-tik) [acelum, vinegar]. Pertaining to acetum or vinegar; sour. See Acid, Acetic. A. Fermentation, the development of acetic acid by the activity of the Mycoderma aceti.

Acetin $\left(a s^{\prime}-e t-i n\right)$ [acetum, vinegar]. A chemical compound formed by the union of glycerin and acetic acid.

Acetolatum, (as-et-o-la'-tum) [gen., Acetolati : pl., Acetolata]. Distilled vinegar, variously aromatized or medicated.

Acetolature (as-et-ol'-at-ür) [acetoiaturum]. Any acetous tincture, or medicated vinegar.

Acetometer (as-et-om'-et-er) [acetum, vinegar; $\mu \dot{\varepsilon} \tau \rho \circ$, measure]. An instrument used in the quantitive determination of acetic acid.

Ácetometry (as-et-om'-et-re) [acetum, vinegar; $\mu \varepsilon ́ \tau \rho o v$, measure]. The quantitive estimation of the amount of acetic acid in vinegar. Usually made by an acetometer.

Acetone $\left(a s^{\prime}-e t-\bar{o} n\right)$ [acetum, vinegar $], \mathrm{C}_{3} \mathrm{H}_{6} \mathrm{O}$. Dimethyl Ketone. A colorless, mobile liquid, of peculiar odor and burning taste; present in crude wood-spirit; it occurs in small quantities in the blood and in normal urine, and in considerable quantities in the urine of diabetics. Like methyl alcohol it is miscible in al proportions with ether, alcohol, and water. It is an excellent solvent for resins, gums, camphor, fats, and gun-cotton.

Acetones $\left(a s^{\prime}-e t-\bar{o} n z\right)$. A class of compounds that may be regarded as consisting of two alcoholic radicals united by the group $\mathrm{CO}$, or as aldehyds in which hy drogen of the group $\mathrm{COH}$ has been replaced by an alcoholic radical.

Acetonemia (as-et-o-ne'-me-ah) [acetone; aina, blood.] The presence of acetone in the blood. It may result from a number of diseases, but is characteristic of chronic diabetes, and is associated with dyspnea, subnormal temperature, lowered pulse-rate, etc. The patient finally falls into coma. The treatment consists in increasing the secretions and by removing the causes of the diseases.

Acetonuria (as-et-ōn- $\left.u^{\prime}-r e-a h\right)$ [acetone; ov̉pov, urine]. The presence of acetone in the urine.

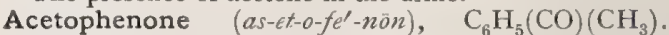
"Hypnone;" a hypnotic and antiseptic. Without satisfactory action. Dose $m_{i v-x v}$. It results from the action of zinc methyl upon benzoyl chlorid. Crystallizes in large plates, melts at $20.5^{\circ}$, and boils at $202^{\circ}$.

Acetosella (as-et-o-sel'-ah). See Oxalis acetosella.

Acetous (as-e'-tus) [acetum, vinegar]. Like or resembling vinegar; pertaining to, or charged with vinegar or acetic acid.

Acetoxim (as-et-oks'-im), $\left(\mathrm{CH}_{3}\right)_{2}$ C.N.OH, A compound formed by the action of hydroxylamin upon acetone; readily soluble in water, alcohol and ether; fuses at $60^{\circ}$, boils at $I 35^{\circ}$.

Acetoxims (as-et-oks'-imz). See Aldoxims.

Acetphenetidin (as-et-fe-net'-id-in). See Phenacetin.

Acetum, (as-e'-tum) [gen,, Aceta : pl., Aceti]. [L.]. Vinegar. An impure, dilute acetic acid produced by acetous fermentation of wine, cider, or other fruit-juice. See Fermentation. In pharmacy, a solution of the active principles of certain drugs in dilute acetic acid. There are four official aceta, each of which contains the soluble principles of ten per cent. of its weight, viz., of lobelia, opium, sanguinaria, and squill; the acetum of cantharides is official in Great Britain. A. aromaticum (N. F.) ["aromatic vinegar"], a mixture of alcohol, water and acetic acid, aromatized with the oils of rosemary, lavender, juniper, peppermint, cassia, lemon and cloves. A. britannicum, an aromatic vinegar consisting of glacial acetic acid 600.0 , camphor 60.0 , oil of cloves 2.0 , oil of cinnamon 1.0 , oil of lavender 0.5 .

Acetyl $\left(a s^{\prime}-e t-i l\right)$ [acetum, vinegar $],\left(\mathrm{C}_{2} \mathrm{H}_{3} \mathrm{O}\right)$. A univalent radical supposed to exist in acetic acid and its derivatives. Aldehyd may be regarded as the hydrid and acetic acid as the hydrate, of acetyl. A. Peroxid, $\left(\mathrm{C}_{2} \mathrm{H}_{3} \mathrm{O}\right)_{2} \mathrm{O}_{2}$, a thick liquid, insoluble in water, but readily dissolved by ether and alcohol. It is a powerful oxidizing agent. It is decomposed in sunlight and explodes violently when heated.

Acetylene (as-et'-il-èn) [acetum, vinegar], $\mathrm{C}_{2} \mathrm{H}_{2}$. A colorless gas, with a characteristic and very unpleasant odor, burning with a luminous, smoky flame. Illuminating gas contains a small amount of it. Formed by the imperfect combustion of illuminating gas and other hydrocarbons. The acetylene series of hydrocarbons has the general formula, $\mathrm{C}_{n} \mathrm{H}_{2 n-2}$. 
Ache $(\bar{a} k)$ [A. S., acan, to ache]. Any continuous or throbbing pain.

Ache (ätch) [Fr.]. An old, or local name for common parsley. See Apium.

Acheilia $\left(a h-k i^{\prime}-l e-a h\right)$ [ $\dot{a}$ priv, ; $\chi \varepsilon i \bar{\lambda} \sigma \varsigma$, a lip $]$. The congenital absence of lips.

Acheilous ( $\left.a h-k i^{\prime}-l u s\right)$ [ả priv.; $\chi \varepsilon \bar{\imath} \lambda o_{s}$, a lip]. Born without lips; affected with acheilia.

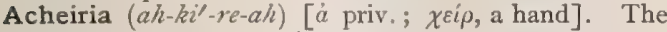
congenital absence of hands.

Acheirous (ah-ki'-rus) [a priv.; $\chi \varepsilon i \rho, a$ hand]. Affected with acheiria; born without hands.

Acheirus $\left(a h-k i^{\prime}-r u s\right)$. An acheirous person, or fetus; one who was born without hands.

Achene $\left(a-k \bar{e} n^{\prime}\right)$. Same as Achenium.

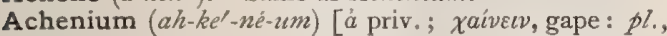
Achenia ]. In biology, a small, dry, one-seeded, indehiscent fruit.

Achenocarp, or Achænocarp (ah-ke'-no-karp) [ả priv.; $\chi \alpha i \nu \varepsilon \imath \nu$, to gape; $\kappa a \rho \pi \delta s$, fruit]. In biology, any dry fruit, not opening spontaneously when ripe. See Achenium.

Achenodium $\left(a k-e n-\sigma^{\prime}-d e-u m\right)$ [L. ]. A cremocarp or double achenium, as produced by some umbelliferous plants. See Achenium.

Achetous, or Achætous (ah-ke'-tus) [ $\alpha$ priv.; $\chi a i \tau \eta$, hair]. In biology, lacking setæ, chætæ, or bristles.

Achilia ( $\left.a h-k i^{\prime}-l e-a h\right)$. See Acheilia.

Achillea $\left(a k-i l-e^{\prime}-a h\right)$ [Achilles, its reputed discoverer]. Milfoil, Yarrow. The herb A. millefolium. Properties due to a bitter, aromatic, astringent, tonic extractive, achillein, and a volatile oil. It has long been used as a vulnerary, and has been highly recommended for intermittents, and in low, exanthematous fevers. Dose Zj-Oj infusion ad lib.; of the extractive, $3 \mathrm{j}-\mathrm{iij}$; of the volatile oil, gtt. $\mathrm{v}-\mathrm{xv}$. Unof. To the genus Achillea belong various other unofficial medicinal plants, as $A$. moschata, of the Alps, used in preparing cordials and a diaphoretic medicine, and $A$. ptarmica, or sneezewort, a strong sialagogue.

Achillein (ak-ill-e-in) [achilleinum; gen., Achilleini]. An extractive from Achillea millifolium. See Achillea.

Achilles Tendon ( $\left.a k-i l^{\prime}-\bar{e} z t \mathrm{t}^{\prime}-d o n\right)$. See Tendon.

Achillodynia (ak-il-o-din'-e-ah) [Achilles; ódviv, pain]. Pain referred to the insertion of the tendo-Achillis, sornetimes with apparent swelling of the tendon and of the os calcis.

Achilous (ah-ki'-lus). See Acheilons.

Achiote $\left(a-c h e-o^{\prime}-t e\right)$. See Annotto.

Achiria (ah-ki'-re-ah). See Acheiria.

Achirous ( $\left.a h-k i^{\prime}-r u s\right)$. See Acheirous.

Achirus (ah-ki'-rus). See Acheirus.

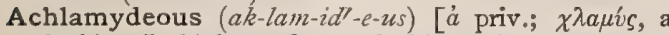
cloak). In biology, flowes lacking calyx, corolla, or perianth.

Achlorophyllous (ah-klo-ro-fil'-us) [á priv,; $\chi^{\lambda \omega} \omega \delta^{\prime} s$, green; $\phi \dot{v} \lambda \lambda_{o \nu}$, leaf ]. In biology, without chlorophyll, or leaf-green.

Achloropsia ( $\left.a h-k l o-r o p{ }^{\prime}-s e-a h\right)$ [ả priv.; $\chi \lambda \omega \rho b s$, green ; ö $\psi s$, vision]. Green-blindness.

Achlys $\left(a k^{\prime}-\mathrm{lis}\right)$ [à $\chi \hat{i} v s$, gloom, mist]. Cloudiness of the cornea.

Achne $\left(a k^{\prime}-n e\right)$ [ä $\chi v \eta$, anything shaved off $]$. I. Lint, or charpie; floss. 2. Mucus upon the eye.

Acholia $\left(a h-k o^{\prime}-l e-a h\right)$ [ $\alpha$ priv.; $\chi 0 \lambda \dot{n}$, bile]. Non-secretion or non-excretion of bile.

Acholic $\left(a h-k o l^{\prime} i k\right)[\alpha ; \chi 0 \lambda \dot{h}]$. Affected with acholia.

Acholous (ak'-o-lus) [á priv.; $\chi \circ \lambda \dot{n}$, bile]. Pertaining to or affected with acholia.

Achondroplasia (ah-kon-dro-pla'-se-ah) [á priv.; $\chi 60 v-$ $\delta \rho o s$, cartilage; $\pi \lambda a ́ \sigma \sigma \varepsilon \imath \nu$, to form]. Lack of development in a cartilaginous structure; the absorption of cartilage during its transformation into bone.
Achondroplasy (ah-kon'-alro-pla-se) [ $\dot{a}$ priv, ; $\chi \dot{b} \nu \delta \rho o s$, cartilage; $\pi \lambda a \sigma \sigma \varepsilon \iota \nu$, to form]. Lack of the normal development of cartilage. Parrot's term for a form of fetal rickets in which the limbs are short, the curves of the bones exaggerated, and there is an absence of the proliferating zone of cartilage at the junction of the epiphyses. The children are generally still-born. This condition is very much like a fetal cretinism.

Achor $\left(a^{\prime}-k o r\right)[\dot{a} \chi \omega \rho$, chaff, scurf, or dandruff: $p l$., Achores $\left(a-k a r^{\prime}-\bar{e} z\right)$ ]. Crusta lactea. A small pustule, followed by a scab, upon the heads of infants.

Achordal $\left(a h-k o r^{\prime}-d a l\right)$ [ $\dot{\alpha}$ priv.; $\chi \delta \rho \delta \eta$, cord]. Not derived from the notochord.

Achorion (a-ko'-re-on) [dim. of ' $\alpha \chi \chi \omega \rho$, chaff]. A genus including several species of fungous (or fungoid) organisms (possibly modified forms of Penicillium glaucum), found in the skin, especially the hair follicles. A. keratophagus, the form causing Onychomycosis, q. v. A. lebertii, the parasite of Tinea tonsurans. A. schönleinii, the species occurring in ringworm or Tinea favosa.

Achroa (ah-kro'-ah). See Achroia.

Achroia (ah-kroi'-ah). Same as Achroma, q.v.

Achroicythemia (ah-kroi-si-the'-me-ah). Same as Achroiocythemia. See also Oligochromemia.

Achroiocythemia (ah-kroi-o-si-the'-me-ah), or Achroeocythæmia (ah-kre-o-si-the'-me-ah) [åxpocos, colorless; кítos, cell; aíu, blood]. A deficiency of hemoglobin in the red blood corpuscles; also, the diseased state that is associated with such deficiency.

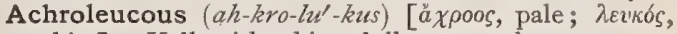
white]. Yellowish-white, dull cream color.

Achroma $\left(a h-k r o^{\prime}-m a h\right)$ [á priv ; $\chi \rho \ddot{\omega} \mu a$, color $]$. Absence of color. Pallor. Paleness, from whatsoever cause. A., Congenital. See Albinism. A. Cutis. See Leucoderma.

Achromasia (ah-kro-ma'-ze-ah). See Achroma:

Achromatic (ah-kro-mat'-ik) [á priv.; $\chi \rho \tilde{\omega} \mu a$, color $]$. Pertaining to achroma; without color. A. Lens, one the dispersing power of which is exactly neutralized by another lens having the same curvature but of unequal refractive index. See also Aberration and Objective. A. Triplet. See Microscope.

Achromatin (ah-kro'-mat-in) [a priv.; $\chi \rho \tilde{\omega} \mu \alpha$, color]. The substance in the nucleus of a cell prior to division. So called because not readily stained by coloring agents. See Cell Body. A. of Flemming. See Paralinin.

Achromatism (ah-kro'-mat-izm) [ả priv.; $\chi \rho \tilde{\omega} \mu \alpha$, color]. Absence of chromatic aberration.

Achromatopsia (ah-kro-mat-ōpl-se-ah) [á priv.; $\chi \rho \tilde{\omega} \mu a$, color; ŏ $\psi \iota$, eyesight]. Color-blindness; Daltonism; dyschromatopsia.

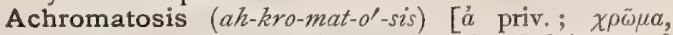
color]. Any disease characterized by deficiency of pigmentation in the integumentary tissues.

Achromatous (ah-kro'-mat-us) [á priv.; $\chi \rho \tilde{\omega} \mu \alpha$, color]. Deficient in color.

Achromia (ah-kro'-me-ah) [á priv.; $\chi \rho \tilde{\omega} \mu a$, color $]$. Albinism; achroma.

Achromodermia (ah-kro-mo-der'-me-ah) $[\dot{a}$ priv.; $\chi \rho \omega \tilde{\omega} \mu a$, color; $\delta \dot{\rho} \rho \mu \alpha$, skin $]$. An albinotic, or colorless state of the skin.

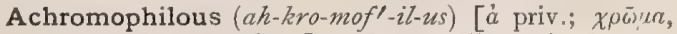
color; $\phi i \lambda \varepsilon i \nu$, to love]. Not readily stained; not chromophilous.

Achromotrichia (ah-kro-mo-trik'-e-ah) [á priv.; $\chi \rho \tilde{\omega} \mu \alpha$, color; $\theta \rho i \xi$, hair $]$. Absence of pigment from the hair.

Achromous (ah-kro'-mus) [á priv.; $\chi \rho \tilde{\omega} \mu \alpha$, color $]$. Päle, colorless; having no color.

Achroödextrin (ah-kro-o-deks'-trin) [ả $\chi \rho n o s$, colorless; dexter, right]. A reducing dextrin formed by the action 
of the diastatic ferment of saliva upon starch or glycogen. It is a modification of dextrin that may be precipitated by alcohol, and is not altered by ptyalin, nor colored by iodin.

Achylia $\left(a h-k i i^{\prime}-l e-a / \ell\right)$ [à priv.; $\chi v \lambda o ́ s$, juice $]$. Absence or deficiency of juice, or of chyle.

Achylosis $\left(a h-k i-l \sigma^{\prime}-s i s\right)$ [á priv.; $\chi v \lambda o ́ s$, juice]. Deficient chylification.

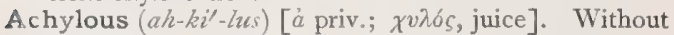
chyle; deficient in chyle or juice.

Achymosis $\left(a h-k i-m o^{\prime}-s i s\right)$ [á priv.; $\chi v \mu b s$, chyme]. Deficient chymification.

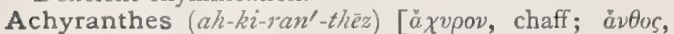
a flower]. A genus of amyrantaceous plants. $A$. calea, of Mexico, is febrifugal. A. repens, of Europe and the United States, is diuretic. Unof.

Acicula $\left(a s-i k^{\prime}-u-l a h\right)$ [dim. of acus, a needle]. In biology, a spine, bristle, or prickle; the bristle-like flower of a grass.

Acicular (as-ik'-u-lar) [acus, a needle]. Needle-like.

Aciculum $\left(a s-i k^{\prime}-u-l u m\right)$ [dim. of acus, a needle: pl., Acicula $]$. In biology, one of the slender sharp bristles in the rudimentary limbs of some worms.

Aciculus (as-ik'-u-lus) [acus, a needle]. In biology, a stout bristle or prickle.

Acid $\left(a s^{\prime}-i d\right)$ [acere, to be sour]. A name loosely applied to any substance having a sour taste. A compound of an electro-negative element with one or more atoms of hydrogen which can be replaced by electropositive or basic atoms. Acids vary in their terminations according to the quantity of oxygen or other electro-negative constituent. Those having the maximum of oxygen end in -ic; those of a lower degree in -ous. Where there are more than two combinations the preposition hyper-is prefixed to the highest, and hypo- to the lowest. Acids that end in $-i c$, as sulphuric acid, form salts terminating in -ate; those ending in -ous form salts terminating in -ite. Physiologic ally, acids in concentrated form act as caustics; diluted and in medicinal doses they check acid-producing and increase alkaline secretions. A., Abietic. See Abietic. A., Abric $\left(\mathrm{C}_{12} \mathrm{H}_{24} \mathrm{~N}_{3} \mathrm{O}\right)$, a crystallizable acid, said to exist in jequirity. A., Aceric, found in the juice of Acer campestre, the common English maple. A., Acetic, an acid solution composed of 36 parts of absolute acetic acid $\left(\mathrm{C}_{2} \mathrm{H}_{4} \mathrm{O}_{2}\right)$, and 64 parts water. Has strong acid properties. Miscible with water and alcohol. A., Acetic, Glacial, the absolute acid in crystalline form. An escharotic. A., Acetic, Dilute, contains six per cent. of absolute acid. Dose $\overline{\mathbf{j}} \mathrm{j}-\mathrm{ij}$. An impure form obtained by the destructive distillation of wood is known as wood vinegar, or pyroligneous acid. A., Acetic, Test. See Tests, Table of. A., Aconitic $\left(\mathrm{C}_{6} \mathrm{H}_{6} \mathrm{O}_{6}\right)$, occurs in different plants, as Aconitum napellus, sugar cane, and beet-roots. It may be obtained by heating citric acid alone or with concentrated $\mathrm{HCl}$. It crystallizes in small plates, that dissolve readily in alcohol, ether and water, and melt at $186^{\circ}-7^{\circ}$. An acid found in aconite. A., Adibasic. See $A$., Suberic. A., Adipic $\left(\mathrm{C}_{6} \mathrm{H}_{10} \mathrm{O}_{4}\right)$, obtained by oxidizing fats with nitric acid. Crystallizes in shining leaflets, or prisms; soluble in thirteen parts of cold water; melts at $148^{\circ}$. It is dibasic and diatomic. A., Agaricic $\left(\mathrm{C}_{16} \mathrm{H}_{30} \mathrm{O}_{5}+\mathrm{H}_{2} \mathrm{O}\right)$, a resin acid obtained from the fungus Polyporus officinalis, growing on larch trees. The acid has been recommended for the checking of night-sweats. It also checks the other excretions and diminishes thirst. It is mildly cathartic. Unof. A., Alanthic $\left(\mathrm{C}_{15} \mathrm{H}_{20} \mathrm{O}_{2}\right)$, Inulic acid, found in Inula helenium. Occurs in needle-like crystals. A., Aldepalmitic $\left(\mathrm{C}_{16} \mathrm{H}_{30} \mathrm{O}_{2}\right)$, the chief component of the butter of the cow. A., Alginic. See Algin. A.,
Alloxanic $\left(\mathrm{C}_{4} \mathrm{H}_{2} \mathrm{~N}_{2} \mathrm{O}_{4}\right)$, a crystalline acid, obtained by treating alloxan with alkalies. A., Alpha-oxynaphthoic $\left(\mathrm{C}_{11} \mathrm{H}_{8} \mathrm{O}_{3}\right)$, a fragrant crystalline acid, derived from alpha-naphthol. It is strongly antiseptic and deodorant; useful in wound-dressing; but appears to be toxic when taken by the stomach. Unof. A., Alphatolinic. See $A$., Phenyl-acetic. A., Amalic $\left(\mathrm{C}_{8}\left(\mathrm{CH}_{3}\right)_{4} \mathrm{~N}_{4} \mathrm{O}_{7}\right)$, [áuaioos, weak], tetramethylalloxantin, formed by the action of $\mathrm{HNO}_{3}$, or chlorine water, upon thein, or, better, by the reduction of dimethyl alloxan with $\mathrm{H}_{2} \mathrm{~S}$. Consists of colorless, sparingly soluble crystals, that impart a red color to the skin. A., Amido-acetic. See Glycin. A., Amidobenzoic $\left(\mathrm{C}_{7} \mathrm{H}_{7} \mathrm{NO}_{2}\right)$, occasionally found in the urine. A., Amido-succinamic, same as Asparagin. A., Angelic $\left(\mathrm{C}_{5} \mathrm{H}_{8} \mathrm{O}_{2}\right)$, a crystalline monobasic acid. Exists free along with valeric and acetic acids in the roots of Angelica archangelica, and as butyl and amyl esters in Roman oil of cumin. Crystallizes in shining prisms, melts at $45^{\circ}$, and boils at $185^{\circ}$. It has a peculiar smell and taste. A., Anisic $\left(\mathrm{C}_{8} \mathrm{H}_{8} \mathrm{O}_{3}\right)$, obtained by oxidizing anisol and anethol with $\mathrm{HNO}_{3}$, and from aniseed by the action of oxidizing substances. Crystallizes from hot water in long needles, from alcohol in rhombic prisms; melts at $185^{\circ}$, boils at $280^{\circ}$. It is antiseptic and antirheumatic. A., Anthranilic $\left(\mathrm{C}_{7}\right.$ $\mathrm{H}_{7} \mathrm{NO}_{2}$ ), prepared by oxidizing indigo by boiling it with manganese dioxid and sodium hydroxid. It sublimes in long needles, is readily soluble in hot water and alcohol, and melts at $144^{\circ}$. A., Anthro-

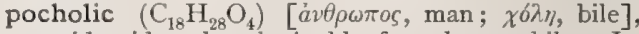
an acid said to be obtainable from human bile. Its existence is doubtful. A., Anticylic, a white fragrant powder with pleasant acid taste, readily soluble in water, alcohol, and glycerin, used as an antipyretic. Dose gr. $\frac{1}{10} 0^{\circ}$ A., A posorbic $\left(\mathrm{C}_{5} \mathrm{H}_{8} \mathrm{O}_{7}\right)$, produced on oxidizing sorbin with $\mathrm{HNO}_{3}$. It crystallizes in small leaflets that melt with decomposition at $110^{\circ}$. Easily soluble in water. A., Arabic. See Arabin. A., Arabonic $\left(\mathrm{C}_{5} \mathrm{H}_{10} \mathrm{O}_{6}\right)$, tetraoxyvaleric acid, obtained by the action of bromin water or $\mathrm{HNO}_{3}$ upon arabinose. A., Aromatic, a name applied to certain organic acids occurring in the balsams, resins, and other odoriferous principles. Also, in pharmacy, a dilute mineral acid reinforced by aromatic substances in order to modify their flavor. A., Arsenous, and Arsenic. See Arsenic. A., Aspartic $\left(\mathrm{C}_{4} \mathrm{H}_{7} \mathrm{NO}_{4}\right)$, occurs in the vinasse obtained from the beet root, and is procured from albuminous bodies in various reactions. It is prepared by boiling asparagin with alkalies and acids. It crystallizes in rhombic prisms, or leaflets, and dissolves with difficulty in water. A., Atrolactinic $\left(\mathrm{C}_{9} \mathrm{H}_{10} \mathrm{O}_{3}\right)$, obtained from acetophenone by means of prussic acid and $\mathrm{H}_{2} \mathrm{SO}_{4}$ or dilute $\mathrm{HCl}$. Dissolves very readily in water; crystallizes with onehalf $\mathrm{H}_{2} \mathrm{O}$ in needles or plates; melts at $9 \mathbf{I}^{\circ}$. A , Atropic $\left(\mathrm{C}_{9} \mathrm{H}_{8} \mathrm{O}_{2}\right)$, results from atropin, tropic acid, and atrolactinic acid when they are heated with concentrated $\mathrm{HCl}$. Crystallizes from hot water in monoclinic plates; is sparingly soluble in cold water, easily in ether and benzene; melts at $106^{\circ}$. A., Auric $\left(\mathrm{Au}(\mathrm{OH})_{3}\right)$, gold trihydroxid. A. Bath. See Bath. A., Behenolic $\left(\mathrm{C}_{22} \mathrm{H}_{40} \mathrm{O}_{2}\right)$, derived from the bromids of erucic and brassidic acids. Melts at $57.5^{\circ}$. A., Benzoic $\left(\mathrm{C}_{7} \mathrm{H}_{6} \mathrm{O}_{2}\right)$, occurs free in some resins, chiefly in gum benzoïn, and in coal tar. It crystallizes in white, shining needles, or leaflets, melts at $120^{\circ}$, and distils at $250^{\circ}$. It volatilizes readily, and its vapor possesses a peculiar odor that produces coughing. A., Boric. See Borcn. A., Brassidic $\left(\mathrm{C}_{22} \mathrm{H}_{42} \mathrm{O}_{2}\right)$, isomeric with erucic acid; produced by the action of nitric acid on erucic acid; melts at $56^{\circ}$. A., Brenz 
catechin sulphuric $\left(\mathrm{C}_{6} \mathrm{H}_{4}(\mathrm{HO})_{2} . \mathrm{O} . \mathrm{SO}_{2}\right)$, has been found in human urine, mainly after the ingestion of salicin, hydroquinon, etc. A., Butyric $\left(\mathrm{C}_{4} \mathrm{H}_{8} \mathrm{O}_{2}\right)$ [Gutyrum, butter], an acid having a viscid appearance and rancid smell. It is obtained commercially by the fermentation of a mixture of sugar and butter or cheese in the presence of an alkaline carbonate, but occurs in various plants, in cod-liver oil, in the juice of meats, and in the perspiration. Combined with glycerin as glyceryl butyrate, it is essentially butter. The ether derived from butyric acid is the natural flavor of the pineapple. A., Caffeic $\left(\mathrm{C}_{9} \mathrm{H}_{8} \mathrm{O}_{4}\right)$, obtained when the tannin of coffee is boiled with potassium hydroxid; crystallizes in yellow prisms, and is very readily soluble in hot water and alcohol. A., Campholic $\left(\mathrm{C}_{10} \mathrm{H}_{18} \mathrm{O}_{2}\right)$, produced on distilling camphor over heated soda-lime, or with alcoholic potash; it melts at $95^{\circ}$, and is a white, volatile solid, insoluble in cold water. A., Camphoric $\left(\mathrm{C}_{10} \mathrm{H}_{16} \mathrm{O}_{4}\right)$, a dibasic acid, obtained by boiling camphor with $\mathrm{HNO}_{3}$; crystallizes from hot water in colorless leaflets; melts at $178^{\circ}$, and decomposes into water and its anhydrid, $\mathrm{C}_{8} \mathrm{H}_{14}(\mathrm{CO})_{2} \mathrm{O}$. Used in nightsweats of phthisis. Dose gr. $\mathrm{x}-\mathrm{xxx}$. A., Camphoronic $\left(\mathrm{C}_{9} \mathrm{H}_{12} \mathrm{O}_{5}+\mathrm{H}_{2} \mathrm{O}\right)$, produced by the further oxidation of camphoric acid; it occurs in the mother liquor. Loses its water of crystallization at $100-120^{\circ}$ and melts at $135^{\circ}$. It forms colorless microscopic needles that are volatile and readily soluble in water. A., Capric $\left(\mathrm{C}_{9} \mathrm{H}_{19} \mathrm{CO} . \mathrm{OH}\right)$, occurs in small quantity, as a glycerid in cow's butter. Crystallizes in fine needles, melting at $30^{\circ} \mathrm{C}$., very insoluble in boiling water. A., Caproic $\left(\mathrm{C}_{6} \mathrm{H}_{12} \mathrm{O}_{2}\right)$, the sixth in the series of fatty acids; a clear, mobile oil, colorless, inflammable, and with a very acid and penetrating taste. Prepared from butter, cocoanut oil, and various other sources. A., Caprylic $\left(\mathrm{C}_{7} \mathrm{H}_{15} \mathrm{CO} . \mathrm{OH}\right)$, an acid combined with glycerin, forming a glycerid existing in various animal fats; liquid at ordinary temperatures. A., Carbamic $\left(\mathrm{H}_{2} \mathrm{~N} . \mathrm{CO} . \mathrm{OH}\right)$, an acid not known in the free state; its ammonium salt is contained in commercial ammonium carbonate. The esters of carbamic acid are called urethanes. A., Carbazotic. See $A$., Picric. A., Carbolic $\left(\mathrm{C}_{6} \mathrm{H}_{5} \mathrm{OH}\right)$, Phenol-the correct designation of this substance-is procured from coal tar by fractional distillation. It has a very peculiar and characteristic odor, a burning taste, is poisonous, and has preservative properties. The sp. gr. at $0^{\circ}$ is 1.084; it crystallizes in colorless rhombic needles that melt at $42.2^{\circ}$, boiling at $180^{\circ}$, and it is not decomposed upon distillation. At ordinary temperatures it dissolves in water with difficulty (I: I5), but is soluble in alcohol, ether, glacial acetic acid, and glycerin in all proportions. Upon exposure to light and air it deliquesces and acquires a pinkish color. It is used in the manufacture of many of the artificial coloring matters, e. $g$. , picric acid, used as a yellow dye. Large quantities of various qualities of carbolic acid are consumed for antiseptic purposes. It is a powerful antiseptic and germicide, and a violent poison. Internally it is used in vomiting and intestinal fermentation. Dose gr. $1 / 4-j$. A., Carb., Aqua, contains ro drachms of the glycerit to I pint of water. Dose 3 j- - ss. A., Carb., Gargarisma grs. ij- 3 j, for fetid sore throat. A., Carb., Glycerit, contains acid I, glycerin 4 parts. A., Carb., Liquefactum, (B. P.). Dose $m_{\text {j-ij. A., Carb., }}$ Solutions, vary from $\mathbf{I}$ to 5 per cent. in water. A., Carb., Suppos. cum Sapone (B. P.), each containing gr. j of carbolic acid. A., Carb., Unguent, contains acid 10, ointment 90 parts. A., Carbol., Injectio Hypoderm., 2-5 per cent., for anthrax, and erysipelas. A., Carbonic $\left(\mathrm{CO}_{2}\right)$, carbon dioxid; a product of combustion; a colorless, transparent, odorless gas, heavier than air; incapable of sustaining respiration. It is eliminated by the lungs, and when retained in the system gives rise to cyanosis. A., Carminic $\left(\mathrm{C}_{17} \mathrm{H}_{18} \mathrm{O}_{10}\right)$, coloring matter found in the buds of certain plants, and especially in cochineal, an insect inhabiting different varieties of cactus. It is an amorphous purple-red mass, very readily soluble in water and alcohol. Yields red salts with the alkalies. A., Cathartinic, an active principle from several species of Cassia. It occurs in brown hygroscopic scales. Used as a laxative in doses of gr. iv-vj. A. Cerebrinic $\left(\mathrm{C}_{59} \mathrm{H}_{113} \mathrm{NO}_{3}\right)$, an acid found in the brain and belonging to the group called cerebrinacides. A., Cerotic $\left(\mathrm{C}_{27} \mathrm{H}_{54} \mathrm{O}_{2}\right)$ [knporós, waxy], a fatty acid, existing in the free state in beeswax, and combined with ceryl as an ether in Chinese wax. It crystallizes from alcohol in delicate needles, melting at $78^{\circ}$. A., Chelidonic $\left(\mathrm{C}_{7} \mathrm{H}_{4} \mathrm{O}_{6}\right)$, occurs together with malic acid in Chelidonium majus. Crystallizes in silky needles with one molecule of water, and melts at $220^{\circ}$. A., Chloracetic [chlorin and acetic], an acid, called also Monochloracetic acid, produced by the substitution of chlorin for the hydrogen of the radicle in acetic acid. It is sometimes used as a caustic. A., Chloric $\left(\mathrm{HClO}_{3}\right)$, an acid known only in its compounds and its aqueous solution. Some of its compounds, the chlorates, are of great service in medicine. A., Cholalic. See $A$., Cholic. A., Cholic $\left(\mathrm{C}_{24} \mathrm{H}_{42} \mathrm{O}_{5}\right)$, Cholatic Acid, from glycocholic and taurocholic acids; crystallizes from hot water in small anhydrous prisms, sparingly soluble in water, and melting at $195^{\circ}$. A., Choloidinic, derived from Cholalic Acid, and probably a mixture of this with dyslysin ; all three decomposition products of bile acids. A., Chromic, strictly the compound $\mathrm{H}_{2} \mathrm{CrO}_{4}$; chromium trioxid combined with water; it forms salts called chromates. In most books the chromium trioxid, $\mathrm{CrO}_{3}$, is called by this name. It is a crystalline solid, and is a useful escharotic for the destruction of syphilitic warts and similar growths. A solution of I: 40 is used as an antiseptic wash for putrid sores and wounds. A., Chrysanisic $\left(\mathrm{C}_{7} \mathrm{H}_{5} \mathrm{~N}_{3} \mathrm{O}_{6}\right)$, an acid forming goldenyellow crystals, used in the preparation of certain anilin dyes. It melts at $259^{\circ}$ and sublimes. A., Chrysenic $\left(\mathrm{C}_{17} \mathrm{H}_{12} \mathrm{O}_{3}\right)$, produced when chrysene is fused with caustic alkali. Forms silver-white leaflets and melts at $186^{\circ}$. A., Chrysophanic $\left(\mathrm{C}_{15} \mathrm{H}_{10} \mathrm{O}_{4}\right)$, Rheinic Acid, exists in the lichen, Parmelia parietina, in senna leaves, and in the rhubarb root. Crystallizes in golden yellow needles or prisms, melting at $162^{\circ}$. See Chrysarobin. A., Cinchoninic $\left(\mathrm{C}_{9} \mathrm{H}_{6} \mathrm{~N}\left(\mathrm{CO}_{2} \mathrm{H}\right)\right)$, produced by oxidizing cinchonin with potassium permanganate, or $\mathrm{HNO}_{3}$. Crystallizes in needles, containing $2 \mathrm{H}_{2} \mathrm{O}$, in thick prisms, or plates, with $2 \mathrm{H}_{2} \mathrm{O}$; melts at $254^{\circ}$. A., Cinnamic $\left(\mathrm{C}_{9} \mathrm{H}_{8} \mathrm{O}_{2}\right)$, occurs in Peru and Tolu balsams, in storax, and in some benzoin resins. Crystallizes from hot water in fine needles, from alcohol in thick prisms; is odorless, melts at $133^{\circ}$; soluble in hot water and in alcohol. It has been used in tuberculosis, both internally and externally. Dose $m$ j-x, hypodermatically. A., Citric $\left(\mathrm{C}_{6} \mathrm{H}_{8} \mathrm{O}_{7}\right)$, occurs free in lemons, black currants, bilberry, beets, and in various acid fruits. It crystallizes with one molecule of water in large rhombic prisms, which melt at $100^{\circ}$, are colorless, inodorous, and extremely sharp in taste. It is used as a discharge in calico-printing. It is refrigerant, antiseptic, and diuretic. A., Comanic $\left(\mathrm{C}_{6} \mathrm{H}_{4} \mathrm{O}_{4}\right)$, obtained from chelidonic acid by the loss of carbon dioxid. It dissolves with difficulty in water; melts at $250^{\circ}$. A., Comenic $\left(\mathrm{C}_{6} \mathrm{H}_{4} \mathrm{O}_{5}\right)$, is produced by heating meconic acid to $\mathbf{I} 20-200^{\circ}$. It is rather insoluble in water and crystallizes in hard, warty masses. 
A., Coumalic $\left(\mathrm{C}_{6} \mathrm{H}_{4} \mathrm{O}_{4}\right)$, identical with comanic acid. Produced when malic acid is heated together with concentrated $\mathrm{H}_{2} \mathrm{SO}_{4}$; dissolves with difficulty in cold water and melts with decomposition at $206^{\circ}$. A., Coumaric $\left(\mathrm{C}_{9} \mathrm{H}_{8} \mathrm{O}_{3}\right)$, an acid derived from coumarin and intimately related to salicylic acid, being converted into the latter by fusion with potassium hydrate. A., Coumarilic $\left(\mathrm{C}_{9} \mathrm{H}_{6} \mathrm{O}_{3}\right)$, a monobasic acid obtained from coumarin dibromid; crystallizes from hot water in delicate needles, melting at $190^{\circ}$; moderately soluble in water and extremely soluble in alcohol. A.,

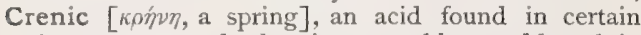
spring waters and also in vegetable mould and in ochreous deposits. A., Cresolsulphuric $\left(\mathrm{C}_{7} \mathrm{H}_{7} \mathrm{O}\right.$.S$\mathrm{O}_{2} \cdot \mathrm{OH}$ ), exists in the urine in small traces; also found in the urine of herbivorous animals. A., Cresylic. See Cresol. A., Croconic $\left(\mathrm{C}_{5} \mathrm{H}_{2} \mathrm{O}_{5}\right)$, is produced by the alkaline oxidation of most of the hexasubstituted benzene-derivatives; crystallizes in sulphur-yellow leaflets, readily soluble in water and alcohol; has an acid taste and reaction. A., Cumic $\left(\mathrm{C}_{10} \mathrm{H}_{12} \mathrm{O}_{2}\right)$, is produced by the oxidation of cuminic alcohol with dilute $\mathrm{HNO}_{3}$. Very soluble in water and alcohol, crystallizes in colorless needles or leaflets, melts at $116^{\circ}$, and boils at about $290^{\circ}$. A , Cyanic (CONH), obtained by heating polymeric cyanuric acid. It is a mobile, volatile liquid, only stable below $\mathrm{O}^{\circ}$; reacts strongly acid; has an odor like that of glacial acetic acid; vesicates the skin; dissolves in alcohols. A., Cyanuric. See A., Tricyanic.

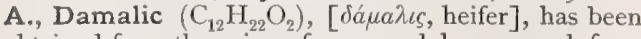
obtained from the urine of cows and horses, and from

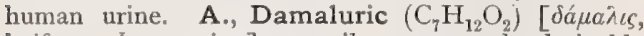
heifer; ovipov, urine], an oily compound, derivable from the urine of cattle and of mankind. A., Desoxalic $\left(\mathrm{C}_{5} \mathrm{H}_{6} \mathrm{O}_{8}\right)$, is seen in large, shining crystals, that melt at $85^{\circ}$ A., Diacetic $\left(\mathrm{C}_{4} \mathrm{H}_{6} \mathrm{O}_{3}\right)$, an acid present in the urine in some diseased conditions, e. g., acetonuria. With a solution of ferric chorid it gives a Burgundy-red color. A., Durylic $\left(\mathrm{C}_{10} \mathrm{H}_{12} \mathrm{O}_{2}\right)$, obtained by the oxidation of durene; crystallizes in hard prisms and melts at II $5^{\circ}$. A., Elaïdic $\left(\mathrm{C}_{18} \mathrm{H}_{34} \mathrm{O}_{2}\right)$, a fatty acid, produced by the action of nitrous acid on oleic acid. Isomeric with the latter. Consists of brilliant leaflets, melting at $44-45^{\circ}$. A., Ellagic $\left(\mathrm{C}_{14} \mathrm{H}_{8} \mathrm{O}_{9}\right)$, occurs in the bezoar stones (an intestinal calculus of the Persian goat). Occurs in the form of a powder containing I molecule of water of crystallization. Insoluble in water; light pale yellow in color; tasteless. A., Enanthylic, or Enanthylic [oivát $\eta$, wine flower, a plant (oivos, wine; à $\nu$ tos, flower); $v \lambda \eta$, principle], a complex ether formed by the action of nitric acid on fatty substances, especially castor oil. A., Erucic $\left(\mathrm{C}_{22} \mathrm{H}_{42} \mathrm{O}_{2}\right)$, present as glycerid in rape-seed oil and in the fatty oil of mustard. Prepared by saponifying rape-seed oil with lead oxid. Crystallizes from alcohol in long needles that melt at $33-34^{\circ}$. A., Euchroic $\left(\mathrm{C}_{12} \mathrm{H}_{4} \mathrm{~N}_{2} \mathrm{O}_{8}\right)$, an amid of mellitic acid, produced by dry distillation of the ammonium salt. It crystallizes in large prisms and is sparingly soluble in water. A., Eugenic. See Eugenol. A., Euxanthinic $\left(\mathrm{C}_{19} \mathrm{H}_{18}\right.$ $\left.\mathrm{O}_{11}\right)$, Porrisic Acid, occurs as a magnesium salt in so-called purrée, a yellow coloring matter from India and China. Crystallizes from alcohol in yellow prisms with $\mathrm{H}_{2} \mathrm{O}$. A., Everninic $\left(\mathrm{C}_{9} \mathrm{H}_{10} \mathrm{O}_{4}\right)$, produced on boiling evernic acid $\left(\mathrm{C}_{17} \mathrm{H}_{16} \mathrm{O}_{7}\right)$ (from Evernia prunastri, a lichen formerly much used in dyeing and for making a hair powder), with baryta. It melts at $157^{\circ}$. A., Ferulic $\left(\mathrm{C}_{10} \mathrm{H}_{10} \mathrm{O}_{4}\right)$, corresponds to vanillin. It is found in asafetida, from which it may be obtained by precipitation with lead acetate. It is very soluble in hot water, crystallizes in shining needles or prisms, and melts at $169^{\circ}$. A., Filicic, the main ingredient of Male Fern. It is a white crystalline powder with slight taste and odor, insoluble in water. A., Fluoric (HF), gaseous and soluble in water, a strong escharotic. The dilute acid, I : 200, is used as an internal remedy in goiter. Dose $\eta_{x x-x x x}$. A. Formic $\left(\mathrm{CH}_{2} \mathrm{O}_{2}\right)$, an acid obtained from a fluid emitted by ants when irritated; also found in stinging nettles, in shoots of the pine, and in various animal secretions. Prepared by heating oxalic acid and glycerin. It is a colorless, mobile fluid, with a pungent odor, and vesicates the skin if dropped upon it. It boils at $99^{\circ}$ and at $0^{\circ}$ has a sp. gr. of I.223. A., Galactonic. See A., Lactonic. A., Gallic $\left(\mathrm{C}_{7} \mathrm{H}_{6}\right.$ $\mathrm{O}_{5}$ ), occurs free in gall nuts, in tea, in the fruit of Casalpinia coriaria, mangoes, and various other plants. Obtained from ordinary tannic acid by boiling it with dilute acids. Crystallizes in fine, silky needles, containing one molecule of water. Dissolves slowly in water and readily in alcohol and ether; has a faintly acid, astringent taste; melts near $220^{\circ}$. Astringent and disinfectant; useful in night sweats, diabetes, and chronic diarrhea. A., Gallic, Unguent, benzoated lard 9o, gallic acid Io. A., Pyrogallic (unofficial), obtained from gallic acid by heating the Iatter. Recommended locally in phagedenic chancres as an antiseptic and disinfectant in $\mathbf{I}-2 \mathrm{r} / 2$ per cent. solutions. Dose, internally, gr. j-ij. A., Gluconic $\left(\mathrm{C}_{6} \mathrm{H}_{12} \mathrm{O}_{7}\right)$, is formed by the oxidation of dextrose, cane sugar, dextrin, starch, and maltose with chlorin or bromin water. Most readily obtained from glucose. It is dextro-rotatory, but does not reduce Fehling's solution. It melts at $200^{\circ}$. A., Glutaric $\left(\mathrm{C}_{5} \mathrm{H}_{8} \mathrm{O}_{4}\right)$, normal pyrotartaric acid. Crystallizes in large monoclinic plates, melts at $97^{\circ}$, and distils at $303^{\circ}$, at $14^{\circ}$ soluble in 1.2 part of water. A., Glycocholic $\left(\mathrm{C}_{26} \mathrm{H}_{43} \mathrm{NO}_{6}\right)$, a monobasic acid found in bile; sparingly soluble in water; crystallizes in minute needles, melting at $133^{\circ}$. A., Glycollic $\left(\mathrm{C}_{2} \mathrm{H}_{4} \mathrm{O}_{3}\right)$, Oxyacetic Acid, produced by the action of nascent hydrogen upon oxalic acid. It is a thick syrup that gradually crystallizes on standing over sulphuric acid; the crystals melt at $80^{\circ}$ and deliquesce in the air. It dissolves easily in water, in alcohol, and in ether. A., Glycoluric $\left(\mathrm{C}_{3} \mathrm{H}_{6} \mathrm{~N}_{2} \mathrm{O}_{3}\right)$, Hydantoïc Acid, prepared by heating urea with glycocoll to $120^{\circ}$. It is a monobasic acid; very soluble in hot water and in alcohol. Crystallizes in large, rhombic prisms. A., Glycuronic $\left(\mathrm{C}_{6} \mathrm{H}_{10} \mathrm{O}_{7}\right)$, obtained by decomposing euxanthic acid on boiling with dilute $\mathrm{H}_{2} \mathrm{SO}_{4}$. It is a syrup that decomposes readily into the lactone, $\mathrm{C}_{6} \mathrm{H}_{8} \mathrm{O}_{6}$, on warming. It is levo-rotatory. This acid has been found in urine; it probably does not exist in normal urine; but it appears after taking certain drugs, as benzol, indol, nitro-benzol, and the quinin derivatives. A., Glyoxylic $\left(\mathrm{C}_{2} \mathrm{H}_{2} \mathrm{O}_{3}\right)$, obtained by oxidizing glycol, alcohol, and aldehyd. It is a thick liquid, readily soluble in water. Crystallizes in rhombic prisms by long standing over sulphuric acid. A., Guanido-Acetic. See Glycocyamin. A., Gynocardic $\left(\mathrm{C}_{14} \mathrm{H}_{24} \mathrm{O}_{2}\right)$, derived from the seeds of the Gynocardia odorata. It occurs as a yellowish oily substance melting at $30^{\circ} \mathrm{C}$. $\left(86^{\circ} \mathrm{F}\right.$. $)$, with a distinct odor and acid taste. Used as an antisyphilitic and antirheumatic. Dose gr. $1 / 2-i i j$. Used externally as a liniment (I to 10 or 20). A., Haloids (as'-id hal'-oidz), derivatives that arise in the replacement of the hydroxyl of acids by halogens. They are liquids of sharp odor, fuming in the air and undergoing transformation into acids and halogen hydrids. They are heavier than water. They decompose at ordinary temperatures, forming acids. A., Hemipinic $\left(\mathrm{C}_{10} \mathrm{H}_{10} \mathrm{O}_{6}\right)$, formed by oxidizing 
narcotin with dilute $\mathrm{HNO}_{3}$. Melts at $182^{\circ}$. A., Hesperetinic $\left(\mathrm{C}_{10} \mathrm{H}_{10} \mathrm{O}_{4}\right)$, obtained from the glucoside hesperidin. Melts at $228^{\circ}$. A., Hippuric $\left(\mathrm{C}_{9} \mathrm{H}_{9}\right.$

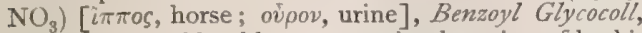
occurs in considerable amount in the urine of herbivorous animals, sometimes in that of man. Crystallizes in rhombic prisms, and dissolves readily in hot water and alcohol. It melts at $187^{\circ}$. Its salts (hippurates of lime, lithium, and sodium) are regarded as good solvents of the urates, and are recommended in gout, rheumatism, and calculous diseases. Dose grs. ivxvj. Unof. A., Hircic, a peculiar-smelling acid contained in goat's milk. A., Homogentisic, an acid separated by Baumann from highly-colored urine, believed to be formed by the action of bacteria on the tyrosin normally found in pancreatic digestion. A., Homophthalic $\left(\mathrm{C}_{9} \mathrm{H}_{8} \mathrm{O}_{4}\right)$, obtained by fusing gamboge with caustic potash. Crystallizes from hot water in stout prisms, melting at $175^{\circ}$. A., Hydantoìc. See A., Glycoluric. A., Hydriodic (HI), Acidum Hydriodicum; a gaseous acid. Its solution and a syrup prepared from it are used as alteratives, with the general effects of iodin. Unof. A., Hydrobromic $(\mathrm{HBr})$; the dilute acid, which is the chief form used, consists of Io per cent. acid and 90 per cent. water. A good solvent for quinin. Useful in hysteria, congestive headaches, and neuralgia. Is recommended as a substitute for potassium and sodium bromids. Dose $m x x-z^{i j}$. A., Hydrocaffeìc $\left(C_{9}-\right.$ $\left.\mathrm{H}_{10} \mathrm{O}_{4}\right)$, obtained from caffeîc acid by the action of sodium amalgam. A., Hydrochloric, Muriatic Acid ( $\mathrm{HCl}$ ), a liquid consisting of 31.9 per cent. of $\mathrm{HCl}$ gas in 68. I per cent. of water. Colorless, pungent, and intensely acid. Valuable as an aid to digestion. A., Hydrochloric, Dilute, a ten per cent. solution of absolute acid in water. Dose $\mathrm{miij}_{\mathrm{iij}} \mathrm{x}$. A., Hydrocinnamic $\left(\mathrm{C}_{6} \mathrm{H}_{5^{*}}\left(\mathrm{CH}_{2}\right)_{2} \mathrm{CO}_{2} \mathrm{H}\right)$, Phenyl-propionic Acid, obtained by the action of sodium amalgam upon cinnamic acid. Very soluble in hot water and alcohol; crystallizes in needles, melts at $47^{\circ}$, and distils at $280^{\circ}$. A., Hydrocyanic, Dilute (HCN), Prussic Acid, a liquid consisting of two per cent. of the acid with 98 per cent. of water and alcohol. Generally prepared by the action of $\mathrm{H}_{2} \mathrm{SO}_{4}$ on potassium ferrocyanid. It is a mobile liquid, of a sp. gr. of .697 at $18^{\circ}$; becomes crystalline at $-15^{\circ}$; boils at $+26.5^{\circ}$; possesses an odor like that of bitter almonds ; is extremely poisonous; a feeble acid. Prussic acid is found in the bitter almond, the leaves of the peach, and in the cherry laurel, from the leaves of which it is distilled. It is the most violent poison known, death from complete asphyxia being almost instantaneous. Valuable for its sedative and antispasmodic effects in vomiting, whooping-cough, and spasmodic affections. Dose $m j-v$. The following preparations are employed: Aqua Laurocerasi, water distilled from the leaves of the cherry laurel. Dose $\eta^{\nabla-x x x}$, with caution. Scheele's Dilute Hydrocyanic Acid, is a 4 or 5 per cent. solution; dangerous. Amygdala Amara, oil of bitter almond; used in cosmetics. A., Hydrocyanic, Vapor, $\eta x-x v$ of dilute acid in $3 j$ of water, warmed and the vapor inhaled to relieve irritable coughs. A., Hydrofluoric (HF), an aqueous solution of hydrofluoric gas, administered in dilute form as an inhalation in phthisis and goiter. See Fluorin. A., Hydrosulphuric $\left(\mathrm{H}_{2} \mathrm{~S}\right)$, an acid which, both in its pure and gaseous form and in its watery solution, is much used as a chemical reagent. The gas has been employed by inhalation and by rectal injection in cases of tuberculosis. (See Bergeron's Method.) Called also Hydrogen Sulfid and Sulfydric Acid. A., Hydrurilic $\left(\mathrm{C}_{8} \mathrm{H}_{6} \mathrm{~N}_{4} \mathrm{O}_{6}\right)$, obtained by decomposing the copper salt with $\mathrm{HCl}$. Occurs in little prisms. A., Hyperosmic.

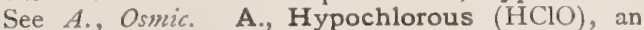
unstable compound, important as a disinfecting and bleaching agent. Some of its salts, the hypochlorites, have a limited use in medicine. A., Hypophosphorous $\left(\mathrm{H}_{3} \mathrm{PO}_{2}\right)$, its salts (hypophosphites), also the dilute acid, and a syrup prepared with it, are used as remedial agents. (See Calcii Hypophosphis, Ferri Hypophosphis, Sodii Hypophosphis, Potassii Hypophosphis). A., Igasuric, an acid occurring in St. Ignatius Bean and certain other plants containing strychnia. It occurs in small, hard crystals with an acid, astringent taste. A., Indoxylic $\left(\mathrm{C}_{9} \mathrm{H}_{7} \mathrm{NO}_{3}\right)$, produced from its ethyl ester by fusion with caustic soda at I80. Appears as a white crystalline mass, melting at $123^{\circ}$. A., Iodic $\left(\mathrm{HIO}_{3}\right)$, a monobasic acid. Its solution (two per cent.) has been recommended as an alterative subcutaneous injection. A., Isopropyl Succinic. See $A$. Pimelic. A., Isosaccharic $\left(\mathrm{C}_{6}-\right.$ $\mathrm{H}_{10} \mathrm{O}_{8}$ ), an acid very soluble in water and alcohol, forming rhombic crystals, and melting at $185^{\circ}$. Its solution is dextro-rotatory. A., Kephalo-phosphoric, a brain-acid differing from ordinary phosphoric acid in that three molecules of its hydroxyl are replaced by one molecule each of kepalyl, stearyl, and glyceryl. A., Lactic $\left(\mathrm{HC}_{3} \mathrm{H}_{5} \mathrm{O}_{3}\right)$, a liquid containing 75 per cent. of absolute acid in 25 per cent. of water. Produced in the fermentation of milk. Generally found impure from subsequent fermentation, except when freshly made. Useful in aiding digestion, in diabetes, and as a solvent of false membrane in diphtheria. Dose $z^{\text {ss }}-\zeta_{\text {ss. }}$ A., Lactic, Dil., (B. P.). Dose $3^{\mathrm{ss}-\mathrm{ij}}$. A., Lactonic $\left(\mathrm{C}_{6} \mathrm{H}_{12} \mathrm{O}_{7}\right)$, Galactonic Acid, produced from milk-sugar, galáctose, and gum arabic by the action of brorain water. It crystallizes, on standing over $\mathrm{H}_{2} \mathrm{SO}_{4}$, in small needles. A., Leuconic $\left(\mathrm{C}_{5} \mathrm{O}_{5}+4 \mathrm{H}_{2} \mathrm{O}\right)$, an acid produced by oxidizing croconic acid with $\mathrm{HNO}_{3}$ or chlorin. Very soluble in water; occurs in small, colorless needles. A., Levulinic $\left(\mathrm{C}_{5} \mathrm{H}_{8} \mathrm{O}_{3}\right)$, obtained from levulose, cellulose, cane-sugar, etc. Isomeric with methyl acetoacetic acid; dissolves readily in water, alcohol, and ether; crystallizes in scales that melt at $33.5^{\circ}$; boils with slight decomposition at $239^{\circ}$. A., Linoleic $\left(\mathrm{C}_{16} \mathrm{H}_{28} \mathrm{O}_{2}\right)$, occurs as glycerid in drying oils, such as linseed oil, hemp oil, poppy oil, and nut oil. Prepared by saponifying linseed oil with potash. It is a yellowish oil that has a sp. gr. of $0.92 \mathbf{I}$. A., Maizenic, an acid derived from the stigmata (silk) of Indian corn; said to be a good diuretic. Unof. A., Malic $\left(\mathrm{C}_{4} \mathrm{H}_{6} \mathrm{O}_{5}\right)$, a bibasic acid, occurring free or in the form of salts in many plant juices, in unripe apples, in grapes, and in mountain-ash berries. It forms deliquescent crystals, that dissolve readily in alcohol, slightly in ether, and melt at $100^{\circ}$; it has a pleasant acid taste. A., Malonic $\left(\mathrm{C}_{3} \mathrm{H}_{4} \mathrm{O}_{4}\right)$, occurs in the deposit found in the vacuum pans employed in the beetsugar manufacture; obtained by the oxidation of malic acid with chromic acid; crystallizes in large tables or laminæ; easily soluble in water, alcohol, and ether; melts at $132^{\circ}$; at higher temperatures it decomposes into acetic acid and carbon dioxid. A., Mandelic $\left(\mathrm{C}_{6} \mathrm{H}_{5} \cdot \mathrm{CH}(\mathrm{OH}) \cdot \mathrm{CO}_{2} \mathrm{H}\right)$, is formed from benzaldehyd by the action of prussic acid and $\mathrm{HCl}$. Obtained naturally from amygdalin; is levo-rotatory, and forms brilliant crystals, melting at $132.8^{\circ}$. A., Mannitic $\left(\mathrm{C}_{6} \mathrm{H}_{12} \mathrm{O}_{7}\right)$, obtained by the action of platinum black upon aqueous mannitol. It is a very soluble, gummy mass, and reduces Fehling's solution. A., Mannonic $\left(\mathrm{C}_{6} \mathrm{H}_{12} \mathrm{O}_{7}\right)$, produced by oxidizing mannose with bromin water. A., Meconic $\left(\mathrm{C}_{7} \mathrm{H}_{4} \mathrm{O}_{7}\right)$, a tribasic acid, occurring in opium in union with mor 
phin. Crystallizes with $3 \mathrm{H}_{2} \mathrm{O}$ in white laminæ, readily soluble in hot water and alcohol. Ferric salts color the acid solutions dark red. A., Melilotic $\left(\mathrm{C}_{6} \mathrm{H}_{4}\left(\mathrm{CH}_{2}\right)_{2}, \mathrm{OH} \cdot \mathrm{CO}_{2} \mathrm{H}\right)$, occurs free and in combination with coumarin in the yellow melilot. Crys tallizes in long needles, dissolves easily in hot water, and melts at $8 \mathrm{I}^{\circ}$. A., Mellitic $\left(\mathrm{C}_{12} \mathrm{H}_{6} \mathrm{O}_{12}\right)$, occurs in mellite or honey-stone, which is found in some lignite beds. Honey-stone is an aluminium salt of mellitic acid, $\mathrm{C}_{12} \mathrm{Al}_{2} \mathrm{O}_{14}+\mathbf{I} 8 \mathrm{H}_{2} \mathrm{O}$, and affords large quadratic pyramids of a bright yellow color. Mellitic acid crys tallizes in fine, silky needles, readily soluble in water and alcohol; has a sour, bitter taste. A., Mellophanic $\left(\mathrm{C}_{6} \mathrm{H}_{2}\left(\mathrm{CO}_{2} \mathrm{H}\right)_{4}\right)$, formed by the oxidation of isodurene. Very soluble in cold water and crystallizes in small prisms. Melts at $240^{\circ}$. A., Mesidic. See $A$. Uritic. A., Mesitylenic $\left(\mathrm{C}_{9} \mathrm{H}_{10} \mathrm{O}_{2}\right)$, obtained by gradually oxidizing mesitylene with dilute $\mathrm{HNO}_{3}$ Crystallizes from alcohol in large prisms, from water in needles. Melts at $166^{\circ}$ and sublimes very readily. A., Metaphosphoric $\left(\mathrm{HPO}_{3}\right)$, a glassy solid, not volatile by heat. It is freely soluble in cold water, and is converted by boiling into orthophosphoric acid. Used as a test for albumin in the urine. A., Metasaccharic $\left(\mathrm{C}_{6} \mathrm{H}_{10} \mathrm{O}_{8}\right)$, produced by oxidizing arabinose carboxylic acid with $\mathrm{HNO}_{3^{\circ}}$. Melts at $68^{\circ}$ when air-dried. A., Mucic $\left(\mathrm{C}_{6} \mathrm{H}_{10} \mathrm{O}_{8}\right)$, is obtained in the oxidation of dulcitol, milk-sugar, galactose, galac tonic acid and nearly all the gum varieties. A white crystalline powder, almost insoluble in cold water and alcohol. It melts at $210^{\circ}$ with decomposition. A., Muriatic. See $A$., Hydrochloric. A., Myronic [ $\mu$ ípov, unguent] $\left(\mathrm{C}_{10} \mathrm{H}_{19} \mathrm{NS}_{2} \mathrm{O}_{10}\right)$, an acid that occurs as a potassium salt in the seeds of black mustard. Crystallizes from water in bright needles. A., Nitric $\left(\mathrm{HNO}_{3}\right)$, a liquid consisting of 68 per cent. absolute acid in 32 per cent. of water. The pure acid is colorless, fuming, and highly caustic. A very powerful escharotic used in cauterization of chancres and phagedenic ulcers. A., Nit., Dilute, contains ten per cent. absolute acid. Dose $\eta_{i i j-x v}$, well diluted. A., Nitrohydrochloric, Aqua Reoia, a golden yellow, fuming mixture of four parts nitric and $\mathbf{I} 5$ of hydrochloric acid. A ready solvent of gold. Valuable in affections of the liver. Dose $\eta_{v-x x}$, very dilute. A., Noropianic $\left(\mathrm{C}_{8} \mathrm{H}_{6} \mathrm{O}_{5}\right)$, is obtained from opianic acid by heating with hydriodic acid. Readily soluble in water; melting at $171^{\circ}$. A., Oleic $\left(\mathrm{C}_{18} \mathrm{H}_{34} \mathrm{O}_{2}\right)$, a constituent acid present in many fats and oils. Obtained in the manufacture of stearin candles. Soluble in alcohol, benzol, and the essential oils; insoluble in water. Saponifies when heated with alkaline bases. Used in making the oleates. It is a colorless oil that crystallizes on cooling. Melts at $+\mathbf{1} 4^{\circ}$. Odorless in a pure condition, but becomes rancid on exposure to the air. A., Opianic $\left(\mathrm{C}_{10} \mathrm{H}_{10} \mathrm{O}_{5}\right)$, dimethyl ether of noropianic acid. Crystallizes from hot water in fine prisms, melt ing at $150^{\circ}$. A., Orsellinic $\left(\mathrm{C}_{8} \mathrm{H}_{8} \mathrm{O}_{4}\right)$, is found in different lichens of the genera Roccella and $\mathrm{Le}$ canora. Consists of easily soluble prisms, melting at I $76^{\circ}$. A., Ortho-oxybenzoic. See $A$. Salicylic. A., Orthophosphoric $\left(\mathrm{H}_{3} \mathrm{PO}_{4}\right)$, ordinary phosphoric acid, as distinguished from metaphosphoric and pyrophosphoric acids. A., Osmic $\left(\mathrm{OsO}_{4}\right)$, the oxide of osmium, one of the rarer elements; it occurs as yellow crystals, acrid, burning, yielding an intensely irritating vapor; it has been recommended for hypodermatic use in sciatica, strumous glands, and cancer. A., Osmic, Liq., one per cent. Dose $\mathrm{m}$ iv-vj, hypodermatically for sciatica, neuralgia, etc. Potassium Osmate $\left(\mathrm{K}_{2} \mathrm{OsO}_{4}+\right.$ $2 \mathrm{H}_{2} \mathrm{O}$ ), given in epilepsy. Dose gr, $\frac{1}{6}$. A., Oxalic $\left(\mathrm{C}_{2} \mathrm{H}_{2} \mathrm{O}_{4}\right)$, a colorless crystalline solid obtained by treating sawdust with caustic soda and potash. It occurs in many plants chiefly as potassium oxalate; with two parts of water, it crystallizes in fine, transparent monoclinic prisms that at $20^{\circ}$ effloresce in dry air and fall in a white powder. It is soluble in nine parts of water at moderate temperature and quite easily in alcohol. In $1 / 2 \mathrm{gr}$. doses a depressant to respiratory centers. In large doses a violent poison. Unof, A. Oxamic $\left(\mathrm{C}_{2} \mathrm{O}_{2}\left(\mathrm{NH}_{2} \mathrm{OH}\right)\right)$, a monobasic acid occurring as a crystalline powder that dissolves with difficulty in cold water and melts at $173^{\circ}$. A., Oxyacetic. See $A$. Glycollic. A., Oxycitric $\left(\mathrm{C}_{6} \mathrm{H}_{8} \mathrm{O}_{8}\right)$, is produced by boiling chlorcitric acid with alkalies or water. A., Oxyuvitic $\left(\mathrm{C}_{9} \mathrm{H}_{8} \mathrm{O}_{5}\right)$, is produced by the action of chloroform upon sodium aceto-acetic ester. Crystallizes from hot water in fine needles, and melts with decomposition at about $290^{\circ}$. A., Palmitic $\left(\mathrm{C}_{10} \mathrm{H}_{32} \mathrm{O}_{2}\right)$, an acid existing as a glycerin ether in palm-oil and in most of the solid fats. It forms fine, white needles, or pearly crystalline scales. A., Palmitolic $\left(\mathrm{C}_{16} \mathrm{H}_{28} \mathrm{O}_{2}\right)$, an acid that is isomeric with linoleic acid; melts at $42^{\circ}$. A., Palmitoxylic $\left(\mathrm{C}_{16} \mathrm{H}_{28} \mathrm{O}_{4}\right)$, a monobasic acid, produced from palmitolic acid on heating with fuming $\mathrm{HNO}_{3}$. Melts at $67^{\circ}$. A., Paracresotic $\left(\mathrm{C}_{8} \mathrm{H}_{9} \mathrm{O}_{3}\right)$, a preparation from paracresylol. It is employed usually in the form of its sodium salt, $\mathrm{C}_{8} \mathrm{H}_{7} \mathrm{NaO}_{3}$, which is a safe and reliable antipyretic. It is especially of service in the rheumatism of children. Dose, to children, gr. ijiij ; to adults up to 3 ij. Unof. A., Paralactic. See $A$. Sarcolactic. A., Paratartaric. See A., Racentic. A., Pelargonic $\left(\mathrm{C}_{9} \mathrm{H}_{18} \mathrm{O}_{2}\right)$, a complex ether that imparts the specific flavor to geranium and certain other aromatic oils. A., Perosmic. Same as A., Osmic. A., Phenylacetic $\left(\mathrm{C}_{6} \mathrm{H}_{5} \cdot \mathrm{CH}_{2} \cdot \mathrm{CO}_{2} \mathrm{H}\right)$, Alphatoluic Acid, obtained from benzyl cyanid when boiled with alkalies. Crystallizes in shining leaflets, resembling those of benzoic acid; melts at $76.5^{\circ}$, and boils at $262^{\circ}$. It is prescribed in coughs and tuberculosis; is stimulant and antihectic. Dose of alcoholic solution gtt. x-xx. Unof. A., Phenyl-propionic. See $A$., Hydrocinnamic. A., Phenyl Sulphate, a solution of three grammes of phenol in 20 c.c. of strong sulphuric acid. Used for the detection of nitrates in water. A., Phosphoric $\left(\mathrm{H}_{3} \mathrm{PO}_{4}\right)$, Orthophosphoric Acid, contains 50 per cent, each of acid and water. Of value in strumous affections, and thought to be serviceable in dissolving phosphatic deposits. Has none of the effects derived from free phosphorus or the hypophosphites. A., Phosphoric, Dilute, contains ten per cent. of absolute acid. Dose $\eta_{v} v-x x x$. See Sodium, Potassium, Calcium, etc. A., Phosphorous $\left(\mathrm{H}_{3} \mathrm{PO}_{3}\right)$, a compound of hydrogen with phosphorus and hydrogen with phosphorus anhydrid. Its salts are called phosphites. A., Phthalic $\left(\mathrm{C}_{8} \mathrm{H}_{6} \mathrm{O}_{4}\right)$, the ortho-dicarboxylic acid of benzene, obtained by oxidizing naphthalene with $\mathrm{HNO}_{3}$. It crystallizes in short prisms or in leaflets readily soluble in hot water, alcohol, and ether. It melts at above $200^{\circ}$. See Phthalate. A., Picric $\left(\mathrm{C}_{6} \mathrm{H}_{2}\left(\mathrm{NO}_{2}\right)_{3} \mathrm{OH}\right)$, obtained by the nitration of phenol. It crystallizes from hot water and alcohol in yellow leaflets or prisms which possess a very bitter taste. Readily soluble in hot water, its solution imparting a beautiful yellow color to silk and wool. It melts at $122.5^{\circ}$; a saturated solution is of some value as a wash in erysipelas. An excellent test for albumin and sugar in urine. Dose gr. v-xv. A., Pimelic $\left(\mathrm{C}_{7} \mathrm{H}_{12} \mathrm{O}_{4}\right)$, Isopropyl Succinic Acid, melts at $\mathrm{II}_{4}^{\circ}$. A., Piperic $\left(\mathrm{C}_{12} \mathrm{H}_{10} \mathrm{O}_{4}\right)$, a monobasic acid, consisting of shining prisms; almost insoluble in water, and crystallizes from alcohol in long needles, melting at $217^{\circ}$. It is produced from piperin by boiling with alcoholic potash. A., Porrisic. See A., Euxanthinic. A., 
Prehnitic $\left(\mathrm{C}_{10} \mathrm{H}_{6} \mathrm{O}_{8}\right)$, results from oxidizing prehnitol with potassium permanganate. Very soluble in water, and crystallizes in warty masses that melt at $238^{\circ}$. A., Propargylic. See A., Propiolic. A., Propiolic. $\left(\mathrm{C}_{3} \mathrm{H}_{2} \mathrm{O}_{2}\right)$, Proparsylic Acid, a liquid with an odor resembling that of glacial acetic acid; when cool, it solidifies to silky needles, that melt at $+6^{\circ}$; dissolves readily in water, alcohol, and ether; boils with decomposition at $\mathrm{I}_{44^{\circ}}{ }^{\circ}$ A., Protocatechuic $\left(\mathrm{C}_{7} \mathrm{H}_{6} \mathrm{O}_{4}\right)$, obtained from many benzene derivatives as well as from various resins (benzoin, asafetida, myrrh) on fusion with potassium hydroxid. Crystallizes with one molecule of water in shining needles or leaflets, and dissolves readily in hot water, alcohol, and ether. A., Prussic. See A., Hydrocyanic. A., Purpuric $\left(\mathrm{C}_{8} \mathrm{H}_{5} \mathrm{~N}_{5} \mathrm{O}_{6}\right)$, an acid not known in the free state, since as soon as it is liberated from its salts by mineral acids it immediately decomposes into alloxan and uramil. - Produced by the action of $\mathrm{HNO}_{3}$ upon uric acid. A., Pyrogallic $\left(\mathrm{C}_{6} \mathrm{H}_{6} \mathrm{O}_{3}\right)$, pyrogallol, formed by heating gallic acid with water to $210^{\circ}$ It forms white leaflets or needles, melts at $I 15^{\circ}$, and sublimes when carefully heated. Readily soluble in water, less so in alcohol and ether. It is useful in the treatment of certain skin diseases, but is poisonous, and must be used with caution. A., Pyroligneous, the crude acid obtained in the destructive distillation of wood. It is a clear liquid of reddish-brown color and strong acid taste, with a peculiar penetrating odor described as empyreumatic, due largely to the furfurol it contains. It possesses a sp. gr. of from I.OI8 to 1.030, and contains from four to seven per cent. of real acetic acid. A., Pyromellitic $\left(\mathrm{C}_{10} \mathrm{H}_{6} \mathrm{O}_{8}\right)$, is produced by oxidizing durene and durylic acid with potassium permanganate. Crystallizes in prisms, readily soluble in hot water and alcohol, melts at $264^{\circ}$. A., Pyrophosphoric, the dihydric phosphate $\left(2 \mathrm{H}_{2} \mathrm{O}_{2} \mathrm{P}_{2} \mathrm{O}_{5}\right)$, one of the forms of the so-called phosphoric acid. It differs from the ordinary (trihydric or orthophosphoric) acid, and also from the monohydric, or metaphosphoric, acid, in its reactions. It is also poisonous, which they are not. Its iron salt is used in medicine. The pure acid is a soft, glassy mass. A., Pyrotartaric $\left(\mathrm{C}_{5} \mathrm{H}_{8}\right.$ $\left.\mathrm{O}_{4}\right)$, is obtained by heating tartaric acid in a close vessel ; consists of small, rhombic prisms, readily soluble in water, in alcohol, and in ether; it melts at $112^{\circ}$. A., Pyruvic $\left(\mathrm{C}_{3} \mathrm{H}_{4} \mathrm{O}_{3}\right)$, a monobasic acid forming crystalline compounds with the acid alkaline sulphites. A., Quillaic, an acid existing in commercial saponin. Injected into the tissues it is said to be extremely poisonous, though not when taken by the mouth. Unof. A., Quinaldinic $\left(\mathrm{C}_{9} \mathrm{H}_{6} \mathrm{~N}\left(\mathrm{CO}_{2} \mathrm{H}\right)\right)$, crystallizes from hot water in needles containing $2 \mathrm{H}_{2} \mathrm{O}$; effloresces in the air; melts at $156^{\circ}$. Prepared by oxidizing $a$-methyl-quinolin with chromic acid in sulphuric acid solution. A., Quinic $\left(\mathrm{C}_{7} \mathrm{H}_{12} \mathrm{O}_{6}\right)$, is present in the cinchona barks, coffee beans, bilberry, and other plants. Obtained as a secondary product in the preparation of quinin. Consists of rhombic prisms, easily soluble in water; melting at $162^{\circ}$. A., Quininic $\left(\mathrm{C}_{9} \mathrm{H}_{5}\left(\mathrm{O} . \mathrm{CH}_{3}\right) \mathrm{N}\left(\mathrm{CO}_{2} \mathrm{H}\right)\right)$, obtained by oxidizing quinin and quinidin with chromic acid in sulphuric acid solution. Crystallizes in long, yellow prisms; dissolves in alcohol with a blue fluorescence, and melts at $280^{\circ}$. A., Racemic $\left(\mathrm{C}_{4} \mathrm{H}_{6} \mathrm{O}_{6}\right)$, Paratartaric Acid, differing from common tartaric acid, not in chemical but in physical properties. A., Rheinic. See A., Chrysophanic. A., Rhodanic $\left(\mathrm{C}_{3} \mathrm{H}_{3} \mathrm{~S}_{2} \mathrm{ON}\right)$, obtained by the action of $\mathrm{CNS}\left(\mathrm{NH}_{4}\right)$ upon chloracetic acid. Consists of yellow prisms, or plates, that melt at $\mathbf{1} 69^{\circ}$ with decomposition. A., Ricinoleic $\left(\mathrm{C}_{18} \mathrm{H}_{34} \mathrm{O}_{3}\right)$, is present in castor oil in the form of a glycerid. It is a colorless oil that solidifies in the cold to a hard, white mass, melting at $16-17^{\circ}$. A., Rosolic $\left(\mathrm{C}_{20} \mathrm{H}_{16} \mathrm{O}_{3}\right)$, a phenol compound, derived from rosanilin; valued as a dye and as a staining agent. See Stains. A., Rufigallic $\left(\mathrm{C}_{14} \mathrm{H}_{8} \mathrm{O}_{8}+2 \mathrm{H}_{2}\right.$ $\mathrm{O})$, a derivative of anthracene; obtained by heating gallic acid with four parts of $\mathrm{H}_{2} \mathrm{SO}_{4}$ to $\mathrm{I}_{4} 0^{\circ}$. Consists

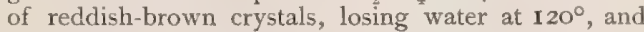
subliming in red needles. A., Saccharic. I. Acidum saccharicum $\left(\mathrm{C}_{6} \mathrm{H}_{10} \mathrm{O}_{8}\right)$, a dibasic acid; a deliquescent, gummy mass, readily soluble in alcohol. It turns brown at $100^{\circ}$ and decomposes. Prepared by the action of $\mathrm{HNO}_{3}$ on sugar and various other carbohydrates. 2. $\left(\mathrm{C}_{6} \mathrm{H}_{12} \mathrm{O}_{6}\right)$, Tetraoxycaproic Acid, a monobasic acid readily changeable, when free, into its lactone, saccharin. Not known in its free state. A., Saccharonic $\left(\mathrm{C}_{6} \mathrm{H}_{10} \mathrm{O}_{7}\right)$, formed by oxidizing saccharin by $\mathrm{HNO}_{3}$. Very soluble in water; forms large crystals. A., Salicylic $\left(\mathrm{C}_{7} \mathrm{H}_{6} \mathrm{O}_{3}\right)$, Ortho-oxybenzoic Acid, occurs in a free condition in the buds of Spircea Ulmaria, in the oil of wintergreen, and in other varieties of gaultheria. It consists of four-sided prisms and crystallizes readily from hot water in long needles. Is soluble in water, and very soluble in chloroform; melts at $155^{\circ}-156^{\circ}$. Is a powerful antiseptic ; also used in the treatment of acute articular rheumatism and myalgia. A., Santoninic $\left(\mathrm{C}_{15} \mathrm{H}_{20} \mathrm{O}_{4}\right)$, an acid into which santonin is changed under the influence of the alkalies. A., Sarcolactic $\left(\mathrm{C}_{3} \mathrm{H}_{6} \mathrm{O}_{3}\right)$, occurs in muscles, to which it gives their acid reaction, and in blood, especially after the muscles have been in a state of contracting activity, It is also found in urine in phosphorus poisoning. A. Sclerotinic. An acid found in ergot, of which it is one of the active principles. Given, hypodermically it has acted as an ecbolic. See Sclerotis. A., Sorbic $\left(\mathrm{C}_{6} \mathrm{H}_{8} \mathrm{O}_{2}\right)$, occurs together with malic acid in the juice of unripe mountain-ash berries. An oil that does not solidify until it has been heated with potash; almost insoluble in cold water, but crystallizes from alcohol in long needles, melting at $\mathbf{1} 34.5^{\circ}$, distilling at $228^{\circ}$ without decomposition. A., Sozolic. See Aseptol. A., Sphingostearic, an acid closely resembling stearic acid, derivable from sphingomyelin. A., Stearic $\left(\mathrm{C}_{18} \mathrm{H}_{36} \mathrm{O}_{2}\right)$, associated with palmitic and oleic acids as a mixed ether, in solid animal fats, the tallows; crystallizes from alcohol in brilliant leaflets, melting at $62.2^{\circ} \mathrm{C}$. A., Stearoleic $\left(\mathrm{C}_{18} \mathrm{H}_{32} \mathrm{O}_{2}\right)$, obtained from oleic and elaîdic acids. Melts at $48^{\circ}$. A., Stearoxylic $\left(\mathrm{C}_{18} \mathrm{H}_{32} \mathrm{O}_{4}\right)$, produced by warming stearoleic acid. Melts at $86^{\circ}$. A., Suberic $\left(\mathrm{C}_{8} \mathrm{H}_{14} \mathrm{O}_{4}\right)$, a dibasic acid obtained by boiling corks or fatty oils with $\mathrm{HNO}_{3}$. Melts at $\mathbf{I}_{4} 0^{\circ} \mathrm{C}$. Forms small granular crystals very soluble in boiling water, in alcohol, and in ether. It fuses at about $300^{\circ} \mathrm{F}$, and sublimes in acicular crystals. A., Succinic $\left(\mathrm{C}_{4} \mathrm{H}_{6} \mathrm{O}_{4}\right)$, an acid prepared by the distillation of amber, and artificially in many other ways; occurs in certain hydatid cysts of the liver; diuretic, stimulant, and antispasmodic. Unof. A., Sulfydric. See A., Hydrosulphuric. A., Sulphanilic $\left(\mathrm{C}_{6} \mathrm{H}_{4}\left(\mathrm{NH}_{2}\right) \cdot \mathrm{SO}_{3} \mathrm{H}\right)$, obtained by heating anilin (I part) with fuming $\mathrm{H}_{2} \mathrm{SO}_{4}$ (2 parts) to $180^{\circ}$ until $\mathrm{SO}_{2}$ appears. Crystallizes in rhombic plates with one molecule of water, which effloresce in the air. A., Sulphichthyolic, an acid that appears to be the principal component of commercial ichthyol. Its sodium, ammonium, lithium, and zinc salts have been highly praised as efficacious in cystitis, nephritis, and diabetes. Dose grs. iss in pill or capsule. A., Sulphocarbolic $\left(\mathrm{C}_{6} \mathrm{H}_{5} \mathrm{HSO}_{4}\right)$, phenyl bisulphate, formed by the union of carbolic and sulphuric acids. Its salts, the sulpho-carbolates, are used in medicine as intestinal antiseptics, etc. See Aseptol. A., 
Sulphonic. See Aseptol. A., Sulphoricineolic, an acid prepared from castor oil acted upon by sulphuric acid. It is a thick syrup, that has the power of dissolving and emulsifying many substances; recommended for pharmaceutical uses. A., Sulphuric $\left(\mathrm{H}_{2} \mathrm{SO}_{4}\right)$, Oil of Vitriol, a heavy, oily, corrosive acid, consisting of not less than 92.5 per cent. sulphuric anhydrid and 7.5 per cent. of water. Of value in lead poisoning. Sometimes used as a caustic. A., Sulph., Aromatic, contains 20 per cent. acid, diluted with alcohol and flavored with cinnamon and ginger.

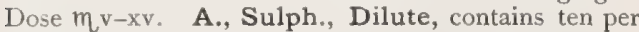
cent. strong acid to 90 of water. Dose $m x-x v$, well diluted. A., Sulphurous $\left(\mathrm{H}_{2} \mathrm{SO}_{3}\right)$, a colorless acid containing about 6.4 per cent. of sulphurous anhydrid in 93.6 per cent. of water. The gas $\left(\mathrm{SO}_{2}\right)$ is a very valuable disinfectant. The acid is used as a spray or lotion in diphtheria, stomatitis, and as a wash for indolent and syphilitic ulcers. The various hyposulphites are mainly valuable in that they decompose and give off sulphur dioxid. Dose $\eta^{v-}$ 3j. See, also, Sodium, Potassium, and Magnesium. A., Tannic $\left(\mathrm{C}_{14} \mathrm{H}_{10} \mathrm{O}_{9}\right)$, Tannin, an astringent acid obtained from nutgalls, occurring in yellowish, scaly crystals. Soluble in water and alcohol. Internally it is an antidote in poisoning by alkaloids and tartar emetic, and in hemorrhoids and catarrh of mucous membrane. Useful mainly as an astringent lotion in many skin diseases. Dose gr. j-xx. A., Tan., Glycerit, one part tannin in four of glycerin. A. Tan., Suppositories, one part of tannin to five of butter of cacao. A., Tan., Troches, each contain $1 / 2$ gr. of tannic acid. A., Tan., Unguent, a ten per cent. ointment of the acid incorporated with benzoated lard. . A., Tartaric $\left(\mathrm{C}_{14} \mathrm{H}_{10} \mathrm{O}_{9}\right)$, an astringent acid, chiefly employed in refrigerant drinks and in baking powders; 20 grains neutralize 27 of potassium dicarbonate, 22 of sodium dicarbonate, and $15 \mathrm{I} / 2$ of ammonium carbonate. Dose gr. $\mathrm{x}-\mathrm{xxx}$. Widely distributed in the vegetable world, and occurs principally in the juice of the grape, from which it deposits after fermentation in the form of acid potassium tartrate (argol). It results on oxidizing saccharic acid and milk sugar with $\mathrm{HNO}_{3}$. It crystallizes in large monoclinic prisms, which dissolve readily in water and alcohol, but not in ether. It melts at $167^{\circ}$ $170^{\circ}$. Its salts are the tartrates. A., Tartronic $\left(\mathrm{C}_{3}\right.$ $\mathrm{H}_{4} \mathrm{O}_{5}$ ), occurs in large prisms that are easily soluble in water, alcohol, and ether. It melts at $\mathbf{1} 84^{\circ} \mathrm{C}$. Produced from glycerol by oxidation with potassium permanganate. A., Taurocholic $\left(\mathrm{C}_{24} \mathrm{H}_{45} \mathrm{NOS}_{7}\right)$, occurs in bile; very soluble in water and alcohol, crystallizes in fine needles. A., Teracrylic $\left(\mathrm{C}_{7} \mathrm{H}_{12}\right.$ $\mathrm{O}_{2}$ ), obtained by the distillation of terpentic acid. It is an oily liquid, with an odor resembling that of valeric acid, and boiling at $208^{\circ}$ without decomposition. A., Terebic $\left(\mathrm{C}_{7} \mathrm{H}_{10} \mathrm{O}_{4}\right)$, a monobasic acid formed when turpentine oil is oxidized with $\mathrm{HNO}_{3}$. Sparingly soluble in cold water, crystallizes in shining prisms, and melts at $175^{\circ}$. A., Tetraoxycaproic. See A., Saccharic. A., Tetraoxyvaleric. See A., Arabonic. A., Thebolactic $\left(\mathrm{C}_{3} \mathrm{H}_{6} \mathrm{O}_{3}\right)$, a crystalline principle obtained from opium. A., Tide $\left(a s^{\prime}-i d-t i d\right)$. See Tide. A., Trichloracetic $\left(\mathrm{HC}_{2}\right.$ $\mathrm{Cl}_{3} \mathrm{O}_{2}$ ), an acid formed from acetic acid, three atoms of the hydrogen of which is (in the new acid) replaced by chlorin. It is considered one of the best reagents for the detection of albumin in the urine, and is a valuable caustic, especially for rhinopharyngological purposes. A., Trichlorlactic $\left(\mathrm{C}_{3} \mathrm{H}_{3} \mathrm{O}_{3} \mathrm{Cl}_{3}\right)$, made by heating chloralcyanhydrin with concentrated $\mathrm{HCl}$. It is a crystalline mass that melts at from $105^{\circ}$ to $110^{\circ}$.
Soluble in water, in alcohol, and in ether. A. Tricyanic $\left(\mathrm{C}_{3} \mathrm{~N}_{3} \mathrm{O}_{3} \mathrm{H}_{3}\right)$, Cyanuric Acid, obtained from tricyanogenchlorid by boiling the latter with water and alkalies. It crystallizes from aqueous solution with two molecules of water in large rhombic prisms; soluble in 40 parts of cold water; easily soluble in hot water and in alcohol. A., Trimesic $\left(\mathrm{C}_{9}\right.$ $\left.\mathrm{H}_{6} \mathrm{O}_{6}\right)$, formed when mesitylenic and uvitic acids are oxidized with a chromic acid mixture. Crystallizes in short prisms, readily soluble in hot water and alcohol, melts about $300^{\circ}$, and sublimes near $240^{\circ}$. A., Tropic $\left(\mathrm{C}_{6} \mathrm{H}_{5}, \mathrm{C}_{2} \mathrm{H}_{3}(\mathrm{OH}) \cdot \mathrm{CO}_{2} \mathrm{H}\right)$, obtained by digesting the alkaloids, atropin, and belladonna with baryta water. Slowly soluble in water; crystallizes in needles or plates, and melts at $\mathbf{I} 7^{\circ}$. A., Umbellic $\left(\mathrm{C}_{6} \mathrm{H}_{8} \mathrm{O}_{4}\right)$, obtained by digesting umbelliferon with caustic potash, and then precipitating with acids. It is a yellow powder, decomposing at about $240^{\circ}$. A., Undecolic $\left(\mathrm{C}_{11} \mathrm{H}_{18} \mathrm{O}_{2}\right)$, obtained from the bromid of undecylenic acid. It fuses at $59.5^{\circ}$. A., Uric $\left(\mathrm{C}_{5} \mathrm{H}_{4} \mathrm{~N}_{4} \mathrm{O}_{3}\right)$, an acid found in the urine of man and the carnivorararely in the herbivora-abundantly in the excrement of birds, reptiles, and molluscs. Crystallizes in small, white, rhombic crystals, insoluble in alcohol and ether, soluble in I900 parts of boiling water, and in hydrochloric acid. Exists usually in combination with the metals of the alkaline group. Separated from urine by adding ten per cent. of hydrochloric acid and allowing the crystals to settle for 48 hours, when they may be separated and weighed. Haycraft's method is a more exact but extended process. A., Uric, Murexid, Test for. See Murexid. A., Uroleucic $\left(\mathrm{C}_{9} \mathrm{H}_{10^{-}}\right.$ $\left.\mathrm{O}_{5}\right)$ [uro-, leucin $]$, a stellate, crystalline acid found in the urine in alkaptonuria. A., Uvitic $\left(\mathrm{C}_{9} \mathrm{H}_{8} \mathrm{O}_{4}\right)$, Mesidic Acid, obtained by oxidizing mesitylene with dilute $\mathrm{HNO}_{3}$. Crystallizes from hot water in needles, melting at $287^{\circ}$. A., Valeric $\left(\mathrm{C}_{5} \mathrm{H}_{10} \mathrm{O}_{2}\right)$, formed by oxidizing normal amyl alcohol. Similar to butyric acid, but is more sparingly soluble in water; boils at $186^{\circ}$; $\mathrm{sp}$. gr. at $\mathrm{O}^{\circ}$ is 0.9568 . It congeals in the cold and melts at $20^{\circ}$. A mobile liquid with caustic acid taste and the pungent smell of old cheese. Its salts have been somewhat used in medicine. A., Veratric $\left(\mathrm{C}_{9} \mathrm{H}_{10} \mathrm{O}_{4}\right)$, occurs with veratrin in the sabadilla seeds; crystallizes from hot water in short, white, transparent needles, melting at $179.5^{\circ} \mathrm{C}$.; soluble in water and alcohol. A., Vulpic $\left(\mathrm{C}_{19} \mathrm{H}_{14} \mathrm{O}_{5}\right)$, occurs in the lichen Cetraria vulpina, from which it may be extracted by chloroform or lime water. Sparingly soluble in water and ether, crystallizes from alcohol in yellow prisms, melting at II $0^{\circ}$ and subliming. A., Xanthic $\left(\mathrm{C}_{2} \mathrm{H}_{5}\right.$. O.CS.SH $)$, a heavy, oily liquid, not soluble in water, with a penetrating smell and a sharp, astringent taste, many of whose salts have a yellow color. A., Xylic $\left(\mathrm{C}_{6} \mathrm{H}_{3}\right.$ $\left.\left(\mathrm{CH}_{3}\right)_{2} \cdot \mathrm{CO}_{2} \mathrm{H}\right)$, produced by the oxidation of pseudocumene. Crystallizes from alcohol in long prisms; dissolves with difficulty in water; melts at $126^{\circ} \mathrm{C}$., and sublimes readily. A., Xylidic $\left(\mathrm{C}_{8} \mathrm{H}_{8} \mathrm{O}_{4}\right)$, obtained by oxidizing xylic acid with dilute $\mathrm{HNO}_{3}$; separates from boiling water in flocculent masses; melts at $282^{\circ}$.

Acida $\left(a s^{\prime}-i d-a h\right)$ [L.]. Plural of Acidum, q.v.

Acid-Albumin (as'-id al'-bu-min). A derived albumin. A proteid having been acted upon or dissolved in the stronger acids, and yielding an acid reaction.

Acidiferous (as-id-if'-er-us) [acidum, acid; ferre, to bear]. Containing an acid; producing acidity.

Acidifiable $\left(a s-i d^{\prime}-i f-i-a-b l\right)$ [acidum, acid; fieri, to be come]. Capable of becoming an acid, or of becoming sour.

Acidification (as-id-if-ik-a'-shun) [acidum, acid; facere, to make]. Conversion into an acid; the process of becoming sour. 
Acidimeter (as-id-im'-et-er) [acidum, acid; $\mu \hat{\varepsilon} \tau p o \nu$, a measure]. An instrument for performing acidimetry.

Acidimetry (as-id-im'-et-re) [acidum, acid; $\mu \varepsilon ́ \tau \rho o v$, a measure]. Determination of the free acid in a solution by an acidimeter, or by chemical reactions.

Acidity $\left(a s-i d^{\prime \prime}-i t-e\right)$ [acidum, acid]. The quality of being acid; sourness; excess of acid.

Acidology (as-id-ol'-o-je) [ákís, a bandage, a point; $\lambda 6 \gamma o 5$, a treatise]. The science of surgical appliances.

Acidometry (as-id-om'-et-re). See Acidimetry.

Acidopeirastic (as-iøl-o-pi-ras'-tik) [ákis, a point; $\pi \varepsilon \iota \rho \dot{a} \zeta \varepsilon \iota \nu$, to test]. See Akidopeirastic.

Acidosteophyte (as-id-os'-te-o-fit) [ákis, a point; osteophyte]. A sharp, or needle-shaped, osteophyte.

Ac'ids, Aromat'ic. Acids derived by replacing hydrogen in the benzenes by carboxyls. They are crystalline solids that generally sublime undecomposed. Most of them dissolve with difficulty in water. A., Diazo. See Diazo Acids. A., Dibasic, acids containing two carboxyl groups. They are solids, crystallizable, and generally volatile without decomposition. They are mostly soluble in water and have a strong acid reaction. See Table. A., Fatty, a class of monobasic acids, formed by the oxidation of the primary alcohols. The more complex fatty acids are found in all oleaginous compounds, where they exist combined with glycerin, forming fats. The fatty acids have a general formula $\mathrm{C}_{\mathrm{n}} \mathrm{H}_{2 \mathrm{D}} \mathrm{O}_{2}$. See Table. A., Monobasic, products of the replacement by oxygen of the two hydrogen atoms attached to the carbon-carrying $\mathrm{OH}$. These acids enter into combination with a univalent basic radical to form a neutral salt, or a salt containing one equivalent of a base. A., Organic, acids characterized by the carboxyl group $\mathrm{CO} . \mathrm{OH}$.

\section{TABLE OF DIBASIC ACIDS OF THE FATTY COMPOUNDS.}

I. FIRST SERIES. $\mathrm{C}_{n} \mathrm{H}_{2 n-2} \mathrm{O}_{4}$.

\begin{tabular}{|c|c|c|c|c|}
\hline NAME. & FORMULA. & $\begin{array}{l}\text { PHYSICAL } \\
\text { CONDITION. }\end{array}$ & $\begin{array}{c}\text { Melting } \\
\text { PoINT. } \\
\text { (Centigrade.) }\end{array}$ & Solubility. \\
\hline Oxalic,............... & $\mathrm{C}_{2} \mathrm{H}_{2} \mathrm{O}_{4}$ & Solid. & $101^{\circ}$ & Slowly in water. Easily in alcohol. \\
\hline Malonic, .............. & $\mathrm{C}_{3} \mathrm{H}_{4} \mathrm{O}_{4}$ & Solid. & ${ }^{1} 32^{\circ}$ & Easily in water, alcohol, ether. \\
\hline 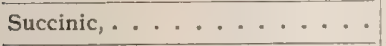 & $\mathrm{C}_{4} \mathrm{H}_{6} \mathrm{O}_{4}$ & Solid. & $180^{\circ}$ & Slowly in water and alcohol. \\
\hline Pyrotartaric, ........... & $\mathrm{C}_{5} \mathrm{H}_{8} \mathrm{O}_{4}$ & Solid. & $112^{\circ}$ & Readily in water, alcohol, ether. \\
\hline Adipic, $\ldots \ldots \ldots$ & $\mathrm{C}_{6} \mathrm{H}_{10} \mathrm{O}_{4}$ & Solid. & $148^{\circ}$ & Slowly in water. \\
\hline Pimelic, ............... & $\mathrm{C}_{7} \mathrm{H}_{12} \mathrm{O}_{4}$ & Solid. & $102-104^{\circ}$ & $\cdots$ \\
\hline Suberic, $\ldots \ldots \ldots \ldots$ & $\mathrm{C}_{8} \mathrm{H}_{14} \mathrm{O}_{4}$ & Solid. & $140^{\circ}$ & $\begin{array}{l}\text { Slowly in water. Readily in alco- } \\
\text { hol, ether. }\end{array}$ \\
\hline Lepargylic (Azelaic), $\ldots \ldots$ & $\mathrm{C}_{9} \mathrm{H}_{16} \mathrm{O}_{4}$ & Solid. & $106^{\circ}$ & Slowly in water. \\
\hline 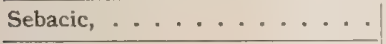 & $\mathrm{C}_{10} \mathrm{H}_{18} \mathrm{O}_{4}$ & Solid. & $127^{\circ}$ & $\cdots$ \\
\hline 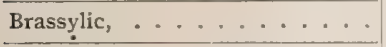 & $\mathrm{C}_{11} \mathrm{H}_{20} \mathrm{O}_{4}$ & Solid. & $108^{\circ}$ & Almost insoluble in water. \\
\hline 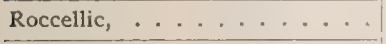 & $\mathrm{C}_{17} \mathrm{H}_{32} \mathrm{O}_{4}$ & Solid. & $132^{\circ}$ & $\therefore$ \\
\hline Cetyl Malonic, ........... & $\mathrm{C}_{19} \mathrm{H}_{36} \mathrm{O}_{4}$ & Solid. & $121^{\circ}$ & $\cdots$ \\
\hline
\end{tabular}

2. SECOND SERIES. UNSATURATED DICARBOXYLIC ACIDS. $\mathrm{Cn}_{2 n} \mathrm{H}_{4} \mathrm{O}_{4}$.

\begin{tabular}{|c|c|c|c|c|}
\hline Fumaric, . . . . . . . & $\mathrm{C}_{4} \mathrm{H}_{4} \mathrm{O}_{4}$ & Solid. & $\cdots$ & Almost insoluble in water. \\
\hline Maleic, . . . . . . . . & $\mathrm{C}_{4} \mathrm{H}_{4} \mathrm{O}_{4}$ & Solid. & $130^{\circ}$ & Readily soluble in water. \\
\hline Ethidene Malonic, ........ & $\mathrm{C}_{5} \mathrm{H}_{6} \mathrm{O}_{4}$ & Solid. & $220^{\circ}$ & $\cdots$ \\
\hline 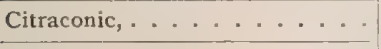 & $\mathrm{C}_{5} \mathrm{H}_{6} \mathrm{O}_{4}$ & Solid. & $80^{\circ}$ & $\cdots$ \\
\hline 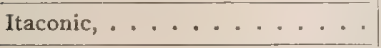 & $\mathrm{C}_{5} \mathrm{H}_{6} \mathrm{O}_{4}$ & Solid. & $16 \pi^{\circ}$ & Slowly soluble in water. \\
\hline Mesaconic, ............ & $\mathrm{C}_{5} \mathrm{H}_{6} \mathrm{O}_{4}$ & Solid. & $202^{\circ}$ & Slowly soluble in water. \\
\hline Allyl Malonic, ........... & $\mathrm{C}_{6} \mathrm{H}_{8} \mathrm{O}_{4}$ & Solid. & $103^{\circ}$ & $\cdots$ \\
\hline Propylidene Malonic, $\ldots . .$. & $\mathrm{C}_{6} \mathrm{H}_{8} \mathrm{O}_{4}$ & Solid. & $\cdots$ & $\cdots$ \\
\hline Hydromuconic, ........... & $\mathrm{C}_{6} \mathrm{H}_{8} \mathrm{O}_{4}$ & Solid. & $195^{\circ}$ & Slowly soluble in water. \\
\hline Pyrocinchonic, . . . . . . & $\mathrm{C}_{6} \mathrm{H}_{8} \mathrm{O}_{4}$ & $\begin{array}{l}\text { Only exists in the } \\
\text { salts. }\end{array}$ & $\cdots$ & $\cdots$ \\
\hline Allyl Succinic, ........... & $\mathrm{C}_{7} \mathrm{H}_{10} \mathrm{O}_{4}$ & Solid. & $94^{\circ}$ & $\cdots$ \\
\hline Carbocaprolactonic, ........ & $\mathrm{C}_{7} \mathrm{H}_{10} \mathrm{O}_{4}$ & Solid. & $69^{\circ}$ & $\cdots$ \\
\hline 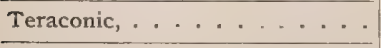 & $\mathrm{C}_{7} \mathrm{H}_{10} \mathrm{O}_{4}$ & Solid. & $162^{\circ}$ & $\cdots$ \\
\hline Xeronic, $\ldots \ldots \ldots$ & $\mathrm{C}_{8} \mathrm{H}_{12} \mathrm{O}_{4}$ & $\cdots$ & $\ldots$ & $\cdots$ \\
\hline
\end{tabular}


TABLE OF DIBASIC ACIDS OF THE FATTY COMPOUNDS,-Continued.

3. THIRI) SERIES. $\mathrm{CnH}_{2 n}-6 \mathrm{O}_{4}$.

\begin{tabular}{|c|c|c|c|c|}
\hline NAME. & FORMULA. & $\begin{array}{l}\text { PHYSICAL } \\
\text { CONDITION. }\end{array}$ & $\begin{array}{c}\text { MELTING } \\
\text { PoINT. } \\
\text { (Centigrade) }\end{array}$ & SOLUBILITY. \\
\hline Acetylene Dicarboxylic, ..... & $\mathrm{C}_{4} \mathrm{H}_{2} \mathrm{O}_{4}$ & Solid. & $175^{\circ}$ & . . \\
\hline Glutinic, ............. & $\mathrm{C}_{4} \mathrm{H}_{2} \mathrm{O}_{4}$ & Solid. & $145-146^{\circ}$ & $\cdots$ \\
\hline Muconic, .......... & $\cdots$ & Solid. & $260^{\circ}$ & 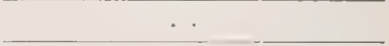 \\
\hline Diallyl Malonic, .......... & $\therefore$ & Solid. & $133^{\circ}$ & . . \\
\hline Diacetylene Dicarboxylic, .... & $\mathrm{C}_{6} \mathrm{H}_{2} \mathrm{O}_{4}$ & Solid. & $\cdot \cdot$ & $\begin{array}{l}\text { Readily soluble in water, alcohol, } \\
\text { ether. }\end{array}$ \\
\hline Tetra-acetylene Dicarboxylic, . . & $\mathrm{C}_{10} \mathrm{H}_{2} \mathrm{O}_{4}$ & Solid. & $\cdots$ & $\cdots$ \\
\hline
\end{tabular}

4. KETONE DICARBOXYLIC ACIDS.

\begin{tabular}{|c|c|c|c|c|}
\hline Mesoxalic, ........... & $\mathrm{C}_{3} \mathrm{H}_{2} \mathrm{O}_{5}$ & Solid. & $115^{\circ}$ & $\cdots$ \\
\hline 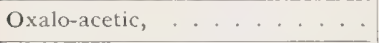 & $\mathrm{C}_{4} \mathrm{H}_{4} \mathrm{O}_{5}$ & $\cdots$ & $\cdots$ & $\cdots$ \\
\hline Aceto-malonic, . . . . . . & $\mathrm{C}_{5} \mathrm{H}_{6} \mathrm{O}_{5}$ & $\cdots$ & $\cdots$ & $\cdots$ \\
\hline Acetone Dicarboxylic, ....... & $\mathrm{C}_{5} \mathrm{H}_{6} \mathrm{O}_{5}$ & Solid. & $130^{\circ}$ & Readily soluble in water and ether. \\
\hline Aceto-succinic, $\ldots \ldots \ldots$ & $\mathrm{C}_{6} \mathrm{H}_{8} \mathrm{O}_{5}$ & Solid. & $244-245^{\circ}$ & $\cdots$ \\
\hline Aceto-glutaric, $\ldots \ldots \ldots$ & $\mathrm{C}_{7} \mathrm{H}_{10} \mathrm{O}_{5}$ & $\cdots$ & $\cdots$ & . \\
\hline
\end{tabular}

5. DIKETONE-DICARBOXYLIC ACIDS.

\begin{tabular}{|c|c|c|c|c|}
\hline Oxal-diacetic, $\ldots \ldots \ldots$ & $\mathrm{C}_{6} \mathrm{H}_{6} \mathrm{O}_{6}$ & Solid. & $77^{\circ}$ & \\
\hline Oxal-levulinic, . . . . . . & $\mathrm{C}_{7} \mathrm{H}_{8} \mathrm{O}_{6}$ & Liquid. & $\ldots$ & . \\
\hline Diaceto-succinic, $\ldots \ldots \ldots$ & $\mathrm{C}_{8} \mathrm{H}_{10} \mathrm{O}_{6}$ & Solid. & $78^{\circ}$ & \\
\hline
\end{tabular}

6. URIC ACID GROUP (CARBAMIDES OF THE DICARBOXYLIC ACIDS).

\begin{tabular}{|c|c|c|c|c|}
\hline Parabanic Acid (Oxalyl Urea), . . & $\mathrm{C}_{3} \mathrm{H}_{2} \mathrm{~N}_{2} \mathrm{O}_{3}$ & Solid. & . & Soluble in water and ether. \\
\hline Oxaluric Acid, . . . . . . . & $\mathrm{C}_{3} \mathrm{H}_{4} \mathrm{~N}_{2} \mathrm{O}_{4}$ & Solid. & . $\quad \cdot$ & Slowly soluble in water. \\
\hline Barbituric Acid (Malonyl Urea), & $\mathrm{C}_{4} \mathrm{H}_{4} \mathrm{~N}_{2} \mathrm{O}_{3}$ & Solid. & $\cdots$ & $\cdots$ \\
\hline Dialuric Acid (Tartrony? Urea), & $\mathrm{C}_{4} \mathrm{H}_{4} \mathrm{~N}_{2} \mathrm{O}_{4}$ & Solid. & $\therefore$ & $\therefore$ \\
\hline Alloxan (Mesoxalyl Urea),.... & $\mathrm{C}_{4} \mathrm{H}_{2} \mathrm{~N}_{2} \mathrm{O}_{4}$ & Solid. & $\cdots$ & Readily soluble in water. \\
\hline 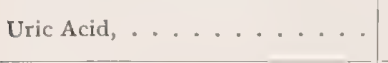 & $\mathrm{C}_{5} \mathrm{H}_{4} \mathrm{~N}_{4} \mathrm{O}_{3}$ & Solid. & $\cdots$ & $\begin{array}{l}\text { Insoluble in alcohol and ether. } \\
\text { Slowly soluble in water. }\end{array}$ \\
\hline 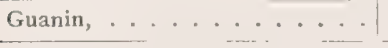 & $\mathrm{C}_{5} \mathrm{H}_{5} \mathrm{~N}_{5} \mathrm{O}$ & Solid. & $\cdots$ & Insoluble in water, alcohol, ether. \\
\hline 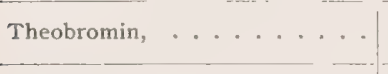 & $\mathrm{C}_{7} \mathrm{H}_{8} \mathrm{~N}_{4} \mathrm{O}_{2}$ & Solid. & $290^{\circ}$ & $\begin{array}{l}\text { Slowly soluble in hot water and } \\
\text { alcohol. }\end{array}$ \\
\hline Caffein $($ Thein), . . . . . . & $\mathrm{C}_{8} \mathrm{H}_{10} \mathrm{~N}_{4} \mathrm{O}_{2}$ & Solid. & $225^{\circ}$ & $\begin{array}{l}\text { Slightly soluble in cold water and } \\
\text { alcohol. }\end{array}$ \\
\hline
\end{tabular}

TABLE OF FATTY ACIDS.

FIRST SERIES. $\mathrm{C}_{n} \mathrm{H}_{2 n} \mathrm{O}_{2}$

\begin{tabular}{|c|c|c|c|c|c|c|c|c|c|c|c|}
\hline$\sum_{z}^{\mid \frac{5}{2}}$ & 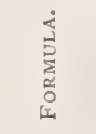 & 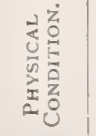 & 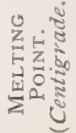 & 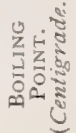 & 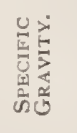 & 突 & 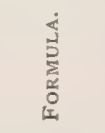 & 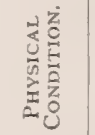 & 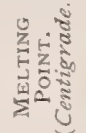 & 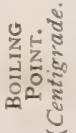 & 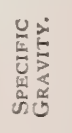 \\
\hline Formic, ... & $\mathrm{CH}_{2} \mathrm{O}_{2}$ & Liquid. & & $99^{\circ}$ & 1.223 & Valerianic, . . & $\mathrm{C}_{5} \mathrm{H}_{10} \mathrm{O}_{2}$ & Liquid.] & $-20^{\circ}$ & $186^{\circ}$ & 0.9568 \\
\hline Acetic, ... & $\mathrm{C}_{2} \mathrm{H}_{4} \mathrm{O}_{2}$ & Liquid. & & $118^{\circ}$ & I. 0514 & Caproic, ... & $\mathrm{C}_{6} \mathrm{H}_{12} \mathrm{O}_{2}$ & Liquid. & $-2^{\circ}$ & $205^{\circ}$ & 0.928 \\
\hline Propionic, . . & $\mathrm{C}_{8} \mathrm{H}_{6} \mathrm{O}_{2}$ & Liquid. & & $140^{\circ}$ & 0.992 & Enanthylic, . & $\mathrm{C}_{7} \mathrm{H}_{14} \mathrm{O}_{2}$ & Liquid.! & $-10.5^{\circ}$ & $223^{\circ}$ & . \\
\hline Butyric, ... & $\mathrm{C}_{4} \mathrm{H}_{8} \mathrm{O}_{2}$ & Liquid, & . & $x 63^{\circ}$ & 0.9587 & Caprylic,... & $\mathrm{C}_{8} \mathrm{H}_{16} \mathrm{O}_{2}$ & Liquid.! & $16.5^{\circ}$ & $236.5^{\circ}$ & . \\
\hline
\end{tabular}


TABLE OF FATTY ACIDS-Continued.

FIRST SERIFS.- Continued.

\begin{tabular}{|c|c|c|c|c|c|}
\hline 这 & 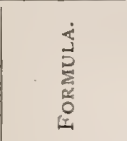 & 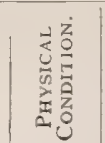 & 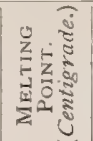 & 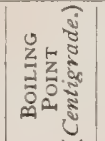 & 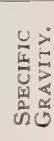 \\
\hline Pelargonic, . & $\mathrm{C}_{9} \mathrm{H}_{18} \mathrm{O}_{2}$ & Liquid. & $12^{\circ}$ & $253.5^{\circ}$ & . \\
\hline Capric, ... & $\mathrm{C}_{10} \mathrm{H}_{20} \mathrm{O}_{2}$ & Solid. & $31.4^{\circ}$ & $268^{\circ}$ & $\therefore$ \\
\hline Undecylic, .. & $\mathrm{C}_{11} \mathrm{H}_{22} \mathrm{O}_{2}$ & Solid. & $28.5^{\circ}$ & $212^{\circ}$ & . \\
\hline Lauric, ... & $\mathrm{C}_{12} \mathrm{H}_{24} \mathrm{O}_{2}$ & Solid. & $43.6^{\circ}$ & $269^{\circ}$ & . \\
\hline Tridecylic, & $\mathrm{C}_{13} \mathrm{H}_{26} \mathrm{O}_{2}$ & Solid. & $40.5^{\circ}$ & $235^{\circ}$ & $\therefore$ \\
\hline Myrisțic, . . . & $\mathrm{C}_{14} \mathrm{H}_{28} \mathrm{O}_{2}$ & Solid. & $54^{\circ}$ & . . & . \\
\hline Pentadecatoic, & $\mathrm{C}_{15} \mathrm{H}_{30} \mathrm{O}_{2}$ & Solid. & $5^{1^{\circ}}$ & $257^{\circ}$ & . \\
\hline Palmitic, ... & $\mathrm{C}_{10} \mathrm{H}_{32} \mathrm{O}_{2}$ & Solid. & $62^{\circ}$ & $\therefore$ & . \\
\hline Margaric, ... & $\mathrm{C}_{17} \mathrm{H}_{3,} \mathrm{O}_{2}$ & Solid. & $60^{\circ}$ & . . & . \\
\hline Stearic, ... & $\mathrm{C}_{18} \mathrm{H}_{36} \mathrm{O}_{2}$ & Solid. & $\overline{62.2^{\circ}}$ & $\cdots$ & . \\
\hline Nondecylic, . & $\mathrm{C}_{19} \mathrm{H}_{38} \mathrm{O}_{2}$ & Solid. & $65.5^{\circ}$ & $\therefore$ & . \\
\hline Arachidic, . . & $\mathrm{C}_{20} \mathrm{H}_{40} \mathrm{O}_{2}$ & Solid. & $75^{\circ}$ & $\therefore$ & . \\
\hline Medullic, ... & $\mathrm{C}_{21} \mathrm{H}_{42} \mathrm{O}_{2}$ & Solid. & $72^{\circ}$ & $\therefore$ & : \\
\hline Behenic, ... & $\mathrm{C}_{22} \mathrm{H}_{44} \mathrm{O}_{2}$ & Solid. & $73^{\circ}$ & $\cdots$ & . \\
\hline Lignoceric, . & $\mathrm{C}_{24} \mathrm{H}_{48} \mathrm{O}_{2}$ & Solid. & $80.5^{\circ}$ & $\cdots$ & . \\
\hline Hyenic, ... & $\mathrm{C}_{25} \mathrm{H}_{50} \mathrm{O}_{2}$ & Solid. & $77^{\circ}$ & $\cdots$ & $\therefore$ \\
\hline Cerotic, ... & $\mathrm{C}_{27} \mathrm{H}_{54} \mathrm{O}_{2}$ & Solid. & $79^{\circ}$ & $\cdot \cdot$ & - $\cdot$ \\
\hline Melissic, ... & $\mathrm{C}_{30} \mathrm{H}_{60} \mathrm{O}_{2}$ & Solid. & $88^{\circ}$ & $\cdots$ & . \\
\hline Theobromic, . & $\mathrm{C}_{64} \mathrm{H}_{128} \mathrm{O}_{2}$ & Solid. & $72^{\circ}$ & $\cdots$ & - \\
\hline SECOND S & SERIES. & OLEIC A & CIDS. & $\mathrm{C}_{n} \mathrm{H}_{2 n-2}$ & $\mathrm{O}_{2}$ \\
\hline Acrylic, ... & $\mathrm{C}_{3} \mathrm{H}_{4} \mathrm{O}_{2}$ & Liquid. & $+7^{\circ}$ & $139.5^{\circ}$ & . \\
\hline Crotonic, . . & $\mathrm{C}_{4} \mathrm{H}_{6} \mathrm{O}_{2}$ & Solid. & $72^{\circ}$ & $182^{\circ}$ & . \\
\hline Angelic, ... & $\mathrm{C}_{5} \mathrm{H}_{8} \mathrm{O}_{2}$ & Solid. & $45^{\circ}$ & $185^{\circ}$ & . \\
\hline
\end{tabular}

SECOND SERIES.-Continued.

\begin{tabular}{|c|c|c|c|c|c|}
\hline$\sum_{z=}^{\infty}$ & 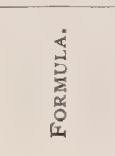 & 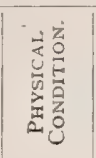 & 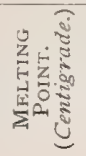 & 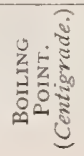 & 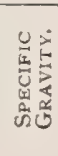 \\
\hline Pyroterebic, . & $\mathrm{C}_{6} \mathrm{H}_{10} \mathrm{O}_{2}$ & Liquid. & $\cdots$ & & . \\
\hline Teracrylic, . . & $\mathrm{C}_{7} \mathrm{H}_{12} \mathrm{O}_{2}$ & Liquid. & . & $208^{\circ}$ & . \\
\hline Nonylenic,... & $\mathrm{C}_{9} \mathrm{H}_{16} \mathrm{O}_{2}$ & Liquid. & $\ldots$ & $\ldots$ & . \\
\hline Decylenic, . . & $\mathrm{C}_{10} \mathrm{H}_{18} \mathrm{O}_{2}$ & Solid. & $+10^{\circ}$ & 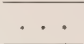 & . \\
\hline Campholic, & $\mathrm{C}_{10} \mathrm{H}_{18} \mathrm{O}_{2}$ & Solid. & $95^{\circ}$ & $\cdots$ & $\cdots$ \\
\hline Undecylenic, & $\mathrm{C}_{11} \mathrm{H}_{20} \mathrm{O}_{2}$ & $\cdots$ & $24 \cdot 5^{\circ}$ & $275^{\circ}$ & $\cdots$ \\
\hline Cyminic,... & $\mathrm{C}_{15} \overline{\mathrm{H}_{23} \mathrm{O}_{2}}$ & $\cdot$ & $\cdots$ & . & $\cdots$ \\
\hline Hypogaic, . . & $\mathrm{C}_{16} \mathrm{H}_{30} \mathrm{O}_{2}$ & Solid. & $33^{\circ}$ & $\cdots$ & . \\
\hline Oleic, .... & $\mathrm{C}_{18} \mathrm{H}_{34} \mathrm{O}_{2}$ & Liquid, & $+14^{\circ}$ & . & $\cdots$ \\
\hline Elaïdic, ... & $\mathrm{C}_{18} \mathrm{H}_{34} \mathrm{O}_{2}$ & Solid. & $44-45^{\circ}$ & $\cdots$ & $\cdots$ \\
\hline Doeglic, ... & $\mathrm{C}_{19} \mathrm{H}_{36} \mathrm{O}_{2}$ & - & $\cdots$ & . & $\cdots$ \\
\hline Erucic, ... & $\mathrm{C}_{22} \mathrm{H}_{42} \mathrm{O}_{2}$ & Solid. & $33^{-34^{\circ}}$ & $\ldots$ & $\cdots$ \\
\hline Brassidic, . & $\mathrm{C}_{22} \mathrm{H}_{42} \mathrm{O}_{2}$ & Solid. & $5^{6^{\circ}}$ & & \\
\hline
\end{tabular}

THIRD SERIES. PROPIOLIC ACIDS. $\mathrm{Cn}_{n} \mathrm{H}_{2 \mathrm{n}}-4 \mathrm{O}_{2}$.

\begin{tabular}{|c|c|c|c|c|c|}
\hline Propiolic, . - & $\mathrm{C}_{3} \mathrm{H}_{2} \mathrm{O}_{2}$ & Liquid. & $+6^{\circ}$ & $144^{\circ}$ & . \\
\hline Tetrolic, ... & $\mathrm{C}_{4} \mathrm{H}_{4} \mathrm{O}_{2}$ & Solid. & $75^{\circ}$ & $203^{\circ}$ & $\cdots$ \\
\hline Sorbic, .... & $\mathrm{C}_{6} \mathrm{H}_{8} \mathrm{O}_{2}$ & Liquid. & $134.5^{\circ}$ & $228^{\circ}$ & - \\
\hline Diallylacetic, & $\mathrm{C}_{8} \mathrm{H}_{12} \mathrm{O}_{2}$ & Liquid. & $\cdots$ & $22 \mathrm{I}^{\circ}$ & . \\
\hline Undecolic, .. & $\mathrm{C}_{11} \mathrm{H}_{18} \mathrm{O}_{2}$ & $\therefore$ & $59.5^{\circ}$ & . & . \\
\hline Palmitolic, .. & $\mathrm{C}_{16} \mathrm{H}_{28} \mathrm{O}_{2}$ & Solid. & $42^{\circ}$ & $\cdots$ & $\cdots$ \\
\hline Stearoleic, . & $\mathrm{C}_{18} \mathrm{H}_{32} \mathrm{O}_{2}$ & Solid. & $4^{\circ}$ & $\cdots$ & \\
\hline Linoleic, ... & $\mathrm{C}_{18} \mathrm{H}_{32} \mathrm{O}_{2}$ & Liquid. & $\cdots$ & $\cdots$ & 0.921 \\
\hline Behenolic, & $\mathrm{C}_{22} \mathrm{H}_{40} \mathrm{O}_{2}$ & Solid. & $57.5^{\circ}$ & . & $\cdots$ \\
\hline
\end{tabular}

Acidulated ( $a s-i d^{\prime}-u$-la-ted) [acidulare, to make sour]. Somewhat sour or acid; sourish.

Acidulous (as-id'-u-luss) [acidulare, to make sour]. Sourish; subacid; moderately sour.

Acidum $\left(a s^{\prime}-i d-u m\right)$ [L.]. See Acid.

Acidurgia (as-id-ur'-je-ah). See Aciurgia.

Acies $\left(\boldsymbol{a}^{\prime}-\right.$ she-ẽz) [L., sharpness, edge, steel]. I. Sharpness; keenness. 2. A sharp or cutting instrument. 3. Iron or steel as a medicine.

Acinaceous (as-in-a'she-us) [acinus, a berry or grapestone]. Possessing or made of kernels, small seeds, or drupelets, as a grape or raspberry.

Acinacifolious (as-in-as-if-o'-le-us) [acinaces, a simitar; folium, a leaf ]. In biology, having simitar-shaped leaves.

Acinaciform (as-in-as'-e-form) [acinaces, a simitar; formis, shape]. In biology, a leaf, pod, or other object, having one straight, thick edge, and one thin and convex; simitar-shaped.

Acinarious (as-in-a'-re-zs) [acinus, the grape]. In biology, having the surface covered with grape-like vesicles, as in certain algæ.

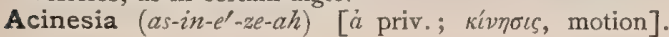

Motor paralysis. A loss of motion in any or all parts of the body; abstinence from motion. Also, the interval between consecutive throbs of the heart. See also Diastole.

Acinesis (as-in-é-sis). Same as Acinesia.

Acinetan (as-in-e $e^{\prime}$ tan) [ảkívntos, motionless]. An infusorian having suctorial, tubular processes instead of cilia; one of the Acinete.

Acinetatrophia (as-in-et-at-rol-fe-ah) [acinesis; atrophia]. Atrophy due to lack of exercise.

Acinetic (as-in-et'-ik) [ákívntos, motionless]. Relating to, or affected with, acinesia.

Acinetiform (as-in-et'-e-form). In biology, an acine$\tan$-like infusorian.

Acini $\left(a s^{\prime}-i n-i\right)$ [L. ]. Plural of Acinus, q. $v$.

Aciniform (as-in'-e-form) [acinus, a grape]. Grapelike.

Acinus $\left(a s^{\prime}-i n-u s\right)$ [acinus, a grape : pl., Acini]. Any one of the smallest lobules of a conglomerate gland; a saccule of a compound racemose gland; a lobule of the liver, etc.

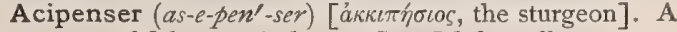
genus of fishes. A. huso. See Iihthyocolla. 


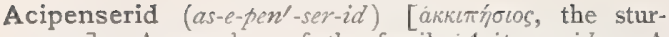
geon]. A member of the family Acipenserida. A sturgeon.

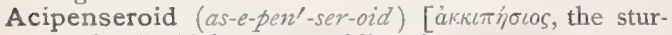
geon]. In biology, resembling the sturgeon.

Aciurgia (as-e-er'-je-ah), or Aciurgy (as'-e-er-je) [ákis, point; $\check{\varepsilon} \rho \gamma \varepsilon \iota \nu$, to work]. Operative surgery

Ack'ermann's An'gles. See Angle

Aclastic (ak-las'-tik) [a priv. ; kiácıv, to break]. Not refracting

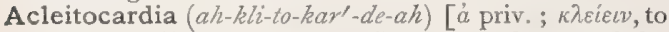
close; $\kappa a \rho d i a$, the heart]. Imperfect closure of the foramen ovale, a fetal opening between the auricles of the heart, which prevents perfect aëration of the blood. It is thought to be connected with the disease variously known as cyanopathy, "Blue Disease," "Blue Jaundice,

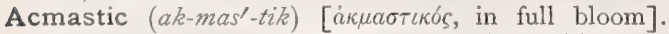
Having no acme, or culminating point (said of fevers); continuous.

Acme $\left(a k^{\prime}-m e\right)[a k \mu \eta \dot{n}$, a point]. The critical stage of a disease; the crisis. The highest point or degree of anything.

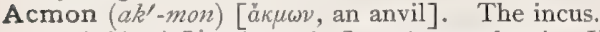

Acne $\left(a k^{\prime}-n e\right)\left[a ́ \chi \nu^{\prime}\right.$, a point]. Acne vulgaris; Varus; a very common, usually chronic, inflammatory disease of the sebaceous glands, occurring mostly about the face, chest, and back. The lesions may be papular, pustular, or tubercular. It occurs usually between the ages of puberty and twenty-four years, is usually worse in winter, and is associated with menstrual and gastrointestinal troubles. The individual lesions consist of minute pink, acuminate papules or pimples, in the center of which is a black-topped comedo ( $A$. punctata, A. papulosa). A. adenoid. See Lupus, Disseminated Follicular. A. adolescentium. Synonym of A. vulgaris. A. albida. Synonym of Milium. A. artificialis, that form that disappears when the cause is removed. A. atrophica. Synonym of $A$. varioliformis. A. cachecticorum, a form occurring only in starved or debilitated persons after long, wasting diseases, as phthisis. It consists of flat, livid, acneiform papules and pustules without comedones, resulting in deep pigmented scars. They are situated chiefly on the trunk and lower extremities. A. ciliaris, acne at the edges of the eyelids. A. disseminata. Synonym of $A$. vulgaris. A. erythematosa. Synonym of $A$. rosacea. A. frontalis. Synonym of $A$. varioliformis. A. generalis, acne that has become general over the surface of the body. A. hypertrophica, stage of $A$. rosacea in which there is a permanent, intensely red, non-inflammatory, nodulated thickening of the tips and sides of the nose, expanding it, both laterally and longitudinally. A. indurata, a variety of $A$. vulgaris, characterized by chronic, livid indurations, the result of extensive perifollicular infiltration. Especially seen in strumous subjects. A. keloid. See Dermatitis papillomatosa capillitii. A. keratosa, a rare form of acne in which a horny plug takes the place of the comedone, and by its presence excites inflammation. A. mentagra. See Sycosis. A. necrotica. Synonym of $A$. varioliformis. A. papulosa. See Acne. A. picealis, Tar Acne; a form of dermatitis that involves chiefly the extensor surfaces of the limbs, common in fiberdressers who work with paraffin and in persons otherwise brought in contact with tar or its vapor. A. punctata, a variety of $A$. vulgaris. See Acne. A. pustulosa, a variety of $A$. vulgaris, characterized by dermic abscesses. A. rodens. Synonym of $A$. varioliformis. A. rosacea. Rosacea; Telanyiectasis faciei; Nevus araneus; Brandy Nose ; Whisky Nose ;
Spider Nernes; Spider Cancer. A chronic, hyperemic, or infiammatory affection of the skin, situated usually upon the face, especially the nose, cheeks, forehead, and chin. It starts as a redness, which later becomes permanent and is then associated with the development of papules, pustules, and varicose vessels. In the latest stages there is an excessive formation of new tissue. Its causes are some reflex irritation of the stomach, bowels, or sexual apparatus. Common in drunkards. A. scrofulosa, a variety of $A$. cachecticorum, that occurs in strumous children. A. sebacea. Synonym of Seborrhea. A. simplex, a variety of $A$. vulgaris. A. sycosiformis. Same as Sycosis non-parasitica. A. tarsi, an inflammatory affection of the large sebaceous glands of the eyelashes (Meibomian glands). A. variolifo $\mathrm{mis}$, a rather rare disease, situated chiefly about the forehead, at the junction with the hairy scalp, and extending into the hair. It is especially abundant on the temples, and may spread over the face and body. It is a disease of adult life, but may occur before the age of twenty years. The pustules appear in groups, and each has a hard, central, necrotic scab, which presses into the skin, and when separated leaves a deep pit, at first dark red, but eventually becoming white. It is a very chronic disease, appearing in successive crops. Its etiology is unknown. A. vulgaris. See Acne.

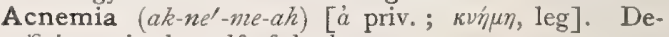
ficiency in the calf of the leg.

Acnitis $\left(a k-n i^{\prime}-t i s\right)$ [á $\chi \nu \eta ́$, a point ; $\iota \iota \iota$, inflammation]. See Hydrosadenitis phlegmonosa.

Acœ-. See Ace-

Acclius (ah-se'-le-us). See Acelius.

A colasia $\left(a k-o-l a^{\prime}-z e-a h\right)$ [ $\alpha \kappa o \lambda \alpha \sigma i \alpha$, intemperance]. Unrestrained self-indulgence; lust; intemperance.

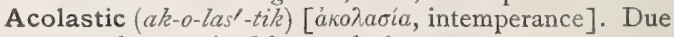
to, or characterized by, acolasia.

Acology ( $\left.\alpha k-o l^{\prime \prime}-o-j e\right)$ [ăkos, remedy; $\lambda 6 \gamma o s$, a discourse]. Aceology.

Acolous $\left(a h-k o^{\prime}-l u s\right)$ [ả priv.; $\kappa \tilde{\omega} \lambda o v$, limb]. Having no limbs.

Acomia ( $\left.a h-k o^{\prime}-m e-a h\right)$ [ả priv. ; кó $\mu \eta$, hair]. Baldness. A deficiency of hair arising from any cause.

Acomous (ah-ko'-mus) [á priv.; кá $\mu \eta$, hair]. Hairless, bald.

Acondylose $\left(a \hbar-k o n^{\prime}-d i t-\bar{o} s\right)$. See Acondylous.

Acondylous (ah-kon'-dil-us) [ $\dot{a}$ priv. ; condyle]. Having no condyles; having no joints.

Aconine $\left(a k^{\prime}-0-n \bar{n} n\right)$ [akovitov], $\mathrm{C}_{26} \mathrm{H}_{39} \mathrm{NO}_{11}$. A decomposition product of aconitin.

Aconite $\left(a k^{\prime}-0-n \bar{\imath} t\right)$. See Aconitum.

Aconitia (ak-o-nish'-e-ah). Aconitin, or aconitina; a very poisonous alkaloid, the active principle of aconite.

Aconitic Acid (ak-o-nit'-ik). See Acid.

Aconiti folia $\left(a k-0-n i-t \bar{\imath} f o^{\prime}-l e-a h\right),[\mathrm{L}$.$] . Aconite$ leaves. See Aconitum. A. radix (ak-o-ni-ti ra'-dix), aconite root. See Aconitum.

Aconitina (ak-on-it-i'-nah). Same as Aconitia. See Aconitum.

Aconitum $\left(a k-a-n i^{\prime}-t u m\right)$ [L. ]. The root of Aconitum napellzes. Possesses a bitter, pungent taste. Produces numbness and persistent tingling in the tongue and lips. It is very poisonous. Exerts great depression of the heart, respiration, circulation, and nerves. It is antipyretic, diaphoretic, and diuretic. The active principle is Aconitin. Highly beneficial in fevers, acute throat affections, and inflammation of the respiratory orgens. Dose gr. ss-ij. A. Abstractum, has double the strength of the powdered drug, or its fluid extract. Dose gr. $1 / 4-j$. Unof. A. Extractum. Dose gr. $1 / 6-1 / 3$. A. Ext. Fld., has a strength of one drop to the grain of powdered drug. Dose $\eta^{y} / 2-i j$. A. Liniment 
(B. P.), aconite-root, camphor, and rectified spirit. A. Tinct., contains aconite 35 , alcohol and water each q. s. Dose $m^{1 / 2}-\mathrm{iv}$. The following are unofficial: Aconitina $\left(\mathrm{C}_{33} \mathrm{H}_{43} \mathrm{NO}_{12}\right)$ (aconitin), an amorphous solid. Dose gr. $\frac{1}{0}-\frac{1}{50}$. A. ferox, a plant of the Himalayas, used internally for pneumonia and pleurisy; externally for neuralgia. Dose of the tincture ( $\mathrm{I}$ in $\mathrm{IO}$ ) $\mathrm{mj}-\mathrm{v}$. A. Injectio Hypodermica, one grain in $1 / 2$ ounce. Dose $m j-i v$. A. Napellina, Dose gr. $\frac{1}{2}-\frac{3}{5}$. St. Jacob's Oil, a weak aconite liniment. A. Oleatum, a two per cent. solution of aconitin in oleic acid. A. Ung. (B. P.), eight grains to the ounce.

Aconuresis (ah-kon-u-re'sis) [á priv.; conari, to

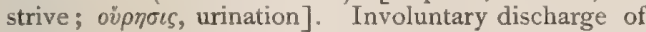
urine.

Acopa $\left(a k^{\prime}-o-p a / h\right)$. Plural of Acopon, q. $z^{\prime}$

Acopia $\left(a h-k o^{\prime}-p e-a h\right)[a k o \pi i a]$. Freedom from weariness.

Acopic $\left(a h-k o p^{\prime}-i k\right)$ [see Acopia]. Refreshing; restorative ; restful.

Acopon (ak'-o-pon) [áa priv.; kótos, fatigue]. A restorative, or cordial medicine or application.

Acoprosis (ah-kop-ro'-sis) [ả priv.; kó $\pi \rho o s$, excrement]. Deficient formation of feces.

Acor $\left(a^{\prime}-k o r\right)$ [L.]. Acrimony : acidity, as of the stomach.

Acorea $\left(a h-k o-r e^{\prime}-a h\right)$ [ả priv.; $\kappa b \rho \eta$, pupil]. Absence of the pupil.

Acoretin (ak-o-rel-tin) [acorus; ’’ntivn, resin]. A resinous principle obtained from Acorus calamus.

Acoria $\left(a h h-k \sigma^{\prime}-r 2-a h\right)$ [’̉ priv.; kópos, satisfaction]. A greedy or insatiable appetite.

Acorin ( $\left.a k^{\prime}-a-r i n\right)[a$ priv.; $\kappa 6 ́ \rho \eta$, the pupil]. A bitter glucoside obtained from Acorus calamus, or sweet flag.

Acormous (ah-kor'-mus) [á priv.; kop $\mu \delta \varsigma$, the trunk of a tree]. Trunkless; of the nature of an acormus.

Acormus (ah-kor'-mus) [áa priv. ; knpuós, the trunk]. A monster without a trunk or body.

Acorn $\left(a^{\prime}-k o r n\right)$ [L.]. The fruit or nut of the oak. See Camata and Camatina.

Acorn-cups ( $a^{\prime}$-korn-kups). The capsules in which acorns are seated. See Valonia.

Acorus (ak'-o-rus) [áa priv.; $\kappa o ́ p \eta$, the pupil]. See Calamus.

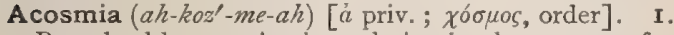
Poor health. 2. An irregularity in the course of a disease.

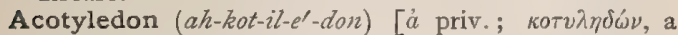
hollow vessel]. In botany, a plant producing an embryo without seed-leaves or cotyledons.

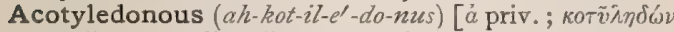
a hollow vessel]. Destitute of embryo or embryonic leaves, or cotyledons.

Acouchi $\left(a h-k o o^{\prime}-c h \bar{e}\right)$. See Acuchi

Acoumeter, or Acouometer (ah-koo'-met-er, a-koo-

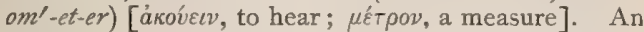
instrument for measuring the acuteness of hearing.

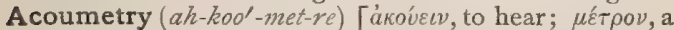
measure]. The measurement or testing of the acuteness of the hearing.

Acouophonia (ah-koo-o-fo'-ne-ah) [ákov́etv, to hear; $\phi \omega v \eta \dot{n}$, sound]. Auscultatory percussion.

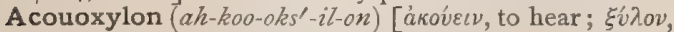
wood]. A wooden (pine) stethoscope.

Acousimeter (ah-koo-sin'-et-er) [äkovols, a hearing;

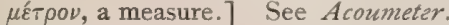

Acousma (ah-koos'- or kovez'-mah) [äkovoua, thing heard: $p[.$, Acousmata $]$. An auditory hallucination; a condition in which imaginary sounds are noticed by the patient, and are believed by him to be real.

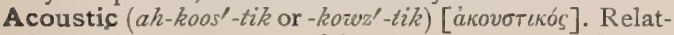
ing to the ear or sense of hearing. A. Duct, the ex- ternal meatus of the ear. A. Nerve, the portio mollis of the seventh pair. See Nerves. A. Tetanus, the rapidity of the induction shocks in a frog's nervemuscle preparation, as measured by the pitch of a vibrating rod. A. Tubercle, a rounded elevation on either side of the floor of the fourth ventricle.

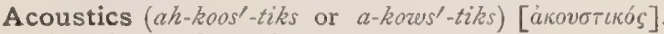
The science of sound.

Acquetta (ak-zuet'-tah) [Ital.]. Same as Aqua tofana.

Acquired Movements (ak-zvi'-erd moov'-mentz). Those brought under the influence of the will only after conscious and attentive effort and practice, in distinction from reacquired movements, those reinstated in their former proficiency after injury to the motor regions of the brain.

Acræpalous (ah-krep'-al-zis). See Acrepalous.

Acramphibryous $(a k$-ram-fibl-ri-us) [àkpos, at the end; áudi, on both sides; $\beta \rho \dot{v} o v$, blossom]. In biology, pertaining to plants that produce lateral as well as terminal buds.

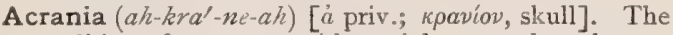
condition of a monster with partial or complete absence of the cranium.

Acranial (ah-kra'-ne-al) [ả priv.; крaviov, skull]. Having no cranium.

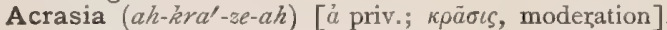
I. Intemperance; lack of self-control, 2. Acratia.

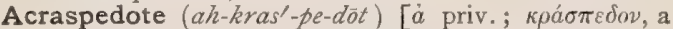
hem or border]. In biology, pertaining to Gegenbaur's group of medusæ, Acraspeda; having a disk without velum or marginal fold.

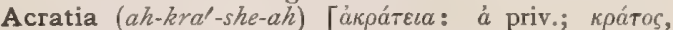
force]. Impotence, loss of power.

Acraturesis (ah-krat-u-re'-sis) [ákpátela, lack of strength ; ov $\rho \eta \sigma \iota s$, micturition]. Inability to micturate, from atony of the bladder.

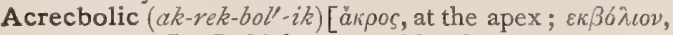
to throw out]. In biology, capable of protrusion by an outward movement of the tip; the introverted and eversible proboscis of certain worms and molluscs.

Acrembolic (ak-rem-bol'-ik) [äkoos, at the apex; $\varepsilon \mu \beta a ́ \lambda \lambda \varepsilon \varepsilon v$, to throw in, insert]. In biology, introversion by an inward movement of the tip, as the everted proboscis of certain worms and molluscs.

Acrepalous, or Acræpalous (ahh-krep'-al-us) [ả priv.; $\kappa \rho a \iota \pi a ́ \lambda \eta$, debauch]. Correcting the nausea that follows excess in drinking, or in eating.

Acrid $\left(a k^{\prime}-r i d\right)$ [acer, acris, sharp]. Pungent, irritating; producing an irritation, as of the tongue, fauces, or stomach.

Acridian $\left(\bar{a} k-r i d^{\prime}-i-a n\right)$ [dim. of ákpis, a locust]. Pertaining to the acridia or grasshoppers.

Acridin (ak'-rid-in) [acer, acrid], $\mathrm{C}_{13} \mathrm{H}_{9} \mathrm{~N}$. A substance produced by heating anilin and salicylic aldehyd to $260^{\circ}$ with $\mathrm{ZnCl}_{2}$. Very soluble in alcohol and ether. It occurs in crude anthracene and dissolves in dilute acids with a beautiful green fluorescence. It readily sublimes in colorless leaflets; melts at $110^{\circ}$; and has a very pungent odor.

Acridins (ak'-rid-inz) [acer, acrid]. Substances obtained when diphenylamin is heated to $300^{\circ}$ with fatty acids. They are feeble bases; their salts are decomposed by boiling water.

Acridophagus (ak-rid-of'-a-gus) [ákpis, a locust; payein, eat]. The eater of locusts.

Acrimony (ak'-rim-o-ne) [acrimonia]. Irritating quality, pungency, corrosiveness : an acrid quality or state.

Acrinia (ah-krin'-e-ah) [á priv; kpiveıv, to separate] Diminution or suppression of a secretion or excretion. 
Acrinyl (ak-rin'-il) [arer, acrid], $\mathrm{C}_{7} \mathrm{H}_{7} \mathrm{O}$. One of the univalent radicles. A. Sulphocyanate, $\mathrm{C}_{7} \mathrm{H}_{7} \mathrm{O}$.SCN, an acrid and vesicating substance found in white mustard, corresponding to the essential oil of the black mustard.

Acrisia (ah-kris'-e-ah) [ả priv. ; crisis]. The absence of a crisis from a disease; an unfavorable crisis or turn in the course of an attack of disease.

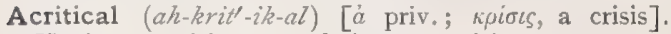
Having no crisis; not relating to a crisis.

Acritochromacy (ah-krit-o-kro'-mas-e) [äkptros, undistinguished; $\chi \rho \tilde{\omega} \mu \alpha$, color $]$. Color-blindness, achromatopsia.

Acroæsthesia (ak-ro-es-the'-ze-ah). See Acroesthesia.

Acroanesthesia (ak-ro-an-es-the'-ze-ah) [ăkpov, ex-

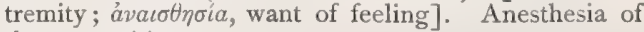
the extremities.

Acroarthritis (ak-ro-arth-ri'-tis) [ǎkpov, extremity; a $\rho f \rho o v$, a joint; $\iota \tau \iota$, , inflammation ]. Inflammation of the joints of a limb.

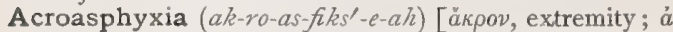
priv.; $\sigma \phi i \xi \iota \varsigma$, pulse]. Asphyxia of the extremities, the so-called phenomena of Raynaud.

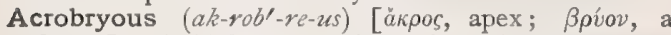
flower]. In biology, growing only at the apex.

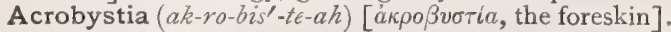
The prepuce.

Acrobystiolith (ak-ro-bis'-te-o-lith) [ákpoßvoría, the prepuce; $\lambda i \theta 0 s$, a stone]. A preputial calculus.

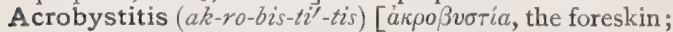
$\iota \tau \iota$, inflammation]. Posthitis.

Acrocarpous (ak-ro-kar'-pus) [àkpos, at the apex; $\kappa \propto \rho \pi o ́ s$, fruit]. In biology, fruiting at the tips, as mosses.

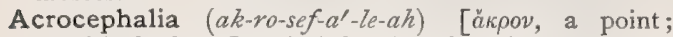
$\kappa \varepsilon \phi a \lambda$, the head]. A deformity of the head in which the vertical diameter is increased and the top is more or less pointed.

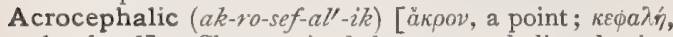
the head]. Characterized by acrocephalia; having the top of the head unusually high.

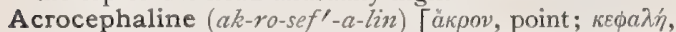
head]. In biology, resembling birds of the genus Acrocephatus, the large-billed reed warblers.

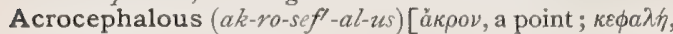
the head]. Characterized by or affected with acrocephalia.

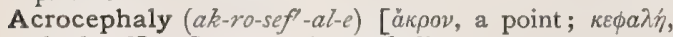
the head]. Same as Acrocephalia.

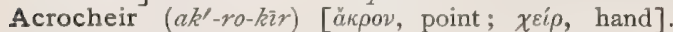
The ends of the fingers considered together; the forearm and hand.

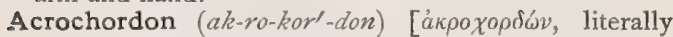
the end of a catgut cord]. A pedunculated or pensile wart. Synonym of Molluscum fibrosum.

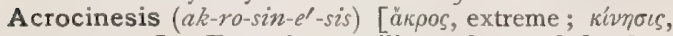
movement]. Excessive motility; abnormal freedom of movement, as seen in certain cases of hysteria.

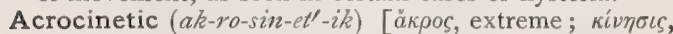
movement]. Characterized by acrocinesis.

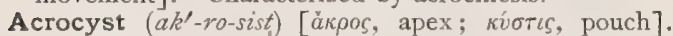
In biology, a sort of broad sac at the top of the gonangium in certain hydroids.

Acrodermatitis (ak-ro-der-mat- $i^{\prime}$-tis) [äkpov, extremity; $\delta \varepsilon \rho \mu a$, skin; $\iota \tau \iota \varsigma$, inflammation]. Inflammation of the skin of an extremity.

Acrodont (ak'-ro-dont) [àkpos, apex or edge; ódoús, tooth]. In biology, one of or pertaining to those lizards with teeth attacked to the edge of the jaw, without alveoli.

Acrodynia (ak-ro-din'-e-ah) [ăkoos, an extremity; ádívn, pain]. Epidemic erythema; a disease closely allied to pellagra. It is characterized by gastro-intestinal symptoms, redness of the conjunctivæ, edema of the face, formication, pricking pains in the palm and soles, hyperesthesia followed by anesthesia of these parts, and an erythematous eruption preceded by bullæ, chiefly on the hands and feet, but spreading over the limbs and trunk. This is followed by exfoliation and dark brown or black pigmentation, greatest in the warm regions of the body. Wasting of the limbs, with edema, cramps, pareses, and spasms may be present, and death may follow in the old or feeble. The disease is probably due to some noxious constituent of or defect in the diet.

Acroesthesia, or Acroæsthesia (ak-ro-es-the'-ze-ah)

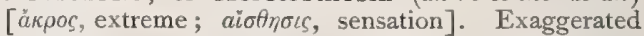
sensitiveness, or sensibility. Sense of pain in the extremities.

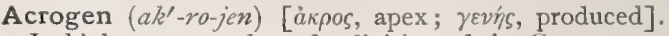
In biology, a member of a division of the Cryptogams which grow by terminal buds, as ferns and mosses.

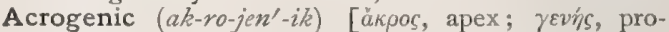
duced]. In biology, partaking of the character of an acrogen.

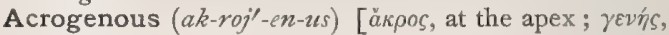
produced]. In biology, growth by increase at the summit, as ferns, mosses, and certain zoöphytes.

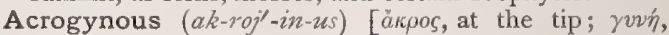
female]. In biology, having the archegonia formed from or near the apical cell, as certain of the Hepaticae

Acrolein (ak-ro'-le-in) [acer, sharp; oleum, oil], $\mathrm{C}_{3} \mathrm{H}_{4} \mathrm{O}$. Acrylic Aldehyd. A highly volatile liquid derived from the decomposition or the destructive distillation of glycerin. See Acrylaldehyd.

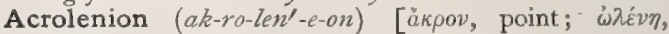
elbow]. Same as Olecranon.

Acromania (ak-ro-má-ne-ah) [äkpos, extreme; $\mu a v i a$, madness]. Incurable or extreme insanity.

Acromastitis (ak-ro-mas-ti'-tis) [acromastium; itis, inflammation]. Inflammation of the nipple.

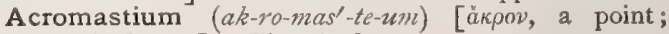

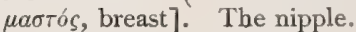

Acromegalia (ak-ro-meg-a $\left.a^{\prime}-l e-a h\right)$, or Akromegaly

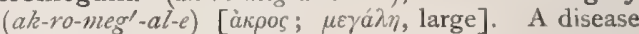
characterized by abnormally great development of the extremities, and of the features of the face, including the bony as well as the soft parts. The disease is of long duration, twenty years or more, the patient finally dying of exhaustion. The etiology is unknown, although Virchow believes heredity to have an important share in its causation.

Acromial (ak-ro'-me-al) [äkons, extremity; $\omega \mu o s$, the shoulder]. Relating to the acromion.

Acromicria (ak-ro-mik'-re-ah) [àkoos, extremity; $\mu \prime \kappa \rho o ́ s, ~ s m a l l]$. Abnormal smallness of the extremities. A condition in which there is a reduction in the size of the nose, ears, and face, as well as hands and feet.

Acromio-clavicular $\left(a k-r o^{\prime}-m e-o-k l a-v i k^{\prime}-\imath t-l a r\right)[a ̆ k \rho o s$, extremity; $\Phi \mu \rho$, the shoulder; clavus, a key]. Relating to the acromion and the clavicle.

Acromio-coracoid ( $a k-r o^{\prime}-m e-0-k o^{\prime}-r a k$-oid). See Acromio-coracoideus.

Acromio-coracoideus (ak-ro'-me-o-ko-rak-oid-e'-us)

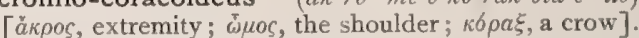
A triangular ligament lying between the acromion and the coracoid process.

Acromio-deltoideus (ak-ro'-me-o-del-toid-e'-us) [ăkpos,

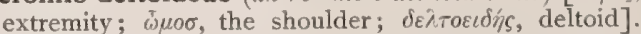
In comparative anatomy, a muscle having as its origin the acromion, and the deltoid ridge of the humerus as its insertion. 
Acromio-humeral (ak-ro'-me-o-hu'-mer-al) [äkpns, 'extremity; $\delta$ os, the shoulder; humerus]. Relating to the acromion and the humerus. A. Muscle, the deltoid.

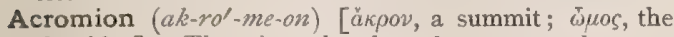
shoulder]. The triangular-shaped process at the summit of the scapula, that forms the attachment of the deltoid muscle.

Acromio-thoracic $\left(a k-r o^{\prime}-m e-o-t h o-r a^{\prime}-s i k\right)$ [äkpósutov, shoulder; $\theta \omega \rho a \xi$, thorax $]$. In anatomy, relating to the shoulder and thorax, as the acromio-thoracic artery.

Acromio-trapezius $\left(a k-r o^{\prime}-m e-o-t r a-p e^{\prime}-z e-u s\right)$ [akp'́$\mu(o v$, shoulder; trapezium ]. In anatomy, a part of the trapezius muscle.

Acromphalon (ak-rom'-fal-on) [äkpov, a point; $\dot{\alpha} \mu \phi a-$ $\lambda 6 s$, the navel]. See Acromphalus.

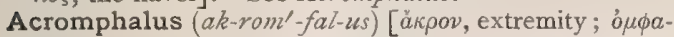
$\lambda 6 c$. the navel]. I. The center of the umbilicus to which the cord is attached. 2. The first stage of umbilical hernia, marked by a pouting of the navel.

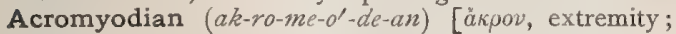

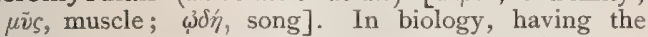
syringeal muscles attached to the ends of the upper bronchial rings, as in certain singing birds, the Acromyodi.

Acromyodic (a-kro-me-od'-ik). Same as Acromyodian.

Acromyodous (ak-ro-mi'-o-dus). Same as Acromyodian.

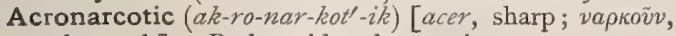
to benumb]. Both acrid and narcotic.

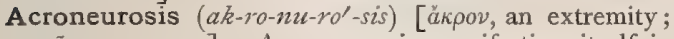

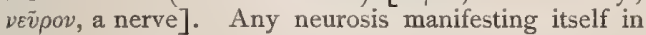
the extremities.

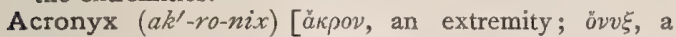
nail]. The ingrowing of the nail.

Acroparalysis (ak-ro-par-al'-is-is) [äkpov, an extreme;

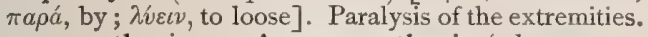

Acroparesthesia, or Acroparæsthesia (ak-ro-par-es-

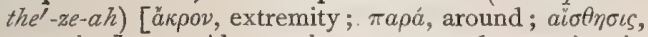
sensation]. I. Abnormal, or perverted sensation in the extremities. 2. Extreme or confirmed paresthesia.

Acropathology (ak-ro-path-oll-o-je) [àkpov, an extremity; $\pi a ́ \theta 0 \varsigma$, disease; $\lambda \sigma \gamma o s$, treatise ]. The pathology of the extremities.

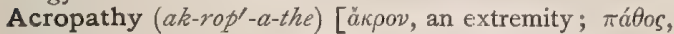
suffering]. Any disease of the extremities.

Acropetal $\left(a k-r o p^{\prime}-e t-a l\right)\left[a \kappa_{\alpha} \rho \nu\right.$, the top; petere, to seek]. In biology, developing from the base or center, upward and outward, as many leaves, lateral shoots, or flower clusters.

Acrophobia (ak-ro-fol-be-ah) [ăkpov, a height; $\phi \sigma \beta \beta o s$, fear]. Morbid dread of being at a great height.

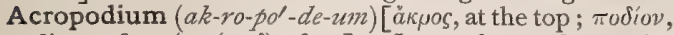
dim. of $\pi$ oús $(\pi \circ \delta)$, foot]. In zoölogy, the entire upper surface of the foot.

Acroposthia ( $\left.a k-r o-p o s^{\prime}-t h e-a h\right)$ [äkpos, extreme ; $\pi 6 \sigma \theta \eta$, foreskin]. The distal part of the prepuce.

Acroposthitis (ak-ro-pos-thi'-tis) [äkpos, extreme; $\pi 6 \sigma \theta \eta$, foreskin]. Posthitis.

Acrorrheuma (ak-ro-r $\left.u^{\prime}-m a h\right)$ [ǎkpov, an extremity; $\dot{\rho} \varepsilon \tilde{v} \mu \alpha$, a flux]. Rheumatism of the extremities.

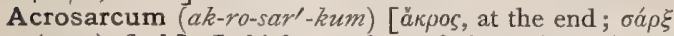
$(\sigma \alpha \rho \kappa)$, flesh]. In biology, a berry fruit produced by an ovary with an adnate calyx, e.g., a currant or cranberry.

Acroscleriasis (ak-ro-skle-ri'-as-is) [äkpov, extremity; $\sigma \kappa \lambda \eta \rho 6 \varsigma^{\prime}$, hard]. Sclerotic changes in the extremities.

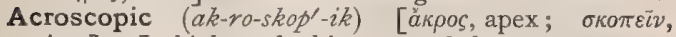
view]. In biology, looking toward the top.

Acrosphacelus (ak-ro-sfas'-el-zes) [ăkpov, extremity; $\sigma \phi a ́ k \varepsilon \lambda o s$, dead]. Gangrene of an extremity.

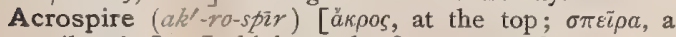
coil, spire]. In biology, the first sprout of a grain.

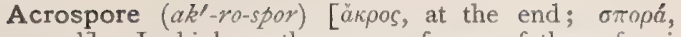
seed]. In biology, the spore of one of those fungi that fruit at the summit of simple erect hyphæ. Peronospora.

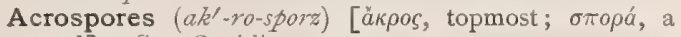
seed]. See Conidia.

Acrosporous (ak-ros'-po-rus) [àkpos, topmost; $\sigma \pi o \rho a ́$, a seed]. Same as Acrospore.

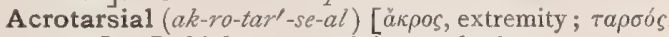
tarsus]. In biology, pertaining to the instep.

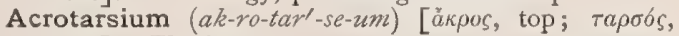
tarsus]. The instep.

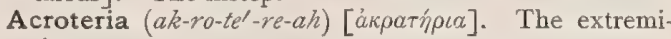
ties.

Acrothymion, or Acrothymum (ak-ro-thi'me-on) [åkoos, summit; Avuos, thyme]. A rugose wart with a broad top.

Acrotic $\left(a k-r o t^{\prime}-i k\right)$ [ăkpos, extreme, outmost]. Relating to the glands of the skin; affecting the surface.

Acrotica $\left(a k-r o t^{\prime}-i k-a h\right)$ [ăkpos, extreme]. Acrotic diseases.

Acrotism (ah'-krot-izm) [á priv.; крótos, striking]. Any defective beating of the pulse; failure of the pulse.

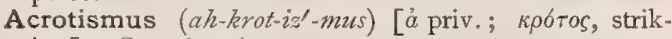
ing]. See Acrotism.

Acrylaldehyd (ak-ril-al'-de-hì ) [acer, sharp; aldehyd], $\mathrm{C}_{3} \mathrm{H}_{4} \mathrm{O}$. Acrolein, the aldehyd of the allyl series; obtained by distilling glycerin to which strong phosphoric acid has been added, or by the dry distillation of fatty bodies; a colorless, mobile liquid, boiling at $52^{\circ}$, possessing a sp. gr. of 0.8410 at $20^{\circ}$. It has a pungent odor and attacks the mucous membranes in a violent manner. It occasions an odor of burning fat. It is soluble in $2-3$ parts of water.

Actea, or Actæa $\left(\alpha k-t e^{\prime}-\alpha h\right)$ [ $\alpha \kappa \tau \tilde{\eta}$, the elder]. A genus of ranunculaceous plants having active medicinal qualities. A. alba, the white cohosh, has much the same qualities as $A$. spicata. $A$. cimicifiga is more important. See Cimicifuga. A. racemosa. See Cimicifuga. A. nubra, red cohosh, and A. spicata, are purgative and emetic.

Actinal ( $\left.a k^{\prime}-t i n-a l\right)$ [akris, a ray]. In biology, pertaining to the oral pole, surface, or aspect of a radiate animal.

Actine (ak'-tin) [áktís, a ray]. In biology, a spicular ray, in sponges.

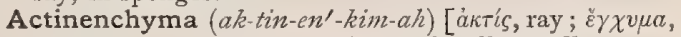
infusion]. In biology, a tissue of stellate cells.

Actinic (ak-tin'-ik) [ákTis, a ray]. Referring to those wave-lengths of the spectrum corresponding to the violet and ultra-violet parts of the same that produce chemical changes in the haloid salts of silver, and are therefore valuable in photography.

Actiniochrome $\left(a k-t i n^{\prime}-e-o-k r o ̄ m\right)$ [ákTis, a ray; $\chi \rho \tilde{\omega} \mu \alpha$, color]. A red pigment obtained from certain Actinias.

Actinism (ak'-tin-izm) [aktis, a ray]. The chemical quality of light, or of the sun's rays.

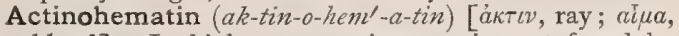
blood]. In biology, a respiratory pigment found by MacMunn in Actinia.

Actinoid (ak'-tin-oid) [ákris, ray; zidos, form]. In zoölogy, radiate, as a star fish.

Actinologous (ak-tin-ol'-o-gus) [áktis, a ray; $\lambda \dot{6} \gamma o s, a$ word]. In biology. exhibiting actinology.

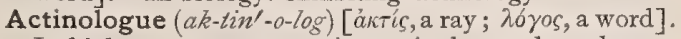
In biology, a part possessing actinologous homology.

Actinology $\left(a k-t i n-o l^{\prime}-o-j e\right)$ [aktis, a ray; $\lambda 6 \gamma o s$, a word]. In biology, that kind of homological relation that exists between the successive segments, regions, or divisions of a part or organ, in that they radiate or spring from it. 
Actinomere (ak-tin'-o-mër) [ákrís, ray; $\mu$ ḱpos, a part]. In zoölogy, one of the radiating partitions characteristic of the Actinozoa.

Actinomeric (ak-tin-o-mer'-ik) [akris, a ray; $\mu \hat{\varepsilon} \rho \circ \varsigma, a$ part]. In biology, radiately divided.

Actinomorphic (ak-tin-o-morf'-ik) [ákTic, a ray; $\mu \circ \rho \phi \dot{n}$, form ]. Same as Actinomorphous.

Actinomorphous (ak-tin-o-morf'-us) [ákтis, ray; $\mu \circ \rho \phi \dot{n}$, form]. Regularly radiated, as flowers divisible into similar portions in two or more vertical planes.

Actinomyces $\left(a k-t i n-o m^{\prime}-i s-\bar{e} z\right)$ [ảktís, a ray; $\mu \dot{\kappa} \kappa \eta \zeta$, mushroom]. A genus of parasitic fungoid organisms. One species, $A$. bovis, causes the disease actinomycosis. Called also the Ray Fungus.

Actinomycoma (ak-tin-o-mi-ko'-mah) [ákTis, a ray; $\mu v \kappa \eta s$, a fungus: $p l .$, Actinomycomata $]$. A tumor such as is characteristic of actinomycosis.

Actinomycosis $\left(\alpha k-t i n-0-m i-c 0^{\prime}-s i s\right)$ [ákrís, a ray; $\mu \dot{v} k \eta s$, a fungus]. A parasitical, infectious, inoculable disease first observed in cattle, and also occurring in man, and characterized by the manifestations of chronic inflammation, with or without suppuration, often resulting in the formation of granulation tumors. The disease is due to the presence of a characteristic microparasite, the ray fungus, Actinomyces bovis, which is composed of fine mycelial threads and club-shaped bodies. The most frequent and most curable form is when the abscesses form about the jaws and teeth. The best mode of staining the threads is by Gram's method. To stain the clubs as found in man is diffcult; the best results have been obtained with orange rubin or eosin. The only treatment of the disease is removal of the infected tissue. When the parasite has found a nidus in the lungs or digestive tract, all treatment is so far useless. The disease is often called lumpy-jaw and holdfast.

Actinomycotic $\left(a k^{\prime}-t i n-o-m i-k o t^{\prime}-i k\right)$ [ảkTis, ray; $\mu v_{k} \eta s$, fungus]. Pertaining to or affected with actinomycosis.

Actinophore (ak-tin'-o-fôr) [ảktis, a ray; $\phi \varepsilon ́ p \varepsilon \imath \nu$, to bear]. In biology, one of the peripheral elements affording support to the true fin rays in typical fishes and selachians.

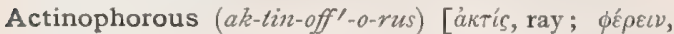
to bear]. In biology, bearing ray-like spines.

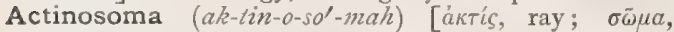
body]. In biology, the entire body of a simple or composite actinozoan.

Actinospora chartarum (ak-tin-o-spo'-rah char-ta'num) [ákтív, ray; $\sigma \tilde{\omega} \mu a$, body; charta, paper]. A parasitic fungus developing on paper and books.

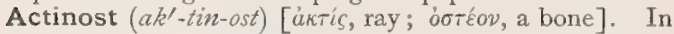
ichthyology, one of the bones supporting the pectoral and ventral fins in true fishes.

Actinosteophyte (ak-tin-os'-te-o-fit) [ảkTis, a ray; osteophyte]. An osteophyte of radiated form.

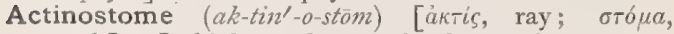
mouth]. In biology, the mouth of an actinozoan.

Actinotrichium (ak-tin-o-trik'-e-um) [ảkтis, ray; $\theta \rho i \chi$, a hair]. In biology, a fiber in the fin-fold of an embryo fish, the forerunner of the adult fin-ray.

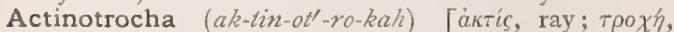
ring]. The larva of certain gephyrean worms, characterized by rings of cilia about the mouth and anus.

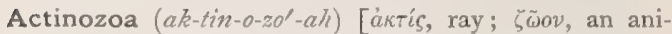
mal]. A division of celenterates including the seaanemones, coral-polyps, etc., having rayed tentacles about the mouth, and a digestive sac connected to the body wall by radial dissepiments called mesenteries.
Actinula $\left(a k-t i n^{\prime}-u\right.$-lah) [dim. of áktis, ray: $p l$. , Actimula]. In biology, the oval generative zoöid of a gymnoblastic hydroid, developing without intermediate metamorphosis into a hydroid of the adult form.

Action $\left(a k^{\prime}-\operatorname{shun}\right)$ [agere, to do, or perform]. In physiology, a term used to denote the function of an organ. A., Reflex, an involuntary movement of an organ or part of the body resulting from an impression carried by a sensory or afferent nerve to a subordinate center, and then sent back by an efferent nerve to some point at or near the source of irritation.

Active (ak'-tiv) [agere, to do, or perform]. In medicine, a term applied to treatment the reverse of passive, that is, where the pathological conditions are acted upon directly rather than partly controlled. Also, in a growing condition; opposed to dormant. A. Insufficiency of Muscles, See Insufficiency. A. Spots, the cortical centers of the brain, especially those that control definite muscular movements.

Activity (ak-tiv'-it-e) [agere, to do or perform]. Capacity for acting ; sensibility ; vitality ; potency; energy.

Actual $\left(a k^{\prime}-c h u-a l\right)$ [agere, to do]. Real, effective; not potential. A. Cautery. See Cautery.

Actuation $\left(a k-c h u-a^{\prime}-s h u n\right)$ [agere, to do, or perform]. That mental function that is exercised between the impulse of volition and its actualization or performance.

Acuchi $\left(a h-k o o^{\prime}-c h \bar{e}\right)$. The resin or balsam obtained from Icica heterophylla, a tree of tropical America. It is almost identical with elemi. Unof.

Acufilopressure (ak-u-fil-lo-pres-ur) [acus, needle; flum, a thread; pressure $]$. A combination of acupressure and ligation.

Acuity (ak-u'-it-e) [acuitas; acuere, to sharpen]. Acuteness or clearness of visual power in the perception of small or distant objects.

Aculeate $\left(a k-u^{\prime}-l e-\bar{a} t\right)$ [aculeus, a sting, prickle]. In botany, armed with prickles, i.e., aculii; as the rose and brier. In biology, having a sting.

Aculeiform (ak-u-le'-if-orm) [aculeus, prickle; forma, shape]. Resembling a prickle.

Aculeolate $\left(a k-u^{\prime}-l e-o-l a t\right)$ [aculeolus, a little prickle]. In biology, beset with small prickles.

Aculeus $\left(a k-u^{\prime}-l e-u s\right)$ [dim.of acus, a needle: $p l$., Aculei]. In biology, a prickle or pointed excrescence of the bark, as in the rose or raspberry; the modified ovipositor or sting of a hymenopterous insect.

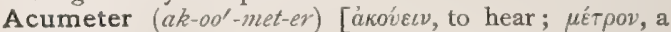
measure]. Instrument for testing hearing.

Acuminate $\left(a k-u^{\prime}-m i n-\bar{a} t\right)$ [acuminatus, pointed, acute]. Taper-pointed or sharp-painted.

Acuminose, or Acuminous $\left(a k-u^{\prime}-m i n-\bar{o} s\right.$, or $\left.-u s\right)$ [acumen, point]. In biology, same as Acuminate.

Acuminulate $\left(a k-u-m i n^{\prime}-u\right.$-lät $)$ [dim. of acumen, a point]. Slightly taper-pointed.

Acupression (ak-u-presh'-un) [acus, a needle; premere, to press]. Acupressure.

Acupressure $\left(a k^{\prime}-u\right.$-presh-ür) [acus, a needle; premere, to press]. An operation to stop hemorrhage or aneurysm by the compression of a needle inserted into the tissues upon either side, either above or below the vessel. There are a variety of methods of performing acupressure.

Acupuncturation (ak-u-pungk-chu-ra'-shun) [acus, a needle; punctura, a puncture]. Acupuncture.

Acupuncturator (ak-u-pung $k^{\prime}-c h u$-ra-tor) [acus, a needle; punctura, a puncture]. An instrument used in performing acupuncture.

Acupuncture $\left(a k^{\prime}-u\right.$-punk-chür $)$ [acus, a needle; pungere, to prick]. Puncture of the skin or tissue by one or more needles for the relief of pain, the exit of fluid, the coagulation of blood in an aneurysm, etc. 
Acus $\left(a^{\prime}-k u s\right)$ [L.]. A needle. A. Ad Cataractam, a cataract needle. A. Cannulata, a trocar to be used with a cannula. A. Electrica, a needle for use with electricity. A. Exploratoria, an exploring needle. A. Interpunctoria, a needle for eye-operations. A. Invaginata, a sheathed needle. A. Sutoria, a needle for stitching wounds.

Acute $(a k-\bar{u} t)$ [acutus, sharp]. Merely sharp-pointed or ending in a point less than a right angle. Sometimes used in the sense of forming a sharp angle. Used of disease having a rapid and severe onset, progress, and termination. When applied to pain, sound, vision, etc., means sharp, keen.

Acutenaculum $(a k-u$-ten-ak'-u-hım) [acus, a needle; tenaculum: pl., Acutenacula]. A needle-holder.

Acuteness (ak-üt'-nes) [acutus, sharp]. The quality of being acute, rapid, or sharp. Referring to vision, used as a synonym of keenness or acuity.

Acutifoliate $(a k-u$-te-fo'-le-ät) [acutus, sharp; foliatus, leaved]. In biology, bearing sharp-pointed leaves.

Acutilobate $\left(a k-u-t e-l 0^{\prime}-b \bar{a} t\right)$ [acutus, sharp; lobatus, lobate]. In biology, possessing acute lobes, as a leaf.

Acutorsion ( $a k$-u-tor'-shun) [acus, a needle ; torsion]. The twisting of an artery with a needle as a means of controlling hemorrhage.

Acyanoblepsia (ah-si-an-o-bleṕ-se-ah) [ả priv.; kv́avos, blue; $\beta \lambda \varepsilon \psi i a$, sight]. Same as Acyanopsia.

Acyanopsia (ah-si-an-op'-se-ah) [u priv.; kíavos, blue; ơ $\psi \iota \varsigma$. sight]. Inability to distinguish blue colors.

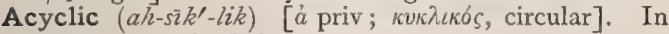
botany, not whorled.

Acyesis (ah-si-e'-sis) [á priv.; kúnoıs, pregnancy]. I. Sterility of the female. 2. Non-pregnancy.

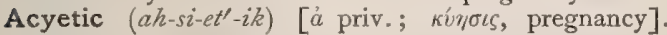
Relating to acyesis.

Acyprinoid (ah-sip'-rin-oid) [á priv.; cyprinoid]. In biology, a region in the fauna of which the Cyprinidie and Labyrinthici are wanting.

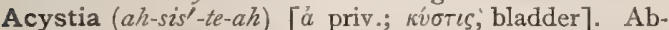
sence of the bladder.

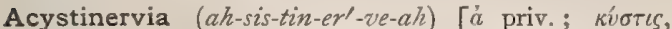
bladder; nervus, a nerve]. Paralysis or lack of nerve stimulus in the bladder.

Ad $[a d$, to $]$. A Latin prefix of words and terms, signifying to, toward, at, etc. Ad deliquizm, to fainting. Ad libitum, at pleasure, or according to discretion.

Ad, or Add. A contraction of Adde, or Additur, meaning, add, or let there be added; used in prescription writing.

Adacrya (ah-dak'-re-ah) [ả priv.; dákpvov, tear]. Absence or deficiency of the secretion of tears.

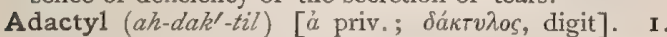
Without fingers or without toes. 2. A monstrosity that has an absence of digits.

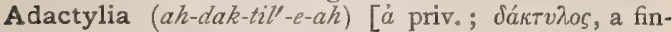
ger]. Absence of the digits.

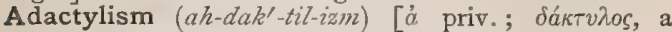
finger]. The absence of the digits.

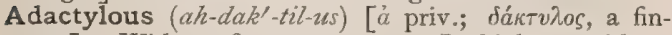
ger]. Without fingers or toes. In biology, without claws.

Adæmonia (ad-e-mo'-ne-ah). See Ademonia.

Adamantin (ad-am-an'-tin) [ádáuas, from à priv.; $\delta a \mu \alpha ́ \xi \varepsilon \iota \nu$, to overpower]. Pertaining to adamant. A. Cement, a substance used for filling teeth, consisting of finely powdered silex or pumice stone mixed with an amalgam of mercury and silver. See Amalgam. A. Substance, the enamel of the teeth.

Adambulacral (ad-am-bu-la'-kral) $[a d$, against; $a m$ bulacrum]. In biology, adjoining the ambulacra, as certain ossicles in echinoderms.
Adamita $\left(a d^{\prime}-a m-i^{\prime}-t a h\right)[\mathrm{L}$.$] . A white vesical calculus.$ Adam's Apple (ad'-amzap'-pl). See Pomum Adami. A. Operation. See Operations, Table of.

Adansonia digitata ( $a d^{\prime}-a n-s o^{\prime}-n e-a h$ dij-it-a'-tah) The Baobab tree, a native of Africa. The bark is used in the form of an infusion, $₹ \mathrm{j}$ to $\mathrm{Oj}$, as a remedy for intermittent fever. Unof.

Adansonin (ad-an'-so-nin). A febrifugal alkaloid from the leaves and bark of Adansonia Divitata. Unof.

Adaptation ( $a d$-ap-ta'-shon) [adaptare, to adjust]. In biology, favorable organic modifications suiting a plant or animal to its environment. A. of the Retina, the faculty possessed by the retina of accommodating the power of vision to a diminished amount of light, as in a darkened room.

Adarce $\left(a d-a \gamma^{\prime}-s e\right)$ [ádá $\rho \kappa \eta$, a salty efflorescence]. A salty alkaline concretion found in salt-marshes in Asia Minor. It is detergent and has been much used in leprosy and skin diseases. Unof.

Adarticulation (ad-ar-tik-u-la'-shun) [ad, to ; articulatio, a jointing]. See Arthrodia.

Addephagia (ad-e-fa'-je-ah) [L.]. See Bulimia.

Adder's-tongue $\left(a d^{\prime \prime}\right.$-erz-tun $\left.\mathrm{s}^{\circ}\right)$. The leaves of Ophioglossum vulsatum, a common perennial herb; mucilaginous, and used in the preparation of salves. Unof. A.-wort ( $a d^{\prime \prime}$-erz-wert). See Bistort.

Add'ison's Disease. Melasma suprarenale, dermatomelasma-supra-renale, or cutis ærea ("bronzed skin "), a disease of the supra-renal capsules, first described by Dr. Addison, and characterized by tubercular infiltration of the capsules, discoloration of the skin, progressive anemia, and asthenia, ending in death from exhaustion. See Diseases, Table of. A. Keloid. See Keloid and Morphea.

Additamentum (ad-it-am-en'-tum) [L.]. Any appendix, as an epiphysis. A. Coli, the appendix vermiformis.

Adducens $\left(a d^{\prime}-d u^{\prime}-\operatorname{sen} z\right)$ [L.]. An adductor, a term applied to certain muscles. A. Oculi, the internal rectus muscle of the eye.

Adducent (ad-du'-sent) [adducens]. Performing adduction.

Adduction (ad-duk'-shun) [adductio; adducere, to bring toward]. Any movement whereby a part is brought toward another or toward the median line of the body. A. of the Eyes, the power of the internal recti measured by the maximum ability to preserve singleness of the image with prisms placed bases toward the temples. It varies from $30^{\circ}$ to $50^{\circ}$. See also Abduction.

Adductive $\left(a d-d u k^{\prime}-t i v\right)$ [adducens]. Same as Adducent.

Adductor (ad-dukf-tor) [adducere, to bring forward]. Any muscle effecting adduction.

Adelarthrosomatous (ad-el-ar-thro-so'-mat-us) [ [ă

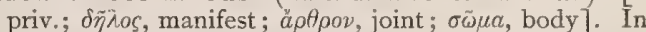
biology, indistinctly segmented, or articulated.

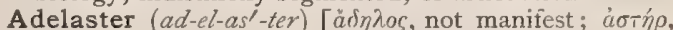
star]. In biology, a cultivated plant that for the time being cannot be referred to its proper genus.

Adelocodonic ( $\left.a d^{\prime}-e l-o-k o-d o n^{\prime}-i k\right)$ [ $\ddot{\alpha} \delta \eta \hat{n} o s$, not manifest; $\kappa \omega \delta \delta \omega v$, a bell]. In biology, lacking a disc or umbrella; said of a gonophore.

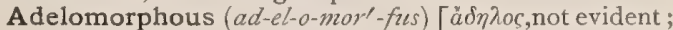

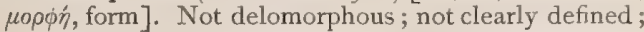
not having a determinate form (a term applied to certain cells in the gastric glands.)

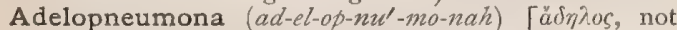

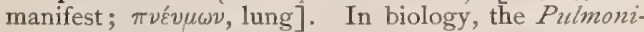
fera among gasteropods, the pulmonary cavity being hidden by the mantle. 


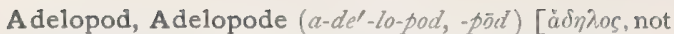
manifest; $\pi$ oús, foot]. In biology, an animal with concealed or inconspicuous feet.

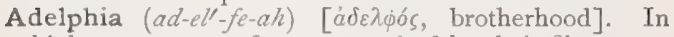
biology, a group of stamens united by their filaments.

Adelphous ( $\left.a d^{\prime}-e^{\prime \prime}-f u s\right)[a ̀ \delta \varepsilon \lambda \phi \sigma s$, brotherhood]. Having stamens with more or less coalescent filaments.

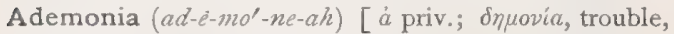
distress]. Mental distress

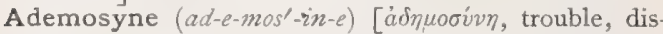
tress]. Depression of spirits; home-sickness.

Aden $\left(a^{\prime}-d e n\right)$ [ $a \dot{d} \delta^{\prime} v$, an acorn, a gland]. A gland; a bubo. A. Fever. See Dengue. A. Ulcer. See Phagedena tropica.

Adenalgia ( $\left.a d-e n-a l^{\prime}-j e-a h\right)$ [ád́nv, gland; ăhyos, pain]. Glandular pain.

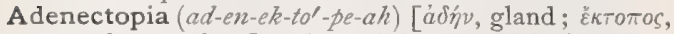
away from a place]. A condition in which the gland does not occupy its proper position.

Adenemphraxis (ad-en-em-fraks'-is) [ádin, gland; $\varepsilon \varkappa \mu \phi \rho \alpha \xi \iota \varsigma$, a stoppage]. Glandular obstruction.

Adenia $\left(a d-e^{\prime}-n e-a h\right)\left[\dot{a} \delta \gamma^{\prime} \nu\right.$, gland]. Enlargement of the glands; Lymphadenoma, q.v.

Adenic $\left(a d-e n^{\prime}-i k\right)$ [ádín, gland]. Relating to or of the nature of a gland.

Adeniform ( $\left.a d-e n^{\prime}-e-f o r m\right)$ [ád'v, gland; forma, resemblance]. Of the shape of a gland; glandlike.

Adenin $\left(a d^{\prime}-e n-i n\right)$ [ajin, a gland-first discovered in pancreatic glands], $\mathrm{C}_{5} \mathrm{H}_{5} \mathrm{~N}_{5}$. A leucomainne discovered in 1885 by Kossel; the simplest member of the uric acid group of leucomaines. A relation exists between hydrocyanic acid and all the members of this group, and the base, adenin, seems to be formed by polymerization of hydrocyanic acid. It occurs, with other bases, as a decomposition product of nuclein, and may be obtained from all animal and vegetable tissues rich in nucleated cells. It crystallizes in leaflets with pearly luster. It exists largely in the liver and urine of leucocythemic patients, as a result of the breaking up of the nucleated white blood corpuscles. It appears to be necessary to the formation and building up of organic matter, playing an important part, together with guanin, in the physiological function of the cell nucleus. Nuclein, the parent of adenin and guanin, has been credited with a direct relation to the reproductive powers of the cell. Adenin is not poisonous. Its physiological action is not definitely known.

Adenitis $\left(a d-e n-i^{\prime}-t i s\right)$ [ $a \delta \dot{\eta} v$, gland; itis, inflammation]. Inflammation of a gland. See Bubo and Lymphadenitis.

Adenization $\left(a d^{\prime}-e n-i-z a^{\prime}-\operatorname{shun}\right)$ [ád'n, a gland]. Adenoid degeneration.

Adeno- $\left(a d-e^{\prime}-n o\right)$ [ $a \delta j \nu$, gland]. A prefix used to denote relation to glands.

Adenoblast ( $a d^{\prime}-$-en-o-blast) [ád'n, a gland; $\beta \lambda a \sigma \tau o ́ c$, a germ]. Any functionally active gland-cell; a cell that assists in the glandular action.

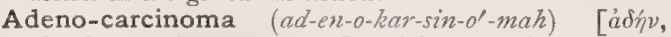
gland; каркivor, a cancer]. Adenoma blended with carcinomatous elements.

Adenocarcinomatous ( $a d-e n-o-k a r-\sin -o^{\prime}-m a t-u s$ )

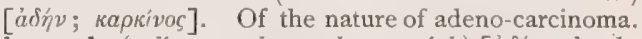

Adenocele $\left(a d^{\prime}-e n-o-s e \bar{e} l\right.$, or $\left.a d-e n-o-s e^{\prime}-l e\right)[a \delta j w$, gland; $\kappa \dot{\lambda} \lambda \eta$, a tumor]. See Adenoma.

Adenochirapsology (ad-en-o-ki-rap-sol'-o-je) [ádín, gland; $\chi \varepsilon i \rho$, hand; $\dot{a} \pi \tau \varepsilon \iota v$, to touch; $\lambda \dot{b} \gamma o s$, treatise]. The obsolete doctrine of the healing of scrofula by the touch of a king's hand.

Adeno-chondroma (ad-en-o-kon-drol-mah) [ajín,

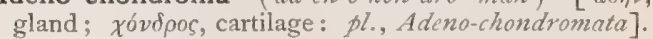
A tumor consisting of both glandular and cartilaginous tissue.
Adeno-cystoma (ad-en-o-sis-to'-mah) [ádív, gland:

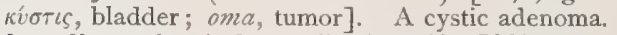

Adenodiastasis (ad-en-o-di-as'-tas-is) [ádín, gland;

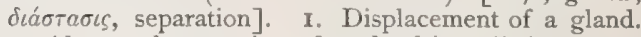
2. Abnormal separation of a gland into distinct parts.

Adenodiastatic (ad-en-o-di-as-tat'-ik) [ajón, gland;

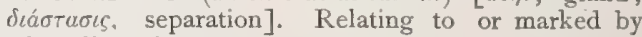
adenodiastasis.

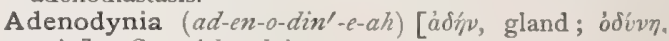
pain]. See Adenalgia.

Adeno-fibroma (ad-en-o-fi-bro'-mah) [ádiv, gland; fibra, a fiber]. A combination of adenoma and fibroma.

Adenofibromatous (ad-en-o-fe-brof-mat-us) [ảdinv, gland; fibra, a fiber]. Of the nature of adenofibroma.

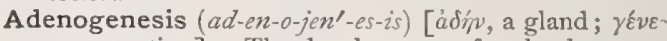
$\sigma i s$, a creation]. The development of a gland.

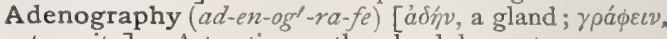
to write]. A treatise on the glandular system.

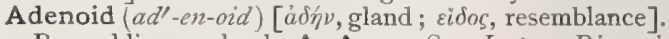
Resembling a gland. A. Acne. See Lupus, Disseminated Follicular. A. Body, the prostate gland. A. Disease. Synonym of Hodgkins's Disease. A. Tissue. See Animal Tissue. A. Tumor. See Adenoma. A. Vegetations, a term applied to an hypertrophy of the adenoid tissue that normally exists in the nasopharynx. This hypertrophy is associated with the following characteristic symptoms: Vacant expression of the child, open mouth, noisy breathing, more or less impairment of the hearing, a hacking cough, a peculiar muffling of the voice, and an enlargement of the tonsils. The vegetations exert an injurious influence on the physical development of the children so affected. The most important predisposing cause is youth; they are met with in all classes of life and in all climates. Treatment consists in the early and complete removal of the growths.

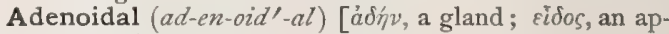
pearance $]$. Somewhat resembling a gland.

Adenologaditis (ad-en-o-log-ad-i'-tis) [aj'v, a gland; $\lambda o \gamma a ́ \delta \varepsilon s$, whites of the eyes; $\iota \tau \iota$, inflammation]. I. Ophthalmia neonatorum. 2. Inflammation of the glands and conjunctiva of the eyes.

Adenology $\left(a d-e n-o l^{\prime}-o-j e\right)[\dot{a} \delta h v$, gland; $\lambda \hat{o} \gamma o s$, a dis course]. The science of the glandular system.

Adeno-lymphocele (ad-en-o-limf'-o-se $l)$ [ádin, gland;

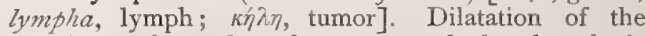
lymph-vessels and enlargement of the lymphatic glands.

Adenoma (ad-en-o'-mah) [ádív, gland; oma, tumor: pl., Adenomata $]$. A tumor that has sprung from a gland or is constructed after the type of a secreting gland. A. destruens, a destructive form of adenoma, involving the stomach walls. A. sebaceum, neoplastic papules on the face, of congenital origin but of later development. The disease occupies the position of acne rosacea, $i$. $e$., the middle two-thirds. The lesions are roundish, convex papules, from a millet to a hempseed in size, of a bright crimson color, but may be quite colorless and slightly translucent. They do not pale on pressure. They are usually associated with intellectual inferiority, a large proportion of the patients being imbeciles or chronic epileptics.

Adenomalacia (ad-en-o-mal-a'-she-ah) [adjv, a gland; $\mu a \lambda a \kappa i a$, softening ]. Abnormal softness of a gland.

Adenomesenteritis (ad-en-o-mes-en-ter-i'tis) [adiv, a

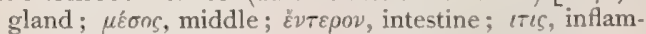
mation]. Inflammation of the mesenteric glands.

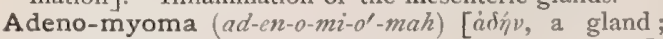
$\mu \tilde{v}$, a muscle; ona, tumor: plo, Adeno-myomata]. A tumor composed of glandular and muscular tissues. 
Adeno-myxoma (ad-en-o-miks-ó-mah) [ádív, a gland; uviza, mucous; oma, tumor: pl., Adeno-myxomata $]$. A growth having the characters of adenoma and myxoma.

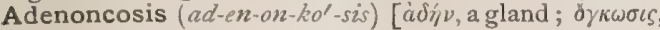
swelling]. The enlargement of a gland.

Adenoncus (ad-en-ong'-kus) [ádív, gland; öyкоs, a mass]. A glandular tumor.

Ad'eno-ner'vous Fe'ver. Synonym of Plague.

Adeno-neurotic (ad-en-o-nu-rot'-ik) [ád́n, a gland;

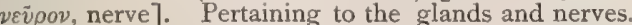
A. Fever, the plague.

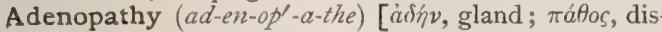
ease]. Any disease of a gland or of the glands.

Adenopharyngitis (ad-en-o-far-in-jí-tis) [ảjin, a gland; $\phi a ́ \rho v \gamma \xi$, the throat; $\iota \tau \iota \zeta$, inflammation]. Inflammation of the tonsils and pharynx.

Adenophlegmon (ad-en-o-fleg'-mon) [ád'́n, a gland; $\phi \lambda \hat{\varepsilon} \gamma \mu o \nu \eta$, inflammation]. Suppurative inflammation of a lymphatic gland.

Adenophore (ad-en'-o-for) [ádív, a gland; $\phi \varepsilon \rho \varepsilon \varepsilon v$, to bear]. In biology, the pedicle or stalk supporting a nectar gland.

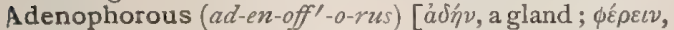
to bear]. Glandular, or gland-bearing.

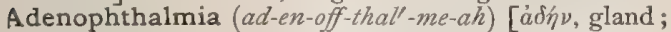

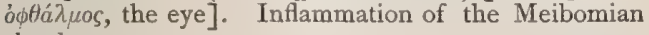
glands.

Adenophthalmitis (ad-en-off-thal-mi'tis). Same as Adenophthalmia.

Adenophyllous (ad-en-off'-il-us) [ádív, a gland; $\phi \dot{u} \lambda \lambda o v$, a leaf ]. In biology, with leaves which bear glands.

Adenophyma (ad-en-o-f $\left.f^{\prime}-m a h\right)$ [ảón $\nu$, gland; $\phi \vec{v} \mu \kappa$, growth]. A swelling of a gland or ganglion; a bubo.

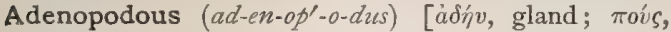
foot]. In biology, bearing glands on the footstalk or petiole.

Adeno-sarcoma (ad-en-o-sar-ko'-mah) [ảdív, a gland; oá $\rho \xi$, flesh; oma, a tumor: pl., Adeno-sarcomata]. A tumor with the characters of adenoma and sarcoma.

Adeno-scirrhus (ad-en-o-skir'-us) [ảjin, gland; бкípos]. Adenoma with scirrhous or carcinomatous elements.

Adenosclerosis (ad-en-o-skle-ro'-sis) [ảd́n, a gland; $\sigma \kappa \lambda \eta \rho \delta s$, hard]. A hardening of a gland, with or without swelling.

Adenose $\left(a d^{\prime}-e n-\bar{o} s\right)$ [áśn', gland]. Glandular; abounding in glands; gland-like.

Adenosis $\left(a d-e n-o^{\prime}-s i s\right)$ [ád́n, a gland]. I. Any glandular disease. 2. Any chronic glandular disorder.

Adenotomy (ad-en-ot'-o-me) [ád'́v, a gland; $\tau o ́ \mu \eta$, a cutting]. The anatomy of the glands; dissection or incision of a gland.

Adenous ( $\left.a d^{\prime}-e n-u s\right)$ [ádív, gland]. See Adenose.

Adephagia $\left(a d-e-f a^{\prime}-j e-a h\right)$ [ản $\phi a \gamma i a$, gluttonous]. gluttonous appetite; bulimia.

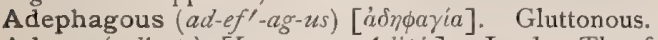

Adeps ( $\left.a d^{\prime \prime}-e p s\right)$ [L., gen., Adipis]. Lard. The fat obtained from the abdomen of the hog, Sus Scrofa. Composed of 38 per cent. stearin and margarin, and 62 per cent. olein. Forms 70 per cent. of ceratum and 80 of unguentum, $q . v$. A. anserinus, goosegrease. A. benzoinatus, contains two per cent. of benzoin. A. lanæ hydrosus, hydrous wool-fat, the purified fat of the wool of sheep. A. ovillus, mutton suet. Adipis, Oleum, a fixed oil expressed from lard. A. præparatus (B. P.), purified fat of the hog. Ung. Simp., contains white wax, benzoated lard, and almond-oil. A. suillus, hogs' lard; adeps.

Adepsin $\left(\alpha d^{\prime} \cdot p^{\prime}-\sin \right)$ [adeps, lard]. A petrolatum much like vaselin.
Adermia (ah-der'-me-ah) [ả priv.; Jépua, skin]. Absence or defect of the skin.

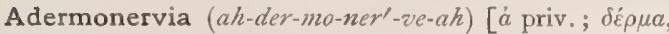
skin ; nervus, a nerve]. Loss or lack of nerve-stimulus in the skin.

Adermotrophia (ah-der-mo-tro'-fe-ah) [á priv.; dép $\mu \alpha$, skin; $\tau \rho \circ \phi \dot{\eta}$, nutrition]. Atrophy of the skin.

Adesmia (ah-des'-me-ah). See Adesmy.

Adesmosis (ah-des-mo'-sis) [á priv.; $\delta \sigma \mu o ́ s$, a band]. Atrophy of the cutaneous connective tissue

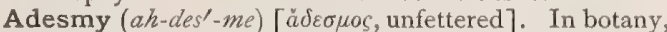
the separation of parts normally entire or united.

Adglutinate (ad-glu'-tin-att). Same as Agolutinate.

Adhatoda Vasica (ad-hat'-o-dah vas'-ik-ah). Malabar nut; leaves of $A$. justicia, a tree of the order of Acanthacex, growing in India. Expectorant and anti-spasmodic. Dose of the fld. ext. $3^{1 / 4}-\mathrm{j}$.

Adherence (ad-he'-rens) [adhareve, to adhere]. See Adhesion.

Adherent (ad-he'-rent) [adharere, to adhere]. In botany, adnate; the union of unlike structures.

Adhesion (ad-he'-zhun) [adharere, to stick to]. Abnormal union of two surfaces as a result of abrasion, inflammation, etc. A., Primary, called also Healing by First Intention and by Imnediate Union, a method of healing of wounds by the production of lymph, followed by the vascularization and cicatrization of the exudate. A., Secondary, or Healing by Second Intention, or by Granulation, is that mode of healing attended by the production of pus and the formation of granulations. A. Plaster. See Emplastrum.

Adhesive $\left(a d-h e^{\prime}\right.$-siv) [adharere, to adhere]. Sticky, tenacious. A. Inflammation, inflammation accompanied by plastic exudation, and tending to the union of apposed surfaces. It may be reparative in its effect, as in wounds, or it may be injurious in its results, as in some cases of pleurisy. A. Plaster. See Resin and Emplastrum.

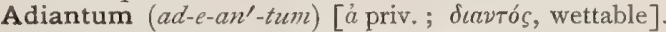
A genus of ferns; the maiden-hair. $A$. capillus veneris and $A$. pedatum, of $N$. America, are serviceable in coughs. The demulcent and anti-hectic remedy, capillaire, is prepared from the former. Unof.

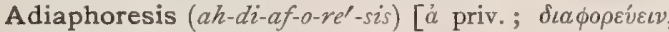
to perspire ]. Deficient sweat.

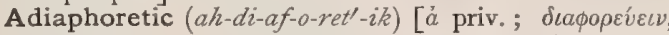
to perspire]. Reducing the sweat; anidrotic.

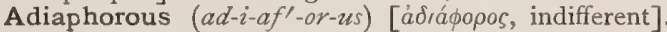
Neutral; inert; doing neither harm nor good.

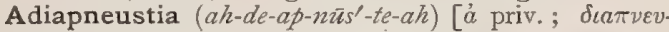
$\sigma \tau \varepsilon \varepsilon \varepsilon v$, to perspire]. A stoppage of perspiration.

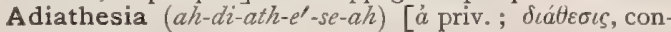
dition]. A condition or particular disease that is not congenital.

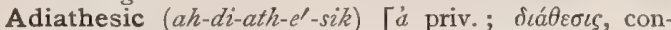
dition]. Not connected with any diathesis.

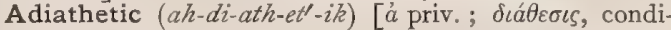
tion]. Adiathesic.

Adicity $\left(a d^{\prime}-i s^{\prime}-i t-e\right)$. In chemistry, combining capacity, according as an element or a compound is a monad, dyad, etc. Same as Valency.

Adinin $\left(a d^{\prime}-i n-i n\right)$. See Adenin.

Adipate $\left(a d^{\prime}-i p-\bar{a} t\right)$ [adeps, fat]. Any salt of adipic acid.

Adipic $\left(a d-i p p^{\prime}-i k\right)$ [adeps, lard]. Of or belonging to fat. A. Acid. See Acid.

Adipoceration $\left(a d^{\prime}-i p-o s-e r-a^{\prime}-s h u n\right)$ [adeps, fat; cera, wax ]. The formation of adipocere.

Adipocere $\left(a d^{\prime}-i p-o-s e \bar{r}\right)$ [adeps, fat; cera, wax]. A waxlike substance formed by the exposure of fleshy tissue to moisture, with the exclusion of air, i. e., in the 
earth or under water. It consists of the fatty acids in combination with the alkaline earths and ammonium. Human bodies in moist burial places often undergo this change.

Adipogenous (ad-ip-oj"-en-us) [adeps, fat; gignere, to produce]. Producing fat and adipose tissue.

Adipoma (ad-ip-o'-mah) [adeps, fat; oma, a tumor: $p l$. Adiponata]. A fatty tumor; lipoma.

Adipomatous (ad-ip-o'-mat-zs) [adeps, fat; oma, a tumor]. Of the nature of adipoma.

Adipose $\left(a d^{\prime \prime}-i p-\bar{o} s\right)$ [adeps, fat]. Fatty. A. Fin, the fleshy, rayless, dorsal fin of some fishes. A. Tissue, fat cells united by connective tissue; distributed extensively through the body. It is composed of triolein, tripalmitin, and tristearin, and is liquid during life or at the temperature of the living body.

Adiposis (ad-iph-o-sis) [adeps, fat; osis, state]. Corpulence; fatty degeneration; fatty infiltration. A. hepatica, fatty degeneration or infiltration of the liver.

Adipositas (ad-ip-os'-it-as) [L.]. Fatness; corpulency. Adiposity $\left(a d-i p-o s^{\prime}-i t-e\right)$. Fatness; corpulency.

Adipsia $\left(a / h-d i p^{\prime}-s e-a / h\right)$ [a priv. ; di $\psi a$, thirst]. Absence of thirst.

Adipsic (ah-diph-sik) [ $\alpha$ priv.; di $\psi a$, thirst]. Pertaining to adipsia; quenching thirst.

Adipsous (ah-dip'-sws) [a priv. ; di $\psi \alpha$, thirst]. Quenching thirst.

Aditus $\left(a d^{\prime}-i t-z l s\right)$ [ $a d$, to ; ire, to go]. In anatomy, an entrance, as to any one of the radial canals of a sponge. A. laryngis, the entrance to the larynx.

Ad'jective Col'oring Mat'ter. See Pigments, Colors, and Dye-stuffs.

Adjuster (ad-jus'-ter) [Fr., adjuster, to adjust]. He who or that which adjusts. A device formerly used for the forcible reduction of dislocations.

Adjust'ing Col'lar. See Collar.

Adjust'ment, Coarse. Commonly, the rack and pinion for raising or lowering the tube of a microscope a considerable distance. without lateral deviation. A., Fine, the micrometer screw generally at the top of the column of a microscope for raising or lowering the tube slowly through a short distance.

Adjuvant (aj'-u-vant $)$ [adjuvare, to assist]. A medicine that assists the action of another to which it is added.

Admortal (ad-mor'-tal) [ad, to ; mors, mortis, death]. Moving from living muscular tissue toward that which is dead or dying, as electric currents.

Adnascent $\left(a d-n \bar{a} s^{\prime}-e n t\right)$ [ $a d$, to ; nasci, to grow]. In biology, growing upon or attached to something.

Adnata $\left(a d-n \alpha^{\prime}-t a h\right)$ [ad, to; nasci, to be born, to grow]. I. The tunica adnata; the conjunctiva; more correctly, a tendinous expansion of the muscles of the eye; it lies between the sclerotic and the conjunctiva. 2. One of the coats of the testicle. . In zoölogy, appendages of the skin, as scales, hair, feathers.

Adnate $\left(a d^{\prime}-n \bar{a} t\right)$ [adnatus, grown to]. In biology, congenitally attached or united.

Adnation $\left(a d-n a^{\prime}-\operatorname{shun}\right)$ [adnatus, grown to]. The state of being adnate.

Adnerval (ad-ner'-val) $[a d$, to ; nervus, a nerve $]$. Moving toward a nerve; said of electric currents in muscular fiber.

Adneural (ad'-nu'-ral) [ad, to ; véfoov, a nerve]. A term used to describe a nervous afiection in which the disease is at the very point of the symptoms exclusively, as in the form of an adventitious deposit.

Adnexa $\left(a d^{\prime}-n e k s^{\prime}-\alpha h\right)[a d$, to ; nectere, to joint: $p l$.$] .$ Adjunct parts, as the adnexa of the uterus. A. bulbi, the appendages of the bulb of the eye.

Adolescence (ad-o-les'-ens) [adolescere, to grow]. Youth, or the period between puberty and maturity, usually reckoned as extending in males from about 14 to 25 years, and in females from 12 to 21 years.

Adonidin $\left(a d-o n^{\prime}-i d-i n\right)$ [Adonis]. A glucosid derived from Adonis vernalis; a plant indigenous in Europe and Asia. Recommended in cardiac dropsy. Dose gr. $1 / 8-1 / 4$. Unof.

Adonis æstivalis ( $a d^{\prime}-o^{\prime}-n i s$ es-tiv- $a^{\prime}$-lis). A plant much used in Italy as a cardiac tonic. Similar properties possessed by $A$. vernalis. Dose of fld. ext.

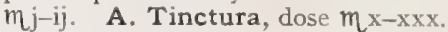

Adoral (ad-o'-ral) [ad, near to; os, the mouth]. Situated near the mouth.

Adosculation ( $\left.a d-o s-k u-l a^{\prime}-s h u n\right)$ [ $a d$, to ; osculari, to kiss]. Impregnation by external contact without intromission.

Adpressed, or Appressed (ad-presd' or ap-resd') [adpressus]. Brought into contact with but not united.

Adradial ( $\left.a d-r \alpha^{\prime}-d e-a l\right)$ [ad, near to ; radius, a ray]. Near a ray, as the third series of tentacles in certain hydrozoöns. Cf. Interradial, Perradial.

Adradii ( $\left.a d-r a^{\prime}-d e-i\right)$ [ad, near to ; radius, a ray]. Special organs lying between the perradii and interradii of medusae.

Adrectal ( $\left.a d-r e k^{\prime}-t a l\right)$ [ $a d$, near by; rectus, straight]. In biology, near the rectum, as certain glands.

Adrenal $\left(a d-r e^{\prime}-n a l\right)[a d$, near to ; ren, the kidney]. In biology, adjacent to the kidney.

Adrenais (ad-re'-nalz) [ad, near to; ren, the kidney]. The supra-renal capsules.

A'drian's Mix'ture. A hemostatic mixture containing chloride of iron 25 parts, chloride of sodium I 5 parts, and water 60 parts.

Adrostral (ad-ros'-tral) [ad, to, at; rostrum, beak]. In biology, belonging to or placed near the beak or snout.

Adrue $\left(a d-r u^{\prime}-e\right)$. Anti-emetic root. The root of $C y$ perus articulatus. Strongly recommended to check black vomit of yellow fever; anthelmintic, aromatic, stomachic. Dose of the fld, ext. gtt. $\mathrm{xx}-\mathrm{xxx}$. Unof.

Adscendent (ad-sen'-dent). See Ascending.

Adstriction (ad-strik'-shun) [adstrictis, a binding]. Ligation; astringent action; constipation.

Adsurgent, or Assurgent (ad-ser'-jent, as-ser'-jent) [ad, to; surgere, to rise]. Same as Ascending.

Adterminal (ad-ter'-min-al) [ad, near to; termimus, the end]. Moving toward the insertion of a muscle; said of electric currents in muscular fiber.

Adul Oil. An oil used in India for treating rheumatism.

Adult (ad-ult') [adolescere, adultus, to grow]. Mature; of full legal age. One of mature age. A. Sporadic Cretinism. See Myxedema.

Adulteration (ad-ul-ter-a'-shun) [adulterare, to corrupt]. The admixture of inferior, impure, inert, or less valuable ingredients to an article for gain, deception, or concealment. - Medicines, wines, foods, etc., are largely adulterated.

Adumbrella (ad-um-brel'-ah). In biology, the upper surface of the velum in the medusx, the opposite of exumbrella or Abumbrella.

Adumbrellar (ad-um-brel'-ar). In biology, pertaining to the upper or outer surface of the velum in the medusæ; opposed to abumbrellar.

Aduncous (ad-ung $\left.\sigma^{\prime}-k u s\right)$ [ad, to ; uncus, a hook, barb]. In biology, hooked, as the bill of a parrot or hawk.

Adust $\left(a d-u s t^{\prime}\right)$ [adusius, burned up]. Hot and dry; parched.

Adustion (ad-us'-chun) [adustus, burned up]. r. The quality of being adust. 2. Cauterization.

Advancement (ad-vans'-ment) [M. E., avancement]. An operation to remedy strabismus, generally in conjunction with tenotomy, whereby the opposite tendon from the over-acting one, having been cut, is brought 
forward, so that, growing fast in a more advanced position, it shall have more power to act upon the globe of the eye. A., Capsular, an operation similar to that on the tendon upon Tenon's capsule. It must be distinguished from advancement by the fact that the tendon itself is not divided.

Adventitia (ad-ven-tish'-e-ah) [adventitius, foreign]. The external covering or coat of the blood-vessels.

Adventitious (ad-ven-tish'-us) [adventitius, foreign]. Accidental, foreign, acquired, as opposed to natural or hereditary; occurring out of the ordinary or normal place or abode.

Adventive $\left(a d^{\prime}-v e n^{\prime}-t i v\right)$. In biology, an incompletely naturalized exotic.

Adverse ( $a d^{\prime}$-vers) [adversus, opposite]. In biology, turned or directed toward the axis.

Adversifoliate $(a d$-ver-se-fo'-le-ät $)$ [adverszes, opposite; folium, leaf ]. See Adversifolious.

Adversifolious (att-ver-se-fo'-le-us) [adversus, opposite; folium, leaf ]. In biology, having opposite leaves.

Adynamia ( $a h$-din- $\left.a^{\prime}-m e-a h\right)$ [ả priv. ; dovauıs, power]. Deficiency or loss of vital or muscular power.

Adynamic (ah-din-am'-ik) [ả priv.; duvauks, power]. Pertaining to or characterized by adynamia. $\mathbf{A}$. Fever. Synonym for Typhus Fever, $q$. $v$.

EE-. See $E$-。

Ecidioform (e-sid'-e-o-form) [aikia, a wheal; forma, form]. See Ecidiostage.

Ecidiomycetes (e-sid-e-a-mi-se'-tēz) [aikía, a wheal;

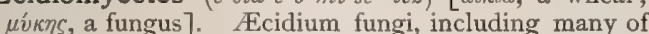
the rusts, blights, and mildews.

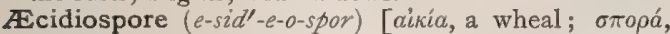
seed, spore]. In biology, a fungal spore developed by abstriction in a member of the genus Ecidium.

Acidiostage (e-sid'-e-o-siäj) [aikia, a wheal; M. E.; stage]. The first stage in the reproduction of uredine fungi. Same as Ecidioform.

Accidium (e-sid"-e-um) [aikia, a wheal; dim., idıov]. The cup-shaped organ producing the recidiospores in ihe uredine fungi.

Edœeagra (e-de-a'-grah). See Edeagra.

Edœeatrophia (e-de-at-ro'-fe-ah). See Edeatrophia.

Edceauxe (e-de-auks'-e). See Edeauxe.

Addcitis (e-de-i'-tis). See Edeitis.

Adcodynia (e-de-o-din'-e-ah). See Edeodynia.

Adcogargalismus (e-de-o-gar-gal-iz'-mus). See Edeogargalismus.

Adoeography (e-de-og'-ra-fe). See Edeography.

Edceology $(e$-de-ol'-o-je). See Edeology.

Edœomania (e-de-o-ma'-ne-ah). See Edeomania.

\#dœoomycodermitis (e-de-o-mi-ko-der-mi'-tis). See Edeomycodermitis.

AEdœopsy (e-de'-op-se). See Edeopsy.

Edœoptosis (e-de-op-to'sis). See Edeoptosis.

Adœooscopy (e-de-os'-ko-pe). See Edeoscopy.

AEdcotomy (e-de-ot'o-me). See Edeotomy.

Aggagropila (e-gag-rop'-il-ah). Plural of Agagropilus.

Egagropilus (e-gag-rop'-it-us) [aiyáypos, a wild goat; $\pi i \lambda o s$, felt $]$. An intestinal concretion formed of hair, found in animals and occasionally in man. A bezoar.

Egilops ( $\left.e^{\prime}-j i l-o p s\right)$. See Egilops.

Egithognathous (e-jith-og'-na-thus) [aǐytos, the hedge-sparrow; yvátos, jaw]. Characterized by having an anteriorly truncated vomer in union with the alinasal wall and turbinals, as in passerine birds.

Egobronchophony (e-go-brong-kaff'-o-ne). See Egobronchophony.

Egonia (e-go'-ne-ah) [L.]. A minor or slight egophony. Egophony (e-goff'-o-ne). See Egophony.

Egyptia ulcera (e-jiph-she-ah ul'-ser-ah) [L.]. Egyptian ulcers; a form of ulceration of the tonsils and fauces.

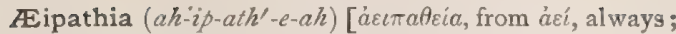
$\pi \alpha$ tlos, a suffering]. Constant and incurable suffering.

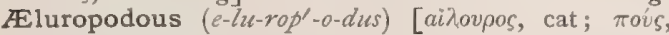
foot]. Cat-footed.

Eluropsis (el-u-rop'-sis) [ainvpos, cat; ö $\psi \iota s$, appearance]. Obliquity of the eye or of the palpebral fissure.

Equabiliter justo major, or minor Pelvis (e-kwa bil'-it-er). See Pelvis.

Equator Oculi (e-kwa'-tor o $k^{\prime}-u$-li). See Equator.

Equilibrium (e-kwil-ib'-re-um). See Equilibrium.

Aer $\left(a^{\prime}-e r\right)$. See Air

Aerrated $\left(a^{\prime}\right.$-er-a-ted $)$ [án $\rho$, the atmosphere]. Impreg nated or charged with carbon dioxid or air.

Aèration $\left(a-e r-a^{\prime}-\operatorname{shun}\right)[a \dot{n} \rho$, air $]$. The process of supplying or charging with air or with some gas, such as carbon dioxid; the state of being supplied with air or gas.

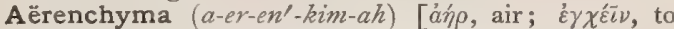
pour]. In biology, cork-like plant tissue.

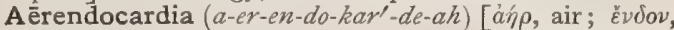
within; kapdia, heart]. The existence of air within the heart.

Aërenterectasia (a-er-en-ter-ek-ta'-se-ah) [án $\rho$, air;

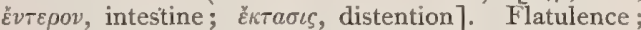
distention of the abdomen by gas within the intestines.

Aërhemoctonia (a-er-hem-ok-tó-ne-ah) [ản $\rho$, air ; aliua, blood; ктб́vos, killing]. Death by the entrance of air into the veins.

Aërhemotoxia (a-er-hem-o-toks'-e-ah) [ảh $\rho$, air; ai $\mu a$, blood; $\tau \circ \xi \iota k \sigma$, poison]. See Aërhemoctonia.

Aèrial $\left(\alpha-e^{\prime}-r e-a l\right)$. Pertaining to the air. A. Fistula. See Fistula.

Aëriferous (a-er-if'-er-us) [án $\rho$, air; ferre, to bear]. Conveying air, as the trachea and its branches.

Aërification $\left(a-e r-i f-i k-a^{\prime}-\operatorname{shun}\right)[a ́ n \rho$, air; facere, to make]. I. The process of charging with air; the state of being charged with air. 2. Emphysema.

Aêrifluxus (a-er-if-luks'-us) [àn $\rho$, air; fluxus, flow]. Any abnormal escape of air, as by belching, flatulence, etc.

Aëriperitonia (a-er-ip-er-it-o-ne'-ah) [árí $\rho$, air; $\pi \varepsilon \rho \iota^{\prime}$, around; $\tau \varepsilon i v \varepsilon i v$, to stretch ]. Peritoneal tympanites.

Aèrobe $\left(a^{\prime}-e r-\bar{o} b\right)$ [án $\rho$, air; $\beta$ íos, life]. One of the aërobia. See $A \ddot{e} r$ robic.

Aërobia $\left(a-e r-o^{\prime}-b e-a h\right)$ [án $\rho$, air; ßíos, life]. Plural of Aërobe. Organisms that require air or free oxygen for the maintenance of life. A., Facultative, organisms normally or usually anaërobic, but under certain circumstances acquiring aërobic power.

Aërobic $\left(a-e r-\bar{o} b^{\prime}-i k\right)$ [án $\rho$, air; Bios, life]. Requiring oxygen (air) in order to live. A term applied to those bacteria requining free oxygen. Those that do not grow in its presence are called anaêrobic. Between these extremes there are forms that are able to grow without oxygen under favorable conditions, though they make use of it when present; others that may grow in its presence, though flourishing best in its absence; these are called respectively facultative aërobes or facultative anaërobes, in distinction from those first mentioned, which are called obligatory aêrobes or anaërobes.

Aërobiosis $\left(\alpha-e r-o-b i-o^{\prime}-s i s\right)$ [án $\rho$, air; ßios, life]. Life that requires the presence of air, or free oxygen

Aèrobiotic $\left(a-e r-o-b i-o t^{\prime}-i k\right)$ [án $\rho$, air ; $\beta \iota \omega \tau \iota \kappa o ́ s$, pertaining to life]. Thriving only in the presence of free oxygen.

Arocomia sclerocarpa (e-ro-ko'-me-ah skle-ro-kar'. pah). A South American plant, very popular as a remedy in leucorrhea, diarrhea, and albuminuria. It is astringent. Unof. 
Aëroconiscope $\left(\alpha-e r-o-k o n^{\prime}-i s-k o p p\right) \quad[a \dot{n} \rho$, air; $k \dot{v} v \iota s$, dust; $\sigma \kappa o \pi \varepsilon i v$, to inspect]. A device for collecting dust from the air for microscopical observation.

A èrocyst $\left(a^{\prime}\right.$-er-o-sist $)$ [ánp, air; kíotıs, bladder $]$. In biology, the air-bladder of sea-weeds.

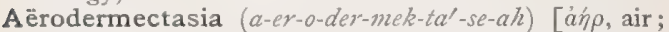

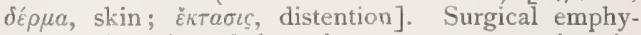
sema; distention of the subcutaneous connective tissue by air.

Aëroenterectasia $\left(a-e r-o-e n-t e r-e k-t \alpha^{\prime}-s e-a h\right)[a ̉ h \rho$, air ;

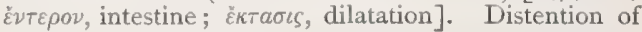
the bowels with gas.

Aërognosy $\left(a-\ell r-o \sigma^{\prime}-n o-s e\right) \quad[a \dot{n} \rho$, air; $\gamma \nu \tilde{\omega} \sigma \iota \varsigma$, knowledge]. See Aërology.

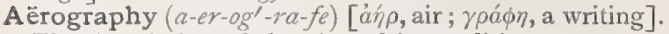
The description of the air and its qualities.

Aerrohydropathy $\left(\alpha-e r-\alpha-h i-d r o p^{\prime}-\alpha-t h e\right)[a ́ n \rho$, air ; $v \delta \omega \rho$, water; $\pi a ́ \theta o s$, disease]. Pneumatic treatment of disease, combined with hydropathy.

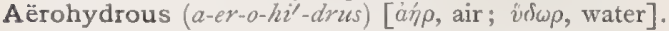
Containing air and water, as certain minerals.

Aërology $\left(a-e r-o l^{\prime}-o-j e\right)$ [áh $\rho$, air; $\lambda b_{\gamma o s}$, treatise $]$. The science of the air and its qualities.

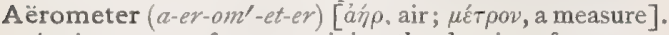
An instrument for ascertaining the density of gases.

Aërometry $\left(a-e \gamma-o n^{\prime}-e t-r e\right)$ [án $\rho$, air; $\mu \dot{\tau} \tau \rho o \nu$, a measure]. The science of measuring the density of gases.

Aërophobia (a-er-o-fo'-be-ah) [án $\rho$, air; $\phi \hat{b} \beta o s, f e a r]$. Dread of a current of air; a symptom of hydrophobia and hysteria.

Aërophoby $\left(a^{\prime}-\varepsilon r-o-f o-b e\right)[a ́ n \rho$, air; $\phi \hat{b} \beta o s, f e a r]$. See Aërophobia.

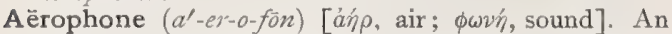
instrument for increasing the amplitude of soundwaves.

Aẽrophore ( $\alpha^{\prime}$-er-o-for) [án $\rho$, air ; $\phi \rho \rho \varepsilon i \nu$, to carry]. I. A device for the inflation of the lungs of a still-born child with air. 2, A breathing apparatus to be used by firemen and others, to prevent the inhalation of noxious gases.

Aèrophyte (a-er-o-fit $)$ [ản $\rho$, air ; фítov, plant]. An airplant.

Aëropinic (a-er-o-pin'-ik) [án $\rho$, air ; $\pi i v \varepsilon \iota \nu$, to drink]. Affected with the habit of wind-sucking. Applied to a horse that habitually bites his crib or manger and swallows air.

Aëroplethysmograph (a-er-o-pleth-iz'-mo-graf) [áń $\rho$, air; $\pi \lambda \tilde{n} \theta 0 s$, fulness; $\gamma \rho \alpha \dot{\phi} \varepsilon \iota v$, to write]. An apparatus for registering graphically the expired air; the latter raises a very light and carefully equipoised box placed over water, and this moves a writing-style.

Aëropneumonectasia (a-er-op-nu-mo-nek-tal-se-ah)

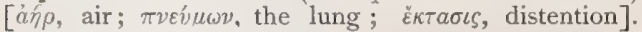
Emphysema of the lungs.

Aërorrhachia $\left(a-e r-o-r a^{\prime}-k e-a h\right)\left[a \dot{n} \rho\right.$, air; $\rho a^{\prime} \chi \iota s$, the spine]. An accumulation of air or gas in the spinal canal.

Aéroscepsy (a-er-o-skep'-se) [áń $\rho$, air; $\sigma \kappa \varepsilon ́ \psi \iota s$, a viewing]. In zoollogy, the power of perceiving atmospheric changes.

Aëroscope (ál-er-o-skōpl) [áń $\rho$, air ; $\sigma \kappa o \pi \varepsilon i \nu$, to observe]. An instrument for the examination of air-dust. Also, an instrument for estimating the purity of the air.

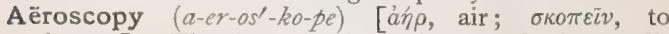
observe]. The investigation of atmospheric conditions.

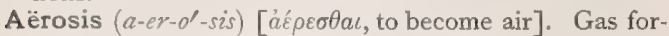
mation within the body.

Aërotherapeutics (a-e-ro-ther-a-pu-tiks) [áh $\rho$, air ; $\theta \varepsilon \rho r \pi \varepsilon v \varepsilon \varepsilon \nu$, to serve]. Pneumatotherapeutics; a mode of treating disease by varying the pressure or the composition of the air breathed.

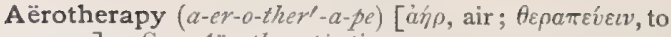
serve]. See Aërotherapeutics.

Aërothorax (a-er-o-tho'-raks) [anp, air; $\theta \omega \rho a \xi$, the chest]. See Pneumothorax.

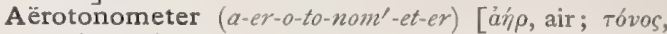
tension; $\mu \varepsilon^{\prime}$ pov, measure]. An instrument for estimating the tension of gases in the blood.

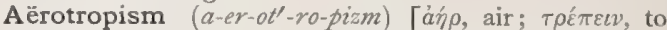
turn]. In biology, the deflection of roots from the normal direction of growth by the action of gases.

Aërourethroscopy (a-er-o-u-rêth'-ro-sko-pe) [àn.p, air ; oujpíf $\rho a$, urethra; $\sigma \kappa o \pi \varepsilon \bar{\nu}$, to examine]. Urethroscopy conjoined with inflation of the urethra with air.

Aërozoa $\left(a-e r-o-z o^{\prime}-a h\right)$ [ản $\rho$, air ; $\xi \hat{\omega} o v$, animal $]$. Same as Aërobia.

Aērteriversion (a-er-ter-iv-er'-shun) [ản $\rho$, air; $\tau \eta \rho \varepsilon \varepsilon \varepsilon \nu$, to hold; vertere, to turn]. A method of arresting hemorrhage by everting the cut end of an artery, invaginating the vessel in itself and fixing the parts by a needle.

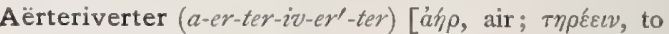
hold; vertere, to turn]. An instrument used in perforating aērteriversion.

Eruginous (e-ru'-jin-us). See Eruginous.

Erugo $\left(e-r u^{\prime}-g^{\circ}\right)$ [L., gen. Arruginis]. I. Rust of a metal. 2. Subacetate of copper. FE. Ferri, the subcarbonate of iron. $\mathbb{E}$. Plumbi, lead carbonate, or subcarbonate.

Arumna (e-mu'-nah) [L.]. Mental distress, or mental and physical distress combined.

AEs (ēz) [L. ]. Copper or brass. See Copper.

Aschrolalia (es-kro-la'-le-ah). See Eschrolalia

Eschromythesis (es-kro-mi-the'-sis). See Eschromythesis.

\#sculin (es'-ku-lin). See Esculin.

Esculus hippocastanum (es'-ku-lus hip-o-kas'-tanum ) [L.]. Horse-chestnut. The fruit of the common "buckeye," or horse-chestnut. Recommended in hemorrhoids. Dose gr. iij. Unof.

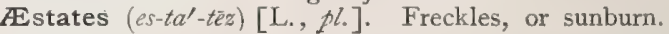
See Ephelis and Lentigo.

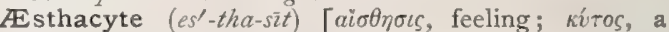
cell]. In biology, one of the sense-cells of sponges, discovered by Stewart.

Esthematology (es-the-mat-ol'-o-je). See Esthematology.

Asthesia (es-the'-ze-ah). See Esthesia.

Esthesin (es'-the-sin). See Esthesin.

Esthesiogen (es-the'-se-o-jen). See Esthesiogen.

Esthesiography (es-the-se-og'-ra-fe). See Esthesiography.

Esthesiology (es-the-se-ol'-o-je). See Esthesiology.

Esthesiomania (es-the-se-o-ma'-ne-ah). See Esthesiomania.

Esthesiometer (es-the-se-om'-et-er). See Esthesiometer.

Esthesiometry (es-the-se-om'-et-re). See Esthesiometry.

Esthesioneurosis (es-the-se-o-nu-ro'-sis). See Esthesioneurosis.

Esthesis (es-the'-sis). See Esthesis.

Esthesodic (es-the-sod'-ik). See Esthesodic.

Asthete $\left(e s^{\prime}-t^{-} \bar{e}^{t}\right)$ [aiotintós, perceived by the senses]. In biology, one of the sense-organs of the Chitonida described by Moseley.

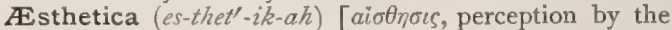
senses]. Diseases characterized by impairment or abolition of any of the senses.

Esthophysiology (es-tho-fiz-e-ol'-o-je). See Esthophysiology.

Astival (es'-tiv-al). See Estival.

Astivation (es-tiz'-a'-shun). See Estivation. 
Astuarium (es-tu-a'-re-um). See Estuarium. Estuation (es-tu-a $\left.a^{\prime}-\operatorname{shun}\right)$. See Estuation.

Estus (es'tus) [I..]. Heat; especially a flushing, or sudden glow of heat. $\mathbb{E}$. volaticus, wildtire rash; strophulus.

Atas $\left(e^{\prime}\right.$-tas $)$ [L.]. Age; a period of life. See Age.

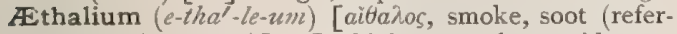
ring to the spores)]. In biology, a placentoid compound plasmodium formed by certain mycetozoa, e. g., the flowers of $\tan$.

Ether $\left(e^{\prime}\right.$-ther). See Ether.

Etherism (e'ther-izm). See Etherism.

Ethiopification $\left(c^{-}-t h e^{\prime}-o p-i f-i k-a^{\prime}-s h u n\right)$. See Ethiopification.

AEthiopiosis (e-the-op-e-o'-sis). See Ethiopification.

Ethiops ( $e^{\prime}$-the-ops) [aitio\%, an Ethiopian]. An old term for any black mineral powder used in medicine. AE. antimonialis, a black triturate of mercury, antimony, and sulphur, made after several distinct formula. E. martialis, black iron deutoxid. $\mathbb{E}$. mineralis, black amorphous triturate of mercury with sulphur, in various proportions.

Ethusa (e-thu'-sah). See Ethuse.

Ethusin $\left(e-t h u^{\prime}-\sin \right)$. See Ethusin.

Etiology (e-te-ol'-o-je). 'See Etiology.

Afebrile (ah-fe'-bril) [ $\dot{a}$ priv.; febritis, feverish]. Without fever.

Afetal (ah-fe'tal) [á priv.; fetus, an offspring]. Without a fetus.

Affection $\left(a f-e k^{\prime}-\operatorname{shun}\right)$ [afficere, to affect]. A synonym of disease.

Affective $\left(a f-e k^{\prime}-t i v\right)$ [afficere, to affect]. Exciting emotion. A. Faculties, the emotions and propensitiesespecially those peculiar to man. A. Insanity, emotional or impulsive insanity.

Affectus $\left(a f-e k^{\prime}-t u s\right)$ [L.]. A disordered condition. A. animi, an affection of the mind; mental disorder. A. suffocatorius. Synonym of Diphtheria.

Afferent (af'-er-ent) [afferens, carrying to]. Carrying toward the center. Of nerves: conveying impulses toward the central nervous system; sensory, centripetal. Of blood-vessels: those, as arteries, conveying blood to the tissue, sometimes also to the gills. Of lymphatics: those conveying lymph to a lymphatic gland. Compare Efferent.

Afferentia, or Vasa afferentia $\left(v a^{\prime}-s a h\right.$ af-er-en'-sheah) $[\mathrm{L}$.$] . I. The lymphatic vessels. 2. Any vessels$ carrying blood or lymph to an organ.

Affiliation $\left(a f-i l-e-a^{\prime}-s h u n\right)[a d$, to; filizes, son $]$. In medical jurisprudence, the act of imputing or affixing the paternity of a child in order to provide for its maintenance.

Affinity $\left(a f-i n^{\prime}-i t-e\right)$ [affinis, akin to]. Relationship. A synonym of Attraction. A., Chemical, the force exerted at inappreciable distances, and between definite and invariable weights of two or more combining substances, whereby bodies of dissimilar nature unite to form new compounds. Contradistinguished from cohesion, which is an attraction between molecules. A., Elective, the preference of one substance for another rather than for a third or fourth. Affinity is spoken of as compound, developed, disposing, divellent, intermediate, quiescent, reciprocal, or synthetic, according to the part it plays, or is conceived to play, in any chemical process.

Affium $\left(a f^{\prime}-\ell-\imath \iota m\right)$ [Arab., Afrun]. The Asiatic name for opium.

Afflate $\left(a f-l \bar{a} t^{\prime}\right)$ [afflatus, blown upon]. Sudden in its attack ; overwhelming.

Afflatus (af-la'-tus) [L., "a blowing upon"]. I. A draft or blast of air. 2. A sudden attack. 3. A supposed inspiration or divine influence.
Affluence (af'-lu-ens) [affuentia, from affuere, to flow to]. A determination or influx, as of blood to a part.

Affluent (af'-lu-ent) [affluens, flowing to]. Producing a congestion; determinant; flowing in or upon.

Afflux (af'-lux) [afluere, affuxus, to flow toward]. The flow of the blood or other liquid to a particular part.

Affluxion (af-luk'-shun) [affuere, affuxus, to flow toward]. See Affux.

Affusion (af-u'-zhun) [affusio, affundere, to pour upon]. Pouring water upon a substance to cleanse it, or upon the body in fevers to reduce temperature and calm nervous symptoms.

A-form Chronoscope. See Chronoscope.

African (af'-rik-an) [Africa, Latin name of the country]. Pertaining to Africa. A. Arrow-poison. See Strophanthus. A. Date-mark. See Furunculus orientalis. A. Fever. Synonym of Dengue. A. Gum, gum arabic. See Acacia. A. Lethargy, or Nelávan, a "sleeping sickness" affecting negroes of the West African coast. Increasing somnolence is the characteristic symptom. It is very fatal. Death after emaciation follows in from three to six months. Post-mortem examination has revealed hyperemia of the arachnoid, and it is asserted that this "sleeping sickness" is only one of the symptoms of Filariasis, q. $v$. No treatment avails. A. Pepper, Chillies; the intensely biting fruit of Capsicum fastigiatum. See Capsicum.

After (af'-ter) [A.S., after, back]. I. The anus. The buttocks. 2. Next in succession. A. Action, the negative variation in an electrical current continuing for a short time in a tetanized muscle. A. Birth, the popular designation of the placenta, cord, and membranes, sometimes called the secundines. A. Brain. See Hindbrain and Metencephalon. A. Care, the care or nursing of convalescents ; specifically, the treatment of patients discharged as cured from lunatic asylums. A. Cataract, Cataracta Secundaria; an opacity of the media of the eye after operation for cataract due to opacification of the capsule or to non-absorption of the remains of the lens-substance. A. Damp, a poisonous mixture of gases, such as carbon monoxid and carbon dioxid, found in coal mines after an explosion of inflammable gases. A. Hearing, a neurotic condition in which sounds are heard after the wave-motion that produces them has ceased. A. Images, continued retinal impressions after the stimulus of the light or image has ceased to act. A positive afterimage is a simple prolongation of the sensation; a negrative after-image is the appearance of the image in complementary colors. After-sensations may be also experienced with other senses. A. Milk, the strippings; the last milk taken from the teat at any one milking. It is peculiarly rich in butter, as compared with the fore-milk. A. Pains. See Pains. A. Perception, the perception of a sensation after the stimulus has passed away. A. Sensation, a sensation lasting longer than the stimulus producing it. A. Taste, $\mathbf{a}$ gustatory sensation produced some time after the stimulus has been removed. A. Treatment. See A. Care. Afterings (af'-ter-ingz) [A. S., after, after]. See After-milk,

Agacement des Dents [Fr.]. The unpleasant sensation of teeth " set on edge" from contact of acids.

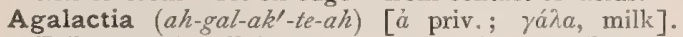
Failure or insufficiency of the mother's milk after childbirth.

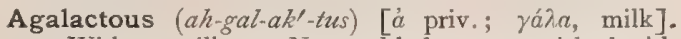
I. Without milk. 2. Not suckled; not nourished with milk.

Agalaxy (ah-gal'-ak-se). See Agalactia. 
Agallocha (ag-all-o-kah) [áyá $\lambda \lambda_{0} \times \nu$, the lignum aloes]. The milky juice of Excacaria agallochum, a small tree of India. The juice is very acrid, and when brought in contact with the skin blisters it. Used locally for the cure of leprosy. Unof.

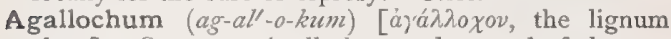
aloes]. Same as Agallocha, or the wood of the tree that produces it; eagle-wood, or aloes-wood.

Agalorrhea, or Agalorrhcea (ah-gal-o-re'-ah) [á priv.;

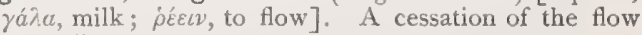
of milk.

Agamic $\left(a h-g a m^{\prime}-i k\right)$ [á priv.; yáuos, marriage]. I. In biology, not sexual; not pertaining to the sexual relation; asexual reproduction; parthenogenesis.

Agamogenesis (ah̆-gam-o-jen'-es-is) [ả priv.; yáuos,

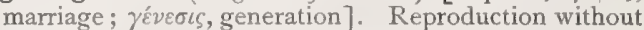
fecundation, as, e.g., by gemmation. See Parthenogenesis.

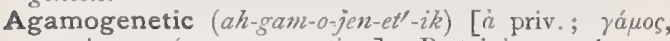

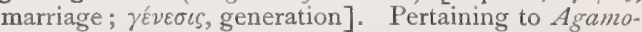
genesis.

Agamospore (ah-gam'-o-spōor) [ả priv.; yáuos, marriage; $\sigma \pi 0 \rho a ́$, offspring]. In biology, an asexually produced spore.

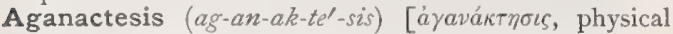
pain ]. Irritation; physical pain or uneasy sensation.

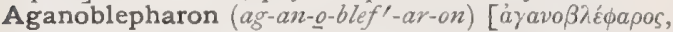
mild-eyed]. Adhesion of the eyelids to each other.

Agar-agar $\left(a^{\prime}-g a r-a^{\prime}-g a r\right)$ [Ceylon]. A kind of glue made from certain sea-weeds, such as Gracilaria lichenoides and Gigartina speciosa, used in medicine to make suppositories, and in bacteriological studies to make a solution in which microörganisms are bred or kept. See Gelose.

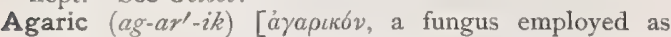
tinder by the Agari of Sarmatia]. A fungus of the genus Agaricus, e.g., the mushroom and toadstool. See Agaricus.

Agaricic Acid (ag-ar-is'-ik as'-id). See Acid, Agaricic.

Agaricin (ag-ar'-is-in) [see Agaric], $\mathrm{C}_{16} \mathrm{H}_{30} \mathrm{O}_{5}+\mathrm{H}_{2} \mathrm{O}$. A white crystalline substance, the active principle of Agaricus albus. It has proved useful in the night sweats of phthisis where atropia has failed. Dose gr. $\frac{1}{20}-\frac{1}{15}$. Unof.

Agaricus $(a g$-arl-ik-us) [see Agaric]. A genus of the family of Agaricini or Mushrooms. $A$. albus, Purging Agaric, unof., a fungus parasite upon the European Larch; it contains an alkaloid, agaricin, and agaric acid. It is used as a drastic purgative, and is valuable in night sweats. Dose gr. $\mathrm{xxx}-\mathrm{z} \mathrm{j}$ as a purgative; gr. Xv in night sweats. A., Ext., Alcohol.

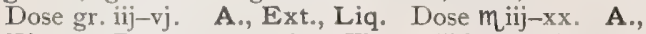
Tinct. Dose $m \times x-3 j$. The edible species, $A$. campestris, is characterized by a brownish color, that does not change when cut, and an agreeable taste. $A$. chirurgorum, Surgeon's Agaric, a parasitic fungus formerly used for Moxa, $q . v$. Soaked in solution of potassium nitrate it forms spunk. A. mus. carius, Fly Agaric, a poisonous mushroom, containing an alkaloid, Muscarin, q.v., a powerful cardiac depressant. Dose of the alkaloid gr. 1/8-ij. Muscarin Nitrate, used hypodermatically. Dose gr. $\frac{1}{10}-\frac{3}{4}$.

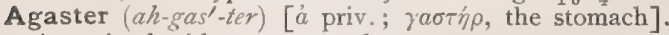
An animal without a stomach.

Agastric (ah-gas'-trik) [a priv.; yaoth́p, the stomach]. Having no intestinal canal, as the tape-worms.

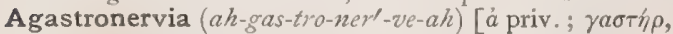
the stomach; nervus, a nerve or sinew ]. See Agastroneuria.

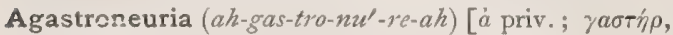
the stomach; veipov, a nerve]. Deficiency in the nerve-stimulus sent to the stomach.
Agathin $\left(a g^{\prime}-a t h-i n\right)$ [áyatós, good], $\mathrm{C}_{6} \mathrm{H}_{4}(\mathrm{OH}) . \mathrm{CH}_{\text {.- }}$ N.N $\left(\mathrm{CH}_{3}\right) \cdot \mathrm{C}_{6} \mathrm{H}_{5}$. Salicyl-alpha-methyl-phenyl-hydrazone, obtained by the interaction of salicylic aldehyd, and alpha-methyl phenyl-hydrazin. It is a greenishwhite, crystalline substance, without odor or taste, insoluble in water, soluble in alcohol and ether, and melts at $74^{\circ} \mathrm{C}$. Used as an anti-neuralgic in doses of eight grains, two or three times daily. Its action is cumulative. Unof.

Agave $\left(a-g a^{\prime}-v e\right)[\not \partial \gamma \alpha v \dot{\eta}$, noble]. A large genus of amaryllidaceous plants, natives of North America. $A$. americana, American Aloe, the leaves of a plant growing in North America. It is diuretic and antisyphilitic. Dose of the fld, ext. $3 \mathrm{ss}-\mathrm{j}$. The fresh juice is also similarly employed. The fermented juice, called pulque, is a moderately stimulant drink, very popular in Mexico. Unof.

Age $(\bar{a} j)$ [M. E., age]. The length of time a being has existed; also, a certain stage in life. The period of life is divided into a succession of ages, as follows: I. Infancy, from birth to the appearance of the temporary teeth. 2. Childhood, from the cutting of the first permanent teeth to puberty. 3. Youth, from puberty to the attainment of the full stature, that is, 18 or 19 for girls, 2 I to 22 for boys. 4. Maturity, covers the interval from youth to the climacteric. 5. Old-age, or period of decline. Other divisions may be made, as, e.g., those of embryonic life, of immaturity, of maturity, of sterility, etc.

Agenesia (ah-jen-e'-se-ah) [ả priv.; $\gamma^{\prime} v \varepsilon \sigma \iota \varsigma$, generation]. A term somewhat loosely used to designate abnormal or imperfect development. Also impotence and sterility. In botany, the asexual development of the flower.

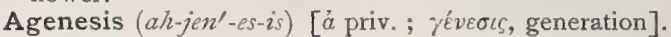
I. Impotence; barrenness. 2. Incomplete and defective development.

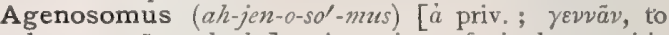
beget; $\sigma \tilde{\omega} \mu a$, body]. A variety of single autositic monsters, of the species Celosomia in which there is a lateral or median eventration occupying principally the lower portion of the abdomen, while the genital and urinary organs are either absent or very rudimentary.

Agens $\left(a^{\prime}-j e n z\right)$ [L.]. An agent. A. Morbi. See Mor-bi.

Agent $\left(a^{\prime}\right.$-jent $)$ [agere, to act, to do]. A substance or force that by its action effects changes in the human body.

Agenus $\left(a j^{\prime}-e n-u s\right)$ [ả priv.; $\gamma^{\prime} v o s$, offspring]. Cellular plants.

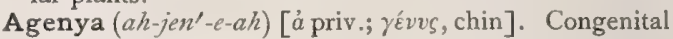
absence of the chin.

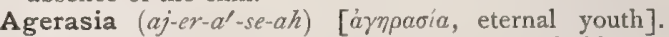
Vigorous old age; age without its wonted feebleness and decay.

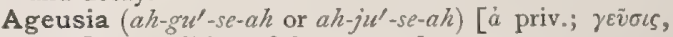
taste]. Abolition of the sense of taste.

Ageustia $\left(a h-g \bar{u} s^{\prime}-t e-a h\right)$ [à priv.; $\gamma \varepsilon \bar{v} \sigma \iota s$, taste]. Same as Agezesia.

Agger $\left(a j^{\prime}-e r\right)[\mathrm{L}$.$] . In anatomy, a pile or mound. A.$ nasi, an anterior prolongation and elevation of the mucous membrane covering the middle turbinated bone; its direction is almost parallel with the dorsal ridge of the nose, running forward and downward till it reaches very nearly to the anterior aperture of the nostril. A. valvulæ venæ $[p / .$. Ag'geres valvula' mum vena'rum], the eminence of a venous valve; a projection within the lumen of a vein at the junction of a valve.

Agglomerate $\left(a g-l o m^{\prime}-e r-\bar{a} t\right)$ [agglonnerare, to wind into a ball]. Grouped or clustered; massed. Crowded into a dense cluster. A. Glands. See Gland. 
Agglutinant (ag-lu'-tin-ant) [agglutinare, to paste to]. Promotive of repair by adhesion; favorable to agglutination.

Agglutinate ( $a g$-lu'-tin-ät) [agglutinare, to paste to]. In biology, to glue together; to unite by adhesion.

Agglutination (ag-lu-tin-a'-shun) [agglutinare, to glue upon or to]. A joining together; applied to the healing of wounds; it is called immediate, if by the first intention; mediale, if through the intermediation of some natural plastic material.

Agglutinative $\left(a g-l u^{\prime}-t i n-a-t i v\right)$ [agglutinare, to glue upon or to]. I. Favoring agglutination; adhesive. 2. Any substance with adhesive properties, fitted to retain the edges of wounds in apposition. Such are caoutchouc, collodion, etc.

Aggravation (ag-ra-val-shun) [aggravare, to make worse]. Increase in severity, as of a disease, symptom, or pain.

Aggregate $\left(a g^{\prime}-r e-g \bar{a} t\right) \quad[a d$, to gregare, to collect into a flock]. Grouped into a mass. A. Glands. See Gland.

Aggregation (ag-re-ga'-shun) [ad, to ; gregare, to collect into a flock]. I. The massing of materials together. 2. A congeries or collection of bodies, mostly of such as are similar to each other.

Agitation $\left(a j-i t-a^{\prime}-s h u n\right)$ [agitare, to excite, arouse]. I. Fatiguing restlessness with violent motion; mental disturbance, 2. A stirring or shaking, as in pharmacy.

Aglet, Aiglet $\left(a g^{\prime}-l e t, \bar{a} g^{\prime}-l e t\right)$ [M. E.]. In biology, a drooping anther or catkin.

Aglia $\left(a g^{\prime}-l e-a h\right)$ [L.]. A speck or spot upon the cornea or on the white of the eye.

Aglobulia ( $a h$-glo-bu'-le-ah) [à priv.; globulus, a globule]. A decrease in the quantity of red blood corpuscles, with corresponding increase of serum.

Aglobulism (ah-glob'-u-lizm) [á priv.; globulus, a globule]. Aglobulia; oligocythemia.

Aglobulous (ah-glob'-u-lus) [a priv.; globulus, a globule]. Characterized by aglobulia.

Aglossia (ah-glos'-e-ah) [a priv.; $\gamma \lambda \tilde{\omega} \sigma \sigma a$, the tongue]. Congenital absence of the tongue.

Aglossostoma ( $a h$-glos-os'-to-mah) [a priv. ; $\gamma \lambda \tilde{\omega} \sigma \sigma a$, the tongue; $\sigma \tau \delta \mu a$, the mouth]. A fetal monster in which there is a mouth without a tongue.

Aglossus ( $a h$-glos'- $u s)$ [à $\gamma \lambda \omega \sigma \sigma o s$, without a tongue]. A person without a tongue.

Aglutition (ah-glu-tish'-un) [ả priv.; glutire, to swallow]. Difficulty in swallowing; inability to swallow.

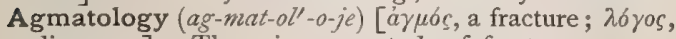
discourse]. The science or study of fractures.

Agmen (ag'-men) [agmen, a multitude]. In biology, a taxonomic group between a class and an order.

Agminate (agl-min-ät) [agmen, a multitude]. Aggregated, clustered. A. Glands. See Gland, Peyer's.

Agnail $\left(a g^{\prime}-n \vec{a} l\right)$ [A.S., angnagl] . I. Hangnail. 2. A whitlow. 3. A corn on the toe or foot

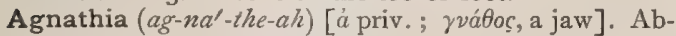
sence or defective development of the jaws.

Agnathus ( $a g^{\prime}$-na-thus) [áa priv.; yvátos, a jaw]. A monster with no lower jaw.

Agnea, or Agncea $\left(a g-n e^{\prime}-a h\right)[a ̈ \gamma v o \iota$, want of perception]. A condition in which the patient does not recognize things or persons.

Agnew's Operations. See Operations, Table of.

Agnew's Rectal Chemise, An appliance for controlling hemorrhage from the rectum. It consists of a gum catheter to the end of which are attached three square pieces of mosquito-netting. These are moistened with a solution of the persulphate of iron, and the whole introduced into the rectum, where it acts as a plug.
Agnin $\left(a g^{\prime}-n i n\right)$ [agnus, a lamb]. A fatty substance derivable from sheep's wool, unmixed with water; it is harder, darker, and less agreeable in color and odor than lanolin. See Lanolin and Suint.

Agnina Membrana (ag-ni'-nah mem-bra'nah) [L.]. "The lamb-like, or woolly, membrane," - the amnion. Agnus castus (agl-mus kas'-tus) [L.]. The chaste tree, Vitex agnus castus; its leaves and seeds were formerly used as a preservative of chastity, and its homeopathic preparations are still exhibited as anaphrodisiacs.

-ago'ga, -agogue [áywyós, one who leads]. A suffix, denoting agents that drive out other substances, as emmenagogues, lithagogues, etc.

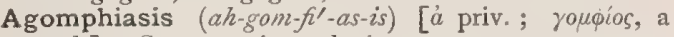
tooth]. Same as Agomphosis.

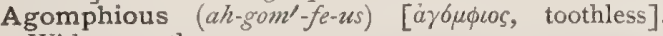
Without teeth.

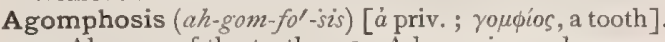
I. Absence of the teeth. 2. A loosening or looseness of the teeth.

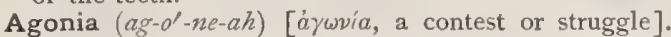
I. Distress of mind; extreme anguish. 2. The death struggle. [á yovos, barren]. Barrenness; sterility; impotence. A. Bark. See Agoriada.

Agoniadin (ag-on-i'-ad-in) [áyovos, barren], $\mathrm{C}_{10} \mathrm{H}_{14} \mathrm{O}_{6}$ A glucosid found in Agonia bark, and used as an antiperiodic.

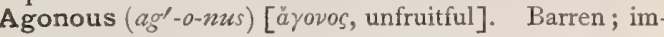
potent.

Agony $\left(a g^{\prime}-o-n e\right)$ [ả $\gamma \omega v i a$, a contest or struggle]. Violent pain; extreme anguish; the death-struggle.

Agoraphobia (ag-o-ra-fó-be-ah) [áyopá, a market-place, assembly; $\phi 6 \beta \circ \varsigma$, fear]. I. A morbid fear of open places or spaces; kenophobia: 2. Dread of assemblies; morbid dislike of crowds or of associating with others.

Agoriada (ag-o-re-ah'-dah) [Sp.]. The Brazilian tree, Plumieria lancifolia, and its febrifuge bark.

Agoriadin (ag-o-ri'-ad-in) [Sp.], $\mathrm{C}_{10} \mathrm{H}_{14} \mathrm{O}_{6}$. A glucosid, probably the active principle of Agoriada.

-agra [ăy $\rho a$, a seizure]. A Greek word added as a suffix to various roots to denote seisure, severe pain; as podagra, etc.

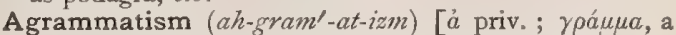
word]. A phenomenon of aphasia, consisting in the inability to form words grammatically, or the suppression of certain words of a phrase. See Aphasia.

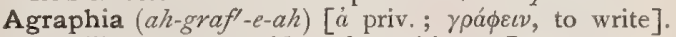
Inability to express ideas by writing. In some cases not a single letter can be formed; in others, words, and a number of words, without meaning, can be written. See Aphasia. A., Musical, pathological loss of the ability to write musical notes.

Agraphy $\left(a g^{\prime}-r a-f e\right)$ [ả priv.; $\gamma \rho a ́ \phi \varepsilon \iota \nu$, to write]. Same as Agraphia.

Agrestial (ag-res'-te-al) [agrestis, rural]. In biology, growing wild in the fields.

Agria $\left(a g^{\prime}-r e-a h\right)$ [a้ $\gamma \rho c o s$, wild]. A pustular eruption; malignant pustule; herpes.

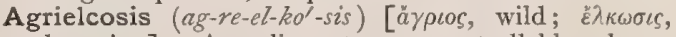
ulceration]. A malignant or uncontrollable ulceration.

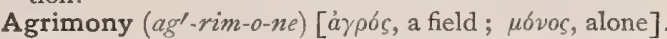
The root of Agrimonia eupatoria. A mild astringent. Dose of fld. ext. 3 ss-ij. Unof.

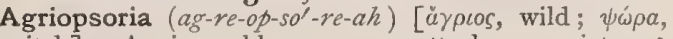
itch]. An incurable or severe attack, or variety, of itch.

Agrioriganum (ag-re-o-rig'-an-um) [ăypıos, wild; opízavov, origanum]. Wild Marjoram, Origanum vulgare. 


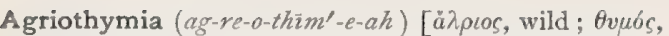
mind, will]. Maniacal fury; it is variously divided or classed as ambitious, hydrophobic, religious, etc

Agrippa $(a h$-grip'-ah) [L.]. A person born with the feet foremost.

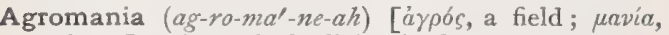
madness]. A mania for living in the country.

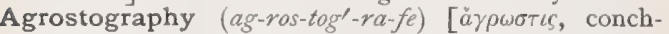

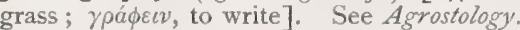

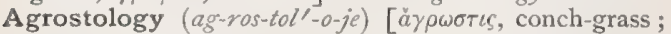
$\lambda \varepsilon \gamma \varepsilon \imath \nu$, to speak of]. The botany of grasses.

Agrypnetic (ah-grip-net'-ik) [á priv,; invos, sleep]. I. Sleepless; wakeful. 2. Preventing sleep; agrypnotic.

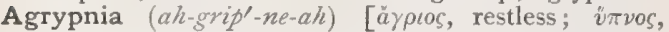
sleep]. Loss of sleep, sleeplessness, Insomnia, q.v.

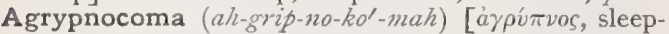
less; $\kappa \tilde{\omega} \mu a$, coma]. Coma vigil; wakeful lethargy, with low-muttering delirium.

Agrypnotic (ah-grip-not'-ik) [ả priv.; $v \pi \nu o s$, sleep]. I. Preventing sleep; causing wakefulness. 2. A medicine that prevents sleep.

Aguardiente $\left(a \bar{h}-g u a r^{\prime}-d_{\ell}-e n^{\prime}-t \bar{a}\right)[\mathrm{Sp}$.$] . Ardent spirits;$ brandy or rum.

Ague $\left(a^{\prime}-g u\right)$ [acutus, sharp, acute; Fr., aigu]. Malarial or intermittent fever, characterized by paroxysms, or stages, of chill, fever, and sweating at regularly recurring times, and followed by an interval or intermission whose length determines the epithets, quotidian, tertian, etc. In some cases there is a double paroxysm, and hence called double quotidian, double tertian, etc. The duration of each paroxysm varies from two to twelve hours. The most frequent and important complication of intermittent fever is pneumonia, the consolidation occurring very suddenly. In the blood of many malarial patients a minute hematozoan, the hematomonas malaria, has been found. They are seen in the red corpuscles, are hyaline, and include pigment granules. They gradually increase in size, fill the cell, a process of segmentation occurs, the cell wall breaks down, and the segments, each containing a pigment granule, are set free. These are oval and possess one to three flagella. These bodies disappear under the use of quinin. A. Aden. See Dengue. A., Brass-founders', a disease common among brass-founders, characterized by symptoms somewhat resembling an imperfect attack of intermittent fever, the recurrence of the paroxyms, however, being irregular. The direct cause is generally thought to be the inhalation of the fumes of deflagrating zinc or "spelter." A., Brow, intermittent neuralgia of the brow. A. Cake, chronic enlargement of the spleen in diseases of malarial origin. A., Catenating, ague associated with other diseases. A. Drop. See Fozvler's Solution. A., Dumb, latent ague; masked ague; ague with no well-marked chill, and with at most only partial or slight periodicity. A., Latent, see $A$., Dumb. A., Leaping, a term for the dancing mania. A., Masked, See A. Dumb. A. Tree, common Sassafras. A. Weed. I. See Grindelia. 2. The Eupatorium perfoliatum, or thorough-wort.

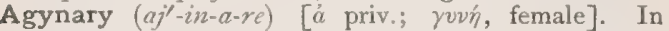
biology, having no pistil, as a double flower.

Agynous $\left(a j^{\prime}-i n-u s\right)$ [ $\alpha$ priv.; $\gamma v v \dot{\eta}$, female]. In biology, destitute of female reproductive organs.

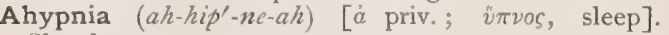
Sleeplessness.

Ahypnosis (ah-hip-no'-sis) [ávrvía, sleeplessness]. Entire absence of the capacity to sleep, most marked in insanity.

Aichmophobia $\left(\bar{a} k-m o-f o^{\prime}-b e-a h\right)\left[a i \chi \mu \dot{\eta}^{\prime}\right.$, a spear point ; $\phi o \beta \varepsilon \varepsilon v \nu$, to fear]. An extravagant dread of sharp or pointed instruments.
Aid-Forceps (ād'-for-seps) [Fr, aide; forceps]. A device for making safe and effective traction upon the obstetrical forceps by means of a fillet or tape and a dynamometer.

Aidoio- $\left(a-d o i^{\prime}-o\right)$. See Edeo-

Aidoiomania (a-doi-o-ma'-ne-ah). See Edeomania.

Aiglet $\left(\bar{a} g^{\prime}\right.$-let $)$. See Aglet.

Aigret, Aigrette ( $a^{\prime}$-gret, $a$-gret' $)$. In biology, same as Egret.

Ailanthus (a-lan'-thus) [Malacca, Ailanto, "tree of heaven" ]. The bark of $A$. glandulosa, commonly known as Tree of Heaven. Properties due to an oleoresin and a volatile oil. A nauseant and drastic purgative, constituting an excellent anthelmintic against tape-worm. A., Ext. Fld. Dose $\eta_{x}-3 j$. A., Tinct. Dose $m x-3$ ij.

Ailing $\left(\bar{a} l^{\prime}-i n g\right)$ [M. E., eyle]. Indisposed; out of health; not well.

Ailment $\left(\bar{a} l^{\prime}-m e n l\right)$ [M.E., eyle]. A disease; sickness ; complaint; usually used in reference to chronic disorders.

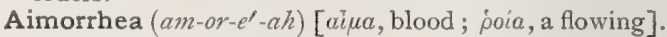
A bleeding, or hemorrhage.

Ainhum (in-yoon') [negro word, meaning to saw)]. A disease in Guinea and Hindostan, peculiar to negroes, in which the little toes are slowly and spontaneously amputated at about the digito-plantar fold. The process is very slow, does not affect other toes or parts, is unaccompanied by any constitutional symptoms, and its cause is unknown. It sometimes attacks the great toe. Called also Dactylalysis spontanea.

Air [ánp from à $\varepsilon v$, to blow, or breathe]. The chief part of the atmosphere. Atmospheric air consists of a mixture of 77 parts by weight, or 79.19 by volume, of nitrogen, and 23 parts by weight, or $20.8 \mathrm{I}$ by volume, of oxygen, with 3.7 to 6.2 parts by volume of $\mathrm{CO}_{2}$ in 10,000 parts. 100 cubic inches weigh 30,935 grains. The pressure of the air at sea-level is about I $43 / 4$ pounds upon the square inch. A., Alkaline, free or volatile ammonia. A., Azotic, nitrogen. A. Bag. See A. Cushion. A. Bath, therapeutic exposure to air that may be heated, condensed, or variously medicated. See Bath. A.-bed, an airtight, rubber, inflated mattress employed in conditions requiring long confinement to bed. A.-bladder. See A.-vesicle. A. Bubbles, in microscopy, are prepared by heating a drop of thin mucilage. They are useful as a test for central light. In oblique light the bright spot will appear on the side away from the mirror. A.-cell, an air-sac; an air-vesicle of the pneumonic tissue. A., Complemental, is that that can still be inhaled after an ordinary inspiration. A. Conduction, a method of testing the hearing-power by means of a watch held at varying distances from the ear, or by the employment of a number of tuning forks of varying pitch. See Bone Conduction. A.cure, the therapeutic employment of air. A.-cushion. A cushion filled with air ; usually made of soft india-rubber. A., Dephlogisticated, an old name for Oxygen. A.-douche. The inflation of the middle ear with air. A.-duct. See Duct. A.embolism, free air in the blood-vessels during life, or the obstruction due to it. A., Expired, that driven from the lungs in expiration. A., Factitious, carbon dioxid. A., Fixed, an old name for carbon dioxid (carbonic acid). A. Hunger. See Diabetes mellitus. A., Inspired, that taken into the lungs on inspiration. A., Mephitic, carbon dioxid. A.-meter. See Anemometer. A. Passages, the nares, mouth, larynx, trachea, and bronchial tubes. A., Phlogisticated, nitrogen. A.-pump, an apparatus for exhausting or compressing air. A., Reserve 
or Supplemental, that that can still be exhaled after an ordinary expiration. A., Residual, that remaining in the lungs after the most complete expiration possible. A.-sac. See Air-vesicle. A.-space, a space in tissue filled with air or other gases arising from the separation, rupture, or absorption of cells. A., Stationary, that remaining in the lungs during normal respiration. A., Supplemental. See $A$., Reserve. A.-tester, an instrument for testing the impurity of the air. A., Tidal, that taken in and given out at each respiration. A.-vesicle, any small air-space, especially the expanded terminal portion of a minute or ultimate bronchial vessel. A., Vital, an old name for Oxygen. See Atmosphere.

Ajowan $\left(a j j^{\prime}-00-a n\right)$ [E. Ind.]. Bishop's Weed. The fruit of Ammi copticum. Carminative and antiseptic. It has been recommended in coiic, diarrhea, etc. Dose of the fld. ext. $m x-x x x$.

Akamathesia, Akamathesis. See Akatamathesia.

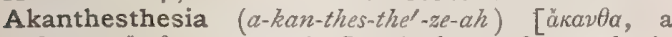
thorn; a้ $\iota \theta \eta \eta \iota \varsigma$, sensation]. A form of paresthesia or perverted sensation in which there is a feeling as of a sharp point.

Akanthion (a-kan'-the-on). See Acanthion.

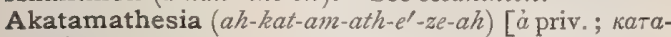
$\mu a ́ \theta \eta \sigma \iota s$, understanding]. Inability to understand.

Akataphasia (a-kat-af-a'-se-ah). See Acataphasia.

Akazga $\left(a-k a z^{\prime}-g a h\right)$ [African]. A poisonous plant of West Africa, probably a Strychnos. Also its bark, and an amorphous extractive derived from it. It is one of the African ordeal poisons and contains akazgin.

Akazgin ( $\alpha$-kaz'-gin) [African]. An alkaloid from akazga; its effects are much like those of strychnia.

Akene $\left(a k^{\prime}-\bar{e} n\right)$. See Achenium.

Akido-galvano-cautery ( $\left.a k-i d-o-g a l-v a n-o-k a v v^{\prime}-t e-r e\right)$ [ákis, needle; Galvani; кavт́n Galvanic cauterization by the needle electrode.

Akidopeirastic (ak-id-o-pi-ras'-tik) [ákń, ákis, needle ; $\pi \varepsilon \iota \rho a \sigma \tau \iota \kappa \delta$ s, proving]. Relating to the exploratory puncture of a diseased area by means of a stout needle.

Akinesia $\left(a h-k i n-e^{\prime}-s e-a h\right)$. See Acinesia.

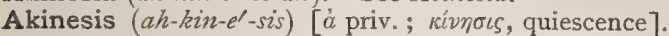
Absence or imperfection of movement. Applied to the heart's diastole and to immotility of the iris ; also to any lack of motility, especially when due to some central or cerebral cause. A. Algera, an affection manifested by voluntary abstinence from movement on account of the pain of movement, without any apparent cause of pain.

Aknemia (ak-ne'-me ah). See Acnemia.

Akology $\left(a k-o l^{\prime}-o-j e\right)$. See $A c e o l o g y$.

Akral (ak'-ral) [äkos, extreme]. See Cephalic.

Akrokinesis (ak-ro-kin-e'-sis). See Acrocinesis.

Akromegaly (ak-ro-meg'-a-le). See Acromegalia.

Akromikria ( $a k$-ro-mik'-re-ah). See Acromicria.

Akroposthitis (ak-ro-pos-thi'-tis). See Acroposthitis.

Akyanopsia (ah-ki-an-op'-se-ah). See Acyanopsia.

A1. The Arabic definite article, the, prefixed to many words to designate preëminence, etc, , as alkali, alcohol. In chemical nomenclature it is used as a suffix to denote similarity to or derivation from an aldehyd, as chloral, butyral, etc.

Ala $\left(a^{\prime}-l a h\right)$ [L., a wing: $p l$, , Alce $]$. A name of various wing-shaped parts or appendages. In biology, the side petal of a papillonaceous corolla. A. Auris, the pinna of the ear. A. Cinerea, a triangular space of gray matter in the fourth ventricle of the brain, probably giving origin to the pneumogastric nerves. A. Majores, I. The greater wings of the sphenoid. See Alisphenoid: 2. The external labia pudendi. A. Minores. I. The lesser wings of the sphenoid. 2.
The labia minora pudendi. A. Nasi, the lateral cartilage of the nose. A. Pontis. See Ponticulus. A. Pulmonum, the lobes of the lung. A. of Sacrum, the flat triangular surface of bone extending outwara from the base of the sacrum, supporting the psoas magnus muscle. A. Vespertilionis, the broad liga. ment of the uterus. A. Vulvæ, the labia of the pudendum. Applied also to the armpits, parts of the sphenoid, vomer, etc.

Alalia $\left(a l-a^{\prime}-l e-a h\right)\left[\dot{a}\right.$ priv, ; $\lambda a \lambda \iota \alpha^{\prime}$, talk $]$. I. Impaired or lost articulation from paralysis of the muscles of speech or from local laryngeal disease. 2. Aphasia due to a psychic disorder.

Alalic $\left(a l-a^{\prime}-l i k\right)$ [á priv.; $\lambda a \lambda \iota a ́$, talk]. Characterized by or pertaining to alalia.

Alanin $\left(a l^{\prime}-a n-i n\right)$ [L., aldehyde], $\mathrm{C}_{3} \mathrm{H}_{7} \mathrm{NO}_{2}$. Lactamic acid. An organic base obtained by heating aldehyd ammonia with hydrocyanic acid in the presence of an excess of $\mathrm{HCl}$; it occurs in aggregated hard nodules with a sweetish taste; soluble in five parts of cold water; with more difficulty in alcohol; insoluble in ether. When heated, it commences to char at about $237^{\circ}$; it melts at $255^{\circ}$ and then sublimes.

Alaninate $\left(a l-a n^{\prime}-i n-\bar{a} t\right)$ [L., aldehyde]. A salt of alanin. A. of Mercury, a crystalline, soluble compound of mercury and alanin; antisyphilitic. Dose gr. $\frac{1}{32}$ to $1 / 4$. Unof.

Alan'son's Operation. See Operations, Table of.

Alant Camphor. See Helenin.

Alantin (al-an'-tin) [Ger., alant, elecampane]. Same as Inutin.

Alantol (al-an'-tol) [Ger, alant, elecampane; oleum, oil], $\mathrm{C}_{20} \mathrm{H}_{22} \mathrm{O}$. Inulol. An aromatic liquid obtained from elecampane; used like creosote for phthisis.

Alar $\left(a^{\prime}\right.$-lar $)$ [ala, wing]. Winglike. In biology, situated in the forks of a stem. A. Ligaments, lateral synovial folds of the ligament of the knee-joint. A. Odontoid Ligaments, lateral ligaments of the odontoid process. Alares musculi, the pterygoid muscles. Alares venæ, superficial veins at the bend of the arm. Alaria ossa, lateral processes of the sphenoid bone.

Alaris (al-al-ris) [ala, wing]. Wing-shaped. See Alar.

Alary $\left(a^{\prime}-l a r-e\right)$ [ala, a wing]. In biology, pertaining to wings; wing-shaped.

Alate $\left(a^{\prime}\right.$-lāt $)$ [ala, a wing]. In biology, winged or having winglike borders or expansions; aliferous; aligerous.

Alate-pinnate $\left(a^{\prime}-l \bar{a} t-p i n^{\prime}-\bar{a} t\right)$ [ala, a wing; pinna, a feather]. In biology, a pinnate leaf having a winged petiole.

Alba $(a l$ lbah) [L., "white"]. The white fibrous tissue of the brain and nerves.

Albadara ( $\left.a b^{-} b a d^{-}-a^{\prime}-r a h\right)$ [Arabic]. An old name for the basal joint of the great toe.

Alban (al'-ban) [albus, white], $\mathrm{C}_{10} \mathrm{H}_{16} \mathrm{O}$. A white resin that may be extracted from gutta percha.

Albedo $\left(a l-b e^{\prime}-l o\right)$ [L., "whiteness"]. Whiteness. A. retinæ, retinal edema. A. unguis, or unguium, the lunula of the nail; the white semilunar place at the root of a finger nail.

Albescent (al-bes'-ent) [albescere, to become white]. Whitish; moderately white.

Albicans (al'-be-kanz) [albicare, to grow white]. White; whitish. Used as the name of either of the corpora albicantia at the base of the brain.

Albicant (al'-be-kant) [albicare, to be white]. See $A l$ bescent.

Albicantia (al-be-kan'-she-ah) [L.]. Plural of Alóicans. See Corpora.

Albication (al-be-ka'-shun) [albicare, to be white]. In biology, a growing white. 
Albicomus (al-be-ko'-mus) [albus, white ; coma, hair]. Having white hair.

Albiduria (al-bid-ut're-ah) [albidus, white; ovjpov, urine]. White urine.

Albiflorous (al-bif-lo'-rus) [albus, white; flos, a flower]. In biology, bearing white flowers.

Albinism (al'-bin-izm) Albinismus (al-bin-iz'-mus) [albus, white]. Congenital Achroma; Congenital Leucoderma. That condition of the skin in which there is a congenital absence of pigment unaccompanied by textural changes in the skin, and involving its entire surface, including the pilary filaments and the choroid coats and irides of the eyes. Usually associated with nystagmus, photophobia, and astigmatism.

Albino $\left(a l-b i^{\prime}-n o\right)$ [Sp.]. A person affected with al binism. Also an animal or plant differing from the normally colored members of its kind by being white or colorless.

Albinotic $\left(a l-b i n-o t^{\prime}-i k\right)$ [Sp.]. Affected with albinism.

Albinuria (al-bin-u'-re-ah) [albus, white; ovpeiv, to micturate]. 1. Chyluria; whiteness of the urine. 2. Albuminuria.

Albizzia (al-bitz'-e-ah) [Ital., Albizzi, a Tuscan proper name]. A genus of leguminous plants. $A$. anthelminthica. See Moussena.

Albolene (al'-bo-lèn) [albus, white; oleum, oil]. A hydrocarbon oil, colorless, tasteless, odorless, and not affected by exposure to air or strong acids. It is $\mathbf{\Omega}$ form of lanolin, and is used as an application to inflamed surfaces and for spraying the respiratory passages.

Albuginea $\left(a l-b u-j i n^{\prime}-e-a h\right)$ [albus, white]. White, or whitish. A. oculi, the sclerotic coat of the eye. A. ovarii, and testis, the tunica albuginea of the ovary and testicle. The spleen, the epididymis, the penis, and the kidneys have each an investment or capsule called albuginea or tunica albuginea.

Albugineous (al-bu-jin'-e-us) [albus, white]. I. Whitish. 2. Resembling the white of an egg.

Albuginitis (al-bu-jin-i'-tis) [albus, white; $\iota \tau \iota$, inflammation]. Inflammation of a tunica albuginea.

Albugo $\left(a l-b u^{\prime}-g^{\circ}\right)[\mathrm{L}$.]. I. A white spot, as upon the cornea. 2, A whitish, scaly eruption. 3. The white of an egg,

Albumen (al'-bu-men or $\left.a l-b u^{\prime}-m e n\right)$ [albus, white]. The white of an egg. See Albumin.

Albumenoid (al-but-men-oid). See Albuminoid.

Albumenuria ( $\left.a l-b u-m e n-u^{\prime}-r e-a h\right)$. See Albuminuria.

Albumimeter (al-bu-mim'-et-er) [albus, white ; $\mu \varepsilon ́ \tau \rho o \nu$, measure]. An instrument for determining the quantitive estimation of albumin in urine, or in any compound or mixture.

Albumin (al-bu'-min) [albus, white]. A proteid substance, the chief constituent of the body. Its molecule is highly complex and varies widely within certain limits in different organs and conditions. It contains approximately the following percentages: Carbon 51.5 to 54.5 ; hydrogen 6.9 to 7.3 ; nitrogen 15.2 to 17.0 ; oxygen 20.9 to 23.5 ; sulphur 0.3 to 2.0 Its approximate formula is $\mathrm{C}_{72} \mathrm{H}_{112} \mathrm{~N}_{18} \mathrm{O}_{22} \mathrm{~S}$. Albumen, white of egg, often called albumin, is largely composed of it. Other varieties are called after their sources or characteristic reactions, as acid-albumin, alkali-albumin, muscle-, serum-, ovum-, vegetable-albumin, etc. Normal albumin is the type of a group of proteids known as albumins. For the various tests for albumin, see Table of ALBUMm TER. Tests, under Test. See also, Proleids and Native Albumins. A. of Bence-Jones, a variety found in pseudo-albuminuria. It does not give a precipitate with an excess of $\mathrm{HNO}_{3}$ except on standing, when a coagulum forms that will be redissolved on heating. A., Blood. See Serum-albumin. A., Caseiform, that variety not coagulated by heat, but precipitated by acids. A., Circulating, that found in the fluids of the body. A. Crystals. See Crystalloids. A., Derived, a modification of albumin resulting from the action of certain chemicals. A., Egg-. See Ego-albumin. A., Muscle-, a variety found in muscle-juice. A., Native, any albumin occurring normally in the organism. A., Organic, that forming an integral part of the tissue. A., Serum-. See Serumalbumin. A., Test Solution of, a filtered solution of the white of an egg in IOo c.c. of distilled water. A., Vegetable, that form that is found in various vegetable juices.

Albuminate $\left(a l-b u^{\prime}-m i n-\bar{a} t\right)$ [albus, white]. The compound of albumin and certain bases, as albuminate of iron, or of iron and potassium, etc.

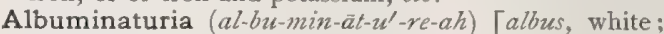
oipov, urine]. The abnormal presence of albuminates in the urine.

Albuminiferous (al-bu-min-if'-er-us) [albumin," ferre, to bear]. See Albuminiparous.

Albuminimeter (al-bu-min-im'-et-er). See Albumimeter. Albuminin (al-bu'-min-in) [albumin]. The non-nitrogenous substance of the cells that enclose the white of birds' eggs.

Albuminiparous (al-bu-min-ip'-ar-us) [albumin; pareve, to produce]. Yielding albumin.

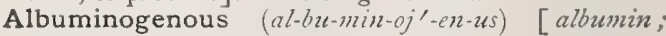

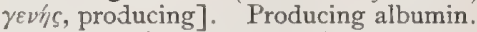

Albuminoid (al-bu'-min-oid) [albumin; eidos, form]. I. Resembling albumin. Applied to certain compounds having many of the characteristics of albumin. 2. Any nitrogenous principle of the class of which normal albumin may be regarded as the type. A Disease, also spoken of as lardaceous, waxy, or amyloid degeneration. A form of degeneration usually affecting simultaneously a number of the viscera, and occurring secondarily to some preëxisting disease. Those viscera most usually the seat of the change are, in the order of frequency, the spleen, liver, kidneys, intestine and lymph glands. The tissues around the capillary vessels are first affected; from these centers it spreads till the whole organ or section presents a pale, glistening, waxy, or bacon-like appearance. This is due to the infiltration of a peculiar proteid substance, lardacein, which, with iodin, gives a deep mahogany brown color, the characteristic test for the disease. The preexxisting trouble is either some chronic suppuration, as in bone or joint disease, or some wasting disease like pulmonary tuberculosis, syphilis, etc. The only way in which the disease may be arrested is by thorough removal of the cause.

Albuminoids (al-bu'-min-oidz) [albumin]. Substances resembling true proteids in their origin and composition. They are amorphous non-crystalline colloids, occurring as organized constituents of the tissues, and also in fluid form. Mucin, Nuclein, Keratin, Fibroin, Spongin, Elastin, Gelatin, Chondrin, etc., are the principal members of the group.

Albuminometer (al-bu-min-om'-et-er). See Albumimeter.

Albuminone $\left(a l-b u^{\prime}-\min -\bar{o} n\right)$ [albumin]. A principle derivable from certain albuminoids; it is not coagulable by heat, and is soluble in alcohol.

Albuminorrhea (al-bu-min-or-e'-ah) [albumin; poía, a flow]. Copious abnormal discharge of albumins.

Albuminose (al-but'-min-ōs) [albumin]. I. A product of the digestion of fibrin or any albuminoid in very 
dilute hydrochloric acid; acid albumin. 2. Albumose, or the product of the digestion of albumin by the gastric juiçe.

Albuminosis (al-bu-min-o'-sis) [albumin]. Abnormal increase of the albuminous elements in the blood, or the condition that results from such increase.

Albuminous (al-bu'-min-us) [albumin]. Containing, or of the nature of an albumin.

Albumin-Peptone $\left(a l-b u^{\prime}-m i n-p p^{\prime} p^{\prime}-t \bar{n} n\right)$. Same as Albuminase ( $2 d$ def.).

Albumins (al-bu'-minz). See Albumin.

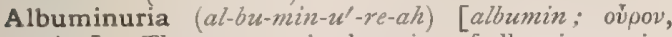
urine ]. The presence in the urine of albumin, a mixture of serum-albumin and serum-globulin in various proportions. True albuminuria must be distinguished from the presence of albumin due to an admixture with the urine of blood, pus, or other albuminous fluid. However, even under these circumstances it must be remembered that true albuminuria may be coexistent. Albumin in the urine may result from a number of causes, $e . g$. , mechanical interference with the renal circulation; from congestion, lesions, and organic diseases of the kidneys themselves; from toxic substances in the blood, such as lead, in which case there is a granular form of nephritis; from changes in the blood due to various diseases, as anemia, purpura, scurvy, and sepsis; in pyrexia; in certain nervous disorders, such as tetanus, delirium tremens, apoplexy, Graves's disease, and epilepsy; in various functional disorders, as dyspepsia, high living, great exertion, etc., and during pregnancy. The etiology of albuminuria is still undetermined, but it is now recognized that it will be produced by any condition that interferes with the nutrition of the glomeruli or renal epithelium. A. of Adolescence. See A., Cyclic. A., Adventitious. See A., Pseudo-. A., Cardiac, that due to chronic valvular disease. A., Cyclic, a condition also known as physiological, simple, functional, or transient albuminuria, or the albuminuria of adolescence, in which a small quantity of albumin' appears in the urine, especially of the young, at stated times of the day; hence the term "cyclic." The nature of this phenomenon is not positively known, but it is probably the result of some changes in the renal circulation. A., Dietetic, that due to the ingestion of certain forms of food, especially eggs, cheese, and pastry. A., Dyscrasic. See A., Hematogenous. A., False, a mixture of albumin with the urine during its transit through the urinary passages, where it may be derived from blood, pus, or special secretions that contain albumin. A., Febrile, that due to fever, or associated with acute infectious diseases, slight changes occurring in the glomeruli without organic lesion. A., Functional. See $A$., Cyclic. A., Gouty, albumin in the urine of elderly people, who secrete a rather dense urine containing an excess of urea. A., Hematogenous, that resulting from some abnormal blood-condition, and not due to nephritis. A., Hepatic, that form associated with marked disturbance of the hepatic function, as shown by slight jaundice and vague dyspeptic attacks. A., Intrinsic. See $A$., True. A., Mixed, the presence of a true- and pseudo-albuminuria. A., Morbid, that due to any pathological condition. A., Nephrogenous, that due to renal disease. A., Neurotic, that due to nervous disorders. A., Paroxysmal. See A., Cyclic. A., Physiological, the presence of albumin in normal urine, without appreciable coëxisting renal lesion or diseased condition of the system. A., Pseudo-, A., Adventitious: albuminuria dependent upon the presence of such fluids as blood, pus, lymph, spermatic fluid, or the contents of an abscess-cavity, in the urine. A., Simple. See
A., Cyclic. A., Temporary, that lasting but for a short time. A., Tests of. See Table of Tests, under Test. A., Transient. See A., Cyclic. A., True, $A$., Intrinsic; that due to the excretion of a portion of the albuminous constituents of the blood with the water and salts of the urine.

Albuminuric (al-bu-min-u'-rik) [albumin; vépov, urine]. Associated with, of the nature of, or affected by, albuminuria. A. Retinitis. See Retinitis.

Albuminurorrhea (al-bu-min-u-ror-rel-ah) [albumin; oúpov, urine; joia, a flowing]. See Albuminuria.

Albumose $\left(a l^{\prime}-b u-m \bar{s} s\right)$ [albumin]. Any albuminoid substance ranking among the first products of the splitting up of proteids by enzymes, and intermediate between the food-albumins and the typical peptones. According to Kühne there are at least two albumoses, antialbumose and hemialbumose. The latter, after the precipitation and filtering off of the para-peptones, $\ell . g$., in the peptic digestion of fibrin, yields the following: I. Protalbumose, soluble in hot and cold water and precipitable by $\mathrm{NaCl}$ in excess. 2. Deuteroalbumose, soluble in water, not precipitated by $\mathrm{NaCl}$ in excess, unless an acid be added at the same time. 3. Heteroalbumose, insoluble in hot or cold water, soluble in dilute or more concentrated solutions of $\mathrm{NaCl}$, and precipitable from these by excess of the salt. 4. Dysalbumose, same as heteroalbumose, except that it is insoluble in salt solutions.

Albumosuria (al-bu-mōs- $\left.\boldsymbol{u}^{\prime}-r e-a h\right)$ [albumose; ỡpov, urine]. The abnormal presence of an albumose in the urine.

Alburnum (al-ber'-num) [L., "sap-wood"]. In biology, young wood, sap-wood.

Alcahest (al'-ka-hest) [Uncertain derivation]. An old name for the supposed universal solvent, and for a medicine curative of all congestions. A. of Glauber, a crude potassium carbonate derived from the burning of potassium nitrate with hot coals.

Alcali $\left(a l^{\prime}-k a-l i\right)$. See Alkali.

Alcaptone $\left(a l-k a p^{\prime}-t o ̄ n\right)$. See Alkaptone.

Alcaptonuria (al-kap-tōn-u'-re-ah). See Alkaptonuria.

Alchemist (al'-kem-ist) [Origin doubtful]. One who practices alchemy.

Alchemy (al'-kem-e) [Arab, of doubtful derivation]. The supposed art of the transmutation of metals (into gold) and of finding a remedy for all diseases. Modern chemistry is the development of this chimerical medieval dream.

Al'cock's Canal. See Canal.

Alcohol ( $\left.a l^{\prime}-k a-h o l\right)$ [ $a l$, the ; koh'l, finely powdered antimony]. Ethyl alcohol, $\mathrm{C}_{2} \mathrm{H}_{6} \mathrm{O}$. A liquid obtained by the distillation of fermented grain or starchy substance. It is used in pharmacy as a solvent for resins, and as a base for all tinctures. Commercial alcohol contains 9 I per cent. of absolute alcohol, with 9 per cent. of water. It is inflammable, colorless, and possesses a pungent odor and burning taste. Sometimes it is used externally as a stimulant lotion. Internally, it is a powerful cerebral excitant; in large doses a depressant, narcotic poison, producing muscular incoördination, delirium, and coma. It is a food within the limits of $3 \mathrm{j}-\xi_{\mathrm{j}} \mathrm{j}$ per day; its continued use is apt to result in epilepsy, amblyopia, and insanity. In the form of wine, whisky, or brandy, it is valuable in diphtheria, adynamic fevers, and poisoning by cardiac depressants. A., Absolute, spirit containing no water. A., Amyl, $\mathrm{C}_{5} \mathrm{H}_{12} \mathrm{O}$, commonly known as "Potato Spirit" and "Fusel Oil"; a transparent, colorless liquid. A., Anhydrous, one free from water. A., Aromatic, an alcohol containing phenyl. A., Benzyl, $\mathrm{C}_{7} \mathrm{H}_{8} \mathrm{O}$, obtained from benzaldehyd by the action of sodium amalgam. It is a 
colorless liquid, with a faint aromatic odor; boils at $206^{\circ}$; its sp. gr. at $0^{\circ}$ is $\mathrm{x} .062$. It dissolves with difficulty in water, but readily in alcohol and ether. A. deodoratum, deodorized alcohol, containing 92.5 per cent. by weight of ethyl-alcohol and 7.5 per cent. of water. A., Dilute, composed of $4 \mathrm{I}$ per cent. by weight of ethyl-alcohol. A., Ethyl. See Alcohol. A. of Fermentation, has a disagreeable odor; boils at $\mathrm{I} 29-\mathrm{I} 3 \mathrm{O}^{\circ}$; occurs in fusel-oil ; consists mainly of inactive isobutyl carbinol. A., Methyl, $\mathrm{CH}_{4} \mathrm{O}$, known as "Wood Spirit." A., Phenic. See Acid, Carbolic.

Alcoholate $\left(a l^{\prime}-k o-h o l-\bar{a} t\right)[a l$, the ; koh'l, finely powdered antimony]. I. A chemical compound, as a salt. into which an alcohol enters as a definite constituent. 2. A preparation made with alcohol.

Alcoholature (al-ko-hol'-at-chür) [al, the; koh'l, finely powdered antimony; Fr. alcoolature]. An alcoholic tincture, especially one prepared with fresh plants.

Alcoholic (al-ko-hol'-ik) [al, the; koh'l, finely pow dered antimony]. r. Pertaining to, containing, or producing alcohol. 2. One addicted to the use of spirituous drinks. A. Radicals, the name applied to the univalent radicals, $\mathrm{C}_{\mathrm{n}} \mathrm{H}_{2 \mathrm{n}}+1$.

Alcoholica $\left(a l-k o-h o l^{\prime}-i k-a h\right)[a l$, the ; koh'l, finely powdered antimony]. In pharmacy, alcoholic preparations.

Alcoholimeter (al-ko-hol-im'-et-er). See Alcoholometer. Alcoholimetry (al-ko-hol-im'-et-re). See Alcoholometry.

Alcoholism (al'-ko-hol-izm) [al, the ; koh'l, finely powdered antimony]. The morbid results of excessive or prolonged use of alcoholic liquors. The term acute $\mathbf{A}$. has been used as a synonym for inebriety. The chronic form is associated with severe lesions or disturbances of the digestive, respiratory, and nervous systems.

Alćoholismus (al-ko-hol-iz'-mus). Syn. of Alcoholism. Alcoholization (al-ko-hol-iz-a'shun) [al, the ; koh'l finely powdered antimony]. The art or process of alcoholizing; the state of being alcoholized; the product of the process of alcoholizing.

Alcoholize $\left(a l^{\prime}-k o-h o l-i z\right)$ [al, the; koh'l, finely powdered antimony]. I. To impregnate with or blend with alcohol. 2. To convert into an alcohol. 3. To reduce to a very subtle powder.

Alcoholometer (al-ko-hol-om'-et-er) [alcohol; $\mu$ étpov, a measure]. A hydrometer or other instrument used in determining the percentage of alcohol in any liquid.

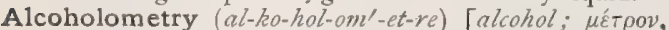
a measure]. The determination of the proportion of alcohol present in any liquid.

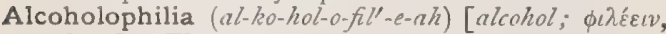
to love]. The appetite for strong drink; a craving for intoxicants.

Alcohols (al'-ko-holz) [al, the; koh'l, finely powdered antimony]. A series of neutral compounds resembling bases exhibiting gradations corresponding to their increase in molecular weight. They are derived from the normal hydrocarbons by replacing hydrogen with the group $\mathrm{OH}$. The lower alcohols are mobile liquids, readily dissolving in water and possessing the characteristic alcohol odor; the intermediate members are more oily, and dissolve with difficulty in water; while the higher are crystalline solids without odor or taste. The alcohols resemble the fats. Their boiling-points increase gradually (with similar structure) in proportion to the increase of their molecular weights. See Table. A., Diatomic, those formed by replacing two atoms of hydrogen in a hydrocarbon by two molecules of hydroxyl. A., Dibasic. See A., Diatomic. A., Dihydric. See Glycols, and Table of Alcohols. A., Divalent. See

\section{ALCOHOLS}

Glycols. A., Hexahydric, alcohols containing six hydroxyl groups attached to six different carbon atoms. They approach the sugars very closely in their properties, having a very sweet taste, but differ from them in

\section{TABLE OF THE ALCOHOLS.}

I. OF THE FATTY COMPOUNDS.

Series I. Alcohols, $\mathrm{C}_{\mathrm{H}} \mathrm{H} 2 \mathrm{n}+\mathrm{j} . \mathrm{OH}$,

\begin{tabular}{|c|c|c|c|c|}
\hline 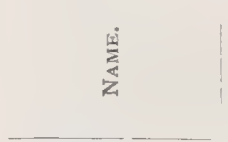 & 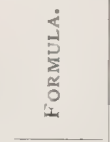 & 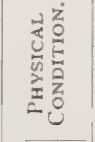 & 造 & 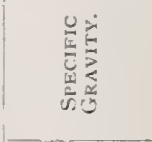 \\
\hline $\begin{array}{l}\text { Iethyl (Wood Spir } \\
\text { it), }\end{array}$ & $\mathrm{CH}_{4} \mathrm{O}$ & Liquid. & $66^{\circ}$ & 0.796 at $20^{\circ}$ \\
\hline thyl, ..... & $\mathrm{C}_{2} \mathrm{H}_{6} \mathrm{O}$ & Liquid. & $78-3^{\circ}$ & $\begin{array}{l}0.78945 \text { at } 20^{\circ} \\
0.80625 \text { at } 0^{\circ}\end{array}$ \\
\hline ropyl, ....... & $\mathrm{C}_{3} \mathrm{H}_{8} \mathrm{O}$ & quid. & $97 \cdot 4^{\circ}$ & 0.8044 at $20^{\circ}$ \\
\hline Butyl, $\ldots \ldots$ & $\mathrm{C}_{4} \mathrm{H}_{10} \mathrm{O}$ & Liquid. & $116.8^{\circ}$ & 0.8099 at $20^{\circ}$ \\
\hline Amyl, ...... & $\mathrm{C}_{5} \mathrm{H}_{12} \mathrm{O}$ & Liquid. & $137^{\circ}$ & 0.8168 at $20^{\circ}$ \\
\hline Hexyl, ..... & $\mathrm{C}_{6} \mathrm{H}_{14} \mathrm{O}$ & Liquid. & ${ }^{1} 57^{\circ}$ & $0.8 \mathrm{Ig}$ at $23^{\circ}$ \\
\hline Heptyl (Enanthyl), & $\mathrm{C}_{7} \mathrm{H}_{16} \mathrm{O}$ & Liquid. & $175^{\circ}$ & $\cdots$ \\
\hline Octyl, $\ldots \ldots$ & $\mathrm{C}_{8} \mathrm{H}_{18} \mathrm{O}$ & Liquid. & $190-192^{\circ}$ & 0.830 at $16^{\circ}$ \\
\hline Nonyl, ...... & $\mathrm{C}_{9} \mathrm{H}_{20} \mathrm{O}$ & $\cdots$ & $\ldots$ & . \\
\hline Decyl, ..... & & Solid. & $43.5^{\circ}$ & $\cdots$ \\
\hline Indecatyl, ... & $\mathrm{C}_{11} \mathrm{H}_{24} \mathrm{O}$ & Solid. & $\cdots$ & $\cdots$ \\
\hline Dodecatyl, .... & $\mathrm{C}_{12} \mathrm{H}_{26} \mathrm{O}$ & Solid. & $119^{\circ}$ & $\cdots$ \\
\hline Tridecatyl, . . & $\mathrm{C}_{13} \mathrm{H}_{28} \mathrm{O}$ & 1. & $\cdots$ & $\therefore$ \\
\hline Tetradecatyl, . . & $\mathrm{C}_{14} \mathrm{H}_{30} \mathrm{O}$ & Solid. & $167^{\circ}$ & $\cdots$ \\
\hline entadecatyl, . . & $\mathrm{C}_{15} \mathrm{H}_{32} \mathrm{O}$ & Solid. & & . \\
\hline Hexadecyl (Cetyl), & $\mathrm{C}_{16} \mathrm{H}_{34} \mathrm{O}$ & Solid. & $\because$ & $\cdots$ \\
\hline Heptadecyl, & $\overline{\mathrm{C}_{17} \mathrm{H}_{36} \mathrm{O}}$ & Solid. & $\cdots$ & $\cdots$ \\
\hline Octodecyl, .... & $\mathrm{C}_{18} \overline{\mathrm{H}_{38} \mathrm{O}}$ & Solid. & $210^{\circ}$ & $\cdots$ \\
\hline eryl (Cevotin),... & $\mathrm{C}_{27} \mathrm{H}_{56} \mathrm{O}$ & Solid. & & \\
\hline Mellissyl, & $\mathrm{C}_{30} \mathrm{H}_{62} \mathrm{O}$ & Solid. & & $\cdots$ \\
\hline
\end{tabular}

Series 2,-Unsaturated Alcohols, $\mathrm{C}_{n} \mathrm{H}_{2 n-1.0 H}$.

\begin{tabular}{|c|c|c|c|c|}
\hline Vinyl, ..... & $\mathrm{C}_{2} \mathrm{H}_{4} \mathrm{O}$ & $\begin{array}{l}\text { Does } \\
\text { not ex- } \\
\text { ist in } \\
\text { the free } \\
\text { state. }\end{array}$ & . & $\cdots$ \\
\hline Allyl, . . . . . & $\mathrm{C}_{3} \mathrm{H}_{6} \mathrm{O}$ & Liquid. & $96-97^{\circ}$ & 0.8540 at $20^{\circ}$ \\
\hline
\end{tabular}

Series 3,-Unsaturated Alcohols, $\mathrm{Cn}_{2} \mathrm{n}-3 . \mathrm{OH}$. Acetylene Series.

Propargyl, .... $\mathrm{C}_{3} \mathrm{H}_{4} \mathrm{O}$ Liquid. $\left|\mathrm{II}_{4}-\mathrm{II} 5^{\circ}\right| 0.9715$ at $20^{\circ}$

The only known alcohol of this series.

2. OF THE AROMATIC OR BENZENE SERIES.

SERIES I.-PRIMARY ALCOHOLS.

\begin{tabular}{|c|c|c|c|c|}
\hline Benzyl, . . . . & $\mathrm{C}_{7} \mathrm{H}_{3} \mathrm{O}$ & | Liquid. & $206^{\circ}$ & x.062 at $0^{\circ}$ \\
\hline Tolyl, ..... & $\mathrm{C}_{8} \mathrm{H}_{20} \mathrm{O}$ & Liquid. & $212^{\circ}$ & $x .033$ at $20^{\circ}$ \\
\hline Phenyl Propyl, .. & $\mathrm{C}_{9} \mathrm{H}_{12} \mathrm{O}$ & Liquid. & $235^{\circ}$ & \\
\hline umin, & $\mathrm{C}_{10} \mathrm{H}_{14} \mathrm{O}$ & $\mathrm{Li}$ & $246^{\circ}$ & \\
\hline
\end{tabular}


TABLE OF THE ALCOHOLS.Continued?

Series 2.-Divalent (Dihydric) Alcohols.

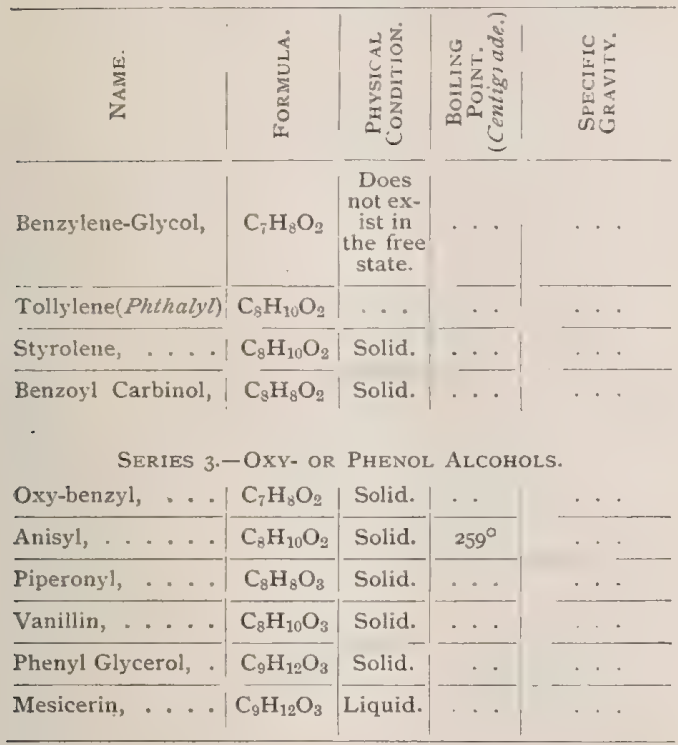

that they do not reduce an alkaline copper solution and are not fermented by yeast. Moderate oxidation converts them into glucoses, $\mathrm{C}_{6} \mathrm{H}_{12} \mathrm{O}_{6}$. They are obtained from the latter by the action of sodium amalgam. A., Monatomic. See A., Monovalent. A., Monohydric. See A., Monozalent. A., Monovalent (Monohydric), products of the replacement of one atom of hydrogen of the hydrocarbons by the hydroxyl group HO. A., Normal, primary alcohols in which the replacing group possesses normal structure. A., Primary, products of the replacement of one hydrogen atom in carbinol by alkyls. A., Secondary, products of the replacement of two hydrogen atoms in carbinol by alkyls. A., Tertiary, products of the replacement of all of the three hydrogen atoms of carbinol by alkyls. A., Triatomic, those formed by replacing three atoms of hydrogen in a hydrocarbon by three molecules of hydroxyl. A., Unsaturated, those derived from the unsaturated alkylens in the same manner as the normal alcohols are obtained from their hydrocarbons. In addition to the general character of alcohols, they are also capable of directly binding two additional affinities. See Table.

Alcoömeter (al-ko-om'-et-er). See Alcoholometer.

Alcornin (al-kor'-nin) [Sp.]. A peculiarly fatty, crystallizable substance, supposed to be the active principle of alcornoque.

Alcornoque (al-kor-no'-kwa) [Sp.]. I. Cork, or the cork-oak. 2. The Alchornea latifolia, a euphorbiaceous tree of tropical America. Its bark is bitter and tonic, and has been used as a remedy in phthisis. Unof.

Aldane $\left(a l^{\prime}-d \bar{a} n\right)$ [See Aldehyd]. A chemical compound formed by uniting two or more molecules of an aldehyd and removing the aqueous elements.

Aldehyd $\left(a l^{\prime}-d e-h i d\right)$ [ $a l$, the first syllable of alcohol; dehyd, from dehydratus], $\mathrm{C}_{2} \mathrm{H}_{4} \mathrm{O}$. Alcohol deprived of two atoms of hydrogen, or acetic aldehyd. It is a colorless, limpid liquid, with a characteristic odor. When exposed to the air or to oxygen it is converted into acetic acid. It boils at $208^{\circ}$, and has a sp. gr. of 0.8009 at $0^{\circ}$. It is miscible in all proportions with water, ether, and alcohol. Internally it produces intoxication, anesthesia, and asphyxia. The vapor is used in catarrhal congestions and ozena. A., Anisic, $\mathrm{C}_{8} \mathrm{H}_{8} \mathrm{O}_{2}$, results on oxidizing various essential oils (anise, fennel, etc, ) with dilute $\mathrm{HNO}_{3}$. A colorless oil of sp. gr. I.I23 at $\mathbf{I} 5^{\circ}$, and boiling at $24^{\circ}$. A., Benzoic, $\mathrm{C}_{7} \mathrm{H}_{6} \mathrm{O}$, the oil of bitter almonds. A., Cinnamic, $\mathrm{C}_{9} \mathrm{H}_{8} \mathrm{O}$, the chief ingredient of the essential oil of cinnamon and cassia. It is a colorless, aromatic oil, that sinks in water and boils at $247^{\circ}$. A., Formic, is asserted to have extreme value as a microbicide and antiseptic, even its fumes and its solution of one part in 20,000 being destructive to various pathogenic germs. A., Protocatechuic, $\mathrm{C}_{6} \mathrm{H}_{3}(\mathrm{OH})$ $(\mathrm{OH}) \cdot \mathrm{CHO}$, the parent substance of vanillin and piperonal, prepared from pyrocatechin by the action of chloroform. It dissolves readily in water, forms brilliant crystals, and melts at $150^{\circ}$. A., Salicylic, $\mathrm{C}_{6} \mathrm{H}_{4}(\mathrm{OH})$. CHO, occurs in the volatile oils of the different varieties of Spirca. It is an oil with an aromatic odor, boiling at $196^{\circ}$, with a sp. gr. at $15^{\circ}$ of I. I72; easily soluble in water, and colors the skin an intense yellow.

Aldehydene (al-de-hi'-dèn) [aldehyd], $\mathrm{C}_{2} \mathrm{H}_{3}$. A chemical radicle derived from ethylene.

Aldehyds $\left(a l^{\prime \prime}-d e-h i d z\right)$ [See Alilehyd]. A class of compounds intermediate between alcohols and acids, derived from their corresponding primary alcohols by the oxidation and removal of two atoms of hydrogen, and converted into acids by the addition of an atom of

\section{TABLE OF THE ALDEHYDS.}

A. OF THE FATTY COMPOUNDS.

I. Aldehyds of the Paraffin Series, $\mathrm{Cn}_{n} \mathrm{H}_{2} \mathrm{O}$.

\begin{tabular}{|c|c|c|c|c|c|}
\hline 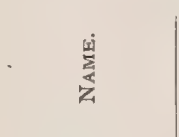 & 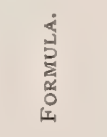 & 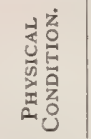 & 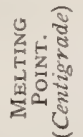 & 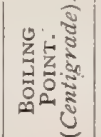 & 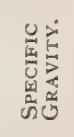 \\
\hline $\begin{array}{l}\text { Methyl } \\
\quad \text { (Formic), .. }\end{array}$ & $\mathrm{CH}_{2} \mathrm{O}$ & Gas & . $\cdot$ & $\cdot \cdot$ & $\cdot$ \\
\hline Acetaldehyd, . & $\mathrm{C}_{2} \mathrm{H}_{4} \mathrm{O}$ & Liquid & . . & $20.8^{\circ}$ & $\begin{array}{r}0.8009 \\
\text { at } 0^{u}\end{array}$ \\
\hline Propionic, . . & $\mathrm{C}_{3} \mathrm{H}_{6} \mathrm{O}$ & Liquid & $\cdots$ & $49^{\circ}$ & $\begin{array}{l}0.8066 \\
\text { at } 20^{\circ}\end{array}$ \\
\hline Butyraldehyd, & $\mathrm{C}_{4} \mathrm{H}_{8} \mathrm{O}$ & Liquid & $\cdots$ & $75^{\circ}$ & $\begin{array}{l}0.8170 \\
\text { at } 20^{\circ}\end{array}$ \\
\hline Amyl,..... & $\mathrm{C}_{5} \mathrm{H}_{10} \mathrm{O}$ & Liquid | & $\therefore$ & $102^{\circ}$ & $\cdots$ \\
\hline Caproyl, : . & $\mathrm{C}_{6} \mathrm{H}_{12} \mathrm{O}$ & Liquid & $\therefore$ & $128^{\circ}$ & $\cdots$ \\
\hline Enanthylic,. . & $\mathrm{C}_{7} \mathrm{H}_{14} \mathrm{O}$ & Liquid & $\therefore$ & $153^{-154^{\circ}}$ & . . \\
\hline $\begin{array}{l}\text { Decatoic } \\
\text { (Capric) } \ldots\end{array}$ & $\mathrm{C}_{10} \mathrm{H}_{20} \mathrm{O}$ & Solid & $\cdots$ & $\begin{array}{c}106^{\circ} \\
(15 \mathrm{~mm} .)\end{array}$ &. \\
\hline $\begin{array}{l}\text { Dodecatylic } \\
\quad(\text { Lauric), . . }\end{array}$ & $\mathrm{C}_{12} \mathrm{H}_{24} \mathrm{O}$ & Solid & $44 \cdot 5^{\circ}$ & $\left(\begin{array}{c}142^{\circ} \\
(22 \mathrm{~mm} .)\end{array}\right.$ & $\cdots$ \\
\hline $\begin{array}{r}\text { Tetradecatylic } \\
(\text { Myrisitalde- } \\
\text { hyd }), \ldots .\end{array}$ & $\mathrm{C}_{14} \mathrm{H}_{28} \mathrm{O}$ & Solid & $52.5^{\circ}$ & $\begin{array}{c}168^{\circ} \\
(22 \mathrm{~mm} .)\end{array}$ & $\cdots$ \\
\hline $\begin{array}{l}\text { Hexdecatylic } \\
\text { (Palmitic), }\end{array}$ & $\mathrm{C}_{16} \mathrm{H}_{32} \mathrm{O}$ & Solid & $5^{8} \cdot 5^{\circ}$ & $\left.\begin{array}{c}192^{\circ} \\
(22 \mathrm{~mm} .\end{array}\right)$ &. \\
\hline $\begin{array}{l}\text { Octdecatylic } \\
\text { (Stearaldehyd), }\end{array}$ & $\mathrm{C}_{18} \mathrm{H}_{36} \mathrm{O}$ & Solid & $63.5^{\circ}$ & $\left(\begin{array}{c}192^{\circ} \\
(22 \mathrm{~mm})\end{array}\right.$ & . $\cdot$ \\
\hline
\end{tabular}


TABLE OF THE ALDEHYDS.-Continued.

2. UnSATURATEd Aldehyds, $\mathrm{C}_{\mathrm{n}} \mathrm{H}_{2 \mathrm{n}-2} \mathrm{O}$.

\begin{tabular}{|c|c|c|c|c|c|}
\hline$\frac{\sqrt[\mid g]{z}}{z}$ & 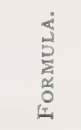 & 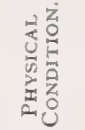 & 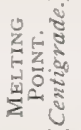 & 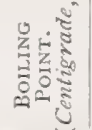 & 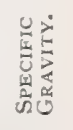 \\
\hline Acrylaldehyd, & $\mathrm{C}_{8} \mathrm{H}_{4} \mathrm{O}$ & Liquid & . & $52^{\circ}$ & $\begin{array}{l}\text { o } 8410 \\
\text { at } 20^{\circ}\end{array}$ \\
\hline Crotonaldehyd, & $\mathrm{C}_{4} \mathrm{H}_{6} \mathrm{O}$ & Liquid & . . . & $\mathrm{IO}_{4}-\mathrm{rO}^{\circ}$ & $\begin{array}{l}\text { I. } 033 \\
\text { at } 0^{\circ}\end{array}$ \\
\hline
\end{tabular}

B. OF THE AROMATIC OR BENZENE SERIES.

I. Monovalent Aldehyds.

\begin{tabular}{|c|c|c|c|c|c|}
\hline Benzaldehyd, . & $\mathrm{C}_{7} \mathrm{H}_{6} \mathrm{O}$ & Liquid & . & $179^{\circ}$ & $\begin{array}{r}1.050 \\
\text { at } 15^{\circ}\end{array}$ \\
\hline Toluic, .... & $\mathrm{C}_{8} \mathrm{H}_{8} \mathrm{O}$ & Liquid & $\cdots$ & $206^{\circ}$ & . . \\
\hline Phenyl-propyl, & $\mathrm{C}_{9} \mathrm{H}_{10} \mathrm{O}$ & I.iquid & . & . &. \\
\hline umic, ... & $\mathrm{C}_{10} \mathrm{H}_{12} \mathrm{O}$ & Liquid & $\cdots$ & $235^{\circ}$ & $\begin{array}{l}0.973 \\
\text { at } 13^{\circ}\end{array}$ \\
\hline
\end{tabular}

2 Dialdehyds.

\begin{tabular}{l|l|l|l|l|} 
Phthalaldehyd, & $\mathrm{C}_{8} \mathrm{H}_{6} \mathrm{O}$ \\
\hline Phenyl-lactic, & $\frac{\text { Liquid }}{\mathrm{C}_{9} \mathrm{H}_{10} \mathrm{O}_{2}}$ & $\frac{\ldots}{\ldots}|\ldots|$ & $\ldots$ \\
$\ldots$ & $\ldots$
\end{tabular}

\begin{tabular}{|c|c|c|c|c|c|}
\hline Salicylic, ... & $\mathrm{C}_{7} \mathrm{H}_{6} \mathrm{O}_{2}$ & Iiquid & . & $196^{\circ}$ & $\begin{array}{l}\text { I. I72 } \\
\text { at } 15^{\circ}\end{array}$ \\
\hline Anisic, .... & $\mathrm{C}_{8} \mathrm{H}_{8} \mathrm{O}_{2}$ & Liquid & . & $24^{\circ}$ & $\begin{array}{l}\text { I. } 123 \\
\text { at } 15^{\circ}\end{array}$ \\
\hline Protocatechuic, & $\mathrm{C}_{7} \mathrm{H}_{6} \mathrm{O}_{3}$ & Solid & $150^{\circ}$ & . . & 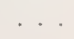 \\
\hline Vanillin, ... & $\mathrm{C}_{8} \mathrm{H}_{8} \mathrm{O}_{3}$ & Solid & $80-81^{\circ}$ & $\cdots$ & $\cdots$ \\
\hline
\end{tabular}

oxygen. They contain the group COH. They exhibit in their properties a gradation similar to that of the alcohols. The lower members are volatile liquids, soluble in water, and have a peculiar odor, but the higher are solids, insoluble in water, and cannot be distilled without decomposition. See Table.

Aldepalmitic Acid (al-de-pal-mit'-ik as'-id). See Acid, Aldepalmitic.

Alder (all-der). See Alnus.

Al'derman's Nerve. See Arnold's Nerve, in Nerve Table.

Aldin (al'-din) [see Aldehyd]. An amorphous basic chemical substance, formed from an ammonia compound of aldehyd. Several aldins are known.

Aldol $\left(a l^{\prime}-d o l\right)$ [see Aldehyd], $\mathrm{C}_{4} \mathrm{H}_{8} \mathrm{O}_{2}$. A colorless, odorless liquid, obtained by the action of dilute $\mathrm{HCl}$ on crotonaldehyd and acetaldehyd. It is miscible with water, and at $0^{\circ}$ has a sp. gr. of I.I2O; upon standing, it changes to a sticky mass that cannot be poured.

Aldoses $\left(a l^{\prime}-d o-s e z\right)$ [see Aldehyd]. The aldehyd alcohols, containing the atomic group $\mathrm{CH}(\mathrm{OH})$. $\mathrm{CHO}$.

Aldoxim, or Aldoxime $\left(a l\right.$-doks $\left.s^{\prime}-i m\right)$ [See Aldehyd]. Products of the combination of aldehyds or ketones and free hydroxylamin. They are usually liquid bodies that boil without decomposition.

Ale $(\vec{a} l)[\mathrm{A} . \mathrm{S}$, ealw]. An alcoholic beverage brewed from malt and hops. It contains from three to seven per cent. of alcohol. See Malt Liquors.

Aleatico $\left(a l-e-a^{\prime}-t i k-o\right)$ [It.]. An excellent sweet red wine, prepared in Tuscany, and esteemed one of the best and most delicate stimulants of its class.
Alecithal (ah-les'-ith-al) [áa priv.; $\lambda \varepsilon \kappa i \theta o s$, yolk $]$. A term applied to certain ova having the food-yolk absent, or present only in very small quantity.

Alegar $\left(\bar{a}^{\prime}-l e-g a r\right)$ [A.S., ealw; egar, sour]. Vinegar made of ale.

Alembic (al-em'-bik) [Arab., $a l$, the; $\alpha \mu \beta \iota \xi$, a cup]. A vessel used for distillation.

Alembroth (al-ent'-broth) [Origin unknown]. An old name for a compound of the chlorid of ammonium and mercury. Its solution has been used of late as an antiseptic.

Alepidote $\left(a h-l e p^{\prime}-\ell-d \bar{o} t\right)$ [ $\hat{\alpha}$ priv.; $\lambda \varepsilon \pi i s$, a scale]. Without scales, as certain fishes.

Aleppo Boil, Button, Evil, Pustule, or Ulcer. See Furunculus orientalis.

Aletrin $\left(a l^{\prime}\right.$-et-rin). See Aletris.

Aletris $\left(a l^{\prime}\right.$-et-ris). Star Grass, Unicorn Root, Starwort, Colic Root. The root of $A$. farinosa. Tonic, diuretic, and anthelmintic. Formerly a popular domestic remedy in colic, dropsy, and chronic rheumatism. Dose of fld. ext. $m x-x x x$; of tincture ( 1 in 8 proof spirit) $3 \mathrm{i}-\mathrm{ij}$; of aletrin, the extractive, gr. $1 / 4-i v$ A. Cordial. Dose $3 j$ three times daily. Unof.

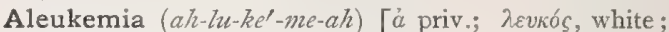
ai $\mu a$, blood]. Deficiency in the proportion of white cells in the blood.

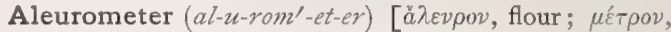
a measure]. An instrument used for the examination of crude gluten as to its power of distending under the influence of heat, as a means of judging of the value of a flour for bread-making. A. similar instrument, termed an aleuroscope, has also been invented.

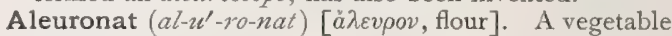
albumin used as a substitute for bread in cases of diabetes.

Aleurone $\left(a l-u^{\prime}-r o ̄ n\right)$ [ǎ $\lambda \varepsilon v \rho o v$, fine flour]. Proteid matter in the form of small rounded particles, found in seeds.

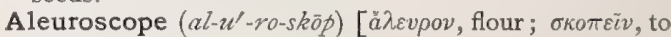
view]. See Aleurometer.

Alexander-Adam's Operation. See Operations, Table of.

Alexanderism (al-eks-an'-der-izm) [Alexander]. The insanity of conquest; agriothymia ambitiosa.

Alexander's Operation. See Operations, Table of.

Alexeteric (al-eks-e-ter'-ik) [à $\dot{\alpha} \xi \eta \tau \eta \dot{\eta} \rho$, defender]. Good against poison, venom, or infection.

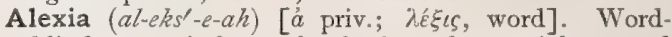
blindness. A form of aphasia and a special type of psychical blindness, in which the patient is unable to recognize ordinary written or printed characters. A., Musical, musical blindness; pathological loss of the ability to read music.

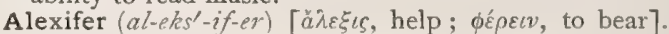
A remedy or object that serves as an amulet or antidote against poison.

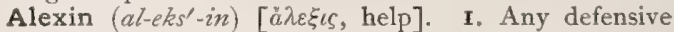
proteid; any phylaxin or sozin. 2. An antibacterial substance found by Hankin in the blood of certain animals and giving immunity to certain toxins. 3 . A synonym for Tuberculocidin.

Alexipharmac, or Alexipharmic $\left\{a l-e k s-e-f a r^{\prime}-m a k\right.$, or

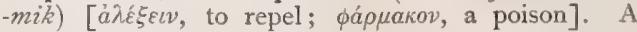
medicine neutralizing a poison.

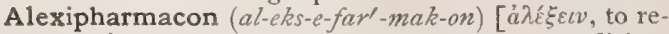

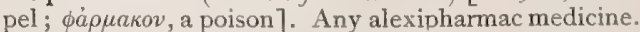

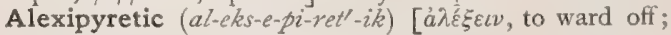

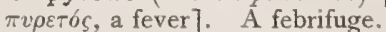

Alexiteric $\left(a l-e k s-e-t e r^{\prime}-i k\right)$. See Alexeteric.

Aleze $(a h$-lèz $)$ [Fr., alèze]. A cloth to protect the bed from becoming soiled by excreta, etc. 
Alfonsin (al-fon'-sin) [from Alfonso Ferri, a sixteenth century surgeon]. An old form of bullet extractor.

Algæ $\left(a l^{\prime}-j e\right)$ [alga, a seaweed]. A group of acotyledonous plants, of simple vegetable construction, living mostly in the water.

Algaroth (al'-gar-oth) [It., Algarotti, the Veronese physician]. Oxychlorid of antimony.

Algedo $\left(a l-j e^{\prime}-d o\right)[a \lambda \gamma \eta \delta \omega v$, pain]. Severe pain in the generative organs and extending to the urinary organs, sometimes arising from a sudden stoppage of gonorrhea.

Algefacient (al-je-fa'-shent) [algere, to be cool; facere, to make]. Cooling.

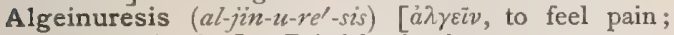
ov̉p $\sigma \iota \varsigma$, urination]. Painful urination.

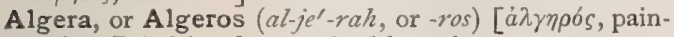
ful]. Painful; characterized by pain.

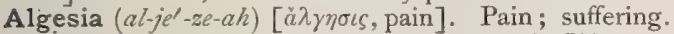

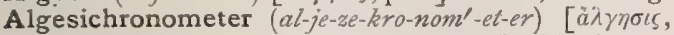

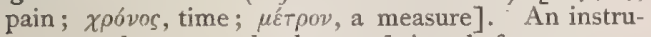
ment used to note the lapse of time before a nerve center responds to a painful stimulus.

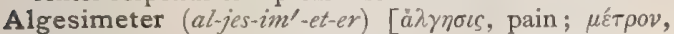
a measure]. An instrument for determining the acuteness of the sense of pain.

Algesis $\left(a l-j e^{\prime}-s i s\right)$. See Algesia.

Algesthesis, or Algæsthesis (al-jes-the'-sis) [ä $\lambda$ yos, pain; nīflnois, feeling]. The perception of pain; any painful disease.

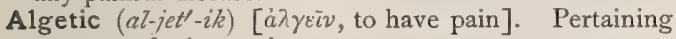
to, or producing, pain.

-algia $\left(a l^{\prime}-j e-a h\right)$ [ãnyos, pain]. A suffix denoting pain, as odontalgia, neuralgia, etc.

Algid (al'-jid) [aloridus, cold]. Cold, chilly. A. Fever, a pernicious intermittent fever, with great coldness of the surface of the body. A. Cholera, Asiatic cholera.

Algin $\left(a l^{\prime \prime}-j i n\right)$ [alga, a seaweed]. Alginic acid; a gummy substance derivable from seaweeds and forming a good substitute for gum arabic.

Algology (al-gol-ō-ji) [alga, a seaweed; $\lambda \dot{\varepsilon} \gamma \varepsilon \iota v$, speak]. That department of botany treating of algæ, phycology.

Algometer (al-gom'-et-er) [ăn̂yos, pain; $\mu \dot{\varepsilon} \tau \rho o v$, a measure]. An instrument for testing the sensibility of a part to pain.

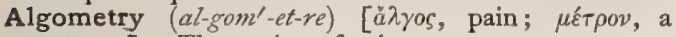
measure]. The testing of pain.

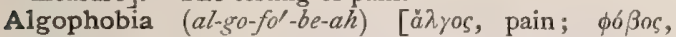
dread]. Unreasonable or morbid dread of pain.

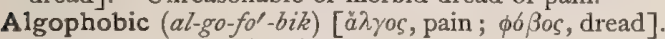
Characterized by algophobia.

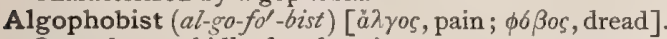
One who morbidly dreads pain.

Algor (al'-gor) [L.]. A sense of chilliness or coldness. A. Progressivus. Syn. of Scleroderma Neonatorum.

Algos (all-gos) [ádyos, pain]. Pain; a painful disease, or attack.

Algosis (al-go'-sis) [alga, seaweed]. The causation of disease by certain plants, as algæ.

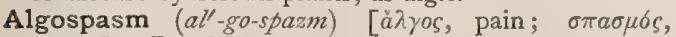
spasm]. Painful spasm or cramp.

Al'ibert's Ke'loid. See Keloid and Diseases, Table of.

Alibility $\left(a l-i b-i l^{\prime}-e-t e\right)$ [alibilis, nutritive]. Availability of a nutritious substance for absorption and assimilation.

Alible $\left(a l^{\prime}-i-b l\right)$ [alibilis, nutritive]. Nutritive; absorbable and assimilable.

Alicant (all-ik-ant) [from Alicante, in Spain]. strong, sweet, and dark-colored Spanish wine.

Alices $\left(a l^{\prime}-i \bar{s}+\bar{e} z\right)$ [L.]. Red spots preceding the pustulation in smallpox.
Alienation (ál-yen-a'-shun) [alienatio; alienare, to withdraw ]. Mental derangement, insanity.

Alienist $\left(\bar{a}^{\prime}\right.$-yen-ist $)$ [alienare, to withdraw]. One who treats mental diseases; a specialist in the treatment of insanity.

Aliethmoid (al-e-eth'-moid) [ala, a wing; $\dot{\eta} \theta \mu b \zeta s$, a strainer]. In birds, the wing of the ethmoidal portion of the orbito-nasal cartilage.

Aliferous (al-if'-er-zes) [ala, a wing; ferre, to bear]. Winged; alate; aligerous.

Aliform (all-if-orm) [ala, wing; forma, shape]. Wingshaped. A. Process, the wing of the sphenoid. See Alisphenoid. Aliformes musculi (al-if-or'-mèz mus'-ku-li). The aliform or wing-shaped muscles; the pterygoid muscles.

Aligerous (al-ij'-er-us) [ala, wing; gevere, to bear]. Having wings; alate; aliferous.

Aliment (al'-im-ent) [alimentum, from alimentare, to nourish]. Nourishment, food. A substance that, acted upon by the digestive and assimilative organs, yields the sources and repairs the losses of heat, force, or the tissues of the body.

Alimentary (al-im-en'-ta-re) [alimentum, from alimentare, to nourish]. Nourishing. A. Bolus, the food after mastication and just prior to swallowing. $\mathbf{A}$. Canal, Duct, System, or Tube, the digestive tube from the lips to the anus, with its accessory glands.

Alimentation (al-im-en-ta'-shun) [alimentare, to nourish]. The process of the reception and conversion of food into material fit for nourishment. A., Rectal, the nourishing of a patient by the administration of small quantities of concentrated food through the rectum. There are many formulx for these nutritious enemata, the most important of which are the following: I. Leube's Pancreatic-meat Emulsion."For rectal alimentation: chop five ounces of finelyscraped meat still finer, add to it one and a-half ounces of finely-chopped pancreas, free from fat, and then three ounces of lukewarm water; stir to the consistence of a thick pulp. Give at one time, care being taken to wash out the rectum with water about an hour before." 2. Mayet's Formula._-"Fresh ox-pancreas 150 to 200 grams; lean meat 400 to 500 grams. Bruise the pancreas in a mortar with water at a temperature of $37^{\circ} \mathrm{C}$, and strain through a cloth. Chop the meat and mix thoroughly with the strained fluid, after separating all the fat and tendinous portions. Add the yolk of one egg, let stand for two hours, and administer at the same temperature, after having cleansed the rectum with an injection of oil. This quantity is sufficient for 24 hours' nourishment, and should be administered in two doses." 3. Rennie's Formula. - "Add to a bowl of good beef-tea one-half pound of lean, raw beefsteak pulled into shreds. At $99^{\circ} \mathrm{F}$. add one drachm of fresh pepsin and one-half drachm of dilute $\mathrm{HCl}$. Place the mixture before the fire and let it remain for four hours, stirring frequently. The heat must not be too great, or the artificial digestive process will be stopped altogether. It is better to have the mixture too cold than too hot. If alcohol is to be given it should be added at the last moment. Eggs may also be added, but should be previously well beaten." 4. Peaslee's Formula._- "Crush or grind a pound of beef-muscle fine; then add one pint of cold water; allow it to macerate 40 minutes, and then gradually raise it to the boiling point; allow it to boil for two minutes-no more-and then strain."

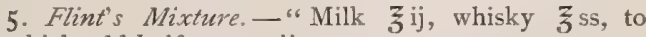
which add half an egg.'

Alimentivity (al-im-en-tiv'-i-te) [alimentare, to nourish]. The instinct that impels the animal organism to take food or nourishment. 
Alinasal (al-in-a'-sal) [ala, a wing; nasus, the nose] Pertaining to the ala nasi, or wing of the nose.

Aliped $\left(a l^{\prime}-i p-e d^{\prime}\right)$ [ala, a wing; pes, a foot]. Charac terized by having the fingers or toes connected by a membrane, for purposes of flight.

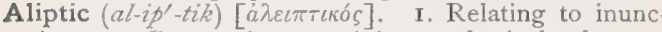
tion. 2. Gymnastic; pertaining to physical culture.

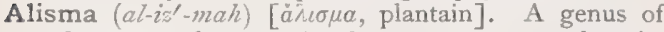
endogenous plants. $A$. plantago, or water plantain, has pungent, acrid qualities, and is used as a diuretic and stimulant. Unof.

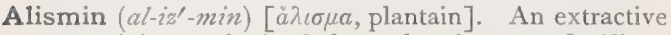
or precipitate, obtained from the tincture of Alisma plantago.

Alisphenoid (al-is-fe'-noid) [ala, a wing; $\sigma \dot{\phi} \dot{n} v$, a wedge; eidos, form ]. I. Pertaining to the greater wing of the sphenoid bone. 2. That bone which in adult life forms the main portion of the greater wing of the sphenoid.

Alizarin $\left(a l-i z-a^{\prime}-r i n\right)$ [Arab., $a l$, the ; ácarah, to extract], $\mathrm{C}_{14} \mathrm{H}_{8} \mathrm{O}_{4}$. The red coloring principle occuring in the madder plant, Rubia tinctorium, and in anthracene, a coal-tar product. It occurs in red prismatic crystals, readily soluble in ether and alcohol. The alizarins form a group of the anthracene colors. See Conspectus of Pigments under Pigment. A. Blue, a crystalline blue coloring matter formed by heating nitroalizarin in combination with $\mathrm{H}_{2} \mathrm{SO}_{4}$ and glycerin.

A. Red, a pale flesh-color used in dyeing.

Alkahest (al'-ka-hest). Same as Alcahest.

Alkalescence ( $a l$ - $\left.k a-l e s^{\prime}-e n s\right)$ [ Arab., al-qalî, sodaash]. Slight or commencing alkalinity; alkaline quality or tendency.

Alkalescent (al-ka-les'-ent) [Arab., al-qalî, soda-ash] Somewhat alkaline; mildly alkaline.

Alkali (al'-ka-li) [Arab., al-qali, soda-ash]. The term includes the hydrated oxids of the alkali metals; these are electro-positive, are strong bases, uniting with acids to form salts, turn red litmus blue, and saponify fats. A., Caustic (usually potash), when so concentrated as to possess caustic properties; potash and soda are called fixed alkalies, because permanently solid; soda is called a mineral, potash a vegetable, and ammonia a volatile alkali.

Alkali-albumin $\left(a l^{\prime}-k a-l i-a l-b u^{\prime}-m i n\right)$. A derived albumin; a proteid having been acted upon by dilute alkalies and yielding an alkaline reaction.

Alkaligenous (al-ka-lij'-en-us) [alkali; yev'hs, producing]. Affording or producing an alkali.

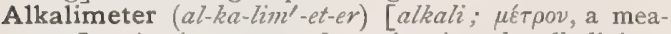
sure]. An instrument for estimating the alkali in a substance.

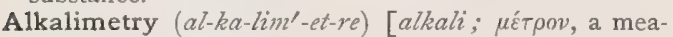
sure]. The measurement of the amount of an alkali in a substance.

Alkaline $\left(a l^{\prime}-k a-\hbar \hbar n\right)$ [alkali]. Having the qualities of or pertaining to an alkali. A. Bath. See Bath. A. Copper Test. See Tests, Table of. A. Tide. See Tide.

Alkalinity (al-ka-lin'-it-e) [alkali]. The quality of being alkaline.

Alkalinuria (al-ka-lin-u'-re-ah) [alkali; ov́oov, urine]. Alkalinity of the urine.

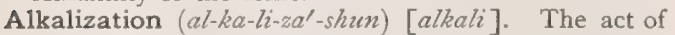
rendering a thing alkaline; the state or quality of being rendered alkaline.

Alkaloid (al'-ka-loid) [alkali; cífos, likeness]. Resembling an alkali.

Alkaloidal (al-ka-loid'-al) [alkali; Eidos, likeness]. Having the qualities of an alkaloid.

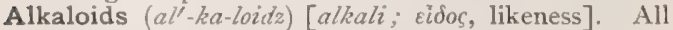
nitrogenous vegetable compounds of basic and alka- line character, or their derivatives, from which bases may be isolated. They are chief constituents of the active principles of the vegetable drugs employed as medicines or poisons. Those alkaloids containing no oxygen are generally liquid and volatile; such are nicotin and conein. The others are solid, crystallizable, and non-volatile. A., Putrefactive. See Ptomaînes.

Alkaluretic (al-ka-lu-ret'-ik) [alkali; ov pov, urine]. Causing or tending to cause a flow of alkaline urine.

Alkanet (al'-kan-et) [Sp., dim, of alcaña, henna]. The root of the herb, Alkanna (Anchusa) tinctoria, yielding a red dye that is used in staining wood, coloring adulterated wines, and in pharmacy to give a red color to salves, etc

Alkan'na Red. See Alkannin.

Alkannin (al'-kan-in) [Sp., dim. of alcaña, henna]. Alkanna red; a valuable coloring matter obtained from alkanet. It is a dark, brownish-red, resinous mass, or powder, insoluble in water, but soluble in alcohol and ether, neutral in reaction.

Alkapton ( $a l-k a p^{\prime}$-ton). A yellowish resinous body occasionally found in urine, which on exposure to air acquires a brownish tint. It does not ferment and does not reduce bismuth like glucose, though it throws down a somewhat brownish mass. It is highly soluble in water, but only sparingly in ether.

Alkaptonuria (al-kap-ton-u'-re-ah) [alkapton; ojpov, urine]. The presence of alkapton in the urine. It has been found in cases of pulmonary tuberculosis, and in other instances in which there are no local lesions or general disease. It is without clinical significance.

Alkarsin (al-kar'-sin) [alcohol; arsenic]. Cadet's Fuming Liquid; an extremely poisonous liquid containing cacodyl. It is of a brown color, and on exposure to the air ignites spontaneously.

Alkophyr $\left(a l^{\prime}-k o-f r\right)$. Brücke's name for a variety of peptone soluble in alcohol.

Alkoxid (al-koks'-id) [alcohol; oxid]. A chemical compound formed by the union of an alcohol with a metallic base.

Alkylogens (al-kill-o-jenz). See Esters, Haloid.

Alkyls (al'-kilz) [alkali]. The name applied to the univalent alcohol radicals, $\mathrm{C}_{\mathrm{n}} \mathrm{H}_{2 \mathrm{n}+1}$; methyl, ethyl, etc., are alkyls.

Alkyl-sulphids ( $\left.a l^{\prime}-k i l-s u l^{\prime}-f i d s\right)$. Thio-ethers. Sulphur analogues of the ethers. They are colorless liquids, mostly insoluble in water and possessing a disagreeable odor resembling that of garlic.

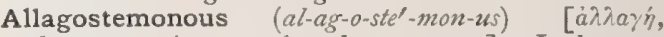
change; $\sigma \tau^{\prime} \mu \omega \nu$, a thread or stamen]. In botany, the alternate insertion of the stamens on the receptacle and corolla.

Allamanda (al-am-an'-dah) [Allamand, a Swiss scientist]. A genus of apocynaceous climbing shrubs of tropical America. A. cathartica is diaphoretic, emetic, cathartic, and refrigerant. Unof.

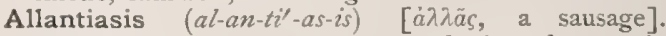
Sausage poisoning, due to putrefactive changes in imperfectly cured sausages, or in those made from bad materials.

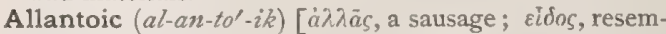
blance]. Pertaining to the allantois. A. Parasite, a form of autosite in which the weaker fetus forms anastomoses with the allantoic or placental circulation of the stronger, thus becoming directly dependent for its nutrition upon the circulation of the latter. It is characterized by a partial or complete disappearance of the heart of the parasite.

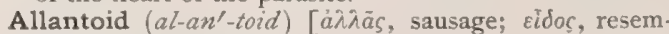
blance]. I. Resembling or like a sausage. 2. Relating to the allantois. 
Allantoidian $\left(a l-a n-t o i d^{\prime}-\ell-a n\right)[\dot{\alpha} \lambda \lambda \bar{a} S$, a sausage ; $\varepsilon i \delta$ ido resemblance]. Any animal which in its fetal condition possesses an allantois.

Allantoin $\left(a l-a n^{\prime}-t o-i n\right)[a \lambda \lambda \lambda a ̈ s$, a sausage, $\varepsilon i \delta o s$, resemblance], $\mathrm{C}_{4} \mathrm{H}_{6} \mathrm{~N}_{4} \mathrm{O}_{3}$. A crystalline substance occurring in traces in normal urine, and prepared from uric acid by oxidation processes. Also the characteristic constituent of the allantoic fluid, and likewise found in fetal urine and amniotic fluid. It crystallizes in small, shining, colorless, hexagonal prisms, soluble readily in hot water. It reduces Fehling's solution on prolonged boiling.

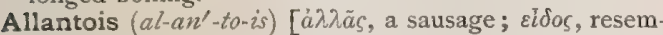
blance]. One of the fetal appendages or membranes, derived from the mesoblastic and hypoblastic layers. Its function is to convey the blood-ressels to the chorion. The lower part finally becomes the bladder, the rest, the urachus.

Allantotoxicon $\left(a l-a n-t o-t o k s^{\prime}-i k-o n\right)[a \dot{\lambda} \lambda \tilde{a} s$, a sausage : $\tau o \xi \kappa 6 v$, a poison]. A name applied to a poisonous substance, probably a ptomaĩne, that develops during the putrefactive fermentation of sausage, especially that made of blood and liver.

Allarton's Operation. See Operations, Table of.

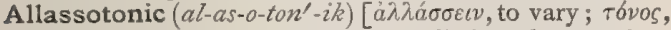
tension]. In biology, a term applied to the transient movements produced by stimulation, in mature plant organs; opposite of Auxotonic.

Allen's Closet. See Servage, Disposal of. A. Tests. See Tests, Table of.

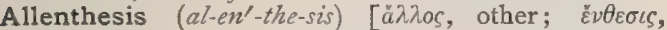
insertion]. The presence or the introduction of foreign bodies into the organism.

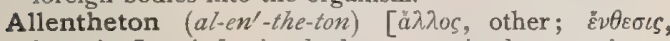
insertion]. A foreign body present in the organism.

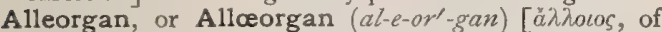
another sort; ópyavov, organ]. Same as Alloplast.

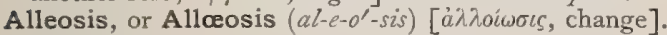
I. Change; alterative effect; recovery from illness. 2. Mental disorder.

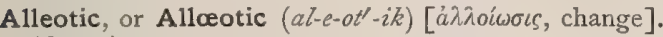
Alterative.

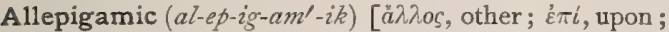
yaukós, relating to marriage]. In biology, a term applied by Poulton to the colored foreign objects displayed by certain animals during courtship, as by the bower birds.

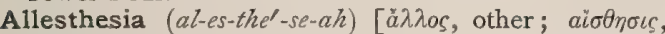
feeling]. Same as Allochiria.

Allevation (al-e-va'-shun) [ad, to ; levare, to lift up]. x. The relief of pain. 2. The raising or lifting of a patient from the bed or from the reclining posture.

Alleviation (al-e-ve-a'-shun) [alleviatus; ad, to ; levare, lift up]. The relief or palliation of pain.

Alleviative $\left(a l-e^{\prime}-v e-a-t i v\right)$ [allevare, to lighten]. $\mathbf{r}$. Tending to mitigate or relieve pain. 2. A remedy for the relief of pain.

Alleviator (al-e'-ve-a-tor) [allevare, to lighten]. A device for raising or lifting a sick person from the bed.

Allex (all-eks) [L.]. Same as Hallux.

Allheal (arri-hell') [A. S., all; halan, to heal]. The officinal valerian, Valeriana officinalis; also the plant Stachys palustris.

Alliaceous (al-e-a'-shus) [allium, garlic]. Resembling garlic or pertaining to the same.

Alligator-forceps $\left(a l^{\prime \prime}-e-g a\right.$-tor-for'-seps). A surgeons' toothed forceps, one of the jaws of which works with a double lever.

Alligator Pear $\left(a l^{\prime}-e-g a-t o r ~ p a \bar{r}\right)$. The seeds of Persea gratissima, or Avocado Pear. A Mexican remedy for intercostal neuralgia, and internally, an anthelmintic (?). Dose, internally, of the fld. ext. $m x x x-3 j$.
Allingham's Operations. See Operations, Table of.

Allingham's Rectal Plug. An appliance for controll ing hemorrhage from the rectum.

Allis's Inhaler. See Anesthetic.

Allis's Sign. See Signs and Symptoms, Table of.

Alliteration ( $\left.a l-i t-e r-a^{\prime}-s h u n\right)$ [ad, to ; litera, letter]. A form of dysphrasia in which the patient arranges his words according to the sound.

Allium $\left(a l^{\prime}-2-u m\right)$ [L.]. Garlic. The bulb of $A$. sativum. Contains a pungent volatile oil (allyl sulphid), that is found also in the leek and the onion. The tubers are used both as a food and as a condiment, and are stimulants to digestion. A. cepa, the common onion, and A. porrum, the leek, have similar qualities. A., Syr., contains, fresh garlic 20 , sugar 80 , dil. acetic acid q. s. Dose 3 j- 3 iv.

Allochetia (al-o-ke'-te-ah). Same as Allocheria.

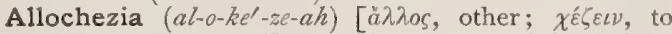
desire to go to stool]. I. The passage of feces from the body through an abnormal opening. 2. The passing of non-fecal matter from the bowels.

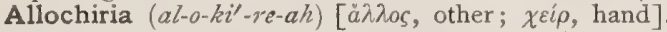
An infrequent tabetic symptom, in which, if one extremity be pricked, the patient locates the sensation in the corresponding member of the other side.

Allochroic $\left(a l-l o-k r o^{\prime}-i k\right) \quad[\tilde{\lambda} \lambda \lambda o s$, another; $x \rho \tilde{\omega} \mu \alpha$, color]. Of changeable or diversified color.

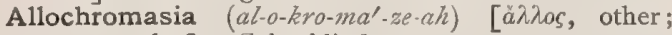
$\chi \rho \tilde{\omega} \mu \alpha$, color]. Color-blindness.

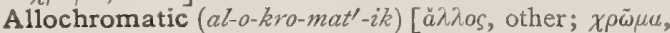
color]. Of a changeable color.

Allocinetic (al-o-sin-et'-ik). See Allokinetic.

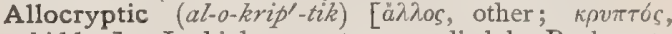
hidden]. In biology, a term applied by Poulton to mimetic coloration in animals produced by covering themselves with foreign objects.

Allceosis $\left(a l-e-o^{\prime}-s i s\right)$. See Alleosis.

Alløotic $\left(a l-e-o t^{\prime}-i k\right)$. See Alleotic.

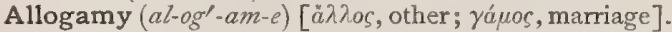
In biology, cross fertilization.

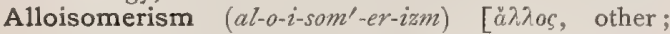

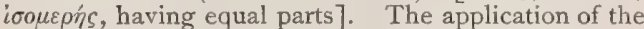
same structural formula to many different compounds; a variety of isomerism.

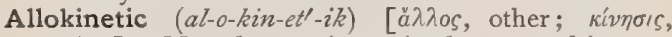
motion]. Moved or set in motion by external impressions or forces; not autokinetic.

Allolalia $\left(a l-o-l a^{\prime}-l e-a h\right)[a / \lambda \lambda o s$, other; $\lambda a \lambda \varepsilon i \nu$, to speak $]$. Any perversion of the faculty of speech.

Allolalic $\left(a l-o-l a l^{\prime}-i k\right)$ [ $\alpha \lambda \lambda n s$, other; $\lambda a \lambda \varepsilon i \nu$, to speak]. Affected with allolalia.

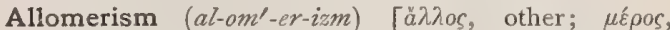
shape]. In chemistry, the property of retaining a constant crystalline form while the chemical constituents present, or their proportions, vary.

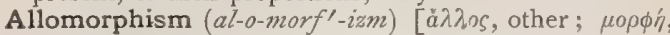
shape]. The property possessed by certain substances of assuming a different form while remaining unchanged in constitution.

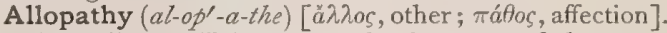
According to Hahnemann, the inventor of the term, that method of the treatment of disease consisting in the use of medicines the action of which upon the body in health produces morbid phenomena different from those of the disease treated. Opposed to homeopathy. It need hardly be said that modern scientific medicine is based upon no such theory, or definition, as that supplied by homeopathy. See Regular.

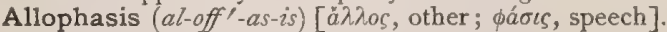
Incoherency of speech; delirium.

Allophemy $(a l$-off'-e-me) [ă $\lambda \lambda$ os, other; $\phi \dot{\eta} \mu \iota$, to speak]. See Heterophemy. 


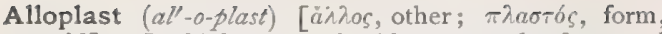
mold]. In biology, a plastid composed of several tissues; the opposite of homoplast.

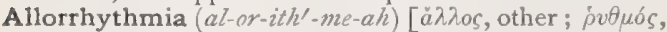
rhythm]. Variation in interval of the pulse. See P'ulse, Pulsus, and Cardiac Rhythm.

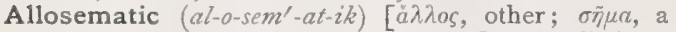
sign, mark, or significant character]. Applied to coloration which enables an animal to associate itself with some large or dangerous animal.

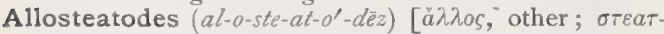
$\omega \delta \eta s$, fat-like]. Marked by perversion or morbidity of the sebaceous secretion.

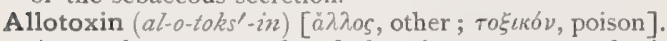
Any substance, produced by tissue metamorphosis within the organism, that tends to shield the body by destroying microbes or toxins that are inimical to it.

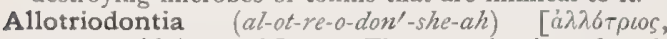
strange; odoirs, tooth]. I. The transplanting of teeth from one person to another. 2. The existence of teeth in abnormal situations, as in tumors.

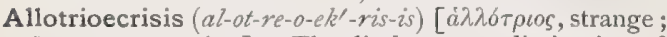

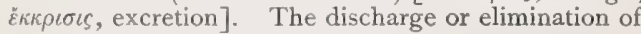
foreign matters with the excretions.

Allotriogeusia (al-ot-re-o-gu'-se-ah). Same as Allotriogeustia.

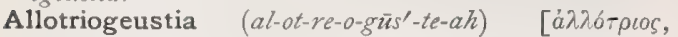
strange; $\gamma \varepsilon \bar{v} \sigma \iota s$, taste]. Perversion of the sense of taste; abnormality of the appetite.

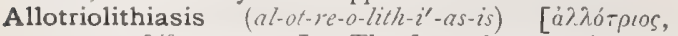
strange; $\lambda i \theta 0 \varsigma$, a stone $]$. The formation or existence of a calculus of unusual material, or composed entirely or in part of a foreign body.

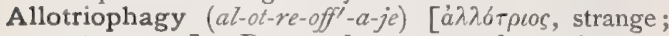
$\phi a \gamma \varepsilon i v$, to eat ]. Depraved or unnatural appetite.

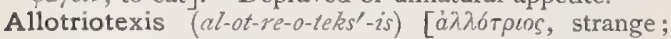
$\tau \hat{\varepsilon} \xi \iota s$, birth]. I. Abnormality in delivery. 2. The birth or delivery of a monstrosity.

Allotriuria ( $\left.a l-o t-\gamma e-u^{\prime}-\gamma e-\alpha h\right) \quad[a \lambda \lambda \sigma \tau \rho \iota s$, strange; ov $\rho o v$, urine]. Abnormality of the urine.

Allotrope $\left(a l^{\prime}-o\right.$-trōos [à $\bar{\lambda} \lambda o s$, different; $\tau \rho o \pi \dot{\eta}$, a change]. One of the forms in which an element capable of assuming different forms may appear.

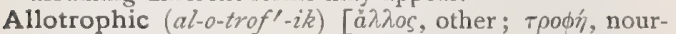
ishment]. Having perverted or modified characters as a nutrient.

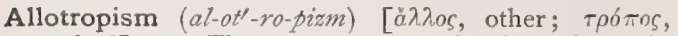
method]. I. The term expresses the fact of certain elements existing in two or more conditions with differences of physical properties. Thus carbon illustrates allotropism by existing in the forms of charcoal, plumbago, and the diamond. See Isomeric. 2. Appearance in an unusual or abnormal form.

Allotropy $\left(a l-o t^{\prime}-r o-p e\right)$. Allotropism.

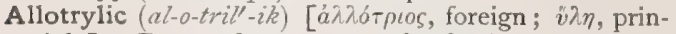
ciple]. Due to the presence of a foreign principle or material; enthetic. A. Affections, morbid states caused by the lodgment of foreign substances in the organism. The foreign substance may be animate or inanimate, organic or inorganic.

Alloxan (al-oks'-an) [allantoin; oxalic], $\mathrm{C}_{4} \mathrm{H}_{2} \mathrm{~N}_{2} \mathrm{O}_{4}$. The ureid of mesoxalic acid; it is produced by the careful oxidation of uric acid, or alloxantin with nitric acid or chlorin and bromin. It appears in long, shining, rhombic prisms, easily soluble in water, with a very acid reaction, and possessing a disagreeable taste. The solution placed on the skin slowly stains it a purple red. It occurs in the intestinal mucus in cases of diarrhea.

Alloxanic Acid (al-oks-an'-ik). See Acid.

Alloxantin (al-oks-an'-tin) [allantoin; oxalic], $\mathrm{C}_{8} \mathrm{H}_{4}$ $\mathrm{N}_{4} \mathrm{O}_{7}+{ }_{3} \mathrm{H}_{2} \mathrm{O}$. A substance obtained by reducing alloxan with $\mathrm{SnCl}_{2}$, zinc and $\mathrm{HCl}$, or $\mathrm{H}_{2} \mathrm{~S}$ in the cold. It occurs in small, hard, colorless prisms that turn red in air containing ammonia. Its solution has an acid reaction.

Alloy $\left(a l-o i^{\prime}\right)$ [from the French word aloi, a contraction of a la loi]. I. A compound of two or more metals by fusion. See Gold Plate and Gold Solder. 2. The least valuable of two or more metals that are fused together.

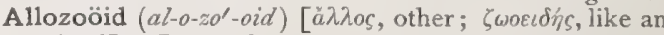
animal]. In zoölogy, a zoöid differing from the organism producing it.

Allspice (awl'-spis). See Pimenta, and Florida Allspice.

Allure (al-ur'). Synonym of Influenza.

Allyl $\left(a l^{\prime}-i l\right)$ [ $v \lambda \eta$, matter], $\mathrm{C}_{3} \mathrm{H}_{5}$. A non-saturated univalent alcohol-radical of the oils obtained from alliaceous plants. It does not exist in the free state. A. Alcohol, $\mathrm{C}_{3} \mathrm{H}_{5} \mathrm{HO}$, a colorless inflammable liquid, with pungent odor, boiling at $97^{\circ} \mathrm{C}$. A. Aldehyd, $\mathrm{C}_{3} \mathrm{H}_{4} \mathrm{O}$, a syn. of Acrolein. A. Cyanid. See Sinamin. A. Mustard Oil, CS.N.C. $\mathrm{H}_{5}$, Allyl thiocarbimid. The principal constituent of ordinary mustard oil. It is a liquid not readily dissolved by water; boils at $150.7^{\circ}$; at $10^{\circ}$, it has a sp. gr. of I.OI7; it has a pungent odor and vesicates the skin. A. sulphid, $\left(\mathrm{C}_{3} \mathrm{H}_{5}\right)_{2} \mathrm{~S}$, the essential oil of garlic. A. thiocarbimid. See A. Mustard Oil. A. tribromid, $\mathrm{C}_{3} \mathrm{H}_{5} \mathrm{Br}_{3}$, a colorless liquid used as an antispasmodic. Dose, five drops. Unof.

Allylamin (al-il'-am-in) [i $\lambda \eta$, matter; ammonia], $\mathrm{NH}_{2}\left(\mathrm{C}_{3} \mathrm{H}_{5}\right)$. Ammonia in which a hydrogen atom is replaced by allyl. It is a sharply caustic mobile liquid.

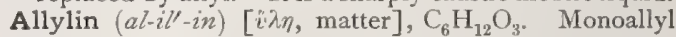
ether, produced by heating glycerol with oxalic acid. It is a thick liquid, boiling at $225-240^{\circ}$.

Almeciga (al-ma'-thig-ah) [Sp.]. See Elemi.

Almen and Nylander's Test. See Tests, Table of.

Almen's Tests. See Tests, Tabie of.

Almond (am'-und) [M. E., almonde]. See Amygdala. A. Bread, a variety of bread made from almond flour, for use by diabetics. It is made as follows : Take of blanched sweet almonds a quarter of a pound. Beat them as fine as possible in a stone mortar, remove the sugar by putting in a linen bag and steeping for a quarter of an hour in boiling water acidulated with vinegar; $\mathrm{mix}$ this paste thoroughly with three ounces of butter and two eggs. Add the yolks of three eggs and a little salt, and stir well for some time. Whip up the whites of three eggs and stir in. Put the dough thus obtained into greased moulds and dry by a slow fire. $\mathbf{A}$. of the Ear, the tonsil. A. Mixture. See Amygdalce Mistura. A. Oil, oleum amygdalæ, the fixed oil obtained from both the sweet and the bitter almond. It is odorless, agreeable to the taste, and of a yellow color; sp. gr. .919 at $15^{\circ} \mathrm{C}$. It is used in pharmacy and medicine and in soap-making. A. Oil, Bitter, Oleum amygdalæ amaræ. See Amygdala. A. Paste, a magma of bitter almonds, alcohol, white of egg and rose-water, used to soften the skin and prevent the hands and lips from chapping. A. of the Throat, the tonsil.

Alnuin $\left(a l^{\prime}-n u\right.$-in) [Celtic, al, near; lan, a river-bank]. A precipitate from the tincture of Almus rubra. Said to be alterative and resolvent. Dose gr. $\mathrm{i}-\mathrm{x}$. Unof.

Alnus (al'-nus) [Celtic, $a l$, near; lan, a river-bank]. Alder Bark. The bark of the American Alder. $A$. serrulata, contains tannic acid. The decoction of bark and leaves is astringent, and used as a gargle and as a lotion for wounds and ulcers. Dose of powdered bark gr. $x$.

Alochia $\left(a h-l \sigma^{\prime}-k e-a h\right)$ [ $\alpha$ priv.; $\lambda 6 \chi \iota a$, the lochia]. Absence of the lochia. 
Aloe $\left(a l^{\prime \prime}-0\right)[\dot{a} \lambda \hat{n} \eta$, the aloe]. The inspissated juice of several species of aloe, of which the $A$. socotrina, $A$. barbadensis, and $A$. capensis are most commonly used. Its properties are due to a glucosid, aloin, $\mathrm{C}_{17} \mathrm{H}_{18} \mathrm{O}_{7}$. A tonic astringent, useful in amenorrhea, chronic constipation, and atonic dyspepsia. It is also an emmenagogue and anthelmintic. Dose gr. j-v. A. americana. See Agave. A. Decoct., Comp. (B.P.). Dose gr. ss-ij. A. Enema (B.P.), aloes, carbonate of potassium ; mucilage of starch. A. et Asafotida, Pil., aloes and asafetida āâ gr. 11/3. A. et Canellæ, Pulv., contains powdered bark of Canella alba. Dose gr. v-xx. A. et Ferri, Pil., contains gr, j each of aloes, ferrous sulphate, and aromatic powder, incorporated with confection of roses. A. et Mastich, Pil., "Lady Webster's" pill, contains each aloes gr. ij, mastich and red rose gr. ss. A. et Myrrh, Pil., contains each aloes gr. ij, myrrh, gr. j, aromatic powder gr. ss, mixed with syrup. A. et Myrrh, Tinct., aloes Io, myrrh Io, alcohol 100 parts. Dose $\mathbf{3}^{\mathrm{ss}-} \mathbf{3}$ ij. A. Ext. Aquosum, prepared by mixing I with Io parts boiling water, straining and evaporating. Dose gr. ss-v. A. Pil., aloes and soap àa gr. ij. A. Purificata, the common drug purified by solution in alcohol and evaporation. Dose gr. $j-v$. A. Socotrin, Pil. (B. P.), contains socotrin, aloes, hard soap, oil of nutmeg and confection of roses. Dose gr. $\mathrm{v}-\mathrm{x}$. A. Tinct., consists of aloes IO, glycyrrhiza IO, dil. alcohol Ioo parts. Dose $3^{\mathrm{ss}-} \mathbf{3}_{\mathrm{ij} .}$ A. Vin., has aloes 6 , cardamon $\mathbf{I}$, ginger $\mathbf{I}$, str. white wine $\mathbf{I} 00$ parts. Dose $3 \mathrm{j}-3 \mathrm{iv}$.

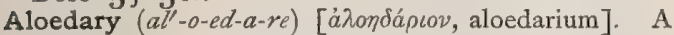
compound aloetic purgative medicine.

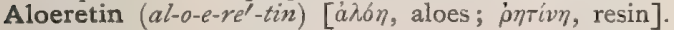
A brown resin contained in aloes.

Aloes $\left(a l^{\prime}-o z\right)$. See Aloe, A. Caballine [caballus, a horse]. Coarse aloes, used in veterinary medi. cine. A. Hepatic, dark liver-colored aloes, mostly Socotrine or Barbadian. A. Lign. See Agallochum.

Aloes-wood (al'oz-wood). See Agallochum, and Aquilaria.

Aloetic $\left(a l_{-0}-e t^{\prime}-i k\right)$ [ádón, the aloe]. Containing or pertaining to aloes.

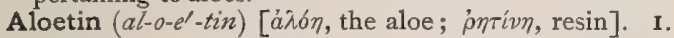
Aloeretin. 2. A yellow crystalline principle obtainable from aloes; aloeretic acid.

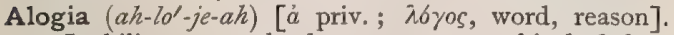
I. Inability to speak, due to some psychical defect. 2. Stupid or senseless behavior.

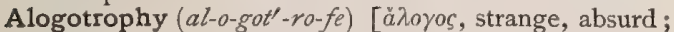
троф́, nutrition]. Irregular and perverted nutrition, leading to deformity.

Aloin $\left(a l^{\prime \prime}-0-i n\right)[a \lambda \hat{n} \eta$, the aloe]. A bitter principle found in aloes. It forms fine needles, possesses a very bitter taste, and acts as a strong purgative. Several glucosids of this name are described; as Barbaloin, Nataloin, Zanaloin, Socaloin, q. $v$.

Alonette's Operation. See Operations, Table of.

Alonsenel (al-on-sen-el') [Fr.]. A variety of the Cowania mexicana, a tall, rosaceous shrub of Mexico and the Rocky Mountain region. It is also called Cowan Plant and Cliff-rose. It is locally valued as a styptic and astringent. Unof.

Alopecia $\left(a l-o-p e^{\prime}-s e-a h\right)[\alpha \lambda \omega \pi \eta \xi$, a fox]. Baldness; Calvities; a term employed to designate the forms of baldness occurring in any disease as a symptom of the latter, or occurring as a purely local affection of the follicles in which the pilary filaments are lodged. It may be universal or partial, congenital or acquired, physiological or pathological, symmetrical or asymmetrical. It follows a large number of systemic affections. A. adnata. See A., Congenital. A. areata; Area celsi; Tinea decalvans; Porrigo decalvans; Alopecia circumscripta; that condition in which suddenly or slowly one or several, usually asymmetrically distributed, patches of baldness appear upon the hairy regions of the body, more often upon the scalp and parts covered by the beard. The patches vary in size from a pin-head to an involvement of the entire surface from the coalescing of many patches. The disease may be produced by traumatism of the head, nervous shock, neurasthenia, ringworm of the scalp and syphilis. A. circumscripta. See $A$. are ata. A., Congenital, a rare form, seldom complete, due to absence of hair-bulbs. A. furfuracea; $\mathrm{Alo}$ pecia pityroides capillitii; Pityriasis capitis; Seborrhea capillitii: Pityriasis simplex; Dandruff; a form of baldness associated with a disorder of the scalp marked by hyperemia, itching, and exfoliation of dry or fatty scales from its surface. It may be acute or chronic, and produce a dryness, brittleness, and lack of luster in the hair. A. localis: $A$. neuritica; that form occurring in one or more patches at the site of an injury, or in the course of a recognizable nerve. A. neuritica. See $A$. localis. A. neurotica, a name given to baldness of trophoneurotic origin. A. orbicularis. Same as $A$. circumscripta. A. pityroides capillitii. See $A$. furfuracea. A. pityroides universalis, a rapid and general denudation of hair occurring in debilitated states, preceded by abundant desquamation of fatty scales. The skin is rather firmer and stiffer than normal. A. senilis; Senile Calvities; that occurring in old age from atrophy and sclerosis of the scalp. A. simplex, the idiopathic premature baldness of young adults. Most common in males. Often associated with premature grayness. A. syphilitica, that due to syphilis. A. universalis, that in which there is a general falling out of the hairs of the body.

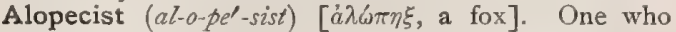
makes a specialty of the treatment of baldness.

Alopecoid (al-o-pe'-koid) [ $\dot{\alpha} \lambda \omega \pi \eta \xi$, a fox ; $\varepsilon i \delta o s$, form] Resembling a fox; vulpine.

Alouchi (al-oo'-chi). See Acuchi.

Alouette's Amputation. See Operations, Table of.

Aloxanthin (al-oks-an'-thin), $\mathrm{C}_{15} \mathrm{H}_{10} \mathrm{O}_{6}$. A yellow substance obtained from barbaloin and socaloin by the action of bichromate of potassium.

Alpestrine (al-pes'-trin) [alpestris, alpine]. Peculiar to mountain districts, as alpestrine diseases.

Alpha $\left(a l^{\prime}-f a h\right)[\alpha \lambda \phi a$, the first letter of the alphabet]. The Greek letter $\alpha$, used in combination with many chemical terms to indicate the first of a series. A. Angle. See Angle. A.-dextrin. Same as Erythro-dextrin. A. Kava Resin. See Lezinin. A.naphthol. See Naphthol. A.-naphthol Test. See Tests, Table of. A.-oxynaphthoic Acid. See Acid, Alpha-oxynaphthoic.

Alphenic $\left(a l-f e n^{\prime}-i k\right)$ [Fr., Alphénic]. White barley sugar.

Alphonsin (al-fon'-sin). See Alfonsin.

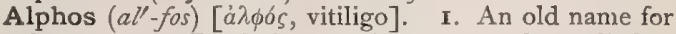
leprosy. 2. Psoriasis. 3. A term vaguely applied to various skin diseases. See Psoriasis.

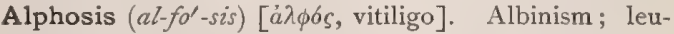
coderma.

Alpinia (al-pin'-e-ah) [Alpinus, Italian botanist of the sixteenth century]. A genus of zingiberaceous tropical plants. $A$. officinarum, $A$. chinensis, and other species furnish Galangal, q.v. Still other species are medicinal. Unof.

Alsace Gum (al-sās's gum). See Dextrin. 
Alstonidin (al-ston'-id-in) [Alston, a Scotch botanist]. An amorphous substance contained in a variety of Dita bark

Alstonin (al'-sto-nin) [Alston, a Scotch botanist]. I. An amorphous substance contained in a variety of Dita bark. 2. A crystalline alkaloid, $\mathrm{C}_{21} \mathrm{H}_{20} \mathrm{~N}_{2} \mathrm{O}_{4}$, obtained from Alstonia Constricta.

Alter $(a w l$ ler $)[$ L., "other" ]. To castrate, or spay.

Alterant (azel'ter-ant). Same as Alterative.

Alteration (awot-ter-a'-sinun) [alterare, to make other]. A change, as of form. A. Theory. See Difference 7heory.

Alterative (azul'-ter-a-tiv) [alter, another]. A medicine that alters the processes of nutrition and excretion, restoring, in some unknown way, and without sensible evacuation, the normal functions of an organ or of the system. It seems to be a necessary or convenient term covering our ignorance of the modus operandi of certain medicines, as mercury, iodin, etc. A., Compound, a domestic remedy consisting of bamboo, brier-root, stillingia, burdock-root, and poke-root,

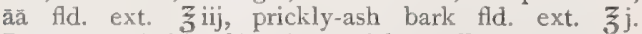
Recommended by Sims in scrofulous affections. Dose $3 \mathrm{j}-\mathrm{ij}$.

Alternate (azul'-ter-nät) [alternare, to do by turns]. In botany, applied to that form of leaf-arrangement in which only one leaf occurs at a node. A. Generation. See Alternation of Generations.

Alternating (awl'-ter-nät-ing) [alternare, to do by turns]. Occurring successively. A. Insanity, a form of insanity in which there are regular cycles of exaltation and depression.

Aiternation (awl-ter-na'-shun) [alternare, to do by turns]. Repeated transition from one state to another. A. of Generations. I. In biology, a generative cycle in which the young do not resemble the parent, but like forms are separated by one or more unlike generations. 2. That form of reproduction in which some of the members of the cycle can produce new beings non-sexually, while in the final stage reproduction is always sexual. Tenia or tapeworm, is an example. The segments, Proglottides, are hermaphrodite, and are evacuated with the feces. From the egg, fertilized after it is shed, is developed the embryo, that is swallowed by another animal, in whose tissues it forms an encysted stage (Cysticercus, Comurus, or Echinococcus). To undergo further development the cysticercus must find another host, where it forms new segments

Althaus's Oil. A modification of Lang's Oil. It is made as follows: Metallic mercury I part, pure lanolin 4 parts, 2 per cent. carbolic oil 5 parts. It forms a homogeneous gray cream that has no tendency to decomposition. It is used in the treatment of syphilis in injections of $m v$ at a dose.

Althea or Althæa $\left(a l-t h e^{\prime}-a h\right)$ [L.]. Marsh-mallow. The peeled root of $A$. officinalis, a plant of the mallow family. It consists of about one-third of vegetable mucus and starch, together with the alkaloids Asparagin and Althein (latterly regarded as identical). Its decoction is employed as a mucilaginous drink. A. syrupi contains four per cent. althea. Dose indefinite. Asparagin possesses sedative and diuretic properties, and is useful in ascites and gout. Dose gr. ij-iij.

Althein $\left(a l^{-t h e}-i n\right)$. See Althea.

Alticomous (al-tik'-o-mus) [altus, high; coma, head of hair, foliage]. In biology, leafy at or near the summit only.

Altitude $\left(a l^{\prime}-t e-t \bar{u} d\right)$ [altitudo, height]. The height, as of an individual. In climatology, the elevation of a place above the sea-level. A.-staff, a device em- ployed for measuring the exact height of recruits. It consists of a rigid upright with a vertex-bar moving without play at right angles to the upright.

Altricious (al-trish'-us) [altrix, a nurse]. Requiring a long nursing; hence, slow of development (the reverse of precocious).

Aluchi $\left(a t-o o^{\prime}-c h i\right)$. See Acuchi.

Aludel $\left(a l^{\prime}-u\right.$-del) [Arab., $a l$, the; uthäl, utensil]. In chemistry, a pear-shaped glass or earthen vessel used in sublimation.

Alum $\left(a l^{\prime \prime}-u m\right)$ [alumen, alum]. Any one of a class of double sulphates formed by the union of one of the sulphates of certain non-alkaline metals with a sulphate of some alkaline metal. The standard (or common commercial) alum, the official Alumen, U. $\mathrm{S}$. $\mathrm{P}$., is the aluminium-potassium sulphate, $\mathrm{Al}_{2}$ $\left(\mathrm{SO}_{4}\right)_{3}+\mathrm{K}_{2} \mathrm{SO}_{4}+24 \mathrm{H}_{2} \mathrm{O}$. It is a powerful astringent and styptic in medicine, and is extensively used in the arts. It is employed by bakers to whiten their bread, but the effect upon the system is probably injurious. Ordinary A. Ammoniz is the same as the above, except that the potassium is replaced by ammonium. It is official in Great Britain, and is extensively used on account of its cheapness. What is known as concentrated or patent alum, is the normal aluminium sulphate (aluminii sulphas) which is not a true alum. A. Ammonio-ferric (Ferri et Ammoniz sulphas), U. S. P., is strongly styptic, and is useful in leucorrhea. Dose gr. $\mathrm{v}-\mathrm{x} . \mathrm{A}$. Potassio-ferric is extremely similar to the A. ammonio-ferric. (For A. Rubidium, see Rubidium). A. Sodæ, double sulphate of sodium and aluminium, is too soluble for ordinary uses. The other alums are very numerous, but they are of little interest to the physician. A. Whey, a preparation obtained by boiling 3 ij of alum in a pint of milk, and straining. It is used as an astringent and internal hemostatic, in wineglassful doses.

Alumen (al-u'-men) [L., gen., Aluminis]. See Alum. A. exsiccatum, burnt or dehydrated alum.

Alumina $\left(a l-u^{\prime}-m i n-a h\right)$ [L.]. Sesquioxid of aluminium; the principal ingredient of clay, and of many stones, earths and minerals.

Aluminate $\left(a l-u^{\prime}-m i n-\bar{a} t\right)[$ alumina]. A basic salt of alumina.

Aluminated Copper. See Lapis divinus.

Aluminiferous (al-u-min-if'-er-us) [alumen, alum; ferre, to form]. Vielding alum.

Aluminium $\left(a \bar{l}-u t-m i n^{\prime}-\ell-u m\right)[\mathrm{L}.] . \quad \mathrm{A} l=27$. Quantivalence II, IV. A silver white metal distinguished by its low sp. gr., about 2.6. A. hydrate, $\mathrm{Al}_{2}(\mathrm{HO})_{6}$, a tasteless white powder, feebly astringent. Dose gr. iij-xx, A. and Potassium sulphate, $\mathrm{K}_{2} \mathrm{Al}_{2}\left(\mathrm{SO}_{4}\right)_{4}$ (Alum, q. v.), a valuable astringent used in catarrh, leucorrhea, gonorrhea, Dose gr. $\mathrm{x}-\mathrm{xx}$. In teaspoonful doses, an emetic. A. sulphate, $\mathrm{Al}_{2}\left(\mathrm{SO}_{4}\right)_{3}$, an antiseptic and astringent used as a lotion in 5 per cent. solution. A. acetate, unof.; a disinfectant. A. acetotartrate, unof.; a disinfectant.

Aluminosis (al-u-min-o'-sis) [aluminium]. A pulmonary disease common among workers in aluminium; the dust collects within the lung tissue.

Alumnol $\left(a l-u m^{\prime}-n o l\right)$ [aluminium]. An astringent and antiseptic "sulphur combination of aluminium." Useful in gonorrhea, endometritis, ear, nose and skin diseases, etc. Used in the main externally. Unof.

Alum Root. The root of Heuchera americana. Prop erties due to gallic and tannic acids. It is very astringent. Dose of the fld. ext. gtt. $\mathrm{x}-\mathrm{xx}$. Also the root of Geranium maculatum, a mild and safe astringent. See Geranium. Unof.

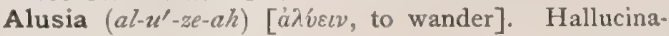
tion; morbid state of mind. 
Alutaceous (al-u-ta'-she-us) [aluta, soft leather]. In botany, of a pale brown color, like untanned leather. Alvearium $\left(a l-v e-a^{\prime}-r e-u m\right)$ [L.]. The external auditory canal or meatus.

Alveloz (al-vel-oth') [Sp.]. An extractive from Euphorbia icterodoxa, having diuretic properties. It is highly recommended as a topical application in cancer. Unof.

Alveolar (al-ve'-o-lur ) [alveolus, a small hollow]. Pertaining to the alveoli or sockets of the teeth. A. Abscess, a gum-boil. A. Arch, the alveolar surface of the jaw. A. Artery, a branch of the internal maxillary. A. Border, the face margin of the jaws. A. Cancer. See Cancer. A. Index, in craniometry, the gnathic index; the ratio of the distance between the basion and alveolar point, to the distance between the basion and the nasal point, multiplied by 100. (Sometimes the basilar index is called the alveolar index.) See Index and Craniometrical Points. A. Point. See Craniometrical Points. A. Process, the border of the superior maxilla in which the alveoli are placed. A. Sarcoma. See Sarcoma.

Alveolarium (al-ve-o-la'-re-um) [alveus, a bee-hive]. A name sometimes applied to the external meatus of the ear. It is so called because the wax of the ear gathers in that place.

Alveolate (al-ve'-o-lāt, or $a l^{\prime}$-ve-o-lāt) [alveolatus, hollowed out like a little tray]. In biology, pitted, honey. combed.

Alveoli $\left(a l-v \ell^{\prime}-o-l i\right)$. Genitive and plural of Alveolus.

Alveolitis (al-ve-o-li'-tis) [alveolus, a hollow; $\iota T \iota s$, inflammation]. Inflammation of the alveolus of a tooth.

Alveolo-condyiean (al-ve'-o-lo-kon-dil'-e-an) [alveolus, a hollow; $\kappa 6 v \delta v i \lambda o s$, a knuckle]. In craniometry, pertaining to the alveolus and condyle. A. Plane. See Plane.

Alveolo-dental (al-ve'-o-lo-den'-tal) [alveolus, a hollow; dens, dentis, a tooth]. Pertaining to the teeth and their sockets.

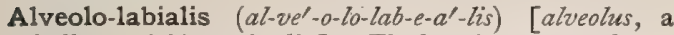
hollow; labium, the lip]. The buccinator muscle.

Alveolo-subnasal (al-ve'-o-lo-sub-na'-sal) [alveolus, a hollow; sub, under; nasus, nose]. In biology, pertaining to the alveolar and subnasal points of the skull. A. Prognathism. See Prognathism.

Alveolus (al-ve'-o-lus) [L.; pl., Alveoli]. The bony socket of a tooth. A. of Glands, the ultimate sacs of a racemose gland. A. of the Lungs, are the air cells. A. of the Stomach, or the alevolar structures, are depressions, like honeycomb cells, found in the stomach, intestines and esophagus.

Alvergnat's Pump. An instrument used in estimating the gaseous constituents of the blood.

Alveus (all-ve-us) [alveus, a trough]. A trough, tube, or canal; applied to ducts and vessels of the body. A. communis, the utricle of the ear. A. hippocampi, a certain structure in the cerebral hemisphere investing the convexity of the hippocampus major.

Alviduca (al-ve-du'-ka) [alvus, the belly; ducere to lead]. Laxative or cathartic medicines.

Alvifluxus (al-ve-fuks'-us) [alvus, the belly; fluxus, a flow]. A free alvine discharge; a diarrhea. A. Torminosus. A synonym of Dysentery.

Alvine $\left(a l^{\prime \prime}-y_{i n}\right.$ or -vin $)$ [alvinus; alvus, belly]. Pertaining to the belly. A. Concretion, an intestinal calculus. A. Dejections, the feces. A. Discharges, the feces. A. Obstruction. Synonym of Constipation.

Alvus $\left(a l^{\prime}-v u s\right)$ [L.]. The belly, or its contained viscera.

Alymphia (ah-limf'-e-ah) [ả priv.; lympha, clear water]. A deficiency of lymph.
Alysm, or Alysmus $\left(a l^{\prime}-i z m\right.$, or $\left.a l-i z^{\prime}-m u s\right)[a \hat{\lambda} v \sigma u o ́ s$, a wandering]. Disquietude; restlessness; mental disquiet; sadness ; anxiety.

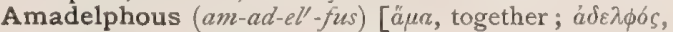
brother]. In zoölogy, gregarious.

Amadou $\left(a m^{\prime}-a-d o o\right)$ [Fr., amadouer, to coax]. Ger man tinder or touchwood; Boletus igniarius, a fungus found on old tree-trunks, used to stanch local hemorrhage, as a dressing of wounds, etc.

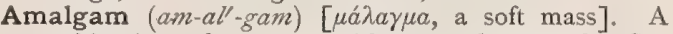
combination of mercury with any other metal. See Copper Amalgam. A. Carrier and Plugger, an instrument designed for carrying and introducing amalgam into the cavity of a tooth. A. Manipulator, an instrument used by dentists for preparing amalgam fillings

Amalgamation (am-al-gam-a'-shun) [ $\mu a ́ \lambda a \gamma \mu a$, a soft mass]. In metallurgy, the process of combining mercury with some other metal, as practiced in separating silver and gold from some other ores.

Amalic Acid $\left(a m-a l^{\prime}-i k\right)$. See Acid.

Amandin (am-an'-din) [Fr., amande, almond]. A proteid contained in sweet almonds.

Amandine $\left(a m-a n^{\prime}-d i n\right)$ [Fr., amande, almond]. A kind of cold cream or almond paste.

Amanitin (am-an'-it-in) [áuavitaı, a kind of fungus]. I. A principle identical with cholin, obtained from the fly agaric. 2. A poisonous glucosid obtainable from various species of agaric.

Amara $\left(a m-a^{\prime}-r a\right)$ [amarus, bitter]. Bitters.

Amaranthus spinosus (am-ar-an'-thus spi-no'-sus) [L.]. The fresh root of the shrub is used in India as a specific in gonorrhea. An emollient and diuretic. Dose indefinite. Unof.

Amarin (am-a'-rin) [amarus, bitter], $\mathrm{C}_{21} \mathrm{H}_{18} \mathrm{~N}_{2}$. Triphenyl dihydroglyoxalin, results from boiling hydrobenzamid with caustic potash. It crystallizes from alcohol and ether in prisms, melting at $113^{\circ}$. It exerts a poisonous effect on animals.

Amarone $\left(a m-a r-\bar{o} n^{\prime}\right)$ [amarus, bitter], $\mathrm{C}_{16} \mathrm{H}_{11} \mathrm{~N}$. A crystalline substance produced by the dry distillation of hydrobenzamid and other substances.

Amarthritis (am-ar-thri'-tis) [ä $\mu a$, together; ă $\rho \rho \rho v$, a joint; $t \tau \iota$, inflammation]. Arthritis affecting many, or several joints at once.

Amasesis (ah-mas-e'-sis) [ả priv. ; $\mu a ́ \sigma \eta \sigma \iota$, chewing] Inability to chew the food.

Amassette $\left(a m-a s-e t^{\prime}\right)$ [Fr.]. A kind of spatula, often of horn, used in color-grinding and in pharmacy.

Amasthenic (am-as-then'-ik) [äua, together; of'vos, strength]. Uniting the chemical ray of light in a focus, as a lens.

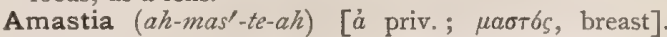
The condition of being without mammæ or nipples.

Amativeness (am'-at-iv-nes) [amare, to love]. The sexual passion.

Amatory (am'-at-o-re) [amator, a lover]. Pertaining to love. A. Fever, love-sickness; chlorosis. A. Muscles, the oblique muscles of the eye, used in ogling.

Amaurosis (am-aw-ro'-sis) [áuavpócev, to darken]. A term that, from its vagueness, is happily becoming disused, signifying partial or total loss of vision. When partial, the word amblyopia is now used; when complete, blindness. The word is still sometimes used to express blindness when the cause is unknown or doubtful. A. Albuminuric, that due to renal disease. A., Cerebral, that due to lesion of the brain. A., Congenital, that form existing from birth. A., Diabetic, that associated with diabetes. A., Hysteric, that associated with hysteria, usually in the female. A., Reflex, that resulting from 
a reflex action upon the optic nerve following some remote source of irritation. A. Saburral, sudden temporary blindness occurring in an attack of acute gastritis. A. Uremic, that due to an acute attack, or an exacerbation of a chronic form of nephritis.

Amaurotic (am-azv-rot'-ik) [áuavpócev, to darken]. Relating to, or affected with amaurosis. A. Cats-eye, a light-reflex through the pupil in suppurative choroiditis.

Amaxophobia (am-aks-o-fo'-be-ah) [ă $\mu a \xi a$, a car ; $\phi b \beta o s$, fear]. Morbid dread of being in, or riding upon, a car or wagon.

Amazia $\left(a h-m a^{\prime}-z e-a h\right)$ [a priv.; $\mu a \zeta b s$, the breast]. Congenital absence of the mammary gland. See Amastia.

Amber $\left(a m^{\prime}-b c r\right)$. See Succinum.

Ambergris (am'-ber-gris) [amber; Fr. gris, gray]. A substance excreted by the sperm whale, Physeter macrocephalus. It is not known whether it is a pathological product or not. It exhales a fragrant, musky odor when warmed, and is used in adynamic fevers, chronic catarrh, and nervous diseases. Dose, gr. j-iij. Unof. See Ambrein.

Ambidexter (am-be-deks'-ter) [ambo, both; dexter, the right hand]. An ambidextrous person.

Ambidextrous (am-be-deks'-trus) [ambo, both ; dexter, the right hand]. Able to use both hands equally well.

Ambigenous (am-bij'-en-us) [ambi, both; genus, born]. In biology, having a perianth with parts resembling sepals and petals.

Ambiparous (am-biph-ar-us) [ambi, on both sides; parere, to produce]. In biology, producing both kinds; as a bud that produces both leaves and flower.

Ambloma (am-blo'-mah) [à $\mu \beta \lambda \omega \mu a$, an abortion: $p l$., Amblomata]. An amblosis or abortion: an aborted fetus.

Amblosis (am-blo'-sïs) [ă $\mu \beta \lambda \omega \sigma \iota s$, an abortion]. An abortion.

Amblothridium ( $\left.a m-b l o-t h r i d^{\prime \prime}-e-u m\right)[a \mu \beta \lambda \omega \theta \rho i \delta \iota o v$, an aborted fetus: pl., Amblothridia]. I. An aborted fetus. 2. An abortifacient drug or agent.

Amblotic $\left(a m-b l o t^{\prime}-i k\right)$ [a $\alpha \mu \beta \lambda \omega \tau \iota k o s$. See Amblosis]. Abortifacient.

Amblyaphia $\left(a m-b l e-a^{\prime}-f e-a h\right) \quad[a ̉ \mu \beta \lambda v ́ s, d u l l ; \dot{a} \phi \dot{n}$, touch]. Dulness of the sense of touch.

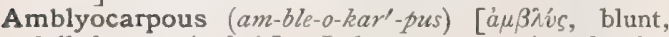
dulled; $\kappa a \rho \pi \delta \varsigma$, fruit]. In botany, possessing abortive seeds.

Amblyopia ( $\left.a m-b l e-o^{\prime}-p e-a h\right)[\alpha \mu \beta \lambda u ́ s$, dulled; $\omega \varpi$, eye $]$. Subnormal acuteness of vision, due neither to dioptric abnormalism nor to visible organic lesion. It may be congenital; from the use of tobacco ( $A$.nicotinica), or alcohol, or other toxic influences; from traumatism; or it may be hysterical. Nyctalopia or day-blindness, and hemeralopia or night-blindness, are other forms; it may arise from entoptic phenomena, such as musce volitantes, micropsia, megalopsia, metamorphopsia, etc. It may take the form of contracted fields of vision, of color-blindness, or anesthesia of the retina. A. exanopsia, amblyopia from disuse, or from non-use: argamblyopia is a preferable term. A. post-marital, A. due to sexual excess, called Burns's Amaurosis.

Amblyopiatrics (am-ble-o-pe-at'-riks) [amblyopia; iaT $\rho$ $\kappa \delta s$, belonging to medicine]. The therapeutics of amblyopia.

Ambolic $\left(a m-b o l^{\prime}-i k\right)[a \dot{a} \beta \beta \lambda \eta \dot{n}$, a putting off ]. Causing abortion; abortifacient.

Ambon $\left(a m^{\prime}-b o n\right)[a ̈ \mu \beta \omega n$, the lip of a cup]. The fibrocartilaginous ring that surrounds a socket in which the head of a large bone is received, such as the acetabuIum, or the glenoid cavity.

Ambos $\left(a m^{\prime}-b o s\right)$ [Ger.]. The incus, or anvil bone.
Ambosexous $\left(a m-b o-s e k s^{\prime}-u s\right)$ [ambo, both; sexus, sex] Hermaphroditic

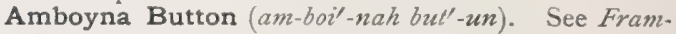
besia.

Ambra Grisea (am'-brah gris'-e-ah). Synonym of Ambergris.

Ambrein $\left(a m^{\prime}-b r e-i n\right)$ [Fr., Ambre]. A substance much resembling cholesterin; it is obtained from ambergris by digestion in hot alcohol.

Ambrette (am-bret') [Fr]. The seed of Abelmoschus moschatus, q. v.; musk-seed. Used in perfumery, and formerly prescribed as a substitute for musk. Unof.

Ambrosia (am-bro'-zhe-ah) [außporia, the food of the gods]. A genus of coarse composite-flowered herbs. A. artemisiafolia, common hog-weed of North America ; is stimulant, tonic, antiperiodic, and astringent. A. trifida, of the United States, has similar properties. The pollen of these plants is by some regarded as a cause of hay-fever. Unof.

Ambulacral (am-bu-la'-kral) [ambulacrum, a walk, alley]. In biology, related to an ambulacrum.

Ambulacrum (am-bu-la'-knum) [ambulacrum, a walk, alley: $p l .$, Ambulacra $]$. In biology, one of the radiating series of perforations in the shell of an echinoderm.

Ambulance (am'-bu-lans) [ambulare, to walk about]. In Europe the term is applied to the surgical staff and arrangements of an army in service. In the United States the word is restricted to a vehicle for the transference of the sick or wounded from one place to another.

Ambulatory (am'-bu-lat-o-re) [ambulare, to walk about]. Relating to walking. A. Blister, a blister that changes its location. A. Clinic, a clinic for patients that can walk. A. Erysipelas, erysipelas that shifts from place to place. A. Tumor, a pseudo-tumor. A. Typhoid, walking typhoid; enteric fever in which the patient does not, or will not take to his bed.

Ambulo $\left(a m^{\prime}-b u-l o\right)$ [ambulare, to walk about]. A pseudo-tumor of the abdomen; a painful and shifting abdominal distention due to flatulence.

Ambury (am'-ber-e). See Anbury.

Ambustion (am-bus'-chun) [ambustio, a burn]. A burn or scald.

Ameba or Amœba ( $\left.a m-e^{\prime}-b a h\right)$ [á $\mu \circ \measuredangle \not \dot{\eta}$, a change]. A colorless, single-celled, jelly-like protoplasmic organism found in sea and fresh waters, constantly undergoing changes of form, and nourishing itself by surrounding objects. The white corpuscles of the blood perform ameboid movements, i.e., changes of form, consisting of protrusions and withdrawals of substance. $A$. buccalis and $A$. dentalis (perhaps identical species) have been found upon human teeth. $A$. coli, ameba of dysentery. A. uro-genitalis, has been observed in urine and in vaginal secretions.

Ameban $\left(a m-e^{\prime}-b a n\right)$ [áuoc $\beta \dot{n}$, a change]. I. Of the nature of or pertaining to an ameba. 2. Any organism that may be classed as an ameba.

Amebic $\left(a m-e^{\prime}-b i k\right)$ [áua $\beta \dot{\eta}$, a change]. Pertaining to or characterized by amebæ.

Amebicidal ( $\left.a m-e-b i s-i^{\prime \prime}-d a l\right)$. See Amebicide.

Amebicide $\left(a m-e^{\prime}-b i s-\bar{l} d\right)$ [áuo $\beta \dot{n}$, a change; cadere, to kill]. I. Destructive of amebæe. 2. A remedy that destroys amebr.

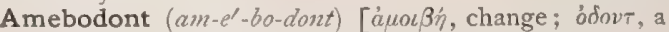
tooth]. In biology, pertaining to molar teeth in which the ridges or crests are alternate; the opposite of antiodont.

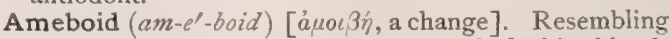
an ameba in form or in changes; used of white blood. cells, etc. 
Amel $\left(a m^{\prime}-e l\right)$ [Anglo-French, amal, enamel]. An old name for Enamel.

Amelectic (am-el-ekl-tik). Affected with ameleia; apathetic.

Ameleia $\left(a m-\ell l-i^{\prime}-a h\right)$ [á $\mu \varepsilon^{\prime} \imath \varepsilon \iota a$, indifference]. Morbid apathy ; indifference.

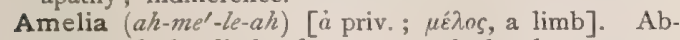
sence of the limbs from arrested development, or atrophy.

Amelification (am-el-if-ik-a'-shun) [M. E., amell; facere, to make]. The formation of the enamel of the teeth by means of the enamel cells-ameloblasts.

Amelioration (am-êl-yo-rat-shun) [ad, to; melior, better]. Improvement or amendment, as in symptoms.

Ameliorative (am-êl'-yo-ra-tiv) [ad, to ; melior, better]. Tending to produce an amendment of symptoms.

Ameloblast (am-el'-o-blast) [Anglo-French, amal,

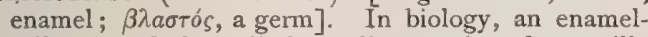
cell, one of the cylinder cells covering the papilla of the enamel organ, and forming a beautifully regular epithelial layer that produces the enamel, the Membrana adamantina of Raschkow.

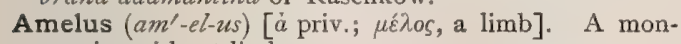
strosity without limbs.

Amendment (am-end"-ment) [M. E., amendement]. Improvement or recovery of health, more or less complete.

Amenia (ah-me'-ne-ah), See Amenorrhea.

Amenomania (am-en-o-ma'-ne-ah) [amanus, agreeable; $\mu$ avia, madness]. A mild form of mania in which the symptoms are manifested under the form of gayety, fondness of dress, exaggeration of social condition, etc. ; a cheerful, or joyous delirium; a morbid elevation of the spirits.

Amenorrhea (ah-men-o-rel-ah) [á priv.; $\mu$ ív, month; $\dot{\rho}^{\prime} \varepsilon \iota \nu$, to flow]. Absence, irregularity, or suppression of menstruation when it should normally be present. The secretion may be retained, the result of congenital or acquired atresia of some part of the lower genital tract; or it may not take place in consequence of an imperfect development of the ovaries or uterus; or it may be suppressed because of some form of constitutional disease, especially anemia. Primitive, is a term applied to those cases in which the catamenia have not appeared at the proper time, and Secondary, to those in which the discharge has been arrested after it has existed during the reproductive period of life.

Amenorrheal (ah-men-o-re'-al) [a priv.; $\mu$ '́v, month; '́́ $\varepsilon \iota \nu$, to flow]. Pertaining to amenorrhea.

Ament $\left(a^{\prime}\right.$-ment) [ab, from; mens, mentis, the mind]. A person affected with amentia; an idiot.

Ament or Amentum (am'-ent, am-ent'-um) [amentum, a strap or thong]. In biology, a scaly spike or catkin.

Amentaceous (am-en-ta'-she-us) [amentum, a strap or thong]. In biology, related in some way to an ament.

Amentia (ah-men'-she-ah) ['a priv. ; mens, mind]. Defective intellect; a vague term synonymous with idiocy or imbecility.

Amentum (am-ent'-um). See Ament.

Amenty (ah-men'-te) [a priv.; mens, mind]. Amentia. American (am-er'-ik-an) [America]. Peculiar, or belonging, to America. A. Aloe. See Agave americana. A. Catarrh, a synonym for chronic postnasal catarrh. A. Centaury, the herb Sabbatia angularis, employed as a substitute for gentian. A. Columbo, the root of Frasera carolinensis. Tonic, aperient; in large doses, purgative. Dose of the fld. ext. $m x x-3 \mathrm{j}$. Fraserin, a concentrated extract. Dose gr. j-iij. Unof. A. Hellebore. See Veratrum viride. A. Ipecac. See Gillenia. A. Ivy, the twigs and bark of Ampelopsis quinquefolia. Alterative, tonic, astringent, and expectorant. Dose of the fld. ext. $\eta \times x x-3 \mathrm{j}$. Ampelopsin, the concentrated ext. Dose gr. ij-iv. Unof, A. Saffron. See Carthamus. A. Senna. See Senna. A. Spikenard, the rhizome of Aralia racemosa. Aromatic, diuretic and alterative. Used in rheumatism, dropsy, and scrofulous affections. Dose of the decoction indefinite. Unof. A. Swiss Food, a variety of infant milk food with the following composition: Water 5.68, fat $6.8 \mathbf{I}$, grape-sugar and milk-sugar 5.78, cane-sugar 36.43 , starch 30.85 , soluble carbohydrates 45.35 , albuminoids I0.54, ash I.21. A. Valerian. See Cypripedium. A. Wormseed. See Chenopodium.

Amertume (am-ar-tüm') [Fr.]. A disease of wine, characterized by bitterness, and caused by a specific bacillus.

Ametabolic (ah-met-ab-ol'-ik) [á priv.; $\mu \varepsilon \tau a \beta o ́ \lambda o s$, changeable]. Not due to, or causing, or undergoing, metabolism.

Ametria (ah-met'-re-ah) [ả priv.; $\mu \eta \dot{r} \rho \rho$, womb]. Absence of the uterus.

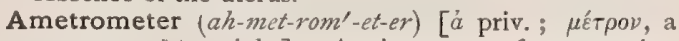
measure; ö $\psi \iota$, sight]. An instrument for measuring ametropia.

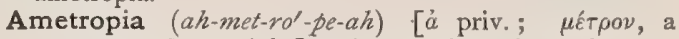
measure; $\delta \psi \iota \varsigma$, sight]. Ametropia exists when an imperfect image is formed upon the retina, due to defective refractive power of the media, or to abnormalities of form of the eye. In myopia the anteroposterior diameter is too great, or the power of the refractive media is too great; hypermetropia (or hyper. opia) is the exact reverse of the last; astigmatism is due to imperfect curvature of the cornea, or of the retina, or to inequality of refracting power in different parts of the lens; presbyopia is due to inelasticity of the lens, producing insufficient accommodation; aphakia, or absence of the lens, produces both insufficient refracting power and loss of accommodation.

Ametropic $\left(a h\right.$-met-rop $\left.{ }^{\prime}-i k\right)$ [á priv. ; $\mu \dot{\varepsilon} \tau \rho o v$, a measure ; ö $\psi s$, sight]. Affected with or pertaining to ametropia.

Amianthium (am-e-an'-the-un) [áuiavros, unspotted; àv 0 , , flower]. A genus of liliaceous or melanthaceous plants. A. musce toxicum ("fly poison"), a handsome flowering plant of the United States; has properties not unlike those of veratrum. Unof.

Amiantus (am-e-an'-tus), or Amianthus (am-e-an'thus). See Asbestos.

Amic $\left(a m^{\prime}-i k\right)$ [ammonia]. Pertaining to an amin, or having the nature of an amin.

Amici Prism (am-e'-che prizm). See Prism.

Amicrobic (ah-mi-kro'-bik) [á priv.; microbion, microbe]. Not due to, or associated with, microbes.

Amid $\left(a m^{\prime}-i d\right)$ [ammonia]. A chemical compound produced by the substitution of an acid radical for one or more of the hydrogen atoms of ammonia. The amids are primary, secondary, or tertiary, according as one, two, or three hydrogen atoms have been so replaced. They are white crystalline solids, often capable of combining with both acids and bases. A. Bases. See Amins, Primary. .

Amidin (am'-id-in) [Fr., amidon, starch]. Starch altered by heat into a horny, transparent mass; soluble starch; that part of starch which is soluble in water.

Amidins (am'-id-inz) [ammonia]. Mono-acid bases produced from the nitrites by heating with ammonium chlorid. In the free condition they are quite unstable. They contain the group C. NH. NH ${ }_{2}$.

Amido-acetic Acid $\left(a m^{\prime}-i d^{\prime}-o-a s-e^{\prime}-t i k a s^{\prime}-i d^{\prime}\right)$. See Glycocoll and Glycin.

Amido-acid (am'-id-o-as'-id) [ammonia; acetum, vinegar]. An acid containing the amido-group, $\mathrm{NH}_{2}$. 
Amidogen (am-id'-o-jen) [amid; yevvãv, to produce]. The hypothetical radical, $\mathrm{NH}_{2}$, regarded as an essential part of all amids. See $A$ mid.

Amido-glycerol $\left(a m^{\prime}-i d-o-g l i s^{\prime}-e r-o l\right)$. See Serin.

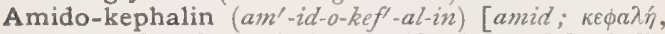
the head]. One of the modifications of kephalin found in the brain tissue. The name is sometimes extended to other similar principles, the amidokephalins

Amido-lipotide $\left(a m^{\prime}-i d^{\prime}-0-l i p^{\prime}-0-l i d\right)$. Any one of a very peculiar group of nitrogenous fats said to exist in the brain.

Amidomyelin (am'-id-o-mi'el-in) [amid; $\mu v \varepsilon \lambda o_{s}$, marrow], $\mathrm{C}_{44} \mathrm{H}_{92} \mathrm{~N}_{2} \mathrm{PO}_{10}$. A dipolar alkaloid or basic principle, derivable from brain tissue. It gives name to a group of similar bodies, the amidomyelins.

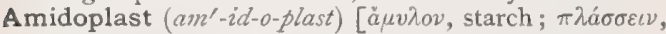
to form]. In biology, a name proposed by Errera for leukoplastids. Proteid granules whose functions it is to form starch grains.

Amido-succinamic Acid (an'-id-o-suk-sin-am'-ik as'-id). Same as Asparagin.

Amidoxim, or Amidoxime (am-id-oks'-im). See Oxamidin.

Amidulin (am-id'-u-lin) [Fr., amidon, starch]. Soluble starch ; prepared by the action of $\mathrm{H}_{2} \mathrm{SO}_{4}$ on starch, thus removing the starch-cellulose.

Amimia $\left(a h-m i m \iota^{\prime}-e-a h\right)$ [á priv.; $\mu \tilde{\mu} \mu o s$, a mimic]. An aphasic symptom consisting in loss of the power of imitation or of pantomime speech. A. Musical, pathological loss of the power of playing musical instruments.

Amin $\left(a m^{\prime}-i n\right)$ [ammonia]. The Amins are chemical compounds produced by the substitution of a basic atom or radical for one or more of the hydrogen atoms of ammonia; or basic derivatives of carbon, containing nitrogen and viewed as ammonia derivatives. In deportment they bear some similarity to ammonia. The lower members are gases with ammoniacal odor and are readily soluble in water; they differ from ammonia in their combustibility. The highest members are liquids soluble in water, only the highest are sparingly soluble. They are called Monamins, Diamins, Triamins, etc., according to the number of amidogen molecules, $\mathrm{NH}_{2}$, substituted for $\mathrm{H}$. A. Colors. Same as Anilin Colors, q. v. A. Primary, an amin in which one hydrogen atom is replaced by a monovalent alkyl. A. Secondary, an amin in which two hydrogen atoms are replaced by monovalent alkyls. A. Tertiary, an amin in which three hydrogen atoms are replaced by monovalent alkyls.

Aminol (am'-in-ol) [amin]. A gaseous substance derived from the methylamin of herring-brine mixed with milk of lime. This gas is cheap and powerfully disinfectant, and it has been used in the purification of sewage.

Amins Process. See Sezuerage, Disposal of.

Amitosis (a/l-mit-o'-sis) [á priv.; mitosis, indirect celldivision, karyokinesis; $\mu i$ itos, a thread; osis]. Cell multiplication by direct division, or simple cleavage, the nucleus usually assuming an hour-glass shape and dividing before the protoplasm. The opposite of mitosis.

Amitotic $\left(a h-m i t-o t^{\prime}-i k\right)$ [á priv.; piros, thread]. Of the nature of, or characterized by, amitosis. A. Cell Division, direct nuclear subdivision, as distinguished from karyokinesis.

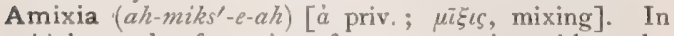
biology, the formation of a new species without the mingling of two individuals or their germs; asexual reproduction, parthenogenesis.

Amma $\left(a n t^{\prime}-a h\right)[a \mu \mu a$, a tie: $p l$., Ammata]. A truss or girdle for hernia.

Ammelid (am'-el-id) [Ammonia; melamid], $\mathrm{C}_{3} \mathrm{H}_{4} \mathrm{~N}_{4}$ -
$\mathrm{O}_{2}$. A substance produced by boiling melamin with alkalies or acids; it is a white powder that forms salts with both acids and bases.

Ammelin (am'-el-in) [Ammonia; melam], $\mathrm{C}_{3} \mathrm{H}_{5} \mathrm{~N}_{5} \mathrm{O}$. A white powder, insoluble in water, soluble in alkalies and mineral acids. Produced by boiling melamin with alkalies and acids.

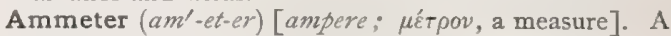
form of galvanometer in which the value of the current is measured directly in ampères.

Ammi $\left(a m^{\prime}-i\right)$ [á $\mu \mu \iota$, an African plant]. A genus of umbelliferous herbs bearing aromatic seeds or fruits. The seeds of several species are locally used in medicine. Unof. A. copticum. See Ajowan.

Ammism $\left(a m^{\prime}-i z m\right)$ [ă $\mu \nu$ s, sand]. Ammotheraphy ; psammism.

Ammonemia, (am-o-ne'-me-ah). See Ammoniemia.

Ammonia $\left(a m-o^{\prime}-n e-a h\right)$ [L.]. A volatile alkali, $\mathrm{NH}_{3}$. See Ammonium, A. Carmin. See Stains, Table of.

Ammoniac (am-o'-ne-ak). See Ammoniacum.

Ammoniacal (am-o-ni'-ak-al) [ammonia]. Containing or relating to ammonia.

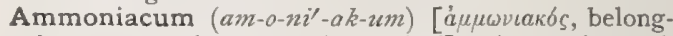
ing to ammonia ; gen., Ammoniaci]. Ammoniac. A gum obtained from a Persian plant, Dorema Ammoniacum. A stimulating expectorant and laxative, resembling asafetida. Employed in chronic bronchial affections. Dose gr. $\mathbf{x}-\mathbf{x} x \mathbf{x}$. A. cum Hydrargyro Emplastrum, ammoniac 72 , mercury 18 per cent., oleate of mercury .8, dilute acetic acid 1oo, lead plaster, with sulphur, and oil, q. s. A. Emplastrum, IOO parts of ammoniac, digested with 140 parts of acetic acid, diluted, strained, and evaporated. A. Emulsum, a four per cent. emulsion in water, the resin being suspended by the contained gum. Dose zss-j.

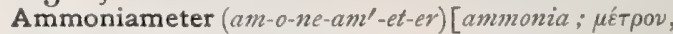
a measure]. An instrument for testing the strength of solutions of ammonia.

Ammoniemia, or Ammoniæmia (am-o-ne-e'-me-ah) [ammonia; àlua, blood]. The theoretical decomposition of urea in the blood, yielding ammonium carbonate.

Ammoniorrhea (am-o-ne-or-e'-ah) [ammonia; $\dot{\rho} \varepsilon \bar{\imath}$, to flow]. The passage of ammoniacal urine.

Ammonium (am-o'-ne-um) [from the name of Jupiter Ammon, because first discovered near his temple in Libya; gen., Ammonii]. A hypothetical alkaline base, having the composition $\mathrm{NH}_{4}$. Exists only in combination. It occurs most commonly in the form of ammonia gas, $\mathrm{NH}_{3}$, which, dissolved in water, is the water of ammonia of commerce. Inhatation of the gas causes suffocation and edema of glottis. The salts first stimulate and then paralyze the motor nerves. It is useful as a stimulant, as an antagonist in cardiac depression, and locally in bites and stings of venomous reptiles and insects. Ammonia Aqua, water of ammonia, a solution containing ten per cent. of the gas in water. Dose $\eta_{v} v-z^{s s}$, well diluted. A. Aqua Fortior, contains 28 per cent. of the gas in solution. A. Aromatic Spt., spirit of ammonia, with am. carb., am. aq., ol. lemon, lavender and pimenta, alcohol and water. Dose $3 \mathrm{ss-ij.} \mathrm{Ammonii} \mathrm{acetas} \mathrm{liq.}$ Spirit of Mindererus, dilute acetic acid neutralized with ammonia. Dose $3 \mathrm{j}-\xi_{\mathrm{j}}$. A. benzoas, $\mathrm{NH}_{4} \mathrm{C}_{7} \mathrm{H}_{5} \mathrm{O}_{2}$. Dose gr. $\mathrm{v}-\mathrm{xv}$. A. Bicarbonas. Dose gr. ij-x, A. bromid, $\mathrm{NH}_{4} \mathrm{Br}$. Dose gr. $\mathrm{x}-3$ ss. A. carbonas, $\mathrm{NH}_{4} \mathrm{HCO}_{3} . \mathrm{NH}_{4} \mathrm{NH}_{2} \mathrm{CO}_{2}$, a mixture of carbonate and dicarbonate. Dose gr. $\mathbf{v - x}$. A chlorid, $\mathrm{NH}_{4} \mathrm{Cl}$, sal ammoniac. Dose gr. j-xx. A. chloridi trochisci, each lozenge contains gr. ij of the salt. A. fluorid, used in hypertrophy of the spleen. 
Dose gr. $\frac{1}{2} T^{-\frac{1}{2}}$. A. glycyrrhizas. Unof. An expectorant. ${ }^{2}$. iodidum, $\mathrm{NH}_{4} \mathrm{I}$. Dose gr. ij-x. A. liniment, am. aq. 35, alcohol 5, cottonseed oil 60 . A. Molybdenate Test. See Tests, Table of. The following salts and their preparations are official: $\mathbf{A}$. nitras, $\mathrm{NH}_{4} \mathrm{NO}_{3}$, used only in preparing nitrous oxid. A. phosphas, $\left(\mathrm{NH}_{4}\right)_{2} \mathrm{HPO}_{4}$. Dose gr. v-xx. A. picras, $\mathrm{C}_{6} \mathrm{H}_{2}\left(\mathrm{NH}_{4}\right)\left(\mathrm{NO}_{2}\right)_{3} \mathrm{O}$, a salt in yellow needles, of bitter taste; like other picrates it is explosive, and must be handled with care. It is antipyretic and antiperiodic, and tends to correct gastric disturbances. Dose gr. $v$ in 24 hours; best given in wafers, each containing half a grain. A. Spt., a ten per cent. solution of aqua ammonize in alcohol. Dose $m x-z j$, diluted. A. sulphas, $\left(\mathrm{NH}_{4}\right)_{2} \mathrm{SO}_{4}$, used only in the preparation of other ammonium salts. A. valerianas, $\mathrm{NH}_{4} \mathrm{C}_{5} \mathrm{H}_{9} \mathrm{O}_{2}$. Dose gr. j-v, Raspail's Eau Sedatif (unof.), aqua ammoniæ $\xi_{\mathrm{ij}}$, sodium chlorid 亏ij, spt. vini camph. 3 iij, aq. 3 xxxij. For local use.

Ammon's Fissure. See Fissure. A.'s Horn. See Hippocamp. A.'s Operation. See Operations, Table of. A.'s Posterior Scleral Protuberance, a variety of posterior ectasia of the sclera of the eye.

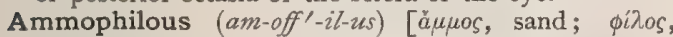
loving]. In biology, inhabiting sandy places.

Ammotherapy (am-o-ther'-a-pe) [à $\mu \mu \rho$, sand; $\theta \varepsilon \rho a-$ $\pi \varepsilon \varepsilon_{\varepsilon} \nu$, to heal]. The use of sand-baths in the treatment of disease.

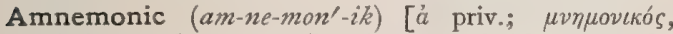
relating to the memory]. Accompanied by or resulting in impairment of the memory.

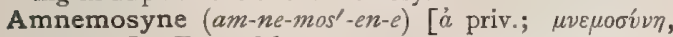
memory]. Forgetfulness.

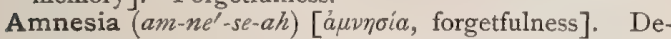
fect of memory. Loss of the memory for words. A. Acustica, word-deafness. A. Periodic. See Double Consciousness.

Amnesic $\left(a m-n e^{\prime}-s i k\right)$. Relating to amnesia.

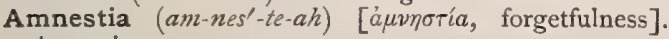
Amnesia.

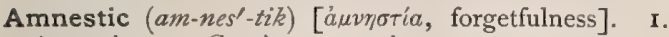
Amnesic. 2. Causing amnestia.

Amnia (am'-ne-ah) [áviov, a young lamb]. Plural of Amnion, q. $v$.

Amniac $\left(a m^{\prime}-n \ell-a k\right)$ [ápviov, a young lamb]. Amnionic.

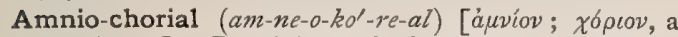
membrane]. Pertaining to both amnion and chorion.

Amnioclepsis (am-ne-o-klep'-sis) [áuviov, amnion; $\kappa \lambda \varepsilon \pi \tau \varepsilon i \nu$, to steal away]. The slow and unnoticed escape of the liquor amnii.

Amnion (am'-ne-on) [a aviov, a young lamb]. The innermost of the fetal membranes; it is continuous with the fetal epidermis at the umbilicus, forming a complete sheath for the umbilical cord and a sac or bag in which the fetus is enclosed. It contains one or two pints of liquor amnii. It is a double non-vascular membrane, the inner layer or sac derived from the epiblast, the outer from the mesoblast. The cavity of the inner folds is called the true amnion, that of the outer, the false. A., Dropsy of, excessive secretion of liquor amnii.

Amnionic (am-ne-on'-ik) [áuviov, a young lamb]. Relating to the amnion.

Amniorrhea, $\left(a m-n e-o-r e^{\prime}-a h\right)$ [áuvios, amniotic liquor;

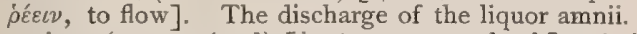

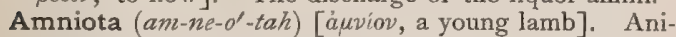
mals with an amnion and allantois, comprising mammals, birds, and reptiles. Those without an amnion are called Anamnia

Amniotic (am-ne-st'-ik) [álıvion, a young lamb]. Re- lating to the amnion, as the A. Flatid. A. Fluid. Same as Liquor amnit.

Amniotis (am-ne-ó-tis) [áuviov, a young lamb]. See Amniotitis.

Amniotitis (am-ne-o-ti'-tis) [áuviov, a young lamb; iT $\iota$, inflammation]. Inflammation of the amnion.

Amniotome (am'-ne-o-tōm) [ákviov, a young lamb; $\tau \delta ́(\eta$, a cut]. An instrument for puncturing the fetal membranes.

Amnitis (am-ni'tis). Same as Amniotitis.

Amœba (am-e'-bah). See Ameba.

Amœboid ( $\left.a m-e^{\prime}-b o i d\right)$. See Ameboid.

Amcebodont (am-e'-bo-dont). See Amebodont.

Amœnomania (am-e-no-ma'-ne-ah). See Amenomania.

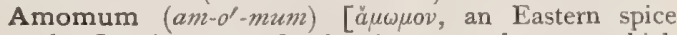
plant]. A genus of scitaminaceous plants to which the cardamom (A. cardamomum) and Grains of Paradise (A.granum paradisi) belong.

Amorphia (ah-mor'-fe-ah) [a priv. ; $\mu о \rho \varphi \eta ́$, form]. Shapeless condition.

Amorphinism (ah-mor'-fin-izm) [à priv.; Morpheus, the god of sleep]. The condition resulting from the withdrawal of morphine from one habituated to the drug.

Amorphism (ah-mor'-fizm) [ả priv.; $\mu \rho \rho \phi \dot{n}$, a form]. The state or quality of being amorphous or without shape; specifically, absence of crystallization; want of crystalline structure.

Amorphous (ah-mor'-fus) [á priv.; $\mu \rho \rho \varphi \eta ́$, a form]. Formless, shapeless, non-crystallized. A. Quinin, quinoidin, its salts being non-crystallizable.

Amorphus (ah-mor'-fus) [a priv.; $\mu \circ \rho \phi \dot{\eta}$, a form]. An acardiacus without head or extremities. See also Anideus. A. Globulus. See Anideus.

Amotio $\left(a m-o^{\prime}-s h e-o\right)[\mathrm{L}$.$] . A detachment. A. Re-$ tinæ. See Ablatio Retina.

Ampac $\left(a m^{\prime}-p a k\right)$ [E. Indian]. An Fast Indian rutaceous tree of the genus Xanthoxylum or Ampacus. Its leaves are used in medicating baths, and its odoriferous resin is a stimulant. Unof.

Ampelopsin (am-pel-op'-sin). See American Ivy.

Ampelopsis (am-pel-op'-sis). See American Yvy.

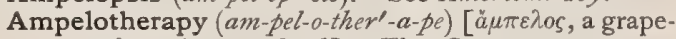
vine; $\theta \varepsilon \rho a \pi \varepsilon v \varepsilon \imath v$, to heal]. The Grape-cure, $q . v$.

Amperage (om'-pār-ahj) [Fr.]. The number of ampères passing in a given circuit.

Ampere (om-pār $\left.r^{\prime}\right)$ [a French physicist]. See Electrical Units. A.'s Laws relate to the forces between conductors carrying electric currents. Avogadro's laze, that equal volumes of a gas when under the same conditions contain the same number of molecules, is also called Ampère's Law. In honor of Ampère, the unit of measurement of an electric current is called an Ampère.

Ampèremeter $\left(a m^{\prime}-p \bar{a} r-m e-t e r\right)$ [Ampère; $\mu$ ćtpov, to measure]. An instrument for estimating the current of an electric circuit in amperes.

Ampère's Law. See Law.

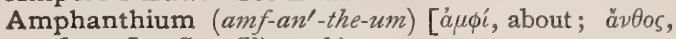
a flower]. See Clizanthium.

Amphemerina (am-fe-mer'-in-ah) [ă $\mu \phi \eta \mu \varepsilon \rho v v o ́ s$, daily]. A hectic or intermittent fever that recurs daily.

Amphi- $\left(a m^{\prime}-f e\right)\left[a \mu \phi \iota^{\prime}\right.$, around]. A prefix signifying about, on both sides, around, etc., as amphiarthrosis, amphibia, etc.

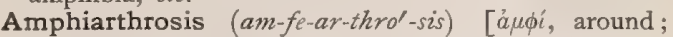
à $\rho \rho \rho \nu$, a joint]. A form of mixed articulation in which the surfaces of the bones are connected by broad discs of fibro-cartilage, or else they are covered with fibro-cartilage and connected by external ligaments. It is distinguished by limited flexion in every direction, as, e.g., between the vertebra. 
Amphiaster $\left(a m l^{\prime}-f e-a s-t e r\right)$ [ảudi, around; $\dot{a} \sigma \dot{\eta} \rho$, a star]. In biology, the figure formed in both direct and indirect cell division, by the achromatin threads and chromatin granules united to form the so-called nuclear spindle, together with the threads of cell-protoplasm radiating from a rounded clear space at each end of the spindle known as the stars or suns.

Amphibia $\left(a m-f i b^{\prime}-e-a h\right)[\dot{a} \mu \phi \hat{l}$, both; Bios, life $]$. A class of the Vertebrata, living during their life both in the water and upon the land, as the frog, newt, etc.

Amphibious $\left(a m-f i b b^{\prime}-\ell-2 \epsilon s\right)$ [a $\mu \phi i$, both; $\left.\beta i o s, l i f e\right]$. Living both on land and water.

Amphiblastic (am-fe-blas'-tik) [á $\mu \phi \dot{c}$, on both sides; $\beta \lambda a \sigma \tau b s$, a germ]. In biology, pertaining to that form of complete segmentation that gives rise to an amphiblastula.

Amphiblastula (amfe-blus'-fu-luh) $\{$ (iul-
oi, on both sides; dim. of $\beta \lambda c o \tau \sigma s$, a germ]. In biolngy, the mulberrymass or morulastage in the development of a holoblastic egg. It follows the stage known as amphimorula.

Amphiblestritis (amfe-bles-tri'-tis) $[a \mu-$

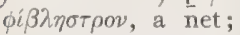
iTes, inflammation]. Inflammation of the retina.

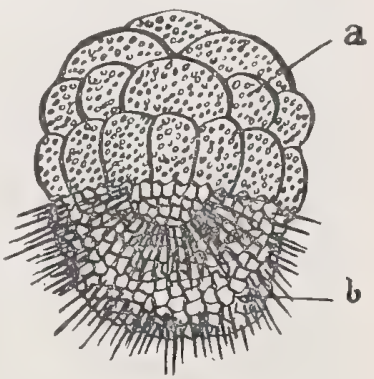

AMPHIBLASTULA.

$a$, Granular cells which will form the epiblast. $b$, Ciliated cells which become invaginated to form the hypoblast. (After Balfour.)

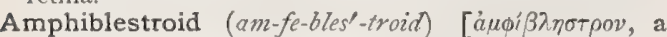
net; $\varepsilon i \delta o s$, form ]. Net-like. A. Membrane, the retina.

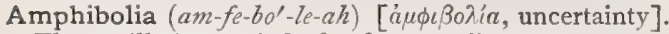
The vacillating period of a fever or disease.

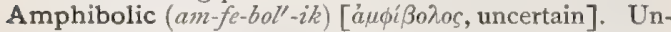
certain; donbtful. A qualification applied by Wunderlich to a period in the febrile process occurring between the fastigium and the defervescence, and marked by irregular exacerbations and remissions.

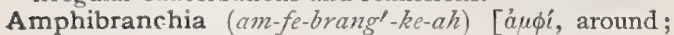
$\beta \rho \alpha^{\prime} \gamma \lambda^{\imath} \iota \pi$, the gills]. The tonsils, pharynx, and nasopharynx.

Amphicarpic (am-fe-kar'-pik). Same as Amphicarpous.

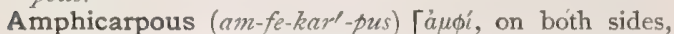
around; $\kappa a \rho \pi \delta \varsigma$, fruit]. In biology, producing fruit of two kinds, either as regards form or season of ripening.

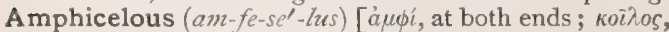
hollow]. In biology, biconcave, as the center of the vertebræ of fishes.

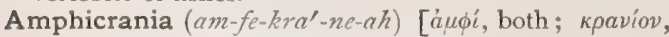
the skull]. Headache affecting both sides of the head.

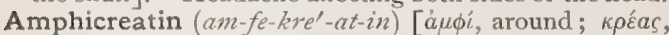
flesh], $\mathrm{C}_{9} \mathrm{H}_{19} \mathrm{~N}_{7} \mathrm{O}_{4}$. One of the muscle-leucomaines. It crystallizes in brilliant oblique prisms of a yellowishwhite color. It is tasteless and faintly basic. It resembles creatin in its properties.

Amphicreatinin (am-fe-kre-at'-in-in) [á $\mu \phi^{\prime}$, around;

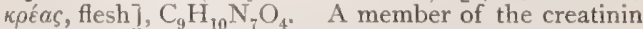
group of le:scomaines said to have toxic qualities. It is derived from muscle.
Amphid $\left(a m^{\prime}-f d\right)$ [á $\mu \dot{\phi}$, both]. In chemistry, a name given to a salt of an acid containing oxygen; that is, a name given to salts other than haloid.

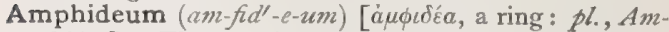
phidea]. The margin or edge of the os uteri.

Amphidiarthrosis (am-fe-di-ar-thro'-sis) [à $\dot{\alpha}^{\prime} \dot{i}$, both; $\delta i a \rho f \rho \omega \sigma / s$, articulation]. The articulation of the lower jaw, as it partakes of the nature both of ginglymus and arthrodia.

Amphidisc, Amphidisk ( $\left.a m^{\prime}-f e-d i s k\right)$ [á $\mu \phi i$, at both ends; ঠібкоs, a round plate]. In biology, a spongespicule consisting of an axil terminated by two toothed discs.

Amphigenous $\left(a m-f j^{\prime}-e n-u s\right)$ [á $\mu \phi i ́$, both; yévos, kind]. In biology, growing indifterently on both sides, as certain parasitic fungi.

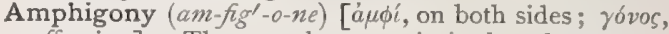
offspring]. The sexual process in its broadest sense; gamogenesis.

Amphimixis $\left(a m-f i-m i k s^{\prime}-i s\right)$ [áud, on both sides; $\mu i \xi \iota s$ mixing]. In biology, the mingling of two individuals or their germs; sexual reproduction.

Amphimonerula (am-fe-mo-ner'-u-lah) [á

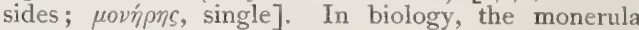
or cytode-stage of an unequally segmenting, holoblastic egg.

Amphimorula (am-fe-mor'-u-lah) [amphi, on both sides; morula, a mulberry]. In biology, the morula, or globular mass of cleavage cells resulting from unequal segmentation, the cells of the hemispheres being unlike in size.

Amphioxus (am-fe-oks'-us) [áudi, both; ókic, sharp]. A genus of fishes tapering at both ends, the lancelet.

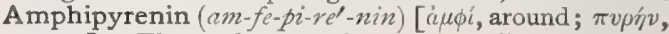
mass]. The nuclear membrane of a cell.

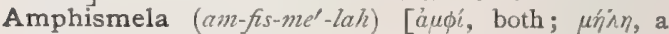
probe]. A double-edged surgical knife.

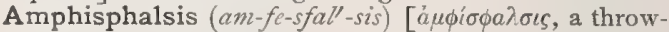
ing or turning round]. Circumduction, as of a $\operatorname{limb}$ in reducing a luxation.

Amphistoma (am-fis'-6o-mah) [á $\mu \phi i$, double; $\sigma \tau b \mu a$, mouth]. A genus of trematode worms, named from the mouth-like apparatus at either end. One species, $A$. hominis, has been found in the large intestine of man, in the tropical regions. See Parasites, Table of.

Amphistylic (am-fe-sti'-lik) [á $\mu \phi^{\prime}$, , on both sides; $\sigma \tau \bar{v} \lambda o s$, a pillar]. In biology, having styles or supports on both sides, as the mandibular arches of sharks.

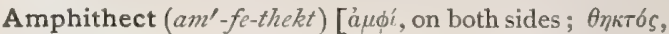
sharpened]. In biology, having unequal angles or surfaces.

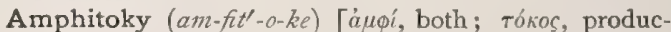
ing]. The production of both male and female forms in parthenogenesis.

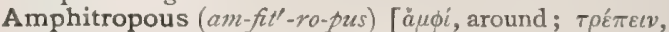
to turn]. I. In biology, having the funiculus attached to the ovule midway between the chalaza and micropyle. 2. Having a $\mathbf{C}$-shaped embryo.

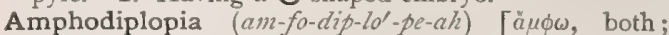
$\delta \iota \pi \lambda \delta$ os, double; $\omega \psi$, eye]. Double vision affecting each of the eyes.

Ampho-peptone (am-fo-peṕ-tōn). See Peptones.

Amphophile (am'-fo-fil $)$ [à $\mu \phi \omega$, both; $\phi i \lambda \varepsilon \bar{i} v$, to love]. Readily stainable alike with acid and basic dyes (a qualification applied to certain histological and pathological elements).

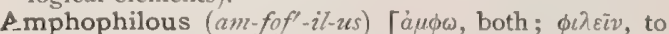
love]. Staining with either alkaline or acid dyes.

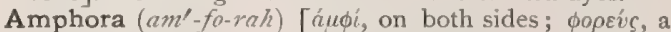
bearer]. In biology, the lower portion of a seed capsule, or pyxidium. 
Amphoric (am-forl-ik) [amphora, a two-handled vessel]. Like the sound produced by blowing across the mouth of a bottle. A. Breathing, breath sounds with an amphoric or musical quality heard in diseased conditions of the lung, as in phthisis with cavity-formation. A. Resonance, in auscultation, a metallic sound like that of blowing into a bottle, caused by the reverberation of sound in a cavity of the lung. A. Respiration. See A. Breathing.

Amphoricity (am-for-is'-i-te) [amphora, a two-handled vessel]. The quality of being amphoric; the giving forth of amphoric sounds.

Amphoriloquy (am-for-il"-o-kwe) [amphora, a bottle : loqui, to speak]. The production of amphoric sounds in speaking.

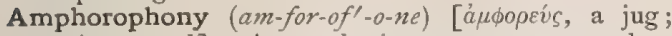
$\phi \omega v \dot{\text {, }}$ a sound]. An amphoric resonance or sound.

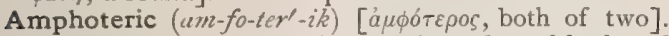
Having the power of altering the color of both red and blue test paper, as milk. Neither acid nor alkaline; applied to such substances as glucose, gums, etc.

Amplectant (am-ple $h^{\prime}$-tant) [amplecti, embrace]. In biology, embracing; winding about, as a tendril or petiole.

Amplexation (am-pleks-a'-shun) [amplexatio, an embrace]. The treatment of a fractured clavicle by an apparatus that fixes the shoulder and covers a part of the chest and neck.

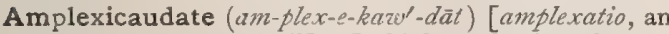
embrace; cauda, a tail]. In biology, having the entire tail included in the interfemoral membrane.

Amplexicaul (am-pleks'-e-kazul) [amplexus, embracing; caulis, a stem]. In biology, clasping or embracing the stem, as a leaf.

Amplexifoliate (am-pleks-e-fol-le-ât) [amplexus, embracing; folium, leaf]. In biology, plants, the leaves of which embrace the stem.

Ampliation ( $\left.a m-p l e-a^{\prime}-s h u n\right)$ [ampliare, to increase]. Dilatation or distention of a part or cavity.

Amplification (am-plif-ik-a'shun) [amplificare, to enlarge ]. I. Increase of the visual area, in microscopy. 2. Enlargement, as of a diseased organ.

Amplifier $\left(a m^{\prime}-p l e-f-e r\right)$ [amplificare, to enlarge]. An apparatus sometimes used in microscopy for increasing the magnification. It consists of a diverging lens or combination placed between the objective and the ocular, and giving to the image-forming rays from the objective an increased divergence. A., Tolles's, an accessory used in magnification and first made effective by a manufacturer named Tolles.

Amplitude $\left(a m^{\prime}-p l e-t \bar{u} d\right)$ [amplitudo, the extent of a thing]. The range or extent, as of vibrations and undulations, the pulse, etc.

Ampulla (am-pul'-ah) [L., A Roman wine jug]. The trumpet-mouthed or dilated extremity of a canal, as of the lachrymal canal, the receptaculum chyli, the Fallopian tubes, mammary ducts, semicircular canals, vas deferens, etc. Chemically, the term denotes a large-bellied bottle. A. of Bryant, the apparent distention of an artery immediately above a ligature, due to the contraction of the vessel above the ampulla where it is not completely filled with clot. A. Chyli, the receptaculum chyli. A., Lieberkühn's, the cecal terminus of one of the lacteals in the villi of the intestines. A of Rectum, the portion above the perineal flexure. A. of Vater, the site of entrance of the common bile-duct and pancreatic duct into the duodenum.

Ampullula (am-pul'-u-lah) [dim. of ampulla, a Roman wine jug]. A small ampulla, as in the lymphatic or lacteal vessels.

Amputation (am-pu-ta'-shun) [amputare, to cut away]. The removal of a limb or part of the body by the knife, ligature, or other means, or as a result of gangrene, constriction (e.g., of the cord, in the fetus), or the disease, ainhum. For special amputations see Uperations, Table of. A., Accidental, the separation of a limb by some form of accident. A., Bloodless, one in which there is but slight loss of blood, on account of the circulation being controlled by mechanical means. A., Central, one in which the scar is situated at or near the center of the stump. A., Circular, that performed by making a single flap, by circular sweeps of a long knife, through skin and muscles, in a direction vertical to the plane of the limb. A., Circular Skin Flap, a modification of the circular, in which the skin flap is dissected up, and the muscles divided at a higher level. A., Coat-sleeve, a modification of the circular, in which the cutaneous flap is made very long, the end being closed by being gathered together by means of a tape. A.. Congenital, amputation of fetal portions due to constriction by amniotic bands of lymph. A. in the Contiguity, amputation at a joint. A. in the Continuity, amputation of a limb elsewhere than at a joint. A., Consecutive, an amputation during the period of suppuration or later. A., Cutaneous, one in which the flaps are composed exclusively of the integuments. A., Diclastic, one in which the bone is broken with an osteoclast, and the soft tissues divided by means of an écraseur. Its object is to avoid hemorrhage and purulent infection. A., Double Flap, one in which two flaps are formed from the soft tissues. A., Dry. See A., Bloodless. A., Eccentric, one in which the scar is situated away from the center of the stump. A., Elliptical, one that may be performed by a single sweep, as in the circular method; the wound, however, having an elliptical outline, on account of the oblique direction of the incision. A. of Expediency, one performed for cosmetic effect. A., Flap, one in which one or more flaps are made from the soft tissues, the division being made obliquely. A., Flapless, one in which, on account of destruction of the soft parts, flaps cannot be formed, the wound healing by granulation. A., Galvano-caustic, one in which the soft parts are divided with the galvano-cautery, followed by division of the bone by the saw. A., Immediate, one done within twelve hours after the injury, during the period of shock. A., Intermediary or Intermediate, one performed during the period of reaction, and before suppuration. A., Intrauterine. See $A$., Congenital. A., Major, amputation of the extremities above the wrist or ankle joints. A., Mediate. See A., Intermediary. A., Minor, amputation of the extremities below the wrist or ankle joints. A., Mixed, a combination of the circular and flap methods. A., Multiple, amputation of two or more members at the same time. A., Musculo-cutaneous, one in which the flaps consist of skin and muscle. A., Musculo-tegumentary. See A., Musculo-cutaneous. A., Natural. See A., Congenital. A., Oblique. See A., Oval. A., Osteoplastic, one in which there is section and apposition of portions of bone, in addition to the amputation. A., Oval, a modification of the elliptical, in which the incision consists of two reversed spirals, instead of the one oblique. A., Partial, I. One in which but a portion of the extremity is removed. 2. An incomplete congenital amputation. A., Pathological, one done for tumor or other diseased condition. A., Primary, one done after the period of shock and before the occurrence of inflammation. A., Racket, a variety of the oval amputation, in which there is a single longitudinal incision continuous below with a spiral incision on either side of the limb. A., Secondary, one performed during the period of sup- 
puration. A., Spontaneous. See A., Congenital. Also occurs in the disease, ainhum. A., Subperiosteal, one in the continuity, the cut end of the bone being covered by periosteal flaps. A., Surgical, a formal amputation in contradistinction to accidental or congenital A. A., Synchronous. See A., Multiple. A. by Transfixion, one done by thrusting a long knife completely through a limb, and cutting the flaps from within out. A., Traumatic, one performed on account of injury.

Amputatura (am-pu-tat-u'-rah) [L.; pl., Amputature] An amputation; loss of a member.

Amuck $\left(a-m u k^{\prime}\right)$ [Malay]. In a state of murderous frenzy; in Oriental regions persons, mostly hashish eaters, often attack and kill those whom they meet while in a state of wild fury. In some cases the infuriated persons take this method of seeking death, for they are shot down at sight.

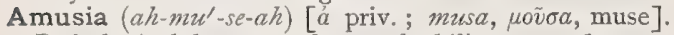
Pathological loss or subnormal ability to produce or comprehend music or musical sounds, an abnormality as regards music analogous to aphasia as regards the faculty of speech. Motor A., the music is understood, but there is loss of the power of singing or of otherwise reproducing music. Paramusia, faulty and imperfect reproduction of music. Sensory A., musical deafness, or the loss of the power of comprehension of musical sounds. See also Alexia, Musical; Agraphia, Musical; and Amimia, Musical.

Amussat's Operations. See Operations, Table of.

Amyelencephalia (ah-mi-el-en-sef-a'-le-ah) [ả priv. ; $\mu v \varepsilon \lambda \sigma \nu$, marrow; $\kappa \varepsilon \varphi a \hat{n} \eta$, the head]. Congenital absence of both brain and spinal cord.

Amyelencephalus (ah-mi-el-en-sef'-al-us) $[\dot{\alpha}$ priv.; $\mu v \varepsilon \lambda \sigma \nu$, marrow; $\kappa \varepsilon \phi a \lambda \dot{n}$, the head]. A fetal monster having neither brain nor spinal cord.

Amyelia $\left(a h-m i-e^{\prime}-l e-a h\right)$ [á priv,; $\mu v \varepsilon \lambda o ́ s$, marrow]. The congenital absence of the spinal cord.

Amyelinic $\left(a h-m i-e l-i n^{\prime}-i k\right)$ [á priv. ; $\mu v \varepsilon \lambda^{\prime} \sigma s$, marrow]. Having no myelin; applied to certain nerve fibers, especially those seen in neuromata.

Amyelonervia (ah-mi-el-o-ner'-ve-ah). See Amyeloneuria.

Amyeloneuria (ah-mi-el-o-nu'-re-ah) [á priv.; $\mu v \varepsilon \lambda \sigma o s$, marrow; veṽ pov, a nerve]. Paresis of the spinal cord.

Amyelotrophy (ah-mi-el-ot'-ro-fe) [á priv.; $\mu v \varepsilon \lambda o ́ s$,

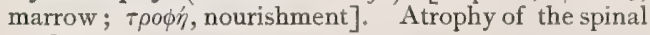
cord.

Amyelus $\left(a h-m i^{\prime}-e l-u s\right)$ [á priv. ; $\mu v \varepsilon \lambda b s$, marrow]. A fetal monstrosity with partial or complete absence of the spinal cord.

Amyencephalus (ah-mi-en-sef'-al-us). See Amyelencephalus.

Amygdala (am-ig'-dal-ah) [L.: gen., Amygdale]. I. Almond. The seeds of Prunus Amygdalus, var. amara and dulcis, containing the principle Emulsin or Synaptase. The former contains Amysdalin. The expressed oil of the sweet almond is a demulcent useful in skin-affections; in doses of $3 \mathrm{j}-\mathrm{ij}$ it is a mild laxative. The oil of $A$. amara is used in cosmetics. 2. The tonsil. A. amaræe, Aq., a I : 1000 solution of the oil in water Dose indefinite. A. amaræ, Ol., a volatile oil, bitter to the taste. Contains 3-14 per cent. of hydrocyanic acid. Dose $m^{1 / 4}-\mathrm{j}$. A. amaræ, Spt., oil of bitter almond I, alcohol 80, distilled water q. s. A., Emulsum, oil of sweet almonds 6 per cent., sugar, water, and acacia q. s. Dose 3 jzss. A. expressum, Ol., oil of sweet almonds. A., Pulv., Comp. (B. P.), contains sweet almonds, refined sugar, and gum acacia. Used to make $A$., Emulsum. A., Syr., sweet almond 14, bitter almond 4, sugar 20 , orange-flower water 10 , water 13 , syrup q. s.
Amygdalæ $\left(a m-i g^{\prime}-d a l-e\right)[L ., p l$.$] . The tonsils.$

Amygdalin (am-ig'-dal-in) [Amygdala], $\mathrm{C}_{20} \mathrm{H}_{27} \mathrm{NO}_{11}$. $+3 \mathrm{H}_{2} \mathrm{O}$. A substance that occurs in bitter almonds, and in various plants, as well as in the leaves of the cherry laurel. It forms white, shining leaflets, of a bitter taste, readily soluble in water and hot alcohol.

Amygdaline (am-ig'-dal-in) [ $\alpha \mu v \gamma \delta a ́ \lambda \eta$, almond]. I Almond-like. 2. The fissure ectad of, or collocated with the amygdaloid tubercle. See Fissure.

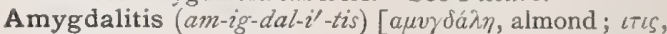
inflammation]. Tonsillitis.

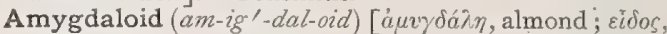
form]. Like a tonsil, or almond. A. Fossa, the depression for the lodgment of the tonsil. A. Tubercle, a projection of gray or cortical matter at the end of the descending cornu of the lateral ventricle of the brain. It is attached to the temporal lobe, and appears to be nearly isolated by white substance.

Amygdalolith $\left(a m-i g-d a l^{\prime}-o-l i t h\right)$ [á $\mu v \gamma \delta a ́ \lambda \eta$, an almond; $\lambda i \theta 0 s$, a stone]. A concretion or calculus found in the tonsils.

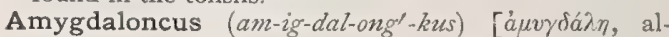

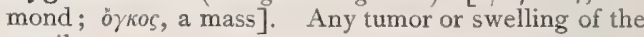
tonsil.

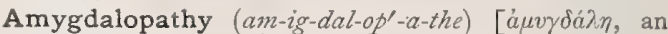
almond; $\pi \dot{a} \theta 0 s$, a disease]. Any disease of the tonsils.

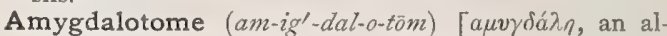

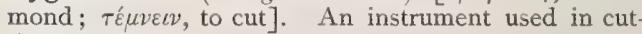
ting the tonsils.

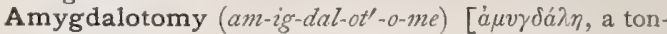

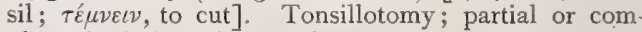
plete abscission of a tonsil.

Amykos (ah-mí-kos) [á priv.; $\mu \tilde{v} \kappa o s$, a fungus]. An antiseptic fluid composed of boric acid, glycerin and infusion of cloves. Of reputed service in gonorrhea, dental caries, and catarrhs. Unof.

Amyl $\left(a m^{\prime}-i l\right)$ [ă $\mu v \hat{n} o v$, fine starch]. The hypothetical radical $\mathrm{C}_{5} \mathrm{H}_{11}$ of amyl alcohol, the fifth term of the series of alcohol radicals, $\mathrm{C}_{\mathrm{n}} \mathrm{H}_{2 \mathrm{n}+1}$. A. Alcohol. See Amylic Alcohol. A. Hydrate. See Amylic Alcohol. A. Nitrite, nitrite of amyl, $\mathrm{C}_{5} \mathrm{H}_{11} \mathrm{NO}_{2}$, a clear, yellowish liquid, ethereal, aromatic, volatile ; produces vascular dilatation and great cardiac activity, and hence is useful in angina pectoris, respiratory neuroses, etc. Dose, internally, $m, x / 4-j$ dissolved in alcohol; by inhalation, $m$ ij-v. A. Valerianate. See Apple Oil.

Amylaceous (am-il-a'-se-us) [amylum, starch]. Containing starch; starch-like. See Corpora amylacea.

Amylene $\left(a m^{\prime}-i l-\bar{e} n\right)$ [ă $\mu v \hat{h} o v$, starch $], \mathrm{C}_{5} \mathrm{H}_{10^{*}} \quad \mathrm{~A}$ transparent, liquid hydrocarbon, having anesthetic properties, but dangerous to use. See Anesthetic. A. Hydrate, $\mathrm{C}_{5} \mathrm{H}_{12} \mathrm{O}$, a tertiary alcohol having hypnotic effects, and antagonistic to strychnin. Dose $m \times x x x-$ 3j. Unof.

Amylic $\left(a m-i l^{\prime}-i k\right)$ [àuviov, starch]. Pertaining to Amyl. A. Alcohol, Fusel Oil, Potato Starch Alcohol, Amyl Hydrate. An alcohol having the composition $\mathrm{C}_{5} \mathrm{H}_{12} \mathrm{O}$, occurring in the continued distillation of fermented grain. The pure substance has considerable value as a hypnotic. In large doses it sup presses tactile sensibility and produces motor paralysis. It is employed with advantage in mental disorders. It was formerly much used to adulterate whisky. Dose $m$ I5-75. Unof.

Amylo-dextrin (am-il-o-deks'-trin). Same as Erythro-dextrin. See Soluble Starch.

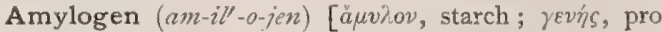
duce]. Soluble starch.

Amylogenic (am-il-o-jen'-ik) [iluvhou, starch; yevńs produce]. Starch-producing. 


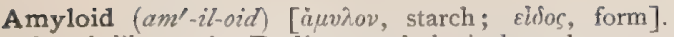
Starch-like. A. Bodies, pathological products resembling starch grains found in the membranes of the brain and other nervous tissues, the prostate, etc. A. Degeneration, waxy, fatty, or lardaceous degeneration; a disease occurring in most of the organs of the body, and indicative of impaired nutritive function. It is a nitrogenous, not starchy body, of uncertain composition. For staining see lodin, Methyl Violet, Safranin, Rose Bengale, in Table of Stains. A. Kidney. See Bright's Disease.

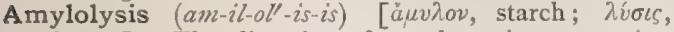
solution]. The digestion of starch, or its conversion into sugar.

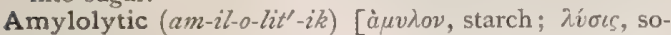
lution]. Pertaining to or effecting the digestion of starch. Pertaining to ferments, like the saliva and pancreatic juice, that convert starch into sugar.

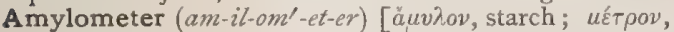
a measure]. An apparatus for estimating the dmount of starch in a solution.

Amyloplast (am'-il-o-plast) [à $\mu v \lambda o \nu$, starch; $\pi \lambda a ́ \sigma \sigma \varepsilon \imath \nu$, to form ]. A leucoplast; a starch-forming protoplasmic granule.

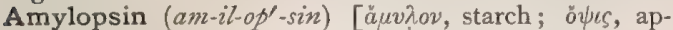
pearance]. A ferment said to exist in pancreatin. See Ferments.

Amylose $\left(a m^{\prime}-i l-o s\right)$ [ă $\mu v \lambda o v$, starch]. Any one of a certain group of the carbohydrates, comprising starch, glycogen, dextrin, inulin, gum, cellulose, and tunicin.

Amylum $\left(a m^{\prime}-i l-u m\right)$ [L., gen. Amyli ], $\mathrm{C}_{6} \mathrm{H}_{10} \mathrm{O}_{5}$. Starch. The internal cells of Triticum vulgaris, common wheat, all other cereals, and many tubers, piths, and roots, such as potato, cassava, etc.; it constitutes nearly the whole of arrow-root, tapioca, and sago. It is converted into glucose by boiling with mineral acids. It is one of the most valuable nutrients known, but inert medicinally. A. glyceritum, a jelly for external application. Starch Io, water 10, glycerin 8o. A., Mucilago (B. P.), used in making enemata. A. iodatum, contains starch 95 , iodin 5 per cent., triturated with distilled water and dried. Dose 3 j3 ss. See Table of Carbohydrates under Carbohydrate.

Amyocardia (am-i-o-kar'-de-ah) [á priv. ; $\mu \tilde{v} s$, muscle ; kapdia, the heart]. Lack of muscular power in the heart's contractions.

Amyosthenia (am-i-o-sthe'-ne-ah) [ả priv. ; $\mu \vec{v} \varsigma$, muscle; of́́vos, force]. Deficient muscular power without obvious disease or lesion

Amyosthenic (am-i-o-sthen'-ik) [á priv. ; $\mu$ ṽs, muscle ; бӨ́์vos, force]. Pertaining to amyosthenia. Also, a medicine or agent depressing muscular action.

Amyotrophia (am-i-o-tro'-fe-ah) [ả priv.; $\mu \bar{v} s$, muscle;

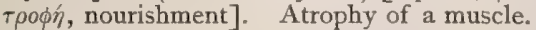

Amyotrophic (am-i-o-trof'-ik) [d priv.; $\mu \tilde{v} \varsigma$, muscle; $\tau \rho \circ \phi \dot{n}$, nourishment]. Dependent on or relating to muscular atrophy. A. Paralysis, that which is due to muscular atrophy.

Amyotrophy (am-i-ot'-ro-fe). See Amyotrophia.

Amyous $\left(a m^{\prime}-i-z t s\right]$ [à priv.; $\mu \tilde{v} s$, muscle]. Weak; deficient in muscle or muscular strength.

Amyrin (am'-e-rin) [amyris], $\mathrm{C}_{40} \mathrm{H}_{66} \mathrm{O}$. A resinous principle derived from Mexican Elemi. Amyris elemifera, L.

Amyris $\left(a m^{\prime}-e-r i s\right)$ [L.]. A genus of tropical trees and shrubs producing fragrant resins and gums, such as Elemi, etc.

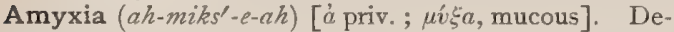
ficiency in the normal secretion of mucus.

Ana $\left(a n^{\prime}-a h\right)$ [àvá, so much each]. A Greek preposition signifying through, $u p$, again, etc. In prescriptions contracted to $\bar{a} \bar{a}$, meaning of each.
Anabamous $\left(a n-a b^{\prime}-a m-u s\right)$ [ává, upward; $\beta a ́ v \varepsilon \iota v$, to go]. In biology, climbing, as certain fishes ( $\ln \alpha$. bas scandens).

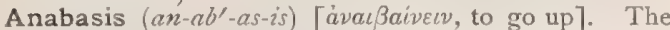
increasing stage of a fever or other acute disease; the stage preceding the climax.

Anabatic $\left(a n-a b-a t^{\prime}-i k\right)$ [ávaßatıkós, ascending]. Increasing; growing more intense; as the anabatic stage of a fever.

Anabiosis $\left(a n-a b-i-\sigma^{\prime}-s i s\right)$ [avaßió $\varepsilon v$, to come to life again]. The phenomenon of a restoration of vitality possessed by certain organisms after apparent death, or even after heating to $140^{\circ} \mathrm{C}$

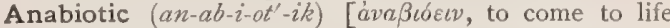
again]. I. Relating to anabiosis. 2. Restoring the strength or activity

Anabole $\left(a n-a b^{\prime}-0-l e\right)[a \dot{v} a \beta a ́ \lambda \lambda \varepsilon \iota v$, to throw up]. A throwing up; what is thrown up; vomit ; vomiting; expectoration; regurgitation.

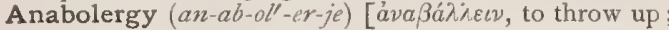
है formed in anabolism, or in anabolic processes

Anabolic $\left(a n-a b-o l^{\prime}-i k\right)$ ['a $a \beta a \lambda \lambda \lambda \varepsilon v$, to throw or build up]. Pertaining to or characterized by anabolism.

Anabolin $\left(a n-a b^{\prime}-o-l i n\right)$ [ávaßá $\lambda \lambda \varepsilon \iota \nu$, to throw or build up]. Any substance formed during the anabolic process.

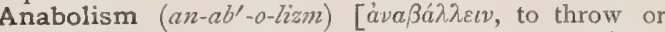
build up]. Synthetic or constructive metabolism. Activity and repair of function. Opposed to Catabolism. The process by which simpler elements are built up into more complex. See Metabolism.

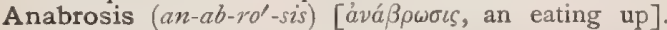
Corrosion, or superficial ulceration.

Anabrotic $\left(a n-a b-r o t^{\prime}-i k\right)$ [áváß $\rho \omega \sigma \iota s$, an eating up]. Pertaining to anabrosis; corrosive.

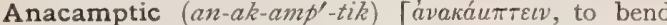
back]. Reflected, as sound or light; pertaining to or causing a reflection.

Anacanthous (an-ak-an'-thus) [ávákavfos, spineless]. Without spines.

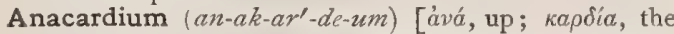
heart, from its heart-shaped seeds]. I. A genus of tropical trees. A. occidentale yields cashew gum and the cashew nut. 2. The oil of the pericarp of the cashew nut, known as cardol, and used as an escharotic. Of reputed value in leprosy. A. Tinct., I to 10 of rectified spirit. Dose, $\mathrm{mij}_{\mathrm{ij}} \mathrm{x}$. A. Ung., one part of the tar to eight of lard or vaselin. Used as a blistering ointment.

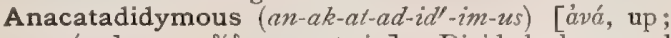

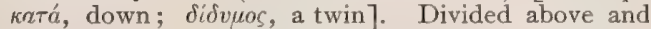
below, but jointed centrally into one; said of certain twin monsters.

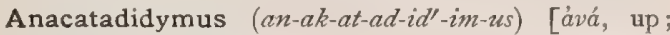

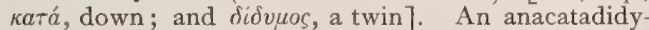
mous monstrosity.

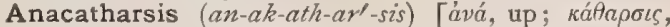
purgation]. Expectoration; vomiting.

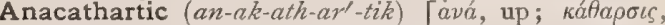
purgation]. Causing anacatharsis.

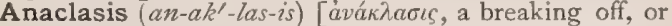
back]. r. Reflection or refraction of light or sound. 2. A fracture; forcible flexion of a stiff joint.

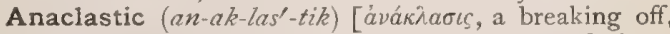
or back ]. Pertaining to refraction, or to anaclasis.

Anaclisis $\left(a n-a k^{\prime}-l i s-i s\right)$ [ávák $\lambda \iota \sigma \iota$, a reclining]. Decubitus; the reclining attitude.

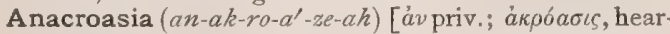
ing]. Inability to understand words that are heard, while the same words if read by the patient are understood. 
Anacrotic ( $\left.a n-\alpha k-r o t^{\prime}-i k\right)$ [av priv, ; akp $\sigma a \sigma \iota$, hearing]. Relating to or characterized by anacrotism.

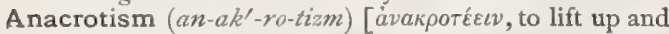
strike together]. A

peculiarity of the pulse-curve, when a series of closely-placed elastic vibrations occur in the upper part of the line of ascent, so that the apex appears dentate and forms an angle with the line of descent. It is constant in the venous pulse ; is

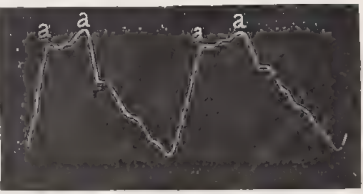

Anacrotic Radial PulseRACING $a, a$, the anacrotic parts. found in the arterial pulse when the systole of the left ventricle continues until the walls of the arteries begin to oscillate during the diastole. It occurs in hypertrophy and dilatation of the left ventricle (aortic insufficiency).

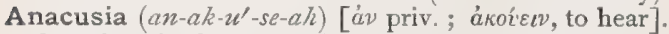
Complete deafness; abolition of the sense of hearing.

Anadenia (an-ad-e'-ne-ah) [áv priv.; ádín, gland]. Insufficiency of glandular function. Chronic want of gastric secretion.

Anadicrotic (an-ah-di-krot'-ik) [ává, upward; Sis, twice; кро́тos, a stroke]. Characterized by anadicrotism.

Anadicrotism (an-ah-di'-krot-izm) [ává, upward; dis, twice; кро́тos, a stroke]. Dicrotism of the pulsewave occurring in the upward stroke.

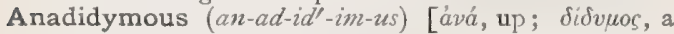
twin]. Cleft upward into two, while single belowsaid of certain joined twins.

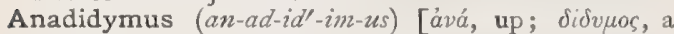
twin]. An anadidymous monster.

Anadiplosis $\left(a n-a h-d i p-l o^{\prime}-s i s\right)$ [avá, up, back ; $\delta \imath \pi \lambda o^{\prime} \varepsilon v$, to double ]. The reduplication or redoubling of a feverparoxysm.

Anadiplotic (an-ah-dip-lot'-ik) [ảvá, up; $\delta \iota \pi \lambda .6 \varepsilon \iota \nu$, to double ]. Characterized by anadiplosis.

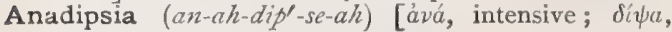
thirst]. Intense thirst.

Anadipsic $(a n-a h$-diph-sik) [ảvá, intensive; Si $\psi a$, thirst]. Causing or relating to great thirst.

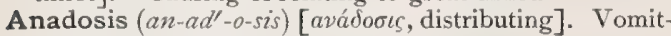
ing; upward determination of blood.

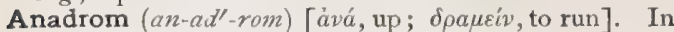
biology, a fish that ascends rivers to spawn.

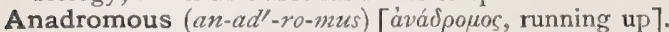
Ascending ; moving upward. Said of pains, etc.

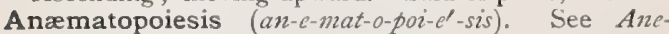
amatopoiesis.

Anæmatosis (an-e-mat-o'-sis). See Anematosis,

Anæmia $\left(a n-e^{\prime}-m e-a h\right)$. See Anemia.

Anæmotrophy (an-e-not'-ro-fe). See Anemotrophy.

Anaërobia (an-a-er-o'-be-ah) [àv priv, ; án $\rho$, air; ßins, life]. Microörganisms having the power of living without either air or free oxygen. A., Facultative, applied to organisms normally or usually living in the presence of oxygen, but under certain circumstances becoming anaērobic.

Anaërobic $\left(a n-a-\ell-r o^{\prime}-b i k\right)$ [áv priv. ; án $\rho$, air; $\beta$ íos, lifé]. A term used of microorganisms, that live in the absence of free oxygen or air. See Aërobic.

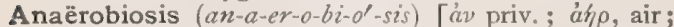
$\beta i o s$, life]. Life sustained in the absence of free oxygen; the power of living where there is no free oxygen.

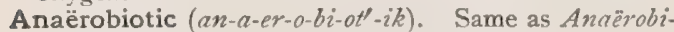
outs.

Anaerobious (an-a-e-ro'-be-us) [áv priv.; ámp, air; Bios, life]. In biology, capable of existing without free oxygen by a power of obtaining oxygen from organic substances.

A naërophyte $\left(a n-a^{\prime}-e-r o-f i t\right)$ [á priv.; án $\rho$, air ; $b v \tau b \nu$, a plant]. In biology, a plant capable of living without a direct supply of oxygen.

Anaëroplastic (an-a-er-o-plas'-tik) [áv., priv.; ánp, air; $\pi \lambda a ́ \sigma \sigma \varepsilon \iota \nu$, to shape]. Pertaining to anaëroplasty.

Anaëroplasty (an-á-er-o-plas-te) [àv priv.; án $\rho$, air; $\pi \lambda a \sigma^{\prime} \varepsilon \varepsilon \nu$, to shape ]. The treatment of wounds by immersion in warm water, so as to exclude the air.

Anæsthesia (an-es-the'-ze-ah). See Anesthesia.

Anæsthetic (an-es-thet'-ik). See Anesthetic.

Anætiological (an-e-te-o-loj'-ik-al). See Anetiological.

Anagallis $\left(a n-a s^{\prime}-a l^{\prime}-i s\right)[\mathrm{L}$.$] . A genus of plants. A.$ arvensis, Pimpernel. An herb having some local reputation as a remedy for rheumatism and as a preventive of hydrophobia. Dose of the fluid extract $3 \mathbf{j}$.

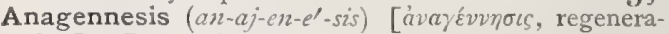
tion 7. Reparation or reproduction of tissues.

Anagnostakis's Operation. See Operations, Table of. Anagraph (an'-a-graf) [avaypaun, a writing out]. A physician's prescription or recipe.

Anagyrin (an-aj-i'-rin) [Anaoyris, from ává, backward; rĩpos, a circle $], \mathrm{C}_{14} \mathrm{H}_{18} \mathrm{~N}_{2} \mathrm{O}_{2}$. An alkaloid from the seeds of Anagyris fotida, L., a leguminous shrub of Southern Europe. Its hydrochlorate is poisonous, slowing the respiration, and interfering with the heart's action. Unof.

Anakroasia (an-ak-ro-a'-ze-ah). See Anacroasia.

Anakusis (an-ak-u'-sis). See Anacusia.

Anal $\left(a^{\prime}-n a l\right)$ [amus, the fundament]. Pertaining to the anus.

Analepsia (an-al-ep'-se-ah). See Analepsis.

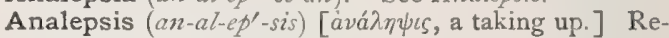
covery of strength after disease.

Analepsy $\left(a n^{\prime}-a l-e p-s e\right)$. See Analepsis.

Analeptic $\left(a n-a l-e p^{\prime}-t i k\right)$ [ $\dot{\alpha} \nu a \lambda \eta \pi \tau i \kappa o ́ s$, restorative]. I. Restorative. 2, Any agent restoring strength after illness, as nourishing foods and tonics.

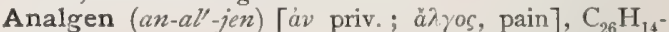
$\mathrm{N}_{2} \mathrm{O}_{4}$. A white, tasteless, crystalline powder, almost insoluble in water, soluble with difficulty in cold alcohol, but more readily in hot alcohol and dilute acids. It melts at $405.4^{\circ} \mathrm{F}$. It is employed as an analgesic, antineuralgic, and antipyretic, in doses of from seven and a half to thirty grains. Unof.

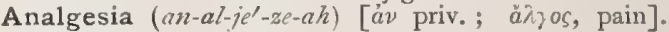
Insensibility to or absence of pain.

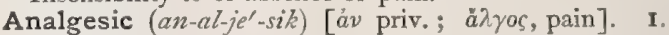
Anodyne; relieving pain. 2. Affected with analgesia. 3. A remedy that relieves pain either by depressant action on the nerve centers or by impairing the conductivity of nerve fibers.

Analgesin (an-al-je'-sin). See Antipyrin.

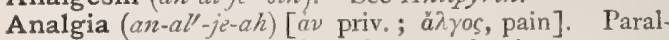
ysis of the sense of pain; absence of pain.

Analgic $\left(a n-a l^{\prime}-j i k\right)$ [ $a v$ priv.; $a \dot{\lambda} \gamma o s$, pain]. Analgesic.

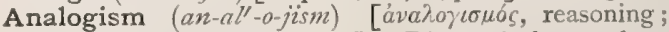
ává, through; $\lambda o ́ \gamma o s$, ratio]. Diagnosis by analogy or by reasoning.

Analogous (an-al'-o-gus) [áváhoyos, conformable]. Conforming to, proportionate, answering to. See, also, Analogue. A. Tissues, morbid tissues similar to the elementary and normal tissues of the body.

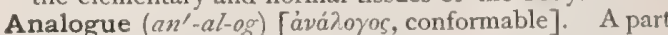
or organ having the same function as another, but with a difference of structure. The correlative term, homologue, denotes identity of structure with differ. ence of function. The wing of the butterfly and that of the bird are analogous, but the wing of a bird and the arm of a man are homolegous. A., Nonhomologous, are parts that have a similarity of 
function without any similarity as to relative position, e.g., the legs of a lizard and those of a lobster. A., Homologous, is used of parts that are similar both as to function and relative position, e.g., the wings of a bat and of a bird.

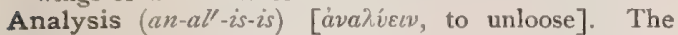
resolution of compound bodies into simpler, or constituent parts. A., Densimetric, analysis of a subject by means of determining the specific gravity of the solution and thus estimating the amount of dissolved matter. A., Gasometric, the determination of the constituents of gaseous compounds, especially the delermination of the amount of oxygen in samples of atmospheric air. A., Gravimetric, the quantitative determination by weight of the elements of a body. A., Organic, the determination of the elements of matter formed under the influence of life. The analysis of animal and vegetable tissues. A., Proximate, the determination of the simpler compound elements into which a substance may be resolved.

- A., Qualitative, the determination of the nature and number of elements that compose a body. A., Quantitative, the determination of the proportionate parts of the various elements of a compound. A., Spectral, the determination of the composition of a body by means of the spectroscope. A., Ultimate, the resolution of a compound, not into its simpler constituents, but its ultimate elements. A., Volumetric, the quantitative determination of a constituent by ascertaining the volume of a liquid required to complete a given reaction.

Analyzer $\left(a n^{\prime}-a l-i-z e r\right)$ [ava ${ }^{\prime} v \dot{v} \iota v$, to unloose]. In microscopy, the Nicol prism placed at some level above the object which receives and exhibits the properties of light after polarization.

Anamirtin (an-am-er'-tin) [Anamirta, a genus of plants ], $\mathrm{C}_{19} \mathrm{H}_{36} \mathrm{O}_{2}$. A glycerid derived from Cocculus indicus, the berry-like fruit of Anamirta paniculati, L.

Anamnesia (an-am-ne'-ze-ah). See Anamnesis.

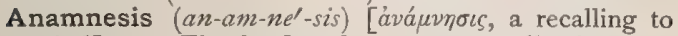
mind]. I. The faculty of memory; recollection. 2. That which is recollected: information gained regarding the past history of a case from the patient or from his friends or from other persons.

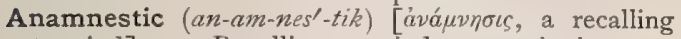
to mind]. I. Recalling to mind; remembering. 2 . Restorative of the memory.

Anamnia (an-an'-ne-ah). See Ammiota.

Anamnionic (an-am-ne-on'-ik). Same as Anamniotic.

Anamniotic $\left(a n-a m-n e-o t^{\prime}-i k\right)$ [áv priv.; áuvíov, amnion]. In biology, without an amnion, as fishes.

Anamorphism (an-am-orf'-izm). Same as Anamorphosis.

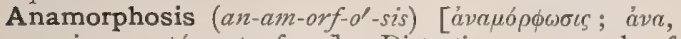
again; $\mu \rho \rho \phi \sigma \varepsilon \iota \nu$, to form]. Distortion or anomaly of development. In biology, gradual change of form in successive members of a group.

Anamorphosy (an-am-or'-fo-se). See Anamorphosis.

Anam Ulcer. A form of phagedena such as is common in hot countries. It begins with an inflammation starting from a small abrasion of the skin, generally on the foot and leg, with sloughing of the inflamed skin, producing a sharp-cut ulcer that spreads slowly, preceded by an area of inflammation. Its course is remarkably slow, and its resistance to treatment obstinate. Syphilis and anemia are predisposing factors.

Anandria (an-an'-dre-ah) [ảv priv.; ảvńp, man]. Lack of virility; male impotence.

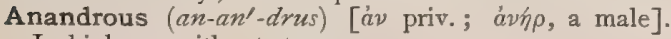
In biology, without stamens.
Anantherous $\left(a n-a n^{\prime}\right.$-ther-us) [àv priv. $\dot{\xi}$ antherce, anther]. In biology, without anthers.

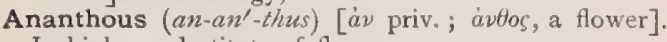
In biology, destitute of flowers.

Anantochasmus (an-an-to-kaz'-mus) [ávávtns, steep; $\chi \dot{\sigma} \sigma \mu \alpha$, a chasm]. Lissauer's term for a skull in which there is a forward inclination of the line connecting the basion and staphylion.

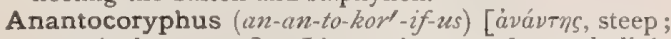
корvфí, the crown]. Lissauer's term for a skull in which the angle formed between the radius fixus and the line connecting the bregma and lambda is between $52^{\circ}$ and $41^{\circ}$.

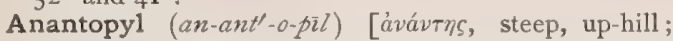
$\pi \hat{\imath} \lambda \eta$, an entrance]. A term applied by Lissauer to skulls in which the foramen magnum looks slightly forward when referred to the radius fixus as a horizontal.

Ananturaniscus (an-an-tu-ran-is'-kus) [ảvávtns, steep;

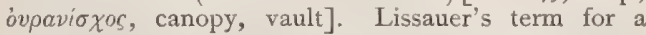
skull in which there is a forward inclination of the line joining the alveolar point and the posterior border of the incisive foramen.

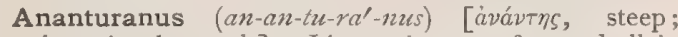
ovpavós, the vault]. Lissauer's term for a skull in which the radius fixus being horizontal, there is a forward-looking of the palate.

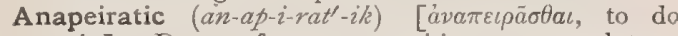
again]. Due to frequent repetition; a general term for such affections as writers' and telegraphers' cramp, or paralysis.

Anaphalantiasis (an-af-al-an-ti'-as-is) [avá, up; $\phi a ́ \lambda a v \theta 0 \varsigma$, bald in front]. The falling out of the eyebrows.

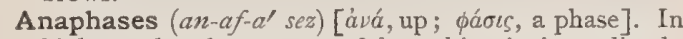
biology, the phenomena of karyokinesis immediately preceding the formation of the daughter stars, and up to the formation of the resting daughter nuclei. See Metaphases.

Anaphia $\left(a n-a^{\prime}-f e-a h\right)$ [àv priv; ád’́, touch]. Defect in the sense of touch.

Anaphrodisia (an-af-ro-diz'-e-ah) ['à priv.; 'A $\phi p o \delta i T \eta$, Venus]. Absence or impairment of sexual appetite.

Anaphrodisiac (an-af-ro-diz'-e-ak) [à priv.; 'A $\phi \rho o \delta i T \eta$, Venus]. I. Relating to, affected by, or causing anaphrodisia. 2. An agent that allays the sexual desire.

Anaphroditic (an-af-ro-dit'-ik) [ảv priv.; A $\phi \rho o \delta i T \eta$, Venus]. Asexually produced.

Anaphroditous (an-af-rod"-it-us) ['av priv.; A $\phi \rho o \delta i \tau \eta$, Venus]. Having no sexual impulses or appetite.

Anaplase (an'-ap-lāz) [ává, up; $\pi \lambda \dot{a} \sigma \sigma \varepsilon \iota \nu$, to build]. The stage of growth and development; the period before full maturity.

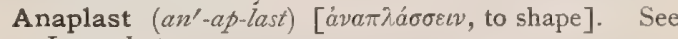
Leucoplast.

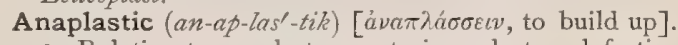
I. Relating to anaplasty; restoring a lost or defective part. 2. An agent that facilitates repair by restoring or increasing the plastic elements of the bloud.

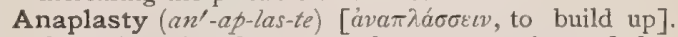
Operation for the renewal or restoration of lost parts, commonly called a plastic operation; plastic surgery.

Anaplerosis (an-ap-le-ro'-sis) [ává, up; $\pi \hat{\lambda} \eta \rho \delta \varepsilon \iota \nu$, to fill]. The restoration or repair of a wound, sore, or lesion in which there has been a loss of substance.

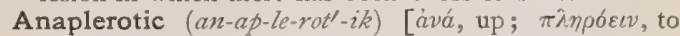
fill]. 1 . Promotive of repair, favoring granulation. 2. A remedy or application that promotes repair.

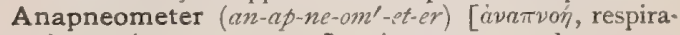

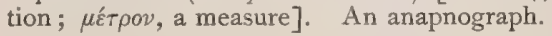




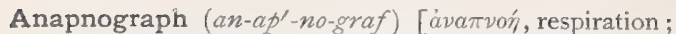
$\gamma$ já $\_\varepsilon \imath$, to write]. An apparatus registering the movements of inspiration and expiration, together with the quantity of air inhaled.

Anapnoic $\left(a n-a p-n o^{\prime}-i k\right)$ [ává, against; ă $\pi \nu o \iota c$, want of breath]. Favoring respiration; relieving dyspnea.

Anapnometer $\left(a n-a p-n o m^{\prime}-e t-e r\right)[\dot{\alpha} \nu \alpha \pi \nu o \dot{n}$, respiration;

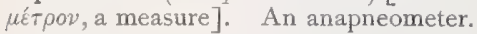

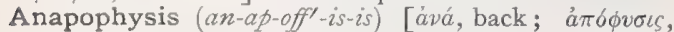
an offshoot]. An accessory process of a lumbar or posterior dorsal vertebra, corresponding to the inferior tubercle of the transverse process of a typical dorsal vertebra.

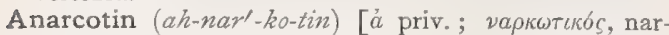
cotic]. Narcotin, so called from its lack of narcotic power.

Anargyrus (an-ar'-jir-us) [ảv priv.; à $\rho \gamma v \rho o s$, silver: pl., Anargyri]. An old name for a practitioner who treated the sick gratuitously.

Anarrhea, or Anarrhoea (an-ar-el-ah) [ává, up; poía, flow ]. Afflux to an upper part, as of blood to the head.

Anarrhexis $\left(a n-a r-e k s^{\prime}-i s\right)$ [ává, up; $\dot{\rho} \tilde{\eta} \xi \iota s$, fracture]. Surgical refracture of a bone.

Anarthria (an-ar'-thre-ah) [àv priv. ; ă $\rho \partial \rho o v$, articulation]. I. Partial aphasia from partial destruction of the paths of the motor tracts of speech, and characterized by defective articulation. 2. Without joints.

Anarthrous (an-ar'-thrus) [ảv priv.; á $\rho \theta \rho o v$, a joint]. Jointless. So corpulent that no joints are visible.

Anasarca (an-ah-sar'-kah) [ává, through; $\sigma a ́ \rho \xi$, the flesh]. An accumulation of serum in the areolar tissues of the body. If associated with effusion of fluid into serous cavities it is called general dropsy. If the affection is local, it is called edema. This local form is generally the result of some mechanical obstruction to the flow of blood in the part.

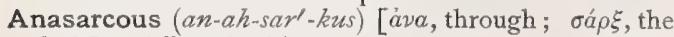
flesh]. Affected with anasarca.

Anaspadias (an-as-pa'-de-as) [ávó, up; $\sigma \pi a ́ \varepsilon \iota \nu$, to draw]. An urethral opening upon the upper surface of the penis.

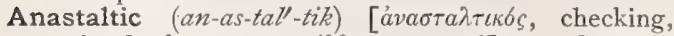
putting back, or up; $\sigma \tau \varepsilon \hat{\lambda} \lambda \varepsilon \varepsilon \nu$, to send]. I. Strongly astringent. 2. Centripetal; afferent; used of nervecurrents.

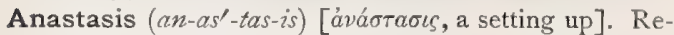
covery; convalescence; a state of improving health, vigor, or development.

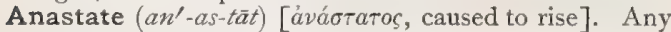
substance that appears in or is characteristic of an anabolic process.

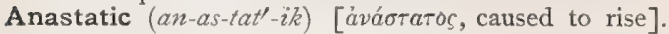
Tending to recovery; restorative.

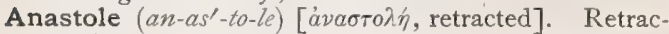
tion; shrinking away, as of the lips of a wound.

Anastom (an'-as-tōm) [àva, above; $\sigma \tau \sigma \mu \alpha$, mouth]. Any mouthless organism; specifically, a member of the genus Anastoma, among the Gasteropods or Orthoptera, or Anactomus among the Salmonidæ.

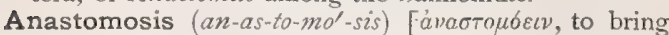
to a mouth]. The intercommunication of vessels. Anastomotic arteries of the thigh, etc., branches of the brachial, femoral, etc., whereby the collateral circulation is established after ligature for aneurysm, etc. The term has been inaccurately used of the junction of the nerve-filaments. A., Crucial, an arterial anastomosis in the upper part of the thigh, formed by the anastomotic branch of the sciatic, the first perforating, the internal circumflex, and the transverse branch of the external circumflex. A., Intestinal, an operation consisting in establishing a communication between the intestine above and that below the obstruc- tion, in cases of intestinal obstruction. In this way the impermeable portion of the bowel is excluded from the fecal circulation.

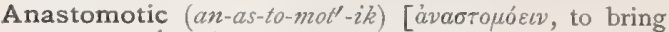
to a mouth]. Pertaining to anastomosis.

Anatherapeusis (an-ath-er-ap-u'-sis) [ảvá, forward; $\theta \varepsilon \rho a \pi \varepsilon i j \sigma \iota s$, medical treatment]. Treatment by increasing doses.

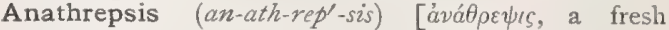
growth]. A renewal of lost flesh after recovery.

Anathreptic $\left(a n-a t h-r e p^{\prime}-t i k\right)$ [àvát $\rho \varepsilon \psi \iota s$, a fresh growth]. Restorative of lost flesh; nutritive.

Anatomical (an-at-om'-ik-al) [ávatopía, anatomy]. Pertaining to anatomy. A. Tubercle. See Verruca necrogenica.

Anatomism (an-at'-om-izm) [ávatouia, anatomy]. The theory that anatomical conditions determine all the phenomena of life, health, and disease.

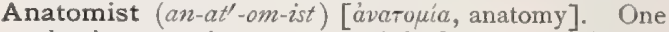
who is expert in anatomy. A.'s Snuff-box, the triangular space between the tendons of the extensor of the metacarpal bone of the thumb and the extensor of the first phalanx on the back of the hand.

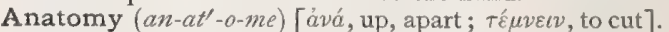
The dissection of organic bodies in order to study their structure, the situations and uses of their organs, etc. A., Applied, anatomy as concerned in the diagnosis and management of pathological conditions. A., Comparative, the investigation and comparison of the anatomy of different orders of animals or of plants, one with another. A., Descriptive, a study of the separate and individual portions of the body, apart from their relationship to surrounding parts. A., Gross, anatomy of the macroscopic tissues. A., Homological, the study of the correlations of the several parts of the body. A., Minute, that studied under the microscope. A., Morbid or Pathological, a study of diseased structures.'A., Physiognomical, the study of expressions depicted upon the exterior of the body, especially upon the face. A., Regional, a study of limited parts or regions of the body, the divisions of which are collectively or peculiarly affected by disease, injury, operations, etc. A., Surgical, the application of anatomy to surgery. A., Topographical, the anatomy of a single portion or part of the body. A., Transcendental, the study of the general design of the body, and of the particular design of the organs. A., Veterinary, the anatomy of domestic animals.

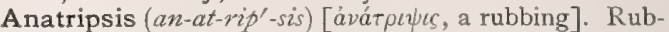
bing; the removal of a part or growth by scraping or rubbing; inunction. Also an upward or centripetal movement in massage.

Anatripsology (an-at-rip-sol'-o-je) [ảvát $\rho \iota \iota s$, a rubbing; $\lambda 6 \gamma o s$, science]. The science of friction as a remedial agent.

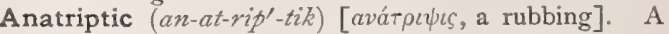
medicine to be applied by rubbing.

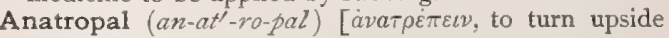
down]. See Anatropous.

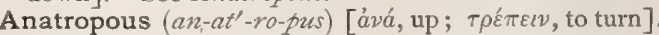
In biology, inverted. Applied to the ovule when completely inverted, so that the hilum and micropyle are brought close together.

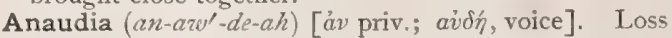
of voice; dumbness; inability to articulate.

Anaxonia (an-aks-o'-ne-ah) [av priv,; à $\alpha^{\prime} \omega \nu$, axle, axis]. In biology, organic forms wholly irregular or varying, and without axes.

Anazoturia (an-as-ot-u'-re-ah) [av priv, ; azotum, nitrogen; ovpov, urine]. A name applied to that form of chronic diuresis in which urea is deficient or absent from the urine. 
Anbury $\left(a n^{\prime}-b e r-e\right)$ [E. dialect]. A soft tumor or pendulous wart, chiefly on horses and cattle.

Ancecerite $\left(a n-s \epsilon^{\prime}-s e r-i t\right)$ [ $\dot{a} \gamma \kappa \dot{\eta}$, bent; $\kappa \hat{\varepsilon} \rho a \varsigma$, a horn]. In biology, a curved process attached to the peduncle of the second pair of antennæ in certain crustacea.

Ancestral germ-plasms. Weismann's "Ahnenplasmen." See $I d$.

Anchieta $\left(a n-c h e-a^{\prime}-t a h\right)$ [Anchietea, a Brazilian botanist]. A genus of violaceous plants. A. salutaris, vegetable mercury. The root of a violaceous plant growing in Brazil, highly recommended as a purgative, and as an alterative in syphilitic affections; it is possibly identical with Manaca, $q$. $v$.

Anchilops (ang $\sigma^{\prime}$-kil-ops). See Anchylops.

Anchorage (ang'-kor-ajj) [M. E., ankren, an anchor]. The fixation of a floating or displaced viscus, whether by a natural process or by surgical means.

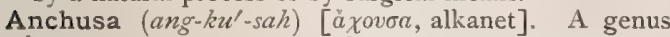
of boraginaceous herbs. See Alkanet.

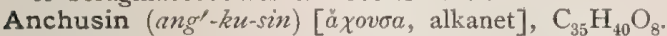
The red coloring matter characteristic of alkanet-root. See Alkanet.

Anchyloglossia (ang-kil-o-glos'-e-ah). See Tongue-tie.

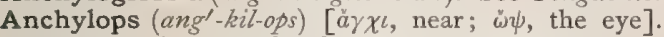
Abscess at inner angle of eye, prior to rupture.

Anchylosis (ang-kil-o'-sis). See Ankylosis.

Anchylostomiasis (ang-kil-o-sto-mi'-as-is). See Dochmiasis.

Anchylostomum (ang-kil-os'-to-mum) [áyкínos, crooked; бтб́ $\mu a$, mouth]. A genus of slender nematoid worms inhabiting the human intestines. Dochmius (Anchylostoma) duodenalis. Leuck. See Parasites, Animal, Table of.

Ancipital (an-sip'-it-al) [anceps, double]. In biology, two-edged.

Ancome $\left(a n^{\prime}-k u m\right)$ [E. dialect]. An inflammation or swelling that comes on suddenly.

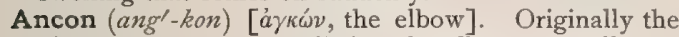
olecranon process; applied to the elbow generally.

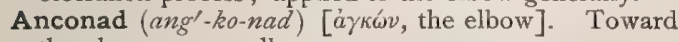
the olecranon, or elbow.

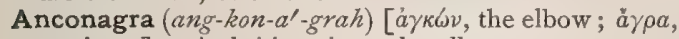
a seizure]. Arthritic pain at the elbow.

Anconal $\left(a n g^{\prime}-k o n-a l\right)$ [á $\gamma \kappa \omega \nu$, the elbow]. Pertaining to the elbow.

Anconeal (ang-ko'-ne-al). Same as Anconal.

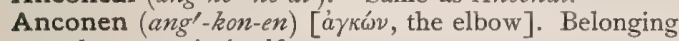
to the ancon in itself.

Anconeus (ang-ko-ne'-us) [áyḱ, $\nu$, the elbow]. A small muscle, an extensor of the forearm, inserted into the olecranon and upper third of the forearm. It arises from the external condyle of the humerus. See Muscles, Table of.

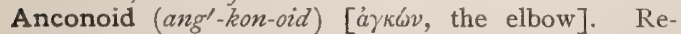
sembling the elbow.

Ancora (ang'-ko-rah) [L., an anchor]. In biology, an anchor-shaped Synapta spicule.

Ancyloblepharon (an-sil-o-blef'-ax-on). See Ankyloblepharon.

Ancyloglossum (an-sil-o-glos'-um). See Tongue-tie.

Ancylomele (an-sil-o-me'-le). See Ankylomele.

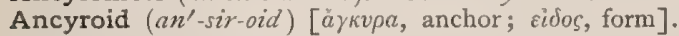
Shaped like an anchor.

Andersch's Ganglion. See Ganglia, Table of.

Anderson's Antipruritic Powder. A powder used in eczema. It consists of powdered starch, $3 \mathrm{vj}$; oxid of zinc, 3 iss; powdered camphor, 3 ss.

Anderson's ( $M C$ Call) Ointment. An ointment consisting of powdered bismuth oxid $z$, oleic acid $f \xi j$, white wax 3 iij, vaselin 3 ix. These are heated together and when nearly cool a little oil of rose is added. It is an excellent soothing ointment for the skin.
Anderson's Pill. The compound gamboge pill.

Andira $\left(a n-d i^{\prime}-r a h\right)[\mathrm{L}$.$] . A genus of tropical legumi-$ nous trees. A. araroba, affords the Goa Powder (see Araraba). Several species yield active medicines, chiefly of local repute. $A$. inermis (Cabbage-tree). $A$. anthelmintica, of Brazil, and $A$. retusa, of Guiana, have barks efficacious against worms.

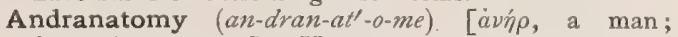
ávatopia, anatomy]. Human anatomy; the anatomy or dissection of the male human subject.

Andrecium, or Andrœcium (an-dre'-se-um) [ảví $\rho$, a man; wikos, a house]. In biology, a term applied to the stamens as a whole.

Androclinium $\left(a n-d r o-k l i n^{\prime}-e-u m\right)$. See Clinandrium.

Andro-diecious (an-dro-di-e $\left.e^{\prime}-s h e-u s\right) \quad[a ́ v n \rho$, male; dis, two; oikos, a house]. In biology, flowers staminate on one plant, perfect on another.

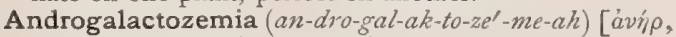

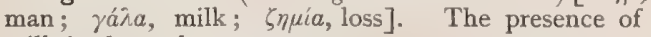
milk in the male mammæ.

Androgonidium (an-dro-gon-idl-e-um). See Androspore.

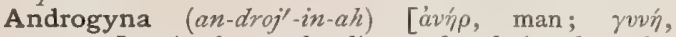
woman]. An hermaphrodite; a female in whom the genital organs are similar to those of the male.

Androgyneity (an-droj-in-el-it:e) [ávíp, man; $\gamma v v \dot{\eta}$, woman]. Hermaphroditism.

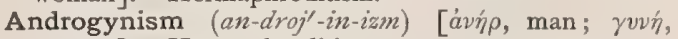
woman]. Hermaphroditism.

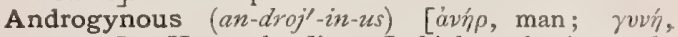
woman]. Hermaphrodite. In biology, having male and female flowers in the same inflorescence.

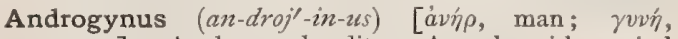
woman]: An hermaphrodite. A male with genital organs similar to those of the female.

Androgyny (an-droj'-in-e). See Androgynism.

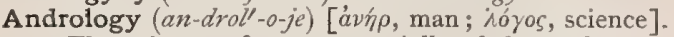
I. The science of man, especially of the male sex. 2. The science of the diseases of the male genitourinary organs.

Andromania (an-dro-ma'-ne-ah) [ávíp, a man; $\mu \alpha v i a$, madness]. Nymphomania, $q . v$.

Andromeda (an-drom'-e-dah) ['A $\nu \delta \rho o \mu \varepsilon \delta \eta$, a mythological character]. A genus of ericaceous shrubs having poisonous or narcotic properties. The leaves of A. mariana and $A$. nitida, of North America, and of $A$. polyfolia of both continents, are useful in the external treatment of old ulcers, a decoction being applied hot to the sore. Unof.

Andromoncecious (an-dro-mo-ne'-she-us) [avhp, male;

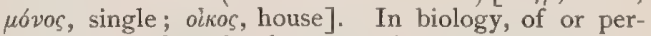
taining to a plant that bears staminate and perfect, but no pistillate flowers.

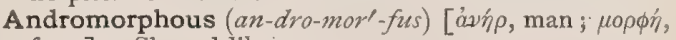
form ]. Shaped like a man.

Androphobia (an-dro-fo'-be-ah) [ávhp, man; $\phi b \beta o s$, dread]. Fear or dislike of man.

Androphonomania (an-dro-fo-no-ma'-ne-ah) [àvjoo-

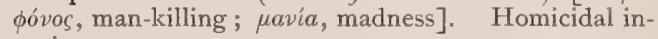
sanity.

Androphore $\left(a n^{\prime}-d r o-f o ̄ r\right) ~\left[\alpha \nu^{\prime} \rho, \operatorname{man} ; \phi \varepsilon \varepsilon \rho \varepsilon \nu\right.$, to bear]. In biology, a stalk supporting an andrecium, a stamineal column, or a body supporting an antheridium. In biology, a generative bud of a hydrozoan producing male elements only.

Andropogon (an-dro-po'-gon) [ávíp, man; $\pi \dot{\omega} \gamma \omega \omega v$, beard]. A genus of coarse grasses of many species. $A$. nardus affords oil of citronella; $A$. citratus, lemongrass oil; $A$. schenanthus, oil of rusa, etc. These oils are employed in perfumery, and are said to be useful in rheumatism. The oil-bearing andropogons are chiefly S. Asiatic. Unof. 


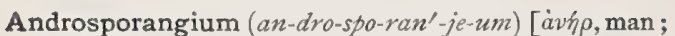

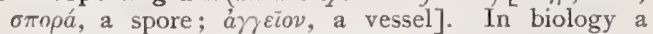
sporangium producing androspores.

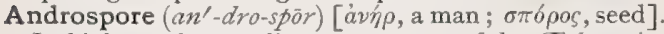
In biology, the peculiar swarmspore of the CEdogoniea which develops to a "dwarf male" and gives rise to antherozoids.

Androtomous (an-drot'-o-mus) [ávíp a man; $\tau \varepsilon \mu \nu \varepsilon i \nu$, to cut]. In biology, characterized by congenital division of the stamens into several parts.

Androtomy (an-drot'-o-me). See Andranatomy.

Andrum (an'-drum) [Guzerali andrum; avóóp $u$ ]. A form of elephantiasis Arabum characterized by edema of the scrotum.

Aneccrisia (an-ek-ris'-e-ah) [ád priv.; $\varepsilon \kappa$, out; $\kappa \rho i \sigma \iota \varsigma$, separation]. The suppression or deficiency of any excretion.

Anechinoplacid (an-ek-i-no-plas'-id) [àv priv, ; $\varepsilon$ zivos, a hedgehog; $\pi \hat{\lambda} a ́ \xi$, a plate]. In biology, having the madreporic plate destitute of spines; the opposite of Echinoplacid.

Anectasia (an-ek-ta'-se-ah). See Anectasis.

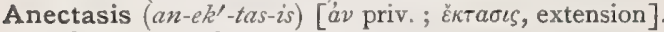
Deficient size of an organ or part.

Aneilema (an-i-le'-mah) [avá, up; $\varepsilon^{\prime} \lambda \varepsilon \varepsilon^{\prime} \varepsilon v$, to roll] Flatulence; air or wind in the bowels; colic.

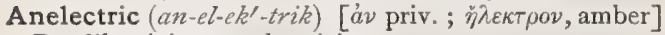
Readily giving up electricity.

Anelectrode (an-el-ek'-trōd) [ává, upward; $\ddot{\eta} \lambda \varepsilon \kappa \tau \rho o v$, amber; ósós, a path]. The positive pole of a galvanic battery.

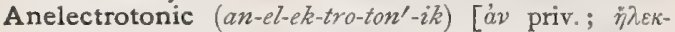
$\tau \rho o v$, electricity ; $\tau o ́ v o s$, tension]. Relating to anelectrotonus. A. Zone. See Zone.

Anelectrotonos (an-el-ek-trot'-o-nos) [áv priv.; $\ddot{\eta} \lambda \varepsilon \kappa-$ $\tau \mu o v$, electricity; $\tau o ́ v o s$, tension]. Anodal electrotonus.

Anelectrotonus (an-el-ek-trot'-o-nus) [a'v priv ; $\eta \dot{\lambda} \lambda \varepsilon$ $\tau \rho o \nu$, electricity; $\tau o ́ v o s$, tension]. In electrotherapy, the decreased functional activity that occurs in a nerve in the neighborhood of the anode. See Electrotonus and Catelectrotonus.

Anel's Operation. See Operations, Table of. A. Probe, or Sound, a fine probe used in operations upon the lachrymal passages. A. Syringe, a syringe used in injecting fluids into the lachrymal passages.

Anelytrous (an-el'-it-rus) [av priv.; $\varepsilon \lambda \nu \tau \rho o v$, shard]. In biology, with membranous wings, and no elytra.

Anematopoiesis (an-e-mat-o-poi-e -sis) [àv priv.;

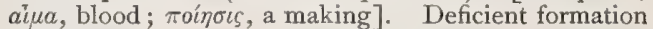
of blood.

Anematosis, or Anæmatosis (an-e-mat-o'-sis) ['avaíua-

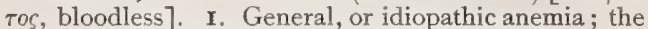
morbid state or process that leads to anemia; that diathesis that is associated with an anemic tendency. 2. Anemia dependent on want of development of the red corpuscles of the blood.

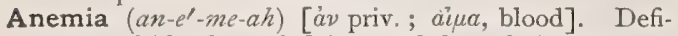
ciency of blood, or deficiency of the relative number of its red corpuscles, the latter being the most generally understood meaning and use of the term. It may be general or local. Ischemia is a form of local anemia, and is the result of mechanical interference with the circulation of the affected part, either from vaso-motor spasm, thrombosis, embolism, or the action of styptics. The' cause of general anemia is often obscure, or it may be due either to an insufficient food-supply and excessive drain or blood-waste, or from repeated hemorrhages or exhausting discharges. The action of certain poisons, as mercury and lead, will also produce a form of anemia. Prolonged anemia will give rise to fatty degeneration of the organs and tissues. Idiopathic, pernicious, es- sential, progressive, malignant, etc., are terms denoting a type resisting all treatment and steadily progressing to a fatal termination. A., Idiopathic, advances to a fatal issue, and is associated with febrile symptoms; its causation is not evident; it is called also Primary Anemia. A., Local. See Hyperemia, Ischemia, and Anemia. A. lymphatica. Synonym of Hodgkin's Disease. See Lymphadenoma. A., Primary. See A. Idiopathic. A., Secondary, or Symptomatic, follows some ascertainable lesion or injury, or from some other disease. A., Symptomatic. See A., Secondary.

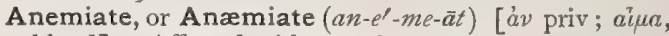
blood]. Affected with anemia.

Anemiated, or Anæmiated (an-e'-me-a-ted). See Anemic.

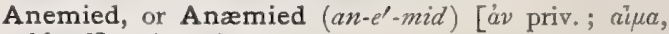
blood]. Anemic.

Anemic, or Anæmic (an-em'-ik, an-ef-mik) [ás priv.; ai $i \alpha$, blood]. Pertaining to anemia. A. Murmur, a blood murmur, or soft murmur heard at the base of the heart over the great vessels. A. Necrosis, a necrosis or death of scattered patches of the heart muscle, due to a want of nourishment. It arises from atheroma occluding the cardiac arteries and their branches.

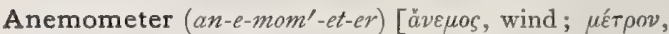
a measure]. An instrument for measuring the velocity of the wind.

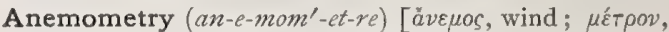
a measure]. The art of measuring the velocity and direction of the wind, principally by means of the anemomiter.

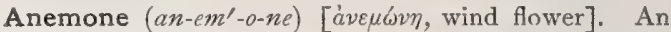
important genus of ranunculaceous herbs, most of which have active medicinal and poisonous qualities, and some of which are used in medicine. See Pulsatilla.

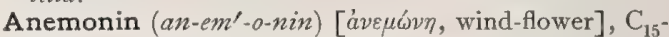
$\mathrm{H}_{12} \mathrm{O}_{6^{*}}$. The active principle of the Anemone. It is given in bronchitis, asthma, and convulsive cough. Dose gr. $1 / 4-3 / 4$ twice daily.

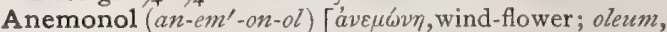
oil ]. The volatile oil extracted from anemone; it is a powerful vesicant.

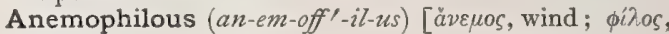
loving]. Depending for cross-fertilization upon the agency of the wind, as certain flowers.

Anemosis, or Anæmosis (an-em-o'-sis) [áv priv.; aiua, blood]. Defective supply of blood; anemia dependent on want of red blood corpuscles. See $A n$ ematosis.

Anemotrophy, or Anæmotrophy (an-em-ot'-ro-fe) [áv

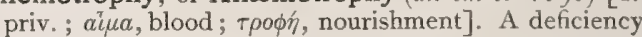
of blood nourishment; an impoverished state of the blood.

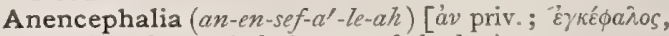
brain]. Congenital absence of the brain.

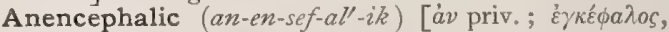
brain ]. Pertaining to or characterized by anencephalia.

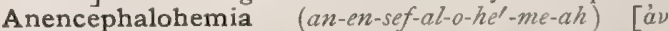

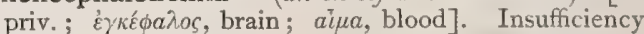
of blood in the brain.

Anencephaloid (an-en-sef'-al-oid) [ảv priv. ; $\varepsilon \gamma \kappa \varepsilon \dot{\phi} \phi a \lambda$ os, brain]. Pertaining to anencephalia.

Anencephaloneuria (an-en-sef-al-on-u'-re-ah) [à

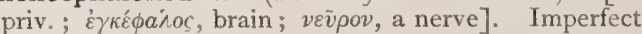
nerve-action of the brain.

Anencephalotrophia, or Anencephalotrophy (an-en-

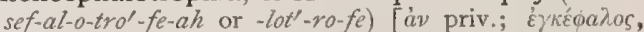

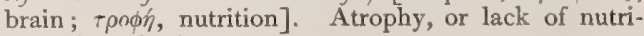
tion of the brain. 
Anencephalus $\left(a n-e n-s e f^{\prime}-a l-u s\right)$ [äv priv. ; $\varepsilon \gamma \kappa \varepsilon \dot{\phi} a \lambda o s$, brain]. I. A species of single autositic monsters in which there is neither a trace of the brain nor a rudimentary representative of it. 2. According to SaintHilaire, a variety of the above species in which there is extensive laying open of the spinal canal with absence of the spinal cord.

Anencephaly (an-en-sef'-al-e). See Anencephalia.

Anenergesia (an-en-er-je'-ze-ah). See Anenergia.

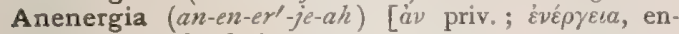
ergy]. Lack of vigor or power.

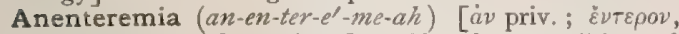
an intestine; ai $\mu a$, blood]. Bloodless condition of the bowels.

Anenteroneuria (an-en-ter-o-nu'-re-a/h) [av priv. ;

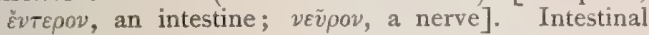
atony.

Anenterotrophia (an-en-ter-o-tro'-fe-ah) [áv priv.; $\varepsilon \dot{\varepsilon} \nu \rho \rho \nu$, an intestine; $\tau \rho \circ \phi \dot{\eta}$, nourishment]. Defective intestinal nutrition.

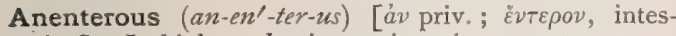
tine]. In biology, having no intestine, as a tapeworm or a fluke.

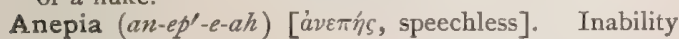
to speak.

Anepiploic (an-ep-ip-lo'-ik) [áv priv.; $\varepsilon \pi i \pi \lambda o o v$, the caul]. Having no epiploön.

Anepithymia (an-ep-e-thim'-e-ah) [áv priv. ; $\dot{\varepsilon} \pi \imath v \mu i a$, desire]. Loss of any natural appetite.

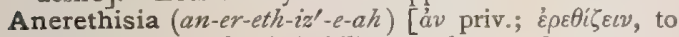
excite]. Imperfect irritability, as of a muscle or nerve.

Anergia (an-er'-je-ah) [ảv priv.; éprov, work]. Sluggishness; inactivity.

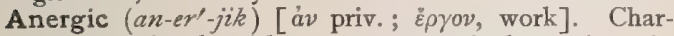
acterized by sluggishness; as anergic dementia. A. Stupor. See Insanity, Sizporous.

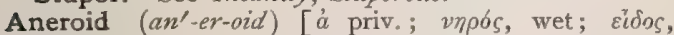
form]. Dispensing with a fluid, as quicksilver. A. Barometer. See Barometer.

Anerythroblepsia (an-er-ith-ro-blep'-se-ah). Same as Anerythropsia.

Anerythroblepsy (an-er'-ith-ro-blep-se). Same as $A n$ erythropsia.

Anerythropsia (an-er-ith-rop'-se-ah) [á priv.; غ $\rho v$ $\theta \rho o ́ s$, red; $\ddot{\psi} \psi s$, sight]. Subnormal color perception of red. See Blindness.

Anesis $\left(a n^{\prime}-e s-i s\right)$ [ávtols, remission]. An abatement or relaxation in the severity of symptoms.

Anesthesia, or Anæsthesia (an-es-the'.-ze-ah) [ávaı$\theta \eta \sigma i a$, want of feeling]. A condition of insensibility or loss of feeling due to pathological conditions of the centers, conducting paths of the nerves, or the peripheral terminations of the same, or to artificial production by means of anesthetics. A., Bulbar or Central, due to central disease. A., Crossed, anesthesia on one side of the organism, due to a central lesion of the other side. A., Doll's Head, a form of anesthesia extending over the head, neck, and upper part of the chest. A. dolorosa, severe pain experienced after the occurrence of complete motor and sensory paralysis, a symptom observed in certain diseases of the spinal cord. A., Local, of a limited part of the body. A., Muscular, loss of the miscular sense. A., Peripheral, depending upon conditions of the end-organs of the nerves. A., Surgical, by means of anesthetics for the purpose of preventing pain, producing relaxation of muscles, or for diagnostic purposes.

Anesthesimeter (an-es-thes-im'-et-er) [avalobinoia, want of feeling; $\mu$ ćtpov, a measure]. An instrument to measure the amount of an anesthetic administered in a given time.
Anesthetic, or Anæsthetic (an-es-thet"ik) [à priv. :

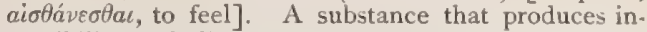
sensibility to feeling or to acute pain, diminished muscular action, and other phenomena. Anesthetics may be general, local, partial and complete. A., General ; the following are the substances that have been used for general anesthesia: AMYLENE, $\mathrm{C}_{5} \mathrm{H}_{10}$, a mobile liquid, thin, colorless, translucent; action rapid, producing partial anesthesia. It is used in Germany under the name of Pental; it is best administered by means of Junker's inhaler, which modifies its unpleasant odor; it should not be brought near a flame. CARBON TETRACHLORID, not so irritating to the organs of respiration, but far more dangerous than chloroform. CHLORAL HYDRATE, action indirect and incomplete. Rarely, if ever, now used. CHLORO. FORM, by inhalation. Largely employed in general surgery. It seems to have a selective action upon the nervous system, and also exercises a direct influence upon the muscular tissues of the heart. It paralyzes the vaso-motor system, and death results from cardiac paralysis. Chloroform should always be administered freely mixed with air. The Method of definite mixtures, however, as recommended by Clover, and Bert, while admirable in theory, is not entirely practical. The Lister Method, also known as the Scotch or open Method of administering chloroform, consists in pouring a small amount of the anesthetic upon a common towel arranged in a square of six folds, and holding this as near to the face as can be borne without inconvenience. Various inhalers have been devised for the administration of chloroform, the best of which are Clover's, which consists of a large bag capable of containing a given volume of air, into which the vapor of a given quantity of chloroform is allowed to enter, the mixture being so arranged that the tension of chloroform vapor in the air is maintained below 4.5 per cent; Junker's, as modified by Dudley Buxton, which consists in the inhalation of air containing the chloroform vapor, the latter being taken up by pump. ing the air through a bottle containing half an ounce of the anesthetic; Krohne and Sesemann have modified the foregoing by doing away with the intermittent, jerky delivery of the vapor and by adding to the face-piece an expiration-valve guarded by a stiff feather, which, rising in expiration and falling in in. spiration, registers the force and strength of respiration (Feather respiration register); Sansom's apparatus is a modification of Snow's, substituting a gutta-percha covering for the cold-water jacket of Snow; Snow's inhaler consists of a metallic cylindrical vessel, con. taining two coils of blotting paper, permitting free circulation of air, and surrounded by another cylinder containing water, the latter being for the purpose of equalizing the temperature. Syncope resulting from chloroform administration should be treated by lowering the head, artificial respiration, inhalation of nitrite of amyl, electrical stimulation, and possibly acupuncture of the heart. ETHENE CHLORID, formerly called ethylene chlorid, Dutch liquid, chloric ether, closely resembles chloroform, but is less of a cardiac depressant. It is considered safer than chloroform. Death results from paralysis of the respiratory centers. ETHER, by inhalation, is probably the safest known agent for the production of prolonged narcosis. Its action is directed largely to the nervous system, which becomes profoundly affected. It frequently causes spasmodic action and suspension of respiratory action. Death results from paralysis of respiration. It may be administered alone or in combination with nitrous oxid gas, in which case the patient is more rapidly narcotized. A variety of inhalers have been devised 
for its administration, as follows: Allis's is probably the best form of open inhaler. It consists of a metal frame, so arranged that a flannel bandage can be stretched across and the whole surrounded with a leather case, which acts as a face-piece. Clover's portable ether inhaler consists of a dome-shaped receptacle pierced by a central shaft connecting with a rubber bag into which the patient breathes. Moving with the face-piece is a metal indicator to register the amount of ether admitted. A water chamber surrounds the ether vessel to regulate the temperature. The Cone is much used in America. A towel is folded into the shape of a cone, a sponge is placed at the apex, and the ether poured upon this. Hervitt's apparatus may be used for giving gas and ether. In his inhaler the inspiratory and expiratory valves are placed in a little chamber near the face-piece; a free draught of air is permitted. Ormsby's inhaler consists of a leather face-piece, crowned with a cone-shaped wire cage covered with leather and joined to a soft leather bag, covered by a loose net to prevent excessive expansion. The wire cage contains a sponge on which the ether is poured. Rendle adds to a cone containing a flannel cap a mask for the face. Rectal etherization may be resorted to in operations about the face and throat. The ether vapor is introduced into the bowel, the process taking longer for complete anesthetization than by the usual method. ETHIDENE CHLORID is similar in its action to chloroform. Patients take a longer time to recover consciousness than when chloroform is used, but they experience fewer after-effects, and recover rapidly. Anesthetization occurs in three to five minutes. HYDROBROMIC ETHER (bromid of ethyl) produces unconsciousness and anesthesia in one minute, and complete muscular relaxation in two or three minutes. The heart's action is somewhat weakened. Return to consciousness after withdrawal of the ether is very prompt. Its use may be followed by romiting. According to some observers, death resvits from cardiac failure, while others believe it kills by direct action upon the respiratory center. It is best administered by an Allis inhaler, and is of most service in minor surgery for short operations. NiTrous OxID, by inhalation, is much used by dentists for extraction of teeth. The symptoms resemble those of asphyxia, hence it is more important to watch the respiration than the pulse. It may be employed in minor surgical operations. There are but few after-effects, those most often observed being headache and malaise. Bert's method of administering nitrous oxid consists in giving it in conjunction with oxygen under pressure; by this method the administration may be prolonged indefinitely. Clover's Gas and Ether Inhaler is intended for the administration of a mixture of these anesthetics; it is so arranged that gas can be given alone, or in combination with the ether. Buxton's apparatus is used for the administration of gas only, and possesses a special contrivance to filter the air. Fontaine's chamber is an apparatus devised to keep the patient under an atmospheric pressure equal to 26 inches mercury, so that the vapor inhaled would be 50 per cent. gas and 50 per cent. air, and asphyxia thus be prevented. The employment of supplemental bags has been advocated by Braine. The patient breathes into these bags, the gas supply being turned off and the expiratory valve closed. It is claimed that this method produces a more prolonged period of unconsciousness. Various accessory instruments are needed in the use of gas, such as gags, mouth openers, and mouth props, spoons, etc. A., Local, an anesthetic that, locally applied, produces absence of sensation in the organ or tissue so treated.
ALCOHOL, locally, removes sensation to pain, while tactile sense persists. Cool the alcohol to about $10^{\circ}$ below the freezing point, by placing it in ice and salt, and place the part to be numbed in it. BIsUlphid OF CARBON, by spray or irrigation, has a disgusting odor, and is a powerful poison. CARBOLIC ACID, painted over the skin-its action, however, is caustic. CHLORETHYL, in vapor form, is useful in minor and dental surgery. CHLORID OF METHYL, $\mathrm{CH}_{3} \mathrm{Cl}$, allowing the liquid chlorid to drop on the skin or mucous membrane. Unless kept carefully under control the vitality of the tissues may be affected. CocAIN is used in subcutaneous injections, by painting over mucous surfaces, or by instillation into the eye. As a paint a 20 per cent solution is used, weaker preparations being of little value over cutaneous surfaces; several coats are necessary. A 10 per cent. solution should be used on mucous surfaces; for the eye a 4 per cent. solution will answer, and this solution is strong enough when cocain is employed as a spray. Hypodermatically, $m_{i j-v}$ of a IO to 20 per cent. solution are usually injected, and this may be repeated two or three times during the operation. DRUMIN is oxalate of lime prepared from a euphorbiaceous plant. It was formerly suggested as a local anesthetic, but has been found not to possess anesthetic properties. Ether, in spray, is recommended by Dr. B. W. Richardson. The anesthesia thus produced is confined to the skin, and is very transient. It may produce a slough from excessive freezing. FARADIC CURRENTS were formerly used by dentists, but are of no value. RHIGOLENE, in spray, its use being similar to that of ether. A. Mixtures contain combinations of substances for producing anesthesia. The following are the most important: A. C. E. Mixture:alcohol, sp. gr. .838, I part; chloroform, sp. gr. I.497, 2 parts; ether, sp. gr. 735,3 parts. BILlRoth's: -chloroform 3 parts, alcohol and ether each I part. It is best administered by the open method. LINHART'S:-alcohol I, chloroform 4. It is administered similarly to chloroform. MARTINDALE's:a volumetric mixture, the ingredients of which evaporate almost uniformly ; it consists of absolute alcohol, sp. gr. .795, one volume; chloroform, sp. gr. I.498, two volumes; pure ether, sp. gr. .720, three volumes. Medico-ChiruRgical Society of London:- - ether 3, chloroform 2, alcohol I. METHYLENE, or BICHLORID OF METHYLENE, a mixture of methylic alcohol 30 per cent., and chloroform 70 per cent. The so-called "Liquid of Regnauld" consisted of 80 per cent. chloroform, 20 per cent. methylic alcohol. Methylene is not much used, several deaths from cardiac paralysis having occurred from its employment. NUSSBAUM's, ether 3, chloroform I, alcohol I. RICHARDSON'S:-alcohol 2, chloroform 2, ether 3 . SANFORD'S:-the so-called "CHLORAMYL" is a mixture of chloroform and amyl nitrate in the proportion of two drachms of the nitrate to the pound of chloroform. It is a dangerous mixture, both drugs depressing the heart. Vienna General Hospital :- - ether 9, chloroform 30, alcohol 9. Vienna Mixture:ether 3, chloroform I. VON MERING's:-chloroform one volume, dimethylacetal two volumes. It is said to produce no failure of respiration or heart, and no lowering of the blood pressure. WACHSMUTH's :one-fifth part of oil of turpentine is added to the chloroform. It is said to prevent any danger of heartfailure.

Various methods have been suggested by means of which the influence of the anesthetic may be prolonged or its dangers and sequelæ largely averted. The following are the most important:-DASTRE-MORAT's ; con- 
sists in the injection of 1 or 1.5 c. c. of the following mixture :-morph. hydrochlor. Io centigrm., atropin. sulph. 5 milligrm., aq. destill. Io grms. The atropin is said to lessen the after-sickness and abrogate salivation and bronchial secretion. FOR NÉ's :- - the preliminary administration of chloral before using chloroform, 2 to 5 grams an hour before. KAPPELER's :- a combination of chloral hydrate and ether, 40 grains of the former. The duration of anesthesia is prolonged and the recovery retarded, but the after-effects are more marked. NUSSBAUM's:-injection of $\frac{1}{6}$ to $\frac{1}{3}$ grain of morphin previous to the administration of chloroform. Less of the anesthetic is needed, while the stupor is prolonged; vomiting is increased. OBALINSKI's :hypodermatic injection of cocain, 2 to 5 centigrams of a three per cent. solution during chloroform anesthetization. TRÉLAT'S:-administration of 2 to $4 \frac{1}{2}$ grams of chloral hydrate, and Io to 20 grams of syrup of morphin in 60 grams of water, repeating the dose in 15 minutes, and following by chloroform anesthesia.

Attempts have repeatedly been made to estimate the comparative safety of the various anesthetics used for the production of general anesthesia. In I 879 the "Glasgow Committee" of the British Medical Association concluded in favor of ether, declaring that chloroform lowered the blood tension and depressed the action of the heart. In I 889 the HYDERABAD CoMmission arrived at the conclusion that chloroform produced an arrest of respiration before there was a stoppage of the heart. It is thought, however, that the climate-that of India-may have had some effect in producing this result, since in temperate climates the heart usually fails before there is a depression of respiration.

Anestheticism (an-es-thet'-is-izm) [avaiofntos, insensible]. The quality of being anesthetic.

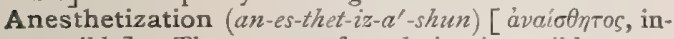
sensible]. The process of rendering insensible.

Anesthetize (an-es'-thet-iz) [ávai $\sigma \theta \eta \pi 0 s$, insensible]. To put under the influence of an anesthetic.

Anesthetizer (an'-es-thet-i-zer) [ávaíotrios, insensible]. One who administers an anesthetic.

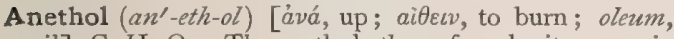
oil ], $\mathrm{C}_{10} \mathrm{H}_{12} \mathrm{O}$. The methyl ether of anol; it occurs in ethereal oils, from which it separates in the cold in the form of white, shining scales, melting at $2 \mathrm{I}^{\circ}$ and boiling at $232^{\circ}$. It is the chief constitutent of the essential oils of anise and fennel. It is employed in preparing the Elixir anethi, N. F., being more fragrant and agreeable than the anise oil.

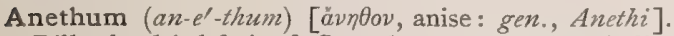
Dill; the dried fruit of Peucedanum graveolens, indig. enous to Southern Europe. Aromatic, carminative, and stimulant. A. Aqua (B. P.). Dose $\xi^{i-i j}$. A. Oleum (B. P.). Dose $m$ i-iv.

Anetic $\left(a n-e t^{\prime}-i k\right)$ [ávetıkós, relaxing]. Soothing; calmative; anodyne.

Anetiological (an-e-te-o-loj'-ik-al) [àv priv.; airia, cause; $\lambda 6$ yos, word]. Having no known cause; dysteleological.

Anetus $\left(a n^{\prime}-e t-u s\right)$ [áverbs, loosened]. Any intermittent fever.

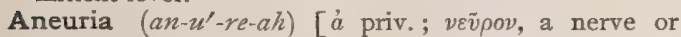
fiber]. Lack of nervous power or stimulus.

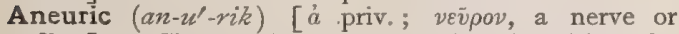
fiber]. Characterized by aneuria; impairing the nervous activity.

Aneurysm (an'-u-rizm) [ảvév $\rho v \sigma \mu a$, a widening]. A tumor consisting of a dilated artery, or communicating with an artery. In the early stages there is an expansile pulsation of the tumor generally associated with a systolic murmur or bruit. In the later stages the laminated coagulum increases, so that pulsation may be absent, and pressure of the growing aneurysm upon the adjacent organs may give rise to secondary troubles, as pain, dyspnea, dysphagia, paralysis, or spasm. Inequality in the pupils follows from pressure on the sympathetic in thoracic aneurysm. Aneurysm may be caused by rupture, wounding, disease, or weakness of the arterial walls, or by increased blood pressure following over-exertion. Embolism also may be a cause; gout and alcoholism act as predisposing causes. Cardiac dilatation is sometimes spoken of as aneurysm of the heart. A., Abdominal, one of the abdominal aorta. A. by Anastomosis, a dilatation of a large number of vessels-small arteries, veins, and capillaries-the whole forming a pulsating tumor under the skin. This form of aneurysm is especially seen upon the scalp. A., Arterio-venous, the formation of an abnormal communication between an artery and a vein. If the communication is direct it is termed aneurysmal varix, but when there is an intervening sac it is called a varicose aneurysm. A., Bérard's, a varicose aneurysm with the sac in the tissues immediately around the vein. A., Cirsoid, a tortuous lengthening and dilatation of a part of an artery. A., Compound, one in which one or several of the coats of the artery are ruptured and the others merely dilated. A., Consecutive, or Diffused, follows rupture of all the arterial coats with infiltration of surrounding tissues. A., Dissecting, when the blood forces its way between the media and adventitia. A., Ectatic, an expansion of a portion of an artery due to yielding of all the coats. It is merely a dilatation of the vessel. A., Endogenous, one formed by disease of the vessel walls. A., Exogenous, one due to traumatism. A., False, or Spurious, one in which there has occurred a rupture of all the coats, and the effused blood is retained by the surrounding tissues. A., Fusiform, a spindle-shaped dilatation of the artery. A., Medical, an internal aneurysm; i. e., one situated within the thoracic or abdominal cavity. A., Mixed. See A., Compound. A., Sacculated, a sac-like dilatation of an artery communicating with the main arterial trunk by an opening that may be relatively large or small. A., Park's, a variety of arterio-venous aneurysm in which the arterial dilatation communicates with two contiguous veins. A., Pott's. Same as Aneurysmal Varix. A., Rodrigues's, a varicose aneurysm in which the sac is immediately contiguous to the artery. A., Spurious. See $A$., False. A., Verminous, one containing hematozoa.

Aneurysmal (an-u-riz'-mal) [avev́pvo $\mu a$, a widening]. Of the nature of or pertaining to an aneurysm. A. Varix. See Aneurysm.

Aneurysmatic (an-u-riz-mat'-ik) [ávevipvoua, a widening]. Affected with or of the nature of aneurysm.

Aneuthanasia ( $\left.a n-u-t h a n-a^{\prime}-z e-a h\right)$ ['a priv. ; $\dot{a} \dot{\theta} a \nu a \sigma i a$, an easy death]. A painful or difficult death.

Anfract (an'-frakt) [anfractus, a winding]. An anfractuosity or sinuosity; an anfractuous organ or structure.

Anfractuose (an-frak'-tu-ōs) [anfractus, a winding]. In biology, bent back and forth, winding, as certain stamens, or the brain fissures.

Anfractuosity (an-frak-tu-os'-it-e) [anfractus, a bending round ?. Any one of the furrows or sulci between the cerebral convolutions.

Anfractuous (an-frak'-tu-us) [anfractus, a bending round]. Characterized by windings and turnings; sinuous.

Angeiectasis (an-je-ek'-tas-is). See Angiectasis.

Angeio- $\left(a n^{\prime}-j e-0\right)$. See Angio-. 
Angelic Acid (an-jell'-ik as'-id). See Acid.

Angelica (an-jel'-ik-ah) [L.]. The seeds and root of Archangelica officinatis and other species. An aromatic stimulant and emmenagogue. Dose of the fld. ext. : Seeds $m, v-x$; root 3 ss-j. Unof.

Angel's Wing (än'-jelz zoing). A deformity of the scapula in which it turns forward and then backward, giving the shoulder a peculiar dorsal bulge, as in a scoliotic chest.

Anger's Operation. See Operations, Table of.

Angiectasis (an-je-ek'-tas-is) [áryciov, a blood-vessel;

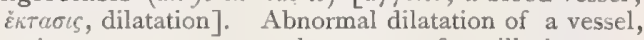
as in aneurysm, etc. ; enlargement of capillaries.

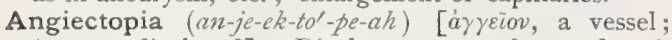
غкктоло , displaced]. Displacement or abnormal position of a vessel.

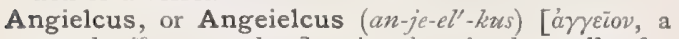
vessel; $\varepsilon \lambda \kappa{ }^{\prime}$, an ulcer]. An ulcer in the walls of a vessel.

Angiemphraxis (an-je-em-fraks'-is) [áryciov, a vessel ; $\dot{\varepsilon} \mu \varphi \rho \alpha \xi \iota$, obstruction]. Obstruction of a vessel, or of vessels.

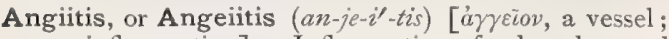
$\iota_{T} \iota$, inflammation]. Inflammation of a lymph vessel or blood vessel.

Angina (an'-jin-ah or an-ji'-nah) [angere, to strangle]. A sense of choking or suffocation, a symptom of inflammatory affections of the pharynx. It is synonymous with Cynanche. A. acuta or simplex, simple sore-throat. A. externa. Synonym of Mumps. A., Hogskin. Synonym of Diphtheria. A. laryngea. Synonym of Laryngitis. A. lingualis. Same as Glossitis. A., Ludwig's, acute suppurative inflammation of the connective tissue surrounding the submaxillary gland. A. membranacea. Synonym of Croup. A. parotidea, the mumps, or Parotitis, q. v. A. pectoris, a paroxysmal neurosis with intense pain and oppression about the heart. It usually occurs in the male after forty years of age, and is generally associated with diseased conditions of the heart and aorta. There is a sense of impending death, and frequently there is a fatal termination. $\mathbf{A}$. pectoris-vasomotoria, a term given by Nothnagel and Landois to an angina associated with vaso-motor disturbances, coldness of the surface, etc., but never resulting fatally. A., Pseudo-, is a neurosis occurring in young anemic females, characterized by a less grave set of symptoms and never resulting fatally. $\mathbf{A}$. simplex. See $A$. acuta. A. tonsillans, Quinsy, $q . v$. A. trachealis, the Croup, q. v. A. ulcero-membranous. See Tonsillitis, herpetic.

Anginoid (an'-jin-oid) [angere, to strangle]. Resembling angina.

Angioasthenia (an-je-o-as-the'-ne-ah) [áryeĩov, a vessel;

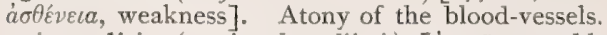

Angiocarditis (an-je-o-kar-di'-tis) [aryeiov, a blood-

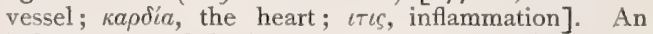
inflammation of the heart and blood-vessels (hypothetical).

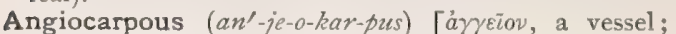
$\kappa a \rho \pi \delta \varsigma$, fruit]. In biology, having the fruit invested with a distinct covering or husk; having a closed apothecium; having the hymenium inclosed by the sporocarp.

Angiochalasis, or Angeiochalasis (an-je-o-kal'-as-is)

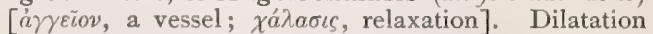
or relaxation of the blood-vessels.

Angiocholitis (an-je-o-ko-li'tis) [à $\gamma \gamma \varepsilon i o \nu, a$ vessel; $\kappa \circ \lambda \dot{n}$, bile; $\iota \tau \iota \varsigma$, inflammation]. Inflammation of the biliary ducts.

Angioderma pigmenotosum (an-je-o-der'-mah pigmen-to'-sum). See Atrophoderma.

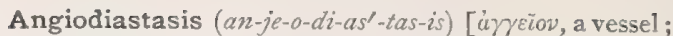

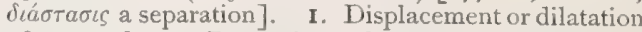
of a vessel. 2. Retraction of the severed ends of a blood-vessel.

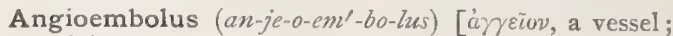
$\varepsilon \mu \beta \propto \lambda o s$, anything thrown in]. A plug (as of clotted blood) in a vessel.

Angiogenesis (an-je-o-jen'-es-is). See Angiogeny.

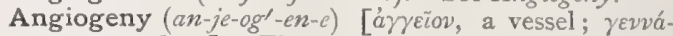
$\varepsilon(\nu$, to produce]. The development of the vessels.

Angioglioma (an-je-a-gli-o'-mah) [á $\gamma \gamma \varepsilon i o v$, a vessel;

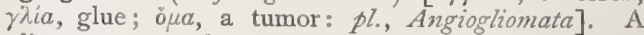
gliomatous vascular tumor of the spinal cord.

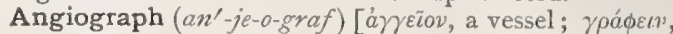
to write]. A form of sphygmograph invented by Landois.

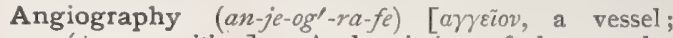
$\gamma \rho a ́ \phi \eta$, a writing]. A description of the vessels; angiology.

Angiohemothrombus (an-je-o-hem-o-throm'-bus) [à

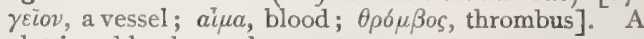
clot in a blood-vessel.

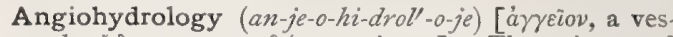
sel; $v \delta \omega \rho$, water; $\lambda \dot{b} \gamma o s$, science]. The science of the lymphatic vessels, their contents, etc.

Angiokeratoma (an-je-o-ker-at-o'-mah) [aryeion, a ves-

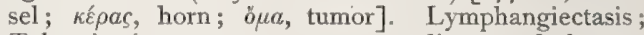
Telangiectic warts; a very rare disease of the extremities characterized by warty-looking growths that develop on dilated vessels in persons with chilblain, etc. Dark spots the size of pins' points or pins' heads, evidently vascular, develop as an attack of chilblains is subsiding. The disease is peculiar to childhood, and especially occurs in females.

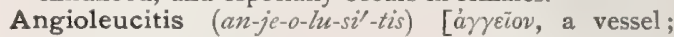
$\lambda \varepsilon v \kappa \delta_{s}$, white; $\iota \tau \iota s$, inflammation]. Inflammation of the lymphatic vessels.

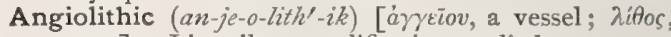
a stone]. Literally, a qualification applied to a vascular and crystalline formation. Practically applied to neoplasms in which crystalline or mineral deposits take place, with hyaline degeneration of the coats of the vessels.

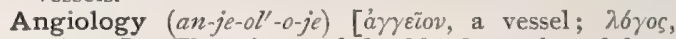
science]. The science of the blood-vessels and lymphatics.

Angiolymphitis (an-je-o-limf-i'tis) [ángeiov, a vessel;

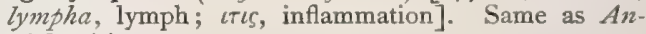
gioleucitis.

Angiolymphoma (an-je-o-limf-o'-mah) [ảyrzĩon, a vessel; lympha, water; bua, tumor: pl., Angiolymphomata]. A tumor formed of lynaphatic vessels.

Angioma (an-je-o'-mah) [áy yeiov, a vessel; b̆ $\mu a$, a tumor: pl., Angiomata]. A tumor formed of bloodvessels. Called also Erectile or Vascular Tumor. A., Cavernous, with communicating alveolar spaces. See Varix, Cirsoid. Capillary and venous angiomata are called Nevi, or Mother's' Marks. A., Cystic. Synonym of Lymphangioma circumscriptum. A., Infective. See A. serpiginosum. A. pigmentosum atrophicum. See Xeroderma pigmentosum. A. serpiginosum, infective angioma; nevus lupus; a very rare disease of the skin in which minute vascular points are formed in rings or other groups, that spread at the borders, while fresh points are continually developing beyond them. The points look like grains of cayenne pepper. It occurs usually in girls, but its etiology and pathology are unknown.

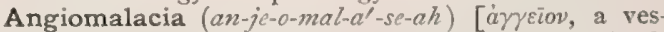

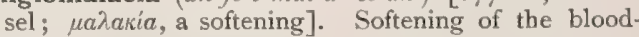
vessels.

Angiometer (an-je-om'-et-er). See Sphygmograph. 


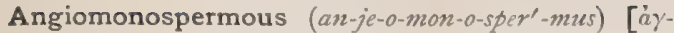

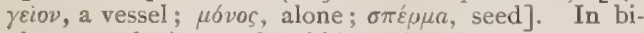
ology, producing seeds within a closed ovary.

Angiomyoma, or Angimyoma (an-jc-o-mi-o'-mah or

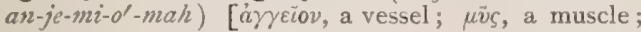
ö $\mu a$, a tumor: pl., Angiomyomata]. A vascular and erectile muscular tumor.

Angioneoplasm (an-je-o-ne'-o-plasm). See Angioneoplasma.

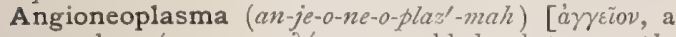
vessel; $\nu \varepsilon \delta \varsigma$, new; $\pi \lambda a ́ \sigma \mu a$, moulded substance: $p l$., Angioneoplasmata]. A neoplasm made up of bloodvessels or lymph-vessels.

Angioneurosin (an-je-o-nu'-ro-sin). Synonym of Nitroglycerin.

Angioneurosis (an-je-o-nu-ro'-sis) [áryeiov, a vessel; ขยṽ $\rho o v$, a nerve]. A neurosis of the blood-vessels; a disturbance of the vaso-motor system,-a symptom of many diseases.

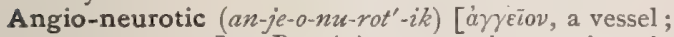

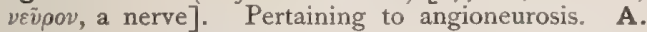
Edema, a swelling, with associated symptoms, probably due to vaso-motor lesion.

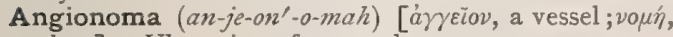
ulcer]. Ulceration of a vessel.

Angioparalysis (an-je-o-par-al'-is-is) [áyriou, a vessel; $\pi \alpha \rho a \lambda v \varepsilon \iota v$, to disable on one side]. Vaso-motor paralysis.

Angioparalytic $\left(a n-j e-o-p a r^{2}-a l-i t^{\prime}-i k\right)[a ́ \gamma \gamma \varepsilon \tilde{i} o v$, a vessel; $\pi a \rho a \lambda v \varepsilon \iota v$, to disable on one side]. Relating to or characterized by angioparalysis.

Angioparesis (an-je-o-par'-es-is) [áryciov, a vessel; $\pi \alpha \rho \varepsilon \sigma \iota \zeta$, a letting go]. Paresis or partial paralysis of the vaso-motor apparatus.

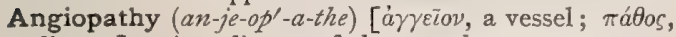
disease]. Any disease of the vascular system.

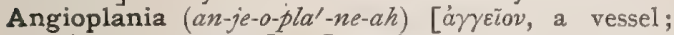
$\pi \lambda a ́ \nu \eta$, a wandering]: Irregularity or abnormality in the course of a vessel.

Angioplastic (an-je-o-plas'-tik). See Vasifactive.

Angiorrhagia or Angeiorrhagia (an-je-or-a'-je-ah) [áy vessel.

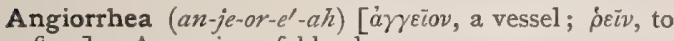
fiow]. An oozing of blood.

Angiorrhexis (an-je-o-reks'-is) [áryeıov, a vessel; $\dot{\rho} \dot{\eta} \xi \iota \zeta$, a bursting]. Rupture of a blood-vessel.

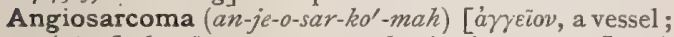

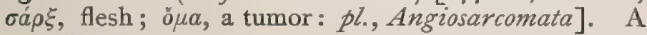
vascular sarcoma.

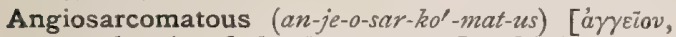
a vessel; $\sigma a ́ \rho_{\zeta}$, flesh; ö $\mu \alpha$, a tumor]. Of the nature of or affected with angiosarcoma.

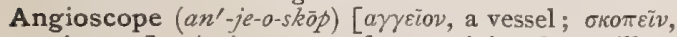
to inspect]. An instrument for examining the capillary vessels.

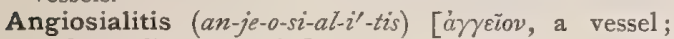
$\sigma i a \nu_{0}$, saliva; $\iota \tau \iota \varsigma$, inflammation]. Inflammation of the duct of a salivary gland.

Angiosis (an-je-o'-sis) [âyrion, a vessel]. Any disease of blood-vessels or lymphatics.

Angiospasm (an'-je-o-spazm) [áryciov, a vessel; $\sigma \pi a \sigma u o s$, a spasm]. A convulsive neurosis of the blood-vessels; a vaso-motor spasm.

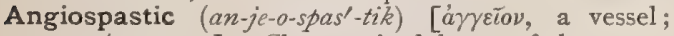
$\sigma \pi \alpha \sigma \mu \sigma s$, spasm]. Characterized by or of the nature of angiospasm.

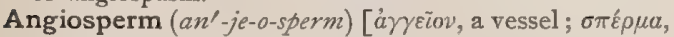
seed]. In biology, a plant the seeds of which are produced within a closed vessel.

Angiosporous (an-je-os'-po-rus) [áryeiov, a vessel; $\sigma \pi 6 \rho \circ$, a seed]. In biology, producing spores or asci within a hollow receptacle, said of fungi.

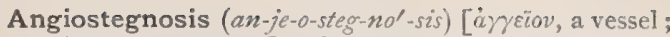

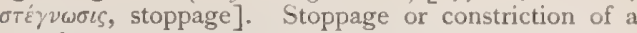
vessel.

Angiostegnotic (an-je-o-steg-not'-ik) [änziov, a vessel ;

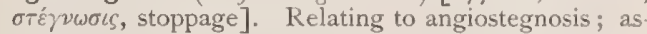
tringent; causing contraction of blood-vessels.

Angiostenosis (an-je-o-sie-no'-sis) [á $/ \gamma \varepsilon i o v$, a vessel;

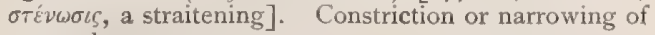
a vessel.

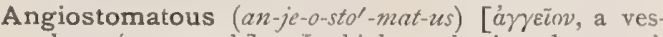
sel; бтб $\mu a$, mouth]. In biology, having the mouth or opening narrow or not dilatable.

Angiostrophe (an-je-os'-tro-fe) [áyjīov, a vessel;

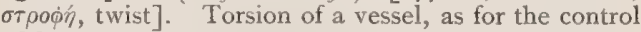
of hemorrhage

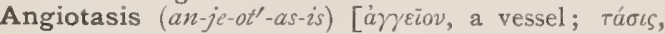
tension]. The tension of the vessels.

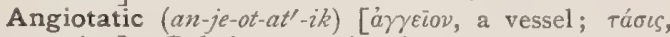
tension]. Relating to angiotasis.

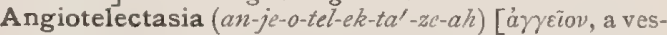
sel; $\tau \dot{\lambda} \lambda o s$, end; $\varepsilon \kappa \tau a \sigma \iota s$, dilatation]. Dilatation of capillary vessels.

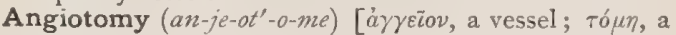
cutting]. The incision or dissection of a vessel.

Angle $\left(a n g^{\prime}-g l\right)$ or Angulus (ang $g^{\prime}-g u$-lus) [angulus, an angle]. The degree of divergence of two lines that meet each other; the space between two such lines. A. a., that one of Lissauer's angles between the radius fixus and a line joining the alveolar and subnasal points. A. of Aberration. See $A$. of $D_{e}$ viation. A., Ackermann's, certain angles, characteristic of kyphosis, which mark the base of the skull in cases of encephalocele and hydrocephalus; for example, the occipito-sphenoidal angle is abnormally sharp. A., Acromial, that formed between the head of the humerus and the clavicle. A., Alpha. I. In optics, that formed by the intersection of the visual line and optic axis. 2. In craniometry, that one of Lissauer's angles between the radius fixus and a line joining the hormion and subnasal point. A., Alveolar, that formed between a line passing through a spot beneath the nasal spine and the most prominent point of the lower edge of the alveolar process of the superior maxilla and the cephalic horizontal line. A., Alveolo-condylar. See A., Orbito-alveolo-condylar. A., Anterior (of Ilium). See A., External (of Ilium). A., Anterior (of Scapula). See A., Cervical (of Scaprila). A., Anterior Parietal. See A., Parietal (of Quatrefages). A., Antero-external (of Ischium), in veterinary anatomy, the posterior extremity of the supracotyloid crest. A., Anterointernal (of Ischium), in veterinary anatomy, the portion of the ischium that helps to close the obturator foramen inwardly. A. of Aperture, in optics, that included between two lines joining the opposite points of the periphery of a lens and the focus. A.. Auricular, in craniometry, those cephalic angles having their apices at Broca's auricular point. A., Auriculo-cranial, in craniometry, the auricular angles whose sides pass through the cranium. A., Auriculofacial, in craniometry, those auricular angles whose sides pass through the face. A., Auriculo-frontal. See A., Frontal. A., Auriculo-occipital, in craniometry, the combined sub-occipital and supra-occipita! angles. A., Auriculo-parietal. See $A$., Parieial (of Broca). A. b., that one of Lissauer's angles included between the radius fixus and a line joining the bregma and nasion. A., Barclay's. See $A_{\text {. }}$, Orifacial. A., Basifacial, in craniometry, that between the basi-cranial and basifacial axes. "A., Basilar, in craniometry, that between the naso-basilar and basialveolar lines. A., Beta, that one of Lissauer's angles 
included between the radius fixus and a line joining the hormion and bregma. A., Bi-orbital, in optics, that formed by the intersection of the axes of the orbits. A., Broca's. See A., Facial, A., Occipital, and $A$., Parietal. A. c., that one of Lissauer's angles included between the radius fixus and a line joining the lambda and opisthion. A., Camper's. See $A$., Facial, and A., Maxillary. A., Carpal, in biology, the bend of the wing. A., Cephalic, in craniometry, a general term for the cranial and facial angles. A., Cerebellar. See A., Suboccipital. A., Cerebral. I. In craniometry, that formed by the frontal, Broca's parietal, and the supra-occipital angles. 2. See $A$. of Segond. A., Cervical (of Scapula), in veterinary anatomy, the point of union of the anterior and superior borders of the scapula. A., Chi, that one of Lissauer's angles included between two lines run ning from the hormion to the basion and staphylion. A., Cloquet's. See A., Facial. A., Condylar, that between the planes of the basilar groove and the occipital foramen. A., Co-orbital, in craniometry, that formed by the crossing of the anatomical plane of the head by the bi-orbital plane. A., Coracoscapular, in biology, that between the axes of the coracoid and scapula. A., Coronofacial (of Gratiolet), in craniometry, the angle that the facial line of Camper forms with the plane passing through the coronal suture. A., Costal. See A., Subcostal. A., Cotyloid, in veterinary anatomy, the portion of the ilium included between the cotyloid foramen and the supracotyloid crest. A., Cotyloidean. See A., Anteroexternal (of Ischium). A., Cranial, in craniometry, angles corresponding to the auricular angles, but having their apices at the anterior border of the occipital foramen. A., Craniofacial (of Ecker). See A., Metafacial. A., Craniofacial (of Huxley), in craniometry, that formed at the middle of the anterior border of the jugum sphenoidale by lines drawn from the basion and nasal spine. A., Critical, that made by a beam of light passing from a rarer to a denser medium, with the perpendicular, without being entirely reflected. A. of Cuvier. See A., Facial. A. of Daubenton. See $A$., Occipital. A., Deschamps's. See A., Iniofacial. A. of Deviation. I. In botany, that formed by a leaf, branch, or root with the axis upon which it is borne. 2. In magnetism, the angle traversed by the needle when disturbed by some magnetic force. 3. In optics, that formed by a refracted ray and the prolongation of the incident ray. A. of Divergence, in botany, that formed between succeeding organs in the same spiral or whorl. A., Dorsal (of Scapula), in veterinary anatomy, the junction of the superior and posterior borders of the scapula. A. of Dürer. See A., Facial. A., Ecker's. See A., Sphenoidal and A., Craniofacial. A. of Elevation, in optics, that made by the visual plane with its primary position when moved upward or downward. A., Ephippial (Welcker's). See A., Sphenoidal. A., Ethmocranial. See A., Olfactory. A., External (of Ilium), in veterinary anatomy, the anterior superior spine of the ilium. A., External (of Mulder), in craniometry, that produced by the junction of Camper's line and a line joining the basi-occipital bone and the nasion. A., External (of Pubes), in veterinary anatomy, the portion of the pubic bone constituting the chief part of the cotyloid cavity. A. of the Eye. See Canthus. A. $f_{\text {. }}$ that one of Lissauer's angles included between the radius fixus and a line joining the inion and opisthion. A., Facial (of Broca). See A., Ophryospinal Facial. A., Facial (of Camper), in craniometry, that between the facial line of Camper and the line drawn through the auricular and subnasal points.
A., Facial (of Cloquet), in craniometry, that between the line drawn through the ophryon and the alveolar point and the auricular-alveolar line. A., Facial (of Cuvier). See A., Facial (of Geoffroy St. Hilaire). A., Facial (of Dürer), in craniometry, that formed by a line tangent to the brow and the lobule of the nose and a line joining the lobe of the ear and the lower part of the nasal septum. A., Facial (of Jacquart), in craniometry, that between the line joining the subnasal point and the glabella and the line joining the subnasal and auricular points. A., Facial (of Segond). See A. of Segond. A., Facial (of Geoffroy St. Hilaire), in craniometry, that between the facial line of Camper and the line joining the auricular point and the edge of the incisors. A., Facial (of Topinard.) See A., Ophryo-spinal Facial. A., Facial (of Virchow and Holder), in craniometry, that formed by the union of a line joining the naso-frontal suture and the most prominent point of the lower edge of the superior alveolar processes, and a line joining the superior border of the external auditory meatus and the lower border of the orbit. A., Fick's, in craniometry, one formed by the intersection of the basilar groove, and a line joining the symphysis menti and the basion. A., Frontal, in craniometry, one formed by lines joining the auricular point and the ophryon and bregma. In ornithology, that formed between the forehead and the upper margin of the beak. A., Frontal (of Lissauer), that one included between lines joining the metopion and the bregma and nasion. A., Fronto-glabellar, the degree of inclination of the forehead. A., Gamma, in optics, that formed at the center of rotation of the eyes by the optic and visual axes. A., Genal, in biology, the posterior angle of the movable gena of trilobites. A., Gratiolet's. See A., Coronofacial. A., Humeral (of the Scapula), in veterinary anatomy, a name given to the head of the shoulder blade. A., Huxley's. See A., Craniofacial. A. i., that one of Lissauer's angles included between the radius fixus and a line joining the posterior border of the incisor foramen and the alveolar point. A., Ilio-ischial, that between the ischium and the cotylo-sacral rib of the ilium. A., Ilio-pubic, in veterinary anatomy, that existing between the ilium and pubes. A., Iliovertebral, that existing between the iliac bones and the spinal column. A. of Incidence, in optics, the angle at which a ray of light strikes a denser medium and undergoes reflection or refraction. A. of Inclination (of Pelvic Canal), in obstetrics, that formed by the anterior wall of the pelvis with the conjugate diameter. A. of Inclination (of Pelvis), in obstetrics, that formed by the pelvis with the general line of the trunk, or that formed by the plane of the inferior strait with the horizon. A., Inferior (of Scapula). See $A$., Humeral. A. of Inflexion, in veterinary anatomy, that formed by the quarter of the hoof of a soliped with the commencement of the bar. A., Inio-facial, in craniometry, Deschamps's modification of Camper's line. It is the angle included between the two lines extending from the inion to the glabella and from the inion to the symphysis of the chin. A., Internal (of Ilium), in veterinary anatomy, the posterior superior spine of the ilium. A., Internal (of Pubes), in veterinary anatomy, the name for the angle of the pubes. A., Internal (of Walther), in craniometry, that included between a line joining the glabella and the nasion and another from the occipital protuberance to the crista galli. A., Interradial, in biology, that formed in the star-fish by the coming together of the lateral walls of two adjacent ambulacral grooves. A. of the Ischio-pubic 
Arch, that formed by the junction of the ischio-pubic rami, A. of Jacquart. See $A$., Facial. A. of Jaw, the junction of the lower border of the ramus of the mandible with its posterior border. A. of Landzert, that formed by the plane of the basilar groove and the horizontal line of the jugum sphenoidale. A. of Lavater, in craniometry, that contained between a line joining the point of the nose and the outer angle of the eye, and a line running from the same point to the angle of the mouth. According to Lavater, the greater the angle the more intelligent the individual. A., Limiting. See A., Critical. A. of the Lips, those formed by the union of the lips at either extremity of the mouth. A., Lissauer's, in craniometry, a number of angles in the median plane of the skull included between lines radiating from a fixed line connecting the inion and hormion (radius fixus.) See also A., Frontal, and A., Parietal. A., Louis's, that between the manubrium and gladiolus of the sternum due to retraction in the upper part of the thorax. A. of Ludovici. See A., Louis's. A., Ludwig's. See $A$., Louis's. A., Lumbo-iliac, in veterinary anatomy, that formed by the junction of the sacrum and ilia. A. m., that one of Lissauer's angles included between the radius fixus and a line joining the opisthion and the basion. A., Maxillary (of Camper), in craniometry, that included between two lines extending from the point of contact of the upper and lower central incisor teeth, one to the ophryon and the other to the most prominent point of the lower jaw. A., Metafacial (of Serres), that which the pterygoid processes form with the base of the skull. A., Meter-, in optics, the degree of convergence of the eyes when centered on an object one meter distant from each. A. of the Mouth. See $A$. of the Lips. A., $\mathbf{M u}$, that one of Lissauer's angles included between the radius fixus and a line joining the hormion and basion: A., Mulder's. See A., External. A. n., that one of Lissauer's angles included between the radius fixus and a line joining the nasion and alveolar point. A. $\mathbf{n}^{\prime}$., that one of Lissauer's angles included between the radius fixus and a line joining the nasion and subnasal point. A., Nasal (of Ranke), in craniometry, that included between the horizontal plane of the skull and a line passing through the middle of the alveolar border beneath the nasal spine and the center of the naso-frontal suture. A., Nasal (of Welcker), in craniometry, that included between the naso-basilar and naso-subnasal lines. A., Nasobasal (of Welcker). See A., Nasal. A., Nasomalar, in craniometry, that formed by two lines converging from the outer margins of the orbits to the base of the nose. A. of the Neck. See A. of the Nucha. A. of the Neck of the Femur, that formed between the neck and shaft of the femur. A., Negative, the name given to Quatrefages' parietal angle when it is inversed. A. of the Nose, that between the nose and the cheek. A., Nu, that one of Lissauer's angles included between the radius fixus and a line joining the hormion and nasion. A. of the Nucha, that formed by the junction of the nucha with the neck. A. o., that one of Lissauer's angles included between the radius fixus and a line joining the lambda and bregma. A. of Obliquity of Femur, that formed by the shaft of the femur and a vertical line. A., Occipital, in craniometry, that formed by the intersection of the basicranial axis and the plane of the occipital foramen. A., Occipital (of Broca), in craniometry, that between the lines joining the opisthion and the basion and nasal points. A., Occipital (of Daubenton), in craniometry, the angle that Daubenton's line makes with the line joining the basion and opisthion. A.,
Occipital, Second, in craniometry, that formed by two lines joining the opisthion and the nasion and nasal spine. A., Olfactory, in craniometry, that formed by the intersection of the plane of the cribriform plate of the ethmoid and the basicranial axis. A., Omega, that one of Lissauer's angles between the radius fixus and a line joining the hormion and lambda. A., Ophryo-alveolo-auricular. See $A$., Facial (of Cloquet). A., Ophryo-spinal-facial, in craniometry, that included between two lines from the nasal spine to the ophryon and auricular point. A., Optic, that included between lines joining the extremities of an object and the nodal point. The smallest is about 30 seconds. A., Orbito-alveolocondylar, in craniometry, that included between the horizontal visual and alveolo-condylar planes. A., Orbito-basilar, in craniometry, that included between Barclay's basifacial plane and the plane of the orbital axes. A., Orbito-facial. See $A$., Orbito-maxillary. A., Orbito-maxillary, in craniometry, that included between the two lines joining the auricular point and the glabella and alveolar border. A., Orbito-occipital, in craniometry, that included between the plane of the occipital foramen and the bi-orbital plane. A., Orifacial (of Barclay). I. That included between Camper's line and the plane of mastication. 2. That included between the median antero-posterior line of the palatine arch and the median antero-posterior line of the plane of the lower border of the inferior maxilla. A. p., that one of Lissauer's angles included between the radius fixus and a line joining the staphylion and alveolar point. A., Palatine, in craniometry, that included between Camper's line and a line on the plane of the alveolar arch. A., Parietal (of Broca), in craniometry, that included between two lines joining the auricular point and the bregma and lambda. A., Parietal (of Lissauer), that included between lines drawn from the bregma and lambda to the most prominent point of the parietal bone. A., Parietal (of Quatrefages), in craniometry, that formed by the lines drawn through the extremities of the transverse maximum or bizygomatic diameter and the maximum transverse frontal diameter (called positive when it opens downward, negative when it opens upward). A., Parietal, Posterior, in craniometry, that included between two lines tangent to the parietal eminence and the most prominent points of the zygomatic arch. A., Pi, that one of Lissauer's angles included between the radius fixus and a line joining the hormion and alveolar point. A. of Polarization, in optics, the angle of reflection at which light is most completely polarized. A., Positive. See A., Parietal (of Quatrefages). A., Posterior (of Ilium). See A., Cotyloid. A., Posterior (of Pubes), in veterinary anatomy, that portion of the pubes that helps to close in the obturator foramen internally. A., Posterior (of Scapula). See A., Dorsal (of Scapula). A., Postero-external (of Ischium), in veterinary anatomy, the tuberosity of the ischium. A., Postero-internal (of Ischium), in veterinary anatomy, the ischiadic arch. A., Premaxillary. See A., Basifacial. A., Prepubic, that formed by the male urethra in front of the pubes, the penis being in a flaccid state. A. of Prognathis $m$, in craniometry, the angle indicating the degree of forward projection of the face. A., Psi. I. That one of Lissauer's angles included between the radius fixus and a line joining the hormion and opisthion. 2. In optics, that between the optic axis and line of fixation. A. of the Pubes, that formed by the junction of the pubic bones at the symphysis. A., Pyramidal. See $A$., Positive. A. of Quatrefages. 
See A., Parietal. A. of Ranke. See A., Nasal. A. of Reflection, in optics, that which a reflected ray of light makes with a line drawn perpendicular to the point of incidence. A. of Refraction, in optics, that which exists between a refracted ray of light and a line drawn perpendicular to the point of incidence. A. of Rib, a line on the external surface of the shaft of the vertebral extremity of the rib, to which is attached the tendon of the sacro-lumbalis muscle. A.s., that one of Lissauer's angles included between the radius fixus and a line joining the basion and staphylion. A., Sacro-vertebral, that which the sacrum forms with the last lumbar vertebra. A. of Segond, in craniometry, angles formed between lines drawn from the basion to the various other craniometrical points. The Facial angle of Segond is that between the line passing through the basion and mental points and the line passing through the basion and ophryon. The Cerebral angle of Segond is that between the line passing through the basion and ophryon, and the line passing through the basion and opisthion. A. of Serres. See A., Metafacial. A. Sigma, that one of Lissauer's angles included between the radius fixus and a line drawn from the hormion to the staphylion. A., Sincipital. See $A$., $E x$ ternal (of Mulder). A. Spal. See $A$. Summi Palati. A., Sphenoidal, in craniometry, that included between two lines joining the nasion and the basion with the center of the transverse groove of the optic commissure, at the point where the sloping anterior surface of the sella turcica passes over into the horizontal surface of the olivary eminence. A., Squinting, that indicating the degree of divergence of the affected eye in strabismus. A., Sterno-clavicular, that existing between the clavicle and the sternum. A. of St. Hilaire (Geoffroy). See A., Facial. A., Subcostal, that formed by the outward inclination of the false ribs with the middle line of the body. A., Suboccipital, in craniometry, that included between two lines joining Broca's auricular point with the posterior border of the occipital foramen and the external occipital protuberance. A., Subpubic, that formed at the pubic arch. A., Summi Occipitis, Lissauer's angle included between lines connecting the most prominent point of the occipital squama and the lambda and inion. A., Summi Palati, Lissauer's angle included between lines drawn from the staphylion and alveolar point to the highest point of the arch of the palate. A., Supra-occipital, in craniometry, that formed by two lines joining Broca's auricular point with the lambda and the external occipital protuberance. A., Symphysian, that which the profile of the symphysis of the lower jaw makes with the plane of the inferior border of the lower jaw. A., Tentorial, in craniometry, that included between the plane of the tentorium and the basicranial axis. A. of Topinard. See A., Facial. A. of Torsion, the amount of twisting in the shaft of a bone. A., Total Cranial, in craniometry, that measuring the cranial cavity between lines drawn from the auricular point to the ophryon and opisthion. A. of the Uterus, that at the cornua of the uterus, where the oviducts enter. A., Venosus, that formed between the right and left brachio-cephalic veins. A., Vertebro-iliac. See A., Ilio-vertebral. A., Vestibular, that formed in the vestibule by the junction of its posterior and middle walls. A. of Virchow and Holder. See A., Facial. A., Visual. See $A$., Optic. A. of Vogt, in craniometry, that included between lines joining the nasion and the basion and alveolar point. A., Walther's. See $A$., Internal. A., Welcker's. See A., Ephippial, A., Nasal, and
A., Nasobasal. A., Xiphoid, in anatomy, that formed by the sides of the xiphoid notch. A. y., that one of Lissauer's angles included between the radius fixus and a line joining the lambda and inion.

Angleberry (ang-gl-ber-e) [M. E., angle; bery]. Butchers' name for bovine tuberculosis. See Grapes.

Anglesey Leg (ang'-gl-se leg) [so called after the Marquis of Anglesey]. An artificial limb formed from a solid piece of wood hollowed out to receive the stump and provided with a steel joint at the knee. The ankle joint was made of wood, to which motion was communicated by strong cat-gut strings posteriorly and a spiral spring anteriorly.

Anglicus sudor $\left(a n g^{\prime}-l i k-u s\right.$ su'-dor) [L.]. English sweating fever. A contagious malignant fever, also known as Ephemera maligna, characterized by black or dark-colored sweat.

Anglo-Swiss Food, an artificial infant food with the following composition: Water, 6.54 ; fat, 2.72 ; grapesugar and milk-sugar, 23.29; cane-sugar, 21.40; starch, 34.55 ; soluble carbohydrates, 46.43 ; albuminoids, I0.26; ash, I.20.

Angophrasia (ang-go-fra'-ze-ah) [ä $\gamma \chi \varepsilon t v$, to choke; $\phi \rho a ́ \sigma \iota \varsigma$, utterance]. A speech-defect consisting of a choking, drawling, and agitated utterance, with repetitions and nasal sounds, occurring in paralytic dementia.

Angor (ang'-gor) [angor, a strangling]. Synonymous with Angina. Applied by some to epigastric pain.

Angry (ang'-gre) [M. E., angerich]. Characterized by acute inflammation and pain, as an angry sore.

Angström's Law. See Law.

Anguilulidæ (ang-gwill-u-lid-e) [anguilla, an eel]. The small nematoid worms that live in vinegar and sour paste.

Anguilliform (ang-gwill-if-orm) [anguilla, an eel; forma, form]. In biology, having the characters or form of an eel.

Anguillula (ang-gwill-u-lah) [dim. of anguilla, an eel]. A genus of parasitic round worms. A. Stercoralis. See Thread-worms and Parasites, Animal, Table of.

Anguine (ang'-gwin) [anguis, a snake]. In biology, snake-like.

Anguish (ang'-gzuish) [angustia, narrowness, distress]. Extreme bodily or mental distress.

Angular (ang'-gu-lar) [angulus, an angle]. Pertaining to an angle. A. Artery and Vein, the terminal branches of the facial artery and vein. A. Gyrus, or Convolution, the pli courbe, a convolution of the brain. A. Movement, the movement between two bones that may take place forward and backward, or inward and outward. A. Processes, the external and internal extremities of the orbital arch of the frontal bone.

Angularis scapulæ Muscle (ang-gu-la'-ris skap'-u-le). The levator anguli scapula. See Muscles, Table of. Anguliferous (ang-gu-lif'-er-us) [angulus, an angle; ferre, to bear]. In biology, having the last whorl angled or cornered.

Angulinerved (ang'-gu-lin-ervd) [angulus, an angle; nervum, a nerve]. In biology, said of leaves in which the veins or nerves diverge from the midrib; pinnately nerved.

Angulo-dentate (ang'-gu-lo-den'-tāt) [angulus, an angle; dentatus, toothed]. With angular teeth.

Angulus (angr'-gu-lus) [L.]. See Angle.

Angustate (ang-gus'-tāt) [angustare, to straiten; to narrow]. Narrow.

Angustia (ang-gus'-te-ah) [L.]. Constriction; abnormal narrowness; distress.

Angusticollis (ano-gus-te-kol'-is) [angustus, narrow; collum, a neck]. In biology, with a slender neck. 
Angustidentate (ang-gus-te-den'-tāt) [angustus, nar row; dens, a tooth]. In biology, with slender teeth.

Angustifoliate (ang-grus-te-fo'-le-eat) [anguestus, narrow; foliatus, leaved]. In biology, with narrow leaves.

Angustirostrate (ang-gus-te-ros'-trät) [angustus, narrow; rostrum, beak]. In biology, having a narrow or compressed beak.

Angustiseptate (ang-gus-te-sept-tāt) [angustus, narrow ; septum, a partition]. In biology, having a narrow septum.

Angustura (ang-gus-t $\left.u^{\prime}-r a h\right)$ [Sp., Angostura, a S. A. town]. Cusparia Bark. The bark of Galipea cusparia. A stimulant tonic and febrifuge used in malignant bilious fever, intermittent fever, and dysentery. In large doses emetic. Dose of fld. ext. $\eta x-x x x$; of the bark gr. $x-x l$. Unof, Infus, Cuspariæ (B. P.). Dose $\overline{3} \mathrm{i}-\mathrm{ij}$.

Angusturin (ang-gus'-tu-rin) [Sp., Angostura, a S. A. town]. Synonym of Brucin, $q . v$.

Anhaloin (an-hal'-o-in) [Anhalonium]. An intensely poisonous alkaloid, derived from the fruit of Anhalonium (Mamillaria) lewinii, a cactus. It produces collapse, followed by tetanus. Unof.

Anhalonium lewinii (an-ha-lo'-ne-um le-win'-e-i) [L.]. The cactus of this name is a native of Mexico. Its active principle is intensely poisonous and resembles strychnin in action. Dose of the extract gtt. $j$. Unof.

Anhaphia $\left(a n-h a^{\prime}-f e-a h\right)$. See Anaphia.

Anhela (an-he'-lah) [anhelatio, asthma]. A difficulty in breathing. A. amphemerina, A. asinina, A. canina, A. clamosa, A. clangosa, A. delassans, A. perennis, A. puerilis, A. spasmodica, A. strangulans, A. suffocans, A. tussiculosa, synonyms of Pertussis.

Anhelation (an-he-la'-shun) [anhelare, to pant]. Shortness of breath; dyspnea.

Anhematosis (an-hem-at-o'-sis) [av priv.; áiuatóelv, to make bloody]. Defective formation of the blood.

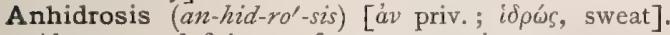
Absence or deficiency of sweat excretion.

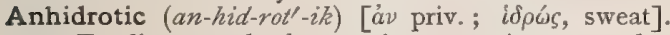
I. Tending to check sweating. 2. An agent that checks sweating.

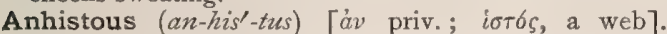
Structureless; not organized; plasmic.

Anhydremia (an-hi-dre'-me-ah) [áv priv.; v" $\delta \omega \rho$, water; ai $\mu a$, blood]. The opposite of hydremia; an abnormal decrease in the relative proportion of the water to that of the salts of the blood.

Anhydrid ( $\left.a n-h i^{\prime}-d r i d\right)$ [áv priv. ; $v \delta \omega \rho$, water]. One of a class of chemic compounds that may be regarded as made up of one or more molecules of water in which the whole of the hydrogen is replaced by negative or acid radicals (that may themselves contain hydrogen).

Anhydro-ecgonin (an-hi'-dro-ek'-go-nin) ['av priv.; $\ddot{v} \delta \omega \rho$, water; $\dot{\varepsilon} \kappa$, out of; yovós, born]. A basic substance in the cocain and ecgonin series, but more remote from cocain than ecgonin.

A n hydro-glycochloral (an-hi'-dro-gli-ko-klo'-ral). See Chloralose.

Anhydromyelia (an-hi-dro-mi-e'-le-ah) [àv priv.; $v \delta \omega \rho$, water; $\mu v \varepsilon \lambda \dot{v} v$, marrow $]$. A deficiency of the fluid that normally fills the spinal cavity.

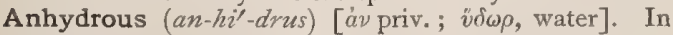
chemistry, a term used to denote the absence of hydroxyl or of constitutional water.

Anhysteria (an-his-te'-re-ah) [àv priv.; vorépa, the womb]. Absence of the uterus.

Anideus $\left(a n-i d^{\prime}-e-u s\right)$ [à priv.; $\varepsilon i \delta o s$, form]. The lowest form of omphalosite, in which the parasitic fetus is reduced to a shapeless mass of flesh covered with skin.

Anidous $\left(a n-i^{\prime}-d u s\right)$ [áv priv. ; $\varepsilon i \delta o s$, form]. Formless, from general arrest of development; used of fetal monsters.

Anidrosis (an-id-rol-sis). See Anhidrosis.

Anidrotic (an-id-rot'-ik). See Anhidrotic.

Anile $\left(a n^{\prime}-i l\right)$ [anitis, an old woman]. Imbecile.

Anilid $\left(a n^{\prime}-i l-i d\right)$ [Arab., $a l$, the; nìl, dark blue]. Compounds formed by the action of acid chlorids or acid anhydrids upon the anilins. They are very stable derivatives.

Anilin $\left(a n^{\prime}-i l-i n\right)$ [Arab., $a l$, the; nill, dark blue], $\mathrm{C}_{6} \mathrm{H}_{7} \mathrm{~N}$. Amidobenzene; formed in the dry distillation of bituminous coal, bones, indigo, isatin, and other nitrogenous substances. It is made by reducing nitrobenzene. It is a colorless liquid with a faint peculiar odor, boiling at $183^{\circ}$; its sp. gr. at $0^{\circ}$ is 1.036 . When perfectly pure it solidifies on cooling, and melts at $-8^{\circ}$. It is slightly soluble in water, but dissolves readily in alcohol and ether. Combined with chlorin, the chlorates, and hypochlorites, the various anilin dyes are produced. It is a powerful narcotic poison. It is used in chorea and epilepsy with benefit in one-half grain doses. Unof. A. Black, $\mathrm{C}_{18} \mathrm{H}_{15} \mathrm{~N}_{3}$, one of the indulins formed by the oxidation of anilin by means of potassium chlorate in the presence of copper or vanadium salts. It is a dark-green amorphous powder, insoluble in the ordinary reagents, and is used in calico printing as a black color. See Conspectus of Pigments, under Pigment. A. Colors. See Conspectus of Pigments, under Pigment. A. Red. See Fuchsin. A. Sulphate, $\left[\mathrm{C}_{6} \mathrm{H}_{3} \mathrm{NH}_{2}\right] \mathrm{SO}_{4} \mathrm{H}_{2}$, used as a test for lignin. See Stains, Table of. A. Violet. See Tyrolin.

Anilinophile (an-il-in'-o-fll) [anilin; $\phi i \lambda \varepsilon \varepsilon c \nu$, to love]. Readily stained with anilin.

Anilism $\left(a n^{\prime}-i l-i z m\right)$ [anilin]. An acute or chronic disease produced in workmen in anilin factories by the poisonous fumes.

Anility $\left(a n-i l^{\prime}-i t-e\right)$ [anilis, an old woman]. The state of being imbecile or childish.

Anima (an'-im-ah) [animus, spirit]. The soul; the vital principle; formerly, the active principle of a drug or medicine.

Animal (an'-im-al) [anima, the spirit, breath, or life]. An organic being having life and power of motion. Pertaining to the same. The animal kingdom is composed of the Vertebrata, Mollusca, Articulata, and Radiata. A. Black. See Conspectus of Pigments, under Pigment. A. Charcoal, bone-black, ivoryblack, etc., is the product of calcining bones in close vessels. A. Chemistry, that concerning itself with the composition of animal bodies. A. Electricity, electricity generated in the body. A. Function, any physiological action or process. A. Gum, $\mathrm{C}_{12} \mathrm{H}_{20} \mathrm{O}_{10}+$ $2 \mathrm{H}_{2} \mathrm{O}$. A substance prepared from mucin by Landwehr, and so named on account of its resemblance to the gum of commerce. It occurs in many tissues of the body, is soluble in water, and in alkaline solution readily dissolves cupric oxid, the solution not being reduced on boiling. It yields no coloration with iodin, and is very feebly dextrorotatory. A. Heat, the normal temperature of the body, about $98.5^{\circ} \mathrm{F}$. A. Kingdom, a name for all animals considered collectively. A. Magnetism, mesmerism, hypnotism, etc. A. Oil. See Dippel's Oil. A. Starch. See Glycogen. A. Tissue. See Tissue.

Animalcule $\left(a n-i m-a l^{\prime}-k \bar{u} l\right)$ [animalculum, dim. of animal, a minute animal: pl., Animalcula]. An organism so small as to require the microscope for its examination. 
Animalculism (an-im-al'-ku-lizm) [animalculum, a little animal]. See Spermism and Incasement.

Animalculist (an-im-al'-ku-list) [animalculum, a little animal]. See Incasement.

Animalization (an-im-al-iz-a'-shun) [animalis, animate]. The process of assimilating food to the tissues of the body

Animation (an-im-a'-shun) [animare, to have life or existence]. To be possessed of life. Formerly used to denote the effect of the vital principle by which the fetus acquires the power of continuing its existence. A., Suspended, a condition marked by interrupted respiration and consciousness; caused by strangulation, the inhalation of carbon dioxid or other gases, etc.

Anime $\left(a n^{\prime}-i m-e\right)$ [Fr., animé, origin doubtful]. A name of various resins, especially that of Hymenca courbaril, a tree of tropical America; sometimes used in plaster, etc. Unof. See Copal.

Animism $\left(a n^{\prime}-i m-i z m\right)$ [anima, soul]. Stahl's theory of life and disease, namely, that the soul is the source of both normal and pathologic activities.

Anion $\left(a n^{\prime}-e-o n\right)$ [ává, up; ‘́w , going]. In electrolysis, an electro-negative element. See Ion.

Anions $\left(a n^{\prime}-e-o n s\right)$ [ávíw, going up]. The atoms that collect around either pole when a compound is decomposed by electricity.

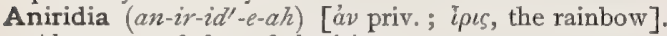
Absence or defect of the iris.

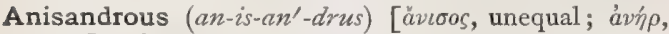
male]. Same as Anisostemenous.

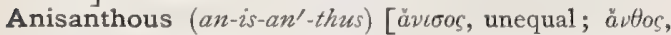
flower]. In biology, varying as to the form of the perianth.

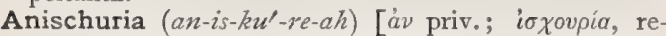
tention of urine 1. Enuresis or incontinence of urine.

Anise $\left(a n^{\prime}-i s\right)$. See Anisum.

Anisic $\left(a n-i s^{\prime}-i k\right)$ [anisum, anise]. Pertaining or belonging to anise. A. Acid. See Acid. A. Aldehyd. See Aldehyd.

Anisin $\left(a n^{\prime}-i s-i n\right)$ [anisum, anise], $\mathrm{C}_{22} \mathrm{H}_{24} \mathrm{~N}_{2} \mathrm{O}_{3}$. An artificial crystalline alkaloid, a derivative of anise.

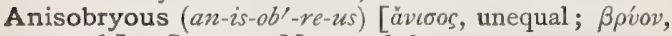
growth]. Same as Monocotyledonous.

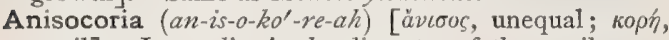
pupil]. Inequality in the diameter of the pupils.

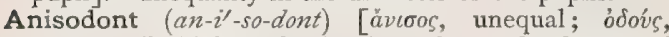
tooth]. In biology, having irregular teeth of unequal length.

Anisognathous (an-is-og'-na-thus) [ävioos, unequal; yváfos, jaw]. In biology, having the two jaws unlike as to the molar teeth.

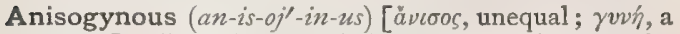
female]. In biology, with fewer carpels than sepals.

Anisol $\left(a n^{\prime}-i s-o l\right)$ [anisum, anise], $\mathrm{C}_{7} \mathrm{H}_{8} \mathrm{O}$. Methyl phenyl ether, produced by heating phenol with potassium and methyl iodid or potassium methyl sulphate in alcoholic solution. It is an ethereal-smelling liquid, boiling at $152^{\circ}$; its sp. gr. at $\mathbf{I} 5^{\circ}$ is 0.991 .

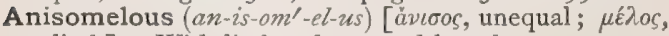
a limb]. With limbs of unequal length.

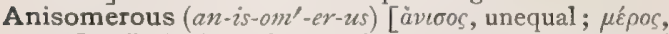
part]. In biology, having the parts or organs unequal in successive series, as parts of the flowers in different whorls, or ridges, or successive molar teeth.

Anisometropia (an-is-o-me-tro'-pe-ah) [ảv priv.; i $\sigma o s$,

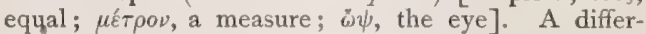
ence in the refraction of the two eyes.

Anisometropic (an-is-o-me-trop'-ik) [ảv priv.; i $\sigma o s$,

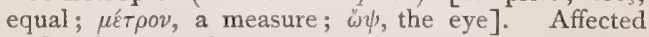
with anisometropia.

Anisopetalous (an-is-o-pet'-al-us) [àvons, unequal;

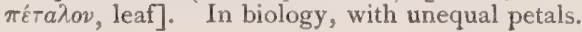

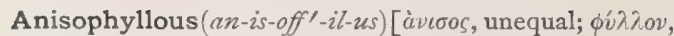
leaf]. In biology, applied to the leaves of a pair of whorls when they are unequal.

Anisopia (an-is-o'-pe-ah) [àvloos, unequal; $\omega \psi$, eye]. Inequality of visual power in the two eyes.

Anisopleural (an-is-o-plu'-ral) [àvloos, unequal; $\pi \lambda \varepsilon v p a ́$, the side]. In biology, bilaterally asymmetric.

Anisopogonous (an-is-o-pogr-o-nus) [ävroos, unequal; $\pi \omega \gamma \omega \nu$, beard]. In biology, applied to feathers the vanes of which are asymmetric.

Anisopterous (an-is-oṕlter-us) [àvtoos, unequal; $\pi \tau \varepsilon \rho \delta ́ \nu$, a wing]. In biology, with asymmetric or unequal wings.

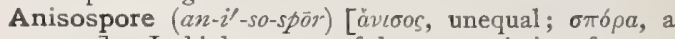
spore]. In biology, one of the two varieties of spores produced by colonial species of Radiolarians.

Anisostemenous (an-iswo-stem'-en-us) [ávıos, unequal; $\sigma \tau \eta \dot{\mu} \omega \nu$, a thread]. In biology, applied to plants the stamens of which are not of the same number as the petals.

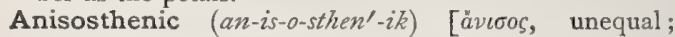
oӨćvos, strength]. Not of equal power; used of pairs of muscles, etc.

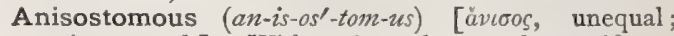
$\sigma \tau b \mu a$, mouth]. With an irregular mouth or orifice.

Anisotropic $\left(a n-i s-o-t r o p^{\prime}-i k\right)$ [àvioos, unequal; $\tau \rho \measuredangle \pi \circ$, turning]. Not possessing the same properties in all directions with respect to light. In biology, varying in irritability in different parts or organs.

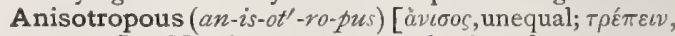
to turn]. Not isotropous; not having the same refracting power in all directions. A term applied to doubly refracting bodies.

Anisum $\left(a n^{\prime}-i s-u m\right)$ [L.; gen., Anisi]. Anise. The fruit of Anisum pimpinella. Its properties are due to a volatile oil. It is slightly stimulant to the heart action. It is useful chiefly to liquefy bronchial secretions, and is therefore a favorite ingredient in cough mixtures. Dose gr. $\mathrm{x}-\mathrm{xx}$. A. Aqua, oil of anise $\mathbf{I}$, water 500 parts. Dose indefinite. A. Essentia (B. P.). Dose $\eta_{x-x x}$. A. Oleum, an ingredient in tinct. opii camph. Dose, $m_{j}-v$. A. Spt., a ten per cent. solution of the oil in alcohol. Dose, $3 \mathrm{i}-\mathrm{ij}$.

Anisyl (an'-is-il) [anisum, anise], $\mathrm{C}_{8} \mathrm{H}_{7} \mathrm{O}_{2}$. ${ }^{\prime} \mathrm{A}$ hypothetic radicle supposed to be found in anise and its derivatives.

Anitrogenous (ah-ni-troj'-en-us) [ $\dot{\alpha}$ priv.; nitrum, niter; $\gamma \varepsilon v$ 'n, producing]. Non-nitrogenous.

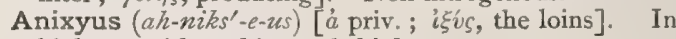
biology, without hips and thighs.

Ankle $\left(a n g^{\prime}-k l\right)$ [M. E., ancle]. The joint between the tibia and fibula above and on the sides, and the astragalus below. It is a ginglymus joint, with three ligaments, the anterior, internal, and external. A.-bone, the astragalus. A. Clonus, the succession of a number of rhythmic muscular contractions in the calf of the leg, when the limb is extended and the foot flexed suddenly by a pressure upon the sole. It is a symptom of various diseases of the myelon, such as meningo-myelitis. See Reflexes, Table of. A.-jerk. See A. Clonus, A.-joint. See Ankle, In biology, the tarsal joint. A. Reflex. See $A$. Clonus.

Anklet $\left(a n g k^{\prime}-l e t\right)$ [M. E., ancle]. A leathern band to pass around and support the ankle.

Ankuroid (ang'-ku-roid). See Ankyroid.

Ankylenteron (ang-kil-en'-ter-on) [á $\gamma \kappa \dot{\lambda} \lambda \eta$, a coil ;

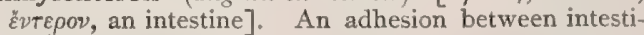
nal coils.

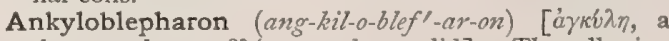
thong or loop; $\beta \lambda \varepsilon$ éapov, the eyelid]. The adhesion of the ciliary edges of the eyelids. 


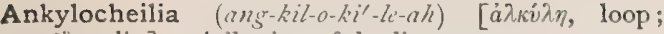
xeitos, lip]. Adhesion of the lips.

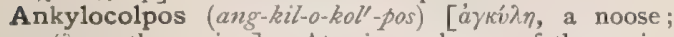
$\kappa \delta \lambda \pi \%$, the vagina]. Atresia or closure of the vagina or vulva.

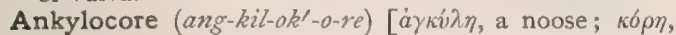
the pupil]. Obliteration of the pupil by closure and adhesion.

Ankylodontia (ang-kil-o-don'-she-ah) [ả $\gamma \kappa \hat{\lambda} \lambda \eta$, a loop; odous, a tooth]. Irregularity in the position of the teeth.

Ankyloglossia (ang-kil-o-glos'-e-ah) [ảykíñn, a noose; $\gamma \lambda \tilde{\omega} \sigma \sigma a$, the tongue]. Tongue-tie.

Ankyloglossotome (ang-kil-o-glos'-o-tōm) [ả noose; $\gamma \lambda \bar{\omega} \sigma \sigma a$, the tongue; $\tau \delta \dot{\mu} \eta$, a cut]. An instrument used in treating tongue-tie.

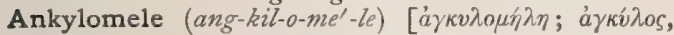
bent; $\mu \dot{\eta} \lambda \eta$, a probe]. A curved probe.

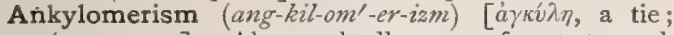
uर́pos, a part]. Abnormal adherence of parts to each other.

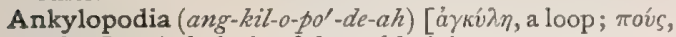
a foot]. Ankylosis of the ankle-joint.

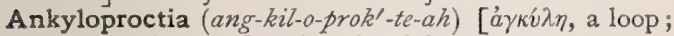
$\pi \rho \omega k \tau 6 s$, the anus]. Atresia of the anus.

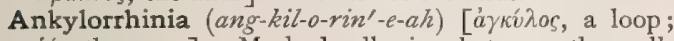
pis, the nose]. Marked adhesion between the walls of a nostril.

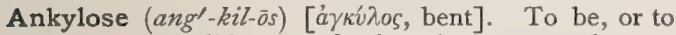
become, consolidated or firmly united, as two bones; used commonly of pathologic, but sometimes of normal, union.

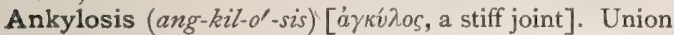
of the bones forming a joint, resulting in a stiff joint. A., False, or Spurious, is due to the rigidity of surrounding parts. A., True, or Bony, when the connecting material is bone. A., Ligamentous, when the medium is fibrous.

Ankylostoma (ang-kil-os'-to-mah), or Ankylostomum

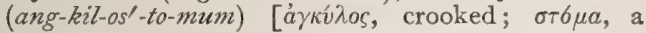
mouth]. A genus of nematoid worms, one species of which, $A$. duodenale, is found in the human intestine. This is now referred to the genus Dochmius. See Ankylostomiasis.

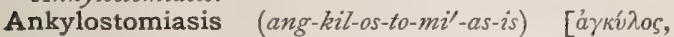
crooked; $\sigma \tau b \mu a$, a mouth]. A peculiar anemia produced by the parasite Ankylostoma duodenale (Dochmius duodenalis. Leuck), sucking the blood from the walls of the duodenum. It is especially prevalent among brickmakers and other workmen in Europe. It is called also Dochmiasis, Brickmakers' Anemia, Tunnel Anemia, Miners' Cachexia, Egyptian Chlorosis, Tropical Chlorosis, etc. Male fern and thymol expel the worm.

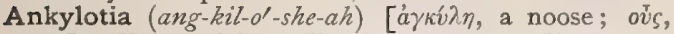
ear]. Union of the walls of the meatus auditorius.

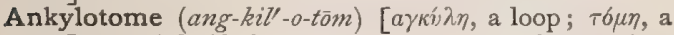
cut]. I. A knife for operating on tongue-tie. 2. Any curved knife.

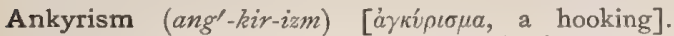
Articulation or suture by one bone hooking upon another.

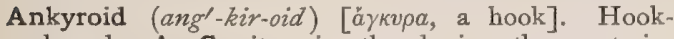
shaped. A. Cavity, in the brain, the posterior cornu of the lateral ventricle. A. Process, the coracoid process.

Anlage ( $\left.a n^{\prime}-l a g-e\right)$ [Ger., "a laying out"]. In biology, a term adopted from the German to indicate (I) a primary constituent of the germ or organism; (2) a constitutional predisposition.

Annandale's Operation. See Operations, Table of. Annatto $\left(a n-a t^{\prime}-o\right)$. See Annotto.
Anneal ( $\left.a n-\bar{e} l^{\prime}\right)$ [Saxon, annelan, to heat]. To heat and cool slowly, as gold or other metals.

Annealing (an-êl'-ing) [Saxon, annelan, to heat]. The process of applying heat to a metal for the purpose of removing brittleness and increasing its ductility and malleability.

Annectent (an-ek'-tent) [ad, to; nectere, to bind]. In biology, linking or binding together.

Annelism $\left(a n^{\prime}-e l-i z m\right)$ [anellus, dim. of annulus, a ring]. In biology, possessing a ringed structure.

Annidalin (an-id'-al-in). See Aristol.

Annotin (an'-o-tin) [annotinus, of last year]. In biology, one year old.

Annotinous (an-ot'-in-us) [annotinus, of last year]. In biology, having distinct yearly growths.

Annotto $\left(a n-o t^{\prime}-a\right)$ [native American]. Annatto, arnotto. A coloring matter obtained from the pellicles of the seeds of Bixa arellana. L. Used to color plasters. Also employed as an artificial color for butter. See Pigments, Conspectus of.

Annual $\left(a n^{\prime}-u-a l\right)$ [annus, a year]. Yearly. In biology, plants that mature and die in one year.

Annuens $\left(a n^{\prime}-u-e n z\right)$ [annuere, to nod]. The rectus capitis anticus minor muscle. See Muscles, Table of.

Annuent (an'-u-ent) [annuere, to nod]. Serving to bend the head forward; as annuent muscles.

Annular (an'-u-lar) [annulus, a ring]. Ring-like. A number of ligaments of the joints are called annular, as those of the ankle, wrist, etc. A. Cartilage, the cricoid cartilage. A. Finger, the ring finger. A. Muscle of $\mathbf{M}$ üller, the circular fibers of the ciliary muscle. A. Process, or Protuberance, the pons varolii. A. Reflex (of macula), a ring-like reflection sometimes seen with the ophthalmoscope surrounding the macula.

Annulism (an'-u-lizm) [annulus, a ring]. The state or quality of being ringed, as shown in certain worms.

Annulose $\left(a n^{\prime}-u-l o ̄ s\right)$ [annulus, a ring]. In biology, possessing rings.

Annulus (an'-u-lus) [annulus, a ring]. A ring-shaped or circular opening. A circular or rounded margin. In biology, an encircling band, as those about the capsules of mosses; the spore-cases of ferns, the mantle. Cf. Molluscs, etc. A. abdominalis, the external and internal abdominal rings. A. abdominis, the inguinal ring. A. ciliaris, the boundary between the iris and choroid. A. fibrosus, the external part of the intervertebral discs. A. membrani tympani, an incomplete bony ring that forms the fetal auditory process of the temporal bone. A. osseus, the tympanic plate. A. ovalis, the rounded or oval margin of the Foramen ovale. A. subgenitalis, a firm, cartilaginous-like, subgenital ring, the supporting plate of the subumbrella in medusæ. A. tracheæ, any tracheal ring. A. umbilicus, the umbilical ring. A. of Vieussens. Same as $A$. ovalis.

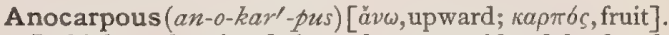
In biology, bearing fruit on the upper side of the frond.

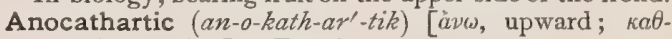
a

Ano-coccygeal $\left(\alpha-n o-k o k-s i j^{\prime}-e-\alpha l\right)$ [anus, the funda-

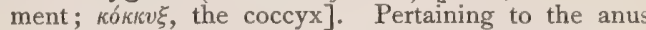
and the coccyx. A. Ligament, connects the tip of the coccyx with the external sphincter ani muscle.

Anodal (an'-o-dal) [ává, up; ódós, a way]. Relating to an anode; electrically positive. A. Diffusion. Same as Cataphoresis. A. Opening Contraction. See Contraction.

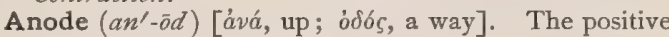
pole of a galvanic battery.

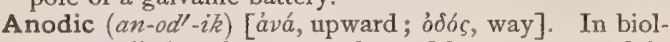
ogy, applied to the upper edges of leaves arranged in ascending spirals. 
Anodontia (an-o-don'-she-ah) [áv priv.; bdov́s, tooth]. Absence of the teeth.

Anodyne $\left(a n^{\prime}-o-d i n\right)$ [àv priv, ; ódv́vz, pain]. A medicine that gives relief from pain. From their tendency to produce sleep they are called hypnotics. A., Hoffman's. See Ether.

Anodynia $\left(a n-o-d i n^{\prime}-e-a h\right)$ [àv priv.; ódúm, pain]. Absence of pain.

Ancea $\left(a n-e^{\prime}-a h\right)$. See Anoia.

Anoesia $\left(a n-o-e^{\prime}-z e-a h\right)$ [ávonoía, a want of sense]. Want of understanding.

Anogenic $\left(a n-o-j e n^{\prime}-i k\right)$ [ává, upward; yevńs, produced]. In biology, of ascending or inward growth.

Anoia $\left(a n-o i^{\prime}-a h\right)$ [ävola, idiocy]. Synonym of Idiocy. Anol $\left(a n^{\prime}-o l\right)$ [see Anethol], $\mathrm{C}_{9} \mathrm{H}_{10} \mathrm{O}$. A substance obtained from anethol by heating it with caustic alkali to $200-230^{\circ}$ It consists of brilliant leaflets, melting at $92^{\circ}$.

Anomaliflorous (an-om-al-if-lo'-rus) [anomalus, irregular; flos, flower]. In biology, bearing irregular flowers.

Anomaliped (an-om'-al-ip-ed) [anomalus, irregular; pes, foot]. In biology, characterized by having one of the phalanges of the middle toe joined to the inner toe, and three to the outer toe, as in syndactylous birds, the kingfisher, etc.

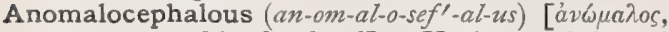
strange; $\kappa \varepsilon \phi \alpha \lambda \eta$, the head]. Having a deformed head.

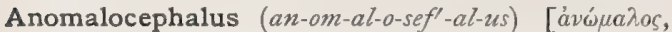

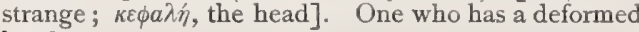
head.

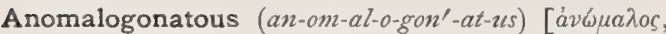
strange; yovátıov, hip-joint]. In biology, said of birds (Passeres) having no ambiens muscle.

Anomalous (an-om'-al-us) [ávw $\mu a \lambda o s$, not ordinary]. Irregular; characterized by deviation from the common or normal order.

Anomalus $\left(a n-o m^{\prime}-a l-u s\right)$ [ávbuà̃os, not ordinary]. A muscle or muscular slip sometimes occurring beneath the levator labii superioris alæque nasi.

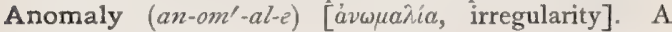
marked deviation from the normal or typical structure or occurrence.

Anomobranchiate (an-o-mo-brang'-ke-āt) [àvouos, irregular; $\beta \rho a ́ \gamma \chi \iota a$, gills]. In biology, characterized by having anomalous gills.

Anomo-carpous (an-o-mo-kar'-pus) [àvouos, irregular; $\kappa a \rho \pi \delta \varsigma$, fruit]. In biology, producing anomalous or irregular fruits.

Anomocephalus (an-o-mo-sef'-al-us) [á priv,; vónos,

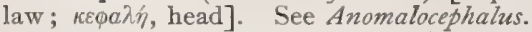

Anomophyllous (an-o-mof'-il-us) [á priv.; vóuos, a law; $\phi \dot{u} \lambda \bar{\imath} o v$, a leaf ]. In biology, with irregularlyarranged leaves.

Anomphalous $\left(a n-o m^{\prime}-f a l-u s\right)$ [àv priv.; $\dot{\alpha} \mu \phi a \lambda \sigma c$, navel]. Having no navel, a condition that may result from disease or from a surgical operation.

Anomural (an-o-mu' ral) [àvouos, irregular; ov́ó, tail]. In biology, characterized by having a small, irregular tail.

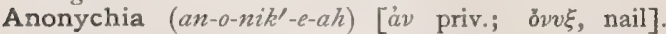
Absence or defect of the nails.

Anonym (an'-o-nims) [ávívvros, nameless]. In biology, an insignificant or unscientifically formed name.

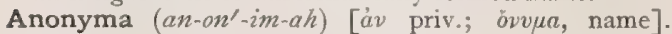
The innominate artery.

Anonymous (an-on'-im-us) [ảv priv.; övvua, a name]. Nameless. A. Bone. See Innominatum.

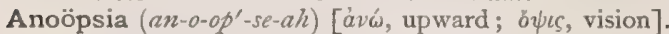
Strabismus in which the eye is turned upward.

Anophthalma (an-off-thal'-mah). See Anophthalmia.
Anophthalmia (an-off-thal'-me-ah) [ảv priv.; ó $\theta a \lambda u o ́ s$, eye]. Congenital absence of the eyes. A. cyclopica, a congenital malformation in which the eyesocket is very ill-developed and the orbit rudimentary or altogether absent.

Anophthalmos (an-off-thal'-mus) [áv priv.; $\dot{\phi} \theta a \lambda \mu \delta \varsigma$, eye]. I. Congenital absence of the eyes. 2. A person born without eyes.

Anopia $\left(a n-o^{\prime}-p e-a h\right)$ [a $\alpha \nu$ priv.; $\omega \psi$, the eye]. Absence or rudimentary development of the eye.

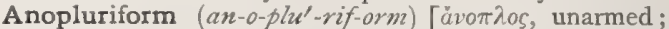
ovipá, tail; forma, form]. Resembling or related to a louse.

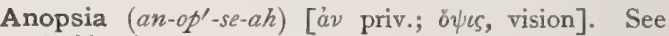
Amblyopia.

Anopsy (an'-op-se). Same as Anopsia.

Anopylus $\left(a n-o-p i^{\prime}-l u s\right)$ [àv $\omega$, forward; $\pi \hat{v} \lambda \eta$, a gate]. Lissauer's term for a skull in which there is a strong forward inclination of the foramen magnum.

Anorchia (an-or'-ke-ah). See Anorchism.

Anorchism (an'-or-kizm) [av priv. ; $\not \rho \chi \iota s$, the testicle]. Absence of the testicles.

Anorchous (an-or'-kus) [av priv.; $a \rho \chi \iota \varsigma$, the testicle]. Without testicles.

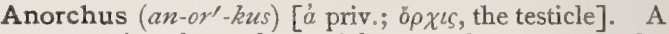
person in whom the testicles are absent or not descended.

Anorectic, Anorectous (an-o-rek'-tik, an-o-rek'-tus) [áv priv.; ó $\rho \xi \iota \varsigma$, appetite]. Without an appetite.

Anorexia $\left(a n-o-\gamma e k^{\prime}-s e-a h\right)$ [áv priv. ; o $\rho \varepsilon \xi \iota s$, appetite]. Absence or diminution of appetite, occurring in gastric diseases, fevers, and many chronic affections. A., Hysteric. See Apepsia, Hysteric. A. nervosa, an hysteric affection occurring chiefly in young neurotic females. It is characterized by extreme emaciation. and a great aversion to food.

Anorganic (an-or-gan'-ik) [á priv. ; ópyavov, an organ]. Not containing organs, as the epidermis.

Anorhin $\left(a n^{\prime}-o r-i n\right)$ [àvw, upward; pis, the nose]. A term applied by Lissauer to skulls in which the subnasal point lies above the radius fixus taken as a horizontal.

Anorophos (an-o'-ro-fos) [áa priv.; ópoфos, a roof ]. Not having the skull-cap.

Anorthopia (an-or-tho'-pe-ah) [áv priv. ; o $\rho \theta b s$, straight ; $o$ o $\iota$, vision]. x. A defect in vision in which straight lines do not seem straight, and parallelism or symmetry is not properly perceived. 2. Squinting; obliquity of vision.

Anorthosis (an-or-tho'-sis) [àv priv. ; b̆ $\theta \omega \omega \iota \iota$, a making straight]. Absence or defect of erectility.

Anosia $\left(a n-o^{\prime}-s e-a h\right)$ [ $a$ priv.; vóoos, disease $]$. Without disease; normal health.

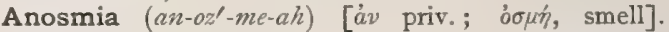
Partial or complete loss of the sense of smell, due either to local disease or disease of the olfactory nerves or bulb. It is associated with impairment or loss of the sense of taste.

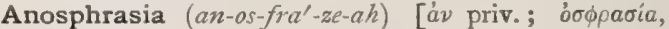
smell]. Defect or absence of the sense of smell.

Anosphresia (an-os-fre'-se-ah). See Anosphresis.

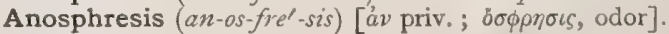
Same as Anosphrasia.

Anosphresy (an-os'-fre-se). See Anosphresia.

Anospinal (a-no-spi'-nal) [anus, the fundament; spina, the backbone]. Relating to the anus and the spinal cord. A. Center is situated in the lumbar portion of the spinal cord; it controls the anal sphincters.

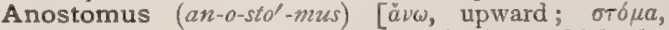
mouth]. Lissauer's term for a skull in which the alveolar point is elevated above the radius fixus, the latter being horizontal. 
Anostosis (an-os-to'-sis) [àv priv. ; óctéov, bone]. Defective development of bone.

Anotus (an-o'-tus) [áv priv, ; ois, the ear]. An earless monstrosity.

Anovesical (a-no-ves'-ik-al) [anus, the fundament; vesica, the bladder]. Pertaining conjointly to the anus and urinary bladder.

Anoxyemia (an-oks-e-e'-me-ah) [ảv priv.; oxygen; ai ua, blood]. An abnormal condition due to the breathing of an insufficient amount of oxygen; mountain sickness; balloon sickness.

Ansa $\left(a n^{\prime}-s a h\right)$ [L., a "handle :" pl., Ansa ]. A loop or curved structure suggesting by its form the handle of a vessel; a loop in a nerve, intestine, or vessel, or in a surgeon's thread. A. capitis, the zygomatic arch. A., Haller's, the loop formed by the nerve joining the facial and glosso-pharyngeal nerves. A., Henle's. See Henle's Loop. A. hypoglossi, a loop formed at the middle of the neck by the junction of the descendens noni nerve with branches of the second and third cervical nerves. A. of Reil, the name given to that portion of the brain just ventrad of the thalamus. A. sacralis, a loop joining the ganglion impar (G. Walteri) with the sympathetic trunks of the two sides. A. of Vieussens, a loop extending from the third cervical ganglion and surrounding the subclavian artery. A. of Wrisberg, the nerve joining the right great splanchnic and right pneumogastric nerves.

Anserine (an'-ser-in) [anserinus; anser, a goose]. Resembling a goose. A. Disease, an emaciation of the hands, rendering the tendons unduly prominent, and suggesting the appearance of a goose's foot. A.

Skin. See Cutis anserina.

Anstie's Test. See Tests, Table of.

Ansulate $\left(a n^{\prime}-s u\right.$-lāt) [ansula, a little handle]. The coiled and bent-over extremity of a stem or tendril.

Ant-, Anti- (ant-or $\left.a n^{\prime}-t e\right)$ [ávrí, against]. Prefixes to compound words signifying opposed to, against, counteracting, etc.

Antacid (ant-as'-id) [anti, against; acidus, acid]. A substance counteracting or neutralizing acidity; an alkali.

Antacrid (ant-ak'-rid) [anti, against; acer, sharp]. Correcting acridity in the secretions. A. Tincture. See Guaiac Mixture, Fenner's.

Antadiform (ant-ad'-if-orm) [anti, opposite; $a d$, toward; forma, form]. In biology, having the dorsal and ventral contours inversely similar, as in certain fishes.

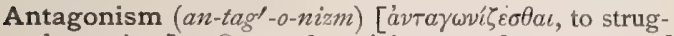
gle against]. Opposed activity, as of two sets of muscles or of two remedial agents.

Antagonist (an-tag-o-nist) [aviayovlotís, counteracting]. A term applied to a drug that neutralizes the therapeutic effects of another. In anatomy, a muscle that acts in opposition to another. Applied also to diseases that seem to exclude each other. See Drug. A., Associated, a name given to that muscle of a healthy eye that turns the globe in the same direction as the affected muscle of the opposite eye would, if normal, turn the eye to which it belongs.

Antagonistic (an-tag-o-nis'-tik) [ávtayoviorís, counteracting]. Opposing. A. Drugs, Table of. See Drug.

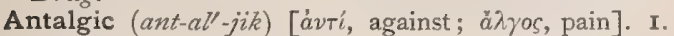
Relieving pain. 2. A remedy relieving pain.

Antalkaline (ant-al'-kal-in or -ên). An agent neutralizing alkalies, as acids.

Antambulacral $\left(a n t-a m-b u-l a^{\prime}-k r a l\right)$ [ávtí, against; ambulacrum, a walk]. In biology, located opposite or away from the ambulacra.

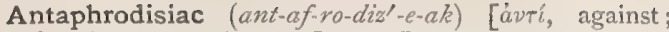
a $\phi p o \delta i \sigma i a$, sexual desire]. I. Lessening the venereal desires. 2. An agent that lessens the venereal impulse; an anaphrodisiac.

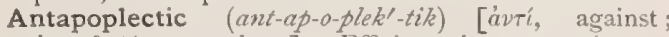
$\dot{a} \pi 0 \pi \dot{\lambda} \eta \xi i a$, apoplexy]. Efficient in preventing or treating apoplexy.

Antarthritic (ant-ar-thrit'-ik) [ảvti, against; $a \rho \theta \rho \iota \tau \iota k o ́ s$, gouty]. I. Relieving the gout. 2. A medicine for the relief of gout.

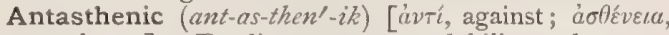
weakness]. Tending to correct debility and restore the strength.

Antasthmatic (ant-az-mat'-ik) [ảvTi, against; $\alpha{ }^{\prime} \sigma \mu \alpha$, short breath]. I. Relieving the asthma. 2. A medicine serving for the relief of asthma.

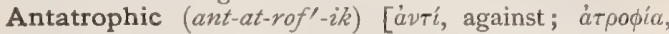
wasting]. I. Preventing atrophy. 2. A drug that will prevent wasting or atrophy.

Antebrachium (an-te-bra'-ke-um) [ante, before; brachium, the arm]. The forearm.

Antechamber (an'-te-chäm-ber) [ante, before; ME. chamber, a room]. In biology, the space between the guard-cells of a stoma.

Antecoxal (an-te-koks'-al) [ante, before; coxa, the hip joint]. In biology, located anterior to a coxa.

Antecurvature (an-te-ker'-vat-chür) [ante, forward; curvatus, bent]. A forward curvature.

Antedisplacement (an-te-dis-plās'-ment) [ante, forward; O. F., desplacer, to put out of place]. Forward displacement of a part or organ.

Antedonin (an-te-don'-in) [Antedon, a crinoid, from á $\vartheta \eta \delta \omega \nu$, the Greek medlar]. A pigment obtained from Comatula rosacea, a crinoid echinoderm.

Anteflexion (an-te-flek'-shun) [ante, before; flectere, to bend]. A bending forward. A. of Uterus, a condition in which the fundus sinks between the cervix and the neck of the bladder.

Antefurca (an-te-fer'-kah) [ante, before; furca, a fork]. In biology, a $Y$-shaped chitinous prop affixed to the under surface of the thorax of insects and projecting into the thoracic cavity. Cf. Medifurca and Postfurca.

Antegrade (an'-te-grād) [antegredi, to precede]. Anabolic; not retrograde or catabolic.

Antehelix (an-te-he'-liks). See Anthelix.

Antelocation (an-te-lo-ka'shun) [ante, before; locus, a place]. The forward displacement of an organ or viscus.

Antembasis (ant-em'-bas-is) [ávтદ́ $\mu \beta a \sigma \iota$, interlocking]. The setting or locking of bones.

Antemetic (ant-e-met'-ik). See Antiemetic.

Ante mortem (an'-te mor'-tem) [L.]. Before death.

Antenarial (an-te-na'-re-al) [ante, before; nares, the nostrils]. Situated in front of the nostrils.

Antenna (an-ten'-ah) [ávreíveıv, to stretch out]. In biology, one of the paired, articulated, sensory appendages of the head of an arthropod. One of a pair of long additions to the male flower in certain orchids.

Antennaria (an-ten- $\left.a^{\prime}-r e-a h\right)$. See Everlasting.

Anteocular (an-te-ok'-u-lar) [ante, before; oculus, the eye]. In biology, situated in advance of the eyes.

Anteoperculum (an-te-o-per'-ku-lum) [ante, before; operculum, a lid]. In biology, the Preoperculum,

Anteorbital (an-te-or'-bit-al) [ante, before; orbita, the track of a wheel]. In comparative anatomy, placed in advance of the eyes.

Ante partum $\left(a n^{\prime}-t e p a \gamma^{\prime}-t u m\right)[\mathrm{L}$.$] . Before delivery.$

Antepectoral (an-te-pek'-tor-al) [ante, before; pectus, the breast]. Placed in front of the chest.

Antepectus (an-te-pek'-tus) [ante, before; pectus, the breast]. In biology, the sternal region of the prothorax. 


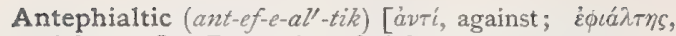
nightmare]. Preventive of nightmare.

Antepileptic (ant-ep-il-ep'-tik) [avтi, against; $\varepsilon^{\prime} \pi i \lambda \eta \psi \iota s$, epilepsy]. Relieving epilepsy.

Anteprostatic (an-ti-pros-tat'-ik) [ante, before; $\pi \rho \circ \sigma$ -

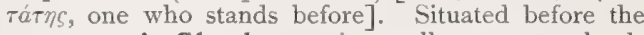
prostate. A. Glands, certain small accessory glands sometimes found between Cowper's gland and the prostate.

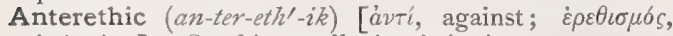
irritation]. Soothing; allaying irritation.

Anterior (an-te'-re-or) [anterius, forward]. Situated ventrad or hemad of a corresponding organ, the latter being designated as posterior (or posterius). A. Poliomyelitis, inflammation in the anterior horns of the spinal cord, giving rise to a characteristic paralysis; common in children. A. Rotation, the forward turning of the presenting part in labor.

Antero-(an'-te-ro-) [anterior, before]. A prefix signifying position in front.

Anterograde (an'-te-ro-gräd) [anterior, before; gredi, to go]. Proceeding from before; moving back.

Antero-inferior (an'te-ro-in-fe'-re-or) [anterior, forward; inferior, lower]. Situated in front and below.

Antero-lateral (an'-te-ro-lat'-er-al) [anterior, before; latus, a side]. In front and to or on one side; from the front to one side.

Antero-parietal (an'-te-ro-par-i'-et-al) [anterior, before; paries, a wall]. Anterior and also parietal. A Area, the anterior part of the parietal area of the cranium. A. Gyrus, or Convolution, the ascending frontal convolution of the brain.

Antero-posterior (an'-te-ro-pos-te'-re-or) [anterior, forward; posterior, backward]. From before backward. A. Plane. See Median plane.

Antero-superior (an'-te-ro-su-pe'-re-or) [anterior, forward; superior, upper]. In front and above.

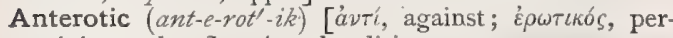
taining to love]. Anaphrodisiac.

Ante-uterine $\left(\right.$ an-te- $u^{\prime}$-ter-in) [ante, before; uterus, the womb]. In front of the womb.

Anteversion (an-te-ver'-shun) [ante, before; vertere, to turn]. A turning forward. A. of Uterus, the fundus is bent toward the symphysis pubis, the cervix toward the sacrum.

Anthela ( $\left.a n^{\prime}-t h e-l a h\right)[a v \theta \eta \lambda n$, the downy plume of the reed]. In biology, an open paniculate cyme.

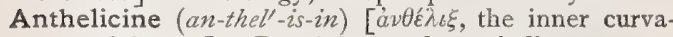
ture of the ear]. Pertaining to the anthelix.

Anthelix (ant'-he-liks or $\left.a n^{\prime}-t h e-l i k s\right)[a v \theta \varepsilon \lambda \iota \xi$, the inner curvature of the ear]. The ridge surrounding the concha of the external ear posteriorly.

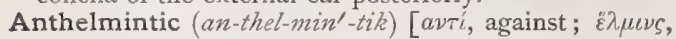
a worm]. I. Efficacious against worms. 2. A vermicide. An agent either killing or rendering powerless intestinal parasites; a vermifuge expels worms.

Anthemis (an'-them-is) [av6ruis, a flower]. Camomile. The flower-heads of $A$. nobilis, with properties due to a volatile oil, a camphor, and a bitter principle. Useful in coughs and spasmodic infantile complaints. An excellent stomachic tonic. Infusion of 3 iv to $O \mathrm{j}$, given in doses of $\xi_{j}-i j$. No official preparations. A., Extract (B. P.), dose gr. ij-x. A., Infus. (B. P.), dose jj-iv. A. O1., the volatile oil of camomile. Dose $m \mathrm{ij}-\mathrm{x}$, in sugar.

Anthemoptyic (ant-hem-op'-te-ik) [ári, against; ai $\mu \alpha$, blood; $\pi$ tvors, a spitting]. Checking pulmonary hemorrhage.

Anthemorrhagic (ant-hem-or-aj'-ik) [ảví, against; ai $\mu a$, blood; $\rho c \gamma i ́ a$, a bursting]. Checking or tending to prevent hemorrhage.

Anther (an'-ther) [ávonpós, in full bloom]. In biology, the male sexual organ in plants; the summit and essential part of the stamen. It contains the pollen or fecundating substance of the flower.

Antheridia (an-ther-id'-e-ah). Plural of Antheridi$u m, q . v$.

Antheridium (an-ther-id'-e-um) [anthera, anther; Gr. dim., idiov]. The male or fertilizing organ of higher cryptogams; the organ that produces antherozoids.

Antherozoid ( $a n^{\prime}$-ther-o-zo-id) [anthera, anther; zoöides, zoöid]. In biology, one of the motile fertilizing bodies of higher cryptogams, analogous to the spermatozoid of animals. The male reproductive cell of cryptogams.

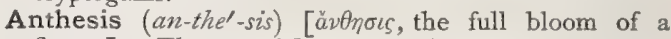
flower]. The act of flowering; florescence.

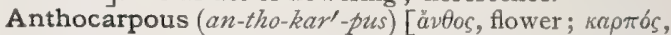
fruit]. In biology, applied to collective or accessory fruits characterized by thickened foral envelopes.

Anthoclinium $\left(a n-t h o-k l i n^{\prime}-e-u m\right)$ [àv $\theta 0 s$, flower; $k \lambda i v \eta$, a bed]. See Clinanthium.

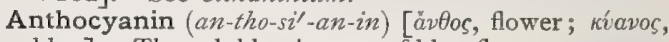
blue]. The soluble pigment of blue flowers.

Anthodium $\left(a n-t h o^{\prime}-d e-u m\right)$ [àvtos, a flower; Eidos, form]. In biology, the so-called "flower" of the Composite, really a capitulum or head of flowers.

Anthogenesis (an-tho-jen'-es-is) [àvtos, a flower;

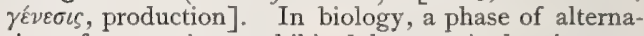
tion of generations exhibited by certain hemipterous insects, plant lice, etc.

Antholeucin $\left(a n-t h o-h u^{\prime}-\sin \right)$ [à $\nu 0 \varsigma$, a flower; $\lambda \varepsilon v \kappa o ́ s$, white]. The soluble pigment of white flowers.

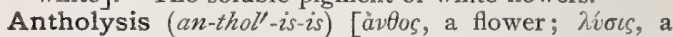
breaking up]. In biology, that retrograde metamorphosis in which the normal character or location of the parts of a flower is altered.

Anthony's Fire, St. A popular name for Erysipelas.

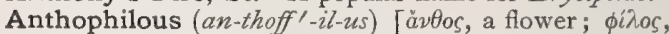
loving]. In biology, fond of flowers, as a bee.

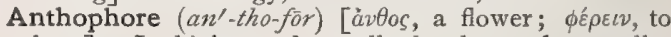
bear]. In biology, the stalk that bears the corolla, stamens, and pistil in certain flowers, formed by the elongation of the internode between the calyx and corolla.

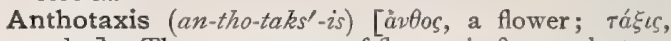
order ]. The arrangement of flowers in flower-clusters.

Anthoxanthin, Anthoxanthine (an-tho-zan'-thin)

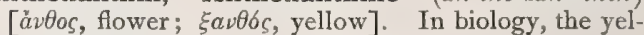
lowish pigments of fruits and flowers.

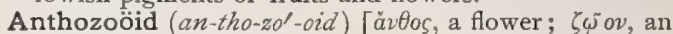
animal; हioos, likeness]. A single zoöid of the flowerlike animals, Actinozoa; e. g., a coral polyp.

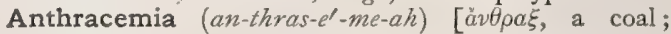
ali $\mu a$, blood]. Wool-sorter's disease; splenic fever of animals; the presence in the blood of Bacillus anthracis, the microbe of true anthrax or malignant pustule.

Anthracene $\left(a n^{\prime}-t h r a-\operatorname{sën}\right)$ [àv $\theta \rho a \xi$, a coal], $\mathrm{C}_{14} \mathrm{H}_{10}$. A hydrocarbon formed from many carbon compounds when they are exposed to a high heat; also from coal-tar. It crystallizes in colorless, monoclinic tables, showing a beautiful blue fluorescence; dissolves with difficulty in alcohol and ether, but easily in hot benzene; melts at $213^{\circ}$. It is the base from which artificial alizarin is prepared. A. Colors. See Pigments, Conspectus of. A. Oil, the fraction of coal. tar distilling from $270^{\circ} \mathrm{C}$. and over. It consists of that portion of the tar that is made up of bodies possessing the highest boiling points, and is distinguished from the heavy oil fraction by a separation, on cooling, of solid matters. In it has been found naphthalene, methyl-naphthalene, anthracene, phenanthrene, methyl-anthracene, pyrene, carbazol, etc. 


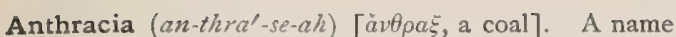
for diseases characterized by the formation of carbuncles. A. pestis, the plague. A. rubula. Synonym of Frambesia.

Anthracic (an-thras'-ik) [à $\theta \rho a \xi$, a coal]. Pertaining to or of the nature of anthrax.

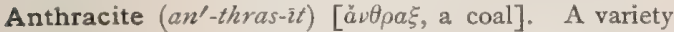
of mineral coal containing but little hydrogen, and therefore burning almost without flame.

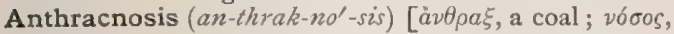
disease ]. Black rot, a fungus disease of vines, caused by the Phoma wicola, or Sphaceloma ampelium.

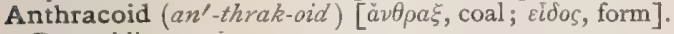
Resembling anthrax.

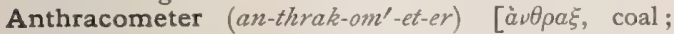
$\mu \varepsilon ́ \tau \rho o \nu$, a measure]. An instrument for estimating the amount of carbon dioxid in the air.

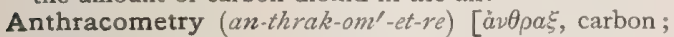
$\mu$ étpov, a measure]. The determination of the amount of carbon dioxid in air.

Anthraconecrosis (an-thrak-o-ne-kro'-sis) [aे $\theta \rho a \xi$,

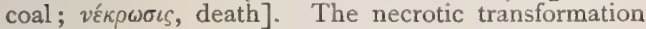
of a tissue into a black mass, as in dry gangrene.

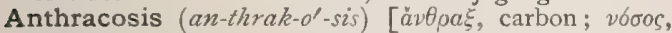
disease]. A chronic interstitial pneumonitis with pigmentation of the lung, in coal-miners.

Anthracotyphus (an-thrak-o-ti'-fics) [à $\theta \rho a \xi$, a coal; Tï申os, smoke, stupor]. Synonym of the Plague.

Anthrakokali (an-thrak-o'-kal-e) [à $\nu \theta \rho a \xi$, coal; Ar., galì, soda ash]. An alkaline powder made by heating powdered mineral coal with a strong solution of caustic potash, with or without sulphur. It is used internally and externally in skin diseases, rheumatism, etc. Unof

Anthranilic Acid (an-thran-il'-ik). See Acid.

Anthranol (an'-thran-ol) [àv $\theta \rho a \xi$, coal; oleum, oil], $\mathrm{C}_{14} \mathrm{H}_{10} \mathrm{O}$. A body isomeric with anthrol. It is produced by the careful reduction of anthraquinone with tin and acetic acid. It crystallizes from alcohol in shining needles, melting with decomposition at $\mathbf{1} 65^{\circ}$.

Anthraquinone (an-thra-kwin-ōn') [ăv $\theta \rho a \xi$, coal ; Sp., quina, bark], $\mathrm{C}_{14} \mathrm{H}_{8} \mathrm{O}_{2}$. Produced by oxidizing anthracene with $\mathrm{HNO}_{3}$. It sublimes in yellow needles, melting at $277^{\circ}$, soluble in hot benzene and $\mathrm{HNO}_{3}$.

Anthrarobin (an-thra-ro'-bin) $[a ̀ \nu \theta \rho a \xi$, coal ; aroba, E. Ind. name for the bark of a leguminous tree]. A derivative of alizarin, similar to chrysarobin. A yellowish-white powder, insoluble in water, but soluble in alcohol and dilute alkaline solutions. Useful in psoriasis. Unof.

Anthrax ( $a n^{\prime}$-thraks) [ã $\nu \theta \rho a \xi$, a coal or carbuncle]. I. A carbuncle; a painful, dark-colored tumor of the cellular tissue, ending in mortification of the part and the discharge of a fetid, bloody pus. The benignant anthrax has no fatal consequences. 2. The true or malignant anthrax, called also malignant pustule, is caused by the infection from animals suffering from splenic apoplexy, and is due to a specific bacillus, which, from a single center, may extend over the body and invade the intestinal tract, producing in this way, or by direct infection of diseased meat, the intestinal type of the disease. See Bacillus (anthrax). 3. The disease called black-leg, or quarter-evil (of sheep, cattle, etc.), is associated with what is called symptomatic anthrax. It is due to the microörganism called Bacillus chauvai, (Arloing, Cornevin and Thomas). A. Fever. Synonym of Anthrax. A., Internal. See Pustula maligna. A., Symptomatic. See Black-leg. Anthrol (an'-throl) [à $\nu \rho \rho \xi \xi$ a coal], $\mathrm{C}_{14} \mathrm{H}_{10} \mathrm{O}$. A body obtained from anthracene-sulphonic acid. It crystallizes in leaflets, dissolving with a yellow color in the alkalies, and in $\mathrm{H}_{2} \mathrm{SO}_{4}$ with a blue color when heated.
Anthrophobia (an-thro-fo'-be-ah). See Anthropophobia. Anthropiatrics (an-thro-pe-at'-riks) [àv $\theta \rho \omega \pi o s, \operatorname{man}$

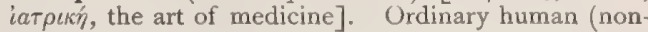
veterinary) medicine.

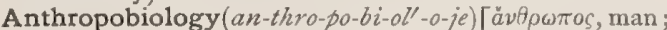
Bios, life; ióyos, word]. The science of the life history of man.

Anthropocholic Acid (an-thro-po-kol'-ik). See Acid. Anthropogenesis (an-thro-po-jen'-es-is) [av $\theta \rho \omega \pi o s$, man;

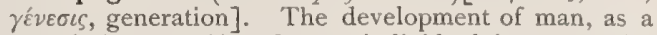
race (phylogenesis) and as an individual (ontogenesis).

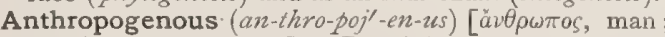
yevváelv, to produce]. Pertaining to Anthropoge nesis.

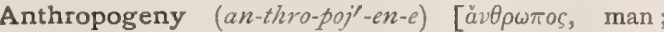

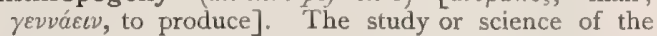
descent of man.

Anthropoglot (an'-thro-po-glot) [äv $\theta \rho \omega \pi o s, \operatorname{man} ; \gamma \lambda \bar{\omega} \sigma$ $\sigma \alpha$, the tongue]. Human-tongued, as a parrot.

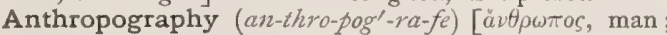

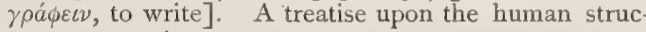
ture or organism.

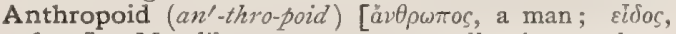
form]. Man-like, as an ape, or as all primates above the lemuroids.

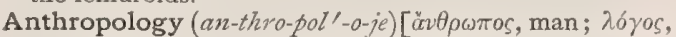
discourse]. The science of the nature, physical and psychological, of man and of mankind.

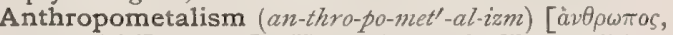
man; M.E., metal]. Hypnotism or the like condition, induced by looking at a metallic disc.

Anthropometer (an-thro-pom'-et-er) [ä $\theta \rho \rho \omega \pi o s, \operatorname{man}$; $\mu \varepsilon ́ \tau \rho o \nu$, a measure]. An instrument used in anthropometry.

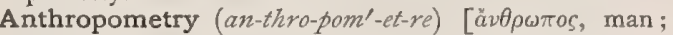

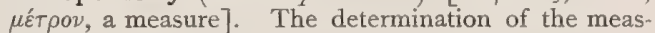
urement, weight, strength, and proportions of the human body.

Anthropomorphic (an-thro-po-mor'-fik) [älipwtor, man; $\mu \rho \rho \phi \eta$, form ]. Man-like.

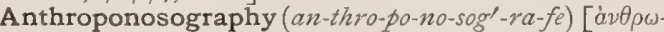

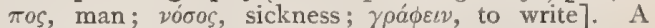
description of the diseases of mankind.

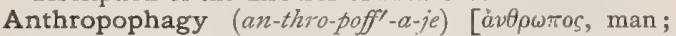
$\phi a \gamma \varepsilon i \nu$, to devour]. I. Cannibalism. 2. Sexual perversion leading to rape, mutilation, and cannibalism.

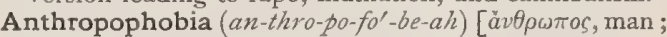
$\phi \delta \beta o s$, fear]. A symptom of mental disease consisting in fear of society.

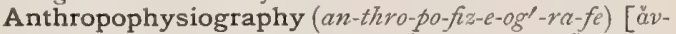

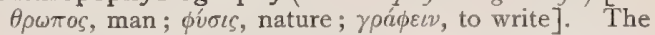
science or description of the natural characters of the human species.

Anthroposomatology (an-thro-po-so-mat-ol'-o-je) [avv$\theta \rho \omega \pi 0 \varsigma$, man; $\sigma \tilde{\omega} \mu a$, body; $\lambda \sigma_{\gamma}$ s, science]. The sum of what is known regarding the human body.

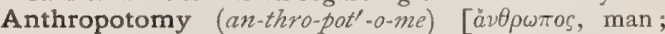
$\tau o \mu \eta$, section]. Human anatomy, or dissection of the human body.

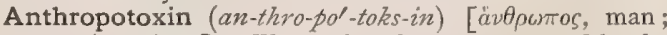
$\tau 0 \xi$ $\leftarrow \delta v$, poison]. The toxic substance excreted by the lungs of human beings.

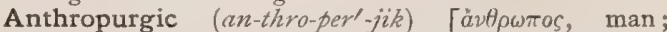

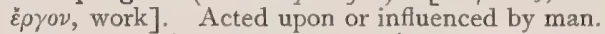

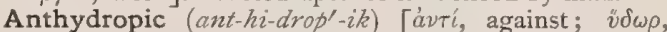
water]. Effective against dropsy.

Anthypnotic (ant-hip-not'-ik) [ávri, against; vinvos, sleep]. 1. Preventive of sleep. 2. An agent that tends to induce wakefulness.

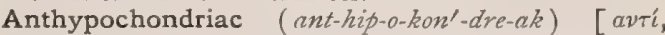

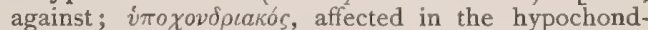
rium]. Efficient in overcoming hypochondriasis. 


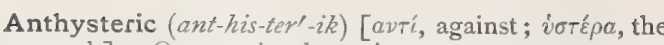
womb]. Overcoming hysteria.

Anti- $\left(a n^{\prime}-t e-\right)$ (sometimes contracted to $\left.a n t-\right)$ [avTi, against]. A prefix of compound words signifying counteraction, opposition, etc.

Antiaditis (an-ti-ad-i'-tis) [ávreás, a swollen tonsil ; $\iota \tau \iota$, inflammation ]. Tonsillitis.

Antiadoncus (an-ti-ad-on $\left.g^{\prime}-k u s\right)$ [ávriás, a swollen tonsil; ŏ үкоs, a heap]. Any tumor or swelling of the tonsils

Antiæ $\left(a n^{\prime}-t i-e\right)$ [antiae, the hair growing on the forehead]. In biology, the frontal points or feathers growing forward on the base of the upper mandible.

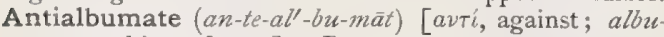
men, white of egg]. Parapeptone; a product of hydrochloric-acid digestion on albumin. The pancreatic ferment changes it into antipeptone. When treated with acids it is converted into the substance called by Kühne antialbumid, which is identical with the hemiprotein of Schützenberger and the dyspeptone of Meissner, q. $v$.

Anrialbumid (an-te-al'-bu-mid). See Antialbumate. Anti-albumin (an-te-al-bu'-min) [ávií, against; albumen, white of egg]. An alleged product of the action of dilute hydrochloric acid upon albumin; it is probably one of the preformed substances existing in the proteid molecule. The other has been called hemi-albumin. Gastric juice first converts them into anti-albumose and hemi-allumose, and these finally into anti-peptone and hemi-peptone.

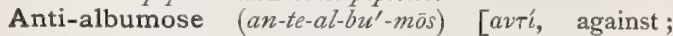
albumen, white of egg]. One of the albumoses produced by the action of pancreatic juice on albumin. It resembles syntonin or acid albumin, and is convertible into antipeptone.

Antiaphrodisiac (an-te-af-ro-dis'-e-ak). See Anaphrodisiac.

Antiar (an'-te-ar). See Antiarin.

Antiarin (an'-te-ar-in) [Javanese, antiar or antschar], $\mathrm{C}_{14} \mathrm{H}_{20} \mathrm{O}_{5}+2 \mathrm{H}_{2} \mathrm{O}$. The active principle of Antiaris toxicaria or Upas antiar, the Javanese poison-tree. It is used as an arrow poison, and is intensely poisonous. It is a cardiac depressant. Dose gr. $\frac{1}{100}$.

Antiarthritic (an-te-ar-thrit'-ik) [ávTi, against; a $\rho \theta \rho i \tau \iota \zeta$, the gout]. A remedy against gout.

Antiasthmatic $\left(a n-t e-a z-m a t^{\prime}-i k\right)$ [áv $\tau^{\prime}$, against ; $\alpha \tilde{\sigma} \theta \mu \alpha$, short breath]. Relieving or preventing asthma.

Antibacterial (an-te-bak-té-re-al) [ávTí, against; $\beta a \kappa \tau \eta \rho i \alpha$, a staff, stick]. Opposed to the germ theory of disease.

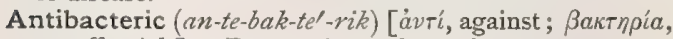
a staff, stick]. Destructive to bacteria.

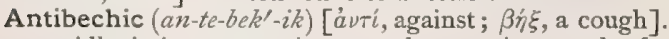
I. Alleviating or curing cough. 2. A remedy for cough or hoarseness.

Antibilious (an-te-bil'-yus) [ávrí, against; biliosus, full of bile]. Effective against bilious disorders.

Antibiotic $(a n-t e-b i$-ot' $-i k)$ [áví, against; $\beta i o s, ~ l i f e]$. I. Tending to destroy life. 2. Antagonistic to a belief in life.

Antiblenorrhagic (an-te-blen-or-aj'-ik) [ávii, against;

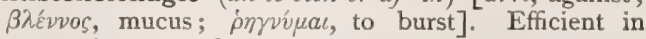
preventing gonorrhea.

Antibrachial (an-te-bra'-ke-al) [á $\nu \tau i$, against; $\beta \rho a \chi i \omega \nu$, the arm]. Pertaining to the forearm.

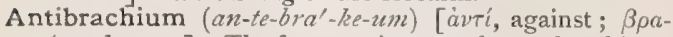
$\chi^{\prime}(\omega v$, the $a r m]$. The forearm; incorrectly antebrachium.

Antibromic (an-te-bro'-mik) [ávTi, against; $\beta \rho \tilde{\omega} \mu o \zeta$, a stench]. I. Deodorant. 2. A drug that destroys oflensive smells. A deodorizer.

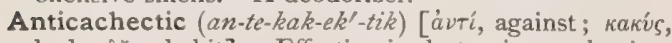
bad; $\hat{\varepsilon} \xi \iota s$, habit]. Effective in destroying cachexia.
Anticalcareous (an-te-kal-ka'-re-us) [ávti, against; calx, lime]. In veterinary medicine, preventing glanders.

Anticalculous (an-te-kall-ku-lus) [ávti, against ; calculus, a pebble]. Good against calculus; antilithic.

Anticarcinomatous (an-te-kar-sin-o'-mat-us) [ávri,

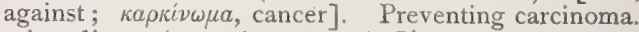

Anticardium (an-te-kar'-de-um) ['่vti, over against; кapdia, the heart]. The scrobiculus cordis, or pit of the stomach; the infrasternal depression.

Anticarious (an-te-ka'-re-us) [avti, against; caries, decay]. Preventing decay, as of the teeth.

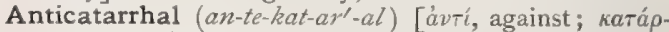
poos, a flowing down]. Counteracting catarrh.

Anticausotic (an-te-kaut-sot'-ik) [ávTí, against; $\kappa \alpha \tilde{v} \sigma o s$, heat]. Counteracting fever.

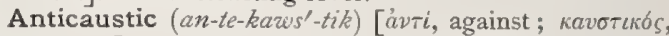
caustic]. Arresting the action of a caustic agent.

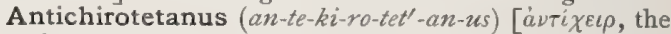
thumb; Tétavos, spasm]. Same as Antichirotonus.

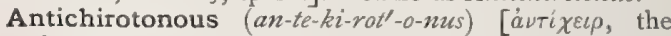
thumb; $\tau$ bos, convulsive tension]. Affected with or manifesting antichirotonus.

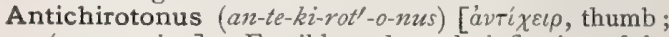
$\tau$ tovos, tension]. Forcible and steady inflection of the thumb, seen in or before some attacks of epilepsy.

Antichlorotic (an-te-klo-rot'-ik) [ávтi, against; $\chi \lambda \omega-$ ро́тभS, greenness]. Counteracting chlorosis.

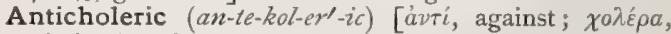
cholera]. Good against cholera.

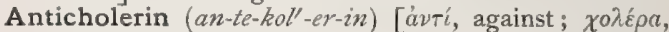
cholera]. A product isolated by Klebs from cultures of cholera-bacilli, and thought to be bactericidal, curative, and immunifying.

Anticipating (an-tis'-ip-a-ting) [anticipare, to take before]. Applied to the occurrence of periodical phenomena in disease or health, before their customary time, as in intermittent fever or the catamenia.

Anticlinal (an-te-kli'-nal) [ávii, against; $\kappa \lambda i \nu \varepsilon \imath \nu$, to slope]. Sloping in opposite directions. A. Vertebra, in man, the tenth thoracic vertebra, where the thoracic vertebræ begin to assume the characters of the lumbar.

Anticnemion (an-tik-ne'-me-on) [ảvtí, against; $\kappa \nu \eta \mu \eta$, leg]. The shin or front of the leg.

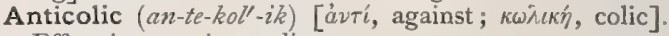
Efficacious against colic.

Anticontagious (an-te-kon-ta'-jus) [ávTí, against ; contagiosus, contagious]. Counteracting contagion.

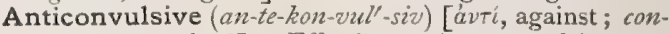
vulsus, convulsed]. Effective against convulsions.

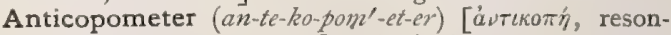
ance; $\mu$ ćroov, a measure]. A pleximeter.

Anticous (an-ti'-kus) [anticus, that which is in front]. In biology, turned toward the center of the flower, as introrse anthers.

Anticritical (an-te-krit'-ik-al) [ảví, against; kpírı, a crisis]. Preventing the crisis of a disease.

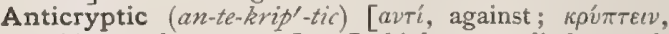
to hide, to keep secret]. In biology, applied to such mimetic colors as enable animals to approach their prey, as in the frog, Ceratophrys cornuta.

Anticus (an-ti'-kus) [anticus, that in front]. Anterior, in front of.

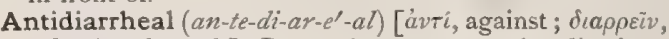
a flowing through]. Preventing or overcoming diarrhea.

Antidigestive (an-te-di-jes'-tiv) [avTi, against; digestio, digestion]. Preventing the proper digestion of the food.

Antidinic (an-te-din'-ik) [ávti, against; divos, a whirl]. Curing or preventing vertigo.

Antidotal (an-te-do'-tal) [ávTi, against; didoval, to give]. Of the nature of an antidote. 
Antidote $\left(a n^{\prime}-t e-d o t\right)$ [àvti, against; dífoval, to give]. An agent preventing or counteracting the action of a poison. The official A., Arsenical, of the German Pharmacopeia is prepared by dissolving 100 parts of the hydrated sulphate of iron in 250 parts of water, to which add (without heat) I5 parts of burnt magnesia and 250 parts of water. A., Chemical, changes the chemical nature of the poison so that it becomes insoluble or harmless. A., Mechanical, prevents absorption by holding the poison in mechanical suspension or by coating the stomach. A., Physiological, supplies its own peculiar and neutralizing effect upon the system. A., Universal, a mixture of one part of dissolved iron sulphate in two parts of magnesia water. See Drug.

Antidotum (an-tid'-o-tum). See Antidote.

Antidromy (an-tid'-ro-me) [ávTi, against; $\delta \rho a \mu \varepsilon i v$, to run]. In biology, having a spiral arrangement the opposite of that of contiguous parts. Cf. Heterodromy.

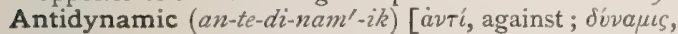
force]. Weakening; depressing.

Antidyscratic (an-te-dis-krat'-ik) [ávti, against; $\delta v \sigma-$ крaбia, bad temperament]. Tending to overcome, as a dyscrasia.

Antidysenteric (an-te-dis-en-ter'-ik) [áv '́, against;

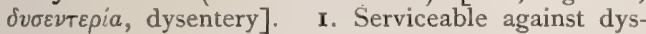
entery. 2. A remedy for dysentery.

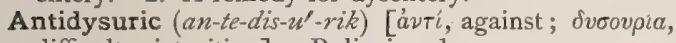
difficult micturition]. Relieving dysury.

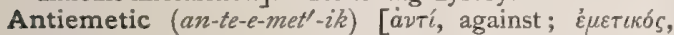
causing vomit]. Preventing emesis; relieving nausea. A. Root. See Adrue.

Antifat (an'-te-fat). See Fucus vesiculosus.

Antifebrile (an-te-feb'-ril) [ávtí, against; febris, a fever]. An agent reducing a fever; a febrifuge.

Antifebrin $\left(a n-t e-f e b^{\prime}-r i n\right)$ [ávii, against; febris, a fever], $\mathrm{C}_{6} \mathrm{H}_{5}-\mathrm{C}_{2} \mathrm{H}_{3} \mathrm{O} . \mathrm{NH}$. Phenyl-acetamid acetanilid. A white, crystalline powder insoluble in water, freely soluble in alcohol. An antipyretic more powerful than quinin. Its effects are manifest in one hour, passing away in 3-10 hours. It is efficacious in fevers characterized by high temperature, and also is a valuable analgesic and antispasmodic. Dose gr. iv-xv. Unof. A., Bromated. See Antisepsin.

Antiferment (an-te-fer'-ment) [ávti, against ; fermentum, leaven]. An agent that prevents fermentation.

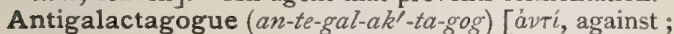

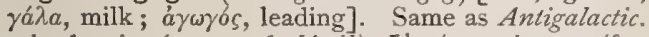

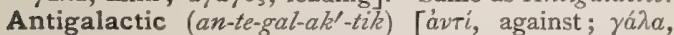
milk]. I. Lessening the secretion of milk. 2. A drug that lessens the secretion of milk.

Antigeny (an-tij'-en-e) [ảvtí, against; yévos, race]. In biology, existing in two distinct sexual forms.

Antiguggler (an-te-gug'-ler) [ávтi, against; gurgle]. A tube inserted into the mouth of a bottle to prevent the splashing or gurgling of liquid that is poured out.

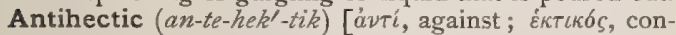
sumptive]. A remedy preventing or overcoming a hectic condition.

Antihelix (an-te-he'-lik). See Anthelix.

Antiherpetic (an-te-her-pet'-ik) [ävTi, against; $\tilde{\varepsilon} \rho \pi \eta s$, herpes]. Preventing herpes.

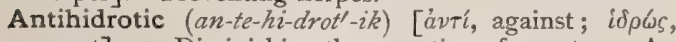
sweat]. I. Diminishing the excretion of sweat. 2. An agent lessening the secretion of sweat.

Antihydropic (an-te-hi-drop'-ik). See Anthydropic.

Antihydropin (an-te-hi'-dro-pin) [avti, against; $v \delta \omega \rho$, water]. A crystalline principle obtainable from the common cockroach, Blatta (Periplaneta) orientalis, said to be a good diuretic. Formerly used in dropsy.

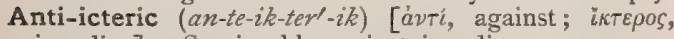
jaundice]. Serviceable against jaundice.
Antikamnia (an-te-kam'-ne-ah) [ávTí, against ; кá $\mu \nu \varepsilon \imath \nu$, to suffer pain]. A proprietary remedy said to be composed of sodium bicarbonate, antifebrin, and caffein. Used as a nervin in doses of gr. $\mathrm{v}-\mathrm{x}$. Unof.

Antikol ( $\alpha n^{\prime}$-tik-ol). A proprietary antipyretic mixture said to contain acetanilid, soda bicarbonate and tartaric acid.

Antilemic, or Antilœmic (an-te-le'-mik), or Antiloimic

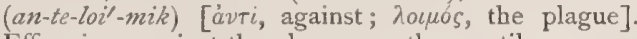
Efficacious against the plague or other pestilence.

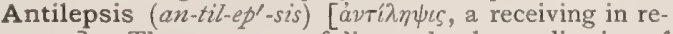
turn]. The treatment of disease by the application of the remedy to a healthy part; revulsive treatment.

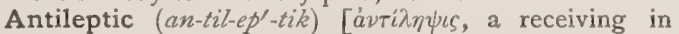
return]. Revulsive.

Antilithic (an-te-lith'-ik) [ávri, against; $\lambda i \theta o s, a$ stone]. I. Efficacious against calculus. 2. An agent preventing the deposit of urinary calculi or sediment.

Antilobium (an-te-lo'-be-um) [avi i, against; $\lambda o \beta b s$, the lobe of the ear]. The tragus or part of the ear opposite the lobe.

Antilcemic. See Antilemic.

Antiluetic (an-te-lu-et'-ik) [avri, against; lues, the plague; syphilis]. Efficacious against syphilis.

Antilyssic (an-te-lis'-ik) [àvtí, against; $\lambda \dot{v} \sigma \sigma a$, rabies]. I. Tending to cure rabies. 2. A remedy for rabies.

Antilytic (an-te-lit'-ik) [ $\alpha \dot{v} \tau i$, against ; $\lambda v \varepsilon \varepsilon v$, to loosen]. Antiparalytic.

Antimaniacal (an-te-ma-ni'-ak-al) [ávTl, against; uavia, madness]. Overcoming insanity.

Antimephitic (an-te-mef-it'-ik) [á $\nu \tau i$, against ; mephitis, a pestilential exhalation]. Efficacious against foul exhalations or their effects.

Antimere $\left(a n^{\prime}-t e-m \bar{e} r\right)$ [áv $\tau^{\prime}$, against; $\mu$ épos, a part]. Any one of the segments of the body that are bounded by planes typically at right angles to the long axis of the body.

Antimiasmatic (an-te-mi-as-mat'-ik) [ảvri, against; $\mu i \alpha \sigma \mu \alpha$, exhalation]. Preventive of malaria.

Antimicrophyte (an-te-mik'-ro-fit) [avii, against; $\mu \iota \kappa \rho \sigma \varsigma$, small ; $\phi v \tau o ́ v$, plant]. A germicide.

Antimonial (an-te-mo'-ne-al) [antimonium, antimony]. Containing antimony.

Antimonic (an-te-mon'-ik) [antimonium, antimony]. A term applied to those compounds of antimony that correspond to its higher oxid.

Antimonii (an-te-mo'-ne-i). Genitive of Antimonium, q.v.

Antimonious (an-te-mo'-ne-us) [antimonium, antimony]. A term noting those compounds of antimony that correspond to its lower oxid.

Antimonium (an-te-mo'-ne-um) [L., gen, Antimonii] $\mathrm{Sb}=\mathbf{1 2 2}$; quantivalence $\mathrm{r}$, III, V. A non-metal, having a metallic luster. Only the combinations are used in medicine. Antimonial salts are cardiac depressants and promote rapid excretion of waste products of the body ; in large doses they produce vomiting and purging, with symptoms similar to those of cholera. They are valuable in inflammatory ailments of the respiratory organs, puerperal peritonitis and muscular rheumatism. A. chlorid., $\mathrm{SbCl}_{3}$, the "butter" of antimony; a strong caustic. Unof. A. Comp., Pil., Plummer's pills, contain calomel and antimony sulphuratum, āā gr. ss. A. oxid., $\mathrm{Sb}_{2} \mathrm{O}_{3}$; soluble in hydrochloric and tartaric acids. Dose gr. j-ij. A. oxychlorid., the "powder of algaroth"; now little used. Unof. A. et Potass. tartras, (A. tartaratum) (B. P.), $2 \mathrm{~K} \mathrm{SbOC}_{4} \mathrm{H}_{4} \mathrm{O}_{6} \cdot \mathrm{H}_{2} \mathrm{O}$, tartrate of antimony and potassium, "tartar emetic." Dose gr. $\frac{1}{16}-1 / 4 . \quad$ A. pulvis, powder of antimony, James' powder, consists of antimonious oxid 33, and calcium phosphate, 67 parts. A prompt diaphoretic. Dose gr. iij-viij. In larger doses, emetic and cathartic. 
A. sulphid, $\mathrm{Sb}_{2} \mathrm{~S}_{3}$, black sulphid of antimony. Dose gr. $1 / 4-\mathrm{j}$. A. sulphuratum, the sulphid with a small but indefinite amount of the oxid. Dose gr. j-v. A. sulph. purificatum. Dose gr. $1 / 4-$ j. Syr. Scillæ Comp., Cox's hive mixture, hive syrup. Each $\xi_{j}$ contains gr. $3 / 4$ of tartar emetic. Dose $m v-z^{j}$ cautiously. A. tartarato, Ung. (B. P.), one part of tartar emetic to five of simple ointment. A. vinum, wine of antimony, boiling water 60 , tartar emetic 4, stronger white wine 1000 parts. A good expectorant. Dose $m_{\mathrm{v}} \mathrm{-xv}$.

Antimycotic (an-te-mi-kot'-ik) [ávti, against; $\mu v_{k} \eta s$, a fungus]. Destructive of fungal microörganisms.

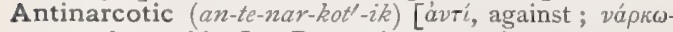
$\sigma \iota \zeta$, a benumbing]. Preventing narcosis.

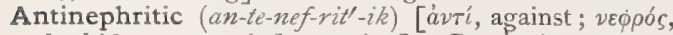
the kidney; $\iota \tau \iota \zeta$, inflammation]. Preventing or curative of renal disease.

Antinervin (an-te-ner'-vin) [ávтí, against; nervus, a tendon or nerve]. Salbromalid, a mixture of bromacetanilid and salicylanilid; used for the relief of neuralgia. Unof.

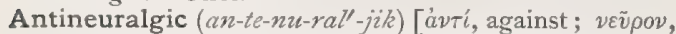
a nerve; ăd yos, pain]. Overcoming neuralgia.

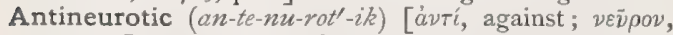
a nerve]. A remedy of service in nervous diseases.

Antiniad (an-tin'-e-ad) [avti, against; iviov, the nape of the neck]. Toward the antinion; glabellad.

Antinial (an-tin'-e-al) [ávTi, against; iviov, the nape of the neck]. Pertaining to the antinion.

Antinien (an-tin'-e-en) [avti, against; iviov, the nape of the neck]. Belonging to the antinion in itself.

Antinion (an-tin'-e-on) [ávtí, against; iviov, the nape of the neck]. See Craniometrical Points.

Antiodont (an'-te-o-dont) [ảv í, opposite to; ódov́s, tooth]. A form of dentition in which the crown ridges of the molar teeth are opposite, instead of alternate as in amebodont dentition.

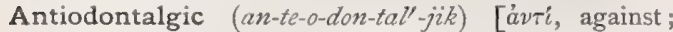
ódovs, tooth; àn yos, pain]. Curative of toothache.

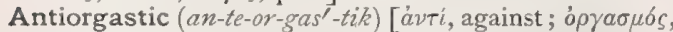
swelling, excitement]. Anaphrodisiac.

Antiopelmous (an-te-o-pel'-mus) [ávríos, set against; $\pi \varepsilon \dot{\varepsilon} \mu \alpha$, the sole]. In biology; characterized by having the flexor perforans supply the third toe only and the Alexor hallucis the first, second and fourth toes. Cf. Sympelmous, Heteropelmous.

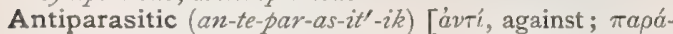
бıtos, a parasite]. I. Destroying parasites. 2. An agent destroying or preventing increase of parasites. Insecticide.

Antiparastatitis (an-te-par-as-tat-i'-tis) ['avti, over against; $\pi \alpha \rho \alpha \sigma \tau a ́ \tau \eta s$, a testicle]. Inflammation of Cowper's glands.

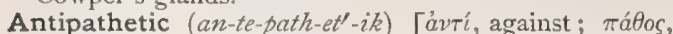
feeling, i.e., antipathy or constitutional aversion]. In biology, applied to plants not easily grafted.

Antipathic (an-te-path'-ik) [ảvrí, against; $\pi a ́ \theta 0 s$, disease]. A synonym of allopathic, both terms alike being rejected by the advocates of rational medicine.

Antipathy (an-tiṕ-a-the) [ávri, against; $\pi a ́ \theta o s$, affection]. Aversion; an opposing property or quality.

Antipeduncular (an-te-pe-dung -ku-lar) [áví, against; pedunculus, a little foot]. In biology, placed opposite a peduncle.

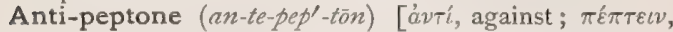
to cook, digest]. A variety of peptone formed in the pancreatic digestion, and incapable of further peptonic change.

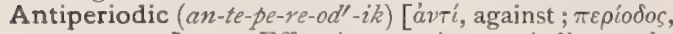
a paroxysm]. 1. Efficacious against periodic attacks of disease. 2. A remedy against periodic disease, especially intermittent fever. Quinin is the best known. A. Tincture. See Warburg's Tincture.

Antiperistalsis (an-te-per-is-tal'sis) [ávri, against; $\pi \varepsilon \rho i$, around; $\sigma \tau a ́ \lambda \sigma \iota s$, compression]. Reversed peristalsis ; inverted or upward peristaltic action.

Antiperistaltic (an-te-per-is-tal'tik) [ávri, against $\pi \varepsilon \rho i$, around; $\sigma \tau \alpha \dot{\lambda} \sigma \iota s$, compression]. Relating to antiperistalsis.

Antipestilential (an-te-pes-til-en'-shal) [ávrí, against; pestilentia, the plague]. Counteracting the influence of the plague.

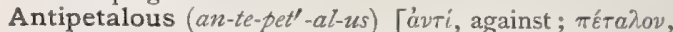
a leaf ]. In biology, inserted opposite to, instead of alternate with, the petals.

Antipharmic (an-te-far'-mik). See Alexipharmac.

Antiphlogistic (an-te-flo-jis'-tik) [ávri, against; $\phi \lambda o ́ \gamma \omega \sigma \iota s$, inflammatory heat]. I. Counteracting or directed against fever. 2. An agent subduing or reducing inflammation or fever. A. Treatment, consists in bloodletting, the application of cold, administration of antipyretics, etc.

Antiphysic (an-te-fiz'-ik) [ávтí, against; $\phi \tilde{v} \sigma \alpha$, wind]. Carminative; overcoming flatulence.

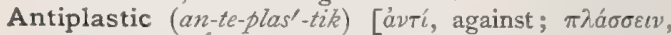
to form]. I. Unfavorable to granulation or the healing process. 2. An agent impoverishing the blood.

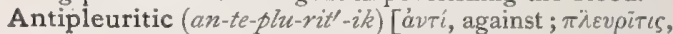
pleurisy]. Overcoming pleurisy.

Antipneumonic (an-te-nu-mon'-ik) [ávi', against ; $\pi \nu \varepsilon v \mu$ via, pneumonia]. Of value in treating pneumonia.

Antipneumotoxin (an-te-nu-mo-toks'-in). See Pneumotoxin.

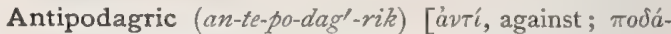
$\gamma \rho \alpha$, gout in the feet]. Efficacious against gout.

Antipodal Cells (an-tip $\left.p^{\prime}-o-d a l\right)$ [ávtí, opposite; $\pi b v c$, foot]. A term applied to a group of four cells formed in the lower end of the embryo-sac opposite to the cells constituting the egg-apparatus.

Antipoison ( $\left.a n^{\prime}-t e-p o i-z n\right)$ [ảvi, against; ME., poisoun, a potion ]. A counter poison.

Antipraxia (an-te-praks'-e-ah) [ávti, against; $\pi \rho a ́ \sigma \sigma \varepsilon \iota v$, to do]. Antagonism of functions or of symptoms.

Antiprostate (an-te-pros'-tät). See Anteprostate.

Antipruritic (an-te-pru-rit'-ik) [avi i, against; prurilus, itching]. I. Relieving the sensation of itching. 2 . A drug that relieves the sensation of itching.

Antipsoric (an-tip-so'-rik) [ávTi, against; $\psi \omega ́ \rho a$, the itch]. Effective against the itch.

Antiputrefactive (an-te-pu-tre-fak'-tiv). See Antiseptic.

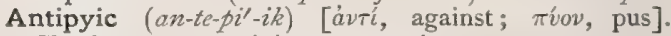
Checking or restraining suppuration.

Antipyresis (an-te-pi-re'-sis) [ảvti, against ; $\pi \nu \rho \varepsilon ́ \sigma \sigma \varepsilon \iota \nu$, to be feverish]. The employment of antipyretics in fever.

Antipyretic (an-te-pi-ret'-ik) [ávтi, against; $\pi v \rho \varepsilon \tau^{\prime} s$, fever]. I. Cooling; lowering the temperature. 2. An agent reducing the temperature of fever; any antifebrile medicine, or febrifuge. Most such also reduce the normal bodily temperature slightly. They act either by preventing oxidation processes, or encouraging the radiation of heat.

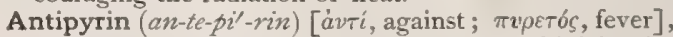
$\mathrm{C}_{20} \mathrm{H}_{18} \mathrm{~N}_{4} \mathrm{O}_{2}$. Phenazonum. Dimethyl-oxy-chinicin. An alkaloidal product of the destructive distillation of coal-tar. It may be produced by heating acetoacetic ester with methyl-phenyl hydrazin. It is a grayish or reddish-white crystalline powder, slightly bitter, soluble in water, alcohol, and chloroform, and crystallizes from ether in shining leaflets, melting at $\mathbf{I} 3^{\circ}$. Adult dose gr. $\mathbf{v}-\mathrm{xv}$ every hour for two or three hours. It 
reduces the temperature three to five degrees in fevers, causes sweating, at times vomiting, but no serious result. Antipyrin is incompatible with nitrous compounds. It is a powerful antipyretic, a local anesthetic, and a general analgesic. It is efficient in hyperpyrexia from any cause, and in rheumatism. Injectio antipyrin hypodermica, gr. jin $\eta_{\mathrm{ij}}$. Dose $\eta_{\text {viij-xxx. }}$ Antipyrotic $\left(a n-t e-p i-r o t^{\prime}-i k\right)$ [ávi $i$, against; $\pi v j \omega \sigma \iota$, a burning]. x. Efficacious against burns. 2. An agent curative of burns

Antirabic (un-tc-rab'-ik) [àvti, against; rabies, madness]. Effective against rabies; antagonistic to rabies.

Antirhachitic (an-te-rak-it'-ik) [àvTi, against; $\rho a ́ \chi \iota s$, the spine]. Serviceable against rickets.

Antirheumatic (an-te-ru-1nat'-ik) [avví, against; $\dot{\rho} \varepsilon v-$

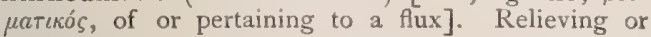
curing rheumatism.

Antirrhinum (an-te-ri'-num) [L.]. A genus of scrophulariaceous plants. A. linaria. Called also Linaria vulgaris, Toad-flax, Ramsted, Butter-and-Eggs; a herbaceous plant of Europe and North America; diuretic, cathartic, and irritant ; used as a poultice and fomentation. Unof.

Antiscolic (an-te-skoll-ik) [ávii, against; $\sigma \kappa \omega \lambda \eta \xi \xi$, a worm]. Vermifuge. See Anthelmintic.

Antiscorbutic (an-te-skor-bu'-tik) [avti, against; scorbutus, scurvy]. I. Effective against scurvy. 2. A remedy for or preventive of scurvy; such are mainly vegetable acids.

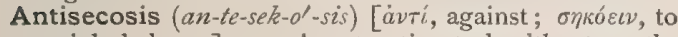
weigh, balance]. I. A restoration to health, strength, etc. 2. Regulation of the food.

Antisepalous (an-te-sepp'-al-us) [a'vit, against; Fr., sépale]. In biology, placed opposite the sepals.

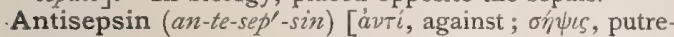
faction ], $\mathrm{C}_{6} \mathrm{H}_{4} \mathrm{BrNHC}_{2} \mathrm{H}_{3} \mathrm{O}$. Asepsin; bromated antifebrin; soluble in alcohol and ether. Recommended for use as an antipyretic and analgesic but is dangerous as a febrifuge. It has antiseptic properties. Dose gr. j, four times daily.

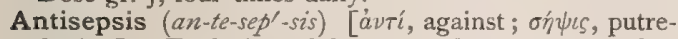
faction]. Exclusion of the germs that cause putrefaction; the totality of measures taken to prevent septic poisoning.

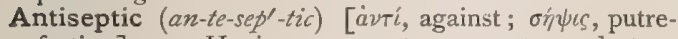
faction]. I. Having power to prevent or destroy putrefaction, or, what is the same thing, the bacteria upon which putrefaction depends. 2. A remedy or agent that prevents a septic process. The principal in use are corrosive sublimate, creolin, carbolic acid, iodoform, thymol, salicylic acid, boric acid, etc. A. Gauze, open cotton cloth charged with carbolic acid, resin, and paraffin. A. Ligature, catgut or other material rendered aseptic by soaking in antiseptic solutions. The antiseptic treatment of wounds looks to thorough asepsis and antisepsis as regards the wound, the instruments, the operator's hands, the dressings, etc. See, also, Listerian Method.

Antisepticism (an-te-sep'-tis-izm) [ả $\nu \tau i$, against ; ón $\psi s$, putrefaction]. The theory or systematic employment of antiseptic methods.

Antisepticize (an-te-sep'-tis-īz) [ávtí, against; ónłrs, putrefaction]. To render antiseptic; to treat with antiseptics.

Antiseptin (an-te-sep'-tin) [avri, against; ón $\psi \iota s$, putrefaction]. Zinc boro-thymate iodid. Consists of 85 parts zinc sulphate, 2.5 parts each of zinc iodid and thymol, and ten parts boric acid. An antiseptic. Unof.

Antiseption (an-te-seṕ-shun) [ảvrí, against; ońls, putrefaction]. Same as Antisepsis.

Antiseptol (an-te-sep'-tol) [ávii, against; ónłus, putre- faction]. Cinchonin iodosulphate. An odorless and fairly effective substitute for iodoform.

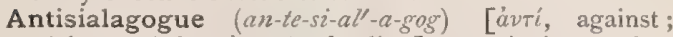

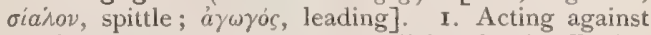
ptyalism. 2. A remedy or a medicine that is effective against salivation.

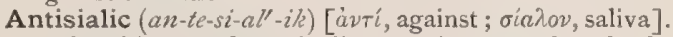
1. Checking the flow of saliva. 2. An agent that checks the secretion of saliva.

Antispadix (an-te-spa'-diks) [ávti, against; $\sigma \pi a ́ d \iota \xi$, a palm branch]. In biology, a group of four tentacles on the right side of the male Nautilus, the spadix, an organ analogous to the hectocolylised arm, being on the left side.

Antispasis (an-tis'-pas-is) [ảvri, against; $\sigma \pi a ́ \varepsilon v$, to draw]. Revulsion; revulsive treatment.

Antispasmodic (an-te-spas-mod'-ik) [ávTi, against; $\sigma \pi a \sigma \mu o ́ s$, a spasm]. I. Tending to relieve spasm. 2. An agent allaying or relieving convulsions or spasmodic pains, as the narcotics, the nitrites, etc.

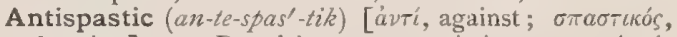
drawing]. 1. Revulsive; counter-irritant. 2. Antispasmodic. 3. A revulsive agent. 4. That which counteracts spasm. An antispasmodic.

Antisplenetic (an-te-splen-et'-ik) [àvTí, against; splen, the spleen]. Remedial in diseases of the spleen.

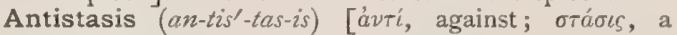
standing]. Opposition; opposing effect.

Antistrumatic (an-te-stru-mat'-ik). Same as Antistrumous.

Antistrumous (an-te-stru'-mus) [ảvi', against ; struma, a scrofulous tumor]. Effective against struma or scrofula.

Antisudorific (an-te-su-dor-if'-ik) [ávti, against; sudor, sweat; facere, to make]. Checking the excretion of sweat.

Antisyphilitic (an-te-sif-il-it'-ik) [avti, against ; Syphilus, a Latin proper name]. I. Effective against syphilis. 2. A remedy directed against, or used for the relief of, syphilis. Usually an alterative.

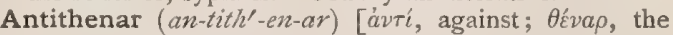
hollow of the hand or foot]. I. Opposite to the thenar. 2. A muscle that extends the thumb, or opposes it to the hand: an antithenar muscle. A. Eminence, the border of the. palm of the hand from the base of the little finger to the wrist. A. Muscles, of the toe and of the thumb: the abductor pollicis pedis, and the flexor brevis pollicis manus; also, the first dorsal interosseous muscle. See Muscles, Table of.

Antithermic (an-te-ther'-mik) [à ${ }^{\prime} i$, against; $\theta^{\prime} \rho \mu \eta \eta$ heat]. Cooling; antipyretic.

Antithermin (an-te-ther'-min) [ávti, against; $\theta \dot{\varepsilon} \rho \mu \eta$, heat], $\mathrm{C}_{11} \mathrm{H}_{14} \mathrm{O}_{2} \mathrm{~N}_{2}$. Phenylhydrazin-Ievulinic acid, a coal-tar derivative used in four to eight grain doses as an antipyretic, analgesic, and antiseptic. It is apt to give rise to gastralgia. Unof.

Antitoxic (an-te-toks'-ik) [ávтi, against; $\tau o \xi \iota \kappa b \nu$, poison]. Antidotal; counteracting poisons.

Antitoxin (an-te-toks'-in) [avii, against; toxin, a toxic ptomaïne; $\tau 0 \xi \iota \kappa o ́ v$, poison]. A substance formed in the body of animals, either naturally or in consequence of inoculation with some pathogenic bacteria, that neutralizes the toxic products of these organisms.

Antitragic $\left(a n-t i t-r a j^{\prime}-i k\right)$ [ávrí, opposite to; $\tau \rho a ́ \gamma o s$, the tragus]. Pertaining to the antitragus.

Antitragicus (an-tit-raj'-ik-zes) [ávti, opposite to ;

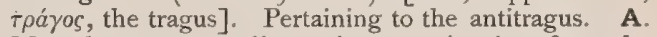
Muscle, a mere rudiment in man; it arises from the antitragus, and extends to the cauda of the helix.

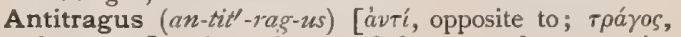
the tragus]. An eminence of the external ear opposite the tragus. 
Antitrochanter (an-te-tro-kan'-ter) [àvi, opposite to;

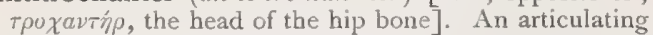
surface on the ilium for the great trochanter.

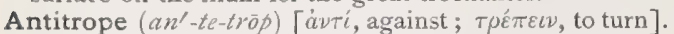
Any organ set over against another to form a symmetric pair. Thus, the right eye is an antitrope to the left.

Antituberculotic (an-te-tu-ber-ku-lot'-ik) [ávi, against; tuberculum, a tubercle]. Good against tuberculosis.

Antitype $\left(a n^{\prime}-t e-t i p\right)$ [ $\dot{a} v \tau i$, against, corresponding to; T'vлos, a type]. In biology, same as Antitrope.

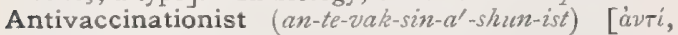
against; vaccinus, of a cow.]. One who opposes vaccination.

Antivaccinist (an-te-vak'-sin-ist). Same as Antivaccinationist.

Antivenene (an-te-ven'-èn) [ávrí, against; venenum, poison]. A term given to the blood-serum of animals rendered immune against snake-poison, on account of its antidotal properties.

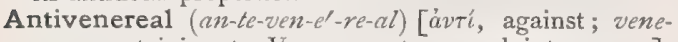
reus, pertaining to Venus, or to sexual intercourse]. Antisyphilitic; anaphrodisiac.

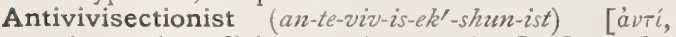
against; vivus, living; sectio, a cutting.] One who opposes the practice of vivisection.

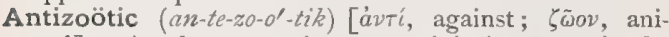
mal]. A substance poisonous or injurious to animals.

Antizymic, Antizymotic ( $a n-t e-z i^{\prime}-m i k$, an $-t e-z i-$

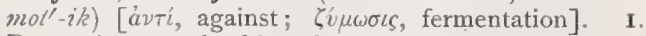
Preventing or checking fermentation. 2. An agent preventing the process of fermentation; an antiferment.

Antlia $\left(a n t^{\prime}-l e-a \hat{h}\right)$ [ává, up; $\tau \lambda a \varepsilon i v$, to lift]. A syringe or pump. In biology, the flat spiral, suctorial tube or proboscis of lepidopterous insects. A. lactea, a pump for drawing milk from the breast. A. mammaria, same as $A$. lactea.

Antodontalgic (an-to-don-tal'-jik). See Antiodontalgic. Antophthalmic (ant-off-thal'-mik) [ávti, against; ó$\phi \theta a \lambda \mu i a$, ophthalmia]. Preventive or curative of ophthalmia.

Antorgastic (ant-or-gas'-tik). See Antiorgastic.

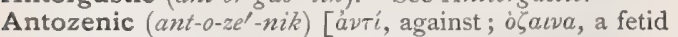
nasal polypus]. Curative of ozena.

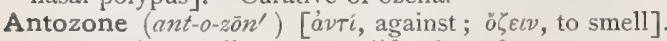
An imaginary allotropic modification of oxygen, now known to be only hydrogen peroxid.

Antozostomatic (ant-o-zos-to-mat'-ik) [àvi, against; ó̧óoropos, having a foul breath]. Corrective of a foul breath.

Antra $\left(a n^{\prime}-t^{\prime} a h\right)$. Plural of Antrum,q.v. A. Gastralia, four broad perradial niches or pouches in the gastric cavity of scyphomedusæ. A. Rhopalaria, niches formed on the umbrella margin of most Discomedusa for the reception of sense-clubs or rhophalia.

Antracele (an'-tras-êl) [antrum, a cavity; $\kappa \dot{\eta} \lambda \eta$, a tumor]. Dropsy of the antrum; an accumulation of fluid in the maxillary sinus.

Antral (an'-tral) [antrum, a cave]. Relating to an antrum.

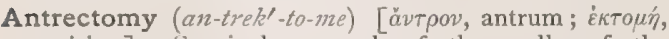
excision]. Surgical removal of the walls of the antrum.

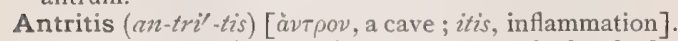
Inflammation of any of the cavities of the body, especially the $A$. highmorianum.

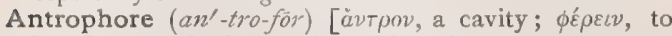
bear]. A soluble, medicated bougie.

Antrorse (an-trôr-s') [ante, before; versus, turned]. In biology, directed upward or forward.

Antro-tympanic (an-tro-lim-pan'-ik) [àvtpov, a cave ; Tíntavov, a drum]. Relating to the cavity of the tympanum as well as to the tympanic antrum.
Antrum (an'-trum) [L.]. A physiological cavity or hollow pkace, especially in a bone. A. ethmoidale, the ethmoidal sinuses. A. highmorianum, Antrum of Highmore, a cavity in the superior maxillary bone. A. highmori testis. See Mediastinum testis. A. of Malacarne. See Tarinus, Space of. A., Mastoidal, the hollow space beneath the roof of the mastoid process. A., Maxillary. See $A$. highmorianum. A. pyloricum willisii, the cavity of the pylorus.

Antwerp Blue. Same as Mineral Blue. A. Brown. See Conspectus of Pigments, under Pigment.

Antyllus-Kuhnt's Operation. See Operations, Table of.

Antyllus's Operation. See Operations, Table of.

Anuresis (an-u-re'-sis) [áv priv.; ov pov, urine]. Anuria.

Anuretic (an-u-ret'-ik) [ảv priv.; oṽoov, urine]. Pertaining to or affected with anuria.

Anuria $\left(a n-u^{\prime}-r e-a h\right)[a v$ priv.; urina, urine]. Absence, deficiency, or retention of the urine.

Anuric $\left(a n-u^{\prime}-\gamma^{i} k\right)$ [av priv. ; urina, urine]. Pertaining to anuria.

Anurous $\left(a n-u^{\prime}-m^{\prime} u s\right)$ [ảv priv.; ov̉pá, a tail]. In biology, without a tail.

Anus $\left(a^{\prime}-n u s\right)$ [anus, the fundament]. The extremity of the rectum; the lower opening of the alimentary canal. A., Artificial, an artificial opening, the natural for any reason being closed. A., Fissure of, rupture of the skin at the side, due to passage of hardened feces. A., Fistula of, a sinus, or fistulous ulcer opening from the rectum into the connective tissue about the rectum, or discharging externally. A., Imperforate, absence of the anus, the natural opening being closed by areolar tissue or a membranous septum. A., Prolapse of, protrusion of the rectum or its mucous membrane. A., Pruritus of, persistent itching of the anal orifice.

Anvil (an'-vil). See Incus.

Anxietas (ang-zi'-et-as). See Anxiety.

Anxiety (ang-zi'-et-e) [anxius, anxious]. Restlessness, agitation, and general malaise, or distrèss, often attended with precordial pain, and a noticeable appearance of apprehension or worry visible in the features.

Anydremia or Anydræmia (an-id-re'-me-ah) [ál. priv.; $v \delta \omega \rho$, water; aima, blood]. A deficiency of water in the blood.

Anypnia $\left(a n-i p^{\prime}-n e-a h\right)$ [áv priv.; $i \pi v o s$, sleep]. Sleeplessness.

A. O. C. Anodic opening contraction.

Aochlesia $\left(a h-o k-l e^{\prime}-z e-a h\right)[\dot{a}$ priv. ; ó $\chi \lambda y \sigma \iota \varsigma$, disturbance $]$. Rest; tranquillity; catalepsy.

Aorta $\left(a-o r t^{\prime}-a h\right)$ [aoprín, aorta]. The great arterial vessel arising from the left ventricle and ending with its bifurcation into the two common iliacs at the fourth lumbar vertebra. The arch, that extending from the heart to the third thoracic vertebra, is divided into an ascending, a transverse, and a descending part. The thoracic portion extends to the diaphragm; the abdominal, to the bifurcation. The diseases of the aorta are acute aortitis, due to traumatism, thrombosis, etc. ; and the chronic form, or atheroma of the aorta; fulty degeneration; stenosis; aneurysm. See Artery.

Aortal $\left(a-o r t^{\prime}-a l\right)$ [aoprí, the aorta]. Relating to the aorta.

Aortarctia ( $a$-ort-ark'-she-ah) [áoprí, aorta ; arctare, to constrict]. A constriction or stenosis of the aorta.

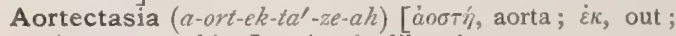
ráots, a stretching]. Aortic dilatation.

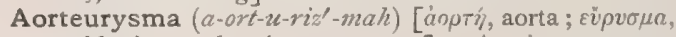
a widening: pl., Aorteurysmata $]$. Aortic aneurysm or dilatation.

Aortic $\left(a-o n t^{\prime}-i k\right)$ [aoprí, the aorta]. Pertaining to the aorta. A. Arch. See Aorta. A. Foramen. See $A$. 
Opening of Diaphragm. A. Murmur. See Murmur. A. Opening of Diaphragm, the lowest and most posterior of the three large apertures connected with this muscle. It is situated in the middle line, immediately in front of the bodies of the vertebra, and is behind the diaphragm, not in it. A. Opening of Heart, a small circular aperture in front and to the right side of the auriculo-ventricular opening, from which it is separated by one of the segments of the mitral valve. A. Plexus, the plexus of sympathetic nerves, situated on the front and sides of the aorta, between the origins of the superior and inferior mesenteric arteries. A. Sinus, a deep depression between each valve and the cylinder of the aorta.

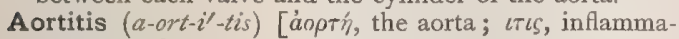
tion]. Inflammation of the aorta.

Aortomalacia, or Aortomalaxia ( $a$-ort-o-mal-a'-se-ah,

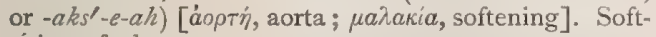
ening of the aorta.

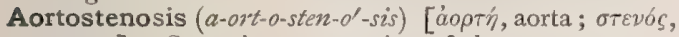
narrow]. Stenosis or narrowing of the aorta.

Aosmic $\left(a-o z^{\prime}-m i k\right)$ [á priv. ; $\dot{\sigma} \sigma \dot{\prime}$, smell]. Having no odor.

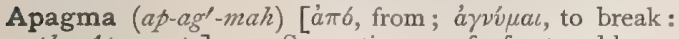
$p l$., Apagmata]. I. Separation, as of a fractured bone. 2. The part separated.

Apandria $\left(a p-a n^{\prime}-d r e-a h\right)$ [ $\dot{a} \pi b$, from; $a \dot{v} \eta \dot{\rho}, a$ man] Morbid dislike of the male sex.

Apanthropia (ap-an-thro'-pe-ah). See Apanthropy.

Apanthropy $\left(a p-a n^{\prime}-t h r o-p e\right) \quad[a \pi \delta$, from; à $\theta \rho \omega \pi o \varsigma$, man]. Aversion to society; morbid desire for solitude.

Aparthrosis (app-ar-thro'-sis) [ảnó, from; à $\rho \rho \rho o v, a$ joint]. x. Dislocation; luxation of a joint. 2. In anatomy, diarthrosis.

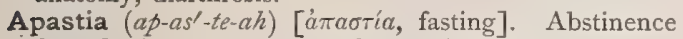
from food, as a symptom of mental disorder.

Apathetic $\left(a p-a t h-e t^{\prime}-i k\right)$ [a priv.; $\pi a ́ \theta o s$, feeling]. Affected with apathy; listless; without emotion.

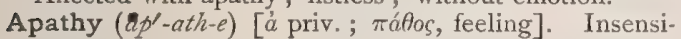
bility; want of passion or feeling.

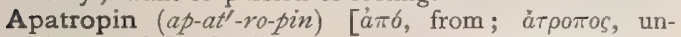
changeable], $\mathrm{C}_{17} \mathrm{H}_{21} \mathrm{NO}_{2}$. A compound derivable from atropin by the action of nitric acid. It is said to produce peculiar convulsions.

Ape $(\bar{a} p)$ [ME., $a p e]$. A man-like monkey. A. fissures, those fissures of the human brain that are also found in apes. See Fissure. A.-hand, wasting of the thumb-muscles, as seen in some cases of progressive muscular atrophy.

Apella $\left(a p-e l^{\prime \prime}-l a h\right)$ [á priv. ; $\pi \varepsilon ́ \lambda \lambda \alpha$, skin]. A circumcised person; one with a short prepuce.

Apellous $\left(a p-e l^{\prime}-2 u s\right)$ [a priv.; $\pi \dot{\varepsilon} \lambda \lambda a$, skin]. Skinless; having no skin.

Apepsia $\left(a h-p e p^{\prime}-s e-a h\right)$ [ $\dot{a}$ priv ; $\pi \dot{\varepsilon} \pi \tau \varepsilon \nu \nu$, to digest $]$. Cessation or absence of the digestive function. A., Hysteric, an hysterical condition with deficient nerve power, and impaired function of the stomach, and very possibly of the abdominal glands. Also called Hysteric anorexia. A. nervosa. See Anorexia nervosa.

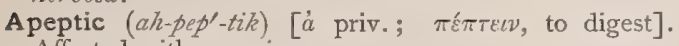
Affected with apepsia.

Aperient (ap-e'-re-ent) [aperive, to open]. I. Laxative; deobstruent; mildly purgative. 2. A mild purgative; a laxative, or aperitive.

Aperinous $(a h$-per'-in-us) [á priv. ; $\pi \eta p i v$, the scrotum]. I. Having no scrotum. 2. Castrated.

Aperispermic $(a / h$-per-is-per'-mik) [à priv.; $\pi \varepsilon \rho \hat{\imath}$, around; $\sigma \pi \varepsilon ́ \rho \mu a$, seed]. See Exalbuminous.

Aperistalsis $\left(a h-p e r-i s-t a l^{\prime}-s i s\right) \quad[\dot{a}$, without; $\pi \varepsilon \rho \dot{i}$, around; $\sigma r a ́ \lambda \sigma \iota \varsigma$, cqnstriction]. Absence or cessation of the movements of the intestine, due to lack of stimulus to Auerbach's plexus.

Aperitive $\left(a p-e r^{\prime}-i t-i v\right)$ [aperive, to open]. Aperient.

Apertor (ap-er'-tor) [ [L., an opener or beginner]. In anatomy, anything that opens. A. Oculi, the levator palpebræ muscle.

Aperture $\left(a p^{\prime}-e r-c h \bar{u} r\right)$ [apertura, an opening]. An opening. A., Angular, in the microscope, the angle formed between a luminous point placed in focus and the most divergent rays that are capable of passing through the entire system of an objective. A. antri, the aperture of the umbrella cavity in medusæ. A., Numerical, the capacity of an objective for admitting rays from the object and transmitting them to the image. A common measure is obtained as proposed by Abbé, by taking the product of the half angle into the refractive index of the medium employed. It is usually expressed $\mathrm{n}$. a. $=n \sin u$, $n$ the index of refraction and $u$ the semi-angle of the aperture. A. of Objective, the capacity for receiving and transmitting rays.

Apetalous $(a h$-pet'-al-zes) [’’ priv.; $\pi \dot{\varepsilon} \tau a \lambda o \nu$, a leaf $]$. In biology, without corolla or petals.

Apex ( $\alpha^{\prime}$-peks) [apex, the extreme end of a thing]. The summit or top of anything; the point or extremity of a cone. A. Beat, the impulse of the heart felt in the fifth intercostal space about $3 \frac{1}{2}$ inches from the middle of the sternum. A. Murmur, a murmur heard over the apex of the heart. Apices of the Lungs, the upper extremities of the lungs behind the border of the first rib.

Aphacia $\left(a h-f a^{\prime}-s e-a h\right)$. Same as Aphakia.

Aphacic $\left(a h-f a^{\prime}-s i k\right)$ [a priv.; фakós, the crystalline lens]. Relating to or affected with aphacia.

Aphæresis (af-er'-es-is). See Apheresis.

Aphagia $\left(a h-f a^{\prime}-j e-a h\right)$ [a priv.; $\phi a \gamma \varepsilon i \nu$, to eat]. Inability to eat or to swallow.

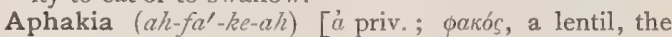
crystalline lens]. The condition of an eye without the lens, whether the result of congenital defect, luxation, traumatism, or cataract operation.

Aphakic $\left(a / h-f\left(\alpha^{\prime}-k i k\right)\right.$ [ $\dot{a}$ priv. ; $\phi a \kappa o ́ s$, the lens]. Having no lens, as the eye after the removal of a cataract.

Aphalangiasis ( $\left.a h-f a-l a n-j e^{\prime}-a s-i s\right)$ [á priv.; $\phi a ́ \lambda a \gamma \xi$, a line of battle; phalanx]. The loss or absence of fingers and toes, as in leprosy. Cf. Ainhum.

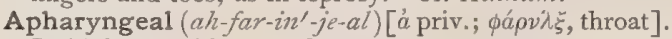
In biology, without a pharynx.

Aphasia $\left(a h-f a^{\prime}-z e-a h\right)$ [á priv. ; $\phi a ́ \sigma \iota s$, speech $]$. Partial or complete loss of the power of expression or of comprehension of the conventional signs of language, from no lesion of the peripheral organs or nerves, but from lesions of the cortical centers concerned. Aphasia may be either motor or sensory. Motor or Ataxic Aphasia consists in a loss of speech owing to inability to execute the various movements of the mouth necessary to speech, the muscles being not paralyzed but not coördinated, owing to disease of the cortical center. It is usually associated with agraphia, "aphasia of the hand," inability to write, and right-sided hemiplegia. Some aphasics can write, but are unable to articulate words or sentences; this variety is variously named aphemia, alalia, or anarthria, according as the impairment of speech is more or less marked. Charcot supposes the center for articulate language divided into four sub-centers, a visual center for words, an auditory center for words, a motor center of articulate language, and a motor center of written language. Lesions of one or more of these centers produce the characteristic forms of aphasia, all of which have clinical exemplifications. Sensory Aphasia, or Amnesia is the loss of memory for words, and may 
exist alone or in association with the motor aphasia. Amnesia appears clinically in three distinct forms; $\mathbf{1}$. Simple loss of memory of words. 2. Word-deafness, or inability to understand spoken words (there is usually some paraphasia connected with this form). 3. Wordblindiness, or inability to understand written or printed words. Paraphasia, a form of aphasia in which there is inability to connect ideas with the proper words to express the ideas. Agrammatism, a phenomenon of aphasia consisting in the inability to form words grammatically, or the suppression of certain words of a phrase. Ataxaphasia, inability to arrange words syrithetically into sentences. Bradyphasia, abnormal slowness of speech, from pathological cause. Tumultus sermonis, a stuttering manner of reading, from pathological cause. A., Conduction, such as is due not to any central lesion, but to defect in some commissural connection between centers. A., Gibberish, aphasia in which the patient can utter many words, but uses them in such a way that they express no meaning

Aphasiac $\left(a / h-f a^{\prime}-z e-a k\right)$ [ả priv.; $\left.\phi a ́ o \iota s, s p e e c h\right]$. One who is aphasic.

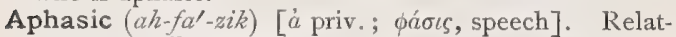
ing te, or affected with aphasia.

Aphelexia $\left(a f-e l-e k s^{\prime}-e-a h\right)$. An incorrect form of the word Aphelxia, q. v.

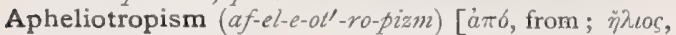
the sun; $\tau \rho o ́ \pi o s$, a turn]. In biology, turning away from the sunlight; negative heliotropism.

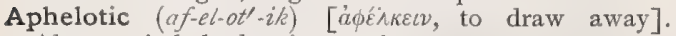
Absent-minded; lost in reverie.

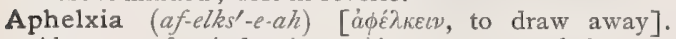
Absence of mind; inattention to external impressions.

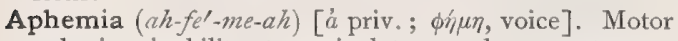
aphasia; inability to articulate words or sentences, from focal and not from peripheral disease of the organs of speech (Alalia). This term is variously used; sometimes it is equivalent to aphasia; sometimes it means loss of voice, from local causes; sometimes hysterical or wilful refraining from speech. See Aphasia.

Aphemic $\left(a h-f e m^{\prime}-i k\right)$ [á priv. ; $\phi h \mu \eta$, voice]. Relating to or affected with aphemia.

Aphephobia $\left(a f-e-f o^{\prime}-b e-a h\right)[a \dot{\phi} \eta$, touch; $\phi b \beta o s$, fear $]$. Hyperesthetic dread of contact with other persons.

Apheresis, or Aphrresis (af-er'-es-is) [áab, away; aipeiv, to take]. Removal; amputation; abstraction, as of blood.

Apheter $\left(a f^{\prime}-e t-e r\right)$ [á $\alpha \varepsilon r^{\prime} \rho$, , one who lets go or sends away]. A supposed impulse-carrying, or triggermaterial, probably a catastate, which communicates to the inogen the nerve impulse that causes its destruction, and the consequent muscular contraction. In a larger sense, any trigger-material that takes part in any functional process may be called an apheter.

Aphidein $\left(a f-i d^{\prime}-e^{\prime}-i n\right)$ [aphis, a plant louse]. A respiratory pigment obtained from the aphis.

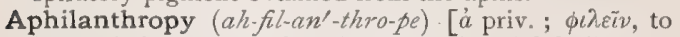

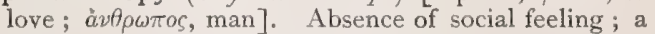
frequent sign of approaching melancholia.

Aphonia $\left(a h-f o^{\prime}-n \ell-a h\right)$ [á priv.; $\phi \omega v \dot{m}$, voice]. I. Dumbness, due to some peripheral lesion. 2. Hysterical, or paralytic absence of the power of speech. 3 . Voicelessness.

Aphonic ( $a h$-fon'-ik) [á priv.; $\phi \omega v \eta ́$, voice]. Speechless; dumb; voiceless.

Aphoresis ( $a h$-for-e'-sis) [ $a$ priv.; $\phi b \rho \eta \sigma \iota$, bearing (by error for Apheresis)]. I. Separation or ablation of a part, either by excision or amputation. 2. Lack of the power of endurance, as of pain.
Aphoria (ah-fo'-re-ah) [á priv.; $\phi \dot{c} \rho \varepsilon \varepsilon \nu$, to bear $]$. Sterility ; unfruitfulness.

Aphrasia (ah-fra'-ze-ah) [ả priv.; $\phi \rho a ́ c \varepsilon \iota \nu$, to utter]. Absence of the power to utter connected phrases.

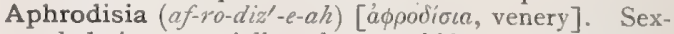
ual desire, especially when morbid, or immoderate; sexual congress.

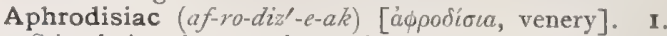
Stimulating the sexual appetite; erotic. 2. An agent stimulating the sexual passion.

Aphtha $\left(a f^{\prime}-t h a h\right)[\check{\alpha} \phi \theta \alpha$, an eruption]. An eruption; an ulcer.

Aphthæ (af'-the) [à $\phi \theta a$, an eruption]. Also called Aphthous stomaticis. Small white ulcers, spots or vesicles of the mouth, chiefly occurring in children under three years of age, and generally associated with some febrile affection. It must not be confounded with thrush, in which disease the spots are smaller and are due to the pre-ence of the parasitic fungus characteristic of that disease. A., Bednar's, two symmetrically placed ulcers seen on the hard palate of certain cachectic infants near the velum, one on either side of the mesial line. The prognosis is exceedingly grave. A., Cachectic, aphthæ appearing beneath the tongue, and associated with grave constitutional symptoms; Riga's disease.

Aphthaphyte (af'-thah-fit). See Aphthophyte.

Aphthenxia (af-thengks'-e-ah) [ả priv.; $\phi \theta \dot{\varepsilon}) \xi \iota c$, utterance]. A form of aphasia with impaired expression of articulate sounds.

Aphthoid (af'-thoid) [à $\theta \theta$, an eruption]. Like or resembling aphthæ.

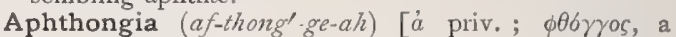
sound]. A peculiar form of aphasia due to spasm of the muscles supplied by the hypoglossal nerve.

Aphthophyte $\left(a f^{\prime}-t h o-f^{2} t\right)$ [à $\phi \hat{\theta} c$, aphtha; $\phi v t o ́ v$, plant]. The Oidium albicans, or Saccharomyces albicans, a yeast-fungus often seen on the mucous membrane of the mouths of infants; regarded by some as the cause of true aphthre. See Sprue.

Aphthous (af'-thus) [à $\theta \theta a$, an eruption]. Pertaining to or affected with aphthæ or thrush.

Aphyllon $\left(a / \imath-f l^{\prime}-o n\right)$ [á priv. ; $\phi \hat{v} \lambda \lambda o v$, a leaf.]. A genus of orobanchaceous plants. A. uniflorum, a plant, the naked broom-rape or cancer-root of North America. It is astringent, and has been employed as a cure for cancer. Unof.

Aphyllous (ah-fil'-us) [á priv.; $\phi \dot{v} \lambda \lambda$ ov, a leaf $]$. In biology, naturally leafless.

Apical $\left(\vec{a}^{\prime}-p i k-a l\right)$ [apex, the top]. Pertaining to the apex. A. Cell, in biology, the cell at the apex of every branch, leaf or other organ, and from the division of which all succeeding cells are formed.

Apices $\left(\alpha^{\prime}-p i s-\bar{e} z\right)$ [L.]. Plural of Apex. Summits.

Apiculus $\left(a p-i k^{\prime}-u-l u s\right)$ [apic, a point]. In biology, a short abrupt point formed by the mid-rib of a leaf projecting beyond the blade.

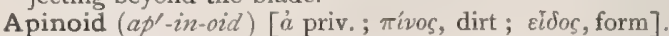
Clean; not foul. A. Cancer, schirrhus; so called from its cleanly section.

Apiol (app-e-ol) [apium, parsley; oleum, oil], $\mathrm{C}_{12} \mathrm{H}_{14}$ $\mathrm{O}_{4}$. A poisonous principle occurring in parsley seeds; it crystallizes in long white needles, with a slight parsley odor; melts at $30^{\circ} \mathrm{C} .\left(86^{\circ} \mathrm{F}.\right)$, and boils at $294^{\circ} \mathrm{C}\left(572^{\circ} \mathrm{F}\right.$.). It is used in dysmenorrhea and in genito-spinal atony. It acts upon the reflex and vasomotor centers. It is also called parsley-camphor. Dose $m_{\text {iij-x. }}$. In doses of $\eta_{x x x}$ it is narcotic. Unof. Apiolin (aṕl-e-o-lin) [apium, parsley; oleum, oil]. A pseudo-apiic alcohol, the active principle of Apium petroselinum, and a reliable emmenagogue. Dose $\eta$ iij in capsule, night and morning. 
Apios $\left(a p^{\prime}-\ell-o s\right)$ [itrtos, a pear]. A genus of plants. A. tuberosa, a twining papilionaceous plant of North America, bearing tubers which when cooked are edible. It is called ground-nut, wild-bern, Indian potato, etc. Said to be alterative. Unof.

Apis $\left(a^{\prime}-p i s\right)$ [L., a bee]. A genus of hymenopterous insects. A. mellifica, the honey-bee; in homeopathy the poison of the honey-bee's sting, or a preparation thereof.

Aprum $\left(a^{\prime}-p e-u m\right)$ [L.]. A genus of umbelliferous plants. A. graveolens. See Celery. A. petroselinum, is the common garden parsley; aperient, diuretic, somewhat antiperiodic; useful in dysmenorrhea. Dose of the fld. ext (of the root) gtt. $x v-3 \mathrm{j}$.

Apjohn's Formula. A formula for determining the dew-point by means of the elastic tension.

Aplacental (ah-plas-en'-tal) [á priv.; placenta, a calie]. Destitute of placenta.

Aplanatic $\left(a h-p l a n-a t^{\prime}-i k\right) \quad[\alpha$ priv. ; $\pi \lambda a v a \varepsilon \varepsilon \nu$, to wander]. Not wandering; rectilinear. A. Lens, a lens corrected for all aberration of light and color. A rectilinear lens. See Objective.

Aplanogamete (ah-plan-o-gamb'-êt-e) [ả priv.; $\pi \lambda a ́ v o s$, roaming; $\gamma \alpha \mu \varepsilon \tau \dot{y}$, a wife]. In biology, the non-motile conjugating cell in certain green algæ, i. e. Conjugata. See Planogamate.

Aplanospore (ah-plan'-o-spōr). Same as Aplanogamete.

Aplasia ( $\left.\alpha h-p l a^{\prime}-s e-\alpha h\right)$ [á priv. ; $\pi \lambda \dot{a} \sigma \sigma \varepsilon \imath v$, to form]. A type of incomplete structure by reason of the non-formation of a necessary cell-group during the developmental stage. Called also Hypoplasia. A., Laminar. Synonym of Facial Hemiatrophy.

Aplastic (ah-plas'-tik) [á priv.; $\pi \lambda a ́ \sigma \sigma \varepsilon \iota \nu$, to form]. I. Structureless, formless. 2. Not characterized by plasticity: preventive of plastic process within the organism. A. Lymph, one of the products of inflammation or disease. A non-fibrinous material incapable of coagulation or organization.

Apleuria $\left(a h-p l u^{\prime}-r e-a h\right)$ [á priv. ; $\pi \lambda \varepsilon v \rho a ́$, a rib]. Congenital absence of the ribs.

Aplotomia ( $a p$-lo-tom'-e-ah), or Aplotomy (ap-lot'-o me). See Haplotomy.

Aplysiopurpurin $\left(a p-l i z-\ell-o-p e r^{\prime-}-p u-r i n\right)[a \dot{a} \lambda v \sigma i a$, filthiness; $\pi \rho \rho \phi v \rho a$, a purple dye]. A reddish pigment derived from the Aplysiidæ.

Apnea $\left(a p-n e^{\prime}-a h\right)$ [á priv.; $\pi \nu \varepsilon \varepsilon \varepsilon v$, to breathe]. Formerly used as synonymous with asphyxia, meaning breathlessness; difficult respiration; partial or complete suspension of breathing. It is employed now only in the physiological sense, to denote the condition in which the blood is too highly oxygenized. The presence of an over-abundance of oxygen prevents stimulation of the medullary respiratory center, and respiration is arrested in consequence. A. infantum. Synonym of Laryngismus stridulus. A. neonatorum, apnea of the newborn child, caused by difficult labor, pressure upon the cord, etc.

Apneumatic (ap-nu-mat'-ik) [á priv. ; $\pi \nu \varepsilon \vec{v} \mu a$, breath]. I. Collapsed; uninflated, not inflatable : said of parts of the lung. 2. Carried on with the exclusion of air, as an apneumatic operation or process.

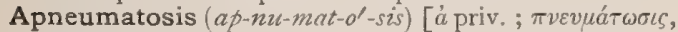
inflation]. Collapse of the air cells of some parts of the lung caused by blocking of the bronchial tubules, and resulting in a condition of non-inflation whereby the lung tissue is reduced to a condition similar to that of atelectasis, or congenital apneumatosis.

Apneumia $\left(a p-n u^{\prime}-m e-a \cdot h\right)$ [ ${ }^{\alpha}$ priv. ; $\pi \nu \varepsilon \dot{v} \mu \omega \nu$, lung]. Congenital absence of the lungs

Apneumonervia $\left(a p-n u-m o-n e r^{\prime}-v e-a h\right)[\dot{\alpha}$ priv.; $\pi v \varepsilon \dot{v} \mu \omega \nu$, lung; nervus, a nerve]. Deficient nerve stimulus in the lung.

Apneumoneuria ( $\left.a p-n u-m o-n u^{\prime}-r e-a h\right)$. Same as $A p$ n'tums miriti.

Apneustia $\left(a p-n \bar{u} s^{\prime}-t e-a h\right)$ [à priv. ; $\pi \nu \varepsilon \varepsilon \varepsilon v$, to breathe] Apnea ; breathlessness.

Apncea $\left(a p-n e^{\prime}-a h\right)$. See Apnea.

Apo- $\left(a p^{\prime}-o\right)[a \pi \hat{o}$, from $]$. A prefix denoting from, azvay, separation.

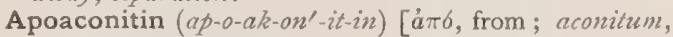
aconite ], $\mathrm{C}_{33} \mathrm{H}_{41} \mathrm{NO}_{11}$. An alkaloid prepared from aconitin by dehydration.

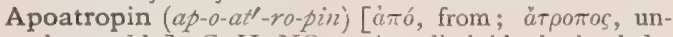
changeable], $\mathrm{C}_{17} \mathrm{H}_{21} \mathrm{NO}_{2}$. An alkaloid obtained by the action of $\mathrm{HNO}_{3}$ on atropin.

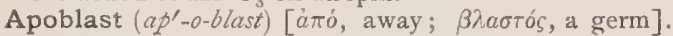
In biology the unimpregnated ovum; an outcast cell. See Outcast Cell.

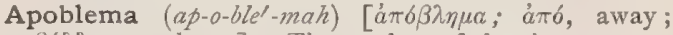
$\beta a ́ \lambda \lambda \varepsilon \iota \nu$, to throw]. The product of abortion.

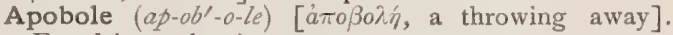
Expulsion; abortion.

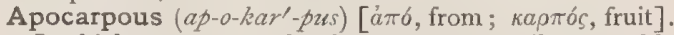
In biology, composed of separate or easily separable carpels.

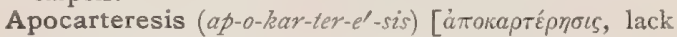
of fortitude]. Suicide by starvation.

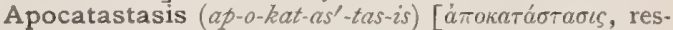
toration]. The subsidence of an abscess or tumor.

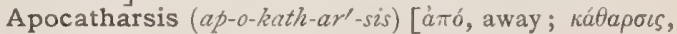
purgation ]. Purgation; abevacuation.

Apocathartic (ap-o-kath-ar-tik). Same as Cathartic.

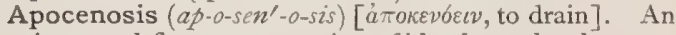
increased flow or evacuation of blood or other humors.

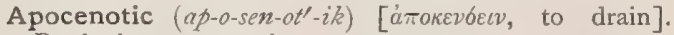
Producing apocenosis.

Apochromatic (ap-o-kro-mat'-ik) [áá, away; $\chi \rho \tilde{\omega} \mu a$, color]. Without color. A Lens, a lens for microscopic and optical purposes, with high correction of spherical and chromatic aberrations, and better " definition." A. Objective. See Objective.

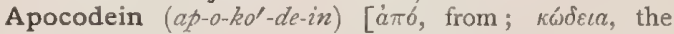
head ], $\mathrm{C}_{18} \mathrm{H}_{19} \mathrm{NO}_{2}$. An alkaloid prepared from colein by dehydration. It is emetic and expectorant, with other qualities much like those of codein, and is recommended in chronic bronchitis. Unof.

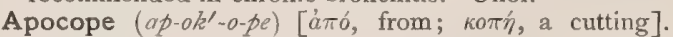
Amputation or abscission; an operation or a wound that results in loss of sulstance.

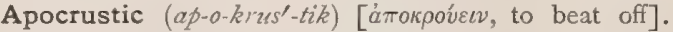
Repellent; defensive ; astringent.

Apocynin (ap-os'-in-in) [apocynon, dogbane]. The precipitate from a tincture of Apocynum cannabinum; tonic, alterative, and evacuant. Dose gr. $1 / 4-j$. Unof.

Apocynum $\left(a p-o s^{\prime}-i n-u m\right)$ [apocynon, dogbane]. Canadian Hemp. The root of A. cannabinum. Properties due to an alkaloid, apocynin. A good expectorant. In full doses an emetic and cathartic. Valuable in dropsy. Dose gr. $v-x x$; of the alkaloid, gr. $1 / 4-1 / 2$. A. Ext., Fld. Dose $\eta^{\nabla-x x}$. A., Tinct. Dose $m v-x l$. Should not be confounded with Cannabis indica. Unof. Another American species, A. androsæmifolium, has similar properties. Unof.

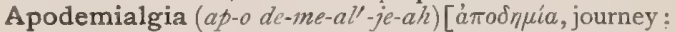
$\alpha \lambda \gamma \varepsilon \iota v$, to grieve]. A morbid dislike of home-life with a desire for wandering.

Apodia (ah-po'-de-ah) [áa priv.; $\pi$ oús, a foot]. Absence of feet.

Apodous $\left(a p^{\prime}-o-d u s\right)$ [á priv.; Tov́s, a foot]. Footless; characterized by apodia.

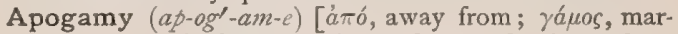
riage]. In biology, I. Asexual reproduction where 
the opposite usually occurs. 2. The total and normal absence of sexual reproductive power

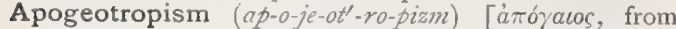
the earth; $\tau \rho \circ \pi \iota k o s$, turning]. In biology, tending to turn upward or away from the ground.

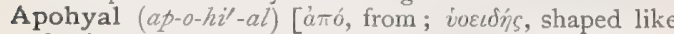
the letter upsilon]. Relating to the anterior (styloid) cornua of the hyoid bone.

Apokenosis (ap-o-ken'-o-sis). See Apocenoris.

A pokenotic $\left(a p-o-k e n-o l^{\prime}-i k\right)$. See Apocenotic.

Apolar $\left(a h-p o^{\prime}-l a r\right)$ [ $a$ priv.; $\pi b \lambda o s$, the end of an axis] Having no pole. A. Cells, nerve cells without pro-

Apolepsis $\left(a p-o-l e p^{\prime}-s i s\right)[\dot{a} \pi \hat{\lambda} \lambda \eta \downarrow \iota s$, a leaving off $]$. Suppression or retention of a secretion or excretion; cessation of a function.

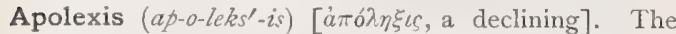
decline of life ; the stage of catabolism or decay.

Apollinaris Water $\left(a p-o l-i n-a^{\prime}-r i s\right)$. A German alkaline mineral water, highly charged with carbonic acid, largely used for gout, rheumatism, etc., but possessing little medicinal value. See Mineral Water.

Apomorphia, or A pomorphin (ap-o-mor'-fe-ah, or -mor' $f i n)\left[a \pi \delta\right.$, from; Morpheus, the god of sleep], $\mathrm{C}_{17} \mathrm{H}_{17}$ $\mathrm{O}_{2} \mathrm{~N}$, = morphia $-\mathrm{H}_{2} \mathrm{O}$. An artificial alkaloid, derived from morphin. The hydrochlorate is the salt used, and is a grayish crystalline powder. It is a systemic emetic acting directly upon the vomiting center, and is the quickest, most certain and least irritating of all emetics. Unof. Dose gr. $\frac{1}{20}-\frac{1}{10}$ hypodermatically, or gr. $\frac{1}{10} \frac{1}{6}$ by the mouth. An expectorant in small doses. A. injectio hypodermica (B. P.). Dose as an expectorant by the mouth, gr. ss; as an emetic, by the mouth, gr. $1 / 3$; hypodermatically, gr. $\frac{1}{5}$. Syrupus apomorph. hydrochloratis. Dose $\overline{3} \mathrm{ss}-\mathrm{j}$.

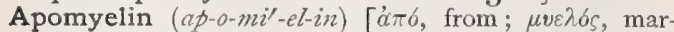
row]. A peculiar phosphatized principle reported to exist in the brain tissue and containing no glycerol.

A pomyttosis $\left(a p-o-m i t-o^{\prime}-s i s\right)$ [ámouv $\sigma \sigma \varepsilon v v$, to blow the nose]. Any disease marked by stertor; a sneezing.

Apone $\left(a p-\bar{o} n^{\prime}\right)$ [Fr.: $\dot{a}$ priv.; Tóvos, pain]. An anodyne; especially the concentrated tincture of capsicum; used externally for the relief of pain, and internally in small doses, diluted, for hemorrhoids, dyspepsia, and mania. Dose gtt. iij-x. Unof.

Aponeurography (ap-o-nu-roul-ra-fe) [ámon'épowous, aponeurosis; ypáon, a writing]. A description of the fasciæ, or aponeuroses.

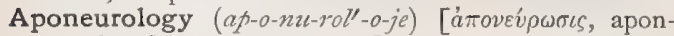
eurosis; $\lambda$ byos, an account]. The science of the fascix or aponeuroses.

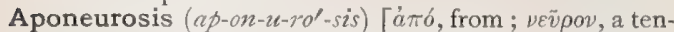
don]. A fibrinous membranous expansion of a tendon giving attachment to muscles or serving to enclose and bind down muscles. Remarkable for their size or importance are the infra-spinous, enclosing the infraspinous muscle; that of the arm, of the deltoid muscle, of the external oblique or abdominal, of the forearm, of the les, of the transversalis, of the head, etc., etc. A. of Occipito-frontalis, the tendinous aponeurosis that separates the two slips of the occipito-frontalis muscle. A. of Soft Palate, a thin but firm fibrous layer, attached above to the hard palate, and becoming thinner toward the free margin of the velum. A. of Subscapular, a thin membrane attached to the entire circumference of the subscapular fossa, and affording attachment by its inner surface to some of the tibers of the subscapularis muscle. A., Supraspinous, a thick and dense membranous layer that completes the osseo-fibrous case in which the supraspinatus muscle is contained, affording attachment by its inner surface to some of the fibers of the muscle.
A., Vertebral, a thin aponeurotic lamina extending along the whole length of the back part of the thoracic region, serving to bind down the erector spinæ, and separating it from those muscles that connect the spine to the upper extremity.

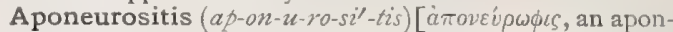
eurosis; $\iota \tau \iota$, inflammation]. Inflammation of an aponeurosis.

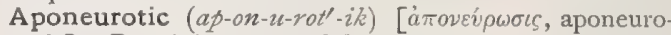
sis]. Pertaining to or of the nature of an aponeurosis.

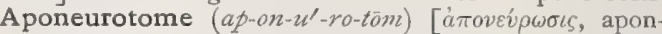
eurosis; $\tau \delta \mu \eta$, a cut]. An instrument for dividing fascize.

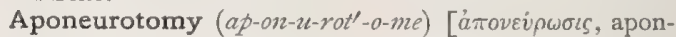
eurosis; $\tau o ́ \mu \eta$, a cut]. The incision, dissection, or anatomy of the fascir; fasciotomy.

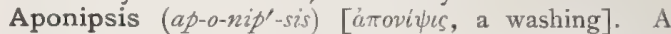
washing; especially an internal washing, anciently performed by copious draughts of milk whey.

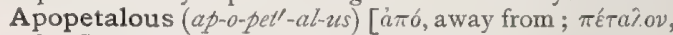
leaf]. In biology, same as Polypetalous.

Apophlegmatic $\left(a p-o-A l g-m a t^{\prime}-i \hbar\right)$ [ätó, away ; $\phi \lambda \varepsilon \varepsilon^{\prime} \mu \alpha$, phlegm]. Promoting the expulsion of mucus from the air passages.

Apophyllous $\left(a p-o-f l^{\prime}-u s\right)$ [áá, from; $\phi \dot{\imath} \lambda \lambda o v$, a leaf $]$. In biology, having distinct calyx or perianth leaves.

Apophysar $\left.\left(a p-o f f^{\prime}-i s-a\right)^{\prime}\right)$. See Apophysary.

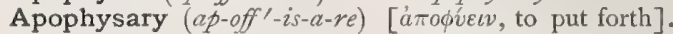
Pertaining to or of the nature of an apophysis.

Apophyseal, Apophysial $\left(a p-o-f i z^{\prime}-e-a l\right)$. Same as Apophysary.

Apophysis (ap-off'-is-is) [áḱ, from; $\phi \dot{v} \sigma \iota s$, growth]. In biology, a process, outgrowth, or swelling of some part or organ, as of a bone, the internal process of the mandible of a crustacean, or some part of a plant, e.g. the seta of certain mosses. A. lenticularis, the orbicular process of the temporal bone. A. raviana, the processus gracilis of the malleus.

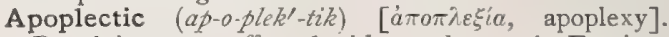
Pertaining to or affected with apoplexy. A. Equivalents, a name given to the premonitory symptoms of apoplexy, indicating that the brain is subject to alterations in the blood pressure, a condition that may lead to serious consequences if the arterial walls are diseased.

Apoplectiform $\left(a p-o-p l e k^{\prime}-t i f-o r m\right)$ [ả $\pi o \pi \lambda \varepsilon \xi i a$, apoplexy; forma, form]. Sudden, like apoplexy.

Apoplectigenous $\left(a p-o-p l e k-t i \gamma^{\prime}-e n-u s\right) \quad[a \pi a \pi \lambda \varepsilon \xi i a$,

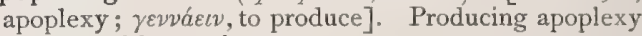
or cerebral hemorrhage.

Apoplectoid (ap-o-plek'-toid). Same as Apoplectiform.

Apoplexia $\left(a p-o-p l e k s^{\prime}-e-a h\right)$ [L.]. Apoplexy. A. splenitis. Synonym of Anthrax.

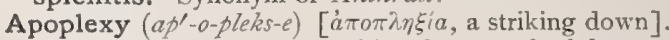
The symptom-complex resulting from cerebral hemorrhage, effusion, or from the plugging of a cerebral vessel. Modern writers mostly describe the postmortem appearances by other terms, as cerebral hemorrhage, effusion, thrombosis, etc. The chief symptom is sudden loss of motion, sensation and consciousness, the patient falling and lying as if dead. There is frequently a conjugate deviation of the eyes and a rotation of the head away from the paralyzed side, and torvard the side on which the cerebral lesion exists. Death may result instantaneously, or shortly, or the patient may recover consciousness and then be found to be suffering from paralysis of one-half of the body (Hemiplegia, q.v.). The bursting of a vessel in the lungs, liver, etc., is sometimes called apoplexy of the lungs, liver, etc. A., Capillary, from rupture and effusion of capillaries. A., Ingravescent, a term applied to a form of apoplexy in which there is a slowly pro- 
gressive loss of consciousness due to a gradual leakage of blood from a ruptured vessel. A., Pulmonary, escape of blood into the pulmonary parenchyma, with laceration of its substance. A., Simple, the name given to those cases of death from coma in which no cerebral lesion is found. A., Spinal. See Hematomveliz. A., Splenic. Synonym of Anthrax.

Apopsychia $\left(a p-o p-s i k^{\prime}-e-a h\right)$ [áó, away ; $\psi v \chi \dot{\eta}$, spirit]. Syncope; fainting; a faint.

Apoptosis $\left(a p-o p-t o^{\prime}-s i c\right)$ [a $[\dot{a} \delta$, away ; $\pi \tau \tilde{\omega} \sigma \iota \varsigma$, a falling]. A falling off, as of a crust, or of the hair; loosening of a scab or crust.

Aporetin (ap-o-re'-tin) [átó, from; $\rho \eta \tau^{\prime} i \eta \eta$, a resin $]$. A resinous substance found in rhubarb.

Aporrhinosis (ap-or-in-o'-sis) [ámó, from; jis, nose]. A discharge from the nostril

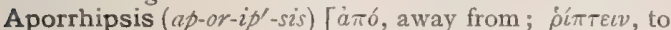
throw]. The throwing off of the clothes or the bed. clothes; a symptom seen in some cases of insanity and in delirium.

Aposcythisis (ap-o-sith'-is-is) [áa $\pi 0 \sigma \kappa v \theta i \xi \varepsilon v v$, to scalp in the Scythian manner]. The surgical or traumatic removal of the scalp.

Aposematic $\left(a p-o-s e m^{\prime}-a t-i k\right)[a \dot{\pi} \sigma o$, away from; $\sigma \bar{\eta} \mu \alpha, \mathrm{a}$ sign]. Applied to such colors as are used by animals as signals or warnings of some dangerous or unpleasant quality, in repelling enemies.

Aposepalous (ap-o-sep'-al-us). See Polysepalous.

Aposepsis $\left(a p-o-s e p^{\prime}-s i s\right)$ [áró $\eta \eta \psi \iota s$, putrefaction; see Sepsis]. Complete putrefaction.

Aposia $\left(a h-p o^{\prime}-z e-a h\right)$ [ả priv. ; $\pi \hat{o} \sigma \iota s$, a drinking]. Absence of thirst; adipsia.

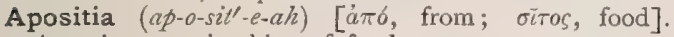
Aversion to or loathing of food.

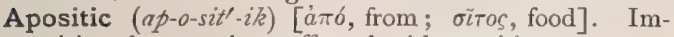
pairing the appetite; affected with apositia.

Aposorbic Acid (ap-o-sor'-bik). See Acid.

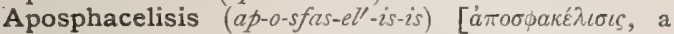
dying of gangrene]. Mortification; gangrene due to constriction.

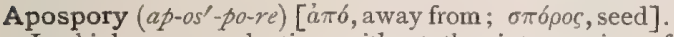
In biology, reproduction without the intervention of spores in cases where sporogenesis ordinarily occurs.

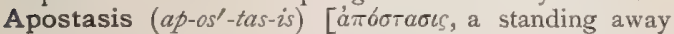
from]. I. An abscess. 2. The end or the crisis of an attack of disease ; termination by crisis. 3. An exfoliation. In biology, the separation of organs by unusual elongation of internodes.

Apostatic $\left(\alpha p-o s-t a t^{\prime}-i k\right)$ [ $[\dot{\alpha} \pi \sigma \sigma \tau \alpha \sigma \iota$, a standing away from ]. Relating to or of the nature of an apostasis.

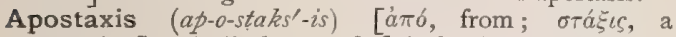
dropping]. A discharge of fluid by drops; epistaxis.

Apostem ( $\left.a p^{\prime}-o-s t e m\right)$, or Apostema (ap-o-ste'-mah)

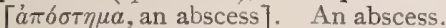

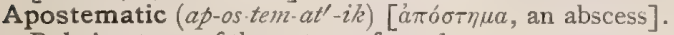
Relating to or of the nature of an abscess.

Apostemation (ap-os-tem-a'-shun) [apostematio, abscess. formation]. The formation of an apostem or abscess.

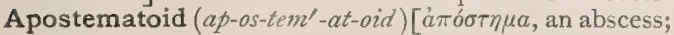
Eiঠos, form]. Resembling an apostem or abscess.

Aposthia ( $\left.a h-p o s^{\prime}-t h e-a h\right)[a$ priv: $\pi \dot{a} \sigma \theta \eta$, penis, prepuce]. Absence of the penis or of the prepuce.

Apostoli's Method. The use of strong electrolytic or chemical galvano-caustic currents in the treatment of diseases of the female generative organs, especially uterine fibroids.

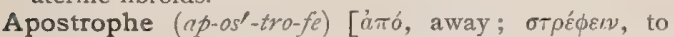
turn]. The arrangement of chlorophyll bodies along the side walls of the cells as a result of excess or deficiency of light. Cf. Epistrophe and Dystrophe.

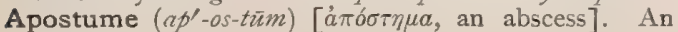
abscess.
Aposyringosis $\left(a p-o-s i r-i n-g o^{\prime}-s i s\right)[\alpha \dot{\alpha} \dot{b}$, from; $\sigma i \rho \iota \gamma \xi$, pipe]. The formation of or change into a fistula.

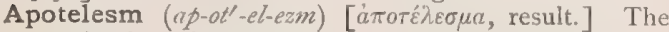
termination of a disease.

Apothecaries' Weight. A system of weights and measures used in compounding medicines. The Troy pound of 5760 grains is the standard. It is subdivided into 12 ounces. The ounce is subdivided into eight drachms, the drachm into three scruples, and the scruple into 20 grains. For fluid measure the quart of 32 fluid ounces is subdivided into pints, the pint into I6 fluid ounces, the ounce into eight fluid drachms, and the fluid drachm into 60 minims. The following abbreviations are used:-

M, minim.
gtt., gutta, a drop.
3, scrupulus, a scruple
3, drachma, a drachm
(6o grains).

$$
\begin{aligned}
& \text { 5, uncia, an ounce ( } 480 \\
& \text { grains). } \\
& \mathrm{Db} \text {, libra, a pound, } \\
& \mathrm{O}, \text { octarius, a pint. } \\
& \text { gr., granum, a grain. } \\
& \text { Ss., semissis, one-half. }
\end{aligned}
$$

See Weiohts and Measures.

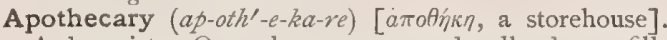
A druggist. One who prepares and sells drugs, fills prescriptions, etc. In Great Britain the apothecary is also a physician, filling his own prescriptions. In the United States it frequently happens that an authorized practitioner is also an apothecary, but without the degree of M. D. the practice of medicine is illegal.

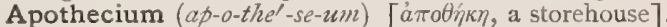
In biology, the saucer-shaped fruiting organ, or ascocarp, of lichens and certain ascomycetous fungi.

Apothem, or Apothema ( $a p^{\prime}-o-t h e m$ or $\left.a p-a t h^{\prime}-e m-a h\right)$ [ámó, from; $\theta \dot{\varepsilon} \mu a$, a deposit]. A brown powder formed by the open-air evaporation of a vegetable infusion or decoction.

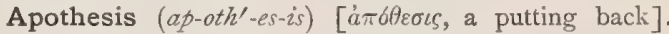
The reduction of a fracture or luxation.

Apotheter (ap-oth'-et-er). A navel-string repositor devised by Braun, consisting of a staff with a sling attached in which the prolapsed funis is placed and carried up into the uterine cavity.

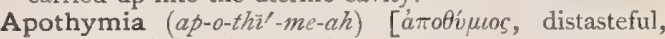
disagreeable]. An aversion.

A potrepsis $\left(a p-o-t r e p^{\prime}-s i s\right)$ [ $\dot{a} \pi o ́ \tau \rho \varepsilon \psi \iota \varsigma$, a turning away]. The resolution of an abscess.

Apozem, or Apozema ( $a p^{\prime}-o-z e m$, or $\left.a p-o z^{\prime}-e m-a h\right)$

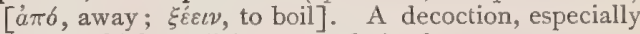
one to which medicines are admixed

Apparatus (ap-ar-a'-tus) [apparatus, prepared]. The instruments used in any science, art, or surgical operation. Anatomically the word is used to designate collectively the organs effecting any specified work or action. A. ligamentosus colli, the occipito-axoid ligament, a broad band at the front surface of the spinal canal that covers the odontoid process.

Apparent $\left(a p-a^{\prime}\right.$-rent $)$ [apparere, to appear]. Seeming : appearing to be like. A. Death. See Death.

Apparition (ap-ar-ish'-un) [apparitio, an appearance]. A visual delusion or hallucination.

Apparitor (ap-ar'-it-or) [L., a helper]. A small coiled tube worn at the ear to assist the hearing.

Appendage $\left(a p-e n^{\prime}-d \bar{a} j\right)$ [appendere, to weigh; hang]. That which is attached to an organ as a part of it. See Appendix. A., Auricular, the projecting part of the cardiac auricle. A., Epiploic. See Appendix. A., Ovarian, the parovarium.

Appendicectomy $\left(a p-e n-d i s-e e^{\prime}-t o-m e\right)$ [appendix; $\varepsilon \kappa \tau о \mu \eta$, excision]. Excision of the appendix vermiformis.

Appendicitis (ap-en-dis-i'tis) [appendere, to hang upon or to : $\iota \tau \iota \zeta$, inflammation]. Inflammation of the appendix vermiformis; ecphyaditis. 
Appendicular (ap-en-dik'-u-lar) [appendicula, a small appendix]. Pertaining to the appendix vermiformis. A. Gland, a biramose gland attached to the spermatheca of queen bees

Appendix (ap-en'-diks) [appendere, to hang upon or to: pl., Appendices]. What is accessory to or dependent upon another. An appendage. A. auricularis, the auricular appendage, a process of the auricles of the heart. A. cæci vermiformis, a worm-shaped process of the cecum. A. cerebri, the pituitary body. A., Ensiform. See Xiphoid. A. epiploicæ, pouchlike, fatty projections of the peritoneum of the large intestine. A., Xiphoid. See Xiphoid.

Apperception (aph-er-sep'-shun) [appercipere, to receive]. The conscious reception or perception of a sensory impression; the power of receiving and appreciating sensory impressions.

Appert's Process. The preservation ("canning") of meat, fruits, and vegetables by exclusion of air and germs; effected by hermetically sealing the substances in tin cans after heating the contents to $110^{\circ}$ or more.

Appetence (ap'-e-tens) [appetentia, appetite]. An appetite, or desire; the attraction of a living tissue for those materials that are appropriate for its nutrition.

Appetency $\left(a p^{\prime}-e-t e n-s e\right) . \quad$ I. See Appetence. 2. In biology, the doctrine propounded by Lamarck, in which it is maintained that new organs can be produced in animals by the simple assertion of the will called into action by new wants, and that the organs thus acquired can be transmitted by generation.

Appetite $\left(a p^{\prime}-e-t \bar{t} t\right)$ [appetere, to desire]. The desire for food; also any natural desire ; lust. A., Perverted, that for unnatural and undigestible things, frequent in disease and pregnancy, Anorexia, loss of appetite; Bulimia, insatiable appetite; Hunger, the strong desire and need of food.

Appetizer $\left(a p^{\prime}-e-t \bar{i}-z e r\right)$ [appetere, to desire]. A medicine, or dose, taken to stimulate the appetite

Applanate $\left(a p^{\prime}-l a n-\vec{a} t\right) \quad[a d$, to; planus, flat $]$. In biology, horizontally flattened.

Applanatio $\left(a p-i a n-a^{\prime}-s h e-0\right)$ [L.]. A flattening. A. corneæ, flattening of the entire surface of the cornea from disease.

Applanation (ap-lan- $\left.a^{\prime}-\operatorname{shun}\right)$ [applanatio, a flattening]. A flattening, as of the cornea.

Apple $\left(a p^{\prime}-l\right)$ [AS, $a p p e l$, an apple]. The fruit of the tree, Pyrus malus. A., Adam's. See Pomum adami. A.-brandy, an alcoholic spirit distilled from cider; cider-brandy. A. Extract. See Extractum ferri pomatum. A.-eye, a synonym of Exophthalmos. A. of the Eye, the pupil ; also, the eyeball. A.-jack. See A.brandy. A.-oil, amyl valerianate; prepared from isoamyl-isovaleric ester.

Application $\left(a p-l i k-a^{\prime}-s h u n\right)$ [applicatio, an application]. The act of applying anything, as a plaster, leech, bandage, lotion, pad, or compress; the thing so applied. A. Colors. See Pigments, Colors, and Dyestuffs.

Applicative $\left(a p^{\prime}\right.$-lik-a-tiv). See Conduplicate.

Applicator ( $\left.a p^{\prime}-l i k-a-t o r\right)[L$.$] . An instrument used$ in making applications; especially, one used in uterine or urethral surgery.

Applier (ap-li'-er) [applicare, to apply]. A dental instrument for making applications to teeth.

Appolito's Operation. See Operations, Table of.

Appolito's Suture. See Suture.

Apposition (ap-o-zish'-un) [apponere, to apply to]. The act of fitting together; the state of being fitted together. A. Theory, a theory concerning the growth of the cell-wall, as held by Schmitz, Strasburger, etc., viz, that stratified and other cell-walls of plants grow in thickness by the deposition of new particles upon the inner face of the cell. Growth in surface is the re- sult of a simple stretching of the wall by the pressure of the contents.

Approach $(a p$-röch') [ME., approche]. Adrawing near. A. Grafting, to inarch.

Appropriation (ap-ro-pre-a'-shun) [appropriatio, a setting apart]. Assimilation of nutriment.

Approximal (ap-roks'-im-al) [ad, to; proximus, next]. That which is next to; contiguous. In dentistry, pertaining to contiguous surfaces, as approximal fillings.

Appun's Apparatus. A device for determining the overtones of a vowel by means of reeds.

Apraxia ( $a h$-prakes'-e-ah) [á priv.; $\pi \rho a ́ \sigma \sigma \varepsilon \imath \nu$, to do $]$. Soul-blindness; mind-blindness; object-blindness ; an affection in which the memory for the uses of things is lost, as well as the understanding for the signs by which the things are expressed.

Aprication (ap-re-ka'-shun) [apricatio, a basking in the sun]. The sun-bath; sun-stroke.

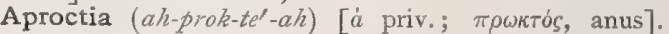
Imperforation of the anus.

Aproctosis ( $\left.a h-p r o k-t o^{\prime}-s \dot{s}\right)$ [à priv.; $\pi \rho \omega \kappa \tau o ́ s$, anus]. See Aproctia.

Aproctous (ah-prok'-tus) [á priv.; $\pi \rho \omega k \tau o ́ s$, the anus]. Having imperforation of the anus

Apron ( $a^{\prime}$-prun) [ME, apern]. I. In surgery, a protection or covering for the body in surgical operations. 2. The omentum. A., Hottentot, artificially elongated labia minora; velamen vulve. A. of Succor, a canvas appliance borne by two men, and used for the transportation of wounded persons.

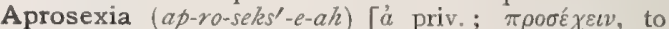
give heed]. A mental disturbance consisting in inability to fix the attention upon a subject. An inability to think clearly and to readily comprehend what is read or heard, sometimes observed in the course of chronic catarrh of the nose or of the nose and pharynx.

Aprosopa (ap-ros'-o-pah). See Aprosopia

Aprosopia $\left(a p-r o-s 0^{\prime}-p e-a h\right)[\dot{a}$ priv. ; $\pi \rho 6 \sigma \omega \pi o v$, the face]. A form of fetal monstrosity with partial or complete absence of face.

Aprosopous (ap-ros'-o-pus) [ $\dot{\alpha}$ priv.; $\pi \rho \sigma \sigma \omega \pi 0 \nu$, the face]. Exhibiting aprosopia.

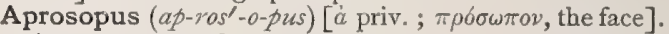
An aprosopous fetus.

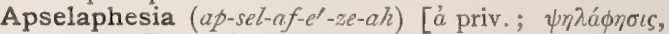
touch ]. Paralysis of the tactile sense.

Apsithyria, or Apsithurea ( $a p-s i t h-\bar{l}^{\prime}-r e-a h$, or $\left.-u^{\prime}-r e-a h\right)$ [a priv.; $\psi \iota \theta v \rho i \zeta \varepsilon \iota v$, to whisper]. A term suggested by Solis-Cohen for hysterical aphonia, in which the patient not only loses the voice, but is unable even to whisper. It is generally accompanied by double paralysis of the vocal cords, but there is no paralysis of the tongue, lips, or expiratory muscles. Charcot especially advocates hypnotism in the treatment of the condition.

Apsychia (ap-sik'-e-ah) ['á priv.; $\psi v \chi \hat{y}$, spirit]. Unconsciousness; a faint or swoon.

Apta viro $\left(a p^{\prime}-t a h v i^{\prime}-r o\right)$ [L.: pl., Ap'a viris]. A young girl who by mechanical means has been rendered available for prostitution.

Apterium (ap-te'-re-um) [á priv. ; $\pi \tau \varepsilon \rho \delta o v$, a feather]. In biology, a normally naked tract on a bird's skin.

Apterous (applter-us) [áa priv. ; $\pi \tau \varepsilon \rho \delta v$, a wing, a feather]. In biology, destitute of wings or membranous expansions.

Aptitude $\left(a p^{\prime}-t e-t \bar{u} d\right)$ [aptitudo, fitness]. Fitness, tendency. The natural proneness of an organism toward certain functions or pathological conditions.

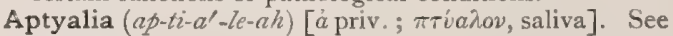
Aptyalism.

Aptyalism ( $\left.a p-t i^{\prime}-a l-i z m\right)$ [a priv. ; $\pi \tau v a \lambda i \xi \varepsilon \imath \nu$, to spit] Deficiency or absence of saliva. 
Aptystia $\left(a p-t i s^{\prime}-t e-a h\right)$ [a priv. ; $\pi \tau v \varepsilon v$, to spit]. See Aptyalism.

Apulosis $\left(a p-u-l o^{\prime}-s i s\right)$ [a் $\pi$ ov́ $\lambda \omega \sigma \iota s ; o v ้ \lambda \varepsilon \iota \nu$, to cicatrize]. Cicatrization, or a cicatrix.

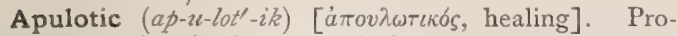
moting cicatrization, or apulosis.

Apus $\left(a^{\prime}-p u s\right)\left[a ́\right.$ priv., and $\pi o^{\prime} s$, foot $]$. I. A monstrosity consisting in absence of the lower limbs, or feet. 2. An apodous fetus.

Apyonin (ah-pi'-on-in) [ả priv.; $\pi \tilde{v} o v$, pus $]$. A remedy introduced as a substitute for pyoktanin in ophthalmic practice. It is said to be identical with yellow pyoktanin. Unof.

Apyretic $\left(a h-p i-r e t^{\prime}-i k\right) \cdot[\dot{a}$ priv.; $\pi v \rho \varepsilon \tau \delta \delta$, fever $]$. Without fever or pyrexia.

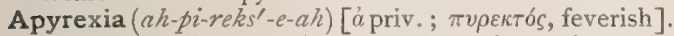
The non-febrile stage of an intermittent fever ; intermission or absence of fever.

Apyrexial (ah-pi-reks'-e-al) [ámípektos, without fever]. Pertaining to, of the nature of, or characterized by, apyrexia.

Apyrexy (ah'-pi-reks-e). See Apyrexia.

Aqua $\left(a^{\prime}-k z v a h\right)$ [L.: gen. and pl., Aqua, $a^{\prime}$-krve]. Water. An oxid of hydrogen having the composition $\mathrm{H}_{2} \mathrm{O}$. It is a solid below $32^{\circ}$, a liquid between $32^{\circ}$ and $212^{\circ}$, vaporizes at $212^{\circ}$ at the sea level (bar. 760 $\mathrm{mm}$.), giving off vapor of tension equal to that of the air. It covers four-fifths of the surface of the earth, but is never pure in nature, containing from a trace of soluble matter, in rain water, to 26 per cent. of soluble mineral salts, in the Dead Sea. Water is an essential constituent of all animal and vegetable tissues. In the human body it forms two per cent. of the enamel of the teeth, 77 per cent. of the ligaments, 78 per cent. of the blood, and 93 per cent. of the urine. Externally, water has a stimulating effect upon the skin, either by direct or reactionary means. Cold water when continued too long may lower the general temperature of the body so as to produce serious depression of the circulation and muscular power. When properly used it is a valuable antipyretic. Hot water and vapor increase circulation and produce diaphoresis. Its too long-continued use debilitates. Internally, water is a diuretic. It is the most useful of all the solvents in pharmacy. The following are the official preparations and forms: A. bulliens, boiling water. A. communis, common water. A. destillata, distilled water. A. fervens, hot water. A. fluvialis, riverwater. A. fontana, well- or spring-water. A. marina, sea-water. A. pluvialis, rain-water. See also Mineral Water. Aqua in pharmacy also designates various medicated waters: as A. ammoniz, water of ammonia; A. anethi, dill water; A. chlori, chlorin water; A. rosæ, rose water. A. fortis. See Acid, Nitric. A. regia. See $A$. Nitrohydrochloric. A. tofana, a celebrated secret poison, prepared in the I 7 th century at Palermo by a woman named Toffana. It was probably arsenical. A. Vitæ, Brandy or Spirit, q. v. In anatomy, A. labyrinthi, the clear fluid existing in the labyrinth of the ear.

Aquæcapsulitis (a-kwe-kap-su-li'-tis) [aqua, water; capsula, a capsule; $\iota \tau \iota s$, inflammation]. Serous iritis.

Aquæductus (a-krve-duk'-tus). See Aqueduct.

Aquamalarial Fever $(a-k$ wea-mal-a'-re-al). Synonym of Malarial Fever. See Fever.

Aquapuncture (ak-wah-pung $\left.k^{\prime}-c h \bar{u} r\right)$ [aqua, water; punctura, a puncture]. Counter-irritation by means of a very fine jet of water impinging upon the skin; useful in neuralgia and other nerve disorders.

Aquatic (a-kwat'-ik) [aqua, water]. Pertaining to water. A. Cancer. Synonym of Cancrum oris.

Aqueduct, or Aqueductus (ak'-ze-dukt, or $a k$-zve- $d u k^{\prime}$-tus ) [aqua, water; ductus, a leading]. Used of ducts or canals in various parts of the body. A. cerebri, the infundibulum. A. cochleæ, aqueduct of the cochlea. A. of Cotunnius, the aqueduct of the vestibule, extending from the utricle to the posterior wall of the pyramid in the brain. A. Fallopii, the canal of the portio dura in the petrous portion of the temporal bone. A. Sylvii, the aqueduct of Sylvius from the third to the fourth ventricle, the iter a tertio ad quartum ventriculum. A. vestibuli, aqueduct of the vestibule of the ear.

Aqueous ( $\left.a^{\prime}-k w e^{-}-u s\right)$ [aqua, water]. Referring to water; watery. A. Chamber of the Eye, the space between the cornea and the lens; the iris divides it into an anterior and a posterior chamber. A. Extract, a solid preparation of a drug made by evaporation of its aqueous solution. A. Humor, the fluid filling the anterior chamber of the eye.

Aquiducous (a-kwe-du'-kus) [aquiducus; aqua, water; ducere, to lead]. Hydragogue.

Aquilaria (a-kwil-a'-re-ah) [L.]. A genus of trees. A. agallocha, a tree of S. E. Asia producing the true aloes-wood, or eagle-wood, valued in perfumery, but no longer employed in regular pharmacy or practice. A. ovata and A. secundaria also furnish varieties of aloes-wood. Unof.

Aquilegia (ak-zil-e'-je-ah) [L.]. A genus of ranunculaceous plants of many species. A. vulgaris has active medicinal qualities; but none of the species are now much used in regular practice.

Aquiparous (a-kwip'-ar-us) [aqua, water; parere, to bring forth]. Producing water, or affording watery secretions; said of glands, as the lachrymal and parotid.

Aquocapsulitis (a-kwo-kap-su-li'-tis) [aqua, water; capsula, a small box]. Serous iritis, $q . v$.

Aquosity $\left(a-k_{\text {kwos }}-i t-\ell\right)$ [aquositas, watery]. The state or condition of being watery.

Aquula (ak-zen'-lah) [L.]. A small aqueous collection. A. cotunnii, the perilymph, $q . v$.

Arabic $\left(a r^{\prime}-a b-i k\right)$ [A $\rho a \beta \iota \kappa o ́ s$, Arabic]. Of or pertaining to Arabia. A. Acid. See Arabin. A. Gum. See Acacia.

Arabin $\left(a r^{\prime}-a b-i n\right)$ [Apaßı́ós, Arabic], $\left(\mathrm{C}_{6} \mathrm{H}_{10} \mathrm{O}_{5}\right)_{2}$ $+\mathrm{H}_{2} \mathrm{O}$. Arabic Acid. A transparent, glassy, amor phous mass, an exudate from many plants, making a clear solution in water. It is the principal constituent of gum arabic. See Carbohydrates, Table of.

Arabinose (ar'-ab-in-ōs) ['A paßєкós, Arabic], $\mathrm{C}_{5} \mathrm{H}_{10} \mathrm{O}_{5}$ One of the glucoses. Made from gum arabic on boiling with dilute $\mathrm{H}_{2} \mathrm{SO}_{4}$. It crystallizes in shining prisms that melt at $100^{\circ}$; is slightly soluble in cold water, has a sweet taste, and reduces Fehling's solution, but is not fermented by yeast. See Carbohydrates, Table of.

Arabis $\left(a r^{\prime}-a b-i s\right)$ ['A $\rho a \beta ı \kappa o ́ s$, Arabic]. A genus of cruciferous herbs; rock cresses, or wall cresses. A. chinensis, of Asia, and A. sagittata and A. thaliana, of Europe, are stimulant and stomachic. The seeds of some species yield an oil much like that of rape-seed. Unof.

Arabite $\left(a r^{\prime}-a b-\bar{z} t\right)$ ['A $\rho \alpha \beta \iota \delta ́ s$, Arabic], $\mathrm{C}_{5} \mathrm{H}_{12} \mathrm{O}_{5}$. A substance formed from arabinose by the action of sodium amalgam. It crystallizes from hot alcohol in shining needles, melting at $102^{\circ}$. It has a sweet taste, but does not reduce Fehling's solution.

Arabonic Acid (ar-ab-on'-ik). See Acid.

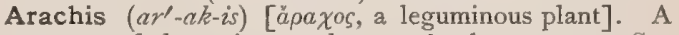
genus of leguminous plants. A. hypogæa. See Ground Nut.

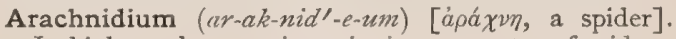
In biology, the secreting spinning apparatus of spiders, 
consisting of five kinds of glands, over one thousand in all, producing a secretion insoluble in water and with a nitrogenous basis, forming the fine, silky threads of the web.

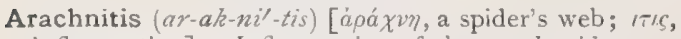
inflammation]. Inflammation of the arachnoid membrane of the brain.

Arachnoid ( $\left.a r-a k^{\prime}-n o i d\right)$ [ápá $\chi v \eta$ a spider's web; Eífos, form]. Resembling a web. A. Cavity, the space between the arachncid membrane and the dura mater. A. Membrane, the delicate serous membrane of the brain and cord between the dura and pia mater. Sub-arachnoid fluid. See Cerebro-spinal Fluid.

Arachnoidal $\left(a r-a k-n o i d^{\prime}-a l\right)$ [ááa $\chi v \eta$, a spider's web; $\varepsilon i \delta \circ$, form]. Pertaining to the arachnoid.

Arachnoiditis (ar-ak-noid-i'-tis). Same as Arachnitis.

Arachno-pia $\left(a r-a k^{\prime}-n o-p i^{\prime}-a h\right)$ [ả á $\chi \nu \eta$, a spider's web; pia, fem. of pius]. The arachnoid and the pia considered together.

Arachnorrhinitis (ar-ak-nor-in-i'-tis) [ả á $\chi v \eta$, spider; $\rho / \zeta$, nose ; $\iota \tau \iota \zeta$, inflammation $]$. A disease of the nasal passages supposed to be due to the presence of a spider.

Arachnotitis (ar-ak-no-ti'-tis) [ááa $\chi \nu \eta$, spider; ov̀s, ear; $\iota \tau \iota \zeta$, inflammation]. Inflammation said to be caused by a spider in the auditory canal.

Arack $\left(a r^{\prime}-a k\right)$ [Ind.]. A spirituous liquor distilled from rice, dates, palm-sap, or cocoanut juice, used in Asia, etc.

Aræometer (ar-e-om'-et-er). See Areometer.

Aræotic (ar-e-ot'-ik). See Areotic.

Aralia $\left(a r-a^{\prime}-l e-a h\right)$ [L.]. A genus of plants, order Araliacex, embracing several species, having aromatic, diaphoretic, and resolvent properties. Ginseng, wild sarsaparilla, petty morrel, and other plants esteemed in popular medicine belong here; few have active qualities of high value in any disease. Unof.

Aran-Duchenne's Disease. See Diseases, Table of.

Araneæ Tela $\left(a r-a^{\prime}-n e-e t e^{\prime}-l a h\right)$. See Cobweh.

Araneous $\left(a r-a^{\prime}-n e-u s\right)$ [aranea, a spider's web]. Full of webs; resembling a cobweb. A. Membrane, the arachnoid.

Arantius, Bodies of. See Corpora. A., Canal of. See Canal. A., Duct of. See Duct. A., Nodules of. See Arantius, Bodies of. A., Valves of. See Valvulce arantii. A., Ventricle of, a small cul-de-sac in the medulla oblongata,

Arar $\left(a^{\prime}-r a r\right)$ [Barbary]. The tree Callitris quadrivalvis of N. W. Africa. It produces sandarac.

Araroba $\left(a r-a r-o^{\prime}-b a h\right)$ [Brazil]. Goa Powder. An oxidation product of resin found deposited in the wood of the trunk of the Andira araroba of Brazil. Its active principle is Chrysarobin or Chrysophanze acid, $q . v$. It is largely used in skin affections.

Arasa $\left(a r-a^{\prime}-s a h\right)$ [S. Am. . The root of a plant native to Brazil and Uruguay. The active principle of the drug is found in the tuberosities of the root, especially in the bark, which is quite thick. In taste a decoction of the drug resembles that of cascarilla. It is an excellent remedy in metrorrhagia, acting where hydrastis is ineffectual. No unpleasant secondary effects have been noted. Unof.

Arbor $\left(a r^{\prime}-b o r\right)[\mathrm{L}$.$] . A name for the arbor vite of the$ cerebellum. A. Vitæ, a term applied to the arborescent appearance of a section of the cerebellum, and also to a similar appearance of the folds of the interior of the cervix uteri. See Thuja.

Arborization (ar-bor-iz-a'-shun) [arbor, a tree]. A form of nerve termination in which the nerve fibers are brought into contact with the muscle fiber by means of an expansion.

Arbuscula (ar-bus'-ku-lah) [L.]. A small shrub having the appearance of a diminutive tree.
Arbutin (ar'-bu-tin) [arbutus, the wild strawberry tree], $\mathrm{C}_{12} \mathrm{H}_{16} \mathrm{O}_{7}$. A bitter glucosid obtained from Uva ursi, or bearberry. It is neutral, crystalline, and resolvable into glucose and hydroquinon. Arbutin is an efficient diuretic. Dose gr. xv-xxx. See Uva ursi.

Arbutus $\left(a r-b u^{\prime}\right.$-tus $)$ [L.]. A genus of ericaceous shrubs and trees. A. menziesii, the madroño of California, has an astringent bark, useful in diarrheas. Unof. A. unedo, the European arbute, is astringent and narcotic. A., Trailing. See Epigrea.

$\operatorname{Arc}(\operatorname{ark})$ [arcus, a bow]. In craniometry, a measurement taken on the outside of the skull, following its curves. A., Binauricular, a measurement from the center of one auditory meatus to the other, directly upward across the top of the head. A., Bregmatolambdoid, a measurement along the sagittal suture. A., Naso-bregmatic, from the root of the nose to the bregma. A., Naso-occipital, measurement from the root of the nose to the lowest occipital protuberance.

Arcanum (ar-ka'-num) [arcanum, a secret]. A inedicine whose composition is kept secret.

Arcate (ar'-kat) [arcatus, bow-shaped]. Bow-shaped; curved; arcuate.

Arch (arch) [arcus, a bow]. A term applied to the curved shape of several various parts of the body. A. of Aorta. See Aorta. A., Branchial, the cartilaginous arches that support the gills (branchix) of fishes. In the human fetus they are also present. See Cleft. A. of Colon. See Colon. A. of Corti, the arch that the pillars of the organ of Corti make over the basilar membrane of the cochlea. A., Crural. See Poupart's Ligament. A. of Fallopius, a name for the arch formed by Poupart's ligament. A. Femoral, same as A.Crural. A., Palmar, the arch formed by the radial artery in crossing the bones of the metacarpus. A., Plantar, the arch made by the external plantar artery. A., Post-oral, arches in the fetus, five in number, that develop into the lower jaw and throat. See A., Branchial. A. of Pubes, that part of the pelvis formed by the convergence of the rami of the ischia and pubes on each side. A., Supra-orbital, the curved and prominent margin of the frontal bone beneath the superciliary ridge, that forms the upper boundary of the orbit. A. of a Vertebra, the part of a vertebra formed of two pedicles and two laminx and enclosing the spinal foramen. A., Zygomatic, the arch formed by the malar and temporal bones.

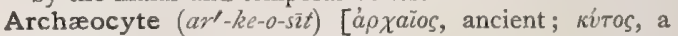
hollow (a cell) ]. In biology, one of the irregular ameboid cells-mesameboids-imbedded in a jelly-like matrix and occurring between the two primitive epithelia of the body, in the Porifera.

Archæostoma, Archæostome (ar-ke-os'-to-mah, ar'ke-o-stōm). See Archistome.

Archæus (ar-ke'-us) [á $\rho \chi a \check{l} o s$, ancient]. In spagiric medicine, the invisible counterpart of the visible body; solar heat as a source of life.

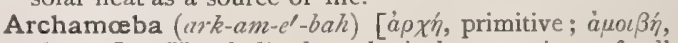
change]. Haeckel's hypothetical progenitor of all amebre and of all higher forms of life.

Archamphiaster, or Archiamphiaster (ark-am-fe-as' ter, or $\left.a r-k e-a m-f e-a s^{\prime}-t e r\right)\left[a \rho \chi^{\prime} \eta\right.$, first ; $a \mu \phi i$, around ; $\dot{a} \sigma \tau \eta \rho$, star $]$. In biology, those amphiasters concerned in the production of the polar globules.

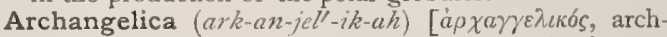
angel]. A genus of umbelliferous plants; A. abropurpurea, officinalis, and sativa afford Angelica Root, q.v.

Archebiology $\left(a \gamma^{-}-k \ell-b i-o l^{\prime}-a-j e\right)[a j \rho \chi \dot{\eta}$, beginning; $\beta i o s$, life; $\lambda \sigma^{\prime} \gamma_{o s}$, discourse $]$. The study of the simplest or most primitive forms or beginnings of life.

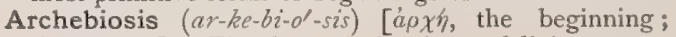
$\beta i \omega \sigma \iota$, life]. The theoretical origin of living organ- 
isms from non-living matter. See Generation, Spontarreus: Biogenesis, and Abiogenesis.

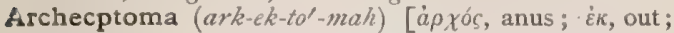
$\pi \tau \bar{\omega} \mu a$, a falling]. Prolapse of the rectum.

Archegenesis (ark-e-jen'-es-is). The same as Archebiosis.

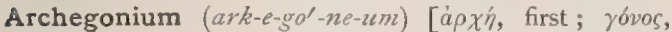
race]. The female reproductive organ of the higher cryptogams.

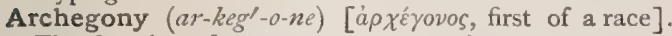
The doctrine of spontaneous generation.

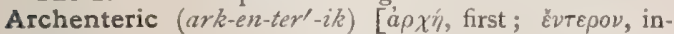
testine]. Relating to the archenteron.

Archenteron (ark-en'-ter-on) [á $\rho \hat{y} \dot{y}$, a beginning;

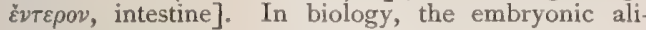
mentary cavity. The entodermal sac of the gastrula; archigaster; cœlenteron.

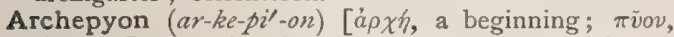
pus]. Pus that has become caseated, or so thick that it does not flow. A term proposed by Roswell Park.

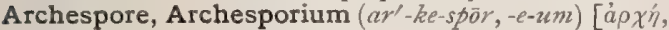
a beginning; $\sigma \pi o \rho a ́$, a seed]. In biology, the cells that give rise to the lining of the anther-cell and to the mother-cells of the pollen.

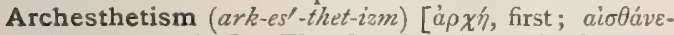
$\sigma \forall a \iota$, to perceive]. The doctrine that animal movements are primitively determined by sensibility or consciousness.

Archet (ar-chet' or $a r$-sha') [Fr.]. A bow formerly used to operate the drill in lithotrity.

Archetype $\left(a r^{\prime}-k e-t \bar{\imath} p\right)$ [á $\rho \chi \chi^{\prime}$, a beginning; $\tau \dot{v} \pi \circ \varsigma$, a type]. In comparative anatomy, an ideal type or form with which the individuals or classes may be compared. A standard type.

Archhydra (ark-hi'-drah) [ $\alpha \rho \chi \eta \dot{\eta}$, first; $v \delta \omega \rho$, water]. A primitive polyp.

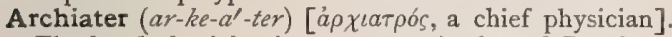
The head physician in a court, as in that of Russia.

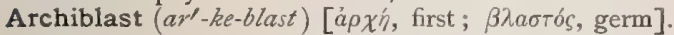
In embryology, the granular areola surrounding the germinal vesicle. It is composed of three layers, the outer, or epiblast, from which the skin and its adnexa, the nervous system, and the terminal portions of the alimentary canal are formed; the middle, or mesoblast, from which the epithelium of the genito-urinary organs and the smooth and striated muscle-tissue is derived; and the inner, or hypoblast, for the development of the epithelium of the respiratory tract and of the alimentary canal.

Archiblastic $\left(a r-k e-b l a s^{\prime}-t i k\right)$ [ả $\rho \chi \dot{\eta}$, first; $\beta \lambda \alpha \sigma \tau b \varsigma$, germ]. Derived or supposed to be derived from the archiblast. The parenchymatous elements are regarded as archiblastic.

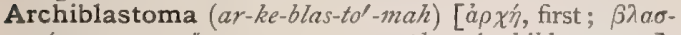

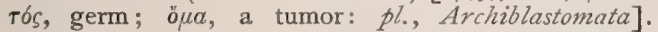
Any tumor composed of archiblastic or parenchymatous elements, such as myoma, neuroma, papilloma, epithelioma, adenoma, carcinoma, etc.

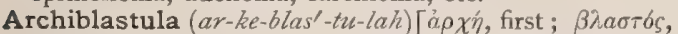
a germ or bud]. In embryology, a ciliated, vesicular morula, resulting from complete and regular yelkdivision and by invagination forming the archigastrula.

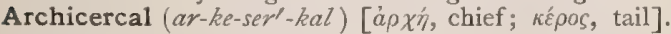
In biology, having the tail primitive, without fin-folds.

Archicharp $\left(a r^{\prime}-k e-k a r p\right)$ [a $a \chi^{\prime} \dot{\eta}$, first; $\kappa \alpha \rho \pi \hat{s}$, fruit]. See Ascogonium.

Archicytula (ar-ke-sit'-u-lah) [ả $\rho \chi \dot{\eta}$, a beginning; кútos, a cell]. A fertilized egg cell in which the nucleus is discernible.

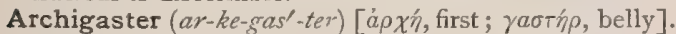
The primitive, perfectly simple intestine; archenteron.

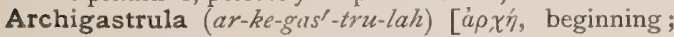

$\gamma a \sigma t h \rho$, belly]. The gastrula as it is observed in the most primitive types of animal development; called also bell-gastrula from its shape.

Archigenesis (ar-ke-jen'-es-is). See Archebiosis.

Archil (ar'-kil) [ME., orchell]. A coloring matter somewhat like litmus, chiefly obtained from the lichen, Roccella tinctoria; used for staining animal tissues. See Conspectus of Pigments, under Pigment.

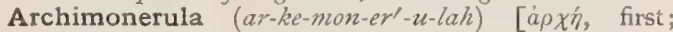

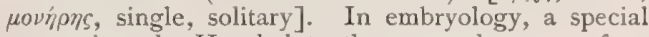
name given by Haeckel to the monerula stage of an egg undergoing primitive and total cleavage.

Archimorula (ar-ke-morl-u-lah) [ápג'n, first; $\mu \delta \rho o \nu$, a mulberry]. In embryology, the solid mass of cleavage cells, or mulberry mass, arising from the segmentation of an archicytula, and preceding the archiblastula and archigastrula.

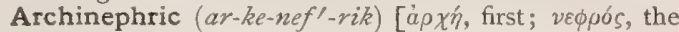
kidney]. Pertaining to the archinephron.

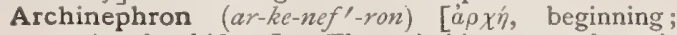
veфóós, the kidney]. The primitive or embryonic stage of the kidney or renal apparatus.

Archipin $\left(a r-k i p^{\prime}-i n\right)$. See Chibou.

Archipterygium (ar-kip-ter-ij'-e-um) [à $\rho \dot{n}$, first; $\pi \tau \varepsilon-$ $\rho o ́ v$, a wing]. In biology, a ground form, persisting in a few cases only, and representing the first and lowest stage of the skeleton of the anterior extremity of vertebrates.

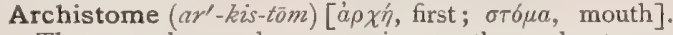
The gastrula mouth or opening to the archenteron; blastoporus.

Architis $\left(a r-k i^{\prime}-t i s\right)$ [a $\rho \chi b \zeta$, anus]. Proctitis; inflammation of the anus.

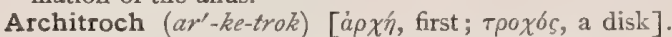
The ciliated band about the mouth of a planula.

Archocele (ar'-ko-sel, or $\left.a r-k o-s e^{\prime}-l e\right)$ [ap $a b s$, anus; $\kappa \dot{\eta} \lambda \eta$, hernia]. Rectal hernia.

Archocystocolposyrinx, or Archocolpocystosyrinx (ar-ko-sis-to-kol-po-sir'-ingks, or ar-ko-kol-po-sis-to-

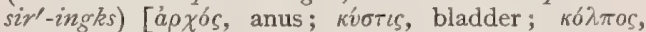
vagina ; $\sigma \tilde{v} \rho \iota \gamma \xi$, fistula]. Recto-vesico-vaginal fistula.

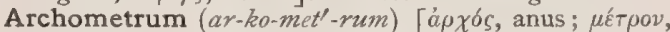
measure]. A device for ascertaining the caliber of the anus, or for dilating its sphincters.

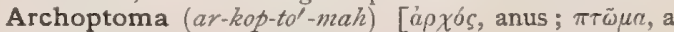
fall]. A prolapse of the rectum.

Archoptotic $\left(a r-k o p-t o l^{\prime}-i k\right)$ [á $\rho \chi o ́ s$, anus; $\pi \tau \tilde{\omega} \mu a$, a fall]. Relating to archoptoma or archoptosis.

Archoptosis $\left(a r-k o p-t o^{\prime}-s i s\right)$ [á $\rho \chi b s$, anus; $\pi \tau \tilde{\omega} \sigma \iota \zeta$, a falling]. Rectal prolapse.

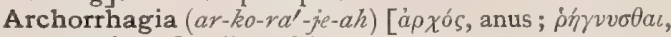
to break out]. Rectal hemorrhage.

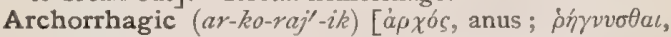
to break out]. Relating to rectal hemorrhage.

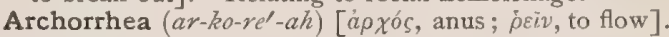
A discharge of blood or of any pathologic fluid from the anus.

Archos $\left(a r^{\prime}-k o s\right)$ [á $\rho$ ós, the anus]. The anus.

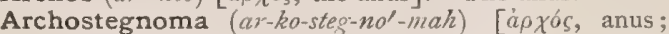

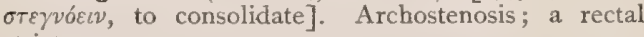
stricture.

Archostegnosis (ar-ko-steg-no'-sis) [ảpxós, anus;

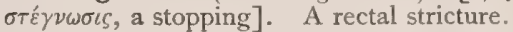

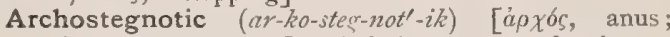
$\sigma \tau \tau^{\prime} \gamma \nu \omega \sigma \iota s$, a stopping]. Relating to a rectal stricture.

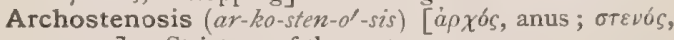
narrow]. Stricture of the rectum.

Archostenotic $\left(a r-k o-s t e n-o t^{\prime}-i k\right)$ [àp $\chi b s$, anus; orevós, narrow]. Relating to rectal stricture.

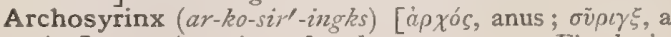
pipe]. I. A syringe for the rectum. 2. Fistula in ano. 
Arciform (ar'-se-form) [arcus, bow, arch; forma, form ]. Bow-shaped; especially used to designate certain sets of fibers in the oblongata.

Arctation (ark-ta'-shun) [arctatio; arclare, to draw close together]. I. Contraction or lessening of an opening or of the lumen of a canal. .2. Infibulation.

Arctium $\left(a r k^{\prime}-s h e-u m\right)$ [L.]. Burdock. See Lappa.

Arctostaphylos (ark-to-staf'-il-os). See Uva ursi and Manzanita

Arcual (ar'-ku-al) [arcualis, arched]. Arched; bent or curved.

Arcuate $\left(a r^{\prime}-k u-\bar{a} t\right)$ [arcuatio, a bowing]. Arched; curved; bow-shaped.

Arcuation (ar-hu-a'-shun) [arcuatio, a bowing]. Curvature of any bone, as of the tibia or sternum; curvature of the vertebral column.

Arcuatus (ar-ku-a'-tus) [arcus, a bow]. Bent or curved in an arched form. A. morbus, a former name for jaundice.

Arculus (ar'-ku-lus) [dim. of arcus, a bow]. An arching support for bed-clothes.

Arcus $\left(a r^{\prime}-k u s\right)$ [arcus, a bow]. A bow or arch. A. dentalis, the dental arch. A. senilis, in the old, the ring of fatty degeneration of the corneal tissue about the periphery. A. zygomaticus, the zygomatic arch.

Ardent (ar'-dent) [ardere, ardens, to burn]. Burning; fiery; glowing; accompanied by a sensation of burning. A. Fever, heat fever or thermal fever. A. Spirits, alcoholic liquors. See Spiritus.

Ardor (ar'-dor) [ardor, heat]. Violent heat, burning; applied to fevers and the sexual passion. A. urinæ, burning pain in the inflamed urethra during micturition.

Area $\left(\alpha^{\prime}-r e-\alpha h\right)[a r e a$, an open space $]$. Any space with boundaries. A. celsi. See Alopecia areata. A's., Cohnheim's, certain clear-cut areas seen in a transverse section of muscle-fiber. A., Crural, a space at the base of the brain included between the pons and chiasm. A. germinativa, or embryonic spot, the oval germinating spot of the embryo. A. opaca, the opaque circle about the $A$. pellucida. A. pellucida, the light central portion of the $A$. germinativa. A., Postpontile, the ventral aspect of the mesencephalon. A. vasculosa, the vascularization of the A. opaca.

Areca Nut $\left(a r^{\prime}-e k-a h\right)$. See Bctel.

Arecane, Arekane $\left(a r^{\prime}-e k-a n\right)$ [Malay]. An oily and volatile basic substance obtainable from areca nut; said to be a purgative and sialagogue, and to slow the pulse. Unof.

Arecin $\left(a r^{\prime}\right.$-es-in) [Sp., areca], $\mathrm{C}_{23} \mathrm{H}_{26} \mathrm{~N}_{2} \mathrm{O}$. A brownred coloring matter, obtained from areca nuts; areca red.

Arecolin (ar-el-ko-lin) [Sp., areca], $\mathrm{C}_{8} \mathrm{H}_{13} \mathrm{NO}_{2} . \quad \mathrm{A}$ liquid alkaloid isolated from the seeds of Areca catechu. It is strongly alkaline, very soluble in water, alcohol, ether, or chloroform, and boils at $220^{\circ} \mathrm{C}$. It is a powerful poison, affecting the heart similarly to muscarin. It has anthelmintic properties. Dose gr. $\frac{1}{15}-\frac{1}{10}$.

Arefaction (ar-e-fak'-shun) [arefactio; arefacere, to make dry]. I. Exsiccation or desiccation. The removal of the structural or constitutional water from a substance. 2. The drying of drugs before powdering them. 3. Dryness, as of the skin. 4. Withering, as of a paralyzed limb.

Arena $\left(a r-e^{\prime}-n a h\right)[a r e n \alpha$, sand $]$. I. Brick-dust deposit from urine; gravel. 2, Sabulous matter ; brain-sand.

Arenaceous (ar-e-na'-se-us) [arenaceus; arena, sand]. Of the nature of sand or gravel; sabulous.

Arenation (ar-e-na'-shun) [arena, sand]. A sand-bath. The application of hot sand to a limb or part of the body. See Ammotherafy.
Areola $\left(a r-\epsilon^{\prime}-0-l a h\right)$ [dim. of area, an open space: $p l$., Areole]. I. The brownish space surrounding the nipple of the female breast. This is sometimes called Areola papillaris. A secondary areola, surrounding this, occurs during pregnancy. The pigmentation about the umbilicus is called the umbilical areola. 2. Any interstice or minute space in a tissue.

Areolar (ar-e'-o-lar) [areola, dim. of area, an open space]. Relating to or characterized by areolæ. A. Tissue, cellular tissue; connective tissue.

Areolate, or Areolated (ar-é-o-lāt, or $\left.a r-e^{\prime}-a-l a-t e d\right)$ [areola, dim. of area, an open space]. Marked or characterized by areolæ.

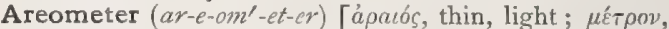
a measure]. An instrument for estimating the specific gravity or strength of Jiquids, especially alcoholic liquids.

Areometry (ar-e-om'-et-re) [áprtós, thin, light; $\mu \hat{\varepsilon} \tau \rho o \nu$, a measure]. The use of the areometer; estimation of the specific gravity of fluids.

Areotic $\left(a r-e-o t^{\prime}-i k\right)$ [ápatós, thin]. I. Attenuant; thinning the humors; increasing perspiration. 2. An attenuant remedy.

Arethusa (ar-eth-u'-sah) ['A $\rho$ ć $\theta 0 v \sigma a$, a fountain]. A genus of orchidaceous plants. A. bulbosa, of North America, has root-tubes that are popularly used as a material for poultices, and are said to form a useful application for toothache. Unof.

Arevareva (ar-a-var-a'-vah) [Tahitian]. A scaly skin-disease said to be caused by the habitual use of the drug Kava, q. $v$. It is accompanied by eye-disease, with dimness of vision.

Argal (ar'-gal). See Argol.

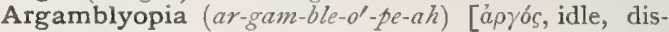
used; $\alpha \mu \beta \lambda v \omega \pi i a$, dim-sightedness]. Amblyopia due to disuse of the eye.

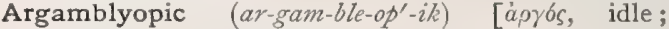
$\dot{a} \mu \beta \lambda v \omega \pi i a$, dim-sightedness]. Affected with argamblyopia.

Argand-lamp. A form of lamp with a tubular wick.

Argan-oil (ar-gan-oil) [Arab., argān]. An oil derived from the seeds contained in the fruit of the argan-tree. It is a good substitute for olive-oil.

Argan-tree (ar'-gan-tre) [Arab., argän]. The Argania sideroxylon, an evergreen tree of the N. W. of Africa, order Sapotacea ; it yields a useful oil.

Argel $\left(a r^{\prime}-g e l\right)$ [Syrian]. A plant, Solenostemma argel, of the eastern Mediterranean region; also its leaves, which are used to adulterate senna; also the Gomphocarpus fruticosus, of Africa, whose leaves are similarly employed. Unof.

Argema $\left(a r^{\prime}-j e m-a h\right)$ [ä $\rho \gamma \varepsilon \mu \alpha$, an ulcer: pl., Argemata]. A white ulcer of the margin of the cornea, following phlyctenula.

Argemone $\left(a r-j e m-o^{\prime}-n e\right)$ [å $\rho \gamma \varepsilon \mu o v$, an ulcer]. A genus of plants. A. mexicana, the horned or prickly poppy, a plant native to North America. It is said to have hypnotic qualities, and its seeds afford a purgative oil. Unof.

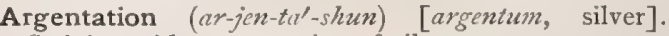
Staining with a preparation of silver.

Argentic $\left(a r-j e n^{\prime}-t i k\right)$ [argentum, silver]. Pertaining to, or of the nature of silver. Containing silver as a univalent radical.

Argentine $\left(a r^{\prime}-j e n-t i n\right)$ [argentum, silver]. Containing or resembling silver.

Argentum (ar-jen'tum) [L. : gen., Arsenti]. Silver. $\mathrm{Ag}=\mathbf{1 0 8}$; quantivalence, $\mathbf{I}$. A malleable and ductile metal of brilliant white luster. It tarnishes only in the presence of free sulphur, sulphur gases, and phosphorus. It is an excellent substance for vessels used in pharmacy and for sutures used in surgery. The following salts 
are used: A. cyanidum, $\mathrm{AgCN}$, used in the preparation of hydrocyanic acid. A. iodidum, AgI, sometimes used internally instead of A. nitras. Dose gr. $1 / 4-j$. A. nitras, $A g \mathrm{NO}_{3}$, " nitrate of silver," argentic nitrate, "lunar caustic," a powerful astringent and an escharotic of moderate strength. It stains skin and other tissues black when applied in strength. In small doses it stimulates the heart and nerve centers. If too long continued, it leaves a slate-colored, insoluble deposit of silver under the skin (Argyria). Dose gr. $1 / 6-1 / 2$. A. nitras dilutus, the mitigated caustic or dilute stick is fused with an equal weight of potassium nitrate. A. nitras fusus, "stick caustic." Contains four per cent. of silver chlorid. It is used locally. A. oxidum, $\operatorname{Ag}_{2} \mathrm{O}$, explosive when treated with ammonia. Dose gr. $1 / 2-i j$. A. vivum, an old name for mercury or quicksilver.

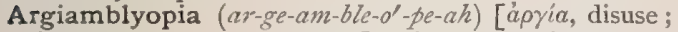

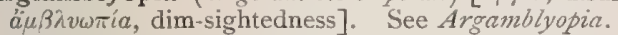

Argilla (ar-jill'-ah) [ǎ $\rho \gamma \iota \lambda \lambda a s$, potter's clay]. White or potter's clay, alumina. See Bole.

Argol $\left(a r^{\prime}-g o l\right)$ [ajobs, white]. The impure tartar derived from wine. See Tartar.

Argyll-Robertson Pupil. See Signs and Symptoms, Table of, and Pupil.

Argyll-Robertson's Operation. See Operations, Table of.

Argyria (ar-jir'-e-ah) [argentum, silver]. A form of chloasma or discoloration of the skin and mucous membranes produced by the prolonged administration of nitrate of silver, the molecules of silver being deposited in much the same position as those of the natural pigment of the skin. It may be general, from internal administration, or local, from its local application.

Argyriasis (ar-jir-i'-as-is). See Argynia.

Argyrosis (ar-jir-o'-sis). Same as Argyria, q.v.

Arhinia (ah-rin'-e-ah) [à priv.; p’ís, nose]. Congenital absence of the nose.

Arhythmia (ar-ith'-me-ah). See Arrhyihmia.

Aricin $\left(a r^{\prime}-i s-i n\right)$ [Arica, in Peru], $\mathrm{C}_{23} \mathrm{H}_{26} \mathrm{~N}_{2} \mathrm{O}_{4}$. An alkaloid obtained from several varieties of cinchona bark.

Ariditas (ar-id"-it-as) [L., "dryness" ]. A dried or withered condition of any part or organ.

Aridura $\left(a r-i d-u^{\prime}-r a h\right)$ [L.]. Dryness; a drying up, withering, or wasting of a part, or of the organism as a whole.

Aril, or Arillus (ar'-il, or $\left.a r^{\prime}-i l-u s\right)$ [aridus, dry]. In biology, the accessory coat of certain seeds, growing from the funiculus, hilum, or placenta, as the mace of nutmegs.

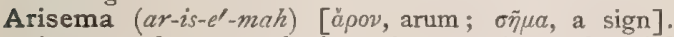
A genus of araceous herbs. A. atrorubens, the wild or Indian turnip, or Jack-in-the-Pulpit of Eastern N. America. Its corm is strongly stimulant and acrid, with emetic, expectorant, and sternutatory qualities. Other species have similar properties. Unof.

Arista $\left(a r-i s^{\prime}-t a h\right)[\mathrm{L}$.$] . In biology, the awn or beard$ of certain flowers or animals.

Aristate $\left(a r-i s^{\prime}-t a \vec{t}\right)$ [arista, the awn or beard of grain]. In biology, awned. Tipped with a bristle.

Aristol (ar'-is-tol) [ăptoTos, best; oleum, oil], $\left(\mathrm{C}_{6} \mathrm{H}_{2}-\right.$ $\left.\mathrm{CH}_{3} \mathrm{OI} . \mathrm{C}_{3} \mathrm{H}_{7}\right)_{2}$. Annidalin; Dithymol-iodid. An iodin compound used as a substitute for iodoform as an antiseptic dressing. It has the advantage of being odorless, and is used either in the powder form or as a five to ten per cent. ointment with vaselin or lanolin.

Aristolochia (ar-is-to-lo'-ke-ah) [ă $\rho \iota \sigma \tau o s, b e s t ; \lambda_{0} \chi \varepsilon \bar{a}$, the lochia]. A genus of exogenous herbs, many species of which have active medicinal qualities. A. clematitis, of Europe, has been used as a tonic, stimu- lant, and diaphoretic. A. cymbifera, of S. America, furnishes a part of the drug called cuaco $(q, v$. $)$, and is a good tonic and stimulant. A. serpentaria (see Serpentaria) is at present more used in medicine than any other species.

Aristolochic $\left(a r-i s-t o-l o^{\prime}-k i k\right)$ [áolotos, best; $\lambda o x \varepsilon i a$, the lochia]. I. Having the property of expelling the placenta, or of exciting or promoting the lochial dis. charge. 2. A medicine used for expelling the secundines or for exciting the lochial flow.

Aristolochin (ar-is to-lo'-kin) [áplotos, best; hoxeia, the lochia]. A bitter principle found in Virginia snake-root. See Serpentaria.

Aristotle's Experiment. The double feeling experienced by the fingers when a single pebble is placed between the crossed fingers of one hand.

Aristulate (ar-is'-tu-lāt) [aristula, dim. of Arista, awn or beard of grain]. In biology, having a short awn.

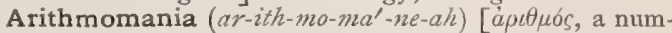
ber; uavia, madness]. An insane anxiety with regard to the number of things that fall under the observation. Sometimes it consists in constant or uncalled-for counting, either of objects or in mere repeating of consecutive numbers.

Arlt-Jaesche's Operation. See Operations, Table of.

Arlt's Ointment. An ointment containing grs. viiss of belladonna to $3 \mathrm{j} 1 / 4$ of blue ointment, for use in blepharospasm.

Arlt's Operation. See Operations, Table of.

Arm (arm) [armare, to arm]. I. That part of the upper extremity from the shoulder to the wrist. 2. That portion of the stand connecting the body or tube of a microscope to the pillar.

Armadillo (ar-ma-dil'-o) [Sp., dim. of armado, armed]. A trade-name for a proprietary arrangement of plates, straps, and buckles worn upon the person for its alleged electric effects.

Armamentarium $\left(a r-m n-m e n-t a^{\prime}-r e-u m\right) \quad[\mathrm{L}$, , an arsenal]. The outfit of medicines or instruments of the physician or surgeon.

Armarium (ar-ma'-re-um) [L.]. See Armamentarium. Armature (ar'-mat-chür) [armatura, equipment]. A mass of soft iron at the extremity of a magnet. Also, the core of iron around which coils of insulated wire are wound or disposed.

Arma urticaria $\left(a \gamma^{\prime}-m a h e r-t i k-a^{\prime}-r e-a h\right)$ [L.]. The urticating weapons of Colenterates.

Arm-chair, Charcot's. See Shaking Cure.

Armed Tape-worm. See Tenia solium.

Armenian (ar-me'-ne-an) [Armenia]. Of or belonging to Armenia. A. Blue. Same as Ultramarine. A. Bole, a reddish, unctuous earth or clay formerly much used in medicine, now used in tooth-powders and in veterinary practice. It is absorbent and astringent.

Armilla (ar-mil'-ah) [armilla, a bracelet, ring]. I. In biology, the annular ligament of the wrist; a colored ring on the tibia of a bird or the plaited frill on the stipe of certain mushrooms. 2. The Gasserian ganglion.

Armpit (arm'-pit) [armus, shoulder; puteus, a well]. The axilla.

Armus (ar'-mus) [armus, áp $\mu$ ós, the shoulder]. The arm, or the arm and shoulder.

Army Itch (ar'-me itch). A distressing chronic form of itch prevalent in the United States at the close of the civil war. The itching was intense. The eruption was seen especially on the arms, forearms, chest, abdomen, and lower extremities, particularly on the ulnar side of the forearm and inner aspect of the thigh. It resembled prurigo associated with vesicles, pustules, and eczema. 
Arnandon Green. Same as Milller's Green.

Arnatto $\left(a r-n a t^{\prime}-o\right)$. See Annotto.

Arnica $\left(a r^{\prime}-n i k-a h\right)$ [L.: gen., Arnica]. A genus of composite-flowered plants. The name in medicine denotes the plant commonly known as "Leopard's bane," A. montana. Both flowers and roots are used in medicine. Its properties are probably due to an alkaloid, trimethylamin, $\mathrm{C}_{3} \mathrm{H}_{9} \mathrm{~N}$. In small doses it is a cardiac stimulant; in larger doses a depressant. In toxic doses it frequently causes death. It is a popular remedy, when locally applied, for sprains, bruises and surface wounds, and is valuable also in typhus and typhoid fevers as an antipyretic. A., Emplastrum, contains ext. of root 33 , resin plaster 67 parts. A., Ext. Radicis. Dose gr. j-iij. A., Ext. Rad. Fld. Dose $\eta_{\mathrm{v}-\mathrm{xx}}$. A., Infusum, 20 parts flowers, I00 parts water. Superior to the tincture for local use. A., Tinct., 20 per cent. Dose $\eta^{v-x x x . ~ A ., ~ T i n c t . ~ R a d ., ~}$

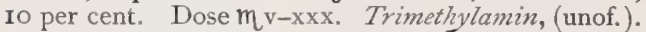
Dose gr. ij-iij in syrup. Arnicæ flores, arnica flowers. Arnicæ radix, the root of arnica.

Arnicin $\left(a r^{\prime}-n i s-i n\right)$ [arni $\left.a\right], \mathrm{C}_{20} \mathrm{H}_{30} \mathrm{O}_{4}$. A brownish, bitter glucosid extracted from the flowers of Amica montana.

Arnold's Convolution. See Convolutions, Table of. A. Fold, valvula lachrymalis superior, a fold of the mucous membrane seen in the lachrymal sac. A. Ganglion. See Ganglia, Table of. A. Nerve. See Nerves, Table of. A. Plexus. See Plexus.

Arnott's Method. See Treatment, Methods of. A. Mixture. See Frigorific Mixture. A. Ventilator. See Ventilation.

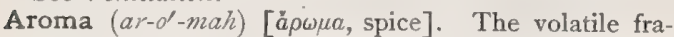
grant or odorous emanation of certain vegetable substances.

Aromatic (ar-o-mat'-ik) [å $\rho \mu a$, spice]. I. Having a spicy odor. 2. A substance characterized by a fragrant, spicy taste and odor, as cinnamon, ginger, the essential oils, etc. A stimulant to the gastro-intestinal mucous membrane. 3. A qualification applied to a series of carbon compounds originating from a nucleus composed of six carbon-atoms, $\mathrm{C}_{6} \mathrm{H}_{6}$. Their stability is relatively great as compared to the fatty bodies. A. Acids, those of the benzin-group of hydrocarbons. A. Compound, any benzyl-derivative. A. Fld. Ext., aromatic powder Ioo, alcohol q. s. A. Group, a series of hydrocarbons having the composition $\mathrm{C}_{10}$ $\mathrm{H}_{16}$. A. Powder. See Cinnamomum. A. Vinegar, any mixture of aromatic oils with vinegar. It is used as a stimulating agent. See Acetum.

Aromin $\left(a r-o^{\prime}-m i n\right)$ [à $\rho \omega \alpha$, spice]. An alkaloid obtainable from urine, after creatinin, etc., have been removed from the mother-liquor. When heated it emits a fragrant odor.

Arquatus $\left(a r-k w a^{\prime}\right.$-tus) [L., a rainbow]. Showing several colors. A. morbus, an old name for jaundice, from the discoloration of the skin; rainbow disease.

Arrack $\left(a r^{\prime}-a k\right)$ [Ind.]. Any alcoholic liquor is called arrack in the East, but arrack proper is a liquor distilled from toddy, malted rice, or dates.

Arrak $\left(a r^{\prime}-a k\right)$. See Arrack.

Arrector (ar-ek'-tor) [L., an erector]. A name applied to certain muscles. A. pili Muscle, a fan-like arrangement of a layer of smooth muscular fibers surrounding the hair follicle, whose contraction erects the follicle and produces cutis anserina or "gooseskin."

Arrest $(a r$-est' $)$ [ad, to; restare, to withstand]. Stoppage, detention. Arrested development, is when an organ or organism fails in its normal evolution, stopping at the initial or intermediate stages of the process. Arrested head, when in parturition the child's head is hindered but not impacted in the pelvic cavity.

Arrestation (ar-es-ta'-shun). Same as Arrest.

Arrhea $\left(a h-r e^{\prime}-a h\right)$ [a priv; $\dot{\rho} o i a$, a flow]. The cessation or suppression of any discharge.

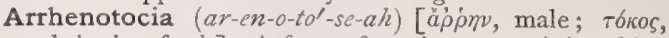
a bringing forth]. A form of parthenogenesis in which without coitus male eggs are deposited, as in bees.

Arrhinia ( $a h$-rin'-e-ah). Same as Arhinia.

Arrhizous (ah-ri'-zus) ['a priv.; $\dot{\rho} \iota \zeta \alpha$, a root]. In biology, destitute of roots or rhizoids, as parasitic plants, certain mosses, hepaticæ, etc.

Arrhythmia (ah-rith'-me-ah) [á priv. ; $\dot{\rho} v \mu$ ós, rhythm]. Absence of rhythm; chiefly used in the expression ar. rhythmia cordis, denoting irregularity or lack of rhythm in the heart's action. See Cardiac Rhythm.

Arrhythmic (ah-rith'-mik) [à priv.; '́vtjuós, rhythm]. Without rhythm; irregular.

Arrhythmous (ah-rith'-mus). See Arrhythmic.

Arrhythmy (ah-rith'-me). Same as Arrhythmia.

Arrow-poison $\left(a r^{\prime}-o-p o i^{\prime}-z u n\right)$. See Curare and Guachamaco.

Arrowroot (ar'-o-root) [ME., arow; roote]. A kind of starch derived from Maranta arundinacea of the West Indies, Southern States, etc. It is a popular remedy for diarrhea, and is widely used as a food. Many other starchy preparations are sold as arrowroot.

Arsenate, or Arseniate $\left(a r^{\prime}-s e n-\bar{a} t, a r-s e^{\prime}-n e-\bar{a} t\right)$ [arsenium]. Any salt of arsenic acid. Ferrous arseniate, arseniate of iron, sparingly used in medicine: it is the ferri arsenias of the B. P. It is a tasteless, greenish powder, combining the effects of iron and arsenic; used largely in anemia and skin diseases. Dose gr. $\frac{1}{16}-\frac{1}{2}$.

Arseniasis (ar sen-i'-as-is). Same as Arsenism.

Arsenic, Arsenicum, or Arsenum (ar'-sen-ik, ar$\mathrm{sen}^{\prime}-i k \cdot u m$, or $\left.a r-s e^{\prime}-n u m z\right)$. As $=75$; quantivalence III, V. A non-metal having a metallic luster and crystalline structure. In small doses it is a stomachic and general tonic, promoting appetite and cardiac action, and stimulating mental activity. It is of great value in irritative dyspepsia, and is sometimes used internally to blanch and clear the skin. In larger doses it creates skin-eruptions and behaves as a violent corrosive poison. acting with cumulative effect. Externally, it is a powerful escharotic, used in cancer. Only the salts and oxids are used in medicine. A. acid., arsenous acid, white arsenic, "ratsbane," $\mathrm{As}_{2} \mathrm{O}_{3}$. Dose gr. $\frac{1}{30} \frac{1}{10}$. A., acid., liquor. (Liq. arsenici hydrochlorici, B. P.), a $I$ per cent. solution of the acid in hydrochloric acid and distilled water. Dose $m$ ij-x. Ferri arsenas, $\mathrm{Fe}_{3} \mathrm{As}_{2} \mathrm{O}_{8}$. Dose gr. $\frac{1}{16} \frac{1}{2}$. Liq. Arsenici hydrochlor. (B. P.). Dose mij-viij. Potassii arsenit., Liq. (Liquor Arsenicalis, B. P.). Fowler's solution, contains A. acid I, potass. bicarbonate I, comp. tinct. lavender 3 , and distilled water

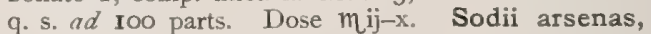
$\mathrm{Na}_{2} \mathrm{HAs}_{4} .7 \mathrm{H}_{2} \mathrm{O}$. Dose of the dried salt gr. $\frac{1}{2}-\frac{1}{12}$. Sodii arsenat., Liq., Pearson's solution. Dose, mij-xv. A. iodid, AsI. Dose gr. $\frac{1}{20}-\frac{1}{8}$. A. et hydrargyri iod., Liq., liquor of the iodid of arsenic and mercury, Donovan's solution, contains A. iodid I, mercuric iodid I, distilled water Ioo parts. Dose mij-x. A. bromas, AsBr, valuable in diabetes. Dose gr. $\frac{1}{50}$. A. brom., Liq., Clemens' solution, a one per cent. solution of the arsenite of bromin. Dose m j-iv. The tests for arsenic are Fleitmann's, Marsh's, and Reinsch's, for which see Tests, Table of.

Arsenical (ar-sen'-ik-al) [arsenum, arsenic]. Pertaining to arsenic. A. Devitalizing Fiber, used 
in places where pastes would be dangerous, from leakage.

R. Absorbent cotton (cross-cut fine) Arsenous oxid, Acetate of morphin, gr. $x$ Oily carbolic acid, q. s., to very thin paste.

Saturate cotton with paste and dry.

A. Paste (Pâte Arsenicale), a French composition, used as application for destroying the pulps of decayed teeth.

\section{H. Arsenous oxid,} Acetate of morphin,

Mull in tnortar: moisten cotton pellet in either oil of cloves, eugenol, oily carbolic acid, or dental aconite, and dip into powder. See also Frère Corne.

Arsenicalism (ar-sen'-ik-al-izm). Same as Arsenism.

Arsenicism (ar-sen'-is-izm). Same as Arsenism.

Arsenicophagy (ar-sen-ik-off'-a je) [arsenum, arsenic ; $\phi a \gamma \varepsilon i \nu$, to eat]. The habitual eating of arsenic

Arsenism (ar/-sen-izm) [arsenum, arsenic]. Chronic arsenical poisoning; arsenicalism.

Arsenite $\left(a r^{\prime}-\operatorname{sen}-\bar{\imath} t^{\prime}\right)$ [arsenum, arsenic]. Any salt of arsenous acid.

Arsenization (ar-sen-iz-a'-shun) [arsenum, arsenic]. Treatment with arsenical remedies.

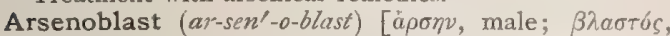
germ]. In biology, the male element of the sexual cell, capable of multiplication by division; the opposite of the thelyblast or female element.

Arsenous, or Arsenious ( $\left.a r^{\prime}-s e n-u s, a r-s e^{\prime}-n e-u s\right)$ [arsenum, arsenic]. Containing arsenic. A. Acid. See Arsenic.

Arse-smart (ars'-smart). See Polygonum hydropiper.

Arsins $\left(a r^{\prime}-\sin z\right)$ [arsenum, arsenic]. Peculiar volatile arsenical bases found by Selmi to be produced by the contact of arsenous acid and albuminous substances.

Arsonium (ar-so'-ne-um) [arsenum, arsenic; ammonizem $], \mathrm{AsH}_{4}$. A univalent radical in which arsenic replaces the nitrogen of ammonium.

Arsura (ar-su'-rah) [L., a "burn"]. An old name for gonorrhea.

Art (art) [ars, artis, skill]. Skill; dexterity. A., Dental, the application of the rules of dental surgery to the treatment of the diseases of the teeth and the replacement of the loss of those organs.

Artanthe (ar-tan'-the) [L.]. A genus of piperaceous plants. A. elongata, the plant that affords the drug Matico, q.v. It is a vine of the pepper family, a native of Peru.

Artefact $\left(a r^{\prime}-t e-f a k t\right)$. See Artifact.

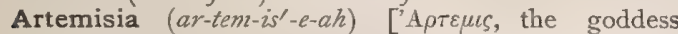
Diana]. A genus of plants of the order compositx. A. abrotanum, southern wood, is stimulant, tonic, and vermifuge, and is popularly used as a vulnerary. It is similar in properties to wormwoad. Dose of fld. ext. $m_{x \rightarrow x x}$ Unof. A. absinthium. See $A b$ sinthe. A. maritima affords pure Wormseed, $q . v$. A. vulgaris, mugwort, is a popular remedy in various diseases.

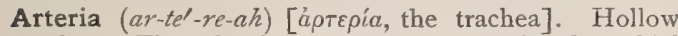
tubes. The plural was applied to the bronchial tubes. The ancients supposed these filled with vital spirit during life. See Artery.

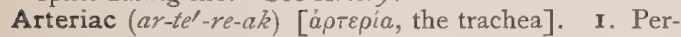
taining to the trachea, or to the arteries. 2. A remedy used in diseases of the trachea or of the arteries.

Arteriagra (ar-ter-e-a -grah) [á $\rho \tau \varepsilon \rho i \alpha$, trachea; à $\gamma \rho \alpha$, a seizure]. Neuralgia of an artery.

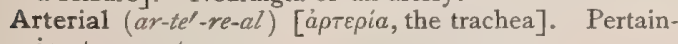
ing to an artery.

Arterialization (ar-te-re-al-iz-al-shun) [áprepia, the trachea]. The process of making or becoming arte- rial; the change from dark, venous blood into that which is bright-red, as in the arteries.

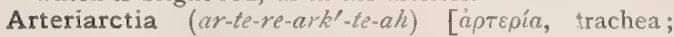
arctus, bound]. Constriction or stenosis of an artery.

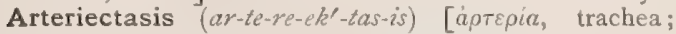

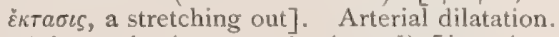

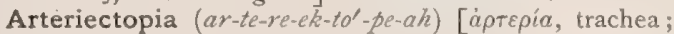
$\tilde{\varepsilon} \kappa \tau о \pi о \varsigma$, out of place]. Displacement or abnormality in the course of an artery.

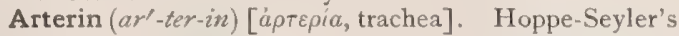
term for the arterial blood-pigment as contained in the corpuscles.

Arterioarctia (ar-te-re-o-ark'-te-ah). See Arteriarctia.

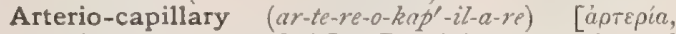
trachea; capillus, a hair]. Pertaining to arteries and capillaries. A. Fibrosis, the undue augmentation, or abnormal preponderance, of connective-tissue elements in the walls of capillaries and arteries.

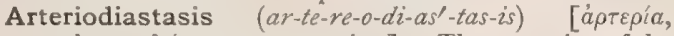
trachea; diáotaoıs, separation]. The retraction of the two ends of a divided artery.

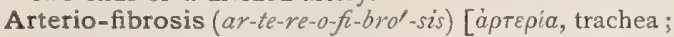
fibra, a fiber]. A term applied to the condition of the arterial capillaries in chronic interstitial disease.

Arteriogram (ar-te'-re-o-gram). See Sphygmogram.

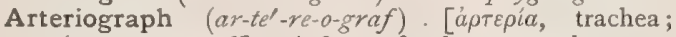
$\gamma \rho a ́ \phi \varepsilon \iota v$, to record]. A form of sphygmograph.

Arteriography (ar-te-re-og'-ra-fe) [aprepia, trachea;

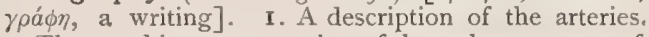
2 . The graphic representation of the pulse-waves or of the arterial blood-current.

Arteriola $\left(a r-t e-r i^{\prime}-0-l a h\right)$ [L.: pl., Arteriola $]$. An arteriole.

Arteriolæ Rectæ (ar-te-re-ó-le rek'-te) [L.]. The small blood-vessels that supply the medullary pyramids of the kidneys.

Arteriole $\left(a r-t e^{\prime}-r e-\bar{l} l\right)$ [arteriola]. A very small artery.

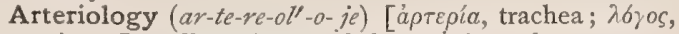
science]. The science of the arteries; the anatomy, physiology, and pathology of the arteries.

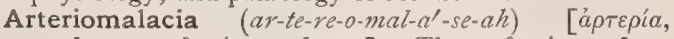
trachea; налакí, softness]. The softening of an artery.

Arteriopathy (ar-te-re-op'-a-the) [áotepia, trachea; $\pi \dot{t} \theta 0 \varsigma$, illness]. Any disease of an artery or of arteries.

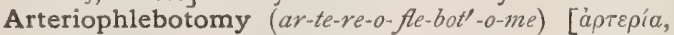
trachea; $\phi \lambda \hat{\varepsilon} \psi$, a vein; $\tau \hat{\varepsilon} \mu \nu \varepsilon \varepsilon \nu$, to cut]. Local bloodletting.

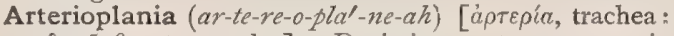
$\pi \lambda a v \bar{\alpha} \sigma \theta a \iota$, to wander]. Deviation or tortuousness in the course of an artery.

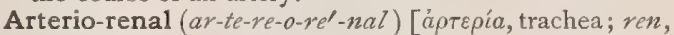
the kidney]. Pertaining to the renal blood-vessels. A. Disease, a pathologic condition of middle life characterized by an early stage of renal cirrhosis due primarily to vascular lesions. Its symptoms are mainly high vascular tension, albuminuria, and tendency to apoplectic seizures.

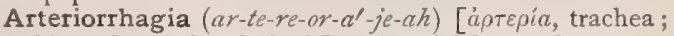
$\dot{p}$ 'rvvoflal, to break forth]. Arterial hemorrhage.

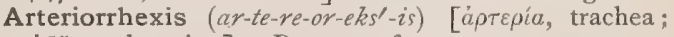
$\dot{\rho} \tilde{\eta} \xi \iota$, a bursting]. Rupture of an artery.

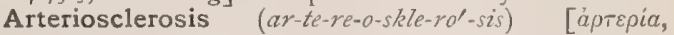

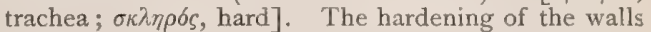
of an artery, and especially of the intima. See Endarteritis.

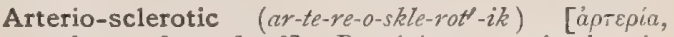
trachea; $\sigma \kappa \lambda \eta \rho \sigma s$, hard]. Pertaining to arteriosclerosis. A. Kidney. See Bright's Disease.

Arteriosity (ar-te-re-os'-il-e) [áptepía, trachea]. The quality of being arterious, or arterial. 


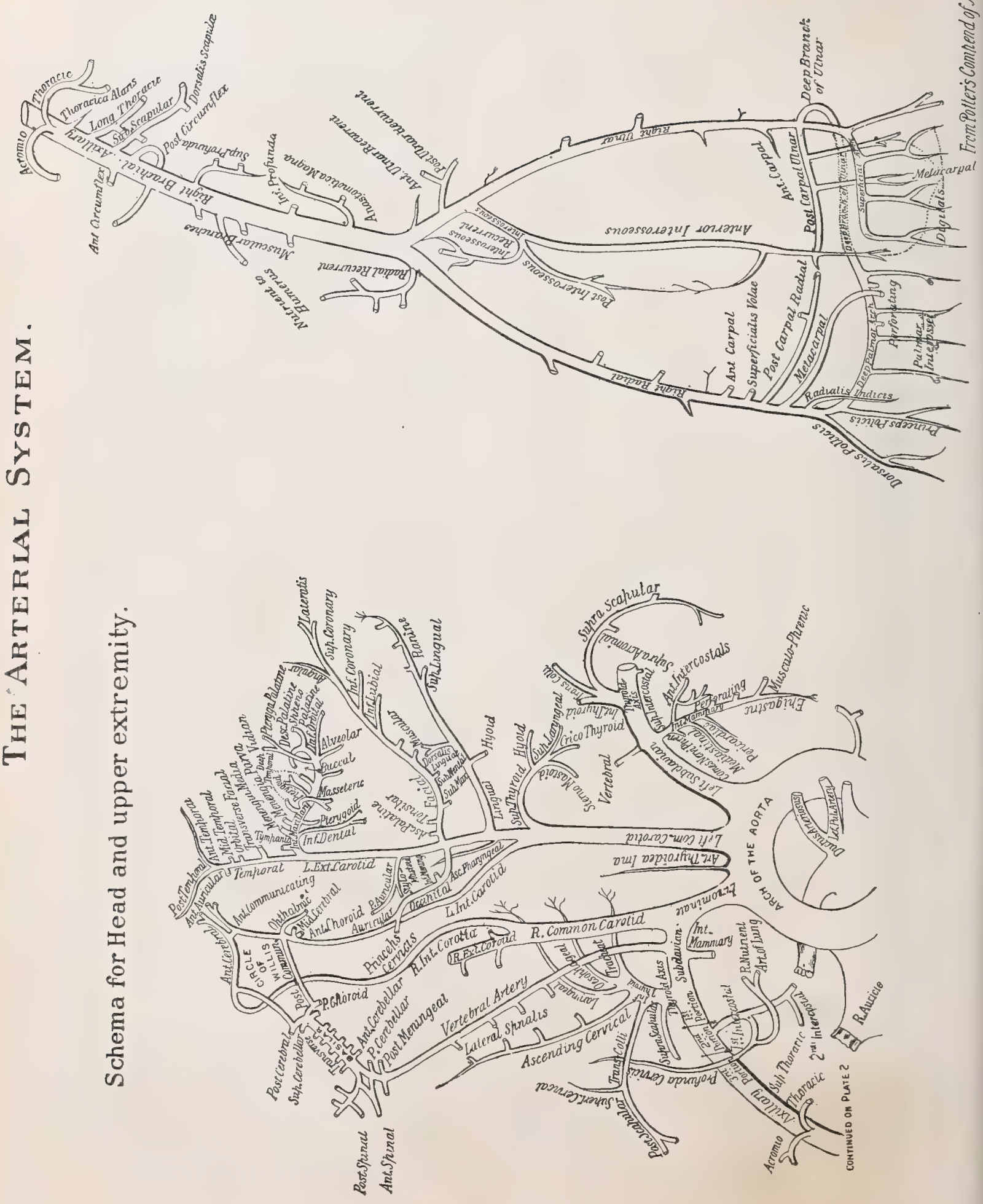




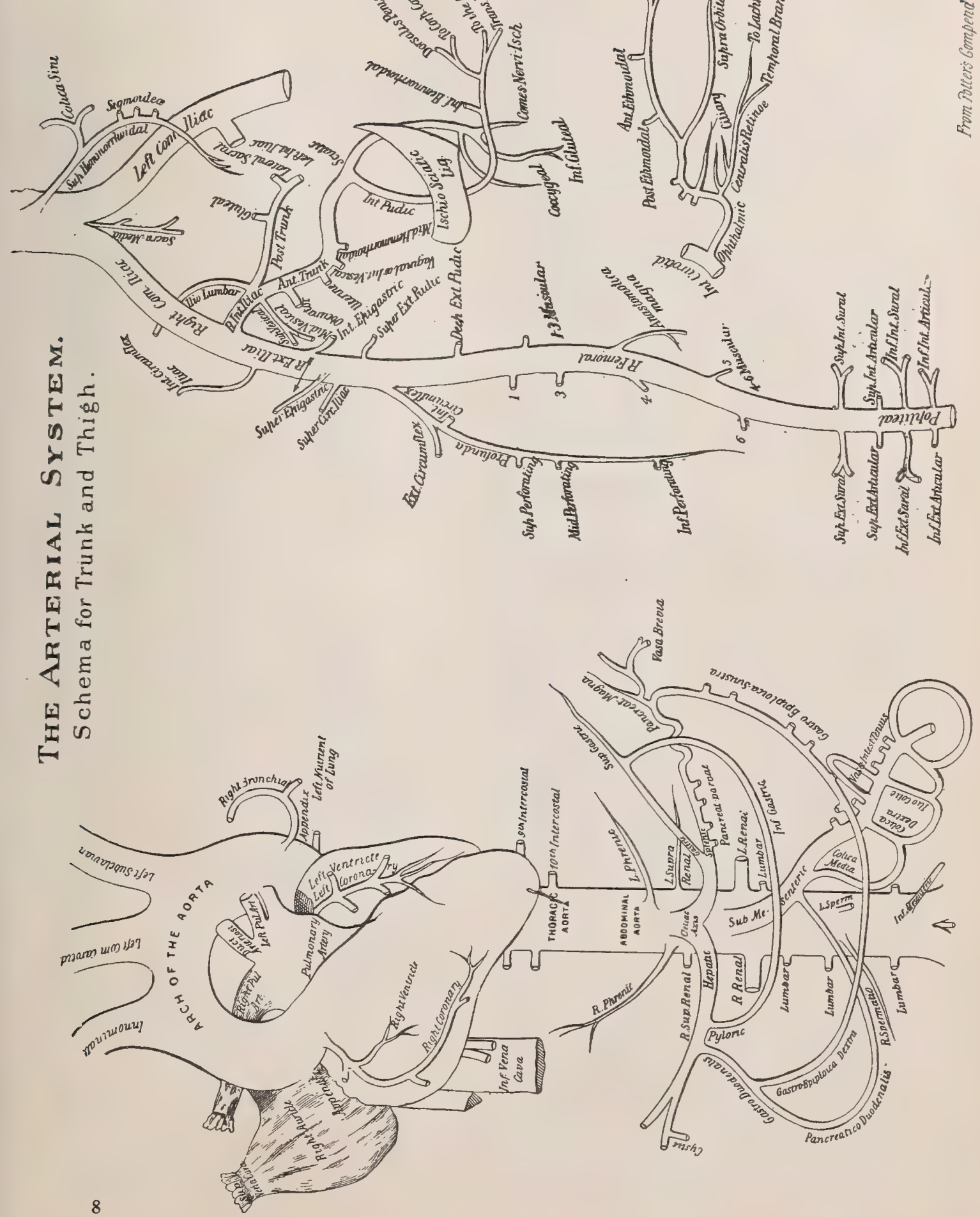



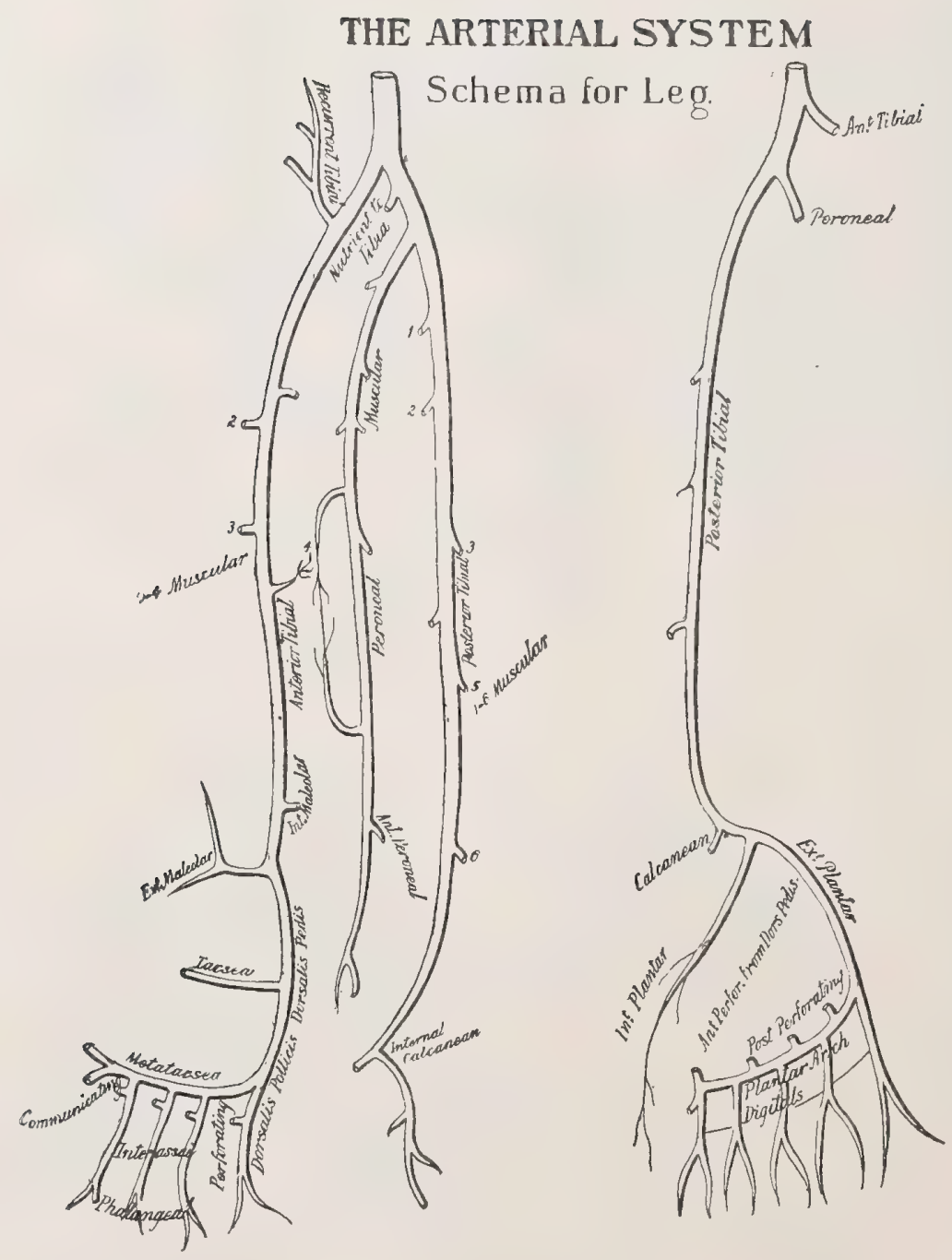

From Botter's Compend of Anatomy. 
Arteriostenosis (ar-te-re-o-ste-no'-sis) [iptepia, trachea ; otevos, narrow]. The narrowing of the caliber of an artery in any part.

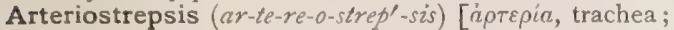

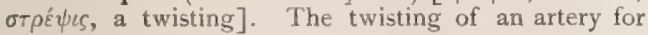
the purpose of staying a hemorrhage.

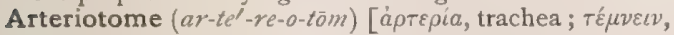
to cut]. A knife for use in arteriotomy.

Arteriotomy (ar-te-re-ol'-o-me) [áptepia, trachea;

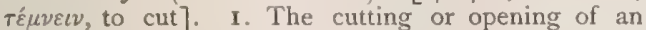
artery, as for the purpose of letting blood. 2. Dissection or anatomy of the arteries.

Arterious ( $\left.a r-t \ell^{\prime}-r e-u s\right)$ [ $\alpha \rho \rho \tau \rho i \alpha$, trachea]. Relating to anatomy or to the arteries; arterial.

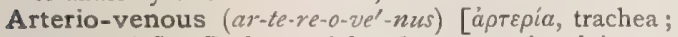
vena, vein]. Both arterial and venous; involving an artery and a vein, as an arterio-venous aneurysm.

Arterio-version (ar-te-re-o-ver'-shun) [ảprepin, trachea ; vertere, to turn]. Weber's method of arresting hemorrhage by turning vessels inside out by means of an instrument called the arterio-verter.

Arterio-verter. See Arterioversion.

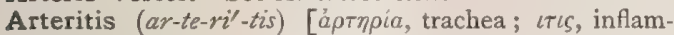
mation ]. Inflammation of an artery. The acute form, always local, is generally consecutive to trauma, thrombosis, or embolism, and may be purulent in character, and attended with ulceration; the chronic, more properly Endarteritis, q.v., arterial sclerosis, leading to atheroma or atheromatous changes, is a frequent disease of the aged. A. deformans, the result of atheromatous changes producing crumpling or irregularities of the walls. See Chronic Endarteritis. A. obliterans, great inflammatory development of the endothelium of an artery, resulting in obliteration of the lumen by thrombosis. See Endarteritis obliterans.

Artery $\left(a r^{\prime}\right.$-ter-e) [arteria; áotnoía, trachea]. Arteries are the tube-like vessels through which the blood is propelled by the heart to the peripheral organs. They end in arterioles and capillaries. They are composed of three layers : the outer, or tunica adventitio; the middle, or tunica media, the muscular coat; the internal, or intima, composed of nucleated endothelial cells, connective and elastic tissue. A. T e r m in a 1, an artery whose branches do not form anastomoses with other arteries. A table of the arteries is appended.

Arthragra (ar-thra'-grah) [à $\rho f p o v, a$ joint; $\grave{a} \gamma \rho a$, seizure]. Gout.

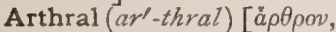
a joint]. Articular; relating to an arthron.

Arthralgia (ar-thral'-je-ah)

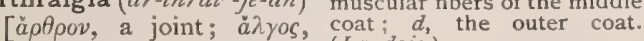
pain ]. Pain in a joint; (Landois.) gout; arthritis; rheumatism.

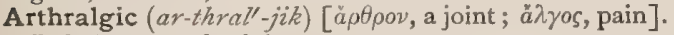
Relating to arthralgia.

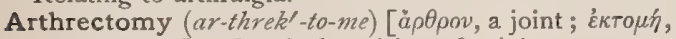
a cutting out]. Surgical excision of a joint.

Arthrelcosis (ar-threl-ko'-sis) [ă $\rho$ Apov, a joint; $\varepsilon \ddot{\lambda} \kappa \omega \sigma \iota s$, ulceration]. Ulceration of a joint.
Arthremia (ar-thre'-me-ah) [àptpov, a joint; aipa, blood]. A congested condition of a joint.

Arthrempyema (ar-threm-pi-e'-mah) [äpopov, a joint; $\varepsilon$, $\pi i \eta n \alpha$, suppuration]. Suppuration or abscess of a joint.

Arthrempyesis (ar-threm-pi-e'-sis). See Arthroempyesis.

Arthritic (ar-thrit'-ik) [ả $\rho \theta \rho o v$, a joint]. Relating to arthritis or to gout.

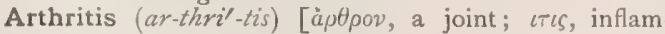
mation]. Inflammation of a joint. A. chlorotica. Synonym of Enteritis pseudomembranous. A. deformans, chronic inflammation of a joint with deformity ; rheumatoid arthritis. A. fungosa, scrofulous or tubercular disease of the joints; white swelling. A. pauperum. Synonym of Rheumatoid arthritis. A proliferating. See A. deformans. A. rheumatic, Chronic rheumatoid arthritis; Osteo-arthritis; Rheumatic gout; Nodular rheumatism; Arthritis ileformans; a chronic joint-affection characterized by inflammatory overgrowth of the articular cartilages and synovial membranes, with destruction of those parts of the cartilages subject to intra-articular pressure, and progressive deformity. The disease attacks those who present the rheumatic diathesis, and is chiefly seen in advanced life, though the young are not exempt. A., rheumatoid. See $A$. deformans, A. uritica, arthritis due to gout.

Arthritism (ar'-thrit-izm) [åptpov, a joint]. Gout or the gouty diathesis.

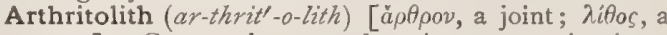
stone]. Gouty calcareous deposit or concretion in or around a joint.

Arthrobranchia (ar-thro-brans'-ke-ah) [à $\rho \theta \rho o v$, a joint ; $\beta p a ́ \gamma \chi \iota a$, gills]. In biology, a branchial plume attached to the membranous articulation between the coxa and the body of decapod crustaceans.

Arthrocace (ar-throk'-as-e) [à 0 pov, a joint; кaкós, ill] Fungous, strumous, or tuberculous arthritis.

Arthrocacology (ar-thro-kak-ol'-o-je) [ăotpov, joint;

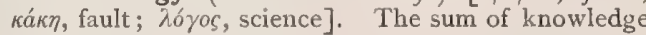
regarding joint-diseases.

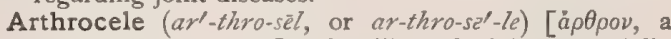
joint; $\kappa \hat{\eta} \lambda \eta$, a tumor]. Swelling of a joint, especially of a knee-joint in gonorrheal rheumatism.

Arthrochondritis (ar-thro-kon-dri'-tis) [ápelpov, a joint ; $\chi o ́ v \delta \rho \circ$, a cartilage ; $\iota \tau \iota$, inflammation]. Inflammation of the cartilaginous parts of a joint.

Arthroclasia (ar-thro-kla'-se-ah) [à $\rho \theta \rho o v$, a joint ; $\kappa \lambda a ́ \varepsilon \iota v$, to break]. The breaking down of ankyloses in order to produce free movement of a joint.

Arthroclasy (ar'-thro-kla-se). Same as Arthroclasia.

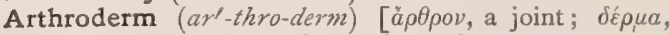
skin]. The parietes of an arthropod.

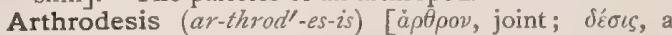
binding]. Surgical fixation of paralyzed joints.

Arthrodia $\left(a r-t h r o^{\prime}-d e-a h\right)$ [à $\rho$ t $\omega \omega \delta i a$, a kind of articulation]. A form of joint permitting a gliding movement. See Diarthrosis.

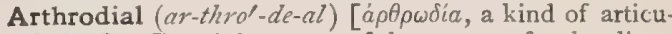
lation ]. Pertaining to or of the nature of arthrodia.

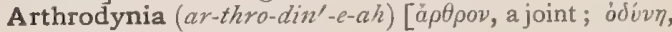
pain]. See Arthralgia.

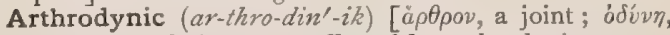
pain]. Relating to or affected by arthrodynia.

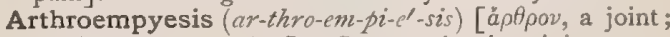

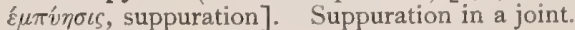

Arthrography (ar-throg'-ra-fe) [à $\theta \rho \rho \nu$, a joint ; ypá $\phi \varepsilon \iota v$, to write]. A description of the joints.

Arthrogryposis (ar-thro-orip-o'-sis) [à $\rho \theta \rho o v$, a joint ;

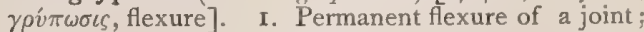
ankylosis. 2. Persistent idiopathic contracture of a joint. 3. Tetany or tetanilla. 


\section{TABLE OF ARTERIES.}

\begin{tabular}{|c|c|c|c|}
\hline NAME. & ORIGIN. & DISTRIBUTION. & BRANCHES. \\
\hline $\begin{array}{l}\text { Aberrant (from brach- } \\
\text { ial or axillary). }\end{array}$ & $\begin{array}{l}\text { Connect the brachial } \\
\text { or axillary with the } \\
\text { radial usually, at } \\
\text { times with the ulnar } \\
\text { or interosseous. }\end{array}$ & & \\
\hline Acromial. & Acromio-thoracic. & $\begin{array}{l}\text { Deltoid muscle (in part), assists in the } \\
\text { formation of the acromial rete. }\end{array}$ & \\
\hline Acromial. & Suprascapular. & Acromial rete. & \\
\hline $\begin{array}{l}\text { A crom io-thoracic } \\
\text { (thoracic axis). }\end{array}$ & $\begin{array}{l}\text { Second branch of first } \\
\text { part of axillary. }\end{array}$ & $\begin{array}{l}\text { Shoulder, arm, upper anterior part of } \\
\text { chest, and mammary gland. }\end{array}$ & $\begin{array}{l}\text { Acromial, humeral, pectoral, clavicu- } \\
\text { lar. }\end{array}$ \\
\hline Adipose. & Thoracic aorta. & Adipose tissue of heart. & \\
\hline Afferent. & Interlobular of kidneys. & Glomeruli. & \\
\hline Alar thoracic. & Second part of axillary. & Lymphatic glands in axilla. & \\
\hline Alveolar (gingival). & Posterior dental. & The gums. & \\
\hline $\begin{array}{l}\text { Anastomotic (of exter- } \\
\text { nal plantar). }\end{array}$ & External plantar. & Outer border of foot. & $\begin{array}{l}\text { Anastomoses with the tarsal and } \\
\text { metatarsal branches of the dorsalis } \\
\text { pedis. }\end{array}$ \\
\hline $\begin{array}{l}\text { Anastomotic (of inter- } \\
\text { nal plantar). }\end{array}$ & Internal plantar. & Inner side of foot. & $\begin{array}{l}\text { Anastomoses with internal tarsal } \\
\text { branch of the dorsalis pedis. }\end{array}$ \\
\hline $\begin{array}{l}\text { Anastomotic (of mid- } \\
\text { dle meningeal), also } \\
\text { called perforating. }\end{array}$ & Middle meningeal. & Around greater wing of sphenoid. & Anastomose with deep temporal. \\
\hline $\begin{array}{l}\text { Anastomotic (of sci- } \\
\text { atic). }\end{array}$ & Sciatic. & External rotator muscles of thigh. & $\begin{array}{l}\text { Assists in the formation of the crucial } \\
\text { anastomosis. }\end{array}$ \\
\hline $\begin{array}{l}\text { Anastomotica magna } \\
\text { (of brachial). }\end{array}$ & Brachial. & Elbow. & Posterior and anterior. \\
\hline $\begin{array}{l}\text { Anastomotica magna } \\
\text { (of superficial fe- } \\
\text { moral). }\end{array}$ & $\begin{array}{l}\text { Superficial femoral (in } \\
\text { Hunter's canal). }\end{array}$ & Knee. & Superficial and deep. \\
\hline Angular. & $\begin{array}{l}\text { The termination of the } \\
\text { facial. }\end{array}$ & $\begin{array}{l}\text { Lachrymal sac and lower part of or- } \\
\text { bicularis palpebrarum. }\end{array}$ & Anastomoses with infraorbital. \\
\hline $\begin{array}{l}\text { Anterior (of corpora } \\
\text { quadrigemina). }\end{array}$ & Posterior cerebral. & $\begin{array}{l}\text { Anterior portion of corpora quadri- } \\
\text { gemina. }\end{array}$ & \\
\hline $\begin{array}{l}\text { Anterior (of recepta- } \\
\text { cle). }\end{array}$ & Internal carotid. & $\begin{array}{l}\text { Dura mater of cavernous sinus and ad- } \\
\text { jacent parts. }\end{array}$ & \\
\hline Antral. & Posterior dental. & Antrum of Highmore. & \\
\hline Aorta, abdominal. & Thoracic aorta. & Two common iliacs. & $\begin{array}{l}\text { Phrenic (right and left), celiac axis, } \\
\text { suprarenal or capsular (right and } \\
\text { left), superior mesenteric, lumbar } \\
\text { (four pairs), renal (right and left), } \\
\text { spermatic (right and left), inferior } \\
\text { mesenteric, right and left common } \\
\text { iliac, middle sacral. }\end{array}$ \\
\hline Aorta, arch. & Left ventricle of heart. & Thoracic anrta. & $\begin{array}{l}\text { Two coronary, innominate, left com- } \\
\text { mon carotid, left subclavian. }\end{array}$ \\
\hline Aorta, primitive. & $\begin{array}{l}\text { That portion from the } \\
\text { origin to the point at } \\
\text { which the first branch } \\
\text { is given off. }\end{array}$ & & \\
\hline Aorta, thoracic. & Arch of aorta. & Abdominal aorta. & $\begin{array}{l}\text { Two or three pericardiac, three } \\
\text { bronchial, four or five esophageal, } \\
\text { twenty intercostal, subcostal (or } \\
\text { twelfth dorsal), diaphragmatic, } \\
\text { aberrans. }\end{array}$ \\
\hline Aortæe, primitive (2). & $\begin{array}{l}\text { Cardiac (in the em- } \\
\text { bryo). }\end{array}$ & Pass through the first visceral arch. & Unite to form the dorsal. \\
\hline Appendicular. & Ilio-colic. & Mesentery of vermiform appendix. & \\
\hline $\begin{array}{l}\text { Articular, middle (of } \\
\text { knee). }\end{array}$ & Popliteal & Crucial ligaments and joint. & \\
\hline $\begin{array}{l}\text { Articular, superior ex- } \\
\text { ternal (of knee). }\end{array}$ & Popliteal. & Crureus and knee. & \\
\hline
\end{tabular}


TABLE OF ARTERIES.-Continued.

\begin{tabular}{|c|c|c|c|}
\hline NAME. & ORIGIN. & DISTRIBUTION. & BRANCHES. \\
\hline $\begin{array}{l}\text { Articular, superior, in- } \\
\text { ternal. }\end{array}$ & Popliteal. & Knee. & \\
\hline Ascending. & External circumflex. & $\begin{array}{l}\text { Deep structures of gluteal region and } \\
\text { hip-joint. }\end{array}$ & \\
\hline Asternal. & Internal mammary. & Inner surface of costal cartilages. & \\
\hline $\begin{array}{l}\text { Atrabiliary. See Cap- } \\
\text { sular. }\end{array}$ & & & \\
\hline Auditory, internal. & Basilar. & Internal ear. & \\
\hline Auricular. & Occipital. & Pinna and concha. & \\
\hline $\begin{array}{l}\text { Auricular, anterior, in- } \\
\text { ferior. }\end{array}$ & Superficial temporal. & Auricle and external auditory meatus. & \\
\hline $\begin{array}{l}\text { A uricular, anterior, } \\
\text { superior. }\end{array}$ & Superficial temporal. & Auricle and external meatus. & \\
\hline Auricular, deep. & $\begin{array}{l}\text { Internal maxillary (first } \\
\text { part). }\end{array}$ & $\begin{array}{l}\text { Membrana tympani and skin of ex- } \\
\text { ternal auditory meatus. }\end{array}$ & \\
\hline Auricular, left. & Left coronary artery. & $\begin{array}{l}\text { Left auricle, pulmonary artery, and } \\
\text { commencement of aorta. }\end{array}$ & \\
\hline Auricular, posterior. & $\begin{array}{l}\text { Fifth branch of external } \\
\text { carotid. }\end{array}$ & Back of auricle, scalp, and part of neck. & $\begin{array}{l}\text { Parotid, muscular, stylo-mastoid, an- } \\
\text { terior terminal or auricular, and pos- } \\
\text { terior terminal or mastoid. }\end{array}$ \\
\hline Auricular, right. & Right coronary artery. & Right auricle, aorta, auricular septum. & \\
\hline Axillary. & Subclavian. & Brachial and seven branches. & $\begin{array}{l}\text { Superior thoracic, acromio-thoracic, } \\
\text { long thoracic, alar thoracic, subscap- } \\
\text { ular, anterior and posterior circum- } \\
\text { flex. }\end{array}$ \\
\hline $\begin{array}{l}\text { Azygos (articular, of } \\
\text { external plantar). }\end{array}$ & External plantar. & Articulations of tarsus. & \\
\hline $\begin{array}{l}\text { Azygos (articular, of } \\
\text { internal plantar). }\end{array}$ & Internal plantar. & Articulations on inner side of foot. & $\begin{array}{l}\text { Anastomoses with branches of external } \\
\text { plantar. }\end{array}$ \\
\hline $\begin{array}{l}\text { Azygos (articular, of } \\
\text { popliteal). }\end{array}$ & Popliteal. & Knee. & \\
\hline $\begin{array}{l}\text { Azygos (articular, of } \\
\text { sciatic). }\end{array}$ & Sciatic. & Posterior part of capsule of hip-joint. & \\
\hline $\begin{array}{c}\text { Azygos (articular, of } \\
\text { superior profunda). }\end{array}$ & Superior profunda. & Elbow-joint, posterior part. & $\begin{array}{l}\text { Anastomoses with anastomotica mag- } \\
\text { na and interosseous recurrent. }\end{array}$ \\
\hline $\begin{array}{l}\text { Azygos (articular, of } \\
\text { suprascapular). }\end{array}$ & Suprascapular. & $\begin{array}{l}\text { The acromio-clavicular and shoulder } \\
\text { joints. }\end{array}$ & \\
\hline $\begin{array}{l}\text { Azygos (articular, of } \\
\text { temporal). }\end{array}$ & Temporal. & Temporo-maxillary joint. & \\
\hline Basilar. & $\begin{array}{l}\text { By confluence of right } \\
\text { and left vertebral. }\end{array}$ & Brain. & $\begin{array}{l}\text { Transverse (or pontile), internal audi- } \\
\text { tory, anterior cerehellar, superior } \\
\text { cerebellar, two posterior cerebral. }\end{array}$ \\
\hline $\begin{array}{l}\text { Bicipital (or ascend- } \\
\text { ing). }\end{array}$ & Anterior circumflex. & $\begin{array}{l}\text { Long tendon of biceps and shoulder- } \\
\text { joint. }\end{array}$ & \\
\hline Brachial. & Axillary. & Arm and forearm. & $\begin{array}{l}\text { Superior and inferior profunda, anas- } \\
\text { tomotica magna, nutrient, muscular, } \\
\text { radial and ulnar. }\end{array}$ \\
\hline Brachio-cephalic. & See Innominate. & & \\
\hline Bronchial (inferior). & Thoracic aorta. & Bronchi and parenchyma of the lungs. & \\
\hline Bronchial (superior). & Arch of aorta. & Bronchi. & \\
\hline Buccal. & Facial. & Muscles of cheek. & $\begin{array}{l}\text { Anastomoses with buccal branch of } \\
\text { internal maxillary, the transverse } \\
\text { facial and infraorbital. }\end{array}$ \\
\hline Buccal. & Internal maxillary. & $\begin{array}{l}\text { Buccinator muscle and mucous mem- } \\
\text { brane of mouth. }\end{array}$ & $\begin{array}{l}\text { Anastomoses with the buccal branch } \\
\text { of the facial, the transverse facial } \\
\text { and infraorbital. }\end{array}$ \\
\hline Buccal. & Posterior dental. & Buccinator muscle. & \\
\hline Of the bulb. & $\begin{array}{l}\text { First part of internal } \\
\text { pudic. }\end{array}$ & $\begin{array}{l}\text { Erectile tissue of the bulb and the cor- } \\
\text { pus spongiosum. }\end{array}$ & \\
\hline
\end{tabular}


TABLE OF ARTERIES.-Continued.

\begin{tabular}{|c|c|c|c|}
\hline NAME. & ORIGIN. & DISTRIBUTION. & BRANCHES. \\
\hline $\begin{array}{l}\text { Calcanean, ext e r n a } 1 \\
\text { and internal. }\end{array}$ & Peroneal. & $\begin{array}{l}\text { Over the os calcis and surrounding } \\
\text { soft parts. }\end{array}$ & \\
\hline $\begin{array}{l}\text { Calcanean, inferior (of } \\
\text { external plantar). }\end{array}$ & External plantar. & Over inner surface of os calcis. & $\begin{array}{l}\text { Anastomoses with internal calcanean } \\
\text { of peroneal. }\end{array}$ \\
\hline Calcanean, middle. & Posterior tibial. & Os calcis. & \\
\hline Callosal. & See Calloso-marginal. & & 1 \\
\hline Calloso-marginal. & Anterior cerebral. & $\begin{array}{l}\text { Callosal and upper part of marginal } \\
\text { convolutions. }\end{array}$ & \\
\hline $\begin{array}{l}\text { Capsular (or atrabili- } \\
\text { ary). }\end{array}$ & Abdominal aorta. & Suprarenal capsule. & \\
\hline Capsular. & See Perirenal. & & \\
\hline Cardiac. & Gastric. & Cardiac end of stomach. & \\
\hline $\begin{array}{l}\text { Cardiac, right. See } \\
\text { Coronary, right (of } \\
\text { heart). }\end{array}$ & & & \\
\hline Carotid, common. & $\begin{array}{l}\text { Right side, innominate; } \\
\text { left side, arch. }\end{array}$ & External and internal carotid. & External and internal carotid. \\
\hline Carotid, external. & Common carotid. & $\begin{array}{l}\text { Anterior part of neck, face, side of } \\
\text { head, integuments and dura mater. }\end{array}$ & $\begin{array}{l}\text { Ascending pharyngeal, superior thy- } \\
\text { roid, lingual, facial, occipital, pos- } \\
\text { terior auricular, temporal, internal } \\
\text { maxillary. }\end{array}$ \\
\hline Carotid, internal. & Common carotid. & $\begin{array}{l}\text { Greater part of brain, the orbit, inter- } \\
\text { nal ear, forehead, and nose. }\end{array}$ & $\begin{array}{l}\text { Tympanic, vidian, arteria receptacuii, } \\
\text { pituitary, gasserian, meningeal, oph- } \\
\text { thalmic, posterior communicating, } \\
\text { anterior choroid, anterior cerebral, } \\
\text { middie cerebral. }\end{array}$ \\
\hline $\begin{array}{l}\text { Carotid, primitive. See } \\
\text { Carotid, common. }\end{array}$ & & & \\
\hline $\begin{array}{l}\text { Car otid, superficial. } \\
\text { See Carotid, exter- } \\
\text { nal. }\end{array}$ & & & \\
\hline Carpal. & Radial. & $\begin{array}{l}\text { Branches to lower end of radius, wrist, } \\
\text { and carpal-joints. }\end{array}$ & $\begin{array}{l}\text { Enters into formation of anterior car- } \\
\text { pal rete. }\end{array}$ \\
\hline Carpal. & Ulnar. & Carpus. & $\begin{array}{l}\text { Enters into formation of the posterior } \\
\text { carpal rete. }\end{array}$ \\
\hline Caudate. & Middle cerebral. & Head of caudate nucleus. & \\
\hline Caval. & Right phrenic. & Vena cava. & \\
\hline Cecal, anterior. & Inferior mesenteric. & Anterior surface of cecum. & \\
\hline Cecal, posterior. & Posterior mesenteric. & Posterior part of cecum. & \\
\hline Celiac. & Abdominal aorta. & $\begin{array}{l}\text { Stomach, duodenum, spleen, pancreas, } \\
\text { liver and gall-bladder. }\end{array}$ & Gastric, hepatic, splenic. \\
\hline Central (of retina). & Ophthalmic. & Retina. & \\
\hline $\begin{array}{l}\text { Central, of Zinn. See } \\
\text { Central (of retina). }\end{array}$ & & & \\
\hline Cerebellar, anterior. & Basilar. & Anterior inferior surface of cerebellum. & \\
\hline Cerebellar, inferior. & Vertebral. & $\begin{array}{l}\text { Vermiform process, and cortex of cere- } \\
\text { bellum. }\end{array}$ & $\begin{array}{l}\text { Inferior vermiform and the hemi- } \\
\text { spheral. }\end{array}$ \\
\hline Cerebellar, superior. & Basilar. & $\begin{array}{l}\text { Superior vermiform process and cir- } \\
\text { cumference of cerebellum. }\end{array}$ & Superior vermiform and hemispheral. \\
\hline Cerebral, anterior. & Internal carotid. & Anterior portion of cerebrum. & $\begin{array}{l}\text { Anterior communicating, ganglionic } \\
\text { (or central), commissural, hemi- } \\
\text { spheral (or cortical). }\end{array}$ \\
\hline Cerebral, inferior. & See Cerebral, posterior. & & \\
\hline Cerebral, middle. & Internal carotid. & Middle portion of cerebrum. & $\begin{array}{l}\text { Ganglionic (or central), hemispheral } \\
\text { (or cortical). }\end{array}$ \\
\hline Cerebral, posterior. & Basilar. & $\begin{array}{l}\text { Temporo-sphenoidal and occipital } \\
\text { lobes. }\end{array}$ & $\begin{array}{l}\text { Ganglionic (or central), and hemi- } \\
\text { spheral (or cortical). }\end{array}$ \\
\hline Cervical. & Uterine. & Cervix uteri. & \\
\hline
\end{tabular}


TABLE OF ARTERIES.-Continued.

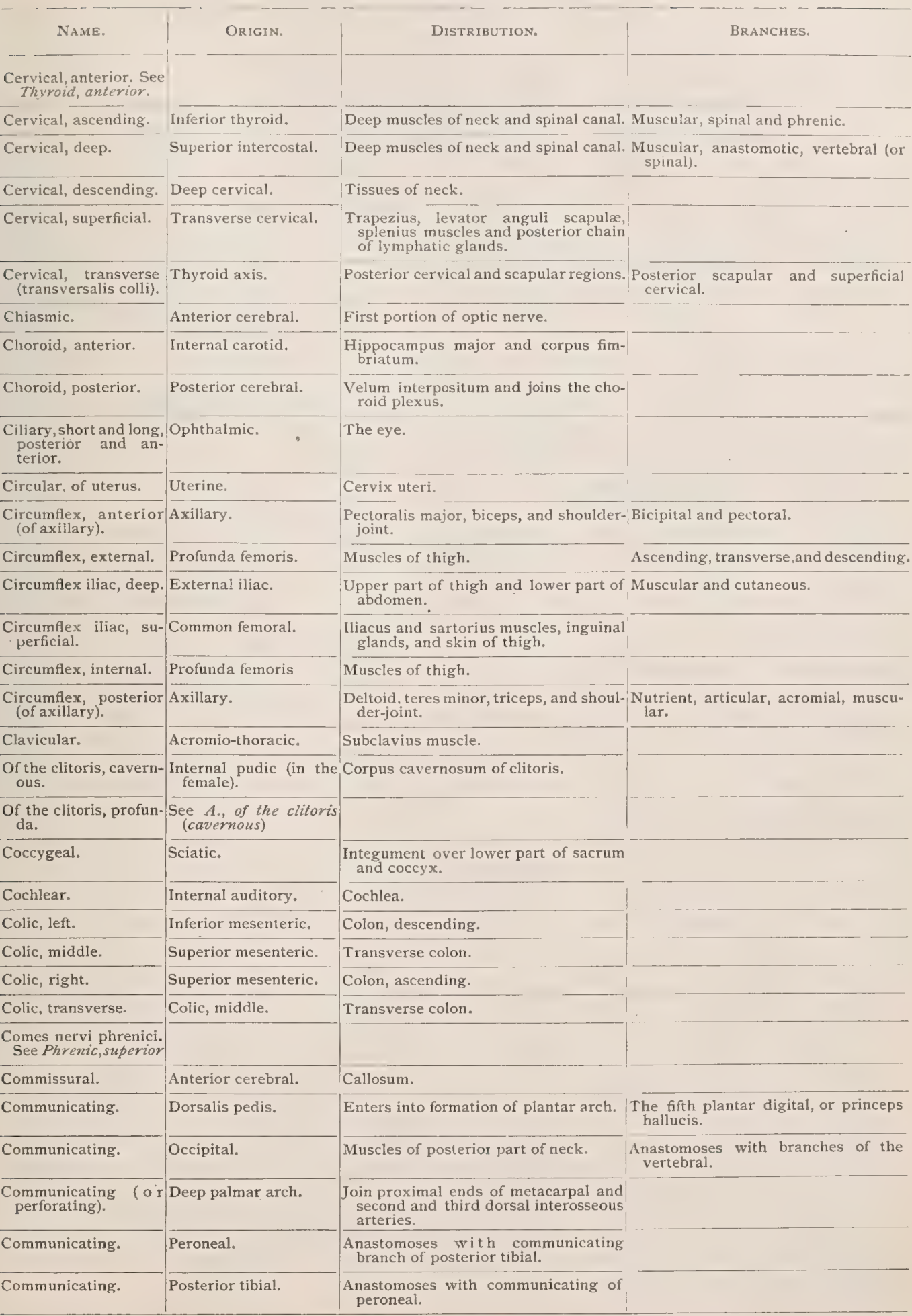


TABLE OF ARTERIES.-Continued.

\begin{tabular}{|c|c|c|c|}
\hline NAME. & ORIGIN. & DISTRIBUTION. & BRANCHES. \\
\hline $\begin{array}{l}\text { Communicating, ante- } \\
\text { rior. }\end{array}$ & Anterior cerebral. & $\begin{array}{l}\text { Assists in formation of anterior boun- } \\
\text { dary of circle of Willis; sends bran- } \\
\text { ches to caudate nucleus. }\end{array}$ & \\
\hline $\begin{array}{l}\text { Communicating, pos- } \\
\text { terior. }\end{array}$ & Posterior carotid. & $\begin{array}{l}\text { Enters into formation of circle of Wil } \\
\text { lis; uncinate convolution and optic } \\
\text { thalamus. }\end{array}$ & Uncinate, middle thalamic. \\
\hline \multicolumn{4}{|l|}{$\begin{array}{l}\text { Coronary. See Gas- } \\
\text { tric. }\end{array}$} \\
\hline Coronary, inferior. & Facial. & Lower lip. & \\
\hline Coronary, left. & $\begin{array}{l}\text { Left anterior sinus of } \\
\text { Valsalva. }\end{array}$ & Heart. & $\begin{array}{l}\text { Left auricular, anterior interventricu- } \\
\text { lar, left marginal, terminal. }\end{array}$ \\
\hline Coronary, right. & $\begin{array}{l}\text { Right anterior sinus of } \\
\text { Valsalva. }\end{array}$ & Heart. & $\begin{array}{l}\text { Right auricular, preventricular, right } \\
\text { marginal, posterior interventricular, } \\
\text { transverse. }\end{array}$ \\
\hline \multicolumn{4}{|l|}{$\begin{array}{l}\text { Coronary, right, of } \\
\text { stomach, See } P y- \\
\text { loric. }\end{array}$} \\
\hline Coronary, superior. & Facial. & Upper lip. & Arteria septum narium. \\
\hline $\begin{array}{l}\text { Of the corpus caverno- } \\
\text { sum. }\end{array}$ & $\begin{array}{l}\text { Dorsal artery of the } \\
\text { penis. }\end{array}$ & Corpus cavernosum. & \\
\hline Costo-cervical. & $\begin{array}{l}\text { That part of superior } \\
\text { intercostal between } \\
\text { its origin and first } \\
\text { branch. }\end{array}$ & & \\
\hline Cremasteric. & Deep epigastric. & Cremaster muscle. & \\
\hline Cremasteric. & Spermatic. & Cremaster muscle. & $\begin{array}{l}\text { Anastomoses with cremasteric from } \\
\text { deep epigastric. }\end{array}$ \\
\hline \multicolumn{4}{|l|}{$\begin{array}{l}\text { Cremasteric. See Sper- } \\
\text { matic, external. }\end{array}$} \\
\hline Crico-thyroid. & See Laryngeal, inferior & & \\
\hline \multicolumn{4}{|l|}{ Crural, see Femoral. } \\
\hline \multicolumn{4}{|l|}{ Cubital, see Ulnar. } \\
\hline \multicolumn{4}{|l|}{$\begin{array}{l}\text { Cubital recurrent, an- } \\
\text { terior. See Ulnar } \\
\text { recurrent, anterior. }\end{array}$} \\
\hline \multicolumn{4}{|l|}{$\begin{array}{l}\text { Cubital recurrent, pos- } \\
\text { terior. See Ulnar } \\
\text { recurrent, posterior. }\end{array}$} \\
\hline Cystic. & Hepatic. & Gall-bladder. & \\
\hline Deferential. & Superior vesical. & Vas deferens. & \\
\hline Dental, anterior. & Infraorbital. & $\begin{array}{l}\text { Incisor and canine teeth, and mucous } \\
\text { membrane of antrum. }\end{array}$ & . \\
\hline Dental, inferior. & See Mandibular. & & \\
\hline $\begin{array}{l}\text { Dental, posterior (or } \\
\text { alveolar). }\end{array}$ & Internal maxillary. & Antrum, teeth, gums, and cheek. & Antral, dental, alveolar, buccal. \\
\hline Dental, superior. & Posterior dental. & $\begin{array}{l}\text { Molar and bicuspid teeth of superior } \\
\text { maxilla. }\end{array}$ & \\
\hline Descending. & External circumflex. & Muscles of thigh. & \\
\hline $\begin{array}{l}\text { Descending, superfi- } \\
\text { cial. }\end{array}$ & External carotid. & Neck. & \\
\hline Diaphragmatic. & Thoracic aorta. & Diaphragm. & \\
\hline Digital. & External plantar. & $\begin{array}{l}\text { Outer side of the } 2 d \text { and } 3 d, 4 \text { th and } \\
5 \text { th toes. }\end{array}$ & \\
\hline Digital, palmar. & Superficial palmar arch. & $\begin{array}{l}\text { Both sides of little, ring, and mid- } \\
\text { dle finger and ulnar side of index } \\
\text { finger. }\end{array}$ & \\
\hline $\begin{array}{l}\text { Digital, plantar. See } \\
\text { Communicating, of } \\
\text { dorsalis pedis. }\end{array}$ & & & \\
\hline
\end{tabular}


TABLE OF ARTERIES.-Continued.

\begin{tabular}{|c|c|c|c|}
\hline NAME. & ORIGIN. & DISTRIBUTION. & BRANCHES. \\
\hline Digital, superficial. & Internal plantar. & Toes. & \\
\hline Diploic. & Supraorbital. & Diploë of frontal sinuses. & \\
\hline Dorsal. & Intercostal. & Spine and muscles of throat. & Spinal and muscular. \\
\hline Dorsal. & Lumbar. & Muscles of back. & \\
\hline Dorsal, interosseous. & Radial. & Contiguous of $2 \mathrm{~d}, 3 \mathrm{~d}, 4^{\mathrm{th}}$, and 5 th toes. & \\
\hline Dorsal (of penis). & Termination of pudic. & Penis. & \\
\hline Dorsal (scapular). & Subscapular. & Muscles of scapula and shoulder-joint. & Infrascapular. \\
\hline Dorsal of tongue. & Lingual. & $\begin{array}{l}\text { Dorsum of tongue, tonsils, and epi- } \\
\text { glottis. }\end{array}$ & \\
\hline $\begin{array}{l}\text { Dorsal (tath). See } \\
\text { Subcostal. }\end{array}$ & & & \\
\hline Dorsalis hallucis. & $\begin{array}{l}\text { Continuation of dor- } \\
\text { salis pedis. }\end{array}$ & Great and second toe. & \\
\hline Dorsalis indicis. & Radial. & Index finger. & \\
\hline Dorsalis lingux. & Lingual. & $\begin{array}{l}\text { Mucous membrane of tongue, pillars } \\
\text { of fauces and tonsils. }\end{array}$ & \\
\hline Dorsalis pedis. & $\begin{array}{l}\text { Continuation of ante- } \\
\text { rior tibial. }\end{array}$ & Assists to form plantar arch. & $\begin{array}{l}\text { Tarsal, metatarsal, dorsalis hallucis, } \\
\text { communicating. }\end{array}$ \\
\hline Dorsalis pollicis. & Radial. & Thumb. & \\
\hline Dorso-scapular. & See Scapular, superior. & & \\
\hline $\begin{array}{l}\text { Duodenal, superior, } \\
\text { right. See Pancrea- } \\
\text { tico=duodenal, supe- } \\
\text { rior. }\end{array}$ & & & \\
\hline Duodeno-gastric. & See Gastro-duodenal. & & \\
\hline Dural. & See Meningeal. & & \\
\hline Emulgent. & See Renal. & & \\
\hline $\begin{array}{l}\text { Epicondyloid. See } \\
\text { Uinar. }\end{array}$ & & & \\
\hline Epididymal. & Spermatic. & Epididymis. & \\
\hline $\begin{array}{l}\text { Epigastric, deep (or } \\
\text { inferior). }\end{array}$ & External iliac. & Abdominal wall. & $\begin{array}{l}\text { Cremasteric, pubic, muscular, cuta- } \\
\text { neous, terminal. }\end{array}$ \\
\hline Epigastric, superficial. & Common femoral. & $\begin{array}{l}\text { Inguinal glands, skin, superficial fascia, } \\
\text { and abdominal wall. }\end{array}$ & \\
\hline Epigastric, superior. & Internal mammary. & $\begin{array}{l}\text { Abdominal wall and diaphragm, liver } \\
\text { and peritoneum. }\end{array}$ & $\begin{array}{l}\text { Phrenic, xiphoid, cutaneous, muscular, } \\
\text { hepatic and peritoneal. }\end{array}$ \\
\hline Epiploic. & $\begin{array}{l}\text { Right and left gastro- } \\
\text { epiploic. }\end{array}$ & Omentum. & \\
\hline \multicolumn{4}{|l|}{ Epiploic. SeeOmental. } \\
\hline Esophageal. & Gastric. & Esophagus. & \\
\hline Esophageal. & Inferior thyroid. & Esophagus. & \\
\hline Esophageal. & Left phrenic. & Esophagus. & \\
\hline Esophageal (4 or 5 ). & Thoracic aorta. & Esophagus. & \\
\hline Esophageal, inferior. & Coronary (of stomach). & Esophagus. & \\
\hline Ethmoidal, anterior. & Ophthalmic. & $\begin{array}{l}\text { Part of anterior portion of brain, nose, } \\
\text { frontal sinuses and skin of face. }\end{array}$ & $\begin{array}{l}\text { Ethmoidal, meningeal, nasal, frontal, } \\
\text { cutaneous. }\end{array}$ \\
\hline Ethmoidal, posterior. & Ophthalmic. & $\begin{array}{l}\text { Posterior ethmoidal cells, dura mater, } \\
\text { nose. }\end{array}$ & Ethmoidal, meningeal, nasal. \\
\hline Eustachian. & Pterygo-palatine. & Eustachian tube. & \\
\hline Facial. & $\begin{array}{l}\text { Third branch external } \\
\text { carotid. }\end{array}$ & Pharynx and face. & $\begin{array}{l}\text { Ascending, or inferior palatine, tonsil- } \\
\text { lar, glandular, muscular, submental, } \\
\text { masseteric, buccal, inferior labial, } \\
\text { inferior and superior coronary, lat- } \\
\text { eralis nasi, angular. }\end{array}$ \\
\hline
\end{tabular}


TABLE OF ARTERIES.-Continued.

\begin{tabular}{|c|c|c|c|}
\hline NAME. & ORIGIN. & DISTRIBUTION. & BRANCHES. \\
\hline Facial, transverse. & Temporal. & $\begin{array}{l}\text { Parotid gland, masseter muscle, skin } \\
\text { of face. }\end{array}$ & \\
\hline Faliopian. & Ovarian. & $\begin{array}{l}\text { Isthmus, ampulla and fimbriated ex- } \\
\text { tremity of fallopian tube. }\end{array}$ & \\
\hline Femoral, common. & \multicolumn{2}{|c|}{$\begin{array}{l}\begin{array}{l}\text { Continuation of exter- Lower part of abdominal wall, upper } \\
\text { nal iliac. }\end{array} \\
\text { part of thigh and genitalia. }\end{array}$} & $\begin{array}{l}\text { Superficial epigastric, superficial cir- } \\
\text { cumflex iliac, superficial external } \\
\text { pudic, deep external pudic, pro- } \\
\text { funda. }\end{array}$ \\
\hline \multicolumn{4}{|c|}{$\begin{array}{l}\text { Femoral, deep, see } \\
\text { Femoral, profunda. }\end{array}$} \\
\hline Femoral, profunda. & Common femoral. & \multirow{3}{*}{$\begin{array}{l}\text { Muscles of thigh. } \\
\text { Muscles of thigh and knee-joint. } \\
\begin{array}{l}\text { Soleus and peroneus tertius muscles } \\
\text { and integument. }\end{array}\end{array}$} & $\begin{array}{l}\text { External circumflex, internal circum- } \\
\text { flex and three perforating. }\end{array}$ \\
\hline Femoral, superficial. & $\begin{array}{l}\text { Continuation of com- } \\
\text { mon femoral. }\end{array}$ & & \multirow{2}{*}{$\begin{array}{l}\text { Muscular, saphenous, anastomotica } \\
\text { magna. }\end{array}$} \\
\hline Fibular, superior. & $\begin{array}{l}\text { Anterior or posterior } \\
\text { tibial or popliteal. }\end{array}$ & & \\
\hline Of the frenum linguae. S & Sublingual. & \multicolumn{2}{|l|}{ Frenum of tongue. } \\
\hline Frontal, anterior. & Anterior cerebral. & \multicolumn{2}{|l|}{ Inferior frontal convolutions. } \\
\hline Frontal, ascending. & Middle cerebral. & \multicolumn{2}{|l|}{$\begin{array}{l}\text { Lower part of ascending frontal con- } \\
\text { volution. }\end{array}$} \\
\hline Frontal, internal. & Anterior cerebral. & \multirow{2}{*}{\multicolumn{2}{|c|}{ Inferior frontal convolutions. }} \\
\hline Frontal, middle. & See Medifrontal. & & \\
\hline Funicular. & Superior vesical. & \multicolumn{2}{|l|}{ Round ligament. } \\
\hline Gasserian. & Internal carotid. & \multicolumn{2}{|l|}{ Gasserian ganglion. } \\
\hline Gasserian. & Middle meningeal. & \multicolumn{2}{|c|}{$\begin{array}{l}\text { Gasserian ganglion, and Meckel's } \\
\text { space. }\end{array}$} \\
\hline$\overline{\text { Gastric (or coronary). }}$ & Celiac axis. & \multirow[t]{2}{*}{ Stomach, liver, and esophagus. } & \multirow[t]{2}{*}{$\begin{array}{l}\text { Esophageal, cardiac, gastric, and hepa- } \\
\text { tic. }\end{array}$} \\
\hline \multicolumn{2}{|c|}{$\begin{array}{l}\text { Gastric, right. See } \\
\text { Gastro-epiploic, } \\
\text { right. }\end{array}$} & & \\
\hline Gastro-duodenal. & Hepatic. & Stomach and duodenum. & $\begin{array}{l}\text { Right gastro-epiploic and superior pan- } \\
\text { creatico-duodenal. }\end{array}$ \\
\hline Gastro-epiploic, left. & Splenic. & \multicolumn{2}{|l|}{ Stomach and omentum. } \\
\hline Gastro-epiploic, right & Gastro-duodenal. & \multicolumn{2}{|l|}{ Stomach and omentum. } \\
\hline Gastro-hepatic. & $\begin{array}{l}\text { See Coronary, of stom- } \\
\text { ach. }\end{array}$ & & \\
\hline Geniculate. & Posterior cerebral. & \multicolumn{2}{|l|}{ Geniculate convolution. } \\
\hline \multicolumn{4}{|c|}{ 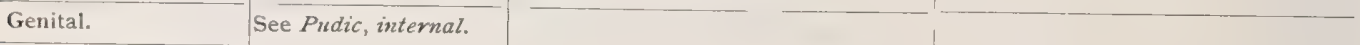 } \\
\hline \multicolumn{4}{|c|}{$\begin{array}{l}\text { Gingival. See Alveo- } \\
\text { lar. }\end{array}$} \\
\hline Glandular. & Facial. & Submaxillary gland. & \\
\hline $\begin{array}{l}\text { Glaserian (or tym-I } \\
\text { panic). }\end{array}$ & Internal maxillary. & \multicolumn{2}{|l|}{$\begin{array}{l}\text { Lining membrane of tympanum and. } \\
\text { laxator tympani muscle. }\end{array}$} \\
\hline Gluteal. & $\begin{array}{l}\text { Internal iliac, posterior } \\
\text { division. }\end{array}$ & Pelvic and glutei muscles, etc. & Muscular, superficial and deep. \\
\hline Gluteal, deep. & Gluteal. & \multicolumn{2}{|l|}{$\begin{array}{l}\text { Deep muscles of posterior gluteal } \\
\text { region. }\end{array}$} \\
\hline Gluteal, inferior. & Sciatic. & \multicolumn{2}{|l|}{ Gluteus maximus. } \\
\hline Gluteal, superficial. & Gluteal. & $\begin{array}{l}\text { Gluteus maximus and integument over } \\
\text { sacrum. }\end{array}$ & \\
\hline Gluteal, superior. & Deep gluteal. & Muscles adjacent. & \\
\hline Gustatory (or lingual). I & Inferior dental. & Lingual nerve. & \\
\hline $\begin{array}{l}\text { Guttural, superior. } \\
\text { See Thyroid, supe- } \\
\text { rior. }\end{array}$ & & & \\
\hline
\end{tabular}


TABLE OF ARTERIES.-Continued.

\begin{tabular}{|c|c|c|c|}
\hline NAME. & ORIGIN. & DISTRIBUTION. & BRANCHES. \\
\hline \multicolumn{4}{|l|}{$\begin{array}{l}\text { Gutturo-maxillary. See } \\
\text { Maxillary, internal. }\end{array}$} \\
\hline Helicine. & & \multicolumn{2}{|l|}{$\begin{array}{l}\text { The arteries found in cavernous tissue, } \\
\text { as in the uterus, ovary, etc. }\end{array}$} \\
\hline Hemispheral. & Inferior cerebellar. & \multicolumn{2}{|l|}{ Cortex of cerebellum. } \\
\hline Hemispheral. & Superior cerebellar. & \multicolumn{2}{|l|}{ Cortex of cerebellum. } \\
\hline \multirow{2}{*}{\multicolumn{4}{|c|}{$\begin{array}{l}\text { Hennorrhoidal, inferior, } \\
\text { (or external). } \\
\text { Hemorrhoidal, inter- } \\
\text { nal, See Hemorrhoi- } \\
\text { dal, superior. }\end{array}$}} \\
\hline & & & \\
\hline $\begin{array}{l}\text { Hemorrhoidal, middle I } \\
\text { (rectal, middle). }\end{array}$ & $\begin{array}{l}\text { Internal iliac, anterior } \\
\text { division. }\end{array}$ & \multicolumn{2}{|l|}{ Middie part of rectum. } \\
\hline $\begin{array}{l}\text { Hemorrhoidal, supe- I } \\
\text { rior. }\end{array}$ & Inferior mesenteric. & \multicolumn{2}{|l|}{ Upper part of rectum. } \\
\hline Hepatic. & Celiac axis. & $\begin{array}{l}\text { Liver, pancreas, part of duodenum, } \\
\text { and stomach. }\end{array}$ & $\begin{array}{l}\text { Pancreatic, sub-pyloric, gastro-duode- } \\
\text { nal, right and left terminal. }\end{array}$ \\
\hline Hepatic. & Gastric. & Left lobe of liver. & - \\
\hline Hepatic. & Right phrenic. & Liver. & \\
\hline Hepatic. & Superior epigastric. & Liver. & \\
\hline Hepatic, right. & Hepatic. & Liver substance. & Cystic. \\
\hline \multicolumn{4}{|l|}{$\begin{array}{l}\text { Humeral. See Brach- } \\
\text { zal. }\end{array}$} \\
\hline Humeral, thoracic. & Acromio-thoracic. & \multirow[t]{2}{*}{$\begin{array}{l}\text { Pectoralis major, deltoid and adjacent } \\
\text { int guments. }\end{array}$} & $\begin{array}{l}\text { Anastomoses with anterior and pos } \\
\text { terior circumflex. }\end{array}$ \\
\hline $\begin{array}{c}\text { Humeral, transverse. } \\
\text { See Sipprascapular. }\end{array}$ & & & \\
\hline \multicolumn{4}{|c|}{$\begin{array}{l}\text { Hyaloid. Central ar- Crystalline lens, } \\
\text { tery of retina. }\end{array}$} \\
\hline \multicolumn{4}{|l|}{$\begin{array}{r}\text { Hyoid. See Infra-hy- } \\
\text { oid and Supra-hyoid. }\end{array}$} \\
\hline Hypogastric. & $\begin{array}{l}\text { Continuation of ante- } \\
\text { rior branch of inter- } \\
\text { nal iliac. }\end{array}$ & $\begin{array}{l}\text { Vesical branches, impervious in the } \\
\text { aduit. }\end{array}$ & \\
\hline Ileo-colic. & Superior mesenteric. & Cecum and adjacent bowel. & \\
\hline Iliac. & Ilio-lumbar. & lliac fossa and ilium. & \\
\hline lliac. & Obturator. & Ilium. & \\
\hline \multicolumn{4}{|l|}{$\begin{array}{l}\text { Iliac, circumflex deep. } \\
\text { See Circumflex iliac, } \\
\text { deep. }\end{array}$} \\
\hline $\begin{array}{l}\text { Iliac, circumflex, su- } \\
\text { perficial. }\end{array}$ & $\begin{array}{l}\text { See Circumflex iliac, } \\
\text { supericial. }\end{array}$ & & \\
\hline lliac, common. & $\begin{array}{l}\text { Terminal branch of ab- } \\
\text { dorninal aorta. }\end{array}$ & $\begin{array}{l}\text { Peritoneum, subperitoneal fat, ureter, } \\
\text { and terminates in external and inter- } \\
\text { nal iliac. }\end{array}$ & $\begin{array}{l}\text { Peritoneal, subperitoneal, ureteric, ex- } \\
\text { ternal and internal iliac. }\end{array}$ \\
\hline Iliac, external. & Cormmon iliac. & Lower limb. & $\begin{array}{l}\text { Deep epigastric, deep circumflex iliac, } \\
\text { muscular, and continues as femoral. }\end{array}$ \\
\hline \multicolumn{4}{|l|}{$\begin{array}{l}\text { Iliac, external, small. } \\
\text { See Circumflex iliac, } \\
\text { external. }\end{array}$} \\
\hline Iliac, internal. & Common iliac. & $\begin{array}{l}\text { Pelvic and generative organs, and inner } \\
\text { side of thigh. }\end{array}$ & Anterior and posterior trunk. \\
\hline $\begin{array}{l}\text { Iliac, internal, anteric-r. } \\
\text { trunk. }\end{array}$ & Internal iliac. & Pelvic and generative organs and thigh. & $\begin{array}{l}\text { Hypogastric, superior middle and vesi- } \\
\text { cal, middle hemorrhoidal, uterine, } \\
\text { vaginal, obturator, sciatic, internal } \\
\text { pudic. }\end{array}$ \\
\hline $\begin{array}{l}\text { Iliac, internal, poste:- } \\
\text { rior trunk. }\end{array}$ & Internal iliac. & Muscles of hip and sacrum. & Ilio-lumbar, lateral sacral and gluteal. \\
\hline
\end{tabular}


TABLE OF ARTERIES.-Continued.

\begin{tabular}{|c|c|c|c|}
\hline NAME. & ORIGIN. & DISTRIBUTION. & BRANCHES. \\
\hline \multicolumn{4}{|l|}{$\begin{array}{l}\text { Iliac, primary. Sec } \\
\text { Iliac, conmon. }\end{array}$} \\
\hline \multicolumn{4}{|l|}{$\begin{array}{l}\text { Iliac, primitive. See } \\
\text { Iliac, common. }\end{array}$} \\
\hline llio-lumbar. & $\begin{array}{l}\text { Internal iliac, posterior } \\
\text { trunk. }\end{array}$ & Muscles of pelvis and pelvic bones. & \multirow[t]{2}{*}{ Iliac and lumbar. } \\
\hline Incisive. & Mandibular. & Incisor teeth. & \\
\hline Infracostal, labial. & Internal mammary. & Ribs. & \\
\hline Infrahyoid. & Superior thyroid. & $\begin{array}{l}\text { Infrahyoid bursa and thyro-hyoid mus- } \\
\text { cle. }\end{array}$ & \\
\hline Infraorbital. & Internal maxillary. & $\begin{array}{l}\text { Upper lip, lower eye-lid, lachrymal sac, } \\
\text { side of nose. }\end{array}$ & Orbital, anterior dental, nasal. \\
\hline Infrascapular. & Dorsal scapular. & $\begin{array}{l}\text { Subscapularis, scapula, and shoulder- } \\
\text { joint. }\end{array}$ & \\
\hline Infraspinous. & Posterior scapular. & Infraspinous fossa. & \\
\hline Infraspinous. & Suprascapular. & Infraspinous fossa. & \\
\hline Innominate. & Arch of aorta. & Right side of head and right arm. & $\begin{array}{l}\text { Right common carotid, right subcla- } \\
\text { vian, occasionally thyroidea ima. }\end{array}$ \\
\hline Intercostal, anterior. & Internal mammary. & $\begin{array}{l}\text { Intercostal muscles, ribs (upper } 5 \text { or } 6 \text { ), } \\
\text { and pectoralis major. }\end{array}$ & \\
\hline Intercostal, anterior. & Musculo-phrenic. & Lower 5 or 6 intercostal spaces. & \\
\hline $\begin{array}{l}\text { Intercostal, aortic. } 10 \\
\text { pairs. }\end{array}$ & Thoracic aorta. & Lower intercostal spaces. & $\begin{array}{l}\text { Dorsal, intercostal collateral, pleural, } \\
\text { muscular, lateral cutaneous, mam- } \\
\text { mary glandular. }\end{array}$ \\
\hline Intercostal, first. & Superior intercostal. & First intercostal space. & \\
\hline Intercostal, superior. & Subclavian. & Neck and upper part of thorax. & $\begin{array}{l}\text { Deep cervical, first intercostal, arte- } \\
\text { ria aberrans. }\end{array}$ \\
\hline $\begin{array}{l}\text { Interlobular (of kid- } \\
\text { ney). }\end{array}$ & Renal. & $\begin{array}{l}\text { Malpighian bodies and uriniferous } \\
\text { tubules. }\end{array}$ & \\
\hline Interosseous, anterior. & Interosseous (common). & Muscles of forearm. & \\
\hline Interosseous, common. & Ulnar. & $\begin{array}{l}\text { Interosseous membrane and deep mus- } \\
\text { cles of the forearm. }\end{array}$ & Anterior and posterior interosseous. \\
\hline $\begin{array}{l}\text { Interosseous, d orsa l } \\
\text { (3). }\end{array}$ & Metatarsal. & $\begin{array}{l}\text { Contiguous sides of } 2 \mathrm{~d} \text { and } 3 \mathrm{~d} \text {, and } 4 \text { th } \\
\text { and } 5 \text { th toes. }\end{array}$ & \\
\hline Interosseous, dorsal. & Posterior radial carpal. & Dorsal aspect of fingers. & \\
\hline $\begin{array}{l}\text { Interosseous, palınar } \\
(3) \text {. }\end{array}$ & Deep palmat arch. & $\begin{array}{l}\text { Interosseous muscles, bones, and } 2 \mathrm{~d}, \\
3 \mathrm{~d} \text {, and } 4^{\text {th }} \text { lumbricales. }\end{array}$ & \\
\hline Interosseous, plantar. & Plantar arch. & Toes. & \\
\hline $\begin{array}{l}\text { Interosseous, posterior } \\
\text { (forearm). }\end{array}$ & Common interosseous. & Muscles, back of forearm. & Posterior interosseous recurrent. \\
\hline \multicolumn{4}{|l|}{$\begin{array}{l}\text { Interosseous, posteri- } \\
\text { or, recurrent. See } \\
\text { Radial recurrent, } \\
\text { posterior. }\end{array}$} \\
\hline $\begin{array}{l}\text { Interosseous, recur- } \\
\text { rent. }\end{array}$ & Interosseous, posterior. & Elbow-joint. & \\
\hline Interpeduncular. & Posterior cerebral. & $\begin{array}{l}\text { Posterior perforated space and lower } \\
\text { part of peduncles. }\end{array}$ & \\
\hline $\begin{array}{l}\text { Interventricular, ante- } \\
\text { rior. }\end{array}$ & Left coronary. & $\begin{array}{l}\text { Both ventricles and interventricular } \\
\text { septum. }\end{array}$ & \\
\hline $\begin{array}{l}\text { Interventricular, pos- } \\
\text { terior. }\end{array}$ & Right coronary. & $\begin{array}{l}\text { Both ventricles and interventricular } \\
\text { septum. }\end{array}$ & \\
\hline $\begin{array}{l}\text { Intestinal (vasa intes } \\
\text { tini tenuis), } 12 \text { to } 16 .\end{array}$ & Superior mesenteric. & Mesentery. & \\
\hline \multicolumn{4}{|l|}{$\begin{array}{l}\text { Ischiadic. See Gluteal, } \\
\text { inferior. }\end{array}$} \\
\hline Labial, inferior. & Facial. & Muscles and integuments of lower lip. & \\
\hline
\end{tabular}


TABLE OF ARTERIES.-Continued.

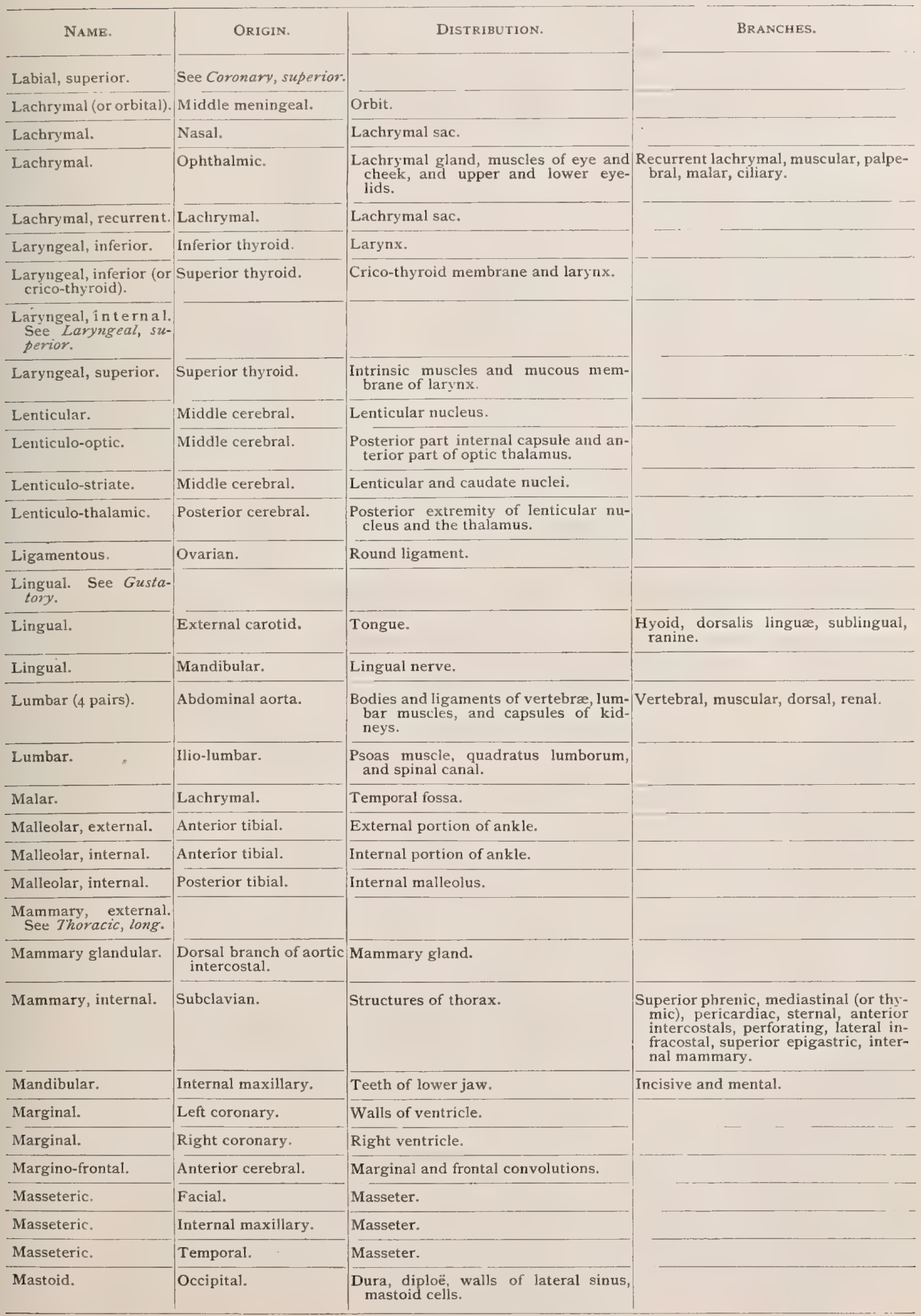


TABLE OF ARTERIES.-Continued.

\begin{tabular}{|c|c|c|c|}
\hline NAME. & ORIGIN. & DISTRIBUTION. & BRANCHES. \\
\hline Mastoid. & Posterior auricular. & $\begin{array}{l}\text { Occipito-frontalis muscle (posterior } \\
\text { belly). }\end{array}$ & \\
\hline Mastoid. & Stylo-mastoid. & Mastoid cells and mastoid antrum. & \\
\hline $\begin{array}{l}\text { Mastoid, middle. See } \\
\text { Sterno-mastoid. }\end{array}$ & & & \\
\hline $\begin{array}{l}\text { Maxillary, external. } \\
\text { See Facial. }\end{array}$ & & & \\
\hline $\begin{array}{l}\text { Maxillary, inferior. } \\
\text { See Dental, inferior. }\end{array}$ & & & \\
\hline $\begin{array}{l}\text { Maxillary, in terna li } \\
\text { (maxillary group). }\end{array}$ & External carotid. & $\begin{array}{l}\text { Structures indicated by names of } \\
\text { branches. }\end{array}$ & $\begin{array}{l}\text { Deep auricular, tympanic, middle } \\
\text { meningeal, mandibular, small men- } \\
\text { ingeal. }\end{array}$ \\
\hline $\begin{array}{l}\text { Maxillary, inter nal } \\
\text { (pterygoid group). }\end{array}$ & External carotid. & $\begin{array}{l}\text { Structures indicated by names of } \\
\text { branches. }\end{array}$ & $\begin{array}{l}\text { Masseteric, posterior deep temporal, } \\
\text { internal and external pterygoid, buc- } \\
\text { cal, anterior deep temporal. }\end{array}$ \\
\hline $\begin{array}{l}\text { Maxillary, in terna I } \\
\text { (sph en o-maxillary } \\
\text { group). }\end{array}$ & External carotid. & $\begin{array}{l}\text { Structures indicated by names of } \\
\text { branches. }\end{array}$ & $\begin{array}{l}\text { Posterior dental (or alveolar), infraor- } \\
\text { bital, posterior (or descending) pala- } \\
\text { tine, vidian, pterygo-palatine, nasal, } \\
\text { or spheno-palatine. }\end{array}$ \\
\hline Meatal. & Stylo-mastoid. & External auditory meatus. & \\
\hline $\begin{array}{l}\text { Median (arteria comes } \\
\text { nervi mediani). }\end{array}$ & Anterior interosseous. & $\begin{array}{l}\text { Median nerve and superficial palmar } \\
\text { arch. }\end{array}$ & \\
\hline $\begin{array}{l}\text { Median anterior (of } \\
\text { spinal cord). }\end{array}$ & $\begin{array}{l}\text { Formed by union of the } \\
\text { anterior spinal arte- } \\
\text { ries. }\end{array}$ & Spinal cord. & \\
\hline $\begin{array}{l}\text { Mediastinal, anterior } \\
\text { (or thymic). }\end{array}$ & Internal mammary. & $\begin{array}{l}\text { Connective tissue, fat and lymphatics, } \\
\text { in superior and anterior mediastina, } \\
\text { thymus glatid. }\end{array}$ & \\
\hline $\begin{array}{l}\text { Mediastinal, posterior } \\
\text { (several). }\end{array}$ & Thoracic aorta. & $\begin{array}{l}\text { Glands and loose areolar tissue in me- } \\
\text { diastinum. }\end{array}$ & \\
\hline Medicerebellar. & $\begin{array}{l}\text { Cerebellar, anterior, in- } \\
\text { ferior. }\end{array}$ & Middle cerebellar crus. & \\
\hline $\begin{array}{l}\text { Medicerebral. Se e } \\
\text { Cerebral, middle. }\end{array}$ & & & \\
\hline Medichoroid. & See Choroid, posterior & & \\
\hline $\begin{array}{l}\text { Medidural. See } M e- \\
\text { ningeal, middle. }\end{array}$ & & & \\
\hline Medifrontal. & Anterior cerebral. & $\begin{array}{l}\text { Callosal convolution and paracentral } \\
\text { lobule. }\end{array}$ & \\
\hline $\begin{array}{l}\text { Medioptic (or median } \\
\text { quadrigeminal) }\end{array}$ & Posterior cerebral. & Crus cerebri and optic lobes. & \\
\hline Medullary. & Peroneal. & Fibula. & \\
\hline Medullary. & Posterior tibial. & Tibia. & Ascending and descending. \\
\hline Medullary. & Renal. & Malpighian pyramids. & \\
\hline Meningeal. & Ascending pharyngeal. & Membranes of brain. & \\
\hline Meningeal. & Posterior ethmoidal. & Dura mater. & \\
\hline Meningeal, anterior. & Internal carotid. & Dura mater. & \\
\hline $\begin{array}{l}\text { Meningeal, inferior: } \\
\text { See Meningeal (of } \\
\text { ascending pharyn- } \\
\text { geal). }\end{array}$ & & & \\
\hline $\begin{array}{l}\text { Meningeal, middle or } \\
\text { great. }\end{array}$ & Internal maxillary. & Cranium and dura mater. & Anterior and posterior. \\
\hline Meningeal, posterior. & Occipital. & Dura mater. & \\
\hline Meningeal, posterior. & Vertebral. & Dura mater. & \\
\hline Meningeal, small. & Internal maxillary. & $\begin{array}{l}\text { Gasserian ganglion, walls of cavernous: } \\
\text { sinus and dura mater. }\end{array}$ & \\
\hline
\end{tabular}


TABLE OF ARTERIES.-Continued.

\begin{tabular}{|c|c|c|c|}
\hline NAME. & ORIGIN. & DISTRIBUTION. & BRANCHES. \\
\hline Mental. & Facial. & Muscles of chin and lower lip. & \\
\hline Mental. & Mandibular. & Muscles of chin and under lip. & Lingual and mylo-hyoidean. \\
\hline $\begin{array}{c}\text { Mesenteric accedens, } \\
\text { pracipua. See Mes- } \\
\text { enteric, superior. }\end{array}$ & & & \\
\hline Mesenteric, inferior. & IAbdominal aorta. & Lower half of large intestine. & $\begin{array}{l}\text { Left colic, sigmoid, superior hemor- } \\
\text { rhoidal. }\end{array}$ \\
\hline Mesenteric, middle. & $\begin{array}{l}\text { Common iliac (occa- } \\
\text { sional branch). }\end{array}$ & Transverse and descending colon. & \\
\hline Mesenteric, superior. & Abdominal aorta. & $\begin{array}{l}\text { Whole of small intestine and upper } \\
\text { half of large. }\end{array}$ & $\begin{array}{l}\text { Inferior pancreatico-duodenal, middle } \\
\text { right and ilio-colic, vasa intestina } \\
\text { tenuis. }\end{array}$ \\
\hline $\begin{array}{l}\text { Meso-lobar. See Cere- } \\
\text { bral, anterior. }\end{array}$ & & . & \\
\hline $\begin{array}{l}\text { Metacarpal (Ist dorsal } \\
\text { interosseous). }\end{array}$ & Radial. & Sides of fingers on dorsal aspect. & \\
\hline Metatarsal. & Dorsalis pedis. & Toes. & Third dorsal interosseous. \\
\hline $\begin{array}{l}\text { Middle (of corpora! } \\
\text { quadrigemina). }\end{array}$ & Posterior cerebral. & $\begin{array}{l}\text { Space between the corpora quadri- } \\
\text { gemina. }\end{array}$ & \\
\hline $\begin{array}{l}\text { Muscular, deep. See } \\
\text { Femoral, deep. }\end{array}$ & & & \\
\hline Musculo-phrenic. & Internal mammary. & $\begin{array}{l}\text { Diaphragm, fifth or sixth lower inter- } \\
\text { costal spaces, oblique muscles of ab- } \\
\text { domen. }\end{array}$ & $\begin{array}{l}\text { Phrenic, anterior intercostals, muscu- } \\
\text { lar. }\end{array}$ \\
\hline Mylo-hyoidean. & Mental. & Mylo-hyoid muscle. & \\
\hline Nasal. & Infraorbital. & Nose. & \\
\hline Nasal. & Ophthalmic. & $\begin{array}{l}\text { Lachrymal sac and integuments of } \\
\text { nose. }\end{array}$ & Lachrymal, and transverse nasal. \\
\hline Nasal. & Spheno-palatine. & $\begin{array}{l}\text { Turbinated bones, lateral walls of nose } \\
\text { ethmoidal and frontal sinuses and } \\
\text { lining membrane of antrum. }\end{array}$ & \\
\hline Nasal, anterior. & Anterior ethmoidal. & Nose. & \\
\hline Nasal, lateral. & Facial. & $\begin{array}{l}\text { Integuments, muscles and cartilage of } \\
\text { nose. }\end{array}$ & \\
\hline $\begin{array}{l}\text { Nasal, middle, See } \\
\text { Nasal, anterior. }\end{array}$ & & & \\
\hline Nasal, transverse. & Nasal. & Integuments of nose. & \\
\hline $\begin{array}{l}\text { Naso-palatine. See } \\
\text { Spheno-palatine. }\end{array}$ & & & \\
\hline Navel. See Umbilical. & & & \\
\hline Neubauer's. & See Thyroid, deep. & & \\
\hline Nutrient. & Brachial. & Humerus. & \\
\hline Nutrient. & Interosseous, anterior. & Radius. & \\
\hline Nutrient. & Interosseous, anterior. & Ulna. & \\
\hline Nutrient. & $\begin{array}{l}\text { Middle perforating } \\
\text { branch of profunda } \\
\text { femoris. }\end{array}$ & Femur. & - \\
\hline Nutrient. & Obturator. & Ilium. & \\
\hline $\begin{array}{l}\text { Nutrient (of peroneal). } \\
\text { See Medullary. }\end{array}$ & 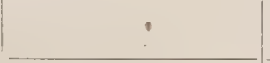 & & \\
\hline Nutrient. & Posterior tibial. & Tibia. & \\
\hline Nutrient. & Suprascapular. & Clavicle. & \\
\hline Obturator. & $\begin{array}{l}\text { Anterior division, inter } \\
\text { nal iliac. }\end{array}$ & Pelvis and thigh. & $\begin{array}{l}\text { Iliac (or nutrient), vesical, pubic, ex- } \\
\text { ternal and internal pelvic. }\end{array}$ \\
\hline Obturator, external. & Obturator. & Muscles about obturator foramen. & \\
\hline
\end{tabular}


TABLE OF ARTERIES.-Continued.

\begin{tabular}{|c|c|c|}
\hline ORIGIN. & DISTRIBUTION. & BRANCHES. \\
\hline Obturator. & Muscles about obturator foramen. & \\
\hline $\begin{array}{l}\text { Fourth branch of ex- } \\
\text { ternal carotid. }\end{array}$ & Muscles of neck, and scalp. & $\begin{array}{l}\text { Sterno-mastoid, posterior meningeal, } \\
\text { auricular, mastoid, princeps cervi- } \\
\text { cis, communicating, muscular, ter- } \\
\text { minal. }\end{array}$ \\
\hline Vertebral. & Dura mater. & \\
\hline Hepatic. & Omentum. & \\
\hline Primitive aorta. & Subsequently becomes the umbilical. & \\
\hline Internal carotid. & $\begin{array}{l}\text { The eye, adjacent structures, portion of } \\
\text { face. }\end{array}$ & $\begin{array}{l}\text { Lachrymal, supraorbital, central ar- } \\
\text { tery of retina, muscular, ciliary, pos- } \\
\text { terior and anterior ethmoidal, pal- } \\
\text { pebral, frontal, nasal. }\end{array}$ \\
\hline $\begin{array}{l}\text { Posterior communicat- } \\
\text { ing. }\end{array}$ & Optic thalamus. & \\
\hline $\begin{array}{l}\text { Posterior communicat- } \\
\text { ing or posterior cer- } \\
\text { ebral. }\end{array}$ & Optic thalamus. & \\
\hline \multicolumn{3}{|c|}{$\begin{array}{l}\text { Orbital. See Lachry- } \\
\text { mal. }\end{array}$} \\
\hline Anterior cerebral. & $\begin{array}{l}\text { First frontal convolution and olfactory } \\
\text { bulb. }\end{array}$ & \\
\hline Infraorbital. & $\begin{array}{l}\text { Fat of orbit : inferior rectus and in- } \\
\text { ferior oblique muscles. }\end{array}$ & \\
\hline Temporal. & Orbicularis palpebrarum and orbit. & \\
\hline Middle cerebral. & Inferior frontal convolutions. & \\
\hline Abdominal aorta. & Ovary, ureter, fallopian tube, uterus. & $\begin{array}{l}\text { Ureteral, fallopian, uterine, ligament- } \\
\text { ous. }\end{array}$ \\
\hline Ascending pharyngeal. & Soft palate and its muscles. & \\
\hline First branch of facial. & $\begin{array}{l}\text { Upper part of pharynx, palate and } \\
\text { tonsils. }\end{array}$ & Palatine, tonsillar. \\
\hline Internal maxillary. & To soft and hard palate. & Anterior and posterior. \\
\hline \multicolumn{3}{|c|}{$\begin{array}{l}\text { Palatine, inferior. See } \\
\text { Palatine, ascending. }\end{array}$} \\
\hline Internal maxillary. & Hard palate. & Anterior and posterior. \\
\hline \multicolumn{3}{|c|}{$\begin{array}{l}\text { Palatine, superior. See } \\
\text { Palaline descending. } \\
\text { Palato-maxillary }\end{array}$} \\
\hline \multicolumn{3}{|c|}{$\begin{array}{l}\text { Palmar, digital. See } \\
\text { Digital, palmar. }\end{array}$} \\
\hline \multicolumn{3}{|c|}{$\begin{array}{l}\text { Palmar, interosseous. } \\
\text { Se e Incerosseums, } \\
\text { palmar. }\end{array}$} \\
\hline $\begin{array}{l}\text { Radial and communi- } \\
\text { cating of ulna. }\end{array}$ & Palm and fingers. & $\begin{array}{l}\text { Princeps pollicis, radialis indicis, pal- } \\
\text { mar interosseous }(3) \text {, recurrent car- } \\
\text { pal, posterior perforating. }\end{array}$ \\
\hline $\begin{array}{l}\text { Ulnar and superficialis } \\
\text { volæ. }\end{array}$ & Palm and fingers. & Digital (4), muscular, cutaneous. \\
\hline Lachyrmal. & Eye-lids and conjunctivæ. & \\
\hline Supraorbital. & Upper eye-lid. & \\
\hline Ophthalmic. & Eye-lid. & \\
\hline Ophthalmic. & $\begin{array}{l}\text { Conjunctiva, lachrymal sac, caruncle } \\
\text { and lower lid. }\end{array}$ & \\
\hline Ophthalmic. & Upper eye-lid. & \\
\hline Hepatic. & Pancreas. & \\
\hline Splenic. & Pancreas. & -- \\
\hline
\end{tabular}


TABLE OF ARTERIES.—Continued.

\begin{tabular}{|c|c|c|c|}
\hline NAME. & ORIGIN. & DISTRIBUTION. & BRANCHES. \\
\hline $\begin{array}{l}\text { Pancreatico-duodenal, } \\
\text { inferior. }\end{array}$ & Superior mesenteric. & Pancreas and duodenum. & \\
\hline $\begin{array}{l}\text { Pancreatico-duodenal, } \\
\text { superior. }\end{array}$ & Gastro-duodenal. & Duodenum and pancreas. & \\
\hline Parietal. & Middle cerebral. & $\begin{array}{l}\text { Inferior and ascending parietal convo- } \\
\text { lutions. }\end{array}$ & \\
\hline Parietal, anterior. & Middle cerebral. & Second frontal convolution. & \\
\hline Parietal, ascending. & Middle cerebral. & $\begin{array}{l}\text { Ascending parietal convolution and } \\
\text { superior parietal lobule. }\end{array}$ & \\
\hline Parieto-sphenoidal. & Middle cerebral. & $\begin{array}{l}\text { Inferior parietal lobule, angular gyrus, } \\
\text { cortex of sphenoidal lobe. }\end{array}$ & . \\
\hline Parieto-temporal. & Middle cerebral. & $\begin{array}{l}\text { Convolutions around posterior limb of } \\
\text { fissure of Sylvius. }\end{array}$ & \\
\hline Parotid. & Posterior auricular. & Parotid gland. & \\
\hline Parotid. & Temporal. & Parotid gland. & \\
\hline \multicolumn{4}{|c|}{$\begin{array}{l}\text { Parvidural. See Me- } \\
\text { ningeal, small. }\end{array}$} \\
\hline Pectoral. & Acromio-thoracic. & Pectoral muscles and mammary gland. & \\
\hline Pectoral. & Anterior circumflex. & Pectoralis major. & \\
\hline \multicolumn{4}{|l|}{$\begin{array}{l}\text { Pedal. See Dorsal of } \\
\text { foot. }\end{array}$} \\
\hline Peduncular, anterior. & Posterior cerebral. & Internal surface of peduncle. & \\
\hline Peduncular, external. & $\begin{array}{l}\text { Posterior, communicat- } \\
\text { ing. }\end{array}$ & Peduncles of the cerebellum. & \\
\hline Peduncular, internal. & Posterior cerebral. & Internal surface of peduncle. & \\
\hline \multicolumn{4}{|l|}{$\begin{array}{l}\text { Of the penis, perforat- } \\
\text { ing. See } A \text {, of the } \\
\text { corpus cavernosum. }\end{array}$} \\
\hline $\begin{array}{l}\text { Perforans stapedis } \\
\text { (branch of internal } \\
\text { carotid or stylo-mas- } \\
\text { toid). }\end{array}$ & Tympanum. & No branches. & \\
\hline $\begin{array}{l}\text { Perforating (or poste- } \\
\text { rior communicat- } \\
\text { ing), (3). }\end{array}$ & Deep palmar arch. & Interosseous spaces. & \\
\hline Perforating. & Middle meningeal. & Sphenoid. & \\
\hline Perforating. & Profunda femoris. & Hamstring muscles. & \\
\hline Perforating. & Spheno-palatine. & Ethmoidal cells. & Anastomoses with ethmoidal arteries. \\
\hline Perforating. & Submental. & Mylo-hyoid. & \\
\hline $\begin{array}{l}\text { Perforating, anterior } \\
(5 \text { or } 6) .\end{array}$ & Internal mammary. & $\begin{array}{l}\text { Pectoralis major and integument, and } \\
\text { mammary gland. }\end{array}$ & \\
\hline Perforating, posterior. & External plantar. & Dorsal interosseous muscles. & \\
\hline Pericardiac. & Internal mammary. & Anterior surface of pericardium. & \\
\hline Pericardiac. & Right and left phrenic. & Pericardium. & \\
\hline Pericardiac. & Thoracic aorta. & Pericardium. & \\
\hline \multicolumn{4}{|l|}{$\begin{array}{c}\text { Pericephalic. See } \\
\text { Carotid, external. }\end{array}$} \\
\hline Perineal, superficial. & Pudic. & $\begin{array}{l}\text { Muscles of perineum and integuments } \\
\text { of scrotum. }\end{array}$ & Transverse perineal. \\
\hline Perineal, transverse. & Perineal, superficial. & Muscles and integuments of perineum. & \\
\hline Perirenal (or capsular). & Renal. & Capsule of kidney and perirenal fat. & \\
\hline Peritoneal. & Iliac, common. & Peritoneum. & \\
\hline Peritoneal. & Superior epigastric. & Peritoneum. & \\
\hline
\end{tabular}


TABLE OF ARTERIES.-Continued.

\begin{tabular}{|c|c|c|c|}
\hline NAME. & ORIGIN. & DISTRIRUTION. & BRANCHES. \\
\hline Peroneal. & Posterior tibial. & $\begin{array}{l}\text { Muscles and integument of leg and } \\
\text { foot. }\end{array}$ & $\begin{array}{l}\text { Anterior peroneal, muscular, medul- } \\
\text { lary, communicating, cutaneous, ex- } \\
\text { ternal calcaneum, terminal (or pos- } \\
\text { terior peroneal). }\end{array}$ \\
\hline Peroneal, anterior. & Peroneal. & $\begin{array}{l}\text { Peroneus tertius and inferior tibio-fibu- } \\
\text { lar joint. }\end{array}$ & \\
\hline Peroneal, posterior. & Peroneal. & External malleolus and heel. & \\
\hline Petrosal. & Middle meningeal. & Tympanum. & \\
\hline Pharyngeal. & Pterygo-palatine. & Roof of pharynx. & \\
\hline Pharyngeal. & Spheno-palatine. & $\begin{array}{l}\text { Roof and contiguous portions of pha- } \\
\text { rynx. }\end{array}$ & \\
\hline Pharyngeal. & Vidian. & Roof of pharynx. & \\
\hline $\begin{array}{l}\text { Pharyngeal, ascend- } \\
\text { ing. }\end{array}$ & $\begin{array}{l}\text { First branch external } \\
\text { carotid. }\end{array}$ & $\begin{array}{l}\text { Pharynx, soft palate, tympanum, pos- } \\
\text { terior part of neck, and membranes } \\
\text { of brain. }\end{array}$ & $\begin{array}{l}\text { Prevertebral, pharyngeal, palatine, } \\
\text { tympanic, meningeal. }\end{array}$ \\
\hline $\begin{array}{l}\text { Pharyngeal, descend- } \\
\text { ing. }\end{array}$ & Spheno-palatine. & Roof of mouth and of pharynx. & \\
\hline $\begin{array}{l}\text { Pharyngeal, inferior. } \\
\text { See Pharyngeal, as- } \\
\text { cending. }\end{array}$ & & & \\
\hline $\begin{array}{l}\text { Pharyngeal, superior } \\
\text { See Pterygo-pala- } \\
\text { tine. }\end{array}$ & & & \\
\hline Phrenic. & Ascending cervical. & Phrenic nerve. & \\
\hline Phrenic. & Musculo-phrenic. & Diaphragm. & \\
\hline Phrenic. & Superior epigastric. & Diaphragm. & \\
\hline Phrenic, inferior, left. & Aorta, abdominal. & $\begin{array}{l}\text { Diaphragm and structures indicated } \\
\text { by names of branches. }\end{array}$ & $\begin{array}{l}\text { Esophageal. left superior suprarenal, } \\
\text { splenic, pericardiac, terminal. }\end{array}$ \\
\hline $\begin{array}{l}\text { Phrenic, in fer io } r \\
\text { right. }\end{array}$ & Aorta, abdominal. & $\begin{array}{l}\text { Diaphragm and structures indicated } \\
\text { by names of branches. }\end{array}$ & $\begin{array}{l}\text { Right superior suprarenal, caval, } \\
\text { hepatic, pericardiac, and terminal. }\end{array}$ \\
\hline $\begin{array}{l}\text { Phrenic, superior (or } \\
\text { comes nervi phre- } \\
\text { nici). }\end{array}$ & Internal mammary. & Pleura, pericardium and diaphragm. & \\
\hline Pituitary. & Internal carotid. & Pituitary body. & \\
\hline Plantar arch. & $\begin{array}{l}\text { External plantar art- } \\
\text { ery. }\end{array}$ & Anterior part of foot and toes. & Articular and plantar digital. \\
\hline Plantar, deep. & Metatarsal. & Assists in formation of plantar arcb. & \\
\hline Plantar, digital (4). & Plantar arch. & $\begin{array}{l}\text { Third, fourth, and fifth toes, and outer } \\
\text { side of second. }\end{array}$ & \\
\hline Plantar, external. & External, tibial. & Sole and toes. & $\begin{array}{l}\text { Muscular, calcaneal, cutaneous, anas- } \\
\text { tomotic, posterior perforating, plan- } \\
\text { tar arch. }\end{array}$ \\
\hline Plantar, internal. & Posterior tibial. & Inner side of foot. & $\begin{array}{l}\text { Muscular, cutaneous, articular, anas- } \\
\text { tomotic, superficial digital. }\end{array}$ \\
\hline $\begin{array}{l}\text { Plantar, interosseous. } \\
\text { S e e Interosseous, } \\
\text { plantar. }\end{array}$ & & & \\
\hline $\begin{array}{l}\text { Plantar, metatarsal. } \\
\text { Se e Interosseous, } \\
\text { Dlaniar. }\end{array}$ & & & \\
\hline Plantar, pollicar. & $\begin{array}{l}\text { Anterior tibial, or ex- } \\
\text { ternal plantar. }\end{array}$ & Great toe. & \\
\hline Pleural. & Intercostal. & Pleura. & \\
\hline Pontal. & Basilar. & Pons. & \\
\hline Popliteal. & $\begin{array}{l}\text { Continuation of femo- } \\
\text { ral. }\end{array}$ & Knee and leg. & $\begin{array}{l}\text { Cutaneous, musculat (superior and in- } \\
\text { ferior) or sural, articular, superior } \\
\text { and inferior external, superior and } \\
\text { inferior internal and azygos, ter- } \\
\text { minal (anterior and posteriortibial). }\end{array}$ \\
\hline
\end{tabular}


TABLE OF ARTERIES.-Continued.

\begin{tabular}{|c|c|c|c|}
\hline NAME. & ORIGIN. & DISTRIBUTION. & BRANCHES. \\
\hline \multicolumn{4}{|l|}{$\begin{array}{l}\text { Post-cerebellar. See } \\
\text { Cerebellar, posterior. }\end{array}$} \\
\hline \multicolumn{4}{|l|}{$\begin{array}{c}\text { Post-cerebral. S e e } \\
\text { Cerebral, posterior. }\end{array}$} \\
\hline \multicolumn{4}{|l|}{$\begin{array}{l}\text { Post choroid SeeCho- } \\
\text { roid Posterior. }\end{array}$} \\
\hline \multicolumn{4}{|l|}{$\begin{array}{l}\text { Post-communicant. } \\
\text { See Communicating, } \\
\text { posterior. }\end{array}$} \\
\hline \multicolumn{4}{|l|}{$\begin{array}{c}\text { Post-dural. See Men- } \\
\text { ingeal, posterior. }\end{array}$} \\
\hline Postero-lateral. & Posterior cerebral. & $\begin{array}{l}\text { Hind part of optic thalamus, crus and } \\
\text { optic lobes. }\end{array}$ & \\
\hline Postero-median. & Posterior central. & $\begin{array}{l}\text { Inner part of thalamus, neighboring } \\
\text { wall of third ventricle. }\end{array}$ & \\
\hline Post-frontal. & Anterior meningeal. & $\begin{array}{l}\text { Precuneus and part of occipital fis- } \\
\text { sure. }\end{array}$ & \\
\hline Post-temporal. & Posterior cerebral. & Basal surface of occipital lobe. & \\
\hline Post-thalamic. & Posterior cerebral. & Thalamus. & \\
\hline \multicolumn{4}{|l|}{$\begin{array}{c}\text { Precerebellar. S e e } \\
\text { Cerebellar, superior. }\end{array}$} \\
\hline \multicolumn{4}{|l|}{$\begin{array}{l}\text { Precerebral. See Cere- } \\
\text { bral, anterior. }\end{array}$} \\
\hline \multicolumn{4}{|l|}{$\begin{array}{l}\text { Prechoroid. See Cho- } \\
\text { roid, anterior. }\end{array}$} \\
\hline \multicolumn{4}{|l|}{$\begin{array}{l}\text { Precommunicant. See } \\
\text { Communicaling, an- } \\
\text { terior. }\end{array}$} \\
\hline \multicolumn{4}{|l|}{$\begin{array}{l}\text { Predural. See Mening- } \\
\text { eal, anterior. }\end{array}$} \\
\hline Prefrontal. & Anterior cerebral. & $\begin{array}{l}\text { Mesal and convex surfaces of super- } \\
\text { frontal and part of medi-frontal con- } \\
\text { volutions. }\end{array}$ & \\
\hline $\begin{array}{l}\text { Preoptic (or anterior } \mathrm{I} \\
\text { quadrigeminal). }\end{array}$ & Posterior cerebral. & Optic lobe. & \\
\hline Preperforant. & Anterior cerebral. & Caudate nucleus. & \\
\hline Pretemporal. & Posterior cerebral. & $\begin{array}{l}\text { Uncinate and basal surface of temporal } \\
\text { lobe. }\end{array}$ & \\
\hline Prethalamic. & $\begin{array}{l}\text { Posterior communicat- } \\
\text { ing }\end{array}$ & Thalamus. & \\
\hline Preventricular (2) & $\begin{array}{l}\text { Right and left coron- } \\
\text { aries. }\end{array}$ & Walls of ventricle, heart. & \\
\hline \multicolumn{4}{|l|}{$\begin{array}{l}\text { Primitive, See Aorta, } \\
\text { primitive. }\end{array}$} \\
\hline Princeps cervicis. & Occipital. & Muscles of neck. & Superficial and deep. \\
\hline Princeps hallucis. & $\begin{array}{l}\text { Communicating } \\
\text { dorsalis pedis). }\end{array}$ & First and second toes. & \\
\hline Princeps pollicis. & Radial. & Thumb. & \\
\hline $\begin{array}{c}\text { Profunda (or deep } \\
\text { femoral). }\end{array}$ & Femoral. & Thigh. & $\begin{array}{l}\text { External and internal circumflex, three } \\
\text { perforating. }\end{array}$ \\
\hline Profunda, inferior. & Brachial. & Triceps, elbow-joint & \\
\hline Profunda, superior. & Brachial. & Humerus, muscles and skin of arm. & $\begin{array}{l}\text { Ascending, cutaneous, articular, nutri- } \\
\text { ent, muscular. }\end{array}$ \\
\hline Pterygoid, external. & Internal maxillary. & External pterygoid muscle. & \\
\hline Pterygoid, internal. & Internal maxillary. & Internal pterygoid muscle. & \\
\hline $\begin{array}{l}\text { Pterygo-palatine (or I } \\
\text { pterygo-pharyngeal) }\end{array}$ & Internal maxillary. & $\begin{array}{l}\text { Pharynx, Eustachian tubes and sphe- } \\
\text { noidal cells. }\end{array}$ & Pharyngeal, Eustachian, sphenoidal. \\
\hline
\end{tabular}


TABLE OF ARTERIES.-Continued.

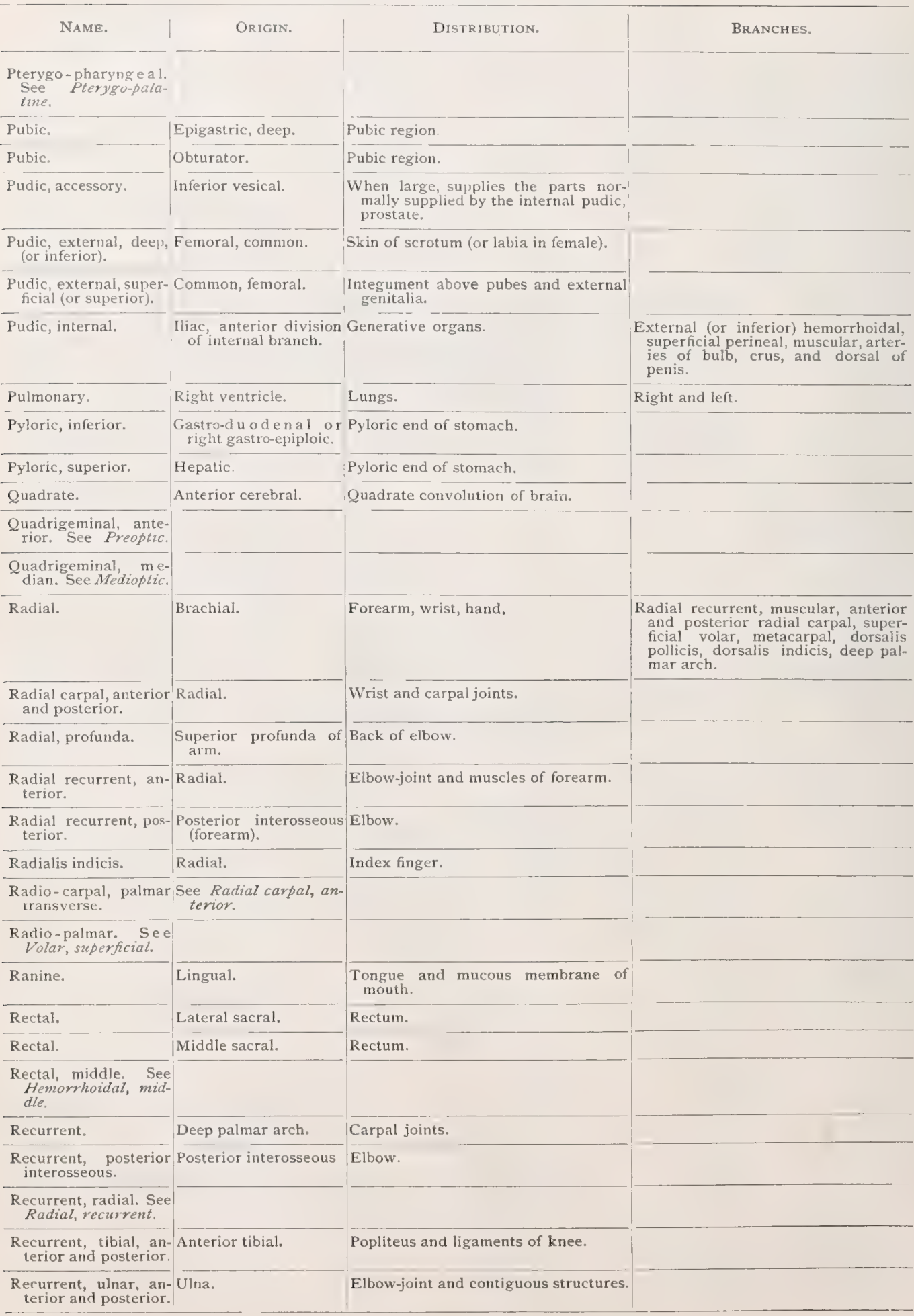


TABLE OF ARTERIES.-Continued.

\begin{tabular}{|c|c|c|c|}
\hline NAME. & ORIGIN. & DISTRIBUTION. & BRANCHES. \\
\hline Renal. & Abdominal aorta. & Kidney. & $\begin{array}{l}\text { Inferior suprarenal, capsular (or peri- } \\
\text { renal), uretera!. }\end{array}$ \\
\hline \multicolumn{4}{|l|}{$\begin{array}{l}\text { Rhachidian. See } \\
\text { Spinal. }\end{array}$} \\
\hline \multicolumn{4}{|l|}{$\begin{array}{l}\text { Sacra media. See } \\
\text { Sacral, middle. }\end{array}$} \\
\hline Sacral, lateral ( 1 or 2 ). & $\begin{array}{l}\text { Internal iliac, posterior } \\
\text { division. }\end{array}$ & Struclures about sacrum. & \multirow[t]{3}{*}{ Spinal, rectal, muscular. } \\
\hline Sacral, middle. & Continuation of aorta. & Sacrum and coccyx. & \\
\hline $\begin{array}{l}\text { Saphenous (occasional } \\
\text { branch of common } \\
\text { femoral). }\end{array}$ & $\begin{array}{l}\text { Accompanies saphen- } \\
\text { ous vein. }\end{array}$ & & \\
\hline Saphenous, small. & Popliteal (occasional) & External malleolus. & \\
\hline Scapular, dorsal. & Subscapular. & Muscles of infraspinous fossa. & Infrascapular. \\
\hline \multicolumn{4}{|l|}{$\begin{array}{l}\text { Scapular, external. } \\
\text { See Acromial. }\end{array}$} \\
\hline \multicolumn{4}{|l|}{$\begin{array}{l}\text { Scapular, inferior. See } \\
\text { Subscapular. }\end{array}$} \\
\hline \multicolumn{4}{|l|}{$\begin{array}{l}\text { Scapular, internal. See } \\
\text { Subscapular. }\end{array}$} \\
\hline Scapular, posterior. & $\begin{array}{l}\text { Continuation of trans- } \\
\text { verse cervical. }\end{array}$ & Muscles of scapular region. & $\begin{array}{l}\text { Supra-spinous and infra-spinous, sub- } \\
\text { scapular, muscular. }\end{array}$ \\
\hline \multicolumn{4}{|l|}{$\begin{array}{l}\text { Scapular, superficial. } \\
\text { See Suprascapular. }\end{array}$} \\
\hline \multicolumn{4}{|l|}{$\begin{array}{l}\text { Scapular, superior. } \\
\text { See Suprascapular. }\end{array}$} \\
\hline \multicolumn{4}{|l|}{$\begin{array}{l}\text { Scapular, transverse. } \\
\text { See Suprascapular. }\end{array}$} \\
\hline \multicolumn{4}{|l|}{$\begin{array}{l}\text { Scapulo-humeral. See } \\
\text { Circumflex, posterior }\end{array}$} \\
\hline Sciatic. & $\begin{array}{l}\text { Internal iliac, anterior } \\
\text { division. }\end{array}$ & $\begin{array}{l}\text { Pelvic muscles and viscera, and } \\
\text { branches. }\end{array}$ & $\begin{array}{l}\text { Coccygeal, inferior gluteal, muscular, } \\
\text { anastomotic, articular, cutaneous, } \\
\text { comes nervi ischiadici, vesical, rec- } \\
\text { tal, prostatic, etc. }\end{array}$ \\
\hline Scrotal, anterior. & Inferior external pudic. & Anterior portion of scrotum. & \\
\hline Scrotal, posterior. & Internal pudic. & Posterior part of scrotum. & \\
\hline Septal, ascending. & Spheno-palatine. & $\begin{array}{l}\text { Upper part of mucous membrane of } \\
\text { nasal septum. }\end{array}$ & \\
\hline Sigmoid. & Inferior mesenteric. & Sigmoid flexure. & \\
\hline Spermatic. & Abdominal aorta. & Scrotum and testis. & $\begin{array}{l}\text { Ureteral, cremasteric, epididymal, tes- } \\
\text { ticular. }\end{array}$ \\
\hline Spermatic, external. & Deep epigastric. & Cremaster muscle, and spermatic cord. & \\
\hline Sphenoidal. & Middle cerebral. & Sphenoidal lobe, lower part of cortex. & \\
\hline Sphenoidal. & Pterygo-palatine. & Sphenoidal cells. & \\
\hline Sphenoidal. & Spheno-palatine. & Sphenoidal cells. & \\
\hline $\begin{array}{l}\text { Spheno-palatine (or } \\
\text { naso-palatine). }\end{array}$ & Internal maxillary. & Pharynx, nose, and sphenoidal cells. & $\begin{array}{l}\text { Pharyngeal, sphenoidal, nasal, ascend- } \\
\text { ing septal. }\end{array}$ \\
\hline \multicolumn{4}{|l|}{$\begin{array}{l}\text { Spheno-spinous. See } \\
\text { Meningeal, middle. }\end{array}$} \\
\hline Spinal. & Ascending cervical. & Spinal canal. & \\
\hline Spinal. & Intercostals. & Spinal canal and spine. & \\
\hline Spinal. & Lateral sacral. & $\begin{array}{l}\text { Spinal membranes and muscles and } \\
\text { skin over sacrum. }\end{array}$ & \\
\hline Spinal, anterior. & Vertebral. & Spinal cord. & \\
\hline Spinal, lateral. & Vertebral. & Vertebræ and spinal canal. & । \\
\hline
\end{tabular}


TABLE OF ARTERIES.-Continued.

\begin{tabular}{|c|c|c|c|}
\hline NAME. & ORIGIN. & DISTRIBUTION. & BRANCHES. \\
\hline Spinal, posterior. & Vertebral. & Spine. & \\
\hline Splenic. & Celiac axis. & $\begin{array}{l}\text { Spleen, pancreas, part of stomach, } \\
\text { omentum. }\end{array}$ & $\begin{array}{l}\text { Small and large pancreatic, left gastro- } \\
\text { epiploic, vasa brevia, terminal. }\end{array}$ \\
\hline Splenic. & Left phrenic. & Spleen. & \\
\hline Splenico-pancreatic. & Splenic. & Spleen. & \\
\hline Stapedic. & Stylo-mastoid. & Stapedius muscle. & \\
\hline Staphylini. & See Palatine, posterior. & & \\
\hline Sternal. & Internal mammary. & Sternum and triangularis sterni. & \\
\hline Sterno-mastoid. & Occipital. & Sterno-mastoid muscle. & \\
\hline $\begin{array}{l}\text { Sterno-mastoid (or } \\
\text { middle mastoid). }\end{array}$ & Superior thyroid. & $\begin{array}{l}\text { Sterno-mastoid, and other muscles of } \\
\text { neck. }\end{array}$ & \\
\hline $\begin{array}{l}\text { Sterno-mastoid, infe- } \\
\text { rior. }\end{array}$ & Suprascapular. & Sterno-mastoid muscle. & \\
\hline Stylo-mastoid. & Posterior auricular. & Mastoid cells, tympanic cavity, etc. & $\begin{array}{l}\text { Meatal, mastoid, stapedic, tympanic, } \\
\text { vestibular, terminal. }\end{array}$ \\
\hline Subcerebellar. & Basilar. & $\begin{array}{l}\text { Inferior and anterior portion of cere- } \\
\text { bellum. }\end{array}$ & \\
\hline Subclavian. & $\begin{array}{c}\text { Right, in } \mathrm{n} \text { o m in a te } \\
\text { Left, arch of aorta. }\end{array}$ & $\begin{array}{l}\text { Neck, thorax, arms, brain, meninges, } \\
\text { etc. }\end{array}$ & $\begin{array}{l}\text { Vertebral, thyroid axis, internal mam- } \\
\text { mary, superior intercostal. }\end{array}$ \\
\hline Subclavian. & Suprascapular. & Subclavius muscle. & \\
\hline \multicolumn{4}{|c|}{$\begin{array}{l}\text { Subclavian, right. A } \\
\text { term so metimes } \\
\text { given to the inno- } \\
\text { minate. }\end{array}$} \\
\hline $\begin{array}{l}\text { Subcostal (or i2th dor- } \\
\text { sal). }\end{array}$ & Thoracic aorta. & Intercostal space. & \\
\hline \multicolumn{4}{|c|}{$\begin{array}{l}\text { Subdural. See Menin- } \\
\text { geal (of ascending } \\
\text { pharyngeal). }\end{array}$} \\
\hline Subfrontal. & Anterior cerebral. & Olfactory groove. & \\
\hline Sublingual. & Lingual. & $\begin{array}{l}\text { Sublingual gland, side of tongue, and } \\
\text { floor of mouth. }\end{array}$ & Artery of frenum. \\
\hline \multicolumn{4}{|c|}{$\begin{array}{l}\text { Submaxillary. Se e } \\
\text { Glandular. }\end{array}$} \\
\hline Submental. & Facial. & Tissues under jaw. & $\begin{array}{l}\text { Muscular, perforating, cutaneous, } \\
\text { mental. }\end{array}$ \\
\hline \multicolumn{4}{|l|}{$\begin{array}{l}\text { Suborbital. See Infra- } \\
\text { orbital. }\end{array}$} \\
\hline \multicolumn{4}{|c|}{$\begin{array}{l}\text { Subsacral. See Sacral, } \\
\text { lateral. }\end{array}$} \\
\hline Subscapular. & Axillary. & $\begin{array}{l}\text { Subscapularis, teres major, latissimus } \\
\text { dorsi, serratus magnus, axillary } \\
\text { glands. }\end{array}$ & Dorsal and infrascapular. \\
\hline Subscapular. & Posterior scapular. & Subscapular fossa. & \\
\hline Subscapular. & Suprascapular. & Subscapular fossa. & \\
\hline \multicolumn{4}{|l|}{$\begin{array}{l}\text { Super-cerebellar. See } \\
\text { Cerebellar, superior. }\end{array}$} \\
\hline \multicolumn{4}{|l|}{$\begin{array}{l}\text { Supermaxillodental. } \\
\text { See Denial, superior. }\end{array}$} \\
\hline \multicolumn{4}{|l|}{$\begin{array}{l}\text { Superscapular. Se e } \\
\text { Suprascapular. }\end{array}$} \\
\hline Supra-acromial. & Suprascapular. & Acromial region. & . \\
\hline Supra-dural. & External carotid. & Meninges. & \\
\hline Supra-hyoid (or hyoid) & Lingual. & Muscles above hyoid bone. & \\
\hline $\begin{array}{l}\text { Supramaxillary. See } \\
\text { Dental, superior. }\end{array}$ & & & \\
\hline
\end{tabular}


TABLE OF ARTERIES.-Continued.

\begin{tabular}{|c|c|c|c|}
\hline NAME. & ORIGIN. & DistriblTion. & BRANCHES. \\
\hline Supraorbital. & Ophthalmic. & $\begin{array}{l}\text { Orbit, frontal sinuses, diploë and upper } \\
\text { eye-lid. }\end{array}$ & $\begin{array}{l}\text { Periosteal, muscular, diploic, troch- } \\
\text { lear, palpebral. }\end{array}$ \\
\hline Supra-renal, inferior. & Renal. & Supra-renal body. & \\
\hline $\begin{array}{l}\text { Supra-renal, middle } \\
\text { (or supra-renal). }\end{array}$ & Aorta. & Supra-renal bodies. & \\
\hline Supra-renal, superior. & Phrenic. & Supra-renal bodies. & \\
\hline $\begin{array}{l}\text { Suprascapular (or } \\
\text { transversalis hum- } \\
\text { eri). }\end{array}$ & Thyroid axis. & Muscles of shoulder. & $\begin{array}{l}\text { Inferior sterno-mastoid, subclavian, } \\
\text { nutrient, supra-sternal, acromial, } \\
\text { articular, subscapular, supra-spinous } \\
\text { and infraspinous. }\end{array}$ \\
\hline Supraspinous. & Posterior scapular. & Supraspinous muscles and trapezius. & \\
\hline Supraspinous. & Suprascapular. & Supraspinatus muscle. & \\
\hline Suprasternal. & Suprascapular. & Skin of upper part of chest. & \\
\hline Sural (or muscular). & Popliteal. & Muscles of popliteal space and calf. & \\
\hline $\begin{array}{l}\text { Tarsal, external and } \\
\text { internal. }\end{array}$ & Dorsalis pedis. & Skin and joints, etc., of foot. & \\
\hline Temporal. & External carotid. & $\begin{array}{l}\text { Forehead, parotid gland, masseter, } \\
\text { ear. }\end{array}$ & $\begin{array}{l}\text { Parotid, articular, masseteric, anterior } \\
\text { auricular, transverse facial, middle, } \\
\text { temporal, and anterior and posterior } \\
\text { terminal. }\end{array}$ \\
\hline Temporal. & Posterior cerebral. & Inferior part of temporal lobe of brain. & \\
\hline $\begin{array}{l}\text { Temporal, deep, an- } \\
\text { terior. }\end{array}$ & Internal maxillary. & Anterior part of temporal fossa. & \\
\hline $\begin{array}{l}\text { Temporal, deep, ex- } \\
\text { ternal. See Tem- } \\
\text { poral, deep, ante- } \\
\text { riur. }\end{array}$ & & & \\
\hline $\begin{array}{l}\text { Temporal, deep, in- } \\
\text { ternal. }\end{array}$ & $\begin{array}{l}\text { See Temporal, deep, } \\
\text { posterior. }\end{array}$ & & \\
\hline $\begin{array}{l}\text { Temporal, deep, post- } \\
\text { erior. }\end{array}$ & $\begin{array}{c}\text { Interna } 1 \text { maxillary, } \\
\text { pterygoid portion. }\end{array}$ & Temporal fossa. & \\
\hline $\begin{array}{c}\text { Temporal, frontal. See } \\
\text { Temporal, anterior. }\end{array}$ & & & \\
\hline Temporal, middle. & Temporal. & Squamous portion temporal lobe. & \\
\hline Temporal, posterior. & Superficial temporal. & Side of head and vertex. & \\
\hline Temporal, superficial. & See Temporal. & & \\
\hline Temporo-occipital. & Posterior cerebral. & $\begin{array}{l}\text { Cuneus, lingual, convolution and ex- } \\
\text { terior of occipital lobe. }\end{array}$ & \\
\hline Termatic. & $\begin{array}{l}\text { Anterior communicat- } \\
\text { ing. }\end{array}$ & Cinerea and callostum. & \\
\hline Testicular. & Spermatic & Testicle. & \\
\hline $\begin{array}{r}\text { Testiculat, great. See } \\
\text { Spermatic, internal. }\end{array}$ & & & \\
\hline $\begin{array}{l}\text { Testicular, small. See } \\
\text { Spermatic, external }\end{array}$ & & & \\
\hline Thalamic, middle. & $\begin{array}{l}\text { Posterior communi- } \\
\text { cating. }\end{array}$ & Optic thalamus. & \\
\hline $\begin{array}{l}\text { Thoracic, acromial } \\
\text { (thoracic axis). }\end{array}$ & Axillary. & Muscles of shoulder, arm, and chest. & $\begin{array}{l}\text { Acromial, humeral, pectoral, clavic- } \\
\text { ular. }\end{array}$ \\
\hline Thoracic, alar. & Axillary. & Axillary glands. & \\
\hline $\begin{array}{c}\text { Thoracic axis. See } \\
\text { Thoracic, acromial. }\end{array}$ & & & \\
\hline $\begin{array}{l}\text { Thoracic, external. } \\
\text { See Mammary, } e x- \\
\text { ternal. }\end{array}$ & & & \\
\hline $\begin{array}{l}\text { Thoracic, inferior. See } \\
\text { Mammary, external. }\end{array}$ & & & \\
\hline
\end{tabular}


TABLE OF ARTERIES.-Continued.

\begin{tabular}{|c|c|c|c|}
\hline NAME. & ORIGIN. & DISTRIBUTION. & BRANCHES. \\
\hline \multicolumn{4}{|l|}{$\begin{array}{l}\text { Thoracic, in te rn a } 1 . \\
\text { See Mammary, inter- } \\
\text { ral. }\end{array}$} \\
\hline $\begin{array}{l}\text { Thoracic, long (exter- } \\
\text { nal mammary). }\end{array}$ & Axillary. & $\begin{array}{l}\text { Pectoral muscles, serratus magnus, } \\
\text { mammary and axillary glands. }\end{array}$ & \\
\hline $\begin{array}{l}\text { Thoracic, short (or } \\
\text { superior). }\end{array}$ & Axiliary. & Intercostal muscles, serratus magnus. & \\
\hline \multicolumn{4}{|l|}{$\begin{array}{l}\text { Thoracic twelfth. See } \\
\text { Subcostal. }\end{array}$} \\
\hline Thymic. & Internal mammary. & $\begin{array}{l}\text { Connective tissue, fat and lymphatics, } \\
\text { or mediastinum and thymus. }\end{array}$ & \\
\hline \multicolumn{4}{|l|}{$\begin{array}{l}\text { Thymic. See Medias- } \\
\text { tinal. }\end{array}$} \\
\hline \multicolumn{4}{|l|}{$\begin{array}{l}\text { Thyroid, ascending } \\
\text { See Thyroid, infe- } \\
\text { rior. }\end{array}$} \\
\hline Thyroid axis. & Subclavian. & Shoulder, neck, thorax, spine, cord. & $\begin{array}{l}\text { Inferior thyroid, suprascapular and } \\
\text { transverse cervical. }\end{array}$ \\
\hline Thyroid, deep. & $\begin{array}{l}\text { Arch of aorta, innom- } \\
\text { inate (occasional } \\
\text { branch). }\end{array}$ & Same as inferior thyroid. & \\
\hline \multicolumn{4}{|l|}{$\begin{array}{l}\text { Thyroid, descending. } \\
\text { See Thyroid, supe- } \\
\text { ror. }\end{array}$} \\
\hline Thyroid, inferior. & Thyroid axis. & $\begin{array}{l}\text { Larynx, esophagus and muscles of } \\
\text { neck. }\end{array}$ & $\begin{array}{l}\text { Muscular, ascending cervical, esopha- } \\
\text { geal, tracheal and inferior laryngeal. }\end{array}$ \\
\hline \multicolumn{4}{|l|}{$\begin{array}{l}\text { Thyroid, middle. See } \\
\text { Thyroidea ima. }\end{array}$} \\
\hline Thyroid, superior. & External carotid. & $\begin{array}{l}\text { Omo-hyoid, sterno-hyoid, sterno-thy- } \\
\text { roid, thyroid gland. }\end{array}$ & $\begin{array}{l}\text { Hyoid, sterno-mastoid, superior } \\
\text { laryngeal, crico-thyroid. }\end{array}$ \\
\hline Thyroidea ima. & Innominate (usually). & Thyroid body. & \\
\hline Thyro-laryngeal. & Thyroid superior. & Larynx and thyroid body. & \\
\hline Tibial, anterior. & Popliteal. & Leg. & $\begin{array}{l}\text { Posterior and anterior tibial recurrent, } \\
\text { muscular, internal and external mal- } \\
\text { leolar. }\end{array}$ \\
\hline $\begin{array}{l}\text { Tibial, anterior, recur- } \\
\text { rent. }\end{array}$ & Anterior tibial. & Tibialis anticus muscle. & \\
\hline Tibial, posterior. & Popliteal. & Leg, heel and foot. & $\begin{array}{l}\text { Peroneal, muscular, medullary, cuta- } \\
\text { neous, communicating, malleolar, } \\
\text { calcanean, internal and external } \\
\text { plantar. }\end{array}$ \\
\hline $\begin{array}{l}\text { Tibial, profunda (of } \\
\text { foot). }\end{array}$ & $\begin{array}{l}\text { Internal plantar, (in- } \\
\text { nermost branch). }\end{array}$ & Abductor pollicis muscle. & Unites with the plantar pollicar. \\
\hline $\begin{array}{l}\text { Tibial, recurrent, post- } \\
\text { erior. }\end{array}$ & Anterior tibial. & Back of knee joint. & $\begin{array}{l}\text { Anastomoses with the inferior articu- } \\
\text { lar arteries of } \mathrm{knee} \text {. }\end{array}$ \\
\hline Tonsillar. & Ascending palatine. & Tonsil and Eustachian tube. & \\
\hline Tonsillar. & Facial. & Tonsil and root of tongue. & \\
\hline Tracheal. & Inferior thyroid. & Trachea. & \\
\hline \multicolumn{4}{|l|}{$\begin{array}{l}\text { Trachelo-musc u lar. } \\
\text { See Cervical, infe- } \\
\text { rior. }\end{array}$} \\
\hline Transversalis colli. & Thyroid axis. & Neck and scapular region. & $\begin{array}{l}\text { Superficial cervical and posterior } \\
\text { scapular. }\end{array}$ \\
\hline \multicolumn{4}{|l|}{$\begin{array}{l}\text { Transversalis humeri. } \\
\text { See Suprascapular. }\end{array}$} \\
\hline Transverse. & External circumflex. & Muscles of upper part of thigh. & \\
\hline \multicolumn{4}{|l|}{$\begin{array}{l}\text { Transverse. See Pon- } \\
\quad \text { tal. }\end{array}$} \\
\hline Transverse. & Right coronary. & Heart muscle. & \\
\hline
\end{tabular}


TABLE OF ARTERIES.-Continued.

\begin{tabular}{|c|c|c|c|}
\hline NAME. & ORIGIN. & DISTRIBUTION. & BRANCHES. \\
\hline \multicolumn{4}{|l|}{$\begin{array}{l}\text { Transverse humeral. } \\
\text { See Suprascapular. }\end{array}$} \\
\hline Transverse nasal. & Nasal (of ophthalmic). & Root of nose. & \\
\hline Transverse perineal. & Superficial perineal. & Muscles and integuments of perineum. & \\
\hline Tricipital. & Posterior circumflex. & Triceps muscle (of arm). & \\
\hline \multicolumn{4}{|l|}{$\begin{array}{l}\text { Tympanic. See Gla-1 } \\
\text { serian. }\end{array}$} \\
\hline Tympanic. & Ascending pharyngeal. & Tympanum. & \\
\hline Tympanic. & Middle meningeal. & Tensor tympani. & \\
\hline Tympanic. & Stylo-mastoid. & Membrana tympani. & \\
\hline Tympanic. & Vidian. & Tympanum. & \\
\hline Tubal. & Ovarian. & Fallopian tube. & \\
\hline Ulnar. & Brachial. & Forearm, wrist, and hand. & $\begin{array}{l}\text { Anterior and posterior ulnar recur- } \\
\text { rent, common interosseous, muscu- } \\
\text { lar, nutrient, anterior and posterior } \\
\text { ulnar carpal, palmar arch. }\end{array}$ \\
\hline $\begin{array}{l}\text { Ulnat carpal, anterior } \\
\text { and posterior. }\end{array}$ & Ulnar. & Carpal region. & \\
\hline $\begin{array}{l}\text { Ulnar, recurrent, ante- } \\
\text { rior and posterior. }\end{array}$ & Ulnar. & Muscles of arm and elbow-joint. & \\
\hline Ulno-carpal, anterior. & Ulnar. & Muscles of hand. & \\
\hline Umbilical. & Hypogastric. & Chorionic villi. & \\
\hline Uncinate. & Posterior cerebral. & Uncinate convolution. & \\
\hline Uracheric. & Superior vesical. & Urachus. & $\cdot$ \\
\hline Ureteral. & Ovarian. & Ureter. & \\
\hline Jreteral. & Renal. & Ureter. & \\
\hline Ureteral. & Spermatic. & Ureter. & \\
\hline Ureteric. & Common iliac. & Ureter. & . \\
\hline Ureteric, inferior. & $\begin{array}{l}\text { Superior vesical (or } \\
\text { uterine). }\end{array}$ & Ureter and bladder. & \\
\hline Ureteric, middle. & $\begin{array}{l}\text { Of aorta, common iliac, } \\
\text { or internal spermatic }\end{array}$ & Middle part of ureter. & \\
\hline Ureteric, superior. & Renal. & Upper part of ureter. & \\
\hline Urethro-bulbar. & $\begin{array}{l}\text { See Perineal, trans } \\
\text { verse. }\end{array}$ & & \\
\hline Uterine. & $\begin{array}{l}\text { Internal iliac, anterier } \\
\text { branch. }\end{array}$ & Uterus. & Cervical, vaginal, azygos. \\
\hline Uterine. & Ovarian. & Uterus. & \\
\hline Utero-placental. & Uterine. & Gravid uterus and placenta. & \\
\hline $\begin{array}{c}\text { Uveal. See Ciliary, } \\
\text { posterior and shori }\end{array}$ & & & \\
\hline Vaginal (2 or 3 ). & $\begin{array}{l}\text { Internal iliac, anterior } \\
\text { division. }\end{array}$ & Vagina. & \\
\hline Vaginal azygos. & Uterine. & Vagina. & \\
\hline Vasa brevia. & Splenic. & Stomach. & \\
\hline Vermiform, inferior. & $\begin{array}{l}\text { Cerebellar, posterior in- } \\
\text { ferior. }\end{array}$ & Vermiform process of cerebellum. & \\
\hline Vermiform, superiot. & Superior cerebellar. & $\begin{array}{l}\text { Superior vermiform process of cerebel- } \\
\text { lum. }\end{array}$ & \\
\hline Vertebral. & Subclavian. & Neck of cerebrum. & $\begin{array}{l}\text { Lateral spinal, muscular, anastomotic, } \\
\text { posterior meningeal, posterior and } \\
\text { anterior spinal, posterior cerebellar. }\end{array}$ \\
\hline
\end{tabular}


TABLE OF ARTERIES.-Continued.

\begin{tabular}{|c|c|c|c|}
\hline NAME. & ORIGIN. & I)ISTRIBUTION. & BRANCHES. \\
\hline \multicolumn{4}{|l|}{$\begin{array}{l}\text { Vertebral, posterior. } \\
\text { See dortc, primitive }\end{array}$} \\
\hline Vesical, inferior. & $\begin{array}{l}\text { Internal iliac, anterior } \\
\text { division. }\end{array}$ & $\begin{array}{l}\text { Bladder, prostate, seminal vesicles, and } \\
\text { vagina (in female). }\end{array}$ & \\
\hline Vesical, middle. & Superior vesical. & Bladder. & \\
\hline Vesical, superior. & $\begin{array}{l}\text { Internal iliac, anterior } \\
\text { division. }\end{array}$ & Bladder. & $\begin{array}{l}\text { Deferential, uracheric, ureteric, mid- } \\
\text { dle vesical (occasionally). }\end{array}$ \\
\hline Vesico-prostatic. & Middle hemorrhoidal. & Prostate and seminal vesicles. & \\
\hline \multicolumn{4}{|l|}{$\begin{array}{l}\text { Vesico-vaginal. See } \\
\text { Vaginal. }\end{array}$} \\
\hline Vestibular. & Internal auditory. & Membranous labyrinth. & \\
\hline Vestibular. & Stylo-mastoid. & Vestibule and semicircular canals. & \\
\hline Vidian. & Internal maxillary. & $\begin{array}{l}\text { Roof of pharynx, Eustachian tube, and } \\
\text { tympanum. }\end{array}$ & Pharyngeal, Eustachian, tympanic. \\
\hline \multicolumn{4}{|l|}{$\begin{array}{l}\text { Vitelline. See Om- } \\
\text { phalo-mesenteric. }\end{array}$} \\
\hline Volar, superficial. & Radial. & Ball of thumb. & $\begin{array}{l}\text { Enters into formation of superficial } \\
\text { palmar arch. }\end{array}$ \\
\hline \multicolumn{4}{|l|}{$\begin{array}{c}\text { Volar, superior. See } \\
\text { Volar, superficial. }\end{array}$} \\
\hline Xiphoid. & Superior epigastric. & Ensiform cartilage. & \\
\hline $\begin{array}{l}\text { Zygomatico-orbital. } \\
\text { See Orbital (of tem- } \\
\text { poral). }\end{array}$ & & & \\
\hline
\end{tabular}

Arthromeningitis (ar-thro-men-in-jï-tis) [à $\rho \theta \rho o v$, a joint; $\mu \dot{\eta} v \iota \gamma \xi$, membrane]. Synovitis.

Arthromere (ar'-thro-mêr) [ă $\rho \theta \rho o v$, a joint ; $\mu \varepsilon p o s, a$ part]. In biology, one of the rings or somites characteristic of the articulated invertebrates.

Arthron (ar'-thron) [ă $\rho \rho \rho o v$, a joint]. A joint; especially a movable joint.

Arthronalgia (ar-thron-all-je-ah). See Arthralgia.

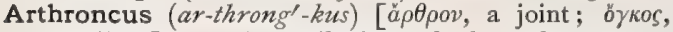
a swelling]. I. A cartilaginous body such as occasionally forms within the knee-joint. 2. Swelling of a joint.

Arthropathia (ar-thro-path'-e-ah). See Arthropathy. A. Tabidorum. See Charcot's Disease.

Arthropathics (ar-thro-path'-iks) [ä $\rho f \rho o v$, a joint; $\pi a$ toc, disease]. Disease of the joints.

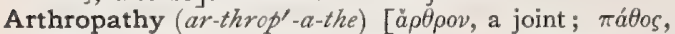
disease]. I. Any joint disease. 2. A peculiar disease of the joints similar to rheumatoid arthritis, but, according to Charcot, a distinct disease. It belongs to the prodromal stage of tabes, rapidly destroys the joint, is painless, without fever or inflammation, prefers the large joints, and is connected with hydrarthrosis and swelling of the joints.

Arthrophlogosis (ar-thro-flo-go'-sis) [ă $\rho$ A $\rho o v$, joint ; $\phi \lambda \varepsilon \gamma \varepsilon \iota \nu$, to burn]. Inflammation of a joint.

Arthrophragm (ar'-thro-fram) [ä $\rho \theta \rho \circ \nu, a$ joint ; $\phi \rho a ́ \gamma \mu a$, a fence]. Partitions between the articulations of arthropods.

Arthroplasty (ar'-thro-plas-te) [äptoov, a joint ; $\pi \wedge a ́ \sigma \sigma \varepsilon \iota \nu$, to form]. The making of an artificial joint.

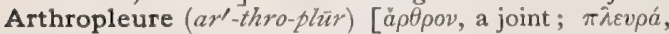
the side]. One of the pleurites or lateral pieces composing a somite of an arthropod.

Arthropodous (ar-throp'-o-dus) [à. $\rho \rho \rho \nu$, a joint; $\pi$ oús, a foot]. In biology, having jointed legs.
Arthropyosis (ar-thro-pi-o'-sis) [ă $\rho \theta \rho o v$, a joint; $\pi v \omega \sigma \iota \zeta$, suppuration]. Pus-formation in a joint.

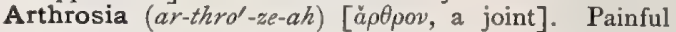
inflammatory or other affection of a joint.

Arthrosis (ar-thro'-sis) [ă $\rho \theta \rho \delta \varepsilon \iota \nu$, to fasten by a joint]. Articulation or jointing.

Arthrospore (ar'-thro-spōr) [à $\rho \theta \rho o v$, a joint; $\sigma \pi \hat{\alpha} \rho o s$, a seed]. In biology, a spore formed by fission, as opposed to an endospore.

Arthrosterigma (ar-thro-ster-ig'-mah) [à $\rho \theta \rho o v$, a joint ; $\sigma \tau \eta \dot{\rho} \rho \gamma \mu \alpha$, a support: $p l .$, Arthrosterigmata]. In biol. ogy, a jointed sterigma, as in many lichens.

Arthrostome (ar'-thro-stōm) [ă $\theta \rho \rho o v$, a joint ; $\sigma \tau b \mu \alpha$, a mouth]. L. Agassiz's name for the mouth of articulates. Compare Actinostome.

Arthrosyrinx (ar-thro-sir'-ingks) [ǎ $\rho \rho o v$, a joint ; $\sigma \tilde{v} \rho \iota \gamma \xi$, a pipe]. A fistulous opening into a joint.

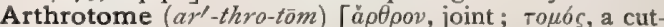
ting]. A stout knife used in the surgery of the joints.

Arthrotomy (ar-throl'-o-me) [ă $\rho \theta \rho o v$, a joint ; $\tau \dot{\varepsilon} \mu \nu \varepsilon \iota \nu$, to cut]. Incision of a joint.

Arthrous ( $a r^{\prime}$-thrus) [å $\rho \theta \rho o v$, a joint]. Pertaining to a joint or joints ; jointed.

Arthroxesis (ar-throks'-es-is) [à $\rho$ A $\rho \circ v$, joint ; $\xi \varepsilon \sigma \iota s, a$ scraping]. The surgical treatment of an articular surface by scraping.

Artiad $\left(a r^{\prime}-t e-a d\right)$ [à $\rho \tau \iota o s$, even]. In chemistry, a term used to designate atoms having an even quantivalence, as oxygen, which is bivalent, iron quadrivalent, and sulphur hexivalent.

Articular (ar-tik'-u-lar) [articularis, of the joints]. Pertaining to an articulation or joint.

Articulate $\left(a r-t i k^{\prime}-u-l \bar{a} t^{\prime}\right)$ [articulare to divide in joints]. Divided into joints, distinct. A. Speech, the communication of ideas by spoken words. 
Articulation (ar-tik-u-lut-shun) [articulus, a joint]. I. A joint or arthrosis; a connection between two or more bones, whether allowing movement between them or not. The articulations are divided into: (I) Synarthroses, immovable, subdivided into schindyleses, or grooved joints, gomphoses, in sockets, as the teeth, and suture, as in the bones of the skull; (2) Diarth. roses, or movable joints, subdivided into the arthrodia, or gliding joints, the ginglymus, or hinge-like, the enarthroses, or ball-and-socket joints; (3) Amphiarthroses, or those of a mixed type. 2. The enunciation of spoken speech. A. of Artificial Teeth, the adjustment and arrangement of one or more artificial teeth, so that it, or they, when placed in the mouth, shall sustain the same relationship to the organs with which they antagonize, when the jaws are closed, as the natural teeth did previous to their loss. A., Confluent, the clipping of words, or running together of syllables-a symptom of certain cerebral diseases. A. of Models. See Models for Artificial Teeth, Antagonizing. A. Positions. See Consonants. A. of the Teeth. See Teeth, Articulation of:

Articulator (ar-tik'-u-la-tor) [articulus, a joint]. An instrument used in mechanical dentistry for holding the models in position while the artificial teeth are being arranged and antagonized upon the plates.

Articuli (ar-tik'-u-li). See Lenticula.

Articulo mortis, In (ar-tik'-u-lo mor'-tis) [L.]. At the moment of death. In the act of dying.

Artifact (ar'-te-fact) [ars, art; facere, to make]. In microscopy and histology, a structure that has been produced by mechanical, chemical, or other artificial means; a structure or tissue that has been changed from its natural state.

Artificial (ar-te-fish'-al) [artificialis]. Made or imitated by art. A. Anus, an opening in the abdomen to give exit to the feces; an opening made in case of imperforate anus. A. Crowns, porcelain crowns of teeth designed to be united to the roots of natural teeth; what is commonly called by the misnomer "pivot tooth." A. Dentine, a preparation composed of pure gutta-percha, while in a softened state, mixed with mineral substances, and used for temporary fillings. See Temporary Stopping. A. Eye, a film of glass, celluloid, rubber, etc., made in imitation of the front part of the globe of the eye and worn in the socket or over a blind eye for cosmetic reasons. A. Feeding, the feeding of an infant by other means than mother's milk. Various mixtures and foods are to be had, such as Meigs's, Rotch's, Biedert's Mixtures, etc., $q . v$. See Table at end of this article. A. Joint, or false joint, the non-united ends of a broken bone. A. Leech. See Leech. A. Palate, a mechanical contrivance for supplying the loss of the whole or a portion of the hard or soft palate, or both. A. Pupil, removal of a piece of the iris (ividectomy, iridodialysis, etc.), to allow the light to pass through the opening. A. Respiration, the aerration of the blood by artificial means. A method of inducing the normal function of respiration when from any cause it is temporarily in abeyance, as in asphyxia neonatorum, drowning, etc. Bain's Method, a modification of Sylvester's method, the axilla itself being seized so that the traction is made directly upon the pectoral muscles. Byrd's (H.L.) Method; the physician's hands are placed under the middle portion of the child's back with their ulnar borders in contact.and at right angles to the spine. With the thumbs extended, the two extremities of the trunk are carried forward by gentle but firm pressure, so that they form an angle of 45 degrees with each other in the diaphragmatic region. Then the angle is reversed by carrying backward the shoulders and the nates. Dew's Method; the infant is grasped in the left hand, allowing the neck to rest between the thumb and forefinger, the head falling far over backward. The upper portion of the back and scapulæ rest in the palm of the band, the other three fingers being inserted in the axilla of the babe's left arm, raising it upward and outward. The right hand grasps the babe's knees, and the lower portion of the body is depressed to favor inspiration. The movement is reversed to favor expiration, the head, shoulders, and chest being brought forward and the thighs pressed upon the abdomen. Forest's Method; the child is placed on its face and quick, violent pressure is made on the back; then it is placed in a pail of hot water, and the hands carried upward until the child is suspended by its arms, and mouthto-mouth insufflation is practised; the arms are then lowered and the body doubled forward; these movements are repeated at the rate of 40 per minute. Hall's Method; by turning the body alternately upon the side or face to compress the chest, and then upon the back to allow the lungs to expand. Howard's Method; by pressure upon the lower ribs every few seconds. Pacini's Method; for resuscitating asphyxiated infants. The child lying on its back, the operator stands at its head, and grasps the axillæ, pulling the shoulders forward and upward to compress the thorax, and allowing them to fall in order to expand the chest. Satterthwaite's Method; pressure upon the abdomen alternating with relaxation to allow descent of the diaphragm. Schroeder's Method; the babe while in a bath is supported by the operator on the back, its head, arms, and pelvis being allowed to fall backward; a forceful expiration is then effected by bending up the babe over its belly, thereby compressing the thorax. Schultze's Method: the child is seized from behind with both hands, by the shoulders, in such a way that the right index finger of the operator is in the right axilla of the child from behind forward, and the left index finger in the left axilla, the thumbs hanging loosely over the clavicles. The other three fingers hang diagonally downward along the back of the thorax. The operator stands with his feet apart and holds the child as above, practically hanging on the index fingers in the first position, with the feet downward, the whole weight resting on the index fingers in the axillæ, the head being supported by the ulnar borders of the hands. This is the first inspiratory position. At once the operator swings the child gently forward and upward. When the operator's hands are somewhat above the horizontal the child is moved gently, so that the lower end of the body falls forward toward its head. The body is not flung over, but moved gently until the lower end rests on the chest. In this position the chest and upper end of the abdomen are compressed tightly. The child's thorax rests on the tips of the thumbs of the operator. As a result of this forcible expiration the fluids usually pour out of the nose and mouth of the infant. The child is allowed to rest in this position (the first expiratory position) about one or two seconds. The operator gradually lowers his arms, the child's body bends back, and he again holds the infant hanging on his index fingers with its feet downward; this is the second inspiratory position. These movements are repeated $I_{5}$ to 20 times in the minute. Sylvester's Method, chiefly by movements of the arms. This method is valueless in asphyxia neonatorum, owing to non-development of the pectoral muscles. A. Urticaria, a condition much resembling that seen in the autographic skin q.v. A. Vitreous. See Evisceration. 
ARTIFICIAL FEEDING OF INFANTS.

TABLE OF QUANTITY REQUIRED.

\begin{tabular}{l|c|c|c|c|c|c|}
\hline & & & \\
\end{tabular}

Artus (ar'-tus) [L.: pl., Artus]. A joint; a limb; the joints collectively.

Aryepiglottic (ar-e-ep-e-glot'-ik). Same as Arytenoepiglottic

Arytenoepiglottic (ar-i'-ten-o-ep-e-glot'-ik) [ápv́talva,

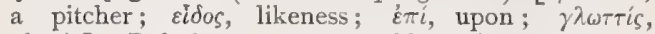
glottis]. Relating to an arytenoid cartilage and to the epiglottis ; as the aryteno-epiglottic fold (or folds), consisting of a fold of mucous membrane that extends from either arytenoid cartilage to the epiglottis.

Arytenoid (ar-i-te'-noid) [ápítaıva, a pitcher; $\varepsilon \bar{l} \delta o s$, likeness]. Resembling the mouth of a pitcher. A. cartilages, two cartilages of the larynx regulating, by the means of the attached muscles, the tension of the vocal cords. A. Glands, muciparous glands found in large numbers along the posterior margin of the aryteno-epiglottidean fold in front of the arytenoid cartilages. A. Muscle, arises from the posterior surface of one arytenoid cartilage and is inserted into the corresponding parts of the other. It is composed of three planes of fibers, two oblique and one transverse. It draws the arytenoid cartilages together.

Arythmia (ar-ith'-me-ah). See Arrhythmia.

Arythmic (ar-ith'-mik). See Arrhythmic

Asa $\left(a^{\prime}-s a h\right)$ [Pers., $\bar{a} z \bar{a}$, mastic]. A gum. A. dulcis, benzoin; also the drug called laser.

Asafetida (as-a-fet'-id-ah) [asa, gum; fotida, stinking]. A resinous gum obtained from the root of Ferula fortida and F. scordosoma. It is somewhat soluble in alcohol and forms an emulsion with water. Its properties are due to allyl sulphid, $\mathrm{C}_{6} \mathrm{H}_{10} \mathrm{~S}$. It is a powerful antispasmodic, stimulant, and expectorant, and is very serviceable in hysteria and bronchial affections. Dose gr. v-xx. A. tinct., strength 20 per cent. Dose

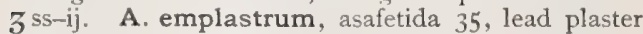
35, galbanum I5, yellow wax I5, alcohol 120 parts. A., Enema (B. P.), asafetida and distilled water. A., Emulsum, a 4 per cent. emulsion. Dose $\tilde{5} s-z \mathrm{ij}$. A. et magnesiæ mist., Dewees's carminative, magnesium carb. 5, tinct. asafetida 7 , tinct. opii $\mathbf{I}$, sugar $\mathbf{1 0}$, aq. dest. ad 100 parts. Dose $3 \mathrm{ss}-\overline{3} \mathrm{ss}$. A. pilulæe, contain each gr. iij of asafetida and gr. $\mathrm{j}$ of soap. Dose j-iv. A. et Aloes pil., have gr. I I/3 of each ingredient. A. pil. comp. (B. P.). Galbani pil. comp. SeeGalbanum. Ammonia fretidus spt., contains asafetida $I \frac{1}{2}$, liq, ammoniæ fort. 2, spirit 20 parts. Dose $3 \mathrm{ss}-\mathrm{j}$. Unof.

Asagrea, or Asagræa (as-a-gre'-ah) [Asa Gray, an American botanist]. A genus of melanthaceous herbs. A. officinalis. See Cebadilla.
Asak $\left(a s^{\prime}-a k\right)$. See Saraca indica.

Asaphatum (as-af'-at-um) [Arab.]. An old name for comedones.

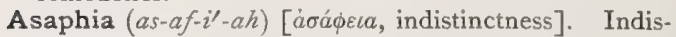
tinctness of utterance, especially that due to cleft palate.

Asaprol (as'-ap-rol), $\mathrm{Ca}\left(\mathrm{OH} . \mathrm{C}_{10} \mathrm{H}_{6} \mathrm{SO}_{3}\right)_{2}, 3 \mathrm{Aq}$. Calcium- $\beta$-naphthol- $\alpha$-mono-sulphonate, a substance readily soluble in water and alcohol, and recommended as an antiseptic in 5 per cent. solution. It is also used in acute articular rheumatism in doses of from 15 to 60 grains.

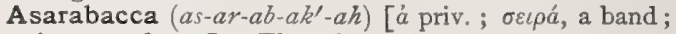
bacca, a berry]. The plant Asarum europaum, an errhin, aperient, and emetic. Unof.

Asarcia (ah-sar'-se-ah) [ádpriv.; $\sigma a ́ \rho \xi$, flesh]. Emaciation; leanness.

Asarin $\left(a s^{\prime}-a r-i n\right)$. Same as Asarone.

Asarkia (ah-sar'-ke-ah). See Asarcia.

Asarol $\left(\alpha s^{\prime}-a r-\bar{o} l\right)$ [ǎ $\sigma a \rho o \nu$, asarabacca; oleum, oil], $\mathrm{C}_{10} \mathrm{H}_{18} \mathrm{O}$. A camphor-like body derived from asarum.

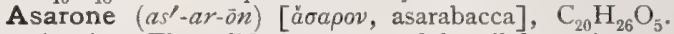
Asarin. The solid component of the oil from Asarum europaum. It forms monoclinic prisms, melting at $6 \mathrm{I}^{\circ}$, and boils at $295^{\circ}$. It has an aromatic taste, and smells like camphor.

Asarum (as'-ar-um) [äбapov, asarabacca]. A genus of aristolochiaceous plants. A. europæum has diaphorectic, emetic, purgative, and diuretic qualities, but is now little used except in veterinary practice. A. canadense, called wild ginger, Canada snakeroot, with other N. American species, are used chiefly in domestic practice. A. canadense is a fragrant, aromatic stimulant. Dose of fld. ext. $m$ xv- 3 ss. Unof.

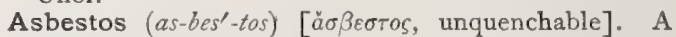
mineral more or less flexible and fibrous. It is used in mechanical dentistry, mixed with plaster, as a substitute for sand, to form the investment preparatory to soldering. . In surgery, it has also a limited use.

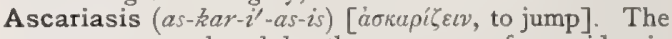
symptoms produced by the presence of ascarides in the gastro-intestinal canal.

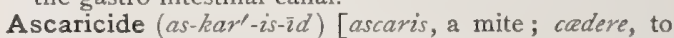
kill]. A medicine that kills ascarides.

Ascarides (as-kar'-id-ēz). See Thread-worms.

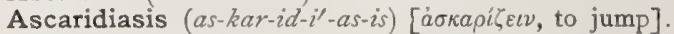
The presence of ascarides in the intestine.

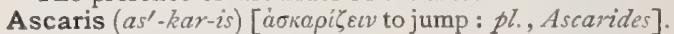
A genus of the family Ascarida. Parasitical worms inhabiting the bodies, and especially the intestines, of most animals. A. lumbricis, is found in the ox, hog and man. It inhabits the small intestine, especially of children. A. mystax, the round-worm of the cat, and $\mathbf{A}$. alata have rarely been found in man. A. vermicularis, a synonym of Oxyuris vermicularis. See Parasites, Table of.

Ascending (as-end'-ing) [ascendere, to rise]. Taking an upward course (as parts of the aorta, and colon, and as one of the venæ cavæ). A. Current, in electricity, one going from the periphery to a nerve-center. A. Metamorphosis. Same as Anabolism. A. Paralysis. See Prralysis.

Ascherson's Vesicles. The peculiar small globules formed when oil and an albuminous fluid are agitated together. Formerly thought to be cells.

Ascheturesis (as-ket-u-re'-sis) [ă $\sigma \chi \varepsilon \tau o s$, resistless; oúpnoıs, urination]. An uncontrollable desire to urinate; irrepressible urination.

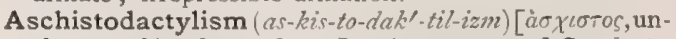

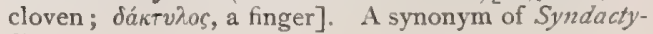
lism. 


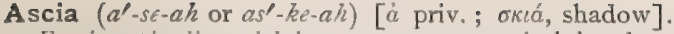
Fascia spiralis; dolabra currens; a spiral bandage applied without reverses, each turn of which overlaps the preceding for about a third of its width. Dolabra repens, is the same as the preceding, in which, however, the spirals are formed more obliquely, and do not overlap each other, but are separated by a greater or less interval.

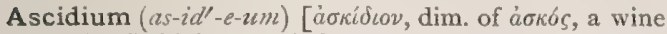
skin ]. In biology, a pitcher, or a pitcher-shaped organ, as in the pitcher plant or bladder wort.

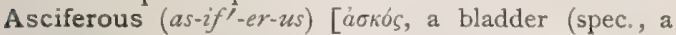
spore case); ferre, to bear]. Producing asci.

Ascigerous (as-ijl-er-us) [ascus, a spore case; gevere, to bear]. Ascus-bearing.

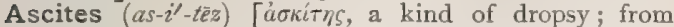
áokós, a bag]. An abnormal collection of serous fluid in the peritoneal cavity ; dropsy of the peritoneum. It is either local in origin or a part of a general dropsy. The ascitic fuid is usually clear, yellow, coagulating on standing, and if renal in origin contains ureà. It may be turbid, blood-stained, and contain lymph-particles or shreds. There is a uniform enlargement of the abdomen, fluctuation, percussion-dulness, etc. A. adiposus. A milky appearance of ascitic fluid due to the presence in it of numerous cells that have undergone fatty degeneration and solution. It is seen in certain cases of cancer, tuberculosis, or chronic inflammation of the peritoneum. A. chylosus. The presence of chyle in a greater or less degree of purity in ascitic fluid. It follows rupture of the chyle duct.

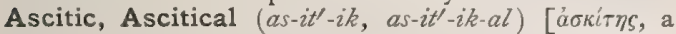
kind of dropsy]. Pertaining to or affected with ascites.

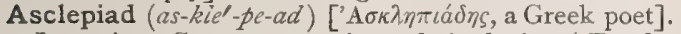
In ancient Greece, any priest of Asclepias (AEsculapius), of the family or class that claimed descent from that hero or demigod. The Asclepiads were also physicians, at least in some period of their history.

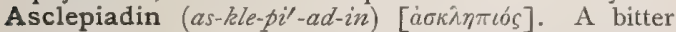
glucosid obtainable from various species of Asclepias. It is poisonous, with emetic, purgative, and sudorific effects. Unof.

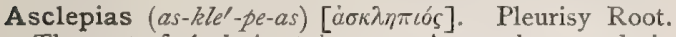
The root of Asclepias tuberosa. A popular remedy in the Southern States for pleurisy. A powerful diaphoretic and a moderate emetic and cathartic. The infusion recommended has a strength of $\bar{\zeta}$ of the powdered root to $\xi \times x x i j$ of water. Dose, a teacupful every 3 or 4 hours. Also, A. curassavica, Bloodflower, an herb common to tropical America; astringent, styptic, and anthelmintic against the tapeworm. A popular remedy for checking capillary hemorrhage. Dose of fld. ext. $3 \mathrm{j}-\mathrm{ij}$; of the drug, gr. $\mathrm{xx}-\mathrm{xl}$. Unof. Many other species of this genus have active medicinal qualities, at present but little understood. A., Ext., Fld., the fluid extract. Dose $3 \mathrm{i}-\mathrm{ij}$.

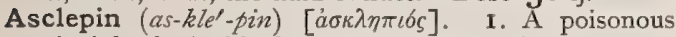
principle obtainable from asclepiadin by the separation of glucose from the latter. It is a heart paralyzant, with reputed alterative, purgative, and diaphoretic effects. It is offensive to the taste and smell. Unof. 2. The precipitate from a tincture of Asclepias tuberosa; alterative, evacuant, tonic, sedative. Dose grs. ij-iv. Unof.

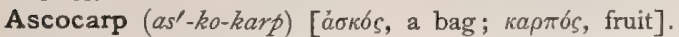
In biology, the organ that in Ascomycetes and Lichenes produces ascospores.

Ascococcus (as-ko-kokl-us) [áokós, a leather bag;

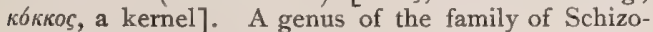
mycetes. The ascococci are microörganisms made up of round or ovoid cells; with elements united in massive colonies, surrounded by tough, thick, gelatin- ous envelops. A. Billrothii, found in putrefied meat; its natural habitat is the air; zymogenic, probably not pathogenic. See Bacteria, Table of.

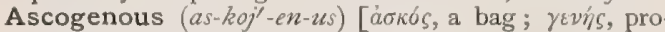
ducing]. In biology, producing asci.

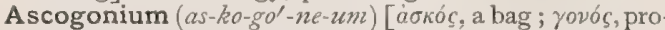
ducing]. In biology, the corkscrew-shaped female organ of the mould-fungi. It is formed by several fine branches given off from a mycelium; an archicarp, or, generally, an imperfectly developed carpogonium.

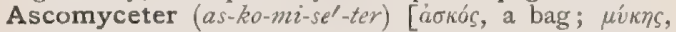
mushroom]. In biology, a group of fungi including morchella, helvella, leotia, etc., which have cup-shaped depressions, lacunæ, and sinuosities. Aspergillus, penicillium, and oildium belong here.

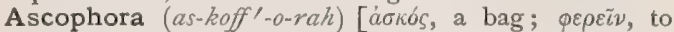
bear]. A genus of fungi. A. elegans, a vegetable growth occasionally found in the ear; bread-mould. A. mucedo, a microscopic fungus, of which the mould of bread is an example.

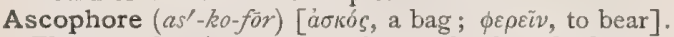
The spore-bearing stage, surface, or hyphæ of a fungus.

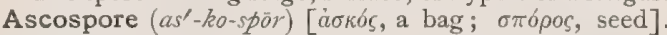
In biology a spore produced by or in an ascus.

Ascus $\left(a s^{\prime}-k u s\right)$ [áokós, a bag, or bladder]. In biology, the characteristic spore case of some fungi and lichens, usually consisting of a single terminal cell containing eight spores.

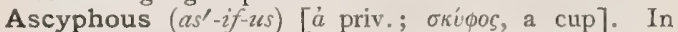
botany, without scyphi or cup-shaped fruiting organs, as some lichens.

Asecretory (ah-se'-kret-a-re) [à priv.; secretus, separate] Dry ; without secretion.

Asellus $\left(a s-e l^{\prime}-u s\right)$ [L.]. An old name for the cod Oleum jecinoris aselli, cod-liver oil.

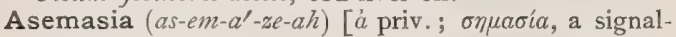
ing]. Absence of the power to communicate either by signs or language.

Asemia (ah-se'-me-ah) [ả priv.; $\sigma \tilde{\eta} \mu \alpha, a$ sign $]$. In ability to form, express, or understand any sign, token, or symbol of thought or feeling, whether speech, writing or gesture.

Asepsable (ah-seṕ-sa-bl) [á priv.; $\sigma \tilde{\eta} \psi r s$, putrefaction]. A less correct form of the word Aseptizable.

Asepsin $\left(a h-s e p^{\prime}-\sin \right)$. See Antisepsin.

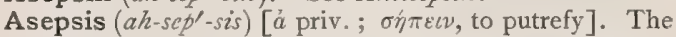
condition of non-putrefaction; absence of all septic material or pathogenic microörganisms.

Aseptic $\left(a h-s e p^{\prime}-t i k\right)$ [ $\dot{a}$ priv.; $\sigma \bar{\eta} \psi \iota s$, putrefaction]. Free from pathogenic bacteria, or septic matter. The antiseptic treatment of wounds, including aseptic and antiseptic dressings, renders the wound aseptic.

Asepticism (ah-seṕ-tis-izm) [’a priv.; $\sigma \eta \pi \tau o s$, septic]. The doctrine or principles of aseptic surgery.

Asepticity (ah-sep-tis'-it-e) [ả priv,; $\sigma \eta \pi \tau b s$, septic] Quality of being aseptic.

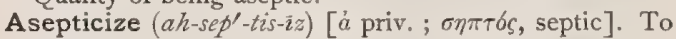
render aseptic; to free from the power of conveying septic poison.

Aseptin (ah-sep'-tin) [á priv.; $\sigma \eta \pi \tau b \zeta$, septic]. A secret preparation containing boric acid, used for preserving articles of food.

Aseptizable (ah-sep'-tiz-a-bl) [á priv.; $\sigma \eta \pi \tau b s$, septic]. Susceptible of being rendered aseptic.

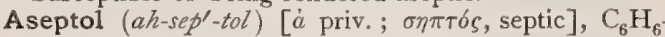
$\mathrm{SO}_{4}$. Sulphocarbolic acid; sozolic acid. A reddish liquid, with an odor of carbolic acid, recommended as a disinfectant and antiseptic. It is used externally ( $\mathrm{I}: \mathbf{1 0 0 0}$ ), and internally in about the same dose as carbolic acid.

Asexual (ah-seks'-u-al) [ả priv, ; sexus, sex]. Without sex; non-sexual. 
Ash (ash) [ME. asch]. See Fraxinus. A. manna. See Fraxinus. A., Poison. See Chionanthus. A., Prickly. See Xanthoxylum.

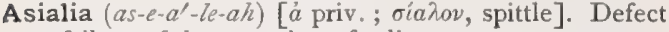
or failure of the secretion of saliva.

Asialorrhea (as-e-al-or-e'-ah). Same as Asialia.

Asiatic $\left(a-z e-a t^{\prime}-i k\right)$ [Asia]. Pertaining or belonging to Asia. A. Cholera. See Cholera. A. Pill, a method of administering arsenic in skin diseases. The formula is, arsenious acid gr. ij ; black pepper, powdered licorice, each gr. xxxij ; mucilage q. s. M. et ft. pil. no. xxxij. S. One to be taken $t$. d. after meals.

Asimina $\left(a s-i m-e^{\prime}-n a h\right)$ [L.]. A genus of trees. A. triloba. The papaw or pawpaw tree of North America, bearing an edible fruit.

Asiminin (as-im'-in-in) [asimina]. An alkaloid derived from the seeds of Asimina toiloba. It has active medicinal properties but is not much used. Unof.

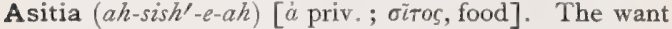
of food. Also a loathing for food.

Asmegmatia (ah-smeg-ma'-she-ah) ['a priv.; $\sigma \mu \tilde{\eta} \gamma \mu \alpha$, an unguent]. Deficiency or lack of smegma.

Asomata (ah-so'-mat-ah) [ả priv. ; $\sigma \tilde{\omega} \mu a$, body]. A species of omphalositic monster characterized by an absence of the trunk. The head is never well-formed, and the vessels run from it to the placenta in the membranes. Beneath the head is a sac in which rudiments of body organs may be found. This is the rarest form of omphalosites. Also called Acardiacus acormus

Asomia (ah-so'-me-ah). See Acormus.

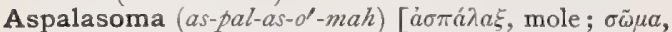
body]. A variety of single autositic monsters of the species celosoma, in which there is a lateral or median eventration occupying principally the lower portion of the abdomen, with the urinary apparatus, the genital apparatus, and the rectum opening externally by three distinct orifices.

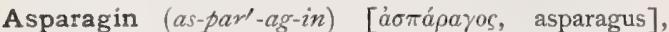
$\mathrm{C}_{4} \mathrm{H}_{8} \mathrm{~N}_{2} \mathrm{O}_{3} \cdot \mathrm{H}_{2} \mathrm{O}_{3}$. An alkaloid isomeric with malamid. It is found in the seeds of many plants, in asparagus, beet root, peas and beans. It forms shining, foursided, rhombic prisms, readily soluble in hot water, but not in alcohol or ether. It is an amid of aspartic acid, and forms compounds with both acids and bases. It is diuretic and sedative to the circulation. Dose gr. j-vj.

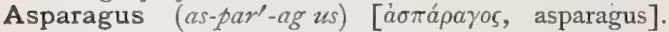
The green root of Asparagus officinalis, a mild

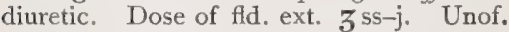

Aspartic Acid (as-par'-tik). See Acid.

Asper-artery (as'-per-ar'-ter-e) [arteria aspera, rough artery]. The trachea.

Aspergilliform (as-per-jill-if-orm) [aspergere, to sprinkle; forma, shape]. In biology, shaped like the brush used to sprinkle holy water; as the stigmas of many grasses.

Aspergillus (as-per-jil'-us) [aspergere, to scatter]. A nominal genus of fungi, probably containing only the conidial forms of Eurotium. A. auricularis, a fungus found in the wax of the ear. A. fumigatus, found in the ear, nose, and lungs. A. glaucus, the bluish mould found, e.g., upon dried fruit. A. mucoroides, a species found in tuberculous or gangrenous lung tissue.

Aspergillusmycosis (as-per-jill-us-mi-ko'-sis). See Otomycosis.

Asperifoliate (as-per-if-o'-le-ät) [asper, rough; folium, a leaf]. With leaves producing a sensation of roughness when handled.

Aspermatia (ah-sper-ma'-she-ah), [a priv.; $\sigma \pi \varepsilon p \mu a$, seed]. Aspermatism.
Aspermatic (ah-sper-mat'-ik) [áa priv. ; $\sigma \pi \varepsilon \rho \mu a$, seed]. Affected with or relating to aspermatism.

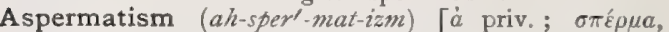
seed]. Non-emission of semen, whether owing to non-secretion or non-ejaculation.

Aspermous (ah-sper'-mus) [ $\dot{a}$ priv.; $\sigma \pi \varepsilon \rho \mu \alpha$, seed]. Without seed.

Aspersion (as-per'-zhun) [aspersio, aspergere, to sprinkle]. Treatment of disease by sprinkling with a medicinal agent, or by dropping a medicine slowly upon the body or part affected

Asperula (as-per'-u-lah) [L.]. A genus of rubiaceous plants, of which the European woodruff ( $A$. odorata) is an example. This plant is a fragrant aromatic, rich in coumarin, and has diaphoretic and astringent qualities. The Maitrank or Maizein of the Germans is flavored with this herb. Unof.

Asphalt $\left(a s^{\prime}\right.$-falt $)[a ̀ \sigma \phi a \lambda \tau o v$, bitumen $]$. Bitumen $(q, v$.$) .$ Asphalt is now scarcely used in medicine, but a varnish prepared with it is employed in making cells for use in microscopy.

Asphyctic (as-fik'-tik), or Asphyctous (as-fik'-tus) [á priv. ; $\sigma \phi v \xi \iota \varsigma$, pulsation]. Affected with asphyxia.

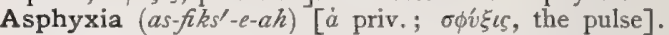
The effect upon the body of the non-oxygenation of the blood; the suspension of vital phenomena when the lungs are deprived of air. The excess of carbon dioxid in the blood at first stimulates, then paralyzes the respiratory center of the medulla. Artificial respiration is therefore required in cases of sudden asphyxia. Asphyxia is characterized by extreme lividity of the features, and prominence of the eyeballs, with obstruction to respiration. It is the cause of death in suffocation, drowning, obstruction of the larynx, etc. A. neonatorum, the inability of new-born infants to begin respiration spontaneously, or to continue it.

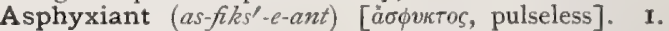
Producing asphyxia, 2. An agent capable of producing asphyxia.

Asphyxiate $\left(a s-f i s^{\prime}-e-a t\right)$ ['a priv, ; $\sigma \phi \dot{v} \xi \varepsilon \iota v$, to pulsate]. To produce or cause asphyxia; to suffocate, or to nearly suffocate.

Aspic $\left(a s^{\prime}-p i k\right)$ [ $a$ and spic, lavender spike]. The great lavender, or spike lavender, Lavandula spica. Its oil is at present used in veterinary practice and occasionally in liniments. Unof.

Aspidium (as-pid'-e-um) [L. : gen. Aspidii]. A genus of ferns, known as shield-ferns. There are many recognized species. The rhizome of Dryopteris filix mas, and of $D$. marginalis or male fern. Its properties are due to a resin containing filicic acid. It is valuable chiefly as a vermicide against tapeworm. Dose $3_{\text {ss }} \bar{\zeta}$ ss. A., Oleoresina, an ethereal extract. Dose

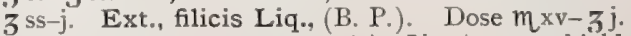

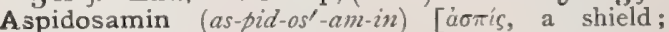

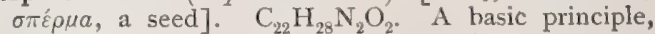
from quebracho-bark. Emetic. Unof.

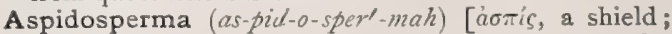
$\sigma \pi \varepsilon \rho \mu a$, seed]. The bark of Aspidosperma quebrachoblanco. A., Ext., Fld., an alcoholic preparation. Dose $3 \mathrm{j}$.

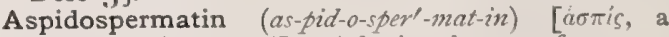
shield; $\sigma \pi \varepsilon \varepsilon^{\prime} \mu a$, seed]. A basic substance, from quebracho bark, said to be isomeric with aspidosamin and to depress the temperature when administered. Unof.

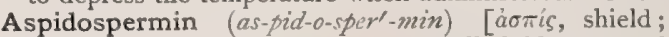
$\sigma \pi \varepsilon \hat{\varepsilon} \mu \alpha$, seed], $\mathrm{C}_{22} \mathrm{H}_{30} \mathrm{~N}_{2} \mathrm{O}_{2}$. An alkaloid extracted from Quebracho, q. v. (Aspidosperma quebracho). It has the general effects of quebracho. Unof.

Aspirate $\left(a s^{\prime}-p i r-\bar{a} t\right)$ [ad, to; spirare, to breathe]. Any consonant sound that is aspirated or pronounced with a rough breathing. See Consonants. 
Aspiration (as-pir-a'-shun) [ad, to spirare, to breathe]. Used as a synonym of inspiration, also of imbibition. The act of using the aspirator. A method of withdrawing the fluids and gases from a wound, organ or cavity. A. of Cataract Extraction. See Extraction of Cataract, Suction Method. A. Theory (of Weber and Hasner), the theory that accounts for the transmission of tears into the nose by suction into the lachrymal sac through the rarefaction of the air in the nose during inspiration.

Aspirator $\left(a s^{\prime}\right.$-pir-a-tor $)$ [ad, to ; spirare, to breathe]. An instrument for withdrawing the contents of an abscess, tumor, etc., without the admission of air.

Asplenium ( $a h$-sple $-n e-u m)$ [ $\not \dot{a}$ priv.; $\sigma \pi \lambda \dot{\eta} \nu$, spleen; a plant of this name was once thought to destroy the spleen]. A genus of ferns called spleen-worts, or miltwastes. $\AA$. ceterach and A. filix-femina formerly had a great repute as medicines, but are now little used. Unof.

Asporogenic (ah-spōr-o-jen'-ik) [ả priv. ; $\sigma \pi 0 \rho a ́$, seed;

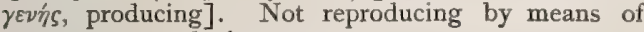
spores; not producing spores.

Assafetida (as-a-fet'-id-ah). See Asafetida.

Assalini's Operation. See Operations, Table of.

Assault (as-awlt') [assalire, to assail]. An attack. A., Criminal, in medical jurisprudence, the touching or attempting to touch, on the part of a male, any of the sexual organs (the breasts included) of a female, against her will, even though they be covered by clothing.

Assibilation (as-ib-il-a'-shun) [assibilare, to whisper to]. The utterance of sounds with a sibilant or hissing quality.

Assideration (as-id-er-a'-shun) [ad, intensive; sideratio, an evil influence]. In forensic medicine, infanticide by immersing in ice-water.

Assimilable (as-im'-il-a-bl) [assimulare, to make like]. Capable of being assimilated; nutritious.

Assimilation (as-im-il-a'-shun) [assimulare, to make like]. The process of transforming food into such a nutrient condition that it is taken up by the circulatory system, to form an integral part of the economy; synthetic or constructive metabolism; anabolism. In biology, the formation of carbohydrate from water and carbon dioxid by the agency of chlorophyll. A., Mental, the mental reception of impressions and their assignment by the consciousness to their proper place. A., Primary, that concerned in the conversion of food into chyle and blood. A., Secondary, that relating to the formation of the organized tissues of the body.

Associated (ss-o'-se-a-ted) [associatus, united]. Joined. A. Antagonist. See Antagonist. A. Movements, coincident or consensual movements of other muscles than the leading one, and which by habit or unity of purpose are involuntarily connected with its action. Both eyeballs move'alike in reading, though one be a blind eye. Movement of the normal arm will sometimes produce slight motion of the opposite paralyzed arm. Uniformity of innervation is usually the cause of these movements. A. Paralysis, a common paralysis of associated muscles.

Assurgent (as-er'-jent). See Ascending.

Assurin ( $\alpha s^{\prime}-u$-rin), $\mathrm{C}_{46} \mathrm{H}_{94} \mathrm{~N}_{2} \mathrm{P}_{2} \mathrm{O}_{9}$. A name given by Thudichum to a complex substance occurring in brain tissue, classed as a di-nitrogenized diphosphatid.

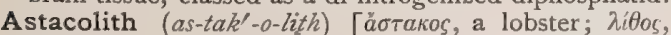
a stone]. A concretion obtainable from the stomach of a European craw-fish, Astacus fuviatilis, and often gathered from brooks. These are called Crabs' Eyes, and Eye-stones, q.v.

Astasia (as-ta'-se-ah) [á priv.; $\sigma \tau a ́ \sigma \iota s, ~ s t a n d i n g]$. Motor incoördination for standing. See Abasia. A.
Abasia, a symptom consisting in inability to stand or walk in a normal manner.

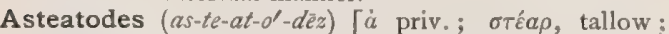
$\omega \delta \eta \zeta$, fullness]. Deficient in the secretion of the sebaceous glands.

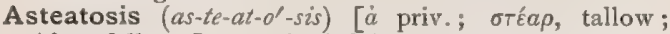
$6 \delta \eta s$, fullness]. I. A deficiency or absence of the sebaceous secretion. 2. Any skin disease (as xeroderma) characterized by scantiness or lack of the sebaceous secretion. A. cutis, a condition of diminished sebaceous secretion, as the result of which the skin becomes dry, scaly, and often fissured.

Aster (as'-ter) [aster, a star]. I. An extensive genus of composite flowered plants, mainly N. American. A. cordifolius is a nervine and antispasmodic. A. puniceus is a stimulant and diuretic. Unof. 2. See Karyokinesis, Mother-star, Dyaster, Amphiaster, and Cytaster.

Asterion (as-te'-re-on). See Craniometric Points.

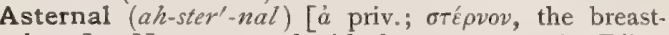
bone]. Not connected with the sternum. A. Ribs, the five lower pairs, because not joined directly to the sternum. Also called false ribs.

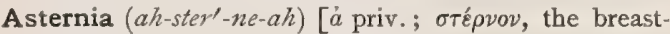
bone]. Absence of the sternum.

Asteroid (as'-ter-oid) [ádín $\rho$, a star; $\varepsilon i \delta o s$, resemblance]. I. Shaped like a star. 2. In biology, with radiate lobes.

Asthenia (as-the'-ne-ah, or as-then-i'-ah) [áoftveıa; $a$ priv.; $\sigma \theta \varepsilon ́ \nu o s$, strength]. General loss or absence of strength; adynamia.

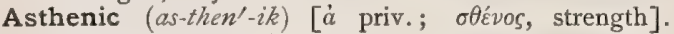
Characterized by asthenia.

Asthenometer (as-then-om'-et-er) [áatévela, want of

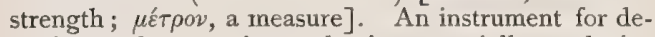
tecting and measuring asthenia; especially, a device for measuring muscular asthenopia.

Asthenopia (as-then-o'-pe-ah) [a priv.; $\sigma \theta^{\prime}$ vos, strength ; $\omega \psi \psi$, eye]. Weakness, speedy fatigue of the ocular muscles or visual powers, due to errors of refraction, insufficiency, over-use, anemia, etc. A., Accommodative, due to hyperopia, astigmatism, or a combination of the two, producing strain of the ciliary muscle. A., Muscular, due to weakness, incoördination (heterophoria), or strain of the external ocular muscies. A., Retinal, or Nervous, a rare variety, caused by retinal hyperesthesia, anesthesia, or other abnormality, or by general nervous affections.

Asthenopic (as-then-op'-ik) [áa priv.; olévos, strength; $\varpi \psi$, eye]. Characterized by asthenopia.

Asthma $\left(a z^{\prime}-m a h\right)[\bar{a} \sigma \theta \mu a$, panting]. Paroxysmal or intermittent dyspnea, generally accompanied by cough, bronchial secretion, and a feeling of constriction and suffocation. The etiology is obscure, being ascribed to heredity, nasal disease, gout, exhalations of plants and atmospheric impurities, colds, etc. It is undoubtedly a neurosis, the spasm of the muscular tissue of the bronchial tubes being due either to central or to peripheral nervous irritation. The duration of a paroxysm may be from two to six hours to four or five nights. When dependent upon disease of the heart, the kidneys, stomach, thymus, etc., it has been designated, cardiac, renal, peptic, thymic, etc. A. convulsivum. Synonym of Bronchial Asthma. A. Crystals, acicular crystals contained in the sputum of asthmatic patients. A. dyspepticum, is due to nervous reflexes through the vagus. A., Grinders'. Same as Fibroid Phthisis. A., Hay. See Hay Fever. A., Heberden's, angina pectoris. A., Kopp's, spasm of the glottis. A., Marine. See Beriberi. A., Millar's. See Laryngismus stridulus. A., Miner's. See Anthracosis. A. nervosum. 
Synonym of Bronchial Asthma. onym of Laryngismus stridulus.

A., Thymic. Syn onym of Hysteria.

Asthmatic (as-mat'-ik) [åot $\mu \alpha$, panting]. Relating to or affected with asthma.

Astigmagraph (as-tig'-ma-graf) [ả priv.; oríyua, a point; y $\rho a ́ \phi \varepsilon \imath \nu$, to write]. An instrument for illustrating the phenomena of astigmatism.

Astigmatic (as-tio-mat'-ik) [a priv.; $\sigma \tau i \gamma \mu \alpha$, a point]. Pertaining to or affected with astigmatism.

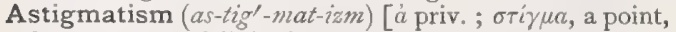
because rays of light from a point are never brought to a point by the refractive media of the eye]. That condition of the eye wherein homocentric rays of light are not brought to a focus by the media. It is usually due to inequality of curvature of the different meridians of the cornea (corneal A.), but may be caused by imperfections of the lens (lenticular), unequal con-
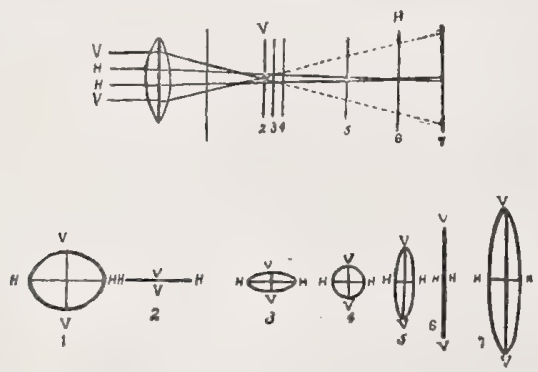

Diagram Illustrating the Formation of Astigmatic IMAGES.

The figures below give the images corresponding to the positions of the perpendicular lines above. The vertical rays are brought to a focus anterior to the horizontal. V.=vertical rays; $\mathrm{H}$. $=$ horizontal

traction of the ciliary muscle, or may perhaps be due to retinal imperfection. It may be acquired or congenital, and may complicate hypermetropia or myopia, producing either simple hypermetropic A., in which one principal meridian is emmetropic, the other hypermetropic ; or compound hypermetropic A., in which both meridians are hypermetropic, but one more so than the other. Complicating myopia, we may in the same way have simple myopic or compound myopic A. In mixed A., one principal meridian is myopic, the other hypermetropic. Regular A. is when the two principal meridians are at right angles to each other. Irregular A., when different parts of a meridian have different refracting powers.

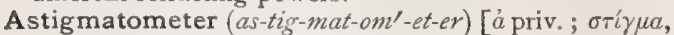
a point; $\mu \dot{\varepsilon} \tau \rho o \nu$, a measure]. An instrument for measuring the degree of astigmatism.

Astigmometer (as-tig-mom'-et-er). See Astigmatometer.

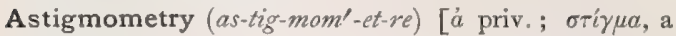
point; $\mu \hat{\varepsilon} \tau$ r $о \nu$, a measure ]. The measurement of astigmatism.

Astomous (ah-sto'-mus) [ả priv.; $\sigma \tau b \mu a$, mouth]. In biology, without a mouth or aperture.

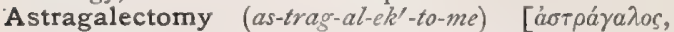
astragalus; $\dot{\kappa} \kappa \tau o \mu \eta$, excision]. Surgical excision of the astragalus.

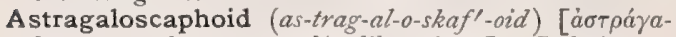

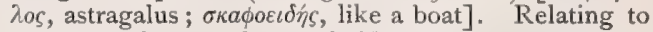
the astragalus and the scaphoid bone.

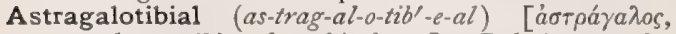
astragalus; tibia, the shin-bone]. Relating to the astragalus and the tibia.

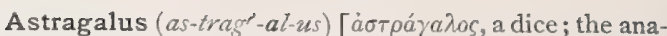
logous bones of the sheep were used by the ancients as dice]. The ankle-bone, upon which the tibia rests. Also, a genus of leguminous plants from some varieties of which gum tragacanth is derived. A. mollissimus, Loco Plant. The active principle of this plant has mydriatic properties. Unof

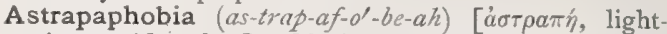
ning; $\phi \sigma \beta o s, f e a r]$. Morbid and unreasonable fear of lightning.

Astraphobia (as-trah-fo'-be-ah). See Astrapaphobia.

Astriction (as-trik'-shun) [astrictio; ad, to ; stringere, to bind]. Constipation or any condition resulting from the use of astringents.

Astringency (as-trin'-jen-se) [ad, to; stringere, to bind]. The quality of being astringent.

Astringent (as-trin'-jent) [ad, to; stringere, to bind]. I. Causing contraction; binding. 2. An agent producing contraction of organic tissues, or that arrests hemorrhages, diarrheas, etc. Tannin, alum, opium, alcohol, the salts of silver, lead, etc., are examples.

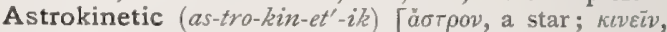
to move]. In biology, applied by Ryder to the phenomena of motion as exhibited by the centrosomes of cells.

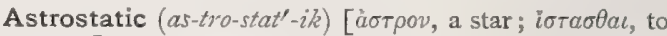
stand]. In biology, applied by Ryder to the resting condition of the centrosomes of cells.

Asylum (as-i'-lum) [asylum, a place of refuge]. An institution for the support, safe-keeping, cure, or education of those incapable of caring for themselves, such as the insane, the blind, etc. A. Ear. See Hematoma auris, and Ear Deformities.

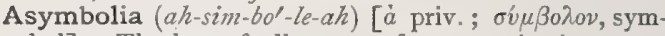
bol]. The loss of all power of communication, even by signs or symbols.

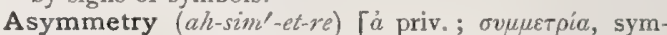
metry]. I. Unlikeness of corresponding organs or parts of opposite sides of the body that are normaliy of the same size, etc., as $e . g$. , asymmetry of the two halves of the skull or brain. 2. The linking of carbon atoms to four different groups; the combination of carbon atoms with different atoms or atomic groups.

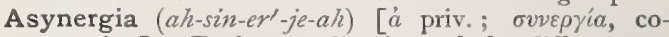
operation]. Faulty coördination of the different organs or muscles normally acting in unison.

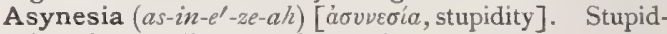
ity; loss or disorder of mental power.

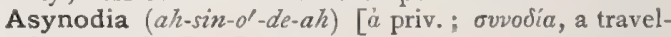
ling together]. Impotence.

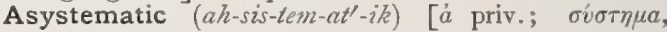
system ]. Diffuse; not restricted to any one or several systems of nerve fibers; applied to nervous diseases that are general.

Asystole (ah-sis'-to-le) [ả priv; $\sigma v \sigma \tau o \lambda \eta ́$, a shortening]. Absence or imperfection of the cardiac systole, due to feebleness, dilatation, etc., of the heart.

Asystolic (ah-sis-tol'-ik) [á priv; $\sigma v \sigma \tau o \lambda \dot{\eta}$, a shortening]. Marked by, due to, or suffering from asystole.

Asystolism $(a h$-sis'-tol-izm) [ả priv.; $\sigma v \sigma \tau o \dot{\lambda} \eta \dot{n}$, a shortening]. Inability of the right ventricle of the heart to empty itself of its contents, a condition encountered in the last stages of mitral incompetence. See Asystole.

Asystoly (ah-sis'-to-le). Same as Asystole.

Atactic (at-ak'-tic) [ăтakтos, irregular]. Irregular, incoördinate. Pertaining to muscular incoördination, especially in aphasia. Also applied to atypical fevers.

Atavic $\left(a t-a v^{\prime}-i k\right)$ [atavus, a forefather]. Relating to or characterized by atavism.

Atavism (at'-avizm) [atavus, a forefather]. The reappearance of an anomaly, physical, mental, or pathologic, in an individual whose more or less remote 
progenitors were similarly affected, but in whose immediate ancestors it had not been shown.

Atavistic $\left(a t-a v^{-}-i s^{\prime}-t i k\right)$. Same as Atavic.

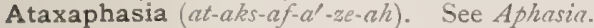

Ataxia $\left(a t-a k s^{\prime}-e-a h\right)$ [áta $\imath^{\prime} a$, want of order]. The word means primarily irregularity or want of order, but it is most commonly used to express incoördination of muscular action; an excess or deficiency in contraction of the various muscles concerned in a given action. Both static and locomotor ataxia are prominent symptoms of tabes or disease of the posterior columns of the cord, but it is absurd to speak of ataxia as if it were a disease itself, instead of being only one of many symptoms of many diseases. A., Briquet's, a hysterical state marked by loss of sensation in the skin and in the leg muscles. A. cordis. See Delirium cordis. A. of Drunkards. See Polyneuritis potatorum. A., Family. See A., Hereditary. A., Hereditary, Friedreich's ataxia, a family disease of children and the young. See Friedreich's Disease. A., Locomotor, the failure of muscular coördination as regards movements, and especially in walking. A., Motor, inability to coördinate the muscles in walking. A., Signs of. 1. Romberg (or Braih-Romberg sign), swaying of the body with closed eyes. 2, Signe de cloche-pied; standing on one leg with open eyes, and with closed eyes. The ataxic finds difficulty in standing upon one foot while the other is raised from the ground, particularly when the eyes are closed. 3. Sign of crossing the legs; in crossing the legs a normal person raises the one leg to the level of the other knee and deposits the former upon the latter. The ataxic raises the one leg a considerable distance above the other knee, and in depositing the former upon the latter makes the arc of a large circle. 4. Sign "de l'escatier;" sign of descending stairs; difficulty in descending stairs experienced by the ataxic. 5. Marching at command; a. march! $b$. halt! $c$. about face! $a$. When an ataxic that has been seated is told to walk, he manifests uncertainty or hesitation in his effort, first on rising, to gain his equilibrium. $b$. The marching ataxic finds great difficulty and is likely not to succeed in halting with precision when commanded to do so. $c$. The ataxic patient cannot turn about face with the same promptitude and the same certainty as the normal individual. 6. Westphal's sign; abolition of the knee-jerk. A., Static, the failure of muscular coördination in standing still, or in fixed positions of the limbs. A., Thermal, peculiar large and irregular fluctuations of the body temperature, due to a condition of incoördination, or a disordered or weakened thermotaxic mechanism. This may give rise to the so-called paradoxic or hysterical temperatures, rising occasionally to $108^{\circ}$ or I $10^{\circ} \mathrm{F}$., without grave or permanent injury.

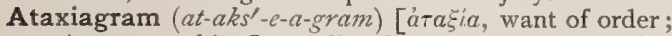
үра́ $\mu \mu a$, a marking]. A line drawn by a patient suffering with an ataxial disease. The patient's eyes are open or closed and he attempts to make a straight line. The character. of the deviations from a straight line that result are conceived to have a certain diagnostic value.

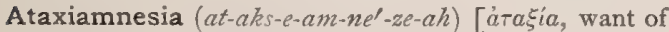

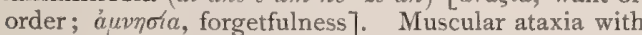
loss of or impairment of memory.

Ataxic $\left(a t-a k s^{\prime}-i k\right)$ [átałia, want of order]. 1. Pertaining to or affected with ataxia. 2. A person affected with ataxia. A. Aphasia. See Aphasia. A. Fever. Synomyn of Typhus Fever, q. v.

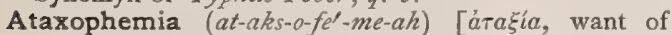
order; $\phi \eta \mu l$, to speak]. Lack of coördination in speech.
Ataxy $\left(a t-a k s^{\prime}-e\right)$. See Atrxia

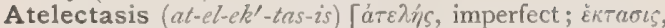
expansion]. Pulmonary collapse, with failure of the air to enter the vesicles. It may be either acquired (apneumatosis), or fetal. The condition is due not to disease of the lungs, but to nerve injuries, weakness, etc. In fetal cases the lung has never been inflated, whilst in apueumatosis it has been inflated.

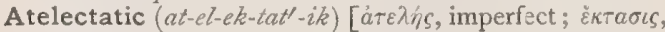
expansion]. Relating to or characterized by atelectasis

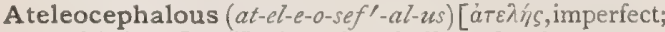
$\kappa \varepsilon \phi a \hat{\eta}$, head]. Having the skull or head more or less incomplete.

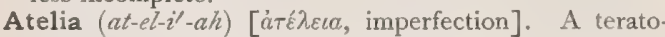
logic term for imperfection or failure of development of some part of the fetus. The word is compounded with others to designate the member wanting, as atelocardia, etc., expressing such a defect of the heart, etc.

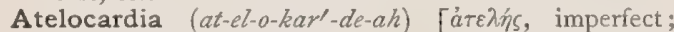
кapiia, heart]. An imperfect or undeveloped state of the heart; cardiatelia.

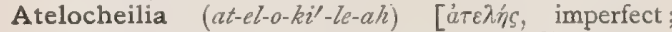
$\left.\chi \varepsilon i \lambda_{0}, \mathrm{lip}\right]$. Defective development of a lip.

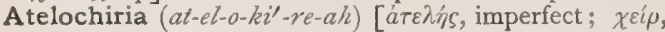
hand]. Deficiency in the development of the hand.

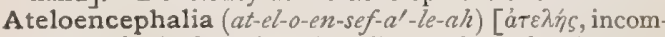

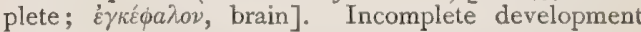
of the brain.

Ateloglossia (at-el-o-glos'-e-ah) [ảrchís, imperfect; $\gamma \lambda \tilde{\omega} \sigma \sigma \alpha$, tongue]. Congenital defect in the tongue.

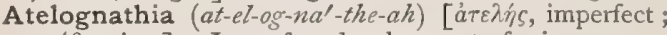
$\gamma \nu a ́$ os, jaw]. Imperfect development of a jaw, especially of the lower jaw.

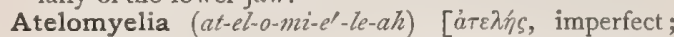
$\mu v \varepsilon \lambda \sigma ́ \varsigma$, marrow]. Congenital defect or incompleteness of the spinal cord.

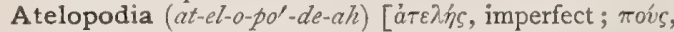
foot]. Defective development of the foot.

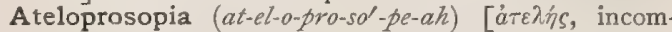
plete; $\pi \rho o ́ \sigma \omega \pi o v$, face]. Incomplete facial development.

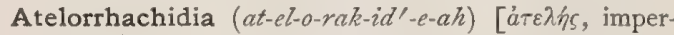
fect; '́á $\chi \iota_{\varsigma}$, spine]. Imperfect development of the spinal column, as in spina bifida.

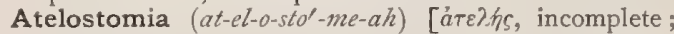
$\sigma \tau o ́ \mu \alpha$ mouth]. Incomplete development of the mouth.

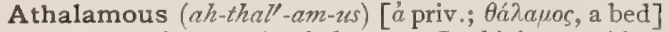
Absence of the optic thalamus. In biology, without apothecia, as certain lichens.

Athalline $\left(a h\right.$-thal'-in) [a priv, ; $\theta a \lambda \lambda b_{s}$, a frond]. In biology, destitute of a thallus.

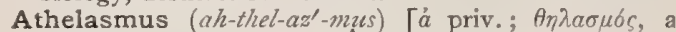
suckling]. Inability to give suck, from defect or want of the nipples.

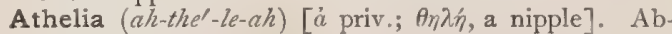
sence of the nipple.

Athermasia (ah-ther-ma'-ze-ah) [á priv.; $\theta \varepsilon \rho u a \sigma i \alpha$, heat]. Lack or deficiency of heat.

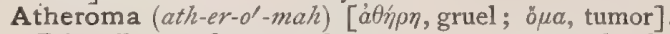
Primarily, a soft encysted tumor; more commonly, the fatty degeneration of the walls of the arteries in consequence of chronic arteritis, and called atheromatous degeneration. Atheromatous abscess, resulting from chronic arteritis, is a collection of soft matter beneath the intima, while an atheromatous ulcer is formed by the abscess breaking through the intima.

Atheromasia $\left(a t h-e \gamma^{\prime}-0-m a^{\prime}-z \ell-a h\right)[\dot{a} \theta \dot{n} \rho \omega \mu a$, an athero matous tumor]. Atheromatous degeneration; the condition of atheroma. 


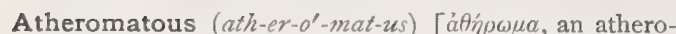
matous tumor]. Characterized by or affected with atheroma.

Atherosperma (ath-er-o-sper'-mah) [áAnj $\rho$, beard; $\sigma \pi \varepsilon \varepsilon^{\prime} \mu \alpha$, seed]. A genus of trees. A. moschatum, Australian sassafras, a diaphoretic and diuretic sometimes used in pulmonary affections and asthma. Dose of the tincture. $3 \mathrm{ss}-\mathrm{j}$. Unof.

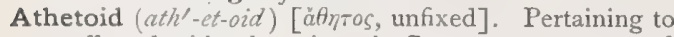
or affected with athetosis. A. Spasm, a symptom of hemiplegia and some cerebral lesions.

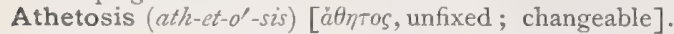
A symptom most frequently occurring in children, and characterized by continual change of position of the fingers and toes, and inability to keep them still, save in sleep. It is due to some lesion or derangement of the brain or cord. It is also called "post-hemiplegic chorea," from its occurrence after hemiplegia, in adults. A., Double Congenital. See Paraplegia, Infantile Spasmodic; also Double Athetosis.

Athlete $\left(a t h-l e t^{\prime}\right)$ [ả $\theta \lambda \varepsilon i \nu$, to contend with]. Robust ; vigorous. A.'s Heart, incompetency of the aortic valves, a condition frequently found in athletes.

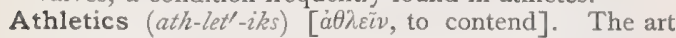
of physical exercise for development or for health.

Athrepsia ( $a h$-threps'-e-ah) [á priv ; $\tau \rho \dot{\varepsilon} \phi \varepsilon \iota \nu$, to nourish]. The symptom-complex resulting from imperfect nutrition in children.

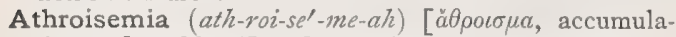
tion; aipa, blood]. Congestion or accumulation of blood.

Athymia (ah-thi'-me-ah) [á priv.; $\theta \dot{v} \mu o s$, mind]. I. Despondency. 2. Loss of consciousness. 3. Insanity.

Athymic $\left(\alpha h_{l}-t h i^{\prime}-m i k\right)$ [a priv.; $\theta \dot{v} \mu o s$, mind]. Affected with athymia.

Atlantad (at-lan'-tad) [ $A \tau \lambda a s$, a Greek hero]. Toward the atlas in situation or direction.

Atlantal (at-lan'-tal) ["A $\lambda \alpha \varsigma$, a Greek hero]. Relating to the atlas.

Atlanten ( $a$ t-lan'-ten) ["A ${ }^{\prime} \lambda \alpha_{s}$, a Greek hero]. Belonging to the atlas in itself.

Atlanti-obliquus (at-lan'-ti-ob-li'-kzus) [L.]. The obliquus capitis superior muscle.

Atlanti-rectus (at-lan'-ti-rek'-tus) [L.]. The muscle called rectus capitis posticus minor.

Atlanto- $\left(a t-l a n^{\prime}-t o\right)$ ["A $\tau \lambda a s$, a Greek hero]. A prefix signifying relation to the atlas; seen in the words Atlanto-axial, (relating to the atlas and the axis) Atlanto-occipital, Atlanto-odontoid, etc.

Atlas $\left(a t^{\prime}-l i s\right)$ [ă $\left.\tau \lambda a s, a b l e\right]$. The uppermost of the cervical vertebræ. It articulates with the occipital bone of the skull, A. Silk. See Silk.

Atlee's Operation. See Operations, Table of.

Atlodidymus (at-lo-did'-im-us). Same as Allodymus.

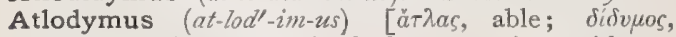
double]. A monosomic dual monstrosity; with two heads and a single body.

Atloido- $\left(a t-L o i^{\prime}-d o\right)[\dot{a}-\lambda a s$, able]. In composition, the same as atlanto; seen in such examples as atloidoaxoid, atloido-odontoid, etc.

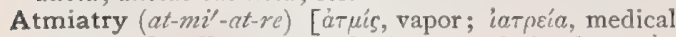
treatment]. Treatment of diseases of the lungs or mucous membranes, by inhalation, fumigation, or by directing a current of vapor or gas upon the part.

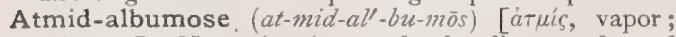
albumen]. Neumeister's term for the albumose formed by the action of superheated steam.

Atmidometer (at-mid-om'-et-er). See Atmometer.

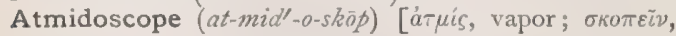
to view]. See Atmometer.

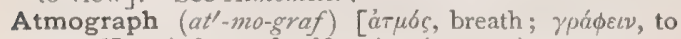
record]. A form of self-registering respirometer.
Atmometer, or Atmidometer (at-mzom'-et-er; at-mid-

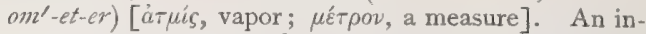
strument to measure the amount of water exhaled from a given surface in a given time, in order to determine the humidity of the atmosphere.

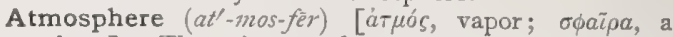
sphere]. The mixture of gases, vapor of water, and other suspended matters, surrounding the earth, as an elastic fluid envelop, to the height of about 200 miles.

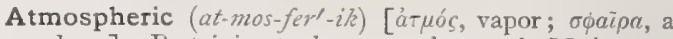
sphere]. Pertaining to the atmosphere. A. Moisture, the vapor of water mingled with the atmosphere. It varies in quantity according to the temperature. A. Pressure Cavity, a cavity formed on the palatine surface of a set of artificial teeth to retain them in the mouth. A. Tension, the pressure of the air per square inch on the surface of a body. Normally, at the sea level it is about 14.7 lbs. per square inch, or equal to that of a column of mercury about 30 in. in height. It decreases about $\frac{1}{10} \mathrm{in.}$, or $\frac{1}{20} \mathrm{Hb}$. per square inch for every 90 feet of altitude. Above 10,000 feet, the rarity of the atmosphere is usually noticeable in quickened breathing and pulse rate.

Atocia $\left(a t-o^{\prime}-s e-a h\right)$ [à female.

Atom $\left(a t^{\prime}-u m\right)$ [' $a$ priv.; $\tau \varepsilon \dot{\varepsilon} \mu \nu \varepsilon v$, to cut]. The ultimate unit of an element; that part of a substance incapable of further division, or the smallest part capable of entering a chemical compound, or uniting with another to form a Molecule-which last is the smallest quantity of a substance that can exist free or uncombined. See Elements, Table of.

Atomic $\left(a t-o m^{\prime}-i k\right)$ [ $\dot{a}$ priv.; Té $\mu \nu \varepsilon \iota v$, to cut]. Of or pertaining to atoms. A. Heat of an atom is its specific heat multiplied by its atomic weight. A. Theory, the theory of Dalton, that all matter is composed of atoms, the weight of each atom differing for the different substances. A. Valence, Equivalence, or the Atomicity of an element, is the saturating power of its atom as compared with that of hydrogen. A. Weight, the weight of an atom of an element as compared with the weight of an atom of hydrogen.

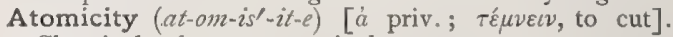
Chemical valence; quantivalence.

Atomization $\left(a t-a m-i z-a^{\prime}-s h u n\right) \quad[\dot{a}$ priv, ; Tर́ $\mu \nu \varepsilon v v$, to cut]. The mechanical process of breaking up a liquid into fine spray.

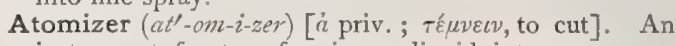
instrument for transforming a liquid into a spray or mist.

Atonia $\left(a t-a^{\prime}-n e-a h\right)$ [árovia, want of tone]. Atony.

Atonic $\left(a t-o n^{\prime}-i k\right)$ [átovia, want of tone]. Relating to. or characterized by, atony.

Atony $\left(a t^{\prime}-o-n e\right)[\dot{a}$ priv.; tóvos, tone]. Want of tone. Debility. Loss or diminution of muscular or vital energy.

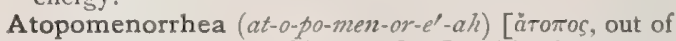
place; $\mu$ ín, month; $\dot{\varepsilon} \varepsilon \varepsilon \nu$, to flow]. Vicarious menstruation.

Atoxic $\left(a / 2-10 k s^{\prime}-i k\right)$ [á priv.; $\tau o_{s}^{\xi} \iota \kappa \delta \nu$, poison $]$. Not venomous; not poisonous.

Atrabiliary (at-rah-bil'-e-a-re) [ater, black; bilis, bile]. An obsolescent term relating to melancholy and hypochondriasis; also referring to the renal and supra-renal glands, once believed to produce black bile, or atrabilis, the cause of the gloomy disposition. A., Capsules, an old name for the supra-renal capsules.

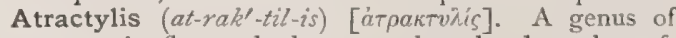
composite-flowered plants, nearly related to the safflower (Carthamus). A. gummifera, of the Mediterranean region, affords acanthomastic. A. lancea, of 
China and Japan, is stomachic and tonic. A. ovata, of the same regions, is tonic, diuretic, sudorific, and stimulant.

Atramental (at-ram-en'-tal) [atramentum, ink]. Of an inky-black color.

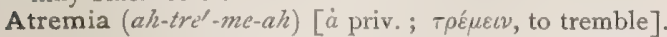
1. An absence of tremor. 2. An hysterical condition in which there is an imaginary inability to walk, stand, sit, or read.

Atreselytria (at-res-el-i'-tre-ah), See Atretelytria.

Atresenteria (at-res-en-te'-re-ah). See Atretenteria.

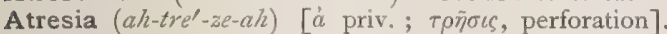
Imperforation, either congenital or acquired, of a normal opening or canal, as of the anus, vagina, meatus auditorius, pupil, etc. The word is often compounded with the name of the organ affected; e. g., atrestocystia, atretenteria, etc., denoting, respectively, imperforation of the bladder, intestine, etc.

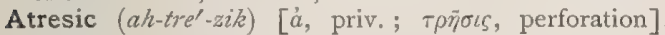
Marked by atresia or imperforation. See Teratism.

Atresoblepharea (at-res-o-blef-a'-re-ah). See Alreto. blepharea.

Atresocysia (at-res-o-sis'-e-ah). See Atretocysia

Atresocystia (at-res-o-sis'-te-ah). See Atretocystia.

Atresogastria (at-res-o-gas'-tre-ah). See Atretogastria.

Atresometria (at-res-o-me'-tre-ah). See Atretometria.

Atresopia (ah-tres-o'-pe-ah). See Atretopsia.

Atretelytria (at-ret-el-i'-tre-ah) [à $\rho \eta \tau$ os, imperforate; $\dot{\varepsilon} \lambda v т \rho 0 \nu$, sheath]. Atresia of the vagina.

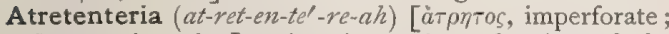
$\varepsilon ้ \nu \tau \varepsilon \rho \circ$, intestine]. Atresia, or imperforation of the intestinal canal.

Atreto- $\left(a t-\right.$ ret'-o $^{\prime}$. As a prefix, represents the Gr. àr $\eta \tau T$, imperforated.

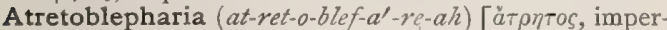
forate; $\beta \lambda \dot{\varepsilon} \phi a \rho o v$, lid]. Symblepharon, $q . v$.

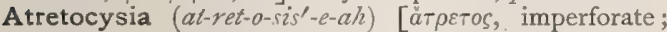
$\kappa v \sigma o ́ s$, anus]. Atresia of the anus.

Atretocystia (at-ret-o-sis'-te-ah) [ăTperos, imperforate;

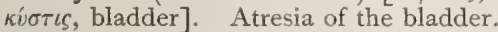

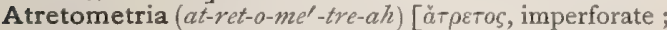
$\mu$ ít $\rho$, womb]. Atresia of the uterus.

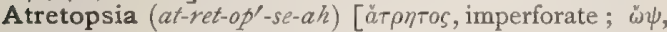
eye]. Imperforation of the pupil.

Atrial $\left(\alpha^{\prime}\right.$-tre- $\left.\alpha l\right)$ [atrium, the fore-court, or hall]. Relating to an atrium.

Atrichia (ah-trik'-e-ah) [áa priv. ; $\theta \rho i \xi$, hair]. Loss or absence of the hair.

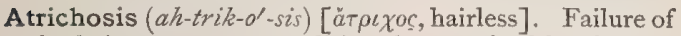
the hair to grow; a condition characterized by absence of hair.

Atrioventricular (a-tre-o-ven-trik'-u-lar) [atrium, the hall; ventriculus, ventricle]. Relating both to the atrium (or auricle) and to the ventricle of the heart.

Atrium ( $a^{\prime}$-tre-um) [atrium, the fore-court, or hall]. I. That part of the auricle of the heart into which the venous blood is poured. 2. The principal part of the tympanic cavity of the ear, exclusive of the attic. A. cordis, the auricle of the heart: A. vaginæ, the vestibule of the vulva.

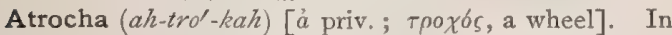
biology, wheelless, as certain annelid embryos, rotifers, etc. ; destitute of cilia.

Atrolactinic Acid (at-ro-lak-tin'-ik). See Acid.

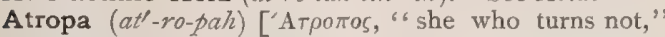
undeviating; one of the three Fates, who cut the thread of life, in allusion to the poisonous effects of the plant]. A genus of the natural order Solanacea. A. belladonna, the deadly nightshade, whence is obtained atropin. See Belladonna.

Atropal, or Atropous (at'-ro-pal: at'-ro-pus). See Orthotropous.
Atrophia (at-ro'-fe-ah) [a priv.; $\tau \rho \circ \phi \dot{y}$, nourishment]. Atrophy, q. $v$. A term applied to a condition marked by wasting or innutrition. A. cordis, atrophy of the heart, following senile changes, or occurring in cachectic conditions, or as a result of pressure exerted by mediastinal tumors, etc. A. cutis, Atrophoderma ; a term applied to various changes in the skin characterized by the diminution or disappearance of certain of its elements, especially seen in advanced age. The skin becomes thin, loose, wrinkled, and discolored. A. cutis senilis, Senile Atrophoderma; an atrophy of the skin usually associated with general signs of senile degeneration. The whole skin may be affected, together with its appendages and the subcutaneous tissues. The skin is in folds, slightly shrunken, wrinkled, and dry. It feels thin, and is transparent and shining. Pruritus is sometimes present, and there is usually an increased pigmentation, with warty de velopments. A. infantum. Synonym of Tabesmesenterica. A. mesenterica. Synonym of Tabes mesen terica. A. pilorum propria, atrophy of the hair, either symptomatic or of idiopathic origin. It may be local or generalized. The hair becomes lusterless, brittle, fibrillated, readily cleft, and readily fractured. A. unguis, atrophy of the nails; marked by pitting, brittleness, furrowing, thinning, crumbling, etc. It may be symptomatic of such disorders as lepra and syphilis, or it may be idiopathic.

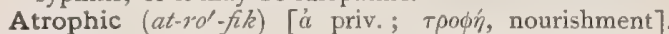
Pertaining to, affected with, due to, characterized by, or causing atrophy. A. Catarrh, a chronic form of rhinitis in children characterized by marked atrophy and anemia of the pituitary membrane, with the formation of crusts in the nasal and naso-pharyngeal cavities and a peculiar and offensive odor. A. Forms, the name suggested by His for those malformations that are characterized by want of general development, and, in some instances, by subsequent atrophy, whereby all resemblance to the human embryo is lost.

Atrophicum melanosis progressiva (at-ro'-fik-um mel-an-o'-sis pro-gres'-iv-ah). See Atrophoderma.

Atrophied ( $a t^{\prime}-r o-f d$ ) [a priv. ; $\tau \rho o \phi \dot{\eta}$, nourishment]. Wasted; affected with atrophy.

Atrophoderma (at-ro-fo-der'-mah) [ả priv.; $\tau \rho o \phi \dot{n}$, nourishment; $\delta \dot{\varepsilon} \rho \mu a$, the skin]. Atrophia cutis, atrophy of the skin, a wasting of the skin due to innutrition. See Atrophia cutis. A. albidum, a type of xeroderma in which the skin from the middle of the thigh to the sole, more rarely from the upper arm to the palm, is in places very white, stretched, and difficult to pick up, with the epidermis extremely thinned, faintly glistening, wrinkled, and peeling off in thin, shining flakes. There is extreme sensibility on the finger-tips, palms, and soles. The condition remains stationary from the earliest childhood. A. neuriticum, Glossy Skin; an atrophy of the skin in the area of a nerve affected by disease or injury. It chiefly attacks the extremities. The skin of the affected part becomes very dry, smooth, and glossy, like a thin scar; the fingers are tapering, hairless, and almost void of wrinkles and of a pink or deep-red color. A severe and persistent burning pain precedes and accompanies this condition. The nails become curved both longitudinally and transversely, and there is some thickening of the cutis beneath the free end. A. pigmentosum. See Xeroderma pigmentosum. A., Senile. See Atrophia cutis senitis. A. striatum et maculatum, an atrophic condition of the skin of adults characterized by streaks of a pearly or bluishwhite color, glistening, scar-like, from one inch to several inches long and a quarter of an inch or more wide, and which follow the natural cleavage of the 
skin, and are situated chiefly about the buttocks, anterior border of the ilium, trochanters, and thighs. The "spots" are less common, small, usually isolated, and are seen mostly on the trunk and neck.

Atrophy $\left(a t^{\prime}-r o-f e\right)$ [ároopia, want of nourishment]. A retrogressive change in parts originally well-formed and well-nourished, consisting in loss of weight, size, and function of an organ or tissue, owing to some disorder of nutrition, disuse, continuous pressure, or a diminished blood-supply to the part. A., Active, due to the inherent inability of the cells of a tissue to assimilate the nutriment brought to them. A., Acute Yellow. See Icterus gravis. A., Brown, a form of atrophy in which the normal pigment of the organ is retained, and in which there is also frequently the addition of new pigment from the blood and disintegrated albuminates. It occurs most frequently in the heart, muscles, and liver, and is caused by chronic congestion; also called Pigmented Atrophy. A. of the Bulb, progressive shrinking of the eyeball. A., Correlated, an atrophy of certain portions of the body following the removal or destruction of other portions. Thus amputation of an arm will be followed by an atrophy of the scapula; of a leg, of the corresponding os innominatum, together with a diminution in the size of the heart and large blood-vessels. A., Cruveilhier's. See Diseases, Table of. A., Gray, a degenerative change in the optic disc in which the latter assumes a grayish color. A. of Hair, a wasting or deficient growth of the hair. A., Idiopathic Muscular, primary muscular dystrophy; muscular wasting, with or without an initial hypertrophy, beginning in various groups of muscles, usually progressive in character, and dependent on primary changes in the muscles themselves. There is a strong hereditary predisposition to the disease. A., Muscular, affects the muscles and may be hereditary or acquired, idiopathic, myelopathic, myopathic, neuropathic, primary, secondary, simple, or progressive. A., Passive, caused by diminished nutrition supplied to the part. A., Pigmentary, so called from a deposit of pigment (yellow or yellowishbrown) in the atrophied fat-cells. A., Pigmented. See A., Brozon. A., Progressive Muscular; Chronic Anterior Poliomyelitis; Wasting Palsy. A chronic disease characterized by progressive wasting of individual muscies or physiologic groups of muscles, and by an associated and proportional amount of paralysis. It is due to a degeneration and atrophy of the multipolar cells in the anterior gray matter of the cord, with consecutive degeneration of the anterior nerve-roots and muscles. The right hand is usually the part first attacked, and it takes on a peculiar clawlike form (main en griffe). The disease is most frequent in males of adult life, and follows excessive muscular exertion. A., Progressive Unilateral Facial, a disease characterized by progressive wasting of the skin, connective tissue, fat, bone, and more rarely the muscles of one side of the face. It is most common in females; its course is slow and generally progressive. Opinions vary as to whether the disease is central or peripheral in origin. A., Red, a form of cirrhosis of the liver due to chronic congestion, as seen in mitral and tricuspid valvular lesions. It is also seen in emphysema and chronic pleurisy with contraction. The cut surface of the liver presents a nutmeg appearancé, and is therefore called the nutmeg liver. A., Serous, that characterized by a transudation of serum into the tissue after the fat has gone, giving it a gelatinous appearance. A. Senile, the physiological variety of Simple Atropliy. A., Simple, the retrogressive processes and shrinking due to patho- logic causes, allied to the physiologic retrogression of senility, but occurring, as it were, prematurely. A. of the Teeth, a name formerly used to designate erosion of the teeth, an affection characterized either by perforations in, or discolored spots of a shriveled, yellowish, or brownish aspect, on the enamel, of two, four, or more teeth in each jaw. A., Trophoneurotic, that dependent upon abnormality of the nervous supply or control of an organ or tissue, best illustrated in muscular atrophy from injury of the proper nerves of the muscle, or in disease of the anterior horns of gray matter of the cord.

Atropina, or Atropin (at-ro-pi'-nah; at'-ro-pin) ["A $\tau \rho o-$ $\pi \circ$, one of the Fates who cut the thread of life: gen., Atropince], $\mathrm{C}_{17} \mathrm{H}_{23} \mathrm{NO}_{3}$. A crystalline alkaloid derived from Atropa belladonna. The sulphate is a white powder of bitter taste, neutral reaction, soluble in water. Homatropin, $\mathrm{C}_{16} \mathrm{H}_{21} \mathrm{NO}_{3}$, is a derivative alkaloid, the hydrobromate being used by ophthalmologists as a mydriatic, principally because its effects pass off more quickly than those of atropin. Homatropin slows the heart, atropin quickens it. Atropin is an irritant narcotic, a mydriatic, antispasmodic, and anodyne; in small doses a cardiac, respiratory, and spinal stimulant, in large doses a paralyzant of the cardiac and respiratory centers, the spinal cord, motor nerves, and voluntary muscles. It produces congestion and dryness of the mucous membrane of the mouth, nose, pharynx, and larynx, at first lessening the gastric and intestinal secretion, to be followed by an increase of the same. It is extensively used in ophthalmic practice to dilate the pupil, paralyze accommodation, and also in various corneal, iritic, and other ocular diseases. Its therapeutic use in general medicine is also manifold; $e . g$., in inflammatory affections and the pain of cerebral and spinal hyperemia, atonic constipation, cardiac failure, hypersecretions, etc., and as a physiologic antagonist in opium poisoning. Dose of atropin sulphate gx. $1 \frac{1}{20}-\frac{1}{60}$. Injectio Homatropina Hypodermica, I in 120. Dose gr. $-\frac{1}{120}-\frac{1}{20}$. A.-catarrh. See Conjunctivitis, Atropin. A.-conjunctivitis. See Conjunctivitis.

Atropinism (at'-ro-pin-izm). See Atropism.

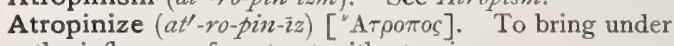
the influence of, or treat with atropin.

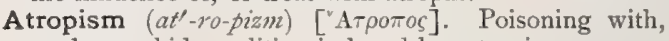
or the morbid condition induced by, atropin.

Attachement (at-tash'-mon(g)) [Fr.]. In massage, concentric curves eccentric; starting from a point taken as a center, one describes, by circular movements, circumferences wider and wider till the outside of the part is reached; return is then made by circles smaller and smaller till the starting point is reached.

Attack $\left(a t-t a k^{\prime}\right)$ [Fr., attainue]. The onset of a seizure or of a disease.

Attar $\left(a t^{\prime}-a r\right)$ [Pers., atar ]. A general name for any of the volatile oils. A. of Rose, Oil of Rose. The volatile oil distilled from the fresh flowers of the Damascene rose. It comes mainly from E. Roumelia and is generally adulterated with other volatile oils. It is used only as a perfume.

Attendant (at-ten'-dant) [attendere, to attend]. A nonprofessional attaché of an asylum or hospital, especially of an insane asylum.

Attention (at-ten'-sinun) [attentio, a giving heed to]. The direction of the will or thought upon an object or to a particular sensation. A. Time. See Time.

Attenuant (at-ten'-u-ant) [attenuare, to make thin]. A medicine or agent increasing the fluidity or thinness of the blood or other secretion.

Attenuating (at-ten'-u-a-ting) [attenuare, to make thin]. Making thin. A. Medium. See Fractional Cultization. 
Attenuation (at-ten-u-a'shun) [attenuare, to make thin]. A thinning, narrowing, or reduction of the strength or size of a substance. A. of Microbes, weakening the pathogenic virulence of microbes by successive cultures and other methods, so that they may be used as a vaccine to confer immunity from future attacks of the disease. A., Sanderson's Method of, by passing the virus through the system of another animal (e.g., the guinea-pig, in anthrax), so that it becomes modified in virulency. Toussaint and Chauveau have shown that heat is a valuable means of attenuation; oxygen, chemical reagents, exposure to sunlight, etc., have also been used.

Atterminal (at-er'-min-al). See Adterminal,

Attic $\left(a t^{\prime}-i k\right)$ [Atticus, Attic]. Part of the tympanic cavity situated above the atrium. A. Disease, chronic suppurative inflammation of the attic of the tympanum.

Attitude (at'-e-tüd) [aptitudo, aptitude]. See Posture. A., Crucifixion, in hystero-epilepsy, a rigid state of the body, the arms stretched out at right angles. A., Frozen, a peculiar stiffness of the gait characteristic of disease of the spinal cord, especially of amyotrophic lateral sclerosis. A., Passionate, the assumption of a dramatic or theatrical expression, a position assumed by some hysterical patients.

Attollens (at-ol'-enz) [attollere, to rise up]. Applied to muscles raising or elevating the part, as the A. Auris, a muscle raising the external ear. See Muscles, Table of.

Attraction (at-rak'-shun) [attrahere, to draw to]. The tendency of one particle of matter to approach another. Affinity. As existing between celestial bodies it is termed gravitation, while molecular attraction or cohesion expresses the force aggregating molecules into masses. A., Chemical, the attraction of affinity', relates to the attraction of atoms of one element to those of others, resulting in chemical compounds. A., Capillary, the tendency of a curved surface or a tube to exert traction on a liquid. A., Electrical, the tendency of bodies toward each other when charged with opposite electricities. A., Magnetic, the influence of a magnet upon certain metallic substances, chiefly iron.

Attrahens (att-rah-enz) [attrahens, drawing]. Applied to muscles, as Attrahens aurem, a muscle drawing the ear forward and upward. See Muscles, Table of: Also applied to medicines attracting fluids to a part, as stimulants, epispastics, etc.

Attrahent (at'-rah-ent) [atirahens, drawing]. I. Drawing to; adducent. 2. A drawing application; an epispastic or rubefacient.

Attrition (at-rish'-un) [atterere, to rub against]. An abrasion or chafing of the skin. In physics, any rubbing or friction that breaks or wears the surface.

Attypic $\left(a t-i p^{\prime}-i k\right)$ [at, to; $\tau i$ isos, a type]. In biology, possessing by acquisition or specialization the characters of a prototype.

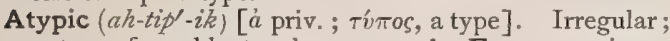
not conformable to the type. A. Fever, an intermittent fever with irregularity of the paroxysm.

Atypical (ah-tip'-ik-al). See Atypic.

Auante $\left(a z v-a n^{\prime}-t e\right)$ [avavtín; avaíveıv, to dry]. A wasting or atrophy.

Auantic (aw-an'-tik) [avaviıb́s, wasted]. Characterized by wasting; atrophic.

Aubernage $\left(0-b \bar{a} r-n a h z h^{\prime}\right)$ [Fr.]. A contagious disease of the vine, called by the Italians the Black Disease. It is doubtful whether it is due to a fungus or a bacterium. Cf. Bacterium gummis, comes, under Bacteria, Synonymatic Table of.

Auburn System. See Ventilation.

Auctioneers' Cramp. See Cramp.
Audimeter (azv-dim'-et-er). See Audiometer

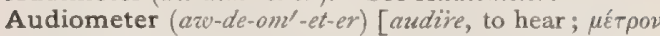
a measure]. An instrument for measuring the acuteness of hearing.

Audiometric (aw-de-o-met'-rik) [audive, to hear; $\mu \varepsilon-p o \nu$, a measure]. Relating to audiometry.

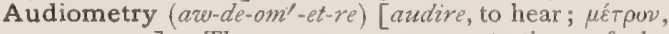
a measure]. The measurement, or testing, of the sense of hearing.

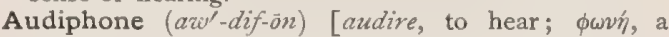
sound]. An instrument for improving the power of hearing by conveying sounds through the bones of the head to the labyrinth.

Audition (aw-dish'-un) [audire, to hear]. 'The act of hearing. A. colorée, a peculiar association between the auditory and optic nerves, by which a certain sound or musical note will give rise to a subjective sensation of color, the same note in the same person being always associated with the same color.

Auditory (aw'-dit-o-re) [audire, to hear]. Pertaining to the act or the organs of hearing. A. After-Sensations, the sensations of sounds continuing or occurring after the cessation of the stimulus. A. Amnesia. See Mind-deafness. A. Area, the cerebral center for hearing; its location is not definitely determined. A. Aura, auditory sensation preceding an attack of epilepsy. A. Center, same as A. Area. A. Hairs, the processes of the crista acustica, at present of indeterminate function. A. Meatus (external and internal), the external and internal canals or openings of the ear. A. Nerve, the portio mollis of the seventh pair of cranial nerves. A. Ossicles, the chain of small bones of the middle ear. A. Sac, the labyrinth, pit, or depression in the epiblast on both sides of the embryologic after-brain. When cut off from the epiblast it is called the vesicle of the labyrinth, or Primary Auditory Vesicle. A. Teeth. See Teeth. A. Vertigo, dizziness due to pathologic conditions of the ear. See Vertigo and Ménière's Disease.

Auditus ( $\left.a w-d^{\prime} i^{\prime}-t u s\right)$ [L.]. Hearing; the sense or power of hearing.

Auerbach's Ganglia. See Ganglia, Table of.

Auerbach's Plexus. See Plexuses, Table of.

Augment (avogi-ment) [augmentum, increase]. The increasing stage of a fever or other acute disease.

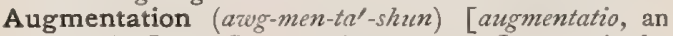
increasing]. I. Same as Augment. 2. Increase in the violence of symptoms.

Augnathus (areg-na'-thus) [aṽ, besides; yvátos, the jaw]. A monster with two lower jaws. See Diprosopus.

Aula $\left(a w^{\prime}-l a h\right)[a \dot{v} \hat{n}$, a hall or open court]. I. The common mesal cavity of the cerebrum, it being also the anterior portion of the third ventricle. 2. In biology, a space or cavity formed by a colony of infusorians.

Aulatela (aw-lat-e'.lah) [aula, a hall; tela, a web] The roof or covering membrane of the aula.

Aulic $\left(a w^{\prime}-l i k\right)$ [ $a \dot{i} \lambda \eta^{\prime}$, a hall]. Belonging or pertaining to the aula. A. Recess, a triangular depression between the precommissure and the two fornicolumns of the brain.

Auliplexus (ave-le-pleks'-us) [aula, hall; plexus, a network]. The choroid plexus of the aula.

Aulix (azo'-liks)[aulix, a furrow]. The sulcus of Monro, a groove on the mesal surface of the thalamus just ventrad of the medicommissure.

Aulophyte $\left(a \tau v^{\prime}-l o-f i t\right)[a \dot{\nu} \lambda \sigma s$, a pipe or tube ; $\phi v \tau o ́ v$, a plant]. In biology, a symbiotic plant; one that lives within another, but not as a parasite.

Aura $\left(a v^{\prime}-r a h\right)$ [ [av $\rho a$, a breath]. A breath of wind; a soft vapor. A sensation sometimes like a gentle 
current of air rising from the limbs or body to the head; a frequent forerunner of an epileptic attack,aura epileptica. Also applied to any slight symptom preceding an attack of any disease or paroxysm, as the aura hysterica, aura vertiginosa, etc. A. seminalis theory, a theory of Swammerdam, who, observing a strong odor from drone bees, supposed that this, permeating the body of the queen, fertilized the eggs.

Aural (azo'-ral) [auris, the ear]. Relating to the ear or to hearing. A. Vertigo. See Ménière's Disease.

Aurally (aw'-ral-e) [auris, the ear]. By means of the ear.

Auramin (aw-ram-in) [aurum, gold; amin]. Yellow Pyoktanin, $q . v$; a yellow anilin color used to some extent as a bactericide and preventive of suppuration. Unof. See Conspectus of Pigments, under Pigment.

Aurantia (aw-ran'-she-ah) [aurantium, an orange]. An orange coal-tar dye; an ammonium salt of hexanitro-diphenyl-amin. The use of this dye has been said to produce skin-diseases. See Conspectus of Pigments, under Pigment.

Aurantium (aw-ran'-she-um) [L. : gen., Aurantii]. Orange. The fruit of Citrus vulgaris and $C$. aurantium. Both the flowers and the rind of the fruit are employed in medicine. The volatile oil from the rind is aromatic and a mild tonic but is used mainly as a flavor. A. amara, Ext. Fld., bitter orange peel, alco-

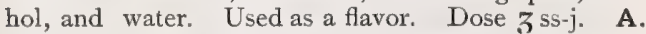
amara, Tinct., bitter orange peel 20 , dilute alcohol, q. s. ad Ioo. Dose $3 \mathrm{j}-\mathrm{ij}$. A. corticis, O1., the volatile oil expressed from the rind of the orange. Dose gtt. j-v. A. dulcis, Tinct., sweet orange peel 20, dilute alcohol, q. s. ad 100. Dose 3 j-ij. A., Elixir, oil of orange I, sugar Ioo, alcohol and water, q. s. ad 300. A. flores, Aq., fresh orange flowers 40 , water 200. Distil to I00 parts. A. florum, Ol., " oil of neroli," a volatile oil distilled from fresh orange flowers. Dose gtt. j-v. A. florum, Syr., sugar 85, orange-flower water q. S. A flavoring-agent. A., Infus. (B. P.). Dose $\zeta j-i j$. A., Infus., Comp. (B. P.). Dose Zj-ij. A., Spt., oil of orange 6, alcohol 94. Dose according to quantity of alcohol desired. A., Spt., Comp., oil of orange-peel, 20, oil of lemon 5 , oil of coriander 2 , oil of anise 5 , deodorized alcohol q. s. A., Syr., sweet-orange peel, precipitated calcium phosphate, each 5, sugar 70, alcohol and water q. s. A., Tinct. (B. P.). Dose $3 \mathrm{j}-\mathrm{ij}$. A., Tinct. Recentis (B. P.), tinct. of fresh orange-peel. Dose 3 j-ij. A., Vinum (B. P.), I 2 per cent. of alcohol. Auricle (az $\left.\ell^{\prime}-r i k-l\right)$ [auricula, the outer ear]. The pinna and external meatus of the ear. The auricles of the heart are the two cavities between the veins and the ventricles. See Circulation, and Heart.

Auricular (aw-rik'-u-lar) [auricula, the outer ear]. Relating to the auricle, or to the ear; as the auricular nerve, arteries, veins, etc. The Auricular arteries, anterior and posterior, are branches of the temporal and external carotid, supplying the auricle of the ear. A. Finger, the little finger. A. Fissure. See Fissure. A. Foramen, the outlet of the meatus of the ear. A. Lymphatics, small lymphatic glands near the upper end of the sterno-mastoid muscle. A. Point, the central point of the auricular foramen. See Craniometrical Points.

Auriculars (aw-rik'-u-larz) [auricula, the ear]. In biology, the feathered area that conceals the ears in most birds; regio-auricularis.

Auriculo-bregmatic (aw-rik'-u-lo-breg-mat'-ik) [auricula, the ear; $\beta \rho \varepsilon \gamma \gamma \mu \alpha$, a soft spot]. Relating to the auricle and to the bregma.

Auriculo-occipital (arb-rik'-u-lo-ok-sip'-it-al) [auricula, the ear; occiput, the back of the head]. Pertaining both to the ear and the back of the head. A. Triangle. See Triangle.

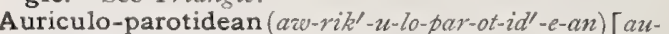
ricula, the ear; $\pi a \rho \omega r i s$, the parotid gland]. Relating to the auricle and to the parotid gland.

Auriculo-temporal (azt-rik'-u-lo-tem'-po-ral) [auricula, the ear; tempora, the temples]. Relating to the auricle and to the temporal region. A. nerve, a branch of the inferior maxillary, supplying superficial parts about the auricle.

Auriculo-ventricular (aze-rik'-u-lo-ven-trik'-u-lar) [auricula, the ear; ventriculus, the ventricle]. Relating to an auricle and a ventricle of the heart. A. opening, the opening between the auricles and the ventricles of the heart.

Auriform (azv'-rif-orm) [auris, the ear; forma, shape]. Ear-shaped.

Aurigo $\left(a z w-r i^{\prime}-g o\right)[\mathrm{L}$.$] . An incorrect form of the word$ aurugo.

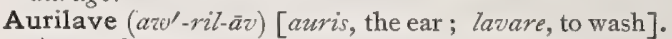
An ear-brush or ear-sponge mounted upon a handle.

Aurin (aw'-rin) [aurum, gold], $\mathrm{C}_{19} \mathrm{H}_{14} \mathrm{O}_{3}$. Pararosolic acid; a body produced on boiling the diazo-hydrochlorid of para-rosanilin with water. It dissolves in glacial acetic acid and alcohol, crystallizes in dark-red needles or prisms with metallic luster, and decomposes when heated above $220^{\circ}$. It is a dye-stuff used in printing calicoes and woolens, and for pigments, and produces orange-red colors. See Conspectus of Pigments, under Pigment.

Auripigment (avo-rip-ig'-ment) [auripigmentum, golden pigment]. See Orpiment.

Auripuncture (aw'-re-punkt-chür) [auris, ear; punctura, puncture]. Surgical or traumatic puncture of the membrana tympani.

Auris $\left(a z \omega^{\prime}-r i s\right)$ [L. ]. The ear.

Auriscalp (aw'-ris-kalp) [auris, the ear; scalpare, to scrape]. An ear-pick or probe for the ear.

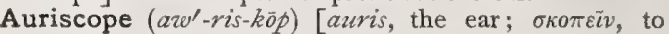
examine]. An instrument for examining the ear, and especially the Eustachian passage; an otoscope.

Aurist (aw'-rist) [auris, the ear]. A specialist in diseases of the ear.

Aurugo $\left(a w-r u^{\prime}-g o\right)$ [L.]. Yellowness; jaundice; icterus.

Aurum (aw'-rum) [L.: gen., Auri]. Gold. Au= I96.7; quantivalence, III. One of the metals characterized as "noble" by the ancients, because of its weight and luster. It has a brilliant yellow color and will not tarnish. The metal is sometimes used as a plate on which artificial teeth are set. The chlorid locally is an escharotic. Internally its action resembles that of mercuric chlorid. In small doses it promotes digestion and stimulates the functions of the brain ; in large doses it is a violent poison. It is useful in certain forms of dyspepsia, hypochondriasis, amenorrhea, and functional impotence. Poisoning is treated by albumen (eggs) or flour, and evacuation of the stomach. A. brom., $\mathrm{AuBr}_{3}$, is used in epilepsy and migraine. Dose gr. $\frac{1}{20} \frac{1}{6}$. A. et sodii chlor., soluble in water. Dose gr. $\frac{1}{30}-\frac{1}{10}$. A. chloridum (unof.). Soluble. Dose gr. $\frac{1}{50}-\frac{1}{80^{\circ}}$. Gold chlorid is also valued as a stain for sections of braintissue and of nerve-ganglia; it has been vaunted as a cure for the alcoholic habit

Auscult, or Auscultate (azes-kult'; aros'-kul-tät) [auscultare, to listen to]. To perform or practise auscultation; to examine by auscultation.

Auscultation (aws-kul-ta'-shun) [auscultare, to listen to]. A method of investigation of the functions and condition of the respiratory, circulatory, digestive, and other organs by the sounds they themselves give out, or 
that are elicited by percussion. It is called immediate, when the ear is directly applied to the part, and mediate, if by the aid of the stethoscope. Obstetric auscultation is practised in pregnancy to detect or study the fetal heart-sounds or the placental murmur. See Murmur, Respiration, Râles, Rhonchus, Bronchophony, Pectoriloquy, Egophony, Bruit, Souffle, etc. A.-tube, in otology, an instrument for listening to the forced passage of air through the ear of another.

Auscultatory (azvs-kul'-tat-or-e) [auscultare, to listen to]. Relating to auscultation. A. Percussion, the practise of auscultation by one person, while another practises percussion.

Australian (azus-träl'-yan) [Australia]. Of or belong ing to Australia. A. Blight. See Angio-neurotic Edema. A. Sassafras. See Atherosperma moschata.

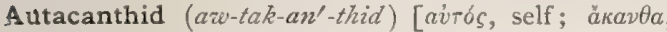
a spine]. In biology, applied to a star-fish having many of the spines on special plates.

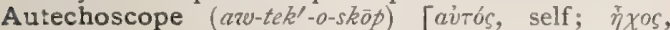

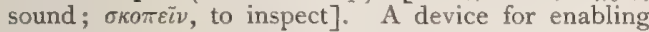
a person to listen to sounds produced within his own body.

Autecious, or Autcecious (azv-te'-shus) [av́tós, self; oikos, dwelling]. In biology, same as Monecious; also applied to parasitic fungi that pass through all the stages of their existence on the same host.

Autenrieth and Hinsberg's Test. See Tests, Table of.

Autocarpous (av-to-kar'-pus) [avjtbs, self; $\kappa a \rho \pi \delta \zeta$, fruit]. In biology, said of a fruit consisting of a superior and free ovary.

Autocatheterism (ave-to-kath'-et-er-izm) [avibs, self; $\kappa a \theta \varepsilon т \dot{\rho} \rho$, a catheter]. The passage of a catheter by a person upon himself.

Autocatheterist (aw-to-kath'-et-er-ist) [aviós, self; $\kappa \iota \theta \varepsilon \tau \dot{\eta} \rho$, a catheter]. One who practises autocatheterism.

Autocatheterization (aw-to-kath-et-er-iz-a'-shun). The process of catheterizing one's self.

Autochthon (aw-tok'-thun) [avib $\chi \theta \omega \nu$, sprung from the land]. An aboriginal inhabitant.

Autochthonous (az-tok'-thon-us) [av̉ó́ $\chi \theta \omega v$, sprung from the land]. Aboriginal; formed (as a clot) in the place where it is found.

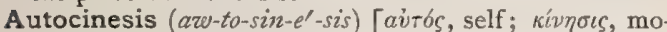
tion]. Motion that is voluntary, or apparently so.

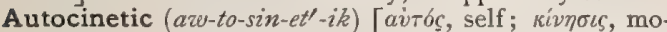
tion]. Possessed of the power of spontaneous motion. Autoclave (aw'-to-klāv) [aítós, self; clavis, a key] I. Self-fastening; closing itself. 2. An instrument for sterilizing or killing germ-life by steam-heat, the gauge indicating automatically the pressure, and therefore the degree of heat, to which the microörganism is sub. jected.

Autodiagnosis (aw-to-di-ag-no'-sis) [aivós, self $\delta \iota a ́ \gamma \nu \omega \sigma \iota s$, a discovering]. Self-diagnosis; the morbid impression sometimes possessed by a patient that he is affected with some particular disease. This impression may amount to a fixed and dominant idea.

Autodidact $\left(a w v^{\prime}-t o-d i-d a k t\right)$ [aviós, self; $\delta \delta \alpha \kappa \tau o ́ s$, taught]. One who is self-taught in his profession.

Autodigestion (azu-to-di-jes'-chun) [aviós, self; digere, to digest]. Digestion of the walls of the stomach by the gastric juice consequent upon loss of the epithelium, or upon other gastric disease. Autopepsia.

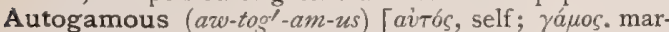
riage]. In botany, a name applied to flowers that are habitually self-fertilizing.

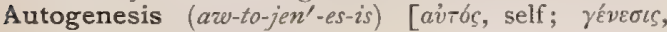
production]. Spontaneous generation; self-production.

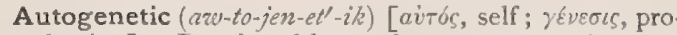
duction]. Developed by or due to autogenesis; produced, as disease, within the organism; not enthetic

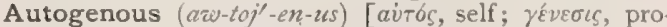
duction]. Pertaining to diseases or conditions selfproducing within the body and not derived from external or objective sources; applied to poisons generated in the body by its inherent processes, - $\ell . g$. , puerperal fever has been falsely supposed to be due to self-generation of the septic material.

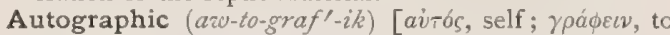
write]. Self-registering. A. Skin, a condition of vaso-motor paralysis, usually in hysterical patients, in which markings made upon the skin form quite persistent and intensely red traces. A. Woman, one with an Autographic Skin.

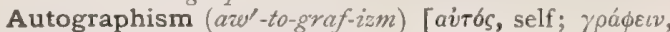
to write]. The condition observed in the so-called autographic skin; dermographism. See Urticaria factitia.

Autographist (aw $v^{\prime}$-to-graf-ist) [aviós, self ; $\gamma \rho a ́ \phi \varepsilon c \nu$, to write]. One who has an autographic skin.

Autohypnotism (aw-to-hiṕ-not-izm) [avitós, self; $\ddot{\pi} \pi$ os, sleep]. Mental stupor induced by dwelling intensely upon some all-absorbing delusion. See also Staturolence.

Autoinoculation ( $\left.a z v-t o-i n-o k-u-l a^{\prime}-s h u n\right)$ [avirós, self; inoculare, to implant]. Reinoculation by virus obtained from the same person.

Autointoxication (aw-to-in-toks-ik-a'shun). See $A u$ totoxic.

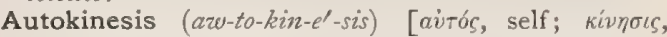
movement]. I. Voluntary movement; movement not reflex or allokinetic. 2. Movement that is apparently not volitional, but that arises from causes within the organism.

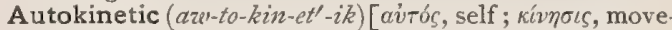
ment]. Pertaining to, or of the nature of, autokinesis.

Autolaryngoscopy (azo-to-lar-ing-gos'-ko-pe) [avibs,

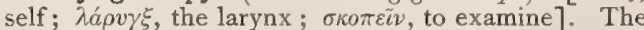
examination of one's larynx by himself.

Auto-massage (are-to-mas-sahzh') [avitbs, self; $\mu a ́ \sigma$. $\sigma \varepsilon \iota v$, to knead]. Self-massage ; therapeutic manipula tions of the body performed by the patient himself.

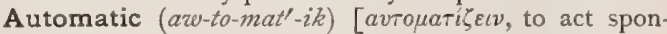
taneously]. Performed without the influence of the will. A. Plugger, an instrument adapted for pounding gold foil in the cavities of teeth.

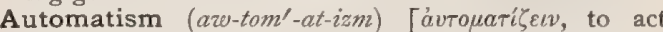
spontaneously]. The performance of acts without apparent volition, as seen in certain somnambulists and in some hysterical and epileptic patients.

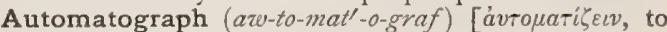
act spontaneously; ypá $\varphi \varepsilon \iota v$, to record]. An instrument for registering involuntary movements of the hand.

Automaton (aw-tom'-at-on) [aviountos, spontaneous]. One who acts in an involuntary or mechanical manner. A. Blowpipe. See Blowpipe.

Automysophobia (arv-to-mis-o-fo'-be-ah) [avitó, self; $\mu$ vi $\sigma o \varsigma$, filth; $\phi \dot{\beta} \beta o \varsigma$, fear]. Insane dread of personal uncleanliness.

Autonomy (azv-ton'-o-me) [aviós, self; vó $\mu o s$, law]. The independent existence of a disease or of a materies morbi within the organism.

Autonyctobatesis (arw-to-nik-to-bat-e'-sis) [avitbs, self;

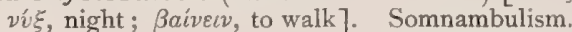

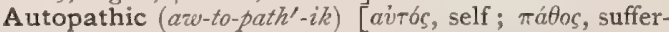
ing]. The same as Endopathic.

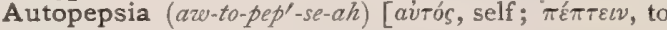
digest $]$. Autodigestion.

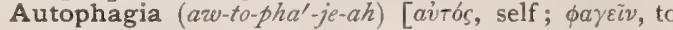
eat]. Self-consumption; emaciation. 


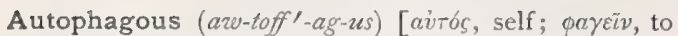
eat]. In biology, self-feeding as soon as hatched.

Autophagy (aw-toff'-a-je) [aviós, self; $\phi a \gamma \varepsilon \tilde{i} \nu$, to eat]. In starvation the absorption of the tissues themselves for nutrition. Life may be thus continued until about half the body-weight has been consumed.

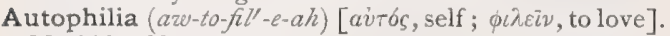
Morbid self-esteem

Autophobia (au-to-fo'-be-ah) [avitós, self; $\phi 6 \beta o s$, fear]. A morbid dread of one's self, or of solitude.

Autophonia (are-to-fo'-ne-ah). See Autophony.

Autophonomania (aw-to-fo-no-ma'-ne-ah) [avioфovia, suicide; $\mu a v i ́ a$, madness]. Suicidal mania.

Autophonous (aw-toff'-on-us) [aírós, self; $\phi \omega \nu \eta ́$, ,
[ voice]. Having the character of autophony.

Autophony (aw-toff'-o-ne) [av่tós, self; $\phi \omega \nu \eta ́$, voice]. In auscultation, the peculiar quality of the physician's own voice while listening to the patient's chestsounds

Autophthalmoscope (aw-toff-thal'-mo-skopp). See $O p h$ thalmoscope.

Autophyllogeny (azv-to-fil-oj'-en-e) [aviós, self; $\phi \hat{v} \lambda \lambda o \nu$,

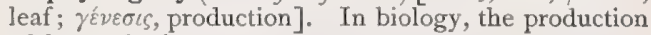
of leaves by leaves.

Autoplast (aw'-to-plast $)$ [aviós, self; $\pi \lambda a ́ \sigma \sigma \varepsilon \omega$, to form]. In biology: 1. The chlorophyll body. 2. A cell of independent spontaneous origin.

Autoplasty (azo'-to-plas-te) [aivós, self; $\pi \lambda a ́ \sigma \sigma \varepsilon \imath \nu$, to form]. A method of repairing the effects of a wound or lesion involving loss of tissue by grafting or implanting fresh parts taken from other portions of the patient's body.

Autopsic $\left(a r v-t o p^{\prime}-s i k\right)$ [avंtós, self; ó $\psi \iota s$, a seeing]. Relating to an autopsy.

Autopsy (aw'-top-se) [aítós, self; ö $\psi \iota s$, a seeing]. I. Examination, or seeing one's own self; self-inspection. 2. The post-mortem study of the body of another. The use of the word in this sense, however, is etymologically absurd. See Necropsy..

Autoscope (aw'-to-skōp) [aj̃ós, self; $\sigma \kappa o \pi \varepsilon i v$, to see]. An instrument, e.g., the ophthalmoscope, arranged for the examination of an organ by oneself.

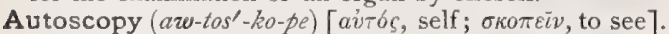
The examination of one's own organs or disease by means of an autoscope.

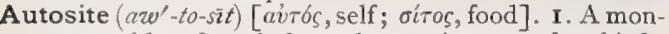
ster capable of an independent existence after birth. 2. That member of a double fetal monstrosity that nourishes itself by its own organs as well as the other member, which is called the parasite.

Autositic $\left(a w-t o-s i t^{\prime}-i k\right)$ [avitós, self; aitos, food]. Of the nature of an autosite.

Autostethoscope (aw-to-steth'-o-skopp) [avibs, self; $\sigma \tau \tilde{\eta} \theta 0$, the breast; $\sigma \kappa o \pi \varepsilon i v$, to examine]. A stethoscope so arranged that by it one may listen to his own chest-sounds.

Autosuggestion (aw-to-sug-jes'-chun) [aviós, self; suggestio, an intimation]. A term suggested by Page for that peculiar mental condition, often developing after railway accidents; it is intimately associated with the hypnotic state. In both of these conditions the mental spontaneity, the will, or the judgment, is more or less suppressed or obscured, and suggestions become easy. Thus the slightest traumatic action directed to any member may become the occasion of a paralysis, of a contracture, or of an arthralgia. It is also called traumatic suggestion.

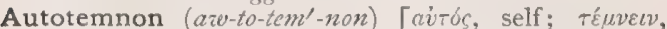
cut]. In biology, the self-dividing unicellular organism.

Autotherapy (aze-to-ther'-a-pe) [airós, self; Beparcia, a waiting on]. The spontaneous or self-cure of a disease.

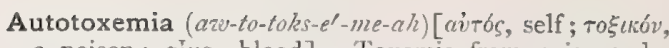
a poison; aika, blood]. Toxemia from poisons derived from the organism itself.

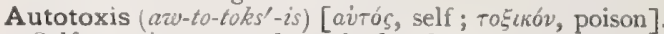
Self-empoisonment through the absorption of noxious products of katabolism, as in uremia. Cf. Autointoxication.

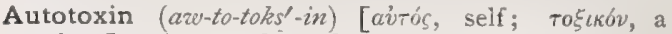
poison]. Any product of tissue-metamorphosis within the organism that has a toxic effect upon that organism.

Autotransfusion (azu-to-tranz-fu'-zhun) [av่tós, self; transfusio, a pouring from one vessel into another]. The transfer of the blood to the brain and other central organs by elevating the hips and legs, and by the use of elastic bandages.

Autovaccination (aw-to-vaks-in-a'-shun) [aviós, self; vaccinare, to vaccinate]. The reinsertion of fresh vaccine-lymph upon the same person from whom it is taken, either by the vaccinated person himself or by some other person, whether intentionally or by accident.

Autumn (aze'tum) [autumnus, autumn]. The fall of the year. A. Catarrh. Synonym of Hay-fever, occurring in August and the fall of the year.

Autumnal (arv-tum'-nal) [autumnus, autumn]. Pertaining to the fall of the year. A. Fever. Synonym of Typhoid Fiever, $q . v$.

Auxanometer (awks-an-om'-et-er) [niv cavecv, to grow; $\mu \varepsilon ́ \tau \rho o \nu$, measure]. An instrument used in biologic study for measuring the growth of young organisms.

Auxe $\left(a z v k s^{\prime}-e\right)[a v \xi \eta$, increase]. Enlargement in bulk or volume.

Auxesis (awks-e'-sis) [av $e_{\zeta} \eta \sigma \iota s$, enlargement]. Increase in size or bulk. Hypertrophy is a word often incorrectly used where Auxesis is meant.

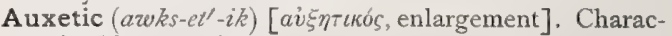
terized by auxesis.

Auxiliary (awks-i $\left.l^{\prime}-e-a-r e\right)$ [auxitium, a helper]. Aiding.

Auxilium (aroks-il"-e-um) [L., "help"]. A wheeled vehicle or ambulance with couch and mattresses, for use in the service of field military hospitals.

Auxocardia (azeks-o-kar'-de-ah) [av̌ $\xi^{\prime} \eta$, an increase; $\kappa a \rho \delta i \alpha$, the heart]. The normal increase of the volume of the heart during diastole, in distinction from meiocardia, the diminution during systole.

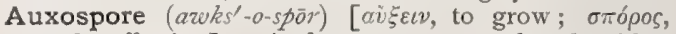
seed, offspring]. A large spore produced, either asexually, or by conjugation, in the Diatomacex.

Auxotonic (aroks-o-ton'-ik) [av $\xi \varepsilon \iota v$, to grow; $\tau 6 \nu 0 s$, tension]. Determined by growth. A. Movements, in biology, movements due to growth rather than to stimulation.

Ava Kava (ah'-vah kah'-vah). See Kava-Kava.

Avalanche Theory. Pfliger's opinion that nerveenergy gathers intensity as it passes toward the muscles.

Aveling's Apparatus. An apparatus employed in the immediate transfusion of blood. A. Curve. The S-shaped curve of the handles of obstetric forceps. A. Operation. See Operations, Table of.

Avena $\left(a v-e^{\prime}-n \alpha h\right)$ [L.]. A genus of plants. Oat. A. farina, oatmeal. A. sativa, the embryo of the the seed of the common oat plant. It contains starch, gluten, a ferment called diastase, and a small amount of allialine phosphates, and is a nutritious food. Dose of the concentrated tinct. or fid. ext. $m x-3 i j$. The pericarp contains an alkaloid possessed of slight narcotic powers. Unof.

Avenin (av-é-nin) [avena, the oat]. I. A precipi. tate made from a tincture of arena sativa, or the oat. It is a nerve-stimulant and tonic. Unof. 2. A 
nitrogenous principle obtained from the oat, and nearly identical with legumin; the gluten-casein of oats.

Avens $\left(a v^{\prime}-e n z\right)$ [Welsh, afans]. A name given to several plants of the genus Geum. A. Root, the root of Geum rivale, a tonic and astringent. It contains

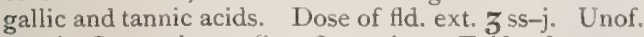

Avery's Operation. See Operations, Table of.

Aviation (a-ve-a'-shun) [avis, a bird]. Artificial flight.

Avidity (av-id'-it-e) [avidus, greedy]. In chemistry, the tendency of certain weak acids, in suitable conditions, to dispossess even the strongest acids and to unite with their bases.

Avocado Pear $\left(a v-o-k a^{\prime}-d o\right)$. See Alligator Pear

Avogadro, Law of. See Law and Ampère.

Avoirdupois Weight (av-or-du-poiz' weatt) [Fr., avoir, to have; du poids, of weight]. The common English weight used for all commodities except precious metals, gems and medicines. The pound is equal to 7000 grains Troy, or 453.54 grams, or I 6 ounces. The ounce is divided into 16 drams, each of 27.34 grains. See Weights and Measures.

Avulsion (av-ul'-shun) [avulsio; avellere, to tear away]. A traumatic or surgical tearing or wrenching away of a part, as a polypus, a limb, etc.

Awn (aivn) [ă $\chi v a$, chaff]. The bristle or beard of barley, oats, etc ; or any other similar appendage.

Axial $\left(a k s^{\prime}-e-a l\right)$ [axis, axis]. Pertaining to or situated in an axis. A. Current. Same as A. Stream. A Hypermetropia. See Hypermetropia. A. Stream. The name given to the red column in a vessel at the seat of inflammation. The blood-corpuscles are separated, the red being packed together in the center of the vessel, while between this and the walls of the vessel is a clear layer of serum in which the white corpuscles roll along. See Poisenille's Space.

Axiferous (aks-if'-er-us) [axis, axis; ferre, to bear]. In biology, producing a stem-like, leafless axis, as certain fungi and algæ.

Axilemma (aks'-il-em-ah) [axis, axis ; $\lambda \varepsilon \mu \mu \alpha$, husk, skin]. In histology, an elastic sheath composed of neurokeratin enclosing the axis cylinder of medullated nerve-fibers.

Axilla $(a k s-i l$-ah) [L.: pl., Axillee]. The armpit.

Axillar $\left(a k s^{\prime}-i l\right.$-ar $)$ [axilla, axil]. In biology, one of the tufts of soft feathers growing from the axilla, and forming part of the under wing-coverts of a bird.

Axillary $\left(a k s^{\prime}-i l-a-r e\right)$ [axilla, axil]. Pertaining to the axilla. A. Artery, the continuation of the subclavian artery, extending from the lower border of the first rib to the insertion of the pectoralis major muscle, where it becomes the brachial. See Arteries, Table of. A. Glands, the lymphatic glands in the axilla. A. Plexus, the brachial plexus, formed by the last three cervical and the first dorsal nerves. A. Space, the irregular conical space of the axilla. A. Vein, a continuation of the brachial, corresponding with the artery and terminating in the subclavian vein.

Axin $\left(a k s^{\prime}-i n\right)$ [axinus]. A fatty and varnish-like substance produced in Mexico by an insect, Coccus aximus. It is used in the arts and locally in medicine, being regarded as a good vulnerary and resolvent.

Axis $\left(a k s^{\prime}-i s\right)$ [L. for axletree]. I. An imaginary line passing through the center of a body. 2. The second cervical vertebra. A., Basicranial, in craniometry, a line drawn from the basion to the middle of the anterior border of the cerebral surface of the sphenoid bone. A., Basifacial, in craniometry, a line drawn from the anterior border of the cerebral surface of the sphenoid to the alveolar point. A., Binauricular, in craniometry, the imaginary line joining the two auricular points. A., Cerebrospinal, the central nervous system. A. Cylinder (of a nerve), the conducting or essential part of a nerve lying in the center and surrounded by the sheath of Schwann. It is also called the axis-cylinder of Purkinje. A., Frontal (of the eye), an imaginary line running through the eyeball from right to left, and corresponding with the movements of elevation and depression of the eyeball. A., Optic, the line from the corneal apex to the macula lutea. A., Optical, an imaginary line passing from the center of the eye-piece of a microscope through the body, objective, stage and sub-stage, to the mirror. A., Sagittal (of the eye), an imaginary line running through the eyeball from before backward, and coinciding with the line of vision. A., Visual, the line from the object through the nodal point to the macula.

Axle Teeth $\left(a k s^{\prime}-l\right.$ teth $)$. See Azzle Teeth.

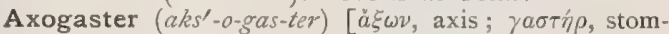
ach]. In biology the principal intestine, the gaster principalis.

Axon $\left(a k s^{\prime}-o n\right)[\ddot{a} \xi \omega \nu$, an axis]. The axis of the body ; especially the bony axis of the neuro-skeleton.

Axospermous (aks-o-sperm'-us) [ $[\hat{a} \xi \omega \nu$, axis; $\sigma \pi \varepsilon \rho \mu a$, seed]. In biology, applied to fruits the seeds of which are attached to an axial placenta.

Axungia (aks-un'-je-ah) [L.: gen., Axungia]. Fat; lard; adeps.

Ayres's Operation. See Operations, Table of.

Azale $\left(a z-\bar{a} l^{\prime}\right)$. See Conspectus of Pigments, under Pigment.

Azalein $\left(\alpha z-a^{\prime}-l e-i n\right)$. Same as Rosanilin. See also Conspectus of Pigments, under Pigment.

Azarin $\left(a z^{\prime}-a r-i n\right)$. See Conspectus of Pigments, under Pigment.

Azedarach $\left(a z-e d^{\prime}-a r-a k\right)$ [Pers. $\hat{a} z a \hat{d}$, free; dirakht, a tree]. Pride of China, the bark of Melia azedarach, an Asiatic tree naturalized in the southern U. S. It occurs in curved pieces or quills, having a sweetish taste. The decoction, $\zeta_{\mathrm{jj}}$ to $\mathrm{Oj}$, is a gastro-intestinal irritant and anthelmintic against the round-worm. Dose Zss-j. A., Ext. Fld. Dose 3j. A., Tinct-

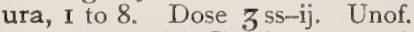

Azerin $\left(\alpha z^{\prime}-e r\right.$-in $)$ [badly formed from $a$ priv. ; $\xi \eta \rho o ́ c$, dry]. A ferment analogous to ptyalin and found in the digestive secretions of Drosera, Nepenthes, and probably all other insectivorous plants. It is actively antiseptic and strongly deliquescent, and hastens rapidly the wetting of flies that fall into its solution.

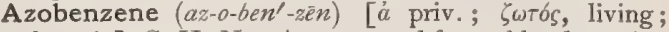
benzoin $], \mathrm{C}_{12} \mathrm{H}_{10} \mathrm{~N}_{2}$. A compound formed by the action of sodium amalgam upon the alcoholic solution of nitro-benzene. It forms orange-red, rhombic crystals, readily soluble in alcohol and ether, but sparingly soluble in water. It melts at $68^{\circ}$, and distils at $293^{\circ}$.

Azo-compounds. In chemistry, compounds intermediate between the nitro-compounds and the amidocompounds, and made from the former by partial reduction, or from the latter by partial oxidation.

Azodiphenyl Blue. Same as Coupier's Blue.

Azo-dyes. A well defined group of the coal-tar colors, all containing the diatomic group $-\mathrm{N}=\mathrm{N}-$, bound on either side to a benzene radical. They may be prepared by reduction of the nitro-compounds in alkaline solutions, or by acting on diazo-compounds with phenols or amins of the aromatic series. The azo-dyes are the amido-derivatives of simple azocompounds, and are to be distinguished as amidoazodyes and oxyazo-dyes. See Conspectus of Pigments, under Pigment.

Azoic $\left(a z-o^{\prime}-i k\right)$ [á priv.; $\zeta \omega \dot{m}$, life]. In biology, destitute of living organisms. 


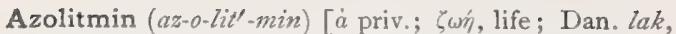
lac; moes, pulp ], $\mathrm{C}_{7} \mathrm{H}_{7} \mathrm{NO}_{4}$. A deep blood-red coloring matter obtained from litmus. See Conspectus of Pigments, under Pigment.

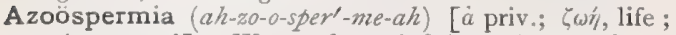
$\sigma \pi \varepsilon \rho \mu a$, seed]. Want of, or deficient vitality of, the spermatozoids.

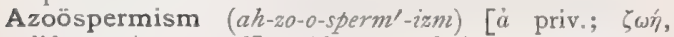
life; $\sigma \pi \varepsilon p \mu \alpha$, seed]. Absence of the spermatic elements from the seminal fluid.

Azorella (az-o-rel'-ah) [L.]. A genus of umbellifer ous plants. A. glebaria. See Balsam Bog.

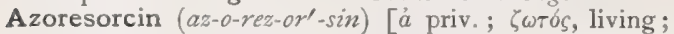
Fr., résorcine], $\mathrm{C}_{12} \mathrm{H}_{9} \mathrm{NO}_{4}$. A derivative of resorcin, occurring as dark-red and greenish crystals.

Azote $\left(\alpha z^{\prime}-\bar{o} t\right)$ [ả priv.; $\zeta \omega \dot{m}$, life]. A synonym of nitrogen. Azotic acid, nitric acid.

Azotemia ( $\left.a z-o-t \ell^{\prime}-m e-a h\right)$ [azotum, nitrogen; ai $\mu a$, blood]. The presence of nitrogenous compounds in the blood; uremia.

Azotenesis (az-o-ten- $\left.\ell^{\prime}-s i s\right)$ [azotum, nitrogen]. Any one of a class of diseases said to be due to a superabundance of nitrogen in the system, such as carcinoma, scurvy, gangrene, etc.

Azotometer (az-o-tom'-et-er) [azotum, nitrogen; $\mu \varepsilon ́ \tau \rho o v$, a measure]. A device for the measurement of nitrogen.

Azoturia (az-o-tu'-re-ah) [azotum, nitrogen; urina, the urine]. An increase of the urea and urates in the urine.

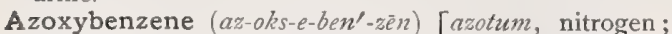
ókus, sharp; benzene $], \mathrm{C}_{12} \mathrm{H}_{10} \mathrm{~N}_{2} \mathrm{O}$. A compound obtained by the reduction of nitrobenzene. It forms long yellow needles, easily soluble in alcohol and ether, but not in water. It melts at $36^{\circ}$.

Azulene $\left(a z^{\prime}-u\right.$-lèn $)$. Same as Cerulein.

Azulin (az'-u-lin). See Conspectus of Pigments, under Pigment

Azure $\left(a z^{\prime}-\bar{u} r\right)$ [ME., azure, blue]. Sky-blue. A. Blue. Same as Cobalt Blue, and Ultramarine, A. Mala chite. See Azurite in Conspectus of Pigments, under Pigment.

Azurin $\left(a z^{\prime}-\bar{u} r-i n\right)$. Same as Azulin.

Azurite $\left(\alpha z^{\prime}-\bar{u} r-\bar{i} t\right)$. See Conspectus of Pigments, under Pigment.

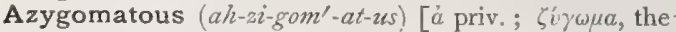
zygomatic arch]. Destitute of zygomatic arches, as the shrews.

Azygos $\left(a z^{\prime}-i g-o s\right)$ [á priv. ; $\zeta v \gamma^{\prime} \delta$ s, a yoke]. Applied to parts that are single, not in pairs. A. uvulæ, a small muscle of the uvula. A. Vein, a vein connecting the superior and inferior venæ cavæ.

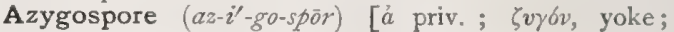
$\sigma \pi \circ \rho a ́$, seed]. An asexually produced spore, but resembling the sexual spore or zygospore.

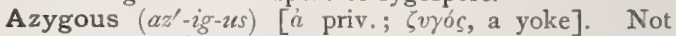
paired ; or, if paired, so blended as to seem one organ.

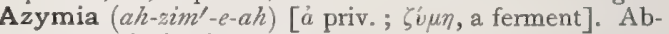
sence or lack of ferment.

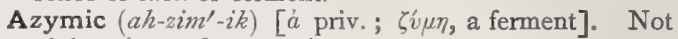
giving rise to fermentation.

Azzle Teeth (az'-l-tèth) [E. dial., assal teeth]. A name given to the molar teeth.
B. In chemical terminology the symbol of Boron.

Ba. The chemical symbol of Barium.

B. A. A contraction of Balneum aqua, a water-bath; also, of Balneum arence, a sand-bath, and of Artium Baccalaureus, Bachelor of Arts.

B. M. A contraction of Balneum maris a sea-water bath; also of Medicine Baccalaureus, Bachelor of Medicine

B. V. A contraction of Balneum vaporis, a vapor-bath.

Babbitt Metal, a compound of metals used in prosthetic dentistry for dies in swaging plates.

Babe $(b \bar{a} b)$ [ME., babe]. An infant.

Babes' Method. See Stains, Table of. B. Oven. See Oven.

Babul Gum ( $b a-b o o l)$ [Bengal]. The gum of the tree Acacia arabica, or babul; an inferior sort of gum arabic.

Baby $\left(b a^{\prime}-b e\right)$. Same as Babe. B.-farm. An institution for raising orphan and pauper infants. B.farming, the business of receiving and caring for the infants of those who, for any reason, may be unable or unwilling to bring up their own children.

Baccaceous $\left(b a k-a^{\prime}-s h e-z e s\right)$ [bacca, a berry]. Like a berry; baccate.

Baccate $\left(b a k^{\prime}-\bar{a} t\right)$ [bacca, a berry]. Berry-like, or bearing berries.

Baccelli's Method. A method of treating aneurysm by passing a wire thread into the sac. See Treatment. B. Sign. See Signs and Symptoms, Table of.

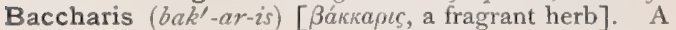
genus of composite trees. B. halimifolia, the ground- sel tree, a composite-flowered shrub of N. America; a decoction of the leaves and bark is a popular demulcent and pectoral medicine. Unof.

Bacchia (bak-'e-ah, or bak-i'-ah) [Bacchus, the god of wine]. A synonym of Acne rosacea, a condition often found in drunkards. B. rosacea. Synonym of Acne rosacea.

Bacillar, or Bacillary (bas'-il-ar; bas'-il-a-re) [bacillum, a rod; bacillus]. I. Relating to bacilli or to a bacillus. 2. Consisting of or containing rods.

Bacilli (bas-il'-i) [bacillum, a rod]. I. Plural of Bacillus, q.v. 2. In pharmacy, cylindrical lozenges made by cutting the lozenge mass, and rolling it into a soft cylinder, on a pill-machine.

Bacillicidal (bas-il-is-i $\left.d^{\prime}-a l\right)$ [bacillum, a rod; cadere, to kill]. Destructive to bacilli.

Bacillicide (bas-il'-is-id) [bacillum, a rod; cadere, to kill]. I. Destructive to bacilli. 2. An agent that destroys bacilli.

Bacilliculture (bas-il'-e-kul-chür) [bacillum, a rod; cultura, cultivation]. The artificial culture of bacilli for the purpose of studying their nature and life.

Bacilliform (bas-il'-if-orm) [bacillum, rod; forma, form]. Having the shape or appearance of a bacillus.

Bacillum (bas-il'-um) [L., a rod, a stick]. A stick; a cylindrical troche; an instrument for carrying a sponge; any one of the rods in the layer of rods and cones of the retina.

Bacilluria (bas-il-u'-re-ah) [bacillum, a rod; ovpov, urine]. The presence of bacilli in the urine. 


\section{TYPES OF BACILLI,} SHOWING MORPHOLOGIC CHARACTERS AND ARRANGEMENT.

\section{䟢}

B. acidiformans $(X 1000)$

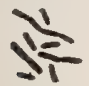

B. acidi lactici $(\times 1000)$.

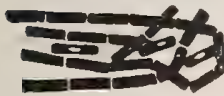

B. œdematis maligni ( $\times$ rooo).

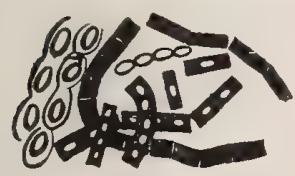

B. anthracis ( $\times 1200)$.

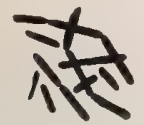

B. arborescens $(\times 1200)$.

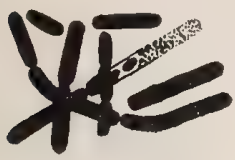

B. buccalis maximus $(X$ I000)

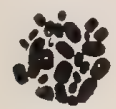

B. buccalis minutus $(\times$ rooo).

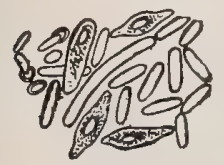

B. butyricus ( $X 1000)$.

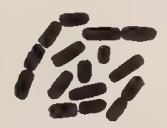

B. cadaveris $(X$ I000)

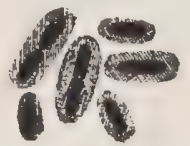

B. capsulatus ( $X$ I200).

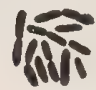

B. cavicida havaniensis ( $X 1000)$.

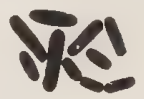

B. circulans $(X 1200)$.

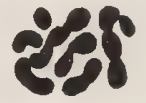

B. crassus sputigenus ( $X \pm 200$ ).

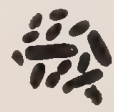

B. cuniculicida havaniensis ( $X 1200$ )

\section{yetos}

B. cyanogenus $(\times 700)$.

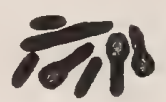

B. of Dantec $(\times 1000)$.

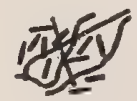

B. diffusus $(\times 1000)$.

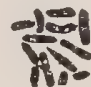

B. diphtheriæ ( $X$ rooo).
B. erysipelatos suis ( $X$ I000).

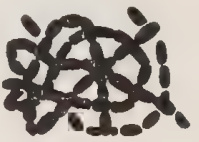

B. gracilis cadaveris $(\times 1200)$.

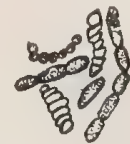

B. granulosus $(\times 800)$ Those without granules represent ab. normal forms.

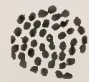

B. havaniensis ( $\times$ I000).

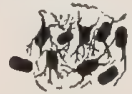

B. of Hog Cholera (X I000),

B. of influenza ( $X 1000)$.

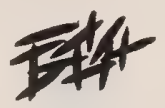

B. lepræ (X 1200).

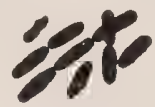

B. limosus (X 1000)

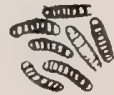

B. mallei ( $X$ 1200), 


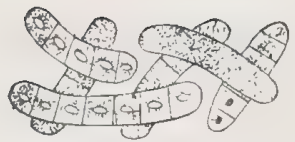

B. megaterium ( $X$ Izoo),

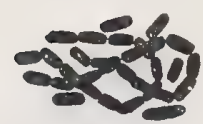

B. mesentericus vulgatus ( $X$ i200).

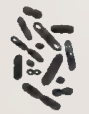

B. neapolitanus $(\times 1000)$.

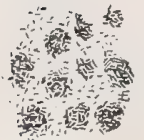

Nitrifying B. of Winogradsky ( $\times 900)$.

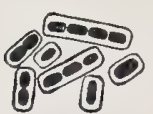

B. pneumoniæ friedländeri $(x$ rooo).

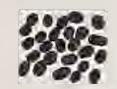

B. prodigiosus ( $\times 1000)$.

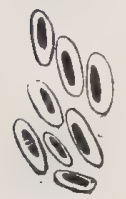

B. rhinoscleromatis $(X \times 400)$.

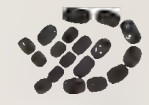

B. scissus ( $\times$ 1200).

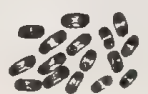

B. septicæmiæ hæmorrhagicæ (X I200).

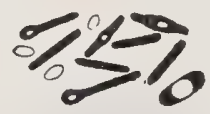

B. of symptomatic anthrax ( $\times 1000)$.

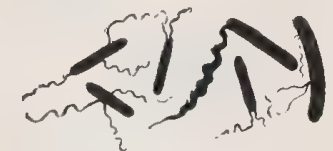

B. of symptomatic anthrax, flagellate form $(\times 1000)$.

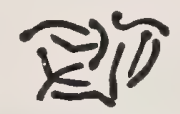

B. syphilidis (Lustgarten) ( $X$ I000).

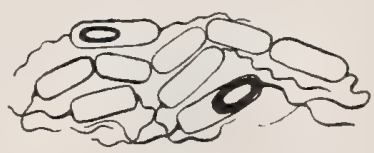

B. subtilis (X 1200$)$.

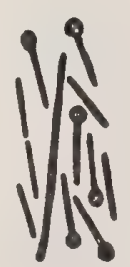

B. totani $(\times$ I200),

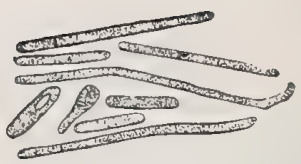

B. thalassaophilus $(\times 1000)$.

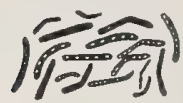

B. tuberculosis ( $X$ 1000),

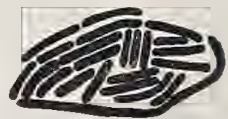

B. typhi abdominalis (X I200).

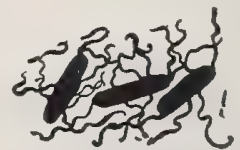

B. typhi abdominalis, showing flagella (X I200).

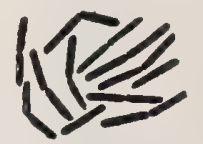

B. ulna of Vignal $(\times 1000)$.

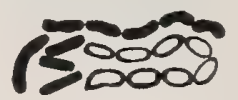

B. vermicularis $(X$ rooo).

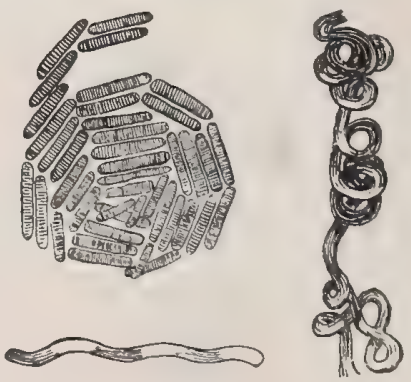

B. zopfii (various stages of growth) (X 1000). 
Bacillus (bas-it'-us) [dim, of baculum; bacillum, a small staft: pl., Bacilli]. (a) A genus of the Schizomycetes established by Cohn; synonym, Bacteridium, Davaine; Bacterium, Delafond; Vibrio, Cohn ; and including all the elongated forms except such as are spiral and have a gyratory motion, which are classed in the genus Spirillum. The bacilli are rigid or flexible, motile or non-motile, and reproduce either by direct fission or by endogenous spore-formation. See Bacteria, Synonymatic Table of. (b) An individual of the genus Bacillus. (c) A medicated rod or bougie. (d) Any rod-like body, or specifically, one of the retinal rods. (e) In botany, the term applied to the cotyledon of certain plants, e. $g$., the hyacinth; or to the basal portion of some flower-clusters.

Back $(b a k)$ [ME., bak]. Dorsum; posterior aspect. B. Combination. See Combination. B. Draught (bak' draft), the inspiration of whooping-cough. B. Posture. See Postures. B. Stroke of the Heart. See Diastole.

Backache $\left(b a k^{\prime}-\bar{a} k\right)$ [ME., bak; aken]. Pain in the back.

Backbone $\left(b a k^{\prime}-b o \bar{n}\right)$ [ME., bak; boon]. The vertebral column.

Back-cut of Salmon. See Salmon, and Operations, Table of.

Bacony Infiltration $\left(b a^{\prime}-k o n-e\right.$ in-fl-tra'-shun). Same as Albuminoid Infiltration.

Bacteremia (bak-ter-e'-me-ah) [bacterium, rod; ai $\mu a$, blood]. The presence of bacteria in the blood.

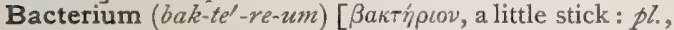
Bacteria]. I. A genus of schizomycetous fungi established by Ehrenberg $\left(183^{8}\right)$ and Dujardin (1841); characterized by short, linear, inflexible, rod-like forms, without tendency to unite into chains or filaments. 2. The distinction between the genus Bacte rium (Dujardin), and the genus Bacillus (Cohn) is not well founded, and all straight, elongated forms should be referred to the latter genus. The word bacteria as now employed is practically synonymous with Schizomycetes, Microörganisms, or Microbes, and includes those minute Thallophytes, with or without chlorophyll, related on the one hand to the Nostocacece, and on the other to the Flagellata. Morphologically, bacteria are either spherical (cocci); in the form of straight rods (bacilli); or of twisted rods (spirilli). They occur either free, as filaments in layers, or in cube-like packets. Frequently large gelatinous masses called Zoögloa are formed. As regards growth they are grouped either as Endosporous bacteria, including those that form spores endogenously; or as Arthrosporous bacteria, including those that multiply by fission. Bacteria are either aërobic, $i . e_{\text {., }}$ dependent upon the presence of free oxygen for the purpose of vegetation, or anaërobic, in which free oxygen is not essential, as they possess the power of appropriating the oxygen of unstable organic combinations, thus acting as disorganizing, fermentative, or putrefactive agents. Again, certain forms appear to possess the ability to flourish in either condition, and are known as facultative anaërobic. Bacteria are either motile or non-motile; they may exist as saprophytes, facultative parasites, strict, obligate, or true parasites. Those that produce pigment are known as chromogenic; those that produce fermentation as zymogenic; those that affect adversely the health of plants or animals as pathogenic. See Bacteria, Synonymatic Table of, and special terms under appropriate headings.
SYNONYMATIC TABLE OF BACTERIA.*

Actinobacter du lait visqueux, Duclaux. Found in ropy milk. aër., nliqf., npg. Actinobacter polymorphus. See Bacillus butyricus, Prazmowski. Actinomyces bovis, Harz. Syn. Cladothrix bovis, Cladothrix canis, Rabe (?) Found in Actinomycosis and in sputum of tuberculous patients. Discovered by Langenbeck (1845); first correctly described by Israel (1878). Bollinger first to recognize it in cattle. Considered by Paltauf, Israel, and Wolf as a pleomorphic schizophyte. Occurs in grains the size of a poppy-seed; composed of radiating threads. Stains with anilin dyes; is not decolorized by Gram's method. Grows on egg albumin, gelatin, potato, and bouillon. liqf., pg., chg. (Sulphur-yellow.) Æthylbacillus de Fitz. See Bacillus subtilis, Ehrenberg, etc. Amylobacter clostridium, Trecul. See Bacillus butyricus, Prazmowski. A New Bacillus of $\mathbf{M a}$ lignant Edema, Klein. See Bacillus adematis aẽrobicus, Klein. Anthrax bacillus. See Bacillus anthracis, Pollender and Davaine. Arthrobacterium aceti, De Bary. See Bacillus aceti, Kützing. Arthrobacterium chlorinum, De Bary. See $B a$ cillus chlorinus, Engelmann. Arthrobacterium merismopœdioides, De Bary. See Bacillus meris mopcedioides, Zopf. Arthrobacterium pastorianum, De Bary. See Bacillus pasteurianus, Hansen. Arthrobacterium viride, De Bary. See Bacilius viridis, Van Tieghem. Arthrobacterium zopfii. See Bacillus zopfii. Arthro-kokkaceen, Ger. Arthrospore bacteria forming only cocci and cocci-chains. Ascobacillus citreus, Unna and Tommasoli. Syn. Ascococcus citreus. On the skin, in cases of eczema seborrhœicum. aër., liqf, mot., chg. (lemon-yellow), $n p g$. Ascobacterium ulvina, Van Tieghem. Short rods occurring in liquids containing decaying leguminous seeds. Ascococcus billrothii, Cohn. Lobulated masses, producing a viscous fermentation of saccharine fluids and evolving butyric acid in solution of ammonium tartrate. Ascococcus citreus, Unnà and Tommasoli. See Ascobacillus citreus. Ascococcus johnei, Cohn. See Micrococcus botryogenus, Rabe. Ascococcus mesenteroides, Cienkowski. See Leuconostoc mesenteroides, Cienkowski. Ascococcus vibrans, Van Tieghem. Upon water containing Beggiatoce; distinguished from $A$. billrothii by the whirling and oscillating of the cells. Aussatzbacillus, Ger. See Bacillus lepra, Hansen. Bacille aérogène, Fr. See Bacillus lactis aërogenes, Miller. Bacille áerophile, Fr. See Bacillus aërophilus, Liborius. Bacille brun de la pomme de terre, Fr. See Bacillus mesentericus fuscus, Flïgge. Bacille butylique, Fr. See Bacillus butylicus, Fitz. Bacille butyrique, Fr. See Bacillus butyricus, Pasteur. Bacille commune de la pomme de terre, Fr. See Bacillus mesentericus vulgatus, Flügge. Bacille coprogène fétide, Fr. See Bacillus coprogenes fotidus, Schottelius. Bacille cyanogène, Fr. See Bacillus cyanogenus, Hueppe. Bacille de Bienstock, I, II, Fr. See Bacillus subtilis simulans, Bienstock. Bacille de Brieger, Fr. See Bacillus cavicidus, Brieger. Bacille de Denecke, Fr. See Spirillum tyrogenum, Denecke. Bacille de Finkler et Prior, Fr. See Spirillum of Finkler and Prior. Bacille de Hauser. See Proteus mirabilis, Proteus vulgaris, Proteus zenkeri, Hauser. Bacille de Koch. See Bacillus tuberculosis, Koch. Bacille de la chylurie, Fr. See Bacillus of chyluria, Wilson.

* Abbreviations,-aër. = aërobic, anaër. =anaërobic. chg. = chromogenic. facanaër. = facultative anaërobic. liqf. = liquefactive. monom $=$ monomorphic mot. $=$ motile. nligf $=$ non-liquefactive, nmot. $=$ non-motile. npg. $=$ non-pathogenic obl. = obligate. oscl. = oscillating, $p g .=$ pathogenic. phos. = phosphorescent pleom. $=$ pleomorphic. sap. = saprophytic 
Bacille de la coqueluche, Fr. See Bacillus tussis convulsiva, Afanassiew. Bacille de la décomposition de l'albumine, Fr. See Bacillus putrificus coli, Bienstock. Bacille de la diarrhée verte infantile, Fr. See Bacillus of green diarrhea in children, Lesage. Bacille de la diphthérie. See Bacillus diphiheria, Löfler. Bacille de la diphthérie des pigeons, Fr. See Bacillus diphtherice columbarum, Löfler. Bacille de la diphthérie des veaux, Fr. See Bacillus diphtherice vitulorum, Löfler. Bacille de la diphthérie intestinale chez les lapins, Fr. See Bacillus of intestinal diphtheria in rabbits, Ribbert. Bacille de la dysenterie epidemique, Fr. See Bacillus dysenteria, Chantemesse and Widal. Bacille de la dysenterie epizoötique des poules et des dindes, Fr. See Bacillus of Lucet. Bacille de la fermentation butyrique, Fr. See Bacillus butyricus, Prazmowski. Bacille de la fermentation lactique, Fr. See Bacillus acidi lactici, Hueppe. Bacille de la fièvre jaune, Fr. See Bacillus of yellow fever. Bacille de la fièvre puerpérale, Fr. See Bacillus of puerperal fever. Bacille de la fièvre typhoïde, Fr. See Bacillus typhi abdominalis, Eberth. Bacille de la gangrène emphysémateuse progressive. Bacille de la gangrène gazeuse, Fr. See Bacillus actematis maligni, Koch. Bacille de la gangrène senile, Fr. See Bacillus of senile gangrene, Tricomi. Bacille de la lèpre, Fr. See Bacillus lepro, Hansen. Bacille de la malaria, Fr. See Bacillus malaria, Klebs and Tommasi-Crudeli. Bacille de la morve, Fr. See Bacillus mallei, Löffler. Bacille de la nécrose du foie des cochins d'inde, Fr. See Bacillus of necrosis of the liver of guineapigs, Eberth. Bacille de la pest porcine, Fr. See Bacillus of swine-plague, Marseilles, Rietsch, and Jobert. Bacille de la pseudo-tuberculose du lapin, Fr. See Bacillus of pseudo-tuberculosis in rabbits, Mallassez and Vignal. Bacille de la pyemie, Fr. See Bacillus of pyemia, Beltzow. Bacille de la rage, Fr. See Bacillus lyssa, Pasteur. Bacille de la scarlatine, Fr. See Bacillus of scarlet fever, Crooke. Bacille de la septicémie. See Bacillus of septicemia in man, Klein. Bacille de la septicémie du lapin, Fr. See Bacillus septicamice hamorrhagica, Sternberg. Bacille de la septicémie de la souris, Fr. See Bacillus erysipelatos suis, Löfler, Schütz. Bacille de la septicémie gangréneuse de la grenouille, Legrain, Fr. See Bacillus hydrophilus fuscus, Sanarelli. Bacille de la sueur des pieds, Fr. See Bacillus saprogenes, II, Rosenbach, Bacillus fotidus, Passet, and Bacillus graveolens, Bordoni-Uffreduzzi. Bacille de la syphilis, Fr. See Bacillus syphilidis, Lustgarten. Bacille de la tuberculose, Fr. See Bacillus tuberculosis, Koch. Bacille de la tuberculose des vignes, Fr. See Bacillus of tuberculosis of vines, Corvo. Bacille de la tuberculose zoögléique, Fr. See Bacillus of pseudo-tuberculosis in rabbits, Mallassez and Vignal. Bacille de la tetanie, Fr. See Bacillus tetani, Nicolaier. Bacille de l'érysipèle du lapin, Fr. See Bacillus of erysipelas in rabbits, Koch. Bacille de liborius, Fr. See Bacillus butyricus, Prazmowski. Bacille de l'œdème, bacille de l'œdème malin, Fr. See Bacillus adematis maligni, Pasteur, Koch. Bacille de l'urée, Fr. See Bacillus urea, Miquel. Bacille de Lustgarten, Fr. See Bacillus syphilidis, Lustgarten. Bacille de pneumonie, Fr. See Bacillus pneumonice friedländeri. Bacille de Prazmowski, Fr. See Bacillus butyricus, Prazmowski.
Bacille des pomme de terre, Fr. See Bacillus mesentericus vulgatus, Flügge. Bacille du beriberi, Fr. See Bacillus beribericus, De Lacerda. Bacille du cancer, Fr. See Bacillus of carcinoma, Rappin and Scheurlen. Bacille du catarrhe conjonctival. See Bacillus of conjunctival catarrh, Koch. Bacille du charbon, Fr. See Bacillus anthracis, Pollender. Bacille du charbon symptomatique, Fr. See Bacilhus chauvai, Bollinger and Feser. Bacille du choléra, Fr. See Spirillum cholerce asiatice, Koch. Bacille du choléra des poules, Fr. See Bacillus septicamia hamorrhagica, Sternberg. Bacille du érysipèle du porc, Fr. See Bacillus erysipelatos suis, Pasteur. Bacille du farcin du bcuf, Fr. See Bacillus of Nocard. Bacille du foin, Fr. See Bacillus subtilis, Cohn. Bacille du jequirity, Fr. See Bacillus of jequirity ophthalmia. Bacille du lait bleu, Fr. See Bucillus cyanogenus, Hueppe. Bacille du lait jaune, Fr. See Bacillus synxanthus, Ehrenberg. Bacille du lait rouge, Fr. See Bacillus prodigiosus, Ehrenberg. Bacille du mal rouge, Fr. See Bacillus erysipelatos suis, Pasteur. Bacille du pain rouge, Fr. See Bacillus prodigiosus, Ehrenberg. Bacille du rouget du porc, Fr. See Bacillus erysipelatos suis, Pasteur. Bacille du pus bleu, Fr. See Bacillus pyocyaneus, Gessard. Bacille du pus vert, Fr. See Bacillus pyocyaneus, Gessard: Bacille du rhinosclerome, Fr. See Bacillus rhinoscleromatis, Cornil and Alvarez. Bacille du rhumatisme, Fr. See Bacillus rheumarthritidis, Kussmaul. Bacille du rouge de morue, Fr. See Bacillus of Dantec. Bacille du tétanos, Fr. See Bacillis tetani, Nicolaier. Bacille du xerosis conjunctiva, Fr. See Bacillus of xerosis epithelialis conjunctivæ, Leber, Kuschbert, and Neisser. Bacille en virgule, Fr. See Spirillum cholera asiatica, Koch. Bacille erythrospore, Fr. See Bacillus erythrosporus, Eidam, Cohn. Bacille muriseptique, Fr. See Bacillus erysipelatos suis, Pasteur. Bacille mycoide, Fr. See Bacillus mycoides, Flügge. Bacille néapolitaine, Fr. See Bacillus neapolitanus, Ermmerich. Bacille pneumonique, Fr. See Bacillus pneumonicus agilis, Schou. Bacille puerpérale, Fr. See Bacillus puerperalis, Spillman. Bacille pyogène fetide, Fr. See Bacillus pyogenes fatidus, Passet. Bacille rouge de globig, Fr. Bacille rouge de la pomme de terre, Fr. See Bacillus mesentericus ruber, Globig. Bacille saprogène, Fr. See Bacilius saprogenes, Rosenbach. Bacille septique. See Bacillus septicus, Klein. Bacille septique agrigene, Fr. See Bacillus septicus agregenus, Nicolaier. Bacille typhique, Fr. See Bacillus typhi abdominalis, Eberth. Bacille virgule, bacille virgule cholérique, Fr. See Spirillum cholera asiatica, Koch. Bacillen der Vergährung von Kohlenhydraten, Ger. See Bacilli of fermentation of carbohydrates. Bacillen aus Faeces, Ger. Microbes of the feces. Bacilles de la bouche, Fr. Microbes of the mouth. Bacilles de la fermentation des carbohydrates, Fr. See Bacilli of fermentation of carbohydrates. Bacilles de l'air, Fr. Microbes of the air. Bacilles de l'eau, Fr. Microbes of water. Bacilles de l'intestin, Fr. Microbes of the intestine. Bacilles de l'urine, Fr. Microbes of the urine. Bacilles de, la terre, Fr. Microbes of the soil. Bacilles des selles, Fr. Microbes of the feces. Bacilles du crachat, Fr. Microbes of the sputum. Bacilles du pus, Fr. Microbes of pus. Bacilles chromogéniques, Fr, Chromogenic microbes. Ba-

Abbreviations. $-a \ddot{e} r$. = aërobic. anaër. = anaërobic. chg. = chromogenic. facanaër. = facultative anaërobic. ligf. $=$ liquefac tive. monom. = monomorphic. mot. = motile. nliqf. = non-liquefactive. nmot. = non-motile. np.g. = non-pathogenic. $o b l_{\text {. }}=$ obligate. $0 s c l_{0}=$ oscillating. $p g .=$ pathogenic. phos, $=$ phosphorescent. pleom. $=$ pleomorphic. sap. $=$ saprophytic. 
cilles fluorescentes, Fr. Fluorescent microbes. Bacilles pathogéniques, Fr. Pathogenic microbes. Bacilles du sang, Fr. Microbes of the blood. Bacilles du smegma, Fr. Microbes of the smegma. Bacilles zymogènes, Fr. Zymogenic microbes. Bacilli zymogeni, L. Zymogenic microbes. Bacilli of Butyric Acid Fermentation. Syn., Bacilles de la fermentation butyrique, Fr.; Bacillen der Buttersăuregährung, Ger. See Bacillus butyricus, Hueppe and Prazmowski. Bacillus butylicus, Fitz, Bacilli of Fermentation of Carbohydrates. Syn., Bacilles de la fermentation des carbohydrates, Fr.; Bacillen der Vergährung von Kohlenhydraten, Ger. See Bacillus acidi lactici, Hueppe. Bacillus butyricus, Hueppe and Prazmowski. Bacillus butylicus, Fitz. Bacillus dysodes, Zopf. Bacillus polymixa, Prazmowski. Bacilli of Guillebeau ( $a, b, c)$, obtained from milk of cows with mastitis; give rise to a peculiar fermentation of cheese. (a) aër., facanaër., mot., nliqf. aër., facanaër., liqf., mot.; (c) aër., nliqf. Bacill of Ice. Syn., Eisbacillen. Microbes of ice. Bacilli of Pus. Syn., Bacilles du pus, Fr. ; Eiterbacillen, Ger. Microbes of pus. Bacilli of Putrefaction. Syn., Fäulniss erregende Bacillen, Ger. Microbes of putrefaction. Bacilli of Sputum. Microbes of the mouth. Bacilli of the Air. Syn., Bacilles de l'air, Fr.; Luftbacillen, Ger. Microbes of the air. Bacilli of the Feces. Syn., Bacilles des selles, Fr.; Kotbacillen, Bacillen aus Faeces, Ger. Microbes of the feces. Bacilli of the Intestine. Syn., Bacilles de l'intestine, Fr.; Darmbacillen, Ger. Microbes of the intestine. Bacilli of the Mouth. Syn., Bacilles de la bouche, Fr.; Mundhöhlebacillen, Ger. Microbes of the mouth. Bacilli of the Soil. Syn., Bacilles de la terre, Fr.; Erdbacillen, Bodenbacillen, Ger. Microbes of the soil. Bacilli of the Urine. Syn., Bacilles de l'urine, Fr.; Bacillen des Harns, Ger. Microbes of the urine. Bacilli of Water. Syn., Bacilles de l'eau, Fr. ; Wasserbacillen, Ger. Microbes of water. Bacillo a virgola, Ital. See Spirillum cholere asiatica, Koch. Bacillo buterrico, Ital. See Bacillus butyricus, Prazmowski. Bacillo del carbonchio, Ital. See Bacillus anthracis, Pollender. Bacillo del carbonchio sintomatico, Ital. See Bacillus chanvai, Bollinger and Feser. Bacillo del fieno, Ital. See Bacillus subtilis, Cohn. Bacillo della malaria, Ital. See Bacillus malaria, Klebs and Tommasi-Crudeli. Bacillo del mollusco contagioso, Ital. See Bacillus mollusci, Dominico. Bacillo del sifilide, Ital. See Bacillus syphilidis, Lustgarten. Bacillo della tuberculosi, Ital. See Bacillus tuberculosis, Koch. Bacillo tifoso, Ital. See Bacillus typhi abdominalis, Eberth. Bacillo tuberculare, Ital. See Bacillus tuberculosis, Koch. Bacillo virgolato, Ital. See Spirillum cholere asiatica, Koch. Bacillus a, Vignal. See Bacillus buccalis, Vignal. Bacillus aceti, Kützing, Sommer. Syn., Arthrobacterium aceti, De Bary. Bacillus aceticus, Flügge; Bactérie du vinaigre; Bacterium aceti, Lanzi. Bacterium der Essiggährung; Essigferment; Essigpilz; Micrococcus aceti; Mycoderma aceti, Pasteur. Mycoderme du vinaigre. Ulvina aceti, Kützing. Found in air and vinegar; c-mmon. Large cylindrical cells of varying size. Absorbs oxygen from air and oxidizes alcohol to ace ${ }^{\circ}$ : acid; produces vinegar; may, by further oxidation, convert this into carbonic acid and water. aër., nliqf., mot., npg., pleom. Cf. Bacillus pasteurianum, Hansen; Bacterium xylinum, A. J. Brown. Bacillus aceticus,
Flügge. See Bacillus aceti, Kützing, Bacillus acidiformans, Sternberg. Obtained from the liver of a yellow fever cadaver. aër., facanaër., nliqf., nmot., pg. Bacillus acidi lactici, Hueppe. Syn., Bacterium lactis, Lister. Bactérie ou Bacille de la fermentation lactique, Fr.; Bacterium der Milchsäuregährung, Ger. Found in the air and in sour milk. aër., facanaër., nliqf., nmot., npg. Bacillus actinobacter, Duclaux. Syn., Actinobacter polymorphus. A minute capsulated bacillus, rendering milk gelatinous and ropy. aër., nmot. See Bacillus butyricus, Prazmowski. Bacillus aërogenes, I, II, III, Miller. Syn., Bacterium cërogenes, Miller. Helicobacterium aërogenes, Miller. Three small bacilli from the alimentary tract of healthy persons. aër., nligf., mot., npo. See Bacillus lactis aërogenes, Escherich. Bacillus aërogenes capsulatus, Welch and Nuttall. Found in the bloodvessels in a case of thoracic aneurysm. anaër., nliqf., nmot., $n p g$. Bacillus aërophilus, Liborius. Obtained from the air. dër., liqf., nmot., npg. Syn., Bacille aërophile, Fr. Bacillus aëruginosum. See Bacillus pyocyanezes, Gessard. Bacillus albuminis, Bienstock. Found abundantly in feces. Decomposes albumin, hence its name. aër., mot., npg. Bacillus albus, Becker, Eisenberg. The white bacillus of water. Weisser Bacillus aus Wasser, Ger. aër., nliqf., mot., $n p g$. Bacillus albus anaërobiescens, Vaughan. Found in water. aër., facanaër., nliqf., nmot., npg. Bacillus albus cadaveris, Strassmann and Stricker. Found in blood of cadaver. aër., liqf., mot., pg. Bacillus albus putridis, De Bary. Found in water. aër., liqf., mot., npg. Bacillus allantoides, Klein. Obtained from the air. ä̈r., mot., $n p g$. Not sufficiently studied. Bacillus allii, Griffiths. Syn., Bacterium allii. Found on surface of decaying onions. aër., chg. (green), npg. Bacillus alvei, Cheshire and Cheyne. Syn., Bacillus preussii, Ciesielski. Bacillus melittopthorus, Cohn. Bacillus of foul brood. Bacillus der Faulbrut, Ger. Obtained from bee larva infected with "foul brood." aër., facanä̈r., liqf., mot., pg. Also pathogenic for mice and guinea pigs. Cf. Bacillus of Canestrini. Bacillus amylobacter, Van Tieghem. See Bacillus butyricus, Prazmowski. Bacillus amylovorous, Burrill. See Bacillus butyricus, Botkin, Prazmowski. Bacillus amylozyma, Perdrix. Found in hydrant water (Paris). anaër., nliqf., mot. Pathogenesis not determined. Bacillus anaërobicus liquefaciens, Sternberg. Obtained from contents of intestine of yellow fever cadaver. anaër., ligf., nmot. Pathogenesis not determined. Bacillus anthracis, Pollender and Davaine. Syn., Bacterium anthracicum, Bollinger. Bacterium anthracis, Zopf. Bacterium carbunculare, Pollender, Brauell, Delafond, Davaine. Metallacter anthracis, Trevisan. Bacille du charbon, Fr. ; Bactéridie charbonneuse, Fr.; Bactéridie du charbon, Fr.; Bacillus anthracis e carbonchio, Bacillo del carbonichio, It.; Milzbrandbacillus, Ger. Bacillus of Braxy. Found in the blood of animals and persons infected with anthrax. aër., facanaër., liqf., nmot., pg. Bacillus aquaticus liquefaciens, Pokrowsky. Found in river water (Kura), and hydrant water (Tiflis). Bacillus aquatilis, Frankland. Found in well-water in the chalkformations of Kent, Eng. aër., liqf., mot., npg. Bacillus aquatilis sulcatus, I, II, III, IV, V, Weichselbaum. Found in hydrant water (Vienna). aër., facanaër, nliqf., mot, npg. Bacillus arborescens, Frankland. Found in hydrant water (Lon-

Abbreviations. - aër, = aërobic. anaër. = anaërobic. chg.= chromngenic, facanaër. =facultative anaërobic, liqf.=liquefac tive. monom, = monomorphic, mot. $=$ motile. nliqf, $=$ non-liquefactive nmot. $=$ non-motile. npg. $=$ non-pathogenic. obl. = obligate. ${ }^{\prime} s l_{0}=$ oscillating. $p g,=$ pathogenic. phos. = phosphorescent. pleom. $=$ pleomorphic. sap. $=$ saprophytic 
don). aèr., liqf., oscl., chg. (orange red), nps. Bacillus argenteo-phosphorescens, I, II, III, Katz. Obtained respectively from sea-water, phosphorescent pieces of fish, and cuttle-fish (Sydney, N. S. W). aër., nliqf., mot. (except II), phos., npg. Bacillus argenteo-phosphorescens liquefaciens, $\mathrm{Katz}$. Obtained from sea-water, near Sydney, N. S. W. aër. fucanaër., liqf., mot., phos., npo. Bacillus aurantiacus, Frankland. Found in well-water. aër., nliqf. mot., cho. (orange), npg. Bacillus aureus, Adametz. Found in water; also on the skin in cases of eczema seborrhceicum, Unna and Tommasoli. aër., nligf., mot., cho. (golden yellow). Bacillus 6 , Vignal. See Bacillus buccalis, Vignal. Bacillus B., Hofmann. Found in the larvæ of Liparis monacha. The cause of Flacherie, or Schlaffsucht. Bacillus bei Diphtherie des Menschen, Ger. See Bacillus diphtheria, Klebs and Löffler. Bacillus bei Erysipel am Kaninchen, Bacillus bei Erysipel am Kaninchenohr, Ger. See Bacillus erysipelatosus leporis, Koch. Bacillus bei Lichen ruber, Ger. See Bacillus of Lichen ruber, Laser. Bacillus bei Keuchhusten, Ger. See Bacil lus tussis convulsive, Afanassiew. Bacillus beri-bericus, Lacerda. Syn., Micrococcus of beri-beri, Lacerda, Neisseria, Winkleri. Bacille du beri-beri, Fr. Bacillus of Beri-beri, Eykmann. Found by Lacerda, Pekel haring, and Winkler, in the blood of persons affected with beri-beri. Negative results were obtained by Eykmann and Sternberg. The disease is now held to be identical with dochmiasis, produced by the nematode worm Docltmius duodenalis, Leuckart. See Beri-beri. Bacillus berolinensis indicus, Clässen. Found in water of the Spree. aër., nligf., mot., chg. (indigoblue), $n p g$. Bacillus bienstockii, Bienstock. Found in human feces. mot., pg. Bacillus brassicæ, Pommer. Found in infusions of cabbage-leaves. aër., facanaẹr., liqf., nmot., npg. Bacillus brunneus, Adametz and Weichmann. Found in water. aër., facanaër., nliqf., nmot., npg. Bacillus buccalis, Vignal. Syn., Bacillus ulna, Vignal. Bacillus a, Vignal; Bacillus $b$, Vignal; Bacillus $f$, Vignal; Bacillus g, Vignal; Bacillus $j$,Vignal. Bacillus buccalis fortuitus, Vignal. Bacillus buccalis minutus, Vignal. Leptothrix buccalis, Vignal. From the salivary secretions of healthy persons. aër., liqf., $n p g^{\circ}, \mathrm{chg}$. (golden yellow). Bacillus buccalis maximus, Miller. Found in the mouth of man. Common. Biologic characters undetermined. Bacillus buccalis minutus, Vignal. See Bacillus buccalis, Vignal. Bacillus butylicus, Fitz. Syn., Bacille butylique, Fr. See Bacillus butyricus, Hueppe. Bacillus butyricus, Botkin, Hueppe, Prazmowski. Obtained from milk, hydrant water and well-water, old cheese, garden earth, dust, etc. Syn., Actinobacter polymorphus, Duclaux. Amylobacter clostridium, Trecul. Bacillus actinobacter, Duclaux. Bacillus amylobacter, Van Tieghem. Bacillus butylicus, Fitz. Bacterium navicula, Reinke and Berthold. Clostridium butyricum, Prazmowski. Micrococcus anylovorous, Burrill. Vibrione butyrique, Pasteur. Bacille de la fermentation butyrique, Bacille de Liborius, Bacille de Prazmowski, Bactérie de la fermentation butyrique, Fr.; Bacillo buterrico, Ital. Bacterium der Buttersäuregährung, Butterbacillus, Buttersäurebacillus, Fettbacillus, Liborius' Buttersäure bildender Bacillus, Kartoffelfäulebacillus, Ger. Butylbacillus; Bacillus of butyric acid fermentation; Bacillus of fire-blight; Bacillus of pear-blight; Micrococcus of apple-blight; Micrococcus of pear-blight. One of the most widely diffused forms, exceedingly important and varied in its powers of decomposition. It is typically anaërobic and the chief of all the ferments giving rise to butyric acid as a primary product. It plays an important part in the human economy and in the destruction of plant cellulose. Botkin regards the form observed by him as distinct. aër., facanaër., liqf., mot., npg., pleom. Bacillus butyri fluorescens, Lafar. Occurring in every sample of natural butter examined. See Bacterium butyri colloideum, Lafar. Bacillus melochloros, Winkler and Schröter. Bacillus butyri viscosus, Lafar. Found in butter. aër., nligf., npg. Bacillus cadaveris, Sternberg; obtained from yellow fever cadavers. obl., anaër. (strict), nmot., $p g$. Bacillus canalis capsulatus, Mori. Found in sewer water. aër., facanaër., nliqf., nmot., pg. (for mice; guinea pigs, and rabbits immune). Bacillus canalis parvus, Mori. Found in sewer water. aër., nliqf., nmot., $\not g$. (for mice and guinea pigs). Bacillus candicans, Frankland. Found in soil. aër., nliqf., nmot., npg. Bacillus capsulatus, Pfeiffer. Obtained from the blood of a guinea pig. aër., facanaër., nliqf., nmot., $p g$. (for white mice and house mice, guinea pigs, rabbits and pigeons (septicemia). Cf. Capsule bacillus of Loeb. Bacillus capsulatus mucosus, Fasching. Found in the nasal secretions of man in cases of influenza. aër., facanaër., nmot., nliqf., pg. (for white mice and field mice), $n p g$. (for rabbits and pigeons). Bacillus capsulatus smithii, $a, b, c$, Theobald Smith. Syn., Capsule bacillus of Smith. Found in the intestines of swine. aër., facanaër., nliqf., nmot., $n p g$. According to Smith, possibly identical with $B a$ cillus lactis aërogenes, Escherich. Bacillus carabiformis, Kaczynsky. Found in the stomach of meatfed dogs. aër., liqf., mot., npg. Bacillus carotarum, A. Koch. Obtained from cooked carrots and sugar beets. aër., liqf., nmot., npg. Bacillus catenula, Duclaux. Syn.,7yrothrix catenula. Found in cheese. ancër. (will however grow in air), nmot, $n p g$. Bacillus caucasicus, Kern. Syn., Bacterium caucasicum. Dispora caucasica, Kern. Grains de Kephyr, Fr.; Kefirbacillus, Kefirferment, Kefirpilzglomerat, Hirse des Propheten, Ger. Used in the preparation of the peculiar milk-wine, "Kefir." aër., facanaër., nmot., npg. Bacillus cavicida, Brieger. See Bacillus cavicidus, Brieger. Bacillus cavicida havaniensis, Sternberg. Obtained from intestine of yellow fever cadaver. aër., facancër. nligf. mot. Bacillus cavicidus, Brieger. Syn., Bacillus cavicida. Brieger's bacillus. Bacillus de Brieger, bacterie de la fermentation propionique, Fr. Obtained from human feces. aër., facanaër., nliqf., $p g$. (not for rabbits or mice). Perhaps identical with Bacillus neapolitanus, Emmerich. Bacillus caviæ fortuitus, Sternberg. Found in exudates of guinea pig inoculated with liver from yellow fever cadaver. aër., facanaër., nliqf., mot., npg. Bacillus chauvæi, Bollinger and Feser, Arloing, Cornevin, and Thomas. Syn., Bacillus of symptomatic anthrax. Bacille du charbon symptomatique, Bactéridie du charbon symptomatique, Fr.; Rauschbrandbacillus, Bacillus des Rauschbrandes, Ger. ; Bacillo del carbonchio sintomatico, Ital. Clostridium of symptomatic anthrax. Neelsen and Ehlers. Found in tissues of cattle suffering from symptomatic anthrax, "black leg," or "quarter evil." anaër., liqf., mot., pg. Bacillus chlorinus, Engelmann. Syn., Arthrobacterium chlorinum, De Bary. Bacterium chlorium, Engelmann. Found in infusions of decaying vegetable matter. $a \ddot{e} r .$, sap., chg. (green), $n p g$.

Abbreviations.-aёr. = aërobic. anaër. = anaërobic. chg. = chromogenic. facanaër. $=$ facultative anaërohic. liqf. =lique factive. monom. = monomorphic, mot, = motile. nliqf. =non-liquefactive. nmot. = non-motile. $n p g$. $=$ non-pathngenic $o b l_{0}=$ obligate. $o s c l_{0}=$ oscillating. $p g,=$ pathogenic, phos, = phosphorescent. pleom, $=$ pleomorphic. sap. $=$ saprophytic 
Bacillus choleræ asiaticæ, Koch. See Spirillum cholere asiatica, Koch. Bacillus choleræ gallinarum, Flügge. See Bacillus septicamice homorrhagica, Sternberg. Bacillus chromo-aromaticus, Galtier. Obtained from the carcass of a diseased pig. aër., facanaër., liqf., mot., pg. (for rabbits). Bacillus circulans, Jordan. Found in the water of Merrimac River. aër., facanaër., liqf., mot., npg. Bacillus citreus. See Ascobacillus citreus, Unna and Tommasoli. Bacillus citreus cadaveris, Strassmann. Found in cadaver. aêr., liqf., nmot., chg. (yellow). Bacillus claviformis, Duclaux. Syn., Tyrothrix claviformis, Duclaux. Found in fermenting casein. anaër., pg. Bacillus cloacæ, Jordan. One of the most common microbes in sewage. aër., facanaër., ligf., mot., npg. Bacillus cœruleus, Smith. Found in river water (Schuylkill). aër., liqf., chg. (blue), nipg. Bacillus coli communis. See Bacillus neapolitanus, Emmerich. Bacillus coli similis, Sternberg. Obtained from human liver. aër., facinaër., nligf., nmot., npg. Bacillus constrictus, Zimmermann. Found in water. aër., facanaër., nliqf., mot., chg. (cadmium yellow), npg. Bacillus coprogenes fœtidus, Schottelius. Syn., Darmbacillus von Schottelius, Ger.; Bacille coprogène fetide, Fr. Obtained from intestinal contents of pigs dead of malignant erysipelas. ä̈r., nliqf., nmot., pg. Bacillus coprogenes parvus. Syn., Mäuseseptikämieähnlicher Bacillus, Eisenberg. Obtained from human feces, aèr., nliqf., nmot., pg. Bacillus crassus, Van Tieghem. The broadest known bacterium, $4 \mu$. mot., npg. Bacillus crassus sputigenus, Kreibohm. Syn., Bacillus sputigenus crassus. From the sputum and tongue of man. aër., nliqf., nmot., pg. Bacillus crystallosus. Bacillus cuneatus. Syn., Bacterium cuneatum, Rivolta. Found in the blood and viscera of horses, cattle, and dogs dead of septic processes. pg. Bacillus cuniculicida, Flügge. Bacillus cuniculicidus, Koch. See Bacitlus septicamia hamorrhagica, Sternberg. Bacillus cuniculicida havaniensis, Sternberg. Found in viscera of yellow fever cadavers. aër., facanaër., nliqf. $p g$. Bacillus cuticularis, Tils. Found in water. aër., liqf., mot., chg. (yellow), npg. Bacillus cyaneo phosphorescens, Katz. Obtained from sea water (Australia). aër., facanaër., liqf., mot., phos., chg. (greenish), npg. Bacillus cyanofuscus, Beyerinck. Obtained from glue and Edam cheese. aër., chg., (green, changing to blue, brown, black), liqf., mot., npg. Bacillus cyanogenus, Fuchs. Hueppe, Neelsen. Syn., Bacillus lactis cyanogenus. Bacillus syncyanum. Bacterium cyanogenum, Fuchs, Bacterium syncyanum, Ehrenberg, Schröter. Vibrio cyanogenus, Fuchs. Vibrio syncyanus, Ehrenberg. Bacille du lait blue, Bacille cyanogène, Microbe du lait blue, Fr. Pilz der blauen Milch, Ger. Bacillus of blue milk. Found in milk. aër., nliqf., mot., chg. (grayish blue), npg. Bacillus cystiformis, Clado. Found in urine of patient with cystitis. aerr., nliqf., mot., npg. Bacillus delicatulus, Jordan. Found in hydrant water (Lawrence, Mass.). aër., liqf., mot., npg. Bacillus dentalis viridans, Miller. Syn., Miller's bacillus. Found in carious dentine. cër., facanaër., nliqf., po. Bacillus denitrificans, Giltay and Aberson. Obtained from the soil, air, and sewage. aër., nliqf., mot., npg. Cf. Bacterium denitrificans, Gayon and Dupetit. Bacillus der Akne contagiosa des Pferdes. See Bacillus of horse pox. Bacillus der amerikanischen
Rinderseuche, Canerva. See Bacillus of swine plague, Marseilles. Bacillus des Bindehautcatarrhs, Koch. See Bacillus of conjunctival catarrh. Bacillus der blauen Milch. See Bacillus cyanogenus, Fuchs. Bacillus der Büffeiseuche, Oreste, Armenni. See Bacillus septicamice hamorrhagice, Stemberg. Bacillus der Buttersäuregährung. See Bacillus butyricus, Prazmowski. Bacillus der Chyluria. See Bacillus of chyluria, Wilson. Bacillus der Dachsleber, Marpmann. Found in the necrotic portions from the abscesses in the liver of a badger. Bacillus der Eiweisszersetzung. See Bacillus putrificus coli, Bienstock. Bacillus der Faulbrut. See Bacillus alvei, Cheshire and Cheyne. Bacillus der Frettchenseuche (ferret disease), Eberth and Schimmelbusch. See Bacillus of swine plague, Marseilles. Bacillus des gelben Fiebers. See Bacillus of yellow fever. Bacillus der Hadernkrankheit. See Bacillus hominis capsulatus, BordoniUffreduzzi. Bacillus der Harnstoffgährung. See Bacillus urea, Leube. Bacillus der Hühnercholera. See Bacillus septicamice hamorrhagice, Sternberg. Bacillus der Jequirity Opthalmie, Ger. See Bacillus of jequirity ophthalmia, De Wecker. Bacillus der Kälberdiphtherie, Ger. See Bacillus diphtheria vitulorum, Löfller. Bacillus der Kaninchenseptikämie, Koch. See Bacillus septicamice hamorrhagica, Sternberg. Bacillus der Lepra. See Bacillus lepre, Hansen. Bacillus der Lungen des Rindviehs, Ger. See Bacillus of the lungs of cattle, Lüstig. Bacillus der Malaria, Ger. See Bacillus malaria, Klebs and Tommasi Crudeli. Bacillus der Mäuseseptikämie. See Bacillus erysipelatos suis, Sternberg. Bacillus der Pseudotuberculose der Kaninchen, Ger. See Bacillus of pseudotuberculosis in rabbits. Bacillus des Puerperalfiebers, Ger. See Bacillus puerperalis, Engel and Spillman. Bacillus der Pyämie, Ger. See Bacillus of pyemia, Beltzow. Bacillus der Rinderseuche, Kitt., Ger. See Bacillus septiccmice homorrhagica, Sternberg. Bacillus der roten Milch. See Bacillus prodigiosus, Ehrenberg. Bacillus der schleimigen Milch, Löffler, Ger. See Bacillus lactis pituitosi, Löffer. Bacillus der Schweinepest, Ger. See Bacillus ex pneumo-enteritide suis, Klein. Bacillus der Schweineseuche, Löffler and Schutz. See Bacillus septicamice hamorrhagica, Sternberg. Bacillus der Schweineseuche Marseilles, Rietsch and Jobert. See Bacillus of swine plague, Marseilles. Bacillus der Septikämie bei Mäusen, Ger. See Bacillus erysipelatos suis, Sternberg. Bacillus der Taubendiphtherie. See Bacillus diphtherice columbarum, Löfller. Bacillus der Wildseuche, Hueppe, Ger. See Bacillus septicamice hamorrhagica, Sternberg. Bacillus der Wurmkrankheit. See Bacillus of Nocard. Bacillus der Xerosis epithelialis conjunctivæ. See Bacillus of xerosis epithelialis conjunctivæ, Leber, Kuschbert, and Neisser. Bacillus des Aussatzes, Ger. See Bacillus lepre, Hansen. Bacillus des Blutes, Ger. See Bacillus of the blood. Bacillus des Erysipelas malignum beim Schwein, Ger. See Bacillus erysipelatos suis, Sternberg. Bacillus des Geflügeltyphoid, Ger. See Bacillus septicamice homorrhagica, Sternberg. Bacillus des grünblauen Eiters, Ger, also Bacillus des grünen Eiters. See Bacillus pyocyaneus, Gessard. Bacillus des Harns, Ger. Microbe of the urine. Bacillus des Keuchhustens, Ger. See Bacillus tussis convulsiva, Afanassiew. Bacillus des

Abbreviations.-aër. = aërobic. anä̈r. = anaërobic. chg. = chromogenic. facanaër. = facultative anaërobic. liqf. =liquefactive. $\operatorname{monom} .=$ monomorphic. mot. $=$ motile. nliqf. $=$ non-liquefactive. $n$ mot. $=$ non-motile. npg. $=$ non-pathogenic. $o b l$. = obligate. osct. = oscillating. $p g .=$ pathogenic. phos. = phosphorescent. pleom. $=$ pleomorphic. sap. $=$ saprophytic. 
Milchfaeces, Bacillus des Milchkotes, Ger. See Bacillus neapolitanus, Emmerich, and Bacillus lactis aërogenes, Escherich. Bacillus des Pseudoschweinerotlaufs, Ger. See Bacillus parvus ova tus, Löffler. Bacillus des Rauschbrandes, Ger. See Bacillus chauvai, Bollinger and Feser. Bacillus des Rhinoscleroms, Ger. See Bacillus rhinoscleromatis, Cornil and Alvarez. Bacillus des roten Brodes, Ger. See Bacillus prodigiosus, Ehrenberg. Bacillus des Rotzes. See Bacillus mallei, Löffler. Bacillus des Schweinerotlaufs, Löffler and Schütz, Ger. Syn.,Bacillus erysipelatos suis, Sternberg. Bacillus des Wundstarrkrampfes, Ger. See Bacillus tetani, Nicolaier. Bacillus devorans, Zimmermann. Found in well water. aër. facanaër., ligf., mot., npg. Bacillus diffusus, Frankland. Found in the soil, aër., liqf., npg. Bacillus diphtheriæ, Klebs and Löffler. Syn., Bacillus diphtheriticus, Bacillus diphtheritidis, Micrococcus diplatheriticus, Cohn. Bacillus bei Diphtherie des Menschen, Bacterie der Diphtherie, Ger. Bacille de la diphtherie, Bactérie de la diphtherie, Fr. Found in diphtheritic false membranes. aër., nliqf., nmot., facanaër., pg. Bacillus diphtheriæ columbarum, Löffler. Bacillus der Taubendiphtherie, Bacterium der Diphtherie bei Menschen und Tauben, Ger. Bacille de la diphtherie des pigeons, Fr. From the pseudomembranes in the mouths of pigeons infected with pigeon diphtheria. aerr., nliqf., nmot., pg. Bacillus diphtheriæ vitulorum, Löffler. Bacille de la diphtherie des veaux, Fr. Bacillus der Kälberdiphtherie, Ger. From the pseudomembranes in the mouths of calves infected with epidemic diphtheria; culture experiments unsuccessful. $p g$. Rabbits and guinea pigs immune. Bacillus diphtheriticus, Bacillus diphtheridis, Bacillus diphtheritis. See Bacillus diphtherie, Klebs and Löffler. Bacillus distortus, Duclaux. Syn., Tyroth ix distortus. Found in milk and cheese. aerr., mot., npg. Bacillus dysenteriz, Chantemesse and Widal. Syn., Bacille de la dysenterie epidemique; Microbe de la dysenterie epidemique, Fr. Found in the intestinal contents and viscera of dysentery cadavers. aër., nliqf., $p g$. Bacillus dysodes, Zopf. Syn., Bacterium dysodes. Found in yeast, inducing fermentative changes in bread, causing it to smell disagreeably and to become greasy and unfit for use. Bacillus Emmerich. See Bacillus neapolitanus, Emmerich. Bacillus endocarditidis capsulatus, Weichselbaum. From viscera of man who died of endocarditis with thrombi. aër., nligf., $p g$. Bacillus endocarditidis griseus, Weichselbaum. From the heart in a case of endocarditis recurrens ulcerosa. aër., nliqf., mot., pg. Bacillus enteritidis, Gärtner. Obtained from the tissues of a cow killed on account of sickness attended with mucous diarrhea, and from the spleen of a man who died shortly after eating of the flesh of this cow. aër., nliqf., mot., pg. Dogs, cats, chickens, and sparrows are immune. Bacillus epidermidis, Bizzozero. Syn., Leptothrix epidermidis. Microsporon minutissimum, Burchart. From the epidermis between the toes. aër., nliqf., npg. Bacillus epidermidis, Bordoni-Uffreduzzi. See Bacillus of Scheurlen. Bacillus Epsilon, von Miller. See Spirillum, Finkler-Prior. Bacillus erysipelatos suis, Koch, Löffler, Schütz, Pasteur. Syn., Bacillus erysipelas malionum, Bacillus minimus, Bacillus murisepticus, Flügge. Bacillus septicus, Koch. Bacille de la septicèmie de la souris, Bacille du èrysipèle du porc, Bacille du mal rouge,
Bacille du rouget du porc, Pasteur, Bacille muriseptique, Fr. Bacillus der Mäuseseptikämie, Koch. Bacillus des Rotlaufs, Bacillus des Schweinerot laufs, Löffler, Schütz. Rotlauf bacillus, Ger. Bacillus of mouse septicemia. Bacillus of hog erysipelas. First obtained by Koch by injecting putrefying flesh beneath the skin of mice, afterward by Loffler and Schütz from carcasses of swine dead of "Rotlauf." aër., faca naër., nliqf., pg. Bacillus erysipelatos leporis, Koch. Syn., Bacillus bei Erysipel am Kaninchen, Bacillus bei Erysipel am Kaninchenohr, Ger. Bacille de l'erysipèle du lapin, Fr. Bacillus of erysipelas in the rabbit. Found in the erysipelatous inflammation in a rabbit's ear caused by the injection of mouse's dung. Bacillus erythrosporus, Eidam, Cohn, and Miflet. Syn., Bacille érythrosopore, Fr. Found in putrefying albuminous fluids, water, etc. aër., nligf., mot., chg. (greenish yellow, fluorescent), npg. Bacillus ethaceticus, Frankland. Cause of fermentation of arabinose. Bacillus ex pneumo-enteritide suis, E. Klein, Schütz, Salmon, Cornil, Chantemesse, Selander. Syn., Microbe der Schweinspocken, Ger.; Bacille de la pneumo-entérite du porc, Fr. Bacillus of hog cholera. Found in the intestinal contents, blood, and viscera of swine dead of hog cholera. aër., facanaër. nliqf., mot., pg. Bacillus $f$, Vignal. See Bacillus buccalis, Vignal. Bacillus facultatus, Sadebeck and E. Fränkel. Found in non-malignant pharyngeal mycosis. Bacillus figurans, Crookshank. See $\mathrm{Ba}$ cillus mesentericus vulgatus. Bacillus figurans, Vaughan. Found in water. aër., liqf., mot., nps. Bacillus filiformis, Duclaux. Syn., Tyrothrix filiformis. Found in cheese and milk. aër., mot., npg. Bacillus filiformis, Tils. Found in water. aër., ligf., oscl., npg. Bacillus filiformis havaniensis, Sternberg. From the liver of a yellow fever cadaver. anaër., facanaër., nliqf., nmot., npg. Bacillus fitzianus, Zopf. See Bacillus subtilis, Cohn. Bacillus flavescens, Pohl. Found in swamp water. aër. nligf., chg. (yellow). Bacillus foetidus, Liborius. Syn., Bacterium foetidum. Clostridium foetidus, Liborius. Corpuscles brillants, Micrococci of S. Le. M. Moore. Obtained from soil. anaër, liqf., mot. Bacillus fœtidus lactis, Jensen. From milk. aër., nliqf., $n p g$. Bacillus fotidus ozænæ, Hajek. Obtained from nasal secretions of patients with ozena. aër., facanaër., liqf., mot., pg. Bacillus flavocoriaceus, Eisenberg. Syn, Sulphur yellow bacillus (Adametz). Found in water. aër., nliqf., nmot., chg. (sulphur yellow), npg. Bacillus flavus, Macé. Found in drinking water. aër., liqf., chg. (golden yellow), nmot. Bacillus fluorescens aureus, Zimmermann. Found in hydrant water (Chemnitz). aёr., nliqf., mot., chg. (ocher yellow), npg. Bacillus fluorescens longus, Zimmermann. Found in hydrant water (Chemnitz). aër., nliqf., mot., chg. (grayish yellow), npg. Bacillus fluorescens liquefaciens, Flügge. Common in water and putrefying infusions. aër., liqf., mot., chg. (greenish yellow), npg. Cf. Bacillus viscosus, Frankland. Bacillus fluorescens liquefaciens minutissimus, Unna and Tommasoli. Found upon skin in cases of eczema seborrhœicum. aër., facanaër., liqf., mot., chr., (greenish yellow), $n p g$. Possibly identical with the preceding species. Bacillus fluorescens nivalis, Schmolck. Syn., $B a$ cillus nivalis, Gletscher bacillus, Glacier bacillus. Found in snow and ice water from Norwegian glaciers. aër., liqf., mot., chg. (bluish green), $n p g$. Bacillus fluorescens non-liquefaciens, Schiller.

Abbreviations.-aër. = aërobic. anaër, = anaërobic, chg.= chromogenic. facanaër.=facultative anaërobic. liq̨. = liquefactive, monom, = monomorphic. mot. = motile. nlig.$=$ non-liquefactive, nmot. $=$ non-motile. npg. $=$ non-pathogenic $o b l=$ obligate. ${ }_{0} c l_{0}=$ oscillating. $p g,=$ pathogenic, phos, = phosphorescent. pleom, $=$ pleomorphic. sap. $=$ saprophytic. 
Found in water. aër., nliqf., nmot., chg. (greenish yellow), $n p g$. According to Baumgarten identical with the Bacillus of Lesage. Bacillus fluorescens putidus, Flügge. Found in water. aër, nliqf., mot., chg. (greenish), nfg. Bacillus fluorescens tenuis, Zimmermann. Found in hydrant water (Chemnitz). aër., nliqf., nmot., chg. (greenish yellow), npg. Bacillus fœtidus, Passet. Syn., Bac. terium foetidum, Thin. Clostridium fotidum, Liborius. Corpuscles brillants. Found in cases of fetid sweating feet, in the exudations of mice inoculated with garden earth, and in cases of malignant edema. anaër., liqf., mot., npg. Bacillus foetidus lactis, Jensen. Found in milk. aër., nliqf., npg. Resembles Bacillus neapolitanus, Emmerich. Bacillus fulvus, Zimmermann. Found in hydrant water, (Chemnitz). aër., liqf., nmot., chg. (gamboge yellow), $n p g$. Bacillus fuscus. Obtained from a putrefying infusion of maize, from the air, etc. Cf. Bacterium brunneum, Schröter. Bacillus fuscus limbatus, Scheibenzuber. Obtained from rotten eggs. aër. facanaër., nliqf., mot., chg. (brown), npg. Bacillus galinarum, Klein. Found in blood of chickens dead of a disease resembling chicken cholera. aër. nliqf., nmot.,pg. Bacillus gasoformans, Eisenberg. Found in water. aër., facanaër., liqf., mot., npg. Bacillus gaytoni, Cheshire. The cause of a disease of honey-bees. Cf. Bacillus alvei, Cheshire and Cheyne. Bacillus geniculatus, De Bary. Syn., Tyrothrix geniculatus, Duclaux, Bacterium en zigzag, Fr. Found in the contents of the stomach. aër., nliqf., mot., npg. Bacillus gingivæ, Miller. Bacillus gingivæ pyogenes, Miller. See Bacterium gingive pyogenes, Miller. Found in a filthy mouth, and in purulent dental pulp. aër., facanaër., liqf., $p g$. (for white mice, guinea pigs, and rabbits). $\mathrm{Ba}-$ cillus glaucus, Maschek. Found in water. aër., ligf., nmot., chg. (gray), npg. Bacillus gliscrogenum. See Bacterium gliscrogenum, Malerba. Bacillus glycerinæ, Buchner. See Bacillus subtilis, Cohn. Bacillus gracilis, Zimmermann. Found in hydrant water, (Chemnitz). aër., facanaër., liqf., oscl., npg. Bacillus gracilis anærobiescens, Vaughan. Found in water. aër., facanaër., nliqf., mot., npg. Bacillus gracilis cadaveris, Sternberg. Obtained in human liver. aër., facanaër., nmot., nliqf., pg. Bacillus granulosus, Russel. Found in mud (Bay of Naples). ä̈r., facancër., liqf., nmot. Pathogenesis not determined. Bacillus graveolens, Bordoni and Uffreduzzi. Syn., Bacille de la sueur des pieds, Fr. Compare Bacillus saprogenes, II, Rosenbach, and Bacillus fretidus, Passet. Found on epidermis between the toes of man. aër., liqf., npg. Bacillus guttatus, Zimmermann. Found in hydrant water (Chemnitz). aër. facanaër., liqf., mot., npg. Bacillus halophilus, Russel. Obtained from water and mud (Bay of Naples). aër., liqf., mot. Pathogenesis not determined. Bacillus hansenii, Raspmussen. Found in various nutrient liquids. cièr., mot, chg. (chrome yellow to yellowish brown). Bacillus havaniensis, Sternberg. Syn, , Micrococcus havaniensis, (?) Sternberg. Bacillus havaniensis liquefaciens, Sternberg. Obtained from the surface of the body of patients in the hospital at Havana. aër., nliqf., chg. (blood-red). Bacillus helvolus, Zimmermann. Found in hydrant water (Chemnitz). aër., liqf., mot. (rotary only), chg. (Naples yellow), npg. Bacillus heminecrobiophilus, Arloing. Found in a caseous lymphatic gland of a guinea pig. aër., facanaër., nliqf., mot., pg. Bacillus hepaticus fortuitus, Sternberg. Obtained from the exudations of a guinea pig inoculated with liver from a yellow fever patient. aër., nliqf., mot., npg. Bacillus hessii, Guillebeau. Found in cow's milk. aër., liqf. mot. Pathogenesis not determined. Bacillus hominis capsulatus, Bordoni. Uffreduzzi. Syn., Proteus capsulatus septicus, Banti. Proteus hominis capsulatus, Bordoni-Uffreduzzi. Bacillus der Hadernkrankheit, Bacillus of rag-picker's disease. Obtained from persons dead from rag-picker's disease. cër., nliqf., nmot., $\mathrm{pg}$. Bacillus hyacinthi septicus, Heinz. Found in diseased hyacinths. aër., facanaër., nliqf., mot., npg. Cf. Bacterium hyacinthi, Wakker. Bacillus hyalinus, Jordan. Found in hydrant water (Lawrence, Mass.). aër., facanaër., liqf., mot., npg. Reduces nitrates rapidly. Bacillus hydrophilus fuscus, Sanerelli. Syn., Bacille de la septicémie gangréneuse de la grenouille, Legrain. From the lymph of diseased frogs. aër., liqf., mot., pg. Bacillus implexus, Zimmermann. Found in hydrant water (Chemnitz), aër., ligf., mot., npg. Bacillus incanus, Pohl. Found in swamp water. aër., liqf., mot. Not sufficiently studied. Bacillus indicus, Koch. Syn., Bacillus indicus meber, Koch. Micrococcus indicus, Koch. Found in the intestinal contents of a monkey. aër., facanaër., liqf., mot., chg. (brick-red), pg.(for rabbits). Bacillus indigoferus, Classen. Found in river water (Spree). aër., nliqf., mot., chg. (deep indigo blue), npg. Bacillus indigogenus, Alvarez. Found in an infusion of the leaves of the indigo plant. (Indigofera tinctoria, L.). aër., mot. chg. (indigo blue), pg. Bacillus inflatus, A. Koch. Obtained from the air. aër., liqf., mot., npg. Bacillus intestinus motilis, Sternberg. From the intestinal contents of yellow fever cadavers. aër., facanaër., nliqf., mot., $n p g$. Bacillus inunctus, Pohl. Found in swamp water. aër., facanaër., liqf., mot. Pathogenesis not determined. Bacillus invisibilis, Vaughan. Found in water. aër., facanaër., nliqf., mot., npg. Bacillus iodococcus vaginatus, Miller. See Iodococcus vaginatus. Bacillus iris, Frick. aër., nliqf., nmot. (green), npg. Bacillus janthinus, Zopf. Syn., Bacterium janthinus, Zopf. Violet bacillus, found in sewage (Lawrence, Mass.). aër., liqf., mot., chg. (bluish violet), npg. Bacillus kaukasicus, Ger. See Bacillus caucasicus, Kern. Bacillus klebsii. See Bacillus syphilidis, Lustgarten. Bacillus lacticus, Pasteur. See Bacillus acidi lactici, Hueppe. Bacillus lactis aërogenes, Escherich and Abelous. Syn., Bacillus aërogenes, Bacillus capsulatus, Smith. Bacterium lactis aërogenes, Escherich. Bacille aérogène, Fr.; Bacillus des Milchkotes, Bacillus des Milchfaeces, Ger. Found in the stomach and intestine of healthy adults. aër., facanaër., nliqf., $n p g$. Bacillus lactis albus, Löffler. Found in milk. aër., liqf., mot., npg. Bacillus lactis cyanogenus. See Bacillus cyanogenus, Hueppe. Bacillus lactis erythrogenes, Hueppe and Baginsky. Syn., Bacillus of red milk. Found in milk and the feces of a child. aër., liqf., nmot., chr. (yellow and red), npg. Bacillus lactis pituitosi, Löffler. Syn., Bacillus lactis viscosus, Adametz, Löfler'che Bacillus der schleimigen Milch. Found in milk. aër., nliqf., npg. Bacillus lactis viscosus, Adametz. Found in ropy milk. aër., nliqf., nmot., npg. Capsulated. Bacillus latericeus, Eisenberg. Syn., Ziegelroter bacillus, Adametz. Found in water. aër., nliqf., nmot., chg. (brick red), npg. Bacillus leiodermos, Löffler. Syn., Bacillus liodermos, Flïgge.

Abbreviations. - aër. = aërobic. anaër $=$ anaërobic. $c h g .=$ chromogenic. facanaër. $=$ facultative anaërobic. liqf. $=$ liquefactive. monom. = monomorphic. mot. = motile. nligf. = non-liquefactive. nmot. = non-motile. npg. $=$ non-pathogenic. obl. =obligate. oscl. = oscillating. $\mathrm{pg} .=$ pathogenic. phos. = phosphorescent. pleom. $=$ pleomorphic. sap. $=$ saprophytic. 
Glatthautbildender Kartoffelbacillus, Gummibacillus. Found in milk. aër., liqf., mot., npg. Bacillus leporis lethalis, Gibier and Sternberg. From the intestinal contents of yellow fever patients. aer., ligf., mot., pg. Bacillus lepræ, Armauer and Hansen. Syn., Aussatzbacillus, Bacillus der Lepra, Bacillus des Aussatzes, Ger.; Bacille de la lèpre, Fr.; Bacillo della lebbra, It. Found in leprous tubercles. Cannot be cultivated in ordinary media. Specific pathogenesis settled by inoculation of a condemned criminal. Bacillus leptosporus, L. Klein. Obtained from the air. aër., mot., npg. Bacillus lethalis, Babes. Syn., Proteus lethalis. Proteus bei Lungengangräne des Menschen. Obtained from spleen and lung of patient dead of septicemia. aër., facanaër., liqf., mot., pg. Bacillus limbatus acidi lactici, Marpmann. Found in cow's milk. aër., nliqf., nmot., $n p s$. Bacillus limosus, Russel. Obtained from mud (Bay of Naples). aër., liqf., mot. Pathogenesis not determined. Bacillus lineola. See Bacterium lineola, Cohn. Bacillus liodermos, Flügge. See $B a$ cillus leiodermos, Löffler. Bacillus liquefaciens, Eisenberg. Found in water. aër., liqf., mot., npg. Bacillus liquefaciens bovis, Arloing. Syn., Pneumobacillus liquefaciens bovis. From the lungs of a diseased ox. aër., facanaër., ligf., nmot., pgo. Bacillus liquefaciens communis, Sternberg. Obtained from the feces of yellow fever patients. aër., facanaër., liqf., mot., npo. Bacillus liquefaciens magnus, Lideritz. Found in the exudates of mice inoculated with garden earth. anaër., liqf., mot, npg. Bacillus liquefaciens parvus, Lüderitz. Source same as last. anaër., liqf., nmot., npg. Bacillus liquidus, Frankland. Found in river water (Thames). Common. aër., liqf., mot., npg. Bacillus litoralis, Russel. Obtained from mud (Bay of Naples). ä̈r., facanaër., liqf., mot. Pathogenesis not determined. Bacillus lividus, Plagge and Proskauer. Found in hydrant water (Berlin). aër., facanaër., liqf., mot., chg. (brick red), npor. Bacillus lucens, Van Tieghem. Syn., Bacterium lucens, Van Tieghem. Found on the surface of water: aër., nmot. Brilliant. Bacillus luteus, Flügge. Syn., Bacterium huteum, List. Gelber Bacillus, Ger. Found in superficial layers of gelatin plate culture. ä̈r., nmot., nliqf., chg. (yellow), npg. Bacillus luteus suis, Salmon and Smith. Found in the perivisceral fluids of swine. aër., liqf., mot., chg. (yellow red). Smells like glue. Bacillus lyssa, Pasteur. Syn., Coccobacterium lysse, Rivolta. Lissophyton suspectum, Hallier. Micrococci della rabbia, Ital. Bacille de la rage, Fr.; Hundswutbacillus, Ger. Cf. Bacterium septicum sputigenum, Fraenkel. Found in saliva of hydrophobic patients and animals. Cf. Bacillus septicus sputigenus, Flügge. Bacillus maĩdis, Cuboni. From macerated corn and the feces of pellagra patients. aër., liqf., mot., npg. Bacillus malandriæ, Israel. See Bacillus mallei, Löfler. Bacillus malariæ, Klebs and Tommasi-Crudeli. Syn., Bacille de la malaria, Bacille du sang, Fr.; Bacillus der Malaria, Bacillus des Blutes, Blutbacillus, Ger.; Bacillo della malaria, It. Bacillus of the blood. Obtained from the soil and air of the Campagnia, from swamps, from the blood of malarial patients, etc. Pathogenesis disputed. Bacillus mallei, Löffler. Syn., Bacillus malandria, Israel ; Rotzbacillus, Bacillus des Rotzes, Ger.; Bacille de la morve, Fr. Found in the nasal discharges, nodules, etc., of animals with glanders. aër., facanaër., nmot. (strictly parasitic), $\not g$. (proven by inoculation).
Bacillus martinez, Sternberg. Obtained from the liver of a yellow fever cadaver. aër., facanaër., nliqf., nmot., npg. Bacillus maydis. See Bacillus maidis, Cuboni. Syn., Bacterium maydis, Cuboni ; Batterio della pellagra, It. Bacillus megaterium, De Bary. Found on the leaves of boiled cabbage. aër., liqf., mot., npo. Bacillus melanosporus, Eidam. Obtained from the air. aër., facanaër., chg. (black), npg. Bacillus melittopthorus. See Bacillus alvei, Cheshire and Cheyne. Bacillus melochloros, Winkler and Schrötter. Syn., Bacillus butyri fuorescens, Lafar. Obtained from the dejections of the larva in a wormy apple. aër., liqf., mot., chg. (emerald green), $p_{g}$. (for rabbits). Bacillus membranaceus amethystinus, Eisenberg. Found in well water (Spalato). aër., liqf., nmot., chg. (dark violet), npg. Bacillus meningitidis purulentæ, Naumann and Schäffer. Obtained from pus taken from beneath the pia mater in a person dead of purulent meningitis. aër., facanaër., nliqf., mot., pg. Bacillus merismopœdioides, Zopf. Syn., Arthrobacterium or Bacterium merismopcectioides, De Bary. Obtained from sewage mud; the type of the so-called "tablet cocci." Bacillus mesentericus fuscus, Flügge. Syn., Kartoffelbacillus, Ger. ; Bacille brun de la pomme de terre, Fr. Potato bacillus. Obtained from the air, hay dust, water, etc. Common. aër., liqf., mot., npg. Bacillus mesentericus ruber, Globig. Syn., Kartoffelbacillus; Roter Kartoffelbacillus, Ger.; Bacille rouge de la pomme de terre, Bacille rouge de Globig, Fr. Potato bacillus. Found upon potatoes. aër., liqf., mot., chg. (reddish yellow or pink), $n p g$. Bacillus mesentericus vulgatus, Flügge. Syn., Bacillzes figurans, Crookshank. Proteus vulgaris. Bacille commun de la pomme de terre, Bacille des pomme de terre, Fr.; Kartoffelbacillus, Ger. Potato bacillus. Common. Found in potatoes, water, milk, intestinal contents of man, etc. aër., liqf., $n p g$. Bacillus miniaceus, Zimmermann. See Bacillus muber, Frank and Cohn. Bacillus minimus, Klebs. See Bacillus erysipelatos suis, Koch, etc. Bacillus miriabilis, $\mathrm{Hau}$ ser. Syn., Proteus mirabilis. Bacille de Hauser, Fr. Obtained from decaying animal matter. aër., facanaër., liqf., mot., pg: Bacillus mollusci, Domenico. Syn., Bacillo del mollusco contagioso, Dominico, Ital. Found in molluscum contagiosum: resembles somewhat Bacillus lepre and Bacillus malarice. Pathogenesis disputed, the disease being attributed by some to psorosperms. Bacillus multipediculosus, Flügge. Syn., Bacillus multipediculus. Found in air and water, aër., nliqf., nmot., npg. Bacillus murisepticus, Flügge. See Bacillus erysipelatos suis, Koch. Bacillus murisepticus pleomorphus, Karlinski. Found in purulent uterine discharges. aër., facanaër., liqf., mot., pg. Probably identical with Proteus vulgaris, Hauser. Bacillus muscoides, Liborius. Found in soil, old cheese, cow dung, etc. anaër., nliqf., mot., npg. Bacillus mycoides, Flügge. Syn., Erdbacillus, Ger.; Bacille mycoide, Fr. Common in soil and water. aër., nliqf., mot., $n p g$. Bacillus mycoides roseus, Scholl. Found in the soil. aër., liqf., chg. (red), npg. Bacillus neapolitanus, Emmerich. Syn., Bacillus toli communis, Bacterium coli commune, Escherich, Bacterium neapolitanum, Colon bacillus of Escherich, Emmerich's Bacillus, Emmerich's Neaplerbacillus; Bacille neapolitaine, Fr.; Bacillus des Milchkotes, Bacillus des Milchfaeces, Ger.; Bacillus of Booker, $a$ to $n$.

Abbreviations. - ä̈r. = aërobic. anaër. = anaërobic. cho. = chromogenic. facanaër. = facultative anaërobic. lnqf. $=$ liquefactive. monom. = monomorphic. mot, = motile. nliqf. = non-liquefactive. nmot. = non-motile. npg. = non-pathogenic. $o b l_{0}=$ obligate. oscl.= osciliating. $p g .=$ pathogenic. phos, $=$ phosphorescent. pleom. $=$ pleomorphic. sap. $=$ saprophytic. 
Found in the air, in putrefying infusions and constantly in the alvine discharges of healthy and unhealthy human beings, also in those of many animals. From the blood, various organs and feces of cholera patients at Naples, hence the name. aër., facanaër., nliqf., pg. Bacillus necrophorus, Löffler. Obtained from rabbits after inoculation in the anterior chamber of the eye with portions of condyloma, aër., facanaër., nliqf., pleom., pg. Bacillus nivalis, Schmolck. See Bacillus fuorescens nivalis, Schmolck. Bacillus nodosus parvus, Lustgarten. From the healthy urethra of man. aër., facanaër., nliqf., nmot., npg. Bacillus nubilus, Frankland. From hydrant water (London). aër., facanaër., liqf., npg. Bacillus ochraceus, Zimmermann. From hydrant water (Chemnitz). aër., liqf., mot., chg. (ocher-yellow), $n p g$. Bacillus cedematis aërobicus. A new bacillus of malignant edema, Klein. Found in the exudates of guinea pigs after inoculating with garden earth. aër., facanaër., nliqf., mot., py. Bacillus adematis maligni, Koch. Syn., Bacillus adematis, Koch; Bacillus septicus, Pasteur; Vibrion septique, Vibrion pyogenique, Pasteur; Bacille de l'œè̀me, Bacille de l'œdème malin, Bacille de la gangrène emphysematéuse progressive, Bacille de la gangrène gazeuse, Fr.; Microben der gasigen Gangräne, Ger. Bacillus of gangrene, Bacillus of gangrenous septicemia. Pink bacillus of spreading edema, A. B. Harris. A widely scattered species, obtained from surface soil, dust, putrefying matter, foul water, etc., and from the exudates produced by inoculating animals with garden earth. anaër., liqf., mot., $p g$. Bacillus of Acne Contagiosa of Horses. See Bacillus of horse pox. Bacillus of Afanassiew. See Bacillus tussis convulsive, Afanassiew. Bacillus of Albuminous Decomposition. See Bacillus putrificus coli, Bienstock. Bacillus of Allantiasis, Müller, HoppeSeyler. See also Sarcina botulina, Van den Corput. Cf. Bacillus of choleraic diarrhea from meat poisoning, Klein. Found in poisonous sausages, particularly in "Blunzen." aër., liqf., pg. Bacillus of Alopecia areata, Kasauli. Found attached to the hairs from the diseased patches; easily cultivated. See Micrococcus of Alopecia areata, Robinson, and Bacterium decalvans, Thin. Bacillus of Babes and Oprescu. Obtained from a case presenting symptoms of typhus fever. aër., facanaër., nliqf., mot., pg. Bacillus of Belfanti and Pascarola. Syn., Impftetanusbacillus, Ger. From the pus of wounds in a person dead of tetanus. aër., facanaër., nliqf., nmot., pg. Bacillus of Beri-beri, Eykmann. See Bacillus beribericus, Lacerda. Bacillus of Blue Milk. See Bacillus cyanogenus, Hueppe. Bacillus of Blue or Green Pus. See Bacillus pyacyaneus, Gessard. Bacillus of Booker, $a$ to $n$. Found in alvine discharges of children suffering from cholera infantum; probably varieties of Bacillus neapolitanus, Emmerich. Bacillus of Bovet. Obtained from the intestines of a woman dead of acute choleraic entertis. aër., nliqf., mot., pg. Bacillus of Braxy. See Bacillus anthracis, Pollender and Davaine. Bacillus of Bronchitis, Lumnitzer. Syn., Bacillus of Lumnitzer. From the bronchial secretions in cases of putrid bronchitis. aër., mot. Cf. Micrococcus of bronchitis, Picchini. Bacillus of Butyric Acid Fermentation. See Bacillus butyricus, Prazmowski. Bacillus of Carcinoma, Rappin and Scheurlen and Domingo-Freire. Syn., Bacille du cancer, Fr. See Bacillus of Scheurlen. Bacillus of Canestrini.
Found in larvæ and bees suffering from a malady com mon among bees in certain parts of Italy. ä̈r., liqf., mot., chg. (pink), pg. Bacillus of Canon and Pielicke. See Bacillus of measles. Bacillus of Cattle Plague, Metschnikoff. See Bacillus septicamia hemor. rhagice, Sternberg. Bacillus of Cazal and Vaillard. Obtained from cheesy nodules upon the peritoneum and in the pancreas. aër., fucanaër., liqf., mot., pg. Bacillus of Chancroid, Ducrey. Found in pustules developed upon the arm from the inoculation of chancroidal virus; does not grow in artificial cultures. Cf. Micrococcus ulceris mollis. Bacillus of Cheese. See Spirillum tyrogenum, Denecke. Bacillus of Chicken Cholera. See Bacillus septicamice hamorrhagice, Sternberg. Bacillus of Cholera. See Spirillum cholera asiatice, Koch. Bacillus of Choleraic Diarrhea from Meat Poisoning, Klein. Found in the blood and feces of persons poisoned with tainted meat. Cf. Bacillus of allantiasis, Müller and Hoppe-Seyler. Bacillus of Cholera in Ducks, Cornil and Toupet. Obtained from the blood of ducks that had died of an epidemic disease characterized by choleraic symptoms. aër., nliqf., nmot., pg. (for ducks, but not for chickens or pigeons). Bacillus of Chyluria, Wilson. Syn., Bacillus der Chyluria, Ger. ; Bacille de la chylurie, Fr.; Found in the coagulum of chylous urine. aër., facanaër., mot. Bacillus of Colomiatti. Obtained from cases of conjunctivitis and xerotic masses in the eye. aër., nliqf., nmot., npg. Cf. Bacillus of xerosis epithelialis conjunctivæ, Leber. Bacillus of Conjunctival Catarrh, Koch. Syn., Bacille du catarrhe conjonctival, Fr.; Bacillus des Bindehautcatarrhs, Ger.; Bacillus of conjunctivitis, Bacillus of pink eye, Weeks. aër., nliqf., pg. Resembles Bacillus xerosis. Bacillus of Dantec. Syn., Bacille du rouge de morue, Fr. Obtained from salted codfish to which it gives a red color. aër., liqf., mot., chg. (red), npg. Bacillus of Davaine's septicemia. See Bacillus septicamice hamorrhagice, Sternberg. Bacillus of Demme. Obtained from the contents of tumors and pustules and from the blood of patients suffering from erythema nodosum. aër., facanaër., (?) nliqf., pg. (to guinea pigs; rabbits, dogs and goats refractory). Bacillus of Diphtheria in Calves. See Bacillus diphtheria vitulorum, Löffler. Bacillus of Diphtheria in Doves. See Bacillus diphtherice columbarum, Löffler. Bacillus of Diphtheria in Man. See Bacillus diphtherie, Klebs and Löffler. Bacillus of Döderlein. See Bacillus vaginalis, Döderlein. Bacillus of Endocarditis. See Bacillus pyogenes fotidus, Fränkel and Saenger. Bacillus of Egyptian Catarrhal Conjunctivitis. See Bacillus of Kartulis. Bacillus of Erysipelas in the Rabbit, Koch. See Bacillus erysipelatos leporis, Koch. Bacillus of False Hog Cholera. See Bacillus parvus ovatus, Löffler. Bacillus of False Tuberculosis in Rabbits. See Bacillus of pseudo-tuberculosis in rabbits, Malassez and Vignal. Bacillus of Fiocca. Found in the saliva of cats and dogs. aër., facanaër., nligf., nmot., po. (for rabbits, guinea pigs, rats, mice). Bacillus of Foot Sweat. Syn.; Fussschweissbacillus, Ger. ; Bacille de la sueur des pieds, Fr. See Bacillus fertidus, Bacillus saprogenes No. II, and Bacterium oraveolens. Bacillus of Foul Brood of Bees. See Bacillus alvei, Cheshire and Cheyne. Bacillus of Fowl Cholera. See Bacillus septicamia hamorrhagica, Sternberg. Bacillus of Friedländer. See Bacillus pneumonice friedländeri. Bacillus of Fulles, III.

Abbreviations. $-a \ddot{e} r,=$ aërobic, anaër, = anaërobic, chg. = chromogenic. facanaër. =facultafive anaërobic. liqf. $=$ liquefac, tive, monom. $=$ monomorphic. mot. = motile nliqf. = non-liquefactive, nmot. = non-motile. npg. = non-pathogenic. $o b l_{.}=$obligate. $o s c l .=$ oscillating. $p g .=$ pathogenic. phos. $=$ phosphorescent. pleom. $=$ pleomorphic. sap. $_{0}=$ saprophytic. 
Found in the soil. aer., nliqf., mot., npg. Bacillus of Gangrene. See Bacillus exdematis maligni, Koch. Bacillus saprogenes, III, Rosenbach, and Bacillus of senile gangrene. Bacillus of Gangrenous Septicemia. Syn., Bacille de la gangrène gazeuse See Bacillus cedematis maligni, Koch. Bacillus of Gessner. See Bacterium tholoideum, Gessner. Bacillus of Glanders. See Bacillus mallei, Löffler. Bacillus of Green Diarrhea in Children, Lesage. See Bacillus of Lesage. Bacillus of Green Pus. See Bacillus pyocyaneus, Gessard. Bacillus of Grouse Disease, Klein. Obtained from the lungs and liver of grouse that had died of an epidemic disease. aër., nliqf., nmot., $p g$. (for mice, guinea pigs, linnets, green finches, sparrows; chickens, pigeons and rabbits immune). Bacillus of Hay Infusions. See Bacillus subtilis, Ehrenberg. Bacillus of Heminecrobiophilus, Arloing. Obtained from the callous lymphatic glands of a guinea pig. aër., facanaër., nliqf., mot., pleom., pg. Bacillus of Hog Cholera, Salmon and Smith. See Bacillus ex pneumo-enteritide suis, Klein. Bacillus of Hog Erysipelas. See Bacillus erysipelatos suis, Koch, etc. Bacillus of Horse Pox, Dieckerhoff and Grawitz. Syn., Bacillus of acne contagiosa of horses. Bacillus der Akne contagiosa des Pferdes, Ger. Obtained from the pustules of horses suffering from acne contagiosa. aër., nliqf., pg. Bacillus of Hydrophobia. See Bacillus lyssa, Pasteur. Bacillus of Icterus, Karlinsky and Ducamp. Found in the blood during an attack of infectious icterus. Did not thrive on ordinary culture media. Bacillus of Influenza, Pfeiffer, Kitasato and Canon. Syn., Bacille de Pfeiffer, Bacille de l'influenza, Influenza bacillus. Found in the purulent bronchial secretions and in the blood of persons suffering from epidemic influenza. äer nmot., pg. Cf. Micrococcus infuenze, Letzerich. Bacillus of Intestinal Diphtheria in Rabbits, Ribbert. Syn., Bacille de la diphthérie intestinale chez les lapins, Fr. Obtained from the viscera of rabbits dead of a disease characterized by a diphtheritic inflammation of the intestinal mucous membrane. aër. nliqf., nmot. (?) pg. Bacillus of Jeffries. A group (A, G, J, K, P, S, Z, ) of bacilli, resembling Bacillus neapolitanus, Emmerich, and Bacillus lactis aërogenes, Escherich. Found in the alvine discharges of children suffering from summer diarrhea, anaër., $n p g$. Bacillus of Jequirity Ophthalmia, DeWecker and Sattler. Syn., Bacille du jequirity, Fr. ; Jequiritypilz, Ger. Found in cases of jequirity ophthalmia and in infusions of jequirity seeds (Abrus precatorizs), the supposed source of Abrin. aër., liqf., mot., npg. The disease is now held to be caused by a soluble poison, jequiritin. Bacillus of Karlinski. See Bacillus murisepticus pleomorphus, Karlinski. Bacillus of Kartulis, Koch and Kartulis. Obtained from the conjunctiva in cases of Egyptian catarrhal conjunctivitis. aër. Pathogenesis not well determined. Bacillus of Koubasoff. Obtained from carcinomatous growth in the human stomach. aër., facanaër., nliqf., mot., pg. (for guinea pigs and rabbits). Cf. Bacillus of Scheuerlen. Bacillus of Lactic Acid Fermentation. See Bacillus acidi lactici. Hueppe. Bacillus of Laser. Obtained from mice infected with an epidemic disease, aër., facanaër., nliqf., mot., pg. (for field mice, guinea pigs, rabbits and pigeons). Bacillus of Leprosy. See Bacillus lepre, Hansen. Bacillus of Lesage. Syn., Bacille de la diarrhéa verte infantile, Fr. Bacillus of green diarrhea in children. Obtained in the green alvine discharges of infants suffering from green diarrhea. aër., nliqf., mot., pg. According to Baumgarten identical with Bacillus fuorescens non-liquefaciens, Schiller. $\mathbf{B a -}$ cillus of Letzerich. Obtained from the urine of children suffering from nephritis interstitialis primaria. $a \ddot{r}$., liqf., $p g$. Bacillus of Liborius. See Bacillus amylobacter, Prazmowski. Bacillus of Lichen Ruber, Laser. Syn., Bacillus bei Lichen ruber, Ger. Found in the lymph passages in cases of lichen ruber. Bacillus of Lucet. Syn., Bacille de la dysenterie epizoötique des poules et des dindes, Fr. Obtained from chickens and turkeys suffering from an infectious form of septicemia characterized by dysenteric discharges. aër., facanaër., nliqf., nmot., pg. Bacillus of Lumnitzer. See Bacillus of Bronchitis. Bacillus of Lupus. See Bacillus Tuberculosis, Koch. Bacillus of Lustgarten. See Bacillus syphilidis, Lustgarten. Bacillus of Lymph in Fishes, Oliver and Richet. Observed in the lymph of certain fishes. aër. mot., npg. Bacillus of Malaria. See Bacillus malaria, Klebs and Tommasi-Crudeli. Bacillus of Malignant Edema. See Bacillus adematis maligni, Koch. Bacillus of Measles, Canon and Pielicke. Syn., Bacillus of Canon and Pielicke. Found in the blood and in the secretions of the nose and conjunctiva of persons with measles. Cf. Micrococcus of measles, Klebs and Keating. Bacillus of Mouse Septicemia. See Bacillus erysipelatos suis, Pasteur. Bacillus of Necrosis of the Liver in Badgers, Eberth. . Found in the necrotic liver of a badger. Bacillus of Necrosis of the Liver in Guinea Pigs, Eberth. Found in the necrotic liver of a guinea pig. Bacillus of Nephritis, Letzerich. See Bacillus of Letzerich. Bacillus of Nocard. Syn., Bacille du farcin du bœuf, Fr.; Bacillus der Wurmkrankheit, Ger. Found in the superficial abscesses of cattle suffering from farcy. aër., nmot., pg. Bacillus of Okada. Obtained from the dust between the boards of a floor. aër., facanaër., nliqf., nmot., pg. Bacillus of Osteomyelitis, Kraske and Becker. Found in cases of osteomyelitis. aêr., ligf. (or in some forms nligf.), mot., pleom., pg. Held by Pasteur as identical with the micrococcus of furuncle, q. v. Bacillus of Phthisis. See Bacillus tuberculosis, Koch. Bacillus of Pink Eye, Weeks. See Bacillus of conjunctival catarrh, Koch. Bacillus of Potato Rot, Kramer. Syn., Nassfäulebacillus. Obtained from potatoes affected with wet rot. aër., liqf., mot., npg. Putrefies the albuminous substances of potatoes. $\mathrm{Ba}$ cillus of Pseudo-tuberculosis in Rabbits, Eberth, Malassez, and Vignal. Syn., Bacille de la tuberculose zoögléique, Bacille de la pseudo-tuberculose du lapin, Fr.; Bacillus der Pseudo-tuberculose der Kaninchen, Ger. Found in the nodular deposits characteristic of this disease. Bacillus of Puerperal Fever. See Bacillus puerperalis, Engel and Spillmann. Bacillus of Purpura Hæmorrhagica of Babes. Obtained from the viscera of a patient dead of purpura hæmorrhagica. aër., facanaër., liqf., nmot., pg. Resembles the next two forms. Bacillus of Purpura Hæmorrhagica of Kolb. Obtained from the viscera of patients dead of purpura. aër. facanaër., nliqf., nmot., pg. Bacillus of Purpura Hæmorrhagica of Tizzoni and Giovannini. Obtained from the blood of two children dead of purpura hæmorrhagica. aër., facanaër., niqf., nmot., ps. Bacillus of Pyemia, Beltzow. Syn., Bacille de la pyémie, Fr.; Bacillus der Pyämie, Ger. Two forms found in pyemia, one of which resembles Bacillus adematis

Abbreviations, -aër, = aërobic, anaër, = anaërobic. chg. = chromogenic. facanä̈r. = facultative anaërobic. liqf. =liquefactive. monom, = monomorphic. mot. = motile. nliqf. = non-liquefactive. nmot. = non-motile. nog. $=$ non-pathogenic. $o b l_{0}=$ obligate, $o s c l_{0}=$ oscillating. $p g,=$ pathogenic . phos. $=$ phosphorescent. pleom. = pleomorphic. sap. = saprophytic. 
maligni; Koch. Bacillus of Rabbit Septicemia. See Bacillus septicamia hamorrhagica, Sternberg. Bacillus of Rabies. See Bacillus lyssa, Pasteur. Bacillus of Rag Pickers' Disease. See Bacillus hominis capsulatis, Bordoni-Uffreduzzi. Bacillus of Red Bread. See Bacillus prodigiosus, Ehrenberg. Bacillus of Red Milk. See Bacillus lactis erythrogenes, Hueppe; and Bacillus prodigiosus, Ehrenberg. Bacillus of Rheumatism. See Bacillus rhezmar thritidis, Kussmaul. Bacillus of Rhinoscleroma. See Bacillus rhinoscleromatis, Cornil and Alvarez. Bacillus of Roth, I, II. Obtained from old rags. aër., facanaër., nliqf., nmot., pg. Resembles Bacillus neapolitanus, Emmerich; and Bacillus cavicidus, Burger. Bacillus of Rouget. See Bacillus erysipelatos suis, Koch, etc. Bacillus of Scarlet Fever, Crooke. Syn., Bacille de la scarlatine, Fr. Found in the nasal mucus and tissues of the throat in a case of anginose scarlet fever. mot. Resembles Bacillus adematis maligni, Koch, and the Proteus of Hauser. According to Dohle the parasite of this disease is a protozoön. Cf. Micrococcus Scarlatina. Bacillus of Scheurlen, Scheuerlen, Rapin, and Domingo-Freire. Syn., Bacillus epidermidis, Bordoni Uffreduzzi. From cancerous tissues and from mammary epithelia of healthy persons. According to Macé possibly identical with a variety of Bacillus mesentericus vulgatus, Flügge. aër., liqf., mot., $n p g$. Bacillus of Schimmelbusch. Obtained from the necrotic tissues of a case of cancrum oris or noma. aër., nliqf., pg. Bacillus of Schou. See Bacillus pneumonicus agilis, Schou. Bacillus of Senile Gangrene, Tricomi. Syn., Bacille de la gangrene sénile, Fr. Bacillus of gangrene, Bacillus of Tricomi. Found in the blood, in the tissues along the line of demarcation, in the subcutaneous tissue and the lymph spaces of the skin, and in the ichorous discharge. aër., liqf., nmot., pg. Cf. Bacillus adematis maligni, Koch, and Bacillus saprogenes, $I I I$, Rosenbach. Bacillus of Septicemia in Man, Klein. Syn., Bacille de Ia septicémie, Fr. Bacillus of Southern Cattle Plague, F. S. Billings. Syn., Bacillus of Texas fever in cattle. Bacillus der amerikanischen Rinderseuche, Canerva. Found in the blood, viscera, and manure of cattle infected with cattle plague or Texas fever; also in the ticks (Boöphilus bovis, Curtice) infecting the cattle, and in their discharges. The spread of the disease is largely due to the manure of the cattle and also indirectly to the ticks. aër., nliqf., mot., pleom., $p g$. Smith and Kilborn now attribute this disease to the psorosperm Pyrosoma bigeminum. Bacillus of Spontaneous Rabbit Septicemia, Eberth. See Bacillus of swine plague, Marseilles. Bacillus of Symptomatic Anthrax. See Bacillus chauvai, Bollinger and Feser. Bacillus of Swine Pest, Selander. See Bacillus ex pneumo-enteritide suis, Klein. Bacillus of Swine Plague, Marseilles, Reitsch, and Jobert. Syn., Bacillus suis, Detmers. Bacillus der Schweineseuche, Marseilles; Bacillus der Frettchenseuche (ferret disease), Eberth and Schimmelbusch; Bacille de la pest porcine, Fr.; Bacillus of spontaneous rabbit septicemia; Bacillus of swine plague, Detmers and Billings; Swine plague, Schizophyte, Detmers. First obtained from swine attacked by a fatal epidemic disease in Marseilles. aër., nliqf., mot., pg. Canerva and others identify this with the Bacillus of ferret disease and with that of American swine plague; also with the Bacillus of Southern cattle plague, Billings; but this latter seems to be a distinct species. See Bacillus tardigradus. Bacillus of Syphilis. See Bacillus syphilidis, Lustgarten. Bacillus of Tetanus. See Bacillus tetani, Niculaier. Bacillus of Texas Cattle Fever, F. S. Billings. See Bacillus of Southern cattle plague. Bacillus of the Blood. Syn., Bacille du sang, Fr.; Blutbacillus, Bacillus des Blutes, Hoffmann, Ger. Bacillus of the Lungs of Cattle, Lüstig. Found in the lungs of healthy and diseased cattle. aër., liqf. Bacillus of the Meconium, Escherich. Found in the meconium. Bacillus of the Pneumo-enteritis of the Pig. See Bacillus ex pneumo-enteritide suis, Klein. Bacillus of the Smegma. Syn., Bacille du smegma préputial, Fr.; Smegmabacillus, Ger. Found in the smegma of the male and female genitals. Bacillus of Tommasoli. See Bacillus sycosiferus fotidus, Tommasoli. Bacillus of Tricomi. See Bacillus of senile gangrene. Bacillus of Tuberculosis of Vines. Syn., Bacille de la tuberculosis des vignes, Corvo, Fr. Regarded by Corvo as the cause of the diseased condition of vines usually attributed to Phylloxera vastatrix, Planchon. Bacillus of Ulcerative Stomatitis of Cattle, Lingard and Batt. ' Found on the skin, the mucous membranes, and in the lungs of young cattle. Cf. Streptocytus of eczema epizootica, Schottelius. Bacillus of Ulcus Molle, Kröfting. Identical with that described by Ducrey as the BacilIus of Chancroid. Bacillus of Utpadel, Utpadel and Gessner. Obtained from the stuffing of the bed quilts in a military hospital (Augsburg), and from the intestinal contents of man. aër., nliqf., mot., pg. Bacillus of Vagus Pneumonia. See Bacillus pneumonicus agitis, Schou. Bacillus of Verruga Peruana, Izqui . erdo. Found in the intercellular spaces and bloodvessels in the nodules characteristic of Peruvian wart. Bacillus of Vignal. See Bacillus buccalis minutus, Vignal. Bacillus of Whooping Cough. See Bacillus tussis convinlsiva, Afanassiew. Bacillus of Xerosis Epithelialis Conjunctivæ, Leber, Kuschbert, Fränkel, and Neisser. Syn., Bacillus xerosis, Fränkel; Bacillus of Colomiatti, Bacillus of xerosis, Schreiber; Xerosebacillus, Bacillus der Xerosis epithelialis conjunctivæ, Ger. ; Bacille du xerosis conjonctivæ, Fr. Found in the white, fatty scales of the conjunctivæ in cases of Xeropthalmia. nmot. Does not grow on gelatin or potato. Pathogenesis not fully determined. Bacillus oxytocus perniciosus, Wyssokowitsch. Found in milk left standing a long time. aër., nliqf., pg. Bacillus ovatus minutissimus, Unna. Found upon the skin in cases of eczema seborrhœicum. aër., facanaër., nliqf., npg. Bacillus of Yellow Fever. Bacille de la fièvre jaune, Fr.; Bacillus des gelben Fiebers, Ger. Found in the mucous membrane of the small intestine in two cases of yellow fever. Sternberg has found many forms in the intestinal contents and viscera of yellow fever cadavers, the most frequent and abundant being the Bacillus neapolitanus, Emmerich; Bacillus cadaverus, Sternberg; and Bacillus $X$, Sternberg. This latter is held by Sternberg as being possibly concerned in the etiology of yellow fever. Cf. Microbe de la fièvre jaune, Freire et Rebougeon. Bacillus of Yellow Milk. See Bacillus synxanthus, Ehrenberg and Schröter. Bacillus panificans, Laurent. Claimed as the active agent in the raising of bread. Fourd especially in black bread. Dunnenberger considers it a mere impurity and not concerned in the leavening processes. Bacillus parvus ovatus, Löffler. Syn., Pseudorotlaufbacillus, Ger. Bacillus of false hog

Abbreviations.-aër. = aërobic. anaër. = anaërobic. chg.= chromngenic. facanaër. = facultative anaërobic. liqf.=liquefactive. monom. = monomorphic. mot. = motile. nliqf. = non-liquefactive. nmot. $=$ non-motile. npg. $=$ non-pathogenic $o b l_{.}=$obligate. $o s c l_{.}=$oscillating. $p g .=$ pathogenic. phos. = phosphorescent. pleom. $=$ pleomorphic. sap. = saprophytic. 
cholera. Found in the carcass of a pig dead of a disease resembling rouget. It resembles Bacillus septicamia hamorrhagica, Sternberg. Bacillus pasteurianus, Hansen. Syn., Bacterium pasteurianum, Arthrobacterium pasteurianum, Micrococcus pasteurianus. Found in beer-wort and beer, especially that poor in alcohol. Resembles Bacillus aceti, Kützing and Sommer. Bacillus pestifer, Frankland. Found in the air. ä̈r., liqf., mot., npg. Bacillus phosphorescens, Fischer. Syn., Bacillus phosphorescens indicus, Fischer; Photobacterium indicum, Fischer; In discher Leuchtbacillus, Ger. Found in sea water (Gulf of Mexico). aër., liqf., mot., phos., npg. Bacillus phosphorescens gelidus, Forster. See Bacillus phosphoreus, Cohn. Bacillus phosphorescens indicus, Fischer. See Bacillus phosphorescens, Fischer. Bacillus phosphorescens indigenus, Fischer. Syn., Einheimischer Leuchtbacillus, Ger. Found in sea water (Harbor of Kiel) and upon herring. aër., ligf., mot., phos., npg. Bacillus phosphoreus, Cohn. Syn., Micrococcus phosphoreus, Cohn; Bacterium phosphorescens, Hermes; Bacillus phosphorescens gelidus, Forster. Found on sea fish, raw and cooked (cooked salmon, Cohn). aër., nliqf., phos., npg. Bacillus plicatus, Zimmermann. Found in hydrant water (Chemnitz). aër, liqf., nmot., chg. (grayish yellow), npg. Bacillus pneumoniæ, Flügge. See Bacillus pneumonice friedländeri. Bacillus pneumoniæ friedländeri. Syn., Bacillus pneumonia, Flügge; Diplococcus pneumonia fibrinose, Friedländer; Micrococcus pneumonice infectiose, Friedländer; Bacille de pneumonie, Fr. ; Bacillus of Friedländer; Microbe of Friedländer. Occasionally obtained from the exudates in the pulmonary alveoli in cases of croupous pneumonia. aër., facanaër., nliqf., nmot., pg. Bacillus pneumonicus agilis, Schou. Syn., Bacillus of Schou; Bacillus of Vagus pneumonia; Bacille pneumonique, Fr. Obtained from rabbits suffering from pneumonia induced by section of the vagi. aër., liqf., mot., pg. Bacillus pneumosepticus, Babes. Obtained from the blood and tissues of a person dead of septic pneumonia. aër., facanaër., nliqf., nmot., pg. Bacillus polymyxa, Prazmowski. Syn., Claustridium polymyxa, Prazmowski. Found in infusion of potatoes, lupin seeds, etc. aër., facanaër., $n p g$. Bacillus polypiformis, Liborius. Found in cow dung and in the exudates of mice inoculated with garden earth. anaër., nliqf., mot., npg. Bacillus preussii, Ciesielski. See Bacillus alvei, Cheshire and Cheyne. Bacillus prodigiosus, Ehrenberg. Syn., Bacteridium prodigiosum, Schröter; Bacterium prodigiosum, Micrococcus prodigiosus, Cohn; Micrococcus imetrophus, Trevisan; Monas prodigiosa, Ehrenberg; Palmella prodigiosa, Mont; Zoogalactina imetropa, Sette; Bacille du lait rouge, Bacille du pain rouge, Fr.; Bacillus der roten Milch, Bacillus des roten Brotes, Hostienblut, Wunderblut, Blutpilz, Ger. Frequently found upon food-stuffs, boiled potatoes, hardboiled eggs, moist bread, etc. aër., facancër., liqf., mot., chg. (red), npg. Acts as a protective to rabbits against anthrax. Bacillus pseudœdema, Liborius. Syn., Bacillus pseudosepticus, Macé ; Pseudo-cedembacillus, Ger. Obtained from the exudates of mice, after inoculation with garden earth. anaër., liqf., pg. Resembles Bacillus adematis maligni, Koch. Bacillus pseudopneumonicus, Passet. Syn., $B a c$ terium pseudo-pneumonicum. Found in pus. aër., nligf., nmot., pg. Resembles Micrococcus pneumonice crouposa, Fränkel. Bacillus pseudosepticus, Macé.
See Bacillus pseudcedema, Liborius. Bacillus pseudosepticus of Mice, Bienstock. Syn., Bacillus of pseudosepticemia of mice. Found in feces. aër., nliqf., nmot., $p g$. Found after inoculation, mostly in the edematous fluid and not in the blood. Bacillus pseudo-tuberculosis, Píeiffer. Obtained from the viscera of a horse killed on suspicion of having glanders. aër., nliqf., nmot., pg. Bacillus puerperalis, Engel and Spillmann. Syn., Leptothrix puerperalis, Fettz; Bacillus des Puerperal-Fiebers, Ger.; Bacille puerperale, Fr. ; Leptothrix of puerperal fever; Bacillus of puerperal fever. Found in two cases of puerperal sepsis. $p g$. (for mice and rabbits). Considered by Pasteur to be identical with Bacillus anthracis. Bacillus pulpæ pyogenes, Miller. Obtained from gangrenous tooth-pulp. aër., facanaër., liqf., pg. Bacillus punctatus, Zimmermann. Found in hydrant water (Chemnitz). aër., liqf., npg. Bacillus putrificus coli, Bienstock. Syn., Bienstock's putrefactive bacillus from the feces; Bienstock's putrefactive bacillus; Bacillus of albuminous decomposition ; Drumstick bacillus; Trommelschlägelbacillus; Bienstock's Bacillus aus Faeces; Bacillus der Eiweisszersetzung, Ger.; Bacille de la decomposition de l'albumine, Fr. Found in human feces. aër., facanaër., nliqf., mot., $n p g$. Bacillus pyocyaneus $a$, Gessard. Syn., Bacillus aëruginosus, Bacterium aëruginosum, Schröter; Micrococcus pyocyaneus, Gessard. Bacillus of blue or green pus. Bacille, Bactérie ou Microbe du pus bleu, Bacille du pus vert, Bacille pyocyanique, Fr.; Bacillus des grünblauen Eiters. A widely distributed form, found in purulent and serous wounds, in perspiration, and in the viscera of human cadavers. aër., facanaër., liqf., mot., chg., pg. Two pigments, one fluorescent green, the other blue, pyocyanin. Bacillus pyocyaneus $\beta$, Ernst. Found in pus from bandages stained green. aër., liqf., mot., chg. (yellowish green), $n p g$. Bacillus pyogenes fœetidus, Passet. Syn., bacille pyogène fétide, Fr. Obtained from an ischio-rectal abscess. aër., nliqf., mot., pg. Bacillus pyogenes soli, Bolton. Obtained from the exudates of a rat after inoculation with garden earth. aër., facanaër., nliqf., nmot., npg. Bacillus radiatus, Lijderitz. Obtained from the exudates of mice and guinea-pigs after inoculation with garden earth. anaër., liqf., mot., $n p g$. Bacillus radiatus aquatilis, Zimmermann. Found in hydrant water (Chemnitz). aër., liqf., mot., npg. Bacillus ramosus, Eisenberg. Syn., Wurzelbacillus. Common in soil and water. aër., ligf., npg. Bacillus ramosus liquefaciens. Obtained from the air. aër., Tiqf., mot., npg. Bacillus reticularis, Jordan. Found in hydrant water (Lawrence, Mass.). aër., liqf., mot., npg. Bacillus rheumarthritidis, Kussmaul. Syn., Bacillus rheumarthritis, Micrococcus rheumarthritis, Leyden. Bacillus of rheumatism. Bacille du rhumatisme, Fr. Gelenkrheumatismus Mikro-organismen, Mikrokokken bei Gelenkrheumatismus, Ger. Found in the effusions in the joints in articular rheumatism. Bacillus rhinoscleromatis, Cornil and Alvarez, Von Frisch, Paltauf, Von Eiselsberg, Dittrich, Stepanow, etc. Syn., Bacille du rhinosclérome, Fr. Found in the newly formed tubercles of rhinoscleroma. aër. facanaër., nliqf., usually nmot. (becomes motile on cultivation), pg. Etiologic relations not established. Considered by many as identical with Bacillus pneumonice friedländeri. It is less virulent, gelatin cultures more transparent and the capsules more persistent. Bacillus rosaceum metalloides, Dowdeswell.

Abbreviations. - aër. = aërobic, anaèr, = anaërobic, chg. = chromogenic, facanaër. $=$ facultative anaërohic. liqqf $=$ liquefactive. monom $=$ monomorphic, mot. = motile. nliq $f_{\text {. }}=$ non-liquefactive. nmot. $=$ non-motile. nsg. $=$ non-pathogenic $o b l .=$ obligate. oscl. = oscillating. $p g_{0}=$ pathogenic. phos. = phosphorescent. pleom, $=$ pleomorphic. sap. $=$ saprophytic. 
See Bacillus mber, Frank and Cohn. Bacillus rubefaciens, Zimmermann. Found in hydrant water (Chemnitz). aër., nliqf., mot., chg. (pale pink), npg. Bacillus rubellus, Okada. Found in the exudates of guinea-pigs after inoculation with street dust. anaër., liqf., mot., chg. (red), npg. Bacillus ruber, Frank, Cohn, and Becker. Syn., Bacillus miniacers, Zimmermann. Bacillus (or Bacterium) rosaceum metalloides, Dowdeswell. The red bacillus of water. Found in water and on boiled rice. aër., liqf., mot., chg. (magenta red), npg. Bacillus ruber indicus. See Bacillus indicus, Koch. Bacillus rubescens, Jordan. Found in sewage (Lawrence, Mass.). ä̈r., nliqf., mot., chg. (pale pink), npg. Bacillus rubidus, Eisenberg. Found in water. aër., liqf., mot., chg. (brownish red), npg. (Lustig describes a red bacillus from river water which he claims to be different from this). Bacillus salivarius septicus, Biondi. See Bacillus septicus sputigenus, Flügge. Bacillus sanguinis typhi, Brannan and Cheesman. Obtained from the blood of typhus-fever patients. $a \bar{r}$., facanaër., nmot. Bacillus saprogenes, I, II, III, Rosenbach. Syn., Bacille saprogène, Bacille de la sueur des pied, Fr. Fäulnisbacillus, Ger. Found in putrefying matter on fetid feet, the white plugs of the pharyngeal follicles, etc. aër., facanaër., pg. Bacillus scaber, Duclaux. Syn., Tyrothrix scaber. Found in cheese. aër, nliqf., mot. (in early stages becoming non-motile), $n p g$. Bacillus schäfferi, Freudenreich. Obtained from cheese and fermenting potato infusion. aër., facanaër., nliqf., mot., npg. Closely resembles Bacillus neapolitanus, Emmerich. Bacillus scissus, Frankland. Found in the soil. aër., nliqf., nmot., npg. Bacillus septicæmiæ hæmorrhagicæ, Sternberg. Bacillus cholere gallinarum, Flïgge. Bacillus cuniculicida, Flügge. Bacillus cuniculicidus, Koch. Bacterium septicamie, Koch. Bacterium morbilli, Lanzi. Coccobacteria septica, Billroth. Micrococcus septicus, Cohn. Micrococcus cholere gallinarum, Micrococcus gallicidus, Microsporon septicus, Klebs. Bacillus der Hühnercholera, Bacillus der Kaninchenseptikämie (Koch). Bacterium der Septikämie bei Kaninchen, Bacillus der Rinderseuche, Kitt. Bacillus der Schweineseuche, Löffler and Schuitz. Bacillus der Wildseuche, Hueppe. Bacillus der Büffelseuche, Oreste-Armanni. Rinderpestbacillus, Ger. Bacille de la septicémie du lapin. Bacille du choléra des poules. Microbe du choléra des poules, Pasteur, Fr. Bacillus septicus, Koch. See Bacillus erysipelatos suis, Koch. Bacillus septicus, Pasteur. See Bacillus adematis maligni, Koch. C. Proteus septicus. Bacillus septicus acuminatus, Babes. Obtained from the umbilical stump, blood and viscera of a five days old child, dead of septic infection. aër. (no growth on gelatin), pg. (for rabbits and guineapigs, not for mice). Bacillus septicus agrigenus, Nicolaier. Obtained from manured garden soil. aër., nligf. (?) Resembles Bacillus septicamice hamorrhagica, Sternberg. Bacillus septicus aus Speichel. See Bacillus septicus sputi, I, II, Kreibohm. Bacillus septicus keratomalaciæ, Babes. Obtained from the corneal tissues and viscera of a child that died of septicemia following keratomalacia. aër., facanaër., nliqf., $p g$. (for rabbits and mice, slightly for birds, not for guinea-pigs). Bacillus septicus sputi, I, II, Kreibohm. Syn., Bacillus septicus aus Speichel, Ger. Obtained from human buccal secretions. Does not grow in any known culture-medium. Resembles Bacillus septicamice hamorrhagica, Stern- berg. Bacillus septicus sputigenus, Flïgge, Syn., Bacillus salivarius septicus, Biondi. Bacterium septicum sputigenum, Fränkel. Micrococcus pneumonie croupose, Fränkel. Micrococcus pasteuri, Sternberg. Diplococcus pneumonia, Weichselbaum. Streptococcus lanceolatus pasteuri, Gamaleia. Microbe of Pasteur. Micrococcus of Salvioli. Micrococcus of sputum septicemia, Fränkel. Fränkel'scher Diplococcus. Fränkel'scher Pneumobacillus. Fränkel'scher Pneumonie-Diplococcus. Lancet-shaped micrococcus, Talamon. Lanceolatecoccus, Talamon. Found both in healthy and in pneumonic sputum, in the fibrinous exudates of croupous pneumonia, and in the pus of meningitis. aër., facanaër., nmot., nliqf., pg. Held to be the cause of croupous pneumonia in man, and by some to be identical with Bacillus lyssae, Pasteur. Bacillus septicus ulceris gangrænosi, Babes. Found in the blood and viscera of a boy dead of septicemia following gangrene of the skin. aër., liqf., mot., pg. Bacillus septicus vesicæ, Clado. Found in the urine of a patient with cystitis. aër., facanaër., nligf., mot., pg. Bacillus sessilis, L. Klein. Found in the blood of a cow supposed to have died of anthrax. aër., mot. (convulsive jerking), npg. Bacillus similis, Bienstock. See Bacillus subtilis simulans, I, II, Bienstock. Bacillus smaragdinus fotidus, Reimann. Found in the nasal secretions in a case of ozena. aër., facanaër., liqf., pg. Bacillus smaragdino phosphorescens, Katz. Obtained from a herring in fish market (Sidney, N. S. W.). aër., nliqf., nmot., phos. (emerald green), npg. Resembles Photobacterium phosphorescens, Cohn, and Photobacterium pflïgeri, Ludwig. Bacillus solidus, Lüderitz. Found in the exudates of mice inoculated with garden earth. ä̈r, nliqf., mot., npg. Bacillus spiniferus, Unna. Found upon the skin in cases of eczema seborrhœicum. aër., nliqf., chg. (grayish yellow), npg. Bacillus sputigenus crassus. See Bacillus crassus sputigenus, Kriebohm. Bacillus stolonatus, Adametz. Found in water. aër., nliqf., mot., npg. Bacillus stoloniferus, Pohl. Found in swamp water. aër., liqf., mot. Pathogenesis not determined. Bacillus striatus albus, Von Besser. Found in the nasal secretions of healthy persons. aër., nliqf., npo. Bacillus striatus flavus, Von Besser. Occasionally found in nasal mucus. aër., nliqf., chg. (sulphur yellow), npg. Bacillus subflavus, Zimmermann. Found in hydrant water (Chemnitz). aër., nliqf., mot., chg. (pale yellow), npg. Bacillus subtilis, Ehrenberg, Cohn, Brefeld, Prazmowski, and Fitz. Syn. Bacillus glycerina, Fitz; Bacillus fitzianus, Zopf; Bacterium subtile, Zopf; Metallacter subtile, Pertz; Vibrio subtilis, Ehrenberg; Bacille du foin, Fr.; Bacillo del fieno, Ital.; Heubacillus; Fitz'scher Aethylbacillus, Ger. DeBary confines $B$. subtilis to the form described by Brefeld and Prazmowski. The relation of the starch fermentation species of Fitz remains doubtful. An abundant form obtained from the air, water, soil, and on plants. aër., liqf., oscl., npg. Bacillus subtiliformis, Bienstock. See Bacillus subtilis sinulans, I, II, Bienstock. Bacillus subtilis simulans, I, II, Bienstock. Syn., Bacillus similis, Bienstock. Heubacillusähnlicher Bacillus, Ger. Bacille de Bienstock, I, II, Fr. Found in human feces. aër., nliqf., nmot., npg. Bacillus suis, Detmers. See Bacillus tardigradus. Bacillus sulf-hydrogenus, Miquel. Found in water. aër., mot. Decomposes albumin with cvolution of $\mathrm{H}_{2} \mathrm{~S}$. Bacillus sulfureum, Holschewnikoff and Rosenheim. Two forms found in urine and in mud.

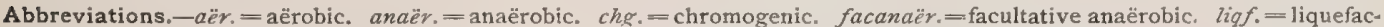
tive. monom, = monomorphic. mot. = motile. nliqf. $=$ non-liquefactive, nmot. $=$ non-motile. npg. $=$ non-pathogenic $o b l=$ obligate. oscl. = oscillating. $p g .=$ pathogenic. phos. = phosphorescent. pleom. $=$ pleomorphic. sap. $=$ saprophytic. 
(I) aër., facanaër., nliqf., (2) liqf., mot., chg. (reddish brown), npg. Syn., Proteus sulfureus, Lindenborn. Found in water. Bacillus superficialis, Jordan. Common in sewage (Lawrence, Mass.). aër., liqf., mot., npg. Bacillus sycosiferus fœetidus, Tommasoli. Syn., Bacillus sycosiferus. Bacillus of Tommasoli. Found on the hairs of the head of a patient affected with sycosis. aër., nliqf., nmol., pg. Bacillus syncyanum. See Bacillus cyanogenus, Hueppe. Bacillus synxanthus, Ehrenberg and Schröter. Syn., Bacillus xanthorenus, Fuchs and Ehrenberg. Bacterium xanthinum, Schröter. Vibrio synxanthus, Ehrenberg. Vibrio xanthogenus, Fuchs, Bacillus of yellow milk. Bacille du lait jaune, Fr. Found in milk that has been boiled. aër. mot., chg., (golden yellow), npg. Precipitates the casein, renders the milk alkaline. Bacillus syphilidis, Lustgarten. Syn., Bacillus syphitis, Lustgarten. Bacille de la syphilis, Bacille de Lustgarten, Fr. ; Syphilis bacillus, Luësbacillus, Ger.; Bacillo del sifilide, Ital.; Bacillus of Lustgarten. Found in syphilitic new growths and secretions; does not develop in ordinary culture media. In staining, reaction seems to be identical with that of the Bacillus of the Smegma. Doehle describes parasitic infusoria as the causative agents of syphilis. Cf. Helicomonas, Klebs, and Syphilis of bacillus of Eve and Lingard. Bacillus tardigradus. Syn., Bacillus suis, Detmers. Micrococcus suis, Burrill. Found in dew, water, and in the fluids of pigs affected with swine plague. aër., mot., npg. Cf. Bacillus of Swine plague, Marseilles, Rietsch and Jobert. Bacillus tenuis, Duclaux. Syn., Tyrothrix tenuis, Duclaux. Found in decomposing albuminoid matter, cheese, etc. aër., facanaër., (?) $m o t ., n p g$. Used in ripening certain French cheeses. Bacillus tenuis sputigenus, Pansini. Obtained from sputum. aër., nliqf., nmot., ps. Bacillus termo, Dujardin and Ehrenberg. See Bacterium termo, Cohn. Bacillus tetani, Nicolaier. Syn., Bacillus tetani traumatici, Rosenbach; Bacille du tétanos, Bacille de la tétanie, Fr.; Tetanusbacillus, Bacillus des Wundstarrkrampfes, Ger. ; Bacillus of tetanus. Found in garden earth and in the wounds of persons dead of tetanus. anaër., liqf., mot., pg. Specific etiologic relations determined by Carle and Rattome. Bacillus tetani traumatici, Rosenbach. See next preceding. Bacillus thalassophilus, Russel. Obtained from mud (Bay of Naples). anaër., liqf., mot. Pathogenesis not determined. Bacillus thermophilus, Miquel. Found in the intestinal tract of man and animals, in sewage and in the soil. aër., nmot., $n p g$. Bacillus tremelloides, Schottelius. Found in hydrant water (Freiburg). aër., liqf., chg. (golden yellow), npg. Bacillus tremulus, Koch. Syn., Metallacter tremulus, Trevisan. Found as a surface pellicle on decomposing plant infusions. Resembles Bacillus subtilis, Ehrenberg. Bacillus tuberculosis, Koch. Syn., Bacterium tuberculosis, Zopf; Bacterium tuberculosum, Bacillus tuberculi, Bacillus tuberculosus, Bacille de la tuberculeux. Bacille de la tuberculose; Bacille de Koch, Fr.; Tuberkelbacillus, Bacillus der Tuberculose, Ger.; Bacillo tubercolare, Bacillo della tuberculose, Ital.; Bacillo de la tuberculosi, Sp. Found in the sputum, in tuberculous organs, and elsewhere in persons and animals affected with tuberculosis. Parasitic. $a \ddot{e} r$., facanaër., nmot., po. Bacillus tuberculosis gallinarum, Maffucci. Obtained from cases of spontaneous tuberculosis in fowls. This seems to be a distinct species, characterized by its staining reactions, etc., its growth in pure cultures, and its pathogenic qualities, Koch. Bacillus tumescens, Zopf. Syn., Bacterium tumescens, Zopf. Found upon beets. aër., liqf., mot., npg. Bacillus turgidus, Duclaux. Syn., Tyrothrix turgidus, Duclaux. Found in cheese. aër. Produces alkaline reaction (carbonate and butyrate of ammonia) in milk. Bacillus tussis convulsivæ, Afanassiew. Syn., Bacillus of Afanassiez, Bacille de la coqueluche, Fr., Keuchhustenpilz, Ger., Burger. Found in the sputum of persons affected with pertussis. aër., nliqf., mot., pg. Bacillus typhi abdominalis, Eberth, Gafiky, Klebs, Eppinger, Brautlecht. Syn., Bacillus typhosus, Bacterium typhosum, Bacille typhique, Bacille de la fiévre typhoide, Microbe de la fiévre typhoide, Fr.; Typhusbacillus, Ger.; Bacillo tifoso, Ital. Found in water and in milk, and in the feces and organs in typhoid fever. aër, nliqf., facanaër. Bacillus typhi murium, Löffler, Obtained from mice affected with an epidemic disease. aër., facanärr., nliqf., mot. Bacillus typhosus. See Bacillus typhi abdomi nalis, Eberth, etc. Bacillus ubiquitus, Jordan. Found in air, water, sewage (Lawrence, Mass.). aër., facanaër., nliqf., nmol., npg. Resembles Bacil lus candicans, Frankland. Bacillus ulna, Cohn, and Prazmowski. Syn,, Vibrio b, Ehrenberg. Bacterium ulna, Miller. Vibrio bacillus, Müller, Ehrenberg. Found in egg albumin. aër., mot., $n p g$. Bacillus ulna of Vignal. Found in saliva of healthy persons; perhaps identical with the preceding form, aër., liqf., npg. Bacillus ureæ, Miquel. Found in the air. aër., facanaër., nliqf., $n p g$. Perhaps identical- with the preceding form. Bacillus ureæ, Leube. Found in old urine, three varieties. aër., nliqf., npg. Converts urea into ammonium carbonate. Bacillus urocephalus, Duclaux. Syn., Tyrothrix urocephalus, Duclaux. One of the commonest forms associated with putrefaction of animal matter. aër., facanaër., npg. Bacillus vasculosis, Sternberg. Obtained from the intestine and stomach of yellow-fever cadavers. aër., liqf., mot., npg. Bacillus vaginalis, Döderlein. Syn., Döderlein'scher Scheidenbacillus, Döderleins Bacillus, Scheidenbacillus, Ger. Constantly found in the normal vaginal secretions of adults. aêr. facanaër., nmot. (no growth in gelatin), npg. Bacillus varicosus conjunctivæ, Gombert. Found in the healthy conjunctival sac of man. aër., facanaër., nliqf., mot., pg. Bacillus venenosus, Vaughan. Found in water. aër., facanaër., nliqf., mot., pg. Bacillus venenosus brevis, Vaughan. Found in water. aër., facanaër., nliqf., mot., pg. Bacillus venenosus invisibilis, Vaughan. Found in water. aër., facanaër., nliqf., mot., pg. Bacillus venenosus liquefaciens, Vaughan. Found in water. aër., facanaër., liqf., mot., pg. Bacillus ventriculi, Raczynssky. Obtained from the stomach of meatfed dogs. aër., facancër., nliqf., mot., npg. Bacillus vermicularis, Frankland. Found in river water. aër., liqf., oscl., npg. Bacillus vermiculosus, Zimmermann. Found in water. aër., liqf., oscl., npo. Bacillus violaceus, Becker. Found in river water. aër., facanaër., liqf., mot., chg. (dark violet). Bacillus violaceus laurentius, Jordan. Found in hydrant water (Lawrence, Mass.). aër., facanä̈r., ligf., mot., npe. Bacillus virens, Van Tieghem. Syn., Sporonema gracile. Found in stagnant water. aër., mol., chg. (green, held by some to be chlorophyll,

Abbreviations, - aër, = aëtobic, anaër, = anaërobic, chg. = chromogenic, facanaër. = facultative anaërobic. liqf. $=$ liquefactive. monom. = monomorphic. mot. = motile. nligf. = non-liquefactive, nmot. $=$ non-motile. npg. $=$ non-pathogenic obl. = obligate. oscl. = oscillating. pg. = pathogenic. phos. = phosphorescent. pleom. = pleomorphic. sap. = saprophytic. 
but not suficiently studied), npg. Bacillus virescens, Frick. Found in green sputum. aer., nliuf., mot., chy. (green), npg. Bacillus virgula, Duclaux. Syn., Tyrothrix virgula, Duclaux. Found in albuminous solutions. aër., nmot., npg. Bacillus virgula. See Spirillum cholere asiatica, Koch. Bacillus viridis flavus, Frick. Syn., Bacillus viridis pallescens, Frick. aër., nligf., mot., chg. (yellowish green), npg: Resembles Bacillus virescens, Frick. Bacillus viridis, Van Tieghem. Syn. Bacterizm viride, Van Tieghem, Arthrobacterium viride, De Bary. Found in water collected in the hollow of a polyporous fungus. aër., chy. (green). Not thoroughly investigated. Bacillus viridis pallescens, Frick. See Bacillus viridis favus, Frick. Bacillus viscosus, Frankland. Found in river water. aër. ligf. mot. chg. (fluorescent green). Perhaps identical with Bacillus fuorescens, Flügge. Bacillus viscosus, I, II, Van Laer. Found in ropy milk, aër., nliqf., npg. Bacillus viscosus cerevisiæ, Van Laer. Found in viscous beer and in milk. aër., ligf., $n p g$. Bacillus viscosus sacchari, Kramer. Found in viscous saccharine fluids. aër., liqf., $n p g$. Bacillus von Denecke. See Spirillum tyrogenum, Denecke. Bacillus von Finkler-Prior. See Spirillum Finkler-Prior. Bacillus vulgaris, Hauser; Syn., Proteus vulgaris. Proteus sulfureus, Holschenikoff. Proteus of Hauser. Commonly associated with putrefaction. aër., facanaër., liqf., mot., pg. This species is probably one of those formerly included under $B a c$ terium termo. Bacillus X, Sternberg. Found in yellow-fever cadavers. Sternberg thinks it possible that this form is concerned in the etiology of yellow fever. pg. (for rabbits). Bacillus xanthogenus, Fuchs and Ehrenberg. See Bacillus synxanthus, Ehrenberg. Bacillus xerosis, Fränkel. Syn., Xerose bacillus. See Bacillus of xerosis epithelialis conjunctivæ, Leber. Bacillus zenkeri, Hauser. Syn., Proteus zenkeri. Bacille de Hauser, Fr. Found in putrefying animal matter. aër., facanaër., nliqf., mot., pg. Bacillus zopfii. Syn., Bacterium zopfi, Kurth. Arthrobacterium zopfii, De Bary. Knäuelbildender Bacillus, Ger. Found in the intestinal tract of fowls. ä̈r., nliqf., mot., npg. Bacillus zurnianum, List. Found in water. aër., nliqf., nmot., npg. Bacilo virgula, Bacilo virgulado, Sp. See Spirillum cholere asiatica, Koch. Bacteria of pus. Syn., Eitermicroben, Ger. Bacteria of putrefaction. Syn., Bactéries de la putrefaction, Fr.; Fäulnisbacterien, Ger. Bacteria of sea water. Syn., Bactéries de l'eau de mer, Fr.; Bacterien des Meerwassers, Ger. Bacteria of the air. Syn., Bactéries de l'air, Fr. ; Luftbacterien, Ger.; micrococci of the air. Bacteria of the mouth. Syn., Bactéries de la bouche, Fr. Bacterien der Mundhöhle. Bacteria of the soil. Syn., Bactéries de la terre, Fr.; Erdebacterien, Ger. Bacteria of urine. Syn., Bactéries de l'urine, Fr.; Bacterien des Harns, Ger. Bacteria of water. Bactéries de l'eau, Fr.; Wasserbacterien, Ger. Bactéridie charbonneuse. See Bacillus anthracis, Pollender and Davaine. Bactéridie du charbon. See Bacillus anthracis, Pollender and Davaine. Bactéridie du charbon symptomatique. See Bacillus chauvici, Arloing, Cornevin, Thomas. Bacteridium prodigiosum, Schröter. See Bacillus prodigiosus, Ehrenberg. Bactérie chainette. See Bacterium catenula, Dujardin. Bactérie chromogène. Chromogenic bacteria. Bactérie commune, Miquel. See Bacil- lus termo, Dujardin. Bactéries de la bouche. Bacteria of the mouth. Bactéries de la diphtherie, Emmerich. See Bacillus diphtheriu, Klebs. Bactérie de la fermentation butyrique. See Bacillus butyricus, Prazmowski. Bactérie de la fermentation lactique. See Bacillus acidi lactici, Hueppe. Bactérie de la fermentation propionique. See Bacillus cavicidus, Brieger. Bactéries de l'eau. Microbes of water. Bacteries de la putrefaction. Microbes of putrefaction. Bacterium der Brustseuche des Pferdes. See Streptococcus coryza contagiosa equorum, Schuitz. Bacterium der Buttersäuregährung. See Bacillus butyricus, Prazmowski. Bacterium der Diphtherie, Emmerich. See Bacillus diphtheria, Klebs. Bacterium der Milchsāuregährung. See Bacillus acidi lactici, Hueppe. Bactérie du pus bleu. See Bacillus pyocyaneus a, Gessard. Bactérie point. Bacterium lineola, Cohn. Bacterium des Sauerteigs. See Bacterium farinaceum, Wigand. Bactérie du vinaigre. See Bacillus aceti, Kützing. Bactérie lumineuse de la mer du Nord. See Photobacterium luminosum, Beyerinck. Bactéries de la terre. Microbes of the soil. Bacterien der Mundhöhle. Microbes of the mouth. Bacterien des Meerwassers. Microbes of sea water. Bacterium aceti, Lanzi. See Bacillus aceti, Kiitzing. Bacterium aërogenes, Miller. See Bacillus aërogenes, II, Miller. Bacterium aëruginosum, Schröter. See Bacillus pyocyaneus a, Gessard. Bacterium allii. See Bacillus allii, Griffiths. Bacterium anthracis, Zopf. See Bacillus anthracis, Pollender and Davaine. Bacterium articulatum, Ehrenberg. See Bacterium lineoln, Cohn. Bacterium aurantiacum, Trelease; a chromogenic form. Bacterium bacillus, Pasteur. See Bacillus termo, Davaine. Bacterium aus Diphtherie bei Menschen. See Bacillus diphtheric, Klebs. Bacterium aus der Diphtherie bei Tauben. See Bacillus diphtherice columbanum, Löffler. Bacterium brunneum, Schröter. Found in a putrid infusion of Indian corn, chg. (brown). Perhaps identical with Bacillus fuscus, Zimmermann. Bacterium butyri colloideum, Lafar. Found in every sample of natural butter examined. Cf. Bacillus butyri fuorescens, Lafar. Bacterium candidum, Trelease. A chromogenous form, identical with Bacillus mesentericus fuscus, Flïgge. Bacterium capitatum, Davaine. Found in an infusion of albuminous matter. aër., mot. Bacterium carbuncolare, Pollender, Brauell, Delafond, and Davaine. See Bacillus anthracis, Pollender and Davaine. Bacterium carlsbergense, Hansen. Found in the air. Cf. Bacterium kochii, Hansen. Bacterium catenula, Dujardin. Syn., Bacterium chainette. Bactérie chainette, Fr. Observed especially in putrid wine or putrefying blood, generally in albu minous liquids in contact with air. Coze and Feltz found it in typhoid fever in man and rabbits. It resembles Bacillus acidi lactici, Davaine, Hueppe. Bacterium caucasicum. See Bacillus caucasicus, Kern. Bacterium chainette. See Bacterium catenula, Dujardin. Bacterium chlorinum, Engelmann. Found in water. $a \ddot{e r} ., c h g$. (green). Engelmann holds this to be chlorophyll; as a small amount of oxygen is given off, indicating the assimilation of carbon. Bacterium coli commune, Escherich. See Bacillus neapolitanus. Bacterium commune, Pasteur. See Bacterium termo, Dujardin. Bacterium cuneatum, Rivolta. See Bacillus cuneatus. Bacterium cyanogenum, Fuchs. See Bacillus cyanogenus, Hueppe. Bacterium

Abbreviations. - aёr, = aërobic. anaër. = anaërobic. $c h g .=$ chromogenic. facanaër. = facultative anaërobic. liqf. = liquefac tive. monom. = monomorphic. mot. = motile. nliqf. $=$ non-liquefactive. nmot. $=$ non-motile. npg. $=$ non-pathogenic. $o b l_{\text {. }}=$ obligate. oscl. = oscillating. $p g .=$ pathogenic. phos. = phosphorescent. pleom. = pleomorphic. sap. = saprophytic. 
decalvans, Thin. See Micrococcus area celsii, Buchner and Sehlen. Bactérie de la pourriture. See Bacterium putredinis. Bacterium denitrificans, $a \beta$, Gayon and Dupetit. See Bacillus denitrificans, Giltay and Aberson. Bacterium der Brustseuche des Pferdes. See Streptococcus coryza contagiosa equorum, Schütz. Bacterium der Essiggährung. See $B a$ cillus aceti, Kützing. Bacterium der Milchsäuregährung. See Bacillus acidi lactici, Davaine and Hueppe. Bacterium der Septikämie bei Kaninchen. See Bacillus septicamia hamorrhagica, Sternberg. Bacterium dysodes, Zopf. See Bacillues dysodes, Zopf. Bacterium enchelys, Ehrenberg. Found in river water. Thought by Ehrenberg to be an infusorian. Bactérie en zigzag, Fr. See Bacilhus geniculatus, De Bary. Bacterium farinaceum, Wigand. Syn., Bacterium des Sauerteigs. Found in sour sponge or dough. Bacterium fitzianum, Zopf. See Bacillus subtilis, Ehrenberg. Bacterium fœtidum, Thin. See Bacillus foetidus, Passet. Bacterium fusiforme, Warming. Found in sea water. Bacterium gingivæ pyogenes, Miller. See Bacillus gingiva pyogenes. Bacterium gliscrogenum, Malerba. See Bacillus gliscrogenus. Found in viscid acid urine. aër., nliqf., mot., npg. Bacterium griseum, Warming. Syn., Micrococcus grisezs, Winter, a doubtful form. Bacterium gummis, Commes. Syn., Microbe de la mal nero, Ital. The cause of the gummous disease of the fig, almond, and orange trees, and the mal nero of vines. Cf. Bacterium putredinis, Davaine. Bacterium gummosum, Ritsert. Found to produce the viscosity of infusions of Digitalis. aër.,liq $f$., pleom. Bacterium hessii, Guillebeau. One of the two forma found by Gillebeau to cause milk to become ropy. Thrives best in Pasteurized milk. aër., liqf., mot., npg. Cf. Micrococcus freudenreichii. Bacterium hyacinthi, Wakker. Found in the bulbs and leaves of the hyacinth and causing the yellows of hyacinths. Cf. Bacterium hyacinthi septicus, Heinz. Bacterium janthinum, Zopf. See Bacillus janthinus, Zopf. Bacterium kochii, Hansen. Found in the air of Carlsberg. Cf. Bacterium carlsbergense, Hansen. Bacterium lactis, Lister. See Bacillus acidi lactici, Hueppe. Bacterium lactis aërogenes, Escherich. See Bacillus lactis aërogenes, Abelous. Bacterium lineola, Müller, Cohn. Syn., Bacterium punctum, Rivolta. Bacterium tremulans, Trevisan. Bacterium triloculari, Ehrenberg. Bacterium articulatum, Ehrenberg. Vibrio lineola (Müller), Ehrenberg. Vibrio tremulans, Ehrenberg. Bacillus lineola, Bactérie point, Fr. Found in well and other water, in infusions, soil on vegetables, etc. aër., mot. (trembling and darting back and forth), pleom., npg. Probably represents several species, or a developmental form of a spirillum. Bacterium litoreum, Warming. Found only in sea water. aër., mot., npg. Bacterium lucens, Van Tieghem. See Bacillus lucens, Van T. Bacterium luteum, Trelease. See Bacillus huteus, Flügge. Bacterium maidis, Cuboni. See Bacillus maidis, Cuboni. Bacterium merismopœdioides, Zopf. See Bacillus merismopodioides, Zopf. Bacterium morbilli, Lanzi. Syn., Microbe di morbillo. Found in the urine of persons with measles. Cf. Bacillus septicamia hamorrhagica, Sternberg. Bacterium navicula, Reinke and Berthold. See Bacillus butyricus, Prazmowski. Bacterium neapolitanum. See Bacillus neapolitanus. Emmerich. Bacterium oblongum, Boutroux. Syn., Micrococcus oblonous, Boutroux. Found in beer; the agent of gluconic fermentation. Bacterium of $\mathrm{Bu}$ - tyric Acid Fermentation. See Bacillus butyricus, Prazmowski. Bacterium of Diphtheria, Emmerich. Syn., Bactérie de la diphthérie, Fr. Bacterium der Diphtherie, Ger. Found in cases of diphtheria in man and doves. Bacterium of Fire Blight. See $B a$ cillus butyricus, Prazmowski. Bacterium of Infectious Pneumonia in the Horse. See Sireptococcus coryze contagiosce equorum, Schütz. Bacterium of Kefir. See Bacillus cancasicus, Kern. Bacterium of Pear Blight. Cf. Bacillus butyricus, Prazmowski, and Micrococcus amylovorus, Burrill. Bacterium of Sheep Pox. Syn., Microbe de la clavelée. Found in cases of sheep pox, or "Schafblattern." Bacterium of variola, Cose and Feltz. Syn., Bactérie de la petite variole, Fr. Bacterium der Variola (oder der Blattern). Found in the vesicles of smallpox; pathogenic for rabbits. Bacterium oleæ, Arcangeli. Said to cause the so-called tuberculosis ("Maladie de la loupe;" "Rogner") of olives. Bacterium ovatum, Lebert. See Nosema bombycis, Nägeli. Bacterium pasteurianum, or Bacterium pastorianum. See Bacillus pasteurianus, Hansen. Bacterium periplanetæ, Tichomirow. Found in the common cockroach (Periplanetce orientalis), and producing in it a specific disease. Bacterium pflügeri, Lüdwig. See Photobacterium pflügeri, Ludwig. Bacterium phosphorescens, Hermes. See Bacillus phosphoreus, Cohn. Bacterium Phosphorescens, Cohn. See Photobacterium phosphorescens. Bacterium photometricum, Engelmann. Found in water; motion dependent on light; possibly not a bacterium at all. Bacterium pneumoniæ, Bacterium pneumoniæ crouposæ, Friedländer. See Bacillus pneumonice friedländeri. Bacterium porri, TommasiCrudeli. Found in warts. Bacterium prodigiosum. See Bacillus prodigiosus, Ehrenberg. Bacterium pseudopneumonicum. See Bacillus pseudopneumonicus, Flügge. Bacterium punctum, Rivolta. See Bacterium lineola (Müller), Cohn. Bacterium putredinis, Davaine. Syn., Bactérie de la pourriture. Found in rapidly-decaying plants. Cf. Bacterium gummis, Comes. Bacterium pyriforme, Hansen. Found in the air. Bacterium radicicola, Prazmowski. Syn., Bacillus radicicola, Beyerinck; Rhizobium leguminosarum, Frank. Found in the soil, particularly in the roots of the Lesuminose, where they are held to stimulate the cells to unusual growth, affect nitrification, constitute the " bacteroids" of Woronin, and form the so-called "bacteroid tissue." Bacterium rosaceum metalloides, Dowdeswell. See Bacillus ruber, Frank, Cohn. Bacterium rubescens, Lankester. See Beggiatoa roseopersicina, Zopf. Bacterium septicæmiæ, Koch. See Bacillus septicamice hamorrhagica, Sternberg. Bacterium septicum sputigenum. See Bacillus septicus sputigenus, Flügge. Bacterium subtile, Buchner. See Bacillus subtilis, Ehrenberg. Bacterium sulfuratum; Bacterium sulphuratum, Warming. See Beggiatoa roseo-persicina, Zopf. Bacterium sulfureum, Rosenheim. Found in wine. nligf. Evolves $\mathrm{H}_{2} \mathrm{~S}$. Bacterium syncyaneum, Ehrenberg, Schröter. See Bacillus cyanogenus, Hueppe. Bacterium synxanthum, Schröter. See Bacillus synxanthus. Bacterium termo, Dujardin and Ehrenberg. Syn., Bacillus termo, Davaine. Bactérie (Bacterium) commune, Pasteur. Bacterium bacillus, Pasteur. Cryptococcus natans, Kützing. Cryptococcus nebulosus, Kützing. Micrococcus crepusculum, Cohn. Zoogloca termo (Müller), Cohn. Monas

Abbreviations, - aër. = aërobic. anaër = anaërobic. chg. = chromngenic. facanaër. = facultative anaërobic. liqf. =liquefactive monom. = monomorphic, mot. = motile. nliqf. = non-liquefactive. nmot. $=$ non-motile. npg. $=$ non-pathogenic. $a b l_{0}=$ obligate. $o s c l_{0}=$ oscillating. $p g .=$ pathogenic. phos. = phosphorescent. pleom, = pleomorphic. sap, = saprophytic. 
termo, Müller. Palmella infusionum, Ehrenberg. Long considered the most characteristic microbe of filth and putrefaction; but shown by Hauser to be a collective species. The name is now reserved for Vignal's species, while Bacillus termo may perhaps be reserved for the flagellate forms studied by Dallinger and Drysdale, or discarded entirely. Bacterium termo, Vignal. Found in the saliva of healthy persons. aër., liqf., mot., chg. (yellowish gray), npg. Bacterium tholoideum, Gessner. Syn., Bacillus of Gessner. Found in the intestinal contents of healthy persons. Resembles Bacillus lactis aërogenes, Escherich. pg. (for mice and guinea-pigs). Bacterium tremulans, Trevisan. See Bacterium lineola, Cohn. Bacterium triloculare, Ehrenberg. See Bacterium lineola, Cohn. Bacterium tuberculosis, Zopf. Bacterium tuberculosum, Koch. See Bacillus tuberculosis, Koch. Bacterium tumescens, Zopf. See Bacillus tumescens, Zopf. Bacterium typhosum. See Bacillus typhi abdominalis, Eberth and Gaffky. Bacterium ulna. See Bacillus ulna, Cohn. Bacterium ulna, Cohn. See Micrococcus urea. Bacterium ureæ, Jaksch. Found in ammoniacal urine. aër., facanaër., nliqf. Not sufficiently investigated. Bacterium vermiforme, Ward. Found in fermented ginger beer. Bacterium viride, See Bacillus viridis, Van Tieghem. Bacterium violaceum, Bergonzini. Syn., Chromobacterium violaceum, Bergonzini. Found in putrefying solutions of egg albumen. chg. (violet). Bacterium xanthinum. See Bacillus synxanthus, Ehrenberg and Schröter. Bacterium xylinum, A. J. Brown. Found in solutions of carbohydrates, giving rise to acetic acid, and converting dextrose into gluconic acid, and mannitol into levulose. Bacterium zopfii, Kurth. See Bacillus zopfi. Bacteroides, Woronin. Microorganisms forming tubercles in the roots of leguminous plants, and assisting in the fixing of nitrogen. Batteria chromogène, Ital. Chromogenic microbes. Batterio della pellagra, Ital. See Bacillus maidis, Cuboni. Beggiatoa alba, Vaucher. Syn., Beggiatoa punctata, Trevisan. Beggiatod leptomitiformis, Meneghi. Oscillaria alba, Vaucher. Hygrocrocis vandelli, Meneghi. Next to Cladothrix the most common bacterium of water, forming a superficial layer in the mud called barégine or glairine, $q . v$. Beggiatoa alba, var. marina, Cohn. Syn., Beggiatoa cerstedti, Rabenhorst. See Begriatoa marina, Cohn. Beggiatoa arachnoidæ, Agardh. Syn., Oscillaria arachnoidea, Agardh. Oscillaria versatitis, Kutz. Found in swamps and sulphur springs. Beggiatoa leptomitiformis, Meneghi and Trevisan. Syn., Oscillaria lestomitiformis, Meneghi. Found in sulphur springs. Beggiatoa marina, Cohn. Syn., Bescriatoa alba, var. marina, Cohn. Begriatoa cerstedii, Rabenhorst. Found in a salt water aquarium, forming a whitish slimy layer on dead fish. Beggiatoa minima, Warming. Found in sea water; gray. Beggiatoa mirabilis, Cohn. Found in a salt water aquarium; snow white. Beggiatoa multisepta. See Pragmidiothrix multisepta, Engler. Held by Zopf to be identical with Beggiatoa alba, Vaucher. Beggiatoa nivea, Rabenhorst. Syn., Leptonema niveum, Symphiothrix nivea, Brugger. Found in sulphur springs. Beggiatoa nodosa, Van Tieghem. A doubtful form characterized by nodes in the filaments, which differ from other members of the genus in the absence of sulphur grains and of motion. Beggiatoa œerstedtii. Rabenhorst. See Beggiatoa alba, var. marina, Cohn.
Beggiatoa pellucida, Cohn. Found in a marine aquarium; sulphur grains few. Beggiatoa punctata, Trevisan. See Begriatoa alba, Cohn. Beggiatoa roseo-persicina, Zopf. Syn., Bacterium rubes cens, Lankester. Bacterium sulfuratum or Bacterium sulphuratum, Warming. Clathrocystis roseo-persicina, Cohn. Cohnia roseo-persicina, Winter, Kützing. Microhaloa rosea, Kutz. Ophidiomonas sanguinea, Ehrenberg. Pleurococcus roseo-persicina, Rabenhorst. Peach-colored bacterium. Morphologically identical with Beggiatoa alba, Vaucher. Forms rose-colored to violet pellicles on putrid matter. Produces bacterio-purpurin. Beggiatoa tigrina, Rabenhorst. Syn., Oscillaria tigrina, Romer. Found in swamps on submerged wood. Forms a thin white layer. Bienenfaulbrutbacillus. See Bacillus alvei, Cheshire and Cheyne. Bienstock's Bacillus. Bienstock's Bacillus aus Fæces. Bienstock's Putrefactive Bacillus. Bienstock's Putrefactive Bacillus from the Feces. See Bacillus putreficus coli, Bienstock. Blutbacillus. Microbe of the blood. Blutpilz. See Bacillus prodigiosus, Ehrenberg. Bodenbacillus. Microbe of the soil. Bollingera equi, Saccardo. See Micrococcus botryogenes, Rabe. Brauner Kartoffelbacillus, Ger. See Bacillus mesentericus fuscus, Flügge. Brieger's Bacillus. See Bacillus cavicidus, Brieger. Brunnenfaden. See Crenothrix kïhniana Rabenhorst. Buff Bacillus of Spreading Edema, A. B. Harris. nliqf., aër., chg. (buff), pleom. Butterbacillus, Ger., Buttersäurebacillus, Butylbacillus, Ger. See Bacillus butrricus, Prazmowski. Capsule Bacillus of Loeb. Obtained from a case of keratomalacia infantum. aër., facanaër., nliqf., nmot., po. Resembles Bacillus capsulatus, Pfeiffer. Capsule Bacillus of Ozena, Marano. Found in the nasal secretions in ten cases of ozena. Resembles Bacillus pneumonice friedländerii. Cf. Micrococcus lorvenbergii. Capsule Bacillus of Smith. See Bacillus capsulatus smithii. Champignon du tube digestif du lapin et autres herbivores, Remack. See Saccharomyces guttulatus, Robin. Cheese Spirillum. See Spirillum tyrogenum, Denecke. Chromo bacterium violaceum, Bergonzini. See Bacterium violaceum, Bergonzini. Chromogene Bacterien Ger. Syn., Bactéries chromogènes, Fr. Batteria chromogeni, It. Chromogenic bacteria. Chromogenic Micrococci. Chromogenous Micrococci. Microcoque chromogène, Fr. Chromogenic micrococci. Chromogenous Bacteria. Bactéries chromogènes, Fr. Batteria cromogeni, Ital. Chromogenic bacteria. Cladothrix bovis. See Actinomyces bovis, Harz. Cladothrix canis. Held by Rabe to be very like Actinomyces bovis. Cladothrix dichotoma, Cohn and Zopf. See Leptothrix ochracea, Kützing. Myconostoc gregarizen, Cohn. Cladothrix foersteri, Cohn. Syn., Crenothrix farsteri, Streptothrix forsteri, Cohn. Leptrothrix der Thränenröhrchen, Graefe, Ger. Forms yellowish or grayish concretions in the human lachrymal ducts. Cladothrix intricata, Russel. Obtained from sea mud (bay of Naples). aër., liqf., mot. Clathrocystis roseo-persicina, Cohn. See Beggiatoa roseo-persicina, Zopf. Clostridium butyricum, Prazmowski. See Bacillus butyricus, Prazmowski. Clostridium fœetidum, Liborius. See $B a-$ cillus fotidus, Passet. Clostridium of Symptomatic Anthrax (or Charbon), Neelsen and Ehlers. See Bacillus chauvai, Bollinger and Feser. Clostridium polymyxa, Prazmowski. See Bacillus polymyxa, Prazmowski. Coccobacillus pyogenes ureæ, Rör-

Abbreviations.-aër. = aërobic. anaër $=$ anaërobic. $c h g .=$ chromogenic. facanaër. $=$ facultative anaërobic. ligf. $=$ liquefac' tive. monom. = monomorphic. mot. = motile. nliqf. = non-liquefactive. nmot. $=$ non-motile. npg. $=$ non-pathogenic. $o b l_{0}=$ obligate. oscl. = oscillating. $p g_{*}=$ pathogenic. phos. = phosphorescent. pleom. $=$ pleomorphic. sap. $=$ saprophytic 
sing. See Diplococcus pyogenes urea, Rörsing. Coccobacteria septica, Billroth. The single term under which Billroth includes all putrefactive bacteria. See Bacillus sefticamice hamorrhagice, Sternberg. Coccobacteria ureæ, Rörsing. See Diplococcis pyogenes urea, Rörsing. Coccobacterium lyssæ, Rivolta. See Bacillus lysse, Pasteur. Cohnia roseo-persicina, Winter and Küitzing. See Beggiatoa roseopersicina, Zopf. Colon Bacillus of Escherich. See Bacillus neapolitanus. Comma Bacillus, Comma bacillus of Koch, Comma-shaped Bacillus, Waten. Bacillo en virgule, bacille virgule, Fr. Kommabacillus, Ger. Bacillo virgola, bacillo virgolato, Ital. Bacillo vergula, bacillo virgulado, Sp. See Spirillum cholerce asiatica, Koch. Cornalian Corpuscles. See Microbe de la pebrine. Corpuscles brillants. See Bacillus fotidus, Passet. Corpuscles du ver du soie. See Micrococcus ovatus. Coryza diplococci. See Micrococcus cereus aureus, Schröter and Winckler. Crêmefarbiger Micrococcus, List, Ger. See Micrococcus citreus, List. Crenothrix forsteri, Cohn. See Cladothrix fiersteri. Crenothrix kühniana, Saccardo and Rabenhorst. Syn., Crenothrix polyspora, Cohn. Hypaothrix kiüniana, Leptothrix kïhniana, Brunnenfaden. Found in drinking water, to which they impart a disagreeable taste. Crenothrix polyspora, Cohn. See Crenothrix kïhniana, Saccardo and Rabenhorst. Cryptococcus alveareus. See Bacillus alvei. Cheshire and Cheyne. Cryptococcus clava, Wedl. Found in the stomachs of ruminants. Cryptococcus cerevisiæ, Robin. Cryptococcus fermentatum, Kützing. See Saccharomyces cerevisia, Reess and Robin. Cryptococcus glutinis, Fersen. See Saccharomyces glutinis. Cryptococcus guttulatus, Robin. See Saccharomyces guttulatus. Cryptococcus natans, cryptococcus nebulosus, Kützing. See Bacterium termo, Dujardin and Davaine. Cryptococcus of Yellow Fever. See C. xanthogenicus, Freire. Cryptococcus xanthogenicus, Domingo-Freire. Considered by D. Freire to be the cause of yellow fever. Cf. Bacillus of yellow fever. Darmbacillen. Bacilli of the intestine. Darmbacillen von Schottelius. See Bacillus coprogenes fatidus, Schottelius. Denecke's Cheese Bacillus. See Spirillum tyrogenum. Dengue Micrococci. See Scheutzia laughtini. Detionella ochracea, Saccardo. See Leptothrix ochracea, Kützing. Diplococcus albicans amplus, Bumm; Grayish white micrococcus. Found in mucus from the healthy vagina. aër., facanaër., liqf., $n p g$. Diplococcus albicans tardus, Unna and Tommasoli. Found in eczema. aër., nliqf., nmot. Diplococcus albicans tardissimus. Morphologically identical with the Gonococcus; but more adherent, forming small masses. aër., nliqf., npg. Diplococcus citreus conglomeratus, Bumm. Obtained from the air, in dust, and from gonorrheal pus. aër., facanaër., liqf., chg. (lemon-yellow), npg. Diplococcus citreus liquefaciens, Unna and Tommasoli. Found on the skin in cases of eczema seborrhœicum. aër., liqf., nmot., chg. (lemon-yellow), npg. Diplococcus coryzæ, Klebs and Hajek, Obtained from the nasal secretions in cases of acute nasal catarrh. aёr., nliqf., npo. Diplococcus der Pferdepneumonie. See Diplococcus of pneumonia in horses, Schütz. Diplococcus des Pemphigus acutus, Demme. See Diplococcus of pemphigus acutus, Demme. Diplococcus flavus liquefaciens tardus, Unna and Tommasoli. Found on the skin in cases of eczema seborrhoicum. aër., facanaër., liqf., chg. (chrome-yellow), $n p g$. Diplococcus fluorescens fotidus, Klamann. Obtained from the posterior nares. aër., facanaër., liqf., chg. (grass-green to violet), npg. Diplococcus intercellularis meningitidis, Goldschmidt and Weichselbaum. Found within the cells of the exudates in cerebro-spinal meningitis. aër. nliqf., ps. Diplococcus jaune blanc. See Micrococcus subftarus, Bumm. Diplococcus lacteus faviformis, Bumm. Found frequently in the vaginal secretions, aër, nliqf., npg. Diplococcus luteus, Adametz. Found in water. aër., liqf., mot., chg. (yellow), npg. Diplococcus of Gonorrhea. See Micrococcus gonorrhae, Neisser. Diplococcus of Orchitis, Hugouneng and Eraud. Syn., Orchiococcus. Frequently found in gonorrheal pus during the first few days. aër., nligf., pg. The specific microbe of blennorrhagic epididymitis. Diplococcus of Ozena, I.oewenberg. Found in the secretions in cases of ozena. Diplococcus of Pemphigus, Diplococcus of Pemphigus Acutus, Demme. Syn., Micrococcus of Demme. Diplococcus des Pemphigus acutus, Ger. Found in the bullæ of pemphigus. aêr., nliqf., pg. Resembles the Gonococcus. Diplococcus of Pneumonia in Horses, Schütz. Syn., Diplococcus der Pferdepneumonie. Obtained from the lungs of a horse affected with acute pneumonia. ä̈r., nliqf., pg. Diplococcus pneumonix fibrinosæ, Friedländer. See Bacillus pneumonie friedländeri. Diplococcus pneumonia, Weichselbaum. See Bacillus septicus sputigenus, Flügge. Diplococcus pyogenes ureæ, Rörsing. Syn., Diplococcus urea, Rörsing. Coccobacillus pyogenes urea, Rörsing. Coccobacterium urea, Rörsing. Found in purulent urine. Cf. Diplococcus uree trifoliatus, Rörsing. Micrococcus pyogenes urea flavus, Rörsing. Diplococcus roseus, Bumm. Found in the air. aër., facanaër., liqf., chg. (pink), npg. Diplococcus ureæ, Rörsing. See Diplococcus pyogenes urea, Rörsing. Diplococcus urea trifoliatus, Rörsing. Found in purulent urine. Cf. Diplococcus pyogenes urece, Rörsing. Micrococcus pyogenes urea flavus, Rörsing. Dispora caucasica, Kern. See Bacillus caucasicus, Kern. Drumstick Bacillus. See Bacillus putrificus coli, Bienstock, Einheimischer Leuchtbacillus. See Bacillus phosphorescens indigenus, Fisher. Eisbacillen. Bacilli of ice. Eiterbacillen, Eiterkokken, Eitermikroben. Microbes of pus. Eiterkettenkokkus. See Micrococcus pyogenes, Rosenbach. Emmerich's Bacillus, Emmerich's Neapler Bacillus. See Bacillus neapolitanus. Endosporous bacteria. Syn., Bactéries endospores, Fr. EndosporenBacterien, Ger. Bacteria that produce by endogenous spore formation. Epsilon Bacillus, Miller. See Spirillum finkleri. Erdbacillus. See Bacillus myocoides, Flügge. Erdebacillen, Erdebacterien. Microbes of the soil. Erythroconus litoralis, Erstedt. See Sarcina litoralis, Erstedt. Essigferment, Essigpilz. See Bacillus aceti, Kützing. Frecesbacillen, Ger. Bacilli of the feces. Fäulnisbacillen, Ger. See Bacillus saprogenes, I, II, III, Rosengarten, Fäulnisbacterium, Ger. See Bacterium termo. Dujardin and Davaine. Fäulnisbacterien. Bacteria of putrefaction. Feet-sweat Bacillus. See Bacillus fatidus. Bacillus saprogenes, II, and Bacterium graveolens. Ferment de la fermentation butyrique, Fr. See Bacillus butyricus, Prazmowski. Fettbacillus, Ger. See Bacillus butyricus Prazmowski. Finkler-Prior's Bacillus.

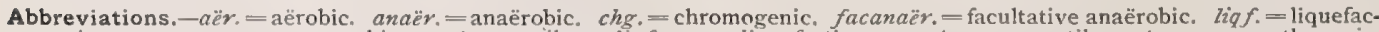
tive, monom. = monomorphic. mot. = motile, nliqf. = non-liquefactive nmot. = non-motile. npg. $=$ non-pathogenic. obl. = obligate. oscl. = oscillating. pg. = pathogenic, phos, = phosphorescent. pleom, $=$ pleomorphic. sap. $=$ saprophytic. 
See Spirillum Finkler-Prior. Fiore del vino e della birra, Ital. See Saccharamyces mycoderma, Reess. Fitz'scher Aethylbacillus, Ger. See Bacillus subtilis, Ehrenberg, etc. Flesh-colored Bacillus, Tils, Found in water. aër., liqf. mot., chg. (pink), npg. Flowers of Wine. See Saccharomyces mycoderma, Reess. Fluorescent bacilli. Bacilles fluorescents, Fr. Fluorescirende Bacillen, Ger. See Bacillus fuorescens putidus, Bacillus erythrosporus, Bacillus Auorescens liquefaciens, etc. Fraenkel's Pneumobacillus, Fraenkel'scher Diplococcus, FraenkelWeichselbaum'scher Pneumococcus, Fraenkel' scher Pneumonie-Diplococcus. See Bacillus septicus sputigenus, Flügge. Frog-spawn Bacterium of Sugar Factories, Frog-spawn fungus, Froschlaich, Froschlaichpilz, Ger. See Leuconostoc mesenteroides. Gaffkya tetragenes, Saccardo. See Micrococcus tetragemus, Gaffky. Gährungerregende Bacillen, Ger. Zymogenic bacilli. Gasbildende Bacillen aus dem Magen, Ger. See Bacillus lactis aërogenes, Escherich. Gasbildende Bacillen aus Wasser, Ger. Bacilli of water. Gas Forming Bacillus. See Bacillus gasoformans, Eisenberg. Gelber Bacillus. See Bacillus luteus, Flügge. Gelber Traubencoccus. See Staphylococcus pyogenes aureus, Ogston. Ginger Beer Plant, Marshall Ward. Forms jelly-like, semi-transparent, yellowish-white, brain-like masses at the bottom of the fermentation; resembles Caucasian kephir grains; it is a symbiotic association of Saccharomyces pyriformis, and of Bacterium vermiforme. Glacier Bacillus, Gletscherbacillus. See Bacillus fuorescens nivalis, Schmolck. Glatthautbildender Kartoffelbacillus, Ger. See Bacillus leiodermos, Löffler. Gliococcus, a micrococcus with a slimy capsule. Glycerinäthylbacillus, Glycerinaethylbacterium. See Bacillus subtilis, Ehrenberg, Cohn, etc. Golden Staphylococcus. See Staphy. lococcus pyogenes aureus, Ogston, Beeker. Gomme de sucrerie. See Leuconostoc mesenteroides, Cienkowski. Gonococcus, Gonococque, Gonorrhcecoccus. Syn., Trippercoccus. See Micrococcus gonorrhcece Neisser. Grains de kephyr. See Bacillus caucas icus, Kern. Gray-white micrococcus, Bumm. See Diplococcus albicans amplus, Bumm. Grüngelber Bacillus aus Wasser, Ger. Greenish-yellow bacillus of water. Gummibacillus, Ger. See, B. liodermos, Löffler. Hæmatococcus bovis, Babes. Syn., Microbe de l'hémoglobinurie du bouf. Zimmermann. Obtained from the blood and viscera of cattle dead of an epidemic, infectious disease characterized by hemoglobinuria (in Roumania). aër., facanaër., nliqf., pg. Harnmicrococcus. See Micrococcus urea, Cohn. Harnsarcine, Hartze, See Sarcina of urine. Harnstoffmicrococcus. See Micrococcus urea, Cohn. Hauser's Fäulnisbacillen. See Proteus vulgaris, Proteus mirabilis, Proteus zenkerii. Hay bacillus, Bacille du foin, Fr. Heubacillus. Ger. Bacillus del fieno, Ital. See Bacillus subtilis, Ehrenberg. Helicobacterium aërogenes, Miller. See Bacillus aërogenes, III, Miller. Helicobacterium klebsii, Escherich. Found in the intestine of guinea pigs. pleom. Helicomonas, Klebs. Syphilis fungus. Cf. Bacillus syphitidis, Lustgarten. Heubacillus. See Bacillus subtilis, Ehrenberg. Heubacillusähnlicher Bacillus, Ger. See Bacillus subtilis simulans, Bienstock. Heupilz, See Bacillus subtilis, Ehrenberg. Hirse des Propheten. See Bacillus caucasicus, Kern. Hormiscium cerevisiæ, Bonard. Hormiscium vini. Hormiscium vini et cerevisix, Bonard. See Saccharomyces myco derma. Hostienblut. See Bacillus prodigiosus, Ehrenberg. Hühnercholerabacillus. Hühnermicrococcus. Bacillus of chicken cholera. See $B a$. cillus septicamia hemorrhagica, Sternberg. Hueppe's Bacillus of Butyric Acid Fermentation -Hueppe's Buttersäurebacillus. See Bacillus butyricus, Hueppe. Hundswutbacillus. See $B a$ cillus lyssa, Pasteur. Hygrocrocis vandelli, Meneghi. See Beggiatoa alba, Trevisan. Hypæothrix kuehniana. See Crenothrix kïhniana. Indischer Leuchtbacillus. See Bacillus phosphorescens indicus, Fischer. Influenzabacillus. See Bacillus of Influenza, Pfeiffer. Iodococcus vaginatus, Miller. Found in unclean mouths; gives peculiar reaction with iodin, the sheath being stained yellow, the cocci dark blue. Jequeritypilz. See Bacillus of jequirity ophthalmia. Kartoffelbacillus. Potato bacillus, applied to Bacillus mesentericus fuscus, Flügge; Bacillus mesentericus ruber, Globig; and Bacillus mesentericus vulgatus, Flügge. Käsespirillum. See Spirillum tyrogenum, Deneke. Kefirbacillus. Kefirferment. See Bacillus caucasicus, Kern. Keuchhustenpilz, Burger. See Bacillus tussis convulsive, Afanassiew. Knäuelbildender Bacillus, Ger. See Bacillus zopfii. Koch's Bacillus, Koch'scher Bacillus, Kommabacillus der Cholera asiaticæ. Koch's Comma Bacillus, Kommabacillus. See Spirillum cholere asiatice, Koch. Kotbacillen. Syn., Bacilles des selles, Fr. Bacilli of the feces. Krankheiterregende Bacillen (or Bacterien). Pathogenic bacilli. Lanceolate Coccus, Lancet-shaped Micrococcus, Talamon. See Bacillus septicus sputigenus, Flügge. Leprabacillus. See Bacillus lepre, Hansen. Leptonema niveum. See Beggiatoa nivea, Rabenhorst. Leptothrix buccalis, Robin. Pilz der Zahncaries, Ger. Syn. Leptothrix gigantea, Miller. Leptothrix pulmonalis, Rasmussenia buccalis, Saccardo. Found in the mouth of man and animals. Falsely considered the cause of dental caries. Leptothrix buccalis of Vignal. See Bacillus buccalis (a), Vignal. Leptothrix epidermidis. Syn., Bacillus epidermidis, Bizzozero. Microsporon minutissimum, Burchart. Found on the epidermis between the toes, and held by $\mathrm{Biz}$ zozero to be non-pathogenic, but by Boeck as the cause of erythrasma. Leptothrix der Thrănenröhrchen. See Cladothrix forsteri, Cohn. Leptothrix gigantea, Miller. Found on the teeth of dogs, sheep, cattle and other animals affected with Pyorrhoa alveolaris. Some consider it identical with Leptothrix buccalis, Robin. Leptothrix hyalina, Reinsch. Found on marine algæ. 'Leptothrix innominata, Miller. See, Leptnthrix buccalis, Robin. Leptothrix kühniana. See Crenothrix kühniana Saccardo. Leptothrix lacrimalis. Syn. Leptothrix der Thränenröhrchen. See Cladothrix forsteri, Cohn. Leptothrix lanugo, Kuitzing. Found on marine algæ near Heligoland. Leptothrix maxima buccalis, Miller. See Bacillus buccalis maximus, Miller. Leptothrix muralis, Kuitaing. See Leptothrix parasitica. Leptothrix natans. See Spharotilus natans, Saccardo. Leptothrix ochracea, Kützing. Syn. Detionella ochracea, Saccardo. Cladothrix dichotoma, Zopf. According to Zopf, this represents filaments of Cladothrix stained witb oxid of iron. Leptothrix of Puerperal Fever, Leptothrix puerperalis, Fettz. See Bacillus puerperalis, Engel and Spillman. Leptothrix parasitica, Kützing. Parasitic on fresh

Abbreviations. - aër. = aërobic. anaër. = anaërobic. chg, = chromogenic. facanaër. = facultative anaërobic. liqf. = liquefactive, monom. = monomorphic. mot. = motile. nligf. = non-liquefactive. nmot. = non-motile. npg. $=$ non-pathogenic $a b l .=$ obligate. oscl. = oscillating. $\mathrm{pg} .=$ pathogenic. phos. = phosphorescent. pleom. $=$ pleomorphic. sap. = saprophytic 
water algæ. This and Leptothrix muralis are genetically connected with Drilosiphon julianus, Kutzing, the ordinary hormogones of which produce filaments known as Nostoc parietinum, Rabenhorst; the cells of these Nostoc filaments eventually separate and produce slender filaments constituting Leptothrix parasitica and muralis, Kützing (Bennet and Murray). Leptothrix pulmonalis. See Leptothrix buccalis, Robin. Leptothrix pusilla, Rabenhorst. Found on fresh water algæ, also in the mouth, Klebs. Leptothrix symplacoides, Dickie. Found on marine algæ. Leptothrix vaginalis. Found in the vagina of animals and women. Leptothrix variabilis, Saccardo. Found in saliva of healthy persons. Leuconostoc mesenteroides, Van Tieghem. Syn., Ascococcus mesenteroides, Cienkowski. Gomme de Sucrerie, Fr. Froschlaich, Froschlaichpilz, Pilz der Dexträngährung, Ger. Frog spawn bacterium of sugar factories, Frog spawn fungus. A source of great loss to the manufacturers of beet sugar, frequently and rapidly converting large quantities of the beet juice into a mucilagino-gelatinous mass. Liborius's Bacillus of Butyric Acid Fermentation, Liborius, Buttersäurebildender Bacillus, Ger. See Bacillus butyricus, Prazmowski. Lissophyton suspectum, Hallier. See Bacillus lysse, Pasteur. Luësbacillus. See Bacillus syphilides, Lustgarten. Luft bacillen. Syn., Bacilli of the air. Bacilles de l'air. Luftbacterien. Bacteria of the air. Lungenseuchemicrococcus. See Micrococcus of bovine pneumonia, Poels and Nolen. Lupusbacillen. Bacilli of lupus, identical with Bacillus tuberculosis, Koch. Mäuseseptikämieähnlicher Bacillus, Eisenberg. See $B a$ cillus coprogenes parvus. Melunella flexuosa, Borg. See Spirillum rugula, Müller. Merismopedia chondroidea, With, Merismopedia glauca. See Sarcina renis, Hepworth. Merismopedia goodsirii. See Sarcina ventriculi, Goodsir. Merismopedia hyalina, Kützing. Sarcina hyalina, Kützing. Merismopedia litoralis, Rabenhorst. See Sarcina litoralis, Erstedt. Merismopedia reitenbachii, Caspary. See Sarcina reitenbachii, Caspary. Merismopedia urinæ, Rabenhorst. See Sarcina urince, Welcker. Merismopedia ventriculi, Husem. See Sarcina ventriculi, Goodsir. Merismopedia violacea, Kützing. See Sarcina violacea, Kützing. Meerschweinchenbacillus, Ger. See Bacillus cavicidus, Brieger. Metallacter anthracis, Trevisan. See Bacillus anthracis, Pollender and Davaine. Metallacter tremulus, Trevisan. See Bacillus tremulus, Koch. Metallacter ulna, Trevisan. See Bacillus ulna, Cohn. Micoderma cerevisiæ, Trecul. See Saccharomyces mycoderma, Reess. Microbe de l'hémoglobinurie du bcuf, Zimmerman. See Hcmatococcus bovis, Babes. Microbe de l'araignée. See $M i$ croccocus mastobius, Nocard and Mollereau. Microbe de la bouton d'Alep, Microbe de la bouton de Nil, Microbe de la bouton d'Orient, Microbe de la clou de Biskra, Microbe de la clou de Gafsa (Poncet). See Micrococcus of Heydenreich. Microbe de la clavelée. See Bacterium of Sheep-pox. Microbe de la dysenterie epidèmique, Chantemesse and Widal. See Bacillus dysenteria, C.\& W. Microbe de la fiévre jaune, Freire, Rebougeon and Carmona y Valle. Syn., Micrococcus (Cryptococcus) xanthogenicus Freire, Micrococcus of Freire. Obtained from the blood of yellow fever patients; attenuated by heat, and used by permission of the Emperor of Brazil (Nov., I882) to inoculate several hundred persons. The organism described Carmona y Valle, appears to be a fungus not related to the bacteria. Cf. Bacillus of yellow fever, Babes. Microbe de la fievre typhoide, Tayon. See Bacillus typhi abdominalis, Eberth. Microbe de la flacherie, Microbe de la maladie des morts-plats. See Micrococcus bombycis, Cohn. Microbe de l'hémoglobinurie du boeuf, Zimmermann. See Hamatococcus bovis. Microbe de la pébrine. Syn., Bacterium ovatum, Lebert; Bacillus pasteurianus, Hansen; Micrococcus ovatus; Micrococcus pasteurianus; Nosema bombycis, Nägeli; Panhystophyton ovatum; Lebert; Micrococcus of pebrine; Cornelian corpuscles; Cornelian bodies; Micrococcus der Fleckenkrankheit, Ger.; Corpuscles du ver a soie, Fr. The specific microbe of a disease of silkworms known for hundreds of years, called pebrine, gattine, petechia, maladie des corpuscles, and spotted disease. It was particularly destructive between $\mathbf{1} 850$ and $\mathbf{1} 875$. According to the investigations of Cornalia, Leydig, Balbiani, Pasteur, and Metschnikoff, these bodies belong to the Psorospermia and are not bacteria at all. Microbe del mal nero, Ital. See Bacterium gummis, Comes; or Bacterium putredinis, Davaine. Microbe des gasigen Gangräns, Ger. See Bacillus cedematis maligni, Koch. Microbe des pus blen norrhagique, Weiss, Fr. See Micrococcus gonorrhace, Neisser. Microbe der Schweinspocken, Ger. See Bacillus ex pneumo-enteritide suis, Klein. Microbe di morbillo, Lanzi, Ital. Microbe du cholera des poules, Fr., Pasteur. See Bacillus septicamia hamorrhagica, Sternberg. Microbe du lait bleu, Fr. See Bacillus cyanogenus, Fuchs. Microbe du pus bleu, Fr. See Bacillus pyocyaneus, Gessard. Microbe of Friedländer. See Bacillus pneumonice friedländerii. Microbe of Pasteur. Microbe septicémique du salive, Fr. See Bacillus sputigenus septicus, Flügge. Micrococci della rabbia, Ital. See Micrococcus lyssa, and Bacillus lysse, Pasteur. Micrococco dell afta epizoötica, Ital. See Streptocytus of eczema epizoötica, Schottelius. Micrococcus aceti. See Bacillus aceti, Kützing. Micrococcus acidi lactici, Marpman. Found in milk; resembles in its action Bacillus acidi lactici, Hueppe. aër., nliqf., mmot., npg. Cf. Spharococcus acidi lactici, Marpman. Micrococcus acidi lactici liquefaciens, Krüger. Found in butter and cheese. aër., fucanaër., liqf., nmot. Micrococcus aërogenes, Miller. Found in the intestinal tract of man. aër., liqf, nmot., npg. Micrococcus agilis, Ali-Cohen. Found in drinking water. aër., liaf., mot., npg. A motile coccus, provided with a flagellum; described by Menge. Micrococcus agilis citreus, Menge. Micrococcus (Diplococcus) albicans amplus, Bumm. Syn., Neisseria albicans. Frequently found in the vaginal secretions. aër., liqf., $n p g$. Micrococcus (diplococcus) albicans tardus, Unna and Tommasoli. Found in eczema. aër., nliqf., nmot. Micrococcus albicans tardissimus, Eisenberg, Bumm. Found in the vaginal secretions of puerperal women. aër., facanaër., nliqf., npg. Micrococcus liquefaciens, Von Besser. Found in the nasal secretions of healthy persons. aër., facanaër. liqf., npg. Micrococcus albus urinæ. See Micrococcus urinalbus. Micrococcus amylovorus, Burrill and Arthur. Syn., Micrococcus of apple blight. Bacterium of pear blight. Produces fermentation in saccharine fluias. aër., nliqf., mot., pg. (for apple and pear trees). Cf. Bacillus, butyricus, Prazmowski. Micrococcus aquatilis, Bolton. Found frequently in water. aër., nliqf., npo. Micrococcus aquatilis

Abbreviations.-aêr. = aërobic. anaër. = anaërobic. chg. $=$ chromogenic. facanaër. = facultative anaërobic. liqf. $=$ liquefactive. monom. = monomorphic, mot. = motile. nliqf. = non-liquefactive. nmot. $=$ non-motile. npg. $=$ non-pathogenic. obl. = obligate. oscl. = oscillating. $\mathrm{pg}_{.}=$pathogenic. phos. = phosphorescent. pleom. $=$pleomorphic. sap. $=$saprophytic. 
invisibilis, Vaughan. Found in water. ä̈r, nliqf., npg. Micrococcus arei celsii, Buchner and Sehlen. Syn., Bacterium decalvans, Thin. Found on the diseased hairs in Alopecia areata. Cf. Bacillus of alopecia areata, Kasauli, and Micrococcus of alopecin areata, Robinson. Micrococcus ascoformans, Johne. See Micrococcus botryogenus, Rabe. Micrococcus aurantiacus, Cohn. Syn., Pediococcus aurantiacus. Found in water. aër, nliqf., ches. (orange-yellow), nipg. Micrococcus bei hepatitis enzoötica porcellorum. See Micrococcus porcellorum. Micrococcus biskræ. See Micrococcus of Heydenreich. Micrococcus blennorrhœus. See Micrococcus gonorthere, Neisser. Micrococcus bombycis, Cohn, Bechamp. Syn., Streptococcus bombycis, Bechamp. Micrococcus de la maladie des morts plat, Fr. Microbe de la flacherie, Fr. Micrococcus der Schlafsucht der Seidenraupen, Ger. Found in the intestinal tract of silkworms and other Lepidoptera dead of the epidemic disease known in France as la facherie; etiologic relation demonstrated by Pasteur. Micrococcus botryogenes, Bollinger, Rabe. Syn., Bollingera equi, Saccardo ; Ascococcus johnei, Cohn; Micrococcus ascoformans, Johne; Micrococcus of myko-desmoids of the horse. Found in colonies in the connective tissue of horses affected with "myko-desmoids." aёr., liqf., $p g$. Micrococcus candicans, Flügge. Found abundantly in air and water. aër., nliqf., npg. Micrococcus candidus, Cohn. Found in water. aër., nliqf., npg. Micrococcus capillorum. Found on the scalp and said to alter the color of the hair. aër., chg. (reddish-yellow). Micrococcus carneus, Zimmermann. Found in water. aër., nliqf., chg. (red to violet), $n p g$. Micrococcus cerasinus siccus, List. aër., nliqf., chg. (cherry red), npg. Micrococcus cereus albus, Passet. Syn., Staphylococcus cereus albus, Passet. Found in the pus of acute abscesses, and by Tils, in hydrant water (Freiburg). aër. nliqf., npg. Micrococcus cereus aureus, Schröter and Winkler. Syn., Staphylococcus cereus aureus, S. and $\mathrm{W}$. Found in the thin secretions of coryza. aër. nliqf., chg. (orange-red), npg. Micrococcus cereus flavus, Passet. Syn., Staphylococcus cereus flcvus, Passet. Staphylococcus passetii. Found in an acute abscess. aёr., nliqf., chg. (lemon-yellow), npg. Micrococcus chlorinus. Occurs in zoogloea masses. aër., chg. (greenish-yellow), npg. Micrococcus choleræ gallinarum, Pasteur. See Bacillus septicamice hamorrhagica, Sternberg. Micrococcus cinnabareus, Flügge. Syn., Streptococcus cinnabareus, Flügge. Found in air and water. aër., nliqf., chg. (reddish-brown), npg. Micrococcus citreus, List. Syn., Staphylococcus citreus, List. Micrococcus couleur crème, Fr. Crêmefarbiger Micrococcus, Ger. Found in water, also by Lannelongue and Achard in the seat of an old osteomyelitis. aër., nliqf, chg. (paleyellow), $n p g$. Micrococcus citreus conglomeratus, Bumm. See Diplococcus citreus conglomeratus, Bumm; Micrococcus concentricus, Zimmermann. Found in water, aër., nliqf., sap., npg. Micrococcus conglomeratus, Weichselbaum. Syn., Neissera conglomerata, W. Micrococcus coronatus, Flügge. Syn., Streptococcus coronatus, Flügge. Found in the air. aër., liqf., npg. Micrococcus couleur créme, List. See Micrococcus citreus, List. Micrococcus cremoides, Zimmermann. Found in water. aër., liqf., chg. (yellowish-white), npg. Micrococcus crepusculum, Cohn. See Bacillus termo, Ehrenberg and Dujardin. Micrococcus cumulatus tenuis, Von Besser. Found in abundance in the nasal mucus of man. aër., facanaër., nliqf., npg. Micrococcus cyaneus, Schröter. Obtained from the air, on boiled potatoes. aër., chg: (cobalt blue, altered to carmine by acids, restored by alkalies). Micrococcus decalvans, Schröter. Syn., Bacterium decalvans, Saccardo. Cf. Bacillus of Alopecia areata, Kasauli, Micrococcus arei celsii, Buchner and Sehlen; Micrococcus of Alopecia areata, Robinson. Micrococcus de la mammite gangréneuse de la brebis, Micrococcus de la mammite contagieuse de la vache, Fr. See Micrococcus mastobius, Nocard and Mollereau. Micrococcus de la nécrose progressive du tissue connective de la souris, Fr. See Micrococcus of progressive tissue necrosis of mice, Koch. Micrococcus de la pyémie du lapin, Fr. See Micrococcus of pyemia in rabbits, Koch. Micrococcus de le rage, Fr. See Micrococcus lyssa, Neisser. Micrococcus de la septicémie consecutive du charbon, Charrin. Found in the blood and tissues of a rabbit inoculated with blood from another rabbit dead of anthrax. aër., mot., $p g$. Micrococcus de la septicémie du lapin, Fr. See Micrococcus of septicemia of rabbits, Koch. Micrococcus de la suppuration progressive du lapin, Fr. See Micrococcus of progressive abscess-formation in rabbits. Micrococcus der Mastitis der Kühe, Ger. See Micrococcus mastobius, Nocard and Mollereau. Micrococcus der Maul- und Klauenseuche. See Streptocytus of eczema epizoötica, Schottelius. Micrococcus des mort plats, Fr. See Micrococcus bomb́ycis, Cohn. Micrococcus der Osteomyelitis, Becker. See Staphylococcus pyogenes aureus, Ogston, Becker. Micrococcus der Fleckenkrankheit, Ger. See Microbe de la pébrine, Pasteur. Micrococcus des Pende'schen Geschwürs. See Micrococcus of Heydenreich. Micrococcus desidens, Flügge. See Micrococcus flavus desidens, Flügge. Micrococcus des roten Schweisses. See Micrococcus hamatodes, Babes. Micrococcus diffuens, Schröter. Found in the air, dust, and in excrement; common. aër., nliqf., chg. (yellow, with a greenish fluorescence; not modified by acids). Resembles Bacillus fuorescens putidus, Fliigge. Micrococcus diphtheriticus, Oertel, Cohn, Löffler. Syn., Streptococcus articulorum, Löffier. Micrococcus en chaines, Fr. Kettenbildender Bacillus, Ger., Löffler. Found in the false membranes, and in the tissues of diphtheria patients; Cornil identifies this with Micrococcus pyogenes, Rosenbach. aër., nliqf., pg. Micrococcus doyenii. See Micrococcus urina albus olearius, Doyen. Micrococcus en chaines, Löffler. See Micrococcus diphtheriticus, Oertel, Cohn. Micrococcus endocarditicus. Syn., Streptococcus endocarditicus. Micrococcus endocarditidis rugatus, Weichselbaum. Found in a case of ulcerative endocarditis. $a \ddot{r}$., nliqf., pg. Micrococcus erysipelatis, Micrococcus erysipelatos, Micrococcus erysipelatosus, Fehleisen. See Micrococcus pyogenes, Rosenbach. Micrococcus fermenti. See Micrococcus viniperda. Micrococcus fervidosus, Adametz. Found in water. aër., nligf., ngp. Micrococcusfickii. Found in healthy and diseased eyes. Micrococcus finlayensis, Sternberg. Obtained from the viscera of a yellow-fever cadaver. aër., ligf., chg. (pale-yellow), npg. Micrococcus flavus. See Micrococcus flavus liquefaciens, Flügge. Micrococcus flavus desidens, Flügge. Found in air and water. aër, liqf., chg. (yellowish-brown), npg. Micrococcus flavus liquefaciens, Flügge. Syn., Micrococcus flavus, Micrococ-

Abbreviations, - aër. = aërobic, anaër. = anaërobic. chg. = chromogenic. facanaẽr. = facultative anaërobic. liqf. = liquefac tive, monom. = monomorphic. mot. = motile, nliqf. = non-liquefactive. nmot. $=$ non-motile. npg. $=$ non-pathogenic. $o b l=$ obligate, oscl. = oscillating. $p g,=$ pathogenic, phos. = phosphorescent. pleom. = pleomorphic. sap. $=$ saprophytic 
cus liquefaciens. Found in air and water. aër., liqf., chg. (yellow), npg. Micrococcus flavus tardigradus, Flügge. Syn., Micrococcus tardigradus. Found in the air and water. aër., nliqf., chg. (dark olive-green), $n p g$. Micrococcus fœtidus, Klamann, Rosenbach. Found in the posterior nares of man. aër., liqf., npg. Micrococcus fervidosus, Adametz. Found in water, aër., nliqf., npg. Micrococcus freudenreichii, Guillebeau. One of the two forms found by Guillebeau to produce ropiness in milk. aër., liqf., npg. Cf. Bacterium hessii, Guillebeau. Micrococcus friedländerii. See Bacillus pneumonice friedländerii. Micrococcus fulvus, Cohn. Syn., Staphylococcus fuluzs. Found in horse and rabbit dung. aër., nmot., nliqf., chg. (rose), npg. Micrococcus fuscus, Maschek. Found in water. aër., nmot., liqf., chg. (sepia-brown), npg. Micrococcus gallicidus. See Bacillus septicamia hamorrhagica, Sternberg. Micrococcus gelatinosus. Found in milk, which it causes to coagulate at about $22^{\circ} \mathrm{C}$. Micrococcus gingivæ pyogenes, Miller. Found in the mouth of a man affected with alveolar abscess. aër., facanaër., nliqf., ps. Micrococcus gonorrhœæ, Neisser. Micrococcus blennorrhaus, Neissera gonorrhae, Micrococcus gonococcus, Microbe du pus blemnorrhagique, Weiss, Fr. Trippercoccus, Gonorrhoëcoccus, Ger. Found in gonorrheal pus. aër. No growth on gelatin; an obligate parasite. $p g$. Micrococcus griseus, Winter. See Bacterium griseum, Warming. Micrococcus hæmatodes, Babes. Syn., Micrococcus of red sweat. Micrococque de la sueur rouge, Fr. Micrococcus des roten Schweisses, Ger. Found in foul sweat from the axilla, aër., chg. (red), npg. Micrococcus havaniensis, Sternberg. Syn., Bacillus havaniensis, Sternberg. Obtained by Sternberg in his investigation of yellow fever, aër., nliqf., chg. (blood-red). Only found in the presence of free oxygen. Micrococcus imetrophus, Trevisan. See Bacillus prodigiosus, Ehrenberg. Micrococcus indicus, Koch. See Bacillus indicus, Koch. Micrococcus influenzæ, Letzerich. Syn., Streptococcus seiferti, Micrococcus of influenza, Seifert. See Bacillus of influenza, Pfeiffer. Micrococcus insectorum, Burrill, Streptococcus insectorum. Found in the cecal appendages or pancreatic organs in the Chinch bug (Blissus leucopterus, Say) and the higher Hemiptera. Especially recommended as a remedy for the Chinch bug and for Halticus minutus, so damaging to the peanut. Micrococcus intercellularis meningitidis, Neumann and Schäffer. Syn., Micrococcus meningitidis, Neumann. Neisseria Weichselbaumii. Found in the tissues of the brain and spinal cord in cases of cerebro-spinal meningitis. Micrococcus lacteus faviformis, Bumm. Syn., Neisseria lactea. Frequently found in normal vaginal mucus. aër., nligf., npg. Micrococcus lactis viscosus, Conn. Syn., Micrococcus of bitter milk, Conn. The cause of the bitter taste of milk and cream. aër., liqf., nmot, npg. Micrococcus liquefaciens. See Micrococcus flavus liquefaciens, Flügge. Micrococcus lœwenbergii. Syn., Micrococcus of ozena, Micrococque de l'ozène, Fr. Found in the secretions, in cases of ozena. aër., liqf., pg. Micrococcus luteus, Cohn. Found in water, the superficial soil, dust of bed-rooms, moist foods, etc. cër., nliqf., chg. (yellow), npg. Micrococcus lyssze, Neisser. Syn., Neisseria lyssa, Micrococcus of hydrophobia, Micrococcus of rabies, Fol. Micrococcus de la rage, Fr. Found in the spinal cord of rabid animals. Cornil and Babes throw doubt on the culture experiments of Fol. Micrococcus major, Doyen. See Micrococcus urince major, Doyen. Micrococcus manfredii. Syn., Streptococcus manfredii. Micrococcus of progressive granuloma formation. Found in the sputum of two cases of pneumonia following measles; aër., nliqf., pg. Micrococcus mastobius, Nocard, Mollereau and Kitt. Syn., Streptococcus nocardi. Micrococcus of bovine mastitis, Kitt. Micrococcus of mastitis in cows. Streptococcus of mastitis in cows. Micrococcus of contagious mammitis. Micrococcus of gangrenous mastitis in sheep, Nocard. Microbe de la mal de pis, Microbe de l'araignè, Micrococcus de la mammite contagieuse de la vache, Nocard and Mollereau, Fr. Micrococcus der Mastitis der Kühe, Ger. Obtained from the milk of cows and sheep affected with mastitis. aër., facanaër. The form found in cattle is said to be non-liquefactive; that of sheep liquefies both gelatin and blood serum. Sternberg recognizes three distinct forms producing mastitis. Micrococcus meningitidis, Neumann. See Micrococcus intercellularis meningitidis, Neumann and Schäffer. Micrococcus meningitidis purulentæ, Heydenreich. Micrococcus morbillosus. Syn., Streptococcus morbillosus. Micrococcus nasalis, Hack. Found in the cavum pharyngonasale. aër., mot., nliqf., npg. Micrococcus nitrificans, Van Tieghem. Syn., Micrococque de la fermentation de l'ammoniaque. Found in water. aër., npg. Micrococcus, II, of Fischel. Found in the blood of two cases of influenza. aër., facanaër., liqf., pg. Micrococcus oblongus. See Bacterium oblongum, Boutroux. Micrococcus ochroleucus, Prove and Legrain. Syn., Streptococcus ochroleucus. Found in urine. aër., nliqf., chg. (sulphur yellow), $n p g$. Micrococcus of Acute Infectious Osteomyelitis. See Micrococcus pyogenes aureus, Rosenbach. Micrococcus of Alopecia areata, Von Sehlen, Robinson, Vaillard and Vincent. Found on the hairs from the diseased patches. aër., liqf., pg. Cf. Bacillus of Alopecia areata, and Micrococcus decalvans. Schröter. Micrococcus of Ammoniacal Urine. See Micrococcus urea, Cohn, and Micrococcus urea liquefaciens, Fliigge. Micrococcus of Apple Blight. See Bacillus butyricus, Botkin, Prazmowski, etc. Micrococcus of Beri-beri, Lacerda. See Bacillus beribericus, Lacerda. Micrococcus of Biskra Button. See Micrococcus of Heydenreich. Micrococcus of Bitter Milk. See Micrococcus lactis viscosus, Conn. Micrococcus of Bronchitis, Picchini. Three distinct forms. aër. nliqf. Cf. Bacillus of Lumnitzer. Micrococcus of Bovine Mastitis, Kitt. See Micrococcus mastobius, Nocard, Mollereau and Kitt. Micrococcus of Bovine Pneumonia, Poels and Nolen. Syn., Lungenseuchemicrococcus, Micrococcus of cattle pneumonia. Found in the lungs of cattle suffering from infectious pleuro-pneumonia. aër., nliqf., pg. Micrococcus of Cerebro-spinal Meningitis. See Micrococcus Intercellularis Meningitidis. Neumann and Schäffer. Micrococcus of Chicken Pox. See Staphylococcus viridis favescens, Guttmann. Micrococcus of Contagious Mammitis. See Micrococcus mastobius, Nocard, Mollereau, and Kitt. Micrococcus of Cow Pox. See Micrococcus variole et vaccine, Cohn. Micrococcus of Dantec. Obtained from salted codfish which had turned red. aër., nliqf., chg. (yellow, changing to deep red), npg. Micrococcus of Demme. See Diplococ-

Abbreviations. - aër. = aërobic. anaèr. = anaërobic. chg. = chromogenic. facanaër. = facultative anaërobic. liqf. $=$ liquefactive. monom $=$ monomorphic. mot, $=$ motile. $n l i q f_{0}=$ non-liquefactive. nmot, $=$ non-motile, $n p g,=$ non-pathogenic $o b l_{0}=$ obligate. $o s c l_{0}=$ oscillating. $p g .=$ pathogenic. phos. $=$ phosphorescent. pleom. $=$ pleomorphic. sap. $=$ saprophytic. 
cus of pemphigus acutus, Demme. Micrococcus of Dental Caries. See Leptothrix vulgaris, Robin; Leptothrix gigantea, Miller; Miller's Epsilon Bacillus, and Spirillum dintium, Arnt. Micrococcus of Dengue, McLaughlin. See Scheutzia laughlini. Micrococcus of Diphtheria. Streptococcus articulorum, Löffler. Micrococcus of Disse and Taguchi. Syn., Tokiobacillen. Obtained from the blood, the secretions of broad condyloma, as well as the primary indurations of syphilitics. Etiologic relations not confirmed. Micrococcus of Drinking Water. See Micrococcus aquatilis, Bolton. Micrococcus of Egyptian Ophthalmia. See Micrococcus of Trachoma, Sattler and Michel. Micrococcus of Endocarditis. See Streptococcus endocarditicus and Micrococcus endocarditicus rugatus, Weichselbaum. Micrococcus of Erysipelas, Fehleisen. See Micrococcus pyogenes, Rosenbach. Micrococcus of Foot and Mouth Disease. Syn., Streptocytus of eczema epizoötica, Schottelius, Sireptocytus apthicola, Hallier. Micrococcus der Maul- und Klauenseuche, Ger. Micrococco dell afta epizootica, Ital. Found in the vesicular eruptions about the mouth and feet of cattle, pigs, and sheep. Communicable to man. aër., facanaër. Pathogenesis not fully settled. Cf, Bacillus of ulcerative stomatitis of cattle. Micrococcus of Forbes. Found in the bodies of larvæ of the cabbage butterfly, Pieris rapa, affected with an infectious disease. Micrococcus of Fowl Cholera. See Bacillus septicamice hamorrhagica, Sternberg. Micrococcus of Freire. See Microbe de la fievore jaune, Domingo Freire Micrococcus of Furuncle, Pasteur. See Bacillus osteomyelitidis, Becker and Kraske. Micrococcus of Gangrenous Mastitis in Sheep, Micrococcus of Gangrenous Mammitis. See Micrococcus mastobius. Nocard, Mollereau and Kitt. Micrococcus of Gonorrhea. See Micrococcus gonorrhoce, Neisser. Micrococcus of Gray Parrot Disease. See Micrococcus psittaci, Eberth and Wolff. Micrococcus of Heydenreich. Syn., Streptococcus biskre. Micrococcus of Biskra Button. Clou de Biskra, Duclaux. Microbe de la bouton de Nil, Chantemesse, Microbe de la clou de Gafsa. Microbe de la bouton d'Alep, Poucet. Microbe de la bouton d'Orient, Fr. Micrococcus of Biskra button, Fr. Pendjehgeschwür, Ger. Found in the tumors and ulcers characteristic of Aleppo boil or Biskra button. aër., liqf., pg. Micrococcus of Hydrophobia. See Micrococcus lyssa, Pasteur. Micrococcus of Infectious Osteomyelitis. See Micrococcus pyogenes aureus, Rosenbach, and Micrococcus osteomyelitidis, Becker and Kraske. Micrococcus of Influenza, Seifert, Streptococcus seiferti. See Micrococcus influenze, Letzerich. Micrococcus of Kirchner. Obtained from the sputum of patients suffering with influenza. aër.,pg. Micrococcus of Manfredi. See Micrococcus manfredii. Micrococcus of Mastitis, Kitt. See Micrococcus mastobizus, Nocard and Mollereau. Microccocus of Measles, Klebs and Keating. Syn. Streptococcus morbillosus, Micrococcus morbillosus. Found in the blood and exudates of persons afflicted with measles. Flügge considers them unimportant. Micrococcus of Myko-desmoids of the Horse. See Micrococcus botryogenes, Rabe. Micrococcus of Osteomyelitis. See Micrococcus pyogenes aureus, Ogston. Micrococcus of Ozena. See Micrococcus lewenbergii. Micrococcus of Pear Blight, Burrill. See Bacillus butyricus, Prazmowski. Micrococcus of Pebrine. See Microbe de la pébrine, Pasteur Micrococcus of Pneumonia. See Bacillus fineumonice friedländerii and Micrococcus septicus, Flügge. Micrococcus of Progressive Abscess Formation in Rabbits, Koch. Syn., Micrococcus de la suppuration progressive du lapin. Fr. Found in the exudates of rabbits inoculated with putrefying blood. $p g$. Micrococcus of Progressive Granuloma Forma tion. See Micrococcus manfredii. Micrococcus of Progressive Tissue Necrosis in Mice, Koch. Syn., Micrococcus de la nécrose progressive du tissue connective de la souris. Found in the exudates of mice inoculated with putrid blood. $p g$. Micrococcus of Pyemia in Rabbits, Koch. Found in the exudates of rabbits inoculated with putrefying flesh infusion. pg. Micrococcus of Rabies, Fol. See Micrococcus lyssa, Neisser. Micrococcus of Red Sweat. See Micrococcus hamatodes, Babes. Micrococcus of S. Le M. Moore. See Bacillus foetidus, Liborius. Micrococcus of Salvioli. See Bacillus septicus sputigenus, Flügge. Micrococcus of Scarlet Fever, Pohl and Pincus. See Micrococcus scarlatina. Micrococcus of Septicemia in Rabbits, Koch. Syn., Streptococcus Kochii. Micrococcus de la septicémie du lapin. Fr. Found in the exudates of rabbits inoculated with putrefying flesh-infusion. pg. Micrococcus of Smallpox. See Micrococcus variole et vaccince, Cohn. Micrococcus of Sputum Septicemia. See Bacillus septicus sputigenus, Flügge. Micrococcus of Swine Plague or Hog Cholera. See Bacillus of swine plague, Marseilles, Rietsch and Jobert, and Bacillus ex pneumo-enteritide suis, Klein. Micrococcus of Syphilis, Haberkorn and Marcus. Found in the white blood corpuscles in cases of syphilis. aër., osc., chs. (red). Micrococcus of Trachoma, Sattler and Michel. Syn., Neisseria rebellis. Trachomcoccus, Ger. Micrococcus of Egyptian ophthalmia. Found in the secretions and nodules of the conjunctiva in cases of trachoma. aër., nliqf., pg. Researches of Baumgarten and Kartulis go to show that this form has no etiologic relation to the diseases mentioned. Micrococcus of Vaccinia. See Micrococcus variolæ et vaccinx, Cohn. Micrococcus of whooping cough, Letzerich. Found in the sputum in cases of whooping cough. See Bacillus tussis convulsive, Afanassiew. Micrococcus olearius. See Micrococcus urina flatus olearius. Micrococcus osteomyelitidis, Becker. Syn., Micrococcus of acute infectious osteomyelitis. See Micrococcus pyogenes aureus, Rosenbach. Micrococcus ovalis, Escherich. Found in the meconium and feces of infants. aër., facanaër., nliqf., npg. Micrococcus ovatus. See Microbe de la pébrine, Pasteur. Micrococcus pasteuri, Sternberg. See Bacillus septicus sputigenus, Flügge. Micrococcus petechialis. Syn., Neisseria petechialis. Micrococcus pflïgeri, Ludwig. See Photobacterium pfügeri, Ludwig. Micrococcus phosphoreus, Cohn. See Bacillus phosphoreus, Cohn. Micrococcus plumosus, Bräutigam. Found in water. aër., nliqf., npg. Micrococcus pneumoniæ crouposæ, Sternberg. See Bacillus septicus sputigenus, Flïgge. Micrococcus pneumoniæ infectiosæ, Friedländer. See Bacillus pneumonia friedländerii. Micrococcus porcellorum. Syn., Micrococcus bei Hepatitis enzoötica porcellorum. Ger. Found in hogs affected with hepatitis (Russia). aër., liqf., pg. Micrococcus prodigiosus, Cohn. See Bacillus prodigiosus, Ehrenberg. Micrococcus pseudo-cyanus, Cohn. Found in boiled potatoes exposed to air. aër., chg. (verdigris green), npg.

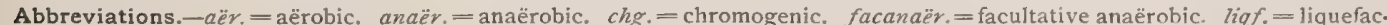
tive monom = monomorphic mot. $=$ motile. nligf $=$ non-liquefactive, nmot. $=$ non-motile. npg. $=$ non-pathogenic obl. = obligate. oscl.= oscillating. $p g .=$ pathogenic. phos. = phosphorescent. pleom. = pleomorphic. sap.=saprophytic. 
Not sufficiently known. Micrococcus psittaci, Wolf. Syn., Streptococcus perniciosus psittaconum, Eberth and Wolf. Micrococcus of gray parrot disease. Micrococcus der Papageimycose. Ger. The cause of a disease of parrots resembling fowl cholera; fatal to many of the parrots imported from Guinea into Europe. Micrococcus putridus. A form emitting a fetid gas from gelatin when mixed with iodoform. Micrococcus pyocyaneus, Gessard. See Bacillus pyocyanezs $a$, Gessard. Micrococcus pyogenes, Rosenbach. Syn., Streptococcus pyogenes, Streptococcus erysipelatos, Streptococcus longus, Von Lingelsheim. Micrococcus erysipelatis (tos) (tosus), Streptococcus of pus. Streptococque pyogène, Vrai Streptococque de l'erysipéle, Fr., Eiterkettenkokkus, Ger., Micrococcus of erysipelas, Fehleisen. Found in the pus of acute abscesses, and in the skin in cases of erysipelas. ä̈r. facanaër., nliqf., $p g$. Micrococcus pyogenes albus, Rosenbach. Syn., Staphylococcus pyogenes albus, Passet. Staphylococcus epidermidis albus, Welch. Frequently found in company with Micrococcus pyogenes aureus. The cause of "stitch abscesses." aër., liqf., $p g$. Micrococcus pyogenes aureus, Rosenbach. Syn., Staphylococcus pyogenes aureus. Stafilococco piogeno aureo, Ital. Staphylococque doré, Fr. Gelber Traubencoccus, Ger. Micrococcus of infectious osteomyelitis. The species most frequently found in pus. Obtained from various suppurations, boils, anthrax, osteomyelitis, ulcerative endocardititis, phlegmon, etc. aër., facanaër., liqf., chg. (brilliant golden yellow), $p g$. Micrococcus pyogenes citreus, Passet. Syn., Staphylococcus citreus, Passet. Micrococcus pyogenes flavus. Found associated with the forms frrst described in acute abscesses and with Bacillus tuberculosis, Koch. aër., facanaër., liqf., chg. (lemon yellow), $p g$. Held by some to be but a variety of $M i$ crococcus pyogenes aureus. Micrococcus pyogenes tenuis, Rosenbach. Syn., Micrococcus rosenbachii. Found in pus. Culture thin, varnish-like; pathogenesis not settled. Cf. Micrococcus septicus, Flügge. Micrococcus pyogenes ureæ flavus, Rörsing. Found in purulent urine. Cf. Diplococcus pyogenes urea, Rörsing; Diplococcus urea trifoliatus, Rörsing. Micrococcus pyosepticus, Richet. Syn., Staphylo. coccus pyosepticus, Hericourt and Richet. Obtained from a carcinomatous tumor in a dog. aër., liqf., pg. Resembles Micrococcus pyogenes albus, Rosenbach. Micrococcus radiatus, Flügge. Syn., Strcptococcus radiatus, Flügge. Found in air and water. aër., tiqf., npg. Micrococcus rheumarthritidis, Küssmaul. See Bacillus rheumarthritidis, Küssmaul. Micrococcus rosenbachii. See Micrococcus pyogenes tenuis, Rosenbach. Micrococcus rosettaceus, Zimmermann. Found in water. aër., nligf., npg. Micrococcus roseus, Eisenberg. Found in the sputum of a person suffering from influenza. aër., facanaër., liqf., chg. (pink), npg. Micrococcus roseus, Bumm. See Diplococcus roseus, Bumm. Micrococcus roseus, Maggiora, Flügge. Syn., Neisseria rosea. Found on the skin. aër., $n p g$. Micrococcus salivarius pyogenes, Biondi. Syn., Staphylococcus varius pyocenes, Biondi. Found in an abscess produced in a guinea-pig by inoculation with saliva from a child affected with anginose scarlatina. aër., liqf., po. Micrococcus salivarius septicus, Biondi. Obtained from animals after inoculation with saliva from a person with puerperal septicemia. aër., nliqf., pg. Cf. Micrococcus sialosepticus. Micrococcus scarlatinæ, Micrococcus scarlatinosus, Coze and Feltz. Syn., Perroncitoa scarlatinosa. Micrococcus of scarlet fever, Pohl and Pincus. Found in the blood on the desquamating skin, and on the palate of scarlet fever patients; resembles Micrococcus septicus, Flügge. Cf. Streptococcus rubiginosus, Edington, and Bacillus of scarlet fever, Crooke. Micrococcus septicus, Cohn. See Bacillus septicamice hamor. rhagica, Sternberg. Micrococcus septicus, Flügge. Syn., Streptococcus septicus, Flügge, and Streptococcus pyogenes, Saccardo, Streptococcus pneumonia, Weichselbaum. Found in soil. aër., nliqf., pg. Micrococcus septopyæmicus. Syn., Streptococcus septopycmicus. Obtained from cases of phlegmonous angina and erysipelas of the larynx. aër., nliqf., pg. Resembles Micrococcus septicus, Flïgge. Micrococcus sialosepticus. Found in the saliva in a case of puerperal septicemia. aër., nligf., pg. Cf. Micrococcus salivarius sepiticus, Biondi. Micrococcus subflavus, Flügge, Neisser. Syn., Neisseria subfava. Yellowishwhite micrococcus or diplococcus, Bumm. Diplococcus jaune blanc, Fr. Obtained from the lochla of puerperal women, and from vaginal mucus. aër, liqf., pg. Micrococcus suis, Burrill. See BacilLus tardigradus. Micrococcus tardigradus. See Micrococcus flavus tardigradus, Flügge. Micrococcus tetragenes, Micrococcus tetragenus, Gaffky. Syn.,Gaffkya tetragenus, Saccardo. Obtained from a cavity in the lung of a person with pulmonary tuberculosis. aër., facanaër., nliqf., pg. Micrococcus tetragenus, Marotta. Constantly found in smallpox vesicles and pustules. aër., liqf., pg. Produces vaccinia in calves. Micrococcus tetragenus febris flavæ, Finlay. Syn., Micrococcus tetragenus versatilis, Sternberg. Obtained from the excrements of mosquitoes which had drawn blood from yellow fever patients; also from the surface of the body in the same disease, (Sternberg). aër., liqf., chg. (lemon-yellow), $n p g$. Micrococcus tetragenus subflavus, Von Besser. Found in nasal mucus. aër., facanaër. (no growth in gelatin), npg. Micrococcus tetragenus mobilis ventriculi, Mendosa. Found in the contents of the stomach of man. aër., nliqf., mot., npg. Micrococcus tetragenus versatilis, Sternberg. See Micrococcus tetragenus febris flave, Finlay. Micrococcus toxicatus, Burrill. Syn., Micrococcus variole et vaccine, Cohn. Streptococcus toxicatus, Burrill. Found in the poison of the poison ivy, Rhus toxicodendron. Micrococcus ulceris mollis. See Bacillus of chancroid, Ducrey. Micrococcus ureæ, Cohn. Syn, Bacterium urece, Cohn. Streptococcus urea. Torula urea, Pasteur. Found in urine, in which it produces ammoniacal fermentation. Micrococcus ureæ, Pasteur and Van Tieghem. Found in the air and in ammoniacal urine. aër., facanaër., nliqf., $n p g$. Possibly the last two forms and the Bacterium uree, Jaksch, are identical. Micrococcus ureæ liquefaciens, Flügge. Syn., Streptococcus athebius. Found in ammoniacal urine. aër., facanaër., liqf., nps. Micrococcus urinalbus. Syn., Micrococcus albus urine. Found in the urine in cases of pyelonephritis and cystitis. Micrococcus urinæ albus olearius, Doyen. Syn., Micrococcus doyenii. Found under the same circumstances as the last form. aër., liqf. Micrococcus urinæ flavus olearius, Doyen. Syn., Micrococcus olearius. Found in the urine of cystitis, with the two preceding forms. aër., liqf., chg. (golden-yellow). Micrococcus urinæ major, Doyen. Syn., Micrococcus major. Found in same circumstances as the three preceding forms. Micrococcus variolæ, Micrococcus variolæ et vaccinæ,

Abbreviations.-aër. = aërobic, anaër. = anaërobic, chg.= chromogenic. facanaër. $=$ facultative anaërobic, liqf. = liquefac-

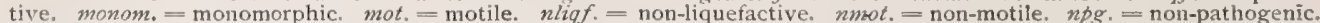
$o b l_{.}$obligate. $o s c l_{0}=$ oscillating. $p g .=$ pathogenic. phos. = phosphorescent. pleom. $=$ pleomorphic. sap. $=$ saprophytic. 
Cohn. Syn., Streptococcus variole, Micrococcus of smallpox, Micrococcus of vaccinia. Obtained by Cohn, Guttmann, Marotta, Hlava and others from the lymph of vaccine pustules in man and animals; by Coze and Feltz from the blood of persons affected with variola; by Cornil and Babes, in the lacunae of the mucous bodies of variola papules; by Quist and Voigt from vaccine; (Pfeiffer and Loeff find certain ameboid or coccidian protozoans which they regard as specific; also a ferment). Cf. Saccharomyces vaccince. Micrococcus viridis Aavescens, Guttmann. Micrococcus versatilis. Found on the skin of healthy persons, also in the liver, spleen and kidneys after death by yellow fever. Not sufficiently studied. Micrococcus versicolor, Flügge. Found in water. aër., nliqf., chg. (yellow), npg. Micrococcus vini perda. Syn., Streptococcus fermenti, Micrococcus fermenti. Found in spoiled wine. Micrococcus violaceus, Cohn. Found in water. aër., nliqf., chg. (violet), $n p g$. Micrococcus viridis flavescens, Guttmann. Found in the lymph of a varicella pustule. aër., nliqf., npg. Micrococcus viscosus, Pasteur. Found in the disease of wine known as la graisse. Micrococcus viticulosus, Flügge, Katz. Found in air and water. aër., facanaër., nliqf., npg. Micrococcus xanthogenicus. Cryptococcus xanthogenicus, Freire. Found in cases of yellow fever. Cf. Microbe de la fiévre jaune. Micrococque de la fermentation de l'ammoniaque, Fr. See Micrococcus nitrificans, Van Tieghem. Micrococque chromogène, Fr. Any Chromogenic Micrococcus. Micrococque de la mammite gangrèneuse des brebis laitères. See Micrococcus mastobius, Nocard, Mollereau, and Kitt. Micrococque de la sueur rouge. See Micrococcus hamatodes, Babes. Micrococque de l'ozène. See Micrococcus loernenbergii. Microhaloa rosea, Kützing. See Beggiatoa roseo-persicina, Zopf. Microsporon minutissimum, Burchardt. See Bacit. lus epidermidis, Bizzozero. Microsporon septicum, Klebs. See Bacillus septicamia hcemorrhagica, Sternberg. Microzyma bombycis, Béchamp. See Micrococcus bombj'cis, Cohn, Beck. Milchsäurebacillus. See Bacillus acidi lactici, Hueppe. Milkwhite Micrococcus, Bumm. See Micrococcus albicans tardissimus, Eisenberg. Milk Yeast. See Saccharomyces lactis, Adametz, Miller's Bacillus. See Bacillus dentalis viridans, Miller, and Spirillum of Miller. Miller's Bacillus of the Intestine. See Bacillus aërogenes, $I, I I, I I I$, Miller. Miller's Epsilon Bacillus. See Epsilon Bacillus, Miller. Milzbrandbacillus. See Bacillus anthracis, Pollender and Davaine. Monas prodigiosa, Ehrenberg. See Bacillus prodigiosus, Ehrenberg. Monas termo, Müller. See Bacillus termo, Dujardin. Mundhöhlebacillen, Bacilli of the mouth. Mycoderma aceti, Mycoderm du vinaigre, Pasteur. See Bacillus aceti, Kützing. Myconostoc gregarium, Cohn. A spiral or crumpled condition of a filamentous schizomycete, perhaps Cladothrix dichotoma, Cohn. Mycoderma cerevisiæ et vini, Desm. Mycoderma mesentericum, Pers. Mycoderma vini, Pasteur. See Saccharomycetes mycoderma, Reess. Nasenschleirn vibrio, Weibel. See Spirillum nasale, Weibel. Nassfaulebacillus. See Bacillus of potato rot, Kramer. Neapler Bacillus. See Bacillus neapolitanus, Emmerich. Neisseria albicans. See Micrococcus albicans amplus, Neisser. Neisseria citrea. See Micrococcus citreus conglomeratus, Bumm. Neisseria conglomerata. See Micrococcus conglomeratus, Weichselbaum. Neisseria gonorrhœæ. See Micrococcus gonorrhoe, Neisser. Neisseria lactea. See Micrococcus lacteus favifor mis, Neisser. Neisseria lyssæ. See Micrococcus lyssa, Neisser. Neisseria petechialis. See Micrococcus petechialis, Neisser. Neisseria rebellis. See Micrococcus of trachoma, Sattler. Neisseria rosea. See Micrococcus roseus, Maggiora. Neisseria subflava. See Micrococcus subflavus, Flügge. Neisseria tardissima. See Micrococcus albicans tardissimus, Bumm. Neisseria weichselbaumii. See Micrococcus intercellularis meningitidis, Neumann and Schäffer, Neisseria winckleri. See Bacillus beribericus, Lacerda. Nitrifying Bacillus of Winogradsky, Nitromonas of Winogradsky. Obtained from the soil. No growth on ordinary culture media. One of the very few nitrifying ferments. Nosema bombycis, Nägeli. See Microbe de la pébrine, Pasteur. Obermeier'scher Recurrensfaden, Weigert. Obermeier'scher Recurrensspirillum, Engelmann. See Spirillum obermeierii. Ophidomonas jenensis, Ophidomonas sanguinea, Ehrenberg. See Beggiatoa roseo-persicina, Zopf. Orchiococcus. See Diplococcus of Orchitis, Hugouneng and Eraud. Oscillaria alba, Vaucher. See Besgiatoa alba, Trevisan. Oscillaria arachnoidea, Agardh. See Beggiatoa arachnoidea, Trevisan. Oscillaria leptomitiformis, Meneghi. See Beggiator leptomitiformis, Trevisan. Oscillaria tigrina. See Begriatoa tigrina, Rabenhorst. Oscillaria versatilis, Kützing. See Bergiatoa arachnoidea, Trevisan. Osteo-myelitis. kokken, Becker. See Staphylococcus pyogenes aureus, Ogston. Palmella infusionum, Ehrenberg. See Bacillus termo, Dujardin. Palmella prodigiosa, Mont. See Bacillus prodigiosus, Ehrenberg. Palmellina capillorum (Radlkoffer), Bulh. Syn., Zöglcaa capillonm, Bulh. Found in the epidermis of the head; supposed to affect the color of the hair. Panhystophyton ovatum, Lebert. See Microbe de la pébrine, Pasteur. Passet's Fäulnissbacillus. Passet's Putrefying Bacillus of Pus. See Bacillus pyogenes fotidus, Passet. Peach-colored Bacterium, Lankester. See Beggiatoa roseo-persicina, Zopf. Pediococcus acidi lactici, Lindner. Found in hay infusion and in mash from malt. aër., facanaër., nliqf., npg. Pediococcus albus, Lindner. Found in well water. aër., liqf., npg. Pediococcus aurantiacus, Cohn. See Micrococcus aurantiacus, Cohn. Pediococcus cerevisiæ, Balcke. Syn., Sarcina cerevisia, Lindner. Found in beer and in the air of breweries. aër., facanaër., nliqf., npg. Peroncitoa scarlatinosæ. See Micrococcus scarlatina, Pohl-Pincus. Pfeiffer's Bacillus. See Bacillus capsulatus, Pfeiffer. Photobacterium balticum, Fischer. Found in the waters of the Baltic. aër., ligf., phos., npg. Cf. Bacillus phosphorescens indigen$u s$, Fischer. Photobacterium fischeri, Katz. Found in the waters of the Baltic. aerr., liqf., phos., np. Photobacterium indicum, Fischer. See Bacillus phosphorescens, Fischer. Photobacterium luminosum, Beyerinck. Syn., Bactérie lumineuse de la mer du nord. Found on many of the phosphorescent animals, crustaceous polyps, infusoria, of the North Sea. aër., liqf., phos., npg. Photobacterium pflügeri, Ludwig. Syn., Bacterium pfïgeri, Micrococcus pfü̈geri. Found upon butcher's meat and upon market fish. The most phosphorescent of all light-producing bacteria. ärr., liqf., phos., ngp. Photobacterium phosphorescens, Fischer. See Bacillus phosphoreus, Cohn. Photobacterium phosphorescens, Cohn. Syn., Bacterium phosphorescens,

Abbreviations,-aër. = aërobic, anaër. $=$ anaërobic, chg. = chromogenic. facanaër. = facultative anaërobic. liqf. = liquefactive. monom. monomorphic mot. = motile. nligf. = non-liquefactive, nmot. = non-motile. npg. = non-pathogenic. obl. = obligate. oscl. = oscillating. $\not g .=$ pathogenic, phos. = phosphorescent. pleom. = pleomorphic. sap. = saprophytic. 
Cohn. Found upon fish and in sea water. aër., nilif., npg. Pilz der blauen Milch. See Bacillus cyanogenzs, Fuchs. Pilz der Dexträngährung. See Leuconostoc mesenteroides, Cienkowski. Pilz der Zahncaries. See Leptothrix buccalis, Robin. Pink Bacillus of Spreading Edema, A. B. Harris. aër., nliqf., pleom., chg. (pink), npg. Cf. Bacillus adematis, Koch. Pleurococcus roseo-persicina, Rabenhorst. See Begriatoa roseo-persicina, Zopf. Pneumobacillus von Friedländer, Pneumobacillus friedländeri. See Bacillus pneumonice friedlünderi. Pneumobacillus liquefaciens bovis. See Bacillus liquefaciens bovis, Arloing. Pneumococcus von Fränkel. See Bacillus septicus sputigenus, Flügge. Pneumococcus, Friedländer. Pneumonia-coccus of Friedländer, Sternberg. See Bacillus pneumonice friedländeri. Pneumococque de Fraenkel. See $B a$ cillus septicus sputigenus, Fliigge. Pneumococcenähnliche Bacillen, Ger. See Bacillus pseudopneumonicus, Passet. Potato Bacillus. Applied to Bacillus mesentericus fuscus, Flügge. Bacillus mesentericus vulgatus, Flügge. Bacterium mesentericus nuber, Globig. Pragmidiothrix multisepta, Engler. Syn., Beggiatoa multisepta. Found in sea water upon crustaceans (Kieler Bucht). It is distinguished from Beggiatoa by the absence of sulphur grains. Prazmowski's Bacillus of Butyric Acid Fermentation, Prazmowski's Buttersäurebacillus, Ger. See $B a$ cillus butyricus, Botkin, Prazmowski. Proteus bei Lungengangrän des Menschen, Babes. Bacillus lethalis, Babes. Proteus capsulatus septicus, Proteus hominis capsulatus. See Bacillus hominis cap. sulatus, Banti, Bordoni-Uffreduzzi. Proteus lethalis. See Bacillus lethalis, Babes. Proteus mirabilis. See Bacillus mirabilis, Hauser. Proteus of Karlinski. See Bacillus murisepticus pleomorphus, Karlinski. Proteus septicus. See Bacillus septicus, Pasteur. Proteus sulfureus. See Bacillus sulfureus, Lindenborn. Proteus sulfureus of Holochenikoff, Proteus vulgaris, Hauser. See Bacillus vulgaris, Hauser. Proteus zenkeri. See Bacillus zenkeri, Hauser. Pseudodiphtheric Bacillus, Löffler, Von Hoffmann, Roux, Yersin and Abbott. Found in the mucus from the pharynx and tonsils of children suffering from non-diphtheric throat affections. Pseudodiplococcus pneumonice, Bonome. Obtained from the sero-fibrinous exudate of a person dead of cerebrospinal meningitis. aër., nliqf., pg: Cf. Micrococcus meningitidis, Neumann, and Bacillus meningitidis purulenta, Neumann. Pseudoödembacillus. See Bacillus pseudadematis, Liborius. Pseudorotlaufbacillus, Ger. See Bacillus parvus ovatus, Löffler. Pseudotuberkulöser Bacillus, Ger. See Bacillus of pseudo-tuberculosis of rabbits, Eberth. Rasmussenia buccalis, Saccardo. See Leptothrix buccalis, Robin. Rauschbrandbacillus. See Bacillus chauvai, Bollinger and Feser. Recurrensspirochæte, Birsch-Hirschfeld. See Spirillum obermeierii. Red Bacillus of Water. See Bacillus ruber, Frank and Becker. Rhinosclerombacillus. See Bacillus rhinoscleromatis, Cornil and Alvarez. Rinderpestbacillus. See Bacillus septicamie hamorrhagica, Sternberg. Rod Bacteria, Bactéries en bâtonet, Fr. Rosenbach's Putrefaction Bacilli, Rosenbach's Fäulnisbacillen, Ger. See Bacillus saprogenes, $I, I I, I I I$, Rosenbach. Roter Bacillus aus Wasser. See Red bacillus of water. Roter Kartoffelbacillus, Globig. See Bacillus mesentericus ruber, Globig. Rotlaufbacillus. See Bacillus erysipelatos swis, Koch and Löffler. Rotzbacillus. See Bacillus mallei, Löffler. Saccharomyces albicans, Robin. Syn., Ordium albicans, Robin. Saccharomyces apiculatus, Reess. Occurs in fermented wine and beer, and, in the hot seasons, on sweet succulent fruits; in winter, in the soil beneath the trees that bear these fruits; a bottom yeast. Saccharomyces cerevisia, Reess and Robin. Syn., Cryptococcus cerevisia, Kützing, Cryptococcus fermentatum, torula cerevisia, yeast plant. Under this heading are included a series of different over and under yeasts. Saccharomyces conglomeratus, Reess. As the result of Hansen's investigations this species has been dropped by recent writers. Saccharomyces ellipsoideus I, II, Hansen, a "wild" species of wine ferment, II; gives rise to the muddiness of beer: Saccharomyces exiguus, Hansen. Found in German yeast; acts toward sugar exactly as does Saccharomyces marxianus. Saccharomyces glutinis. Syn., Cryptococcus glutinis, Fersen. A pullulating yeast that forms beautiful rose-colored patches on cooked potatoes. Saccharomyces guttulatus, Robin. Syn., Cryptococcus guttulatus, Robin, Winter. Champignon du tube digestif du lapin et autres herbivores, Remack. Found in the esophagus, stomach and intestines of mammals, birds, and reptiles. The feces of patients suffering from tunnel anemia, or anchylostomiasis, frequently contain this species of saccharomyces. Saccharomyces inequalis, a doubtful species. Saccharomyces lactis, Adametz. Syn., Milk-yeast. Found in milk, of which it ferments the milk-sugar. Saccharomyces marxianus. Found in wine; acts vigorously on saccharose, inverting and fermenting it with great activity; it also acts on dextrose. Saccharomyces membranifaciens. Forms a bright yellow, tough scum on beer-wort; liquefies gelatin; has no fermentative action on ordinary carbohydrates, and does not invert cane-sugar. Saccharomyces minor, Engel. According to Engel this is the cause of fermentation in bread. Saccharomyces mycoderma, Reess. Syn., Mycoderma mesentericum, Pers. Mycoderma cerevisice et vini, Desm. Hormiscium vini et cerevisia, Bonard. Mycoderma vini, Pasteur. Mycoderma cerevisia, Trecul. Fiore del vino e della birra, Ital. Found on the surface of wine and beer, forming the so-called "flowers of wine." Saccharomycetes nebulosus, a doubtful species. Saccharomyces pasteurianus, Reess. According to Hansen, this represents a group of three forms that cause disease in beer and wine. Saccharomyces pyriformis, Ward. Found in the fermentation of ginger-beer. A bottom yeast which develops much $\mathrm{CO}_{2}$ but little alcohol; it inverts canesugar and ferments the products; does not ferment milk-sugar. aër., facanaër. Saccharomyces ruber, Demme. Found in milk and cheese, forming red spots in the latter, and a red sediment in the former. nliqf. Saccharomyces vaccinæ, Pfeiffer. Found in the lymph of a vaccinia pustule; nothing known of its action. Saprogenic bacillus. Syn., Bacille saprogène, Fr. Any bacillus which produces putrefaction, e. $\sigma_{.}$, Bacillus saprogenes, Rosenbach, $q . v$. Sarcina alba, Eisenberg. Found in air and water. aër., liqf., npg. Sarcina aurantiaca. Syn., Orange Sarcina, Koch. Found in air and water. aër., liqf., chg. (orange yellow), npg. Sarcina aurea, Mace. Found in the pulmonary exudates of a person dead of a bastard pneumonia complicated with purulent pleurisy. aër., ligf., chg. (brilliant

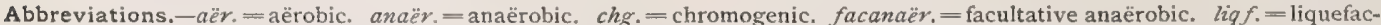
tive. monom, = monomorphic. mot. = motile. nliqf. non-liquefactive nmot. $=$ non-motile. nps. $=$ non-pathogenic. $a b l_{0}=$ obligate. oscl. $=$ oscillating. $p g .=$ pathogenic. phos. $=$ phosphorescent. pleom. $=$ pleomorphic. sap. $=$ saprophytic. 
golden yellow). Sarcina botulina, Van den Corput Found in cases of poisoning with tainted sausage, (botulismus) and believed to be the active agent. Cf Bacillus of allantiasis. Sarcina candida, Reinke. Found in the air of breweries. aër., liqf., $n p g$. Sarcina cerevisia, Lindner. Syn., Pediococcus cerevisice, Balcke. Found in beer and the air of breweries, aër., facanaër., nliuf., npo. Sarcine de l'estomac. See Sarcina ventriculi, Goodsir. Sarcina flava, De Bary. Found in beer. aër., liqf. chy. (yellow), npg. Sarcina fuscescens, Falken heim. Found in the human stomach. Sarcina hya lina, Kützing. Syn., Merismopedia hyalina, Kütz ing. Found in swamps. Sarcina intestinalis, Zopf. Found in the intestines of chickens and turkeys, principally in the cecum. Sarcina in the Mouth and Lungs, Fischer. According to De Bary the original description is not sufficiently clear for comparison. Sarcina litoralis, CErstedt. Syn:, Merismopedia litoralis, Rabenhorst, Erythroconis, Erstedt. Found in sea water; forms a thin reddish layer between decomposing algæe on the shore. Sarcina lutea, Schröter. Found in the air, and in fungus cultures. aër., liqf., chg. (yellow), npg. Sarcina minuta, De Bary. Occurred spontaneously in a culture of sour milk on a microscopic slide; resembles Sarcina welckeri. Sarcina mobilis, Maurea. Found in old ascitic fluid. aër., liqf., mot., chg. (brick-red). Sarcina morrhuæ. Obtained from codfish. Sarcina of the Lungs. See Sarcina pulmonum, Hauser. Sarcina of the Urine. See Sarcina urina, Welcker. Sarcine paludosa, Schröter. Found in bog water. Sarcina pulmonum, Hauser. Syn., Sarcina of the lungs. Lungensarcine, Ger. Found in sputum. ä̈r., nliqf., npg. Sarcina reitenbachii, Caspary. Syn., Merismopedium reitenbarhii, Caspary-(also misprinted Reichenbachii). Found in fresh water on decaying plants. Sarcina renis, Hepworth. Found in the lungs of persons dead of pulmonary tuberculosis. Sarcina rosea, Menge. Found in milk and other food-stuffs. Held to be distinct from the form described by Schröter. aër., liqf., chg. (rose-red), npg. Sarcina rosea, Schröter. Found in the air. aër., liqf., chg. (intense red, giving same reaction as the pigment of Sarcina aurantiaca), $n g p$. Sarcina urinæe, Welcker. Syn., Merismopedia urine, Rabenhorst. Sarcina of the urine; sarcine de la urine, Fr., Hartze. Found in the bladder; appears to be destitute of zymotic action. Sarcina ventriculi, Goodsir. Syn., Sarcine de l'estomac, Fr. Harnsarcine, Ger. Common in the stomach of man and animals. De Bary finds two forms side by side, but offers no information as to their genetic relations. aër., nliqf., npg. Sarcina welckeri, Rossmann. Repeatedly found in the human bladder and voided for months at a time in the urine, which is usually abnormally rich in phosphates, the patient retaining good health. Scheidenbacillus. See Bacillus vaginalis, Döderlein. Scheutzia laughlini. Syn., Micrococcus of Dengue, Staphylococcus of Dengue, Dengue Micrococci. Found in the blood of patients suffering from dengue. Pathogenetic relations not determined. Schweinerotlaufbacillus. See Bacillus erysipelatos suis, Koch. Septischer Erdbacillus. See $B a$ cillus septicus agrigenus, Nicolaier. Septischer Sputumbacillus. See Bacillus septicus sputigenus, Flügge. Smegma bacillus. See Bacillus of the Smegma. Sphærococcus acidi lactici, Marpmann. Found in fresh cow's milk. aër., nliqf., npg. Sphærotilus natans, Kützing, Saccardo. Syn, Leptothrix natans. Found in running and stagnant water. Old portions yellowish, younger portions colorless. Spirille du choléra. See Spirillum cholerce asiatica, Koch. Spirille du mucus nasal. See Spirillum nasale, Weibel. Spirillo colerogeno di Koch, Ital. See Spirillum cholerce asiatice, Koch; Spirillum amyliferum, Van Tieghem. Found in water. Forms granu lose at certain developmental stages; gives the blue reaction with iodin. Cf. Bacillus butyricus, Praz mowski. Spirillum anserum. Syn., Spirochate anserina, Sakharoff. Found in the blood of geese affected with a fatal form of septicemia due to this microbe. A disease prevalent in the swampy region of Caucasia. aër., mot., pg. (not for chickens). Spirillum $a$ of Weibel. See Spirillum saprophiles a, Weibel. Spirillum attenuatum, Warming. Found in sea water. Spirillum aureum. Syn., Vibrio aureus, Weibel. Found in the air and the slime of sewers. aër., nliqf., nmot., chg. (golden yellow), $n p g$. Spirillum $\beta$ of Weibel. See Spirillum saprophiles $\beta$, Weibel. Spirillum choleræ asiaticæ, Koch. Syn., Spirillum cholera. Spirillum of cholera, Bacillus of cholera, Comma bacillus of Koch, Spirille du choléra, Bacille du choléra, Bacille en virgule, Bacille virgula choléregène, Fr. Bacillo a virgola, Bacillo virgulato, Ital. Found in the discharges of cholera patients and in the intestines of cholera cadavers. aër. facanaër., liqf., mot., $p g$. Spirillum concentricum, Kitasato. Found in putrefying blood. aër, nliqf., mot., npg. Spirillum denticola, Miller; or, Spirillum dentium, Arnt. Syn., Spirochata denticola, Spirochata dentium. Found under the margins of the gums in the mouths of healthy persons; biologic characters unknown, as it does not thrive in culture fluids. Spirillum endoparagogicum, Sorokin. Found in a glairy liquid exuding from a poplar tree. Spirillum finkleri, Spirillum Finkler-Prior. Syn., Vibrio proteus. Bacillus von Finkler-Prior, Bacillus Epsilon von Miller. Found in the feces of persons affected with cholera nostras, after allowing the discharge to stand for some time. aër., facanaër. liqf., mot. Pathogenetic relation not confirmed. Spirillum flavescens. Syn., Vibrio favescens, Weibel. Found in the slime of sewers. aër., nliqf., nmot., chg. (yellowish-green), npg. S Spirillum flavum. Syn., Vibrio flavescens, Weibel. Found in the slime of sewers. aër., nliqf., nmot., chg. (ocher yellow), npg. Spirillum jenensis, Ehrenberg. Syn., Ophidomonas jenensis, Ehrenberg. A doubtful species. Spirillum leucomelænum, Perty. Found in water containing decaying algæ. Spirillum linguæ. Syn., Vibrio lingualis, Zungenbelagvibrio, Weibel. Found in the deposit on the tongue of a mouse, after inoculation. aër., facanaër.. nliqf., nmot., npg. (for mice). Spirillum litorale, Warming. Syn., Vibrio spirillum, Müller; Melunella spirillum, Borg. Found in bog water. Spirillum metschnikovi. Syn,, Vibrio metschnikovi, Gameleia. Found in the intestinal contents of chickens affected, in Russia, with an epidemic infectious disease resembling fowl cholera. dër., facanaër, (?)liqf., mot., pg. Spirillum nasale. Syn., Vibrio nasale, Weibel. Nasenschleimvibrio, Ger. Spirilie du mucus nasale, Fr. Found in nasal mucus. aër., facanaër, nliqf., nmot., npg. Spirillum obermeieri, Cohn. Syn., Spirochata obermeieri. Spirillum of relapsing fever. Recurrensspirochæte, Obermeier'scher Recurrensfaden, Weigert, Obermeier'scher Recurrensspirillum, Engel. Found in the. blood

Abbreviations, -aër. = aërobic. anaër. = anaërobic. $c h g .=$ chromogenic. facanaër. $=$ facultative anaërobic. ligf. $=1$ liquefactive, monom. = monomorphic. mot. = motile. nligf. $=$ non-liquefactive, nmot. $=$ non-motile. npg. $=$ non-pathogenic. $o b l_{0}=$ obligate. oscl. $=$ oscillating. $p g .=$ pathogenic. phos. = phosphorescent. pleom. $=$ pleomorphic. sap. $=$ saprophytic. 
of persons affected with relapsing fever. aër., mot. (efforts to cultivate thus far unsuccessful), $p g$. Spirillum of Asiatic cholera. Spirillum of cholera. See Spirillum cholere asiatica, Koch. Spirillum of Denecke. See Spirillum tyrogenum, Denecke. Spirillum of Finkler and Prior. See Spirillum finkleri. Spirillum of Miller. Syn., Miller's bacillus. Found in carious teeth. aër., facanaër. liqf., mot., npg. Spirillum of Relapsing Fever. See Spirillum obermeieri, Cohn. Spirillum of Smith. Found in the intestines of swine. aër., nliqf., mot., npg. Spirillum plicatile, Dujardin. Syn., Spirochate plicatilis, Ehrenberg; Spirulina plicatilis, Cohn. Found in water containing decomposing algx, Biologic characters undetermined. Spirillum rosaceum. Observed upon excrement in water. aër., $c h g$. (red), npg. Spirillum rosenbergii, Warming. Found in brackish water. Contains refractive sulphur grains, aër., mot. Spirillum roseum, Macè. Found in a tube culture of blennorrhagic pus. aër., nliqf., mot., chg. (rose-red), npg. Spirillum rubrum, von Esmarch. Obtained from the putrefying body of a mouse. aër., facanaër, nliqf., mot., chg. (pink), npg. Spirillum rufum, Perty. Found in cistern water. aër., mot., chg. (rose-red), $n p g$. Spirillum rugula, Müller. Syn., Vibrio rugula. Found in swamp water and frequently in the alimentary canal, on the teeth, etc. aër. facanaër., mot., npg. According to Prazmowski this species gives rise to decomposition of cellulose. Spirillum sanguineum. See Beggiatoa roseopersicina, Zopf. Spirillum saprophiles $\alpha$ of Weibel. Syn., Vibrio saprophites a of Weibel. Found in rotting hay infusion and in the slime of sewers. aër., nliqf., mot., npg. Spirillum saprophiles $\beta$ of Weibel. Syn., Vibrio saprophiles $\beta$, Weibel. Found in rotting hay infusion. aër., nliqf., mot., npg. Spirillum saprophiles $\gamma$ of Weibel. Syn., Vibrio saprophiles $\gamma$, Weibel. Found in the slime of sewers. aër., nliqf., mot., npg. Spirillum serpens, Müller. Syn., Vibrio serpens, Müller. Found in stagnant water containing decaying plants, etc. Biologic characters not determined. Spirillum sputigenum, Miller. Common in the neglected mouths of healthy persons. Does not grow on culture media. Spirillum tenue, Ehren. berg. Found in putrefying plant infusions. Biologic characters undetermined. Spirillum tyrogenum, Denecke. Syn., Bacille de Denecke, Fr. Bacillus von Denecke, Käsespirillum, Ger. Spirillum of Denecke, Bacillus of cheese, Denecke's cheese spirillum. Found in old cheese. aër., facanaër., liqf., mot., pg. (for guinea pigs). Spirillum undula, Cohn, Müller. Syn., Vibrio undula, Müiller; Vibrio prolifer, Ehrenberg. Found in zoöglea masses in swamp water, vegetable infusions, etc. aër., mot., np. Spirillum violaceum, Warming. Found in brackish water; cell contents violet, with a few sulphur grains. Spirillum volutans, Ehrenberg. Syn., Vibrio spirillum, Müller; Melunella spirillum, Borg. Found in infusions and in bog water. Biologic characters undetermined. Spirochæte anserina, Sakharoff. See Spirillum anserum. Spirochæte denticola, Miller. Spirochæte dentium, Arnt. See Stivillum dentium. Spirochæte obermeieri. See Spirillum obermeieri, Cohn. Spirochæte plicatilis, Ehrenberg. See Spirillum plicatile, Dujardin. Spiromonas cohnii, Warming. Found in foul water. Spiromonas volubilis, Pertz. Found in putrefy- ing infusions and in bog water. Sporonema gracile. See Bacillus virens, Van Tieghem. Sputumbacillus, Ger. See Bacillus septicus sputigenus, Flügge. Stafilococco piogeno aureo, Ital. See Micrococcus pyogenes aureus, Rosenbach. Staphylococcus albus liquefaciens, Escherich. Syn., White liquefying staphylococcus. Found in the alvine discharges of healthy infants. aër., liqf., npg. Staphylococcus biskræ. See Micrococcus of Heydenreich. Staphylococcus cereus albus, Passet. See Micrococcus cereus albzrs, Passet. Staphylococcus cereus aureus, Schröter and Winkler. See Micrococcus cereus aureus, S. and W. Staphylococcus cereus flavus, Passet. See Micrococcus cereus flavus, Passet. Staphylococcus citreus. See Micrococcus citreus, List. Staphylococcus epidermidis albus, Welch. See Micrococcus pyogenes albus, Rosenbach. Staphylococcus pulvus. See Micrococcus pulvus, Cohn. Staphylococcus of Dengue, McLaughlin. See Scheutzia lauhglini. Staphylococcus of pemphigus, De Michele. Obtained from the skin, kidney and spleen of a case of pemphigus chronica. Staphylococcus passetti. See Micrococcus cereus favus, Passet. Staphylococcus pyogenes albus, Rosenbach. See Micrococcus pyogenes albus, Rosenbach. Staphylococcus pyogenes aureus, Ogston, Becker. Syn., Staphylococco pyogeno aureo, Ital. See Micrococcus pyogenes aureus, Rosenbach. Staphylococcus pyogenes citreus, Passet. See Micrococcus pyogenes citreus, Passet. Staphylococcus pyosepticus, Hericourt and Richet. See Micrococcus pyosepticus, Richet. Staphylococcus salivarius pyogènes, Biondi. See Micrococcus salivarius p10genes, Biondi. Staphylococcus viridis flavescens, Guttmann. Syn., Micrococcus of chicken-pox. Found in the vesicles of varicella. ä̈r., nliqf., chg. (greenish yellow), npg. Streptococcus acidi lactici, Grotenfeldt. Found in coagulated milk in Finland. anaër. (not strictly), nliqf., npg. Streptococcus aethebius. See Micrococcus urea liquefaciens, Flïge. Streptococcus albus, Maschek. Syn., Weisser Streptococcus, Ger. Found in hydrant water (Freiburg). ä̈r., liqf., $n p g$. Streptococcus apthicola, Hallier. See Streptocytus of eczema epizoötica, Schottelius. Streptococcus articulorum, Löftler. Syn., Micrococcus of diphtheria. Obtained from the affected mucous membrane in cases of diphtheria. Possibly a variety of Micrococcus pyogenes. pg. (for mice). Streptococcus bombycis. See Micrococcus bontbycis, Cohn. Streptococcus brevis, Von Lingelsheim. Obtained from normal human saliva. aër., facanaër., nliqf., $n p g$. Streptococcus cadaveris, Sternberg. Found in the liver of a yellow-fever cadaver. aër., facanaër., ntiqf., npg. Probably identical with the preceding species. Streptococcus cinnabareus. See Micrococcus cinnabareus, Flügge. Streptococcus coli gracilis, Escherich. Found in the feces of healthy children living on a meat diet. aër., facanaër. liqf., $n p g$. Streptococcus conglomeratus, Kurth. Obtained from cases of scarlet fever. $p g$. (for mice). Streptococcus coronatus, Flügge. See Micrococcus coronatus, Fligge. Streptococcus coryzz contagiosæ equorum, Schütz. Syn., Streptococcus der Druse des Pferdes. Bacterium der Brustseuche des Pferdes, Ger. Bacterium of infectious pneumonia in the horse. Found in the pus from diseased lymphatic glands in horses suffering with infectious pneumonia, the disease being known in Germany as Druse des Pferdes. aёr., facanaër., pg. (for horses and mice),

Abbreviations. - aër. = aërobjc, anaër. = anaërobic. chg. = chromogenic. facanaër. =facultative anaërobic. liqf. = liquefactive. monom. = monomorphic. mot. = motile. niqf. = non-liquefactive. nmot. = non-motile. npg. $=$ non-pathogenic. $o b l$. = obligate. oscl. = oscillating. $p g .=$ pathogenic. phos. = phosphorescent. pleom. = pleomorphic. sap. $=$ saprophytic. 
$n p g$. (for rabbits, guinea pigs and pigeons). Streptococcus des Gelenkrheumatismus, Leyden. See Bacillus rheumarthritidis, Kussmaul. Streptococcus endocarditicus. See Microcorcus endocarditicus rugatus, Weichselbaum. Streptococcus erysipelatis (erysipelatos), Fehleisen. See Micrococcus pyogenes, Rosenbach. Streptococcus fermenti. See Micrococcus viniperda. Streptococcus giganteus urethræ, Lustgarten and Manneberg. Found in the healthy human urethra. aër., npg. Streptococcus havaniensis, Sternberg. Found in the acid vomit of a yellow-fever patient. Biologic characters undetermined. Streptococcus insectorum, Burrill. See Micrococcus insectorum, Burrill. Streptococcus kochii. See Micrococcus of septicemia in rabbits, Koch. Streptococcus lanceolatus pasteuri, Gamaléia. See Bacillus septicus sputigenus, Flügge. Streptococcus liquefaciens, Stemberg. Obtained from the intestines and livers of yellow-fever cadavers. aër., facanaër., liqf., npg. Streptococcus longus, von Lingelsheim. See Micrococcus pyogenes, Rosenbach. Streptococcus lucæ. See Micrococcus ulceris mollis. Streptococcus manfredii. See Micrococcus manfredii. Streptococcus meningitidis. See Micrococcus intercellularis meningitidis, Naumann and Schäffer. Streptococcus monomorphus, Bujwid, Heryng. Found in benign pharyngeal ulcers. $n p g$. Streptococcus morbillosus. See Micrococcus of measles. Streptococcus nocardi. See Micrococcus mastobius, Nocard. Streptococcus ochroleucus. See Micrococcus ochroleucus, Prove and Legrain. Streptococcus of Bonome. Obtained from the exudations in the cerebro-spinal meninges and from hemorrhagic extravasations in the lungs, in cases of epidemic cerebro-spinal meningitis. $p g$. (for white mice and rabbits). Streptococcus of granuloma fungoides, Rindfleisch and Auspetz. See Streptococcus of mycosis fungoides. Streptococcus of Manneberg. Obtained from the urine in cases of acute nephritis. aër., facanaër., nliqf., pg. (for dogs and rabbits). Streptococcus of mastitis in cows. See Micrococcus mastobius, Nocard and Mollereau. Streptococcus of mycosis fungoides. Streptococcus of granulomafungoides, Rindfleisch and Auspetz. Found in the capillaries and subcutaneous tissue in the parts affected by this disease. Not sufficiently investigated. Streptococcus of pus. See Micrococcus septicus, Flügge. Streptococcus perniciosus psittacorum, Eberth and Wolf. See Micrococcus psittaci, Wolf. Streptococcus pneumonia, Weichselbaum. See Micrococcus pyogenes, Flügge. Streptococcus putrefaciens, Micrococcus of putrefaction. Refers to any one of the many micrococci found in putrefying substances. Streptococcus pyogenes, Rosenbach. See Micrococcus pyogenes, Rosenbach. Streptococcus pyogenes, Saccardo. See Micrococcus septicus, Flügge. Streptococcus pyogenes maligni, Krause and Flïgge. Found in necrotic masses in a leukemic spleen. $p g$. (for mice and rabbits). Streptococcus pyogenes ureæ, Rörsing. Found in purulent urine. Cf. Micrococcus pyogenes urece favus, Rörsing. Streptococcus radiatus. See Micrococcus radiatus, Flîgge. Streptococcus rubiginosus, Edington. Found in cases of scarlatina. $n p g$. Does not appear till late in the disease. Streptococcus seiferti. See Micrococcus infuenze, Letzerich. Streptococcus septicus, Flïgge. See Micrococcus septicus, Flïgge. Streptococcus septicus liquefaciens, Babes. Obtained from the blood and viscera of a child who died of septicemia following scarlatina. är., liqf., $\mathrm{kg}$. (for mice and rabbits). Streptococcus septopyæmicus. See Micrococcus seplopycenicus, Biondi. Streptococcus toxica tus. See Micrococcus toxicatus, Burrill. Streptococcus ureæ. See Micrococcus urea, Cohn. Streptococcus ureæ rugosus, Rörsing. Found in urine. Streptococcus variolæ. See Micrococcus variole et vac cine, Cohn. Streptococcus vermiformis, Maschek. Syn., wurmförmiger Streptococcus, Ger. Found in hydrant water (Freiburg). aër., liqf., nps. Streptococque de l'érysipèle, Streptococque pyogène vrai. See Micrococcus septicus, Flügge. Streptocytus puerpérale, Doléris. See Bacillus puerperalis, Engel and Spillman. Streptocytus of Eczema epizoötica, Schottelius. Syn., Streptococcus apthicola, Hallier. Micrococcus of foot-and-mouth disease. Micrococcus der Maul- und Klauenseuche, Ger., Micrococco del afta epizootica, Ital. Found in vesicular eruptions about the mouth and feet of cattle, pigs and sheep. Communicable to man, aër., facanaër. Pathogenesis not fully settled. Cf. Bacillus of ulcerative stomatitis of calves. Streptothrix fœersteri, Cohn. See Cladothrix forsteri, Cohn. Swine Plague Schizophyte, Detmers. See Bacillus of swine plague, Marseilles, Rietsch and Jobert. Syphilis Bacillus. See Bacillus syphilidis, Lustgarten. Syphilis Bacillus of Eve and Lingard. Obtained in cultures from the blood and diseased tissues of syphilitics who have not undergone mercurial treatment. aër., chg (pale yellow or brown). Pathogenetic relations not settled. Not stained by Lustgarten's method; capable of development on blood-serum. Tetanus Bacillus. See Bacillus tetani, Nicolaier. Thiothrix nivea. See Begriatoa nivea, Rabenhorst. Thiothrix tenuis, Winogradsky. Found in sulphur springs. Thiothrix tenuissima, Winogradsky. Found in sulphur springs. Torula cerevisiz. See Saccharomyces cerevisia, Reess and Robin. Torula urea, Pasteur. See Micrococcus urea, Cohn. Trachomcoccus, Ger. See Micrococcus of Trachoma, Sattler and Michel. Trippercoccus, Ger. See Micrococcus gonorrhace, Neisser. Trommelschlägerbacillus, Ger. See Bacillus putrificus coli, Bienstock. Tubercle-bacillus. See Bacillus tuberculosis, Koch. Typhus bacillus. See Bacillus typhi abdominalis, Eberth. Tyrothrix catenula, Duclaux. See Bacillus catenula, Duclaux. Tyrothrix claviformis, Duclaux. See Bacillus claviformis, Duclaux. Tyrothrix distortus, Duclaux. See Bacillus distortus, Duclaux. Tyrothrix filiformis, Duclaux. See Bacillus filiformis, Duclaux. Tyrothrix geniculatus, Duclaux. See Bacillus geniculatus, Duclaux. Tyrothrix scaber, Duclaux. See Bacillus scaber, Duclaux. Tyrothrix tenuis, Duclaux. See Bacillas temiis, Duclaux. Tyrothrix turgidus, Duclaux. See Bacillus turgidus, Duclaux. Tyrothrix urocephalus, Duclaux. See Bacillus urocephalus, Duclaux. Tyrothrix virgula, Duclaux. See Bacillus virgula, Duclaux. Ulvina aceti, Kützing. See Bacillus aceti, Kützing. Urobacillus duclauxi, Miquel. Found in sewage and river water. aër., facanaër., mot., liqf. Pathogenesis not determined. Urobacillus freudenreichii, Miquel, Obtained from air, dust, sewage. aër., liqf., mot. Pathogenesis not determined. Urobacillus maddoxi, Miquel. Obtained from sewage and river water. ä̈r,, liqf., mot. Pathogenesis not determined. Urobacillus pasteuri, Miquel. Obtained from decomposing urine. är\%, liqf., mot. Pathogenesis not

Abbreviations.-aër. = aërobic, anaër. = anaërobic, cho. = chromogenic. facanaër. = facultative anaërobic. liqf.=liquefactive, monom = monomorphic. mot $=$ motile. nligf $=$ non-liquefactive, nmot. $=$ non-motile. npg. $=$ non-pathogenic. $o b l_{0}=$ obligate. oscl. = oscillating. $p g .=$ pathogenic. phos. = phosphorescent. pleom. = pleomorphic. sap. $=$ saprophytic. 
determined. Urobacillus schützenbergii, Miquel Obtained from sewage and river water. aér., liqf., mot. Pathogenesis not determined. Verfiussigender Bacillus aus Wasser, Ger. Liquefying bacillus of water. See Bacillus aquaticus liquefaciens, Pokrowsky. Vibrio aureus, Weibel. See Spirillum aureum. Vibrio bacillus, Müller, Ehrenberg. See Bacillus ulna, Cohn. Vibrio choleræ. See Spirillum cholerce asiatica, Koch. Vibrio cyanogenus, Ehrenberg. See Bacillus cyanogenus, Fuchs. Vibrio flavescens, Weibel. See Spirillum flavescens, Weibel. Vibrio flavus, Weibel. See Spirillum flavum, Weibel. Vibrio lineola, Müller and Ehrenberg. See Bacterium lineola, Cohn. Vibrio lingualis. See Spirillum linguce, Weibel. Vibrio metschnikovi, Gamaleia. See Spirillum metschnikovi, Gamaleia. Vibrio nasalis, Weibel. See Spirillum nasale, Weibel. Vibrio proteus. See Spirillum finkleri. Vibrio rugula, Müller. See Spirillum rugula, Müller, Vibrio saprophiles a, Weibel. See Spirillum saprophiles a, Weibel. Vibrio saprophiles $\beta$, Weibel. See Spirillum saprophiles $\beta$, Weibel. Vibrio saprophiles $\gamma$, Weibel. See Spirillum saprophiles $\gamma$, Weibel. Vibrio serpens, Müller. See Spirillum serpens, Müller. Vibrio syncyanus, Ehrenberg. See Bacillus cyanogenus, Fuchs. Vibrio synxanthus, Ehrenberg. See Bacillus synxanthus, Ehrenberg and Schröter. Vibrio tremulans, Ehrenberg. See Bacterium lineola, Cohn. Vibrio undula, Müller. See Spirillum undula, Müller. Vibrio Xanthogenus, Fuchs. Bacillus synxanthus, Ehrenberg and Schröter. Vibrion butyrique, Pasteur. See Bacillus butyricus, Prazmowski. Vibrion septique. See Bacillus adematis maligni, Koch. Violet Bacillus. See Bacillus janthinus, Zopf. Violetter Bacillus aus Wasser, Ger. See Bacillus violaceus, Becker. Wasserbacillen, Wasserbacterien, Ger. Bacilli and bacteria of water. Weisser Bacillus aus Wasser. Ger. See Bacillus albus, Becker. Weisser Streptococcus, Ger. See Streptococcus albus, Maschek. White Bacillus of Water. See Bacillus albus, Becker. White Liquefying Staphylococcus. See Staphylococcus albus liquefaciens, Escherich. Wunderblut, Ger. See Bacillus prodigiosus, Ehrenberg. Wurzelbacillus, Ger. See Bacillus ramosus, Eisenberg. Wurzelbacillus aus Erde. See $B a$ cillus mycoides, Flügge. Xerosebacillus, Ger. See Bacillus of xerosis epithelialis conjunctivæ, Leber. Yellowish-white Micrococcus, Bumm. See Micrococcus subflavus, Flügge. Ziegelroter Bacillus, Adametz. See Bacillus latericeus, Eisenberg. Zoöglœa capillorum, Buhl. See Palmellina capitlorum, Radlkofer. Zoöglca termo, Müller, Cohn. See Bacillus termo, Dujardin. Zoöglœa ramigera. A tree-like variety of Cladothrix dichotoma, q. $v$. Zoögalactina imetropa, Sette. See Bacillus prodigiosus, Ehrenberg. Zungenbelagvibrio, Ger. See Spirillum linsua, Weibel.

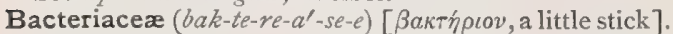
A group or order of microscopic fungi; the same as Schizomycetes.

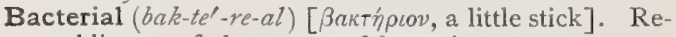
sembling or of the nature of bacteria.

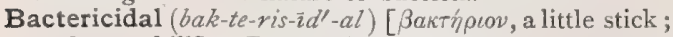
cadere, to kill]. Destructive to bacteria.

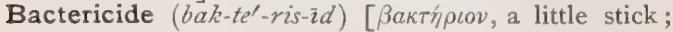
cadere, to slay]. I. Destructive to bacteria. 2. An agent that destroys bacteria.

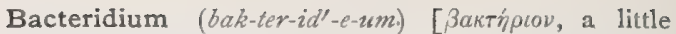
stick: pl., Bacteridia $]$. According to Davaine, a genus of Bacteriaceæ characterized by immobility of the elements at all periods of their existence. The distinetion does not now obtain.

Bacteriemia (bak-te-re-e'-me-ah) [ßaкти́ptov, a little stick; ai $\mu$, blood]. The presence of bacteria in the blood.

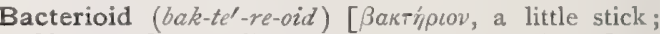

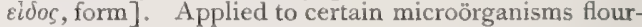
ishing in and around the roots of leguminous plants, assisting in the accumulation of nitrogen, and giving rise to tubercles. They may be cultivated in artificial media like ordinary bacteria. (Brunchoist, Nobbe, etc.)

Bacteriologist (bak-te-re-ol'-o-jist) [ stick; $\lambda \hat{o} \gamma o s$, science]. One who makes a special study of bacteriology.

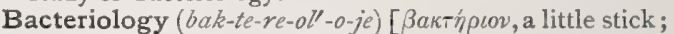
$\lambda o ́$ yos, science]. That department of science that is concerned with the study of bacteria.

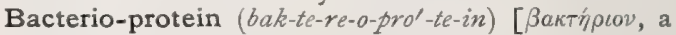
little stick; $\pi \rho \tilde{\omega}$ Tos, furst]. A protein contained in bacteria.

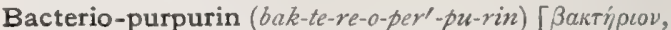
a little stick; purpura, purple]. A peach-colored pigment found by Lankester in the protoplasm of Beggiatoa roseo-persicina. It is insoluble in water, alcohol, chloroform, ammonia, acetic and sulphuric acids, etc.

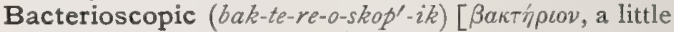

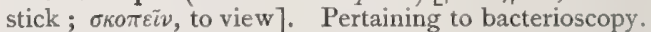

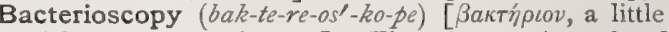

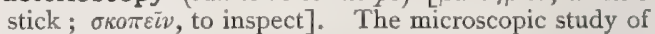
bacteria.

Bacterio-therapeutic ( $b a k$-te-re-o-ther-ap-u'-tik) [ $\beta a \kappa-$

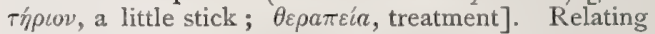
to bacterio-therapy.

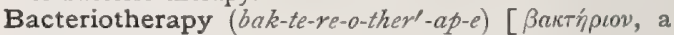
little stick; $\theta \varepsilon \rho a \pi \varepsilon i a$, treatment]. The treatment of disease by the introduction of bacteria into the system.

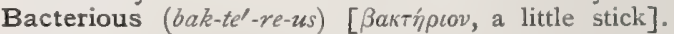
Bacterial.

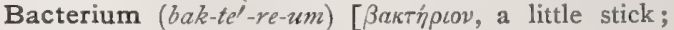

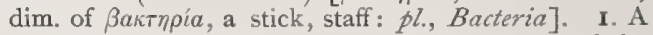
term used to distinguish in a general way some of the simplest microscopic fungi, the Bacteriacea, Fissionfungi, or Schizomycetes, and other closely allied microbes, 2. A genus of short, cylindrical, motile Fission-fungi.

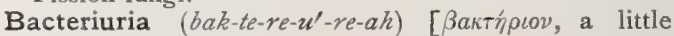
stick; ovpov, urine]. The presence of bacteria in the urine.

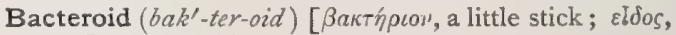
form]. Resembling bacteria.

Bad Disorder. Synonym of Syphitis.

Badal's Operation. See Operations, Table of.

Bader's Operations. See Operations, Table of.

Badiaga (bah-de-ah'-gah) [Rus., badyaga]. A Russian fresh-water sponge, Spangia lacustris, valued as a discutient and as a remover of the marks of bruises. Unof.

Badian $\left(b a^{\prime}-d e-a n\right)$ [badius, bay]. The Star-anise. See Illicium.

Baer's Law. See Law. B. Operations. See Operations, Table of. B. Plane. See Plane.

Bag (bag) [AS., balg]. I. A sac. 2. The scrotum. B., Barnes's. See Barnes's Dilators. B., Politzer's, a soft rubber bag for inflating the internal ear. B. of

Abbreviations, $-a \ddot{e} r_{0}=$ aërobic. anaër, $=$ anaërobic. $c h g_{,}=$chromogenic. facanaër, $=$facultative anaërobic. liqf. $=$liquefactive, monom $=$ monomorphic $m o t$. $=$ motile, $n l i g f,=$ non-liquefactive, $n m o t,=$ non-motile. $n p g$, $=$ non-pathogenic.

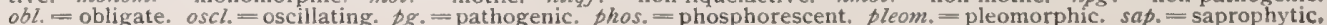


Waters, the fetal membranes enclosing the liquor amnii, projecting through the os uteri early in labor. The sac usually ruptures when the cervix is dilated.

Bagnio $\left(b a n^{\prime}-y 0\right)$ [It., bagno]. I. A house of prostitution. 2. A bath-house.

Bailey's Flask. In dentistry, an apparatus for making metal dies. It consists of two semi-elliptic rings of iron-one nearly straight, the other a truncated cone with four keys-jointed so as to fit together. The straight ring is used as a casting-box for the sand as well as a form for the lead; the other gives the proper shape to the zinc.

Baillarger's Lines. See Lines, Table of. B. Streak. Same as Baillarger's Lines.

Bain-Marie (bän-mah-ré) [Fr.]. An instrument for immersing solutions, microörganisms, etc., in water or chemical solutions, thus keeping them at a desired temperature.

Bain's Method. See Treatment, Methods of; also Artificial Respiration.

Bakers' Itch. An eczematous affection of the hands, caused by the irritation of the yeast. B. Salt, a synonym of smelling salts, or the subcarbonate of ammonia ; it is sometimes used by bakers in leavening cakes.

Baker's Leg, knock-knee, or genu valgum. B. Operations. See Operations, Table of. B. Pins, heavy pins used to hold bone surfaces in apposition after resection of a joint.

Balance (bal'-ans) [bilanx, a balance]. I. A device or apparatus for weighing; an indispensable adjunct of the art of pharmacy. 2. The harmonious adjustment of corresponding parts.

Balanic $\left(b a l^{\prime \prime}-a n-i k\right)$ [ $\beta a \lambda^{\prime} \alpha \nu o s$, the glans penis]. Pertaining to the gland of the penis or of the clitoris.

Balanism (bal'-an-izm) [ $\beta a$ 'a $a v o s$, acorn; pessary; the glans penis]. The application of a pessary or suppository.

Balanitis (bal-an-i'-tis) [ $\beta a$ havos, the glans penis; $\iota \tau \iota \zeta$, inflammation]. Inflammation of the glans penis, sometimes called Balano-posthitis. Phimosis is a frequent complication. See Posthitis.

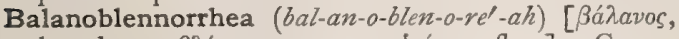
the glans; $\beta \lambda$ ćvvos, mucus; poía, a flow $]$. Gonorrheal balanitis.

Balano-chlamyditis (bal-an-o-klam-id-i'-tis) [ $\beta a ́ \lambda a v o s$, the glans penis; $\chi \lambda$ a auis, cloak; $\iota \tau \iota \varsigma$, inflammation]. Inflammation of the glans and preputium of the clitoris.

Balanoplasty (ball-an-o-plas-te) [ $\beta a$ havos, the glans penis ; $\pi \lambda a ́ \sigma \sigma \varepsilon \iota \nu$, to form]. Plastic surgery of the glans penis.

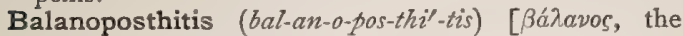
glans penis; $\pi 6 \sigma \theta \eta$, prepuce ; $\iota \iota \iota$, inflammation]. Inflammation of the glans penis and of the prepuce.

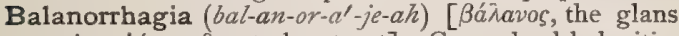

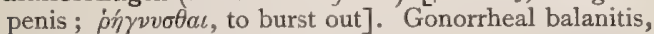
with copious discharge of pus.

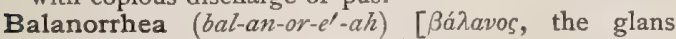

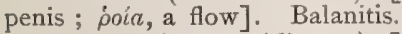

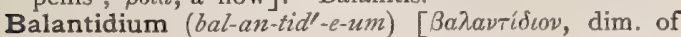

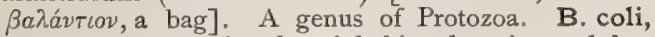
a protozoan parasite that inhabits the pig, and has been found in the human intestine. See Parasites, Animal, Table of.

Balanus $\left(b a l^{\prime}-a n-u s\right)$ [ $\beta a ́ \lambda a v o s$, an acorn]. 1. The glans of the prepuce or of the clitoris. 2. A pledget, suppository, or pessary.

Balata (bal'-at-ah) [Native Guiana]. The dried, milky juice of the bully-tree (Sapota milleri) of Guiana. In its properties it is intermediate between caoutchouc and gutta-percha, and is used chiefly in England as a substitute for these materials.
Balaustine (bal-awos'-tin) [ $\beta a \lambda a v \sigma \tau \imath o \nu$, the flower of the wild pomegranate]. The flower of the Pomegranate, q. v. , formerly used in medicine.

Balbuties (bal-bu'-she-ēe) [balbutire, to stammer]. Stammering.

Bald (bazuld) [ME., balde, bald]. Wanting hair. A term applied to one who has lost the hair of the scalp. B. Ringworm. See Tinea tonsurans.

Baldness (bawld'-nes) [ME., balde, bald]. Alopecia, whether congenital or acquired. When the loss of hair is circumscribed it is called tinea decalvans; when general, it is called alopecia. Senile baldness is called calvities. Premature baldness is caused by disease. See Alopecia.

Bâle Blue. See Pigments, Conspectus of. B. Green. Same as Schweinfurt Green.

Balfour's Test. See Death, Signs of. B.'s Treatment. See Treatment, Methods of:

Ball (bavel) [ME, bal]. 1. In veterinary medicine, a pill or bolus. 2. Vulgarly, a testicle. B.-blue. Same as Prussian Blue. B.-and-Socket Joint. See Diarthrosis and Enarthrosis. B. Thrombus. See Thrombus.

Ballast Fever (bal'-ast fe'-ver). See Fever.

Ballet-dancer's Cramp. See Cramp.

Balling's Saccharometric Beer-test. As by fermentation, IOO parts of malt-extract yield 50 parts of alcohol, twice the quantity of alcohol found will indicate the quantity of malt-extract necessary for its formation. This quantity of malt-extract added to that still existing in the beer indicates the whole of the malt-extract existing in the wort before fermentation.

Ballingall's Operation. See Operations, Table of.

Ballismus (bal-iz'-mus) [ $\beta a \lambda \lambda \iota \sigma \mu o ́ s$, a leaping]. I. Chorea. 2. Paralysis agitans.

Ballonnement (bal-tōn-mon $(g))$ [Fr.]. The ballooning or distending of a part for operative or diagnostic purposes.

Balloon (bal-oon') [Mod. E., baloon, a large bag]. In chemistry, a spherical glass receiver with a short neck. B. Sickness. See Anoxyemia and Hypsonosus.

Ballooning (bal-oon'-ing) [Mod. E. baloon, a large bag]. Surgical distention of the vagina by air-bags or waterbags.

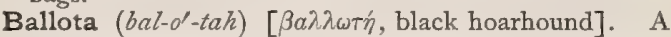
genus of labiate plants. B. nigra, or black hoarhound, was formerly much used in medicine. B. (or Hyptis) suaveolens, of the $\mathrm{E}$. and W. Indies, has been lately introduced into general practice as a powerful and yet safe nervin, antilithic, diuretic, evacuant, and laxative remedy. Unof. B. lanata, of N. Asia, has similar uses. Unof.

Ballottement (bal-ot'-mon $(g))$ [Fr., from ballotte, a ball]. A method of diagnosticating pregnancy from the fourth to the eighth month. A push is given the uterus by the finger inserted into the vagina, and if the fetus be present, it will rise and fall again like a heavy body in water.

Ball's Operations. See Operations, Table of:

Balm (bahm) [balsamum, a balsam]. A popular synonym of balsamum. Any soothing application or ointment. B. of Gilead. See Balsam, Abies, and Melissa.

Balmony (bal'-mo-ne) [origin uncertain]. The herb Chelone glabra; cathartic and anthelmintic. Dose of the fld. ext. 3 ss-j. Chelonin, the concentrated ext. Dose gr. j-iv. Unof.

Balneography (bal-ne-og'-ra-fe) [balneum, a bath;

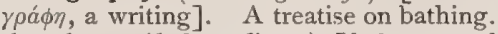

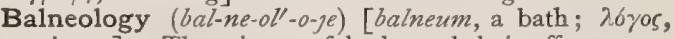
science]. The science of baths and their effects upon the system. 
Balneotherapeutics (bal-ne-o-ther-ap-u'-tiks). See Balneotherapy.

Balneotherapy (bal-ne-o-ther'-ap-e) [balneum, a bath ;

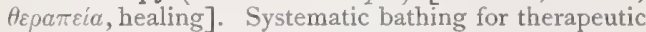
purposes, or the treatment of disease by baths or bathing.

Balneum (bal'-ne-um) [L.]. A bath. See Bath. B. arenæ, a sand bath. See Ammotherapy. B. lacteum, a milk bath. B. luteum, a mud-bath. See Illatation. B. pneumaticum, an Air-bath, q.v.

Balonea (bal-ó-ne-ah). See Valonia.

Balsam (bazol'-san) [ $\beta a ́ \lambda \sigma a \mu o v$, the resin of the balsam tree]. The resinous, volatile, aromatic substance, liquid or concrete, obtained from certain trees by natural exudation or by artificial extraction. Balsams are divided into two classes, those with, and those without, benzoic and cinnamic acids. In general they are mixtures of various essential oils, resins, and acids. B. Apple, the plant Momordica balsamina, and its warty, gourd-like fruit. It is purgative, but its tincture is chiefly used in domestic medicine as a vulnerary. Unof. B. Bog, a singular stone-like, woody, umbelliferous plant, Bolax or Azorella glebaria, of the Falkland Islands and Patagonia. Its aromatic gum is locally prized as a vulnerary, desiccative, and anti-gonorrheal remedy. Unof. B., Canada, a turpentine gathered from the natural blisters of the bark of Abies balsamum. It is much used as a mounting medium by microscopists. B. of Copaiba. See Copaiba. B. of Fir. Same as Canada Balsam. See Abies. B., Friar's. See Benzoin. B. of Gilead, the balm of the Old Testament; an oleo-resin obtained from the Balsamodendron gileadense. B. of Peru, the balsam obtained from Toluifera pereira ; antiseptic, stimulant to the circulation, and sedative to the nervous system; generally a tonic, and expectorant in bronchitis. Applied locally it is useful in chronic inflammatory skindiseases. Dose of the emulsion $m^{x}-\mathrm{xxv}$. B.-root, a popular name for certain composite-flowered plants of the genus Balsamorrhiza. $B$. hookerii, $B$. macrophylla, $B$, sagittata are common in the Pacific States and are rich in a resinous balsam. Unof. B. of Tolutan, or of Tolu, obtained from Toluifera balsamum. Its properties are due to a volatile oil, toluene. It possesses an agreeable odor, and is a basis for many cough-mixtures. It is a fair expectorant. $T$. Tinct. contains ten per cent. of the balsam in 90 per cent. of alcohol. Dose $m x-x x x$. T. Syr., balsam four parts; simple syrup 96 . Dose $3 \mathrm{j}-\mathrm{ij}$.

Balsamation (bawl-sam-a -shun) [ $\beta a \dot{\lambda} \sigma a \mu o v$, the resin of the balsam tree]. Embalmment with balsamic or aromatic spices.

Balsamic (bazol'-sam-ik) [ $\beta a ́ \lambda \sigma a \mu o v$, the resin of the balsam tree]. Having the nature or qualities of a balsam.

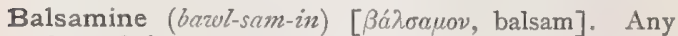
plant of the genus Impatiens, q. $v$.

Balsamito $\left(\right.$ bazel' - sam-e $\left.e^{\prime}-t o\right)$ [Sp.]. A tincture of balsam of Peru in rum; anthelmintic, diuretic, and tonic; it is used externally as a cosmetic and a stimulant wash for sores. Unof.

Balsamodendron (bazul-sam-o-den'-dron). See Myrrh and Bdellium.

Balsams (bazul'-sams) [ $\beta a \lambda_{1} \sigma \alpha \mu o v$, the resin of the balsam tree]. The natural, thick solutions of the gum resins in the essential oils and turpentines. See Resins.

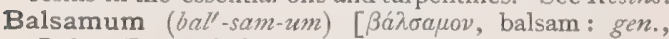
Balsami]. A balsam, $q . v$. B. dipterocarpi. See Gurjun Balsam.

Balser's Fatty Necrosis. See Diseases, Table of.

Bambalia (bam-ba'-le-ah) [L.]. Stammering; thickness of speech, or other impediment to utterance.
Bamberger's Fluid. An albuminous mercuric compound used in the treatment of syphilis. It is made as follows: To IOO c.c. of a filtered solution of white of egg (containing $40 \mathrm{c} . \mathrm{c}$. of albumin and 60 c.c. of water) there are added 60 c.c. of a solution of mercuric chlorid (containing 5 per cent, or 3 grams, of bichlorid of mercury) and $60 \mathrm{c}, \mathrm{c}$. of a solution of sodium chlorid (containing 20 per cent.); finally, 80 grams of distilled water are added, which brings the bulk of the solution up to 300 , containing 0.010 mercuric chlorid in every cubic centimeter.

Bamboo (bam-boo') [E. Ind., bambu ]. A popular name for many tree-like, woody-stemmed grasses, especially those of the genus Bambusa. Apart from a limited use in surgery, none of the bamboos is employed in regular medicine. Locally, $B$. arundinacea is employed as an alterative, anthelmintic, and depurative. Unof. See also Tafasheer. B. Brier, the root of Smilax sarsaparilla, habitat, Southern United States. Its properties are identical with those of sarsaparilla. Dose of the fld. ext. 3 ss-ij. Unof.

Banana (ban-an'-ah) [Sp.]. The root of the common banana, Musa sapientum, said to be a valuable alterative, and useful in strumous affections. Dose of the fld. ext. $\eta_{x-x x x}$ Unof.

Band (band) [ME., bande]. That which binds. A stripe. A ligament. B., Axis, Baer's primitive streak. B., Belly, a band to pass around the abdomen. B., Head, a strap for securing a mirror to the forehead. B., Horny, of Tarinus, the fore part of the tenia semicircularis. B., Moderator. See $B$, Reits. B., Reil's, a fibrous muscular fillet that frequently extends across the right ventricle of the heart; it is called also the moderator band. B. of Remak. See Fiber, axial; also Purkinje, Axis $\mathrm{Cyl}$ inder of. B. of Tarinus. See B., Horny.

Bandage $\left(b a n^{\prime}-d \bar{a} j\right)$ [Fr., bande, a strip]. Bandages are usually strips of muslin or other material, of varying widths and lengths, used in surgery for the purpose of protecting, compressing, etc., a part, or for the retention of dressings and applications. A simple bandage or roller consists of one piece; a compound, of two or more pieces. Starch, plaster-of-Paris, silica, dextrin, tripolith, etc., etc., are used or recommended for making stiff and immovable dressings or bandages. According to their direction bandages are classed as: I. Circular, circular turns about the part. 2. Figure-of-8, the turns crossing each other like that figure. 3. Oblique, covering the part by oblique turns. 4. Recurrent, the tums returning successively to the point of origin. 5. Spica, the turns resembling the arrangement of the husks of an ear of corn. 6. Spiral, each turn covering one-half of the preceding. 7. Spiral reverse, the bandage is reversed in order to better adapt it to the part. Bandages are also classed according to the part to which they are applied. Of Bandages of the head we have: I. Circular, of the forehead, to retain dressings upon the head. 2. Circular, of the eyes. 3. Crossed, of the eyes, to hold dressings upon one or both eyes. 4. T., of the eye, a small piece of muslin cut in the shape of a right-angled triangle, and sufficiently large to cover the eye, is sewn by its base, with the perpendicular toward the ear, to a horizontal strip of a length to encircle the head. The apex of the triangle is sewn to a vertical strip long enough to pass under the jaw and meet the horizontal strip on the opposite side. 5. Crossed, of the angle of the jaze, to support the parts in fracture of the angle of the jaw. 6. Knotted, of the head, a double-headed roller with compress, to make compression in wound of the temporal artery. 7. Recurrent, of the head, a single-headed or double-headed roller, to 


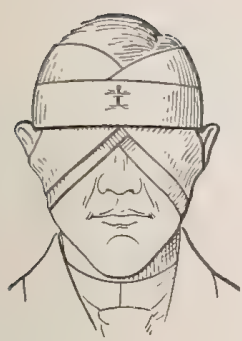

Crossed Bandage of both Eyes.

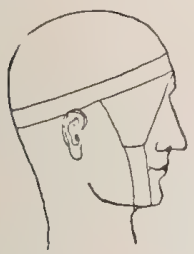

T-Bandage of the Eye.

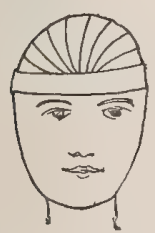

Recurrent Bandage of the Head.

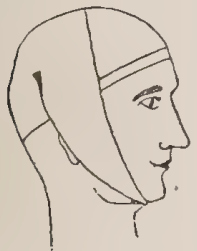

Four-tailed Bandage of the Head.

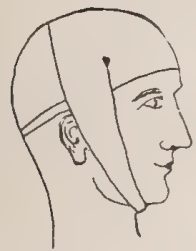

Four-tailed Bandage of the Head.

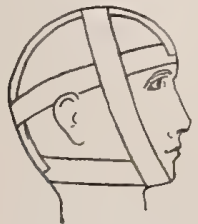

Gibson's Bandage.

\section{BA N D A GES.}

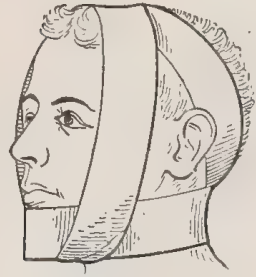

Barton's Bandage.

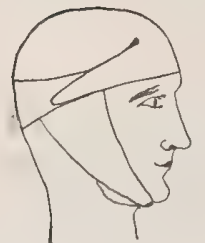

The Six-tailed Bandage of Galen.

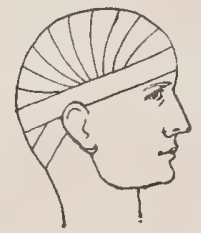

Transverse Recurrent of the Head.

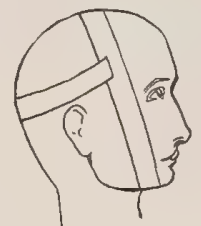

Agnew's Bandage.

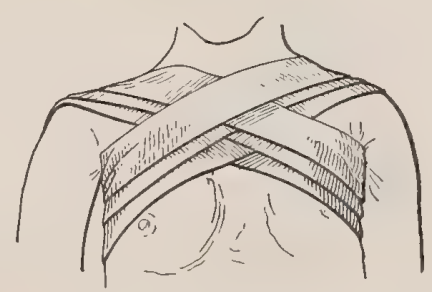

Anterior figure-of-8 Bandage of the Chest.

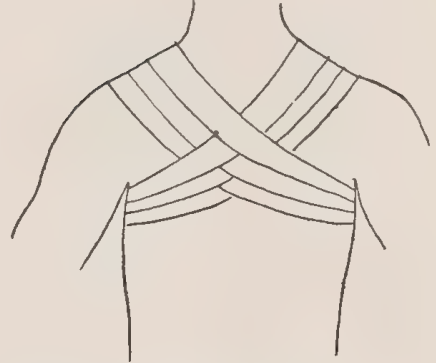

Posterior Figure-of-8 Bandage of the Chest.

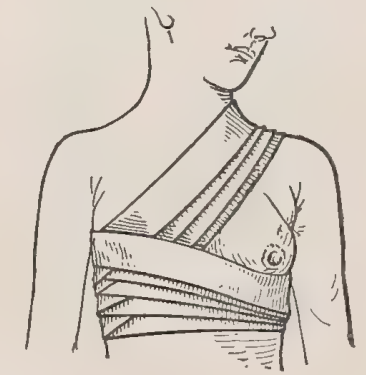

Suspensory and Compressor Bandage of the Breast.

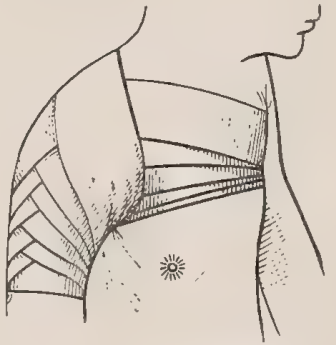

Spica Bandage of Shoulder.

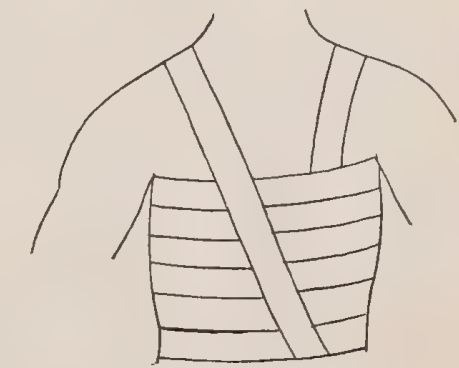

Spiral of the Chest. 


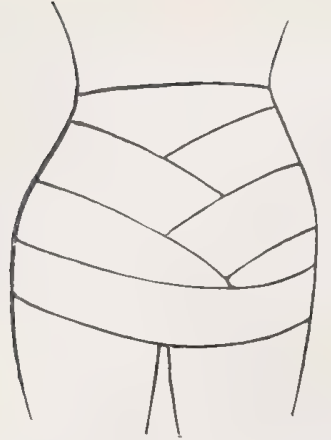

Eight-tailed Bandage of the Abdomen.

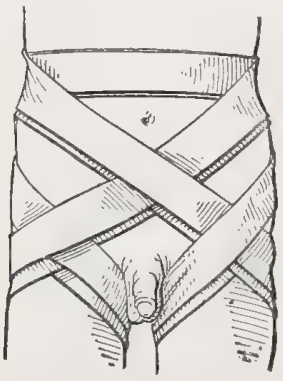

Duuble Spica Bandage of the Groins.

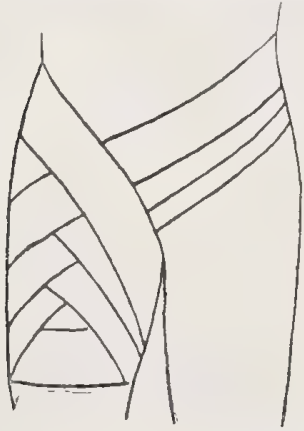

Ascending Spica of the Groin.

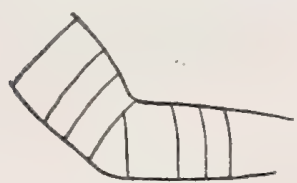

Figure-of- 8 of the Elbow.

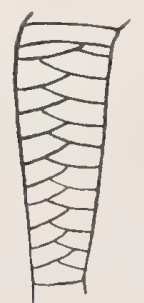

Spiral Reversed of the Forearm (or Leg).

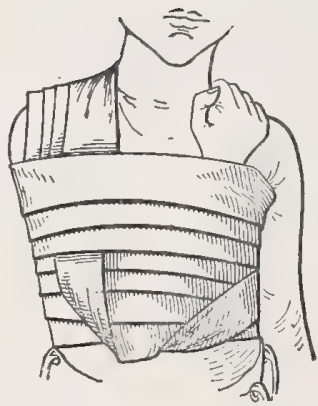

Velpeau's Bandage.

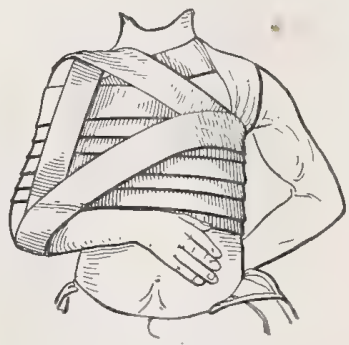

Desault's Bandage.

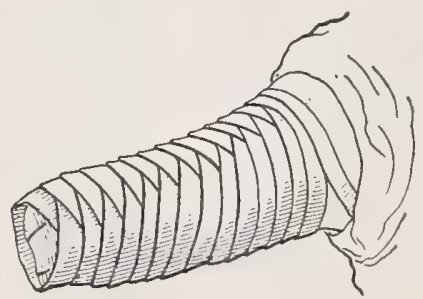

Recurrent Bandage of Stump.

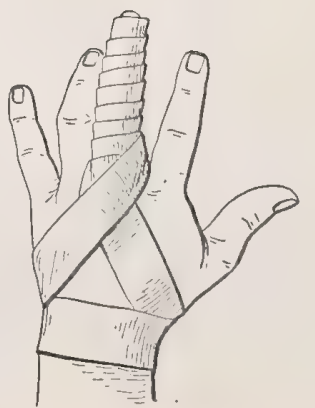

Spiral Bandage of the Finger.

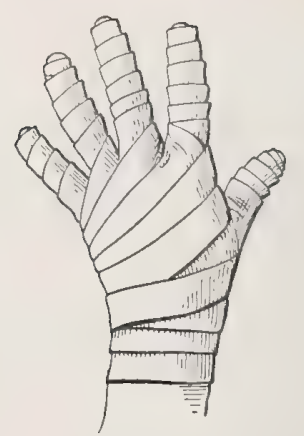

Gauntlet Bandage.

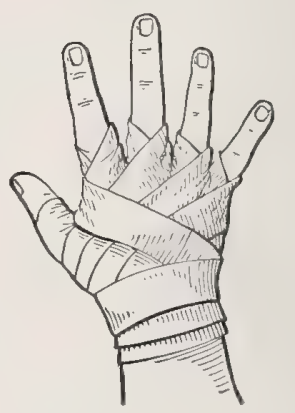

Demi-Gauntlet Bandage.

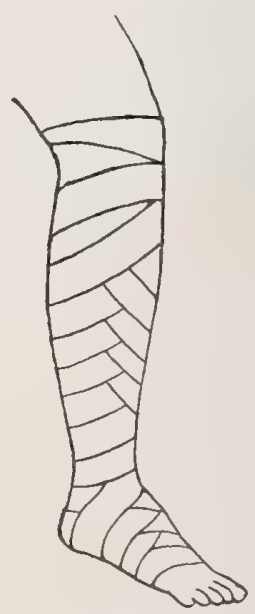

Modified Figure-of- 8 Bandage of the Lower Extremity.

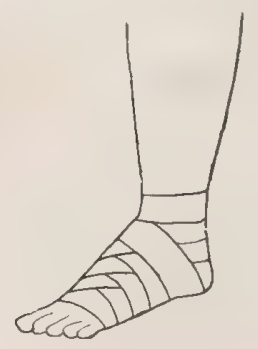

Spica of the Foot. 
retain dressings upon the head. 8. Four-tailed, of the head, a piece of cloth eight inches wide and long enough to pass over the head and under the chin, is torn from either end to within three or four inches of the middle. The body of the bandage is placed on the top of the head, the posterior ends are tied under the chin, and the two anterior ends carried backward and tied at the nape of the neck. 9. Gibson's, for the body of the lower jaze, to support the parts in fracture. IO. Rhen Barton's, for the same purpose. II. Capeline or Mitra Hippocratis; made by a double-headed roller (one which is rolled from each end, the two heads lying on the same side of the bandage and being of equal size). One roll being taken in each hand, the intervening strip is applied low down over the center of the forehead, and the bandage unrolled on either side until the two heads meet posteriorly below the occipital protuberance. From this point the two rollers are applied in different directions, one passing continuously around the head in a circle, the other forward and backward over the cranium until the latter is entirely covered. 12. Galen's six-tailed bandage, the bandage is so arranged that it has three strips at each end. The middle portion is placed on the crown of the head, the anterior ends are tied at the back of the neck, the middle under the chin, and the posterior at the forehead. 13. Garretson's, a bandage for the lower jaw, passing above the forehead and back again to cross under the occiput, and finally ending in front of the chin. I4. Pressure-bandage, an eye-bandage applied with a considerable degree of firmness in order to afford pressure. 15. Protective-bundage, a bandage for the eye, lightly applied. I6. Hamilton's, a form of compound bandage for the lower jaw, consisting mainly of a firm leather strap to support the jaw. I7 7 . Liebreich's, a variety of bandage for the eye, made from a knitted-cotton band. I8. Thillaye's, a compound bandage for joining the edges of the wounds in hare-lip operation. Of Bandages of the trunk there are: I. Circular, of the neck. 2. Figure-of-8, of the neck and axilla, to retain dressings upon the shoulder or in the axilla. 3. Anterior figure-of-8, of chest, to draw the shoulder forward and to retain dressings on the anterior surface of the chest. 4. Posterior figure-of-8, of chest, to draw the shoulders back in fractured clavicle, or to retain dressings on the posterior surface of the chest. 5. Crossed, of one or both breasts, to support the breasts in excessive lactation or in mammary disease. 6. Spica, of shoulder, to retain the head of the humerus in place after dislocation. 7. Spiral, of the chest, to make compression in fracture of the sternum or ribs. 8. Circular, of the abdomen, to support the abdominal walls. 9. Spiral, of the abdomen, to compress the abdominal walls or to retain dressings. Io. Spica, of one or both groins, to compress groin or retain dressings. I I. Spiral reverse, of the penis, to retain dressings upon this organ. The Bandages of the arm are: I. Circular, of the wrist. 2. Figure-of-8, of wrist, to compress the joint or retain dressings. 3. Figure-of-8, of elbow. 4. Circular, of arm or forearm. 5. Oblique, of arm or forearm. 6. Spiral, of arm, to retain dressings. 7 . Spiral reverse, of upper extremity, to support the arm in dislocations, fractures, etc. 8. Velpeau's, used to support the arm in fracture of the clavicle, the neck, or acromial process of the scapula. The hand of the injured side being placed on the sound shoulder, an oblique turn is made from the axilla of the sound side, across the back of the chest to the opposite shoulder, covering the fracture, down under the elbow in front to axilla of the sound side, then across the back over the outside of the point of the elbow to the axilla of the sound side, thus continuing the oblique and circular turns alternately and advancing over the arm till it is held firmly. 9. Desault's Apparatus, consists of an axillary pad held by tapes about the neck, a sling for the hand, and two single-headed rollers. The forearm is placed at right angles with the humerus, held in place by many circular and oblique turns about the shoulder and body. Io. Boyer's, a form of apparatus consisting of a chest-belt, an arm-belt, and an axillary pad. It is used in treating fractured clavicles. The Bandages of the hand are: I. Spiral, of the finger. 2. Spiral, of all the fingers, or gauntlet. 3 Spiral, of palm, or demi-gauntlet. 4. Spica, of thumb. All the bandages of the hand are used in cases of fracture or to retain dressings. The Bandages of the lower extremity are: $\mathbf{x}$. Figure-of-8, of ankle, to cover the part or retain dressings. 2. Figure-of -8 , of knee, to cover the part or compress it. 3. Figure-of 8 , of thighs, to compress the part after wounds or operations. 4. Spica, of instep, to compress the parts. 5. Spiral reverse, of whole lower extremity, to support the limb after fracture, etc. 6. Baynton's, a series of straps of adhesive plaster used in the treatment of chronic leg ulcers. 7. Ribbail's, a spica bandage of the foot. B., Genga's. See B., Theden's. B., Heliodorus's. The T-bandage. B., Hippocrates'. See B., Capeline. B., Hueter's, a spica bandage for the perineum. B., Langier's, a many-tailed paper bandage. B., Larrey's, a form of many-tailed bandage, the edges being glued together. B., Maisonneuve's, a variety of Plaster-of-Paris bandage, formed from cloths folded, these being supported by other bandages. B. of the Poor. See Galen's Bandage. B., Recurrent, for stumps, is used after amputations, to support the flaps. B., Richet's, a form of Plasterof-Paris bandage to which a small amount of gelatin has been added. B. of Scultetus, a compound bandage, similar to a spiral reverse in appearance and action, used in compound fractures, so that the short pieces of which it is composed may be removed without motion of the limb. T-Bandages are compound, and resemble that letter; the menstrual napkin is an example. B., Theden's, a form of roller bandage applied from below upward over a graduated compress, to control hemorrhage from a limb. See Hand. kerchief Dressing.

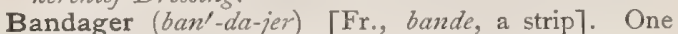
skilled in the application of bandages. See Dresser.

Bandagist (ban'-da-jist) [Fr., bande a strip]. A maker of trusses, bandages, and other surgical appliances to be worn upon the person.

Banded Hair (ban'-ded hār). See Ringed Hair.

Band1, Operation of. See Operations, Table of. B., Ring of, the superior limit of the cervical canal, in pregnancy at a level with the pelvic inlet, marking the boundary between the lower uterine segment and the rest of the uterus. It is about six inches above the os externum.

Bandolin (ban'-do-lin) [origin uncertain]. A mucilage made usually of quince-seeds, or of gum-tragacanth, used mainly as a paste for confining the hair and making it lustrous ; it is called also fixature. See Cydonium.

Bandy Leg (ban'-de leg). Bow-leg, $q . v$.

Baneberry (bān'-ber-e). See Actaa.

Bang, Bhang, or Bangue (bang). See Cannabis indica. Banian (ban'-yan) [Ar., banyan, a trader]. A South Asiatic fig-tree, Ficus bengalensis, remarkable for the development of roots and secondary trunks from its branches. Its juice is antodontalgic; the bark and seeds tonic, diuretic, and antipyretic. Unof.

Banks's Operations. See Operations, Table of.

Banting Treatment. See Treatment, Methods of. 
Bantingism (ban'-ting-izm) [From Banting, the name of the inventor]. A method proposed for the reduction of corpulence, by abstinence from saccharine and farinaceous foods. See Treatment, Methods of.

Banyan (ban'-yan). See Banian.

Baobab Tree. See Adansonia digitata.

Baptin (baṕl-tin) [ $\beta a ́ \pi \tau \iota \sigma \iota s$, a dipping]. A moderately purgative glucosid, obtainable from Baptisia tinctoric.

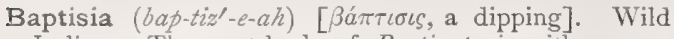
Indigo. The root bark of $B$. tinctoria with properties due to an impure glucosid, the so-called Baptisin. It is laxative and stimulant in moderate doses; emetic and cathartic in large doses, and is valuable in amenorrhea, typhus and typhoid fevers. It is excellent for local application to indolent ulcers and gangrenous sores. B., Extract. Dose gr, j-x. B., Ext. Fld. Dose $m_{\mathrm{ij}-\mathrm{xx}}$. B., Tinct. Dose $\eta^{v-x x x}$. Dose of the resin gr. $j-v$. All unof.

Baptisin (bap'-tiz-in) [ $\beta a ́ \pi \tau \iota \sigma / s$, a dipping]. I. A precipitate from the tincture of Baptisia tinctoria; antiseptic, evacuant, ecbolic, resolvent. Dose one to three grains. Unof. 2. A bitter glucosid obtainable from the plant, Baptisia tinctoria; it has little medicinal activity.

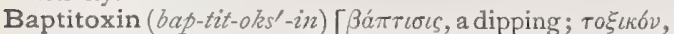
a poison]. A poisonous alkaloid obtained from Baptisia tinctoria. It hastens respiration and exaggerates vasomotor activity.

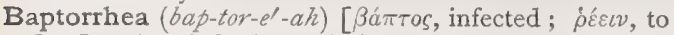
flow]. Any infectious discharge from a mucous surface, as gonorrhea.

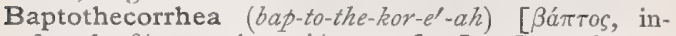
fected; $\theta \hat{n} \kappa \%$, vagina; $\dot{\rho} \varepsilon \varepsilon \nu$, to flow]. Gonorrhea in women.

Bapturethrorrhea (bap-tu-rēth-ro-re'-ah) [ $\beta a ́ \pi \tau o s$, infected; ov́phi $\theta \rho \alpha$, urethra; $\dot{\varepsilon} \varepsilon \varepsilon v$, to flow]. Urethral gonorrhea; gonorrhea of men.

Baranilin (bar-an'-il-in) [ $\beta a \rho u s$, heavy; anilin]. Heavy anilin oil. See Heavy Oil and Creasote Oil.

Baraquet (bar-ah-kzvet') [Fr.]. Synonym of Infuenza.

Barb (barb) [barba, a beard]. I. In biology, the retrorse tooth of an awn or prickle. 2. One of the narrow acute plates diverging from the rachis and going to form the vane of a feather.

Barba (bar'-bah) [L.]. The beard.

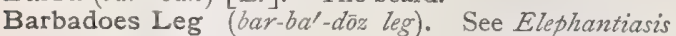
Arabum. B. Nut. See Purging Nut. B. Tar, a form of bitumen $(q . v$. ) formerly employed in medicine.

Barbaloin (bar-bal'-o-in) [Barbadoes; ánón, aloe], $\mathrm{C}_{17} \mathrm{H}_{20} \mathrm{O}_{7}$. The aloin derived from Barbadoes aloes.

Barbarossa's Pills. A mercurial preparation containing in addition rhubarb, scammony, musk, etc.

Barbasco (bar-bas'-ko) [verbascum, mullein]. A composite-flowered plant of tropical America, the Clibadium biocarpum. The stalks are used in preparing hair-washes, and are said to restore gray hair to its natural color. The plant is also used in eye-troubles. It is said to be very poisonous. Unof.

Barbellate $\left(b a r-b e l^{\prime}-\bar{a} t\right)$ [barbella, dim. of barba, a beard]. In biology, applied to the bristles of the pappus of some compositæ when beset with short, stiff hairs, longer than when denticulate, but shorter than when plumose.

Barben Cholera (bar-ben kol'-er-ah). A form of poisoning resulting, in Central Europe, from the eating of the barb.

Barber's Itch (bar'-berzich). The disease called Tinea barbe, Sycosis parasituria, or Tinea sycosis, q. $v$.

Barberry (bar'-ber-e). See Berberis. B. Gum, a commercial name of certain varieties of gum-arabic
Barber-Surgeon (bar'-ber ser'-jun) [barba, a beard; ME, sourgeon]. Formerly, a barber who also practised surgery.

Barbicel (bar'-bis-el) [barbicella, dim. of barba, a beard]. In biology, one of the fringes of a barbule of a feather.

Barbiers (bar'-bèrz) [E. Ind.]. A paralytic affection common in India, and probably a myelitis. It is often confounded with beriberi.

Barbigerous (bar-bij'-er-us) [barba, a beard; gerere, to carry]. In biology, bearded; hirsute; coarsely pubescent; applied to petals.

Barbotine (bar-bo-teen') [Fr., wormwood]. Levant worm-seed.

Barbule $\left(b a r^{\prime}-b \bar{u} l\right)$ [barbula, dim. of barba, beard]. In biology, one of the fringes of the barb in a feather, going to make up the vane of the barb, as the barbs make the vane of the feather.

Barclay's Angles. See Angle. B.'s Plane. See Plane.

Barcoo $\left(b a r^{\prime}-k o o\right)$ [Australian]. A peculiar disease, marked by nausea and vomiting, common in Australia. Its cause is unknown. It is also called "Fly-sickness."

Bardana (bar-da'-nah) [L.]. The burdock. See Lappa.

Bardeleben's Operation. See Operations, Table of.

Bardenheuer's Operations. See Operations, Table of

Barden's Operation. See Operations, Table of.

Baregin (bar-a'-zhin). See Glaisin.

Baresthesiometer (bar-es-the-ze-om'-et-er) [ßápos,

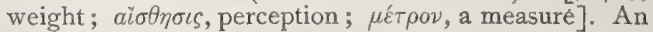
instrument for estimating the weight-sense in disturbances of sensibility.

Baresthesiometric (bar-es-the-ze-o-met'-rik) [ $\beta a ́ \rho o s$,

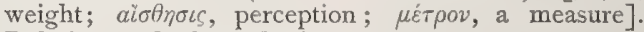
Relating to the baresthesiometer.

Bareswill's Solution. A solution for the detection of sugar in the urine. It consists of sulphate of copper, acid potassium tartrate and sodic hydrate. See Tests, Table of.

Barford's Test. See Tests, Table of.

Baric $\left(b a^{\prime}-r i k\right)$ [ $\left.\beta a ́ \rho o s, ~ h e a v y\right]$. Pertaining to or containing barium.

Barilla $\left(b a r-i l^{\prime}-a h\right)$ [Fr., barille, impure soda]. Impure sodium carbonate; being the ashes obtained by burning various chenopodiaceous plants of the genera Salicomia and Salsola.

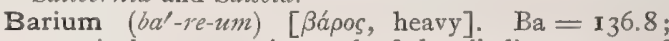
quantivalence II. A metal of the alkaline group, of pale yellow color, characterized by a strong affinity for oxygen. Neither the metal nor its salts are much employed in medicine; all are poisonous. B. Carbonate, $\mathrm{BaCO}_{3}$, used in the preparation of the chlorid. B. Chlorid, $\mathrm{BaCl}_{2} \cdot 2 \mathrm{H}_{2} \mathrm{O}$, soluble, used as a reagent, and also as a cardiac and vasomotor stimulant in the treatment of aneurysm. Dose gr. ss-v. B. Chlorid Test. See Tests, Table of. $\mathbf{B}$. dioxid. $\mathrm{BaO}_{2}$, used for making aqua hydrogenii dioxid. B. iodid, formerly used as an alterative. Dose gr, $\frac{1}{8}$. Mainly employed in ointments. Unof. B. monohydrate, caustic baryta; reagent. B. oxid, $\mathrm{BaO}$, baryta. B. sulphate, $\mathrm{BaSO}_{4}$, used as a pigment; formerly used in the treatment of skin-diseases, and in lotions.

Bark (bark) [ME., barke]. The cortex or covering surrounding the wood of exogens. It is sometimes used as a synonym of cinchona or calisaya bark. B. Peruvian. See Cinchona. (For other barks, see the names of the plants or trees that produce them.)

Barker's Operations. See Operations, Table of.

Barking (bar'-king). [ME., barken, to bark.] 'The uttering of a peculiar sharp, short cry, as a dog. See 
Aboiement. B. Disease, a guttural, barking cough, with nervous disorder and impairment of the will; cynobex hebetis.

Barleria (bar-le'-re-ah) [L.]. A genus of acanthaceous plants. B. buxifolia and B. ciliata, of India, are aperient. B. prionitis, of S. Asia, is employed as a polychrest. Unof.

Barley $\left(b a r^{\prime}-l e\right)$ [ME., barly]. A cereal belonging to the order Graminece; the most common variety, Hordeum distichon, is much used as a food, and also in the preparation of malt. B. Decoct. (B. P.). Dose $\bar{z}$ j-iv. B. Pearl, is the decorticated grain, rounded and polished. B. Water, decoctum hordei, a decoction consisting of two ozs. of Pearl B. boiled in one and one-half pints of water and afterward strained. See Ptisan. B. Sugar, saccharum hordeatum; practically a glucose. Applied also to an amorphous mass obtained by melting cane-sugar.

Barnes's Curve. In obstetrics, the segment of a circle, having for its center the sacral promontory, its concavity looking backward. B.'s Dilators, graduated rubber bags used for dilating the cervix uteri in the induction of abortion or premature labor. B.'s Method. See Treatment, Methods of.

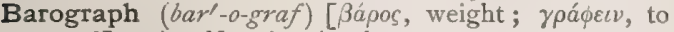
record]. A self-registering barometer.

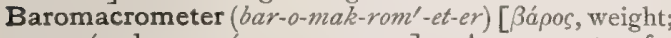

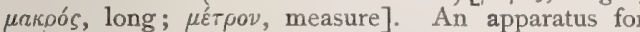
ascertaining the weight and length of new-born infants.

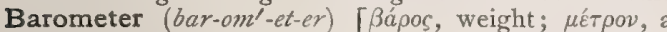
measure]. An instrument for determining the weight and tension of the atmosphere. It consists essentially of a glass tube about 36 inches long, closed at one end, filled with mercury, and inverted in a basin of mercury. The mercury will sink in the tube until it rests at a height of about 30 inches at the sea-level, the height varying as the atmospheric pressure increases or diminishes. B., Aneroid, a metallic box from which the air has been exhausted, the tension being indicated by the collapsing or bulging of the thin corrugated cover, which is connected with a movable index. B.-maker's Disease, a form of chronic mercurial poisoning among the workmen who make barometers. It is due to the inhalation of the fumes of mercury.

Barometrograph (bar-o-met'-ro-graf). See Barograph.

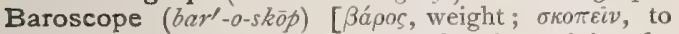
observe]. An instrument used for determining the loss of weight of a body in air, compared with its weight in a vacuum. A form of baroscope has been invented by Esbach for the quantitative determination of urea.

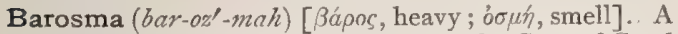
plant of the order Rutacere, native to the Cape of Good Hope and vicinity; several species of which yield the Buchu of commerce.

Barosmin (bar-oz'-min) [ßápos, heavy; óoún, smell]. A precipitate from the tincture of Barosma crenata. Dose grs. ij-iij. Unof.

Barras $\left(b a r^{\prime}-a s\right)$ [Fr.]. Turpentine obtained in the S. of France, chiefly from Pinus pinaster.

Barrel-shaped Chest. See Emphysema.

Barrenness (bar'-en-nes) [ME., bareynesse]. Sterility in the female.

Barrier's Method. See Treatment, Methods of.

Barruel's Apparatus. An arrangement for charging water with carbonic acid.

Barsac $\left(b a r-s a h k^{\prime}\right)[\mathrm{Fr}$.$] . A white French wine, often$ with a bitter-sweet, resinous flavor.

Bartholin, Canal of. See Duct. B., Duct of. See Durt. B., Foramen of. See Foramina, Table of. B., Glands of. See Gland.

Bartholinitis (bar-tho-lin-i'-tis) [Bartholin, a Danish I 3 physician; $\iota \tau \iota s$, inflammation ]. Inflammation of the vulvo-vaginal gland.

Bartisch's Operation. See Opurations, Table of.

Bartlett's Apparatus. A splint or dressing for fracture of the clavicle with dislocation.

Barton's Bandage. See Brndage. B. Fracture. See Fracture and Diseases, Table of. B. Handkerchief, a form of temporary dressing for a wound. See Handkerchief Dressing. B. Operations. See Operations, Table of.

Baruria (bar-u'-re-a/z) [ $\beta a$ áos, heavy; ov̉pov, urine]. Abnormally high specific gravity of the urine; also the condition of the body associated therewith.

Barwell's Apparatus. An apparatus for the treatment of talipes by means of continuous traction on the foot. B. Operations. See Operations, Table of.

Barwood Red. See Pigments, Conspectus of.

Baryacoia (bar-e-ak-oi'-ah). See Baryecoia.

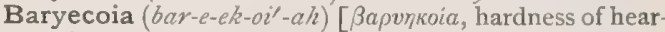
ing]. Hardness of hearing; partial deafness.

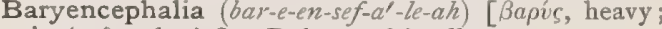
$\dot{\varepsilon} \gamma \kappa \varepsilon \dot{\phi} \alpha \lambda \sigma_{\text {s }}$, brain]. Dulness of intellect.

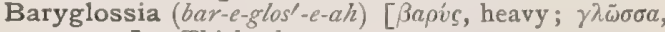
a tongue ]. Thick, slow utterance.

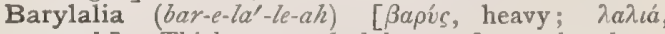
speech]. Thickness and dulness of speech; baryphonia.

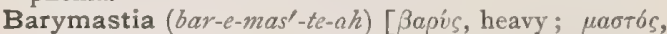
breast]. Same as Barymazia.

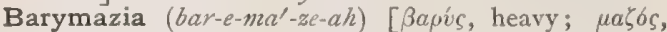
breast]. Heaviness or large size of the mamme.

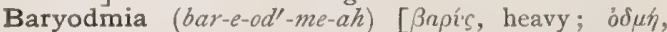
odor]. A heavy, disagreeable odor; also a subjective sensation as of a disagreeable smell.

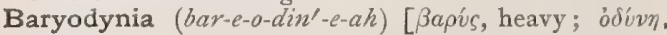
pain ]. Severe pain.

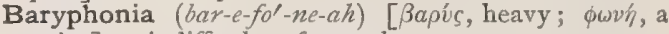
voice]. A difficulty of speech.

Baryphonic (bar-e-fon'-ik) [ $\beta a \rho{ }^{\prime} s$, heavy ; $\phi \omega v \eta ́$, voice] Affected with baryphonia.

Barysomatia (bar-e-so-ma'-she-ah) [Bapus, heavy; $\sigma \bar{\omega} \mu a$, body]. Excess in the weight of the body.

Baryta, or Barytes (bar-i'-tah, or bar-i'-tes) [ $\beta a \rho v s$, heavy]. Oxid of barium. See Barium. B. Green. Same as Manganese Green.

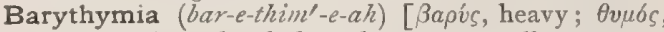
mind]. A melancholy, gloomy, or sullen state of mind.

Basaal $\left(b a^{\prime}-s a-a l\right)$ [Malay]. An East Indian tree, Embelia basal; its fruit is a vermifuge; its leaves are soothing and demulcent. Unof.

Basad (ba'-sad) [ßárs, a foundation]. Toward the basal aspect.

Basal $\left(b a^{\prime}-s a l\right)$ [ $\beta a ́ \sigma \iota s$, a foundation]. Pertaining to or located at the base. See Basilar. B. Ganglia. See Ganglion.

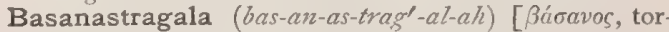

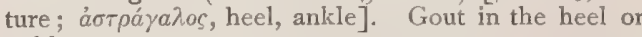
ankle.

Basculation (bas-ku-lat-shun) [Fr., basculer, to swing]. The movement by which retroversion of the uterus is corrected when the fundus is pressed upward and the cervix drawn downward.

Bascule Movement (bas'-kül moov'-ment) [Fr., bascule, a swing]. The recoil of the heart in its systolic motion.

Base $(b \vec{a} s)$ [ $\beta a \dot{\sigma} \sigma \iota$, a foundation]. The lower part, as, the base of the brain. In chemistry, an element or radicle that combines with an acid to form a salt. The electro-positive molecule or radicle of a compound. In dentistry, the plate upon which artificial teeth are held. In pharmacy, the most important part of the prescription. 
In microscopy, the portion of the stand of a microscope upon which it rests. It is important for steadiness. In electro-therapeutics, the part of a battery upon which are fastened the coil-posts and switches. B., for Artificial Teeth; in the construction of a base for artificial teeth, a transfer or model of plaster-ofParis is first obtained. Then a metallic die and counter-die, if the base is to be of metal, are procured, and between these a plate of suitable size and thickness is swaged. See Metallic Base and Vulcanite Base. B., Organic, a term including a large number of organic compounds, especially nitrogen compounds, which, like ammonium, unite with acids to form salts. They are commonly called alkaloids.

Base-ball Pitcher's Arm, a peculiar condition of the arm arising from over-use, characterized by loss of strength, tenderness, neuralgic pains, and inflammation and hypertrophy of the bone.

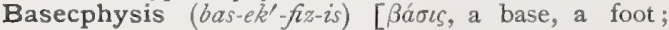
$\check{\varepsilon} \kappa \phi \tilde{v} \sigma \iota$, a growing out, a shoot]. In biology, a branch springing from the basal joint, as in the limbs of crustacea. Synonyms Exognathite, Exopodite.

Basedow's Disease. An exophthalmic bronchocele; called also, Exophthalmic Goiter, and Graves' Disease. See Goiter and Diseases, Table of.

Basement $\left(b \bar{a} s^{\prime}-m e n t\right)$ [Fr., bassement $]$. The fundamental portion. B. Membrane. See Membrane. B. Tissue. See Tissue.

Bas Fond $(b a h f o n(g))$ [Fr.]. The floor of the urinary bladder.

Basham's Mixture. Mistura ferri et ammonii acetatis. B. Test. See Tests, Table of.

Basial $\left(b a^{\prime}-z e-a l\right)$ [ $\beta a ́ \sigma \iota s, a$ foundation]. Relating to a base, as to the basion.

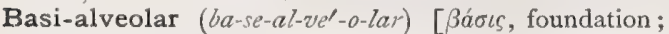
alveolus, a little trough]. Relating to the basion and the alveolar point.

Basiarachnitis ( $\left.b a-s e-a r-a k-n i^{\prime}-t i s\right)$ [ $\beta a ́ \sigma \iota s$, foundation; á $\rho \alpha \chi v \eta$, a spider; $\iota \tau \iota \zeta$, inflammation]. Inflammation of that part of the arachnoid that corresponds to the base of the skull.

Basiator (ba-ze-a'-tor) [basiare, to kiss]. The orbicularis oris muscle. See Muscles, Table of.

Basibracteolate (ba-se-brak'-te-o-lāt) [basis, a base; bracteola, a little bract]. In biology, having the base surrounded by bracts, as the dandelion.

Basibranchial (ba-se-brang'-ke-al) [basis, a base; branchice, gills]. In biology, applied to the one or more skeletal pieces forming the base of gills or branchiæ.

Basic $\left(b a^{\prime}-s i k\right)$ [ $\beta a ́ \sigma \iota s$, a foundation]. Having properties the opposite of those of acids. An acid capable of uniting with a single monad atom or radical is called monobasic. One that will unite with two monad or one dyad atom or radical, etc., is said to be dibasic. This measure of the power of an acid is called its basicity. B. Blue. Same as Spirit Blue.

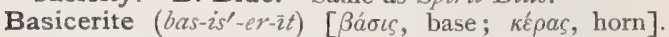
The second joint of the antenna in a crustacean.

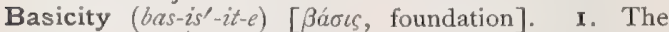
quality of being basic. 2. The combining power of an acid.

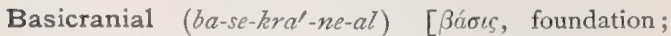
kpaviov, the skull]. Relating to the base of the skull. B. Axis, a line running from a point midway between the occipital condyles through the median plane to the junction of the ethmoid and presphenoid.

Basidigital (ba-se-dij"-it-al) [ $\beta a ́ \sigma \iota s$, foundation; digitus, a finger]. Pertaining to the bases of the digits. B. Bone, any metacarpal, or metatarsal bone.

Basidiogenetic (bas-id-e-o-jen-et'-ik) [basidium, a spore-producing cell ; $\gamma \varepsilon \varepsilon \varepsilon \sigma \iota \varsigma$, origin]. In biology, produced on a basidium.
Basidiospore (bas-i $\left.d^{\prime \prime}-\ell-o-s p o ̄ r\right)$ [basidium, a spore-producing cell; $\sigma \pi o p a ́$, seed]. One of the spores produced upon a basidium.

Basidium $\left(b a s-i d^{\prime}-\ell-\imath m\right)$ [dim. of $\beta a ́ r \iota c$, a base: $p l$. , Basidia]. In biology, a large cell in the higher fungi, borne on the hymenium and producing spores at its free end.

Basifacial (bas-e fa'-shal) [basis, foundation; facies, face]. Pertaining to the lower portion of the face. B. Axis, in craniometry, a line from the anterior point of the premaxilla to the anterior point of the basicranial axis.

Basifixed (ba'-se-fikst) [basis, base; fixus, fixed]. In biology, attached by the base.

Basifugal (bas-if'-u-gal) [basis, a base; fugere, to flee]. In biology, derived from, or proceeding away from the base; acropetal ; centrifugal.

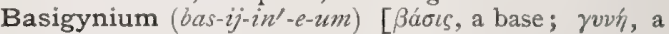
female: pl., Basigynia]. See Gynophore.

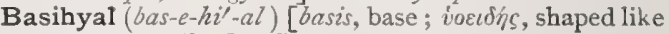
the letter upsilon]. Either one of the two bones, one on each side, that form the principal part of the body of the hyoid arch.

Basihyoid (bas-e-hi'-oid). See Basihyal.

Basil $\left(b a^{\prime}-s i l\right)$ [ $\beta a \sigma \iota \lambda \iota \kappa o ́ s$, royal]. A kind of mint, Ocymum basilicum; aromatic and carminative. The name is given to other related plants. Unof.

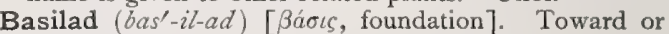
to the base or basilar aspect.

Basilar $\left(b a s^{\prime}-i l-a r\right)$ [ $\beta a ́ \sigma \iota s$, base]. Pertaining to the base, usually of the skull. B. Artery, the artery extending between the borders of the Pons Varolii; through its branches it supplies the substance of the pons. See Arteries, Table of. B. Aspect, the view of the head looking toward the base of the skull. B. Membrane, a membranous division-wall separating the scala vestibuli from the scala tympani, extending from the base to the apex of the cochlea, and supporting the organ of Corti. B. Process, a strong quadrilateral plate of bone in front of the foramen magnum. B. Suture, the suture formed by the junction of the basilar surface of the occipital bone with the posterior surface of the body of the sphenoid.

Basilary (bas'-il-a-re). See Basilar.

Basilateral (bas-e-lat'-er-al) [basis, base; latus, side]. Both basilar and lateral.

Basilen (bas'-il-en) [basis, base]. Belonging to the basilar portion in itself.

Basilic (bas-il'-ik) [basilicus: $\beta a \sigma i \lambda \iota \kappa b s$, royal]. Any structure or medicine of importance (obsolescent). B. Vein, a large vein of the arm on the inner side of the biceps. See Vein.

Basilicon Ointment (bas-it'-ik-on oint'-ment). An ointment composed of yellow wax, yellow resin, and Burgundy pitch āā I tô, olive oil fl. $\bar{\zeta} x v j$, to which, when melted, turpentine 3 iij are added. It is called also the "four drug" ointment. There are several other ointments bearing this name. See Resina.

Basilo-bregmatic (bas-il-o-breg-mat'-ik) [ $\beta a ́ \sigma c \zeta$, foundation; $\beta \rho \varepsilon \varepsilon \gamma \mu \pi$, the sinciput]. Pertaining to the base of the skull and the bregma.

Basilo-mental (bas-il-o-men'-tal) [basis, base; mentum, the chin]. Pertaining to the base of the skull and to the chin.

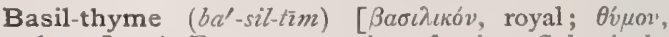
thyme]. A European species of mint, Calamintha acinos; aromatic and calmative. Unof.

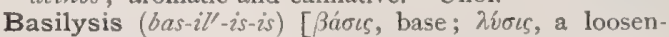
ing]. The breaking up of the fetal skull in craniotomy.

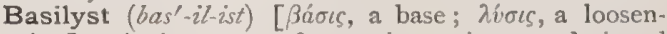
ing]. An instrument for use in craniotomy, designed 
to perforate the cranial vault and break up the base of the skull.

Basin $\left(b a^{\prime}-\sin \right)$ [ME., basin]. I. The third ventricle of the brain. 2. The pelvis. B.-Trap. A trap or seat in the outlet of the basin of a water-closet, placed there to prevent the entrance into the apartment of noxious and offensive vapors and gases.

Basinasal (bas-e-na'-sal) [basis, base; nasus, the nose]. Relating to the basion and the nasion.

Basinerved (bas'-in-ervd) [basis, a base; nervus, nerve]. In biology, applied to a leaf having all the veins or nerves springing from the base.

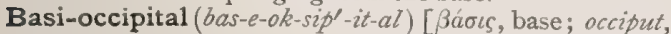
the back of the head]. A bone, separate in many of the lower vertebrate animals, forming the central axis of the skull. In adult human life, it is the basilar process of the occipital bone.

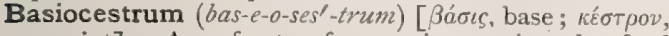
a point]. A perforator for use in opening the fetal head in craniotomy.

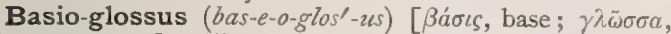
the tongue]. That part of the hyoglossus muscle that is attached to the base of the hyoid bone.

Basion $\left(b a^{\prime}-s e-o n\right)$ [ $\beta a ́ \sigma \iota s$, base]. In biology, a point of measurement in craniometry, located at the middle of the anterior margin of the foramen magnum. See Craniometric Points.

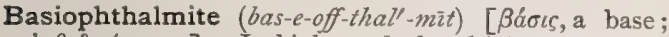
óftàuós, eye]. In biology, the basal joint of the eyestalk in a stalk-eyed crustacean.

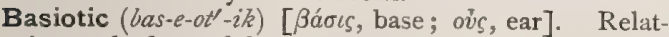
ing to the base of the ear.

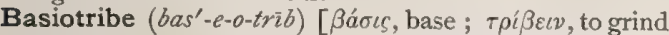
or crush]. An instrument used in craniotomy for perforating or crushing the fetal head.

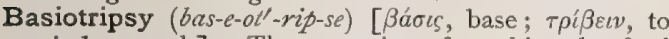
grind or crush]. The operation of crushing the fetal head.

Basipetal (bas-ip'-it-al) [basis, a base ; petere, to seek]. In biology, applied to growth in plants from the apex toward the base.

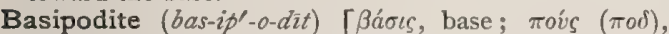
foot]. The basal joint of an arthropod limb, or the joint between the first and third.

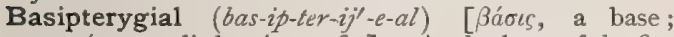

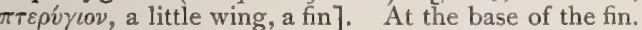

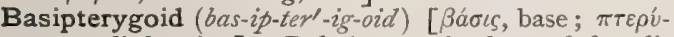
$\gamma\llcorner o v$, a little wing]. Relating to the base of the alisphenoid bone.

Basirostral (bas-e-ros'-tral) [basis, a base ; rostrum, a beak]. In biology, having to do with the base of a bird's beak.

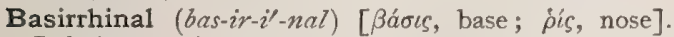
Relating to the base of the brain and to the nose. Applied to a cerebral fissure located at the base of the olfactory lobe.

Basis $\left(b a^{\prime}-s i s\right)$ [ $\left.\beta a ́ \sigma \iota s, b a s e\right]$. Base, q.v. The Latin form is used to designate the lower or fundamental part of any organ, as $B$. cerebri, $B$. corda, etc.

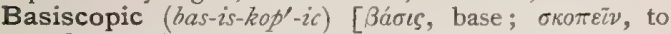
see]. Looking toward or on the side of the base.

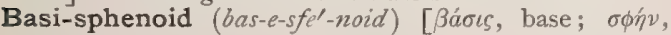

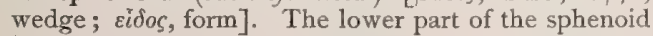
bone.

Basisylvian (bas-e-sill-ve-an) [basis, base; Sylvizes, an anatomist]. Applied by Wilder to the transverse basilar portion or stem of the Sylvian fissure. See Fissure, Table (and Diagram).

Basitemporal (bas-e-tem'-po-ral) [basis, base; tempora, the temples]. Relating to the base or lower part of the temporal bone.

Basivertebral (bas-e-ver-te-bral) [basis, base; verte- bra, a joint]. Relating to the basis or centrum of a vertebra.

Basophile $\left(b a s^{\prime}-0-f i\right)$. See Basophilous.

Basophilic (bas-o-fil'-ic) [ $\beta a ́ \sigma \iota s$, base ; $\phi \iota \lambda \varepsilon \varepsilon \iota \nu$, to love] Combining readily with bases; stainable by means of basic dyes.

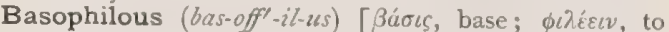
love]. Stained by basic rather than by acid dyes (applied to certain cells and tissue-elements)

Bassalia $\left(b a s-a^{\prime}-l e-a h\right)$ [ $\beta a ́ \sigma \sigma \omega \nu-\beta a ́ \theta v s$, very deep ; ània, an assemblage]. In biology, a deep-sea realm distinguished by a characteristic fauna

Bass-deafness (bās-def'-nes) [OF., basse, low ; ME., defen ]. Deafness to certain bass-notes, the perception of the higher notes being retained.

Bassia (bas'-e-ah) [Bassi, an Italian botanist]. A genus of $\mathbf{E}$. Indian and African sapotaceous trees. The mahua, $B$. latifolia, is cultivated in India for its edible flowers, which afford on distillation an alcoholic drink. $B$. longifolia and $B$. butyracea afford a sort of vegetable butter. The bark and leaves of these three species are used in rheumatism. Unof.

Bassini's Operation. See Operations, Table of.

Bassora Gum (bas'-o-rah-gum). An inferior gum, much used in adulterating tragacanth.

Bassorin (bas'-o-rin) [Bassora, an Asiatic city], $\mathrm{C}_{6} \mathrm{H}_{10} \mathrm{O}_{5}$, or $2 \mathrm{C}_{6} \mathrm{H}_{10} \mathrm{O}_{5}$. A tasteless, odorless vegetable mucilage, insoluble in cold water, but rendered soluble by alkalies; it is found in gum tragacanth (of Bassora) and in cherry and plum gums. See Carbohydrates, Table of.

Bast (bast) [AS., bcst, a lime-tree]. The inner bark of exogenous plants. The fibrous parts of the bark are used in making cordage, and have a limited use in surgery

Bastard (bas'-tard) [bastardus, a bastard]. I. Illegitimate. 2. In biology, having the appearance of being genuine.

Bastards (bas'-tardz) [bastardus, a bastard]. The name given to an impure sugar procured by concentrating molasses and allowing it to crystallize slowly in moulds.

Bastelaer's Test. See Tests, Table of.

Bastose (bas'-tōs) [AS., bast, a lime-tree]. A com. bination of cellulose and lignin, comprising a complete bundle of fibers, as in jute, or merely a covering upon the unaltered cellulose.

Basyl $\left(b a^{\prime}-s i l\right)$ [ $\beta a ́ \sigma \iota \varsigma$, base; $i \lambda \eta$, principle]. The electro-positive constituent of any compound.

Bat (bat) [ME., bat]. An instrument of great delicacy employed by Dr. Marshall Hall for the detection of minute air-currents issuing from the lungs of those apparently dead.

Bateman's Drops. The tinctura pectoralis, N. F.; a weak tincture of opium, camphor, and catechu; a popular remedy in coughs.

Bates's Operation. See Operations, Table of.

Bath $(b a t h)$ [AS., bath, a bath]. A bathing place or room. The medium in which the body is wholly or partly immersed. As therapeutic agents, baths are classified according as water, vapor, air, etc., is used ; according to the temperature, as hot, temperate, cold, etc. ; according to the end desired, as nutritional, medicinal, stimulant, etc. Special forms of bath are the moor, peat, mud-slime, pine-leaf, herb (hay, gentian, camomile, juniper, marjoram, etc.), brine, sand, tan, bran, malt, glue, soup, milk, whey, blood, wine, guano, starch, soap, acid, iron, sulphur, carbonic acid, compressed air, mustard, electric, etc. B., Acid, add $\mathrm{I} \mathrm{I} / 2$ ounces of nitric acid and I to 3 ounces of $\mathrm{HCl}$ to 30 gallons of warm water in a wooden or earthenware vessel, and immerse the patient in this for about 10 to 
20 minutes. For a foot-bath, add $\mathrm{J} / 2$ ounce of nitric acicl and $\mathrm{I}$ ounce of $\mathrm{HCl}$ to 4 gallons of warm water. This is said to be useful in cases of dyspepsia with slugrish liver and constipation. B., Air, a bath in which but little water is employed, the body being exposed freely to the air. It is employed in those cases in which there is a tendency to catch cold from undue facility to perspire. B., Alcohol, one in dilute alcohol, used to reduce temperature in fever. B., Alkaline, add 3 ounces of potassium carbonate, or 6 of sodium carbonate, to 25 or 30 gallons of hot water. It is used in chronic squamous skin diseases, chronic rheumatism, and lithemia. It should be taken in a wooden, earthenware, or enamelled bath. B., Arsenical, baths at a temperature of from $90^{\circ}$ to $97^{\circ} \mathrm{F}$., containing a small quantity of arsenic. They are used occasionally in the treatment of rheumatoid arthritis. B., Blanket, a method employed in chronic nephritis to stimulate the diaphoretic action of the skin. The patient is placed in bed and closely wrapped in blankets, a hot pouttice being applied at the same time to the loins, and renewed as often as it becomes cool. B., Blood, one consisting of the blood of an animal, freshly shed. B., Bog, a bath formed by mixing bog-earth (generated by the decomposition of plants in the presence of water and found at iron and sulphur springs) with warm water to form a pulpy or mushy consistence. This is used as a mud bath. B., Borax, borax, 4 ounces; glycerin, three ounces; water, thirty gallons. I $x$ is used in the same class of cases as the bran bath. B., Bran, boil one pound of bran in one gallon of water, strain, and add thirty gallons of water. This is a soothing and emollient bath, and is of service in squamous and irritable conditions of the skin. B., Brand; Cold bath. The tub is filled with water of $68^{\circ}$. The patient is given a stimulant of one-half to two ounces of brandy, the face and chest are laved with ice-water, and then he is gently placed in the water. The attendants should gently pass the flattened outstretched hands over successive parts of the body to dilate the superficial cutaneous vessels. Remove the patient as soon as the teeth begin to chatter, or if cyanosis of the lips or face appears. Usually the bath should be continued fifteen minutes. Then the patient is laid wet on a sheet and quickly wrapped from head to foot, then dried in five minutes and hot water applied to the feet. See Treatment, Methods of. B., Chemical, in chemistry, an apparatus for regulating the temperature of chemical processes by surrounding the substance with water, sand, oil, or mercury, through which the heat is communicated. B., Cold. See B., Brand. B., Corrosivesublimate, made by adding mercuric chlorid three drams, and $\mathrm{HCl}$ one dram, to 30 gallons of water. It is sometimes of service in secondary syphilis and in certain slin-diseases. B., Creasote, cumposed of creasote three drams, glycerin four ounces, and water 30 gallons. It is used in squamous skin diseases. B., Electro-therapeutic, a bath furnished with suitable electrodes and used in the application of electricity for curative purposes. B., Foot, a bath for the feet only. This is used as a derivative agent in cases of cold, etc. B., Full, this consists of a tub about two-thirds full of water, the duration and temperature being adapted to the purpose in view. The patient's body may be entirely covered by water, so that his chin just clears it. B., Gelatin, dissolve one pound of common glue in hot water, and add the solution to the plain bath, or to the bran bath, and use in the same class of cases as the latter. B., Graduated Full, a modification of the Brand bath.
The tub is filled with sufficient warm water to cover two-thirds of the recumbent body. The patient is then laid in and the temperature gradually lowered by the addition of cold or ice-water, while warm water is being removed. Friction is practised, as in the Brand bath. This bath lasts half an hour, and the water should be reduced to $68^{\circ}$ as rapidly as possible. B., Half, the patient is seated in a tub containing eight or ten inches of water of a temperature suited to the case. A wet towel is tied around the head, and the bath water is poured and dashed over the back, head, and shoulders with the attendant's right hand, while friction is practised with the left, and the patient does the same on the anterior portion of the body. The temperature of the water may be lowered if a more decided impression is desired. The bath is continued for from five to twenty minutes with active friction. It is indicated in all fevers involving a depressed nervous system, as shown by ataxia, delirum, or coma. B., Herb, made by using the extract of pine-needles, or of some aromatic herbs. The bath is used as a tonic. B., Hip. See B., Sitz. B., Hot, the temperature ranges from $104^{\circ}$ to $I 10^{\circ} \mathrm{F}$. It acts upon the skin, producing free perspiration, and accelerates the pulse and respiration. B., Hot-air; Turkish bath; the patient is placed in a box (French method), his head being outside, and the box is filled with hot air furnished by a lamp. In the ordinary Turkish bath the patient is compelled to inhale the air within a closed compartment. Hot-air baths can be borne of a much higher temperature than vapor baths. They provoke more profuse sweating, and raise the temperature of the body to a greater extent. They are useful as a diaphoretic, and in catarrhal, neuralgic, and rheumatic conditions. They are contraindicated, as is also the vapor bath, in fatty degeneration of the heart. B., Iron, half an ounce of sulphate of iron to four gallons of water. Use in an earthenware or wooden vessel. This is valuable for strumous or rachitic children. B., Medicated, a bath in which medicinal substances, as mineral salt, sulphur, etc., are dissolved or held in suspension. B., Mercurial, for the treatment of syphilis. Calomel, 20 to 60 grains, or a mixture of 15 grains of calomel and 20 grains of cinnabar are fused over a water bath. The patient is stripped and enveloped in one or more blankets, or a mackintosh or India-rubber blanket lined with flannel. The lamp and mercury are placed under his chair, and the former lighted. In a few minutes perspiration is induced and the sublimed calomel is deposited upon the body. Twenty to thirty minutes are sufficient for a bath, after which the patient is allowed to cool off slowly. This is best taken before retiring. B., Milk, a bath in milk, for nutritive purposes. B., Moor, a bath in water mixed with the earth of moors. B., Mud, a bath prepared by mixing wellseasoned earths, containing more or less mineral matter, with water containing the same substances. The body is surrounded with this mixture at various temperatures from $90^{\circ}$ to $100^{\circ}$. The patient is then rinsed with warm water. This is of value in some uterine diseases, and in obstinate rheumatism. B., Mustard, made by enclosing two to four ounces of ordinary mustard in a piece of muslin or thin linen and hanging it in about four gallons of hot water until the latter becomes yellow. It is used as a general bath for infants in collapse, convulsions, or severe bronchitis, the child being left in until the skin becomes distinctly reddened. It is also used as a foot or sitz-bath in amenorrhea. B., Pack, or Sheet, one in which the body is wrapped in cloths. B., Permanent. See $B .$, Warm. B., Pine, prepared by adding a decoction 
of pine-needles, or some pine extract, to hot water. It is mildly stimulating, and is employed in hysteria, gout, and rheumatism. B., Rain, consists of from four to six three-fourths circles of pipes secured together at a distance of two to three inches. Each pipe has three lines of fine perforations, from which the stream issues under pressure, striking the body of the patient at all points with considerable force. This may be used as a substitute for the dripping sheet. B., Russian, one in which the air of the room is saturated with steam by throwing water upon heated mineral or metallic substances, after which the bather is rubbed down, finishing with a cold douche. See B., Vapor. B., Sand, the body of the patient is surrounded in a tub with a layer of dry, warm sand that has been naturally or artificially heated, the temperature ranging from $95^{\circ}$ to $120^{\circ}$. The duration of the bath is from one to one and a half hours. The head is wrapped in a wet towel and permitted to lie outside of the sand. The after-treatment is the same as that after a hot-air bath. This is of value as an emollient procedure. In chemistry, the immersion of a crucible, etc., containing a chemic compound in a vessel containing fine sand, the latter being heated gradually to a high temperature. B., Sea-water, more stimulating and tonic in its effects than fresh water. It may be given cold, tepid, or hot. It may be made away from the seashore by dissolving bay-salt or rock-salt in fresh water, four to nine pounds of salt to 30 gallons of water. It is useful in convalescence, chlorosis, and strumous diseases. B., Sheet, the application of cold water to the body through the medium of a sheet or towel of fine or coarse texture, placed upon the skin. The patient is wrapped in a linen sheet, wrung not quite dry out of water at a temperature of from $60^{\circ}$ to $70^{\circ}$. A rubber cloth and a blanket are spread over the bed to protect it. As the sheet dries small quantities of water are poured with one hand from a vessel or sponge upon a limited part of the body, beginning with the chest. With the other extended hand rapid passes are made over this spot until it becomes a little warmer. Successive parts of the body are thus treated except the forearms, hands, feet, and legs. The patient is then dried and made comfortable. This is applicable in all febrile affections with high temperatures, except in chest or abdominal diseases. B., Shower, a familiar form of the douche. The water is delivered from a nozzle with numerous perforations, that may be attached to a hose, striking the body in a divided stream. B., Sitz, the patient sits in the tub with the feet outside upon a raised surface and blanket, so that the popliteal spaces are not encroached upon by the edge of the tub. The water should reach the umbilicus. It is useful in obstinate diarrhea, menorrhagia, subinvolution of the uterus, and pelvic inflammations. B., Slime, a bath in water mixed with the slimy deposit of organic matter found in rivers or ponds. B., Sponge, one in which the patient's body is rubbed with a sponge and water. It is used to reduce temperature. B., Starch, starch, one pound; water, 30 gallons. This is used as the bran bath. B., Sulphur, potassium sulphid four to eight ounces in 30 gallons of water; a little sulphuric acid may be added. It is used in certain skin diseases, scabies, lead colic, and lead palsy. B. Sulphurous-acid, a means of applying the fumes of burning sulphur to the body. The patient is seated on a cane-bottomed chair, and a blanket or oil-cloth is thrown round him, the head remaining uncovered. On the floor beneath the chair is a pan containing a little water, and in this is placed a smaller vessel containing small pieces of sulphur. A little spirit of wine is poured over this, and ignited, and sulphurousacid gas is evolved. B., Sun, the therapeutic exposure of the naked body to the sun's rays. B., Surprise, an ancient and obsolete form of bath for insane and hysterical patients, who were unexpectedly plunged into cold water. B., Tepid, the temperature of the water ranges from $85^{\circ}$ to $95^{\circ} \mathrm{F}$. It acts mainly upon the skin as a sedative, cleansing, and detergent agent the pulse, respiration, excretion, secretion, and temperature are practically unaflected. B., Turkish, one in which the bather is placed successively in rooms of higher temperature, then shampooed or rubbed, and finally stimulated by a douche of cold water. See Bath, Hot-air. B., Vapor; Russian bath; this may be given, as the Turkish bath, in a box, by permitting steam from a pipe to permeate it, providing for its escape, or the patient may inhale the vapor within a closed compartment, the whole surface being at the same time exposed to its influence. A higher temperature can be borne than in the hot-water bath, though for a shorter time. It is useful to provoke profuse per spiration. It should be followed by brisk frictions. B., Warm, the tub is filled with water at any temper ature near that of the body, say $90^{\circ}$ to $104^{\circ}$. The patient lies quietly in it, and obtains the effect of warmth, moisture, and water-pressure. It is used to calm the nervous system, produce sleep, and allay reflex instability. The continuous warm bath, called by Hebra the permanent bath, is made by suspending a sheet in the tub as a hammock. The patient lies upon this surrounded by water that is kept at an equable temperature (warm) by a proper arrangement of in-and-out-flow It is used in the treatment of extensive burns and wounds. B., Water, a bath of water. It may be cold $\left(60^{\circ}-75^{\circ}\right)$ or tepid $\left(85^{\circ}-95^{\circ}\right)$, or hot. In chemistry, a bath of water for immersing vessels containing substances that must not be heated above the boiling-point of water. See B., Mud; B., Sand; B., Sun.

Bathmic (bath'-mik) [ $\beta a \theta \mu o ́ s$, a threshold]. Relating to bathmism.

Bathmis (bath'-mis). See Bathmos.

Bathmism (bath'-mizm) [ $\beta a \theta \mu b s$, a threshold]. That supposed modification of chemical force which is active in the processes of nutrition.

Bathmos (bath'-mos) [ $\beta a t \mu o ́ s, \beta a \theta \mu i s$, a little fossa]. A shallow depression or fosset.

Bathwort (bath'-zert) [Corruption of birthwort]. The plant Trillium erectum; also $T$. pendulum; esteemed in domestic practice as deobstruent. Unof.

Bathybius (hath-ib'-e-us) [Bath's, deep; Bios, life]. A name applied by Huxley to a sticky form of deep-sea ooze, formerly supposed by him to be a widely-extending sheet of living, primitive protoplasm.

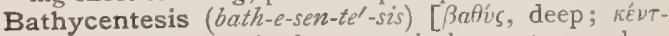
nots, puncture]. A deep surgical puncture; deep acupuncture.

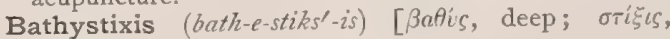
puncture]. Deep acupuncture.

Batiator (bat-e-a'-tor). See Vemonia nigritiana.

Batoir (bah-tivar') [Fr., beater]. See Percutor.

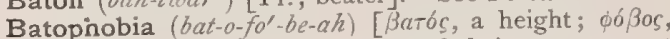
fear]. I. Acrophobia; dread of being at a great height. 2. Dread of high objects; fear of passing near a high building, or of going through a deep valley.

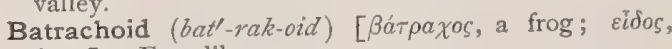
form ]. Frog-like.

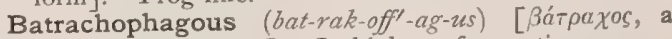
frog; $\phi a \gamma \varepsilon i \nu$, to eat]. In biology, frog-eating.

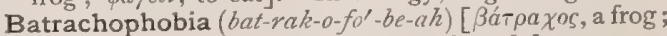
фóßos, fear]. Morbid dread of toads and frogs. 


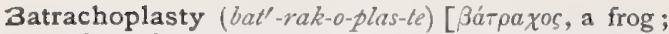
ranula; $\pi \lambda a \sigma \sigma \sigma \varepsilon v$, to mold]. Plastic surgical operation for the cure of ranula.

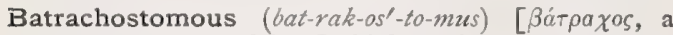
frog; бтó $\mu a$, mouth]. In biology, frog-mouthed.

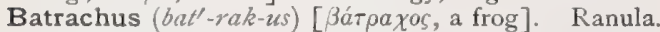

Battalism (bat'-al-izm). See Battarism.

Batțarism (bat'-ar-izm) [ $\beta a \tau \tau a \rho \iota \sigma \mu o ́ s$, a stuttering]. Stuttering or stammering.

Battery (bat'-er-e) [batteria, a beating; battery]. A series of two or more pieces of apparatus arranged to produce increased or multiple effect, as battery of boilers, prisms, lenses, galvanic cells. Usually applied to a series of cells producing electricity (voltaic or galvanic battery); also, frequently to a single cell. B., Primary, the combination of a number of primary cells so as to form a singie battery. B., Secondary, the combination of a number of storage cells to form a single electric source. The following table shows the materials used in the more important batteries, and the electro-motive force (E.M. F.) in volts. Storage or secondary batteries are not included in the table. The common form of these is a series of lead plates carrying masses of lead oxid.

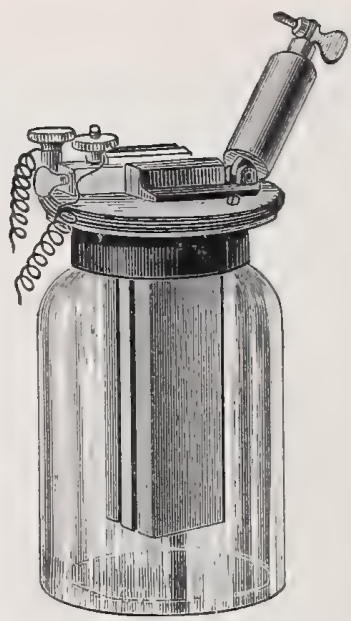

Grenet Cell for therapeutic apparatus.

NAMES, ELEMENTS, FLUIDS, ETC., OF THE PRINCIPAL BATTERIES.

\begin{tabular}{|c|c|c|c|c|c|}
\hline NAME OF CELl. & $\begin{array}{c}\text { Positive Ele- } \\
\text { MENT. }\end{array} \mid$ & Negative Element. & EXCITING AGENT. & DEPOLARIZING AGENT. & $\begin{array}{l}\text { E. M. F. IN } \\
\text { VOLTS. }\end{array}$ \\
\hline Bunsen. & Zinc. & Carbon. & Sulphuric acid, dilute. & Nitric acid. & I. 75 to $\mathrm{x} .96$ \\
\hline Beetz. & Zinc. & Copper. & $\begin{array}{l}\text { Zinc sulphate in plaster } \\
\text { of Paris. }\end{array}$ & $\begin{array}{l}\text { Copper sulphate, in plas- } \\
\text { ter of Paris. }\end{array}$ & I.04 \\
\hline Callaud. & Zinc. & Copper. & $\begin{array}{l}\text { Solution of zinc sul- } \\
\text { phate. }\end{array}$ & Cupric sulphate. & T.o to I I4 \\
\hline Daniel. & Zinc. & Copper. & Zinc sulphate. & Cupric sulphate. & I. to I.I4 \\
\hline Edison-Lalande. & Zinc. & $\begin{array}{l}\text { Cupric oxid and car- } \\
\text { bon. }\end{array}$ & Potassium hydroxid. & Cupric oxid. & 0.75 \\
\hline Fuller. & Zinc. & Carbon. & Zinc chlorid. & $\begin{array}{l}\text { Potassium dichromate } \\
\text { and hydrochloric acid. }\end{array}$ & 1.5 \\
\hline Gravity. See Call & aud. & & & & \\
\hline Gaiffe. & Zinc. & Silver. & Zinc chlorid. & Silver chlorid. & 1.02 \\
\hline Grenet. & Zinc. & Carbon. & $\begin{array}{l}\text { Sulphuric acid and po- } \\
\text { tassium dichromate. }\end{array}$ & Chromic acid. & 2.0 \\
\hline Grove. & Zinc. & Platinum. & Sulphuric acid, dilute. & Nitric acid. & I. 94 to 5.97 \\
\hline Latimer Clark. & Zinc. & Mercury. & Mercuric sulphate. & Mercuric sulphate. & $I .436$ \\
\hline Leclanché. & Zinc. & Carbon. & Ammonium chlorid. & Manganese dioxid. & I. 42 \\
\hline $\begin{array}{l}\text { Lelande } \\
\text { Chaperone }\end{array}$ & Zinc. & Copper or iron. & Potassium hydroxid. & Cupric oxid. & 0.98 \\
\hline Maische. & $\begin{array}{l}\text { Zinc scraps in } \\
\text { a bath of mer- } \\
\text { cury. }\end{array}$ & Platinized carbon. & $\overline{\text { Common salt solution. }}$ & None separate. & I.25 \\
\hline Marié Davy. & $\overline{\text { Zinc. }}$ & Carbon. & Sulphuric acid, dilute. & Mercuric sulphate. & 152 \\
\hline Maynooth. & Zinc. & Iron. & Sulphuric acid, dilute. & Nitric acid (strong). & \\
\hline Niaudet. & Zinc. & Carbon. & Common salt solution. & Chlorated lime. & 1.63 \\
\hline Poggendorf. & Zinc. & Carbon. & $\begin{array}{l}\text { Potassium dichromate } \\
\text { and sulphuric acid. }\end{array}$ & Chromic acid. & I. 98 \\
\hline Schanschieff. & Zinc. & Carbon. & Mercurial solution. & None separate. & I. 56 \\
\hline Scrivanoff. & Zinc. & Silver. & Potassium hydroxid. & Silver chlorid. & I 5 \\
\hline Smee. & Zinc. & Platinized silver. & Sulphuric acid, dilute. & None. & 0.5 to 1.0 \\
\hline Walker & Zinc. & Platinized carbon. & Sulphuric acid, dilute. & None. & 0.66 \\
\hline Warren de la Rue. & Zinc. & Silver. & Ammonium chlorid. & Silver chlorid. & I.05 \\
\hline
\end{tabular}


Battey's Operation. See Operations, Table of.

Battledore (bat'-l-dôr) [ME., batyldore]. An instrument shaped like a racket. B. Hands. See Acromegaly. B. Placenta, one in which there is a marginal insertion of the cord.

Battology (bat-ol'-o-je) [ $\beta a \tau \tau o \lambda o \gamma i a$, a vain repetition] The idle or meaningless repetition of words.

Baudelocque's Diameter. In obstetrics, the external conjugate diameter of the pelvis. B. Method. See Treatment, Methods of.

Bauden's Apparatus. See Seutin's Apparatus. B. Law. See Law. B. Operations. See Operations, Table of.

Bauer's Apparatus, an apparatus for extending the leg in hip-disease. The extension may be varied by means of a rack-and-pinion arrangement.

Bauhin, Valve of. The ileo-cecal valve.

Bauhin's Glands. See Gland.

Baum's Operation. See Operations, Table of.

Baunscheidt's Method. See Treatment, Methods of.

Baunscheidtism (bawn'-shït-izm). [Named from Baunscheidt, the inventor]. A mode of treating rheumatism or other chronic neuralgias by counter-irritation, the latter being produced by pricking the exterior of the part affected with fine needles dipped in oil of mustard, formic acid or other irritant.

Bavarian (bav-a'-re-an) [Bavaria]. Pertaining to $\mathrm{Ba}$ varia. B. Blue. See Pigments, Conspectus of. B. Splint, a variety of immovable dressing in which the plaster is applied between two flannel cloths.

Bay-berry $\left(b a^{\prime}\right.$-ber-e $)$ [ME., bay; bery]. I. The berry of the Laurus nobilis, bay, or noble laurel. 2. The wax-myrtle, Myrica cerifera, and its fruit. See Myrica. 3. The pimento, or allspice. B. Rum and B., Oil of. See Myrcia. B. Tree, the Laurus nobilis; also Prunus laurocerasus; commonly called the laurel and the cherry laurel. B. Aqua Laurocerasi. See Acid Hydrocyanic, Dilute.

Baycuru (bi-koo'-roo) [native S. A.]. The root of a S. American plant, Statice braziliensis, one of the most powerful astringents known. It is used for ulcers of the mouth and for glandular enlargements. Dose of the fld. ext., $m v-x x x$. Unof.

Bayer's Test. See Tests, Table of.

Baynton's Bandage. See Bandage.

Bazin (ba'-sin). Synonym of Molluscum contagiosum.

Bazin's Disease. See Diseases, Table of.

Bdella $\left(d e l^{\prime}-a h\right)$ [ $\beta \delta \varepsilon ́ \lambda \lambda a$, a leech]. A leech. See Hirudo.

Bdellatomy (del-at'-o-me). See Bdellotomy.

Bdellium (del'-e-um) [Heb., b'dolach]. A resinous gum exuding from various species of balsamodendron. B., Indian, somewhat valuable as an emmenagogue.

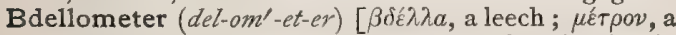
measure]. A mechanical substitute for the leech, consisting of cupping glass, scarificator, and exhausting syringe.

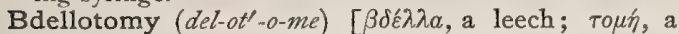
cut]. The opening with the knife of the body of a leech that is drawing blood; by this means the activity of the leech may be considerably prolonged.

Bdelygmia (del-ig'-me-ah) [ $\beta \delta \varepsilon \lambda v \gamma \mu i a$, disgust]. Abnormal disgust for food. That which is abhorrent or repulsive.

Beaded Hair. Synonym of Monilethrix

Beads, Rhachitic. " Rhachitic rosary;" the so-called "beading of the ribs" in rickets; a succession of visible and palpable swellings at the points where the ribs join their cartilages.

Beak $(b \bar{e} k)$ [ME., beeke]. I. The mandibular portion of a forceps. 2. The lower end of the calamus scriptorius. 3. The pad or splenium of the callosum. 4.
In biology, the rostrum, snout, or some corresponding part of an animal. The apex of a bivalve, or the cannular lips of a univalve shell.

Beaker (be'-ker) [ME., biker]. A wide-mouthed glass vessel much used in chemic laboratories. B. Cells. See Cell.

Beale's Cold-flowing Fluids. For injecting tissues. (a) Blue: Dissolve $0.777 \mathrm{gm}$. of potassium ferrocyanid in $30 \mathrm{c}$. c. of glycerin; $\operatorname{mix} 3.6 \mathrm{c}$. c. of tinct. ferri chlor. with $30 \mathrm{c}$. c. of glycerin; add the iron mixture, drop by drop, to the potassium ferrocyanid solution. Then add to this mixture $5.5 \mathrm{c}$. c. of methylic alcohol, $30 \mathrm{c}$. c. of alcohol, and $88 \mathrm{c}$. c. of water, shaking strongly, (b) Acid Glycerin Fluid: Dissolve $0.194 \mathrm{gm}$. of potassium ferrocyanid in 30 c. c. of strong glycerin; to $30 \mathrm{c}$. c. of strong glycerin add 10 drops of tincture ferri chlor. Add the latter, drop by drop, to the former, with constant shaking. Then add $30 \mathrm{c}$. c. of water, to which 3 drops of $\mathrm{HCl}$ have been added. This fluid flows well and does not exude from the capillaries, (c) Carmin: Mix I gm. of pulverized carmin with a little water and sufficient ammonia to dissolve the carmin; add $50 \mathrm{c}$ c of glycerin and shake well. Then add gradually, with constant shaking, IOO c. c. of glycerin, acidulated with 25 to 30 drops of $\mathrm{HCl}$ or acetic acid. Test the fluid with litmus paper, and if not decidedly acid add a few more drops of acid. Then add $25 \mathrm{c}$. c. of alcohol and 75 c. c. of water. See Stains, Table of. B. Solution, for staining histologic preparations. It consists of carmin, I gm. ; ammonia, 3 c. c. ; glycerin, 96 c. c.; distilled water, 96 c. c; alcohol, 95 per cent., 24 c. c. Dissolve the carmin in the ammonia with the aid of heat, boil for a few moments, and allow to cool. After the odor of ammonia has disappeared add the glycerin, water, and alcohol, and filter. If, after standing for some time, the carmin precipitates, add a few more drops of ammonia.

Bean (bèn) [ME., bene]. The seeds of several plants, mostly Leguminosa, especially that of the common bean, Faba vulgaris. In biology, the rounded, white, fleshy, saccular termination of the ductus ejaculatorius in the drone bee. B. of St. Ignatius. See Ignatia. See also Tonka, Vanilla, Castor oil, etc.

Bearberry (bārl-ber-e). See Uva ursi.

Beard (berd) [ME., berde]. The hair on the lips, cheeks and chin of adult men. On women, a beard is of rare occurrence, and is sometimes accompanied by other characteristics proper to the male sex.

Bearing-down. The feeling of weight or pressure in the pelvis in certain diseases. B.-d. Pains, uterine pains in labor. Bearing-seat, a variety of the Apron of Succor, $q . v$.

Bear's-foot. Leaf cup. A composite-flowered plant, Polymnia uvedalia of N. America. A popular remedy for enlargement of the spleen, or the " ague-cake" of malarious regions. B. Ext. Dose gr. ss-j. B. Fld. Ext. Dose miij-x. B. Infus., $3 j$ of an $\zeta_{j}$ to Oj. Unof.

Beat $(\bar{b} \bar{e} t)[\mathrm{ME}$. beten]. The pulsations of the blood in the arteries, or the impulse of the heart. See Pulse.

Beaten Woman's Herb. The European plant, Tamus communis; so called from its vulnerary qualities. See 7 amus.

Beating (bet'ting). See Tapotement.

Beaufils's Operation. See Operations, Table of.

Beauperthuy's Method. A method of treating leprosy by bathing with olive oil, the internal administration. of mercuric chlorid, abstinence from salted meats: and good hygiene.

Bebeerin (be-be'-rin). See Nectandra and Barine.

Bebeeru Bark (be-be'-ru). See Nectandra. 
Beccabunga (bek-ah-bung'-gah). A plant of Europe, Veronica beccabunga, formerly much prized in medicine. See Veronica.

Beccaria, Test of. See Tests, Table of.

Bêche-de-mer (bāsh'-de-mār) [Port, bicho-do-mar, seaworm]. The smoked and dried bodies of Holothuria argus, a sea-slug; valued by the Chinese as a culinary delicacy, and an aphrodisiac. Unof.

Bechesthesis (bek-es'-thes-is) [ $\beta i_{1}^{\prime} \xi$, cough; aĭ $\theta$ nous, sensation]. The sensation in the throat or air-passages that prompts one to cough.

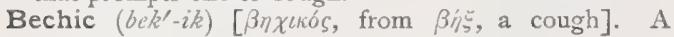
remedy for a cough; an antibechic.

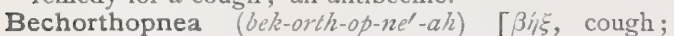
ófobs, straight; $\pi \nu \varepsilon \varepsilon i \nu$, to breathe]. Cough associated with orthopnea. A synonym of Whooping-cough.

Bechous (bek'-us) [ $\beta \dot{\eta} \xi$, a cough]. Pertaining to or affected with cough.

Bechterew's Nucleus. The accessory auditory nucleus.

Becker's Test. A test for astigmatism, made by means of a set of parallel lines in triplets placed in various meridians.

Beckmann, Method of. A method for the determination of the depression of the freezing-point. A hard glass tube, from 2 to $3 \mathrm{~cm}$. in diameter, with a lateral projection, is filled with from 15 to 20 grams of the solvent (weighed out accurately in centigrams), and closed with a cork in which are placed an accurate thermometer and a stout platinum wire serving as a stirringrod. The lower part of the tube is attached by means of a cork to a somewhat larger, wider tube, which serves as an air-jacket. The entire apparatus projects into a beaker-glass filled with a freezing-mixture. Cold water will answer for glacial acetic acid and ice-water for benzene. The congealing-point of the solvent is determined by cooling this to from $1^{\circ}$ to $2^{\circ}$ below its freezing-poiut; then by agitation with the platinum rod (after addition of platinum dippings) the formation of crystals is induced. The thermometer rises. When the mercury becomes stationary, the reading indicates the freezing-point of the solvent. The mass is allowed to melt and an accurately weighed amount of substance is introduced through the lateral projection. When this has dissolved, the freezing-point is determined as before.

Béclard's Hernia. See Diseases, Table of. B. Operation. See Operations, Table of. B. Suture. See Sutuere.

Becorthopnea (bek-orth-op-ne'-ah). See Bechorthopnea.

Becquerel's Pills. Pills containing quinin, extract of digitalis and colchicum seeds, for use in gout.

Becuiba (bek-zue'-bah) [native Brazilian name]. The tree Myristica bicuhyba of Brazil. Its nuts afford a "tallow," or balsam, useful in rheumatism and piles. Unof.

Bed (bed) [AS., bedd]. The couch or support on which the body may rest in sleep; usually a mattress of straw, hair, or similar substance. B., Air, a mattress of rubber or leather that can be inflated with air. B.-bug an apterous insect, Cimex lectularius, that infests filthy bedsteads, and at times is parasitic upon the human body. See Cimex. B.-case, a form of hysteria or hypochondriasis in which the patient, without cause, persistently remains in bed. B.-pan, a large shallow vessel for receiving the alvine discharges from bedridden patients. B.-rest, an apparatus for propping up patients in bed. B.ridden, confined to bed. B.-sore, a sore produced on any projecting part of the body by prolonged pressure against the bed, and by nutritive changes in paralyzed parts. B., Water, a rubber mattress containing water; it is used to prevent the formation of bed-sores.

Bedegar, Bedeguar (bed'-e-gar) [Ar., Pers., bādāwar, a white thorn]. An insect-made gall found on rosebushes of various species. It is astringent, but is not now used in regular medicine.

Bedlam (bed"lam) [ME, bedlem, a corruption of Bethlehem]. A mad-house.

Bedlamism (bed'-lam-izm) [see Bedlam]. Insanity.

Bedlamite (bed'-lam-it) [see Bedlam]. A madman; an insane person.

Bednar's Aphthæ. See Aplitha, and Diseases, Table of.

Bedouin Itch. A synonym of the vesicular variety of Lichen tropicus.

Bee $(b e)\left[\mathrm{AS}, b_{\bar{c}}\right]$. A genus of insects belonging to the Hymenoptera, commonly used to designate the common Honey Bee, Apis mellifica $(q . v)$. . B.-bread, a preparation of pollen with which bees fill certain cells. (The propolis, or hive-resin, is also incorrectly called bee-bread.) B.-poison, the irritating secretion discharged through the sting of the bee. See formic Acid.

Beech (bèch). See Fagus.

Beech-drop (béchl'drop). See Cuncer Root.

Beef $(b \bar{e} f)$ [ME., befe]. The flesh of domestic satile. Good beef should be of red color, possess firm texture, and be free from unpleasant smell. Beef consists mainly of water 73 , fibrin $\mathbf{1 5}$, gelatin 4 , albumen, 3 , fat and other substances 5 per cent. B.-extract, the soluble fibrin of lean meat partly desiccated. B.measles. See Cysticercus bovis. B.-tea, the soluble extractive matter of beef, made by steeping finely-cut lean beef with its weight of water, and straining.

Beer $(b \bar{e} r)$. See Malt Liquors. B.-vinegar. See Vinegar.

Beer's Cataract Knife. A knife with a triangular-shaped blade, for maling section of the cornea in the removal of the crystalline lens. B. Operations. See Operations, Table of.

Beeswax (béz'-ruaks). Cera fava; wax secreted by bees, of which their cells are constructed; ordinarily it is a mixture of cerotic acid, myricyl palmitic ester, heptacosane, hentriacontane, and several alcohols. The crude melted wax is a tough, compact mass of yellow or brownish color, granular structure, faint taste, and honey-like odor. When bleached it becomes white. Its specific gravity is .959 to .969 ; its melting-point $62^{\circ}$ to $64^{\circ} \mathrm{C}$. It is used in making candles, ointments, and pomades.

Beet (bét). See Beta.

Begbie's Disease. Siee Diseases, Table of.

Beggiatoa (bed-je-at-o'-ah) [after the Italian botanist, J. Beggiato]. A genus of arthrosporous bacteria founded by Trevisan (1833), consisting of swinging or gliding, milk-white, gray, rosy to violet threads. They decompose sulphur compounds, and store up sulphur granules in their protoplasm. They are found in stagnant, fresh, or salt water, particularly that contaminated by sewage or factory waste. See Bacteria, Synonymatic Table of.

Begin's Operation. See Operations, Table of.

Begma (beg-mah) [ $\beta \tilde{\eta} \gamma \mu a$, a cough: pl., Begmata]. A cough; the matter expectorated by coughing.

Begonia (be-go'-ne-ah) [after Bégon, a French savant]. An extensive genus of flowering-plants, mostly natives of warm regions. B. octopetali and tomentosa, of Peru, are astringent. B. balmisicne, of Mexico, and various other species are locally prized as alteratives. Unof.

Beguan $\left(b e g^{\prime}-z\right.$ ran $)$ [native S. America]. A bezoar obtained from the iguana, a large species of lizard. 
Behen-Nut (be'-hen nut). The seed of Moringa pterygosperma, and $M$. aptera, trees of tropical countries. They afford Oil of Behen, or Oil of Ben.

Behenolic Acid (be-hen-olth-ik). See Acid.

Beindorff's Apparatus. A furnace for boiling water, in use in pharmacies.

Bela $\left(b e^{\prime}-l a h\right)$ [Hind.]. The dried, half-ripe fruit of Aegle marmelos, or Bengal quince. It is a valuable remedy for chronic diarrhea and dysentery. The ripe fruit is slightly laxative. Dose $3 \mathrm{ss}-\mathrm{j}$. B., Ext. Liq. (B. P.). Dose 3 j-ij. Unof.

Belching (belch'-ing) [ME., belchen]. The expulsion or throwing up of gas from the stomach. Eructation.

Belemnoid (bel-em'-noid) [ $\beta \dot{\varepsilon} \lambda \varepsilon \mu \nu \circ \nu$, a dart]. I. Dartshaped; styloid. 2. The styloid process of the ulna or of the temporal bone.

Belenoid (bel'-en-od). See Belonoid.

Bell (bel) [ME., $\left.b_{e l}\right]$. A hollow, metal sounding instrument. B. gastrula. See Archigastrula. B. Metal, an alloy of copper, zinc, tin, and antimony. B., Nerves of. The external and internal respiratory nerves, etc. B. Sound, the sound produced in pneumothorax by striking a coin, placed flat upon the chest, by another coin. It can be heard through the stethoscope placed over the affected side.

Bell's Disease. See Periencephatitis and Diseases, Table of. B. Law. See Law. B. Mania. See Periencephalitis and Diseases, Table of. B. Operations. See Operations, Table of. B. Palsy or Paralysis. See Diseases, Table of.

Belladonna (bel-ah-don'-ah) [It., belladonna, beautiful lady]. Deadly Night-shade. A perennial plant of the order Solanacea, indigenous to Southern Europe and Asia, and cultivated in the U. S. Its properties are due to two alkaloids, atropin and belladonnin, the latter thought to be identical with hyoscyamin. Both leaves and root are employed: It is a mild narcotic and anodyne and a powerful mydriatic; also an antispasmodic, and in small doses a cardiac, respiratory and spinal stimulant. It is valuable in the inflammation of rheumatism, in gout, and in neuralgia. Dose of the root and leaves gr. j. B., Folia, the leaves of belladonna. B., Radix, the root of belladonna. The preparations of the leaves are : B., Extractum Alcoholicum. Dose gr. $\frac{1}{1} \frac{1}{7}$. B., Tinct., 15 per cent. Dose $m j-x x x . ~ B .$, Unguent., contains extract Io, dilute alcohol 6 , benzoated lard 84 parts. From the root are prepared: B., Abstractum. Dose gr. $\frac{1}{10}-\mathrm{j}$. Unof. B., Emplastrum, alcoholic ext. of leaves 20. resin-plaster 40, soap-plaster, 40. B., Extractum Fluidum. Dose $m_{j-v}$, B., Linimentum, fluid extract 95, camphor 5. B., Succus (B. P.). Dose mv-xv. B., Japanese. See Scopolia. Atropin sulphate, an excellent antidote in opium-poisoning. Lamellæ atropinæ (B. P.), each containing of atropin $\frac{1}{5000}$ grain. Liq. atropinæ sulphatis (B. P.). Dose $m$ j-vj. Unguentum atropinæ (B. P.), grs, viij to the ounce. See Atropin. Dose gr. $\frac{1}{2}=-\frac{1}{60}$. Homatropin. See Atropin.

Belladonnin (bel-ah-don'-in) [see Belladonna], $\mathrm{C}_{17} \mathrm{H}_{23}$ $\mathrm{NO}_{3}$. An alkaloid found in Belladonna. It resembles atropin, hyoscyamin, and hyoscin. It occurs with atropin, and is likewise decomposed into tropic acid and oxytropin $\left(\mathrm{C}_{8} \mathrm{H}_{15} \mathrm{NO}_{2}\right)$. See Belladonna.

Belleric (bel-er'-ik) [Pers., balilah]. A variety of myrobalan $(q \cdot v$.$) ; the fruit of Terminalia fellerica.$

Bellini, Ducts of. See Ducts.

Bellocq's Canula. An instrument used in plugging the nares.

Bellon (bel'-on) [origin unknown]. Painter's (or lead) colic. See Colic.

Bellows $\left(b e l^{\prime \prime}-\bar{o} z\right)$ [ME. belowes]. An instrument for propelling air through a tube or small orifice. B. and Blow-Pipe, a circular bellows nine or ten inches in diameter, with a small gum-elastic tube, three or four feet in length, terminating in a tapering metallic tube, to be attached to a blow-pipe leading from it. The bellows is worked by the foot, while with the blow pipe held in the hand, a jet of flame from a lamp may be projected on the object designed to be heated. $D$. Murmur, the Bruit-de souffe, q. v.; also the funic or placental souffle.

Belly (bel'-e) [ME., bely']. See Abdomen. B.-ache. See Colic. B.-bound, vulgar for constipated. B.button, the navel.

Belmas's Operation. See Operations, Table of.

Beloid (be'-loid) [ $\beta \dot{\varepsilon} \lambda_{0}$, , an arrow]. Arrow-shaped or styloid.

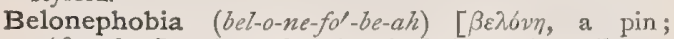
$\phi 6 \beta \circ \varsigma$, fear]. A morbid dread of pins and needles.

Belonoid (bel'-on-oid) [ $\beta \varepsilon \lambda 6 \nu \eta$, a needle, bodkin]. Styloid; needle-shaped.

Belt (belt) [ME., belt ]. A girdle about the waist. B., Abdominal, a broad, elastic belt worn about the abdomen as a support during pregnancy. B., Magnetic, a belt consisting of plates of metal fastened upon a strip of felt moistened with dilute acid. It is a cure-all largely sold by empirics.

Ben, or Benne Oil (ben, or ben' $-e$ ). Oleum balatinum, is obtained by expression from the seeds of the several species of Moringia. It is a colorless, odorless oil, not readily turning rancid. It is used by perfumers for extracting odors, and for lubricating clocks and light machinery. See Behen-nut and Sesame.

Bence Jones's Albumin. See Albumin.

Bendas's Method. See Stains, Table of

Bending (bend'-ing) [ME., bend]. Active Swedish movements in which the body is bent or inclined in various directions in order to develop certain portions of the muscular system.

Benedictine (ben-e-dik'-tin) [benedicere, to bless]. A liquor or cordial originally prepared by Benedictine monks, and distilled at Fécamp, in France. It much resembles chartreuse and trappistine.

Benedikt, Syndrome of. Paralysis of the muscles supplied by the oculo-motor nerves of one side and tremor and paresis of the upper extremity of the other side.

Beng (beng). See Cannabis Indica.

Bengal (ben'-gal) [Hind., Bengāl]. A province of India. B. Quince. See Bela. B. Red. Same as Rose Bengale.

Bengalin (ben'-gal-in) [Hind., Bengāl]. Same as Coupier's Blue.

Benger's Food. Partially digested and solidified beeftea, used as a food for invalids.

Benham, Gland of. See Gland.

Benham's Operation. See Operations, Table of.

Benign (be-nì $n^{\prime}$, or Benignant (be-nig'-nant) [benigmus, kind]. A term applied to medicines that are characterized by mildness. It is used chiefly to distinguish tumors that are not malignant $(q \cdot v$.$) or$ carcinomatous.

Benjamin, or Gum Benjamin (ben'-jam-in). See Binzoin.

Bennett's Operation. See Operations, Table of.

Benson's Operation. See Operations, Table of.

Bent's Operation. See Operations, Table of.

Benzal (ben'-zal). See Benzylidene. B. Green. Same as Malachite Green.

Benzaldehyd (ben-zal'-de-hĩd) [benzoin; aldehyd], $\mathrm{C}_{7} \mathrm{H}_{6} \mathrm{O}$. Bitter-almond oil ; a compound that results from the oxidation of benzyl alcohol; it is a colorless liquid with a pleasant odor, and boils at $179^{\circ}$; its specific gravity is 1.050 at $15^{\circ}$. It is soluble in 30 
parts water, and is miscible with alcohol and ether. It is used in making benzoic acid as well as various pigments. B. Green. Same as Malachite Green.

Benzaldoxin (ben-zal-doks'-in), $\mathrm{C}_{7} \mathrm{H}_{9} \mathrm{NO}$. A thick oil formed by the action of hydroxylamin upon benzaldehyd.

Benzamid (ben'-zam-id) [benzoin; amid], $\mathrm{C}_{7} \mathrm{H}_{7} \mathrm{NO}$. A compound that results when benzoyl chlorid acts upon alcoholic ammonia. It is best obtained by heating benzoic acid and ammonium thiocyanate to $170^{\circ} \mathrm{C}$. It crystallizes in pearly leaflets, melts at $I 30^{\circ}$, and boils near $288^{\circ}$; it is readily soluble in hot water, alcohol, and ether. It may be regarded as the amid of benzoyl.

Benzanilid (ben-zan'-il-id) [benzoin; anilin], $\mathrm{C}_{13} \mathrm{H}_{11}$ NO. Benzoyl-anilid, prepared by the action of benzoyl chlorid on anilin. It is used as an antifebrile in children, in doses of gr. iij-viij. Unof.

Benzene (ben'-zèn) [benzoin], $\mathrm{C}_{6} \mathrm{H}_{6^{\circ}}$ A hydrocarbon contained in coal-tar. It is formed by the dry distillation of all benzene acids. It is a mobile, etherealsmelling liquid, of specific gravity 0.899 at $0^{\circ}$. It solidifies about $0^{\circ}$, melts at $+6^{\circ}$, and boils at $80.5^{\circ}$. It burns with a luminous flame. It readily dissolves resins, fats, sulphur, iodin, and phosphorus. It is the material from which anilin and the anilin colors are derived. B.-sulphonic Acid, $\mathrm{C}_{6} \mathrm{H}_{5} \cdot \mathrm{SO}_{3} \mathrm{H}$, is prepared by boiling together equal parts of benzene and $\mathrm{H}_{2} \mathrm{SO}_{4}$. It occurs in small plates, readily soluble in alcohol and water, and which deliquesce in the air. In its dry distillation the acid yields benzene phenylsulphone, and when fused with caustic potash phenol is produced.

Benzidin (ben'-zid-in) [benzoin], $\mathrm{C}_{12} \mathrm{H}_{12} \mathrm{~N}_{2}$. Diamidodiphenyl; a compound obtained by the action of tin and $\mathrm{HCl}$ upon the alcoholic solution of azo-benzene. Benzidin dissolves easily in hot water and alcohol, and crystallizes in silvery leaflets, melting at $\mathbf{1 2 2 ^ { \circ }}$.

Benzil (ben'-zil) [benzoin], $\mathrm{C}_{14} \mathrm{H}_{10} \mathrm{O}_{2}$. A compound produced in the oxidation of benzoin with chlorin. It crystallizes from ether in large, six-sided prisms, melting at $90^{\circ}$ and boiling at $347^{\circ}$.

Benzimid (ben'-zim-id) [benzoin; amid], $\mathrm{C}_{23} \mathrm{H}_{18} \mathrm{~N}_{2} \mathrm{O}_{2}$. A compound formed by the action of hydrocyanic acid on hydrid of benzoyl. It occurs also in the resinous residue of the rectification of the oil of bitter almonds.

Benzine (ben'-zin). See Benzinum.

Benzinum (ben-zi'-num) [L. : gen., Benzini]. Benzine, Petroleum Ether. A purified distillate from American petroleum, having a specific gravity of .77 to .79 , boiling at $80^{\circ}$ to $90^{\circ} \mathrm{C}$, colorless, of ethereal odor, and a slightly peppermint-like taste. It is a valuable solvent for oils, fats, resins, caoutchouc, and some alkaloids. It is a vermicide against tapeworm. It should be distinguished from Benzol, which is called Benzene by English chemists. Dose gtt. $\mathrm{v}-\mathrm{x}$, on sugar or in mucilage.

Benzoate (ben'-zo-āt) [benzoin]. Any salt of benzoic acid. B. of Naphthol. See Benzo-naphthol.

Benzoated (ben'-zo-ät-ed) [benzoin]. Impregnated with benzoin or with benzoic acid.

Benzoic (ben-zol-ik) [benzoin]. Pertaining to or derived from benzoin. B. Acid. See Acid.

Benzoin (ben'-zo-in or -zoin) [origin obscure]. A resin obtained from Styrax benzoin, a tree native to Sumatra and Siam. It is also a ketone alcohol, $\mathrm{C}_{14} \mathrm{H}_{12} \mathrm{O}_{2}$, and may be produced by oxidizing hydrobenzoin with concentrated $\mathrm{HNO}_{3}$. It is sparingly soluble in water, cold alcohol, and ether, and crystallizes in shining prisms, melting at $134^{\circ}$. It is used as a remedy for bronchitis and in making court-plaster. It occurs in tears con- sisting of several resins agglutinated by a balsam. It yields benzoic and cinnamic acids, is antiseptic and disinfectant, and is used mainly as a stimulant expectorant in chronic bronchitis. Sodium and potassium compounds are sometimes used in place of like salicylic acid compounds. Adeps benzoinatus, benzoinated lard, contains 2 per cent. of benzoin. B., T'inct., 20 per cent. of the resin in alcohol. Dose $\mathbf{3} \mathrm{ss}-\mathbf{j}$. B., Tinct. Comp., Friar's Balsam, benzoin I2, aloes 2, styrax 8, balsam of Tolu 4, alcohol, q. s. ad 100 parts. Dose 3 ss-ij. Benzoic Acid, $\mathrm{C}_{7} \mathrm{H}_{6} \mathrm{O}_{2}$, alcohol the best solvent. A constituent of opii, tinct. camphorat. Dose gr. $\mathrm{x}-\mathrm{xxv}$. - Trochisci Acidi Benzoici (B. P.). Unguentum Cetacei (B. P.). See Cetaceum. Ammonium Benzoate, water the best solvent. Dose gr. v-xxx. Bismuth Benzoate, an antiseptic dressing for chancroid. Lithium Benzoate. Dose gr. v-xxx. Sodium Benzoate, water the best solvent. Dose gr. $\mathrm{v}-\mathbf{3} \mathrm{j}$.

Benzol (ben'-zol) [benzoin], $\mathrm{C}_{6} \mathrm{H}_{6}$. A hydrocarbon formed by the dry distillation of organic substances, but derived chiefly from coal-tar. It is inflammable and very volatile, and is an excellent solvent for grease. It is used internally to destroy epizoa. Its vapor is used in whooping-cough. Dose gtt. v-x. See, also, Stains, Table of. B. Balsam. See Stains, Table of. B. Colors. See Conspectus of Pigments, under Pigment.

Benzo-naphthol (ben-zo-naf'-thol) [benzoin; vá $\phi \theta \alpha$, a kind of asphalt], $\mathrm{C}_{10} \mathrm{H}_{7} \mathrm{O}\left(\mathrm{C}_{7} \mathrm{H}_{5} \mathrm{O}\right)$. The benzoate of beta-naphthol, used as an intestinal antiseptic in typhoid fever and other intestinal diseases. Dose gr. ij to viij.

Benzonitrile (ben-zo-ni'-tril) [benzoin; nitrum, niter], $\mathrm{C}_{7} \mathrm{H}_{5} \mathrm{~N}$. Cyanbenzene; a compound isomeric with phenyl carbylamin. It is obtained from benzene sulphonic acid by distillation with potassium cyanid. It is an oil with an odor resembling that of oil of bitter almonds, and boils at $\mathbf{I} 9 \mathbf{I}^{\circ}$; its specific gravity is I. 023 at $0^{\circ}$.

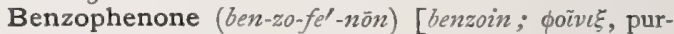
ple-red], $\mathrm{C}_{13} \mathrm{H}_{10} \mathrm{O}$. Diphenyl ketone; a compound obtained by distilling calcium benzoate. It is dimorphous, but generally crystallizes in large, rhombic prisms, melting at $48-49^{\circ}$, sometimes in rhombohedra, that melt at $27^{\circ}$. It has an aromatic odor and boils at $295^{\circ}$.

Benzophenoneid (ben-zo-fe-no'-ne-id) [benzoin; doiv $\boldsymbol{b}_{\text {, }}$ purple-red]. Tetramethyl-diapsido-benzo-phenoid; an anilin dye. A solution of one part in 200 parts of water has been pronounced a valuable bactericide, neither caustic nor irritant, and very serviceable in eye-diseases. Unof.

Benzopurpurin. See Pigments, Conspectus of.

Benzoquinone (ben-zo'-qrin-ön). See Quinone.

Benzosalicin (ben-zo-sal'-is-in). See Populin.

Benzosol (ben-zo'-sol) [benzoin], $\mathrm{C}_{15} \mathrm{H}_{12} \mathrm{O}_{3}$. Benzoylguaiacol, an agreeable and harmless substitute for creasote in tuberculous affections. It also has antipyretic properties. Dose gr. iv-x.

Benzoyl (ben'-zo-il, or -zoil) [benzoin], $\mathrm{C}_{7} \mathrm{H}_{5} \mathrm{O}$. The radical of benzoic acid, of oil of bitter almonds, and of an extensive series of compounds derived from this oil, or connected with it by certain relations. B.ecgonin, $\mathrm{C}_{16} \mathrm{H}_{18} \mathrm{NO}_{4} \mathrm{H}$, a substance intermediate in composition between cocain and ecgonin. B.-Glycocoll. See Acid, Hippuric. B. Green. Same as Malachite Green. B.-Pseudo-tropein. See Tropacocain.

Benzyl (ben'-zil) [benzoin], $\mathrm{C}_{7} \mathrm{H}_{7}$. An organic radical that does not exist in the free state, but in combination forms a considerable number of compounds. B. Alcohol. See Alcohol. B. Violet. See Pigments, Conspectus of. 
Benzylidene (ben-zil'-id-en) [benzoin $], \mathrm{C}_{7} \mathrm{H}_{6^{\circ}}$ A bivalent radical derived from benzoin compounds.

Beral's Apparatus. In pharmacy, an apparatus for effecting lixiviation.

Bérard's Aneurysm. See Aneurysm and Diseases, Table of. B.'s Operation. See Operations, Table of.

Beraud, Ligament of. The ligament that suspends the pericardium. B., Valve of, a valve supposed to exist at the bottom of the lachrymal sac over the entrance to the nasal duct.

Berberin (ber'ber-in) [berberina: gen., Berberina], $\mathrm{C}_{20} \mathrm{H}_{17} \mathrm{NO}_{4}$. An alkaloid found in the bark of Berberis, and in many other plants of exceedingly various botanic character. It is a tonic to the capillary vessels and increases the blood-pressure. It is recommended as a tonic and antiperiodic, and is an ingredient of various lotions for the mucous membranes; it is useful in nasal catarrh, etc. Dose gr. j-x. Unof.

Berberis (ber'-ber-is) [L.]. Barberry. The root of Berberis vulgaris, or common barberry. Its properties are due to an alkaloid, berberin, $\mathrm{C}_{20} \mathrm{H}_{17} \mathrm{NO}_{4}$. It is an astringent, bitter tonic; in large doses a cathartic. It is used locally in conjunctivitis, and internally in malarial and typhoid fevers. B., Ext. Fld. Dose $m$ $v$-xxx. B., Tinct., contains 20 per cent. of the root. Dose $m x-3 j$. Berberin, the alkaloid. Dose gr. j-x. B., Hydrochl., an efficient injection in gonorrhea. All unof. $B$. asiatica, $B$. aquifolium (or Oregon grape), and $B$. lycium are all medicinally active, and have similar properties to those of the common barberry.

Bergamii, Oleum (ber-g $\left.a^{\prime}-m e-i o^{\prime}-l e-u m\right)$. Oil of Bergamot. See Bergamot.

Bergamot, Oil of (ber'-gam-ot) [Bergamo, a town in Italy $], \mathrm{C}_{10} \mathrm{H}_{16^{*}}$ A volatile oil derived from the rind of the Citrus bergamia. It is used mainly as a perfume, and as a clearing-agent in histologic work.

Bergeron's Disease. See Diseases, Table of. Method. See Treatment, Methods of.

Bergkrankheit $\left(b \bar{a} r g^{\prime}-k r a(h) n k\right.$-hit $)$. See Mountain Sickness.

Bergmann's (von) Operations. See Operations, Table of.

Beri-beri (ber'-e-ber'-e) [Singalese, beri, weakness]. A dropsical ailment, occurring in an acute and chronic form, and characterized by the appearance of pleuritic or pericardial effusions, with general anasarca, anemia, extreme weakness, and paraplegia. The acute form is generally fatal; recovery frequently takes place in the chronic form. It is prevalent in India, Japan, and Ceylon, and is most common among men. Its cause is not known, but possibly it is of microbic orign. Improper diet also has some influence upon the production of the disease.

Berlier System of Sewage. See Servage, Disposal of.

Berlin Blue. See Pigments, Conspectus of.

Berlin's Operation. See Operations, Table of.

Berlinghieri's Operation. See Operations, Table of.

Bernard, Canal of. See Canals, Table of. B.'s Granular Layer, the inner zone of the cells lining the acini of the pancreas. It is granular in appearance and stains but slightly with carmin.

Bernay's Operation. See Operations, Table of.

Bernheim's Operation. See Operations, Table of.

Bernstein's Theory of Muscular Contraction. He claims that the seat of the contraction is in the interstitial material surrounding the system of inotagmata, and that it consists in the migration of that labile material from pole to equator, this being synchronous with explosive chemic change, sudden disengagement of heat, and change in the electric state of the living substance.
Berried Tea (ber'-èd te). A popular name for Gaultharia procumbens.

Berry $\left(\right.$ ber' $\left.^{\prime}-\varepsilon\right)$ [ME., bery]. An indehiscent fruit with a pericarp that is succulent throughout, as the grape and gooseberry

Bert's Experiment. Bert removed the skin from the tip of the tail of a rat, stitched it into the skin of the back of the animal, and after union had taken place the tail was divided at its base. Sensation was preserved. Nerve-fibers were thus proved capable of transmitting impulses in both directions. B's. Method. See Anesthetic.

Berthold's Method. See Myringo-plastic Method.

Bertillonage (ber-til-lon- $a(h) j$ ) [Bertillon, a French criminologist]. A system of carefully-recorded measurements and descriptions of criminals, for the purpose of future identification, introduced into France by M. Bertillon and adopted by the police of many lärge cities.

Bertin, Bones of. The sphenoidal turbinated bones, partly closing the sphenoidal sinuses. B., Column of, a cortical column of the kidney; the part separating the sides of any two pyramids. B., Ligament of, the ilio-femoral ligament. See Ligament.

Bertrandi's Suture. See Suture.

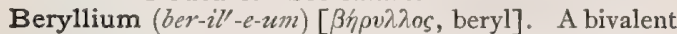
metal obtainable from the beryl, whence its name ; it is called also glucinum. See Elements, Table of.

Besnier's Lotion. A wash used in treating acne. It consists of precipitated sulphur, I 1 $1 / 2$ ounces; glycerin, 4 to 6 drams ; to which are added after mixing, spirits of camphor, 6 drams, rose-water, a sufficient quantity.

Besoin (bez-zan $\left.(g)^{\prime}\right)$ [Fr.]. A desire; an impulse. Besoin de respirer, the sense of the need of air experienced when respiration is impeded.

Bestiality (bes-che-al'-it-e) [bestia, a beast]. Unnatural intercourse with an animal.

Bestiarian (bes-te-a'-re-an) [bestia, a beast]. An antivivisectionist, contemptuously so called as being a professed friend of the beasts.

Bestucheff's Mixture or Tincture. The ethereal tincture of chlorid of iron, used in erysipelas. It is made as follows: $\mathrm{B}$. Tinct. ferri sesquichloridi, I part; spt. ether. nit., 4 parts. Mix and expose to the rays of the sun in well-closed bottles until the brownish color disappears. The dose is one to two teaspoonfuls every three hours.

Beta $\left(b e^{\prime}-t a h\right)$ [L.]. I. The beet. See Betin. 2. The second letter of the Greek alphabet, used in chemic nomenclature. B. Angle. See Angle. B.-naphthol. See Naphthol.

Betacism $\left(b a^{\prime}\right.$-tas-izm) [beta, $\beta \tilde{\eta} \tau a$, the second letter of the Greek alphabet]. The too-frequent use of the $b$ sound in speech, or the conversion of other sounds into it.

Betain (be-ta'-in) [beta, a beet], $\mathrm{C}_{5} \mathrm{H}_{11} \mathrm{NO}_{2}$, or $\mathrm{C}_{10} \mathrm{H}_{22}$ $\mathrm{N}_{2} \mathrm{O}_{4}$. Called also Oxyneurin and Lycin. A basic substance obtained by the careful oxidation of cholin. It occurs already formed in the sugar-beet (Beta vulgaris) and crystallizes from alcohol with one molecule of water in shining crystals that deliquesce in the air ; it has an alkaline reaction and a sweetish taste.

Betel (be'-tel) [E. Ind.]. A masticatory used in the East. A few grains of the nut of the Catechu palm, Areca $C$., are rolled up with a small amount of quicklime in a leaf of Piper betel, and chewed. It is tonic, astringent, stimulant, and aphrodisiac, and increases the powers of endurance. Dose of fld. ext. $3 j$-iij. Unof.

Beth Root (beth root). The rhizome of Trillium erecta, astringent and tonic, Dose of fld. ext. $m x x x-3 j$. Tritiin, a concentrated ext. Dose gr. ij-iv. Unof. 
Betin (be'-tin) [beta, a beet]. A precipitate prepared from a tincture of the common beet. It has been proposed as a substitute for ergot. Unof.

Betol (bel-tol), $\mathrm{C}_{10} \mathrm{H}_{7} \mathrm{O} . \mathrm{C}_{7} \mathrm{H}_{5} \mathrm{O}_{2}$. Salinaphthol. Naphthalol. A salicylic ether of naphthol, of alleged value in rheumatism and cystitis. It resembles salicylic acid in its properties. Dose gr. $\mathrm{x}-\mathrm{xv}$. Unof.

Betony (bet'-o-ne) [betonica, a corrupt form of vettonica] Any labiate plant of the genus Betonica, especially $B$. officinalis, of Europe, formerly highly prized for its medicinal virtues, which are, however, unimportant. Unof.

Bettmann's Method. See Cataract, Artificial Maturation of.

Betula (bet'-u-lah). See Birch.

Betulin (bet'-u-lin) [betula, birch], $\mathrm{C}_{36} \mathrm{H}_{60} \mathrm{O}_{3}$ (Hausmann). Birch resin, or birch camphor, derived from the bark of the white birch.

Between-brain. The interbrain; also the midbrain.

Betz's Cells. See Cell.

Bex (beks) [ $\beta \eta \xi \xi$, a cough]. A cough, or disease characterized by coughing. B. convulsiva, whoopingcough. B. theriodes. Synonym of Whoopingcough.

Bezet or Bezette (be-zet'). See Pigments, Conspectus of. Bezoar (be'-zo-ar) [Ar., bāzahr, the bezoar-stone]. A name for certain calculi or concretions found in the stomach or intestines of some animals (especially ruminants), formerly supposed to be efficacious in preventing the fatal effects of poison. B., Vegetable. See Calapite.

Bezoardic (bez-o-ar'-dik) [Ar., ba $\bar{a} a h r$, the bezoarstone]. 1. Acting as a bezoar; antidotal. 2. Any alexipharmic agent.

Bezold's (von) Ganglion. See Ganglia, Table of.

Bhang (bang). See Cannabis indica.

Bhel (bel). See Bela.

$\mathrm{Bi}$ - (bi) [bis, twice]. A prefix signifying "twice" or "two;" as bicuspid, with two cusps; bilobed, twice lobed; bivalved, with two valves; bilateral, twosided, etc. In chemistry, the prefix $d i$ is commonly employed.

Biacid $\left(b i-a s^{\prime}-i d\right)$ [bi, two; acidum, an acid]. In chemistry, a term applied to a base that may combine in two proportions with an acid.

Biauricular (bi-atj-rik'-u-lar) [bis, twice; auriculn, the ear]. Relating to two auricles, or to two corresponding auricular points.

Bibirin (bi-bir'-in). See Buxin.

Bibiru (bi-be'-ru). Same as Bebeeru.

Bibitorius (bib-it-o'-re-us) [bibere, to drink]. The rectus internus muscle of the eye; so called because it turns the eye inward in the act of drinking.

Bibliography (bib-le-og $\left.\sigma^{\prime}-\gamma \alpha-f e\right) \quad[\beta \iota \beta \lambda i o v$, a book; $\gamma \rho a ́ \phi \varepsilon(\nu$, to write]. A classified list of references, books, or authorities on any subject.

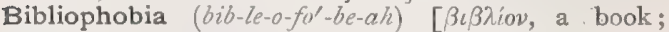
$\phi \sigma \beta O s$, dread]. Morbid dislike of books.

Bibron's Antidote. Formerly quite a famous remedy for rattlesnake bite. It consists of bromin, 3 iiss; potassium iodid, gr. ij; corrosive chlorid of mercury, gr. $\mathrm{j}$; dilute alcohol, $\overline{\mathrm{xxx}}$. Of this a teaspoonful is given in wine or brandy, p. r. n.

Bibulous $\left(b i b^{\prime}-u\right.$-lus) [bibere, to drink]. Having the property of absorbing moisture or liquids. B. lapis, pumice stone. B. Paper, used in dentistry for drying cavities preparatory to introducing the filling. Blotting paper.

Bicarbonate $\left(b i-k a \mu^{\prime}-b o n-a \bar{t}\right)$ [bis, twice; carbo, a coal]. Any supercarbonate that has two carbonic acid equiv. alents for one of the base.

Bicarinate (bi-kar'-in-ät) [bi, two; carinatus, keel- shaped]. In biology, having two keel-like projections, as certain grasses.

Bicaudal (bi-kaw'-dal) [bicaudalis, two-tailed]. Having two tails or appendages. B. Muscle, the abductor auris. See Mruscles, Table of.

Bicephalium (bi-sef-a'-le-um) [bi, two; $\kappa \varepsilon \phi a \lambda \dot{n}$, head]. A tumor of the scalp so large that it gives the patient the appearance of having two heads.

Biceps (bi'-seps) [bis, twice; caput, the head]. A term applied to several muscles, as $B$. brachii, $B$. extensor, B. flexor cruris. They are so called from their double origin. See Muscles, Table of. B. Reflex. See Reflexes, Table of.

Bichat, Canal of. See Canal. B., Fissure of. See Fissure. B., Foramen of. See Foramina, Table of. B., Tunic of, the intima of the blood-vessels.

Bichlorid (bi-klo'-rid) [bi, two; chlorin]. In chemistry, a basic compound containing two equivalents of chlorin. B. of Gold. See Gold. B. of Mercury. See Hydrargyrum.

Bicho do mar (be'-cho-do-mär). See Bèche de mer.

Bichromate (bi-kro'-māt $)$ [bit, two; chromium]. In chemistry, a basic compound containing two equivalents of chromium. B. of Potash. See Potassium.

Bicipital (bi-sipp'it-al) [bi, two; caput, the head]. Pertaining to the biceps muscle.

Bi-concave (bi-kon'-kär). See Lens.

Biconvex (bi-kon'-veks). See Lens.

Bicornute (bi-kor'-nut $)$ [bicomnutus, with two horns]. Having two horns, as a bicornute uterus.

Bicuspid (bi-kus'-pid) [bi, two; cuspis, the point of a spear]. Having two cusps, as B. Teeth, the fourth and fifth teeth. B. Valve, the mitral valve of the heart.

Bidder and Schmidt's Method. A method of estimating the amount of acids in the stomach. It consists in performing an ultimate analysis, apportioning the chlorin to the metals and ammonium present, and calculating the remainder as $\mathrm{HCl}$.

Bidder's Ganglia. See Ganglia, Table of. B.'s Organ, a singular structure found in male toads and sometimes in male frogs, between the testis and fat-body; it is a rudimentary ovary, and in conjunction with the testis forms an ovotestis; the development of the Müllerian duct, or oviduct, being in direct proportion to the size of "Bidder's Organ." These functionless ducts frequently become cystic (in ten per cent. of male frogs, and in fifteen per cent. of male toads)

Bidens $\left(b i^{\prime}\right.$-denz) [bidens, having two teeth]. A genus of herbaceous composite plants. B. bipennata, Spanish needles, an herbaceous composite-flowered plant. The seeds and roots are said to be emmenagogue and antibechic. Dose of fld. ext. gtt. $x v-\bar{j}$. Unof.

Bidet $\left(b e-d e t^{\prime}\right.$, or $-d a$ ) [Fr. for pony]. A tub or basin with fixed attachments for the administering of injections; also for use as a sitz-bath or hip-bath.

Biebrich Scarlet. See Pigments, Conspectus of.

Biedert's Cream Mixture. An infant's food made by mixing $4 \mathrm{oz}$. of cream with $\mathrm{I} 2 \mathrm{oz}$. of warm water, and adding $1 / 2 \mathrm{oz}$. of milk-sugar. It contains $I$ per cent. of casein, 2.5 per cent. of fat, and 3.8 per cent. of sugar. As the child grows older a larger proportion of milk is added.

Bi-electrolysis (bi-e-lek-trol'-is-is) [bi, two; $\ddot{\eta} \lambda \varepsilon \kappa \tau \rho o \nu$, amber; $\lambda \hat{v} \iota \iota$, resolution]. The electrolysis of two substances at the same time.

Biennial (bi-en'-e-al) [bi, two; annus, a year]. Every two years. In botany, plants that produce foliage and a root-stalk the first year, flowering and maturing the second. 
Biermer's Change of Note. See Signs and Symptoms, Table of.

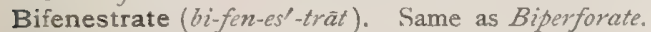

Bifid $\left(b i^{\prime}-f i d\right)$ [bis, twice; findere, to cleave]. Divided in two; cleft, as the spina bifida.

Bifocal (bi-fo'-kal) [bi, two; focus, a point]. With a double focus. Applied to a system of lenses or spectacleglasses with two foci, chiefly used for the correction of presbyopia, when there is at the same time an error of refraction for distant vision. The distance lens is above that for near work. These are sometimes
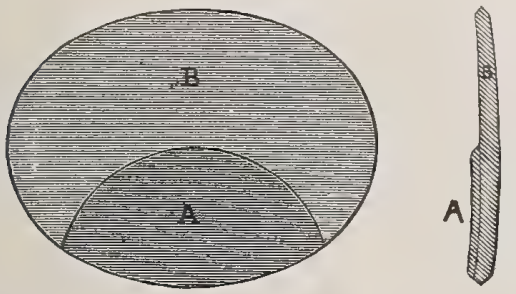

Bifocal Lens.

B. Distance Lens. A. Reading Lens, cemented to the Distance lens.

called Pantoscopic lenses, and also Franklin spectacles, because the device was first made by Benjamin Franklin. They are also called Cement lenses, because now made by cementing the lower segment to the distance lens.

Biforate $\left(b i-f o^{\prime}-r \bar{a} t\right)$ [bi, two; foratus, perforated]. Having two foramina.

Biforin (bi'-for-in) [biforis, having two doors]. In biology, the name applied by Turpin to raphidesbearing cells in which the raphides are discharged from woth ends of the cell.

Bifurcate $\left(b i-f e r^{\prime}-k a \hat{a} t\right)$ [bi, two; furca, a fork]. Divided into two, like a fork.

Bifurcation (bi-fer-ka'-shun) [bifurcatio; from bi, two; furca, a fork]. Division into two branches, as of a tooth into two roots; of the trachea and of the aorta into two branches.

Big (big) [ME, big, large]. Great with young; pregnant. B.-jaw, actinomycosis in the ox.

Bigarade (be-gah-ra(h)d') [Fr.]. The bitter orange. Its volatile oil (essence or huile de bigarade) is used in pharmacy and in perfumery.

Bigelovia (big-lo'-ve-ah) [Bigelow, an American botanist]. A genus of composite-flowered plants. See Damiana.

Bigelow's Ligament. The Y-ligament; ilio-femoral ligament. B.'s Method. See Treatment, Methods of. B.'s Operation. See Operations, Table of. B.'s Septum, in anatomy, a layer of hard bony tissue in the neck of the thigh-bone.

Bigeminate (bi-jem'-in-āt) [bigeminus, doubled]. In biology, forked, doubled.

Bigeminum (bi-jem'-in-um) [bi, two; geminus, a twin]. One of the corpora bigemina of the brain ; one of the optic lobes of the brain.

Biglenoid $\left(b i-g l l^{\prime}-n o i d\right) \quad[b i$, two; $\gamma \lambda \dot{\eta} v \eta$, a socket;

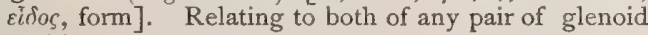
cavities.

Bignonia (big-no'-ne-ah) [Bignon, a French savant]. A genus of climbing-plants, often woody. B. alliacea, of the W. Indies, and B. capreolata, of N. America, are regarded as antisyphilitic. Several other species are reputed to be actively medicinal. Unof.

Bigoniac $\left(b i-g o^{\prime}-n e-a k\right)[b i$, two; $\gamma \omega \nu i a$, an angle]. Relating to the two gonions.
Bijugular (bi-ju'-gu-lar) [bi, two; jugulum, the collarbone]. Relating to the two jugular points.

Bikh (bik) [native Nepalese]. The Nepalese poison, bish ; it is derived from the roots of Aconitum ferox. See Aconite.

Bilabe $\left(b i^{\prime}-l \bar{a} b\right.$, or $\left.b e-l a(h) b^{\prime}\right)$ [Fr.; $b i$, two; labium lip]. A surgical instrument for removing foreign bodies from the bladder through the urethra.

Bilateral (bi-lat'-er-al) [bi, two; latus, a side]. Relating to two sides; sinistrodextral. B. Symmetry, the symmetry of right and left halves. B. Operation. See Lithotomy.

Bilateralism (bi-lat'-er-al-izm) [bi, two; latus a side]. Bilateral symmetry.

Bile $(b \bar{l} l)$ [bilis; $\chi o \lambda \dot{n}$, the bile]. The substance secreted by the liver. It is mucilaginous, golden-brown in man, golden-red in carnivora, brownish-green in herbivora, and green in birds. It is composed of biliary salts, cholesterin, mucus, and certain pigments. The principal acids are taurocholic $\left(\mathrm{C}_{26} \mathrm{H}_{45} \mathrm{NSO}_{7}\right)$ and glycocholic $\left(\mathrm{C}_{26} \mathrm{H}_{43} \mathrm{NO}_{6}\right)$, both commonly combined with sodium. The taste of bile is intensely bitter; its reaction feebly alkaline, and its density from 1026 to 1032. It exercises a diastatic action on starch, emulsifies fats, and precipitates soluble peptone. Its composition varies, but according to Hoppe-Seyler, in 100 parts bile there are of

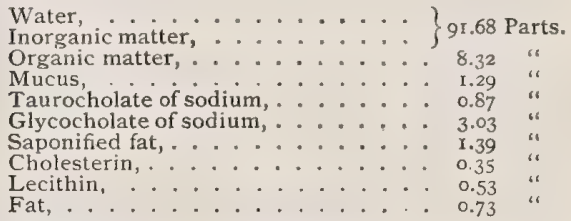

B. Pigments, the coloring-matters of the bile. B. P., Tests for. See Tests, Table of.

Bilharzia (bit-har'-ze-ah) [named after Theodor Bilharz, an helminthologist]. A genus of trematode helminths, established by Cobbold, characterized by having the sexes separate. See Gynecophorus and Parasites (Animal), Table of. B. hæmatobia. See Distoma.

Bilharziosis (bil-har-ze-o'-sis) [Bilharzia]. The ensemble of symptoms produced by the presence in the intestine of worms of the genus Bilharzia.

Biliary (bil'-e-a-re) [bilis, bile]. Pertaining to the bile. B. Acids, glycocholic and taurocholic acids formed in the liver. For tests for B. A. in the urine, see Tests, Table of. B. Colic, colic produced by the passage of gall-stones. See Gall-stones. B. Ducts, the hepatic, the cystic and the ductus communis choledochus. The first leads from the liver, the second from the gall-bladder. The third is a common excretory duct. See Liver.

Bilicyanin (bil-e-si'-an-in) [bitis, bile; кvávعos, blue]. Cholecyanin, choleverdin. A blue pigment obtained from bilirubin.

Biliflavin (bil-e-fla'-vin) [bilis, bile; flavus, yellow]. A yellow coloring-matter derivable from biliverdin.

Bilifulvin (bil-e-full-vin) [bilis, bile; fulvus, fulvous]. An impure form of bilirubin; also a yellow bile-color from ox-gall, not normally present in human bile.

Bilifuscin (bil-e-fus'-in) [bilis, bile; fuscus, brown], $\mathrm{C}_{16} \mathrm{H}_{20} \mathrm{~N}_{2} \mathrm{O}_{4}$. A pigmentary matter occurring in bile, and in human gall-stones.

Bilihumin (bil-e-hu'-min) [bilis, bile; humus, earth]. An insoluble residue left after treating gall-stones with various solvents.

Bilin $\left(b i^{\prime}-l i n\right)$ [bilis, bile]. A mixture of the taurocholate and glycocholate of sodium, forming a copious resinoid constituent of the bile. 
Bilineurin (bil-e-nu'-rin). See Cholin.

Bilious (bil'yus) [biliosus, full of bile]. A term popularly applied to disorders supposed to arise from a too free secretion of bile. B. Fever, a term loosely applied to certain enteric and malarial fevers.

Biliphein (bit-e-fe'-in) [bilis, bile; qaı́s, gray]. A supposed bile-color, now regarded as an impure bilirubin; called also cholophein.

Biliprasin (bil-e-pra'-sin) [bilis, bile; $\pi \rho a ́ \sigma o v$, leek; $\pi$ páoivos, leek-green ], $\mathrm{C}_{16} \mathrm{H}_{22} \mathrm{~N}_{2} \mathrm{O}_{6}$. A pigmentary substance occurring in gall-stones, icteric urine and bile.

Bilipurpin, or Bilipurpurin (bil-e-per'-pin, bil-e-per'pu-rin) [bitis, bile; purpura, purple]. A purple coloring-matter derivable from biliverdin.

Bilipyrrhin (bil-e-pir'-in). See Cholepyrrhin.

Bilirubin (bil-e-ru'-bin) [bilis, bile; ruber, red], $\mathrm{C}_{16} \mathrm{H}_{18}$ $\mathrm{N}_{2} \mathrm{O}_{3}$. A red coloring-matter, the chief pigment of the bile. It is found also in the urine in jaundice. It is insoluble in water, and almost so in ether and alcohol, but it is readily soluble in alkaline solutions. It crystallizes in rhombic plates or prisms. B. Icterus, icterus or jaundice with discoloration of the skin and urine from the presence of an abnormally large percentage of bilirubin.

Biliverdin (bil-e-ver'-din) [bilis, bille; viridis, green], $\mathrm{C}_{12} \mathrm{H}_{20} \mathrm{~N}_{2} \mathrm{O}_{5}$, or $\mathrm{C}_{8} \mathrm{H}_{9} \mathrm{NO}_{2}$. A green pigment, the first product of the oxidation of bilirubin. It gives the characteristic color to the bile of herbivora, and occurs in the urine of jaundice and in traces in gall-stones.

Billroth's Mixture. See Anesthetic. B.'s Operations. See Operations, Table of.

Bilsted, or Bilsterd (bil'-sted, or bil'-sterd). See Liquidamber.

Bimana (bim'-an-ah) [bi, two; manus, a hand]. An order of the division of mammalia including man only.

Bimanual (bi-man'-u-al) [bi, two; manus, a hand]. Two-handed. Ambidextrous.

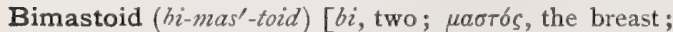

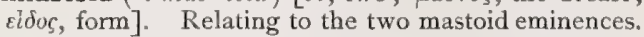

Binary (bi'-nar-e) [binus, a couple]. In chemistry, compounded of two elements. In anatomy, separating into two branches. B. Theory, in chemistry, the theory that considers all salts as double compounds.

Binate (bin'-ät) [binus, two by two]. In biology, bifoliate; bidigitate; occurring in pairs.

Binaural (bin-aw'-ral) [bis, twice; auris, ear]. Pertaining to or having two ears.

Binauricular (bin-aze-rik'-u-lar) [bis, twice; auricula, the ear]. Pertaining or belonging to both ears. B. Arc. See Arc

Binder $($ bind'-er) [ME., byndere]. A wide bandage about the abdomen, worn by women during or after labor, or celiotomy, to support the abdominal walls. B., Mammary, a sling or suspensory for the mamma.

Binder's Board. A thick, strong variety of pasteboard for bookbinders' use; it has a limited use in surgery.

Binding Posts. Clamps for connecting conducting wires with the electric apparatus.

Bindschedler's Green. Same as Dimethylphenylene Green.

Bindweb (bind'-web) [ME., binden; zebbe]. The neuroglia.

Binelli's Styptic. A nostrum formerly famous as a styptic. It is supposed to have contained creasote.

Biniodid (bin-i'-o-did). See Jodid.

Binocular (bin-ok'-u-lar) [bi, two; oculus, an eye $]$. In anatomy, having or pertaining to two eyes. In optics, an instrument with two eye-pieces for use with both eyes at once. B. Vision, the faculty of using both eyes synchronously and without diplopia.
Binoculus (bin-ok'-u-lus) [L., two-eyed]. A figureof-eight bandage for both eyes.

Binoxid (bin-oks'-id) [bi, two; oxid]. Same as Dioxid. Binuclear (bi-nu'-kle-ar) [bi, two; nucleus, a kernel]. Having two nuclei.

Binucleolate (bi-nu-kle'-o-lāt) [bi, two; nucleolus, a little kernel]. Having two nucleoli.

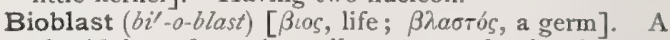
plastidule or formative cell; a corpuscle that has not yet become a cell.

Biocellate $\left(b i-o-s e l^{\prime}-a t\right)$ [bi, two; ocellus, a little eye]. In biology, having two spots resembling eyes.

Biochemics (bi-o-kem'-iks) [Bios, life ; $\chi \eta \mu \varepsilon i a$, chemistry]. The chemistry of life. See Biochemy.

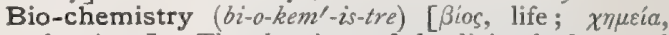
chemistry]. The chemistry of the living body, or of life.

Biochemy $\left(b i^{\prime}-o-k e m-\varepsilon\right)$ [ $\beta i o s$, life ; $\chi \eta \mu \varepsilon i a$, chemistry]. Chemic force as exhibited in living organisms.

Biochyme $\left(b i^{\prime}-o-k i m\right)[\beta i o s$, life; $\chi v \mu \sigma s$, juice]. In biology, the sap or cell-juice of plants.

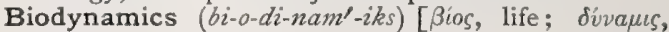
power]. The dynamics of life ; dynamic biology.

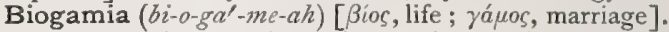
The hypothetic union of opposing vital forces (as of contractility and sensibility), resulting in reproduction.

Biogenesis (bi-o-jen'-es-is) [ $\beta i o s, ~ l i f e ; ~ \gamma e ́ v e \sigma \iota s, o r i g i n]$. I. The doctrine that living things are produced only from living things-the reverse of abiogenesis. 2. Reproduction from living parents.

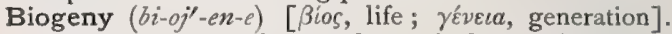
In biology, the evolution of organic forms, either considered individually (ontogeny) or tribally (phylogeny).

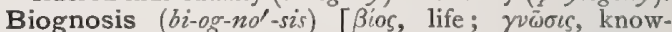
ledge]. The study of life and its phenomena; biology.

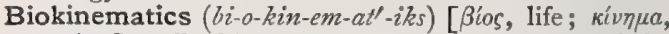
motion]. The kinematics of life; the science of the motions or movements that are essential to life.

Biokinesigenesis (bi-o-kin-es-ij-en'-es-is) [ßios, life;

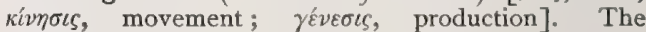
origination of the movements of living matter.

Biokinetics (bi-o-kin-el'-iks) [Bios, life; kimmous, motion]. The kinetics of life: the science of the movements that are necessary parts of the process of development. See Karyokinesis.

Biologic, or Biological (bi-o-loj"-ik, bi-o-loj'-ik-al) [ $\beta$ ios, life; $\lambda 6 \gamma o s$, science]. Pertaining or belonging to biology. B. Law. See Phylogeny and Hackel.

Biologist (bi-ol'-o-jist) [ $\beta$ ios, life; $\lambda b^{\prime} \gamma o s$, science]. One who is a student of biology.

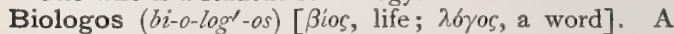
designation proposed for the intelligent living power displayed in cellular and organic action and reaction.

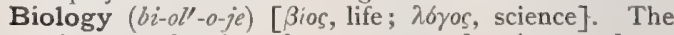
science embracing the structure, function, and organization of life-forms.

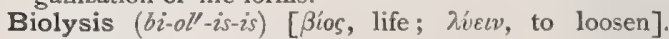
The destruction of life. The devitalization of living tissue.

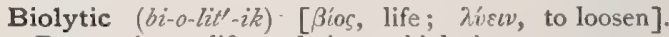
Destructive to life ; relating to biolysis.

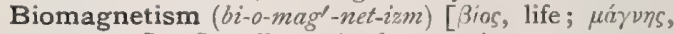
a magnet]. So-called animal magnetism.

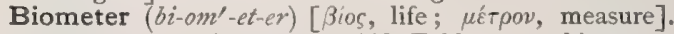
Dr. Farr speaks of the Life-Table as a biometer, and of equal importance in all inquiries connected with human life or sanitary improvements with the barometer or thermometer, etc., in physical research ; and the keystone or pivot on which the whole science of life-assurance rests. 


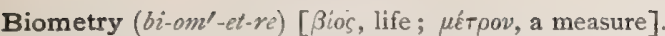
Life-measurement; the estimation of the probable duration of any given life-form-in the past or future.

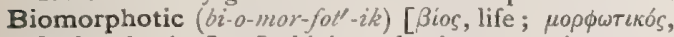
fit for shaping]. In biology, having an active pupa. Biondi's Fluid. A staining-medium used in histologic laboratories. It is a mixture of orange-G. methyl-green, and acid fuchsin. See Stains, Table of.

Bionergy $(b i$-on'-er-je) [ $\beta i o s$, life; $\varepsilon \rho \gamma o \nu$, work]. Lifeforce; force exercised in the living organism.

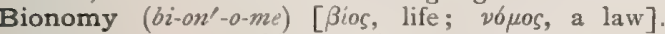
Dynamic biology; biodynamics; the science of the laws of life.

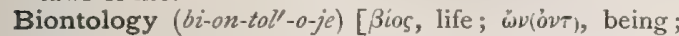
$\lambda \varepsilon \varepsilon_{\varepsilon} \nu$, to speak]. In biology, the physiology of the species or genus, embracing the transcendental or strictly philosophic in physiology (J. Aitken Meigs.)

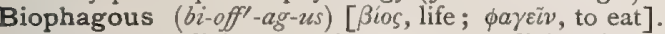
Feeding upon living organisms, or upon living tissue, as.insectivorous plants.

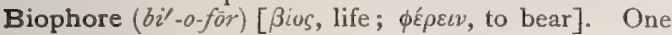
of Weismann's hypothetic " bearers of vitality," corresponding to the "plasomes" of Wiesner and Briicke and to the "pangenes" of de Vries, the smallest units that exhibit the primary vital forces, the bearers of the cell-qualities.

Biophysiography $\left(b i-o-f i z-e-o g^{\prime}-r a-f e\right)$ [ $\beta i o s$, life ; $\phi \dot{v} \sigma \iota s$,

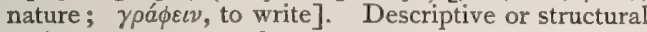
biology; organography, as distinguished from biophysiology.

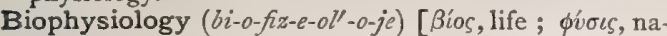
ture; $\lambda \delta$ бos, science]. That branch of biology that includes organogeny, morphology and general physiology.

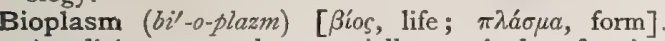
Any living matter, but especially germinal or forming matter; matter possessing reproductive vitality. See Protoplasm.

Bioplasmic (bi-o-plaz'-mik) [ßios, life; $\pi \lambda a ́ \sigma \mu a$, form] Relating to or of the nature of bioplasm.

Bioplasson $\left(b i-o-p l a s^{\prime}-o n\right)$ [ $\beta i o s$, life ; $\pi^{\lambda} \lambda a ́ \sigma \sigma \omega v$, form ing]. Elsberg's term for living matter. A synonym of protoplasm or bioplasm.

Bioplast (bi'-o-plast) [ $\beta$ íos, life; $\pi \lambda a \sigma \tau o ́ s$, formed]. A mass or cell of bioplasm which is a unit of living matter.

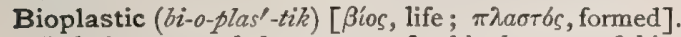
Relating to or of the nature of a bioplast or of bioplasm.

Biopsic $\left(b i-o p^{\prime}-s i k\right)$ [ $\beta i o s$, life ; bै $\psi \iota$, vision]. Pertaining to biopsy.

Biopsy $\left(b i^{\prime}-o p-s e\right)$ [ $\beta i o \varsigma$, life; ǒ $\psi \iota$, vision]. Observation of the living subject; opposed to necropsy.

Biorbital (bi-orb'-it-al) [bi, two; orbita, a path]. Relating to both orbits.

Bioscope $\left(b i^{\prime}-o-s k o ̄ p\right)$ [ $\beta i ́ o s$, life; $\sigma \kappa о \pi \varepsilon i v$, to view]. An instrument used in bioscopy.

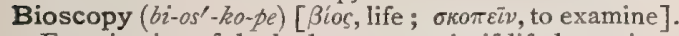
Examination of the body to ascertain if life be extinct. B., Electro-, examination by the aid of the electric current. The muscular reaction is lost to faradic stimulation in about two hours after death in the tongue; after three or four hours in the extremities; after five or six hours in the trunk. The reaction to galvanism persists somewhat longer.

Biosis $\left(b i-o^{\prime}-s i s\right)$ [ $\beta i o s$, life]. Life; vitality.

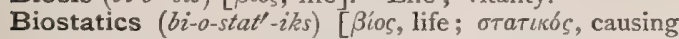
to stand]. Static biology; the science of the determinate parts of biology, including anatomy, and the physics of the living body.

Biot's Respiration. See Respiration.

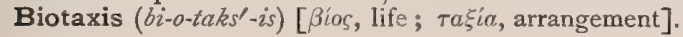

I. The selective and arranging function or activity of life, or of living cells. 2. Systematic biology; the classification of living organisms.

Biotaxy (bi'-o-taks-e). See Biotaxis.

Biothalmy (bi'-o-thal-me) [ $\beta \iota 0 A a ́ \lambda \mu \iota s$, vigorous; $\beta$ ios, life; $\theta$ án $\lambda \varepsilon \iota \nu$, to be vigorous]. The art of living long and well.

Biotic $\left(b i-o t^{\prime}-i k\right)$ [ $\left.\beta \iota \omega \tau \iota k o ́ s\right]$. Pertaining to life or to the laws of animal and vegetable progress and evolution.

Biotome (bi'-o-töm) [ßios, life; touń, a cutting]. A term applied by Cobbold to a stage in the development of certain entozoa.

Biotomy (bi-ot'-o-me) [Bios, life; $\tau \varepsilon \dot{\varepsilon} \mu \nu \varepsilon v$, to cut]. Vivisection.

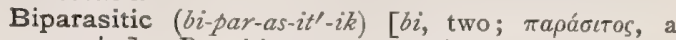
parasite]. Parasitic upon a parasite.

Biparietal (bi-par-i'-et-al) [bi, two; parietes, a wall]. Relating to both parietal bones. B. Diameter, the distance from one parietal eminence of the cranium to the other

Biparous (bip'-ar-us) [bi, double; parere, to bring forth]. Producing two at a birth.

Bipartite (bi-par'-titt) [bi, two; pars, a part]. In biology, composed of two parts or divisions.

Biped (bi'-ped) [bi, two; pes, a foot]. With or having two feet.

Biperforate $\left(b i-p e r^{\prime}-f o-r \bar{a} t\right)[b i$, two; perforatus, bored through]. Having two perforations; as a biperforate hymen.

Bipetalous (bi-pel'-al-us) [bi, two; $\pi \dot{\varepsilon} \tau a \lambda o v$, a petal] In biology, having two petals.

Biphosphate (bi-fos'-fät) [bi, two; phosphorus]. In chemistry, an acid phosphate.

Biphosphid (bi-fos'-fid) [bi, two; phosphorus]. In chemistry, a phosphid containing twice as much phosphorus as the lower member of the phosphid series.

Biphosphite (bi-fos'-fit) [bi, two; phosphorus]. In chemistry, an acid phosphite.

Bipinnate $\left(b i-p i n^{\prime}-\bar{a} t\right)$ [ $b i$, two; pinnatus, feathered] In biology, doubly pinnate, as a leaf.

Bipolar (bi-po'-lerr) [bi, two; polus, a pole]. Having two poles. B. Nerve-cells, nerve-cells that have two prolongations of the cell-matter. They are found chiefly in the ganglia of the gray matter of the brain.

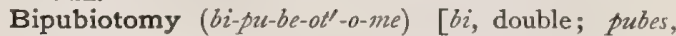
pubes; $\tau \dot{\varepsilon} \mu \nu \varepsilon \iota \nu$, to cut]. An obsolete operation (in the place of the Cesarean section) in which the pubic bones were both divided. See Galbiati's and Farabeuf's Operations.

Birch (berch) [AS., birce]. Any tree of the genus Betula. Birch tar, or the tarry oil of $B$. alba, is useful in certain skin diseases. The bark of $B$. lenter, the American black birch, yields a fragrant volatile oil, identical with that of Gaultheria procumbens, for which it is often substituted. B. Camphor. Same as B. Resin. B. Resin. See Betulin. Oleum betulæ volatile, volatile oil of betula, oil of sweet birch.

Bird-lime (berd'-lim). A viscous vegetable substance used in Japan as a local dressing for wounds.

Bird's Formula. The last two figures of the specific gravity of urine nearly represent the number of grains of solids to the ounce contained in the urine. The same two figures multiplied by 2 (Trapp's Factor) give the parts per 1000. Hæeser's Factor is 2.33 . B. Operations. See Operations, Table of.

Bird's-nest Bodies, or Cells. The cells of certain forms of carcinoma, distinguished by the concentric arrangement of their cell-walls. See also Cancer Nests. B. Edible, the nest of certain species of swift, used by the Chinese as food. It consists of marine algæ, Gelidium, cemented by the salivary 
mucus of the bird. B. Sternum, a deformity of the sternum found in lateral curvature of the spine

Birhinia (bi-rin'-e-ah) [bi, two; ṕis, the nose $]$. A congenital defect in which there is the formation of two noses.

Birth (berth) [ME., byrth]. I. The delivery of a child; parturition. 2. That which is brought forth in parturition. B.-mark. See Nevus pigmentosus. B.palsy, any paralytic affection due to an injury received at birth; less correctly, a congenital paralytic affection due to a lesion that existed in the fetal state. See Paraplegia, Infantile Spasmodic. B., Partial the incomplete expulsion of a child in labor; of legal value in lawsuits for property. B., Plural, the birth of more than a single child. B., Posthumous, the birth of a child after the death of its father. B. Precocious, the occurrence of natural labor after a shorter pregnancy than is usual. B., Premature. See Labor. B.-rate, the proportion of births per thousand. B.-root. See Beth Root. B.-wort, the plant Aristolochia climatitis (see Aristolochia), so called from its former employment as a depurant after childbirth. Unof. B., Still. See Still-born. Some of the Tests of live birth are appended: Breslau Test. If the intestines and stomach of the infant float in water on removal from the body it was thought to be proof that the child was born alive. This test is of no value. Hydrostatic Test. Suggested by Raygat. It consists in placing the lungs in water and noting their specific gravity. If inflation has occurred they will float. "This test is valuable. Ploucquet's Test. This consists in estimating the ratio of the weight of the lungs to the weight of the body of the child. Ploucquet laid down this rule, that before respiration the weight of the lungs compared to the weight of the body was in the ratio of I to 70 , and that after respiration it was in the ratio of $I$ to 35. The test is of but slight value. Static test. Also called Foderé's or Schmidt's Test. This consists in ascertaining the absolute weight of the lungs, and comparing this weight with the average lung-weights of stillborn children, and of children who have died soon after birth. Foderé fixes the weight of the lungs of stillborn children born at term at 480 grains ( $\mathbf{I}$ oz.), and 960 grains $(2 \mathrm{oz}$.) as the weight of the lungs soon after breathing has been established. This test is also of but slight value.

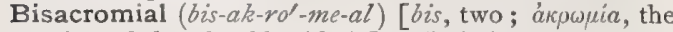
point of the shoulder-blade]. Relating to the two acromia.

Biscara Button (bis'-kar-ah but'-un). See Furunculus orientalis.

Bischoff's Operation. See Operations, Table of.

Biscuit (bis'-kit) [Fr., "twice baked"]. A kind of cake; properly, a small, hard cake. In French pharmacy, medicated biscuits of various kinds are known. B., Camplin's, biscuits made of bran for the use of diabetics. They are made as follows: Take one quart of wheat-bran and boil in two successive waters for fifteen minutes, straining the mixture through a sieve until the water comes through clear; after each washing squeeze in a cloth until perfectly dry; spread thinly on a dish and place in a slow oven. If put in at night, let it remain in until morning, when, if dry and srisp, it is fit for grinding. The mass so obtained must be ground in a fine mill and passed through a wire sieve so fine that a brush will be required to push the flour through. Grind again that which remains in the sieve until quite soft and fine. Take three ounces of the powder, three new-laid eggs, from one and a half to two ounces of butter and about half a pint of milk. Mix the eggs with a little of the milk, and warm the butter with the other portion. Stir the whole well together, adding a little nutmeg and ginger or other spices. Bake in small well-buttered tins in a rather quick oven for about half an hour. Make the cake a little thicker than a captain's biscuit.

Biscuiting (bis'-kit-ing). See Block Teeth.

Bisection (bi-sek'-shun) [bi, two; sectio, a cutting]. In obstetrics, embryotomy.

Bisexual (bi-seks'-u-al) [bi, two; sexus, sex]. Having the reproductive organs of both sexes. Hermaphrodite.

Bish (bish). Same as Bikh.

Bishop's (Stanmore) Operation. See Operations, Table of. B.'s Weed. See Ajozuan.

Bishoping (bish'-op-ing) [ME., bischopen]. In farriery, filing a space between the teeth of a horse.

Bisiliac (bis-il'-e-ak) [bis, two; iliacus]. Relating to the two most distant points of the two iliac crests.

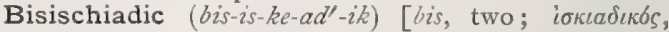
relating to the hip]. Relating to corresponding points on the two ischia.

Biskra Boil, or Button. See Furunculus orientalis.

Bismarck Brown. Same as Phenylene Brown and Vesurvin.

Bismuth, or Bismuthum (biz'-muth) [L., gen., Bismuthi $]$. $\mathrm{Bi}=2 \mathrm{IO}$; quantivalence I, III, v. A pinkish-white crystalline metal, not used in medicine in its metallic form. Its commercial salts are likely to contain arsenic. The insoluble salts of bismuth are feebly astringent and are useful in disordered digestion, acne, eczema, etc. B. et Ammonii Citras, soluble in water. Dose gr. j-v. B. et Ammon. Citras, Liquor (B.P.). Dose $3 \mathrm{ss}-\mathrm{j}$. B. Carbonas (B.P.), $\left(\mathrm{Bi}_{2} \mathrm{O}_{2} \mathrm{CO}_{3}\right)_{2}, \mathrm{H}_{2} \mathrm{O}$. Dose gr. $\mathrm{v}-\mathrm{xx}$. B. Citras, $\mathrm{BiC}_{6}$ $\mathrm{H}_{5} \mathrm{O}_{7}$, soluble in water of ammonia; used in the U. S. only for pharmaceutic purposes. Dose gr. ij-v. B. Oxid. (B.P.), $\mathrm{Bi}_{2} \mathrm{O}_{3}$, Dose gr. $\mathrm{v}-\mathrm{xv}, \mathrm{B}$. Oxychlorid, pearl white. Unof. It is used as a cosmetic. B. Pulvis, Comp., Ferrier's Snuff. Contains two grains of hydrochlorate of morphin in one ounce, with bismuth and acacia. It is used for treating coryza. B. Salicylas. $\mathrm{Bi}\left(\mathrm{C}_{7} \mathrm{H}_{5} \mathrm{O}_{3}\right)_{3} \cdot \mathrm{Bi}_{2} \mathrm{O}_{3}$. Dose gr. v-x. B. Subcarbonas, $(\mathrm{BiO})_{2} \mathrm{CO}_{3} \cdot \mathrm{H}_{2} \mathrm{O}$, insoluble; it is best given in emulsion with milk. Dose gr. $x-z j$. B. Sub gallate. See Dermatol. B. Subiodid, BiOI, used as an antiseptic dusting-powder, like iodoform. B. Subnitras, $\mathrm{BiONO}_{3} . \mathrm{H}_{2} \mathrm{O}$, the salt chiefly used in medicine. It is also used as a cosmetic. Dose gr. $\mathrm{x}-\mathbf{3} \mathrm{j}$. B. Test. See Tests, Table of. B., Trochisci (B.P.); each contains gr. ij. B., Unguent., 60 grains to one ounce. For herpes, piles, etc. B. White. See Conspectus of Pigments, under Pigment.

Bissa (bis'-ah) [native African]. An affection of man and sheep, common in Egypt, and characterized by the production of edema. B. Bol, a kind of myrrh, from Balsamodendron $K a f a l$, a tree of E. Africa. It is used largely in adulterating the finer grades of myrrh, and is said to stimulate powerfully the flow of milk in cows. Unof.

Bistellate (bi-stel' $\bar{a} t)[b i$, two; stella, a star $]$. Shaped like a double star.

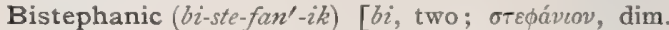
of orḱoqvos, a wreath]. Relating to the stephanions.

Bistort (bis'-tort) [bis, twice; tortus, twisted]. Snakeweed, Adder's-wort. The rhizome of Polygonum bistorta, an astringent. Dose of fld. ext. $m \times x-x l$. Unof.

Bistoury (bis'-10-re) [Fr. bistouri]. A small (straight or curved) knife used in surgery. B.-cache, one that has the blade concealed for passing to the point to be incised, and by pressure on the handle the blade is exposed and the incision made.

Bisulcate $\left(b i-s u l^{\prime}-k \bar{a} t\right)$ [bi, two; sulcus, a furrow]. Having two furrows or grooves. 
Bisulphate (bi-sul'-fat) [bi, two; ME., sulphur]. Any acid sulphate having twice the amount of acid contained in the corresponding normal sulphate.

Bisulphid $\left(b i-s u l^{\prime}-f d d^{\prime}\right)$ [bi, two; sulphur]. In chemistry, a sulphur compound in which there are two atoms of sulphur to one atom of the other substance of the compound. B. of Carbon. See Anesthetic

Bisulphite (bi-sul'-fit) [bi, two; sulphur]. An acid sulphite. The bisulphite of lime is used as an antiferment.

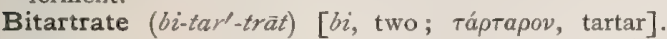
Any tartrate in which one normal hydrogen atom has been replaced by a base. See Tartaric acid.

Bitemporal (bi-tem'-por-al) [bi, two; tempora, the temples]. Pertaining or belonging to the two temples. B. Triangle. See Triangle.

Biti $\left(b e^{\prime}-t e\right)$ [E. Ind.]. The E. Indian tree Dalbergia latifolia; the oil of the root is said to cure or prevent baldness. Unof.

Bitnoben (bit-no'-ben) [Hind. for "black salt" ]. An East Indian polychrest remedy composed of salt, myrobalan and iron.

Bitter (bit'-er) [AS., bitan, to bite]. A peculiar, wellknown taste, of which quinin presents an example; unpalatable. B. Almond, the nut of the Amygdalum amarum. It contains hydrocyanic acid. B. Almond Green. Same as Malachite Green. B. Almond Oil, oleum amygdalæ amaræ. See Benzaldehyd. B. Apple, the fruit of the colocynth, a purgative remedy. $\mathbf{B}$. Blain, a West Indian herb, Vandellia diffusa, employed in fevers and in hepatic disorders. Unof. B. Bloom. The same as American Centaury, q. v. B. Bugleweed, the herb Lycopus europaus, alterative and tonic. Dose of fld. ext. $\zeta s s-j$. Unof. B. Cup, a cup made of quassia wood. It is a tonic. $\mathbf{B}$. King, the shrub or tree, Soulamea amara, intensely bitter in all parts, and reputed to be antiperiodic. Unof. B. Purging Salt, sulphate of magnesia. B. Root, the root of Gentiana catesbei, a tonic. B. Tincture, the tinctura amara (N.F.), prescribed also in the German pharmacy; it is a tincture of gentian, centaury, bitter orange-peel, orange-berries, and zedoary ; it is known also as Stomach Drops. B. Wine of Iron, a solution of white wine, syrup, citrate of iron and quinin. Tonic. See Iron.

Bittering (bit'-er-ing) [AS., bitan, to bite]. A disease of wine in which it acquires a bitter flavor, due to the formation of a substance that develops as the wine ages, or if it be exposed to too high a temperature.

Bitters (bit'-ers) [AS., bitan, to bite]. Medicines characterized by a bitter taste. B., Aromatic, medicines that unite the properties of aromatics with those of simple bitters. B., Simple, medicines that stimulate the gastro-intestinal tract without influencing the general system. B., Styptic, medicines that add styptic and astringent properties to those of bitterness. See Angustura.

Bittersweet (bitt-er-swêt). See Dulcamara. B., False. See Climbing Staff Tree.

Bitumen (bit-u'-men) [L., bitumen]. Mineral pitch or oil composed of various hydrocarbons. In the solid form it is usually called asphalt; in the liquid form, petroleum. An intermediate form is known as mineral tar or maltha. By distillation, bitumen yields benzol, naphtha, paraffin, and various other hydrocarbons, liquid and gaseous.

Bituminous (bit-u'-min-us) [bitumen, bitumen]. Of the nature of or containing bitumen. B. Coal. See Coal.

Biuret $\left(b i^{\prime}-u\right.$-ret $)[b i$, two; ovpov, urine $], \mathrm{C}_{2} \mathrm{H}_{5} \mathrm{~N}_{3} \mathrm{O}_{2}+$ $\mathrm{H}_{2} \mathrm{O}$. A compound formed by exposing urea to a high temperature for a long time. It is readily soluble in water and in alcohol; it crystallizes with one molecule of water in the form of warts and needles. When anhydrous, biuret melts at $190^{\circ}$ with decomposition. B. Reaction, or Test. See Tests, Table of.

Bivalence (biv'-al-ens) [bi, two; valens, having power] In chemistry, a valence or saturating power that is double that of the hydrogen atom.

Bivalent (biv'-al-ent) [bi, two; valens, having power]. In chemistry, applied to an element of which an atom can replace two atoms of hydrogen or other univalent element, or to a radical that has the same valence as a bivalent atom

Bivalve ( $\left.b i^{\prime}-v a l \imath^{\prime}\right)$ [ $b i$, two; valva, a valve]. Having two valves or shells, as a mollusc or a speculum.

Biventer (bi-ven'-ter) [bi, two; venter, a belly]. Having two bellies, as a muscle. B. cervicis, the inner portion of the complexus muscle. B. maxillæ, the digastricus muscle.

Biventral (bi-ven'-tral) [bi, two ; ventrum, a stomach] Having two stomachs; having two bellies; as a digastric muscle.

Bixin (biks'-in) [Bixa, a genus of plants], $\mathrm{C}_{16} \mathrm{H}_{26} \mathrm{O}_{2}$. An orange-red coloring-matter found in Annatto. See Pigments, Conspectus of.

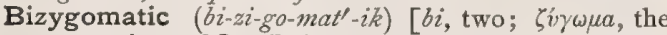
zygomatic arch]. Relating to the most prominent points on the two zygomatic arches.

Bizzozero's Blood-plates. See Blood-plates. B. Method, a method of studying blood-plaques: A drop of a three-quarter per cent. sodium chlorid solution with one part of a concentrated aqueous solution of methyl violet for every 5000 of salt solution, is placed on the finger, which is then punctured. The blood and solution are mixed on the finger.

Bjeloussow's Gum Arabic and Borax Mass. For injecting tissues. Take one part, by weight, of gum arabic and make a syrupy solution in water. Take a half part, by weight, of sodium biborate and make a solution in water. Mix the two solutions, when a mass resembling gelatin will be obtained. This mass, which is almost insoluble in water, is rubbed up with water and forcibly strained through linen. Repeat the operation, when a solution miscible in all proportions with water is obtained. This may be colored by carmin or any pigment except cadmium and cobalt.

Black (blak) [AS., blac]. Absence of color or light. The appearance of an object from whose surface none of the spectrum colors is reflected. B. Alder. See Prinos: B. Antimony, antimonium tersulphid, Sb$\mathrm{S}_{3}$. B. Ash, the bark of Fraxinus sambucifolia, a mild tonic and astringent. Dose of fld ext. $3 \mathrm{ss}-\mathrm{j}$. Unof. B. Asphaltum. Same as Japan Black. B. Birch. See Birch. B. Blood, venous blood. B. Cancer. See Melanosis. B. Cohosh. See Cimicifuga. B.-damp, carbon dioxid gas, which is found in greater or less quantity in all collieries, being given off by many coals, either mixed with fire-damp, or separately, or produced in various other ways, as by the exhalations of the men, by fires, and by explosions of fire-damp. Also called choke-damp. B. Death. See Plague. B. Disease, I. A disease of malarial origin and pernicious course, characterized by extreme darkening of the skin, which may be brown or black in color. It occurs in the Garo Hills in Assam. 2. See Aubernage. B. Draught. See Senna. B. Drop. See Opium. B. Erysipelas. Synonym of Anthrax. B. Eye, livor (or sugillatio) oculi. See Ecchymosis. B. Haw. See Viburnum. B.-head. See Comedo. B. Hellebore. See Hellebore. B. Hoarhound. See Ballota. B. Induration. See Induration. B. Infiltration. See Miner's Phthisis. B. Jaundice, an excessive jaun- 
dice arising from obstruction of the gall-ducts. The color of the skin is greenish-black. B. Lead, a form of carbon properly known as the mineral graphite. B.-Leg, I. A febrile, generally fatal disease, chiefly affecting cattle and sheep, which is characterized by the rapid appearance of irregular nodules in the skin and muscular tissues, that are at first tense and very painful, but rapidly become painless and crepitating. There is no enlargement of the spleen. It is caused by anaẽrobic bacilli. It is also called Symptomatic Anthrax. 2. A synonym of the severe form of Purpura. B. Leprosy. See Leprosy. B. Measles, I. The local Californian name for a disease of the grape, due to Plasmodiophora californica (Viala and Sanragean). Cf. Brunissure. 2, Rubeola nigra; a grave or malignant form of measles. B. Pepper. See Piper nigrum. B. Phthisis. A synonym of Miners'Asthma. B. Quarter. Synonym of Anthrax. See also Black Leg. B. Sampon. See Echinacea Angustifolia. B. Snake-root. See Cimicifuga. B. Spauld. See Black-Leg. B. Spit. See Miner's Phthisis. B. Sweat. See Chromidrosis. B. Tongue, I. See Glossophytia. 2. A name given to a condition characterized by the formation upon the dorsum of the tongue of a hair-like deposit that passes through various stages of coloration from yellow to brown and finally black, ultimately disappearing by desquamation as gradually as it came. Repeated recurrence is the rule. It is probably an undue proliferation of the epithelium, the result of irritation. 3. See Nigrities. 4. A term applied to erysipelatous glossitis. B. Vomit, the coffee-ground vomit of yellow fever, etc. B. Wainut, the leaves of Juglans nigra, a tonic, alterative and deobstruent. Dose of fld. ext. $m \times x x-$ xxx. Unof. B. Wash. See Hydrargyrum. B. Willow, the buds of Salix nigra, a bitter tonic with aphrodisiac properties. Dose of fld. ext. $m \times x v-3 j$. Unof.

Blackberry (blak'-ber-e) [AS., blac; berie, berry]. See Rubus. B. Cordial, the cordiale rubi fructus (N.F.). Its formula is: blackberry juice, 3 pints; cinnamon in coarse powder, $2 \mathrm{Tr}$. oz. ; cloves and nutmeg, in coarse powder, each $1 / 2 \mathrm{Tr}$. oz.; dilute alcohol, 2 pints ; syrup, 3 pints.

Blackboy Gum. See Acaroid Resin.

Blackley Blue. Same as Soluble Blue.

Blackwater Fever (blak'-wat-er fe'-ver). See Fever. Bladder (blad'-er) [AS., bladre, a blister]. The membranous, sac-like reservoir or receptacle for the urine. B., Atony of, inability to expel the urine, from deficient muscular power. B., Catarrh of. See Cystitis. B., Extrophy, or Extroversion of, absence of the anterior wall of the bladder, and more or less deficiency of the corresponding part of the abdomen. B., Fasciculated, the walls thrown into ridges by chronic cystitis. B.-green. See Pigment, Conspectus of. B., Hernia of. See Cystocele. B., Inflammation of. See Cystitis. B., Inversion of, a protrusion or an invagination of the bladder through the urethra. B., Irritable, a condition characterized by constant desire to urinate. B., Neck of, the constricted portion continuous with the urethra in front. B., Nervous, a condition in nervous patients in which there is a frequent desire to pass water, with inability at the same time to perform the act perfectly, and consequent slight dribbling at its close. B., Paralysis of, the same symptoms as in atony, but more marked and due to nervous or central disease. If affecting the neck alone, there is incontinence; if the body of the organ, retention of urine. B., Sacculated, pouches formed between the hypertrophied muscular fibers. B. Senna, the plant Colutea arborescens of Europe; its leaves are used as a substitute for senna. Unof. B. Tetter. See Pemphigus. B., Trigone of, the triangular, smooth surface upon the inner surface of the base of the bladder, immediately behind the urethral orifice. B. Worm. See Worm. B.wort. See Utricularia. B.-wrack. See Fucus vesiculosus.

Bladdery Fever (blad'-er-e fever). See Fever.

Blade (bla d) [ME., blad, a leaf of grass]. In biology, the broad part of a leaf. B.-bone. The scapula or shoulder-blade.

Blæsitas (ble'-sit-as). See Blesitas.

Blain (blän) [ME., blane, a blister]. I. A blister; an elevation of the cuticle containing serum. Synonym of Anthrax. 2. A disease peculiar to the ox, marked by sudden swelling of the head, neck, and throat, and by the development of several large vesicles on the tongue that tend to cause suffocation.

Blainville's Ear. See Diseases, Table of, and Ear, Deformities of.

Blair's Wheat Food. A variety of farinaceous food for infants.

Blake's Disc. A device used in treating purulent otitis media. It is a paper disc pasted over the perforation of the tympanic membrane after the discharge has ceased.

Blanc $(b l o h(n g))$ [Fr.]. White. B. d'argent. See Pigment. B. fixe. Same as Permanent White. B.-mange, a jelly-like food-preparation, having as a basis gelatin, carragheen, isinglass, starch, or arrowroot, boiled with milk and variously flavored.

Blancard's Pills. Pills containing the iodid of iron.

Bland (bland) [blandus, mild]. A term applied to mild and soothing medicines and applications.

Blandin (blan'-din). See Glairin.

Blandin's Glands. See Gland. See Operations, Table of.

Blanket (blan'-ket) [Fr., blanc, white]. A woolen covering, so called because originally of white color. B. Bath. See Bath, Sheet or Pack.

Blasius's Operations. See Operations, Table of.

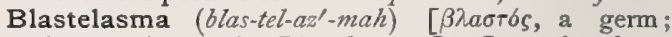
$\varepsilon \ddot{\lambda} \alpha \sigma \mu \alpha$, plate: pl., Blastelasmata]. In embryology, any secondary germ-layer appearing from, or later than, the endoderm and ectoderm.

Blastema (blas-te'-mah) [ $\beta \lambda a ́ \sigma \tau \eta \mu a$ from $\beta \lambda \alpha \sigma \tau a ́ v \varepsilon \iota v$, to germinate]. The formative lymph or pabulum of capillary exudation. A synonym of protoplasm.

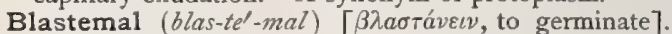
Of the nature of a blastema; pertaining to a blastema.

Blastematic (blas-tem-at' $i k$ ), or Blastematous (blas-

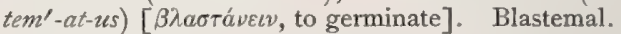

Blastemic (blas-tem'-ik) [ $\beta \lambda a \sigma \tau a ́ v \varepsilon \iota v$, to germinate]. Relating to blastema; rudimentary; bioplasmic.

Blastide (blas'-tid) [ $\beta \lambda a \sigma \tau b s$, a germ]. In embryology, a very small clear spot on the fecundated ovum marking the place of the nucleus or cytoblast.

Blasting Gelatin (blas'-ting jel'-at-in). Gelatin Dynamite. A mixture of about 80 parts of nitroglycerin with 20 of nitro-cellulose. Any non-nitrated cotton or trinitro-cellulose interferes with the solution of the nitro-glycerin. The addition of 4 per cent. of camphor renders the mixture incapable of exploding when struck by a rifle-bullet, but it can be detonated by a strong dynamite cap.

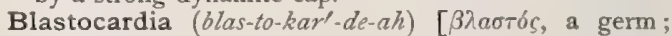
$\kappa a \rho \delta i \alpha$, the heart]. The germinal spot.

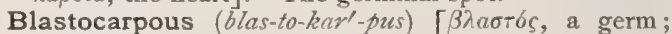
$\kappa a \rho \pi \delta \varsigma$, a fruit]. In biology, developing in the fruit.

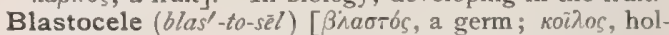
low]. The central cavity of the blastula or vesicular morula. 


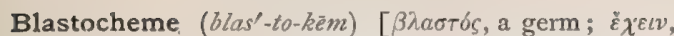
to hold, to have]. In biology, a medusiform zoöid that gives origin to generative elements not immediately, but through the intervention of sexual buds. (Allman.)

Blastochyle (blas'-to-kil) [ $\beta \lambda a \sigma \tau b s$, a germ; $\chi v \lambda \hat{s}$, juice]. In biology, the colorless fluid in the blastodermic vesicles.

Blastocclum, Blastocceloma (blas-to-se'-lom, blas-tose-lo'-mah). Same as Blastocele.

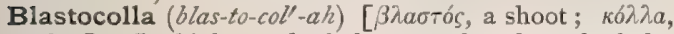
glue]. In biology, the balsam produced on buds by glandular hairs.

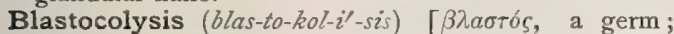

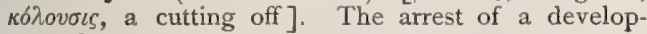
mental process.

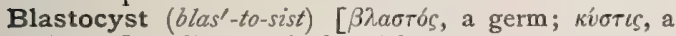
bladder]. The germinal vesicle.

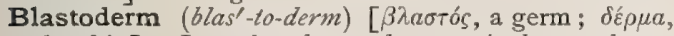
the skin]. In embryology, the germinal membrane formed by the cells of the morula, lying on the internal surface of the vitelline membrane of the impregnated ovum. The whole hollow sphere, with its surrounding cells, is called the blastodermic vesicle, and is formed about the tenth day. The ectoderm (or epiblast) and the endoderm (entoderm or hypoblast) layers are simply due to a proliferation of the blastodermic cells about the germinal area, whereby the blastoderm is doubled, thus forming these outer and inner layers. The mesoblast or middle layer is developed after the latter, and probably from the hypoblast.

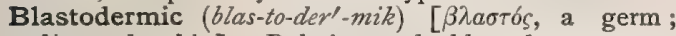
$\delta$ ¿́p $\mu a$, the skin]. Relating to the blastoderm.

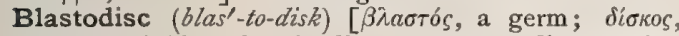
disc]. A blastodermic disc; a mass or disc capping one pole of the yolk.

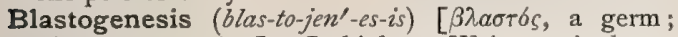

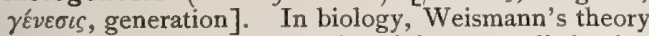
of origin from germ-plasm $(q . v$.$) in contradistinction$ to Darwin's theory of Pangenesis.

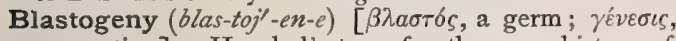
generation]. Haeckel's term for the germ-history of an individual organism; a division of ontogeny.

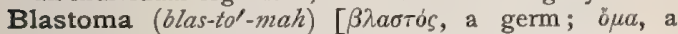
tumor: pl., Blastomata $]$. A granular growth due to the presence of a germ or microörganism.

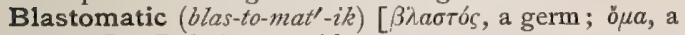
tumor]. Relating to a blastoma.

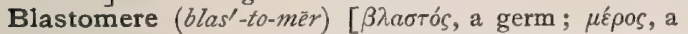
part]. Any one of the nucleated cells or segments into which the fecundated vitellus divides.

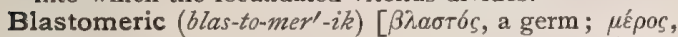
a part]. Relating to or of the character of a blastomere.

Blastoneuropore (blas-to-nu'-ro-por) [ $\beta \lambda \alpha \sigma \tau b s$, a germ ;

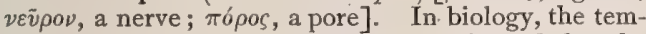
porary aperture in certain embryos formed by the coalescence of the blastopore and neuropore.

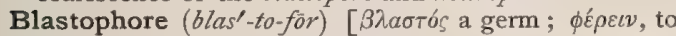
bear]. That part of a sperm-cell that does not become converted into spermatozoa.

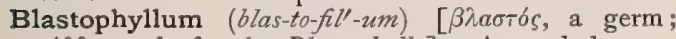

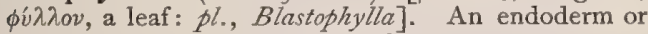
an ectoderm; a primitive germ-layer.

Blastophyly (blns-toff'-il-e) [ $\beta \lambda \alpha \sigma \tau b \varsigma$, a germ; $\phi v \lambda \dot{n}$, a tribe]. The tribal history of individual organisms.

Blastopore (blas'-to-pōr) [ $\beta \lambda a \sigma \tau b s$, a germ; $\pi 6 \rho \circ \varsigma$, passage, pore]. In biology, the primitive mouth or archistome, the orifice to the two-layered embryo (blastula). "The blastopore is the small opening which leads into the notochordal canal, or after the canal has fused with the yolk-cavity, leads into the archenteron. It is situated at the hind end of the primitive axis (head-process) and marks the anterior boundary of the anus of Rusconi in amphibia, or of the primitive streak, properly so-called, of amniota.' (Minot). "Van Beneden's blastopore" is formed previously to the blastodermic cavity.

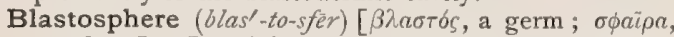
a sphere]. In biology, the "blastula," "germinal vesicle," or "vesicular germ." A hollow sphere composed of a single, simple layer of germinal cells. A vesicular morula.

Blastostyle (blas'-to-stīl) [ $\beta \lambda n \sigma \tau \delta \varsigma$, a germ; $\sigma \tau \bar{v} \lambda o s$, a pillar]. In biology, a columnar zoöid devoted to the origination of sexual buds.

Blastula (blas'-tu-lah) [dim. of $\beta \lambda a \sigma \tau b s$, a germ : pl., Blastulie]. In embryology, "The earliest form of the diaderm, a simple epithelial vesicle, the cavity of which is the large segmentation cavity" (Minot). Cf. Blastosphere.

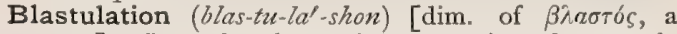
germ]. In embryology, the conversion of a morula or mulberry-germ into a blastula or vesicular germ.

Blatta (blat'-ah) [L., "blood-colored"]. A genus of the Blattida. B. (Periplaneta) orientalis, the cockroach; the powdered body of the cockroach. A popular remedy for dropsy among Russian peasants. It increases the amount of urine and diminishes the amount of albumin. Dose gr. iv-xx. Unof. See Antihydropin.

Blaud's Pill. A pill containing sulphate of iron and carbonate of potash; for use in amenorrhea, etc. See Pill.

Bleach (blēch) [ME., blechen, to make white]. To make white or pale, to diminish the intensity of color. Bleached Lac. See Lac. Bleaching Powder, chlorinated lime, a mixture of calcium chlorid and calcium hypochlorite, containing free chlorin gas. It is much used as a disinfectant. Bleaching Fluid, eau de Javelle, a similar composition obtained by passing chlorin gas into an emulsion of calcium hydrate. The most important bleaching agents are the following : BLEACHING AGENTS.-Acids: Hydrochloric, Nitric, Sulphurous; Carbonate of Potassium $\left(\mathrm{K}_{2} \mathrm{CO}_{3}\right)$; its value depends upon the percentage of carbonate it contains; Caustic Soda (NaOH), a coarse white powder; Chlorid of lime, a white powder with a chlorinous odor; it is the most important of all; Hydrogen dioxid $\left(\mathrm{H}_{2} \mathrm{O}_{2}\right)$, a colorless, odorless liquid. It is called "Golden Hair-dye;" Permanganate of Potassium $\left(\mathrm{K}_{2} \mathrm{Mn}_{2} \mathrm{O}_{8}\right)$; Soaps: Tallow, Rosin, and Olive $\mathrm{Oil}$; Soda $A s h\left(\mathrm{Na}_{2} \mathrm{CO}_{3}\right)$; its value depends on the amount of $\mathrm{Na}_{2} \mathrm{O}$ it contains ; Soda Crystals $\left(\mathrm{Na}_{2} \mathrm{CO}_{3}\right.$.Io $\mathrm{H}_{2} \mathrm{O}$ ).

Bleacher's Eczema (blech'-erz ek'-zem-ah). Eczema of the hands of bleachers, due to their continuous immersion in hot water and strong lye.

Blear Eye (blèr'-i). See Blepharitis ulcerosa.

Bleb (bleb). See Bulla.

Blebby $($ bleb'-e) [Scotch, bleb, " a blister' ]. Covered with blebs.

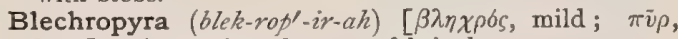
heat]. A transient fever; a febricula.

Blechrosphygmia (blek-ro-sfig'-me-ah) [ $\beta \lambda \eta \chi \rho o ́ s$, weak; $\sigma \phi v \gamma \mu \sigma ́ s$, pulse]. Weakness or slowness of the pulse.

Bleed (blèd) [AS., bledan, to bleed]. To shed or give vent to blood.

Bleeders (ble'-derz) [AS., blédan, to bleed]. A popular term for those who are subjects of the hemorrhagic diathesis. B.'s Disease. See Hemophilia.

Bleeding (ble'-ding). See Bloodletting and Hemorrhage. 


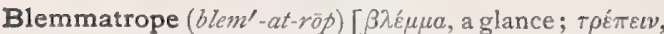
to turn]. An apparatus for showing the various positions of the eye in its orbit.

Blennadenitis (blen-ad-en-i'tis) [ $\beta \lambda \imath^{\prime} v v o s$, mucus; ádin, gland]. Inflammation of the mucous glands and follicles.

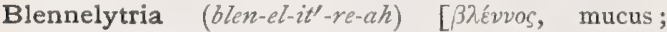

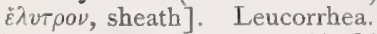

Blennemesis (blen-em'-es-is) [ $\beta \lambda \varepsilon^{\prime} v \nu \alpha$, mucus ; $\varepsilon \dot{\mu} \varepsilon \varepsilon(\nu$, to vomit]. The vomiting of mucus.

Blennemetic (blen-emt-et'-ik) [ $\beta \lambda \dot{\varepsilon} \nu \nu \alpha$, mucus ; $\varepsilon \mu \varepsilon \dot{\varepsilon} \varepsilon \nu$, to vomit]. Relating to or of the nature of blennemesis.

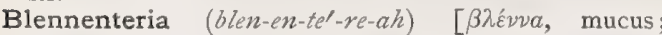

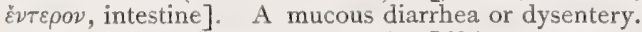

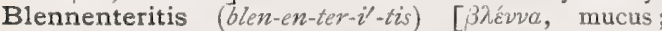

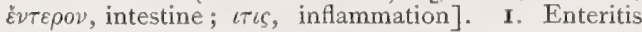
with a copious discharge of mucus. 2. Inflammation of the mucous membrane of the bowel.

Blennentery (blen'-en-ter-e). Same as Blennenteria.

Blennogenic, or Blennogenous (blen-o-jen'-ik, or

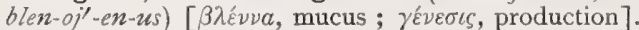
Producing or secreting mucus; muciparous.

Blennoid (blen'-oid) [ $\beta \lambda \varepsilon \dot{v} v \alpha$, mucus; $\varepsilon i \delta o s$, form]. Resembling mucus; myxoid; muciform; mucoid.

Blennoma (blen-o'-mah) [ $\beta \lambda \varepsilon ́ v v a$, mucus; ö $\mu \alpha$, a tumor : pl., Blennomata]. I. A mucous polypus. 2. A myxoma.

Blennometritis (blen-o-me-tri'-tis) [ $\beta \lambda \varepsilon ́ \nu v a$, mucus; $\mu \eta ́ \tau \rho a$, womb ; $\iota \tau \iota$, inflammation]. Catarrhal metritis.

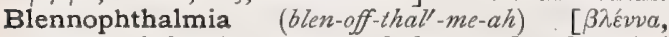
mucus; $\partial \phi \theta \alpha \lambda \mu i \alpha$, disease of the eyes]. Catarrhal conjunctivitis.

Blennoptysis (blen-op'-tis-is) [ $\beta \lambda \varepsilon v \nu v a$, mucus ; $\pi \tau v \sigma \iota \zeta$, a spitting]. Bronchial mucous expectoration.

Blennorrhagia (blen-or- $\left.a^{\prime}-j e-a h\right) \quad[\beta \lambda \varepsilon ́ v v a$, mucus ; ómvíva, to burst forth]. An excessive catarrhal discharge from the urethra or vagina. See Gonorrhea.

Blennorrhagic (blen-or-a'-jik) [ $\beta \lambda \varepsilon ́ v v a$, mucus; $\dot{\rho} \eta \gamma-$ vv́vaı, to burst forth]. Relating to blennorrhagia.

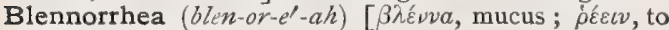
flow]. Same as Blennorrhagia.

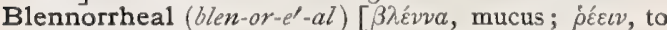
flow]. Relating to blennorrhea.

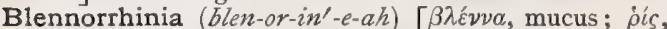
the nose]. Coryza; nasal catarrh.

Blennosis (blen-o'-sis) [ $\beta \lambda \varepsilon v v v a$, mucus; vóros, disease : pl., Blennoses]. Any disease of a mucous membrane.

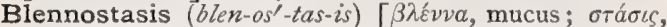
a staying]. The checking or suppression of any mucous discharge.

Blennostatic (blen-os-tat'-ik) [ $\beta \lambda \varepsilon ́ v \nu \alpha$, mucus; $\sigma \tau a ́ \sigma \iota s$, a staying]. Effecting a blennostasis; checking mucous discharges.

Blennothorax (blen-o-tho'-raks) [ [ $\beta \lambda \varepsilon v v a$, mucus; $\theta \omega \rho \alpha \xi$, the thorax $]$. Pulmonary catarrh.

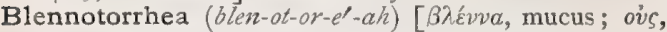
ear; poía, a flow]. A mucous discharge from the ear.

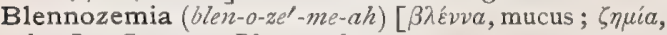
loss]. Same as Blennorrhea.

Blennuria (blen-u'-re-ah) [ $\beta \lambda \varepsilon ́ v v \alpha$, mucus; oṽpov, urine]. The presence of mucus in the urine.

Blennymenitis (blen-im-en-i'-tis) [ $\beta \lambda$ ćvv $^{\prime}$, mucus; vuŕv, membrane]. Inflammation of any mucous surface.

Blephara (blef'-ar-ah), Plural of Blepharon, q. $v$.

Blepharadenitis (blef-ar-ad'-en-i'-tis) [ $\beta \lambda \dot{\varepsilon} \phi a \rho o v$, the

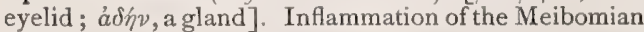
glands.

Blepharal (blef'-ar-al) [ $\beta \lambda \varepsilon ́ \phi a \rho o \nu$, the eyelid]. Relating to an eyelid or to the eyelids.

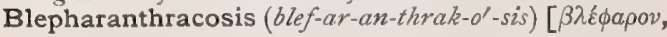

the eyelid ; ảvfpák $\omega \sigma \iota \varsigma$, a charring ; carbunculization] Carbuncular inflammation of the eyelid.

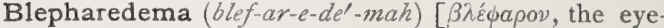
lid; oidinua, a swelling]. Swelling or edema of the eyelids.

Blepharelosis (blef-ar-el-o'-sis) [ $\beta \lambda \varepsilon$ capov, the eyelid; eidetv, to roll]. Synonym of Entropion.

Blepharemphysema (blef-ar-em-fis-e $\left.e^{\prime}-m a h\right)$ [ $\beta \lambda \varepsilon \dot{\varepsilon} \phi a \rho o v$, eyelid; $\dot{\varepsilon} \mu \varphi \dot{v} \sigma \eta \mu \alpha$, an inflation]. Emphysema of an eyelid.

Blepharis (blef'-ar-is) [ $\beta \lambda \varepsilon \phi a \rho i s$, an eyelash]. An eyelash.

Blepharism (blef'-ar-izm) [ $\beta \lambda \varepsilon \phi a \rho i \zeta \varepsilon \iota v$, to wink]. Rapid involuntary winking; morbidly excessive nictitation.

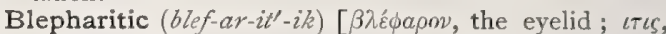
inflammation]. Relating to or affected with blepharitis.

Blepharitis (blef-ar-i'-tis) [ $\beta \lambda \varepsilon^{\prime} \phi \alpha \rho o v$, the eyelid; $\iota \tau \iota s$, inflammation]. Inflammation of the eyelids. B. ciliaris, tarsal ophthalmia; a pustular disease of the border of the eyelids, often the result of local irritation arising from habits of uncleanliness. B. marginalis, inflammation seated at the marginal border of the lids. B. ulcerosa, an ulcerative inflammation of the eyelids.

Blepharo-adenitis (blef'-ar-o-ad-en-i'-tis). See Blepharadenitis.

Blepharo-adenoma (hlef'-ar-o-ad-en-o'-mah) [ $\beta \lambda \varepsilon^{\prime} \phi-$ $a \rho o \nu$, the eyelid; $a \delta \eta \eta$, a gland; ö $u a$, a tumor: $p l .$, Blepharo-adenomata]. An adenoma on the ciliary margin of the eyelid.

Blepharo-atheroma (blef'-ar-o-ath-er-o'-mah) [ $\beta \lambda$ ć $\phi-^{\prime}$ $\alpha \rho o v$, an eyelid; $\alpha$ An $\rho \omega \mu \alpha$, a tumor full of gruel-like matter]. An atheromatous tumor imbedded in the tarsus of the lid; it is cystic and contains a semifluid detrital substance.

Blepharochromidrosis $\left(b l e f^{\prime}-a r-o-k r o-m i d-r o l-s i s\right)[\beta \lambda \varepsilon$

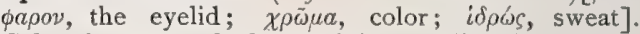
Colored sweat of the eyelids, usually of a bluish tint.

Blepharocleisis (blef-ar-o-kli'-sis) [ $\beta \lambda \bar{l}^{\prime} \phi a \rho o v$, the eyelid; $\kappa \lambda \varepsilon i \sigma \iota s$, closure]. Ankyloblepharon; abnormal closure of the eyelids.

Blepharodyschrea (blef-ar-o-dis-kre'-ah), or Blepha-

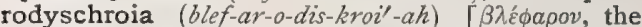
eyelid; $\delta v \sigma-$, bad; $\chi \rho o \iota x$, color]. Discoloration of the eyelid from nevus or from any other cause.

Blepharoedema (blef-ar-o-e-de'-mah). See Blepharedema.

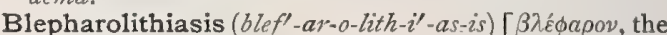

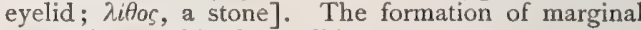
concretions within the eyelid.

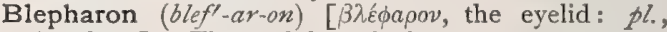
Blephara]. The eyelid; palpebra.

Blepharoncus (blef-ar-ong-kus) [ $\beta \lambda \varepsilon$ coapov, the eyelid; ö $\gamma$ kos, an enlargement]. A swelling of the eyelid.

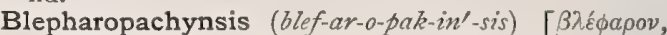
the eyelid; $\pi a \chi^{\hat{v}} \varsigma$, thick]. Morbid thickening of the eyelid.

Blepharophimosis (blef-ar-o-fi-mo'-sis) [ $\beta \lambda \varepsilon \phi a \rho o v$, the eyelid; $\phi i \mu \omega \sigma / \varsigma$, a shutting up $]$. Abnormal smallness of the palpebral openings.

Blepharophryplastic (blef-ar-o-frip-las'-tik) [ $\beta \lambda \varepsilon ́ \phi a \rho o v$, the eyelid; ö $\phi \rho v \varsigma$, brow; $\pi \dot{\lambda} \alpha \sigma \tau \iota \kappa \delta \varsigma$, plastic]. Pertaining to the plastic surgery of the lid and eyebrow.

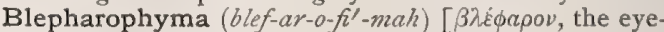
lid; фúva, a growth: pl., Blepharophymata]. A tumor of, or outgrowth from, the eyelid.

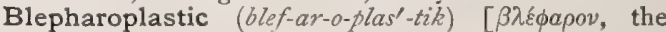
eyelid; $\pi \lambda a \sigma \tau \iota \kappa \sigma \varsigma$, plastic]. Pertaining to blepharoplasty. 
Blepharoplasty (blef'-ar-o-plas-te) [ $\beta \lambda \varepsilon \dot{\phi} a \rho m$, the eyelid; $\pi \lambda a ́ \sigma \sigma \varepsilon \iota \nu$, to form $]$. An operation for the formation of any part of the eyelid destroyed by wound or lesion, by engrafting or transplanting from a contiguous healthy part.

Blepharoplegia (blef-ar-o-plé-je-ah) [ $\beta \lambda \varepsilon \phi a \rho o v$, the eyelid; $\pi \lambda \eta \gamma^{\prime}$, a stroke]. Paralysis of an eyelid.

Blepharoptosis (blef-ar-op-to'-sis) [ $\beta \lambda \varepsilon \phi a \rho o \nu$, the eyelid; $\pi \tau \tilde{\omega} \sigma \iota s$, a fall]. Ptosis of an upper eyelid. See Ptosis.

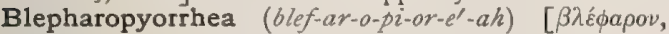
the eyelid; rivov pus; $\dot{\rho} \varepsilon \varepsilon v$, to flow ]. A flow of pus from the eyelid.

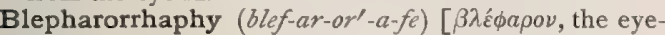
lid; $\dot{p} a \phi \hat{n}$, a seam ]. The stitching together of a part of the blepharal slit.

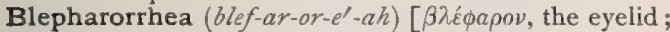
poía, a flow]. A discharge from the eyelid.

Blepharospasm (blef'-ar-o-spazm) [ $\beta \lambda \varepsilon \dot{c} \phi a \rho o \nu$, the eyelid; $\sigma \pi a \sigma \mu \delta s$, a spasm]. Spasm of the orbicularis palpebrarum muscle. Excessive winking.

Blepharospath (blef'-ar-o-spath) [ $\beta \lambda \varepsilon ́ \phi a \rho o v$, the eyelid; $\sigma \pi a \dot{\theta} \eta$, a blade]. A forceps for taking up or holding an artery; for use in operations on the eyelid.

Blepharostat (blef'-ar-o-stat) [ $\beta \lambda \varepsilon \dot{\varepsilon} \phi \rho o v$, the eyelid ; ¿ớavaı, to cause to stand]. An instrument for holding the eyelids apart or firm whilst performing operations upon the eyes or lids.

Blepharostenosis (blef-ar-o-ste-no'-sis) [ $\beta \lambda \varepsilon$ sapov, the

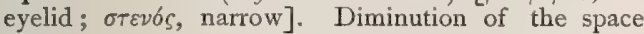
between the eyelids.

Blepharosynechia (blef-ar-o-sin-ek-i'-ah) [ $\beta \lambda \varepsilon ́ \phi a \rho o v$,

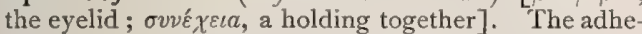
sion or growing together of the eyelids.

Blepharotomy (blef-ar-ot'-o-me) [ $\beta \lambda \varepsilon \dot{\varepsilon} \phi a \rho o v$, the eyelid; $\tau \varepsilon \mathcal{L} \varepsilon \varepsilon v$, to cut]. Incision into the eyelid. B., Oblique. Sphincterotomy, or Stellwag's operation. See Operations, Table of.

Blesitas (ble'-sit-as) [blesus, a lisping]. Stammering or lisping; the use of a vocalized consonant instead of a mute ; as $b$ for $p$. Also the condition of one with distorted limbs. Applied also to an angular curvature of the spine. The term is loosely used.

Blessed Thistle. (bles'-ed this'-l). See Carduus.

Blight (blīt) [origin unknown]. A partial paralysis of certain facial nerves, arising from sudden or extreme cold. B. of the Eye, an extravasation of blood within the conjunctiva.

Blind (blind) [AS., blind]. Without sight. Deprived of sight. B. Spot, that part of the area of the fundus of the eye where the optic nerve enters. B. Staggers. See Staggers.

Blinder (blind'-er) [AS., blind]. A shield worn before an eye, to temporarily throw it out of function. See Gould, Method of. B. Treatment of monocular amblyopia. See Gould, Method of.

Blindness (blind'-nes) [AS., blind]. Want of vision. Color-B., subnormal perception of colors. This condition is found in about 4 per cent. of people, is more frequent in men than in women, and is probably due to non-exercise of the color-sense. Complete Color$B$. is very rare, the different colors probably appearing as different intensities or shades of white light. In Partial Color-B. subnormal perception of red is the most frequent, green, blue and yellow, respectively, being next in order. Tests for Color-B. usually consist in matching and classifying colored yarns. Cortical B., B. due to lesion of the cortical center of vision. Day-B. See Nyctalopia. Mind-B. See Psychic B. Moon-B., a rare condition of retinal anesthesia said to be due to exposure of the eyes to the moon's rays in sleeping. Night-B. See Hemeralopia. B., Object-. See Apraxia. Psychic B., loss of conscious visual sensation from destruction of the cerebral visual center; there is sight but not recog nition. Snow-B., photophobia and conjunctivitis due to exposure of the eyes to the glare of sunlight upon snow. B., Word-. See Aphasia.

Blister (blis'-ter) [ME., blister, a vesicle]. A vesicle resulting from the exudation of serous fluid between the epidermis and true skin. Also the agent by which the blister is produced. B., Fly, a beetle, Cantharis vesicatoria, the body of which is used as a blistering agent; a blister of cantharides. B., Flying, a blister that remains long enough to produce redness of the skin and not vesication. B. Test, for gout. The serum from a blister in a gouty individual will yield crystals of uric acid when examined by Garrod's thread test $(q \cdot v$.$) , only, however, when the blister is situated$ at a distance from the affected joint. According to Garrod the acid cannot be detected in the fluid from a blister in the neighborhood of the gouty articulation, and he infers that gouty inflammation causes a local destruction of uric acid.

Bliștering (blis'-ter-ing) [ME., blister, a vesicle]. Forming a vesicle upon the skin. B. Collodion, a solution of cantharidin in ether. B. Liquid. Same as B. Collodion. B. Paper, paper saturated with cantharides; used for producing vesication.

Bloat (blöt) [ME., blote, swelling]. I. Puffiness; edema; turgidity from any cause, as from anasarca. 2. A form of colic in the horse produced by tympanitic distention of the intestines. Also called Wind Colic.

Block $(b l o k)$ [ME, $b l o k$, a piece of wood]. In dentistry a mass of gold foil for filling teeth, made by folding a tape of foil upon itself several times by means of pliers. B. Teeth. Two or more artificial teeth carved from a piece of ivory, or carved or moulded from a mass of porcelain paste and afterwards baked and enamelled. B. Teeth, Biscuiting, or Crucing of. The teeth, after being moulded or carved, are placed on a slide and put in the muffle of a furnace and subjected to a bright-red heat, by which process the particles become sufficiently agglutinated and hardened to receive the enamel. This is called biscuiting or crucing

Blond (blond) [Fr., blond, light, fair]. r. Light complexioned; fair. 2. A person with a fair complexion. Blood (blud) [ME., blood]. The fluid that circulates through the heart, arteries, and veins, supplying nutritive material to all parts of the body. In the human being the blood of the arteries is bright-red; that of the veins dark-red. Blood consists of colorless plasma in which are suspended the red and colorless corpuscles. When exposed to the air it coagulates, forming a red-clot and a yellowish fluid called serum. Healthy blood consists of 79 per cent of water, and $2 \mathbf{I}$ per cent. solids. B.-Casts, tubecasts to which red-blood corpuscles are attached. B.-Corpuscles, small, circular, biconcave discs floating in the blood. Red corpuscles are circular in mammals (except the camel), and elliptical in birds and reptiles. In man they are about $\frac{1}{3 \frac{1}{2}}$ inch in diameter and $\frac{1}{2000}$ inch thick. Colorless corpuscles are about one-third larger in diameter and comparatively few. They exhibit movements similar to those of amebce.

The coloring-matter of the $B$, is found in a substance

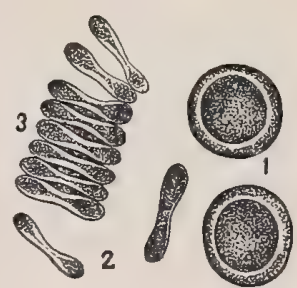

Human Colored BloodCORPUSCLES.

1 , on the flat; 2 , on edge: 3 , rouleau of corpuscles. (After Landois.) 
known as hemoglobin, and is said to be due to minute quantities of the salts of iron. B.-cure, the therapeutic employment of fresh blood, mainly that of bullocks.

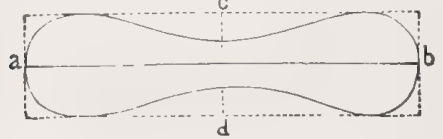

Ineal Transverse Section of a Human Red BloodCORPUSCLE (magnified, 500 times).

$a, b$, diameter; $c, d$, thickness. (After Landois.)

B.-crystals, crystals of a substance known as hematoidin. B., Defibrinated, freshly shed blood that has been beaten with a glass rod or tongs until the fibrin has all adhered to the rod in the form of a solid, fibrous, yellowish-white, elastic mass. B.-flower. See Asclepias. B.-fluke. See Bilharzia Hematobia. B., Gases of, certain gases given off when blood is exposed to the vacuum produced by an air-pump. They are carbonic acid, nitrogen, and oxygen, and constitute about half of the volume of the blood. B.-globules. Same as B.-corpuscles. B.-heat, a temperature varying from $98^{\circ}$ to $100^{\circ} \mathrm{F}$. B.-islands, a term applied to the groups of corpuscles developed during the first days of embryonic life, within the large branched cells of the mesoblast. B., Loss of. See Hemorrhage. B.-mole, in obstetrics, a mole consisting of the decidua only, interspersed with effusions of blood, the fetus having been expelled. B.plaque. See B.-platelets. B.-plasma, the liquor sanguinis, or fluid part of the blood. B.-plate. See $B$-platelets. B.-platelets ; besides the red and colorless corpuscles, the blood contains smaller formed elements, concerning which there are many theories and names. Hayem describes Hematoblasts; Pouches describes Globulins; Max Schultze, Körnchen (elementary bodies); Bizzozero, Blut-plättchen, or Bloodplatelets. They are circular or oval, light gray, and in human blood destitute of nuclei. They are from I to I. $3 \mu$ in size, there being from $\mathbf{1} 8,000$ to 300,000 in the cubic millimeter. B.-poisoning, a common term denoting any ailment arising from the introduction of decomposing organic matter or putrefactive germs into the blood. See Anthrax, Pyemia and Septicemia. B.-pressure, the force of compression exerted by the blood upon the walls of the vessels under the influence of the heart's action, the elastic walls, etc. Various instruments have been devised to estimate the amount of this pressure, the Hemadynamometer of Poisewille, Ludwig's Kymograph, Fick's Spring Kymograph, v. Basch's Sphygmomanometer, the Graduated Sphyomograph, Manomiter, etc. B.-root. See Sanguinaria. B.-shot, extravasated with blood. B.-spavin. See Spavin. B.-stone. See Conspectus of Pigments, under Pigment. B.-striking. Synonym of Antlerax. See also Black-leo. B-tablet. See Blood-plate. B.-tumor. See Hematoma. B.-vessel, a tube-like structure for conveying the blood through the body. Cf. Artery and Vein.

Bloodless (blud'-les) [ME., blood]. Without blood. B; Operations, surgical operations, such as amputations, in which the member is so bandaged by compresses and elastic bands that the blood is expelled and kept from the part to be operated upon.

Bloodletting (blud-let'-ing) [ME., blood; leten]. The artificial abstraction of blood from the body. B., General, venesection or phlebotomy ; it acts by reducing the heart's action and diminishing the quantity of blood. It is occasionally used with excellent results in pneumonia, sunstroke, etc. B., Local or Topical. See Cupping, Leeching or Scarification. It is useful in certain inflammatory conditions.

Bloody $\left(b l_{u d} d^{\prime}-e\right)$ [ME., blood.] Having the nature of, or filled with blood. B. Flux. See Dysentery. B. Milk. See Red Mitk Bacillus and Bacteria, Synonymatic, Table of. B. Murrain. Synonym of Anthrax. B. Sweat. See Ephidrosis.

Bloom $(b l u \bar{m})$ [ME., blom, a blossom]. I. A blossom. 2. A state of health. 3. See Lubricating Oils.

Blossom $\left(\right.$ blos' $^{\prime}$ um $)$ [ME., blossome, a flower]. In biology, (I) the flower of a plant; (2) to put forth flowers.

Blotch (bloch) [origin uncertain]. A pimple or blain; a small discolored patch of skin; a group of small pustules.

Blow $(b l o)$ [AS., blôvan]. 1. To pant. 2. To deposit eggs upon, as flies.

Blowing Sound. See Bellozes Murmur.

Blown (blōn) [ME., blowen]. In farriery, with the stomach distended from gorging with food. B. Meat, meat that has been blown up with air in order to give it a white color and to hide defects in its condition.

Blow-pipe $\left(b l \sigma^{\prime}-p \bar{i} p\right)$. A cylindrical tube, from twelve to eighteen inches long, about half an inch in diameter at one end, and gradually tapering to a fine point or nozzle, which may be straight or bent at a right angle; it is used in directing the flame of a lamp in a fine conical tongue. B., Automaton, in dentistry, a blow-pipe especially designed for crown and bridgework, into which the air is admitted and conducted through a small tube to the upper end of another which admits illuminating gas. The supply of both air and gas is regulated by the presssure of the thumb or fingers on the rubber tubes of the appliance. B., Oxyhydrogen, an apparatus for producing intense heat by burning hydrogen or illuminating gas at the end of a mixing nozzle.

Bloxam's Test. See Tests, Table of.

Blue $(6100)$ [ME., blew]. One of the colors of the spectrum. B., Alexandria. Same as Egyptian Blue. B.-Baby, a child with blue disease. B.-bottle. See Centaurea. B. Blindness, acyanopsia. B. Cohosh. See Caulophyllum. B. Disease, cyanosis of the new-born, due frequently to congenital disease of the heart. This usually consists in constriction of the pulmonary artery with deficiency in the septum of the ventricles, the aorta communicating with the right ventricular cavity. See Cyanopathy. B. Flag. See Iris. B. Gentian, the root of Gentiana catesbrei, tonic and stomachic. Dose of fld. ext. $m \times x-x l$ Unof. B. Gum. See Gingival. B. Gum Tree. See Eucalyptus. B. Cardinal Flower. Synonym of Lobelia syphilitica. B. Edema, a puffed and bluish appearance of the limb sometimes seen in hysterical paralysis. B. Jaundice. See Acleitocardia. B. Line. See Lead Line. B. Malachite. Same as Azurite. B. Mass. See Hydrargyrum. B.-milk Bacillus, Bacillus cyanogenus; it imparts a blue color to milk and renders it irritating to the stomach and intestine. See Bacteria, Synonymatic Table of. B. Ocher. See Conspectus of Pigments under Pigment. B. Ointment. See Hydrargyrum. B. Pill. See Hydrargyrum. B., Prussian. See Pigment, B. Stick. Same as B. Stone. B. Stone. See Copper and B. Vitriol. B. Verditer. Same as Bremen Blue. B. Vervain. See Verbena. B. Vitriol. See Conspectus of Pigments, under Pigment. Blues (blooz) [ME., blew]. A popular name for short periods of mental depression; they are usually associated with indigestion.

Blumenbach, Clivus of. See Clivus. B., Plane of. See Plane. 
Blunt-hook (blunk'-hook). An obstetric instrument, used mainly in embryotomy.

Blunzen (blunz'-en) [Ger.]. A peculiar Würtemberg sausage, made by filling the stomachs of hogs with meat, and cured by a method favoring putrefaction. This is the most common source of sausage-poisoning. See Allantiasis and Botulismus.

Blushing (blush'-ing) [ME., blushen, to glow]. The reddening of the face through shame, modesty, or confusion. See Rubor.

Boa $\left(b o^{\prime}-a h\right)[\mathrm{L}$.$] . An ancient name applied to various$ eruptions and eruptive diseases, as measles, smallpox, hydroa, syphilis. B. Vista Fever. See Fiever.

Boas's Test. See Tests, Table of.

Boat-belly (bōt'-bel-e). See Scaphoid Abdomen.

Bobb's Operation. See Operations, Table of.

Bochdalek's Ganglion. See Ganglia, Table of. B's Pseudo-ganglion. See Pseudo-ganglion.

Bock, Nerve of. See Nerves, Table of:

Bockhart's Blood-serum Mercury. A mercurial used in the treatment of syphilis. It is prepared as follows from the blood of sheep, horses, or oxen: Io $1 / 2$ drams of blood-serum, sterilized after Koch's method, are placed in a graduated glass, and then mixed with a solution of 45 grains of bichlorid of mercury dissolved in one ounce of boiling distilled water. The precipitate formed is redissolved by the addition of IO5 grains of chlorid of sodium, dissolved in five drams of distilled water. This compound is then a three per cent. solution of blood-serum mercury. By adding enough distilled water to make six ounces five drams, we have the solution generally used, containing one and one-half per cent of the mercurial salt. Injections of 15 minims (containing one-quarter grain of sublimate, combined with albumin) are made daily.

Bodo $\left(b 0^{\prime}-d o\right)$ [L.]. A genus of flagellate protozoans. B. saltans has been reported as living in great numbers in unhealthy ulcerations. B. urinarius has been found in the urine of cholera-patients.

Body $\left(b_{o d} d^{\prime}-e\right)$ [AS., bodig]. I. The animal frame with its organs. Also a cadaver or corpse. 2. This term is applied by the manufacturer of porcelain teeth to the parts composing the principal portion of the artificial organ. 3. The tube of a microscope, including the draw-tube; it is the tube receiving the ocular at one end and the objective at the other. See also Corpus, and Corpora. B. Cells. See Heredily. B. Louse. See Pediculus. B.-plasm. See Somatoplasm, under Heredity. B., Sub-thalamic. See Luys, Body of.

Boeckel's Operations. See Operations, Table of.

Boerhaave, Glands of. See Gland.

Bog $(b \circ g)$ [E. dial.]. To ease the body by stool.

Bog (bog) [Gael., bogan, a bog]. Ground that is wet and spongy. B.-bean. See Buckbean. B.-spavin. See Spavin.

Bogue's Operation. See Operations, Table of.

Böhm's Acid Carmin. See Stains, Table of. B.'s Operation. See Operations, Table of.

Böhmer's Hematoxylin Solution. See Stains, Table of.

Bohun Upas (bo'-hun-u'-pas). See Antiar and Cpas.

Boil (boil) [ME., boile]. A furuncle; a localized inflammation of the skin and subcutaneous connective tissue attended by the formation of pus. See Furunculus. B., Aleppo or B., Delhi, a peculiar ulcerative affection endemic in India, due to a specific and pathogenic microbe. It has been proposed by Heydenreich to call this Tropical Boil. Other names are Penjdeh Boil and Bouton Biskra. B.-plague. Synonym of Anthrax.

Boiled Oil. Linseed oil that has been heated to a high temperature $\left(130^{\circ} \mathrm{C}\right.$. and upward), while a current of air is passed through or over the oil, and the temperature increased until the oil begins to effervesce from evolution of products of decomposition. B.-sago Matter. Vitreous-looking bodies frequently seen in the stools of dysentery. They are simply granules of starch ingested as food and remaining partially or wholly undigested. They are also called Frogs'-spazen matter.

Boiler-makers' Deafness. See Deafness.

Boiling (boil'-ing) [ME., boilen, to stir]. The vaporization of a liquid when it gives off vapor having the same tension as the surrounding air. Most tissues, animal and vegetable, are softened and rendered more or less soluble by boiling. Albumin and most albuminoids, however, are rendered insoluble. The temperature of boiling water at the level of the sea is $212^{\circ} \mathrm{F} .\left(100^{\circ} \mathrm{C}\right.$.) ; it decreases with increasing altitude. B. Test. See Tests, Table of.

Boissons (bwah'-song) [ Fr. ]. Cheap fermented liquors made from raisins or other dried fruits to which sweetened water is added and fermentation allowed.

Bola (bo'-lah). See Myrrh.

Bolary (bo'-lar-e) [bolus, clay]. Of the nature of bole.

Bolax (bo'-laks). See Balsam-bog. B. Gum. See Balsam-bog.

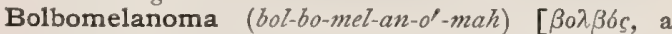
bulb; $\mu \varepsilon \lambda a ́ v \omega \mu a$, blackness]. Melanotic carcinoma of the eyeball.

Boldin (bol'-din). See Boldus.

Boldo $\left(b o l^{\prime}-d o\right)$. See Boldus. B.-glucine, an aromatic glucosid obtained from Peumus boldus and other species. It is a hypnotic in doses of gr. $x x-3 j$. Unof.

Boldoa (bol'-do-ah) [Chilian, Boldu]. A genus of monimiaceous trees. B. fragrans, the tree Peumus boldus. See Boldus.

Boldus (bol'-dus) [L. $]$. Boldo. The leaves and stems of an evergreen, Peumus boldus, native to Chili and vicinity, sometimes used in anemia and general debility as a substitute for quinin. It contains a bitter alkaloid, Boldin, an hypnotic in doses of gr. iij. B., Ext., Fld. Dose $m_{\text {j-iv. B., Tinct., contains }}$ 20 per cent. of the drug. Dose $\eta^{v}$-viij.

Bole $(b \bar{o} l)[\beta \tilde{\omega} \lambda \circ s$, a clod of earth]. I. A translucent, soft variety of clay formerly much used in medicine, internally as an astringent, externally as an absorbent. Dose gr. $v-x$. Several varieties are used, as the Armenian bole; the Lemnian, and the French bole. 2. A bolus. See Bolus.

Boletus (bo-le'tus) [ $\beta \omega \lambda i \tau \eta s$, a kind of mushroom]. A genus of fungi, some species of which are edible, while others are highly poisonous. None is official.

Bologna (bo-ton'-yah) [It. ]. A city of northern Italy. B. Lime. Same as Vienna White. B. Phosphorus, a sulphid of barium, having the property of emitting a pale, feeble light in the dark.

Bolus (bo'llus) [L. : pl., Boli; Eng.pl., Boluses]. I. A mass of medicine exhibited in the form of a large pill. 2. A mass of masticated food ready to swallow.

Bombardier Beetle. See Brachenin.

Bombax (bom'-baks) [bombyx, cotton]. A genus of huge tropical malvaceous trees of many species. Some of these trees afford demulcent diuretic medicines. Mocmain, q.v., is a product of $B$. malabaricum.

Bombus (bom'-bus) [ $\beta 6 \mu \beta o s$, a humming sound]. A ringing or buzzing sound in the ears; tinnitus. Also a sonorous movement or rumbling flatus of the intestines: borborygmus.

Bona Fever $\left(b o^{\prime}\right.$-nah fe'-ver $)$. See Fever.

Bonbon (bon'-bon) [Fr.]. A confection. B., Pectoral, a medicated antibechic confection.

Bond's Operation. See Operations, Table of.

Bonduc Seeds (bon'-duk sëdz). See Bonducella. 
Bonducella (bon-du-sel'-ah) [L. ]. Bonduc Seeds. The seeds of Cesalpinia bonducella, a tropical plant. It is a bitter tonic and antiperiodic in intermittent fevers, Dose gr. x-xv.b B., Pulv., Comp., contains bonduc and black pepper. Dose gr. $\mathrm{xv}-\mathrm{xx}$.

Bone $(\bar{b} \bar{n})$ [AS., bān, a bone]. A hard tissue that constitutes the framework or skeleton of the body. It is composed mainly of tri-calcium phosphate and cartilage. Bone usually consists of a compact outer mass covered with periosteum, surrounding a reticulated inner structure that encloses a central cavity filled with marrow. A transverse section of a long bone shows bone-tissue to be composed of a number of nearly circular zones, each having a central tube, the Haversian canal, through which the blood circulates. Surrounding the Haversian canal are concentrically arranged belts of oblong spaces called lacuno. Each lacuna is the outlet of a number of canaliculi, through which the nutrition is conveyed to all parts of the bone. A table of bones is appended. B. Ash, the calcic phosphate remaining after bones have been incinerated. B. Binder. See Osteocolla. B.-black. Same as Animal Black. B.-brown. See Pigments, Conspectus of. B. Cartilage. See Ostein. B.conduction, the transmission of sound-waves to the auditory nerve by means of sonorous vibrations communicated to the bones of the skull, the impression reaching the nerve in part directly and in part by way of the tympanic structure. The tuning-fork is the instrument most commonly used as a test of boneconduction. Bone-conduction is lost or diminished in many of the typical labyrinthine lesions, e.g., in true Menière's disease. See Air-conduction. B. Earth. See Ossiterra. B., Epipteric [ $[\dot{\varepsilon} i$, upon; $\pi \tau \varepsilon \rho \delta ́ v$, a wing], a small Wormian bone sometimes found between the great wing of the sphenoid and the anterior inferior angle of the parietal. B.-fat, a whitish-yellow fat obtained by boiling bones. It is used in soap making. B.-gelatin. See Gelatin. B.glue. See Glue, B. incarial. See Incarial. B.nippers, surgical cutting-forceps for use on bones. B.-oil, a foul-smelling oil obtained in the dry distillation of bone. B.-setter, a specialist at setting bones; usually an uneducated empiric, and often a pretender to hereditary skill in the business. B.-spavin. See Spavin. B.-tumor. Synonym of Actinomycosis.

Bonelet $\left(b \bar{o} n^{\prime}\right.$-let $)$. See Ossicle.

Bonellein (bo-nel'-in) [Bonellia, a genus of gephyrean worms, named after F. A. Bonelli, an Italian naturalist]. In biology, the green pigment of certain annelids, as Bonellia viridis.

Boneset. See Eupatorium.

Bonnafond's Apparatus. An apparatus for generating vapors and injecting them into the middle ear through the Eustachian tube.

Bonnet's Capsule. See Ocular Sheath. B. Operations. See Operations, Table of.

Bontius, Pills of. Purgative pills used in dropsy. They contain gamboge, Socotrin aloes, and gum ammoniac.

Bonwill's Crown. In dentistry, an artificial crown of all porcelain to be engrafted on a natural root. B's. Method, I. A method of producing anesthesia. It is done by rapid breathing of the ordinary atmospheric air. The patient opens his mouth and breathes freely, quickly, and deeply, and in a few seconds or minutes partial anesthesia supervenes. 2. A method of articulating teeth.

Bonzel's Operation. See Operations, Table of.

Booboo $\left(b o o^{\prime}-b o o\right)$. See Boohoo.

Boohoo $\left(b 00^{\prime}-h o o\right)$ [native S. Pacific]. A kind of gastritis with slight fever and with great nostalgia and depression of spirits. It attacks strangers in some of the Pacific Islands.

Booker, Bacillus of. See Bacteria, Synonymatic Table of.

Boot, Junod's. See Junod's Boot.

Boracic Acid (bo-ras'-ik as'-id). See Acid, Boric; also Boron.

Borage (bo'-rāi) [ME., borage]. The plant Borago officinalis, a demulcent, mild refrigerant and diaphoretic. Dose of fld. ext., $3 \mathrm{j}$. Unof.

Boraginaceous (bo-raj-in- $\left.a^{\prime}-s e-u s\right)$ [Boraginaced, a natural order of plants]. Pertaining to the Boraginacer.

Borate $\left(\bar{b} o^{\prime}-r \bar{a} t\right)[$ Ar., bōraq, borax]. Any salt of boric acid.

Borax (bol-raks). See Boron. B. Bath. See Bath.

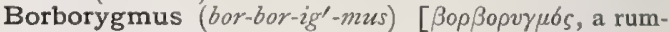
bling: plo, Borborygmi]. A rumbling of the bowels.

Bordeaux Method. A form of cotton antiseptic dressing for stumps.

Borelli's Operation. See Operations, Table of.

Boric Acid (bo'-rik as'-id). See Boron.

Born (born) [AS., boren, to bear, bring forth]. Brought into the world by the process of parturition. B. Alive. See Live Birth.

Borneo Camphor (bor'-ne-a-kam'-for). See Borneol. Borneol (bor'-ne-ol) [Borneo], $\mathrm{C}_{10} \mathrm{H}_{18} \mathrm{O}$. Borneo Camphor; a substance that occurs in Dryobalanops camphora, a tree growing in Borneo and Sumatra. It is artificially prepared by acting with sodium upon the alcoholic solution of common camphor. It is quite like Japan camphor, and has a peculiar odor resembling that of peppermint. It sublimes in six-sided leaflets, melts at $198^{\circ}$ and boils at $212^{\circ}$. It produces spasms of an epileptiform character.

Born's Method. A method of reconstructing objects from microscopic sections; by means of a camera, the outlines are transferred to wax plates, which are then cut out so as to correspond to the sections.

Boro-borax (bo-ro-bo'-raks). A crystalline combination of borax and boric acid. It is used as an antiseptic.

Borofuchsin. See Stains, Conspectus of.

Boroglycerid (bo-ro-glis'-er-id). See Boroglycerin. "

Boroglycerin (bo-ro-glis'-er-in) [Ar., böraq, borax;

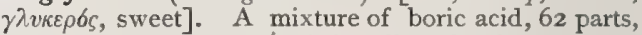
with glycerin, 92 parts, it is called also boroglycerid, and glyceryl borate. It is a solid preparation, soluble in water. It is used as a local application in eye and skin affections. It is an active antiseptic in a solution of $\mathrm{I}$ to 40 . Unof.

Boron $\left(b o^{\prime}\right.$-ron $)$ [Ar., bōraq, borax]. B=II; quantivalence III, V. The base of boric acid and of the mineral borax. Boracic, or, more properly, Boric Acid, $\mathrm{H}_{3} \mathrm{BO}_{3}$, a crystalline substance, found native in the volcanic lagoons of Tuscany. It occurs in white, transparent crystals, soluble in water and alcohol; it is an active antiseptic, and is much used in parasitic diseases of the skin. Dose gr. v-xx. Unguent. Acidi Borici (B. P.), contains hard paraffin 2, soft paraffin 4, boric acid $\mathbf{I}$. It is used as an antiseptic and in dermatology. Borax, $\mathrm{Na}_{2} \mathrm{~B}_{2} \mathrm{O}_{7}, \mathrm{I}_{\mathrm{OH}} \mathrm{O}$, sodium biborate, occurs in lacustrine deposits as white, transparent crystals, soluble in water, alcohol and glycerin. It is used as an antiseptic wash for ulcers and indolent lesions and is valuable also as an emmenagogue, and in leucorrhea. Dose gr. v-xl. All unof. Glycerinum Boracis (B. P.), contains borax, glycerin and distilled water; it is used as a local application. Mel Boracis (B. P.), borax honey, contains borax, clarified honey and glycerin (about $I$ in 7 ); it is used as a local application. 


\section{TABLE OF BONES.}

\begin{tabular}{|c|c|c|c|}
\hline NAmE. & PRINCIPAL FEATURES. & ARTICULATIONS AND VARIETY. & $\begin{array}{l}\text { MUSCULAR AND LIGAMENTOUS } \\
\text { ATTACHMENTS. }\end{array}$ \\
\hline Astragalus. & $\begin{array}{l}\text { Irregularly cubical; forms the key- } \\
\text { stone of arch of foot; head, neck, } \\
\text { six articular surfaces. }\end{array}$ & 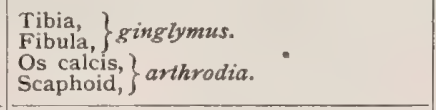 & Internal and external lateral ligaments. \\
\hline Atlas. & $\begin{array}{l}\text { First cervical vertebra; ring-like; } \\
\text { anterior and posterior arches and } \\
\text { tubercles; articular surfaces. }\end{array}$ & $\begin{array}{l}\text { Occipital bone-double arthrodia. } \\
\text { Axis, four joints-diarthrodia rota- } \\
\text { toria and double arthrodia. }\end{array}$ & $\begin{array}{l}\text { Longus colli (tubercle), rectus capitis } \\
\text { posticus minor (spinous process). }\end{array}$ \\
\hline Axis. & $\begin{array}{l}\text { Second cervical vertebra; body, } \\
\text { odontoid process, pedicles, lam- } \\
\text { inæ, spinous process, transverse } \\
\text { processes, articular surfaces. }\end{array}$ & $\begin{array}{l}\text { First cervical vertebra-diarthrodia } \\
\text { rotatoria and double arthrodia } \\
\text { Third cervical vertebra-double ar- } \\
\text { throdia. }\end{array}$ & Longus colli, check ligaments. \\
\hline Calcaneum. & $\begin{array}{l}\text { The heel bone; irregularly cu- } \\
\text { boidal; lesser process [sustenta- } \\
\text { culum tali], greater process, pero- } \\
\text { neal ridge or spine, superior } \\
\text { groove, articular surfaces. }\end{array}$ & $\left.\begin{array}{l}\text { Astragalus, } \\
\text { Cuboid, } \\
\text { Scaphoid, }\end{array}\right\}$ arthrodia. & $\begin{array}{l}\text { Tibialis posticus, tendo Achillis, plant- } \\
\text { aris, abductor pollicis, abductor mini- } \\
\text { mi digiti, flexor brevis digitorum, } \\
\text { flexor accessorius, extensor brevis } \\
\text { digitorum. }\end{array}$ \\
\hline Carpal. & $\begin{array}{l}\text { Consists of scaphoid, semilunar, } \\
\text { cuneiform, pisiform, trapezium, } \\
\text { trapezoid, os magnum, unciform. } \\
\text { See Indiviaual Bones. }\end{array}$ & & \\
\hline Clavicle. & $\begin{array}{l}\text { Collar bone, resembles the italic } \\
\text { "f"; conoid tubercle, deltoid } \\
\text { tubercle, oblique line. }\end{array}$ & $\left.\begin{array}{l}\text { Sternum, } \\
\text { Scapula, } \\
\text { Cartilage of first rib, }\end{array}\right\}$ arthrodia. & $\begin{array}{l}\text { Sterno-cleido-mastoid, trapezius, pec- } \\
\text { toralis major, deltoid, subclavius, } \\
\text { sterno-hyoid, platysma. }\end{array}$ \\
\hline Coccyx. & $\begin{array}{l}\text { The last bone of the vertebral col- } \\
\text { umn ; resembles a cuckoo's beak; } \\
\text { usually composed of four small } \\
\text { segments ; base, apex, cornua. }\end{array}$ & Sacrum-amphiarthrodia. & $\begin{array}{l}\text { Coccygeus, gluteus maximus, extensor } \\
\text { coccygis, sphincter ani, levator ani. }\end{array}$ \\
\hline Cranial. & $\begin{array}{l}\text { Occipital, parietal (two), frontal, } \\
\text { temporal (two), sphenoid, eth- } \\
\text { moid. See Individual Bones. }\end{array}$ & . & \\
\hline Cuboid. & Somewhat pyramidal ; tuberosity. & $\left.\begin{array}{l}\text { Os calcis, } \\
\text { External cuneiform, } \\
\text { 4th and 5th metatarsal } \\
\text { bones. }\end{array}\right\}$ arthrodia. & Flexor brevis pollicis. \\
\hline $\begin{array}{l}\text { Cuneiform } \\
\text { (of carpus). }\end{array}$ & Pyramidal. & $\left.\begin{array}{l}\text { Semilunar, } \\
\text { Pisiform, } \\
\text { Unciform, } \\
\text { Interarticular fibro-car- } \\
\text { tilage. }\end{array}\right\}$ arthrodia. & \\
\hline $\begin{array}{l}\text { Cuneiform } \\
\text { (of tarsus). } \\
\text { Internal. }\end{array}$ & $\begin{array}{l}\text { Irregularly wedge-shaped; the } \\
\text { largest of the three. }\end{array}$ & $\left.\begin{array}{l}\text { Scaphoid, } \\
\text { Middle cuneiform, } \\
\text { First and second meta- } \\
\text { tarsal bones. }\end{array}\right\}$ arthrodia. & Tibialis anticus and posticus. \\
\hline Middle. & $\begin{array}{l}\text { Wedge-shaped; smallest of the } \\
\text { three. }\end{array}$ & $\left.\begin{array}{l}\text { Scaphoid, } \\
\text { Internal cuneiform, } \\
\text { External cuneiform, } \\
\text { Second metatarsal. }\end{array}\right\}$ arthrodia. & Tibialis posticus. \\
\hline External. & Wedge-shaped. & $\left.\begin{array}{l}\text { Scaphoid, } \\
\text { Middle cuneiform, } \\
\text { Cuboid, } \\
\begin{array}{l}\text { Second, third, and fourth } \\
\text { metatarsal bones. }\end{array}\end{array}\right\}$ arthrodia. & Tibialis posticus, flexor brevis pollicis. \\
\hline Ethmoid. & $\begin{array}{l}\text { Irregularly cubical ; situated at an- } \\
\text { terior part of base of skull; hori- } \\
\text { zontal or cribriform plate, per- } \\
\text { pendicular plate, two lat e r a } 1 \\
\text { masses, crista galli. }\end{array}$ & $\begin{array}{l}\text { Sphenoid, } \\
\text { Two sphenoidal- } \\
\text { turbinated, } \\
\text { Frontal, } \\
\text { Two nasal, } \\
\text { Two superior max- } \\
\text { illary, } \\
\text { Two lachrymal, } \\
\text { Two palate, } \\
\text { Two inferior turb- } \\
\text { inated, } \\
\text { Vomer. }\end{array}$ & None. \\
\hline Femur. & $\begin{array}{l}\text { Cylindrical ; longest, largest, and } \\
\text { strongest bone in the body ; shaft } \\
\text { and two extremities, head, neck, } \\
\text { greater and lesser trochanters, } \\
\text { linea aspera, condyles; a long } \\
\text { bone. }\end{array}$ & $\begin{array}{l}\text { Os innominatum-enarthrodia. } \\
\text { Tibia-ginglymus. } \\
\text { Patella-arthrodia. }\end{array}$ & $\begin{array}{l}\text { Gluteus medius, gluteus minimus, pyri- } \\
\text { formis, obturator internus, obturator } \\
\text { externus, gemellus superior, gemel- } \\
\text { lus inferior, quadratus femoris, psoas } \\
\text { magnus, iliacus, vastus externus, } \\
\text { gluteus maximus, short head of the } \\
\text { biceps, vastus internus, adductor } \\
\text { magnus, pectineus, adductor brevis, } \\
\text { adductor longus, crureus, subcrureus, } \\
\text { gastrocnemius, plantaris, popliteus. }\end{array}$ \\
\hline
\end{tabular}




\section{BONES OF THE HUMAN SKELETON.}

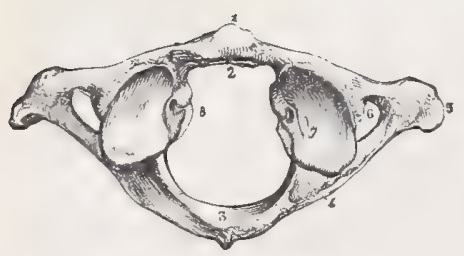

Atlas, Superior Surface.

I. Tubercle of anterior arch. 2

Articular facet for odontoid process of axis. 3 Posterior arch and posterior tubercle. 4 Groove for vertebral artery and first cervical nerve. 5. Transverse process. 6 verse process. 6. Foramen for vertebral artery. 7 Superior articular process, 8. Tubercle for attachment of transverse ligament.

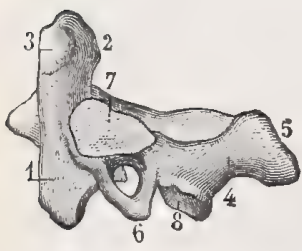

Axis, Lateral Aspect.

I. Body, 2. Odontoid process. 3. Facet for articulating with anterior arch of atlas. 4. Lamina. 5 Spinous process. 6. Transverse process. 7. Superior
articular process. 8. Infearticular process. 8 . I
rior articular process.

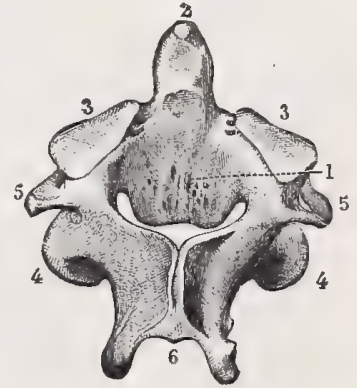

Axis, Postero-Superior VIEW.

I. Posterior surface of body. 2 . Odontoid process, 3, 3. Superior articular processes 4,4 . Inferior articular processes. 5, 5. Transverse processes. 6 . Spinous process.

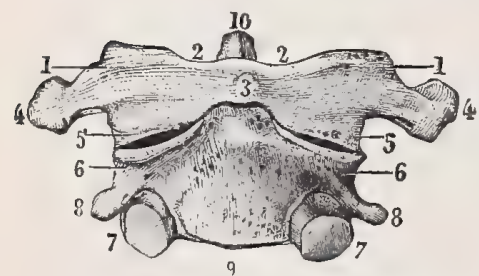

I,I. Lateral masses of atlas. 2, 2 Anterior arch of atlas, including odontoid process of axis. 3 . Tubercle of an terior arch. 4,4 . Transverse processes of atlas. 5, 5 Inferior articular processes of atlas. 6,6 . Superior

Atras and Axis, ANTerior Surface. articular pro-

Atras and Axis, ANTerior Surface. articular pro7. 7. Inferior articular processes, 8, 8. Transverse processes, process.

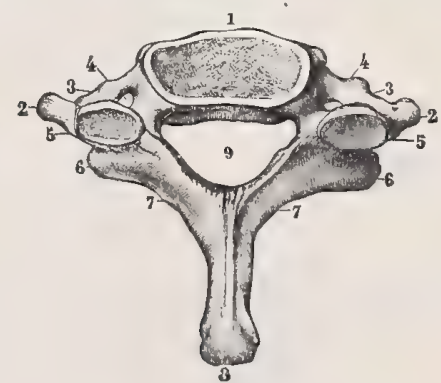

Seventh Cervical Vertebra, Postero-Superior View.

I. Body. 2, 2. Transverse processes. 3, 3. Anterior or costal roots of transverse processes. 4, 4. Foramina for vertebral arteries. 5, 5. Superior articular processes. 6, 6. Inferior articular processes. 7,7. Laminæ. 8. Spinous process. 9. Spinal foramen.

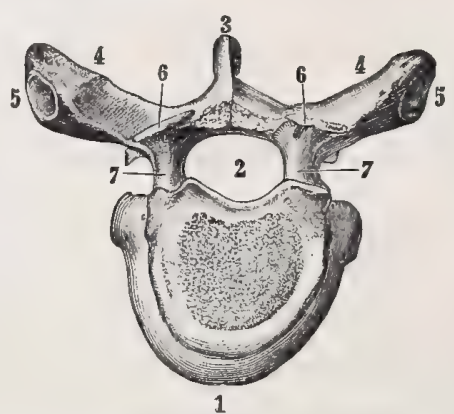

Dorsal Vertebra, ANtero-Superior View.

x. Anterior surface. 2. Vertebral foramen. 3. Spinous process. 4, 4. Transverse processes. 5, 5. Articular surfaces for tubercles of ribs. 6,6 . Superior articular processes. 7,7 . Pedicles.

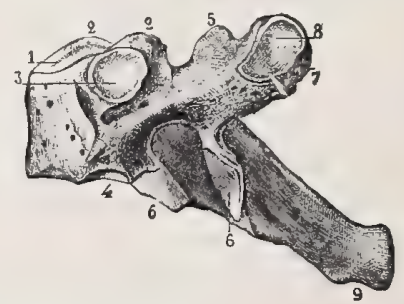

First Dorsal Vertebra, Lateral View.

I. Superior surface of body. 2, 2. Semi-lunar processes. 3 Articular facet for head of first rib. 4. Demi-facet for head of second rib. 5. Superior articular process. 6, 6. Inferior articular processes. 7. Transverse process. 8. Articular facet for tubercle of first rib. 9. Spinous process.

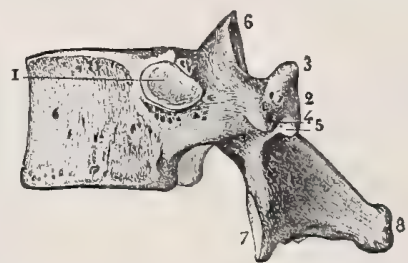

Eleventh Dorsal Vertebra, Lateral View.

I. Articular facet for head of eleventh rib. 2. Transverse process. 3. Superior tubercle of transverse process, 4. In ferior and anterior tubercle. 5. Inferior and posterior tubercle. 6. Superior articular process. 7. Inferior articular process. 8. Spinous process.

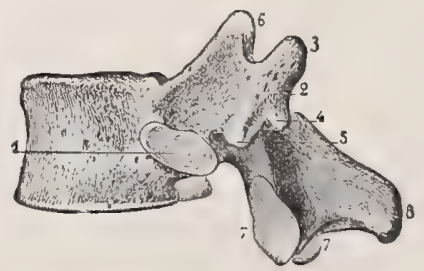

Twelfth Dorsal Vertebra, Lateral View,

I. Articular facet for head of twelfth rib. 2. Transverse process. 3. Superior and posterior tubercle of transverse process. 4. Inferior and posterior tubercle. 5- Inferior and anterior tubercle. 6. Superior articular process. 7, 7. Inferior articular processes. 8. Spinous process. 
TABLE OF BONES.-Continued.

\begin{tabular}{|c|c|c|c|}
\hline NAME. & PRINCIPAL FEATURES. & ARTICULATIONS AND VARIETY. & $\begin{array}{l}\text { MUSCULAR AND LIGAMENTOUS } \\
\text { ATTACHMENTS. }\end{array}$ \\
\hline Fibula. & $\begin{array}{l}\text { Long bone; shaft, upper extremity } \\
\text { or head, lower extremity or ex- } \\
\text { ternal malleoius. }\end{array}$ & $\begin{array}{l}\text { Tibia-arthrodia. } \\
\text { Astragalus, with the tibia and fibula } \\
\text { - ginglymus. }\end{array}$ & $\begin{array}{l}\text { Biceps, soleus, peroneus longus, ex- } \\
\text { tensor longus digitorum, peroneus } \\
\text { tertius, extensor proprius pollicis, } \\
\text { tibialis posticus, flexorlongus pollicis, } \\
\text { peroneus brevis. }\end{array}$ \\
\hline Foot. & $\begin{array}{l}\text { Composed of tarsus, metatarsus } \\
\text { and phalanges, } q \cdot v \text {. }\end{array}$ & & \\
\hline Frontal. & $\begin{array}{l}\text { The forehead bone; a flat bone; a } \\
\text { frontal portion and an orbito- } \\
\text { nasal portion; frontal eminences, } \\
\text { superciliary ridges, supraorbital } \\
\text { arches, supraorbital notches or } \\
\text { foramina, internal and external } \\
\text { angular processes, tem pora } 1 \\
\text { ridges, nasal notch, nasal spine, } \\
\text { nasal eminence or glabella. }\end{array}$ & $\begin{array}{l}\text { Two parietal, } \\
\text { Sphenoid, } \\
\text { Ethmoid, } \\
\text { Two nasal, } \\
\text { Two superior max- } \\
\text { illary, } \\
\text { Two lachrymal, } \\
\text { Two malar, }\end{array}$ & $\begin{array}{l}\text { Corrugator supercilii, orbicularis pal- } \\
\text { pebrarum, and temporal on each side. }\end{array}$ \\
\hline Hand. & $\begin{array}{l}\text { Composed of carpus, metacarpus } \\
\text { and phalanges, } q . v \text {. }\end{array}$ & & \\
\hline Humerus. & $\begin{array}{l}\text { Largest bone of upper extremity; } \\
\text { long bone; a shaft and two ex- } \\
\text { tremities. Upper extremity pre- } \\
\text { sents a head, neck and greater } \\
\text { and lesser tuberosities. Lower } \\
\text { extremity, trochlea, olecranon } \\
\text { fossa, coronoid fossa, external } \\
\text { and internal condyles, supra- } \\
\text { trochlear foramen, supracondy- } \\
\text { loid ridges. }\end{array}$ & 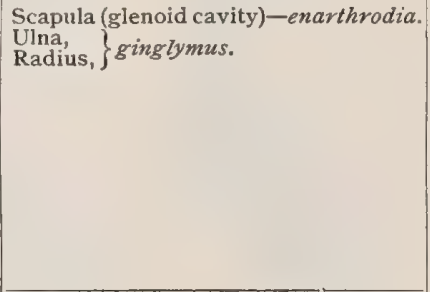 & $\begin{array}{l}\text { Supraspinatus, infraspinatus, teres } \\
\text { minor, subscapularis, p e ctor a lis } \\
\text { major, latissimus dorsi, d e } 1 \text { t o id, } \\
\text { coraco-brachialis, brachialis anticus, } \\
\text { triceps, sub-anconeus, pronator radii } \\
\text { teres, flexor carpi radialis, palmaris } \\
\text { longus, flexor digitorum sublimis, } \\
\text { flexor carpi ulnaris, supinator longus, } \\
\text { extensor carpi radialis longior, exten- } \\
\text { sor carpi radialis brevior, extensor } \\
\text { communis digitorum, extensor mini- } \\
\text { mi digiti, extensor carpi ulnaris, sup- } \\
\text { inator brevis and anconeus. }\end{array}$ \\
\hline Hyoid. & $\begin{array}{l}\text { A bony arch; irregular bone; a } \\
\text { body, two greater and two lesser } \\
\text { cornua. }\end{array}$ & None. & $\begin{array}{l}\text { Sterno-hyoid, thyro-hyoid, omo-hyoid, } \\
\text { digastricus, stylo-hyoid, mylo-hyoid, } \\
\text { genio-hyoid, genio-hyo-glossus, hyo- } \\
\text { glossus, middle constrictor of the } \\
\text { pharynx. }\end{array}$ \\
\hline Ilium. & See Innominate. & & \\
\hline Incus. & $\begin{array}{l}\text { Resembles a bicuspid tooth with } \\
\text { two roots, body, and two pro- } \\
\text { cesses. }\end{array}$ & $\begin{array}{l}\text { Malleus-arthrodia (trigger-joint). } \\
\text { Stapes-arthrodia. }\end{array}$ & None. \\
\hline $\begin{array}{l}\text { In ferior } \\
\text { maxillary. }\end{array}$ & $\begin{array}{l}\text { Body and two rami ; contains the } \\
\text { teeth of the lower jaw; symphy- } \\
\text { sis, mental process, mental fora- } \\
\text { men, coronoid and condyloid } \\
\text { process, head, neck, sigmoid } \\
\text { notch; irregular bone. }\end{array}$ & $\begin{array}{l}\text { The two temporal bones-bilateral } \\
\text { condyloid-diarthrodia. }\end{array}$ & $\begin{array}{l}\text { Levator menti, depressor labii infe- } \\
\text { rioris, depressor anguli oris, platysma } \\
\text { myoides, buccinator, masseter, orbi- } \\
\text { cularis oris, genio-hyo-glossus, genio- } \\
\text { hyoideus, mylo-hyoideus, digastric, } \\
\text { superior constrictor, temporal, in- } \\
\text { ternal pterygoid, external pterygoid, }\end{array}$ \\
\hline $\begin{array}{l}\text { Inferior tur- } \\
\text { binated. }\end{array}$ & $\begin{array}{l}\text { Situated on the outer wall of the } \\
\text { nasal fossa ; irregular bone. }\end{array}$ & $\left.\begin{array}{l}\text { Ethmoid, } \\
\text { Superior maxillary, } \\
\text { Lachrymal, } \\
\text { Palate, }\end{array}\right\}$ synarthrodia. & None. \\
\hline Innominate. & $\begin{array}{l}\text { Large, } 3 \text { parts; flat bone; with its } \\
\text { fellow and sacrum and coccyx } \\
\text { forms pelvis. } \\
\text { Ilium-superior broad expanded } \\
\text { portion, crest, superior, middle } \\
\text { and inferior curved lines, ilio- } \\
\text { pectineal line, venter, auricular } \\
\text { surface, anterior and posterior, } \\
\text { superior and inferior spinous } \\
\text { processes, } \frac{2}{5} \text { (about) of acetabu- } \\
\text { lum. } \\
\text { Ischium-lower and back portion, } \\
\text { body, tuberosity and ramus, } \\
\text { spine, greater and lesser sacro- } \\
\text { sciatic notches, external and in- } \\
\text { ternal lips of tuberosity, lower } \\
\text { boundary of obturator foramen, } \\
\text { } \text { (about) of acetabulum. } \\
\text { Pubis-body, horizontal ramus, } \\
\text { descending ramus, spine, ilio- } \\
\text { pectineal line, angle, symphysis, } \\
\text { obturator foramen (upper bound- } \\
\text { ary), } \frac{1}{5} \text { of acetabulum. }\end{array}$ & $\left\{\begin{array}{l}\text { With its fellow of } \\
\text { opposite side, } \\
\text { Sactum, } \\
\text { Femur-enarthrodia. }\end{array}\right\}$ synarthrodia. & $\begin{array}{l}\text { Iium-tensor vaginæ femoris, external } \\
\text { oblique, latissimus dorsi, iliacus, } \\
\text { transversalis, quadratus lumborum, } \\
\text { erector spinæ, internal oblique, glu- } \\
\text { teus maximus, medius and mini- } \\
\text { mus, rectus, pyriformis, multifidus } \\
\text { spinæ, sartorius. } \\
\text { Ischium-obturator externus and in- } \\
\text { ternus, gracilis, levator ani, gemelli } \\
\text { superior and inferior, coccygeus, bi- } \\
\text { ceps, semi-tendinosus, semi-mem- } \\
\text { branous, quadratus femoris, adductor } \\
\text { magnus, transversus perinei, erector } \\
\text { penis. } \\
\text { Pubis-internal and external oblique, } \\
\text { transversalis, rectus, pyramidalis, } \\
\text { psoas parvus, pectineus, adductor } \\
\text { magnus, longus and brevis, gracilis, } \\
\text { external and internal obturator, leva. } \\
\text { tor ani, compressor urethra, accele- } \\
\text { rator urinæ. }\end{array}$ \\
\hline
\end{tabular}




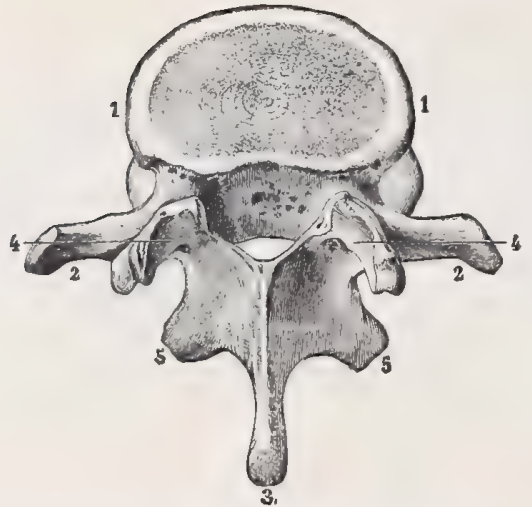

Lumbar Vertebra, Postero-Superior View. 1, I. Anterior surface of body. 2, 2. Transverse processes. 3. Spinous process. 4, 4. Superior articular processes. 5,5. Inerior articular processes.

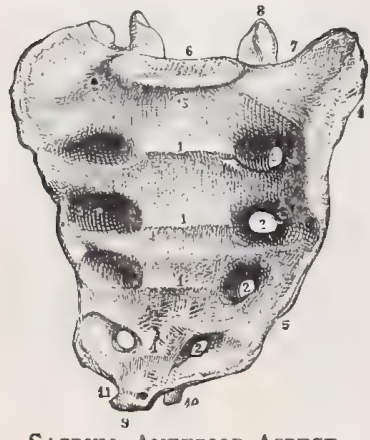

SACRUM, ANTERIOR AsPECT. \&, I, I, I. Bodies of sacral vertebræ, with transverse lines of union. 2,2 , 2 2. Anterior sacral foramina. 3 Base. 4. Auricular surface of lat eral aspect. 5. Its inferior portion. 6. Articular surface of base. 7 . Notch for formation of last lumbar intervertebral foramen. 8 Superior articular process of first sacral vertebra. 9. Apex of sacrum. 1o. Cornu. Ir. Notch for transmission of fifth sacral nerve.

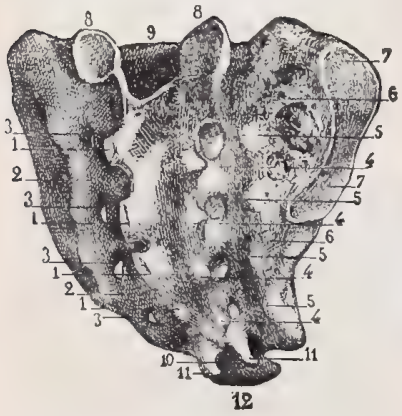

SaCrum, Posterior Aspect.

I, I, I, I. Spinous processes of sacral vertebræ. 2,2. Sacral groove. 3, 3, 3, 3. Posterior sacral foramina. $4,4,4,4$. Articular processes, united. $5,5,5,5$. Transverse processes. 6 , 6. Cribriform fossa. 7 7. Auricular surface. 8, 8. Superior articular processes of first sacral vertebra. 9. Superior orifice of sacral canal. Io Groove representing inferior orifice. II, II. Cornua. I2. Apex.

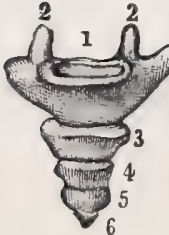

CoccyX, ANTERIOR ÁSPECT.

I. Base. 2,2. Cornua. 3. Secvertebra. 4. geal vertebra. 5. Fourth cocbra. 6. Fifth coccygeal vercoccygeal ver-

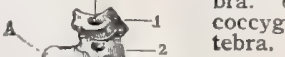
ond coccygeal Third coccy-

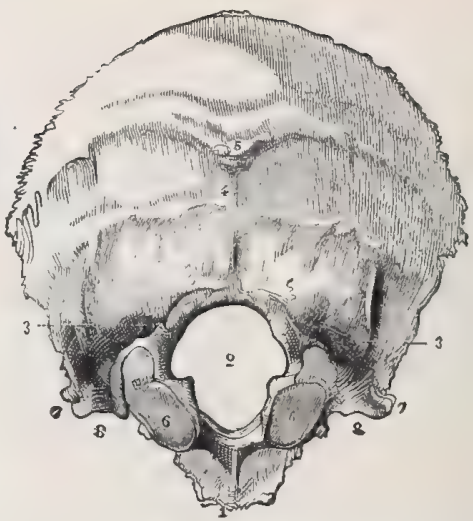

OCcipital Bone, Postero-INFERIor VIEW

I. Basilar process. 2. Foramen magnum 3. 3. Posterior condyloid foramina. 4 Crest. 5. External occipital protuberance. 6,6. Condyles. 7,7. Jugular processes. 8, 8 . Jugular fossæ..

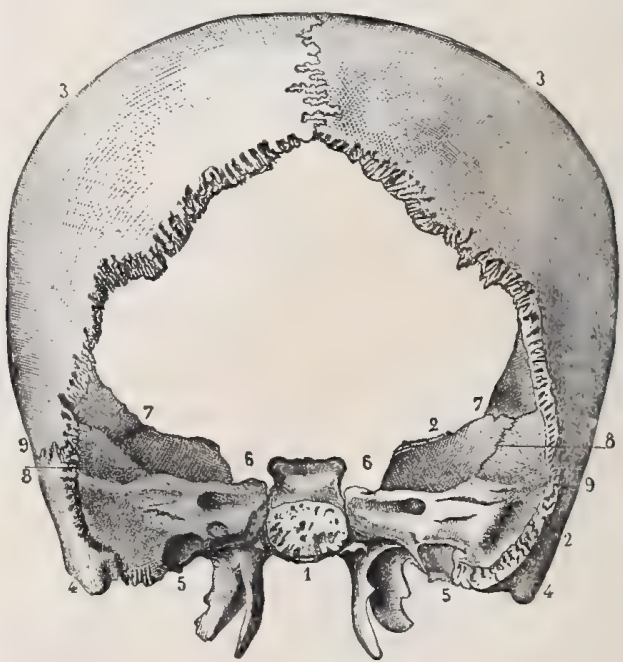

PARIETAL, TEMPORAL, AND SPHENOID BONES; Posterior ASPECT.

x. Body of sphenoid bone. 2, 2. Sphenoid and temporal bones 3. 3. Parietal bones. 4, 4. Mastoid processes. 5, 5. Jugula fossæ. 6,6 . Notches entering into formation of sphenoidal fissures. 7, 7. Spheno-parietal sutures. 8, 8. Spheno-temporal sutures. 9, 9. Temporo-parietal sutures.

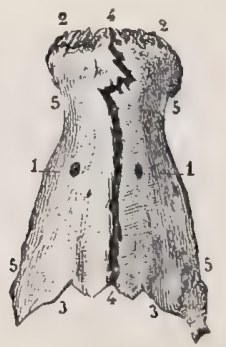

NAsal Bones, External Aspect. ten dorsal vertebra. C. Auricular surface of sacrum. D. Foramina in transverse processes of cervical vertebra.
VERTEBraI COLUMN, LATERAL ASPECT.

$\rightarrow$. Cervical vertebræ. 8-19. Dorsal vertebræ. 20-24. Lumbar vertebræe A, A. Spinous rocesses, B, B. Ar 
TABLE OF BONES.-Continued.

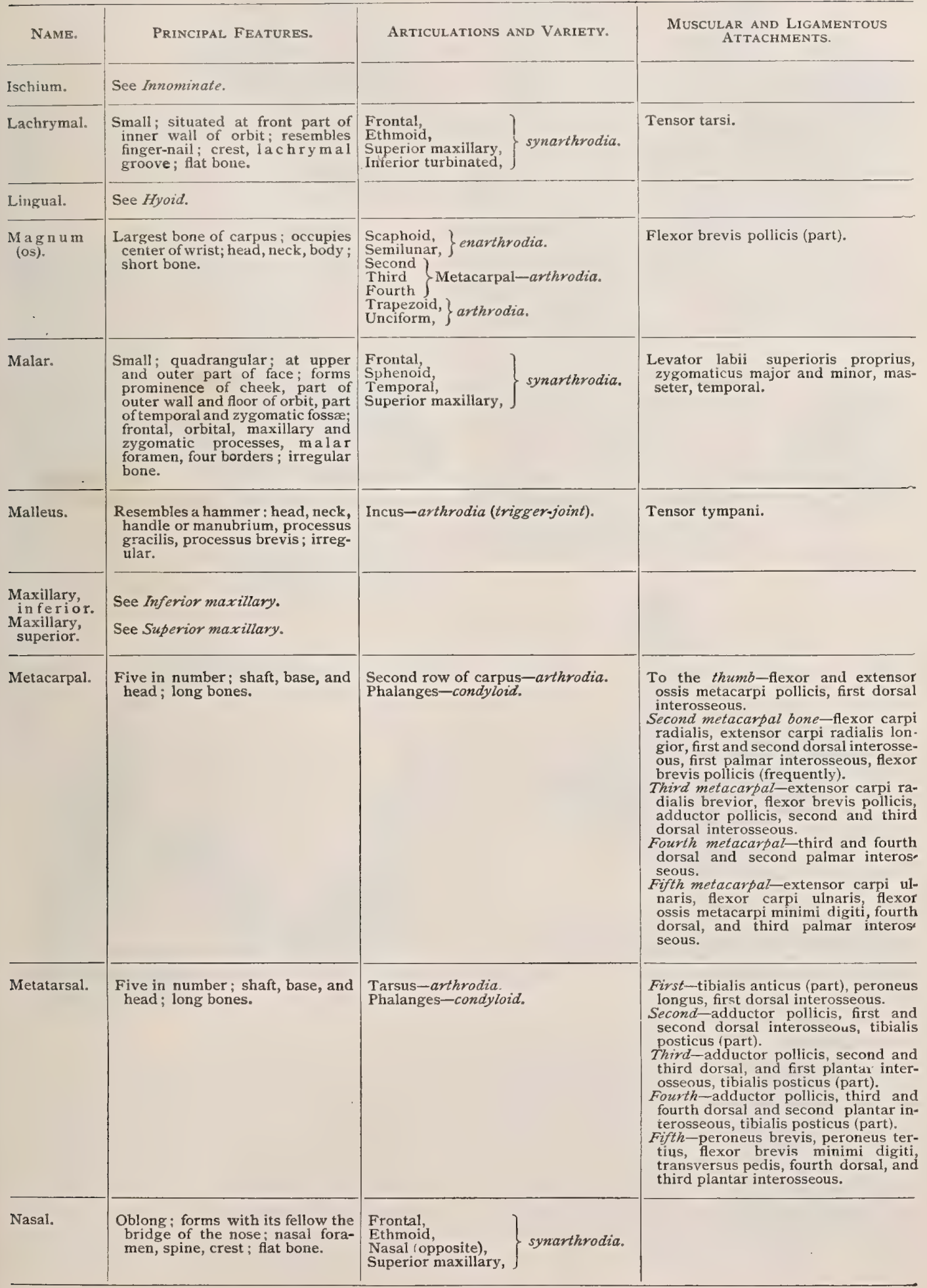




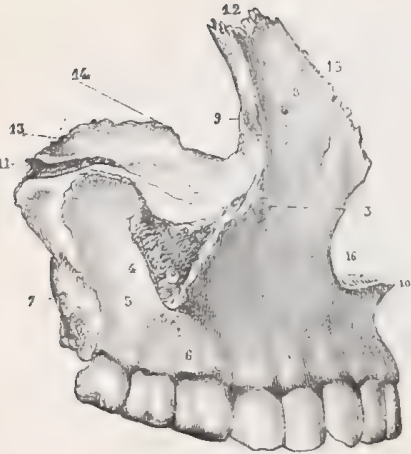

Superior Maxillary Bone, Exter NAL ASPECT. nasal process. I6. Notch for anterior opening of nasal fossa.

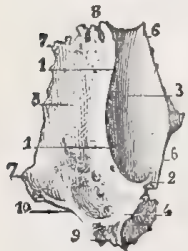

I, r. Vertical crest, dividing external surface into two parts. 2. Spine, in which crest terminates. 3. Sulcus contributing to formation of lachrymal canal. 4. Continuation of preceding, contributing to formation of nasal canal. 5. Posterior division of external surface, contributing to formation of orbit. 6, 6. Anterior border. 7,7. Posterior border. 8. Superior extremity. 9. Portion of inferior border that articulates with lachrymal process of inferior turbinated bone. Io. Portion that articulates with orbital plate

LACHRYMAZ BONE, of superior maxillary bone.

\section{EXTERNAL ASPECT.}

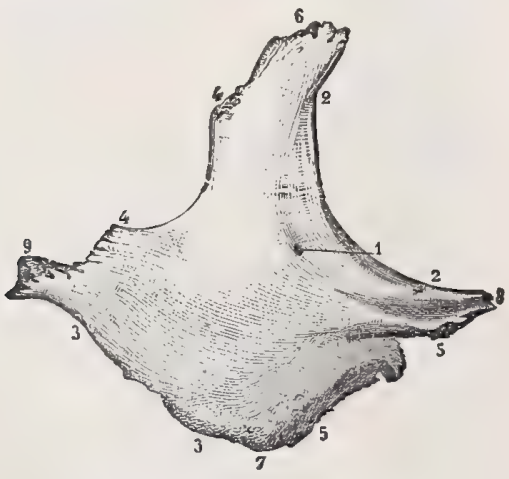

Malar Bone, External Aspect.

1. Orifice for malar nerve. 2, 2, Superior or orbital border. 3. 3. Inferior or zygomatic border. 4, 4. Posterior or temporal border. 5, 5. Anterior or maxillary border. 6. Superior angle. 7. Inferior angle. 8. Anterior angle. 9. Posterior angle.

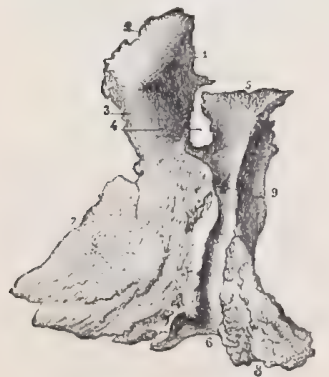

I. External surface of orbital process. 2. Superior or orbital surface. 3. Anterior or maxillary surface. 4. Notch forming greater part of spheno-palatine foramen. 5. Sphenoidal process. 6. Groove entering into forma. tion of posterior palatine canal. 7. Surface that enters into the formation of base of maxillary sinus. 8. External surface of pterygoid process. 9. Groove to receive posterior border of internal plate of pterygoid process.

Palate Bone, External ASPECT.

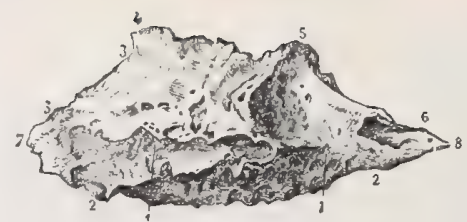

I. Antero-posterior ridge, dividing the internal surface into two almost equal parts. 2. 2. Inferior border. 3, 3, Anterior portion of superior border, articulating with nasal process of superior maxillary bone. 4. Lachrymal proOR CONVEX ASPECT. cess. 5. Ethmoidal process. 6. Portion of superior border
that articulates with palate bone. 7. Anterior extremity. 8. Posterior extremity.

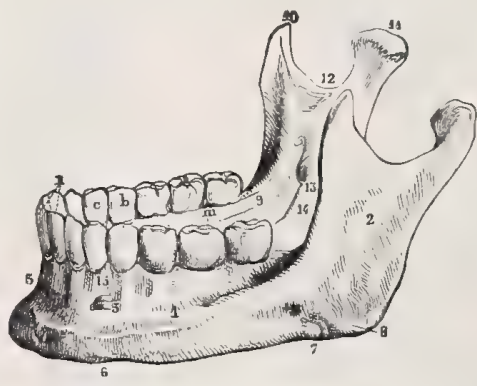

r. Body of bone and external obilique line. 2. Ramus. 3. Symphysis. 4. Incisive fossa. 5 . Mental foramen. 6. Depression in inferior border for attachment of digastric muscle. Depression for passage of facial artery. 8. Angle of jaw. 9. Yosterior extremity of internal oblique line. ro. Coronoid process. ASPECT.

II. Condyle, 12. Sigmoid notch. 13. Origin of inferior dental canal. I4. Mylo-hyoid groove. I5. Alveolar border. $a$. Incisors. $b$. Bicuspids. c. Canines. $m$. Molars.

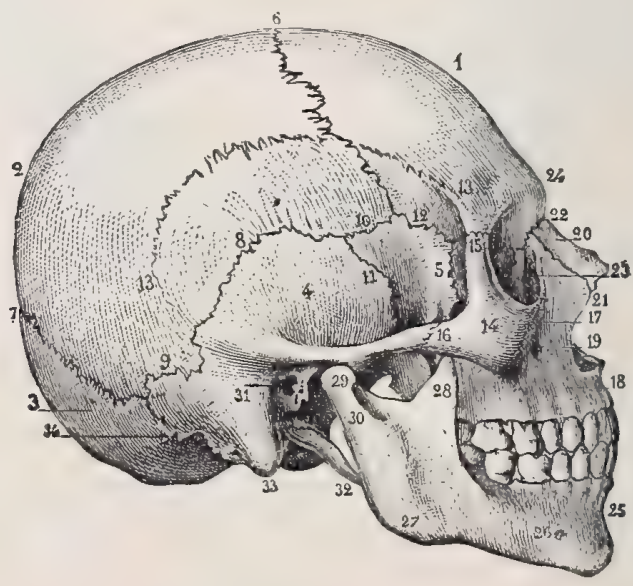

Lateral Aspect of Skull.

I. Frontal bone, 2, Parietal bone. 3. Occipital bone. 4. Temporal bone. 5. Greater wing of sphenoid bone. 6. Lambdoid suture. 7. Occipito-parietal suture. 8. Squamo-parietal suture. 9. Masto-parietal suture. Io. Spheno-parietal suture. II. Spheno-temporal suture. 12. Spheno-frontal suture. 13. 13. Temporal ridge, 14. Malar bone. 15. Fronto-malar suture. 16. Malo-temporal suture. Malo-maxillary suture. 18. Superior maxillary bone. I9. Infraorbital foramen. 20. Nasal bone. 21. Naso-maxillary suture. 22. Naso-frontal suture. 23. Lachrymal groove, at the bottom of which may be seen the suture between the lachrymal and the superior maxillary bones. 24. Nasal eminence. 25, Inferior maxillary bone. 26. Mental foramen. 27. Angle of lower jaw. 28. Coronoid process. 29. Condyle. 30. Neck of condyle. 31. External auditory canal. 32. Styloid process. 33. Mastoid process. 34. Masto-occipital suture. 
TABLE OF BONES.-Continued.

\begin{tabular}{|c|c|}
\hline NAME. & Principal Features \\
\hline Occipital. & $\begin{array}{l}\text { Back part and base of cranium } \\
\text { trapezoid in shape ; outer and } \\
\text { inner tables; external protuber- } \\
\text { ance, external occipital crest, } \\
\text { superior and inferior curved } \\
\text { lines, foramen magnum, con- } \\
\text { dyles, jugular process, anterior } \\
\text { and posterior condyloid forami- } \\
\text { na, basilar process, pharyngeal } \\
\text { spine, } 4 \text { fossa on internal sur- } \\
\text { face, internal occipital protuber- } \\
\text { ance and crest, grooves for the } \\
\text { cerebral sinuses, torcular Hero- } \\
\text { phili, jugular foramen; flat bone. }\end{array}$ \\
\hline Palate. & $\begin{array}{l}\text { Back part of nasal fossa; helps to } \\
\text { form floor and outer wall of nose, } \\
\text { the roof of mouth and floor of } \\
\text { orbit, also spheno-maxillary and } \\
\text { pterygoid fossa and the spheno- } \\
\text { maxillary fiss ure ; L-shaped, } \\
\text { inferior or horizontal plate, su- } \\
\text { perior or vertical plate, posterior } \\
\text { palatine canal, posterior nasal } \\
\text { spine, inferior and superior tur- } \\
\text { binated crests, maxillary pro- } \\
\text { cess, pterygoid process, acces- } \\
\text { sory descending palatine canals, } \\
\text { orbital process, sphenoidal pro- } \\
\text { cess, spheno-palatine foramen. }\end{array}$ \\
\hline
\end{tabular}

Parietal. Form sides and roof of skull;

Patella. Flat; triangular; sesamoid; an-

Pelvic.

Phalanges of Two of great toe, three of each of foot.

Phalanges, of hand. irregular, quadrilateral; two sur faces, four borders, four angles. parietal eminence, temporal ridge, parietal foramen, furrows for cerebral sinuses, depressions for Pacchionian bodies; flat bone. terior part of knee-joint; two surfaces, three borders, apex. surfaces,
flat bone.

Composed of two ossa innomi-

nata, sacrum and coccyx, $q . v$. the others; shaft, base, head long bones.

Articulations and Variety.

Parietal (two),

Temporal (two),
Sphenoid,

Atlas-double arthrodia.

Sphenoid

Sphenoid,
Ethmoid,
Superior maxillary,

Inferior turbinated, synarthrodia.

Vomer,

Opposite palate

$\left.\begin{array}{l}\text { Opposite parietal, } \\ \text { Occipital, } \\ \text { Frontal, } \\ \text { Temporal, } \\ \text { Sphenoid, }\end{array}\right\}$ synarthrodia.

Condyles of femur-partly arthrodial.

First row with metatarsal and second phalanges-condyloid. Second of great toe with first phalanx; of other toes, with first and third phalanges, ginglymus. Third row

14 in number, three for each finger and two for thumb; shaft, head, base; long bones.
First row with metacarpal bones and second row of phalanges-condyloid. second row with first and third rows, and third rows,
Third row with second $\}$ ginglymus.
row,
MUSCULAR AND Ligamentous ATTACHMENTS.

Twelve pairs-occipito-frontalis, tra pezius, sterno-cleido-mastoid, complexus, biventer cervicis, spleniu capitis, superior oblique, rectus capitis posticus, major and minor rectus lateralis, rectus capitis anticus, major and minor, superior constrictor of the pharynx.

Tensor palati, azygos uvulæ, internal and external pterygoid, superior constrictor of pharynx.

\section{Temporal.}

Rectus, crureus, vastus internus, vastus externus.

First-great toe-inner tendon extensor brevis digitorum, abductor pollicis, adductor pollicis, flexor brevis pollicis, transversus pedis.

Second toe-first and second dorsa! interosseous, first lumbrical.

Third toe-third dorsal and first plantar interosseous, second lumbrical.

Fourth toe-fourth dorsal and second plantar interosseous, third lumbrical Fifth toe-flexor brevis minimi digiti abductor minimi digiti, third plantar interosseous, fourth lumbrical.

Second-great toe-extensor longus pollicis, flexor longus pollicis.

other toes-flexor brevis digitorum one slip of common tendon of extensor longus and brevis digitorum.

Third-two slips from the common tendon of the extensor longus and extensor brevis digitorum, and flexor longus digitorum.

Thumb-extensor primi internodii pol licis, flexor brevis pollicis, abductor pollicis, adductor pollicis, flexor longus pollicis, extensor secundi internodii.

First-index finger-first dorsal and first palmar interosseous.

Middle finger-second and third dorsal interosseous.

Ring finger - fourth dorsal and second palmar interosseous.

Little finger-third valmar interosseous, flexor brevis minimi digiti, abductor minimi digiti.

Second-to all-flexor sublimis digit- 


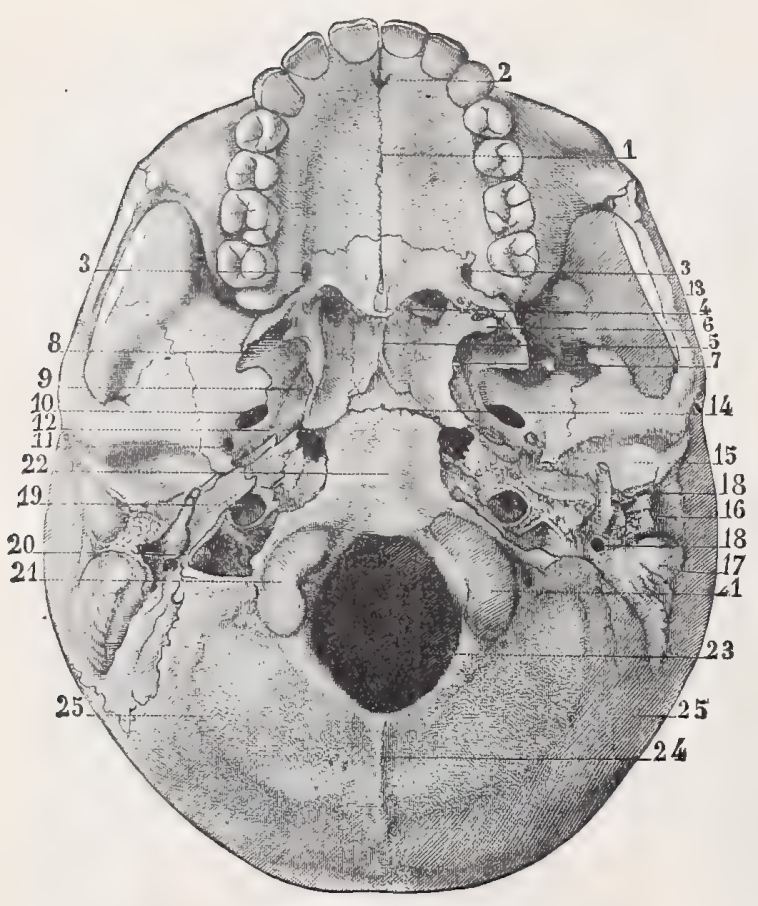

BASE OF SKull.

I. Median suture of palatine vault. 2. Inferior orifice of anterior palatine canal. 3, 3. Inferior openings of posterior palatine canals. 4. Posterior border of palatine vault ; posterior nasal spine. 5. Posterior border of nasal septum. 6. Hamular process of internal pterygoid plate of sphenoid bone. 7. Internal pterygoid plate. 8. External pterygoid plate. 9. Scaphoid fossa. Io. Oval or inferior maxillary foramen. II. Foramen spinosum. I2. Foramen lacerum medium. 13. Zygomatic arch. I4. Spheno-occipital suture. 15. Glenoid cavity. I6. External auditory canal. I7. Mastoid process. I8, 18 . Styloid process and stylo-mastoid foramen. Ig. Inferior orifice of carotid canal 20. Foramen lacerum posterius. 2I, 2I. Occipital condyles. 22. Basilar process. 23. Foramen magnum. 24. External occipital crest. 25, 25. Inferior curved lines of occipital bone.

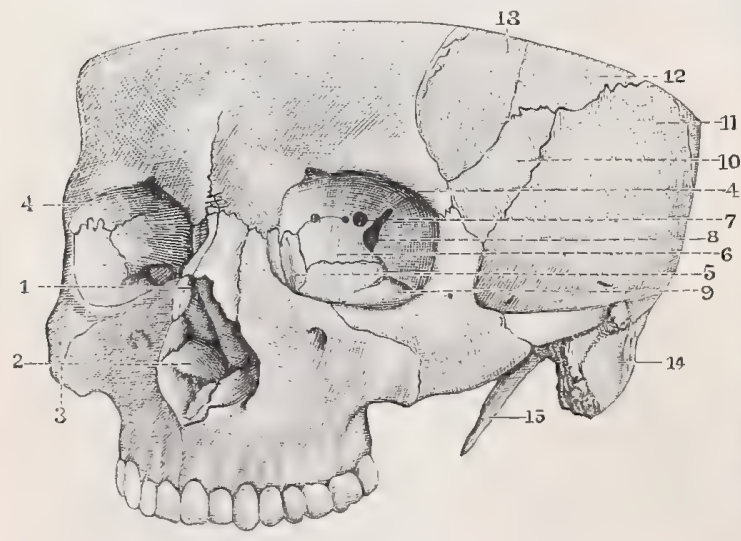

The Orbital Cavities.

I. Anterior opening of nasal fossæ. 2. Anterior extremity of inferior turbinated bone. 3. Malar bone. 4, 4. Orbital cavities. 5. Lachrymal canal. 6. Os planum of ethmoid. 7 . Optic foramen. 8. Sphenoidal fissure. 9. Spheno-maxillary fissure, ro. Great wing of sphenoid. II. Squamous portion of temporal. 12. Antero-inferior angle of parietal. 13. Portion of frontal entering into formation of temporal fossa. I4. Mastoid process. 15. Styloid process.

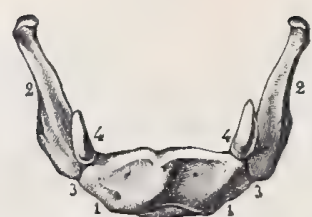

HYOID BONE, ANTERIOR ASPECT.

I, I. Anterior or convex surface of body. 2, 2. Greater cornua. 3, Junction of greater cornua with body. 4, 4. Lesser cornua.

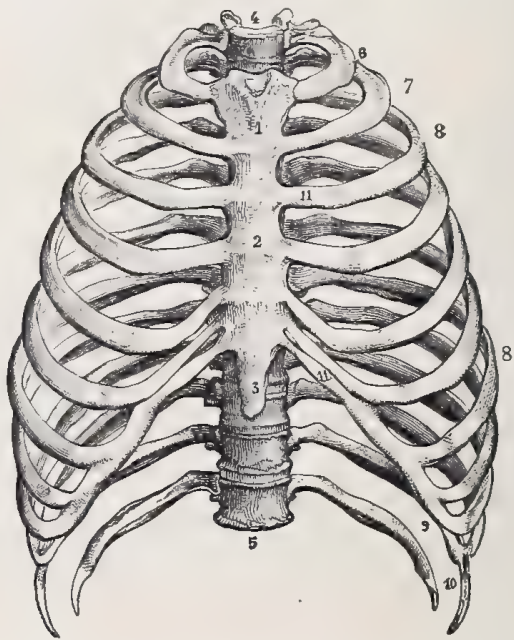

THORAX, ANTERIOR VIEW.

I. Manubrium sterni. 2. Gladiolus. 3. Ensiform cartilage or xiphoid appendix. 4. Circumference of apex of thorax. 5 Circumference of base. 6 . Ist rib. $7,2 \mathrm{~d}$ rib. $8,8,3 \mathrm{~d}, 4 \mathrm{th}$ sth, 6 th and 7 th ribs. 9 . 8 th, gth and Io ribs. 10.1 th and I2th ribs. II, II. Costal cartilages.

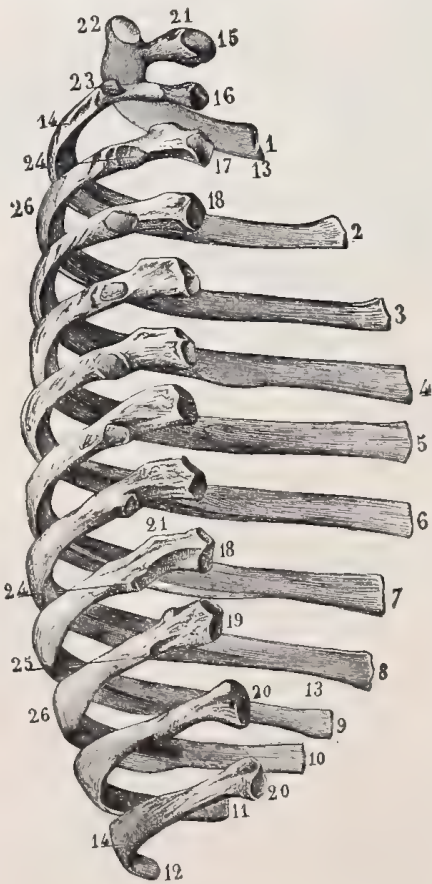

RIBSOF LEFT SIDE, POSTERIOR ASPECT.

1-12. Anterior extremities of ribs of left side I3, I3. Internal surface. I4, I4. External surface 15. Head of 1st rib. 16. Head of $2 d$ rib. 17. Head of $3 \mathrm{~d}$ rib. 18,18 $\mathrm{Heads}$ of ribs from 4th to 9 th. I. Head of Ioth rib. 20,20 . Heads of IIth and I2th ribs. 2I,21. Necks of ribs. 22. Tuber cle of Ist rib. 23 Articular facet of tubercle of $2 \mathrm{~d}$ rib. 24, 24. Articular facets of tubercles of ribs from $3 \mathrm{~d}$ to th. 25. Articular facet for tu26,26 . Angles of ribs. 
TABLE OF BONES.-Continued.

\begin{tabular}{|c|c|c|}
\hline NAME. & PRINCIPAl FEATURES. & ARTICULATIONS AND VARIETY. \\
\hline \multicolumn{3}{|l|}{$\begin{array}{l}\text { Phalanges, of } \\
\text { h a nd. } \\
\text { Continued. }\end{array}$} \\
\hline Pisiform. & $\begin{array}{l}\text { Anterior and inner side of carpus; } \\
\text { small; spherical; one articular } \\
\text { facet; short bone. }\end{array}$ & Cuneiform-arthrodia. \\
\hline Pubis. & See Innominate. & \\
\hline Radius. & $\begin{array}{l}\text { Outer side of forearm ; shaft, head, } \\
\text { neck, tuberosity, lower extrem- } \\
\text { ity, oblique line, sigmoid cavity, } \\
\text { styloid process. }\end{array}$ & $\begin{array}{l}\text { Humerus-ginglymus. } \\
\text { Ulna, }\left\{\begin{array}{l}\text { superior-diarthrodia rota- } \\
\text { toria. } \\
\text { middle-membranous. } \\
\text { Inferior - diarthrodia rota- } \\
\text { toria. }\end{array}\right. \\
\text { Semilunar-condyloid. }\end{array}$ \\
\hline Ribs. & $\begin{array}{l}\text { Twelve in number on each side; } \\
\text { shaft, head, neck, tuberosity, } \\
\text { angle (anterior and posterior), } \\
\text { anterior or sternal extremity; } \\
\text { first, second, tenth, eleventh and } \\
\text { twelfth are peculiar; flat bones. }\end{array}$ & $\begin{array}{l}\text { Vertebræ-arthrodia. } \\
\text { Sternum, } \begin{array}{l}\text { First rib-synarthrodia. } \\
\text { Others-arihrodia. }\end{array}\end{array}$ \\
\hline Sacrum. & $\begin{array}{l}\text { Large triangular bone at lower } \\
\text { part of vertebral column, and } \\
\text { upper and back part of pelvic } \\
\text { cavity; composed of five verte- } \\
\text { bræ; base, promontory, four sur- } \\
\text { faces, apex, central canal, an- } \\
\text { terior and posterior sacral fora- } \\
\text { mina, lateral masses, laminæe, } \\
\text { articular processes, sacral cor- } \\
\text { nua, transverse processes, sacral } \\
\text { groove, ala ; irregular bone. }\end{array}$ & $\left.\begin{array}{l}\text { Last lumbar ver- } \\
\text { tebra, } \\
\text { Coccyx, } \\
\text { Ossa innominata } \\
\text { (two), }\end{array}\right\}$ amphiarthrodia. \\
\hline $\begin{array}{l}\text { Scaphoid, of } \\
\text { carpus. }\end{array}$ & $\begin{array}{l}\text { Largest bone of first row; boat- } \\
\text { shaped; upper and outer part } \\
\text { of carpus; four surfaces; tuber- } \\
\text { cle; short bone. }\end{array}$ & $\left.\begin{array}{l}\text { Radius-condyloid. } \\
\text { Trapezium, } \\
\text { Trapezoid, } \\
\text { Os magnum, } \\
\text { Semilunar, }\end{array}\right\}$ arthrodia. \\
\hline $\begin{array}{l}\text { Scaphoid, of } \\
\text { tarsus. }\end{array}$ & $\begin{array}{l}\text { Or navicular bone; boat-shaped; } \\
\text { inner side of tarsus, four sur- } \\
\text { faces, tuberosity ; short bone. }\end{array}$ & $\left.\begin{array}{l}\text { Astragalus, } \\
\text { Cuneiform (three), } \\
\text { Cuboid (occasionally), }\end{array}\right\}$ anthrodia. \\
\hline Scapula. & $\begin{array}{l}\text { Back part of shoulder; triangular; } \\
\text { posterior aspect and side of } \\
\text { thorax; two surfaces, three } \\
\text { borders, three angles, subscapu- } \\
\text { lat fossa, subscapular angle, } \\
\text { dorsum, spine, supra-spinous and } \\
\text { infra-spinous fossa, acromion } \\
\text { process, glenoid cavity, neck, } \\
\text { head,coracoid process; flat bone. }\end{array}$ & $\begin{array}{l}\text { Humerus-enarthrodia. } \\
\text { Clavicle-arthrodia. }\end{array}$ \\
\hline Semilunat. & $\begin{array}{l}\text { Upper row of carpus; four sur- } \\
\text { faces, crescentic outline. }\end{array}$ & $\left.\begin{array}{l}\text { Radius-condyloid. } \\
\text { Os magnum, } \\
\text { Unciform, } \\
\text { Cuneiform, } \\
\text { Scaphoid, }\end{array}\right\}$ arthrodia. \\
\hline Sesamoid. & $\begin{array}{l}\text { Small, rounded masses, cartila- } \\
\text { ginous in early life, osseous in } \\
\text { the adult; developed in tendons; } \\
\text { inconstant, except patella. }\end{array}$ & \\
\hline Sphenoid. & $\begin{array}{l}\text { Anterior part of base of skull; } \\
\text { bat-shaped,with wings extended; } \\
\text { body, two greater and two lesser } \\
\text { wings, two pterygoid processes, } \\
\text { ethmoidal spine, optic groove, } \\
\text { optic foramen, olivary process, } \\
\text { pituitary fossa, anterior, middle } \\
\text { and posterior clinoid processes, } \\
\text { sella turcica, carotid or cavern- }\end{array}$ & $\left.\begin{array}{l}\text { All the bones of cra- } \\
\text { nium, } \\
\text { Malat (two), } \\
\text { Palate (two), } \\
\text { Vomer,. }\end{array}\right\}$ synarthrodia. \\
\hline
\end{tabular}

MUSCULAR AND Ligamentous ATTACHMENTS.

orum and extensor communis digitorum ; in addition.

To index finger-extensor indicis.

7o litlle finger - extensor minimi digiti

Third-flexor profundus digitorum, extensor communis digitorum.

Flexor carpi ulnaris, abductor minimi digiti, anterior annular ligament.

Biceps, supinator brevis, flexor sublimis digitorum, flexor longus pollicis, pronator quadratus, extensor ossis metacarpi pollicis, extensor primi internodii pollicis, pronator radii teres, supinator longus.

Internal and external intercostals scalenus, anticus, medius and posti cus, pectoralis minor, serratus magnus, obliquus externus, transversalis, quadratus lumborum, diaphragm, latissimus dorsi, serratus posticus superior and inferior, sacro-lumbalis, musculus accessorius ad sacro-lumbalem, longissimus dorsi, cervicalis ascendens, levatores costarum, infracostales.

Pyriformis, coccygeus, iliacus, gluteus maximus, latissimus dorsi, multifidus spinæ, erector spinæ, extensor coccygis.

External lateral ligament of wrist.

Tibialis posticus (part).

Subscapularis, supraspinatus, infraspinatus, trapezius, deltoid, omohyoid. serratus magnus, levator anguli scapulæ, rhomboideus major and minor, triceps, teres major and minor, biceps, coraco-brachialis, pectoralis minor, platysma, latissimus dorsi.

Temporal, external and internal ptery goids, superior constrictor, tensor palati, levator tympani, levator palpebræ, obliquus superior, superior, inferior, internal and external recti. 


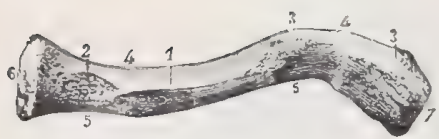

Clavicle, INFERIOR ASPECT.
Longitudinal depression for inser tion of subclavius muscle. 2. Rough impression for attachment of costo-clavicular ligament. 3,3. For at tachment of coraco-clavicular ligaments. 4, 4. Posterior border. 5, 5. Anterior border. 6. Facet for articulation with sternum. 7. Facet for articulation with acromion.

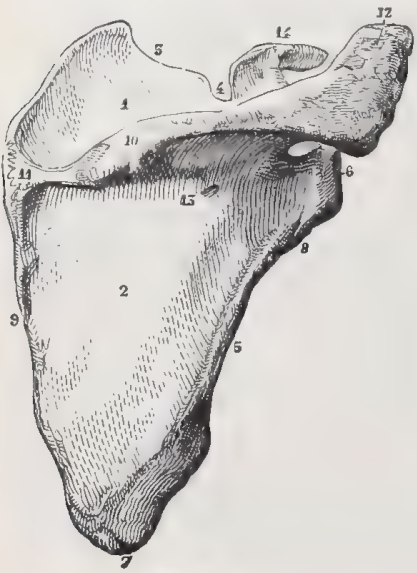

SCAPUla, Postero-EX TERNAL ASPECT.

I. Supraspinous fossa. 2. Infra-spinous fossa. 3. Superior or coracoid border. 4. Coracoid or suprascapular notch. 5. Axillary or external border. 6 . Anterior angle and glenoid cavity. 7 . Inferior angle. 8. Rough impression for long head of triceps. . Internal or spina or vertebral border. IO Spine II. Smooth surface over which trapezius muscle glides. I2, Acromion. I3. Base of spine. I4. Coracoid process.
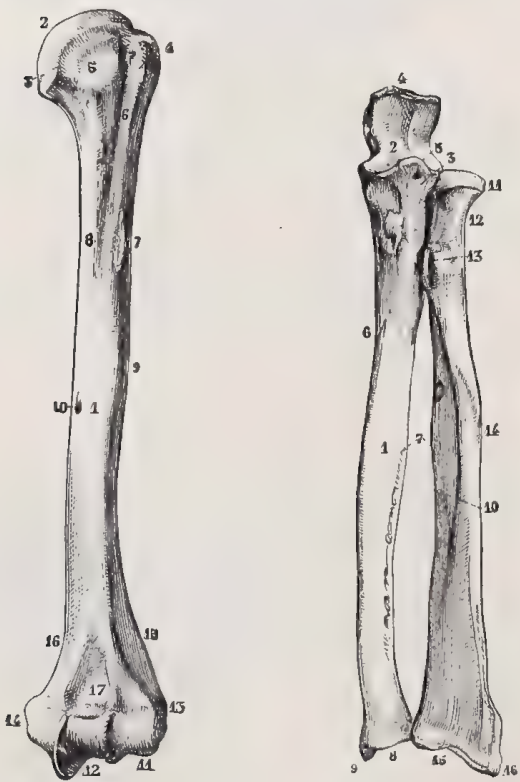

Humerus, Anterior Aspect. Radius and Ulna, Anterior I. Diaphysis. 2. Humeral head.

3. Anatomic neck. 4.Greater I. Anterior surface of body of or external tuberosity. 5. Lex er anterior tuberosity. 6. Bicipital groove. 7. Ridge 6. Bicipital groove. 7 . Ridge
for attachment of coracobrachialis muscle. 8. Anterior border of shaft. 9. External surface. Io, Orifice of nutrient canal. II. Lesser or radial head. 12 . Trochlea. 13. External condyle or epicondyle. 14. Internal condyte or epitrochlea. 15. Inferior portion of external border. x6. Inferior portion of internal border. 17. Coronoid fossa.

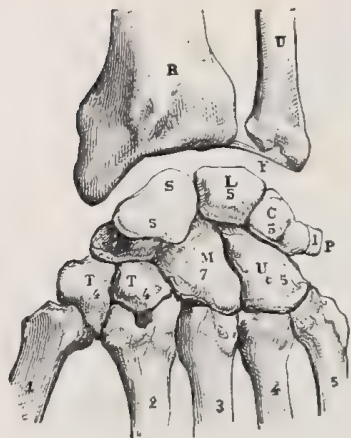

BONES OF CARPUS, DORSAL ASPECT

R. Inferior extremity of radius $U$ Inferior extremity of ulna. F. Interarticular fibro-cartilage. S. Scaphoid. L. Semilunar. C. Cuneiform. P. Pisiform. T. Trapezium. T Trapezoid. M. Os magnum. U. Unciform. The numbers upon these bones indicate the number of others with which each articulates. I, 2, 3, 4, 5. Proximal extremities of 1 st, $2 \mathrm{~d}$, $3 \mathrm{~d}, 4^{\text {th }}$ and 5 th metacarpal bones.

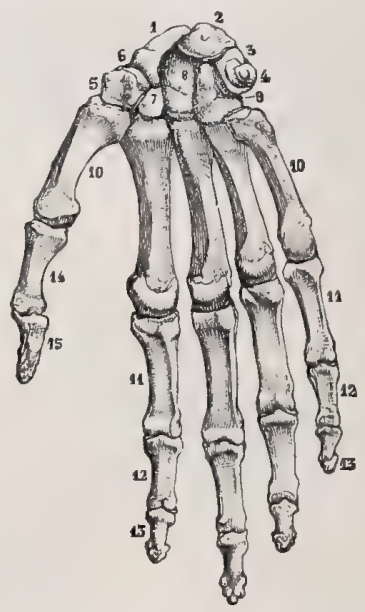

HAND, PALMAR SURface.

I. Scaphoid 2 Semilunar 3. Cuneiform. 4. Pisiform. 5. Trapezium 6. Groove for tendon of flexor carpi radialis 7. Trapezoid. 8. Os magnum. 9. Unciform. IO, ro. Metacarpal bones. II, Ix. First phalanges of fingers. I2, I2 Second phalanges. 13, 13. Third phalanges. 14. First phal anx of thumb. I5. Second phalanx.

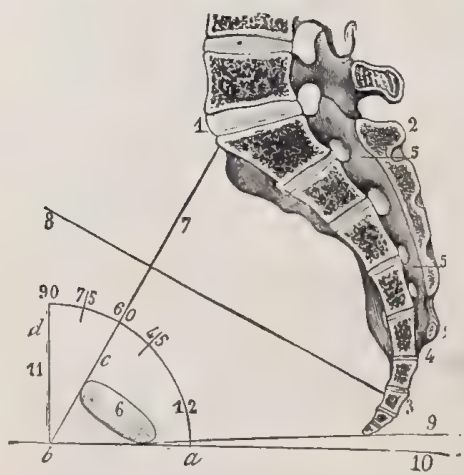

Sacro-vertebral dian section of sacrum. $\mathrm{Me}$ dian section of coccyx. 4. Junc tion of sacrum and coccyx. 5,5 . Median sec mphysis pubis. 7. Antero posterior or sacro pubic diameter of pelvic inlet. $b$. Prolong ation of this diameter. 8. Line perpendicular to this diameter at its middle. Antero-posterior or cocci-pubic diameter of pelvic outlet. Io. vic outlet. Io.
Horizontal line AXIS OF SUPERIOR STRAIT. passing through inferior margin of symphysis pubis. Is. Line perpendicular to last. 12. Arc of angle between these two. 
TABLE OF BONES,-Continued.

\begin{tabular}{c|l}
\hline NAME. & \multicolumn{1}{|c}{ PRINCIPAL FEATURES. } \\
\hline Continued. & $\begin{array}{l}\text { ous groove, lingula, ethmoidal } \\
\text { crest, sphenoidal cells or sin- } \\
\text { uses, sphenoidal turbin at ed } \\
\text { bones, rostrum, vag in } 1 \text { pro- } \\
\text { cesses, pterygo-palatine canal, } \\
\text { spinous processes, round fora- } \\
\text { men, oval foramen, foramen }\end{array}$ \\
$\begin{array}{l}\text { Vesalii, foramen spinosum, ptery- } \\
\text { goid ridge, external orbitail fora- } \\
\text { mina, vidian canal, plerygoid } \\
\text { fossa, internal and external } \\
\text { pterygoid plates, hamular pro- } \\
\text { cess, scaphoid fossa. }\end{array}$ \\
\hline Situated at anterior and inferior
\end{tabular}

Sphenoidal

turbinated

or suhenoid-

al s pongy

bones.

Stapes.

Situated at anterior and inferior part of body of sphenoid; exist as separate pieces untii puberty and occasionally are not joined in the adult.

Resembles a stirrup; one of the ossicles of the tympanum; head neck, two branches (crura), base irregular bone.

Sternum.

The breast bone; manubrium, gladiolus, ensiform cartilage, or anterior and posterior surface, borders.

Superior Forms with its fellow the whole maxillary.

Tarsa1.

Temporal.

Tibia.

Trapezium

Trapezoid.

Triquetral. alveolar and palatine processes hollow (the antrum of Highmore or maxillary sinus), incisive or myrtiform fossa, canine fossa, canine eminence, infra-orbital foramen, posterior dental canals maxillary tuberosity, posterior palatine canal, infra-orbita groove; irregular bone.

Consist of calcaneum, or os calcis, astragalus, cuboid, scaphoid, internal, middle and external cuneiform. See Individualbones.

Situated at side and base of skull squamous, mastoid and petrous portions, temporal ridge, zygoma or zygomatic process, eminentia articularis, Glaserian fissure, tubercle, glenoid fossa, post-glenoid process, tympanic plate, mastoid foramen, digastric fossa, occipital groove, sigmoid fossa, occipital groove, sigmoid fossa, mastoid cells, meatus audi-
torius externus, hiatus Fallopii, meatus auditorius internus la mina cribrosa, aquæductus vestibuli, styloid process, stylomastoid foramen, auricular fissure; irregular bone.

At front and inner side of leg next to femur in length and size; prismoid in form; upper extremity or head, tuberosities, spinous process, tubercle, popliteal notch, shaft, crest (the shin) oblique line, internal malleolus long bone.

In lower row of carpus; very irregular; six surfaces, groove short bone

Smallest bone in second row of carpus; wedge-shaped ; six surfaces; short bone.

See Wormian bones
ARTICULATIONS AND VARIETY.

Muscular and Ligamentous ATTACHMENTS. first, second and third pieces

$\left.\begin{array}{l}\text { Ethmoid, } \\ \text { Palate, }\end{array}\right\}$ synarthrodia.
Incus-arthrodia.
Clavicles (two)_arthrodia.

Costal cartilages (seven on each side) first-synarthrodia; others, arthrodia.

Frontal

Ethmoid

Nasal, boidal; body and malar, nasal.

Lachrymal,

Inferior turbinated, synanthrodia.

Palate

Vomer,

Fellow of opposite

Occipital

Parietal,

Sphenoid,

Inferio synarthrodia.

Femur-ginglymus.

fsuperior-arthrodia.

Fibula, $\{$ middle-membranous.

Astragalus with fibula-ginglymus. $\left.\begin{array}{l}\text { Scaphoid, } \\ \text { Trapezoid, } \\ \text { First and second meta- }\end{array}\right\}$ arthrodia. carpal,

Scaphoid,

Trapezium Os magnum,

Pectoralis major, sterno-cleido-mastoid, sterno-hyoid, sterno-thyroid, triangularis sterni, aponeuroses of the obliquus and internus, and transversalis muscles, rectus, diaphragm.

Orbicularis palpebrarum, obliquus inferior oculi, levator labii superioris alæque nasi, levator labii superioris proprius, levator anguli oris, compressor nasi, depressor alæ nasi, dilator naris posterior; masseter, buccinator, internal pterygoid, orbicularis oris.

Temporal, masseter, occipito-frontalis, sterno-mastoid, splenius capit is trachelo-mastoid. digastricus, retrahens aurem, stylo-pharyngeus, stylohyoideus, stylo-glossus, levator palati, tensor tympani, tensor palati, stapedius.

Semi-membranosus, tibialis anticus, extensor longus digitorum, biceps, sartorius, gracilis, semi-tendinosus, tibialis anticus, popliteus, soleus, flexor longus digitorum, tibialis pos* ticus, ligamentum patellæ.

Adductor pollicis, flexor ossis metacarpi pollicis, flexor brevis pollicis (part).

Flexor brevis pollicis (part). 


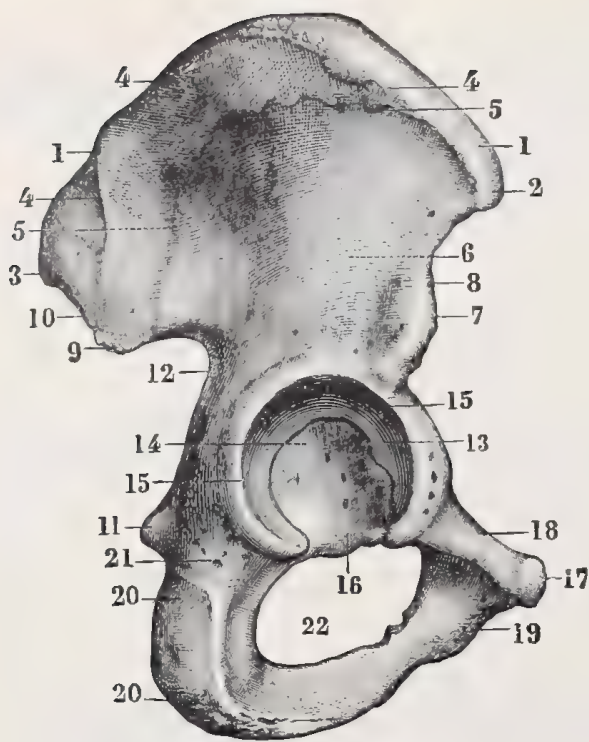

Right Innominate Bone, External Aspect.

I. Superior border, or crest. 2. Anterior superior iliac spine. 3. Posterior superior iliac spine. 4, 4, 4. Superior curved line. 5, 5. Inferior curved line. 6. Surface between inferior curved line and acetabulum. 7. Anterior inferior iliac spine. 8. Anterior interspinous notch. 9. Posterior inferior iliac spine. Io. Posterior interspinous notch. II. Spine of ischium. 12. Great sacro-sciatic notch. 13. Acetabulum, I4. Fundus of acetabulum. 15, 15. Circumference of acetabulum. 16. Cotyloid notch. I7. Spine of pubes. 18. Horizontal branch of pubes. 19. Descending branch of pubes. 20, 20. Ischium. 21. Groove for tendon of obturator externus muscle. 22. Obturator foramen.

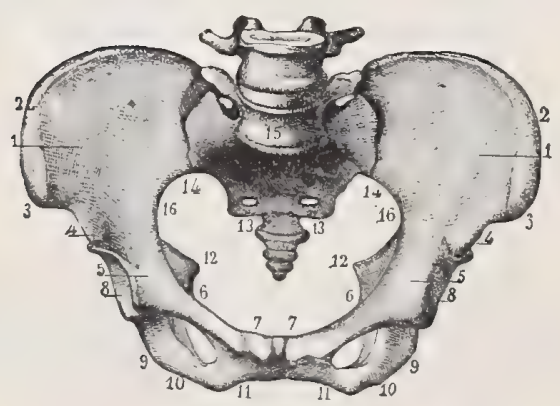

Pelvis, Antero-superior View, Superior Strait,

I, I. Internal iliac fossæ. 2, 2. lliac crests. 3, 3. Anterior superior iliac spines. 4, 4. Anterior inferior iliac spines. 5 , 5. Ilio-pectineal eminences. 6, 6. Horizontal branches of pubes. 7,7 . Bodies and symphysis of pubes. 8, 8. Acetabula. 9, 9. Tuberosities of ischia. 10, 10. Ascending rami of ischium. I1, I1. Descending rami of pubes. 12, I2. Spines of ischia. 13, 13. Posterior wall of pelvic cavity. 14, 14. Sacro-iliac symphyses. 15. Sacro-vertebral angle. 16, 16. Superior strait.
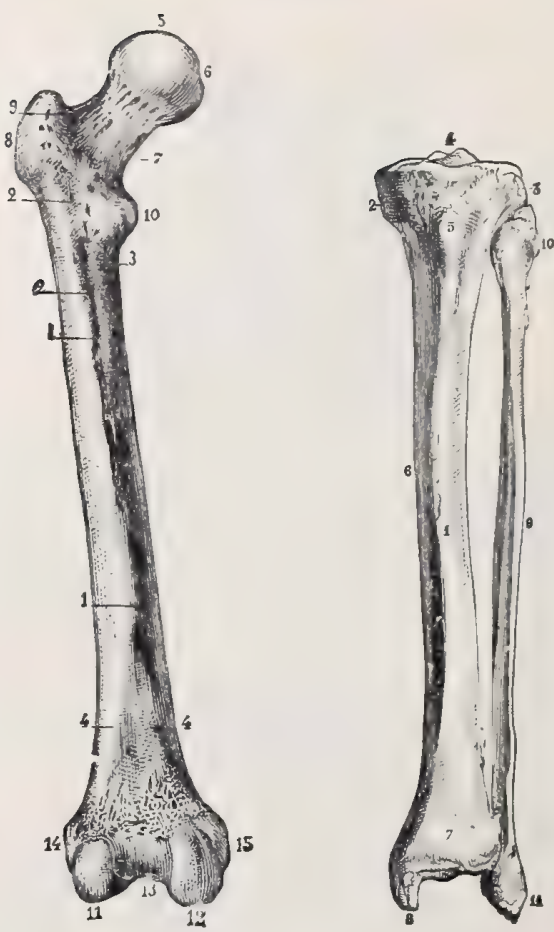

Femur, Posterior Aspect. Tibia and Fibula, Anterior ASPECT.

I, I. Linea aspera. 2, 2, External division. 3. Internal 1. Shaft of tibia. 2. Internal division. 4, 4. Inferior divi- tuberosity. 3. External tusions. 5. Head. 6. Depres- berosity. 4. Spine. 5. Tubersions. 5. Head. 6. Depres- berosity. 4. Spine. 5 . Tubersion for attachment of round cle. 6. Crest. 7. Interior extrochanter. 9. Digital or lus. 9. Shaft of fibula. 10. trochanteric fossa. Io. Lesser Superior extremity. Ir. Introchanter. Ir. Outer con- ferior extremity and external dyle. I2. Inner condyle. I3. Intercondyloid notch. 14. Outer tuberosity. 15. Inner Outer tuber
tuberosity.

Foot, Plantar Aspect. I. Inferior surface of calcaneum. 2. Inner tuberosity. 3. Outer tuberosity. 4. Angular depression between these tuberosities. 5. Inferior portuberosities. 5. Inferior portion of head of astragalus.
6 . Plantar surface of cuboid, for attachment of inferior calcaneo-cuboid ligament. ? Tuberosity of cuboid. 8 . Scaphoid 9. Tuberosity of scaphoid. 9. Tubersity of sca-
phoid. Io. Inferior portion phoid. Io. Inferior portion Apex of middle cuneiform. 12. Apex of internal cuneiform. 13, 14, 15, 16, 17. First, second, third, fourth and fifth metatarsal bones osity of fifth metatarsal bone. osity of fifth metatarsal bone. 19. Two sesamoid bones. 20 2I. Last phalanx of great toe 22, 22. First phalanges of remaining toes. 23, 23. Second and third phalanges of ond and thir malleolus.

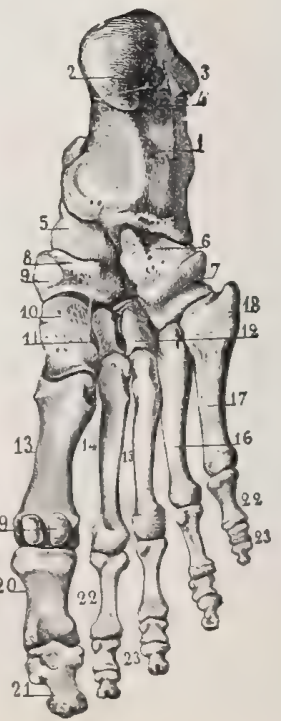


TABLE OF BONES.-Continued.

NAME.

\section{Principal FEATURES}

Turbinate, inferior. middle.

Turbinate, superior.

Tympanic.

Ulna.

Unciform.

Wedge-shaped; hook-like process; in lower row of carpus short bone.

\section{Vertebræ.}

Twenty-six ; cervical seven, dorsal twelve, lumbar five, sacrum (composed of five), coccyx (composed of four; each has a body and an arch; latter has two pedicles, two laminze and seven processes, viz.: four articular, two transverse, one spinous. Peculiar vertebræ, first, second and seventh cervical; first, $\mathrm{ninth}$, tenth, eleventh and twelfth dorsal, sacrum, coccyx; irregular bones.

\section{Humerus-ginglymus. superior-diarthrodia ro- tatoria. \\ Radius, middle-membranous. inferior-diarthrodia rota- toria.}

Triceps, anconeus, flexor carpi ulnaris brachialis anticus, pronator radi teres, flexor sublimis digitor um, flexor profundus digitorum, flexor longus pollicis (occasionally), pronator quadratus, supinator brevis, extensor ossis metacarpi pollicis, extensor secundi internodii pollicis, extensor indicis, extensor carpi ulnaris.

\section{Semilunat \\ Fourth and fifth meta- carpa: Cuneiform, Os magnum,}

Articulate with each other, and with occipital and innominate bones and ribs $\left(q \cdot v_{-}\right)$.

Intervertebral articulations, between the bodies-amphiarthrodia.

Between articular processes-arthrodia.
Flexor brevis minimi digiti, flexor ossis metacarpi minimi digiti, anterior annular ligament.

Attachment of muscles.-To the Atlas are attached nine pairs: the longus colli, rectus anticus minor, rectus lateralis, rectus posticus minor, obliquus superior and inferior, splenius colli, levator anguli scapula and first intertransverse.

To the $A x$ is are attached eleven pairs the longus colli, obliquus inferior rectus posticus major, semispinalis colli, multifidus spinze levator anguli medius, transversalis colli, intertrans versales, interspinales.

To the remaining vertebra generally are attached thirty-five pairs and a single muscle: anteriorly, the rectus anticus major, Iongus colli, scalenus anticus, medius, and posticus, psoas magnus, psnas parvus, quadratus lumborum, diaphragm, obliquus internus and transversalis ; posteriorly. the trapezius, latissimus dorsi, levator anguli scapulæe, thomboideus major and minor serratus posticus superior and inferior, tor spinæ, sacro-lumbalis, longissimus dorsi, spinalis dorsi, cervicalis ascendens, transversalis colli trachelo-mastoid, complexus, biventer cervicis, semispinalis dorsi and colli, multifidus spina, rotatores a, interspinales, supraspinales, intertransversales, levatores costarum.

Sphenoid,

Situated vertically at hack part of nasal fossæ; forms part of septum of nose; somewhat like a plow-share; two surfaces and four borders.

Wormian.
Supernumerary bones; irregular, inconstant, isolated, interposed between the cranial bones, most frequently in the $1 \mathrm{amb}$ doid suture.
Sphenoid

Superior maxillary (two),

Palate (two)

Cartilage of the sep-

tum, synarthrodia. 
Bose's Operation. See Operations, Table of.

Boss (bos) [ME., bos]. A wide, flattish protuberance, as on the skull or on a tumor.

Bosselated (bos'-el-a-ted) [ME, bos]. Covered with bosses or small nodules.

Bosselation (bos-el- $\left.a^{\prime}-\operatorname{shu} n\right)$ [ME., bos]. A boss-like elevation of the surface.

Bostock's Catarrh. See Diseases, Table of.

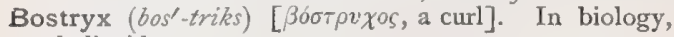
a helicoid cyme.

Boswellia (boz-zuel'-e-ah) [after Boszuell, a Scotch botanist]. A genus of burseraceous trees of $\mathrm{S}$. Asia and E. and Central Africa. B. carteri furnishes olibanum, as also $B$. serrata.

Bosworth's Operation. See Operations, Table of.

Bot (bot) [botus, a belly worm]. The larva of certain species of files of the genus CEstrus, which are conveyed into the stomach of man, where they hatch. Also the thread-worm, Oxyuris vermicularis. See Parasites (Animal), Table of.

Botal, or Botallo, Duct of. See Duct. B., Foramen of. See Foramina, Table of. B., Valve of. See B., Foramen of.

Botalismus (bot-al-iz'-mus). See Botulismus.

Botanic (bot'-an-ik) [ $\beta o \tau a ́ v \eta$, an herb]. Pertaining to botany. B. Physician, a title assumed by certain persons who profess to use only vegetable remedies. See Eclectic.

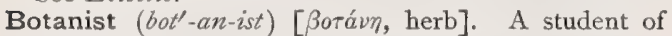
botany

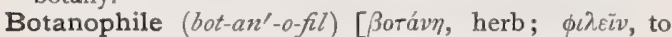
love]. Botanic dilettanti. Persons fond of botany, but not true botanists.

Botany (bot'-an-e) [ßotávn, an herb]. The science of plants-their classification and structure. B. Bay Gum. See Acaroides.

Bote $(b o ̈ t)$. See Passivism.

Bothria (both'-re-ah) [L.]. Plural of Bothrion, or of Bothrium.

Bothriocephalus (both-re-o sef'-al-us) [ $\beta 0 \theta \rho i o v$, a pit; $\kappa \varepsilon \phi a \lambda \eta \dot{n}$, a head]. A genus of tapeworms. See Tapeworm. B. latus, the Broad tapeworm; a common parasite of man in certain European localities. It may reach twenty-five feet in length, with a breadth of three-fourths of an inch. It is also called Tania lata, and Dibothrium latum. See Parasites (Animal), Table of.

Bothrion (both'-re-on) [Botpiov, a pit]. I. A small cavity; the socket of a tooth. 2. A facet, or fosset, such as is seen upon the head of most of the tapeworms. 3. A deep corneal ulcer.

Bothrium (both'-re-um). See Bothrion.

Botium $\left(6 o^{\prime}-s h e-\imath m\right)$ [L.]. A goiter or tumor of the neck. B. trachelophyma. Synonym of Goiter.

Botrel's Operation. See Operations, Table of.

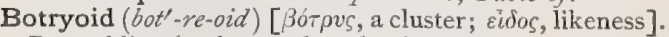
Resembling in shape a bunch of grapes.

Botryomycosis (bot-re-o-mi-ko'-sis) [ $\beta \delta$ T $\rho v s$, a bunch of grapes; $\mu$ v́kns, a fungus]. A disease of horses in which fibromatous nodules form in the lungs. It is dependent upon the presence of a microörganism called Botriomyces.

Botryose $\left(b o t^{\prime}-r e-\bar{o} s\right)$ [ $\beta \sigma \sigma \rho \varphi s$, a cluster of grapes]. An inflorescence constructed on the plan of a raceme.

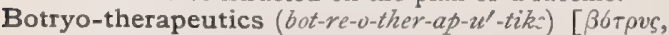
a bunch of grapes; $\theta \varepsilon \rho a \pi \varepsilon v т \iota \kappa \dot{\eta}$, medical art]. See Grape-Cure.

Bots (botz), Bott (bot). See Bot.

Böttcher's Cells. Small cells in the cochlea, occurring in a single layer in the basilar membrane. B.'s Crystals, peculiar microscopic crystals formed by adding a drop of a one per cent. solution of phos- phate of ammonia to a drop of prostatic secretion. They are composed of a phosphate formed from a base that exists in prostatic fluid, and that is supposed to impart to it its peculiar odor. B.'s Test. See Tests, 7 able of

Bötteker's Test. See Tests, Table of.

Böttger's Test. See Tests, Table of.

Bottini's Operation. See Operations, Table of.

Bottle (bot'-l) [ME., botel; Fr., bouteille]. A vessel, usually of glass, with a narrow neck. B., Feeding, a flat flask with a nipple of India-rubber attached, used for feeding infants. B. Nose, a common name for Acne rosacea. B., Specific Gravity, a Florence flask graduated to contain 500-1000 grains of water, with the weight of which an equal volume of any other liquid may be compared. B.-stoop, in pharmacy, a block so grooved that it serves to hold a wide-mouthed bottle in an oblique position while a powder is being dispensed from it. B.-wax, a hard, stiff variety of wax used in sealing bottles.

Botts (botz). See Bot.

Botulinic Acid (bot-u-lin'-ik as'-id) [botulus, a sausage]. An acid asserted to exist in putrefying sausages, and to constitute their specific poison.

Botulism (bot'-u-lizm), Botulismus (bot-u-liz'-mus) [botulus, a sausage]. Sausage-poisoning. See Allantiasis, Blunzen, and Allanto-toxicon.

Bouchard's Diet. See Treatment, Methods of. B.'s Method. See Treatment, Methods of. B.'s Nodules, nodules appearing upon the phalangeal joints of the hands of persons suffering with gastrectasis.

Bouchut's Tubes. A variety of tubes for intubation of the larynx.

Bougard's Paste. A caustic paste containing bichlorid of mercury, chlorid of zinc, arsenic, cinnabar, starch, and wheat flour. It is used as an application to carcinoma.

Bougie (boo-zhe') [Fr., a candle]. A slender, cylindrical instrument made of waxed silk, catgut, etc., for introduction into the urethra or other passage, for the purpose of dilation, exploration, etc. Sometimes bougies are covered with preparations that are thus conveyed to the inner mucous surfaces. B., Armed, a bougie with a piece of nitrate of silver or other caustic attached to its extremity. B., Filiform, a whalebone or other bougie of very small size.

Bouhou (boo-hoo'). See Boohoo.

Bouillaud's Disease. See Endocarditis, and Diseases, Table of.

Bouillon $\left(b o o-e-y o n^{\prime}(g)\right)$ [Fr.]. An alimentary broth made by boiling meat, usually beef, in water. A soup. Also a liquid nutritive medium made by boiling meat, for the culture of microörganisms. Peptonized bouilIons and solutions of powdered meats have also been used. B. of Liebig, made by dissolving Liebig's meat extract, 5 grams, in boiling water, Ioo grams, neutralizing with bicarbonate of soda and filtering. Its nutritive value is increased by adding glucose.

Bouisson's Operation. See Operations, Table of.

Bouknemia (book-ne'-me-ah). Synonym of Elephantiasis arnbum.

Boulesis (boo-le'-sis). See Bulesis.

Boulimia (boo-lim'-e-ah). See Bulimia.

Boulopeithia (boo-lo-pi'-the-ah). See Bulopeithia.

Boulton's Solution. A solution used in the form of a spray in the treatment of rhinitis. Its formula is, compound tincture of iodin $m \times x$; carbolic acid (cryst.), mvj; glycerin, 3 vij; distilled water, $\xi \mathrm{v}$. This is placed in a water bath at $100^{\circ}$, in a tightly-corked bottle until the solution becomes.colorless, and is then filtered.

Bouquet $\left(b 00-k a^{\prime}\right)$ [Fr.]. I. In anatomy, a cluster, of nerves, blood-vessels, or muscles. 2. The delicate 
perfume and flavor of good wine. 3. The odor characteristic of a disease. B. of Riolan, the cluster of ligaments and muscles attached to the styloid process.

Bourdin's Paste. A mixture of nitric acid with flow ers of sulphur; used as an escharotic.

Bourdonnement (boor-don-mon $\left.(g)^{\prime}\right)$ [Fr., bourdonner, to buzz]. Any buzzing sound. The murmur that is heard when the stethoscope is applied to any part of the body. It is thought to result from contraction of the muscular fibrillæe. See, also, Bombus.

Boutha (boo'-thah). A non-alcoholic, stimulating, aêrated beverage, containing thein; proprietary.

Bouton $\left(600-\operatorname{ton}(g)^{\prime}\right)$ [Fr.]. 1. A bud or bulb. 2. A pimple. B. d'Alep, the Aleppo button or boil. See Furunculus orientalis. B. de Biskra. See Furunculus orientalis.

Boutons Terminals. Small terminal enlargements or tactile-cells of sensory nerves, as in the nose of the guinea pig and mole.

Boutonnière Operations. See Operations, Table of.

Bovet, Bacillus of. See Bacteria, Synonymatic Table of.

Bovey Coal (bo'-ve köl). See Lignite.

Bovina Fames $\left(b o-v i^{\prime}-n a h f\left(a^{\prime}-m e \bar{z}\right)\right.$ [L.]. Bovine hunger; bulimia.

Bovine $\left(b o^{\prime}\right.$-vin) [bovinus, of an ox]. Ox-like. B. Heart, the immensely hypertrophied heart of aortic valvular disease. B. Hunger. See Bovina Fames.

Bovinine (bo'-vin-in) [bos, bovis, an ox]. A proprietary preparation of beef used as a food for invalids and convalescents.

Bovista (bo-vis'-tah) [L.]. I. A genus of fungi closely allied to Lycoperdon; some of the species are edible. 2. The Lycoperdon bovista, a fungus or puff-ball. When dry it is a good styptic, and its tincture is used for nervous diseases. It is chiefly employed by homeopathists.

Bow $\left(b_{0}\right)$ [ME., bozve]. A bending. B.-drill, a kind of drill worked by a bow and string, formerly employed in lithotripsy. B.-leg, a bending outward of the lower limbs. See Genu varum.

Bowditch Island Ringworm. See Tinea imbricata.

Bowels (bow'-elz) [ME., borvele: botellus, a sausage]. The intestines.

Bowman's Capsule. The hyaline membrane that forms the wall of the enlargement at the origin of a uriniferous tubule. Same as Malpighian Capsule. B. Discs, the products of a break. ing up of musclefibers in the direction of the transverse striations. These correspond to the discs of "principal substance" of Dobie. B. Glands. See Gland. B. La mellæ of the Cornea. See Membrane of Descemet. B. Membrane, a thin homogeneous membrane - representing the uppermost layer of the stroma of the cornea, with which it

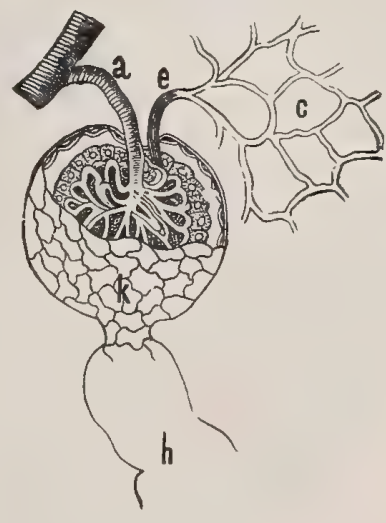

BOWMAN'S CAPSULE AND GLOMERULUS.

a. Vas afferens. $e$. Vas efferens. c. Capillary network of the cortex. $k$. Endothelium of the capsule. $h$. Origin of a convoluted tubule. (After Landois.)
Table of. B. Operations. See Operations, Table of. B. Physic. See Gillenia. B. Probe. See Lachrymal. B. Root. See Gillenia. B. Tubes, artificial passages made by forcing air or fluids between the corneal lamellx.

Box, Boxwood (boks, boks'-wood). See Buxus, B.berry, a popular name for Gaultheria procumbens. B. Plate, a metallic plate with an air-tight chamber, used as an obturator, or in connection with artificial teeth, for the replacement of the loss of natural structure. See Raised Base. B. Pulse-measurer, an instrument for measuring the pulse by its action upon a column of liquid when the exposed artery is placed within an oblong box communicating with the column.

Boyer's Apparatus. An apparatus for reducing frac tures of the humerus; it is composed of four splints and two spiral bandages, one within and one around the splints. B. Bandage. See Bandage. B. Cyst. See Diseases, Table of. B. Splint. See B.'s Apparatus.

Boyle's Law. See Law. B. Ventilator. See Ven tilation.

Boynton's Method. See Operations, Table of. B. Treatment. See Treatment, Methods of.

Bozeman's Apparatus. A wooden framework intended to hold a patient in the knee-elbow posture in the operation for vesico-vaginal fistula. B. Catheter, a double-current catheter. B. Operation. See Operations, Table of.

Braccate (bra $\left.k^{\prime}-\bar{a} t\right)$ [braca, breeches]. In biology, having the feet completely feathered.

Brachelytrous (bra-kel'-it-rus) [ $\beta \rho \alpha \chi \dot{v}$, short ; $\dot{\varepsilon} \lambda v \tau \rho o v$, a sheath]. In biology, with short elytra or wingcovers.

Brachia (bra'-ke-ah). Plural of Brachium.

Brachial (bra'-ke-al) [brachium, the arm]. Pertaining to the arm, especially the upper arm. B. Artery, the continuation of the axillary artery, extending along the inner side of the arm. See Arteries, Table of. B. Diplegia. See Paralysis. B. Glands, the Iymphatic glands of the arm. See Gland. B. Plexus, the plexus of the fifth, sixth, seventh, and eighth cervical and the first dorsal pair of nerves. See Plexuses, Table of: B. Veins, the veins of the arm that accompany the brachial artery. See Vein.

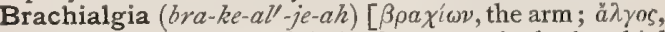
pain]. Pain or neuralgia in the arm or in the brachial plexus.

Brachialis anticus (bra-ke-a'-lis $\left.a n^{\prime}-t i k-u s\right)$. See Muscles, Table of.

Brachiate (bra'-ke-ät) [brachium, an arm]. In biology, possessing arms or branches.

Brachinin (brak'-in-in). [ $\beta \rho a \chi v ́ s$, short]. A substance obtained from the Bombardier Beetle, Brachinus crepitans, of Europe. It is said to be efficacious against rheumatism. Unof.

Brachiocephalic (bra-ke-o-sef-al'-ik) [ $\beta \rho a \chi i \omega v$, the arm; $\kappa \varepsilon \phi a \lambda \dot{\eta}$, head]. Pertaining to the arm and the head. B. Artery and Vein, the innominate artery and vein.

Brachiocubital (bra-ke-o-ku'-bit-al) [ $\beta \rho a \chi^{i} \omega \nu$, the arm; cubitus the forearm]. Relating to the arm and forearm; as the brachio-cubital ligament.

Brachiocyllosis (bra-ke-o-sil-o'-sis) [ $\beta \rho \alpha \chi^{i \omega \nu}$, the arm; $\kappa v ́ \lambda \lambda \omega \sigma \iota s$, a bending]. A crookedness of the arm; also the paralysis that may accompany it.

Brachiodermian (bra-ke-o-der'-me-an) [ $\beta \rho \alpha \chi^{i}(\omega)$, the arm; $\delta \dot{\varepsilon} \rho \mu a$, the skin]. Relating to the skin of the arm.

Brachioncus (bra-ke-ong'-kus) [ $\beta \rho a \chi i \omega v$, the arm;

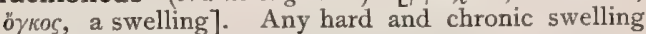
of the arm.

Brachionigraph (bra-ke-on'-ig-raf) [ $\beta \rho a \chi i \omega v$, the arm;

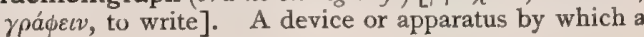

is intimately connected. B. Muscle. See Muscles, 
person who has lost the hand, or who has writer's cramp, can write by means of the muscles of the upper arm.

Brachioradial (bra-ke-o-ra'-de-al) [ $\beta \rho \alpha \chi i \omega \nu$, the arm; radius, a staff]. The supinator radii longus muscle. See Muscles, Table of.

Brachiorrheuma (bra-ke-o-ru'-mah) [ $\beta \rho a \chi i \omega \nu$, the arm; $\dot{\rho} \varepsilon \bar{v} \mu \alpha$, a flux]. Rheumatism of the arm.

Brachiostrophosis (bra-ke-o-stro-fo'-sis) [ $\beta \rho a \chi i \omega \nu$, the arm; $\sigma \tau \rho \varepsilon ́ \phi \varepsilon \iota \nu$, to turn]. A twist or twisted deformity of the arm.

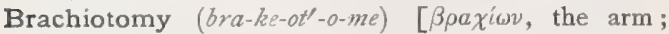

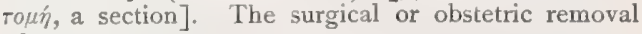
of an arm.

Brachiplex (bra'-ke-pleks) [ $\beta \rho a \chi i \omega v$, the arm; plexus, a twining]. The brachial plexus.

Brachiplexal (bra-ke-pleks'-al) [ $\beta p a \chi i \omega \nu$, the arm; plexus, a twining]. Relating to the brachiplex.

Brachistocephalic, or Brachistocephalous (bra-kis-

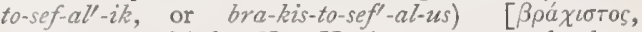
shortest; $\kappa \varepsilon \phi i \lambda \dot{\eta}$, head]. Having an extremely short and very broad head.

Brachium (bra'-ke-um) [brachium, $\beta \rho a \chi^{\prime} \omega \nu$, the arm: pl., Brachia $]$. The arm, especially the upper arm; the arm above the elbow. An extensor process of an organ. B. Cerebri or B. of Optic Lobes, the bands connecting the nates and testes with the optic thalamus. B. Pontis, the brachium of the pons, being also the middle peduncle of the cerebellum. Brachia cerebelli, the peduncles of the cerebellum.

Brach-Romberg Symptom. See Signs and Symptoms, Table of.

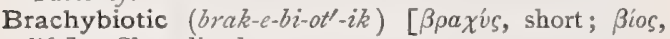
life]. Short-lived.

Brachycardia (brak-e-kar'-de-ah). Same as Bradycardia.

Brachycephalia (brak-e-sef-a'-le-ah) [ $\beta \rho \alpha \chi u ́ s$, short; $\kappa \varepsilon \phi a \lambda \dot{n}$, a head]. The quality of being brachycephalic.

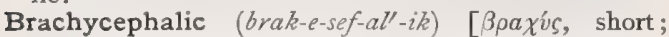
$\kappa \varepsilon \phi a \lambda \eta$, a head]. In biology, applied to skulls of an egg-like shape, with the larger end behind. Having a skull, the transverse diameter of which is more than eight-tenths of the long diameter. See Index.

Brachycephalism (brak-e-sef'-al-izm). See Brachycephalia.

Brachycephalous (brak-e-sef'-al-us) [ $\beta \rho a \chi v ́ s$, short; $\kappa \varepsilon \dot{p} a \lambda \eta$, a head]. Brachycephalic.

Brachycephaly (brak-e-sef'-a-le). See Brachycephalia.

Brachydactylia (brak-e-dak-till-e-ah) [ $\beta \rho a \chi v i s$, short:

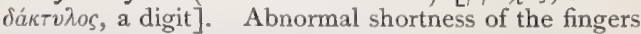
or toes.

Brachydactylism (brak-e-dak'-til-izm). See Brachy. dactylia.

Brachydactylous (brak-e-dak'-til-us) [ $\beta \rho a \chi v$, short;

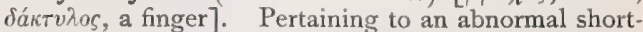
ness of the fingers or toes.

Brachygnathism (brak-iof-näth-izm) [ $\beta \rho \alpha \chi v ́ s$, short; $\gamma v a ́ \theta 0 s$, a jaw]. Excess of length of the superior incisive arch, as in a horse.

Brachykephalia (brak-e-kef-a'-le-ah). See Brachycephalia.

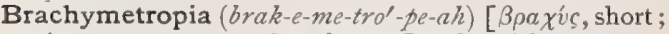

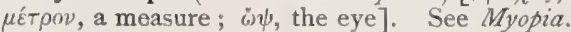

Brachymetropic (brak-e-me-trop $\left.{ }^{\prime}-i k\right)$ [ $\beta \rho a \chi^{\prime} v s$, short;

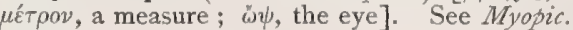

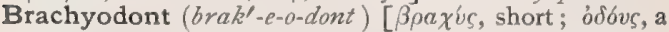
tooth]. In biology, applied to low-crowned teeth : the opposite of Hypsodont.

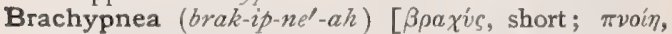
breath]. Abnormal shortness of breath.
Brachypodous (brak-iph-o-dus) [ $\beta \rho \alpha \chi^{i} \zeta$, short; $\pi b v \zeta$, foot]. In biology, possessing a short foot or stalk.

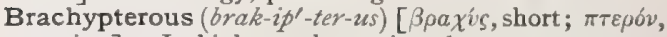
a wing]. In biology, short-winged.

Brachyrrhinia (brak-e-rin'-e-ah) [ $\beta \rho a \chi v ́ s$, short; p’s, a nose]. Abnormal shortness of the nose.

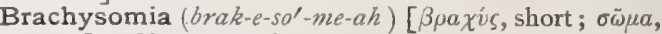
body]. Shortness of the body.

Brachyurous (brak-e-u'-rus) [ $\beta \rho \alpha \chi v ́ s$, short; ov $\rho a ́$, taill]. In biology, short-tailed.

Bracklet (brak'-let) [bracteola, a thin leaf]. In biology, the smaller bract borne on pedicles.

Bract (brakt) [bractea, a thin plate]. In biology, the name of the modified leaves borne on flower-peduncles or at the base of flower-clusters

Bracteole. Same as Bracklet.

Bradesthesia (brad-es-the'-ze-ah). See Bradyesthesia.

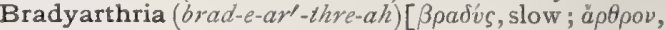
articulation]. Abnormally slow articulation of words: bradylalia.

Bradybolism (brad-ib'-o-lizm) [ $\beta \rho a \delta v ́ s$, slow; $\beta a ́ \lambda \lambda \varepsilon v v$, to throw]. Same as Bradyspermatism.

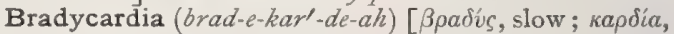
the heart]. Slow pulse-the opposite of tachycardia.

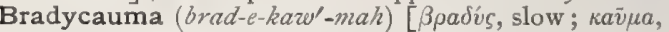
burn: pl., Bradycaumata]. Slow cautery, as with the moxa.

Bradycrote (brad'-e-krōt) [ $\beta \rho a \delta v ́ s$, slow; крótos, a beating]. Marked by or relating to slowness of the pulse.

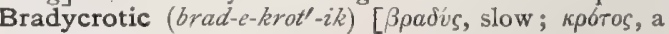
beating]. Bradycrote.

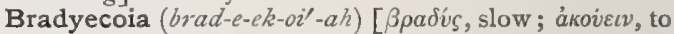
hear]. Hardness of hearing.

Bradyesthesia (brad-e-es-the'-ze-ah) [ßpadus, slow;

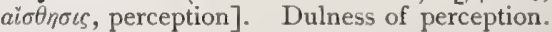

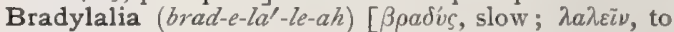
talk]. A slow and disordered utterance.

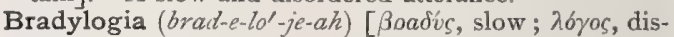
course]. Bradylalia.

Bradymasesis, Bradymassesis (brad-e-mas-e'-sis), or Bradymastesis (brad-e-mas-te'-sis) [ßpadús, slow; $\mu a ́ \sigma \eta \sigma \iota \varsigma$, mastication]. Slow or difficult mastication, especially that seen in general paralysis, or after lesions of the fifth nerve.

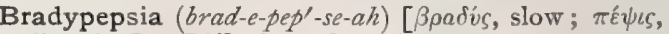
digestion]. Difficult or slow digestion.

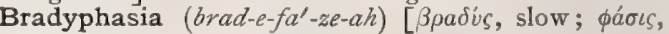
speech]. Bradylalia.

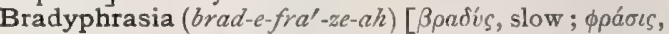
utterance]. Slowness of speech; it occurs in some types of mental disease.

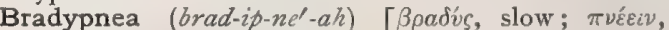
to breathe]. Abnormal slowness of breathing.

Bradyspermatism (brad-e-sper'-mat-izm) [Boadis, slow; $\sigma \pi \varepsilon \rho \mu a$, seed]. Abnormally slow emission of semen.

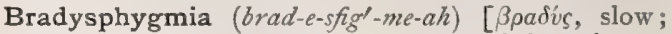

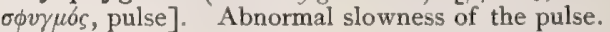

Bradysuria (brad-iss $\left.u^{\prime}-r e-a h\right)$. See Bradyurit.

Bradytocia (brad-e-to'-se-ah) [Bpadv́s, slow; $\tau \delta \kappa o s$, birth]. Abnormally slow or protracted parturition.

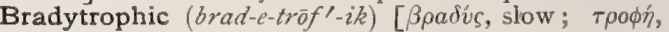
nutrition]. Characterized by slowness of trophic changes.

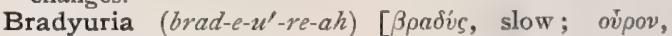
urine]. Slow passage of urine.

Braidism (brā $\left.d^{\prime}-i s m\right)$ [Braid, the originator]. The hypnotic state produced by fixation of the eyes upon a shining object; described by James Braid in 1842 . See Hypnotism.

Brain (brān) [Low Ger., bragen]. The general contents of the cranium, especially the cerebrum. B., 


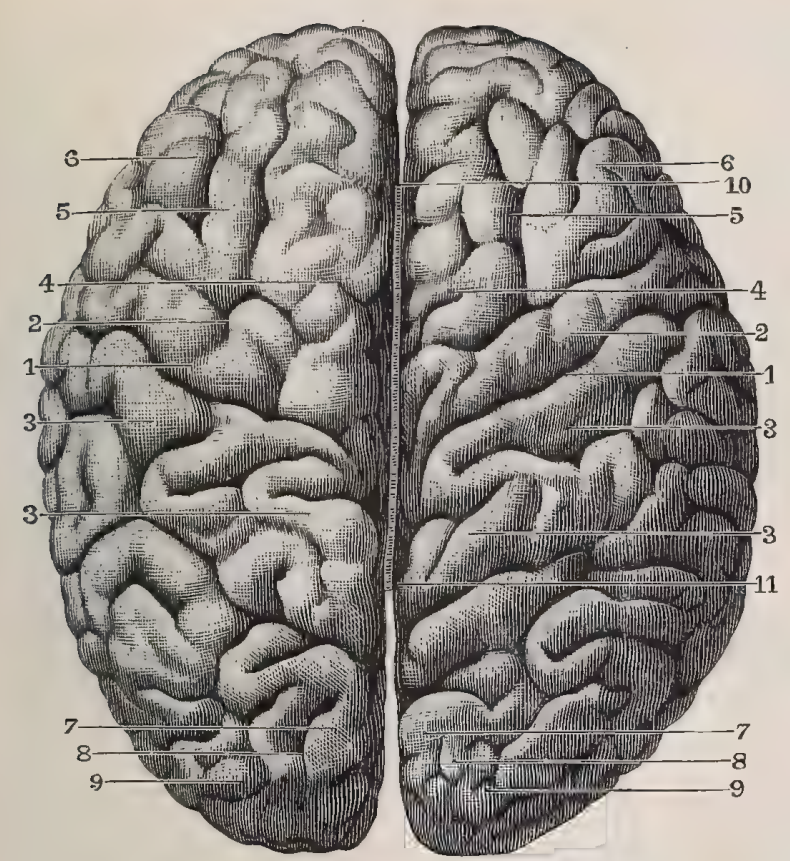

SUPERIOR ASPECT, OR CONVEXITY OF THE BRAIN.

I, I. Fissure of Rolando. 2, 2. Ascending frontal convolution. 3, 3. Ascending and superior parietal convolutions. 4, 4. First frontal convolution. 5,5 . Second frontal, 6, 6. Third frontal. 7, 7. First occipital. 8, 8. Second occipital. 9, 9. Third occipital. 10. Anterior extremity of corpus callosum. ir, II. Posterior extremity.

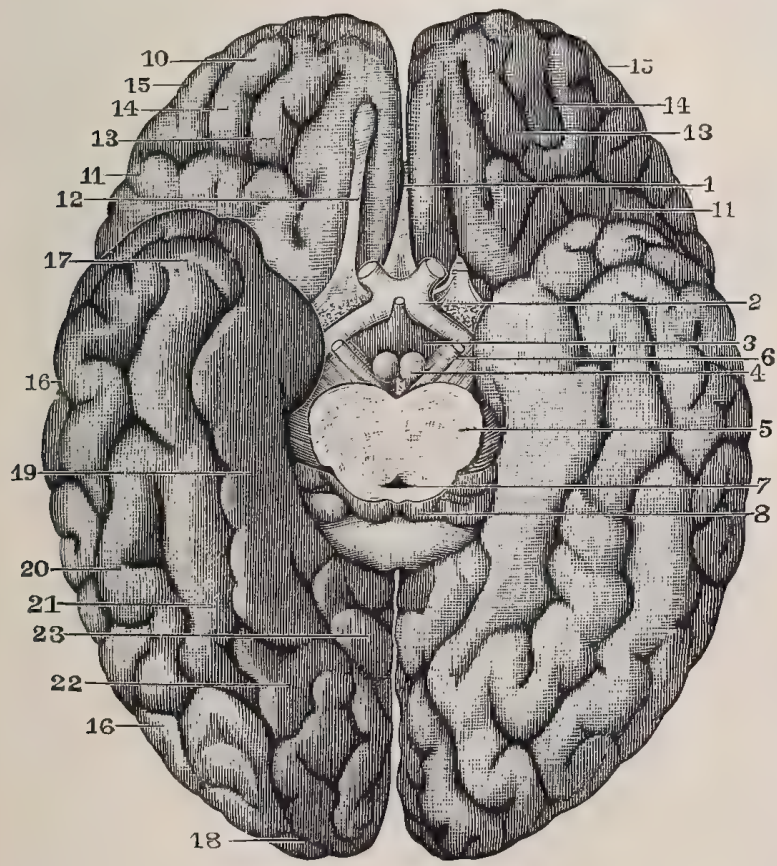

INFERIOR ASPECT OF THE BRAIN.

I. Anterior extremity of corpus callosum 2, Optic chiasm, 3uber cinereum and infundibulum. 4. Corpora albicantia, or mamillaria. 5. Pons vatolii. 6. Third nerve. 7. Aqueduct of Sylvius. 8. Testes. Io. Inferior surface of frontal lobe. 1I. Convolution of the fissure of
Abdominal. See Solar Plexus. B., After-. See Metencephalon. B. Axis, that portion of the brain-substance including the island of Reil, the basal ganglia, the crura, pons. medulla, and cerebellum. B.-bladder, a cerebral vesicle of the embryo. B., Compression of, may arise from injury or disease, from serous exudation, blood extravasation, etc. See Compression. B., Concussion of, is the result of injury producing symptoms of loss of power and function generally. See Concussion. B.-fag, mental exhaustion due to overwork. B. Fever See Meningitis; also Synonym of Typhoid Fever. B., Fore-. See Prosencephalon. B., Hind-. See Epencephalon. B., Incallosal, one in which there is a complete absence of the corpus callosum. This is commonly associated with mental and physi cal weakness, amounting often to idiocy. B., Inter-. See Diencephalon. B., Irritation of, follows injury, and is marked by symptoms of irritability and often by convulsive phenomena. B., Little, the cerebellum. B.-mantle, that portion of the brain-substance including the convolutions, corpus callosum, and fornix. B., Mid-, See Mesencephalon. B.-pan, the cranium. B., Railway, a neurosis sometimes occurring in those who ride constantly on railway trains. It is characterized by anesthesia, or spinal hyperesthesia, insomnia, paresis, etc. B. Sand, a gritty mineral matter found in and about the pineal gland, consisting mainly of calcium and magnesium carbonates and phosphates. Its function is not known. B.-shake. Synonym of $B$., Concussion of. B.-stem, the pons, medulla, and crura cerebri. B.-storm, a succession of sudden and severe phenomena, due to some cerebral disturbance. B.-tire, a condition of brain-exhaustion due to excessive functional activity. See B.-fag. B.-wave, the supposed telepathic vibration of a "mentiferous ether," by which thoughts and impressions may be transferred from one person to another. B.-wax. See Cephalot.

Brainard's Operations. See Operations, Table of.

Bramah's Apparatus. An apparatus by which water may be charged with $\mathrm{CO}_{2}$ by the continuous method.

Bramble (bram'-bl). See Rubus.

Bran (bran) [ME., bran]. The epidermis or outer covering of the seeds of most cereals. It contains woody matter 35 , starch 22, albumin and gluten I3, water I2, gum 8 , other matters, including a small amount of silica, ro per cent. It contains, also, a diastatic ferment that converts the starch into dextrin. B. Bath. See Bath. B. Tea, a decoction of bran, used in coughs.

Sylvius. 12. Olfactory nerve. 13. Third convolution of inferior surface of frontal lobe. I4. Fourth convolution. 15. Third convolution of external surface of frontal lobe. 16. External border of posterior lobe. 17. Sphenoidal extremity. I8. Occipital extremity. 19. Hippocampal convolution. 20. External convolution of posterior lobe. 2I. Middle convolution. 22. Internal convolution. 23. Gyrus fornicatus. 
Branch (branch) [ME, branche]. A name given to the divisions or offshoots of blood-vessels, lymphatics, or nerves, from the trunk or main stem.

Branchize (brang'-ke-e) [ $\beta \rho a ́ \gamma \chi \iota a$, gills]. The gills of fishes.

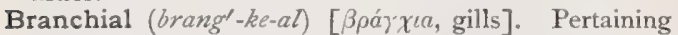
to branchiæ. B. Arches. See Arches. B. Openings. See Clefts, Visceral.

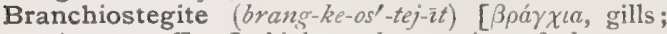
$\sigma \tau \hat{\varepsilon} \gamma \eta$, a roof]. In biology, that portion of the carapace of a crustacean that covers the gills and branchial chamber

Branchireme (brang'-ke-rèm) [branchia, gills; remus, an oar, hand or foot of a swimmer]. In biology, a crustacean having gill-bearing legs.

Branchus (brang-kus) [ $\beta \rho a ́ \gamma \chi o s$, hoarseness]. Hoarseness.

Brand Bath. See Bath. B. Method. See Treatment, Methods of.

Brandt's Method. See Treatment, Method's of. B.'s Operation. See Operations, Table of.

Brandy (bran'-de). See Spiritus. B. Nose. See Acne rosacea.

Branks (brangks) [Gael., brancas, a kind of pillory]. The mumps.

Branny (bran'-e) [ME., bran]. Like bran. Kidney. Same as Large White Kidney, q. v. B. Tetter. Synonym of Pityriasis.

Brasdor's Operation. See Operations, Table of.

Brash (brash) [Dutch, braaken, to vomit]. A common name indicating almost any disorder of the digestive system; any rash, or eruption; a short fit of illness. B., Water. See Pyrosis.

Brasilin (bra'-zil-in) [ME., brasil], $\mathrm{C}_{16} \mathrm{H}_{14} \mathrm{O}_{5}$. Brazilin, a coloring-matter found in Brazil-wood and red-wood; it crystallizes in white, shining needles, and dissolves in alkalies with a carmin-red color on exposure to the air. See Pigments, Conspectus of.

Brass (bras) [ME., bras]. An alloy of copper with 2540 per cent. of zinc. B.-Founder's Ague. See Ague.

Brassica (bras'-ik-ah) [AS., brassica, cabbage]. A genus of plants, Nat. Order, Cruciferce, including the common cabbage. B. acidulata, sour crout (or Sauer Kraut). B. asperifolia esculenta, the common turnip. B. cauliflora (or florida), the cauliflower. B. cumana or rubra, the red cabbage. B. napus, the rape plant. B. nigra, the black mustard. B. sativa, the common cabbage.

Brassidic Acid (bras-id'-ik). See Acid.

Braun's Canal. See Canal. B. Operation. See Operations, Table of. B. Test. See Tests, Table of.

Braune (braun). See Brunissure.

Braune's Canal. See Canal.

Brawn (brawn) [ME., braun, a piece of flesh]. The flesh of a muscle; well-developed muscles.

Brawny (brawn'-e) [ME, brazen, a piece of flesh]. Fleshy; muscular. B. Induration, pathologic hardening and thickening of the tissues.

Braxy (braks'-e) [E. dial.]. A term applied to certain forms of blood-disease, as anthrax in sheep. Three forms are recognized by shepherds: $a$, turnip; $b$, wet; $c$, red. B., Red, a form of septicemia in sheep in which the tissues are uniformly stained of a deepred color by the coloring-matter of the blood. $\mathbf{B}$., Turnip, a form of malnutrition of the blood occurring in sheep that are fed on an unlimited supply of roots, particularly of swedes. The attack is sudden in onset, short in duration, and fatal in termination. See Bacillus anthracis, Pollender and Davaine, under Bacteria, Synonymatic Table of.
Brayera (bra-y $\left.c^{\prime}-r a h\right)$ [Fr., brayer]. Koosoo, koosso, koso, kousso, cusso. The female inflorescence of Hagenia abyssinica, containing tannic acid, a volatile oil and a crystalline principle, Koussin, $\mathrm{C}_{31} \mathrm{H}_{38} \mathrm{O}_{10}$. In large doses it produces nausea and emesis. It is valuable mainly as an anthelmintic against tapeworm. Dose $3 \mathrm{ij}-\overline{3} \mathrm{ss}$, in infusion of boiling water. B., Ext., Fld., dose $3^{i j}-\zeta_{j}$. Infusum Cusso (B. P.). Dose 亏iv-viij.

Bread (bred) [Sax., bredan to nourish; Lat., panis, Gr., ă $\rho \tau$ c ]. A mixture of flour and water made porous by carbon dioxid and then baked. The flour may be of wheat, corn, oat, or rye. The carbon dioxid may be introduced by decomposing an alkaline varbonate (sodium or potassium), by an acid ("cream of tartar"), or by fermenting the starch with yeast. B., Brown, a kind of bread made from a mixture of corn, rye and wheat flour. B., Graham, made from unbolted wheat flour; it contains more gluten, diastase and mineral phosphates than ordinary bread. B., White, bread made from bolted wheaten flour, and therefore deficient in diastase, gluten and mineral phosphates. Other kinds, such as rye (or black), corn, bran, barley, etc., indicate their composition by their name. B.jelly, a food of service as an occasional change from mushes, but with a tendency to constipate if given freely. It is prepared by pouring boiling water upon stale bread and allowing it to soak for an hour. The water is then removed, fresh water added, and the whole boiled until a thick mass forms. On pouring off the excess of water and cooling, a jelly-like material remains which may be eaten with milk or sugar. B.-mould. See Ascophora. B.-paste, a culturemedium for bacteria. Stale, coarse bread is dried, ground to powder and made into a paste with water. It is well suited for the growth of moulds.

Break (brāk) [ME., breken, to break]. In electricity, an opening in the circuit of a battery. See Make. In surgery, a fracture. B.-bone Fever. See Dengue. B. Shock, a term sometimes employed in electrotherapeutics for the physiologic shock produced on the opening or breaking of an electric circuit.

Breast (brest) [ME., brest, the breast]. The upper anterior part of the body between the neck and abdomen. Also, the mamma. B.-bone. See Sternum. B., Broken, abscess of the mammary gland. B., Chicken, Pectus carinatum; a deformity marked by prominence of the sternal portion of the chest. B. Glass, a glass receptacle for the overflow of milk from the breast. B. Pang, angina pectoris. See Stenocardia. B. Pump. See Antlia. B., Pigeon. Same as B., Chicken. B. Tea, German, a mixture of althea, or marshmallow, eight parts ; coltsfoot leaves, four parts; liquorice, three parts; anise and mullein leaves, each two parts; orris, one part : this is called also species pectoralis.

Breastweed. See Saururus cernuus.

Breath (breth) [AS., brath]. The air exhaled from the lungs. It has lost a part of its oxygen and gained a certain but varying amount of ammonia, aqueous vapor and carbon dioxid from the oxidation of the wastematter of the blood. Also applied to the air inspired. B. Sounds, the respiratory sounds heard upon auscultation. In the healthy chest three varieties of respiratory sounds may be recognized: $: \boldsymbol{I}$. Those produced in the glottis, and audible over the lower end of the trachea-tracheal or bronchial breathing. 2 . Those produced in the alveoli and audible over the lungs-vesicular breathing. 3. Those audible about the roots of the lungs, combining the character of the two preceding-broncho-vesicular breathing. A Table of Breath-Sounds is given on the next page. 
TABLE OF BREATH-SOUNDS IN HEALTH AND DISEASE.

(Altered and enlarged from $J . K$. Fowler).

\begin{tabular}{|c|c|c|c|c|c|c|c|c|}
\hline $\begin{array}{c}\text { VARIETY } \\
\text { OF } \\
\text { BREATHING. }\end{array}$ & PERIOD. & PITCH. & QUALITY. & INTERVAL. & DURATION. & INTENSITY. & $\begin{array}{l}\text { WHERE } \\
\text { HEARD. }\end{array}$ & $\begin{array}{l}\text { CONDITION } \\
\text { IN WHICH } \\
\text { HEARD. }\end{array}$ \\
\hline Vesicular. & $\begin{array}{l}\text { 1. Inspira- } \\
\text { tion. } \\
\text { 2. Expira- } \\
\text { tion. }\end{array}$ & $\begin{array}{l}\text { Low. } \\
\text { Lower. }\end{array}$ & $\begin{array}{l}\text { Vesicular. } \\
\text { Blowing. }\end{array}$ & $\begin{array}{l}\text { None. } \\
. .\end{array}$ & $\begin{array}{l}\text { Shorter than in- } \\
\text { spiration or } \\
\text { absent. }\end{array}$ & $\begin{array}{l}\text { Variable. } \\
\text { Faint or ab- } \\
\text { sent. }\end{array}$ & $\begin{array}{l}\text { Over the lungs, } \\
\text { in health. }\end{array}$ & In health. \\
\hline Bronchial. & $\left\{\begin{array}{l}\text { T. Inspira- } \\
\text { tion. } \\
\text { 2. Expira- } \\
\text { tion. }\end{array}\right.$ & $\begin{array}{l}\text { High. } \\
\text { Higher. }\end{array}$ & $\begin{array}{l}\text { Tracheal. } \\
\text { Tracheal. }\end{array}$ & $\begin{array}{c}\text { Distinct. } \\
. . .\end{array}$ & $\begin{array}{l}\text { Equal to or } \\
\text { longer than } \\
\text { inspiration. }\end{array}$ & $\begin{array}{l}\text { Variable. } \\
\text { Greater. }\end{array}$ & $\begin{array}{c}\text { In health, over } \\
\text { the seventh } \\
\text { cervicalspine } \\
\text { In disease, } \\
\text { over areas of } \\
\text { consolidation }\end{array}$ & $\begin{array}{l}\text { In health; } \\
\text { pulmonary } \\
\text { tuberculosis, } \\
\text { lobar pneu- } \\
\text { monia, large } \\
\text { pleuritic } \\
\text { effusions, } \\
\text { thoracic } \\
\text { aneurysm, } \\
\text { mediastinal } \\
\text { tumors. }\end{array}$ \\
\hline $\begin{array}{l}\text { Broncho- } \\
\text { vesicular. }\end{array}$ & $\begin{array}{l}\text { x. Inspira- } \\
\text { tion. } \\
\text { 2. Expira- } \\
\text { tion. }\end{array}$ & $\begin{array}{l}\text { Higher than } \\
\text { in vesicular } \\
\text { breathing. } \\
\text { H igher than } \\
\text { in vesicular } \\
\text { breathing. }\end{array}$ & $\begin{array}{l}\text { More or less } \\
\text { tracheal. } \\
\text { More or less } \\
\text { tracheal. }\end{array}$ & $\begin{array}{l}\text { Slight. } \\
. .\end{array}$ & $\begin{array}{c}\text { About equal to } \\
\text { inspiration. }\end{array}$ & $\begin{array}{l}\text { Variable. } \\
\text { Greater. }\end{array}$ & \begin{tabular}{|} 
In health, ant., \\
over sternal \\
portion of in- \\
fra-clavic. \\
region; post., \\
upper part of \\
inter-scapular \\
reg ion. In \\
disease, over \\
slight con- \\
solidation. \\
\end{tabular} & $\begin{array}{l}\text { In health; } \\
\text { pneunonia, } \\
\text { pulmonary } \\
\text { tuberculo- } \\
\text { sis. }\end{array}$ \\
\hline Amphoric. & $\begin{array}{l}\text { I. Inspira- } \\
\text { tion. } \\
\text { 2. Expira- } \\
\text { tion. }\end{array}$ & $\begin{array}{l}\text { Low. } \\
\text { Lower. }\end{array}$ & $\begin{array}{l}\text { Hollow and me- } \\
\text { tallic. } \\
\text { Both characters } \\
\text { more marked. }\end{array}$ & $\begin{array}{c}\text { Distinct. } \\
.\end{array}$ & $\begin{array}{c}\text { Longer than } \\
\text { inspiration. }\end{array}$ & $\begin{array}{l}\text { Variable. } \\
\text { Greater. }\end{array}$ & $\begin{array}{l}\text { Over a large } \\
\text { cavity com- } \\
\text { municating } \\
\text { with an open } \\
\text { bronchus. }\end{array}$ & $\begin{array}{l}\text { Pulmonary tur } \\
\text { berculosis. }\end{array}$ \\
\hline Cavernous. & $\begin{array}{l}\text { 1. Inspira- } \\
\text { tion. } \\
\text { 2. Expira- } \\
\text { tion. }\end{array}$ & $\left\{\begin{array}{l}\text { Low. } \\
\text { Lower. }\end{array}\right.$ & $\begin{array}{l}\text { Blowing and } \\
\text { hollow. } \\
\text { Both characters } \\
\text { more marked. }\end{array}$ & $\begin{array}{c}\text { Distinct. } \\
. .\end{array}$ & $\begin{array}{c}\text { Longer than } \\
\text { inspiration. }\end{array}$ & $\begin{array}{l}\text { Variable. } \\
\text { Greater. }\end{array}$ & $\begin{array}{l}\text { Over a cavity } \\
\text { communicat- } \\
\text { ing with an } \\
\text { open bron- } \\
\text { chus. }\end{array}$ & $\begin{array}{l}\text { Pulmonary } \\
\text { tuberculo- } \\
\text { sis. }\end{array}$ \\
\hline Tubular. & $\begin{array}{l}\text { I. Inspira- } \\
\text { tion. } \\
\text { 2. Expira- } \\
\text { tion. }\end{array}$ & $\begin{array}{l}\text { H igher than } \\
\text { in bronchial } \\
\text { breathing. } \\
\text { Higher. }\end{array}$ & $\begin{array}{c}\begin{array}{r}\text { Laryngeal } \\
\text { whiffing. }\end{array} \\
\text { Laryngeal } \\
\text { whiffing. }\end{array}$ & Distinct. & $\mid \begin{array}{c}\text { Equa l to or } \\
\text { longer tha n } \\
\text { inspiration. }\end{array}$ & $\begin{array}{l}\text { Variable. } \\
\text { Greater. }\end{array}$ & $\begin{array}{l}\text { Over consolid- } \\
\text { ated areas. }\end{array}$ & $\begin{array}{l}\text { Lobar pneu- } \\
\text { monia, pul- } \\
\text { monary tus } \\
\text { berculosis. }\end{array}$ \\
\hline
\end{tabular}

Breathing (breth'-ing) [AS., brath]. See Respiration. B., Abdominal, breathing in which the abdominal walls move decidedly and in which the diaphragm is actively engaged. B., Diminished, is the reverse of $B$. Exaggerated. The normal breath-sound is present, but its intensity is much diminished. It is very frequently heard at the apex in the early stage of pulmonary tuberculosis. B., Exaggerated, is the normal breath-sound of children, but when occurring in adults, it indicates a compensatory action of one part of the lungs for deficient action elsewhere. It is an exaggerated degree of the normal vesicular breathing. B., Interrupted, Wavy or Cogwheel, a broken or interrupted inspiratory sound produced by nervousness, irregular contraction of the muscles of respiration, or irregular expansion of the lung from disease. B., Mouth, habitual respiration through the mouth. B., Puerile. See B., Exaggerated. B., Suppressed, entire absence of breath-sounds, as in pleuritic effusion and certain solid conditions of the lung. B., Thoracic, respiration in which the thoracic walls are actively moved.

Bredsore (bred'-sōr) [Vulgar]. A sore coming without any visible cause; a whitlow; also called Breeder.

Breech (brēch) [ME, breech]. The buttocks. B. Position. See Fetus, Position of.
Breeches Splint. A splint that surrounds the leg; oftenest made of woven wire.

Breed (bréd) [AS., brēdan, to nourish]. To beget, produce ; to nurse ; to develop.

Breeder (bréd'-er). See Bredsore.

Breeding-season (bre'-ding se'-zun) [AS., brédan, to nourish]: The period during which certain species of animals, especially the lower forms of vertebrates, beget and rear their young.

Breeze (brẽz). See Head-breeze and Static-breeze.

Brefeld and Nägele's Method. See Fractional Cultivation.

Bregenin (breg'-en-in) [Low Ger., bregen, brain], $\mathrm{C}_{40} \mathrm{H}_{87} \mathrm{NO}_{5}$. A name given by Thudichum to a viscous principle, soluble in and crystallizable from alcohol, by means of which it has been extracted from brain-tissue. It is fusible like a fat, but is miscible with water.

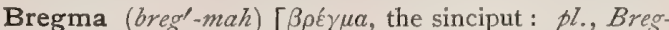
mata]. A term applied to the anterior fontanelle. See Cranionetric Points.

Bregmatic $\left(b_{r e g}-m a t^{\prime}-i k\right)$ [ $\beta \rho \varepsilon ́ \gamma \mu \alpha$, the sinciput]. Relating to a bregma.

Bregmato-anterior (breg'-mat-o-an-te'-re-or) [ $\beta \rho \varepsilon^{\prime} \gamma \mu a$, the sinciput; anterius, front]. Having the bregma in the anterior portion of the mother's pelvis; applied to the presentation in labor. 
Bregmato-cotyloid (breg'-mat-o-kot'-il-oid) [ $\beta \rho \dot{\varepsilon} \gamma \mu \alpha$,

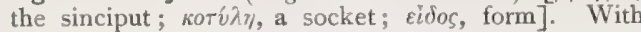
the bregma toward the cotyloid depression (acetabulum) of the mother's pelvis ; a term used in obstetrics.

Bregmatodymia (breg-mat-o-dim'-e-ah) [ $\beta \rho c^{\prime} \gamma \mu a$, the

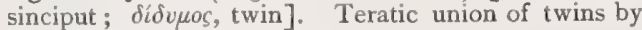
the bregmata.

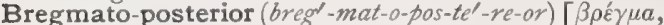
the sinciput; posterius, backward]. Having the bregma toward the rear of the mother's pelvis; a term used in obstetrics.

Bremen (brem'-en) [Ger.]. A town in Germany. B. Blue. See Conspectus of Pigments, under Pigment. B. Green. See Conspectus of Pigments, under Pigment.

Bremer's Test for Diabetic Blood. Diabetic bloodcorpuscles stained with eosin for ten minutes in an oven at $35^{\circ} \mathrm{C}$. yield a greenish yellow tint; in normal blood the color is brownish.

Bremond's Method. See Treatment, Methods of.

Brenner's Formula. The feeble tone heard when the anode is opened in galvanic stimulation of the auditory nerve. This tone corresponds with the resonance fundamental tone of the sound-conducting apparatus of the ear itself.

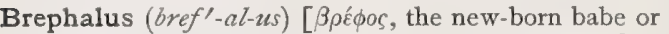
young]. In biology, applied to the young of a crustacean just as it quits the ovum, in whatever stage. Bates's substitute for larva.

Brephopolysarcia (bref-o-pol-e-sar'-ke-ah) [ $\beta \rho \hat{\varepsilon} \phi a s$, an infant; $\pi \circ \lambda v s$, much; $\sigma a ́ \rho \xi$, flesh]. Excess of flesh in an infant.

Brephotrophium (bref-o-tro-fe'-um) [ $e^{\prime} \rho \dot{c} \phi o s$, infant; трє́ $\phi \varepsilon \iota \nu$, to nourish]. An infant-asylum; a foundlinghospital.

Breschet, Canals of. See Canal. B., Sinus of, the spheno-parietal sinus. See Simus. B.'s Veins. See Vein.

Bresgen's Formulæ. Silver-nitrate powders of varying strengths, with powdered starch, for use in rhinitis.

Breslau Fever. See Fever. B. Test. See Birth.

Brevē extensor digitorum (brev-e-eks-ten'-sor dig-it-o'$12 \mathrm{~m})$ [L.]. The extensor brevis digitorum. See Muscles, Table of.

Brevicaudate (brev-e-kaze'-dāt) [brevis, short; cauda, tail]. In biology, short-tailed.

Breviductor (brev-e-duk'-tor) [L.]. The adductor brevis muscle of the thigh. See Muscles, Table of.

Breviflexor (brev-e-fleks'-or) [L.]. Any short, flexor muscle.

Brevifoliate (brev-e-fo'-le-ät) [brevis, short; folium, a leaf]. In biology, short-leaved.

Brevilingual (brev-e-ling'-grval) [brevis, short; lingua, a tongue]. In biology, short-tongued.

Breviped (brev'-e-ped) [brevis, short; pes, a foot]. In biology, short-footed.

Brevipen (brev'-e-pen) [brevis, short; penna, a wing]. In biology, short-winged.

Brevirostrate (brev-e-ros'-trät) [brevis, short ; rostrum, a beak. In biology, short-billed.

Brevissimus oculi (bre $z^{\prime}-i z^{\prime}-e m-u s$ o $k^{\prime}-u$-li) [L. ]. The shortest muscle of the eye; the obliquus inferior. See Muscles, Table of.

Brewcke's Test. See Tests, Table of.

Briançon Manna (bre-an-sōn' man'-ah). A kind of manna from the twigs of the European larch-tree.

Bribosia's Operation. See Operations, Table of.

Brick-Dust Deposit (brik'-dust de-pos'-it). A lateritious sediment from urine.

Bricklayers' Itch (brik-la'-erz ich). Eczema due to irritation of lime mortar.
Brick-makers' Anemia. See Anchylostomiasis.

Bridge (brij) [ME., brisge]. I. The upper ridge of the nose formed by the union of the two nasal bones. 2 . In electricity, an apparatus for measuring the resistance of a conductor. B. Coloboma. See Coloboma. B., Herpetic, a term for Fascicular Keratitis, q. v. B. of Nose, the prominent ridge formed by the nasal bones. B. of Varolius, the pons Varolii. B.-Work, in dentistry, the adaptation of artificial crowns of teeth to and over spaces made by the loss of natural teeth, by connecting such crowns to natural teeth or roots for anchorage by means of a bridge, and thereby dispensing with plates covering more or less of the roof of the mouth and the alveolar ridge.

Bridle $\left(b r i^{\prime}-d l\right)$ [ME., bridel]. I. A Firenum, q.v. 2. A band or filament stretching across the lumen of a passage, or from side to side of an ulcer, scar, or abscess. B. Stricture, a stricture due to the presence of a bridle traversing the caliber of the urethra.

Brieger, Bacillus of. See Bacteria, Synonymatic Table of. B.'s Method, a method of separating ptomaines from a putrefying mass.

Briggs's Operation. See Operations, Table of.

Brightic (brit'-ik) [Bright, an English physician]. A person suffering from Bright's disease.

Bright's Disease (brits dis-êz') [Bright, an English physician]. A name formerly incorrectly used as a synonym of albuminuria, and at present covering several forms of disease of the kidney associated with albumin in the urine. It may be acute (acute parenchy. matous nephritis) or chronic (which includes chronic parenchymatous nephritis, granular contraction of the kidneys, and albuminoid degeneration of the kidneys). Bright's disease is considered by Fothergill as a secondary condition arising from a tendency toward the reversion to that preanthropic type in which the liver performed the additional office of excreting uric acid. Acute Bright's Disease is sudden in its onset, and is associated with chills, headache, backache, vomiting, and edema, especially marked in the eyelids and the cheeks. The urine is scanty or even suppressed, of a dark, smoky hue, and contains a large amount of albumin, and blood. Microscopically, bloodcorpuscles, renal epithelium, débris, and hyalin, epithelial, and blood-casts are found, and occasionally, also, granular casts. Occasionally the glomeruli of the kidney are the seat of the most marked changes, and to this condition the term "glomerulo-nephritis," has been given. The most frequent cause of acute Bright's disease is exposure to cold. It is often a complication of the specific fevers, especially scarlet fever. Death frequently results from uremia or cardiac failure, or the disease may assume a chronic form. Chronic Bright's Disease embraces, as has been said, three distinct diseases of the kidney. Chronic parenchymatous nephritis, usually following an acute attack, is also known as chronic tubal and chronic desquamative nephritis, and from its size and pallor, the kidney resulting from the disease is called the " large white kidney," The capsule peels off readily and leaves a smooth or very slightly granular surface. The tubules are most involved in the change; they are enlarged and distended with proliferated and swollen epithelial cells. There is some thickening of the interstitial tissue, as a rule. This large kidney is prone to undergo degenerative changes, the protoplasm of the cells in the tubules breaking down into an amorphous débris. The kidney shrinks, and at the same time undergoes an increase in the interstitial tissue, forming what is known as the " small white kidney." Granular contraction of the kidney is also known as chronic interstitial nephritis, 
and the kidney resulting is called the "small red granular kidney," the " red contracted kidney," and at times the "gouty kidney" or the "arteriosclerotic kidney." This kidney is usually much diminished in size and weight; the capsule is greatly thickened and adherent, so that it cannot be removed without tearing the kidney-tissue. The renal substance is reddish, granular, with small cysts, and firm on section. Microscopically, there is found a great increase in the interstitial tissue, reducing the caliber of the tubules. This excess of fibrous tissue has given origin to the name " cirrhotic kidney," and this form of Bright's disease is frequently associated with gout, syphilis, chronic lead-poisoning, or alcoholic excess. Albuminoid degeneration of the kidneys is also known as the amyloid, ivaxy, or lardaceons kidney. This kidney is enlarged and quite pale; its consistence is firm, and the section has a peculiar, glistening, baconlike appearance. The glomeruli stand out as bright points upon the surface; the capsule peels off easily and leaves a smooth surface. Iodin applied to the surface of the section turns the diseased portions a mahogany-brown color. The change in this disease is most marked in the glomeruli and the blood-vessel walls, but may be found elsewhere ; it is most frequently due to prolonged suppuration, bone and joint disease, tuberculosis, syphilis, malaria, and mercurial poisoning. The onset of chronic Bright's disease is usually insidious, and may only be indicated by slight puffiness of the eyelids or the ankles, shortness of breath, dull and persistent headache, disorder of vision and hebetude. The pulse is one of high arterial tension, and there is hypertrophy of the left ventricle of the heart, especially in the case of the contracted kidney; there is frequent micturition, progressive anemia, dryness of the skin, indigestion, and a tendency to uremia. The urine is always scanty with the large white kidney, but abundant with the other forms of the disease. The specific gravity and the reaction vary; occasionally there may be present a small quantity of blood, and albumin is always present at some period in chronic Bright's disease. The quantity of albumin is very large in the large white and amyloid kidneys ; very slight in the contracted form. Microscopically, the urine contains renal epithelium, granular and fatty matter, and tube-casts. The latter are most plentiful in the large white kidney, but are never so numerous as in acute nephritis; they are granular, fatty, and hyaline in nature. A frequent symptom of chronic Bright's disease is the so-called "albuminuric retinitis," in which condition there are ecchymoses of the retina, together with white glistening spots, most numerous near the macula lutea, and frequently arranged in lines like the radiations from a star. This is diagnostic of chronic renal disease. The prognosis of chronic Bright's disease is bad, death eventually resulting from uremia or apoplexy.

Brilliant (bril'-yant) [Fr.]. Bright, glittering. B. Green. See Pigments, Conspectus of. B. Yellow. See Pigments, Conspectus of.

Brim (brim) [ME., brim]. An edge or margin. B. of Pelvis. See Pelvis.

Brimstone (brim'-stön). See Sulphur.

Brine Test. See Tests, Table of.

Brinton's Operation. See Operations, Table of.

Briquet's Ataxia. See Ataxia, and Diseases, Table of. Briquettes (brik-etz'). See Pitch.

Brise-coque (brē $\left.z^{\prime}-k \bar{o} \bar{k}\right)$ [Fr., "shell-breaker"]. An instrument for crushing the shell of a calculus after its inner part has been pulverized.

Brisement (brês-mon $\left.\left(g^{\prime}\right)^{\prime}\right)$ [Fr.]. A crushing; the forcible breaking up of an ankylosis.
Brise-pierre $\left(b r \bar{e} z^{\prime}-p e-\bar{a} r^{\prime}\right)$ [Fr., "stone-crusher"]. An old form of lithotrite.

Bristle (bris'-l) [ME., bristel]. In biology, a stiff, coarse hair on certain animals and plants. A stiff feather. B.-cell, any one of the ciliated cells at the terminations of the auditory nerve-filaments. B., Dentist's. See Nerve-Bristles.

British (brit'-ish) [L., Britanni, the original inhabitants of Britain]. Of or pertaining to Great Britain. B. Gum. See Dextrin. B. Oil, a mixture of petroleum, Barbadoes tar, oil of amber, oil of juniper, oil of turpentine and linseed oil ; it is prized as a domestic remedy. Unof.

Broach, Watchmaker's (brooch). A five-sided steel instrument used by dentists for enlarging the canal in the root, and the opening into a decayed cavity in the crown of a tooth.

Broad (brod) [ME, brood]. Wide; extensive. B. Land Irrigation. See Sezvage, Disposal of. B.leafed Laurel. See Kalmia. B. Ligament. See Ligament. B. Tapeworm. See Bothriocephalus latus.

Broca, "Grand Lobe Limbique" of. The cortical cerebral convolution formed by the continuation of the gyrus hippocampi with the gyrus fornicatus. This should not be confused with "Broca's Convolution," $i . e_{\text {., the third left frontal. }}$

Broca's Angles. See Angle. B. Aphasia. See Diseases, Table of. B. Area, the speech-center of the frontal convolution. B. Auricular Point, the center of the external auditory meatus. B. Center. See Center. B. Convolution. See Convolutions, Table of. B. Fissure. See Fissures, Table of. B. Plane, the alveolo-condyloid plane. A line passing from the alveolar process of the superior maxilla and through the lowest part (condyles) of the occipital bone, the shaven head being so placed that this line shall be horizontal. This is employed in craniocerebral topography. B. Speech-center, the folded part of the base of the third frontal gyrus.

Brochus (bro'-kus) [L.]. A person whose teeth project, or one who has a prominent upper lip.

Brocq's Pomade. A pomade used in lupus erythematosus. It consists of salicylic and lactic acids, each 3 ss ; resorcin, grs. xiv; oxid of zinc, 3 ij ; pure vaselin, 3 xvij.

Brodie's Disease. Same as Brodie's Knee. B. Knee. See Diseases, Table of.

Brokaw Ring (brok'-aw ring). A ring used in intestinal anastomosis, made of segments of rubber drainage-tubing and threaded with catgut strands.

Broken (bro'-ken) [AS., brocen, to break]. In surgery, fractured, as a bone. B. Breast, abscess of the mammary gland. B. Wind, B.-winded, in farriery, a term applied to a condition of heart-strain following severe muscular effort. It is characterized by paroxysms of cardiac dyspnea. See Heaves. B.-wing Fever. Synonym of Dengue.

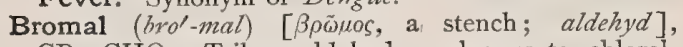
$\mathrm{CBr}_{3}$. CHO. Tribromaldehyd, analogous to chloral. It is produced by the action of bromin on alcohol. It is a colorless, oily fluid, of a penetrating odor, and sharp burning taste, boiling at $172^{\circ}-173^{\circ}$; it has been used in medicine, having properties similar to those of chloral. B. Hydrate, $\mathrm{CBr}_{3}$. $\mathrm{CHO}+\mathrm{H}_{2} \mathrm{O}$, a fluid of oily consistence, having a structure similar to that of chloral hydrate, but more irritating and narcotic than the latter. It is used as a hypnotic and in epilepsy. Dose gr. j-v. Unof.

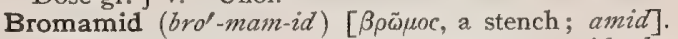
A bromin compound of the anilid group with the formula, $\mathrm{C}_{6} \mathrm{H}_{2} \mathrm{Br}_{3} \mathrm{NH}$. $\mathrm{HBr}$. It contains 75 per cent. 
of bromin, and is much used as an antipyretic, in Io- to I5-grain doses.

Bromanil (bro'-man-il) [ $\beta \rho \omega ̈ \mu o s$, a stench; anilin], $\mathrm{C}_{6} \mathrm{Br}_{4} \mathrm{O}_{2}$. A compound obtained by heating phenol with bromin and iodin in water. It consists of goldenyellow, shining leaflets or thick plates that melt and sublime.

Bromated Antifebrin (bro'-ma-ted an-te-feb'-rin). See Antisepsin

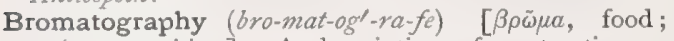
$\gamma \rho \alpha ́ \phi \eta$, a writing]. A description of or treatise on foods.

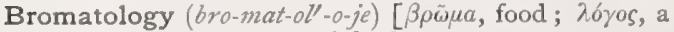
science]. The science of foods.

Bromethyl (bröm-eth'-il). See Ethyl Bromid.

Bromid, or Bromide (bro'-mid, or -mĩa) [ $\beta \rho \bar{\omega} \mu \omega s$, a stench]. Any haloid of bromin; those of calcium, iron, ammonium, potassium, and sodium are the ones mainly used in medicine. They allay nervous excitement, promote tranquillity, and are largely employed as sedatives. B. of Ethyl. See Hydrobromic Ether.

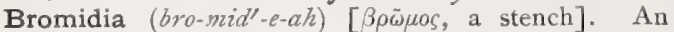
American nostrum containing in each fluid dram chloral hydrate and potassium bromid, each gr. 15, extract of cannabis indica and extract of hyoscyamus, each gr. one-half. Dose $3 \mathrm{j}$.

Bromidrosiphobia (bro-mid-ros-e-fo'-be-ah) [ $\beta \rho \tilde{\omega} \mu o s, a$ stench ; $i \delta \rho \omega \varsigma$, sweat; $\phi \delta \beta o s$, fear $]$ Insane dread of offensive personal smells, with hallucinations as to the perception of them.

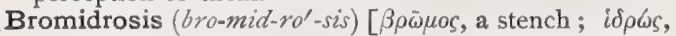
sweat]. Osmidrosis; an affection of the sweat-glands in which the sweat has an offensive odor. It is usually associated with chronic local hyperidrosis,especially of the feet. The odor is due to a specific decomposition of the sweat from the presence of the bacterium fatidam.

Bromidum (bro'-mid-um) [ $\beta \rho \tilde{\omega} \mu o s$, a stench]. Bromid; a salt of bromin.

Bromin, Bromine, or Bromum (bro-min, or -mum) [ $\beta \rho \tilde{\omega} \mu a s, a$ stench]. $\mathrm{Br}=80$; quantivalence $\mathrm{I}$. A reddish-brown liquid, which, at ordinary temperatures, gives off a heavy, suffocating vapor. In its elementary form it is a very active escharotic, and internally a violent poison. It is used by inhalation and as an escharotic. Dose gtt. ij, largely diluted. The salts of bromin are cerebral and cardiac depressants, and highly valuable as hypnotics. The salts of the alkaline metals are those most commonly used. They are cerebral and spinal depressants, also alterative, antispasmodic, and hypnotic. Ammonii bromidum, $\mathrm{NH}_{4} \mathrm{Br}$, prismatic crystals. Dose gr. v-xx. Auri bromidum. See Aurum. Calcii bromidum, Ca$\mathrm{Br}_{2}$, granular and deliquescent. Dose gr. $\mathrm{v}-\mathbf{z} \mathrm{j}$. Ethyl bromid, $\mathrm{C}_{2} \mathrm{H}_{5} \mathrm{Br}$, useful in spasmodic coughs. Dose $m_{\mathrm{x}}-3 \mathrm{j}$. Ethylene bromid. See Ethylene. Ferri bromidi, Syr., contains ten per cent. of the salt. Dose $3^{\mathrm{ss}-\mathrm{j}}$. Lithii bromidum, LiBr, granular and deliquescent. Dose gr. v-xx. Nickel bromidum. See Nickel. Potassii bromidum, $\mathrm{KBr}$, colorless, cubical crystals. Dose gr. $\mathrm{v}-z_{\mathrm{j}}$. Sodii bromidum, $\mathrm{NaBr}$, colorless, monoclinic crystals. Dose gr. $\mathrm{v}-\mathbf{3}$ j. Zinci bromidum, $\mathrm{ZnBr}_{2}$, granular, deliquescent powder. Dose gr. $1 / 2-\mathrm{ij}$.

Brominism, Bromism (bro'-min-izm, bro'-mizm) $[\beta \rho \tilde{\omega} \mu \circ \varsigma$, a stench]. Certain peculiar phenomena produced by the excessive administration of the bromids. The most marked symptoms are headache, coldness of the extremities, feebleness of the heart's action, somnolence, apathy, anesthesia of the soft palate and pharynx, pallor of the skin, and a peculiar eruption of acne which is one of the earliest and most constant symptoms. There is also anorexia with loss of sexual power and atrophy of the testes or mammæ. The patient may become almost imbecile.

Bromo-Caffein (bro-mo-kaf'-e-in) [bromin; caffein]. A proprietary effervescing preparation containing caffein. It is used for the relief of headaches.

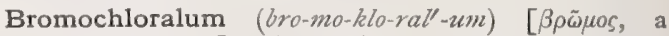
stench; chloral]. A proprietary antiseptic and disinfecting compound, containing the bromid and chlorid of aluminum.

Bromoform (bro'-mo-form) [ $\beta \rho \omega \tilde{\omega} \mu o s$, a stench; forma, form], $\mathrm{CHBr}_{3} . \quad \mathrm{A}$ bromid having a structure like that of chloroform, $\mathrm{CHCl}_{3}$; it is an active anesthetic. Its use is not followed by vomiting. It causes irritation of the conjunctiva and respiratory organs. It is used in whooping-cough in doses of $\mathrm{gtt}$. ij-v in a mixture of wine and water. Unof.

Bromography (bro-mog'-ra-fe). Same as Bromatography.

Bromoiodism (bro-mo-i'-o-dizm) [Bromism; iodism]. Poisoning by bromin and iodin compounds together.

Bromol (bro'-mol), $\mathrm{C}_{6} \mathrm{H}_{2} \mathrm{Br}_{3} \mathrm{OH}$. Tribromophenol ; an antiseptic substance used in the form of a powder, solution (I : 30 olive oil), or ointment (I: IO). Internally it is used in cholera infantum and typhoid fever. Dose gr. $\frac{1}{10}-\frac{1}{3}$. Unof.

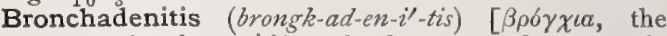
bronchial tubes; $a \dot{\delta} \dot{\gamma} v$, gland; $\iota \tau \iota$, inflammation]. Inflammation of the bronchial lymphatic glands.

Bronchaphrosia (brongk-af-ro'-ze-ah) [ $\beta \rho \sigma \gamma \chi \ell a$, bronchial tubes; áppos, foam]. Obstruction due to the presence of froth in the bronchioles.

Bronchi (brong'-ki) [ $\beta \rho \sigma \gamma \chi o s$, the windpipe]. The two tubes into which the trachea divides opposite the third dorsal vertebra, called respectively the right and the left bronchus.

Bronchia (brong'-ke-ah) [ $\beta \rho 6 \gamma \chi o s$, the windpipe]. The bronchial tubes, especially those that are smaller than the two bronchi.

Bronchial (brong'-ke-al) [ $\beta \rho b \gamma \chi o s$, the windpipe]. Relating to the bronchi or to their branches, or to the smaller air-passages in the lungs. B. Arteries, branches of the thoracic aorta, three or four in number. They are the nutrient vessels of the lungs. See Arteries, Table of. B. Catarrh, the simplest form of acute inflammation of the bronchi. It is the so-called "cold on the chest." The feeling of oppression and constriction, with slight mucous discharge, is due to hyperemia and swelling of the mucous membrane of the larger bronchi. B. Fluke. See Distoma ringeri. B. Glands, the chain of glands running beside the bronchi. They frequently undergo pathologic enlargement and give rise to a group of symptoms-cough, pain, spasmodic dyspnea, dysphagia, and change in the voice. The enlargement is usually tuberculous in nature.

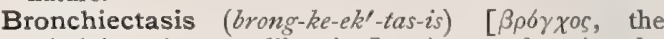

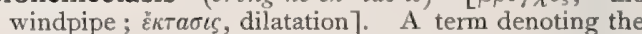
dilatation or relaxation of the walls of the bronchi, arising from inflammation and other causes. It is very rare as a primary condition, but is frequently associated with some chronic pulmonary disease. It occurs most frequently in pulmonary tuberculosis at the apex of the lung, but is also frequently seen in the bronchi at the base of the lung. It may involve a tube uniformly for some distance, producing the cylindrical form; or it may occur irregularly in sacs or pockets, the sacculated form. If the whole lung be involved in the change we have produced the so-called turtle lung. The characteristic symptom of bronchiectasis is paroxysmal coughing, with the expectoration of large quantities of muco-purulent, often fetid, 
matter. Cavernous breathing will be heard over the dilated tubes.

Bronchiocele (brong'-ke-o-sēl) [bronchiolus, a little air passage; $\kappa \dot{n} \lambda \eta$, tumor]. A swelling or dilatation of a bronchiole.

Bronchiole (brong'-ke-öl) [dim. of bronchus]. One of the smallest subdivisions of the bronchi.

Bronchiolitis (bron-ke-o-li'-tis) [bronchiolus, a little bronchus; $1 \tau \iota \zeta$, inflammation]. Inflammation of the bronchioles. B. exudativa, an inflammation of the bronchioles, with exudation. Curschmann's theory of the production of bronchial asthma.

Bronchiostenosis (brong-ke-o-ste-no'-sis) [ $\beta \rho 6 \gamma \chi o s$, the windpipe; $\sigma \tau \varepsilon \nu \sigma s$, narrow]. Contraction of a bronchus or of any one or more of the bronchial tubes.

Bronchitic (brong-kit'-ik) [ $\beta \rho \delta \gamma \chi \chi o s$, the windpipe]. Relating to, of the nature of, or affected with, bronchitis.

Bronchitis (brong-ki'-tis) [ $\beta \rho o ́ \gamma \chi O S$, the windpipe ; $\iota T \iota s$, inflammation]. Inflammation of the mucous membrane that lines the bronchial tubes. It is usually attended with soreness, cough, alteration of the voice, and febrile symptoms. B., Acute, a severe form of simple bronchial catarrh. It is the initiatory stage of the other forms of the disease, and is usually the result of a chill, though it may be associated with some other disease, as the exanthemata, and affections of the kidney and heart. Sibilant and sonorous rhonchi and bubbling râles may be heard on auscultation. B., Acute Capillary, a variety in which there is an involvement of the minute tubes of the lung. It is most frequently met with in children, usually secon. darily to other diseases of the lung or other organs. The symptoms are urgent-dyspnea, short, irritating cough, nervous depression, and excited action of the heart. Collapse of portions of the lung frequently occurs, and the patient may die of asphyxia and extreme exhaustion. B., Catarrhal, a form attended with profuse muco-purulent discharges. B., Chronic, 2 form occurring either as an independent disease or as the result of repeated attacks of the acute variety. It is generally associated with organic changes in the lungs and other organs, such as emphysema, bronchiectasis, pulmonary tuberculosis and pleurisy. Occurring in old people, it produces the well-known "zvinter cough" of the aged. B., Croupous, Fibrinous, or Plastic, a rare variety attended with the expectoration of casts of the bronchial tubes, after a paroxysm of dyspnea and violent coughing. The casts are fibrinous in nature, hollow, yellowish-white, and vary from one to seven inches in length. This form of bronchitis is usually seen in males, and between the ages of ten and thirty. B., Mechanical, or Potter's, a form caused by the inhalation of dust, etc. B., Potter's. See B., Mechanical. B., Putrid, or Fetid, a variety of chronic bronchitis characterized by the discharge of a copious, half-liquid, extremely offensive sputum. The peculiar odor is thought to be due to a microörganism, especially to a short, slightlycurved bacillus described by Lumnitzer. B., Summer. Synonymous with Hay Fever, q. $v$.

Bronchlemmitis (brong-klem-i'-tis) [ $\beta \rho b \gamma \chi 0 s$, the windpipe; $\lambda \varepsilon \mu \mu a$, a skin]: Croupous bronchitis.

Bronchoxgophony (brong-ko-e-goff'-o-ne). See Bronchoegophony.

Bronchocele (brong'-ko-sêl, or -se'-le) [ $\beta \rho \delta \gamma \chi o s$, the windpipe; $\kappa \hat{\lambda} \lambda \eta$, a tumor]. See Goiter.

Bronchocephalitis (brong-ko-sef-al-it-tis). Synonym of Whooping-cough.

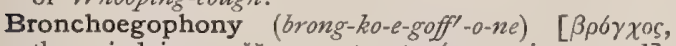
the windpipe; $a \check{\iota} \xi$, a goat; $\phi \omega v \eta$, a voice, sound]. Bronchophony combined with egophony.
Broncholemmitis (brong-ko-lem-i'tis). See Bronchlemmitis.

Broncholith (brong'-ko-lith) [ $\beta \rho 6 \gamma \chi x o s$, the windpipe 2iflos, a stone]. A calculus or concretion formed in a bronchial tube.

Bronchomycosis (brong-ko-mi-ko'sis) [ $\beta \rho o^{\prime} \gamma o s$, the windpipe; $\mu \bar{v} \kappa \eta \varsigma$, a fungus]. The growth or presence of fungi in a bronchial tube.

Bronchopathy (brong-kop'-a-the) [ $\beta \lambda 6 \gamma \chi 0 s$, the wind

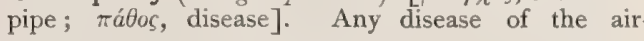
passages.

Bronchophonic (brong-ko-fon'-ik) [ $\beta \rho o ́ \gamma \chi o s$, the windpipe; $\phi \omega \nu \eta$, a voice]. Relating to bronchophony.

Bronchophony (brong-koff'-o-ne) [ $[\beta \rho \delta \gamma \chi o s$, the windpipe; $\phi \omega \nu \eta$, the voice]. The resonance of the voice within the bronchi as heard through the stethoscope. It is normally present over the lower cervical spines, in the upper inter-scapular region, and over the sternal portion of the infra-clavicular regions. B., Whispered, bronchophony elicited by causing the patient to whisper.

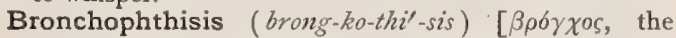
windpipe; $\phi \theta i \sigma \iota s$, a wasting]. Pulmonary tuberculosis characterized by extensive lesions of the bron chial tubes.

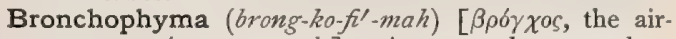
passage; $\phi u \mu \alpha$, a growth]. Any growth, as a tubercle, in a bronchial tube.

Bronchoplasty (brong $-k o-p l a s-t e) \quad[\beta \rho 6 \gamma \chi 0 s$, the trachea; $\pi \lambda a ́ \sigma \sigma \varepsilon \iota \nu$, to form]. The surgical closure of a tracheal fissure or fistula.

Broncho-pneumonia (brong-ko-nu-mo'-ne-ah) [ $\beta \rho o ́ \gamma$ $\chi \circ s$, the windpipe; $\pi \nu \varepsilon v \mu \omega \nu$, the lung]. Lobular pneumonia, a term applied to inflammation of the lungs, which, beginning in the bronchi, finally involves the parenchyma of the lungs. This disease is most frequently encountered in children, but may occur in old age. Three varieties are described: I. A simple, acute form, following a severe bronchial catarrh. 2. A secondary form, occurring after whooping-cough or some general febrile infective disease. 3. A rare suppurative form, with the formation of abscesses throughout the lung. The patient suffering with broncho-pneumonia presents the following symptoms: dyspnea, cough, fever, often high, restlessness, and occasionally marked cerebral symptoms. If convalescence be not properly guarded relapses are likely to occur. The physical signs vary greatly, and are often not marked. The course of the disease is generally chronic, and the prognosis must be guarded.

Bronchorrhagia (brong-kor-a'-je-ah) [ $\beta \rho b \gamma \chi 0 s$, the bronchus; ’ $m \gamma \nu v ́ v a \iota$, to burst forth]. Hemorrhage from the air-passages.

Bronchorrhea (brong-kor-e'-ah) [ $\beta \rho b \gamma \chi 0 \varsigma$, the bronchus; $\dot{\varepsilon} \varepsilon \varepsilon v$, to flow]. A form of bronchitis attended with profuse expectoration.

Bronchostenosis (brong-ko-ste-no'-sis) [ $\beta \rho 6 \gamma \chi \alpha o s$, the windpipe; $\sigma \tau \varepsilon \nu o ́ s$, narrow]. Contraction of a bronchus.

Bronchotome (brong'-ko-tōm) [ $\beta \rho o ́ \gamma \chi o \varsigma$, the windpipe; $\tau \varepsilon \mu \nu \varepsilon v$, to cut]. An instrument for cutting the larynx or trachea in the operation of bronchotomy.

Bronchotomy (brong-kot'-o-me) [ $\beta \rho o ́ \gamma x o s$, bronchus; $\tau \varepsilon$ kves $v$, to cut]. A surgical cutting-operation upon the bronchus, larynx, or trachea.

Broncho-tracheal (brong-ko-tra'-ke-al) [ $\beta \rho 6 \gamma \chi 0 \varsigma$, the bronchus; $\tau \rho a \chi \varepsilon \tilde{a} a$, the windpipe]. Relating to a bronchus (or to both bronchi) and to the trachea.

Broncho-vesicular (bron-ko-ves-ik'-u-lar) [ $\beta \rho b \gamma \chi o s$, the bronchus; vesicula, a vesicle]. Both bronchial and vesicular. See Breath-Sounds, Table of.

Bronchus (brong'-kus). See Bronchi. 
Bronson's Method. See Treatment, Mithods of. Bronze (bronz) [bronzium, bronze]. An alloy of copper and tin. B. John, a popular term for Yellozu Fever, q. v. B. Liver, a dark reddish-brown or olive-black color of the liver, seen in post-mortem examinations of certain cases of chronic malarial poisoning.

Bronzed (bronzd) [bronzium, bronze]. Tanned; of a bronzed color. B. Skin, a symptom of Addison's Disease. B.-skin Disease. See Addison's Disease. Brood (brood) [ME., brood]. In biology, offspring; progeny. B.-cells, in cell-division, the mothercells inclosing the daughter-cells. B.-food, a highly nitrogenous tissue-forming pap, derived by bees from pollen by digestion.

Brooke's Ointment. An ointment for treating lupus. It is composed of oxid of zinc and powdered starch each 1/4 ounce; white vaseline $1 / 2$ ounce; hyd. oleatis (five per cent.) one ounce; salicylic acid 20 grains; ichthyol 20 minims; oil of lavender q. s.; enough red Armenian bole and raw umber may be added to match the color of the skin.

Broom (broom). See Scoparius.

Brosimum (bro'-sim-um) [ $\beta \rho \omega \bar{\omega} \sigma \varsigma$, food]. A genus of moraceus trees of S. America. B. galactodendron, the Venezuelan cow-tree; its milky sap is nutritious, and yields both a cheesy food and a wax ( galactin) serviceable for candles.

Broth (broth). See Bouillon.

Brother Ulcer (bruth'-er ul'-ser). See Donda Ndugu.

Brousrika (broos'-ne-kah) [Rus.]. The berries of red whortleberry, red bilberry (Vaccinium vitis idcea), used in the form of a decoction in Russia for the relief of rheumatic affections. Unof.

Broussaisism (brüs-a $\left.a^{\prime}-i z m\right)$ [Broussais, a French physician]. The physiologic, pathologic, and therapeutic doctrines taught by J. V. Broussais.

Broussaism (brüs-a $\left.a^{\prime}-i z m\right)$. See Broussaisism.

Brow (brow) [ME., browe]. The forehead; the upper anterior portion of the head. B.-Ague, neuralgia of the first division of the fifth cranial nerve, commonly met with in malarious districts, though at times occurring independently of such surroundings, and then dependent upon some diathesis, especially the gouty. B. Presentation, presentation of the fetal brow in labor. See Fetus, Position of.

Brown (brown) [ME., brown]. A dark reddish-yellow color. B. Atrophy, an atrophy of a tissue associated with a deposit therein of a brown or yellow pigment. B. Coal. See Coal and Lignite. B. Crown, in dentistry, an artificial, all-porcelain crown, which is attached to a natural root by means of an iridioplatinum pin baked in position. The pin has the greatest strength at the neck of the tooth, where the strain is heaviest, and this strength is further increased by extending the porcelain upon the pin. B. Edema. See Edema. B. Induration of Lung, a state of the lung due to long-continued congestion, usually arising from marked incompetency or from constriction of the mitral valve. The lungs are enlarged and do not collapse on opening the thorax, and have a peculiar tint of yellow shading into a brown or reddish-brown; a brownish fluid exudes on pressure. The color is due to pigment-granules in the epithelial cells of the air-vesicles. B. Madder. See Pigments, Conspectus of. B. Mixture. See Mistura ferri composita and Glycyrrhiza. B. Ointment, the unguentum fuscum, N. F.; called also unguentum matris, or "mother's salve." It is composed of " brown plaster," two parts; oil, one part; suet, one part. B. Pink. See Pigments, Conspectus of. B. Plaster, the emplastrum fuscum camphoratum, N. F.; called also emplastrum matris camphoratum, or " camphorated mother's plaster;" official in German pharmacy. It is made of red oxid of lead, thirty parts ; oil of olives, sixty parts; yellow wax, fifteen parts; camphor, one part. B. Study. See Cenospudia. B. Wort, the plant Brunella vulgaris, popularly reckoned a good vulnerary, as well as a cure for sore-throat. Unof.

Brown's Operation. See Operations, Table of.

Browne's Operation. See Operations, Table of

Brownian Movement. An oscillation or agitation observed under the microscope in very fine granules, drops, etc., when suspended in a liquid. The movement is not locomotion, and is to be distinguished from that of the self-motility of living microörganisms. Its cause is not definitely known, but it may be due to heat, light, electricity, osmosis, etc. See Pedesis.

Brownism (brown'-izm). See Brunonian Theory.

Brown-Sequard's Combination of Symptoms. See Signs and Symptoms, Table of. B. Disease. See Diseases, Table of. B. Method of Treatment. See Treatment, Methods of. B. Paralysis. See Diseases, Table of.

Bruch, Clusters of. See Gland, Aggregated, of Bruch. B., Glands of. See Gland.

Brucin (bru'-sin) [Brucea, a genus of shrubs], $\mathrm{C}_{23} \mathrm{H}_{26}$ $\mathrm{N}_{2} \mathrm{O}_{4}$, A poisonous alkaloid found in Strychnos nux vomica and in Strychnos ignatius. It crystallizes in prisms containing ${ }_{4} \mathrm{H}_{2} \mathrm{O}$, and melts at $178^{\circ}$. Its taste is exceedingly bitter and acrid. Its action on the animal economy is similar to but much less powerful than that of strychnin. See Nux Vomica.

Brücke's Berlin Blue Mass. A warm-flowing mass for injecting tissues. It is made as follows : potassium ferrocyanid, 217 gm.; water, I000 c.c ; ferrous chlorid I part; water Io parts. Take equal volumes of these solutions and add to each twice its volume of a cold saturated solution of sodium sulphate. Add the iron solution to the ferrocyanid solution, with constant stirring. Filter and wash the precipitate with the filtrate until it runs through clear, then wash with water until the filtrate runs off blue. Dry the precipitate. To a concentrated solution of this blue add enough gelatin to make a firm jelly when cold. Heat to $60^{\circ} \mathrm{C}$. and filter through flannel. B.'s Fluid, potassio-mercuric iodid, employed in the precipitation of proteids. B.'s Method, a method of removing all the proteids from a substance. Acidulate the liquid with $\mathrm{HCl}$, and then add to it a solution of potassio. mercuric iodid, made by saturating with mercuric iodid a boiling solution of potassium iodid. B.'s Muscle. See Muscles, Table of. B.'s Reagent. See Tests, Table of. B.'s Red Mass, a material for injecting the body. A concentrated solution of potassium ferrocyanid is injected into the artery until it runs clear from the vein. Then as much as possible is allowed to drain away. Next a concentrated solution of cupric sulphate free from iron is injected. By this method the red cupric ferrocyanid is precipitated in the vessels. B.'s Test. Same as B.'s Reagent.

Bruise (brooz). See Contusion.

Bruit (bru-e') [Fr., a noise or report]. A term used by French physicians to designate the various specific sounds of auscultation. B. d'airain, Trousseau's term for the ringing note heard through the stethoscope applied to the chest wall when a coin is struck against another pressed against the surface of the chest on the opposite side. It is pathognomonic of a collection of gas in the pleural cavity. B. de clapotement, a splashing sound often heard in cases of well-marked dilatation of the stomach when pressure is made upon the abdominal walls. It is best elicited when the 
patient is in the recumbent position, with relaxed abdominal walls, by palpating near the left border of the ribs. The same sound can be produced by shaking the patient (bruit de glou-glou). B. de braquement, a crackling sound. B. de cuir neuf, the newleather murmur of the French; the creaking quality occasionally heard in pericardial friction-sounds. B. de diable, a venous murmur, of a whistling or rushing character, arising in the bulb of the common jugular vein, and due to such diseases as anemia, leadpoisoning, etc.; it is more common in the young, and is caused immediately by the vibration of the blood flowing from the narrow part of the common jugular vein into the wide, bulbous portion of the vessel. See also Murmur. B. de galop, a cantering rhythm of the heart frequently heard in mitral stenosis, in which three distinct heart-sounds are audible. It is due to a reduplication of the second sound. See also Gallop Rhythm. B. de glou-glou. See $B$. de clapotement. B. de lime. See $B$. de scie. B. de moulin, water-wheel sound; a peculiar friction-sound mixed with splashing and gurgling, heard in pneumohydropericardium. B. d'oboe, a musical heart-murmur. B. de pot fêlé, the cracked-pot sound. B. de parchemin, a rattling, as of parchment. B. de râpe. See Bruit de scie. B. de rappel, a sound resembling the double beat upon a drum. This doubling of the heart-sounds may be noted in different stages of chronic interstitial nephritis, when it is the first sound that is duplicated; and in mitral stenosis, when the second sound is doubled. B. de scie, a murmur sounding like that made by a saw or file. Also called $B$. de rape and $B$. de lime. B. skodique, an amphoric note heard in the pleural cavity, especially near the apex anteriorly, when there is a fluid accumulation not filling the whole of the plural sac. Also called Skoda's tympany. B. de soufflet, a bellowsmurmur. B. de soupape, a flapping sound. B. de de va et vient, a to-and-fro friction-sound.

Brün's Operations. See Operations, Table of.

Brinet, or Brunette (bru-net') [Fr.]. I. Of a dark complexion. 2. One with a dark complexion.

Brïining's Red. Same as Rosanilin.

Brunissure (brun-is-ur') [Fr., brunisseur, that which browns]. A disease of the grape, attacking the leaves only, caused by Plasmodio pora vitis. (Viala and Sauvageau). Also called Braune.

Brunner's Glands. See Glands.

Brunonian Movement. See Brownian Movement, B. Theory, brownism; a doctrine taught by Dr. J. Brown (1735-88) that both physiologic and pathologic phenomena are due to variations in a natural stimulus, its excess causing sthenic and its deficiency producing asthenic diseases.

Brunswick (brunz'-wik) [Ger.]. A town in Germany. B. Black. Same as Japan Black. B. Green. See Conspectus of Pigments, under Pigment.

Brush (brush) [ME., brusshe]. An instrument consisting of a collection of some flexible material fastened to a handle. In surgery, various forms of brush are employed; as the acid brush, of glass threads; the electric brush, a form of electrode; the laryngeal brush; the nasal, pharyngeal, and stomach brush. See also Pencil. 2. A thicket of small trees. B.-burn, the injury produced by violent friction, and the resulting heat; it often resembles a burn or scald. B.-cells. See Cell.

Bryant, Ampulla of. See Ampulla

Bryant's Line. See Lines, Table of. B.'s Method. See Treatment, Methods of. B.'s Operations. See Operations, Table of. B.'s Triangle. See Triangles, Table of.
Bryce's Test. A test to determine if systemic infection has taken place after vaccination. It consists in repeating the inoculation during the evolution of the vaccine disease. If systemic infection has occurred, the second inoculation will mature rapidly, so as to overtake the first.

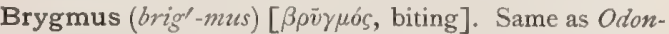
toprisis.

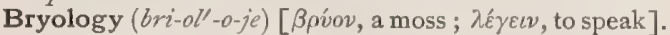
The science of mosses.

Bryonia (bri-o'-ne-ah) [ $\beta$ pvwvia, bryony]. Bryony. The root of $B$. alba and $B$. dioica; indigenous to Europe, with properties due to an intensely bitter glucosid, Bryonin, $\mathrm{C}_{48} \mathrm{H}_{80} \mathrm{O}_{19}$, a strong irritant when applied to the skin or mucous membrane, often producing vesication. It is a remedy of great value in pleurisy, pleuro-pneumonia, and rheumatic fever, and an excellent agent in colds. Dose of the powdered root gr. $\mathrm{x}-\mathrm{xxx}$. B., Infusum (unof.), has a strength of $\xi j$ to the Oj of water. Dose $\xi_{s s-i j}$. B., Tinct., a 10 per cent. solution of the root in alcohol. Dose m v $-\bar{z} s$.

Bryonin (bri-o'-nin) [ $\beta \rho v \omega v i a$, bryony]. A precipitate from the tincture of Bryonia alba; useful as a hydragogue, and in rheumatism and bronchial affections. Dose gr. ij-1/4. Unof. See Bryonia. Dose as a drastic purgative, gr. $1 / 6-1 / 3$.

Bryony (bri'-o-ne). See Bryonia. B. Black. See Tamus.

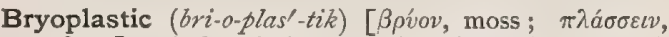
to form]. A descriptive term loosely applied to such abnormal growths of tissue as resemble vegetable forms.

Bryoretin (bri-o-re'-tin) [ [ $\beta v \omega \nu i \alpha$, bryony; $\rho \eta \tau i \nu \eta$, resin]. A resin-like substance obtainable from the glucosid bryonin.

Bubaline (bu'-bal-in) [bubalimus, pertaining to the bubalus, buffalo]. In biology, resembling or pertaining to the buffalo.

Bubby $\left(b u b^{\prime}-\varepsilon\right)$ [E. dial.]. I. A vulgar name for the mamma. 2. A local name for Calycanthus floridus.

Bubo $\left(b u^{\prime}-b_{0}\right)$ [ $\beta o v \beta \omega v$, the groin]. Inflammation and swelling of a lymphatic gland, properly and generally of the groin, and usually following chancroid, gonorrhea or syphilitic infection. B., Parotid. See Parotitis. B., Primary, a slight adenitis of the groin due to mechanical irritation, or other cause; formerly supposed to be due to syphilis without a chancre having preceded. B., Sympathetic, one caused by irritation, friction, injury, etc., and not arising from an infectious disease.

Bubonadenitis $\left(b u-b o n-a d-e n-i^{\prime}-t i s\right)[\beta o v \beta \omega v$, the groin ; $a \delta \dot{v} v$, a gland; $\iota \tau \iota \zeta$, inflammation]. Inflammation of an inguinal gland.

Bubonalgia (bu-bon-all-je-ah) [ $\beta o v \beta \omega v$, the groin; $a \grave{\lambda}$ yos, pain]. Pain in the inguinal region.

Bubonic $\left(b u-b o n^{\prime}-i k\right)$ [ $\beta o v \beta \omega v$, the groin]. Relating to a bubo. B. Plague. Synonym of the Plague, $q . v$.

Bubonocele $\left(b u-b o n^{\prime}-o-s \bar{e} l\right)[\beta o v \beta \omega \nu$, the groin; $\kappa \dot{\eta} \lambda \eta$, tumor]. Inguinal hernia when the gut does not extend beyond the inguinal canal.

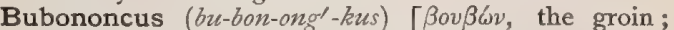

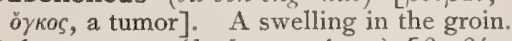

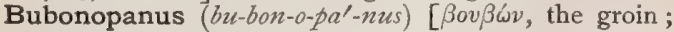

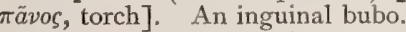

Bubonulus (bu-bon'-u-lus) [1., dim. of bubo]. Lymphangitis of the dorsum of the penis, often with abscesses; due to chancroidal virus.

Bucca $\left(b u k^{\prime}-a h\right)[\mathrm{L}$.$] . I. The mouth; the hollow of$ the cheek, or its inner surface. 2. The vulva.

Buccal (buk'-al) [bucca, the cheek]. Pertaining to the cheek. B. Coitus. See Irrumation and Name- 
less Crime. B. Glands. See Gland, B. Teeth, the teeth behind the canines are so called because they are situated on the inside of the cheeks. In the human subject they are the bicuspids and molars.

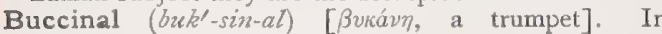
biology, trumpet-shaped.

Buccinator (buk'-sin-a-tor) [ $\beta v \kappa a ́ m$, a trumpet]. The thin, flat muscle of the cheek. See Muscles, Table of.

Bucco (buk'-o). Same as Buchu.

Bucco-labial (buk-o-la'-be-al) [bucca, the mouth; labizm, a lip]. Pertaining to the mouth and lip. B. Muscle, the buccinator. See Muscles, Table of.

Bucco-pharyngeal (buk-o-far-in'-je-al) [bucca, the mouth; $\theta a \rho^{\prime} v \lambda \xi$, the pharynx]. Relating to the mouth and to the pharynx.

Buccula (buk'-u-lah) [L., dim. of bucca, the cheek]. The fleshy fold seen beneath the chin, and forming what is called a double chin

Buchanan's Operations. See Operations, Table of. Buchu $\left(b u^{\prime}-k u\right)$ [native African]. The leaves of several species of Barosma, yielding a volatile oil, to which its properties are probably due, and a bitter extractive, Barosmin. Dose gr. j-v. It causes a sensation of glowing warmth over the body, stimulates the appetite, and increases the circulation. It is useful in urethritis and affections of the genito-urinary mucous membrane. Dose of the leaves, gr. xv-xxx. B., Ext., Fld. Dose $m_{x-z}$ j. B., Infusum (Unof.),

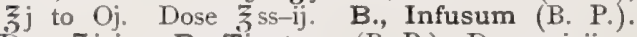

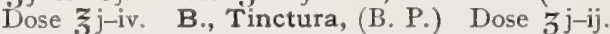

Buck's Apparatus. An apparatus consisting of a weight and pulley for applying extension to a limb. B. Fascia, the superficial perineal fascia. B. Method. See Treatment, Method's of. B. Operations. See Operations, Table of.

Buckbean (buk'-bèn) Bog-bean. The rhizome of Menyanthes trifoliata, tonic, antiscorbutic, and emmenagogue. It has been recommended as a vermifuge, and has been used in functional amenorrhea. Dose of fld. ext. $m v-x x x$. Unof.

Bucket Fever $\left(b u k^{\prime}-e t f^{\prime}-v e r\right)$. See Fever.

Buckeye Bark (buk'-i bark). The bark of Esculus glabra, astringent and tonic, and serviceable in rectal irritation, prolapsus, and various uterine derangements. Dose of fld, ext. gtt. iij-v. Unof.

Buckhorn (buk'-horn). The horn of a buck. When powdered or calcined, it is used by dentists for polishing enamel, and fillings, and for removing light deposits of tartar. B. Fern, a fern, called also royal fern, Osmunda regalis; it is vaunted as a cure for rickets. Unof.

Buckle-shell (buk'-l-shel) [New Eng. dialect]. A recently moulted lobster; also called paper-shell lobster, June lobster, or sand-lobster.

Bucko (buk'-o). Same as Buchu.

Buckthorn (buk'-thorn). See Frangula. B., California. See Cascara Sagrnda.

Bucku (buk'-u). Same as Buchu.

Buckwheat (buk'-hruct). The seed or grain of Fasropyrum esculentum and of other species of the same genus. It is used to some extent as a substitute for the true cereals. In theory, it takes a high rank as a food ; but its free use tends to constipation, indigestion and headache, and especially to a peculiar roughness and itching of the skin. The flowers of the plant afford rich bee-pasturage, but the honey is inferior.

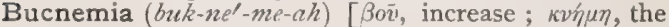
leg]. Inflammation of the leg characterized by tenseness and swelling; elephantiasis; also phlegmasia dolens. B. Tropica. See Elephantiasis arabum.

Bud (bud) [ME., budde, a bud]. In biology, the undeveloped germ-state of a leaf or flower.
Budd's Disease. See Diseases, Trable of.

Budding (bud'-ing) [ME., budden]. In biology, a form of reproduction or cell-division, occurring among the polyps and infusoriæ, in which a bud is given off by the parent and comes to resemble the latter. The bud may remain permanently attached or may form a colony, each member acquiring a differentiation of function, even to the formation of male and female elements. The process is also called Gemmation, $q . v$.

Budge's Center. See Center.

Buffalo Rubin (buf'-al-o m'-bin). -See Pigments, Conspectus of.

Buffers' Consumption (buf'-erz con-sump'-shun). The phthisis occurring among metal-polishers.

Buffy Coat $\left(b u f^{\prime}-e-k o ̈ t\right)$. A grayish or buff-colored crust or layer sometimes seen upon a blood-clot, after phlebotomy, and once looked upon as a sign of inflammation. It is caused by the partial subsidence of the red blood-corpuscles.

Bufidin $\left(b u^{\prime}-f d-i n\right)$ [bufo, the toad]. Phrynin; an alkaloid from the venom of the toad; it is poisonous, and said to resemble digitalin in its effects.

Bufoniform (bu-fon'-if-orm) [bufo, a toad; forma, shape]. In biology, toad-like.

Bugbane $\left(b u g^{\prime}-b \bar{a} n\right)$. See Cimicifuga.

Buggery (bug'-er-e) [OF., bougre, an heretic]. Sodomy; bestiality.

Bugleweed ( $\left.b u^{\prime}-g l-w e \bar{d}\right)$. The herb, Lycopus virginicus, narcotic and astringent. Dose of fld, ext. 3 ssij. Lycopin, concentrated extract. Dose gr, j-iv. Unof.

Buhach (bu'-hatch) [Serbo-croatian for flea-bane; buha, a flea]. The plant Pyrethrum cinerariafolium. See Insect Powder.

Buhl's Disease. See Diseases, Table of.

Bulam, or Bulama Boil (bu'-lam or bu-lam'-ah boil) A boil occurring on the African island of Bulam; probably caused by a burrowing-worm or insectlarva. B. Fever, a West-Africa coast fever, said to be identical with yellow fever.

Bulata $\left(b u l^{\prime}-a t-a h\right)$. See Balata.

Bulb (bulb) $[\beta 0 \lambda \beta \sigma \varsigma$, a bulb]. I. The expansion or dilatation of a canal or vessel. 2. Applied to the oblongata and pons. 3. A short underground stem covered with fleshy leaf-bases or fleshy leaves, as the onion and squill. B. of Aorta, the dilatation of the aorta near its beginning. B. of Corpus Cavernosum, the muscle beneath the bulb of the urethra. B. of an Eye, the eyeball. B. of Fornix. See Corpora. B. of a $\mathrm{Hair}$, the swelling at the root of a hair. B., Olfactory, the expanded end of the narrow olfactory lobe, commonly called olfactory nerve or first cranial nerve. B. of a Tooth, the papilla that forms the germ of a tooth. B. of Urethra, the posterior expanded part of the corpus spongiosum penis. B. of the Vagina, a small body of erectile tissue on each side of the vestibule of the vagina, homologous to the bulb of the urethra of the male. B. of Vena Jugularis, the dilatation at the beginning of the external jugular vein.

Bulbar (bull-bar) [ $\beta o \lambda \beta \delta s$, a bulb]. Bulbous. Pertaining to the medulla. B. Disease, or Paralysis, a term applied to the progressive and symmetrical paralysis of the facial muscles about the mouth, including those of the tongue, pharynx, and sometimes those of the larynx. This paralysis is due to a disease of the motor nuclei in the medulla oblongata; an acute and a chronic form are met with. The acute form is due to hemorrhage or softening; the chronic to degeneration. The chronic form is insidious in its approach, the tongue often being the first organ involved; the 
course is slow but progressive, and death usually results in from one to four years. Bulbar paralysis usually occurs after forty years of age. Syphilis is not a predisposing cause. The disease is also called Labio-glosso-laryngeal Paralysis. There is also a psendo-bulbar paralysis, due to symmetrical lesions of the motor cerebral cortex.

Bulbi vestibuli (bul'-bi ves-tib'-u-li) [L.]. A name sometimes given to the glands of Bartholin.

Bulbil, or Bulblet (bul'-bil, bulb'-let) [ $\beta 0 \lambda \beta o ́ s, ~ a ~ b u l b]$. Small bulbs of fleshy buds frequently occurring on above-ground parts of plants, as the bulblets of some onions and of the tiger-lily.

Bulbillæ $($ bul-bil'-e) [bulbillus, dim. of bulbus, a bulb]. In biology, gemmæ of hydroid zoöphytes that become detached at an early stage, and are then capable of independent development.

Bulbo-cavernosus (bul-bo-kav-ern-o'-sus) [ $\beta 0 \lambda \beta b c$, a bulb; caverna, a cavern]. A perineal muscle in the male subject, corresponding to the sphincter vaginæ of the female. See Muscles, Table of.

Bulbo-urethral (bul-bo-u-rêth'-ral) [ $\beta 0 \lambda \beta \sigma o s$, a bulb; ov $\rho$ in $_{\rho} \rho a$, the urethra]. Relating to the bulb of the urethra.

Bulbus (bul'-bus) [L.]. A bulb. B. arteriosus; in a certain stage in the development of the heart, the upper aortic enlargement is so called. B. cornu posteriorus. See Uccipital Eminence. B.rhachidicus, the oblongata.

Bulesis $\left(b u-l e^{\prime}-s i s\right)$ [ $\beta o v i \lambda \eta \sigma \varsigma$, the will]. The will, or an act of the will.

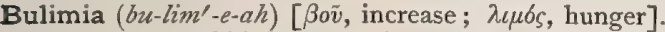
Excessive, morbid hunger; it sometimes occurs in idiots and insane persons, and it is also a symptom of diabetes mellitus.

Bulimic $\left(b u-l i m^{\prime}-i k\right)$ [ $\beta o v$, increase; $\lambda \iota \mu \delta \varsigma$, hunger] Pertaining to or affected with bulimia.

Bulithos $\left(b u^{\prime}\right.$-lith-os) [ $\beta o \tilde{v} s, \quad o x ; \lambda i t o s$, stone]. A bezoar from the ox or the cow.

Bulla (bul'-ah) [bulla, a bubble: pl., Bulla]. A bleb or "blister," consisting of a portion of the epidermis detached from the skin by the infiltration of watery fluid. The bulla differs from the vesicle mainly in size. B. ethmoidalis, a rounded projection into the middle meatus of the nose, due to an enlarged ethmoid cell. B., Hemorrhagic. See Purpura. B. ossea, the inflated or dilated part of the bony external meatus of the ear.

Bullate $\left(b \bar{u} l^{\prime}-\bar{a} t\right)$ [bulla, a bubble]. Inflated; fornicated and with thin walls; blistered; marked by bullæ.

Bullet Extractor ( $b \vec{u} l^{\prime}$-et eks-tra $k^{\prime}$-tor). See Forceps.

Bullous (būll'-us) [bulla, a blister]. Marked by bullæ; of the nature of a bulla.

Bully's Toilet Vinegar. A cosmetic consisting of tincture of benzoin, 1.0; acetic acid, 4.0; Cologne water, I00.0.

Bully Tree $\left(b \bar{u} l^{\prime}\right.$-e-tre $)$. See Balata.

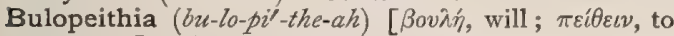
persuade]. An exaggerated hopefulness or morbid expectation of that which is desired.

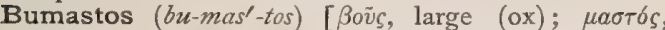
breast]. A very large or hypertrophied mamma.

Bumble Foot $\left(b u m^{\prime}-b l\right.$ foot). A disease of poultry, appearing as a wart-like substance growing in the ball of the foot. It is caused by high perches or by constant walking on cement or stone.

Bump (bump) [origin uncertain]. Any one of those eminences of the external surface of the skull that are conceived by phrenologists to mark the localities of the various "organs" of the brain.

Bumstead's Operations. See Operations, Table of.
Bundle (bun'-dl) [ME, bundel]. In biology, a fascicular grouping of elementary tissues, as nerve-fibers or muscle-fibers. B. of Vicq d'Azyr, a thick bundle of nerve-fibers arising in the more caudad of the two median nuclei of the corpus candicans of the brain, and extending to the anterior tubercle of the thalamus. It was formerly called the fornix descendens. B.sheath, "In many plants a ring of cells, often with strongly-thickened and lignified walls, developed only on the outside of the bast, or around the entire bundle, or around the whole mass of fibro-vascular bundles.' (Thoma.)

Bunion (bun'-yun) [origin uncertain]. A swelling of a bursa of the foot, especially of the great toe.

Bunodont (bu'-no-dont) [ßovvós, a hill, mound; ódóvs, tooth]. Pertaining to tuberculate molar teeth.

Bunsen Burner. See Burner. B. Cell. See Cell.

Bunt (bunt). See Smut.

Buphthalmia (büf-thal'-me-ah), or Buphthalmos

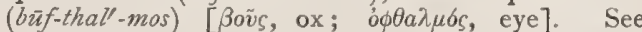
Keratoglobus.

Bupleurum (bu-plu'-num) [L.]. A genus of umbelliferous herbs. Several old-world species were formerly employed in medicine, especially $B$. rotundifolium, of which the leaves and fruit are considered vulnerary and discutient. Unof.

Bur, or Burr [ME., burre, a bur]. I. In botany, a rough, prickly shell or case. 2. The lobe of the ear. 3. In dentistry, an instrument for polishing the teeth. B. Drills, dental instruments of spherical, cone-shape, cylindrical, and wheel-forms, for opening and forming cavities. Flexible burs and drills having springtempered stems are used for opening and preparing nerve canals. B. Thimble, in dentistry, an open ring for the middle or index finger, with a socket attached, in which rests the end of the handle of the drill used in excavating a cavity in a tooth, preparatory to filling it

Burckhardt's Operation. See Operations, Table of.

Burcquism (boork'-izm). See Metallotherapy.

Burdach, Column of. See Funiculus cuneatus and Column. B., Cords of, the cords formed in the dorsal zone of the human spinal cord by the meeting of the oval bundles of His below the cords of Goll. B.'s Fissures. See Fissures, Table of

Burdock (ber'-dok). See Lappa.

Burdwan Fever (berd'-wan fe'-ver). See Fever.

Buret, or Burette (bu-ret') [Fr.]. A graduated tube designed for measuring small quantities of a reagent. It is usually held vertically in a stand and provided with a stopcock.

Burggrave's Apparatus. Same as Seutin's Apparatus, with the addition of a layer of wool around the limb.

Burgundy Pitch. See $P$ ix.

Burking [Burke, a noted criminal]. Suffocation produced by a combination of pressure on the chest with closure of the mouth and nostrils. This was the method employed by Burke.

Burmah Boil. A form of endemic ulcer common in Burmah.

Burmese (bur-mēz') [native]. Pertaining to Burmah, a province of Farther India. B. Lacquer. See Lacquer. B. Ringworm, Fox's name for a severe and troublesome form of Tinea circinata.

Burn [ME., bernen, to burn]. I. To become inflamed. 2. To be charred or scorched. 3. To have the sensation of heat. 4. An injury caused by fire or dry heat. 5. A disease in vegetables. 6. In chemistry, to oxygenize. 7. In surgery, to cauterize.

Burner [ME, bernen, to burn]. A common name for a lamp or heating apparatus used in laboratories 
for chemic and pharmaceutic purposes. B., Argand, uses gas or oil, and contains an inner tube for supplying the flame with air. B., Bunsen, a form in which the gas is mixed with a sufficient quantity of air to produce complete oxidation before ignition.

Burnett's (Sir W.) Disinfecting Fluid. A strong soJution of zinc chlorid (gr. $x x v$ to $\xi j$ of water) with a little iron chlorid. This is added to one quart of water for use. It is serviceable as an antiseptic and deodorizer, and as a preserver of dead bodies.

Burning (bern'-ing) [ME., bernen to burn]. Consum ing with heat or fire. B. of the Feet, a neurotic af fection of the soles of the feet, common in India. B. Oil, kerosene. The different burning oils are graded according to the two standards of color and fire-test. The colors range from pale-yellow (standard white) to straw (prime white) and colorless (water white). The fire-tests to which the commercial oils are mostly brought are $110^{\circ} \mathrm{F}, 120^{\circ} \mathrm{F}$, and $150^{\circ} \mathrm{F}$.; that of $110^{\circ}$ going mainly to the continent of Europe and to China and Japan, and that of $120^{\circ}$ to England. An oil of $150^{\circ} \mathrm{F}$. fire-test, and waterwhite in color, is known in the trade as "headlight oil." An oil of $300^{\circ} \mathrm{F}$, fire-test, and specific gravity .829 is known as "mineral sperm," or "mineral colza oil." "Pyronaphtha" is a product of Russian petroleum, somewhat similar to mineral sperm oil. It has a specific gravity of .865 , and a fire-test of $265^{\circ}$ F. B. Point, in testing petroleum oils, the temperature at which a spark or lighted jet will ignite the liquid itself, which then continues to burn. This point is usually $6^{\circ}$ to $20^{\circ} \mathrm{C}$. higher than the flashpoint, but there is no fixed relation between the two.

Burnisher [ME., burnischen, to polish]. An instrument used in polishing different kinds of metals, and in the laboratory of the dentist, for finishing pieces of dental mechanism.

Burns, Ligament of. The falciform process of the fascia lata.

Burns's Amaurosis. See Amblyopia, Post-Marital; also Amaurosis.

Burnt [ME., bernen, to burn]. Scorched; injured by dry heat. Consumed by fire. B. Alum. See Alumen exsiccatum. B. Sponge. See Spongia usta. B. Ocher. Same as Ocher.

Burow's (von) Operations. See Operations, Table of. B. Veins, small veins joining the portal and general circulations.

Burra Gookeroo (bur'-ah gook'-er-oo) [E. Ind.]. The spring carpels of Tribulus lanuginosus, a plant of the guaiacum order growing extensively throughout the East, and largely used as a diuretic and aphrodisiac. It has been employed for the relief of nocturnal emissions and impotence. Dose of the fluid extract $m x x-1$; of the infusion $3 \mathrm{j}-\mathrm{ij}$; of the syrup (for children) $3 \mathrm{ss}-\mathrm{j}$.

Burras Pipe (bur'-as pìp) [burra, coarse-hair; ME., pipe]. A port-caustic.

Burring (bur'-ins) [ME., borre, a harshness in the throal]. Rhotacism; in stammering, the mispronunciation of the letter $r$. B. Engine, a dental appliance for the use of burs, etc., in forming cavities, etc. See Dintal Engine.

Burrow (bur'-o) [ME., borow, a hole]. I. To make a hole or furrow, as in the skin; said of the itch insect. 2. To force a way through, as pus through the tissues.

Burrowing (burl-o-ing) [ME., boroze, a hole]. The term given to the passage of pus through the tissues, after the formation of an abscess that has not burst or been evacuated by surgical methods.

Bursa (bur'sah) [bursa, a purse: pl., Bursce]. A small sac interposed between parts that move upon one another. B. anserina, a pouch situated between the long internal lateral ligament and the lower internal hamstring tendons. $\mathbf{B}$. colera, the gall-bladder. B. cordis, the pericardium. B. fabricii, "A glandular organ existing in both sexes and all species of birds; most developed in young birds, more or less atrophied in adults; it opens on the dorsal wall of the cloaca, into the lowest chamber of that organ." (Forbes.) B. mucosæ, a bursa situated in subcutaneous areolar tissue. B., Plantar, a bursa situated over the instep, either above or below a tendon. B., Popliteal, a bursa situated in the popliteal space between the tendon of the semimembranosus and the tendon of the inner head of the gastrocnemius, where they rub against each other. B., Prepatellar, a bursa situated over the patella and over the upper part of the patellar ligament. B., Synovial, found between tendons and bony surfaces. B. vaginalis, the synovial sheath.

Bursal (bur'-sal) [bursa, a purse]. Pertaining to a bursa, sac, or follicle.

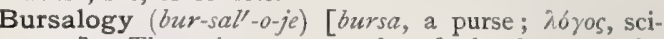
ence]. The science or study of the bursæ; the anatomy, physiology, and pathology of the bursæ.

Bursera (bur'-ser-ah) [Burser, a German botanist]. A genus of tropical trees, several species of which afford resinous gums, $B$. acuminata affords caranna; $B$. tomentosa furnishes tacamahac.

Burseraceous (bur-ser-a'-se-us) [Burser, a German botanist]. Pertaining to or resembling the genus Bursera.

Bursiculate (bur-sik'-u-lät) [bursicula; dim. of bursa, a purse]. In biology, pouch or purse-like, or possessing a bursa.

Bursiform (bur'-sif-orm) [bursa, a purse ; forma, form]. Resembling a bursa.

Bursitis (bur-si'tis) [bursa, a purse; $\iota \tau \iota \zeta$, inflammation]. Inflammation of a bursa. B., Tornwaldt's, catarrhal inflammation of the anterior portion of the median recess of the naso-pharnyx.

Bursula (bur'-su-lah) [dim. of bursa, a purse]. A small bursa; the scrotum.

Burton's Sign. See Signs and Symptoms, Table of.

Busch's Operations. See Operations, Table of. B.'s Version, in obstetrics, direct version, the head being grasped by one hand; while the other hand pushes the breech of the child upward, the head is pulled down into the cervix.

Bushmaster (bush'-mast-er). See Lachesis.

Busk, Diameter of. In craniometry, the auriculobregmatic diameter. B., Horizontal Plane of. See Plane.

Butalanin (bu-tal'-an-in) [butyl; alanin], $\mathrm{C}_{5} \mathrm{H}_{9}$ $\left(\mathrm{NH}_{2}\right) \mathrm{O}_{2}, \quad a$-amidoisovaleric acid; it consists of shining prisms that sublime without fusing. It is found in the pancreas of the ox.

Butcher's Operations. See Operations, Table of.

Butea (bu'-te-ah) [John, Earl of Bute (1713-92)]. $A$ genus of leguminous tropical trees and shrubs. $B$. frondosa and $B$. superba afford Bengal Kino (see Kino); also called Butea Gum, B. Gum. See Kino.

Butter (but'-er) [butyrum, butter]. The fatty part of the milk obtained by rupturing the cells of the fatglobules by "churning" or mechanical agitation. Also, various vegetable fats having the consistency of butter, as B. of Cacao. See Theobroma. Also applied to certain chemical products having the appearance or consistence of butter, as B. of Antimony, antimonious chlorid; B. of Tin, stannic chlorid; B. of Zinc, zinc chlorid. See, also, Acid, Butyric. B.-and-Eggs. See Antirrhinum linaria. 
B.-fat. I. The oily portion of the milk of mammalia. 2. The fatty portion of butter, made up of the glycerids of oleic, palmitic, and stearic acids (the socalled insoluble acids), and the glycerids of butyric, caproic, caprylic, and capric acids (the so-called soluble acids). The average proportion of the insoluble acids present in butter-fat is 88 per cent., and the average proportion of the soluble acids from five to six per cent. This gives a very important means of distinguishing between a natural butter and oleomargarin. The pure fat has a sp. gr. of from . 910 to .914 , and its melting-point varies from $85^{\circ}$ to $92^{\circ} \mathrm{F}$. B.-fly, a winged pledget or tampon of cotton for vaginal application. B.-fly Lupus. Synonym of Lupus erythematosus. B. Kidney. See Amyloid Kidney. B.-nut. See Juglans.

Butterin (but'-er-ên) [butynum, butter]. An artificial substitute for butter, made principally of beef-fat. See Oleomargarin.

Buttocks (but'-uks) [ME., buttok]. The nates. The fleshy part of the body posterior to the hip-joints, formed by the masses of the glutei muscles.

Button (but'-un) [ME, boton]. See Furunculus orientalis. B., Amboyna. See Frambesia. B., Belly, the navel. B., Biskra, the Aleppo Ulcer. B., Corrigan's, a steel button-shaped cautery-iron, introduced by Sir J. C. Corrigan (1802-80). B.-bush, the bark of Cephalanthus occidentalis, a tonic, febrifuge, and

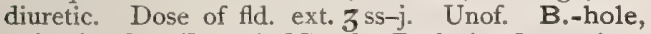
Mitral. See Funnel, Mitral. B.-hole Operation. See Boutonnieve Operation and Operations, Table of. B.-lac. See Lac. B.-maker's Chorea. See Chorea. B.-scurvy, a disease of privation, apparently similar to sibbens or to yaws. B.-snakeroot, the root of Liatris spicata, and of Eryngium yuccafolium; a stimulant, tonic, diuretic, and emmenagogue. Dose of fld. ext. 3 ss-j. Unof.

Butyl (bu'-til) [butyrum, butter], $\mathrm{C}_{4} \mathrm{H}_{9}$. A hydrocarbon alcohol radical, that cannot be isolated, and that occurs only in combination with other radicals. B. Chloral. See Chloral butylicum. B.-chloral Hydrate. See Chloral butylicum.

Butylamin (bu-till-am-in) [butyrum, butter; amin]. Any primary amin of butyl. The butylamin of codliver oil is said to be one of its medicinal constituents.

Butylene (bu'-til-ēn) [butyrum, butter], $\mathrm{C}_{4} \mathrm{H}_{8}$. A hydrocarbon belonging to the olefin series. It exists in three isomeric forms, all of which are gases at ordinary temperatures.

Butyric Acid (bu-tir'-ik). See Acid', Butyric.

Butyrin (bu'-tir-in) [butyrum, butter], $\mathrm{C}_{3} \mathrm{H}_{5}\left(\mathrm{C}_{4} \mathrm{H}_{7} \mathrm{O}_{2}\right)_{3}$. A constant constituent of butter, together with olein, stearin, and other glycerids. It is a neutral yellowish liquid fat, having a sharp, bitter taste.

Butyrone (bu'-tir-on) [butyrum, butter], $\mathrm{C}_{7} \mathrm{H}_{14} \mathrm{O}$. Dipropyl ketone. The principal product of the distillation of calcium butyrate. It boils at $144^{\circ}$ and at $20^{\circ}$ has a sp. gr. of . 82 .

Buxin (buks'-in) [buxus, the box-tree]. Bibirin; bebeerin; pelosin; the alkaloid of Nectandra. It is a white, amorphous powder with a persistent bitter taste; very insoluble in water, but easily soluble in alcohol and chloroform. Dose of it or its salts, from grains three to six in pill-form. It is used as a febrifuge. Unof.

Buxton's Apparatus. See Anesthetic.

Buxus $\left(b u k s^{\prime}-u s\right)$ [L., the box-tree]. A genus of trees affording boxwood. B. sempervirens, the common box or box-tree of Europe and Asia. Its leaves, wood, and oil have been employed in medicine. Unof.

Buzzi's Operation. See Operations, Table of.

Byrd's Method. See Artificial Respiration. B. Operation. See Operations, Table of.

Byrne's Method. See Treatment, Methods of.

Byrsa (bur'-sah). Same as Bursa.

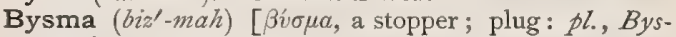
mata]. A plug or tampon.

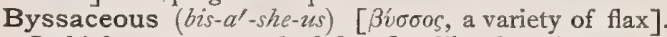
In biology, composed of fine flax-like threads.

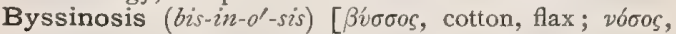
disease]. A diseased condition of the lungs due to the inhalation of cotton-dust in factories.

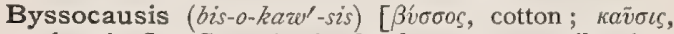
a burning]. Cauterization by the moxa ; moxibustion.

Byssogenous (bis-oj'-en-us) [ $\beta \hat{v} \sigma \sigma o s, \operatorname{cotton} ; \gamma^{\prime} \varepsilon \nu \eta s$, producing]. In biology, producing a byssus.

Byssus $\left(b i s^{\prime}-u s\right)$ [ $\beta \hat{v} \sigma \sigma o \varsigma$, cotton, flax]. I. Charpie, lint, or cotton. 2. The hairy growth of the pubic region. 3. In biology, a bunch of silky filaments secreted by the foot, in several molluscs. A name formerly given to the mycelium of large fungi. B. Gland. See Gland.

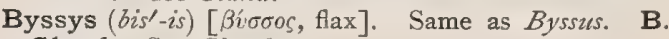
Gland. See Gland.

Bythus (bith'-us) [ $\beta v \theta 6 s$, the depth]. The lower or vesical portion of the abdomen. 
C. The chemic symbol of Carbon. Abbreviation of centigrade.

c.c. Abbreviation of cubic centimeter.

$\mathrm{cm}$. Abbreviation of centimeter.

C. M. Abbreviation of cras mane, to-morrow morning.

C. $\mathbf{N}$. Abbreviation of cras nocte, to-morrow night.

Caballine Aloes (kabl-al-in al'-ös). See Aloes.

Cabbage $\left(k a b^{\prime}-\bar{a} j\right)$. See Brassica. C. Rose. See Rosa centifolia. C., Skunk, a fetid plant of N. America, Symplocarpus fotidus. Its tincture and fluid extract are prescribed as antispasmodic and antasthmatic. Unof. C.-Tree. See Andira.

Cabinet (kab'-in-et) [Fr., a closet]. A closed compartment. C., Pneumatic. See Pneumatic.

Cacæmia (kas-e'-me-ah or kak-e'-me-ah). See Cacemia.

Cacæmic (kas-or kak-em'-ik). See Cacemic

Cacain $\left(k a k-a^{\prime}-i n\right)$ [Nahuatl, cacauatl, cacao]. Theobromin, q. $v$.

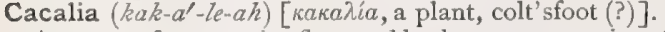
A genus of composite-flowered herbs, many species of which have been used in medicine. C. suaveolens, is the sweet centaury of N. America. Unof.

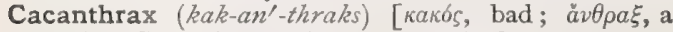
coal]. Contagious anthrax. See Anthrax.

Cacao $\left(k a k-a^{\prime}-o\right)$. See Theobroma. C. Butter, oleum theobromæ is obtained from seeds or nibs of Theabroma cacao. It is a pure white fat, with a pleasant odor and taste ; it fuses at $86^{\circ} \mathrm{F} .\left(30^{\circ} \mathrm{C}\right.$. $)$; its specific gravity is .945 to $.95^{2}$. It is used in cosmetics, and for pharmaceutic preparations. See also Theobroma.

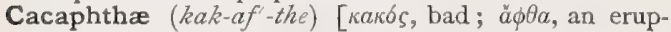
tion]. Malignant or cachectic aphthæ. See Aphthae.

Cacation $\left(k a k-a^{\prime}-s h u n\right)$ [cacatio, a going to stool]. Defecation; alvine discharge.

Cacatory (kak'-at-o-re) [cacatio, a going to stool]. Attended with diarrhea; as a cacatory fever.

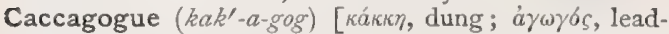
ing]. I. Aperient; laxative. 2. An aperient, especially an ointment or suppository that induces gentle purgation. [Archaic.]

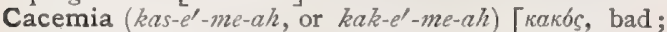
alua, blood]. An ill-condition of the blood; depravity of the blood.

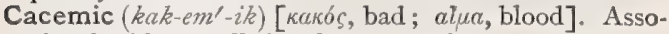
ciated with or suffering from cacemia.

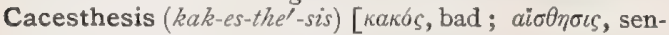
sation]. Morbid sensation.

Cachæmia $\left(k a k-e^{\prime}-m e-a h\right)$. See Cacemia.

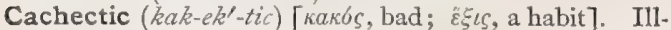
conditioned: marked by cachexia. C. Aphthæ. See Aphthe.

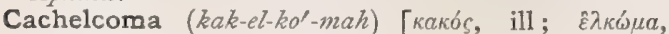
ulcer: $p l$, Cachelcomata]. A malignant or foul ulcer.

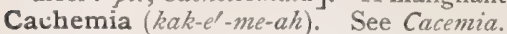

Cachet (ka-sha') [Fr.]. A pharmaceutic preparation consisting of two concave pieces of wafer, varying in size from $3 / 4$ to $\mathbf{I} 1 / 8$ inches in diameter, round or oblong in shape, in one of which the powder to be administered is placed, and the other, having previously been moistened, is then laid over the powder and the two margins are pressed together, when they adhere and completely enclose the powder. C. de Pain. Same as Cachet, $q . v$.

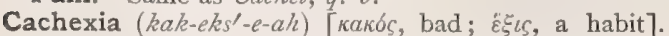
A term used to designate any morbid tendency, dyscrasia, depraved condition of general rutrition, or impoverishment of the blood, etc. It is applied particularly to scrofulous, syphilitic, or carcinomatous patients. It is characterized by emaciation and a peculiar sallow or muddy complexion. C. africana, dirt-eating: geophagy. A disease supposed to be identical with miners' anemia. C. aquosa, a dropsical and anemic state. C. icterica, jaundice. C., Lymphatic. Synonym of Hodgkin's Disease. C., Negro. Same as C. africana. C., Pachydermic. See Myxedema. C. strumipriva, the condition allied to if not identical with myxedema, following the extirpation or arrest of function of the thyroid gland. It is a cretinoid state, characterized in monkeys by hebetude, malnutrition, muscular tremor, puffy edema, leukocytosis, and the presence of mucin in the blood and connective tissue. C. thyreopriva. See Myxedema. C. virginum. See Chlorosis.

Cachexy (kak-eks'-e). See Cachexia.

Cachibou (kash-e-boo'). See Chibou.

Cachinnation (kak-in-a'-shun) [cachinnare, to laugh loudly]. Immoderate laughter, as in the insane.

Cachou (kash-oo') [Fr. for "catechu" ]. An aromatic pill or tablet for concealing the odor of the breath.

Cachunde $\left(k a-c h u n^{\prime}-d e\right)$ [Sp.]. An oriental electuary used as a breath-perfume, and also as a stomachic and carminative. Unof.

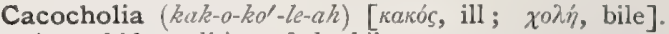
A morbid condition of the bile.

Cacochroia (kak-o-kroi'-ah) or Cacochrœa (kak-o.

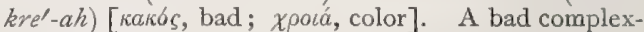
ion; unnatural color of the skin.

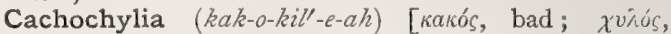
juice]. Imperfect or disordered digestion.

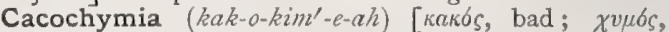
juice]. A morbid state of the fluids, humors, blood, or secretions; faulty stomachic digestion.

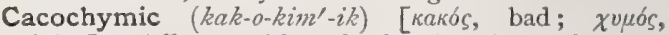
juice]. Affected with cachochymia; dyspeptic.

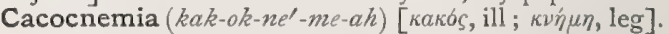
Thinness or ill-condition of the leg or shin.

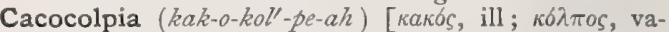
gina]. A diseased state of the vagina.

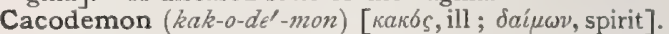
An old name for a supposed besetting evil spirit; also, the nightmare.

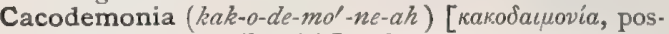
session by an evil spirit]. Supposed possession or obsession by an evil spirit.

Cacodemonomania (kak-o-de-mo-no-ma'-ne-ah) [кakodacuovia, possession by an evil spirit; $\mu a v i a$, madness]. A delusional belief, on the part of a patient, that he is possessed of a devil.

Cacodontia (kak-a-don'-te-ah) [kakós, bad; ódoús, tooth]. A bad condition of the teeth.

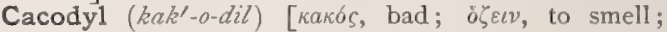
$v \lambda \eta$, matter], As $\left(\mathrm{CH}_{3}\right)_{2}$. Kakodyl; dimethylarsin: a radical containing arsenic, hydrogen, and carbon. It is a colorless, heavy liquid, with an extremely offensive odor, and poisonous vapor; it is inflammable when exposed to air. Its protoxid is called alkarsin, q. $v$.

Cacoesthesis (kak-o-es-the'-sis). See Cacesthesis.

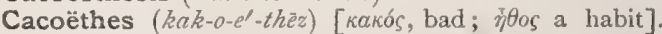
Any bad habit, disposition, or disorder.

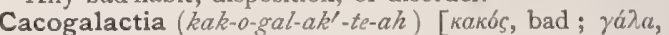
milk]. A bad or abnormal condition of the milk.

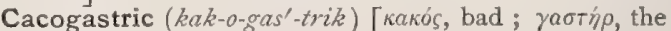
stomach]. Dyspeptic.

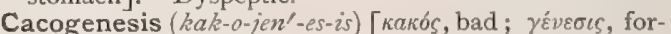
mation]. Any morbid, monstrous, or pathologic growth or product. 


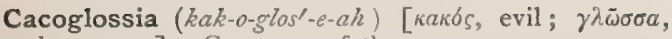
the tongue]. Gangrene of the tongue.

Cacolet $\left(k a k^{\prime}-0-l a\right)$ [Fr.]. A mule-chair or horsepannier for the transportation of the wounded.

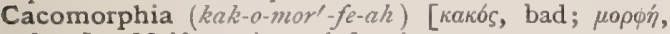
form ]. Malformation; deformity.

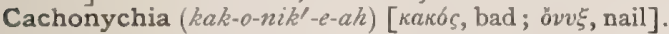
Disease or defect of a nail or of the nails.

Caconym (kak'-o-nim) [kakós, bad; òvora, a name]. An undesirable or objectionable name, e.g., in biologic nomenclature or terminology.

Cacopathy, or Cacopathia (kak-op'-a-the or kak-o-

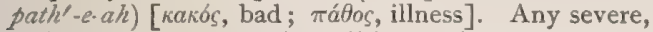
malignant, or untoward condition or disease.

Cacophonia (kak-o-fo'-ne-ah) [какós, bad; $\phi \omega \nu \eta ́$, , voice]. An altered, depraved, or abnormal voice.

Cacophonic (kak-o-fon'-ik) [kakós, bad; $\phi \omega \nu \eta ́$, voice]. Affected with cacophonia.

Cacoplastic (kak-o-plas'-tik) [kakós, bad; $\pi \lambda a \sigma \tau o ́ s$, formed]. r. Characterized by or adapted to a low degree or kind of organization. 2. Relating to, causing, or attended with defective formation; liable to be changed into an abnormal tissue.

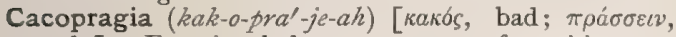
to do]. Functional derangement, as of nutritive processes, or of organs.

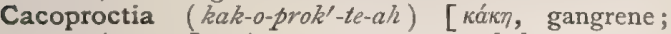
$\pi \rho \omega \kappa \tau \sigma \zeta$, anus]. A gangrenous state of the rectum.

Cacorrhachis (ka-kor'-rak-is) [кakbs, ill; $\rho a ́ \chi \iota s$, spine]. A diseased state of the vertebral column.

Cacorrhinia (kak-or-in'-e-ah) [kakós, ill; pis, nose]. Any diseased condition of the nose.

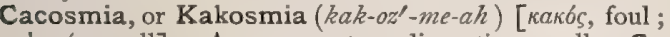
b́ $\mu^{\prime}$, smell]. A repugnant or disgusting smell. C., Subjective, a disturbance of the olfactory nerve or center, from hysteria or from other disease, giving rise to the perception of an offensive smell.

Cacosomium (kak-o-so'-me-um) [какós, bad; $\sigma \tilde{\omega} \mu a$, body]. A hospital for leprosy and other incurable diseases.

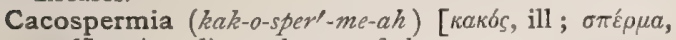
weed]. Any diseased state of the semen.

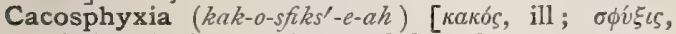
pulse ]. A disordered state of the pulse.

Cacostomia (kak-o-sto'-me-ah) [kakbs, ill; $\sigma \tau b \dot{\alpha} \alpha$, mouth]. Any diseased or gangrenous state of the mouth.

Cacothanasia (kak-o-than-n'-ze-ah) [kakbs, bad; өávaros, death]. A painful death.

Cacothelin ( $k a k$-oth'-el-in) $\mathrm{C}_{42} \mathrm{H}_{22} \mathrm{NO}_{20}{ }^{\circ}$ An alkaloid produced from brucin by the action of $\mathrm{HNO}_{3}$.

Cacothymia (kak-o-thim'-e-ah) [кakós, bad; $\theta v \mu \delta s$, mind]. A disordered state of the mind or disposition; mental disorder with moral depravity; insane malignity of temper.

Cacotrophia (kak-o-tro'-fe-ah). Same as Cacotrophy.

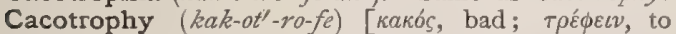
nourish ]. Disordered or defective nutrition.

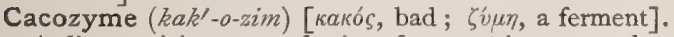
A disorganizing, putrefactive, fermentative, or pathogenic microörganism.

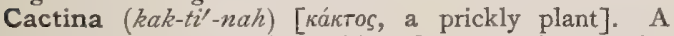
proprietary preparation said to be a proximate principle derived from night-blooming cereus (Cereus grandiflora and $C$. mexicana). It is a cardiac stimulant recommended as a substitute for digitalis. Unof.

Cactus (kak'-tus) [кákтos, a prickly plant]. A genus of plants. C. grandiflorus. See Night-blooming Cereus. C. Nipple. See Mammillaria.

Cacumen (kak-u'-men) [L.: pl., Cacumina]. 1. The top, as of a plant. 2. The culmen of the vermis superior of the cerebellum.
Cadaver (kad-av'-er) [cadere, to fall]. The dead body, especially that of man. A corpse. C. Tubercle, anatomic wart. A peculiar circumscribed hyperplasia of the papillary structures of the skin occurring chiefly on the dorsal surface of the hands and fingers of persons who are in the habit of handling dead and decomposing bodies.

Cadaveric (kad-av-er'-ik) [cadere, to fall]. Pertaining to the cadaver or dead body. C. Alkaloids, Ptomaines, q.v. C. Ecchymoses, certain postmortem stains, closely resembling in their general appearance the effects of bruises or contusions. They occur, both externally and internally, on the lowest and most dependent parts of the body. They are also called hypostases, sugillations, and vibices. C. Spasm, the early, at times instantaneous, appearance of rigor mortis, seen after death from certain causes. It is also called instantaneous rigor and tetanic rigidity.

Cadaverin (kad-av'-er-in) [cadere, to fall], $\mathrm{C}_{5} \mathrm{H}_{14} \mathrm{~N}_{2}$. A ptomaine, isomeric with neuridin, and, like it, occurring very frequently in decomposing animal tissues. It is obtained from human hearts, lungs, livers, etc., after three days' decomposition at ordinary temperature, -also from horseflesh, from putrid mussel, from herring and haddock. It is a constant product of the growth of the comma-bacillus, irrespective of the medium. It does not occur in culture-media from which bacteria are absent. It is a thick, water-clear, syrupy liquid, having an exceedingly unpleasant odor, somewhat resembling that of coniin and semen. It is certainly identical with so-called "animal coniin." Putrescin and cadaverin were both formerly believed to be physiologically indifferent; but recent investigations show both bases capable of producing active inflammation and necrosis. The necrosis of the intestinal epithelium in Asiatic cholera seems due to their presence. They also have the power, even in small quantities, of preventing blood from coagulating, and rendering it "laky." Cadaverin is believed by Grawitz to hinder the growth of bacteria. Cadaverin hydrochlorid, on dry distillation, decomposes into ammonium chlorid, $\mathrm{NH}_{3} \mathrm{HCl}$, and piperidin, $\mathrm{C}_{5} \mathrm{H}_{11} \mathrm{~N}$. Whether or not this change, whereby the non-poisonous cadaverin becomes a toxic base, can take place under the influence of bacteria during putrefaction, is not known.

Cadaverization (kad-av-er-iz-a - shun) [cadere, to fall] The passage of a living body to the state of a cadaver. Applied to the algid and cyanotic stage of cholera.

Cadaverous (kad-av'-er-us) [cadere, to fall]. Resembling a cadaver; ghastly; of a deathly pallor.

Cade $(k \vec{a} d)$ [a Languedoc name]. See Juniperus. C., Oil of (oleum cadinum), a tarry oil from the wood of Juniperus oxycedrus; it is used in the treatment of skin-diseases.

Cadet's Fuming Liquid. See Alkarsin. C.'s Test. See Tests, Table of.

Cadiva Insania (kad-i'-vah in-sa'-ne-ah) [L.]. Falling insanity; an old name for epilepsy.

Cadlock (kad'-lok). Wild mustard, Brassica sinapistrum. See Brassica.

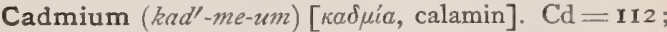
quantivalence II. A bluish-white metal resembling zinc in its general properties. Only the sulphate and iodid are used in medicine. In its physiologic action it is escharotic and astringent, producing in large doses emesis and violent gastritis. See Elements, Table of. C. iodidum, $\mathrm{CdI}_{2}$, used as an ointment, I to 8 of lard. C. sulphas, $\mathrm{CdSO}_{4} .4 \mathrm{H}_{2} \mathrm{O}$, a valuable astringent in gonorrhea and in corneal opacities; used in a lotion in strength of gr. $1 / 2$ or 4 to $\xi j$ of 
water, or as an ointment I to 40 of fresh lard. Unof. C.-Red. See Conspectus of Pigments, under Pisment. C.-Yellow. See Conspectus of Pigments, under Pigment.

Caduca (kad-du'-kah) [cadere, to fall]. See Decidua. C. Passio. See Caducus Morbus.

Caducibranchiate (kad-u-se-brang'-ke-ät) [caducus, falling off; branchice, gills]. In biology, applied to such amphibia as lose the gills or branchiæ upon reaching maturity.

Caducicorn (kad-u'-se-korn) [caducus, falling off; cornu, horn]. In biology, applied to animals that shed their horns or antlers.

Caducity (kad-du'-sit-e) [caducitas, senility]. Senility; the feebleness of advanced age.

Caducous (kad- $\left.u^{\prime}-k u s\right)$ [caducus, falling off]. In biology, the shedding or falling off of certain parts, as gills, antlers, horns. Dropping off very early, as compared with other parts.

Caducus Morbus (kad-du'-kus mor'-bus) [L.]. Falling sickness; an old name for epilepsy.

Cracal $\left(s e^{\prime}-k a l\right)$. See Cecal.

Cæcitas Verbalis. See Word-blindness.

Cæcitis (se-si'-tis). See Cecitis.

Cæcum (se'-kum). See Cecum.

Cænæsthesis (cen-es-the'-sis). See Cenesthesis.

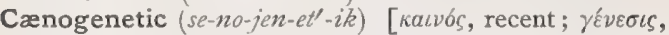
generation]. In biology, the appearance of a new character very late in the course of development. This usually arises from comparatively recent variations of the type-form.

Cæruleus (se-ru'-le-zes) [L.]. Sky-blue. C. morbus, blue disease. See Cyanosis.

Cærulosis (se-ru-lo'-sis). See Cyanosis.

Cæsalpinia (ses-al-pin'-e-ah) [L.]. A genus of tropical leguminous trees. C. bonducella. See Bonducella. C. moringa has a diuretic bark. All unof.

Cæsarean Operation $\left(s e-s a r^{\prime}-e-a n\right)$. See Cesarean.

Cresium (se'-se-um). See Cesium.

Caffea $\left(k a f^{\prime}-e-a h\right)$ [L.]. The seeds of C.arabica. The dried and roasted seeds are almost universally used in infusion as a beverage, forming a cerebral stimulant and stomachic tonic. They are valuable in promoting digestion and allaying hunger and fatigue. Coffee frequently causes excessive palpitation of the heart. Its properties are due to an alkaloid, Caffein, $\mathrm{C}_{8} \mathrm{H}_{10} \mathrm{~N}_{1} \mathrm{O}_{2} \cdot \mathrm{H}_{2} \mathrm{O}$, identical with Thein. See Tea. Dose of the alkaloid gr. j-v. C. citrate. Dose gr. j-v. C. valerianas, for nervous vomiting in hysteria. Dose gr. j-iv. Ext. Caffeæ Viridis Fld. Unof. Intended as a substitute for the Fluid Extract of Guarana. Dose $35 s-i j$. See Guarana. Injectio Caf. Hypodermatica, one grain of caffein in three minims. Dose $m \mathrm{j}-\mathrm{vj}$.

Caffein (kaf'-e-in) [caffea, coffee]. $\mathrm{C}_{8} \mathrm{H}_{10} \mathrm{~N}_{4} \mathrm{O}_{2}+\mathrm{H}_{2} \mathrm{O}$. Thein; an alkaloid that occurs in the leaves and beans of the coffee-tree, in tea, in Paraguay tea, and in guarana, the roasted pulp of the fruit of Paullinia sorbilis. It occurs in long, silky needles, slightly soluble in cold water and alcohol, with a feebly bitter taste. It is a cerebral and spinal stimulant. See Caffea. C. citrata, citrated caffein, prepared by dissolving equal weights of caffein and citric acid in double the quantity of hot distilled water. Dose gr. ij-x. C. citrata effervescens, effervescent citrated caffein. Dose $3 \mathrm{j}$-ij in water. C.-iodol, a crystalline additionproduct obtained by mixing alcoholic solutions of caffein and iodol in molecular proportion. It contains 74.6 per cent. of iodol and 25.4 per cent. of caffein, and is a light-gray, odorless, tasteless, and nearly insoluble compound. It is proposed as a substitute for iodol. Unof.
Caffeina $\left(k a-f e^{\prime}-i n-a h\right)$. See Caffein.

Caffeinism (kaf-e'-in-izm) [caffea, coffee]. Chronic coffee-poisoning; a train of morbid symptoms due to excess in the use of coffee.

Cagot (kah-go') [Fr.]. I. A member of an outcast race or clan in the S. W. of France; formerly regarded as lepers. 2. (By error) a cretin. C. Ear. See Ear Deformities.

Cahinca, or Cainca (kah-hing'-kah) [native S. American]. The diuretic root of Chiococca racemosa, C. densifolia, or $C$. anguifuga, rubiaceous shrubs of tropical America. Unof.

Cahn and V. Mering's Method. A method of estimating the amount of acids in the stomach. It consists in distilling the contents of the stomach with water three times. The volatile acids are estimated in the distillate. The residue is shaken six times with 500 c.c. of etber, and this is evaporated to dryness, and the lactic acid estimated by titration. The residue contains the $\mathrm{HCl}$, and this also can be estimated by titration.

Cailcedra ( $\left.k \bar{a} l-s e^{\prime}-d r a h\right)$ [origin unknown]. I. The Cedrela odorata, a large tree of tropical America. The bark and wood are used in intermittent fevers; a fragrant oil (cedar-wood oil) is distilled from the wood. The tree also affords a resin. 2. The Khaya senegalensis of Africa and tropical America, a tree that closely resembles the foregoing.

Cailletet's Test. See Tests, Table of.

Caillian's Test. See Tests, Table of.

Caisson Disease $\left(k a^{\prime}\right.$-son $\left.d i z-\bar{e} z^{\prime}\right)$. The symptoms due to increased atmospheric pressure sometimes occurring in divers, caisson workers, etc. Paraplegia, hemiplegia, anesthesia, or apoplectic attacks are common, but paralysis of the legs is the most frequent symptom, coming on only after return to the normal atmosphere. The nature of the lesion is obscure.

Cajeput Oil (kaj'-e-put oil). See Cajuputi, oleum.

Cajuputene (caj-u-pu-tèn') [Malay], $\mathrm{C}_{10} \mathrm{H}_{16}$. The principal constituent of cajeput oil ; it is a liquid of an agreeable odor.

Cajuputi, Oleum (kaj-u-pu'-te, $\left.\bar{o} l^{\prime}-e-u m\right)$. [Malay, "white wood;" olezm, oil]. Oil of Cajuput. A volatile oil distilled from the leaves of Melaleuca leukadendron. It resembles oil of turpentine in its general effects, being irritant externally and produc ing a sense of warmth internally, with accelerated pulse. It is used with benefit for flatulent colic, dropsy, hysteria, and cutaneous disorders; it also relieves toothache. Dose $m_{j}-v$. C., Spiritus (B.P.). Dose 3 ss-j.

Cajuputol (kaj-u-pu'-tol) [Malay, Cajuputi, white wood]. The more limpid part of oil of cajuput; it is found also in some other fragrant volatile oils.

Cake Colors (käk kul'-orz). See Pigments, Colors, and Dyestuffs.

Caked $(k \bar{a} k d)$ [ME., cake]. Compressed or hardened into a solid mass. C. Breast, a breast in a puerperal woman in which the milk has become hardened and inspissated. C. Bag, in cows, an inflammation of the mammary gland.

Calabar Bean (kal'-ab-ar hēn). See Physostioma.

Calabarin $\left(k a l-a b^{\prime}-a r-i n\right)$ [Calabar]. An alkaloid from Calabar bean, apparently acting much like strychnin.

Caladana (kal-ad-a'-nah). See Kaladana.

Caladium $\left(\mathrm{kal}-\mathrm{a}^{\prime}-\mathrm{de}-\mathrm{um}\right)$ [L.]. A genus of largeleaved araceous plants. C. bicolor, of Brazil, is anthelmintic and cathartic. Various other species are employed locally in medicise. Unof.

Calage (kal-ahzh') [Fr., wedging]. A method of prophylaxis or treatment of sea-sickness by fixation of the viscera by pillows placed between the abdomen and 
the wall of the cabin and between the back and edge of the berth, the patient lying upon the side.

Calamary (kal'-am-a-re) [kañapa, inkstand]. Same as Cuttle-bone.

Calamin (kal'-am-in) [calamina, a corruption of $\mathrm{cad}$ mia]. Native zinc carbonate. Calamina praparata, the prepared calamin, washed and pulverized, is used mainly as an external exsiccant and astringent. Unguentum calamina, Turner's cerate. Unof.

Calamint, Calaminth (kal'-am-int or -minth). Any plant of the labiate genus Cirlamintha. The calamints are aromatic stimulants, with the general properties of the other mints, such as pennyroyal. Unof.

Calamistrum (kal-am-is'-trum) [calamus, a reed]. In biology, one of the spines found on the hind-legs of spiders, used in arranging the silk as it issues from the spinnerets.

Calamus (kal'-am-us) [L., a reed: gen., Calami]. Sweet Flag. The rhizome of Acorus calumus. It contains a volatile oil and acorin, a bitter nitrogenous principle. The root is an aromatic, stomachic tonic, and a common ingredient of many popular "bitters." C., Ext., Fld. Dose $\eta_{\text {xy }}-3 j$. C., Draco, a species of rattan-palm that affords a part of the so-called Dragon's Blood $\left(q . v_{0}\right)$ of commerce. C. scriptorius (a writing pen or reed). The groove on the floor of the fourth ventricle, at the end of which is the ventricle of Arantius.

Calapitte (kal'-ap-it) [Mex., calappa, the cacao-tree]. A concretion found occasionally in the cocoa-nut: vegetable bezoar. It is valued as an amulet in the East.

Calathidium or Calathium (kal-ath-id'-e-um or kal-

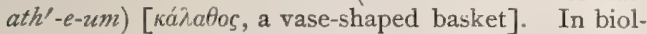
ogy, applied to the flower-head in certain of the Composita.

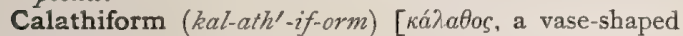
basket; forma, form]. In biology, shaped like a cup, vase, or bowl, hemispherical, or concave.

Calberla's Method. A method of imbedding microscopic specimens in egg-emulsion. The white of several eggs is separated from the yolks, the chalazæ removed, and the white cut up with a pair of scissors. To each 15 parts of white add one part of a Io per cent. solution of sodium carbonate (Io parts of calcined sodium carbonate to 100 parts of water). To this solution add the well-shaken yolks and again shake well. Pour the mixture into a deep vessel, allow to settle, remove the scum, and the mass is ready for use. The specimens, after being well washed in water, are placed in this mass until permeated. They are then fastened with pins to the freshly-cut surface of a piece of hardened mass.

Calcaneal (kal-ka'-ne-al) [calcaneum, the heel]. In biology, relating to the heel-bone, or calcaneum, or to a tuberosity in birds, resembling the calcaneum.

Calcaneo-astragalar ( $k a l-k a^{\prime}$-ne-o-as-trag'-al-ar). See Calcaneo-astragaloid. C.-astragaloid, relating to the calcaneum and the astragalus. C.-cavus, a clubfoot that combines the characters of calcaneus and cavus. C.-cuboid, belonging to the calcaneum and the cuboid. C.-scaphoid, belonging to the calcaneum and the scaphoid bone. C.-valgo-cavus, club-foot combining the features of calcaneus, valgus and cavus.

Calcaneum (kal-ka'-ne-um) [L., the heel]. A common name for the os calcis or heel-bone.

Calcaneus (kal-ka'-ne-us) [calcaneum, the heel]. Club-foot in which the heel alone touches the ground, the instep being drawn up toward the shin.

Calcar (kal'-kar) [L., a spur]. I. Any spur or' spurlike point, as the hippocampus minor. 2. Ergot of rye. 3. The calcaneum. C. avis, the hippocampus minor.
Calcareous (kal-ka'-re-us) [calx, limestone]. Per. taining to or having the nature of limestone. C. Degeneration. See Degeneration.

Calcarine (kal'-kar-in) [calcar, a spur]. Relating to the hippocampus minor. C. Fissure. See Fissure.

Calceiform (kal"-se-if-orm) [calceus, a shoe; forma, form]. In biology, resembling in shape a shoe or slipper, as the corolla of certain flowers.

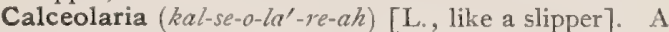
genus of scrophulariaceous plants, mostly of the Andean region. Many of the species have a high local repute as alteratives and antisyphilitics; several are emetic and purgative. Unof.

Calcic $\left(k a l^{\prime}-s i k\right)$ [calx, lime]. Of or pertaining to lime. C. Inflammation of Gums and Peridental Membrane. Inflammation caused and maintained by deposits of calculus on the necks of the teeth.

Calcicosis (kal-sik-o'-sis) [calx, lime; vóros, disease]. Marble-cutter's phthisis; phthisis due to the inhalation of marble-dust.

Calcification (kal-sif-ik-a'-shun) [calx, lime; fiere, to become]. The deposit of calcareous or other insoluble crystalline matter within the tissues of the body.

Calcigerous (kal-sij'-er-us) [calx, lime; gerere, to bear]. Containing lime or a lime-salt; as the calcigerous cells of the dentine, or calcigerous tubules in bone.

Calcigrade (kal'-sig-rād) [calx, heel; gredi, to walk] Walking on the heels.

Calcination (kal-sin-a'-shun) [calcinare, to calcine]. The process of driving off the volatile chemical constituents from inorganic compounds. The expulsion of carbon dioxid from carbonates.

Calcine (kal'-sin or kal-sin') [culcinare, to calcine]. To separate the inorganic elements of a substance by subjecting it to an intense heat.

Calcium (kal'-se-um) [calx, lime.][gcn., Calciii]. Ca $=$ 40; quantivalence 1I. A brillian, silver-white metal, the basis of lime and limestone, characterized by strong affinity for oxygen, and isolated with great difficulty. See Elements, Table of. It is best known in the form of calcium oxid, quicklime; $C$. hydrate, slaked lime; and $C$. carbonate, chalk. The preparations of lime used in medicine are usually alkaline and slightly astringent. Calcium oxid is a powerful escharotic. C. benzoas, $\mathrm{Ca}\left(\mathrm{C}_{7} \mathrm{H}_{5} \mathrm{O}_{2}\right)_{2}$, used in nephritis and albuminuria of pregnancy. Dose gr, $\forall-x$. C. carbonate Test. See Tests, Table of. C. chloridum, $\mathrm{CaCl}_{2}$, soluble in water. Dose gr. $\mathrm{x}-\mathrm{xx}$. C. chlorid. Liq. (B. P.): Dose $\eta_{x v-1}$ Calcii bromidum. See Bromin. C. Carb. Precipitatus, $\mathrm{CaCO}_{3}$, insoluble in water, but soluble in acids, with effervescence. Dose gr. $\nabla-\mathrm{xx}$. C. hypophosphis, $\mathrm{Ca}_{2} \mathrm{PH}_{2} \mathrm{O}_{2}$. See Phosphorus. C. Phosphas Precipit., $\mathrm{Ca}_{3}\left(\mathrm{PO}_{4}\right)_{2}$. See Phosphorus. Calcis Liniment, carron oil, contains equal parts of lime-water, and olive oil. C., Liquor, lime-water, contains about $1 \mathrm{I} / 2$ parts of lime in $\mathbf{I 0 0 0}$ of water. Dose $\xi$ ss-ij. C. Liq. Saccharatus (B. P.). Dose $\eta_{x v-z j}$. C., Syr., saccharated syrup of lime, contains lime 65 , sugar 40 , water q. s. It is the antidote to poisoning by carbolic

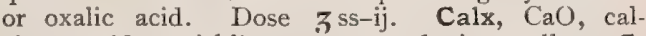
cium oxid, quicklime, not used internally. C. chlorinata. See Chlorin. C. Sulphurata. Dose gr. $\frac{1}{10}$. Creta, native calcium carbonate; chalk. C. Mist., consists of C. pulv, comp. 20, cinnamonwater 40 , water 40 . Dose 3 ss. C. Preparata, chalk freed from impurities by washing and elutriation. Dose gr. $\mathrm{v}-\mathrm{xx}$. C. Pulv. Aromat. (B.P.). Dose gr. $x-3$ j. C. Pulv. Aromat. cum Opii (B.P.). Dose gr. $\mathrm{X}-\mathrm{z}_{\mathrm{j}}$. C. Pulv. Comp., compound chalk-powder. 
consists of C. prep. 30, acacia 20, sugar 50 parts. Dose gr. $\mathrm{v}-3 \mathrm{j}$. Testa præparata, prepared oystershell. Unof. Dose gr. $x-x x$. C. trochisci, each contains prepared chalk 4 gr., acacia 1 , sugar 6 , with a little nutmeg.

Calculary (kal'-ku-la-re) [calculus, a stone]. Relating to or of the nature of a calculus.

Calculifragous (kal-ku-lif'-rag-us) [calculus, a stone; frangere, to break]. Lithotritic; breaking or reducing a stone in the bladder.

Calculous (kal'-ku-lus) [calculus, a stone]. Of the nature of a calculus.

Calculus (kal'-ku-lus) [dim. of calx, chalk: pl., Calculi]. A calcareous or stone-like concretion found in the bladder, kidney, etc. C., Arthritic, a gouty concretion. C., Biliary, a gall-stone. C., Bronchial, a concretion in an air-passage. C., Cutaneous. See Milium. C. Dental, tartar on the teeth or gums. C., Fusible, a urinary calculus composed of phosphates of ammonium, calcium, and magnesium. C., Lacteal, or Mammary, a calcareous nodule sometimes obstructing the lactiferous ducts. C., Mulberry, the oxalateof-lime variety, resembling a mulberry in shape and color. C., Nasal. See Rhinolith. C., Prostatic, one in the prostate gland. C., Renal, a calculus found in the kidney, producing what has been called nephritic colic. C., Salivary, one forming in the ducts of the salivary glands. C., Uterine, an intrauterine concretion; a wombstone; formed mainly by calcareous degeneration of a tumor. C., Vesical, one that may have originally descended from the kidney or formed primarily in the bladder.

Calea (kal'-e-ah) [L.]. A genus of tropical American composite-flowered plants. C. zacatechichi, a Mexican plant, tonic, antiperiodic, and a hepatic stimulant. Unof.

Caledonia Brown. See Conspectus of Pigments, under Pigment.

Calefacient (kal-e-fo'-she-ent) [L., calidus, warm; facere, to make]. I. Warming; producing a sensation of heat. 2. A medicine, externally applied, that causes a sensation of warmth.

Calefactor ( $k a l-e-f a k^{\prime}$-tor) [caledus, warm; facere, to make]. A warmer; a little, portable stove ; a pocket stove; a chafing-dish.

Calendula (kal-en'-du-lah) [calenda, the first day of the month: gen., Calendula]. Marigold. The flowering plant known as the garden-marigold, $C$. offcinalis. C., Tinct., contains 20 per cent. of the leaves and stems. It is used exclusively as a local application to wounds, bruises, and ulcers, and has been vaunted as a cure for carcinoma.

Calendulin (kal-en'-du-lin) [calende, the first day of the month]. An amorphous principle obtainable from calendula.

Calentur (kal"-en-tūr) [Sp., calentura, heat; L., calere, to be hot]. A tropical remittent fever with delirium; formerly, a supposed fever of this kind that attacked mariners, leading them to leap into the sea.

Calf [ME., calfe]. The thick fleshy posterior portion of the leg. See Sura. C.-bone, the fibula. C.knee. See Genu Valoum.

Calices of the Kidneys ( $\left.k a^{\prime}-l i s-\bar{e} z\right)$. Plural of Calyx. The cup-like tubes of the ureter that encircle the apices of the Malpighian pyramids of the kidneys.

Calico Bush (kal'-ik-o boosh). See Kalmia

California (kal-if-or'-ne-ah) [Mex.]. A western State. C. Buckthorn. See Cascara Sagrada. C. Elm. See Fremontia. C. Feverbush. See Garrya. C. Laurel, the leaves of Umbellularia californica, common to the Pacific slope. It is recommended for nervous headaches, cerebro-spinal meningitis, neu- ralgia, etc. Dose of fld. ext, gtt. $x-x x x$. C. Poppy. See Eschscholtzia californica.

Caligated (kal'-igr-a-ted) [caliga, a boot]. In biology, applied to the booted tarsus of the typical oscine birds.

Caligation (kal-ig-a'-shun), or Caliginosity (kal-ij-inos $\left.^{\prime}-i t-e\right)$. See Caligo.

Calignani's Operation. See Operations, Table of.

Caligo (kal-i/go) [L.]. Dimness of vision; an opacity of the cornea, lens, or vitreous humor.

Caligula (kal-ig'-u-lah) [caliga, a boot]. In biology, applied to the tarsal envelop of oscine birds.

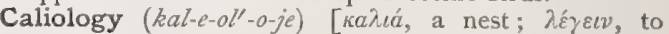
speak]. In biology, the systematized knowledge of birds'nests.

Calipers (kal'-ip-erz) [corruption of caliber]. Compasses with curved legs; they are used in vulcanite and celluloid dental work to measure the thickness of the plate. Calipers are used also in pelvimetry, craniometry, and other measurements of parts of the body.

Calisaya (kal-is-a'-yah) [South America]. Cinchona bark, especially that of Cinchona calisaya. See Cinchona.

Calisthenics, or Callisthenics (kal-is-then'-iks) [kanbs, beautiful; oftévos, strength]. The practice of various rhythmic movements of the body and of the limbs, intended to develop the muscles and produce gracefulness of carriage; light gymnastics, especially designed for the use of girls and young women.

Callaway's Test. In dislocation of the shoulder the loss of from one to two inches in the vertical circumference of the shoulder-joint of the injured side, as determined by measuring with a tape-line over the acromion and through the axilla. This test is not reliable after traumatic swelling has set in.

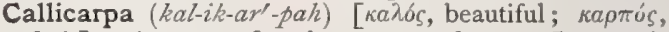
fruit]. A genus of verbenaceous plants. C. americana, a shrub of the U. S., called "French Mulberry," is used locally for skin-diseases and for dropsy. Unof. C. bonplandiana, of South America, and C. cana, C. lanata, and C.rheedii, of the E. Indies, are similarly employed. All unof.

Callisection (kal-is-ek'-shun) [callus, insensibility; sectio, a cutting]. Painless vivisection.

Callisen's Operation. See Operations, Table of.

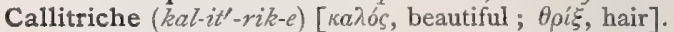
A genus of aquatic herbs. C. heterophylla and C. verna are diuretic; these and other species afford a mucilage employed as a hair-dressing and they are used in domestic practice for making poultices. Unof.

Callosal (kal-o'-sal) [callosus, hard]. Pertaining to the corpus callosum.

Callose $\left(\mathrm{kal}^{\prime}-\overline{o s}\right)$ [callosus, thick-skinned, hard]. In biology, having hardened spots or protuberances.

Callositas (kal-os'-it-as). See Callosity.

Callosity (cal-os'-it-e) [callus, hardness]. Callositas, Tylosis, Tyloma, Keratoma. A hard, thickened patch on the skin produced by excessive accumulation of the horny layers.

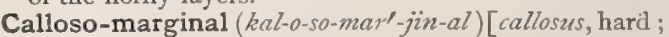
margo, margin]. Relating to the callosal and marginal gyri of the brain.

Callosum (kal-o'-sum). The bridge of white nervesubstance joining the hemispheres of the brain. It has also been called Corpus callosum, Trabs cerebri, and Commissura magna. See illustrations under Brain.

Callous (kal'-zls) [callosus, hard]. Hard; tough, like callus.

Callus $\left(k a l^{\prime}-u s\right)$ [L. ]. I. A callosity ; hardened and thickened skin. 2. The new growth of incomplete osseous tissue that surrounds the ends of a fractured 
bone, during the process of repair. See Callosity. C., Permanent, the permanent bond of bony union after re-absorption of the C. Provisional, or cartilagelike, plastic material first thrown out. C. of Skin, induration and thickening of the skin.

Calmant (kahm'-ant) [ME., calme]. A calmative medicine.

Calmative $\left(k a(h) l^{\prime}\right.$-mat-iv) [ME, calme]. x. Calming; sedative. 2. An agent that produces a calming or sedative effect.

Calomel (kal'-o-mel). See Hydrargyrum.

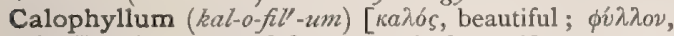
leaf]. A genus of large tropical guttiferous trees. Several of the species (as C. tacamahaca, C. inophyllum) yield medicinal oils and resins. Unof.

Calor $\left(k a^{\prime}-\right.$ lor $)$ [L. "heat" ]. I. Heat. 2. Moderate fever heat; less than fervor and ardor. C. animalis, animal heat. C. febrilis, fever-heat. C. fervens, boiling heat. C. innatus, natural or normal heat. C. mordicans, biting or pungent heat (an unfavorable symptom of typhus). C. nativus, native or animal heat; blood heat; normal heat. $\mathbf{C}$. internus, inward fever: fever not appreciable on the surface of the body.

Caloricity (kal-or-is'-it-e) [calor, heat].. The heat-producing power of the living animal body.

Calorie $\left(k a l^{\prime}-o r-e\right)[\mathrm{Fr}$. ]. See Calory.

Calorifacient (kal-or-if-a'-she-ent) [calor, heat; facere, to make]. Heat-producing (applied to certain foods).

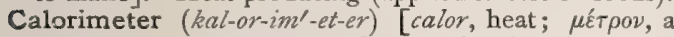
measure]. An instrument for transforming the potential energy of the food into heat, and for measuring the number of heat-units produced. Two forms are used, the Water-Calorimeter and the Ice-Calorimeter.

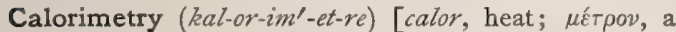
measure]. The estimation of the heat-units by the calorimeter.

Calorimotor (kal-or-im-ol-tor) [calor, heat; motor, mover]. A galvanic battery that produces heatingeffects, generating electricity in large quantity, but not necessarily with a high electro-motive force.

Calorinesis (kal-or-in'-es-is) [calor, heat : pl., Calorineses]. Any disease characterized by an alteration in the quantity of animal heat.

Calory (kal'-or-e) [Fr., Calorie]. A heat-unit; the amount of heat required to raise the temperature of one kilogram of water one degree Centigrade. See Unit.

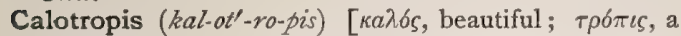
ship's keel]. A genus of E. Indian asclepiadaceous trees and shrubs. See Madar.

Caltha (kal'-thah) [L.]. A genus of ranunculaceous herbs, C. palustris, the marsh-marigold of cold and cool regions; it is vesicant when fresh. It is often cooked and eaten as a pot-herb. Unof.

Calumba (kal-um'-bah) [native Mozambique, kalumb]. Columbo. The root of Jateorrhiza columha, native to $\mathrm{S}$. Africa and parts of the E. Indies. It is an excellent example of a simple bitter, and contains a bitter principle, Calumbin, $\mathrm{C}_{21} \mathrm{H}_{22} \mathrm{O}_{7}$, of which the dose is gr. $\mathrm{j}$-iij. It is not astringent, and may be prescribed with salts of iron. It is useful in atonic dyspepsia, and as a mild, appetizing tonic in convalescence. C., Ext. (B. P.). Dose gr. ij-x. C., Fld. Ext. Dose $\eta^{\nabla-x x x}$. C., Infus. (B. P.), Dose $\zeta j-i j$. C., Tinct., contains ten per cent. of C. Dose $3^{\text {ss-ij. See also }}$ American Columbo.

Calumbin (kal-um'-bin). See Calumba.

Calva (kal"-vah). Same as Calvaria.

Calvaria (kalva'-re-ah) [calva, the scalp]. The upper part of the skull.

Calvarian (kal-va'-re-an) [calvia, the scalp]. Relating to the calvaria.
Calvarium (kal-va'-re-um). See Calvaria.

Calvert's Test. See Tests, Table of.

Calvities (kal-vish'-e-ẽz) [calvus, bald]. Baldness, especially general or senile baldness. See Alopecia. C. senilis. See Alopecia senilis.

Calx (kalks) [L.]. The heel. In chemistry, a name formerly applied to any oxid of a metal, especially an alkaline metal, and chiefly to lime, or oxid of calcium, $\mathrm{CaO}$. See Calcium.

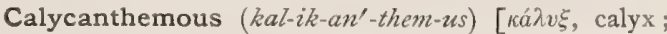
à $\nu \varepsilon \mu \nu \nu$, a flower]. In biology, with petaloid sepals.

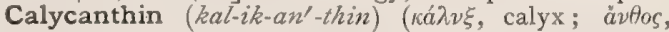
flower], $\mathrm{C}_{50} \mathrm{H}_{28} \mathrm{O}_{22}$. A glucosid obtained from certain plants of the genus Calycanthus.

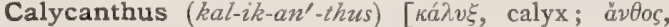
flower]. A genus of North American shrubs. C. floridus, the Carolina allspice, sweet-shrub, or bubby, is tonic, emetic, and antifebrile. C. occidentalis is the California sweet-shrub. Unof.

Calyciflorate (kal-is-e-flo'-rat) [calyx, calyx; flos, flower]. In biology, with the petals and stamens borne on the calyx.

Calycine $\left(k a l^{\prime}\right.$-is-in) [calyx, calyx]. In biology, pertaining to or resembling a calyx.

Calycle $\left(k a l^{\prime}-i k-l\right)$ [calyculus, a little calyx]. In biology, applied to parts that resemble a calyx, as the bracts or leaflets of certain plants, or the cup-cells of zoö phytes.

Calycular (kal-ik'-u-lar) [calyculus, a calycle]. I. In biology, having bracts resembling accessory calices or a cup-cell resembling a calycle. 2. An old name for the plant Hyoscyamus.

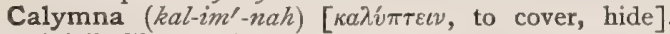
A jelly-like envelop of radiolarians.

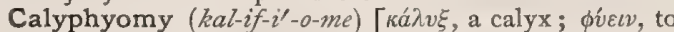
grow]. In biology, the growing together of sepals and petals.

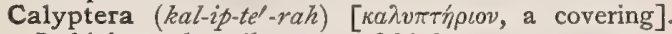
In biology, the tail coverts of birds.

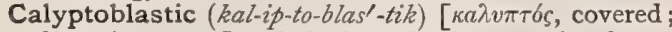
$\beta \lambda a \sigma \tau o ́ s$, a germ]. In biology, having capsulated generative buds, as the campanularian and sertularian hydroids.

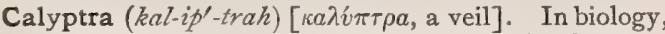
a hood-like body covering the fruit-organ in plants, as the modified archegonium of mosses, or the united bracts of some flowers.

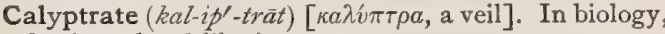
having a hood-like investment.

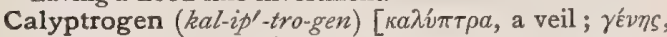
producing]. In biology, the root-cap.

Calyx ( $k a^{\prime}$-liks) [ $\kappa a ́ \lambda v \xi$, the cups or calyx of a flower: pl., Calices]. In biology, applied to various cup-like ensheathing structures, as the funnel-shaped tissues surrounding the Malpighian pyramids of the kidney, the cups of a polyzoan, or a Crinoid; an ovarian capsule. C. of Ovum, the wall of the Graafian follicle from which the ovum has escaped.

Camass (kam-as') [nat. American Indian]. The edible bulb of Camassia esculenta, $C$. fraseri, or $C$. leicht. linii, squill-like plants of Western N. America. Death Camass, the poisonous root or bulb of Zygadenus venenosus; called also hog's potato, as it is eaten by swine. The bulb or corm of the Blue Camass (Brodica grandiflora), is also considered poisonous, although it may be eaten.

Camata (kah-mah'-tah) [origin unknown]. The dried acorns of Quercus cegilops, used in the arts for their astringency. See Camatina and Valonia.

Camatina (kah-mah-te'-nah) [origin unknown]. The immature acorns of Quercus cegilops, used in the arts for their astringency. See Camata and Valonia. 
Cambiform (kam'-bif-orm) [cambium, cambium ; forma, shape]. In biology, applied to narrow, thinwalled succulent cells, often found in connection with sieve-tubes, but whose nature is not well understood.

Cambi-Resin [East Indian]. The resinous juice of Gardenia lucida an E. Indian plant. It has been recommended for use in hospital dressings, from which it is said to expel flies.

Cambium (kam'-be-um) [L.]. In biology, a layer of tissue formed between the wood and the bark of exogenous plants. It is composed of extremely delicate, thin-walled cells, filled with protoplasm and organizable nutrient matter, and appearing like a thin film of mucilage.

Cambogia (kam-bo'-je-ah) [Camboja, or Cambodia, a country in Farther India]. Gamboge. A resinous gum from Garcinia hanburyi, a tree native to Southern Asia. Its properties are due to gambogic acid. It is a drastic hydragogue cathartic, decidedly diuretic. C., Pil. Comp., (B. P.), contains gamboge, Barbadoes aloes, hard soap, compound powder of cinnamon, and syrup. Dose gr. $\mathrm{v}-\mathrm{x}$. It is also officially a constituent of Pil. Cath. Comp. See Colocynth. Dose gr. ij-v.

Cambuca (kam-bu'-kah) [L.]. An old name for a bubo or venereal ulcer.

Camel's Hair. The hair of the camel, used in Africa, Asia Minor, and the Caucasus, and latterly in Europe, for the manufacture of woven goods, that are made from the unbleached hair. C.'s-h. Brush, a small fine brush used for making various applications to the surface of the body, and for cleansing the ear, etc.

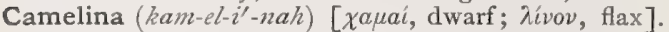
A genus of cruciferous plants. C. sativa, the gold of pleasure. A cruciferous plant of the old world, naturalized in N. America. Its seeds afford a fixed oil; the plant itself was formerly esteemed in eyediseases. Unof.

Camellia (kam-el'-e-ah) [after Kamel, a scientist of the seventeenth century]. A genus of shrubs. C. theifera. See Tea.

Camellin (kam-el'-in) [see Camellia], $\mathrm{C}_{53} \mathrm{H}_{84} \mathrm{O}_{19^{\circ}} \quad \mathrm{A}$ glucosid obtained from the seeds of Camellia japonica. Camembert Cheese, See Cheese.

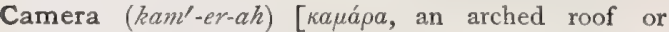
chamber]. In biology, a chamber or vaulted structure. In optics, the chamber or dark-box of the apparatus used for photography. C. cordis, the enveloping membrane of the heart, the pericardium. C. of Cranium, the chamber of the skull. C. lucida, an optical device for superimposing or combining two fields of view in one eye, invented by the chemist Wollaston. C. oculi, the chamber of the eye.

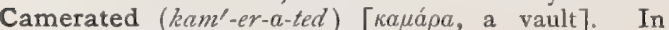
biology, chambered, vaulted.

Camerer's Method. A method of estimating uric acid in the urine. It is done by means of Salkowski's magnesia mixture (one part of crystaliized magnesium sulphate, two parts of ammonium chlorid, four parts of ammonia solution, of sp. gr. 0.924 , and eight parts of water), to remove the phosphates, and the addition of silver nitrate.

Camerine (kam'-er-in) [кauápa, a vault]. In biology, a foraminiferous shell of the numulite limestone.

Cameritelous (kam-er-it-e'-lus) [camera, a vault; tela, a web]. Applied to spiders that spin intricate webs or hiding-chambers.

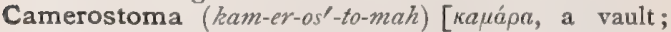
$\sigma \tau \sigma \mu \alpha$, a mouth]. In biology, the vaulted cover of the manducatory organs of spiders.

Camisole (kam-is-ōll') [Fr.]. The straight-jacket, formerly used for the restraint of violently insane persons.
Camomile, or Chamomile (kam'-o-mil). See Anthemis and Matricaria.

Campana (kam-pa'-nah). See Pulsatilla.

Camp Cure. Life in camp and in the open air, adopted as a therapeutic measure. C. Fever. Synonym of Typhus Fever. C. Measles, an epidemic of measles among soldiers.

Campani's Ocular. See Ocular. C. Tests. See Tests, Table of

Campanula (kam-pan'-u-lah) [L., "a little bell"]. I. Any bell-shaped part or process. 2. A genus of plants with bell-shaped flowers: blue-bell : Canterbury bell. Several of the species, as $C$. trachelium and $C$. glomerata have been employed in medicine, as detergents, astringents, and vulneraries. Unof.

Campanulate (kam-pan'-u-lāt) [campanula, a little bell]. Bell-shaped.

Camper's Angles. See Angle. C. Ligament. See Ligament. C. Lines. See Lines, Table of. C. Plane. See Plane. C. Profile Line. See Profile Line.

Camphene (kam-fên', or kam'-fèn) [camphor], $\mathrm{C}_{10} \mathrm{H}_{16}$. The solid terpene obtained from pinene halogen hydrid by the elimination of the haloid acid.

Camphenes (kam'-fenz) [camphor]. The volatile oils or hydrocarbons having the general formula $\mathrm{C}_{10} \mathrm{H}_{16}$, isomeric with oil of turpentine. Many camphenes exist ready-formed in plants, as oil of cloves, etc. They are liquid at ordinary temperatures. They are also called terpenes, but by some authorities the latter is made the generic name of all the volatile hydrocarbons having the formula $\mathrm{C}_{10} \mathrm{H}_{16}$, while the name camphene is limited to those terpenes that are solid at ordinary temperatures.

Camphoid (kam'-foid) [camphor]. A substitute for collodion. It is a solution, one in 40 , of pyroxylin, in equal parts by weight of camphor and absolute alcohol. It may be used as a vehicle for applications to the skin. The application dries in a few minutes, leaving an elastic opaque film, not easily washed off.

Campholic Acid (kam-fol'-ik). See Acid, Campholic.

Campho-phenique (kam-fo-fen-ék') [Fr.]. A proprietary preparation combining camphor and phenol; it is recommended as an antiseptic and local stimulant.

Camphor (kam'-for) [camphora, camphor: gen., Camphora], $\mathrm{C}_{10} \mathrm{H}_{16} \mathrm{O}$. A solid volatile oil obtained from Cinnamomum camphora, a tree indigenous to Eastern Asia. It yields camphoric and camphretic acids, also $C$. Cymol when distilled with zinc chlorid. It is a valuable antispasmodic, anodyne and diaphoretic. Applied locally, it is an excellent rubefacient. It is a moderate cerebral excitant. It is effectual in cholera, vomiting, cardiac depression and affections requiring an antispasmodic. C., aqua, consists of camphor 8 , alcohol 5 , precipitated calcium phosphate 5 , distilled water q. s. ad 1000 parts. Dose 3j-iv. C. Ball, an English preparation used as an application to chapped-skin. Its composition is spermaceti 4, white wax 12 , oil of almonds 5; melt in a water bath, and add flowers of camphor 4. Dissolve and when nearly cold pour into boxes or mould in gallipots. C. Borneo. See Bomeol. C. Carbolated, a mixture of $2 \mathrm{x} / 2$ parts of camphor with one each of carbolic acid and alcohol. A good antiseptic dressing for wounds. C., ceratum, consists of camphor liniment I, white wax 3 , and lard 6 . Used for itching skin-affections. C., Chloral, a fluid prepared by mixing equal parts of camphor and chloral hydrate. It is an excellent solvent for many alkaloids. Used externally. C.-ice, the ceratum camphore compositum, N. F. C., linimentum, has camphor 20, cottonseed oil 80 parts. C., Liniment. Comp. (B. P.), contains camphor and oil of 
lavender dissolved in rectified spirit, and strong solution of ammonia added. C., Monobromated, $\mathrm{C}_{10} \mathrm{H}_{15}$. $\mathrm{BrO}$, camphor in which one atom of bydrogen has been replaced by an atom of bromin. It resembles the bromids in therapeutic action. Dose gr. $\mathrm{j}-\mathrm{x}$, in emulsion. C. salicylate, prepared by heating together I4 parts of camphor with II of salicylic acid. It is used as an ointment. C., Spt., contains camphor Io, alcohol 7o, water 20 parts. Dose $\eta_{\mathrm{v}-\mathrm{xx}}$. C., Tinct., Comp. (B. P.), contains opium, benzoic acid, camphor, oil of anise, and proof spirit. Dose $m x v-3 j$. C. Tinct., Rubini's. Unof. A saturated solution of camphor in alcohol. Dose gtt. iv-x. Raspail's "Eau Sedative." Unof. Contains aq. ammoniæ $\zeta$ ij, sodium chlorid $\xi^{\mathrm{ij}}$, camph. spt. wine $3 \mathrm{ij}$, water Oij. Used externally.

Camphoric Acid (kam-for'-ik). See Acid.

Camphoronic Acid (kam-fo-ron' $i k$ ). See Acid.

Camphors (kam'-forz) [camphora, camphor]. Peculiarsmelling substances containing oxygen and intimately related to the terpenes. They are often found with the latter in plant-secretions and can be artificially prepared by oxidizing the same.

Camphylene (kam'-fil-ēn) [camphora, camphor], $\mathrm{C}_{10} \mathrm{H}_{16}$. I. A liquid terpene produced by decomposing camphene with lime at a great heat. 2. A commercial name for naphthalin, occurring in blocks that are sold for protecting furs and woolens from moths, and are placed in urinals for disinfecting purposes.

Campimeter (kam-pim'-et-er). See Perimeter.

Camplin's Biscuits. See Biscuits.

Campsis (kamp'-sis) [ká $\mu \psi \iota \varsigma$, a curving]. Any abnormal curvature or flexion.

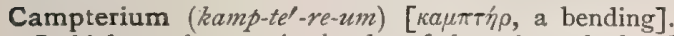
In biology, the anterior border of the wing; the bend of the wing.

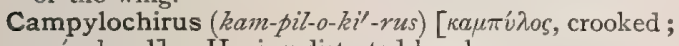
$\chi \varepsilon i \rho$, hand]. Having distorted hands.

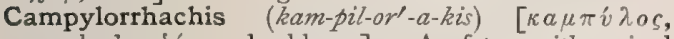

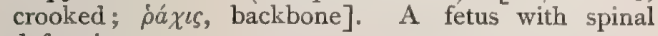
deformity.

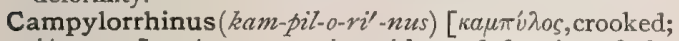
píc, nose]. A monstrosity with a deformity of the nose.

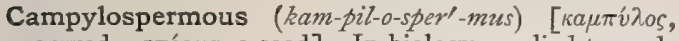
curved; $\sigma \pi \varepsilon ́ \rho \mu \alpha$, a seed]. In biology, applied to seeds having the material curved so as to form longitudinal furrows.

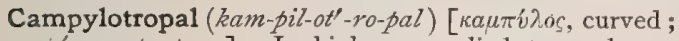
$\tau \rho \varepsilon ́ \pi \varepsilon \iota \nu$, to turn]. In biology, applied to ovules or seeds that are bent or curved on themselves.

Canada (kan'-a-dah) [Sp.]. A British possession in North America. C. Balsam. See Balsamum canadense. For its uses in microscopy, see Mounting Media. C. Snakeroot, the root of Asarum canadense. See Asarum. C. Hemp. See Apocynum.

Canadian (kan-a'-de-an) [Canada]. Pertaining or belonging to Canada.

Canadol $\left(k a n^{\prime}-a d-o l\right)$. A transparent volatile liquid resembling benzene in smell. It is an excellent local anesthetic for minor surgical operations. Unof. See also Gasolene.

Canaigre (kan-a'-gra) [Sp.]. The Rumex hymenosepalus, a plant of Texas, Mexico, Utah and California. The root is highly astringent: the sour stalks are used, like rhubarb-stalks, in making pies. Unof.

Canal, or Canalis (kan-al', or kan-a'-lis) [canna, a reed or tube]. I. A tube or duct for carrying the fluids of the body. 2. A hollow instrument used as a splint. C., Abdominal. See C., Inguinal. C., Abital. See C., Aphodal. C., Aërial. See C., Air. C., Afferent. See C., Incurrent. C., Air, a cavity containing air, such as exists in most vegetable organs; it is formed by an arrest of development or by a destruction of some of the anatomic elements. C., Alcock's, a strong sheath of the obturator layer of the pelvic fascia containing the internal pudic artery. C., Alimentary, the whole digestive tube from the mouth to the anus. C., Alisphenoid, in comparative anatomy, a canal in the alisphenoid bone, opening anteriorly into the foramen rotundum, and transmitting the external carotid artery. C., Alveolar, Anterior, one located in the superior maxilla; it transmits the anterior superior dental nerve. C., Alveolar, Inferior, the inferior dental canal. C., Alveolar, Median, one located in the superior maxilla and transmitting the middle superior dental nerve. C., Alveolar, Posterior, one situated in the superior maxilla; it transmits the posterior superior dental nerve. C., Alveolo-dental, See C., Dental. C., Ambulacral, in the Echinodermata, branches of the circular canal. C., Anal, leads from the rectum to the external opening of the anus. C., Aphodal, in certain sponges, one connecting a chamber with an excurrent canal. C., Apical, in the Ctenophora, two canals extending from the funnel to the apical pores. C., Aquiferous. I. Canals that in many molluscs traverse the substance of the foot, opening externally by pores, or internally into the blood-sinuses. 2. In the Entozoa, a series of ramifying excretory canals, with blind extremities, converging to a common canal that opens externally. C., Arachnoid, a space formed beneath the arachnoid membrane of the brain; it transmits the venæ magnæ Galeni. C. of Arantius, the ductus venosus. C., Archinephric, the duct of the archinephron or primitive kidney. C., Arterial. See Ductus arteriosus. C., Atrial, the cavity of the atrium. C., Auditory, External, that from the auricle to the tympanic membrane. C., Auditory, Internal, that beginning on the posterior surface of the petrous bone, and extending outward and backward for a distance of about four lines ; it transmits the auditory and facial nerves, and the auditory artery. C., Auricular. 1. See C., Auditory, External. 2. The constriction between the auricular and ventricular portions of the fetal heart. C., Avant, the anterior portion of the male urethra. C., Axial, in certain Echinodermata, the central canal of a brachium, opening into the alimentary canal. C., Bartholin's, the duct of Bartholin's gland. C. of Bernard, a supplementary duct of the pancreas. Also called Santorini's canal. C., Bichat's. See C., Arachnoid. C., Biflex. See Gland, Interungulate. C., Biliary. See C., Hepatic. C., Biliary, Interlobular, canals situated between the acini of the liver, containing small branches of the portal vein, etc. C., Blastoporic. See C., Neurenteric. C. of Bone, a canaliculus of bone. C., Braun's. See C., Neurenteric. C., Braune's, the continuous passage formed by the uterine cavity and the vagina during labor, after full dilatation of the os. C., Breschet's. See C. of the Diploë. C., Bullular. See C. of Petit. C., Carinal, an air-canal in the Equisetc, situated on the inner side of the xylem. C., Carotic. See $C$., Carotid. C., Carotico-tympanic, two or three short canals extending from the carotid canal to the tympanum; they transmit branches of the carotid plexus. C., Carotid, one in the petrous portion of the temporal bone; it transmits the internal carotid artery. C. of Cartilage, the canals in ossifying cartilage, during its vascularization intended to receive prolongations of the osteogenetic layer of the periosteum. They radiate in all directions from the center of ossification. $C_{\text {., }}$ Central (of the modiolus), a canal running from the base to the apex of the cochlea. C., Central (of spinal 
cord), the small canal that extends through the center of the spinal cord from the conus medullaris to the lower part of the fourth ventricle. It represents the embryonic ectodermal canal. C., Cerebro-spinal, I. The neural or cranio-vertebral canal, formed by the skull and the spine, and containing the brain and spinal marrow. 2. The primitive continuous cavity of the brain and spinal cord, not infrequently more or less extensively obliterated in the latter, but in the former modified in the form of the several ventricles and other cavities. C., Cervical. See C. of Cervix Uteri. C., Cervico-uterine. See C., Uterine. C. of Cervix Uteri, that portion of the uterine canal that extends between the internal and external os. C. of Chorda Tympani, a small canal in the temporal bone, between its squamous and petrous portions, parallel with the Glaserian fissure ; it transmits the chorda tympani nerve. C., Chyleaqueous, in certain invertebrates, a system of canals containing water and digestive products. C., Ciliary. See C., of Fontana. C., Circular, in the Echinodermata, a vessel surrounding the esophagus, connected with the exterior by the madreporic canal, and giving off the ambulacral canals. C. clavellaris, in biology, a cecal canal running into the olfactory clubs of Medusce. C., Cloacal. See C., Excurrent. C. of Cloquet. See C., Hyaloid. C., Cochlear, the spiral and snail-like cavity of the cochlea, 28 to $30 \mathrm{~mm}$. long. The base is turned inward toward the internal auditory meatus, and the apex outward toward the tympanum. C. of Communication, in the embryo of the fowl, canals that run from the cavity of each protovertebra to the pleuroperitoneal space. C., Connecting, the arched or coiled portion of a uriniferous tubule, joining with a collecting tubule. C., Corona, in biology, the coronal intestine of Meduse. Same as Pouch corona. C. of Corti, the triangular canal formed by the pillars of Corti, the base of which corresponds to the membrana basilaris. It extends over the entire length of the lamina spiralis. C. of Cotunnius. See Aqueduct of the Vestibule. C., Cranio-vertebral. See C., Cerebro-spinal, and C., Neural. C., Crural. See C., Femoral. C., Ctenophoral, in the Ctenophora, eight canals connected at right angles with the tertiary radial canals, and corresponding in their course with the eight locomotive bands. C. of Cuvier, the ductus venosus. C., Cystic, the cystic duct. C. of De Candolle. See C., Medullary. C., Deferent, the vas deferens. C., Demicircular. See $C$., Semicircular. C., Dental, Anterior, one extending into the facial portion of the superior maxilla; it transmits the anterior dental vessels and nerves. C., Dental, Inferior, the dental canal of the inferior maxilla; it transmits the inferior dental nerve and vessels. C., Dental, Posterior, two canals in the superior maxilla. They transmit the superior posterior dental vessels and nerves. C., Dentinal, the minute canals in dentine, extending approximately at rightangles to the surface of a tooth from the pulp-cavity, into which they open, to the cementum and enamel. C., Digestive. See C., Alimentary. C. of Diploë, canals in the diploe of the cranium transmitting Breschet's veins. C., Efferent. I. See C., Excurrent. 2. In the Cestoda, canals connecting the testicles with the deferent canals. C., Ejaculatory. See Duct, Ejaculatory. C. of Epididymis, a convoluted tube, about 20 feet long when straightened, forming the epididymis and continuous with the vas deferens. C., Eschricht's Yellow, in certain of the Cestoda, a system of canals, opening into the fertilizing canal, and terminating in round or oval sacs. C., Ethmoidal, Anterior, one between the ethmoid and frontal bones; it transmits the nasal branch of the ophthalmic nerve, and the anterior ethmoidal vessels. C., Ethmoidal, Posterior. See C., Orbital, Posterior, Internal. C., Eustachian, one in the petrous portion of the temporal bone, containing a portion of the Eustachian tube. C., Excurrent, in sponges, the tubes that carry water from the ciliated chambers to the exterior. C., Facial, the aqueduct of Fallopius; it transmits the facial nerve: C., Fallopian. See Aqueduct of Fallopius. C., Femoral. I. The inner compartment of the sheath of the femoral vessels behind Poupart's ligament; a femoral hernia descends through this. 2. See C., Hunter's. C. of Ferrein, a triangular channel, supposed to exist between the free edges of the eyelids when they are closed, and to serve for conducting the tears toward the puncta lachrymalia during sleep. C., Fertilizing, in many cestoda, a tube connecting the vagina and the uterus. C., Fibro-adipose, in certain fishes, a canal, filled with adipose tissue, on the dorsal side of the neural canal. C. of Fontana, a series of small spaces formed by the interlacing of the connective-tissue fibers of the framework of the peripheral processes of the iris, situated in the angle of the anterior chamber, and serving as a medium for the transudation of the aqueous humor from the posterior to the anterior chamber of the eye. They are also called $C$. of Hovius, C., Ciliary, and Fontana's spaces. C., Galactophorous, the lactiferous tubules of the mammary gland. C. of Gärtner, in the female, a relic of the main portion of the Wolffian duct of the embryo; it is a tube extending from the broad ligament of the uterus to the wall of the uterus and vagina. C., Gastro-vascular, in the Hydrozoa, canals extending from the stomach into the substance of the disc of the umbrella. C., Genital, in comparative anatomy, any canal designed for copulation or for the discharge of ova. C., Gonocalycine, a system of canals found in the gonocalyx of the $\mathrm{Hy}$ drozoa, C. of Groin. See C., Inguinal. C. of Guidi. See C., Vidian. C., Gynecophoric, in Bitharzia, a groove extending from a little below the ventral sucker to the end of the tail. It lodges the female during copulation. $\mathrm{C}$. of Havers. See $C$., Haversian. C., Haversian, canals in the compact substance of bone forming a wide-meshed network, and establishing communication between the medullary cavity and the surface of the bone. Their average diameter is $\frac{1}{5 n}$ inch, and they are lined by a continuation of the endosteum; they transmit blood-vessels, lymph-vessels and nerves. C., Hemal, one in the ventral surface of the vertebral column, enclosed by the hemal arches; it is incomplete in certain portions. C. of Henle, a portion of the uriniferous tubules. C., Hepatic. I. The excretory duct of the liver. 2. The radicles of the hepatic duct. C., Hernial, one transmitting a hernia. C. of Hovius. See $C$. of Fontana. C. of Huguier. See C. of the Chorda Tympani. C., Hunter's, a triangular canal formed in the adductor magnus muscle of the thigh; it transmits the femoral artery and vein and internal saphenous nerve. C. of Huschke, one formed by the junction of the tubercles of the annulus tympanicus. This is generally obliterated after the fifth year, but may persist through life. C., Hyaloid, an irregularly-cylindrical canal running antero-posteriorly through the vitreous body, through which in the fetus the hyaloid artery passes, to ramify on the posterior surface of the crystalline lens. C., Hyapophyseal, in birds, that formed by the inferior spinous processes of the upper cervical vertebræ; it transmits the carotid artery. C., Inci- 
sive. See C., Incisor. C., Incisor, a canal that opens into the mouth by an aperture just behind the incisor teeth of the upper jaw; it is formed by a groove on the adjoining surfaces of the superior maxillæe, and has two branches that open into the nasal fossæe. C., Incurrent, in sponges, the canals that convey water from the exterior to the ciliated chambers. C., Infraorbital, a small canal running obliquely through the bony floor of the orbit; it transmits the infraorbital artery and nerve. C., Inguinal, a canal about one an 1 one-half inches long, running obliquely downward and inward from the internal to the external abdominal ring, and constituting the channel through which an inguinal hernia descends; it transmits the spermatic cord in the male, and the round ligament of the uterus in the female. C., Inter-. See $C$., Incurrent. C., Intercellular, in biology, canals formed by the interspaces between vegetable cells. C., Intestinal, that portion of the alimentary canal that is included between the pylorus and the anus. C., Intrafascicular, one formed in a fibro-vascular bundle by the destruction of the vascular tissue and parenchyma. C., Intralobular, Biliary, the radicles of the bile-ducts, forming a fine network in and around the hepatic cells, and communicating with vacuoles in the cells. C. of Jacobson. See C., Tympanic. C., Kidney, in the Platelminthes, excretory tubes that take up excrementitious matter from the tissues. C., Kidney, Primitive, in some of the lower animals canals that appear to replace the kidneys. C. of Kowalevsky. See C., Neurenteric. C., Lacrymal. I. The bony canal that lodges the nasal duct. 2. One of the lachrymal canaliculi. C., Lateral, in most fishes, two canals, one on each side, that communicate with cavities in the head, and with the exterior, by apertures in each overlying scale; they are probably sensory in function. C. of Laurer, in certain worms, one by which the oviduct opens externally on the dorsal surface; according to some, the vitellarian duct. C., Lingual, in the horse, etc., the floor of the mouth, from its lodging the tongue. C. of Loewenberg, that portion of the cochlear canal that is situated above the membrane of Corti. C., Longitudinal, in the Cestoda, canals, one on each side of a joint; they are of uncertain function. C., Looped, in the Annulata, the segmental organs. C., Macro-myelonal, the central canal of the spinal cord. C., Madreporic, in the Echinodermata, one joining the madreporite, and the circular canal. C., Malar, one in the malar bone transmitting the malar division of the temporo-malar branch of the superior maxillary nerve. C. of Marrow. See C., Cartilage. C., Maxillary. See C., Dental. C., Median. I. The central canal of the spinal cord. 2. The aqueduct of Sylvius. C., Medullary. I. The hollow cavity of a long bone, containing the marrow. 2. See $C$., Vertebral. 3. The central canal of the spinal cord. 4. An Haversian canal. 5. The canal of De Candolle, enclosing the pith in the stem of plants. 6. In embryology, the medullary tube. C., Medullary, Cerebro-spinal, the central canal of the spinal cord. C., Membranous, of the Cochlea, a canal in the cochlea, following the turns of the lamina spiralis; it is bounded by the basilar membrane, the membrane of Reissner, and the wall of the cochlea. C., Membranous, Semicircular. See C., Semicircular. C. of Modiolus, the spiral canal of the cochlea. C., Muciparous. See $C$., Mucous. C., Mucous, in general, canals lined with mucous membrane. In zoölogy, canals found beneath the scales of fishes and other scaly animals, furnishing the mucus that lubricates the surface. C. of Muiller. See Müllerian Duct. C., Myelonal, the central canal of the spinal cord. C., Nasal. I. See
C., Lachrymal. 2. An occasional canal found in the posterior portion of the nasal bone; it transmits the nasal nerves. C., Naso-lachrymal. See C., Lach. rymal. C., Naso-palatine. See C., Incisor. C., Neural. 1. See C., Vertebral. 2. In Echinoderms, a canal a part of the wall of which is formed by the ambulacral nerve and its connections. C., Neurenteric, of Kowalewsky, also called Blastoporic Canal, in the embryo, a passage leading from the posterior part of the medullary tube into the archenteron. C., Neuro-central. See C., Vertebral. C. of Nuck, a pouch of peritoneum which, in the female fetus, descends for a short distance along the round ligament of the uterus into the inguinal canal; it is the analogue of the processus vaginalis in the male. It sometimes persists after birth. C., Nutritive. See $C$., Haversian. C., Obstetric. See $C$., Parturient. C., Obturator, a canal in the ilium transmitting the obturator nerve and vessels. C., Olfactory, in the embryo, the nasal fossæ at an early period of development. C., Omphalo-mesenteric, in the embryo, a canal that connects the cavity of the intestine with the umbilical vesicle. C., Optic. See Optic Foramen. C., Orbital, Anterior Internal. See C., Ethmoidal, Anterior. C., Orbital, Posterior Internal, the posterior of two canals formed by the ethmoid bone and the orbital plate of the frontal. It transmits the posterior ethmoidal vessels. C., Palatine, Accessory Posterior, one or two canals in the horizontal plate of the palate bone, near the groove entering into the formation of the posterior palatine canal. C., Palatine, Anterior, formed by the union of the incisive canals; it opens on the palate behind the incisor teeth. C., Palatine, Descending. See C., PalatoMaxillary. C., Palatine, External, Small; a small canal in the pyramidal process of the palate bone, close to its connection with the horizontal plate. It transmits the external palatine nerve. C., Palatine, Posterior. See C., Palato-maxillary. C., Palatine, Smaller. See C., Palatine, Posterior. C., Palatine, Superior, one formed by the palate bone and the superior maxilla, transmitting the large palatine nerve and blood-vessels. C., Palato-maxillary, one formed by the outer surface of the palate bone and the adjoining surface of the superior maxilla. It transmits the large palatine nerve and blood-vessel. C., Paragastric, in the Ctenophora, one that branches off on each side of the funnel, and terminates near the oral extremity of the funnel. C., Parturient, the channel through which the fetus passes in parturition, including the pelvic canal, and the uterus and vagina considered as a single canal. C., Pelvic, the canal of the pelvis, from the superior to the inferior strait. C., Pericardio-peritoneal, in some of the lower vertebrates; canals connecting the pericardium and the peritoneal cavity. C., Perigastric, in the Hydrozoa, two canals running parallel to the stomach, from the infundibulum, and terminating in culs-de-sac near the mouth. C., Peritoneal, in the Plagiostomata, etc., two canals leading from the peritoneal cavity, one to each side of the cloaca. C., Perivascular, the circumvascular lymph spaces. C. of Petit. Properly, a space, intersected by numerous fine interlacing fibers, existing between the anterior and posterior laminx of the suspensory ligament of the crystalline lens. It extends from the periphery of the lens, nearly to the apices of the ciliary process, and transmits the secretion from the posterior chamber. C., Petro-mastoid, a small canal not always present, situated at the angle of union between the mastoid and petrous bones. It transmits a small vein from the middle fossa of the skull to the transverse sinus. C., Petrosal, two canals 
on the upper surface of the petrous portion of the temporal bone, transmitting the large and small superficial petrosal nerves. C., Plasmatic. I. An Haversian canal. 2. In the Teniadce, canals given off from the Iongitudinal vessels, containing a homogeneous fluid which is supposed to serve for the nutrition of the animal. C., Poison, in snakes, the canal in the poison-fang, serving for the ejaculation of the venom. C., Pore. See C., Porous. C., Porous, in the ovule, supposed to serve for the entrance of the spermatozoids in fecundation. C., Portal. See Intraiobular, Biliary. C., Preputial, in the lower animals, the sheath of the penis. C., Primitive, the neural canal of the embyro. C., Prosodal, in sponges, a canal connecting the chamber with the prosopyle. C., Pseudostomatous, the processes of branched cells that extend from a sub-epithelial or endothelial layer to the free surface, their free ends forming the pseudostomata. C., Pterygoid. See C, Vidian. C., Pterygo-palatine, one formed by the root of the internal pterygoid plate of the sphenoid bone and the sphenoidal process of the palate bone. It transmits the pterygo-palatine vessels and nerve. C., Pulmoaortic. see Ductus arteriosus. C., Radial, in the Ctenopkora, two canals that branch off laterally from the funnel. Each divides into two (the secondary radial), which themselves divide into two (the tertiary radial), which open into the ctenophoral canals. C. of Recklinghausen, minute channels supposed to exist in all connective tissue, which are directly continuous with the lymphatic vessels, and hence may be said to form their origin. C. of Reissner. See $C$., Membranous, of the Cochlea. C., Resin. See C., Resiniferous. C., Resiniferous, a canal in which resin is secreted. C., Rhachidian. See $C_{\text {. }}$, Vertebral. C. of Rivinus, the duct of the sublingual gland. C. of Rosenthal. See C., Spiral, of the Modiolus, C., Sacculo-cochlear, one connecting the sacculus and the cochlea. C., Sacculo-utricular, one connecting the sacculus and the utricle. C., Sacral, the continuation of the vertebral canal in the sacrum. C., Sand. See C., Madreporic. C., Santorini's. See C. of Bernard. C. of Schlemm, an irregular space or plexiform series of spaces occupying the sclero-corneal region of the eye; it is regarded by some as a venous sinus, by others as a lymph-channel. C., Secretory, an interspace between the cells of vegetable tissue, lined with special cells, secreting various products such as oils, balsams, gum-resins, etc. C., Semicircular, bony canals of the labyrinth of the internal ear. They are three in number, the external, superior, and posterior, and contain the membranous semicircular canals. C., Semicircular, Anterior. See C., Semicircular, Superior. C., Semicircular, Anterior Vertical. See C., Semicircular, Superior. C., Semicircular, External, that one of the semicircular canals of the labyrinth having its plane horizontal and its convexity directed backward. C., Semicircular, Frontal. See C., Semicircular, Superior. C., Semicircular, Horizontal. See $C_{\text {. }}$, Semicircular, External. C., Semicircular, Inferior. See C., Semicircular, Posterior. C., Semicircular, Inner. See C., Semicircular, Posterior. C., Semicircular, Internal. See C., Semicircular, Posterior. C., Semicircular, Lateral. See C., Semicircular, External. C., Semicircular, Osseous. See C., Semicircular. C., Semicircular, Posterior, that one of the semicircular canals having its convexity directed backward, and its plane almost parallel to the posterior wall of the pyramid. C., Semicircular, Posterior Vertical. See C., Semicircular, Posterior. C., Semicircular, Sagittal. See C., Semirircular,
Posterior. C., Semicircular, Superior, that one of the semicircular canals having its convexity directed toward the upper surface of the pyramid. C., Seminal, the seminiferous tubules. C., Serous, any minute canal connected with the lymph vessels and supposed to be filled with lymph. C., Sheathing, the communication between the cavity of the tunica vaginalis of the testicle and the general peritoneal cavity. It soon closes in man, leaving the tunica vaginalis closed sac. C., Side, blind canals in the ventral skin of amphioxus, supposed to have a urinary function. C., Spermatic. I. The vas deferens. 2. The inguinal canal in the male. C., Spheno-palatine. See $C$., Pterygo-palatine, C., Spinal. See $C$., Vertebral. C., Spiral, of the Cochlea, one that runs spirally around the modiolus, taking two turns and a half, diminishing in size from the base to the apex, and terminating in the cupola. C., Spiral, of the Modiolus, a small canal winding around the modiolus of the base of the lamina spiralis. C., Spiroid, of the Temporal Bone. See Aqueduct of Fallopius. C of Stenson. See Stenson's Duct. C., Sternal, in the Crustacea, one formed by the union of the mesophragms of the endosternites. C. of Stiebel, in certain Mollusca the embryonic renal organ. C. of Stiega. See C. of Laurer. C. of Stilling. See C., Hyaloid, and C., Central, of Spinal Cord. C., Stone. See C., Madreporic. C., Suborbital. See C., Infraorbital. C., Supraorbital, one at the upper margin of the orbit. It transmits the supraorbital artery and nerve. C., Temporal. See C., Zygomaticotemporal. C., Temporo-malar. See C., Zygomatico-temporal. C., Thoracic, the thoracic duct. C., Tympanic, one that opens on the lower surface of the petrous bone, between the carotid canal and the groove for the internal jugular vein. It transmits Jacobson's nerve. C., Urethro-sexual, in some mammals the vagina and urethra combined. C., Urinary, the urethra. C., Uro-genital. See Urogenital Sinus. C., Uterine, the canal of the uterus, including the body and neck. C., Utero-cervical, the cavity of the cervix uteri at the time of labor. C., Uterovaginal. I. The common canal formed by the uterus and vagina. 2. In embryology, the duct of Müller. C., Vaginal, the canal of the vagina. C., Vascular. See C., Haversian, and C., Cartilage. C., Vector, the oviduct. C., Venous, the ductus venosus. C., Vertebral, the canal formed by the vertebræ. It transmits the spinal cord and its membranes. C., Vertebrarterial, the osseous canal through which the vertebral artery runs. C., Vestibular. See C., Incurrent. C., Vidian, a canal of the sphenoid bone at the base of the internal pterygoid plate, opening anteriorly into the spheno-maxillary fossa, and posteriorly into the foramen lacerum. It transmits the Vidian nerve and vessels. C., Vitelligene, in comparative anatomy, canals leading to the vitelligene glands. C., Vitellin, a supposed canal leading from the central cavity of the vitellus, in birds' eggs, to the cicatricula. C., Vulvar, the vestibule of the vagina. C., Vulvo-uterine, the vagina. C., Vulvo-vaginal. $\mathbf{I}$. The vagina and the vulva considered as a single canal. 2. The orifice of the hymen. C., Watervascular. See C., Aquiferous. C. of Wharton. See Wharton's Duct. C., White, of Malpighi, in insects, two white convoluted urinary tubules opening into the large intestine. C. of Wirsung, the pancreatic duct. C. of Wolff. See Wolffian Duct. C., Yellow, of Malpighi, in insects, two yellowish convoluted tubes opening at the junction of the stomach and intestine; they are regarded as urinary. C., Zygomatic. See C., Zjgomatico-temporal and $C$., 
Zygomatico-facial. C., Zygomatico-facial. See $C_{\text {., }}$, Walar. C., Zygomatico-temporal, the temporal canal of the malar bone, running from its orbital to its temporal surface. It transmits a branch of the superior maxillary nerve.

Canalicular (kan-al-ik'-u-lar) [canalis, a channel]. In biology, canal-shaped.

Canaliculization (kan-al-ik-zb-liz-a'-shun) [canaliculus, a little canal]. The formation of canaliculi, as in bone, or as in calcified cartilage.

Canaliculus (kan-al-ik'-u-lus) [L. : pl., Canaliculi]. A small canal; especially that leading from the punctum to the lachrymal sac of the eye ; and in the plural, the minute canals opening into the lacunæ of bone. See Bone.

Canalization (kan-al-iz-a'-shun) [canalis, a canal]. I. The formation of canals, as in tissues, etc. 2. A system of wound-drainage without tubes. C. of the clot, formation of a channel through a clot in a vessel for the passage of the blood-current, occurring from the 5 oth to the 7oth day after ligation. See Cells, Vasifactive.

Canarin (kan'-ar-in). See Pigments, Conspectus of.

Canarium (kan-a'-re-um) [E. Ind., canari]. A genus of burseraceous trees and shrubs of warm regions. C., commune affords a part (at least) of the manila elemi, and also a balsam resembling copaiba. Other species yield similar products.

Canatillo (kah-nah-tell-yo). See Tepopote.

Cancellate $\left(k a n^{\prime}-s e l-\bar{a} t\right)$ [cancellare, to provide with a lattice]. Reticulated, or characterized by latticed lines, as the spongy tissue of bones, or certain leaves consisting entirely of veins.

Cancellation (kan-sel-a'-shun) [cancelli, lattice-work]. The quality of being cancellate ; cancellous structure.

Cancellous (kan'-sel-zes) [cancelli, lattice-work]. Resembling lattice-work. C. Tissue. See Tissue.

Cancellus (kan'-sel-us) [cancelli, lattice-work]. A space, or unit of structure, in cancellous bone; any one of the minute divisions in spongy bone. The spongy, lattice-work texture of bone.

Cancer (kan'-ser). See Carcinoma. C., Alveolar, a carcinoma with an alveolar structure. C. aquaticus. Synonym of Stomatitis, Gangrenous. C.-bandage, a crab-shaped bandage; a split-cloth of eight tails. C.-cell, a peculiar cell sometimes seen in adenoid cancer and in sarcoma. It was formerly thought to be pathognomonic of the malignant quality of a tumor. C., Clay-pipe. See C., Smokers'. C., Colloid, one containing colloid material. C. en cuirasse, disseminated lenticular cancer of the skin. C.-Juice, the milky fluid yielded by the cut surface of a hard cancer on scraping. C., Melanotic, a malignant pigmented form. C., Smokers', epithelioma of the lip due to the irritation of a pipe. C.-root, a name of Epiphegus virginiana, Aphyllon uniflorum, Conopholis americana and other plants vaunted as cancer-cures. The above are all either root-parasites or saprophytes. Unof. See Aphyllon. C. $-r$. Beech-drop, a name for a plant used as a local application for cancer. C.-weed, Prenanthes alba, a plant. C.-wort, Limuria spuria and $L$. elatine, European herbs.

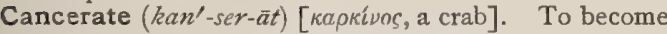
cancerous ; to be developed into a cancer.

Canceration (kan-ser-a'-shun) [каркivos, a crab]. Development into a cancer; the assumption of malignant qualities by a tumor.

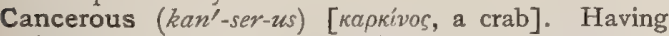
the qualities of a cancer; malignant.

Canchalagua (kan-cha-la'-gwah) [Sp.]. A SpanishAmerican name for various plants, chiefly of the genus Erythraa, (as E. chilensis, $E$. venusta, E. trichantha). They are bitter tonics, with the qualities of gentian. Unof.

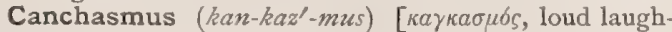
ter]. Hysterical or immoderate laughter.

Cancriform (kang'-krif-orm) [cancer, a crab; forma, form]. Resembling a cancer in appearance.

Cancrisocial (kang-kris-o'-shal) [cancer, a crab; socias, a companion]. In biology, a communalistic association of sea-anemonies, sponges, molluscs, etc. on the shell inhabited by a hermit crab.

Cancrivorous (kang-kriv'-o-mus) [cancer, a crab; vorare, to eat]. Applied to animals that feed upon crabs.

Cancroid (kang'-kroid) [cancer, a crab]. Cancer-like; semi-malignant. C. Ulcer. See Rodent Ulcer.

Cancroin (kan'-kro-in) [cancer, a crab]. A substance (said to be identical with neurin), introduced by Adamkiewicz as a material for hypodermatic injection in cases of malignant disease, it being regarded by him as an alexin destructive of cancer-tissue.

Cancrophagous (kang-kroff'-ag'us) [cancer, a crab; payeiv, to eat]. Same as Cancrivorous.

Cancrum (kang'-krum) [L., "a cancer"']. A cancer or rapidly-spreading ulcer. C. Oris, also called Canker of the Mouth, Gangrenous Stomatitis, Noma, Gangrenous Ulceration of the Mouth. It is a disease of childhood between the ages of one and five, characterized by the formation of foul, deep ulcers of the buccal surfaces of the cheeks or lips. There is but slight pain, but the prostration is great, and death usually results from exhaustion or blood-poisoning. The disease is generally the result of poor hygienic surroundings acting upon a debilitated system. C. Nasi, gangrenous rhinitis of children.

Candela (kan-de'-lah) [candere, to glow] I. A medicated candle for fumigation. 2. A wax bougie.

Candle $\left(\mathrm{kan}^{\prime}-\mathrm{dl}\right)$ [candela, a candle]. A taper; a bougie. C.-berry, the bay-berry, Myrica cerifera, or its waxy fruit, from which a greenish wax is obtained. See Myrica. C.-fish Oil. See Eulachoni Oleum. C.-foot. See Unit Quantity of Light. C.house, an establishment in which candles are manufactured. C.-power, in photometry, the candle-power of a lamp is measured by the ratio of the illumination of the light considered to that of a standard candle, both sources being at the same distance from the object illuminated.

Cane Sugar (kān-shug'-ar). See Saccharum.

Canella (kan-el'-ah) [dim. of Canna, a reed]. The bark of $C$. alba deprived of its corky layer and dried. It is a native of the West Indies and is an aromatic tonic and bitter stomachic. Dose of the powdered bark, gr. $x v-x x x$. Officinal in the B. P.

Canelle-Brown. Same as Phenylene Broren.

Canescent (kan-es'-ent) [canus, white or hoary]. In biology, applied to the gray, hoary or white plumage or fur of animals and to the pubescence of plants.

Canestrini, Bacillus of. See Bacteria.

Canine $\left(k a^{\prime}-n i \bar{n}\right.$ or $\left.k a-n \bar{i} n^{\prime}\right)$ [canis, a dog]. Partaking of the nature of, relating to, or resembling a dog, or the sharp tearing-teeth of mammals, located between the incisors and the molars. C. Appetite, bulimia, $q . v$. C. Eminence, a prominence on the outer side of the upper maxillary bone. C. Fossa. See Fossa. C. Laugh, a sardonic smile, or grin. C. Madness, rabies, hydrophobia. C. Muscle, the levator anguli oris. See Muscles, Table of. C. Teeth, dentes canini ; cynodontes; dentes laniarii ; dents angulaires; cuspidati; conoides; eye-teeth. The cuspid teeth next to the lateral incisors; so called from their re. semblance to a dog's teeth. 
Caniniform (kan-in'-if-orm) [caninus, pertaining to the dog ; forma, shape]. Applied to teeth resembling canines.

Canis $\left(k a^{\prime}\right.$-nis) [L., "a dog" ']. I. The dog. 2, A genus of animals. C. rabiosa. Synonym of Hydrophobia.

Canities (kan-ish'-e-êz) [Lat.]. Poliosis; hoariness; hair-blanching; Trichonosis cana; Trichonosis discolor; a premature or senile, partial or universal decolorization of the hair, the change varying from black or brown through every gradation to the whiteness of wool. This change may be physiologic or pathologic, gradual or rapid, general or confined to localized patches.

Canker (kang'-ker) [cancrum, a cancer]. An ulceration of the mouth, or any ulcerous or gangrenous sore; cancrum oris; in farriery, a fetid abscess of the horse's foot. See Cancrum Oris. C.-rash. Synonym of Scarlet Fever.

Canna (kan'-ah) [кávva, a cane]. A genus of largeleaved marantaceous plants. C. indica, has an acrid and stimulant root; it is alterative, diuretic and diaphoretic. Unof. The rhizome of $C$. speciosa affords canna-starch, or tous-les-mois, a good substitute for true arrow-root. C. Starch. See Tous-les-mois.

Cannabene $\left(k a n^{\prime}-a b-\bar{e} n\right)$. See Cannabis.

Cannabin. See Cannabis.

Cannabinin (kan-ab'-in-in) [cannabis, hemp]. volatile alkaloid from cannabis indica.

Cannabinon, Cannabinone (kan-ab'-in-ön) [cannabis, hemp]. An amorphous bitter resinoid from Indian hemp, used as an hypnotic. Dose I to 3 grains. Unof.

Cannabis (kan'-ab-is) [L.]. Hemp. Indian hemp. The flowering tops of $C$. sativa, of which there are two varieties, $C$. indica and $C$. americana, the former being the more potent. They contain a resin, cannabin, and a volatile oil, from which are obtained Cannabene $\mathrm{C}_{18} \mathrm{H}_{20}$, a light hydrocarbon, and Hydrid of Cannabene, a crystalline body. It is an antispasmodic, anesthetic, narcotic, and a powerful aphrodisiac. In large doses it produces mental exaltation, intoxication, and a sensation of double-consciousness. It is a valuable hypnotic in delirium tremens, and is useful for painful affections of the bladder and for functional impotence. Bhang, Gunjah, Churrus, and Hashish are the various Indian names by which the drug is known. Strychnin and faradism are antagonistic. C. Indica, Ext., dose gx. I/6-j. C. Ind., Ext. Fld., an alcoholic preparation. Dose $m_{\mathrm{i}}-\mathrm{v}$. C. Ind., Tinct., contains 15 per cent. of the drug. Dose $m x x-z j$. Cannabin Tannate, the tannate, a glucosid. Dose as a hypnotic gr. v-x.

Cannabism (kan'-ab-izm) [cannabis, hemp]. The habitual use of Cannabis indica; ill-health caused by the misuse of Cannabis indica.

Cannabist (kan'-ab-ist) [cannabis, hemp]. A devotee to the use of Cannabis indica.

Cannel Coal (kan'-el köl). See Coal.

Cannoid (kan'-oid) [kávva, a reed; eỉos, form]. Tubular, as the skeleton of certain radiolarians.

Cannon-bone $\left(k a n^{\prime}-o n b o n n\right)$. One of the functional and complete metacarpal or metatarsal bones of a hoofed quadruped, supporting the weight of the body upon the feet.

Cannula (knn'-u-lah) [dim. of canna, a tube]. A surgical instrument consisting of a tube or sheath obliquely pointed and a stiletto. It is used for tapping and draining tumors and cavities.

Cannulated (kan'-u-lat-ed) [cannula, a little tube]. Made hollow: as a cannulated needle.

Canquoin's Paste. A paste of flour, water, and zinc chlorid; it is a powerful escharotic.
Cantani's Diet. An exclusive meat-diet in diabetes. Canterbury Bell (kan'-ter-ber-e bel). See Campanula. Cantering Rhythm (kan'ter-ing rithm). See Bruit de Galop.

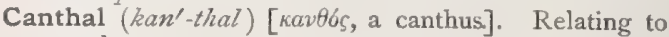
a canthus.

Canthariasis (kan-thar-i'-as-is) [kávtapos, a kind of beetle]. A term proposed by Hope for the diseases that originate from the presence in the body of coleop. terous insects or their larvæ.

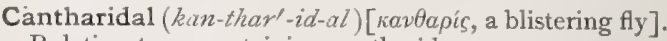
Relating to or containing cantharides.

Cantharides (kan-thar'-id-ēz). Plural of Cantharis.

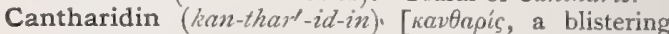
fly], $\mathrm{C}_{10} \mathrm{H}_{12} \mathrm{O}_{4}$. The bitter principle contained in Spanish flies and other insects; it crystallizes in prisms or leaflets, and melts at $218^{\circ}$. It has an extremly bitter taste, and produces blisters on the skin. See Cantharis.

Cantharidism (kan-thar'-id-izm) [kavAnpis, a blistering fly]. Cantharidal poisoning.

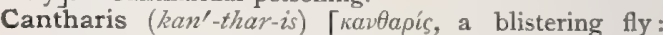
pl., Cantharides]. Spanish Fly. The dried body of a species of beetle, $C$. vesicatoria (nat. ord. Coleopiera). It contains a powerful poisonous principle, cantharidin, $\mathrm{C}_{10} \mathrm{H}_{12} \mathrm{O}_{4}$. Locally applied, cantharis is a rubefacient and vesicant ; internally it is an irritant, causing gastralgia and vomiting. In toxic doses it produces severe gastro-enteritis, strangury, and priapism. It is used chiefly as an external counter-irritant in the form of "blisters." C., acetum (B. P.), of the strength of 3 ij to $\mathrm{Oj}$. C., Ceratum, cantharides 32 , yellow wax 18, resin 18, lard 22, oil of turpentine 15. C., Ext., Ceratum, cantharides 30 , resin 15 , yellow wax 35 , lard 35, alcohol q. s. C., Charta, cantharides I, Canada turpentine $I$, olive-oil 4 , spermaceti 3 , white wax 8 , water ro parts. Charta epispastica (B. P.), blisteringpaper (white wax, spermaceti, olive-oil, resin, Canada balsam, cantharides, distilled water). Collodium cantharidatum, cantharides 60 , flexible collodion 85, chloroform q. s. C. cum picis emplast., Warming Plaster, Burgundy pitch 92, cerat. canthar. 8 parts. Emplastrum calefaciens (B. P.), cantharides, expressed oil of nutmeg, yellow wax, resin, resin-plaster, soap-plaster, boiling water. C., emplastrum (B. P.), cantharides, yellow wax, prepared suet, prepared lard, resin. C., liniment., cantharides 15 , oil of turpentine q. s. ad 1oo. C. Tinct., contains 5 per cent. of the drug. Dose $\eta_{j}-x x$. C., unguent. (B. P.), cantharides, yellow wax, olive oil.

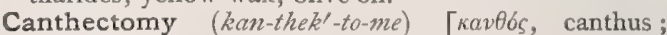
$\varepsilon \kappa \tau o \mu \eta$; a cutting out]. Excision of a canthus.

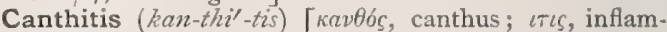
mation]. Inflammation of a canthus.

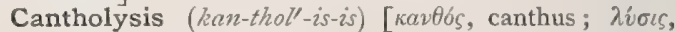
a loosening]. Canthotomy with section of the external canthal ligament.

Canthoplastic (kan-tho-plas'-tik) [kavtlos, the canthus; $\pi \lambda \dot{a} \sigma \sigma \varepsilon \iota \nu$, to form]. Relating to canthoplasty.

Canthoplasty (kan'-tho-plas-te) [kavtos, the angle of the eye; $\pi \lambda a ́ \sigma \sigma \varepsilon \imath \nu$, to form]. A surgical operation for increasing the size of the palpebral fissure by cutting the outer canthus.

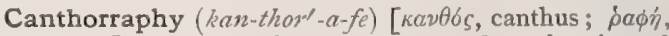
a seam]. A surgical operation to reduce the size of the palpebral fissure by suture of the canthus.

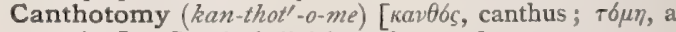
cutting]. Surgical division of a canthus.

Canthus (kan'-thus) [kavtlós, canthus]. The inner or outer angle formed by the juncture of the eyelids.

Cantus galli (kant"-us gal"-i) [L., "cock-crowing"] Same as Child-crowing. 
Canula (kan'-u-Zah). See Canmula.

Canutillo (kahn-oo-tell'-yo). See Tepopote.

Caoutchouc (koo-chook') [S. American]. India-rubber. The chief substance contained in the milky juice that exudes upon incision of a number of tropical trees belonging to the natural orders Euphorbiacer, Artocarpacee, and Apocynacee. The juice is a vegetable emulsion, the caoutchouc being suspended in it in the form of minute transparent globules. When pure, caoutchouc is nearly white, soft, elastic, and glutinous; it swells up in water without dissolving; the best solvents are carbon disulphid and chloroform. It melts at about $150^{\circ} \mathrm{C}$, and decomposes at $200^{\circ} \mathrm{C}$,

Capacity (kap-as -it-e) [capacitas, capacity]. Mental receptivity; passive (or active) mental capability; moral or legal responsibility. C., Vital. See Vital.

Capax Doli (ka'-paks do'-li). See Doli Capax.

Capelina (kap-el-i'-nah). See Capistrum.

Capeline $\left(k a p^{\prime}-e l-i n\right)$. See Bandage.

Capeman's Method. See Treatment, Methods of. Caper $\left(k a^{\prime}-p e r\right)$. See Capparis.

Capiat $\left(k a^{\prime}-p e-a t\right)$ [L., "let it take]. An instrument intended for use in removing remnants of the placenta, polypi, or the like, from the uterine cavity.

Capillaire (kap-il-är $\left.r^{\prime}\right)$ [Fr.]. The plant Adiantum capillus veneris, a species of maiden-hair fern; also a cough-syrup prepared from the same. See Adiantum.

Capillarity (kap-il-ar'-it-e) [capillus, a hair]. Capillary attraction: the force that causes fluids to rise in fine tubes or bores, or in very thin chinks. In an electric battery, the disturbing effects of the proper action of a voltaic cell caused by capillary action.

Capillary (kap'-il-a-re, or kap-il'-ar-e) [capillus, a hair]. I. A minute blood-vessel connecting the smallest ramifications of the arteries with those of the veins. Also a very minute fissure of the skull. Also the intercellular biliary passages. 2. Hair-like : relating to a hair, or to a hair-like filament, or to a tube with a hair-like bore. C. Attraction capillarity. C. Bronchitis. See Bronchitis. C. Embolism. See Embolism. C. Fissure, C. Fracture, a linear fracture, without displacement. C. Nevus. See Navus Vascularis. C. Pulse, a visible change of color or an artificial blush in aortic regurgitation. C. Vessels, the capillaries. Capillaries, Meigs's, branching capillaries discovered by A. V. Meigs in the human heart. C., Pulmonary, a name used to designate the plexuses beneath the mucous membrane, on the walls and septa of the alveoli of the lungs.

Capilli (kap-il'-i) [Plural of Capillus, hair]. In biology, applied to the hairs on the front and top of an insect's head.

Capilliculture (kap-ill-e-kul-chür) [capillus, hair; cultura, culture]. Systematic treatment for the improvement or restoration of the hair.

Capilliculus $\left(k a p-i l-i k^{\prime}-u-l u s\right)$ [dim. of capillus: $p l$., Capilliculi]. Any one of the very smallest of the capillary vesicles.

Capillifolious (kap-il-if-o'-le-us) [capillus, hair; folium, a leaf]. Characterized by hair-like leaves.

Capilliform (kap-il'-if-orm) [capillus, hair; forma, form]. Hair-shaped.

Capillitium (kap-il-ish'-e-um) [capillus, the hair]. In biology, the hair-like threads within the spore-cases of many fungi.

Capillus $\left(k a p-i l^{\prime}-u s\right)$ [L. : pl., Capilli]. A hair; the hair of the head.

Capistrum (kap-is'-trum) [L., a muzzle or halter : pl., Capistra]. I. A bandage for the head or for the lower jaw. Called also Capelina. 2. In biology, a mask or hood-like coloration of the face and part of the head in certain birds.
Capital $\left(k a p^{\prime}-i t-a l\right)$ [caput, the head]. I. Pertaining to the head, or to the summit of a body or object. 2. Of great importance; as a capital operation in surgery.

Capitalis reflexa (kap-it-a'-lis re-fleks'-ah). A recurrent bandage for a stump.

Capitate (kap'-it-āt) [caput, head]. In biology, having a head or a head-like termination.

Capitellate $\left(k a p-i t-l^{\prime}-\bar{a} t\right)$ [capitellum, a little head]. In biology, bearing small heads.

Capitellum (kap-it-el'-um) [dim. of caput]. The rounded, external surface of the lower end of the humerus.

Capitiluvium (kap-it-el-u'-ve-um) [caput, head; luere, to wash]. A washing or bathing of the head; a wash for the head.

Capitopedal (kap-it-o-ped'-al) [caput, a head; pes, foot]. In biology, pertaining to or near the junction of the head and foot.

Capitular (kap-it'-u-lar) [caput, head]. Pertaining to a capitulum or head. C. Process of a vertebra, one with which the head of a rib articulates.

Capitulum (kap-it'-u-lum) [capitulum, a small head]. In anatomy and biology, the enlarged terminal portion of an organ, plant, or animal, as the head of a bone; the enlarged free portion of a stalked animal; the knobbed end of an antenna or of an insect's poiser; a dense cluster or head of flowers, leaves, or spores in plants. C. of Santorini, a small elevation on the apex of the arytenoid cartilage corresponding in position to the posterior extremity of the vocal band.

Cappa $\left(k a p^{\prime}-a h\right)$. The ectocinereal lamina of the mesencephal.

Cappagh Brown. See Pigments, Conspectus of.

Capparis (kap'-ar-is) [L., the caper-bush]. A genus of shrubs including the caper-bush, C. spinosa. Its flower-buds (capers) are pickled, or made into a piquant sauce. The bark of the root and the flowers are official remedies in some countries (as Spain); it is diuretic, cathartic, depurative, stimulant. Unof.

Cappazwoli's Test. See Tests, Table of.

Capped Elbow (kapdel'-boze). See Shoe-boil.

Capped Hock (kapd' hok). In farriery, the development of a bruise at the point of the hock of a horse, with the formation of an hygroma, the result of rubbing or striking that part against the partition of the stall.

Capped Knee (kapd'ne). A dropsical collection in the bursa in front of the knee-joint of the horse.

Capranica's Tests. See Tests, Table of.

Caprantilopine (kap-ran-til'-o-pin) [capra, a she-goat; antilopinus, antelope]. Uniting the characters of a goat and an antelope.

Capre (kap'-er). See Mulatto.

Capreolar (kap-re'-o-lar), Capreolary (kap'-re-o-la-re), Capreolate (kap'-re-o-lät) [capreolus, a tendril]. In biology, climbing, furnished with tendrils; in anatomy. resembling tendrils, as the spermatic vessels, vasa capreolaria. C. Vessels, the spermatic vessels, from their twined and twisted appearance.

Capreolus (kap-re'-o-lus) [capreolus, a wild goat; a tendril of a plant]. I. A buck or he-goat. 2. The tendril of a plant.

Capric Acid (kap'-rik as'-id). See Acid.

Caprification (kap-rif-ik-a'-shun) [caprificus, the wildfig tree]. In biology, the process of hastening fertilization and ripening of cultivated figs by the introduction of gall-insects, by hanging a branch of the wild fig in the tree, or planting a wild fig in the midst of the fig orchard.

Caprify (kap'-rif-i) [caprificus, the wild-fig tree]. To fertilize by means of Caprification, $q . v$. 
Capriloquium (kap-ril-o'-kwe-um) [crper, a goat ; loqui, to speak]. Same as Egophony.

Caprin (kap'-rin) [caper, a goat]. An oily and flavoring constituent of butter; glycerin caprate.

Caproic Acid (kap-ro'-ik $\left.a s^{\prime}-i d\right)$. See Acid.

Caprolactone (kap-ro-lak'-tön) [caper, a goat; lac, milk], $\mathrm{C}_{6} \mathrm{H}_{10} \mathrm{O}_{2}$. A compound obtained from bromcaproic acid on heating the latter with water. It is a liquid boiling at $200^{\circ}$

Caprone (kaṕl一ön) [caper, a goat], $\mathrm{C}_{11} \mathrm{H}_{22} \mathrm{O}$. Caproic ketone; a clear, volatile oil found in butter, and forming the larger part of the oil of rue.

Caproylamin (kap-ro-il'-am-in) [caper, a goat; amin], $\mathrm{C}_{6} \mathrm{H}_{15} \mathrm{~N}$. Hexylamin. A ptomaine found in the putrefaction of yeast.

Caprylic Acid (kap-ril'-ik as'-id). See Acid.

Capsella (kap-sel'-ah) [dim. of capsa, a box]. The leaves and stems of $C$. bursa pastoris, common in temperate climates. It is considered an excellent hemostatic and antiscorbutic, and is slightly stimulant and astringent. Unof. C. bursa pastoris. See Shepherit's Purse.

Capsicin (kapp'sis-in), $\mathrm{C}_{9} \mathrm{H}_{14} \mathrm{O}_{2}$. The active principle of Cayenne pepper. It is a thick, yellowish-red substance, scarcely flowing at ordinary temperatures, but becoming very limpid if warmed. See Capsicum.

Capsicol (kap'-sik-ol) [capsicum; oleum, oil]. A red oil obtainable from the oleo-resin of capsicum.

Capsicum (kap'-sik-um) [capsa, a box; gen., Capsici]. Cayenne Pepper. The fruit of $C$. fastigiatum, native to tropical Africa and America. Its odor and hot taste are due to a volatile oil, capsicin, $\mathrm{C}_{9} \mathrm{H}_{14} \mathrm{O}_{2}$, which is irritant to the skin and mucous membranes. Internally, it is a stomachic tonic, diuretic and aphrodisiac. It is useful in atonic dyspepsia, flatulent colic, and in intermittent fever. C., emplastrum, prepared from the oleoresin and resin plaster. C., Ext. Fld. Dose $m_{v-3}-3$. C., linimentum, I in Io, for chest affections, rheumatism, etc. C., Oleoresin, Ethereal. Dose $m_{j}-\mathrm{v}$. C., Tinct., contains 5 per cent, of capsicum. Dose $m x-3 j$.

Capsitis (kap-si'-tis). Same as Capsulitis.

Capsula (kap'-su-lah) [capsula, a small box]. The internal capsule of the brain; it is the thick layer of fibers between the caudatum and thalamus mesad and the lenticula laterad; it is continuous with the crura caudad, and its expansion is called the corona.

Capsular (kap'-su-lar) [capsula, a small box]. Pertaining to a capsule. C. Artery, the middle suprarenal artery. See Arteries, Table of. C. Ligament, the sac or membranous bag that surrounds every movable joint or articulation. It contains the synovial fluid. C. Vein, the supra- renal vein. See Vein.

Capsule (kap'-sull) [dim. of caps 2 , a chest]. A tunic or bag that encloses a part of the body or an organ. In biology, the investment of a part or organ, as a dehiscent pod or seed-vessel, the egg-case of an insect, the test of a radiolarian. Also, in pharmacy, a small, spheroidal shell composed of glycerin and gelat $n$, divided so that the parts fit together like a box and cover. It is used for the administration of nauseous and repulsive medicines, C., Bonnet's, the posterior portion of the sheath of the eyeball. C., Bowman's. See Bozuman's Capsule. C., External, a layer of white nerve-fibers forming part of the external boundary of the lenticular nucleus. C.-filler, a contrivance consisting of a funnel, tube and plunger, or other device, used for introducing medicines into capsules. C. of Glisson, the cellulo-vascular membrane enveloping the hepatic vessels. C., Internal, a layer of nerve-fibers beneath and on the inner side of the optic thalamus and caudate nucleus, which it separates from the lenticular nucleus, and containing the continuation upward of the crus cerebri. C. of the Lens, a transparent, structureless membrane enclosing the lens of the eye. C., Malpighian, the commencement of the uriniferous tubules. See Malpishian Bodies. C., Suprarenal, the ductless glandular body at the apex of each kidney. C. of Tenon, the tunica vaginalis of the eye.

Capsuliferous (kap-sül-ifi-er-us) [capsula a little box; ferre, to bear]. In biology, producing capsules.

Capsulitis (kap-su-li'tis) [capsula, a small box; $\iota \tau \iota s$, inflammation]. Inflammation of the capsule of the lens, or of the fibrous capsule of the eyeball.

Capsulo-ciliary (kap-su-lo-sill-e-a-re) [capsula, a little box; cilizm, an eyelid]. Relating to the capsule of the lens and to the ciliary organ.

Capsulogenous (kap-sül-oj'-en-us) [capsula, a little box; gena, born]. Capsule-producing, as the cocoon or capsule-glands of the earthworm.

Capsulo-lenticular (kap-su-lo-len-tik'-u-lar) [capsula, a little box ; lenticula, a lentil]. Relating to the lens and to its capsule.

Capsulo-pupillary (kap-su-lo-pu'-pil-a-re) [capsula, a little box; pupilla, the pupil of the eye]. Relating to the capsule of the lens and to the pupil.

Capsulotome (kap'-su-lo-tôm). See Cystotome.

Capsulotomy (kap-su-lot'-o-me) [capsula, a capsule; $\tau \varepsilon$ ' $/ \nu \varepsilon \iota v$, to cut]. The operation of rupturing the capsule of the crystalline lens in cataract-operations.

Captage $(c a p-t a h j)$ [Fr.]. The measures to be applied to a natural spring of water, to secure the entire product of the spring, and the purity of the water, by the prevention of any admixture of deleterious or foreign matter.

Captation (kap-ta'-shun) [captare, to desire]. The first or opening stage of the hypnotic trance.

Capucin Madder $\left(k a p^{\prime}-u\right.$-sin mad'-er). See Pigments, Conspectus of.

Capuron, Cardinal Points of. See Pelvis.

Caput $\left(k a p^{\prime}-z t\right)$ [L.]. I. The head; also the chief part or beginning of an organ. 2. The cephalic or precornual portion of the caudatum of the prosencephal. C. coli, the head of the colon. C. cornu posterioris. Same as C. gelatinosum. C. gallinaginis. See Verumontanum. C. gelatinosum, the name given to the translucent gray matter covering the dorso-mesal periphery of the dorsal horn of the spinal cord. It is a nervous substance composed of numerous closely crowded nerve-elements, with an intricate intervening plexus of very fine nerve-fibrils, derived from the dorsal (posterior or "sensory") nerve-roots. C. medusæ. See Medusa, Caput. C. obstipum. Synonym of $W r y$-neck. C. quadratum, the rectangular head of rickets, flattened upon the top and at the sides, with projecting occiput and prominent frontal bosses. C. succedaneum, a tumor composed of a sero-sanguineous infiltration of the connective tissue situated upon the presenting part of the fetus.

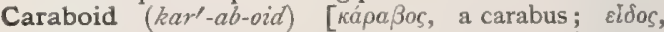
form]. In biology, the second larval stage of certain insects.

Carajura (kar-ah-ju'-rah) [Brazil]. Same as Chica Red.

Caramania Gum. See Bassora Gum.

Caramel (kar'-am-el) [Fr., burnt sugar]. Cane-sugar deprived of two molecules of water. It is a viscid, brown-colored liquid.

Caranna (kar-an'-ah) [Sp., caraña]. An aromatic oleoresin produced by the tree Protium carana, of tropical America; it was formerly used in plasters: also a name for similar gummy resins from Icica altissima, Bursera acuminata, etc., all tropical American trees. 
Carapa (kar'-ap-ah) [caraipi, a native Guiana name]. A genus of tropical meliaceous trees. C. guianensis has an antispasmodic and febrifuge bark, and its seeds afford carapa oil, a protective against insects and vermin. C. touloucouna, of W. Africa, and $\mathbf{C}$. indica, of Asia, have similar properties. Unof.

Carate $\left(k a h-r a h^{\prime}-t e\right)$ [S. America]. I. A skin-disease local in tropical America, marked by blue, brown, scarlet, or rosy patches on the skin; it is usually confined to persons not of the white race. 2. A kind of camphor produced in S. America from the plant Momordica charantia.

Carauna (kar-aw'-nah). See Caranna.

Caraway (kar'-ah-wa). See Carum.

Carbacidometer (karb-as-id-om'-et-er) [carbo, a coal; acidum, acid; $\mu$ étpov, a measure]. A form of airtester for estimating the amount of carbonic acid gas in the atmosphere of a room or compartment.

Carbamic Acid (kar-bam'-ik as'-id). See Acid.

Carbamid (karl-bam-id, or -míd) [carbo, a coal; amid], $\mathrm{CH}_{4} \mathrm{~N}_{2} \mathrm{O}$. Urea. Amid of carboxyl. It is prepared from urine, and crystallizes in long, rhombic prisms or needles that have a cooling taste. It is soluble in one part of cold water and in five parts of alcohol, but almost insoluble in ether; it melts at $132^{\circ}$; at a higher temperature it decomposes into ammonia, ammelid, biuret, and cyanuric acid; it is found in urine and in various animal fluids.

Carbanil (kar'-ban-il) [carbo, a coal; anilin], $\mathrm{C}_{7} \mathrm{H}_{5} \mathrm{NO}$. Phenyl isocyanate; a compound produced in the distillation of oxanilid. It is a mobile liquid, boiling at $163^{\circ}$, and has a pungent odor, provoking tears.

Carbanilamid (kar ban-il'-am-id) [carbo, a coal; anilin; amid], $\mathrm{C}_{7} \mathrm{H}_{8} \mathrm{~N}_{2}$. Phenylurea; prepared by evaporating the aqueous solution of anilin hydrochlorid and potassium isocyanid. It forms needles easily soluble in hot water, alcohr, , and ether, and melting at $144-145^{\circ}$.

Carbanilid (kar-ban'-il-id) [carbo, coal; anilin], $\mathrm{C}_{13} \mathrm{H}_{12} \mathrm{~N}_{2} \mathrm{O}$. Diphenyl urea; a compound formed by the action of phosgene gas on anilin, or by heating carbanilamid with anilin to $190^{\circ}$. It consists of silky needles, easily soluble in alcohol and ether, but sparingly soluble in water, and melts at $235^{\circ}$.

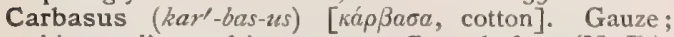
thin muslin used in surgery. C. carbolata (N. F.), carbolized gauze. C. iodoformata (N. F.), iodoform gauze.

Carbazol (kar'-baz-ol) [carbo, coal; azolum, nitrogen], $\mathrm{C}_{12} \mathrm{H}_{9} \mathrm{~N}$. Diphenylimid; a body produced when the vapors of anilin are conducted through a tube heated to redness. It is a by-product in the manufacture of anilin. It dissolves in hot alcohol, ether, and benzene, and crystallizes in colorless leaflets that melt at $238^{\circ}$.

Carbazotate (kar-baz-o'-tāt) [carbo, a coal; azotum, nitrogen]. Same as Picrate.

Carbazotic Acid (kar-baz-ot'-ik). See Picric Acid.

Carbo $\left(k a r^{\prime}-b o\right)$ [L.]. A coal; charcoal. C. animalis, animal charcoal; bone-black; it is used in pharmacy and in manufacturing chemistry largely as a decolorizing-agent and as a filter. C. animalis purificatus, purified animal charcoal. C. ligni, woodcharcoal; an absorbent, disinfectant, and deodorizer, used in poulticing wounds and dressing ulcers. Given powdered, in capsules, it relieves gastric irritation.

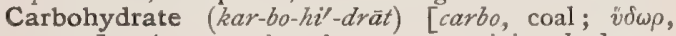
water]. An organic substance containing hydrogen and oxygen in the proportion in which they form water: that is, twice as many hydrogen as oxygen atoms, and usually six carbon atoms or some multiple of six. The carbohydrates form a large group of interesting organic compounds, and may be arranged into three groups: the glucoses (monoses); the disaccharids, or sugars; and the polysaccharids. The glucoses are the aldehyd-derivatives or ketone-derivatives of the hexahydric alcohols, into which they may be converted by the absorption of two hydrogen atoms. They are mostly crystalline substances, very soluble in water, but dissolving with difficulty in alcohol. They possess a sweet taste The disaccharids and polysaccharids are ethereal anhydrids of the glucoses. All of them may be converted into the glucoses by hydrolytic decomposition. The disaccharids are ether-like anhydrids of the hexoses. A Table of Carbohydrates is added. C., Test for. See Tests, Table of.

\section{SERIES OF THE CARBOHYDRATES.}

I. GLUCOSES.

\begin{tabular}{|c|c|c|c|c|}
\hline Name. & FORMULA. & FERMENTATION. & Optic Activity. & Reducing Power. \\
\hline $\begin{array}{l}\text { Monoses. } \\
\text { Glycerose, ..... }\end{array}$ & $\mathrm{C}_{3} \mathrm{H}_{6} \mathrm{O}_{3}$ & . & $\ldots$ & $\cdots$ \\
\hline Erythrose, ..... & $\mathrm{C}_{4} \mathrm{H}_{8} \mathrm{O}_{4}$ & $\ldots$ & $\cdots$ & $\cdots$ \\
\hline $\begin{array}{l}\text { Pentoses. } \\
\text { Arabinose, ..... }\end{array}$ & $\mathrm{C}_{5} \mathrm{H}_{10} \mathrm{O}_{5}$ & Unfermentable. & $\cdots$ & Reduces Fehling's solution. \\
\hline Xylose, ....... & $\mathrm{C}_{5} \mathrm{H}_{10} \mathrm{O}_{5}$ & Unfermentable. & $\therefore$ & Reduces Fehling's solution. \\
\hline Rhamnose, ..... & $\mathrm{C}_{6} \mathrm{H}_{12} \mathrm{O}_{5}$ & Unfermentable. & . & Reduces Fehling's solution. \\
\hline $\begin{array}{l}\text { Hexoses. } \\
\text { Mannose, . . . . . . }\end{array}$ & $\mathrm{C}_{6} \mathrm{H}_{12} \mathrm{O}_{6}$ & Fermented by yeast. & $\begin{array}{l}\text { Exists in three forms: } \\
\text { I, dextro-rotatory } \\
2, \text { levo-rotatory ; } 3 \\
\text { inaclive. }\end{array}$ & Reduces Fehling's solution. \\
\hline Glucose, .... & $\mathrm{C}_{6} \mathrm{H}_{12} \mathrm{O}_{6}$ & Fermented by yeast. & $\begin{array}{l}\text { Exists in three forms } \\
\text { I, dextro- rotatory } \\
2, \text { levo-rotatory; } 3, \\
\text { inactive. }\end{array}$ & Reduces Fehling's solution. \\
\hline Galactose, ..... & $\mathrm{C}_{6} \mathrm{H}_{12} \mathrm{O}_{6}$ & Fermented by yeast. & Dextro-rotatory. & Reduces Fehling's solution. \\
\hline Fructose, ..... & $\mathrm{C}_{6} \mathrm{H}_{12} \mathrm{O}_{6}$ & Fermented by yeast. & Levo-rotatary. & Reduces Fehling's solution. \\
\hline
\end{tabular}


SERIES OF THE CARBOHYDRATES.-Continued.

I. GLUCOSES.

\begin{tabular}{|c|c|c|c|c|}
\hline NAME. & FORMULA. & FERMENTATION. & Optic Activity. & REDUCiNG POWER. \\
\hline Sorbinose, $\ldots \ldots$ & $\mathrm{C}_{8} \mathrm{H}_{12} \mathrm{O}_{6}$ & $\begin{array}{l}\text { Unfermentable by } \\
\text { yeast. }\end{array}$ & $\cdots$ & Reduces Fehling's solution. \\
\hline Methyl-hexose, . . . & $\mathrm{C}_{7} \mathrm{H}_{14} \mathrm{O}_{6}$ & $\cdots$ & $\cdots$ & $\cdots$ \\
\hline $\begin{array}{l}\text { Heptoses. } \\
\text { Mamno-heptose, .. }\end{array}$ & $\mathrm{C}_{7} \mathrm{H}_{14} \mathrm{O}_{7}$ & $\begin{array}{l}\text { Unfermentable by } \\
\text { yeast. }\end{array}$ & . & \\
\hline Gluco-heptose, ... & $\mathrm{C}_{7} \mathrm{H}_{14} \mathrm{O}_{7}$ & $\begin{array}{l}\text { Unfermentable by } \\
\text { yeast. }\end{array}$ & . . & . \\
\hline Gala-heptose, . . . & $\mathrm{C}_{7} \mathrm{H}_{14} \mathrm{O}_{7}$ & $\begin{array}{l}\text { Unfermentable by } \\
\text { yeast. }\end{array}$ & . & \\
\hline Methyl-heptose, .. & $\mathrm{C}_{8} \mathrm{H}_{16} \mathrm{O}_{7}$ & $\begin{array}{l}\text { Unfermentable by } \\
\text { yeast. }\end{array}$ & $\cdots$ & . \\
\hline $\begin{array}{l}\text { Octoses } \\
\text { Manno-octose, ... }\end{array}$ & $\mathrm{C}_{8} \mathrm{H}_{16} \mathrm{O}_{8}$ & $\begin{array}{l}\text { Unfermentable by } \\
\text { yeast. }\end{array}$ & $\cdots$ & $\cdots$ \\
\hline $\begin{array}{l}\text { Nonoses. } \\
\quad \text { Manno-nonose, . . . }\end{array}$ & $\mathrm{C}_{9} \mathrm{H}_{18} \mathrm{O}_{9}$ & Fermented by yeast. & $\cdots$ & Reduces Fehling's \\
\hline
\end{tabular}

2. DISACCHARIDS.

\begin{tabular}{|c|c|c|c|c|}
\hline $\begin{array}{l}\text { Saccharose (Cane-Su- } \\
\text { gar), ......... }\end{array}$ & $\mathrm{C}_{12} \mathrm{H}_{22} \mathrm{O}_{11}$ & $\begin{array}{l}\text { Unfermentable by } \\
\text { yeast. }\end{array}$ & Dextro-rotatory. & Does not reduce Fehling's solution. \\
\hline Lactose (Milk-Sugar), & $\mathrm{C}_{12} \mathrm{H}_{22} \mathrm{O}_{11}+\mathrm{H}_{2} \mathrm{O}$ & Fermented by yeast. & Dextro-rotatory. & $\begin{array}{l}\text { Reduces Fehling's solution on } \\
\text { boiling. }\end{array}$ \\
\hline Maltose, ...... & $\overline{\mathrm{C}_{12} \mathrm{H}_{22} \mathrm{O}_{11}}+\overline{\mathrm{H}_{2} \mathrm{O}}$ & Fermented by yeast. & Dextro-rotatory. & Reduces Fehling's solution. \\
\hline Mycose (Trehalose), & $\mathrm{C}_{12} \mathrm{H}_{22} \mathrm{O}_{11}+{ }_{2} \mathrm{H}_{2} \mathrm{O}$ & Fermented by yeast. & Dextro-rotatory. & Does not reduce Fehling's solution \\
\hline Melebiose, & $\mathrm{C}_{12} \mathrm{H}_{22} \mathrm{O}_{11}$ & - & 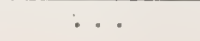 & $\ldots$ \\
\hline
\end{tabular}

3. TRISACCHARIDS.

\begin{tabular}{l|l|l|l|l} 
Melitose (Raffinose), . & $\mathrm{C}_{18} \mathrm{H}_{32} \mathrm{O}_{16}+{ }_{5} \mathrm{H}_{2} \mathrm{O}$ \\
Melezitose, . . . . Fermented by yeast. & $\mathrm{C}_{18} \mathrm{H}_{32} \mathrm{O}_{16}+2 \mathrm{H}_{2} \mathrm{O}$ & $\frac{\text { Dextro-rotatory. }}{\text { Dextro-rotatory. }}$ & Does not reduce Fehling's solution \\
$\ldots$
\end{tabular}

4. POLYSACCHARIDS.

\begin{tabular}{|c|c|c|c|c|}
\hline NAME. & FORMULA. & Optic Activity. & IODIN REACTION. & $\begin{array}{l}\text { REDUCING POWER AND FER- } \\
\text { MENTATION. }\end{array}$ \\
\hline Starch (Amylum), ... & $\mathrm{C}_{6} \mathrm{H}_{10} \mathrm{O}_{5}$, or $\mathrm{C}_{36} \mathrm{H}_{62} \mathrm{O}_{31}$ & Dextro-rotatory. & Blue coloration. & Fermentable. \\
\hline Paramylum, .... & $\mathrm{C}_{6} \mathrm{H}_{10} \mathrm{O}_{5}$ & $\cdots$ & Negative. & $\therefore$ \\
\hline Lichenin (Moss-starch), & $\mathrm{C}_{0} \mathrm{H}_{10} \mathrm{O}_{5}$ & Dextro-rotatory. & Dirty blue color. & $\cdots$ \\
\hline Inulin, $\ldots \ldots$ & $\mathrm{C}_{6} \mathrm{H}_{10} \mathrm{O}_{5}$ & $\cdots$ & Yellow color. & $\cdots$ \\
\hline $\begin{array}{c}\text { Glycogen } \\
\text { starch), A n i m a l } \\
\end{array}$ & $\mathrm{C}_{6} \mathrm{H}_{10} \mathrm{O}_{5}$ & Dextro-rotatory. & Reddish-brown color. & Fermentable. \\
\hline Cellulose, . . . . . & $\mathrm{C}_{12} \mathrm{H}_{20} \mathrm{O}_{10}$ & Dextro-rotatory. & Blue color. & $\cdots$ \\
\hline $\begin{array}{l}\text { The Gums. } \\
\text { Dextrin, ...... }\end{array}$ & $\mathrm{C}_{6} \mathrm{H}_{10} \mathrm{O}_{5}$ & Dextro-rotatory. & $\cdots$ & $\begin{array}{l}\text { Does not reduce Fehling's solu- } \\
\text { tion. Unfermentable. }\end{array}$ \\
\hline Arabin,...... & $\left(\mathrm{C}_{6} \mathrm{H}_{10} \mathrm{O}_{5}\right)_{2}+\mathrm{H}_{2} \mathrm{O}$ & Dextro-rotatory. & ... & $\begin{array}{l}\text { Does not reduce Fehling's solu- } \\
\text { tion. Unfermentable. }\end{array}$ \\
\hline $\begin{array}{c}\text { Bassorin (Vegetable } \\
\text { Gum), }\end{array}$ & $\mathrm{C}_{6} \mathrm{H}_{10} \mathrm{O}_{5}$ & Dextro-rotatory. & . & $\begin{array}{l}\text { Does not reduce Fehling's solu- } \\
\text { tion. Unfermentable. }\end{array}$ \\
\hline
\end{tabular}


Carbohydraturia (kar-bo-hi-drat-u'-re-ah) [carbohy. drate; ovfov, urine]. The presence of an abnormally large proportion of carbohydrates in the urine.

Carbolic (kur-bol'-ik) [carbo, a coal; oleum, oil]. Containing or derived from coal-tar oil. C. Acid. See Acid, Carbolic. C. Mask, Curschmann's respirator for use in fetid bronchitis. It is fastened in front of the nose and mouth, and contains cotton in a special receptacle, impregnated with carbolic acid, equal parts of carbolic acid and alcohol, turpentine, creasote, etc.

Carbolism (kar'-bol-izm) [carbo, a coal ; oleum, oil]. Carbolic-acid poisoning: a diseased state induced by the misuse or maladministration of carbolic acid.

Carbolize (kar'-bol-iz) [carbo, a coal; oleum, oil]. To impregnate with carbolic acid. To render aseptic or antiseptic by the use of carbolic acid.

Carboluria (kar-bol-u'-re-ah) [carbo, a coal ; oleum, oil ; ovpov, urine]. The presence of carbolic acid in the urine, producing a dark discoloration. It is one of the signs of carbolic-acid poisoning.

Carbon (kar'-bon) [carbo, charcoal]. Charcoal. $\mathrm{C}=$ I2; quantivalence II, IV. A non-metal occurring in the various forms of diamond, graphite or "black lead," and charcoal. In medicine only the last named form is employed, which may be,-C., Animal, useful as a deodorant and disinfectant, as it readily absorbs and aids in oxidizing many gases. It is used internally to absorb fermenting products of digestion. Carbo animal., purificat., purified animal charcoal. Dose gr. $x x-3$ j. C. Cataplasma (B. P.), charcoal poultice; wood-charcoal I, bread-crumb I, linseed meal 3 , boiling water 20 . C. dioxid, the acid, gaseous product, having the composition of $\mathrm{CO}_{2}$, commonly known as "carbonic acid gas," or carbonic acid. It is a colorless gas having a sp. gr. of $\mathbf{1} .5^{2}$, soluble in cold water, and possessing a pungent smell and an acid taste. Inhaled, it destroys animal life by asphyxiation. In solution, it is an excellent refrigerant and stomachic. Its inhalation is fatal in a short time, even when diluted with 95 parts of air. It is a product of respiration. It is used in medicine for inhalation in whooping cough, asthma, and to stop hiccough. It is also used as a local anesthetic in minor surgery. C. disulphid, bisulphid of carbon, $\mathrm{CS}_{2}$, a colorless, transparent liquid of offensive odor, highly inflammable, very poisonous. A good solvent for caoutchouc. A diluted spray of it is recommended in diphtheria. Dose $\eta_{s s-j}$. Carbo ligni, wood charcoal. C. monoxid, CO, carbonic oxid, a colorless, tasteless, and inodorous gas, one of the products of imperfect combustion. When inhaled it is actively poisonous. C. tetrachlorid, $\mathrm{CCl}_{4}$, anesthetic, recommended locally for asthma, by inhalation. Unof. See Anesthetic. C. oxysulphid, a body, COS, formed by conducting sulphur vapor and carbon monoxid through red-hot tubes; it is a colorless gas, with a faint and peculiar odor. It unites readily with air, forming an explosive mixture. It is soluble in an equal volume of water. It is present in the waters of some mineral springs.

Carbonaphtholic Acid (kar-bon-af-thol'-ik). See Acid alpha-oxynaphthoic.

Carbonemia (kar-bon-e'-me-ah) [carbon, charcoal; ai $\mu x$, the blood]. A word denoting the accumulation of carbon dioxid in the blood.

Carbonic Acid (kar-bon'-ik $\left.a s^{\prime}-i d\right)$. See Carbon dioxid.

Carbonis detergens, Liquor. See $P i x$.

Carbonization (kar-bon-iz-a'-shun) [carbo, coal]. The process of decomposing organic substances by heat without air, until the volatile products are driven off and the carbon remains.
Carbonyl (kar-bon-il) [carbo, charcoal]. A hypothetic organic radical having the formula $\mathrm{CO}$

Carbostyril (kar-bo-stir'-il) [carbo, charcoal; styrax, storax ], $\mathrm{C}_{9} \mathrm{H}_{7} \mathrm{NO}$. Oxyquinolin; a compound prepared by digesting quinolin with a bleaching-lime solution. It crystallizes from hot water in fine needles, and from alcohol in large prisms, that melt at $198-199^{\circ}$.

Carboxyl (kar'-boks-il) [carbo, charcoal; óvos, sharp]. The atomic group, $\mathrm{CO} . \mathrm{OH}$, characteristic of the organic acids. The hydrogen of this can be replaced by metals, forming salts.

Carbuncle, or Carbunculus (kar-bung-kel, or karbun $g^{\prime}-k u$-lus) [carbo, a live coal]. A hard, circumscribed, deep-seated, painful inflammation of the subcutaneous tissue, accompanied by chill, fever, and constitutional disturbance. It differs from a boil in having greater size, a flat top, and several points of suppuration. It is erroneously called anthrax.

Carbuncular (kar-bung'-ku-lar) [carbo, a live coal]. Pertaining to a carbuncle. C. Disease. See $A n$ thracosis.

Carbunculo contagioso. Synonym of Anthrax.

Carbyl (karl-bil) [carbo, charcoal; $i \lambda \eta$, matter]. A name given by Magnus to the hydrocarbon ethylene when it acts as a basic radical.

Carbylamin (kar-bil'-am-in) [carbo, charcoal; amin]. I. A name for hydrocyanic acid. 2. One of a series of compounds parallel to, and isomeric with, the nitrites, characterized by their ready decomposition by dilute acids into formic acid and amins. They are colorless liquids that can be distilled, and possess an exceedingly disgusting odor. They are sparingly soluble in water, but readily soluble in alcohol and ether.

Carcassonne's Ligament. See Ligament.

Carcerule (kar'-ser-ool) [carcer, a prison]. In biology, a many-celled, many-seeded, indehiscent pericarp.

Carcharodont (kar-kar'-o-dont) [ká $\rho \chi \alpha \rho o s$, sharp, jagged; ódov́s, tooth]. In biology, having compressed, trenchant, acute, pointed teeth, as sharks and snakes.

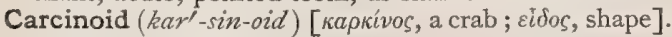
In biology, crab-like.

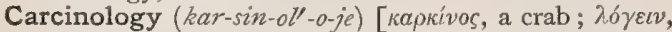
to speak]. The systematized knowledge of crustaceans, or crabs, etc., a department of zoölogy.

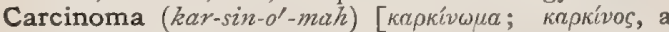
$\mathrm{crab}$, thus called from the appearance of the veins]. A malignant tumor, characterized by a network of connective tissue whose areolæ are filled with cellmasses resembling epithelial cells. See Tumors, Table of. C., Chimney-Sweepers'. See Epithetioma. C., colloid (Alveolar), affects chiefly the alimentary canal, uterus, peritoneum, etc.; the delicate connective-tissue stroma is filled with colloid matter in alveoli, or cysts. C. cutis, cancer of the skin. See Epithelioma. C., desmoid. See Hodgkin's Disease. C., encephaloid, is of rapid growth, with a small amount of stroma, large alveoli, and greater amount of cells and blood-yessels. Hematoid (bloody), Osteoid (in bones), Villous (papillary), etc., are other varieties, encephaloid in character. C., epitheliomatous, or squamous-celled, the cells resemble squamous epithelium, and they invade the adjacent tissue in a columnar manner. C. lenticulare, the most common form of cutaneous scirrhus. It begins as small, shot-sized, flattish, red papules, that enlarge to the size of a pea, bean, or filbert, most of them projecting above the surface, while others are subcutaneous. They are generally seated on a red or violaceous surface, and these coalesce into large irregular masses that sooner or later break down, ulcerate, and fungate, sometimes bleeding profusely. 
The patient soon dies of exhaustion. C., lipomatous, contains cells infiltrated with fat. C., medullary. Same as C., Encephaloid. C. melanodes, similar to $C$. Lenticulare, but marked by dark-blue, brown or black papules, that break into fungous growths. C., melanotic, has cells filled with dark pigment. C., scirrhous, or Hard, most commonly in the breast; it has a stout fibrillated stroma, closely packed with large nucleated cells. C. tuberosum, a rarer form of cutaneous scirrhus in which the nodules are of a larger size, even up to that of a hen's egg. The patient speedily dies of exhaustion consequent upon ulceration of the tubercles. C., Stiles's Test for; the excised part is washed in a five per cent. solution of nitric acid for ten minutes, washing it then in cold water for five minutes. The carcinomatous tissue appears a dull-white, the normal tissue translucent.

Carcinomatous (kar-sin-o'-mat-us) [kapkivos, a crab]. Relating to or affected with carcinoma.

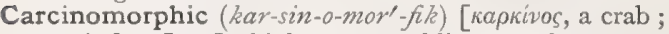
$\mu о \rho \phi \dot{n}$, form]. In biology, resembling a crab.

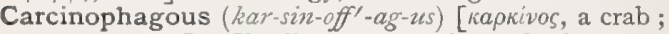
$\phi a \gamma \varepsilon \tilde{\imath}$, to eat]. Feeding upon crabs and other crustaceans.

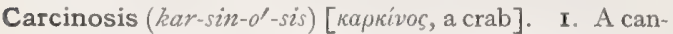
cerous cachexia; a tendency to the development of malignant disease. 2. A form of cancer, usually fatal, beginning generally in the uterus or the stomach and spreading to the peritoneum. C., Acute, rapidly fatal carcinosis. C., Miliary, carcinosis in minute foci.

Carcinus (kar'-sin-us) [каркivos, crab]. Same as Cancer, or Carcinoma.

Cardamom (kar'-dam-om). See Cardamomum.

Cardamomum (kar-dam-o'-mum) [L.; gen. Cardammi ]. Cardamom. The fruit of Elettaria repens, cultivated in Malabar. Its properties are due to a volatile oil, $\mathrm{C}_{10} \mathrm{H}_{16}$. It is an aromatic, carminative stomachic, used as an ingredient of several "bitters." It is useful when combined with purgatives to prevent griping. C., infusum. Unof. Consists of cardamom $3 \mathrm{j}$, water $\mathrm{O} / 2$. Dose a wineglassful. C., Tinct., Io per cent. strength. Dose $\mathbf{3} \mathrm{j}-\mathrm{ij}$. C., Tinct. Comp., cardamom 20 , cinnamon 20 , caraway Io, cochineal 5 , glycerin 6o, dilute alcohol, q. s. ad I0oo parts. Dose $3 j-i j$.

Carden's Operations. See Operations, Table of.

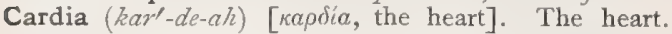
C. of the Stomach, the esophageal orifice of the stomach.

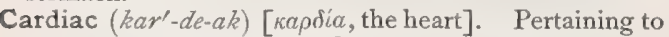
the heart. C. Aspect, that nearest the heart. C. Cycle, the total cardiac movement or revolution. C. Dropsy. See Dropsy. C. Dulness, the region covering the position of the heart, as shown by percussion. C. Dyspnea. See Dyspnea. C. Epilepsy, a rare affection, with intense pain in the region of the heart, occurring in paroxysms. This paroxysm usually follows a momentary loss of consciousness, and at times is associated with twitching of the facial muscles and other spasmodic movements. C. Facies. See Facies. C. Ganglia, lie in the grooves and substance-the principal are Remak's and Bidder's, the first on the surface of the sinus venosus, and the latter (two) at the auriculo-ventricular groove. See Ganglia, Table of. C. Impulse, the elevation caused by the movement of the heart, usually seen in the fifth left intercostal space. C. Murmurs. See Murmurs. C. Orifice, of the stomach, the esophageal orifice. C. Passion, pain in the heart, or the stomach. C. Plexus. See Plexus. C. Rhythm, the term given to the normal regularity in the force and volume of the individual heart-beats. In cases of cardiac insufficiency this regularity is disturbed to a greater or less degree, as is also the interval between the beats, and this condition has been termed arrhythmia. The name allorrhythmia has been applied to various perversions of rhythm. These abnormal conditions are due very probably to some derangement of the intrinsic nerve-apparatus of the heart, and are considered as unfavorable indications.

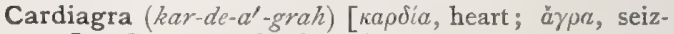
ure]. Gouty attack of the heart.

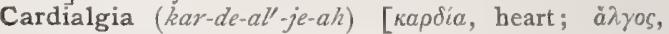
pain]. A term loosely used as a synonym of gastrodynia in general, heartburn, and stomachic pains on the left side.

Cardiamorphia (kar-de-am-or'-fe-ah) [kapdia, heart ; $\dot{a}$ priv. ; $\mu \circ \rho \phi \dot{y}$, form]. Deformity or malformation of the heart.

Cardianastrophe (kar-de-an-as'-tro-fe) [kapdia, heart;

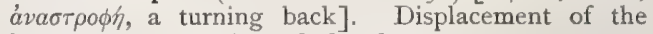
heart to the right side of the chest.

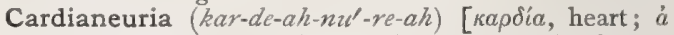

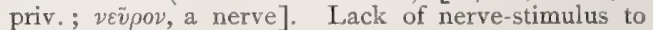
the heart.

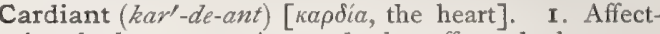
ing the heart. 2. A remedy that affects the heart.

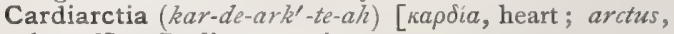
bound]. Cardiac stenosis.

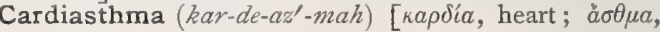
asthma]. Dyspnea or so-called asthma due to heartdisease.

Cardiatelia (kar-de-a/l-te'-le-ah). See Atelocardia.

Cardiatrophia (kar-de-at-ro-'-fe-ah) [kapdia, heart; átpopia, wasting]. Atrophy of the heart.

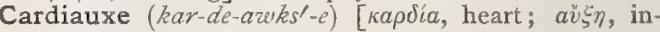
crease]. Enlargement of the heart.

Cardicentesis (kar-de-sen-te'-sis). See Cardiocentesis.

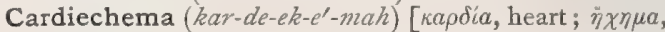
sound: $p l$, Cardiechemata]. A sound produced in or by the heart.

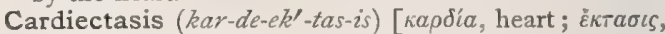
a stretching out]. Dilatation of the heart.

Cardielcosis (kar-de-el-ko'-sis) [ $\kappa a \rho \delta i a$, heart ; $\varepsilon \lambda \kappa \omega \sigma \iota s$, ulceration]. Ulceration of the heart.

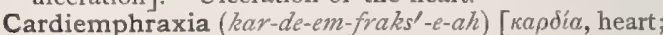
$\tilde{\varepsilon} \mu \phi \rho a \xi \iota s$, obstruction]. Obstruction to the blood-current in the heart.

Cardieurysma (kar-de-u-riz'-mah) [kapdia, heart;

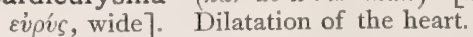

Cardiform (kar'-dif-orm) [cardus, a card; forma, shape]. In biology, having the teeth set as in a card.

Cardinal (kar'-din-al) [cardo, a hinge]. A chief or principal part. C. Flower, a common name for several species of Lobelia, chiefly $L$. cardinalis. C. Points. See Eve, Diagrammatic. C. Points of Capuron. See Pelvis. C. Veins, the venous trunks which, in the embryonic stage, form the primitive jugular veins.

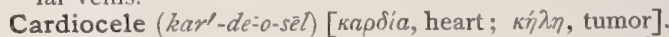
Hernial protrusion of the heart, chiefly through the diaphragm. 
Cardiocentesis (kar-de-o-sen-te'-sis) [kapdia, heart;

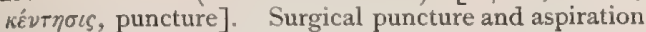
of one of the chambers of the heart.

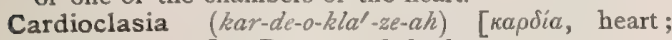
$\kappa \lambda a ́ \sigma \iota s$, rupture]. Rupture of the heart.

Cardiocrystallus (kar-de-o-kris-tal'-us) [кapdia, heart ;

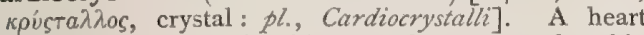
crystal; a microscopic white crystal sometimes found in the tissues of the heart.

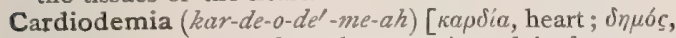
fat]. Fatty heart; fatty degeneration of the heart.

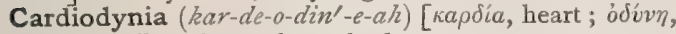
pain ]. Pain in or about the heart.

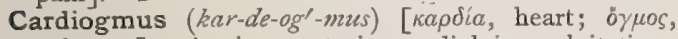
a furrow]. Angina pectoris; cardialgia; palpitation; aneurysm of a vessel near the heart; exophthalmic goiter. C. strumosus. Synonym of Exophthalmic Goiter.

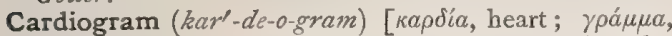
a writing]. The tracing made of the cardiac impulse by the cardiograph. See, also, Heart.

Cardiograph (kar'-de-

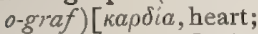

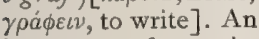
instrument for registering graphically the modifications of the pulsations of the heart.

Cardiographic (karde-o-graf'-ik) [krpdia, the heart; $\gamma \rho a \dot{\phi} \varepsilon \iota v$, to write]. Pertaining to or recorded by the cardiograph.

Cardiography (kar-de- $t$. Exit tube. $\begin{gathered}e . \text { Spring. } \\ \text { (Landois.) }\end{gathered}$. Button.

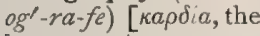

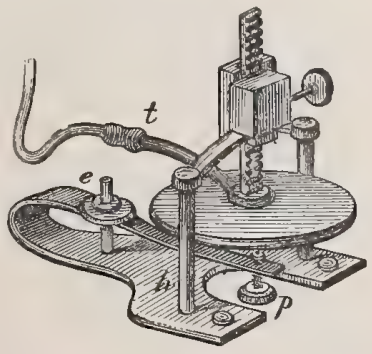

CARDIOGRAPH OF v. KNOLL. heart; yoá $\phi \varepsilon \imath$, to write]. I. The use of the cardiograph. 2. A description of the anatomy of the heart.

Cardiohemothrombus (kar-de-o-hem-o-throm'-bus)

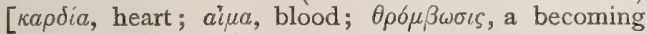
curdled]. Heart-clot.

Cardio-inhibitory (kar-de-o-in-hib'-it-o-re) [kapdia, the heart; inhibere, to restrain]. Pertaining to the diminution of the heart's action. C.-i. Center, located in the oblongata. C.-i. Nerves, the fibers of the spinal accessory supplied to the vagus.

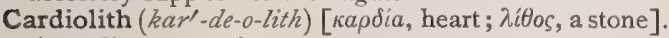
A cardiac concretion.

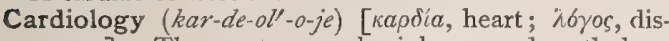
course]. The anatomy, physiology, and pathology of the heart.

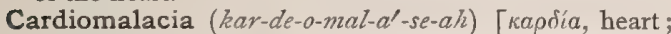
$\mu a \lambda a \kappa i a$, softness]. Morbid softening of the substance of the heart.

Cardiomegalia (kar-de-o-meg-a $\left.a^{\prime}-l e-a h\right)$ [kapdia, heart; $\mu \varepsilon^{\prime} \gamma a \varsigma$, large]. Cardiac enlargement.

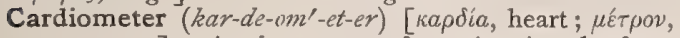
a measure]. An instrument for estimating the force of the heart's action.

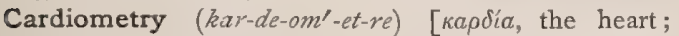
$\mu \varepsilon \tau^{\prime} \rho \nu$, a measure]. The estimation of the size and dimensions of the heart (as by means of auscultation and percussion).

Cardiopalmus (kar-de-o-pal'-mus) [kapdia, heart; $\pi a \lambda \mu \sigma \delta$, palpitation]. Palpitation of the heart.

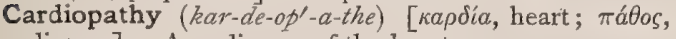
disease]. Any disease of the heart.

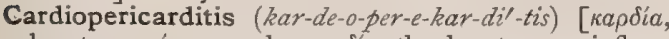
heart; $\pi \varepsilon \mu i$, around; kapdia, the heart; $\iota \tau \iota \varsigma$, inflammation]. Carditis and pericarditis together; inflammation of the heart-tissues and of the pericardium.

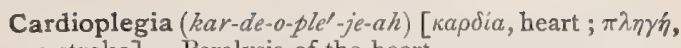
a stroke]. Paralysis of the heart.

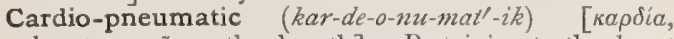
heart; $\pi \nu \varepsilon \tilde{v} \mu \alpha$, the breath]. Pertaining to the heart and the breath. C.-p. Movements. Those movements of the air in the lungs that are caused by the pulsations of the heart and larger vessels.

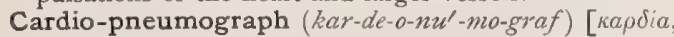
heart; $\pi \nu \varepsilon v \tilde{\nu} \alpha$, breath; $\gamma \rho a ́ \phi \varepsilon \iota v$, to write]. An instrument designed for graphically recording cardiopneumatic movements.

Cardiopuncture (kar-de-o-punk'-chür) [kapdia, heart; punctura, a puncture]. I. Cardiocentesis. 2. Any surgical or vivisectional puncture of the heart.

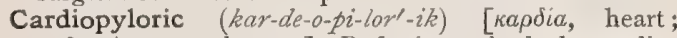
$\pi v \lambda \omega p o ́ s$, a gate-keeper]. Referring to both the cardiac and pyloric portions of the stomach.

Cardiorrhexis (kar-de-o-reks'-is) [kajdia, heart; $\rho \vec{\eta} \xi \iota s$, rupture]. Rupture of the heart.

Cardiosclerosis (kar-de-o-skle-ro'-sis) [кapdia, heart; $\sigma \kappa \lambda \eta \rho \delta \varepsilon \iota \nu$, to harden]. Induration of the tissues of the heart. See Fibroid Heart.

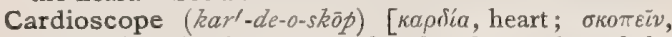
to view]. An instrument for the observation of the movements or of lesions of the heart.

Cardiostenosis (kar-de-o-ste-no'-sis) [kapdia, heart;

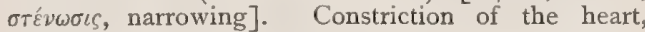
especially of the conus arteriosus; also the development of such a constriction.

Cardio-thyroid Exophthalmos (kar'-de-o-thi-roid eksoff-thal'-mos). Synonym of Exophthalmic Goiter.

Cardiotomy (kar-de-ot'-o-me) $[\kappa \alpha \rho \delta i a$, heart ; $\tau o \mu n$, cutting]. The anatomy or dissection of the heart.

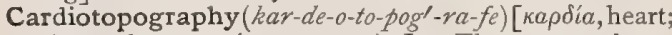

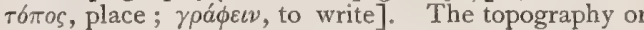
topographic anatomy of the heart and the cardiac area.

Cardiotoxic (kar-de-o-toks $-i k)$ [ $\kappa a \rho \delta i a$, heart; $\tau o \xi \iota \kappa o ́ v$, poison]. Having a poisonous effect upon or through the heart.

Cardiotrauma (kar-de-o-traw'-mah) [kapdia, heart; $\tau \rho a \tilde{v} \mu a$, a wound]. Traumatism or wound of the heart.

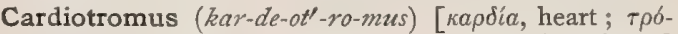
$\mu \circ$ s, a quivering]. A fluttering or slight palpitation of the heart.

Cardiovascular (kar-de-o-vas'-ku-lar) [knpdía, heart; vasculum, a small vessel]. Both cardiac and vascular; pertaining to the blood-vessels of the heart.

Carditic (kar-dit'-ik) [ $\kappa a \rho \delta i \alpha$, the heart; $\iota \tau \iota \zeta$, inflammation]. Relating to or affected with carditis.

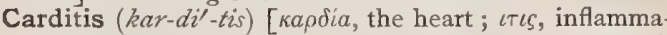
tion]. Inflammation of the heart. C., Internal. Synonym of Endocarditis.

Cardo $\left(k a r^{\prime}-d o\right)$ [cardo, a hinge]. In biology, a hingejoint, as that of a bivalve shell or the maxilla of an insect.

Cardol (kar'-dol). See Anncardium.

Carduus (kar'-du-us) [L., a thistle]. The seeds of $C$. marianus, St. Mary's thistle, and $C$. benedictus, blessed thistle. A decoction of the former, $3 \mathrm{ij}$ ad $\mathrm{Oj}$, constitutes an old and popular remedy for hemoptysis. The latter is also a popular cure-all, used mainly as a tonic bitter. Dose of decoction $3 \mathrm{j}-\bar{\xi} \mathrm{ss}$; of a tincture, $m \mathrm{x}-\mathrm{xx}$.

Carferal (kar'-fer-al) [carbon, charcoal ; ferrum, iron; aluminum.] A proprietary combination of carbon, iron oxid, and clay; it is used as a filtering material for water.

Carica Papaya (kar'-ik-ah pap-a'-yah). See Papain. Caricin (kar'-is-in). See Papain.

Caricologist (kar-ik-ol'-oniist) [carex, sedge; $\lambda \hat{\varepsilon} \gamma \varepsilon \iota v$, to speak]. A student of sedges. 
Caricous (kar'-ik-us) [carica, a fig]. Fig-shaped, as a caricous tumor

Caries (ka'-re-ezz) [caries, rottenness]. A chronic inflammation of bone with rarefaction or absorption of bony tissue, followed usually by pus-formation; molecular death of bone, with the accompanying process, as ulceration. C. fungosa, tuberculosis of a bone with attached sequestrum, the meshes of the latter being filled with granulations growing into them from the inner surface of the cavity. C., necrotic, when portions of the bone lie in a suppurating cavity. C. sicca, a form of tuberculous caries characterized by absence of suppuration, obliteration of the cavity of the joint, and sclerosis and concentric atrophy of the articular extremity of the bone. C. of Spine, or Pott's Disease, osteitis of the bodies of the vertebre and intervertebral fibro-cartilage, producing curvature of the spine. C. of Teeth, a chemical decomposition of the earthy part of any portion of a tooth, accompanied by a partial or complete disorganization of the animal framework of the affected part.

Carina (kar-i'-nah) [carina, the keel]. In biology, one of many keel-like structures; as the breast-bone of most birds, the median piece to the carapace of a cirriped, etc.

Carinate (kar'-in-at) [carinatus, keel-shaped]. Keeled.

Carinated Abdomen (kar'-in-a-ted $\left.a b^{\prime}-d o-m e n\right)$. See Scaphoid Abdomen.

Cariniform (kar-in'-if-orm) [carina, keel; forma, shape]. In biology, applied to the keel-like fins of certain fishes, and to other structures.

Carino-lateral (kar-in-o-lat'-er-al) [carina, a keel; latus, side]. Placed at the side of the carina of an animal.

Cariol $\left(k a^{\prime}-r e-o l\right)$. A poisonous active principle obtainable from parsley. It resembles apiol in its physiologic effects, but produces a peculiar uterine vascular congestion; it is useful in genito-spinal atony. Unof.

Carious ( $\left.k a^{\prime}-r e-u s\right)$ [caries, rottenness]. Pertaining to or affected with caries. C. Teeth, Effects of; carious teeth may occasion facial neuralgia, facial paralysis, sciatica, hemiplegia and spinal irritation, paraplegia, tetanus, headache, epilepsy, hysteria, chorea, insanity, etc.

Carissa $\left(k a r-i s^{\prime}-a h\right)$ [L.]. A genus of shrubs. schimperi. See Ouabain.

Carius, Method of. A method for the quantitative determination of halogens. The substance, weighed out in a small, glass tube, is heated together with concentrated $\mathrm{HNO}_{3}$ and silver nitrate to from $150^{\circ}$ to $300^{\circ} \mathrm{C}$, in a sealed tube, and the quantity of the resulting silver haloid determined.

Carlsbad Water. A famous mineral water used largely for chronic affections of the gastro-intestinal tract, obesity, gout, and diabetes.

Carmin (kar'-min) $\mathrm{C}_{17} \mathrm{H}_{18} \mathrm{O}_{10^{\circ}}$ A coloring-matter extracted from Cochineal, q. $v$. C. Naphtha. See Pigments, Conspectus of. C. Red. Same as Cochineal.

Carminant (kar-min-ant) [carmen, a charm]. I. Carminative. 2. A carminative agent or medicine.

Carminative (kar-min'-at-iv) [carmen, a charm]. A calming or soothing medicine, chiefly for children, that acts by relieving pain from flatulence.

Carminic Acid (kar-min'-ikas'-id) See Acid.

Carminophile (kar-min'-o-fīl) [carmin; $\dot{\phi}(\lambda \varepsilon i \bar{v}$, to love. $]$ Readily stainable with carmin.

Carnal (karl-nal) [camalis, fleshly]. Pertaining to flesh. C. Knowledge, sexual intercourse. In forensic medicine it signifies penetration merely, which penetration need only be vulval without seminal emission.
Carnauba $\left(k a r-n a-o o^{\prime}-b a h\right)$ [Braz.]. The root of Corypha cerifera, a wax-producing palm-tree of tropical America. It is used in Brazil as an alterative and resembles sarsaparilla in its properties. Dose of the fld. ext. $m \times x x x-3$ j. Unof. C. Wax, obtained from the leaves of the carnauba-palm, Copernicia cerifere, of Brazil. Its specific gravity is.999 and its meltingpoint $185^{\circ} \mathrm{F}$. $\left(84^{\circ} \mathrm{C}\right.$.). It is brittle and of a yellowish color. It is extensively used in the manufacture of candles.

Carneous (kar'-ne-us) [cameus, of flesh]. Fleshy. C. Columns, See Columna Carnece.

Carnification (kar-nif-ik-a'-shun) [caro, flesh; fieri, to become]. A term indicating the alteration of tissue to an unnatural, fleshy appearance. Also, the amyloid degeneration of certain tissues.

Carnin (kar'-nin) [caro, flesh], $\mathrm{C}_{7} \mathrm{H}_{8} \mathrm{~N}_{4} \mathrm{O}_{3}$. A leukomaïne isolated from American meat-extract, but not from muscle-tissue itself; also obtained from yeast and wine. It crystallizes in white masses composed of very small irregular crystals; it is soluble with great difficulty in cold, readily soluble in hot water, insoluble in alcohol and in ether. It is not thought to be very poisonous, but experiments made by Brücke show that it causes a fluctuation in the rate of the heart-beat.

Carnivorous (kar-niv'-o-mus) [caro, flesh; vorare, to devour]. In surgery, caustic, escharotic; flesh-eating.

Carnochan's Operations. See Operations, Table of.

Carnose (kar'-nös) [carnosus, fleshy]. Resembling or having the consistence of flesh.

Carnosity (kar-nos'-it-e) [carnosus, fleshy]. A fleshy growth or excrescence.

Carnot's Doctrine. An absurd theory advanced as an objection to vaccination. It is the doctrine of the "displacement of mortality." Carnot claimed that while certain diseases (small-pox, measles, croup, etc., ) were decreasing, other diseases (cholera, typhoid fever, dysentery) were increasing, and that vaccination was the cause of all the disturbance.

Caro $\left(k a^{\prime}-r o\right)[\mathrm{L}$.$] . Flesh: muscular tissue.$

Caroba $\left(k a r-o^{\prime}-b a h\right)$ [L.]. The leaflets of Jacaranda procera and of Cybistax antisyphilitica. It is a popular Brazilian remedy as an emeto-cathartic, alterative, and tonic in syphilis and in yaws. Dose of the fld. ext. $m \times v-3 j$. Unof.

Carobin $\left(k a r-a^{\prime}-b i n\right)$ [caroba]. An alkaloid said to be found in the leaves of Jacaranda procera.

Carolina (kar-o-li'-nah) [Carolus, Charles]. A name given to two Southern States of the Union. C. Allspice. See Calycanthus. C. Pink. See Spigelia.

Carotic $\left(k a r-o t^{\prime}-i k\right)$ [kápos, stupor]. Of the nature of carus; stupid ; stupefying.

Carotico-clinoid (kar-ot'-ik-o-kli'-noid) [kápos, stupor; kiivvs, a bed]. Relating to a carotid artery and a clinoid process of the sphenoid bone.

Carotico-tympanic (kar-ot'-ik-o-tim-pan'-ik) [kópns,

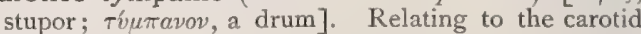
canal and the tympanum.

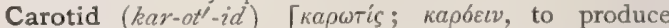
sleep]. I. The principal (right and left) artery of the neck. (They were thought to give origin to sleep.) See Arteries, Table of. 2. Of or relating to either of the two great arteries of the neck, or their principal branches. See Canal, Foramen, Ganglion, Plexus, etc.

Carotin (kar'-o-tin) [carota, carrot], $\mathrm{C}_{18} \mathrm{H}_{24} \mathrm{O}$. An oily coloring matter found in carrot-root and tomato. It is a lipochrome.

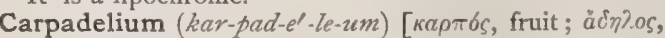
not manifest]. Same as Crenocarp.

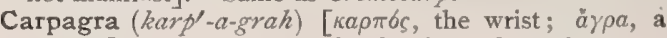
seizure]. A sudden attack of pain at the wrist. 
Carpain (kar-pa'-in), $\mathrm{C}_{14} \mathrm{H}_{27} \mathrm{NO}_{2}$. An alkaloid extracted from the leaves of Carica papaya. It forms well-defined, beautiful crystals, with a very bitter taste, and melting at $I I 5^{\circ} \mathrm{C}$. It is recommended for the subcutaneous treatment of heart-disease. Dose, grain $\frac{1}{10}$ to $\frac{1}{6}$ subcutaneously, every day, or every second day.

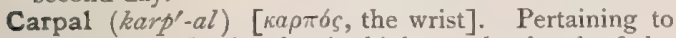
the wrist. C. Angle, in biology, the bend of the wing.

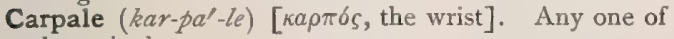
the wrist-bones.

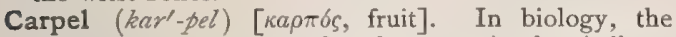
ovule-producing organ of a plant; a simple pistil, or the homologous portion of a compound pistil.

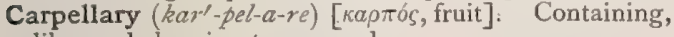
like, or belonging to a carpel.

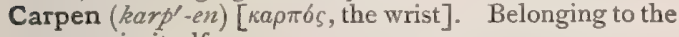
carpus in itself.

Carphologia (kar-fo-lo'-je-ah). See Carphology.

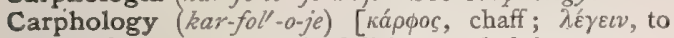
collect]. A symptom in delirious and dying persons consisting in picking at the bedclothes. It is generally looked upon as an unfavorable omen. Floccilatio, or floccilation, was the term formerly given to this symptom.

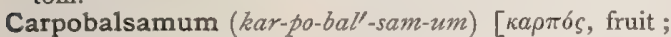
$\beta a ́ \lambda \sigma a \mu o v$, balsam]. The fruit of Balsamodendron (Commiphora) opobalsamum, the Mecca balsam-tree; also a fragrant volatile oil from the same fruit. It is highly prized in the Orient. Unof.

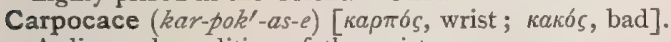
A diseased condition of the wrist.

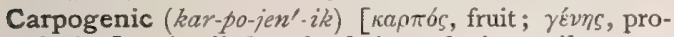
ducing]. Applied to the fruit-producing cell or system of cells in certain algæ.

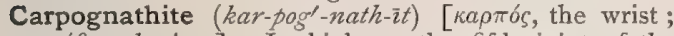

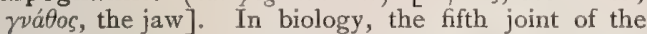
gnathopodite or foot-jaw of a crustacean. See Carpos.

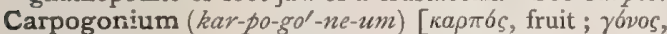
producing]. In biology, the unfertilized female reproductive organ of certain thallophytes.

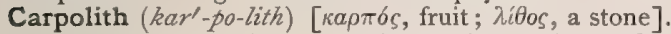
I. A hard concretion formed in a fruit. 2. A petrified fruit.

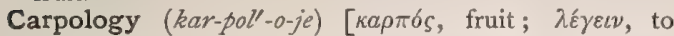
speak]. That department of botany that treats of fruits.

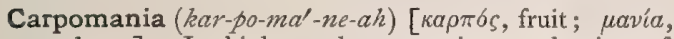
madness]. In biology, the excessive production of fruit by trees that are cultivated.

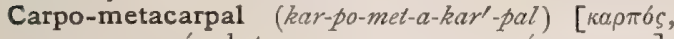
carpus ; $\mu \varepsilon \tau a ́$, between, among; $\kappa a \rho \pi \delta s$, carpus]. Relaling to the carpus and to the metacarpus.

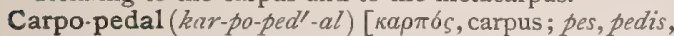
a foot]. Affecting the wrists or the hands and feet. C. Spasm, a spasm of the hands and feet, or of the thumbs and great toes, associated with the laryngismus stridulus of children. C. Contractions. See Contraction.

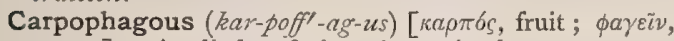
to eat]. Applied to fruit-eating animals.

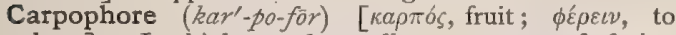
bear]. In biology, the stalk or support of fruits, corresponding to the receptacle in the flower. Also an organ, in some thallophytes, that bears spores.

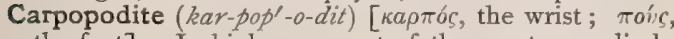
the foot]. In biology, a part of the crustacean limb, i.e., the fifth joint of the endopodite. See Carpos.

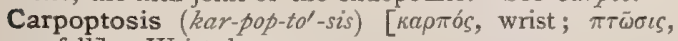
a fall]. Wrist-drop.

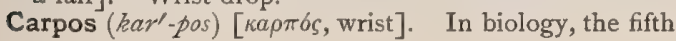

joint of any crustacean appendage (Bate). The same as Carpognathite and Carpopodite (Milne Edwards).

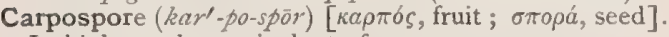
In biology, the equivalent of spore.

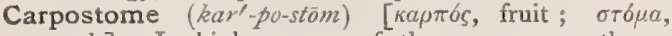
mouth]. In biology, one of the narrow mouths or canals through which spores are discharged from the cystocarp or sporocarp.

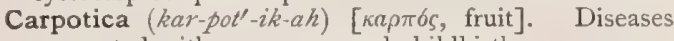
connected with pregnancy and childbirth.

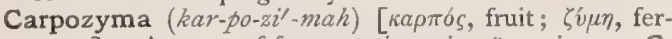
ment]. A genus of fermentative microörganisms. C. apiculata, a widely-diffused alcoholic ferment found in all fruits.

Carpue's Operation. See Operations, Table of.

Carpus $\left(k a r p^{\prime}-u s\right)[k \alpha \rho \pi \delta s$, the wrist]. The eight bones collectively forming the wrist. See Bones, Table of.

Carr's Method. See Treatment, Methods of.

Carrageen, or Carragheen (kar'-ag-een) [Carragheen in Ireland]. Irish moss. See Chondrus.

Carragheenin (kar-ag-ên'-in), $\mathrm{C}_{6} \mathrm{H}_{10} \mathrm{O}_{5}$. A mucilaginous constituent of carragheen, apparently identical with pararabin.

Carré's Apparatus. An apparatus for manufacturing ice by means of the evaporation of ether.

Carriage $\left(k a r^{\prime}-\bar{a} j\right)$. See Ward-carriage, Ambulance, Cacolet.

Carrick Bend (kar'-ik-bend $)$. A form of knot for fastening together two ligatures. The merit of the knot consists in the free end being held firmly between the two long portions.

Carron Oil (kar'-on oil). See Linum and Calcium.

Car-sickness (kar'-sik-nes). The well-known symptoms of sea-sickness produced by journeying in railway cars.

Carswell's Grapes. Pulmonary tubercles when they occur by racemose distribution at the extremities of several adjacent bronchioles. See Diseases, Table of.

Carter's Operation. See Operations, Table of. C. Test. See Tests, Table of.

Carthamin (karth'-am-in) [Ar., qartama, paint], $\mathrm{C}_{14}$ $\mathrm{H}_{16} \mathrm{O}_{\eta}$. The coloring-matter in safflower, the blossoms of Carthamus tinctorius. It is precipitated from its soda solution by acetic acid as a dark-red powder, which, on drying, acquires a metallic luster. It dissolves with a beautiful red color in alcohol and the alkalies. It is used for surface-coloring or dyeing. See Pigments, Conspectus of.

Carthamus (karth'-am-us) [Ar., qartama, paint]. American or bastard saffron or safflower. The flowers of C. tinctorius. An infusion, "Saffron tea," is a popular domestic remedy as a diuretic in measles and other exanthematous affections. Unof.

Cartilage (kar'-til-āj) [cartilago, gristle]. Gristle; a white, semi-opaque, non-vascular tissue composed of a matrix containing nucleated cells. When boiled, cartilage yields a substance called Chondrin, q. v. C., Articular, that lining the articular surfaces of bones. C., Bone-, bone that takes its origin from cartilage, and not from a membrane. C., Costal, that occupying the interval between the true ribs and the sternum or adjacent cartilages. C., Ensiform, the third piece of the sternum. It is also called the xiphoid appendix. C., Epactal, small cartilaginous nodules on the upper edge of the alar cartilages of the nose. C., Hyaline, distinguished by a granular or homogeneous matrix. C., Fibro-, distinguished by a fibrous matrix. Cartilages of Larynx, the cartilages of the larynx take part in producing the various modulations of the pitch and intensity of the voice. They are the thyroid, cricoid, epiglottis, and a pair each of arytenoid, cornicula laryngis, and cuneiform, q.v. C. of Meckel. 
See Meckel. C., Mucronate, the ensiform cartilage. C., Nasal, the cartilaginous framework of the nose, consisting of five pieces, the two upper and two lower cartilages, and the cartilage of the septum. C., Reticular, a peculiar cartilage found in the auricle of the ear, the epiglottis, and Eustachian tubes. Its peculiarity consists in a network of yellow elastic fibers pervading the matrix in all directions. C. of Santorini, a nodule at the apex of each arytenoid cartilage, the corniculum laryngis. C. of Weitbrecht, the interarticular fibro-cartilage that exists in the acromio-clavicular articulation. C. of Wrisberg, the cuneiform cartilages, one on each side of the fold of membrane stretching from the arytenoid cartilage to the epiglottis. C., Yellow. See C., Reticular.

Cartilagin (kar-til'-aj-in) [cartilago, cartilage]. A characteristic principle of hyaline cartilage. Boiling changes it into chondrin.

Cartilaginification (kar-til-aj-in-if-ik-a'-shun) [cartilago, cartilage; facere, to make]. A change into cartilage.

Cartilaginiform (kar-til-aj-in'-if-orm) [cartilago, cartilage; forma, form]. Resembling cartilage.

Cartilaginoid (kar-til-aj'-in-oid) [cartilago, cartilage; cidos, form]. Resembling cartilage.

Cartilaginous (kar-til-aj'-in-us) [cartilago, cartilage]. Made up of or resembling cartilage.

Cartilago (kar-til-a'-go) [L. : gen., Cartilaginis]. Cartilage. C. triticea, a small, oblong, fibro-cartilaginous mass, often found in the elastic ligament, the thyrohyoid, connecting the superior cornu of the thyroid cartilage with the greater cornu of the hyoid bone.

Carum (ka'-rum) [kápov, caraway]. Caraway. The seeds of $C$. carui, indigenous to Europe and an allied species native to the Pacific coast of America. Its odor and taste are due to a volatile oil. It is valuable in infantile colic, but is used chiefly as a flavor. C., Aqua (B. P.). Dose $\zeta_{j}$-ij. C., Infusum, unof., $3 j-i j$, ad Oj. Dose 3 ss-ij. C., Oleum. Dose $m_{\mathrm{j}-\mathrm{v}}$. Caruncle $\left(k a^{\prime}{ }^{\prime}-u n g-k i\right)$ [caruncula, dim. of caro, flesh]. A small, abnormal fleshy growth. In biology, applied to certain elevations, protuberances, or excrescences on animals or plants, as the comb of a bird, the fleshy papilla at the inner canthus of the eye, the growths on insect larvæ, and the small masses about the hilum of some seeds. C., Lachrymal, one upon the con. junctiva near the inner canthus. C., Urethral, a small, bright-red growth situated on the posterior lip of the meatus urinarius; a frequent condition in women. The caruncle varies in size from a hempseed to a filbert; it is very painful, especially during micturition and coitus, and bleeds readily.

Caruncula (kar-ung $\left.g^{\prime}-k u-l a h\right)$ [dim. of caro, flesh: pl., Caruncule]. A caruncle. C. mammillaris, the olfactory tubercle, an eminence of gray matter between the roots of the olfactory nerve.

Carunculæ (kar-uns-ku-le) [canuncula, a caruncle]. The nymphæ. C. myrtiformes, the projections of membrane near the orifice of the vagina, thought to be the remains of the hymen after its rupture. They have also been found in the imperforated hymen.

Caruncular (kar-ung $g^{\prime}$-ku-lar) [caruncula, a caruncle]. Like or pertaining to a caruncle.

Carus $\left(k a^{\prime}-r u s\right)$ [kápos, stupor]. Deep, lethargic sleep. C. cataleptica, catalepsy. C. ecstasis, trance, or catalepsy. C. lethargus, lethargy.

Carus, Curve or Circle of. See Curve.

Carvacrol (karv'-ak-rol) [Ital., carvi, caraway; ăkpos, sharp], $\mathrm{C}_{10} \mathrm{H}_{1.3}$. OH. A liquid body occurring in the oil of certain varieties of satureja. It is produced on heating carvol with glacial phosphoric acid. It is a thick oil, solidifying at low temperatures; it melts at $0^{\circ}$ and boils at $236^{\circ}$. It has a very disagreeabie odor and strong taste. It has been used to relieve toothache.

Carvene (karv'-èn) [It., carvi, caraway], $\mathrm{C}_{10} \mathrm{H}_{16} . \quad \mathrm{A}$ hydrocarbon contained in caraway. It is a iight terpene. See also Citrene.

Carvol (kary'-ol) [It., carvi, caraway; oleum, oil], $\mathrm{C}_{10} \mathrm{H}_{14} \mathrm{O}$. An aromatic alcohol isomeric with carvacrol, and obtained from oil of cumin. It is an oil with a pleasant odor, boiling at $225^{\circ} \mathrm{C}$.

Caryoblast (karl-e-o-blast) [kápvov, a nucleus; $\beta \lambda a \sigma \tau \delta s$, a germ]. Any nucleated plastidule.

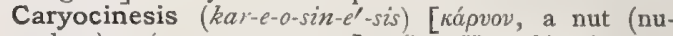
cleus); kivnoıs, movement]. See Karyokinesis.

Caryocinetic (kar-e-o-sin-et'-ik). See Karyokinetic.

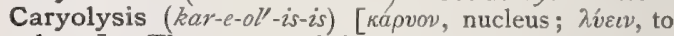
loose]. The process of the dissolution of cell-nuclei.

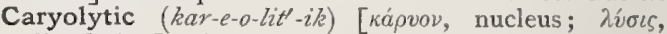
dissolution]. Pertaining to Caryolysis.

Caryomitosis (kar-e-o-mit-o'-sis). See Karyomitosis.

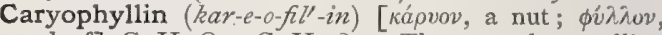
a leaf], $\mathrm{C}_{10} \mathrm{H}_{16} \mathrm{O}$ or $\mathrm{C}_{20} \mathrm{H}_{32} \mathrm{O}_{2}$. The neutral crystalline principle of cloves. It occurs in tasteless and odorless silky acicular crystals, soluble in warm alcohol and ether. See Caryophyllus.

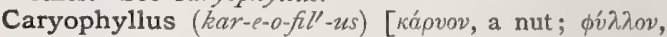
a leaf]. Clove. The unexpanded flowers of Eugenia caryophyllata, distinguished by their pungent, spicy taste. Its properties are due to a volatile oil, which is antiseptic, stimulant, and irritant. It also contains a crystalline body, Eugenin, $\mathrm{C}_{10} \mathrm{H}_{12} \mathrm{O}_{2}$, and a camphor, Caryophyllin, $\mathrm{C}_{10} \mathrm{H}_{16} \mathrm{O}$. It is useful as a stomachic, and to prevent griping when combined with purgatives. C., Infusum (B. P.). A strength of I to 40 recommended. Dose $\zeta_{j}-\mathrm{ij}$. C., Ol., contains an acid and a phenol compound. Dose $m j-i v$. It is used also by microscopists to clarify preparations and tissues for mounting.

Caryoplasm (kar-e-o-plazm) [кápvov, a nucleus; $\pi \lambda \alpha \sigma \mu \alpha$, that which is formed]. The plasm of a cellnucleus; nuclear plasm.

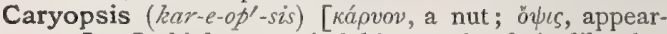
ance]. In biology, an indehiscent dry fruit, like that of the wheat, in which the single seed is enveloped in the closely-adhering pericarp.

Casali Green. See Conspectus of Pigments, under Pigment.

Casali's Test. See Tests, Table of.

Casamajor's Test. See Tests, Table of.

Casaubon's Apparatus. One for charging water with $\mathrm{CO}_{2}$ by the intermittent method.

Casca Bark (kas'-kah bark). Sassy Bark; Ordeal Bark. The bark of Erythrophloum guinensè, a tree native to Africa, with properties due to an alkaloid. It produces nausea and vomiting. It is valuable in intermittent fevers, and is a more powerful heart-tonic than digitalis. C., Tinct., 25 per cent. in strength. Dose mx. Unof. C., Ext. Aq. Dose gr. j. C., Ext. Fld. Dose $m \nabla-x v$. Erythrophlein, the active alkaloid, unof., is locally an anesthetic.

Cascadöe (kas-kad-o'-e). See Tinea imbricata.

Cascara (kas'-kar-ah) [Sp., "bark"]. The bark. C. amarga, Honduras Bark. The bark of a tree native to Mexico, much used as an alterative tonic in syphilis and skin-affections. C. Cordial, a trade preparation. Dose $\eta_{x v-z}$ ij. C., Fld. Ext. Dose 3 ss-j; of the powdered extract gr. $\mathrm{v}-\mathrm{x}$. Unof. C. sagrada, Chittem Bark, Sacred Bark. The bark of Rhamnus purshiana, or California Buckthorn. Its properties are due to a volatile oil. It is useful in the treatment of chronic constipation. All unof. Casc. sagrad., Ext. (B. P.). Dose gr. ij-viij. Casc.sagrad., Exx. Liquidum (B. P.). Dose $m v-3 j$. 
Cascarilla (kas-kar-ill-ah) [Sp., dim. of casca, bark]. The bark of Croton eluteria, native to the Bahama Islands, an aromatic bitter, increasing the natural secretions of the digestive organs. C., Infus. (B. P.). Dose $\overline{3}_{j}$-ij. C., Tinctura (B. P.). Dose 3 ss-ij.

Cascarilin (kas-kar-il'-in) [cascarilla, dim. of casca, bark], $\mathrm{C}_{6} \mathrm{H}_{9} \mathrm{O}_{2}$. The active principle of cascarilla bark; a white, crystalline, bitter substance, scarcely soluble in water.

Case (kass) [cadere, to happen]. A single instance or example of a disease. A covering, or box-like structure. C., Brain-, the calvaria. C., Muscle-. See Muscle. C.-taking, the collection of memoranda and notes of an individual case for service in diagnosis or prognosis, or for use in a medico-legal inquiry. C., Trial-, in ophthalmology, a case containing various lenses for refracting the eye, etc.

Caseation (ka-ze-a'-shun) [caseum, cheese]. The precipitation of casein during the coagulation of milk. Also a fatty degeneration of pus, tubercle, etc., in which the structure is converted into a soft, cheeselike substance.

Casein $\left(k a^{\prime}-z e-i n\right)$ [caseum, cheese]. A derived albumin, the chief proteid of milk, precipitated by acids and by rennet at $40^{\circ} \mathrm{C}$. It is closely allied to alkalialbumin, but contains more nitrogen and a large amount of phosphorus. It constitutes most of the curd of milk. Two varieties of C., Vegetable, have been described,-Legumin, in peas, beans, etc., and Conglutin, in hops and almonds. C. Saccharid, a compound of dry casein one part, cane-sugar nine parts, and sodium bicarbonate enough to render it slightly alkaline. It is useful in preparing emulsions, whether of oils, balsams, terpenes, resins, or gum-resins.

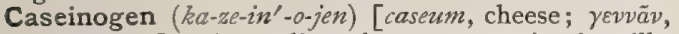
to produce]. A peculiar substance occurring in milk, neither an alkali-albumin nor a globulin, but occupying a distinct position among proteîds. When acted upon by a digestive ferment it produces casein, or the curd of milk. Caseinogen is a proteid analogous to fibrinogen, myosinogen, etc.

Caseose $\left(k a^{\prime}-z e-\bar{o} s\right)$ [caseum, cheese]. A product of the gastric digestion of casein.

Caseous $\left(k a^{\prime}-z e-u s\right)$ [caseum, cheese]. Having the nature or consistence of cheese.

Cashew $\left(k a s h-00^{\prime}\right)$. The cashew-nut, the product of Anacardium occidentale. See Acajou.

Cashoo (kash-oo'). Same as Catechu.

Cassava $\left(k a s-a^{\prime}-v a h\right)$ [Sp., casabe]. The fecula of manioc, Janipha manihot, separated from the juice. Unof. See Tapioca.

Cassel Brown. Same as Vandyke Brown. C. Green. Same as Manganese Green. C. Yellow. See Conspectus of Pigments, under Pigment.

Cassel's Operation. See Operations, Table of.

Casselmann's Green. See Conspectus of Pigments, under Pigment.

Cassena (kas- $\left.\ell^{\prime}-n a h\right)$ [L.]. The Ilex cassine, the youpontree of the Southern U. S. Its leaves are expectorant, cathartic, emetic, and stimulant. Unof.

Casser, Ganglion of. See Ganglia, Table of. C., Nerve of. See Nerves, Table of.

Casserian Ganglion. See Ganglia, Table of.

Cassia (cash'-e-ah) [kaбia, a perfume]. I. A genus of leguminous plants, several species of which afford Senna, q. v. 2. An old name, still used commercially, for the coarser varieties of cinnamon. See Cinnamon. C. Bark, Cassia lignea. See Cinnamon. C. Buds, the immature fruit of Chinese cinnamon; used chiefly as a spice. C. marilandica, of N. America, produces the leaves called American senna, which are less active as a cathartic than the true senna. C. Oil, a variety of oil of cinnamon, used in pharmacy and in perfumery. C., Purging, is the fruit of a tree, C. fistula, growing in tropical regions. The pulp, C. Pulpa (B. P.), in $3 \mathrm{j}^{-\mathrm{ij}}$ doses is a mild laxative.

Cassideus (kas-id'-e-us) [cassis, a helmet]. In biology, helmet-shaped.

Cassimuniar, or Cassumunar (kas-im-u'-ne-ar, or kas-um-u'-nar). The plant Zingiber cassumunar and its aromatic rhizome, formerly used like true ginger; now scarcely known in commerce or in pharmacy. It is tonic and stimulant. Unof.

Cassius's Purple. See Pigments, Conspectus of.

Cassonade $\left(k a s-o n-\bar{a} d^{\prime}\right)$ [Fr.]. A name formerly applied in the French colonies to Muscovado Sugars, $q . v$.

Cast (kast) [ME., casten, to throw]. I. A mass of fibrous or plastic material that has taken the form of some cavity in which it has been moulded. From their source, casts may be classified as bronchial, intestinal, nasal, esophageal, renal, tracheal, urethral, vaginal, etc. Of these, the renal casts are the most important, by reason of their significance in diseases of the kidney. Classed according to their constitution, casts are epithelial, fatty, fibrinous, granular, hyaline, mucous, sanguineous, waxy, etc. See Tube-casts. 2. To throw off; applied to labor in cattle. 3. Strabismus.

Castanea (kas-ta'-ne-ah) [L.]. Chestnut. The leaves of $C$. vesca. They contain tannic and gallic acids and other principles whose value is not known. They are used in infusion or decoction as a remedy for whooping-cough. C., Fld. Ext. Dose $m$ v-lx.

Castillon's Powders. Powders containing sago, salep, tragacanth, of each 8 parts, prepared oyster-shells, 2 , cochineal, I. They are used in treating diarrhea and dysentery.

Casting (kast'-ing) [ME., casten, to throw]. In dental mechanism, running fused lead, tin, zinc, or brass into a mould made in sand, with a plaster transfer of any portion or the whole of the alveolar border and so many of the teeth as may be remaining in it, and the palatine arch when it becomes necessary to adapt a plate to it.

Castor (kas'-tor). See Castoreum. C. Bean and C. Oil. See Ricini.

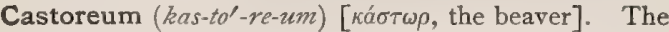
dried preputial follicles and their secretion, obtained from the beaver, Castor fiber. It is a reddish-brown substance with a strong odor. It is antispasmodic and stimulant, its action resembling that of musk. C., Tinct. Dose $3 \mathrm{ss}-\mathrm{j}$. Unof.

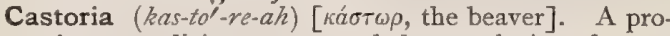
prietary medicine recommended as a substitute for castor oil.

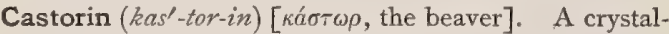
line substance obtained from castor.

Castration (kas-tra'-shun) [castrare, to cut]. Orchectomy; the excision of one or both testicles. C., Female, removal of the ovaries; oöphorectomy ; spaying.

Casts (kasts). See Cast, and Tube-Casts.

Casual $\left(k a z^{\prime}-u-a l\right)$ [casus, chance]. Fitted or set apart for the treatment of accidental injuries, as a casual ward in a hospital.

Casualty ( $k a z^{\prime}-u$-al-te $)$ [casus, chance]. An accidental injury; a wound, or loss of life, accidentally incurred; an injury in a battle.

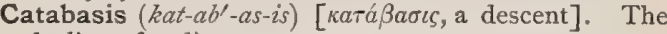
decline of a disease.

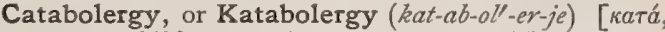
down; $\beta a ́ \lambda \lambda \varepsilon \iota v$, to throw; $\varepsilon \rho \gamma o \nu$, work]. Energy expended in katabolic processes.

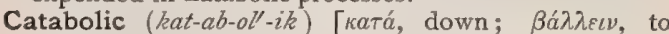
throw]. Of the nature of, or pertaining to, catabolism. 
Catabolism $\left(k a t-a b^{\prime}-o l-i z m\right)[\kappa a \tau \dot{x}$, down; $\beta a ́ \lambda \lambda \varepsilon t \nu$, to throw]. Destructive metamorphosis; disassimilation; physiologic disintegration; movement toward a catastate.

Catabythismomania (kat-ab-ith-iz-mo-ma'-ne-ah) [kat$\alpha \beta v \theta \iota \sigma \mu o ́ s$, submergence; $\mu a \nu \iota a$, madness]. Insane impulse to suicide by drowning.

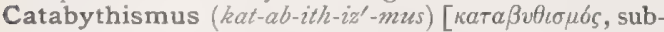
mergence]. Drowning; especially suicidal drowning.

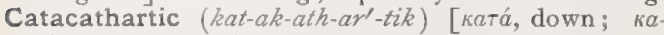
$\theta a ́ \rho \sigma \iota s$, purgation]. 1. Purging. 2. A medicine or agent that causes purgation.

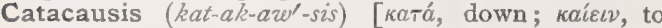
burn]. Spontaneous combustion.

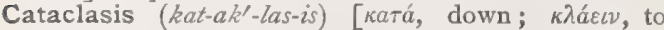
break]. A fracture.

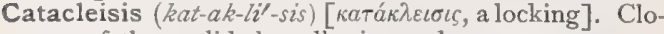
sure of the eyelids by adhesion or by spasm.

Catacorolla (kat-a-ko-rol'-ah) [katá, against ; corolla, a little crown]. In biology, a secondary corolla either within or without the true corolla.

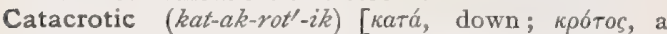
striking]. Interrupting the line of descent in a sphygmogram.

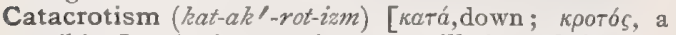
striking]. An interruption or oscillation of the line of descent in a sphygmogram; the quality of being catacrotic or of being marked by oscillation in the sphygmographic line of descent.

Catadicrotism, or Katadicrotism (kat-ad-ik'-rot-izm) [катá, down; фікротоs, double beating]. The occurrence of a divided or double pulsation in the downward stroke of the sphygmograph.

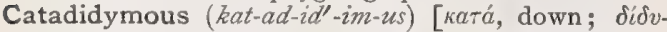
$\mu$ s, twin]. Joined into one, as a twin monstrosity, but with a downward cleavage, so that the upper parts are double.

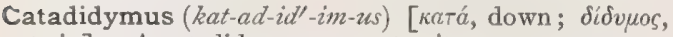
twin]. A catadidymous monstrosity.

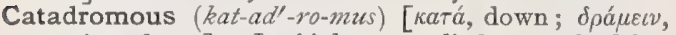
running down]. In biology, applied to such fishes as descend rivers to spawn in the sea, e.g., the eel.

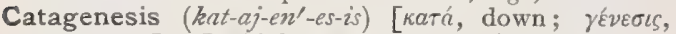
generation]. In biology, the process of creation by retrograde metamorphosis of energy, or by the specialization of energy (Cope).

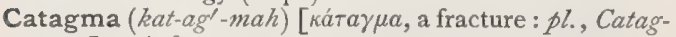
mata]. A fracture.

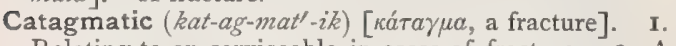
Relating to or serviceable in cases of fracture. 2. A remedy that promotes the union of broken parts.

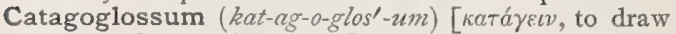
down; $\gamma \lambda \bar{\omega} \sigma \sigma \alpha$, the tongue]. A tongue-depressor.

Catalepsia (kat-al-ep'-se-ah). See Catalepsy. C. artificialis, artificial or hypnotic catalepsy. C. accessoria, catalepsy associated with some other leading nervous affection. C. cerea, waxen catalepsy; catalepsy in which the limbs if placed in any given position will retain it as if they were made of wax. C. epidemica, the epidemic or imitative variety. C. spuria, or false catalepsy. See Ecstasy.

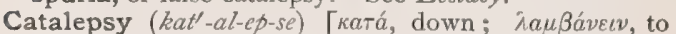
seize]. A peculiar neurosis characterized by loss of will and muscular rigidity, due to a diseased condition of the central nervous system. It occurs in those of the neurotic diathesis, and usually between the ages of 20 and 30 years. It is commonly associated with hysteria, but may be found in conjunction with tetanus and the various psychoses. It often forms a part of the hypnotic state. See Somnambulism. C., Local, that affecting a single organ or group of muscles. C., Plastic. See Catalepsia cerea.

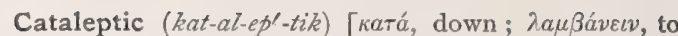
seize]. Relating to, affected with, or of the nature of, catalepsy.

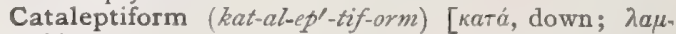
ßáveıv, to seize; forma, form]. Resembling catalepsy.

Catalpa (kat-al'-pah) [native Am. Indian]. A genus of American and Asiatic bignoniaceous trees. A. bignoniodes and A. speciosa, of North America, have astringent, anthelmintic, and tonic qualities; the leaves and pods are reputed anodyne, emollient, and antasthmatic. Unof.

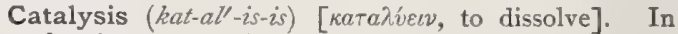
chemistry, a reaction that appears to take place owing to the mere presence of another body that apparently undergoes no change.

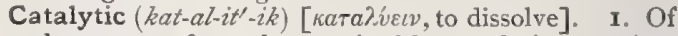
the nature of, or characterized by, catalysis. 2. Any medicine that is supposed to break down, destroy, or counteract morbid agencies existing within the economy. See Alterative.

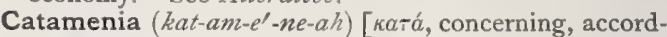
ing to; $\mu$ in, month]. The recurrent monthly discharge of blood during sexual life from the genital canal of the female.

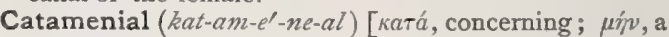
month]. Pertaining to the catamenia.

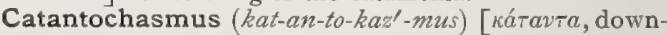
ward ; $\chi a ́ \sigma \mu \alpha$, an expanse]. In craniometry. Lissauer's term for a skull in which the angle between the radius fixus and a line joining the anterior point of the foramen magnum and the posterior nasal spine is less than $13^{\circ}$.

Catantopylus (kat-an-toṕ-il-us) [káтavтa, downward; $\pi \hat{v} \lambda \eta$, an opening]. In craniometry, Lissauer's term for a skull in which the angle between the radius fixus and the line joining the anterior and posterior points of the foramen magnum is between one and eight degrees.

Catantorrhinus (kat-an-tor-i'-nus) [кáтavтa, downward; pis, the nose]. In craniometry, Lissauer's term for a skull in which the angle between the radius fixus and the line joining the wing of the vomer and the anterior nasal spine is between $I^{\circ}$ and $16.5^{\circ}$.

Catantostomus (kat-an-tos'-to-mus) [кáтavтa, downward; $\sigma \tau \sigma \mu \alpha$, the mouth]. In craniometry, Lissauer's term for a skull in which the angle between the radius fixus and a line joining the premaxillary point and the wing of the vomer is between $9^{\circ}$ and $25.5^{\circ}$.

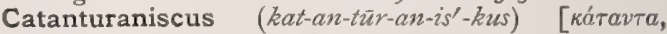
downward; ovpaviokos, the roof of the mouth]. In craniometry, Lissauer's term for a skull in which the angle between the radius fixus and the line joining the posterior rim of the incisor foramen and the premaxillary point is between $\mathrm{I}^{\circ}$ and $20^{\circ}$.

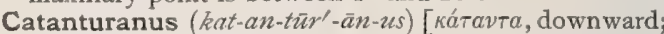
ovpavós, the palate]. In craniometry, Lissauer's term for a skull in which the angle between the radius fixus and the line joining the premaxillary point and the nasal spine is between $I^{\circ}$ and $17^{\circ}$.

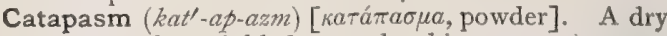
powder to be sprinkled upon the skin or upon a sore.

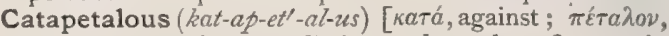
a leaf]. In biology, applied to polypetalous flowers in which the bases of the petals are adherent to the bases of the stamens.

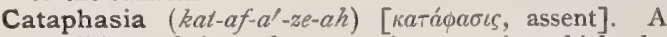
condition of imperfect consciousness, in which the patient repeatedly utters the same word or words spontaneously, or in reply to a question.

Cataphora (kat-af'-o-rah) [кaтaфopá, a fall]. Lethargy ; imperfect or restless coma, with intervals of coma-vigil. 


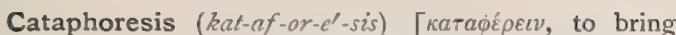
down]. The introduction of drugs into the system through the skin, by means of ointments or solutions applied by the electrode of a battery.

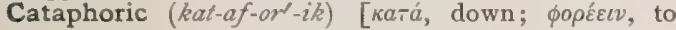
carry]. Passing, or causing a passage, from the anode to the kathode, through a diaphragm or septum.

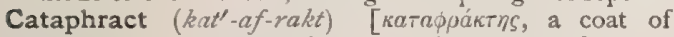
mail]. In biology, the protective armor-plates or scales of some animals.

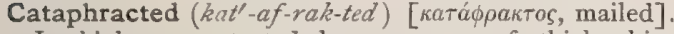
In biology, protected by an armor of thick skin, heavy plates or scales.

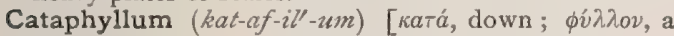
leaf]. In biology, a rudimentary scale-like leaf, as a cotyledon or bud-scale.

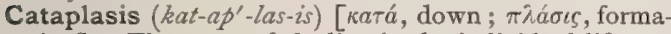
tion]. The stage of decline in the individual life.

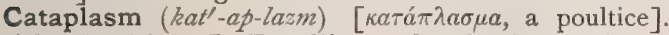
See Poultice. C., Emollient. See Species emollientes.

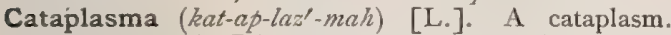
C. fermenti (B.P.), beer yeast, wheaten flour, water at $100^{\circ}$ F. A stimulant and antiseptic for indolent ulcers.

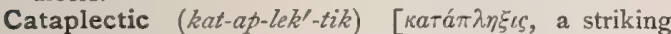
down]. Fulminant; sudden and overwhelming

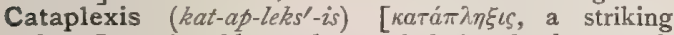
down]. I. A sudden and overwhelming shock or attack of disease ; prostration by the onset of disease, or by shock. 2. Hypnotic sleep.

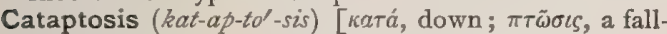
ing]. Apoplexy; epilepsy; paralysis ; ptosis.

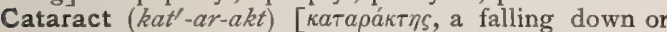
over, as of something over the vision]. Diminished transparency or an opacity of the crystalline lens, or of its capsule. C., Artificial Maturation of, Förster's Method consists in friction of the cornea against the lens by pressure upon the cornea. Beltmann's Method consists in "direct trituration" of the lens with a spatula introduced into the anterior chamber. Both methods are preceded by an iridectomy. C., Black, the lens is pigmented, and of a dark-brown color. C., Capsular, consists in non-transparent deposits on the inner surface of the capsule. C., Cortical, opacification of the outer layers of the lens. C., Diabetic, is associated with diabetes. C., Discission of, an operation preliminary to absorption, or extraction by suction, consisting in rupturing the capsule, so that the aqueous humor gains access to the lens. C., Extraction of, removal of the cataractous lens by surgical operation. See Extraction of C. C., Fluid, C., Lacteal, the breaking up of an opaque lens into a milky fluid. C., Green, a name given to a grayishgreen reflex seen in glaucoma; it is also seen when the pupil is dilated and at the same time the media are not completely transparent. C., Immature, or Unripe, only a part of the lens-substance is cataractous. C., Lacteal. See C., Fluid. C., Lamellar, or Zonular; certain layers between the cortex and nucleus are opaque, the remaining layers being transparent. C., Mature, or C., Ripe, the whole lens-substance is cataractous. C., Morgagnian, when a hypermature or overripe $C$. shrinks and leaves a nucleus floating in the dissolved outer layers. C., Naphthalinic, an opacity of the lens of a rabbit following the administration of naphthalin. C., Polar (anterior or posterior), the opacity is confined to one pole of the lens. C.pricker. See Cataract-pricking. C.-pricking, a name given to the old method of artificial luxation of the lens in cases of cataract. A needle was passed into the sclera on the outer margin of the cornea and into the lens, which was then depressed into the vitreous. Those who performed this operation were called cataract prickers. C., Pyramidal, the opacity is at the anterior pole and is conoid, the apex extending forward. C., Recurrent Capsular, or Secondary, capsular cataract, appearing after the extraction of the lens. C., Senile, the cataract of old persons, the most frequent form, and that understood when not specified as congenital, jurenile, traumatic, soft, etc. C., Soft, is especially that of the young ; the lens-matter is of soft consistency and milky appearance.

Cataracta (kat-ar-ak'-tah). See Cataract. C. secundaria. See After-cataract.

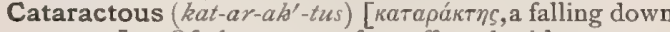
or over]. Of the nature of or affected with cataract.

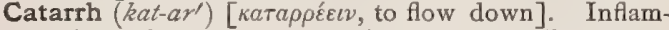
mation of a mucous membrane, especially of the respiratory tract, but also applied to the bladder, etc. Its main symptoms are redness and swelling of the affected membrane with a more or less profuse mucous discharge. C., Epidemic. See Influenza. C., Gastric, gastritis, acute or chronic. C., Intestinal, enteritis, acute or chronic. C., Nasal, coryza, $q . v$. See also Rhinitis. C., Pulmonary, bronchitis, acute or chronic. C., Suffocative. Synonym of Capillary Bronchitis, q.v. See also Suffocative Catarrh. C., Uterine, endometritis. C., Venereal. Synonym of Gonorrhea. C., Vesical, cystitis.

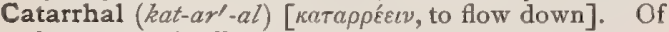
the nature of, affected with, or relating to catarrh. C. Fever. Synonym of Influenza.

Catarrhine (kat'-ar-in) [kará, down; pis, the nose]. In biology, of or pertaining to those monkeys and apes that have approximated nostrils directed downward and separated by a narrow septum.

Catarrhus (kat-ar'-us). See Catarrh. C.genitalium. Synonym of Leukorrhea.

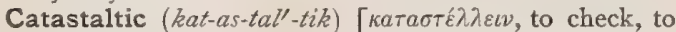
send downward]. 1. Astringent. 2. Passing from above downward (as a nerve impulse).

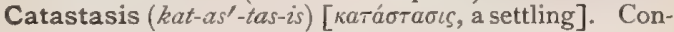
dition, state, habit; a decline, or quieting of symptoms; restitution, as of a displaced part.

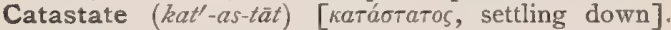
Any one of a series of successive catabolic states, substances, or conditions, each one of which is less complex, more stable, and exhibits less functional activity than its predecessor.

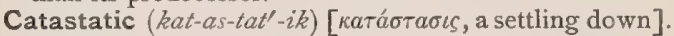
Relating to a catastasis, or to a catastate.

Catatonia, or Katatonia (kat-at-o'-ne-ah) [katá,down; Tóvos, tension]. A form of mental derangement progressing from melancholia successively through mania and stupidity to imbecility and tonic convulsions.

Catatony (kat-at'-o-ne). See Catatonia..

Catechin (kat'-e-chin) [catechu], $\mathrm{C}_{21} \mathrm{H}_{20} \mathrm{O}_{9}+5 \mathrm{H}_{2} \mathrm{O}$. Catechinic acid, the active principle of catechu. It crystallizes in shining needles of a snow-white, silky appearance.

Catechol (kat'-e-chol). See Pyrocatechin.

Catechu $\left(k a t^{\prime}-e-c h o o\right)$ [E. Ind.]. An extract prepared from the wood of Acacia calechu, a native of the East Indies. It contains 50 per cent. of tannic acid, and hence is a powerful astringent. It is used for the diarrhea of children and as a gargle and mouth-wash. Dose of the powdered extract gr. j- 3 ss. See also Pigments, Conspectus of. C., Infusum (B. P.). Dose そj-iss. C., Pulv. Comp. (B. P.). Contains catechu, kino, and rhatany. Dose gr. $\mathrm{xx}-\mathrm{xl}$. C., Tinct. Composita, contains catechu 10, cassia cinnamon 5 , dilute alcohol q. s. Dose $m x-3 j$. C., Trochisci, each contains one grain of catechu with sugar, tragacanth, and orange-flower water. 
Catelectrotonus (kat-el-ek-trot'-o-nus) [katá, down; $\ddot{\eta} \lambda \varepsilon \kappa \tau \rho o v$, amber; tóvos, tension]. The state of increased irritability of a nerve near the cathode. See Anelectrotonus.

Catenulate (kat-en'-u-lāt) [catenula, a small chain]. In biology, having a chain-like arrangement.

Catgut $\left(k a l^{\prime}-g u t\right)$. The intestines of a sheep treated to make ligatures. C., Carbolized, catgut rendered aseptic by soaking in a solution of carbolic acid. C., Chromicized, treated with chromic acid. C. Mat, an appliance used in intestinal anastomosis for the purpose of approximating the edges of the severed intestines. C. Plate, an appliance for uniting the intestinal edges in intestinal anastomosis. It is made of a solid catgut sheet; is thin, large, and flat, and resembles the Senn decalcified bone-plates.

Catha $\left(k a^{\prime}-t h a h\right)$ [Ar., $\left.k a t\right]$. A genus of celastraceous plants. C. edulis affords leaves and twigs which the Arabs use as a substitute for tea and coffee.

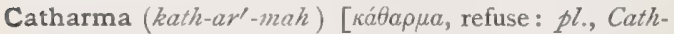
armata]. That which is removed by purgation; excrement.

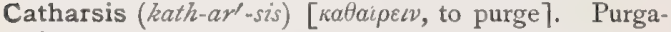
tion.

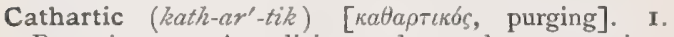
Purgative. 2. A medicine used to produce evacuations of the bowels. A purgative. C. Acid. See Senna. C. Pill, Compound. See Colocynth.

Cathelectrotonus See Catelectrotonus.

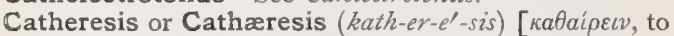
cut down]. I. Prostration or weakness induced by medication. 2. Caustic action; it often designates a feebly caustic action.

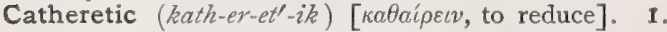
Reducing; weakening; prostrating. 2. Caustic. 3. A reducing or caustic agent.

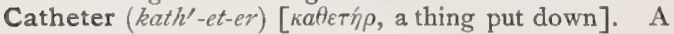
tube-like instrument for evacuating the liquid of a cavity, usually the bladder. C., Bozeman's, a doublecurrent uterine catheter. C., Eustachian, an instru-

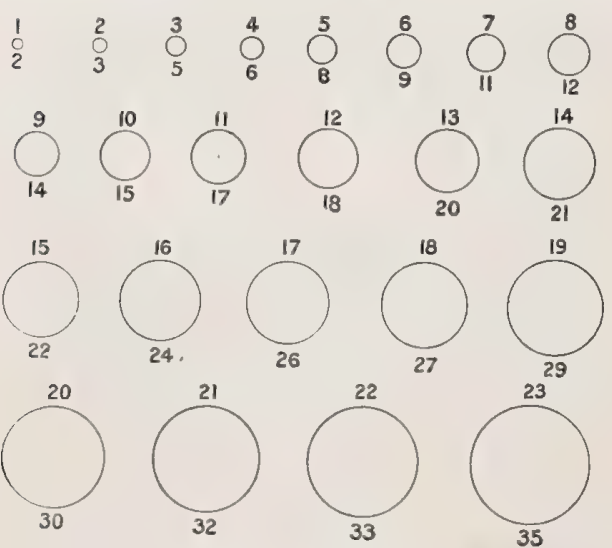

ThE Sizes of CATHETERS.

The upper number indicates that of the American system; the lower, that of the French.

ment for examining the $\mathbf{E}$. tube, distending or making applications to it. C. Fever, systemic disturbance, with fever, following the introduction of the catheter into the urethra. C., Gouley's, a solid curved-steel instrument grooved on its inferior aspect, for passing over a guide, through a stricture into the bladder. C., Lung, a soft-rubber tube that may be passed down the trachea. C., Schrötter's, instruments of hard rubber and of varying caliber, somewhat triangular on section, used for the dilatation of laryngeal strictures. C., Self-retaining, one that will hold itself within the bladder without other appliances to assist it.

Catheterism, or Catheterization (kath'-et-er-izm, or

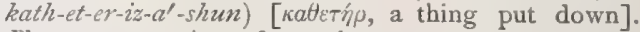
The use or passing of a catheter.

Catheterize $\left(k a t h^{\prime}-e t-\varepsilon r-\bar{\imath} z\right)$ [ $\kappa a \theta \varepsilon r \eta \dot{\rho}$, a thing put down]. To operate upon with a catheter.

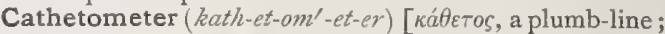

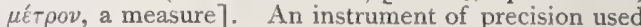
in craniometry for determining the length, breadth, height, and possible abnormity of the skull.

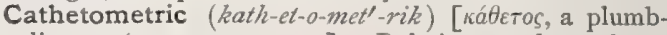
line; $\mu \varepsilon$ t $\rho \circ \nu$, a measure]. Relating to the cathetometer.

Cathetometry (kath-et-om'-et-re) [кádetos, a plumb-line;

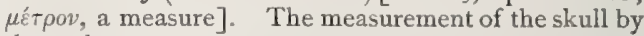
the cathetometer.

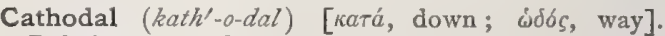
Relating to a cathode.

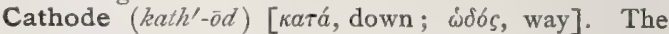
negative electrode or pole of an electric circuit.

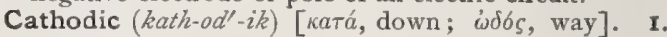
Relating to a cathode. 2. Proceeding downward; efferent or centrifugal (applied to a nerve-current or nerve-impulse).

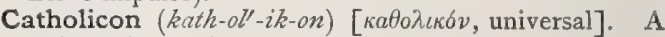
universal remedy ; a cure-all.

Cation (kat'-e-on) [katá, downward; léval, to go]. An electro-positive element; one that accumulates at the cathode in electrolysis. See Ion.

Catkin (kat'-kin) [Ger., Kätzchen, dim, of cat]. In biology, the indeterminate deciduous, scaly spike of unisexual sessile flowers, forming the inflorescence of many trees, e.g., the willow and birch. Cf. Ament.

Catling, or Catlin (kat'-ling, or kat'-lin). A long, pointed, two-edged knife for amputating.

Catnep, or Catnip (kat'-nep, or -nip) [corruption of catmint]. The leaves and tops of the herb Nepeta cataria, a stimulant and tonic; a popular remedy for chlorosis, hysteria, etc. Dose of fld. ext. $3 \mathrm{j}-\mathrm{ij}$. Unof.

Catocathartic (kat-o-kath-ar'-tik). See Catacathartic.

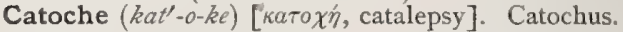

Catochus (kat'-o-kus) [кátoxos, a holding down]. I. Catalepsy ; coma-vigil. 2. Apparent death; trance.

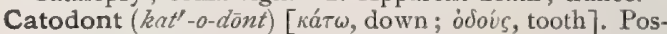
sessing teeth only in the lower jaw.

Catoptric Test, the diagnosis of cataract by means of the reflection of images from the cornea and lenscapsules.

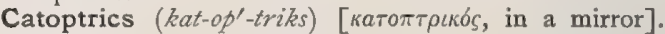
The laws of the reflection of light.

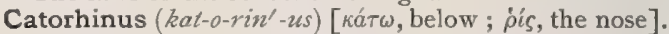
In craniometry, Lissauer's term for a skull in which the angle between the radius fixus and the line joining the wing of the nose and the anterior nasal spine is between $16.5^{\circ}$ and $33^{\circ}$.

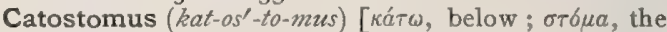
mouth]. In craniometry, Lissauer's term for a skull in which the angle between the radius fixus and the line joining the premaxillary point and the wing of the vomer is between $25.5^{\circ}$ and $42.5^{\circ}$.

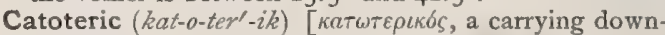
ward]. A purgative or cathartic.

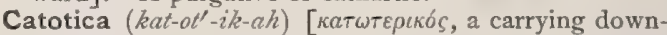
ward]. Medicines or diseases that affect the internal surfaces of the body.

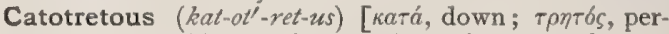
forate]. In biology, having the oral and anal apertures on the ventral surface. C., Amaurosis, a condition noted in suppurative choroiditis in which the 
exudate is visible at a distance as a vivid whitish or yellowish reflex from the pupil. C. Pupil. See Pupil.

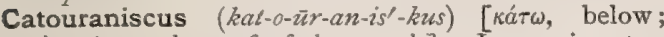
ovpavíкоs, the roof of the mouth]. In craniometry, Lissauer's term for a skull in which the angle between the radius fixus and the line joining the center of the posterior margin of the incisor foramen and the premaxillary point is between $20^{\circ}$ and $40^{\circ}$.

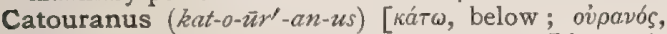
the roof of the mouth]. In craniometry, Lissauer's term for a skull in which the angle between the radius fixus and the line joining the premaxillary point and the posterior nasal spine is between $17^{\circ}$ and $34^{\circ}$.

Cattimandu $\left(k a t-i n-a n^{\prime}-d o o\right)$ [E. Ind.]. An E. Indian tree, Euphorbia cattimandoo; also its medicinal gum. It is used as a cement and as a remedy for rheumatism. When fresh it is an active vesicant. Unof.

Cattle Plague (kat'-l plāg). See Rinderpest.

Caucasian Idiocy (kaw-kaz'-yan id'-e-o-se). See Idiocy, Ethnic.

Cauda (kaw'-dah) [L.]. A tail-shaped appendage. The tail-like part of the caudatum. C. cerebelli, the vermiform process. C. cerebri, the part of the encephalon between the pons and optic thalami, consisting of the crura and the tegmentum. C. dorsalis. I. The spinal cord. 2. The oblongata. C. epididy midis, the inferior part of the epididymis. C. equina, the terminal extremity of the spinal cord, in conjunction with the roots of the sacral nerves. C. pancreatis, the slender left extension of the pancreas.

Caudad (kaw $\left.e^{\prime}-d a d\right)$ [cauda, the tail; $a d$, to]. Toward the tail or cauda; opposed to cephalad; in man, downward.

Caudal (kaze'-dal) [cauda, the tail]. Pertaining to a cauda, or tail. The term Ural has been proposed to take the place of caudal.

Caudalis (kare-da'-lis) [cauda, a tail]. In biology, applied as the specific name of fins or other organs near the tail.

Caudate (kaw'-dat) [cauda, a tail]. Having or resembling a tail. C. Lobe of Liver, a small elevation of the liver. C. Nucleus, the intra-ventricular portion of the corpus striatum. See also Caudatum.

Caudatum (kavi-da'-tum) [cauda, a tail]. A ganglion or free ring of gray matter circling round the lenticularis of the brain. It is massive in the frontal portion, but becomes attenuated caudad; the anterior portion is called the head, the posterior the tail.

Caudex (kazo'-deks) [caudex, a tree-stem]. In biology, applied to the scaly, unbranching trunk of a palm tree or tree fern.

Caudicle (kaw'-dik-l) [caudex, the stem of a tree]. In biology, a little stalk, as that of the pollen-masses in orchideous plants.

Caudiduct (kaw'-de-dukt) [cauda, tail ; ducere, to draw]. In biology, to draw or carry backward toward the tail.

Cauditrunk (kaze'-de-trunk) [cauda, tail; truncus, trunk]. In biology, that part of the body behind the head of fishes and fish-like mammals.

Caudle $\left(k a w w^{\prime}-d l\right)$ [ME., caudel, a warm drink]. A nutritious food for invalids. It is made as follows : Beat up an egg to a froth; add a glass of sherry and half a pint of gruel. Flavor with lemon-peel, nutmeg, and sugar.

Caudula (kaw'-du-lah) [cauda, a tail]. In biology, a marginal tail-like process.

Caul (kawl) [ME., calle, a hood]. I. A portion or all of the fetal membranes covering the head and carried out in advance of it in labor. 2. The great omentum.
Caulescent (kaw-les'-ent) [caulis, a stalk]. In biology, applied to plants having a distinct leaf-bearing stem.

Caulicle (kaw $\left.w^{\prime}-l i k-l\right)$ [caulis, a stalk]. In biology, that portion of the stem of an embryo plant that is below the cotyledons and above the radicle.

Cauliflower Excrescence (kaze-le-floz'-er eks-kres'ens). Epithelioma of the cervix uteri. See also Verruca acuminata.

Cauliform (kaw'-lif-orm) [caulis, a stalk; forma, shape]. In biology, resembling a stem.

Cauligenous (kaw-lij'-en-us) [caulis, a stalk; genus, producing]. Borne upon the stem.

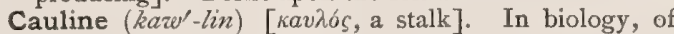
or pertaining to the stem.

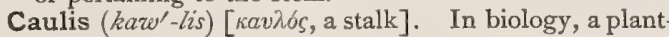
stem.

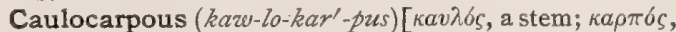
fruit]. In biology, applied to plants that bear fruit from year to year upon the same stem.

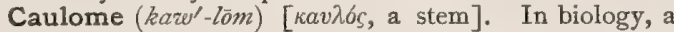
general term for all kinds of stems.

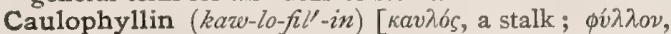
a leaf]. A resinoid precipitate from the tincture of caulophyllum. See Caulophyllum.

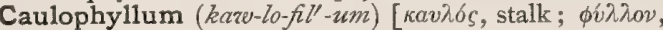
leaf]. Blue Cohosh, "Squaw-root;" the rhizome and rootlets of $C$. thatictroides, growing in Canada and the northern U. S. It contains a glucosid, Saponin, and two resins, one of which is Caulophyllin. It produces intermittent contractions of the gravid uterus, and possesses diuretic, emmenagogue, and antispasmodic powers. There are no official preparations. Dose of the powdered drug gr. $\mathbf{v}-\mathrm{xx}$; of Caulophyllin, gr: ij-v.

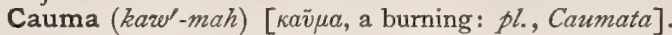
Fever; heat; pyresis; an inflammatory fever; a burn. C. enteritis. Synonym of Intestinal Catarrh, Acute.

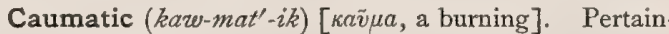
ing to cauma.

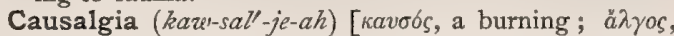
pain]. Neuralgia with burning pain, often of the foot; sometimes with a local glossiness of the skin due to impairment of the normal nerve-stimulus of the part.

Causation (kawz-a'-shun). See Etiology.

Cause (kawz) [causa, a cause]. The sources, conditions and origins of a result. The preceding factors that unite to produce a given condition. Causes are spoken of as efficient, instrumental, final, primary, secondary, predisposing, controlling, determining, ultimate, exciting, etc. C. Causans, the causing cause or the essential predetermining factor. C., Exciting, the immediately preceding and conditioning factor. C., Predisposing, that which tends to the development of a condition.

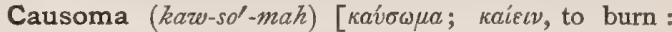
$p l .$, Causomata $]$. A burning; usually an inflammation.

Caustic [kazes'-tik) [Kaikw, to burn]. A substance that disorganizes or destroys living tissue ; it is mostly used in surgery to destroy unhealthy growths. C. Alkali, a pure alkaline hydrate or oxid. C., Common, potassa fusa or potassa cum calce. C., Dubois's, arsenious acid I, mercuric sulphite I6, dragon's blood 8 parts. C.-holder, a porte-caustic. C., Lunar, argentic nitrate, or nitrate of silver. C., Mitigated, argentic nitrate made less active by fusion with potassium nitrate or argentic chlorid. C. Potash, potassium hydrate. See Potassium. C. Soda, sodium hydrate.

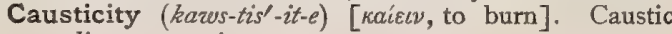
quality ; corrosiveness. 
Causticum (kaws'-tik-um). See Caustic.

Cauter (kaw'-ter) [kavтijp, a burner]. A searing-iron or cautery-iron; any caustic application.

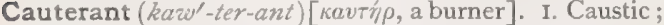
escharotic. 2. Any caustic substance; a caustic.

Cauterism (kaw'-ter-izm). See Cauterization.

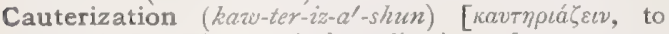
cauterize]. The surgical application of a cautery; the effect of such application.

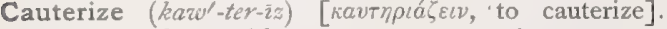
To sear or burn with a cautery or a caustic

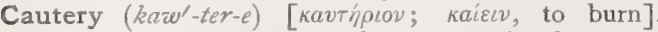
Primarily, the term was applied to caustics, but more frequently now to the platinum-wire heated by an electric current, or the hot iron, for counter-irritation, removal of tissue, etc. C., Actual, the white-hot iron. C. Button, iron heated in hot water. C., Corrigan's. See Button. C., Dento-Electric, consists of a looped wire, held by set-screws, in contact with metal conductors that pass through a hardrubber handle. The battery wires are coupled to two terminals. This appliance is held in the hand like a pencil in writing, and the current is closed by pressing a spring with the forefinger, when the resistance of the loop of wire causes it to become heated. It is employed for obtunding sensitive dentine. C., Galvanic, a platinum wire heated by electricity. C., Gas, cauterization by a stream of burning gas directed upon the part. C., Paquelin's, or C., Thermo-, a hollow platinum point kept at \& uniform temperature by a current of benzene vapor. C., Potential, or C., Virtual, the application of caustic substances.

Cava $\left(k a^{\prime}-v a h\right)$ [L.: pl., Cava]. A vena cava.

Caval ( $\left.k a^{\prime}-v a l\right)$ [cava, a hollow]. Relating to a vena cava.

Cavalry Bone (kav'-al-re bön). A bony deposit in the adductor muscles of the thigh.

Cavernoma (kav-ern-o'-ma) [caverna, a cavern; o $\mu a$, a tumor]. A cavernous tumor; a cavernous angioma.

Cavernous (kav'-ern-us) [caverna, a cave]. Having cave-like spaces or hollow places. C. Bodies, the corpora cavernosa of the penis. C. Breathing, the reverberating or hollow sound of bronchial breathing in dilated or abnormal bronchi. C. Groove, the carotid groove. C. Plexus. See Plexus. C. Râle. See $C$. Breathing. C. Sinus, situated at the side of the body of the sphenoid. C. Tissue, erectile tissue. C.Tumor, See Angioma. C. Whisper, whispering resonance in auscultation, modified by transmission through a cavity. C. Voice. See Pectoriloquy.

Cavernula Tentacularis. In biology, a subumbral tentacle-funnel, surrounding the base of each tentacle in many Cubomedusa and Peromedusce.

Cavernulæ Subumbrales. In biology, niches of the subumbral cavity in Meduse.

Caviar, or Caviare (kav-e-ar') [Fr.]. The salted hard roe of the sturgeon and other large fish.

Cavicorn (kav'-ik-orn) [cavus, hollow; cornu, horn]. In biology, having hollow horns; or a hollow-horned ruminant.

Cavitary (kav'-it-a-re) [cavilarius, hollow]. Hollow ; applied to any nematode worm; any intestinal worm that has a body-cavity; a worm that is not anenterous.

Cavitas (kav'-it-as) [L.]. A hollow. C. cochleata. See Duct, Spinal. C. pulpæ, the pulp-cavity of a tooth. See Dental Cavity.

Cavity (kav'-it-e) [cavitas, from cavus, hollow]. Any hollow, normal or pathologic. Among the normal cavities are the abdominal, arachnoid, axial, buccal, cranial, frontal, nasal, pelvic, pleural, thoracic, ventricular, etc:; among the abnormal are pulmonary and dental cavities. C.-plate, a term applied in mechan- ical dentistry to a metallic base for artificial teeth, so constructed as to have one or more vacant spaces between it and the gums, which, when applied, and the air exhausted, contributes very greatly to the firmness of its adhesion. C., Preperitoneal, a name given by Retzius to the loose and yielding subperitoneal tissue in front of the bladder, under the supposition that it could be inflated. It is not a true cavity, but merely a succession of areolar spaces. C., Sigmoid. See Signzoid.

Cavo-valgus (ka'-vo-val'-gus) [cavus, hollow; valgus, bow-legged]. Cavus combined with valgus. See Chubfoot.

Cavum ( $k a^{\prime}-$ vum) [L.]. Any hollow or cavity, normal or pathologic. C. dentis. See Dental Cavity.

Cavus (ka/uns) [L.]. I. A hollow; a cavity. 2 Talipes arcuatus; hollow-foot.

Cayenne Pepper $\left(k i^{\prime}-e n\right.$ pep'-er). See Capsicum.

Cazenave's Lupus. See Diseases, Table of. C. Solution. An animal parasiticide used in dermatology. It consists of lodid of sulphur, iodid of potassium, of each I I $/ 2$ drams, water 32 ounces.

Cazeneuve's Test. See Tests, Table of.

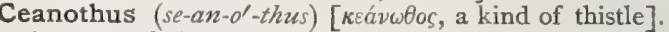
A genus of rhamnaceous shrubs, chiefly N. American. C. americanus, New Jersey tea, red root, is used in domestic medicine as an astringent and alterative; its leaves are substituted for tea. Unof.

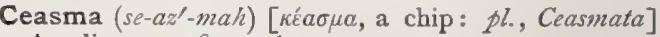
A splinter; a fissured state.

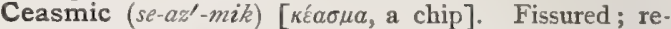
maining in the primitive fissured state of the embryo. See Teratism.

Cebadilla (thez-ad-ēl'-yah) [Sp., "little barley"]. The seed of Asagraca officinalis, or Schonocaulon officinale; official in the B. P., and important as the principal source of the alkaloid veratrin. It is highly poisonous.

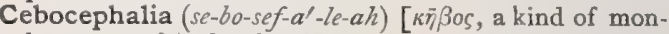
key; $\kappa \varepsilon \phi a \lambda \eta \eta$, the head]. The condition of being cebocephalic

Cebocephalic (se-bo-sef-al'-ik) [ $\kappa \bar{\eta} \beta o s$, a kind of monkey; $\kappa \varepsilon \phi a \lambda \eta n$, the head]. Of the nature or appearance of a cebocephalus.

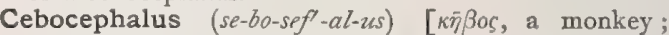
$\kappa \varepsilon \phi a \lambda \eta$, head]. A variety of single autositic monsters of the species cyclocephalus, in which there is entire absence of the nose, with, however, two orbital cavities and two eyes, although the interocular region is narrow and perfectly flat.

Cecal (se'-kal) [creum, blind]. Relating to or of the nature of the cecum; cæcal.

Cecitas (se'-sit-as) [L.]. Blindness.

Cecitis (se-sit-tis) [cacum, the cecum; $\iota \tau \iota s$, inflammation]. Inflammation of the cecum; typhlitis, q.v.

Cecity (ses'-it-e) [cacus, blind]. Blindness.

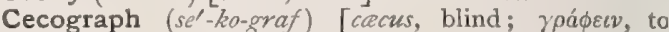
write]. A writing-machine for the use of the blind.

Cecum (se'-kum) [cacus, blind]. The large blind pouch or cul-de-sac in which the large intestine begins.

Cecutiency (se-ku'-shen-se) [cacutire, to become blind]. Tendency to, or the commencement of, blindness.

Cedar (se'-dar) [cedrus, cedar]. One of the genus of coniferous trees, Cedrus. C.-apple, an excrescence or gall produced upon the red cedar, Juniperus virginiana, by the fungus called Gymnosporangium macropus. Cedar-galls are popularly esteemed as an anthelmintic. Dose gr. viij-xviij, in powder. Unof. C.Gum, the fragrant resin of Callitris arborea, a coniferous South African tree. It is used in making plasters. Unof. C.-wood Oil. See Cailcedra. 


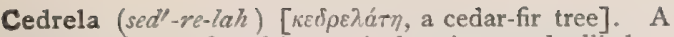
genus of trees found in tropical regions and allied to mahogany. C. febrifuga, of Southern Asia; C. odorata, bastard cedar, of tropical America (see Cailcedra); C. rosmarinus, of Indo-China, and C. toona, of India, are among the species that afford active medicines. All unof.

Cedrene $\left(s e^{\prime}-d r e ̄ n\right)$ [cedrus, cedar], $\mathrm{C}_{15} \mathrm{H}_{24}$. A volatile liquid hydrocarbon found in oil of red cedar (see Juniperus virginiana), oil of cloves and oil of cubebs. C. Camphor, $\mathrm{C}_{15} \mathrm{H}_{26} \mathrm{O}$, a camphor that separates from the oil of red cedar.

Cedrin (se'-drin) [cedrus, cedar]. A bitter crystalline substance obtained from cedron.

Cedriret (sed"-re-ret). See Caroulignone.

Cedron (se'-dron) [cedrus, cedar]. The seeds of $C$. simaba, a popular external remedy in tropical America for the bites of venomous insects and serpents, and of reputed value in malarial fevers. Dose of the fld. ext. $m$ j-viij.

Ceke $\left(t h \bar{e}^{\prime}-\ell\right)$. A Feejee term for elephantiasis of the scrotum.

Celandini (sel'-an-dìn), See Chelidonium.

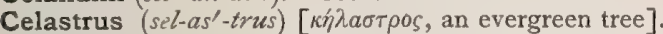
A genus of trees and shrubs, nearly allied to Euonymus. Many of the species are medicinal, and some are poisonous. C. scandens, the climbing staff-tree of North America, is cathartic, diuretic, and alterative; it is called waxwork, bitter-sweet, and fever-twig.

Celation (sel-a $\left.a^{\prime}-s h u n\right)$ [celatio, a hiding]. The concealment of illness, of a birth, or of pregnancy.

Cele (sêl) $[\kappa o i n i a$, cavity]. An encephalic cavity; used instead of ventricle.

-cele (sel) [ $\kappa \hat{\lambda} \lambda \eta$, a tumor]. A suffix denoting a tumor.

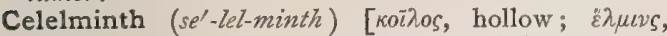
worm]. A parasitic worm with a digestive canal or cavity; a cavitary worm.

Celery $(s e l l-e r-e)$ [ $\sigma \varepsilon \hat{c}^{\prime} \iota \nu \nu v$, a kind of parsley]. The stalk of Apium graveolens, or common garden celery. It contains Apiol, $q . v$. It is reputed to be antispasmodic and nervine. Dose indefinite. C. Seed, used to cover the taste of other drugs. Unof.

Celia $\left(s e^{\prime}-l e-a h\right)[\kappa o \iota \lambda i \alpha$, the belly]. I. The belly: the stomach. 2. Any ventricle, or normal cavity of the brain.

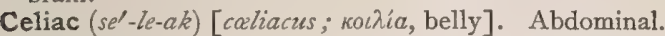
Pertaining to the belly. C. Affection, a chronic intestinal disorder most commonly met with in children between the ages of one and five, characterized by the occurrence of pale, loose stools, not unlike gruel or oatmeal-porridge ; they are bulky, not watery, yeasty, frothy, and extremely offensive, and are accompanied by anemia and debility without much emaciation. The exhaustion may be aggravated by intercurrent attacks of watery diarrhea, and death may supervene. It is also called Diarrhcea alba or Diarrhaa chylosa. It is due probably to a temporary suspension of the pancreatic function. C. Artery. Same as C.Axis. See Arteries, Table of. C. Axis, a branch of the abdominal aorta; it divides into the gastric, hepatic, and splenic arteries. See Arteries, Table of. C. Ganglion. See Ganglion, Semilunar. C. Passion, painful diarrhea, or dysentery. C. Plexus. See Plexuses, Table of.

Celiaca $\left(s e-l l^{\prime}-a k-a h\right)$ [koLhia, the abdomen]. Diseases of the abdominal organs.

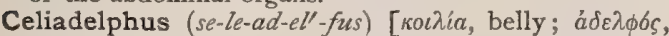
brother]. A monstrosity having two bodies joined at the abdomen.

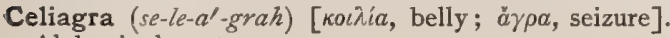
Abdominal gout.

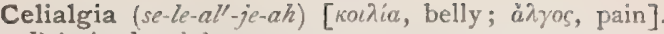
Pain in the abdomen.

Celian, Celine (se'-le-an, se'-lin). Same as Celia

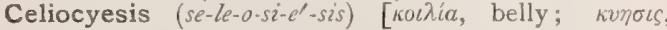
pregnancy]. Abdominal extra-uterine gestation.

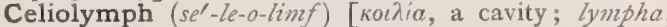
water]. The cerebro-spinal fluid.

Celiomyalgia (se-le-o-mi-al'-je-ah) [koinía, belly; $\mu$ is, muscle; $\dot{a} \lambda \gamma o s$, pain ]. Pain in the abdominal muscles.

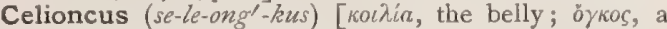
swelling]. A tumor of the abdomen.

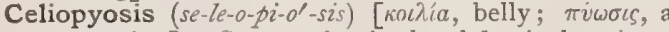
suppuration]. Suppuration in the abdominal cavity.

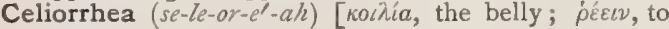
flow]. Diarrhea.

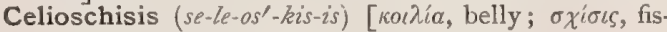
sure]. Congenital abdominal fissure.

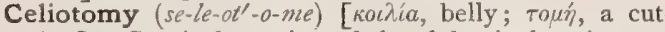
ting]. Surgical opening of the abdominal cavity.

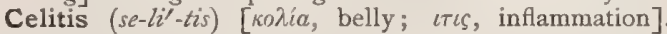
Inflammation of the abdominal organs.

Cell (sel) [cella, a small, hollow cavity]. I. In anatomy, any one of the interstitial spaces and small cavities of the bones, etc. 2. In biology, a nucleated mass of protoplasm capable of reproduction. A mass of protoplasm, with or without a cell-wall and with or without a nucleus. 3. A galvanic element, or single member of a galvanic battery without the connecting wire between the metals. See Battery. 4. The case or cup in which a zoöid or larva is located. See Cell-body. C., Abbe-Zeiss Counting, a glass receptacle cemented upon a glass slide, its floor being marked in microscopic squares. It is used for counting the blood-corpuscles. C., Air. See Air-cell. C., Ameboid, a cell capable of changing its form and of moving about like an ameba. C., Apolar, a nerve-cell without processes or poles, such as has been ascribed to the sympathetic system. C., Beaker. See C., Goblet. C., Betz's, the motor or ganglionic cells comprising the fourth layer of the motor area of the gray matter of the brain. C.-body, the mass of a cell, composed of two substances, the mitoma, or cytomitoma, and the paramitoma. The first is the thread-like basis of the cellbody, the latter, the homogeneous filar and interfilar substance. The nucleus is composed of the karyomitoma, or nuclear network, otherwise called the chromatin, the nuclear sap, or substances contained in the meshes of the chromatin, and from its non-staining quality called achromatin; and the nuclear membrane, made up of two layers, the outer achromatic, the inner chromatic, or staining. The mucleoli are usually multiple, and are composed of more refractile matter. C., Bunsen, the same as the Grove cell except that the platinum electrode of the latter is replaced in the Bunsen by a stick of carbon. C.-capsule, a thick or unusually strong cell-wall. C., Ciliated, one provided with cilia. C. of Corti, any one of the haircells on the outer surface of the organ of Corti. C. Cylindrical, a variety of epithelial cell. C., Daniell's, a battery cell containing two fluids, viz., a saturated solution of sulphate of copper and a semi-saturated solution of sulphate of zinc. In the former is placed a sheet of metallic copper, and in the latter a mass of zinc, these two metals forming the electrodes of the cell. C., Daughter-, a cell originating from the division of the protoplasm of a mother-cell; any one of the young cells found within the substance of an undivided mother-cell. C. of Deiters, one of the cells with fine processes resting on the basilar membrane of the cochlea, beneath the air-cells; also a nucleated cell of the neuroglia. C., Demilune, Giannuzzi's cells, granular protoplasmic cells found in mucous glands, 
lying between the mucous cells and the basement membrane. They play an important part in the functional activity of the gland. C.-Doctrine, the theory that the cell is the unit of organic structure, and that cell-formation is the essential process of life and its phenomena. C., Edison-Lalande, a variety of cell used in making galvanic batteries. C., Electrolytic, a cell or vessel containing an electrolyte, in which electrolysis is carried on. C., Endothelial, one of those lining the intima of the blood-vessel system. C., Epidermic, or Epithelial, one of those covering the membranes of the free surface of the body. C., Ethmoidal, any one of the cellular cavities of the lateral masses of the ethmoid bone. Called also ethmoidal sinuses. C., Ganglion, a cell of the gray matter of the brain or spinal cord. C. of Giannuzzi. See $C$, Demilune. C., Giant, any polynucleated body of protoplasmic matter occurring in tuberculosis, sarcoma, etc. C.-globulins, Halliburton's name for forms of globulin that occur in lymph-corpuscles and extracted from them by solutions of sodium chlorid. C., Goblet, a form of epithelial cell. C., Gowers's, an apparatus for counting blood-corpuscles. C., Grenet, a variety of open cell used in making galvanic batteries. C., Grove, a two-fluid battery cell, the fluids being dilute sulphuric and nitric acids and the metals immersed in them respectively zinc and platinum. C.-islets, the centers of most active growth and proliferation in young cellular tissues. They contain the stores of nutriment that are gradually dissolved and digested. C., Law, a variety of cell used in making galvanic batteries. C., Leclanché, a variety of cell used in making galvanic batteries. It may be made as a liquid cell or as a dry cell, the latter being preferable. C., Lymphoid, a large ameboid cell. C., Mother-, a cell that divides its protoplasm and gives each part a new cell-wall. C., Mounting. See Mounting-cell. C.-Multiplication, Cytogenesis, a name given to the process of reproduction of cells. It may be endogenous, as when the cell-contents break up by segmentation into separate nucleated masses within the cell-wall; gemmiparous, as when new cells bud from the mother-cell; and fissiparous, as when the mother-cell divides by cleavage into two or more cells. C., Neuro-muscular, a name given to certain cells of lower life-forms, that act in part as nerves and in part as muscles. C.-nests, Epidermic Pearls: globular masses of flattened cells contained in epitheliomata. C., Olfactory, any one of the cells that lie between the network of epithelial cells in the nasal fossæ. They consist of a body and two processes, one running outward to the surface of the mucous membrane, the other running inward and connected with filaments of the olfactory nerve. C.-parasite, in biology, applied to any one of various microparasites, as, $e_{.}$, ., a coccidium, living within a cell, C.sap, in biology, the more fluid portion of the cell-contents. C. of Schultze. Same as C., Olfactory. C., Seminal, any one of the epithelial cells contained in the membrana propria and constituting the seminal tubes. C., Sphenoidal, one of the two large cavities in the interior of the body of the sphenoid bone. C., Squamous, a variety of epithelial cells. C., Stammer's, a variety of cell used in making galvanic batteries. C.-substance, in biology, the material composing a cell. C., Thoma-Zeiss. Same as $C$., Abbe-Zeiss. C., Vasofactive, or Vasoformative, a cell that in embryonic or very early life, and probably in certain neoplasms, anastomoses with other similar cells so as to form blood-vessels.

Cella $\left(\mathrm{sel}^{\prime}-a h\right)$ [L.]. A portion of the paracele extending caudad from the porta. C. lateralis, the lateral ventricle of the brain, or one of its cornua. C. media, the central cornu of the lateral ventricle, or that part of the ventricle whence the cornua extend.

Cellæform (sel'-e-form) [cella, a cell; forma, shape]. Resembling a cell, but not such morphologically. Cf. Celliform.

Celliferous (sel-if'-er-us) [cella, cell; ferre, to bear]. Producing, forming, or bearing cells.

Celliform (sel"-if-orm). See Celleform.

Celloid (sel'-oid) [cella, a cell; cisos, form]. Resembling a cell.

Celloidin (sel-oid'-in). A concentrated form of collodion for use in imbedding objects for histologic purposes.

Cellula (sel'-u-lah). See Cellule.

Cellulæ gangliosæ. Ganglion cells, or mesodermal nerve celis; neuroblasts. C. palpantes, tactile cells.

Cellular (sel'-u-lar) [cella, cell]. Relating to or composed of cells. C. Cartilage, cartilage composed mainly of large cells, with but little intercellular substance. C. Membrane, C. Tissue, areolar tissue; bony connective tissue; cancellous tissue. C. Therapy, the name applied by Aulde to the method in therapeutics of exhibiting properly-selected medicaments with a view to restoration of cell-function. It aims to apply scientifically those remedies that experience has shown to possess special curative properties in the restoration of disordered functions.

Cellule $\left(\mathrm{sel}^{\prime}-\bar{u} l\right)$ [cellula, a small cell]. A small cell or cavity.

Celluliferous (sel-u-lif'-er-us) [celluln, a little cell; ferre, to bear]. In biology, producing small cells.

Cellulitis (sel- $u$-li'-tis) [cellula, a small cell ; $\iota \tau \iota s$, inflammation]. A diffuse inflammation of cellular tissue. C., Pelvic. See Parametritis.

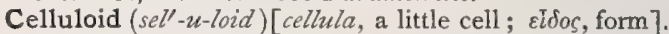
A valuable product of the action of camphor upon pyroxylin. It is prepared in a great variety of forms, both transparent and opaque, colored uniformly or mottled and striated. It cannot be caused to explode by heat, friction, or percussion. When brought into contact with flame it burns like paper. It dissolves in warm, moderately concentrated sulphuric acid, and is also soluble in glacial acetic acid, rapidly in warm, moderately concentrated nitric acid (four volumes of fuming acid to three of water), and in a hot, concentrated solution of caustic soda. The density of celluloid ranges from I.3Io to I.393. When heated to $125^{\circ}$ C. it becomes plastic and can be moulded into any desired shape. Separate pieces can also be welded together by simple pressure at this temperature. It is useful in various ways in surgery. It is used sometimes to form a plastic base for artificial teeth, known by various names, as "Rose Pearl," "Pyroxylin," etc. See Zylonite.

Cellulose (sel'-u-loss) [cellula, a little cell], $\mathrm{C}_{12} \mathrm{H}_{20} \mathrm{O}_{10}$. Wood fiber; lignose. The principal ingredient of the cell-membranes of all plants. It is a white, amorphous mass, insoluble in most of the usual solvents. In biology, the primary substance of organic cell-walls, characteristic of plant-cells, but found in the Tunicata among animals. It is dissolved by Schweitzer's reagent (ammonium-cupric-oxid) and decomposed by several forms of bacteria, e.g., Bacillus butyricus, Prazmowski ; Bacterium gummis, Comes, and Bacterium putredinis, Davaine. To stain.-Use Grenacher's Alcoholic Borax-Carmin, Ehrlich's or Delafield's Hematoxylin, Methyl-Green, Methylene-Blue, Safranin, Fuchsin, Chlor. Zinc, Iodin, Phloroglucin, Anilin, Chlorid. See, also, Carbohydrates, Table of.

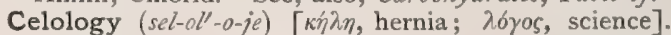
That branch of surgical science that treats of hernia. 


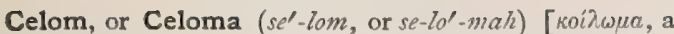
cavity]. A term used by embryologists and others to denote the body-cavity in its widest morphologic sense; the space between the ectoderm and the entoderm.

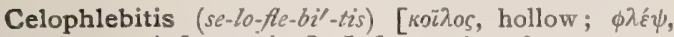
vein; $\iota \tau \iota s$, inflammation]. Inflammation of a vena cava.

Celophthalmia (se-loff-thal'-me-ah) [koĩhos, hollow; $\dot{b} \phi a \lambda \mu \sigma \delta$, eye]. Hollowness of the eyes.

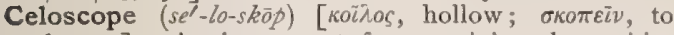
observe]. An instrument for examining the cavities of the body by means of the electric light, enclosed in a flask and mounted upon a glass shank.

Celosis $\left(s e-l o^{\prime}-s i s\right)$ [koinos, hollow]. The formation of any cavity.

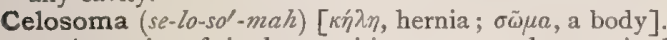
I. A species of single autositic monsters characterized by "more or less extensive body-cleft with eventration, associated with various anomalies of the extremities, of the genito-urinary apparatus, of the intestinal tract, and even of the whole trunk." 2. A variety of the foregoing species in which there is a lateral or median eventration, with fissure, atrophy, or even total absence of the sternum, and protrusion of the heart.

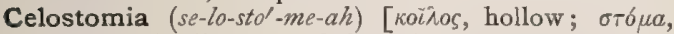
mouth]. Hollowness of the voice.

Celotome $\left(s e^{\prime}-l o-t \bar{m} m\right)$ [ $\kappa \dot{\eta} \lambda \eta$, hernia; $\tau \hat{\varepsilon} \mu \nu \varepsilon \iota \nu$, to cut]. A hernia-knife.

Celotomy (se-lot'-o-me) [ $\kappa \dot{\lambda} \lambda \eta$, hernia ; $\tau \hat{\varepsilon} \mu \nu \varepsilon \imath \nu$, to cut]. The operation for strangulated hernia by incision of the stricture.

Celsus's Operations. See Operations, Table of.

Celtis (sel'tis) [L., an African species of lotus]. A genus of ulmaceous trees. C. australis, the European nettle-tree, honey-berry, or lote, has mild, astringent leaves and bark. C. occidentalis, the hackberry of N. America, has edible, astringent berries; the bark is said to be anodyne, astringent, febrifuge. Unof.

Cement (se-ment') [cementum, a rough stone]. Any plastic material capable of becoming hard and of binding together the objects that are contiguous to it; filling-material for the teeth; the crusta petrosa of the teeth. See Teeth. C.-disc, the glandular disc of orchids. C.-duct, the duct of the cement-gland in cirriped crustaceans. C., Shellac, a cement for sealing microscopic preparations and for making shallow cells. It is prepared by dissolving the gum or scales of shellac in about an equal volume of alcohol. Decant or filter the fluid, and to prevent brittleness add to every 50 parts 5 parts each of castor oil and Venetian turpentine.

Cementoblast (se-ment'-o-blast) [camentum, cement ; $\beta \lambda$ aotós, germ]. A cement-corpuscle in tooth-tissue; more correctly, an osteoblast that takes part in the development of the dental cement.

Cemento-dentinary (se-ment-o den'-tin-a-re) [camentum, cement; dens, dentis, a tooth]. Relating to the cement and dentine of a tooth.

Cementoma (se-ment-o'-mah) [camentum, cement; ö $\mu \alpha$, tumor: pl., Cementomata]. A tumor thrown out by the irritated alveolar periosteum.

Cementum (se-ment-um). See Tooth and Cement.

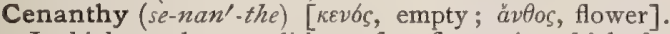
In biology, that condition of a flower in which the stamens and pistils are suppressed.

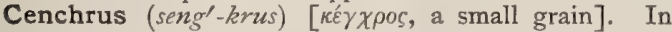
biology, a small spot on the metathorax of an insect.

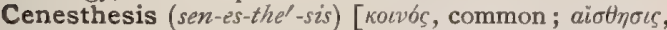
feeling]. A sense of existence, either painful or pleasurable. It is the prevailing conscious state of feeling, either of depression or of exaltation, which is the resultant of the subconscious organic sympathies of the whole organism. It does not exceed physiologic limits so long as it does not exclude the normal exercise of mental functions.

Cenogenetic (se-no-jen-et'-ik) [ [ olvos, common $\varepsilon \sigma \iota$, generation]. In biology, a modified, shortened, and simplified mode of development.

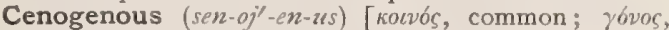
produced]. In biology, the power of reproducing by means of eggs at one time and viviparously at another, as seen in the Aphides.

Cenosis (sen-o'-sis) [ $\sigma^{\prime} v \omega \sigma \iota \zeta$, a draining]. Evacuation; apocenosis.

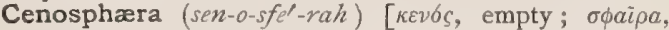
sphere]. In biology, the spherical skeleton of certain radiolarians.

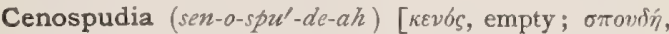
zeal]. "Brown study ; " mental absorption, or anxiety with regard to unimportant matters.

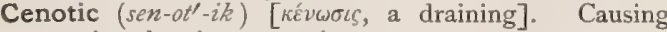
cenosis ; drastic ; purgative.

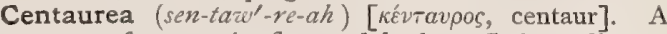
genus of composite-flowered herbs. C. benedictus. See Carduus. C. centaurium, the greater centaury of Europe, is aromatic, astringent, diaphoretic, and stomachic. C. cyanus, corn-flower, blue-bottle; once used for fevers and in preparing collyria. C. solstitialis, Barnaby's thistle; diuretic and antipyretic. C. nigra, of Europe (knap-weed, centaury), is astringent and diuretic. All unof.

Centaury (sen'-taz-re) [centauria]. A popular name for various plants of the genera Centaurea, Erythraa, Sabbatia, Chlora, etc. It is used as a simple, bitter tonic. Dose $3^{\mathrm{ss}-\mathrm{j}}$ in decoction several times a day. Unof.

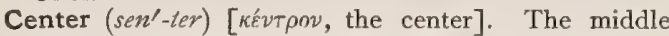
point of any surface or of a body. The ganglion or plexus whence issue the nerves controlling a function. C., Accelerating, a probable center in the oblongata sending accelerating fibers to the heart. They leave the cord through the rami communicantes of the lower cervical and upper six thoracic nerves, passing thence into the sympathetic. C., Anospinal, controls defecation; it is situated at the level of the 5 th, 6 th, and 7 th lumbar vertebræ; but for the coordinated activity it must remain in connection with the brain. C., Auditory, probably in the temporosphenoidal lobes, upon each side. C., Broca's. See C., Speech. C., Cardioinhibitory, in the oblongata, carried by the vagus. C., Ciliospinal, connected with the dilatation of the pupil; it is in the lower cervical part of the cord. It controls the movements of the ciliary body. C., Convulsional, in the oblongata, on the floor of the 4 th ventricle. C. for Closure of Eyelids, in the oblongata, a part of the facial center. C., Coughing, in the oblongata, above the respiratory center. C., Diabetic, in the posterior part of the anterior half of the floor of the $4^{\text {th }}$ ventricle, in the median line. C., Ejaculation, Budge's genitospinal center, 4th lumbar vertebra (rabbit). C., Erection, is in the spinal cord, but is controlled from the oblongata. C. for Mastication and Sucking, facial and hypoglossal centers. C. for Secretion of Saliva, on the floor of the 4 th ventricle. C., Gustatory and Olfactory, in the uncinate gyrus. C., Heat-regulating or Temperature, the center for the control of body-temperature. See Thermotaxis. C., Leg, in the ascending frontal convolution. C., Micturition, the vesico-spinal center of Budge, at the level of the lumbar vertebræ; coördination requires cerebral connection. C. of Ossification, the place in bones at which ossification begins. C., Parturition, at the level of the Ist and 2 d lumbar vertebræ. C., Respir- 
atory, in the oblongata, between the nuclei of the vagus and accessorius; called by Fluorens the Naud Vital, or Vital Point. C., Sensory, or Psychosensorial Areas, occipital and temporosphenoidal lobes, probably the same as, or intimately associated with, the motor centers of the parts. C., Sneezing, same as for nerves for the muscles of expiration. C., Spasm, in the oblongata, at its junction with the pons. C., Speech, in the third left frontal convolution in right-handed people. C., Swallowing, on the floor of the 4th ventricle. C., Sweat, the dominating center is in the oblongata, with subordinate spinal centers. C., Trophic. See Trophic. C., Upper, for Dilator Pupillæ, in the oblongata. C., Vasodilator, probably exists in the oblongata, with a function the opposite of that of the vaso-motor. C., Vasomotor, in the oblongata. C., Vesicospinal. See Micturition C. C., Visual, in the occipital lobe, especially in the cuneus.

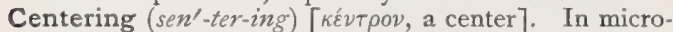
scopy, the arrangement of an object or an accessory so that its center coincides with the optic axis of the microscope. In optics, having the pupil and the optical center of the refracting lens in the same axis.

Centesimal. In the proportion of $\mathbf{I}$ to $\mathbf{I} 00$.

Centigrade (sen'-te-grad) [centum, a hundred; gradus, a step]. Abbreviation, C. Having Ioo divisions or degrees. C. Thermometer, a thermometer with zero as the freezing point and $100^{\circ}$ as the boiling point of water. See Thermometer.

Centigram (sen'-te-gram) [centum, a hundred; $\gamma \rho a ́ \mu \mu a$, a small weight]. The hundredth of a gram, equal to 0.1543 of a grain avoirdupois, or one-sixth of a grain Troy.

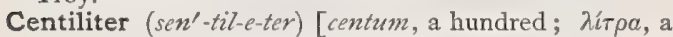
pound]. The hundredth of a liter, equal to 0.6102 of an English cubic inch.

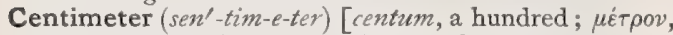
a measure]. The hundredth part of a meter, equal to 0.3937I (or about $\frac{2}{5}$ ) of an English inch.

Centinormal (sen-te-nor'-mal) [centum, a hundred; norma, normal]. The $\frac{1}{100}$ of the normal; applied to a solution the $\frac{1}{100}$ of the strength of a normal solution.

Centrad (sen'-trad) [centrum, the center; $a d$, to]. Toward the center, or toward the median line. See Position and Direction, Table of.

Central (sen'-tral) [centrum, the center]. Relating to the center; passing through the center. See Position and Direction, Table of. C. Artery, an artery in the optic nerve and retina; it passes to the optic papilla and then divides. See Arteries, Table of. C. Ganglia, the corpora striata and thalami optici. C. Ligament, the terminal filum of the spinal cord. See Ligament. C. Lobe, the island of Reil. C. Stop. See Diaphragm.

Centraxonial (sen-traks-o'-ne-al) [кévtpov, center; $\dot{a} \xi \omega \nu$, axis]. In biology, having a central axial line.

Centre (sen'ter). See Center.

Centren (sen'tren) [centrum, a center]. Belonging solely to a center.

Centric, Centrical (sen'-trik, sen'-trik-al) [centrum, a center]. Relating to a center, especially to a nervecenter. In biology, a term applied to the internal structure of such leaves as show no distinctly developed pallisade-tissue, and no considerable structural differences between the upper and under surfaces.

Centricipital (sen-tris-ip'-it-al) [centrum, center; caput, a head]. Relating to the centriciput; parietal. C. vertebra, the second or more central of the three principal cranial vertebree.

Centriciput (sen-tris'-ip-ut) [centrum, center; caput, head]. The mid-head: the second cranial segment situated between the sinciput and occiput.
Centrifugal (sen-trif'-u-gal) [centrum, the center; fugere, to flee]. Receding from the center toward the periphery. C. Nerves, those (mostly motor) conveying impulses toward the peripheral parts of the body.

Centrifugalized Milk. Milk from which the cream has been separated by whirling it in a centrifugal machine.

Centripetal (sen-trip'-et-al) [centrum, the center; petere, to seek]. Traveling toward the center from the periphery. C. Nerves, those (mostly sensory) conveying impressions from the peripheral organs toward the cerebro-spinal nervous system.

Centro-acinal, or Centro-acinar (sen-tro-as'-in-al, or cen-tro-as'-in-ar) [centrum, center; acinus, a grape]. Belonging to the center of an acinus. C. Cells are found in the acini of the pancreas, etc.

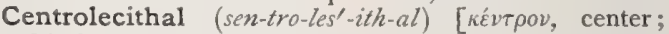

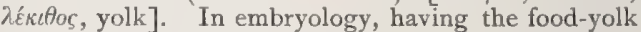
centrally located in the protoplasm.

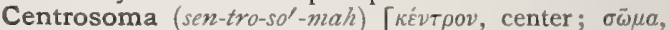
body: pl., Centrosomata]. The central mass or body of any corpuscle, as distinguished from its appendages. C. of Boveri, in embryology, a separate central body contained in the sphere of attraction, at the pole of the resting nucleus in a dividing ovum.

Centrosome (sen'-tro-sôm). See Centrosoma.

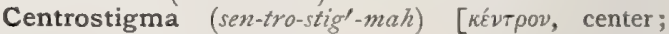

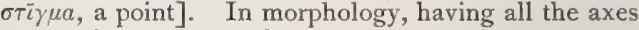
converging to a central point.

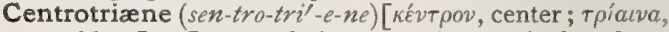
a trident]. In morphology, a triæne spicule whose arms arise from a central bundle or rhabdom.

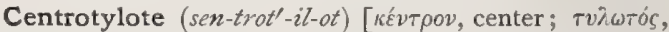
knobbed]. In biology, swollen in the middle.

Centrum (sen'-trum) [L.]. The center or middle part; the body of a vertebra, exclusive of the bases of the neural arches. C. Anospinale, Budge's, the center for the movements of the anal sphincters, located in the cord at the level of the fifth lumbar vertebra in the dog, and between the sixth and seventh in the rabbit. C. Ovale Majus, the large mass of white matter appearing when either of the hemispheres is cut down to the level of the corpus callo zum. C. Ovale Minus, the white matter appearing when the upper part of a hemisphere of the brain is removed.

Cenurus (sèn- $\left.u^{\prime}-r u s\right)$. See Conurus.

Cepaceous (se-pa'-she-us) [capa, an onion]. Having the smell of onions.

Cephaelis (sef-a-'el-is). See Ipecacuanha.

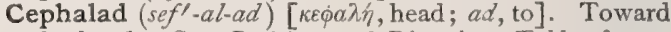
the head. See Position and Direction, Table of.

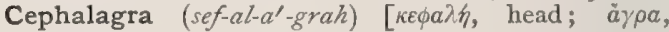
seizure]. Gouty headache.

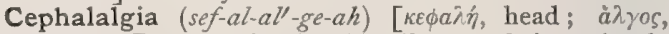
pain]. Pain in the head. The word is variously qualified, as C. Anemica, C. Contagiosa, C. Influenza, C. Epileptica, C. Nerrosa, etc.

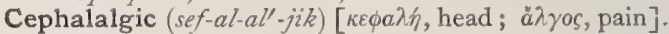
Relating to headache.

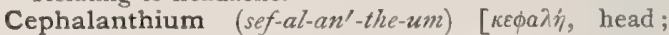
$\dot{\alpha} \nu$ Ons, a flower]. In biology, the capitulum, or flower cluster, of one of the Composita.

Cephalanthus (sef-al-an'-thus). See Button-bush.

Cephalate $\left(s e f^{\prime}-a l-a \bar{t}\right)$ [ $\kappa \varepsilon \phi a \lambda \hat{\eta}$, head]. In biology, possessing a head.

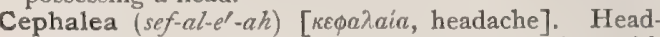
ache; especially severe or chronic headache, with intolerance of light and sound.

Cephalematocele. See Cephalhematocele.

Cephalematoma. See Cephalhematoma. 


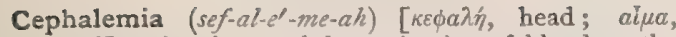
blood]. An abnormal determination of blood to the head.

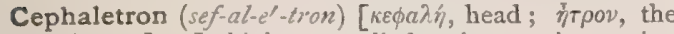
abdomen]. In biology, applied to the anterior portion of the body of certain crustaceans.

Cephalhæmatoma (sef-al-he-mat-d'-mah). See Cephalhematoma.

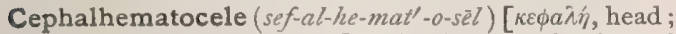
ai $\mu a$, blood; $\kappa \eta \dot{\lambda} \eta$, tumor]. An hematocele situated beneath the scalp, and communicating with a dural sinus.

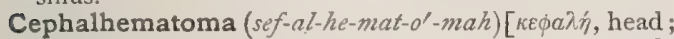
alua, blood; ö $\mu a$, tumor: pl., Cephathematomata]. A collection of blood between the pericranium and the exterior of one or more bones of the skull.

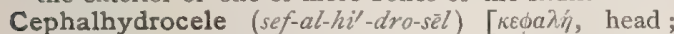
ij $\omega \rho$, water; $\kappa \eta ் \eta \eta$ tumor]. Effusion of cerebral fluid beneath the occipito-frontal aponeuroses in fractures of the skull.

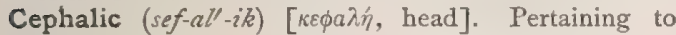
the head. The terms Proral, Cranial, Rostral, Akral have been proposed to take the place of Cephalic. See Position and Direction, Table of. C. Index. See Index. C. Souffle, a blowing murmur sometimes heard in auscultation of the head; a sign of aneurysm or of anemia. C. Vein. See Vein. C. Version. See Version. C. Tetanus. See Kopf-Tetanus

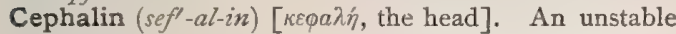
phosphatic substance obtained from brain-substance; it is allied to lecithin; at least five modifications of it are reported to exist; it is called also Kephalin.

Cephalitis $\left(s e f-a l-i^{\prime}-t i s\right)$. See Encephalitis.

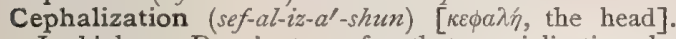
In biology, Dana's term for that specialization the tendency of which is to concentrate important parts and organs at the head region of the trunk.

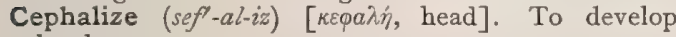
head-organs.

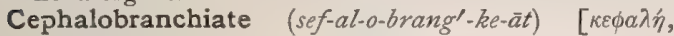
head; $\beta \rho a ́ \gamma \chi \iota a$, gills]. In biology, with external branchial tufts in the head-region.

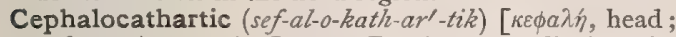
каөартіко́s, purging]. I. Purging or relieving the head. 2. A medicine that relieves the head.

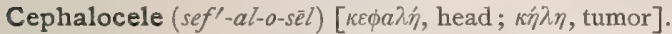
Hernia of the brain; protrusion of a mass of the cranial contents.

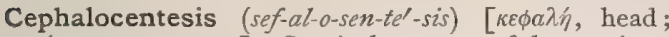
$\kappa \varepsilon ́ \nu \tau \eta \sigma \iota \zeta$, puncture]. Surgical puncture of the cranium.

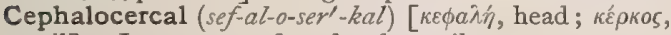
tail]. In anatomy, from head to tail.

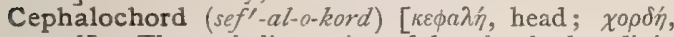
cord]. The cephalic portion of the chorda dorsalis in embryonic life.

Cephaloclast (sef'-al-o-klast). See Cephalotribe.

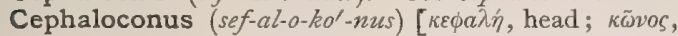
a cone]. In biology, applied to one of the processes on the head of a pteropod.

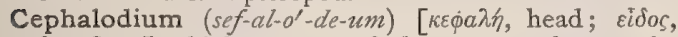
form]. In biology, one of the outgrowths on the thallus of a lichen, and in which gonidia or algal cells are found.

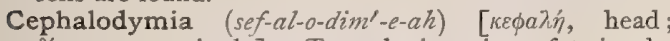

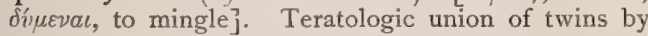
the merging of their heads together.

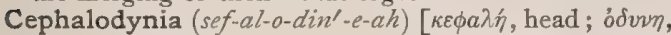
pain]. Rheumatism affecting the occipito-frontalis muscle, the pain being chiefly experienced in the forehead or occiput, and at times involving the eyeballs.

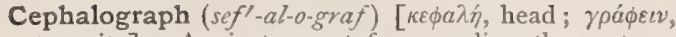
to write]. An instrument for recording the contours of the head.

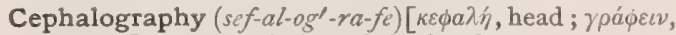
to write]. A description of the head.

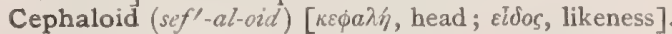
Resembling the head.

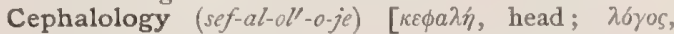
science]. The science of cranial measurements and indications.

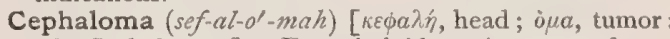
pl., Cephalomata]. Encephaloid carcinoma; soft carcinoma.

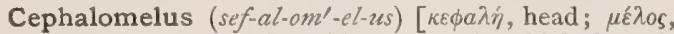
a part]. A form of double monster in which there is a supernumerary limb attached to the head.

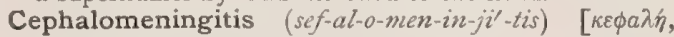
head; $\mu \tilde{\eta} \nu \iota \gamma \xi$, a membrane; $\iota \tau \iota \zeta$, inflammation]. Cephalic meningitis; inflammation of the cephalic meninges.

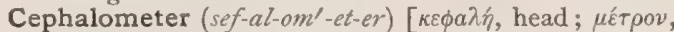
a measure]. An instrument for measuring the head.

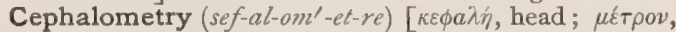
a measure]. I. The use of the cephalometer: craniometry. 2. The art of taking measurements of the head to determine the position of the fissures and convolutions of the brain.

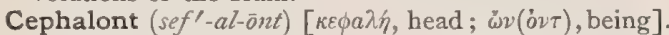
In biology, that phase of a gregarine in which an epimerite is added to the anterior cyst or protomerite.

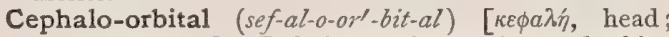
orbita, an orbit]. Relating to the cranium and orbits C. Index. See Index.

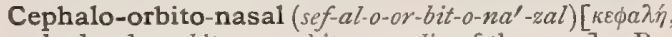
the head; orbita, an orbit; nasalis, of the nose]. Relating to the cranium, orbits, and nose.

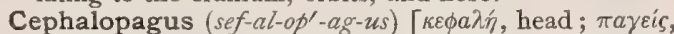
joined]. An ensomphalic monstrosity having the heads united at the top.

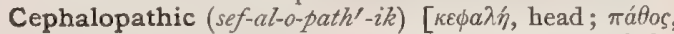
disease]. Pertaining or belonging to a disease of the head.

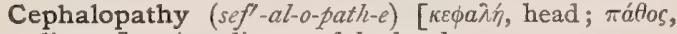
disease]. Any disease of the head.

Cephalophalsia (sef-al-o-fal'-se-ah). Same as Cephalotripsy.

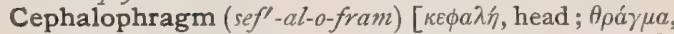
division]. In biology, a $\mathrm{Y}$-shaped septum transversely dividing the head-chamber of certain insects.

Cephalophyma (sef-al-o-fi'-mah). Synonym of Cephalhematoma.

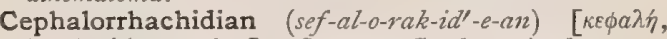
head; $\rho a ́ \chi \iota s$, spine]. Same as Cerebro-spinal.

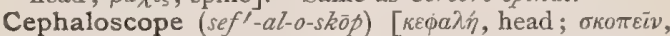
to examine]. A stethoscope for use in auscultation of the head or the ear.

Cephalo-spinal (sef-al-o-spi'-nal). See Cerebro-spinal.

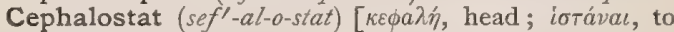
cause to stand]. A vise or clamp for holding a patient's head.

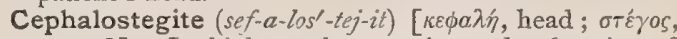
a roof ]. In biology, the anterior or head region of the carapace of a crustacean.

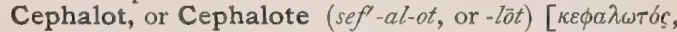
headed]. A brown, resinoid fat obtainable from brainsubstance. Cf. Cerebrot.

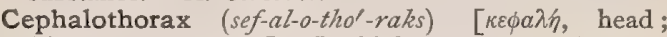
$\theta \dot{\omega} \rho a_{\xi}$, a breastplate]. In biology, the anterior portion of the body of an arthropod formed by the union of the head and thorax.

Cephalothryptor (sef-al-o-thrip'-tor). See Cephalotribe. 


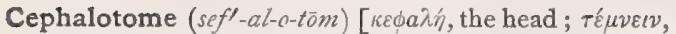
to cut]. The instrument used in performing cephalotomy

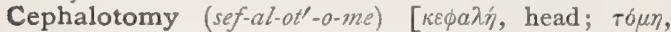
section]. The opening or division of the head of the fetus in labor.

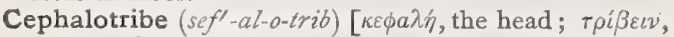
to crush]. An instrument for crushing the fetal head.

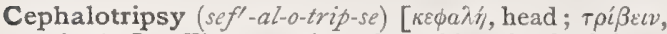
to bruise]. The operation of crushing the fetal head when delivery is otherwise impossible.

Cephalotriptor (sef-al-o-trip'-tor). See Cephalotribe.

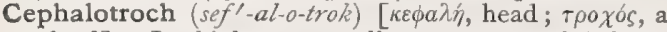
wheel]. In biology, a molluscan or annelid larva having a cephalic circlet of cilia.

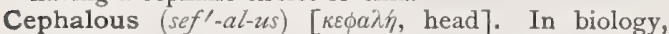
having a head. The opposite of Acephalous.

Cephaloxia (sef-al-oks'-e-ah). Synonym of Torticollis.

Cera (se'-rah) [I.]. Wax. A mixture of cerotic acid, cerolein, and myricin, gathered by the honey-bee from the pollen of flowers and the leaves of plants. C. alba, white wax; prepared by bleaching yellow wax. It is valuable as an ingredient of cerates and ointments C. flava, yellow wax; it possesses an agreeable balsamic odor. It is soluble in ether, hot alcohol, and chloroform.

Ceraceous $\left(s e-r \alpha^{\prime}-s e-u s\right)$ [cera, wax $]$. Waxy; resembling wax.

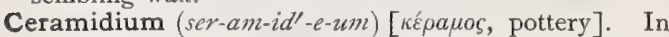
biology, the urn-shaped spore-bearing receptacle of certain algæ.

Cerasein $\left(\right.$ ser- $\alpha^{\prime}-$ se-in $)$ [cerasus, a cherry-tree]. A precipitate from a tincture of the bark of choke-cherry, Prunus virginiana (true); used as a quinin-substitute, and as a diaphoretic and sedative. Dose 2 to Io grains. Unof.

Cerasin $\left(\right.$ ser $\left.^{\prime}-a s-i n\right)$ [cerasus, a cherry-tree]. I. An ingredient of the gum of cherry, peach, and plum trees, apparently identical with bassorin. 2. A crude precipitate from tincture of Choke-cherry, $q . v$.

Cerasinose (ser-as'-in-ös) [cerasus, a cherry-tree]. A crystalline carbohydrate isomeric with arabinose; it is derivable from cherry-gum.

Cerate $\left(s e^{\prime}-r \bar{a} t\right)[c e r a$, wax $]$. In pharmacy, an unctuous preparation consisting of wax mixed with oils, fatty substances, or resins, and of such a consistence that at ordinary temperatures it can be readily spread upon linen or muslin, and yet is so firm that it will not melt or run when applied to the skin. There are eight official cerates. C., Goulard's. See Goulard. C., Hufeland's. See Hufeland.

Ceratectasia (ser-at-ek-ta'-ze-ah). See Keratectasia.

Ceratectomy (ser-at-ek'-to-me). See Kerectomy.

Ceratiasis (ser-at-i'-as-is). See Keratiasis.

Ceratin (ser'-at-in). See Keratin.

Ceratitis (ser-at-i'-tis). See Keratitis.

Cerato- $\left(\operatorname{ser}^{\prime}-a t-o-\right)$. See Kerato-.

Ceratum (se-ra'-tum). See Cerate.

Cerbera (ser'-ber-ah) [Cerberus, a dog of mythology]. A genus of apocynaceous old-world trees, several of them actively poisonous. C. odollam, of India, has purgative leaves and bark; it contains Cerberin, q.v. C. tanghin, the ordeal-tree of Madagascar, is highly poisonous; one seed is said to have destroyed 20 people.

Cerberin (ser'-ber-in) [Cerberus, a dog of mythology]. A poisonous glucosid from the seeds of Cerbera odollam and other related trees.

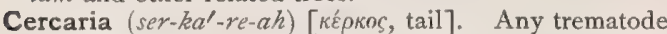
worm (fluke) in its second (or tailed) stage of larval life.

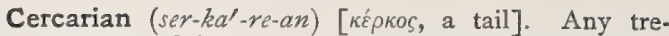
matode, or fluke-worm, in the Cercaria stage.

Cerchnus (serk'-nus) [ ḱ́ $\chi^{\prime} v o s$, rough, hoarse]. Hoarseness; noisy respiration.

Cercis (ser'-sis). See Judas Tree.

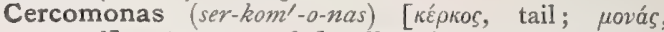
monad]. A genus of flagellate infusorians. C. intestinalis, a minute animal parasite, a protozoön, occasionally found in the fecal discharges of patients suffering with typhoid fever, chronic diarrhea, and cholera. Its pathologic significance has not yet been ascertained. C. urinarius. See Bodo.

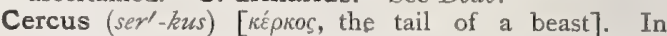
biology, one of the antenna-like structures projecting from the hinder parts of certain insects.

Cere (sēr) [cera, wax]. In biology, that portion of the sheath of the bill in certain birds, e. g., parrots and birds of prey, which has a waxy appearance.

Cereal (se'-re-al) [Ceres, the goddess of agriculture]. I. Relating to edible grains. 2. Any edible grain or bread-corn; also the plant that produces it. The composition of the more important cereals is thus given by Bell :-

\begin{tabular}{|c|c|c|c|c|c|c|c|}
\hline Constituents. & 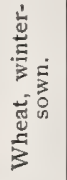 & 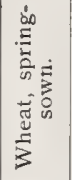 & 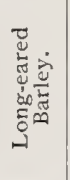 & 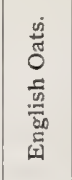 & $\frac{\stackrel{N}{\pi}}{\pi^{\pi}}$ & ๙ิ & 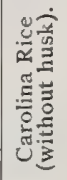 \\
\hline Fat, ......... & I. 48 & 1.56 & 1.03 & 5.74 & $3.5^{8}$ & I. 43 & 0.19 \\
\hline Starch, ..... & $63.7 x$ & 65.86 & $63.5 \mathrm{I}$ & 49.78 & 64.66 & 61.87 & 77.66 \\
\hline $\begin{array}{l}\text { Sugar (as su* } \\
\text { crose), . . . }\end{array}$ & 2.57 & 2.24 & I.34 & 2.36 & I.94 & $4.3^{\circ}$ & 0.38 \\
\hline $\begin{array}{l}\text { Albumin (insolu- } \\
\text { ble in alcohol), }\end{array}$ & 10.70 & 7.19 & 8.18 & 10.62 & 9.67 & 9.78 & 7.94 \\
\hline $\begin{array}{c}\text { Nit roge nous } \\
\text { matter (solu- } \\
\text { ble in alcohol), }\end{array}$ & 4.83 & 4.40 & 3.28 & 4.05 & 4. 60 & 5.09 & 1.40 \\
\hline Cellulose, ... & 3.03 & 2.93 & 7.28 & 13.53 & $\mathbf{x} .86$ & 3.23 & $\begin{array}{l}\text { Tra- } \\
\text { ces. }\end{array}$ \\
\hline Mineral matter, & 1.60 & 1.74 & 2.32 & 2.66 & I.35 & r. 85 & 0.28 \\
\hline Moisture, ... & 1208 & 14.08 & 13.06 & 11.86 & 12.34 & 12.45 & I2.15 \\
\hline Total, .... & 100.00 & 100.00 & 10000 & 100.00 & 100.00 & 100.00 & 100.00 \\
\hline
\end{tabular}

Cerealin (se'-re-al-in) [Ceres, the goddess of agriculture]. An albuminoid found in various cereals and obtainable from bran. See Flour.

Cerebel (ser'-e-bel). See Cerebellum.

Cerebellar (ser-e-bell-ar) [dim. of cerebrum]. Relating to the cerebellum. C. Fossa. See Fossa. C. Ganglion. See Ganglion.

Cerebellic $\left(s e r-e-b e l^{\prime}-i k\right)$. See Cerebellar.

Cerebellitis (ser-e-bel-i'-tis) [cerebellum, a little brain; $\iota \tau \iota$, inflammation]. Inflammation of the cerebellum.

Cerebellocortex (ser-e-bel-o-kor'-teks) [cerebellum, the little brain; cortex, bark]. The cortex of the cerebellum.

Cerebello-spinal (ser-e-bel-o-spi'-nal) [cerebellum, the little brain; spina, the spine]. Relating to the cerebellum and the spinal cord.

Cerebellous (ser-e-bel'-us). See Cerebellar. 
Cerebellum (ser-e-bell-um) [dim. of cerebrum]. The inferior part of the brain lying below the cerebrum.

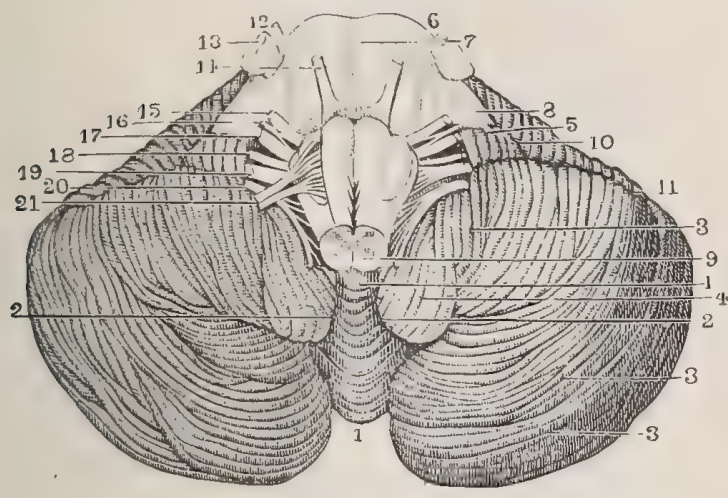

INFERIOR ASPECT OF THE CEREBELLUM

I, I. Inferior vermiform process. 2, 2, Median fissure. $3,3,3$ Lobes and lobules. 4. Amygdala or tonsil. 5. Flocculus subpeduncular lobe or preumogastric lobule. 6. Pons varolii. 7. Median fissure of pons. 8. Middle cerebellar peduncle. 9. Medulla oblongata. 10. Anterior extremity of circumferential fissure of cerebellum. II. Anterior border of superior surface. I2. Small or motor root of trigeminus. I3. Large or sensory root. 14. 6th nerve. 15. Facial nerve. I6 Nerve of Wrisberg. 17. Auditory nerve. I8. Glossopharyngeal 19. Preumogastric. 20. Spinal accessory. 2I. Hypoglossal.

Cerebral (ser'-e-bral) [cerebrum, the brain]. Relating to the cerebrum. C. Apoplexy. See Apoplexy. C. Arteries. See Arteries, Table of. C. Index. See Index. C. Maculæ, spots on the skin caused by slight irritation, and abnormally persistent. They may indicate disorder of the vaso-motor mechanism. C. Nerves. See Nerves, Table of. C. Pneumonia. See Pneumonia. C. Surprise, the speedy, but not long-persistent stupor that often follows sudden mental shock or grave lesion or injury of the brain. C. Vesicles. See Brain-bladder.

Cerebralgia(ser-e-bral'-je-ah) [cerebrum, the brain; àd yos, pain]. Pain in the head.

Cerebralism (ser'-e-bral-izm $)$ [cerebrum, the brain]. The theory that mental operations are due to the activity of the brain; or that thought is a function of the brain.

Cerebrasthenia (ser-e-bras-the'-ne-ah) [cerebrum, the brain; $\dot{a} \sigma \theta \varepsilon v \dot{s} s$, without strength]. Cerebral asthenia. See Phrenasthenia.

Cerebrasthenic (ser-e-bras'-then-ik) [cerebrum, the

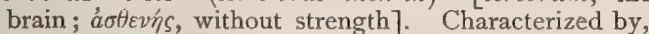
or pertaining to, cerebrasthenia.

Cerebration (ser-e-bra'-shun) [cerebrum, the brain]. Mental and cerebral activity. C., Unconscious, mental activity of which the subject is not conscious.

Cerebria (ser-e'-bre-ah) [cerebrum, the brain]. Temporary cerebral exhaustion (but the term is variously applied by different writers); acute, chronic, partial, and sympathetic cerebria are among the varieties described.

Cerebric Acid (ser'-e-brik). Same as Cerebrinic Acid.

Cerebrifugal (ser-e-brif'-u-gal) [cerebrum, the brain; fugere, to flee]. Centrifugal; efferent; transmitting or transmitted from the brain to the periphery.

Cerebrin (ser'-e-brin) [cerebrum, the brain], $\mathrm{C}_{17} \mathrm{H}_{33} \mathrm{NO}_{3}$. A nitrogenous glucosid obtained from brain-tissue, nerves, and pus-corpuscles. It is a light, colorless, exceedingly hygroscopic powder. The term has been applied to an "organic extract" of unknown constitution, derived from brain-tissue.
Cerebrinacide (ser-e-brin'-as-ī $d$ ) [cerebrum, the brain] One of certain substances found in brain-tissue, and capable of combining with metallic oxids.

Cerebrinic Acid (ser-e-brin'-ik). See Acid.

Cerebripetal (ser-e-brip'-et-al) [cerebrum, the brain; petere, to seek]. Centripetal; afferent; transmitting or transmitted from the periphery to the brain.

Cerebritis (ser-e-bri'-tis) [cerebrum, the brain; $\iota t \iota s$, inflammation]. Inflammation of the proper substance of the cerebrum, due to traumatism, contiguous inflam mation, or septic influence. Headache, possibly vomiting, and convulsions are the most marked symptoms. C., Enzoötic-of horses. Also called staggers, or mad staggers. A disease of horses in the Western United States caused by eating corn that has been attacked by a mold, Aspergillus glaucus, the spores of which, finding lodgment in the kidneys and liver, germinate and cause derangements of the circulation with central abscesses. Neither mules, cattle, nor pigs appear to contract this disease.

Cerebrogalactose (ser-e-bro.gal-ak'-tōs). Same as Cerebrose.

Cerebro-hyphoid (ser-e-bro-hi'-foid) [cerebrum, the

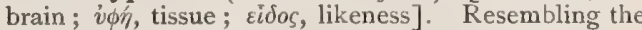
substance of the brain.

Cerebrol (ser'-e-bröl) [cerebrum, brain; oleum, oil]. An oily, reddish fluid obtainable from brain-tissue.

Cerebroma (ser-e-bro'-mah) [cerebrum, the brain; $0 / \mu \alpha$, a tumor: pl., Cerebromata]. A growth, outside the cranium, that contains cerebral tissue.

Cerebromalacia (ser-e-bro-mal-a $\left.a^{\prime}-s e-a h\right)$ [cerebrum, the brain; $\mu a \lambda a \kappa i \alpha$, softness]. Softening of the braintissue.

Cerebromedullary (ser-e-bro-med-ul'-ar-e) [cerebrum, the brain; medulla, marrow]. Relating to the brain and spinal cord.

Cerebropathy (ser-e-brop'-a-the) [cerebrum, the brain; $\pi a ́ \theta 0 \varsigma$, illness]. I. A train of symptoms following overwork and approaching the character of insanity. 2. Cerebral disease in general.

Cerebropsychosis (ser-e-brop-sik-o'-sis) [cerebrum, the

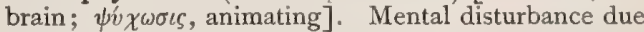
to a disease of the psychic centers.

Cerebrosclerosis (ser-e-bro-skle-ro'-sis) [cerebrum, the brain; $\sigma \kappa \lambda \eta \rho o ́ s$, hard]. Sclerosis of cerebral tissue.

Cerebroscopic (ser-e-bro-skop'-ik) [cerebrum, the brain; $\sigma \kappa o \pi \varepsilon i \nu$, to inspect]. Pertaining to cerebroscopy.

Cerebroscopy (ser-e-bros'-ko-pe) [cerebrum, the brain; $\sigma \kappa o \pi \varepsilon \check{\imath}$, to inspect]. Ophthalmoscopy in the diagnosis of brain-disease.

Cerebrose (ser'-e-brōs) [cerebrum, the brain], $\mathrm{C}_{6} \mathrm{H}_{12} \mathrm{O}_{6}$. A crystallized sugar isomeric with glucose, occurring in brain-tissue.

Cerebro-sensorial (ser-e-bro-sen-so'-re-al) [cerebrum, the brain; sensorium, the organ of sensation]. Pertaining to the cerebral sensorium.

Cerebroside (ser'-e-bro-sid $)$ [cerebrum, the brain]. One of a class of substances occurring in brain-tissue, containing cerebrose, just as glucosid's contain glucose.

Cerebrosis (ser-e-bro'-sis) [cerebrum, the brain]. Any cerebral disorder.

Cerebrospinal (ser-e-bro-spi'-nal) [cerebrum, the brain; spina, the spine]. Pertaining to the whole of the brain and spinal structure. C. Axis. See Axis. C. Fluid, the fluid between the arachnoid and the pia. C. Meningitis. See Fever, Cerebrospinal. C. System, the brain, spinal cord, and nerves.

Cerebrospinant (ser-e-bro-spi'-nant) [cerebrum, the brain; spina, the spine]. A medicine that acts upon the brain and spinal cord.

Cerebrosulphatid (ser-e-bro-sull-fat-id) [cerebrun, the brain; sulphur]. Any cerebrinacide containing sulphur. 
Cerebrot, Cerebrote (ser'-e-brot, ser'-e-brōt) [cerebrum, the brain]. - A white, fatty principle obtainable from brain-substance. Cr. Cephalot.

Cerebrotomy (ser-e-brot'-o-me) [cerebrum, the brain;

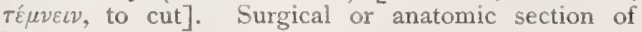
brain-tissue.

Cerebrum (ser'-e-brum) [L.]. The chief portion of the brain, occupying the whole upper part of the cranium. See Brain.

Cerectomy (ser-ek'-to-me). See Kerectomy.

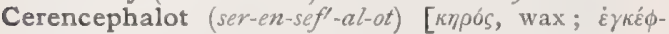
$a \lambda o s$, brain]. Cephalot.

Cereolus (ser-e'-o-lus) [cera, wax: pl., Cereoli]. A bougie of waxed linen, often medicated.

Ceresin (ser'-es-in) [cera, wax]. Ozokerite that has been bleached without distillation; it is used as a substitute for beeswax.

Cereus (se'-re-us) [L., "a wax candle" ]. A genus of cactaceous plants. C. grandiflorus, See Nightblooming Cerezes.

Cerevisia (ser-e-vis'-e-ah) [L.]. Ale or beer. C. fermentum, beer-yeast. The ferment obtained in brewing beer, and produced by Saccharomyces cerevisia. It is given in low states of the system. Dose $3 \mathrm{ss}-\mathrm{j}$.

Cerin $\left(s e^{\prime}-r i n\right)[$ cera, wax $]$. An ether of cerotic acid; one of the substances found in wax.

Cerise $\left(\right.$ ser-ēe $\left.z^{\prime}\right)$ [cerasus, a cherry-tree]. A pigment of a cherry color. See Pigments, Conspectus of.

Cerium $\left(s e^{\prime}-r e-u m\right)$ [named after the planet Ceres]. Ce = I40; quantivalence II, IV. One of the rarer metals. See Elements, Table of. C. oxalas, $\mathrm{Ce}_{2}-$ $\left(\mathrm{C}_{2} \mathrm{O}_{4}\right)_{3 \cdot 9} \mathrm{H}_{2} \mathrm{O}$, a white, granular powder, insoluble in water or alcohol, but soluble in hydrochloric acid. The oxalate is the only salt commonly employed in medicine. It is a gastric sedative useful in the vomiting of pregnancy. Dose gr. $\mathrm{j}-\mathrm{x}$, in pill. C. valerianate has been used in the same class of cases. Dose gr. iss.

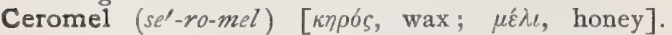
Honey cerate ; wax one part, honey two or four parts. It is applied to wounds and ulcers, chiefly in Asiatic countries.

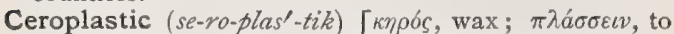
mould]. Modeled, or as if modeled, in wax]. C. Catalepsy. See Catalepsy.

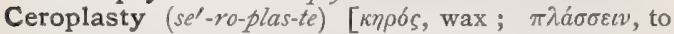
mould]. The modeling of anatomic preparations in wax.

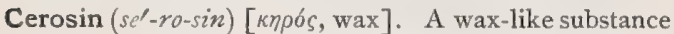
forming a white or grayish-green coating on some species of sugar-cane. When purified, it yields fine, light pearly scales.

Cerosis $($ ser-o'-sis) [knpós, wax ]. That morbid condition of a membrane in which it seems to consist of waxlike scales.

Cerotene $\left(s e^{\prime}-r o-t e ̄ n\right)$ [ $k \eta p b s$, wax ]. An alkylen or olefin, $\mathrm{C}_{27} \mathrm{H}_{54}$, obtained from Chinese wax; it melts at $58^{\circ}$; cerylene.

Cerotic Acid (se-rot'-ik). See Acid, Cerotic

Certificate (ser-tif'-ik-ât) [certificare, to certify]. A written statement, as for insurance, or in case of birth or death.

Cerulean Blue. See Pigments, Conspectus of.

Cerulein $\left(\operatorname{ser}-u^{\prime}-l_{e-i n}\right)$. Same as Alizarin Green, one of the Alizarins. See Pigments, Conspectus of.

Cerumen $\left(\right.$ ser- $\left.u^{\prime}-m e n\right)$ [cera, wax]. The wax of the ear.

Ceruminous (ser-u'-min-us) [cer $\alpha$, wax $]$. Pertaining to cerumen.

Ceruse $\left(s e^{\prime}-r \bar{s}\right)$ [cerussa, white lead]. I. White lead: basic carbonate and hydrate of lead. 2. A white face-powder. C. of antimony, white oxid of antimony; also antimonic acid.
Cervical (ser'-vik-al) [cervix, the neck]. Pertaining to the neck, or to the cervix uteri. C. Carcinoma, carcinoma of the neck of the womb. C. Choke, in the horse, the lodgment of a foreign body in the esophagus at any point between the "throat-latch" and the shoulder. C. Endometritis. See Endometritis. C. Pregnancy, a rare condition in which from atrophy of the decidual membranes the impregnated ovum is not properly held in place, and dropping, lodges in the cervical canal, where it develops until the uterus, not being able to hold it longer, expels it.

Cervicen (ser'-vis-en) [cervix, the neck]. Belonging solely to the cervix.

Cervicicardiac (ser-vis-ik-ar'-de-ak) [cervix, the neck; $\kappa \alpha \rho \delta i \alpha^{\prime}$, the heart]. Relating to the neck and the heart, as the cervicicardiac nerves, branches of the vagus.

Cerviciplex (ser-vis-ip-leks) [cervix, the neck; plexus, a network]. The cervical plexus.

Cervicitis $($ ser-vis-i'-tis) [cervix, the neck; $\iota T \iota s$, inflammation]. Inflammation of the cervix uteri.

Cervicobrachial (ser-vik-o-bril'-ke-al) [cervix, the neck; brachium, the arm]. Relating to the neck and the arm.

Cervico-bregmatic (ser-vik-o-breg-mat'-ik) [cervix, the neck; $\beta \rho \varepsilon \varepsilon^{\prime} \gamma n$, the sinciput]. Relating to the cervix or nucha and the bregma.

Cervicodynia (ser-vik-o-din'-e-ah) [cervix, the neck; ódviv, pain]. Cramp or neuralgia of the neck.

Cervico-facial (ser-vik-o-f $a^{\prime}$-shal) [cervix, neck; facies, face]. Relating to the neck and the face.

Cervico-occipital (ser-vik-o-ok-sip'-it-al) [cervix, the neck; occiput, the back of the head]. Relating to the neck and the back of the head.

Cervico-orbicular (ser-vik-o-or-bik'-u-lar) [cervix, neck; orbicularis, circular]. Relating to the neck and the orbicular muscle.

Cervico-vaginal (ser-vik-o-vaj'-in-al) [cervix, the neck; vagina, a sheath]. Relating to the cervix uteri and the vagina.

Cerviculate (ser-vi $k^{\prime}-u$-lät) [cervicula, a little neck]. In biology, having a slender neck.

Cervix (ser'-viks) [L.]. The neck; also the posterior part of the neck. Applied also to constricted parts of other organs, as the cervix of the bladder, or of the penis. C. Uteri, the neck of the womb. C. Vesicæ, the neck of the bladder.

Ceryl (se'-ril) [cera, wax], $\mathrm{C}_{27} \mathrm{H}_{55^{\circ}}$. An organic radical found in combination in beeswax.

Cerylene $\left(s e^{\prime}-y_{i l}-\bar{e} n\right)$. See Cerotene.

Cesarean, or Cæsarean, Operation (se-za'-re-an op-er$a^{\prime}$-shun) [cadere, to cut]. Extraction of the fetus through an incision made in the abdomen. C. O., Conservative, the removal of the fetus through an opening in the anterior abdominal wall, without removing the uterus or its appendages. C. O., Elective, one done at a selected time prior to labor. C. O., Improved. See Sänger's Operation, Porro's Operation, etc. C. O., Post-mortem, extraction of the child after the mother's death. For the various methods proposed of performing the Cesarean Operation, see Gastro-elytrotomy, Laparo-elytrotomy, Gastro-hysterectomy, Gastro-hysterotomy, and the operations of Porro, Sänger, Porro-Müller, Kehrer, and Thomas, under Operations, Table of.

Cesarean Section. See Operations, Table of.

Cesium, or Cæsium (se'-ze-um) [L., "bluish-gray "'], $\mathrm{Cs}=132.6$; quantivalence I. A rare alkaline metal resembling potassium in physical and chemic properties. C. bromid, like the other bromids, is a good sedative, but its cost is very great. The oxalate and nitrate have also been employed medicinally. 
Unof. C. chlorid, unof,, lowers the pulse-rate and raises the arterial pressure. Dose gr. ij-v.

Cespitose (ses'-pit-ös) [cespes, a turf or sod]. In biology, growing in or characterized by tangled or matted tufts.

Cesspool (ses'-pool) [E. dial., suss, a puddle; ME., pool]. A reservoir for water; a privy.

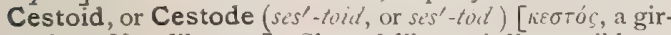
dle; eidos, likeness]. Shaped like a girdle, or ribbon; applied to worms, of which Tenia is a type.

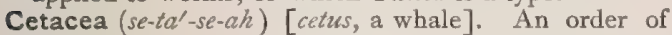
mammals living in the sea, as the whale, dolphin, etc.

Cetaceum (se-ta'-se-um) [L.: gen., Cetacei]. Spermaceti. A fatty substance somewhat resembling paraffin in its physical properties. It is obtained from the head of the sperm whale, Physeter macrocephalus. It is soluble in ether, chloroform, and boiling alcohol, and is employed only as an emollient. C., Ceratum, contains spermacti Io, white wax 35 , olive oil 55 parts. C., Ung. (B. P.), contains spermaceti, white wax, almond oil, and benzoin.

Cetraria (se-tra'-re-ah) [catra, a short Spanish shield]. I. A genus of lichens. 2. Iceland moss. A lichen, C. Islandica, found in Iceland and other northern countries. It contains a form of starch, Lichenin, that gelatinizes when boiled with water. It is a feebly tonic demulcent, sometimes recommended in pulmonary affections. C., Decoct., contains five per cent. of the lichen. Dose 3 ij-iv.

Cetrarin (se-tra'-rin) [catra, a short Spanish shield]. The bitter principle of Iceland moss, crystallizing in fine needles, and nearly insoluble in water.

Cetyl (se'-til) [cetus, a whale], $\mathrm{C}_{16} \mathrm{H}_{33}$. An alcoholic radical existing in beeswax and spermaceti.

Cetylid (se'-til-id) [cetus, a whale], $\mathrm{C}_{22} \mathrm{H}_{42} \mathrm{O}_{5}$. Geoghegan's term for the substance in the brain that reduces alkaline solutions of cupric salts.

Cevadilla (ser-ad-il'-ah). See Cebadilla.

Cevadillin (sev-ad-il'-in) [cevadilla], $\mathrm{C}_{34} \mathrm{H}_{53} \mathrm{NO}_{8}$. uncrystallizable alkaloid obtained from cevadilla.

Cevadin (sev'-ad-in), $\mathrm{C}_{32} \mathrm{H}_{49} \mathrm{NO}_{9}$. A crystalline alkaloid of cevadilla. See Veratrin.

Ceylon Sickness. See Beriberi.

Chabert's Disease. See Diseases, Table of.

Chreraphrosyne (ke-raf-ros'-in-e) [xaípelv, to rejoice ; á $\phi \circ \sigma u ́ v \eta$, senselessness]. Amenomania.

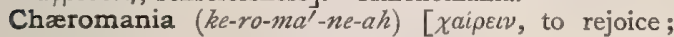
uavia, madness]. Amenomania.

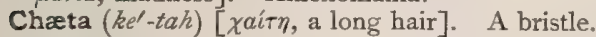

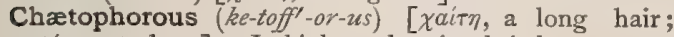
$\phi \varepsilon ́ \rho \varepsilon \imath \nu$, to bear]. In biology, bearing bristles.

Chaffbone (chaf'-bön) [AS., ceaf, husk; bān, a bone]. A name for the inferior maxilla.

Chagres Fever. See Fever.

Chain (chän) [ME, chaine, a chain]. I. A series of connected links of metal, etc. 2. In chemistry, a group of like atoms joined together by chemic affinity without the intervention of atoms of another kind. C. Ecraseur, an écraseur of which a chain forms the cutting part. C.-saw, a surgeon's saw, the teeth of which are linked together like a chain.

Chair (châr) [ME., chaire, a chair]. I. A seat of office, as that of a professor. 2. A piece of furniture consisting of a seat with a back support. C., Vibrating. See Shaking Cure. C., Whirling, a revolving-chair in which formerly a maniacal patient was rapidly whirled. This was regarded as both a sedative and a curative procedure.

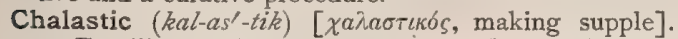
I. Emollient, softening. 2. An emollient or laxative medicine.

Chalastodermia (kal-as-to-der'-me-ah). Synonym of Dermatolysis.

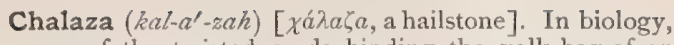
one of the twisted cords binding the yolk-bag of an egg to the lining membrane of the shell; or that part of a seed where its coats unite with each other and the nucleus.

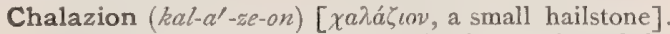
A tumor of the eyelid from retained secretion of the Meibomian glands : a Meibomian cyst.

Chalazonephritis (kal-a-zo-nef-ri'-tis) [ $\chi \chi^{\alpha} \lambda \alpha \zeta a$, hail ; $\nu \varepsilon \dot{\phi} \rho \circ \nu$, the kidney; $\iota \tau \iota s$, inflammation]. Granular nephritis.

Chalicosis (kal-ik-ó-sis) [ $\chi a^{\prime} \lambda \iota \xi$, gravel]. A disease of the lungs of workmen caused by the inhalation of dust or sand.

Chalk (chazok) [ME., chalk, lime]. Carbonate of lime. See Calcium. C. Stone, gout-stone-a deposit beneath the skin in gouty patients.

Chalot's Operation. See Operations, Table of.

Chalybeate $\left(k a-l i b^{\prime}-e-\bar{a} t\right)$ [ $\chi \alpha^{a} \lambda v \psi$, iron]. Containing iron.

Chalybs $\left(k a^{\prime}-l i b z\right)$ [L.]. See Ferrum

Chamber (chän'-ber) [ME., chamber, a room]. A cavity or space. C., Anterior (of the eye), the space between the cornea and the iris. C., Posterior (of the eye), the space between the iris and the lens. The chambers of the eye contain the aqueous humor.

Chamberlaine's Operations. See Operations, Table of.

Chamberland's Bougie or Filter. See Filter.

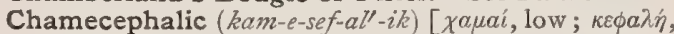
head]. Characterized by chamecephaly.

Chamecephalous (kam-e-sef'-al-us). See Chamecephalic.

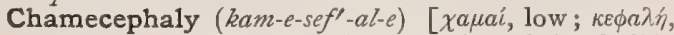
head]. In craniometry, that condition of the skull in which the cephalic index is $70^{\circ}$ or less. A flat and receding skull.

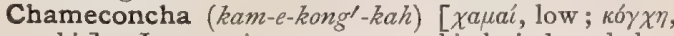
orbit]. In craniometry, an orbital index below 80.01.

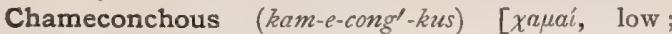
$\kappa 6 \gamma \chi \eta$, concha]. In craniometry, having an orbital index of not more than $80^{\circ}$.

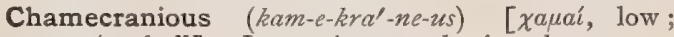
$\kappa \rho a v \iota \delta v$, skull]. In craniometry, having the greatest length of the skull proportioned to its height.

Chameleon Mineral (kam-el-le-on min'-er-al). An old name for a crude mixture of potassium manganate with potassium nitrate

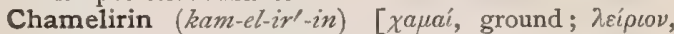
lily]. A poisonous glucosid from Chamelirion luteum; it is a strong heart-depressant.

Chamelirion (kam-el-ir'-e-on) [ $\chi a \mu a i$, ground; $\lambda \varepsilon i \rho \iota o v$, lily]. A genus of liliaceous plants having active medicinal and poisonous properties. C. luteum, or carolinianum, of the U. S. (called Helonias dioica), is a uterine tonic and diuretic. Unof.

Chameopisthius (kam-e-o-pis'-the-us) [xquai, low ; ó $\pi i \sigma \theta i o \nu]$. In craniometry, Lissauer's tenn for a skull in which the angle between the radius fixus and the line joining the hormion and the lambda is from $17^{\circ}$ to $24.5^{\circ}$.

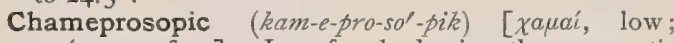
$\pi \rho 6 \sigma \omega \pi o v$, face]. Low-faced; having the zygomatic facial index below $90^{\circ}$.

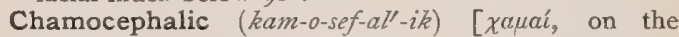
ground, low; $\kappa \varepsilon \dot{\alpha} \hat{\lambda} \dot{\eta}$, head]. See Chamecephalic.

Chamois Leather (sham'-zwah, or sham'-e). See Leather.

Chamois-skin (sham'-vwah-, or sham'-e-skin). Properly the skin or tanned leather of the chamois; now prepared from split sheep-skin. It is used in surgery and for underclothing. 
Chamomile (kam'-o-mìl). See Anthemis and Matricaria.

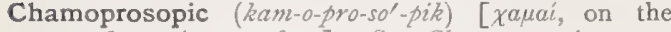
ground; $\pi \rho 6 \sigma \omega \pi 0 \nu$, face $]$. See Chameprosopic.

Champagne (sham-pān') [Fr.]. An efiervescent wine (see Vinum), sometimes prescribed as a remedy for nausea and vomiting. For Champagnes see Wines.

Champak (cham'-pak) [Beng., champaka]. A magnoliaceous tree of India and Indo-China, Michelia champaca. Its highly-fragrant flowers are used for nasal catarrhs and for headaches and eye-disorders; its bark is febrifuge and emmenagogue. See Michelia. Unof.

Chancebone (chans'-bön). A name for the ischium.

Chancre (shang'-ker) [Fr., same] A term formerly used indiscriminately for any primary venereal ulcer, but now generally conceded to signify the initial lesion of syphilis, a true infecting sore, followed by constitutional symptoms (see Syphilis); while chancroid is employed to designate the infectious but non-constitutional sore. C., Hard, Hunterian, Indurated, Infecting, Non-suppurating, or True, the ulcer of venereal origin, that is followed by constitutional syphilis. C., Non-incubatory, Non-infecting, Simple, or Soft, a contagious, suppurating, nonsyphilitic venereal ulcer, properly called chancroid. C., Phagedenic, chancroid with a tendency to erosion. C., Serpiginous, a variety of the last that spreads superficially in curved lines.

Chancroid (shang'-kroid) [chancre]. A local, infective process transmitted by sexual intercourse, and characterized by ulceration, local glandular involvement, and often suppuration. It has been variously termed the soft, non-indurated, simple, or non-syphilitic chancre. See Chancre.

Change (chänj) [ME., changen, to change]. Death. The word is colloquially used either for the establishment or the cessation of the menstrual function. C. of Life, the cessation of the catamenia ; the menopause.

Channel-bone (chan'-el-bon) [ME, chanel, a canal; boon, a bore]. The clavicle.

Chantreuil's Method. In pelvimetry, a method of ascertaining the distance between the tuberosities of the ischia ( $\mathrm{I} \mathrm{cm}$.) in estimating the size of the pelvic outlet. The two thumbs are placed upon the uberosities, and a:1 assistant measures the distance between them.

Chap (chap) [ME., chappen, to cleave]. I. The jaw (usually in the pl.). 2. A slight or superficial fissure of the skin, usually upon the lips, hands, or nipples.

Chaptalization (chap-tal-iz-a'-shun). A method of improving wines consisting in neutralizing the excess of acidity in the must by the addition of marble-dust, and increasing the saccharine content by the addition of a certain quantity of cane-sugar. The wine becomes richer in alcohol, poorer in acid, and the bouquet is not injured.

Charbon (shar'-bon) [Fr]. The French term for anthrax, or pustula maligna.

Charcoal (char'-kol) [ME., charco'e]. Coal made by subjecting wood to a process of smothered combustion. See Carbo animalis and Carbo ligni.

Charcot Pain. Pain in the ovarian region.

Charcot's Disease, Sclerose en plaques. Disseminated, multiple, or insular sclerosis. See Diseases, Table of. C.'s Joint, or Joint Disease. See Arthropathia and Diseases, Table of. C.-Leyden Crystals, microscopic, colorless, octahedral or rhomboidal crystals found in the intestinal tract in leukemic and anemic patients and in the sputum of asthmatic and bronchitic patients; so called by Bäumler. Same as Charcot-Newmann Crystals. See Spermin. C.'s Method. See Hypno- tism. C.-Neumann Crystals. See Spermin. C.Robin Crystals, crystals forming upon leukemic blood when allowed to stand exposed for a few days. C.'s Vibrating Arm-chair. See Shaking Cure.

Charlatan (shar'-lat-an) [Sp., charlar, to prattle]. A quack; a pretender to medical skill; an advertising doctor.

Charlatanoid (shar'-lat-an-oid) [Sp.. charlar, to prattle]. A term applied to an organism so closely resembling a charlatan as at times to be almost indistinguishable.

Charles's Law. See Law.

Charpie (shar'-pe) [carpere, to pluck]. Picked or shredded lint; linen shreds for dressing wounds.

Charqui (char'-ke) [Chilian]. A name given in South America to strips and slices of beef freed from fat and dried rapidly by sun-heat and sprinkled with maize.

Charrière's Guillotine. An instrument for excising the tonsils. See Operations, Table of.

Charta $\left(k a r^{\prime}-t a h\right)$ [ $\chi \alpha \hat{\rho} \tau \tau \eta$, paper: gen. and pl., Charta]. A paper. In pharmacy, a strip of paper as an excipient, the fibers of which are impregnated with the prescribed medicinal substance. Also a wrapper for holding powders or medicines. Of the three official charta, two are intended as vesicants. C. epispastica, or C. cantharidis, blistering-paper. C. emporetica, porous or bibulous paper. C. exploratoria, test-paper. C. sinapis, mustard-paper.

Chartreuse (shar-tres') [Fr.]. A tonic cordial, obtained by distillation from various plants growing on the Alps.

Chartula (kart'-u-lah) [dim. of charta]. A little paper, especially a paper containing a single dose of a medicinal powder.

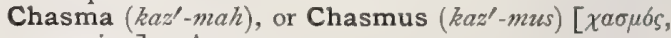
a gaping]. A yawn.

Chassaignac's Operations. See Operations, Table of. Chaste Tree (chäst tre). See Agnus castus.

Chaulmugra Oil (chawl-moog'-rah) [E. Ind.]. A fixed oil expressed from the seeds of Gynocardia odor$a t a$, a tree native to the $\mathbf{E}$. Indies. It is soluble in alcohol, and its properties are due to gynocardic acid. It is thought to be useful in leprosy and is recommended in scaly eczema, psoriasis, and syphilitic skinaffections. For external use, gr. $x x$ of the acid ad $\xi \mathrm{j}$ of petrolatum. Internally, dose gtt. $\mathrm{v}-\mathrm{x}$ of the oil, or gr. ss-iij of the acid, in capsules. All unof.

Chaussier, Line of. See Lines, Table of.

Chautard's Test. See Tests, Table of.

Chauvel's Operation. See Operations, Table of.

Chavibetol (chav-e-be'-tol) [chavica, or piper; betel], $\mathrm{C}_{10} \mathrm{H}_{12} \mathrm{O}_{21}$. A substance isomeric with eugenol; it occurs in oil of betel.

Chavica (chav'-ik-ah) [native South Sea Island name]. A genus of plants including the long pepper and betel. pepper.

Chavicin (chav'-is-in) [chavica, a genus of plants]. An organic basic principle analogous to piperin, found in pepper.

Chavicol (chav'-ik-ol) [chavica, a genus of plants], $\mathrm{C}_{6} \mathrm{H}_{4} \mathrm{OH} . \mathrm{C}_{3} \mathrm{H}_{5}$. A substance occurring in the oil obtained from the leaves of Chavica betel. It is a colorless oil with a peculiar odor, and boils at $237^{\circ}$; its sp. gr. at $20^{\circ}$ is I.0 35

Chawstick (chaze'-stik). See Chewstick.

Check (chek) [ME., chek, a sudden stop]. Something restraining. C.-experiment. See Control. C.ligament. See Ligament. C.-observation. See Control.

Checker-berry (chek'-er-ber'-e). A popular name for Gaultheria procumbens.

Cheddar Cheese. See Cheese. 
Cheek (chek) [ME., cheke]. The side of the face; it is composed of fat, areolar tissue, muscles, etc.

Cheese (chès) [ME., chase]. A food prepared from the casein of skimmed or unskimmed milk. In the following table the results of the researches of Payen on the composition of cheese are quoted in 100 parts for the following kinds: (I) Brie, (2) Camembert, (3) Roquefort, (4) Double cream, (5) Old Neufchâtel, (6) New Neufchâtel, (7) Cheshire, (8) Gruyère, (9) Ordinary Dutch, (IO) Parmesan. The varieties under I, exhibit an alkaline reaction, and contain, with ammonia, cryptogamic plants, or, as it is termed, are moldy. The varieties under II, so-called boiled, strongly pressed, and salted cheese, exhibit an acid reaction, as also does freshly prepared casein.

\begin{tabular}{|c|c|c|c|c|c|}
\hline & \multicolumn{5}{|c|}{ I. } \\
\hline & $\mathbf{I}$ & 2 & 3 & 4 & 5 \\
\hline Water, .... & 45.20 & 51.90 & 34.50 & 9.50 & 34.50 \\
\hline Nitrogenous matter, & 18.50 & 18.90 & 26.50 & 18.40 & 13.00 \\
\hline Nitrogen, ..... & 2.93 & 300 & $4.2 \mathrm{I}$ & 2.92 & 3.31 \\
\hline Fatty matters, . . . & 25.70 & 21.00 & 30. I0 & 59.90 & 41.90 \\
\hline Salts, ....... & 5.60 & 4.70 & 5.00 & 6.50 & 3.60 \\
\hline \multirow{3}{*}{$\left.\begin{array}{c}\text { Non-nitrogenous } \\
\text { organic matter } \\
\text { and loss, }\end{array}\right\}$} & 5.00 & $4 \cdot 50$ & 3.90 & 5.70 & 7.00 \\
\hline & \multicolumn{5}{|c|}{ II. } \\
\hline & 6 & 7 & 8 & 9 & Io \\
\hline Water, ..... & 36.60 & 35.90 & 40.00 & 36. 10 & 27.60 \\
\hline Nitrogenous matter, & 8.00 & 26.00 & 31.50 & 29.40 & 44.10 \\
\hline Nitrogen, ..... & 1.27 & $4 \cdot 13$ & 5.00 & 4.80 & 7.00 \\
\hline Fatty matters, . . . & 40.70 & 26.30 & 24.00 & 27.50 & 16.00 \\
\hline Salts, ....... & $0.5^{\circ}$ & 4.20 & 3.00 & 0.90 & 5.70 \\
\hline $\left.\begin{array}{l}\text { Non- nitrogenous } \\
\text { organic matter } \\
\text { and loss, }\end{array}\right\}$ & I 4.20 & 7.60 & I.5O & 6.10 & 6.60 \\
\hline
\end{tabular}

The character of a few of the different varieties of cheese is as follows: Neufchâtel cheese is a Swiss cream cheese. Limburger cheese is a soft, fat cheese. Fromage de Brie is a soft French cheese, rapidly ripening and developing ammoniacal compounds. Camembert cheese is also a cream cheese. Roquefort cheese is a cheese made from the milk of the ewe. Gruyère cheese is a peculiarly flavored Swiss cheese. Cheddar cheese is a hard cheese made from whole milk. Single and double Gloucester are made, the first from a mixture of skimmed and entire milk, and the second from the entire milk. Parmesan cheese is a very dry cheese, with a large amount of casein and only a moderate percentage of fat. Eidam cheese is a Dutch cheese, also relatively dry, and covered with red coloring. As to the bacillus of cheese see Spirillum tyrogenum, Denecke, under Bacteria, Table of.

Cheese-rennet (chèz'-ren-et). See Ladies' Bed-strazu. Cheesy $\left(c h e z^{\prime}-e\right)[\mathrm{ME}$., chese]. Of the nature of cheese. C. Degeneration, caseous degeneration, or caseation. C. Tubercle, a mass of caseously degenerated tissue.

Cheil-, or Cheilo- (kil-, or kill-o-). For words thus beginning see Chil-, or Chilo-

Cheiro- $\left(k i r^{\prime}-0\right)$. For words thus beginning see Chiro-.

Chekan, or Cheken (chek'-en) [Chilian]. I. The leaves of Eugenia cheken, a South American shrub. Its properties are due to an alkaloid and a volatile oil. It is diuretic and expectorant and similar in action to eucalyptus. It is serviceable in chronic catarrh, laryngitis, etc. Dose of the fluid extract $3 \mathrm{ss}-\mathrm{j}$. Unof. 2. The crude resin obtained from Cannabis indica.

Chela $\left(k e^{\prime}-l a h\right)[\chi \eta \lambda \eta$, a claw $]$. In biology, the claw or pincers of a crustacean.

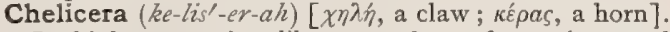
In biology, a claw-like appendage of scorpions and spiders, containing a poison-gland in the latter.

Chelidonic Acid (kel-id-on'-ik). See Acid.

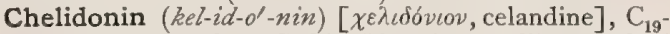
$\mathrm{H}_{17} \mathrm{~N}_{3} \mathrm{O}_{3}+\mathrm{H}_{2} \mathrm{O}$, or $\mathrm{C}_{19} \mathrm{H}_{17} \mathrm{NO}_{4}$. A crystalline alkaloid of celandin (Chelidonium majus), of a bitter and acrid taste, and forming colorless salts with acids. It is not a very active substance. See Sanguinarin.

Chelidonium (kel-id-o'-ne-um) [ $\chi \varepsilon \lambda \iota \delta o ́ v \iota o v$, celandine]. Celandin. The leaves and stems of $C$. majus, with properties due to a number of alkaloids and acids. It is a drastic cathartic, and externally an irritant, and is of service in jaundice, whooping-cough, and catarrhal pneumonia. Dose of the plant gr. $\mathrm{x}-\mathrm{xxx}$; of the juice $\mathrm{m}_{\mathrm{v}-\mathrm{xx}}$. Unof.

Chelidoxanthin (kel-id-aks-an'-thin) [ $\chi \varepsilon \lambda \iota \delta \sigma v \iota o v$, celandine]. One of the bitter, crystalline constituents of celandin.

Cheloid (ke'-loia) [ $\chi \eta \lambda \eta ́$, a claw; $\varepsilon i \delta o s$, form]. A raised or elevated fibroma of the skin; so called from its frequent claw-shape. See also Keloid.

Cheloma (ke-lo'-mah). Same as Keloid.

Chelonin (kel'-on-in). See Balmony.

Chelotomy $\left(k e-l o t^{\prime}-o-m e\right)$. See Kelotomy.

Chematropism (kem-at'-ro-pizm). See Chemotropism, and Chemotaxis.

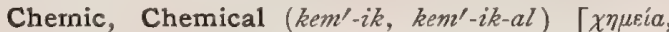
chemistry]. Of or pertaining to chemistry. C. Black. See Pigments, Conspectus of. C. Food, compound syrup of the phosphates, a very complex preparation used in disorders attended with impaired nutrition. C. Lung. See Neale's Lung. C. Pathology, the chemistry of disease.

Chemico-radical Theory. A theory of the constitution of the carbon compounds. It is that the object of organic chemistry is the investigation and isolation of radicals as the more intimate components of the organic compounds.

Chemiotaxis, Chimiotaxis (kem'-e-o-taks-is, kim'-e-otaks-is). See Chemotaxis.

Chemise, Rectal (she-mēz'). A form of surgical dressing made of muslin and applied after operations upon the rectum to control or prevent hemorrhage.

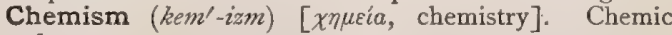
force.

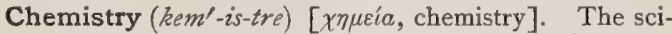
ence of the molecular and atomic structure of bodies.

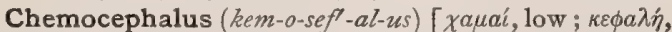
head]. An individual possessed of a flat head.

Chemosis $\left(k e-m o^{\prime}-s i s\right)$ [ $\chi \dot{\eta} \mu \omega \sigma \iota s$, a gaping]. Conjunctival and sub-conjunctival swelling. 


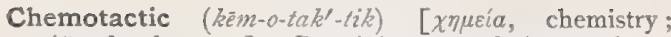
$\tau a ́ \xi \iota s$, battle-array]. Pertaining or relating to chemotaxis.

Chemotaxis (kem-o-taks'-is), Chemiotaxis (kem-e-otaks'-is) [ $\chi \eta \mu \varepsilon i a$, chemistry; $\tau a ́ \sigma \sigma \varepsilon \imath$, to order, arrange]. The property of cellular attraction and repulsion. It is displayed by the proteid constituents of the protoplasm of various. species of bacteria, as well as by proteids from a great variety of sources. The qualifications positive and negative are added according as the phenomenon is one of attraction or repulsion.

Chemotic (ke-mot'-ik) [ $\chi \dot{\eta} \mu \omega \sigma \iota s$, a gaping]. Pertaining to or marked by chemosis.

Chemotropism (kēm-ot'-ro-pizm) [ $\chi \eta \mu \varepsilon t a ́$, chemistry ; $\tau \rho о \pi \dot{n}$, a turning, a rout, a putting to flight]. In biology, the destruction of bacteria by phagocytes; the victory of the phagocytes over bacteria, or of bacteria over phagocytes. In biology, the attraction of leukocytes by certain chemic substances held in solution in the blood, either positive or negative. Cf. Chemotaxis.

Chenopodium (ken-o-po'-de-um) [ $\chi \dot{\eta} \nu$, a goose; $\pi \delta \delta\llcorner 0 \nu$, a little foot]. American Wormseed; the fruit of $C$. ambrosioides, or anthelminticum, a plant native to the United States with properties due to a volatile oil, which is the only preparation used. It is a mild cardiac stimulant, promoting the secretions of the skin and kidneys, and also a very efficient anthelmintic against the round-worm. Dose of the oil $m v-x v$.

Cheoplastic (ke-o-plas $-t i k)$ [ $\chi^{\prime} \varepsilon \iota \nu$, to pour ; $\pi \lambda a \sigma \tau \iota \kappa \delta s$, plastic]. Made soft and yielding by heat. C. Metal, an alloy composed of tin, silver, and bismuth, with a small trace of antimony.

Cherry $\left(\right.$ cher'-e) $^{\prime}$ ME., chery $]$. The bark of the common cherry, Prunus serotina, a mild bitter and tonic, containing tannin. Dose of fld. ext. $3^{\text {ss-j. }}$. Prunin, a concentrated ext. Dose gr. j-iij. C.-Compound, each $O_{j}$ represents cherry-bark 3 viij, lettuce $\zeta$ iij, horehound $\bar{\zeta}$ iijss, bloodroot $\bar{\xi}$, veratrum viride $\bar{\zeta}$ ss. Dose $m x v-z j$. All unof. See also Choke-cherry and Prunis virginiana. C.-laurel, the European evergreen cherry, Prunus lauro-cerasus. Water distilled from its leaves is used in the same way as dilute hydrocyanic acid. See Acid, Hydrocyanic.

Cheselden's Operations. See Operations, Table of.

Chest. See Thorax. C., Barrel-, a peculiar formation of the chest observed in cases of long-standing emphysema of the lungs; it is round like a barrel, and in respiration is lifted vertically instead of being expanded laterally. See Emphysema. C.-founder. See Founder. C. Sweetbread. See Siveetbread.

Chestnut. See Castanea. C. Extract. See Horsechestnut-bark. C.-wood, a wood used in leathermanufactures, derived from the Castanea vesca, and containing from eight to ten per cent. of a tannin that closely resembles gallotannic acid. The extract, containing from $\mathrm{I}_{4}$ to $20 \mathrm{per}$ cent. of tannin, is used largely to modify the color produced by hemlock extract and for tanning and dyeing.

Chevreul's Test. See Tests, Table of.

Chevron-bone (shev'-ron-bön) [ML., capro, a rafter; boon, bone]. One of two bones forming a V-shaped arch beneath the caudal portion of the back-bone of many animals.

Chewstick [ME., chewen, to chew ; stiken, to pierce]. The bark of Gonania domingensis, a popular aromatic bitter in the West Indies. It is also used as a dentifrice and masticatory. Dose of the fld. ext. $3 \mathrm{j}-\mathrm{ij}$. Unof.

Cheyne's Operation. See Operations, Table of.

Cheyne-Stokes Breathing or Respiration. See Signs and Symptoms, Table of. C. Nystagmus, a variety of nystagmus in which the oscillations of the

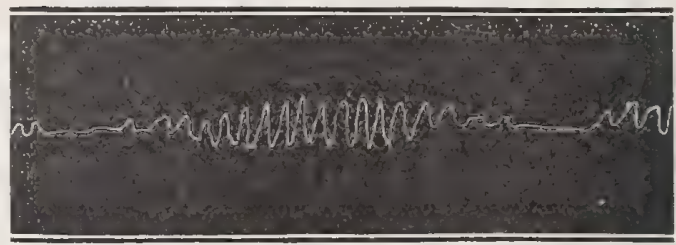

TRACING OF CHEYNE-STOKES BREATHING.

eyeball have a rhythmic variation similar to the rhythm of Cheyne-Stokes respiration.

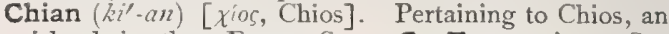
island in the Agean Sea. C. Turpentine. See Terebinthina.

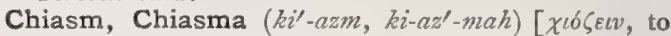
make a cross, as an X]. The optic commissure.

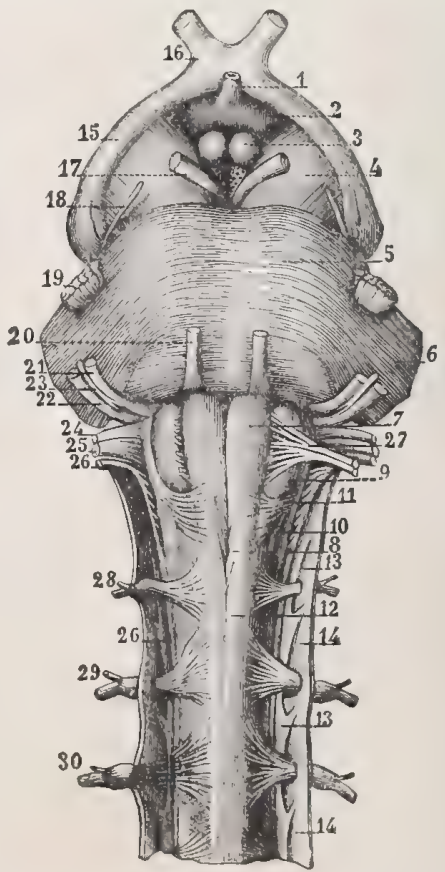

Optic Chiasm and Adjacent Parts.

I. Infundibulum. 2. Tuber cinereum. 3. Corpora albicantia, or mammillaria. 4. Crus cerebri. 5. Pons varolii. 6. Middle cerebellar peduncle. 7. Anterior pyramid. 8. Decussation. 9. Olivary body. Io. Gray tubercle of Rolando. Ir. Arciform fibers, 12. Superior extremity of spinal cord. 13, I3. Denticulate ligament. I4. Spinal dura mater. I5, Optic tract. 16. Optic chiasm. I7. 3d nerve. 18. 4th nerve. 19. $5^{\text {th }}$ nerve. 20. 6th nerve. 21. Facial nerve. 22. Auditory nerve. 23. Nerve of Wrisberg. 24. Glosso-pharyngeal nerve. 25. Pneumogastric nerve. 26, 26. Spinal accessory nerve. 27. Hypoglossal. 28 Ist cervical pair. 29. $2 \mathrm{~d}$ cervical pair. 30 . 3d cervical pair.

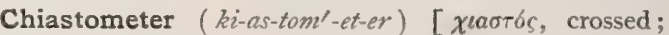

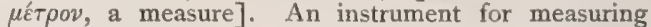
any deviation of the optic axes from parallelism.

Chibou (see-boo') [Fr.]. The resin or gum of Bursera gummifera, a tree of Florida and tropical America; it is locally valued in diseases of the lung and kidneys, and is used in various plasters and ointments; it is called also cachibou and archipin. Unof.

Chibret's Operation. See Operations, Table of. 
Chica Red (che'-kah) [S. Amer.]. See Pigments, Conspectus of.

Chick Pea (chile pe) [ME., chich-pea]. The plant Cicer arielinum; also the pulse derived from it ; much used as an article of food in various countries. Lathyrism (apparently chronic oxalic-acid poisoning), q. $v$., sometimes results from the too free use of the chickpea as a food.

Chickahominy Fever (chik-a-hom'-in-e fe'-ver). See Fever.

Chicken (chik'-en) [ME., chiken, a chicken]. A domes. tic fowl. C. Breast, an abnormally prominent condition of the sternum and of the sternal region; pigeonbreast ; it is seen in rhachitic persons, etc. C. Cholera See Cholera. C.-fat Clot. A clot of blood consisting largely of fibrin, yellowish in color, and containing but few red-cells. C.-pox. See Varicella.

Chicle $\left(c^{\prime} i k^{\prime}-l\right)$ [S. Amer.]. A gum obtained from the Achras sapota, a tree of tropical America, and used as a masticatory.

Chico Red (che'-ko) [S. Amer.]. Same as Chica Red.

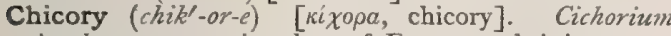
intybus, a composite plant of Europe and Asia, naturalized and growing in the United States. Its groundroot is used to adulterate coffee.

Chicot $\left(c h e^{\prime}-k o\right)$ [Fr.]. Kentucky Coffee Bean. The seeds of Gymnocladus canadensis. Chicot contains a volatile oil and a glucosid, and is probably a cerebro-spinal stimulant. It is sometimes used as a substitute for coffee. Unof.

Chiene's (John) Method. A method of locating the fissure of Rolando. A square piece of paper is folded once, so as to form a triangle. Either of the two equal angles is then $45^{\circ}$. One free edge is then folded back so that this angle is bisected, thus forming an angle of $22.5^{\circ}$. The paper is then unfolded at the first crease, so as to secure an angle of 67.5 , the apex of which is placed $1 / 2$ inch behind the mid-point between the glabella and the inion, so that the straight side of the paper corresponds to the middle of the anterior aspect of the head; the other margin of the paper, the fold, corresponds to the fissure of Rolando, the length of which is about $3 \frac{3}{8} 8$ inches. C.'s Operation. See Operations, Table of.

Chignon Fungus (shēn-yōn') [Fr.]. A fungoid disease of the hair in which oval or roundish masses surround the hair-shaft at irregular intervals. It is also miscalled Chignon gregarine.

Chigoe (chigl-o) [Fr., Chique]. Sand-flea; Sarcopsylla penetrans, a small parasite of the skin, affecting usually that portion between the toes and fingers; also the red harvest mite, Leptus irritans. It is also written chigo, chegoe, chigga, chiggre, chigger, jigger. See Parasites (Animal), Table of.

Chilblain (chill-blān) [AS., cele, cold ; blegan, to boil]. Pernio; Erythema pernio. An erythematous local inflammation and swelling of the skin, due to cold. It is most common in the young of lymphatic constitution. The symptoms are an eruption of circular, raised erythematous spots, attended with severe itching or burning; later, bullæ may form, and these may lead to ulceration.

Child (child) [ME., child: pl., Children]. A young person. C.-bed, the popular term for the condition of a woman during and after labor. C.-bed Fever. See Puerperal Fever. C.-birth, parturition. C.crowing, the crowing sound of the respiration that characterizes Laryngismus stridulus, q. v. C.-hood, the age of childishness; the period before puberty. C.-murder. See Infanticide. Children's Diseases. See Pediatrics.

Chile (chill-e). See Capsicum.
Chili Saltpeter. See Sodium.

Chilitis $\left(k \bar{i} l-i^{\prime}-t i s\right)[\chi \varepsilon i \lambda o s$, lip $]$. Inflammation of a lip. Chill (chil) [ME., chil]. A sensation of cold accompanied by shivering, usually appearing shortly after exposure to cold or wet. It is frequently the initial symptom of grave acute disorders, as pneumonia, etc. It is a prominent symptom of various forms of malarial fever. See Rigor.

Chilli (chill-e). See Capsicum and African Pepper.

Chills and Fever. A popular term for intermittent fever.

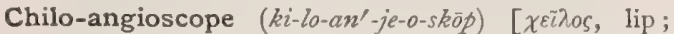
$\bar{a} \gamma \gamma \varepsilon$ lov, vessel; $\sigma \kappa o \pi \varepsilon \dot{\iota} v$, to look]. An apparatus for observing the circulation of the blood in the human lip.

Chilocace $\left(k \bar{\imath} l-o k^{\prime}-a s-e\right)$ [ $\chi \varepsilon i \lambda \circ \varsigma$, lip; $\kappa a \kappa b s$, evil]. A firm, reddish swelling of the lip in scrofulous children.

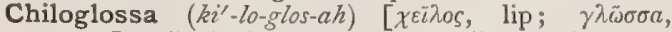
tongue]. In biology, the anterior lip, or the membranous protuberance that lies in front of the mandibles and is continued under these in certain arthropods.

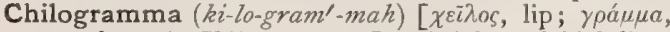
a mark: pl., Chilogrammata]. Jadelot's labial line. See Lines, Jadelot's.

Chiloma (ki-lo'-mah) [ $\chi \varepsilon \hat{\imath} \lambda \omega \mu a$, a lip]. In biology, a projecting thickened upper lip-as in the camel.

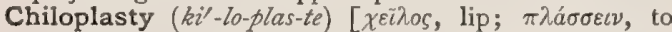
form]. Any plastic operation upon the lip.

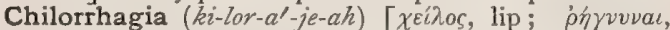
to burst forth]. Hemorrhage from the lips.

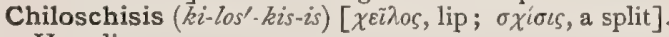
Hare-lip.

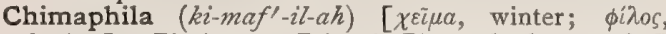
loving]. Pipsissewa, Prince's Pine; the leaves of $C$. umbellata, an evergreen found in the U.S, an astrin. gent tonic and excellent diuretic. The bruised leaves are used as a rubefacient. It is valuable in dropsy, several forms of kidney disease, and for affections of the urinary passages. C., Fld. Ext. Dose $\mathbf{3}^{\text {ss-ij. }}$ C., Decoctum. I to I7. Dose $\overline{3}$ j-iij. Unof.

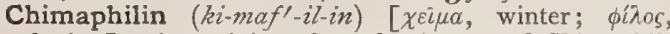
loving]. A precipitate from the tincture of Chimaphila umbellata, used in cancers; it is a diuretic, discutient, and alterative. Dose two to three grains. Unof.

Chimiotaxis (kim-e-o-taks'-is). See Chemotaxis.

Chimiotetic (kim-e-o-tet'-ik). See Chemotactic.

Chimney-sweep's Cancer. Cancer of the scrotum. formerly not uncommon among chimney-sweepers.

Chin [ME., chin]. The mentum; the lower part of the face, at or near the symphysis of the lower jaw. C., Double. See Buccula. C.-cough, whooping-cough. C.-jerk. See Jaw-jerk, and Reflexes, Table of. C. Reflex. See Reflexes, Table of.

China (kin'-ah, or $\left.k e^{\prime}-n a h\right)$ [Sp.]. Same as Cinchona. China (chi'-nah) [Pers., Chini, China]. A country of Asia. C.-blue. See Pigments, Conspectus of. C.clay. See Pigments, Conspectus of. C.-grass, Ramie; a soft, silky vegetable substance used as a surgical dressing; the fiber of Bchmeria nivea. C.root, the rhizome of Smilax china, a plant of Eastern Asia ; it is used as a substitute for true sarsaparilla. Unof. C.-root, False, the plant Smilax psezdochina of N. America. Unof. C.-white. Same as White Lead.

Chinese (chi-nēes', or -nēz) [Pers., Chīnì, China]. Pertaining or belonging to China. C. Catarrh. Synonym of Infuenza. C. Foot, a deformed and undeveloped foot due to atrophy from compression. It is a popular fashion among Chinese ladies. C. Green. See Prgments, Conspectus of. C. Red. Same as Ver. mition. C. Twist, a name given to a variety of silk-thread used in surgery. C. Wax, Insect Wax; a 
substance deposited by an insect, Coccus cerifera, upon the Chinese ash-tree. It is a white, very crystalline, and brittle wax, resembling spermaceti in appearance, with a specific gravity of .973 at $15^{\circ} \mathrm{C}$; it fuses at $82^{\circ}$ to $83^{\circ} \mathrm{C}$. It is slightly soluble in alcohol and ether, very soluble in benzene. It is used in candlemaking. C. White. Same as Zinc-white. C. Yellow. Same as King's Yellow and Ocher.

Chinoidin, or Chinoidinum (kin-oi'-din, or kin-oi-din' um) [Sp., China]. Quinoidin. A mixture of amorphous alkaloids obtained in the manufacture of quinin. It has the therapeutic properties of quinin.

Chinolin (kin'-o-lin). See Chinolina and Quinolin.

Chinolina (kin-o-li'-nah) [china, quinin], $\mathrm{C}_{9} \mathrm{H}_{7} \mathrm{~N}$. Chinolin, Leukolin. An alkaloidal derivative of quinin and cinchonin, occurring also in coal-tar. It is now generally prepared by heating anilin or nitro-benzol with glycerin and a dehydrating agent. It is a valuable antiseptic and antipyretic, and is useful in pneumonia and typhus and other fevers. It is commonly used in the form of the tartrate because of the deliquescence of the other salts. Dose $m$ iij to $x$; of the tartrate gr. $\mathrm{v}-\mathrm{xv}$. Unof.

Chinovin (kin'-o-vin) [china, quinin], $\mathrm{C}_{30} \mathrm{H}_{38} \mathrm{O}_{8^{*}} \quad \mathrm{~A}$ glucosid obtained from Cinchona.

Chinwhelk. Synonym of Tinea sycosis.

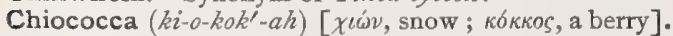
A genus of rubiaceous plants. See Cahinca.

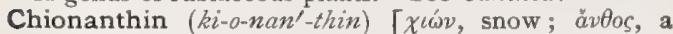
flower]. A precipitate from the tincture of the rootbark of Chionanthus virginiana; it is an aperient, diuretic, tonic, and narcotic. Dose $I$ to 3 grains. Unof.

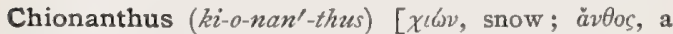
flower]. A genus of oleaceous trees and shrubs. C. virginiana, fringe-tree or poison-ash. The root is used as a vulnerary. See also Fringe-tree. Unof.

Chionyphe $\left(k i-o n^{\prime}-i f-e\right)$ [ $\chi \iota \omega \omega$, snow; $v \phi^{\prime}$, a texture]. A genus of fungi. C. carteri, a parasitic fungus, apparently the cause of the disease known as Fungus Foot, or Madura Foot, q. v.

Chip Blower (chip blo'-er). A warm-air blow-pipe.

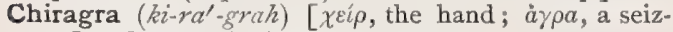
ure]. Gout in the hand.

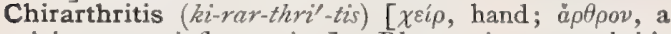
joint; $\iota \tau \iota \varsigma$, inflammation]. Rheumatism or arthritis of the hand.

Chirata $\left(k e-r a^{\prime}-t a h\right.$, or che-ra'-tah) [Hind., chiräet $\vec{a}$ a species of gentian]. Chiretta. The entire plant, Szuertia chirata. It resembles gentian in its thera peutic properties. and is an excellent tonic. It does not contain any tannin. Dose of the powdered plant gr. $x v-x x x . \quad$ C., Fld. Ext., in glycerin and alcohol. Dose $\mathrm{qux}_{\mathrm{x}-\mathrm{xxx}}$. C., Infusum (B. P.). Dose a wineglassful. C., Tinct., ten per cent. in strength. Dose $3 \mathrm{ss}-\mathrm{ij}$.

Chiratin (kir-at'-in) [Hind., chirāeta, a species of gentian], $\mathrm{C}_{26} \mathrm{H}_{48} \mathrm{O}_{15^{*}}$ A light-yellow, crystalline, bitter glucosid, obtained from Chirata.

Chiretta (kir-et'-ah). See Chirata.

Chirettin (kir-et'-in) [Hind, chirāetā, a species of gentian]. A precipitate obtained from the tincture of chirata.

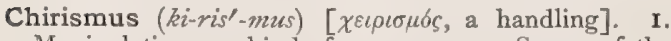
Manipulation; a kind of massage. 2. Spasm of the hand.

Chiromancy (ki'-ro-man-se). See Palmistry.

Chiropelvimeter (ki-ro-pel-vim'-et-er) [ [ $\chi \varepsilon i \rho$, the hand;

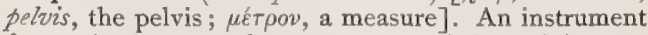
for use in the manual measurement of the pelvis.

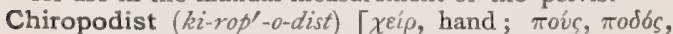
foot]. A surgeon or person who professionally treats diseases of the hands and feet, especially corns, bunions, etc.

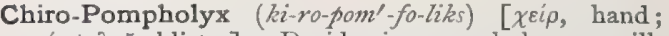
$\pi o ́ \mu \phi o \lambda v \xi$, blister $]$. Dysidrosis; pompholyx; an illdefined, inflammatory skin-disease confined to the hands and feet, and characterized by the development of peculiar vesicles or blebs, arranged in groups. They are deeply seated and distributed chiefly on the soles and palms and sides of the fingers. Itching, burning, pain, and stiffness are present. The disease is common in neurotic women in the prime of life; it is almost invariably recurrent, and is rare in winter.

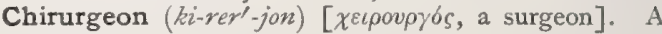
surgeon.

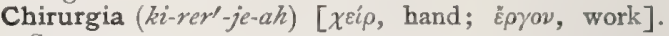
Surgery.

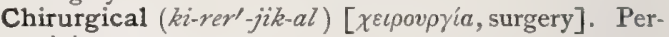
taining to surgery.

Chirurgien Dentiste (ki-rer'-je-enden-tist') [Fr.]. Surgeon-dentist.

Chisel Cramp (chiz'-el-kramp). See Cramp.

Chitin (ki'-tin) [ $\chi \imath \tau \omega v$, a tunic], $\mathrm{C}_{15} \mathrm{H}_{26} \mathrm{~N}_{2} \mathrm{O}_{10^{\circ}}$ The substance composing the chief part of the exoskeleton of many invertebrates, as crabs, lobsters, etc: It is the animal analogue of the cellulose of plants. When heated with concentrated $\mathrm{HCl}$ it is decomposed into glycosamin and acetic acid. Glycosamin $\left(\mathrm{C}_{6} \mathrm{H}_{13} \mathrm{NO}_{5}\right)$, crystallizes from alcohol in fine needles, is dextro-rotatory, and reduces Fehling's fluid to the same extent as does dextrose, but is not fermentable. C. Substance, a gelatinous substance found in hydatid cysts.

Chittim Bark (chit'-im bark). See Cascara Sagrada.

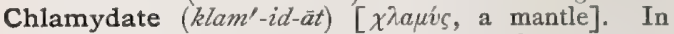
biology, provided with a pallium or mantle.

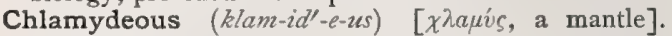
In biology, pertaining to the floral envelops.

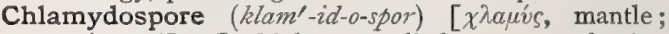
$\sigma \pi \circ \rho \hat{x}$, seed]. In biology, applied to a spore having its own protective envelop.

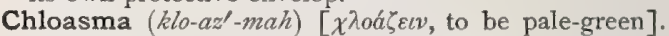
Melanoderma; melasma; a condition characterized by dyschromix of the skin of various sizes and shapes, and of a yellow, brown, and black color. They occur chiefly upon the face, and are idiopathic or symptomatic in character. An old name for Tinea versicolor. C. hepaticum, Liver-spots; a form following dyspepsia and popularly associated with hepatic disturbance. $\mathbf{C}$. phthisicorum, the brown patches upon the skin of the forehead or upper portions of the cheeks in tuberculous patients. C. uterinum, chiefly located on the forehead, temples, cheeks, nipples, and median line of abdomen. They are marked during pregnancy, and often during menstruation.

Chloracetic Acid (klo-ras-e'-tik). See Acid.

Chloral (klo'-ral) [chlorin; aldehyd], $\mathrm{C}_{2} \mathrm{Cl}_{3} \mathrm{HO}$. A pungent, colorless, mobile liquid. The name is often misapplied to chloral hydrate. C. Butylicum, ButylChloral Hydrate (B.P.), croton-chloral, $\mathrm{C}_{4} \mathrm{H}_{5} \mathrm{Cl}_{3} \mathrm{O}$,$\mathrm{H}_{2} \mathrm{O}$, a solid occurring in crystalline scales, resembling chloral hydrate, but made with butyl, $\mathrm{C}_{4} \mathrm{H}_{9}$, as a base, instead of ethyl, $\mathrm{C}_{2} \mathrm{H}_{5}$. Its properties are parallel to those of chloral, but are much feebler. Dose gr. $\mathrm{v}-\mathrm{xx}$ in syrup. Syrupus Butyl-Chloral, 16 grains to the ounce. Dose $\mathbf{3}$ j-iv. Unof. C. Hydrate, a colorless, crystalline solid having the composition $\mathrm{C}_{2} \mathrm{HCl}_{3}(\mathrm{HO})_{2}$, the hydrate of chloral. It is a powerful hypnotic, antispasmodic, and depressant to the cerebral, medullary, and spinal centers, and, to a limited extent, is an anesthetic. It is serviceable in fevers, accompanied by cerebral excitement, in chorea, convulsions, and all affections requiring a cerebral depressant, and is excellent in delirium tremens, but should be used with 
great caution. Dose gr. $\mathrm{v}-\mathrm{xx}$; smaller if combined with potassium or sodium bromid. C., Syrupus (B.P.). Dose $3_{\mathrm{ss}-\mathrm{ij} .}$ C.-urethane. See Uralizm. Chloralamid (klo-ral-am'-id) [chloral; amid], $\mathrm{CCl}_{3} \mathrm{CH}$ $\mathrm{OH}$

$<\mathrm{NHCHO}$. A name inaptly applied to chloral formamidate. In doses of 30 to 45 grains it is a hypnotic. Chloralid (klo'-ral-id) [chloral $], \mathrm{C}_{5} \mathrm{H}_{2} \mathrm{Cl}_{6} \mathrm{O}_{3}$. A substance obtained when trichlorlactic acid is heated to $150^{\circ}$, with an excess of chloral ; it crystallizes from alcohol and ether in large prisms, is insoluble in water, and melts at from $I I 4^{\circ}$ to $I 15^{\circ}$; it boils at from $272^{\circ}$ to $273^{\circ}$.

Chloralimid (klo-ral'-im-id) [clloral; imid], $\mathrm{CCl}_{3}$. CH.NH. A hypnotic allied to chloral, soluble in alcohol. Dose same as that of chloral hydrate. Unof.

Chloralism (klo'-ral-izm) [chloral]. r. Chloralpoisoning; the morbid state caused by the injudicious use of chloral. 2. The habit of using chloral.

Chloralize $\left(k l_{0}^{\prime}-r a l-\bar{z} z\right)$ [chloral $]$. To put under the influence of chloral.

Chloralose (klo'-ral-ōs) [chloral; glucose]. Anhydroglycochloral; a product of the action of anhydrous chloral upon glucose.

Chloramyl (klo'-rami-il). See Anesthetic.

Chloranemia (klo-ran-e'-me-ah). Synonym of Chlorosis.

Chloranil (klo'-ran-il) [chlorin], $\mathrm{C}_{6} \mathrm{Cl}_{4} \mathrm{O}_{2}$. A compound obtained from many benzene compounds (anilin, phenol, isatin) by the action of chlorin or potassium chlorate and $\mathrm{HCl}$. It consists of bright, golden leaflets, insoluble in water, but soluble in hot alcohol and ether.

Chlor-anodyne (klor-an'-o-din) [chlorin; áv priv. ; ódviv, pain]. A proprietary remedy introduced as an improvement on chlorodyne. It contains morphin hydrochlorate, tinct. cannab. Ind., chloroform, dilute hydrocyanic acid, and aromatics. Dose for an adult mxv. Unof.

Chloranthus (klo-ran'-thus) [ $\chi \lambda$ twós, yellowish-green; a้ $\nu$ $0 \varsigma$, a flower]. A genus of chloranthaceous plants of hot climates. C. officinalis, of Java, is a valuable febrifuge and anti-spasmodic. Unof.

Chlorate $\left(k l \sigma^{\prime}-r \bar{a} t\right)[c h l o r i n]$. Any salt of chloric acid. See Potassii chloras; Sodii chloras, etc.

Chloremia (klo-re'-me-ah) [ $\chi^{\lambda} \omega \rho b s$, green; ai $e^{\gamma} a$, blood] A blood-disorder, either idiopathic or associated with other ailments, consisting in a diminution of the percentage of the hemoglobin and a decrease in the number of red blood-corpuscles.

Chlorethyl (klo-reth'-il). See Ethyl chlorid.

Chloric (klo'-rik) [chlorin]. Pertaining to or containing chlorin. C. Acid. See Acid. C. Ether. I. See Ethyl chlorid. 2. See Spiritus Chloroformi.

Chlorid (klo'-rid) [chlorin]. In chemistry, a binary compound, one of the elements of which is chlorin. C. of Iron Test. See Tests, Table of. C. of Methyl: See Anesthetic. Chlorids, Test for. See Tests, Table of.

Chlorin, or Chlorine $\left(k l o^{\prime}-r i n\right)$ [ $\chi \lambda$ copós, green]. $\mathrm{Cl}$ $=35.5$; quantivalence $\mathrm{I}$. A non-metallic element. At ordinary temperatures it is a greenish-yellow gas, prepared by decomposing sodium chlorid, $\mathrm{NaCl}$. It is highly irritative to the skin and mucous membranes, producing spasmodic closure of the glottis. It is the most valuable of disinfectants. Chlori, Aqua, C., Liquor (B.P.), chlorin water, contains 4 per cent. of the gas in solution. It is a good antiseptic wash. Dose, internally, $m x-\mathrm{xxx}$. Calx Chlorinata, "chlorid of lime," a hypochlorite of calcium containing free chlorin; a valuable disinfectant. Dose, internally, gr. iij-vj. Calx Chlorat, Liq. (P. B.), con- tains I pound of the salt per gallon of water. Sodiun Chlorat., Liq., Labarraque's Solution, sodium carbonate 10 , calx chlorinata 8 , water ad 100 . Dose $m x$ $3 \mathrm{j}$ in 20 parts of water. Chlorin Vapor (B. P.), used for inhalation. C.-Hunger, the condition of the body when chlorin (usually in the form of common salt) is lacking. Among the immediate results of this deficiency are indigestion and albuminuria.

Chloroanemia (klo-ro-an-e'-me-ah). Synonym of Chlorosis.

Chlorobrom (klo'-ro-bröm) [chlorin; bromin]. A solution each ounce of which contains 30 grains of chloralamid and potassium bromid. It is a hypnotic.

Chlorocruorin (klo-ro-knu'-or-in) [ $\left[\chi^{\lambda} \omega \rho b_{s}\right.$, green; cruor, blood]. A green respiratory pigment from the greenish blood of the Sabella.

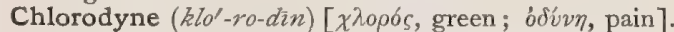
A proprietary remedy supposed to contain chloroform, ether, morphin, cannabis Indica, hydrocyanic acid, and capsicum. The various imitations differ widely. It is a good anodyne and narcotic. Dose $m \mathrm{x}-\mathrm{xxx}$, with care. Unof.

Chloroform (klo'-ro-form) [chloroformum, chloroform : gen., Chloroformi ]. Methyl Terchlorid, $\mathrm{CHCl}_{3}$. A heavy, acolorless, volatile liquid obtained by the action of chlorinated lime on methyl alcohol. (The commercial article, $C$. venale, contains 2 per cent. of impurities and is unfit for administration.) Administered internally, chloroform produces narcosis and violent gastroenteritis. Chloroform has an agreeable odor and a sweetish taste. It solidifies in the cold, melts at $7 \mathrm{x}^{\circ} \mathrm{C}$., boils at $6 \mathrm{I}^{\circ} \mathrm{C}$, and its specific gravity is 1.526 . It is excellent in true cholera and in similar diseases of the stomach and bowels. Externally, it is much employed as an ingredient of rubefacient and anodyne liniments. Mixed with a large per cent. of air and inhaled, the vapor is one of the most valuable of general anesthetics. but occasionally $(\mathbf{I}: 3000)$ causing death by cardiac paralysis. See Anesthetic. Deep injections in the vicinity of the sciatic nerve are recommended in sciatica. C., Alcoholized, a mixture of chloroform and alcohol. C., Ammoniated, equal parts of ammonia in alcohol and chloroform; antipyretic and anodyne. Unof. C., Aqua. Dose 3 ss-ij. C., Liniment, contains chloroform 30, soap-liniment 7o. C., Liniment., Comp., contains chloroform ${ }^{3}$, oil of turpentine $\bar{\xi}$, tincture of opium $z$ iv, tincture of aconite 3 ij. Unof. C., Emulsum, chloroform 4, expressed oil of almond 6 , tragacanth I.5, water q. s. Dose 3 j- 3 ij. C., Spt., pure chloroform 6, alcohol 94 parts. Dose $m x-3 j$. Tinct. chloroformi et morphinæ (B. P.), a substitute for chlorodyne. Each dose of ten minims contains chloroform $m^{I^{1} / 4}$, ether $\eta^{1} / 3$, alcohol $\eta_{1} 1 / 4$, morphin hydrochlorate gr. $\frac{1}{48}$, dilute hydrocyanic acid $m 5 / 8$, oil of peppermint $m_{\frac{1}{80}}$, fluid extract of licorice $m_{I^{1} / 4}$, treacle and syrup q.s. Tinct. C. Comp. (B.P.), chloroform 2, alcohol 8, comp. tinct. of cardamon ro. Dose $m x x-3 j$.

Chloroformism (klo'-ro-for-mizm) [chloroformum, chloroform]. I. The use of chloroform to excess for its narcotic effect. 2. The symptoms produced by this use of the drug.

Chlorolymphoma (klo-ro-limf-o'-mah) [ $\chi \lambda \lambda \omega \rho o ́ s$, green ; lympha, water; $\delta \mu a$, a tumor]. Another name for chloroma; it is thought by some to be a variety of lymphoma, from its containing lymphocytes.

Chloroma (klo-ro'-mah) [ $\chi^{\lambda \omega \rho o s, ~ y e l l o w i s h-g r e e n ; ~ o ̈ ~} \mu a$, a tumor: pl., Chloromata]. "Green cancer" ; a rare variety of sarcoma, of a greenish tint, usually seated upon the periosteum of the bones of the head, or upon the dura. 


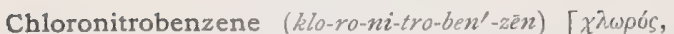
green; nitrum, niter; benzoin $]$. One of the ingredients of Robusite, $q$.

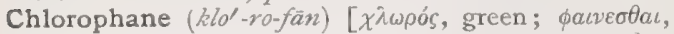
to appear]. A yellowish-green chromophane. See Chromophane.

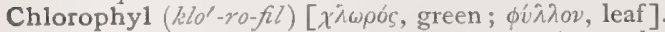
A coloring-matter occurring in the chlorophyl-granules in all the green parts of plants. Wax and other substances are associated witn it. Its constitution is not yet known. It is the substance by whose agency carbohydrates are formed in green plants.

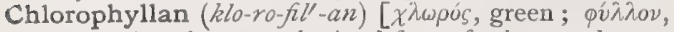
leaf]. A substance obtained from fresh grass by extracting the latter with boiling absolute alcohol. It appears as crystals that melt at $110^{\circ} \mathrm{C}$. to a black liquid, which on further heating burns with a luminous tame. It is easily soluble in ether, benzol, and chloroform.

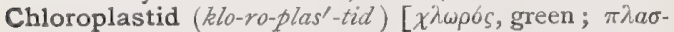
$\tau \delta s$, to form or mold]. In biology, a chlorophylgranule. Applied by Lankester to chlorophyl-bearing cells as seen in Hydra viridis. Probably these are secretory cells or digestive glands comparable to the liver-cells of Amphioxus.

Chlorosarcoma (klo-ro-sar-ko'-mah), See Chloroma.

Chlorosis (klo-ro'-sis) [ $\chi \lambda \omega \rho o ́ s$, green]. The "green sickness," a disease of young women, associated with anemia and menstrual abnormality, usually suppression. It is the most common form of idiopathic anemia. It is favored by a sedentary life and poor hygiene. The blood shows a marked deficiency in hemoglobin, with some decrease in the number of red corpuscles, together with an increase in its watery elements. The patients do not seem to suffer from any interference with the general nutrition; in fact, there is often a tendency to the accumulation of fat in the tissues. There is present well-marked neurasthenia, with, at times, hysterical manifestations. There can always be heard a systolic bruit at the base of the heart and in the neck, anemic in nature. The bowels are constipated, and there may be some fever. C. pituitosis. Synonym of Enteritis, Pseudo-membranous. C. rubra, cases of chlorosis of moderate grade, with a reddish tint of the cheeks, especially on exertion.

Chlorotic (klo rot'-ik) [ $\chi \dot{\lambda} \omega \rho o ́ t \eta s$, paleness]. Relating to chlorosis. A person affected by chlorosis.

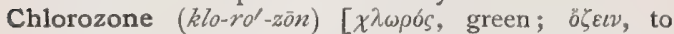
smell]. A yellow liquid assumed to be a mixture of chlorin and ozone; it is formed by passing nascent chlorin through caustic soda; its composition is not known. It is a strong bleaching-agent and disinfectant.

Chlorphenol (klor-fe'-nol) [ $\chi^{\lambda} \omega \rho \sigma o s$, green; $\phi \circ \bar{\imath} \iota \xi \xi$ purple-red], $\mathrm{C}_{6} \mathrm{H}_{4} \mathrm{Cl} . \mathrm{OH}$. Mono-chlor-phenol, a substance possessed of marked antiseptic and antituberculotic properties. It is strongly recommended for inhalation in diseases of the respiratory passages.

Chlorum $\left(k l o^{\prime}-r u m\right)[\chi \ddot{\lambda} \omega \rho o s$, green : gen., Chlori $]$. The official pharmaceutic name of chlorin. See Chlorin.

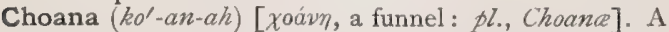
funnel-like opening. A name applied to the posterior nasal orifices.

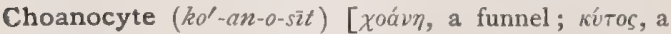
cell]. In biology, a collar-cell.

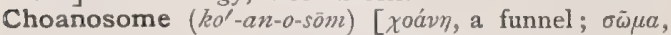
body]. In biology, that portion of the cavity of a snonge that is lined with collar-cells.

Chocolate (chok'-o-lät) [Mex., choco, cacao; latl, water]. I. A dried paste prepared from the powder of cacao-seeds (see Cacao) with various mucilaginous and amylaceous ingredients. 2. A beverage prepared from the foregoing. 3. A sugared comfit, variously compounded and flavored, containing some proportion of the foregoing paste; sometimes medicated, as with cinchona, scammony, or magnesia. C., African. See $16 a$.

Choke $(c h o k)$ [ME., choken, to choke]. To suffocate; to prevent the access of air to the lungs by compressing or obstructing the trachea. C.-cherry, the fruit of Prunus (Cerasus) virginiana, not the $P$. virginiana of the pharmacopeia; common in the U. S. It is antispasmodic, tonic, and slightly astringent. Cerasin is a concentrated extract. Dose gr. ij-viij. Unof. C.-damp, a name given by miners to carbonic acid gas. Called also Black-damp.

Choked Disc (chōkd disk). See Papillitis.

Choking (chok $\left.k^{\prime}-i n g\right)$ [ME., choken, to choke]. Partial or complete suffocation, whether by the lodgment of food, or any foreign body in the larynx, trachea, pharynx, or esophagus, or by the inhalation of any irrespirable gas or vapor. C. Distemper, a name applied in Eastern Pennsylvania to cerebro-spinal meningitis in the horse

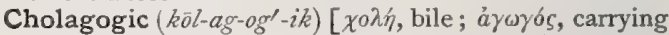
off ]. I. Stimulating the flow of bile. 2. A cholagogue. Cholagogue $\left(k \bar{o} l^{\prime}-a g-o g\right)$ [ $\chi 0 \lambda \dot{n}$, bile; á $\gamma \omega \gamma o ́ s$, leading]. Any medicine that promotes the flow of bile; an agent that is supposed to stimulate the secretion or excretion of bile.

Cholalic Acid (ko-lal'-ik). See Choloidinic Acid.

Cholangitis (ko-lan-jï-tis) [ [ sel]. Inflammation of a bile-duct. It is attended with ague-like paroxysms, chills, fever, and sweating, and jaundice of varying intensity.

Cholate $\left(k \circ l^{\prime}-\bar{a} t\right)[\chi o \lambda \dot{\eta}$, bile]. Any salt of cholic acid.

Choleate $\left(k o l^{\prime}-e-\bar{a} t\right)[\chi o \lambda \dot{\eta}$, bile]. Any salt of choleic acid.

Cholecyanin (kol-e-si'-an-in). See Biticyanin.

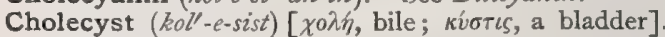
The gall-bladder.

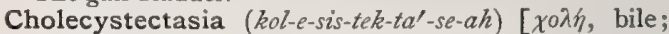

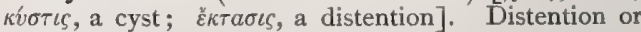
dilatation of the gall-bladder.

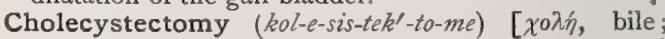

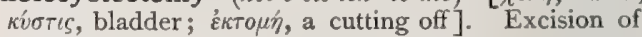
the gall-bladder.

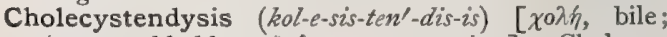

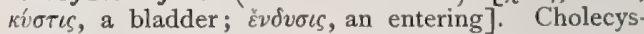
totomy, $q . v$.

Cholecystenterostomy $\left(k o l-e-s i s-t e n-t e r-o s^{\prime}-t o-m e\right)[\chi 0 \lambda \dot{n}$,

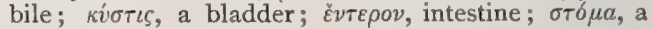
mouth]. Incision of the gall-bladder and intestine, with suture of the intestinal wound to that of the gall-bladder, so as to relieve the effects of obstruction of the gall-duct by opening a new passage into the intestine.

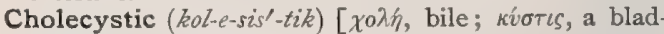
der]. Relating to the gall-bladder.

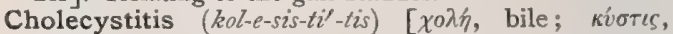
bladder; $\iota \tau \iota \zeta$, inflammation]. Inflammation of the gall-bladder.

Cholecystocolostomy (kol-e-sis-to-ko-los'-to-me) [ $\chi 0 \lambda \dot{n}$,

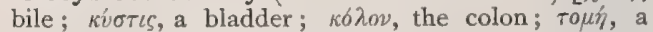
cutting]. The surgical establishment of a passage between the gall-bladder and the colon.

Cholecystolithotripsy (kol-e-sis-to-lith'-o-trip-se) [ $\chi 0 \lambda \dot{n}$, bile; kvorıs, a bladder; $\lambda i \theta o s$, a stone; $\tau \rho i \beta \varepsilon \imath \nu$, to crush]. The crushing of gall-stones in the gall-bladder.

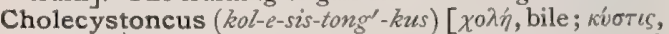
bladder; ő $\gamma \kappa o s$, a tumor]. A swelling or tumor of the gall-bladder.

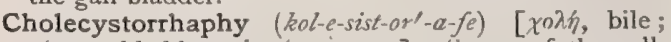

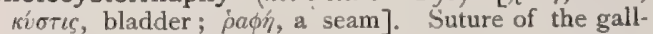
bladder. 


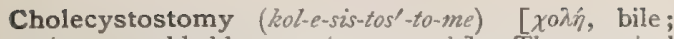

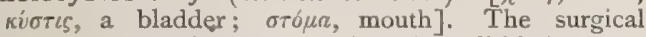
establishment of an opening into the gall-bladder.

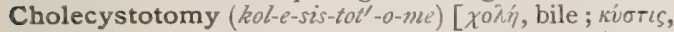
bladder ; $\tau \varepsilon \dot{\varepsilon} \mu \varepsilon \iota v$, to cut]. Incision of the gall-bladder to remove gall-stones, etc.

Choledoch $\left(k \circ l^{\prime}-e-d o k\right)$ [ $\chi 0 \lambda \eta \dot{y}$, bile ; $\delta^{\prime} \chi \varepsilon \sigma \theta a \iota$, to receive]. I. Conducting bile. 2. A bile-duct. 3. The common bile-duct.

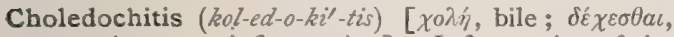
to receive; $\iota \tau \iota \zeta$, inflammation]. Inflammation of the choledoch duct.

Choledocho-duodenostomy (kol-ed-o-ko-du-od-en-os' -

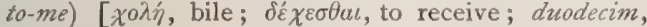
twelve; бтóu, mouth]. The surgical establishment of a passage between the common bile-duct and the duodenum.

Choledocho-enterostomy (kol-ed-o-ko-en-ter-os'-to-me)

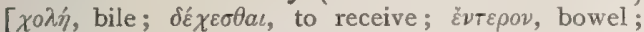
oт6pa, mouth]. The surgical establishment of a passage between the cavity of the choledoch duct and the small intestine.

Choledocholithotripsy (kol-ed-o-ko-lith'-o-trip-se) [ $\chi 0 \lambda \dot{n}$, bile; $\delta^{\prime} \chi \varepsilon \sigma \theta \alpha \iota$, to receive; $\lambda i \hat{\theta} 0$ s, a stone; $\tau \rho i \beta \varepsilon \iota \nu$, to rub]. The crushing of a gall-stone in the ductus choledochus.

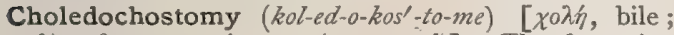
$\delta \delta^{\prime} \chi \varepsilon \sigma \theta a r$, to receive; $\sigma \tau \delta \mu \alpha$, mouth]. The formation of a fistula in the gall-duct through, the abdominal wall.

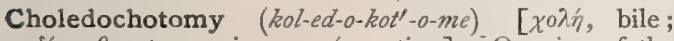
$\delta \varepsilon \dot{\chi} \chi \sigma \theta a \iota$, to receive; $\tau \sigma \mu \eta \dot{n}$, section]. Opening of the common bile-duct by incision.

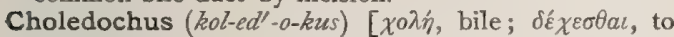
receive]. Receiving or holding bile. C., Ductus Communis, the common excretory duct of the liver and gall-bladder.

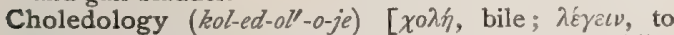
speak]. The sum of knowledge concerning he bile.

Choleic $\left(k o l-e^{\prime}-i k\right)$ [ $\chi 0 \lambda \dot{\eta}$, bile]. Pertaining to the bile.

Cholein (kol'-e-in) [ $\chi 0 \lambda \dot{n}$, bile]. A mixture of several principles of the bile; a fatty principle found in bile.

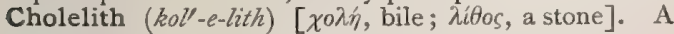
biliary calculus or gall-stone.

Cholelithiasis (kol-e-lith-i'-as-is) [ $\chi \circ 0 \lambda \dot{n}$, bile; $\lambda i$ ifos, a stone]. The presence of, or a condition associated with, calculi in the gall-bladder or in a gall-duct.

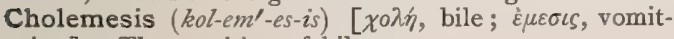
ing]. The vomiting of bile.

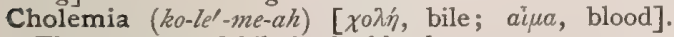
The presence of bile in the blood.

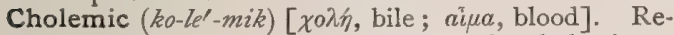
lating to cholemia; marked or caused by cholemia.

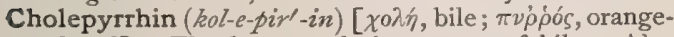
colored]. The brown coloring-matter of bile. Also called Bilepyrrhin

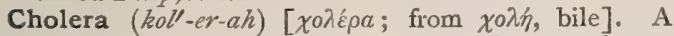
name given to a number of acute diseases characterized mainly by large discharges of fluid material from the bowels. A synonym of $C$. asiatica. C. asiatica, an acute, specific, highly malignant disease, existing in India and the tropics of Asia during the entire year, and occasionally spreading as an epidemic over large areas. It is characterized by excessive vomiting, alvine discharges resembling flocculent rice-water, severe cramps, collapse, and frequently death. The rate of mortality varies from Io to 66 per cent., the average being over 50 per cent. The cause or specific virus is very generally believed to be the so-called "comma bacillus" of Koch. which is contained in the ricewater discharges. Cultures of this germ have in some instances produced the disease and in others have failed. The virus, whatever it may be, commonly gains entrance into the system by means of the drinking-water; hence in cases of threatened epidemic, and during the prevalence of an epidemic the purity of the water-supply should be carefully investigated. C., Bilious, a form of the disease attended with excessive discharge of bile. C., Chicken, a very fatal epidemic disease of fowls, marked by tumefaction of the lymphatic glands, with inflammation and ulceration of the digestive organs. The symptoms peculiar to cholera are wanting. C., English. See $C$. nostras. C., European. See C., Simple, C. gravior. Synonym of $C$. asiatica. C.-hand, a livid, grayishblue, corrugated state of the palms of the hand from immersion in water. It is present in death from drowning, and is also called "washerwoman's hand." C., Hog, an infectious disease attacking swine and characterized by a patchy redness of the skin, with inflammation and ulceration of the bowels, enlargement of the abdominal glands, and congestion of the lungs. C. infantum, the "summer complaint" of infants and young children; an acute disease occurring in warm weather, and characterized by gastric pain, vomiting, purgation, fever, and prostration. The cause of the disease is the prolonged action of heat, together with errors in diet and hygiene. It is most common among the poor and in hand-fed babes. The disease is of short duration, death frequently ensuing in three to five days. C. infectiosa. See Cholera asiatica. C. morbus, an acute catarrhal inflammation of the mucous membrane of the stomach and intestines, with enteric pain, purging, vomiting, spasmodic contractions of the muscles, etc. It is a disease of the heated term and is very similar to Asiatic cholera in its symptomatology. C. nostras, also called English Cholera and Cholerine. Same as C. morbus. C. sicca, a term applied to those cases of Asiatic cholera in which rice-water liquid is found in the intestines after death, though none had been voided during life. C., Simple, the diarrhea with cramps, purging, and collapse, common in the autumn or late summer. C., Summer. See $C$., Simple. C. Voice, the peculiar whispering voice of those in the cold stage of cholera.

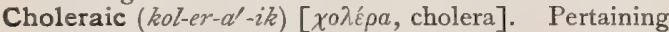
to or resembling cholera. C. Diarrhea. See Diarrhea.

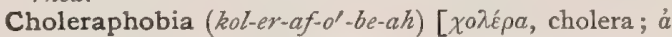
priv.; фó $\beta o s$, fear.] Absence of fear during an epidemic of cholera.

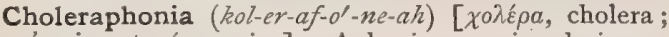
$a ́$ priv.; $\phi \omega \nu \eta ́$, a voice]. Aphonia occurring during an attack of cholera.

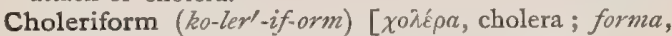
form]. Resembling or appearing like cholera.

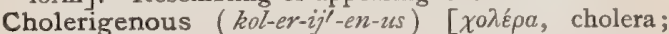
$\gamma \varepsilon v \varepsilon \sigma \iota \varsigma$, production]. Giving origin to cholera.

Cholerine (kol'-er-in) [dim, of cholera]. A mild case of choleraic diarrhea. Also, the initiatory stage of malignant cholera. Also, the zymotic cause or virus of cholera. See Cholera nostras.

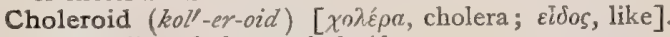
Resembling cholera; choleriform.

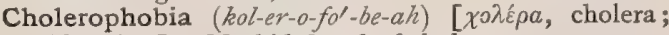
$\phi o ́ \beta o s$, fear]. Morbid dread of cholera.

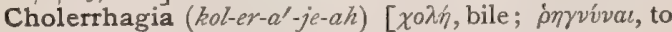
burst forth]. Synonym of Cholera morbus.

Cholesteatoma (kol-es-te-at-o'-mah) [ $\chi 0 \lambda \dot{n}$, bile (chol-

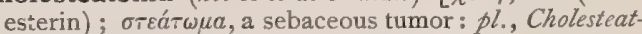
omata]. A tumor containing cells inclosing plates of cholesterin, and occurring most frequently at the base 
of the brain, but occasionally in subcutaneous tissue. It often incloses sebaceous glands, hair-follicles, and other dermal structures.

Cholesteatomatous (kol-es-te-at-om'-at-us) [ $\chi_{0} \lambda \dot{\eta}$, bile;

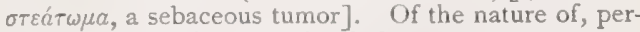
taining to, or affected with, cholesteatoma.

Cholesteremia (kol-es-ter-e'-me-ah), or Cholesterin-

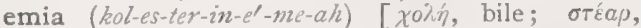
stiff fat; a a ${ }^{2} \mu$, blood]. The retention of cholesterin in the blood; also, the morbid state ascribed to such retention.

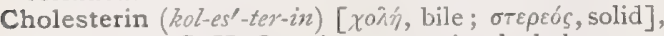
$\mathrm{C}_{26} \mathrm{H}_{44} \mathrm{O}$, or $\mathrm{C}_{25} \mathrm{H}_{42} \mathrm{O}$. A monatomic alcohol, a constituent of bile, and a normal ingredient of nervous tissue. Also the fatty substance forming the acid principle of biliary calculi. It is a glittering, white, crystalline substance, soapy to the touch, crystallizing in fine needles and rhombic plates. It is quite insoluble in water and in cold alcohol, but

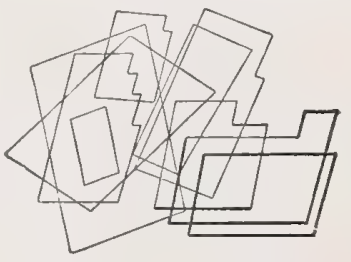

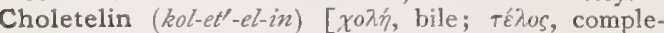
tion], $\mathrm{C}_{16} \mathrm{H}_{18} \mathrm{~N}_{2} \mathrm{O}_{6}$. An amorphous, soluble, yellow pigment derived from bilirubin. It is the final product of the oxidation of bile-pigments. It is readily soluble in alkalies, alcohol, and chloroform.

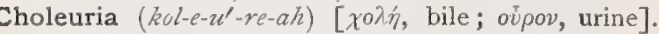
The presence of bile in the urine.

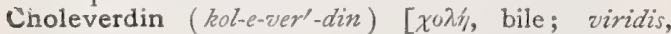
green]. See Bilicyanin.

Cholic $\left(k \circ l^{\prime}-i k\right)$ [ $x_{0 \lambda \hbar}$, bile]. Pertaining to the bile. C. Acid. See Acid.

Cholin $\left(k \circ l^{\prime}-i n\right)$ [ $x \circ \lambda \dot{n}$, bile $], \mathrm{C}_{5} \mathrm{H}_{15} \mathrm{NO}_{0}$. A substance found among the products of the decomposition of pig's bile and ox-bile, hence its name. It is also found in the extracts of the suprarenals, and is a product of the decomposition of lecithin. It is a colorless fluid, of oily consistence, possesses a strong alkaline reaction, and forms with acids very deliquescent salts. It is a very unstable body. It is soluble in alcohol or ether. It is distinct from, though closely related to, neurin. C. Group of Ptomaïnes, four ptomaïnesCholin, Neurin, Betaîn, and Muscarin-have been thus classified. All these bases may be considered as oxidation-products of trimethyl-ethyl-ammonium hydrate.

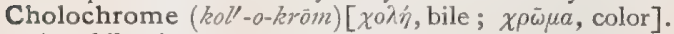
Any bile-pigment.

Cholocyst (kol'-o-sist). See Cholecyst.

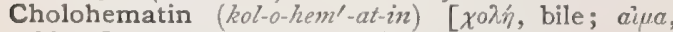
blood]. A pigment found in the bile of the ox and sheep. It is probably a derivative of hematin.

Choloidinic Acid (kol-oi-din'-ik). See Acid.

Chololith (kol'-o-lith). See Cholelith.

Chololithiasis (kol-o-lith-i'-as-is). See Choletithiasis.

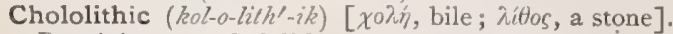
Pertaining to a cholelith.

Cholophein (kol-o-fe'-in). See Biliphein.

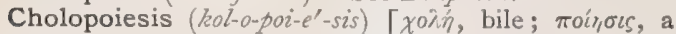
making]. The formation of bile.

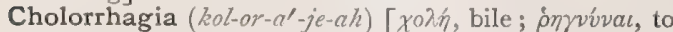
burst forth]. A sudden flow of bile.

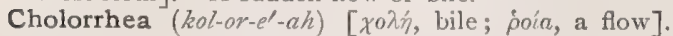
Any excessive discharge of bile.

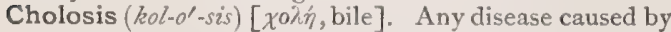
or associated with a perversion of the biliary secretion.

Cholotic $\left(k \circ l-o t^{\prime}-i k\right)$ [ $\chi \circ \lambda \eta \eta y$, bile]. Due to or associated with a cholosis.
Choluria (kol-u'-re-ah) [xohń, bile; oúpov, urine]. The presence of bile, bile-salts, or bile-pigments in the urine. Also, the greenish coloration of the urine.

Chondodendron (kon-do-den'-dron). See Chondrodendron.

Chondral (kon'-dral) [xóvdoos, cartilage]. Cartilaginous; relating to or composed of cartilage.

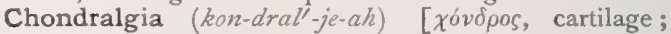
$\dot{a} \lambda$ yos, pain]. Pain in or about a cartilage.

Chondrectomy (kon-drek'-10-me) [ $\chi 60 v \delta \rho o s$, cartilage ; $\dot{\varepsilon} \kappa \tau o \mu \dot{n}$, a cutting out]. Surgical excision of a cartilage, or of a part of one.

Chondren (kon'-dren) [ $\chi 0 ́ v \delta \rho o s$, cartilage]. Belonging to a cartilage in itself.

Chondrification (kon-drif-ik-a'-s/un) [ [ $\chi^{\prime}$ ov pos, cartilage; facere, to make]. The process of being converted into cartilage; the state of being chondrified.

Chondrify (kon'-drif-i) [ $\chi \delta \delta \delta \rho o s$, cartilage; fieri, to become]. To convert into cartilage; to become cartilaginous.

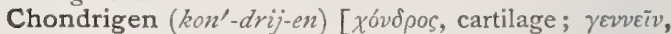
to produce]. That material of the hyaline cartilage which on boiling with water becomes chondrin.

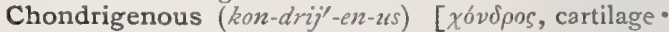

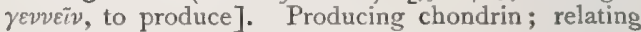
to cartilage that has not hardened.

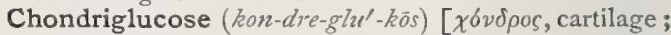
$\gamma \lambda v \kappa u ́ s$, sweet]. A material formed by boiling cartilage with mineral acids. It has a sweet taste and the properties of glucose.

Chondrin (kon'-drin) [ $\chi b^{\prime} \nu \delta \rho o s$, cartilage]. A substance obtained from the matrix of hyaline cartilage by boiling. It resembles gelatin in general properties, but differs from it in not being precipitated by tannic acid. The substance yielding it is chondrigen, probably an anhydrid. See also Glue.

Chondritis (kon-dri'-tis) [ $\chi 6 \delta \nu \delta \rho o s$, cartilage; $\iota \tau \iota s$, inflammation]. Inflammation of a cartilage.

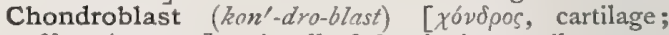
$\beta \lambda a \sigma \tau b$, germ ]. A cell of developing cartilage.

Chondroclasis (kon-drok'-las-is) [ [ 60 vopos, cartilage; $\kappa \lambda a ́ \sigma \iota s$, fracture]. The crushing of a cartilage.

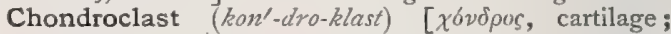
$\kappa \lambda a ́ \varepsilon \iota v$, to break]. A cell supposed to be concerned in the absorption of cartilage.

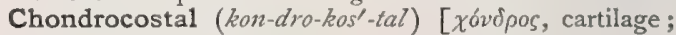
costr, a rib]. Relating to the ribs and their cartilages.

Chondrodendron (kon-dro-den'-dron) [xóvipos, cartilage; $\delta \varepsilon \dot{v} \delta \rho o \nu$, a tree]. A genus of S. American menispermaceous climbing-plants. C. glaberrimum and $C$. tomentosum are among the plants that furnish Pareira brava.

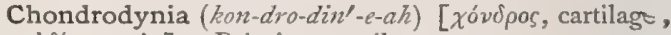
óvivn, pain]. Pain in a cartilage.

Chondrodystrophia (kon-dro-dis-tro'-fe-ah) [ [ $\delta$ vodoos. cartilage; $\delta v \varsigma$, bad; $\tau \rho \varepsilon \dot{\phi \varepsilon} \iota \nu$, to nourish]. Feta rhachitis.

Chondroepiphysis (kon-dro-e-pif'-is-is) [ [ $\hat{\sigma}^{\prime} \nu \delta \rho o s$, cartilage; $\varepsilon \pi i \phi v \sigma \iota \zeta$, an outgrowth]. A cartilage that is destined to become an epiphysis ; an epiphysis that has been developed from cartilage.

Chondrofibroma (kon-dro-fi-bro'-mah) [ $\chi^{\prime} o b \delta \rho o \zeta$, cartilage; fibra, a fiber; ö $a$, a tumor: $p l$., Chondrofibromata. Chondroma with fibromatous elements.

Chondrofibromatous (kon-dro-fi-bro'-mat-us) [ $[\chi b v \delta \rho o s$, cartilage; fibra, a fiber; ö $\mu a$, a tumor $]$. Of the nature of chondrofibroma.

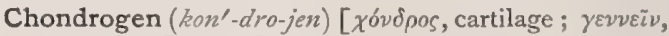
to produce]. I. See Chondrigen. 2. A substance found in fetal and early life, forming a part of the tissue of imperfectly developed cartilage. 
Chondrogenesis (kon-dro-jen'-es-is) [ $\chi^{\prime}$ vifoos, cartilage;

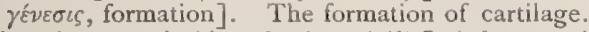

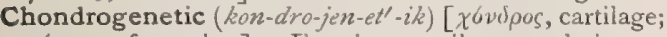
$\gamma^{\prime} \nu \varepsilon \sigma \iota \varsigma$, formation]. Forming cartilage; relating to chondrogenesis.

Chondrogenous (kon-droj'-en-us) [xóvipos, cartilage;

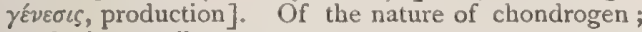
producing cartilage.

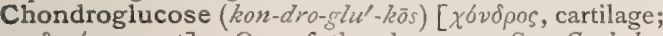

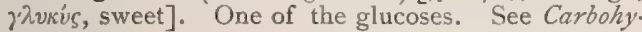
drate and Glucose.

Chondrography (kon-drog'-ra-fc) [ $x^{\prime o v} \delta$ pos, cartilage; $\gamma \rho a ́ \phi \varepsilon \imath \nu$, to write]. An anatomic description of the cartilages.

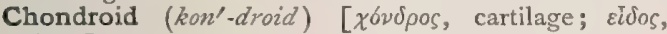
form]. Resembling cartilage.

Chondrology (kon-drol'-o-je) [ $\chi 6 \nu \delta \rho o s$, cartilage; $\lambda 6 \gamma o s$, science]. The science of cartilages.

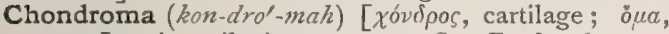
tumor]. A cartilaginous tumor. See Enchondroma.

Chondromalacia (kon-dro-mal-a'se-ah) [ $x \delta v \delta p o s$, cartilage; $\mu a \lambda \alpha \kappa i \alpha$, softening]. Softening of a cartilage. C. auris. Same as Homatoma auris.

Chondromalacosis (kon-dro-mal-ak-o'-sis). See Chondromalacia.

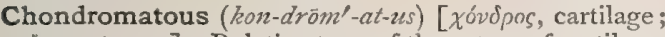
o $\mu \alpha, a$ tumor]. Relating to or of the nature of cartilage

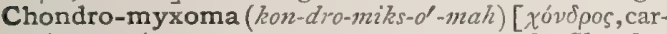
tilage; $\mu i \xi a$, mucus; $\dot{v} u a$, a tumor: pl., Chondromyxomata]. A chondroma with myxomatous elements.

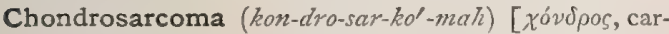

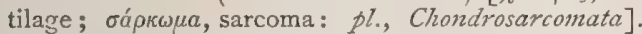
A cartilaginous and sarcomatous tumor.

Chondrosarcomatous (kon-dro-sar-köml-at-us) [xóv-

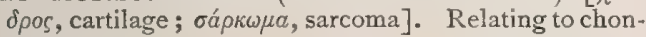
drosarcoma.

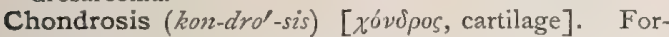
mation of cartilage.

Chondrosteous (konz-dros'-le-us) [ $\chi x^{6} v \delta \rho o s$, cartilage; óotéov, bone]. In biology, having a cartilaginous skeleton.

Chondrotome (kon'-dro-tōm) [ $\chi o ́ \nu \delta \rho o s$, cartilage; тouós, cutting]. An instrument for cutting cartilage.

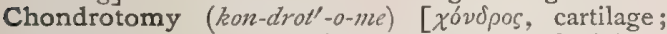

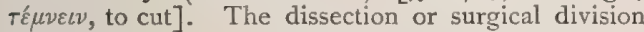
of a cartilage, or the anatomic analysis of a cartilage.

Chondrus (kon'-drus) [ $\chi 6 \hat{v} \delta \rho o s$, a grain; cartilage]. I. Irish Moss. The substance of the algæ $C$. crispus and Gigartina mamillosa. These yield, on boiling with water, a soluble colloid consisting mainly of mucilage. This is demulcent and somewhat nutrient, and is sometimes used in making blanc mange. Dose indefinite. Unof. See Carragheen. 2. A cartilage; the ensiform cartilage.

Chopart's Amputation. See Operations, Table of. C. Operations. See Operations, Table of.

Chopping (chop'-ing). See Percussion.

Chorda (kor'-dah) [L., a cord: pl., Chordec]. A cord, tendon, or filament of nerve. C. caudalis, the urochord. c. dorsalis. See Notochord. C. spinalis, the spinal cord. C. tendiner, the tendinous strings connecting the columne carnece of the heart with the auriculo-ventricular valves. C. tympani, a filament of the Vidian nerve that enters the tympanum. C. umbilicalis, the umbilical cord. C. vertebralis, the notochord; the spinal cord. C. vocalis, one of the vocal bands or thyro-arytenoid ligaments.

Chordal (kor'-dal) [chorda, a cord]. Relating to a chorda, especially to the notochord.

Chordapsus (kor-dap'-sus) [ $\chi 0 \rho \delta^{\prime} \eta$, an intestine ; $a ̈ \pi \tau \varepsilon \iota \nu$, to tie up]. Synonym of Acute Intestinal Calarrh.

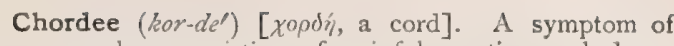
gonorrhea consisting of painful erection and downward curvature of the penis.

Chorditis (kar-di'-tis) [ $\chi^{\prime} o p d y$, a cord; $\iota T / S$, inflammation ]. Inflammation of the vocal bands. C. tuberosa, a localized thickening on the vocal bands, often bilateral, and situated at the junction of the posterior two-thirds with the anterior third.

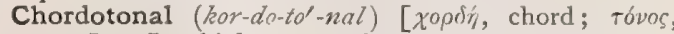
tone]. In biology, applied to sense-organs or parts of arthropods that are responsive to soundvibrations.

Chorea (ko-re'-ah) [Xopeía, dancing]. St. Vitus's dance. A functional nervous disorder, usually occurring in youth, characterized by spasmodic and convulsive contraction and non-rhythmic action of the muscles of the extremities, face, etc. The action of the heart is irregular, and in a large number of cases a systolic murmur is present. Rheumatism is a frequent complication. Chorea may be caused by a number of conditions, among which are fright and reflex irritations, but it is essentially a disease of the later period of childhood, and affects girls about three times as frequently as boys. Occasionally it is seen in the adult, and may become a serious complication of pregnancy, resulting in the death of both fetus and mother. When it occurs late in life it generally resists treatment. C., Automatic, an affection in which paroxysms of apparently purposive actions occur independently of the will, as the result of an impulse that arises spontaneously or that occurs in response to a stimulus received from without. C., Buttonmaker's, a form of chorea in girls employed in button-mills, the result of application at their trade. The fingers move involuntarily when not at work, following the same motions as when guiding the procession of buttons. It is due to an erethism of the centers in the brain for the hands and fingers. C., Chronic. See C., Huntingdon's. C., Electric. See Dubini's Disease. C., Epidemic, dancing mania. See Choromania. C. festinans. See Paralysis agitans. C. germanorum, a term for the major form of chorea. C.-habit. See Spasm. C., Hereditary. See C., Huntingdon's. C., Hysterical. See C., Major. C., Huntingdon's, an affection frequently hereditary, of adult or middle life, characterized by irregular movements, disturbance of speech, and gradual dementia. It was first described by Huntingdon, a physician of Long Island, U. S. C. insaniens, maniacal chorea; a grave form of chorea usually seen in adult women, and associated with maniacal symptoms. This may develop from the ordinary form, and usually ends fatally. It may develop during pregnancy. C., Maniacal. See C. insaniens. C., Major, the hysterical chorea of the French, in which there are regular oscillatory movements of the parts. C., Mimetic, that which is caused by imitation. C., Minor, simple chorea. C. oscillatoria is marked by more or less regular oscillations of the head, trunk, or limbs. C., Post-hemiplegic. See Athetosis. C., Post-paralytic, a form of involuntary movement seen in patients after an attack of hemiplegia. C., Rhythmic. See C., Major. C., Rotatory, a hysterical form associated with rhythmic movements of the body or head. C., School-made, chorea resulting from overstimulation of children at school by parents and teachers. C. scriptorum. See Cramp, Writers'. C., Senile. See Paralysis agitans. C. spastica. See Paraplegia, Infantile Spasmodic. C., Sydenham's, ordinary chorea.

Choreic (ko-rel-ik) [xopsia, dancing]. Relating to, of the nature of, or affected with, chorea. 
Choreiform (ko-re'-if-orm) [xopeia, dancing; forma, form]. Resembling chorea.

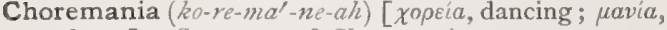
madness]. Synonym of Choromania.

Choreoid (ko-re'-oid) [xopein, dancing; cidos, like]. Pertaining or similar to chorea.

Choreomania (korre-o-ma'-ne-ah). See Choromania.

Chorial $\left(k o^{\prime}-r e-a l\right)[\chi \delta \rho \iota v$, skin $]$. Chorionic.

Chorioblastosis (ko-re-o-blas-to'-sis) [xópıov, skin; $\beta \lambda \alpha \sigma \tau a ́ v \varepsilon(\nu$, to germinate]. Any anomaly of growth of the corium and subcutaneous connective tissue.

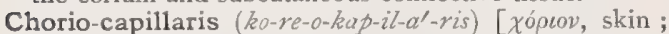
capillus, a hair]. The network of capillaries over the inner portion of the choroid coat of the eye. See Ruysch, Membrane of.

Choriocele (ko'-re-o-sél, or ko-re-o-se'-le) [ $\chi 0$ ópov, a skin; $\kappa \eta \dot{\lambda} \eta$, hemia]. A hernial protrusion of the choroid coat of the eye.

Chorioid (ko're-oid). See Choroid.

Chorioidal (ko-re-oid'-al). See Choroid.

Chorioideremia (ko-re-oid-er-e'-me-ah). See Choroideremia.

Chorioidiritis (ko-re-oid-i-ril-tis). See Choroido-iritis.

Chorioiditis (ko-re-oid-i'-tis). See Choroiditis.

Chorioido-retinitis (ko-re-oid'-o-ret-in $\left.+i^{\prime}-t i s\right)$ See Choroido-retinitis.

Chorion $\left(k o^{\prime}-r e-o n\right)$ [ xóptov, fetal membrane]. The outermost of the fetal membranes, formed from the external layer of the non-germinal epiblast. The chorion lies between the amnion and the decidure (reflexa and vera). C., Cystic Degeneration of, a rare myxomatous disease of the chorion, producing the so-called " hydatid mole." It is characterized by rapid increase in the size of the uterus, hemorrhage, often profuse, beginning during the second month of pregnancy, and the discharge of small cysts, whitish in appearance, surrounded by bloody clots. These cysts vary in size from a pin's-head to a filbert. C. leve, the smooth or non-villous portion of the chorion. C., Primitive, the Vitelline membrane (or Zona pellucida) during the time of the development of the hollow, structureless villi upon its surface. C., Shaggy, or C. frondosum, the part covered by villi.

Chorionic (ko-re-on'-ik) [ $x o ́ \rho t o v$, the chorion]. Relating to the chorion.

Chorionitis (ko-re-on-i'-tis). See Scleroderma.

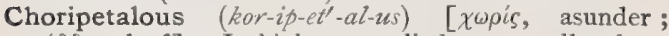
$\phi v i \lambda o v$, leaf]. In biology, applied to a corolla whose petals are distinct.

Chorisis (ko-ri'-sis) [ $\chi \omega ́ \rho \iota \sigma \iota s$, a separation]. In biology, the development of two or more members when but one is expected; a doubling.

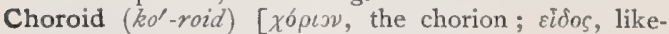
ness]. The second or vascular tunic of the eye, continuous with the iris in front and lying between the sclerotic and the retina. C. Plexus, a vascular plexus in the lateral ventricles of the brain. C. Sulcus (of Schwalbe). See Schualbe, Fissure of. C. Vein. See Vein.

Choroidal (ko-roid'-al). Pertaining to the choroid.

Choroideremia (ko-roid-er-e'-me-ah) [ $[x$ ópov, the cho-

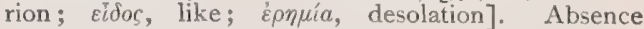
of the choroid; absence of the epithelium of the choroid.

Choroiditis (ko-roid-i'-tis) [ $\chi 6 \rho \iota 0 \nu$, the chorion; $\iota T \iota S$, inflammation]. Inflammation of the choroid coat of the eye. It may be anterior, the foci of exudation being at the periphery of the choroid; or centrat, the exudate being in the region of the macula lutea ; diffuse or disseminated, characterized by numerous round or irregular spots scattered over the fundus; exudative or non-suppurative, when there are isolated focj of inflammation scattered over the choroid metastatic, when due to embolism; and suppurative, when proceeding to suppuration. C. serosa. Synonym of Glaucoma.

Choroido-iritis (ko-roid" $\left.-o-i-r i^{\prime}-t i s\right)$ [ $\chi 6 \rho \iota v$, the chorion;

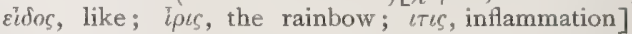
Inflammation of the choroid and the iris.

Choroido-retinitis (ko-roid"-o-ret-in-i'-tis) [kóplov, the chorion; eidos, like; retina, the retina; $\iota T \iota s$, inflammation]. Choroiditis with retinitis. C.-r., Ametropic, caused by ametropia.

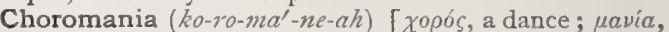
madiness]. A nervous disorder manifest at various times and places, and characterized by dancing or other rhythmic movements; epidemic chorea; dancing mania.

Chrchtschonovitsch's Method. A method of staining tissues. See Stains, Table of.

Christian Science (kris'-chan si'-ens). An alleged system of therapy; faith-cure, or one form of it.

Christison's Formula. A formula for estimating the amount of solids in the urine: Multiply the last two figures of the specific gravity expressed in four figures by 2.33 (or by 2 , Trapp; or by 2.2 , Labisch). This gives the amount of solids in every rooo parts.

Chromate $\left(k r o^{\prime}-m \bar{a} t\right) \quad[\chi \rho \vec{\omega} \mu a$, color $]$. Any salt of chromic acid.

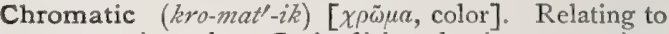
or possessing color. C. Audition, luminous sensations aroused by sound. See Photism. C. Gustation. See Gustation.

Chromatin (kro'-mat-in) [ $\chi \rho \tilde{\omega} \mu a$, color]. The chromatophilous, or tingible portion of the protoplasm, forming a delicate reticular network or plexus of fibrils permeating the achromatin of a typical cell in process of division. It is called also Karyomiton. See Cell-body.

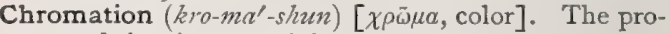
cess of tingeing or staining.

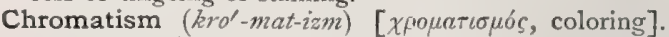
I. Abnormal coloration of any tissue. 2. Chromatic aberration.

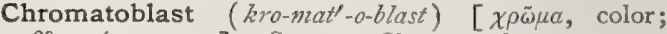
$\beta \lambda \alpha \sigma \tau \sigma s$, a germ]. Same as Chromatofhore.

Chromatodys opia (kro-mat-o-dis $\left.\cdot o^{\prime}-p e-a h\right)[\chi \rho \omega ̈ u a$, color; $\delta v \sigma$, ill; $\delta \psi(s$, vision]. Color-blindness.

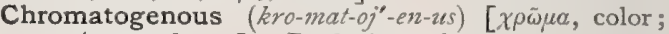
yevváeıv, to beget]. Producing color.

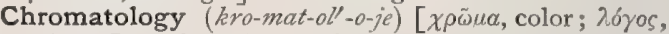
science]. The science of colors. Also the spectroscopic investigation of colors.

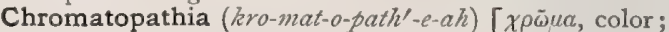
$\pi a ́ f l o s$, disease]. Any pigmentary skin-disease; a chromatosis.

Chromatopathy (kro-mat-op'-a-the). See Chromatopathia.

Chromatophile (kro-mat'-o-fl). Same as Chromophilous.

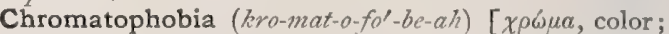
$\phi 6 \beta 0 s$, dread]. Abnormal fear of colors.

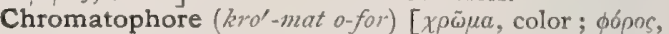
bearing]. In biology, (I) one of the contractile pigment-sacs, abundant in the skin of many animals, e.g., squid, chameleon; (2) one of the pigmented marginal sense-organs of an Actinozoan; "bourse calicinale," (3) a plastid containing chlorophyl, or other coloringmatter; color-granule, chromoplast, chromoleucite.

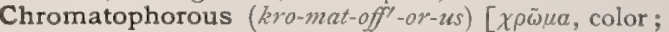
$\phi \varepsilon \rho \varepsilon \iota \nu$, to bear]. Containing pigment or pigmentcells.

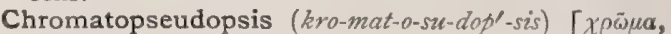

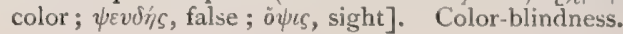




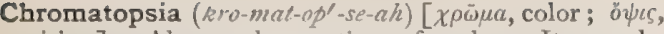
vision ]. Abnormal sensation of color. It may be due to disorders of the optic centers, or to drugs, especially santonin.

Chromatopsy (kro'-mat-op-se). See Chromatopsia.

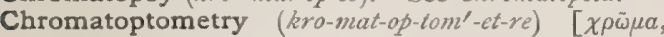
color ; $\ddot{\partial} \pi \tau \varepsilon \iota \nu$, to see; $\mu \dot{\varepsilon} \tau \rho o \nu$, a measure]. The testing of the sensibility of the eye with respect to colorperception.

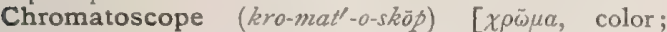
бколєіv, to observe]. An instrument for determining the refractive index of colored light.

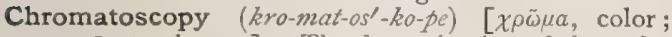

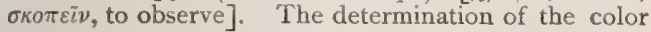
of objects.

Chromatosis (kro-mat-o'-sis) [ $\chi \rho \tilde{\omega} \mu \alpha$, color]. Pigmentation; a pathologic process or pigmentary disease consisting in a deposit of coloring-matter in a locality where it is usually not present, or in excessive quantity in regions where pigment normally exists.

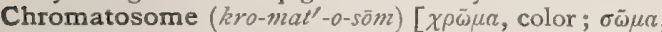
body]. In biology, the " nuclear rods" of the nucleus.

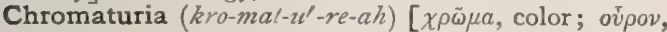
urine]. Abnormal coloration of the urine.

Chrome $(k r o ̄ m)[\chi \rho \bar{\omega} \mu a$, color]. Chromium, q.v. C.alum. See Pigments, Conspectus of. C.-black. See Pigments, Conspectus of. C.-carmin. Same as Chrome-red. C. chlorid. See Pigments, Conspectus of. C.-garnet. Same as Chromerred. C.-green. See Pigments, Conspectus of. C.-orange. Same as Chromered. C.-red, a pigment; basic lead chromate. See Pigments, Conspectus of. C.-vermilion. Same as Chrome-red. C.-yellow, lead chromate, a pigment. See Chromium, and Pigments, Conspectus of.

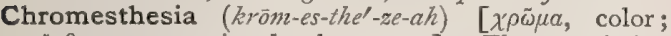

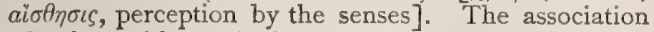
of colors with words, letters, and sounds.

Chromhidrosis (kröm-hid-ro'-sis). Same as Chromidrosis.

Chromic $\left(k r o ̈ m^{\prime}-i k\right)$ [ $\chi \rho \tilde{\omega} \mu \alpha$, color]. Pertaining to or made from chromium. C. Acid. See Acid. C. Acid Test. See Tests, Table of.

Chromicize (kro'-mis-iz). To impregnate with chromic acid.

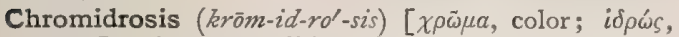
sweat]. A rare condition of the sweat in which it is variously colored, being bluish, blackish, reddish, greenish, or yellowish. Black sweat (Seborrhaca nigricans) occurs usually in hysterical girls, the part affected being the face. It is associated with chronic constipation and is due to the presence of indican in the sweat. Fied sreeat, henatidrosis, may be due to an exudation of blood into the sweat-glands, or to the presence of a microörganism in the sweat. See Micrococcus hamatodes, Babes, under Bacteria, Table of.

Chromium (kro'-me-um) [ $\chi \rho \omega \tilde{\mu} \mu a$ color]. $\mathrm{Cr}=52.2$ quantivalence II and IV. One of the elements of the iron group. The various salts of chromium, especially chromic acid, $\mathrm{Cr}_{2} \mathrm{O}_{3}$, are much used in the manufacture of pigments and in dyeing textile fabrics. All are poisonous, Potassium dichromate (bichromate of potash), $\mathrm{K}_{2} \mathrm{Cr}_{2} \mathrm{O}_{7}$, is used in various pharmaceutic and chemic operations. C.-green. Same as Chromegreen.

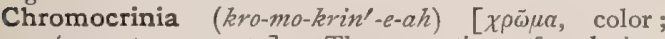
кpivecv, to separate]. The secretion of coloringmatter, as in the sweat, etc.

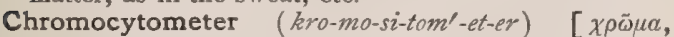

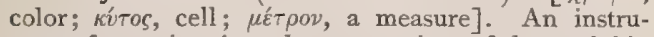
ment for estimating the proportion of hemoglobin present in the blood.

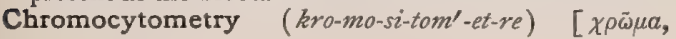

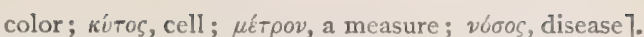
The estimation of hemoglobin by means of the chromocytometer.

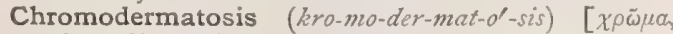
color; dép $\mu a$, skin]. A skin-disease characterized by discoloration of the surfacc.

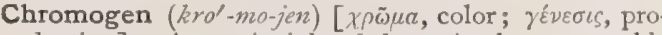
duction]. Any principle of the animal or vegetable economy which (though it is itself not of any pronounced color) is susceptible, under suitable circum stances, of being changed into a coloring-matter.

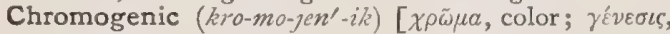
production]. I. Relating to chromogen. 2. Colorproducing.

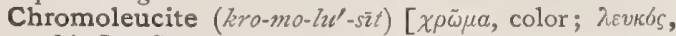
white]. Same as Chromoplastid.

Chromopare $\left(k r o^{\prime}-m o-p \bar{a} \gamma^{\prime}\right)$ [ $\chi \rho \tilde{\omega} \mu a$, color]. In biology, applied by Beyerinck to those chromogenic bacteria that excrete the pigment, remaining colorless themselves. Cf. Chromophore and Para-chromophor.

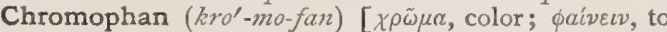
appear]. In biology, the pigment of the inner segments of the retinal cones of certain animals. There are at least three varieties, chlorophan, rhodophan, xanthophan. (Ruhnes).

Chromophile (kro'-no-fil). Same as Chromophilous.

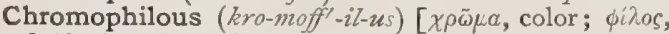
loving]. Readily stained; easily absorbing color; applied to tissues prepared for microscopic study.

Chromophore (kro'-mo-for) [ $\chi \chi \bar{\omega} \mu \alpha$, color; $\phi \varepsilon \rho \varepsilon \imath$, to bear]. In biology, applied by Beyerinck to those chromogenic bacteria that possess pigment as an integral part of their organism. Cf. Chromopare and Para-chromophor.

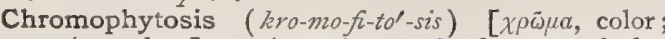
$\phi v \tau \delta$, a plant]. I. Any microscopic plant-growth that produces a discoloration of the skin in which it grows; any pigmentary skin-disease caused by microscopic vegetation. 2. A synonym of Tinea versicolor, or Eichstedt's Disease. See Tinea versicolor, and Diseases, Table of.

Chromoplastid, or Chromoplastidule (kro-mo-plas'-

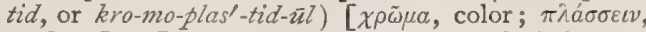
to form]. In biology, a pigment-granule imbedided in the protoplasm of a plant or animal. It is also called chromoleucite.

Chromopsia (krōm-op'-se-ah). See Chromatopsia.

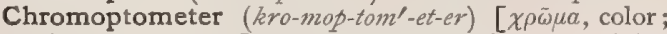

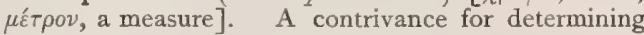
the extent of development of color-vision.

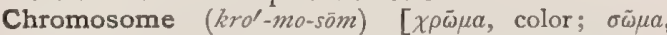
body]. Any one of the nuclear chromatin-fibrils of a cell. According to some observers there is only one such fibril in closely intertwined folds. Others say that the chromosomes are many, and of two varieties, the fine and the coarse.

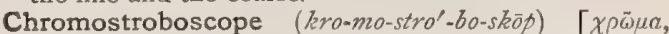

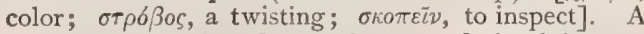
device for showing the persistence of visual impressions of color.

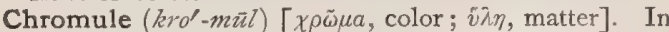
biology, coloring-matter in plants, especially when not green, or when liquid.

Chronic (kron'-ik) [xpóvos, time]. Long-continued; of long duration; slow of progress; opposed to acute, and to subacute.

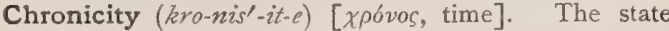
of being chronic or long-continued.

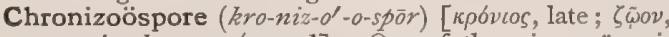
an animal; $\sigma \pi \circ \rho a$, seed]. One of the microzoögoni dia or minute zoöspores or resting-spores, produced by the water-net, Hydrodictyon. 


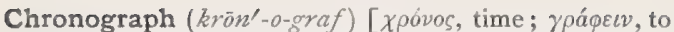
write]. An -instrument for graphically recording intervals of time, in physiologic and psycho-physical experiments.

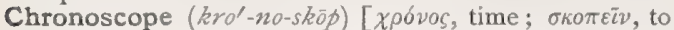
inspect]. An instrument for measuring extremely short intervals of time. C., A-form, an apparatus introduced by Galton for measuring the time of certain psycho-physical reactions. It is so called from its outline, which somewhat resembles that of the letter A.

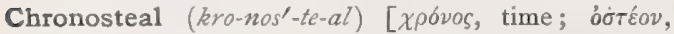
bone]. Relating to the chronosteon.

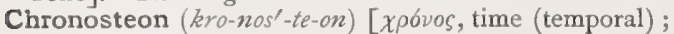
óftevo bone]. The temporal bone.

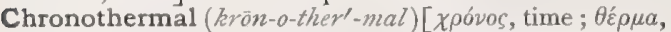
heat]. Pertaining to the theory that all diseases are characterized by periods of intermitting chill and heat; relating to periodicity in changes of bodily temperature.

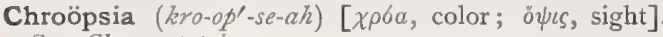
See Chromatopsia.

Chrotal Epithelium (kro'-tal ep-e-the'-le-um). The ectoderm.

Chrotic $\left(k r o^{\prime}-t i k\right)$ [ $\chi \rho \omega \omega^{\prime}$, the skin]. Relating to the skin.

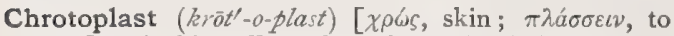
form]. A skin-cell; a dermal or epithelial cell.

Chrymar's Operation. See Operations, Table of.

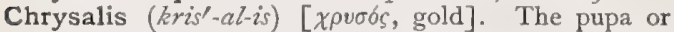
secondary stage in the transformation of insects. So called from the golden color of certain chrysalides.

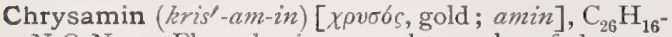
$\mathrm{N}_{4} \mathrm{O}_{6} \mathrm{Na}_{2}$. Flavophenin; a coal-tar color of the oxyazo group, used in dyeing. It dyes on cotton a sulphuryellow, remarkably fast to light. See Pigments, Conspectus of.

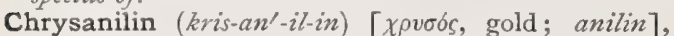
$\mathrm{C}_{19} \mathrm{H}_{11} \mathrm{~N}\left(\mathrm{NH}_{2}\right)_{2}$. A body obtained as a by-product in the manufacture of rosanilin. It crystallizes from dilute alcohol in golden-yellow needles, melting at about $268^{\circ}$. It is used largely as a dye-stuff, yielding a very beautiful yellow color. See Pigments, Conspectus of.

Chrysanisic Acid (kris-an-is'-ik). See Acid.

Chrysarobin, or Chrysarobinum (kris-ar-o'-bin, or

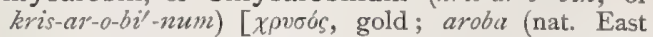
Ind.), bark of a leguminous tree], $\mathrm{C}_{30} \mathrm{H}_{26} \mathrm{O}_{7}$. A reduction-product of chrysophanic acid; it occurs in goapowder and araroba-powder. It is a yellow-colored powder, the product of the decay of Andira araroba, a Brazilian tree. It is a gastro-intestinal irritant, and is almost a specific when applied locally in psoriasis. It stains the skin a dark yellowish-brown color, which may be removed by a weak solution of chlorinated lime. Dose, internally, gr. $\frac{1}{8}-\frac{1}{2}$. C., Ung., contains Io per cent. of the drug with 90 per cent. benzoated lard.

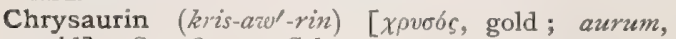
gold]. See Orange Colors.

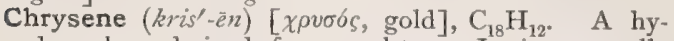
drocarbon derived from coal-tar. It is generally colored yellow, but can be rendered perfectly colorless. It is sparingly soluble in alcohol or ether; melts at $250^{\circ} \mathrm{C} .\left(482^{\circ} \mathrm{F}\right.$.); boils at $436^{\circ}$; crystallizes and sublimes in silvery leaflets, that exhibit an intense violet fluorescence.

Chrysenic Acid (kris-en'-ik). See Acid.

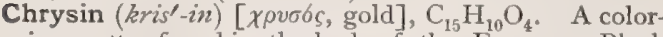
ing-matter found in the buds of the European Black Poplar.

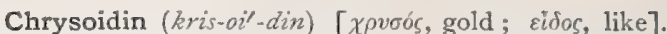
I. $\mathrm{C}_{12} \mathrm{H}_{3} \mathrm{~N}_{4} \mathrm{Cl}$. A coal-tar color used in dyeing. It is the hydrochlorid of diamidoazobenzene. It consists of dark-violet crystals soluble in water. It dyes brightyellow on silk and cotton. See Pigments, Conspectus of. 2. $\mathrm{C}_{7} \mathrm{H}_{22} \mathrm{O}_{4}$. A yellow coloring-substance found in asparagus berries.

Chrysoin (kris'-o-in). See Orange Colors.

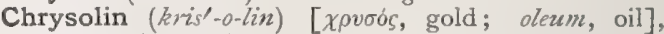
$\mathrm{C}_{20} \mathrm{H}_{10} \mathrm{O}_{3}\left(\mathrm{OC}_{7} \mathrm{H}_{7}\right) \mathrm{OH}$. A coal-tar color of the phthalein group, used in dyeing. It is the sodium salt of benzyl-fluorescein. It produces a yellow color, similar to that of turmeric, on silk, cotton and wool. See Pigments, Conspectus of.

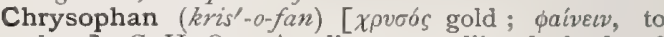
show ], $\mathrm{C}_{16} \mathrm{H}_{18} \mathrm{O}_{8}$. A yellow, crystalline body found in rhubarb. It has a distinctly bitter taste, is readily soluble in warm water and diluted alcohol, but insoluble in ether. It is also called Chrysophanin.

Chrysophanic Acid (kris-o-fan'-ik). See Acid.

Chrysophanin (kris-o-fan'-in). See Crysophan, and Pigments, Conspectus of.

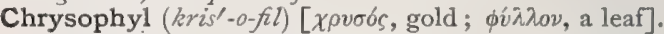
Xanthophyl; a bright golden-yellow crystalline pigment derived from leaves.

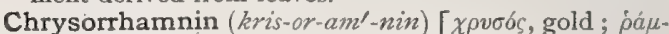
vos, a prickly shrub]. The yellow pigment found in French berries. See Pigments, Conspectus of.

Chthonophagia, or Chthonophagy (thon-o-fa'-je-ah,

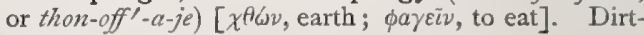
eating; geophagy.

Churning Sound (churn'-ing sound). A peculiar splashing-sound like that made by a churn, heard in the chest in some cases of pleural effusion.

Churrus (chur'-us) [Hind., charas]. Hemp-resin. See Cannabis.

Chvostek's Sign. See Tetany; also Signs and Symptoms, Table of.

Chylaceous $\left(k i-l a^{\prime}-s e-u s\right)$ [chylus, chyle]. Composed of chyle.

Chylangioma (ki-lan-je-o'-mah) [chylus, chyle ; àryeiov, a vessel]. Retention of chyle in lymphatic vessels with dilatation of the latter.

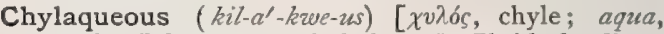
water]. Like water and chyle. C. Fluid, the digested food or nutritive fluid in the somatic or perigastric cavity of invertebrates; it is never enclosed in distinct vessels and represents the blood of higher animals.

Chyle (kîl) [ $\chi v \lambda \sigma_{s}$, juice]. The milk-white fluid absorbed by the lacteals during digestion. On standing, it separates into a thin, jelly-like clot and a substance identical with serum. C.-corpuscle, any floating cell of the chyle. These cells resemble, and are probably identical with, the colorless blood-corpuscles. C.gland, Cheshire's name for system II, of the "salivary glands" of bees.

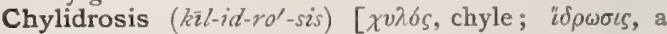
sweating]. Milkiness of the sweat.

Chylifaction (ki-ke-, or kil-if-ak'-shun) [chylus, chyle; facere, to make]. The forming of chyle from food.

Chylifactive (ki-le-, or kil-if-ak'-tiv) [chylus, chyle; facere, make]. Chyle-forming.

Chyliferous (ki-lif'-er-us) [chylus, chyle; ferre, to carry]. I. Chyle-forming. 2. Containing chyle.

Chylific (ki-lif'-ik) [chylus, chyle; facere, to make]. Making chyle; pertaining to chylifaction.

Chylification (ki-le-, or kil-if-ik-a'-shun) [ $\chi v \lambda b s$, chyle; facere, to make]. The process by which the chyle is formed, separated and absorbed by the villi of the small intestine.

Chylificatory (ki-lif'-ik-at-o-re) [chylus, chyle; facore, to make]. Chyle-making. 
Chylify (ki'-lif-i) [chylus, chyle : facere, to make]. To make into chyle. 2. To be made into chyle.

Chylocele $\left(k i^{\prime}-l o-s e ̂ l\right)$ [ $\chi v \hat{\lambda}^{\prime} s$, chyle; $\kappa \dot{\lambda} \lambda \eta$, a tumor] An effusion of chyle into the tunica vaginalis testis. C., Parasitic. See Filaria sanguinis hominis.

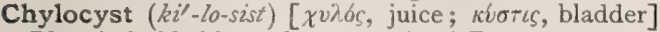
The chyle-bladder; the reservoir of Pecquet.

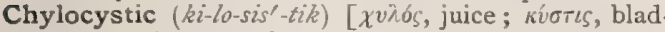
der]. Relating to the chylocyst.

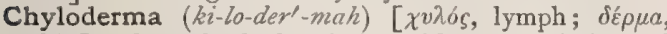
skin]. Scrotal elephantiasis, with accumulation of lymph in the thickened skin and in the enlarged lymphatic vessels; lymph-scrotum.

Chylodochium (kil-o-do'-ki-um) [ $\chi v \lambda \sigma o s$, chyle; do $\chi \varepsilon i o v$, receptacle]. The receptaculum chyli.

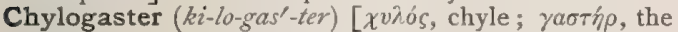
stomach]. The duodenum, so-called because of its being the chief seat of chylous digestion.

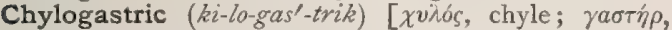
stomach]. Pertaining to the chylogaster.

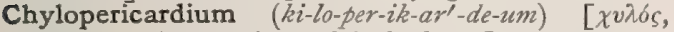
chyle; $\pi \varepsilon \rho i$, around; $\kappa \alpha \rho \delta i a$, the beart]. A rare condition, in which chyle is present in the pericardium, as a consequence of the formation of a channel of communication between a chyle-duct and the cavity of the heart-sac.

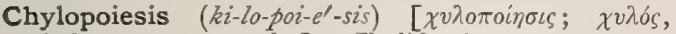

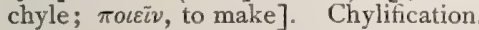

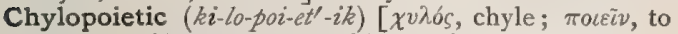
make]. Chylifaction; making or forming chyle.

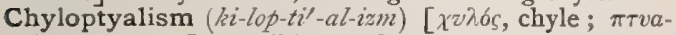
$\lambda i \zeta \in l \nu$, to spit]. Milkiness of the saliva.

Chylorrhea $\left(k i-l o r-e^{\prime}-a h\right)$ [ $\chi \chi^{\nu} \iota b s$, chyle; $\rho \varepsilon \varepsilon \iota \gamma$, to flow ]. The excessive flow of chyle. Also, a diarrhea characterized by a milky color of the feces.

Chylosis $\left(k i-l 0^{\prime}-s i s\right)$ [ $\chi v i \omega \sigma \iota s$, a converting into juice]. Chylification.

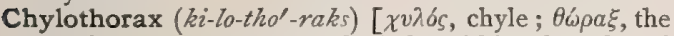
chest]. The presence of chyle within the pleural cavity. It is consequent upon wounds or rupture of the thoracic duct, and is usually fatal.

Chylous ( $\left.k i^{\prime}-l u s\right)$ [ $\chi v \lambda o ́ s$, chyle]. Relating to or resembling chyle.

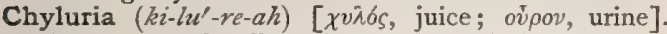
The passage of milky-colored urine. It is thought to be caused by a disordered condition of the lacteals and is also connected with the presence in the blood of Filaria sanguinis hominis. The urine passed is generally above the normal in quantity, has the color of milk, and becomes jelly-like on standing, afterward again becoming liquid. It readily undergoes decomposition. The condition arises from a blocking of the lymph-channels by the parasites. See Bacillus of Chyluria under Bacteria, Synonymatic Table of: also Filaria sanguinis hominis, Lewis, under Parasites (Animal), Table of.

Chyme $(k i m)$ [ $\chi v \mu o ́ s$, juice]. Food that has undergone gastric digestion and has not yet been acted upon by the biliary, pancreatic, and intestinal secretions.

Chymiferous (kim-if'-er-us) [chymus, chyme; ferre, to bear]. Capable of producing chyme.

Chymification (kìm-if-ik-a' shun) [chymus, chyme; facere, to make]. The change of food into chyme by the digestive process.

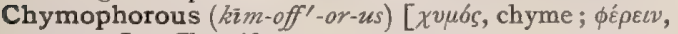
to carry ]. Chymiferous.

Chymoplania (kim-o-pla'-ne-ah) [ $\chi v \mu b s$, juice; $\pi \lambda a^{\prime} \nu \eta$ a roving]. The morbid or abnormal metastasis of chyme or any secretion.

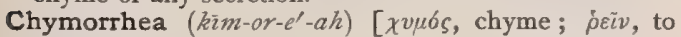
flow]. A discharge of chyme.
Chymosepsis (kim-o-sep'-sis) [ $\chi \nu \mu \delta \varsigma$, chyme; $\sigma \tilde{\eta} \psi \varsigma$, putrefaction]. Putrefactive fermentation of the chyme.

Chyron (ki'-ron) [ciron, cyron]. The name given by ancient writers to the itch-mite, Sarcoptes scabei.

Cibarious (sib-a -re-us) [cibum, food]. Serving as food; nutritious; edible.

Cicatricial (sik-at-rish'-al) [cicatrix, a scar]. Pertaining to or of the nature of a cicatrix. C. Deformities, abnormal contractions caused by cicatrices. C. T is sue, a form of dense connective tissue, seen in cicatrices.

Cicatricula (sik-at-rik'-u-lah) [L., dim. of cicatrix, a scar]. The germinating point of the fecundated egg.

Cicatrisant (sik'-at-ri-sant). See Cicatrizant.

Cicatrisive (sik'-at-ri-siv) [cicatrix, a scar]. Tending to form a cicatrix

Cicatrix (sik-a'-triks) [L.: pl., Cicatrices]. A scar; a connective-tissue new-formation replacing loss of substance in the skin. It extends as far as the corium. It may be depressed below or elevated above the surface; its color is usually whitish and glistening when old, red or purple when young.

Cicatrizant (sik'-at-ri-zant) [cicatrix, a scar]. I. Tending to cicatrize or heal. 2. A medicine that aids the formation of a cicatrix.

Cicatrization (sik-at-riz-a'-shun) [cicatrix, a scar]. The process of healing

Cicer $\left(s i^{\prime}\right.$-ser $)$ [L.]. A genus of leguminous plants. See Chick-pea.

Cicuta (sik-u'-tah) [L.]. A genus of umbelliferous plants. C. virosa. See Cowbane.

Cicutin (sik-u'-tin) [cicuta, hemlock]. I. An alkaloid obtained from Cicuta virosa. 2. The same as Conein.

Cicutoxin (sik-u-toks'-in) [cicuta, hemlock; $\tau o \xi \iota \kappa \delta \nu$, poison]. The poisonous active principle of Cicuta virosa. It is a viscid, non-crystallizable liquid of unpleasant taste and acid reaction.

Cider $\left(s i^{\prime}-d e r\right)$ [ME., cidre]. The expressed juice of apples or pears. C. Brandy. See Apple-Brandy. C. Vinegar. See Vinegar.

Cigaret (sig-ar-et'). See Cigarette.

Cigarette (sig-ar-et') [Fr., dim. of cigare, a cigar]. A roll of inflammable material medicated and adapted for smoking. Nasal catarrhs and spasmodic attacks of dyspnea are among the disorders sometimes treated by cigarette-smoking. C.-makers' Cramp. See Cramp.

Cigarmakers' Cramp. See Cramp.

Ciguë $(s e-g u-e)$ [Fr.]. Cicuta.

Cilia (sil'-e-ah) [cilium, the eyelid or lash]. The eyelashes. Also, the locomotor and prehensile organs of certain infusoria, and the hair-like appendages of certain epithelial cells, whose function it is to propel fluid or particles along the passages that they line.

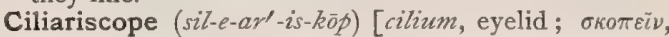
to look at]. An instrument (essentially a prism) for examining the ciliary region of the eye.

Ciliary (sill-e-a-re) [cilium, an eyelash]. Pertaining to the eyelid or eyelash, and also by extension to the $C$. Apparatus, or the structure related to the mechanism of accommodation. C. Arteries-anterior, posterior long, and posterior short, branches of the ophthalmic artery, supplying the recti muscles, the ciliary apparatus, and the posterior structures of the eye, with the exception of the retina. See Arteries, Table of. C. Body, the ciliary muscle and processes. C. Canal, the canal of Fontana. See Canal. C. Ganglion, the ganglion at the apex of the orbit, supplying the ciliary muscle and iris. See Gangtia, Table of. C. Muscle, the muscle of accommodation, whose contraction lessens the tension upon the suspensory ligament of the 
lens. See Muscles, also, Eye. C. Nerves, branches of the ophthalmic ganglion supplying the anterior structures of the eyeball and the accommodative apparatus. See Nerves, Table of. C. Neuralgia, neuralgic pain of the eye, brow, temple, etc. C. Processes, circularly arranged choroidal foldings continuous with the iris in front. C. Region, the pericorneal or "danger" zone, corresponding to the position of the ciliary body. C. Zone, the ciliary processes collectively.

Ciliate, or Ciliated (sil'-e-ät, or-a-ted) [cilium, an eyelash]. Having cilia.

Ciliation (sil-e- $a^{\prime}-$ shun) [cilium, an eyelash]. The condition of having cilia.

Cilio-spinal (sil-e-o-spí-nal) [cilium, an eyelash; spina, the spine]. Relating to the ciliary zone and the spine. C. Center. See Center.

Cilium (sil"-e-um). [L.]. See Cilia and Eyelash.

Cillo (sil'-o), or Cillosis (sil-o'-sis) [cilium, an eyelash]. A continued trembling of the eyelid.

Cillotic $($ sil-ot'-ik) [cilium, an eyelash]. Pertaining to or affected with cillo.

Cimbia $\left(\operatorname{sim}^{\prime}-b_{e-a h}\right)[\mathrm{L}$.$] . The white band seen upon$ the ventral aspect of the crus cerebri, the tractus pedunculi transversus of Gudden.

Cimbial $\left(\sin ^{\prime}-b t^{-}-a l\right)$ [cimbia, a cincture]. Relating to the cimbia.

Cimex (si'-meks) [L., a bug]. A genus of hemipterous insects. C. lectularius, the common bed-bug. A disgusting insect that infests beds, furniture, and the walls of bed-rooms, and that feeds on the human body, puncturing the skin and injecting an irritating fluid to increase the flow of blood. It is characterized by the repulsive odor of its secretion.

Cimicifuga (sim-is-e-fu'-gah) [cimex, a bug; fugare, to drive away]. Black Snake Root, Black Cohosh. The root of $C$. racenosa, ord. Ranunculaceæ. A stomachic, antispasmodic, aphrodisiac, expectorant, and diuretic. Its action on the heart is similar to that of digitalis. It is efficient as a tonic in many cardiac diseases, in functional impotence, and ovarian neural-

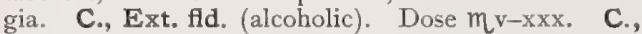

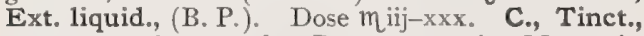
20 per cent. in strength. Dose $m x v-3 j$. Macrotin (unof.), a resinous extract. Dose gr. $1 / 2-i j$.

Cimicifugin (sim-is-e-fu'-gin) [cimex, a bug; fugare, to drive away]. The precipitate from a tincture of the root of Cimicifuga racenosa; it is an antispasmodic, diaphoretic, nervin, emmenagogue, parturient, and narcotic. Dose 1 to 2 grains. As an oxytocic, 2 to 3 grains, to be repeated in from $40-60$ minutes, if necessary. Unof.

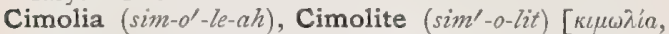
earth]. Cimolian earth; a white, soapy clay formerly brought from the Greek island of Cimolus. The ancients prized it as a remedy; now little used, except in the Levant.

Cina $\left(s^{\prime}-n a h\right)$ [L.]. The plant Artemisia santonica. See Santonica.

Cinchamidin (sin-kam'-id-in) [cinchona; amidin], $\mathrm{C}_{20} \mathrm{H}_{26} \mathrm{~N}_{2} \mathrm{O}$. An alkaloid frequently present in commercial cinchonidin.

Cinchocerotin (sin-ko-ser-n'-tin) [cinchona; cera, wax], $\mathrm{C}_{27} \mathrm{H}_{48} \mathrm{O}_{2}$. A white crystalline alkaloid of calisaya bark.

Cinchona (sin-ko'-nah) [from the Countess of Cinchon]. Peruvian Bark. The bark of several varieties of cinchona, a tree native to the eastern slopes of the Andes and cultivated in India, the most valuable being $C$. calisaya. Other varieties are $C$. succirubra, red bark, C. condaminea, pale bark, C. pitayenis, pitaya bark, and $C$. micrantha. Cinchona bark contains $2 \mathbf{I}$ alkaloids, of which 4, quinin, cinchonin, quinidin and cin- chonidin, are the most important. Cinchona has the same physiologic action and therapeutic uses as its chief alkaloid, quinin. See Quinin. It is also an astringent, bitter and stomachic tonic, stimulating appetite and promoting digestion, beneficial in atonic dyspepsia and adynamia, but especially useful in malarial affections. C., decoctum (B. P.). Dose $\zeta_{j-i j}$. C. Febrifuge. See Quinetum. C., Ext. Dose gr. j-v. C., Fld. Ext, Dose $m_{x}-z_{j}$, C., Ext. liquidum (B. P.). Dose $\eta_{v-x}$. C., infusum, bark 6, arom. sulphuric acid $\mathbf{I}$, water 93 parts. Dose $3 \mathrm{j}-\zeta_{\mathrm{j}}$. C., Infus, Acidum (B. P.). Dose $\xi_{j}$-ij. C. rubra, red cinchona, the bark of C. succirubra. C., Tinct., 20 per

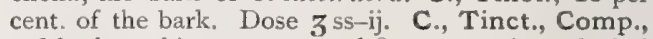
red bark Io, bitter-orange peel 8, serpentaria 2, alcohol 80 parts. Dose $3 \mathrm{j}-\overline{3} \mathrm{ss}$. Huxham's Tinct. of Bark, red bark §iv, orange peel 弓iij, serpentaria gr. lxxx, Spanish saffron gr. clx, cochineal gr. lxxx, brandy . $\mathrm{xl}$, digested four days, expressed and filtered. Dose $3 \mathrm{ss}-\mathrm{ij}$.

Cinchonamin (sin-ko'-nam-in) [cinchona; amin], $\mathrm{C}_{19^{-}}$ $\mathrm{H}_{24} \mathrm{~N}_{2} \mathrm{O}$. An alkaloid of cuprea bark. It occurs in glistening, colorless crystals that are nearly insoluble in water, and but slightly soluble in ether.

Cinchonicin (sin-kon'-is-in) [cinchona], $\mathrm{C}_{20} \mathrm{H}_{24} \mathrm{~N}_{2} \mathrm{O}$. An artificial alkaloid derived from cinchonin.

Cinchonidin, or Cinchonidina (sin-kon'-id-in, or sinkon-id-i'-nah), $\mathrm{C}_{20} \mathrm{H}_{24} \mathrm{~N}_{2} \mathrm{O}$. An alkaloid derived from cinchona. It is a crystalline substance resembling quinin in general properties. C. salicylate (unof.) has decided anti-malarial properties. C. sulph., $\left(\mathrm{C}_{20-}\right.$ $\left.\mathrm{H}_{24} \mathrm{~N}_{2} \mathrm{O}\right)_{2} \mathrm{H}_{2} \mathrm{SO}_{4} \cdot 3 \mathrm{H}_{2} \mathrm{O}$, less bitter than quinin and valuable as an antipyretic. Dose gr. $\mathrm{j}-\mathrm{xx}$ or more.

Cinchonina, or Cinchonin (sin-ko-ni'-nah, or $\sin ^{\prime}-k o-$ nin) [cinchona: gen., Cinchonina], $\mathrm{C}_{19} \mathrm{H}_{22} \mathrm{~N}_{2} \mathrm{O}$. An official alkaloid derived from cinchona. It is a colorless crystalline body, similar to quinin in therapeutic effects, but less active, producing much headache and some muscular weakness. C. sulph., $\left(\mathrm{C}_{19} \mathrm{H}_{22} \mathrm{~N}_{2} \mathrm{O}\right)_{2}$ $\mathrm{H}_{2} \mathrm{SO}_{4} \cdot 2 \mathrm{H}_{2} \mathrm{O}$. Soluble with difficulty in water, but soluble in acidulated water. Dose gr. v-xxx.

Cinchoninic Acid (sin-ko-nin'-ik). See Acid.

Cinchonism (sin'-ko-nizm) [cinchona]. The systemic effect of cinchona or its alkaloids in full doses. The symptoms produced are a ringing in the ears with deafness, headache, often severe, giddiness, dimness of sight, and a weakening of the heart's action.

Cinchonize (sin'-ko-niz) [cinchona]. To bring under the influence of cinchona or its alkaloids.

Cinchotin (sin'-kot-in) [cinchona $], \mathrm{C}_{19} \mathrm{H}_{24} \mathrm{~N}_{2} \mathrm{O}$. An almost insoluble crystalline alkaloid derived from a species of cinchona bark.

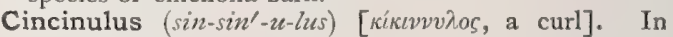
biology, small hooks attached to the stylamblys of crustaceans.

Cincture (sing $\left.k^{\prime}-t \bar{u} r\right)$ [cinctura, a girdle]. A belt or girdle. C.-feeling, a sensation as if the waist were encircled by a tight girdle.

Cinene (si-nèn') [cina, wormseed]. See Dipentene.

Cineol $\left(\sin ^{\prime}-e-\bar{o} l\right)$ [cina, wormseed; oleum, oil $], \mathrm{C}_{10^{-}}$ $\mathrm{H}_{16} \mathrm{O}$. The principal constituent of wormseed, cajeput, and eucalyptus oils. It is a pleasant camphoraceous liquid, inactive to polarized light, that boils between $I 76^{\circ}$ and $I 77^{\circ} \mathrm{C}$, , and crystallizes at $-\mathrm{I}^{\circ} \mathrm{C}$.; its sp. gr. at $16^{\circ}$ is 0.923 .

Cineraria (sin-er-a'-re-ah) [cinerarius, pertaining to ashes]. A genus of composite plants. C. maritima, the juice of this plant has been long used in Venezuela in the belief that, dropped in the eye, it would cause the absorption of cataract. Unof.

Cinerea $\left(\sin -e^{\prime}-r e-a h\right)$ [cincreus, ashen]. The gray, cineritious, or cellular substance of the brain, spinal cord, and ganglia. C., Lamina, a thin layer of gray 
substance extending backward above the optic commissure from the termination of the corpus callosum to the tuber cinereum.

Cinereum, Tuber. See Tuber Cinereum.

Cineritious (sin-er-ish'-us) [cineres, ashes]. Ash-like or pertaining to ashes. C. Substance, the cortex of the brain, from the color of the same. C. Tubercle, the tuber cinereum.

Cinesiology (sin-es-e-ol'-o-je). See Kinesiology.

Cinesis $\left(\sin -e^{\prime}-s i s\right)$. See Kinesis.

Cinesitherapy (sin-es-e-ther'-a-pe). See Kinesitherapy.

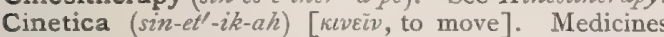
or diseases that affect the motor apparatus.

Cingulum (sing"-gu-lum) [cingere, to gird: $p l$., Cingula]. 1. A girdle or zone; the waist. 2. Herpes zoster, or shingles, $q . v$.

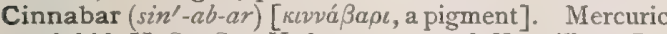
sulphid, HgS. See Hydrargyrum and Vermition. C. green. Same as Chrome-green.

Cinnamene $\left(\sin ^{\prime}-a m-\bar{e} n\right)$. See Styrol.

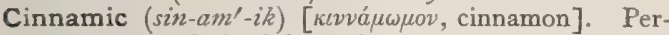
taining to or derived from cinnamon. C. Acid. See Acid. C. Aldehyd. See Aldehyd.

Cinnamomum, or Cinnamon (sin-am-o'-mum, or

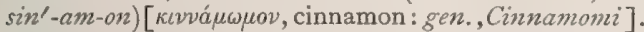
The inner bark of the shoots of several species of Cinnamomum, native to Ceylon and China, the latter being known in commerce under the name of cassia. Its properties are due to a volatile oil. It is an agreeable carminative and aromatic stimulant, useful when combined with opium for flatulence, colic, enteralgia, etc. C., Aqua, 2 parts of oil in 1000 of water. Dose 3 j-ij. C., Ext. Fld. Arom., contains aromatic powder Io parts, alcohol 8 parts. Dose $m x-x x x . \quad C .$, Oleum, the volatile oil. Dose gtt. j-v. C., Pulv. Comp. (B. P.), cinnamon bark, cardamom-seeds, and ginger. Dose gr. iij-x. C. saigonicum, Saigon cinnamon. C., Spt., Io per cent. of the oil in spirit. Dose $m^{\nabla-x x x}$. C., Tinct., IO per cent. of the powdered bark in alcohol. Dose 3 ssij. C. zeylanicum, Ceylon cinnamon. Pulvis aromaticus, aromatic powder, cinnamon, ginger, āā 35, cardamom, nutmeg, $\bar{a} a ̄$ I5. Dose gr. x-xxx. C.brown. Same as Phenylene-brown.

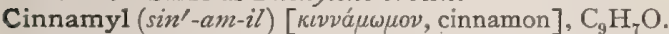
The radicle believed to exist in cinnamic acid.

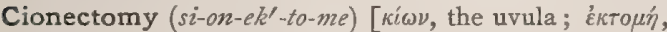
a cutting out]. Ablation of the uvula.

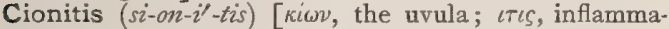
tion]. Inflammation of the uvula.

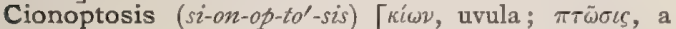
drooping]. Prolapse of the uvula.

Cionorrhaphia (si-on-or-af'-e-ah) [kiwv, the uvula; $\alpha a \phi \dot{n}$, a suture]. See Staphylorrhaphy.

Cionotome (si-on'-o-tom) [kíwv, the uvula; topós, cutting]. An instrument for cutting off the uvula.

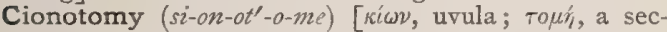
tion]. Incision of the uvula.

Circinate $\left(\operatorname{sir}^{\prime}-\sin -\bar{a} t\right)$ [circinatus, circular]. In biology, rolled inward from the top, like a crozier. C. Eruption. See Wanderino Rash.

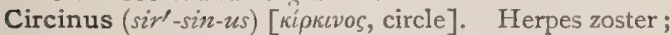
zona.

Circle $\left(\operatorname{sir}^{\prime}-k l\right)$ [кіркоs, a circle]. A ring; a line, every point of which is equi-distant from a point called the center. C. of Diffusion. See Diffusion. C. of Haller, I. The plexus of vessels formed by the short ciliary arteries upon the sclerotic, at the entrance of the optic nerve. 2. The circulus venosus mammæ. See also Circulus. C. of Willis, the remarkable arterial anastomosis at the base of the brain. The passage between the anterior cerebral arteries anteriorly, and the internal carotids and middle and posterior cerebral arteries pos. teriorly, by communicating vessels.

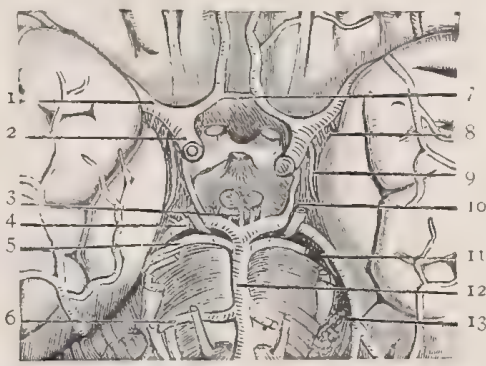

CiRCLE OF WiLlis.

I. Middle cerebral artery. 2. Internal carotid artery. 3. Postero-median perforating. 4. Posterior cerebral artery. 5. Superior cerebellar artery. 6. Anterior inferior cerebellar artery. 7. Anterior communicating artery. 8. Antero-lateral perforating. 9. Anterior choroid. Io. Posterior communjcating. I1. Posterior choroid. 12. Basilar artery. 13. Crus cerebelli cut.

Circuit (ser'-kit) [circuitus, a going round]. The course of an electric current. C.-breaker, an apparatus for interrupting the circuit of an electric current.

Circulation (sir-ku-la-'shun) [circulatio, a circular course]. The passage of the blood through various vessels; distinguished as capillary, fetal, portal, pulmonary, etc. C., Cross, a laboratory experiment in which the vessels in one vascular area of an animal are separated from the rest of the circulation by ligation of anastomosing channels, and then supplied with blood from the circulation of a second animal. In this way, for example, the vascular area of the head may be isolated, and precluded from receiving chloroform inhaled by the lungs, but which is distributed to other parts of the body. By connecting the cerebral ends of the severed carotid arteries of one dog with the cardiac ends of the severed carotids of another dog, the cerebral and general circulatory systems of the first dog may presumably be separated. The first animal is called the fed, and the Scheme of the Circulation. animal supplying the $a$. Right, $b$, left auricle. A. Right, blood the feeder. The experiment is of little value. C., Collateral, that through branches and secondary channels after stoppage of the principal route. C., Fetal, that of the

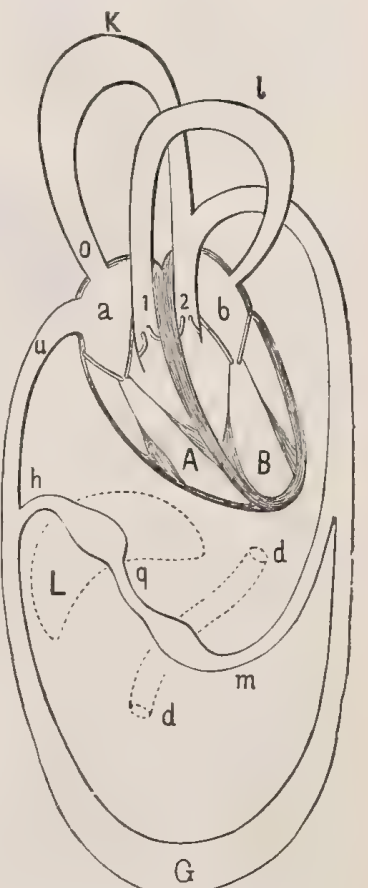
$B$, left ventricle. 1. Pulmonary artery. 2. Aorta. l. Area of pulmonary circulation. K. Upper area of systemic circulation$\mathrm{G}$ Lower area of systemic circulation. 0 . The superior vena culation. 0 . The superior vena
cava. $u$. Inferior vena cava. $d$, $d$. Intestine. $m$. Mesenteric artery o. Portal vein. L. Liver. $h$. Hepatic vein. (Landois.) fetus, including the circulation through the placenta 
ard umbilical cord. C., First, or Primitive, that of the embryo, a closed system, carrying nutriment and oxygen to the embryo. C., Placental, the fetal circulation. C., Portal. See Portal System. C., Pulmonary, the circulation of blood through the

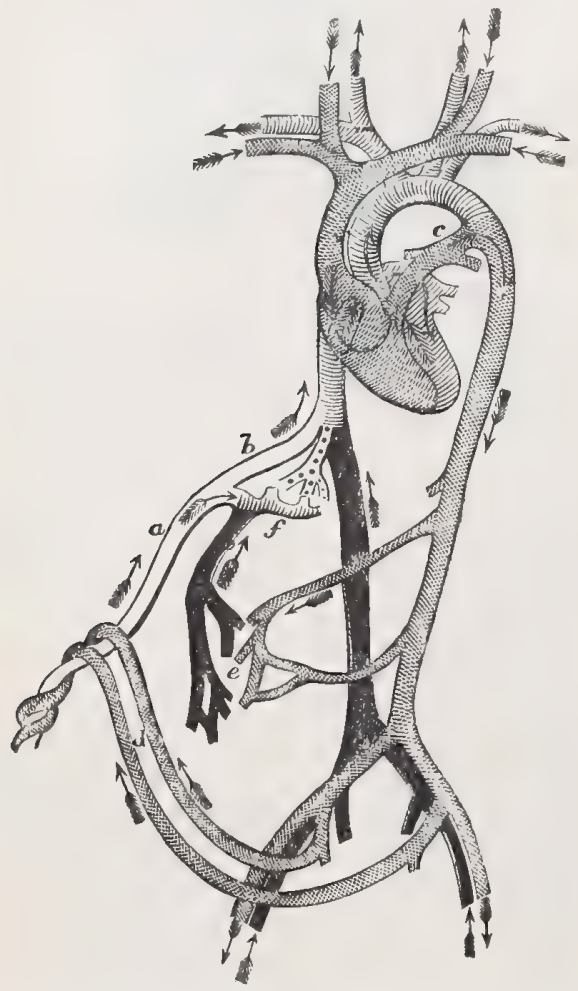

The Fetal Circulation.

$a$. Umbilical vein. b. Ductus venosus. c. Ductus arteriosus. d. Hypogastric arteries. e. Mesenteric arteries and vein. $f$. Portal vein.

lungs by means of the pulmonary artery and veins, for the purpose of oxygenation and purification. C., Second, the fetal circulation, replacing the omphalomesenteric system. C., Systemic, the general circulation, as distinct from the pulmonary circulation. C., Third, that of the adult. C., Vitelline, first, or primitive circulation.

Circulus (sir'-ku-lus) [L.]. A circle. C. arteriosus, the circle of Haller. The plexus of arteries that surrounds the outer border of the iris. C. iridis minor, an arterial circle near the pupillary border of the iris. C. venosus mammæ (or Halleri), a ring of anastomosing veins that surround the nipple.

Circum- (sir'-kum-) [L.]. A prefix meaning around, about.

Circumagontes (sir-kum-aj-en'-têz) [L., "causing to revolve"]. I. The oblique muscles of the eye. 2. The infraspinatus and supraspinatus muscles that revolve the arm.

Circumanal (sir-kum- $\left.a^{\prime}-n a l\right)$ [circum, around; anus, the fundament]. Periproctous; surrounding the anus.

Circumcision (sir-kum-sizh'-un) [circumcidere, to cut around]. Excision of a circular piece of the prepuce.

Circumclusion (sir-kum-klu'-zhun) [circum, around; cludere, to close]. A form of acupressure in which the pin is passed beneath the vessel, a wire loop placed over its point, and its ends brought over the artery and made fast.

Circumcorneal (sir-kum-kor'-ne-al) [circum, about ; corneus, horny]. Around or about the cornea.

Circumduction (sir-kum-duk'-shun) [circumducere, to lead around]. The movement of a limb in such a manner that its distal part describes a circle, the proximal end being fixed. See Motion.

Circumference (sir-kum'-fer-ens) [circumfere, to carry around]. The distance around a part.

Circumflex (sir'-kum-fleks) [circumflectere, to bend about]. Applied to a number of arteries, veins and nerves.

Circumgyration (sir-kum- $\left.i-r a^{\prime}-s h u n\right)$ [circum, around; gyrare, to turn]. See Vertigo.

Circuminsular (sir-kum-in'-su-lar) [circum, about; insula, island]. . Surrounding the island of Reil.

Circumlental (sir-kum-len'-tal) [circum, around; lens, a lentil; lens]. Surrounding the lens. C. Space. See Space.

Circumnuclear (sir-kum-nu'-kle-ar) [circum, about; mucleus, kernel]. Surrounding the nucleus.

Circumnutation (sir-kum-nu-ta'-shun) [circum, around; nutare, to nod]. In biology, a bowing successively toward all points of the compass. Applied to the movements of young and growing organs.

Circumocular (sir-kum-ok'-u-lar) [circum, about ; oculus, eye]. Surrounding the eye.

Circumoral (sir-kum-o'-ral) [circum, about; os, mouth]. Surrounding the mouth.

Circumpolarization (sir-kum-po-lar-iz-a'-shun) [circum, around; polus, pole.] The quantitative estimation of sugar in a suspected liquid by the degree of the rotation of polarized light, sugar rotating the ray to the right, albumin to the left.

Circumrenal (sir-kum-re'-nal) [circum, about; ren, the kidney]. Around or about the kidneys.

Circumscribed (sir'-kum-skribd) [circumscribere, to draw a line around]. Strictly limited or marked off; well defined; distinct from surrounding parts, as a circumscribed inflammation or tumor.

Circumvallate (sir-kum-val'-ät) [circumvallare, to surround with a wall]. Surrounded by a wall or prominence. C. Papillæ, certain papillæ at the base of the tongue.

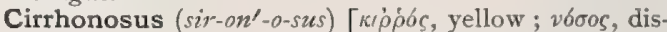
ease]. I. A fetal disorder, marked by yellowness of the serous membranes. 2. Abnormal post-mortem yellowness of any surface or tissue.

Cirrhose $\left(\operatorname{sir}-\bar{o} s^{\prime}\right)$ [cirrus, a tendril]. In biology, provided with tendrils.

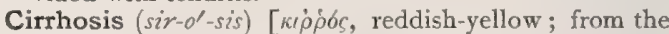
color of the cirrhotic liver]. Increase and thickening of the connective tissue of an organ, especially of the liver. C., Biliary, a form due to chronic retention of bile in the liver from long-continued obstruction in the bile-ducts from any cause. C., Fatty, a rare form in which the hepatic cells become infiltrated with fat. The surface is smooth and the organ enlarged, but very tough, owing to increase in the interstitial connective tissue, which does not contract. This form is usually seen in the intemperate.

Cirrhotic $\left(s i r-o t^{\prime}-i k\right)$ [kiṕós, yellow]. Affected with, or relating to, cirrhosis. C. Kidney. See Bright's Disease.

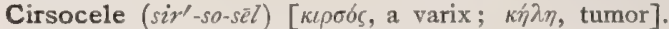
A varicose tumor, especially of the spermatic cord.

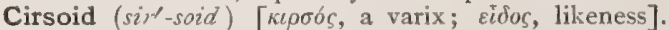
Resembling a varix, or dilated vein.

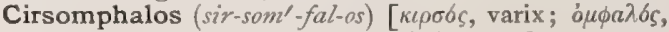
navel]. A varicose condition of the navel. 


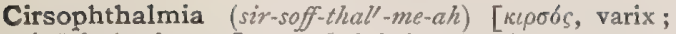
$o \phi \theta a \lambda \mu \delta s$, the eye]. I. Ophthalmia, with an apparent varicose condition of the conjunctival vessels. 2. Corneal staphyloma, with an appearance of varicosity of the surface.

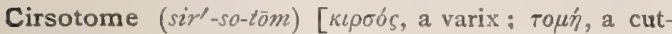
ting]. A cutting instrument for the operation of cirsotomy.

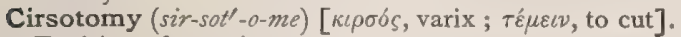
Excision of a varix.

Cisma (siz'-mah). Same as Abszes

Cismatan (sis'-mat-an). Same as Absus.

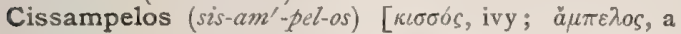
vine]. A genus of climbing menispermaceous plants. The root of C. capensis, of South America, is cathartic and emetic. C. pareira, of tropical America, false pareira brava $(q . v$.$) , is tonic and diuretic.$

Cistern (sis'-tern) [cisterna, a vessel; receptacle]. I. Any dilatation: reservoir. 2. Any dilatation of the space between the pia and arachnoid. The cisterns are true lymph-sacs. C. of Pequet. See Receptaculum chyli. C. of the Cerebrum. See Cistern, 2.

Cisterna (sis-ter'-nah) [L.]. Same as Cistern. ambiens, one of the pockets situated over the optic lobes. C. magna, a large cisterna where the arachnoid spreads across from the caudad border of the cerebellum to the oblongata. C. perilymphatica, in the ear, a large space adjacent to the foot-plate of the stapes.

Cistus (sis'-tus) [kiotos, the rock-rose]. A genus of plants of the order Cistaceæ, growing in the old world. C. oreticus, C. cyprius, C. ladaniferus, and C. ledon afford the drug labdanum, or ladanum.

Citerior (si-te'-re-or) [L., "hither"]. Brainward, centripetal, or afferent.

Citrate (sit'-rät) [citrus, citron-tree]. Any salt of citric acid.

Citrene (sit'-rēn) [citrus, citron-tree], $\mathrm{C}_{10} \mathrm{H}_{16}$. Hesperidene; carvene. The oil of Citrus aurantic, and the chief ingredient of cedar oil, cumin oil, and dill oil. It occurs associated with pinene in lemon oil. It is an agreeable-smelling, colorless liquid, sp. gr. 0.846 at $20^{\circ}$, and boiling at $175^{-1} 76^{\circ}$.

Citric (sit'-rik) [citrus, citron-tree]. Pertaining to or derived from lemons or citrons. C. Acid. See Acid.

Citrine (sit'-rin) [citrus, a lemon]. Yellow; of a lemon color. C. Ointment. See Hydrargyrum.

Citronella (sit-ron-el'-ah) [dim. of kitpov, the citrontree]. A fragrant grass. C. Oil, the essential oil of various grasses, mostly of the genus Andropogon; used chiefly as a perfume; antirheumatic. Unof.

Citrus (sit'-rus) [L.]. A genus of aurantiaceous trees. See Aurantium, Bergamot, Lime, Limon.

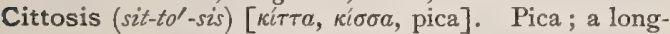
ing for strange or improper food.

Civet $\left(\operatorname{siv}^{\prime}-e t\right)$ [ME.]. A semi-liquid, unctuous secretion from the anal glands of Viverra civetta, $V$. zibetha, and $V$. rasse, carnivorous old-world animals, themselves called civets. It is now used as a perfume; formerly as an antispasmodic and stimulant, like musk. Unof.

Civiale's Operations. See Operations, Table of.

Clacking Pivot, or Tenon ( $k l n k^{\prime}-i n g$ piv'-ot). Clack pivot; a method of attaching an artificial crown to the root of a natural tooth; it was invented by Magiola.

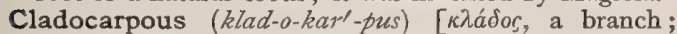
$\kappa a \rho \pi \delta \varsigma$, fruit]. In biology, having the fruit borne at the end of short lateral branches.

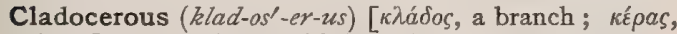
horn]. In biology, with branched antennæ.

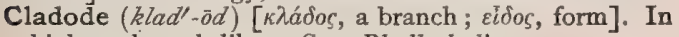
biology, branch-like. See Phyllocladium.

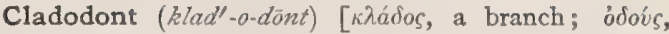
tooth]. Same as Hybodont.

Cladonea (klad-o'-ne-ah) [kidáos, a branch]. A genus of lichens. C. rangiferina, the reindeer-moss; a lichen that grows extensively in Asia, Europe and N. America. It is used as a food in famine-seasons, and is locally distilled, affording an alcoholic spirit.

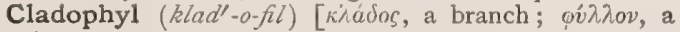
leaf]. In biology, a branch that in form mimics a leaf. Same as Cladode.

Cladoptosis (klad-op-to'-sis) [ $k \lambda a ́ \delta o s$, a branch ; $\pi i \pi \tau \varepsilon \iota \nu$, to fall]. In biology, the annual falling of twigs bearing leaves instead of the leaves alone.

Cladose $\left(k l a d^{\prime}-\overline{o s}\right)$ [ $\kappa \lambda a ́ d o s, a$ branch]. In biology, ramose or branched.

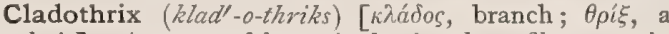
hair]. A genus of bacteria, having long filaments, in pseudo-ramifications, with true spores. See Bacteria, Synonymatic, Table of.

Clairaudience (klär-aw'-de-ens) [Fr. clair, clear; audience, hearing]. The alleged telepathic hearing of sounds uttered at a great distance.

Clairvoyance (klār-voi'-ans) [Fr. clair, clear; voir, to see]. The alleged ability (in certain states), to see things not normally visible; the pretended ability to see the internal organs of a patient, and thus diagnosticate his ailments.

Clamp (klamp) [Ger. Klampe]. An instrument for compressing the parts in surgical operations, to fix them or to prevent hemorrhage, etc. C., Gaskell's, an instrument applied over the heart so that the pulsation of the auricles and ventricles may be separately registered; it is used in the study of cardiac pulsation.

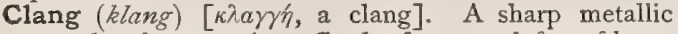
sound ; a hoarse voice. C.-deafness, a defect of hearing in which sounds are heard, but their more delicate qualities are not perceived. C.-tint, the timbre, or delicate shading of a tone. See Timbre.

Clap (klap) [OF., clapoir, a venereal sore]. Gonorrhea. C.-threads, characteristic slimy threads in the urine of gonorrheal cystitis.

Clapotage (klah-po-ta(h)zh') [Fr.]. The splashing sound of a liquid in succussion.

Clapping (klap'-ing). See Percussion and Tapotement.

Clapton's Lines. See Lines, Table of.

Claquement (klahk'-mon(g)) [Fr., clapping, slapping] r. In massage, percussion with the flat of the hand. 2. The clack, or flapping sound caused by sudden closure of the heart-valves.

Claret (klar'-et) [clarus, clear]. A wine of a light-red color. C.-red. See Pigments, Conspectus of. C. Stain. Same as Nerus maternus.

Clarificant (klar'-if-ik-ant) [clarus, clear]. A substance used for the purpose of clearing solutions turbid from insoluble matter.

Clarification (klar-if-ik-a'-shun) [clarus, clear; facere, to make]. The operation of removing the turbidity of a liquid or naturally transparent substance. It may be accomplished by allowing the suspended matter to subside, by the addition of a clarificant or substance that precipitates suspended matters, or by moderate heating. See Fining.

Clarify (klar'-if-i). [clarus, clear; facere, to make]. To free a liquid or solution from insoluble or heterogeneous substances.' To make clear.

Clarifying (klar'-if-i-ing) [clarus, clear; facere, to make]. Clearing; purifying. C. Reagent, any preparation used for purifying microscopic and anatomic preparations that have been mounted in gummy media. Oil of cloves, turpentine, creasote, xylol, and oil of bergamot are the chief. 
Clarionet-player's Cramp. See Cramp.

Clark's Operation. See Operations, Table of. C. (Alonzo), Sign. See Signs and Symptoms, Table of. Clarke's Corroding Ulcer. An ulcer of the cervix uteri that shows a tendency to spread. C. Intermedio-lateral Tract. See Column of. C. Posterior Vesicular Column. See Column of. C. Process. See Water, Softening of. C. Rule, a rule for dosage. The dose is to be graded by the weight of the child. One hundred and fifty pounds is taken as the weight of an average human adult, and in order to obtain the fractional dose this number serves for the denominator of a fraction whose numerator corresponds to the weight of the child in avoidupois pounds. Thus, the formula for a child of 50 pounds would be $\frac{50}{150}$ or $\frac{1}{3}$ of the dose for the adult.

Clasmacytosis (klas-mah-si-to'-sis). Same as Clasmatocytosis.

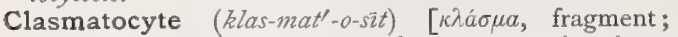
ки́тos, cell]. A form of very large connective-tissue corpuscles that tend to break up into granules or pieces.

Clasmatocytosis (klas-mat-o-si-to'-sis) [ $\kappa \lambda \dot{a} \sigma \mu a$, a fragment; кútos, a cell]. The breaking up of clasmatocytes, and the formation of islands of granules from their débris.

Clasp (klasp) [ME., claspen, to grasp firmly]. In mechanical dentistry, a hook fitted to a tooth and designed for the retention of a dental substitute or other apparatus to be worn in the mouth. In biology, an apparatus at the end of the male abdomen in certain insects, intended to grasp the female. C.-knife Rigidity, a reflex spasmodic action of the legs from increased myotatic irritability, as a result of which extension is, as it were, completed with a "spring," as in the knife.

Classification (klas-if-ik-a'-shun) [classis, a class; facere, to make]. An orderly arrangement of names, objects, diseases, etc., according to their properties and peculiarities.

Clastothrix (klas'-to-thriks). Synonym of Trichorrhexis nodosa.

Clathrate (klath'-rāt) [ $[\lambda \bar{j} \theta p a$, a lattice]. In biology, latticed; a name given by Mohl to cribriform cells; also written clathroid.

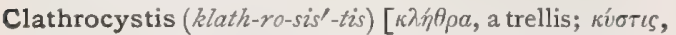
pouch]. A genus of microbes with round or oval cells, forming zoöglœx in the form of circular layers. See Bacteria, Synonymatic Table of.

Clathrose (klath'-rōs) [ $\kappa \lambda \hat{\eta} \theta \rho \alpha$, a lattice]. In biology, having deep furrows crossing at right angles.

Claudication, or Claudicatio (klaw-dik-a'-shun, klaw-dik-a'-she-o) [claudicare, to halt or limp]. The act of limping; lameness.

Claudius, Doctrine of. The doctrine that, in the production of fetal monstrosities, attributes the atrophic changes primarily to the reversal and impairment of the circulation, consequent upon the overpowering vigor of the stronger fetus. C., Cells of, the outer epithelial layer of the ducts of the cochlea.

Claustrophobia (klazvs-tro-fo'-be-ah) [claustra, a bolt; $\phi 6 \beta 0 s$, fear]. Morbid distress at being in any room or confined space; clithrophobia.

Claustrum (klazes'-trum) [claudere, to shut: pl., Claustra]. A barrier; applied to several apertures that may be closed against entrance. Also, a layer of cinerea (gray nervous matter) between the insula and the lenticula.

Clausura (klaw-su'-rah) [L.]. Closure; atresia; as of a passage. C. tubalis, closure of a Fallopian tube. C. uteri, an imperforate state of the uterine cervix.

Clava, Clavola, or Clavolet $\left(k l a^{\prime}-v a h, k l a^{\prime}-v o-l a h\right.$, or $\left.k l a^{\prime}-v o-l e t\right)$ [clava, a club]. I. In biology, clubbed at the end, as the antennæ of certain insects. 2. See Funiculus gracilis.

Clavate $\left(k l a v^{\prime}-\bar{a} t\right)$ [clava, a club.] In biology, clubshaped. Applied to a stigma, antenna, or other organ that is thick toward the apex and gradually narrowed toward the base.

Clavation (klav-a'-shun) [clavatio; clavus, a nail]. Same as Gomphosis.

Clavelization (klav-el-iz-a'shun) [Fr., clavelée, sheeppox]. Inoculation with sheep-pox virus; ovination.

Claven, or Claviculen (kla'-ven, kla-vik'-u-len) [clavis, a key]. Belonging to the clavicle in itself.

Claviceps (klav'-is-eps) [clava, club; caput, head]. A genus of fungi. C. purpurea, the fungus produc. ing the ergot of rye.

Clavicle (klav'-ik-l) [clavicula; clavus, a key]. The collar-bone. See Bones, Taile of.

Clavicular (kla-vik'-u-lar) [clavus, a key]. Relating to the clavicle.

Clavilla marginales (kla-vil'-ah mar-jin-al'-ēz) [L.]. The "olfactory clubs" or marginal clubs in Medusa; also called Cordyli marginales.

Clavula (klav'-u-lah) [clava, a club]. In biology, applied to various clubbed organs; as, a knobbed bristle in echinoderms, or the swollen receptacle of some fungi.

Clavus (kla'-vus) [clavus, a nail, a wart, a corn]. Corn; a hyperplasia of the horny layer of the epidermis, in which there is an ingrowth as well as an outgrowth of horny substance, forming circumscribed epidermal thickenings, chiefly about the toes. Corns may be hard or soft, the latter being situated between the toes, where they are softened by maceration. Both forms are due to pressure and friction. C. hystericus, a local neuralgic pain in hysteria, anemia, etc. in the head, as if a nail were being driven in.

Claw (klaw) [AS., clazen, a claw]. The stalk, or contracted base of a petal. In biology, the hooked limb or appendage of an animal. C.-hand, a condition of the hand characterized by over-extension of the first phalanges and extreme flexion of the others. The condition is a result of atrophy of the interosseous muscles, with contraction of the tendons of the common extensor and long flexor. (French, main-engriffe.)

Clayed Sugars (klād sug'-arz). Sugars that have been freed from the dark molasses by covering them in moulds by moist clay, which allows of a gradual washing and displacement of the adhering syrup.

Cleaning (klèn'-ing) [ME., clensen, to make clean]. Cleansing; removal of dirt; purifying. C. Mixture for Glass, I. Potassium bichromate 2 parts, water Io parts, sulphuric acid Io parts; dissolve the potassium in the water with heat, pour into a warm bottle, add the sulphuric acid slowly and at intervals. 2. Nitric acid (conc.) 2 parts, sulphuric acid 3 parts.

cleansings (klen'-zingz) [ME., clensen, to clean?. The lochia.

Clearer (klèr-er). See Clearing Mixture.

Clearing (klêr'-ing) [ME., cleren, to make clear]. Clarification; making clear. See Fining. C. Agent, a substance used in microscopy to render tissues transparent and suitable for mounting. To replace alcohol in a dehydrated section, creasote, turpentine, xylol, and the oils of bergamot, cedar, cloves, and origanum are used. For celloidin sections, Bergamot or cedar oil or creasote is preferable. Before mounting vegetable sections, glycerin, solution of carbolic acid, liquor potassæ, alcoholic solution of potash, liquor ammoniæ, solution of chloral hydrate, Javelle water, Labarraque's solution, are used. See Stains, Table of. C. Mixture, a fluid used in microscopy for rendering sections trans- 
parent after dehydration. It must be miscible with the mounting medium. A very satisfactory and generally applicable mixture is the following : Carbolic acid crysfals 4 parts, rectified oil of turpentine 6 parts.

Cleavage $\left(k l e^{\prime}-v a j\right)$ [ME., cleven]. 1. The linear clefts in the skin indicating the general direction of the fibers. They govern to a certain extent the arrangement of the lesions in skin-diseases. The lines of cleavage run, for the most part, obliquely to the axis of the trunk, sloping from the spine downward and forward; in the limbs they are mostly transverse to their longitudinal axis. 2. A mode of cell-division.

Cleavers (kle'-verz). See Galium aparine.

Cleft (kleft) [ME., clift]. I. A fissure; crevice. 2. The crotch, or point of junction of the legs. 3. In botany, divided half-way, as a leaf. C. Face. See Schistoprosopia. C., Ocular, a fissure in the embryo, leading from the mouth to the eye. It is situated between the fronto-nasal process and the superior maxillary plate. C., Olfactory. See Olfactory. C. Palate, a congenital malformation of the palate, usually occurring with hare-lip. C. Sternum, congenital fissure of the sternum. C., Visceral, or Branchial. The four slit-like openings on each side in the cervical region in the fetus, sometimes called the Branchial openings. The slits close (in the human fetus), except the upper, from which are developed the auditory meatus, tympanic cavity and Eustachian tube. See Branchial Clefis.

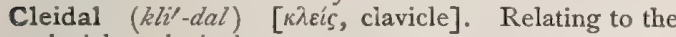
clavicle; clavicular.

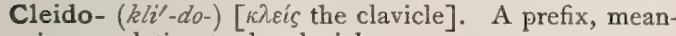
ing a relation to the clavicle.

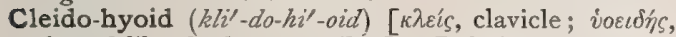
shaped like the letter upsilon]. Relating to the clavicle and the hyoid.

Cleido-mastoid ( $k l i^{\prime}$-do-mas'-toid) [ $[\lambda \varepsilon i s$, the clavicle ;

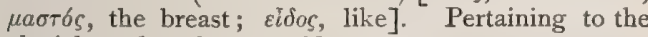
clavicle and to the mastoid process.

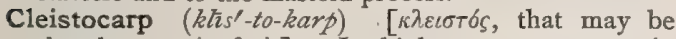
closed; $\kappa a \rho \pi \delta s$, fruit]. In biology, an ascocarp in which the spores are completely enclosed and from which they escape by the rupturing of its walls.

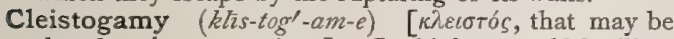
closed; $\gamma a \dot{u} \mu o s$, marriage]. In biology, self-fertilization in closed flowers.

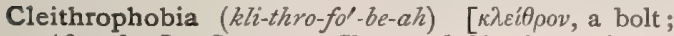
$\phi o ́ \beta o s$, fear]. Same as Claustrophobia, but a better formed word.

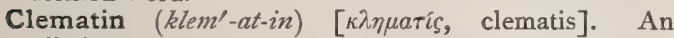
alkaloid from Clematis vitalba.

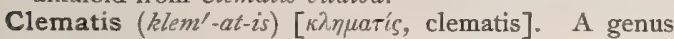
of ranunculaceous plants of many species, most of which are acrid or poisonous. C. corymbosa is powerfully irritant and resistant. C. crispa and $\mathbf{C}$. erecta are diuretic and diaphoretic, and are said to be antisyphilitic. C. viorna, C. virginica, and $C$. vitalba are similar in properties to $C$. erecta.

Clemens' Solution. See Arsenium.

Clemot's Operation. See Operations, Table of.

Cleptomania (klep-to-ma'-ne-ah). See Kleptomania

Cleptophobia (klep-to-fo'-be-ah). See Kleptophobia.

Clergyman's Sore-Throat. A chronic hypertrophic form of pharyngitis, with more or less enlargement of the tonsils and lymph-follicles of the posterior wall, due to excessive and improper use of the voice. Dysphonia clericorum. See also Pharyngitis, Granular.

Clerk-Maxwell's Experiment. See Löwe's Ring.

Clethrophobia (kleth-ro-fo'-be-ah) [ $\kappa \lambda \bar{n} \theta \rho o v$, a bar, bolt ; $\phi \delta \beta$ s, fear]. Same as Claustrophobia.

Clevenger's Fissure. See Fissures, Table of.
Clichy White. Same as White Lead.

Clicking Sounds (klik'-ing soundz). Peculiar sharp sounds heard in auscultating the apex of a tuberculous lung. They indicate the commencement of softening in a tuberculous deposit. See Râle.

Cliff-Rose (klif'-rōz). See Alonsenel.

Climacteria (kli-mak-te'-re-ah). Syn. of Menopause.

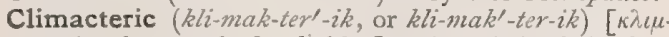
$\alpha \kappa \tau \eta \dot{\rho}$, the round of a ladder]. A period of the lifetime at which the system was believed to undergo marked changes. These were at yearly periods divisible by seven. C. Age, puberty; also in women the time of cessation of the catamenia. C., Grand, the 63 d year, also the 8 Ist year. C. Dentition. See C. Teething. C. Insanity. See Insanity. C. Teething, the development of teeth at a very late period of life, afte: the loss of those of the second dentition, and usually between the sixty-third and eighty-first year, the grand climacteric years of the Greek physiologists.

Climate $\left(k l^{\prime}-m a t\right)$ [ $k \lambda i \mu a$, a region, or zone, of the earth]. The sum of those conditions in any region or country that relate to the air, the temperature, moisture, sunshine, winds etc., especially in so far as they concern the health or comfort of mankind. Climate is an essential factor in the production of or modification of certain diseased conditions. This influence depends upon the nearness of the country to large bodies of water, its altitude above the sea-level, the peculiarities of its atmosphere, the nature and composition of its soil and subsoil, and the character of its vegetation. The most equable climate is that of the ocean, and next from a therapeutic point of view stands the sea-coast. The climate of mountains is especially lauded for the treatment of pulmonary disease. Its value consists in the rarefaction of the atmosphere and the freedom from particles and germs. Climate also plays an important part in the management of hay-fever and other diseases.

Climatic $\left(k l i-m a t^{\prime}-i k\right)[\kappa \lambda i \mu \alpha$, a region or zone of the earth]. Pertaining to climate.

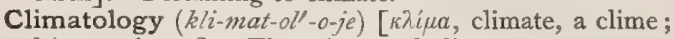
$\lambda$ óros, science]. The science of climate.

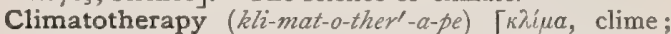
$\theta \varepsilon p a \pi \varepsilon i a$, a waiting on]. The employment of climatic measures in the treatment of disease.

Climbing Staff-tree. False Bittersweet. The bark of the root of Celastrus scandens, alterative, diuretic and slightly narcotic. It has been advantageously employed in syphilitic and scrofulous affections. Dose of fld. ext. $3 \mathrm{j}-\mathrm{ij}$. Unof. See Celastrus.

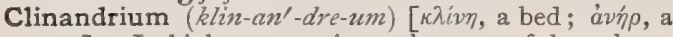
man]. In biology, a cavity at the apex of the column in orchids in which the anthers rest. This is also called the Androctinium.

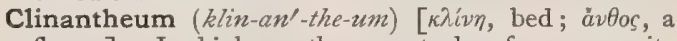
flower]. In biology, the receptacle of a composite plant.

Clinic $\left(k l i n^{\prime}-i k\right)[\kappa \lambda \iota \nu \iota \kappa o ́ s$, pertaining to a bed]. I. Medical instruction given at the bedside, or in the presence of the patient whose symptoms are studied and whose treatment is considered. 2. A gathering of instructors, students, and patients, for the study and treatment of disease.

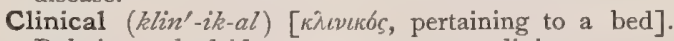
Relating to bedside treatment, or to a clinic.

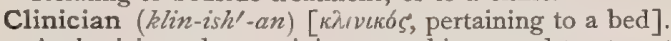
A physician whose opinions, teachings, and treatment are based upon experience at the bedside; a clinical instructor; one who practises medicine.

Clinicist (klin'-is-ist) [ $\kappa \lambda \iota \nu \iota \kappa o ́ s$, pertaining to a bed]. A clinician. 


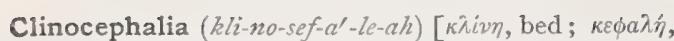
head]. Abnormal flatness of the top of the head.

Clinocephalous (kli-no-sef'-al-zes) [kiivn, bed: $\kappa \varepsilon \phi a \lambda \dot{\eta}$, head]. Having the top of the head abnormally flat.

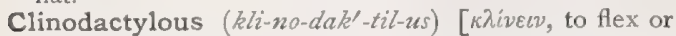

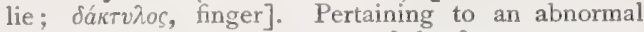
flexure, deviation or curvature of the fingers or toes.

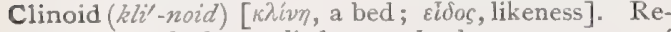
sembling a bed; applied to sundry bony structures of the body, as the clinoid processes, plate, walls, etc.

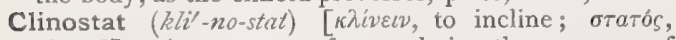
placed]. An apparatus for regulating the exposure of plants to the sunlight.

Clip (klip). See Compressor.

Clire, or Clyers ( $k l i^{\prime}-e r$, or $\left.k l i^{\prime}-e r z\right)$ [E. dial.]. Tuberculous disease of cattle. See Kernels.

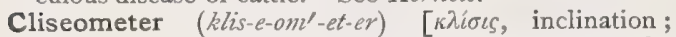
$\mu \varepsilon \dot{\tau} \tau \rho \circ \nu$, a measure]. An instrument for measuring the degree of inclination of the pelvic axis.

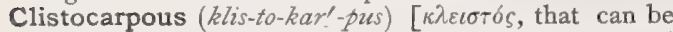

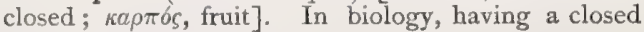
capsule, as certain mosses.

Clithrophobia (klith-ro-fo'-be-ah). Same as Cleithrophobia.

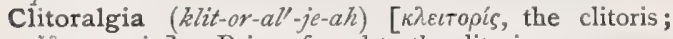
$a \lambda y o s$, pain]. Pain referred to the clitoris.

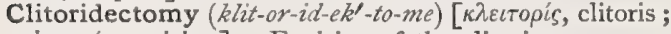

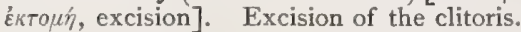

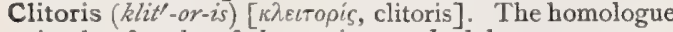
in the female of the penis, attached by two crura or branches to the ischio-pubic rami, which meet in front of the pubic joint to form the body, or corpus. The so-called "gland" is such only in appearance and name. C. Crises, paroxysms of sexual excitement in women suffering from tabes.

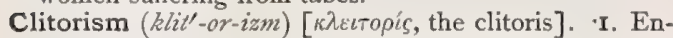
largement or hypertrophy of the clitoris. 2. Tribadism.

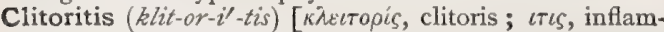
mation]. Inflammation of the clitoris.

Clitorotomy (klit-or-ot'-o-me). Incision of the clitoris.

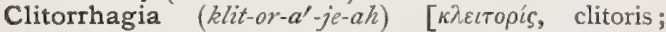

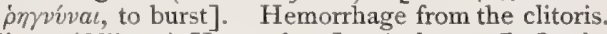

Clivus (kli -vus) [L., a slope]. A slope. C. Ossis, or C. of Blumenbach, the slanting surface of the body of the sphenoid between the dorsum sellæ and the basi-occipital.

Cloaca $\left(k l o-a^{\prime}-k a h\right)$ [cloaca, a sewer]. I. In early fetal life, the common orifice of the intestine and the allantois. 2. In surgery, the long canal of escape of pus from a necrotic sequestrum. 3. In biology, the chamber into which open the large intestine and urogenital ducts of birds, amphibians and monotremata.

Cloacal $\left(k l o-a^{\prime}-k a l\right)$ [cloaca, a sewer]. Pertaining to or serving as a cloaca.

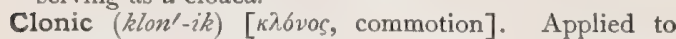
convulsive and spasmodic conditions of muscles in which alternate contractions and relaxations occur involuntarily.

Clonici $\left(k l o n^{\prime}-i s-i\right)$ [L.]. Diseases marked by clonic spasm.

Clonism, Clonismus ( $\left.k l \sigma^{\prime}-n i z m, k l o-n i z^{\prime}-m u s\right)$ [ $[\kappa \lambda \sigma v o s$, commotion]. A clonic spasm; clonospasm.

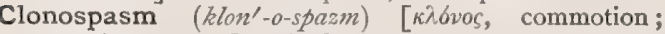
$\sigma \pi a \sigma \mu \delta ́ s$, a spasm]. A clonic spasm.

Clonus $\left(k l 0^{\prime}-n u s\right)$ [ $k \lambda 6 v o s$, commotion]. Involuntary, reflex, irregular contractions of muscles when put suddenly upon the stretch. According to the part stimulated, the phenomenon is spoken of as ankle, foot, rectus, or wrist $C_{0}$, etc. See Reflexes, Table of. It is a valuable diagnostic sign in certain lesions of the spinal cord. Cathodal closure clonus, and Catho- dal opening clonus, etc. See Contraction. See Ankle C., Wrist C., etc.

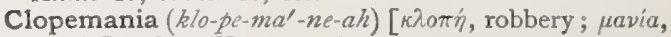
mania]. See Kleptomania.

Cloquet, Angle of. See Angle. C., Canal of. 'See Canals, and Hyaloid Artery. C., Fascia of, the septum crurale, q.v. C., Ganglion of. See Ganglia, Table of. C., Hernia of. See Hernia, and Diseases, Table of. C., Needle Test of. See Death, Signs of. C., Operation of. See Operations, Table of. C., Pseudoganglion of. See Pseudoganglion.

Closing Tetanus (klo'-zing tet'-an-us). See Galvanotonus.

Clostridial (klos-trid'-e-al) [ $\kappa \lambda \omega \sigma \tau \eta ́ p$, a spindle]. Referring to spindle-shaped bacilli and especially to the agent of the butyric acid fermentation.

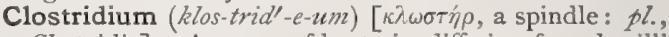
Clostridia]. A genus of bacteria, differing from bacilli in the fact that their spores are formed in characteristically enlarged rods. See Bacillus butyricus, under Bacteria.

Closure $\left(k l l^{\prime}-z \bar{u} r\right)$ [clausura, a closing]. The act of completing or closing an electric circuit. According as a closure is anodal or cathodal, its effects may so differ as to give it a marked significance in diagnosis.

Clot (klot) [ME., clot, a round mass]. A coagulum, especially that of blood; a crassamentum. See Thrombus, Embolism. White clots are formed of the pure fibrin of white corpuscles and of blood-plaques. If the white clot has become slightly stained with red bloodcells, it becomes yellowish (chicken-fat clot); if it be red and soft, it is a currant-jelly clot. Stratified clots contain layers of more than one variety. C., Distal, a clot formed in a vessel beyond the seat of ligature. C.-districts, the small divisions into which a clot is broken by the dissemination through it of the fibroblastic plasma-corpuscles. C., Proximal, the clot formed in a vessel above the seat of ligature.

Clotbur (klot'- or klōt'-bur). The leaves of Xanthium strumarium, much used as a domestic remedy for bites of poisonous insects and venomous serpents. Also an active styptic. Dose of the fluid extract $3 \mathrm{j}-\mathrm{ij}$. Unof. See also Spiny Clotour.

Clottage of the Ureters. An operation proposed in case of hematuria from a kidney hopelessly crushed or with advanced carcinoma. The procedure consists in blocking or corking up the ureter with a clot.

Cloudberry (klowd'-ber-e). The leaves of Rubus chamamorus, used in Russia as a diuretic. Dose $3 \mathrm{j}$ to a cupful of boiling water. Unof.

Cloudy Swelling. Parenchymatous degeneration; a swelling up of the elements of a tissue by imbibition or accretion, a form of hypertrophy with a tendency to degeneration.

Clove (klōv). See Caryophyllus. C.-hitch Knot, a form of double-knot in which two successive loops are made close to one another on the same piece of cord or bandage, a half-twist being given to the junction of each loop at the time of making it. See Knot.

Clover's Gas and Ether Inhaler. See Anesthetic.

Clownism (klown'-izm) [ME., cloune]. Charcot's term for that stage of hystero-epilepsy in which there is an emotional display and a remarkable series of contortions or cataleptic poses.

Club (klub) [ME., club, a club]. In biology, a broad ending of an antenna. C.-foot. See Talipes. C.hand, a deformity of the hand similar to that of clubfoot.

Clubbed Fingers (klubd fing'-gerz). Knobbed deformity of the finger-ends, with curvature of the nails, seen in some cases of pulmonary and cardiac disease. 
Clyers (kli'-erz). See Clive and Kernels.

Clypeate (klip'-e-at) [clypeus, a shield]. In biology, shaped like a buckler.

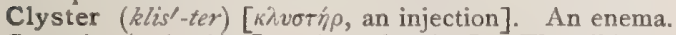

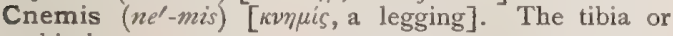
shin-bone.

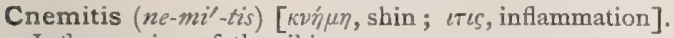
Inflammation of the tibia.

Cnicin $\left(n i^{\prime}-\sin \right)$ [ $\kappa \nu \tilde{\eta} \kappa o s$, a plant of the thistle kind], $\mathrm{C}_{42} \mathrm{H}_{56} \mathrm{O}_{15}$. A crystalline bitter substance found in Blessed Thistle.

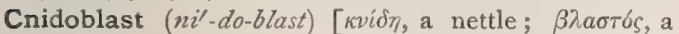
germ]. In biology, the budding thread-cell or urticating cell.

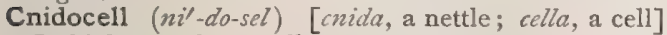
In biology, a lasso-cell, nematocyst, or urticating cell.

Cnidocil (ni'-do-sil) [cnida, a nettle; cilium, an eyelash]. In biology, the thread of a nematocyst.

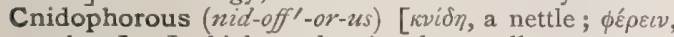
to bear]. In biology, 'bearing lasso-cells or nematocysts.

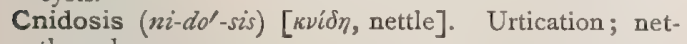
tle-rash.

Coacervate (ko-as-em $\left.v^{\prime}-a t\right)$ [coacervare, to heap up]. In biology, clustered, bunched; said of grains or flowers.

Coach $(k \bar{c} c h)$. See Quizzer.

Coachmen's Cramp. See Cramp.

Coädnate (ko-ad'-nät) [con, together; adnatus, bunched]. In biology, clustered.

Coagulant (ko-ag/-u-lant) [coagulare, to curdle]. I. Causing the formation of a clot or coagulum. 2. A coagulating agent.

Coagulated (ko-ag'-u-la-ted) [coagulare, to curdle]. Clotted; curdled. C. Proteids, a class of proteids produced by heating solutions of egg-albumin or serum-albumin globulin suspended in water or dissolved in saline solutions, up to $100^{\circ} \mathrm{C}$. At the bodytemperature they are readily converted into peptones by the action of the gastric juice in an acid, or of pancreatic juice in an alkaline medium.

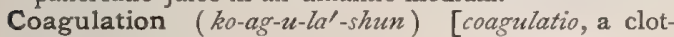
ting]. The formation of a coagulum or clot, as, in blood or in milk.

Coagulative (ko-agf-u-la-tiv) [coagulare, to curdle]. Causing or marked by coagulation. C. Necrosis. See Necrosis.

Coagulum (ko-agf-u-lum) [coagulare, to curdle: pl., Coagula]. Clot. The mass of fibrin, enclosing red and colorless corpuscles and serum, that forms from the plasma of the blood after the latter has been drawn from the body. Also, the curd of milk, and the insoluble form of albumin.

Coal $(k \bar{o} l)$ [ME., cole]. A solid and more or less distinctly stratified mineral, varying in color from darkbrown to black, brittle, combustible, and used as a fuel ; not fusible without decomposition, and very insoluble. C., Anthracite, the hard variety of coal, used largely as a heating-agent. It contains but little hydrogen, and is mainly (over 90 per cent.) composed of pure carbon. C., Bituminous, is black or grayish-black in color, of a resinous luster, and somewhat friable, being easily broken into cubical fragments of more or less regularity; upon ignition it burns with a yellow flame. When heated to bright redness in retorts or ovens, free from the access of air, the volatile matter, composed of carbon compounds of hydrogen and oxygen with water, passes off. It is used in the manufacture of gas. C., Cannel is much more compact than gas or coking coals, duller in appearance, possessing a grayish-black to brown color, and burning with a clean candle-like flame. It does not soil the hands, and is not readily fractured. C., Brown, or Lignite, appears to occupy an intermediate position between the bituminous coals and wood. It retains the ligneous structure of the material from which it is formed, hence the name Lignite. The vegetable remains are in a great many cases quite distinct. The color varies from yellowishbrown in the earthy, to black in the more compact, coal-like varieties. It does not yield coke. It is used as fuel in some localities. Peat, or Turf, occurring in large areas in Ireland and in some parts of Europe, consists of the decayed remains of certain forms of plants. It has been destructively distilled for tarry products, without profit, however. C.-miner's Lung. See Miner's Lung. C--tar, a by-product in the manufacture of illuminating gas; it is a black, viscid fluid of a characteristic and disagreeable odor. The specific gravity ranges from $\mathbf{I}$. Io to $\mathbf{1} .20$. Its composition is extremely complex, and its principal constituents are separated, one from the other, by means of fractional distillation. C.-tar Colors. See Pigments, Colors, and Dyestuffs.

Coalescence (ko-al-es'-ens) [coalescere, to grow togetber]. The union of two or more parts or things.

Coaptation (ko-ap-ta'-shun) [con, together; aptare, to fit]. The proper union or adjustment of the ends of a fractured bone, the lips of a wound, etc.

Coarctate (ko-ark'-tāt) [coarctare, to press together]. Crowded together

Coarctation (ko-ark-ta'-shun) [coarctare, to put together]. A compression of the walls of a vessel or canal, thus narrowing or closing the lumen; reduction of the normal or previous volume, as of the pulse; shrivelling and consequent detachment, as of the retina. A stricture.

Coarctotomy (ko-ark-tot'-o-me) [coarctatus, constricted; $\tau \varepsilon \dot{\varepsilon} \mu \nu \iota \nu$, to cut]. The cutting of a stricture.

Coarse (kors) [ME., course]. Not fine; gross. C. Adjustment. See Adjustment. C. Features of Disease, macroscopic organic lesions, such as tumor, hemorrhage, etc.

Coarticulation (ko-ar-tik-u-la'-shun) [con, together; articulare, to join, articulate]. A synarthrosis.

Coat (kōt) [cottus, a tunic]. A cover, or membrane covering a part or substance. C., Buffy, the upper fibrinous layer of the clot of coagulated blood, marked by its color, and absence of red-corpuscles.

Coates's Operation. See Operations, Table of.

Coating $\left(k \bar{o} t^{\prime}-i n g\right)$ [cottus, a tunic]. A covering, as of a wound, the tongue, etc. C. of the Tongue, a condition of the tongue indicative of abnormality of the digestive tract. C. of Pills, a covering of various substances to conceal the taste in swallowing.

Cobalt (ko'-bawilt) [Kobold, a German mythologic goblin]. A tough, heavy metal having some of the general properties of iron. Its oxids have been employed in medicine, but are now very little used. See Elements, Table of. C.-blue. See Pigments, Conspectus of. C--green. Same as Rinmann's Green. C.-red. See Pigments, Conspectus of. C.-ultramarine. Same as Cobalt-blue. C.-yellow. See Pigments, Conspectus of.

Cobweb (kob'-zeb) [ME., cobrueb, a spider's web]. Tela aranea, spider's web. The web of a common house spider, Tegeneria domestica. It is a styptic recommended for bleeding after tooth-extraction, and in pulmonary tuberculosis, in 30-grain doses. It forms a serviceable moxa, with the aid of the blowpipe.

Coca $\left(k o^{\prime}-k a h\right)$. See Erythroxylon.

Cocain $\left(k o^{\prime}-k a h-i n\right.$, or $\left.k o^{\prime}-k a \bar{a}\right)$ [S.A., coca], $\mathrm{C}_{17} \mathrm{H}_{21} \mathrm{NO}_{4}$. The chief alkaloid extract of Ervthroxylon coca. It is at first stimulant and afterward narcotic, and resembles caffein in its action on the nerve-centers, and 
atropin in its effects on the respiratory and circulatory organs. Its long-continued use (cocain-habit) is followed by insomnia, decay of moral and intellectual power, emaciation, and death. Locally, it is a powerful anesthetic in a limited area of surface. It acts most rapidly on mucous tissues. Applied to the conjunctiva of the eye it causes also dilatation of the pupil and paralysis of the function of accommodation. Applied to the tongue it temporarily destroys the sense of taste. Dose gr. 1/8-ij. See also Anesthetic. C.Bug, an imaginary insect which cocainomaniacs frequently think they are infested with; a belief that is probably due to some formicational sense-perversion. C., Ceratum, I in 30 , for burns, etc. C. Citras, used in dentistry to ease aching teeth. C. Hydrochloras, or chlorid of cocain, $\mathrm{C}_{17} \mathrm{H}_{21} \mathrm{NO}_{4} \mathrm{Cl}$, more properly cocain chlorid, most commonly used for local anesthesia in 2-8 per cent. solution. Dose, internally, gr. $\frac{1}{8}$ ij. C. Hydrochlorat, Liquor. (B.P.). Dose $m_{i j-x}$. Injectio C. Hydrochlorat., Hypoderm.; I grain in 20 minims. C., Lamellæ (B.P.), each containing gr. $\frac{1}{100}$ of cocain hydrochlorate. C. Oleas, a Io per cent. solution in oleic acid, for external use. C. Phenas or Carbolas, a topical application in catarrhs and in rheumatism. Used as a five to ten per cent. alcoholic solution, also internally, gr $\frac{1}{12}-\frac{1}{6}$.

Cocainism (ko-ka'-in-izm) [S. Amer, coca]. The cocain-habit.

Cocainization (ko-ka-in-iz-a'-shun) [S. Amer., coca]. The bringing of the system or organ under the influence of cocain.

Cocainomania ( $\left.k o-k a-i n-o-m a^{\prime}-n e-a h^{\prime}\right)$ [cocain; $\mu a v i a$, madness]. The habit of using cocain; properly, insanity due to the cocain-habit.

Cocainomaniac (ko-ka-in-o-ma'-ne-ak) [cocain; $\mu a v i \alpha$, madness]. One who is insane from the effects of cocain.

Cocamin (kol-kam-in) [S. Amer. coca; amin], $\mathrm{C}_{19} \mathrm{H}_{23} \mathrm{NO}_{4}$. Truxillin, or Isotropyl-cocain; an alkaloid from coca. It has active properties, but its physiologic effects are little known.

Cоссасег (kok-kas'-e-e) [Fr., coccaceёs; ко́ккоs, a kernel]. A group of schizomycetous fungi, or bacteria, including as genera the Micrococcus, Sarcina, Ascococcus, and Leuconostoc. The elements are normally spherical, reproduction usually taking place by division. Some writers place the genus Leuconostoc alone in this group; others exclude it entirely.

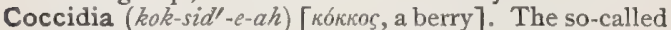
psorospermice -minute oval structures about $0.035 \mathrm{~mm}$. long, with a thick capsule and coarsely granular contents. They are frequently found in the liver of the rabbit, and have been found in the liver, in a pleuritic exudate, and in the kidney, ureter, and heart-muscle in man. The organism is more properly called Coccidium oviforme, while the spores that it forms are termed psorospermix.

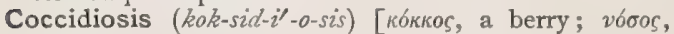
disease]. The group of symptoms produced by the presence of coccidia in the body.

Coccidium (kok-sid'-e-um) [кókкos, a berry: pl., Coccidia]. I. In biology, applied $(a)$ to the spore-bearing conceptacle of certain algæ, and $(b)$ to egg-shaped psorosperms. 2. A genus of protozoans, by some referred to as the so-called psorosperms (see Psorosperm). See Coccidia. C. oviforme has been found in intestinal epithelium, and in the liver of man, and often in the liver of the rabbit. True coccidia are non-motile cell-parasites. C. sarkolytus, the name given by Adamkiewicz to the parasite of carcinoma.

Coccillana (kok-sil-a'-nah) [S. Amer.]. The bark of Guarea swartzii, of the W. Indies, a tree of the fam- ily Meliacea, an emetic and purgative ; in over-doses it is poisonous as an irritant narcotic. It acts locally upon the mucous membrane when directly applied or when absorbed. It is commended for bronchial catarrh. Dose

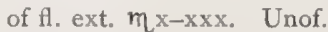

Coccinella (kok-sin-el'-ah). See Cochineal.

Coccinellin (kok-sin-el'-in), or Coccinellina (kok-senel'-lei-na). See Carmin.

Coccinin (kok'-sin-in) [coccinus, scarlet], $\mathrm{C}_{14} \mathrm{H}_{12} \mathrm{O}_{5}$. I. A substance obtained by heating carmic acid with potassium hydrate. It crystallizes in yellowish leaflets from an alcoholic solution. 2. A coal-tar color belonging to the azo-group. Same as New Coccin and Phenetol Red.

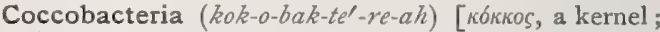

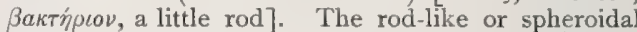
bacteria found in putrefying liquids, and called $\mathbf{C}$. septica. See Bacteria, Synonymatic Table of.

Coccoloba (kok-oll'-o-bah) [cocolobis, a kind of grape]. A genus of polygonaceous trees of tropical America. C. uvifera, the sea-side grape, has a hard and valuable wood, which, when boiled, yields what is called Jamaica kino.

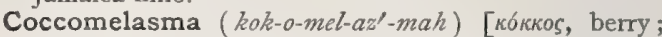
$\mu \varepsilon ́ \lambda a \sigma \mu a$, blackness]. A granular dermal melanosis.

Cocculus (kok'-u-lus) [dim. of coccus, a berry]. A genus of menispermaceous plants of the tropics. C. indicus, is the dried fruit of Anamirta cocculus. It is an active narcotic poison, and is employed as a destroyer of vermin; its preparations have proved serviceable for headaches, dysmenorrhea, etc. See Picrotoxin.

Coccus (kok'-us) [кókкos, a berry]. I. A cell or capsule. 2. In biology, $(a)$ the separable carpels or mit lets of dry fruits; $(b)$ a spherical bacterium, a micrococcus. C. cacti, the cochineal insect. See Cochineal.

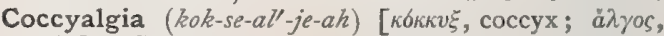
pain]. Coccygodynia.

Coccydynia (kok-se-din'-e-ah). See Coccygodynia.

Coccygalgia (kok-sig-all-je-ah). See Coccygodynia.

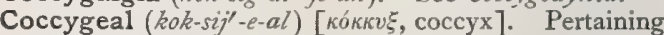
to the coccyx.

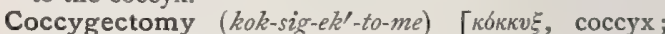
$\varepsilon k T O \mu \tilde{\eta}$, excision]. Surgical excision of the coccyx.

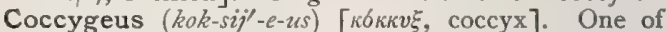
the pelvic muscles. See Muscles, Table of.

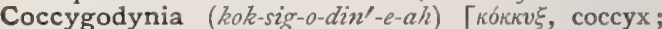
ofvin, pain]. Pain referred to the region of the coccyx; confined almost exclusively to women who have given birth to children. The pain is due to a rupture or stretching of the ligaments surrounding the coccyx, or to fracture or dislocation of that bone.

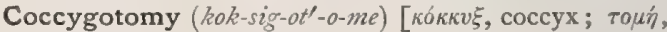
a cutting]. Cutting of the coccyx.

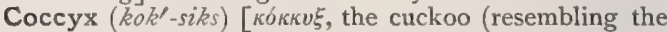
bill) ]. The last bone of the spinal column, formed by the union of four rudimentary vertebræ. See Bones, Table of.

Cochenille [Fr.]. Same as Cochineal.

Cochia ( $k o^{\prime}-k e-a h$, or $\left.k o^{\prime}-c h e-a h\right)$ [L. ; of Gr. коккiov, a pill]. An old, but not obsolete, name for certain drastic and mainly aloetic pills (pilule cochic). The name cochia is now adjectival.

Cochin China ( $k o^{\prime}$-chin chi'-nah) [native Asiatic]. A country of lower Asia. C. Diarrhea, a form of tropical diarrhea dependent upon the presence in the intestine of a thread-worm, Anguillula intestinalis, and its larval offspring. C. Leg. Synonym of Elephantiasis arabum. C. Ulcer, an affection of Cochin China characterized by deep ulceration of the extremities. It is supposed to be the same as Furunculus orientalis. 
Cochineal (koch'-in-èl, or koch-in-êl') [ME., cutchaneal]. The dried insects of a species of plant lice, Coccus cacti, parasitic upon a cactus of Mexico and Central America. It contains a rich red coloringmatter, carmin, used mainly as a dyeing agent. See Pigments, Conspectus of. It is thought to be valuable in infantile whooping-cough. Dose gr. 1/3.

Cochlea $\left(k \circ k^{\prime}-l e-a / 2\right)$ [ $\kappa^{\prime} \chi \lambda{ }^{\prime}$, a conch-shell]. A cavity of the internal ear resembling a snail-shell. It describes two and a half turns about a central pillar called the modiolus or columnella, forming the spiral canal, about $1 \mathrm{I} / 2$ inches in length. The latter is divided into three canals or scalæ, - the scala tympani, vestibuli, and media. See also, Ear. 2. In botany, a coiled legume, like that of Medicago.

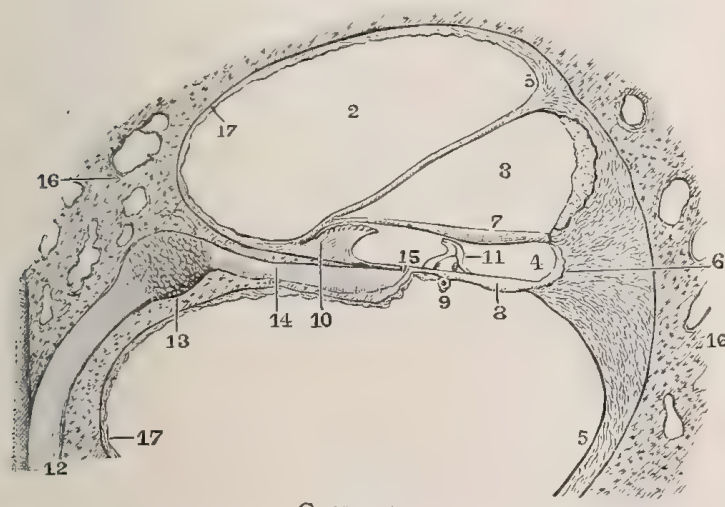

Cochlea.

I. Scala tympani. 2. Scala vestibuli. 3. Anterior or triangular canal. 4. Posterior or quadrilateral canal. 5, 5. Spiral ligament. 6. External spiral sulcus. 7. Membrana tectoria or membrane of Corti. 8. Membrana basilaris. 9. Spiral vessel. 10. Limbus laminæ spiralis. II. Pillars of Organ of Corti. 12. Branch of cochlear nerve. 13. Ganglion spirale. I4. Branch of cochlear nerve between the lamellæ of the lamina spiralis ossea. I5. One of the orifices by which this branch penetrates the canal of Corti. I6. Part of bony cochlea. 17. Lining periosteum. 18. Membrane of Reissner.

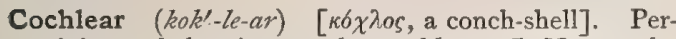
taining or belonging to the cochlea. C. Nerve, the nerve supplying the cochlea. See Nerves, Table of.

Cochlear, or Cochleare (kok'-le-ar, or kok-le-a'-re) [L.: pl., Cochlearia]. A spoon; a spoonful. C. mag num, a tablespoon; C. medium, a dessert-spoon; C. minimum, a teaspoon.

Cochlearia (kok-le-ar'-e-ah). See Horseradish.

Cochleate $\left(k \circ k^{\prime}-l e-\bar{a} t\right)$ [cochleatus, spiral]. Spirally coiled, like a snail-shell.

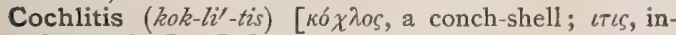
flammation]. Inflammation of the cochlea.

Cockroach (kok'-röch). See Blatta.

Coco $\left(k o^{\prime}-k o\right)$. Synonym of Yazes. See Frambosia.

Coco, or Cocoa $\left(k o^{\prime}-k o\right)$ [Port., cacao]. See Cacao and Theobroma. C.-nut, the nut of Cocos nucifera, a palm-tree of tropical coast-regions. The oil is used as a substitute for cod-liver oil, and in Germany it is employed in pharmacy in the place of lard. C.-nut Fiber, coir. The coarse fibrous covering of the nut of the cocoa-palm is largely used in making brooms, brushes, matting, and coarse carpeting. The fiber is coarse, stiff, very elastic, round, and smooth like hair. It also has great tenacity, and is well adapted for cordage. C.-nut Oil, oleum cocois, is obtained from the dried pulp of the cocoa-nut by expression. It is an oil of the consistency of butter, fusing at from $73^{\circ}$ to $80^{\circ} \mathrm{F} .\left(22.7^{\circ}\right.$ to $26,6^{\circ} \mathrm{C}$.). When fresh, it is white in color and of sweet taste and agreeable odor, but it easily becomes rancid. It is easily saponified, even in the cold. It is used in the manufacture of candles and soap.

Cocomania (ko-ko-ma'-ne-ah). See Cocainomania.

Cocomaniac (ko-ko-ma'-ne-ak). See Cocainomaniac.

Cocoölein (ko-ko-o'-le-in) [Port., cacao; oleum, oil]. A proprietary substitute for cod-liver oil, said to be derived from cocoa-nut oil.

Cocotte (ka-kot') [Fr.]. Synonym of Infuenza.

Coction (kok'-shun) [coctio; coquere, to cook]. I. Digestion. 2. The preparatory alteration that morbific matter undergoes in preparation for its discharge.

Cod $(k o d)$ [ME., cod]. I. The scrotum. 2. The belly. 3. In the plural, the testes. 4. The Gadus morrhua, a fish furnishing a valuable medicinal product, C.liver Oil, an oil derived from the liver of the Gadus morrhua, and ranging in color according to the method of its preparation from pale-straw to dark-brown; its specific gravity is .923 to .924 or even .930 at $15^{\circ} \mathrm{C}$. The finer qualities are used for medicinal purposes, the darker by tanners and curriers. See Morrhua.

Codamin ( $\left.k o^{\prime}-d a m-i n\right)$ [ [ $6 \delta \varepsilon \varepsilon \iota$, the head; poppy-head; amin ], $\mathrm{C}_{20} \mathrm{H}_{25} \mathrm{NO}_{4}$. A crystalline alkaloid of opium, isomeric with laudanin. When ferric chlorid is added to it, it assumes a deep-green color.

Codein $\left(k \sigma^{\prime}-d e n\right)$ [ $\left[\kappa \omega \delta \varepsilon \varepsilon \alpha\right.$, the poppy-head], $\mathrm{C}_{18} \mathrm{H}_{21} \mathrm{NO}_{3}$ $\mathrm{H}_{2} \mathrm{O}$. A white, crystalline alkaloid of opium. It is mildly calmative and is serviceable in diabetes mellitus. It is also valuable in ovarian pain. Dose gr. ss-ij. C. Phosphate, soluble in water. Similar to morphin in action, but less toxic. Dose, hypodermically, gr. ss. C. Sulphas, dose gr. 1/6-1/4. C. Valerianate, an antispasmodic and sedative. Dose gr. 1/4.

Codex (ko'-deks) [L.: pl., Codices]. A pharmacopeia or book of formulæ; specifically, the French pharmacopeia.

Codie Pine Resin. See Cozedie-gum.

Codonostoma (ko-do-nos'-to-mah) [ $\kappa \omega \delta \omega \nu$, a bell; $\sigma \tau b \mu a$, a mouth]. In biology, applied to the oral or disc aperture of certain marine invertebrates, medusæ, etc.

Colelminth (se'-lel-minth). See Celelminth.

Colia $\left(s e^{\prime}-l e-a h\right)$. See Celia.

Coliac $\left(s e^{\prime}-l e-a k\right)$. See Celiac

Cœliaca (se-li'-ak-ah). See Celiaca.

Coliadelphus (se-le-ad-el'fus). See Celiadelphus.

Cœliagra (se-le-a'-grah). See Celiagra.

Colialgia (se-le-al'-je-ah). See Celialgia.

Cœlian, Cœline (se'-le-an, se'-lin). See Celean, Celine.

Cœliocyesis (se-le-o-si-e'-sis). See Celiocyesis.

Caliolymph (se'-le-o-limf). See Celiolymph.

Coliomyalgia (se-le-o-mi-al'-je-ah). See Celiomyalgia.

Colioncus (se-le-ong'-kus). See Celioncus.

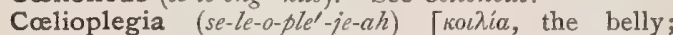
$\pi \lambda \eta \gamma \dot{\eta}$, a stroke]. A synonym of Asiatic cholera.

Cœliopyosis (se-le-o-pi-o'-sis). See Celiopyosis.

Cœliorrhœa (se-le-or-e'-ah). See Celiorrhea.

Colioschisis (se-le-os'-kis-is). See Celioschisis.

Calioscope (se'-le-o-skōop). See Celioscope.

Cœliotomy (se-le-ot'-o-me). See Celiotomy.

Colitis (se-li'tis). See Celitis.

Cœlodont (sel-lo-dont) [koiños, hollow; ódovs, tooth]. Hollow-toothed, as certain lizards - the opposite of Pleodont, or solid-toothed.

Colom, Cœloma (se'-lom, se-lo'-mah). See Celom.

Cœlophlebitis (se-lo-fle-bi'-tis). See Celophlebitis.

Colophthalmia (se-loff-thal'-me-ah). See Celophthalmia.

Calosis $\left(s e-l 0^{\prime}-s i s\right)$. See Celosis.

Cœlosoma (se-Zo-so'-mah). See Celosoma.

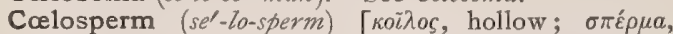
seed]. In biology, a seed so curved as to form a con. cavity on one of its surfaces. 
Calostomia (se-lo-sio'-me-ah). See Celostamia.

Columbrella (sel-um-brel'-ah) [kö̈hos, hollow; umbrella, the disc of acalephs]. In biology, the concave surface of the gelatinous umbrella of Medusce.

Cœnenchyma (se-neng $\left.g^{\prime}-k i m-a h\right)$ [kolvos, common; $\dot{\varepsilon} \gamma \chi \varepsilon i v$, to infuse]. In biology, the calcified tissue common to the several polyps of a compound Actinozoön.

Canesthesis (sen-es-the'-sis). See Cenesthesis.

Conobium (se-no'-be-um) [kolvós, common; Bios, life]. In biology, a composite zoöphyte or any colony of independent cells held together by a common investment.

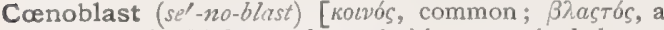
germ]. In biology, the primitive germinal layer, giving rise to the endoderm and mesoderm.

Cœnœcium (se-ne'-se-um) [kouvós, common; olkos a dwelling]. In biology, the common dermal system of a polyzoan colony. The polypidom of Johnson.

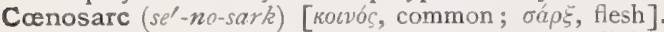
In biology, Allman's term for the "common living basis by which several polyps in a composite zoöphyte are connected with one another."

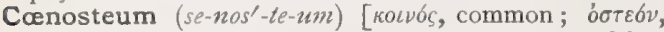
bone]. In biology, the calcareous ectoderm of hydrocorallines.

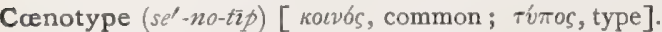
The fundamental type-form of a group.

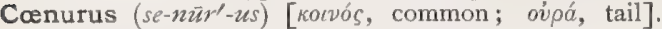
The larva of Tania conurus, Küchenmeister, pro. ducing the disease of sheep called staggers. See also Alternations of Generation. C. cerebralis, a manyheaded hydatid found mainly in the brain and spinal canal of the ox and sheep (mostly in young animals). Occasionally it has been discovered in the muscles of man. It is now known to be the larva of the tapeworm, Tania cœnurus. See Parasites (Animal), Table of.

Cœroulignone (se-ru-lig'-nōn) [coruleus, blue; lignum, wood], $\mathrm{C}_{36} \mathrm{H}_{16} \mathrm{O}_{6}$. Cedriret; a derivative of hexa-oxidi-phenyi. It separates as a violet powder when crude wood-spirit is purified on a large scale by means of potassium chromate. It is insoluble in the ordinary solvents, and is precipitated in fine, steel-blue needles, from its phenol solution, by alcohol or ether.

Coffee $\left(k \circ f^{\prime}-e\right)$. See Caffea. C.-bean, Kentucky, the popular name for Gymnocladus canadensis. C. ground Vomit, the material ejected by emesis in carcinoma and ulceration of the stomach and other gastric conditions. It consists of blood and other contents of the stomach changed by the action of the gastric juice. C--tree, Kentucky. See Chicot.

Coffeinism (kof'-e-in-izm) [caffer, coffee]. Excessive habitual use of coffee, or the state of ill-health that results from it.

Coffer Dam, Barnum's. See Rubber Dam.

Coffeurin $\left(k \circ f-e-u^{\prime}-\operatorname{rin}\right)$ [caffea, coffee; ovoov, urine]. A principle said to sometimes be present in urine after the free use of coffee as a beverage or medicine. The urine then has the odor of coffee, and its color is red, brownish, or deep-brown.

Coffin $\left(k \circ f^{\prime}-i n\right)$ [kó $\iota \iota v o s$, a basket]. I. A case intended to hold the dead body. 2. In farriery, the hollow portion of a horse's hoof. C.-birth, postmortem expulsion of the fetus. C.-bone, the last or distal phalanx of a horse's foot.

Coffnism (kof'-in-izm) [after Dr. Coffin, who advocated it]. A variety of quackery or professed system of medical practice. It resembles so-called Thomsonianism.

Cogged Breath-sound. Cog-wheel respiration or breathing. See Corroheel Sound.
Cogwheel Breathing or Respiration. See Cogwheel Sound and Breath-sound's. C. Sound, a pathologic sound sometimes heard in auscultation of the lungs, due to interruptions in the accession of air to a part; this gives the sound an intermitting character. See Breath-Simuls.

Cohabitation (ko-hab-it-a -shun) [con, together; habitare, to dwell]. The living together of a man and woman, with or without legal marriage. Sexual connection.

Cohen's Method. A method of inducing premature labor. It consists in injecting fluid into the uterine cavity between the uterine wall and the ovum. See Treatment, Methods of.

Cohesion (ko-he'-zhun) [coharere, to stick together]. The force whereby molecules of matter adhere to each other. The "attraction of aggregation."

Cohn's Fluid. A fluid culture-medium. It is composed of potassium phosphate, O.I gm.; magnesium sulphate, O. I gm.; tricalcic phosphate, o.or gm.; distilled water, $20 \mathrm{gm}$; ammonium tartrate, $0.2 \mathrm{gm}$.

Cohnheim's Areas. See Area. C. Fields. See Cohnheim's Areas. C. Frog. See Salt-frog. C. Method, a method of staining tissues. See Stains, Table of. C. Theory, a theory as to the origin of tumors; a satisfactory hypothesis, namely, to the effect that all true tumors are due to faulty embryonal development. The embryonal cells do not undergo the normal changes, are displaced, or are superfluous. When the favorable conditions are presented later in life they take on growth, with the formation of tumors of various kinds.

Cohnstein's Operation. See Operations, Table of.

Cohobation (ko-ho-ba'-shun) [cohobare, to redistil]. I. Redistillation. 2. Recurrence of disease.

Cohosh (ko'-hosh) [Am. Ind.]. A name given to several medicinal plants. C., Black. See Cimicifuga. C., Blue. See Caulophyllum.

Coil (koil) [colligere, to gather together]. Rings formed by winding, as a wire. C.-gland. See Stueat-gland. C., Induction, rolls of wire in which an electric current is induced by the alternate opening and closing of a circuit, C., Leiter's. See Leiter's Tubes. C., Ruhmkorff, an induction-coil, or spark-coil.

Coiling (koil'-ing) [colligere, to bind together]. Forming into spirals or rings. C. of the Cord. See Cord.

Coindication (ko-in-de-ka'-shun) [con, with; indicare, to indicate]. A concurrent indication; a collateral and confirmatory indication. Cf. Contraindication.

Coin-test (koin'-test). See Baccelli's Sign, and BellSound.

Coir (kir) [Tamil, kayaru, a rope]. See Cocoanutfiber.

Coiter's Corrugator. The corrugator supercilii. See Muscles, Table of.

Coition $\left(k o-i s h^{\prime}-u n\right)$ [coire, to come together]. Same as Coitus.

Coitus $\left(k o^{\prime}-i t-u s\right)$ [ coire, to come together]. The act of sexual connection. Copulation. C. Disease, the venereal disease of the horse. C. reservatus, congressus interruptus; incomplete copulation; the incomplete performance of the sexual act; onanism.

Coix $\left(k o^{\prime}-i k s\right)$ [ $k \delta \iota_{\xi}$, an Egyptian variety of palm]. A genus of coarse monecious grasses. C. lacrima, an old-world species of grass, having very large and hard seeds, called Job's tears, from which beads are made which are worn as amulets, and are thought to assist the process of dentition when bitten upon by young teething children. The seeds are used locally for lung-troubles and for dropsy. Unof.

Coke $(k \bar{o} k)$ [origin uncertain]. The solid product of the carbonization of coal. 
Coko Disease $\left(k o^{\prime}-k o\right.$ dis-ez'). A name applied in the Fiji Islands to a disease resembling Yaws.

Cola $\left(k o^{\prime}-l a h\right)$. See Kola-nut.

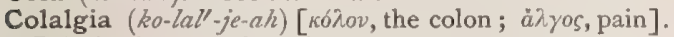
Pain in the great intestine.

Colation (ko-la'-shun) [colare, to strain]. The operation of straining.

Colatorium (kol-at-o'-re-um) [L.]. A sieve, colander, or strainer; used in pharmacy.

Colature $\left(k o^{\prime}-l a t-y \bar{u} r\right)$ [colatura, straining]. In pharmacy, a liquid that has been subjected to colation.

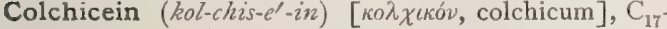
$\mathrm{H}_{21} \mathrm{NO}_{5}+2 \mathrm{H}_{2} \mathrm{O}$. A crystalline decomposition-product of colchicin.

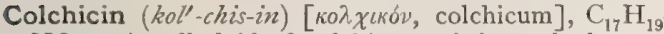
$\mathrm{NO}_{5}$. An alkaloid of colchicum; it is a pale, brownish-yellow, exceedingly bitter powder, freely soluble in water. It is a very active poison. Its dose is $\mathrm{gr}$. $\frac{1}{2}$ or $\frac{1}{2}$ milligram, hypodermatically.

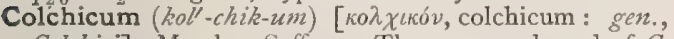
Colchici]. Meadow Saffron. The corm and seed of $C$. autumnale, with properties due to an alkaloid, colchicin. It is an emetic, diuretic, diaphoretic, and drastic cathartic. It is valuable in acute gout, and is used with good results in gonorrhea. Dose of the powdered root gr. ij-viij, of the powdered seeds gr. $\mathrm{j}-\mathrm{v}$. C., Extract. (B.P.). Dose gr. ss-ij. C., Extract., Aceticum (B. P.). Dose gr.ss-ij. C. Rad., Ext., dilute acetic acid 35 , powdered root IoO parts, water q. S. Dose gr. 1/2-ij. C. Rad., Ext., Fld. Dose mij-x. C. Rad., Vinum, 40 per cent. in strength. Dose mv-xv. C. Sem., Ext., Fld. Dose mj-v. C. Sem., Vinum, 15 per cent. in strength. Dose $\eta x-x x x$. C., Tinct., prepared from the seed; strength 15 per cent. Dose $\eta x-x x x$. C., Vinum (B.P.). Dose $m x-x x x$.

Colcothar (kol'-ko-thar) [ML.]. A crude sesquioxid of iron; red oxid of iron; a tonic and hemostatic. Unof. See also Pigments, Conspectus of.

Cold (köld) [AS., ceald]. I. The comparative want of heat. 2. A term used popularly for coryza and catarrhal conditions of the respiratory tract. . Cold is employed largely in various forms as a therapeutic agent, mainly for the purpose of lowering temperature and allaying irritation and inflammation. It may be used in the form of affusion, that is, the sudden application of a considerable volume of cold water to the body. This application of the cold douche is contraindicated in all cases of extreme weakness, with feeble pulse. Cold may be used as an anesthetic (see Anesthetic); in baths (see Bath); in the form of compresses applied over the affected part; in the form of irrigation, especially in the treatment of bruised and injured members; as a lotion, for the purpose of relieving local heat, pain, and swelling; as an injection, in the form of ice-water, into the vagina or rectum, for various conditions; and as the cold pack, which is a valuable means of reducing the body-temperature in cases of hyperpyrexia. The patient is wrapped in a sheet wrung out of cold water; as this becomes warm, it is replaced by a fresh cold one, or iced water may be poured upon it, or lumps of ice placed upon and around it. When the temperature is recluced the wet sheet should be removed and a light covering applied, but not a blanket. This is not as efficacious as the cold bath. Cold may be applied in the dry form by means of the ice-cap or bladder, an india-rubber bag filled with ice, snow, or a freezing mixture. C. Abscess. See Abscess. C.-blooded. See Poikilothermic. C. on the Chest, bronchial catarrh, q. v. C. Coil. See Leiter's Coils. C. Cream. See Rosa. C. Freckles. See Lentigo. C. Pack, See Cold. C. Plague. Synonym of
Cerebro-spinal Meningitis. C. Sore, same as Feverblister. C. Spots. See Temperature Sense. C. Stroke, a condition, the analogue of heat-stroke, in which from excessive cold the patient is suddenly overcome and falls into a comatose state, shortly followed, as a rule, by death. C. Test, a test applied chiefly to lubricating oils to determine the point at which the oil begins to congeal, and ceases to flow.

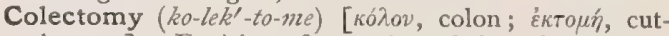
ting out]. Excision of a portion of the colon.

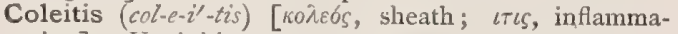
tion]. Vaginitis.

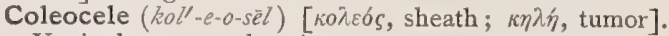
Vaginal tumor or hernia.

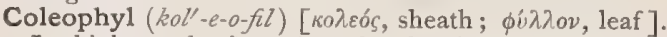
In biology, the investing sheath of the monocotyledonous plumule.

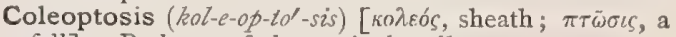
fall]. Prolapse of the vaginal wall.

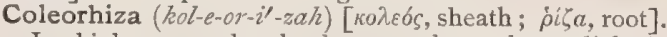
In biology, a sheath that envelops the radicle in some embryos and through which roots penetrate when the seed germinates.

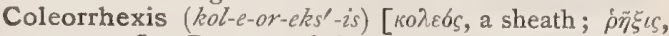
a rupture]. Rupture of the vagina.

Coleostegnosis (kol-e-o-steg-no'-sis) [koגeós, a sheath ; $\sigma \tau \hat{\gamma} \gamma \nu \omega \sigma \iota \varsigma$, a constriction]. Contraction or atresia of the vagina.

Colic $\left(k \circ l^{\prime}-i k\right)$ [colicus, $\kappa \omega \lambda \iota \kappa o s$, pertaining to the colon]. I. Pertaining to the colon. 2. A severe griping pain in the bowels or adjacent organs, as, e.g., hepatic, nephritic, etc. In intestinal colic the pains radiate over the abdomen from the region of the umbilicus. The belly is usually distended (save in Lead-colic, q. $v$.), and pressure will usually relieve the pain. Colic may be due to irritation from the intestinal contents, a diseased condition of the bowel-wall, reflex irritation from other abdominal viscera, and general blood-poisoning. C. of the Antilles, an endemic form of colic somewhat resembling lead-colic. C. Arteries. See Arteries, Table of. C., Biliary. See Gall-stones. C., Bilious. See C., Endemic. C., Copper, a colic or pain in the intestinal canal seen in workers in copper, and differing from lead colic in being attended with extreme prostration and diarrhea. The duration is short and the prognosis favorable. C., Cramp. See Cramp. C., Devonshire Synonym of C., Lead. C., Dry. See C., Endemic. Also a synonym of $C$., Lead. C., Endemic, a variety of colic occurring epidemically in some of the intertropical countries. Its symptoms resemble those of lead-colic. It is not accompanied by any constant lesion; it lasts from eight to fifteen days and may end in general paralysis and death, or it may become chronic. Relapses are frequent. C., Hill. See Hill Diarrhea. C., Horn. Synonym of Priapism. C., Lead, or C., Saturnine, or Colica Pictonum, painter's colic, is that due to lead-poisoning. It is common among those who use or work with lead. It is characterized by excruciating abdominal pain, a hard and retracted condition of the abdomen, slow pulse, and increased arterial tension. C., Madrid. Synonym of C., Lead. C., Meconial, the colic of the new-born. C., Menstrual, the pain of menstruation. C., Mucous. See Enteritis, Pseudo-membranous. C., Nervous. See C., Endemic C., Normandy. Synonym of C., Lead. C. of Poitou. Synonym of C., Lead. C. Root. See Aletris and Dioscorea. C., Sailors', a form of colic common among sailors. C. of Surinam. Synonym of $C$. Lead. C., Uterine, colic-like pains experienced at the menstrual epochs, often coming on in paroxysms. 
C., West Indian. Synonym of C., Lead. C., Zinc, a form of colic due to chronic zinc-poisoning. Colica $\left(k o l^{\prime}-i k-a h\right)$ [L.]. Colic. C. pictonum (literally, colic of the people of Poitou), lead-colic. Painters' Colic. See Colic, Lead. C. pituitosa. Synonym of Enteritis, Pseudo-membranous. C. scortorum, a pain in the pelvis of youthful prostitutes, symptomatic of the ovarian disease that results from their unnatural sexual relations. It is due probably to a pyosalpinx.

Colicodynia (kol-ik-o-din'-e-ah). Pain in the large intestine.

Colicoplegia (kol-ik-o-ple'-je-ah) [ $\kappa \omega \lambda \iota \kappa o ́ s$, pertaining to the colon; $\pi \lambda \eta \gamma_{\eta}$, a stroke]. Paralysis of the intestines. Also a synonym of Lead-colic.

Colitis $\left(k o-l i^{\prime}-t i s\right)$ [ [Kórov, the large intestine; $\iota \tau \iota s$, inflammation]. Inflammation of the colon. See also Dysentery. C., Mucous. See Enteritis, Pseudomembranous. C., Pellicular. A synonym of Membranous Enteritis.

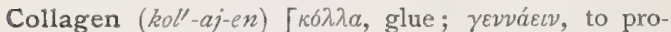
duce]. A substance existing in various tissues of the body, especially bone and cartilage; it is converted into gelatin by boiling

Collapse $\left(k o l-a p s^{\prime}\right)$ [collabere, to fall together]. Extreme depression and prostration from failure of nervous force, as in cholera, shock, hemorrhage, etc. C. of Lung, return of a portion or the whole of a lung to its fetal or airless condition from some mechanical hindrance to the entrance of air. It is characterized by dyspnea, with more or less cyanosis, and is mainly encountered in broncho-pneumonia. C., Parturient, parturient apoplexy; vitular or vitulary fever; puerperal fever in cows.

Collapsing (kol-aps'-ing) [collabere, to fall together]. Suddenly breaking down. C. Pulse. See Corrivan's Pulse.

Collapsus (kol-aps'-us) [L.]. Collapse. C. corneæ, entire collapse of the cornea.

Collar $\left(k o l^{\prime}-a r\right)$ [ME., coler]. Something worn about the neck. C., Adjusting, in microscopes, a ring or collar acting on a screw to increase or decrease the distance between the systems of lenses of an objective. C.-bone. See Clavicle. C.-cell, in biology, a flagellate cell having the base of the flagellum surrounded by a collar-like extension of the cell-wall. C.-crown, in dentistry, an artificial crown, to be engrafted on a natural root, attached to which is a gold collar which encircles the exposed portion of the root, and is soldered to the lining or backing that holds the dowel, or to the dowel by means of a disc between the base of the artificial crown and the natural root.

Collateral (kol-at'-er-al) [con, together; lateralis, of the side]. I. Accessory or secondary; not direct or immediate. 2. One of the first branches of an axis cylinder passing at right angles.

Collecting Tubes of the Kidney. A name given to the ducts discharging into the calices of the kidneys.

Collector (kol-ek'-tor) [collectare, to collect]. A device by which any number of cells may be taken from or added to an electric current.

Collenchyma (kol-en $\left.g^{\prime}-k i m-a h\right)$ [ $\kappa 6 \lambda \lambda a$, glue ; $\varepsilon \gamma \chi v \mu \alpha$, an infusion]. In biology, applied to a modified plantparenchyma in which the cells are thickened at the angles, and swell in water to a glue-like mass.

Collenchyme (kol-eng'-kìm) [ $\kappa \delta \dot{\lambda} \lambda \alpha$, glue; $\bar{\varepsilon} \gamma \chi v \mu a$, an infusion]. In biology, a colorless gelatinous matrix in which are embedded the collencytes of sponges.

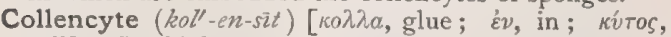
cell]. In biology, the branched connective-tissue cells embedded in the collenchyme of sponges.

Colles' Fascia. The deep layer of the perineal fascia. It is attached to the base of the triangular ligament, to the anterior lips of the rami of the pubes and ischia laterally, and anteriorly it is continuous with the fascia of the scrotum. C. Fracture. See Fracture, and Diseases, Table of. C. Law. See Laz\%. C. Ligament. See Ligament. C. Operation. See Operations, Table of.

Collet (kol'-et) [Fr.; collum, the neck]. A neck or collar. A term applied by some writers on dental anatomy to the neck of a tooth.

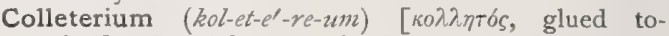
gether]. In biology, a gland in certain insects that secretes a viscid substance for gluing the ova together.

Colletic $\left(k o l-e t^{\prime \prime}-i k\right)$ [ $\kappa \alpha \lambda \lambda \eta \tau \iota \kappa o ́ s ; ~ \kappa \delta \lambda \lambda \alpha$, glue]. Gluey; promoting surgical union in wounds.

Colletocystophore (ko-let-o-sis'-to-for) [ $[\kappa 0 \lambda \lambda \eta \tau \dot{\eta} s$, one

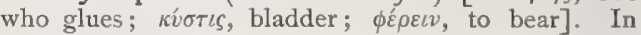
biology, marginal bodies found in lucernarian hydrozoans.

Colliculus (kol-ik'-u-hus) [dim. of collis, hill: $p l$, Colliculi]. Any eminence of the cerebral parietes. The colliculi are the caudatum, hippocamp, calcar, collateral eminence, occipital eminence, and amygdaline eminence.

Collidin $\left(k o l^{\prime}-i d-i n\right)[\kappa \hat{\lambda} \lambda \lambda \alpha$, glue $], \mathrm{C}_{8} \mathrm{H}_{11} \mathrm{~N}$. A name given to Nencki's ptomaine-base, isomeric but not identical with aldehyd-collidin. The ptomaine was obtained from pancreas and gelatin allowed to putrefy together in water. Its constitution is still unknown. The free base is oily, and possesses a peculiar, agreeable odor. Nencki believed it an aromatic base. Its physiologic action appears to be doubtful, but an isomer of it discovered in ox-blood fibrin and in putrefied jelly-fish has a poisonous effect resembling that of curara. Frogs poisoned by the isomer emit an orange-flower odor. Nencki's collidin is isomeric with collidin obtained from coal-tar.

Collier's Lung. Synonym of Anthracosis.

Collilongus (kol-e-long'-gus) [collum, neck; longus, long]. The muscle called longus colli. See Muscles.

Collimator (kol'-im-a-tor) [collimare, to aim at]. The receiving telescope of a spectroscope.

Collin's Black, $\mathrm{C}_{6} \mathrm{H}_{5} \mathrm{~N}$. A name for Anilin Black, employed in staining microscopic sections.

Collinsonia (kol-in-so'-ne-ah) [after Peter Collinson, an English gentleman]. A genus of labiate herbs. $\mathbf{C}$. canadensis (stone-root, heal-all), is a coarse plant with a disagreeable smell ; it has useful tonic, diuretic, and diaphoretic properties, Dose gr. xv-lx in decoction; of the fluid extract $m x-3 j$; of the tincture ( $I$ in $\mathbf{I o}) 3 \mathrm{ss}-\mathrm{ij}$.

Collinsonin (kol-in-so'-nin) [Collinsonia]. A precipitate from the tincture of the root of Collinsonia canadensis. It is tonic, diaphoretic, resolvent, and diuretic. Dose 2 to 4 grains. Unof.

Colliquation (kol-ik-wa'-shun) [con, together; liquare, to melt]. The liquefaction or breaking down of a tissue or organ.

Colliquative (kol-ik'-wa-tiv) [con, together; liquare, to melt]. Exhausting; enfeebling; copiously profuse or excessive; marked by excessive fluid discharge. C. Diarrhea, a profuse watery diarrhea. C. Necrosis, a high degree of inflammatory process in the tissues, with active movement of the leucocytes toward the central focus and rapid breaking down of the tissues, forming an abscess-cavity. C. Sweat, a profuse, clammy sweat.

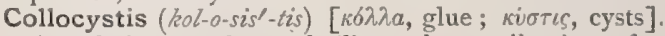
A gelatin capsule to facilitate the swallowing of a drug.

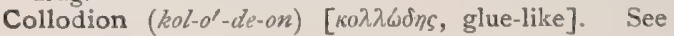
Pyroxylin. 
Collodium (kol-o'-de-t $t m$ ). See Pyroxylin.

Colloid (kol'-oid) [кó $\lambda \lambda a$, glue]. I. A non-crystallizable and generally insoluble organic substance. See Dialysis. 2. A mobile pathologic material, jelly-like, firmer than mucus, and differing in its reactions from albumin and from lardacein. 3. Having the nature of glue. 4. In chemistry, amorphous and non-crystalline. C. Cancer. See Cancer. C. Degeneration of the Skin, a rare disease, occurring chiefly on the upper part of the face, in the form of small, glistening, translucent, flattish elevations, and yielding by pressure a small, jelly-like mass. C. Milium. See Milium.

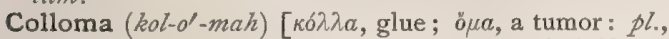
Collomata]. A cystic tumor containing a gelatiniform, amorphous, and non-vascular substance.

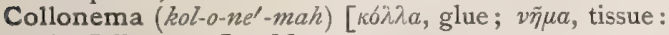
pl., Collonemata]. Myxoma, or myxosarcoma.

Collum $\left(\mathrm{kol}^{\prime}-\mathrm{um}\right)$ [L.]. The neck; especially the anterior part of the neck. C. distortum. Synonym of Torticollis.

Collunarium (kol-un-a -re-um) [L.]. A nasal douche.

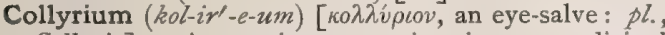
Collyria]. An astringent, antiseptic, or medicinal lotion for the eyes. More rarely, a vaporous or gaseous medicament for application to the eyes, or even a powder, or solid, to be used in treating the eye topically, is called a collyrium. (Anciently, any suppository or medicated bougie was thus called.) C. adstringens luteum. See Graefe's Collyrium and Horst's Eye-water.

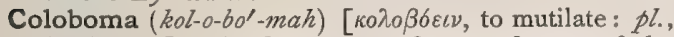
Colobomata]. A cleavage or fissure of parts of the eye, of congenital or traumatic origin. Congenital $C$. are due to imperfect closure of fissures during fetal development. C., Bridge, a variety in which the pupil is separated from the coloboma by a narrow thread of iris-tissue that stretches like a bridge from one pillar of the coloboma to the other.

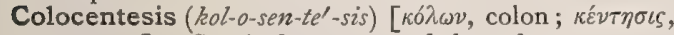
puncture]. Surgical puncture of the colon.

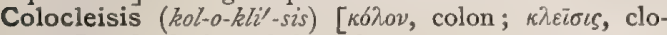
sure]. Occlusion of the colon.

Colocynth (kol'-o-sinth). See Colocynthus.

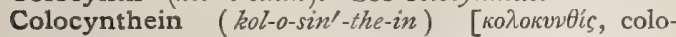
cynth], $\mathrm{C}_{44} \mathrm{H}_{64} \mathrm{O}_{13}$. A resinous decomposition-product of colocynthin.

Colocynthin (kol-o-sin'-thin) [kohokvvfis, colocynth], $\mathrm{C}_{56} \mathrm{H}_{84} \mathrm{O}_{23}$. The active principle of colocynth; an extract, or a yellow amorphous, neutral, exceedingly bitter powder, soluble in water and alcohol, but not in ether. It is an irritant hydragogue cathartic. Dose gr. I $1 / 4$ to $I$. Unof.

Colocynthis (kol-o-sin'-this) [кодокvvtis, colocynth]. Colocynth. The fruit of Citrullus colocynthis, from which the seeds and rind have been rejected. Its properties are due to a bitter glucosid, colocynthin, $\mathrm{C}_{56} \mathrm{H}_{84} \mathrm{O}_{23}$, the dose of which is gr. $\frac{1}{30}-\frac{1}{5}$. It is a tonic and astringent purgative, and is used mainly as an ingredient of compound cathartic pills. It is somewhat useful in colic, sciatic rheumatism, and neuralgia. C., Ext., alcoholic. Dose gr. 1/2-ij. C., Ext., Comp., contains colocynth extract 16 , aloes 50 , cardamom 6 , resin of scammony $I_{4}$, soap I4, alcohol ro. Dose gr. v-xx. C., Pilula Comp. (B. P.) contains colocynth, aloes, scammony, sulphate of potassium and oil of cloves. Dose gr. v-x. Pilulæ Cathartic. Comp., compound cathartic pills ; contain each, comp. ext. of colocynth gr. I. 3 , abstract jalap gr. j, calomel gr. j, gamboge gr. 1/4. Dose j-iij pills. Pil. catharticæ vegetabiles, contain colocynth, hyoscyamus, jalap, leptandra, resin of podophyllum, oil of peppermint. Pil. colocynth et hyoscyam.
Dose gr. $\nabla-x$. Laville's Anti-gout Remedy, contains colocynthin $2 \frac{1}{2}$, quinin, cinchonin aá 5 , Spanish wine 800 , alcohol 100, water 1000 parts.

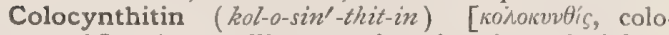
cynth]. A crystalline, tasteless, inactive principle of colocynth.

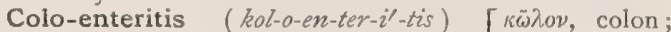

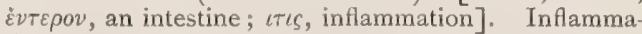
tion of the small and large intestine. See Enterocolitis.

Cologne (kol-ōn'). See Spiritus odoratus. C. Spirit, rectified commercial alcohol. C. Glue. See Glue. C.-water, aqua cologniensis. See Spiritus odoratus. C.-water Habit, the use of cologne-water as a drink for the purpose of experiencing the effects of the alcohol which it contains.

Colognese $\left(k o l-\bar{o} n-\bar{e} z^{\prime}\right)$. Same as Umber.

Colomba, Colombo (kol-om'-bah, kol-om'-bo). See Calumba.

Colomiatti, Bacillus of. See Bacteria.

Colon $\left(k o^{\prime}-l o n\right)[\kappa \sigma \lambda o v, \kappa \omega \hat{\omega} \gamma \nu \nu$, the colon]. The secon. and principal part of the large intestine. In the various parts of its course it is known as the ascending $C$., the transverse $C_{\text {. }}$, the descending $C$., and the sigmoid flexure.

Colonia (ko-lon-i'-ah). Synonym of Dysentery.

Colonic $\left(k o-l o n^{\prime}-i k\right)$ [ $\kappa \tilde{\omega} \lambda o v$, the colon]. Pertaining to the colon.

Colonitis (ko-lon-i'tis). See Colitis.

Colony (kol'-o-ne) [colonia, a colony]. A collection or assemblage, as of microörganisms in a special culture. C. Treatment, for the insane. See Gheel System.

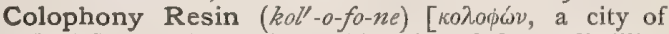
Ionia]. Rosin. The solid residue left on distilling off the volatile oil from crude turpentine. Rosin is a brittle, tasteless, very friable solid, of smooth, shining fracture, specific gravity about 1.08. It softens at $80^{\circ} \mathrm{C} .\left(176^{\circ} \mathrm{F}.\right)$, and fuses completely to a limpid, yellow liquid at $135^{\circ} \mathrm{C}$. $\left(275^{\circ} \mathrm{F}\right.$.). It is insoluble in water, with difficulty soluble in alcohol, freely soluble in ether, acetone, benzene, and fatty oils. See Resin.

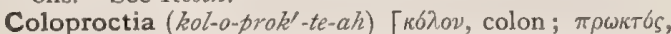
anus]. The formation of an artificial colonic anus.

Colopuncture (kol'-o-punk'-chur) [kóhov, colon; punctura, puncture]. Same as Colocentesis.

Coloquintida (kol-o-kwin'-tid-ah) [ML.]. An old name for colocynth.

Color $\left(k u l l^{\prime}-e r\right)$ [color, color]. The differences in the appearance of a thing seen, other than those due to form and relief. The tint or hue of an object, dependent upon the number of vibrations of the ethereal stimulus. See Pigment. C.-blindness. See Blindness. C., Complementary, any color that added to another color, or to a mixture of colors, produces white. C.-contrast, any two colors that, when mixed, supplement the prevailing tone of the light. C.-cure, the supposed therapeutic effect of exposure to variously colored light. C.-hearing, the excitation of the visual center for color through the auditory nerve; the perception of sound photisms. See Photism. C.image, an image of a highly-colored object lighted with so wide an aperture that the refraction-images are drowned in the light. C.-sensation, depends on the number of vibrations of the ether, the same as the pitch of a note depends on the number of vibrations of the sounding body. Hering's Theory of C.-s predicates disassimilation and assimilation (decomposition and restitution) of the visual substance in visionwhite, red, and yellow representing the sensation of disassimilation, black, green, and blue that of restitution. The Young-Helmholtz Theory assumes three 
kinds of nerve-elements corresponding to the three primary colors. Stimulation of the first develops red, of the second, green, of the third, violet. See Photism. C.-sense, the faculty by which the various colors are distinguished. C.-top, a top containing on the sectors of its disc a number of colors to be "mixed" by rapid whirling. Colors, Mixed, those produced when the retina is excited by two or more simple colors. C., Saturated, those containing little or no white. C., Simple, those of the spectrum.

Colorectitis (ko-lo-rek-ti'-tis) [kbiov, colon; rectus, straight; $\iota \tau \iota \varsigma$, inflammation]. Inflammation of the colon and rectum. Also, a synonym of Dysentery.

Colorectostomy (ko-lo-rek-tos'-to-me) [Kódov, colon;

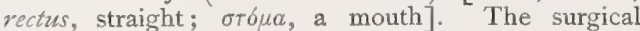
establishment of a passage between the colon and the rectum.

Colorimeter (kull-or-im'-et-er) [color, color; $\mu \varepsilon ́ \tau \rho o v$, measure]. An instrument for determining the quantity of coloring matter in a mixture, as in the blood. See Hemochromometer.

Colorin (kull'-or-in) [color, color]. An alcoholic extract of madder. See Pigments, Conspectus of.

Coloring (kull'-or-ing) [color, color]. A tint or combination of colors. C. Matters. See Pigments, Colors, and Dye-stuffs.

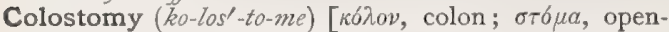
ing]. I. The formation of an artificial anus by an opening into the colon; coloproctia. 2. Any surgical operation upon the colon that makes a permanent opening into it, whether internal or external.

Colostration (kol-os-tra'-shun) [colostrum, the first milk after delivery]. A disease or illness of young infants ascribed to the effects of the colostrum:

Colostric (kol-os'-trik) [colostrum, the first milk after delivery]. Relating to colostrum.

Colostrous (kol-os'-trus) [colostrum, the first milk after delivery]. Of the nature of or containing colostrum.

Colostrum (kol-os'-trum $)$ [L.]. The first milk from the mother's breasts after the birth of the child. It is laxative, and assists in the expulsion of the meconium. C. Corpuscles, small microscopic bodies contained in the colostrum. They are the epithelial cells of the mammary glands, full of oil g]obules. After about the third day these cells burst and set free the fat glcbules before they leave the gland, and in this way the true milk is formed.

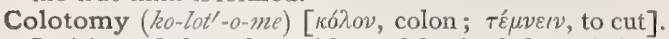
Incision of the colon, either abdominal, lateral, lumbar, or inguinal, according to the region of entrance.

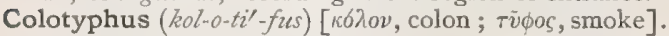
Enteric fever with involvement of the colon. Also a synonym of Dysintery.

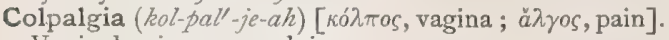
Vaginal pain or neuralgia.

Colpaporrhexis (kol-pap-or-reks'-is) [ [ $6 \lambda \lambda \pi s$, vagina; $\dot{\alpha} \pi b$, from; $\dot{\alpha} \tilde{\xi} \xi \iota$, a tearing, or breakage]. Severance of the cervix from the body of the uterus.

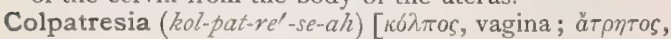
not perforated]. Occlusion or atresia of the vagina.

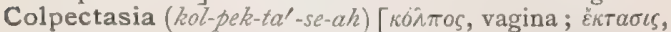
a stretching out]. Vaginal dilatation.

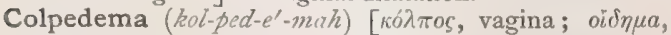
swelling]. Edema of the vagina.

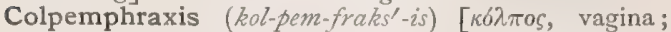

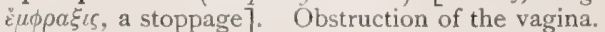

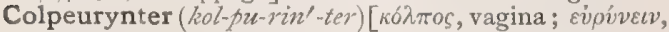
to widen]. An inflatable bag or sac used for dilating the vagina.

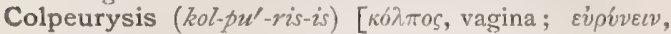
to dilate]. Vaginal dilatation, especially that effected by the colpeurynter.

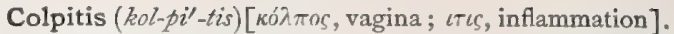
Inflammation of the vagina.

Colpocele $\left(k o l^{\prime}-p o-s e \bar{l}\right.$, or se'-le) [ $\kappa 6 \lambda \pi \circ s$, vagina; $\kappa \eta \lambda \bar{y}$, tumor]. Hernia or tumor in the vagina.

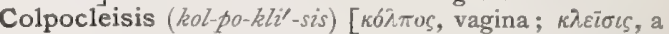
closure]. The surgical closure of the vagina.

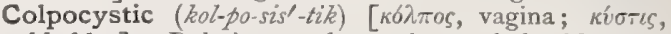
bladder]. Relating to the vagina and the bladder; vesico-vaginal.

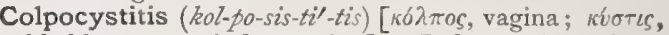
bladder; $\iota \tau \iota s$, inflammation]. Inflammation of the vagina and the bladder.

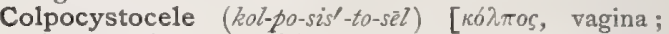

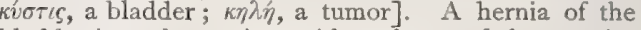
bladder into the vagina, with prolapse of the anterior vaginal wall.

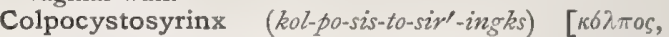

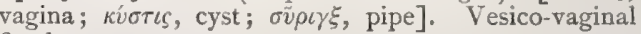
fistula.

Colpocystotomia (kol-po-sis-to-to'-me-ah). See Colpocystotomy.

Colpocystotomy (kol-po-sis-tot'-o-me) [ $\left[\delta \lambda_{\lambda} \pi \mathrm{s}\right.$, vagina;

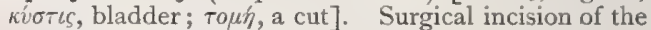
bladder through the vaginal wall.

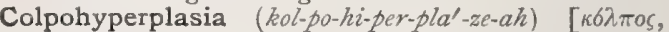
vagina; $i \pi \varepsilon ́ p$, over; $\pi \lambda \dot{a} \sigma \sigma \varepsilon \iota \nu$, to form]. Hyperplasia of the vagina.

Colpo-hysterectomy (kol-po-his-ter-ek'-to-me) [ $\kappa \delta \dot{\lambda} \pi o s$,

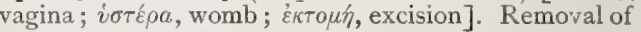
the uterus through the vagina.

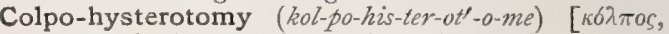

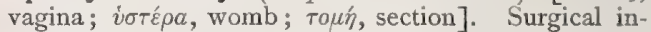
cision of the vagina and uterus.

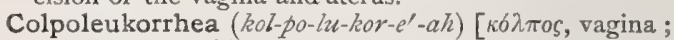

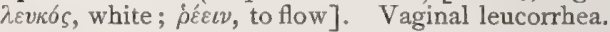

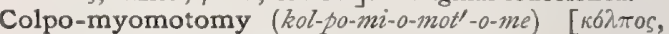
vagina; $\mu \bar{v} s$, a muscle; $\tau \varepsilon \dot{\mu} \mu \nu \varepsilon \imath \nu$, to cut]. Vaginal myomotorny.

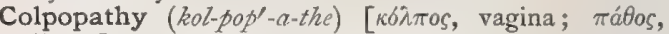
illness]. Any disease of the vagina.

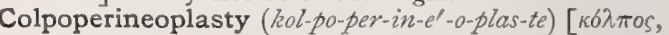
vagina; $\pi \varepsilon \rho i \nu \varepsilon o \nu$, the perineum; $\pi \lambda a \dot{\sigma \sigma \varepsilon \varepsilon \nu}$, to form]. Plastic operation for abnormality of the vagina and perineum.

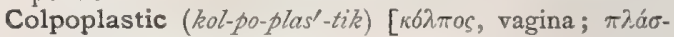
$\sigma \varepsilon \imath \nu$, to form]. Relating to colpoplasty.

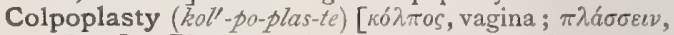
to form]. Plastic surgical operation upon the vagina.

Colpoptosis (kol-pop-to'-sis) [ $[\kappa \delta \lambda \pi o \varsigma$, vagina; $\pi \tau \tilde{\omega} \sigma \iota \varsigma$, a falling]. Prolapse of the vagina.

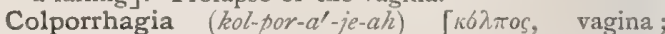
in rvóva, to burst forth]. Vaginal hemorrhage.

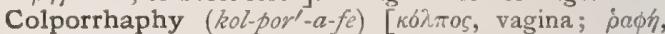
seam]. Suture of the vagina.

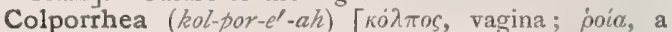
flow]. Vaginal leucorrhea; a mucous discharge from the vagina.

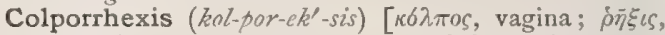
rupture]. Laceration or rupture of the vagina.

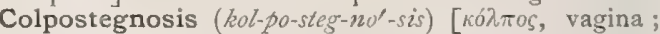
$\sigma \tau \varepsilon ́ \gamma v \omega \sigma \iota s$, closure]. Same as Colpostenosis.

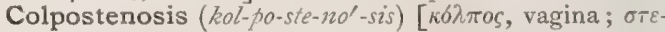
vóc, narrow]. Stenosis or constriction of the vagina.

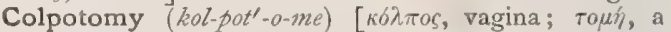
cutting]. Surgical or obstetric incision of the vagina.

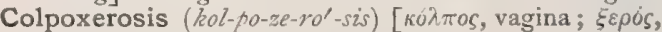
dry]. Morbid dryness of the vagina.

Colt-ill $\left(k \bar{l} l t^{\prime}-i l\right)$. See Strangles.

Coltsfoot (koltz'-foot). The leaves of Tussilago farfara, a demulcent and tonic, sometimes prescribed for chronic cough. Dose of decoction, $\bar{\jmath}$ to $\mathrm{Oj}$, a teacupful; of fld. ext. 3 j-ij. Unof. 
Columbin (kol-um'-bin). An active principle of Calumba. It is a colorless crystalline substance of excessively bitter taste and neutral reaction.

Columbo $\left(k o l-u m^{\prime}-b 0\right)$. See Calumbo.

Columella $\left(k o l-u-m e l^{\prime}-a / \imath\right)$ [L, a little column]. I. The column-like rod of birds and reptiles, a part of the organ of hearing, corresponding to the stapes of the higher animals. 2. The modiolus or central axis of the cochlea of the human ear. See Cochlea and Modiolus. C. res dentes; the cuspid teeth are so called from their shape.

Column (kol'-um) [columna, a column]. A pillar or column. Applied to sundry column-like organs of the body, and especially to certain parts of the spinal cord. C., Anterior, the layer of white matter in either half

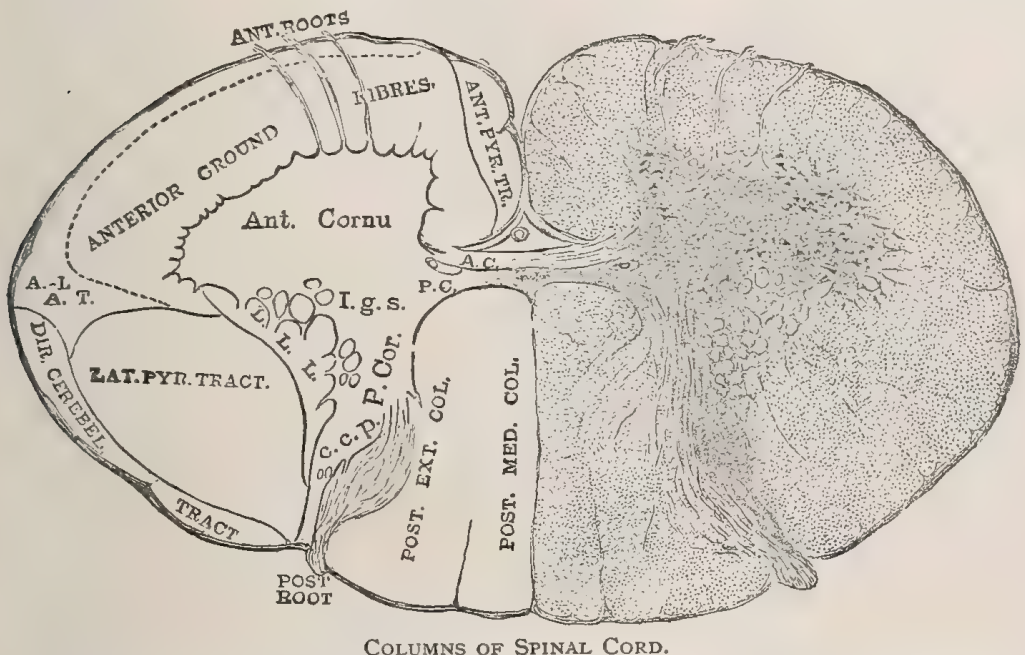

A. C. Anterior commissure. P.C. Posterior commissure I. g. S. Intermediate gray substance. P. cor. Posterior cornu. c. c. p. Caput cornu posterioris. L. L. L. Lateral limiting layer. A.-L. A. T. Antero-lateral ascending tract, which extends along the periphery of the cord. (Gowers.)

of the spinal cord included between the anterior horn and anterior nerve-roots, and the anterior median fissure. It contains the anterior or direct pyramidal tract, a portion of the antero-lateral ascending tract, and a portion of the anterior ground-fibers. C., Antero-lateral Ascending. See C. of Gowers. C. of Burdach, the postero-external column of the cord. C. of Clarke, a column of gray substance occupying the region to the outer and posterior part of the central canal of the spinal cord, at the inner part of the base of the posterior cornu. It is most marked in the dorsal region, and contains fusiform cells, some furnished with axis-cylinder processes. It is also called the posterior vesicular column of the cord. C., Direct Cerebellar, in the spinal cord, is situated outside of the lateral pyramidal tract, and ventrad of the SpitzkaLissauer column. It is sensory or afferent. C., Dorso-mesal, a name for the postero-median column of the spinal cord and medulla oblongata. C. of Goll, the postero-median column of the spinal cord. C., Gowers', in the spinal cord, a bunch of fibers lying in front of the direct cerebellar tract and reaching around upon the periphery of the anterior pyramidal tract. It is probably a sensory column containing the nerves of pain and temperature. C., Lateral, the layer of white matter in either half of the spinal cord included between the posterior horn and posterior nerve-roots, and the anterior horn and anterior nerve- roots. It contains the lateral pyramidal tract, the direct cerebellar tract, and the greater part of the anterior ground-fibers and antero-lateral ascending tract. C. of Morgagni, vertical folds of the rectal mucous membrane seen at the point of union of the latter with the skin of the anus. They diminish, but are not entirely effaced, when the bowel is distended. Between their lower ends little arches are sometimes found stretching from one to the other, forming pockets of skin and mucous membrane. These are the sinuses of Morgagni; they are more developed in old people. C., Posterior, a collection of white-matter situated in the spinal cord on either side between the posterior horns and posterior nerve-roots, and the posterior median fissure. It is divided into two parts by the imperfect intermediate septum, a narrow "postero-median column," and a wide "postero-external column." C., Posteroexternal, the outer wider division of the posterior column of the cord; the column of Burdach. C., Postero-median, the median division of the posterior column of the cord; the column of Goll. C. of Rolando, an eminence on the lateral border of the medulla oblongata. C. of Spitzka-Lissauer, in the spinal cord a group of nerve-fibers lying just in front and just behind the posterior horns or cornua. C., Posterior - vesicular. See Column of Clarke. C. of Türck, the anterior or direct pyramidal tract. Columns of the External Abdominal Ring, the free borders of the aponeurosis of the external oblique muscle.

Columna (kol-um'-na/h) [L.]. A column or pillar. C. bertini, that part of the cortical structure of the kidneys that separates the sides of any two pyramids, and through which the arteries and nerves enter, and the veins and lymphatics emerge. C. nasi, the anteroposterior septum between the nostrils. C. vertebralis, the spinal column. Columnæ carneæ, muscular columns projecting from the inner surface of the cardiac ventricles.

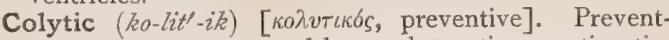
ive ; inhibitory; caused by an obstruction; antiseptic. Coma (ko'-mah) [ $[\kappa \delta \mu \eta$, the hair of the head]. In biology, any tuft, as the top of a pineapple, the hairs on the end of a seed, etc.

Coma $\left(k o^{\prime}-m a h\right)[\kappa \tilde{\omega} \mu a$, deep sleep $]$. Abnormally deep and prolonged sleep, with the cerebral functions in abeyance; it is due to many conditions affecting the cerebrum directly or indirectly. The well-marked form is characterized by stertorous breathing, relaxation of the sphincters, lividity of the face, and loss of parallelism of the optic axes. C., Alcohol, that due to poisoning by alcohol. C., Apoplectic, that due to apoplexy. C. diaceticum, a form of coma occurring in carcinoma of the stomach and in diabetes. It is due to the presence of diacetic acid in the system. It is also called Diabetic coma. C. Kussmaul's. See Kussmaul. C., Uremic, that due to uremia. C. Vigil, a comatose 
condition in which the patient lies with open eyes, but unconscious and delirious. This is occasionally met with in typhoid and typhus fevers, and in delirium tremens.

Comanic Acid (ko-man'-ik). See Acid.

Comatose $\left(k o^{\prime}-m a t-\bar{o} s\right)[\kappa \bar{\omega} \mu \alpha$, a deep sleep]. In a condition of coma.

Combination (kom-bin-a'-shun) [combinare, to combine]. The act of grouping or uniting; chemic union. C.-back, in the microscope, the lens-system of an objective farthest from the object, composed of a plano-concave of flint glass and a bi-concave of crown glass, or a bi-concave and two bi-convex glasses. C.-front, in the microscope, the lens-system nearest the objective.

Combustion (kom-bus'-chun) [comburere, to burn up]. The process of oxidation, attended with the liberation of heat and sometimes of light. It is loosely used as a synonym of inflammation. C., Spontaneous, that due to heat from chemic changes, such as the spontaneous ignition of oiled waste or shoddy in woolen mills, factories, etc. C., Spontaneous Human, the supposed burning of the body without the external application of heat.

Comedo $\left(k o m^{\prime}-e-d o\right)$ [comedo, a glutton: pl., Comedones]. Grubs; Grub-worms; Black-heads. A chronic disorder of the sebaceous glands characterized by yellowish or whitish pin-point and pin-head sized elevations, containing in their center exposed blackish points. They are found usually on the face, back of the neck, chest, and back, and are often associated with acne. They occur as a rule in the young. Occasionally a parasite, the Demodex folliculorum, a small mite, is found in each comedo.

Comenic Acid (ko-men'-ik). See Acid.

Comes (ko'-mēz) [L.: pl., Comites]. A companion, as a vein or nerve to an artery.

Comfrey (kum'-fre) [ME., cunfirie]. The root of Symphytum officinale, a demulcent, slightly astringent and tonic drug. It is a common ingredient of domestic cough-mixtures. Dose of the decoction indefinite; of the fld. ext. $3 \mathrm{j}-\mathrm{ij}$. Unof.

Comma-bacillus (kom'-ah-bas-il'-us). See Bacteria, Synonymatic Table of.

Commensal (kom-en'-sal) [com, together; mensa, table]. In biology, the harmonious living together of two animals or plants. One of two such organisms.

Commi $\left(k o m^{\prime}-e\right)$ [ $\kappa o ́ \mu \mu$, a gum]. Any gum; the purgative gum-resin of Excacaria cochinchinensis, a tree of Indo-china.

Comminution (kom-in-u'-shun) [comminutio; comminuere, to break in pieces]. The process by which a solid body is reduced to pieces of varying sizes. It includes the various operations of cutting, rasping, grating, slicing, pulverizing, levigating, triturating, elutriating, granulating, etc. See, also, Fracture, Comminuted.

Commissure, Commissura (kom'-is-ūr, kom-is-u' rah) [committere, to unite]. A joining or uniting together. C., Anterior (of third ventricle), a rounded cord of white fibers placed in front of the anterior crura of the fornix. It perforates the corpus striatum on either side, and spreads out into the substance of the hemispheres over the roof of the descending horns of the lateral ventricles. C., Anterior White (of spinal cord), a layer of fibers separating the posterior gray commissure from the bottom of the aterior median fissure. C., Gray (of spinal cord), the transverse band of gray matter connecting the crescentic masses of gray matter of each half of the spinal cord. C. magna, the corpus callosum. C., Middle, a band of soft gray matter connecting the optic thalami, and continuous with the gray matter lining the anterior part of the third ventricle. C., Optic, the union and crossing of the two optic nerves in front of the tuber cinereum. C., Posterior (of third ventricle), a flattened white band connecting the optic thalami posteriorly. C., Posterior White (of spinal cord), a band of fibers separating the gray commissure from the bottom of the posterior median fissure. Commissura brevis, a portion of the inferior vermiform process of the cerebellum, situated in the incisura posterior. C. simplex, a small lobe on the upper surface of the cerebellum near the incisura posterior.

Common $\left(k_{0} m^{\prime}-u n\right)$ [communis, common]. Belonging or pertaining to all. Prostitute. C. Black. See Pigments, Conspectus of.

Commotio (kom-o'she-o) [L.]. A commotion or shock. C. cerebri. Synonym of Shock. C. retinæ, the name given to those cases in which a depreciation, or perhaps an entire loss of vision, follows a blow on or near the eye. It can be explained as the result of insensibility due to the same changes in the retina as occur in the central organ of patients suffering from concussion of the brain.

Communicans (kom- $\left.u^{\prime}-n i k-a n s\right)$ [L.]. Communicating. C. noni. See Nerves, Table of.

Communication (kom-u-nik-a'-shun) [communicare, to communicate]. I. The transference of a contagium from one person to another. 2. The channel between two or more parts. C.-plate, in biology, a perforated diaphragm between the zoöids of a composite actinozoön (the "Rosettenplatte" of Reichert, and the Communication-pore of Smith) by means of which communication is maintained between all the cells in a colony and between all the compartments of the stolun in Polyzoa. C.-pore. See C.-plate.

Commutator (kom'-u-ta-tor) [commutare, to exchange]. An instrument for automatically interrupting or reversing the flow of an electric current, making and breaking it with desired frequency. See Electric.

Comose $\left(k o^{\prime}-m o \tilde{s}\right)$ [coma, hair]. Having much hair.

Compass Plant (kum'-pas plant). See Rosin Weed.

Compatibility (kom-pat-ib-il'-it-e) [compati, to suffer with]. The property of being compatible; susceptibility (as of different medicines) of being exhibited in the same solution with no loss of the desired effect, and without change in constitution.

Compensating (kom'-pen-sa-ting) [compensare, to compensate]. Making amends for. C. Ocular. See Ocular. C. Operation, in ophthalmology, tenotomy of the associated antagonist in cases of diplopia from paresis of one of the ocular muscles.

Complaisance, Operations of (kom-pla-zongrs'). See Election.

Complanate (kom'-plan-ät) [complanatus, to make plane or level]. In biology, flattened.

Complemental (kom-ple-men'-tal) [complementum, that which completes or fills up]. Supplying a deficiency. In biology, forming a complement to a female. C. Air. See Air. C. Male, one of such supernumerary males as those cirripedia (Ibla) that lie within the sac of the female.

Complementary (kom-ple-men'-ter-e) [complementare, to fill up; to complete]. Complemental. C. Colors. See Color and Pigment.

Completely Born (kom-plêt'-le born). As employed in legal medicine, this expression implies that the child must be in the world in all its parts, i. e., completely external to the mother. It does not imply that the placenta has been separated or the cord divided.

Complexus (kom-pleks'-us) [complexus, complex]. The totality of symptoms, phenomena, or signs of a morbid. condition. C. Muscle. See Muscles, Table of. 
Complication (kom-plik-a -shun) [complicare, to fold together]. A disease or a process secondary to and more or less dependent upon some primary disease.

Compos Mentis (kom'-pos men'-tis) [L.]. Of sound mind, memory, and understanding. See Non Compos Mintis.

Composite (kom-poz'-it) [componere, to put together]. I. Composed of distinct portions. 2. In biology, belonging to the order Compositæ. C. Monsters; this is a term used to designate any form of monstrosity showing some degree of duplicity in the main regions of the body.

Composition (kom-po-zish'-un) [compositio, a putting together]. Compounding; applied to drugs. The constitution of a mixture. C. Powder, a popular name (originally Thomsonian) for the pulvis myrica compositus, N. F. At present it is a mixture of finely powdered bayberry bark (Myrica cerifera), I2 parts; ginger, 6 parts; capsicum and cloves, each I part. It is useful for sore throat and severe coryza. Unof. C. Tea, a warm drink composed of different spices, and used as a stomachic and to abort an attack of coryza.

Compound (kom'-pound, or kom-pound') [ME., compounen, to mix or compound]. I. To mix, as drugs. 2. Composed of several parts; in chemistry, a com pound body. C. Cathartic Pills. See Colocynth. C. Cavities, cavities in teeth that are produced by the coalescence of two cavities or by the extension of a single cavity in such a manner as to include two surfaces of a tooth. C. Fracture. See Fracture. C. Granule-Cell. See Corpuscle, Gluge's. C. Oxygen, a quack cure-all consisting of a strong solution of potassium nitrate or chlorate through which the air to be inhaled is passed.

Compounding (kom-pound'-ing) [ME., compounen, to mix]. The mixing, manipulation, and preparation of the drugs ordered in a prescription.

Compress (kom'-pres) [compressus, pressed together]. Folded cloths, wet or dry, applied firmly to the part for relief of inflammation, or to prevent hemorrhage. C., Fenestrated, with a hole for drainage or inspection. C., Graduated, the strip applied directly is small; the others, progressively larger, cover it.

Compressed (kom-presd') [compressus, pressed together]. Firmly pressed together; having the lateral diameter reduced. C. Air, air the density of which has been increased by compression. C.-Air Bath. Se Bath.

Compression (kom-presh'-un) [compressus, pressed together]. The state of being compressed. C.-atrophy, atrophy of a part from constant compression. Instances are the Chinese foot, liver-atrophy of tight lacing, atrophy of tissues from pressure by an aneurysm. C. of Brain. See Brain. C.-myelitis, myelitis due to compression. See Myelitis.

Compressor (kom-pres'-or) [comprimere, to press together]. I. An instrument for compressing an artery, vein, etc. 2. It is also applied to muscles having a compressing function, as the $C$. naris, $C$. vence dorsalis penis, etc. See Muscles, Table of. 3. One of the light springs inserted on either side of the stage of a microscope for holding the slide in position; a clip. C. sacculi laryngis, the inferior aryteno-epiglottideus muscle. See Muscles, Table of. C. urethræ, constrictor urethræ. See Muscles, Table of.

Compressorium (kom-pres-o' re-um) [compressor, a compress]. An instrument devised for making pressure on the cover-glass of a microscope-slide in order to favor separation of the elements of the specimen to be examined.

Comptonia (komp-to'-ne-ah) [after Henry Compton,
Bishop of London, a botanist]. A genus of plants. C. asplenifolia. See Liquidambar.

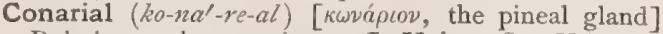
Relating to the conarium. C. Vein. See Vein.

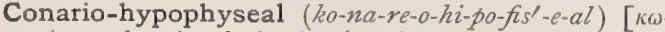

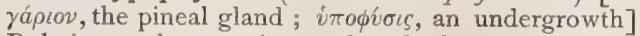
Relating to the conarium and to the hypophysis of the cerebrum; pineo-pituitary.

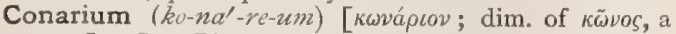
cone]. See Pineal Gland.

Conation (ko-na'-shun) [conari, to endeavor]. The exertive power of the mind, including will and desire; a special act or exercise of the exertive power.

Concassation (kon-kas-a'-shun) [concassatio; con, together; cassare or quassare, to shake, to beat]. I. The shaking of medicines, as in a bottle; the pulverizing of drugs by beating. 2. Mental distress or affliction.

Concato's Disease. See Diseases, Table of, and Polyorrhymenitis.

Concaulescence (kon-kawl-es'-ens) [con, together; caulis, a stalk]. In biology, the partial fusion of the pedicle of a flower with the stem from which it springs.

Concavo-concave $\left(k o n-k a^{\prime}-v o-k o n^{\prime}-k \bar{a} v\right)$. See Lens, Biconcave.

Concavo-convex (kon-ka'-vo-kon'-veks). See Lens, Periscopic.

Conceive (kon-sêv') [concipere, to take in]. To become pregnant.

Concentration (kon-sen-tra'-shun) [con, together; centrum, the center]. 'Evaporation of part of the water or other liquid of a mixture, thus rendering it relatively more dense.

Concentric (kon-sen'-trik) [con, together; centrum, the center]. Arranged in an equidistant manner about a center. C. Hypertrophy of the Heart, increase in the muscular texture of the heart, the capacity of the cavities remaining unchanged.

Conception (kon-sep'-shun) [concipere, to conceive] I. The fecundation of the ovum by the spermatozoid. See Pregnancy. 2. The abstract mental idea of anything ; the power or act of mentally conceiving. C. Imperative, a false idea that an insane person dwells upon, and which he cannot expel from his mind, even when he knows it to be absurd, and which dominates his actions.

Concha (kong'-kah) [ $\kappa o ́ \gamma \chi a$, a shell]. A shell. Applied to organs having some resemblance to a shell, as the patella, vulva, etc., and especially to C. auris, or the hollow part of the external ear. C. narium, the turbinated bones. C. santoriniana, a name applied to a fourth turbinated bone sometimes found in the nose.

Conchiolin (kons-ki'-o-lin) [ $\kappa \delta \gamma \gamma \alpha a$, a shell; iov, a violet], $\mathrm{C}_{30} \mathrm{H}_{48} \mathrm{~N}_{9} \mathrm{O}_{11}$. The skeletin material that forms the organic bases of the shells of gastropods. C. Osteomyelitis. See Osteomyelitis.

Conchitis ( $\left.k o n g-k i^{\prime}-t i s\right)$ [ $\kappa 6 \gamma \chi \alpha \alpha$, a shell ; $\iota \tau \iota \zeta$, inflammation]. Inflammation of the concha.

Concho-anthelix (kong'-ko-ant'-he-liks) [ $6 \delta \gamma \chi \alpha$, a shell; $\dot{a} \nu \theta \dot{\varepsilon} \lambda \iota \xi$, the inner curvature of the ear]. The muscle called obliquus auriculæ. See Muscles, Table of.

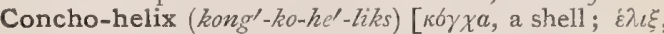
a spiral]. The muscle called transversus auriculæ. See Muscles, Table of.

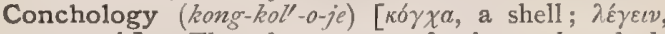
to speak]. That department of science that deals with the shells of molluscs.

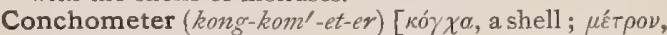
a measure]. An instrument for the measurement of the shells of molluscs.

Conchoscope (kon $\left.{ }^{\prime}-k o-s k o p\right)$ ) [ $\kappa \delta \gamma \chi \alpha$, a shell; the na-

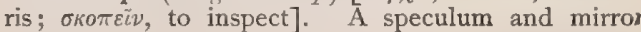
for inspecting the nasal cavity. 
Concoctio (kon-kok'-she-o) [L.]. Digestion. C. tarda. Synonym of Dyspepsia.

Concoction (kon-kok'-shun) [concoguere, to boil together]. The act of boiling two substances together.

Concolor (kon-kull'-or) [con, together; color, color]. In biology, having the same color on both sides or over the entire surface.

Concomitant (kon-kom'-it-ant) [concomitari, to accompany]. Accompanying. C. Strabismus. See Strabismus. C. Symptoms, symptoms that are not in themselves essential to the course of a disease, but that may occur in association with the essential symptoms.

Concrement (kon'-kre-ment) [concrescere, to grow together]. A concretion.

Concresce (kon'-kres) [con, together; crescere, to grow]. In biology, to grow together.

Concrescescence (kon-kres-es'-ens) [con, together; crescere, to grow]. In biology, the union of the germ-bands to form the primitive streak.

Concrete (kon'-krêt, or kon-krēt') [concrescere, to grow together]. Solidified or condensed. Concreted Sugar, the product of the Fryer concretor, or similar form of apparatus. It is a compact, boiled-down mass, containing both the crystallizable sugar and impurities that ordinarily go into the molasses. It shows little or no distinct grain.

Concretion (kon-kre'-shun) [concretio; concrescere, to grow together]. The solidification or condensation of a fluid substance; a calculus; a union of parts normally separate, as the fingers. C., Animal, an earthy deposit found in any of the various organs or secretions of the body. These concretions have a fibrous base containing salts of calcium, phosphorus, or magnesium.

Concubitus (kon-ku'-bit-us) [concumbere, to lie together]. Copulation.

Concursus (kon-ker'-sus) [concursere, to run together]. A synonym of Anastomosis.

Concussion (kon-kush'-un) [concussio, a violent shock]. Shock; the state of being shaken; a severe or injurious shaking or jarring of a part; also, the morbid state resulting from such a jarring. C. of Brain. See Brain. C. of Spinal Cord. A condition caused by severe shock of the spinal column, with or without appreciable lesion of the myelon.

Concussor (kon-kus'-or) [concutere, to shake]. In massage, an apparatus for gently beating the part to be treated.

Condaminea (kon-dam-in'-e-ah) [after Condamine, the botanist]. A genus of Cinchona-yielding trees.

Condensability (kon-dens-ab-ill-it-e) [condensare, to condense]. Capacity for undergoing condensation.

Condensation (kon-den-sa'-shun) [condensare, to condense]. In chemistry, the union of two or more molecules by the linking of carbon-atoms and the formation of complicated carbon-chains. 2. The pathologic hardening, with or without contraction, of a soft organ or tissue.

Condensed (kon-densd') [condensare, to make thick]. Made compact; reduced to a denser form. C. Milk, milk that has had most of its watery elements evaporated according to a known process. Condensed milk prepared with the addition of cane-sugar is a white or yellowish-white product of about the consistency of honey and ranging in specific gravity from 1.25 to I.4I. It should be completely soluble in from four to five times its bulk of water, without separation of any flocculent residue, and then possess the taste of fresh, sweetened milk, Condensed milk prepared without the addition of cane-sugar is not boiled down to the same degree, and therefore remains liquid. Battershall gives the following analysis of both classes:-
CONDENSED MILK WITH ADDITION OF SUGAR.

\begin{tabular}{|c|c|c|c|c|c|}
\hline BRAND. & 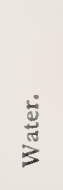 & 芯 & 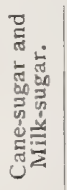 & 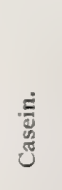 & 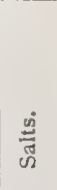 \\
\hline 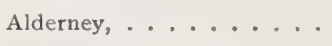 & 30.05 & 10.08 & 46.01 & 12.04 & I.82 \\
\hline Anglo-Swiss (American), .. & 29.46 & 8.II & $50.4 \mathrm{I}$ & 10.22 & 1.8 \\
\hline Anglo-Swiss (English), ... & 27.80 & $8 . \dot{24}$ & 51.07 & 10.80 & 2. \\
\hline Anglo-Swiss (Swiss), . . . & 25.51 & $8.5^{x}$ & 53.27 & 10.71 & 2. \\
\hline Eagle, .......... & 27.30 & 6.60 & $44 \cdot 47$ & 10.77 & | 1. \\
\hline 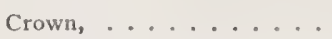 & 29.44 & 9.27 & 49.26 & I0.II & \\
\hline
\end{tabular}

CONDENSED MILK WITHOUT CANE-SUGAR.

\begin{tabular}{|c|c|c|c|c|c|}
\hline BRAND. & $\stackrel{\text { है }}{\stackrel{\text { है }}{3}}$ & $\underset{\pi}{\pi}$ & 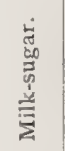 & 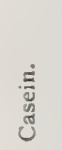 & 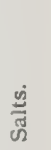 \\
\hline 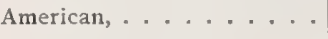 & 52.07 & 15.06 & 16.97 & 14.26 & 2.80 \\
\hline New York, ........ & 56.71 & I4. I3 & I3.98 & 13.18 & 2.00 \\
\hline Granulated Milk Company, . & 55.43 & 13.16 & $14 \cdot 84$ & 14.04 & 2.53 \\
\hline 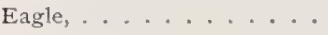 & 56.01 & 14.02 & 14.06 & I3.90 & 2,01 \\
\hline
\end{tabular}

Condenser (kon-den'-ser) [condensare, to make dense]. A lens or combination of lenses used in microscopy for gathering and concentrating rays of light.

Condiment (kon'-dim-ent) [ condimentum, spice]. Spice, sauce, or other appetizing ingredients used with food.

Condom, or Cundum $\left(k o n^{\prime}-d u m\right.$, or kun'-dum) [corruption of Conton, the name of the inventor]. A sheath worn over the penis during copulation for the purpose of preventing conception.

Conduction (kon-du'k'-shun) [conductio; conducere, to draw together]. The passage or transfer of force or material from one part to another. C.-resistance, the resistance encountered by an electric current in passing through a circuit.

Conductor (kon-duk'-tor) [conducere, to draw together]. I. A body that transmits force-vibrations, such as those of heat or electricity. A term applied to the electrodes and cords by which they are joined to the battery. 2. An instrument serving as a guide for the surgeon's knife.

Conduplicate (kon-du'-plik-ät) [conduplicare, to double together]. In biology, doubled or folded together, as leaves or wings.

Condurango Bark (kon-du-rang'-go bark) [native of S. Amer.]. Bark of Gonolobus tetraconus, or of Conglobus condurango; a remedy much used in $\mathrm{S}$. America as an alterative in syphilis. It was introduced into the U. S. as a remedy for carcinoma of the 
stomach, but yielded uncertain results. Dose of the fluid extract $3^{\mathrm{ss}-j}$; of the tincture, $3 \mathrm{j}-\mathrm{ij}$. Unof.

Condy's Fluid. One part of sodium or potassium permanganate dissolved in 500 parts of water; it is a useful disinfectant.

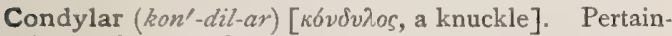
ing to the condyles.

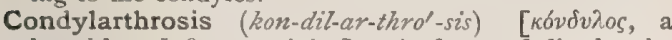
knuckle; ả $\rho \rho \rho o v$, a joint]. A form of diarthrosis, wherein a condyle is set in a shallow and elliptic cavity, and free and varied movement of the joint is possible; condylar articulation.

Condyle (kon'-dil) [ $\delta \delta \delta v i \nu o s$, a knuckle]. Any rounded eminence such ass occurs in the joints of many of the bones, especially the femur, humerus, and lozver jaz.

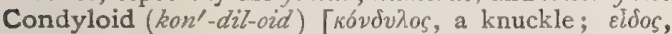
likeness ]. Resembling or pertaining to a condyle.

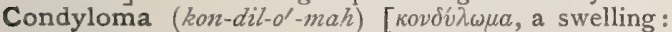
pl., Condylomata]. A wart-like growth or tumor about the anus or pudendum. The term is applied also to syphilitic patches and discolorations.

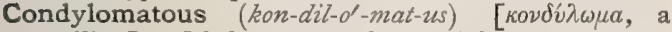
swelling]. Of the nature of a condyloma.

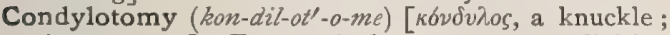
$\tau \varepsilon \dot{\mu \nu} \iota \nu$, to cut]. Extra-articular osteotomy; a division through the condyles of a bone.

Cone, Conus $\left(k \bar{n} n, k o^{\prime}-n u s\right)$ [ body having a circle for its base, and terminating in a point. A patch of choroidal atrophy near the papilla of the eye, in myopia. C., Graduated, a coneshaped body used for measuring the size of orifices of vessels, etc., especially in post-mortem examinations. C. Inhaler. See Anesthetic. C. of Light, the triangular reflection from the normal membrana tympani. C., Retinal, one of the rod-like bodies of elongated conical form, which, with the associated rods, form one of the outer layers of the retina, the so-called rod-and-cone layer. C., Spermatic, one of the series of cones forming the head of the epididymis, and composed of the coiled efferent tubules.

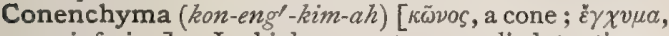
an infusion]. In biology, a term applied to tissues formed of conical cells, as the velvety surface of some petals.

Confectio (kon-fek'-she-o) [L.: gen., Confectionis]. Official name for any confection, $q . v$. C. damocratis. See Mithridate.

Confection (kon-fek'-shun) [confectio, a preparation]. In pharmacy, a mass of sugar and water, or of honey, used as an excipient with a prescribed medicinal substance. There are two official (U.S. P.) confectiones; in the B. P. there are eight.

Confectioners' Disease (kon-fek'-shun-erz dis-ēéz'). A disease frequently occurring in the workpeople manufacturing candied fruits, nuts, etc. It is confined to the nails of the fingers of the hands; the nail loses its polish, and becomes black, and the periungual portion becomes loosened and raised.

Configuration (kon-fig-u-ra'shun) [configurare, to form after something]. In chemistry, a term now designating what was formerly called the "constitution" or "structure" of the molecules.

Confinement (kon-fin'-ment) [L., confiner, to shut up]. The condition of women during childbirth.

Confirmatory (kon-firl-mat-or-e) [confirmare, to confirm]. Confrrming. C. Incision, an abdominal section, made to confirm a diagnosis, as in case of malignant disease of the ovary, uterus, peritoneum, etc.

Confluent (kon'-fu-ent) [confluere, to flow together]. In descriptive pathology, a term applied to eruptions that run together. The opposite of discrete. In anatomy, coalesced or blended ; applied to two or more bones originally separate, but subsequently formed into one.

Conformator (kon'-for-ma-tor) [Fr., conformateur ]. A form of cephalograph used in determining the outlines of the skull in craniometry.

Confrontation (kon-frun-ta'shun) [confrontari, to be contiguous to]. The bringing of one person into the presence of another from whom he or she has con tracted a disease, as an aid in diagnosis.

Confusion (kon-fu'-zhun) [confusio, a confounding]. Mixing; confounding. Embarrassment. C. Colors, a set of colors so chosen with regard to their degree of brilliancy that they cannot be distinguished by one who is color-blind; a good test for color-blindness.

Congelation (kon-jel-a'-shun) [congelatio, a freezing] I. Freezing; frost-bite; intense cold or its effect on the animal economy, or any organ or part. 2. The chilling or benumbing effect of any freezing-mixture or application; mainly employed for its local anes. thetic effect. 3. Coagulation.

Congener (kon'-jen-er) [L., of the same race]. In biology, belonging to the same genus; closely allied.

Congenital (kon-jen'-it-al) [con, together; genitus, born]. Existing at birth.

Congestion (kon-jes'-chun) [congerere, to heap up] An abnormal collection of blood in a part or organ. Congestion may be active or passive, atonic or inflammatory, functional or hypostatic. It is also named from the parts affected; the most important varieties of morbid congestion are the cerebral, spinal, pulmonary, hepatic, and renal.

Congestive (kon-jes'-tiv) [congerere, to heap up] Marked by, due to, or of the nature of congestion.

Congius (kon'-je-us) [L.]. A Roman measure. A gallon.

Conglobate (kon-glo'-bät) [con, together; globare, to make into a globe]. Rounded. C. Glands, the absorbent or lymphatic glands. See Gland.

Conglomerate (kon-glom'-er-at) [conglomerare, to heap up]. I. Massed together; aggregated. 2. A mass of units without order. C. Glands, acinous glands.

Conglutin (kon-glu'-tin) [con, together; gluten, glue]. One of the proteids found in peas, beans, and other kinds of pulse. Vines considers it an artificial product. It is more glutinous and more soluble in acetic acid, and richer in nitrogen, than ordinary legumin. See Casein.

Conglutination (kon-glu-tin- $a^{\prime}-$ shun) [conglutinare, to glue together]. The abnormal union of two contiguous surfaces or bodies, as of two fingers, or of the opposed surfaces of the pleural or pericardial sac.

Congo (kon'-go) [native African]. A country of western Africa. C. Fever. See Fever. C. Paper, a test-paper stained with Congo-red. C.-paper Test. See Tests, Table of. C.-red, a red coloring matter which becomes blue in the presence of free $\mathrm{HCl}$. It is used in chemic investigation of the gastric juice. See Pigments, Conspectus of. C. Solution. See Tests, Table of.

Congress (kong'-gres) [congressus, a meeting together]. An assemblage for deliberative purpose. C., Sexual, coition, or carnal intercourse.

Congressus (kong-gres'-us) [L.]. Congress; sexual intercourse. C. interruptus. See Coitus reservatus.

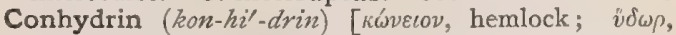
water $], \mathrm{C}_{8} \mathrm{H}_{17} \mathrm{NO}$. A solid alkaloid of conium, an oxyconin, occurring in pearly, iridescent, white, foliaceous crystals, with a faint, conin-like odor, and melting at $\mathbf{I} 2 \mathbf{1}^{\circ} \mathrm{C}$. and distilling at $226^{\circ}$.

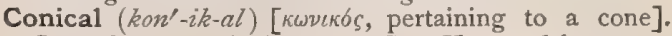
Cone-shaped. C. Cornea. See Kerato-globus. 


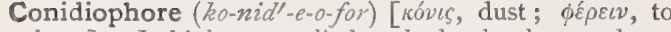
bear]. In biology, applied to the hypha that produces conidia.

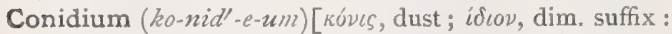
pl. Conidia]. In biology, the deciduous asexual spores of certain fungi. Also called Basidiospore and Acrospore.

Conidosis (kon-id-o'-sis). Synonym of Urticaria.

Coniferin (ko-nif'-er-in) [conifer, cone-bearing], $\mathrm{C}_{16}$ $\mathrm{H}_{22} \mathrm{O}_{8}+2 \mathrm{H}_{2} \mathrm{O}$. A crystalline glucosid found in the cambium of coniferous woods, and consisting of shining needles. It effloresces in the air and melts at $185^{\circ} \mathrm{C}$. It is also called Abietin.

Coniin $\left(k o-n i^{\prime}-i n\right)$. See Conium and Conin.

Conin (ko'-nin) [ $\kappa \omega v \varepsilon \iota \nu$, hemlock $], \mathrm{C}_{8} \mathrm{H}_{15} \mathrm{~N}$. A volatile alkaloid that occurs in hemlock (Conium maculatum), chiefly in the seeds, and is obtained by extraction with acetic acid or distillation with soda. It is a colorless, oily liquid, having the odor of hemlock and boiling at $167-168^{\circ}$; its specific gravity is 0.886 at $0^{\circ}$.

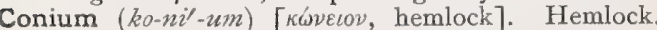
The green, full-grown fruit of the spotted hemlock, $C$. maculatum. It contains three alkaloids and a volatile oil. Its properties are mainly due to the alkaloids coniin, $\mathrm{C}_{8} \mathrm{H}_{15} \mathrm{~N}$, and methylconiin, $\mathrm{C}_{8} \mathrm{H}_{14} \mathrm{NCH}_{3}$. It produces motor paralysis, without loss of sensation or of consciousness. Toxic doses cause death by paralysis of the organs of respiration. It is valuable in acute mania, delirium tremens, tetanus, blepharospasm, asth$\mathrm{ma}$, and whooping-cough. C., Abstract., made from conium 200, dilute hydrochloric acid 6, sugar of milk and alcohol q. S., to make 100 parts of abstract. Unof. Dose gr. ss-iij. C., cataplasma (B. P.), made from the leaves. For external use. C., Ext., Alcoholic. each grain representing one grain of the drug. Dose gr. ij-v-xl. C., Fld. Ext., same strength as preceding. Dose $m_{i j-v-x l}$ C., pilula Comp. (B. P.), contains extract of hemlock and ipecac. Dose gx. v-x. C., succus (B.P.), made from the leaves. Dose $m \times x x-$ 3ij. C., Tinct., I5 per cent. strength. Dose $m x-$ 3j. C. Vapor (B. P.), for inhalations, Coniin, unof., volatile alkaloid of conium. Dose gr, $\frac{1}{60-\frac{1}{10}}$, Coniin Hydrobrom., $\mathrm{C}_{5} \mathrm{H}_{9}\left(\mathrm{C}_{3} \mathrm{H}_{7}\right)$, unof., recommended for spasmodic affections. Dose gr. $\frac{1}{30} \frac{1}{15}$. All preparations uncertain in strength. Coniin. Hydrobrom., Injectio Hypoderm. Dose $\eta_{j}$-iij.

Conjugal (kon'-ju-gal) [conjugalis, a husband or wife]. Pertaining to marriage; connubial. C. Diabetes, diabetes affecting husband and wife together; this is said to be not infrequently observed.

Conjugate (kon'-ju-gät) [con, together; jugare, to yoke]. Yoked or coupled. C. Deviation. See Deviation. C. Diagonal, Internal, an internal measurement of the pelvis from the middle of the sub-pubic ligament to the sacro-vertebral angle. It is $123 / 4 \mathrm{~cm}$. C. Diameter (of the pelvis), the anteroposterior or sacro-pubic. See Diameter. C. Diameter (of the pelvis), external. See Baudelocque, Diameter of. C. Focus. See Focus. C.-symphyseal Angle, the angle that the conjugate diameter of the pelvis makes with the pubic bone at the symphysis. C. True, the minimum useful diameter of the pelvic inlet. See Diameter.

Conjugation (kon-ju-ga'-shon) [conjugatus, joined together]. In biology, that form of sexual reproduction in which two cells, similar in size and appearance, unite to form a spore. The sexual character of conjugation was first pointed out by Vaucher, in 1803 .

Conjunctiva (kon-junk-ti'-vah) [conjunctivus, connecting]. The mucous membrane covering the anterior portion of the globe of the eye, reflected on and extending to the free edges of the lids. Its parts are called palpebral and ocular, or bulbar.
Conjunctival (kon-junl't-tiv-al, or kon-junk-ti'-val) [conjunctious, connecting]. Relating to the conjunctiva.

Conjunctivitis (kon-junk-tiv-i'-tis) [conjunctivus, connecting; $\iota \tau \iota S$, inflammation]. Intlammation of the conjunctiva. It may be catarrhal, croupous, diphtheric (or membranous), gonorrheal, phlyctenular, purulent, etc., in character or origin. C., Atropin, a peculiar idiosyncratic catarrh of the conjunctiva produced by prolonged use of atropin as a mydriatic, and characterized by the formation of numerous follicles. C. crouposa, a form associated with the formation of a whitish-gray membrane that is easily removed. C. diphtheritica, a specific purulent inflammation of the conjunctiva spreading by infection, yielding a contagious secretion, and leading to necrosis of the infiltrated tissue. C. eczematosa. See C. lymphatica. C., Egyptian. See Trachoma. C. exanthematica. See C. lymphatica. C. follicularis, a form characterized by the presence of follicles. C., Granular. See Trachoma. C. lymphatica, that occurring in scrofulous individuals. It is accompanied by the formation of ulcers. C. membranacea. See $C$. crouposa and Ophthalmia. C. phlyctenulosa. See $C$. lymphatica. C. pustulosa. See C. Iymphatica. C. scrofulosa. See C. lymphatica.

Connate $\left(k o n^{\prime}-\bar{a} t\right)$. See Confluent and Congenital.

Connection (kon-ek'-shun) [connectere, to connect]. Sexual intercourse.

Connective (kon-ek'-tiv) [connectere, to connect]. I. Connecting; binding. 2. In botany, the portion of the filament that connects the two cells of an anther. C. Tissue. See Animal Tïsue.

Connivent (kon-i'-vent) [connivere, to wink at]. In botany converging toward each other; applied to stamens that converge above, as those of the violet.

Conocephalic, or Conocephalous (ko-no-sef-al'-ik,

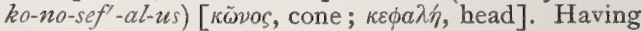
the skull somewhat conoidal.

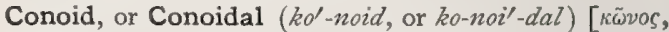
cone; $\varepsilon i \delta o s$, shape ]. Of a conical or approximately conical shape. C. Ligament, the lower and inner part of the coraco-clavicular ligament. C. Tubercle, the eminence on the inferior surface of the clavicle to which the $C$. ligament is attached.

Conquassant (knn-kwas'-ant) [conquassare, to shake severely]. Very severe (applied chiefly to labor-pains at the acme of their intensity).

Conquassation (kon-kwas-a'-shun). See Concassation. Conquinamin (kon-kwin'-am-in). An alkaloid of Cuprea bark.

Conrad's Water. An eye-wash composed of three parts of mercuric chlorid, Ioo of distilled water, and five to ten of tinctura opii crocata.

Conroy's Test. See Tests, Table of.

Consanescent (kon-san-es'-ent) [consanescere, to become sound]. Healing, becoming healed (applied mostly to wounds).

Consanguine (kon-san'-groin) [consanguineus, of the same blood]. Allied by birth or descent; akin by blood-relationship.

Consanguineous (kon-san-gwin'-e-us) [consanguineus, of the same blood]. Related by a common parentage.

Consanguinity (kon-san-grwin'-it-e) [con, together; sanguinis, of blood]. The relationship arising from common parentage; blood-relationship.

Consciousness (kon'-shus-nes) [conscius, knowing]. The state of being aware of one's own existence, of one's own mental states, and of the impressions made upon one's senses ; ability to take cognizance of sensations; applied to ab extra impressions. C., Double, that morbid condition in which there are two separate 
and alternating states of mental consciousness, in either one of which the events that have occurred in the other state are not remembered by the patient.

Consenescence (kon-sen-es'-ens) [consenescere, to grow old]. The state or condition of growing old.

Consensual (kon-sen'-su-al) [consensus, agreement]. Reflex and involving sensation, but not volition; as a consensual act or movement.

Consent (kon-sent') [consentire, to agree]. In forensic medicine, this term signifies willing participation in unnatural or illegal intercourse. In pathology, a sympathetic affection of a part distant from a diseased part.

Consentience (kon-sen'-she-ens) [consentire, to agree]. Undeveloped or unintellectual consciousness; the sum or result of the impressions made by sensations upon the psychic center of the organism.

Conserva, or Conserve (kon-ser'-vah, or con-serv') [conservare, to keep]. A confection, $q$. $v$.

Conservancy (kon-ser'-van-se) [conservare, to keep]. Public conservation of health or of things that make for health; the sum of hygienic or preservative legislation. C. System. See Sezuage, Disposal of.

Conservative (kon-ser'-vat-iv) [conservare, to keep]. Aiming at the preservation and restoration of injured parts ; as conservative surgery or dentistry.

Conservator (kon'-ser-va-tor) [conservare, to preserve]. A person appointed to look after the business interests and general welfare of an insane person or idiot.

Consolidant, Consolidating (kon-sol'-id-ant, or konsol'-id-a-ting) [consolidare, to make firm]. Tending to heal or promoting the healing of wounds or fractures; favoring cicatrization.

Consolidation (kon-sol-id-a $\left.a^{\prime}-s h u n\right)$ [consolidare, to make firm]. The process of becoming firm or solid, as a lung in pneumonia.

Consonants (kon'-so-nants) [con, together; sonare, to sounc]. Non-vowel sounds in speaking produced at certain parts of the resonance-chamber. They are sounded only with a vowel. They consist of Explosives, Aspirates, Vibratives, and Resonants; they are also divided into four classes, according to the situation in which they are produced-the Articulation Positions, - the first boing between the lips; the second between the tongue and hard palate; the third between the tongue and soft palate; the fourth between the vocal bands. Labials, made at the lips, may be explosive $(b, p)$, aspirate $(f, v, w)$, vibrative (the "burr"), and resonant $(m)$. These form the consonants of the first articulation position. Those of the second position are the explosives $t$ and $d$; the aspirates $s, z, s c h$, th; the vibrative $r$; the resonant $n$. Those of the third position are the explosives $k$ and $g$; the aspirates are the unvoiced consonants, unvoiced $c h$ and $j ;$ the vibrative, palatal $r$; the resonant, palatal $n$. That of the fourth position is the aspirate, the glottis-formed $h$.

Constant (kon'-stant) [constans, steady]. Fixed; not changing. C. Battery, Element, or Cell. One yielding a constant current. A galvanic battery, of which the most common types are those of Bunsen, Callaud, Daniell, Grénèt, Grove, Leclanché, and Smee.

Consternatio (kon-ster-na'-she-o) [L.]. See NightTerrors.

Constipation (kon-stip-a'-shun) [constipare, to crush tightly together]. Costiveness; retention and hardness of the feces from functional inactivity of the intestinal canal, or from abnormalism of the biliary or other secretions. It may also be due to mechanical obstruction of the intestinal canal, paresis of the intestinal walls, the use of certain foods, and general depression of vital activity.
Constituent (kon-stit'-u-ent) [constiucere, to establish] A formative element or ingredient. The Constituents of the Organism are organic and inorganic The Inorganic C. are Water, forming 58.5 per cent. of the body; Gases, such as oxygen, marsh-gas, etc.; Salts, of which the chief are sodium chlorid, calcium phosphate (forming more than one-half of the bones), sodium phosphate, sodium carbonate, sodium and potassium sulphates, potassium chlorid, calcium fluorid and carbonate; Free Acids, as hydrochloric, sulphuric, etc.; Bases, such as silicon, manganese, iron. The Organic C. comprise the large classes of the proteids, albuminoids, fats, etc.

Constitution (kon-stit-u'-shun) [constituere, to dispose]. In chemistry, the atomic or molecular composition of a body. In pharmacy, the composition of a substance. In physiology, the general temperament and functional condition of the body.

Constitutional (kon-stit-u'-shun-al) [constituere, to dispose]. Pertaining to the state of the constitution. C. Diseases, in pathology, such diseases as are inherent, owing to an abnormal structure of the body. Also, inherited diseases. Also, a condition in which the disease pervades the whole system. General, in contradistinction to local.

Constrictor (kon-strik'-tor) [constringere, to bind together]. Any muscle that contracts or tightens any part of the body. See Muscles, Table of.

Constringent (kon-strin'-jent) [constringere, to constrict]. Same as Astringent, q. $v$..

Consultation (kon-sul-ta'-shun) [consultare, to take counsel]. A deliberation between two or more physicians concerning the diagnosis of the disease of a patient and the proper method of treatment.

Consumption (kon-sump'-shun) [consumere, to consume or wear away]. Wasting, denutrition, or atrophy, loosely used as a synonym of Tuberculosis, especially pulmonary tuberculosis, Phthisis, $q . v$. C. of the Bowels. See Diarrhea, Chronic Inflammatory.

Consumptive (kon-sump'-tiv) [consumere, to consume or wear away]. I. Of the nature of tuberculosis. 2. One afflicted with pulmonary tuberculosis.

Contact (kon'-takt) [contactus, a touching]. A touching. C. Lenses, in optics, a glass shell the concavity of which is in contact with the globe of the eye, a layer of liquid being interposed between the lens and the cornea. C. Series, a series of metals arranged in such an order that each becomes positively electrified by contact with the one that follows it. The contact-values of some metals, according to Ary. ton and Perry, are as follows:-

DIFFERENCE OF POTENTIAL IN VOLTS.

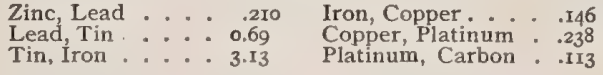

C. Test, Heller's test. See Tests, Table of.

Contactile, or Contactual (kon-tak'-til, or kon-tak' tu-al) [contactus, contact]. I. Tactile. 2. Due to or spreading by actual contact.

Contagion (kon-ta'-jun) [contagio; contingere, to touch]. The process by which a specific disease is communicated between persons, either by direct contact or by means of an intermediate agent. (See, also, Infection.) Also the specific germ of virus from which a communicable disease develops. C., Mental. See Imitation.

Contagionist (kon-ta'-jun-ist) [contagio; contingere, to touch]. One who believes in the contagious origin or transmission of any given disease.

Contagious (kon-ta'-jus) [contagium, a touching]. Communicable or transmissible by contagion, or by a specific contagium. Infectious-applied to a 
disease engendered by a specific agency, which, once present, may multiply and renew itself indefinitely, and which always gives rise to the same disease. (a) Miasmatic-applied to an infectious disease of which the specific cause exists only in certain localities, e.g., malaria, pneumonia, acute rheumatism. (b) Contagiones-applied to a disease of which the cause is transmitted from person to person, through houses, villages, cities, and countries, e.g., variola, morbilli, scarlatina, diphtheria, etc. (c) Miasmaticcontagious - applied to an infectious disease of which the specific cause is carried by persons, or their emanations, to a locality, and in the soil, water or houses of which it multiplies and thence generates the disease, e. $g$., cholera, enteric fever, yellow fever. C. Typhus. Synonym of Typhus Fever, q.v.

Contagium (kon-ta'-je-um) [L.]. Any virus or morbific matter by means of which a communicable disease is transmitted from the sick to the well. C. animatum, same as $C$. vizum. C. vivum ("living contagium"), any living vegetable or animal organism that causes the spread of an infectious disease.

Contest (kon'-test') [contestari, to call to witness]. To dispute; to strive for. C. Theory, the doctrine of chemiotaxis.

Contiguity (kon-tig- $\left.u^{\prime}-i t-e\right)$ [contiguitas, a touching]. Proximity. C., Amputation in the, is performed at a joint, without section of a bone.

Continued (kon-tin'-üd) [continuare, to make continuous]. Persisted in. C. Fever, a fever that is neither intermittent nor typically remittent. See Fever.

Continuity (kon-tin-u'-it-e) [continuitas, uninterruptedness]. In anatomy, the portion lying between two ends, as the shaft of a bone. C., Solution of. See Solution. C., Amputation in the, amputation in which a bone is divided.

Continuous (kon-tin'-u-us) [continuus, joined ; uninterrupted]. Unbroken. C.-gum Work, a method of constructing artificial dentures.

Contortion (kon-tor'-shun) [contorquere, to twist]. A twisting or writhing, as of the body.

Contour (kon-toor') [Fr., contour, circuit]. I. The line that bounds, defines, or terminates a figure. 2. In operative dentistry, to effect the restoration of lost parts of teeth by building them up with gold, etc. C.feather-hair, one of those outer and longer hairs or feathers that go to determine the contour of a bird or mammal, as distinguished from a soft down-feather or a hair of the under-fur. C.-fillings, in dentistry fillings in which the material is so built out as to restore the lost portion of the crown of the tooth; distinguished from plane or flush-fillings.

Contracted Heels. See Hoofbound.

Contractility (kon-trak-till-it-e) [contrahere, to draw together]. The peculiar property of muscular tissue manifested by shortening and concomitant thickening

Contraction (kon-trak'-shun) [contrahere, to draw together]. Approximation of the elements of a tissue or organ, thus diminishing its volume or contents. C., Carpo-pedal, a variety of tetany occurring in infants, and generally associated with dentition or seat-worms. There is a flexing of the fingers, toes, elbows, and knees, and a general tendency to convulsions. C., Closing, muscular contractions produced at the instant that the electric current is closed. C., Fronttap, Gowers' term for a phenomenon often observed in cases with exaggerated knee-jerk. It is a delicate test of increased spinal irritability. The foot is placed at a right angle to the leg, and the muscles of the front of the leg are tapped, the result being extension of the foot from contraction of the gastrocnemius. See $R_{\ell}$ - flexes, Table of. C.-furrows, a number of concentric curved lines near the ciliary margin of the iris: They are produced in the living iris by a folding of the iris upon itself during dilatation of the pupil. C., HourGlass. See Uterus. C., Opening, the muscular contraction produced by opening or breaking the circuit. C., Paradoxic, Westphal's term for a phenomenon that consists in the contraction of a muscle, caused by the passive approximation of its extremities. C.-remainder, the stage of elastic after-vibration or residual contraction persisting in a muscle after withdrawal of the stimulus. C.-ring, the boundary line between the upper and lower uterine segments, often marked by a perceptible ridge. That portion of the uterine canal that must be dilated to allow the escape of the fetus is called the lower uterine segment; that portion above the point at which the dilatation ceases, $i_{2} e_{\text {. }}$, the contracting portion of the muscle, is called the upper uterine segment.

Contractions. See Contracture and also Abbreviations, in Introductory Tables.

Contracture (kon-trak'-chur) [contractus, a drawing together]. Contraction; permanent shortening, as of a muscle; distortion or deformity due to the shortening of a muscle or of various muscles. In electro-therapeutics, muscular spasms, clonic or tonic, the variety determined in regard to time, by the method of application of the current.

Contra-extensio (kon-trah-ek-sten'-se-o) [L.]. Counterextension.

Contra-fissura $\left(k o n^{\prime}-t r a h-f i s-s u^{\prime}-r a h\right)$ [contra, opposite to ; fissura, a fissure]. Cranial fissure or fracture produced by a blow upon the skull at a point distant from or opposite to the seat of the fracture.

Contra-indicant (kon-trah-in'-dik-ant) [contra, opposed to ; indicare, to indicate]. I. Having the effect of a contra-indication. 2. A symptom, indication, or condition that forbids the use of a particular remedial measure or set of measures.

Contra-indication (kon-trah-in-dik-a'shun) [contra, against; indicare, to point out ]. That pathologic or modifying condition in which a remedy or a method of treatment is forbidden that under ordinary cases might be proper.

Contra-stimulant (kon-trah-stim'-u-lant) [contra, against; stimulare, to stimulate]. I. Counteracting the effect of a stimulus; depressing; sedative. 2. A sedative remedy.

Contra-stimulism (kon-trah-stim'-u-lizm) [contra, against; stimulare, to stimulate]. The doctrine of contrastrimulus ; Rasorianism.

Contra-stimulus, or Contro-stimulus (kon-trah-stim' $u$-lus, or kon-tro-stim'-u-lus) [contra, against; stimulus, a stimulus]. An influence that is opposed, or acts in opposition, to a stimulus.

Contrayerva (kon-trah-yer'-vah) [contra, against; herba, an herb]. The root of Dorstenia contrayerva, a stimulant, tonic, and diaphoretic. Its decoction is mucilaginous, and is serviceable in low fevers and malignant eruptive diseases. Dose $3 \mathrm{ss}$. Unof."

Contrecoup $\left(k \circ n^{\prime}-t \gamma-k o o\right)$ [Fr.]. Counter-stroke, a variety of injury by indirect violence, as by a blow on a remote part. See Contra-fissura.

Contrectation (kon-trek-ta'-shun) [contrectatio; contrectare, to touch]. Digital examination; palpation; touch; manipulation, as in massage.

Control (kon-trōl') [contra, against; rotula, a roll]. An experiment performed to test the correctness of the results of another experiment; a standard by which to check observations and insure the validity of their results. Also, a synonym for Control Animal. C. Animal. See C. Experiment. C. Experiment, an 
experiment carried out under normal or common circumstances or conditions, to serve as a standard whereby to test the variation or value of another experiment carried out under peculiar or abnormal circumstances. For instance, an animal is rendered immune by inoculation with some anti-specific agent. Such an animal is called the Immune Animal. Another animal, not having been previously rendered immune, is called the Control Animal. Both animals are then exposed to the action of, or are inoculated with, the specific virus in question, and the relative differences in the reaction of the two animals to the last inoculation or exposure constitute the conclusions of the experiment.

Contusion (kon-tu'-zhun) [contusio; contundere, to bruise]. A bruise or injury by a blunt weapon, or by collision, without breaking the skin or covering. C.pneumonia, a form of pneumonia following traumatișin. It is of frequent occurrence.

Conus $\left(k o^{\prime}-n u s\right)[\kappa \tilde{\omega} \nu o s$, a cone: $p l$., Coni]. A crescentic patch of atrophic choroid tissue near the optic papilla in myopia. C. arteriosus, the conoid eminence of the right ventricle of the heart, whence arises the pulmonary artery. C. medullaris, the cone-like termination of the spinal cord, continuous as the filum terminale. Coni vasculosi, a series of conical masses that together form the globus major of the epididymis.

Convalescence (kon-val-es'-ens) [convalescere, to become well]. A term applied to the restoration to health after the subsidence of a disease or ailment.

Convalescent (kon-val-es'-ent) [convalescere, to become well]. I. One recovering from a sickness. 2. Recovering from sickness.

Convallamarin (kon-val-am'-ar-in) [convallis, a valley; amarus, bitter], $\mathrm{C}_{23} \mathrm{H}_{44} \mathrm{O}_{12 .}$ A bitter, crystalline whitish powder; a glucosid derived from Convallaria. It is a rather active poison. See Convallaria majalis.

Convallaria (kon-val-a'-re-ah) [convallis, a valley]. A genus of liliaceous plants. C. majalis, Lily of the Valley. All parts of the plant are used in medicine. Its properties are due to convallarin, $\mathrm{C}_{34} \mathrm{H}_{62} \mathrm{O}_{11}$, and convallamarin, $\mathrm{C}_{23} \mathrm{H}_{44} \mathrm{O}_{12}$, glucosids. It is a prompt cathartic, diuretic, and cardiac stimulant, valuable as a heart-tonic. Urilike digitalis, it has no cumulative effect. C., Ext., soluble in water. Dose gr. ij-x. C., Ext., F1d., alcoholic. Dose $\eta_{i j-x j}$. C. infusum, prepared with three times its weight of water. Dose §ss-ij. Convallamarin, or Convallamarinum, is soluble in water. Dose gr. $1 / 4-\mathrm{ij}$. All unof.

Convallarin (kon-val'-ar-in) [convallis, a valley], $\mathrm{C}_{34} \mathrm{H}_{62} \mathrm{O}_{11}$. A purging, crystalline glucosid derived from Convallaria.

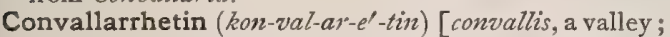
intivn, resin], $\mathrm{C}_{28} \mathrm{H}_{52} \mathrm{O}_{6}$. A poisonous resiniform substance obtainable from convallarin upon the separation of glucose from the latter.

Convection (kon-vek'-shun) [convehere, to carry together]. A transmission or carrying, as of heat or electricity. C.-current, a current of a liquid or gas heated to a temperature above that of the surrounding medium; it rises to the surface because of its lighter density, and thus the entire fluid or gas acquires the same temperature.

Convergence (kon-ver'-jens) [convergere, to tend to a center]. Inclination or a direction toward a common point, center, or focus, as, $e_{.} g$. , of the axes of vision upon the near-point. C.-theory, a theory that accounts for the production of myopia by the pressure exerted by the external ocular muscles upon the eyeball in convergence, this pressure leading to distention of the eyeball.
Convergent (kon-ver'-jent) [con, together; vergere, to incline]. In biology, coming together. Tending to a common center. C. Strabismus. See Strabismus.

Convex (kon-veks') [convexus, vaulted]. Rounded, as a swelling of a round or spheric form on the external surface; gibbous; opposed to concave.

Convexity (kon-veks'-it-e) [convexus, convex]. A surface rounding outward; the quality of being convex.

Convexo-concave and Convexo-convex (kon-veks'o-kon-käv, kon-veks'-o-kon-veks). See Lens.

Convolute $\left(k o n^{\prime}-v o-l u \bar{t} t\right)$ or Convoluted (kon'-vo-luted) [convolutus, rolled together]. Rolled together. C. Bones. See Turbinated Bones.

Convolution (kon-vo-lu'-shun) [convolvere, to roll together]. A folding and turning upon itself of any organ, as the cerebrum and the small intestines; any gyrus of the brain. A Table of the Convolutions of the Cerebrum is added. (See page 323.)

Convolvulin (kon-vol'-z'u-lin) [convolvere, to roll together], $\mathrm{C}_{31} \mathrm{H}_{50} \mathrm{O}_{16}$. A glucosid derived from the roots of Jalap (Convolvulus purga). It is a gummy mass, with active purgative properties.

Convolvulus (kon-vol'-vu-lus) [convolvere, to roll together]. A genus of plants. C. panduratus, wild potato. The tuber is a mild cathartic. Dose gr. xl. Unof. c. purga. See Jalap. C. scammonia. Scammony.

Convulsant (kon-vul'-sant) [convellere, convulsum, to pull together]. A medicine that causes convulsions.

Convulsion (kon-vul'-shun) [convellere, to convulse]. A general paroxysm of involuntary muscular contraction, whether tonic or (more especially) clonic. Loss of consciousness and voluntary control of the muscles, with clonic, tonic, or mixed contraction, etc. It may be due to epilepsy, other functional or organic disease of the brain, circulation, etc. ; or may be cataleptic, hysteric, choreic, etc. See, also, Epilepsy. C., Infantile, due to a number of causes, such as rickets, exhaustion, etc.; sometimes called "screaming fits." C., Puerperal. See Eclampsia. C., Salaam, Eclampsia nutans, q.v. C., Uremic, due to the altered state of the blood in disease of the kidney.

Convulsionary (kon-vul'-shun-a-re) [convellere, to convulse]. One who is subject to convulsions; especially one of a set of patients who are subject to epidemic or imitative convulsions.

Convulsivant (con-vul'-siv-ant) [convellere, to convulse]. An agent that causes convulsions.

Convulsive (kon-vul'siv) [convellere, to convulse]. Marked by convulsions or spasms. C. Cerebral Typhus. See Dubini's Disease. c. Cough. See Cynobex hebetis. C. Tic. See Habit-Spasm. C. Tremor. See Paramyoclonus.

Conydrin (ko-ni'-drin). See Conhydrin.

Cook's (Alleyer) Hematoxylin Solution. A solution for staining microscopic sections. Extract of logwood 6 gm., alum $6 \mathrm{gm}$., cupric sulphate I gm., and water, 40 c. c. are rubbed up into a paste in a mortar. This is allowed to stand for two days, and then filtered, and a crystal of thymol is added to the filtrate for preserving. See Stains, Table of.

Cooper's (Sir Astley) Arsenious Ointment. An ointment composed of arsenious acid and sulphur, each one part, spermaceti cerate, eight parts. It has been used as a local application in skin-affections. C. Fascia. See Scarpa's Fascia. C. Hernia. See Hernia, and Diseases, Table of. C. Irritable Breast. Synonym of Mastodynia. C. Irritable Testicle. Synonym of Orchialgia. C. Ligaments. See Ligaments. C. Method. See Treatment, Method's of. C. Operations. 

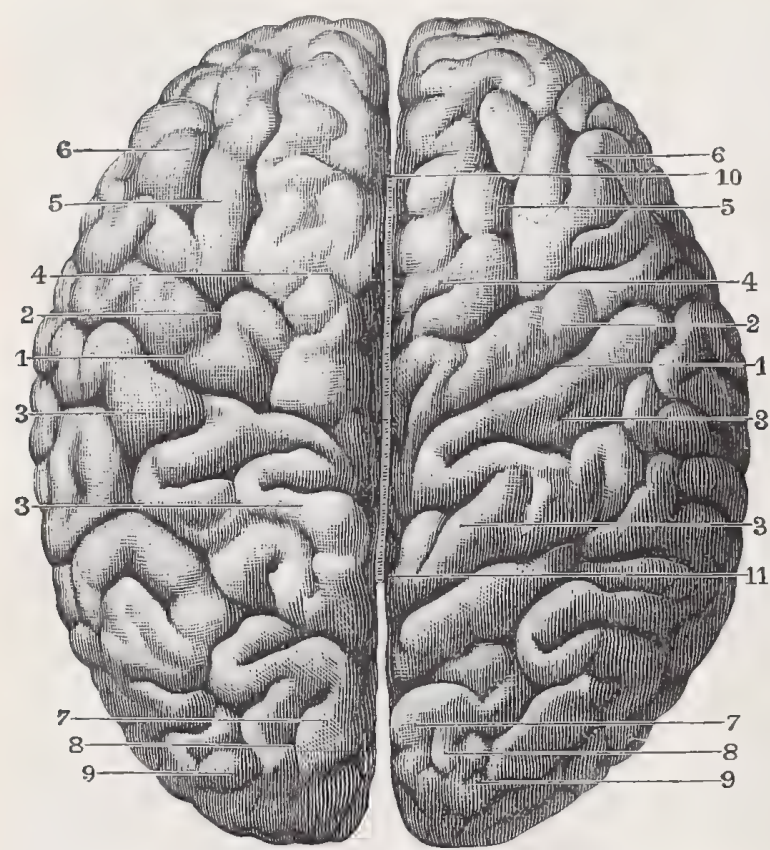

Convolutions of the Superior Aspect or Convexity of THE CEREBRUM

I, I. Fissure of Rolando. 2, 2. Ascending frontal convolution. 3, 3. Ascending and superior parietal convolutions. 4, 4. First frontal convolution. 5, 5. Second frontal. 6, 6. Third frontal. 7, 7. First occipital. 8, 8. Second occipital. 9, Third occipital Io. Anterior extremity of corpus callosum. I1, i1. Posterior extremity.

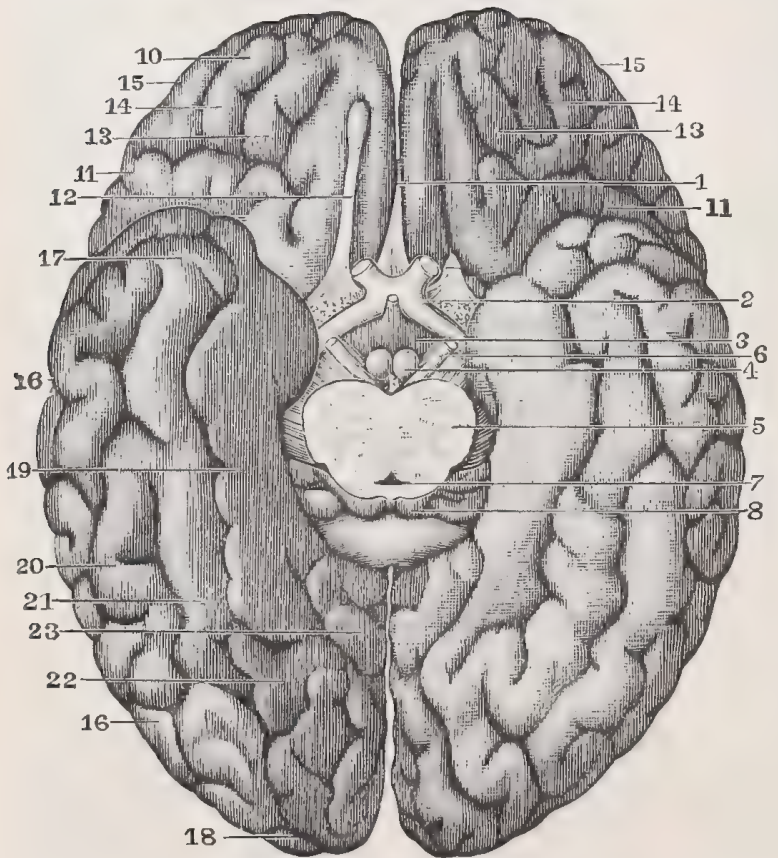

CONYOLUTIONS OF THE INFERIOR ASPECT OF THE CEREBRUM.

I. Anterior extremity of corpus callosum. 2. Optic chiasm. 3. Tuber cinereum and infundibulum. 4. Corpora albicantia or mammillaria. 5. Pons varolii. 6. Third nerve, 7. Aqueduct of Sylvius. 8. Testes 10. Inferior surface of frontal lobe. II. Convolution of the fissure of
See Operations, Table of. C. Ventilator. See Ventilation.

Coopers' Knee. An enlarged bursa patellæ found in coopers, as the result of pressure exerted by the knee against the barrel.

Coördination (ko-or-din-a'-shun) [con, together; ordinare, to regulate]. The harmonious activity and proper sequence of operation of the various organs of the body, especially of those parts that coopperate in the performance of any function.

Copaiba $\left(k o-p a^{\prime}-e-b a h\right)$ [Sp.]. Balsam of Copaiba. The oleoresin of Copaifera offcinalis, $C$. coriacea, $C$. guianensis, $C$. multijuga, $C$. cordifolia, C. laxa, $C$. nitida, $C$. oblongifolia, and $C$. langsdorffi; leguminous trees, native to South America. It is a stimulant, diuretic, diaphoretic, and an expectorant, and is much used in gonorrhea, although now considered of doubtful value. C., Massa, copaiba 94, magnesia 6 parts. Dose $m_{x-3}$ j. C., Mist. Comp., Lafayette's mixture, unof., copaiba 3 vij, oil cubebs $3 j$, glyceriti vitelli 3 vij ; triturate and add syr. aq. menth. piperit. $z$ iiss; then add, with constant stirring, liq. potass. 3 ss, tinct. cardamon comp. 3 ij, spt. æther. nitrosi, 3 ss, aq. menth. piperit. q.s. to make $\zeta$ viij. Dose $3^{j}-z_{s s}$. C., O1. Dose $m_{x-x v}$. C., Resina, mainly copaibic acid. Dose gr. $\mathbf{j}-\mathrm{v}$.

Copal $\left(k o^{\prime}-p a l\right)$ [Mex., copalli, resins]. Anime. These terms include a number of related resins that are of both fossil and recent origin. The copal resins, when of good quality, are too hard to be scratched by the nail, have a conchoid fracture, and a specific gravity ranging from $\mathbf{1} .059$ to 1.080. Unlike others, they are soluble with difficulty in alcohol and essential oils, and are, therefore, valuable for making varnishes. The softer kinds are called anime.

Copalche (ko-pal'-che) [Mex.]. The bark of Croton niveres and other trees of tropical America. The term is a vague one, and is little used in medical literature.

Copalin, Copalm (ko'-pal-in, ko'-palm ) [Mex., copalli, resins]. The sweet-gum tree, Liquidambar styraciflua; also the resin that in warm latitudes exudes from it, the so-called Highgate resin.

Copeman's Method. A method of overcoming the nausea and vomiting of pregnancy. It consists in digital dilatation of the cervix uteri to a slight degree, not sufficient to induce abortion.

Copernicia cerifera (ko-per-nish'-e-ah seriff-er-ah). See Carnauba.

Cophosis $\left(k o-f o^{\prime}-s i s\right)$ [ $\kappa \omega \phi b s$, deaf ]. Deafness or dulness of hearing.

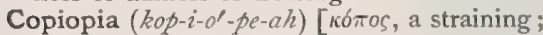
$\omega \psi$, eye]. Eye-strain; weariness of the eyes. C. hysterica, a term applied to those symptoms that indicate hyperesthesia of the fifth and optic nerves.

Sylvius. 12. Olfactory nerve, I3. Third convolution of inferior surface of frontal lobe. I4. Fourth convolution. 15. Third convolution of external surface of frontal lobe. I6. External border of posterior lobe, I7. Sphenoidal extremity. I8. Occipital extremity. I9. Hippocampal convolution. cipital External convolution of posterior lobe. 2I. Middle convolution. 22. Internal convolution. 23. Gyrus fornicatus. 


\section{TABLE OF CONVOLUTIONS OR GYRI OF THE CEREBRUM.}

NAME,

Abrupt.

Angular.

Annectant (4).

Annectant, external.

Annectant, first.

Annectant, second.

Annectant, superior.

Antero-parietal.

Antero-temporal.

Antorbital.

Arcuate.

Of Arnold.

Basilar, internal.

Basirrhinal.

Breves.

Bridging.

Broca's.

Callosal.

Calloso-marginal.

Central, anterior.

Central, posterior.

Choroid, anterior.

\section{Choroid, inferior.}

Choroid, posterior.

Choroid, superior.

Of the corpus callosum.

Cruciate.

Cuneate.

\section{Cuneiform.}

Dentate.

Descending.

Divisus.

D'ourlet.

External (4).
LOCATION.

Small convolutions at the extremity of the occipital lobe.

Posterior portion of inferior parietal lobule.

Occipital lobe.

See Annectant, first.

Occipital lobe; a portion of the superior occipital convolution.

Occipital lobe, posterior part.

See Paroccipital.

See Frontal, ascending.

See Temporal, first.

Frontal lobe (of orang-outang), orbital surface.

See Uncinate.

See Posterior, inferior.

Frontal lobe (orbital face); probably the rectus convolution, $q . v$.

Temporal lobe, near tip.

The larger number of the insular convolutions, as distinguished from the long insular.

See Annectant.

The inferior or third frontal convolution, $q . v$.

See Fornicate.

See Fornicate.

See Frontal, ascending.

See Parietal, ascending.

In the embryo, the convexity of the parietes of the lateral recess of the fourth ventricle.

See Choroid, posterior.

In the embryo, a convexity posterior to the anterior choroid convoiution in the lateral recess of the fourth ventricle.

See Choroid, anterior.

See Fornicate.

See Orbital convolutions.

Occipital lobe, median aspect of cerebrum; wedge-shaped.

See Abrupt.

In the dentate fissure; rudimentary in man.

Occipital lobe.

See Frontal, ascending.

See Fornicate.

Convexity of each cerebral hemisphere (of dog).
BOUNDARIES.

Anteriorly, continuous with the supramarginal convolution. Inferiorly, continuous with the middle temporosphenoidal convolution. Posteriorly, connected with the occipital lobe by the annectant convolutions.

Connect the occipital with the temporo-sphenoidal and parietal lobes.

Joins the superior occipital convolu. tion with the superior parietal lobe.

Connects the angular and middle convolutions.

Internally, olfactory lobe.

Hippocampal and amygdaline fissures.

Above, parieto-occipital fissure. $\mathrm{Be}$ low, calcarine fissure

Above, the taenia hippocampi; terminates in the notch of the uncinate gyrus

Anteriorly, post-calcarine fissure. 
TABLE OF CONVOLUTIONS OR GYRI OF THE CEREBRUM.-Continued.

\begin{tabular}{|c|c|c|}
\hline NAME. & LOCATION. & BOUNDARIES. \\
\hline Fornicate. & $\begin{array}{l}\text { Median surface of cerebrum, immediately above } \\
\text { the corpus callosum. }\end{array}$ & $\begin{array}{l}\text { Above, calloso-marginal fissure. In- } \\
\text { ternally, great longitudinal fissure. } \\
\text { Below, corpus callosum. }\end{array}$ \\
\hline Frontal. & See Frontal, ascending. & \\
\hline Frontal, ascending. & Frontal lobe. & $\begin{array}{l}\text { Above and below, generally continuous } \\
\text { with the ascending parietal convolu- } \\
\text { tion. Posteriorly, fissure of Rolando. } \\
\text { Anteriorly, precentral and supercen- } \\
\text { tral fissures. }\end{array}$ \\
\hline Frontal, first. & See Frontal, superior. & \\
\hline Frontal, inferior. & $\begin{array}{l}\text { Frontal lobe, lower and outer portion. U-shaped } \\
\text { convolution; forms an essential part of Broca's } \\
\text { speech-center. }\end{array}$ & $\begin{array}{l}\text { Above, subfrontal fissure. Posleriorly, } \\
\text { the ascending frontal convolution. } \\
\text { Anteriorly, becomes the posterior } \\
\text { orbital convolution. }\end{array}$ \\
\hline Frontal, lower. & See Frontal, inferior. & \\
\hline Frontal, middle. & See Frontal, second. & \\
\hline Frontal, second. & $\begin{array}{l}\text { Frontal lobe between the superior and inferior } \\
\text { frontal convolutions. }\end{array}$ & $\begin{array}{l}\text { Posteriorly, continuous with the as- } \\
\text { cending frontal convolution. Ante- } \\
\text { riorly, continuous with the middle } \\
\text { orbital convolution. Above, super- } \\
\text { frontal fissure. Below, subfrontal } \\
\text { fissure. }\end{array}$ \\
\hline Frontal, straight. & See Rectus. & \\
\hline Frontal, superior. & Frontal lobe. & $\begin{array}{l}\text { Posteriorly, continuous with ascend- } \\
\text { ing frontal c. Anteriorly, continuous } \\
\text { with the internal orbital. Its mesal } \\
\text { surface is called the marginal c. } B e- \\
\text { low, the superfrontal fissure. }\end{array}$ \\
\hline Frontal, third. & See Frontal, inferior. & \\
\hline Frontal, transverse. & See Frontal, ascending. & \\
\hline Frontal, upper. & See Frontal, superior. & \\
\hline Fronto-marginal. & Frontal lobe of cerebrum, median aspect. & $\begin{array}{l}\text { Above, fronto-marginal fissure. Below, } \\
\text { supercallosal fissure. }\end{array}$ \\
\hline Fronto-parietal, middle. & See Frontal, superior. & \\
\hline Fusiform. & See Subcollateral. & \\
\hline Geniculate. & $\begin{array}{l}\text { "Passes from the anterior extremity of the forni- } \\
\text { cate convolution over the upper surface of the } \\
\text { callosum, becoming the medial and lateral } \\
\text { strize Lancisi." }\end{array}$ & \\
\hline Glossiform. & See Subcalcarine. & \\
\hline Hippocampal. & $\begin{array}{l}\text { Extends from the splenium, dipping behind and } \\
\text { below the callosum, and continuing forward to } \\
\text { the uncinate convolution. }\end{array}$ & $\begin{array}{l}\text { The hippocampal and collateral fis- } \\
\text { sures. Anteriorly, the uncinate con- } \\
\text { volution. Posteriorly, the splenium. }\end{array}$ \\
\hline Infero-frontal. & See Subfrontal. & \\
\hline Inflected. & $\begin{array}{l}\text { A V-shaped convolution about the inflected fis- } \\
\text { sure. }\end{array}$ & \\
\hline Infra-marginal. & $\begin{array}{l}\text { Temporo-sphenoidal lobe, the superior convolu- } \\
\text { tion. }\end{array}$ & $\begin{array}{l}\text { Above, the Sylvian fissure. Below, the } \\
\text { super-temporal or parallel fissure. }\end{array}$ \\
\hline Insular. & $\begin{array}{l}\text { One of a group of small convolutions that form } \\
\text { the island of Reil. }\end{array}$ & \\
\hline Insular, long. & $\begin{array}{l}\text { A portion of the insula; recognized by its length } \\
\text { and horizontal direction. }\end{array}$ & \\
\hline Intercentral. & $\begin{array}{l}\text { The convolution between the two parallel central } \\
\text { fissures, in the rare cases in which two co-exist. }\end{array}$ & The parallel central fissures. \\
\hline Internal. & See Fornicate. & \\
\hline Lingual. & See Subcalcarine. & \\
\hline Longitudinal, superior internal. & See Fornicate. & \\
\hline Marginal. & Frontal lobe. & $\begin{array}{l}\text { Internally, longitudinal fissure. Infe- } \\
\text { riorly, the calloso-marginal fissure. } \\
\text { Posteriorly, the calloso-marginal fis- } \\
\text { sure and fissure of Rolando. }\end{array}$ \\
\hline
\end{tabular}


TABLE OF CONVOLUTIONS OR GYRI OF THE CEREBRUM.-Continued.

\begin{tabular}{|c|c|c|}
\hline NAME. & LOCATION. & BOUNDARIES. \\
\hline Marginal, external. & See Fornicate. & \\
\hline Marginal, inferior. & See Supertemporal & \\
\hline Marginal, internal. & $\begin{array}{l}\text { The lamina of the septum lucidum and dentate } \\
\text { convolution. }\end{array}$ & $\begin{array}{l}\text { Above and externally, by the fornicate } \\
\text { convolution. }\end{array}$ \\
\hline Medifrontal. & See Frontal, second. & \\
\hline Medio-parietal, transverse. & See Parietal, ascending. & \\
\hline Meditemporal. & $\begin{array}{l}\text { Middle of temporal lobe; a small horizontal con- } \\
\text { volution. }\end{array}$ & $\begin{array}{l}\text { Above, the supertemporal fissure. Be- } \\
\text { low, meditemporal fissure. Posteri- } \\
\text { orly, continuous with the angular } \\
\text { convolution. }\end{array}$ \\
\hline Mendel's. & See Opercular. & \\
\hline $\begin{array}{l}\text { Nuclear; also called Rauber's con- } \\
\text { volution. }\end{array}$ & A fold of gray matter in the olivary body. & \\
\hline Occipital, fifth. & $\begin{array}{l}\text { Occipital lobe (of gorilla) Corresponds to the } \\
\text { lingual convolution of man. }\end{array}$ & \\
\hline Occipital, first. & See Occipital, superior. & \\
\hline Occipital, fourth. & $\begin{array}{l}\text { Occipital lobe (of gorilla). Corresponds to the } \\
\text { fusiform of man. }\end{array}$ & \\
\hline Occipital, inferior. & Occipital lobe. & $\begin{array}{l}\text { Above, middle occipital fissure. Below, } \\
\text { inferior occipital fissure. Anteriorly, } \\
\text { continuous with middle temporo- } \\
\text { sphenoidal convolution. }\end{array}$ \\
\hline Occipital, lower. & See Occipital, inferior. & \\
\hline Occipital, middle. & $\begin{array}{l}\text { Occipital lobe, between the first and third occi- } \\
\text { pital convolutions. }\end{array}$ & $\begin{array}{l}\text { Superiorly, transverse occipital fis- } \\
\text { sure. Inferiorly, inferior longitudi- } \\
\text { nal and occipital fissures. Internally, } \\
\text { the median longitudinal fissure. Ex- } \\
\text { temally or anteriorly, it runs into the } \\
\text { angular gyrus. }\end{array}$ \\
\hline Occipital, second. & See Occipital, middle. & \\
\hline Occipital, superior. & $\begin{array}{l}\text { Occipital lobe, superior surface, upper convolu- } \\
\text { tion. }\end{array}$ & $\begin{array}{l}\text { Connected with the superior parietal } \\
\text { by the annectant gyrus. }\end{array}$ \\
\hline Occipital, third. & See Occipital, inferior. & \\
\hline Occipital, upper. & See Occipital, superior. & \\
\hline Occipito-temporal. & Lower surface of temporo-sphenoidal lobe. & \\
\hline Occipito-temporal, inferior. & See Subcollateral. & \\
\hline Occipito-temporal, lateral. & See Subcollateral. & \\
\hline Occipito-temporal, middle. & See Subcalcarine. & \\
\hline Occipito-temporal, superior. & See Subcalcarine. & \\
\hline Olfactory. & $\begin{array}{l}\text { Arises in the anterior perforated space, passing } \\
\text { forward in the olfactory sulcus, and ending in } \\
\text { the olfactory bulb. }\end{array}$ & \\
\hline Olfactory, external. & The lateral root of the olfactory tract. & Internally, the olfactory groove. \\
\hline Olfactory, internal. & $\begin{array}{l}\text { Frontal lobe; the ridge along the inner side of the } \\
\text { olfactory groove. The internal root of the ol- } \\
\text { factory tract. }\end{array}$ & \\
\hline $\begin{array}{l}\text { Opercular; also called Mendel's con- } \\
\text { volution. }\end{array}$ & Frontal lobe. & Enters into the operculum. \\
\hline Of the operculum. & See Breves. & \\
\hline Orbital. & $\begin{array}{l}\text { Frontal lobe; small convolutions on the orbital } \\
\text { surface. }\end{array}$ & \\
\hline Orbital, anterior. & Frontal lobe. & $\begin{array}{l}\text { Continuous with the middle frontal } \\
\text { convolution. Posteriorly, orbital sul } \\
\text { cus. }\end{array}$ \\
\hline Orbital, external. & See Frontal, inferior. & \\
\hline Orbital, internal. & Frontal lobe. & Internally, the rectus convolution. \\
\hline
\end{tabular}


TABLE OF CONVOLUTIONS OR GYRI OF THE CEREBRUM.-Continued.

\begin{tabular}{l} 
NAME. \\
Orbital, lateral. \\
\hline Orbital, middle. \\
\hline Orbital, posterior. \\
Orbital, transverse. \\
\hline Paracentral. \\
\hline Pararolandicus. \\
\hline Parietal. \\
\hline Parietal, ascending. \\
\hline Parietal, middle. \\
\hline Parietal, posterior. \\
\hline
\end{tabular}

See Parietal, superior.

See Subparietal.

See Angular.

See Parietal, ascending.

See Angular and Subparietal.

Parietal lobe.

Parietal, third

Parietal, upper.

Parieto-occipital, lateral

Parieto-occipital, middle (of Schwalbe)

Paroccipital.

Post-central

Postcruciate.

Posterior, inferior (of Arnold).

Postero-parietal

Post-frontal.

Postrolandicus.

Precentral.

Precruciate.

Prefrontal.

Preorbital.

Prerolandicus.

Quadrate.

See Marginal.

See Parietal, superior.

See Occipital, middle.

Occipital lobe; the dorsal surface of the superior occipital convolution.

Occipital and parietal lobes; U-shaped, curving around the dorsal end of the occipital fissure.

See Parietal, ascendine.

Posterior portion of the sigmoid convolution.

Occipito-temporal lobe, ventral aspect.

See Parietal, ascending

See Post-cruciate.

See Parietal, ascending.

See Frontal, ascending.

In the dog's brain, the convolution lying in front of the cruciate fissure.

\section{See Precruciate.}

Prefrontal lohes at junction of frontal and orbital aspects of the cerebrum.

See Frontal, ascending.

Parietal lobe of cerebrum, median surface.

Rauber's.

See Nuclear.

Rectus.

Frontal lobe, orbital aspect.

BOUNDARIES.

The ventral portion of the subfrontal convolution.

Internally, the internal orbital convolution.

Anteriorly and internally, the orbital fissure. Continuous with the inferior frontal convolution.

Below, the paracentral fissure. Dorsal, the precuneus.

Anteriorly, fissure of Rolando. Posteriorly, intraparietal fissure. Below, fissure of Sylvius. Above and beloze, usually continuous with the ascendusually continuous with the ascendsuperior parietal convolutions.

Continuous anteriorly with ascending frontal (generally). Anteriorly, upper part of fissure of Rolando. Posteriorly, the external parieto-occipital fissure. Inferiorly, the intraparietal fissure.

Laterally, the paroccipital fissure. Mesially, the margin of the cerebrum.

Posterionly, the cruciate fissure.

Caudad, preorbital (or orbito-frontal) fissure.

Anteriorly. calloso-marginal fissure. Posteriorly, the parieto-occipital fissure. Below, continuous with the fornicate convolution.

Between the olfactory fissure and the mesial margin. 
TABLE OF CONVOLUTIONS OR GYRI OF THE CEREBRUM.-Continued.

\begin{tabular}{|c|c|c|}
\hline NAME. & LOCATION. & BOUNDARIES. \\
\hline Retrocentral. & See Parietal, ascending. & \\
\hline Rolandicus, anterior. & See Precentral. & \\
\hline Rolandicus, posterior. & See Post-central. & \\
\hline Sagittal. & In Edentata, the longitudinal convolution. & Lies next to the longitudinal fissure. \\
\hline Of Schwalbe. & See Parieto-occipital, middle. & \\
\hline Sigmoid. & $\begin{array}{l}\text { A U-shaped convolution, including important } \\
\text { motor areas. }\end{array}$ & Surrounding the cruciate fissure. \\
\hline Straight. & See Rectus. & \\
\hline Subcalcarine. & $\begin{array}{l}\text { Occipital and temporal lobes; a narrow convolu- } \\
\text { tion. }\end{array}$ & $\begin{array}{l}\text { Above, calcarine fissure, Below, col- } \\
\text { lateral fissure. Peripherad, the cu- } \\
\text { neus. }\end{array}$ \\
\hline Subcallosal (of Zuckerkandl). & Mesial aspect of cerebrum. & $\begin{array}{l}\text { Reaches from the chiasm to the ros- } \\
\text { trum. }\end{array}$ \\
\hline Subcollateral. & Temporal lobe; the fusiform lobules of the brain. & $\begin{array}{l}\text { Connects the occipital and temporal } \\
\text { lobes. Above, collateral fissure. } B e \text { - } \\
\text { low, subtemporal fissure. }\end{array}$ \\
\hline Subfrontal. & See Frontal, inferior. & \\
\hline Subparietal. & Parietal lobe. & $\begin{array}{l}\text { Above, parietal fissure. Anterionly, } \\
\text { continuous with the marginal and } \\
\text { angular convolutions. Posteriorly, } \\
\text { the paroccipital fissure. }\end{array}$ \\
\hline Subtemporal. & See Temporal, inferior. & \\
\hline Superfrontal. & See Frontal, superior. & \\
\hline Superior. & See Temporo-sphenoidal, superior. & \\
\hline Supertemporal. & See Infra-marginal. & \\
\hline Supra-marginal. & Inferior parietal lobe, anterior portion. & $\begin{array}{l}\text { Anteriorly, the inferior extremity of } \\
\text { the intraparietal fissure. Below, con- } \\
\text { tinuous with the ascending parietal } \\
\text { and superior temporo-sphenoidal } \\
\text { convolutions. }\end{array}$ \\
\hline Supra-orbital. & See Frontal, inferior. & \\
\hline Supra-sylvian. & The third external convolution of the dog. & \\
\hline Sylvian. & $\begin{array}{l}\text { In Marsupials, the portion of the brain surround- } \\
\text { ing the fissure of Sylvius. }\end{array}$ & \\
\hline Temporal, first. & See Infra-marginal. & \\
\hline Temporal, inferior. & $\begin{array}{l}\text { Temporo-sphenoidal lobe; the lowest of the three } \\
\text { convolutions. }\end{array}$ & $\begin{array}{l}\text { Posteriorly, connected with the third } \\
\text { occipital convolution. Above, the } \\
\text { meditemporal fissure. Below, the } \\
\text { subtemporal fissure. }\end{array}$ \\
\hline Temporal, inframarginal. & See Temporo-sphenoidal, superior. & \\
\hline Temporal, lateral inferior. & See Temporal, inferior. & \\
\hline Temporal, lower. & See Temporo-sphenoidal, inferior. & \\
\hline Temporal, middle. & See Meditemporal. & \\
\hline Temporal, second. & See Meditemporal. & \\
\hline Temporal, superior. & See Infra-marginal. & - \\
\hline Temporal, third. & See Subtemporal. & \\
\hline Temporal, transverse. & $\begin{array}{l}\text { Temporal lobe, ental surface; a number (2 to } 4) \\
\text { of short convolutions near its extremity. }\end{array}$ & \\
\hline Temporal, upper. & See Infra-marginal. & . \\
\hline Temporo-occipital. & See Occipital, inferior. & \\
\hline Temporo-occipital, internal. & See Fusiform. & \\
\hline Temporo-occipital, middle. & See Calcarine. & \\
\hline Temporo-sphenoidal, first. & See Temporo-sphenoidal, superior. & \\
\hline
\end{tabular}


TABLE OF CONVOLUTIONS OR GYRI OF THE CEREBRUM.-Continued.

\begin{tabular}{|c|c|c|}
\hline NAME. & LOCATION. & BOUNDARIES. \\
\hline Temporo-sphenoidal, inferior. & See Temporal, inferior. & \\
\hline Temporo-sphenoidal, middle. & See Meditemporal. & \\
\hline Temporo-sphenoidal, superior. & See Infra-marginal. & \\
\hline Transeundus. & See Transitional. & \\
\hline Transitional. & A small convolution. & $\begin{array}{l}\text { Anteriorly, the ascending branch of } \\
\text { the fissure of Sylvius. }\end{array}$ \\
\hline Transverse. & See Frontal, ascending. & \\
\hline Triangular. & Frontal lobe. & Posteriorly, the opercular convolution. \\
\hline Unciform. & See Breves. & \\
\hline Uncinate. & Temporo-sphenoidal lobe (median surface). & $\begin{array}{l}\text { Above, the calcarine and dentate fis- } \\
\text { sures. Below, the collateral fissure. } \\
\text { Internally, the great longitudinal fis- } \\
\text { sure. }\end{array}$ \\
\hline Vaulted. & See Fornicate. & \\
\hline Of Zuckerkandl. & See Subcallosal. & \\
\hline
\end{tabular}

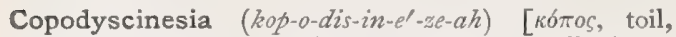

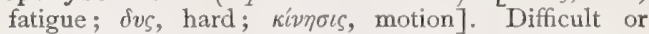
faulty motion due to constant repetition of the same act. Lewis's term for the so-called Fatigue-diseases.

Copopsia (ko-pop'-se-ah). See Copiopia.

Copos $\left(k o p^{\prime}-o s\right)$ [ $\kappa 6 \sigma o \varsigma$, fatigue]. I. Lassitude; exhaustion after illness. 2. Cramp in the calves of the legs.

Copper $\left(k o p^{\prime}-e r\right)$ [ME., coper, copper]. Cuprum. A reddish-brown metal not used in medicine in its metallic form, but represented by several salts. The latter are gastro-intestinal irritants, producing nausea and emesis. See Elements, Table of. C. acetate, $\mathrm{Cu}\left(\mathrm{C}_{2} \mathrm{H}_{3} \mathrm{O}_{2}\right)_{2}$, verdigris, used in pulmonary diseases, and as a lotion in skin-diseases. Dose gr. $\frac{1}{10} \frac{1}{4}$. C. aceto-arsenite, Paris Green, used as a pigment and an insecticide. C. ammoniate, unof, ammonium carbonate 3, copper sulphate 4 parts. Useful in chorea, hysteria, etc. Dose gx. $1 / 6-j$. C. arsenite, a salt valuable in intestinal diseases. Dose gr. $\frac{1}{100}$. C. nitrate (B. P.), $\mathrm{Cu}\left(\mathrm{NO}_{3}\right)_{3} \mathrm{H}_{2} \mathrm{O}$, is used for the same purposes as the sulphate. C. sulphate, $\mathrm{CuSO}_{4} \cdot 5 \mathrm{H}_{2} \mathrm{O}$, soluble in water, valuable as an emetic. Dose, as an emetic, gr. $i j-v$, as a tonic, gr. $1 / 6-1 / 2$. C. Amalgam, a metallic filling-material composed of chemically pure copper and redistilled mercury. C.-colic. See Colic. C.-glass. Same as Egyptian Blue. C.-green. Same as Malachite-green. C. Indigo. Same as Oil Blue. C. Lazulite. Same as Azurite. C.-nose. Synonym of Acne rosacea. C., Potassio-tartrate Sol., Fehling's solution, unof., copper sulphate gr. 7o, distilled water $\eta_{400}$; also dissolve Rochelle salt, gr. 488 , in water $m$ I600; when required, mix and add water to make $m$ 2720. Used as a test for glucose.

Copperas (kop'-er-as) [cupri rosa, rose of copper (?) ]. A common name for ferrous sulphate. See Ferrum.

C.- black. See Pigments, Conspectus of.

Coppice-bark (kop'-is-bark). See Oak-bark.

Copra (kop'-rah) [Hind.]. The dried and crushed kernel of the cocoa-nut, from which cocoa-oil is expressed.

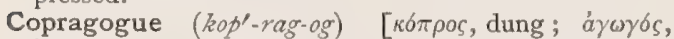
leading]. A remedy to carry off feces; a purgative.

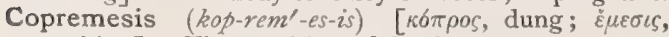
vomiting]. The vomiting of fecal matter.

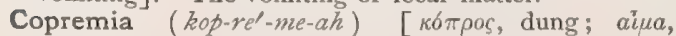
blood]. A form of general blood-poisoning arising from absorption of unduly retained feces. This condition is occasionally met with in chronic constipation. The symptoms are anemia, sallow complexion, anorexia, frontal headache, vertigo, nausea, flatulence, thirst, lithemia, fetid breath, lassitude, hypochondriasis, and irritability of temper.

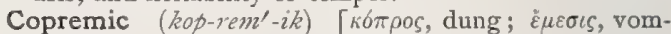
iting]. Relating to or affected with copremia.

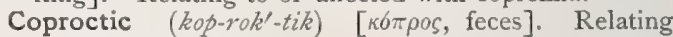
to feces; fecal.

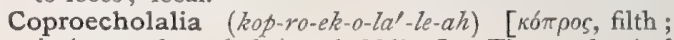

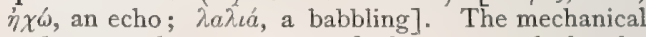
and purposeless utterance of obscene words by the insane.

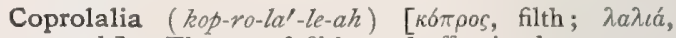
speech]. The use of filthy and offensive language as a manifestation of disease. See Habit-spasm.

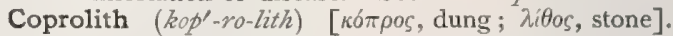
A hard mass of fecal matter in the bowels.

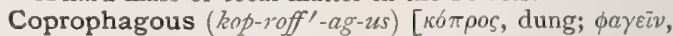
eat]. In biology, applied to dung-feeding beetles.

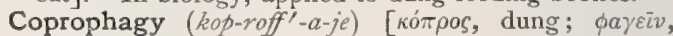
to eat]. The eating of ordure; a symptom sometimes seen in insane and hysterical patients.

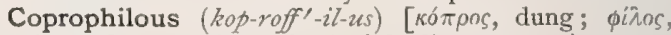
loving]. In biology, fond of feeding or growing upon dung.

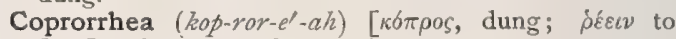
flow]. Synonym of Diarrhea.

Coprostasia (kop-ro-sta'-se-ah). See Coprostasis.

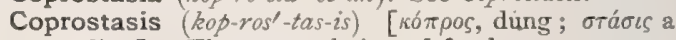
standing]. The accumulation of fecal matter; arrest of the onward movement of fecal matters.

Coptin $\left(k o p^{\prime}-\operatorname{tin}\right)[\kappa 6 \pi \tau \varepsilon \iota \nu$, to cut]. A colorless alkaloid of Goldthread. See Coptis

Coptis (kop'-tis) [ $[\kappa \delta \pi \tau \varepsilon v v$, to cut]. Goldthread. The root of $C$. irifolia, a simple bitter tonic resembling quassia. It contains coptin, an alkaloid closely allied to berberin. Dose gr. $\mathrm{x}-\mathrm{xxx}$.

Copula $(k o p$ 'u-lah) [L., "a band" ]. I. The copula alba cerebri, an anterior commissure of the cerebrum. 2. A thin lamina joining the rostrum with the terma.

Copulation (kop-u-la'-shun) [copulare, to couple]. The act of sexual intercourse.

Copyopia (kop-e-o'-pe-ah). See Copiopia. 
Coqueluche $\left(k \bar{o} k-l \bar{u} s h^{\prime}\right)$ [Fr., a hood or cowl]. Synonym of Infuenza; also of Whooping-cough.

Coquet or Coquette $\left(k o-k e l^{\prime}\right)$ [Fr.]. Synonym of Influ'nza.

Coquilles $\left(k o-k e l^{\prime \prime}\right)$ [Fr.]. A variety of dark eyeglasses curved like shells.

Cor (kor) [L.; gen., cordis]. The heart. See Heart. In biology, according to Crsalpino, the seat of the principle of life in plants. See R'oot-neck. C. adiposum, a heart with a simple excess of the normal subpericardial fat. C. biloculare, reptilian heart; a congenital condition in which there is absence or deficiency of the septa of both cardiac auricles and ventricles. C. bovinum. See Bovine Heart. C. seminis, the heart of the seed; the corcle or corcule. C. villosum, hairy heart; the peculiar shaggy appearance presented by the heart in acute plastic pericarditis, with the deposited fibrin existing in long shreds.

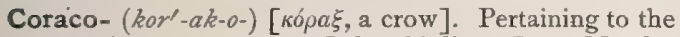
coracoid process, as C.-brachialis. See Muscles, Table of.

Coracoid (kor'-ak-oid) [ $\kappa o p a \xi$, a crow; $\varepsilon i \delta o s$, likeness]. I. Having the shape of a crow's beak. 2. The coracoid process. C. Ligament, a triangular ligament joining the coracoid process to the acromion.

Process, a beak-shaped process of the scapula.

Coracopectoralis (kor-ak-o-pek-tor-a'-lis) [кó $\rho a \xi$, a crow; pectus, the breast]. The pectoralis minor muscle. See Muscles, Table of.

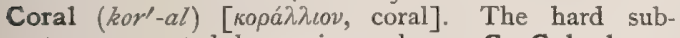
stance secreted by marine polyps. C. Calculus, a peculiar dendritic form of calculus found in the pelvis of the kidney, and forming a complete mold of the infundibula and calices.

Coral Root (kor'-al root). Crawley. The root of Corallorhiza odontorhiza, a prompt and powerful diaphoretic that is used in fevers. Dose gr. xxx.

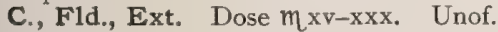

Coralliform (kor-all'-if-orm) [corallum, coral; forma, shape]. In biology, resembling coral.

Corallin (kor'-al-in) [corallinus, coral-red]. A coloring-matter derived from rosolic acid and alcoholic ammonia. It is used for dyeing red, and is noteworthy as being a cause of local and general poisoning, and it is liable to lead to cutaneous and constitutional affections in those who wear garments dyed with it. Some observers ascribe its ill-effects to an arsenical admixture. C.-red. See Pigments, Conspectus of. C.-yellow. See Pigments, Conspectus of.

Corallite (kor'-al-itt) [corallum, coral]. In biology, the calcareous calyx or cup of a single coral polyp.

Corbiculum (kor-bik'-u-lum) [corbis, a basket]. In biology, applied to the pollen-basket or the inner side of the tarsus of a bee.

Cord [chorda, a string]. Used as a synonym for the Umbilical Cord, the vascular, cord-like structure connecting the placenta and fetus. C., Coiling of, loops about the fetus or its members. C., Columns of. See Columns. C., False or Superior (vocal), a fold of mucous membrane on either side of the middle line of the larynx, inclosing the superior thyro-arytenoid ligament. C., Knots of, real knots of the cord formed by the passage of the fetus through a loop. False Knots, accumulations of Wharton's jelly at particular points. C., Presentation of, descent of the cord, at the beginning of labor, between the presenting part and the membranes. C., Prolapse of, descent at the rupture of the bag of waters; incomplete, if remaining in the vagina, complete, if protruding therefrom. C., Spinal. See Spinal Cord. C., Torsion of, twisting upon its axis. The blood-vessels of the cord make about 40 spiral turns. C., Vocal. See Vocal Band. C. of Weitbrecht, the orbicular ligament of the elbow. See also Chorda.

Corda (kor'-dah). See Chorda. C. valvuleux, Dufour's term for the cecal pouches or pancreatic organs invariably and normally loaded with bacteria (Micrococcus insectorum, Burrill) in certain families of the higher Hemiptera (Pentatomida, Scutellerida, Corimelenida); invariably wanting in the lower Hemiptera.

Cordial (kor'-jal) [cor, the heart]. I. Pertaining to the heart; exhilarant; stimulant. 2. An aromatic, spirituous stimulant.

Cordiale $\left(k o r-d e-a^{\prime}-l e\right)$ [L. ]. A cordial. C. rubi fructus. See Blackberry Cordial.

Corditis (kor-di'-tis). See Chorditis.

Cordon (kor'-don) [Fr., a cord or rope]. A chain of posts to enforce a quarantine against a place infected with an epidemic disease.

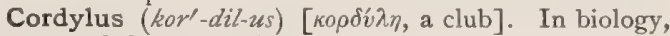
one of the tentacular "auditory clubs" of Hydromeduse.

Core (kor) [ME., core, a core]. I. The central slough of a boil or carbuncle. 2. The axial or central portion of the terminal corpuscle in a nerve. 3. A bundle of soft iron wires used as a magnet in the center of a coil.

Coreclisis (kor-ek-li'-sis). See Coroclisis.

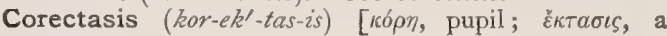
stretching out]. Dilatation of the pupil.

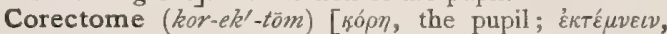
to cut out]. An instrument used in iridectomy.

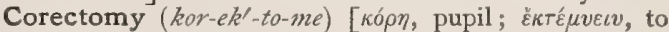
cut out]. See Iridectomy, and Pupil, Artificial.

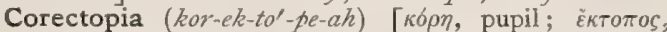
misplaced]. An anomalous position of the pupil; displacement of the pupil.

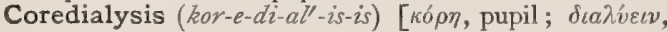
to liberate]. The production of an artificial pupil at the ciliary border of the iris.

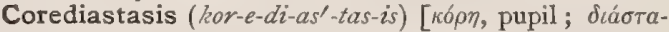
$\sigma \iota s$, dilatation]. Dilatation of the pupil.

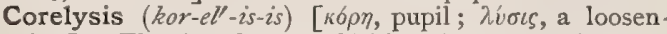
ing]. The detachment of iritic adhesions to the lens, or to the cornea.

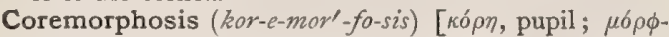

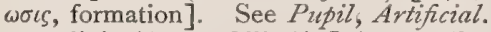

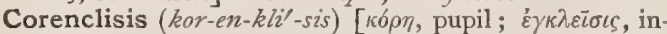
clusion]. The formation of a new pupil by displacement, the iris being drawn aside and in part excised.

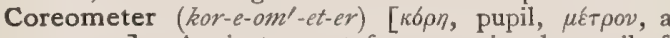
measure]. An instrument for measuring the pupil of the eye.

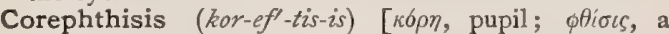
wasting]. See Corophthisis.

Coreplasty (kor'-e-plas-te). See Pupil, Artificial.

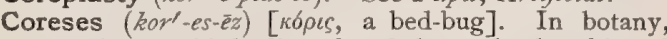
reddish discoid bodies found beneath the skin of grapes.

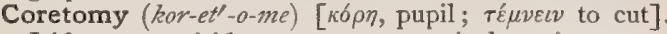
Iridotomy or iridectomy; any surgical cutting operation on the iris.

Coriaceous (kor-e-a'-she-us) [corium, leather]. In biology, leathery.

Coriamyrtin (ko-re-am-er'tin) [corium, a hide; myrtus, myrtle]. An exceedingly poisonous principle, a glucosid, obtained from the fruit of Coriaria myrtifolia.

Coriander, or Coriandrum (ko-re-an'-der, ko-re-an'drum) [kopiavvov, coriander]. Coriander. The fruit of $C$. sativum, an aromatic carminative and stimulant, used mainly to give flavor to other remedies and as a corrective to griping purgatives. Dose gr, $\mathrm{x}-\mathrm{xx}$. C., O1, the volatile oil. Dose $m i j-\nabla$. 
Coriaria (ko-re-a'-re-ah) [L.]. A genus of poisonous shrubs of several species, having a wide geographic distribution. C. myrtifolia, used in dyeing and tanning, has poisonous berries and shoots. The seeds and shoots of C. sarmentosa of New Zealand afford what is called toot-poison. The memory is said to be impaired after recovery from poisoning by this plant. Unof.

Corium $\left(k o^{\prime}-r e-u m\right)$ [L., leather]. The deep layer of the cutis.

Cork (kork) [cortex, bark]. A substance obtained from the outer part of the sub-epidermic bark of certain oaks, as Quercus ruber and Q.occidentalis, of the Mediterranean region; extensively used in pharmacy, and to some extent in surgery. C.-oak. See Oakbark. C.-black. See Pigments, Conspectus of.

Corm (korm) [kopuos the trunk of a tree]. The bulbous underground part of certain plants, as the crocus.

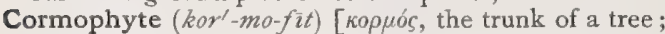
$\phi v \tau o ́ v$ a plant]. In biology, a term formerly applied to vascular cryptogams and flowering plants-to all plants possessing roots, stems and leaves.

Cormus (kor'-mus) [cormus, a tree-trunk: pl., Cormi]. In biology, a colony of animals, associated "personæ." See Corm.

Corn [cornu, horn]. A local induration and thickening of the skin from friction or pressure. See Clavus. C.-flower. See Centaurea. C.-plaster, a thick plaster worn over a corn, sometimes as a direct curative agent, and sometimes to prevent pressure and friction from the shoe. C.-silk, the long, thread-like styles of Indian corn, gathered while still green and succulent. It is used occasionally to relieve the pain and spasm of chronic and subacute cystitis, and is also recommended for gonorrhea, gravel, rbeumatism, gout, etc. Dose of the tincture 3 ss to j. See Zea mays. C.-smut. See Ustilago. C.-starch, the commercial name of a starch derived from maize, and extensively used as an article of food, especially for invalids.

Cornalia's Corpuscles. See Bacteria, Synonymatic Table of.

Cornalian Corpuscles. See Bacteria, Synonymatic Table of.

Corne's Test. See Tests, Table of.

Cornea (kor'-ne-ah) [corneus, horny]. The transparent anterior portion of the eyeball, its area occupying about one-sixth the circumference of the globe. It is continuous with the sclerotic, and is nourished by lymph from the looped blood-vessels at its peripheral border. It is lined posteriorly by Descemet's membrane; the conjunctiva is firmly adherent to its substance in front. C., Conical. See Keratoglobus. C., Leukoma of. See Leukoma. C., Tattooing of. See Tattooing. C., Transplantation of, the operation of engrafting a section of transparent cornea from some animal into the space of an excised portion of leukomatous human cornea.

Corneal (kor'-ne-al) [corneus, horny]. Relating to the cornea. C. Reflex. See Reflexes, Table of.

Cornein (kor'-ne-in) [corneus, horny], $\mathrm{C}_{30} \mathrm{H}_{44} \mathrm{~N}_{9} \mathrm{O}_{11}$. The skeleton of gorgonia and certain corals.

Corneitis (kor-ne-i'tis). See Keratitis.

Corneocalcareous (kor-ne-o-kal-ka'-re-us) [corneus, horny; calcareus, pertaining to lime]. In biology, formed of a mixture of horny and calcareous substances.

Corneosilicious (kor-ne-o-sil is $\left.h^{\prime}-u s\right)$ [comeus, horny; siliceus, pertaining to flint]. In biology, applied to sponges containing both horny and silicious substances.

Corneaus (kor'-ne-us) [corneus, horny]. Horny, or horn-like. C. Tissue, the substance of the nails.

Cornet (kor-net') [cornu, a horn]. A small ear-trum- pet worn within the auricula, and sometimes concealed by the hair of the wearer.

Cornic Acid (kor'-nik). See Cornin.

Cornicle (kor'-nik-l) [corniculum, dim. of cornu, a horn]. In biology, one of the horn-like excretory ducts on the back of a plant-louse.

Corniculum (kor-nik'-u-lum) [cornicula, a little horn: pl., Cornicula]. A small cornu or horn-like process. C. laryngis, a small, horn-shaped mass of cartilage on the arytenoid cartilages; called also the Cartilages of Santorini.

Cornification (kor-nif-ik-a'-shun) [corneus, horny; facere, to make]. The process of hardening or making horny.

Corniform (kor'-nif-orm) [cornu, a horn; forma, shape]. In biology, shaped like the horn of an ox.

Cornin (kor'-nin) [corneus, horny]. A precipitate from the tincture of the bark of Dogwood, Cornus forida; it occurs in white, silky, bitter crystals, and is a tonic, stimulant, and astringent. Dose two to four grains. Unof.

Corning's Method. See Treatment, Methods of.

Cornu (kor'-nu) [L.: pl., Cornua]. A horn. A name applied to any excrescence resembling a horn. C. ammonis, the hippocampus major of the brain. C. cervi, hartshorn or ammonium hydrate. C. cutaneum, cornu humanum, a horn or excrescence arising from the skin, with a deeper portion imbedded within. These horns vary in shape and size, and may resemble the horns of lower animals. They are solid, dry, dense, smooth or corrugated, laminated or excavated on the surface, often elongated and conical at the extremity. In color they are white, gray, yellow, brown, or black. They may be single or multiple, and may involve any region of the body, though usually seen on the scalp and face. They are likely to recur on removal. C. humanum. See $C$. cutaneum. C. sacri, the prominence on each bone of the sacrum.

Cornual (kor'-nu-al) [cornu, a horn]. Relating to a cornu. C. Myelitis, myelitis affecting the anterior cornua of the spinal cord.

Cornuan's Operation. See Operations, Table of

Cornus (kor'-nus) [L.]. Dogwood. The bark of the root of $C$. florida, with properties due to a crystalline principle, cornin. It is a simple stomachic, bitter and somewhat antiperiodic. C., Fld. Ext. Dose $m x-3$ j.

Cornutin (kor-nu'-tin). One of the poisonous basic principles or alkaloids of Ergot. Unof.

Coroclisis, or Corocleisis (ko-ro-kli'-sis) [ $[\kappa o ́ p \eta, p u-$ pil; $\kappa \lambda \varepsilon \tilde{\varepsilon} \sigma \iota \varsigma$, a closure]. Pathologic closure or obliteration of the pupil.

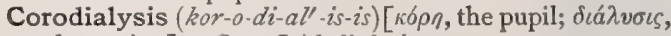
a loosening]. See Iridodialysis.

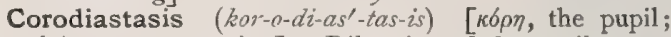

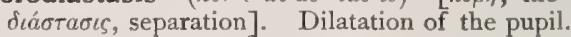

Corolla (ko-rol'-ah) [corolla, dim. of corona, a crown]. In biology, the inner floral envelop.

Corona (ko-ro'-nah) [corona, a garland]. A crown. See, also, Capsula. C. ciliaris, the ciliary ligament. C. dentis, the crown of a tooth, $q . v$. C. glandis, the ridge of the glans penis. C. ovariana, the crescentic area of tympany above the area of dulness in cases of ovarian tumor. C. radiata, a radiating mass of white brain-substance ascending from the internal capsule to the cortex cerebri. C. veneris, a circle of syphilitic blotches occurring on the forehead; sometimes dependent upon caries or inflammation of the frontal bone.

Coronad (kor'-o-nad) [corona, the crown; ad, to]. Toward the coronal aspect of the head.

Coronal (kor-o'-nal) [corona, the crown]. Pertaining to the crown of the head. C. Intestine. See 
Perogaster. C. Suture, the suture joining the frontal with the two parietal bones.

Coronamen (kor-o-na'-men) [L., a crowning: $p l$, Coronamina]. Same as Coronet.

Coronary (kor'-o-na-re) [corona, a crown]. A term applied to vessels, nerves, or attachments that encircle a part or organ. C. Bone, the small pastern or median phalanx of a horse's foot.

Coronate (kor-o-nāt) [coronatus, to crown]. In bi ology, provided with a crown.

Coronen (ko-ro'-nen) [corona, a crown]. Belonging to the corona in itself

Coroner (kor'-o-ner) [coronator, a crown, an officer appointed by the Crown]. An officer who inquires by authority of the law into the causes of deaths of sudden or violent occurrence. C., Inquest of, the legal inquiry before a jury into the cause of a sudden or violent death.

Coronet (kor'-o-net) [Fr., coronette, dim. of corone, a crown]. I. In biology, a crowning circle of hairs. 2. In veterinary surgery, the lowest part of the pastern of the hoof, also called coronamen.

Coronilla (kor-o-nil'-ah) [dim. of corona, a crown]. A genus of leguminous herbs. C. emerus is purgative. C. scorpeoides, abundant in southwestern Europe, has doubtful value in cardiac affections when increased amplitude of pulsation is required. C. varia is diuretic, purgative, and poisonous. Unof.

Coronillin (kor-o-nil'-in) [dim. of corona, a crown]. A glucosid from Coronilla scorpeoides; it is said to be a diuretic cardiant.

Corono-basilar (kor-o-no-ba'-sil-ar) [corona, a crown; basis, the base]. Extending from the coronal suture to the basilar aspect of the head.

Coronofacial (kor-o-no-fa'-shal) [corona, crown; facies, face]. Relating to the crown of the head and to the face.

Coronoid (kor'-o-noid) [corona, crown; Eldos, likeness]. Crown-shaped; as the c. process of the ilna or of the jaw.

Coronule (kor'-o-nül) [coronula, dim. of corona, a crown]. In biology, the tuft of down forming a crown to certain seeds.

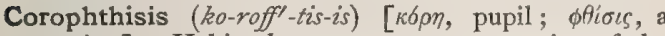
wasting]. Habitual or permanent contraction of the pupil due to a wasting disease of the eye.

Corpora (kor'-por-ah) [pl. of corpus, a body]. A general term applied to certain parts of the body having a rounded or ovoid shape. C. albicantia. See C. mammillaria. C. arantii, the tubercles, one in the center of each segment of the semilunar valves. C. cavernosa, the cylindric bodies of erectile tissue forming the chief part of the penis. Also the two masses of erectile tissue composing the clitoris. See Penis. C. geniculata, two small eminences projecting from the optic thalami. C. libera articulorum. Mures Articulorum; joint - mice ; loose bodies, either fibromatous, lipomatous, or chondromatous in nature, occurring occasionally in $\mathbf{Z}$ joints. They vary in size from that of a pea to that of a walnut, and are of all shapes. They are most frequent in the knee-joint.

They are of traumatic CORPORA CAVERNOSA AND ADorigin. C. mammilla- JACENT PARTS. (Potter.) ria, Corpora albicantia; I. Corpora cavernosa. 2. Corthe mammillary bodies pus spongiosum. 3. Dorsal of the brain. They are Nerves. 4, Arteries. 5, 5. formed by the spreading out on the sufface of Gud. den's ganglion and an adjoining ganglion of the somewhat interwoven fibers of Gudden's and Vicq d'Azyr's bundles. They form the bulbs of the fornix. C. olivaria, the two oval masses behind the pyramids of the medulla oblongata. C. oryzoidea, the ricelike corpuscles or melon-seed bodies of hygromata. C. pyramidalia, the two bundles of white matter of the medulla oblongata, situated below the pons varolii. C. quadrigemina, the optic lobes of the brain, the four rounded eminences situated under the corpus callosum. The anterior pair are called the nates, and the posterior, the testes. C. restiformia, the large columns or cord-like bodies extending from the medulla to the cerebrum. C. striata, two organs, one in each lateral ventricle of the brain, composed of the caudate and lenticular nuclei. The first, or intraventricular portion, extends into the lateral ventricle. C. wolffiana, the " primordial kidney."

Corporeal (kor-por'-e-al) [corpus, a body]. Pertaining to the body. C. Endometritis. See Endometritis.

Corpse (korps) [ME., corps, a dead body]. See Cadaver. C.-plant, the Monotropa unifora, a singular saprophytic plant of Asia and N. America; it is a popular remedy for epilepsy and for sore-eyes. Unof.

Corpulency (kor'-pu-len-se) [corpulentus, corpulent]. Obesity; fatness of the body.

Corpulent (kor'-pu-lent) [corpulentus, corpulent]. Excessively fat ; obese.

Corpus (kor'-pus) [corpus, a body: pl., Corpora]. A body; the human body. C. of Arantius. See Callosum. C. callosum. See Commissure. C. cavernosum vaginæ, the spongy tissue of the vagina. $C$. candicans, corpus mamillare; a small white tubercle lying on the base of the brain, one on each side under the thalamus. The two form the boundary-point between the fore-brain and inter-brain; each is composed of three nuclei. C. ciliare, the ciliary body of the eye. C. dentatum. See Otiziary Body. Also a ganglion of the cerebellum, an open bag or capsule of gray matter, on section of a dentated outline, and open anteriorly. C. highmorianum, the mediastinum of the testis, a reflection inward of the tunica albuginea into the testicle at its posterior border. C. fimbriatum, the lateral thin edge of the tænia hippocampi. See also Fimbria. C. luteum, the yellow body. Hypertrophy of the membrana propria, or reticulata of the ovisac, after the escape of the ovule. C. L., False, that resulting when pregnancy does not occur, called also the C. L. of Menstruation. C. L., True, that resulting when pregnancy takes place, called also the $\mathrm{C}$. L. of Pregnancy, and differing in several respects from the first. C. mamillare. See Corpus candicans. C. pampiniforme, the parovarium. C.spongiosum, the spongy body enclosing the urethra, etc. C. striatum. See Corpora. C. trapezoides, the arbor of the cerebellum. C. trigonum. See Trigonum vesica. C. uteri. See Uterus. C. vertebræ. See Centrum. C. Vitreum. See Vitreous Humor.

Corpuscle (kor'-pus-l) [dim. of corpus]. A name loosely applied to almost any small, rounded, or oval body. C., Bizzozero's. See Blood-platelets. C. of Blood, the minute, biconcave, flat discs, circular in man, elliptic in the camel, and oval in birds and reptiles. They are distinguished as red and white, or colorless. Red corpuscles have been divided, according to their size, into normoblasts (normal in size), megaloblasts or megalocytes (of excessive size), microblasts or microcytes (abnormally small), and poikiloblasts or poikilocytes (of irregular shape and size). The red corpuscles in the blood of man 
are about $\frac{1}{3 \frac{1}{2}}$ in. in diameter and $\frac{1}{2} \frac{1}{400}$ in. thick. They consist of a colorless stroma (paraglobulin, cholesterin, lecithin, and neurin) infiltrated with coloring-matter (hemoglobin). The white or colorless corpuscles are flattened, binucleated or trinucleated cells, about $\frac{1}{2500}$ in. in diameter, and exist in the ratio of 1 : 400 compared with red corpuscles. They possess contractile power, alter their shape readily, and in general appearance closely resemble amebæ. They are most numerous in venous blood. The colorless corpuscles are variously designated as cosinophile, basophile, neutrophile, mononuclear, polynuclear, lymphocytes, transitional, large, small, etc. C. of Donné. See Colostrum-corpuscles. C., Eichhorst's, a special form of microcyte in the blood of those suffering from pernicious anemia. C., Gluge's, a variety of large cells containing fat-drops, myelin, or detritus. They are called also Compound Granule-Cells and Inflamma-

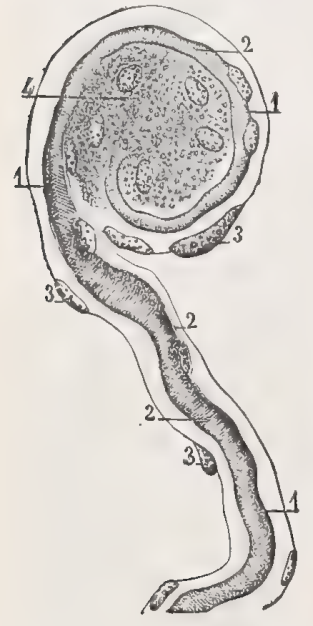

Corpuscle of Krause.

1, I, I. Nerve-tubule. 2, 2. Its medullary substance. $3,3,3$. Nuclei of the sheath of Schwann. 4. Granular substance occupying the center of the corpuscle and the contained nuclei.

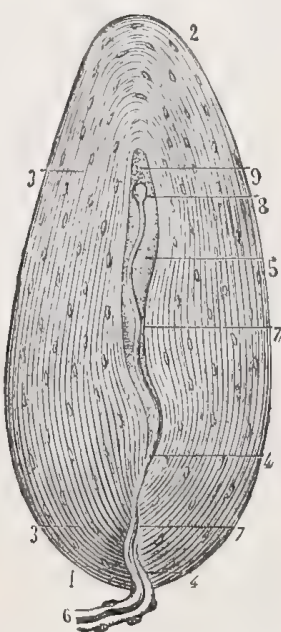

Corpuscle of PACINI.

I. Base, or proximal extremity. 2. Summit, or distal extremity. 3. Capsules displaying nuclei 4. 4. Attachment of capsules to 4, 4. Attachment of capsules to
sheath of nerve-tubule. 5. Cavity of corpuscle. 6 Nerve-tubule. 7,7 . Nerve-tubule successively losing its medullary sheath and neurilemma. 8. Enlargement in which it terminates. 9. Granular matter continuous with the lar matter continuous with

tory Corpuscles. C. of Krause, the spherical or ovoid corpuscles occurring at the ends of the nervetubules that emerge from a nerve-plexus. They occur in the conjunctiva, the edges of the lips, and various mucous and glandular surfaces. C., Malpighian, a name applied to the splenic corpuscles, and to the Malpighian bodies. C. of Neumann, the nucleated colored corpuscles of the blood seen after repeated hemorrhages. C., Norris's Invisible, colorless, transparent, biconcave discs of the same size as the red ones, invisible in the serum because their color and refractive index are the same as those of the liquor sanguinis; they are believed by Norris to exist normally in the blood. They are probably red corpuscles that have lost their hemoglobin. C., Pacinian, certain small corpuscles occurring in the subcutaneous cellular tissue of the fingers and toes. C. of Purkinje, a bonecell. See Purkinje. C., Shadow. See Shadorw. C., Tactile, of Wagner, the small, oval bodies found in the papillæ of the skin and enveloped by nervefibers. C. of v. Tröltsch, a name formerly given to a series of lymph-channels between the two layers of the lamina propria of the ear. They are spindle-shaped on longitudinal section and stellate on transverse section, and are lined with endothelium. C., Valentin's, the small, roundish amyloid bodies found in nerve-substance. C., Weber's, the sinus pocularis.

Corpuscula (kor-pus'-ku-lah) [L.]. Plural of Corpusculum. C. marginalia, in biology, the marginal senseorgans of Medusce.

Corpuscular (kor-pus'-ku-lar) [corpusculum, a little body]. Relating to or of the nature of a corpuscle.

Corpusculation (kor-pus-ku-la'-shun) [corpusculum, a corpuscle]. A condition in which the corpuscles of the blood have undergone hyperplasia, being larger and more numerous than normally.

Corpusculous (kor-pus'-ku-lus) [corpusculum, a corpuscle]. Corpuscular.

Corpusculum (kor-pus'-ku-lum) [L. : pl., Corpuscula ]. A corpuscle.

Correctant, or Corrective (kor-ek'-

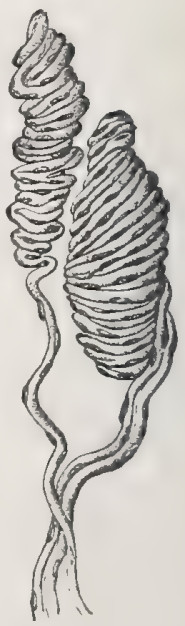
tant or kor-ek'-tiv) [corrigere, to correct]. I. Having the power to correct or to modify favorably. 2. A substance used to modify or make more pleasant the action of a purgative or other remedy.

Correction (kor-ek'-shun) [correctus; corrigere, to amend]. The rectification of any abnormality (as a refractive or muscular defect), or of any undesirable quality (as in a medicine).

Correlated (kor'-el-a-ted) [correlatus, related]. Interdependent; related. C. Atrophy. See Atrophy.

Correlation (kor-el-a'-shun) [correlatus, related]. Interdependence; relationship.

Corrigan's Button. A cautery-iron. It consists of a button of iron, $1 / 2$ inch in diameter by $1 / 4$ inch thick, fastened in a wooden handle by a rod 2 inches long. C. Cautery. Same as C. Button. C. Disease. See Diseases, Table of. C. Line. See Signs and Symptoms, Table of, and Line. C. Pulse, water-hammer pulse. The jerking pulse of aortic regurgitation. The volume of the pulse is large, owing to the hypertrophy and dilatation of the left ventricle; hence there is a sudden expansion of the arteries. The regurgitation of the blood, however, as suddenly empties the artery, and the pulse-wave subsides rapidly. The peculiarities of the radial pulse may usually be intensified by raising the hand. It is also called the collapsing, speaking, reading, locomotive, kicking, and shuttle pulse. See Pulse, and Signs and Symptoms, Table of.

Corrigent (kor'-ij-ent). See Corrective.

Corroborant (kor-ob'-o-rant) [corroborans, strengthening]. I. Tonic; strengthening. 2. A strengthening medicine

Corrosion (kor-o'-zhun) [corrodere, to corrode]. The process of corroding, or the state of being corroded. C.-anatomy, the preparation of any anatomic specimen by means of a corrosive process that eats away those parts which it is not desired to preserve. In some cases a resisting-substance is injected, so as to preserve the ressels and ducts from corrosion. C.preparation, one in which the vessels, ducts, or cavities of organs are filled by a fuid that will harden and preserve the shape of the vessel or cavity after the organ itself is corroded or digested or otherwise de- 
stroyed, the cast remaining. Three methods are used: 1. The injection is composed of rosin and white wax colored with paint, dissolved in balsam of copaiba; after the injection, the organ is destroyed by hydrochloric acid and water. 2. Wood's Frusiform Metal, consisting of 7 parts of bismuth, 4 parts lead, 2 parts tin, and I part cadmium. The tissues are destroyed by caustic potash. 3. Celloidin: The cold celloidin is slowly and forcibly injected by a syringe, and the soft parts eaten by an acid or a digesting fiuid.

Corrosive (kor-o'-siv) [con, intensive; rodere, to gnaw]. A substance that destroys organic tissue either by direct chemic means or by causing inflammation and suppuration. C. Chlorid, mercuric chlorid. C. Sublimate. See Hydrargyrum. C.-sublimate Bath. See Bath.

Corroval (kor'-o-val). A variety of curare, or arrowpoison; a cardiac and muscular paralyzant.

Corrovalin (kor-o'-val-in). A poisonous alkaloid obtained from corroval. Unof.

Corrugator (kor'-u-ga-tor) [corrugere, to wrinkle]. That which wrinkles. See Muscles, Table of.

Corset (kor'-set) [F., dim. of cors, body]. In surgery, an investment for the abdomen or chest, or both; useful in some spinal disorders and deformities, and in fractures or injuries of the thoracic walls. C.-liver, a liver characterized by a furrow resulting from the pressure exerted by a corset and situated chiefly in the right lobe. It is due to habitual tight lacing, and hence is found in women and, rarely, among soldiers. If extreme, the furrow can be felt along the margin of the ribs if the abdominal walls are lax.

Corsican Moss. A mixture of fragments of various seaweeds, brought from Corsica, etc. ; called, also, helminthochorton. It is said to be alterative, febrifuge, anthelmintic, and nutritious. Unof.

Corson's Paint. A substance used as a means of counter-irritation. It consists of croton oil 2 drams, ether 4 drams, compound tincture of iodin sufficient to make 2 ounces. Paint over the affected part with a camel'shair pencil once daily.

Cortex (kor'-teks) [L, bark]. The bark of an exogenous plant. C. aurantii, orange-peel. C. cerebri, the external layer of gray matter of the brain. $\mathbf{C}$. renalis, the cortical substance of the kidney.

Corti $\left(k o r^{\prime}-t e\right)$. A celebrated Italian anatomist, I7291813. C., Arch of. See Arch. C., Canal of. See Canal. C., Cells of, the external hair-cells of the organ of Corti. See Cell. C., Fibers of, the rods of Corti. C., Ganglion of. See Ganglia, Table of. C., Membrane of. See Membrane. C., Organ of, a series of some 3000 arches upon the floor of the basilar membrane within the ductus cochlearis of the internal ear. C., Pillars of, the rods of Corti. C., Rods of, the pillars of the arch of the organ of Corti. C., Rolls of, the fibers forming the inner limb of the arches of Corti. C., Tunnel of, a triangular canal between the layers of the rods of Corti.

Cortical (kor'-tik-al) [cortex, bark]. Pertaining to the cortex or bark, or to the cortex of the brain, or of the kidney. C. Epilepsy, C. Paralysis, such as is due to a lesion of the cortical substance of the brain.

Corticiferous (kor-tis-if'-er-us) [cortex, bark; ferre, to bear]. In biology, producing a bark.

Corticin (kor'-tis-in) [cortex, bark]. I. An alkaloid from poplar-bark. 2. A form of tannin from certain wood-barks.

Corticole (kor'-tik-öl) [cortex, bark; colere, to inhabit]. In biology, growing on bark.

Cortina (kor-ti'-nah) [cortina, a curtain]. In biology, the marginal veil of certain fungi.
Corviform (kor'-ve-form) [corvus, a crow; forma, shape]. In biology, resembling a crow.

Corvisart's Facies. See Signs and Symptoms, Table of.

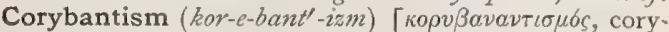
bantic frenzy]. Maniacal frenzy, with sleeplessness, choreic excitement and visual hallucinations.

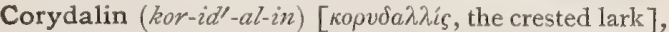
$\mathrm{C}_{18} \mathrm{H}_{19} \mathrm{NO}_{4}$. A precipitate from the tincture of the root of Corydalis formosa; it is tonic, diuretic, antisyphilitic, resolvent, etc. Dose $\mathbf{I}$ to 5 grains. Unof.

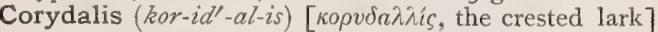
Turkey corn. The tuber of $C$. formosa (Dicentra can adensis), a tonic, diuretic, and alterative. Dose of fld. ext. $m x-x l$. Corydalin, the alkaloid. Dose gr. $\mathrm{j}-\mathrm{v}$. Unof.

Corymb $\left(k o \gamma^{\prime}-i m b\right)[\kappa \sigma \rho v \mu \beta o s$, a head or cluster of fruit or flowers]. In biology, a flower-cluster on the indeterminate plan, in which the axis is somewhat shortened and the pedicels of the lower flowers somewhat lengthened, so as to form a flat-topped cluster.

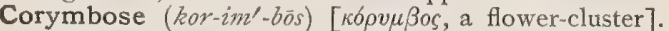
In biology, corymb-like, or arranged in corymbs. $\mathbf{C}$. Eruption, a variety of the eruption of smallpox in which it shows itself in patches or clusters the size of the hand, as thickly set as possible, while the surrounding skin often remains entirely free. The grouping may be symmetrically distributed. This variety of small-pox is very dangerous.

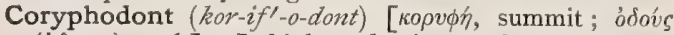

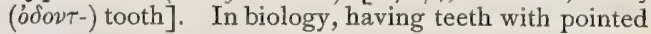
cusps.

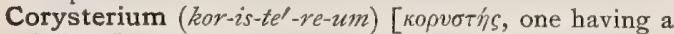
helmet]. In biology, an organ found in the abdomen of certain female insects, that secretes a jelly-like protective envelop for the eggs.

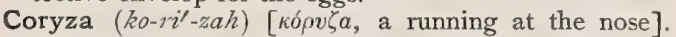
Catarrh of the mucous membrane of the nasal passages and adjacent sinuses, popularly called a "cold in the head." See Rhinitis. C. caseosa, a term applied by Cozzolino to a disease in which the nostrils are filled with caseous masses. C., Idiosyncratic. See Hayfever. C. maligna. Synonym of Snuffles of the Newborn. C., Periodic Vasomotor. See Hay-fever. C., Vasomotor. Synonym of Hay-fever.

Cosme's Paste. See Hebra's Arsenical Paste.

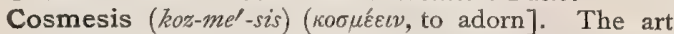
of preserving or increasing beauty.

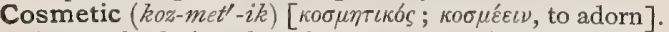
A remedy designed to improve or to hide defects of the skin or other external parts. It may be a white powder, such as starch, magnesic oxid, calcium carbonate (levigated), zinc oxid, mercurous chlorid, or bismuth subnitrate applied externally; it may be a white substance dissolved in dilute alcohol, which is left upon the face after the evaporation of the solvent; or it may be a stimulant to the skin used internally, such as arsenic. C. Operation, a surgical operation to give a natural appearance to a defective or unsightly part.

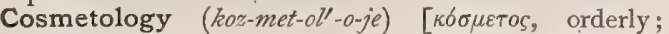
$\lambda 6 \gamma o s$, science]. The science of the proper care of the body with respect to cleanliness, dress, etc.

Cosmic Disease. Syphilis of the heart-valves.

Cosmolin (koz'-mo-lin). See Petrolatum.

Costa $\left(k o s^{\prime}-t a h\right)$ [L.]. A rib. See Rib.

Costal (kos'-tal) [costa, a rib]. Pertaining to the ribs. C. Arch, the arch of the ribs. C. Cartilages, the I 2 cartilaginous extensions of the ribs.

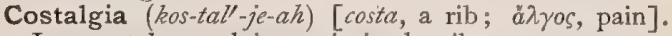
Intercostal neuralgia; pain in the ribs.

Costen $\left(k \mathrm{k}^{\prime}-t e n\right)$ [costa, a rib]. Belonging to a rib in itself. 
Coster's Paste. A remedy of some value in the treatment of Tinea tonsurans. It is made of iodin, 2 drams, in one ounce of oil of pitch. This is to be painted upon the patch and allowed to remain until the crust which is produced by the application falls off.

Costicartilage (kos-te-kar'-til-ajj) [costa, a rib; cartilago, gristle]. A costal cartilage or unossified sternal rib.

Costicervical (kos-te-ser'-vik-al) [costa, a rib; cervix, a neck]. Relating to the neck and ribs.

Costicervicalis (kos-te-ser-vik-a $\left.a^{\prime}-l i s\right)$ [costa, a rib; cervix, the neck]. The cervicalis ascendens muscle. See Muscles, Table of.

Costispinal (kos-te-spi'-nal) [cosia, a rib; spina, the spine]. Relating to the ribs and vertebral column. C. muscles, levatores costarum. See Muscles, Table of.

Costive (kos'-tiv) [constipare, to be bound]. Constipated; affected with costiveness.

Costiveness (kos'-tiv-ness) [constipare, to be bound]. An abnormality of digestion characterized by retention and hardness of the feces.

Costo- (kos'-to-) [costa, a rib]. A prefix denoting connection with the ribs.

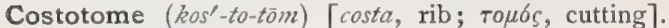
A strong knife for cutting the costal cartilages in dissection, etc.

Costus Root (kos'-tus root). See Putchuk

Cotnar (kot'-nar) [a Moldavian place-name]. A rich, strong, and highly esteemed wine from Roumania.

Coto $\left(k o^{\prime}-t o\right)$ [Sp., a cubit]. Coto Bark. The bark of a tree native to Bolivia. It contains a bitter principle, Cotoin, $\mathrm{C}_{22} \mathrm{H}_{18} \mathrm{O}_{6}$, irritant to the skin and mucous membranes. Its therapeutic properties are not known. It is recommended for diarrhea and zymotic fevers and for the night-sweats of pulmonary tuberculosis. Dose of the powder, gr. j-xv; of the fluid extract gtt. $v-x v$; of the tincture ( $\mathrm{I}$ in $\mathbf{I O}$ ), gtt. $\mathrm{x}-\mathrm{xxx}$; of cotoin, gr. ss-j.

Cotoin (ko'-to-in) [Sp., coto, a cubit], $\mathrm{C}_{22} \mathrm{H}_{18} \mathrm{O}_{6}$. $\mathrm{A}$ crystalline substance found in Coto Bark. See Coto.

Cottage-hospital (kot'-āj-hos'-pit-al). A small establishment for the purpose of providing for the sick in a small and isolated community.

Cotting's Operation. See Operations, Table of.

Cotton $\left(k \circ t^{\prime}-n\right)$ [ME., cotoun]. Gossypium, a white fibrous seed-hair that envelops the seeds of the cottonplant. The structure of the cotton-fiber is very characteristic. It presents a flattened and collapsed tube, slightly twisted in a spiral form, with comparatively thick walls and a small central opening. Chemically, it contains about 9 I per cent. of pure cellulose, 7 per cent. of moisture, and a small amount of fat, nitrogenous material and cuticular substance. C., Absorbent, is the fiber prepared, by removal of oily matters, for the surgeon's use. C.-blue. Same as Soluble Blue. C.-holder, a probe roughened near the end, upon which cotton may be twisted into a pledget. C.-oil. See C.-seed Oil. C.-root. See Gossypium. C.-phthisis, a variety of pulmonary disease occurring among cotton operatives from inhalation of cotton-dust. C.seed Oil or C.-oil, oleum gossypii seminis, an oil obtained by pressure from the hulled seeds of several species of Gassypium. The raw oil is brownish-yellow in color, somewhat viscid, of a specific gravity of .922 to .9306 at $15^{\circ} \mathrm{C}$. The refined oil has a strawyellow color, or is colorless, of a pleasant, nutty flavor, specific gravity .9264 at $15^{\circ} \mathrm{C}$., boiling at about $600^{\circ}$ F. It possesses slight drying properties, and is saponifiable, but is chiefly used in adulterating olive, lard, sperm, and other oils.

Cotton's Test. See Test's, Table of.

Cotunnius, Aqueduct of. See Aqueduct. C., Canal of. See Canals. C., Liquor, or Water of, the perilymph. See Aqua labyrinthi. C., Nerve of, the naso-palatine. See Nerves, Table of.

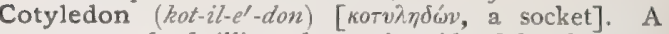
mass or tuft of villi on the uterine side of the placenta; always present upon the human placenta. The placenta of the ruminant mammals has many such masses, hence is polycotyledonous.

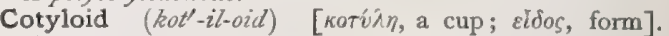
Cup-shape. C. Fossa, or Cavity, the acetabulum. C. Ligament, surrounds the acetabulum. C. Notch, a notch in the anterior and lower border of the acetabulum.

Couch-grass (kozech'-gras). See Triticum.

Couching (kowch'-ing) [Fr., coucher, to depress]. The operation, now fallen into disuse, of depressing a cataractous lens into the vitreous chamber, where it was left to be absorbed.

Couerbe's Test. See Tests, Table of.

Cough (kof) [ME., cough, a cough]. A sudden violent expiratory explosion through the mouth after deep inspiration and closure of the glottis. C.-center. See Center. C., Trigeminal, a reflex paroxysmal cough, occurring in individuals whose respiratory organs are perfectly sound, and due to an irritation of the trigeminal fibers distributed to the nose, pharynx, and external auditory meatus. C., Winter, a short troublesome cough of old people, due to chronic bronchitis, and recurring every winter.

Coulomb (koo-lom') [after Coulomb, a French physicist]. The unit of measurement of electric quan. tity; the quantity of electricity that passes during one second through a conductor having a resistance of one ohm, with one volt of electromotive force. The micro-coulomb is the millionth part of this amount.

Coulomb's Law. See Lazo.

Coumalic Acid (koo-mal'-ik). See Acid.

Coumaric Acid (koo-mar'-ik). See Acid.

Coumarilic Acid (koo-mar-il"-ik). See Acid.

Coumarin (koo'-mar-in), $\mathrm{C}_{9} \mathrm{H}_{6} \mathrm{O}_{2}$. A vegetable proximate principle that occurs in Asperula odorata, in the Tonka bean, and in Melilotus officinalis. It is soluble in hot water, readily so in alcohol and ether; it crystallizes in shining prisms, possesses the odor of the Asperula, and melts at $67^{\circ}$, in the proportion of 2 grains to the dram. It covers the odor of iodoform. Unof.

Coumarone (koo'-mar-on), $\mathrm{C}_{8} \mathrm{H}_{6} \mathrm{O}$. A body, formed by distilling coumarilic acid with lime. It is present in coal-tar. It is an oil that sinks in water, and boils at $169^{\circ} \mathrm{C}$.

Counter-extension (kozon'-ter-eks-ten'-shun). See $E_{x}$ tension.

Counter-indication (kown'-ter-in-dik-a -shun). See Contra-indication.

Counter-irritation (kown'-ter-ir-it-a'-shun) [contra, against; irritare, to irritate]. Superficial and artificially-produced inflammation, in order to exercise a good effect upon some adjacent or deep-seated morbid process. This is generally accomplished by vesicants, rubefacients, etc.

Counter - opening (kown'-ter-öp'-en-ing) [contra, against; ME., openyng, an opening]. An incision made in an abscess or cavity, opposite to another, generally for purposes of drainage.

Counter-poison (kozw'-ter-poi' -zn) [contra, against; ME., poisoun, poison]. A poison given as an antidote to another poison.

Counter-stroke (kown'-ter-strōk). See Contre-coup.

Country Fever. See Fever, Florida. C. F. of Constantinople. Synonym of Mediterranean Fever.

Coup de Soleil (koo duh so-lay') [Fr.]. Sunstroke. See Heat-stroke. 
Coup sur Coup (koo sur koo') [Fr.]. Blow upon blow; a designation for an obsolete method of applying venesection; the successive bleedings following each other rapidly.

Couperose $\left(k u p^{\prime}-r \bar{o} z\right)$ [Fr.]. Synonym of Acne rosacea.

Coupier's Blue. See Pigments, Conspectus of. Red. Same as Rosanilin.

Courses (kors'-ez). See Menses.

Court Plaster (kort plas'-ter). See Ichthycolla.

Courty's Method. See Treatment, Methods of.

Couvade (koo-vah $\left.d^{\prime}\right)$ [Fr., couver, to hatch]. Male child-bed. A custom of certain savage tribes in which, after child-birth, the father goes to bed, etc., and the mother gets up, etc.

Couveuse $\left(k o o-v u(r) z^{\prime}\right)$ [Fr.]. See Incubator.

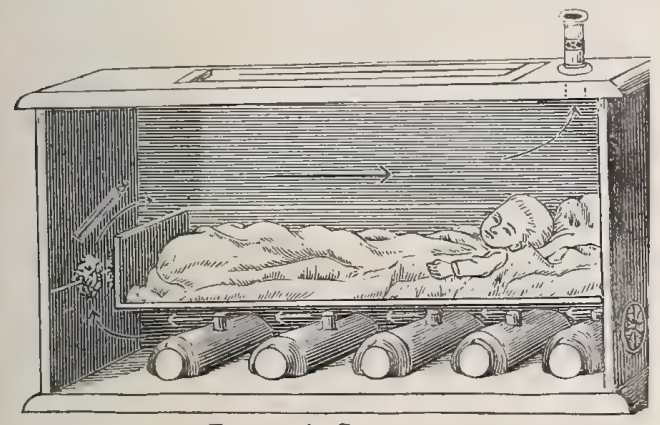

TARNIER'S COUveUSE.

(From Fullerton's "Obstetric Nursing.")

Cover $\left(k u v^{\prime}-e r\right)$ [ME., cuveren, to cover]. I. To protect. 2. To copulate with; said of male animals. C.correction, an arrangement to so adjust the lenses of a microscope that the best definition may be obtained for varying thicknesses of cover-glasses. C.-glass, in microscopy, the thin lamina of glass covering the object mounted on the slide. It should not exceed $\frac{1}{200}$ inch in thickness. On account of its effect on the transmission of light, the thickness of the cover-glass must be considered in correcting the objective. C.glass Preparation, the fixing and staining of a fluid upon a cover-glass. C.-slip. Same as C.-glass.

Cow (kou) [AS., cut, cow]. The female of the genus Bos, and of other large animals. C.-bane, Water Hemlock. The leaves of Cicuta virosa, an acrid narcotic, highly poisonous to cattle, but not affecting sheep and goats. It causes intoxication and spasm. It is sometimes used externally as an anodyne in rheumatism. C.-parsnip. See Masterwort. C.-pox, C.-pock, a variety of pock seen in the cow, and thought to correspond with smallpox in man. C.tree. See Brosimum.

Cowage (kow'-äj) [Hind., kawānch, cowhage]. The external hairs of the pod of Mucuna pruriens, used in medicine as a mechanical vermifuge.

Cowan-plant (kow'-an-plant). See Alonsenel.

Cowdie-gum (kow'-de-gum) [nat. N. Zeal.]. Codie pine resin. The resinous juice from the Dammara australis, a coniferous tree of New Zealand. It is one of the ingredients of copal varnishes. It is also one of the ingredients of the impression-material known as "Modeling Composition." It is one of the varieties of Dammar, q. v., and is also called Kaurigum.

Cowell's Operation. See Operations, Table of:

Cowhage, Cowitch $\left(k o w \mho^{\prime}-\bar{a} j, k o w w^{\prime}-i c h\right)$. See Mucuna and Cowage.

Cowl (kowl) [AS., cüle, a hood]. A cover for a chim- ney, that turns with the wind and assists in ventilation.

Cowling's Rule. A rule for dosage. In his formula the age of the child at the next birthday is the numerator and 24 the denominator. According to this, the dose of a child approaching four years of age would be $\frac{4}{24}=\frac{1}{6}$ of the dose for an adult.

Cowper's Glands. See Gland.

Cowperitis (kow-per-i'tis) [Cozuper, an English anatomist; $\iota \tau \iota \varsigma$, inflammation]. Inflammation of the glands of Cowper, usually gonorrheal in origin.

Cowpoxing (kow-poks'-ing). Synonym of Vaccination. Coxa (koks'-ah) [coxa, hip]. The hip-joint or the hip. In biology, the basal joint of the leg of an arthropod, abbreviated from coxognathite and coxopodite, of Milne Edwards; also Coxopodite. C. vara, bending or twisting of the neck of the femur.

Coxagra (koks-a'-grah) [coxa, the hip; á $\gamma \rho \alpha$, seizure]. Gout in the hip; sciatica.

Coxal (koks'-al) [coxa, the hip]. Relating to the coxa. Coxalgia (koks-al'-je-ah) [coxa, a hip; àkyos, pain]. Pain in the hip-joint. See Sciatica, and Hip-joint Disease.

Coxalgic (koks-al'-jik) [coxa, the hip; ànos, pain]. Relating to coxalgia.

Coxarthrocace (koks-arth-rok'-as-e) [coxa, hip; ă $\rho \rho o v$, joint; какós, bad]. A fungoid inflammation of the hip-joint.

Coxe's Hive-mixture. See Scilla and Antimonium.

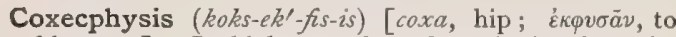
blow out]. In biology, a branch springing from the coxa of an arthropod; synonymous with the epignathite and epipodite of Milne Edwards, and with the podobranchia of Huxley when it is connected with the branchial plumes, as in Homanus.

Coxitis (koks-i'-tis) [coxa, the hip; $\iota \tau \iota s$, inflammation]. Inflammation of the hip-joint.

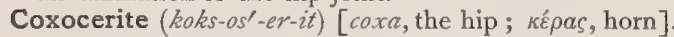
In biology, the basal joint of the antenna of an arthropod.

Coxodynia (koks-o-din'-e-ah) [coxa, hip; ódóvn, pain]. Same as Coxalgia.

Coxo-femoral (koks-o-fem'-or-al) [coxa, the hip femur, the thigh-bone]. Relating to the coxa and the femur.

Coxopodite (koks-oppl-o-dìt) [coxa, hip; $\pi$ ov́s, a foot]. See Coxa.

Coxotuberculosis (koks-o-tu-ber-ku-lo'-sis) [coxa, the hip; tuberculum, a tubercle]. Tuberculous disease of the hip-joint.

Crab Louse (krab'-lones) See Pediculus.

Crab's-eyes $\left(k r a b z^{\prime}-i z\right)$. Flat, calcareous concretions (Lapides cancromm) derived from the stomach of the crab, and used as a means of removing foreign bodies from the eye. Also a name for the seeds of Abrus precatorius.

Crachotement (kra-shot-mon $\left.\left(g^{\prime}\right)^{\prime}\right)$ [Fr.]. A peculiar reflex following operations upon the utero-ovarian organs, marked by a desire to spit, without the ability to do so. It is usually accompanied by a tendency to syncope.

Cracked-metal Sound. See Cracked-pot Sound.

Cracked-pot Sound. A peculiar sound elicited by percussion over a pulmonary cavity communicating with a bronchus.

Crackling (krak'-ling) [ME., crakelen, to crackle]. A sound compared to that produced when salt is thrown into the fire, heard over a lung in which softening of tuberculous deposits has begun to take place.

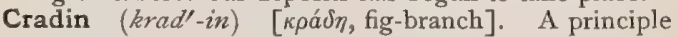
obtainable from the leaves and twigs of the common fig. It is said to be a peptic ferment, in some respects 
more effective than pepsin, and is believed to be iden tical with papain.

Cradle (kra'-dl) [AS., cradol, a cradle]. In surgery, the arculus, a wire or wicker frame so arranged as to keep the weight of the bed-clothing from an injured part of the body. It is employed in the treatment of fractures
wounds, etc. C.-Cap a name given to the scabs composed of dirt and sebum, that form on the scalps of neglected infants and children.

C., Ice-, the suspension

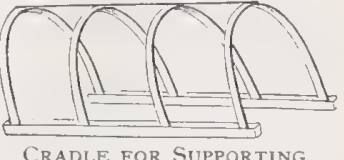

CRADLE FOR SUPPORTING BED-CLOTHES.

(From Fullerton's "Nursing in Abdominal Surgery.") over a febrile patient, by means of iron frames, of a number of zinc buckets, kept half-filled with ice, and inclosed in a light covering. C.-pessary, a cradle-shaped pessary for treating retrodisplacements of the uterus.

Cram (kram) [ME., crammen, to cram]. To store the memory with information for the purpose merely of passing an examination. C.-stunt, arrest in mental development due to over-study. C.-stunted, arrested in mental development"by over-study.

Cramp (kramp) [Teut., kramp]. A spasmodic tonic contraction of the muscles, attended with sharp pain. It is especially prone to attack the muscles of the calf. It occurs frequently in those of neurotic tendency, and is often the forerunner of epilepsy. C., Accommodation, a spasm of the ciliary muscle of the eye. C., Auctioneers', one of the professional neuroses affectting mainly the left side of the orbicularis oris muscle. C.-asphyxia, spinal spasm. C., Ballet-dancers', a neuralgic affection occurring in ballet-dancers, especially premiéres danseuses, characterized by pain and paralytic symptoms, affecting the muscles of the calf. It is the result of local strain upon the parts. C.bone, a name for the patella of a sheep. C., Blacksmiths'. See C., Hammermen's. C., Car-drivers', a professional neurosis seen in car-drivers, and perhaps also in brakemen, characterized by spasm and weakness of the hand from the effort of tightening car-brakes. C., Chisel, a professional neurosis occurring in smiths, affecting the left hand, and produced by the continuous holding of the chisel or similar instrument. C., Cigarmakers', one of the rarer professional neuroses, consisting in a tonic contraction of the flexor muscles of the fingers with pain. The painful sensations also extend up the arm and shoulders. C., Cigaret-makers'. See C., Cigar-makers'. C., Clarionet-players', a cramp of the tongue and of the laryngeal muscles experienced occasionally by players on this instrument. C. Colic, a form of colic in the horse, produced by contraction, or spasm, of a portion of the small intestines from the irritation of indigestible food. C., Coachmen's, contraction of the palmar fascia, occasionally seen in coachmen. C., Cornet-players', a rare and peculiar neurosis of the tongue in cornet-players, in which certain notes cannot be sounded, from inability to direct the tongue for that purpose. C., Dancers'. See C., Ballet-dancers'. C., Elocutionists'. See Dysphonia spastica. C., Flute-players', slight laryngeal spasms occurring occasionally in fluteplayers from excessive use of the instrument. Also a cramp of the flexors and extensors of the hand, from constant use of the instrument. C., Glassblowers', a painless, but decided and permanent flexion of the fingers, the thumb excepted, due to the continuous grasping of the tube with which the glass is worked. C., Goldbeaters', a cramp of the muscles of the arm due to excessive use in beating gold-leaf. C., Hammer. See C., Hammermen's.
C., Hammermen's, a spasmodic affection of the muscles of the arm and shoulder, at times unattended with pain, due to the repeated act of hammering. C., Knitters', a peculiar affection of the hands of those who knit, consisting in a contraction of the extensor muscles, with numbness of the ends of the fingers. C., Milkers', a spasmodic contraction of the extensors and flexors of the forearm in consequence of continuous exertion in milking. C., Milkmaids'. See C., Milkers'. C., Musicians', a general term including pianists' cramp, violinists' cramp, flutists' cramp, the cramp of clarionet-players, etc. C., Nailsmiths'. See C., Hammermen's. C., Photographers', a rare professional neurosis. C., Pianists', a neurosis of the hands and fingers of piano-players, characterized by fatigue, pain, and weakness. The pain extends up the arm to between the shoulders. C., Pianoplayers'. See C., Pianists'. C., Saltatory. See Saltatory Spasm. C., Sawyers', peculiar incoördinated movements of the saw-arm and corresponding side of the body, from excessive use. C., Scriveners'. See C., Writers'. C., Seamstresses', a professional neurosis consisting in a spastic condition of the flexors of the fingers from constantly plying the needle. C., Shoemakers'. See Shoesalesmen's Disease. C., Smiths'. See C., Hammermen's. C., Speakers'. See Dysphonia spastica. C., Swimmers', a painful cramp of the muscles of the calf of the leg of swimmers, frequently causing death by drowning. C., Tailors', a spasmodic affection of the muscles of the thumb, forefinger, hands, and arms, sometimes occurring in tailors, from overwork. C., Telegraphers', a partial paralysis of the muscles of the hand and fingers with spasm, produced by fatigue from long-continued use of Morse's instrument. C., Treadlers', one of the professional neuroses; it is met with in treadlers, and consists in cramps of the leg-muscles from constant use of the machine. C., Violinists', a painful cramp most common in the left shoulder of violinists ; it is due to the peculiar position assumed in holding the violin. C., Watchmakers', a cramp in which there is a flexion of the metacarpo-phalangeal joints, with extension of the other joints of the hand. Also, an inability to retain the glass in the eye-socket. C., Writers', Scriveners' palsy; a difficulty in writing, due to spasmodic action of the muscles of the hand and arm, to pain, to tremulousness of these muscles, or to fatigue and weakness of the extremity. These constitute the four forms, spastic, neuralgic, tremulous, and paralytic.

Crampton's Muscle. See Muscles, Table of. C. Operations. See Operations, Table of.

Crampus (kram'-pus) [L.]. An old name for a cramp, or for any disease characterized by cramps.

Cranberry (kran'-ber-e) [ME., cranebery, a berry]. The acid fruit of Vaccinium oxycoccus and $V$. macrocarpon. It is a popular material for poultices, and is vaunted as a cure for carcinoma. Unof. C.-tree. See Viburnum opulus.

Crane-bark (krān'-bark). See Viburnum opulus.

Crane's-bill Root. See Geranium.

Craniacromial (kra-ne-ak-ro'-me-al) [kpaviov, sikull; áspwiia, the point of the shoulder-blade]. Relating to the cranium and the acromion.

Cranial (kra'-ne-al) [kpaviov, the skull]. Relating to the cranium. C. Bosses, flat, bony elevations of the frontal and parietal bones sometimes seen at the angles of the anterior fontanel. They are said to be a proof of hereditary syphilis. C. Nerves. See Nerve.

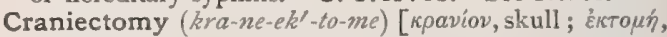
a cutting out]. The surgical removal of strips or pieces of the cranial bones. It is performed in cases of microcephaly. 
Craniocele (kra'-ne-a-sèl) [kpaviov, skull; $\kappa \eta \lambda \eta$, a tumor]. Encephalocele, $q$. 2 .

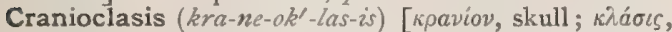
a breaking]. See Cranioclasm.

Cranioclasm (kra'-ne-o-klazm) [kpaviov, the skull ; $\kappa \lambda \varepsilon^{\varepsilon} \varepsilon v$, to break]. The operation of breaking the fetal head by means of the cranioclast.

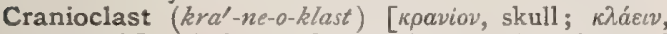
to break]. A heavy forceps for crushing the fetal head.

Craniodiaclast (kra-ne-o-di'-ak-last) [кpaviov skull;

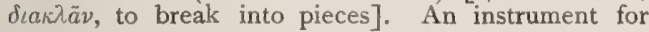
breaking the skull in craniotomy.

Craniodidymus (kra-ne-o-did'-im-us) [кpaviov, skull; dídvpos, double]. Same as Cephalopagus.

Craniofacial (kra-ne-o-fa'-shal) [kpaviov, skull; facies, face]. Relating to the cranium and the face; as the craniofacial axis, the craniofacial notch, etc.

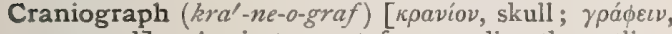
to record]. An instrument for recording the outlines of the skull.

Craniography (kra-ne-og'-ra-fe) [Kpaviov, the skull;

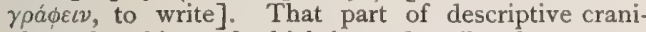
ology the object of which is to describe the parts or regions of the skull or bones of the face.

Cranio-hematoncus (kra'-ne-o-hem-at-ong -kus) [крaviov, skull; ai $\mu \alpha$, blood; бүкоц, a tumor]. Synonym of Cephalhematoma.

Craniology (kra-ne-ol'-o-je) [kpaviov, cranium; $\lambda 6 \gamma o s$, science]. A branch of anatomy based upon the comparative study of skulls.

Craniomalacia (kra-ne-o-mal-a'-se-ah). See Craniotabes.

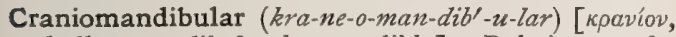
skull; mandibula, the mandible]. Relating to the skull and the lower jaw.

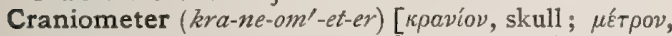
a measure]. An instrument for gauging the dimensions of the skull.

Craniometric, Craniometrical (kra-ne-o-met'-rik,

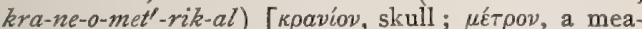
sure]. Pertaining to craniometry. C. Point, any one of the points of measurement used in craniometry. A list of the craniometric points is given.

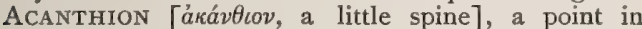
the median line of the skull at the base of the nasal spine. Alveolar Point, the point between the two middle incisors of the upper jaw. Antinion, that point on the glabellum, and in the median line,

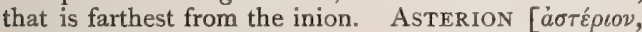
starry], the point behind the ear where the parietal, temporal and occipital bones meet. AURICULAR POINT, the center of the orifice of the external auditory meatus. BAsIon [basis, fundament], the middle point of the anterior margin of the foramen magnum. BREGMA, the point where the coronal and sagittal

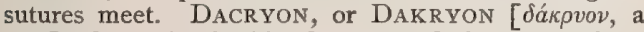
tear], the point beside the root of the nose where the frontal, lachrymal, and superior maxillary bones meet. ENTOMION, the point where the parietal notch of the temporal bone receives the anterior extension of the mastoid angle of the parietal. GLABELLA, or GLABELLUM, the point in the median line between the superciliary arches, marked by a swelling, sometimes by a depression. Grathion, same as Mental Point. GONION, the point at the angle of the lower jaw. HoRMION, the anterior point of the basilar portion of the united spheno-occipital bone, where it is crossed by the median line. INION, the external occipital protuberance. Jugal PoInt, the point situated at the angle that the posterior border of the frontal branch of the malar bone makes with the superior border of its zygomatic branch. KORONION, the apex of the coronoid process of the inferior maxilla. LAMBDA, the point of meeting of the sagittal and the lambdoid sutures. Malar PoInt, a point situated on the tubercle on the external surface of the malar bone, or at the intersection of a line drawn from the external extremity of the fronto-malar suture to the tubercle at the inferior angle of the malar bone and a line drawn nearly horizontally from the inferior border of the orbit over the malar bone to the superior border of the zygomatic arch. Maximum Occipital Polnt, or Occipital Point, the posterior extremity of the antero-posterior diameter of the skull, measured from the glabella in front to the most distant point behind. Mental POINT, the middle point of the anterior lip of the lower border of the lower jaw. Metopion, or Metopic Point, a point in the middle line between the two frontal eminences. NASION, or NASAL PoINT, the middle of the frontal suture at the root of the nose. OBELION, the part of the sagittal suture between the two parietal foramina. Occipital PoInT. See Maximum Occipital Poini. Ophryon, the middle of the supraorbital line, which, drawn across the narrowest part of the forehead, separates the face from the cranium. OPISTHION, the middle point of the posterior border of the foramen magnum. Prosthion, the Alveolar point. PTERION, the point where the frontal, parietal, temporal, and sphenoid bones come together. RHINION, the upper median point of the anterior nasal opening. SPINAL PoINT. Same as Subnasal Point. Stephanion, Inferior, the point where the ridge for the temporal muscle intersects the coronal suture. STEPHANION, SUPERIOR, the point where the coronal suture crosses the temporal ridge. SUBNASAL PoInT, the middle of the inferior border of the anterior nares at the base of the nasal spine. SUPRA-AURICULAR POINT, the point vertically over the auricular point at the root of the zygomatic process. Supranasal PoInt. Same as Ophryon. Supraorbital Point. Same as Ophryon. SymPHYSION, the median point of the outer border of the alveolus of the lower jaw. VERTEX, the superior point of the skull. In obstetrics, that conical portion of the skull whose apex is at the posterior fontanel and whose base is formed by the biparietal and trachelo-bregmatic diameters.

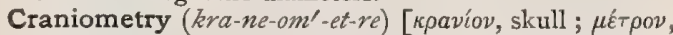
a measure]: The ascertainment of the proportions and measurements of skulls, together with the discussion of the ascertained facts, and the drawing of scientific inferences therefrom. See Angle, Arc, Index, Plane, Point.

Craniopagus (kra-ne-op'-ag-us). See Cephalopagus.

Craniopharyngeal (kra-ne-o-far-in'-je-al) [кoaviov, skull; фá $\rho v \gamma \xi$, the pharynx]. Relating to the cranium and the pharynx.

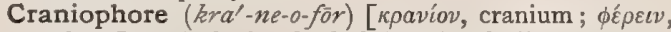
to bear]. A device for holding the skull during craniometric study.

Cranioplasty ( $\left.k r a^{\prime}-n e-o-p l a s-t e\right) \quad[\kappa \rho a v i o v, ~ s k u l l$; $\pi \lambda a \sigma \tau o ́ s$, formed]. The surgical restoration or correction of cranial deficiencies.

Craniosclerosis (kra-ne-o-skle-ro'-sis) [kpaviov, skull ; $\sigma \kappa \lambda \eta \rho 6 s$, hard]. A condition the antithesis of that seen in craniotabes. A thickening of the cranial bones, usually due to rhachitis.

Cranioscopy (kran-e-os'-ko-pe). See Phrenology.

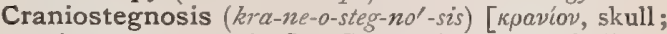

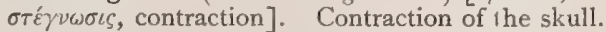

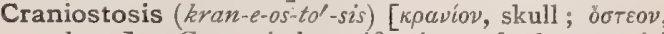
a bone]. Congenital ossification of the cranial sutures. 
Craniotabes (kra-ne-o-ta'-bēz) [Kpaviov, skull; tabere, to waste away]. An atrophy of the cranial bones occurring in infancy, with the formation of small, shallow, conical pits in the bone-substance. These pits are granular within, and present a worm-eaten appearance around the margin. They are most usually found in the posterior inferior region of the parietal bone, but may be seen in any of the other cranial bones. They form from within outward, so that in life often they cannot be found. Craniotabes is probably a result of rhachitis, syphilis, or marasmus. The craniotabetic pits are in some way associated with the rapid growth and development of the brain; they may be due to a premature formation of the markings of the convolutions on the skull. They are only encountered during the first months of life, that is, up to the sixteenth month. This disease is not a serious one as regards danger to life.

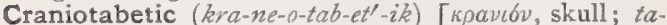
bere, to waste away]. Pertaining or belonging to Craniotabes, $q . v$.

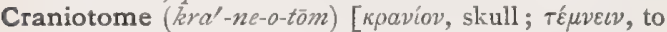
cut]. An instrument used in craniotomy

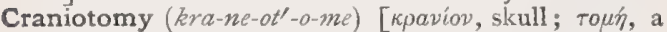
cutting]. I. The operation of reducing the size of the fetal head by cutting or breaking it up, when delivery is otherwise impossible. 2. Excision of a portion of the skull; performed by Prof. Lannelongue in cases of microcephaly to relieve pressure upon the brain and to give the brain space. C., Linear. See Craniectomy.

Craniotractor (kra'-ne-o-trak-tor) [kpaviov, skull ; tractor, a drawer]. A cranioclast designed to be used also, or mainly, as a tractor.

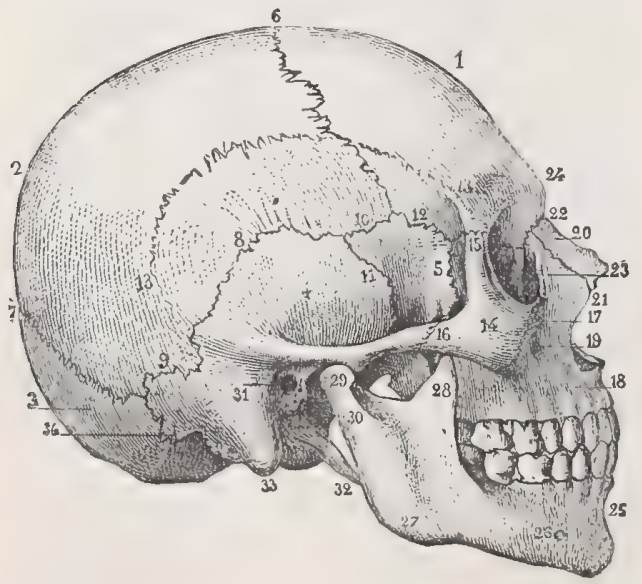

Lateral Aspect of Cranium.

2. Frontal bone. 2. Parietal bone. 3-Occipital bone. 4 Temporal bone. 5. Greater wing of sphenoid bone. 6 . Coronal suture. 7. Lambdoid suture. 8. Squamo-parietal suture. 9. Masto-parietal suture, 10. Spheno-parietal suture. II. Spheno-temporal suture, 12. Spheno-frontal suture. 13, I3. Temporal ridge. I4. Malar bone. 15. Fronto-malar suture. 16. Malo-temporal suture. ture. 18. Superior maxillary bone. I9. Infraorbital foramen. ture. 18. Superior maxillary bone. I9. Infraorbital foramen.
20. Nasal bone. 21. Naso-maxillary suture. 22. Naso-frontal suture. 23. Lachrymal groove, at the bottom of which may be seen the suture between the lachrymal and the superior maxillary bones. 24. Nasal eminence. 25. Inferior maxillary bone. 26. Mental foramen. 27. Angle of lower jaw. 28. Coronoid process. 29. Condyle. 30 . Neck of condyle. 3I. External auditory canal. 32. Styloid process. 33. Mastoid process. 34. Masto-occipital suture

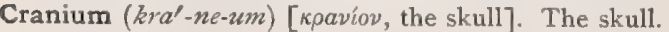
The cavity that contains the brain, its membranes and vessels. It consists of 22 bones, of which I 4 belong to the face, and 8 to the cranium proper. See Skull.

Crank (krank) [Ger, sick]. A popular term for an eccentric individual or a hobby-rider. See Paranoiac.

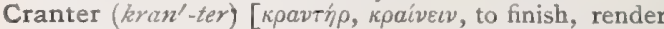
perfect: pl., Cranteres]. A wisdom-tooth. The dentes sapientiæ are sometimes so called because their presence is necessary to a perfect denture.

Crapaudine (krap'-aw-din) [Fr., crapaud, a toad] In veterinary surgery, an ulcer on the coronet of a horse's hoof.

Crapulous (krap'-u-lus) [crapula, drunkenness, surfeit]. Characterized by debauch or excess in drinking or in eating.

Craquement (krahk'-mon(g)) [Fr.]. Any crackling sound heard in auscultation.

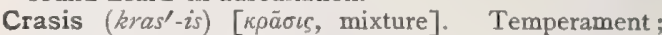
constitution; predisposition. C., Verminous, an old term used to designate a peculiar dyscrasia of the system due to the presence of worms.

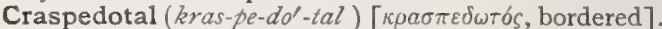
In biology, applied to those Medusæ that have velar otolithic vesicles.

Crassamentum (kras-am-en'-tum) [L., thickness]. A clot, as of blood.

Crateriform (kra-ter'-if-orm) [crater, a crater; forma, shape]. Goblet-shaped or deep-saucer-shaped. Excavated like a crater.

Cratomania (krat-o-ma'-ne-ah) [крátos, power; $\mu a v i a$, madness]. A delirium of exaltation in which the patient conceives himself to possess vast power.

Cravat (kra-vat') [Fr., cravate, a Croat]. I. A neckcloth. 2. A bandage of triangular shape, used as a temporary dressing for a wound or fracture. The middle is applied to the injured part, and the ends are brought around and tied. See Handkerchief Dressings.

Craw-Craw (kraw'-kraw). See Filaria sanguinis hominis, and Parasites (Animal), Table of.

Crawley (kraw'-le). See Coral Root.

Craziness (kra'-ze-nes) [ME., crasen, to break]. Insanity.

Crazy $\left(k r a^{\prime}-z e\right)$ [crasen, to break]. Insane; demented; deranged. C.-bone. See Funny-bone. C.-weed. See Loco.

Cream (krèm) [cremor, thick juice or broth]. The rich, fat part of milk. C., Cold. See Rosa. C., Ripening of. See Ripening. C. of Tartar. See Potassium.

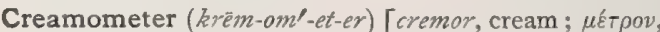
a measure]. An instrument for estimating the amount of cream in milk.

Crease $(k r \bar{s} s)$ [Celtic]. A line made by folding. C., Gluteo-femoral. See C., Ileo-femoral. C., Ileofemoral, is the crease that bounds the buttock below, corresponding nearly to the lower edge of the gluteus maximus muscle. It is of supposed significance in the diagnosis of hip-disease.

Creasol (krél-as-ol) [ $\kappa \rho \varepsilon ́ a \varsigma$, flesh ; oleum, oil], $\mathrm{C}_{8} \mathrm{H}_{10} \mathrm{O}_{2}$ One of the principal phenols contained in creasote. It is formed from guaiacum-resin, and is found in beechwood-tar. It is a colorless, oily liquid of an agreeable odor and a burning taste, boiling at $220^{\circ} \mathrm{C}$. It is very similar to guaiacol.

Creasote, or Creasotum (kre'-as-ōt, -öt'-um) [kpéas, flesh; $\sigma \bar{\omega} \xi \varepsilon \iota v$, to preserve]. The product of the distillation of wood-tar, consisting of a mixture of phenol-compounds. It is an inflammable oily liquid, differing in this respect from carbolic acid. It does not coagulate albumin or collodion. Most of the commercial creasote consists of carbolic acid or contains a large percentage of it. It is valuable for its antiseptic, astringent, styptic, anesthetic, and escharotic properties. 
Dose mi-iij. Beechwood Creasote, from Fagus sylvatica, is best for internal use. Dose $m j$, every three hours. C., Aqua, a one per cent. solution. Dose 3j-iv. C.-bath. See Bath. C., Mistura (B.P.). Dose $3 \mathrm{j}$-ij. C.-oil, Heavy Oil, the third main fraction in the coal-tar distillation-process. It is collected at temperatures of from $230^{\circ}$ to $270^{\circ} \mathrm{C}$, , or until the anthracene commences to distil. The oil has a greenish-yellow color, and is very fluorescent, and becomes progressively more so upon exposure to light and air. The odor is unpleasant and extremely characteristic. The oil is heavier than water, and contains naphthalene, anthracene, phenanthrene, phenol, cresol, etc. It is used mainly in the creasoting or preservation of timber; it is also used as a fuel, and for the production of illuminating gas, as a lubricant, and for the production of lampblack. C., Unguentum (B.P.), for local application. C., Vapor (B.P.), for inhalation.

Creatic $\left(k r e-a t^{\prime}-i k\right)$ [ $\kappa \rho \varepsilon \varepsilon_{S}$, flesh]. Relating to flesh. See Kreatinin. C. Nausea, a loathing of flesh as food.

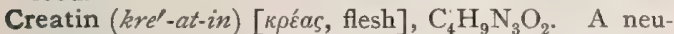
tral organic substance that occurs in the animal organism, especially in the juice of muscles. It crystallizes with one molecule of water in glistening prisms, which, heated to $100^{\circ}$, sustain a loss of water. It has a faintly bitter taste and dissolves rather readily in boiling water. It dissolves with difficulty in alcohol and yields crystalline salts with one equivalent of acid.

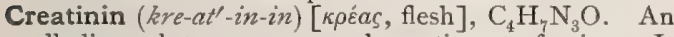
alkaline substance, a normal constituent of urine. It crystallizes in rhombic prisms, and is a strong base. It is much more soluble than creatin.

Crebricostate (kreb-re-kos'-tät) [creber, close; costa, rib]. In biology, characterized by closely-set ridges.

Crebrisulcate (kreb-re-sul'-kat) [creber, close; sulcus, a furrow]. In biology, marked by closely-set furrows.

Crebruria (kreb-ru'-re-ah) [creber, close together; ov pov, urine]. Frequent micturition.

Creche (krâsh) [Fr., a crib]. See Infant Shelter.

Credé's Method (kre-da'). See Treatment, Methods of. C. Operation. See Operations, Table of.

Crédivitè (kra-div-it-a') [Fx.]. See Hypnotism.

Creeping Sickness (krêp'-ing sik'-nes). The gangrenous form of ergotism.

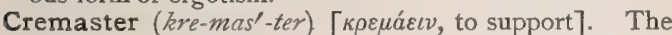
muscle that draws up the testis. See Muscles, Table of.

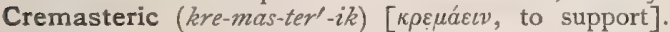
Pertaining to the cremaster muscle. C. Reflex. See Reflexes, Table of.

Cremation (kre-ma'-shun) [cremare, to burn]. The destruction of the body by burning, as distinguished from interment.

Cremator (kre-ma'-tor) [cremare, to burn]. A crematory, $q . \psi$. C., Engle System, a variety of cremator for the destruction of garbage, in which the smoke and gases generated by the destruction of the waste material are consumed by a second fire.

Crematory (krem'-at-or-e) [cremare, to burn]. An establishment for burning the bodies of the dead, or for consuming garbage and other refuse matter.

Cremnitz White. Same as White Lead.

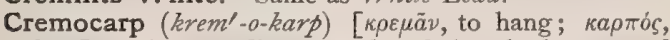
fruit]. The peculiar capsular fruit of the natural order Umbelliferce.

Cremor (kre'-mor) [cremor, broth]. Cream. Any thick substance formed on the surface of a liquid. C. tartari, cream of tartar.

Crena (kre'-nah) [L.]. A notch, especially such a notch as is seen on the sutural margins of the cranial bones.

Crenate $\left(k r e^{\prime}-n \bar{a} t\right)$, or Crenated (kre'-na-ted) [crena, a notch]. Notched or scalloped. In botany, leaves that are serrated. See Crenation.

Crenation (kre-na'-shun) [crena, a notch]. A notched or mulberry appearance of the red corpuscles of the blood; it may be spontaneous or due to poisoning with Calabar bean, etc.

Crenic Acid (kre'-nik). See Acid.

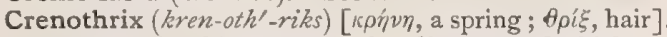
A genus of Schizomycetes the filaments of which are enveloped in a gelatinous sheath. C. kühniana, abundant in fresh waters; when putrefied it gives drinking-water a very bad taste, but the rôle attributed to it in the production of typhoid fever is unjustified.

Crenulate $\left(k_{r e n}^{\prime}-u\right.$-lät $)$ [crena, a notch]. Finely crenate.

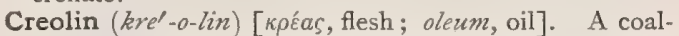
tar product deprived of carbolic acid. It is hemostatic and highly antiseptic, and is more active than carbolic acid in pure cultures of pathogenic microbes, but less efficacious in putrefying masses. It is an excellent non-poisonous deodorizer, used in a two per cent. solution or a five per cent. ointment with lanolin. It is used internally in typhoid fever and catarrh of the bladder in five-drop doses.

Creosol (kre'-o-sol). See Creasol.

Creosote (kre'-o-sōt). See Creasote. C.-bush, Larrea mexicana, an odorous and resinous shrub of the Pacific States and Mexico. It is a local remedy for rheumatism and for wounds and sores. Unof.

Crepitant (krep'-it-ant) [crepitare, to crackle]. Possessing the character of crepitus. C. Rale. See Râle and Breath-sounds.

Crepitation (krep-it-a'-shun), Crepitus (krep'-it-us) [crepitare, to crackle]. The noise produced by escaping flatus. The grating of fractured bones. The crackling of the joints. The noise produced by pressure upon tissues containing an abnormal amount of air or gas, as in cellular emphysema. Also the peculiar murmur of respiration observed in pneumonia during inspiration. It closely resembles the sound produced by rubbing the hair between the fingers held close to the ear. C., Redux, a crepitant râle heard in pneumonia during the stage of resolution; usually the first manifestation of the recession of the disease.

Cresalol (kres'-al-ol) [cresol; salol ], $\mathrm{C}_{6} \mathrm{H}_{4}$. OH.COO.$\mathrm{C}_{6} \mathrm{H}_{4} \cdot \mathrm{CH}_{3}$. Salicylate of cresol. It possesses antiseptic properties very similar to those of salol. Dose gr. iv in water from one to eight times daily. Unof.

Crescent (kres'-ent) [crescere, to grow]. Shaped like the moon in its first quarter. A name given to one form of the malarial hematozoön. C. of Gianuzzi. Groups of non-secreting cells in the acinus of a gland, pushed to one side by the secreting cells. C., Myopic. See Myopia. C. Operation. See Operations, Table of. Crescentia (kres-en'-she-ah) [crescere, to grow]. A genus of bignoniaceous trees and shrubs. C. alata, of tropical Asia and America, affords leaves that are useful in hemoptysis, and the fruit is employed in pulmonary diseases. The pulp of the West Indian C. cujete is similarly used. Unof.

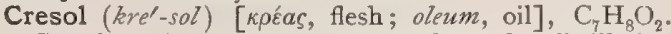
Cresylic acid; a body obtained from the distillation of coal-tar. It is a colorless, caustic liquid, with properties similar to those of phenol, but is superior as an antiseptic. Unof.

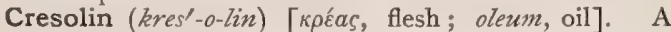
proprietary preparation used as a disinfectant in diphtheria, etc.

Cresosulphuric Acid (kres-o-sul-fu'-rik). See Acid. Crest (krest) [crista, a crest]. The surmounting part of any bone, organ, or process. C., Frontal, a ridge 
along the middle line of the internal surface of the frontal bone. C. of Ilium, the thickened and expanded upper border of the ilium. C., Lachrymal, a vertical ridge dividing the external surface of the lachrymal bone into two parts. C., Nasal, a crest on the internal border of the nasal bone and forming part of the septum of the nose. C., Neural, a series of swellings along each side of the rudimentary spinal cord in the embryo from which the spinal nerves are developed. C., Occipital, a vertical ridge on the external surface of the occipital bone extending from the occipital protuberance to the foramen magnum. C. of Pubes, a crest extending from the spine to the inner extremity of the pubes. C. of Tibia, the prominent border or ridge on the front of the tibia; the shin. C., 'Turbinated, a prominent horizontal ridge on the internal surface of the palate bone. C., Urethral. See Verumontanum.

Cresti's Test. See Tests, Table of.

Cresylic Acid (kres-il'-ik). See Cresol.

Creta (kre'-tah) [L.]. Chalk. See Calcium.

Cretaceous (kre-ta'-she-us) [creta, chalk]. Chalky; abounding in calcium carbonate.

Cretefaction (kre-te-fak'-shun). See Calcification

Cretin (kre'-tin) [Fr., crétin, a simple-minded person]. A person affected with cretinism.

Cretinism (kré-tin-izm) [Fr., crétin, a simple-minded person]. The condition of a cretin. Also an endemic disease, characterized by goiter and a condition of physical, physiologic, and mental degeneracy and non-development. The subjects of this disease seldom reach five feet in height. C., Sporadic, the congenital form of myxedema, characterized by absence of the thyroid gland, diminutiveness of size, thickness of neck, shortness of arms and legs, prominence of abdomen, large size of face, thickness of lips, large and protruding tongue, and imbecility or idiocy. It is popularly supposed that coitus during intoxication is a cause of this condition.

Cretinoid (kre'-tin-oid) [crétin, a simple-minded person]. I. Resembling a cretin; resembling cretinism. 2. A person who resembles a cretin.

Creuse's Test. See Tests, Table of.

Crewels $\left(k r o o^{\prime}-e l z\right)$ [Fr., écrouelles, scrofula]. Synonym of Scrofula.

Crib (krib) [ME., crib, a manger]. A small frame with inclosed sides for a child's bed. 2. A stall for cattle. C. Biting. See Cribbing and Windsucking.

Cribbing (krib'-ing) [ME., crib, a manger]. The peculiar wearing of a horses' teeth, due to a habit of biting his crib or manger, and at the same time sucking air into the stomach.

Cribriform (krib'-re-form) [cribrum, a sieve; forma, form]. Similar to a sieve in being perforated, as the cribriform plate of the ethmoid bone.

Cribrose (krib'-rōs) [cribrum, a sieve]. In biology, sieve-like

Crick (krik) [ME., cricke, a twist in the neck]. Any painful spasmodic affection, as of the back or neck

Crico- (kri'-ko-) [kрikos, a ring]. A prefix denoting connection with the cricoid cartilage.

Cricoid (kri'-koid) [коiкоs, a ring]. Ring-shaped. Cartilage. See Cartilages of the Larynx.

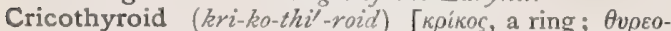
$\varepsilon i \delta h s$, shield-shaped]. Pertaining to the cricoid and thyroid cartilages. C. Artery, a small branch of the superior thyroid, crossing the crico-thyroid membrane. It is of much surgical importance. See Arteries, Table of. C. Membrane, a ligamentous membrane that lies between the cricoid and thyroid cartilages. C. Muscle. See Muscles, Table of.

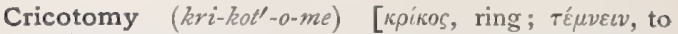
cut]. Surgical laryngotomy by cutting through the cricoid cartilage

Criminal (krim'-in-al) [crimen, a crime]. Of the nature of crime. C. Abortion. See Abortion. C. Assault. See Assault.

Criminalogy (krim-in-al'-o-je). See Criminology.

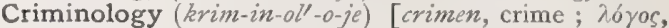
science]. The science of crime and of criminals; criminal anthropology; the study of crime as a branch of morbid psychology.

Crino (kri'-no) [crinis, hair: pl., Crinones]. I. A skin-affection of infants supposed to be due to the presence of a hair-worm. 2. Same as Comedo.

Crinosin (krin'-o-sin) [crinis, hair]. A nitrogenized fat from brain-substance, crystallizing in hair-like threads.

Cripple (krip'-l) [ME., cripel, a paralytic]. One who is unable to walk or to use his members normally.

Cripps' Operations. See Operations, Table of.

Crisis $\left(k r i^{\prime}-s i s\right)$ [kpi $\sigma \iota s$, a decisive point: pl., Crises]. The turning-point in a disease, fever, time of life, etc., and in disease, marking a change either for the better or worse. C. clitoridiennes, periods of voluptuous excitement in women suffering with tabes dorsalis, accompanied by vaginal secretion, analogous to the violent erections and spermatorrhea found in men in the initial stages of tabes. C. gastriques, Charcot's term for certain gastric symptoms sometimes encountered in the course of progressive locomotor ataxia. The symptoms are shooting pains in the groin and abdomen, ending finally in gastralgia, pains in the shoulders and arms, a quick pulse, and often vertigo and vomiting. C., Laryngeal, paroxysmal spasm of the larynx sometimes observed in cases of posterior spinal sclerosis.

Crispate (kris'-pāt) [crispatus, curl]. In biology, crisped on the margin.

Crista (kris'-tah) [L.]. Same as Crest. C. acustica, a yellow elevation projecting into the equator of the ampulla of the ear. C. fornicis, the crest of the fornix; a half-oval or semi-globular mass on the posterior surface of the fornix of the brain. C. galli, cock's crest, the superior triangular process of the ethmoid bone C. helicis, spina helicis; a projection of the helix above the external auditory meatus. C. spiralis, a crest of the limbus of the ear overhanging the internal spiral sulcus of Waldeyer. $c$. urethralis. See Verumontanum.

Critchett's Operations. See Operations, Table of.

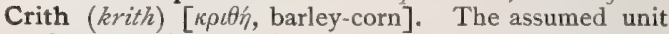
of mass and weight for hydrogen, and hence for gases generally. It is .0896 of a gram or 1.37 grains.

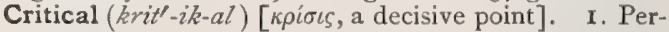
taining to a crisis in disease, period of life, etc. 2. A qualification applied to temperature and to pressure in relation to gases.

Crocein Scarlet (kro'-se-in skar'-let). See Pigments, Conspectus of.

Crochet (kro-sha') [Fr., dim. of croc, a hook]. A hook. C. of Uncinate Gyrus, the narrow portion of the uncinate gyrus at its anterior extremity which is reversed in the form of a hook.

Crocin (kro'-sin), $\mathrm{C}_{16} \mathrm{H}_{18} \mathrm{O}_{6}$. Polychroit ; the coloringmatter of Saffron. It is a deliquescent, orange-red, amorphous substance, odorless, with a sweetish taste, freely soluble in water and diluted alcohol.

Crocitin (kro'-sit-in). A coloring-substance of saffron; a red powder, easily soluble in alcohol, but not in water or ether.

Crocker's Calamin Liniment. A liniment used in the treatment of dermatitis. It consists of prepared 
calamin powder, 2 scruples; powdered zinc oxid, $1 / 2$ dram; olive oil and lime-water each one ounce. It is applied on soft rags.

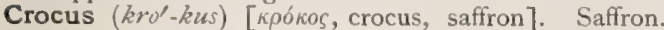
The stigmata of the flowers of $C$. sativus. (This should not be confounded with American Saffron, Carthamus tinctorius.) It is an aromatic stimulant and emmenagogue, commonly used as a cooling-agent. C., Tinct., Io per cent. in strength. Dose $3 \mathrm{j}-\mathrm{ij}$; of the drug, gr. $\mathrm{v}-\mathrm{xx}$, in infusion.

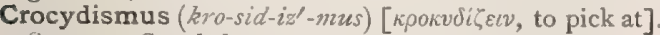
Same as Carphology.

Croft's Operations. See Operations, Table of.

Crooke's Tube. A highly exhausted vacuum-tube used in producing $\mathrm{X}$-rays.

Crop (krop) [ME., crop, the craw of a bird]. The craw or pouch of the esophagus of a bird. C.-bound, a disease of poultry in which the fowls are unable to pass the food from the crop into the gizzard, and the former becomes filled with food, hanging like a bag in front of the bird.

Crosby's Operation. See Operations, Table of.

Cross (kros) [crux, a cross]. In biology, a cross-breed in plants, the result of cross-fertilization. C.-birth, shoulder-presentation, or other presentation requiring version. C--circulation. See Circulation. C-eye. See Strabismus. C.-fertilization, in biology, the fertilization of the ovules of one species by the seedgerms of another. C.-knee. See Genu valgum. C.-leg, a deformity that sometimes follows double hip-joint disease; the legs are crossed in walking. C.-legged Progression, a method of walking in which one foot gets over or in front of the other. It is a symptom of certain cord-lesions.

Crossed (krosd) [crux, a cross]. Having the shape of a cross. Applied to alternate sides of the body. C. Anesthesia. See Anesthesia. C. Hemiplegia. See Stauroplegia. C. Paralysis. See Paralysis. C. Reflexes, an exception to the usual law of reflex movements, in which, $e . g$., excitation of one fore-limb induces movement in the opposite hind-limb. See Reflexes, Table of.

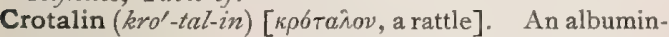
ous body contained in the poison of the cobra. It is not coagulable by heat at $212^{\circ} \mathrm{C}$

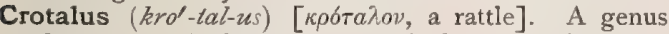
of serpents, including the typical rattlesnakes. C. Poison. The virus of the rattlesnake, used as a remedy by homeopathists.

Crotchet (kroch'-et) [ME., crochett, a little hook]. hook used in extracting the fetus after craniotomy.

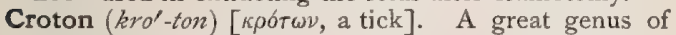
euphorbiaceous plants. C. eleuteria, yields cascarilla. C. tiglium, croton oil ; C. niveus, a part of the product called copalche bark. C. Aldehyd, $\mathrm{C}_{4} \mathrm{H}_{6} \mathrm{O}$, a compound obtained by the condensation of acetaldehyd when heated with dilute $\mathrm{HCl}$, with water and zinc chlorid; it is a liquid, soluble in water, possessing an irritating odor; it boils at from $104^{\circ}$ to $105^{\circ}$ and has a sp. gr. of $\mathbf{1} .033$ at $0^{\circ}$. In the air it oxidizes to crotonic acid. C. Chloral. See Chloral butylicum. C. Oil. See Tiglii, Oleum.

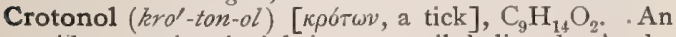
acid, aromatic principle in croton oil, believed to be the vesicant constituent of the oil.

Croup (kroop) [AS., krópan, to cry aloud]. Membranous croup; pseudo-membranous croup; true croup; a disease of the larynx and trachea of children, prominent symptoms of which are a peculiar cough, and difficulty in breathing; it is often accompanied by the development of a membranous deposit or exudate upon the parts. There is doubt as to the real nature of the disease, some contending that it is laryngeal diphtheria, while others believe it a special type of disease. See also Roup. C., Catarrhal, an affection of childhood characterized by paroxysms of intense dyspnea and a peculiar, ringing, metallic cough. C., False, catarrhal or spasmodic croup; catarrhal laryngitis. C., Spasmodic. See C., Catarrhal.

Crown (krown) [ME., crowne, a crown]. See Corona. C. Glass, a kind of glass used in optics. C. Leather. See Leather. C.-setting, the operation of uniting an artificial crown to the root of a natural tooth; the operation being commonly known by the misnomer "pivoting." C. of a Tooth, the exposed part of the tooth above the gums, covered with enamel. C.-work, the adaptation of an artificial crown of porcelain or gold on the cervical portion of the natural root of a tooth. C.-yellow. Same as Chrome-yellow.

Crucial (kru'-shal) [crux, a cross]. Resembling or pertaining to a cross, as a crucial incision.

Cruciate (kru'-she-āt) [crux, a cross]. In biology, shaped like a Greek cross.

Crucible (kru'-sib-l) [crucibulum, a melting pot]. A vessel of conical shape in which substances are exposed to the heat of a fire or furnace; it is formed of clay or earthenware, porcelain, iron, black lead or plumbago or graphite, silver, gold or platinum.

Crucifixion Attitude (kru-se-fik $\left.k^{\prime}-\operatorname{shun}\right)$. See Attitude.

Crucing (kru'sing). See Block Teeth.

Cruels $\left(k \mathrm{roo}^{\prime}-e l z\right)$. Synonym of Scrofula.

Cruentin (kru-en'-tin) [cruentus, bloody]. A precipitate obtained by boiling defibrinated blood with strong $\mathrm{H}_{2} \mathrm{SO}_{4}$, adding water, and filtering.

Crull's Line. See Line.

Cruorin $\left(k n u^{\prime}-o r-i n\right)$ [cruor, blood]. Synonym of Hemorlobin.

Crupper (krup $\left.p^{\prime}-e r\right)$ [Fr., croupe, the rump]. The buttocks of a horse. C.-bone, the coccyx.

Crura (kru'-rah) [Plural of crus, a leg]. A name applied to certain parts of the body, from their resemblance to legs or roots. C. cerebelli, the peduncles of the cerebellum, superior, middle, and inferior. C. cerebri, the peduncles of the cerebrum. C. of Diaphragm, the muscular bundles arising from the vertebræ, etc., and inserted into the central tendon. C. of Penis, the corpora cavernosi.

Crural (kru'-ral) [crus, a leg]. Pertaining to the thigh. C. Arch. See Ligament. C. Hernia, femoral hernia. C. Ring, the femoral ring; the upper opening of the temporal canal, bounded in front by Poupart's ligament and the deep crural arch, behind by the pubis, internally by Gimbernat's ligament, externally by a fibrous band separating it from the femoral ring.

Crureus (kru'-re-zes) [L.]. One of the muscles of the thigh. See Muscles, Table of.

Crus (krus) [L.]. The leg; structures resembling a leg. See the plural, Crura.

Cruso-creatinin (kru-so-kre-at'-in-in), $\mathrm{C}_{5} \mathrm{H}_{8} \mathrm{~N}_{4} \mathrm{O}$. A leucomaine, isolated from muscle-tissue. In this and other leucomaines of the Creatinin Group, as well as in those of the Uric Acid Group, hydrocyanic acid plays an important part in the molecular structure of the bases. Very little is yet known as to the function of this Cyanogen Group in relation to the vital activity of tissues, but recent investigations seem to show that the seat of the cyanogen-formation lies within the nucleated cell, and is intimately connected with the functions of the nuclein-molecule. A number of leucomaines of fresh muscle-tissue are credited with possessing an intensely poisonous action; and, if this be the case, any accumulation of such bases in the 
system, due to interference with elimination, may cause very serious disturbances

Crust (krust) [crusta, a crust]. An irregular, dried mass of exudation, or other effete products of disease of the skin. It varies much in appearance, according to the condition that produces it. It may be adherent or loose, thin and flat, or thick and craggy, light-yellow or blackish in color.

Crusta (krus'-tah) [L., a crust]. The ectal portion of the crus cerebri. C. lactea. See Achor. Also synonym for Eczema. C. petrosa, a thin layer of bone covering the fang of a tooth. C. phlogistica, the yellowish layer of the upper stratum of a bloodclot coagulating slowly.

Crustaceorubrin (krus-ta-she-o-ru'-brin) [crustata, shell-fish; ruber, red]. In biology a red coloringmatter of crustaceans.

Crustaceous (krus-ta'-she-us) [crusta, crust]. In biology, having a thin, hard, brittle, crust-like shell or coating.

Crusted (krus'-ted) [crusta, a crust]. Having crusts or scabs. C. Ringworm. Synonym of Favus. C. Scall. Synonym of Impetigo.

Crusting (krus'-ting) [crusta, a crust]. The formation of crusts or scabs.

Crutch (kruch) [ME., crutche, a crutch]. A staff reaching from the axilla to the ground, for the purpose of aiding the progression of lame or crippled persons. C. Paralysis, paralysis of an upper extremity due to the pressure of the crutch-head upon the nerves of the axilla.

Cruveilhier's Atrophy. See Diseases, Table of. C. Disease. See Diseases, Table of. C. Fascia, the superficial layer of the perineal fascia. C. Plexus. See Plexuses, Table of. C. Paralysis. Same as $C$. Disease.

Cry (kri) [ME., crien, to cry]. The utterance of an inarticulate vocal sound, or the sound so uttered; the sound of the voice in lamentation.

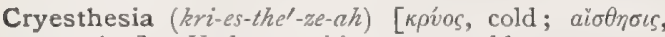
sensation]. Undue sensitiveness to cold.

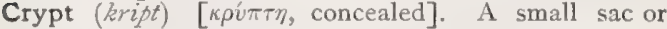
follicle. Crypts of Lieberkühn, minute tubular depressions of the mucous membrane of the small intestine.

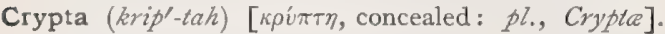
Same as Crypt.

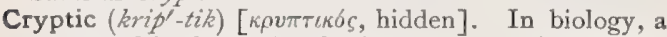
term used in the study of mimicry, for such colors as enable the animal to escape enemies, or to approach its prey; protective, procryptic; agoressive, anticryptic resemblances. Similar effects may be produced by the use of foreign objects with which the animal covers itself to a greater or lesser extent, allocryptic. (Poulton.)

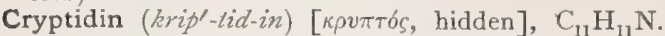
An alkaloid formed by the dry distillation of quinin.

Cryptitis (krip-ti'-tis) [ [ $\rho v \pi \tau \eta$, concealed; $\iota \tau \iota s$, inflammation]. Inflammation of a crypt, or of crypts. C., Urethral, phlegmasia of the mucous follicles of the urethra.

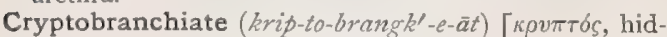
den; $\beta \rho a ́ \gamma \chi \iota a$, gills ]. In biology, having concealed gills.

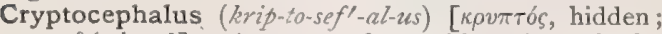
$\kappa € \phi \alpha \lambda \dot{n}$, head]. A monster fetus with an imperfectly. formed and concealed head.

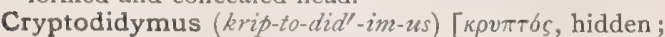

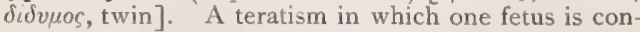
cealed within another.

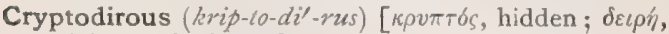
neck]. In biology, having a concealed neck.

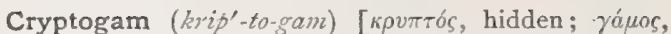
marriage]. In biology, a general term applied to any plant below Phanerogamia; any flowerless plant is called a cryptogam.

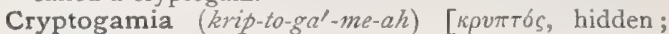
yáuns, marriage]. A division of the vegetable kingdom comprising all plants with concealed sexual organs, without pistils or stamens.

Cryptogamic (krip-to-gan'-ik). See Cryptogamous.

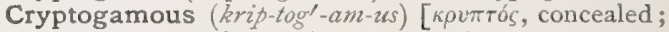
yátes, marriage]. Belonging to the cryptogamia; having the processes of the reproductive function obscured or concealed.

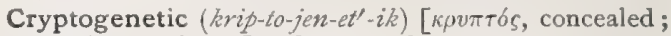

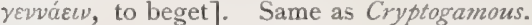

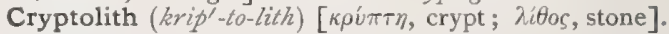
A concretion or calculus formed within a crypt.

Cryptophanic, or Kryptophanic Acid (krip-to-fan'-ik)

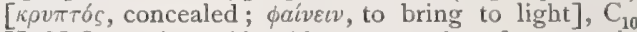
$\mathrm{H}_{18} \mathrm{~N}_{2} \mathrm{O}_{10}$. An acid said to occur in a free state in urine, though regarded by Landwehr as an animal gum.

Cryptophthalmia (krip-toff-thal'-me-ah). Same as Cryptophthalmos.

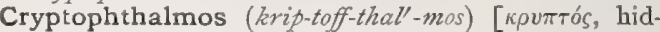
den; $\dot{\omega} \phi \theta \lambda \lambda \mu \sigma_{s}$, the eye]. $\mathbf{1}$. Congenital union of the eyelids, usually over imperfect eyes. 2. A person who has congenital union of the eyelids.

Cryptopia (krip-to'-pe-ah). Same as Cryptopin.

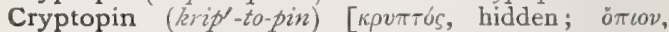
opium], $\mathrm{C}_{21} \mathrm{H}_{23} \mathrm{NO}_{5}$. One of the alkaloids of opium, colorless and odorless. It is said to be anodyne and hypnotic, but it is less safe than morphin. Dose, 1/8 gr. Unof.

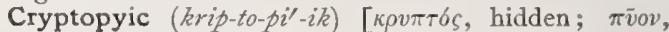
pus]. Characterized by concealed suppuration.

Cryptorchid, or Cryptorchis (krip-tor-kid, -kis)

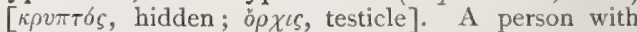
retained testicles, $i$. $\ell$., not descended into the scrotum.

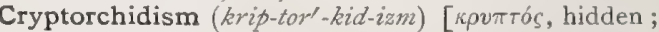
o $\rho$ $\iota$, testicle]. Retention of the testes in the abdominal cavity

Cryptorchism (krip-tor'-kizm). See Cryplorchidism.

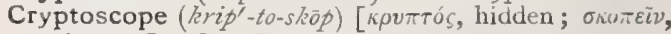
to inspect]. See Fluoroscope.

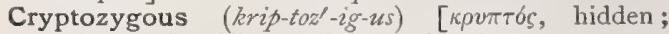
$\zeta v \gamma o$ v, arch]. Having the dental arches or zygomata concealed from view when the skull is viewed from above.

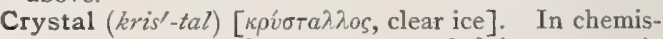
try, a substance that assumes a definite geometric form. C., Charcot-Leyden. See Charcot-Leyden. C. Charcot's, minute colorless crystals found in the sputa of asthmatic and bronchitic patients and others. They are said to consist of tyrosin, or according to some, of mucin. C., Violet. See Pigments, Conspectus of.

Crystalli (kris-tal'-i). Synonym of Chicken-pox

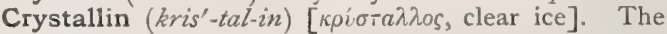
globulin of the crystalline lens.

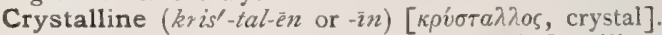
Like a crystal. c. Lens. See Lens. C. Swelling. See Srommering.

Crystallitis (kris-tal-i'-tis). See Phakitis.

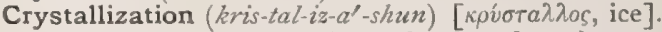
The process by which the molecules of a substance arrange themselves in geometric forms when passing from a gaseous or a liquid to a solid state. C., Water of, the water of salts that cannot be extracted without destruction of their crystalline nature.

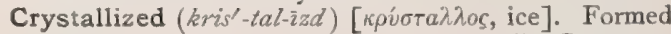
into crystals. C. Green. Same as Lodin Green. 


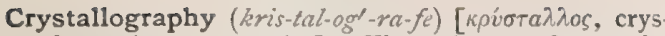
tal; roápes, to write]. The science of crystals, their formation, etc.

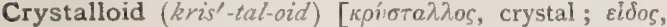
likeness]. Having a crystalline structure, as distinguished from colloid. In biology, one of the crystallike proteid bodies found in seeds, tubers, etc.

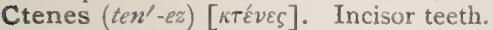

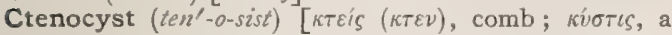
bladder]. In biology, applied to the auditory vesicles of ctenophorans.

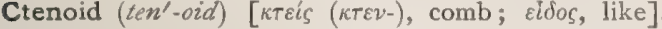
In biology, pectinate or comb-like.

Cubeb, or Cubeba $\left(k u^{\prime}-b e b\right.$, or $\left.k u-b e^{\prime}-b a h\right)$ [Pers., ka$b \bar{a} b a$, cubeb : gen., Cubeba $]$. The unripe fruit of Piper Cubeba, cultivated in Java. Its properties are due to a volatile oil, $\mathrm{C}_{15} \mathrm{H}_{24}$, and an organic acid. It is an aromatic stimulant, diuretic in small doses, and is useful in affections of the bladder and urethra. It is a good remedy (applied by insufflation or smoked in cigarets) for diseases of the fauces, catarrh of the air-passages, etc. Dose gr. $x-z$ ij. C., Fld. Ext., alcoholic. Dose $\mathrm{q}_{\mathrm{v}-\mathrm{xxx}}$. C., Oleoresina, ethereal. Dose $m_{\mathrm{v}-\mathrm{xxx}} \quad$ C., Ol., the volatile oil. Dose $\eta_{\mathrm{v}-}$ xx. C., Tinct., 20 per cent. in strength. Dose $m x-$ 3 iij. C., Trochisci, oleoresin gr. $1 / 2$, oil of sassafras gr. $\frac{15}{100}$, ext. of glycyrrhiza gr. iv, acacia gr. ij, syr. of

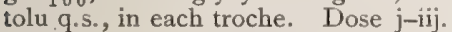

Cubebene $\left(k u^{\prime}-b e b-\bar{e} n\right)$ [cubeb], $\mathrm{C}_{20} \mathrm{H}_{16}$. The light portion of the essential oil of cubebs.

Cubebic Acid (ku-beb'-ik) [cubeb], $\mathrm{C}_{13} \mathrm{H}_{14} \mathrm{O}_{7}$. A resinous acid body from cubebs; actively diuretic and cathartic. Unof.

Cubebin $\left(k u-b e b^{\prime}-i n\right)$ [cubeb], $\mathrm{C}_{10} \mathrm{H}_{10} \mathrm{O}_{3}$. An odorless crystalline substance obtained from cubebs.

Cubic $\left(k u^{\prime}-b i k\right)$ [ $v^{\prime} \beta o s$, a cube]. Pertaining to a cube. C. Space (of air), the amount of space required by persons in health and in disease. In hospitals about Iooo cubic feet to each patient is necessary for proper ventilation.

Cubital (ku'-bit-al) [kúßos, a cube]. Relating to the forearm, to the elbow, or to the ulna.

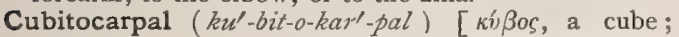
$\kappa a \rho \pi \delta \varsigma$, the wrist]. Relating to the forearm and to the carpus.

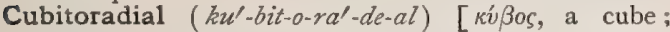
radius, a staff ]. Relating to both the ulna and the radius.

Cubitus $\left(k u^{\prime}-b i t-u s\right)$ [cubitus, the elbow]. The forearm.

Cubitus (ku'-bit-us) [cubare, to lie down]. A bed; a couch.

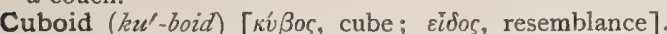
Resembling a cube. C. Bone, a bone of the foot situated at the outer anterior part of the tarsus.

Cuca (koo'-kah). See Erythroxylon.

Cucullate $\left(k u-k u l^{\prime}-\bar{a} t\right)$ [cucullus, a cap, hood]. In biology, hooded.

Cucullus (ku-kul'-us) [L., a hood]. I. In biology, a hood-shaped formation of the head. 2. Synonym of Whooping-cough

Cucumber, Squirting. See Elaterium.

Cucumis ( $k u^{\prime}-k u$-mis) [L., a cucumber]. A genus of plants. C. colocynthis. See Colocynth.

Cucurbit (ku-ker'-bit) [cucurbita, a gourd]. I. A cupping-glass. [Old.] 2. The body of an alembic.

Cucurbitation (ku-ker-bit-a'-shun) [cucurbitatio, a cupping]. The operation of cupping.

Cud (kud) [AS., cudde]. The regurgitated food of ruminants. C.-weed (kud-wëd). See Life Everlasting.

Cudbear (kud'-bār) [After Dr. Cuthbert Gordon]. A purplish-red powder, nearly identical with Orchil, q.v. From it the Tinctura persionis, and Tinctura persionis composita, N. F., are prepared. Both are used mainly in coloring various pharmaceutic preparations. See Pigments, Conspectus of.

Cuichunchulli [Peruvian]. The root of Ionidium parviftorum; said to be diaphoretic, diuretic, siala gogue, emetic, and cathartic; it is useful in elephantiasis. Unof.

Cuirass (kwe-ras') [Fr.]. A close-fitting or immovable bandage for the front of the chest. C. Cancer, a large, flat cancerous growth upon the front of the chest. Cul-de-sac $\left(k u l^{\prime}\right.$-de-sak') [Fr. cul, the bottom; de, of; sac, bag]. A cavity of the body closed at one end. Douglas's C., a pouch between the anterior wall of the rectum and the posterior wall of the uterus, formed by the reflection of the peritoneum. It is called, also, the recto-uterine or relro-uterine cul-de-sac.

Culex $\left(k u^{\prime}-l e k s\right)$ [L., a gnat]. A mosquito. A wellknown insect that punctures the skin to obtain its food, the blood. See Parasites (Animal), Table of.

Culicifuge ( $k u$-lis'-if-izj) [culex, a gnat; fugare, to drive away]. An agent that prevents the biting of mosquitoes; as oil of pennyroyal.

Cullen's Theory. A theory as to the origin of gout, which he claims to be primarily an affection of the nervous system.

Culm (kulm) [culmus, a stalk]. In biology, a hollowjointed stem.

Culmen (kul'-men) [L., the summit]. The cacumen; a portion of the cerebellum situated to the cephalic side of the vermis. In biology, the highest middle lengthwise line of the bill of a bird.

Cultrate (kul'-trät). [culter, a knife]. Sharp-edged; also cultriform.

Cultriform (kul'-trif-orm) [culter, a knife; forma, shape]. See Cultrate.

Culture $\left(k u l^{\prime}-c h \bar{u} r\right)$ [colo, cultum, to till, cultivate]. A name loosely and indiscriminately applied to the act, the liquid or solid medium used, and the product of the process, in culture-experiments upon microörganisms. The culture-media are of various kinds; mineral liquids (see Raulin's Liquid, Cohn's Liquid, etc.), bouillons of various kinds, gelatinous fluids, gelose, potato, serum, etc. These media are first sterilized, usually by heat (see Oven, Sterilization), but possibly also by chemicals, by filtration, by cold, by steam, etc. The infectious matter is then taken upon a sterilized platinum needle-point, pipet, or other instrument, and transferred to the culture-medium. When the latter is of semi-solid consistency, as gelatin, the inoculation by the needle is called Stab-culture, Stichcultur (Ger.), or par piqure (Fr.)., the needle being thrust into the substance. When smeared over the surface, it is called smear-culture, Strichcultur (Ger.), or en stries (Fr.). The macroscopic features of the subsequent development give important means of differ entiation. For example, when the inoculated matter forms a mass in the medium, pointed below and rising like a nail-head above, it is called en clou, nail-shaped. Then the medium may be liquefied or not, variously colored, peculiarly changed, sediment deposited or not, etc. Subsequent microscopic examination of the culture-product, inoculation-experiments upon animals, etc., complete the study. Culture-bulbs, culture-cells, culture-fuids, culture-media, culture-ovens, culturetubes, etc., are among the equipments of the bacteriologist. C.-oven. See Oven.

Culver's Physic, or Root (kul'-verz fiz'-ik or root) See Leptandra.

Cumberland Disease. An Australian term for $A n$ thrax, q. $v$. 
Cumene $\left(k u^{\prime}-m e \ddot{n}\right)$ [cuminum, cumin], $\mathrm{C}_{9} \mathrm{H}_{12}$. Iso propyl benzene; a compound made by distilling cumic acid with lime. It boils at $153^{\circ} \mathrm{C}$., and its specific gravity at $0^{\circ} \mathrm{C}$. is 0.879 .

Cumic $\left(k u^{\prime}-m i k\right)$ [cuminum, cumin]. Derived from or pertaining to cumin. C. Acid. See Acid. C. Aldehyd. See Cuminol.

Cumidin (ku'-mid-in) [cuminum, cumin], $\mathrm{C}_{9} \mathrm{H}_{13} \mathrm{~N}$. A methylated homologue of anilin. It melts at $63^{\circ} \mathrm{C}$., boils at $235^{\circ} \mathrm{C}$. C.-red. See Pigments, Conspectus of.

Cumin ( $\left.k u^{\prime}-\min \right)$ [cuminum, cumin]. A fennel-like, cultivated, umbelliferous plant, Cuminum cyminum, found native in Egypt and Syria. The fruit is agreeably aromatic and possesses well-marked stimulating and carminative properties. Its active principle is an oil.

Cuminol (ku'-min-ol) [cuminum, cumin; oleum, oil], $\mathrm{C}_{10} \mathrm{H}_{12} \mathrm{O}$. Cumic aldehyd, occurs in Roman caraway oil, and in oil of Cicuta virosa, or water hemlock, etc. It possesses an aromatic odor and a burning taste, has a specific gravity of 0.973 at $13^{\circ} \mathrm{C}$., and boils at $235^{\circ} \mathrm{C}$. $\left(430^{\circ} \mathrm{F}\right.$. $)$.

Cumulative (ku'-mu-la-tiv) [cumulare, to heap up]. Increasing; adding to. C. Action, or Effect, the production of a noteworthy and sudden result, after the administration of a considerable number of comparatively ineffective doses. The possible cumulative effect of certain drugs is one of the scurces of danger that attend their administration.

Cumulus ( $k u^{\prime}-m u$-lus) [L., a heap]. A heap or mound. C. ovigerus. See Ovule.

Cundurango (kun-du-ran'-go). See Condurango.

Cuneate (ku'-ne-ät) [cuneus, a wedge]. Wedgeshaped.

Cuneiform (ku-ne'-if-orm) [cuneus, a wedge; forma, shape]. Wedge-shaped, cuneate. C. Bones, three wedge-shaped bones at the anterior part of the tarsus. C. Columns. See Columns of Burdach.

Cuneihysterectomy (ku-ne-i-his-ter-ek'-to-me) [cuneus,

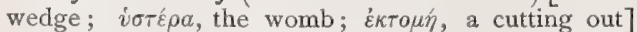
The excision of a wedge-shaped piece of uterine tissue, a procedure that has been advocated in the treat ment of anteflexion of the uterus.

Cuneus $\left(k v^{\prime}-n e-v \imath s\right)$ [L., a wedge]. I. A wedge. 2. A wedge-shaped gyrus on the mesial aspect of the occipital lobe.

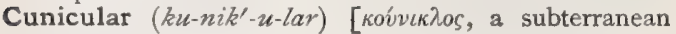
passage]. Furrowed.

Cuniculate $\left(k u-n i k^{\prime}-u-l \bar{a} t\right)$. Same as Cunicular.

Cuniculus $\left(k u-n i k^{\prime}-u\right.$-lus) [L.]. The burrow of the itch-insect.

Cunila $\left(k u-n i^{\prime}-l a h\right)$ [L., a plant]. A genus of labiate plants of the U. S. C. mariana, dittany; a labiate plant of N. America. It is aromatic, carminative, and gently stimulant. Unof.

Cunisset's Test. See Tests, Table of.

Cunnilinguist (kun-i-ling'-grwist) [cunnus, the vulva; lingere, to lick]. One who practices licking the vulva. See Passivism.

Cunnus $\left(k^{\prime} n^{\prime}-u s\right)$ [L.: gen., Cunni]. The vulva.

Cup $(k u p)$ [AS., cuppe, a cup]. I. To bleed. 2. A cupping-glass. C., Dry, a cup for drawing the blood to the surface merely. C., Favus, a depression in a favus scale surrounding a hair, C., Physiologic. See Funnel, Vascular. C., Wet, a cup for abstracting blood through incisions in the skin.

Cuphosis (ku-fo'-sis). See Kryphosis.

Cupola $\left(k u^{\prime}-p o-l a h\right)$ [cupola, a dome]. The domeshaped extremity of the canal of the cochlea. Also, the summit of a solitary gland of the small intestines.

Cupped (kupt) [AS., cuppe, a cup]. Having the upper surface depressed; applied to the coagulum of blood after phlebotomy. C. Disc, excavation of the fundus oculi, normally present in slight degree, but pathologic if excessive.

Cupping (kup'-ing) [AS., cuppe, a cup]. A method of blood-derivation by means of the application of cupping-glasses to the surface of the body. C., Dry, without the abstraction of blood-a form of counterirritation. This is used mainly in inflammatory affections of the lung. C.-glass, a small bell-shaped glass capable of holding three to four ounces, in which the air is rarefied either by heat or exhaustion, and the glass applied to the skin, either with or without scarification of the latter. C., Wet, with the abstraction of blood after scarification.

Cuprea Bark (ku'-pre-ah) [cupreus, coppery; ME., barke, bark]. The bark of certain species of Remijia, q. $v$. ; it affords quinin and the associated alkaloids.

Cuprum (ku'-prum) [L.: gen., Cupri]. See Copper.

Cupule $\left(k u^{\prime}-p \bar{u} l\right)$ [cupula, a little cup]. In biology, a cup-shaped organ, as an acorn-cup, or the sucking apparatus of an insect's foot.

Curaçao (ku-ra-so') [Island of Curaçao, north of Venezuela]. A cordial or elixir prepared from brandy, and variously flavored, principally with orange-peel. It is sometimes used as a vehicle for certain medicines.

Curaçoa (ku-ras-o'-ah). See Curascao.

Curage ( $\left.k u-r a h z h^{\prime}\right)$ [Fr.]. Curettage; cleansing of the eye, or of an ulcerated or carious surface.

Curara (koo-rah'-rah), Curare (koo-rah-re), Curari $($ koo-rah'-re) [S. Am.]. Woorara. Urari. A vegetable extract obtained from Paullinia curare and certain members of the Strychnos family. It is a powerful paralyzant of the motor nerves. Its active principle is Curarin, $\mathrm{C}_{10} \mathrm{H}_{15} \mathrm{~N}$ (Preyer), dose gr. $\frac{1}{2}-\frac{1}{0} \frac{1}{0}$, hypodermatically. It is used in S. America and elsewhere as an arrow-poison. Toxic doses cause death by paralysis of the organs of respiration. It has been reported effectual in two cases of hydrophobia, and has been successful in the treatment of tetanus. Dose by hypodermatic injection gr. $\frac{1}{2} \sigma-\frac{1}{6}$. Injectio Curare Hypodermatica, 5 grains in 60 minims. Dose $\eta_{j} \mathbf{j}-\mathbf{v j}$.

Curarin (koo-rah'-rin). See Curara.

Curarism, Curarization (koo-rah'-rizm, koo-rah-riz-a' shun) [S. A., curare]. The state of one subjected to the full influence of curare by hypodermatic injection. The voice and power of motion are generally abolished, but not the sensibility to pain.

Curatio (ku-ra'-she-o) [cura, care]. The treatment and nursing of a patient.

Curative (ku'-rat-iv) [cura, care]. Having a healing tendency.

Curb (kerb) [ME, courben, to bend]. A hard and callous swelling on various parts of a horse's leg, as the hinder part of the hock, the inside of the hoof, etc.

Curcas (ker'-kas). See Barbaioes Nut.

Curcuma (ker'-ku-mah) [L.]. Turmeric. The rhizome of Curcuma longa of India. Its action is similar to that of ginger. It is employed as a yellow dye ; in chemistry, as a test for alkalies; and in pharmacy, occasionally, to color ointments and other preparations.

Curcumin (ker'-ku-min) [curcuma, saffron], $\mathrm{C}_{74} \mathrm{H}_{14} \mathrm{O}_{4}$. The coloring-matter of turmeric; it crystallizes in orange-yellow prisms, and melts at $177^{\circ} \mathrm{C}$. It dissolves in the alkalies to brownish-red salts. See Pigments, Conspectus of.

Curd (kerd) [ME., curd, curds]. The coagulum of milk that separates on the addition of rennet or an acid. 
Curdling Ferment, Test for. See Tests, Table of. Cure (kür) [cura, care]. The successful treatment of a disease; also, a system of treatment. See Faithcure, Mind-cure, Grape-cure, Water-cure (see Hydropathy), Hunger-cure, Rest-cure, etc. C.-all, a Panacea, $q . v$. C., Herb-juice, a method of treating certain intestinal and gastric troubles. It consists in drinking daily the fresh juice of various herbs and wild plants. C., Potato, Cameron's method of treating foreign bodies in the alimentary tract by the ingestion of mashed potatoes. The body becomes imbedded in the potato-mass that is formed. C., Shaking-. See Shakino-cure.

Curet $\left(\hat{k} u-r e t^{\prime}\right)$ [Fr.]. An instrument shaped like a spoon or scoop, for detaching substances from one another, as the placenta from the uterine wall, etc.

Curettage (ku-ret'-äj). See Currage.

Curling's Operation. See Operations, Table of. $\mathbf{C}$ Ulcer. See Ulcer and Diseases, Table of.

Currant (ker'-ant) [ME.]. I. Uva passa minor; the small, dried, seedless grapes of Greece; formerly used in pharmacy. 2. The fruit of various species of Ribes, as $R$. nigrum, the black currant, preparations of which have long been employed in the hometreatment of sore-throats. Unof. C.-jelly Clot, a soft variety of clot seen in thrombi, the fibrin being stained by the presence of red cells.

Current (ker'-ent) [currere, to run]. In electricity, a term applied to the transference of electric force, which is arbitrarily likened to the flow of a liquid in a confined passage. C., Action, the physiologic current obtained during the activity of a muscle or nerve. C., After, a current produced in nervous or muscular tissue when a constant current which has been flowing through the same has been stopped. C., Alternating, a term applied to a current which, by means of an interrupter, is alternately direct and reverse. This current is employed (in New York) for the execution of capital sentences. C., Ascending, the current formed by placing the positive electrode upon the periphery of a nerve and the negative upon the surface over the nerve-center in the spinal cord. C., Axial, a current passing through a nerve in the direction opposite to that taken by the normal impulse. C., Battery, a galvanic current. C., Blood, the stream of blood as it flows from and back to the heart. C., Centrifugal, a descending current. C., Centripetal, an ascending current. C., Constant. See C., Continuous. C., Continuous, a constant, uninterrupted current in one direction. C., Critical, the current at which a certain result is reached. C., Demarcation, the muscle-current of Du Bois Reymond; the current obtained from an injured muscle. C., Derived, a current drawn off by a derivation-wire from the main current. C., Descending, one passing through a nerve centrifugally, the anode being placed proximally, the cathode distally. C., Diffusion of, the power of a galvanic current to extend its influence in all directions, the same power never being limited to the two electrodes. C., Direct, a current constant in direction, in contradistinction to an alternating current. c., Electrotonic, in electro-therapeutics, a current due to internal polarization in the nerve-fiber between the conducting core of the nerve and the enclosing sheath. C., Faradic, the current produced by an induction-coil, or by a magneto-electric machine. C., Franklinic, a term sometimes used in electro-therapeutics for a current produced by the action of a frictional electric machine. C., Galvanic, a current generated by the decomposition of acidulated water by means of metallic plates. C., Induced. See $C$, Secondary. C., Interrupted, a current that is alter- nately opened and closed. C., Inverse, an ascending or centripetal current. C., Labile, moving one or both electrodes over the surface treated. C., Muscular or Nerve, Alteration Theory of, a theory proposed by $\mathrm{L}$. Hermann, in which the currents of nerve or muscular fibers are regarded as a result of their alteration from any original condition; Molecular Theory of, a theory proposed by Du Bois Reymond, according to which every nerve or muscular fiber is regarded as composed of a series of electro-motive molecules arranged in series and surrounded by a neutral conduct ing fluid. C., Reversed, that produced by changing the poles. C., Secondary, a momentary current produced when a coil of insulated wire is introduced within the field of another coil, through which a continuous current is passing. When the coil is removed from the field there is a momentary current in the opposite direction. C., Secretion, a current following stimulation of the secretory nerves. C.-selector, a device for altering the strength of a current. C., Stabile, a current applied with both electrodes in a fixed position. C., Swelling, one that begins weak and is gradually made stronger, and again gradually diminished. C., To and Fro, a Faradic current. C., Voltaic, the continuous current.

Curry (ker-e) [Canarese, kari]. A sauce, originally Anglo-Indian, containing turmeric, coriander, capsicum, garlic, ginger, etc. ; it is much employed as a relish or appetizer, especially in warm countries; also, a dish seasoned with the foregoing.

Curschmann's Spirals. Corkscrew-like threads of mucin contained in the small, thick pellets that are expectorated during or at the close of an asthmatic paroxysm. They are supposed to be casts of the bronchioles, and have also been seen in simple bronchitis and in pneumonia. C. Theory. See Bronchiolitis exudativa.

Curtate (ker'-tät) [curtatus, shortened]. See Expectation of Life. C. Expectation. See Expectation of Life.

Curtman's Test. See Tests, Table of.

Curvature (ker'-vat-ür) [curvare, to curve]. A bending or curving. C., Angular. See Spondylitis. C., Potts', angular curvature of the spine, with a posterior projection. C. of Spine. See Caries, Kyphosis, Scoliosis.

Curve (kerv) [curvus, bent]. A bending or flexure. C. of Carus, in obstetrics, a portion of the arc of a circle the circumference of which lies in the median line of the pelvis, the center being at the symphysis pubis; the curve is that part of the arc that lies between the planes of the inlet and the outlet.

Curvicaudate (ker-ve-kaw'-dāt) [curvus, curved; cauda, a tail]. In biology, having a curved tail.

Curvidentate (ker-ve-aen'-tât) [curvus, curved; dens, tooth]. In biology, having curved teeth.

Curvifoliate (ker-ve-fol-le-ät) [curvus, curved; folium, leaf ]. In biology, having curved leaves.

Curvinervate (ker-ve-ner'-vāt) [curvus, curved; nervus, nerve]. In biology, applied to leaves the veins of which are curved and nearly parallel in their course.

Curvirostral (ker-ve-ros'-tral) [curvus, curved; rostrum, beak ]. In biology, having a crooked bill or beak,

Curvoisier and Von Hacker's Method. See Operations, Table of.

Cusack's Operation. See Operations, Table of.

Cuscamidin (kus-kam'-id-in) [cusco; amid]. A substance found in Cinchonas.

Cuscamin (kus'-kam-in) [cusco; amin]. A crystalline substance found in Cinchonas.

Cusco Bark (kus'-ko bark). A kind of cinchona; the bark of a variety of Cinchona pubescens. 
Cusconidin (kus-kon'-id-in) [cusco]. An alkaloid found in Cinchonas.

Cusconin (kus'-ko-nin) [cusco], $\mathrm{C}_{23} \mathrm{H}_{26} \mathrm{~N}_{2} \mathrm{O}_{4}$. A crystalline alkaloid found in Cinchona bark.

Cushing's Operation. See Operations, Table of.

Cushion (kush't-un) [ME., cuschone, a cushion]. A soft body used as a pillow, for the purpose of reclining or sitting.

Cusp (kusp) [cuspis, a point]. The pointed crown of a tooth.

Cusparia Bark (kus-pa'-re-ah bark). See Angustura.

Cuspid Teeth $\left(\right.$ kus $\left.^{\prime}-p i d\right)$. The four teeth that have conical crowns. They are situated, one on each side, in each jaw, between the lateral incisor and first bicuspid.

Cuspidate (kus'-pid-ät) [cuspis, a point]. In biology, tipped with a sharp, rigid point.

Cuspidatus (kus-pid-a'-tus) [cuspis, a point: pl., Cuspidati]. A cuspid tooth.

Cuspidor (kus'-pid-or) [Pg., cuspidor, a spittoon]. A spittoon; a vessel for receiving the ejecta from the mouth. C., Sanitary, a small pasteboard or wooden cup with a cover supported in a rim of metal. These cuspidors should contain some water or disinfecting solution, and at the end of the day should be thrown into the fire. They are used to prevent the dissemination of the germs of tuberculosis.

Cusso $\left(k \bar{u} s^{\prime}-s o\right)$. See Brayera and Kooso.

Cut (kut) [ME., cutten, to cut]. To incise, as with a knife. To castrate. An incision. In biology, a cleft. C.-velvet. See Velvet.

Cutaneous ( $\left.k u-t a^{\prime}-n e-u s\right)$ [cutis, the skin]. Pertaining to the skin. C. Calculus. See Milium. C. Emphysema. See Emphysema. C. Horns. See Cornu cutaneum. C. Respiration, the transpiration of gases through the skin.

Cutch (kuch) [Anglo.-Ind.]. I. A name given to Catechu, the dried extract from Acacia catechu, cultivated in India and Burmah, and containing 45 to 55 per cent. of a special variety of tannic acid (catechutannic or mimotannic). It is used in leather-manufactures. 2. The tool, or book of parchment leaves, between which gold is beaten into foil.

Cuticle $\left(k u^{\prime}-t i k-l\right)$ [dim. of cutis, the skin]. The epidermis or scarf-skin. See Skin.

Cuticula (ku-tik'-u-lah) [dim. of cutis, a skin]. The outer, finely lamellated layer of the wall of hydatid cysts. C. dentis, the cuticle of a tooth; Nasmyth's membrane; the delicate horny envelop that covers the enamel of young and unworn teeth.

Cuticular (ku-tik'-u-lar) [cuticula, dim. of cutis, the skin]. Belonging or pertaining to the skin.

Cuticularization (ku-tik-u-lar-iz-a'-shun) [cuticula, dim. of cutis, the skin]. The formation of a cuticula.

Cutin (ku'tin) [cutis, skin]. In biology, cork-substance; a modification of cellulose (Frémy), also called suberin.

Cutipunctor (ku-te-punk'-tor) [cutis, skin; punctor, puncturer]. An instrument for puncturing the skin.

Cutis (ku'-tis) [L.]. The derma, or true skin. C. anserina. See Goose Skin. C.pendula. Synonym of Dermatolysis. C. testacea, a variety of seborrhea in which the trunk and extensor surfaces of the extremities are covered with large, thick plates of greasy, inspissated sebum, usually greenish or blackish, from accumulation of dirt upon them. There is no inflam. mation of the subjacent skin. C. unctuosa. Synonym of Seborrhea.

Cutisation (ku-tis=a'-shun) [cutis, skin]. The acquirement of the characters of true skin by exposed mucous membrane.

Cutisector (ku-tis-ek'-tor) [cutis, skin; sector, a cutter].
An instrument for taking small sections of skin from the living subject for microscopic study.

Cut-off Muscle. A popular designation for the compressor urethræ muscle. See Muscles, Table of.

Cutose $\left(k u^{\prime}-t o \partial s\right)$ [cutis, skin]. In biology, the substance forming the thin outer covering of the aërial organs of plants (Frémy).

Cuttle, Cuttlebone (kut'-l, kut'-lbön). See Sepia.

Cuvier, Angle of. See Angle. C., Canals of. See Canal. C., Ducts of. See Duct.

Cyanalcohol (si-an-al'-ko-hol) [kvavos, dark-blue; alcohol ]. Cyanhydrin; a substance obtained by the union of an aldehyd with hydrocyanic acid.

Cyanaldehyd (si-an-al'-de-hìd) [кv́avos, dark-blue; aldehyd]. A substitution-compound of acetic aldehyd.

Cyanalkin (si-an-all-kin) [kv́avos, blue; alkali]. One of the products of the action of sodium upon the pure nitrites. The cyanalkins are crystalline and strongly alkaline bases, and form salts with one equivalent of the acids.

Cyanamid (si-an'-am-id) [ќ́avos, blue; amid], CN. $\mathrm{NH}_{2}$. A white, crystalline body prepared by the action of ammonia on cyanogen chlorid.

Cyananilid (si-an-an'-il-id) [kíavos, blue; anilin]. $\mathrm{C}_{7} \mathrm{~N}_{7} \mathrm{H}$. Phenylcyanamid, a body formed on conducting $\mathrm{CNCl}$, into a cooled ethereal solution of anilin. It is readily soluble in alcohol and ether, but dissolves with difficulty in water.

Cyambenzene $\left(s i-a n-b e n^{\prime}-z e \bar{n} n\right)$. See Benzonitrile.

Cyanein $($ si-an-e'-in) [кíavos, dark-blue]. In biology, the blue pigment found by Krukenberg in Rhizostoma, Vellella, Aurelia, and Cyanea. It is soluble in water, insoluble in benzene, carbon disulphid, and chloroform.

Cyanephidrosis (si-an-ef-id-ro'-sis) [кvávos, blue;

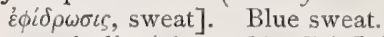

Cyanetholin (si-an-eth'-o-lin) [kvavos, blue; ethyl]. A liquid of ethereal odor, insoluble in water, and decomposing when distilled. The cyanetholins are the esters of the cyanic acids.

Cyanhematin (si-an-hem'-at-in) [кv́avos, blue; ain $\mu a$, blood]. A substance produced by adding a solution of cyanid of potassium to a solution of blood, and heating gently for some time.

Cyanhydrin (si-an-hi'-drin). See Cyanalcohol.

Cyanhydrosis (si-an-hid-ro'-sis). See Cyanephidrosis.

Cyanic $\left(s i-a n^{\prime}-i k\right)$ [kvavos, blue]. Blue or bluish. C. Acid. See Acid, Cyanic.

Cyanid (si'-an-id) [kv́avos, blue]. Any compound of cyanogen with a metal or a radical. Most of the cyanids are actively poisonous.

Cyanidrosis (si-an-id-ro'-sis). Same as Cyanephidrosis.

Cyanin $\left(s i^{\prime}-a n-i n\right)$ [кúavos, dark-blue]. I. In biology, the blue pigment of certain flowers, as the cornflower, violet, iris, etc. 2. $\mathrm{C}_{29} \mathrm{H}_{35} \mathrm{~N}_{2} \mathrm{I}$. A blue dye formerly prepared by heating quinolin amyl iodid with potassium hydroxid. Same as Quinolin-blue. See Pigments, Conspectus of. C.-blue. See Pigments, Conspectus of.

Cyanochroia (si-an-o-kroi'-ah) [kv́avos, blue; xpocá, color]. Cyanosis.

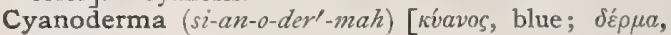
skin]. Cyanosis.

Cyanodermia (si-an-o-rler-me-ah). See Cyanoderma.

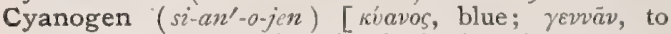
produce]. A radical molecule having the structure $\mathrm{CN}$, an acid-compound of carbon and nitrogen, existing as a colorless, combustible gas, exceedingly poisonous. With hydrogen it forms hydrocyanic or prussic acid; with metals, the cyanids; with oxygen, 
the compound known as fulminic acid. Cyanogen and hydrocyanic acid are usually distinguished by the odor of bitter almonds.

Cyanohemoglobin (si-an'-o-hem-o-glo'-bin) [kivavos, blue; yevvãv, to produce; aiua, blood; globus, a ball]. A peculiar compound of hydrocyanic acid and hemoglobin, made by the addition of hydrocyanic acid to warm blood outside of the body. This substance is entirely wanting in the ozonizing power of normal oxyhemoglobin.

Cyanomycosis $\left(s i-a n^{\prime}-o-m i-k o^{\prime}-s i s\right)$ [kv́avos, blue; $\mu$ ḱкns, fungus]. The production of blue pus, or of pus charged with Micrococcus pyocyaneus. See Bacteria.

Cyanopathy (si-an-op'-a-the). See Cyanosis.

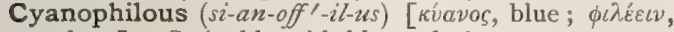
to love]. Stainable with blue coloring-matter.

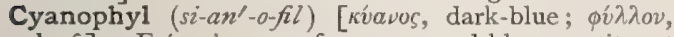
leaf ]. Frémy's name for a supposed blue constituent of chlorophyl.

Cyanopia (si-an-ó-pe-ah) [kv́avos, blue; $\dot{\omega} \psi$, eye]. A perverted state of the visual powers, during which all objects appear blue.

Cyanosin (si-an'-o-sin) [kíavos, blue]. One of the Fluorescein colors. See Pigments, Conspectus of.

Cyanosis (si-an-o'-sis) [kvavos, blue]. A bluish discoloration of the skin from non-oxidation of the blood, caused by local or general circulatory diseases. It may be due to the admixture of arterial and venous blood, as when there is a deficiency of the septum between the auricles and ventricles. It is seen in various diseases of the heart and lungs. C., Congenital. See Blue Disease.

Cyanospermia (si-an'-o-sper'-me-ah) [кv́avos, blue; $\sigma \pi \varepsilon \rho \mu a$, sperm]. A condition wherein the semen has a bluish tint.

Cyanotic (si-an-ot'-ik) [кv́avos, blue]. Relating to or affected with cyanosis.

Cyanuric Acid (si-an-u'-rik). See Acid, Tricyanic.

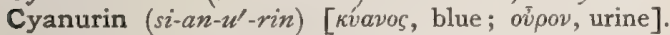
Uroglaucin or urine-indigo; indigo found in the urine in cystitis and in chronic kidney-diseases; it is also occasionally found in apparent health.

Cyar (si'-ar) [kva $\rho$, the eye of a needle]. The internal auditory meatus.

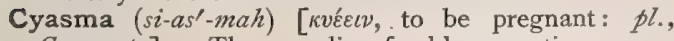
Cyasmata]. The peculiar freckle sometimes seen upon pregnant women.

Cyathiform (si'-ath-if-orm) [cyathus, a cup; forma, shape]. In biology, cup-shaped.

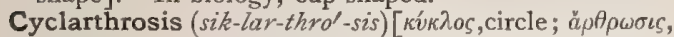
a joint]. A pivot-joint; lateral ginglymus, or rotary diarthrosis; an articulation that admits of decided rotation in one of its elements.

Cyclic $\left(s i^{\prime}-k l i k\right)$ [ $\kappa v \kappa \lambda \iota \kappa o ́ s$, circular]. Having cycles or periods of exacerbation or change, as cyclic insanity. In biology, applied to flowers whose organs are arranged in whorls. C. Albuminuria. See Albuminuria. C. Insanity. See Insanity.

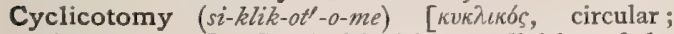
$\tau \varepsilon$ evecv, to cut]. Surgical incision or division of the ciliary body.

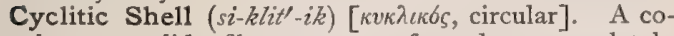
herent, solid, fibrous mass of exudate, completely enveloping the crystalline lens.

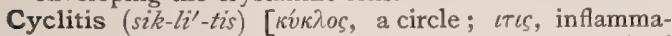
tion]. Inflammation of the ciliary body, characterized by a zone of congestion in the sclerotic coat surrounding the cornea. It is a serious condition, often implicating adjacent structures. It may be serous, plastic, or suppurative. Irido-cyclitis, the involvement of both iris and ciliary body in the inflammatory process.

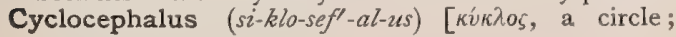

$\kappa \varepsilon \phi c \lambda \eta$, head]. 1. A species of single autositic monsters characterized by a more or less complete absence of the olfactory organs, together with an intimate union of imperfectly developed or rudimentary visual organs, situated in the median line. 2. A variety of this species in which there is a fusion of the orbital cavities and of the eyes, without a vestige of a nose or of a proboscis.

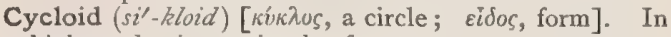
biology, having a circular form.

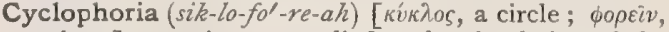
to bear]. I. A term applied to the circulation of the fluids of the body. 2. An insufficiency of the oblique muscles of the eye, giving the eyes a tendency to roll outward or inward, so that the naturally vertical meridians would diverge either at the upper or lower extremities.

Cyclopia (si-klo'-pe-ah). See Synophthalmia.

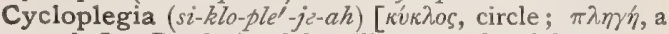
stroke]. Paralysis of the ciliary muscle of the eye.

Cyclops $\left(s i^{\prime \prime}-k l o p s\right)[\kappa \varepsilon ́ \kappa \lambda o s$, circle; $\ddot{\omega} \psi$, eye]. A congenital malformation consisting in a fusion of the two eyes into one. See Rhinocephalus.

Cyclosis $\left(s i-k l o^{\prime}-s i s\right)$ [ ${ }^{\prime} \kappa \lambda o s$, a circle]. In biology, circulation, as of the protoplasm within a cell.

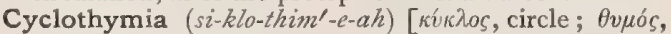
mind]. Cyclic insanity. See Insanity.

Cyclotome $\left(s i k^{\prime}-l o-t o ̄ m\right)$ [ ting]. A kind of knife for performing cyclotomy.

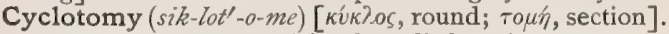
An operation proposed for the relief of glaucoma, consisting of an incision through the ciliary body.

Cydonium (si-do'-ne-um) [ $\kappa v \delta \omega v \iota v v$, a quince]. Quinceseed. The seeds of $C$. vulgaris, employed mainly for the mucilage contained in the epithelial covering, which consists of a compound of gum and glucose. C. mucilago, quince-seeds 2 , macerated in water 100 parts, is a bland demulcent, known as Bandolin, and used as a hair-dressing.

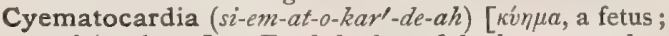

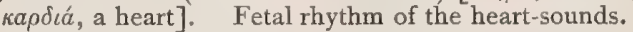

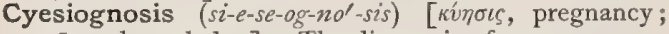

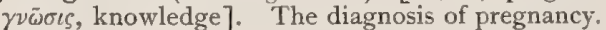

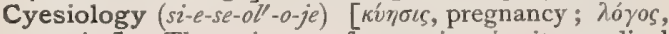
treatise]. The science of gestation in its medical aspects.

Cyesis $\left(s i-e^{\prime}-s i s\right)[\kappa u ́ \eta \iota \varsigma$, pregnancy]. Pregnancy.

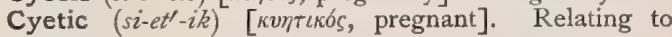
pregnancy.

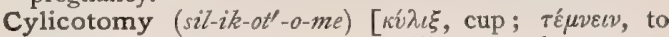
cut]. Surgical incision of the ciliary muscle.

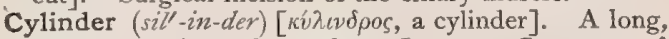
circular body. See, also, Lenses. C.-cone of Kuhnt, one of the conical sections marked off by the "incisures" and going to build up the annular segments of a medullated nerve-fiber. C.-filling, a filling, the material of which is composed of gold-foil or tin-foil cylinders, sometimes called block-filling. C. of Gold-foil, a form of gold-foil for filling teeth, made by rolling a tape of non-cohesive gold upon a fine broach, commencing at one end of the tape and continuing the movement until the desired size of the cylinder is reached.

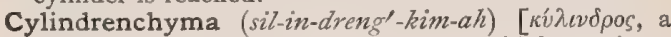
cylinder; है $\gamma \chi v \mu a$, an infusion]. In biology, tissue composed of cylindric cells.

Cylindric (sil-in'-drik), or Cylindrical (sil-in'-drik-al)

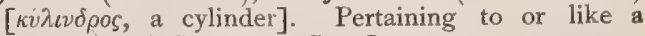
cylinder. C. Lenses. See Lenses.

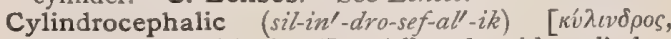
cylinder; $\kappa \varepsilon \phi \alpha \lambda \dot{\eta}$, head]. Affected with cylindrocephaly. 


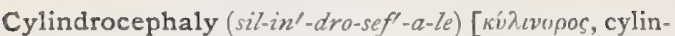
der; $\kappa \varepsilon \phi a \lambda \eta \dot{y}$, head]. A cylindric formation of the skull.

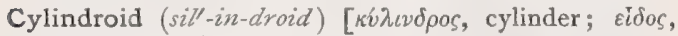
likeness]. A name given to a mucous cast frequently found in the urine in scarlet fever, and other diseases. It closely resembles a hyaline tube-cast. Cylindroids are ribbon-like forms, usually of great length, and of about the same diameter as renal casts. They may assume various shapes, due to bends and twists, giving them a cork-screw appearance. The extremities are narrow and elongated and often bifurcated.

Cylindroma (sil-in-dro' -

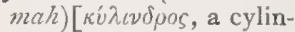
der: pl., Cylindromata].

A tumor peculiar to the orbit of the eye, to the face, and to the stomach, composed of cylindric or club-like hyaline processes. It is a variety of myxo-sarcoma.

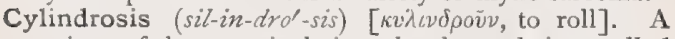
variety of bony articulation, the bone being rolled upon itself to form a canal and then a suture, as in the cranium.

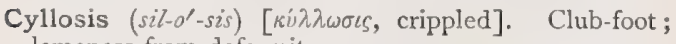
lameness from deformity.

Cyllosoma (sil-o-so'-mah) [ $p l .$, Cyllosomata $]$. A variety of single autositic monsters of the species celosoma, in which there is a lateral eventration occupying principally the lower portion of the abdomen, with absence or imperfect development of the lower extremity on that side occupied by the eventration.

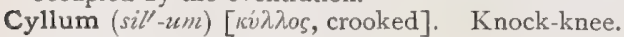

Cymba (sim'-bah) [ $\sin ^{\prime} \beta \eta$, a boat]. In biology, a boatshaped sponge-spicule.

Cymbiform (sim'-bif-orm) [cymba, boat; forma, shape]. In biology, boat-shaped. C. Bone, the scaphoid bone.

Cymbocephalia $($ sim-bo-sef-a'-le-ah). See Cymbocephaly.

Cymbocephalic, or Cymbocephalous (sim-bo-sef-al'-

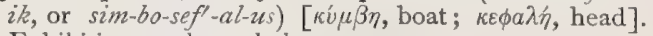
Exhibiting cymbocephaly.

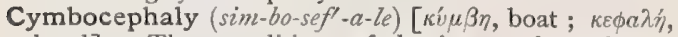
head]. The condition of having a boat-shaped head.

Cyme (sim) [cyme, a young sprout]. In biology, a loose flower-cluster on the determinate or centrifugal plan.

Cymene (si'-mên) [cyminum, cumin], $\mathrm{C}_{10} \mathrm{H}_{14} . \quad$ A hydrocarbon that occurs, together with cumic aldehyd, in Roman caraway oil (from Cuminum cyminum), and in other ethereal oils. It is prepared by treating oil of turpentine with oil of vitriol. It is a pleasantlysmelling liquid, that boils at $175^{\circ}-176^{\circ} \mathrm{C}$; ; its specific gravity at $0^{\circ} \mathrm{C}$. is 0.8722 .

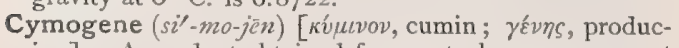
ing]. A product obtained from petroleum, gaseous at ordinary temperatures, but liquefiable by cold or pressure; boiling at $0^{\circ} \mathrm{C} .\left(32^{\circ} \mathrm{F}\right.$.); specific gravity $110^{\circ}$ B. It is used in the manufacture of artificial ice, and is serviceable in the production of great cold for local or minor surgical purposes.
Cymose (si'-môs) [ $\kappa \tilde{v} \mu a$, a young sprout]. In biology, pertaining to a cyme; bearing cymes.

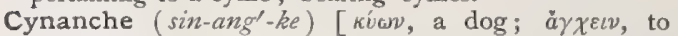
strangle]. An old name for any acute affection of the throat, as diphtheria, croup, tonsillitis, etc., in which the patient struggles for breath (as a panting dog). See also Angina. C. maligna, a fatal form of sore-throat. C. suffocativa. Synonym of Croup. C. tonsillaris. See Quinsy.

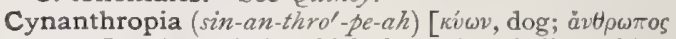
a man]. A mania in which the patient believes himself a dog, and imitates the actions of one.

Cyniatria (si-ne-a-tri'-ah) [kíwv, dog; iarpeia, medication]. The science or treatise of the diseases of the dog and their treatment.

Cynic $\left(\sin ^{\prime}-i k\right)$ [кขvıкós, dog-like]. Pertaining to a dog. C. Spasm, a contraction of the facial muscles upon one side, so as to expose the teeth in the manner of an angry dog.

Cynobex hebetica (si'-no-beks he-bet'-ik-ah) [kíwv, $\operatorname{dog} ; \beta \dot{\eta} \xi$, cough; $\eta \dot{\beta} \eta \tau \iota \kappa \circ$, youthful]. The convulsive cough of puberty; a loud, dry, barking cough that often attacks boys and girls at puberty. General hygienic treatment is usually curative.

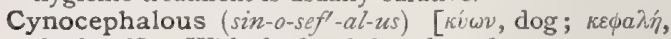
the head]. With the head dog-shaped.

Cynodontes (si-no-don'-tēz) [Kúv, dog; ỏdoús, odóvtos, tooth]. The canine teeth, so called from their resemblance to the teeth of a dog. See Cuspid Tecth.

Cynoglossum (si-no-glos'-um). See Hound's Tongue.

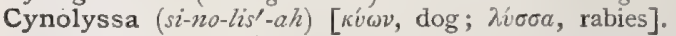
Hydrophobia; rabies.

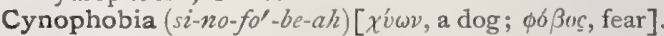
I. Morbid fear of dogs. 2. Imaginary hydrophobia.

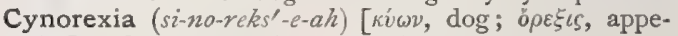
tite]. Canine voracity; bulimia.

Cynospasmus (si-no-spas'-mus) [кúwv, dog; $\sigma \pi \alpha \sigma \mu \sigma s$, spasm]. Same as Cynic Spasm.

Cynurenic Acid (sin-u-ren'-ik) [Kv́wv, a dog; oṽpov, urine ], $\mathrm{C}_{20} \mathrm{H}_{14} \mathrm{~N}_{2} \mathrm{O}_{6}+2 \mathrm{H}_{2} \mathrm{O}$. A crystalline acid found in dog's urine. It is a decomposition-product of proteids. On heating it cynurin is evolved.

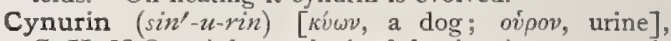
$\mathrm{C}_{18} \mathrm{H}_{14} \mathrm{~N}_{2} \mathrm{O}_{2}$. A base obtained by heating cynurenic acid to $250^{\circ}$.

Cyophoria $\left(s i-o-f o^{\prime}-r e-a h\right)$ [Kv́os, fetus; $\phi \varepsilon \hat{\rho} \varepsilon \iota v$, to carry]. Pregnancy; gestation.

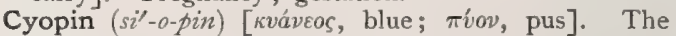
coloring-matter found in blue pus.

Cyphosis $\left(s i-f o^{\prime}-s i s\right)$. See Kyphosis.

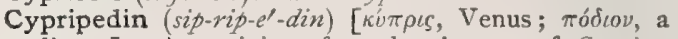
slipper]. A precipitate from the tincture of Cypripedium pubescens; antispasmodic, nervine, narcotic. Dose $1 / 2$ to 3 grains. Unof.

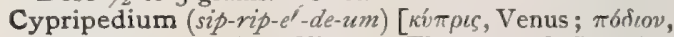
a slipper]. Lady's Slipper, The roots of $C$. pubescens and $C$. parviflorum, American valerian, with properties due to a volatile oil and acid. It is an antispasmodic and stimulant tonic, used instead of valerian, which it resembles. C., Fld. Ext. Dose $\eta x-x \times x$.

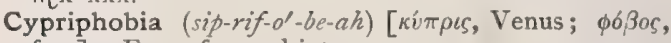
fear]. Fear of sexual intercourse.

Cyprus Vitriol (si'-prus rit'-re-ol). Same as Blue Vitriol. C. Fever. Same as Malta Fever.

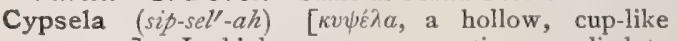
structure]. In biology, a term sometimes applied to an achenium which is invested with an adnate calyx such as that of the Compositx.

Cyron (sir'-on). See Chyron.

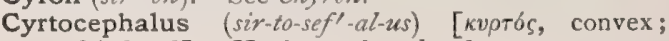
$\kappa \varepsilon \varphi a \lambda \dot{n}$, head]. Having a short head. 


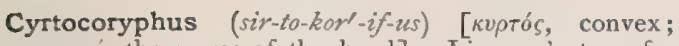
корvai, the crown of the head]. Lissauer's term for a skull with a parietal angle between $\mathbf{1} 22^{\circ}$ and $132^{\circ}$.

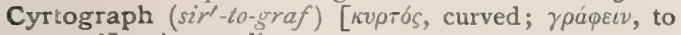
record]. A recording cyrtometer.

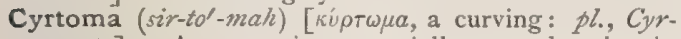
tomata]. A convexity, especially one that is abnormal.

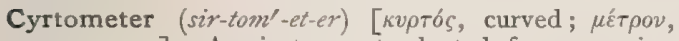
a measure]. An instrument adapted for measuring curves, and especially those of the chest.

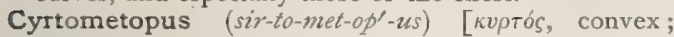
$\mu \varepsilon$ ' in which the angle formed by lines connecting the nasion with the bregma and the metopion is between $120^{\circ}$ and $130.5^{\circ}$.

Cyrtonosus (sir-ton'-o-sus) [кvрт6s, curved; vóoos, a disease]. Synonym for Rhachitis.

Cyrtopisthocranius (sir-to-pis-tho-kra'-ne-us) [ [kvprós,

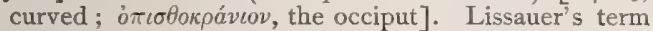
for a skull in which the angle of the summit of the occiput is between $117^{\circ}$ and $140^{\circ}$.

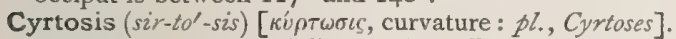
Any deformity, especially one that affects the bones.

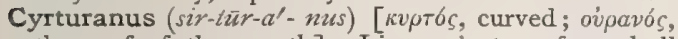
the roof of the mouth]. Lissauer's term for a skull in which the angle at the roof of the mouth is between $132^{\circ}$ and $147.5^{\circ}$.

Cyst (sist) [kírtৎ, a pouch]. A cavity containing fluid and surrounded by a capsule. C., Blood. See Hematoma. C., Cutaneous. See C., Dermoid. C., Dentigerous, one containing teeth ; one form is found in the ovaries. C., Dermoid, a congenital cyst containing bone, hair, teeth, etc.; the cyst-wall is like the skin. C., Echinococcus, a cyst formed in various tissues and organs of man by the larva of the Tonia echinococcus of the dog, taken into the stomach. C., Exudation, one resulting from increase of exudation, or from exudation into a closed cavity. C., Hydatid. See C., Echinococcus. C., Meibomian. See Chalazion. C., Mucous, a retention cyst containing mucus. C., Multilocular, one composed of many separate compartments. C., Müllerian, a cyst containing mucus, blood, or pus, developed in the remnants or rudiments of the inferior or vaginal portion of the duct of Müller. C., Piliferous, a hair-containing or dermoid cyst. C., Primary, one newly formed, not from distention. C., Retention, one that is due to the non-expulsion from its duct of the secretion of a gland, in consequence of closure of the duct, as in mucous or sebaceous cysts. C., Sebaceous, one containing fatty material. C., Secondary, a cyst within a cyst. C., Sublingual. See Ranula. C., Synovial, one resulting from the distention of bursæ or synovial sheaths. C., Tarsal. See Chalazion. C., Unilocular, one having but a single cavity. C., Wolffian, a cyst developed in the inferior vestiges of the canal of Wolff. It is situated in the anterior or antero-lateral vaginal wall, and is frequently prolonged toward the cervix or even into the base of the broad ligament.

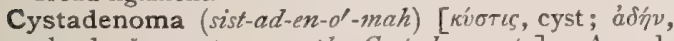
gland; ö $\mu a$, a tumor: pl., Cystadenomata]. An adenoma containing cysts.

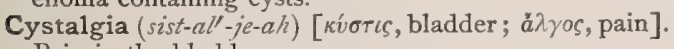
Pain in the bladder.

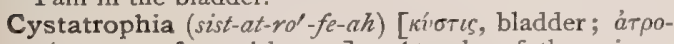
dia, want of nourishment]. Atrophy of the urinary bladder.

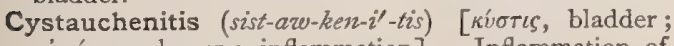
av $\chi \dot{\eta} \nu$, neck; $\iota \tau \iota s$, inflammation]. Inflammation of the neck of the bladder; trachelocystitis.

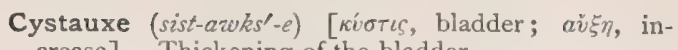
crease]. Thickening of the bladder.

Cystectasia (sist-ek-ta'-ze-ah), or Cystectasy (sist-ek'-

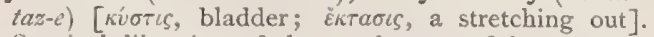
Surgical dilatation of the urethra or of its prostatic portion in certain operations for stone.

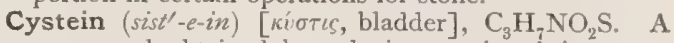
compound obtained by reducing cystin; it is a crystalline powder, soluble in water, yielding an indigoblue color with ferric chlorid; in the air it rapidly oxidizes to cystin.

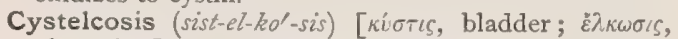
ulceration]. Ulceration of the bladder.

Cystencephalus (sist-en-sef'-al-uss) [kí⿴囗十s, a bladder; $\varepsilon \gamma \kappa \varepsilon \phi a \lambda o ́ s$, the brain]. A form of monstrosity in which the brain is replaced by a cyst-like structure.

Cystenchyma (sist-eng'-kim-ah) [kiotıs, a bladder; $\check{\varepsilon} \gamma \chi v \mu a$, an infusion]. In biology, a connective tissue of large, oval, thin-walled cells, as seen in certain sponges.

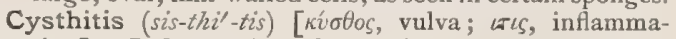
tion]. Inflammation of the vulva.

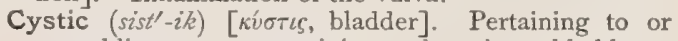
resembling a cyst; pertaining to the urinary bladder or the gall-bladder. C. Angioma. Synonym of Lymphangioma circumscriplum.

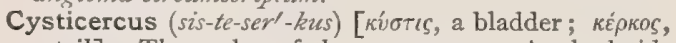
a tail]. The scolex of the tape-worm. An hydatid. C. bovis, a form of hydatid existing in the muscles of the ox (mostly in the calf). Its progenitor is the Tania mediocanellata of man. It produces the disease called Beef Measles. C. cellulosæ, the hydatid found inhabiting the intermuscular connective tissue of the pig, producing the condition known as "measles." Its progenitor is the Tenia solium of man. See Alternation of Generation. C. cellulosæ cutis. An hydatid, or immature form of Tania solium, which is sometimes parasitic upon the subcutaneous tissues of the skin. C. ovis, an hydatid of uncertain origin found in sheep in the condition called Mutton Measles. C. pisiformis, an hydatid found mainly in the abdominal cavity of the rabbit and of the hare, and, in its immature state, in the liver of these animals. Its progenitor is the Tania serrata of the dog. C. tenuicollis, a slender or long-necked hydatid found in the abdominal and pelvic cavity of the sheep, the pig, the ox, and the fowl. Its progenitor is the Tania marginata of the dog. See Parasites (Animal), Table of.

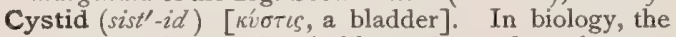
saccular, ciliated, planula-like embryo of a polyzoan; also the cell in which the body of an adult polyzoan is contained.

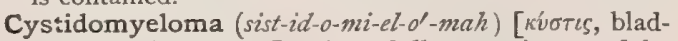
der; $\mu v \varepsilon \lambda \sigma \varsigma$, marrow ]. A medullary carcinoma of the bladder.

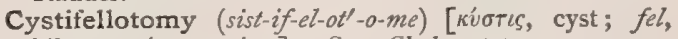
bile; roṕn, a cutting]. See Cholecystotomy.

Cystiform (sist'-if-orm) [cystis, a bladder; forma, shape]. Encysted, cystomorphous.

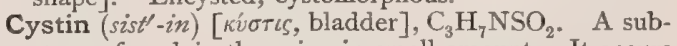
stance found in the urine in small amount. It occurs in regular, colorless, six-sided tables of very characteristic appearance. It is insoluble in water, alcohol, and ether, but readily soluble in ammonia. Test: boil with a solution of lead oxid in sodium hydrate. If cystin is present, black lead sulphid is precipitated.

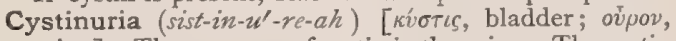
urine]. The presence of cystin in the urine. The cystin may be present in the form of calculi or as a deposit. The urine has a yellowish-green color and a peculiar smell, like that of fresh sweet-briar, but rapidly acquires a putrescent odor on standing, whilst an oily film forms on the surface. 


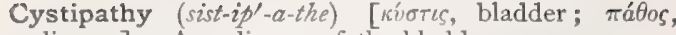
disease]. Any disease of the bladder.

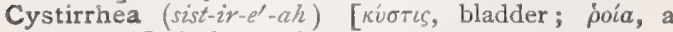
flow]. Vesical catarrh.

Cystis $($ sist'-is). See Cyst.

Cystitic (sist-it'-ik) [kvoT/s, a bladder]. Relating to cystitis.

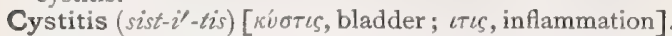
Inflammation of the bladder. C., Exfoliative, that form of cystitis in which the inflammatory process has produced a sloughing of the mucous membrane, or a separation of the whole or a portion of the membrane, which lies loose in the bladder.

Cystitome (sist'-it-om). See Cystotome.

Cystoblast (sist'-o-blast). See Cytoblast.

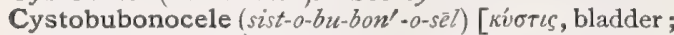
$\beta o v \beta \omega \nu$, groin; $\kappa \hat{n} \lambda \eta$, hernia]. Hernia of the bladder through the inguinal ring.

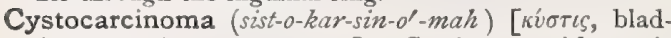

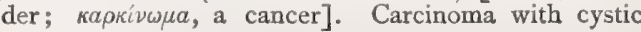
degeneration.

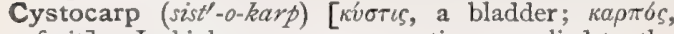
fruit]. In biology, a name sometimes applied to the sporocarp of certain algæ.

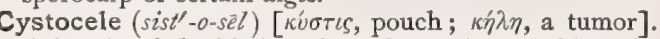
A hernia of the bladder into the vagina, pushing the vaginal wall through the vulvar orifice. In the great majority of cases it is a sequela of childbirth, following laceration of the pelvic floor. It may, however, result from heavy lifting, etc. There is a feeling of weight, with frequent and difficult micturition, and a protrusion between the labia. It is generally associated with a rectocele, and if left uncorrected favors the descent of the uterus.

Cystochondroma (sist-o-kon-dro'-mah) [kv́orıs, bladder; $\chi 6 v \delta \rho o s$, cartilage; $\sigma \mu \alpha$, a tumor: $p l$., Cystochondromata]. A neoplasm presenting the characters of both chondroma and cystoma.

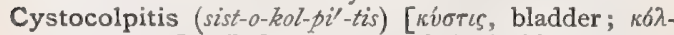
$\pi \circ$, vagina]. Inflammation of both bladder and vagina.

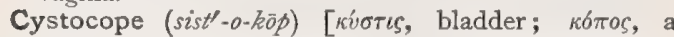
blow]. A urethral sound, having at the proximal extremity a plate to amplify the sound produced by striking against a vesical calculus.

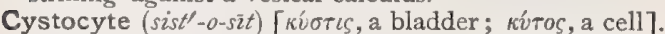
In biology, one of the bladder-like cells of the cys. tenchyma, as in sponges.

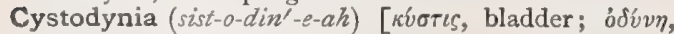
pain]. Same as Cystalgia.

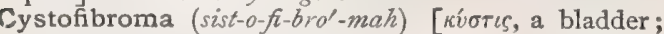
fibra, a fiber; ö $\mu a$, a tumor: pl., Cystofibromata]. A neoplasm presenting the character of both a fibroma and a cystoma.

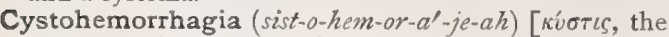
bladder; $\alpha\lceil\mu \alpha$, blood; $\rho \eta \gamma v v ́ v \alpha \iota$, to burst]. Vesical hemorrhage.

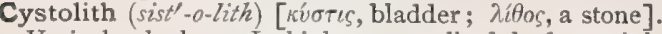
Vesical calculus. In biology, a stalked body mainly composed of calcium carbonate, found in the cells of certain leaves, as in those of the nettle.

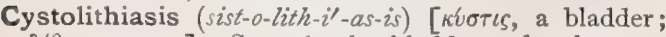
$\lambda i \theta o s$, a stone]. Stone in the bladder; also that condition of the system that is associated with the presence of vesical calculus.

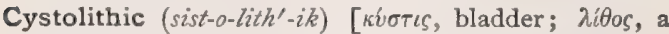
stone]. Pertaining to a vesical calculus.

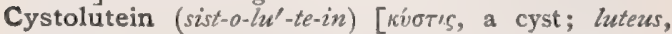
yellow]. A yellow coloring-matter found in cysts.

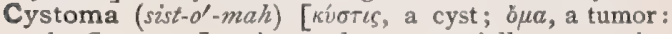
pl., Cystomata]. A neoplasm, especially an ovarian tumor, containing or made up of cysts.

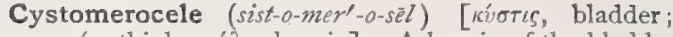

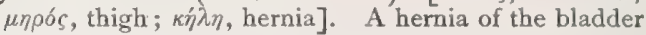
through the femoral ring.

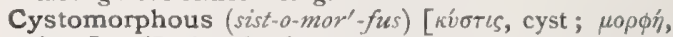
form]. Having the form of a cyst.

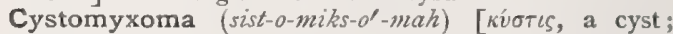
$\mu \hat{v} \xi \alpha$, mucus; ó $\mu \alpha$, a tumor: pl., Cystomyxomata]. A neoplasm presenting the characters of both myxoma and cystoma.

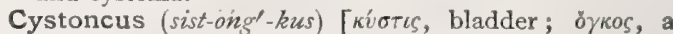
swelling]. Any swelling of the bladder.

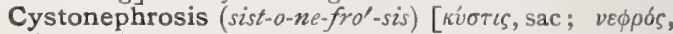
kidney]. A cystic or cystomorphous dilatation of the kidney.

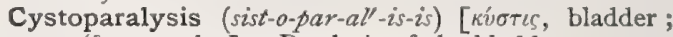

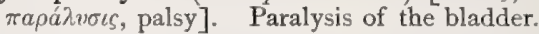

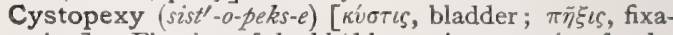
tion]. Fixation of the bladder. An operation for the cure of cystocele, based upon the principle of the Alexander-Adams operation.

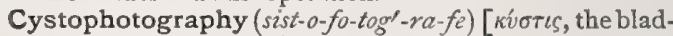
der; $\phi \tilde{\omega} s$, light; $\gamma \rho a ́ \phi \varepsilon \iota \nu$, to write]. Photographing the interior of the bladder for diagnostic purposes.

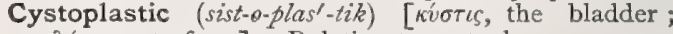
$\pi \lambda a ́ \sigma \sigma \varepsilon \iota \nu$, to form]. Relating to cystoplasty.

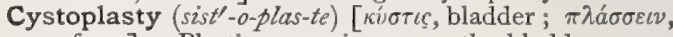
to form ]. Plastic operation upon the bladder, especially for vesico-vaginal fistula.

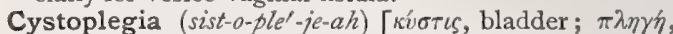
a blow]. Paralysis of the bladder.

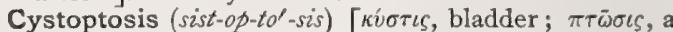
fall]. The projection of some portion of the bladder into the urethra.

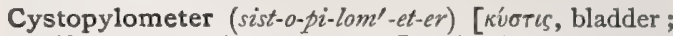

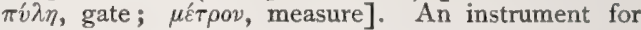
measuring any obstruction (as an enlarged prostate) at the entrance to the bladder; it is called also pylometer.

Cystorrhagia (sist-or-a'-je-ah). See Cystohemorrhagia. Cystorrhea (sist-or- $\left.e^{\prime}-a h\right)$. Same as Cystirrhea.

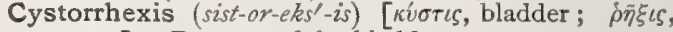
rupture]. Rupture of the bladder.

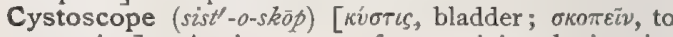
examine]. An instrument for examining the interior of the bladder.

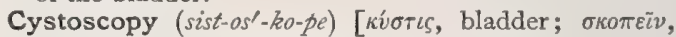
to examine]. Examination of the interior of the bladder by means of the cystoscope.

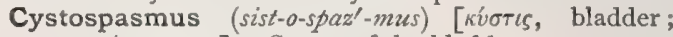
$\sigma \pi a \sigma \mu b s$, spasm]. Spasm of the bladder.

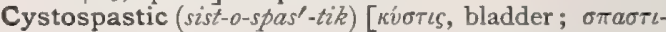
$\kappa o ́ s$, pulling]. Relating to spasm of the bladder.

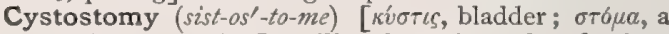
mouth or opening]. The formation of a fistulous opening in the bladder-wall.

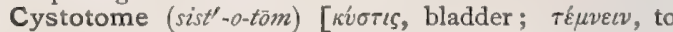
cut]. A knife used in cystotomy; also a knife used in rupturing the capsule of the lens in cataractoperations.

Cystotomia (sist-o-to'-me-ah) [L.]. Same as Cystotomy. C. hypogastrica. Suprapubic cystotomy.

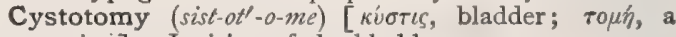
cutting]. Incision of the bladder.

Cyte (sit) [кútos, a hollow]. Any cell; especially a nuclear cell (used mostly in composition).

Cythemolysis (si-lhem-ol'-is-is) [кútos, cell; aipa, blood; $\lambda$ vi $\iota$, dissolution]. Dissolution of the corpuscles of the blood.

Cytin (sí-tin) [кítos, a cell]. An insoluble cellular substance that remains in various residues of animal tissue from which cytoglobin has been removed. By decomposition it is changed into an albuminoid. 


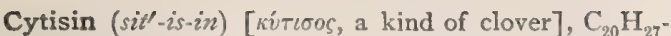
$\mathrm{N}_{3} \mathrm{O}$. A poisonous alkaloid obtained from Cytisus laburnum and other species. It occurs in yellowishwhite, deliquescent crystals. It is chiefly used in the form of the nitrate, a beautiful crystalline salt, paleyellow in color and acid in reaction. It is used subcutaneously in paralytic migraine, and as a diuretic in dropsy and cardiac disease. Dose, grain $\frac{1}{20}$ to $\frac{1}{12}$, hypodermatically.

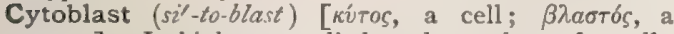
germ ]. In biology, applied to the nucleus of a cell; also one of the ameboid cytodes going to make up the cytoblastema of sponges.

Cytoblastema (si-to-blas-te'-mah) [ кúros, a cell;

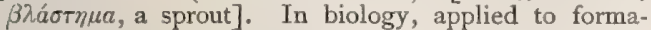
tive material or protoplasm, as giving rise to cells or cytodes; also to the matrix in which the individuals of a protozoan colony are imbedded; the gelatinous matrix of a sponge.

Cytochylema (si-to-ki-le'-mah) [кítos, a cell ; $\chi v \lambda 6 \varsigma$, juice]. Strasburger's term for the inter-reticular portion of protoplasm; cell-juice.

Cytochyma, or Cytochyme (si-to-kim'-ah, or si'-tokim) [кútos, a cell; $\chi v \mu o ́ s$, juice]. The water-sap in the vacuoles of the cytochylema of protoplasm.

Cytococcus (si-to-kokl-us) [кútos, cell ; кб́ккоs, kernel: pl., Cytococci]. The nucleus of a cytula.

Cytode (si'-tód) [kítos, a cell ; cijos, form]. In biology, a term applied by Haeckel to a non-nucleated cell. The simplest, most primitive form of cell, without nucleus or nucleolus; Haeckel therefore calls the Monera cytodes.

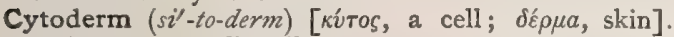
In biology, a cell-wall.

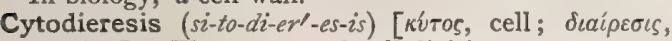
division]. The process of cell-division.

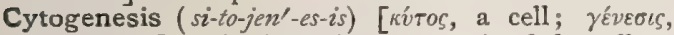
production]. The formation or genesis of the cell, or of cells.

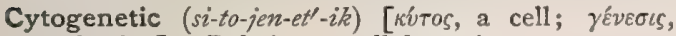
production]. Relating to cell-formation.

Cytogenic $\left(s i-\right.$ to-jen $\left.^{\prime}-i k\right)$. See Cytogenous.

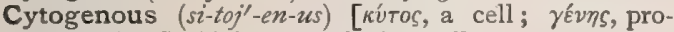
ducing]. In biology, producing cells.

Cytogeny (si-toj'-en-e). See Cylogenesis.

Cytoglobin (si-to-glo'-bin) [кútos, a cell; globus, a ball]. An albuminoid, obtainable in the form of a white, soluble powder. It forms three per cent. of the pulp of the lymphatic glands. It is partially convertible into preglobin.

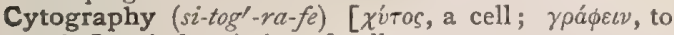
write]. A description of cells.

Cytohyaloplasm (si-to-hi'-al-o-plazm) [кv́tos, a cell;

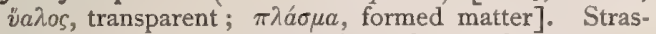
burger's name for the reticulum of protoplasm.

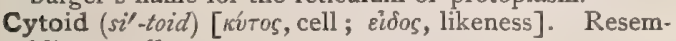
bling a cell.

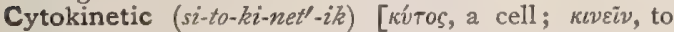
move]. In biology, applied to the phenomena of motion of plasma or cells; the opposite of Cytostatic (Ryder).

Cytolergy (si-tol'-er-je) [Kítos, a cell; Ě $\rho \gamma o v$, work]. Cell-activity.

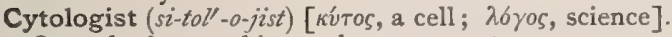
One who is versed in cytology.

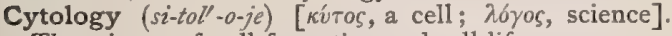
The science of cell-formation and cell-life.

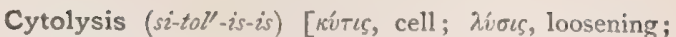
solution]. Cell-catabolism; cell-destruction.

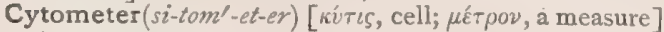
A device for measuring cells.

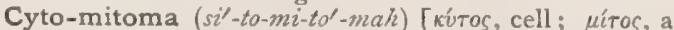
fiber]. The fibrillar part of a cell-body. See Mitoma.

Cytonergy (si-ton'-er-je). Same as Cytolergy.

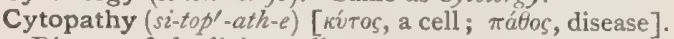
Disease of the living cell.

Cytophagous (si-toff'-ag-us) [Kútos, a cell ; $\phi \bar{a} \gamma \varepsilon \omega$, to devour]. Phagocytic; of the nature of a phagocyte; cell-devouring.

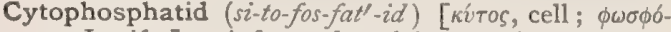
pos, Lucifer]. A form of nuclein, containing sulphur and phosphorus and said to be obtainable from braintissue; gangliocytin.

Cytoplasm, or Cytoplasma (si'-to-plazm, or si-to-plaz'. mah) [kítos, cell; $\pi \lambda a ́ \sigma \mu a$, anything formed]. In biology, Dujardin's name for protoplasm, $q . v$.

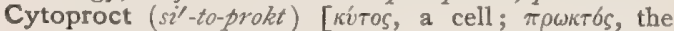
anus]. In biology, an orifice with anal functions in the Infusoria. Cf. Cytopyge.

Cytopyge (si-to-pi'-je) [Kútos, a cell; $\pi v \gamma \dot{\eta}$, the rump] In biology, the anal aperture of a unicellular animal. Cf. Cytoproct.

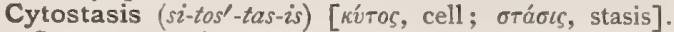
Stoppage or plugging of the capillaries by the bloodcells.

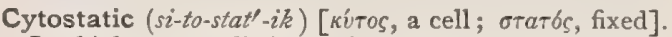
In biology, applied to the static or resting conditions of plasma or cells; the opposite of Cytokinetic (Ryder).

Cytostome (si'-to-stöm) [кútos, a cell; $\sigma \tau b \mu a$, mouth]. In biology, the oral aperture of a unicellular organism.

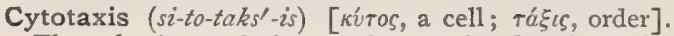
The selective, ordering, and arranging function of a living cell.

Cytotrophy (si-tot'-ro-fe) [кítos, cell ; $\tau p \delta \phi \eta$, nourishment]. The growth of the cell and sustentation of cell-life.

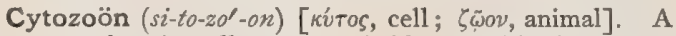
protoplasmic cell-mass, probably parasitic in nature, with independent movement; found by Gaule in defibrinated blood and other structures.

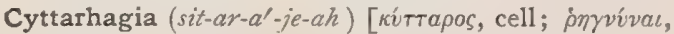
to burst forth]. Hemorrhage from the socket of a tooth.

Cytula (sit'-u-lah) [кítos, a cell]. In biology, an impregnated ovum.

Cytuloplasm (sit'-u-lo-plazm) [кítos, a cell; $\pi \lambda a ́ \sigma \sigma \varepsilon \imath \nu$, to form, mold]. In biology, the mingled ovoplasm and spermoplasm in a cytula.

Czermak's Spaces. Same as Interglobular Spaces, $q . v$.

Czerny's Operations. See Operations, Table of.

Czerny-Lembert Suture. See Suture.

Czerny-Schroder Operation. See Operations, Table of.

Czoker's Alum Cochineal. A solution for staining microscopic sections. Boil 7 grams of pulverized cochineal and 7 grams of alum in $700 \mathrm{c.c}$. of distilled water, until the quantity of fluid is reduced to 400 c.c. ; cool, add a few drops of carbolic acid, and filter. After standing for a few days filter again, after which the fluid will be ready for use. See Stains, Table of. Czumpelitz's Test. See Tests, Table of. 
D. (Dosis). A dose. In Electro-therapeutics an abbreviation of Duration and of Density. In ophthalmology the letter is used as an abbreviation of Dexter and Dioptry. It is also used for detur, let it be given.

Da Costa's Disease. See Diseases, Table of.

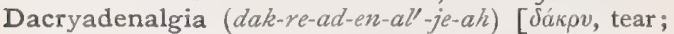
ádín, gland; ànyos, pain]. Pain in a lachrymal gland.

Dacryadenitis (dak-re-ad-en-i'tis). See Dacryoadenitis.

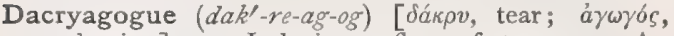
conducting]. I. Inducing a flow of tears. 2. An agent that induces a flow of tears.

Dacrycystalgia (dak-re-sis-tal'-je-ah). See Dacryocystalgia.

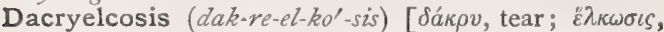
ulceration]. Ulceration of the lachrymal apparatus.

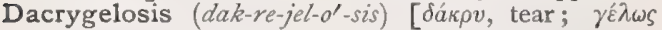
laughter]. Alternate weeping and laughter.

Dacryhemorrhysis (dak-reh-em-or'-is-is) [ $\delta a k \rho v$, tear; ai $\mu a$, blood; jiv tears; a flow of blood from a lachrymal duct.

Dacryin (dak'-re-in) [ $\delta a ́ k \rho v$, a tear]. A peculiar substance contained in tears.

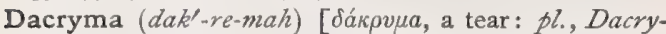
mata]. A tear; the lachrymal secretion.

Dacryoadenitis (dak-re-o-ad-en-i'-tis) [ dákpvov, a tear;

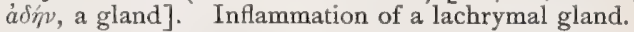

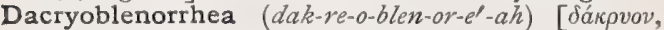
a tear; $\beta \lambda \varepsilon ́ v v o s$, mucus; $\rho o i ́ a$, a flow]. Chronic inflammation and discharge of mucus from the lachrymal sac.

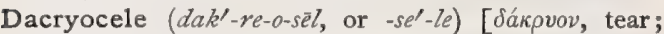
$\kappa \dot{\lambda} \lambda \eta$, hernia]. See Dacryocystocele.

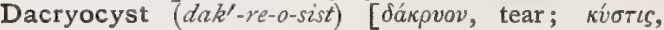
cyst]. The lachrymal cyst.

Dacryocystalgia (dak-re-o-sis-tal'-je-ah) [dákpvov,tear;

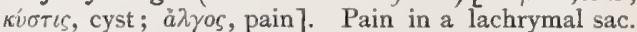

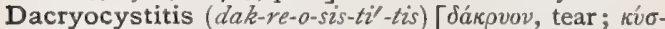
$\tau \ell$, a sac]. Inflammation of a lachrymal sac.

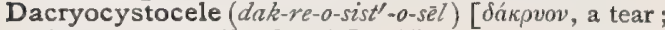

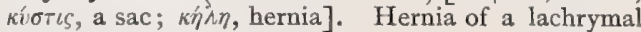
sac.

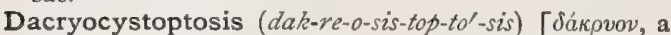

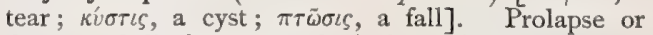
downward displacement of a lachrymal sac.

Dacryohemorrhea (dak-re-o-hem-or-e'-ah). See Dacryhemorrhysis.

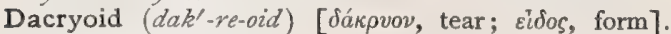
Resembling a tear.

Dacryolite (dak'-re-o-litt). See Dacryolith.

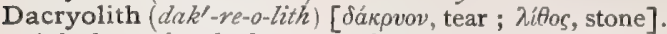
A lachrymal calculus; a calcareous concretion in a lachrymal passage or in the palpebral conjunctiva.

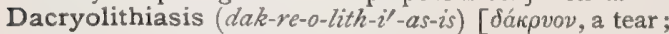
$\lambda i \theta o s$, a stone]. The morbid condition that is attended by the formation of dacryoliths; also, the presence of dacryoliths.

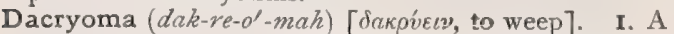
lachrymal tumor, 2. The closure or obstruction of the puncta lachrymalia, causing epiphora.

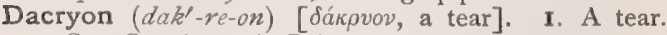
2. See Craniometric Points.

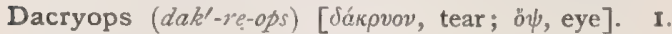
A watery eye. 2. Cyst of the duct of a lachrymal gland.

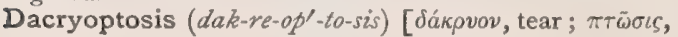

a fall]. I. The falling or shedding of tears. 2. Dacryocystoptosis.

Dacryopyorrhea (dak-re-o-pi-or-e'-ah) [ dákpvov, a tear; $\pi \dot{v} o v$, pus; $\rho$ oi $\alpha$, a flow ]. A discharge of pus from the lachrymal apparatus.

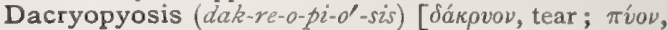
pus]. Suppuration in the lachrymal apparatus.

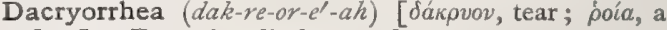
flow]. Excessive discharge of tears.

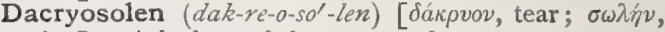
pipe]. A lachrymal duct or canal.

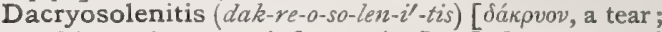
$\sigma \omega \dot{\nu} \nu$, a pipe ; $\iota \tau \iota$, inflammation]. Inflammation of a lachrymal duct.

Dacryostenosis (dak-re-o-ste-no'-sis) [dákpvov, tear; otevós, narrow]. Stenosis or stricture of a lachrymal duct.

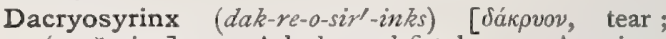
$\sigma v \rho \iota \gamma \xi$, pipe]. I. A lachrymal fistula. 2. A syringe for use in the lachrymal ducts.

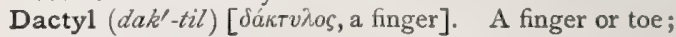
a digit.

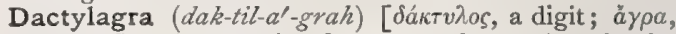
seizure]. An attack of gout or rheumatism in the fingers.

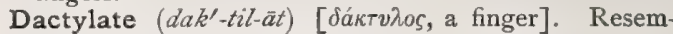
bling a finger. Possessing five rays or appendages.

Dactylion (dak-til'-e-on). See Syndactylism.

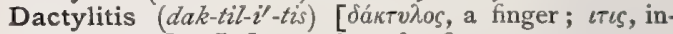
flammation]. Inflammation of a finger or toe.

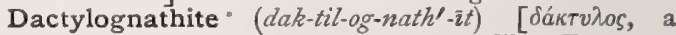
finger; yvátos, jaw]. In biology, Milne Edwards' term for the terminal (distal) joint of one of the footjaws of a crustacean. See Dactylos.

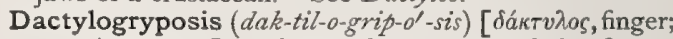

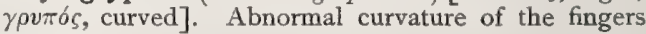
or toes.

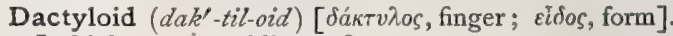
In biology, resembling a finger.

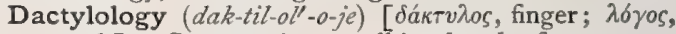
speech]. Conversation or talking by the fingers.

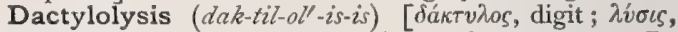
loosening]. The falling off of a finger or toe. D. spontanea. See Ainhum.

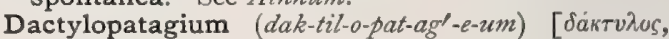
finger; $\pi a \tau a \gamma \varepsilon i ̃ \nu$, a border to a woman's gown]. In biology, that part of the patagium of a bat which is connected with the digits. Cf. Ectopatagium.

Dactylopodite (dak-til-op'-o-dit) [dákrvios, a finger; Toús, a foot]. See Dactylos.

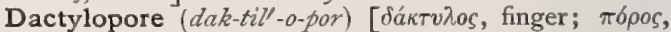
pore]. In biology, applied to the opening of the finger-like, or tentacular dactylozoid of certain hydrozoans.

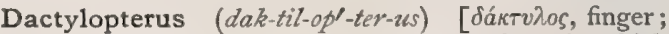
$\pi \tau \varepsilon \rho \delta y$, wing]. In biology, applied to fishes in which certain of the pectoral fin-rays are separate and fingerlike.

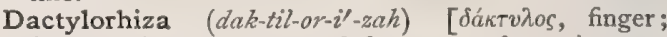
$\rho i \zeta \alpha$, root]. A disease of the roots of certain vegetables, as turnips.

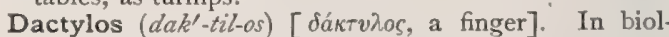
ogy, the seventh joint of any crustacean appendage, as the dactylognathite and dactylopodite of Milne Edwards.

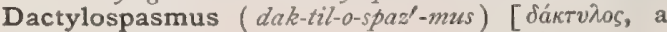
digit; $\sigma \pi \alpha \sigma u o ́ s, a$ spasm]. Spasm of a digit.

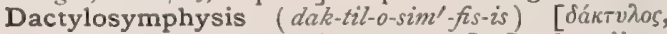
finger; $\sigma v v$, together; $\dot{v} \varepsilon \varepsilon v$, to grow]. Syndactylism. 
Dadi Gogo (da'-de go'-go) [African]. See Gogo.

Damonomania (de-mo-no-mál-ne-ah). See Demonomanici.

Daffy's Elixir. A compound aromatic tincture of senna. Unof.

Dahlia (dahl'-yah). See Pigments, Conspectus of.

Dajaksch (dit-aksh) [Java]. The arrow-poison used in Borneo. It is believed to be distinct from the Java arrow-poison.

Dakryon (dak'-re-on). See Craniometric Points.

Dakryops (dak'-re-ops). Same as Dacryops.

Dalby's Carminative. An old empiric carminative and mildly opiate mixture, answering nearly to the nistura carminativa of the National Formulary. It contains about two and a half minims of tincture of opium to the fluidounce.

Dalgarno Alphabet. Glove-alphabet; a method of manual communication among deaf-mutes, in which the letters are indicated by touching various parts of the hand.

Dallas's Operation. See Operations, Table of.

Dalmatian Insect Powder. See Buhach.

Dalton's Theory. The atomic theory of compounds.

Dalton-Henry Law. See Law.

Daltonism (dall-ton-izm) [Dalton, a physician]. Color-blindness. See Blindness.

Dam. See Rubber Dam and Coffer Dam.

Damalic Acid (dam-al'-ik). See Acid.

Damaluric Acid (dam-al-u'-rik). See Acid.

Damiana (dam-e-an'-ah). The leaves of Turnera aphrodisiaca, found in Mexico and Lower California; a stimulant tonic and said to be a powerful aphrodisiac. It is the basis of a great number of quack remedies. D., Ext. Dose gr. ij-x. D., Fld. Ext. Dose $m x-3 j$. Dose of the leaves 3 j daily. All unot.

Dammar (dam'-ar) [Hind, dāmar, resin]. A gum or resin resembling copal, produced by various species of Dammara and by various other trees. D., True, is obtained from the Dammara orientalis, a coniferous tree, indigenous in the East Indies, and also from Dammara australis, in New Zealand. The latter variety is also known as Kauri, or coudie resin. The former is the variety commonly called dammar in commerce. It occurs in masses, coated on the exterior with white powder from mutual attrition, while the interior is pale-amber colored and transparent. It is harder than rosin, and splits and cracks at the temperature of the hand. It is used in the manufacture of varnishes. See Corvdie Gum.

Damp. See Choke-damp; Black-damp; Fire-damp.

Damping Apparatus. The union of the tympanic membrane of the ear with the auditory ossicles acting as a damper to prevent excessive sympathetic vibration for its own fundamental note.

Dance (dans) [Fr., danser, to dance]. Any measured tread or system of steps accompanied by music. Also, any motion of the body caused by an abnormal nervous stimulus. D., St. Vitus's. See Chorea. D. Plague. Synonym of Chorea.

Dancel's Method. See Treatment, Method's of.

Dancer's Cramp. SeeCramp. D. Palsy. See Palsy.

Dancing Mania. See Choromania.

Dandelion (dan'-de-li-on). See Taraxacum.

Dandruff (dan'-druf). See Seborrhea, Pityriasis, and Alopecia furfuracea.

Dandy (dun'-de) [Hind., dāndi, a boatman]. I. In India, a kind of stretcher or hammock of canvas with a bamboo frame. It is serviceable in the transportation of the sick and wounded. 2. See Colic, Endemic. D. Fever. See Dengue.

Danforth's Oil. See Naphtha.
Daniell (dan'-yel) [Daniell, an electrician]. A unit of electric measurements equal to 1.124 volts. D. Cell. See Cell

Daniella (dan-e-el'-ah) [Dr. Daniell, a traveler]. A genus of leguminous trees of W. Africa. D. thurifera, the only species of this genus affording olibanum, or true frankincense.

Dantec, Bacillus of. See Bacteria, Table of:

Danube Fever $\left(d a n^{\prime}-\bar{u} b f^{\prime} e^{\prime}-v e r\right)$. A febrile affection of remittent or relapsing type observed in sailors and others that have sailed on and have drunk the water of the Danube River, characterized by symptoms of gastro-intestinal derangement, albuminuria, hematuria, edema, uremic symptoms, profuse perspiration, enlarged spleen, and nervous symptoms. Its precise nature is unknown; possibly it is the same as Malto fever, Rock fever, Cretan fever, Mediterranean fever.

Daphne $\left(d a f^{\prime}-n e\right)[\delta a \dot{\phi} v \eta$, the laurel]. A genus of thymelaceous shrubs, mostly poisonous or acrid. See Mezereon.

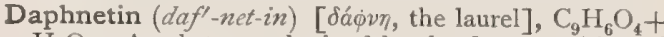
$\mathrm{H}_{2} \mathrm{O}$. A substance obtained by the decomposition of the glucosid daphnin. It crystallizes in yellow needles or prisms, melting at $255^{\circ} \mathrm{C}$

Daphnin (daf'-nin) [dá $\phi v \eta$, the laurel], $\mathrm{C}_{15} \mathrm{H}_{16} \mathrm{O}_{9}+$ $2 \mathrm{H}_{2} \mathrm{O}$. I. A glucosid isomeric with esculin; it is obtained from the bark of Daphne alpina, and forms prismatic transparent crystals having a bitter taste and melting at $200^{\circ} \mathrm{C}$. 2. See also Pigments, Conspectus of.

Darier's Disease. Psorospermose folliculaire végétante : Keratosis follicularis; Ichthyosis sebacea cornea; a disease of the skin commencing on the face or trunk, but ultimately spreading to other parts of the body, and characterized by the development of papules of small size and dirty-red color, with firmly-adherent grayish-brown, black, or gray horny crusts. These crusts can be squeezed out of the papules by the thumb-nails. In some places the lesions may become confluent. The disease progresses slowly, and the papules may assume considerable size. Ulceration of their surfaces may occur, or the tumors may suppurate en masse. The disease occurs usually in males. Its etiology is obscure. See Diseases, Table of.

Darnel (dar'-nel). See Lolium.

D'Arsonval's Oven. See Oven.

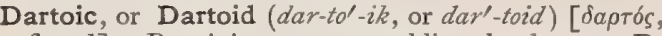
flayed]. Pertaining to or resembling the dartos. D. Myoma. See Myoma.

Darton's Test. See Tests, Table of.

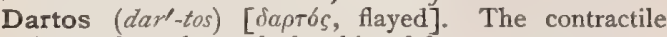
fibrous layer beneath the skin of the scrotum.

Dartre $\left(d a r^{\prime}-t_{r}\right)$ [Fr.]. Any herpetic or other chronic skin-disease; a term vaguely used in French and the older English medical literature.

Dartrous (dar'-trus) [Fr., dartre]. Of the nature of tetter or herpes; herpetic.

Dartsac $\left(d a t^{\prime}-s a k\right)$. A muscular sac containing a calcareous or chitinous dart or rod, opening into the cloaca of certain gasteropods. (Helix.)

Darwin's Ducts. See Ducts. D. Ear. See Ear, Deformities of, Darvinian Tubercle, and Diseases, Table of. D. Theory of Heredity. See Heredity.

Darwinian Tubercle. A nodule or eminence sometimes seen on the edge of the helix of the ear; it is believed to be a relic corresponding to the point of an ape's ear.

Darwinism (dar'-win-izm). [Named after Charles Damin, a celebrated naturalist]. The theory of descent by evolution, as modified by the doctrine of the survival of the fittest. See Neo-Darrinism and Evolution. 
Dastre-Morat's Method. See Anesthetic

Dasyma (das'-im-ah). Same as Hirsuties.

Date-disease. See Aleppo Boil. D.-fever. Synonym of Dengue.

Datisca (da-tis'-kah) [L.]. A genus of herbs, somewhat allied to the cacti. D. cannabina, of Asia and the Levant, is antiperiodic and antiscrofulous. D. glomerata is a Californian species.

Datiscin (da-tis'-in) [Datisca $], \mathrm{C}_{21} \mathrm{H}_{22} \mathrm{O}_{12}$. A starchlike glucosid from Datisca cannabina; it is a good yellow dye.

Datura (da-tu'-rah) [Hind., dhatūra, a certain plant]. A genus of Solanacee, or night-shade family. D. stramonium. See Stramonium. D. tatula, a plant belonging to the nightshade family, closely resembling stramonium in its therapeutic and physiologic properties. It has been smoked with advantage in asthma. Unof.

Daturin (da-t $u^{\prime}-$ rin $)$ [Hind., dhatüra, a certain plant]. A poisonous alkaloid from the thorn-apple. See Atropin.

Daturism (dat'-u-rizm) [Hind, dhatûna, a certain plant]. A morbid condition of mind and body induced by excessive dosing with stramonium (Datura); stramonium-poisoning. It is nearly or quite identical with atropism.

Daubenton's Angle. See Angle. D. Line. See Line. D. Plane. See Plane.

Daughter (daze'ter) [AS., dohtor, daughter]. A female child or descendant. D.-cell. See Cell. D.cyst, a cyst formed within a cyst. D.-nuclei. See Karyokinesis. D.-star, an amphiaster. See Karyokinesis.

Dauvergne's Apparatus. An apparatus used for treating old dislocations of the shoulder.

Davat's Operation. See Operations, Table of.

Davidsohn, Pupillary Reflex of. The light reflected through the pupil in translumination, when the electric light is held in the mouth.

Daviel's Operation. See Operations, Table of.

Davier (dah'-ve-á) [Fr.]. A tooth-forceps; a lion-forceps.

Davies and Dale's Carmin Mass. A warm-flowing mass for injecting tissues. Digest in a flask for thirtysix hours, at the ordinary temperature, I I. 6 grams of carmin in a mixture of $\mathbf{1 5}$ c. c. of ammonia $(0.92$ strength) and $\mathbf{I} \mathbf{I}$ c.c. of water. Filter, and dilute with water to 472 c.c. Dissolve 38.88 grams of potassium alum in 295 c.c. of water, and add, with constant boiling, a solution of sodium carbonate until a slight precipitate is produced. Boil and add to the carmin fluid, shaking vigorously. A drop of the fluid, when placed on a white filter-paper, should show no color-ring. Allow it to cool and settle for a day or two, and draw off the supernatant fluid with a siphon. Wash, by decantation, until the wash-water ceases to give a precipitate with barium chlorid. So much water must be kept with the color that it shall measure II80 c.c. For use soak Ioo grams of gelatin in 750 c.c. of this fluid and melt over a water-bath.

Davies-Colley Operations. See Operations, Table of.

Davis's (Leon) Sign. See Death.

Davy's Method. See Treatment, Methods of. D. Operation. See Operations, Table of. D. Tests. See Tests, Table of.

Day's Test. See Tests, Table of.

Day-Blindness. See Nyctalopia; also Hemeralopia.

Daymare $\left(d a^{\prime}-m \bar{a} r\right)$. A state of temporary distress and terror, resembling nightmare, but coming on when the patient is awake. It is thought to be due to a diseased state of the blood-vessels of the brain.

Dead (ded) [AS., deád, dead]. Without life; desti- tute of life. D.-born. Still-born. D. Finger. See Sphaceloderma and Night-palsy. D. -house, a morgue; an apartment in a public institution for keeping dead bodies. D. Nettle. See Lamium. D. Voice, a voice without nasal resonance. The so-called nasal voice.

Deadly (ded'-le) [AS., deád, dead]. Capable of causing death; fatal; mortal. D. Nightshade. See Atropa and Belladonna.

Deaf (def, or déf) [AS., deáf, deaf]. Without the sense of hearing. A condition of impaired hear. ing. D.-dumbness. See Deaf-mutism. D. fields, two small triangular planes, converging toward the external auditory meatus, and in which the vibrating tuning-fork is not heard. D.-mute, one who suffers from deaf-mutism. D.-mutism, a condition of deafness or impaired hearing, accompanied by imperfect development (congenital), or loss of speech. D.-points, some points near the ear in which a vibrating tuning-fork cannot be heard.

Deafness (def'-nes) [AS., deáf, deaf]. The condition of being deaf; surdity. D., Boilermakers', chronic labyrinthine deafness resulting from constant exposure to loud sounds. Bone-conduction is impaired, and there are destructive and atrophic changes throughout the cochlex, most marked at the base. D., Mind. See D., Psychic. D., Music, a variety of pșychic deafness in which, although musical sounds are heard, they are not recognized as such. D., Paradoxic, called also Paracousia Willissii, deafness for speech in silence, but with ability, e. g., to hear the same voice in a noisy car or street. This is said to be caused by compression of the labyrinth. It is a form of otopiesis. D., Psychic, the deafness from destruction of the auditory center (Munk). Sounds are heard, but not recognized or understood. D., Word, a variety of psychic deafness in which, although words be heard, they are not comprehended.

Death (deth) [AS., death, death]. The cessation of life. D., Apparent, a term applied to a cataleptic state in which respiration and circulation are so feeble as to be inappreciable. D., Black, an exceedingly fatal epidemic called the "Plague," which occurred in Europe during the I4th century, during which it is estimated 20,000,000 people died. D. Camass. See Camass. D., Localized. See D., Somatic. D., Molecular, caries; ulceration. D.-rate, a term arbitrarily expressing the mortality of a place, based upon the number of deaths for each Iooo of population during a period of one year. D.-rattle, the peculiar sound produced by the passage of air through mucus in the throat of a dying person. D., Signs of, certain indications of death, such as cessation of the heart's action, and respiration, vigor of the body, healthiness of the tissues, etc. See D., Tests of. D. Somatic, death of the organism as a whole, in distinction from localized D., or necrosis, and gangrene. D., Tests of: Dr. Richardson summarizes the more important as: 1. Absence of the pulsation of the heart. 2. Absence of the respiratory murmur. 3. Pressure on veins. (Fillet test). 4. Electric test for muscular irritability. 5. The ammonia hypodermatic test (Monteverde's sign). 6. Coagulation of the blood in the veins. 7. Rigor mortis. 8. Decomposition. Balfour's Test, a test for the action of the heart in apparent death. He proposed sticking into the skin over the heart needles having little paper flags fixed in their blunt ends. Should there be contraction of the heart-muscle, such movement would be communicated to the paper flags. Cloquet's Needle Test, a bright needle plunged into the body of the biceps muscle and left there for a time; then ex- 
amined for signs of oxidation. If found, life is present. Davis's (Leon) Sign, after death the arteries are pale or yellowish, and empty of blood, whilst during life the vessels pulsate, and have the color of the surrounding tissues. Diaphanous Test, the scarlet-red color of the finger-edges when held toward the light, due, if life exists, to the blood circulating through the tissues. The scarlet tint does not appear if life is extinct. The test is not to be relied on in all cases, as in syncope the red coloration may be absent. Fillet Test: Richardson's Test, a fillet applied to the veins of the arm will not cause filling of the veins on the distal side of the fillet if death be present. Foubert's Test consists in cutting through one of the intercostal spaces and feeling the heart with the point of the finger. Laborde's Sign. Same as Cloquet's Needle Test. Larcher's Sign, soon after death the conjunctivæ exhibit externally gray, cloudy discolorations, that rapidly become black. They are due either to the formation of films of mucus, or to cadaveric imbibition dependent on putrefactive changes. Levasseur's Sign, the application of a scarificator and cupping-glass will fail to draw blood if life has been extinct for some hours. Magnus's Sign, if a finger be tightly bound round with a ligature, the part beyond the constriction will, if the person be living, become bright red, the tint increasing in depth until it finally assumes a uniformly bluish-red color. At the spot, however, where the ligature is applied, a narrow white ring becomes visible. No change results from the application of the ligature if life be extinct. Monteverde's Sign, the injection subcutaneously during life of a little ammonia solution will be followed by a port-wine congestion in surrounding parts, which does not take place in case of death. Ripault Sign, during life the circular shape of the pupil is influenced by external pressure only during its actual application. After life, however, external pressure is capable of permanently affecting the normal roundness of the pupillary aperture. D. Trance, trance that closely resembles death.

Debilitant (de-bil'-it-ant) [debilitare, to weaken]. I. Weakening. 2. A medicine that weakens.

Debility (de-bil'-it-e). See Asthenia.

Débove's Membrane. See Membrane. D. Method. See Treatment, Methods of.

Debridement $\left(d a-b r e \bar{e} d^{\prime \prime}-\operatorname{mon}(g)\right)$ [Fr., débridement]. The enlarging of a gunshot wound or a hernia with the knife; the slitting of any constricting tissue or band.

Debrunner's Tests. See Tests, Table of.

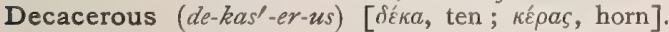
In biology, having ten horn-like processes, tentacles or arms.

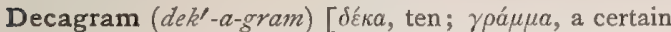
weight]. Ten grams or 154.32349 grains, 0.353 ounce avoirdupois, or 0.3215 ounce troy. See Metric System.

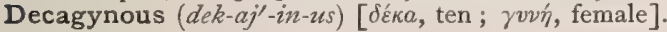
In biology, with ten pistils.

Decalcification (de-kal-sif-ik-a'-shun) [de priv.; calx, lime; facere, to make]. The loss of the lime-constituent of bone in some cases of osteitis.

Decalcified Bone-Drain. A drainage-tube made of a decalcified chicken-bone.

Decalcify (de-kal'-sif-i) [de priv. ; calx, lime; facere, to make]. To remove lime-salts from tissues previously to section-cutting for histologie examination. An acid is usually combined with a hardening agent to prevent swelling of the tissues. The best decalcifying fluids are Arsenious Acid, Chromic Acid, Hydrochloric Acid, Exner's Solution, Hydrochloric Acid and Glycerin, Nitric Acid, Nitric Acid and Chromic Acid, Picric Acid. See Reagents and Stains, Table of.
Decalcifying Fluid (de-kal'-sif-i-ing $\left.f u^{\prime}-i d\right)$. A solution used for the purpose of depriving tissue of its calcium salts. Chromic acid I gram, water 200 c.c., then add 2 c.c. nitric acid,-is commended.

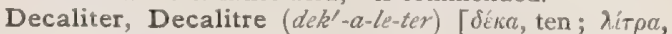
a pound]. Ten liters, or $2 \frac{1}{5}$ imperial gallons, or 2.64 U. S. gallons. See Metric System.

Decalvant (de-kal'-vant) [decalvans, depilatory]. Removing hair ; depilatory; causing baldness.

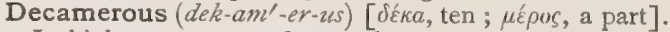
In biology, ten-parted, as a flower.

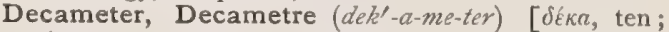

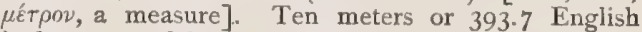
inches, or 32.8 feet. See Metric System.

De Candolle, Canal of. See Canal.

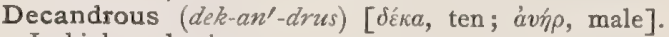
In biology, having ten stamens.

Decane $\left(d^{\prime} k^{\prime}-\bar{a} n\right)[\delta \bar{k} \alpha$, ten $], \mathrm{C}_{10} \mathrm{H}_{22}$. A hydrocarbon of the paraffin series.

Decantation (de-kan-ta'-shun) [de, down; cantus, a side]. The operation of removing the supernatant fluid from a sediment. It may be poured off by means of a guiding-rod, or drawn off by means of a siphon.

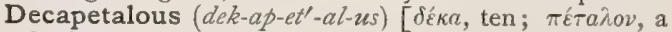
leaf]. In biology, having ten petals.

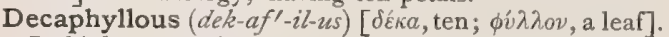
In biology, ten-leaved

Decapitation (de-kap-it-a -shun) [de, from; caput, head]. Division of the neck of the child in labor, when delivery and version are both impossible. This is sometimes called decollation.

Decapitator (de-kap'-it-a-tor) [de, from; caput, head]. An instrument used in performing decapitation.

Decapod (dek'-a-pod) [déka, ten; $\pi$ oús $(\pi o \delta-)$, foot $]$. In biology, having ten feet, rays, or arms.

De Cassis' Operation. See Operations, Table of.

Decay $\left(d e-k a^{\prime}\right)$ [de, down; cadere, to fall]. I. Putrefactive change. 2. The ultimate catabolic state; decline of life, of health, or of any one or more functions.

Dece's Operations. See Operations, Table of:

Decentered Lens (de-sen'-terd lenz). I. A lens thicker at one side than at the other. 2. A lens so mounted that the visual line does not pass through its center.

Decentration (de-sen-tra'-shun) [de, from; centrum, a center]. Removal from a center.

Decephalization (de-sef-al-iz-a'-shun) [de, away from; $\kappa \varepsilon \phi a \lambda \eta$, head]. In biology, applied to retrograde changes or simplification in the head parts.

Decerebrated (de-ser'-e-bra-ted) [de, from; cerebrum, the brain]. Deprived of the cerebrum; said of birds and other animals that have been thus vivisected for observational study.

De Chaumont's Formula. A formula for determining the volume of pure air necessary to maintain a certain standard of purity in the atmosphere. It is as follows : $d=\frac{E}{\rho} ; d=$ the volume of air to be delivered per hour in cubic feet; $\varepsilon=$ the quantity of $\mathrm{CO}_{2}$ that each person is assumed to evolve per hour; $\rho=$ the amount of impurity in a cubic foot of air.

Decidua (de-sid'-u-ah) [deciduus, a falling off]. The membranous envelop of the ovum derived from the mother and cast off at birth with the placenta, etc. D., Ovular. See D. reflexa. D., Placental. See $D$. serotina. D. reflexa, that part of the decidua growing about the ovum and enclosing it as a sac. D. serotina, that part of the decidua vera upon which the ovum lies, and from which the placenta is subsequently formed. D., Uterine. See $D$. vera. D. vera, the thickened, vascular, spongy mucous membrane of the gravid uterus. 
Decidual (de-sid'-u-al) [deciduus, a falling off]. Belonging to the decidua. D. Cells, a proliferation of young connective-tissue cells above the uterine glands, taking place after the ovum is impregnated, and producing an hypertrophy of the mucous membrane of the uterus. D. Endometritis. See Endometritis.

Deciduoma (de-sid-u-o'-mah) [deciduus, a falling off; $\delta \mu a$, a tumor: pl. Deciduomata]. An intra-uterine neoplasm, containing decidual relics, and believed to arise from some hyperplasia of a retained portion of the decidua.

Deciduous (de-sid'-u-us) [de, away, from; cadere, to fall]. In biology, falling off. Applied to leaves that fall in autumn, and to the calyx and corolla when they fall off before the fruit develops. In dental anatoray, applied to the milk-teeth or temporary teeth. D. Skin. See Keratolysis. D. Teeth, the temporary teeth or milk-teeth are so called because, after subserving the purposes of early childhood, they are removed by an operation of the economy, to give place to others of a larger size and of a more solid texture. See Teeth, Temporary.

Decigram (des'-e-gram) [decimus, tenth; gramma, gram]: One-tenth of a gram or $\mathbf{1 . 5 4}$ grains troy. See Metric System.

Deciliter (des'-e-le-ter) [decimus, tenth; litra, liter]. One-tenth of a liter, or 3.52 English fluidounces or 3.38 U. S. fluidounces. See Metric System.

Decimeter (des'-e-me-ter) [decimus, tenth; $\mu$ étoov, a measure]. One-tenth of a meter, or 3.937 inches. See Metric System.

Decinormal (des-e-nor'-mal) [decimus, tenth; norma, normal]. Having one-tenth the strength of the normal, as a solution.

Deck Plug (dek' plug). A short wooden cylinder that may be of various sizes, used by ship-builders, and employed in pathologic laboratories for making paper boxes in which the specimens may be embedded. A strip of thin paper is wound around the plug and held in place by a rubber band, sufficient paper projecting above to form a cylindric box with a wooden bottom.

Declinate $\left(d e k^{\prime}-l i n-\bar{a} t\right)$ [de, down; clinare, to bend]. In biology, bent downward.

Declination (dek-lin-a'-shun) [declinare, to decline]. The dip of the magnetic needle.

Declinator (dek'-lin-a-tor) [declinare, to decline]. An instrument for keeping the dura out of harm's way during the act of trephining.

Decline (de-klin') [declinare, to bend]. A marked deterioration; weakness of the body; an enfeebling chronic state of disease : the decreasing stage, as of a fever. Also a popular term for Pulmonary tuberculosis.

Declivis cerebelli (de-kli'-vis ser-e-bel'-i) [L.]. The sloping posterior aspect of the monticulus of the cerebellum.

Decoction (de-kok'-shun) [decoquere, to boil down]. A decoction, or "tea." In pharmacy, a liquid preparation obtained by boiling vegetable substances in water. There are two official decocta, besides one in the national formulary, and twelve in the British pharmacopeia.

Decoctum (de-kok'-tum) [L.: pl., Decocta $]$. A decoction.

Decollated (de-kol'-a-ted) [de, away, from; collum, neck]. In biology, applied to univalve shells the apices of which have been lost; beheaded.

Decollation (de-kol-a'-shun). See Decapilation.

Decollator (de-kol'-a-tor) [decollare, to behead]. An instrument used in embryotomy for decapitating the fetus.

Decoloration (de-kul-or-a'-shun) [decolorare, to deprive of color]. The operation of discharging the color of an organic substance, usually by bleaching or by filtration through animal charcoal.

Decolorize (de-kul'-or-izz) [decolorare, to deprive of color]. To remove the excess of coloring-matter from stained histologic preparations, for purposes of differentiation.

Decomposition (de-kom-po-zish'-un) [decomponere, to decompose]. The separation of the component principles of a body, either by chemic analysis or by putrefactive fermentation.

Decompound (de-kom'-pound) [de, away, from; composilus, compound]. In biology, many times compound, as certain leaves.

Decongestive (de-kon-jes'-tiv) [de, from; congerere, to bring together]. Relieving congestion.

Decortication (de-kor-tik-a'-shun) [de, from; cortex, the bark]. I. The operation of removing or stripping the bark or husk of a plant. 2. The stripping off of portions of the cortical substance of the brain from the summits of the gyri. This lesion is often witnessed in post-mortem examinations of the brain after death from paretic dementia, and is partly due to the abnormal adhesion of the gray matter to the meninges.

Decrepit (de-krep'-it) [decrepitus, old]. Broken down with age.

Decrepitation (de-krep-it-a'-shun) [decrepitare, to crackle]. The crackling noise made by certain crystalline bodies when their water of crystallization is driven off by heat. It is caused by the conversion of the imprisoned water into steam.

Decrepitude (de-krep'-it-ūd) [decrepitus, decrepit]. The state of being decrepit; senility; the feebleness of old age.

Decrescent (de-kres'-ent) [decrescere, to decrease]. In biology, gradually tapering or diminishing from below upward.

Decubitus (de-ku'-bit-us) [decumbere, to lie down]. A term denoting a recumbent or horizontal position. Also, the position of a sick person while in bed. D., Acute, a form of bed-sore, sometimes seen in con. nection with cerebral lesions.

Decumbent (de-kum'-bent) [de, down; cumbere, to lie ]. In biology, bent to one side; reclining.

Decurrent (de-kur'-ent) [de, down; currere, to run]. In biology, applied to leaves that are prolonged down the side of the stem below the point of their insertion.

Decussate (de-kus'-at) [decussatus, cross]. In biology, arranged in pairs that successively cross each other. To intersect. A term applied to nerve-fibers and to muscle fibers that interlace.

Decussatio (de-kus-af-she-o) [L.]. A crossing. D. pontinalis (more correctly pontilis), in the pons, a decussation of tegmental fibers from the thalamus.

Decussation (de-kus-a'-shun) [decussatio, a crossing]. A chiasma or X-shaped crossing, especially of nerves, or of nerve-filaments. The principal decussations are that of the optic nerve, and that of the pyramids: i. e., of the anterior pyramids of the oblongata.

Decussorium (de-kus-ó-re-zmn) [L.]. An instrument for depressing the dura after the operation of trephining, so as to facilitate the removal of pus, blood, or abnormal effusions.

Dedentition (de-den-tish'-un) [de, down; dens, a tooth]. The shedding of the teeth, especially the milk-teeth.

Dedolation (ded-o-la'-shun) [dedolatio, a hewing off]. The removal of a slice by cutting; a wound by which a part is cut off.

Deduplication [de-du-plik-a'-shun) [deduplicare, to divide in two]. In biology, the same as Chorisis, $q . v$.

Deelinæ Oleum. A highly refined petroleum oil manu- 
factured on the Dee River. It is said to be valuable as a local application in eczema, etc. Unof.

Deemetinize (de-em-et/'-in-iz). To deprive ipecacuanha of its emetic principle, emetin.

Deep (dep) [ME., depe]. Not superficial; not situated near the surface. See Profundus. D. Reflexes. See Reflexes, Table of. D. Water, water obtained from a porous substance beneath the first impervious stratum.

Deer-berry (dér'-ber-e). A popular name for Gaultheria procumbens.

Defatigatio (de-fat-ig-a'-she-o) [L.]. Over-fatigue; overstrain, as of the heart-muscle. D. mentis, brain-fag.

Defecation (def-ek-a'-shun) [defacare, to separate from the dregs]. The evacuation of the bowels, or discharge of feces.

Defect (de-fect') [defectus, a failure]. A lack or failure; absence of any part or organ; absence or failure of a normal function.

Defemination (de-fem-in-a'shun). See Eviration.

Defensive Proteids. Hankin's name for those substances formed in the bodies of animals that render them immune to certain diseases. See also Sozin, Phylaxin, Mycosozin, Toxosozin, Mycophylaxin, Toxophylaxin, Alexin.

Deferent (def'-er-ent) [deferens, carrying away]. Car rying away or down; efferent. See $V$ as.

Deferentitis (def-er-en-ti'-tis) [deferens, carrying away; tT $\ell$, infiammation]. Inflammation of a vas deferens,

Defervescence (de-fer-ves'-ens) [defervescere, to cease boiling]. A term applied to periods during the course of fevers in which the temperature falls.

Defibrillation (de-fi-bril-a'-shun) [de, from; fibrilla, a small fiber]. The tearing of the brain-substance in the direction of the least resistance, in order to make cleavage-preparations.

Defibrination (de-fe-brin- $\left.a^{\prime}-\operatorname{shun}\right)$ [de, from; fibra, a fiber]. The removal of fibrin from blood or lymph.

Definition (def-in-ish'-un) [definitio; definire, to bound by limits]. In optics, the power of an object-glass to show clear outlines of area or structure, free from aberration or distortion.

Defixus (de-fiks'-us) [defigere, to fasten]. Impotent; sexually powerless; an old term based upon the idea of a spell wrought by an enemy being the cause of the condition indicated.

Deflagration (def-lag-ra'-shun) [deflagrare, to be consumed]. A sudden, violent combustion, such as accompanies the oxidation of certain inorganic substances by mixing with an easily decomposing salt, such as the alkaline chlorates and nitrates.

Deflex (de-fleks') [deflexus, to turn aside]. In biology, to bend down.

Deflorate (de-flo'-rāt) [defloratus, to deprive of flowers]. In biology, said of a plant or anther that has lost its pollen or flowers, or is past the flowering state.

Defloration (def-lo-ra'-shun) [de, from; flora, a flower]. On the part of the female the first sexual connection effected by consent, not by rape. The loss of those marks or features that indicate virginity, as rupture of the hymen.

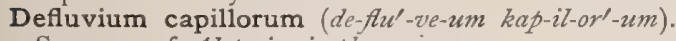
Synonym of Alopecia simplex.

Defluxion (de-fluk'-shun) [defuxio; de, down; fuere, to flow]. I. A catarrh; a descent of the humors or secretions. 2. A rapid falling, as of the hair or eyebrows.

Defœdatio unguium (de-fe-da'-she-o un'-grve-um) [L., "Fouling of the nails" "]. Excessive thickness, with foul appearance of the nails, which often become partly detached from the matrix.

Defoliate (de-fo'-le-at) [de priv.; folium, a leaf]. To destroy the leaves of a plant, or to cause them to drop off.
Deforestation (de-for-es-ta'-shun) [de, down; foresta, a forest]. The stripping of a country or district of its forests, a process that has a direct influence upon the public health for good or for evil.

Deformation (de-for-ma'-shun) [deformere, to disfigure or distort]. A process by which the body or any of its parts acquires an abnormal shape.

Deformity (de-form'-it-e) [deformitas, a deformity] Abnormal shape or structure of a body or any part. D., Anterior. See Lardosis.

Defunctionalization (de-funk-shun-al-iz-a'-shun). Failure or deprival of a function.

Degasify (de-gaz'-if-i) [de priv.; gas]. To expel from wood, coal-tar or other substance all moisture and gaseous material, by means of the application of heat.

Degener's Test. See Tests, Table of.

Degeneration (de-jen-er-a'-shun) [degenerare, to differ from ancestors]. Deterioration, degradation, or retrogression of the molecular or cellular structure of a tissue, organ, or cell, so that it can no longer maintain its function; passage from an anastate to a catastate, or from one catastate to a lower one. Atrophy is a form of degeneration. D., Amyloid or D., Albuminoid, now regarded as an infiltration from without, and not as a degeneration of the proper cells and fibers. See Albuminoid Disease. D., Ascending, that which takes place in centripetal fibers after a destructive lesion of the spinal cord. D., A theromatous. See Endarteritis, Chronic. D., Black. Synonym of Melanosis and of Anthracosis. D., Calcareous, the deposition of insoluble compounds of calcium and magnesium within the tissues. Caseation. See Caseation. Cloudy Swelling. See Cloudy Sruelling. D., Colloid, akin to mucoid, the disorganized material becoming of a structureless, semi-solid, jelly-like consistence. D., Descending, that which takes place in the centrifugal fibers of the cord after a destructive lesion between the central cortex and the anterior nerve-roots. D., Fatty, the conversion of the proteids of a cell or fiber into oil. D., Fibroid, the substitution of fibrous for a higher grade of tissue. D., Glassy, the halo-granular change of the heart-muscle seen in fevers. D., Gray, in nervous tissue a degeneration due to chronic inflammation, and characterized by the production of a gray color. D., Hyaline, the disorganized tissue becomes shining and translucent. D., Hydropsic, a form of degeneration in which the degenerating cells imbibe large quantities of water. D., Lardaceous. See Albuminoid Disease. D., Mucoid, hyper-secretion followed by disorganization of the mucus-cells. D., Reaction of. See Reaction of Degeneration. D. Senile, the widely disseminated degenerative changes, largely fibroid in character, that mark old age. D., System, degeneration of a system of fibers, in contradistinction to insular or scattered degeneration. D., Waxy. See Albuminoid Disease. D., Zenker's. Same as D., Glassy.

Deglutable (deg-lut'-a-bl) [deglutitio, a swallowing; ME., able, capable]. Capable of swallowing, or of being swallowed.

Deglutitio impedita (de-glu-tish'-e-o im-pe-di'-tah). Synonym of Dysphagia.

Deglutition (deg-lu-tish'-un) [deglutitio, a swallowing]. The act of swallowing.

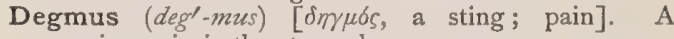
gnawing pain in the stomach.

Degradation (deg-rad-a'-shun) [degradatio, a descent by steps]. Gradual physiologic and histologic change for the worse; degeneration; retrograde metamorphosis. 
DEGRAS

Degras (de'-gras). See Leather.

Degrease (de-grès') [Fr., dégraisser]. To remove fat, as from bones in the preparation of skeletons.

Degreasing (de-grês'-ing) [Fr., dégraisser]. Removing the fat, as from bones.

Degree (de-gre') [de, from; gradus, a step]. Position in a graded series; quality. The units or intervals of thermometric scales. Also, a charter or testimonial of qualification granted by a medical or other college. In trigonometry the $\frac{1}{360}$ part of the arc of a circle. Degut (de-gut') [Russ.]. Birch oil or tar. See Birch.

Dehio's Method. A method of outlining the stomach. About a quart of water is introduced in separate quantities of a half-pint each, and after the ingestion of each portion, the lower crescentic limit of flatness against the tympanitic transverse colon is outlined. The normal stomach with this additional weight will not quite reach the level of the umbilicus, while in case of dilatation its descent will be rapid and considerable.

Dehisce (de-his') [de, off; hiscere, to gape]. In biology, to split open. Applied to the splitting open of anthers to shed their pollen, of antheridia to set free their antherozoids, of sporangia to shed their spores, of certain fruits to shed their seeds, etc.

Dehiscence (de-his'-ens) [de, off ; hiscere, to gape or yawn]. In biology, the act of dehiscing or splitting open.

Dehorn [de, away from; ME., horn]. To deprive cattle of their horns.

Dehumanization (de-hu-man-iz-a'-shun) [de, from; humanus, human]. I. The loss of the proper characteristics of humanity, either by insane persons, or by debased criminals. 2. The supposed loss of some quality pertaining to the human species; as in the alleged dehumanization of vaccine virus.

Dehydration (de-hi-dra'-shun) [de, away from; $v \delta \omega \rho$ $\left(v \delta_{\rho-}\right)$, water $]$. The necessary removal of water from microscopic preparations previously to clearing and mounting in balsam. Absolute alcohol is generally best; anilin is used in special cases in which alcohol is inadmissible. 96 per cent. alcohol will answer if xylol or cedar oil be used as the clearing-agent, and should always be used with celloidin sections. It is also called Anhydration.

Deiters' Cells. Certain cellular structures between the outer hair-cells of the organ of Corti. Also certain nucleated cells at the intersection of the fibers of the white substance of nerves. Deiters' Cells (spidercells) are also found in the neuroglia, especially in that of diseased brain-tissue. D. Nucleus, a nucleus Iying in the direct sensory cerebellar tract of the medulla oblongata. Its function is unknown. See Nucleus magno-cellularis. D. Process, the process of a nervecell, that goes to form an axis-cylinder.

Dejection (de jek'-shun) [dejectio: de, down; jacere, to throw]. The discharge of fecal or other excrementitious matter; the matter so discharged. Also, a state of despondency.

Dejectiones nigra (de-jek-she-o'-nez ni'-gre) [L.]. Synonym of Melena.

Dekagram (dek'-a-gram). See Decagram.

Dekaliter (dek'-a-le-ter). See Decaliter.

Dekameter (dek'-a-me-ter). See Decameter.

Del Toro's Operation. See Operations, Table of.

Delafield's Hematoxylin. See Hematoxylin and Stains.

Delagarde's Operation. See Operations, Table of.

Delamination (de-lam-in-a'-shun) $[d e$, away ; lamina, a thin metal plate]. In biology, applied to the splitting of the blastoderm into two layers.

Dela Rue's Method. A method of preparing carminic acid. Exhaust cochineal in boiling water. Precipitate the extract with plumbic acetate slightly acidulated

\section{DELIRIUM}

with acetic acid, care being taken not to add an excess of the lead. Wash the precipitate with distilled water until the wash-water ceases to give a precipitate with mercuric chlorid; then decompose it with hydrogen sulphid; filter, evaporate the filtrate to a syrupy consistence on a water-bath, and dry; extract the darkpurple product with alcohol, which dissolves out the carminic acid. See Stains, Table of.

Delayed Symptoms. A term used as a synonym of Shock, Deferred, q.v.

Deleterious $\left(d e l-e t-e^{\prime}-r e-u s\right)\left[\delta \eta \lambda \eta \tau \eta^{\prime} \rho \iota s\right.$, hurtful]. Hurtful, injurious.

Delff' Tests. See Tests, Table of.

Delhi Boil (del'-he boil). See Furunculus orientalis.

Delicate (del'-ik-at) [delicatus, delicate]. Of a refined constitution. Feeble. In a condition of poor health.

Deligation (del-ig-a'-shun) [deligatio, a binding]. Ligation, as of an artery; bandaging, as of a wound.

De Lignerolle's Operation. See Operations, Table of.

Deliquescence (del-ik-tues'-ens) [deliquescere, to melt away]. The breaking down as a result of the absorption of water from the atmosphere, characteristic of certain substances. Such substances are said to be hys roscopic.

Deliquescent (del-ik-wes'-ent) [deliquescere, to melt away]. In biology, dissolving; applied to a stem that divides into branches.

Deliquium (del-ik'-we-um) [L.]. An absence. D. animi. I. Failure of the mind; mental decay ; melancholy; lowness of the spirits. 2. Syncope or fainting.

Delirament (de-lir'-am-ent) [deliramentum, delirium]. Delirium.

Deliration (de-lir-a'-shun) [Deliratio, delirium]. Delirium.

Deliriant (de-lirt-e-ant) [de, out of; lira, the furrow]. An agent that acts on the brain, so as to disorder the mental faculties and produce confusion of will-power.

Delirifacient (de-lir-e-fa'-she-ent) [delirium, delirium; facere, to make]. Producing delirium.

Delirious (de-lirl-e-us) [delirus, mad, raving]. Affected with delirium; wandering in mind.

Delirium (de-lir'-e-um) [delirium, madness]. A disturbance of the cerebral functions manifested by im paired action of the nerve-centers, characterized by hallucinations, an incoherence of speech, a staggering gait, etc. D., Alcoholic. See $D$. tremens. D. ambitiosum, a condition of boastfulness that is sometimes manifest in the course of paretic dementia. D. cordis, a peculiar condition of the myocardium resulting when chloroform vapor is administered above a certain point of concentration. The myocardium fails to contract and rapidly becomes insensitive to stimulation, being thrown only into fibrillary contraction. A heart once so dilated beyond the point of its ability to re-contract never recovers, and death results. D. ebrositatis. See $D$. tremens. D., Febrile, the delirium of fever. D. furibundum, acute mania. D. of Grandeur, delirium ambitiosum. D. mussitans, low, muttering delirium. D. nervosum, the delirium following severe surgical operations, or injuries. D. palignosticum, that in which the patient asserts that he has been before in a place to which he has come for the first time. D. persecutionis, that in which the patient imagines himself the object of persecution. D. potatorum, synonym of $D$. tremens. D., Senile, the delirium of old age; dotage. D., Toxic, the delirium caused by poisons. D. tremens, the delirium arising from alcoholic poisoning, and usually following some acute sickness, overwork, or the shock consequent upon an injury or surgical operation. It is characterized by constant 
tremor, great exhaustion, distressing illusions and hallucinations. D. vigilans. See $D$. tremens.

Delitescence (del-it-es'-ens) [delitescere, to lie hid]. The sudden disappearance of inflammation by resolution. Also, the period of incubation of the virus of contagious diseases, such as smallpox, etc.

Delivery (de-liv'-er-e) [Fr., délivrer; deliberare, to set free]. Parturition, childbirth. D., Post-mortem, the birth of a fetus after the death of the mother, from an accumulation of gases in the uterine cavity.

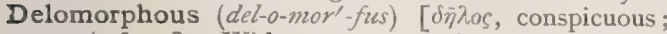

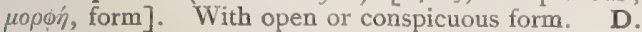
Cells of Rollet, collections of large, oval, or angular, well-defined, granular, reticulated, nucleated cells, between the membrana propria and the adelomorphous cells of the fundus glands of the gastric mucous membrane. They are called, also, Parietal Cells of Heidenhain, or Oxyntic Cells of Langley. The secretory part of the tubes is lined by cells called Adelomorphous, Central, or Principal Cells.

Delore's Operation. See Operations, Table of.

Delpech's Operations. See Operations, Table of.

Delphin (del'-fin). Same as Delphinin.

Delphini Oleum $\left(\operatorname{del}-f^{\prime}-n i o^{\prime}-l e-u m\right)$ [L.]. The oil of the common porpoise, Phocana communis. It is said to have all the medicinal virtues of cod-liver oil, without the disagreeable qualities of the latter.

Delphinin (del'-fin-in) [ dètiviov, larkspur], $\mathrm{C}_{24} \mathrm{H}_{35}$ $\mathrm{NO}_{2}$. A poisonous alkaloid from Staphisagria. See Staphisagria.

Delphinium (del-fin'-e-um). See Staphisagria.

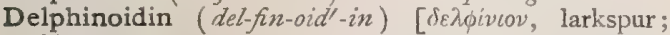
Eidos, like]. An amurphous alkaloid derived from Stavesacre.

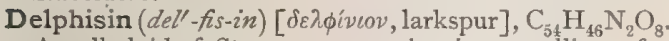
An alkaloid of Stavesacre occurring in crystalline tufts.

Delta (del'-tah) [ $\delta \varepsilon^{\prime} \lambda \tau a$, the fourth letter of the Greek alphabet]. The vulva, from its triangular shape. D. mesoscapulæ, the triangular area at the root of the spine of the scapula.

Deltidium (del-tid'-e-um) [the Greek letter $\Delta, \delta \varepsilon ́ \lambda \tau \alpha]$. In biology, applied to the triangular space on a brachiopod shell, between the beak and the hinge.

Deltoid (del' -toid) [delta, the Greek letter $\Delta$; eidos, likeness]. Having the shape of a delta, or a triangular form, as the D. Muscle. See Muscles, Table of.

Delusion (de-lu'-zhun) [de, from; lusus, play]. A false judgment of objective things, as distinguished from illusion and hallucination. It is the result of an abnormal condition of the brain. A delusion may be systematized or unsystematized, the former being the more serious and met with in the chronically insane.

Delusional (de-lu'-zhun-al) [deludere, to delude]. Of the nature of a delusion; characterized by delusions. D. Stupor. See Insanity, Confusional.

Demarcation (de-mark-a'-shun) [demarcare, to set the bounds of ]. A line of separation, as between gangrenous and healthy tissue.

Demarquay's Operation. See Operations, Table of.

Demembration (de-mem-bra'-shun) [demembrare, to deprive of a limb or limbs]. The cutting off of a member; amputation; castration.

Dement (de'-ment) [demens, insane]. An insane person; one who is demented.

Dementia (de-men'-she-ah) [de, out of; mens, the mind]. A mild form of insanity marked by imperfect conception, illogical sequence of expression, loss of reflection, and impaired perception. There is partial loss of self-control and self-respect. Dementia is often a final stage of other forms of insanity. It is described under the various forms of secondary, senile, organic, and alcoholic. There is a general atrophy of the brain-substance, with a compensatory thickening of the brain-membranes, and an increase of the fluid of the brain and of the neuroglia.

Demersal, or Demersed (de-mer'-sal, or de-merst') [demersus, plunge into]. In biology, growing beneath the surface of water, as the eggs of the catfish.

Demi- $\left(\right.$ dem $\left.^{\prime}-e-\right)$. A Latin prefix denoting one-half.

Demilune Cells (dem'-e-lün selz) [demiius, half; huna, moon]. See Cell. D. C. of Adamkiewicz. A peculiar form of nerve-corpuscle lying below the neurilemma of medullated nerve-fibers; it is stained yellow by safranin. D. C. of Heidenhain, half-moon shaped bodies lying between the cells and the membrana propria of the alveolus in the salivary glands.

Demimonstrosity (dem-e-mon-stros'-it-e) [demi, half; monstruosus, monstrous]. A variety of congenital deformity that does not give rise to appreciable disorder of function.

Demme, Bacillus and Micrococcus of. See Bac teria, Synonymatic Table of.

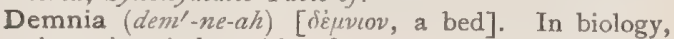
the subgenital cavities found in the Discomeduse; they are also called respiratory cavities, genital cavities, umbrella-cavities of the reproductive organs; infundibula subgenitalia.

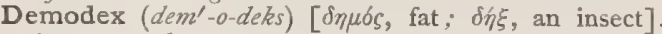
A genus of parasitic insects. D. folliculorum, a minute parasite found in the sebaceous follicles, particularly of the face. It probably does not produce any symptoms, though in large numbers it may produce acne. See Comedo, also Parasites (Animal), Table of.

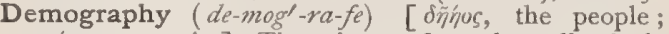

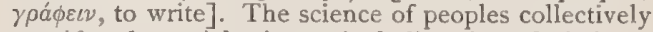
considered; social science, including that of vital statistics and the consideration of various questions of state medicine.

De Moivre's Hypothesis. An hypothesis that the decrements of population are in arithmetic proportion, and that of every 86 persons born, one dies uniformly every year until all are extinct.

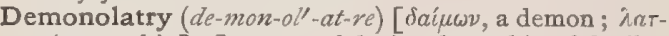
peia, worship]. Insane or delusional worship of devils; the morbid assumption of the character of a witch.

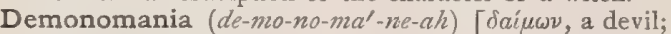
ravia, madness]. A form of madness in which a person imagines himself possessed of a devil.

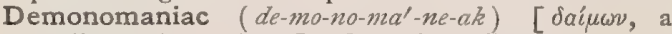
devil ; $\mu$ avia, madness]. One who suffers with demonomania.

Demonopathy (de-mon-op'-a-the) [ daifswv, a demon; $\pi a ́$ tos, disease]. Same as Demonomania.

Demonstrator (dem'-on-stra-tor) [demonstrare, to show]. One who instructs in the practical application of the arts and sciences.

De Morgan's Operation. See Operations, Table of.

Demours, Membrane of. See Descemet's Membrane.

Demulcent (de-mul'-sent) [demulcere, to smooth]. I Soothing; locally softening and lenitive. 2. Any substance that protects the mucous membranes. It is generally of a mucilaginous nature.

Demutization (de-mu-tiz-a'-shun) [de, not; mutus, dumb]. The education of deaf-mutes to speak and to understand spoken language by the movement of the lips, signs, etc.

Denan's Operation. See Operations, Table of.

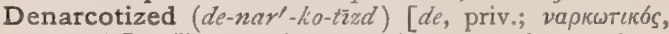
narcotic]. Having the narcotin removed, as opium.

Dendrite $\left(d e n^{\prime}-d r i t\right)$ [ $\delta \delta^{\prime} \nu \delta \rho o \nu$, a tree]. A protoplasmic process of a nerve-cell.

Dendritic, or Dendroid (den-drit'-ik, or den'-droid)

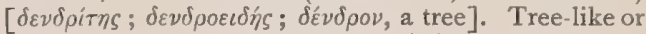
arborescent. The arrangement of the structures that 
make up the arbor vite of the cerebellum, or that of the uterus, is dendritic.

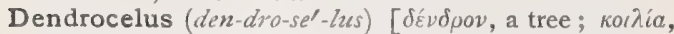
belly]. In biology, having a branched intestine.

Dendrodentine (den-dro-den'-tin) [ $[\delta \varepsilon \delta \delta \rho o \nu$, a tree ; dentine. tooth-tissue]. In biology, a tooth-tissue formed by the blending of the dentine, enamel, and cement of many teeth.

Dendron $\left(d e n^{\prime}-d r o n\right)[\delta \varepsilon ́ v \delta \rho o v$, a tree]. Same as Dendrite.

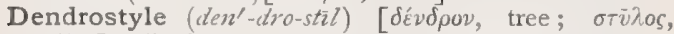
pillar]. In biology, Huxley's term for the stalk of the hydroid stage of certain hydrozoans.

Dengue (deng'-ga) [West Ind.]. A zymotic disease somewhat resembling remittent fever, but much more severe. It is characterized by racking pain in the head and eyeballs, pain in the back and knees, arthralgia, catarrhal inflammation of those mucous surfaces that are exposed to the air, swollen salivary glands, and measly eruptions. Cf. Bacteria, Synonymatic Tible of.

Denidation (de-ni-d $\left.a^{\prime}-s h u n\right)$ [de priv.; nidus, a nest]. During involution after pregnancy, the process of disintegration and casting off of the superficial portion of the uterine mucosa.

Denis's Plasmin. A precipitate of uncoagulated blood with sodic sulphate, and treated with sodic chlorid.

Denneth's System. See Treatment, Methods of.

De novo (de no'-vo) [L.]. Anew.

Dens (denz) [L.: pl., Dentes]. A tooth. See Teeth.

Density (den'-sit-e) [densilas, thickness]. Closeness; compactness. In electro-therapeutics, the amount of electricity accumulated on a unit of surface.

Dent $($ don $(g))$ [Fr.]. A tooth.

Dentagra (den-ta'-grah) [dens, a tooth; à $\gamma \rho \alpha$, a seizure]. I. The Denticeps, an instrument for extracting teeth; a tooth-forceps, 2. The term is also applied to toothache.

Dental (den'-tal) [dens, a tooth : gen., Dentis]. Pertaining to the teeth. D. Apparatus, the teeth, together with the alveoli in which they are implanted, and the jaws; also a set of artificial teeth. The instruments and appliances employed in dental operations are likewise so termed. D. Arches, arcades dentaires. The arches formed by the teeth when arranged in their sockets in the alveolar borders, or the arch formed by the alveolar process of each jaw. D. Arteries, the arteries supplying the teeth. See Arteries, Table of. D. Atrophy, atrophia dentalis. See Atrophy of the Teeth. D. Bone, dentine. The osseous part of a tooth. D. Canals, the canals that perforate the alveoli, and give passage to the blood-vesseis and nerves that enter the teeth at the extremities of their roots. See Canal. D. Caries, caries of the teeth. D. Cavity, cavitas pulpæ; cavum dentis; antrum dentale. The pulp-cavity. The cavity occupied by the dental pulp in the interior of a tooth. Its shape resembles that of the tooth; it is larger in young persons than in old, and when the teeth suffer great loss of substance, either from mechanical or spontaneous abrasion, it sometimes becomes completely obliterated. See Abrasion of the Teeth. D. Engine, a machine first introduced in 1870 , but since greatly improved, and which has almost wholly superseded the use of hand-burs and drills. It is operated like a dental lathe, and possesses a flexible cable, or an adjustable arm and hand-piece, which afford great facility of movement and adaptation. By means of attachments to the hand-piece, drills can be operated at a right angle with the shaft, at an acute angle, or with a backward inclination of nearly forty-five degrees. Burnishers, discs, etc., are also adapted to these dental engines. D. Excavator, an instrument employed for the removal of the decayed part of a tooth, preparatory to the operation of filling. D. Exostosis. See
Exostosis of the Teeth. D. File, a file manufactured for operations on the teeth. See File, Dental. D. Forceps. See Forceps for Extracting Teeth. D. Glands. See Gland. D. Groove, a furrow on the lower border of the upper jaw early in fetal life, in which the teeth are developed. D. Laboratory, a room or place where the operations connected with mechanical dentistry are performed. D. Necrosis, odontonecrosis. See Necrosis of the Teeth. D. Neuralgia, a form of neuralgia the immediate exciting cause of which is owing to some disease of the dental pulp. See Odontalgia. D. Organism, the organism of the teeth; the organic structure of these organs; the vital forces that govern them. D. Orthopedia, the art of correcting deformity occasioned by irregularity of the teeth, or other causes. See Irregularity of the Teeth. D. Pathology, considers the causes and different forms of the various diseases to which the teeth are liable. D. Periostitis, periostitis dentium. Inflammation of the dental periosteum or peridental membrane. See Odontalgia, and Periodontitis. D. Pulp, a soft, vascular, and highly sensitive substance, of a reddish-gray color, occupying the cavity of a living tooth. It also constitutes the rudiment of a tooth. The dental pulp is the principal blood-supply and nerve-supply of the dentine. D. Pulp, Destruction of; there are two methods of destroying the pulp; one by an operation, such as the use of a barbed brooch; the other by the application of some devitalizing agent, as arsenious acid. D. Ridges, the projecting borders of the primitive dental groove. D. Sac, the sac that encloses the developing tooth in the embryo. D. Surgeon (chirurgien dentiste), surgeon-dentist, one who devotes himself to the study and treatment of the diseases of the teeth, and their connections, and the adoption of substitutes for them when, by age, accident or disease, they are lost. D. Therapeutics, considers the methods and medicaments used in the treatment of diseases of the teeth. D. tubuli, the tubes occurring in the structure of the dentine.

Dentalgia (den-tal'-je-ah) [dens, tooth; àn yos, pain]. Tooth-ache.

Dentalis lapis (den-tal-lis $l \alpha^{\prime}$-pis) [L.]. Salivary calculus; tartar of the teeth.

Dentaphone (den'-taf-ōn) [dens, tooth; $\phi \omega \nu \eta$, sound]. A modification of the audiphone, $q$. $v$., by means of which the sound-waves are transmitted through the bones of the head to the auditory apparatus.

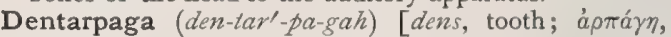
hook]. An instrument for the extraction of teeth.

Dentate (den'-tât) [dens, a tooth]. In biology, applied to leaves, wings, or other flattened organs that have their margins provided with acute teeth that point directly outward from the margin.

Dentatum (den-ta'-tum) [L.]. The dentate nucleus of the cerebellum. D. olivæ. See Dentoliva.

Dentes $\left(d e n^{\prime}-t \bar{e} z\right)$ [L., the plural of denss]. Teeth. See Teeth. D. acuti, the incisor teeth. D. adulti, the teeth of second dentition. D. adversi, the incisor teeth. D. angulares, the canine or cuspid teeth, so called, probably, because they are situated at the angles of the alveolar arch, at the corners of the mouth, or from the angular shape of their crowns. D. bicuspidati, bicuspid teeth. D. canini, the cuspid or canine teeth; so called from their resemblance to the teeth of a dog. D. cariosi, carious teeth. D. columellares, the molar teeth. D. cuspidati, cuspid teeth. D. exserti [exsertere, to thrust out], teeth that project or are in front of the dental arch, but applied more particularly to the cuspidati. D. incisores, incisor teeth. D. lactei, the milk, temporary, or deciduous teeth. See Deciduous Teeth. D. molares, 
molar teeth. D. primores, the incisor teeth; so called because they occupy the front or anterior part of the dental arch. D. sapientiæ, the wisdom-teeth. A name given to the third molar tooth of each half of the jaws. D. tomici [tomicus, cutting], the incisor teeth.

Denticulate (den-tik $\left.k^{\prime}-u-l \bar{a} t\right)$ [denticulus, a small tooth]. In biology, having minute dentations. Furnished with small teeth.

Denticulus (den-tik'-u-lus) [L.]. A little tooth.

Dentier $\left(\right.$ don $(g)$-te- $\left.a^{\prime}\right)$ [Fr.]. A French word signifying a base of metal, ivory or any other substance, employed as a support or attachment for artificial teeth. The term is also sometimes applied to a set of artificial teeth.

Dentification (den-tif-ik-a'-
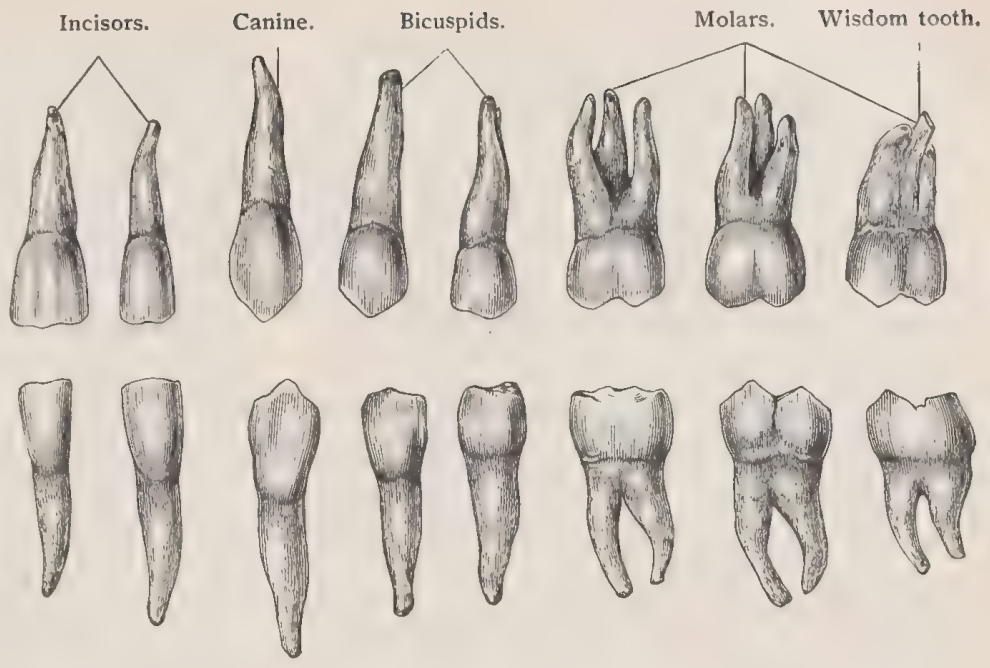

THE TEETH OF AN ADULT.

The top section of illustration is the upper set, and the bottom is the lower set. shun) [dens, a tooth; facere, to make]. The formation of teeth.
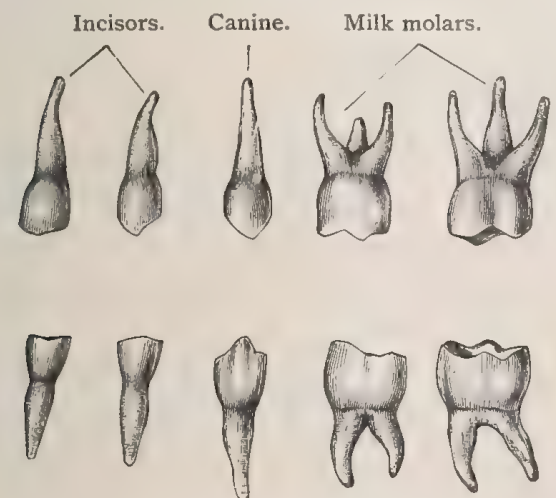

The Temporary TEeTH.

The top section of illustration is the upper set, and the bottom section is the lower set.

Dentiform (den'-tif-orm) [dens, a tooth ; forma, shape]. In biology, tooth-like.

Dentifrice (den'-tif-ris) [dens, tooth; fricere, to rub]. A substance used for cleansing the teeth.

Dentigerous (den-tij'-er-us) [dens, a tooth; gerere, to carry]. In biology, bearing teeth.

Dentinal (den'-tin-al) [dens, a tooth]. Pertaining to or composed of dentine.

Dentinalgia (den-tin-all-je-ah) [dens, a tooth; àn $y o s$, pain]. Pain in dentine.

Dentine $($ den'-tin) [dens, a tooth]. The bony structure of the tooth, lying under the enamel of the crown and the pericementum of the root. D., Sensitiveness of, a hypersensitive condition of the dentine of a tooth, occasioned by distal irritation of the dentinal fibrils. See Sensitive Dentine.

Dentinitis (den-tin- $i^{\prime}$-tis) [dens, a tooth; $\iota \tau \iota s$, inflammation]. Inflammation of the dentinal fibrils.

Dentiphone (den'-tif-ön) [dens, a tooth; $\phi \omega \nu^{\prime}$, a voice]. A form of audiphone in which the vibrating disc is attached to the teeth.

Dentist (den'-tist) [dens, a tooth]. Dentista; odontiater; a dental surgeon. See Dental Surgeon.
Dentistry (den'-tis-tre) [dens, a tooth]. Odontotechny; odontiatria; odontotherapia; dental surgery, embracing everything pertaining to the treatment and replacement of the loss of the natural teeth.

Dentitio (den-tish'-e-0) [L.]. Dentition.

Dentition (den-tish'-un) [dens, a tooth]. The cutting or first appearance of the teeth in infancy. Also, the arrangement and evolution of the teeth. Dentition is primary, that is, the cutting of the temporary or milk teeth, and secondary, or that of the permanent teeth. There are always some vague symptoms associated with the process, such as fretfulness, restlessness, convulsions, diarrhea, painful and swollen gum, which may be relieved by lancing over the protruding tooth.

Dentium (den'-she-um) [L.: gen. of Dentii]. Of the teeth. D. cavernæ, the sockets of the teeth. D. cortex, the enamel of the teeth. D. dolor, pain in the teeth; tooth-ache. D. nitor, enamel of the teeth. D. scalptura, lancing of the gums. D. vacillantia, looseness of the teeth.

Dentography (den-tog-ra-fe) [dens, a tooth; roáon, a description]. A description of teeth.

Dentoliva (den-toll-iv-ah) [dens, a tooth; otiva, an olive]. Dentatum olivæ; olivary nucleus; a capsule of cinerea within the oliva of the brain.

Dentology (den-tol'-o-je) [dens, a tooth; $\lambda b \gamma o s$, science]. A treatise on the teeth.

Dentonomy (den-ton'-o-me) [dens, a tooth; vbros, a law]. The arrangement of the teeth into classes.

Dentos (den'-tos) [dens, tooth; os, bone]. Toothbone; tooth-substance.

Dentrification (den-trif-ik-a'-shun) [dens, a tooth; facere, to make]. The deposition of lime-salts on the enamel and dentine of the teeth.

Dents $(d a h n t)$ [Fr.]. Teeth. D. bicuspidées, the bicuspid teeth. D. coldes, neck of the teeth. D. canides, the canine teeth. D. de lait, the milk or temporary teeth. D. machelures, the molar teeth. D. molares, the molar teeth. D. multicuspidées, the large molar teeth. D. cilleries, canine teeth.

Denture (den'-chür) [dens, a tooth]. A complete set of teeth; the whole assemblage of teeth in both jaws.

Denudate $\left(d e n^{\prime}-u\right.$-dāt) [denudare, to strip]. In biology, lacking covering, as scales, hair, foliage. 
Denuding (den-u'-ding) [denudare, to denude]. A stripping or making bare. D. of the Teeth, an affection that consists in the gradual destruction of the enamel of the anterior or labial surfaces of the incisors, cuspidati, and sometimes of the bicuspids; the molars are rarely affected by it.

Denutrition (de-nu-trish'-un) [de, from; nutriare, to nourish]. The breaking down or atrophy of tissue arising from lack of nutrition. The opposite of nutrition.

Deobstruent (de-ob'-stru-ent) [de, from; obstruere, to obstruct]. A medicine that removes functional obstructions of the body. An aperient.

Deodand (de'-o-dand) [deres, God; dare, to give]. A fine formerly imposed on an inanimate thing or animal that had caused the injury or violent death of a person.

Deodorant (de-ōd'-or-ant) [de priv. ; odorare, to smell]. A substance that removes or corrects offensive odors.

Deodorizer (de-o'-dor-i-zer) [de priv.; odorare, to smell]. A deodorizing agent; a substance that de stroys offensive odors.

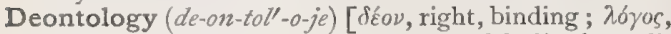
science]. The science of duty. D., Medical, medical ethics.

Deoppilant, or Deoppilative (de-op'-il-ant, or de-op$\left.p^{\prime \prime} \bar{l}^{\prime}-a t-i v\right)$ [de, from; oppilare, to stop]. I. Deobstruent; aperient. 2. An aperient medicine.

Deorsum (de-or'-sum) [L.]. Downward. D. vergens. See Vergens.

Deossification (de-os-if-ik-a'shun) [de, away; os, bone; facere, to do]. The absorption of bony material; the deprivation of any part of its bony character.

Deoxidation (de-oks-id-a'-shun) [de, from; oxidatus, having oxygen]. In chemistry, the separation of an element or compound from the oxygen held in combination. Reduction.

Deozonize (de-o'-zōn-îz) [de, from; ŏ $\zeta \varepsilon v v$, to smell]]. To deprive of ozone.

Depauperate (de-pazv'-per-ât) [de, intensive; pauper, poor]. I. To render poor; to pauperize; to impoverish. 2. Impoverished; ill-nourished; underfed, and under-grown.

Depilation (dep-il- $\left.a^{\prime}-\operatorname{shu}\right)$ [depilatio, removal of hair]. The removal of hairs.

Depilator (de-pill-a-tor) [depilare, to remove the hair]. An instrument for pulling out the hair.

Depilatory (de-pit'-at-or-e) [de, from ; pitus, the hair]. 1. Having the power to remove the hair. 2. A substance used to destroy the hair, usually a caustic alkali.

Deplethoric (de-pleth'-or-ik) [de priv; $\pi \lambda \eta \theta \omega \omega \eta \eta$, plethora]. Marked by absence of plethora.

Depletion (de-ple'-shun) [deplere, to empty]. The process of diminishing the quantity of any tissue or fluid of the body, especially the blood. It may be general or local, the former by venesection and purging, and the latter by leeching, cupping, or scarification.

Depletive, Depletory (de-ple'-tiv, de-ple'-tor-e) [deplere, to empty]. I. Causing or tending toward depletion. 2. A medicine that depletes.

Deplumation (de-plu-ma'-shun) [de, down, off ; pluma, feather]. The loss of the eyelashes.

Depolarization (de-po-lar-iz-a'-shun). Destruction of polarity. The neutralization of the opposite poles of a magnet. The neutralization or recombination of light-waves that have been separated by means of a Nicol prism.

Deposit (de-pos'-it) [de, from; ponere, to place]. A gathering of particles that have been held in suspension. A gathering of morbid or normal matter in any part of the body. See Urinary Deposit.
Deposition (de-po-zish'-un). See Couching.

Depositive (de-poz'-it-iv) [deponere, to lay aside]. Tending to or characterized by a morbid deposit; exudative.

Depravation (dep-rav-a'shun) [depravare, to vitiate]. A deterioration or morbid change in the secretions, tissues, or functions of the body.

Depressant (de-pres'-ant) [deprimere, to press down]. A medicine that retards or depresses the physiologic action of an organ. A sedative. D., Cardiac, one that lowers the action of the heart. D., Cerebral, one that arrests the functions of the cerebrum. D., Motor, one that lowers the activity of the spinal cord and motor apparatus.

Depressio (de-pres'-e-o) [L.]. A depressing. D. cataractze. Synonym of Couching.

Depression (de-presh'-un) [depressio; deprimere, to depress]. In anatomy, a hollow, or fossa. In surgery, displacement inward of the skull, often giving rise to pressure on the brain. D. and Elevation, one of the Swedish movements, either excentric or concentric, in which, while the part is being raised or depressed, resistance is made by the patient or operator. Depressions, Pacchionian. The depressions on the internal surface of the parietal bone that lodge the Pacchionian bodies.

Depressor (de-pres'-or) [deprimere, to depress]. A name given to a muscle or an instrument that depresses. See Muscles, Table of. D. Fibers. See Pressor. D. of Sims, an instrument for holding back the vaginal wall during exploration with the speculum. D., Tongue, an instrument for depressing the tongue in order to examine the throat.

Deprimens (dep'-rim-enz) [L.]. I. Depressing ; pressing down. 2. A depressing muscle, D. auriculæ, the retrahens auris muscle. D. oculi, the rectus inferior of the eye. See Muscles, Table of.

Depurant (dep'-u-rant) [depurare, to purify]. I. Purifying; cleansing. 2. A medicine that purifies the animal economy.

Depurative (depp-u-ra-tive), or Depuratory (depp'u-rntor-e) [depurare, to purify]. Purifying or cleansing. D. Liver, same as Amyloid Liver.

Depurator (dep'-u-ra-tor) [depurare, to purify]. Medicine or device for promoting a depuratory process.

DeR. A contraction and symbol of the term Reaction of Degeneration, $q . v$.

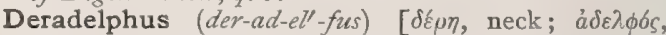
brother]. A monocephalic dual monstrosity, with fusion of the bodies above the umbilicus, and with four lower extremities, and three or four upper.

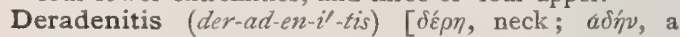
gland; $\iota \tau \iota$, inflammation]. Inflammation of the glands of the neck.

Deradenoncus (der-ad-en-ong'-kus) [ $\delta_{\varepsilon}^{\prime} \rho \eta$, neck; ádn'v, gland; боко,, mass]. A swelling of a gland of the neck; a swollen gland of the neck.

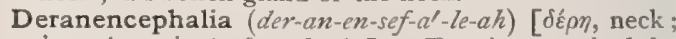

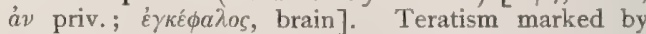
absence of the head and brain, the neck being present.

Derangement (de-rānj'-ment). See Insanity.

Derbyshire Neck (der'-be-shêr nek). See Goitèr.

Dercum's Disease. Adiposis dolorosa. A disorder characterized by irregular, sometimes symmetric, deposits of fatty masses in various portions of the body, preceded by, or attended with, pain.

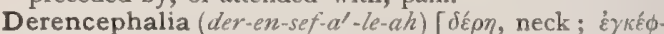
años, brain]. The condition of being derencephalous; teratic absence of cranium, the vestiges of the brain being enclosed in the cervical vertebra.

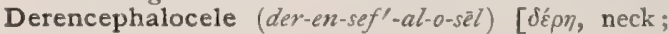

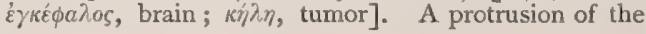


brain through a split in one or more of the cervical vertebre.

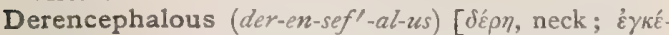
$\phi a \lambda o s$, brain]. Affected with derencephalia; of the nature of derencephalus.

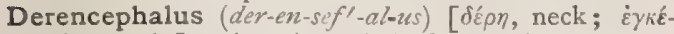

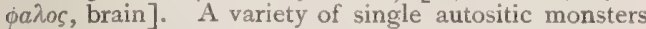
of the species anencephalus, in which the bones of the cranial vault are rudimentary, the posterior portion of the occiput absent, and the upper cervical vertebræ bifid, the brain resting in them.

DeRheim's Plaster. A celebrated plaster for chilblains, made as follows: Capsicum pods $ろ$ j, strong alcohol, 亏ij; macerate several days, then add mucilage of acacia $\jmath_{\mathrm{ij}}$. Stir well and brush over sheets of silk or tissue paper, and apply like court-plaster to the unbroken chilblain.

Derivant (der'-iv-ant) [derivare, to derive]. I. Derivative; revulsive. 2. A derivative medicine or application.

Derivate (der'-iv-ät) [derivare, to derive]. In chemistry, a substance that is derived from another.

Derivation (der-iv-a'-shun) [derivare, to derive]. I. Derivative action; the drawing away of a morbid process from one part to another; revulsive treatment. 2. The supposed suctional power of the heart, or the effect of that power upon the circulation. D. Wire, in an electric battery a wire connecting two points in a closed circuit.

Derivative (de-riv'-at-iv) [derivare, to turn aside a stream ]. Diverting or drawing a morbid process from its seat; revulsive.

Derm. See Derma

Derma (der'-mah) [ $\delta \varepsilon \rho \mu a$, the skin]. The skin. The true skin. See Cuttis.

Dermad (der'-mad) [ $\delta^{\prime} \rho \mu \alpha$, the skin; $a d$, to]. Externally; toward the skin; ectad.

Dermagra (derma'-grah). See Dermatagra.

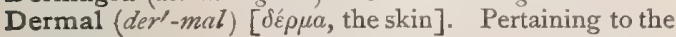
skin.

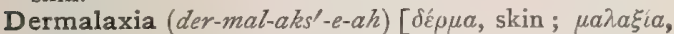
softness]. Morbid softening of the skin.

Dermalgia (der-mal'-je-ah). See Dermatalgia.

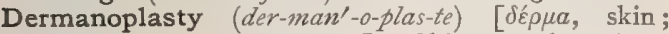

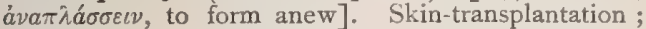
skin-grafting; a method of plastic surgery, in which a piece of the whole thickness of the skin is entirely removed from one part and transferred to another distant part to fill up a gap.

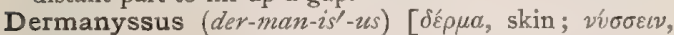
to prick]. A genus of itch-mites. D. avium is a species found on birds and sometimes on the human subject.

Dermapostasis (der-map-os'-tas-is) [ $\delta \varepsilon p \mu a$, skin; i $a b \sigma-$ $\tau a \sigma \iota s$, a falling away]. Any skin-disease dependent upon some constitutional disorder, and marked by metastatic dermal deposits.

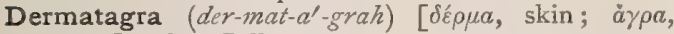
seizure]. See Pellagra.

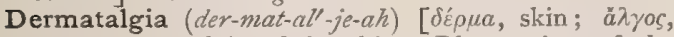
pain]. Neuralgia of the skin. Rheumatism of the skin. Pain in the skin not due to any structural change in it.

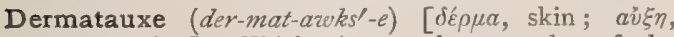
augmentation]. Thickening or hypertrophy of the skin.

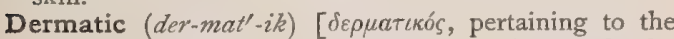
skin]. I. Relating to the skin. 2. A remedy for diseases of the skin.

Dermatitis (der-mat-i'-tis) [ $\delta \varepsilon \rho \mu \alpha$, skin; $\iota \tau \iota \zeta$, inflammation]. A generic term used to designate an ill-defined and extensive group of symptomatic inflamma- tions of the skin, characterized clinically by redness, heat, swelling, and pain, and terminating in resolution, suppuration, gangrene, or chronic dermatitis. D. ambustionis, the form due to burns and scalds. D. bullosa. See Epidermolysis. D. calorica. Synonym of Chilblain. D. congelationis. Same as Frostbite. D. contusiformis. See Erythema nodosum. D. exfoliativa, an acute or chronic, general or partial, inflammation of the skin, in which the epidermis is shed more or less freely in large or small scales. See Pityriasis rubra. D. exfoliativa infantum vel neonatorum, Ritter's Disease; a severe form of exfoliative inflammation of the skin, usually unattended by fever, which begins between the second and fifth weeks of life. About 50 per cent. of those attacked succumb to marasmus. D. gangrænosa; Sphaceloderma; gangrenous inflammation of the skin. It has been observed in cases of cerebral and spinal disorders, diabetes, etc. It may also be primary in those whose constitutions are depraved. The lesions are at first reddish or purplish erythematous spots, usually on the trunk and extremities; these vesicate, rapidly become gangrenous, and slough; they are attended by fever and constitutional disturbance. Spontaneous recovery generally ensues with scar-formation. D. gangrænosa infantum; Varicella gangranosa, pemphigus gangranosus; rupia escharotica; a gangrenous eruption following varicella and other pustular eruptions of children. It is a rare condition. If it occur while the varicellar lesions are still present, it begins on the head or upper part of the body, and, instead of the scab being thrown off, ulceration occurs beneath it, and often a pustular border with a red areola is formed, the whole resembling a vaccination-pustule. On separating, a sharp-edged, roundish or oval, conical ulcer remains, deep or shallow. Death may result if the lesions are numerous, and constitutional disturbance is always great. D. herpetiformis, an inflammatory skin-disease of an herpetic character, the various lesions showing a tendency to group. It is a protean disease, appearing as erythema, vesicles, blebs, and pustules. Itching and burning are the most marked symptoms. See Hydroa herpetiforme. D., Malig. nant, Papillary dermatitis, Paget's disease of the nipple. Carcinoma of the nipple. D. medicamentosa, Drug-eruptions; inflammatory eruptions upon the skin due to the action of certain drugs taken internally. The most prominent are the following: Antifebrin produces a kind of cyanosis; antipyrin, an erythema that may be general or partial, but symmetric, affecting the extensor aspects in preference to the flexor, and the limbs more than the trunk; papules, vesicles, and bullæ have been noted; arsenic produces an urticarial, erysipelatoid dermatitis of the face and eyelids, a papular rash on the face, neck, and hands, herpes zoster, and in large doses pustular, ulcerative, or gangrenous eruptions; belladonna, a diffuse erythematous blush and a scarlatiniform eruption; boric acid, an erythema; borax, psoriasis, eczema, and erythema; bromin and bromids, pustular, erythematous, urticarial, bullous, and squamous eruptions; cannabis indica, a vesicular eruption; chlorate of potash, a fiery, erythematous and papular eruption, and cyanosis; chloroform, purpuric spots; chloral hydrate, erythema, scarlatiniform, bullous, erysipelatous eruptions; chloralamid, scarlatiniform; chrysarobin, erythema, vesicles; cod. liver-oil, vesicular eruption, acne; copaiba, erythematous, urticarial, papular eruption; cubebs, papular erythema; digitalis, scarlatiniform, papular erythema; iodin and iodids, pustular, vesicular or bullous, purpuric, ery thematous, urticarial ; iodoform, punctiform, papular and erythematous; mercury, erythematous, exfoliative 
dermatitis; morphin, erythematous; phosphoric acid, bullous, purpura; quinin, eczema, erythematous, urticarial, purpuric, vesicular, bullous; resin, urticaria ; rhubarb, hemorrhagic and pustular bullæ; salicylic acid, erythema, urticaria, bullæ, petechiæ, vesicles, pustules; santonin, urticaria ; stramonium, erythema; strychnin, scarlatiniform, pruritus, miliaria; sulphonal, erythema, purpura; tannin, urticaria ; tar, erythema, vesicles and bullæ, acne; terebene, papular erythema; tuberculin, scarlatiniform; turpentine, erythema, papules, vesicles. D. papillaris capillitii. Same as $D$. papillomatosa capillitii. D. papillomatosa capillitii. Acne keloid; Sycosis framboesiformis; a rare form of chronic skin-disease affecting the nape of the neck and adjacent portion of the skin. The lesions consist of minute red papules, which occasionally suppurate, and are usually traversed by a hair. Ultimately these unite to form extensive, irregular, hard, white, or reddish keloid-looking growths from which a few brush-like bundles of atrophied, firmly adherent hairs protrude. It occurs usually in males of middle age. D. repens, a spreading dermatitis, usually following injuries, and probably neuritic, commencing almost exclusively in the upper extremities. D., Seborrheic : Seborrheic eczema; a form of inflammation of the skin associated with seborrhea of the scalp, due to the direct transference of the same pathogenic organism from the head to the region affected. D. traumatica, those inflammatory changes in the skin resulting from traumatism. D. venenata, a term embracing all forms of inflammation of the skin produced by external irritating agencies, whether from the animal, vegetable, or mineral kingdom. This includes the dermatitis produced by rhus-poi-oning.

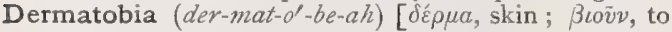
live]. A bot-fly of Central America, the eggs of which are not infrequently deposited in the skin and produce a swelling very like an ordinary boil. See Macaco Worm and Parasites (Animal), Table of.

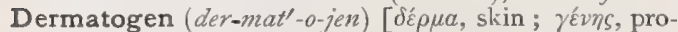
ducing]. In biology, the layer of cells, in a young or growing part, that is destined to become epidermis.

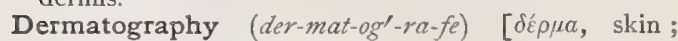
$\gamma \rho a ́ \phi \varepsilon \nu \nu$, to write]. A description of the skin.

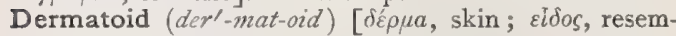
blance]. Like or resembling skin.

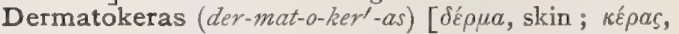
a horn]. See Cornu cutaneum.

Dermatol (der'-mat-ol) $[\delta$ ćpua, skin $], \mathrm{C}_{6} \mathrm{H}_{2}(\mathrm{OH})_{3^{*}}$. $\mathrm{CO}_{2} \mathrm{Bi}(\mathrm{OH})_{2}$. The subgallate of bismuth, which ap pears to be a valuable antiseptic agent. It is especially of service in cutaneous affections or lesions associated with copious secretion. Dose internally in affections of the stomach and intestines, two drams daily. It is valuable as a drying antiseptic for dusting wounds.

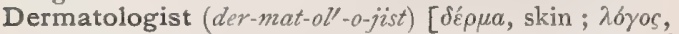
science]. One who is an adept in the treatment of skin-diseases.

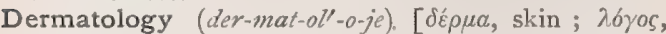
science]. The science of the skin, its nature, structure, functions, diseases, and treatment.

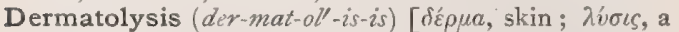
loosing]. An exaggerated form of Molluscum fibrosum, marked by large flaps or folds of hypertrophied skin, their commonest sites being the neck, face, buttocks, and chest. The skin-flaps are often deeply pigmented, thickened, indurated, and warty. Hypertrophy of the bones or other subjacent tissues may also be present.

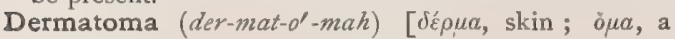

tumor: pl., Dermatomata]. Any tumor of the skin, or one made up of dermal elements.

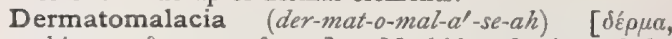
skin; $\mu a \lambda a \kappa \iota$, softness]. Morbid softening of the skin.

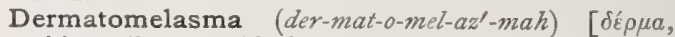
skin; $\mu \hat{\lambda} \lambda a \sigma \mu a$, a black color]. Addison's disease.

Dermatomycosis (der-mat-o-mi-ko'-sis) [ $\delta \varepsilon \rho \mu \alpha$, skin ; $\mu v ́ \kappa \eta s$, fungus]. Any skin-disease caused by a parasitic plant-growth.

Dermatomyoma (der-mat-o-mi-o'-mah) [ $\delta \varepsilon p \mu a$, skin ; $\mu \tilde{s}$, muscle ; ö $\mu a$, a tumor: pl., Dermatomyomata]. Myoma seated upon or involving the skin.

Dermatoneurosis (der-mat-o-nu-ro'-sis) [ $\delta \varepsilon \rho \mu a$, skin ; veṽ $\rho \circ v$, a nerve]. Any neurosis of the skin.

Dermatonosus (der-mat-on'-o-sus) [ dép $\mu \alpha$, skin ; vó $\sigma o s$, disease]. Any skin-disease.

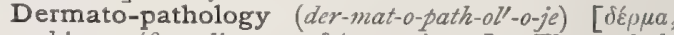

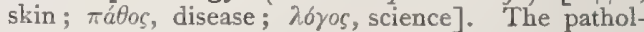
ogy of the skin.

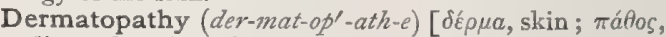
disease]. Any skin-disease.

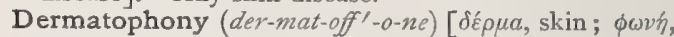
sound]. The auscultation of the skin; a process by which, it is alleged, the sound made by the blood in the vessels of the skin can be heard.

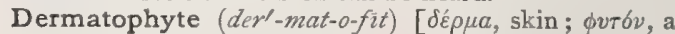
plant]. Any species of fungous vegetation that grows upon the skin.

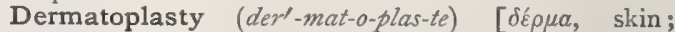
$\pi \lambda a ́ \sigma \sigma \varepsilon \iota \nu$, to form]. Plastic surgery of the skin.

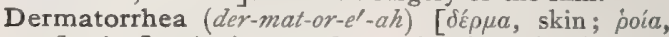
a flowing]. An increased secretion from the skin.

Dermatosclerosis (der-mat-o-skle-ro'-sis). See Scleroderma.

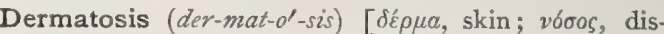
ease: $p l$. Dermatoses ]. Any disorder or disease of the skin. D. Kaposi. Synonym of Xeroderma pigmentosum.

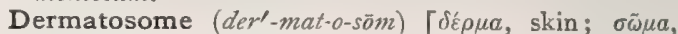
body]. A thickening or knot in the equatorial region of each spindle fiber in the process of cell-division.

Dermatospasmus (der-mat-o-spaz'-mus) [ $\delta \hat{\varepsilon} \rho \mu a$, skin; $\sigma \pi a \sigma \mu \sigma \varsigma$, spasm]. Cutis anserina, or goose-skin.

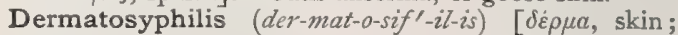
Syphilus, a Latin proper name]. The cutaneous manifestations of syphilis. See Syphiloderma.

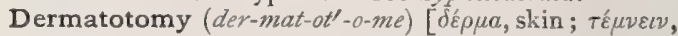
to cut]. The anatomy or dissection of the skin.

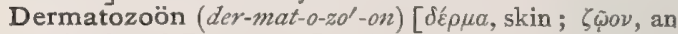
animal: pl.Dermatozoa]. Any animal parasitic upon the skin.

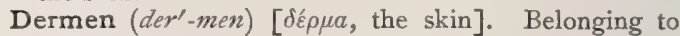
the derma itself.

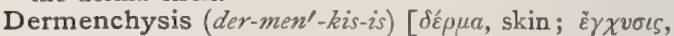
a pouring in]. Hypodermatic injection.

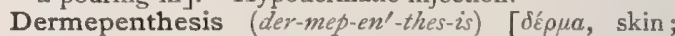
$\dot{\varepsilon} \pi \hat{\varepsilon} v \theta \varepsilon \sigma \iota \varsigma$, insertion]. Synonym of skin-grafting.

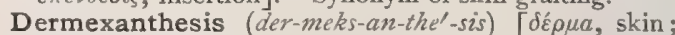

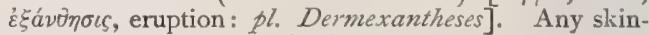
disease marked by a rash-like eruption.

Dermic $\left(d e r^{\prime}-m i k\right)$ [ $\delta \varepsilon \rho \mu a$, the skin]. Relating to the skin.

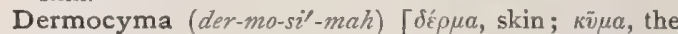
fetus]. A form of double monstrosity in which the parasite is contained within the skin of the host.

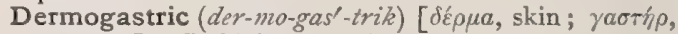
stomach]. In biology, applied to structures having a connection with the skin and the stomach, as dermogastric pores.

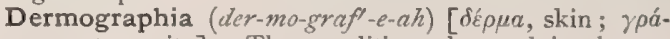
$\phi \varepsilon \iota \nu$, to write]. The condition observed in the so- 
called autographic skin ; autographism. See Urticaria factitia.

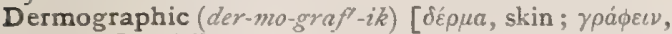
to write]. Aftected with dermographia. D. pseudourticaria. Same as Dermographia.

Dermographism (der-mo-graf'-izm) [

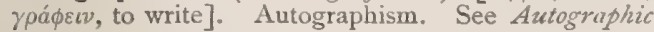
Skin and Urticaria factitia.

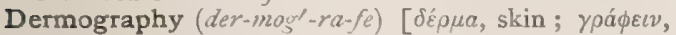
to write]. Dermographia; dermal autographism.

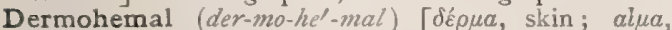
blood]. In biology, applied to parts of the ventral or hemal fins of certain fishes.

Dermoid (der'-moid). See Dermatoid. D. Cyst, a teratoma.

Dermology (der-mol'-o-je). See Dermatology.

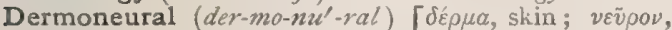
nerve]. In biology, applied to parts of the dorsal or neural fins of certain fishes.

Dermoneurosis (der-mo-nu-ro'-sis). See Dermatoneurosis.

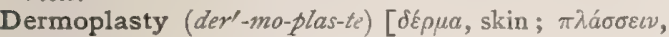
to form]. Restoration of skin; skin-grafting.

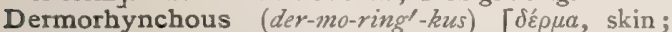

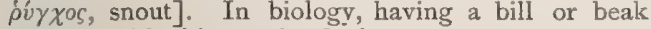
covered with skin, as the duck

Dermorrhagia (der-mor-a'-je-ah) [ $\delta \varepsilon \rho \mu \alpha$, skin; $\rho \eta \gamma v ́ v a \iota$, to break forth]. Hemorrhage from the skin; bloody sweat; hematidrosis.

Dermosclerite (der-mo-skle' -rīt) [ $\delta^{\prime} \rho \mu a$, skin ; $\sigma \kappa \lambda \eta \rho \sigma ́ s$, hard]. In biology, one of the spicular masses found in certain actinozoans.

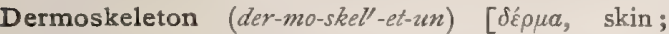
$\sigma \kappa \varepsilon \lambda \varepsilon \tau \delta \nu$, a skeleton]. The exoskeleton of invertebrates; the skin and its appendages.

Dermo-syphilopathy (der-mo-sif-il-op'-a-the) [ $\delta \dot{\varepsilon} \rho \mu a$, skin; syphilis; $\pi a ́ \theta o s$, affection]. A syphilitic skindisease.

Dermotomy (der-mot'-o-me). See Dermatotomy.

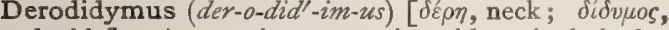
double]. A sysomic monstrosity with a single body, two necks and heads, two upper and lower extremities, with other rudimentary limbs occasionally present.

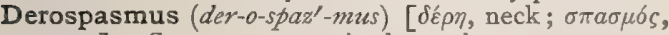
spasm]. Spasm or cramp in the neck.

Dertrotheca (der-tro-the'-kah) [déptoov, a vulture's beak; $\theta \dot{\eta} \kappa \eta$, a sheath]. In biology, the skin of the dertrum or tip of the upper mandible in certain birds.

Dertrum (der'-trum) [ $\delta \tilde{\varepsilon}^{\prime} \rho \tau \rho o \nu$, a beak]. See Dertrotheca.

De Salle, Line of. See Lines, Table of.

Desanimania (des-an-im-a'-ne-ah) [des (dis) priv.;

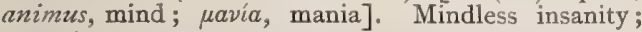
amentia.

Desault's Apparatus or Bandage. See Bandage. D. Operations. See Operations, Table of.

Desbassins' Test. Same as Richmont's Test. See Tests, Table of. D. Splint. See Splint.

Descemet's Membrane. The internal or posterior lining membrane of the cornea. Also called the Membrane of Demours.

Descemetitis (des-em-et-i'-tis) [Descemet; $\iota \tau \iota \zeta$, inflammation]. Inflammation of Descemet's membrane.

Descemetocele (des-em-et'-o-sél) [Descemet; $\kappa \dot{n} \lambda \eta$, hernia]. Hernia of Descemet's membrane.

Descendens (de-sen'-denz) [descendere, to go down] Downward. D. noni, a branch of the hypoglossal nerve. See Nerves, Table of.

Descent (de-sent') [descensus, a going down]. The act of going down; downward motion. D. Stage of Labor, one of the stages in labor, consisting in the entrance of the fetal head into the pelvis. D. of
Testicle. See Testicle. D. of Womb. See Prolapsus.

Deschamps' Angle. See Angle.

Deshler's Salve. The compound resin cerate of the pharmacopeia.

Desiccant $\left(\right.$ des $^{\prime}-i k$-ant $)$ [desiccare, to dry up]. I. Causing desiccation; drying. 2. A drying medicine or application.

Desiccation (des-ik-a -shun) [desiccare, to dry up]. The process of removing moisture from solids and organic tissues.

Desiccative (des'-ik-a-tiv) [desiccare, to dry up]. I Drying; desiccant. 2. A medicine or application having the property of drying moist tissues, ulcers and running sores.

Desma ( dez $\left.^{\prime}-m a h\right)$ [ $\delta^{\prime} \sigma \mu a$, a band]. In biology, a term applied to irregular sponge-spicules.

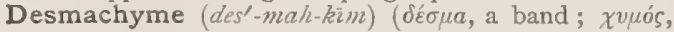
juice]. In biology, the connective tissue of sponge.

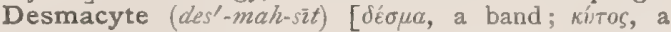
cell]. In biology, one of the connective-tissue cells of a sponge.

Desmarres' Operations. See Operations, Table of.

Desmitis (des-mi'-tis) [ $\delta \varepsilon \sigma \mu o ́ s$, ligament]. Inflammation of a ligament.

Desmobacterium (des-mo-bak-te'-re-um) [ $\delta \varepsilon \sigma \mu o ́ s$, band;

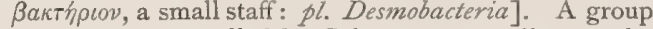
of microbes, so-called by Cohn, corresponding to the genus Bacillus of Klein.

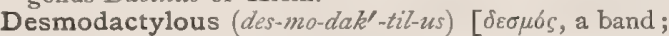
$\delta a ́ \kappa \tau v \lambda o s$, a finger or toe]. In biology, having the flexor tendons of the toes united.

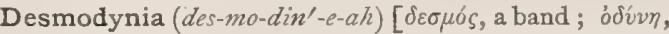
pain]. Pain in a ligament.

Desmognathism (des-mog'-na-thizm) [ $\delta \varepsilon \sigma \mu o ́ s$, a band; $\gamma v a ́ \theta 0 s$, jaw]. Union of the maxillo-palatine bones across the middle line; normal in certain birds, as hawks, ducks, etc.

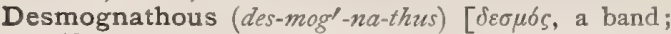
rvátos, a jaw]. In biology, applied to birds of the "bound palate" type, in which the vomer is small or absent, the maxillo-palatines united, and the palatines and pterygoids articulate directly with the sphenoid.

Desmography (des-mog'-ra-fe) [ $\delta \varepsilon \sigma u b s$, a ligament: $\gamma \rho a ́ \phi \varepsilon \iota v$, to write]. The description of the ligaments.

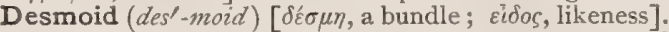
Like a small bundle. D. Carcinoma. Synonym of Hodgkin's Disease.

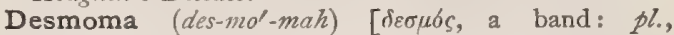
Desmomata]. A connective-tissue tumor.

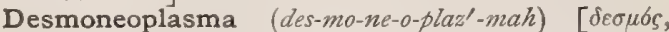
band; véos, new ; $\pi \dot{\lambda} a ́ \sigma \mu \alpha$, plasma: pl., Desmoneoplasmata]. Any neoplasm made up of connective tissue.

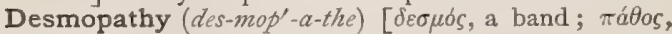
disease]. Any disease of a ligament.

Desmopelmous (des-mo-pel'-mus) [ $\delta \dot{\varepsilon} \sigma \mu a$, a band; $\pi \hat{\varepsilon} \lambda \mu \alpha$, the sole of the foot]. In biology applied to such birds as have the plantar tendons bound together.

Desmosis (des-mó-sis) [ $\delta \varepsilon \sigma \mu \sigma \varsigma$, a band : pl., Desmoses]. Any disease of connective tissue, especially of the connective tissue of the skin.

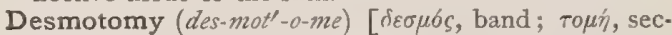
tion]. The dissection and anatomy of the ligaments; surgical cutting of a ligament.

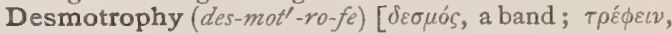
to turn]. Tautomerism.

Desoxalic Acid (des-oks-all-ik). See Acid.

Desprez' Operation. See Operations, Table of.

Despumation (des-pu-ma'-shun) [despumare, to skim froth]. The purification of a liquid by removal of the scum or froth: also the formation of froth ; purification; clarification in general. 
Desquamation (des-krwam-al-s/zun) [desquamare, to scale off]. The exfoliation or falling off of the cuticle in scales. It is bran-like after measles; in layers after scarlet fever.

Desquamative (des-kruam'-at-iv) [desquamare, to scale off]. Characterized by desquamation.

Destructive (de-struk'-tiv) [destructivus, destroying]. Hurtful; tending to destroy. D. Distillation. See Distillation.

Desudation (des-u-da'-shun) [desudatio; de, away; sudare, to sweat]. I. Excessive or morbidly profuse sweating. 2. Sudamina.

Desudatory (de-su'-dat-or-e) [desudatio, a sweating]. A sweating-bath.

Detergent (de-ter'-jent) [detergere, to cleanse]. I. Purifying; cleansing; abluent. 2. A drug, compound, or solution used for cleansing wounds, ulcers, etc.

Determinant or Determining Part (de-ter'-min-ant) [determinare, to limit]. Weismann's name for one of the particles of germ-plasm corresponding to a group of biophors; a primary constituent of a cell or group of cells

Determinate (de-ter'-min-ät) [determinare, to limit] 1. Applied in botany to an inflorescence in which the blossoming takes place centrifugally, the blossoms being from terminal and not from axillary buds. 2. Weismann's name for one of the cells or groups of cells that are independently variable from the germ onward. They are also called hereditary parts.

Determination (de-ter-min- $\left.a^{\prime}-s h u n\right)$ [determinatio, a directing]. The direction or tendency to or toward a part or an organ, as of blood to the head.

Determinism (de-ter'-min-izm) [determinare, to limit, prescribe]. In biology, a term introduced by Claude Bernard to indicate the fatality of the reproduction of phenomena under similar conditions, as seen in Experimental Science.

Detersion (de-ter'-zhun) [detergere, to cleanse]. The action of a detergent; a cleansing.

Detersive (de-ter'-siv). Same as Detergent.

Detmold's Method. See Treatment, Methods of.

Detrition (de-trish'-un) [deterere, to wear off]. The act of wearing or wasting of an organ or part, especially the teeth.

Detritus (det'-rit-us) [deterere, to wear off]. The waste matter resulting from any wearing away, or from a destructive process.

Detumescence (de-tu-mes'-ens) [detumescentia, a subsidence of a tumor]. The subsidence of any swelling.

Deutencephalon (dutt-en-sef'-al-on). See Diencephalon.

Deuteria $(d u$-te'-re-ah) $[\delta \varepsilon v \tau \varepsilon \rho \iota \alpha]$. The secundines.

Deutero-albumose $\left(d u-t e r-o-a l^{\prime}-b u-m o ̄ s\right)$. See Albumose.

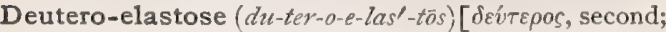
$\dot{\varepsilon} \lambda a \sigma \tau \iota \kappa \delta s$, elastic]. Elastin-peptone; one of the products of the digestion of elastin. It is not precipitable by saturation with sodium chlorid.

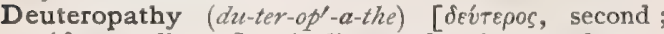
$\pi a ́ \vartheta o s$, a disease]. A disease that is secondary to another.

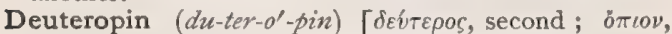
opium ], $\mathrm{C}_{20} \mathrm{H}_{21} \mathrm{NO}_{5}$. An alkaloid of opium.

Deuteroplasm, or Deutoplasm (du-ter-o'-plazm, or

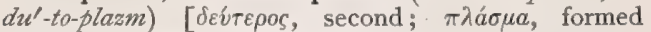
material]. The food-yolk of an egg; a mass of granules of proteid and fatty matter occurring in the ovum.

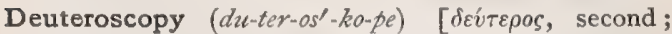

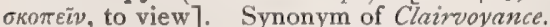

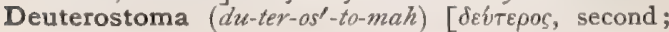
$\sigma \tau b \mu \alpha$, mouth]. In biology, a secondary blastopore.

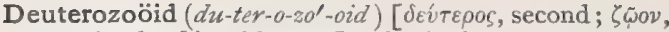
an animal; عidos, likeness]. In biology, a secondary zoöid, developed by budding.

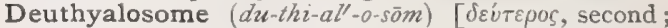
vaios, glass, crystal; $\sigma \tilde{\omega} \mu \alpha$, body]. The remains of the germinal vesicle after the polar bodies have been extruded, formed by the union of portions of the chromatic stars or discs with portions of the prothyal osome.

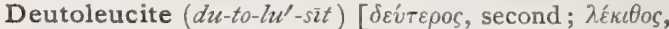
the yolk of an egg]. In biology, a term applied by Salensky to the nutritive vitellus of the eggs of sturgeons; it is homologous to the secondary vitellus (Nebendotter) of osseous fishes. Cf. Protoleucyte.

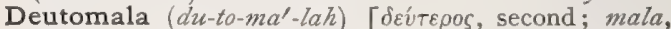
jaw]. In biology, a term applied by A. S. Packard, $\mathrm{Jr}$, to the second pair of mouth-appendages of the Myriopoda, formerly called labium, but really homologous with the first maxillæe of insects.

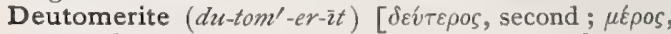
a part]. In biology, the posterior segment of a twocelled organism, as a gregarine, the anterior cell being called the protomerite, $q . v$.

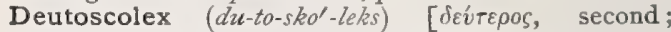
$\sigma \kappa \omega \lambda \eta \xi$, worm]. In biology, applied to secondary or daughter-cysts or bladder-worms that are derived from a scolex or primary bladder-worm.

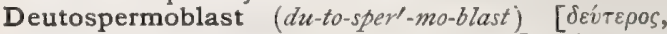
second; $\sigma \pi \hat{\varepsilon} \rho \mu \alpha$, sperm; $\beta \lambda \alpha \sigma \tau o ́ s$, germ ]. Any one of the cells produced by the division of a protospermoblast.

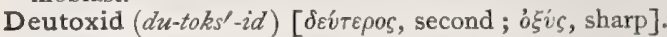
See Dioxid.

Devalgate (de-val'-gät) [de, intensive; valgus, bowleg]. Bowlegged or bandylegged.

Development (de-vell-op-ment) [Fr., developper, to unfold ]. The sequence of organic changes, by which the fertilized ovum becomes the mature animal or plant.

Deventer's Diameter. The oblique diameter of the pelvis. D.'s Method. See Treatment, Method's of.

Devergie's Disease. See Diseases, Table of.

Deviation (de-ve-a'-shun) [deviare, to deviate]. Turning from a regular course, standard, or position. D., Conjugate, the forced and persistent turning of eyes and head toward one side, observed with some lesions of the cerebrum. D., Primary, the deviation of the weaker eye from that position that would make its visual line pass through the object-point of the healthy eye. D., Secondary, the deviation of the healthy eye from that position that would make its visual line pass through the object-point of the weaker eye. D. of Teeth, a faulty direction or position of one or more teeth.

Devitalization (de-vi-tal-iz-a'-shun) [de priv.; vita, life]. Depriving of life or vitality. D. of Dental Pulp. See Dental Pulp, Devitalization of.

Devitalize $\left(d e-v i^{\prime}-t a l-\bar{i} z\right)$ [de, from; vita, life]. To destroy vitality, as that of living tissue.

Devonshire Colic (dev'-on-sher kol'-ik). See LeadColic.

De Vries' Theory of "Intracellular Pangenesis." See Hereciity.

Devys' Operation. See Operations, Table of.

Dew's Method. See Artificial Respiration.

Dew $(d u)$ [AS., deāw, dew]. The water deposited during the night from the atmosphere by the process of condensation. D.-claw, the aborted hallux of a domestic dog, or the false hoof of an ungulate. D.point, the point at which the air cannot take up more vapor at the existing temperature, or loses a portion of its vapor by condensation if the temperature be but slightly reduced. 
DeWecker's Operations. See Operations, Table of. Dewees' Carminative. See Asafetida.

Dewlap $\left(d u^{\prime}-l a p\right)$ [ME., deculappe, a loose, hanging piece ]. The pendulous longitudinal fold of skin seen under the throat of most bovine animals and of some dogs; the wattle of a turkey; colloquially, the similar fold seen occasionally under the chin of old persons.

Dexicardia (deks-e-kar'-de-ah). See Dexiocardia and Dextrocardia.

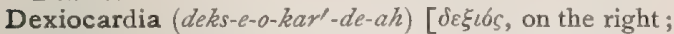
krpoia, the heart]. Transposition of the heart to the right side of the thorax.

Dexter (deks'-ter) [L.]. Right; upon the right side

Dextrad (deks'-trad) [dexter, right; ad, to]. Toward the right side. See Position and Direction, Table of.

Dextral (deks'-tral) [dexter, right]. Pertaining to the right side ; right-handed. See Position and Direction, Table of.

Dextran (deks'tran) [dexter, right], $\mathrm{C}_{6} \mathrm{H}_{10} \mathrm{O}_{5}$. A stringy, gummy substance formed in milk by the action of cocci, and occurring in unripe beet-root.

Dextren (deks'-tren) [dexter, right]. Belonging to the dextral side in itself.

Dextrin (deks'-trin) [dexter, right], $\mathrm{C}_{6} \mathrm{H}_{10} \mathrm{O}_{5}$. The soluble or gummy matter into which starch is converted by diastase or by certain acids. It is white, insipid, odorless, and is remarkable for the extent to which it turns the plane of polarization to the right hand, whence its name. See Carbohydrates, Table of.

Dextrins (deks'-trinz) [dexter, right]. Gummy amorphous masses, readily soluble in water and precipitated by alcohol. Their aqueous solutions are dextro-rotatory, hence their name. They do not reduce Fehling's solution, even on boiling, and are incapable of direct fermentation; in the presence of diastase, however, they can be fermented by yeast.

Dextrocardia (deks-tro-kar'-de-ah) [dexter, right; кapdia, heart]. A congenital condition in which the heart is situated on the right side of the thorax; either alone or as a part of a general transposition of the viscera. See Dexiocardia.

Dextro-compound (deks-tro-com'-pound) [dexter, right; componere, to set together]. In chemistry, a compound body that causes a ray of polarized light to rotate to the right. Dextrin, malic acid, and cinchonin are dextro-compounds.

Dextrogyrate (deks-tro-ji'-rāt). Same as Dextro-rotatory.

Dextrolichenin (deks-tro- $\left.\overline{2}^{\prime}-k e n-i n\right)$ [dexter, right; $\lambda \varepsilon \iota \chi^{\eta} \nu$, a lichen]. A form of lichenin readily distinguished from normal lichenin in being colored blue by iodin, while lichenin is not.

Dextro-rotatory (deks-tro-ro'-tat-or-e) [dexter, right; rotare, to whirl]. Causing to turn toward the right hand, as a dextro-rotatory crystal.

Dextrose (deks'-trōs) [dexter, right], $\mathrm{C}_{6} \mathrm{H}_{12} \mathrm{O}_{6}$. Grapesugar. A sugar belonging to the glucose-group, that crystallizes from aqueous solution with $\mathrm{IH}_{2} \mathrm{O}$ in nodular masses of six-sided scales. It is readily soluble in water and alcohol, has a taste less sweet than ordinary cane-sugar, and directly reduces an alkaline coppersolution. It is dextro-rotatory to polarized light. It is found in most sweet fruits, and in large amount in diabetic urine. See Sugar and Glucose.

Dextro-sinistral (deks-tro-sin-is'-tral) [dexter, right; sinister, left]. Extending from right to left.

Dextroversion (deks-tro-ver'-zhun) [dexter, right; vertere, to turn]. Version to the right side, as when the fundus of the uterus is tilted dextrally; dextral latero-version.
Dezeanneau's Operation, See Operations, Table of. Dhobie's Itch. An Indian name for Ringworm of the body.

Diabetes $\left(d i-a b-e^{\prime}-t \bar{e} z\right)[\delta \iota a \beta \eta ́ r \eta s: \delta i a$, through; $\beta a i v \varepsilon \iota v$, to go]. The habitual excessive discharge of urine; used alone the term often designates $D$. mellitus. D., Artificial, that form produced in the physiologic laboratory by puncturing the floor of the fourth ventricle of the brain. D., Cerebral, diabetes in which cerebrose appears in the urine in place of the ordinary form of glucose or liver-sugar. It indicates a cerebral lesion. D., English. Synonym of $D$. mellitus. D., Fat, a variety in which there is a tendency to obesity. D. insipidus, polyuria, a disease characterized by the excessive secretion of a urine of low specific gravity, associated with a marked degree of thirst, but without the presence of glycosuria. The urine is pale, almost colorless, and with a specific gravity but slightly above that of water, and may be voided in considerable quantities, even as much as fifty pints in a day. Many of the cases progressively emaciate and finally die of exhaustion. There is frequently found some lesion of the central nervous system, as a cerebral tumor; or the disease may be due to some lesion of the vaso-motor system of nerves. It is most frequent in males, and usually occurs between the ages of five and thirty years. D., Lean, a variety in which emaciation is marked. D. mellitus, glycosuria, a disease of the metabolic functions of the system, without gross or clearly defined anatomic lesions, manifesting itself by glycosuria, polyuria, thirst, and progressive loss of flesh and strength, with a tendency to a fatal termination. The onset is generally insidious. The urine is not so excessive as in simple polyuria, but may be as much as thirty pints in twentyfour hours. It contains glucose or grape-sugar, varying in quantity from two to five per cent., but occasionally reaching as high as ten or twelve per cent. The specific gravity is increased to between IO4O and Io6o though it may be as low as IOIO; the quantity of urea is increased; in some cases there is an excess of the phosphates of the urine, and these cases have been termed "phosphatic diabetes." The reaction of the urine is slightly acid; the smell sweetish. The emaciation is very marked and rapid, and persists notwithstanding the fact that the appetite is ravenous and the patient consumes an enormous quantity of food. Toward the end of the disease there is a failure of the mental faculties. Among the complications of diabetes may be mentioned a tuberculous variety of pneumonia, eczema and pruritus of the skin, gangrene of the toes, albuminuria, opacity of the crystalline lens, coma, and cardiac failure. Coma occurs most frequently in the young, and is characterized by an extreme degree of dyspnea both of inspiration and of expiration; it has been called "air hunger" by Kussmaul. No appreciable cause for the dyspnea can be found. As regards the morbid anatomy of diabetes no lesion has as yet been found. The disease occurs most commonly in young males, and in those of the gouty and neurotic diatheses. Exposure to cold, mental strain, injuries of the cerebrum, and the excessive use of starchy and saccharine foods, are given as exciting causes. D., Mosler's, polyuria due to the presence of too much inosit in the blood. D., Nonsaccharine. Synonym of D. insipidus. D., Pancreatic, a variety of glycosuria associated with and probably dependent upon disease of the pancreas. D., Phloretin, that form produced in animals by the administration of phloretin. D., Phloridzin, that following the administration of phloridzin. D., Phos. 
phatic. See $D$. mellitus. D., Saccharine. See $D$. mellitus. D., True. Synonym of $D$. mellitus.

Diabetic $\left(d i-a b-e t^{\prime}-i k\right)$ [ $\delta \dot{i}$, through; $\beta a i v \varepsilon \iota v$, to go]. I. Pertaining or belonging to diabetes, 2. A person suffering from diabetes. D. Cataract, an opacity of the crystalline lens sometimes found in association with and thought to be a complication of diabetes. D. Coma. See Diabetes mellitus. D. Gangrene. See Sphaceloderma. D. Sugar, $\mathrm{C}_{6} \mathrm{H}_{12} \mathrm{O}_{6}$, a form of glucose, present in the urine of diabetes mellitus. It is identical with grape-sugar. D. Tabes, a peripheral neuritis occurring in diabetic patients, characterized by lightning-pains in the legs, loss of knee-jerk, and a loss of power in the extensors of the feet. The gait is the characteristic steppage.

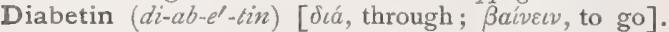
The trademarked name for levulose, which is recommended as an innocuous and palatable sugar, and nourishing substance for diabetics. It is a white granular mass, soluble in water, and has a pure sweet taste.

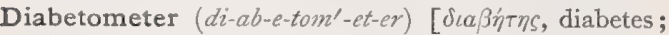

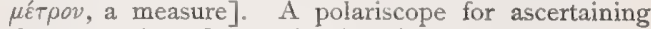
the proportion of sugar in diabetic urine

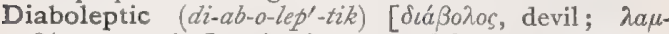
$\beta a ́ v \varepsilon \iota \nu$, to seize]. An insane or deluded person who professes to have supernatural communications.

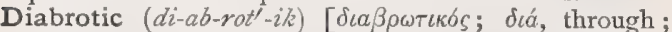
$\beta \iota \beta \rho \omega \sigma \kappa \varepsilon \iota \nu$, to eat]. I. Corrosive. 2. A corrosive substance.

Diacatholicon $\left(d i-a k-a t h-o l^{\prime}-i k-o n\right)$ [ $\delta \dot{\alpha}$, through : $\kappa a \theta 0-$ $\lambda \iota \kappa o ́ s$, universal]. Formerly, a purgative compound.

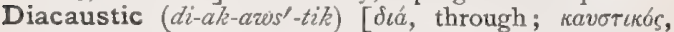
caustic]. A double convex cauterizing lens.

Diacele, Diacole $\left(d i^{\prime}-a s-\bar{e} l\right)[\delta \iota a ́$, between; кoì $\eta$, a hollow]. A term for the third ventricle or cavity of the diencephalon or interbrain. Its walls are the thalami ; its floor the tuber and diaterma.

Diacetic Acid (di-as-e'-tik). See Acid.

Diacetin (di-as'-et-in) [di, two ; acidum, acid], $\mathrm{C}_{3} \mathrm{H}_{5}$. $(\mathrm{OH})\left(\mathrm{C}_{2} \mathrm{H}_{3} \mathrm{O}_{2}\right)_{2}$. A liquid derivative of glycerin, with a bitter taste. It is also called acetidin.

Diaceturia (di-as-et-u'-re-ah) [di, two; acidum, acid; ov $\rho o v$, urine]. The presence of diacetic acid in the urine; it is a precursor of diabetic coma.

Diachorema ( $\left.d i-a k-o-r e^{\prime}-m a h\right)$ [ $\delta a \chi \omega \rho \eta \mu a$, excrement]. Fecal matter; excrement.

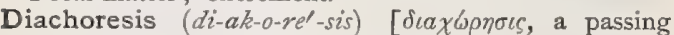
through]. Excretion or passage of feces.

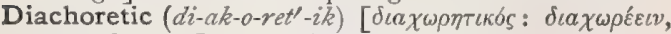
to go through]. Laxative; aperient.

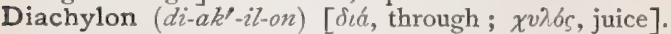
Formerly any emollient plaster composed of the juices of herbs. D. Plaster or Ointment. See Plumbum.

Diacid $\left(d i-a s^{\prime}-i d\right)[d i$, two; acidus, acid]. In chemistry, having an acidity of two; said of an acid or salt.

Diaclasis $\left(d i-a k^{\prime}-l a s-i s\right)$ [ $\downarrow \iota a ́ k \lambda a \sigma \iota s$, a breaking in two]. Refraction. A breaking.

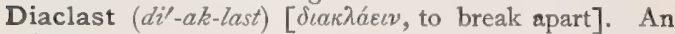
instrument for penetrating and breaking up the fetal head in craniotomy.

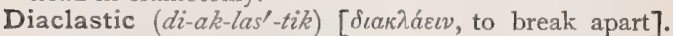
Pertaining to diaclasis. D. Amputation. See Maisonneuve's Amputation, in Operations, Table of.

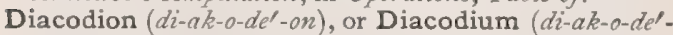

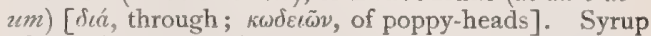
of poppies or of opium.

Diaccle $\left(d i-a s-e^{\prime}-l e\right)$, or Diacœlia $\left(d i-a s-e^{\prime}-l e-a h\right)$. See Diacele.

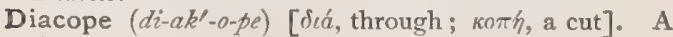
deep, incised wound, especially of the head or skull; a lengthwise fracture or cut, as of a bone.

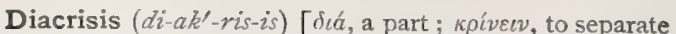
or secrete: pl., Diacrises]. I. A critical discharge. 2. A change or disorder in a secretion. 3. Any disease marked by altered secretions.

Diacritic, or Diacritical (di-ak-rit'-ik, di-ak-rit'-ik-al)

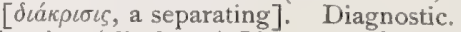

Diactine $\left(d i-a k^{\prime}-t i n\right)[\delta i s$, two ; ákTis, a ray]. In biology, having two rays.

Diad $\left(d i^{\prime}-a d\right)$. See Ouantivalence.

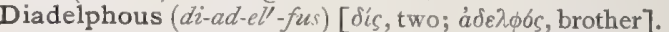
In botany, applied to stamens that are arranged in two sets or brotherhoods.

Diaderm $\left(d i^{\prime}-a-d e r m\right)$ [ $\delta i \zeta$, two; $\delta^{\prime} \rho \mu \alpha$, skin]. In biology, a general term proposed by Minot for that essential differentiation of the segmenting ovum, characterized by the formation of two plates of cells, differing in character, joined at their edges and surrounding a segmentation-cavity; the two plates or lamina are the two primitive germ-layers, the ectoderm and entoderm.

Diadermatic, Diadermic (di-ad-er-mat'-ik, di-ad-er'-

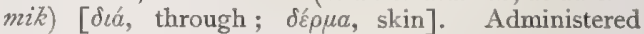
through the skin. Cf. Hypodermatic.

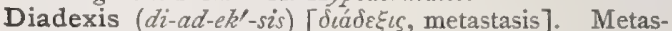
tasis of a disease, with a change of its character; change in the seat and nature of a disease.

Diæresis (di-er'-es-is). See Dieresis.

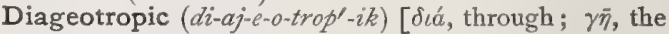
earth; $\tau \rho \varepsilon ́ \pi \varepsilon \imath \nu$, to turn]. In biology, growing at right angles to the direction of gravitation.

Diagnose $\left(d i-a g-n \bar{o} s^{\prime}\right)$. See Diagnosticate.

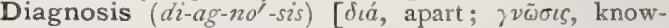
ledge]. The distinguishing, fixation, or interpretation of a disease from its symptoms. D., Differential, the qualitative distinguishing between two diseases of similar character, by comparative symptoms. D., Direct, the recognition of a disease from the existence of one or more signs or symptoms, independently of or in relation with other symptoms, or with age, sex, physical and mental characteristics, residence or occupation, or with the family history. D. by Exclusion, the recognition of a disease by excluding all other known conditions. D., Physical, the application of physical methods to the study of disease.

Diagnostic $\left(d i-a g-n o s^{\prime}-t i k\right)[\delta \iota a ́$, apart; $\gamma \nu \tilde{\omega} \sigma \iota s$, knowledge]. Determining or confirming a diagnosis ; serving as sufficient evidence in a diagnosis. D. Incision, an incision (as through the abdominal wall) made for diagnostic purposes.

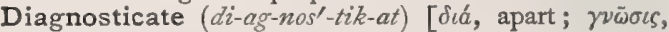
knowledge]. To make a diagnosis.

Diagnostician (di-ag-nos-tish'-an) [dia, through; $\gamma \nu \bar{\omega} \sigma \iota s$, knowledge]. One skilled in making diagnoses.

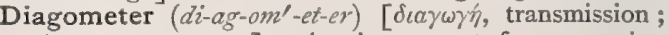

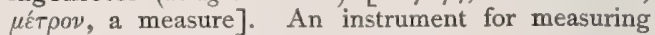
the electric conductivity of bodies.

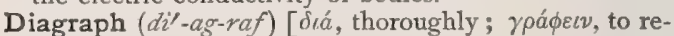
cord]. An apparatus for recording the outlines of crania.

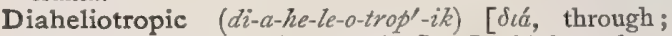
$\eta \lambda \lambda^{\prime}$ s, the sun; $\tau \rho \circ \pi \dot{\eta}$, a turning]. In biology, having a tendency to grow at right angles to the direction of the light.

Dialdan (di-al'-dan) [di, two; aldehyd $], \mathrm{C}_{8} \mathrm{H}_{14} \mathrm{O}_{3}$. A chemic compound prepared by allowing the mixture of aldehyd and $\mathrm{HCl}$ used for the preparation of aldol to stand for some time; it melts at $139^{\circ} \mathrm{C}$.

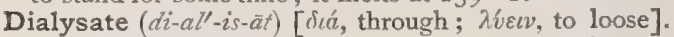
A substance that has been acted upon by dialysis.

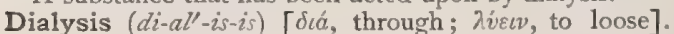
The operation of separating crystalline from colloid 
substances by means of a porous diaphragm, the former passing through the diaphragm into the pure water upon which the dialyzer rests.

Dialyzed $\left(d i^{\prime}-a l-\bar{\imath} z d\right)$ [ $\delta i \dot{\alpha}$, through; $\lambda \dot{v} \varepsilon v v$, to loose]. Prepared, acted upon, or separated, by dialysis.

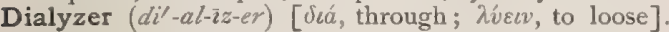
An apparatus for effecting dialysis; also the septum, or diaphragm of such an apparatus.

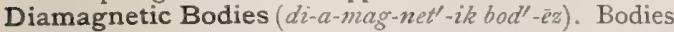
not susceptible of being magnetized.

Diamagnetism $\left(d i-a-m a y^{\prime}-n e t-i z m\right)[\delta \ell \alpha$, across; $\mu a ́ \gamma \nu \eta s$, magnet]. The east-and-west orientation of certain substances, notably antimony, copper, and gold, when placed in the magnetic field.

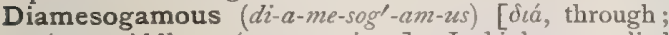

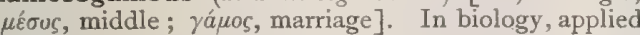
to such flowers as are fertilized by means of the wind, water, insects, or other external agency.

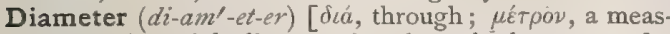
ure]. A straight line passing through the center of a body or figure, or connecting two points at opposite sides. D., Bisacromial, that between the acromial processes. D., Bisiliac, that between the iliac bones. D. Bistrochanteric, that between the two trochanters. D., Craniometric, one of several lines connecting points on opposite surfaces of the cranium. The most important craniometric diameters are the following: Auricular or Biauricular, connecting the centers of the two external auditory meatuses; Basilo-bregmatic, that joining the basilon and the bregma; Biglenoid, that joining the central points of the two glenoid cavities; Bigoviac, that joining the two gonions; Bijugal, that joining the two malar points; Bijugular, that joining the two jugular points; Bimalar, that joining the two malar points; Bimastoid, that joining the apices of the mastoid bones; Biparietal, that joining the parietal eminences; Bistephanic, see Maximum Frontal; Bitemporal, that joining the extremities of the coronal suture; Bizygomatic, that joining the most prominent points of the zygomata; Cervico-bregmatic, that joining the center of the anterior fontanel and the junction of the neck and floor of the mouth; Fronto-mental, that joining the top of the forehead and the point of the chin; Fronto-occipital, see Occipito-frontal; Inial, that joining the most prominent points of the inion and glabella; Maximum Antero-posterior, the distance from the glabella to the furthest point of the occipital bone; Maximum Frontal, that joining the stephanions; Maximum Occipital, that joining the two asterions; Maximum Transverse, the greatest transverse diameter of the cranium, whereever found; Mento-bregmatic, that joining the chin and the middle of the anterior fontanel; Mento-frontal, see Fronto-mental; Minimum Frontal, the supra-orbital line; Occipito-frontal, that joining the root of the nose and the most prominent point of the occiput ; $\mathrm{OC}_{\mathrm{C}}$ cipito-mental, that joining the external occipital protuberance and the chin ; Sarittal, see Basilo-bregmatic; Stephanic, see Maximum Frontal; Sub-temporal, that joining the spheno-temporal sutures on either side of the head; Trachelo-bregmatic, see Cervico-bregmatic; Vertical Diameter, ordinarily the distance from the basion to the bregma, or what is nearly equivalent, the distance from the basion to the point where the line through the basion at right angles to the alveolo-condylean plane intersects the cranial vault; but sometimes the line is drawn at right angles to the foramen magnum. D., Deventer's. See Deventer. D., Pelvic, any one of the diameters of the pelvis. The most important are the following : Antero-posterior (of pelvic inlet), that which joins the sacro-vertebral angle and the pubic symphysis; Antero-posterior (of pelvic outlet), see Coccypubic; Coccypubic, that which joins the tip of the coccyx with the subpubic ligament; the antero-posterior diameter of the pelvic outlet; Conjugate, the antero-posterior diameter of the pelvic inlet; Conjugate, diagonal, that connecting the sacro-vertebral angle and subpubic ligament; Conjugate, external, that connecting the spine of the first sacral vertebra and the middle of the upper border of the symphysis pubis; Conjugate, true, that connecting the sacro-vertebral angle and the most prominent portion of the posterior aspect of the symphysis pubis ; Oblique (of pelvic inlet), left and right, that connecting one sacro-iliac symphysis with the opposite ilio-pectineal eminence; see also Deventer; Oblique (of pelvic outlet), that extending from the middle of the under surface of the sciatic ligament upon one side to the junction of the ischio-pubic rami on the opposite side ; Sucro-pubic, see Antero-posterior; Sacrosubpubic, see Conjugate, diagonal; Sacro-suprapubic, that connecting the sacro-vertebral angle and the upper portion of the symphysis pubis; Transverse (of pelvic inlet), that connecting the two most widely separated points of the pelvic inlet; Transverse (of pelvic outlet), that connecting the ischial tuberosities.

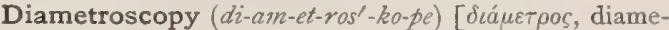

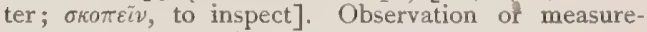
ment of diameters (as of the retinal vessels).

Diamid (di'-am-id). See Hydrazin

Diamin $\left(d i^{\prime}-a m-i n\right)$. See Amin.

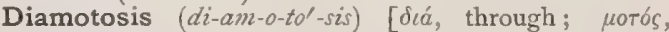
lint]. The packing of a wound or sore with lint.

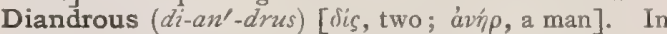
biology; having two stamens.

Dianoux's Operation. See Operations, Table of.

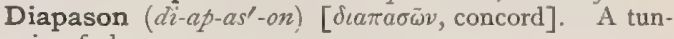
ing-fork

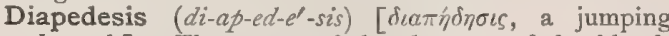
through ]. The escape of the elements of the blood, especially the white corpuscles, through the vesselwall. Also a synonym of Hematidrosis.

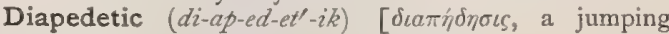
through]. Relating to diapedesis.

Diaper $\left(d i^{\prime}-a p-e r\right)$ [ME., dyaper, diaper; ornamented cloth]. A napkin used as a T-bandage for infants and menstruating women.

Diaphanometer (di-af-an-om'-et-er). See Lactoscope.

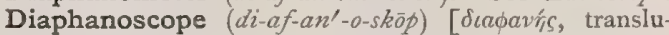
cent; $\sigma \kappa o \pi \varepsilon i \nu$, to inspect]. A form of endoscope in which the walls of the inspected cavity are rendered diaphanous by means of an intense light.

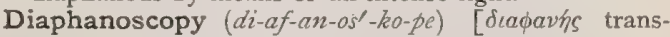
lucent; $\sigma \kappa o \pi \varepsilon i v$, to see]. The examination of cavities of the body by means of an introduced incandescent electric light

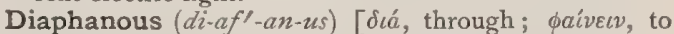
shine]. Transmitting light; translucent. D. Test. See Death.

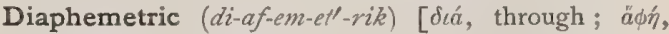
touch; $\mu \varepsilon \tilde{\tau} \rho \circ \nu$, measure]. Pertaining to measurements of tactile sensibility.

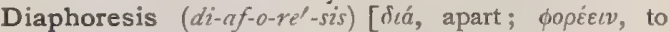
carry]. Perspiration, especially perceptible perspiration, or that induced by medical treatment.

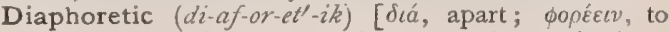
carry]. I. Causing an increase of perspiration; sudorific. 2. A medicine that induces diaphoresis.

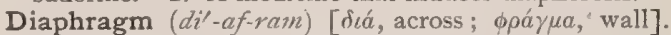
I. The wall, muscular at the circumference and tendinous at the center, that separates the thorax and abdomen. The chief muscle of respiration and expulsion. 2. A thin septum, such as is used in 
dialysis. 3. In microscopy, an apparatus placed between the mirror and object to regulate the amount of light that is to pass through the object. D., Central Stop, in microscopy, a diaphragm having a circular slit

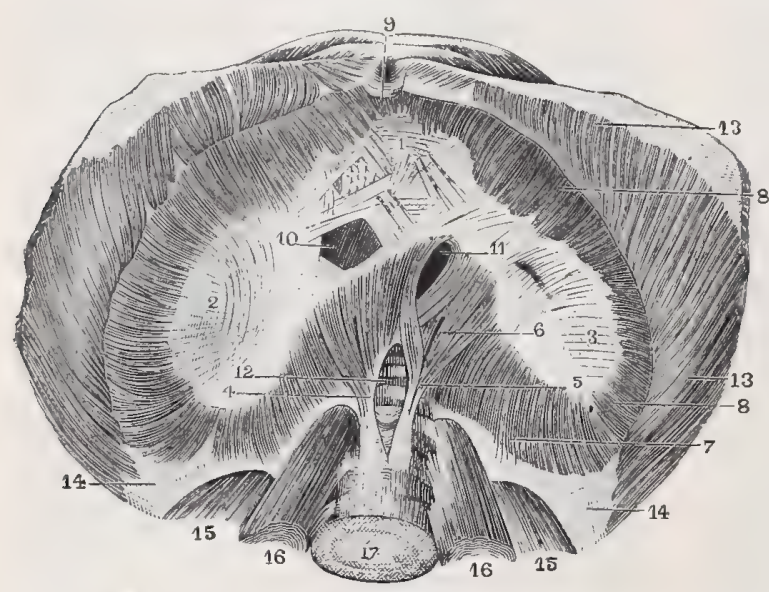

DIAPHRAGM, INFERIOR ASPECT.

r. Anterior and middle leaflet of central tendon. 2. Right leaflet. 3. Left leaflet. 4. Right crus. 5. Left crus 6 Intervals for phrenic nerves. 7 . Muscular fibers, from which the ligamenta arcuata originate. 8. Muscular fibers that arise from the inner surface of the six lower ribs. 9. Fibers that arise from ensiform cartilage. Io. Opening for inferior vena cava. Ir. Opening for esophagus. 12. Aortic opening.

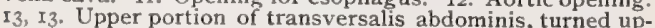
ward and outward I4. Anterior leaflet of transversalis ward and outward Anterior leaflet of transversalis
aponeurosis. I5, I5. Quadratus lumborum. 16, I6. Psoas magnus. 17. Third lumbar vertebra.

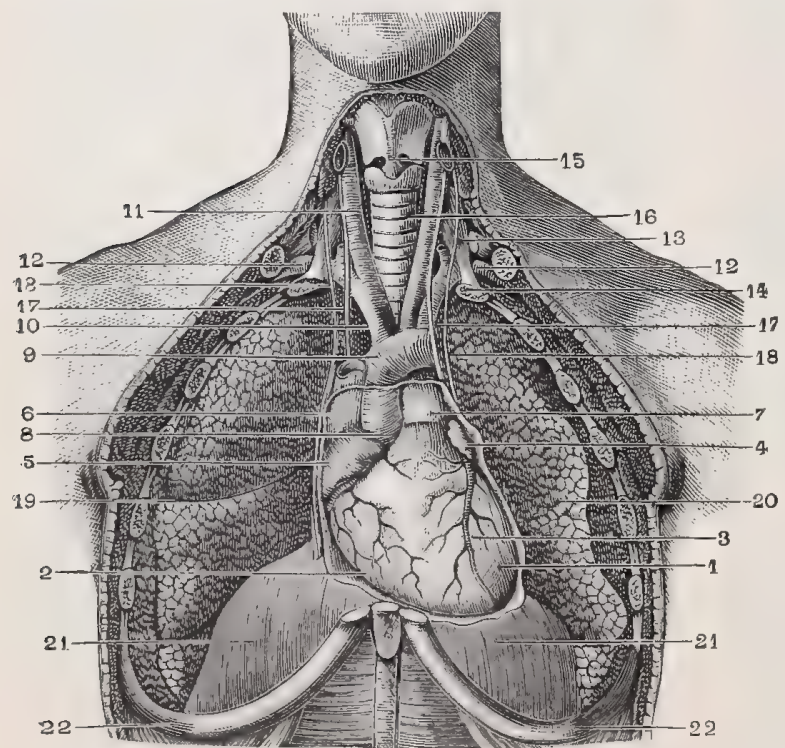

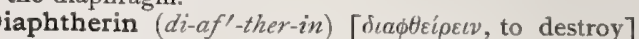
Oxychinaseptol; a coal-tar derivative composed of two molecules of oxychinolin and one of aseptol. It is a yellow powder, with a phenol-like odor. It is used as an antiseptic and bactericide in solutions varying in strength from $I$ to 50 per cent. Its chief drawback is that it attacks silver-plated or nickel-plated instruments, turning them black. Unof.

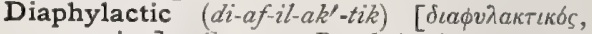
preserving]. Same as Prophylactic.

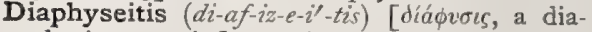
physis ; $\iota \tau \iota s$, inflammation]. Inflammation of a diaphysis.

Diaphysis $\left(d i-a f^{\prime}-i s-i s\right)$ [ $\delta \iota a ́$, between ; $\phi \dot{v} \varepsilon t v$, to grow]. The middle part or shaft of any long, cylindric bone, as considered apart from the apophyses and epiphyses. In biology, applied to an unusually elongated axis, as that of a flower or flower-cluster.

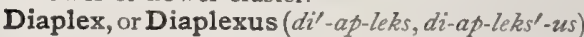

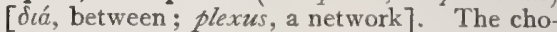
roid plexus of the third ventricle or diacele.

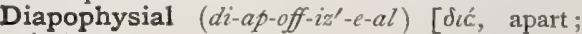
$a \pi b \phi v \sigma \varsigma$, an outgrowth]. Relating to a diapophysis.

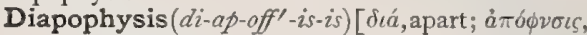
an outgrowth]. The superior or articular part of a transverse apophysis, or its homologue.

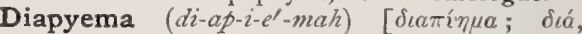
through; $\pi \tilde{v} o v$, pus: pl., Diapyemata]. An abscess.

Diapyesis $\left(d i-a p-i-e^{\prime}-s i s\right)[\delta \iota a \pi v ́ \eta \iota \varsigma ; \delta \iota a ́$, through ; $\pi i$ in $\sigma \iota \zeta$, suppuration]. Suppuration.

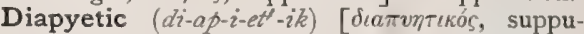
rating]. Promoting diapyesis or suppuration.

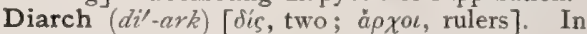

The Diaphragm in its Relations to the Heart AND LUNGS.

1. Left ventricle. 2. Right ventricle. 3. Anterior coronary artery. 4. Left auricle. 5. Right auricle, 6. Superior vena cava. 7. Pulmonary artery. 8. Origin of aorta. 9. Arch of aorta. Io. Innominate artery. II, Right carotid Subclavian arteries. I3 . Scalenus anticus. I4, First rib. 15. Larynx. 16, Trachea. 17, 17. Pneumogastrics. I8, 18. Phrenics. 19. Right lung. 20. Left lung. 2I, 2I. Diaphragm. 22, 22. Seventh pair of ribs. biology, a term descriptive of radial fibro-vascular bundles having two rays.

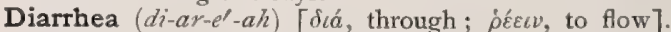
An abnormal frequency of evacuation of the feces, which are watery, and sometimes acrid. D., Acute, that due to cold, or to the ingestion of improper food or chemic poisons. In severe forms it is associated with collapse, and may in rare cases be followed by death. 
D., Acute Inflammatory, a term including the se verer forms of the catarrhal and summer diarrheas of children. It is characterized by griping, vomiting, and the passage of offensive, watery, brown or greenish stools. The child in the latter stage of this disease presents the same appearance as that seen in advanced tuberculous meningitis-pinched features, drowsiness, sunken and half-closed eyes, and rapid irregular pulse-and to this condition the term "spurious hydrocephalus" has been applied. Death frequently results from this form of diarrhea. D., Acute Summer, a term given to sudden attacks of profuse watery diarrhea occurring in children and weak adults during the prevalence of hot weather. (See Cholera infantum). D. alba. See Celiac Affection. D., Cachectic, that depending on some diathetic disease, as syphilis, scurvy, malaria, tuberculosis, and carcinoma, or else on chronic intestinal catarrh. D., Choleraic, severe, acute diarrhea of any form not readily traceable to any recognized cause. D., Choleriform. Synonym of Cholera infantum. D., Chronic Inflammatory, a diarrhea of children either following an acute attack, or developing insidiously. The stools are of a dark-brown color, thin and foul, and may occasionally contain a spinach-like material. There is great emaciation and anemia, and the term "consumption of the bowels," has been given to this condition. The prognosis must be guarded. D., Chronic Tropical, Hill-diarrhea, "white fux," of India, a severe form of chronic intestinal catarrh, and essentially a tropical disease. In India it develops often in those who, after dwelling in the heat of the plains, pass to the changeable temperature of the hilly country, hence the name "Hill-diarrhea." The stools are copious, light, and frothy ; there is progressive failure of strength; the temperature becomes subnormal; albuminuria and edema develop, and death results in many cases from exhaustion. D. chylosa. See Celiac Affection. D., Compensatory. See $D$., Vicarious. D., Dissecting-room, a severe form of diarrhea resulting from exposure to the animal effluvia of the dissecting-room. The discharges are very fetid and may be accompanied by colicky pains, nausea and vomiting, and headache. D., Dysenteric, a form of diarrhea frequently encountered in children in temperate climates. There are tenesmus and colic, the passage of mucous and fecal stools, prolapse of the rectum, and great exhaustion. Death may result. D., Fatty, a rare form, the result of the imperfect performance of the pancreatic or hepatic function. $D$. febrilis. Synonym of Enteritis, Pseudo-membranous. D., Fibrinous. Synonym of Enteritis, Pseudo-membranous. D., Gelatinous. See Enteritis, Membranous. D., Heat. See D., Summer. D., Hill. See D., Chronic Tropical. D., Infantile, a term including various forms of diarrhea occurring in infants and young children. D., Irritative, that due to direct irritation of the intestines by improper food and drink, purgative medicines, poisons, intestinal worms, etc. D., Lienteric, a form of diarrhea common in children over two years of age, and characterized by the passage of fluid stools containing scraps of undigested food, and associated with griping pains. D., Matinal. See D., Chronic Tropical. D., Mechanical, that due to mechanical obstruction to the portal circulation, with consequent gastro-intestinal hyperemia and catarrh. It is seen in cases of mitral lesion. D., Mucous. See Enteritis, Membranous. D., Nervous. See D., Lienteric. D. pituitosa. Synonym of Enteritis, Pseudo-membranous. D., Secondary, symptomatic diarrhea; that secondary to some ulcerative condition of the intes- tines, as in typhoid fever, tuberculosis, pyemia, etc. D., Serous, a variety in which the stools are very watery. D., Simple Catarrhal, a common variety of diarrhea occurring in infants. It is marked by watery evacuations containing feculent matter and undigested curds. It is due to errors in diet or exposure to cold. D., Summer, an acute form due to the intense heat of summer. A synonym of the Summer Complaint of infants. D., Symptomatic. See D., Secondary. D., Tuberculous, that form dependent upon tuberculous disease of the bowels. D. tubularis. Synonym of Enteritis, Pseudo-membranous. D., U1cerative, a grave form due to intestinal ulceration. D., Vicarious, that due to suppression or arrest of the functions of the skin, kidneys, or lungs, so that the bowels do the extra or vicarious work. It is also called Compensatory diarrhea. It is rather salutary than otherwise.

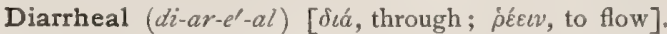
Relating to, or of the nature of diarrhea.

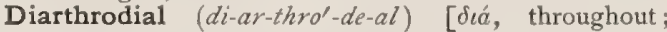
áp $\theta \rho \omega \sigma s$, articulation]. Relating to or of the nature of a diarthrosis.

Diarthrosis (di-ar-thro'-sis) [ $\delta \iota \dot{c}$, throughout ; $a ̊ \theta \rho \omega \sigma / s$, articulation]. A form of articulation characterized by mobility. The various forms are: Arthrodia, in which the bones glide upon plane surfaces; Enarthrosis, best known as ball-and-socket joint, with motion in all directions; Ginglymus, or hinge-joint, with backward and forward motion; and $D$. rotatoria, with pivotal movement.

Diary Fever $\left(d i^{\prime}-a r-e\right)$. See Fever.

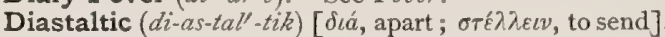
Reflex; performed (as are many reflex actions) through the medium of the spinal cord.

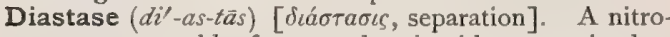
genous vegetable ferment that is either contained or developed in the fermentation of grain, which acts on the molecules of starch, converting this into grapesugar or glucose.

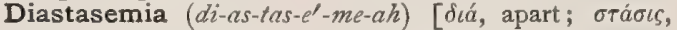
settling; ai $\mu a$, blood]. Acute anasarca.

Diastasic, or Diastatic (di-as-tas'-ik, or di-as-tat'-ik)

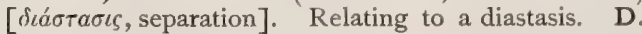
Ferments. See Ferments.

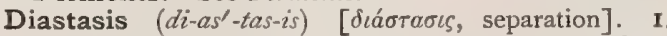
Luxation or dislocation. 2. The separation of an epiphysis from the body of a bone without true fracture.

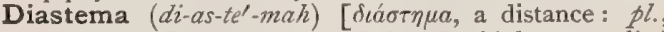
Diastemata]. A space or cleft. In biology, applied to the space between any two consecutive teeth.

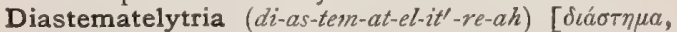

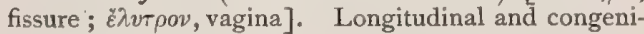
tal fissure of the vagina.

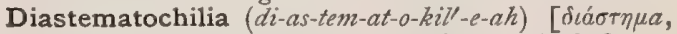
fissure; $\chi \varepsilon i \lambda \circ \varsigma$, lip ]. Congenital longitudinal fissure of the lip; hare-lip.

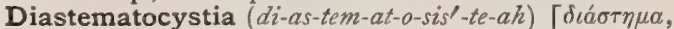
fissure; kíotıs, bladder]. Congenital Iongitudinal fissure of the bladder.

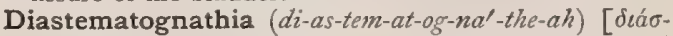

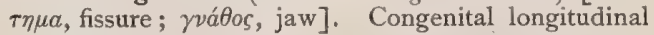
fissure of the jaw.

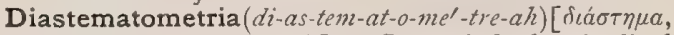
fissure ; $\mu$ ŕ $\rho a$, womb]. Congenital longitudinal median fissure of the uterus.

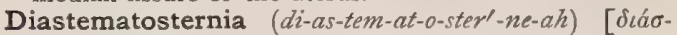

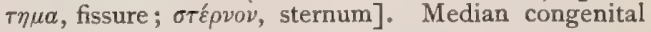
fissure of the sternum.

Diaster (di'-as-ter). See Dyaster and Karyokinesis.

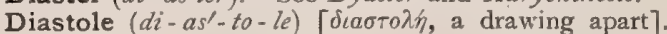
The period of dilatation of either cavity of the heart 
during its rhythmic cycle or beat. It is applied also to the dilatation of the arteries by the heart's contraction.

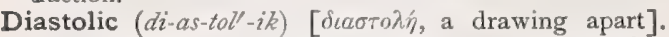
Pertaining to diastole. D. Impulse, the back-stroke. D. Murmur. See Murmur. D. Thrill, the vibration felt in the region of the heart during the diastole of the ventricles.

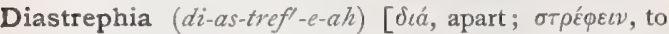
turn]. Insanity marked by acts of cruelty and by gross perversion of the moral sense.

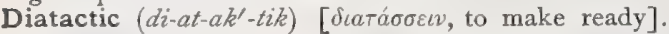
Preparatory. D. Action, the supposed molecular establishment of unions between different brain-cells and nerve-centers preparatory to coördinated motor activity.

Diatela $\left(a i-a t-e^{\prime}-l a h\right)[\delta(\dot{\alpha}$, between; tela, a web]. The membranous roof of the diacele (third ventricle).

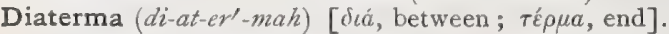
A portion of the floor of the diacele. It has a nearly dorso-ventral direction.

Diathermal or Diathermanous (di-ath-er/-mal, di-

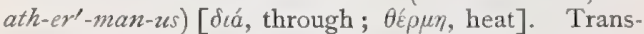
parent or diaphanous to the waves of radiant heat.

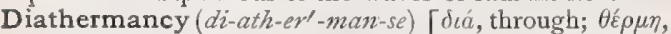
heat]. Permeability to rays of heat.

Diathesis $\left(d i-a t h^{\prime}-e s-i s\right)$ [diá, through ; $\tau \imath \theta \dot{\varepsilon} v a \iota$, to arrange]. A state or condition of the body whereby it is especially liable to certain diseases, such as gout, calculus, diabetes, etc. It may be acquired or hereditary. D., Hemorrhagic. See Hemophilia.

Diathetic $\left(d i-a t^{\prime} h-e t^{\prime}-i k\right)$ [ $\left[\delta a^{\prime}\right.$, through; $\tau \iota \theta \varepsilon v a \iota$, to arrange]. Relating to a diathesis.

Diatom $\left(a t^{\prime}-a t-o m\right)$. One of the Diatomacea, a group of microscopic Alsce.

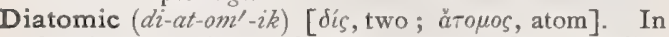
chemistry, consisting of two atoms ; specifically applied to hydrates that have two hydrogen atoms united to the nucleus radical by oxygen.

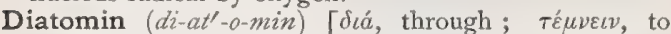
cut]. The yellowish-brown coloring-matter of diatoms. It is also called Phycoxanthin.

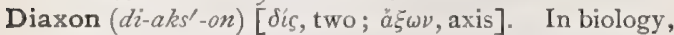
having two axes.

Diazo- $\left(d i-a^{\prime}-z 0^{-}\right)$[ $\delta i_{\zeta}$, two; azotum, nitrogen]. In chemistry, a prefix signifying that a compound contains phenyl, $\mathrm{C}_{6} \mathrm{H}_{5}$, united with a radical consisting of two nitrogen atoms. D.-acid, one of certain volatile liquids of yellow color and peculiar odor, which distil undecomposed with steam or under reduced pressure. They are slightly soluble in water, but mix readily with alcohol and with ether. D.-compound, in chemistry a compound containing a group consisting of phenyl $\left(\mathrm{C}_{6} \mathrm{H}_{5}\right)$ united with a radical consisting of two nitrogen-atoms (whence the name). D.-reaction or test, a urinary test, originally thought to be especially valuable in the diagnosis of enteric fever. It is not found in the urine of bealthy persons. The test is made by mixing 200 parts of sulphanilic acid solution (concentrated solution in water) with 10 parts of pure hydrochloric acid, and 6 parts of nitrite of sodium solution ( $\mathbf{I}: \mathbf{2 0 0}$ ). To this mixture add an equal volume of urine with sufficient ammonia to render the whole alkaline. A bright or carmin-red denotes the reaction. See Tests, Table of.

Diazobenzene $\left(d i-a-z o-b e n^{\prime}-z \bar{e} n\right)$ [dis, two; azotum, nitrogen; benzoin ]. The nitrogenous body called Tyrotoxicon, $q$. $\%$.

Dib [E. dial]. The knee-pan or ankle-bone of a sheep's leg.

Dibasic $\left(d i-b a^{\prime}-s i k\right)$ [dis, twice; $\beta a ́ o \iota s$, base]. Having two bases, D. Acids. See Acids.
Dibenzyl (di-ben'-zil) [ [is, twice; benzoin], $\mathrm{C}_{14} \mathrm{H}_{14}$ A compound prepared by the action of sodium upon benzyl chlorid. It crystallizes in large prisms, melting at $52^{\circ} \mathrm{C}$. and boiling at $284^{\circ} \mathrm{C}$.

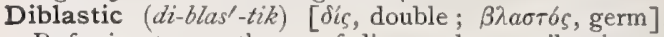
Referring to any theory of disease that ascribes it to a double agency.

Dibothrium (di-both'-re-um) [L.]. A genus of cestode worms. D. latum. See Bothriocephahus latus.

Dibromindone (di-bro-min'-don $)$ [d's, double; $\beta \rho \tilde{\omega} \mu o \varsigma$, a stench], $\mathrm{C}_{9} \mathrm{H}_{4} \mathrm{Br}_{2} \mathrm{O}$. A compound derived from dibromcinnamic acid. It consists of orange-yellow needles, with an odor resembling that of quinone. It melts at $123^{\circ}$.

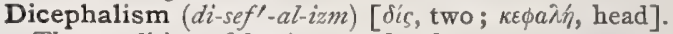
The condition of having two heads.

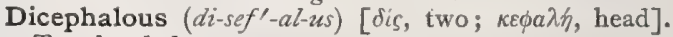
Two-headed.

Dicephalus (di-sef'-al-us) [dis, two; $\kappa \varepsilon \phi a \lambda \eta$, a head]. A monster having two heads.

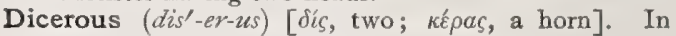
biology, having two antennæ.

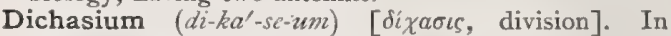
biology, applied to a cyme having two axes.

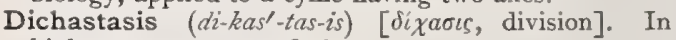
biology, spontaneous fission.

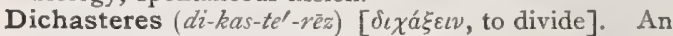
old name for the incisor teeth.

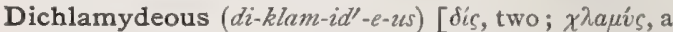
mantle]. In biology, applied to flowers having both floral envelops.

Dichogamy $\left(d i-k o g^{\prime}-a-m e\right) \quad[\delta i \chi a$, in two ; yá $\mu o s$, marriage]. In biology, a provision for cross-fertilization of flowers by the maturation of the reproductive elements of the same flower at different times.

Dichotomous (di-kot'-o-mus) [ [i $\chi \alpha$, in two; $\tau \hat{\varepsilon} \mu \nu \varepsilon \iota \nu$, to cut]. In biology, divided, forked or having a dual arrangement.

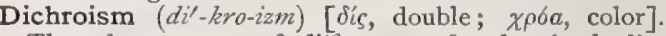
The phenomenon of difference of color in bodies when viewed by reflected or by transmitted light.

Dichromatism (di-kro'-mat-izm). Same as Colorblindness.

Dicinchonin (di-sin'-kon-in) [dis, double; cinchona], $\mathrm{C}_{38} \mathrm{H}_{44} \mathrm{~N}_{4} \mathrm{O}_{2}$. An alkaloid of Cinchona bark, an amorphous solid, melting at $40^{\circ} \mathrm{C}$, readily soluble in alcohol and ether.

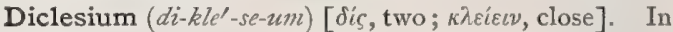
biology, an achenium having a persistent calyx or perianth.

Diclinous (di-kli'-nus) [dis, two; $\kappa \lambda i v \eta$, a bed]. In biology, having the stamens and pistils in separate flowers.

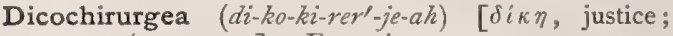

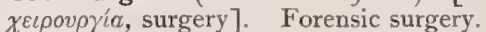

Dicotoin $\left(d i-k o^{\prime}-t o-i n\right)$ [ $\delta i s$, double; Coto $]$. A derivative of cotoin present in coto bark.

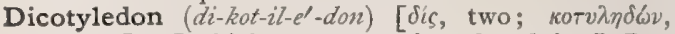
a cavity]. In biology, a term introduced by J. Ray in $\mathbf{I} 682$, for a plant whose embryo has two seed-leaves or cotyledons.

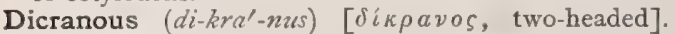
Dicephalous.

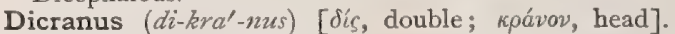
A dicephalous monster.

Dicrotic (di-krot'-ik) [ dinpotos, double beating]. Having a double beat. D. Pulse, a term applied to a pulse that imparts the sensation of a double beat at each pulsation. D. Wave, the wave of recoil, or the second smaller ascending wave of the sphygmographic tracing. It is generated by closure of the aortic valves. 


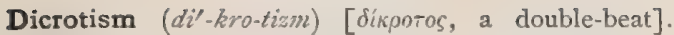
The quality of being dicrotic. A condition of the pulse in which with every wave there is given to the finger of the examiner the sensation of two beats. It is present when the arterial tension is low. The second shock is due to the recoil of the arterial walls when the aortic valves are closed.

Dictyitis (dik-te-i'-tis) [dikrvov, net, retina]. Retinitis.

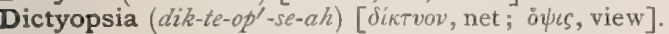
The sensation as if a net were stretched before the eyes.

Dicyanogen (di-si-an'-o-jen) [dis, double; cyanogen], NC.CN. Free cyanogen; a colorless, poisonous gas of peculiar odor, and specific gravity $26(\mathrm{H}=\mathrm{r})$. It may be condensed to a mobile liquid by cold of $-25^{\circ}$ C., or by a pressure of four atmospheres at ordinary temperatures. In this condition it has a specific gravity of .566 , solidifies at $-34^{\circ} \mathrm{C}$. to a crystalline mass and boils at $-2 \mathrm{I}^{\circ} \mathrm{C}$. It burns with a bluishpurple mantled flame.

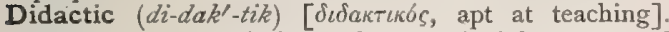
Teaching by description, rules, or principles; opposed to clinical.

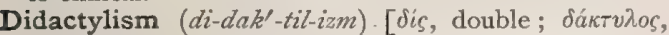
a finger]. The condition of having congenitally but two digits on a hand or foot.

Diday's Operation. See Operations, Table of.

Didot's Operation. See Operations, Table of.

Diduction (di-duk'-shun) [diducere, to draw apart] Abduction of two parts ; the withdrawal of a part.

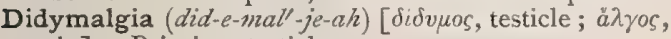
pain]. Pain in a testicle.

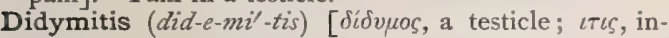
flammation]. Orchitis affecting mainly the body of the testicle.

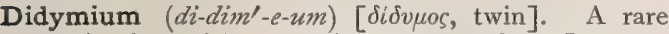
metal of grayish or yellow color. See Elements, Table of.

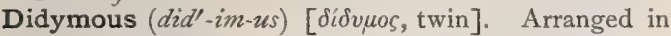
a pair, or in pairs.

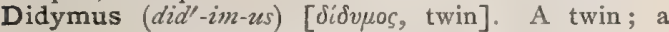
twin-monstrosity; a testis.

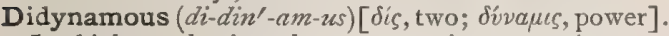
In biology, having the stamens in two pairs, one longer than the other.

Die (di) [ME., dien]. To cease to live; to become dead.

Diecious (di-e'-shus) [ $\delta i s$, two; oikos, house $]$. In biology, having the two sexes in different individuals, or in two households, as staminate and pistillate flowers separate and on separate plants.

Dieffenbach's Operation. See Operations, Table of.

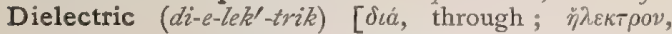
amber]. A non-conducting substance that transmits electricity by induction.

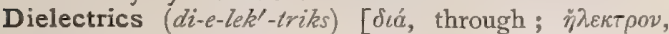
amber]. The property of certain substances to permit an inductive electric influence to act through or across them.

Dielectrolysis (di-e-lek-trol"-is-is) [ $\delta i a ́$, through; $\ddot{\eta} \lambda \varepsilon k-$ $\tau \rho o \nu$, electricity; $\lambda \dot{\varepsilon} \varepsilon v$, to dissolve]. Galvanic electrolysis of a compound, the current passing at the same time through a diseased portion of the body and carrying one of the elements of the compound with it.

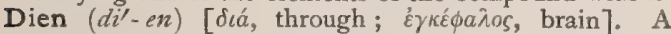
contraction of diencephalon.

Diencephal (di-en'-sef-al). Same as Diencephalon.

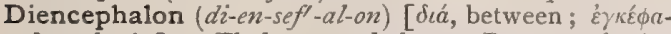
nos, brain]. Thalamencephalon. Between-brain. That part of the brain between the prosencephalon and the mesencephalon. It includes the thalami and the third ventricle.

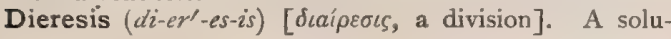

tion of continuity, as a wound, ulceration, etc. In biology, the division of the outer branch of the posterior or caudal pleopod of a crustacean. (Bate).

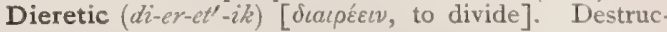
tive; escharotic; corrosive

Dies and Counter-dies. Metallic casts obtained by molding in sand or dipping in molten zinc and lead, or other alloys, such as Babbitt metal, and which are used for stamping up dental plates; they are generally described as male and female castings, between which the plate is swaged.

Diesel's Test. See Tests, Table of.

Diet $\left(d i^{\prime}-e t\right)$ [diatTa, a system or mode of living]. I An arranged selection of food necessary to meet the needs of the body. 2. To regulate the amount and character of the food ingested. D.-drink, a medicated drink, or beverage. D., Lisbon, a draught much resembling the compound tincture of sarsaparilla. D., Milk, one consisting mainly of milk. D., Tuffnell's, a highly nutritious diet including but a small amount of liquids, employed in the treatment of internal aneurysms.

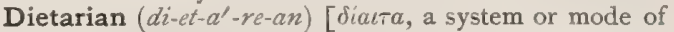
living]. A physician who pays special attention to matters of diet.

Dietary $\left(d i^{\prime}-e t-a-r e\right)$ [ living]. A system of food-regulation intended to meet the requirements of the animal economy

Dietetic $($ di-et-et'-ik) [dialta, a system or mode of living]. Pertaining to diet.

Dietetics $\left(d i-e t-e t^{\prime}-i k s\right)$ [diat $\alpha$, a system or mode of living]. The science of the systematic regulation of the diet for hygienic or therapeutic purposes.

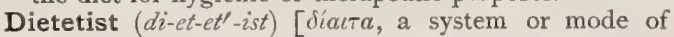
living]. One who is expert in questions of diet; a dietarian.

Diethylamin $\left(d i-e t h-i l^{\prime}-a m-i n\right)$ [dis, double; ethyl, amin], $\mathrm{NC}_{4} \mathrm{H}_{11}$. A ptomaine, obtained from the pike-fish when allowed to putrefy for six days in summer. It is an inflammable liquid of strong basic properties, soluble in water, and boiling at $57.5^{\circ} \mathrm{C}$. It is non-poisonous.

Dietic $\left(d i-e t^{\prime}-i k\right)$ [diaita, a system or mode of living]. Same as Dietetic. D. Diseases, those caused by errors of diet.

Difference-Theory (dif'-er-ens). A theory in explanation of the galvanic phenomena of living tissues. The theory is an expression of these facts: Protoplasm when injured or excited in its continuity becomes negative to the uninjured part ; when heated it becomes positive; and the surface-polarization diminishes with excitement and in the process of dying. It is also called Alteration-theory (Hermann).

Differential (dif-er-en'shal) [differentia, difference]. Pertaining to or creating a difference. D. Diagnosis. See Diagnosis. D. Rheotome. See Rheotome. D. Tone, a tone produced by two primary tones when sounding simultaneously; the number of the vibrations corresponds to the difference between the two primary tones. D. Staining, a method of staining tubercle-bacilli, syphilis-bacilli, etc., founded upon the fact that if deeply-colored, and especially with a mordant, they retain the color in the presence of certain reagents that decolorize the surrounding tissues. Koch, Ehrlich and Weigert, Ziehl and Neelson, Fütterer, Gibbes, etc., have devised various methods of differential staining.

Differentiation (dif-er-en-she- $a^{\prime}$-shun) [differentia, difference]. Specialization of tissues, organs, or functions. The gradual change of homogeneous material into special tissues or organs.

Difficultas intestinorum (dif-ik-ul'-tas in-tes-tin-or'. um) [L.]. Synonym of Dysentery. 
Diffraction (dif-rak'-shun) [dis, apart; fractus, broken]. The deflection suffered by a ray of light when it passes through a narrow slit or aperture, D. Grating, a strip of glass closely ruled with fine lines; it is often used in the spectroscope in the place of the battery of prisms.

Diffuse (dif-us') [de, apart; fundere, to pour over]. Scattered or spread about. In medicine, applied to diseases that involve a large part of the body. D. Aneurysm, one caused by a rupture of the walls of a blood-vessel. D. Cerebral Sclerosis. See Sclerosis. D. Inflammation. See Inflammation.

Diffusible (dif-u'-zib-l) [dis, away; fundere, to pour] Susceptible of being rapidly diffused throughout the system; applied to certain quickly-acting stimulants, usually of transient effect.

Diffusion (dif-u'-zhun) [diffundere, to spread]. A spreading or dissemination. D., Anodal, same as Cataphoresis. D.-circle, the imperfect image formed by incomplete focalization, the position of the true focus not having been reached or else having been passed.

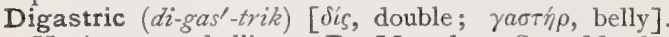
Having two bellies. D. Muscle. See Muscles, Table of. D. Triangle. See Triangles, Table of.

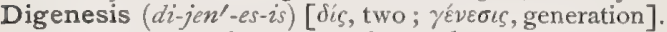
In biology, the alternation of sexual and asexual generation.

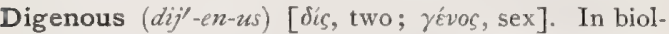
ogy, pertaining to both sexes, or originating from opposite sexes.

Digerent (dij'-er-ent) [digerere, to digest]. A digestant; also a medicine that excites the secretion of pus in wounds.

Digestant (di-jest'-ant) [digerere, to digest]. I. A body or substance that effects solution of the food in the mouth, stomach, and intestines. 2. A remedy for indigestion.

Digestibility (di-jes-tib-il'-it-e) [digestibilis, that can be digested]. Susceptibility of being digested.

Digestible $\left(\right.$ di-jest $\left.^{\prime}-i b-l\right)$ [digestibilis, that can be digested]. Capable of being digested.

Digestio Difficilis (di-jes'-che-o dif-ik'-il-is) [L.]. Synonym of Dyspepsia.

Digestion (di-jes'-chun $)$ '[digerere, to digest]. In biology, that process whereby the food taken into an organism is made fit to become part thereof. D., Artificial, the production of peptones outside of the body. D., Primary, gastro-intestinal digestion. D., Secondary, the assimilation by the body-cells of their appropriate pabulum

Digestive (di-jes'-tiv) [digerere, to digest]. I. Relating to or favoring digestion. 2. An agent that promotes digestion. 3. Pertaining to the process of digestion. D. Apparatus, the organs of digestion considered collectively. D. Tract, the whole alimentary canal from the mouth to the anus. See Illustration.

Digit (dij'-it) [digilus, a finger]. A finger or toe.

Digital (dij'-it-al) [digitus, a finger]. Pertaining to the fingers or toes. D. Arteries, the arteries of the hands and feet supplying the digits. See Arteries, Table of. D. Compression, the stoppage of a flow of blood by pressure with the finger. D. Dilatation, the enlarging of a cavity by means of the finger. D. Examination, examination or exploration with the finger. D. Nerves, the nerves of the hands and feet. D. Phalanges, the bones of the fingers or of the toes.

Digitalein (dij-it-a'-le-in) [digitalis, pertaining to the fingers]. One of the constituents of digitalis.

Digitalin (dij-it-a'-lin) [digitalis, pertaining to the fingers]. I. Digitalinum (U. S. P.); $\mathrm{C}_{5} \mathrm{H}_{8} \mathrm{O}_{2}$ (?), the active principle of Divitalis purpurea, q. $v$ Dose gr. $\frac{1}{60} \frac{1}{30}$. 2. A precipitate from a tincture of Digitalis purpurea. Unof. Besides the foregoing there are various commercial preparations known by this name. Digitalis (dij-it-a'-lis) [digitalis, pertaining to the fingers]. Foxglove. The leaves of $D$. purpurea. It contains an amorphous complex substance, digitalin, that does not, however, represent the full properties of the leaves. It is a cardiac stimulant and excitomotor, and in large doses causes severe gastric dis turbance. It is employed mainly in affections of the heart when the latter is rapid and feeble. Dose of the leaves gr. ss-iij. D. abstractum, strength twice that of digitalis itself. Unof. Dose gr. 1/4-ij. D., Ext., leaves yield 25 per cent. of extract. Dose gr. $1 / 6-1 / 2$. D., Ext., Fld., strength Ioo per cent. Dose $m_{j}$-iij. D. infusum, II/2 per cent. in strength. Dose $3 \mathrm{ss}-\mathrm{j}$. D., Tinct., I 5 per cent. Dose $m \nabla-3$ j . See Digitalin. Digitalose (dij-it-al-ōz') [digitalis. pertaining to the fingers]. A white crystalline constituent of digitalis.

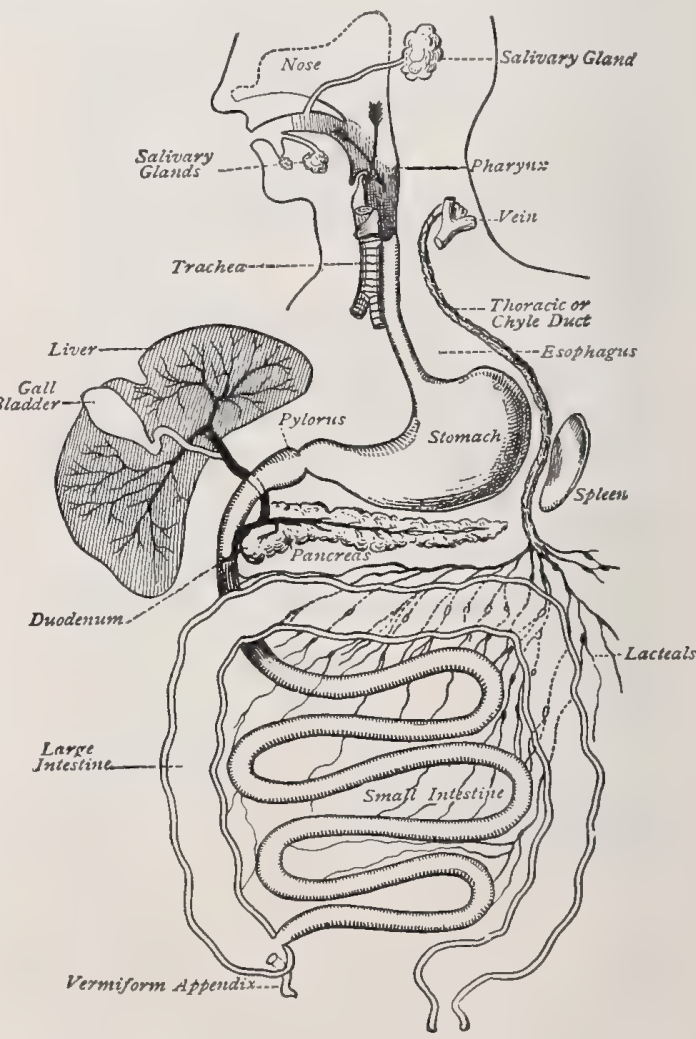

General Scheme of THE Digestive Tract, with THE CHIEF GLANDS OPENING INTO IT; TOGETHER WITH THE LACTEALS ARISING FROM THE INTESTINE AND JOINING THE THORACIC DUCT. (Landois.)

Digitate $\left(d i j^{\prime}-i t-\bar{a} t\right)$ [digitus, finger]. In biology, having finger-like divisions, as when the leaflets of a compound leaf are all borne on the apex of the petiole.

Digitation (dij-it-a'-shun) [digitatus, having digits]. A serration; a finger-like process, or a succession of such processes.

Digiten (dij'-it-en) [digitus, a finger]. Belonging to a digit in itself.

Digiti mortui (dij'-it-i mor'-tu-i) [L.]. . Deadfingers; a cold and white state of the fingers, seen in 
some hysterical women, and in certain types of insanity. It is a manifestation of some vaso-motor disorder.

Digitigrade (dij'-it-ig-rād) [digitus, finger; gradi, to walk]. In biology, walking on the toes.

Digitonin $\left(d i j-i t-0-n i n^{\prime}\right)$ [digitalis, pertaining to the fingers], $\mathrm{C}_{31} \mathrm{H}_{52} \mathrm{O}_{17}$. A white, amorphous mass obtained from digitalis. It is easily soluble in water, slightly so in alcohol; insoluble in ether and chloroform.

Digitoxin (dij-it-oks'-in) [digitalis, pertaining to the fingers ; toxicum, poison], $\mathrm{C}_{21} \mathrm{H}_{32} \mathrm{O}_{7}$, or $\mathrm{C}_{12} \mathrm{H}_{52} \mathrm{O}_{34} \cdot \mathrm{A}$ highly poisonous alkaloid from Digitalis purpurea. Its effects are little understood. Its action is cumulative. Unof.

Digitule $\left(\right.$ dig' $\left.^{\prime}-i t-\bar{u} l\right)$ [digitulus, a little digit]. A little finger, toe, or claw; a small organ or prominence resembling a digit.

Digitus $\left(d i j^{\prime}-i t-u s\right)$ [L.]. A finger or toe

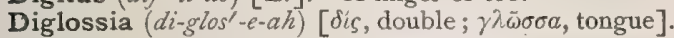
The condition of having a double tongue.

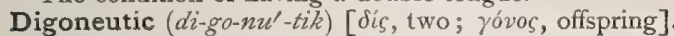
In biology, producing two broods a year.

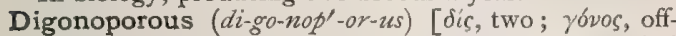
spring; $\pi 6 \rho \circ$, pore $]$. In biology, having the genital pores separate.

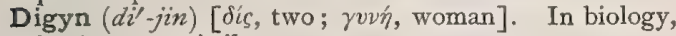
having two pistils.

Dihydrolutidin (di-hi-dro-lu'-tid-in) [dis, double; vi $\omega \rho$, water $], \mathrm{C}_{7} \mathrm{H}_{11} \mathrm{~N}$. One of the alkaloids of codliver oil. See Morrhuolins.

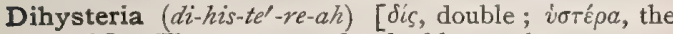
womb]. The presence of a double womb.

Dilaceratio cataractæ (di-las-er-a'-she-o kat-ar-ak'-te) [L.]. See Dilaceration.

Dilaceration (di-las-er-a'-shun) [dilaceratio, a tearing apart]. A tearing apart; division of a membranous cataract by a tearing operation.

Dilatatio cordis (di-lat-a - she-o kor' dis) [L.]. Dilatation of the heart.

Dilatation (di-lat-a'-shun) [dilatare, to spread out]. I An increase in the size of a cavity or of the lumen of a vessel; expansion of an organ without hypertrophy. 2. Surgical stretching out of the walls of a hollow organ. D. of Blood-vessel. See Telangiectasis. D. of Heart, an increase in the size of one or more of the cavities of the heart, arising from a relaxation or weakening of the heart-muscle. It is associated with evidences of failure of circulation, resulting in congestion of the lungs and other viscera and tissues.

Dilatator (di-lat-a'-tor). See Dilator.

Dilator $\left(d i-l a^{\prime}\right.$-tor $)$ [dilatare, to spread out]. An instrument for stretching or enlarging a cavity or opening ; also, a dilating muscle. See Muscles, Table of. D., Barnes', an instrument for dilatation of the os and cervix uteri, consisting of a rubber bag, which, when inserted, is distended with water. D., Intra-uterine, for dilating the uterine cavity by means of air or water. D., Laryngeal, an instrument with two or three blades that may be separated, for freeing or dilating the larynx.

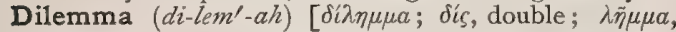
proposition]. In experiments to determine the reaction-time of psychic processes, if the person is told which side is to be stimulated, or what colored disc is to be presented, etc., the time is shorter. Lack of such foreknowledge is called the dilemma.

Dill (dil). See Anethum.

Dilmaisch Disease. See Disease.

Diluent (dit'-u-ent) [diluere, to wash away]. An agent that dilutes the secretions of an organ, or that increases the fluidity of secretions.

Dilution (di-lu'-shun) [diluere, to wash away]. I. The process of mixing with a neutral fluid or substance, in order to attenuate. 2. A diluted substance ; the result of a diluting process.

Dilutionist (di-lu'-shun-ist) [diluere, to wash away]. One who advocates the dilution of medicines. D., High, a homeopathist who advocates the extreme attenuation of medicines.

Dimerosomatous (dim-er-o-som'-at-us) [ $\delta i s$, two; $\mu \varepsilon$ $\rho \circ \varsigma$, a part; $\sigma \tilde{\omega} \mu \alpha$, body]. In biology, applied to animals, as spiders, that have the body divided into two regions, cephalo-thorax and abdomen.

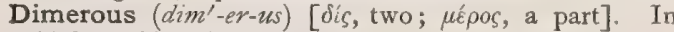
biology, bipartite.

Dimethyl Ketone. See Acetone

Dimethylamin (di-meth-il'-am-in) [Sis, two; methyl, amin $], \mathrm{NC}_{2} \mathrm{H}_{7}$. A non-toxic ptomaine found in putrefying gelatin, old decomposing yeast, certain varieties of fish-decomposition, etc

Dimethylarsin (di-meth-il-ar'-sin). See Cacodyl.

Dimethylphenylene-green. See Pigments, Conspectus of.

Dimetria (di-me'-tre-ah) [dis, double; $\mu$ ír $\rho a$, the womb]. The condition of having a double womb.

Dimidiate (di-mid'-e-ât) [di, apart; medius, middle]. In biology, divided into halves, or represented by one half only; one-sided. Applied to an anther whose lobes are widely separated by a broad connective, or to animals that are male on one side and female on the other.

Diminished Breathing. See Breath-sounds.

Dimorphism (di-morf'-izm) [ $\delta^{\prime} i$, double ; $\mu \circ \rho \phi \dot{\eta}$, form] The property of assuming or of existing under two distinct forms.

Dimorphous (di-morf'-us) [ $\delta^{\prime} \iota$, double ; $\mu$ op $\phi^{\prime}$, form]. In chemistry, having the quality of two forms of crystallization. In biology, existing in two forms, as individuals of the same species that differ in form, structure, size, or color.

Dimple $\left(d^{i} m^{\prime}-p l\right)$ [AS., dynt]. A slight depression.

Dingee (din'-ge). Synonym of Dengue.

Dingler's Green. See Pigments, Conspectus of.

Dinic, Dinical (din'-ik, or din'-ik-al) [divos, whirl]. Pertaining to or useful in the relief of vertigo.

Dinitrobenzene (di-ni-tro-ben'-zèn) [di, two; nitrum, niter; benzene $], \mathrm{C}_{6} \mathrm{H}_{4}\left(\mathrm{NO}_{2}\right)_{2}$. One of the ingredients of Roburite, q.v.

Dinner Pills. A name applied to various mild cathartic pills taken after meals. See Lady Webster Pill.

Dinomania (din-o-ma'-ne-ah) [ divos, a whirling dance; uavia, mania]. Dancing-mania. Choromania, q. $v$.

Dinus $\left(d i^{\prime}-n u s\right)$ [ $\delta i v o s$, whirl]. Vertigo or dizziness.

Dicecious $\left(d i-e^{\prime}-\right.$ shus $)$. See Diecious.

Diogenes' Cup. See Poculum diogenis.

Diogmus $\left(d i-o g^{\prime}-m u s\right)$ [ $\delta \omega \omega \gamma \mu \delta s$, a chase $]$. Palpitation of the heart.

Dionæa $\left(d i-o-n e^{\prime}-\alpha h\right)$ [ $\Delta t \omega v \eta$, Dione]. A genus of plants. D. muscipula, a plant of the Sundew family, growing in the Carolinas; Venus's fly-trap. It captures and feeds upon various insects, and is said to contain droserin and azerin, the same digestive ferments that occur in Drosera, q.v. Unof.

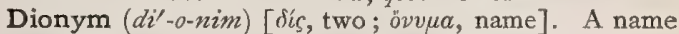
consisting of two words, as medulla oblongata; corpus callosum.

Diophthalmus (di-off-thal'-mus). See Diprosopus.

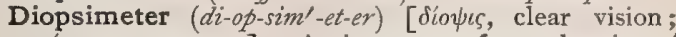

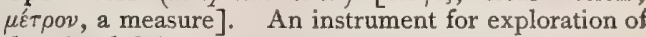
the visual field.

Diopter (di-op'-ter). See Dioptry.

Dioptometer (di-op-tom'-et-er). Same as Optometer.

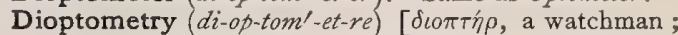
$\mu \varepsilon \dot{\tau} \rho \rho \nu$, a measure]. The measurement of the accommodative and refractive states of the eye. 


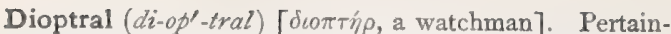
ing to a dioptry; expressed in dioptrics.

Dioptre (di-op'-ter). See Dioptry.

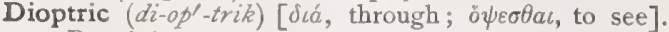
I. Pertaining to transmitted and refracted light. 2. A dioptry

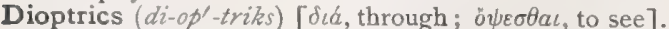
A branch of optics treating of the refraction of light by transparent media, especially by the media of the eye

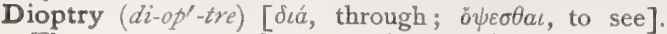
The most commonly accepted unit of measurement for optic lenses. A positive (or plus) spherical (biconvex) lens of one dioptry has a focal distance of one meter; one of two dioptries, a focal distance of onehalf a meter, etc. See Lenses, and Spectacle-lenses.

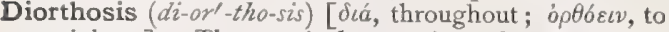
straighten]. The surgical correction of a deformity, or repair of an injury done to a limb.

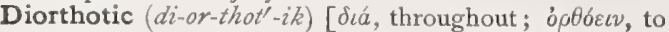
straighten]. Relating to or effecting a diorthosis.

Dioscorea (di-os-ko'-re-ah) [Dioscorides, a famous Greek physician and botanist]. Wild Yam, Colic Root. The rhizome of $D$. villosa, a creeping-plant, indigenous to the eastern U.S. It is claimed to be expectorant, diaphoretic, and stimulant to the intestinal canal, in large doses causing neuralgic pains and erotic excitement. It is used successfully for bilious colic. D., Fld. Ext., of standard strength, dose mxv-xxx. Unof.

Dioscorein (di-os-ko'-re-in) [Dioscorides, a Greek botanist]. A precipitate from a tincture of the root of Dioscorea villosa. It is antispasmodic, expectorant, and diaphoretic. Dose $1 / 2$ to 4 grains. Unof.

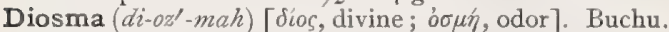
See Barosma.

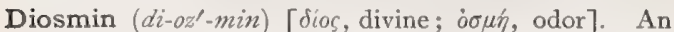
active principle obtained from various species of Buchu. It is an amorphous, bitter substance. Unof.

Diosmosis (di-os-mó-sis). Same as Osmosis

Diotic $\left(d i-o t^{\prime}-i k\right)[\delta i s$, two ; ov $s, \omega t o ́ s$, ear $]$. Binaural ; pertaining to both ears.

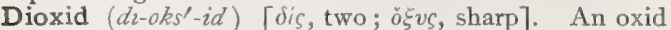
containing two atoms of oxygen and one of a metal.

Dipentene (di-pen'-tên $), \mathrm{C}_{10} \mathrm{H}_{16}$. Cinene; a compound produced by heating pinene, camphor, and limonene to $250-300^{\circ} \mathrm{C}$. It is present in the Russian and Swedish turpentine oil. It is a liquid with an agreeable lemon-like odor; sp. gr. 0.853 ; boils at 175$176^{\circ} \mathrm{C}$.

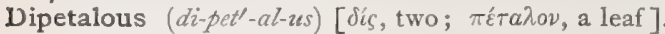
In biology, two-petaled.

Diphenyl $\left(d i-f e n^{\prime}-i l\right)$ [ $\delta i \zeta$, two; $\phi o i v t \xi$, purple-red], $\mathrm{C}_{12}-$ $\mathrm{H}_{10}$. A bydrocarbon resulting from the action of sodium upon the solution of brom-benzene in ether or benzene. It is also present in coal-tar. It crystallizes from alcohol and ether in large colorless leaflets, melting at $7 \mathrm{I}^{\circ} \mathrm{C}$., and boiling at $254^{\circ} \mathrm{C}$. D.-methane, $\mathrm{C}_{13} \mathrm{H}_{12 .}$ Benzyl benzene; a hydrocarbon obtained from benzyl chlorid and benzene. It is easily soluble in alcohol and ether, possesses the odor of oranges, crystallizes in needles, melts at $26.5^{\circ} \mathrm{C}$., and boils at $262^{\circ} \mathrm{C}$.

Diphenylamin (dif-en-il'-am-in) [diphenyl; amin], $\mathrm{C}_{12} \mathrm{H}_{11} \mathrm{~N}$. A compound produced in the dry distillation of triphenyl rosanilin (Rosanilin blue); it is also prepared by heating anilin hydrochlorid and anilin to $240^{\circ}$. It is a pleasant-smelling, crystalline compound, melting at $54^{\circ}$ and boiling at $310^{\circ}$. It is almost insoluble in water, but readily soluble in alcohol and ether. It serves in the preparation of various dyestuffs. D. Orange. See Pigments, Conspectus of.

Diphenylol (di-fen'-il-ol), $\mathrm{C}_{12} \mathrm{H}_{10} \mathrm{O}$. Oxy-diphenyl; obtained by diazotizing amido diphenyl sulphate. It sublimes in shining leaflets, melting at $165^{\circ} \mathrm{C}$, and boiling at $305.8^{\circ} \mathrm{C}$

Diphosphatid (di-fos'-fat-id) [di, twice; phosphorus]. Any phosphatid containing the phosphorized radical twice (such as assurin). Diphosphatids exist in the brain-substance and in other animal tissues.

Diphtheria (dif-, or dip-the'-re-ah) [ $\delta i \omega \theta \varepsilon \rho \alpha$, a skin or membrane]. An acute, epidemic, infectious disease, generally regarded as of specific contagious origin, attacking especially the mucous membrane of the airpassages, and producing profound depression of the vital forces. It is characterized specifically by the formation of layers of whitish or yellowish membrane upon the mucous membrane of the pharynx, nose, and larynx, and upon any existing cutaneous abrasion. The duration of the disease is from one to two weeks, death, when it follows, occurring usually within a week. There are certain grave sequelæ that must be noted; chief among these are various forms of paralysis, especially of the palate. The prognosis is always grave. To stain the microörganisms of diphtheria see Löffler's Method, Gram's Method, - a fragment of false membrane being spread on a cover-glass, dried, and otherwise treated as a cover-glass preparation. D., Antitoxin Treatment of, the treatment of diphtheria with subcutaneous injections of the blood-serum of animals, and more especially the horse, rendered immune to diphtheria by previous and repeated inoculation with progressively increasing doses of the toxic products of the bacillus diphtheriæ. D. circumscripta, a peculiar form of diphtheria described by Barrett, in which a distinct circumscribed slough appears on one tonsil, and death often results. D., Cutaneous, a form involving abrasions of the skin. D., Gangrenous, a gangrene of the skin and mucous membrane sometimes accompanying diphtheria. D., Laryngeal, a form involving the larynx, threatening death by suffocation. D., Malignant, a very fatal form, beginning with rigor, vomiting, and attended with typhoid symptoms. D., Nasal, a form in which the diphtheritic membrane spreads to the nasal passages, and is accompanied by a fetid, brown discharge. D., Secondary, a term designating the occurrence of the disease in association with other acute affections, such as typhoid fever, scarlatina, etc D., Paraffin Treatment of, the membrane is scraped or peeled off, and paraffin is applied to the raw surface every hour by means of a large camel's-hair brush.

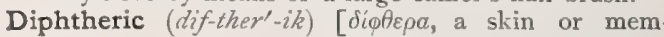
brane]. Pertaining to diphtheria. D. Conjunctivitis, a form of conjunctivitis attended with an infiltration of coagulable matter or inflammatory products. D. Membrane, the pellicle forming on the parts involved in the diphtheric process. D. Paralysis, a paralysis frequently affecting the muscles of the sof palate and larynx, after the healing of the lesions of these parts.

Diphtheritic (dif-ther-it'-ik) [ $[i \phi \theta \varepsilon \rho a$, a skin or membrane], Same as Diphtheric, q.v.

Diphtheritis (dif-ther-i'-tis). See Diphtheria.

Diphtheroid (dif'-ther-oid) [ $\delta i \phi \theta \varepsilon \rho a$, a skin or membrane]. Resembling diphtheria. D. Throat. Synonym of Herpetic Tonsilitis.

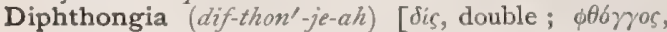
a voice]. The production of a double tone of the voice by the incomplete unilateral paralysis of the recurrent nerve, or by some lesion of the vocal bands that causes each portion of the glottis to produce its own sound.

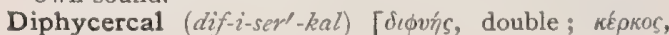
tail]. In biology, applied to fishes that have the 
caudal fin-rays arranged equally above and below the extremity of the spinal column.

Diphygenic $\left(d i f-i-g e n^{\prime}-i k\right)$ [ $\delta \iota v \eta^{\prime}$, of a two-fold nature or form; $\gamma \varepsilon \nu \nu a ̃ \nu$, to produce]. In biology, producing successively two sorts of embryos.

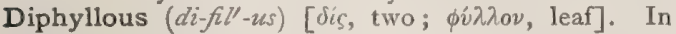
biology, composed of two leaves or sepals.

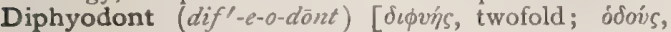
tooth]. In biology, having two sets of teeth, as the milk-teeth and the permanent teeth.

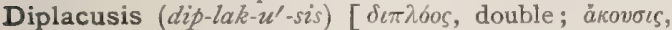
hearing]. I. The hearing of a tone as higher by one ear than by the other; called $D$. binauralis. 2. The hearing of two tones by one ear, when only one tone is produced; called $D$. uniauralis, or $D$. monauricularis.

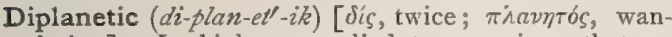
dering]. In biology, applied to organisms that are twrice active with an intervening period of quiescence.

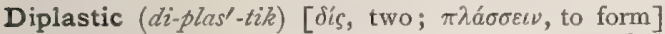
A term applied to cells having two substances in their constitution.

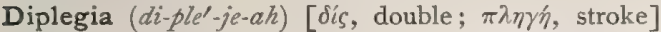
Coincident paralysis of two corresponding parts, as of the two arms. Double or bilateral hemiplegia.

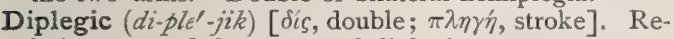
lating to or of the nature of diplegia.

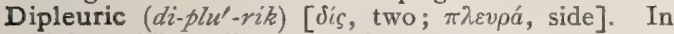
biology, bilaterally symmetric.

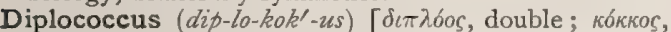
kernel]. A micrococcus whose spherules are joined two and two. See Micrococcus and Bacteria.

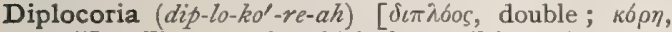
pupil]. That state in which the pupil is double.

Diploë $\left(d^{\prime i p} p^{\prime}-l o-e\right)$ [ $\delta \iota \pi \lambda$ on, a fold]. The lacunar osseous tissue between the tables of the skull.

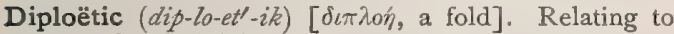
the diploê; diploic.

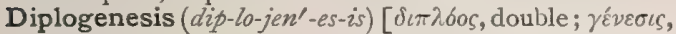
production]. The development of a double or twin monstrosity.

Diploic $\left(d i p-l \sigma^{\prime}-i k\right)\left[\delta \iota \pi \lambda o{ }^{\prime}\right.$, a fold $]$. Pertaining to the diploê.

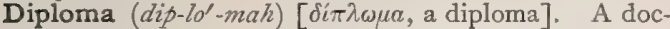
ument granted by an authorized body of men, showing that the recipient has performed certain work under the prescribed conditions, and is entitled to a definite professional rank and title.

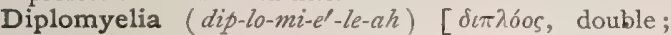
$\mu v \varepsilon \lambda \sigma 6$, marrow]. An apparent doubleness of the spinal cord, produced by a longitudinal fissure.

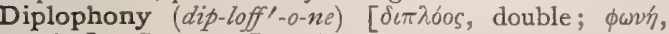
voice]. Same as Diphthongia.

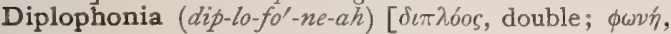
voice]. A rare symptom of laryngeal disease in which a double note is produced in the larynx. It is stated by Gottstein to occur in some cases of paralysis, or when a small tumor is situated so that on phonation it lies between the vocal bands. Cf. Diphthongia.

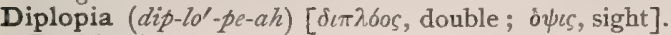
Double vision, one object being seen by the eye or eyes as two. D., Binocular, the most frequent, is due to a derangement of the muscular balance, the images of the object being thereby thrown upon non-identical points of the retinæ. D., Crossed, or D., Heteronymous, the result of divergent strabismus, the image of the right eye appearing upon the left side, and that of the left eye upon the right side. D., Direct, or D., Homonymous, the reverse of Crossed D., due either to paralysis of the external rectus or over-action of the internal rectus. D., Physiologic, that produced when an imperfect image is seen beyond or within the distance of the object accommodated for and transfixed by the visual axes. D., Monocular, or D., Uniocular, diplopia with a single eye, usually due to polycoria or other imperfections of the media.

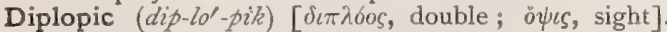
Relating to or affected with diplopia.

Diplopiometer (dip-lo-pe-om'-et-er) ' $[\delta \imath \pi \lambda b o s$, double :

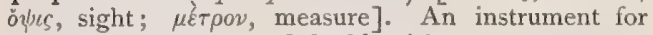
measuring the degree of double vision.

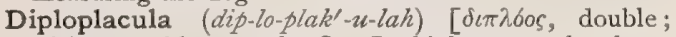
$\pi \lambda a ́ \xi$, a tablet or plate]. In biology, a placula or discoid embryo composed of two layers of cells.

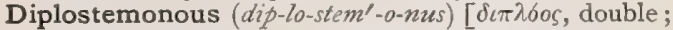
бrí $\mu \omega \nu$, a thread]. In biology, applied to a flower in which the stamens are double the number of sepals and petals.

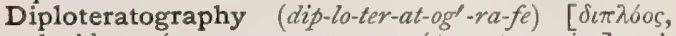
double; $\tau \dot{\rho} \rho a \varsigma$, a monster; $\gamma \rho a ́ \phi \varepsilon \imath \nu$, to write]. A term used by Fisher to denote the description and diagnosis of special forms of double monsters.

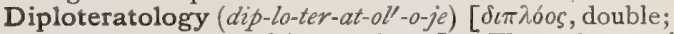

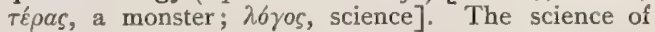
twin monstrosities.

Dippel's Animal Oil. Oleum cornu cervi; a pyroligneous oil, containing ammonium carbonate, amins, and aromatic compounds. It is obtained in distilling bone and deer's horn. It is antispasmodic and stimulant. Unof.

Dipropargyl (di-pro-par'-jil), $\mathrm{C}_{6} \mathrm{H}_{6}$. One of the hydrocarbons; a mobile liquid, of penetrating odor, isomeric with benzene; it boils at $85^{\circ} \mathrm{C}$; its specific gravity at $\mathbf{I} 8^{\circ} \mathrm{C}$. equals $0.8 \mathbf{r}$. If allowed to stand or if heat be applied to it, dipropargyl polymerizes and becomes thick and resinous.

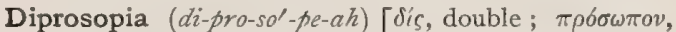
face]. In teratology, the duplication of the face.

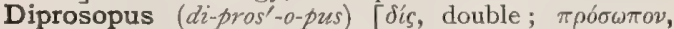
face]. A monster characterized by a duplicity of the face and head, frequently associated with hydrocephalus, acrania, defective development of the brain, and spina bifida. The diprosopi have been classified as follows: 1. Diprosopus diophthalmus. 2. D. distornus. "Fisher has described the first case of diprosopus diophthalmus, or distornus, reported in English.' There was anencephalus, a broad duplex nose, two mouths, one oral cavity, two tongues. 3. D. triophthalmus. In this variety there are three eyes, often with other deformities of the face and head, such as acrania, hare-lip, and cleft-palate. 4. D. tetrophthalmus. In this variety the differentiation of the two faces is further advanced, but there are still but two ears. There are present four eyes. 5. D. triotus. In this variety there are usually four eyes and always three ears. 6. D. tetrotus. In this variety, the intermediate stage between diprosopus and dicephalus, there are four eyes and four ears, with considerable duplicity in the cervical region. This is an extremely rare condition in the human race.

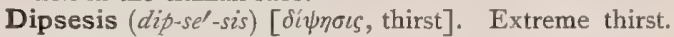

Dipsetic (dip-set' $-i k)$ [ $\delta \iota \psi \eta \tau \kappa o ́ s$, causing thirst]. Causing or attended with thirst.

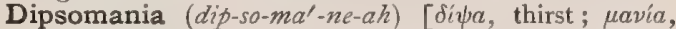
madness]. The uncontrollable desire for spirituous liquors. This is generally considered as a disease.

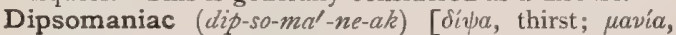
madness]. A person affected with dipsomania.

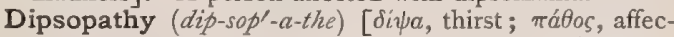
tion]. Any disease depending upon or related to alcoholic excess.

Dipsosis (dip-so'-sis). See Dipsesis. 


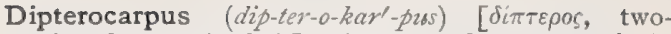
winged; $\kappa \alpha \rho \pi \delta \varsigma$, fruit]. A genus of trees, mostly S. Asiatic. D. alatus, $D$. costatus, $D$. hispidus, $D$. lavis, and $D$. zeylanicus afford wood-oil or gurjun balsam.

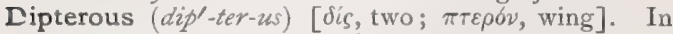
biology, two-winged, as a fly or a seed.

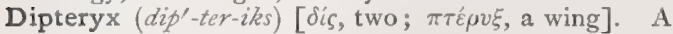
genus of leguminous trees. D. odorata, the tree that produces the Tonka Bean, q. v..

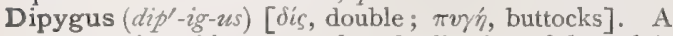
monstrosity with more or less duplication of the pelvis and lower parts of the back.

Dirca (der'-kah) [ $\Delta i \rho \kappa \eta$, a fountain near Thebes]. A genus of apetalous shrubs. D. palustris, wicopy, leatherwood, or moosewood; a N. American thymelaceous shrub, with the properties of mezereon. It is sparingly used in domestic practice for dyspepsia and hemicrania. Unof.

Direct $\left(\right.$ di-rekt $\left.^{\prime}\right)$ [directus, straight]. In a right or straight line, D. Current. See Current. D., Image. See Image, D. Ophthalmoscopy. See Ophthalmoscopy. D. Vision, the perception of an object the image of which falls upon the maculæ.

Direction (di-rek'-shun) [dirigere, to direct]. Relative position considered without regard to linear distance. D.-spindle, a fusiform body of the ovula, stretching from the germinal vesicle toward the surface.

Director (di-rek'-tor) [dirigere, to guide]. Anything that guides or directs. D., Grooved, an instrument grooved to guide the knife in surgical operations.

Dirigomotor (dir-ig-o-mol-tor) [dirigere, to direct; motor, a mover]. Causing or involving motion and at the same time directing that motion to an end.

Dirt (dert) [ME., drit]. Excrement; feces. D.-eating. See Chthonophagia and Geophagism.

Dis [dis, twice]. A prefix used to denote two or double. Also, a prefix to denote apart from.

Disaccharids (di-sak'-ar-ids). See Carbohydrates.

Disarthral (dis-ar'-thral) [dis, twice ; à $\rho \rho \rho \nu$, a joint]. Relating to muscles that pass over two joints, $e . g$., the biceps.

Disarticulation (dis-ar-tik-u-la'-shun) [dis, apart ; articulum, a joint]. Amputation in the contiguity of a part or at a joint.

Disassimilation (dis-as-sim-il-a'-shun) [disassimilatio]. In ophthalmology, the decomposition of visual substances in the retina.

Disassociation (dis-as-o-se-a'-shun) [dis, apart; associare, to unite with]. In chemistry, the decomposition of a compound by heat, the molecules reuniting on the removal of the heat.

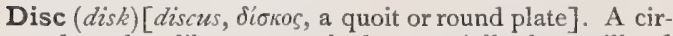
cular, plate-like organ or body, especially the papilla of the eye, the entrance of the optic nerve into the eyeball. Its area corresponds with that of the blind spot. In dentistry, an instrument in the form of a disc, made of emery, cuttle-fish, bone, or sand-paper, for finishing fillings on surfaces between teeth. D., Blood. See Blood-corpuscle. D.-carrier, an instrument applied to the dental engine for the better application of corundum discs to the teeth. D., Choked. See Papillitis. D., Corundum. A device used in dentistry for separating teeth, by cutting away a portion; it is used with the dental engine, and applied by means of carriers, that admit of ready adjustment and change of the disc to any desired angle with the shaft containing it. D., Cupping of. See Excrvation of the Optic Nerve. D., Germinal, the small disc of the blastodermic membrane, in which the first traces of the embryo are seen. D., Hypermetropic, hazy ; simulating optic neuritis, observed in hypermetropia. D., Proligerous. See Discus proligerus.
Discharge (dis-charj') [ME., dischargen, to unload]. Any evacuation; that which is evacuated. See also Pigments, Colors and Dyestuffs.

Discharger (dis-char'-jer). See Electric.

Discharging (dis-charj'-ing) [ME., dischargen, to unload]. Unloading, flowing out, as pus, etc. D. Centers, nerve-centers whence emanate influences which, according to the structures at the other ends of the nerves connected with them, may cause movements (muscles), secretion (glands), or contraction of vessels. D. Lesion, a brain-lesion that causes sudden discharges of nervous motor influence.

Disciferous (dis-if'-er-us) [discus, a disc ; ferre, to bear]. In biology, disc-bearing.

Discifloral (dis'-if-lo-ral) [discus, a disc ; flos (flor), a flower]. In biology, applied to such flowers as have the receptacle expanded into a conspicuous disc.

Discissio cataractæ. See Discission.

Discission (dis-ish'-un) [discissio; discindere, to tear or cut apart]. I. Bilateral incision, as of the cervix uteri. 2. An operation for cataract. See Cataract.

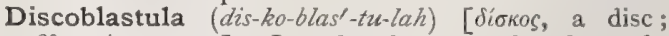
$\beta \lambda \alpha \sigma \tau b s$, a germ]. In embryology, the blastula resulting from the development of a discomorula.

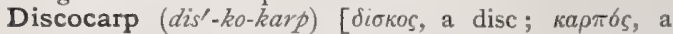
fruit]. In biology, applied to those fruits in which the expanded receptacle encloses the seeds or achenia ; also the same as Apothecium.

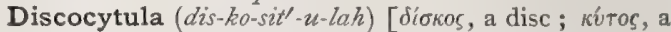
cell]. In embryology, the cytula resulting from the reformation of a nucleus in a discomonerula.

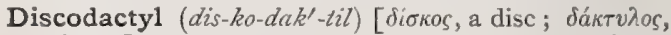
a finger]. In biology, applied to those animals (e.g., toads and frogs) the ends of whose toes are provided with disc-like dilatations.

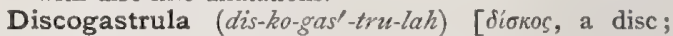
$\gamma \alpha \sigma \tau \eta \dot{ } \rho$, belly ; gastrule, a two-layered germ-cup]. The gastrula resulting from discoid egg-cleavage or discoid segmentation of the yolk.

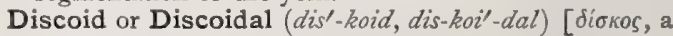
disc]. Somewhat disc-shaped.

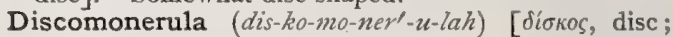

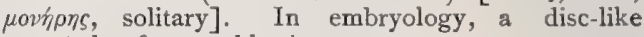
monerula of a meroblastic ovum.

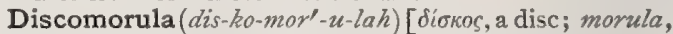
dim. of morum, a mulberry]. In embryology, a disclike morula of a meroblastic ovum.

Discrete (dis-krêt' $t^{\prime}$ [discretus, separaled]. A term applied to exanthematous eruptions in which the pustules or papules remain distinct. The opposite of confluent.

Discus (dis'-kus) [ бiбкоs, a disc]. A disc. D.proligerus, the elevated cells of the membrana granulosa of the ovum, whereby the ovum is attached.

Discussion (dis-kush'-un) [discussio]. The scattering or driving away of a swelling, effusion, or tumor.

Discutient (dis-ku'-shent) [discutere, to shake apart]. I. Capable of effecting resolution or discussion. 2 . A medicine supposed to have the power of scattering or discussing a swelling.

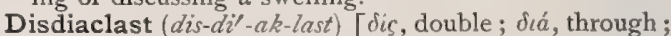
$\kappa \lambda a ́ \varepsilon \imath \nu$, to break down]. Any one of the (supposed) small doubly-refractive elements in the contractile discs changing its position during muscular contraction and relaxation.

Disease (dis-ez') [dis negative; ease, a state of rest]. A condition of the body marked by inharmonious action of one or more of the various organs, owing to abnormal condition or structural change. A Table of Diseases named after men who have described or have especially studied them is appended. D., Acute, a disease marked by rapid onset and course. D., Bad, 
a synonym of syphilis. D., Bleeders', synonym of Hemrophitia. D., Chronic, one that is slow in its course. D., Constitutional, one in which a system of organs or the whole body is involved. D., Coarse, the macroscopic organic lesions in a disease. D., Cretinoid. See Myxedema. D. of Ditmarsch, a form of endemic syphilis that was seen in Ditmarsch from 1762-1842. D., Fatigue. See Fatigue. D., Feigned, the wilful simulation of disease or injury, through malice or for the purpose of attaining a desired end. D., Focal, a centrally localized disease of the nervous system as distinguished from peripherally localized affections. D., Functional, abnormality of function without discoverable organic lesion. D., Grouse. See Grouse Disease. D., Idiopathic, one that exists by itself without any connection with another disorder; one of which the cause is unknown. D., Intercurrent, a disease occurring during the progress of another of which it is independent. D., Knife-grinder's, chronic catarrhal bronchitis met with in knife-grinders. D., Pearl-worker's, a recurrent bone-inflammation, with enormous hypertrophy of the bone, seen in workers in pearl-dust. D., Saint Gothard, a synonym of Anchylostomiasis or Dochmiasis, q. v. D., Septic, one arising from the putrefactive fermentation of some foreign substance within the body. D. of Siam. Synonym of Yellow Fever. D., Specific, one caused by the introduction of a specific virus or poison within the body; also a synonym of Syphilis. D., Subacute, one more protracted and less active than an acute disease. D., Subchronic, one less protracted than a chronic disease, but more protracted than an acute disease. D., Symptomatic, a disease caused by or connected with another ailment of the body. The opposite of idiopathic disease. D., Zymotic, a term used to include the whole class of germ-diseases, or those arising from the introduction and multiplication of some living germ within the body.

Disengagement (dis-en-gāj'-ment) [Fr., desengager, to disengage]. Emergence from a confined state; especially the escape of the fetus from the vaginal canal.

Disfigurement (dis-fig'-ür-ment) [dis, priv.; figurare, to fashion]. Blemish; deformity.

Disinfectant (dis-in-fek'-tant) [dis, neg.; inficere, to corrupt]. An agent that destroys disease-germs and noxious properties of fermentation and putrefaction.

Disinfection (dis-in-fe $k^{\prime}-s h u n$ ) [dis, neg. ; inficere, to corrupt]. The destroying of disease-germs by means of heat, chemic substances, fumigation, or by fresh air. D., Ransom's Apparatus for, a method of disinfection by means of dry heat. Washington Lyon's Apparatus, a method in which steam is employed as the active agent.

Disinfectol (dis-in-fek'-tol) [dis, neg. ; inficere, to corrupt]. An antiseptic substance analogous to creolin and lysol. It is used in the form of a two to five per cent. emulsion.

Disinfector (dis-in-fekl-tor) [dis, neg. ; inficere, to corrupt]. An apparatus for the purpose of disinfection.

Disintegrate (dis-in'-te-grât) [dis, apart; integer, the whole]. To break up or decompose.

Disinvagination (dis-in-vaj-in-a'-shun) [dis, neg. ; in, in; vagina, a sheath]. The reduction or relief of an invagination.

Disjoint (dis-joint') [disjoindre, to disjoin]. To disarticulate; to separate, as bones, from their natural relations.

Disk. See Disc.

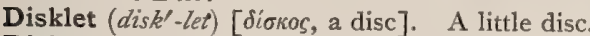

Dislocation (dis-lo-ka'-shun) [dis, apart; locare, to place]. The luxation or abnormal displacement of one or more bones of a joint, or of any organ from its natural position. D., Complete, the bones entirely separated. D., Compound, the coverings of the joint ruptured. D., Consecutive, the displaced bone is not in the same position as when originally misplaced. D. of Eyebal1, displacement of the eyeball outside of the lids. D. of Lens, the crystalline lens thrown out of its capsule, or misplaced so that it does not occupy its proper position behind the pupil. D. Old, inflammatory changes having ensued. D. Partial, or Incomplete, the articulating surfaces re maining in partial contact ; called, also, Subluxation. D., Primitive, the bones remaining as originally displaced. D., Recent, no inflammatory changes having ensued. D., Simple, without laceration of the surrounding parts. Diastasis, dislocation of an amphiarthrotic joint; also a separation, as of the parts of a muscle, or of the epiphysis of a bone from the diaphysis.

Disorder (dis-or'-der). See Disease,

Disorganization (dis-or-gan-iz-a'-shun) [dis, priv.; organizare, to organize]. Destruction or loss of organic structure; complete pathologic or traumatic change in the minute structure of any tissue.

Disparate (dis'-par-ät) [dispar, unequal]. Not alike; unequal or unmated. D. Points, non-identical points of the two retinæ. Diplopia is produced when the images of a single object fall upon such points.

Dispareunia (dis-par-oo'-ne-ah). See Dyspareunia.

Dispensary (dis-pens'-ar-e) [dispensare, to distribute]. A charitable institution where medical treatment is given the poor and medicines are dispensed on prescription.

Dispensatory (dis-pens'-at-or-e) [dispensatorium, an apothecary's diary]. A treatise on the materia medica, and the composition, effects, and preparation of medicines.

Dispensing (dis-pens'-ing) [dispensare, to weigh out]. The measuring, weighing, and issuing of the drugs ordered in a prescription.

Dispersion (dis-per'-shun) [dispersio ; dispersus, scattered]. The resolution, discussion, or scattering of an inflammation or other morbid condition. In physics, the separation of a ray of white light into colored rays; also, any scattering of light, as that which has passed through ground glass.

Dispirem (di-spi-rem) [dis, two; spira, a spiral]. In embryology, the two skeins of a dividing nucleus formed from the nuclear loops and giving rise to the daughter nuclei. It is the seventh stage of Karyokinesis, q. $\%$.

Displacement (dis-plās'-ment) [Fr., desplacer, to displace]. A putting out of place; applied to various organs, as the uterus, heart, etc. D. of Mortality. See Carnot's Doctrine.

Dispora caucasica (dis'-por-ah kaw-kas'-ik-ah). See Bacillus caucasicus, under Bacteria, Synonymatic Table of.

Disposition (dis-po-sish'-un) [dispositio, an arranging] Tendency, either physical or mental, to certain diseases

Dissection (dis-ek'-shun) [dissectio, dissecare, to cut up]. The disassociation and exposition by means of incisions, cutting apart, etc., of the organs of the body, for purposes of scientific study. Dissecting Aneurysm. See Aneurysm. Dissecting Wound, injury during dissection, with consequent introduction of septic material. It may become constitutional and result in septicemia, or it may take the form of warts, Verruca necrogenica. The sore resulting directly from the prick or abrasion is called Post-mortem pustule.

Disseminated (dis-em'-in-a-ted) [disseminare, to scatter seed]. Scattered; spread over a large area. D. Sclerosis. See Insular Sclerosis. 


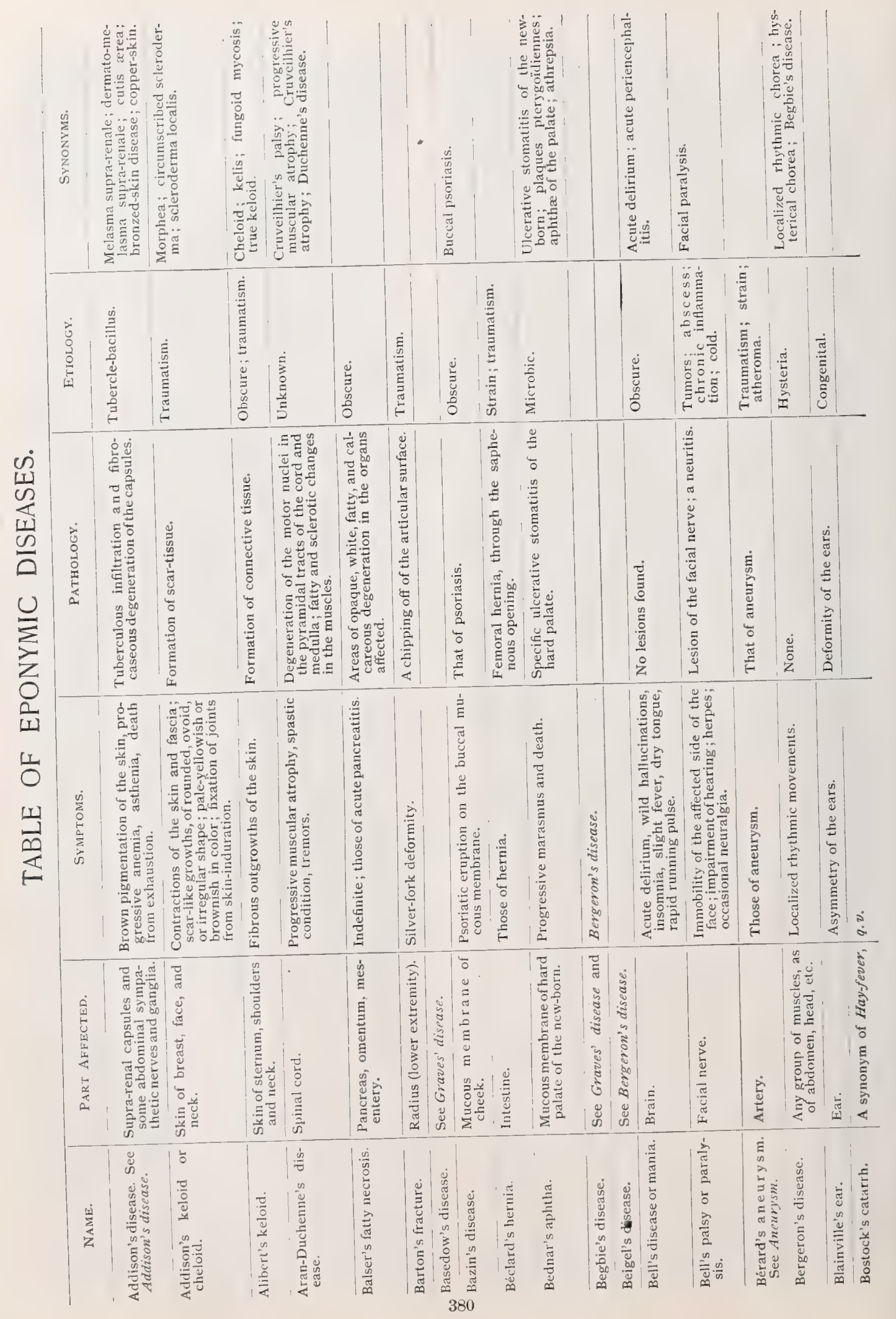




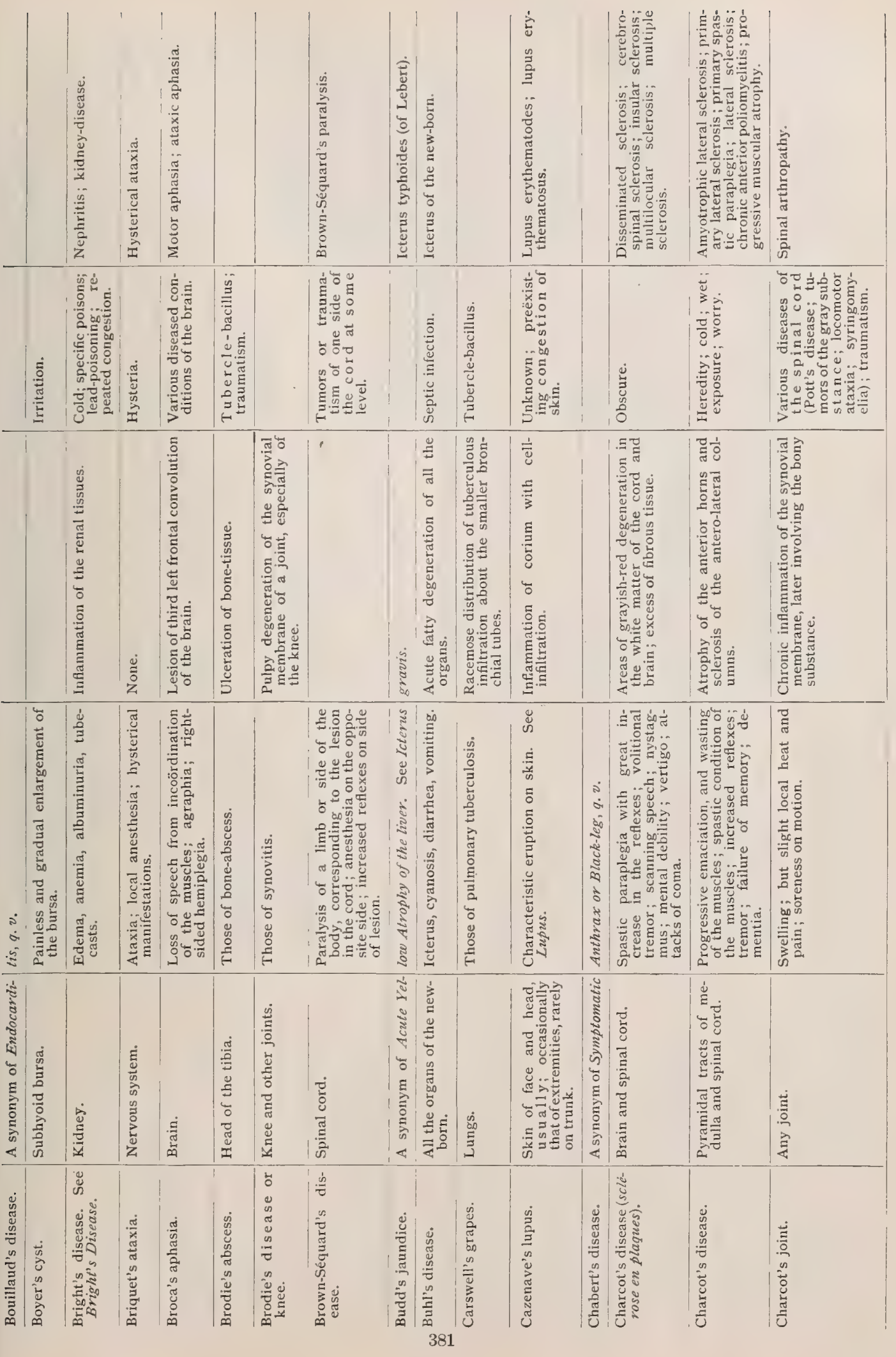




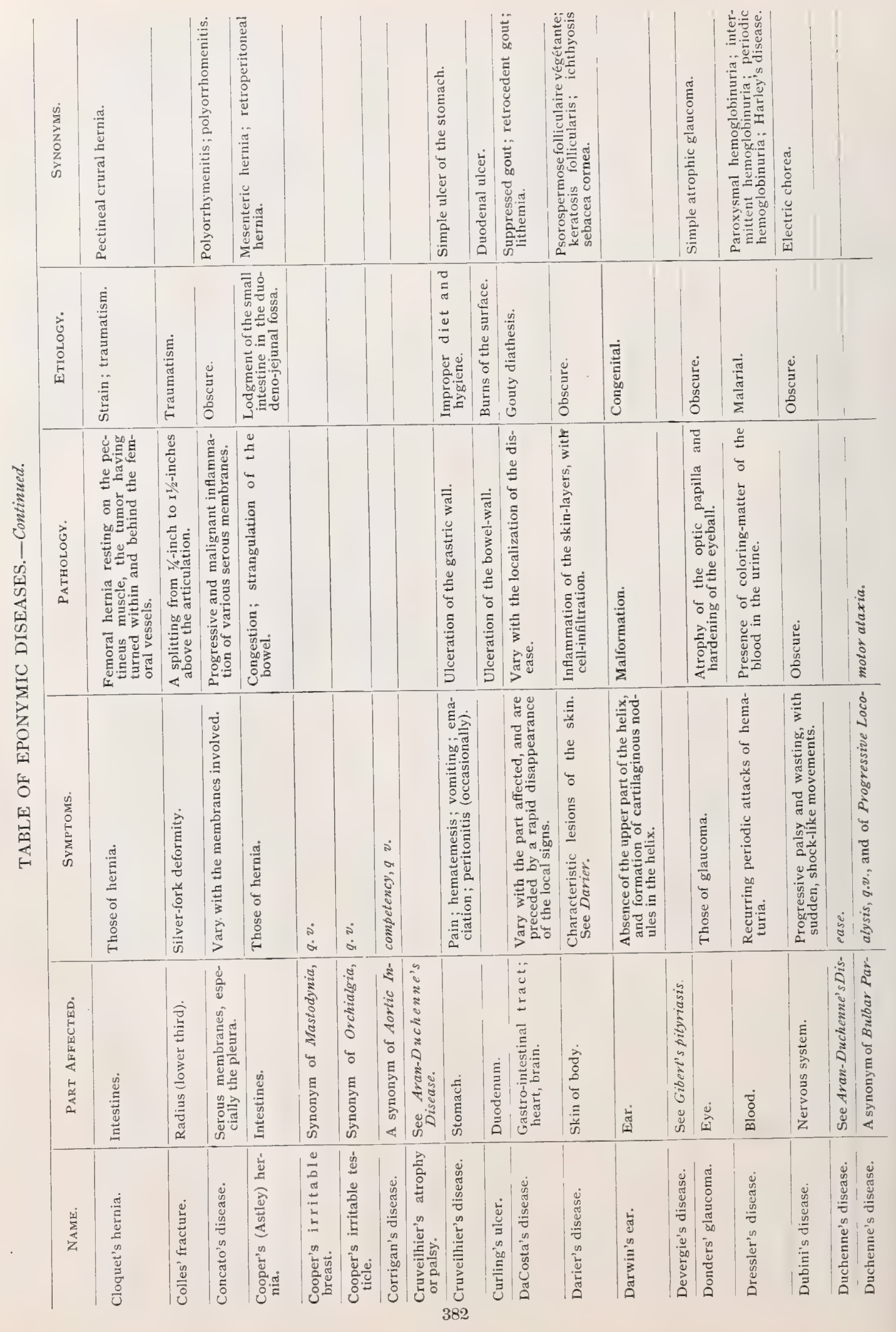



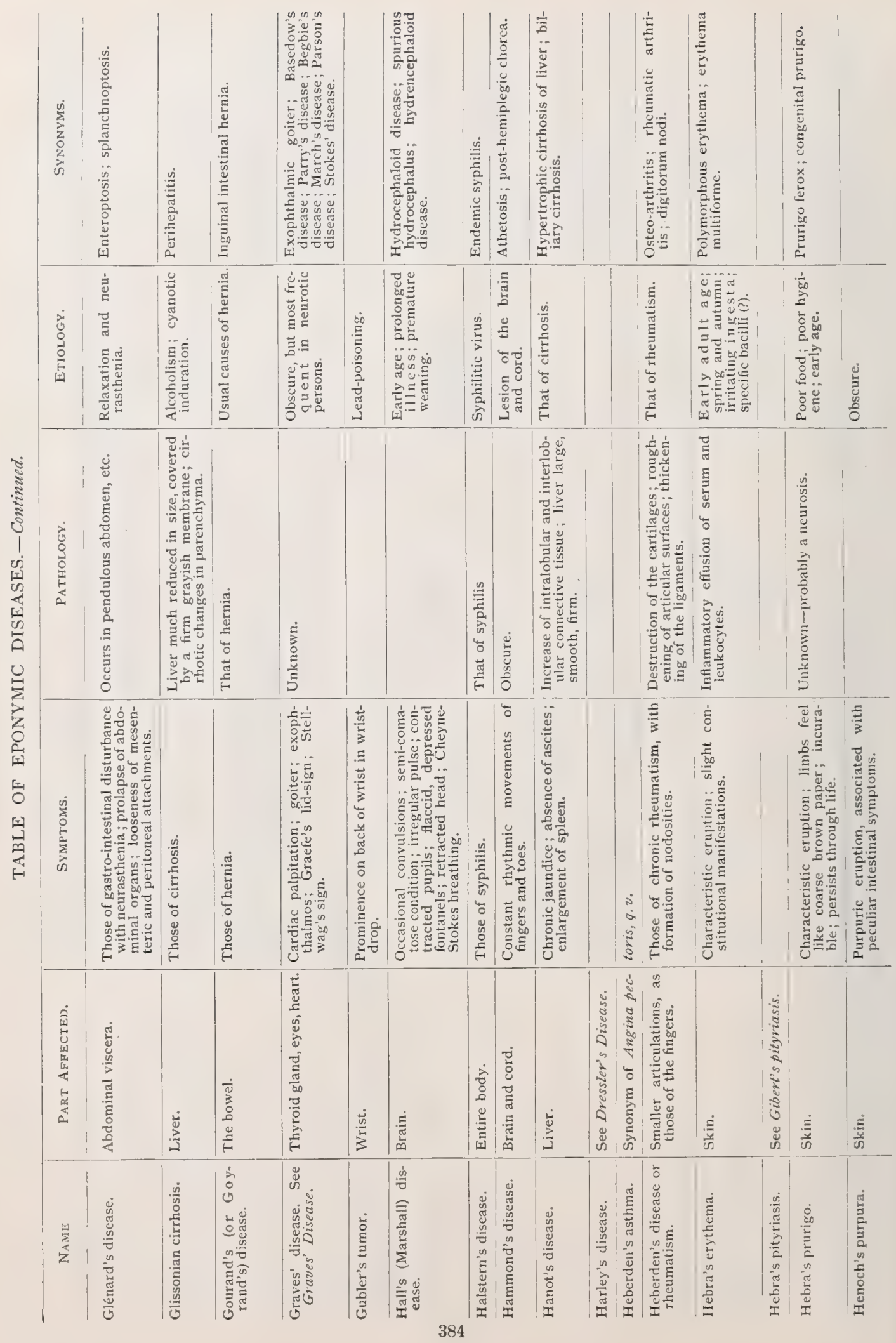


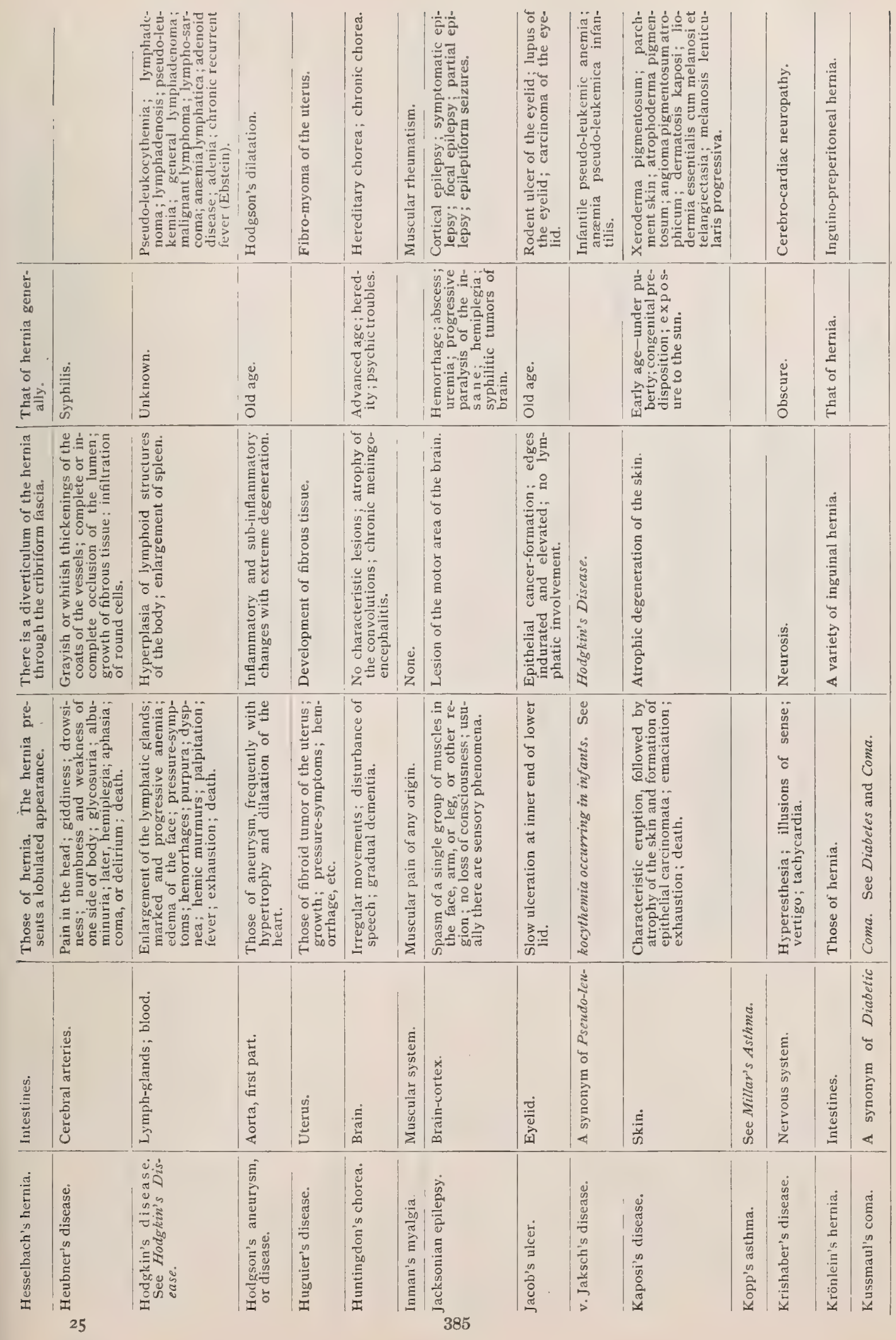



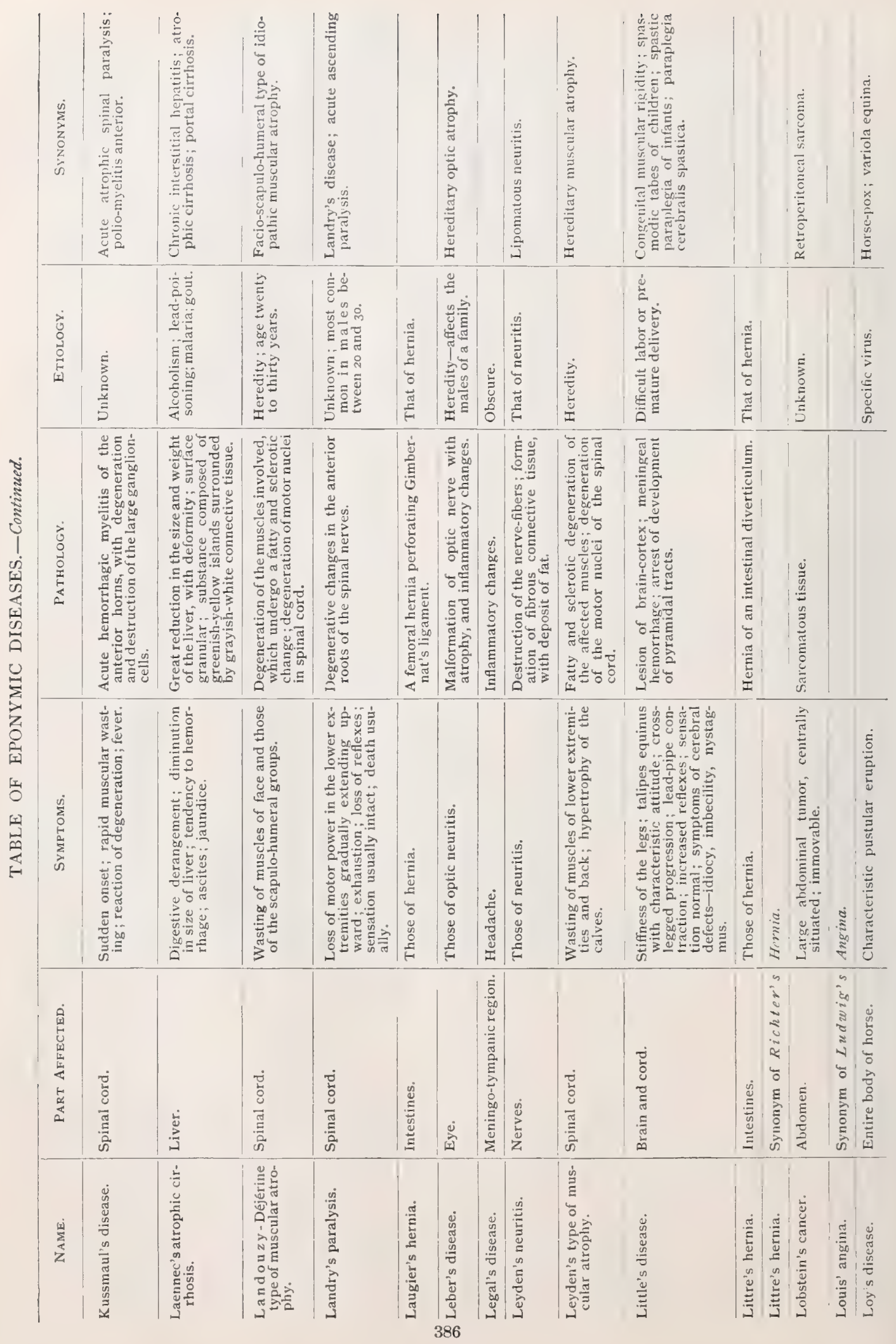


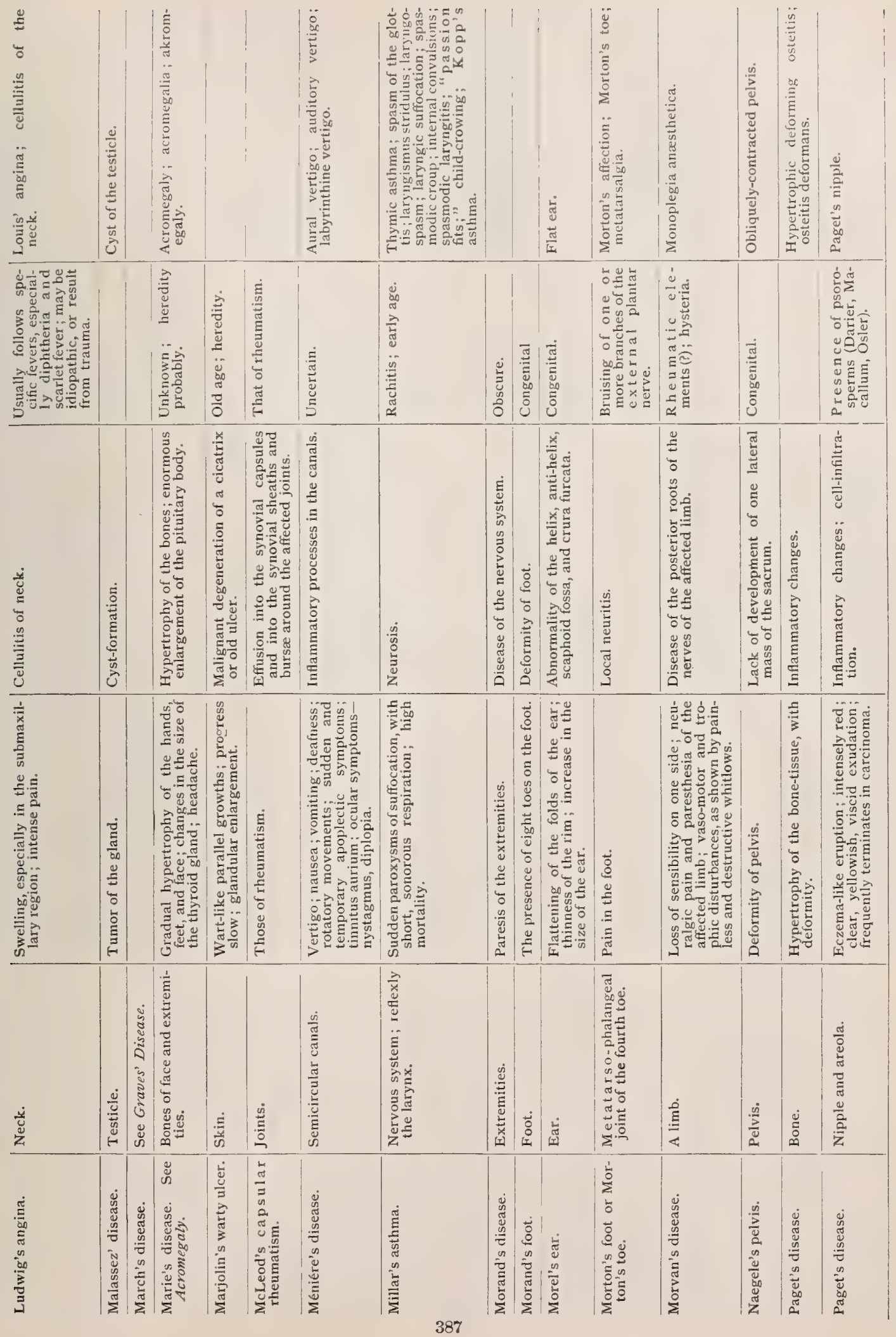




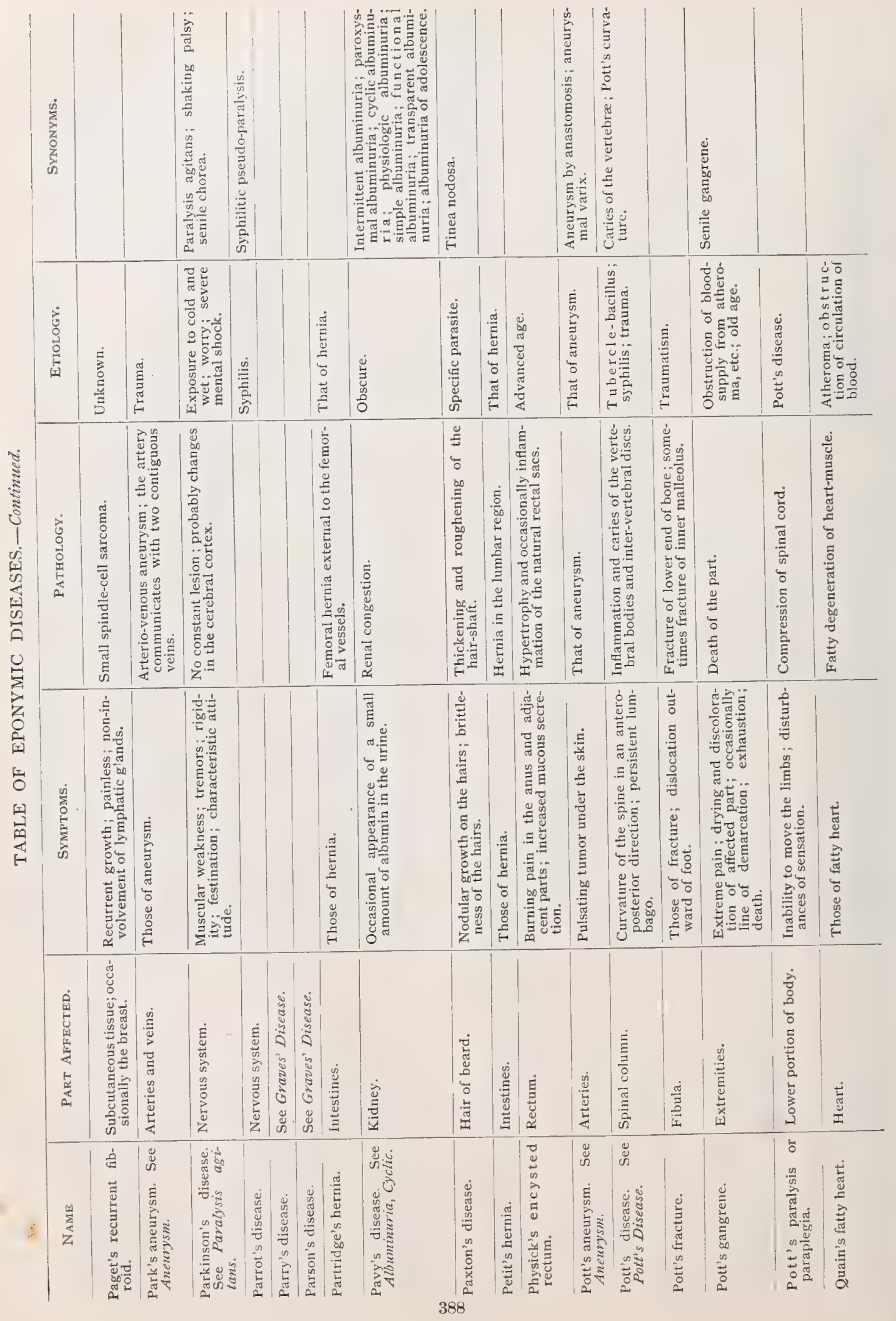



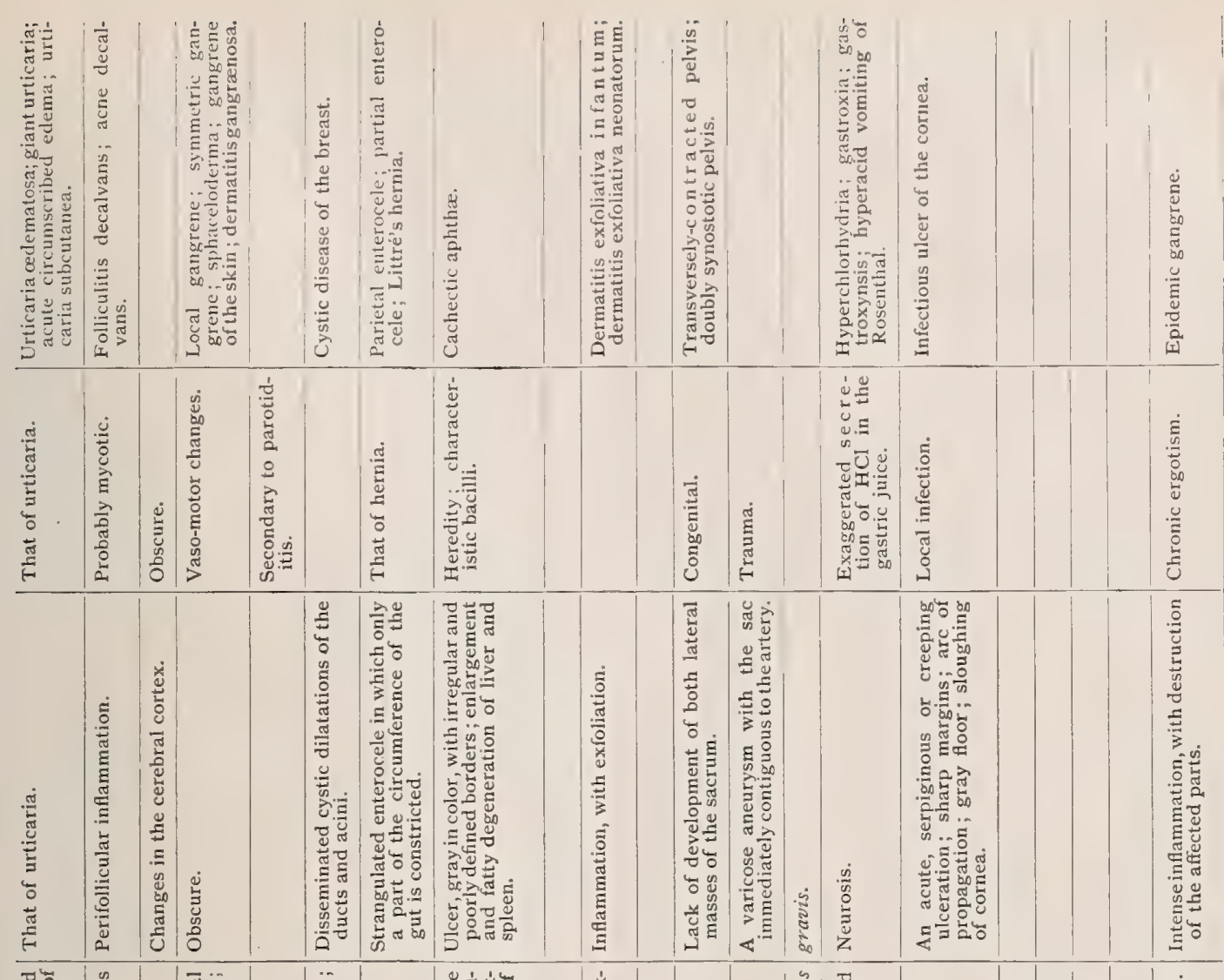

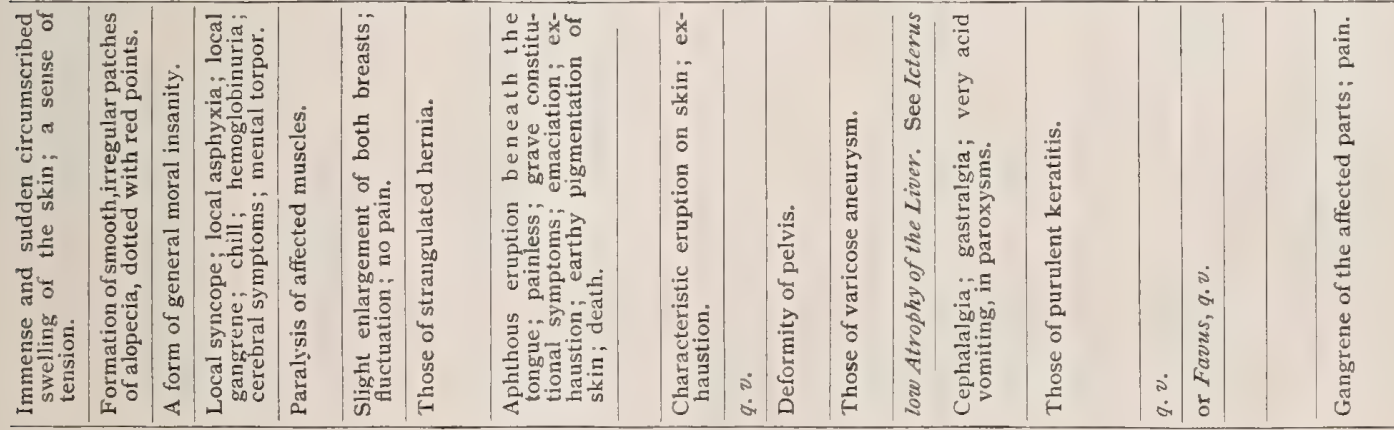
. 

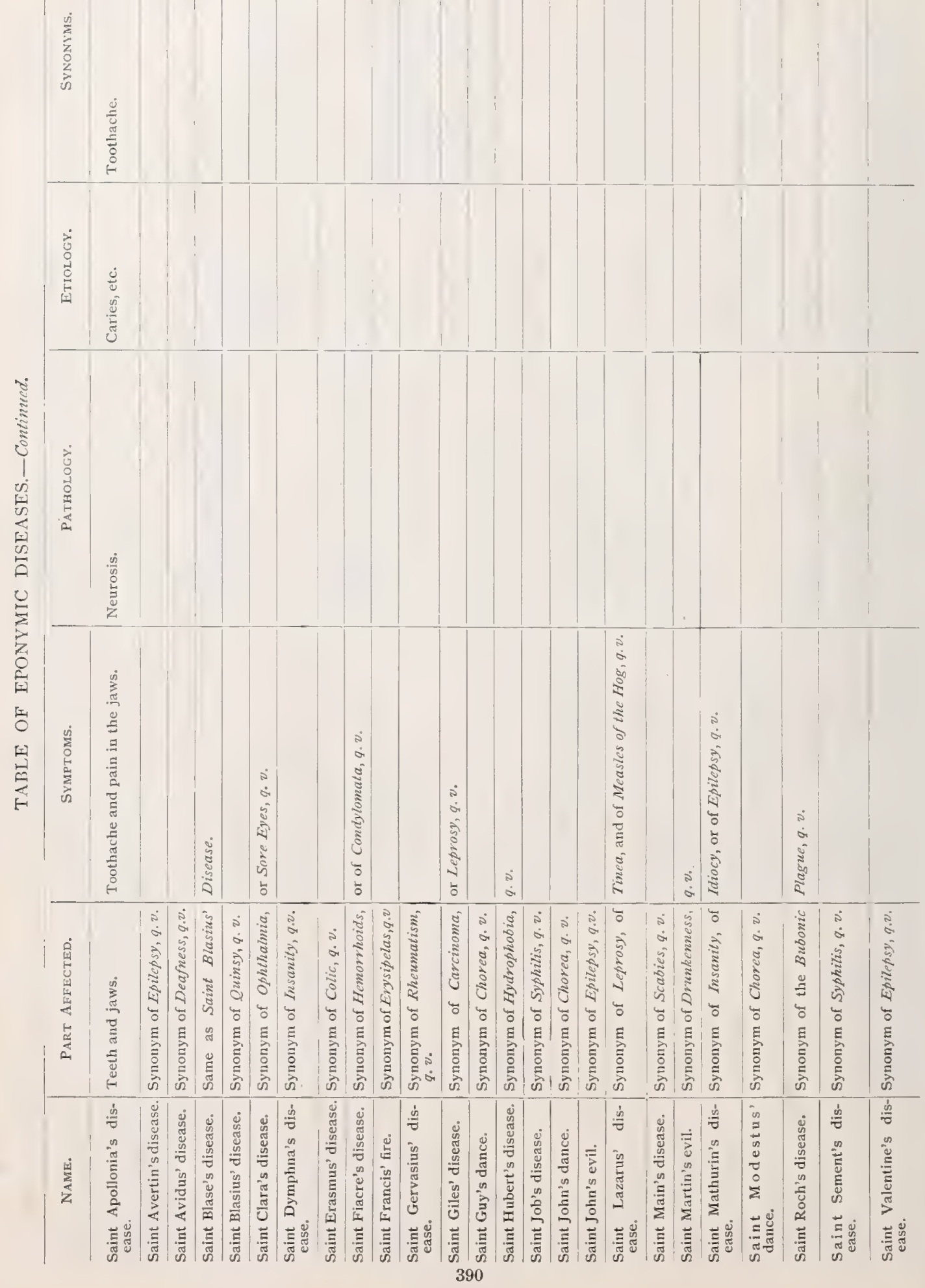


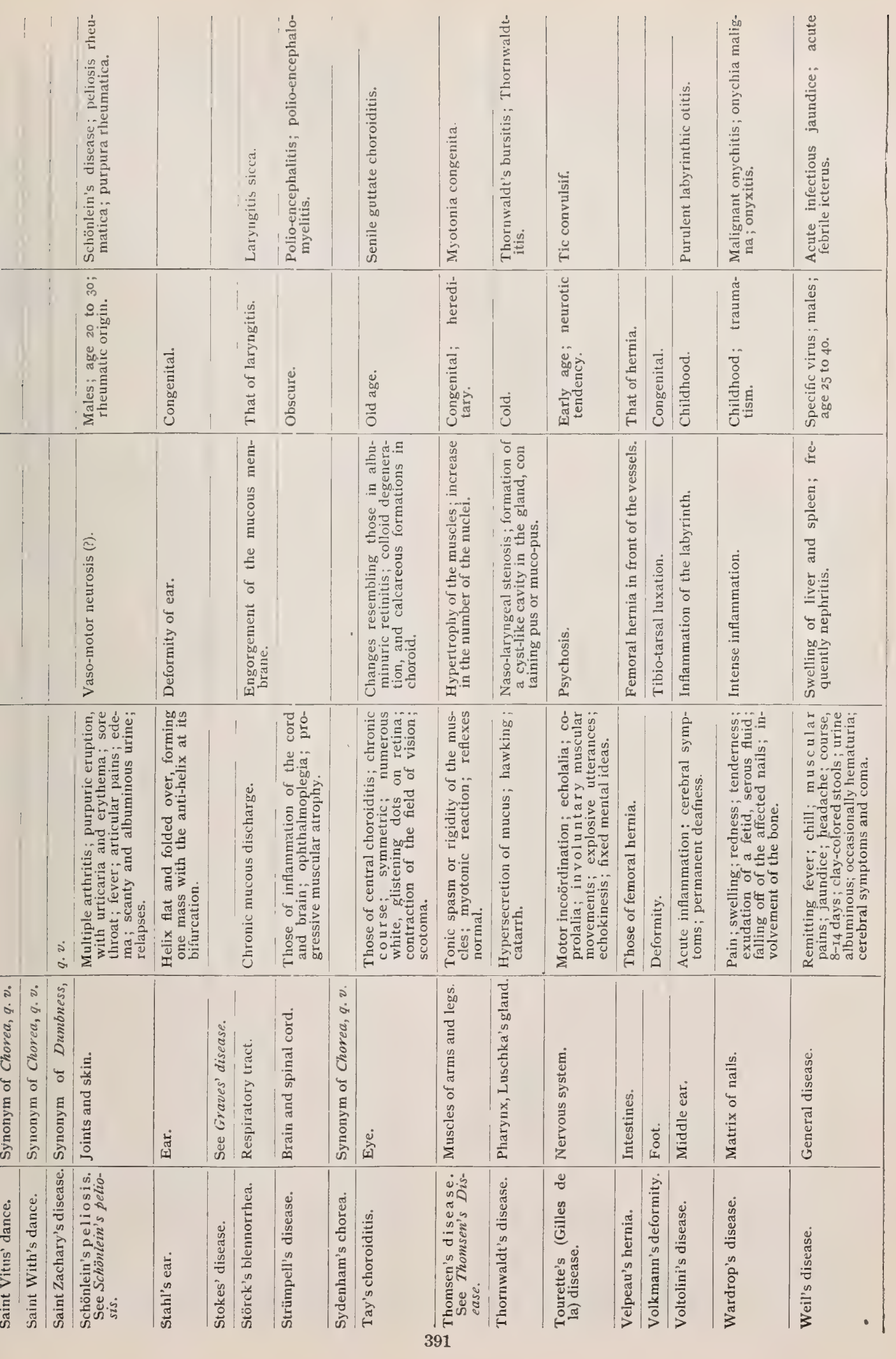




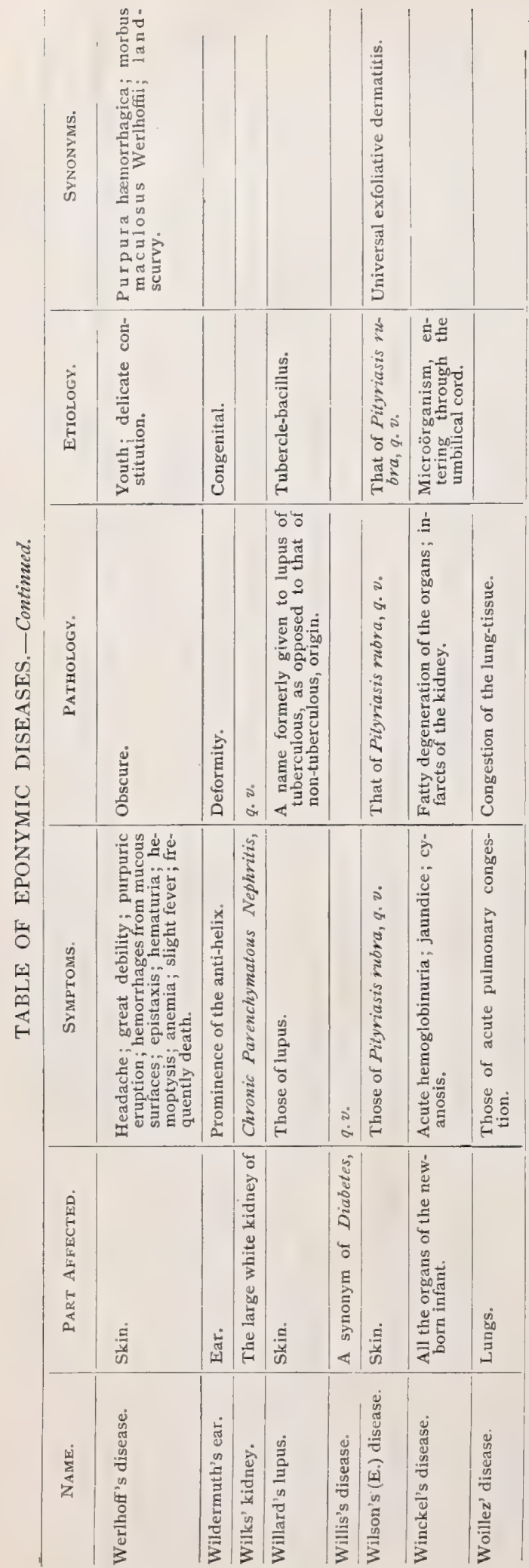

Dissemination (dis-em-in- $\left.a^{\prime}-s h u n\right)$ [dis, apart ; seminare, to sow]. The scattering or dispersion of disease or disease-germs.

Dissepiment (dis-ep'-e-ment) [dis, apart; scepire, to hedge in ]. A partition, septum, or diaphragm.

Dissipation (dis-ip-a'-shun) [dissipare, to scatter]. A dispersion of matter or of the morbid conditions that cause disease.

Dissociation (dis-so-se-a'-shun) [dis, apart; sociare, to associate]. In physiology, the separation of the component elements of a compound. In chemistry, the decomposition of a compound by means of high temperature D. Symptom, anesthesia to pain and to heat and cold, with preservation of tactile sensibility and of the muscular sense; it is observed in syringomyelia.

Dissolution (dis-o-lu'-shun) [dissolutio; dissolvere, to set free]. A solution of the continuity of a part. Decomposition arising from the death of the body or its parts ; death.

Dissolvent (diz-ol'-vent) [dissolvere, to loosen, dissolve]. A solvent.

Dissonance (dis'-o-nans) [dissononare, to disagree in sound]. The combination of such tones as are so different from each other as to produce beats.

Distad (dis'-tad) [distare, to be at a distance; $a d$, to]. In the direction of the free extremity of an appendage or part. See Position and Direction, Table of.

Distal (dis'-tal) [distare, to be at a distance]. At the greatest distance from the trunk, heart, or mesial line. See Position and Direction, Table of. D. Clot. See Clot.

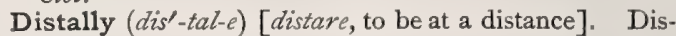
tad.

Distance (dis'-tans) [distantia, distance]. The measure of space between two objects. D., Working, in the microscope, the distance from the front lens of an objective to the object, when the objective is correctly focused.

Distemper (dis-tem' -per) [distemperare, to dissolve]. I. Disease; malady; indisposition; most commonly applied to the diseases of animals. 2. A disease of young dogs, commonly considered as a catarrhal disorder. D. Colors. See Pigments, Colors, and Dyestuffs.

Disten $($ dis'-ten $)$ [distare, to be at a distance]. Belong. ing to the distal aspect in itself.

Distention (dis-ten'-shun) [distendere, to stretch]. The state of being dilated.

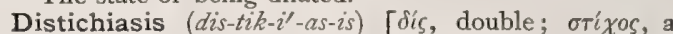
row]. The condition of a double row of eyelashes, the inner rubbing against the globe.

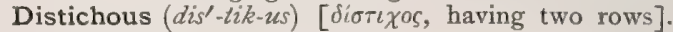
In biology, in two perpendicular rows; applied to the arrangement of leaves or other organs.

Distillation (dis-til-a'-shun) [destillare, to drop little by little]. The double process of vaporization and condensation of the vapor. This is used mainly in purifying liquids by separating them from non-volatile substances. D., Destructive, the decomposition of a substance in a close vessel in such a manner as to obtain liquid products. The substances that are submitted to destructive distillation are in the main solids, as wood, coal, shales, bones, and animal refuse. D., Fractional, a process of decomposition of complex liquid bodies depending upon the fact that, if a mixture of liquids, each having a different boiling-point, be heated, the one having the lowest boiling-point will pass over first, and if the temperature is not increased beyond that point at which the distillation of this fraction takes place, no other constituent will come over; if the temperature be gradually increased the 
others will follow in the order of their boiling-points. In cases in which the boiling-points are close, the action of one substance upon another often prevents exact separations.

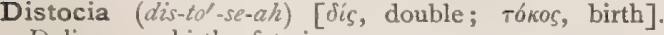
Delivery or birth of twins.

Distoma (dis-to'-mah), or Distomum (dis-to'-mum)

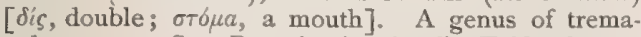
tode worms. See Parasites (Animal), Table of.

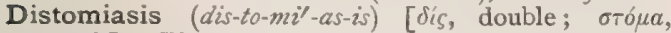
mouth]. The symptoms produced by the presence of certain trematodes or flukes in the human system.

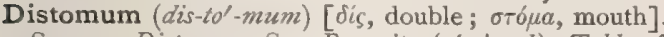
Same as Distoma. See Parasites (Animal), Table of.

Distomus (dis-to'-mus). See Diprosopus.

Distortion (dis-tor'-shun) [distorquere, to distort]. I. A twisted or bent shape; deformity or malformation, acquired or congenital. 2, A writhing or twisting motion, as of the face; a grimace.

Distortor oris (dis-tor'-ter o'-ris) [L., " the distortor of the mouth" ]. The zygomaticus minor muscle. See Muscles, Table of.

Distribution (dis-trib-u'-shun) [distribuere, to distribute]. The branching of a nerve or artery, and the arrangement of its branches within those parts that it supplies.

Distrix (dis'-triks) [ $\delta i s$, two; $\theta \rho i \xi$, hair]. The splitting of the distal ends of the hair.

Disulphate $\left(d i-s u l^{\prime}-f a t\right)$ [dis, two; sulphur]. In chemistry, an acid sulphate.

Disulphone (di-sul'-fón) [dis, double; sulphur]. One of the solid, crystalline, very stable compounds, produced on oxidizing the di-thio-ethers or thio-acetals with a permanganate solution. The disulphones are not attacked by acids or alkalies.

Disuse-amblyopia. See Argamblyopia.

Disvulnerability (dis-vul-ner-ab-it'-it-e) [dis, neg. ; vulnerare, to wound]. The power of abnormally rapid recovery from wounds, said to be a peculiarity of many criminals.

Dita Bark (di'-tah) [L.]. The bark of Alstonia scholaris, native to the Philippine Islands. It is employed as a tonic and antiperiodic in intermittent fever. Dose of the tincture, $\mathbf{z} \mathrm{j}-\mathrm{ij}$; of the fluid extract, gtt. ij-v; of the powder, gr. v. Unof.

Ditain (dit'-a-in) [Dita], $\mathrm{C}_{44} \mathrm{H}_{30} \mathrm{~N}_{2} \mathrm{O}$. An alkaloid of Dita, occurring as a yellow amorphous substance.

Ditamin (dit'-am-in). Same as Ditain.

Ditana digitifolia (dit-a'-nah dij-it-if-o'-le-ah) [L.]. A Mexican plant said to possess galactagogue properties. The existence of such a plant has been questioned.

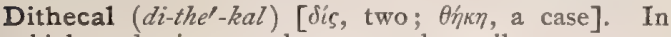
biology, having two thecæ or anther-cells.

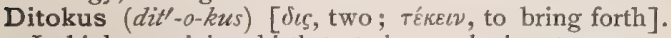
In biology, giving birth to twins, or laying two eggs.

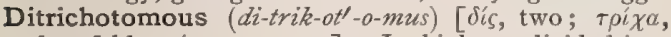
threefold; $\tau_{\varepsilon}^{\prime} \mu \nu \varepsilon \nu v$, to cut]. In biology, divided into twos and threes.

Dittany (dit'-an-e) [American]. See Cunila mariana.

Dittel's Operation. See Operations, Table of.

Dittopsia (dit-top'-se-ah). Synonym of Diplopia.

Dittrich's Plugs. Masses of granular matter, degenerated epithelium, and crystals of the fatty acids (chiefly butyric acid) plugging up the ends of the bronchial tubes in cases of gangrene of the lung. They are yellowish-brown in color, of very fetid odor, and vary in size from a millet-seed to a bean.

Diuresis $\left(d i-u-r e^{\prime}-s i s\right)$ [ [ $\iota^{\prime}$, through; ov̉pé $\varepsilon \iota \nu$, to make water]. Abnormal increase in the secretion of urine.

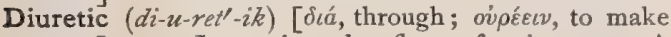
water]. I. Increasing the flow of urine. 2. A medicine that increases the secretion and flow of urine.

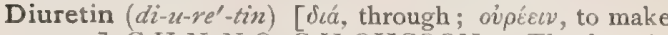
water $], \mathrm{C}_{7} \mathrm{H}_{7} \mathrm{NaN}_{4} \mathrm{O}_{2}, \mathrm{C}_{6} \mathrm{H}_{4} \mathrm{OHCOONa}$. Theobromin sodio-salicylate, containing 50 per cent. of theobromin salicylate. It has been found useful as a diuretic in pleuritic effusion and cardiac dropsy. Dose 90 grains daily, in 15 -grain doses.

Diurnule $\left(d \hat{i}-u r n^{\prime}-\bar{u} l\right)$ [Fr.]. A form of medicinal tablet that contains the maximum quantity of a toxic drug that may be administered to an adult in 24 hours.

Divagation (di-vag-a'-shun) [divagatio, a wandering]. Incoherence of speech or thought.

Divalent (di'-val-ent) [dis, twice; valens, having power]. Having power to combine with two monovalent atoms, as a chemic compound. Thus, the oxygen atom and the radical $\mathrm{CH}_{2}$ are divalent.

Divaricatio palpebrarum (di-var-ik-a'she-o pal-pebra'-rum). Synonym of Ectropion.

Divergent (di-ver'-jent) [divergere, to diverge]. Moving in different directions from a common point. D. Strabismus. See Strabismus.

Divers' Disease. An affection similar to Caissondisease, q. $v_{0}$, common in deep-water divers. D. Paralysis. See Caisson-disease.

Diverticulum (di-ver-tik'-u-lum) [divertere, to turn: pl., Diverticula ]. I. A small cul-de-sac or pouch; an offshoot from a main structure; an organ supposed to be a place of lodgment for superfluous blood. 2. Variation from a normal structure; malformation. D., Meckel's, a sacculation of the ileum, owing to the non-obliteration of the vitelline duct.

Divi-divi (div'-e-div'-e) [S. Amer.]. The seed-pods of Casalpinia coriaria, a small tree found in South America. The pods are about three inches long, brownish in color, and generally bent, by drying, into the shape of the letter S. They contain 30 to 50 per cent. of a peculiar tannin somewhat similar to that of valonia, but liable to fermentation. They are used in leather-manufactures.

Division (div-izh'-un) [divisio, a dividing]. Surgical section into two or more parts; separation into two or more parts, such as occurs in certain cell-nuclei.

Divulsion (di-vul'-shun) [divulsio, a tearing apart]. The surgical or traumatic division of any part by tearing it asunder.

Divulsor (di-vul'-sor) [L.]. An instrument for effecting surgical divulsion, especially of a urethral stricture.

Dizziness (diz'-e-nes). See Vertigo.

Dobell's Spray, or Solution. Liquor sodii boratis compositus (N. F.) ; a solution of borax, sodium bicarbonate, and carbolic acid in glycerin and water; it is valued as a spray for nasal and throat troubles.

Dobie's Line, or Stripe. See Lines, Table of.

Dochmiasis (dok-mi'-as-is) [ $\delta 6 \chi \mu l o s$, crumpled]. The diseased condition caused by the presence in the body of parasites belonging to the genus Dochmius. Cf. Ankylostomiasis.

Dochmius (dok'-me-us) [ $\delta 6 \chi \mu 10 s$, crumpled]. In biology, a genus of thread-worms of the family Strongylidæ. See Parasites (Animal), Table of.

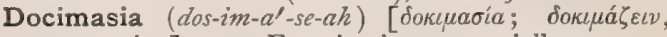
to examine]. I. Examination, especially a postmortem examination. 2. A test, especially a chemic test, of poisons. 3. In pharmacy, the testing or assaying of medicines. D. pulmonum, a mode of determining whether a child has or has not been born alive, by examination of the lungs.

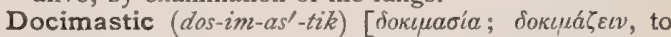
examine]. Making use of tests; testing; proving.

Docimasy (dos'-im-as-e). See Dosimasia. 
Dock (dok). See Rumex.

Dockmackamus, or Dockmackie (dok-mak'-am-us, or $\left.d o k^{\prime}-m a k-e\right)$ [aboriginal]. The shrub Viburnum acerifolium, of N. America; used in domestic practice in poulticing tumors, and as an alterative. Unof.

Doctor (dok'tor) [doctor, a teacher]. A teacher. A title conferred by a university or college. A physician licensed to practise medicine. D. Gum, the resin of Rhus metopium, a poisonous sumach of tropical America ; it is said to be purgative and alterative. The name is given in the W. Indies to various other soft resins.

Dodecadactylitis $\left(d o-d e k-a-d a k-t i l-i^{\prime}-t i s\right)$ [ $\delta \omega \delta \varepsilon \kappa a$,

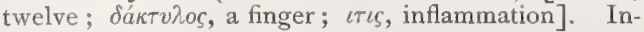
flammation of the duodenum.

Dodecadactylon, or Dodecadactylus (do-dek-a-dak'-

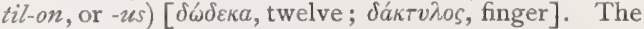
duodenum.

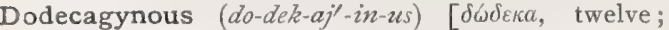
yvví, a female]. In biology, having twelve pistils.

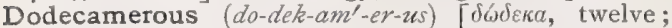
$\mu \varepsilon ́ p o s$, part]. In biology, having the floral organs in twelves.

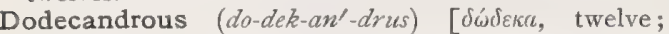
àńp $(a \dot{\nu} \delta \rho-)$, a male]. In biology, having twelve stamens.

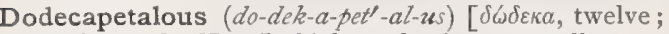
$\pi \varepsilon \tau a \lambda o v$, a leaf $]$. In biology, having a corolla consisting of twelve petals.

Döderlein, Bacillus of. See Bacteria, Synonymatic Table of.

Dodging Time. The popular term among women for the period of irregular menstruation of varying duration preceding the full establishment of the menopause.

Dog-button. See $N u x$ vamica.

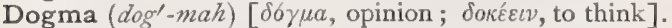
A tenet or principle taught by authority. A statement of medical science.

Dog-rose $\left(\operatorname{dog}^{\prime}-r \bar{o} z\right)$. See Rosa canina.

Dogwood (dog'-wood). See Cornus.

Dohrn's Method. A method of dressing the umbilical cord. The stump is covered with cotton-wool fixed with stumps of adhesive plaster. This dressing is likely to be followed by umbilical ulceration.

Dolabra (do-la'-brah) [I.]. A name applied to various bandages. D. currens. See Ascia. D. repens. See Ascia.

Dolabriform (do-lab'-rif-orm) [dolabra, a kind of hatchet; forma, shape]. In biology, shaped like an axe.

Dolbeau's Operation. See Operations, Table of.

Doliariin $\left(d o-l_{e}-\iota^{\prime}-r e-i n\right)$ [dolium, a cask $]$. A vegetable pepsin, like papain and cradin, obtained from Ficus doliaria, a wild fig-tree of Brazil. It is vermifuge, purgative, and digestive. Unof.

Doli capax (do'-li ka'-paks) [L. : pl., Doli capaces]. In legal medicine, one capable of guilt; one able or old enough to distinguish right and wrong; one morally or legally responsible. D. incapax, one incapable, or not old enough to distinguish wrong from right, or to be legally responsible for wrong-doing.

Dolichocephalia ( $\left.d a l-i k-o-s e f-\alpha^{\prime}-l e-a h\right)$ [ $\delta o \lambda \iota \chi o ́ s, l o n g$; $\kappa \varepsilon \phi a \lambda \dot{\eta}$, head]. The condition of being dolichocephalic.

Dolichocephalic, or Dolichocephalous (dol-ik-o-sef-

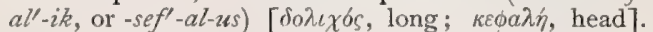
Having a relatively long antero-posterior cephalic diameter (applied to skulls or to persons or races). See Index.

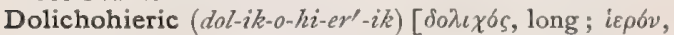
sacrum]. Having a relatively slender sacrum. See Platyhieric.

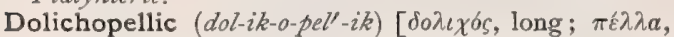
a bowl]. Having a relatively long or narrow pelvis. See Platjpellic.
Dolor $\left(d o^{\prime}-l o r\right)$ [dolere, to feel pain]. Bodily or mental pain or suffering. D. colicus. Synonym of Enteralgia. D. dentium, pain in the teeth. See Udontalgia. Dolores prasagientes, precursory pains felt by women in advance of labor.

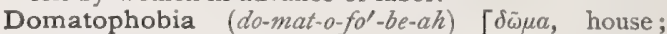
$\phi 6 \beta 0 \varsigma$, fear]. Insane dread of being in a house; a variety of claustrophobia.

Donath's Tests. See Tests, Table of. D. and Mayr hofer's Test. See Tests, Table of.

Donda Ndugu [African]. Brother Ulcer; a disease common on the east coast of Africa, due to some minute organism that infests stagnant water and enters an abraded joint of the lower extremities, especially of the lower third of the leg. The part becomes swollen, and a deep-seated slough occurs that burrows beneath the healthy tissues. Death may follow from exhaustion or hemorrhage. Those who recover are generally permanently lamed.

Donders' Glaucoma. See Diseases, Table of. D. Law. See Law. D. Schematic Eye, in optics, a device for calculating the path of the rays from one refracting surface to the other. D. Theory, a theory of the formation of glaucoma, in which the disease is supposed to originate in an irritation of the choroid nerves.

Donegana's Operation. See Operations, Table of.

Donne's Corpuscles, or Globules. See Globule and Colostrum Corpuscles. D. Test. See Tests, Table of.

Donovan's Solution. See Arsenic.

Doornick's Horizontal Line. See Line.

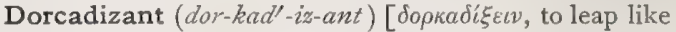
a gazelle; ঠоркás, gazelle]. Leaping; characterized by leaps; applied to certain forms of insanity.

Doremus's Method. A method of estimating the amount of urea in the urine. It is done by allowing the urine to pass through a solution of sodium hypobromite and measuring the gas that is evolved.

Dorsad (dor'-sad) [dorsum, the back]. Toward the dorsal aspect; dorsally. See Position and Direction, Table of.

Dorsal (dor'-sal) [dorsum, the back]. Pertaining to the back, or to the posterior part of an organ. The term Neural is sometimes used in place of dorsal. See Position and Direction, Table of. D. Artery. See Artery. D. Decubitus, recumbency in the supine position. D.-elevated Position. See Postures, Table of. D. Nerves. See Nerves, Table of. D.recumbent Position. See Postures, Table of. D. Reflex. See Reflexes, Table of. D. semi-recumbent Posture. See Postures, Table of.

Dorsalis pedis $\left(d o r-s \alpha^{\prime}-l i s e^{\prime}-d_{i s}\right)$. See Arteries, Table of.

Dorsen (dor'-sen) [dorsum, the back]. Belonging to the dorsum in itself.

Dorsicollar (dor-se-kol'-ar) [dorsum, the back ; collum, the neck]. In biology, having to do with the back and neck.

Dorsicumbent (dor-se-kum'-bent) [dorsum, the back ; cubare, to lie down]. In biology, supine; or lying upon the back.

Dorsigerous (dor-sij'-er-us) [dorsum, the back; gerere, to carry]. In biology, bearing the young upon the back.

Dorsigrade (dor'-sig-rād) [dorsum, the back; gradi, to walk]. In biology, applied to animals that walk upon the back of the toes, as the armadillo.

Dorsi-lumbar (dor-si-lum'-bar). See Dorso-lumbar.

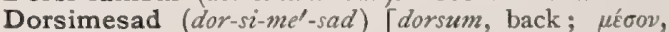
the middle]. Toward the dorsimeson. See Position and Direction, Table of.

Dorsimesal (dor-si-me'-sal) [dorsum, back; $\mu$ coov, the 
middle]. Pertaining to the dorsimeson. See Position and Direction, Table of.

Dorsi-meson (dor-si-me'-son) [dorsum, the back; $\mu \varepsilon$ cov, the middle]. The dorsal edge of the meson or median plane of the body. The dorsal, mesal, or median line. Cf. Ventrimeson; also Position and Direction, Table of.

Dorsiparous (dor-sip'-ar-us) [dorsum, the back; parere, to produce]. Applied to plants that bear fruit on the back of the leaves (ferns), or animals hatching young upon the back (toads)

Dorsi-scapular (dor-si-skap'-u-lar) [dorsum, back; scapula, the shoulder]. Relating to the dorsum of the scapula.

Dorso- (dor'so-) [dorsum, back]. A prefix used in connection with the names of such organs as have their attachment to or about the back.

Dorsocephalad (dor-so-sef'-al-ad) [dorsum, back; $\kappa \varepsilon \phi n \bar{n} \dot{n}$, head]. Toward the dorsal aspect of the head.

Dorsodynia (dor-so-din'-e-ah) [dorsum, back; ódiv $\nu \eta$ pain]. Omodynia; scapulodynia; pain in the dorsal region; rheumatism of the muscles of the shoulders and upper back.

Dorso-lumbar (dor-so-lum'-bar) [dorsum, back; lumbus, loin]. Relating to the back and the loins.

Dorso-sacral Position. See Postures, Table of.

Dorso-thoracic (dor-so-tho-ra'sik) [dorsum, back; $\theta \omega$ ' $a \xi$, thorax]. Relating to the back and the thorax.

Dorstenia (dor-ste'-ne-ah). See Contrayerva.

Dorsulum (dor'-su-lum) [dim. of dorsum, the back]. The second dorsal sclerite of the thorax in certain insects.

Dorsum (dor'-sum $)$ [L.]. I. The back. The rounded part of the back. 2. Any part corresponding to the back; as the dorsum of the foot, hand, tongue, scapula, or penis ; in many cases, the upper surface is thus designated.

Dorsumbonal (dor-sum'-bo-nal) [dorsum, the back; umbo, a boss]. In biology, pertaining to both the dorsal and umbonal regions in a bivalve mollusc.

Dosage $\left(d o^{\prime}-s \bar{a} j\right)$ [ $\delta \sigma \sigma \iota s$, a portion given]. A system or method of dosing. See Posology.

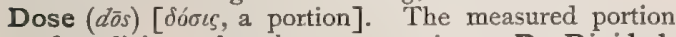
of medicine to be taken at one time. D., Divided, a mode of administration in which a drug is to be taken in fractional portions at short intervals. D., Maximum, the largest portion of medicine ordered to produce a given result, or the largest dose consistent with safety. In this work both minimum and maximum dosage is given under each medicine or preparation. D., Minimum, the smallest quantity of a medicine that will produce physiologic effects.

\section{GAUBIUS' TABLE}

of Proportion of Dose According to Age.

For an adult, suppose the dose to be. . I, or 60 grains

An individual under I year will require 1, vears "

""

\begin{tabular}{|c|c|c|c|}
\hline & & & \\
\hline " & & & \&6 \\
\hline & & "I & 8 \\
\hline ( & & "I & \\
\hline I" & TA & 16 & \\
\hline 16 & & \& & 6 \\
\hline
\end{tabular}

For one of 21 to 60 , the full dose, or

Above this age, an inverse gradation must be observed.

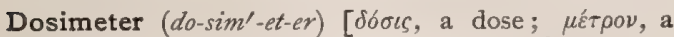
measure]. A drop-meter; an instrument for measuring minute quantities of a liquid.

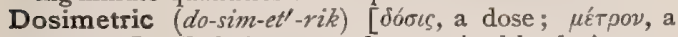
measure]. Relating to or characterized by dosimetry.

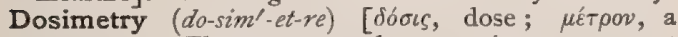
measure]. The accurate and systematic measurement of a dose or prescribed portion; the use of drugs in exact and definite doses.
Dosiology, or Dosology (do-se-ol'-o-je, or do-sol'-o-je)

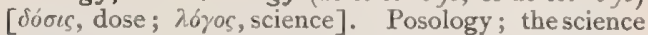
of doses.

Dosis $\left(d d^{\prime}-\right.$ sis). See Dose.

Dossil (dos'-il) [ME., dosil, a spigot]. A pledget or tuft, as of lint,

Dotage $\left(d \bar{o} t^{\prime}-\bar{a} j\right)[\mathrm{ME}$, dotren]. Feebleness of mind; senility.

Dothienenteritis, or Dothinenteritis (doth-e-en-en-ter-

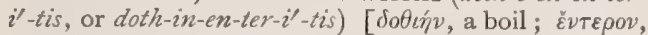
bowel; $\iota \tau \iota s$, inflammation]. Enteric fever, or the enteritis that accompanies it.

Double $\left(d u b^{\prime}-l\right)$ [ME, doublen, to double]. Two-fold. In pairs. D. Athetosis, a manifestation of infantile spastic paraplegia. D. Chin. See Buccula. D. Consciousness, periodic amnesia ; a periodic failure of memory involving all the intellectual functions and the character of the individual; that condition in which a patient seems to have two distinct but alternating lives; it is seen mostly in somnambulists and hypnotics. D. Flap Amputation. See Amputation. D. Hearing. See Diplacusis. D. Monsters. Same as Composite Monsters, q. v. D. Personality, an abnormal condition in which the subject feels as if he were two distinct personalities, the one alternating continually with the other. It is a symptom of insanity and of poisoning by certain drugs. D. Staining, in microscopy, the impregnation of a structure with two colors in order to show its details. Bacteriologically the application of such staining-reagents as will stain the spores one color and the rods another. D. Touch, the exploration of the vaginal and rectal walls by inserting the thumb into the one cavity, and the index finger into the other, so that, e. g., the presence of any abnormal growth may be ascertained. D. Vinegar. See Vinegar. D. Vision. See Diplopia. D. Vitriol, a mixture of copper and iron sulphates crystallized together. D. Voice. See Diphthongia. D.Wedge, an instrument used in dentistry for removing an artificial crown from the root of a tooth upon which it has been set.

Doubler (dub'-ler). See Doubling.

Doublet (dubl-let) [ME., dublet]. In optics, a system consisting of two lenses.

Doubling (dub'-ling) [ME, doublen, to double]. A term given to that duplication of dispensary statistics that results from patients coming twice or oftener with different troubles in the course of a year. Such patients are termed "doublers."

Doubly $\left(d u b^{\prime}-l e\right)$ [ME., doublen, to double]. In a two-fold manner. D. Contoured, in microscopy, an object is doubly contoured when it is bounded by two, usually parallel, dark lines witb a lighter band between them.

Doubt (dowt) [ME., doute, fear]. Uncertainty; fear. D., Insanity of, mental disorder in which the patient is affected by morbid doubts and fears, and sub. jects himself to introspective questionings.

Doubting (dowt'-ing) [ME., doute, fear]. Fearing. D. Mania, a form of volitional disorder in which the reflexive mechanism of the will is over-irritable and reacts to slight stimuli, producing a constant succession of contradictory, absurd, or useless acts.

Douche (doosh) [Fr.]. A stream of water directed against a part, or one used to flush a cavity of the body.

Douglas's Cul-de-sac or Pauch. See Pouch. D. Line. See Lines, Table of. D. Semilunar Fold, a thin curved margin that forms the lower part of the posterior wall of the sheath of the abdominal rectus muscle.

Dourine $\left(\mathrm{doo}^{\prime}-\mathrm{rin}\right)$ [Fr.]. Syphilis in the horse. 
D'Outrepont's Version. In obstetrics, indirect version, the head being seized from without by the hand corresponding to its position, while the other hand, well oiled and folded together like a cone, is introduced into the uterine cavity, grasps the presenting shoulder and pushes it toward the side on which the breech is situated.

Dover's Powder. Pulvis ipecacuanhæ compositus, See Opizm.

Dowel (dow'-el) [Fr., douille, a socket]. In dentistry, the piece of wood or metal uniting any artificial crown to the root of a natural tooth.

Dowell's Operation. See Operations, Table of.

Doyère, Eminence, Hillock, Papilla, or Tuft of. See Sarcoglia.

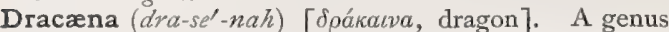
of liliaceous plants, often tree-like. D. cinnabari and D. schizantha (both E. Africa) and D. draco (mainly W. African) afford a part of the so-called dragon's blood of commerce. See Dragon's Blood.

Dracol $\left(d r a^{\prime}-k o l\right)$. Same as Anisol.

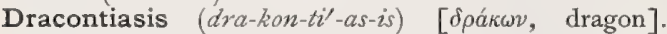
Guinea-worm Disease; a skin-disease due to the presence of the fully developed nematode worm, dracunculus medinensis, and characterized by the development of deep vesicles or abscesses. The disease is endemic in India and various parts of Africa and other tropical regions. The female worm is cylindric, $\frac{T}{10}$ inch in diameter and about 30 inches long, or even much longer. It may be felt like a cord of soft string under the skin. When about to make its escape it produces itching and discomfort, followed by an abscess. The embryo of the worm gains entrance into the human body and there develops with the named results. See Parasites (Animal), Table of.

Dracunculus (dra-kun'-ku-lus) [dim. of draco, a dragon, serpent]. A genus of thread-worms, belonging to the family Filariida. See Parasites (Animal), Table of. D. medinensis. See Dracontiasis.

Draft, Draught (draft) [AS., dragon, to draw]. 1. A quantity of liquid, especially a medicine drunk at one gulp. 2. A mild blister; a poultice. D., Black, compound infusion of senna. D., Chopart's, a mixture containing balsam of copaiba, alcohol, peppermint water, syrup of balsam of tolu, and sweet spirit of niter. D., Effervescing, one containing sodium or potassium bicarbonate and a vegetable acid.

Dragée $\left(d r a h-z h \bar{a}^{\prime}\right)$ [Fr.]. A sugar-coated pill, bolus, or comfit; a sugared confection.

Dragendorff's Tests. See Tests, Table of.

Dragendorff and Kossow's Test. See Tests, Table of.

Dragon Root (drag'-on root). Indian Turnip. The root of Arum triphyllum, acrid, expectorant, and diaphoretic. Dose of the fld. ext. $m x v-3 j$. Unof.

Dragon's Blood (drag'tonz blud). I. The astringent resin of Calamus rotang and $C$. draco, E. Indian rattan-palms. 2. The resin of various species of Draccna, q.v. 3. The resin of Pterocarpus draco, a W. Indian tree. The various kinds of dragon's blood are astringent, but are now used mainly in the arts and in making court-plasters. See Pigments, Conspectus of.

Drain [ME., drainen, to drain]. A channel that receives the drainage or waste water of one building or set of premises. In surgery, a material that affords a channel of exit for the discharge from a wound or cavity. D.-throat, a sore-throat produced by the poison of scarlet fever, and other poisons introduced into the system by breathing the air from defective drains.

Drainage $\left(d r a \bar{n}{ }^{\prime}-a j\right)$ [ME., drainent, to drain]. I. The provision, by means of tubes or strands of fibers, of a channel of exit for the discharge from a wound or cavity, 2, See Sewage, D. Anchor, a rubber filament inserted in an abscess or cavity. D.-tube, a rubber tube with perforations for draining wounds or cavities. D.-tube, Decalcified, a decalcified bone (e.g., of a chicken, etc.) used as a drainage-tube.

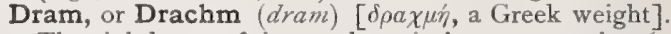
The eighth part of the apothecaries' ounce, equal to 60 grains or 3.8 grams. Also the one-sixteenth part of the avoirdupois ounce, equal to 27.34 grains. D., Fluid, the eighth part of a fluidounce, equal to 60 minims.

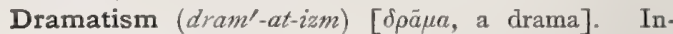
sanely stilted and lofty speech or behavior.

Draper's Test. See Tests, Table of.

Drastic $\left(d r a s^{\prime}-t i k\right)$ [ $\delta a ́ \varepsilon \iota v$, to draw]. I. A powerful and irritating purgative, such as scammony or gamboge. 2. Severe, harsh, powerful.

Draught (draft). See Draft.

Draw [ME., drawen, to draw]. To digest and cause to discharge; said of a poultice. In dentistry, to remove a tooth from its socket. In andrology, to remove the urine from the bladder by means of a catheter. D.-bench, a bench for drawing wire, so constructed as to confine a wire-plate at one end, with a roller and windlass at the other end for drawing the wire through the plate.

Drawer, Gold. An apparatus for use in the dental laboratory to collect gold scraps and filings.

Drayman's Bottom. An enlargement of the bursa situated over the tuberosity of the ischium.

Dream (drēm) [ME., dremen, to dream]. I. An involuntary series of images, emotions, and thoughts presented to the mind during sleep. 2. To be conscious of such manifestations. D., Waking, an illusion or hallucination. D., Wet, a term given to the emission of semen during sleep.

Dreamy $\left(d r e^{\prime}-m e\right)$ [ME., dremen, to dream]. Full of dreams. D. State, a common psychic aura of epilepsy in which the patient experiences a sensation of strangeness or sometimes of terror. It may be associated with flashes of light or auditory auræ.

Drechsel's Test. See Tests, Table of.

Drechsler's Test. See Tests, Table of.

Drench [ME., drenchen, to drench, drown]. In veterinary practice, a draught of medicine.

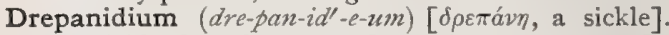
The sickle-shaped young of certain protozoans. D. ranarum, a (probably) parasitic cytozoön of frogs' blood.

Dressed Mouth (drest mozuth). That condition produced by the fraudulent practice of filing the teeth, used to make an old horse appear young.

Dresser (dres'-er) [ME., dressen, to make straight]. An attendant (in English hospitals, usually a student) whose special duty it is to dress and bandage wounds, and attend to other ward work.

Dressing (dres'-ing) [ME., dressen, to make straight]. 1. The application of a bandage, lint, or other substance to a wound or ulcer. 2. The material so applied. 3. In metallurgy, the mechanical treatment that an ore receives after being brought to the surface; concentration.

Dressler's Disease. See Diseases, Table of.

Drewsen's Test. See Tests, Table of.

Drill (dril) [AS., thyrelian, to pierce]. A surgical instrument used in perforating bones, calculi, or teeth. D.-bone, a flat osteoma. D.-bow, a bow and string for rotating a drill-stock, effected by passing the string around it, and moving it backward and forward. D.-stock, an instrument for holding and turning a drill, either by the thumb and finger or by a handle. D.-stock, Flagg's, an instrument for drilling into the 
pulp-cavity of a tooth for the purpose of giving egress to matter formed there in the process of suppuration of the pulp.

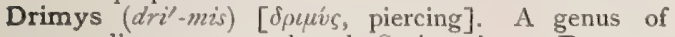
magnoliaceous trees, largely S. American. D. granatensis, D. mexicana, and D. winteri afford Winter's Bark, an aromatic and stimulant tonic, formerly in repute as an alterative. Unof.

Drink [ME., drinken, to drink]. To swallow a liquid. The liquid that is swallowed. A draught.

Dripping Sheet (drip'-ing shèt). A means of reducing temperature in fever, entirely distinct from the wet pack. The patient is placed erect in a tub containing twelve inches of water at $100^{\circ}$. A linen sheet (the coarser the better) is dipped in water at $70^{\circ}$, which is reduced daily two degrees until $48^{\circ}$ is reached. This sheet is thrown over the patient from behind, covering the head and body, so that it clings to the person. The attendant now makes rapid passes with both hands, beginning anteriorly and posteriorly, so as to produce friction and afflux of blood to the surface. Occasionally cold water at from $40^{\circ}$ to $70^{\circ}$ is thrown on from a cup and friction renewed. The procedure is also said to be useful in anemia.

Drivelling (driv'-el-ing) [ME., drinclen]. I. An involuntary flow of the saliva, as in old age, infancy, idiocy, and mental stupor. 2. Senile weakness of mind.

Drivers' Spasm (dri'verz spazm). See Spasm.

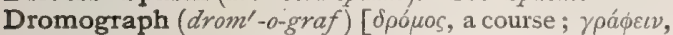
to write]. An instrument for registering the velocity of the blood-current.

Drop. See Gutta and Minim. I. To let fall in globules or drops, as a liquid. 2. To let fall from the womb. 3. A spheric mass of fluid-material. D.culture, in bacteriology, a culture prepared by placing a drop of the infected material in a culture-medium. D.-meter. See Dosimeter. D.-serene. See Gutta serena. D.-shoulder, the condition in which one shoulder is on a much lower level than the other; not uncommonly met with in hysterical girls.

Dropped Hand, or Wrist (dropt hand or rist). A form of paralysis from lead-poisoning, consisting in the inability to contract the extensors of the forearm. D. Foot, a deformity, especially observed in alcoholic peripheral neuritis, and dependent upon weakness of the flexors of the foot.

Dropper $\left(d r o p^{\prime}-e r\right)$ [ME., droppen, to drop]. A bottle, tube, or pipet, fitted for the emission of a liquid drop by drop. See Stopper-dropper.

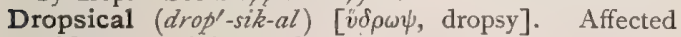
with or pertaining to dropsy.

Dropsy (drop'-se) [i $\delta \rho \omega \psi$, dropsy]. See Hydrops. D. of Belly. See Ascites. D. of Brain. See Hydrocephalus. D., Cardiac, that due to failure of compensation in cardiac disease. D., False, an accumulation of liquid in a cavity of an organ from obstruction of the outlet; a retention-cyst. D. of Chest. See Hydrothorax. D. of Peritoneum, ascites, hydroperitoneum. D. of Pericardium, hydropericardium. D. of Spine. See Spina bifida and Hydrorrhachis. D. of Testicle. See Hydrocele. D. of Uterus. See Hydrometra.

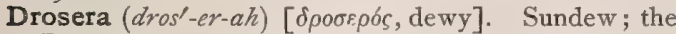
$D$. rotundifolia, native of $\mathrm{U}$. S. and Europe. An antispasmodic, useful in whooping-cough and other spasmodic coughs. Dose of the fluid extract $m v-x x$; of the tincture ( $I$ in $\mathrm{ro}$ ) $\mathrm{m} \mathrm{v}-\mathrm{xv}$. Unof.

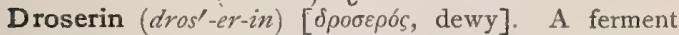
resembling pepsin and found in the digestive secretions of most of the insectivorous plants.

Drown [ME., drozenen, to drown]. To deprive of life by immersion in a fluid.
Drowning (drozon'-ing) [ME., drozonen, to drown]. Depriving of life by immersion in a fluid. D., Intrauterine. See Intra-uterine. D., Treatment of. See Artificial Respiration.

Drowsy (drow'-ze) [AS., drüsan, to sink]. Inclined to sleep; sleepy.

Drug [ME., drugges]. A substance, simple or compound, natural or prepared, single or mixed with other substances used as a medicine. D., Antagonistic, one that neutralizes the action of another by a process other than chemic. D.-eruptions. See Dermatitis medicamentosa. D.-habit, the acquiring of a tolerance for a drug after long administration, by which its physiologic action in normal dose is abolished. This may be avoided by intermitting the remedy from time to time.

Druggist (drug'-ist) [ME., drugges]. One who deals in drugs.

Drum [ME., drumme]. The tympanum. The labyrinth of a bird. D.-belly. See Tympanites. D. of Ear. See Tympanum, D.-head. See Membrana tympani.

Drumin $\left(d \mathrm{um}^{\prime}-\mathrm{in}\right)$ [Drummond, a botanist]. A name given to the alkaloid extractive of Euphorbia drummondii, an Australian plant. It is said to be a local anesthetic, and is claimed, also, to be an impure calcium oxalate. Unof. See Anesthetic.

Drummers' Palsy (drum'-erz pazel'-ze). A form of occupation-neurosis, dependent upon the constrained attitude of the hand in beating a drum.

Drummond's Whiff. See Signs and Symptoms, Table of.

Drumstick - bacillus. See Bacteria, Synonymatic Table of.

Drunkard (drunk'-ard). One given to excessive indulgence in spirituous drinks. D.'s Liver, a cirrhotic liver. D.'s Pneumonia, a grave form of pneumonia occurring in drunkards; it is usually fatal.

Drunkenness (drunk'-en-nes) [AS., druncen, drunken]. Acute or habitual alcoholic intoxication. See Alcoholism, Dipsomania, Inebriety.

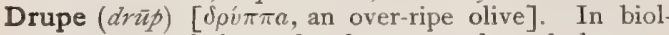
ogy, a stone-fruit, as the cherry, peach, and plum.

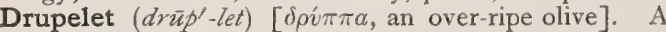
little drupe.

Drupetum (dru-pe'-tum) [drupa, a drupe]. In biology, an aggregation of drupes, as in a blackberry.

Druse (drüs) [Ger.]. A wound that does not communicate with any surface; a rupture of the tissues with no superficial lesion.

Dry (dri) [ME., drye]. I. Without moisture. 2. Barren. 3. To evaporate. D.-ash System. See Dry-earth System. D. Belly-ache. See Girdlepain. D. Caries, See Onychomycosis. D. Cupping. See Cupping. D.-earth System, Dry-ash System; a method of disposing of feces by mingling with them dry earth or ashes in sufficient quantity to absorb all moisture from them, so as to render them inodorous and to prevent decomposition. D. Gangrene. See Gangrene. D. Itch. Synonym of Lichen. D. Labor, one in which there is but a slight discharge of liquor amnii. D. Mouth. See Xerostomia. D.-nurse, a nurse who attends and feeds a child, but does not suckle it. D. Pile, a hemorrhoid that does not bleed. D. Pleurisy, pleurisy without effusion. D.-scall, a synonym of psoriasis. D.swimming, swimming exercise in the air, a useful gymnastic measure. D. Tetter. See Psoriasis. D. Wine, a wine containing little or no sugar. See Wines.

Dryer's Test. See Tests, Table of.

Drying Oils. See Oils and Fats. 
Drysdale's Cells or Corpuscles. Certain microscopic cells in ovarian fluid, generally round, sometimes oval in form, transparent, containing fine granules, but no nucleus. They have been described as pathognomonic of ovarian cysts, but this is disputed.

Dualin $\left(d u^{\prime}-a l-i n\right)$ [dual, of two]. An explosive composed of a mixture of nitro-glycerin 50 parts and nitrated sawdust 50 parts. Giant pozeder and rendrock are similar mixtures.

Dualism $\left(d u^{\prime}-a l-i z m\right)$ [duo, two]. A system by which natural phenomena are explained upon two principles. D., Chancrous, the theory of the existence of two forms of chancre-the non-infecting, or soft chancre, and the infecting, or true (hard) chancre.

Dualistic (du-al-is'-tik) [dual, of two]. Characterized by duality. D. Theory of the Composition of Carbon-compounds; every chemic compound is composed of two groups, electrically different, and these are further made up of two different groups or elements. The Electro-chemic, dualistic theory of Berzelius was prevalent in Germany until about $\mathbf{1} 860$.

Duality $\left(d u-a l^{\prime}-i t-e\right)$ [dualitas, dual]. Dualism; the supposed distinction, and potentially independent action, of each of the cerebral hemispheres.

Dubini's Disease. "Electric chorea ;" myelitis convulsiva; a malady met with in Italy, differing from chorea in the character of the movements, which are sudden and shock-like; in the course of the disease, which is progressive and often fatal; and in the addition of muscular palsy and wasting. Its etiology and pathology are obscure. See Diseases, Table of.

Dublin Method. See Treatment, Methods of.

Dubois' Caustic. See Caustic.

Duboisia (du-bois'-e-ah) [after Dubois, a French botanist]. The leaves of $D$. myoporoides, an Australian tree. It resembles belladonna in physiologic and therapeutic effects. D., Ext. Dose gr. $1 / 6-1 / 4$. D., Ext. Fld. Dose $\eta_{v-x}$. D., Tinct. Dose $\eta_{v-x x}$.

Duboisin $(d u$-bois'-in) [after Dubois, a French botanist], $\mathrm{C}_{70} \mathrm{H}_{23} \mathrm{~N}_{6} \mathrm{O}$. An alkaloid from Duboisia myoporoides, identical with hyoscyamin.

Dubrueil's Operation. See Operations, Table of.

Duchenne's Disease. See Diseases, Table of. D. Paralysis. See Diseases, Table of. D.-Aran Type of Muscular Atrophy. See Disenses, Table of.

Duck-bill Forceps. See Forceps. D. Speculum. See Speculum.

Duckett's Closet. See Servage, Disposal of.

Duck-foot $\left(d u k^{\prime}\right.$-foot). Synonym of Flat-foot.

Duck-legged (duk-leg'-ed). Having very short legs.

Duck-weed Disease $\left(d u k^{\prime}\right.$-wèd dis-ée $\left.z^{\prime}\right)$. A German name for tuberculosis in cattle.

Duckworth's Theory. The neuro-humoral theory of the origin of gout. It is that there is a basic, arthritic stock, a diathetic habit, of which gout and rheumatism are two distinct branches. The gouty diathesis is expressed in $(a)$ an abnormality of the nerve-centers, which may be inherited or acquired; and $(b)$ a peculiar incapacity for normal elaboration within the whole body, whereby uric acid is formed at times in excess or is incapable of being duly transformed into more soluble and less noxious products.

Duct, or Ductus [ducere, to lead]. A tube for the conveyance of the fluids of the body. D., Aberrant, a small, blind, coiled tube, 2 to I 4 inches in length, running from the lower portion of the canal of the epididymis. D., Aberrant Bile, one of a number of biliary ducts, occasionally found in the left lateral ligament of the liver. They are not surrounded by lobules and are the remains of hepatic substance, present at an early stage of development. D., Acoustic, the external auditory meatus. D., Adipose, one of the sacs in cellular tissue containing the fat. D., Air, in biology, one of the intercellular spaces in aquatic plants, containing air. D., Alimentary. See $D$., Thoracic. D., Alveolar, one of the infundibula of the bronchioles. D., Annular, in biology, one of the ring-shaped thickenings of the cells of vascular tissue. D. of Arantius. See D. venosus. D., Archinephric. See D., Mesonephric. D., Arterial. See $D$. arteriosus. D. arteriosus, a short vessel in the fetus between the main pulmonary artery and the aorta. It becomes obliterated at birth. D., Auditory, the space between the membrana tectoria and the membrana basilaris of the cochlea. D. of Bartholin, the larger and longer of the sublingual ducts, opening into the mouth near to, or in common with, Wharton's duct. D. of Bellini, one of the excretory tubes of the kidneys. D., Biliary. See D., Common Bile. D. of Botal. See $D$. arteriosus. D., Branchial, in Myzontes, a short tube between the branchial pouch and the intestinal cavity. D., Canalicular, one of the smaller galactophorous ducts of the mammæ. D., Cement, in Cirripedia, one of a number of tubes that pass through the antennæ from the cement-glands. D. choledochus. See D., Common Bile. D., Cochlear. See Canal, Cochlear. D., Common Bile, a duct about three inches long formed by the union of the cystic and hepatic ducts, and conveying the bile to the duodenum. D. of Cuvier, in the fetus, one of two short transverse venous trunks, on either side, opening into the auricle of the heart, each being formed by the union of a superior vein, the primitive jugular, and an inferior vein. The right one becomes the superior vena cava; the left one disappears. D., Cysthepatic. See Hepato-cystic. D., Cystic, the excretory duct of the gall-bladder; it is about $I \pi / 2$ inches long, runs backward, downward, and to the left and unites with the hepatic duct to form the common bile-duct. D. of Darwin. See $D$., Cement. D., Definitive, one of the straight milk-ducts in the nipple. D., Efferent. Same as Canal, Deferent. D., Egestive. See D., Excretory. D., Ejaculatory, a duct about an inch long, on either side of the body, formed by the union of the vas deferens and the seminal vesicle. The semen passes through it into the urethra. D., Endolymphatic, a tubular process of the membranous labyrinth of the ear, passing through the aqueduct of the vestibule into the cranial cavity, where it terminates below the dura mater in a blind enlargement, the sacculus endolymphaticus. D., Esophagocutaneous, in biology, a duct joining the esophagus with the branchial pore, and thus with the exterior. D., Excretory, the tube through which the secretion of a gland is discharged. D., Galactophorous, one of the 15 or 20 milk-ducts of the lobes of the mammary glands. They converge toward the areola, and terminate upon the surface of the nipple in small depressions. D., Gall. See D., Bile, D., Hepatic, and D., Cystic. D. of Gärtner, the canal of Gärtner. See Canal. D., Genital, the genital canal. See Canal. D., Guttural, the Eustachian tube. D., Hepatic, a duct, $I 1 / 2$ inches long, formed at the margin of the transverse fissure of the liver by the right and left hepatic ducts. It unites with the cystic duct to form the common bile-duct. D., Hepatic, Left, a duct arising from the left lobe of the liver, and joining the right hepatic duct to form the common hepatic duct. D., Hepatic, Middle, an occasional branch of the hepatic duct, conveying the bile from the quadrate lobe of the liver. D., Hepatic, Right, a duct arising from the right lobe of the liver, and joining the left hepatic duct, to form the common hepatic duct. D., Hepato-cystic, one of the biliary ducts emptyıng 
directly into the gall-bladder. D.,Hepato-pancreatic, a duct conveying the secretions of the liver and pancreas into the intestinal canal; the common bile-duct. D., Hermaphrodite, a duct that in hermaphroditic animals receives the male and female elements. D., Hem1thoracic, an ascending branch of the thoracic duct, given off high in the thorax, and opening either into the right lymphatic duct or close to the angle of union of the right subclavian and right internal jugular veins. D. inferens, in certain Edentata, one of the ducts leading from the submaxillary glands to a common receptacle for the secretion of the gland. D., Intercellular, the intercellular canal. See Canal. D., Interlobular, Bile, one of the ducts situated between the lobules of the liver. They are of two varieties, small and large. D., Intralobular, Bile, one of the intralobular canals. See Canal. D., Lachrymal. See D., Nasal. D., Lactiferous. See D., Galactophorous. D., Leydig's. See D., Mesonephric and D., Urogenital. D., Lymph. See D., Thoracic. D., Lymphatic. See D., Thoracic. D., Lymphatic, Left. See $D$., Thoracic. D., Lymphatic, Right, the vessel that receives the lymph from the absorbent vessels of the right arm, the right side of the head and neck, the chest, lung and right side of the heart, and also from the upper surface of the liver. It terminates at the junction of the right subclavian and internal jugular veins. D., Mammary. See D., Galactophorous. D., Mesonephric, an embryonic duct belonging to the mesonephron, and formed by the longitudinal fission of a portion of the segmental duct. In the male, it becomes the vas deferens, while in the female it almost entirely disappears. D., Metanephric, the Ureter, $q . v$. D., Milk. See D., Galactophorous. D., Muco. See Canal, mucous. D., Mucous. See Canal, mucous. D. of Müller, a tube (on either side of the body) formed by the undivided portion of the segmental duct, and of the longitudinal tubes into which it divides. From them in the female are developed the oviducts, uterus and vagina, while in the male they atrophy and disappear. D., Nasal, the duct, $1 / 2$ an inch long, that conveys the tears from the lachrymal sac into the inferior meatus of the nose. D., Naso-lachrymal. See D., Nasal. D., Nuckian, one of the excretory ducts of the orbital gland of the dog. D., Omphalic. See $D$., Vitelline. D., Omphalo-mesenteric. See $D$, Vitelline. D., Pancreatic, a duct that extends from the pancreas to the duodenum at the point where the common bile-duct enters the bowel. D., Pancreatic, Accessory, the excretory duct of the lesser pancreas, opening into the pancreatic duct or into the duodenum, close to the orifice of the common bile-duct. D., Pancreatic, Supplementary. See D., Pancreatic, Accessory. D., Parotid. See D. of Stensen. D. of Pecquet, the thoracic duct. D., Pneumatic, in fishes, the tube that connects the swimming-bladder with the esophagus. D., Pronephric. See D., Segmental. D., Prostatic, one of the ducts conveying the secretion of the prostate into the urethra. D., Reticulate, in biology, an aggregation of parenchymatous tissue-cells, in which the thickenings assume the form of a network. D. reuniens, a small duct leading from the saccule to the membranous labyrinth of the cochlea. D. of Rivini, one of the ducts of the sublingual gland. D., Roriferous. See $D$., Thoracic. D., Sacculo-utricular, a small canal connecting the saccule of the internal ear with the utricle. D. of Santorini. Same as D., Pancreatic, Accessory. D., Scalariform, in biology, one of numerous parallel narrow and elongated bordered pits in plant-cells set close together like the rounds of a ladder. D., Secretory, one of the smaller ducts of a gland, tributaries of the excretory duct. D., Segmental, in embryology, a tube, on either side of the body, situated between the visceral and parietal layers of the mesoblast, opening anteriorly into the body-cavity, and posteriorly into the cloaca. D., Seminal. See D., Ejaculatory. D., Spermathecal, in certain Mollusca, the duct that connects the spermatheca with the hermaphrodite duct. D., Spermatic, the Vas deferens; q. v. D., Spiral, in biology, the prosenchymatous cell-tissue, the walls of which are marked by spiral thickenings. D. of Steno. See $D$. of Stensen. D., Stenon's. See D. of Stensen. D., Stenonine. See $D$. of Stensen. D. of Stensen, I. a duct about $2 \mathrm{I} / 2$ inches long, conveying the secretion of the parotid gland into the mouth, opening on the inner side of the cheek, about opposite to the second upper molar tooth. 2. See Canal, Incisive, D., Sublingual. See $D$. of Rivini and D. of Bartholin. D., Tear, the nasal duct. D., Testicular, the vas deferens, q. v. D., Thoracic, a duct 18 to 20 inches long, extending from the receptaculum chyli, in front of the vertebre as far as the seventh cervical vertebra, where it curves down over the subclavian artery and empties into the left subclavian vein at its junction with the left internal jugular vein. It receives the lymph and chyle not received by the right lymphatic duct. D., Thyroglossus, in the embryo, a duct that terminates upon the tongue as the foramen cecum, and leads to the rudiments of the thyroid body. D., Trabecular, in biology, prosenchymatous tissue-cells, in which thickenings cross the lumen of the cell. D., Urogenital, in biology, a duct that receives the urine and the genital products. D., Uropygial, in birds, a duct leading from the uropygial gland. D., Uroseminal. See $D$., Uro-genital. D. venosus, the smaller, shorter, and more posterior of the two branches into which the umbilical vein divides after entering the abdomen. It empties directly into the ascending vena cava. After the birth of the fetus it becomes obliterated. D., Vitellarian, the canal in which an ovum receives its investment of albuminoid substance. D., Vitelline, a temporary channel of communication between the alimentary canal of the embryo and the umbilical vesicle. D., Vitello-intestinal. See $D$., Vitelline. D. of Wharton, the duct, about two inches long, of the sublingual gland, opening in the mouth at the side of the frenum lingur. D. of Wirsung, the pancreatic duct. D., Wolffian, the mesonephric duct. D., Yellow. See Canal, Eschricht's.

Ductule (duk'-chül) [ductulus, a small duct]. A small duct, as the straight seminal ducts.

Dudgeon's Recipe. A formula for varnish to preserve sphygmographic and cardiographic tracings. It consists of one ounce of gum dammar dissolved in six ounces of rectified benzolin.

Dudley's Operation. See Operations, Table of. D. Tests. See Tests, Table of.

Duflos' Tests. See Tests, Table of.

Dugas' Test. A method of diagnosis in dislocation of the shoulder. If the hand of the affected side is made to clasp the opposite shoulder, the elbow cannot be made to touch the front of the chest.

Dugong Oil $\left(d u^{\prime}\right.$-gong $)$. The fixed oil afforded by the dugong, Halicore australis, a marine sirenian mammal. It is regarded as a good substitute for cod-liver oil.

Duhring's Disease, or Impetigo. See Impetigo, Dermatitis herpetiformis, and Diseases, Table of.

Dulcamara (dul-kam-a'-ra) [dulcamara, bitter-sweet]. Bittersweet. The young branches of $D$. solanum, containing several glucosids and an alkaloid. It: properties are not well understood. It causes nausear 
emesis and convulsive muscular movements, and in toxic doses is a narcotic poison. It is now employed in psoriasis and similar skin-diseases. D., Fld. Ext. Dose 3j. D., Decoctum, unof,, Io per cent. strength. Dose $\bar{z}$ j-ij.

Dulcamarin (dul-kam-a'-rin) [dulcamara, bitter-sweet] $\mathrm{C}_{22} \mathrm{H}_{34} \mathrm{O}_{10^{\circ}}$ An alkaloid of Bittersweet. It is a yellow, amorphous powder, with a sweetish-bitter taste, sparingly soluble in water, freely so in alcohol and acetic acid, insoluble in ether and chloroform.

Dulcin (dul'-sin). See Dulcitol.

Dulcite $\left(d u l^{\prime}-s i \bar{t}\right)$. See Dulcitol.

Dulcitol (dul'-sit-ol) [dulcis, sweet] $\mathrm{C}_{6} \mathrm{H}_{14} \mathrm{O}_{6}$. Dulcin, dulcite; an hexahydric alcohol occurring in various plants, and obtained from dulcitol manna (originating from Madagascar manna). It is made artificially by the action of sodium amalgam upon milk-sugar and galactose. It crystallizes in large monoclinic prisms, having a sweet taste. It is sparingly soluble in water, and melts at $188^{\circ} \mathrm{C}$. It is said to be two hundred times as sweet as sugar.

Dull (dul) [ME., dul, stupid]. I. Slow of perception. 2. Not resonant on percussion. 3. Not bright in appearance. 4. Not sharp; blunt.

Dullness $\left(d u l^{\prime}-n e s\right)$ [ME., dul, stupid]. The quality of being dull, in any sense; lack of resonance on percussion.

Dulong and Petit's Law. See Laze.

Dulse (duls) [Gael., duileasg, dulse]. A popular name for various edible sea-weeds, such as Rhodymenia palmata. These are popularly esteemed as pectoral remedies. Unof.

Dumas, Method of. A method for the determination of nitrogen. In a glass tube (from 70 to $80 \mathrm{~cm}$. long) sealed at one end, place a layer (about $\mathbf{I} \mathbf{~ c m}$.) of dry, primary sodium carbonate or magnesite, then pure cupric oxid $(6 \mathrm{~cm}$.$) , afterwards a mixture of the sub-$ stance with the cupric oxid; then again pure granular cupric oxid (from 20 to $30 \mathrm{~cm}$.), and finally fill the tube with pure copper turnings (about $20 \mathrm{~cm}$.). In the open extremity of the tube is placed a rubber cork, bearing a gas-delivery tube, which extends into a mercury bath. The back part of the combustion-tube, containing the carbonate, is heated first, to expel the air from all parts of the apparatus. A graduated cylinder, filled with mercury, is placed over the extremity of the exit-tube; into the tube containing mercury several cubic centimeters of concentrated potassium hydroxid are introduced by means of a pipet. The metallic copper and the layer of cupric oxid in the anterior portion of the tube are first heated and then gradually the mixture. When the combustion is completed, heat is applied to another part of the sodium carbonate layer. The graduated vessel, containing pure nitrogen, is placed in a large cylinder of water, allowed to stand a short time until the temperature is equalized, when the volume of gas is read and the temperature of the surrounding air and the barometerheight are noted.

$$
\mathrm{G}=\frac{\mathrm{V}}{760}\left\{\frac{(\mathrm{h}-\mathrm{w})}{\mathrm{I}+0.00367} \times 0.0012562\right.
$$

$\mathrm{G}=$ the weight of the nitrogen volume in grams. $\mathrm{V}=$ the absorbed volume in cubic centimeters. $\mathrm{h}=$ the barometric pressure. $w=$ the tension of aqueous vapor at the temperature $x^{\circ} \mathrm{C} .0,0012562=$ the weight, in grams, of I c.c. of nitrogen at $0^{\circ} \mathrm{C}$, and $760 \mathrm{~mm}$. pressure.

Dumb $(d u m)$ [ME., dumb, mute]. Unable to utter articulate speech. D. Ague, a populax expression for ague or malarial sickness marked by obscure symptoms. D.-bell, a weight consisting of two iron balls connected by a shaft, used in exercise for health and development. D.-bell Crystals, crystals of calcium oxalate, sometimes seen in the urine. D.-cane, the Caladium seguineum, or Dieffenbachia seguinea, a W. Indian plant; when bitten it causes the lips and mouth to swell, and thus may produce temporary inability to speak. The plant is used in preparing an ointment, and is said to be useful in dropsies.

Dumbness (dum'-nes) [ME., dumb, mute]. Inability to utter articulate speech.

Dumetose $\left(d u^{\prime}-m e t-\bar{s} s\right)$ [dumus, a bramble]. In biology, belonging to a thicket; bush-like.

Dumont's Blue. Same as Smalts.

Dumose $\left(d u^{\prime}-m \bar{o} s\right)$ [dumus, a thorn-bush]. In biology, bushy, or pertaining to a bush.

Dumoutier's Horizontal Plane. See Plane.

Duncan's Operation. See Operations, Table of.

Dung [ME., dung, dung]. Excrement; feces; ordure. D.-bath. See Pigments, Colors, and Dye-stuffs. D.-hill, a heap of dung.

Dunga (dun'-gah). Synonym of Dengue.

Dunging (dung'-ing). See Pigments, Colors, and Dye-stuffs.

Dunham's Solution. A culture-medium composed of sodium chlorid, 5 parts; dried peptone, I part; distilled water, 100 parts.

Duodenal (du-o-de'-nal, or du-odl-en-al) [duodeni, twelve each]. Relating to the duodenum. D. Ulcer, ulceration of the duodenum. It may be acute, as after severe burns or scalds, or after exposure to extreme cold; or (more commonly) it may be chronic, occurring usually in old alcoholic males. Its most frequent seat is in the first part of the duodenum, either on the anterior or posterior wall. It is probably due to the action of the gastric juice upon the intestinal wall which has been devitalized as the result of some form of malnutrition. Perforation and fatal peritonitis may ensue if the ulcer be situated on the anterior wall.

Duodenitis (du-o-den- $i^{\prime}$-tis) [duodeni, twelve each; iT $\iota$, inflammation]. Inflammation of the duodenum.

Duodeno-cholecystotomy (du-o-de'-no-ko-le-sis-tot' o-me) [duodeni, twelve each; $\chi 6 \hat{\lambda} \eta$, bile; kiorıs, bladder; $\sigma \tau \delta \mu a$, mouth]. An operation for establishing an artificial communication between the gall-bladder and duodenum.

Duodeno-enterostomy ( $d u$-o-de'-no-en-ter-os'-to-me)

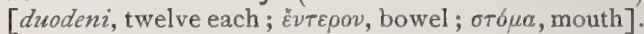
The establishment of an artificial communication between the duodenum and some portion of the small intestine.

Duodeno-jejunal (du-o-de'-no-jej-u'-nal) [duodeni, twelve each; jejunus, dry]. Pertaining to the duodenum and the jejunum.

Duodeno-renal (du-o-de'-nore'-nal) [duodeni, twelve each; ren, the kidney]. Relating to the duodenum and to the kidney.

Duodenostomy (du-o-de-nos'-to-me) [duodenum; $\sigma \tau 6 \mu \alpha$, a mouth ]. The operation of opening the duodenum, and the attachment of the lips of the intestinal slit to the walls of the abdomen, in order to form an artificial mouth for the introduction of nutriment.

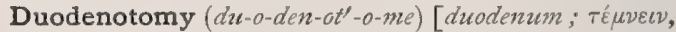
to cut]. Surgical incision of the duodenum.

Duodenum (du-o-de'-num, or $\left.d u-o d^{\prime}-e n-u m\right)$ [duodeni, twelve each; so called because it is about twelve finger-breadths long]. The first part of the small intestine beginning at the pylorus.

Duotal ( $\left(u^{\prime}-0\right.$-tal). Guaiacol carbonate, $\mathrm{C}_{15} \mathrm{O}_{5} \mathrm{H}_{14}$, a crystalline substance ; it is used in tuberculosis. Dose gr. iij-viij, three times a day.

Duplay's Operation. See Operations, Table of.

Duplicana (du-plik-a'-nah) [duplicare, to double]. A double tertian ague. 
Duplication $\left(d u-p l i k-a^{\prime}-s h u n\right)$. Same as Reduplication, q. $v$.

Duplicature $\left(d u^{\prime}\right.$-plik-a-chur) [duplicare, to double]. The reflection, or folding of a membrane upon itself.

Duplicity (du-plis'-it-e) [duplicitas, doubleness]. The condition of being duplex or double.

Dupuytren's Contraction. See Diseases, Table of. D. Hydrocele. See Diseases, Table of. D. Ointment, an ointment used to correct baldness. It contains ox-marrow 250 , lead acetate 4 , balsam of Peru 8 , diluted alcohol 30 , tinct. of camphor, $11 / 2$, tinct. of cloves and tinct. of cinnamon, each I. D. Operation. See Operations, Table of. D. Splint, a splint used in the treatment of Pott's fracture of the leg. D. Suture. See Suture.

Dura (du'-rah) [durus, hard]. The Dura mater, $q . v$. D. mater, the outer membrane of the brain and spinal cord. It is divided into the cerebral and spinal or rhachidian dura, and its cerebral portion is in part identical with the endocranium. D. m. testis, the tunica albuginea of the testis.

Duræmatoma (dur-em-at-o'-mah). See Durematoma.

Dural (du'-ral) [durus, hard]. Pertaining to the dura.

Duramen (dur-am-en) [durare, to harden]. In biology, heart-wood.

Durande's Solvent. A solvent for biliary calculi; it consists of three parts of ether and two of turpentine, administered in capsules immediately before meals. D. Treatment. See Treatment, Methods of.

Duration (du-ra'-shun) [durare, to last]. Continuance in time. D. of Life, several methods of ascertaining the duration of life are employed: I. The Mean Age at Death; 2. the Probable Duration of Life; 3. the Mean Duration of Life; 4. the Expectation of Life, or mean after-lifetime; and 5. the number living out of which one dies annually. According to the English Life-table No. 3, the mean age at death is 40.9 years, but this test is, for several reasons, fallacious, though it is of exceptional interest when the deaths from various diseases are considered. See Probable D. of L., Expectation of Life, and Life-table.

Durematoma (dur-em-at-o'-mah) [dura, hard; aina, blood; $\ddot{b} \mu x$, tumor: $p l$., Durematomata]. Hematoma of the dura; an accumulation of blood between the dura and arachnoid.

Durene $\left(d u^{\prime}-r e ̂ n\right)$ [durus, hard] $\mathrm{C}_{10} \mathrm{H}_{14^{*}}$ A hydrocarbon, present in coal-tar. It is a crystalline substance that possesses a camphor-like odor; it melts at $79-80^{\circ}$ $\mathrm{C}$, and boils at $190^{\circ} \mathrm{C}$.

Dürer, Angle of. See Angle. D., Plane of. See Plane.

Durham's Tube. The lobster-tail tube largely used in tracheotomy.

Durilic Acid (du-ril'-ik). See Acid, Durilic.

Duro-arachnitis (du'-ro-ar-ak-ni'tis) [durus, hard; áó́ $\chi \nu \eta$, a spider; $\iota \tau \iota \varsigma$, inflammation]. Inflammation of the dura and arachnoid membrane.

Duroziez' Murmur. See Signs and Symptoms, Table of.

Dusart-Blondlot's Test. See Tests, Table of.

Dust-occupations. Those that from the nature of the particles of the dust produced may give rise to pneumoconiosis, tuberculosis, or bronchitis.

Dutch (duch) [ME., Dutche]. Pertaining to Holland. D. Bitters. See Latifia. D. Gold, an alloy of copper and zinc. D. Liquid. See Ethene Chlorid. D. Mineral, copper beaten out into very thin leaves. D. White. Same as Hamburg White

Duval's Operation. See Operations, Table of.

Du Verger, Suture of. See Suture. D. Method. See Operations, Table of.

Duverney, Foramen of. See Foramina, Table of. D. Glands. See Gland.
Dware's Test. See Tests, Table of.

Dwarf (dworf) [ME, dwarf]. A being characterized by completed physical development, but having the various parts of unnaturally small dimensions, owing to insufficient growth. This condition is frequently associated with sterility and impotence. See Nanism, Nanus. D. Elder, the Aralia hispidia. Its root is a valuable diuretic. Dose of fld. ext. $3 \mathrm{j}$-ij. Unof. D. Tape-worm. See Tania nana.

Dyad $\left(d i^{\prime}-a d^{\prime}\right)$. See Quantivalence.

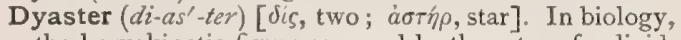
the karyokinetic figure assumed by the aster of a dividing nucleus before the formation of the stars at the ends of the nuclear spindle. It is the sixth stage of Karyokinesis.

Dye (di) [ME., dyen, to dye]. To color a substance by immersing it in some coloring-matter. The material used as a coloring-substance. D.-stuffs. See Pigments, Colors, and Dye-stuffs.

Dyer's Broom. See Pigments, Conspectus of.

Dyerism $\left(d i^{\prime}-e r-i z m\right)$ [Dyer, the physician who proposed it]. A simple means of giving exercise to all the ocular muscles at once. It consists merely in reading a certain definite small amount daily, and increasing that amount systematically as the strength of the eyes increases.

Dyerizing (di'-er-iz-ing). See Dyerism.

Dynam (di'-nam). See Dyne.

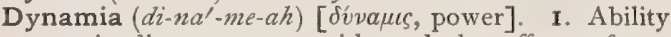
to resist diseases, or to withstand the effects of any strain, physical or mental. 2. The sthenic character of any attack of disease.

Dynamic $\left(d i-n a m^{\prime}-i k\right)$ [ $\delta \dot{v} a \mu \iota \zeta$, energy]. Pertaining to energy. In medicine, a synonym of Sthenic, $q . v . \mathbf{D}$. Squint. See Insufficiency.

Dynamics (di-nam'-iks). See Mechanics.

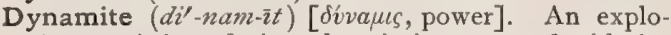
sive consisting of nitro-glycerin incorporated with infusorial earth, to give it consistency. It is eight times as powerful as gunpowder.

Dynamization (di-nam-iz-a -shun) [divauı, power]. The so-called potentizing of medicines by comminution and agitation.

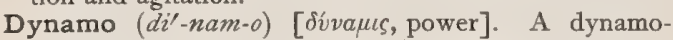
electric machine; a machine that generates dynamic, or current electricity, instead of static electricity; one in which the current is generated by revolving coils of insulated wire through the field of a magnet intensified by the same current.

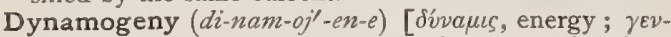
$v \bar{v} v$, to beget]. The production of energy; the physiologic generation of force.

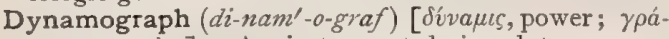
$\phi \varepsilon \iota \nu$, to write]. An instrument designed to measure and graphically record muscular strength.

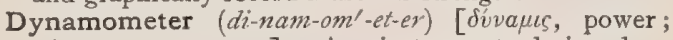

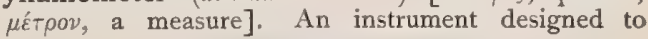

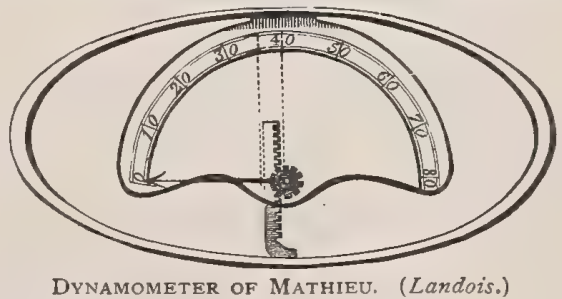

measure force, or one for the measurement of muscular strength, particularly of the hand.

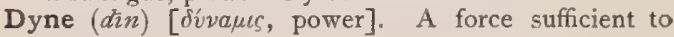


impart a velocity of one centimeter per second to a mass of one gram. See Electric Units.

Dys- $\left[\delta \varsigma_{-},\right]$a prefix implying difficulty, illness, badness; it may be represented by bad, hard, difficult, painful.

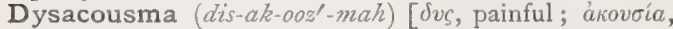
hearing]. A sensation of pain or discomfort caused by loud or even moderate noises.

Dysacusia, or Dysacousis (dis-ak-oo'-ze-ah or -sis)

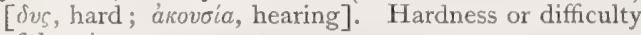
of hearing.

Dysæsthesia (dis-es-the'-ze-rh). See Dysesthesia.

Dysalbumose (dis-all-bu-mōz). See Albumose.

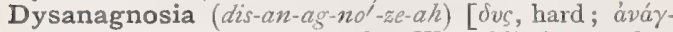
$\nu \omega \sigma \iota \zeta$, recognition, reading]. Word-blindness; dyslexia.

Dysaphe $\left(d i s^{\prime}-a f-e\right)$ [ $\delta v \varsigma$, painful ; $a \dot{\phi} \dot{n}$, touch]. Morbid state of the sense of touch.

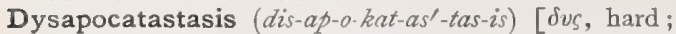

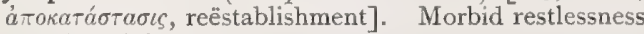
and dissatisfaction.

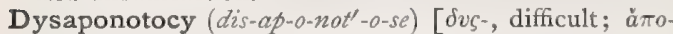
vos, painless; $\tau 6 \kappa o s$, birth.]. Painless, but difficult, labor.

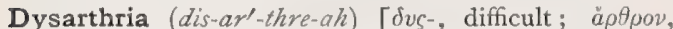
articulation]. Impairment of the power of speecharticulation, from disease of the medulla and pons. D. literalis. Synonym of Stammering.

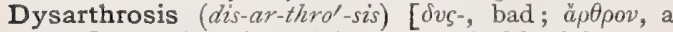
joint]. I. A deformed joint. 2, A false-joint. 3 . A dislocation of a joint.

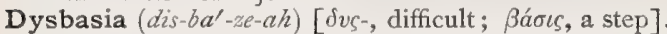
Difficulty of walking. (Proposed instead of abasia, as in the affection there is rarely absolute inability to walk.)

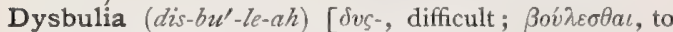
will]. Impairment of will-power.

Dyscataposis (dis-kat-ap'-o-sis). Synonym of Hydrophobia.

Dyschroa, or Dyschrœea (dis'-kro-ah or -kre'-ah) [ $\delta v c_{-}$, bad; $\chi \rho \circ a$, color]. Discoloration, especially of the skin.

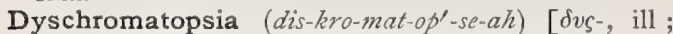
$\chi \rho \tilde{\omega} \mu \alpha$, color; ö $\psi \iota$, , vision]. Difficulty in distinguishing colors.

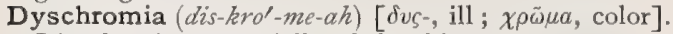
Discoloration, especially of the skin.

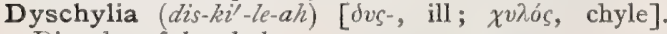
Disorder of the chyle.

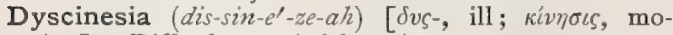
tion]. Difficult or painful motion.

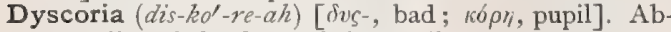
normality of the form of the pupil.

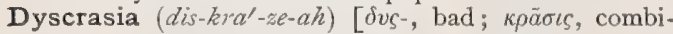
nation]. A depraved or abnormal state; an abnormal or impure condition of the blood, due to general disease.

Dyscrasic, Dyscratic (dis-kraz'-ik, dis-krat'-ik) [dvs-,

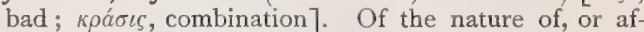
fected with a dyscrasia.

Dysecœa, or Dysecoia (dis-es-e'-ah, or dis-ek-oi'-ah)

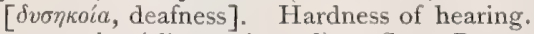

Dysenteria (dis-en-te'-re-ah). See Dysentery. D. splenica. Synonym of Melena.

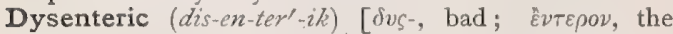
bowels]. Of the nature of or affected with dysentery.

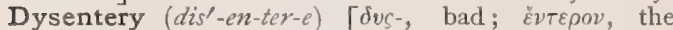
bowels]. An acute specific disease marked by inflammation of the solitary glands and follicles of the large intestine, with tormina and tenesmus, and the frequent passage of scanty and bloody stools. Death may result from asthenia, or peritonitis from perforation.
Toward the close of grave cases of the disease the stools may become watery, black (the so-called "meat'washings"), and of an offensive gangrenous odor. Dysentery is prevalent in all malarious regions, and is also likely to occur among troops when the food is poor and irritating, and the drinking-water impure. D., Algid, that form characterized by great feebleness or absence of the pulse-beat, cyanosis, aphonia, suppression of urine, cold surface, and an early fatal issue. D., Amebic, that in which the Ameba coli is found in the stools. D., Hemorrhagic, a grave bowel-disease in India, marked by profuse hemorrhages from the bowels, with collapse. D., Sporadic, a mild type occurring in temperate climates. D., White, an epidemic variety, with muco-purulent stools.

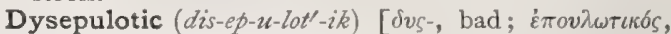
healing]. Cicatrizing slowly and imperfectly.

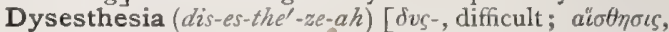
sensation]. Dulness of any sensation, especially that of touch. 2. Painfulness of any sensation not normally painful, D. interna, amnesia. D. receptiva, pain or distress felt in the vertex or occiput, often with a feeling " as if the head were being opened and shut."

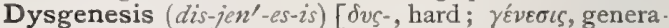
tion]. In biology, the second of Broca's four degrees of fecundity - in the union of two species. Cf. Agenesis, Paragenesis, Eugenesis.

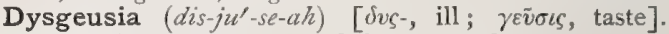
Morbidity or perversion of the sense of taste.

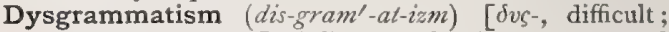

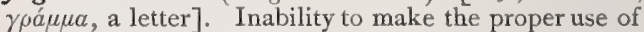
words. It is a symptom of certain cerebral diseases.

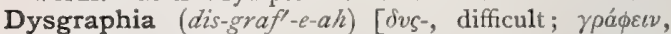
to write]. I. Inability to write, as a result of a brainlesion. 2. Imperfect configuration of an organ.

Dyshidrosis (dis-hid-ro'-sis). See Dysidrosis.

Dysidrosis (dis-id-ro'-sis) [ $\delta v \zeta-$, bad; " $i \delta \rho \omega \sigma \iota$, , sweating]. Excessive activity of the sweat-glands, in association with a retention of their secretion, probably due to some neurotic disorder. See Chiropompholyx, Pompholyx.

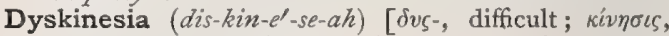
movement]. Impairment of the power of voluntary motion. See Discinesia.

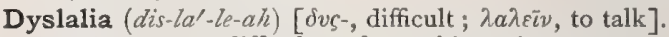
Impairment or difficulty of speaking, due to some non-central lesion (such as a defect of the vocal bands or of the palate).

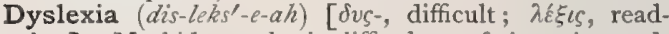
ing]. Morbid or aphasic difficulty or fatigue in reading.

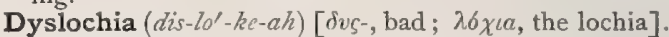
An abnormal condifion of the lochial discharge.

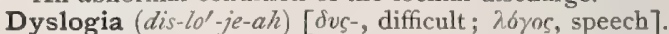
Difficulty in speech, not so much with individual words as with the expression of ideas; it is due to some central lesion. See also Alogia.

Dyslysin (dis'-lis-in) [ $\delta v \varsigma_{-}$, difficult ; $\lambda \dot{v} \varepsilon \nu$, to dissolve], $\mathrm{C}_{24} \mathrm{H}_{36} \mathrm{O}_{3}$. A resinous anhydrid of cholalic acid. It is insoluble in water, alcohol, and alkalies. It is a non-crystalline substance soluble in an excess of ether.

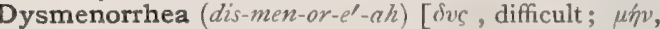
month; $\hat{c}^{\varepsilon} \varepsilon v$, to flow]. Obstructed or difficult menstruation. D., Congestive, a form of painful menstruation in which often no lesion can be found, the pain being due to an intense congestion of the pelvic viscera. In other cases there exists some morbid condition that is aggravated by the menstrual congestion. D., Intermediate, pain occurring regularly each month, but not at the menstrual period. D., Mechanical. See D., Obstructive. D., Membranous, 
painful discharge of the menstrual decidua in one or more large pieces, instead of after undergoing disintegration. D. Mixture. See Guaiac Mixture, Fenner's. D., Neuralgic. See D., Spasmodic. Also, a term applied to Neurotic dysmenorrhea, q. $v$. D., Neurotic, a peculiar form of dysmenorrhea occurring in women of neurotic temperament and marked by neuralgic pains, not confined to the pelvis, but distributed over the body. D., Obstructive, that due to mechanical obstruction to the free escape of the menstrual fluid. It is usually due to contraction of the cervical canal, associated with anteflexion of the uterus. D., Ovarian, that form in which the pain is apparently entirely in the ovaries. It is aching or burning in character and referred to the ovarian center, a spot at the level of and about two inches internal to the anterior superior iliac spine. D., Spasmodic, that form of dysmenorrhea due to spasmodic uterine contraction. It is often associated with deficient uterine development.

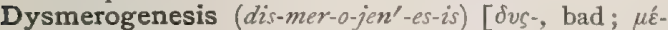
pos, a part; $\gamma \in v \nu \tilde{a} \nu$, to beget]. In biology, a variety of budding in which the various buds are very dissimilar.

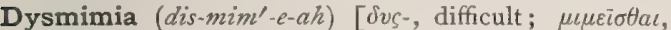
to mimic]. Aphasic difficulty in using signs or symbols in lieu of words.

Dysmnesia (dis-mne'-ze-ah) [dvc-, difficult; $\mu \nu \eta \sigma \iota s$, memory]. Impairment or defect of the memory.

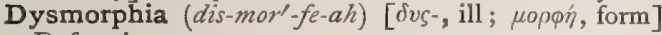
Deformity.

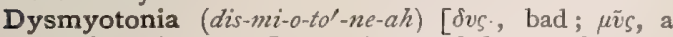
muscle; toros, tone]. I. Atony of the muscles. 2. Excessive tonicity in muscles; myotonia.

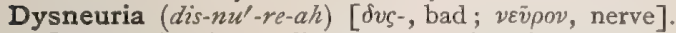
Nervous disorder or distress ; sense-impairment.

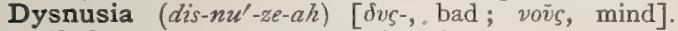
Weakness or impairment of the mind.

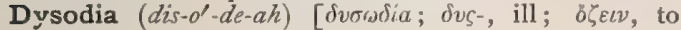
smell]. Fetor; stench; ill smell. Also a synonym of Rhinitis atrophica, q. $v$.

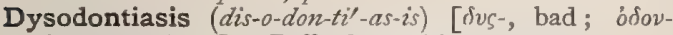

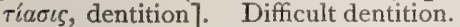

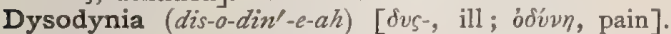
Ineffective labor-pains.

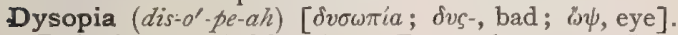
Defective or painful vision. D. tenebrarum. Synonym of Hemeralopia.

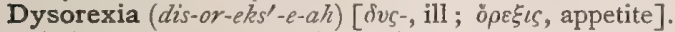
A depraved or unnatural appetite.

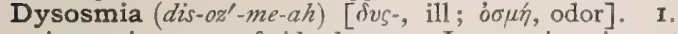
An unpleasant or fetid odor. 2. Loss or impairment of the sense of smell.

Dysosphresia (dis-os-fre'-ze-ah) [dvs-。ill ; ö $\sigma \phi \rho \eta \sigma \varsigma$, smell]. Impairment of the sense of smell.

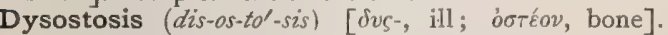
Defective formation of bone.

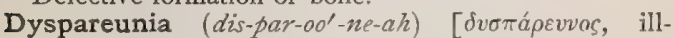
mated]. Painful or difficult performance of copulation from physical incompatibility.

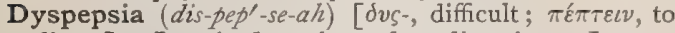
digest]. Impaired or imperfect digestion. It may be acute, from some error in diet, or chronic, due to catarrh of the mucous coat of the stomach, the presence of abnormal ferments, or to other slowly-acting pathologic conditions of the viscus. D., A tonic, a derangement of the stomach, with disorder of its functions, due to insufficient quantity or impaired quality of the gastric juice, or to deficient action of the gastric muscles. D., Colonic. See Enteritis, Membranous. D., Duodenal. See Enteritis, Membranous. D., Follicular. Synonym of Enteritis, Membranous. D., Intestinal, due to defects in the pancreatic, biliary, or intestinal secretions, or to deficient peristalsis. It is marked by borborygmi, flatulence, etc. D., Irritative, the catarrhal form of imperfect gastric digestion. D., Nervous, that form characterized by sensations of distress and uneasiness during digestion, although the act is accomplished within the physiologic timelimit. It occurs most frequently in those of the neurotic constitution. D., Smokers'. See D., Tobacco. D., Tobacco, that due to excessive use of tobacco.

Dyspepsodynia (dis-pip-so-din'-e-ah). Synonym of Gastraligia.

Dyspepsy (dis-pep'-se). See Dyspepsia.

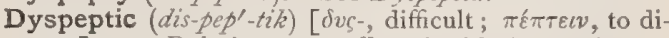
gest]. I. Relating to or affected with dyspepsia. 2. One who has dyspepsia.

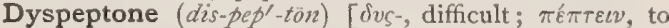
digest]. An insoluble and unassimilable product of the gastric digestion of proteids. See Metnpeptone and Hemiprotein

Dysperistalsis (dis-per-is-tal'-sis) [dvs-, painful; $\pi \varepsilon \rho i$, around; $\sigma \tau a ́ \lambda \sigma \iota \varsigma$, compression]. Violent peristaltic action of the intestine.

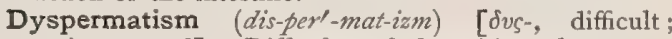
$\sigma \pi \varepsilon \hat{\rho} \mu \alpha$, seed]. Difficulty of depositing the sperm within the vagina.

Dyspermia (dis-perm'-e-ah). See Dysspermia.

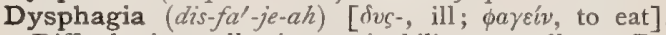
Difficulty in swallowing, or inability to swallow. D., Convulsive. Synonym of Esophagismus. D. globosa, globus hystericus. D. hysterica. Synonym of Globus hystericus. D. spastica, dysphagia due to hysteric spasm of the esophagus or pharynx.

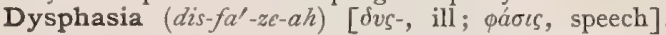
Imperfect or disconnected speech, arising from loss of or faulty arrangement of words, and dependent upon a central lesion.

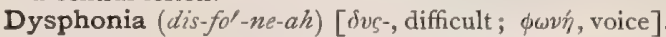
A condition of defective voice; hoarseness. It is due to some acute or chronic inflammatory condition, newgrowths, paralysis, or ulcerations of the vocal bands. D. clericorum, chronic glandular laryngitis; clergyman's sore-throat, $q . v$. D. spastica, speakers' cramp stammering of the vocal bands.

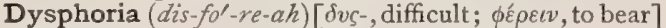
Impatience and restlessness; mental anxiety; fidgets.

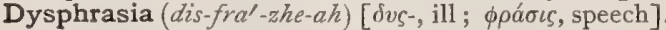
Imperfect speech, due to impairment of the mental powers. Kussmaul's term for a mental condition in which the emotion is opposed to the words designed to express it.

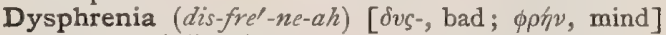
Any mental disorder.

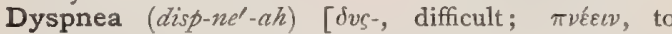
breathe]. Difficult or labored breathing, arising from various causes, as laryngeal or tracheal obstruction, heart-disease, kidney-disease, lung-disease, or anemia. It may be either inspiratory or expiratory, according as it is mainly dependent upon the muscles of inspiration or expiration; or it may be general, that is, both inspiratory and expiratory. D., Asthmatic, that due to asthma. D., Cardiac, that due to heart-disease. D., Postural. See Orthopnea. D., Renal, that due to renal disease. D., Uremic, that due to uremia. D., Rhythmic. See Cheyne-Stokes Respiration.

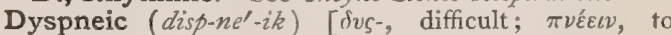
breathe]. Affected with or caused by dysprea. D. Coma. See Coma diaceticum.

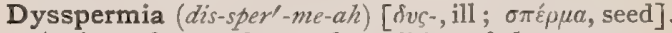
An imperfect or abnormal condition of the semen.

Dysstasia, or Dystasia (dis-t $\left.\alpha^{\prime}-z e-a h\right)$ [dv/-, ill;

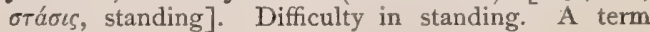


proposed for astasia, as in this affection there is rarely absolute inability to stand. D. Dysbasia. See Astasia-abasia.

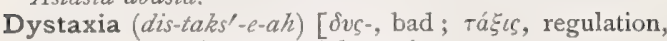
order]. Ataxia, or partial ataxia.

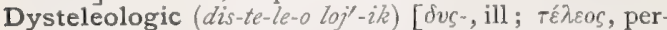
fect; $\lambda \delta$ jos, science $]$. Pertaining to Dysteleology.

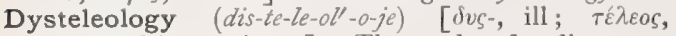
perfect; $\lambda 6$ ros, science]. The study of rudimentary and useless organs, such as the vermiform appendix.

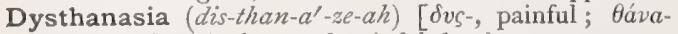
Tos, death]. A slow and painful death.

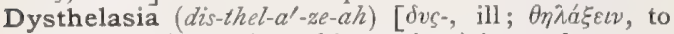
suck]. Difficulty in sucking or in giving suck.

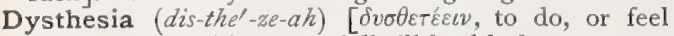
ill]. I. Ill condition, especially ill health due to a nonfebrile disorder of the blood-vessels. 2. Impatience; fretfulness; ill-temper in the sick.

Dysthetic (dis-thet'-ik) [ $\delta v \sigma \theta \varepsilon \tau \varepsilon \varepsilon \varepsilon v$, to do or feel ill]. Of the nature of a dysthesia; cachectic.

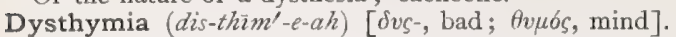
Melancholy or mental perversion. D. algetica, mental perversion due to peripheral nerve-irritation. D. neuralgica, mental perversion due to facial or other neuralgias.

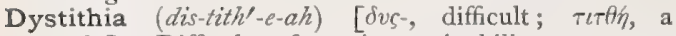
nipple]. Difficulty of nursing or inability to nurse at the breast.

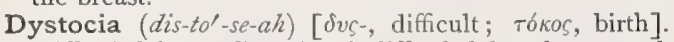
Difficult labor. D., Fetal, difficult labor due to such fetal irregularities as displacement of the arm, excessive size, plural pregnancy, monsters, etc. D., Maternal, due to some defect on the side of the mother, as pelvic deformity or disease.

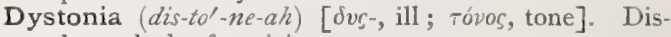
order or lack of tonicity.

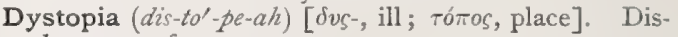
placement of any organ.

Dystrophia (dis-tro'-fe-ah). See Dystrophy.

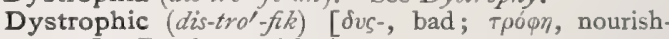
ment]. Poorly nourished.

Dystrophoneurosis (dis-trōf-o-nu-ro'-sis) [dvc-, bad;

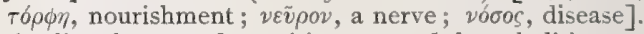
A disturbance of nutrition caused by abolition or perversion of nervous influence; or a nervous disease caused by ill-nutrition.

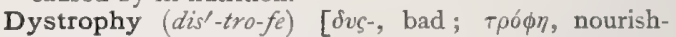
ment]. Imperfect or faulty nourishment. D., Primary Muscular. See Atrophy, Idiopathic Muscular.

Dystropodextrin (dis-tro-po-deks'-trin) [dvs-, bad ; $\tau \rho \varepsilon ́ \pi \varepsilon \iota \nu$, to turn; dexter, right]. A starchy material existing in normal blood, and but slightly soluble.

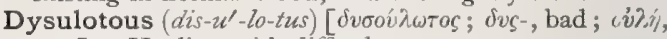
scar]. Healing with difficulty.

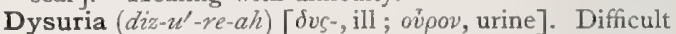
or painful urination; it may be due to calculi, cystitis, spasm, stricture.

Dysuric $\left(d i z-u^{\prime}-r i k\right)$ [ $\delta v \zeta-$, ill; ovpov, urine]. Affected with or relating to dysuria.

Dysury (diz'-u-re). Same as Dysuria.
E. Abbreviation of Eye and Emmetropia.

E. M. F. Abbreviation of Electro-motive Force.

Ext. Abbreviation of Extractum.

Eagle-wood $\left(e^{\prime}-g\right.$-twood $)$. See Asallochum.

Ear (êr) [ME., ere, ear]. The organ of hearing. It consists of the outer or external ear, the middle ear or tympanum, and the internal ear or labyrinth. I1lustrated details are shown in the annexed cuts. E.ache. See Otalgia. E.-bone, an auditory ossicle. E., Cat's, a deformity of the ear, causing it to resemble the ear of a cat. E.-cough, reflex cough from irritation or disease of the ear. E.-crystal, an otolith. E.-deformities. That insane, imbecile, and idiotic persons often have deformities of the external ear is a fact well established. Among the named deformities are the following: Blainville's ear designates asymmetry of the two ears. Cagot ear is an ear with no lower lobe; but it is asserted that this is a peculiarity of the Lapps, and not of the Cagots. Darwin's ear lacks the upper part of the helix, and the remainder of the helix contains nodules of cartilage. Morel's ear is large, flattened down, as if ironed, with a thin rim and depressed folds. In Stahl's ear the helix is flattened and masked with the antihelix, neither the fossa ovalis nor the fossa scaphoidea being visible. In Wildermuth's ear the anti-helix is unduly prominent. See also Hamatoma auris and Diseases, Table of. E., Drum of. See Tympanum. E.-dust, the otoconia, q. $v$. E.-finger, the little finger. E., Flap, a deformity of the ear in which it is pendulous, as in certain animals. E.-giddiness, a synonym of Ménière's Disease. E.-hole, the external auditory meatus. E., Inflammation of. See Otitis. E., Internal, the Labyrinth, q.v. E.-lobe,. the lobe of the ear. E., Middle. See Tympanum. E.-sneezing, sneezing produced by inflammation of the ear. E.-spoon, a curet used in removing cerumen. E.-stone. See Otolith. E.-trumpet, an instrument for gathering a larger number of waves of sound to a focus, and thus improving the hearing of those partially deaf. E-tumor, Hamatoma auris, q. v. E.-vertigo, a synonym of Ménière's Disease. E.-vomiting, reflex vomiting from auditory disease. E.-wax. See Cerumen. E.-wig, an insect (Forficula auricularia) erroneously supposed to have a fondness for secreting itself in the external auditory meatus.

Earth (erth) [ME., erthe, earth]. In chemistry, a name given to various metallic oxids or silicates, not soluble in water and not affected by great heat. E., Alkaline, the oxids and hydrates of calcium, magnesium, strontium, barium, and other metals of the same group. E.-bath, a sand bath. See Bath. E., Cimolian. See Cimolian. E.-closet, a privy in which the dejecta are disposed of by the Dry-earth System, q. v. E.-cure, the therapeutic use of earth, soil, mud, or sand. E.-dressing, a dressing of earth for wounds, bruises, etc. It has marked deodorizing powers. E., Fuller's, a clay used as an absorbent dressing for sores. See also Ammotherapy, Bole. 
E.-worm, a common soil-inhabiting worm, Lumbricus terrestris. An oily liniment prepared from earthworms is vulgarly held in high esteem as a relaxant for contracted tendons. In Russia a preparation of earth-worms is highly valued as a diuretic.

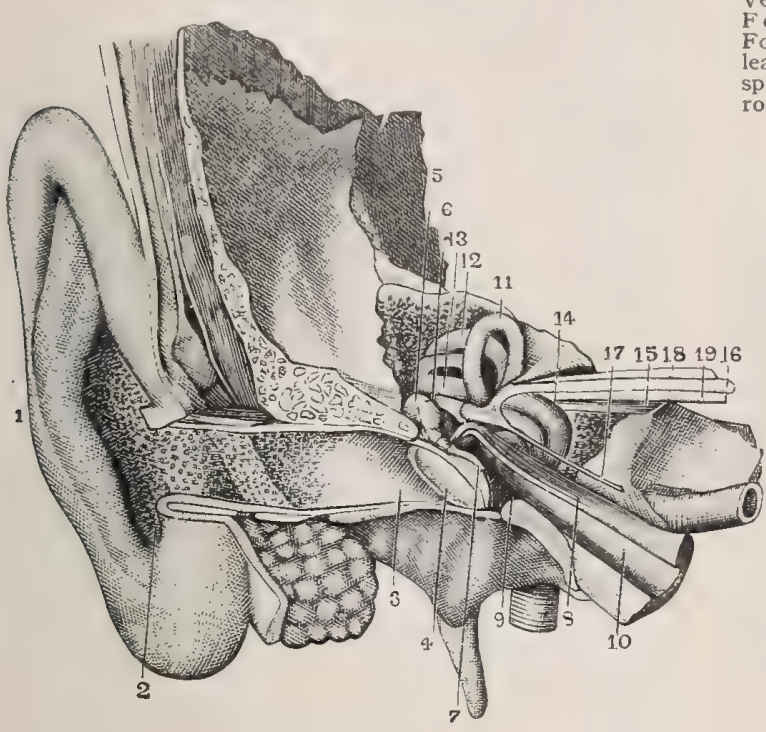

THE EAR,

I Pinna, or auricle. 2. Concha. 3. External auditory canal. 4. Membrana tympani. 5. Incus. 6. Malleus. 7. Manubrium mallei. 8. Tensor tympani. 9. Tympanic cavity. Io. Eustachian tube. II. Superior semicircular canal. I2. Pos. terior semicircular canal. I3. External semicircular canal. 14. Cochlea. 15. Internal auditory canal. I6. Facial nerve. 14. Cochlea. I5. Internal auditory canal. I6. Facial nerve, nerve. I9. Cochlear branch.

AUDITORY OSSICLES.

2. Head of Malleus. 2. Processus brevis. 3. Processus gracilis. 4. Manubrium. 5. Long process of incus. 6. Articulation between incus and stapes. 7. Stapes.
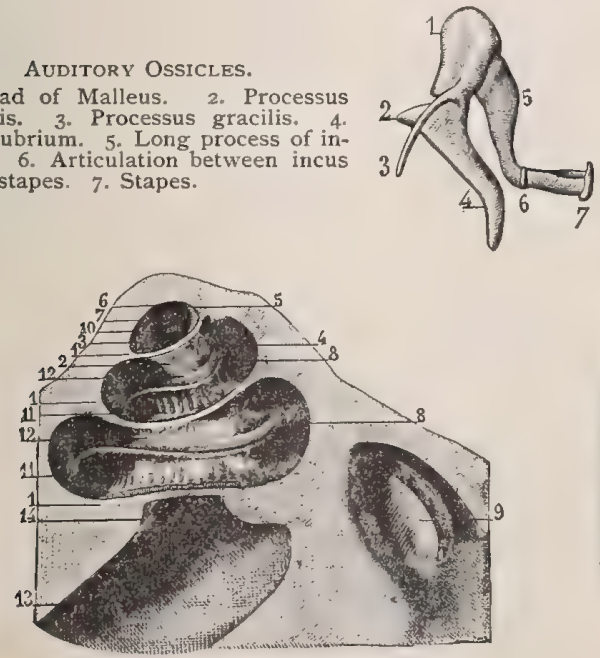

Cochlea (Lamina spiralis ossea).

I, I, I. Surrounding bony structure. 2. Semi-infundibuliform lamella. 3. Its concave surface. 4. Concave border in which it terminates. 5. Anterior extremity of this border. 6. Cupola, superior two-thirds removed. 7. Inferior portion of base of semi-infundibuliform lamella. 8, 8. Lamina spitalis ossea. Its origin. Io. Its beak or terminal portion. I1, II. Scala tympani 12. Scala vestibuli. I3. Internal auditory canal. I4. Fossa at the base of the modiolus.
OSSEOUS LABYRINTH OF THE EAR (LAMINA SPIRALIS OSSEA).

I, 2, 3. Semicircular canals. Vestibule. 5. Ampulla. 6. Fovea semi - elliptica. Fovea hemispherica. 8. Cochea. 9. Origin of $\mathrm{lamina}$ spiralis ossea, 10. Foramen rotundum.

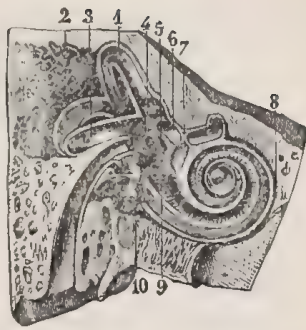

OSSEOUS and MEmbranous LABYRINTH OF THE EAR.

I. Vestibular branch of auditory nerve. 2. Branch for sacculus. 3. Branch for utric ulus. 4. Branch for ampulla of membranous posterio semicircular canal. 5. Branch for ampulla of external canal. 6. Branch for ampulla of supeperior canal ampullar Cochlear

branch of auditory nerve. 8. Cochlea.
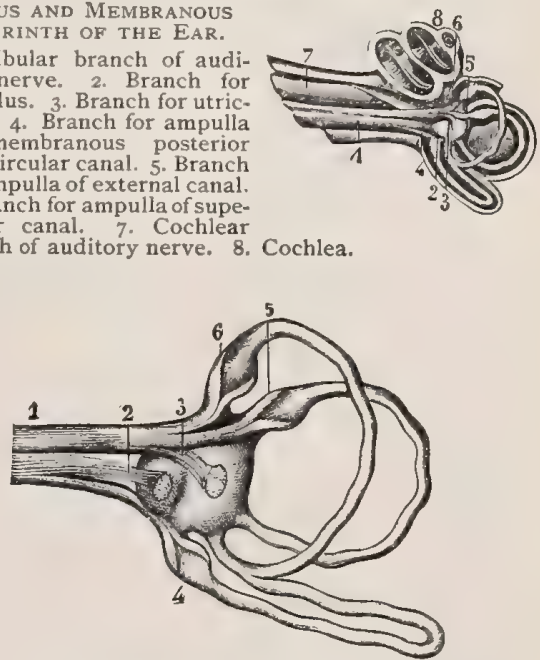

MEMBRANOUS LABYRINTH OF THE EAR.

Distribution of the vestibular branch of the auditory nerve to the membranous labyrinth; membranous vestibule and semicircular canals. $\times 3$

1. Vestibular branch. 2. Saccular branch. 3. Utricular branch. 4. Branch to ampulla of external membranous semicircular canal. 5. Branch to ampulla of superior membranous semicircular canal.

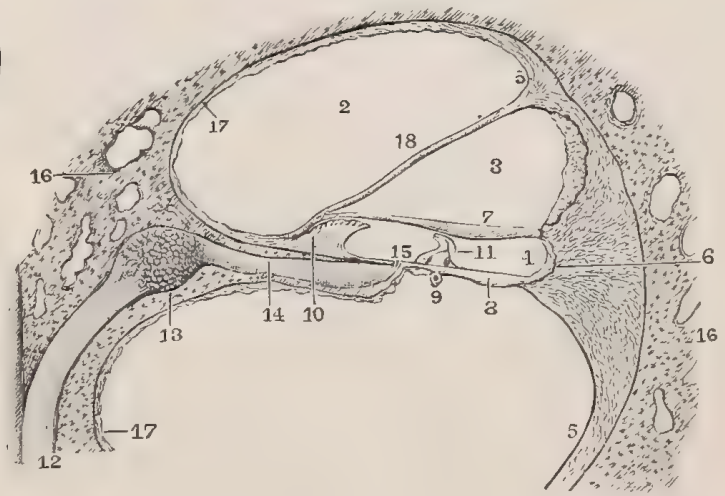

COCHLEA

I. Scala tympani. 2 Scala vestibuli. 3. Anterior or triangu lar canal. 4. Posterior or quadrilateral canal. 5, 5. Spiral ligament. 6. External spiral sulcus. 7. Membrana tectoria or membrane of Corti. 8. Membrana basilaris. 9. Spiral vessel, Io. Limbus laminæ spiralis. Ir. Pillars of organ of Corti. I2. Branch of cochlear nerve. 13. Ganglion spirale. I4. Branch of cochlear nerve between the lamella of the lamina spiralis ossea. 15. One of the orifices by which this branch penetrates the canal of Corti. I6. Part of bony cochlea. 17 . Lining periosteum $18 . M$ Membrane Reissner. 
Easton's Syrup. See Ferrum.

Eat $(\hat{e} t)$ [AS., etan, to eat]. To masticate and swallow food.

Eau(o) [Fr.]. Water, E. de Cologne, cologne water. E. de Vie, brandy; alcoholic spirit.

Eberth's Bacillus. See Bacteria, Synonymatic Table of. E's. Lines. See Lines, T'able of.

Ebner's Glands. See Gland.

Eboli's Test. See Tests, Table of.

Ebonite $\left(e b^{\prime}-o n-\bar{i} t\right)$ [ebon, ebony]. Black hard rubber. See Vulcanite.

Ebracteate (e-brak'-te-āt) [e, priv.; bractea, a thin plate]. In biology, destitute of bracts.

Ebrietas (e-bri'-et-as) [L.]. Synonym of Alcoholism.

Ebriety, Ebriosity (e-bri'-et-e, e-bre-os'-et-e). Synonym of Alcoholism.

Ebstein's Theory. A theory as to the origin of gout. He claims that a nutritive tissue-disturbance is the primary change, leading to necrosis, and in the necrotic areas the urates are deposited. E.'s Treatment. See Treatment, Methods of.

Ebullition (eb-ul-lish'-un). See Boiling.

Ebur $\left(e^{\prime}-b u r\right)[\mathrm{L}$.$] . Ivory. E. dentis, dentine, q . v$.

Eburnation $\left(e-b u \gamma^{-} n \alpha^{\prime}-s h u n\right)$ [ebur, ivory]. I. Increase of the earthy constituents of bone causing greater size and density of the same. 2. Ossification of a cartilage; calcareous infiltration of a tumor.

Eburneous (e-bur'-ne-us) [ebur, ivory]. In biology, ivory-white.

Ecalcarate (e-kal'-kar-āt) [e, priv. ; calcar, a spur]. In biology, destitute of a spur or spur-like process.

Ecarinate (e-kar'-in-āt) [e, priv.; carina, keel]. In biology, destitute of a carina or keel-like structure.

Ecaudate $\left(e-k a z v^{\prime}-d \bar{a} t\right)$ [e, priv.; cauda, a tail $]$. In biology, tailless; without a tail-like appendage. See Acousdal.

Ecballium (ek-bal"-e-um). See Elaterium.

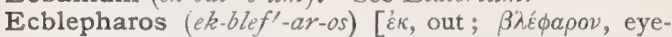
lid]. An ancient form of artificial eye.

Ecbloma (ek-blo'-ntah) [ย́k, out; $\beta a ́ \lambda \lambda \varepsilon \iota \nu$, to cast]. An abortion; an aborted fetus.

Ecbolic $\left(e k-b o l^{\prime}-i k\right)$ [' $\varepsilon \kappa \beta o \lambda \eta$, a throwing out]. I. Abortifacient. 2. A substance used to produce abortion, or to facilitate parturition; an abortifacient.

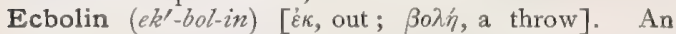
alkaloid said to be one of the active principles of ergot. Little is known about it.

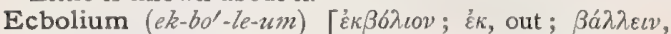
to throw: pl., Ecbolia]. Any abortifacient drug:

Eccentric (ek-sen'-trik) [ $\dot{\varepsilon} \kappa$, out ; $\kappa \hat{\varepsilon} \nu \tau \rho o \nu$, center]. I. See Excentric. 2. Odd or peculiar in behavior, but free from insanity. E. Amputation. See Amputation. E. Convulsion, one due to peripheral irritation.

Eccentricity (ek-sen-tri's'-it-e) [ย́k, out; $\kappa \hat{\varepsilon} v \tau \rho o \nu$, center]. I. Oddness or peculiarity of behavior without true insanity. 2. A peculiarity.

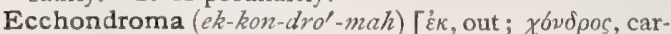
tilage: pl., Ecchondromata]. A cartilaginous tumor; a chondroma.

Ecchondrosis (ek-kon-dro'-sis) [ék, out; $\chi 6 v \delta \rho o s$, cartilage: pl., Ecchondroses]. A cartilaginous outgrowth.

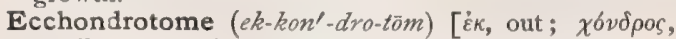
cartilage; $\tau o \mu \sigma s$, cutting]. An instrument for the surgical removal of cartilaginous growths.

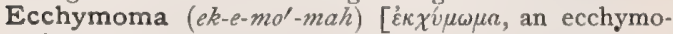
sis: pl., Ecchymomala]. A tumor made up of extravasated blood.

Ecchymosis (ek-e-mó-sis) [ $\dot{\varepsilon} \kappa \chi v \mu b \varepsilon \sigma \theta a \iota$, to extravasate blood]. An effusion of blood into the subcutaneous tissues. It is marked by a purple coloration of the skin, the color gradually changing to brown, green, and yellow. It is often the result of traumatism. See, also, Purpura.

Ecchymotic $\left(e k-e-m o t^{\prime}-i k\right)$ [ $[\varepsilon \kappa \chi v \mu \delta \varepsilon \sigma \theta a \iota$, to extravasate blood]. Relating to or looking like ecchymosis.

Ecchysis (ekl-kis-is) [ $k_{k} \chi v \sigma \iota s$, a pouring out]. Any skin-disease characterized by effusion into the dermal tissue.

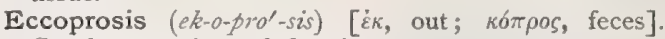
Gentle purgation; defecation.

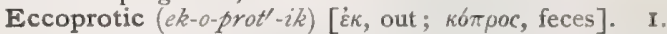
Gently aperient. 2. Any aperient remedy; a purgative.

Eccrinology (ek-rin-ol'-n-je) [ $\dot{\varepsilon} \kappa \rho i v \varepsilon \iota \nu$, to excrete; $\lambda \delta \gamma o s$, science]. The science of excretion, including its physics, physiology, and pathology.

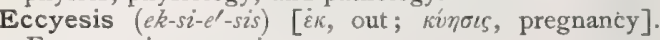
Extra-uterine gestation.

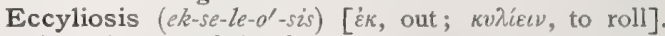
Any'disorder of development.

Ecdemic $\left(e k-a^{\prime} e m^{\prime}-i k\right)$ [E் $\delta \eta \mu o s$, away from home]. Applied to diseases originating in a distant locality; not endemic.

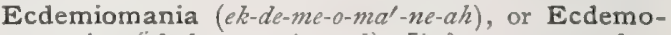

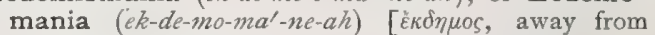
home; $\mu a v i a$, madness]. Insanity marked by a desire for wandering.

Ecdemionosus (ek-de-me-on'-o-sus) [ $\dot{\varepsilon} \kappa \delta \eta \mu \varepsilon \varepsilon \varepsilon v$, to wander; $v 6 \sigma o s$, disease]. Ecdemiomania.

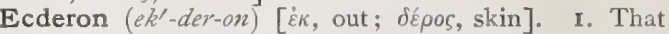
layer of skin or mucous mernbrane that lies outside of the enderon. 2. The outermost or epithelial layer of skin or mucous membrane.

Ecderonic (ek-der-on'-ik) ['́k, out; dépos, skin]. Belonging to or of the nature of the ecderon.

Ecdysis $\left(e k^{\prime}-d i s-i s\right)$ [ $\varepsilon^{\prime} \delta \delta^{\prime} \varepsilon \ell \nu$, to cast off ]. In biology, the sloughing or casting off of the skin.

Ecgonin (ek'-ga-nin), $\mathrm{C}_{9} \mathrm{H}_{15} \mathrm{NO}_{3}+\mathrm{H}_{2} \mathrm{O}$. An alkaloid produced in the decomposition of cocain by $\mathrm{HCl}$. It is very soluble in water, more sparingly in alcohol, and consists of prismatic crystals that melt at $205^{\circ} \mathrm{C}$,

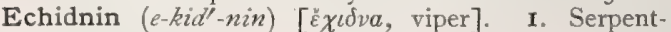
poison; the poison or venom of the viper and other similar serpents. 2. A nitrogenous and venomous principle found in the poison-secretion of various serpents.

Echinacea (ek-in-al-se-ah) ['́kĩvos, a hedgehog]. A genus of coarse composite plants of N. America. E. angustifolia. Black Sampson. The root of a perennial herb growing in the U. S. It is claimed that it possesses marked alterative value in strumous and syphilitic conditions. Dose of the fluid extract $m x v-$ xxx. Unof.

Echinate $\left(e k^{\prime}-i n-\bar{a} t\right)$ [echinatus, prickly, from echinus, a hedgehog]. Beset with prickles.

Echinochrome $\left(e-k i^{\prime}-n o-k r \bar{o} m\right)$ ['́xivos, a sea-urchin; $\chi \rho \tilde{\omega} \mu \alpha$, color]. In biology, a brown pigment of respiratory function found by MacMunn in the perivisceral fluid of Echinus.

Echinochromogen (e-ki-no-kro'-mo-jen) [Éxĩos, a

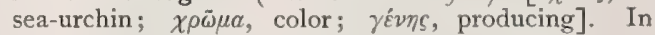
biology, the chromogen causing the deepening of color in echinochrome on exposure to air.

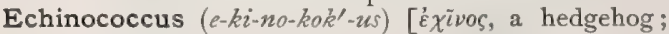

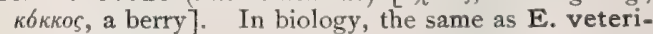
norum, the hydatid of the Tania echinococcus of the $\mathrm{dog}$, the most universally distributed of all the hydatids. It is found mainly in the liver and in the lungs of cattle. See Parasites (Animal), Table of.

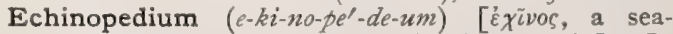
urchin; $\pi \alpha \iota \delta i o v, \operatorname{dim}$. of $\pi a \iota s(\pi a \iota \delta-)$, a child]. In biology, Huxley's term for the bilaterally symmetric larva of an echinoderm just as it leaves the egg. It in many ways resembles a worm-larva. Cf. Pluteus. 
Echinoplacid (e-ki-no-plus'-id) [ ż $^{\prime} i v o s$, a sea-urchin $\pi \lambda a ́ \xi$, a plate]. In biology, applied to echinoderms having spines on the madreporic plate.

Echinorhyncus (e-ki-no-rin'-kus) ['̇xivos, hedgehog '́v $\gamma \chi 0 \varsigma$, beak]. A worm parasitic within certain animals and occasionally found in man. E. gigas is the best-krown species. E. hominis is smaller, and is perhaps an immature form of the other. See Parasites (Animal), Table of.

Echinulate $\left(e-k i n^{\prime}-u-l a \bar{l} t\right)$ [echinulus, dim. of echinus, a hedgehog]. In biology, beset with prickles of small size.

Echitamin (e-kit'-am-in), $\mathrm{C}_{22} \mathrm{H}_{28} \mathrm{~N}_{2} \mathrm{O}_{4}$. An amorphous alkaloid of Dita, with a paralyzing power comparable to that of curare. It is also called Ditcin.

Echitenin (e-kit'-en-in), $\mathrm{C}_{20} \mathrm{H}_{27} \mathrm{NO}_{4}$. An amorphous, brown alkaloid of Dita, soluble in alcohol and water.

Echlorophyllose (e-klo-ro-fll$-\overline{o s}) \quad[\varepsilon$, priv.; $\chi \lambda \omega p o s$, yellowish-green; $\phi v \lambda \lambda \nu^{\prime} v$, a leaf ]. In biology, destitute of chlorophyl.

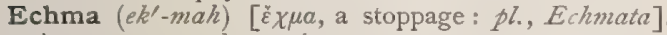
A stoppage or obstruction.

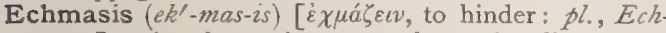
mases]. An obstruction or an obstructive disease.

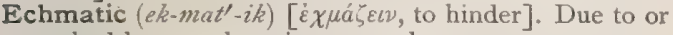
marked by an echmasis or an echma.

Echo $\left(e k^{\prime}-0\right)$ [ $\eta^{\prime} \chi \dot{\omega}$, a sound]. A reverberated sound. E.-sign, a symptom of epilepsy and other brainconditions in which there is a repetition of the closing word or words of a sentence. It is regarded as the result of perverted will, or impaired or defective inhibition. E.-speech, a peculiar method of utterance in one type of hypnotism.

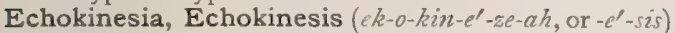

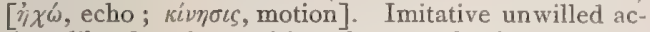
tion, like that observed in palmus or latah. See $\mathrm{Pal}$ mus and Habit-spasm.

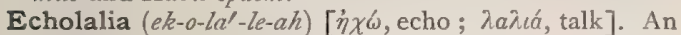
aphasic symptom consisting in a repetition of words spoken to the patient by others.

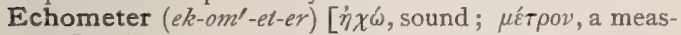
ure]. A stethoscope.

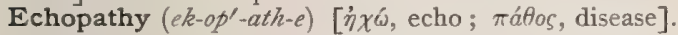
Any automatic and purposeless repetition of a word or sound heard or of an act seen.

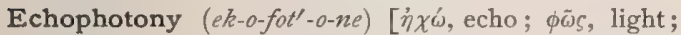
Tóvos, tone]. The production of the sensation of color by the stimulus of aërial waves, or sound. See Phonism, Photism.

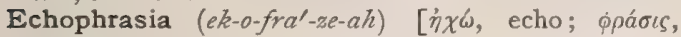
speech]. Same as Echolalia.

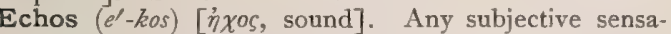
tion, as of a sound that has no objective cause.

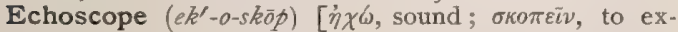
amine]. A stethoscope.

Echuja $\left(e k^{\prime}-u\right.$-jah). An apocynaceous plant, Adenium bohmianum, of Africa. It is extremely poisonous.

Echujin, Echugin $\left(e k^{\prime}-u-j i n\right)$. A poisonous glucosid from the plant called Echuja; it has much the same effects as strophanthin.

Eciomania $\left(e k-e-0-m a^{\prime}-n e-a h\right)$. See Oikiomania.

Ecker's Angle. See Angle. E. Fissure. See Fissure.

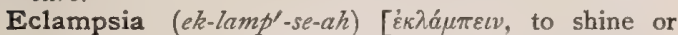
burst forth; from the suddenness of the attack]. I. A sensation as of a light flashing before the eyes. [Obsolete]. 2. Any epileptiform seizure, espepecially one in which consciousness is not lost. 3 . Puerperal convulsion. A convulsive or epileptiform seizure suddenly coming on in a woman prior to or during labor, or in the puerperal state. The convulsions are first tonic and then clonic, and finally affect the involuntary muscles as well as the voluntary; consciousness is lost, and the attack is followed by coma or sleep. The etiology is obscure, the attack generally repeated, the prognosis grave. The term eclampsia is also used as a general designation for convulsions, and besides the puerperal form described there are the infantile and uremic types. See Convulsions. E. nutans, the nodding spasm or salnam convulsion of young children. In this affection the head and upper part of the body are bowed forward several times in succession. The attacks tend to occur in paroxysms, during which the child suffers temporarily from disordered consciousness.

Eclampsic (ek-lamp'-sik). See Eclamptic

Eclamptic (ek-lamp'-tik) [غ่'áa forth]. Relating to, affected with, or of the nature of, eclampsia.

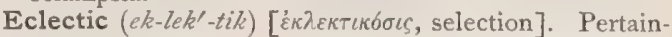
ing to a choosing or selection. Applied by a certain school of physicians to themselves, to denote their principle or plan of selecting or choosing that which is good from all other schools.

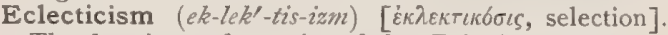
The doctrine and practice of the Eclectics.

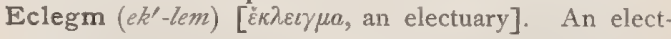
uary.

Eclegma, or Ecleigma (ek-leg'-mah, ek-lig $\left.g^{\prime}-m a h\right)[\dot{\varepsilon} \kappa$, out; $\lambda \varepsilon i \chi \varepsilon \iota \nu$, to lick: $p l .$, Eclegmata $]$. An electuary.

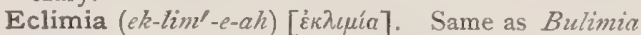

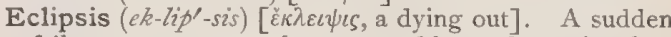
failure; trance; catalepsy; a sudden and transient loss or impairment of consciousness.

Eclysis ( $\left.e k^{\prime}-l i \grave{s}-i s\right)$ [ $\check{k} k \nu \sigma \iota s$, a release, a loosening]. Any loosening, as of the bowels. Also a slight amount of, or merely a tendency to, syncope. It is present in anemia of the brain.

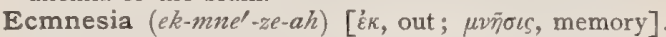
The dropping out of the memory of the events of a certain portion of time.

Ecnea $\left(e k-n e^{\prime}-a h\right)[\hat{\varepsilon} \kappa$, out ; voũs, mind]. Insanity.

Ecoid ( $e^{\prime}$-koid) [oikos, house]. A blood-shadow; the colorless stroma or framework of red corpuscles of the blood that have been deprived of their hemoglobin; a shadow-corpuscle.

Economy (e-kon'-o-me) [oIkos, house; vónos, a law]. A general name for the human being considered as a whole.

Ecorticate (e-kor'-tik-ät) [e, priv.; cortex, bark]. In biology, destitute of a cortical layer.

Ecouvillon $\left(a-k o o-v e^{\prime}-y o n(g)\right)$ [Fr.]. See Ecouvillonage.

Ecouvillonage $\left(a-k o o-v e-j^{\prime} o n-a h z h^{\prime}\right)$ [Fr.]. The operation of cleansing, and carrying medicinal agents to, the inside of the uterus by means of a brush.

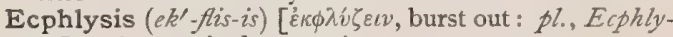
ses]. Any vesicular eruption.

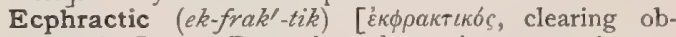
struction]. I. Removing obstructions. 2. An ecphractic medicine.

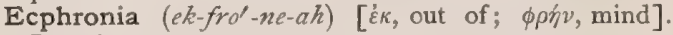
Insanity.

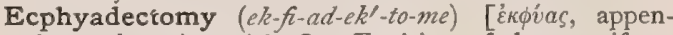
dage; $\varepsilon \kappa т о \mu \eta \dot{n}$, excision]. Excision of the vermiform appendix.

Ecphyaditis (ek-fi-ad-i'-tis) ['̇kфúas, appendage; $\iota \tau \iota$, inflammation]. Inflammation of the vermiform appendix; appendicitis. This term has also been used to include typhlitis, perityphlitis, etc.

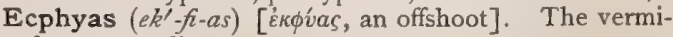
form appendix.

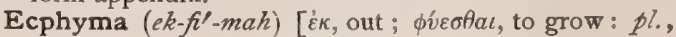
Ecphymata]. An excrescence on the skin. 
Ecphysesis $\left(e k-f z-e^{\prime}-s i s\right)$ [ $\varepsilon \kappa$, out; $\phi v \sigma a ́ v \varepsilon t v$, to blow]. Rapid breathing.

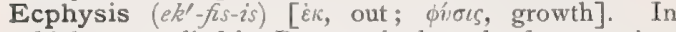
biology, applied by Bate to the branch of any particular crustacean limb; as coxecphysis, a branch springing from the coxa; basecphysis, a branch springing from the base.

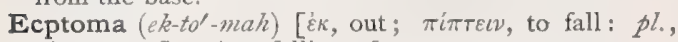
Ecptomata]. Any falling of a part or organ.

Ecpyesis $\left(e k-p i-e^{\prime}-s i s\right)[\dot{\varepsilon} \kappa$, out; $\pi v \varepsilon i \nu$, to suppurate: $p l$, Ekpyeses]. I. Any suppuration or abscess. 2. Âny pustular skin-disease.

Ecpyetic $\left(e k-p i-e t^{\prime}-i k\right)$ [ik, out; $\pi v \varepsilon i v$, to suppurate]. Promoting suppuration.

Écrasement $\left(a-k r a h z^{\prime}-m o n\left(g^{\prime}\right)\right)[$ Fr.]. Surgical removal of a part or growth by means of the écraseur.

Écraseur (a-krah-zer') [Fr.]. An instrument used in the amputation of parts, and consisting of a chain or wire-loop, tightened by a screw, whereby the tissue is slowly crushed apart rather than cut, thus rendering the operation easier and bloodless.

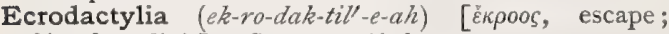
ঠákтvhos, digit]. Same as Ainhum.

Ecstaltic (ek-stal'-tik) [ย́k, out; $\sigma \tau \varepsilon \dot{\lambda} \lambda \varepsilon \imath v$, to send]. Sent out from a nerve-center; applied specially to nerve-impulses originating from the spinal cord.

Ecstasy $\left(e k s^{\prime}-t a-s e\right)$ [ ment of the nervous system characterized by an exalted visionary state, absence of volition, insensibil. ity to surroundings, a radiant expression, and immobility in statuesque positions. It is also called Carusextasis and Catalepsia spuria.

Ecstrophy (ek'-stro-fe) [ík, out; $\sigma \tau \rho \varepsilon \dot{\varepsilon} \phi \varepsilon v$, to turn]. Eversion; the turning inside-out of a part.

Ectad (ek'-tad) [ÉkTó, external; $a d$, to ]. On or toward the ectal part.

Ectal (ek'-tal) [ékTós, external]. At some surface or aspect farther from a supposed center than that with which a given object is compared. External, superficial. See Position and Direction, Table of.

Ectasia $\left(e k-t a^{\prime}-s e-a h\right)$. See Ectasis.

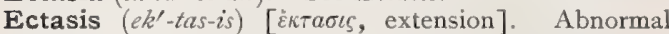
distention or dilatation of a part.

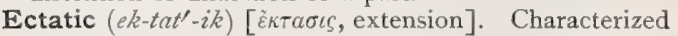
by ectasis.

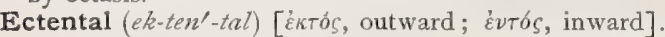
Pertaining to the line of union between the ectoderm and the entoderm. E. Line. See Lines, Table of.

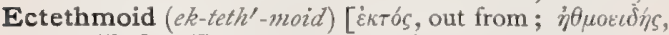
sieve-like]. Either one of the lateral cellular masses of the ethmoid bone.

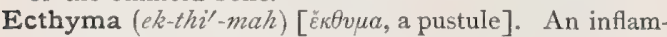
matory skin-disease attended with an eruption of large, flat pustules, which are usually flaccid and of a yellowish or yellowish-red color. They vary in size from a ten-cent piece to a silver quarter-dollar, and are surrounded by a distinct inflammatory areola. Brownish crusts are formed, which on removal leave a slightly excoriated moist surface. The eruption appears as a rule on the legs and thighs where the hairs are thick; it occurs in crops, and may persist for an indefinite period. It is probably due to inoculation with microörganisms, and is prone to occur after local irritation.

Ecthymiform (ek-thi'-mif-orm) [èkfvur, a pustule; forma, form]. Resembling ecthyma.

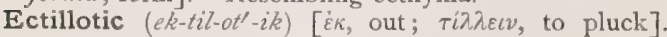
Depilatory; causing the hairs to fall; removing corns from the feet.

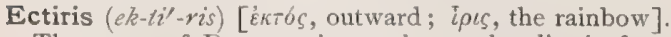
That part of Descemet's membrane that lies in front of the iris.
Ecto- (ek'-to-) [éktós, without]. A prefix signifying without, upon the outer side.

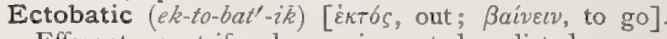
Efferent; centrifugal; moving ectad or distad.

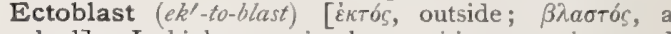
bud]. In biology, a simple, sensitive, covering, and protecting cell-layer; the ectoderm.

Ectobliquus (ek-to-bli'-kwus) [Ékтbs, outward; obliquzes, slanting]. The external oblique muscle of the abdomen. See Muscles, Table of.

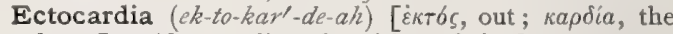
heart]. Abnormality of position of the heart.

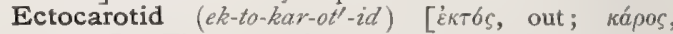
stupor]. The external carotid artery. See Arteries, Table of.

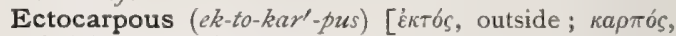
fruii.]. In biology, applied to such animals as have the reproductive organs located in the ectoderm.

Ectoceliac,or Ectocelian (ek-to-se'-le-ak, ek-to-se'-le-an)

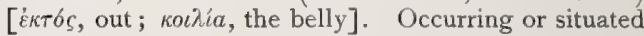
outside a ventricle of the brain.

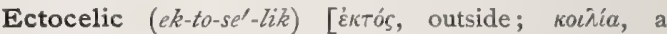
hollow]. In biology, applied to structures placed outside the body-cavity in a celenterate.

Ectochoroidea, or Ectochorioidea (ek-to-ko-roi'-de-

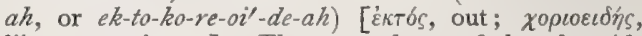
like a membrane]. The outer layer of the choroid, composed mainly of fibro-connective tissue.

Ectocinerea (ek-to-sin- $\left.\ell^{\prime}-r e-a h\right)$ [غ̇krós, out; cinereus, ashy]. The gray substance of the cortex of the brain. Cf. Entocinerea.

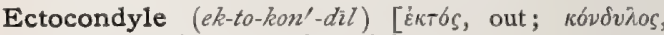
condyle]. An external condyle.

Ectocornea (ek-to-kor'-ne-ah) [ย́kтós, out; corneus, horny]. The corneal conjunctiva.

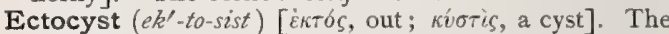
thick, laminated, translucent, and highly elastic membrane of an hydatid cyst. It is lined by a thin cellular membrane called the endocyst. The outer layer of the cenecium (or common dermal system) of a colony of Polyzoa,

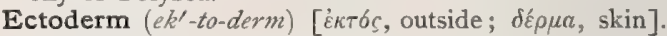
In biology, the primitive outer wall of the body; the animal germinal layer; the term was first applied to the outer of the two membranes of a hydroid zoöphyte. See Blastoderm.

Ectoentad (ek-to-en'-tad) [ $[\dot{\varepsilon} \kappa \tau \delta \delta$, without; $\varepsilon v \tau \delta \varsigma$, within; $a d$, to ]. From without inward.

Ectogastrocnemius (ek-to-gas-trok-ne'-me-us) [żkтós,

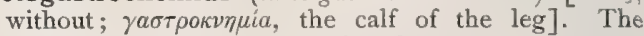
gastrocnemius externus muscle. See Muscles, Table of.

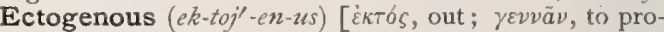
duce]. Developed outside the body (said of certain pathogenic bacteria and of enthetic poisons).

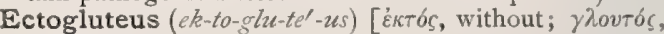
the rump]. The external gluteus muscle. See Muscles, Table of.

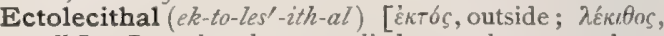
yolk]. In embryology, applied to such eggs as have the formation-yolk enclosed in a superficial layer of food-yolk.

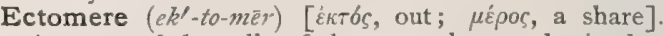
Any one of the cells of the ovum that are destined to take part in forming the ectoderm.

Ectopagia (ek-to-pa'-je-ah) ['́kтós, out; $\pi \dot{\gamma} \gamma o s$, a fixture]. The condition of being ectopagous; an ectopagous monstrosity.

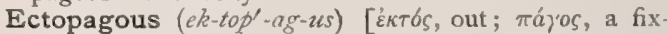
ture]. Of the nature of or pertaining to an ectopagus.

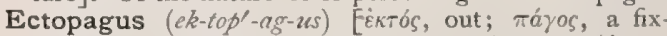
ture]. A monomphalic twin monstrosity united laterally the full extent of the thorax. 
Ectoparasite (ek-to-par'-as-īt) [غ่ntós, outside; $\pi \alpha \rho a ́$ oitos, a parasite]. In biology, a parasite that lives on the exterior of its host.

Ectoparasitic $\left(e k-t o-p a r-a s-i t^{\prime}-i k\right)$ ['ḱtós, out; $\pi a \rho a ́-$ $\sigma \iota t o s$, a parasite $]$. Of the nature of or pertaining to an ectoparasite.

Ectopatagium (ek-to-pat-aj"-e-um) [غ̇krós, outside ;

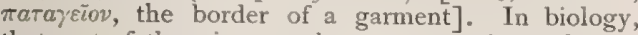
that part of the wing-membrane or patagium of a bat which is limited to the manus; it is also called dacty. lopatagium.

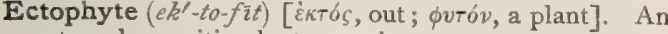
external parasitic plant-growth.

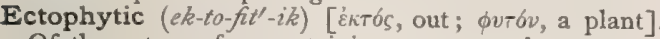
Of the nature of or pertaining to an ectophyte.

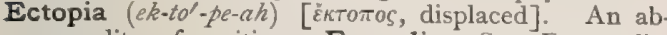
normality of position. E. cordis. See Ectocardia. E. lentis, dislocation or congenital malposition of the crystalline lens. E. oculi, abnormal position of the eyeball in the orbit. E. testis, abnormal position of the testicle. E. vesicæ, protrusion of the bladder through the wall of the abdomen.

Ectopic $\left(e k-t o p^{\prime}-i k\right)$ [ $k$ krotros, displaced]. Pertaining to ectopia; displaced. See also Teratism. E. Gestation. See Gestation.

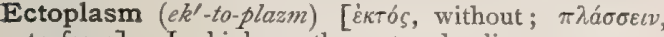
to form ]. In biology, the outer, hyaline, more compact layer of protoplasm in a cell or unicellular organism, as distinguished from the granular endoplasm.

Ectopy $\left(e k^{\prime}-t o-p e\right)$. Same as Ectopia.

Ectoretina (ek-to-ret'-in-ah) ['́kтós, out; retina, retina]. The external and pigmentary layer of the retina.

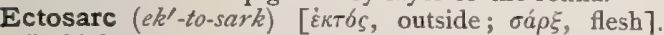
In biology, same as Ectoplasm, q. v.

Ectoskeleton (ek-to-skel'-et-un). Same as Exoskeleton.

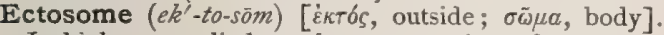
In biology, applied to the outer region of a sponge, which forms the covering of the choanosome, or middle region, with its flagellated chambers.

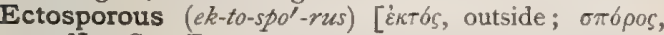
seed]. See Exosporous.

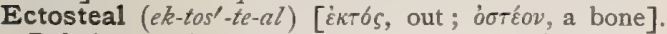
Relating to, situated or occurring outside of, a bone.

Ectostosis (ek-tos-to'-sis) [ $\varepsilon \kappa \tau b s$, out; óotéov, a bone]. The growth of bone from without; ossification that begins at the perichondrium, or future periosteum.

Ectotheca (ek-toth'-ek-ah) [غ́kTós, outside; $\theta \dot{\eta} \kappa \eta$, case]. In biology, applied to the capsule of such compound gonophores as those of Laomedea; also to such thecre or asci as are exposed, e. $g$. those of discomycetous fungi and gymnocarpous lichens.

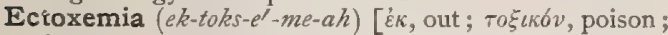
aipa, blood]. Toxemia not originating within the organism; blood-poisoning from some cause not existing within the organism.

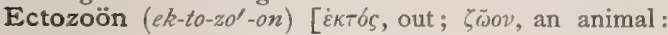
pl., Ectozoa $]$. An external animal parasite; an ectoparasite.

Ectrodactylia, Ectrodactylism (ek-tro-dak-til'-e-ah.

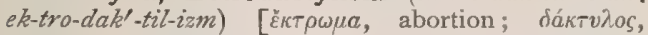
finger]. Congenital absence of any of the fingers or toes.

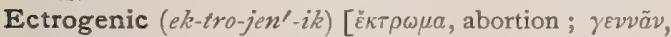
to produce]. Due to some loss of tissue, as from traumatism or surgical operation. See also Teratism.

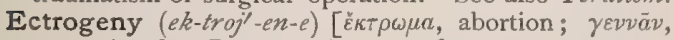
to produce]. Loss or absence of any part or organ.

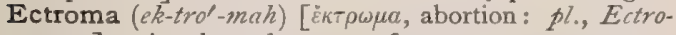
mata $]$. An aborted ovum or fetus.

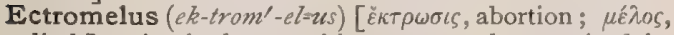
limb]. A single autositic monster characterized by the presence of aborted or imperfectly-formed limbs.
Examples of this anomaly show every degree of arrested development, from entire absence of the limb to simple shortening.

Ectropion (ek-tro'-pe-on) [Ek, out; $\tau \rho \hat{\varepsilon} \pi \varepsilon \varepsilon \nu$, to turn] An everted eye-

lid; abnormal eversion of an eyelid; also, an everted state of the cervical portion of the endometrium. E. Cicatricial, due to destruction of part of the skin of the lid, with cicatricial contraction. E. luxurians, an old name for ec-

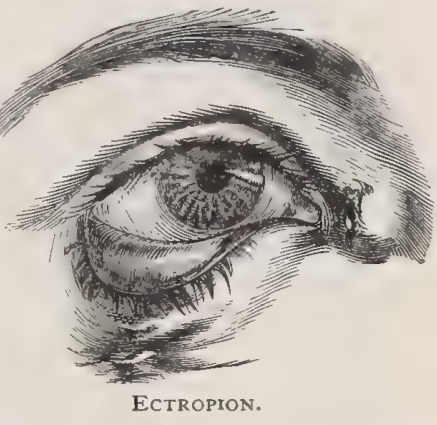
tropion, with a proud-flesh appearance of the conjunctiva. E., Paralytic, that due to paralysis of the orbicularis palpebrarum. E., Sarcomatous. See E. luxurians. E., Senile, found only in the lower lid, due to relaxation of the orbicularis palpebrarum muscle. E., Spastic, due to spastic contraction of the fibers of the orbicular muscle lying near the margin of the orbit.

Ectropium (ek-tro'-pe-um). Same as Ectropion.

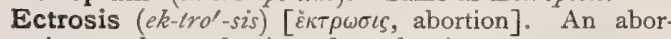
tion, or the production of an abortion.

Ectrotic (ek-trot'-ik) [ $\varepsilon k$, out; $\tau \iota \tau \rho \omega \sigma \kappa \varepsilon \iota \nu$, to wound]. Tending to cut short ; abortive ; abortifacient.

Ectylotic (ek-til-ot'-ik) [ḱk, away; $\tau \hat{\imath} \lambda o s$, callus]. Tending to remove warts or indurations.

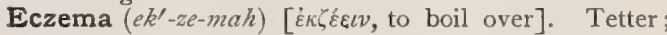
Moist Tetter; an acute or chronic, non-contagious, catarrhal inflammatory disease of the skin, characterized by multiformity of lesion, and the presence, in varying degrees, of itching, infiltration, and discharge. The skin is reddened, the redness shading off insensibly into the surrounding unaffected skin. When well-marked, the skin is fissured, with crusting, leathery infiltration, and scaling. Eczema occurs in skins that are particularly susceptible to the action of external irritants. E. ani-of the anus-a troublesome variety common in children; it may simulate condylomata. E. articulorum, eczema of the flexor surfaces of the joints. E aurium, a common, troublesome, pustular form affecting the ears. E. barbæ, a form resembling sycosis, but more superficial. It attacks the bearded portion of the face, but may spread. E. capitis, a variety confined to the head. It is usually seen in children; is diffuse, pustular, impetiginous, not itchy, and may be associated with pediculi and seborrhea. E. circumscriptum parasiticum, a name given by Crocker to a form of eruption that looks like a dry eczema, but has a border more sharply defined than is usual in $E$. squamosum. It occurs chiefly on the legs below the knee, and is constituted of minute papules aggregated into a uniform moderately red, scaly patch, with sharply defined borders. It is a chronic disease, and is probably parasitic in origin. E. crurum, a form occurring in old people as a result of varicosity of the veins of the leg, and not associated with eczema elsewhere. The skin is much infiltrated, red, scaly, with indolent ulcers. E. crustosum, eczema with the formation of thin and pale-yellowish crusts. If these crusts are thick and dark in color from capillary bleeding the condition is termed $E$. impetiginosum. This latter form occurs frequently on the scalp and face of strumous children. 
E., Diabetic, from the irritation of diabetic urine. E., Epidemic. See Dermatitis, Epidemic Exfolictive. E. epizoötica, a disease of domesticated animals due to a microörganism, attended with a characteristic eczematous lesion of the skin and a catarrhal condition of the respiratory tract. It is also called Foot-and-Mouth Diserse. See Streptocytus of Schottelius under Bacteria, Synonymatic, Table of. E. erythematosum, the mildest form of eczema, in which the skin is reddened, slightly swollen, infiltrated, and tense, from active congestion; the color of the patches is more vivid, and their edges are less well defined, than in true erythema. It is seen in its most typical form on the face. E. faciei, an acute or chronic form affecting the face; it resembles erysipelas, but is attended with no rise of temperature E. fissum, E. rimosum; a form affecting the hands and skin over the articulations, and characterized by the formation of deep, painful cracks or fissures. E. folliculare, a form confined largely to the neigh. borhood of the hair-follicles, where irritable, acuminate papules may persist for prolonged periods. E. genitalium, an acute form common in men; it is attended with great swelling and edema, with excoriation. E. hypertrophicum, $E$. verrucosum; a form characterized by permanent hypertrophy of the papillæ of the skin, giving rise to general or limited warty outgrowths. This variety results from a tendency to passive congestion. See Granuloma fungoides. E. impetiginodes. See $E$. pustulosum. E. impetiginosum. See $E$. crustosum. E., Infantile, a form commencing usually within six months of birth, and making its appearance first upon the head or face. E. intertrigo, a form of $E$. erythematosum occurring in the groins, on the inner surfaces of the nates, below the mammre, etc. It is due to uncleanliness. See Erythema intertrigo. E. labiorum, a very obstinate variety affecting the lips, and associated with painful fissures. E. madidans, E. rubrum; weeping eczema; large, raw, weeping surfaces studded with red points. It follows $E$. vesiculosum. E. mammæ, a variety common in nursing primiparæ; it is at first vesicular, then squamous, with painful fissures and much crusting. It is very obstinate. E. manuum, a common form implicating the whole of both hands. The acute variety is most marked along the edges of the fingers, where deep-seated vesicies abound; the chronic form chiefly involves the palms and knuckles. E, marginatum, Hebra's term for the most severe form of ringworm of the body. Its seats are the groins, axillæ, fork, and occasionally the popliteal spaces. Its lesion is marked by a well-defined, festooned, raised margin. E. meatus, eczema of the external auditory passage. E. mercuriale, that form due to the irritation produced by mercury. E. narium, a form affecting the nos trils. E. palmare, or E. palmarum, confined to the palm of the hand. It is also called Psoriasis palma. E. palpebrarum, Tinea tarsi; an obstinate form affecting the eyebrows; it is common in scrofulous children. E. papillomatosum. Same as $E$. verrucosum. E. papulosum, Lichen simplex, a form associated with the formation of minute intensely-itching papules of a deep-red color and firm consistence, arranged in irregularly-shaped groups. They are about the size of a pin's head, acuminate, of a bright-red color. Vesicles may form on their summits (Lichen agrius). When they are grouped in oval or roundish patches, a form not uncommon on the external aspect of the forearm and hands and on the calves, it is Lichen circumscriptus. E. pedum, eczema of the feet. E. plantarum, con- fined to the sole of the foot. E. pustulosum, $E$. impetiginodes; the stage of eczema in which the vesicles develop into pustules that are usually of larger size than the preceding vesicles. This is most common in strumous children. E. rimosum. See $E$. fissum. E. rubrum. See E. madidans. E. sclerosum, a chronic form of eczema in which there is induration and thickening of the tissues. E., Seborrheic. See Dermatitis, Seborrheic. E. seborrhœicum. Synonym of Seborrhea. E. solare, that form due to irritation from the rays of the sun. E. spargosiforme, a variety of $E$. sclerosum in which the thickening is so very great that a condition indistinguishable from Elephantiasis arabum is produced. E. squamosum, a form in which the surfaces of illdefined irregular patches are covered with more or less adherent scales of shed epithelium. This is often seen on the neck and limbs. E. sulphure, that form due to the irritation produced by sulphur. E. tarsi, a form affecting the edges of the eyelids. E. tuberosum. Synonym of Granuloma fungoides. E. umbilici, a tractable form resembling syphilitic disease of the same part. E. unguium, involvement of the nails in chronic E. manuum. The nails are rough, dull, brittle, and punctate. E. unisquamosum, a rare form having its seat at the root of the nose between the eyebrows. The secretion takes the form of a single epidermic lamella that covers the whole of the affected surface. E. verrucosum. See $E$. hypertrophicum. E. vesiculosum, a stage of vesicular formation in the course of eczema. It is the most common form of the disease. It is best seen on the flexor aspect of the limbs, between the fingers, back of the ears, etc. The vesicles, minute at first and closely aggregated, coalesce and rupture, exuding a clear plasmic fluid that stains and stiffens linen. The burning and itching are worse at night, and the excoriated surfaces continue to weep for a few days, when they gradually heal by crusting. E., Weeping. See $E$. madidans.

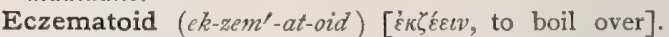
Resembling an eczema.

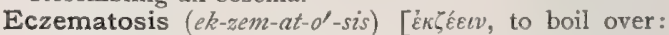
pl., Eczematoses]. Any eczematous skin-disease.

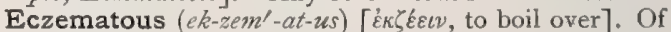
the nature of or affected with eczema.

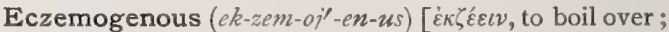
$\gamma \varepsilon v \nu \tilde{a} \nu$, to produce]. Giving rise to eczema.

Edeagra (e-de-a'-grah) [aidoĩa, the genitals; àypa, a seizure]. Pain or gout in the genitalia.

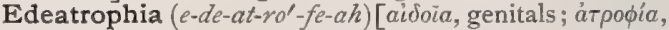
a wasting]. Atrophy or wasting of the genital organs.

Edeauxe $\left(e-d e-a w k s^{\prime}-e\right)$ [aidoĩa, genitals; aṽ $\xi \varepsilon$, increase]. Swelling or hypertrophy of the genitals.

Edebohl's Position or Posture. See Postures, Table of.

Edeitis (e-de-i'-tis) [aidoĩa, genitals; $\iota \tau \iota s$, inflammation]. Inflammation of the genital organs.

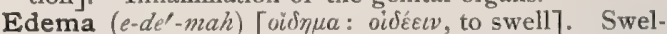
ling, especially such as is due to the effusion of serous fluid into areolar tissues. See Anasarca. E., Acute Circumscribed. See E., Angio-neurotic and Urticaria cedematosa. E., Acute Idiopathic. See E., Angro-neurotic. E., Acute Non-inflammatory. See E., Angio-neurotic. E., Angio-neurotic, Giant urticaria; a vaso-motor disorder, characterized by the abrupt occurrence of edematous swelling of variable extent, sometimes accompanied by gastro-intestinal crises. There may be a marked hereditary feature in the disease. Death may result from edema of the larynx. E., Brown, the brownish fluid that flows from the cut surface of a lung in the state of brown induration. E., Filtration, a peculiar sort of edema 
of the conjunctiva observed after operations or injuries that have produced a perforation in the most anterior sections of the sclera. It is due to the oozing of the aqueous humor between the lips of the wound and under the conjunctiva. E., Intermittent. See $E_{\text {., }}$ Angio-neurotic, E., Malarial. See E., Angio-neurotic. E., Malignant, the term applied by Koch to a parasitic form of gangrenous inflammation that occurs at times after serious bone-injuries, etc. It is characterized by the rapid spread, the septic character of the inflammatory product, and the speedy destruction of the tissue involved, with the formation of gas. It is also called Gangrenous emphysema. E., Menstrual. See E., Angio-neurotic. E. neonatorum, a disease resembling somewhat sclerema neonatorum, the skin, however, being less generally involved and less edematous, filled with a serous fluid, and assuming a livid or purplish, rather than a whitish tint, as in sclerema. The disease begins before the third day of life, with drowsiness, and then the edema appears in the extremities, especially the legs, gradually spreading upward. E., Solid, a form of edema in which puncture gives exit not to serum, but to a sanious, stringy, lymphoid material.

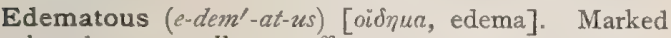
by edema; swollen; puffy.

Edentate $\left(e-\right.$ den $^{\prime}$-tăt $)$ [ $e$, priv. ; dens, a tooth]. In biology, toothless, as an entire leaf, or a member of the Edentata among mammals.

Edentation (e-den-ta'-shun) [e, without; dens, a tooth]. A deprivation of teeth.

Edentulous (e-den'-tu-lus) [e, without; dens, a tooth]. Without teeth (applied to one who has lost his teeth). See Caries of the Teeth.

Edeocephalus (e-de-o-sef'-al-us) [aidoüa, genitals ; from the resemblance of the proboscis to a penis; $\kappa \varepsilon \phi a \lambda \eta \dot{\text {, }}$ head]. A variety of single autositic monsters of the species otocephalus, in which there is synopsia, absence of the mouth, very rudimentary jaws, and the presence of a proboscis.

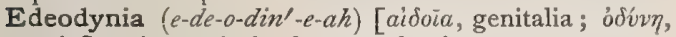
pain]. Any pain in the reproductive organs.

Edeogargalismus (e-de-o-gar-gal-iz'-mus) [aidoüa, genitals; $\gamma \alpha \rho \gamma \alpha \lambda \iota \sigma \mu \delta s$, a tickling]. Masturbation.

Edeography (e-de-og'-ra-fe) [aidoüa, the genitals; $\gamma \rho a ́ \phi \varepsilon \iota \nu$, to write]. A description of the genitalia.

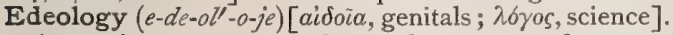
A treatise or monograph on the organs of generation.

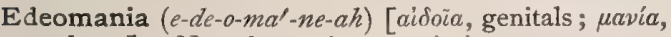
madness]. Nymphomania; satyriasis.

Edeomycodermitis (e-de-o-mi-ko-der-mi'-tis) [aidoĩa, genitals ; $\mu \hat{\kappa} о \varsigma$, mucus: $\delta \varepsilon ́ \rho a$, skin; $\iota \tau \iota \zeta$, infiammation]. Inflammation of the mucous membrane of any of the genital organs.

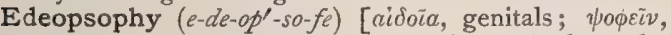
to utter a noise]. The emission of sounds from the genital organs (as from the bladder or vagina).

Edeopsy ( $\left.e^{\prime}-d e-o p-s e\right)$. Same as Edeoscopy.

Edeoptosis (e-de-op-to'-sis) [aidoĩa, genitals; $\pi \tau \tilde{\omega} \sigma \iota \zeta$, a fall]. Prolapse of some portion of the genital apparatus.

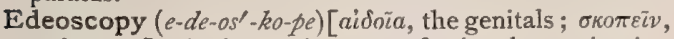
to inspect]. An inspection or professional examination of the genital organs.

Edeotomy (e-de-ot'-o-me) [aidoia, genitals; $\tau 6 \mu \eta$, a cutting]. The anatomy or dissection of the genital organs.

Edgeweed ( $e j^{\prime}$-zvêd). A composite-flowered plant, Sericocarpus tortifolius, of the Southern U. S. It is used as a remedy for colic in horses. Unof.

Edible $\left(e d^{\prime}-i b-l\right)$ [edibilis, eatable]. A qualification applied to food, the condition of which is good and wholesome.

Edison-Lalande Cell. See Cell.

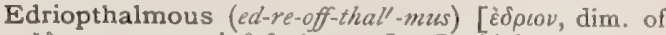
$\check{\varepsilon} \delta \rho a$, a seat; $\dot{\phi} \phi a \lambda \mu \sigma \delta$, eye]. In biology, having fixed, sessile eyes, not borne on a movable stalk.

Educt $\left(e^{\prime}-d u k t\right)$ [e, out; ducere, to draw]. A compound that exists in any substance and is extracted from it by a chemic or pharmaceutic process; opposed to procluct, which designates a body that is produced by a process similar to that used in its extraction.

Edulcorant (e-dul'-kor-ant) [e, out; dulcorare, to sweeten]. Sweetening; corrective of acidity or of acrimony.

Edulcoration (e-dul-kor-a'-shun) [edulcare, to sweeten]. In chemistry, the act or process of sweetening; the removal of soluble or saline matters by washing.

Effeminacy $\left(e f-e m^{\prime}-i n-a s-e\right)$. See Feminism.

Effemination (ef-em-in- $a^{\prime}$-shun) [effeminare, to make womanish]. The state of being effeminate.

Effera (ef'-er-ah) [efferus, fierce, wild]. Sauvage's name for a certain genus of exanthematous diseases.

Efferent (ef'-er-ent) [efferens, carrying from]. Of nerves, conveying impulses from the central nervous system to some tissue; motor; secretory. Of bloodvessels, conveying blood from the tissues toward the heart, veins, or from the gills. Of lymphatics, the vessels leaving or conveying lymph from the lymphatic glands. Compare Afferent.

Effervescent (ef-er-ves'-ent) [effervescere, to boil up]. Susceptible of being made to effervesce, or to dissolve with foaming and with the escape of a gas, such as carbon dioxid.

Effervescing (ef-er-ves'-ing) [effervescere, to boil up]. Boiling up; foaming. E. Powders. See Seidlitz Powders.

Effleurage (ef-fur-azh') [Fr.]. In massage, centripetal strokings, i. e., toward the body or heart. These may be made with the palm of one hand, the palms of both hands, the thumb, or the tips of the fingers. Effleurage increases the circulation in the venous bloodvessels and the lymphatics, thereby causing absorption.

Efflorescence (ef-lor-es'-enz) [efflorescere, to bloom]. r. The flowering of plants. 2. The formation of minute crystals on the surface of certain crystalline bodies, due to the loss of a part or the whole of their water of crystallization. 3. The breaking-out or characteristic eruption of an exanthematous disease.

Effluent (ef-l $u^{\prime}$-ent) [efluere, to flow out]. An outflow. The fluid discharged from works for the treatment of sewage.

Effluvia (ef-lu'-ve-ah) [L.]. Plural of Efluvium, q.v. E., Telluric, emanations arising from the earth.

Effluvium (ef-lu'-ve-um) [effuere, to flow out: $p l$, Effuvia]. Any subtle emanation from a substance or person, especially one that is offensively odoriferous.

Efflux (ef'-fuks), or Effluxion (ef-fluk'-shun) [effuxio; effuxus, an outflow]. I. An outflow; that which flows out. 2. Abortion, or the escape of the embryo from the womb during a very early stage of pregnancy.

Effracture (ef-frak'-chïr) [ex, out ; fractura, a fracture]. Fracture of the cranium, with depression of one or more fragments.

Effusion (ef-u'-zhun) [effundere, to pour out]. A pouring-out. The abormal secretion or transfer of a liquid from its natural organ or place; effused material.

Effusive $\left(e f-u^{\prime}-s i v\right)$ [effundere, to pour out]. Attended with or of the nature of an effusion.

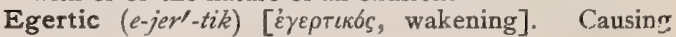
wakefulness. 
Egest (e-jest') [egerere, to discharge]. To void, as excrement; to defecate.

Egesta $\left(e-j e s^{\prime}-t a h\right)$ [pl. of egestum, fecal matter]. The discharges of the bowels or other emunctory organs.

Egestion (e-jes'-chun) [egestio, that which is voided]. Defecation; the expulsion of excrements or excretion.

Egg (eg) [ME., egge, an egg]. See Orule. E.-albumin, a native albumin, or proteid constituent of the human body, of which the unboiled white of egg is the type. It is distinguished from serum-albumin by its precipitation when shaken with ether, and by its appearance unchanged in the urine when injected under the skin or into the intestine. E.-apparatus; in biology, the oösphere and the two companion-cells (called the synergidx) in the upper end of the embryosac, are termed the egg-apparatus. E.-cells, primordial ova; large, spheroidal, granular cells embedded at intervals in the layer of the germ-epithelium of the ovary. They eventually become the ovules of the Graafian follicle. E.-cords, dippings inward into the ovarian substance of the specialized columnar epithelium covering the ovary; these prolongations carry highly-specialized cells, each of which develops into an immature Graafian follicle containing an immature ovum. E.-nog, a nutritious preparation made by adding the beaten yolk of egg and a little spirit to a tumblerful of milk, stirring well, adding sugar and the white of the egg separately beaten. E.-shell Crackling, a peculiar crackling produced by pressure upon a soft tumor springing from the medulla or cancellated tissue of a long bone, and surrounded by a thin bony capsule. E.-tube. See Oviduct. E.water, a nutritious food for infants having summer diarrhea. It consists of the white of a fresh egg, a pint of cold water (previously boiled), a teaspoonful of brandy, and a small pinch of salt.

Egilops ( $\left.\ell^{\prime}-j i l-o p s\right)[a i \xi$, a goat; $\omega \psi$, eye]. Abscess, with perforation, at the inner canthus of the eye, supposed to be a result of lachrymal fistula. See Anchylops.

Eglandular (e-glan'-du-lar) [e, priv.; glandula, a gland]. In biology, destitute of glands.

Eglandulose (e-glan'-du-lōs) [e, priv.; slandula, a gland]. Same as Eglandular.

Egobronchophony (e-go-brong-koff'-o-ne) [aik, a goat ;

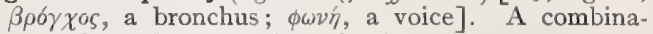
tion of egophony and bronchophony.

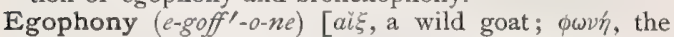
voice]. In auscultation, a term meaning a modification of bronchophony, in which the voice has a bleating character like that of a kid. It is heard in pleurisy with slight effusion, usually near the inferior angle of the scapula.

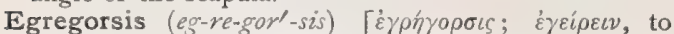
wake]. Morbid wakefulness; insomnia.

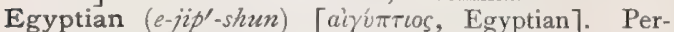
taining to Egypt. E. Blue. See Pigments, Conspectus of. E. Chlorosis. See Anchylostomiasis. E. Ophthalmia. See Ophthalmia, Purulent. E. U1cers. See Esyptia Ulcera.

Ehrenritter's Ganglion. See Ganglia, Table of

Ehrlich's Anilin-water Solution. See Stains, Table of. E. Method, the use of a saturated solution of anilin in water, as a mordant for better fixing the anilin dyes used in staining bacteria. E. Test. See Tests, Table of. E.-Biondi's Fluid. See Biondi's Fluid.

Eichhorst's Corpuscles. See Corpuscles.

Eichstedt's Disease. Synonym of Tinea versicolor, q. $v_{. ;}$see also Diseases, Table of.

Eidam Cheese $\left(i^{\prime}-d a m\right)$. See Cheese.

Eidoptometry (i-dop-tom'-et-re) [eidos, appearance;

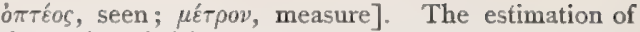
the acuity of vision.

Eilema $\left(i-l e^{\prime}-m a h\right)[\varepsilon i \lambda \eta \mu a$; $\varepsilon i \lambda \varepsilon \iota \nu$, to twist: pl., Eilemata]. A pain or colic of the bowels; volvulus; tormina.

Eiloid $\left(i^{\prime}\right.$-loid $)[\varepsilon i \lambda \varepsilon \varepsilon v$, to coil ; $\varepsilon i \delta o s$, form ]. Having a coiled texture resembling the coils of an intestine; applied to certain skin-tumors.

Einbrodt's Test. See Tests, Table of.

Einhorn's Method. I. A method of ascertaining the condition of the gastric secretion. An apparatus termed a stomach-bucket, consisting of a small oval silver vessel, $13 / 4 \mathrm{~cm}$. long and $3 / 4 \mathrm{~cm}$. wide, is attached to a silk thread, in which at a distance of 40 $\mathrm{cm}$. from the bucket a knot is made. The patient swallows the bucket, and when the knot enters the mouth the operator knows that the bucket is in the stomach. It is withdrawn after remaining there five minutes, and its contents are tested. Resistance to its removal may be overcome by having the patient expire deeply or swallow once. 2. See Gastrodiaphany.

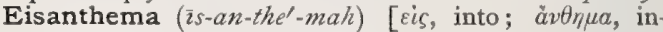
florescence : $p l_{\text {. }}$ Eisanthemata $]$. Same as Enanthema.

Eisel $\left(i^{\prime}-s e l\right)$ [ME.]. An old name for vinegar.

Eisodic $\left(i s-o d^{\prime}-i k\right)$. Same as Esodic.

Eisophobia (i-so-fol-be-ah). Synonym of Agoraphobia.

Eisophoria (i-so-fo'-re-ah). Same as Esophoria.

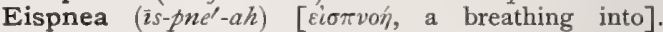
Inspiration; the inhaling of the breath.

Ejaculation (e-jak-u-la'-shun [ejaculatio, a throwing out]. The ejection of the semen. E.-center. See Center.

Ejaculator (e-jak'-u-la-tor) [ejaculare, to throw out]. The accelerator urinæ. See Muscles, Table of.

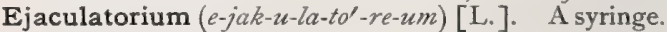

Ejaculatory (e-jak'-u-la-tor-e) [ejaculatio, a throwing out]. Throwing. E. Duct. See Ductus ejaculatorius.

Ejecta, or Ejectamenta (e-jek'-tah, e-jek-tam-en'-lah) $[\mathrm{L} ., p l$.$] . Things or materials cast out; excretions or$ excrementitious matters.

Ejection (e-jek'-shun) [ejectio, a casting out]. The casting out of excretions or of excrementitious matters ; that which is cast out.

Elaboration (e-lab-or-a'-shun) [elaborare, to take pains with]. Careful and exact working. In physiology, any anabolic process, such as that of making crude food into higher tissue-products.

Elaidic Acid (e-la-id'-ik). See Acid.

Elaidin $\left(e-l a^{\prime}-i d-i n\right)$ [e் $\lambda a i \zeta$, the olive-tree], $\mathrm{C}_{57} \mathrm{H}_{104} \mathrm{O}_{6}$. A white, crystalline, fatty substance, isomeric with olein, produced by the action of $\mathrm{HNO}_{3}$ upon certain oils, especially castor-oil.

Elain $\left(e-7 a^{\prime}-i n\right)$. See Eleoptene.

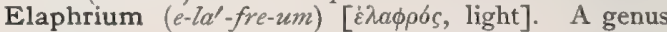
of burseraceous trees. $\mathrm{E}$. copalliferum produces a variety of copal. E. elemiferum is one of the sources of Mexican elemi; E. excelsum and E. tcmentosum, of South America, afford tacamahac.

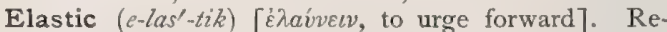
turning to the original form after change of form by external traction or force. E. Bandage, an Indiarubber bandage exerting continuous compression of a part. E. Stocking, an India-rubber stocking exerting continuous pressure. E. Tissue, a variety of connective tissue having elastic properties, and of which some ligaments are composed.

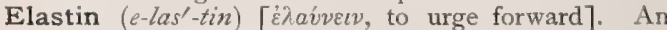
albuminoid substance, the fundamental element of elastic tissue. It yields 36 to 45 per cent. of leucin and $1 / 2$ per cent. of tyrosin. E.-peptone. See Deutero-elastose.

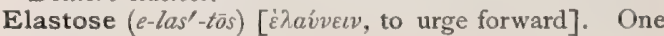


of the forms of peptone resulting from the gastric digestion of elastin.

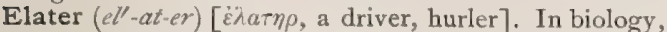
(a) cne of the thread-like, usually spirally-coiled, bodies found in the sporangia of mosses, liverworts, and equisetum. They serve for the dispersion of spores. (b) One of the free filaments of the capillitium of the slime-moulds. (c) One of the elastic anal bristles of the insect called spring-tail.

Elaterin, or Elaterinum (el-at'-er-in, el-at-er-i'-num)

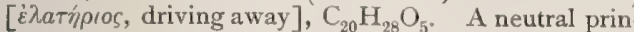
ciple obtained from Elaterium ecballium, or squirting cucumber. It occurs in colorless, hexagonal prisms, that are odorless and have a bitter taste. It is a powerful hydragogue cathartic. In toxic doses, it causes emesis, spasmodic respiration, and death. Dose gr. $\frac{1}{65} \frac{1}{2}$. E., Pulv., Comp. (B. P.), contains elaterin I, sugar of milk 39. Dose gr. j-V. E., Trituratio, elaterin 1o, sugar of milk 90 parts, thoroughly mixed. Dose gr. ss-j.

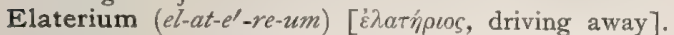
A powerful hydragogue cathartic, being the dried sediment from the juice of the squirting cucumber, $E c b a$ lium elaterium of Europe. Dose $1 / 8 \mathrm{gr}$. every two hours; of the tincture, gtt. $\mathrm{x}-\mathrm{xxx}$.

Elbow $\left(e l^{\prime}-b o\right)$ [ME., elbowe]. The elbow-joint; the articulation of the arm and forearm. That part of the forearm and arm adjacent to the elbow-joint. E.jerk, one of the reflexes. See Refiexes, Table of.

Elcoplasty (el'-ko-plas-te). See Helcoplasty.

Elcosis $\left(e l-k o^{\prime}-s i s\right)$. See Helcosis.

Eider $\left(e l^{\prime \prime}-d e r\right)$. See Sambucus. E., Dwarf. See Dwarf Elder.

Elecampane (el-e-kan'́-pān). See Inula.

Election (e-lek'-shun) [electio, a choosing]. Selection or choice, as of points (points of election) to be operated upon; consideration of circumstances, such as age, condition in life, occupation, sex, etc., in determining whether to proceed with a proposed surgical operation or not. Such operations are called Operations of Election or of Complaisance. E., Triangle of, the Superior Carotid Triangle. See Triangles, Table of:

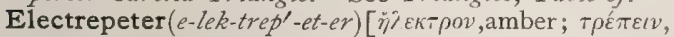
to turn]. An obsolete term for "commutator," $q . v$.

Electric, or Electrical (e-lek'-trik, or e-lek'-trik-al)

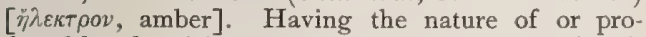
duced by electricity. E. Aura, a current of electrified air. E. Brush, a wire brush used as an electrode. E. Commutator, an instrument for automatically interrupting or reversing the flow of an electric current, making and breaking the same with desired frequency. E. Chorea. See Dubini's Disense. E. Depilation, the permanent removal of hair from any part of the body by the electrolytic destruction of the hair-follicles. E. Discharger, the instrument that directs the charge from a condenser through an object. E. Endosmosis, cataphoresis. E. Fustigation, application of electricity through a metallic brush. E. Head-bath, application of electricity by means of an umbrella-shaped electrode surrounding the head, but separated from it by a distance of from one-half to one inch. E. Inertia, a term sometimes employed instead of electro-magnetic inertia. $\mathbf{E}$. Insolation. See E. Sunstroke. E. Insulation, the placing of non-conducting material with respect to a conductor so as to prevent the loss of a charge or the leakage of a current. E. Irritability, irritability of nervous or muscular tissue to an electric discharge. E. Megaloscope, an apparatus for the medical exploration of the cavities of the body. E. Moxa, a burn made on the skin by electricity. E. Probe, a metallic conductor inserted into the track of a wound in order to ascertain the exact position of a bullet, or other foreign metallic substance. E. Prostration. See E. Sunstroke, E. Reactions, the response of muscles and nerves to electric stimulation. E. Shock, the physiologic shock produced in an animal by an electric discharge. E. Shower-bath, a device for general electrization; one of the poles is immersed in a tub containing an alkaline solution. The patient stands beneath this reservoir on a metallic stool connected with the other pole. The falling water completes the circuit, dispersing the current over the whole body. E. Sphygmograph, an instrument for electrically recording the characters of the pulse, E. Sterilization, sterilizing a solution by depriving it of whatever germs it may contain by means of electric currents. E. Sunstroke, the physiologic effects, similar to those produced by exposure to the sun, experienced by those exposed for a long while to the intense light and heat of the voltaic arc. E. Test, the application of electricity to ascertain the existence or non-existence of central lesions after railway injuries. It must be borne in mind that cutaneous insensibility or absence of response in the muscles is not positive proof of organic lesion; hence the socalled electric test is not so absolutely relied upon as formerly.

Electric Units. The lowest integral electric values. They are as follows:-Ampere, the unit of measurement of an electric current. It is the electro-motive force of one volt produced in a circuit having one ohm of resistance, equal to $\frac{1}{10} \mathrm{C} . \mathrm{G}$. S. electro-magnetic unit. It is sufficient to deposit . 3 grain of copper per minute on the plate of a copper voltameter, or to decompose sufficient acidulated water to generate 10.32 c. c. of mixed hydrogen and oxygen per minute. For convenience the $\frac{1}{1000}$ part is used in medicine, namely, the milliampere. This equals I volt divided by IO0o. Ampere-hour, a unit of electric quantity equal to one ampere flowing for one hour; it is the equivalent of 3600 coulombs. C. G. S. System, Centimeter-gram-second Units, - the system of fundamental units in which a centimeter is adopted as the unit of length, a gram as the unit of mass, and a second as the unit of time. Coulomb, the unit of measurement of electric quantity; the quantity of electricity that passes during one second through a conductor having a resistance of one ohm, with one volt of electromotive force. The micro-coulomb is the millionth part of this amount. Unit of Current, a conductor one $\mathrm{cm}$. long which, if bent into an arc of one $\mathrm{cm}$. radius, will act with the force of one degree on a unit magnet pole at the center. Dyne, the unit of force : $i$. $e_{\text {. }}$ the force which if it acted for one second on a mass of one gram would, if the mass was previously at rest, give it a velocity of one centimeter per second; or if it was previously in motion in the direction of the force, would in that time alter its velocity by that amount. Erg. See Unit of Work. Ergten, I0,000,000,000 ergs. Farad, the unit of electric capacity. Practically, a capacity sufficient to hold one coulomb of current having a potential of one volt. The micro-farad, $150 \frac{1}{10000}$ part of the theoretic farad, is commonly used. A practical form of condenser of one farad capacity consists of 300 leaves of tinfoil, each 16 centimeters in diameter, separated by leaves of mica. The entire surface has an area of about I. I sq. meters. Joule, the unit of electric energy or work. The volt coulomb. It equals 10,000,000 ergs. Unit Magnet Pole, a magnet having a strength of pole sufficient to repel a similar pole at a distance with a force of one degree. Megalerg, I,000,000 ergs. Megavolt, I, 000,000 volts. Micro-coulomb. 
See Coulomb. Microfarad. See Farad. Microvolt, one millionth part of a volt. Milliampère. See Ampere. Ohm, the unit of resistance. Yracti tically, it is the resistance of a pure silver wire one meter in length and one millimeter in diameter. The theoretic or absolute unit is $\frac{1}{1000000}$ part of the unit practically used. Volt, the unit of electro-motive force, or the force sufficient to cause a current of one ampère to flow against a resistance of one ohm. The following is the voltage of several popular cells: Smee, 0.65 ; Bunsen, 1.90; Daniell, 1.05; Callaud, 0.60 ; Leclanche, I.50. Volt-ampere, the unit of electric work. It is the amount of pressure developed by a current of one amperre having an electromotive force of one volt. Its mechanical equivalent is about 44.2 foot-pounds per minute. It is sometimes called a Watt. Volt-coulomb, the unit of electric work. Watt. See Volt-ampère. Weber, an ampère. Unit of Work, the erg; it is equal to the work required to move a body through one centimeter against a force of one dyne. The reciprocal relations of these electric units may be expressed thus :-

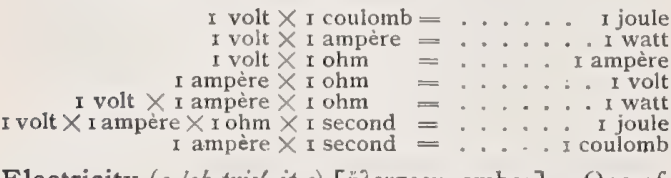

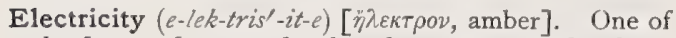
the forces of nature developed or generated by chemism, magnetism, or friction, and probably a mode of ethereal vibration, closely analogous to and convertible into heat and light. It has been largely employed in its various forms for therapeutic purposes. Most animal and vegetable fibers (living) contract when an electric current is passed through them, and, in fact, no substance is known that does not offer some resistance to the passage of an electric current. By the Conducting Power of a substance is meant the ability of a given length and area of a cross-section of that substance to conduct electricity, as compared with an equal length and area of a cross-section of some other substance, such as pure silver or copper. This power may, in various substances, be pronounced, partial, or absent, Good conductors are silver, copper, other metals, charcoal; partial conductors are water, the human body, cotton, wood, marble, paper; non-conductors, oils, porcelain, dry wood, silk, resins, dry air, shellac, gutta-percha, ebonite, paraffin, glass. E., Animal, free electricity in the body. E., Chemic. See E., Galvanic. E., Faradic, that produced by induction. E., Franklinic, frictional or static electricity. E., Frictional, that produced by friction. E., Galvanic, that which is generated by chemic action in a galvanic cell. E., Inductive, that produced in a body by proximity to an electrified body without contact. E., Magnetic, that developed by bringing a conductor near the poles of a magnet. See Current. E., Medical, that used for therapeutic purposes. E., Static, frictional electricity. E., Voltaic, same as galvanic or chemic electricity.

Electrization (e-lek-triz-a'-shun) [ $\ddot{\eta} \lambda \varepsilon \kappa \tau \rho o v$, amber]. The application of electricity to the body. E., General, the therapeutic application of electricity to all parts of the surface of the body.

Electrize $\left(e-l c k^{\prime}-t r i z\right)$ [ $\ddot{\eta} \bar{\lambda} \varepsilon \kappa \rho \rho \nu$, amber]. To treat by means of electricity.

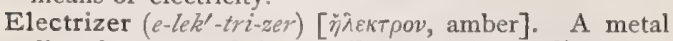
disc of copper and zinc, or silver and zinc applied to the surface of the body, and connected with copper wire, exciting, through the perspiration, a feeble galvanic current.

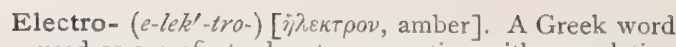
used as a prefix to denote connection with or relation to electricity. E.-anesthesia, inability to perceive the sensation made by electricity upon the skin. E.-biology, the science of the electric relations and laws of organic beings. E.-bioscopy. See Bioscopy. E.-centesis, the use of electrolysis to cause absorption of effusions, as in pleurisy. E.-chemistry, the science of the inter-relations and laws of electricity and chemistry. E.-cystoscopy, examination of the bladder by means of electric illumination. E.-diagnosis, diagnosis by means of the exaggeration or diminution of the reaction of the excitable tissues of the body when subjected to the varying influences of electric currents. E.-esthesia, ability to perceive the sensation made by the reception of an electric discharge; it may co-exist with local anesthesia, or with loss of the power to perceive other sensations. E.-magnet, a mass of soft iron surrounded by a coil of wire. E.-magnetic Inertia, a term sometimes employed instead of inductance or the selfinduction of a current. E.-magnetism, magnetism induced within iron, steel, or nickel, by introducing it within a coil through which a current is passing. E.-massage, the transmission of a current of electricity through a kneading instrument; the use of labile currents applied by means of a rolling or wheel electrode, or by a sponge or brush. E.-motive, pertaining to the mechanic or motor effects of electricity. E.-motor Force, that which sets electricity in motion; the difference of potential between two points. It is estimated in volts. E.-muscular, pertaining to the action of electricity upon muscles. E.-muscular Contractility, the contractile response of a muscle to an electric current. E.-muscular Sensibility, the impression upon a sensory nerve by electric irritation. E.-otiatria, electricity applied to the treatment of diseases of the ear. E.-pathology, the study of morbid conditions by the aid of electric irritation. E.-physiology, the study of electric reactions, properties, and relations of organs and organic tissues. E.-puncturation, or E. -puncture, the use of needles as electrodes, which are thrust into an organ, or tumor, e. $g$., into the cavity of an aneurysm, with the object of coagulating the contained blood. E.-sensibility, an effect produced on a sensory nerve by its electrization. E.-statics, the science of static electricity, or that developed by friction and induction. E.-thanasis, a word proposed for death by electricity. E.-therapeutic Bath. See Bath. E.-therapeutics, the science and art of the application of electricity for therapeutic purposes. E.-therapy. See E.-therapeutics. E.-thermometry, the determination of the radiation of body-heat by means of an electric thermoscope. E.-vital, pertaining both to electricity and to the phenomena of life. E.-vitalism, the theoretic identification of the vital forces with electricity.

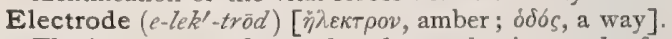
The instruments, fastened to the conducting cords of a battery, that are used in the application of electricity to the body. The standard sizes of electrodes generally adopted in therapy are; according to Erb, as follows :-

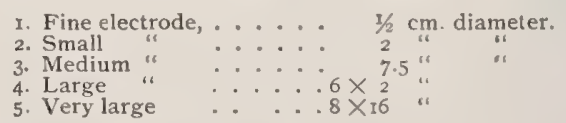

E., Brush, one end fitted with a camel's-hair pencil. E., Clay, a therapeutic electrode of clay shaped to fit the part of the body to be treated. E., Electrotherapeutic, the therapeutic electrode is generally 
placed nearer the organ or part to be treated than the indifferent electrode. E., Indifferent, the electrode that is employed merely to complete the circuit; not directly concerned in the treatment or diagnosis. E., Non-polarizable, zinc wires treated and so arranged as to prevent electrolysis. See Anode and Cathode.

Electrogenesis (e-lek-tro-jen'-es-is) [ $\ddot{\eta} \lambda \varepsilon \kappa T \mu o v$, amber;

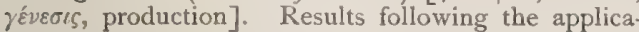
tion of electricity to the spinal cord or nerve after the withdrawal of the electrodes.

Electrolysis (e-lek-trol"-is-is) [ $\ddot{\eta} \lambda \varepsilon \kappa \pi \rho o v$, amber; $\lambda v \sigma \iota s$, solution]. The dissolution of a chemic compound by an electric current; the discussion of any morbid growth by means of an electro-chemic current. It is used in the treatment of hydrocele and some other surgical affections.

Electrolytic (e-lek-tro-lit'-ik). [ $\eta^{\prime} \lambda \varepsilon \kappa \tau \rho o v$, amber; $\lambda \dot{v} \sigma \iota s$, solution]. Relating to electrolysis.

Electrometer (e-lek-trom'-et-er) [ $\ddot{\eta} \lambda \varepsilon \kappa \tau \rho o v$, electricity;

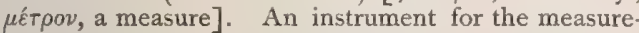
ment of differences of electric potential.

Electrophonize (e-lek-trof'-on-izz) [ $\phi$ bovos, a killing]. To inflict capital punishment by means of electricity.

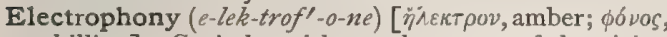
a killing]. Capital punishment by means of electricity.

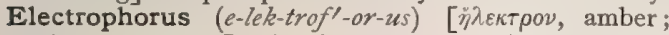
$\phi \varepsilon \dot{\rho} \varepsilon \iota v$, to carry] An instrument used to generate small quantities of static electricity.

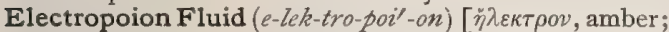
$\pi$ otriv , to make]. A battery fluid made by dissolving I lb. of potassium bichromate in a mixture of water Io lbs. to sulphuric acid (commercial) $2 \pi / 2 \mathrm{lbs}$.

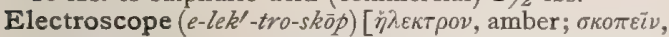
to view]. An instrument for detecting the presence of static electricity and determining whether it is positive or negative.

Electrostixis (e-lek-tro-stiks'-is) [ $\eta \ddot{\lambda} \varepsilon \kappa \tau \rho o v$, amber; $\sigma \tau i \xi \iota \varsigma$, puncture ]. Electro-puncture, $q . v$.

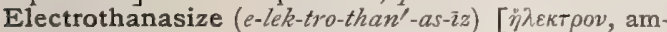
ber; $\theta a v a \tau \delta \varepsilon \imath \nu$, to kill]. To produce death by electricity, but not as capital punishment.

Electrothanatose (e-lek-tro-than'-at-ôs) [ $\ddot{\eta} \lambda \varepsilon \kappa \tau \rho o v, a m-$ ber; Aávaros, death]. Same as Electrothanasize.

Electrothanatosis (e-lek-tro-than-at-o'-sis) [ $\ddot{\lambda} \lambda \varepsilon \kappa \tau \rho o \nu$,

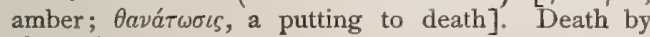
electricity.

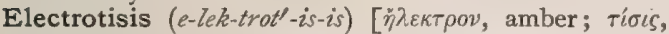
penaltv ]. Capital punishment by electricity.

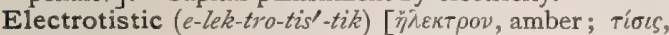
penalty]. Pertaining to capital punishment by means of electricity.

Electrotistis (e-lek-tro-tis'-tis). An incorrect form of Electrotisis, q.v.

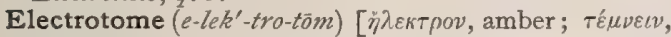
to cut]. The circuit-breaker of an electric battery; especially one that acts automatically.

Electrotonic (e-lek-tro-ton'-ik) [ ${ }^{\prime} \lambda \varepsilon \kappa \tau \rho o v$, amber; tóvos, tension]. Relating to or of the nature of electrotonus. E. Effect, an altered condition of excitability of a nerve produced when in the electrotonic state.

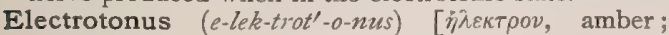
$\tau \delta v o \varsigma$, tension]. The change of condition in a nerve during the application of a current of electricity. A decrease in the electro-motive force of a nerve, effected by sending a current through the nerve in the opposite direction to the nerve-current, is termed the negative phase of electrotonus, while an increase in the electromotive force of a nerve, effected by sending a current through a nerve in the same direction as the nervecurrent, is termed the positive phase of electrotonus.
See Anelectrotonus, Catelectrotonus, and Electrogenesis. E., Law of. See Lave.

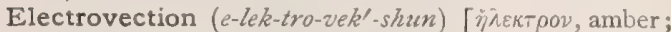
vehere, to carry]. Electric endosmosis; the intro duction of medicaments into the system by means of the electric current ; cataphoresis.

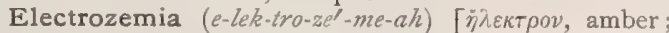
کnuia, penalty]. A word proposed for capital punish ment by electricity; electrotisis.

Electuary (e-lek'-chu-a-re) [electuarium, an electuary] A soft or pasty confection. See Confectio.

Eleidin $\left(e l-e^{\prime}-i d-i n\right)$ [ $\dot{\varepsilon} \lambda a i a$, olive-oil]. A material that forms the elliptic granules of the superficial cells of the stratum granulosum of the epidermis. It is called also keratohyalin.

Element $\left(e l^{\prime}-e m-e n t\right)$ [elementum, a first principle]. In chemistry, a body that cannot be decomposed into simpler substances. The recognized elements now number about 73. See Table of Elements, on p. 416. The term is applied in biology to the ultimate microscopic structures of a tissue. In electricity, one of the generating plates in a galvanic cell. E., Mendelejeff's Classification of, the classification of elements according to their atomic weights. See Elements, Table of, Note.

Elementary (el-e-men'-ta-re) [elementum, a first principle]. Pertaining to an element. E. Cell, an embryonic corpuscle. Also, a synonym of Leukocyte, q. v.

Elemi $\left(e l^{\prime}-e m-i\right)$ [Arab]. A concrete resinous exudation probably derived from the Canarium commune, although its botanic source is still undetermined. It contains a crystalline resin, Elemin or Amyrin. Its action is similar to those of the turpentines generally. E., Unguent. (B. P.), elemi and simple ointment; it is used as an application to indolent sores and boils. Many other resins are known to commerce as eleniz. In general, the elemis are softer than the copals; and they may be classed together as a group of somewhat hard oleo-resins. See Resins.

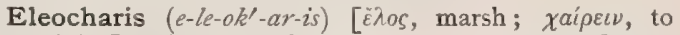
rejoice]. A genus of sedges or cyperaceous plants; the spike-rushes. E. palustris, a plant very common in Europe, Asia, and N. America, is a popular astringent remedy, useful for diarrhea and for hemorrhages. The root, tops, and seeds are used. Unof.

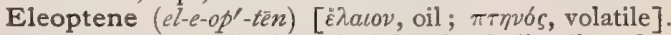
The permanent liquid principle of volatile oils. See Stearoptene.

Eleosaccharum $\left(e-\left[e-0-s a k^{\prime}-a r-u m\right)\right.$ [L.: pl., Eleosacchara]. Same as Oleosaccharum.

Elephant Leg. See Elephantiasis arabum.

Elephant's Foot $\left(e l^{\prime}-e\right.$-fants foot $)$. Any plant of the genus Elephantopus, order Compositæ. The U.S. has several species. Elephantopus tonnentosus is diuretic, expectorant, and emetic. Dose of the fld. ext. $m_{\nabla-\mathrm{xxx}}$. Unof. $E$. carolinianus is tonic and febrifuge, and so are various tropical species.

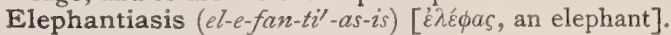
Elephantiasis arabum; Barbadoes leg; Tropical big leg; spargosis; elephant leg; morbus elephas; bucnemia tropica; pachydermia; a chronic affection of the cutaneous and subcutaneous tissues, often occurring as an endemic or sporadic disease, due to obliteration of lymph-vessels, resulting in febrile and other systemic symptoms, redness, tumefaction, and infiltration of the affected part, and the eventual production of a wellmarked hypertrophy that may become gigantic. It is most common in the leg and genitals. E. græcorum. See Leprosy. E. indica. Synonym of E. arabum. E. telangiectodes, a rare vascular form of elephantiasis arabum of congenital origin but of later development. 


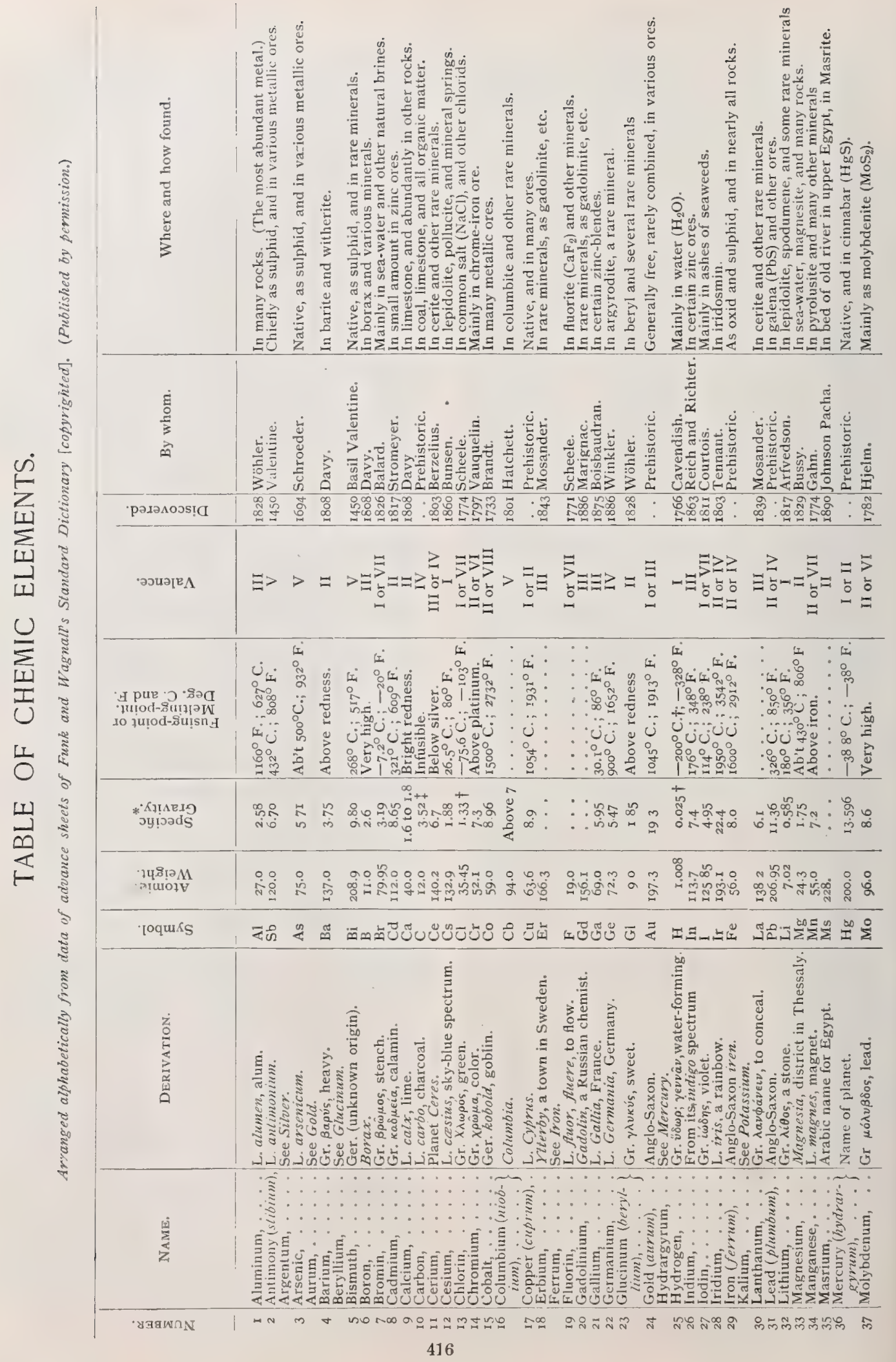




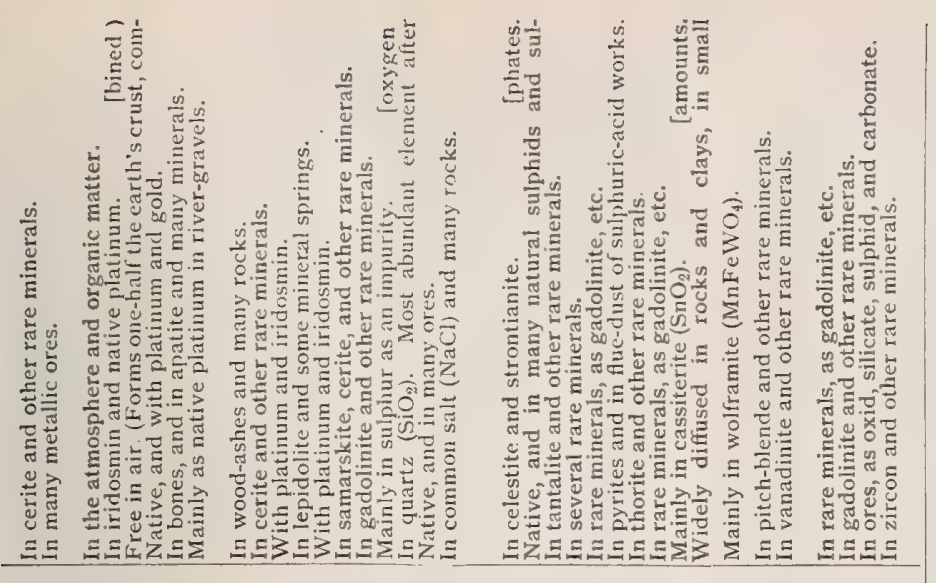

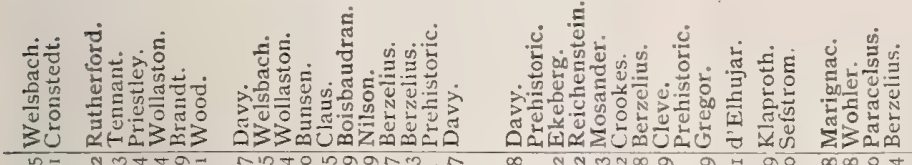

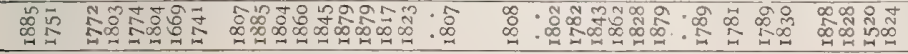

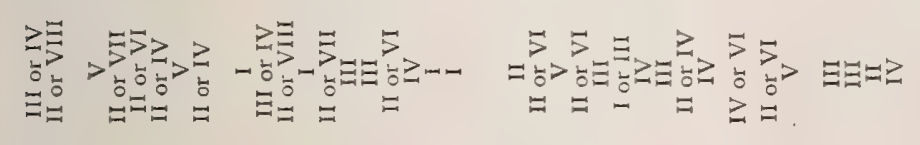

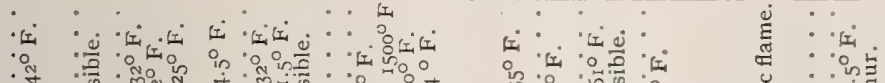

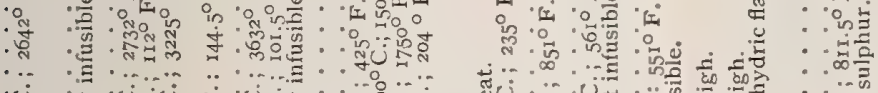

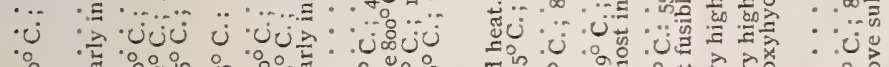

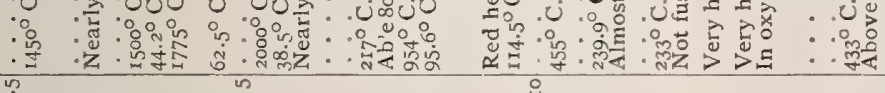

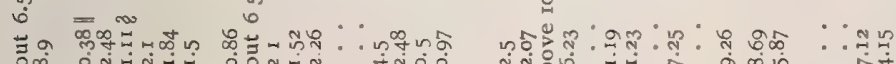
$\int_{0}^{0}$ añ

wo

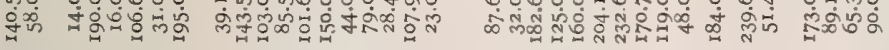

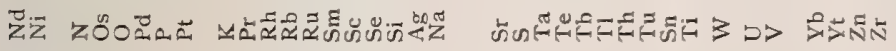

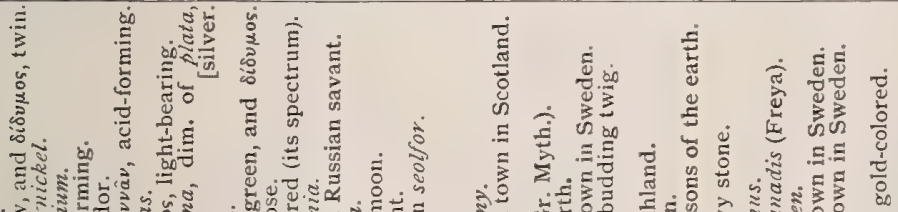

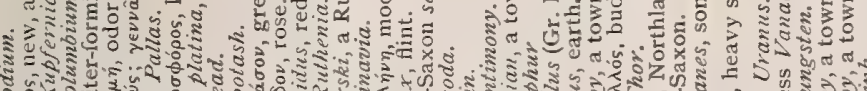

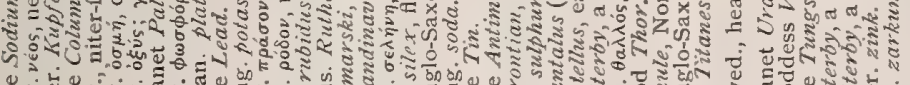

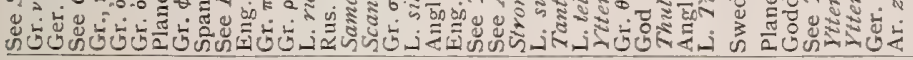

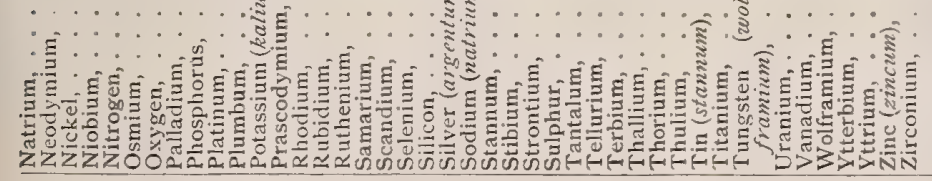

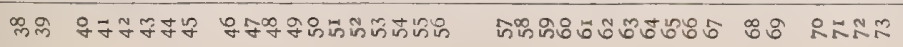


Elephantoid Fever (el-e-fan'-toid). See Fever.

Elephas $\left(e l^{\prime}-e-f a s\right)$ [L.]. Synonym of Elephantiasis a rabum.

Eleuthera Bark (e-lu'-ther-ah). See Cascarilla.

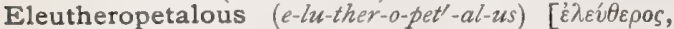

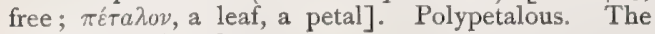
same as choripetalous.

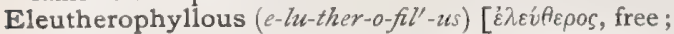
$\phi \hat{i} \lambda \lambda \nu^{2}$, a leaf ]. In biology, made up of distinct leaves; polypetalous or polysepalous.

Elevator $\left(e l^{\prime}-e-v a-t o r\right)$ [elevare, to lift]. I. The same as Levator. See Muscles, Table of. 2. An instrument used in surgery and dentistry. E. Disease, one of the professional neuroses, due to constant traveling in an elevator.

Elimination (e-lim-in-a -shun) [e, out; limen, threshold]. Excretion; the process of putting forth or out.

Eliquation (el-ik-wa'-shun) [eliquare, to melt out]. The separation of one substance from another by fusion or melting.

Elixir (e-liks'-er) [Arab., el iksir, the philosopher's stone]. A sweetened, aromatic, spirituous preparation, which is practically a flavored syrup designed as an excipient for extracts and tinctures. There are many elixirs, only two of which are official in the U. S. $\mathrm{P}$. ; in the N. F. more than seventy are described. $\mathrm{E}$. aromaticum, aromatic elixir, comp. spirit of orange I 2 c. c., syrup 375 c.c., precipitated calcium phosphate $15 \mathrm{gm}$., deodorized alcohol and distilled water, q. s. Elixiviation (e-liks-iv-e-a'-shun). See Lixiviation.

Elkodermatosis (el-ko-der-mat-o'-sis) [ $\varepsilon \bar{\lambda} \kappa o s$, an ulcer;

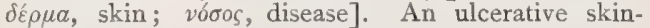
affection.

Ellagic Acid $\left(e l-a j^{\prime}-i k\right)$, See Acid.

Elliot's Bassorin Paste. A paste used in the treat ment of eczema. It consists of bassorin, Io drams ; dextrin, 6 drams; glycerin, 2 drams; water, sufficient to make $251 / 2$ drams. It should be prepared cold.

Elliptic, Elliptical (el-ip’-tik,-al) [ $\varepsilon \lambda \lambda \varepsilon \iota \psi \iota \varsigma$, ellipse]. Having the form of an ellipse. E. Amputation. See Amputation.

Ellis's Curved Line. See Line. E., Ligament of. See Ligament.

Ellison's Ventilating Bricks. See Ventilation.

Elm. See Ulmus and Fremontia.

Elocution (el-o-ku'-shun) [e, out of ; loqui, to speak]. The choice, arrangement, and delivery of words and language, including the use of the voice, the action of the lungs, diaphragm, gesture, etc.

Elocutionist (el-o-ku'-shun-ist) [e, out of ; loqui, to speak]. One who is skilled in the art of elocution. E.'s Cramp. See Cramp.

Elodea $\left(e l-o-d e^{\prime}-a h\right)[\varepsilon \dot{\varepsilon} \lambda \omega \delta \eta s$, marshy]. The marsh St. John's Worts; a genus of hypericaceous plants. E. virginica, common in the U. S. and Canada, is a popular stomachic. Unof.

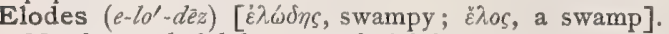
Marsh or paludal fever; malarial fever.

Elsberg, Plastidules of. See Heredity.

Elutriation (e-lu-tre-a'-shun) [elutriare, to wash out]. A water-sifting process whereby the coarser particles of an insoluble substance are separated from the finer.

Ely's Operation. See Operations, Table of. E.'s Table. See Pregnancy.

Elythritis (el-ith-ri'-tis). See Vaginitis.

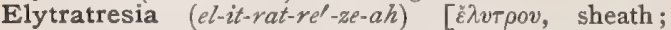
$\dot{a} \tau \rho \eta \tau o$, imperforate ]. Atresia of the vagina; colpatresia.

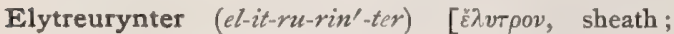
cupóveเv, to make broad]. Same as Colpeurynter.

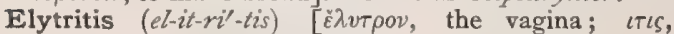
inflammation]. Inflammation of the vagina.
Elytrocele (ell-it-ro-sél) [ $\tilde{\varepsilon}^{\prime} \lambda v \tau \rho o v$, sheath ; $\kappa \dot{\eta} \lambda \eta$, hernia]. Colpocele; vaginal hernia.

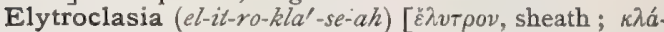
$\varepsilon i \nu$, to break]. Rupture of the vagina.

Elytroncus (el-it-rong'-kus). Same as Elytrophyma.

Elytrophyma (el-it-ro-fi'mah) [Ë $\lambda v \tau \rho o \nu$, sheath; $\phi \tilde{\nu} \mu \alpha$, a tumor]. Swelling or tumor of the vagina.

Elytroplastic (el-it-ro-plas'-tik) [ $\sigma \varepsilon \iota \nu$, to form]. Relating to elytroplasty.

Elytroplasty (ell-it-ro-plas-te) [ $\dot{\imath} \lambda v \tau \rho o \nu$, sheath; $\pi \dot{\lambda} a \sigma-$ $\sigma \varepsilon \iota \nu$, to form]. Plastic operation upon the vagina, especially for vesico-vaginal fistula.

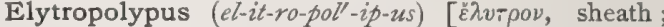

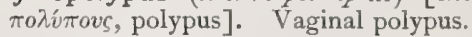

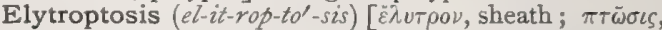
a falling]. Prolapse of the vagina.

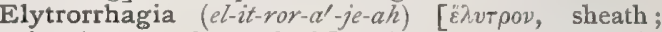
in rvival, to burst forth]. Hemorrhage from the vagina.

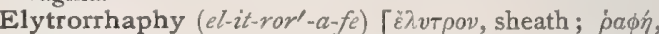
a seam ]. Suture of the vaginal wall. An operation to close the opening of the vagina in procidentia uteri.

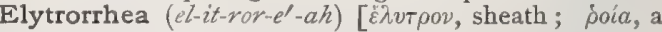
flow]. A vaginal leukorrhea.

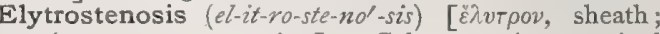
$\sigma \tau \varepsilon ́ v \omega \sigma \iota \varsigma$, a contraction]. Colpostenosis; vaginal stricture.

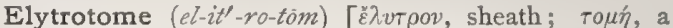
cutting]. In instrument for performing elytrotomy.

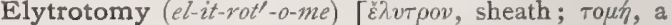
cutting]. Surgical incision of the vaginal wall.

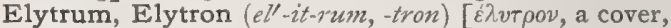
case: pl., Elytra]. In biology, one of the wing-covers, wing-sheaths, or modified fore-wings of beetles; also one of the scales on the back of certain worms.

Emaciation (e-ma-se-a'-shun) [emaciare, to make lean]. Loss of the fat and fulness of the flesh of the body. Leanness.

Emaculation $\left(e-m a k-u-l a^{\prime}-\operatorname{shun}\right)$ [emaculare, to remove spots]. The removal of freckles or other spots from the face.

Emanation (em-an-a'-shun) [emanare, to issue]. I. Emission; radiation. 2. That which flows or issues from a substance; effluvium

Emandibulate $\left(e-m a n-d i b^{\prime}-u-l \bar{a} t\right)[\varepsilon$, priv, ; mandibula, mandible]. In biology, without mandibles, or at least with soft and minute mandibles.

Emansio $\left(e-\right.$ man'-se- $\left.^{\prime}\right)$ [L.]. A failing. E. mensium, delayed menstruation; amenorrhea.

Emarginate (e-mar'-jin-āt) [emarginatus, to deprive of the edge]. In biology, applied to a leaf or feather the margin of which is broken, notched, nicked, or otherwise modified.

Emasculation (e-mas-ku-la'-shun) [emasculare, to make impotent]. Removal of the testicles; impotence. See, also, Eviration.

Embalming (em-bahm'-ing) [Fr., en, in ; bauma, balsam ]. The treatment of a cadaver with antiseptic and preservative substances to keep it from putrefying.

Embedding $\left(e m-b e d^{\prime}-i n g\right)$. The fixation, in order to preserve it intact, of a tissue-specimen in a firmer medium before freezing or otherwise hardening and section.

Embelia (em-be'-le-ah) [Embel, a German traveler]. A genus of shrubs. E. ribes, a myrtaceous shrub that grows in Asia; it is reputed to have anthelmintic properties. Dose of the powdered fruit, $3 \mathrm{j}-\mathrm{iv}$; of the fluid extract, $3 \mathrm{j}$-iv. Unof.

Emblica (em'-blik-ah) [L.]. A genus of euphorbiaceous trees. E. officinalis, a tree of India; its fruit, the Emblica myrobalan (see Myrobalan), is astringent and vermifuge, the seed is febrifuge, and the bark is also medicinal. Unof. 
Emboitment (on $(g)$-breat'-mon $(g))$ [OF., emboister, to inclose, as in a box ]. In biology, Bonnet's doctrine that each germ includes the germs of all generations that shall succeed it

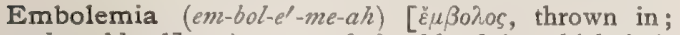
aina, blood]. A state of the blood in which it is said that emboli are readily formed.

Embolic $\left(e m-b o l^{\prime}-i k\right)$ [ $[\mu \beta \beta \lambda o s$, thrown in]. Relating to, associated with, or caused by an embolus.

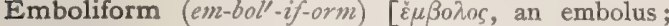
forma, form]. Resembling an embolus.

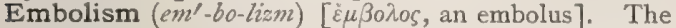
obstruction of an artery or capillary, usually by a blood-clot or embolus, brought from another point by the blood-current. These emboli may be fragments of vegetation from the valves of the heart, clots from a thrombosis or aneurysm, or fragments of atheromatous tissue. Around the seat of an embolus thrombosis'occurs with the production of an infarct, $q . v$. E. Air, by a bubble of air. E., Capillary, obstruction of capillaries by micrococci. This occurs in pyemia. E., Fat, the entrance into the circulation of fluid fat after extensive injuries. Death often follows. The symptoms are restlessness, anxiety, slight dyspnea, accelerated breathing, quickening of the pulse; cyanosis, delirium, and insomnia, followed by coma, are graver symptoms. The temperature may remain subnormal or it may rise. E., Infective, the emboli are metastatic. This occurs in pyemia and ulcerative endocarditis. E., Multiple, numerous small emboli E., Paradoxical, embolism of an artery by a venous thrombus, as may occur in a patulous foramen ovale. E., Pyemic. See E., Infective. E., Retinal, occurring in the arteria centralis retina, followed by sudden loss of vision. E., Venous, occurring in veins, especially of the lungs and liver.

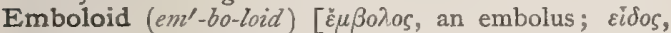
likeness]. Resembling an embolus.

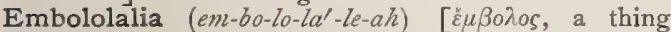
thrown in; $\lambda a \lambda \iota x$, talk ]. The morbid intercalation of words, often meaningless, into the speech.

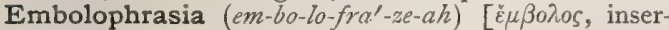

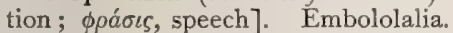

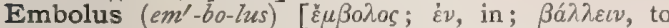
throw]. I. A clot of blood, or plug of other material, brought by the blood-current from a distant artery, and forming an obstruction at its place of lodgment. 2. Wilder's term for the nucleus emboliformis.

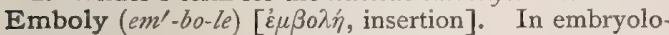
gy, the process of invagination that gives rise to a gastrula from a blastosphere or vesicular morula.

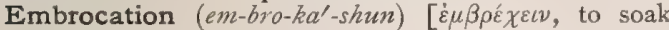
in]. A fluid external application for some injured or diseased part.

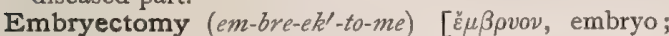
$\varepsilon$ हैo $\mu \eta$, a cutting out]. The surgical removal of the embryo in extra-uterine pregnancy.

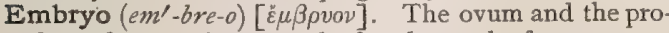
duct of conception up to the fourth month of pregnancy; the fertilized germ of an animal. Applied in botany to the rudimentary plant within the seed. E.-sac. In biology, $(a)$ the cell in the nucleus of the ovule of flowering-plants, that contains the germinal vesicles and finally the embryo; $(b)$ the protoconch or primitive shell of certain cephalopods.

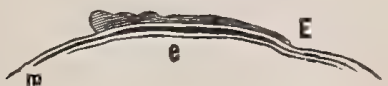

Scheme of a Longitudinal Section of AN EARLy EMBRYO.

E. Epiblast. m. Mesoblast. e. Hypoblast.

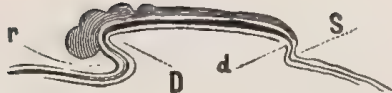

SCHEME OF THE FORMATION OF THE HEAD-AND TAIL-FOLDS. r. Head-fold. D. Anterior extremity of the future intestinal tract. S. Tail-fold, first rudiment of the cavity of the rectum.

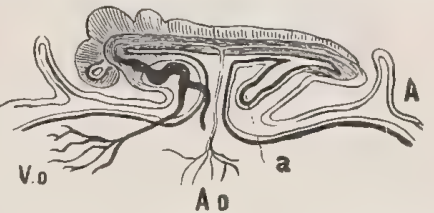

SCHEME OF A LONGITUDINAL SECTION THROUGH AN FMBryo AFTER THE FORMATION OF THE HEAD- AND TAIL-FOLDS. Ao. Omphalo-mesenteric arteries. Vo. Omphalo-mesenteric veins, a. Position of the allantois. A. Amniotic fold.

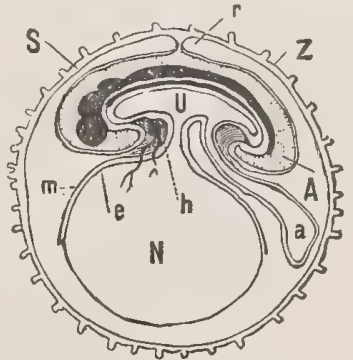

Scheme of a Longitudinal Section through a Human Ovum.

Z. Zona pellucida. S. Serous cavity. Inion of the amniotic folds. A. Cavity of the amnion. Allantois. N. Umbilical vesicle. m. Mesoblast. h. Heart. U. Primitive intestine.

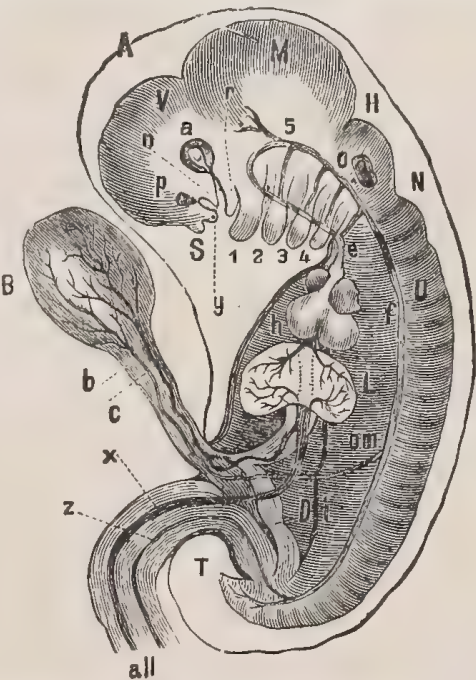

Scheme of Human Embryo, with the Visceral Arches STILl PERsistent

A. Amnion. V. Fore-brain. M. Mid-brain. H. Hind-brain. N. After-brain. U. Primitive vertebræ. a. Eye. p. Nasal pit. S. Frontal process. y. Internal nasal process. n. External nasal process. I Superior maxillary process of the first visceral arch. betwen them. O. Auditory vesicle. h. Heart, with e, primitive aorta, which divides into the five aortic arches. f. Descending aorta. om. Omphalic-mesenteric artery, b. The omphalo-mesenteric arteries of the umbilical vesicle, c. Omphalo-mesenteric vein. L. Liver with venæ advehentes and revehentes. D. Intestine. f. Inferior cava. T. Coccyx. all Allantois, with $z$, one umbilical arterv; and $x$, an umbilical vein. 


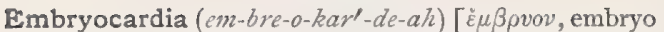
Kapdia, the heart]. An affection of the heart, characterized by a heart-beat like that of a fetus. It is usually associated with tachycardia, and a condition of collapse and cyanosis. See Cyematocardia.

Embryoctony (em-bre-ok'-to-ne) [Ě $\mu \beta \rho v o v$, embryo; ктEiveLv, to kill]. The destruction of the living fetus; the procurement of abortion.

Embryogenesis (em-bre-o-jen'-es-is), Embryogeny

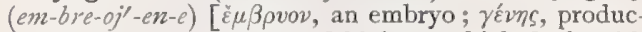
ing]. That department of biology which deals with the development of the fecundated germ.

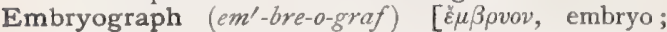
ypádetv, to write]. A form of microscope and camera lucida for use in drawing outlines and figures in embryologic study.

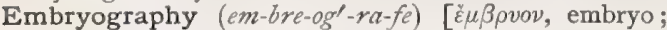
yoá $\varepsilon w$, to write]. A description of embryos.

Embryologic (em-bre-o-loj'-ik), Embryological (em

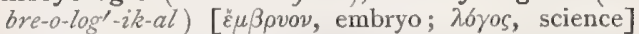
Relating to embryology.

Embryologist (em-bre-oll-o-jist) [ $\tilde{c}_{\mu} \beta \rho v o v$, embryo ; $\lambda 6$ yos, science]. One skilled in the science of embryology.

Embryology (em-bre-oll-o-je) $[\tilde{\varepsilon} \mu \beta \rho v o v$, embryo ; $\lambda$ ó $\gamma o s$, science]. The science of the evolution of the em bryo, or the study of fetal development.

Embryon (em'-bre-on). Same as Embryo.

Embryonal (em-bre-o'-nal). Same as Embryonic.

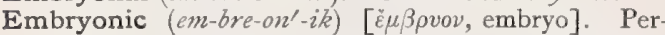
taining to the embryo. E. Area, in embryology, an opaque circular spot that forms on the blastoderm E. Connective Tissue, the primitive condition of connective tissue when first formed, consisting of small, round cells. E. Spot. See E. Area.

Embryotega (em-bre-ot'-e-gah) [ह̌ $\mu \beta \rho v o v$, an embryo;

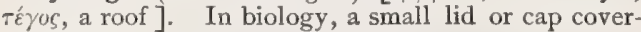
ing the micropyle in certain seeds.

Embryotome (em'-bre-o-tōm) [ $\tilde{\varepsilon} \mu \beta \rho v o v$, embryo; $\tau$ o $\mu$ ń, section]. An instrument used in embryotomy.

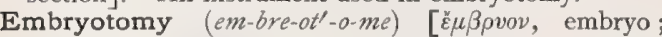
тон' of the fetus to render possible its transmission through the birth-canal. See Cephalotripsy, Cranioclasm, Basiotribe, Basilyst, Decollation, Decapitation, Exenteration, Evisceration, Lamination, Perforation, Spondylotomy, Transforation.

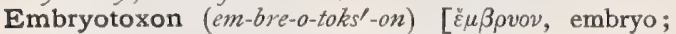
$\tau 6 \xi \circ \nu$, a bow]. A condition resembling arcus senilis, sometimes seen at birth.

Embryotrophe (em'-bre-o-trōf) [ $\tilde{\varepsilon} \mu \beta \rho \nu o \nu$, the embryo; $\tau \rho \circ \phi \eta$, nourishment]. In biology, the food-yolk.

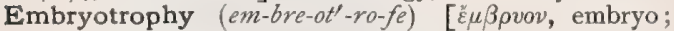

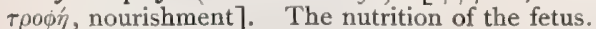

Embryulcia (em-bre-ul'-se-ah)[ $\tilde{\varepsilon} \mu \beta \rho v o \nu$, embryo ; $\tilde{\varepsilon} \lambda \kappa \varepsilon \iota \nu$, to draw]. I. Forcible extraction of the fetus. 2. The operation of embryotomy

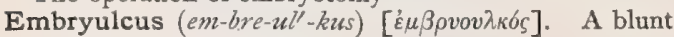
hook, or obstetric forceps.

Emerald-green. See Chrome-green, Mittler's Green, Schweinfurt Green, Brilliant Green.

Emergence (e-mer'-jens) [e, out; mergere, to merge; to rise out]. In biology, one of those structures occurring in higher plants, analogous to hairs, but differing from true hairs in not originating from single epidermal cells; they constitute a transition between trichomes in the stricter sense of the term, and leaves or secondary axes.

Emergency (e-mer'-jen-se) [emergere, to rise up]. A sudden, pressing, and unforeseen occasion for action ; an accident or condition unlooked for, and calling for prompt decision.
Emergent (e-mer'-jent) [emergere, to rise up]. Sudden, unforeseen, and urgent; calling for prompt decision and action; as an emergent case.

Emerod (em'-er-od). See Hemorrhoid.

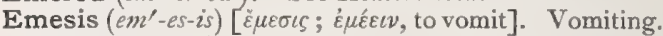

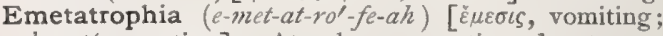
áfpoфía, wasting]. Atrophy or wasting, due to persistent vomiting.

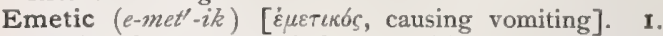
Having the power to induce vomiting. 2. An agent causing emesis, or a dose of such an agent. E., Direct, one acting directly on the nerves of the stomach. E., Indirect, or E., Systemic, one acting through the blood upon the vomiting-center, or by reflex action from other peripheral sources.

Emeticology. See Emetology.

Emetin (em'-et-in). See Ipecacuanha.

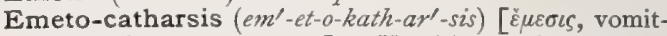
ing; $\kappa \alpha \theta a i \rho \varepsilon \imath \nu$, to purge]. Vomiting and purgation at the same time, or produced by a common agent.

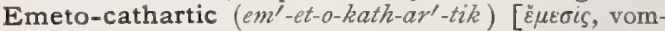
iting; $\kappa a \theta a i \rho \varepsilon \iota v$, to purge]. Having power to induce emeto-catharsis.

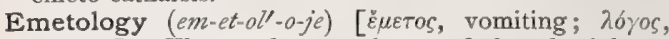
science]. The study or science of the physiology, pathology, and therapeutics of vomiting, and of the nature of emetics.

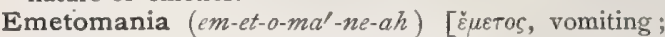
uavin, madness]. Insane desire for frequent emetics.

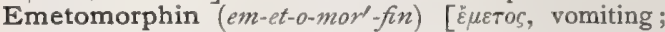
Morpheus, the god of sleep]. Apomorphia.

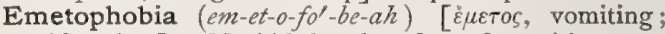
$\phi 6 \beta 0 \varsigma$, fear]. Morbid dread or fear of vomiting.

Emiction (e-mik'-shun) [e, out; mingere, to void urine]. Urination.

Emictory $\left(e-m i k^{\prime}-\right.$ tor-e) $[e$, out; mingere, to void urine]. I. Promoting the secretion of urine. 2, A diuretic medicine.

Emigration (em-ig-ra'-shun) [e, out; migrare, to wander]. The outward passage of a wandering-cell or leukocyte through the wall of a blood-vessel; diapedesis.

Eminence (em'-in-ens) [eminentia, an eminence]. A rounded or protuberant part of an organ, especially of a bone. E., Canine. See Canine. E., Collateral, a triangular elevation in the paracele (lateral ventricle) collocated with the collateral fissure and between the hippocamp and the calcar. E. of Doyère. See Doyere and Sarcoglia. E. facialis, an eminence in the angle formed by the striæ and sulcus ventriculi. E., Frontal, the two eminences of the frontal bone above the superciliary ridges. E., Ilio-pectineal; a ridge on the upper surface of the pubic bone. E. Nasal, the prominence above the root of the nose between the superciliary ridges. E., Occipital, the ridge in the paracele (lateral ventricle) corresponding to the occipital fissure; distinct in the fetus, it is commonly obliterated in the adult; also called bulbus cornu posterioris. E., Parietal, the eminence of the parietal bone.

Eminential (em-in-en'-shal) [eminentia, an eminence]. Relating to an eminence.

Emissarium $\left(e m-i s-a^{\prime}-r e-u m\right)$ [L. ]. A term for any canal or channel conveying a fluid outward. It is applied especially to the veins of the skull.

Emission (e-mish'-un) [emittere, to send forth]. An ejaculation, or sending forth.

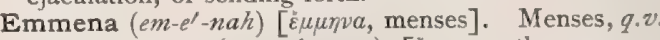

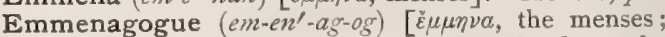
a $\gamma \omega \gamma \sigma \delta s$, leading]. A medicine that stimulates the menstrual flow. E., Direct, one acting directly on the generative organs. E., Indirect, one acting only through other functions and indirectly. 
Emmenia (em-ef-ne-ah) [L.]. The menses.

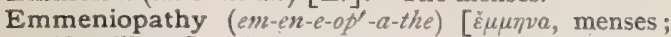
$\pi a ́ b o s$, illness]. Any disorder of menstruation.

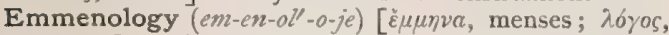
science]. That branch of science that treats of menstruation.

Emmenorrhea (em-en-or-e'-ah) [ $\tilde{\varepsilon} \mu \mu \eta \nu \alpha$, menses ; poía, a flowing]. The menses.

Emmerich, Bacillus of. See Bacteria, Table of.

Emmert's Suture. See Suture.

Emmet's Method. See Treatment, Methods of. E. Operation. See Trachelorrhaphy, and Operations, Table of.

Emmetrope (em'-et-rōpl $[\dot{\varepsilon} \nu$, in; $\mu \dot{t} T \rho o \nu$, measure; $\omega \psi$, eye]. A person whose eyes are emmetropic.

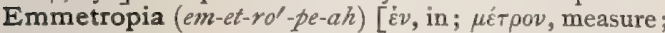
$\dot{\omega} \psi$, the eye]. Normal or perfect vision. The condition of an eye whose shape and refractive media are such that, with suspended accommodation, parallel rays of light are brought to a focus upon the retina. For practical tests, rays of light from a point 20 feet away are considered as parallel.

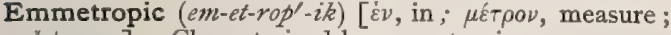
$\check{\omega} \psi$, eye]. Characterized by emmetropia.

Emodin (em'-o-din) [Hind., emodi, rhubarb], $\mathrm{C}_{15} \mathrm{H}_{10}$ $\mathrm{O}_{5}$. A glucosid that occurs with chrysophanic acid in the bark of wild cherry, in cascara sagrada, and in the root of rhubarb. It consists of orange-red crystals, melting at $245-250^{\circ} \mathrm{C}$.

Emollient (e-mol'-yent) [emollire, to soften]. I. Softening; relaxing and soothing. 2. A substance used by external application to soften the skin; or, internally, to sooth an irritated or inflamed surface. E. Cataplasm. Same as Species emollientes.

Emoptoë (em-opplto-e). See Hemoptysis.

Emotion (e-mo'-shun) [emotio, agitation]. Mental feeling, or sentiment, with the associated agitation, and often with more or less bodily commotion. With the emotions, desire, impulse, and will are intimately associated.

Emotional (e-mo'shun-al) [emovere, to move out]. Pertaining to the mental condition of feeling. E. Insanity, insanity characterized by exaggeration and exaltation of feelings.

Empansement $\left(o n(g)\right.$-pon $\left.(g) s^{\prime}-m o n(g)\right)$ [Fr.]. A disease of sheep marked by abdominal swelling.

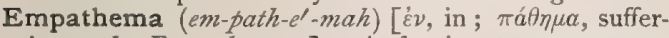
ing: pl., Empathemata]. A dominant or ungovernable passion or source of suffering. E. atonicum, hypochondriasis. E. entonicum, active mania. E. inane, harebrained and purposeless passion and excitement.

Emphlysis (em'-fis-is) [ $\varepsilon \dot{v} \nu$, in, on ; $\phi \lambda \hat{v} \sigma \iota \varsigma$, eruption : pl., Emphlyses]. Any vesicular or exanthematous eruption.

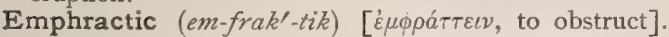
I. Obstructive; closing the pores of the skin. 2. Any agent that obstructs the function of an organ, especially the excretory function of the skin.

Emphraxis (em-fraks' $-i s)$ [ $\varepsilon \mu \phi \rho a \xi c \zeta$, obstruction]. Obstruction; infarction; congestion.

Emphyma (em- $\left.f^{\prime}-m a h\right)$ ' ['ेv, in ; $\phi \tilde{v} \mu \alpha$, growth : $p l$, Emphymata]. A tumor.

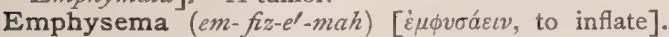
The abnormal collection of air in the connective tissue of a part, causing swelling and crepitation, E., Cutaneous, that occurring in the connective tissues beneath the skin, usually of the face. E., Gangrenous. See Edema, Malignant. E., Interlobular, a form of emphysema following the course of the interlobular septa. This condition is due to traumatism, as after tracheotomy, or in direct injury to the lungs.
E., Pulmonary, a chronic condition of the lungs in which there is a dilatation of the alveoli with destruction of the alveolar walls, resulting in a loss of the normal elasticity of the lung-tissue. This is associated with more or less marked dyspnea, with hacking cough, and defective aëration of the blood, giving rise to a certain degree of cyanosis. The chest becomes full and round - "barrel-shaped" -and a line of distended veins may often be seen surrounding the body at the lower margin of the ribs, constituting the so-called "emphysematous girdle." There is a hyper-resonant note over the chest, with feeble inspiratory sound and numerous râles of all kinds. Hypertrophy and dilatation of the right heart are frequent complications. The margins of the lungs are often the seat of large bullæ due to extensive destruction of the alveolar tissue. The most frequent causes of emphysema are whooping. cough and chronic lung-affections attended with severe coughing-spells. E., Surgical. See Aëroder. mectasia.

Emphysematous (em-fiz-em' -at-us) [ $\dot{\varepsilon} \mu \phi v \sigma a ́ \varepsilon \iota v$, to in flate]. Affected with or of the nature of emphysema. E. Girdle. See Emphysema.

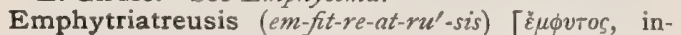

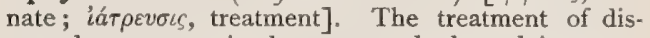
ease by an untrained person, whether clairvoyant, medium, trance-doctor, telepathist, mesmerist, or seventh son of a seventh son.

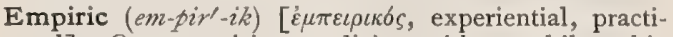
cal]. One practising medicine without philosophic or scientific principles, simply from the results of his own experience, or that of others. As commonly used it is nearly synonymous with quack.

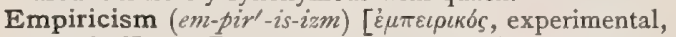
practical]. I. Dependence upon experience or observation. 2. Quackery.

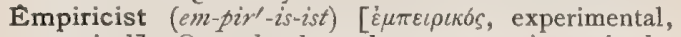
practical]. One who depends upon experience in the treatment of disease.

Emplastrum (em-plas'-trum) [é $\mu \pi \lambda a ́ \sigma \sigma \varepsilon \iota v$, to plaster up: pl., Emplastra]. A plaster. In pharmacy, a cohesive, tenacious substance, insoluble in water, used as an excipient and containing a prescribed medicinal substance intended to be spread in a thin layer upon chamois, kid, or muslin. The excipient is usually lead oleate or Burgundy pitch. (See Lead and Pix.) There are $\mathbf{1} 3$ official emplastra. E. califaciens. See Cantharis.

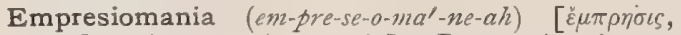
conflagration; $\mu c v i \alpha$, mania]. Pyromania; insane desire to burn houses or other articles; maniacal incendiarism.

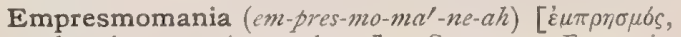
a burning; $\mu a v i a$, madness]. Same as Empresiomania.

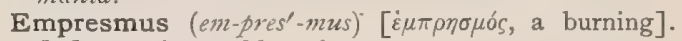
Inflammation; phlogosis.

Emprosthotonia (em-pros-thot-o'-ne-ah). Same as Emprosthotonos.

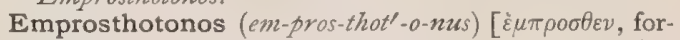
ward; Tóvos, tension]. Tonic muscular spasm that bends the upper and lower parts of the body forward; it is one of the symptoms in some cases of tetanus, etc.

Emptysis (emp'-tis-is) [ $\varepsilon \mu \pi \tau \dot{v} \varepsilon\llcorner$, to spit upon]. Hemorrhage from the lungs; hemoptysis.

Empyema (em-pi-e $-m a h)$ [ $\dot{\varepsilon} \nu$, in ; $\pi v o v$, pus]. Pus in the pleural cavity or in the chest. It may be primary, which is rare, or secondary. There is associated a hectic type of fever, with chills and sweating. If not treated it will rupture spontaneously through the lung or chest-wall. Empyema is most frequently encoun- 
tered in children, but may occur from pleurisy, tuberculosis, septic conditions, and infectious fevers in any individual. E. necessitatis, an empyema in which the pus burrows between the interscostal spaces and appears as a subcutaneous tumor. E., Pulsating, empyema attended with pulsation of the chest-wall.

Empyematous $\left(e m-p_{\left.i-e m^{\prime}-a t-u s\right)}[\dot{\varepsilon} v\right.$, in ; $\pi \dot{v} o v, p u s]$. Of the nature of or affected with empyema.

Empyemic (em-pi-em'-ik). See Empyematous.

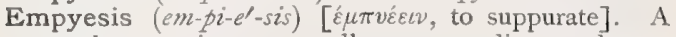
pustular eruption, as smallpox; any disease charac terized by phlegmonous pimples gradually filling with purulent fluid.

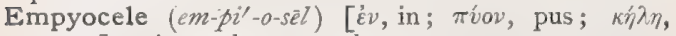
tumor]. A purulent scrotal tumor.

Empyomphalus (em-pi-om'-fal-us) [ $[\dot{\varepsilon} v$, in ; $\pi \hat{v} o v$, pus; $\dot{o} \mu \phi \alpha \lambda \sigma \zeta$, navet]. A collection of pus at or about the navel.

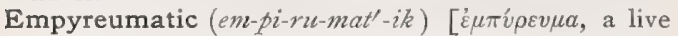
coal; $\varepsilon \mu \pi v \rho o s$, on fire]. Obtained from some organic substance by the aid of strong heat; as an empyreumatic oil

Emulgent (e-mul'-jent) [emulgere, to milk out]. I. Draining; applied to the renal arteries as draining out the urine. 2. An emulgent vessel. 3. Any remedy that stimulates the emunctory organs. E. Veins. See Vein.

Emulsin (e-mul'-sin) [emulgere, to milk out], ro $\left(\mathrm{C}_{9}\right.$ $\left.\mathrm{H}_{18} \mathrm{~N}_{2} \mathrm{O}_{6}\right)+\mathrm{S}($ Bull $)$. A ferment contained in bit ter almonds. It is also called Synaptase. Its union with amygdalin forms hydrocyanic acid. See $A m y g$ dalin.

Emulsio (e-mul'-se-o) [L.: pl., Emulsiones]. See Emulsion.

Emulsion (e-mul'-shun) [emulsio, emulsion]. Water or other liquid in which oil, in minute subdivision of its particles, is suspended. The U. S. P. and N. F. together contain formulæ of some I9 emulsiones.

Emulsionize (e-mull'shun-ĩz) [enulgere, to milk out]. To transform into an emulsion. The pancreatic juice emulsionizes fats.

Emulsive (e-mul'-siv) [emulgere, to milk out]. Forming or readily entering into an emulsion.

Emunctory (e-munk'-tor-e) (emungere, to blow the nose, to wipe out]. I. Excretory; excreting or removing effete matters and waste-products. 2. Any organ or part that has an excretory or purifying function, as the liver, kidneys, bowel, skin, or lungs.

Emydin $\left(e n^{\prime}-i d-i n\right)$ ['́cús, the fresh-water tortoise]. A white proteid substance procured from the yolk of the eggs of turtles.

Enamel (en-am'-el) [ME, enamaile, enamel]. I. The vitreous substance of the crown of the teeth. See Teeth. 2. A vitreous substance used for painting on porcelain, glass, and for covering metals with various kinds of ornamental work. It is composed of coloring matters which consist of metallic oxids, fluxes of vitrifiable substances, as silicates, borates, or boro-silicates. See Porcelain Teeth. E.-blue. See Smalts. E.-cell. See Ameloblast. E.-chisel, a dental instrument shaped like a chisel, with a straight or oblique edge, and used for cutting away the enamel and dentine of the teeth. E.-column, E.-fiber, E.-prism, E.-rod, any one of the minute six-sided prisms of which the enamel of a tooth is composed. E--cuticle. See Cuticula dentis. E.-germ, an Ameloblast, q.v.

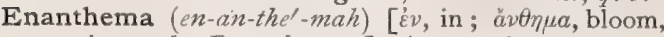
eruption: pl., Enanthemata $]$. An eruption within the body, in distinction from Exanthema.

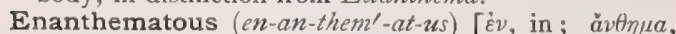
bloom, eruption]. Of the nature of or accompanied by an enanthema.
Enanthesis (en-an'-the-sis) [ $\varepsilon \nu$, in ; av $v \varepsilon i v$, to bloom]. I. An eruption of the skin, not connected with an internal disease. 2. An exanthematous rash.

Enanthylic Acid (en-an-thil'-ik). See Acid.

Enantioblastous (e-nan-te-o-blas'-tus) ['ंvavtios, opposite; $\beta \lambda \alpha \sigma \tau o ́ s$, germ]. In biology, applied to the embryo of orthotropous seeds when placed at the end opposite the hilum.

Enantiomorphous (en-an-te-o-mor'-fus) ['Evavtios, opposite; $\mu \circ \rho \phi \dot{y}$, form $]$. Similar but contrasted or reversed in form. Thus the two hands are enantiomorphous.

Enarthrodia (en-ar-thro'-de-ah). See Enarthrosis.

Enarthrodial (en-ar-thro'-de-al) ['́v, in; à $\rho$ t $\rho o \nu, a$ joint]. Having the character of an enarthrosis.

Enarthrosis (en-ar-thro'-sis) [ $\varepsilon v$, in; à $\rho \rho \rho v$, joint]. A ball-and-socket joint, like that of the hip; a variety of diarthrosis. See Diarthrosis.

Enation (e-na'-shun) [enasci, to be born]. In biology, having outgrowths resulting from excessive development. In ethnology, maternal relationship.

Encanthis (en-kan'-this) ['́v, in; káptos, canthus]. A reddish-colored morbid growth in the inner canthus of the eye.

Encapsulation (en-kap-su-la'-shun) [en, in ; capsula, a capsule]. Fixation as in a capsule; the absorption of a bacillus in a giant-cell; the enclosure of a foreign body in a tough sheath.

Enceinte (on $(g)^{-}$-sant $\left.t^{\prime}\right)$ [Fr., incincta, girdled]. With child; pregnant.

Encephal (en-sef'-al). Same as Encephalon, q. v.

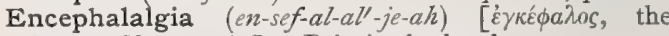

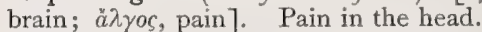

Encephalatrophic (en-sef-al-at-rōf $\left.f^{\prime}-i k\right)$ [ $[\dot{\varepsilon} \gamma \kappa \varepsilon \dot{\varepsilon} \phi a \lambda o s$, brain ; átpoфio, wasting]. Relating to brain-atrophy.

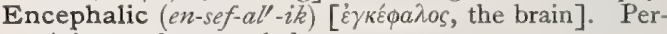
taining to the encephalon.

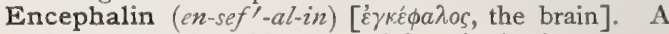
nitrogenous glucosid extracted from brain-tissue.

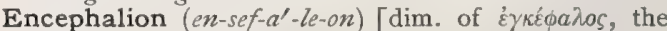
brain ]. The cerebellum.

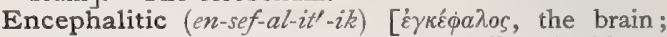
ITLS, inflammation]. Relating to or affected with encephalitis.

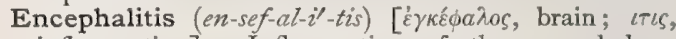
inflammation]. Inflammation of the encephalon: brain-fever.

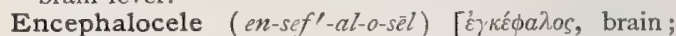
$\kappa \dot{\eta} \lambda \eta$, tumor]. A hernia of the brain through a cranial fissure.

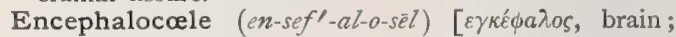
$\kappa o \iota \lambda i a$, hollow]. A ventricle of the brain.

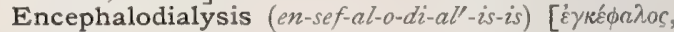
brain; día $\lambda \sigma \iota \varsigma$, dissolution]. Softening of the brain.

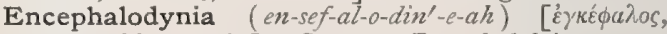
brain; óduvn, pain]. Same as Encephalalgia.

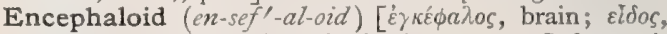
like]. 1. Resembling brain-tissue. 2. Soft carcinoma. See Carcinoma.

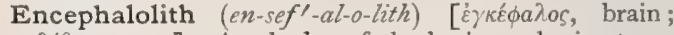
$\lambda i \theta 0 s$, stone]. A calculus of the brain; a brain-stone.

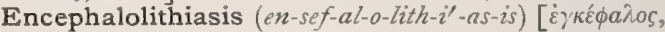

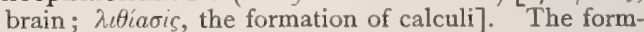
ation of brain-stones.

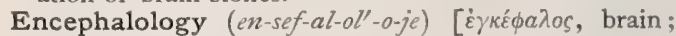
$\lambda 6$ yos, science]. The anatomy, physiology, and pathology of the brain.

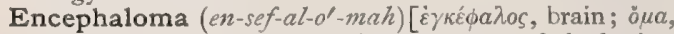
tumor: pl., Encephalomata]. I. Tumor of the brain; hernia cerebri. 2. Encephaloid carcinoma.

Encephalomalacia (en-sef-al-o-mal-a'-se-ah) [ $[\dot{\varepsilon} \gamma \kappa \varepsilon \dot{\phi} a-$

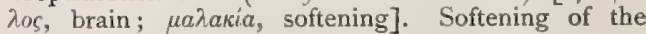
brain-substance. 


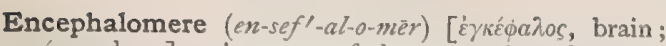
$\mu \varepsilon$ és, share]. Any one of the succession of natural segments of axial parts into which the brain is divisible.

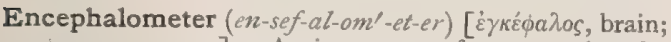
$\mu \varepsilon \tau \rho \circ$, measure]. An instrument for measuring the cranium and locating certain brain-regions.

Encephalo-myelopathy (en-sef'-al-o-mi-el-op'-ath-e)

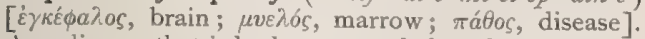
Any disease that is both an encephalopathy and a my elopathy; any cerebro-spinal disease.

Encephalon (en-sef'-al-on) [ $\varepsilon v$, in ; $\kappa \varepsilon \phi a \lambda \eta \dot{\eta}$, the head]. The contents of the cranium. The brain.

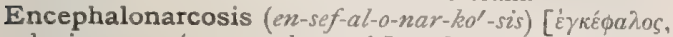

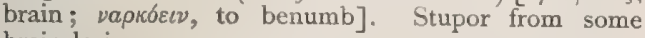
brain-lesion.

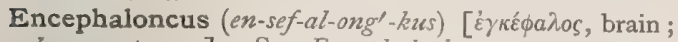
öysos, a tumor]. See Encephalophyma.

Encephalopathy (en-sef-al-op'-ath-e) [ $\varepsilon \gamma \kappa \varepsilon \phi a \lambda o s$, brain;

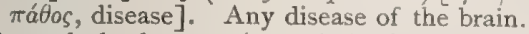

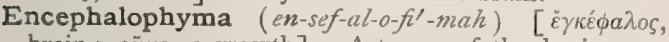
brain; $\phi \tilde{v} \mu a$, a growth]. A tumor of the brain.

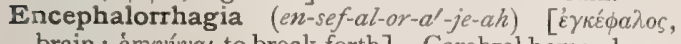

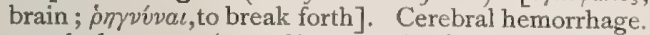

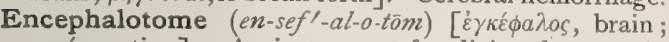
$\tau o \mu \eta$, section]. An instrument for slicing the encephalon for examination or preservation.

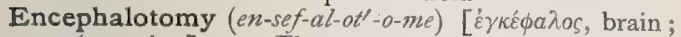
$\tau o \mu \eta$, section]. I. The anatomy or dissection of the brain; surgical incision of the brain. 2. Obstetric craniotomy.

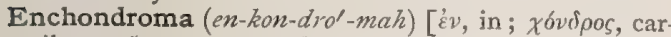
tilage; $\delta \mu \alpha$, tumor: $p l .$, Enchondromata ]. I. A tumor arising from or resembling cartilage in texture, etc.; chondroma. 2. A cartilaginous growth within an organ or tissue.

Enchondrosis (en-kon-dro'-sis) [ $[\hat{r}$ ', within; $\chi 6 \nu \delta \rho o \varsigma$, cartilage: pl., Enchondroses]. An outgrowth of cartilage from an osseous or cartilaginous structure; the process by which an enchondroma is developed.

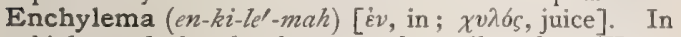
biology, the basal substance of a cell-nucleus (Kernsaft); it is a hyaline, fluid, granular substance, containing the other nuclear elements.

Enchymatous $\left(e n-k i m^{\prime}-a t-u s\right)$ [' $v$, in ; $\chi \varepsilon \tilde{\imath} \nu$, to pour]. In biology, applied to cells that are distended by infusion, as glandular epithelia.

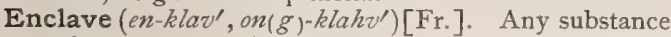
enclosed within a foreign tissue, as an oil-globule in a cell; any exclave $(q . v$.) considered in relation to the part that surrounds it.

Enclavement $\left(o n(g)-k l a h v^{\prime}-m o n(g)\right)[\mathrm{Fr}$.$] . Retention$ due to a constriction; impaction, as of the head in the pelvic strait.

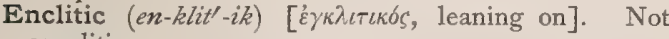
synclitic.

En Clou (on(g)-kloo') [Fr.]. See Culture.

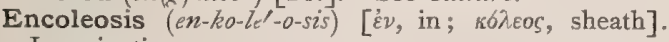
Invagination.

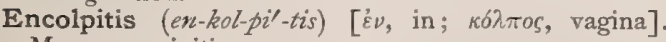
Mucous vaginitis.

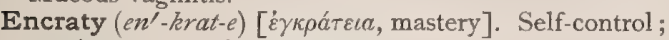
continence or strict temperance.

Encyclic, Encyclical (en-sik'-lik, en-sik'-lik-al) ['́v, in; $\kappa \dot{\kappa} \lambda \circ \varsigma_{,}$a circle]. In biology, applied to flowers having the organs arranged with an equal number of parts, in alternate whorls; isomerous.

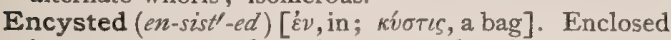
in a cyst, or capsule. Aneurysms, hernix, or tumors may become encysted.

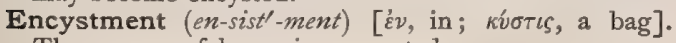
The process of becoming encysted.
End [ME, ende]. The terminal point of a thing. E.bud, or E.-bulb, the terminal bulb of a nerve in the skin. E.-bulb of Krause. See Corpuscle. E.-plate, the expanded terminal of a motor nerve upon a bundle of muscular fibers. E.-organ, the general name for the terminal organ or part of a sensory nerve-fiber, of whatever kind.

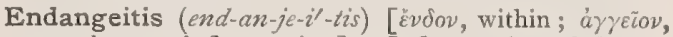
vessel; $\iota \tau \iota$, inflammation]. Inflammation of the endangium.

Endangium, or Endangeion (end-an'-je-um, -on)

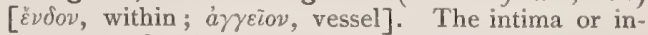
most coat of a blood-vessel. See Intima.

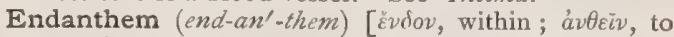
bloom]. A term applied to a mucous exanthem.

Endarteritis (end-ar-ter-i'-tis) [évdov, within; ápтpia, artery; $\iota \tau \iota s$, inflammation]. Inflammation of the intima, or innermost coat of an artery. The acute form is rare, and only occurs in the aorta and the larger arteries. Ulceration is very rarely present. The chronic form, also named Atheroma, and Arteritis deformans, is a peculiar change or degeneration occurring in the arterial coats of the aged, and is preceded by a fatty degeneration of the tissues of the arteries. Syphilis is supposed to play an important part in the production of this condition. The immediate cause, however, is mechanical irritation due to the force of the circulation. The fatty débris and the cholesterin that are formed during the degenerative process accumulate in spaces beneath the intima and constitute the socalled atheromatous abscesses. The so-called atheromatous ulcer is formed by one of these abscesses breaking through the intima. The sequelæ of atheromatous degeneration are very grave. Aneurysm, thrombosis, embolism, and apoplexy frequently result, and hence, the ultimate prognosis is bad. Arterio-capillary Fibrosis, or Arterio-sclerosis, is a peculiar change occurring in the small vessels throughout the body, and consisting in a thickening of the adventitia and intima by a deposit of a hyaline-fibroid material which diminishes the caliber of the vessels, increases the arterial tension, and thus gives rise to the hypertrophy of the heart that is present in this condition.

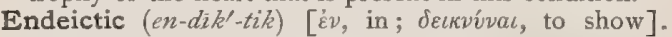
Symptomatic; serving as an indication.

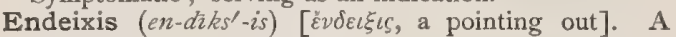
symptom, sign, or indication.

Endemann and Prochazka's Test. See Tests.

Endemic $\left(e n-d e m^{\prime}-i k\right)$ [ $\varepsilon v$, in; $\delta \tilde{\eta} \mu o s$, a people $]$. A term applied to diseases that exist among small numbers of persons or within a limited area. An endemic disease may or may not become epidemic; it is in general due to some local cause. E. Colic. See Colic.

Endemicity, or Endemism (en-dem-is'-it-e, or en'-demizm) [ $\varepsilon v$ in; $\delta \tilde{\eta} \mu o s$, a people]. The quality of being endemic.

Endemiology (en-dem-e-ol'-o-je) [ยv, in; $\delta \tilde{\eta} \mu o s$, a people; $\lambda \dot{o} \gamma o \varsigma$, science]. The science of endemic diseases.

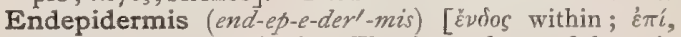
upon; $\delta \varepsilon \rho \mu a$, the skin]. The inner layer of the epidermis.

Endermatic (en-der-mat'-ik) ['́v, in; dép $\mu \alpha$, the skin]. Within the skin. Pertaining to a method of administering medicines through the skin, by rubbing, etc.

Endermic (en-der'-mik). Same as Endermatic.

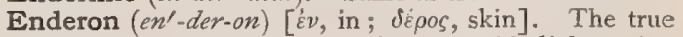
skin or derm, together with the non-epithelial portion of the mucous membrane.

Enderonic (en-der-on'-ik) [ $\varepsilon$ v, in ; dépns, skin]. Pertaining to or of the nature of the enderon.

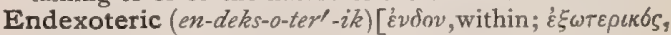
outer]. Due both to internal and external causes. 


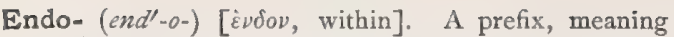
within.

Endo-arteritis (en-do-ar-ter-i'tis). See Endarteritis.

Endo-auscultation (en-do-arvs-kul-ta'-shun) [E้vdov, within; auscultare, to listen to]. A method of auscultation devised by Bianchi by using the ordinary esophageal tube passed into the stomach, to auscult the gullet and stomach, and through them, to a certain degree, the heart and lungs.

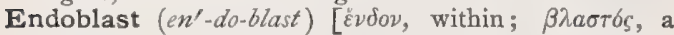
germ]. The cell-nucleus, or cytoblast. See Hypoblast.

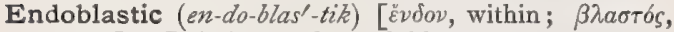
a germ]. Relating to the endoblast.

Endocardiac, Endocardial (en-do-kar'-de-ak, en-do$k a r^{\prime}-d e-a l$ ) [ $\varepsilon \nu \delta o v$, within; $\kappa a \rho \delta i \alpha$, the heart]. Relating to the endocardium; situated within the heart.

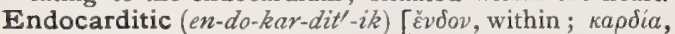
the heart]. Pertaining to or affected with endocarditis.

Endocarditis (en-do-kar-di'-tis) [ $\varepsilon v \delta o v$, within ; кapdia, the heart; $\iota \tau \iota s$, inflammation]. Inflammation of the endocardium or lining membrane of the heart. Acute rheumatism is the most frequent cause, though pneumonia, gout, or any infectious disease may precede. The valves are nearly always the parts affected, and usually those of the left heart. The disease is prone to terminate fatally or result in permanent injury to the valves. Fibrinous deposits or vegetations project into the cavity of the heart; the thickened endocardium is liable to become atheromatous, with chronic ulceration. Acute endocarditis may be divided into simple and malignant. Chronic endocarditis includes chronic disease of the valves of the heart. There is a fibrous or cirrhotic thickening of the latter, associated with contraction and calcification. Usually this chronic disease, like the acute, is confined to the left heart, and it is generally rheumatic in origin. E., Malignant or Ulcerative. Also called diphtheric, infectious, and septic endocarditis. A rapidly fatal type due to septic infection. It is marked by high fever, chills, and profound prostration. This is followed by the development of a murmur, purpuric skin-eruptions, hematuria, delirium, convulsions, hemiplegia, enlargement of the spleen, the typhoid state, and death. Frequently no cause can be found. Ulcerations are found around and in the valves, and in these ulcers micro-organisms are present in large quantities. E. polyposa, a form of ulcerative endocarditis in which there is an excessive deposit of fibrin, producing polypoid masses. E. pustulosa, a form of ulcerative endocarditis in which minute abscesses occur in the substance of the valves. E., Simple, the ordinary variety of acute endocarditis, usually associated with a mitral systolic murmur. E., Chronic, associated with valvular lesions. The following forms are met with: I. Aortic Incompetence; 2. Aortic Stenosis or Obstruction; 3. Mitral Incompetence; 4. Mitral Stenosis: 5. Pulmonary Incompetence; 6. Pulmonary Stenosis or Obstruction; 7. Tricuspid Incompetence; 8. Tricuspid Stenosis; 9. Combined valvular disease. Aortic Incompetence is produced by a retraction of the edges of the valves, which have become rigid and thickened; as a result the aorta is not shut off from the left ventricle during the diastole, and there is a leaking backward of blood into that cavity. A diastolic murmur is thus produced. This is frequently associated with a marked degree of arterio-sclerosis. Sudden death occurs in aortic incompetence more frequently than in any other valvular affection. The pulse is the so-called Corrigan or water-hammer pulse. Aortic Stenosis or Obstruction is due to thickening and curling, with calcification of the valves. This usually occurs in the aged. A systolic murmur is produced, accompanied in the late stages of the disease by a tendency to syncope, giddiness, and anemia. The pulse is slow and small, but regular. Mitral Incompetence, the most frequent of all valvular lesions, is due to curling of the valve-cusps or to shortening of the chordæ tendineæ. There is usually produced an immense hypertrophy of the walls of the ventricles. Late in the disease compensation fails and general edema ensues. Dyspnea is a frequent symptom, associated with cyanosis and albuminuria. The murmur is systolic in time; the pulse is normal during the stage of compensation, afterward small and irregular. This is a common form among children. Mitral Stenosis, due to fibrous thickening and contraction of the mitral cusps. The opening may be reduced to a mere fissure. If due to a thickening and shortening of the chordæ tendineæ the thickened and adherent valves are drawn in a funnel-shape toward the floor of the ventricle. Mitral stenosis usually occurs in women. A presystolic murmur is produced, associated with duplication of the second sound. Pulmonary Incompetence, the rarest of valvular diseases, may be due to congenital abnormalities, or may follow some diseased condition, as malignant endocarditis. The murmur is diastolic in time. Pulmonary Stenosis or Obstruction, usually congenital, is due to fetal heart-disease. The patients usually die before they are ten or twelve years old. A systolic murmur is produced. Tricuspid Incompetence is due to endocarditis or to dilatation of the right ventricle and tricuspid orifice. Compensation is never adequate, and hence venous stasis, cyanosis, and dropsy soon follow. A systolic murmur is produced. Tricuspid Stenosis is a rare condition and usually secondary to mitral stenosis. It is marked by a presystolic murmur. Combined Valvular Disease ; frequently two of the foregoing murmurs may coëxist. The most usual combinations are as follows: I. Aortic obstruction and regurgitation; 2. Mitral obstruction and regurgitation; 3. Mitral obstruction and tricuspid regurgitation; 4 . Aortic obstruction and mitral regurgitation; 5 . Double valvular disease at aortic and mitral orifices (four murmurs). E. ulcerosa, the ulcerative form of endocarditis. E. verrucosa, a form of endocarditis characterized by the production of endocardial vegetations situated mostly upon the curtains of the cardiac valves. It is seen usually upon the left side of the heart.

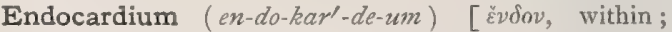

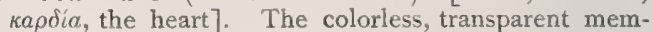
brane lining the interior of the heart.

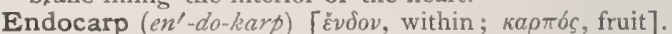
In biology, the inner hard and stony membranous or fleshy layer of a pericarp; $e_{0} g$. , the stone of a peach.

Endocarpoid (en-do-kar'-poid). In biology, applied to lichens that have the apothecia immersed in the thallus.

Endocelarium (en-do-se-la'-re-um) [ Evvov, within; $\kappa o \iota \lambda i a$, the belly]. In biology, the visceral epithelium of the body-cavity.

Endocervical (en-do-ser'-vik-al) [èvdov, within; cervix, neck]. Relating to the inside of the uterine cervix.

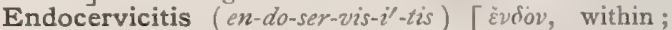
cervix, neck; $\iota \tau \iota \varsigma$, inflammation]. Inflammation within the canal of the cervix uteri.

Endochondral (en-do-kon'-dral) [ Evvov, within; $\chi \delta$ ó $\rho \circ$, cartilage]. Situated or occurring within a cartilage.

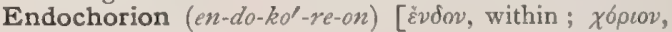
the chorion]. The inner chorion; the vascular layer of the allantois. 
Endochorionic (en-do-ko-re-on'-ik) [žvfov, within xópıov, the chorion]. Relating to the endochorion,

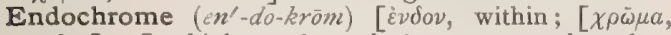
color]. In biology, the coloring-matter, other than green, of the endoplasm of a cell, or that of diatoms or of flowers.

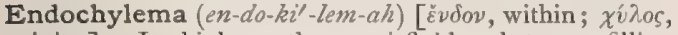
juice]. In biology, the semi-fluid substance filling the protoplasmic reticulum of a cell.

Endochyme (en'-do-kim) [ย̌vdov, within; $\chi v \mu o ́ s$, juice] In biology, the formative cell-sap elaborated from the chyme.

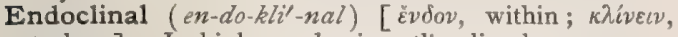
to lean]. In biology, having the clinode, an organ analogous to the hymenium, inclosed in a conceptacle.

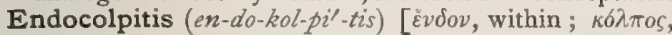
vagina]. Same as Encolpitis.

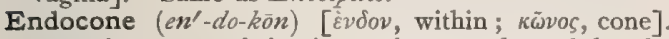
In biology, one of the internal cones formed by the siphon-sheaths in certain cephalopods.

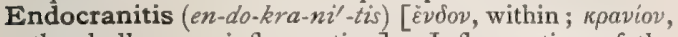
the skull; $\iota \tau \iota$, inflammation]. Inflammation of the endocranium; pachymeningitis externa.

Endocranium (en-do-kra'-ne-um) [ ह้vdov, within; кpaviov, the skull]. That part of the cerebral dura that adheres to the inner surface of the cranial bones. One of the processes projecting into the cephalic cavity, as the tentorium or cephalophragma.

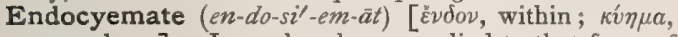
an embryo]. In embryology, applied to that form of development in which the embryo is invaginated in a fold of the blastodermic membrane, an amnion being formed; the opposite of Epicyemate.

Endocyesis (en-do-si-e'-sis) [ $\ell^{\prime} \nu \delta \nu$, within; $\kappa v \varepsilon i v$, to conceive: pl., Endocyeses]. In biology, the process that gives rise to an endocyemate embryo.

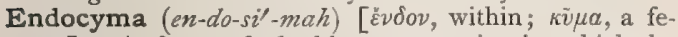
tus]. A form of double monstrosity in which the parasite is contained within the body of the autosite.

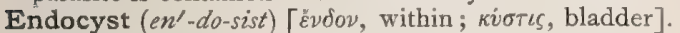
In biology, the endoderm or inner layer of the cenecium or common dermal system of a colony of Polyzoa. See Ectocyst.

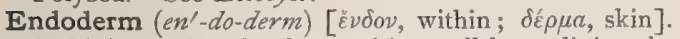
In biology, the simple nutritive cell-layer lining the cavity of the primitive intestine, the enteron, and its modifications or derivatives. The vegetative germinal layer. See Blastoderm.

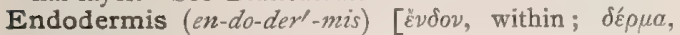
skin]. In biology, the layer of cells surrounding a fibro-vascular cylinder.

Endodontitis (en-do-don-ti'-tis) [êvdov, within; ódovs, a tooth; $\iota \tau \iota s$, inflammation]. Inflammation of the lining membrane of a tooth.

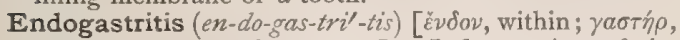
stomach; $\iota T \iota s$, inflammation]. Inflammation of the mucous membrane of the stomach.

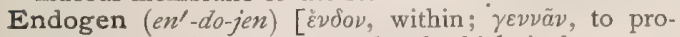
duce]. A plant, the growth of which is by means of new matter deposited in the interior of the trunk or branch. A member of one of the great primary classes of flowering-plants; a monocotyledon. See Exogen.

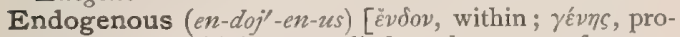
ducing]. In biology, applied to the stems of monocotyledons and their manner of growth; also to sporeformation or cell-formation inside of a parent-cell.

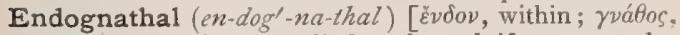
jaw]. In biology, applied to the pulpiform appendages formed by the modification of the three terminal joints of the third thoracic limb in certain crustaceans.

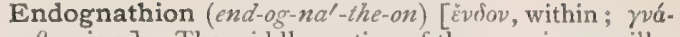
$\theta 0 \varsigma$, jaw ]. The middle portion of the superior maxilla.

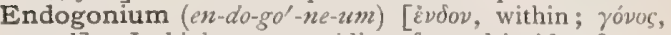
seed ]. In biology, a gonidium formed inside of a receptacle or parent-cell, as in the Saprolegniece, Mucorini, Vaucheria.

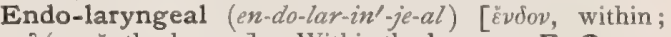
$\lambda a ́ \rho v \gamma \xi$, the larynx]. Within the larynx. E. Opera tions, operations performed within the larynx.

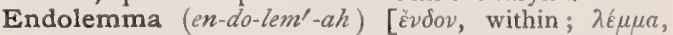
husk]. Same as Neurilemma.

Endolymph (en'-do-limf) [èvdov, within; lympha, water]. The fluid of the membranous labyrinth of the ear.

Endolymphangeal (en-do-lim-fan'-je-al) [Ěvdov, within ; lympha, lymph; áy yeiov, vessel]. Situated or belonging within a lymph-vessel; as an endolymphangeal nodule.

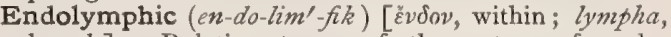
lymph]. Relating to or of the nature of endolymph.

Endomersion (en-do-mer'-shun). See Objective.

Endomesoderm (en-do-me'-so-derm) [Ěvdov, within;

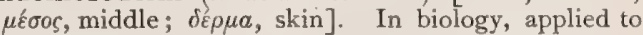
two cells that appear on the side of the blastopore in the embryos of molluscs and annelids, giving rise by division to the two primitive mesoderm cells, and to a portion of the lining of the mesenteron.

Endometrial (en-do-me'-tre-al) [ëvdov, within; $\mu \hat{\hbar} \tau \rho a$, the womb]. Pertaining to the endometrium; situated within the uterus.

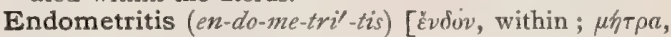
the womb; $\iota \tau \iota \varsigma$, inflammation]. Inflammation of the endometrium. E., Cervical, of the cervical portion. It gives rise to the condition known as erosion, ulceration, or granular degeneration of the cervix, a very frequent condition. There is leukorrhea, pain in the back, and congestion of the cervix and pelvic viscera, with metrorrhagia or menorrhagia, or both, together with some failure of the general health. This condition is due to traumatism, usually in parturition. E., Chronic Purulent, occurs in old women and is marked by an accumulation of pus in the uterine cavity with a purulent leukorrhea. E., Corporeal, that of the body of the uterus. E., Decidual, of the decidual membrane of the impregnated uterus. It may be diffuse (thickening and development of connective tissue) or polypoid (with polypoid growths). E., Fungous, that in which the lining membrane is hypertrophied, with the formation of vascular granulations. This is also called hemorrhagic endometritis. E., Hemorrhagic. See $E$., Fungous.

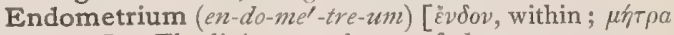
uterus]. The lining membrane of the uterus.

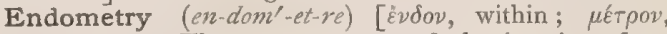
measure]. The measurement of the interior of an organ or cavity, as of the cranium.

Endomyocarditis (en-do-mi-o-kar-di'-tis) [Evvov, within ; $\mu v \tilde{v}$, muscle; $\kappa \alpha \rho \delta i a$, heart; $\iota \tau \iota \zeta$, inflammation]. Inflammation of both endocardium and myocardium.

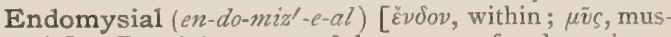
cle]. Pertaining to or of the nature of endomysium.

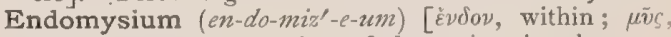
muscle]. The extension of the perimysium between the muscular fibers.

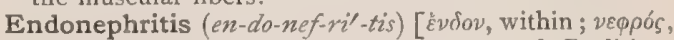
kidney; $\iota \tau \iota s$, inflammation]. Synonym of Pyelitis.

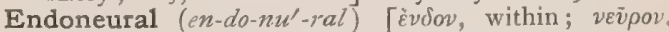
nerve]. Relating to or situated within the interior of a nerve.

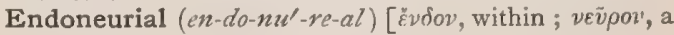
nerve]. Relating to the endoneurium. 


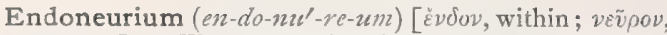
a nerve]. The connective-tissue sheath uniting the fibers of a fasciculus (or funiculus) of a nerve.

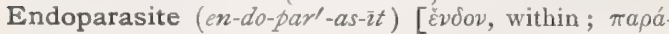
oitos, parasite]. An entozoan or internal parasite; one living within its host.

Endoparasitic (en-do-par-as-it'-ik) [ б८тоS, a parasite]. Of the nature of an endoparasite.

Endopatagium (en-do-pat-a'-je-um) [Eेvdov, within ;

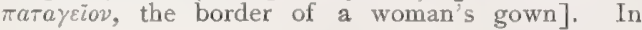
biology, that part of the wing-membrane of a bat lying between the body, the humerus, the lower extremity, and a hypothetic line drawn downward from the elbow and intersecting the free margin of the membrane. (Allen.)

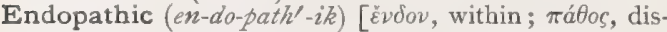
ease]. Pertaining to the origin of disease from conditions or causes not derived from without. See Exopathic.

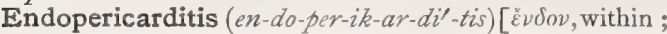
$\pi \varepsilon \rho i$, around; $\kappa a \rho \delta i \alpha$, the heart; $\iota \tau \iota s$, inflammation]. Inflammation of both endocardium and pericardium.

Endoperimyocarditis (en-do-per-e-mi-o-kar-di'-tis)

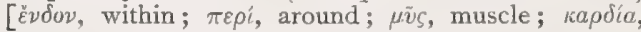
heart; $\iota \tau \iota s$, inflammation]. Inflammation of endocardium, pericardium, and myocardium.

Endoperineuritis (en-do-per-e-nu-ri'-tis) [Evvdov, within; $\pi \varepsilon \rho i$, around; veṽ $\rho o v$, a nerve ; $\iota \tau \iota$, inflammation]. Inflammation of both endoneurium and perineurium.

Endophlebitis (en-do-fle-bi'-tis) [ $\check{c} \nu \delta o v$, within; $\phi \lambda \dot{z} \psi$, vein; $\iota \tau \iota \varsigma$, inflammation]. Inflammation of the inner coat of a vein or veins.

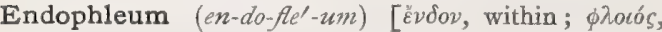
bark ]. In biology, the liber, or inner bark; bast.

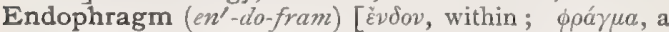
partition]. In biology, a partition formed by the chitinous plates projecting inward from the lateral wall of the somites of a crustacean.

Endophyllous $\left(e n-d o-f l^{\prime}-u s\right)$ [ $\varepsilon \check{v} \nu \delta \nu$, within; $\varphi v \lambda \lambda \alpha o v$, leaf ]. In biology, enclosed within a sheath, as the young leaves of monocotyledons.

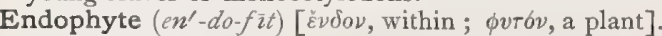
Same as Entophyte.

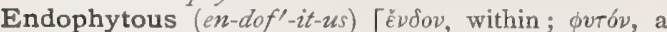
plant]. In biology, applied to the larvæ of certain insects that bore into the stems and roots of plants.

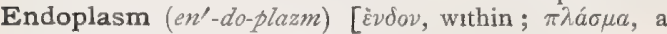
thing formed]. In biology, the inner granular protoplasm of a protozoan or of a histologic cell.

Endoplast (en'-do-plast) [ěvdov, within; $\pi \lambda a \sigma \tau o ́ s$, formed]. In biology, the nuclear body of a protozoan; the homologue of the nucleus of a histologic cell. (Huxley.)

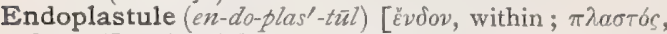
formed]. In biology, a small oval or rounded body, often found attached to the endoplast of a protozoan; the homologue of the nucleolus of a histologic cell. Cf. Entoblast.

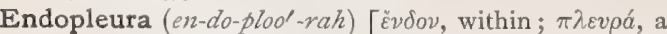
rib: pl., Endopleurce]. In biology, the delicate seed-coat; it is also called tegmen.

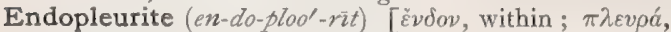
a rib]. In biology, one of the lateral apodemal partitions arising from the interepimeral membrane connecting every pair of somites in certain crustaceans.

Endopodite $\left(e n-d o p^{\prime}-o-d i t\right)$ [ev $\delta o v$, within; rovs, foot]. In biology, the inner of the two main divisions of the crustacean limb; when fully developed it consists of seven joints, becoming in the thoracic region an ambulatory limb.

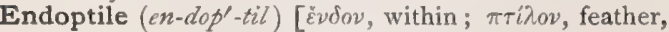
down, leaf ]. Same as Monocotyledonous.

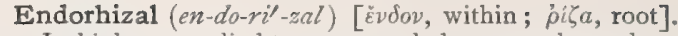
In biology, applied to monocotyledonous embryos having the radicle enclosed within a sheath.

Endosalpingitis (en-do-sal-pin- $\left.\ddot{j}^{\prime}-t i s\right)$ [ $\dot{\varepsilon} v \delta o v$, within ;

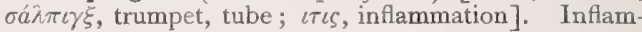
mation of the lining membrane of a Fallopian tube.

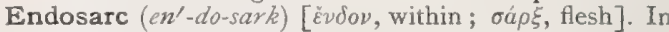
biology, the inner protoplasm of a protozoan; also applied by Hincks to a tissue derived from the endocyst (the inner layer of the common dermal system of a colony of Polyzoa), and composed, for the most part, of fusiform cells, constituting the connection between the polypides

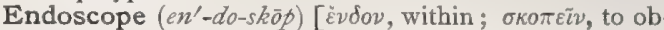
serve]. An instrument for the examination of a bodycavity through its natural outlet.

Endoscopy (en-dos'-ko-pe) [ to observe]. The practice or process of using the endoscope. The examination of cavities or organs within the body by means of an endoscope.

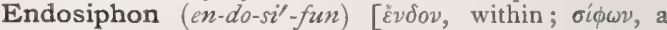
tube]. In biology, the inner siphon of a cephalopod.

Endoskeleton (en-do-skel'-et-un) [ěvdov, within; $\sigma \kappa \varepsilon \lambda \varepsilon \tau \sigma \dot{\nu}$, a dry body]. In biology, as distinguished from exoskeleton, applied to the internal skeletal structures of any animal, whether they are bony, cartilaginous, chitinous, calcareous, or silicious, if covered by flesh and integument.

Endosmometer (en-dos-mom'-et-er) [ $\varepsilon v \delta o v$, within;

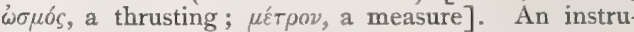
ment for measuring endosmosis.

Endosmose (en'-dos-môs). Same as Endosmosis.

Endosmosis (en-dos-mo'-sis) [èvdov, within; $\omega \sigma \mu o ́ s$, impulsion]. The passage of a liquid from without inward, through a porous septum or diaphragm ; inward osmosis. See Osmosis. E., Electric, cataphoresis.

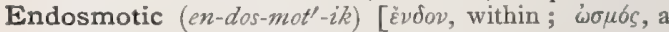
thrusting]. Pertaining to endosmosis. E. Equivalent, the weight of distilled water that passes into the fiask of the endosmometer in exchange for a known weight of the soluble substance. This, e.g., for salt is 4.3 ; for sugar 7.1 .

Endosome $\left(e n^{\prime}-d o-s o ̄ m\right)$ [ In biology, the inner layer of the body of a sponge, developed from the endoderm and associated mesoderm.

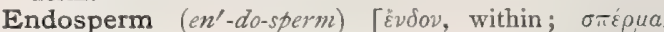
seed]. In biology, the albumin of a seed.

Endospore (en'-do-spōr) [ع̌vdov, within; $\sigma \pi$ ópos, seed]. In biology, (I) a bacterium-spore formed by free cellformation, as distinguished from an arthrospore; (2) the inner coat of a spore.

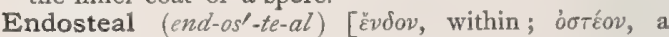
bone]. Relating to endosteum.

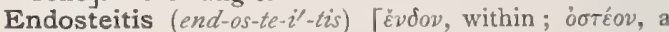
bone; $\iota \tau \iota S$, inflammation]. Inflammation of the endosteum.

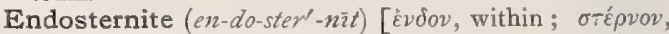
the breast-bone]. In biology, a sternal piece of the endothorax developed to support a series of muscles in various arthropods.

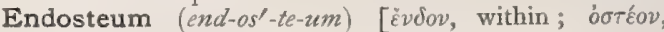
bone]. The vascular membranous layer of connective tissue lining the medullary cavity of bones; the internal periosteum.

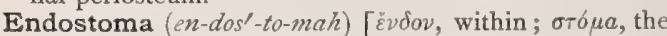
mouth: pl., Endostomata $]$. In biology, a structure found in certain crustaceans behind and giving support to the labrum.

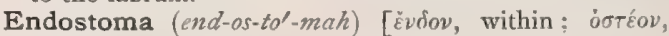
bone: pl., Endostomata]. A bony tumor within a bone, or in a cavity surrounded by bone. 


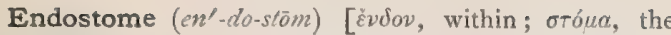
mouth]. In biology, the orifice of the inner coat of an ovule.

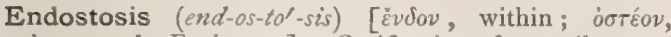
bone: pl., Endostoses]. Ossification of a cartilage.

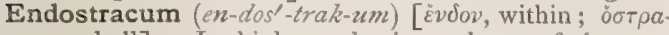
rov, shell]. In biology, the inner layer of the exoskeleton of a crustacean.

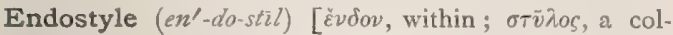
uman. In biology, an organ for the secretion of mucus, forming the ventral edge of the branchial sac, and extending from the peripharyngeal bands anteriorly to the posterior end of the sac of Ascidians; it is also called the hypobranchial groove.

Endotheca (en-do-the'-kah) [Ěvdov, within; $\theta \dot{j} \kappa \eta$, a case: pl., Endothecce]. In biology, the inner layer of the lining investment of the visceral chamber of a coral.

Endothecium (en-do-the'-se-um) [E้vdov, within; $\forall \dot{\eta} \kappa \eta$, a case ]. In biology, the tapetum or inner lining of an anther-cell.

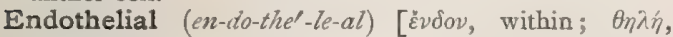
nipple]. Pertaining to endothelium.

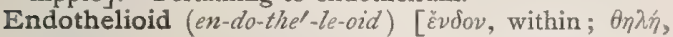
a nipple; $\varepsilon i \delta o s$, form]. Resembling endothelium.

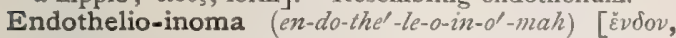
within ; $\theta \eta \lambda \eta ́$, a nipple; is, a fiber; $\not \mu \alpha$, a tumor: pl., Endothelio-inomata]. A malignant inoma or fibroma of endothelial origin.

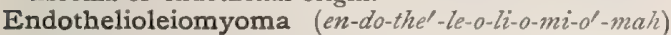

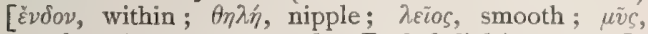
muscle; ó $u a$, tumor: pl., Endothelioleiomyomata]. Endothelial and malignant leiomyoma; myosarcoma.

Endothelioma (en-do-the-le-o'-mah) [E้vdov, within; $\theta \eta \lambda \eta$, a nipple; ö $\mu a$, a tumor : $p l .$, Endotheliomata]. A tumor of the endothelium, usually, if not always, a sarcoma or malignant growth.

Endotheliomyxoma (en-do-the $\left.e^{\prime}-l e-o-m i k s-o^{\prime}-m a h\right)$ [e้v$\delta o \nu$, within ; $\theta \eta \lambda \dot{n}$, nipple ; $\mu \hat{v} \xi \alpha$, mucus ; $\partial \mu \alpha$, a tumor : pl., Endotheliomyxomata]. Endothelial and malignant myxoma.

Endotheliorhabdomyoma (en-do-the'-le-o-rab-do-mi-o' -

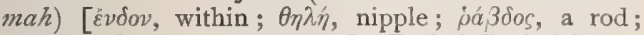
$\mu \bar{n} \varsigma$, muscle; ö $\mu a$, a tumor: pl., Endotheliorhabdomyomata]. Endothelial and malignant rhabdomyoma.

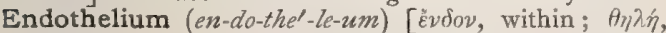
nipple]. The internal lining membrane of serous, synovial, and other internal surfaces; the homologue of epithelium.

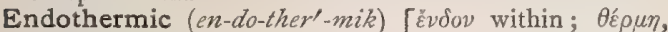
heat]. Relating to the absorption of heat. E. Substances, or Compounds, those of which the formation is attended with an absorption of heat.

Endothoracic (en-do-tho-ra'-sik) [ ${ }^{\prime} \nu \delta o v$, within; $\theta \omega \rho a \xi$, thorax]. Situated or occurring within the thorax.

Endothorax (en-do-tho'-raks) [E้vdov, within; $A \omega \rho \alpha \xi$, a breastplate; the chest]. In biology, the interior framework, or apodemal system of the cephalothoracic region of a crustacean, furnishing processes for the support of the soft parts.

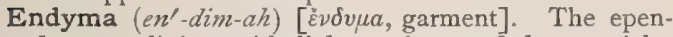
dyma, or lining epithelial membrane of the ventricles of the brain, and of the cavity of the spinal cord.

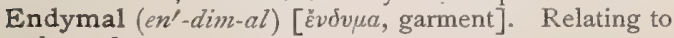
the endyma.

Endysis (en'-dis-is) [ev $v \delta v \sigma \varsigma$, a putting on]. In biology, the process of acquiring plumage by a bird.

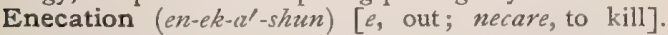
Destruction of life; complete exhaustion.

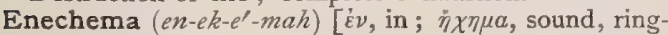
ing]. Tinnitus aurium.

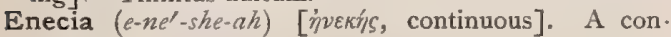
tinuous fever.

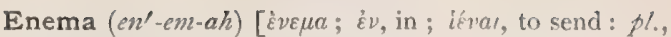
Enemata, Enemas]. A rectal injection for therapeutic or nutritive purposes.

Enepidermatic, or Enepidermic (en-ep-e-der-mat'-ik,

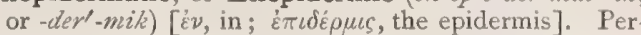
taining to the treatment of disease by applications to the skin.

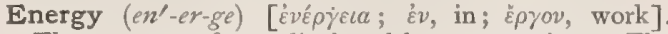
The power or force displayed by an organism. The capacity for doing work. E., Conservation of, the law that the various forms of energy can be transformed one into the other without loss. E., Kinetic, the power of a body in motion. E., Potential, the possible power of a body at rest. Physiologically, its measure is the amount of heat that may be obtained by complete combustion of the chemic compounds representing the potential energy.

Enervate $\left(e-n e r^{\prime}-v \bar{a} t\right)$ [enervare, to weaken]. To weaken.

Enervation (e-ner-va'-shun) [enervatio, weakness]. r. Weakness; lassitude ; languor from lack of nervestimulus ; neurasthenia ; the reduction of the strength. 2. The removal of a section of a nerve.

Enervose (e-ner'-vōs) [enervus, without nerves]. In biology, applied to leaves destitute of nerves or veins.

Eneuresis (en-u-re'-sis). See Enuresis.

Engagement-stage of Labor. See Descent-stage.

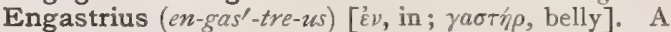
monstrosity in which one fetus is included within the peritoneal cavity of another.

Engelmann's Middle Disc. A light disc, separating two darker discs of a muscle-case. It is also called Hensen's disc.

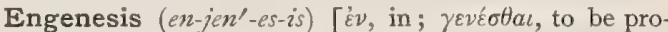
duced]. In biology, the fourth of Broca's four de grees of fecundity in the union of two species. Cf. Agenesis, Dysgenesis, Paragenesis.

Engine (en'-jin) [ME., engin, a mechanical contrivance]. An apparatus for producing some mechanical effect. E., Dental, a foot-power machine, embracing the following devices and combinations: The use of a flexible wire shaft, with a flexible sheath over it. See Dental Engine. E., Surgical, an electric or foot. power machine, used with a flexible wire shaft. It is employed in surgery, in drilling, boring, and smoothing bone, etc.

Engle System. See Cremator.

English (ing'-glish) [ME., English]. Belonging or pertaining to England. E. Cholera. See Cholera. E. Disease. Synonym of Rhachitis. E. Position. See Postures, Table of. E.-red. See Colcothar and Venetian-red. E. Sweating Fever. See Anglicus sudor. E. Teeth, artificial teeth with beautiful coloring, and soft translucency, rendering them well adapted for matching the natural teeth.

Engomphosis (en-gom-fo'-sis) [ย́v, in; $\gamma \delta \mu \phi o s$, nail]. Gomphosis, $q \cdot v$.

Engorged (en-gorjd') [Fr., engorgement, a choking up]. Congested. E. Papilla. See Choked Disc.

Engorgement (en-gorj'-ment) [Fr., engorgement, a choking up]. Over-distention of the vessels of a part, with stagnation of the circulation. Vascular congestion.

Enlargement (en-larj'-ment). See Auxe, Auxesis, Hypertrophy.

Enlarger (en-lar'-jer). See Amplifier.

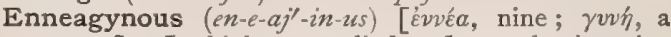
woman]. In biology, applied to flowers having nine pistils.

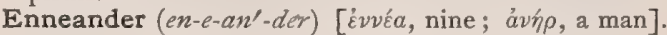
In biology, applied to a flower having nine stamens. 


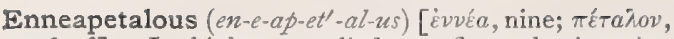
a leaf]. In biology, applied to a flower having nine petals.

Enneaspermous (en-e-as-per'-mus) [ Évvéa, nine; $\sigma \pi \varepsilon \rho \mu a$, seed]. In biology, applied to fruits having nine seeds.

Enodal (e-no'-dal) [e, priv.; nodus, a knot]. In biology, without nodes or joints.

Enoinomania (en-oi-na-mza'-ne-ah) ['่v, in ; oivos, wine;

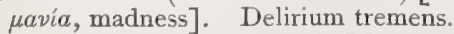

Enomania (e-no-ma'-ne-ah) [oivos, wine; $\mu a v i \alpha$, madness]. Excessive use of or desire for intoxicating liquors; insanity due to intoxication. Also, delirium tremens. See Methomania.

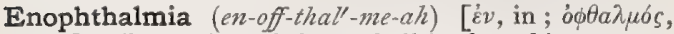
eye]. Retraction of the eyeball in the orbit.

Enophthalmos (en-off-thal'-mos) ['ंv, in; ó $\phi \theta a \lambda \mu o s$, the eye]. Recession of the eyeball into the orbit.

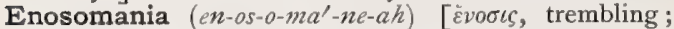
uavia, madness]. Insanity marked by terror, the patient expecting for himself the most dreadful visitations.

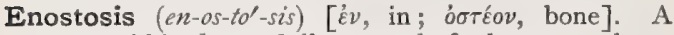
tumor within the medullary canal of a bone, or a bony tumor originating in bone.

En Piquare (on $(g)$ pik-eer') [Fr.]. See Culture.

Ensate $\left(e n^{\prime}-s \vec{a} t\right)$ [ensis, a sword]. In biology, swordshaped ; ensiform.

Ensiform (en'-sif-orm) [ensis, a sword; forma, form]. Shaped like a sword. E. Appendix, the swordshaped, cartilaginous process of the sternum; the xiphoid cartilage.

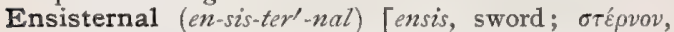
the breast-bone]. Pertaining to the ensisternum.

Ensisternum (en-sis-ter'-numi) [ensis, sword; oтépvov, the breast-bone]. The xiphisternum or ensiform cartilage.

Ensomphalic (en-som-fal'-ik) ['v, in ; $\sigma \tilde{\omega} \mu a$, body; ó $\phi a \lambda b ́ s$, navel]. Pertaining to an ensomphalus. See also Teratism.

Ensomphalus (en-som'-fal-us) ['ंv, in; $\sigma \tilde{\omega} \mu a$, body; ó $\phi a \lambda o ́ s$, navel]. A double monstrosity, with practically complete and functional organs, but united by some more or less superficial bond.

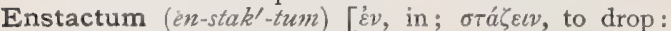
pl., Enstacta]. A liquid collyrium.

Enstrophe (en'-stro-fe) ['ंv, in; $\sigma \tau \rho \dot{\varepsilon} \phi \varepsilon \iota \nu$, to turn]. Inversion, as of the margin of an eyelid.

Entad (en'-tad) [EvvTos, within; ad, to]. From without inward; toward a center ; the opposite of Ectad.

Ental (en'-tal) [évtó, within]. A surface, aspect, or structure farther from the periphery or nearer the center than that with which it is contrasted. Deep, internal, profound. Compare the opposite, Ectal; also Position and Direction, Table of.

Entasia, or Entasis (en-ta'-se-ah, or en'-tas-is) [ $\varepsilon v \tau \sigma \sigma l \zeta$, a straining]. A generic term for spasmodic muscular action; tonic spasm.

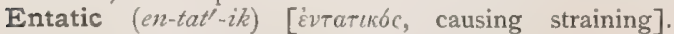
Causing spasm or strain; aphrodisiac.

Entera (en'-ter-ah). Plural of Enteron, q. v.

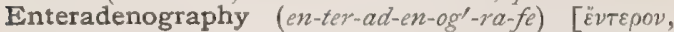

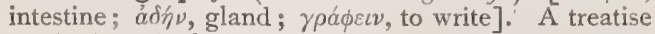
on the intestinal glands.

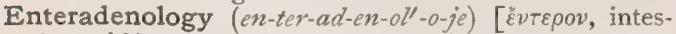
tine; $a \delta \eta v$, gland; $\lambda \sigma \gamma o s$, science $]$. The anatomy, physiology, and pathology of the intestinal glands.

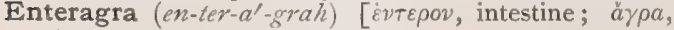
seizure]. Gout in the intestine.

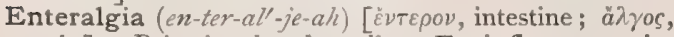
pain]. Pain in the bowels. E. inflammatoria. Synonym of Acute Intestinal Catarrh.

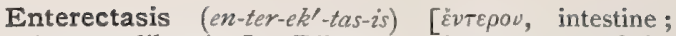
$\dot{\varepsilon} \kappa \tau a \sigma \iota s$, dilatation]. Dilatation of some part of the small intestine.

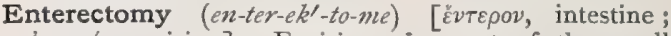

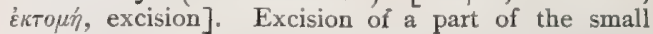
intestine.

Enterelcosis (en-ter-el-ko'-sis) [ย้v $\tau \varepsilon \rho \circ \nu$, intestine; $\varepsilon \lambda \kappa \omega \sigma \iota$, ulceration]. Ulceration of the bowel.

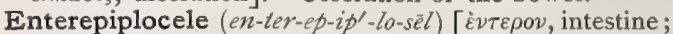
$\dot{\varepsilon} \pi i \pi \lambda$ hov, caul; $\kappa \hat{h} \lambda \eta$, hernia]. Hernia in which both bowel and omentum are involved.

Enterepiplomphalocele (en-ter-ep-ip-lom-fal'o-sêl) [èv$\tau \varepsilon \rho \circ \nu$, bowel; $\varepsilon \dot{\pi} i \pi \lambda o o v$, caul; ó $\mu \phi a \lambda o ́ s$, navel ; $\kappa \hat{\eta} \lambda \eta$. hernia]. Umbilical hernia, with protrusion of the omentum.

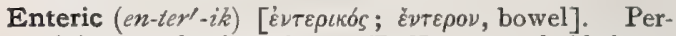
taining to the intestines. E. Fever, typhoid fever. To demonstrate bacilli of enteric fever see Gaffky's Method and Woodhead's Method, under Stains, Table of.

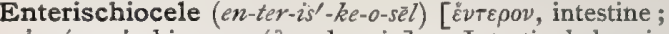
ioxiov, ischium; $\kappa \dot{n} \lambda \eta$, hernia]. Intestinal hernia through the great sciatic notch.

Enteritic (en-ter-it'-ik) [ $\varepsilon^{\prime} \nu \tau \varepsilon \rho o \nu$, bowel; $\iota \tau \iota s$, inflammation]. Relating to enteritis.

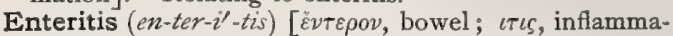
tion]. Inflammation of the small intestine. E., Chronic Exudative. Synonym of E., Pseudo-membranous. E., Membranous. Synonym of E., Pseudomembranous. E., Pellicular. Synonym of E.,Pseudomembranous. E., Pseudo-membranous, a nonfebrile affection of the bowel, consisting in a peculiar, and usually persistent, morbid condition of the intestinal mucous membrane, marked by the periodic formation of viscous, shreddy, or tubular exudates composed chiefly of mucin, on the discharge of which temporary amelioration of the accompanying acute digestive and nervous symptoms occurs. The disease appears mainly in middle life and usually in females.

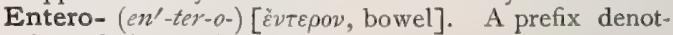
ing relation to the intestines.

Entero-anastomosis (en'-ter-o-an-as-to-mo'-sis) [हैvTE-

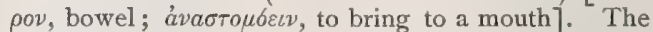
surgical creation of an anastomosis between two parts of the intestine ; or the union of two parts of the intestine after the excision of a segment.

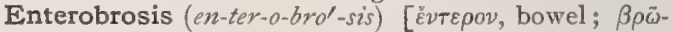
$\sigma \iota s$, an eating]. Perforation or ulceration of the intestine.

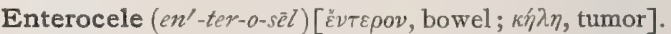
A hernia containing a loop of intestine. E., Rectal, having a covering of the rectal wall. E., Vaginal, having a covering of the vaginal wall.

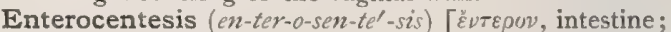
$\kappa \varepsilon \dot{v} \tau \eta \sigma \iota s$, puncture]. Surgical puncture of the intestine.

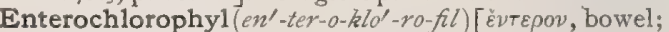

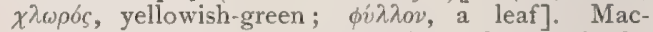
Munn's term for a chlorophyl found by him in the so-called livers of many invertebrates.

Enterocholecystostomy (en-ter-o-ko-le-sis-tos'-to-me)

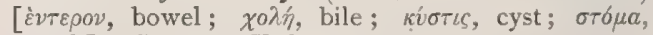
mouth]. Same as Cholecystenterostomy.

Entero-cholecystotomy (en-ter-o-ko-le-sis-tot'-o-me $)$. Same as Cholecystenterotomy.

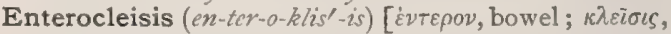
a closing]. Occlusion of the bowel.

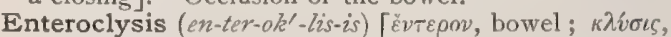
a drenching]. Injection of nutrient-material into the intestine in cholera, collapse, etc.; more generally, any rectal enema or clyster.

Enteroclyster (en-ter-o-klis'-ter) [ $\dot{\varepsilon} \nu \tau \varepsilon \rho o v$, bowel; $k \lambda \dot{v} \sigma$. $\mu a$, a clyster]. A rectal clyster or enema. 


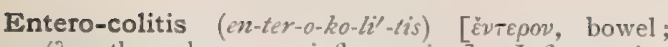
$\kappa \delta \lambda \circ \nu$, the colon; $\iota \tau \iota$, inflammation]. Inflammation of the small intestine and of the colon.

Enterocystocele (en-ter-o-sis'-to-sêl) [ $\tilde{\nu} \nu \tau \varepsilon \rho \nu$, intestine ;

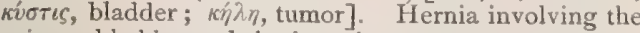
urinary bladder and the intestine.

Enterodynia (en-ter-o-din'-e-ah) [Évtepov, bowel; ódvin, pain]. Pain referred to the intestines.

Entero-epiplocele (en'-ter-o-e-pip'-lo-sèl). See Enterepiplocele.

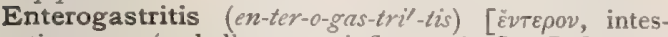

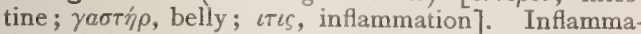
tion of the stomach and intestine.

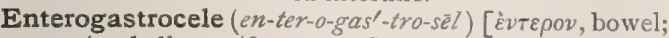
$\gamma \approx \sigma \tau \hat{\eta} \rho$, belly; $\kappa \eta \hat{\lambda} \eta$, tumor]. A hernia containing the gastric and intestinal walls; abdominal hernia.

Enterography (en-ter-og $\left.{ }^{\prime}-r a-f e\right) \quad$ [evvtepov, intestine; $\gamma \rho a ́ \phi \varepsilon \iota \nu$, to write]. A treatise on or a description of the intestines.

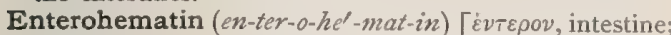
aıpátıvos, of blood]. In biology, a coloring-matter found in many invertebrates (e.g., the livers of molluscs), the mother-substance of histohematin. It is the same as the Hemochiomogen and Helicorubin of Krukenberg.

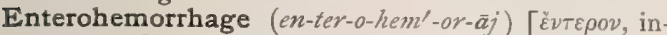
testine; aipa, blood; im ivviva , to burst forth]. Intestinal hemorrhage.

Enterohydrocele (en-ter-o-hi'-dro-sél) [ $[\check{v} v \tau \varepsilon \rho \nu$, intes-

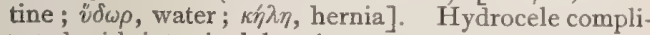
cated with intestinal hernia

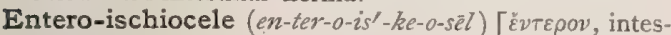

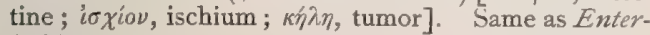
ischiocele.

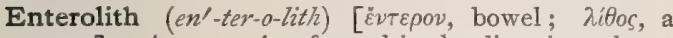
stone]. A concretion formed in the digestive-tube.

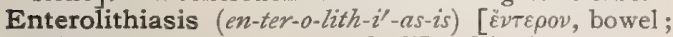

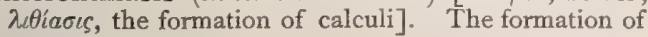
intestinal calculi.

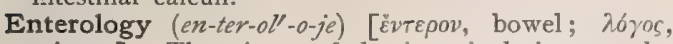
science]. The science of the intestinal viscera; the anatomy, physiology, pathology, and hygiene of the intestines.

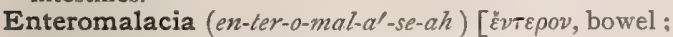

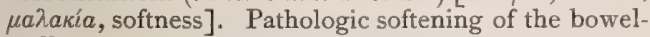
walls.

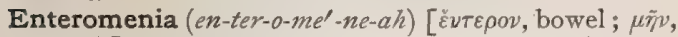
month]. Vicarious menstruation by the bowel.

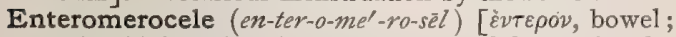
$\mu \eta \rho \delta \delta$, thigh; $\kappa \xi \lambda \eta$, hernia ]. Femoral hernia involving the intestine.

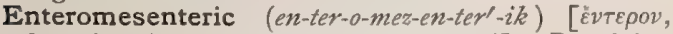

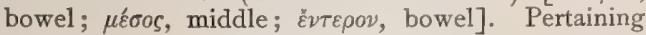
to the intestine and the mesentery.

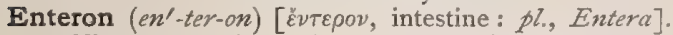
I. The intestinal or alimentary canal, exclusive of those parts that are of ectodermal origin. 2. The intestine.

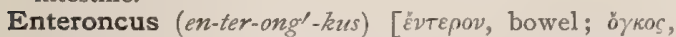
mass]. A tumor of the bowel.

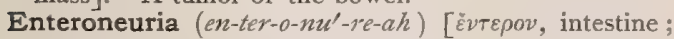
$\nu \varepsilon \tilde{v} \rho o v$, nerve]. An intestinal disease dependent upon some neurosis.

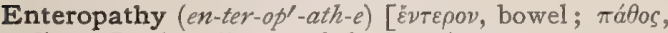
disease]. Any disease of the intestines.

Enteroperistole (en-ter-o-per-is'-to-le) [év $\nu$ te $\rho \nu$, bowel; $\pi \varepsilon \rho \iota \sigma \tau о \lambda \dot{\eta}$, a winding about]. I. Peristaltic motion of the bowels. 2. Any constrictive obstruction of the intestinal-tube.

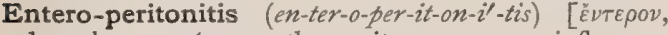
bowel; $\pi \varepsilon \rho \iota \tau o ́ v a \iota 0 v$, the peritoneum; $\iota \tau \iota \zeta$, inflammation]: Combined inflammation of the intestines and adjacent peritoneum; inflammation of the peritoneal coat of the intestine.

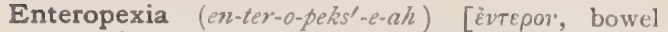
$\pi \bar{\eta} \xi \iota$, fixation ]. Fixation of a portion of the intestine to the abdominal wall, for the relief of enterop tosis, splanchnoptosis, etc.

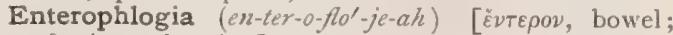
фhoyia, a burning]. Synonym of Acute Intestinal Catarrh.

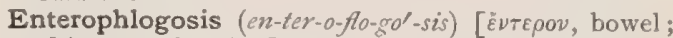

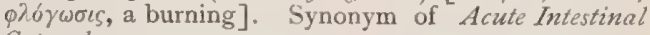
Catarrh.

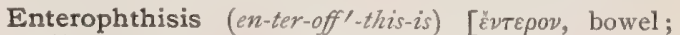
$\phi \theta i \sigma \iota$, wasting]. Intestinal tuberculosis.

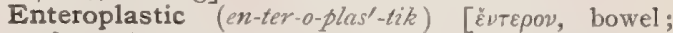
$\pi \lambda a \sigma \tau \iota \kappa \delta s$, formed]. Pertaining to enteroplasty.

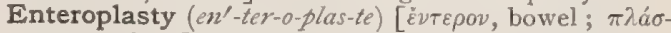
$\sigma \varepsilon \imath v$, to form]. Any plastic operation upon the intestine to repair injuries of its walls.

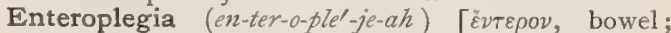
$\pi \lambda \eta \gamma \dot{\eta}$, a stroke]. Paralysis of the bowels.

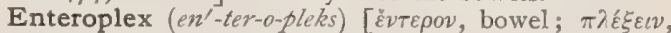
to interlace]. See Enteroplexia.

Enteroplexia, or Enteroplexy (en-ter-o-pleks'-e-ah, or

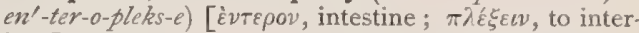
lace]. A method of treatment of wounds of the intestine in which union of the bowel is obtained by different means, but particularly by an apparatus, the enteroplex, without the use of needle and thread. The enteroplex is formed of two aluminum rings so constructed that they will fit the one into the other. These are inserted into the cut ends of the bowel, and then the two are pressed together, the intestinal walls being brought into apposition.

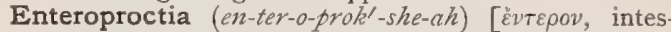
tine; $\pi \rho \omega \kappa \tau \delta$ s, anus]. The existence of an artificial anus, or of an opening into the bowel for fecal discharge.

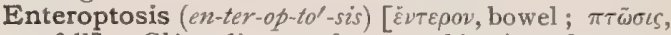
a fall]. Glénard's term for a combination of neurasthenia with gastro-intestinal disturbance and prolapse of the abdominal organs, particularly the transverse colon, with looseness of the mesenteric and peritoneal attachments. It is also called Splanchnoptosis.

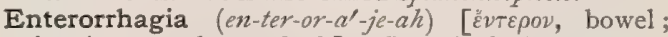
óvvvivat, to burst forth]. Intestinal hemorrhage. Excessive discharge of any kind from the intestine.

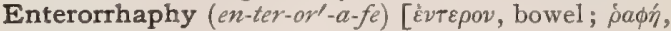
suture]. Suture, or stitching, of the intestine.

Enterorrhea (en-ter-or- $\left.e^{\prime}-a h\right)$ [ a flow]. Diarrhea.

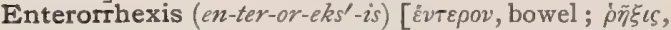
rupture]. Rupture of the bowel.

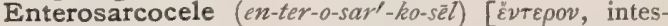
tine; $\sigma a ́ \rho \xi$, flesh; $\kappa \hat{\lambda} \lambda \eta$, a hernia]. Intestinal hernia with sarcocele.

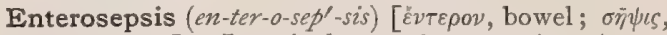
putrefaction]. Intestinal toxemia or sepsis. A condition of unusual activity in the contents of the intestinal canal, by which the ptomaines of putrefaction are produced in such manner, or in such quantity, that they are absorbed and give rise to a state of intoxication.

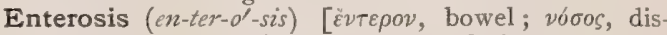
ease : pl., Enteroses]. Any intestinal disease.

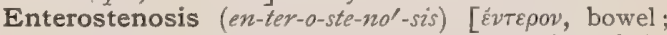
$\sigma \tau \varepsilon ́ v \omega \sigma \iota \varsigma$, contraction]. Stricture or narrowing of the intestinal canal.

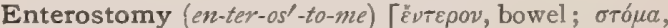
mouth]. Incision and suture of the small intestine to the abdominal wall for introduction of food by this artificial mouth, in case of impossibility of foodentrance by the normal route. 


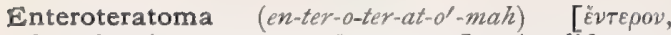
bowel ; $\tau \dot{\varepsilon} \rho \alpha \varsigma$, monster; ó $\mu \alpha$, tumor]. A solid tumor of the umbilicus in new-born infants, composed of the remains of the omphalic duct.

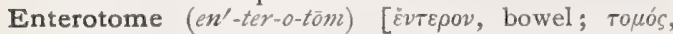
cutting]. The name of various instruments used in cutting-operations upon the intestine.

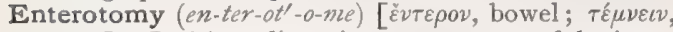
to cut]. Incision, dissection, or anatomy of the intestine.

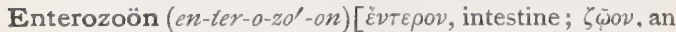
animal : pl., Enterozoa $]$. A parasite of the intestine.

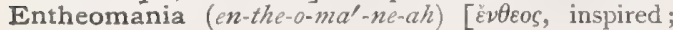
kavia, madness]. Mania in which the patient believes himself to be inspired; religious insanity.

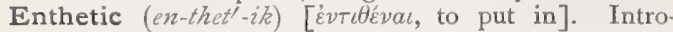
duced; coming from without; applied especially to syphilitic and other specific contagious diseases. The list of enthetic diseases given by Dr. Hartshorne, in Pepper's "System of Medicine," is as follows: I Only produced by contact or inoculation-primary syphilis, gonorrhea, vaccinia, hydrophobia. 2. Contagious also by atmospheric transmission through short distances-variola, varioloid, varicella, measles, diphtheria, scarlatina, rötheln, mumps, whooping cough, typhus, relapsing fever. 3. Endemic, occasionally epidemic - malarial fever, dengue, yellow fever. 4. The zymotic or enthetic diseases-influenza, cerebrospinal fever, erysipelas, puerperal fever, tropical dysentery, typhoid fever, cholera, plague.

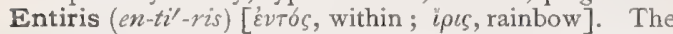
uvea of the iris, forming its inner and pigmentary layer.

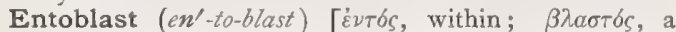
bud, germ]. In biology, the nucleolus or germinal spot of a histologic cell. Cf. Endoplastule.

Entobliquus (en-to-bli'-kwus) ['́vтós, within; obliquus, oblique]. The obliquus internus muscle of the abdomen. See Muscles, Table of.

Entobranchiate (en-to-brang'-ke-ät) ['̌vtós, within; $\beta \rho a ́ \gamma \chi c a$, gills]. In biology, having internal or concealed branchia.

Entocarotid (en-to-kar-ot'-id) [ย́vTós, within; kápos, stupor]. The internal carotid artery. See Arteries, Table of.

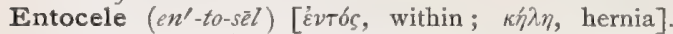
Internal hernia (as through the diaphragm); ectopia; morbid displacement of an internal organ.

Entoceliac, or Entocelian (en-to-se'-le-ak, or en-to-

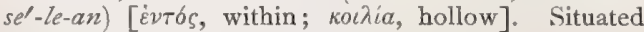
within a brain-cavity or ventricle.

Entochoroidea, or Entochorioidea (en-to-ko-roi'-de-ah,

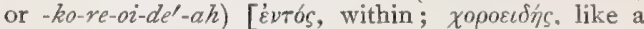
membrane]. The inner lining of the choroid membrane of the eye, made up mainly of capillaries.

Entocinerea (en-to-sin- $\left.e^{\prime}-r e-a h\right)$ ['́v eus, ashy]. Cineritious or gray brain-substance surrounding the cavities of the brain and spinal cord.

Entocondylar (en-to-kon'-dil-ar) [ÉvTbs, within; $\kappa o v \delta v \lambda o s$, a condyle]. Pertaining to an inner condyle,

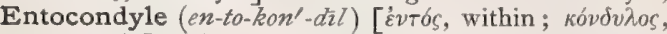
a condyle]. An inner condyle, as of the humerus or the femur.

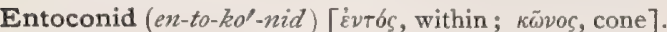
The inner and posterior cusp of a lower molar tooth.

Entocornea (en-to-kor'-ne-ah) ['́vтbs, within; corneus, horny]. That part of Descemet's membrane that lines and adheres to the inner surface of the cornea.

Entocuneiform (en-to-ku'-ne-if-orm) ['́vtós, within ; cuneus, a wedge; forma, form]. The inner cuneiform bone of the foot.

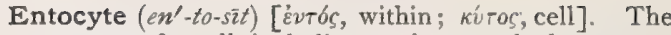
contents of a cell, including nucleus, nucleolus, granulations, etc

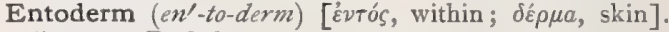
Same as Endoderm.

Entoectad (en-to-ek'-tad) ['́vтós, within; '́kтós, external; ad, to ]. From within outward.

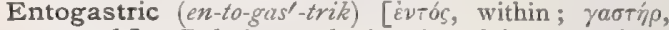
stomach]. Relating to the interior of the stomach.

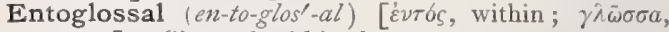
tongue]. Situated within the tongue.

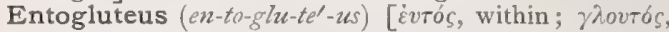
the rump]. The gluteus minimus muscle. See Muscles, Table of.

Entojugular Vein (en-to-ju'-gu-lar) ['évtós, within; jugular, a little yoke]. The internal jugular vein. see $V$ in

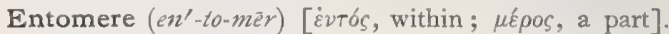
In embryology, one of the cells forming the center of the mass of blastomeres in the developing mammalian ovum, the outer blastomeres being called ectomeres.

Entomion (en-to'-me-on) [Evтoù́, notch]. See Craniometric Points.

Entomogenous (en-to-moj'-en-us) [ÈvTouov, an insect; $\gamma \varepsilon \nu \eta ́$ s, produced]. In biology, applied to fungi growing upon or within insects. Cf. Entomophytous.

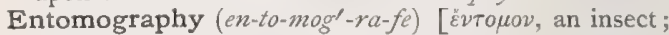
$\gamma \rho a ́ \gamma \varepsilon \iota v$, to write]. A written treatise on insects.

Entomology (en-to-moll-o-je) [èvtouov, insect; $\lambda \dot{\varepsilon} \gamma \varepsilon \iota \nu$, to speak]. That department of zoölogy devoted to the description of insects.

Entomophilous (en-to-moff'-il-us) [E้vтouov, insect; $\phi \iota \lambda \hat{\varepsilon} \varepsilon \iota \nu$, to love]. Insect-loving or insect-attracting. E. Flowers, flowers attracting insects by their secretions and thus securing cross-fertilization through the insects that carry the pollen to other flowers.

Entomophytous (en-to-moff'-it-us) [Ěviouov, insect; фvтós, grown]. In biology, applied to fungi that grow upon or within the bodies of insects. Cf. Entomosenous.

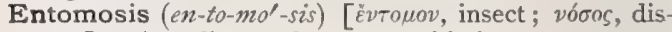
ease]. Any disease due to parasitic insects.

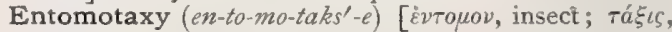
arrangement]. The systematic preparation and arrangement of insects.

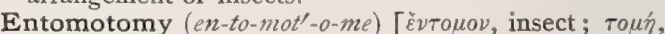
a cutting]. Insect anatomy.

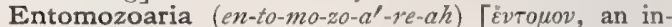

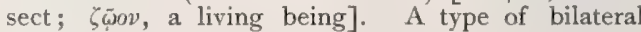
animals nearly equivalent to the Arthropoda.

Entonia (en-to'-ne-ah) [ÉvTovia, tension]. Rigidity or tension of a voluntary muscle; tonic spasm.

Entonic (en-ton'-ik) [évTovia, tension]. Characterized by entonia, or by violent tonic spasm.

Entoparasite (en-to-par'-as-it) ['́vтós, within; $\pi a \rho a ́$ -

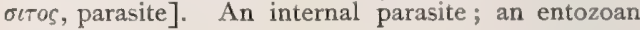
or entophyte.

Entopectoralis (en-to-pek-tor-a'-lis) ['́vTbs, within; pectoralis, of the breast]. The pectoralis minor muscle. See Muscles, Table of.

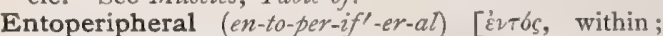
$\pi \varepsilon \rho \iota \phi \varepsilon ́ \rho \varepsilon \imath \nu$, to carry around]. Originating or situated within, and not upon the periphery.

Entophthalmia (en-toff-thal'-me-ah) [ivvbs, within; ostanuia, a disease of the eyes]. Inflammation of the internal parts of the eyeball.

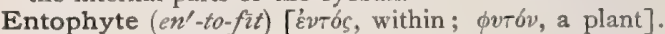
An internal parasite of vegetable nature; as a schizomycete or bacterium.

Entoplastic (en-to-plas'-tik) [غ่vTós, within; $\pi \lambda a ́ \sigma \sigma \varepsilon \nu$, to form]. Same as Endoplastic. 
Entoplastron (en-to-plas'-tron) ['̇vтós, within ; plastron, a breastplate: pl., Entoplastra]. In biology, the internal clavicular scute, or anterior median piece of the plastron of a chelonian.

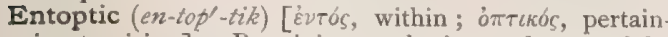
ing to vision]. Pertaining to the internal parts of the eye. E. Phenomena, visual phenomena caused by peculiarities or imperfections of the eye itself, such as musce volitantes.

Entoptoscopic (en-top-to-skop'-ik) ['́vтós, within; $\omega \psi$,

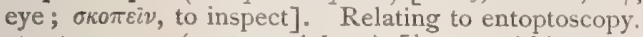

Entoptoscopy (en-top-tos'-ko-pe) ['EvTos, within; $\omega \psi$, eye; бroteiv, to inspect]. The investigation or observational study of the interior of the eye, or of the shadows within the eye.

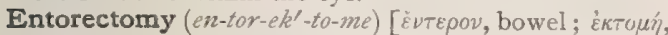
excision]. Resection of a diseased portion of the bowel.

Entoretina (en-to-ret'-in-ah) ['́vTós, within; retina, retina]. The innermost layer of the retina, itself composed of five layers, and an inner limiting membrane.

Entorrhagia (en-tor-a'-je-ah) ['̇vтós, within; ṕnvvival, to burst forth]. Internal hemorrhage.

Entosternite (en-to-ster'-nit). See Endosternite.

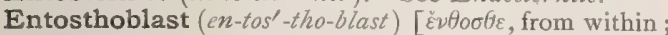
$\beta \lambda a \sigma \tau \delta$, germ]. The supposed nucleus of a nucleolus.

Entostosis, or Entosteosis (en-tos-to'-sis, -tos-te-o'-sis)

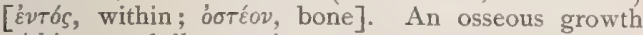
within a medullary cavity.

Entotic $\left(e n-t^{\prime}-i k\right)$ [ÉvTós, within; ov̉s, ear]. Pertaining to the internal ear. E. Phenomena, sounds caused by abnormalities of the auditory mechanism itself.

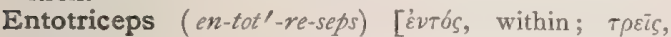
three; $\kappa \varepsilon \phi a \lambda \eta$, head]. The internal head or division of the triceps muscle of the arm.

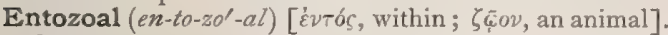
Caused by or dependent upon entozoa.

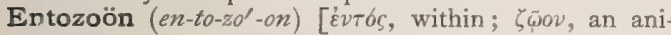
mal: $p l .$, Entozoa $]$. An animal parasite living within another animal.

Entrails (en'-trels) [M.E., entraile]. The bowels and abdominal viscera.

Entropium (en-tro'-pe-um). See Entropion.

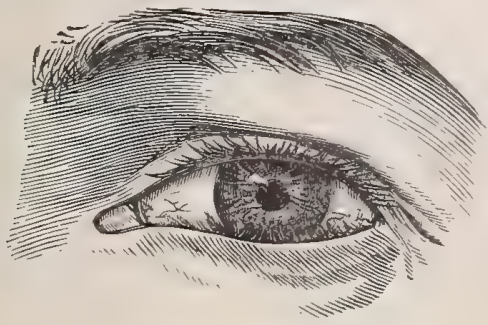

ENTROPION.

Entropion (en-tro'-pe-on) ['́v, in; $\tau \rho \varepsilon \dot{\pi} \pi \varepsilon \nu$, to turn]. Inversion of the eyelid, so that the lashes rub against the globe of the eye, producing inflammation, pannus, etc. It may be cicatricial, organic, or spastic in origin. E., Superciliary, the incurvation of the hairs of the eyebrow into the palpebral fissure and against the conjunctiva, causing the same symptoms as are present in ordinary entropion.

Enucleation (e-nu-kle-a'-shun) [e, out of; nucleus, a kernel]. The operation of exsecting or shelling-out from its seat or capsule a tumor, etc. E. of Eye, excision of the eyeball from the orbit.

Enucleator (e-nu'-kle-a-tor) [e, out of; nucleus, a kernel]. An instrument used in performing enucleation.
Enuresis (en-u-re'-sis) [ $\varepsilon v o v \rho \varepsilon \varepsilon \varepsilon v$, to be incontinent of urine]. Incontinence of urine. A frequent affection of early childhood, due to a variety of pathologic conditions, including the presence of ascarides, phimosis, and vulvitis. E. nocturna, involuntary emptying of the bladder during sleep.

Envelop (en'-vel-opp) [Fr., enveloppc]. An investing membrane, or layer.

Environment (en-vi'-ron-ment) [Fr. environner, to surround]. The totality of influences acting upon the organism from without. See Evolution, Factors of.

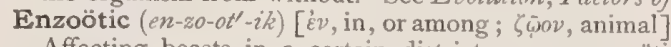
Affecting beasts in a certain district; as an enzoötic disease.

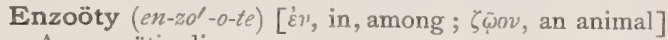
An enzoötic disease.

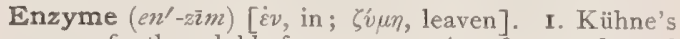
name for the soluble ferments. 2. Any ferment formed within the living organism. 3. Any chemic or hydrolytic ferment, as distinguished from organized ferments, such as yeast. Enzymes are most active between $30^{\circ}$ and $35^{\circ} \mathrm{C}$., and are destroyed by boiling.

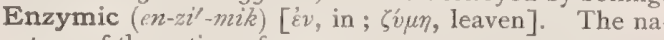
ture of the action of an enzyme.

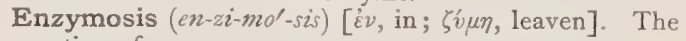
action of an enzyme.

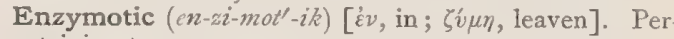
taining to enzymes.

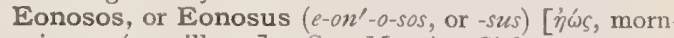
ing; vó́os, illness]. See Morning. Sickness.

Eosin $\left(e^{\prime}-0-\sin \right)$ [ $\eta \omega \sigma$, the dawn], $\mathrm{C}_{20} \mathrm{H}_{8} \mathrm{Br}_{4} \mathrm{O}_{5}$. Tetra bromfluorescein ; an important dye produced by the ac tion of bromin on fluorescein suspended in glacial acetic acid. It occurs in red or yellowish-red crystals, and is used as a stain in histology. See Fuchsin. E. colors. See Pigments, Conspectus of.

Eosinophile $\left(e-0-\sin ^{\prime}-0-f i l\right)$ [eosin from $\dot{\eta} \omega s$, dawn; $\phi \iota \lambda \varepsilon \tilde{\imath} v$, to love]. In bacteriology and histology, applied to $\mathrm{mi}$ crobes or histologic elements showing a peculiar affinity for eosin-stain.

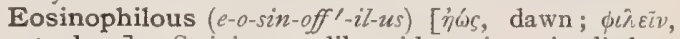
to love]. Staining readily with eosin. Applied to certain granules in the lymphoid blood-cells that stain with acid anilin-dyes.

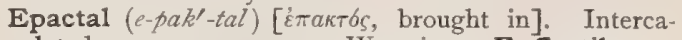
lated; supernumerary; Wormian. E. Cartilages. See Cartilage.

Epanetus $\left(e-p a n^{\prime}-e t-u s\right)$ [ fever.

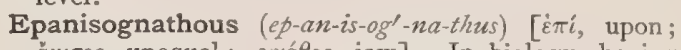

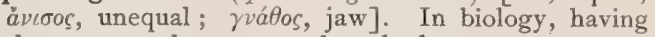
the upper teeth narrower than the lower ones.

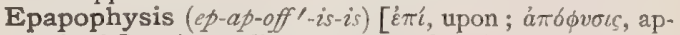
ophysis]. A median process placed dorsad of the centrum of a vertebra.

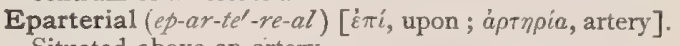
Situated above an artery.

Epaxial (ep-aks'-e-al) [ย́ki, on; axes, axis]. Situated or extending over an axis.

Epencephal (ep-en'-sef-al). See Epencephalon.

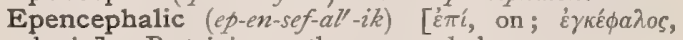
brain]. Pertaining to the epencephalon.

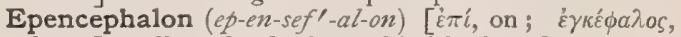
brain]. The after-brain or hind-brain; the cerebellum and pons taken together; or, as some define it, the cerebellum, pons, and oblongata taken together.

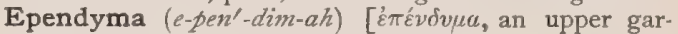
ment]. The lining membrane of the cerebral ventricles and of the central canal of the spinal cord; endyma.

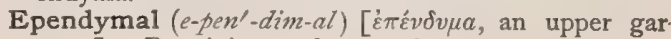
ment]. Pertaining to the ependyma. 


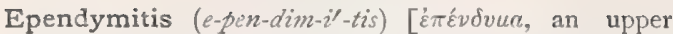
garment; $\iota \tau \iota s$, inflammation]. Inflammation of the ependyma.

Ephebic ( $\left.e f-e^{\prime}-b i k\right)$ [' $\dot{\phi} \phi \beta \kappa \kappa^{\prime} s$, belonging to puberty]. Pertaining to youth, adolescence, or puberty.

Ephebology $\left(e f-e-b o l^{\prime}-o-j e\right) \quad[\tilde{\varepsilon} \phi \eta \beta o s$, youth; $\lambda 6 \gamma o s$, science]. The science of youth, adolescence, and puberty,

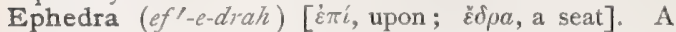
genus of gnetaceous plants with four $N$. American, several S. American, and many other species. See Tepopote. E. antisyphilitica, and E. trifurca, of Texas, etc., are used in gonorrhea, urethritis, and leukorrhea, and as vulneraries. E. andina, of $\mathrm{S}$. America, and E. distachia (or vulgaris), E. equisetina, E. flava, E. fragilis, and E. monostachya, of the old world, have similar properties.

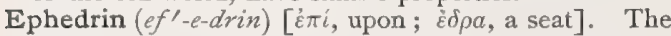
active principle of Ephedra vulgaris, proposed as a mydriatic by Nagai. It is a cardiac depressant and harmless mydriatic. The dose of the hydrochlorate in collyria gr. ss in $亏$ iij distilled water. For instillation gtt. ij-iij. Unof.

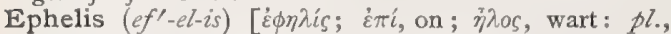
Ephelides]. A freckle. See Lentigo.

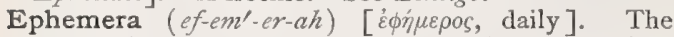
name given by old physicians to short and slight febrile attacks occurring in the lying-in period. These fevers were of frequent occurrence, and of slight significance. They indicated a small amount of septic infection. E. maligna. See Anglicus sudor.

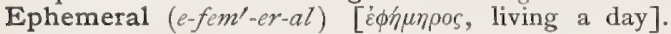
Temporary. Applied to fevers that pass away in a day.

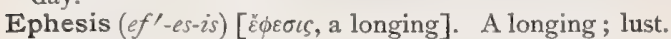

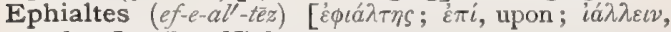
to leap]. See Nightmare.

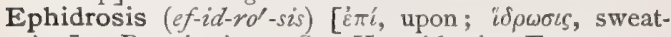
ing]. Perspiration. See Hyperidrosis. E. cruenta, bloody sweat. See Hematidrosis. E. flava, yellow sweat. E. lactea, white or milky sweat. E. nigra, black sweat. E. tincta. See Chromidrosis. E. viridis, greenish sweat.

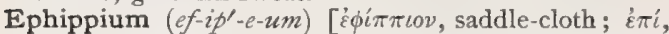
on ; i $\pi \pi$ s, horse: pl., Ephippia]. I. Same as Sella turcica. 2. In biology saddle-shaped capsules formed from the carapace of adult cladocera, and containing the winter (or ephippial) eggs.

Epian $\left(e^{\prime}-p e-a n\right)$ [Fr., a raspberry]. The yaws; frambesia, $q . v$.

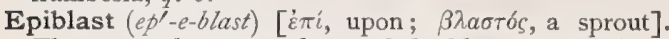
The external or upper layer of the blastoderm, called, also, the ectoderm or neuro-epidermal layer, from which is developed the central nervous system and epidermal tissues, including the epithelium of the sense-organs.

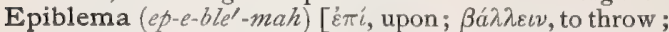
to throw over or to cloak]. In biology, the imperfectly-formed epidermis in submerged plants and on the extremities of growing roots.

Epibole (e-pib'-o-le). See Epiboly.

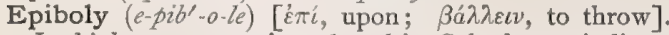
In biology, a term introduced by Salenka to indicate the enclosure of the large yolk-mass by the overgrowth of cleavage-cells. Cf. Emboly.

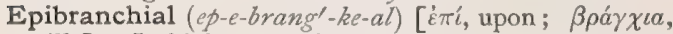
gills]. In biology, applied to various structures; as that portion of the carapace of a crustacean that forms part of the roof of the branchial chamber; the terminal horn of the hyoid bone of a bird, etc.

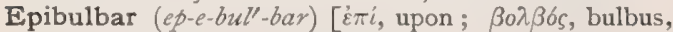
bulb]. Situated upon the globe of the eye ; as an epibulbar tumor.

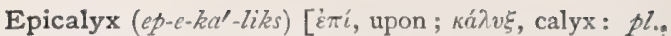
Epicalyces]. In biology, an involucre resembling an exterior or accessory calyx.

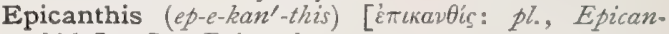
thides]. See Epicanthus.

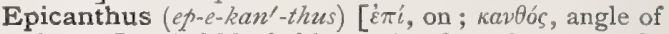
the eye]. A fold of skin passing from the nose to the eyebrow over the inner canthus of the eye.

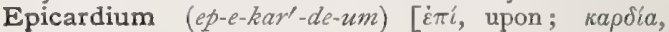
heart]. The visceral layer of the pericardium.

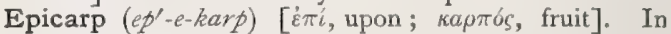
biology, the outer skin of a fruit.

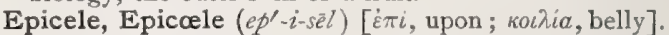
I. In biology, applied to such a body-cavity as that of vertebrates or that represented by the atrium of an ascidium. 2. The cephalic portion of the fourth ventricle, constituting the cavity of the epencephal.

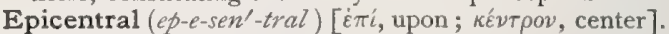
In biology, adhering to a vertebral centrum, as some of the scleral spines in the herring.

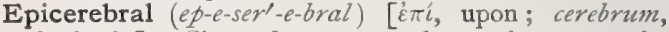
the brain]. Situated over or on the cerebrum; as the epicerebral space between the brain and the pia.

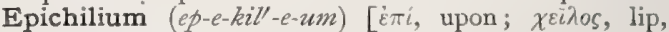
brim: pl., Epichilia]. In biology, applied to the upper portion of the lip of an orchid.

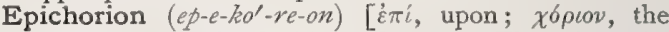
chorion]. I. The decidua reflexa. 2. The epidermis.

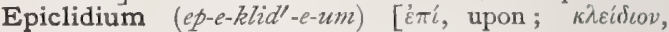
clavicle: pl., Epiclidia]. In biology, a separate ossification of the distal end of the clavicle in birds; according to Parker it represents the precoracoid of reptiles.

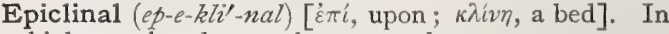
biology, placed upon the receptacle.

Epicclia (ep-e-se'-le-ah). - See Epicele.

Epicoma, Epicomus or Epicome (e-pik'-o-mah,

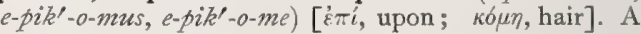
parasitic monstrosity having an accessory head united to the principal fetus by the summit.

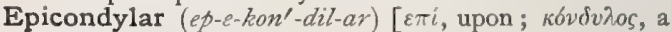
condyle]. Relating to an epicondyle.

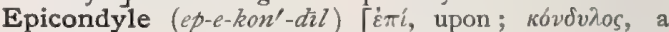
condyle]. I. Any supracondylar eminence upon a bone, as the humerus. 2. Less correctly, the external condyle of the humerus.

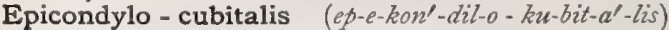

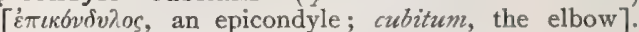
The anconeus muscle. See Muscles, Table of.

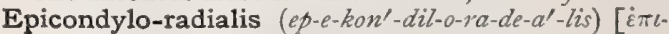
$\kappa \delta v \delta v \lambda o s$, an epicondyle; radius, the radius]. The supinator brevis muscle. See Muscles, Table of.

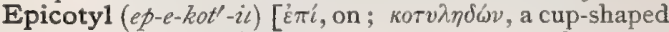
hollow (cotyledon) ]. In biology, the stem of a young plant between the cotyledons and the lowest true leaves.

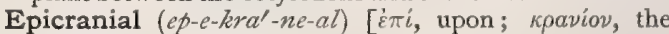
cranium]. Relating to the epicranium.

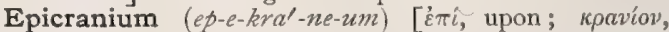
cranium]. The structures covering the cranium.

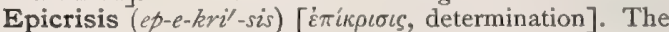
phenomena of disease succeeding the crisis; a secondary crisis.

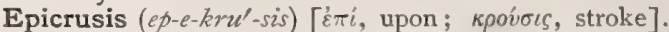
I. Massage by strokes or blows; percussion; therapeutic scourging.

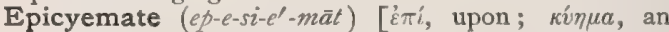
embryo]. In embryology, applied to that form of development in which the embryo remains outside and above the yolk-vesicle. It is characteristic of fishes and batrachians.

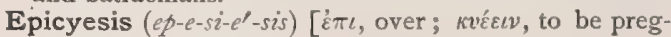
nant]. Superfetation. 


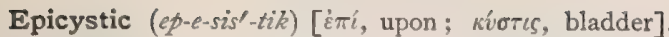
Suprapubic; situated above the urinary bladder.

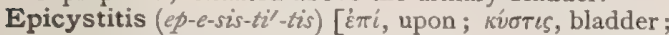
$i \tau \iota$, inflammation]. Inflammation of the tissues above the bladder.

Epicystotomia (ep-e-sis-to-to'-me-ah). Same as Epicystotomy.

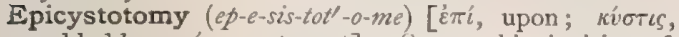
a bladder; t'́p $\mu \nu \varepsilon \nu$, to cut]. Suprapubic incision of the bladder.

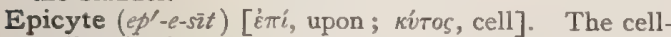
wall or hyaline cuticle of cells.

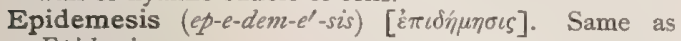
Epidemia.

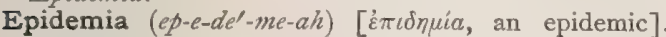
Any epidemic disease, or epidemic of disease. E. puerorum. Synonym of Whooping-cough.

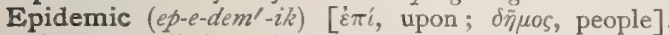
A term applied to diseases that involve large numbers of persons, or spread over a wide area, in contradistinction to Endemic.

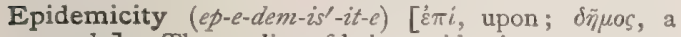
people]. The quality of being epidemic.

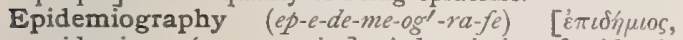

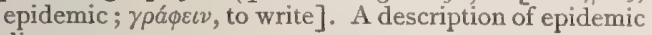
diseases.

Epidemiologic $\left(e p-e-d e m-\ell-0-l o j^{\prime}-i k\right) \quad\left[\dot{\varepsilon} \pi \iota \delta^{\prime} \eta \dot{\mu} \omega s\right.$, epidemic; $\lambda 6 \gamma$ 6 , science ]. Relating to epidemiology.

Epidemiology $\left(e p-\ell-d e m-\ell-o l^{\prime}-o-j e\right)[\hat{\varepsilon} \pi \iota \delta \dot{\eta} \mu \iota s$, epidemic ; $\lambda$ bos, science ]. The science of epidemic diseases.

Epidemy (ep'-e-dem-e). See Epidemia.

Epiderm (ep'-e-derm). See Epidermis.

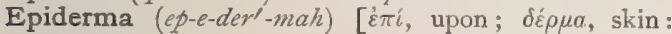
$p l .$, Epidermata]. Any abnormal outgrowth from the epidermis.

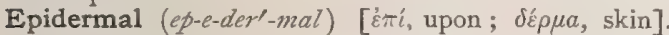
Relating to or composed of epiderm.

Epidermatic, Epidermic (ep-e-der-mat'-ik, -der'-mik)

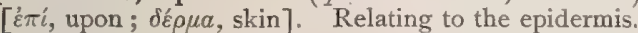
E. Method, a method of administering medicinal substances by applying them to the skin. It is also called Iatraliptic method.

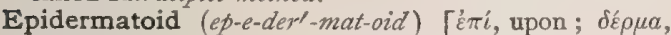
skin; $\varepsilon i \delta o \zeta, ~ l i k e n e s s] . \quad$ Resembling the epidermis.

Epidermic (ep-e-der'-mik). Same as Epidermatic. E. Erythema. See Acrodynia. E. Globes. See Cancer-nests. E. Grafting. See Reverdin's Operation in Operations, Table of. E. Pearls. See Cell-nests.

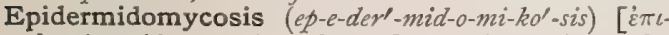

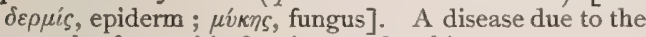
growth of parasitic fungi upon the skin.

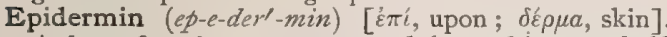
A base for ointments prepared by melting one-half ounce of white wax in a warm mortar and triturating with this one-half ounce of powdered gum arabic until a homogeneous paste is obtained. To this is added a boiling mixture of one-half ounce each of water and glycerin and the whole is stirred until cold. Epidermin, thus prepared, is a semi-fluid, creamy substance, which, when exposed to the air in a thin layer, forms a strongly adherent, flexible pellicle or coating. When medicaments are to be added they are always previously rubbed up in glycerin.

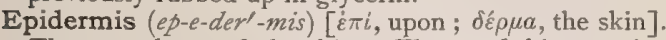
The outer layer of the skin. The scarf-skin, consisting of a layer of horny cells, that protects the true skin. It has neither blood-vessels nor nerve-filaments. E., Appendages of, a generic name for the hair, nails, etc., growing from the epiderm.

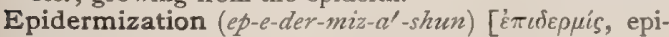
derm]. I. The formation of epiderm. 2. Skingrafting.
Epidermolysis ( $\left.e p-\ell-d e r-m o l^{\prime}-i s-i s\right)$ [ $\varepsilon \dot{\pi} \pi \delta \varepsilon \rho \mu i \zeta$, epidenn: nious, separation]. Acantolysis bullosa; Dermatitis bullosa; a rare skin-disease in which bullæe form upon the slightest pressure. The disease shows itself in infancy, and occurs especially upon the hands and feet. The lesion begins as a red spot, which is itchy; in two hours a bulla forms, enlarges, and then gradually subsides, drying into a scale. It is most pronounced in summer.

Epididymal, or Epididymic (ep-e-did'-em-al, -im-ik)

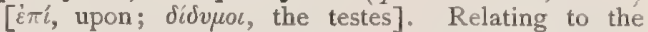
epididymis.

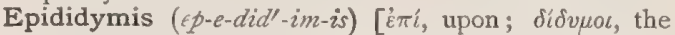
testes]. The small body lying above the testes. The superior end is the globusmajor, the inferior, the globus minor.

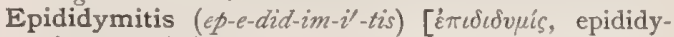
mis; $\iota \tau \iota$, inflammation]. Inflammation of the epididymis.

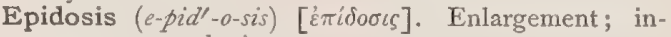
crease ; exacerbation.

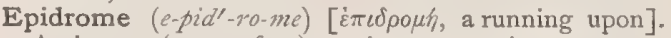
Active, or (more often) passive, congestion.

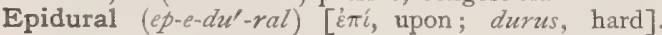
Upon or over the dura. E. Space, the space outside the dura mater of the spinal cord and brain.

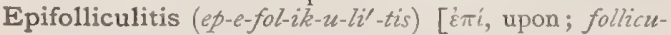
lus, a follicle; $\iota \tau \iota$, inflammation]. Inflammation seated about the hair-follicles of the scalp.

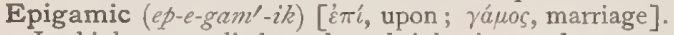
In biology, applied to those bright tints and patterns displayed by many animals during courtship. Cf. Allepigamic.

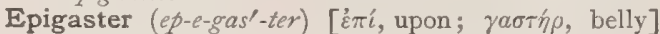
The large intestine; hindgut.

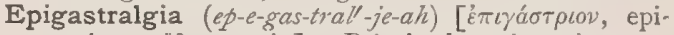
gastrium; àn yos, pain]. Pain in the epigastrium.

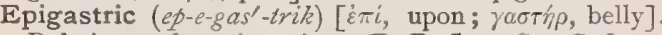
Relating to the epigastrium. E. Reflex. See Reflexes, Table of.

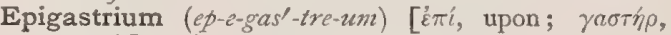
stomach]. The upper and middle part of the abdominal surface; the epigastric region.

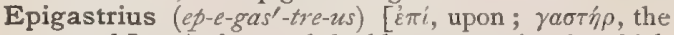
stomach]. A form of double-monstrosity, in which one fetus in an undeveloped condition is contained within the epigastric region of the other.

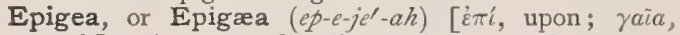
earth]. A genus of trailing ericaceous plants. E. repens, trailing arbutus of N. America, has valuable diuretic properties. See Trailing Arbutus.

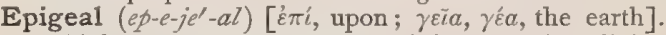
In biology, growing on or out the ground, or living near the surface of the ground.

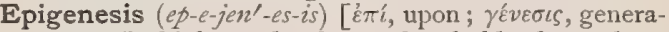
tion]. In biology, the theory that holds the embryo to be the result of the union of the male and female elements, and the fully formed organism the result of a gradual process of differentiation, in distinction to the theory of encasement, preformation, or evolution, which held the embryo to prëexist enfolded in a minute form within the germ.

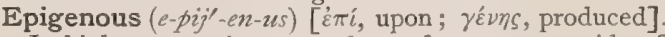
In biology, growing upon the surface or upper side of a leaf or other part, as many fungi. Cf. Epiphyllous.

Epigeous $\left(e p-e-j e^{\prime}-u s\right)$ ['́ri, upon; $\gamma^{\prime} \varepsilon$, the earth]. In biology, growing on or near the ground. Same as Epigeal.

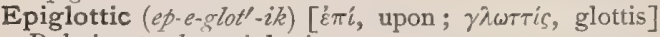
Relating to the epiglottis.

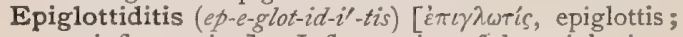
$\iota \tau \iota s$, inflammation]. Inflammation of the epiglottis. 
Epiglottis $\left(e p-e-g l o t^{\prime}-i s\right)$ [' $\pi i$, upon; $\gamma \lambda \omega \tau \tau i s$, glottis]. A thin fibro-cartilaginous valve that aids in preventing food and drink from passing into the larynx.

Epiglottitis (ep-e-glot-i'tis). See Epig-lottiditis.

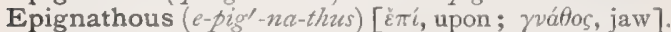
In biology, hook-billed; applied to birds in which the upper half of the beak overreaches the under half and is deflected over it

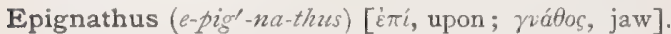
A twin monstrosity in which the parasite is united to the superior maxillary bone of the autosite.

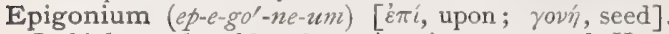
In biology, the old archegonium in mosses and Hepa tica, after the capsule has developed.

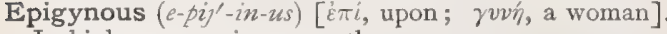
In biology, growing upon the ovary.

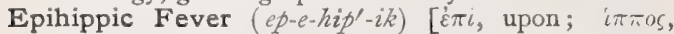
horse]. See Fever

Epilation (ep-il-a'-shun) [e, out of; pilus, a hair]. The extraction of hair.

Epilatorium (e-pil-at-o'-re-um)[L.]. An application for permanently removing hair.

Epilatory $\left(e-p i l^{\prime}-a t-o-r e\right)$ [e, out of; pilus, a hair]. I. Extracting the hairs; depilatory. 2. An epilatorium.

Epilemma (ep-e-lem'-ah) ['́rí, upon; $\lambda \dot{\varepsilon} \mu \mu \alpha$, husk: pl., Epilemmata]. The neurilemma of very small branches or funiculi of nerve-filaments.

Epilepsia (ep-e-lep'-se-ah). See Epilepsy. E. cursiva. See Epilepsy, Accelerative. E. gravis. See Grand mal. E. larvata. See Epilepsy, Masked. E. mitis. See Petit mal. E. saltatoria. Synonym of Chorea. E. vertiginosa, Petit mal, q.v.

Epilepsy (ep'-il-ep-se) ['่ $\pi i \lambda \eta \psi \iota \varsigma$, a laying hold of ]. A nervous affection characterized by sudden loss of consciousness and power of coördination of motion with tonic and clonic convulsions, the paroxysms lasting but a short time. This form of the disease is the "true" affection, the haut mal or grand mal of the French. The petit mal (abortive epilepsy, epileptic vertigo) is less severe, and may consist of only a slight loss of consciousness, with retained coördination of motion. The so-called epileptiform seizure is a localized convulsion without loss of consciousness. See Epilepsy, Jacksonian. An epileptic seizure is often introduced by an aura, a peculiar sensation preceding the spasmodic seizure, which is quickly followed by the characteristic epileptic cry. The origin of the epileptic attack is in all probability a powerful discharge of energy from the cortical cerebral cells. The disease is most common in females, and is influenced by heredity and age; it is rare for it to occur after forty years of age. Traumatism and severe mental strain may act as exciting causes. E., Accelerative, Epilepsia cursiva; epilepsy in which the patient runs before falling down in a fit. E., Acute Infantile, a name given to the eclampsia of infants. E., Cardiac, paroxysmal tachycardia. E., Cortical. See E., Jacksonian. E., Focal. See E., Jacksonian. E., Jacksonian, spasmodic contractions in certain groups of muscles due to local disease of the cortex, always confined to one-half of the body and with retention of consciousness. E., Masked, $E$. larvata, the less severe form of true epilepsy, in which the patient does not fall. E., Partial, E., Jacksonian, q. v. E., Peripheral. Same as E., Jacksonian. E., Pleural. See Pleural. E., Procursive, there is propulsion of the body in some special direction. E., Reflex, due to some reflex neurosis. E. of the Retina, a temporary anemia of the retina occasionally observed during an epileptiform seizure. E., Saturnine, epileptiform convulsions due to lead-poisoning. E., Sensory, Thalamic epilep- sy; a form of epilepsy in which sensory disturbances predominate; it is believed to be due to a lesion of the optic thalamus. E., Spinal, paroxysms of clonic spasm in the lower extremities sometimes observed in the course of spastic paraplegia. E., Symptomatic. See E., Jacksonian. E., Thalamic. See E., Sensory. E., Toxic, that induced by toxic substances in the blood.

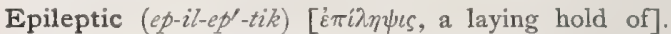
Pertaining to or like epilepsy. Also one affected with epilepsy. E. Aura. See Aura. E. Cry, the vocal sound or cry in epilepsy, from laryngeal spasm. E. Equivalents, instead of the convulsive attacks in epilepsy there may from time to time be transient psychic disturbances that consist in states of either excitement or depression. These are the so-called epileptic equivalents. E. Hemiplegia, sometimes follows the fit, especially after unilateral convulsions. E. Interval, the period of time between the epileptic paroxysms. During this period there are in the majority of cases, if not in all, some abnormal manifestations, as disorders in the cardiac rhythm, irregularity in the pupils, and cerebral disorders. E. Mania, slight maniacal tendencies following or taking the place of the fit. E. Seizure. See Epilepsy. E. State, a state of profound and sometimes comatose depression, with frequently recurring epileptic attacks, often speedily fatal. E. Vertigo, giddiness is a common sensation of epilepsy, but is erroneously applied to attacks of minor epilepsy.

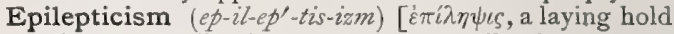
of]. The epileptic state, or status epilepticus.

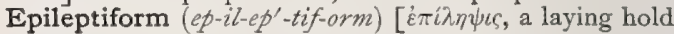
of; forma, form]. Resembling epilepsy in the symptoms. E. Tic, a variety of facial neuralgia accompanied by spasmodic movements of the face. This occurs in the degenerative period of life, and especially in those who present a decided family history of insanity.

Epileptiginous (ep-il-ep-tij'-in-us). Same as Epileptogenous.

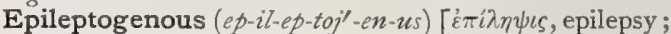

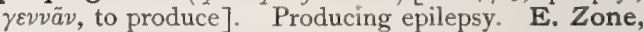
Brown-Séquard's term for that portion of the skin of the face and neck of guinea-pigs which, if irritated after section of the spinal cord near the twelfth dorsal vertebra, will give rise in a short time to epileptiform convulsions.

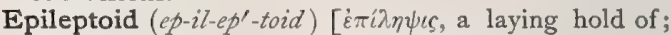

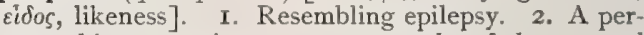
son subject to various nervous attacks of the general nature of epilepsy.

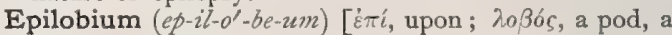
lobe]. A genus of herbs including the willow-herb, a demulcent, tonic, and astringent drug.

Epilose (eṕl-il-ôs) [e, priv.; pilosus, hairy]. Without hair; bald.

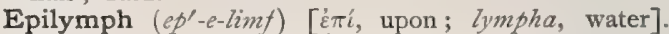
The fiuid between the bony and the membranous labyrinths.

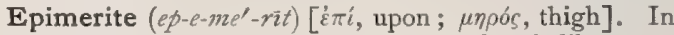
biology, an anterior, deciduous, proboscis-like, prehensile organ, attached to the protomerite or anterior segment of a septate gregarine.

Epimeron (ep-e-mél-ron) [ $\dot{\varepsilon} \pi i$, upon; $\mu \eta \rho b s$, thigh]. In biology, one of the lateral pieces helping to form the pleuron, or a part of the segment of an arthropod, often giving attachment to the legs.

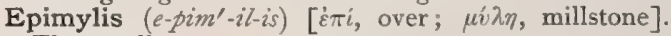
The patella.

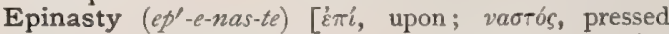
close]. In biology, curvature produced by excessive growth on the upper side of an extended organ. 


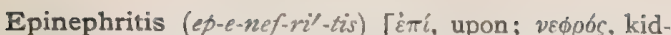
ney; itis]. Inflammation of a supra-renal capsule.

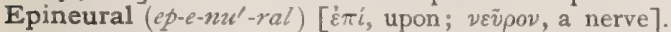
In biology, applied to structures attached to a neural arch.

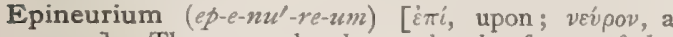
nerve]. The nerve-sheath, or sheath of any of the larger fascicles of nerve-tissue.

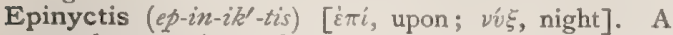
pustule appearing or becoming worse at night.

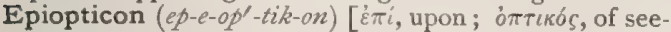
ing]. In biology, a ganglionic swelling in the optic nerve of insects (Hickson).

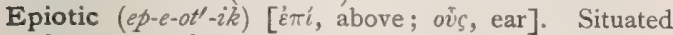
above or on the cartilage of the ear.

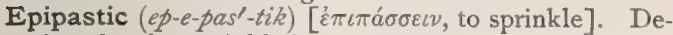
signed to be sprinkled upon some surface; sprinkled with some substance; applied to plasters sprinkled with some agent, as cantharides, used as a vesicant.

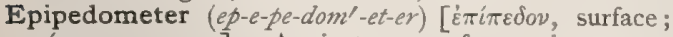

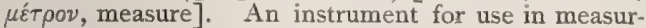
ing various complex deformities of the body.

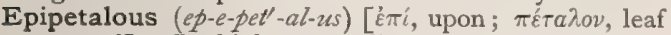
or petal]. In biology, applied to stamens or other structures when borne upon the petals.

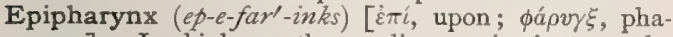
rynx]. In biology, the median projection on the internal surface of the upper lip of an insect.

Epiphenomenon (ep-e-fe-nom'-en-on) [i்i, on; $\phi a l-$ vóucvov, phenomenon: pl., Epiphenomena]. An exceptional sequence or unusual complication arising in the course of a disease.

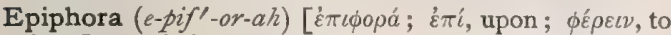
bear]. A habitual or persistent overflow of tears, due to over-secretion or impeded outflow through the normal channels of excretion. Lachrymation, $q . v$.

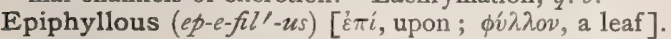
In biology, borne on a leaf, as certain fungi. Cf. Epigenous.

Epiphyseal, or Epiphysial $\left(e p-e-f i z^{\prime}-e-a l\right)$ [ $\dot{\varepsilon} \pi i$, upon; divelv, to grow]. Relating to or of the nature of an epiphysis.

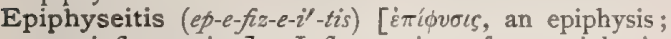
$\iota \tau \iota \zeta$, inflammation]. Inflammation of an epiphysis, or of the epiphyseal part of a bone.

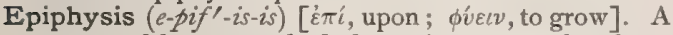
process of bone attached for a time to another bone by cartilage, but in most cases soon becoming consolidated with the principal bone. E. cerebri, the pineal gland.

Epiphysitis (e-pif-is-i'-tis). See Epiphyseitis.

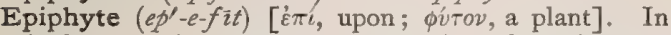
biology, a plant growing on another plant, but not nourished by it; also, a parasitic plant living upon another plant; also, a plant parasitic upon an animal.

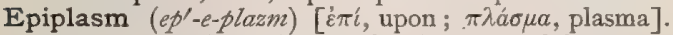
In the sporangium of many fungi, a part of the protoplasm remaining after formation of the spores.

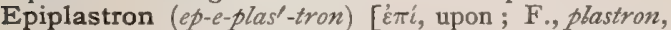
a breastplate]. In biology, one of the two anterior lateral plates of the plastron of a turtle; probably the homologue of the clavicle of other vertebrates.

Epiplerosis (ep-e-ple-ro'-sis) [ย̇ $\pi i$, upon; $\pi \lambda h \rho \omega \sigma \iota s$, filling]. Engorgement; repletion; distention.

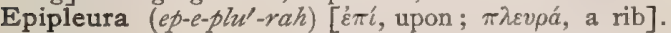
In biology, variously used to designate a structure superposed upon a rib, as the spines of certain fishes, the hooked processes or splint-bones passing from rib to rib in birds, or the inflexed outer border of a beetle's elytrum.

Epiplexus (ep-e-pleks'-us) ['́rí, upon; plexus, a network]. The choroid plexus of the epicele.
Epiplocele (e-piph'-lo-sel) [ $\dot{\varepsilon} \pi i \pi \lambda \circ o v$, caul ; $\kappa \dot{\eta} \lambda \eta$, hernia]. Omental hernia.

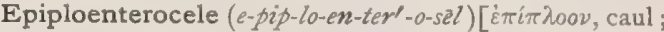

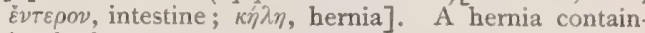
ing both omentum and intestine.

Epiploenteroöscheocele (epp-ip-lo-en-ter-o-os'-ke-o-sēl)

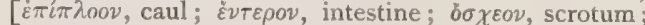
$\kappa \eta \dot{\lambda} \eta$, hernia]. Intestinal and omental hernia into the scrotum.

Epiploic $\left(e p-i p-l 0^{\prime}-i k\right)$ [ $\dot{\varepsilon} \pi i \pi \lambda o o v$, caul]. Relating or belonging to the epiploön.

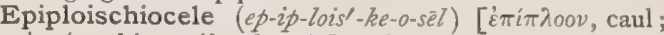

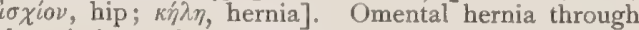
the sciatic notch or foramen.

Epiploitis (e-pip-lo-i'-tis) [ $\varepsilon^{\prime} \pi i \pi \lambda o o v$, caul ; $\iota \tau \iota \zeta$, inflammation]. Inflammation of the omentum; omental peritonitis.

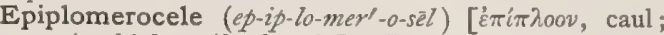
$\mu \eta \rho \sigma s$, thigh; $\kappa \eta \lambda \eta$, hernia]. Femoral hernia containing omentum.

Epiplomphalocele $\left(e p-i p-l o m-f a l^{\prime}-0-s e l l\right)[\dot{\varepsilon} \pi i \pi \lambda o o v, \mathrm{caul}$; ó $\phi a \lambda \sigma \varsigma$, navel ; $\kappa \dot{\lambda} \lambda \eta$, hernia]. Umbilical hernia with protruding omentum.

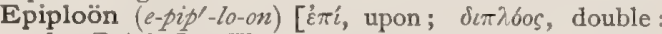
pl., Epiploa]. The great omentum. E., Gastrocolic, the great omentum. E., Gastro-hepatic, the lesser omentum.

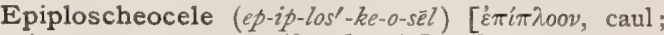
ò $\chi \varepsilon \circ \nu$, scrotum; $\kappa \hat{\eta} \lambda \eta$, hernia]. Omental hernia descending into the scrotum.

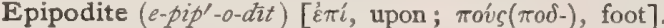
A third appendage of the limb of a crustacean, articulating with the coxopodite, and passing into the branchial chamber; it is also called the frabellum.

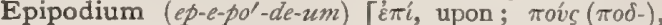
foot]. In biology, one of the lateral appendages of the foot in certain molluscs, as the wing-like structures of pteropods.

Epipsyche $\left(e p-i s-i^{\prime}-k e\right)[\dot{\varepsilon} \pi \dot{\imath}$, after; $\psi v \chi \dot{\eta}$, soul]. Applied by Haeckel to the oblongata proper.

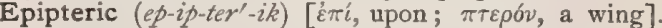
Situated over the alisphenoid. E. Bone. See Bone.

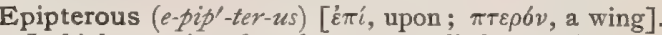
In biology, winged at the top; applied to seeds.

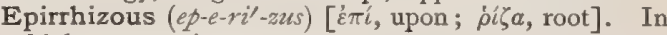
biology, growing upon roots.

Episcleral (ep-e-skle'-ral) ['̇ंi, upon; $\sigma \kappa \lambda \eta \rho b \varsigma$, hard, sclerotic]. Situated on the outside of the sclerotic coat.

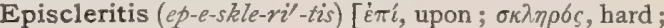
$\iota \tau \iota$, inflammation]. A localized inflammation of the subconjunctival tissues.

Episeio- $\left(e p-i s^{\prime}-e^{-}-0-\right)$. For words thus beginning, see Episio-.

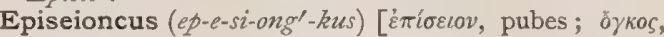
a mass]. A tumor in the pubic region, or of the labia.

Episeitis $\left(e p-i z-e-i^{\prime}-t i s\right)$. See Episioitis.

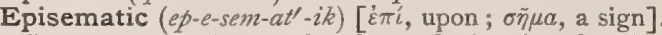
In biology, applied to that form of mimetic coloration which serves as a signal of recognition to other individuals and thus enables them to escape ; as the white tail of the rabbit. (Poulton.)

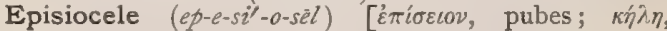
hernia ]. Pudendal hernia; vulvar protrusion.

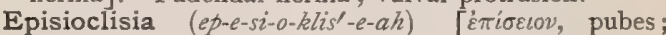
$\kappa \lambda \varepsilon i \sigma \iota s$, locking, closure]. Surgical closure of the vulva.

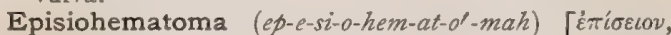
pubes; aira, blood; ö $\mu a$, tumor: pl., Episiohematomata]. Hematoma of the vulva or pudenda. 


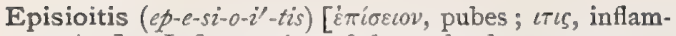
mation]. Inflammation of the pudenda.

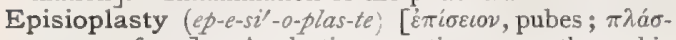
$\sigma \varepsilon \imath$, to form]. A plastic operation upon the pubic region, or on the vulva.

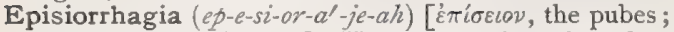
pnyvv́val, to break forth]. Hemorrhage from the vulva.

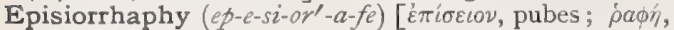
seam]. An operation for the cure of prolapsed uterus or procidentia uteri.

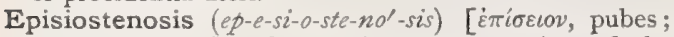

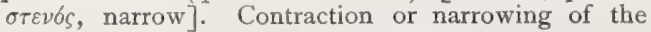
vulva, whether surgical or pathologic.

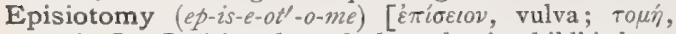
section]. Incision through the vulva in childbirth, to prevent rupture of the perineum and to facilitate labor.

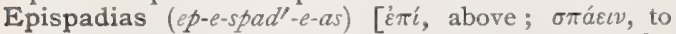
pierce]. Abnormal opening of the urethra upon the upper part of the penis, either on the dorsum or on the glans.

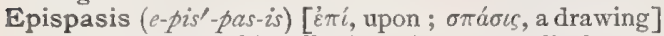
An eruption or skin-affection due to medical treat ment ; a drug-exanthem.

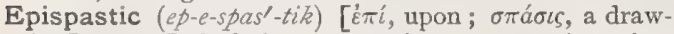
ing]. I. Rubefacient, or vesicatory. 2. A vesicatory or substance producing a blister.

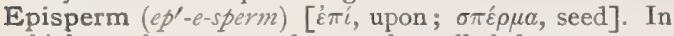
biology, the outer seed-coat, also called the testa.

Episplenitis $\left(e p-e-s p l e n-i^{\prime}-t i s\right)[\dot{\varepsilon} \pi i$, upon; $\sigma \pi \lambda \eta \nu$, spleen; iTıS, inflammation]. Inflammation of the fibrous coat of the spleen.

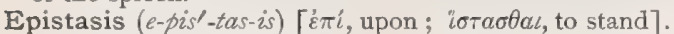
A scum or film of substance floating on the surface of urine.

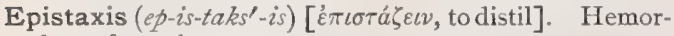
rhage from the nose.

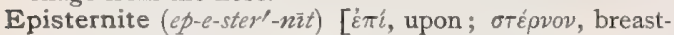
bone]. In biology, applied to the lateral pieces of the segment of an arthropod; a pleurite; specifically one of the valves of the ovipositor in orthopterous insects.

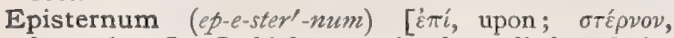
breast-bone]. In biology, variously applied to designate a part above or anterior to the sternum; as the presternum of a mammal, the epiplastron of a turtle, or the anterior of the three pieces of the pleuron of an insect.

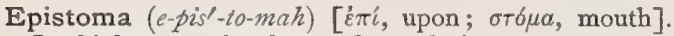
In biology, variously used to designate some part placed above, or anterior to the mouth, as the osseous portion of the metope or facies of a macrurous crustacean, that lies immediately in front of the oral aperture.

Epistrophe (e-pis'-tro-fe) ['́rí, upon; $\sigma \tau \rho \varepsilon \dot{\phi} \varepsilon v v$, to turn]. In biology, applied to the arrangement assumed by chlorophyl-grains under the influence of light, on those surfaces of the cell-wall that are at right angles to the plane of incident light.

Epistropheus (ep-is-tro'-fe-us, e-pis'-tro-phüs) [ $\varepsilon \pi \omega \sigma \rho o-$ фérs]. A synonym of the axis, or second cervical vertebra.

Epithalline (ep-e-thal'-in) [ $\dot{\varepsilon} i$, upon; $\theta a \lambda \lambda \sigma s$, a branch]. In biology, growing upon the thallus.

Epitheca $\left(e p-e-t h e^{\prime}-k a h\right)$ [ $\dot{\varepsilon} \pi \dot{i}$, upon; $\theta \dot{\eta} \kappa \eta$, a case $]$. In biology, a secondary calcareous investment or tegumentary secretion surrounding the theca of certain corals.

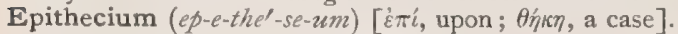
In biology, the surface of the fruiting-disc in certain lichens and fungi.

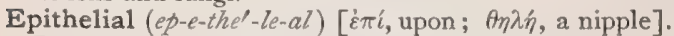
Pertaining to epithelium; made up of the elements of epithelium. E. Pearls. See Pearls.
Epithelicell ( $\left(p p-\ell-t h e^{\prime}-l e-s e l\right)$ [ $\dot{\varepsilon} \pi \hat{\imath}$, upon; $\theta \eta \lambda \dot{\eta}$, a nipple; cella, a cell]. An epithelial cell.

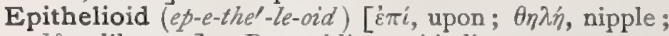
Eidos, likeness]. Resembling epithelium.

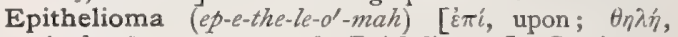
nipple; ö $\mu a$, a tumor: $p l .$, Epitheliomata]. Carcinoma involving skin or mucous membrane. E. molluscum. Synonym of Molluscum contagiosum.

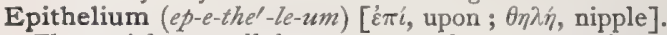
The cuticle or cellular-structure of mucous surfaces, and also of the skin of the body. E. chrotale, the ectoderm. E., Ciliated, a form in which the cells bear vibratile filaments or cilia at their free extremities. E., Columnar, distinguished by prismatic-shaped or columnar cells. E., Nucleated, consisting of circular or hexagonal cells, each containing a nucleus.
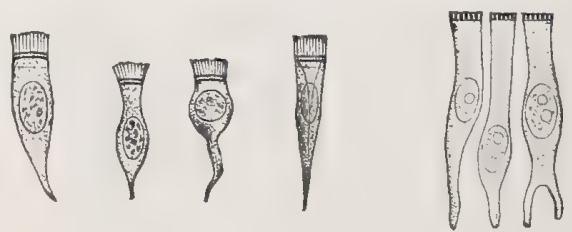

Ciliated Cells.
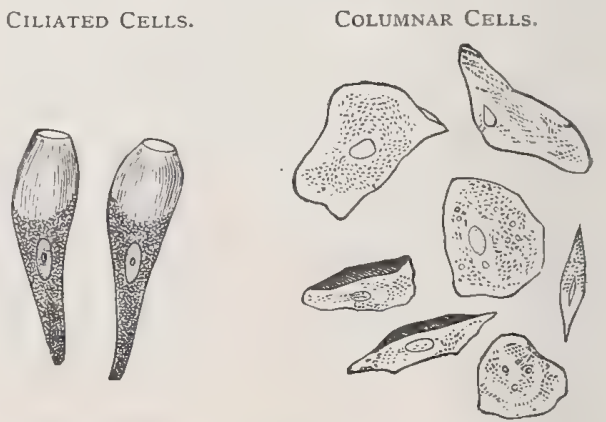

GOBLET-CELLS.

SOUAMOUS-CELLS.

E., Pavement, or Cuboidal, cubical or polygonal cells covering the surface like the stones of a pavement. E., Squamous, the cells have been reduced to flattened, scaly plates. E., Stratified, the cells are arranged in distinct layers. E., Tessellated. Same as E., Pavement. E., Transitional, intermediate between simple and stratified.

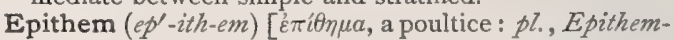
ata]. Any local application; as a compress, fomentation, lotion, or poultice; from this definition some writers exclude salves, plasters, and ointments.

Epithema (ep-ith-e'-mah). See Epithem.

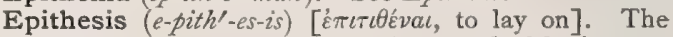
surgical correction of deformed or crooked limbs.

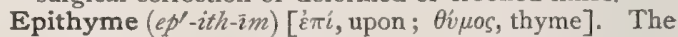
European plant, Cuscuta epithymum, so called as growing parasitically upon thyme; it is said to be useful in melancholy, jaundice, and constipation.

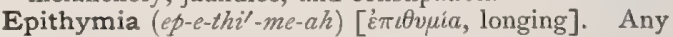
natural longing or desire; a yearning.

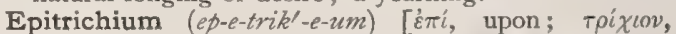
hair]. A superficial cellular layer of epidermis, found in embryonic and fetal life.

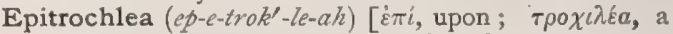
pulley]. The internal condyle of the humerus.

Epixylous (e-piks'-il-us) ['́ri, upon; $\xi \hat{v} \lambda o v$, wood]. In biology, applied to fungi or other plants that grow upon wood.

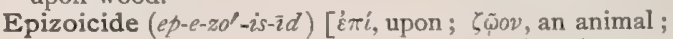
cadere, to kill]. A drug or preparation that destroys external parasites. 


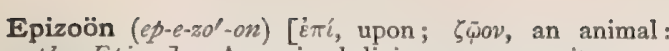
pl., Epizoa]. An animal living as a parasite upon another; an external parasite, as distinguished from an Entozoön.

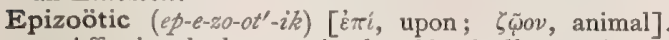
I. Affecting the lower animals epidemically. 2. A con tagious, or generally prevalent disease affecting animals.

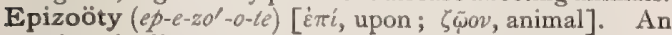
epizoötic disease.

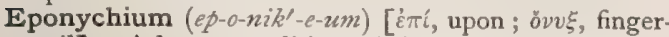
nail]. A horny condition of the epidermis from the second to the eighth month of fetal life, indicating the position of the future nail.

Eponym (epp-o-nim) [ $\dot{\varepsilon} \pi \dot{\omega} \nu v \mu o s$, named after a person]. A term derived from the name of a person. See Table of Eponymic Diseases, under Disease.

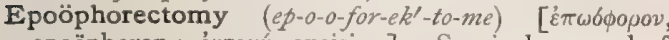

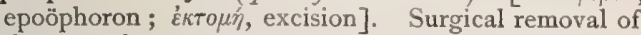
the epoöphoron.

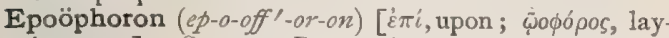
ing eggs]. Same as Parovarium.

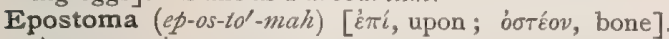
An exostosis.

Epsilon-bacillus. See Bacteria, Synonymatic Table of. Epsom Salts (epp'sum). See Magnesium.

Epstein's Dressing. A method of dressing the um bilical cord. It consists of the ordinary linen quad rangular belly-plastron with a central cap-like recepta cle for the umbilical stump.

Epulis $\left(e p-\imath \iota^{\prime}-l i \hat{s}\right)$ [ $\dot{\varepsilon} \pi i$, upon; $\hat{\imath}^{\dagger} \lambda \alpha$, the gums]. A hard, fibrous tumor of the alveolar processes of the jaws.

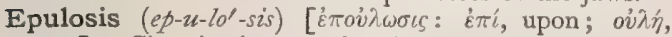
scar]. Cicatrization; a cicatrix.

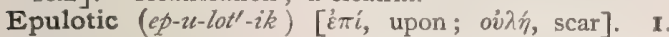
Promoting epulosis or cicatrization. 2. A remedy or application that promotes the healing of wounds or sores.

Equation (e-kwva'-zhun) [aquare, to make equal]. In chemistry, a collection of symbols so arranged as to indicate that if the bodies represented by the symbols be brought together a chemic reaction will take place. E., Personal, an allowance for individual peculiarity or error in an observer's work, in order to render it approximately accurate.

Equator (e-kwa $\alpha^{\prime}$-tor) [øquare, to make equal]. An imaginary circle surrounding a sphere. E. of a cell, the boundary of the plane through which division takes place. E. of the eye, the aquator oculi; the boundary of the transverse and central vertical plane of the eye. E. of a Lens, the angular edge at the meeting of the anterior and posterior surfaces of the lens.

Equatorial (e-krva-tor'-e-al) [aquare, to make equal]. Pertaining or belonging to an equator. E. Plate. See Karyokinesis and Plate.

Equilibration (e-que-lib-ra'-shun) [aquilibrare, to balance equally]. Equipoise; even balance.

Equilibrism (e-quil'-ib-rizm) [aquilibris, evenly balanced]. The opinion that every voluntary act may be counteracted by an opposing inhibitory volition.

Equilibrium (e-kwe-lib'-re-um) [aquus, equal; libro, balance]. An even balancing of a body or condition. E., Stable, when, after slight disturbance, the body will return to its original condition or position. E., Unstable, when it will not so return.

Equination (e-kzein-a'-shun) [equinus, of a horse]. I. Inoculation with the virus of equine smallpox. 2. Inoculation with the virus of equinia.

- Equinia (e-kwin'-e-ah) [equus, a horse]. Glanders. Farcy. A contagious, specific disease, with both local and general symptoms, derived from the horse or ass. It affects chiefly the skin, mucous membranes and lymphatics, and begins with a purulent nasal discharge, the respiratory, ocular and oral membranes being further successively involved. It is of microbic origin. See Bacillus mallei, in Bacteria, Synonymatic Table of.

Equinist (ek'-kwin-ist) [equus, a horse]. One who believes in the equine origin of a disease, $e . g$., of tetanus.

Equipollent (e-kwip'-o-lent) [equus, equal; pollere, to be strong]. Of equal power or efficiency; said, for example, of opposing muscles, or of parents in their influence upon offspring.

Equisetum (ek-wis- $\left.e^{\prime}-t u m\right)$ [equus, a horse ; sata, bristle]. A genus of cryptogamous plants; the horsetails, or scouring rushes. E. hiemah and E. palustre, of Europe and N. America, are reputed to be effective and harmless diuretics.

Equitant (ek'-wit-ant) [equitare, to ride]. In biology, literally, riding. Applied to leaves, like those of the iris, which are vertical and folded lengthwise, so that each leaf, toward the base, overlaps or straddles the next; also applied to the longitudinally folded antennæ of certain insects.

Equivalence, Equivalency (e-kwiv'-al-ens, e-quiv'-alen-se) [aques, equal ; valere, to be worth]. Equality of valence or saturating-power.' See Valence. In chemistry, the property possessed by an element or radical of combining with another element or radical or of replacing it in a compound body in definite and unalterable proportions. It is sometimes used as synonymous with valence or quantivalence.

Equivalent (e-kzviv'-al-ent) [requus, equal; valere, to be worth]. Of equal valency. E. Focus. See Frocus.

Equivocal (e-kwiv'-o-kal) [aquus, equal; vox, sound]. Of doubtful significance, as equivocal symptoms.

Eradication (e-rad-ik-a'shun) [e, out; radicare, to root]. Complete or thorough removal.

Eradiculose (e-rad-ik'-u-lōs) [e, priv.; radicula, a rootlet]. In biology, destitute of rootlets or rhizoids.

Erasene $\left(e r^{\prime}-a s-\bar{e} n\right)$ [evadere, to scratch out; from the power of erasing grease-spots]. A trade-name for California abietene. See Abietene.

Erasion $\left(e-r a^{\prime}-z h u n\right)[e$, out; radere, to scrape]. The act of scraping or cureting.

Erb's Point. See Point. E. Reaction of degeneration. Deviation from the normal formula of muscular response "to galvanism. E. "Upper-arm type" of palsy. A myotrophy characterized by paralysis of the deltoid and often of the supraspinatus and infraspinatus, the biceps, brachialis anticus, and the supinators. See Diseases, Table of.

Erbium (ur'-be-um) [L.]. A rare element; symbol Er. See Elements, Table of.

Erdmann's Test. See Tests, Table of.

Erdmann and Uslar's Test. See Tests, Table of.

Erect (e-rekt') [erectus, set up]. Upright; in the state of erection. E. Posture. See Postures, Table of.

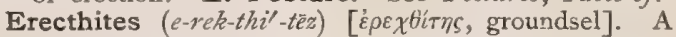
genus of composite plants. E. hieracifolia. Fireweed; a coarse composite-flowered plant common in waste-lands in N. America; it is astringent and tonic. Unof.

Erectile (e-rek'-til) [erigere, to set up]. Pertaining to or possessing the characteristic stiffening, rigidity, or erection. E. Glossitis. See Glossitis, Parenchymatous. E. Tissue, that which is capable of erection; consisting of a network of expansile capillaries that under stimulus becomes engorged with blood.

Erection (e-rek'-shun) [erigere, to set up]. The condition of temporary and functional fulness and firmness of the penis, clitoris, etc., due to sexual excitement, friction, etc., the mechanism consisting in an overfilling of the blood-vessels with inhibition of the 
return circulation. E.-center. See Center. E., Persistent. Synonym of Priapism, q. v.

Erectopatent (e-rek-to-pa'-tent) [erectus, erect; patens, spreading]. In biology, intermediate between erect and spreading, as the fore-wings of a butterfly in repose.

Erector (e-rek'-tor) [erigere, to erect]. Any muscle, the function of which it is to erect or elevate a part. See Muscles, Table of. E. pili, the unstriped muscular fibers causing the erection of the hair and the phenomenon called goose-flesh or goose-skin.

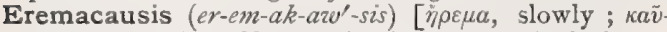
$\sigma \iota s$, burning]. Slow oxidation or gradual decay, without combustion.

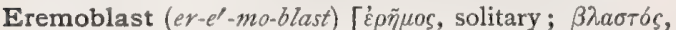
a germ, sprout]. A unicellular plant.

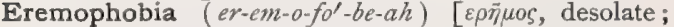
$\phi 6 \beta$ os, fear]. The same as Agoraphobia, q. $z^{\prime}$.

Erethin $\left(e r^{\prime}-e-t h i n\right)$ ['́ $\rho \varepsilon \theta i \xi \varepsilon \iota v$, to irritate]. The name given by Klebs to that constituent of tuberculin which occasions fever.

Erethism (er'-e-thizm), Erethismus (er-e-thiz'-mus)

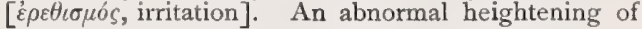
nervous irritability. E. ebriosorum. Synonym of Delirium tremens. E. hydrophobia. Synonym of Hydrophobia. E. tropicus. See Insolation.

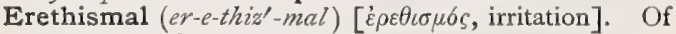
the nature of an erethism.

Erethismic (er-e-thiz'-mik), or Erethistic (er-e-this'-tik)

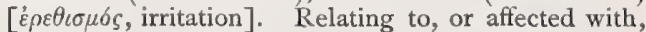
erethism.

Erg [épyov, work]. See Electric Units.

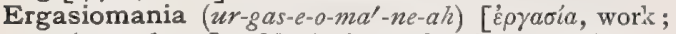

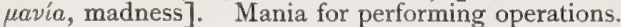

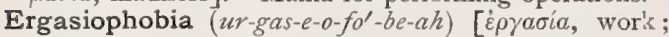

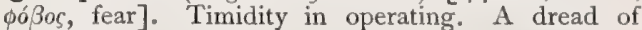
operations.

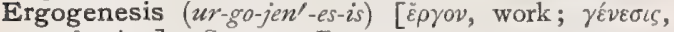
production]. Same as Ergogeny.

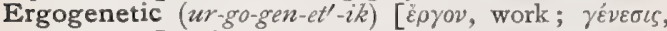
production]. Of the nature of, or pertaining to, ergogeny.

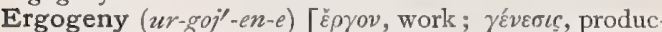
tion]. In biology, the energy, both potential and kinetic, involved in the adaptive processes of living organisms; it includes both kinetogeny and statogeny (Ryder)

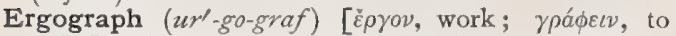
write]. A recording ergometer. An instrument for recording the extent of movement produced by a contracting muscle, or the amount of work it is capable of doing

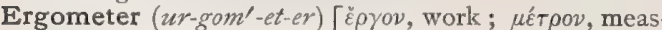
ure]. A variety of dynamometer.

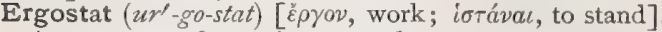
An apparatus for testing muscular strength.

Ergot, or Ergota ( $u \gamma^{\prime}$-got, or $u r^{\prime}-g^{\prime}-$ tah) [Fr., ergot, a spur: gen., Ergota]. I. In farriery, the horny stub below the pastern joint, hidden by the fetlock of the horse. 2. The hippocampus minor. 3. A fungus, Claviceps purpurea, parasitic upon rye. It contains sphacelinic acid, ergotinic acid, and comutin, to which its properties are due. It is a powerful excito-motor, hemostatic, and gastro-intestinal irritant, but is used most frequently to promote uterine contraction in childbirth. It is valuable internally in amenorrhea and atonic spermatorrhea; topically in gonorrhea, conjunctivitis and inflammations of mucous membranes. Its effects are most prompt by hypodermatic injection. Dose gr. $\mathbf{x}-\mathbf{3}$ j. E., Ext., Fld., prepared with dilute hydrochloric acid, alcohol, and water. Dose 3 ss-ij. E., Ext., Liquid (B. P.).
Dose $\eta x-x x x$. E., Ext.,-Ergotin. Dose gr. ij-xx, hypodermatically gr. 1/4 -v. E., Infus. (B. P.). Dose $\xi$ j-ij. Injectio Ergotinæ Hypodermica (B. P.), ergotin I, camphor-water, 2. Dose subcutaneously miij-x. E., Tinctura (B. P.). Dose $m x-z j$. E., Vinum, I5 per cent. Dose $3 \mathrm{j}-\xi_{\mathrm{j}}$. Sclerotinic Acid, thought to be identical with ergotinic acid.

Ergotin (ur'-go-tin) [Fr., ergot, a spur]. I. A precipitate or extract prepared from the tincture of Secale cereale; it is an emmenagogue, and parturient. Dose $\frac{1}{16}$ to $\frac{1}{2}$ grain, repeated as may be needed. Unof. The name is applied in commerce to many different preparations of ergot; often to the extractum ergote, U. S. P. 2. $\mathrm{C}_{50} \mathrm{H}_{52} \mathrm{~N}_{2} \mathrm{O}_{5}$. An amorphous, brown alkaloid found in ergot. It is probably the same as ecbolin.

Ergotinin (ur-got'-in-in) [Fr., ergot, a spur], $\mathrm{C}_{35} \mathrm{H}_{40^{-}}$ $\mathrm{N}_{4} \mathrm{O}_{6}$. An alkaloid from ergot of rye, occurring in white needles; it is effective in hemorrhage, in erysipelas, and in certain brain-affections. For hypodermatic injection, $\frac{1}{65}$ to $\frac{1}{13} \mathrm{gr}$. is used, dissolved in lactic acid and water.

Ergotism (ur'-got-izm) [Fr, ergot, a spur]. The constitutional effects of overdoses of ergot or of the persistent use of food containing ergot. These are manifested by severe cramps, chiefly in the muscles of the leg, ending in tonic contraction of these muscles-the spasmodic form; and secondly by gangrene of the extremities-the gangrenous form. The symptoms may be acute or chronic. See Pellagra.

Ergotol (ur'-got-öl) [Fr., ergot, a spur]. A proprietary liquid preparation of ergot, recommended for hypodermatic injection.

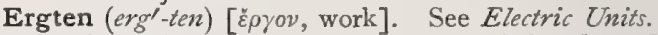

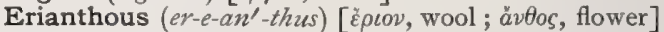
In biology, woolly-flowered.

Erichsen's Disease. See Diseases, Eponymic Table of. E. Operation. See Operations, Table of.

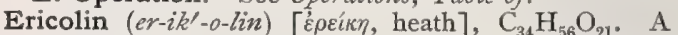
substance found in Uva ursi. It is an amorphous, yellowish glucosid with a bitter taste, yielding with diluted acids sugar and an essential oil-ursone.

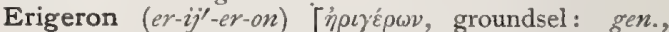
Erigerontis]. Fleabane. The plant $E$. canadense, having physiologic actions like those of oil of turpentine, but less irritant. It is efficient as a hemostatic in menorrhagia. E. bellidifolium and E. philadelphicum afford similar oils, and have the same properties. E., O1, the essential volatile oil of erigeron. Dose $m x-z$ ss. Unof.

Eringo $\left(\right.$ er-ing $\left.g^{\prime}-0\right)$. See Eryngo.

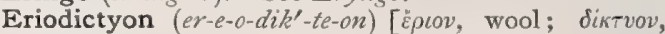
a net]. Yerba Santa or Mountain-balm. The leaves of $E$. glutinosum, a shrub of California, an excellent expectorant, and valuable as an excipient for quinin, the taste of which it largely conceals. It is useful in bronchial affections. E., Ext. Fld. Dose $\eta_{x v}-3 j$. E., Ext. Dose gr. ij-x. E. tomentosum and $\mathrm{E}$. angustifolium have the same uses. The latter are unofficial.

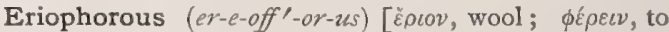
bear]. In biology, wool-bearing.

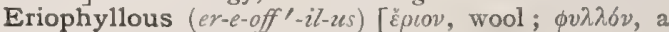
leaf ]. In biology, woolly-leaved.

Erlangen Blue. Same as Berlin Blue.

Erlau Green. Same as Bremen Green.

Erlicki's Fluid. A hardening-fluid used especially for tissues of the central nervous system. It consists of potassium bichromate, 2.5 parts; cupric sulphate, 0.5 parts; water, Ioo parts.

Erodent $\left(e-r o^{\prime}\right.$-dent $)[e$, out ; rodere, to gnaw $]$. I. Caustic ; causing erosion. 2. A caustic application or agent. 
Erogenic, or Erogenous (er-o-jen'-ik or er-oj'-en-zks)

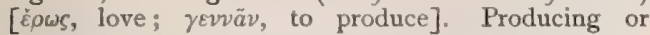
stimulating the sexual appetite.

Eromania (er-o-ma'-ne-ah). See Erotomania.

Erose $\left(e-r o s^{\prime}\right)$ [eroctere, to gnaw off]. In biology, irregularly toothed, as if gnawed.

Erosion (e-ro'-zhun) [erosio; erodere, to eat out]. Disintegration of tissue by mechanical, chemic, or morbid action. E. of the Cervix, an ulcerated condition of the neck of the womb resulting from chronic endometritis. It is also called ulceration or granular degeneration of the cervix.

Erostrate $\left(e-\operatorname{ros}^{\prime}-t r \bar{a} t\right)$ [ $\varepsilon$, priv ; rosimum, a beak $]$. In biology, not beaked.

Erotia (e-ro'-she-ah) [L.]. A genus of composite-flowered plants. E. lanata, white sage or winter-fat ; a composite-flowered forage-plant of the Western U. S. : valued locally in intermittent fevers. Unof.

Erotic $\left(e r-a t^{\prime}-i k\right)$ [ $\varepsilon \omega s$, love]. Pertaining to the sexual passion.

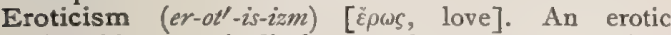
disposition; erotic display; tendency to erotomania.

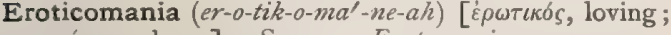
uavia, madness]. Same as Erotomania.

Erotocism (er-ot'-o-sizm). Same as Erotomania, q. v.

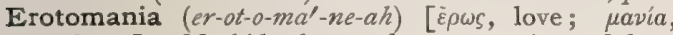
madness]. Morbid, abnormal exaggeration of love generally; more limited to the imaginative than to the carnal aspect of the sentiment ; insanely-perverted sexual feeling. See Nymphomania and Satyriasis. E. personalis. Synonym of Satyriasis and of Nymphomania.

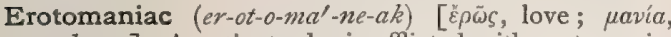
madness]. A patient who is afflicted with erotomania.

Erratic $\left(e r-a t^{\prime}-i k\right)$ [erraticus, wandering]. Moving about from place to place; irregular; strange or unusual; eccentric, peculiar.

Errhine $\left(e r^{\prime}-i n\right)[\dot{\varepsilon} v$, in ; pís, the nose]. I. Causing discharges from the nose. 2. A medicine that, applied to the mucous membrane of the nose, increases nasal secretions. A sternutatory.

Error (er'-or) [L., "wandering "']. Displacement or perversion in any function; aberration, mental or optic.

Erskine's Method. See Treatment, Method's of.

Erubescence (er-u-bes'-ens) [erubescentia, blushing]. Redness of the skin.

Eruca (er-oo'-kah) [L., a caterpillar; a colewort]. A genus of cruciferous plants. E. sativa, the garden rocket, an herb of Asia and Europe, used as a salad. It is a stimulant and diuretic, and is considered to be aphrodisiac and galactagogue. Unof.

Erucic Acid (er-oo'-sik). See Acid.

Eruciform (er-oo'-sif-orm) [eruca, a caterpillar; forma, form ]. In biology, said of larvæ, spores, etc., that are shaped like a caterpillar.

Erucivorous (er-u-siv'-or-us) [eruca, a caterpillar; vorare, to eat]. In biology, applied to birds and other animals that feed upon caterpillars.

Eructation (e-ruk-ta'-shun) [eructare, to belch]. Belching.

Erugation (er-oo-ga'-shun) [emgatio; e, out; ruga, wrinkle]. The removal of wrinkles.

Erugatory (er-oo'-gat-or-e) [e, out; mga, a wrinkle]. I. Tending to remove wrinkles. 2. A remedy for wrinkles.

Erugineous (er-oo-jin'-e-us). Same as Eruginous.

Eruginose (er-oo'-jin-ōs). Same as Eruginous.

Eruginous (er-oo'-jin-us) [cruginosus; arugo, rust]. Having the nature or the color of verdigris.

Erumpent (e-mom'-pent) [erumpere, to break out]. In biology, applied to parts or organs that appear as if bursting out.
Eruption (e-rup'-shun) [erumpere, to burst out]. A bursting forth of any kind or from any part, but applied especially to the chief symptom of certain skindiseases, consisting in pimples, vesicles, rash, etc.; the breaking forth of a tooth from the gum.

Eruptive (e-rup'-tiv) [erumpere, to burst out]. Attended by an eruption, as an eruptive fever.

Eruthrocyte (er-iuth'-ro-sit $)$. Incorrect form of Erythrocyte, $q . v$

Eryngo (er-ing'-go) [ $\eta \rho^{\prime} \gamma \gamma \gamma \eta$, a thistle]. Any plant of the umbelliferous genus Eryngium, especially E. campestre and E. maritimum of Europe. These plants, with others of the genus, were formerly made into sweetmeats, and were regarded as polychrest remedies, but were especially prized as aphrodisiacs. Unof.

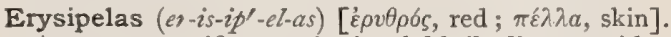
An acute, specific, constitutional febrile disease, with a peculiar redness and inflammation of the skin and subcutaneous tissue, generally of the face. It is due to streptococci. The period of incubation varies from a few hours to three or four days. The symptoms are an initial chill or rigor, malaise, high temperature, vomiting or nausea, and the characteristic rash, with a well-defined margin, upon the skin. It may terminate fatally. Albumin may appear in the urine. At the conclusion of the attack desquamation takes place, either branny or in flakes. The development of erysipelas is favored by filth, over-crowding, and defective ventilation. One attack rather predisposes to subsequent attacks. E. carbunculosum. Synonym of Anthrax. E. malignum internum, an acute, suppurative, rapidly spreading inflammation of cellular tissue beginning in the pelvis after parturition. It is one form of puerperal fever. It is usually rapidly fatal. Antisepsis properly applied at the time of delivery will prevent its occurrence. E. migrans, wandering erysipelas. E. phlegmonodes, a form of erysipelas in which there is pus-formation, with marked constitutional symptoms. E., Recurrent, pseudo-erysipelas, a frequent disease in strumous children, but occurring also in adults, and especially in women. It is entirely confined to the face, especially around the nose and upper lip, and is unattended with marked constitutional symptoms. It is not amenable to treatment, and is very prone to recur. E. simplex, the ordinary facial form of erysipelas. E. suffusum. Synonym of Erythema. E., Wandering, a chronic or subchronic form in which the process successively disappears from one part of the body to appear at another part.

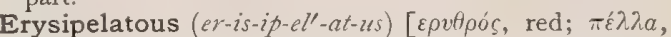
skin]. Of the nature of or affected with erysipelas.

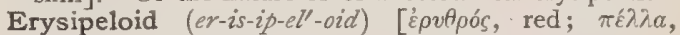

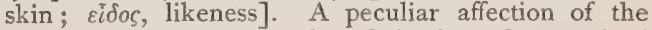
palms of the hands or soles of the feet, characterized by zones of violaceous-red eruption with burning and itching ; it is due to wound-infection.

Erythanthema (er-ith-an'-the-mah) [E $\rho v \theta \rho b s$, red; à $\nu \eta \mu a$, a flowing]. A skin-disease marked by redness. The term is variously applied by some to denote an eruptive disease depending upon vaso-motor, or other nervous disorder. It is used to designate a class of cutaneous efflorescences that have in common a basis of erythema.

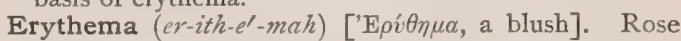
rash: a redness of the skin that may be made to disappear temporarily by pressure. E. ab igne, a form of $E$. hyperemicum produced by the constant irritation of artificial heat. It occurs as rings and gyrate patterns on the front of the legs, and is of a deep-rcd color, gradually becoming browner in tint. This pig- 
mentation is permanent. E. annulare, a form of $E$. multiforme in which the lesions shrink and desquamate at the center, but continue to extend at the periphery by a raised margin. It is also called $E$. circinatum. These rings may wander over the entire body, intersecting each other and forming elaborate figures with crescentic edges ( $E$. gyratum). Occasionally new rings develop concentrically around older ones. The forms and varieties of color produced give rise to the name $E$ iris. E. bullosum. See $E$. vesiculosum. E. circinatum. See E. annulare. E. congestivum, $E$. hypercemicum; a mere congestion of the skin; the simplest form of erythema. Swelling is absent or insignificant in the congested areas, and the tint of redness varies from the brightest red to a rosy or purple hue. E. endemicum. See Pellagra. E., Epidemic. See Acrodynia. E. exudativum, an acute or sub-acute non-contagious, inflammatory skin-disease, characterized by the development of symmetrically distributed, raised erythematous patches, usually discrete, varying greatly in form and size, accompanied by slight transudation of blood or by copious hemorrhage into the skin, occasionally terminating as vesicles or blebs, and specially liable to relapse. This may be attended with constitutional rheumatic symptoms. E. figuratum, is marked by efflorescence in gyrate lines. E. fugax, a variety of $E$. hypercmicum; it consists in a transitory redness of a patchy character, suddenly appearing on the face and trunk of young individuals and gradually disappearing in a few minutes or hours. It is frequently associated with indigestion, worms, etc. E. furfuracea. Synonym of Pityriasis rosea. E. gangrænosum, a term applied to spontaneous patches of superficial gangrene or ulceration seen chiefly in hysterical women. They are undoubtedly self-induced, and are asymmetric, usually on the left side, and in easily accessible positions. E. gyratum. See E. annulare. E. hyperæmicum. See $E$. congestivum. E. induratum, a variety of $E$. exudativum attacking the calf, or the leg immediately below, more frequently than the front of the legs. It occurs either in diffuse, ill-defined patches or in nodules, bright-red at first but gradually assuming a violet hue. The nodules may be superficial or deep, a quarter of an inch to an inch or more in diameter, and may be slowly absorbed, or necrose and slough out, leaving a very indolent ulcer. The condition is most common in strumous individuals. E. intertrigo, intertrigo; eczema intertrigo; a chronic form of $E$. hyperemicum resulting from pressure or the rubbing together of folds of skin. It is common in infants and fat adults. E. iris, Herpes iris. See E. annulare. E. keratodes, a diffuse condition of tylosis of the palms and soles. E. leve, a common skin-affection, a variety of $E$. hypercamicum, likely to appear upon the tense skin of dropsical parts. It may go on to dermatitis and sloughing. E. marginatum, an infrequent variety of $E$. multiforme, which generally begins as a flat disc a quarter or half an inch in diameter, and very rapidly enlarges at the periphery, subsiding pari passu in the center. It joins similar adjacent lesions, and in a few days traverses the circumference of a limb, or a large area on the trunk, leaving a fawn-colored pigmentation that slowly disappears. E. multiforme, $E$. polymorphe; a variety of $E$. exudativum, common in young adults of either sex, and appearing especially in spring and autumn. The eruption first appears almost invariably on the backs of the hands and feet thence spreading to the forearms and legs. In severe cases the trunk and face, and even the mucous membranes may be affected. The lesions consist of flat or slightly convex papules, sharply defined, deep-red or purplish in color, varying in size from a pin's head up, partially disappearing on pressure. This is the commonest form ( $E$. papulatum). If the papules coalesce to form larger lesions the condition is described as $E$. tuberculatum. E. nodosum, dermatitis contusiformis: a further development of $E$. tuberculatum. Multiple (seldom more than a dozen) raised, rosy patches, round or oval in the direction of the limb, from one. half to three inches in diameter, suddenly develop along both tibix, and often along the ulnar side of the forearms. They are exquisitely tender, tense and shining. The condition chiefly occurs in children and delicate young women. See Bacillus of Demme under Bacteria, Synonymatic Table of. E. papulatum. See $E$. multiforme. E. paratrimma, the erythema that appears over a bony prominence, etc., immediately before the formation of a bed-sore. It is a variety of $E$. hypercmicum. E. pellagrosum. A synonym of Pellagra. E. pernio. See Pernio. E. polymorphe. See E. multiforme. E. purpuricum, Purpura thrombotica; a variety of erythema resembling Peliosis rheumatica, but characterized by its erythematous appearance and the absence of alteration by pressure. It is attended with no general symptoms, or with slight pains in some of the joints, or with edema of the legs. E. roseola, a variety of $E$. hyperemicum; it consists in the development of congestive patches of a delicate rose-color, scarcely raised above the surface of the skin, varying in size from a split-pea to a fingernail, and either diffused over the whole surface of the body or in figured groups. It is common in young children in association with digestive troubles. Its different stages have been called Roseola infantilis, astivalis, autumnalis, annulata, but these terms are not now generally used. E. scarlatiniforme, a variety of $E$. hyperamicum; it appears as a vivid, punctiform eruption, sharply defined in places, attendeả with high temperature, often seen after injuries or surgical operations. It is followed by furfuraceous desquamation. E. scarlatiniforme desquamativum, a more pronounced form of $E$. scarlatiniforme, with a greater tendency to be diffuse instead of punctiform, of longer duration, and with a great liability to recur at certain seasons. The mucous membranes are often involved and desquamation occurs in large flakes. E. simplex, a variety of $E$. hyperamicum; characterized by a congestive redness of moderate intensity. It appears as diffuse or circumscribed, variously-sized lesions, which are usually not raised above the integument. It may be idiopathic or symptomatic; and if the latter, brought about by a great number of external irritants, including heat and cold, etc. E. solare, $E$. simplex due to the heat of the sun. E. tuberculatum. See $E$. multiforme. E. tuberosum. Same as E. tuberculatum. E. urticans, the early or pink stage of the urticarial wheal. It is a variety of $E$. hyperamicum. E. vesiculosum, the occurrence of vesication in the progress of $E$. multiforme. If the blebs are large the condition is termed $E$. bullosum.

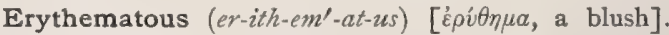
Of the nature of erythema.

Erythemoid (er-ith-em'-oid), Erythematoid (er-ith-

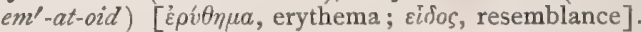
Resembling erythema.

Erythrasma (er-ith-raz'-mah) [ย́ $\rho v \theta \rho b s$, red]. A rare disease of the skin, always attacking the axillæ or inguinal regions, or the nates. It forms reddish or brownish, sharply defined, slightly raised, desquamating patches, that cause no itching or inconvenience. It is due to the microörganism, Microsporon minutissimum, and is readily curable. 
Erythremelalgia (er-ith-rem-el-al'-je-ah). See Ery thromelalgia.

Erythremia (er-ith-re'-me-ah) ['evefoós, red; ả $\mu a$, blood]. I. The normal condition of the arterial blood. 2. Arterial blood in the veins.

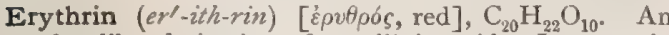
ether-like derivative of orsellinic acid. It occurs in the lichen Roccella fusciformis, and is extracted from it by means of milk of lime. It crystallizes with $I^{1} 1 / 2$ molecules of water and is soluble with difficulty in hot water. Exposure to the air causes it to assume a red color.

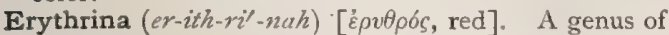
leguminous trees, shrubs and herbs, of some 25 species, three or more of which grow in the U.S. E. coral lodendron, coral tree of tropical America, is sedative, hypnotic, diuretic, purgative, vermifuge and pectoral. Other species have similar properties. Unof.

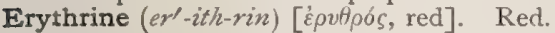

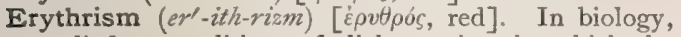
applied to conditions of dichromatism in which the normal colors of the integument are affected by an excess of red pigment, as often shown in the plumage of a bird.

Erythrite (er'-ith-rït). See Erythrol.

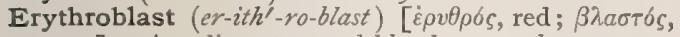
germ]. A rudimentary red blood-corpuscle.

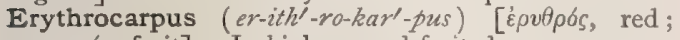
$\kappa a \rho \pi \delta s$, fruit]. In biology, red-fruited.

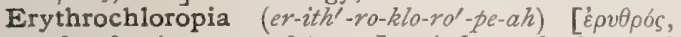
red; $\chi \lambda \omega \rho o ́ s$, green; $\dot{\omega} \psi$, eye]. A form of subnormal color-perception in which green and red are the only colors correctly distinguished.

Erythrochloropy (er-ith'-ro-klor'-o-pe) ['E $\rho v \theta \rho b s$, red; $\chi \lambda \omega \rho b \varsigma$, green]. Ability to distinguish red and green colors only.

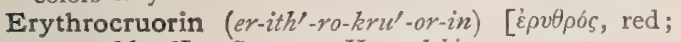
cruor, blood]. Same as Hemoglobin.

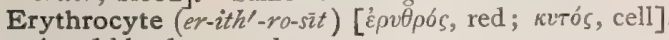
A red blood-corpuscle.

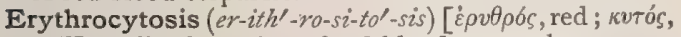
cell]. The formation of red blood-corpuscles.

Erythrodermia (er-ith'-ro-der'-me-ah) [ $[\dot{\varepsilon} \rho v \theta \rho o s$, red; dépua, skin]. Abnormal redness of the skin.

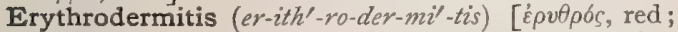

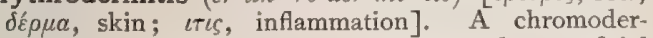
matosis characterized by erythema and superficial dermatitis.

Erythrodextrin (er-ith'-ro-deks'-trin) [ $\varepsilon \rho v \theta \rho b s$, red; dexter, right]. A dextrin formed by the action of saliva on starch. It yields a red color with iodin.

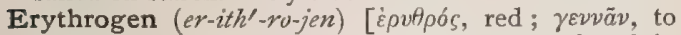
produce]. A green substance that has been found in unhealthy bile, and which (apparently without good reason) has been regarded as "the base of the coloring-matter of the blood."

Erythroglucin (er-ith-ro-glu'-sin). See Erythrol.

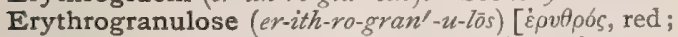
granulum, a little grain]. A granular substance, found in starch-grains, coloring red with iodin.

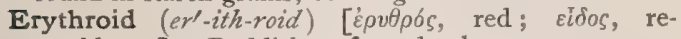
semblance]. Reddish; of a red color.

Erythrol (er'-ith-rol) [غ́pvipós, red], $\mathrm{C}_{4} \mathrm{H}_{10} \mathrm{O}_{4}$. Also called Erythroglucin, Erythrite or Phycite. A principle which exists as erythrin (orsellinate of erythrite) in many lichens and some algæ. It forms large quadratic crystals that dissolve readily in water, with difficulty in alcohol, and are insoluble in ether. It is a poly. hydric alcohol with a sweet taste melting at $126^{\circ} \mathrm{C}$. and boiling at $330^{\circ} \mathrm{C}$.

Erythrolein (er-ith-ro'-le-in) [ $\varepsilon^{\rho} \rho \theta \rho \rho \delta s$, red ; oleum, oil], $\mathrm{C}_{26} \mathrm{H}_{22} \mathrm{O}_{4}$. A fatty liquid compound contained in litmus. It is soluble in alcohol, ether, and alkalies, and in dyeing yields a purple color.

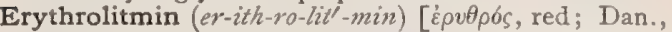
lac, lac; moes, pulp], $\mathrm{C}_{26} \mathrm{H}_{33} \mathrm{O}_{13}$. A red coloringmatter obtained from litmus; it is crystalline and soluble in alcohol.

Erythromelalgia (er-ith-ro mel-al'-je-ah) [iputipór,

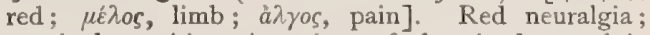
terminal neuritis. A variety of chronic dermatalgia characterized by burning and then aching pain of a part, usually one or more extremities, intensified by warmth and accompanied by flushing and local fever.

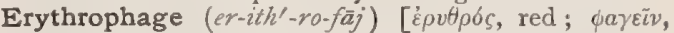
to eat]. Any one of the phagocytic cells which, lying about a hemorrhagic area, take up the pigment of the blood or even red-corpuscles. They are remarkable for their brilliant color (red to golden).

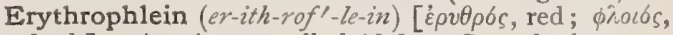
bark]. A poisonous alkaloid from Casca bark.

Erythrophleum (er-ith-ro-fle'-um). See Casca Bark.

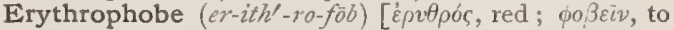
fear]. One fearing or disliking red colors.

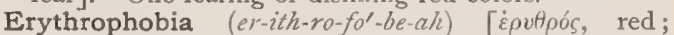
$\phi 6 \beta \rho \varsigma$, fear]. Morbid intolerance of red colors: sometimes observed after operations for cataract.

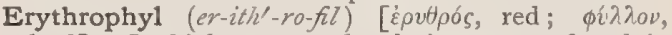
leaf]. In biology, a red coloring-matter found in autumn leaves, ripe fruits, etc. It is also called $P$ hyllerythrin and Phyterythrin.

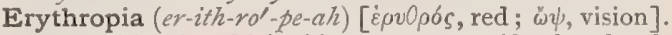
A condition in which objects appear as if colored red.

Erythropsia (er-ith-rop'-se-ah) [ $\varepsilon \rho v \theta \rho \sigma s$, red; oै $\psi \iota$, vision]. An abnormality of vision in which all objects appear red; red vision; it has been observed in alcoholic ataxia with optic atrophy, after subcutaneous injections of strychnin.

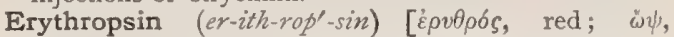
vision]. An organic substance of the retina. In the presence of light it is believed to form different combinations, constituting color-perception. It is called visuql purple and Rhodopsin, q. v.

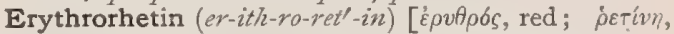
resin ], $\mathrm{C}_{38} \mathrm{H}_{36} \mathrm{O}_{14}$. The red resin of rhubarb.

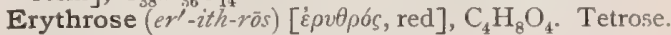
A substance derived from erythrol. It is probably a mixture of an aldose and a ketose. It is next to the lowest glucose. See Carbohydrates, Table of.

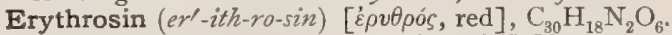
A compound produced by the action of $\mathrm{HNO}_{3}$ on tyrosin. It is used as a coloring-matter. See Pigments, Conspectus of.

Erythrosis (er-ith-ro'-sis) [ $\varepsilon v \theta \theta \rho o ́ s$, ręd]. Arterial plethora, or the redness of the skin due to it.

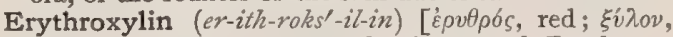
wood]. A precipitate from the tincture of Erythroxylon coca. It is a nervine and stimulant. Dose $1 / 4$ to I grain. Unof.

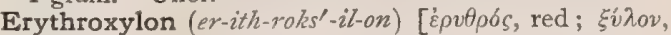
wood: gen., Erythroxyli]. Coca, Cuca. The leaves of $E$. coca, a shrub indigenous to the Andes. (Not to be confounded with cocoa.) It contains an alkaloid, Cocain, $\mathrm{C}_{17} \mathrm{H}_{21} \mathrm{NO}_{4}, q . v$., to which its properties are mainly due. It is an aromatic tonic and cerebral stimulant, developing a remarkable power of enduring hunger and fatigue. Large doses cause hallucinations. Its effects are similar to those of coffee, but are more intense. It is much used by the natives for sustenance during long journeys. The leaves, smoked, are beneficial in hay-fever. E. coca (B. P.). Dose gr. ijxv. E., Ext., Fld. Dose 3 ss-ij. Extractum Cocæ Liquid (B. P.). Dose 3 ss-ij. Wines and elixirs of coca are numerous. 
Erythruria (er-ith-ru'-re-ah) [ $[\dot{\varepsilon} \rho v \theta \rho o ́ s$, red; ov $\rho o \nu$, urine]. The passage of reddish urine. Hematuria.

Esbach's Test. See Tests, Table of.

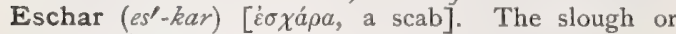
scab following cauterization, burns, etc.

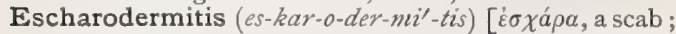
$\delta \varepsilon ́ \rho \mu a$, skin; $\iota \tau \iota s$, inflammation]. A skin-inflammation marked by the formation of eschars.

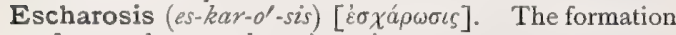
of an eschar; escharotic action.

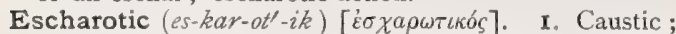
productive of a slough or scab. 2. A substance that, applied to the skin, produces an eschar. A caustic.

Eschel Blue. See Smalts.

Escherich, Bacillus of. See Bacteria, Synonymatic Table of.

Eschka's Test. See Tests, Table of.

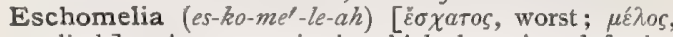
a limb]. A monstrosity in which there is a defective limb.

Eschricht's Yellow Canals. See Canals.

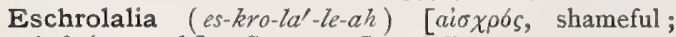
¿àicá, speech]. Same as Coprolatia.

Eschromythesis (es-kro-mi-the'-sis) [aioxpós, base; $\mu v \theta i \zeta \varepsilon c \nu$, to utter $]$. The utterance of obscene language by delirious or insane patients.

Eschscholtzia (esh-sholts'-e-ah) [after Eschscholtz, a German zoölogist]. A genus of papaveraceous herbs. E. californica, California Poppy, a plant growing in California, is recommended as an excellent and harmless soporific and analgesic. Dose of the fluid extract, $m \times x v-x x x$. Unof.

Esculapian (es-ku-la'-pe-an) [Esculapius, the god of medicine]. r. Medical; pertaining to medicine. 2. A physician.

Esculetin (es-ku-lef-tin) [ Esculus, the Italian oak], $\mathrm{C}_{9} \mathrm{H}_{6} \mathrm{O}_{4}$. A substance present in the bark of the horse-chestnut, partly free, and partly as the glucosid esculin, from which it is prepared by decomposition with acids or ferments. It crystallizes with a molecule of water in fine needles or leaflets.

Esculin (es'-ku-lin) [Asculus, the Italian oak], $\mathrm{C}_{15} \mathrm{H}_{16} \mathrm{O}_{9}$. A glucosid contained in the bark of the horse-chestnut, Esculus hippocastanum. It crystallizes in fine needles with $\mathrm{I} 1 / 2 \mathrm{H}_{2} \mathrm{O}$, and melts when anhydrous at $205 \mathrm{C}$.; it is soluble with difficulty in water and alcohol.

Eserin $\left(e s^{\prime}-e r\right.$-in $)$ [Esere, native name of the plant or bean], $\mathrm{C}_{15} \mathrm{H}_{21} \mathrm{~N}_{3} \mathrm{O}_{2}$. A poisonous alkaloid derived from Physostigma, $q . v$. It is chiefly used to produce myosis, to lessen intra-ocular tension, etc.

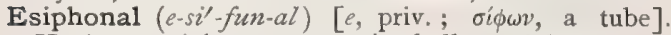
Having no siphons, as certain shells; asiphonate.

Esmarch's Bandage, or Apparatus. An elastic rubber bandage used upon a limb to be amputated, in order to drive the blood out of it by the pressure of progressive application of turns about the limb toward the trunk. E.'s Operation. See Operations, Table of. E.'s Paste, a caustic paste composed of one part each of white arsenic and sulphate of morphin, eight parts of calomel, and forty-eight of gum arabic. E.'s Tubes, test-tubes lined by a thin layer of gelatin for culture-purposes.

Esmarching (es'-mark-ing) [after Esmarch, a German surgeon]. The application of the Esmarch bandage, so as to drive the blood out of a part or member.

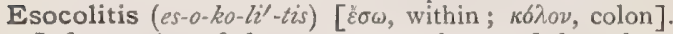
Inflammation of the mucous membrane of the colon; dysentery.

Esoderm (es'-o-derm) [ع̌ $\sigma \omega$, within; $\delta \varepsilon \rho \mu a$, skin]. In biology, the delicate membrane forming the ental surface of the integuments of insects.

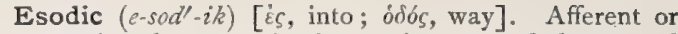
centripetal; conveying impressions toward the central nervous system-applied to certain nerves and nervefilaments.

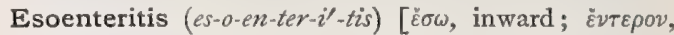
bowel; $\iota \tau \iota s$, inflammation]. Inflammation of the mucous membrane of the intestines.

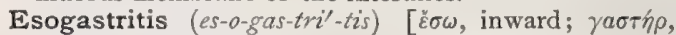

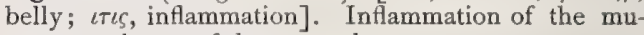
cous membrane of the stomach.

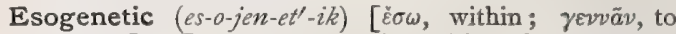
produce]. Produced or arising within the organism.

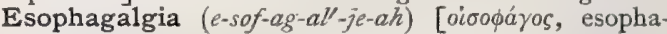
gus; ähyos, pain]. Pain in the esophagus.

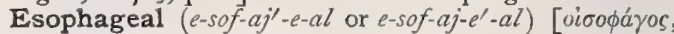
esophagus]. Pertaining or belonging to the esophagus. E. Glands, See Gland. E. Plexus. See Plexus.

Esophagectomy (e-sof-aj-ek'-to-me) [oiroфáyos, esophagus; $\varepsilon \kappa T o \mu \eta ́$, a cutting out]. Extirpation of cancer of the gullet with resection of the walls of the organ.

Esophagectopy (e-sof-aj-ek'-to-pe) [oiøoфáyos, esoph-

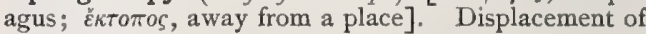
the esophagus.

Esophagism (e-sof'-aj-izm), Esophagismus (e-sof$a j$-iz'-mus) [oíopáyos, esophagus]. Spasmodic contraction of the esophagus.

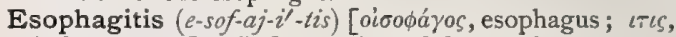
inflammation]. Inflammation of the esophagus.

Esophagocele (e-sof'-aj-o-sêl) [oíoøáros, esophagus; $\kappa \eta \dot{\lambda} \eta$, hernia]. An abnormal distention of a portion of the esophagus or of the entire tube; hence it may be general, annular, or pouched.

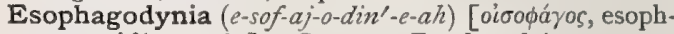
agus; odúv, pain]. Same as Esophagalgia.

Esophagomalacia (e-sof-aj-o-mal-a'-se-ah) [oiroфáros,

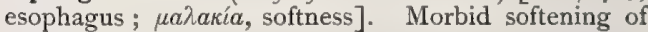
the esophagus.

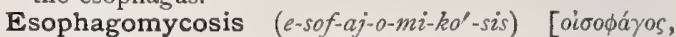
esophagus; $\mu v k \eta s$, a fungus]. Mycotic disease of the esophagus.

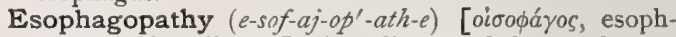
agus; $\pi a ́ t o s$, disease ]. Any disease of the esophagus.

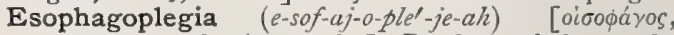
esophagus; $\pi \lambda \eta \gamma \dot{\eta}$, a stroke]. Paralysis of the esophagus.

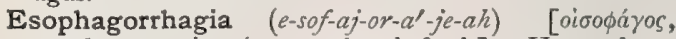

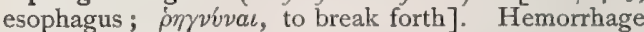
from the esophagus.

Esophagoscope (e-sof-aj'-o-sköp) [oiøoфáyos, esophagus; $\sigma \kappa о \pi \varepsilon i \nu$, to view]. An instrument for examining the interior of the esophagus by artificial light.

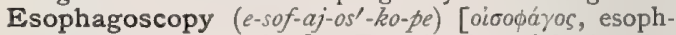
agus; $\sigma \kappa о \pi \varepsilon i \nu$, to view]. Examination of the interior of the esophagus.

Esophagospasm (e-sof'-aj-o-spazm). See Esophagismus.

Esophagostenosis (e-sof-aj-o-ste-no'-sis). [oivoфáyos, esophagus ; $\sigma \tau \varepsilon \dot{\nu} \omega \sigma \iota \zeta$, constriction]. Constriction of the esophagus.

Esophagostomy (e-sof-aj-os'-to-me) [oiooфáyos, esophagus; $\sigma \tau \delta \mu \alpha$, mouth]. The formation of an artificial opening in the esophagus.

Esophagotome (e-sof-rij'-o-tōm) [oíoфíyos, esophagus; $\tau \varepsilon \dot{\mu} \mu \nu \varepsilon \nu$, to cut]. An instrument devised for cutting into the esophagus.

Esophagotomy $\left(e-s o f-a j-o t^{\prime}-o-m e\right)$ [oiøoфáyos, esophagus; $\tau o \mu \eta$, a cutting]. Opening of the esophagus by an external incision.

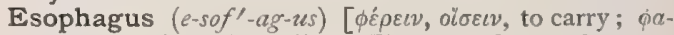
$\gamma \varepsilon i \nu$, to eat]. The gullet. The musculo-membranous canal, about nine inches in length, extending from the pharynx to the stomach. 


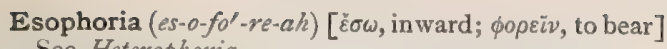
See Heterophoria.

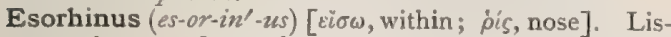
sauer's term for a skull in which the angle formed between the lines running from the premaxillary point and the incisive foramen to the naso-frontal point is between $0^{\circ}$ and $20^{\circ}$.

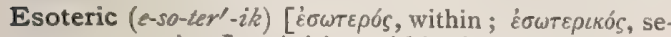
cret, mysterious]. Arising within the organism.

Esotropia (e-so-tro'-pe-ah) [ $\bar{\varepsilon} \sigma \omega$, inward; $\tau \rho \dot{\varepsilon} \pi \varepsilon \iota \nu$, to turn]. Convergent strabismus. See Strabismus.

Essence (es'-ens) [essentia, essence]. I. That quality of a thing giving it peculiarity of power. 2. The peculiar qualities of a drug extracted and reduced to a small compass. 3. A solution of an essential oil in alcohol.

Essential (es-en'-shal) [essentia, essence]. Pertaining to the essence of a substance. Pertaining to the peculiar and distinctive characteristic of a disease. E. Oils ; the essential or volatile oils (attars) are found extensively distributed throughout the vegetable kingdom. They occur in almost all parts of the plants except the cotyledons of the seeds. They impart the peculiar and characteristic odors to the plants, furnish the perfumes, spices, and aromatics, and many of them possess valuable medicinal properties. Chemically, essential oils are often divided roughly into three classes,-oils composed of hydrocarbons only, oils containing hydrocarbons mixed with oxygenated products, and oils containing sulphur compounds. A more exact, but still quite general, chemic division is the following: I. Oils consisting chiefly of terpenes $\left(\mathrm{C}_{10} \mathrm{H}_{16}\right)$ and oxidized products allied thereto; examples, oil of turpentine, oil of lemon, oil of camphor. 2. Oils consisting chiefly of cedrenes $\left(\mathrm{C}_{15} \mathrm{H}_{24}\right)$ and oxidized products allied thereto; examples, oil of cedar, oil of cubebs, oil of cloves. 3. Oils consisting chiefly of aromatic aldehyds and allied bodies; examples, oil of bitter almonds, oil of cinnamon. 4. Oils consisting chiefly of ethereal salts. These may be either $(a)$ oxygen salts, as in oil of wintergreen, or $(b)$ sulphur salts, as in oil of mustard, oil of garlic. E. Paralysis, paralysis without characteristic anatomic lesions.

Ester (es-ter). Any compound ether in which both an alcohol radical and an acid radical are present. E. Halogen, a derivative of the alcohols, obtained by heating them with the hydrogen haloids, or with the halogen derivatives of phosphorus. E. Haloid, also called alkylogen; any product of the action of the halogen hydrid on the alcohols. The haloid esters are perfectly analogous to the true esters produced by the action of alcohols and oxygen acids.

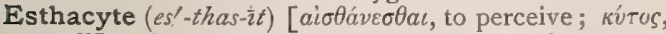
a cell]. In biology, one of the sense-cells of a sponge, granular, spindle-shaped, bearing palpocils.

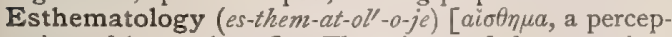
tion; $\lambda 6 \gamma o s$, science]. The science of the sensations and of the sense-apparatus.

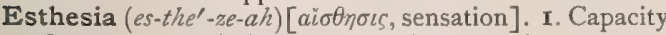
of perception; feeling, or sensation. 2. Any nervous disease that affects the senses or perceptions.

Esthesin (es'-thes-in) [aiotrocs, sensibility], $\mathrm{C}_{35} \mathrm{H}_{69}$ $\mathrm{NO}_{3}$. A feebly basic body, said by Thudichum to be obtainable from brain-tissue.

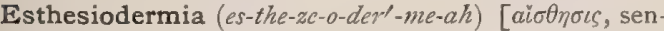
sation; $\delta \varepsilon \rho \mu \alpha$, skin]. An affection of the skin with disturbance of the sensory function, which may be decreased, increased, or abolished.
Esthesiogen (es-the'-ze-o-jen) [ciotnots, sensation; $\gamma \varepsilon v v a \bar{v}$, to produce]. Any material, as a metal, which in certain states of the body appears to have a specific effect upon the sensibility of the patient.

Esthesiogenic (es-the-ze-o-jen'-ik) [ai $\sigma \theta \eta \sigma \iota s$, sensation; $\gamma \varepsilon \nu \nu a \tilde{\nu}$, to produce]. Relating to the production of sensations.

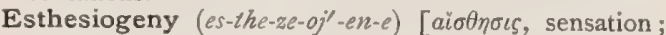
$\gamma \varepsilon \nu \nu \tilde{a} \nu$, to produce]. The production of altered or perverted sensations.

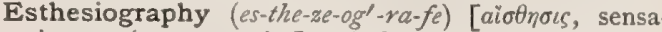

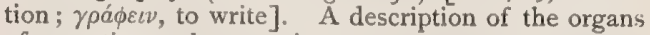
of sensation and perception.

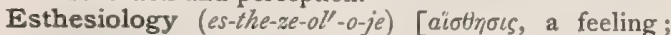
$\lambda 6$ yos, science]. A treatise on, or the science of, the senses.

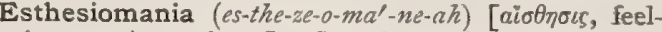
ing; $\mu a v i a$, madness]. Insanity marked by perverted moral feeling and by purposeless eccentricities.

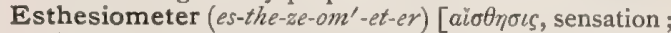

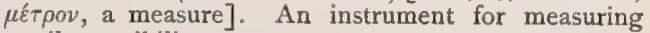
tactile sensibility.

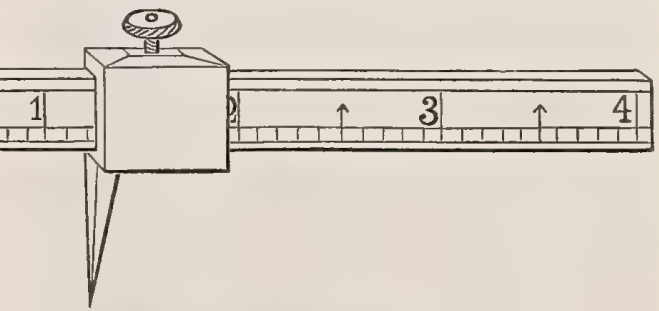

Esthesiometer of Sievering. (From Aitkin.)

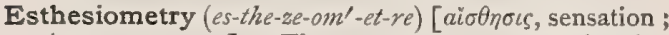
$\mu \varepsilon$ tpov, measure]. The measurement or estimation of tactile sensibility.

Esthesioneurosis (es-the-se-o-nu-ro'-sis) [aï $\theta \eta \eta \iota s$, perception; $\nu \varepsilon \tilde{v} \rho \circ v$, nerve]. Any nervous disease in which there are disorders of sensation.

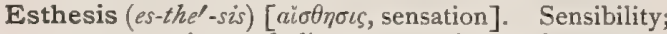
sense-perception; a feeling or sense-impression.

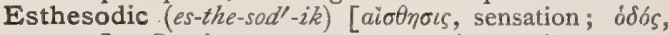
a way]. Serving to convey sense-impressions, as to the brain.

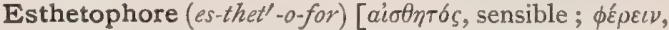
to bear]. In biology, the hypothetic physical basis of consciousness (Cope).

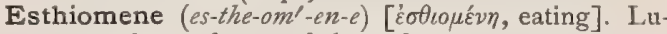
pus exedens; lupus of the vulva; a very rare and chronic disease commencing during the menstrual period. It is a form of ulceration accompanied by fibrous overgrowths of the surrounding and adjacent tissues. It produces hard, cicatricial tissue on healing. There is a process of imperceptible disintegration of the tissues, but no sloughing. Death may result from hemorrhage or perforation into the peritoneal cavity or bladder.

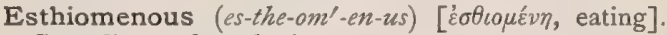
Corroding; phagedenic.

Esthophysiology (es-tho-fiz-e-oll-o-je) [aiothous, sensa-

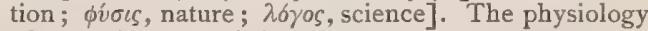
of sensation and of the sense-apparatus.

Estival (es'-tiv-al) [astas, summer]. In biology, produced in summer.

Estivation (es-tiv- $a^{\prime}-$ shun) [astivare, to pass the summer]. In biology, (a) the dormant condition of certain plants and animals during the summer; $(b)$ the arrangement of the floral organs in the bud.

Estlander's Method. See Treatment, Methods of. E. Operation. See Operations, Table of. 


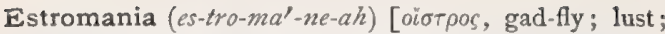
uavia, madness]. Same as Nymphomania.

Estrual (es'-tru-al) [ǒ̌or $\rho \circ$ s, gad-fly]. Pertaining to estruation.

Estruation (es-tru-a'-shun) [olotoos, gad-fly]. The condition of being under the influence of intense sexual passion.

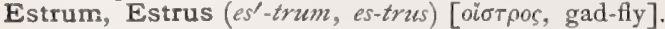
Any vehement passion or desire; the sensation in animals occurring at the crisis of coition. The orgasm.

Estuarium (es-tu-a $\left.a^{\prime}-r e-u m\right)$ [astus, heat]. A vaporbath. Also a stove designed to apply warm, dry air to all parts of the body at the same time.

Estuation (est-u-a'-shun) [astuatin, heat]. Heat; boiling; fever; a heated state.

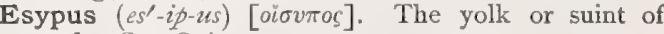
wool. See Suint.

Ethal (e'-thal) [ather, the upper air], $\mathrm{C}_{16} \mathrm{H}_{33} \mathrm{OH}$. Cetyl alcohol; a substance separated from spermaceti by Chevreul, and named by him. It is a solid, fusible at nearly the same point as spermaceti, and on cooling crystallizes in plates. It is susceptible of union with various bases, with which it forms salts or soaps.

Ethaldehyd (eth-al'-de-hĩd). See Acetaldehyd.

Ethane (eth'-än) [ather, the upper air]. Paraffin; any one of the products of the dry distillation of wood, turf, bituminous shales, lignite, and bituminous coal, and other coals rich in hydrogen. The ethanes are thus present in illuminating gas and the light tar-oils. Petroleum contains them already formed. The lowest members, up to butane, are gases at ordinary temperatures, soluble in alcohol and ether. The intermediate members form colorless liquids of faint, characteristic odor, insoluble in water, but miscible with alcohol and ether. The higher members are crystalline solids (paraffins), soluble in alcohol, and more readily in ether. The specific gravities of the liquid and solid hydrocarbons increase with the molecular weights, but they are always less than the specific gravity of water. The boiling-points, too, rise with the molecular weights. The isomerids of normal structure possess the highest boiling-points; the lowest are those of the quaternary hydrocarbons. (For Table of Ethanes see under Hydrocarbons.)

Ethene (e'-thēn). Same as Ethylene. E. Chlorid. See Anesthetic.

Ether ( $e^{\prime}$-ther) [ather; aitn $\rho$, the upper air]. I. The tenuous subtle fluid filling space and interpenetrating all bodies; the medium of transmission of the vibratory activities called light, heat, electricity, and magnetism. 2. A thin, colorless, volatile, and highly inflammable liquid; in composition a di-ethylic oxid $\left(\mathrm{C}_{2} \mathrm{H}_{5}\right)_{2} \mathrm{O}$, known also as ethylic ether. It is used mainly as a solvent for fats and oils, and as an anesthetic. Internally it is anodyne, antispasmodic, diaphoretic, and narcotic. Inhaled it is an anesthetic, and a cardiac stimulant in toxic doses, paralyzing the respiratory centers. See also Anesthatic. The term is used also to designate a large class of organic compounds. See Table an'nexed. E., Acetic, has properties like those of ethylic ether. Dose $m x-3 j$. E., Commercial, contains 94 per cent. of ether. It is unfit for use except as a solvent. E. fortior, should contain 94 per cent. of ethylic oxid. Dose $m x-3 j$. E., Hydriodic, unof. Dose for inhalation $m \times v$, E., Hydrobromic, unof. Dose $\eta x-3 j$. E. Oleum, contains equal parts of ether and heavy oil of wine. E., Spt., of, ether 32.5 and alcohol 67.5. E., Comp. Spt. of, Hoffman's anodyne. Ether 32.5 , alcohol 65 , ethereal oil 2.5 per cent. Dose $\eta_{v-3}-z_{\text {. }}$ E. nitrous, Spirit, szueet spirit of niter, a solution of ethyl nitrite in alcohol. Dose 3 ss3ss. There is also a large class of mainly volatile

\section{ETHICS}

compounds known as ethers which are products of the union of two monovalent alcohol radicals through the agency of an oxygen atom. They are the oxids of the alcohol radicals, and are neutral, volatile bodies, nearly insoluble in water. The lowest members are liquid; the highest are solids. E--acids, the socalled neutral esters. They are not volatile; are soluble in water, and yield bases with salts. E.-drinking, E.-intoxication, a form of tippling somewhat common in some parts of Ireland. Thus taken, ether is similar in effects to alcohol, but more rapid in action, and its use is attended with profound moral degeneration. E., Mixed, ether containing different alcohol radicals. E., Simple, ether containing two similar alcohol radicals.

TABLE OF ETHERS.

OF the FAtTy Compounds.

\begin{tabular}{|c|c|c|c|c|}
\hline NAME. & FORMULA. & 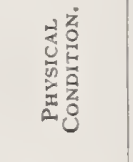 & 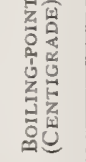 & 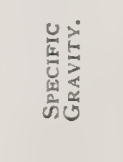 \\
\hline Methyl, ... & $\left(\mathrm{CH}_{3}\right)_{2} \mathrm{O}$ & $\begin{array}{l}\text { Gas, nor- } \\
\text { mally. Li- } \\
\text { quid at } \\
-23^{\circ} \mathrm{C} \text {. }\end{array}$ & & \\
\hline Ethyl, .... & $\left(\mathrm{C}_{2} \mathrm{H}_{5}\right)_{2} \mathrm{O}$ & Liquid. & $35^{\circ}$ & 0.736 at $0^{\circ}$. \\
\hline Propyl, ... & $\left(\mathrm{C}_{3} \mathrm{H}_{7}\right)_{2} \mathrm{O}$ & Liquid. & $60-62^{\circ}$ & \\
\hline Butyl, .... & $\left(\mathrm{C}_{4} \mathrm{H}_{9}\right)_{2} \mathrm{O}$ & & & \\
\hline Amyl, .... & $\left(\mathrm{C}_{5} \mathrm{H}_{11}\right)_{2} \mathrm{O}$ & Liquid. & $176^{\circ}$ & 0.779. \\
\hline Cetyl, .... & $\left(\mathrm{C}_{16} \mathrm{H}_{33}\right)_{2} \mathrm{O}$ & Solid. & $300^{\circ}$ & \\
\hline Vinyl, .... & $\left(\mathrm{C}_{2} \mathrm{H}_{3}\right)_{2} \mathrm{O}$ & & $39^{\circ}$ & \\
\hline Allyl, .... & $\left(\mathrm{C}_{3} \mathrm{H}_{5}\right)_{2} \mathrm{O}$ & & $85^{\circ}$ & \\
\hline Vinyl ethyl, . & $\mathrm{C}_{2} \mathrm{H}_{3} \mathrm{O} \cdot \mathrm{C}_{2} \mathrm{H}_{5}$ & Liquid. & $35.5^{\circ}$ & \\
\hline Allyl ethyl, . & $\mathrm{C}_{3} \mathrm{H}_{5}$. O. $\mathrm{C}_{2} \mathrm{H}_{5}$ & Liquid. & $66^{\circ}$ & \\
\hline
\end{tabular}

Ethereal (e-the'-re-al) [ather, the upper air]. Pertaining to the ether or to ether.

Ethereomania (e-the-re-o-ma'-ne-ah) [ather, ether; uavía, madness]. The mania for drinking ether; ether-intoxication.

Ethereomaniac (e-the-re-o-ma'-ne-ak) [ather, ether; $\mu a v i a$, madness]. One who is addicted to the use of ether as a stimulant.

Etherify $\left(e^{\prime}\right.$-ther-if-i) [ather, ether; facere, to make]. To convert into ether.

Etherism ( $e^{\prime}$-ther-izm) [ather, ether]. The phenomena produced upon the animal economy by the administration of ether.

Etherization (e-ther-iz-a'shun) [ather, ether]. The administration of ether to produce anesthesia. This is effected by inhalation of the vapor.

Etheromania (e-ther-o-ma'-ne-ah) [ather, ether; $\mu a v i a$, madness]. See Ethereomania.

Ethics $\left(e t h^{\prime}-i k s\right)[\dot{\gamma} \theta \iota k \delta s$, moral $]$. The science of human feelings, thoughts, and actions relating to duty or 


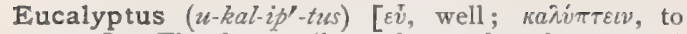
cover]. The leaves (lanceolate, after three years' growth) of E. globulus, or Blue Gum, native to Aus. tralia, but now cultivated in California. It contains a volatile oil, that yields eucalyptol, a camphor, by distillation. It is an aromatic bitter, promoting digestion. It is highly antiseptic and anti-malarial, and is valuable in atonic dyspepsia and in intermittent fevers. E., Ext. Dose gr. iij-x. E., Fld. Ext., alcoholic. Dose $m x-3$ j. E. Gum (B. P.); also called Australian Kino; a red gum from the bark of the $E$. corymbosa, $E$. resinifera, and $E$. rostrata of Australia. It is intensely astringent, and valuable in the treatment of relaxed throat. Dose gr. ij-x. The genus Eucalyptus embraces many species of trees and shrubs, nearly all of which appear to have useful medicinal properties. E. Honey, honey gathered by bees from the flowers of various species of Eucalyptus. It is highly aromatic, containing eucalyptol (I 7 per cent.), cymol, and a terpene. It is valued in Australian domestic practice as a cure for almost all catarrhal troubles. E. Manna, a variety of manna produced in Australia from $E$. viminalis, $E$. mannifera, and E. dumosa. E. Ol., the volatile oil. Dose $\eta^{\mathrm{v}-\mathrm{xxx}}$, in capsules or emulsion. E., Tinct. Unof. Dose

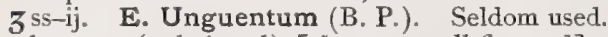

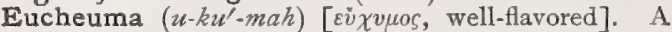
genus of sea-weeds. E. gelatinæ and E. spinosum, from S. E. Asian seas, afford some part of the agaragar of commerce.

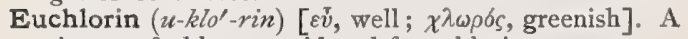
mixture of chlorous acid and free chlorin.

Euchroic Acid ( $u$-kro'-ik). See Acid.

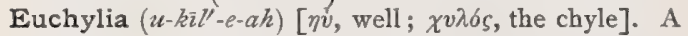
normal condition of the chyle.

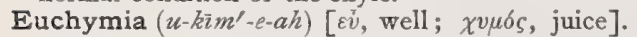
healthy condition of the fluids of the body.

Eucinesia, Eukinesia $\left(u-k i n-e^{\prime}-s e-a h\right)$ [हvं, well;

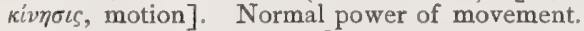

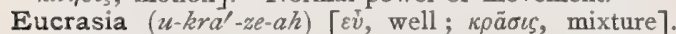
Good health; a sound constitution; the reverse of dyscrasia.

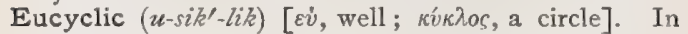
biology, applied to flowers, the organs in each whorl of which equal in number, and alternate with, those of the adjoining whorl.

Eudiometer (u-de-om'-et-er) [Evdia, alm weather; $\mu \varepsilon \dot{\tau} \rho \circ \nu$, measure]. An instrument for ascertaining the purity of the air, and for the analysis of gases.

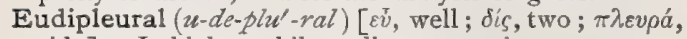
side]. In biology, bilaterally symmetric.

Euesthesia (u-es-th $\left.e^{\prime}-z e-a h\right)$ [ $[\varepsilon v$, well ; ai $\sigma \theta \eta \sigma \iota s$, sensation]. The sense of well-being; vigor and normal condition of the senses.

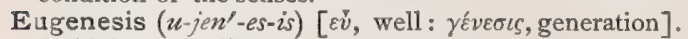
In biology, fertility.

Eugenia $\left(u-j e^{\prime}-n e-a h\right)$ [after Prince Eugene of Savoy]. A genus of more than 500 species of myrtaceous trees and shrubs, mostly tropical. E. caryophylata yields cloves, $q$. $v$. Pimenta is a product of E. pimenta. Various other species are medicinal, and some afford edible fruits. E. cheken. See Cheken.

Eugenic Acid (u-jen'-ik). See Eugenol.

Eugenin $\left(u^{\prime}\right.$-jen-in). See Caryophyllus.

Eugenol (u'-jen-ol) [eugenia; oleum, oil], $\mathrm{C}_{10} \mathrm{H}_{12} \mathrm{O}_{2}$. Eugenic Acid; a substance that occurs in clove-oil, and in allspice. It is an aromatic oil that boils at $247^{\circ} \mathrm{C}$. It is antiseptic, and a local anesthetic in dentistry. Dose gr. $\mathrm{xv}$, well diluted. Unof.

Eukinesia $\left(u-k i n-e^{\prime}-s e-a h\right)$. See Eucinesia.

Eulachon Oil, or Eulachoni Oleum ( $w^{\prime}$-lak-on, or $u-l a k-o^{\prime}-n i o^{\prime}-l e-u m$ ) [native name in North Pacific islands]. Candle-fish Oil. The oil of the fish Thaleichthys pacificus, or candlefish. It is less disagreeable than cod-liver oil, for which it is often substituted. Dose $3 \mathrm{j}-\mathrm{iv}$. Unof.

Eulyptol (u-lip'-tol). An antiseptic substance composed of six parts of salicylic acid and one part each of carbolic acid and essence of eucalyptus. It does not produce albuminates when applied to wounds. Dose internally, 3 ij-iiss per diem. See Eucalyptus.

Eumerism $\left(u^{\prime}-m e r-i z m\right)$ [ $v$, well ; $\mu$ ćpos, a part]. In biology, opposed to dysmerism; an aggregate of eumeristic parts.

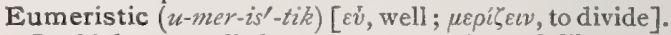
In biology, applied to an aggregation of like parts arranged in a regular series, as a tapeworm.

Eumerogenesis (u-me-ro-jen'-es-is) [ $\varepsilon \dot{v}$, well; $\mu \varepsilon$ pos, division; $\gamma^{\prime} \varepsilon \varepsilon \sigma \iota \varsigma$, generation]. In biology, development by fission, or the multiplication of like parts, producing a regular series.

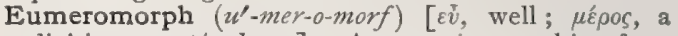
division; $\mu \rho \rho \phi \eta \dot{n}$, shape]. An organism resulting from eumerogenesis, as an arthrosporous bacillus-filament.

Eunuch $\left(u^{\prime}-n u k\right)$ [Evंvoṽ $\chi \circ$, guardian of the couch]. One from whom the genital organs have been removed or mutilated so as to render him impotent.

Eunuchism $\left(u^{\prime}-n u k-i z m\right)$ [ $\dot{v} v o \bar{\prime} \chi o s$, guardian of the couch]. The condition of being a eunuch.

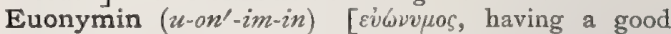
name]. A precipitate from the tincture of Wahoo, Euonymus americanus; it is tonic, laxative, and expectorant. Dose $1 / 2$ to 3 grains. Unof.

Euonymus $\left(u-o n^{\prime}-i m-u s\right)$ [ $\varepsilon \dot{v} \omega \nu v \mu o s$, having a good name]. I. A genus of celastraceous shrubs and trees. 2. Wahoo. The bark of E. atropurpureus is an astringent tonic and purgative, resembling rhubarb, jalap, aloes, etc., but rather milder. It is beneficially employed in dropsy and hepatic affections. E., Ext. Dose gr. j-v. E., Ext., Fld. Dose 3 ss-ij. E., Tinct. ( $\mathrm{I}$ in 5 ). Dose $\eta_{\mathrm{x}-\mathrm{xl}}$. E. americanus has similar properties.

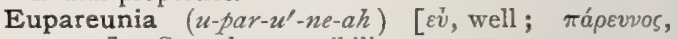
spouse]. Sexual compatibility.

Eupathia, or Eupatheia $\left(u-p a t h-i^{\prime}-a h\right)$ [ $\varepsilon \dot{v} \pi a ́ \theta \varepsilon c \alpha ; \varepsilon v$, well; $\pi \dot{\theta} \theta$ s, feeling]. I. Euphoria. 2. Sensitiveness to impressions.

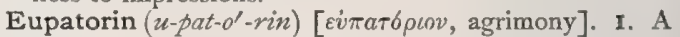
precipitate from the tincture of Thoroughwort, Eupatorium perfoliatum; it is aperient, emetic, febrifuge and tonic. Dose $I$ to 3 grains. Unof. 2. A crystalline glucosid from Eupatorium cannabinum of Europe. "See also Eupurpurin.

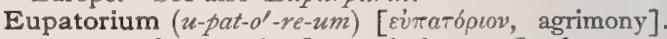
A genus of composite-flowered plants. In pharmacy, Eupatorium denotes the leaves and flowering-tops of $E$. perfoliatum, thoroughwort, or boneset. It is a bitter tonic, diaphoretic, aperient and emetic, of value in remittent and typhoid fevers, and thought, also, to be a teniafuge. E., Fld. Ext. Dose $m^{x}-\mathbf{3}$ j. E. purpureum, trumpet-weed, another American species, has similar qualities (see Eupurpurin), but is more markedly diuretic, as is also $E$. amarissimum, of the U. S. Many other species of this large genus are actively medicinal.

Eupepsia $\left(u-p e p p^{\prime}-s e-a h\right)$ [ $\varepsilon v$, well ; $\pi \varepsilon \pi \tau \varepsilon \imath v$, to digest]. Sound or normal digestion.

Eupeptic $\left(u-p e p^{\prime}-t i k\right)$ [ $\varepsilon \dot{v}$, well ; $\pi \dot{\varepsilon} \pi \tau \varepsilon v$, to digest]. Possessing a good digestion; promoting digestion.

Euperistalsis $\left(u-p e r-i s-t a l^{\prime}-s i s\right)$ [ $\varepsilon \dot{v}$, well; $\pi \varepsilon \rho \hat{\imath}$, around; $\sigma \tau a ́ \lambda \sigma \iota \varsigma$, compression]. The quiet peristaltic movements of the intestines in health. See Peristalsis.

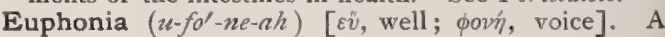
normal, good, and clear condition of the voice. 
Euphony (u'-fon-e). See Euphonia.

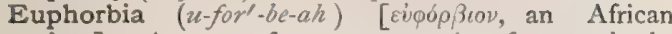
plant]. A genus of some 700 species of trees, shrubs and herbs, mostly with a milky, acrid, or poisonous juice. E. resinifera, of Africa affords euphorbium. E. lathyris, yields oil of euphorbia, an active, but uncertain cathartic. From E. drummondii, drumin is prepared. In N. America, E. corollata, E. ipecacuanha, E. vulgaris, E. prostrate, and other native species have been employed in medicine, there being about Ioo species in the U. S. E. pilulifera, of $\mathrm{S}$. America and Australia, has reputed value in asthma and cardiac dyspnea. Dose of the extract

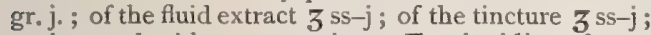
to be used with great caution. E. piscidia, of tropical America, a virulent poison, is locally employed as a caustic. Many other species are actively medicinal.

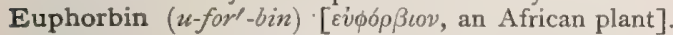
A precipitate from a tincture of the root of Euphorbia corollata; it is an emetic, expectorant, vermifuge and arterial sedative. Dose $1 / 4$ to 3 grains. Unof.

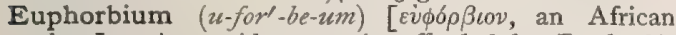
plant]. An acrid gum-resin afforded by Euphorbia resinifera and E.officinarum. It is strongly purgative and vesicant, and is now mainly employed in veterinary medicine.

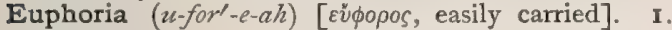
The sense of well-being or health. 2. Ability to endure pain.

Euphoric ( $u$-for'-ik) [ $\varepsilon \tilde{v} \phi o \rho n \varsigma$, easily carried]. Marked by or pertaining to euphoria.

Euphorin $\left(u^{\prime}\right.$-for-in) [ $\varepsilon v \phi o \rho \circ \varsigma$, easily carried], $\mathrm{C}_{9} \mathrm{O}_{2} \mathrm{H}_{11}$. Phenyl-urethan, derived from anilin, a white crystalline powder, nearly insoluble in water, soluble in weak alcohol. It is recommended as a safe and rapid antipyretic in doses of from 5 to 30 grains daily. Unof. See Phenyl-urethan.

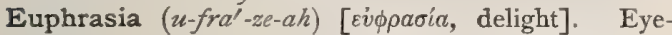
bright. A small annual, formerly much used in eyeaffections. It is of utility as an astringent lotion in conjunctivis, and invaluable in breaking up nasal catarrh and in hay-fever. E., Tinct., strength 1.9. Dose $m$ j-v.

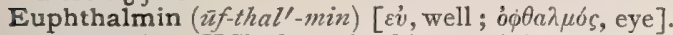
$\mathrm{C}_{17} \mathrm{H}_{25} \mathrm{NO}_{3}$. $\mathrm{HCl}$, the hydrochlorate of the amygdalic acid derivative of the unstable n-methyl-vinyl-diacetonealkamin. It is a colorless, crystalline powder, which freely dissolves in cold water. The instillation of two or three drops of a 2 per cent. solution in the eye produces within 20 to 30 minutes mydriasis of intermediate intensity, which vanishes after 2 or 3 hours. The accommodation is but slightly, if at all, affected.

Eupitton ( $u^{\prime}$-pit-on), $\mathrm{C}_{25} \mathrm{H}_{26} \mathrm{O}_{9}$. Eupittonic acid. An aurin into which six methoxyl groups have been introduced. It forms orange-yellow crystals, melting with decomposition, at $200^{\circ} \mathrm{C}$.

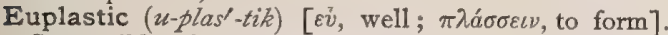
Susceptible of being transformed into sound, healthy, and permanent tissue.

Eupnea $\left(\bar{u} p-n e^{\prime}-a h\right)[\varepsilon \bar{v}$, well; $\pi v \varepsilon \varepsilon \varepsilon v$, to breathe]. Normal and easy respiration.

Eupurpurin (u-pur'-pu-rin) [عv, well; pupura, purple]. A precipitate from the tincture of Eupatorium purpureum; it is diuretic, stimulant, astringent, and tonic. Dose $\mathbf{I}$ to 4 grains. Unof.

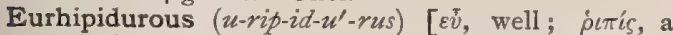
fan; oủá, taill]. In biology, applied to such birds as have a fan-like arrangement of the tail-feathers.

Eurhodins ( $u^{\prime}$-ro-dinz). Dyes derived from the phenazins by the introduction of one or more amido-groups. They are feeble bases.

European Cholera. Synonym of Cholera.
Europhen $\left(u^{\prime}-r^{\circ} 0-f e n\right)$, A preparation of iodin recommended as a substitute for iodoform. It is a valuable antiseptic, antisyphilitic, and antituberculotic. In skindiseases, a 5 to Io per cent. ointment is employed. It is used hypodermatically in doses of gr. $1 / 4$-iss. Chemically, it contains one atom of iodin joined to two molecules of isobutylcresol. Unof. E.-aristol, a preparation of europhen with aristol; a substitute for iodoform.

Eurycephalic, or Eurycephalous, (u-ris-ef-alt-ik,

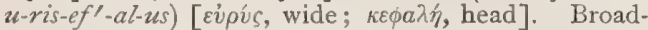
headed; having a very wide skull.

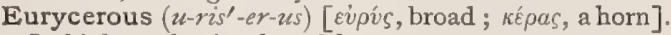
In biology, having broad horns.

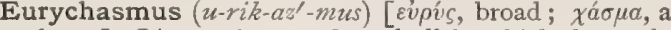
chasm]. Lissauer's term for a skull in which the angle formed between the lines joining the point of the wing of the vomer and the posterior nasal spine and anterior margin of the foramen magnum is between $153^{\circ}$ and $154^{\circ}$.

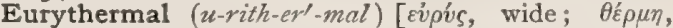
heat]. Capable of sustaining a great range of temper-

Eusomphalus $(u$-som'-fal-us) [evं, good; ó $\mu \phi a \lambda b s$, navel]. A double monstrosity in which the vital functions of each individual are independent, and in which each has a distinct umbilicus.

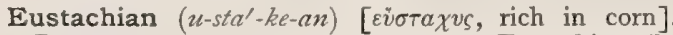
Pertaining to the Italian anatomist, Eustachio. E. Artery. See Arteries, Table of. E. Catheter, an instrument for dilating and otherwise treating the Eustachian tube; it is introduced along the floor of the nose. E. Tube, the canal extending from the tympanum to the pharynx. E. Valve, a prolongation or continuation of the lining membrane of the post-cava into the right auricle of the fetal heart to about half of its breadth. Its function is to direct the blood from the post-cava across the auricle toward the foramen ovale.

Eustachius, Canal of. See Canal.

Eustomatous $\left(u-s t o^{\prime}-m a t-u s\right)$ [Evं, well ; $\sigma \tau \delta \mu a$, mouth]. In biology, having a well-formed oral aperture.

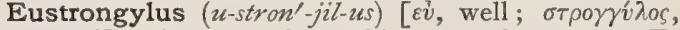
round]. A genus of parasitic nematode worms. E. gigas. See Thread-worms, and Parasites (Animal), Table of.

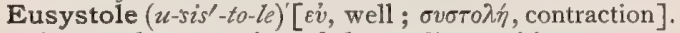
A normal contraction of the cardiac cavities.

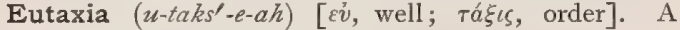
normal condition of the body.

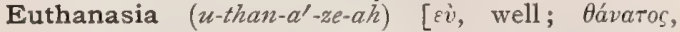
death]. An easy or calm death.

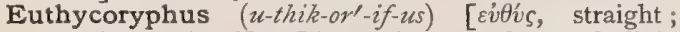
корvфं, the head]. Lissauer's term for a skull in which the parietal angle is between $142^{\circ}$ and $151^{\circ}$.

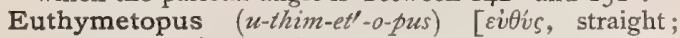
$\mu \varepsilon$ t $\omega \pi \nu \nu$, the forehead]. Lissauer's term for a skull in which the angle between the lines joining the metopion and bregma and nasion is between $I_{4} \mathrm{I}^{\circ}$ and $151.5^{\circ}$.

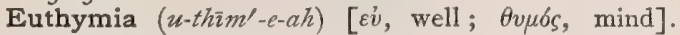
Tranquility; cheerfulness.

Euthyopisthocranius (u-the-o-pis-tho-kra'-ne-us) [ $\varepsilon \dot{v}$ -

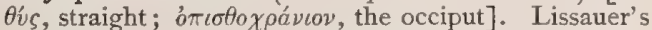
term for a skull in which the angulus summi occipitis is between $154^{\circ}$ and $172^{\circ}$.

Euthyuranus $\left(u-t h e-u^{\prime}-\right.$ ran-us) [Evंfis, straight; ovpavór, the roof of the mouth]. Lissauer's term for a skull in which the angulus summi palati is between $163.5^{\circ}$ and $180^{\circ}$.

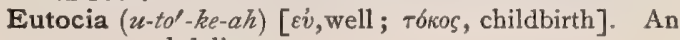
easy natural delivery. 
Eutrophic (u-tro'-fik) [Evं, well; $\tau \rho \varepsilon \dot{\phi} \varepsilon \varepsilon \nu$, to nourish]. Pertaining to eutrophy; promoting the nutritive process ; well-nourished.

Eutrophy, or Eutrophia $\left(u^{\prime}-t r o-f e\right.$, or $\left.u-t r o^{\prime}-f e-a h\right)\left[\varepsilon v^{\prime}\right.$,

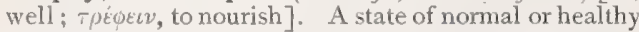
nutrition; the condition of being well nourished.

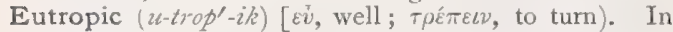
biology, turning or revolving with the sun.

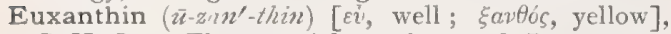
$\mathrm{C}_{19} \mathrm{H}_{16} \mathrm{O}_{10}$. The essential constituent of Purrée, q. $v$. It forms small yellow crystals.

Euxanthinic Acid ( $\left.\vec{u}-z a n-t h i n^{\prime}-i k\right)$. See Acid.

Evacuant (e-vak'-u-ant) [evacuare, to empty]. I. Promoting evacuation. 2. A medicine that increases the secretion or evacuation of an organ, especially the bowels. A purgative.

Evacuation (e-vak-u-a'-shun) [evacuatio, a voiding]. Defecation; the act of voiding; that which is voided.

Evaivular (e-val'-vu-lar) [e, priv, ; valva, a valve]. In biology, destitute of valves.

Evaporation (e-vap-or-a'-shun) [e, priv.; vapor, vapor]. In pharmacy, the process of converting a liquid into vapor by the agency of heat.

Eve and Lingard, Bacillus of. See Bacteria, Synonymatic Table of.

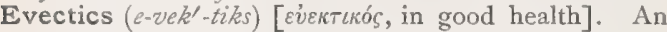
old name for hygiene; the science of good health.

Even-headed ( $e^{\prime}$-ven hed'-ed). Neither right-headed nor left-headed. Even-headedness is a condition common among the lower animals, and among idiots, imbeciles, and races of men of low development.

Evening Primrose ( $\bar{e} y^{\prime}-n i n g$ prim'-rōz). The flowering tops of Enothera biennis, recommended for asthma with gastric irritability. Dose of the fld. ext. $3 \mathrm{ss}-3 \mathrm{j}$. Unof.

Eventration (e-ven-tra'-shun) [e, out of; venter, the belly]. Extrusion of the abdominal viscera, especially in a monstrosity. The term is used also as a synonym of Pendulous Abdomen, $q$. v.

Evergreen-oak (ev'-ur-grēn-ōk). See Oak-bark.

Everitt's Salt. A compound of iron and potassium cyanid. E.'s Test. See Tests, Table of.

Everlasting (ev-ur-las'-ting). A popular name for certain plants of the genera Gnaphalium and Antennaria, small composite-flowered plants. $A$. divica of Europe is antibechic. A. margaritarea of $\mathrm{N}$. America is tonic and astringent, and is considered a good sudorific. A. plantaginifolia has similar qualities. See also Life-everlasting.

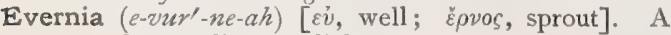
genus of parmeliaceous lichens. E. prunastri. See Acid, Everninic.

Everninic Acid (ev-ur-nin'-ik). See Acid.

Eversion (e-ver'-shun) [eversio, a turning out]. A turning outward. E. of the Eyelid, a folding of the lid upon itself for the purpose of exposing the conjunctival surface or sulcus. See also Ectropizm.

Evertebral (e-ver'-te-bral) [e, priv.,vertebra, a vertebra]. Not vertebral in character, nor derived from vertebra.

Evidence (ev'-id'-ens) [evidens, clear]. In legal medicine, the means by which the existence or non-existence or the truth or falsehood of an alleged fact is ascertained or made evident; proof, as of insanity. E., Circumstantial, evidence the conclusions based upon which are beyond actual demonstration. E., Conclusive or Positive, evidence that admits of no doubt. E., Expert, that given before a jury by an expert in any science, art, profession, or trade.

Evil $\left(e^{\prime}-v i l\right)\left[\mathrm{ME}, e^{2} e^{\prime}, \mathrm{ill}\right]$. 1. A disease. 2. Synonym of Scrofula.

Eviration (ev-ir-a'-shun) [evirare, to castrate]. I. Castration. 2. Emasculation; a form of sexual per- version in which there is a deep and permanent as. sumption of feminine qualities, with corresponding loss of manly qualities. The opposite of this is termed Defemination.

Evisceration (e-vis-er-a'-shun) [e, out ; viscera, the bowels]. The removal of the viscera. E. of the Eye, removal of the entire contents of the globe of the eye, leaving the sclerotic intact, -an operation in place of enucleation, and following which some operators insert a glass or metallic shell-globe, called an artificial vitreous, to preserve the shape, etc., of the eye-ball. E., Obstetric, the removal of the abdominal or thoracic viscera of the fetus in embryotomy.

Evolution (ev-o-lu'-shun) [evolutio, evolvere, to unroll]. I. The development or temporary growth and organic change that take place in the uterus during pregnancy. 2. In biology, (I) the doctrine of incasement or preformation of the early physiologists, which supposed that all parts of the fully-formed animal or plant were present in a minute form in the germ. Cf. Epigenesis. (2) The doctrine of descent often spoken of as Darwinism, based upon the capacity of every plant and animal to produce other individuals of a like kind, but varying to a greater or less degree according to the differentiation induced by special environment and natural selection. Cf. Pangenesis, Blastogenesis, Epigenesis, Ontogeny, Phylogeny, Natural Selection. E., Factors of, the recognized factors of evolution are at least five, viz. : (I) Pressure of an environment affecting function and function affecting structure, and the changed structure and function inherited and integrated through successive generations. (2). Use and disuse of organs reacting on growth-force and producing change in form, structure, and size of parts, and such change inherited and integrated through successive generations. (3) Natural selection among individuals of those most in accord with an ever-changing environment-or, as it has been otherwise called, "survival of the fittest." (4) Sexual selection: the selection by the female, among varying male individuals, of the strongest or the most attractive. Among mammals, the selection is mainly of the strongest, as decided by battle; among birds, of the most attractive, as determined by splendor of color or beauty of song. (5) Physiologic selection, or selection of those varieties the individuals of which are fertile among themselves, but sterile or less fertile with other varieties and with the parent stock. This has also been called "segregate fecundity" by Gulick and homogamy by Romanes. These five factors are not universally recognized. The first two are Lamarckian, the second two Darwinian factors. In the Lamarckian factors the changes occur during individual life, and the offspring is supposed to inherit them unchanged. In the Darwinian factors, on the contrary, the changes are in the offspring, and the individuals during life are supposed to remain substantially unchanged. The fifth factor has been brought forward by Romanes and Gulick and is not yet universally recognized. (6) To these recognized factors of organic evolution must now be added, in human evolution, another and far higher factor, viz., conscious, voluntary coopperation in the zerk of evolution, conscious striving for the betterment of the individual and of the race. This factor consists essentially in the formation and pursuit of ideals. This is called a factor, but it is also much more than a factor. It stands in place of nature herself - it is a higher, rational nature using all the factors of physical nature for its own higher purposes. To distinguish the evolution determined by this factor from organic evolution, it is called progress. Underlying all these factors as their nec- 
essary condition, and therefore themselves not called factors, are two opposite operative principles, viz., heredity and variability. Like the conservative and progressive elements in society, one tends to fixedness, the other to change. The one initiates change, the other accumulates its effects in successive generations. The one tries all things, the other bolds fast to whatever is good. They are both equally necessary to the successful operation of any or all of the factors. E., Ontogenetic, the development of an embryo from an egg. E., Phylogenetic, the evolution of species. E., Spontaneous, a term expressive of the unaided occurrence in childbirth of a series of changes, whereby a shoulder-presentation is transformed within the pelvis into a combined breech-and-shoulder-presentation and delivery effected.

Evulsion (e-vul'-shun) [evulsio; evellere, to pluck out]. The forcible tearing or plucking away of a part, as a polypus, tonsil, etc.

Ewald's Test-breakfast. A method used in ascertaining the condition of the gastric juice. It consists of 35 to 70 grams of white bread and $300 \mathrm{~cm}$. of water, or a cup of weak tea without milk or sugar.

Ewald and Boas's Method. A method of removing the contents of the stomach. It is carried out by causing the patient to make forcible voluntary contraction of the abdominal muscles, steady pressure being applied to the epigastrium.

Exacerbation (eks-as-er-ba'-shun) [exacerbatio; exacerbare, to be violent]. Increased or paroxysmal violence of the symptoms of a disease.

Exaggerated (eks-aj'-er-a-ted) [exaggerare, to heap up] Larger; more marked; increased. E. Breathing. See Breath-sounds. E. Lithotomic Posture. See Postures, Table of.

Exalbuminous (eks-al-bu'-min-us) [ex, priv.; albumen, the white of an egg, from albus, white]. In biology, applied to seeds in which the nutritive matter, endosperm or albumin, is stored within the embryo.

Exalgin (eks-al'-jin) [ $\dot{\varepsilon} \xi$, out; ă $\lambda$ yos, pain], $\mathrm{C}_{9} \mathrm{H}_{11} \mathrm{NO}$. Methylacetanilid; a benzene derivative allied to phenacetin. It is a valuable analgesic and antipyretic in doses of one-half to four grains. Unof.

Exalt (eks-awlt') [exaltare, to lift up; exalt]. In chemistry, to purify or refine.

Exaltation (eks-azel-ta'-shun) [exaltatio, an uplifting]. I. Increase of functional activity. 2. Increase of mental activity. 3. A morbid mental state characterized by self-satisfaction, ecstatic joy, abnormal cheerfulness, or optimism, or by delusions of grandeur.

Examination (eks-am-in-a'-shun) [examinare, to examine]. Investigation, as for the purpose of diagnosis; it is variously qualified as bimanual, digital, oral, physical, etc.

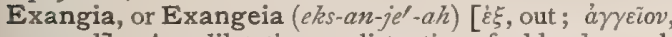
vessel]. Any dilatation or distention of a blood-vessel, such as aneurysm, varix, or capillary enlargement.

Exanimation (eks-an im-a'-shun) [ex, out; anima, spirit]. Real or apparent death; fainting.

Exannulate (eks-an'-u-lāt) [ex, priv; annulus, a ring] In biology, applied to ferns, the sporangium of which lacks the annulus.

Exanthema, or Exanthem (eks-an'-them-ah, or eks'-

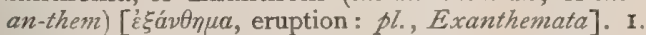
An eruption upon the skin. 2. Any exanthematous or eruptive fever. 3. In biology, any irregular spot on the surface of a leaf or other organ. A Table of the Exanthemata is appended on page 450 . E., Syphilitic. See Roseola, Syphititic.

Exanthematic (eks-an-them-at'-ik). See Exanthematous. E. Typhus. See Typhus Fever.
Exanthematology (eks-an-them-at-oll-o-je) [ $\varepsilon_{\xi a ́} \xi \theta \eta \mu a$, eruption; $\lambda 6 \gamma o s$, science]. The science of the exanthematous diseases.

Exanthematous (eks-an-them'-at-us) [ $\varepsilon^{\prime} \xi a v \theta \eta n \mu a$, eruption]. Of the nature of or characterized by exanthema, or eruption; of the nature of an eruptive fever.

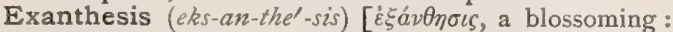
pl., Exantheses]. I. The breaking out or the appearance of an exanthem. 2. Any exanthematous disease. E. rosalia arthrodynia. Synonym of Dengue.

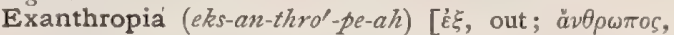
men]. Morbid dislike of human society; apanthropia.

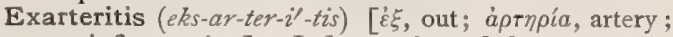
$\iota \tau \zeta$, inflammation]. Inflammation of the outer coat of an artery.

Exarthrima (eks-ar-thrim'-ah) [' $\xi$, out ; ă $\rho \theta \rho o v$, joint : pl., Exarthrimata]. Luxation or dislocation of a joint.

Exarticulate (eks-ar-tik'-u-lāt) [ex, priv. ; articulare, to join]. In biology, applied to limbs, antennæ, palpi, or other appendages destitute of joints.

Exarticulation (eks-ar-tik-u-La'-shun) [ex, out; articulus, joint]. I. Luxation of a joint. 2. Amputation at a joint.

Excandescentia (ex-kan-des-en'-she-ah) [ex, out; candescere, to glow]. Angry or furious mania ; a paroxysm of insane fury.

Excarnation (eks-kar-na'-shun) [ex, out; caro, flesh]. The removal of superfluous tissue from an anatomic preparation.

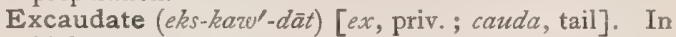
biology, tailless.

Excavation (eks-kav-a'-shun) [excavare, to hollow out]. A hollow or cavity, as in the lungs or in a tissue. E. of the Optic Nerve, a hollowing or "cupping" of the disc, or optic nerve-entrance, that may be physiologic or congenital, and without particular significance; or pathologic, the result of glaucoma, optic atrophy, etc.

Excavator (eks'-kav-a-tor) [excavare, to hollow out]. A dental instrument for opening and forming cavities and removing decayed matter from them; $\iota$. $g$., the hatchet, hoe, and chisel.

Excentric (eks-sen'-trik) [ex, out ; centrum, center]. 1. See Eccentric. 2. Out of the center or median line. E. Pains, radiating pains, symptomatic of spinal disease, due to irritation of the posterior nerveroots. The pains are felt to be in the peripheral organs, hence the name.

Excerebration (eks-ser-e-bra'-shun) [ex, out ; cerebrum, brain ]. The removal of the fetal brain in the process of embryotomy.

Excipient (ek-sip'-e-ent) [excipere, to take up]. In pharmacy, any substance used to give an agreeable or convenient form to the ingredients of a prescription.

Exciple $\left(e k^{\prime}-s i p-l\right)$ [excipulum, a receiving-vessel]. That part of a lichen forming the rim of the perithecium, or immediately surrounding it.

Excision (ek-sizh'-un) [excisio, a cutting out]. The operation of removing a part or tissue by cutting; a cutting out.

Excitability (ek-sit-ab-il'-it-e) [excitare, to rouse]. The property of reacting to stimulus.

Excitant (ek-si'-tant) [excitare, to rouse]. A remedy that stimulates the activity of an organ.

Excitation (ek-si-ta'-shun) [excitare, to rouse]. The act of stimulating or irritating. E., Direct, in electrotherapeutics, the excitement of a muscle by placing an electrode on the muscle itself. E., Indirect, the excitement of a muscle through its nerve. 


\section{TABLE OF THE EXANTHEMATA.}

\begin{tabular}{|c|c|c|c|c|c|c|c|c|c|}
\hline NAME. & $\begin{array}{l}\text { PERIOD } \\
\text { OF } \\
\text { INCUBA- } \\
\text { TION. }\end{array}$ & $\begin{array}{l}\text { STAGE } \\
\text { OF } \\
\text { INVA- } \\
\text { SION. }\end{array}$ & $\begin{array}{l}\text { TIME OF AP- } \\
\text { PEARANCE OF } \\
\text { ERUPTION. }\end{array}$ & $\begin{array}{l}\text { CHARACTER } \\
\text { OF ERUPTION. }\end{array}$ & $\begin{array}{l}\text { DURATION } \\
\text { OF ERUPTION, }\end{array}$ & LOCATION. & $\begin{array}{l}\text { DESQUAMA- } \\
\text { TION. }\end{array}$ & \begin{tabular}{|} 
DURA- \\
TION OF \\
DIS- \\
EASE.
\end{tabular} & $\begin{array}{l}\text { CON- } \\
\text { VALES- } \\
\text { CENCE. }\end{array}$ \\
\hline Erysipelas. & $\left|\begin{array}{c}\text { Few } \\
\text { hours } \\
\text { to } 3 \text { or } \\
4 \text { days. }\end{array}\right|$ & $\begin{array}{l}\text { I to } 3 \\
\text { days. }\end{array}$ & $\begin{array}{l}\text { Within } 24 \\
\text { hours. }\end{array}$ & $\begin{array}{l}\text { Efflorescence; } \\
\text { bright-red; } \\
\text { polis hed; } \\
\text { with well-de- } \\
\text { fined, raised } \\
\text { margin. }\end{array}$ & 4 to 8 days. & Face. & $\begin{array}{l}\text { Branny, or in } \\
\text { large takes. }\end{array}$ & $\left|\begin{array}{r}\text { I to } 3 \\
\text { weeks. }\end{array}\right|$ & Crisis. \\
\hline Measles. & $\begin{array}{l}\text { ro to } 12 \\
\text { days. }\end{array}$ & 4 days. & $4^{\text {th }}$ day. & $\begin{array}{l}\text { Maculæ; small, } \\
\text { dark-red,with } \\
\text { crescentic bor- } \\
\text { ders. Com- } \\
\text { plete in } 24 \\
\text { hours. }\end{array}$ & 4 to 5 days. & $\begin{array}{l}\text { Face ; then } \\
\text { downward } \\
\text { over body. }\end{array}$ & $\begin{array}{l}\text { Branny. } \quad 8-11 \\
\text { days. }\end{array}$ & $\mid \begin{array}{c}2 \\
\text { weeks. }\end{array}$ & Crisis. \\
\hline Rötheln. & $\begin{array}{l}8 \text { to } I 7 \\
\text { days. }\end{array}$ & $\begin{array}{l}24 \text { to } 48 \\
\text { hours. }\end{array}$ & $\begin{array}{l}\text { Within } 48 \\
\text { hours. }\end{array}$ & $\begin{array}{l}\text { Maculæe; rose- } \\
\text { col or e d; } \\
\text { rounded; dis- } \\
\text { crete. }\end{array}$ & 3 days. & $\begin{array}{l}\text { Face and scalp; } \\
\text { then down- } \\
\text { ward over } \\
\text { body. }\end{array}$ & $\begin{array}{l}\text { Slightly bran- } \\
\text { ny. }\end{array}$ & $\begin{array}{l}4 \text { to } 7 \\
\text { days. }\end{array}$ & Crisis. \\
\hline Scarlatina. & $\begin{array}{l}\text { I to } 2 I \\
\text { days. }\end{array}$ & $\begin{array}{l}\text { I to } 2 \\
\text { days. }\end{array}$ & $\begin{array}{l}\text { Within } 24 \\
\text { hours. }\end{array}$ & $\begin{array}{l}\text { Diffuse ; scar- } \\
\text { let; punctate. }\end{array}$ & 7 to ro days. & $\begin{array}{l}\text { Neck, chest, } \\
\text { face; then } \\
\text { over body. }\end{array}$ & $\begin{array}{l}\text { Scales or large } \\
\text { flakes. About } \\
\text { one week. }\end{array}$ & $\mid \begin{array}{c}2 \text { to } 3 \\
\text { weeks. }\end{array}$ & Lysis. \\
\hline $\begin{array}{l}\text { Typhoid } \\
\text { Fever. }\end{array}$ & $\begin{array}{c}5 \text { to } 35 \\
\text { days. }\end{array}$ & $\begin{array}{l}6 \text { to } 8 \\
\text { days. }\end{array}$ & $7_{\text {th day. }}$ & $\begin{array}{l}\text { In crops. Rose- } \\
\text { colored, len- } \\
\text { ticular spots. }\end{array}$ & $\begin{array}{l}\text { Each crop } 3 \text { to } \\
5 \text { days. Last } \\
\text { Io to } 20 \text { days } \\
\text { or through- } \\
\text { out the whole } \\
\text { course of the } \\
\text { fever. }\end{array}$ & $\begin{array}{l}\text { A b d o men, } \\
\text { chest, and } \\
\text { back. }\end{array}$ & $\begin{array}{l}\text { Slightly bran- } \\
\text { ny or none. }\end{array}$ & $\begin{array}{c}3 \text { to } 4 \\
\text { weeks. }\end{array}$ & Lysis. \\
\hline $\begin{array}{l}\text { Typhus } \\
\text { Fever. }\end{array}$ & $\mid \begin{array}{l}4 \text { to } \mathrm{I} 2 \\
\text { days. }\end{array}$ & 5 days. & $\begin{array}{l}\text { Usually } 5 \text { th } \\
\text { day; may be } \\
\text { on } 3 \text { d or not } \\
\text { till } 7 \text { th day. }\end{array}$ & $\begin{array}{l}\text { Measly spots; } \\
\text { petec hix } \\
\text { streaks; col- } \\
\text { or, mulberry- } \\
\text { red. }\end{array}$ & $\begin{array}{l}\text { Few days, or } \\
\text { mas last } \\
\text { throughout } \\
\text { the course of } \\
\text { the disease. }\end{array}$ & $\begin{array}{l}\text { Sides of chest } \\
\text { and abdo- } \\
\text { men; arms ; } \\
\text { back. }\end{array}$ & $\begin{array}{l}\text { Slightly bran- } \\
\text { ny. }\end{array}$ & $\begin{array}{c}2 \text { to } 4 \\
\text { weeks. }\end{array}$ & Crisis. \\
\hline Varicella. & $\begin{array}{l}4 \text { to } 14 \\
\text { days. }\end{array}$ & $\begin{array}{l}\text { I to } 2 \\
\text { days. }\end{array}$ & $\begin{array}{l}\text { Within I } 2 \text { to } \\
24 \text { hours. }\end{array}$ & $\begin{array}{l}\text { In crops. } \\
\text { Vesicles. }\end{array}$ & 5 to 8 days. & $\begin{array}{l}\text { B ack, chest, } \\
\text { arms. }\end{array}$ & $\begin{array}{l}\text { Crusts. } 5^{-8} \\
\text { days. }\end{array}$ & $\begin{array}{c}2 \\
\text { weeks. }\end{array}$ & Lysis. \\
\hline Variola. & $\begin{array}{l}8 \text { to } I_{4} \\
\text { days. }\end{array}$ & 3 days. & $4^{\text {th }}$ day. & $\begin{array}{l}\text { Umbilicated } \\
\text { pustules. }\end{array}$ & $2 I$ to 25 days. & $\begin{array}{c}\text { Face, and over } \\
\text { body. }\end{array}$ & $\begin{array}{l}\text { Crusts. } \quad 12-22 \\
\text { days. }\end{array}$ & $\begin{array}{r}4 \text { to } 5 \\
\text { weeks. }\end{array}$ & Lysis. \\
\hline
\end{tabular}

Excito- (ek-si'-to-) [excitare, to rouse]. A Latin prefix denoting stimulation or excitation. E.-motor, exciting or arousing motor function; also, a drug or agent that increases activity of the motor nerve-centers. E.-nutrient, arousing or quickening the processes of nutrition. E.-reflex, pertaining to a reflex action that ends in muscular action. E.-secretory, arousing the function or process of secretion. E.-vasomotor, carrying stimulus to vaso-motor centers.

Excitor (ek-si'-tor) [excitare, to rouse]. One who or that which stimulates or excites.

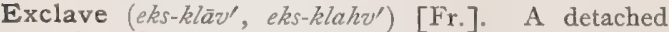
portion of any organ, as of a pancreas or ovary.

Exclusion (eks-klu'-zhun) [excludere, to shut out]. A shutting out. E., Diagnosis by, the reaching of a final or most probable diagnosis by successively excluding one hypothesis after another, as impossible, from a consideration of the symptoms.

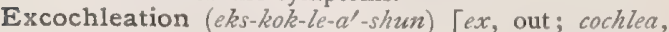
shell, spoon]. The scraping out of material with the curet.

Excoriation (eks-ko-re-a'-shun) [ex, from; corium, the skin]. I. Abrasion or removal, partial or complete, of a limited portion of the skin. 2. A lesion of the skin in which, as a rule, the surface is denuded only as far as the stratum mucosum. It heals without leaving a scar. It is usually seen in pruritic diseases.

Excreation (ex-kre-a'-shun). See Exscreation.
Excrement (eks'-kre-ment) [excernere, to separate; to excrete]. An excreted substance; the feces.

Excrement (eks'-kre-ment) [excrescere, to grow out]. An old name for the hair, nails, etc.

Excrementitious (eks-kre-men-tish'-us) [excernere, to separate ; to excrete]. Pertaining to the excrement.

Excrescence (eks-kres'-ens) [excrescere, to grow out]. An abnormal outgrowth upon the body. See Caulifozver Excrescence.

Excreta (eks-kre'-tah) [pl.; excernere, to separate]. The natural discharges of the body, particularly those of the bowels; feces.

Excretin (eks'-kre-tin) [excernere, to separate], $\mathrm{C}_{20} \mathrm{H}_{36} \mathrm{O}$. One of the constituents of feces. It occurs in little leaves or tufts mixed with needles, insoluble in cold or hot water, soluble in hot alcohol and ether; its reaction is neutral.

Excretion (eks-kre'-shun) [excretio; excernere, to excrete]. The separation of the waste products of an organ, or of the body as a whole, out of the blood. The material so excreted.

Excretory (eks'-kre-tor-e) [excretio; excernere, to excrete]. Pertaining to excretion. E. Duct, a canal conveying the excretion from the excretory organ to the discharging point. See Duct.

Excurrent (eks-kur'-ent) (ex, out; currere, to run]. Leading or going outward, as an excurrent canal.

Excurvation (ex-kur-va'-shun) [ex, out; curvare, to curve]. A deformity of the eyelid affecting almost 
exclusively the upper palpebra, and one in which the tarsal cartilage becomes turned outward. It occasionally develops in protracted cases of granular conjunctivitis.

Exedent (ek'-se-dent) [exedens; ex, out; edere, to eat] Rodent; eating away the tissues.

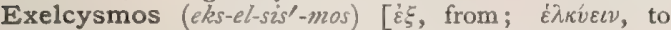
draw]. Extraction, as of teeth.

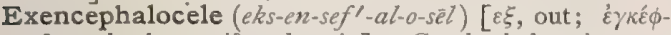
$a \lambda o \nu$, brain; $\kappa \dot{\lambda} \lambda \eta$, hernia]. Cerebral hernia; an exencephalous tumor; a mass of brain-substance outside of the cranial cavity.

Exencephalon (eks-en-sef'-al-on). Same as Exencephalus.

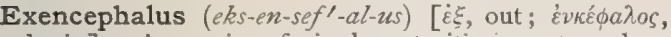
brain]. A species of single autositic monsters characterized by a malformed brain, situated, at least in part, without the cranial cavity, the bony walls of which are themselves imperfect. The specimens of this nature are divided into two main classes-those with and those without a spinal fissure. 2. A variety of autositic monsters of the foregoing species in which there is an arrested development of the cranial bones, with protrusion of the brain, associated with an extensive spina bifida.

Exenteratio bulbi. See Exenteration of the Orbit.

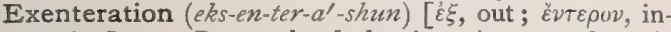
testine]. I. Removal of the intestines or thoracic viscera in embryotomy. 2. In ophthalmology, the operation of evisceration of the contents of the eyeball, leaving the globe as a stump in the orbit. E. of the Orbit, the removal of the contents of the orbital cavity.

Exenteritis (eks-en-ter-i'-tis) [ $[\dot{\xi} \xi$, out; $\varepsilon \nu \tau \tau \rho o \nu$, bowel ; $\iota \tau \iota \zeta$, inflammation]. Inflammation of the outer or peritoneal coat of the intestine.

Exercise (eks'-er-siz) [exercere, to keep busy]. Functional activity of the muscles; often applied to such activity when its purpose is the preservation or restoration of the health. E., Active, that exerted by the will of the patient. E., Passive, when the part is moved by another, or acted upon, as in massage. E. Bones, Rider's bones; osseous growths occasionally found in the muscles.

Exeresis (eks-er'-es-is) [ $\hat{\varepsilon} \xi$, out; aipécuv, to take]. Surgical removal, as by excision or extraction; evacution.

Exfetation (eks-fe-ta'-shun) [exfetatio]. Ectopic or extrauterine fetation.

Exfoliation (eks-fo-le-a'-shun) [exfoliatio; exfoliare, to shed leaves]. The lamellar (or other) separation of bone or other tissue from the living structure in Dry Necrosis, etc.

Exhalant (eks-ha'-tant) [exhalare, to breathe out]. I. Serving for exhalation; exhaling. 2. A pore or organ of exhalation.

Exhalation (eks-hal-a'-shun) [exhalare, to breathe out]. The process of giving off or exhaling vaporous or effluvial matters; the vapor, subtle particles, etc., given off by the body through the skin or lungs.

Exhaustion (eg-zarest'-yun) [exhaurire, to pour out]. Great loss of vital and nervous power from fatigue or protracted disease.

Exhibit $\left(e k-z i b^{\prime}-i t\right)$ [exhibere, to give]. To administer as a medicine.

Exhibition (ek-zib-ish'-un) [exhibere, to give]. In legal medicine, the exposing of the genitalia in public places.

Exhibitionism (ek-zib-ish'-un-izm) [exhibere, to give]. A perversion of the sexual feeling that leads the patient to expose the genital organs.

Exhibitionist (ek-zib-ish'-un-ist) [exhibere, to give]. An insane person who wilfully and indecently exposes himself.
Exhilarant (ek-zil'-ar-ant) [exhilarare, to cheer]. An agent to enliven and cheer the mind. E. Gas, nitrous oxid gas.

Exhumation $\left(e x-h u-m a^{\prime}-\operatorname{shun}\right)$ [ex, out of; humus, the ground]. The digging up after interment of a dead body, for examination in medico-legal inquiries, or for reinterment.

Exindusiate (eks-in-d $\left.u^{\prime}-s e-\bar{a} t\right)$ [ex, priv.; induere, to put on; indusium, the covering of the fruit-dots in ferns]. In biology, applied to such ferns as lack the indusium.

Exner's Solution. See Stains, Table of.

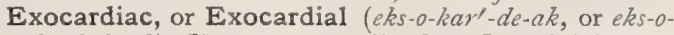
$\left.k a r^{\prime}-d e-\alpha l\right)$ [ $\varepsilon_{\xi} \omega$, out ; $\kappa a \rho \delta i \alpha$, heart]. Originating or situated outside of the heart.

Exocarditis (eks-o-kar-di'-tis) [ $[\check{\xi} \omega$, out; $\kappa \alpha \rho \delta i a$, heart ;

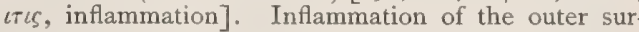
face of the heart. Also a synonym of Pericarditis.

Exocarp (eks'-o-karp) [ $\dot{\varepsilon} \xi \omega$, outside; $\kappa a \rho \pi \delta s$, fruit]. In biology, the outer layer of a pericarp when the latter consists of more than one layer.

Exoccipital (eks-ok-sip'-it-al) [ex, out ; occiput, the oc ciput]. Lying to the side of the foramen magnum. E. Bone, the neurapophysial or condyloid part of the occipital bone, with which in adult life it is consolidated.

Exocelar (eks-o-se'-lar) [ ity]. In biology, situated on the outer or somatic wall of the body-cavity.

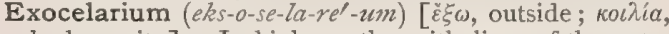
body-cavity]. In biology, the epithelium of the outer wall of the body-cavity

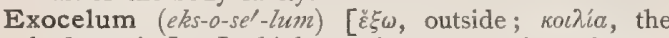
body-cavity]. In biology, the extra-embryonic part of the body-cavity shut off by the somatic and splanchnic stalks at the umbilicus. (Sevenka.)

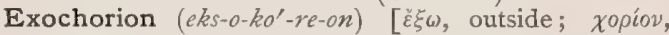
chorion]. The external layer of the chorion.

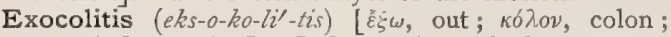
$\iota \tau \iota s$, inflammation]. Inflammation of the outer or peritoneal coat of the colon.

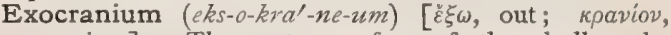
cranium]. The outer surface of the skull; the pericranium.

Exodic $\left(e k s-o d^{\prime}-i k\right)$ [ $\varepsilon \xi \omega$, out; $\delta \delta b s$, a way]. Transmitting impulses outward from the central nervous system; efferent; centrifugal.

Exodontosis (eks-o-don-to'-sis). See Exostosis of the Teeth.

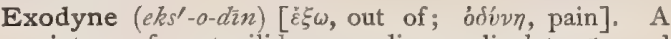
mixture of acetanilid 90 , sodium salicylate 5 , and sodium bicarbonate 5 ; it is used as an anodyne.

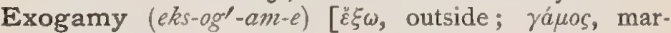
riage]. The law that forbids marriage between persons of the same family. (Lang.)

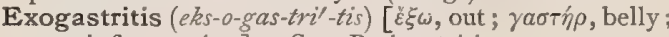
$\iota \tau \iota \zeta$, inflammation]. See Perigastritis.

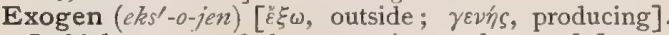
In biology, one of the two primary classes of flowering-plants, characterized by the growth of the stems in concentric layers; more properly called Dicotyledons.

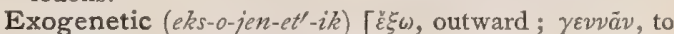
produce]. Due to an external cause; not arising within the organism.

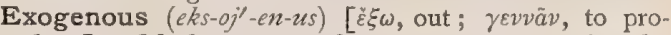
duce]. Of the nature of an exogen; growing by accretions to the outer surface.

Exognathite (eks-og'-näth-ît ). See Basecphysis.

Exogonium (eks-o-go'-ne-um). See Jalap.

Exometritis (eks-o-me-tri'-tis) [Ě $\xi \omega$, out ; $\mu \eta \tau \rho a$, womb ; $\iota \tau \iota$, inflammation]. Perimetritis; less correctly, parametritis. See Metritis. 
Exomphalos (eks-om'-fal-os) [ $\dot{\varepsilon}_{\xi}$, out; ó $\mu \phi a \lambda o s$, navel $]$. Undue prominence of the navel; also, umbilical hernia.

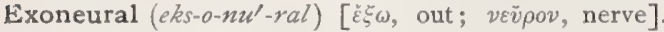
Occurring or situated outside of the nervous apparatus.

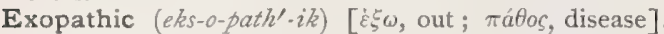
Pertaining to those causes of disease coming from without or beyond the organism. See, also, Endopathic.

Exoperidium (eks-o-per-id'-e-um) [है̌ $\omega$, outside; peridium (from $\pi \eta \rho i \delta i o v$, dim. of $\pi i p \rho a$, a leather pouch), the covering of the spore-case]. The outer peridium of a fungus having more than one, as the earth-star.

Exophoria (eks-a-for'-e-ah). See Heterophoria. E. Pseudo-, an outward tending of the eyes excited by lessening the activity of the accommodative centers, as when hyperopia has been corrected by convex lenses. This condition also exists in uncorrected myopia.

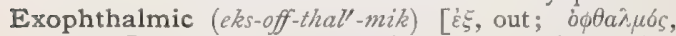
eye]. Pertaining to exophthalmos. E. Goiter. See Goiter.

Exophthalmometer (eks-off-thal-mom'-et-er) [ $[\dot{\varepsilon} \xi$, out ; ó $\phi a \lambda \mu \sigma o s$, eye; $\mu \hat{\varepsilon} \tau \rho o \nu$, measure]. An instrument for measuring the degree of exophthalmus.

Exophthalmos, Exophthalmus (eks-off-thal'-mos,-mus) $[\hat{\varepsilon} \xi$, out; $\dot{\phi} \phi \theta a \lambda \mu \sigma \varsigma$, eye $]$. Abnormal prominence or protrusion of the eyeballs. E., Pulsating, that characterized by a bruit and pulsation, due to an aneurysm that pushes the eye forward.

Exoplasm (eks'-o-plasm) [ $\varepsilon \xi \omega$, outside; $\pi \lambda a ́ \sigma \sigma \varepsilon \iota \nu$, to form]. In biology, the outer protoplasm of a unicellular organism or histologic cell.

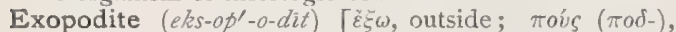
foot]. In biology, the outer of the two main divisions of the typical crustacean limb or appendage. Cf. Endopodite and Basecphysis.

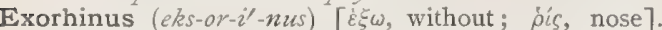
Lissauer's term for a skull in which the angle between the lines joining the nasion and the alveolar point and rhinion is between $\mathrm{I}^{\circ}$ and $20.5^{\circ}$.

Exormia (eks-or'-me-ah) [ $\varepsilon_{\xi} \circ \rho \mu a ́ \varepsilon \iota v$, to go forth]. Any papular skin-disease.

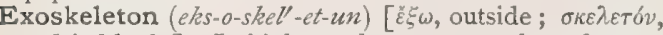
a dried body]. In biology, the outer envelop of many of the lower forms of life for the protection and attachment of organs, representing an integument modified by the deposition of chitin, lime, or other hardening substance. See Dermoskeleton.

Exosmose (eks'-os-moss). See Exosmosis.

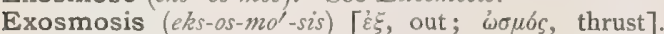
Outward osmosis. See Endosmosis and Osmosis.

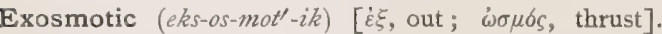
Pertaining to or characterized by exosmosis.

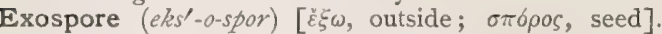
In biology, the outer coat of a spore.

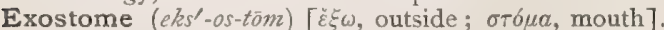
In biology, the orifice in the outer coat of the ovule, or the outer peristome of a moss.

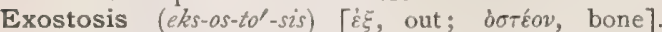
Abnormal enlargement or growth of bone, especially a deposit of bony tissue upon the surface of a preexisting bone. E. of the Teeth, exostosis dentium; exodontosis. An outgrowth from a tooth. The only part of a tooth subject to exostosis is the root, and the development of the affection usually commences at or near the extremity; extending from thence upward, it sometimes covers a greater or less portion of the external surface. E., Ivory, a bony outgrowth of extreme hardness and of small size, rarely exceeding that of a small walnut. It springs usually from the exterior of one of the cranial bones.
Histologically, it is marked by the absence of Haversian canals.

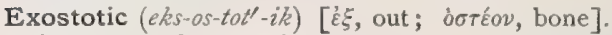

the nature of exostosis.

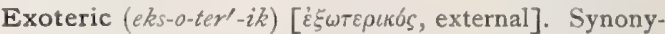
mous with Exopathic.

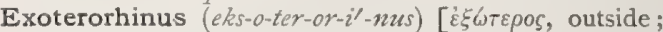
pis, nose]. Lissauer's term for a skull in which the angle between the lines joining the nasion and the alveolar point and rhinion is between $22.5^{\circ}$ and $45^{\circ}$.

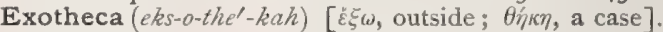
In biology, the proper calcareous investment of the visceral chamber of a coral.

Exothecium (eks-o-the'-se-um) [ $\varepsilon \xi \omega$, outside; $\theta \dot{\eta} \kappa \eta$, a case]. In biology, the epidermis of the anther.

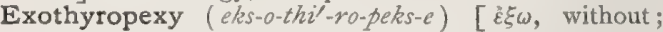
$\theta v \rho \varepsilon \delta ́ s$, a shield; $\pi \tilde{\eta} \xi \iota s$, fixation]. Partial extrusion of goiter, with subsequent atrophy from constriction, cicatrization, etc

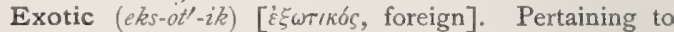
plants and products from another country.

Exotropia (eks-o-tro'-pe-ah). See Strabismus.

Expansive (eks-pan'-sif) [expandere, to spread out]. Comprehensive; wide-extending. E. Delirium, insane over-estimation of one's mental or bodily powers. See Exaltation.

Expectant (eks-pek'-tant) [expectare, to look out for]. Awaiting or expecting; applied to a plan of treatment consisting in watching the progress of a disease, and not interfering with therapeutic measures, unless warranted by special symptoms.

Expectation (eks-pek-ta'-shun) [expectare, to expect]. Same as Expectant. E. of Life, the average number of years that persons of a given age, taken one with another, live, assuming that they die according to a given table of the probabilities of life. It thus has no relation to the most probable life of a single given individual. E. of L., Complete, the addition of one-half year to the curtate expectation to allow for that portion of a year lived by each person in the year of his death. E. of L., Curtate, the average number of whole or completed years lived by each person.

Expectorant (eks-pek'-to-rant) [ex, out; pectus, breast]. I. Promoting expectoration. 2. A remedy that promotes expectoration.

Expectoration (eks-pek-tor-a'-shun) [ex, out; pectus, breast]. I. The ejection from the mouth of saliva or material brought into it by the air-passages, 2. The fluid or semi-fluid matters from the lungs and air-passages expelled by coughing and spitting. E., Prunejuice. See Prune-juice. E., Rusty. See Rusty Expectoration.

Expellent (eks-pel'-ent) [expellere, to drive out]. A medicine that has power to expel a materies morbi.

Experiment (eks-per'-im-ent) [experimentare, to experiment]. A trial or test.

Experimentum (eks-per-im-en'-tum) [L.]. Same as Experiment. E. mirabile of Kirchner, a hypnotic phenomenon in animals, a hen, $e . g .$, remaining in a fixed position when the head is pressed down and a chalk line made from its beak.

Expert (eks'-pert) [expertus, proved]. A person especially qualified in a science or art. E., Medical, a physician peculiarly fitted by experience or special learning to render an authoritative opinion in medico. legal or diagnostic questions.

Expiration (eks-pi-ra'-shun) [expirare, to breathe out]. The act of breathing forth, or expelling air from the lungs.

Expiratory (eks-pi'-rat-or-e) [expirare, to breathe out]. Relating to or concerned in the expiration of air. 
Expire (eks-pir') [expirare, to breathe out]. To breathe out ; to die.

Explanate (eks'-plan-ät) [explanare, to flatten, spread out]. In biology, spread out, flattened; applied to parts usually rolled or folded.

Exploration (eks-plor-a'shun) [explorare, to search out]. The searching out the condition of a diseased organ or part by means of auscultation, palpation, percussion, etc. Also the searching of a wound to learn its nature, course, etc., and if foreign bodies may be present. Also the examination of the female genital organs by the finger or instrument for diagnostic purposes.

Explorator, Explorer (eks'-plor-a-tor, ex-plor'-er) [explorare, to search out]. An instrument for use in exploration. E., Electric, an instrument for detecting a bullet by means of the electric current.

Exploratory (eks-plor'-at-or-e) [explorare, to search out]. Pertaining to exploration. E. Puncture, the puncture of a cavity or tumor and extraction therefrom of some of the contents to learn their nature. E. Trocar, one especially adapted for exploratory puncture.

Explosion (eks-plo'-zhun) [explodere, to drive away]. I. The sudden expansion of a body of small volume into great volume, with the resulting effects. 2. The sudden and violent occurrence of any symptom or function.

Explosive (eks-plo'-siv) [explodere, to drive away]. See Consonants. E. speech, speech characterized by suddenness and explosiveness of enunciation.

Exposure (eks-pol-zhurr) [exponere, to expose]. I. The act of laying bare, as the genitals. 2. The state of being open to some action or influence, as of cold or wet.

Expression (eks-presh'-un) [expressus; exprimere, to press out]. I. A pressing out. The forcible separation of liquids from solids by pressure. 2. The recognizable manifestation through the facial lineaments or the voice of any subjective feeling. E. of Fetus or Placenta, assisting the expulsion of fetus or placenta by pressure upon the abdominal walls.

Expulsion (eks-pul'-shun) [expulsio; expellere, to drive out]. The act of driving out. E., Spontaneous, the extrusion of the fetus or the placenta without external aid.

Expulsive (eks-pul'-siv) [expellere, to drive out]. Pertaining to the extrusion or driving out of the fetus in childbirth, the voiding of the feces, urine, etc.

Exsanguination (ek-sang-gzin- $\left.a^{\prime}-\operatorname{shun}\right)$ [ex, priv.; sanguis, blood]. The forcible expulsion of blood from a part, as before amputation.

Exsanguine (ek-sang'-gwin) [ex, priv.; sanguis, blood] Bloodless.

Exsanguinity (ek-sang-grvin'-it-e) [ex, priv.; sanguis, blood]. Bloodlessness; extreme pallor.

Exscinded (ek-sin'-ded) [ex, out; scindere, to cut]. In biology, terminating abruptly in an angular notch.

Exscreation (ek-skre-a'-shun) [ex, out; screare, to hawk]. The act of clearing the throat by hawking and spitting.

Exsculptate (eks-kulp'-tāt) [exsculpere, to carve out]. In biology, presenting a sculptured appearance.

Exsert, Exserted (ek'-sert, ek-ser'-ted) [exserere, to thrust out]. In biology, projecting, as a stigma beyond the anthers.

Exsertus (ek-ser'-tus) [L.]. Protruding; sometimes applied to teeth that protrude. See Dens exsertus.

Exsiccatæ, Exsiccati $\left(e k-s i k-a t^{\prime}-e,-i\right)$ [exsiccare, to dry up]. In biology, the dried plants of an herbarium.

Exsiccation (ek-sik-a'-shun) [ex, out; siccus, dry]. The process of depriving a solid of its moisture or volatile constituents by the agency of moderate heat.
Exsiccative (ek-sik'-at-iv) [exsiccare, to dry up]. $\mathbf{x}$. Having a strong drying tendency. 2. A desiccating or drying remedy or application.

Exsiccator (ek'-sik-a-tor) [exsiccare, to dry up]. A closed glass vessel containing a tray of $\mathrm{H}_{2} \mathrm{SO}_{4}$, used to dry and cool substances preparatory to weighing.

Exspuition (eks-pu-ish'-un) [ex, out; spuere, to spit]. Expectoration; spitting.

Exstipulate (ek-stip $p^{\prime}-u$-lat $)$ [ex, without; stipula, a stipule]. In biology, destitute of stipules.

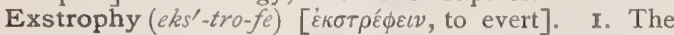
turning of a hollow organ inside out; the state of being turned inside out. 2. Congenital absence of the anterior wall of the bladder and abdomen with extroversion of the bladder.

Exsuccation (ek-suk-ka'-shun) [ex, out; succus, juice]. Same as Ecchymosis.

Exsuccous (ek-suk'-us) [ex, without; succus, juice, sap]. In biology, juiceless. Also written Exuccous.

Exsuffiation (ek-suf-la'-shun) [ex, out; sufflare, to blow]. Forced discharge of the breath.

Exta $\left(e k s^{\prime}-t a h\right)[\mathrm{L} ., p l$.$] . The viscera, especially those$ of the chest.

Extension (eks-ten'-shun) [extendere, to stretch out]. I. The opposite of flexion; the straightening of a flexed limb by the natural and functional process; the state of a limb that is not flexed. 2. Traction made upon a fractured or dislocated limb in order to bring the parts into proper apposition. E., Angular, a method of reducing and maintaining old dislocations of the hip. E., Counter-, traction upon the trunk or the trunk-end of a fractured limb in addition to extension. E., Double, traction applied to both limbs in hip-joint disease, etc. E. Stage in Labor, one of the stages of labor, consisting in the bending of the fetal head, the occiput toward the back.

Extensor (eks-ten'-sor). [extendere, to extend]. That which stretches out or extends. E. Muscles. See Muscles, Table of. E. Tetanus, in general spasms the extensor muscles overcome the flexors, and the spasm thus becomes an extensor tetanus.

Extenuation (eks-ten-u-a'-shun) [ex, out; tenuis, thin]. Thinness; leanness of body; delicacy.

Extern (eks'-tern) [externus, outward]. I. Outside; outside the gates of a hospital. 2. An out-door patient. 3. A medical student, or graduate, who attends to out-door charity cases. E. Maternity, a lying-in in a private house.

Externalization (eks-tern-al-iz-a'-shun) [externus, outward]. The process of externalizing, or embodying. E. of Sensation. See Sensitivisation.

Externomedian (eks-ter-no-me'-de-an) [externus, outward; medius, middle]. In biology, outside the median line.

Extesticulate (eks-tes-tik'-u-lāt) [ex, out ; testiculus, a testicle]. To castrate.

Extinction (eks-tink'-shun) [extinguere, to extinguish]. Complete abeyance or final loss, as of the voice; also, incomplete loss.

Extine (eks'-tin) [externus, outside]. In biology, the outer coat of a pollen-grain. Also Exine (Schacht).

Extirpation (eks-ter-pa'-shun) [extirpare, to root out]. Thorough excision or out-rooting of a part, as of a gland, a tumor, the uterus, the ovaries, etc. E. of the Eyeball, complete removal of the globe of the eye. Enucleation.

Extra- (eks'-trah-) [L.]. A prefix, meaning outside, without. E--axillary, in biology, applied to a branch or bud somewhat out of the axil. E.-current, the induced electric current. E.-enteric. In biology, perivisceral. E.-neural, situated or occurring outside of a nerve. A term applied to certain nervous 
affections of which the true seat is more or less remote from the point which manifests the symptoms of nerve-embarrassment. E.-ocular, outside the eye, or eyeball; in biology, applied to those antennæe of insects that are located at a distance from the eyes. E.-pelvic, situated or occurring outside the pelvis. E.-polar Region, that lying outside the electrodes, as opposed to the Intra-polar Region, or area, that lying within or directly beneath the electrodes. E.-uterine, without the uterus. E.-u. Pregnancy. See Pregnancy. E.-u. Life, that after birth.

Extracapsularium (eks-trah-kap-su-la'-re-um) [extra, beyond, outside; capsula, capsule: pl., Extra-capsularia]. In biology, that portion of a radiolarian outside the central capsule.

Extracardial (eks-trah-kar'-de-al) [extra, without; $\kappa a \rho \delta i a$, heart]. Situated or occurring outside of the heart.

Extracloacal (eks-trah-klo-a'-kal) [extra, without; cloaca, a sewer]. In biology, situated outside the cloaca.

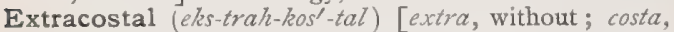
a rib]. Outside of the ribs. E. Muscle, any external intercostal muscle. See Muscles, Table of.

Extracrureus (eks-trah-kru'-re-zes) [extra, outside; crus, a leg]. The vastus externus muscle. See Muscles, Table of

Extract, Extractum $\left(e x^{\prime}-\right.$ trakt, -trakt'-um) [extractus; extrahere, to extract: pl., Extracta]. In pharmacy, a solid or semi-solid preparation, made by extracting the soluble principles of a drug and evaporating the solution to a proper consistence. Alcohol and water are the most common solvents. There are 33 official extracts. E., Alcoholic, that in which alcohol is the solvent. E., Aqueous, that prepared by using water as the solvent. E., Fluid, in pharmacy, an alcoholic or hydro-alcoholic solution of the solid principles of a vegetable drug, of such strength that IOoO grams of the drug are fully represented by one liter of the fluid extract. There are 88 official fluid extracts, besides 53 in the $N . F$.

Extraction (ex-trak'-shun) [extractio; ex, out; trahere, to draw ]. The drawing out of a body, as a calculus, a fetus, or a tooth. Also, the pharmaceutic process of making an extract, chiefly by the action of some menstruum, as alcohol, ether, or water. E. of Cataract, removal of the cataractous lens by surgical operation. The methods proposed or practised are almost numberless. Daviel's Method, improved by Beer, consists in making a semicircular flap (upward in Daviel's, downward in Beer's) in the cornea, or at the margin, with rupture of the capsule and expression of the lens. This method is being revived and, with modification, adopted by a large number of modern operators, and is called the Flap-extraction. The Discissionoperation is used in soft cataract, and consists in introducing a needle, whereby the capsule is broken and the aqueous humor gains access to the lens-substance, which is then absorbed or removed by suction. In v. Graefe's Peripheral Linear Method, the Graefe lance-knife enters the sclerotic $1.5 \mathrm{~mm}$. from the corneal border, and $2 \mathrm{~mm}$. below the horizontal tangent of the upper border of the cornea, and is at first directed downward, but the counterpuncture is finally made opposite the point of puncture. The cut upward is then made parallel to the plane of the iris, followed by an iridectomy, capsulotomy, and expression of the lens. The change in v. Graefe's Modified Linear Extraction consists chiefly in bringing the section to the corneo-scleral junction. Needling, or the needle-operation. See Discission. The Simple Method, now advocated by many ophthalmic surgeons, consists in a flap-forming section and an omission of the iridectomy. The Suction Method consists in the extraction of soft cataracts by sucking the lenticular matter through a syringe nozzle introduced into the lens-substance, or by other methods. See Operations, Table of

Extractive (eks-trak'-tiv) [ex, out; trahere, to draw]. I. In pharmacy, a substance which, during the process of making an extract from a vegetable or drug of vegetable origin, becomes dark, and finally insoluble. 2. Any one of a class of nitrogenous bodies (such as creatin and xanthin) that may be extracted in small amount from various animal tissues. By some writers they are classed as protein compounds.

Extractor (eks-trak'-tor) [ex, out; trahere, to draw]. An instrument for extracting bullets, sequestræ, etc. E., Screw, one armed with a screw-attachment; a tirefond.

Extractum (eks-trak'-tum). See Extract. E. ferri pomatum, or E. pomi ferratum, ferrated extract of apples; official in the German Pharmacy and given in the National Formulary; it is an extract of sour apples, 50 parts, with iron one part. It contains a crude malate of iron.

Extrafloral (eks-trah-flo'-ral) [extra, outside; flos, a flower]. In biology, placed without the flower.

Extrafoliaceous (eks-trah-fo-le-a'-she-zes) [extra, outside; folium, leaf]. In biology, separated from the leaves.

Extralimital (eks-trah-lim'-it-al) [extra, outside; limes, bounds, limit]. In biology, not included in a given area, either on the surface of a plant or animal, or on the earth's surface.

Extramalleolus (eks-trah-mal-e'-o-lus) [extra, without malleolus, a small hammer]. The outer malleolus of the ankle.

Extrambulacral (eks-tram-bu-la'-kral) [extra, without; ambulacrum, a walk, alley]. In biology, located outside the ambulacra.

Extramedullary (eks-trah-me-dul'-ar-e) [extra, without; medulla, marrow]. Situated or occurring outside of the medulla.

Extraneous (eks-tra'-ne-us) [extraneus, external]. Existing or belonging outside the organism. $\mathbf{E}$. Body, a foreign or intrusive body, present within the organism.

Extraordinary (eks-tror'-din-a-re) [extra, beyond; ordo, rule]. Out of the common; special. E. Ray. See Ray.

Extrathecal (eks-trah-the'-kal) [extra, outside; theca, box, case]. In biology, located outside the theca.

Extravasation (eks-trav-as-a'-shun) [extra, outside: vas, a vessel]. Filtration or effusion of blood, serum or fluid from any vessel into adjacent tissues.

Extraversio gonadum (eks-trah-ver'-se-o go-na'-dum) [L.]. In biology, pendent external gastro-genital pouches in certain Medusce.

Extremital (eks-trem'-it-al) [extremus, outermost]. Situated towards, or pertaining to, an extremity; distal.

Extremity (eks-trem'-it-e) [extremus, outermost]. An arm or leg; the distal or terminal end or part of any organ; a hand or foot.

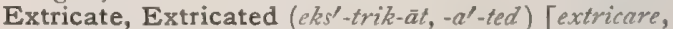
to disentangle]. In biology, applied to the normally extruded parts of certain insects, as the ovipositors.

Extrinsic (eks-trin'-sik) [extrinsicus, from without]. External, outward. E. Muscles, those attached to the trunk and extending to the limbs.

Extrorse (eks-trors') [extrorsus, toward the outside]. In biology, turned outward or away from the body or central axis.

Extroversion (eks-tro-ver'-shun). See Exstrophy. 
Extubation (eks-tu-ba'-shun) [ex, out; tubus, a pipe]. The removal of a laryngeal tube; opposed to intubation.

Extuberance (ex-tu'-ber-ans) [ex, out; tuber, mass]. A swelling or protuberance.

Extumescence (eks-tu-mes'-ens) [ex, out ; tumescere, to swell]. A projection or swelling.

Exuber $\left(e x-u^{\prime}-b e r\right)$ [ex, from ; uber, breast : pl., Exuberes]. A weaned child. Cf. Sububer.

Exudate ( $c k s^{\prime}-u$-dàt $)$ [exudare, to sweat]. Material that has filtered through the walls of vessels into the adjacent tissues.

Exudation (eks-u-da'-shun) [exudare, to sweat]. Filtration or oozing of the serum of the blood through the walls of the vessels; a mass formed by such filtration.

Exudative (eks'-u-da-tiv) [exudare, to exude]. Of the nature of or characterized by exudation.

Exulceration (eks-ul-ser-a'-shun) [ex, out; ulcerare, to ulcerate]. A superficial ulceration.

Exumbilication (eks-um-bil-ik-a'-shun) [exumbilicatio; ex, out; umbilicus, navel]. Marked protrusion of the navel.

Exumbral (eks-um'-bral) [ex, out; umbra, shade]. In biology, all those parts lying above the free margin of the umbrella of Medusæ; the opposite of subumbral.

Exumbrella (eks-um-brel'-ah) [ex, out; umbrella, the disc of acalephs]. In biology, the convex outer surface of the umbrella in Meduse.

Exuviz (eks-u,-ve-c) [L.]. Cast-off matters; shreds of epidermis; also, sloughed materials.

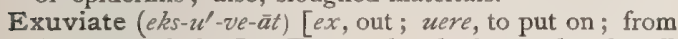
induvice, clothes]. To moult, shed, or slough off skin, shells, hairs, or feathers of animals.

Exuviation (eks-u-ve-a'-shun) [exuvice, slough; exuere, to put off]. The shedding of the deciduous teeth, or other epidermal part.

Eyckmann's Test. See Tests, Table of.

Eye (i) [ME., eye]. The organ of vision. E.. Accommodation of. See Accommodation. E., Appendages of, the eyelids, brows, and lachrymal apparatus. E., Apple of, formerly the eyeball ; the pupil. E., Artificial, a thin shell of glass, celluloid, or other substance, colored like the natural eye, placed in the socket after enucleation. E., Compound, the organ of vision formed of several crystal spheres, as in the lower crabs. E., Diagrammatic, of Listing, a diagram of the eye for the more exact calculation of the passage of rays of light through the eye. E., Pineal or Epiphysial, the rudimentary median eye in some lizards. E., Schematic, an ideal or normal eye. E.-ball, the globe of the eye. E.-ball, Dislocation of. See Dislocation. E.-bone, a sclerotal, q.v. E.-bright. See Euphrasia. E.-brow, the supercilium, the connective tissue, skin, and hairs above the eye. The hairs serve chiefly to prevent the sweat from falling into the eye. E.-cells, cup-shaped cells of porcelain, enameled black, to place over the eye after operations. E.-current, the normal electric current that passes from the cornea (positive) to the optic nerve (negative) under the stimulus of light. E.-doctor, an oculist. E.-drops. See Collyrium. Also an old name for tears. E.-glass, a lens worn in one eye. Eye-glasses, pince-nez, worn instead of spectacles, and held in position by a spring acting upon the bridge of the nose. E.-ground, a synonym of the fundus oculi or internal aspect of the vitreous chamber of the eye. E--lashes, the cilia; the hairs of the eyelid. E.-lashes, Evulsion of, pulling out the lashes. E.-lashes, Transposition of, shifting an excised strip of cilia and lid-edge containing the hair-bulbs to a new position, or otherwise altering the direction of the lashes by operation. E.-lens, the lens of a microscope to which the eye is applied; an eye-piece. E.-lid, the protective covering of the eyeball, composed of skin, glands, connective and muscular tissue, the tarsus and conjunctiva, with the cilia at the free edge. E.-lid Closure. See Reflexes, Table of. E.-piece. Synonym of Ocular. E.-point, the point above an ocular or simple microscope where the greatest number of emerging rays cross. E.-salve, a medicated salve for the eyes. E.-shade, Ward's, a circular disc of black rubber connected by an arm with the tube of the microscope. It enables the observer to keep both eyes open. E.-speculum, an instrument for retracting the eyelids. E.-stone, a small calcareous disc, the operculum of various Gasteropod molluscs (Turbinidæ); or sometimes a flattened concretion from the stomach of a European crawfish (Lapillus cancri). In domestic practice it is placed under the eyelid for the removal of a foreign body that has found its way into the eye. E.-strain, the excess and abnormalism of effort, with the resultant irritation, caused by ametropia or heterophoria. It is applied also to the effects of excessive use of normal eyes. E.souffle, a murmur said to be heard in anemia by means of the stethoscope on the globe of the eye. E.teeth, the canine teeth of the upper jaw; dog-teeth. E.-wash, a medicated water for the eye; a collyrium. E.-water, a collyrium; also the aqueous humor. E.-winker, an eyelash.

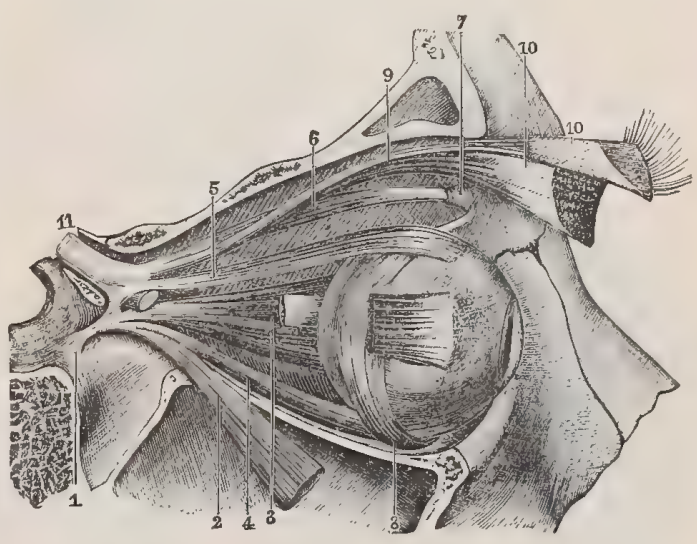

MUSCles of THE EYe. TENDON OR LIGAMENT OF ZiNN. I. Tendon of Zinn. 2. External rectus divided. 3. Internal rectus. 4. Inferior rectus. 5. Superior rectus. 6. Superior rectus. 4. Inferior rectus. 5. Superior rectus. 6. Superior 9. Levator palpebræ superioris. 10, 10. Its anterior expansion. Ir. Optic nerve.

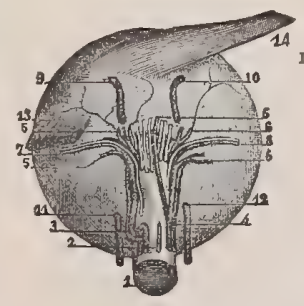

POSTERIOR HEMISPHERE OF THE GLOBE OF THE EYE.
. Optic nerve. 2. Central artery of the retina. 3. Short, posterior, and external ciliary arteries. 4 ary arteries. 5, 5, 6, 6, 6. External and internal posterior ciliary arteries. 7. Posterior long ciliary artery, and long ciliary nerve. 8. Ártery and nerve of opposite side. 9, Io. Superior and external choroid veins. II, I2. Inferior choroid veins. I3. Attachment of inferior oblique muscle. I4. Tendon of superior oblique. 


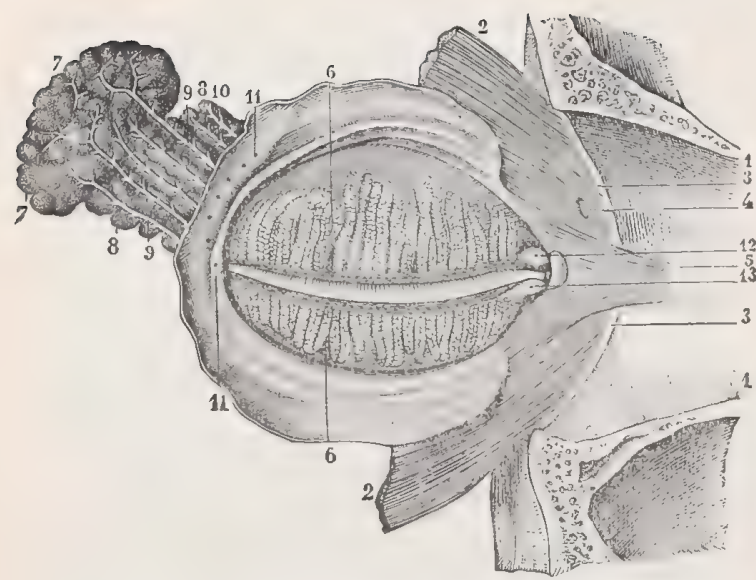

The Lacrymal and Meibomian Glands, and Adjacent ORGANS OF THE EYE.

I, I. Inner wall of orbit. 2, 2. Inner portion of orbicularis palpebrarum. 3, 3. Attachment to circumference of base of orbit. 4. Orifice for transmission of nasal artery. 5. Muscle of Horner (tensor tarsi). 6, 6. Meibomian glands. 7, 7 . Orbital portion of lacrymal gland. 8, 9, 10. Palpebral portion. II, 1I. Mouths of excretory ducts. 12, I3. Lacrymal puncta.

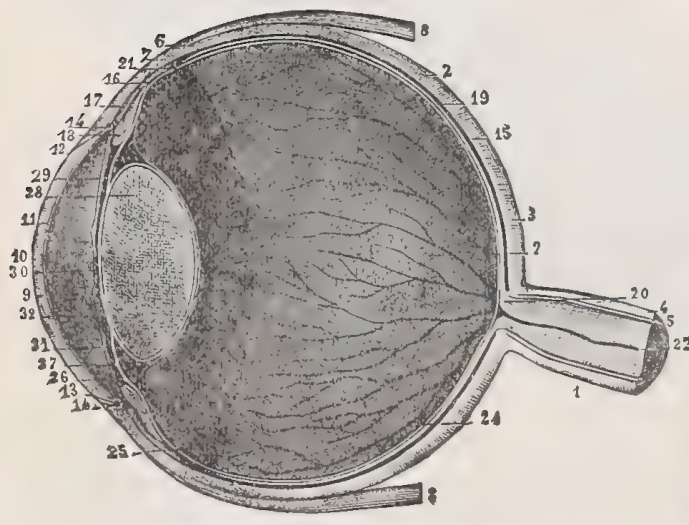

Vertical Section of Eye in its ANTERo-Posterior Axis.

I. Optic nerve, 2. Middie portion of sclerotic. 3. Posterior portion. 4. External of optic nerve. 5. Internal tunic. 6. Sclerotic beneath insertion of superior rectus. 7. Sclerotic in advance of insertion of superior rectus. 8, 8. Superior and inferior recti. 9. Cornea. ro. Its central portion. $x$. Posterior elastic lamina. I2. Junction of cornea and sclerotic superiorly. 13. Inferior junction. I4, I4. Canal of Schlemm. 15. Choroid. 16. Choroidal zone and ciliary processes. I7. Ciliary muscle. I8. Ciliary body. I9. Retina. 20. Origin of retina. 21. Its anterior limit. 22. Central artery of retina. 23. Branches of central artery. 24. Hyaloid membrane. 25. Zone of Zinn. 26. Posterior wall of canal of Petit, formed by hyaloid membrane. 2\%. Anterior wail of same canal, formed by the zone of Zinn. 28. Crystalline lens, 29. Iris. 30. Pupil. 31. Posterior chamber. 32, Anterior chamber.

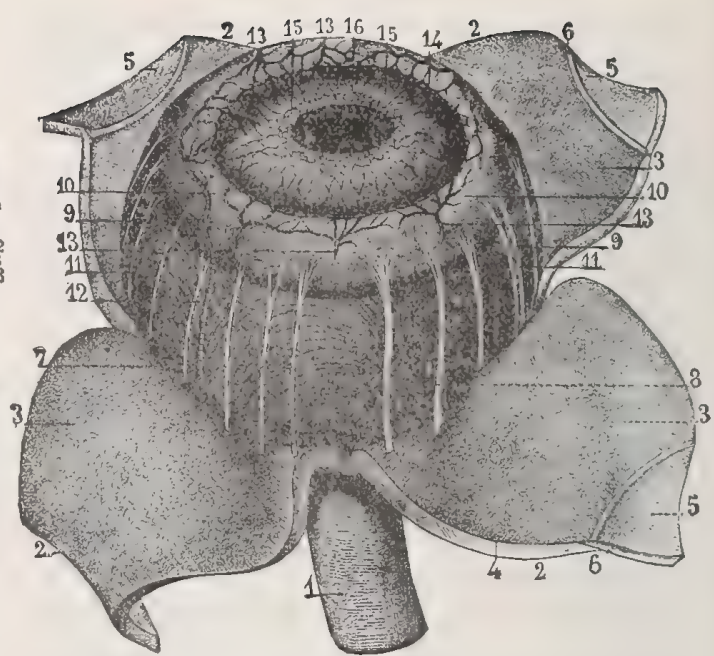

IRIS AND CHOROID.

I. Optic nerve, 2,2,2,2. Sclerotic, divided in fourequal parts and turned back. 3. Pigmentary granulation of its inner layer. 4. Section of lamina fusca. 5, 5, 5, 5. Cornea, divided in four equal parts. 6,6. Canal of Schlemm. 7. Outer surface of choroid. 8. Superior and internal trunk of vasa vorticosa. 9, 9. Irregular border limiting the choroid zone posteriorly. Io, ro. Anterior half of this zone; ciliary mus cle II I Ciliary nerves Ia I ong ciliary artery 13. 13. Anterior ciliary arteries. I4. Iris. I5. Small arterial circle of iris. 16. Pupillary orifice.

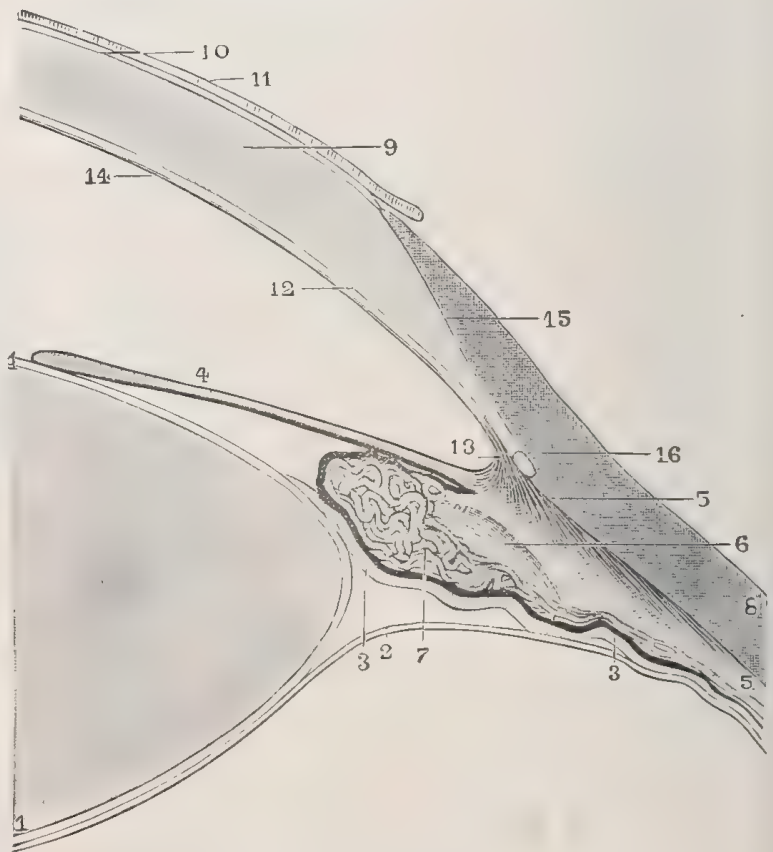

THE CILIARY MUSCle.

I. Crystalline lens, 2. Hyaloid membrane, 3, 3 Zone of Zinn 4 Iris. 5, 5adiating portion of ciliary muscle. 6 Section of circular portion. 7 . Venous plexus of a ciliary process. 8. Sclerotic. 9. Middle layer of cornea. Io. Anprocess. 8. Sclerotic, 9. Middle layer of cornea. Io. An-
terior hyaline layer of cornea. II. Epithelial covering of this layer. I2. Posterior hyaline laver of the cornea, or membrane of Descemet. I3. Fibers in which this layer terminates, or ligamentum pectinatum it. Epithelial covering of posterior hyaline layer. Is. Junction of sclerotic and corof posterior hyaline layer. I5. Junction 
F. Abbreviation of Fahrenheit; also of Fac., make, and of Fiat, let there be made.

F1, or Fld. Abbreviation of Fluid.

Ft. Abbreviation of Fiat, let there be made.

Faam ( $\left.a h-a h m n^{\prime}\right)$ [native Asian]. The plant Angracum fragrans, used in Asia and in France as a substitute for tea.

Faba Ignatii ( $f a^{\prime}-b a h$ ig-na'-she-i). See Ignatia.

Fabella $\left(f a-b e l^{\prime \prime}-a h\right)$ [dim. of $f a b a$, a bean]. A sesamoid fibro-cartilage or small bone occasionally developed in the gastrocnemius muscle at the posterior aspect of the knee-joint.

Fabiana (fa-be-an'-ah). See Pichi.

Face (fäs) [facies, the face]. A name applied to the lower and anterior part of the head, including the eyes, nose, mouth, cheeks, lips, etc. F.-ache. See Tic douloureux. F., Hippocratic. See Facies. F.-plug, a small layer of cerumen lying on the membrana tympani. F.-presentation, a presentation of the fetal face in labor.

Facet $\left(f a s^{\prime}-e t\right)$ [Fr., facette, a little face]. A small plane surface. The articulating surface of a bone. Also, the flat surface occasionally seen on calculi, caused by friction upon each other. In biology, a segment of the compound eye of an insect.

Facial ( $f a^{\prime}-$ shal) [facialis, of the face]. Pertaining to the face, as facial paralysis. F. Angle, the divergence between a line drawn from the upper jaw tangent to the forehead, and another to the external auditory foramen. F. Artery. See Arteries, Table of. F. Nerve. See Nerves, Table of. F. Palsy, or Paralysis. See Paralysis. F. Spasm. See Spasm. F. Trophoneurosis. Synonym of Atrophy, Progressive Unilateral Facial. F. Vein. See Vein.

Facies $\left(f\left(x^{\prime}-s h e-\bar{e} z\right)\right.$ [L., face]. Appearance, especially that of the face. F., Cardiac, an anxious expression occasionally seen in the early stages of chronic valvular disease. F. hepatica, a peculiar earthy appearance of the face, often observed in organic disease of the liver. F. hippocratica, the Hippocratic countenance, indicative of the rapid approach of dissolution; the nose seems pinched, the temples hollow, the eyes sunken, the ears leaden and cold, the lips relaxed, the skin livid. F. ovarina, the characteristic expression of women suffering from ovarian disease. The features are emaciated and sunken, the expression anxious, the forehead furrowed, the eyes hollow, the nostrils open and sharply defined, the lips long and compressed, the angles of the mouth depressed, with wrinkles encircling them. F. stupida, the typhoid face.

Factitious (fak-tish'-us) [factitius; facere, to make]. Made by art. Artificial, as factitious teeth, etc.

Facultas (fak-ul'-tas) [L.]. See Faculty.

Facultative (fak'-ul-ta-tiv) [facultas, capability]. Pertaining to acquired power. Possessing a power that is only incidentally or occasionally exercised. In bacteriology, amphibious as to oxygen, or capable of living either with or without free oxygen. F. aërobia. See Aërobia. F. anaërobia. See Anaërobia. F. Hyperopia, a division of manifest hyperopia. F. Parasite, applied to such a bacterium, dipterous larva, etc., as may at times play the part of a parasite. F. Saprophyte, applied to a fungus that is normally non-parasitic but occasionally parasitic.

Faculty (fak'-ul-te) [facultas, capability]. A special action of the mind through the instrumentality of an organ or organs; any function, particularly any acquired, modified, or facultative function. Also, the corps of professors and instructors of a university and its colleges. F., Medical, the corps of professors and instructors of a medical college.

Frcal, Fæces ( $\left.f e^{\prime}-k a l, f e^{\prime}-s e \bar{z}\right)$. See Fecal, Feces.

Fæcula ( $f e k^{\prime}$-u-lah). See Fecula.

Fæx (feks) [L., "lees": pl., Faces]. The dregs or sediment of any liquid. F. sacchari, treacle or molasses.

Fag [origin uncertain]. Exhaustion; tire. See Brainfag.

Fagara (fag-a'-rah) [L.]. The genus Xanthoxylon, $q . v$.

Fagin $\left(f a^{\prime}-j i n\right)$ [fagus, a beech-tree]. A principle contained in the husks of the nuts of the common beech (Fagus). It is said to be poisonous and narcotic.

Fagopyrum (fag-o-pi'-rum). See Buckwheat.

Fagus ( $f a^{\prime}$-gus) [L., "beech-tree:" gen., Fagi]. A genus of cupuliferous trees; the beeches. F. sylvatica, the common beech. The bark is said to be antipyretic, the nuts anthelmintic and anticalculous. Unof.

Faham $\left(f a h^{\prime}-a h m\right)$. Same as Faam.

Fahrenheit's Thermometer. See Thermomeler.

Faint $\left(f_{a} n t\right)$ [ fingere, to feign ; ME., faynt, weak]. A condition of languor. Also, a state of syncope or swooning.

Fainting ( fant'-ing) [ fingere, to feign; ME., faynt, weak]. A swoon; the act of swooning. F. Sickness. Synonym of Epilepsy.

Faintness ( fänt'-nes). See Syncope.

Faith-cure $\left(f \bar{a} t h^{\prime}-k \bar{u} r\right)$. The system or practice of attempting or pretending to cure diseases by religious faith and prayer alone. "It differs from mind-cure, in that the faith-curers have no mind, while the mindcurers have no faith." F.-doctor. See $F$.-healer. F.-healer, one who-practises the faith-cure.

Falcate $\left(f a l^{\prime}-k \bar{a} t\right)[f a l x$, a sickle]. In biology, sickle-shaped.

Falcial ( fal'-se-al) [falx, a sickle]. Relating to the falx cerebri.

Falcicula ( $f a l-s i k^{\prime}-u$-lah). See Falcula.

Falciform ( $\left.f a l^{\prime}-s i f-o r m\right)$ [ falx, a sickle; forma, form]. Having the shape of a sickle. F, Ligament. See Ligament. F. Process, a process of the dura mater that separates the hemispheres of the brain; the falx. See also Ligament, Femoral, of Hey.

Falcula $(f a l l-k u-l a h)$ [ $\operatorname{dim}$. of $f a l x$, a sickle]. The falx cerebelli.

Fall (favel) [ME, fallen, to fall]. To be dropped in birth, as a lamb. F.-drink, a Swiss and German cordial, of exceedingly varied composition and flavored with many aromatic and other herbs, as arnica, achillea, asperula, etc. It is regarded as a sovereign remedy for bruises and the effects of falls. Unof. F. Fever. Synonym of Typhoid Fever, q. $v$. F.rhéotome, an arrangement whereby a weight injures a muscle, and at the same time breaks and makes a galvanometer circuit; by this instrument it was shown that the demarcation-current took a certain time to develop.

Fallacia ( $\left.f a l-a^{\prime}-s e-a h\right)$ [L.]. An insane delusion; an hallucination. F, auditoria, a delusion as to hearing. F. optica, any visual illusion.

Falling ( favel'-ing) [ME., fallen, to fall]. Dropping; losing one's equilibrium. F.-sickness, a common term for epilepsy. F. of Womb. See Uterus and Prolapsus. 
Fallopian ( fal-of-pe-an) [Falloppius, an Italian anatomist]. Of or pertaining to Falloppius. F. Artery. See Arteries, Table of. F. Tubes. See Oviducts.

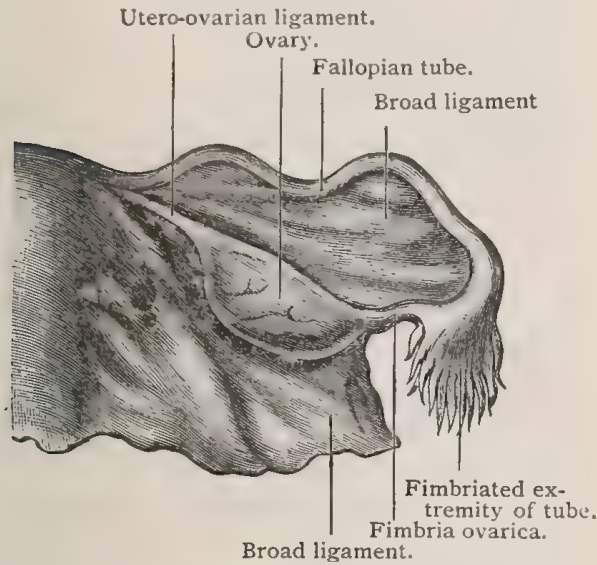

Right Fallopian Tube. (After Morris.)

Fallopius, Aqueduct of. See Aqueduct. F., Arch of. See Arch. F., Canal of. See Aqueduct. F., Hiatus of, an opening in the petrous portion of the temporal bone, for the transmission of the petrosal branch of the Vidian nerve.

Fallow Wards. Certain wards in hospitals that are occasionally cleared of patients and are then temporarily disused.

False (fawls) [falsus, deceptive]. Not genuine. Feigning or closely counterfeiting. F. Amnion, the vesicula serosa, which disappears as the chorion is developed. F. Ankylosis, ankylosis due to rigidity of the soft tissues. F. Bittersweet. See Climbing Staff-tree. F. Conception. See F. Germ. F. Germ, a mole, $q$. v. F. Gromwell, the root of Onosmodium virginianum, reputed to be tonic and diuretic. Dose of the fld. ext. $m_{x v}-3$ ss. Unof. F. Hearing. See Pseudacousma. F. Image, the image of the deviating eye, in diplopia. F. Joint, a result of non-union of a fractured bone. F. Measles. Synonym of Rötheln, $q . v$. F. Membrane, a fibrinous exudate upon a surface, as the fauces. F. Pains, pains that precede true labor-pains. F. Passage, a passage formed by the laceration of any canal, $e . g$., the urethra, caused by the forcible introduction of a catheter or other instrument in the wrong direction. F. Pelvis, the portion of the pelvic cavity situated above the linea ileo-pectinea. F. Peritonitis, hysterical manifestations simulating peritonitis. F. Pneumonia, peripneumonia notha. F. Pox. Synonym of Varicella. F. Ribs, See Ribs. F. Water, a collection of fluid in catarrhal endometritis.

Falsetto (fazol-set'-o) [Ital.]. A voice both highpitched and peculiarly modified as to quality; the highest register of the human voice. It is more obvious in the male than in most female voices.

Falsification (fawl-sif-ik-a'-shun) [ falsus, deceptive ; facere, to make]. The fraudulent adulteration of foods or medicines; counterfeiting.

Falx (falks) [L.]. A sickle. Same as Falx cerebri, In biology, variously used to designate falciform structures; e. $g$, the poison-fangs of a serpent or the cheliceræ of a spider. F. cerebelli, the falcula; a sickle-like process between the lobes of the cerebellum. F. cerebri, the sickle-like process of the dura, separating the hemispheres of the cerebrum.

Famelic $($ fam-el'-ik) [famelicus, hungry]. Marked by extreme hunger; effective in overcoming the sensa. tion of hunger

Famelica ( fim-el'-ik-ah) [famelicus, hungry]. Febris famelica; fever accompanied by hunger.

Fames $\left(f a^{\prime}-m e z\right)$ [L.]. Hunger. F. bovina, bulimia. F. canina ("dog-hunger"), bulimia. F. lupina, ("wolf-hunger"), extreme bulimia.

Family $\left(\mathrm{fam}^{\prime}-i \mathrm{l}-\mathrm{e}\right)$ [familia, a household]. The persons belonging to a household. In biology, a class of genera similar in organic structure. F. Ataxia. See Paramyoclonus multiplex. F. Diseases, those diseases that are hereditary.

Famine $\left(f a m^{\prime}-i n\right)$ [ fames, hunger]. Severe and continued hunger. Also, a general scarcity of food, which results in the starvation of many people. F. Bread, a lichen, Umbilicaria arctica, found in frozen regions, and serviceable, in extremity, as human food. F. Fever. Same as Relapsing Fever, q. v.

Fanaticism (fan-at'-is-izm) [ fanaticus, pertaining to a temple]. Perversion and excess of the religious sentiment. It often trenches upon the domain of insanity; and is sometimes an outcome, at other times a cause, of mental disease.

Fang [ME., feng, a catch]. In biology, any prehensile part or organ. See Teeth.

Fantome (fan'-tum). See Phantom.

Far [E. dial.]. The young of swine; a litter of pigs.

Far [ME., fer, at a distance]. At a distance. F. Point. See Punctum remotum. F.-sightedness, a colloquial term for Hypermetropia.

Farabeuf's Operation. See Operations, Table of.

Farad $\left(f a r^{\prime}-a d^{\prime}\right)$ [after Michael Faraday, a chemist]. The unit of electric capacity. Practically a capacity sufficient to hold one coulomb of current having a potential of one volt. The micro-farad, 1000000 of the theoretic farad, is commonly used. A practical form of condenser of one farad capacity consists of 300 leaves of tinfoil, each 16 centimeters in diameter, separated by leaves of naica. The entire surface is about of I.I sq. meters area. See Electric Units.

Faradic (far-ad'-ik) [named from its discoverer, Michael Faraday]. Pertaining to induced electric currents. F. Current, the induced electric current. See Current. F. Induction is brought about by a current of electricity passing through a wire exciting a wave of electricity in a second wire placed near or parallel with it at the instant of opening and closing the circuit.

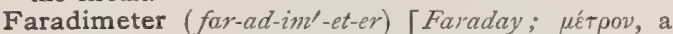
measure]. An instrument for measuring the strength of an induced electric current.

Faradism ( $\left.f a r^{\prime}-a d-i z m\right)$ [after Michael Faraday, a chemist]. I. Induced electricity. 2. The application of induced currents to the treatment of disease.

Faradization, or Faradism (far-ad-iz-a'-shun, or $\left.f a r^{\prime}-a d-i z m\right)$ [after Michael Faraday, a chemist]. The application of the induced current to a diseased part, or for disease.

Farado-puncture (far-ad-o-punk'-chür) [Faraday; punctura, a puncture]. The passage of a faradic current into the tissues by acupuncture.

Farcimen (far-si'-men) [ farciminum, farcy: $p l$., Farcimina]. Farcy; also, a farcy-bud.

Farcin (far'-sin) [Fr.]. Same as Farcy.

Farcinia ( far-sin'-e-ah). Synonym of Equinia.

Farcinoma ( far-sin-o'-mah) [ farciminum, farcy; $b \mu \alpha$, a tumor : pl., Farcinomata]. A farcy-bud, or glanderous tumor; less correctly, farcy, or glanders.

Farctus (fark'-tus) [L., a "stuffing "]. Emphraxis; congestion; infarction.

Farcy (far'-se). See Equinia and Bacillus of Nocard, under Bacteria, Synonymatic Table of. F.-bud, or 
F.-button. A nodular swelling in the course of a lymphatic vessel in glanders.

Fardel-bound ( $f a r^{\prime}$-del-borond) [ fardel, a load; ME., bounden]. I. A term applied to neat cattle or sheep affected with inflammation of the abomasum, or of the omasum, with impaction of food in the latter. Fardel-bound cattle are said to have "lost the cud."

Farding-bag ( $f a r^{\prime}-$ ding $^{-}-b a g^{\circ}$ ). The first stomach of a ruminant animal; the paunch or rumen.

Farfara (far'-far-ah). See Coltsfoot.

Farina $\left(\right.$ far $\left.-e^{\prime}-n a h\right)$ [farina, meal]. The ground or powdered fecula of seeds, especially that of corn, barley, rye, and wheat. In biology, applied to the pollen of flowers, and to the powdery substance found on certain insects.

Farinaceous (far-in- $\left.a^{\prime}-s h e-u s\right)$ [farina, meal]. Having the nature of or yielding flour. Also, applied to very fine furfuraceous exfoliations.

Farinose (far'-in-oss) [farina, meal]. In biology, covered with a flour-like powder, as certain leaves and insects.

Farrant's Solution. See Mounting Fluids, and Media.

Farre's Tubercles. See Signs and Symptoms, Table of.

Farriery (far'-yer-e) [ferraria, pertaining to iron]. The art of treating the diseases of horses; veterinary surgery.

Farrow ( far'-o) [ME., farh, faren, a little pig]. I. A little pig. 2. To bring forth, as pigs.

Fascia (fash'-e-ah) [fascia, a band: pl., Fascia $]$. The membranous, fibrous covering of muscles and other organs. In biology, applied to any broad, transverse band of color on the hair, feathers, scales, or stems. F., Anal. See F., Ischio-rectal. F. of Arm (Brach$\mathrm{ial}$ ), invests the muscles of the arm attached to the clavicle, acromion, and spine of the scapula. F., Cervical, Deep, invests the muscles of the neck and encloses the vessels and nerves. F., Cervical, Superficial, that just beneath the skin. F., Cloquet's. See Septum crurale. F., Cranial, a firm, dense layer, adherent to the skin and occipito-frontalis muscle. F., Cremasteric, forms a looped, thin covering of the spermatic cord. F., Cribriform, the sievelike covering of the saphenous opening. F. dentata, a serrated band of cinerea of the hippocampal gyrus of the cerebrum. F. of the Dorsum of the Foot, forms a sheath for the dorsal tendons of the foot. F., Iliac, lines the back part of the abdominal cavity, covering the psoas and iliacus muscles. F., Infundibuliform, the funnel-shaped membrane enclosing the spermatic cord and testis in a distinct pouch. F., Intercolumnar, from the margins of the external abdominal ring, forming a sheath for the cord and testis. F., Intercostal, a thin, firm layer of fascia covering the outer surface of the external intercostal and the inner surface of the internal intercostal muscles. F. Ischio-rectal, covers the perineal aspect of the levator ani muscle. F. lata, the dense fibrous aponeurosis surrounding the thigh, called the Deep $F$. of the Thigh. F., Deep, of Leg, continuous with the last, surrounds the leg. F., Lumbar, the posterior aponeurois of the transversalis muscle, divided into three layers. F. of Mamma, part of the superficial fascia of the thorax, which divides into two layers, one passing in front, and one behind the mamma. F.nodosa, Packer's Knot, a knotted bandage formerly used to make compression over the temporal artery. F., Obturator, continuation of the pelvic, surrounding the obturator muscle. F., Pelvic, lines the cavity of the pelvis, continuous with the transversalis and the iliac fascia. F., Perineal, the deep, called the triangular ligament, closes the front part of the outlet of the pelvis; it is attached to the pubes and rami of the isch- ium. F., Plantar, the fibrous membrane of the sole of the foot. F., Recto-vesical, the visceral layer of the pelvic fascia, investing the prostate, bladder, and rectum. F., Spermatic, a thin fascia attached to the external abdominal ring, and prolonged down over the outer surface of the chorda testis. F. spirales. See Ascia. F., Temporal, a strong fibrous investment covering the temporal muscle. F., Transversalis, a fascia continuous with the iliac and pelvic fasciæ, and lying between the transversalis muscle and the peritoneum.

Fascial (fash'-e-al) [fascialis, of a fascia]. Pertaining to or of the nature of a fascia.

Fasciate (fash'-e-ät) [fascia, a bundle or band]. In biology, banded; also applied to monstrous stems that grow Hat.

Fasciation (fash-e-a'-shun) [ fasciatio; fascia, a bandage]. The art or act of bandaging.

Fascicle $\left(f a s^{\prime}-i k-l\right)$ [dim. of fascis, a bundle]. In biology, a bundle, as a compact inflorescence or a cluster of leaves. See Fasciculus.

Fasciculate, or Fasciculated ( $f a s-i k^{\prime}-u-l a ̈ t, f a s-i k^{\prime}-u$ la-ted) [fasiculus, a little bundle]. Arranged in fasciculi, or little bundles.

Fascicule (fas'-ik-üi) [fasciculus, a small bundle]. In biology, applied to brush-like bundles of hairs often seen on caterpillars, etc.

Fasciculus (fas-ik'-u-lus) [dim. of fascis, a bundle: pl., Fasciculi]. A little bundle, as the fasciculus of fibers that compose a nerve. F., Olivary. See Fillet, Olivary. F. of Türck, the crossed pyramidal tract of the spinal cord.

Fascination (fas-in-a'-shun) [fascinatio, a bewitching]. A form of incomplete hypnotism, intermediate between somnambulism and catalepsy; the alleged controlling influence of one person over another.

Fasciola (fas- $\left.i^{\prime}-0-Z c h\right)$ [L., a small bandage]. The dorsal continuation of the fascia dentata of the cerebrum. F. hepatica. See Trematodes. F. hepaticum. See Distoma hepaticum.

Fasciole $\left(f a s^{\prime}-e-\bar{l} l\right)$ [fasciola, a small bandage]. In biology, a narrow transverse band or stripe.

Fascioliasis (fas-e-o-li'-as-is) [ fasciola, a small bandage]. A term employed in England for Distomiasis (Wiame), or Distomatosis (Zundel).

Fasciotomy (fash-e-ot'-o-me). See Aponeurotomy.

Fast [ME., fast, firm, stiff; fasten, to fast]. Fixed ; immovable; close; sound, as sleep; to abstain from food; abstinence from food. F. Color. See Pigments, Colors, and Dye-stuffs F.-blue. Same as Alkali Bluc, Coupier's Blue, Methylene-blue. See Pigments, Conspectus of. F.-brown. See Pigments, Conspectus of. F.-green. See Pigments, Conspectus of. F.-red. See Pigments, Conspectus of. F.-yellow. Same as Acid Yellow. See Pigments, Conspectus of.

Fastidium (fas-tid"-e-um) [L., "a loathing" ]. A loathing for food or drink.

Fastigatum (fas-tig- $a^{\prime}$-tum). See Nucleus fastigii.

Fastigiate, Fastigiated ( fas-tij'-e-ät, - - $a^{\prime}$-ted) [ fastigatus, sloping, pointed]. In biology, tapering gradually; close, parallel.

Fastigium $($ fas-tij"-e-um) [L., "summit"] . I. The acme of any disease. 2, A dorsal extension of the adult epicele into the cerebellum; its cephalic and caudal slopes meet like a gable-roof, whence its name.

Fasting ( fast'-ing) [ME., fasten, to fast]. The partial or complete abstinence from food. F.-cure. See Limotherapy. F.-mania, a prevalent or epidemic practice of absolute and complete fasting, mainly for exhibition and profit, such as occurred in $1890-9 x$. Fifty-five days appears to be the extreme limit reached as yet by any professional abstainer from food. F.- 
girls, hysterical women who, for the sake of gaining sympathy and attention, pretend to fast, but for the most part secretly obtain food.

Fat [ME, fat, fat]. See Adeps, Tissue, and Oil. F.ball, a mass of fatty substance on the dorsal aspect of the buccinator muscle; called also Bichat's fatball. F.-cell, a form of connective-tissue cell containing oil-globules. F.-column, a columnar-shaped space filled with adipose tissue found in the thicker portion of the cutis vera. F.-necrosis, a peculiar form of

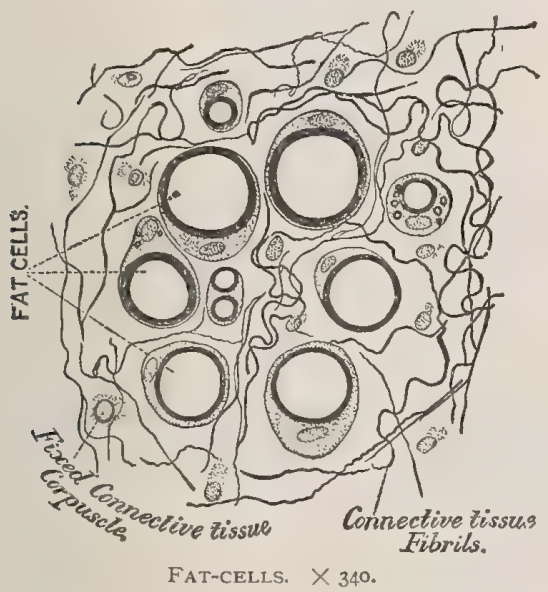

necrosis of a tissue occurring in pin-point sized areas of a dead-white color. It is seen usually in the interlobular pancreatic tissue, mesentery, omentum, and abdominal fatty tissue generally, and frequently in connection with pancreatic disease. F,-rickets, that form of rickets in which there is not excessive emaciation.

Fatal ( $f a^{\prime}$-tal) [fatalis; fatum, fate, destiny, death]. Ending with death; mortal; deadly; as a fatal accident or attack.

Fatigue (fa-teg $\left.g^{\prime}\right)$ [fatigo, weariness]. Weariness, tiredness. That condition of diminished capacity for work produced in a muscle by prolonged activity. F.-diseases, those caused by constant repetition of certain movements, such as Tailors' cramp, Writers' cramp, Scriveners' palsy, etc. See Cramp, and Spasm. F.-stuffs, decomposition products that have accumulated in the muscular tissue during exhaustive efforts; among them are phosphates, phosphoric acid, carbonic acid, and perhaps glycerin-phosphoric acid.

Fatty $\left(f a t^{\prime}-e\right)$ [ME, fat, fat]. A qualification applied to certain carbon derivatives, including fats and fatty acids. They were better called marsh-gas or methane derivatives, as they can all be obtained from methane, $\mathrm{CH}_{4}$. See Acids, Fatty. F. Degeneration. See Degeneration. F. Heart. See Heart. F. Nutmeg. Same as Nutmeg Liver.

Fatuity (fat- $\left.u^{\prime}-i t-e\right)$ [fatuitas, foolishness]. Amentia or dementia.

Fauces $\left(f a w^{\prime}-s e \bar{z}\right)$ [L.]. The gullet or windpipe. The space surrounded by the palate, tonsils, and uvula. In biology, the throat of a monopetalous flower or the cavity of a gasteropod shell as exposed in the first whorl. F., Isthmus of, the space at the back of the mouth enclosed by the margin of the palate, the back of the tongue, the pillars of the soft palate and the tonsils. F., Pillars of, the folds of mucous membrane between the base of the uvula and the posterior border of the tongue.
Fauchard's Disease. See Diseases, Table of.

Faucial (faw'-se-al) [fances, the gullet]. Pertaining to the fauces.

Faucitis (faw-si'-tis) [fauces, the gullet; $\iota t \iota s$, inflammation]. Inflammation of the fauces; isthmitis.

Fault (farult) [ME, faut, a lack]. In electricity, any failure in the proper working of a circuit due to ground-contacts, cross-contacts, or disconnections. These may be of three kinds: I. Disconnections; 2. Earths; 3. Contacts.

Fauna ( $\left.f a w^{\prime}-n a h\right)$ [Faumus, the god of agriculture pl., Faunce or Faunas]. The entire animal life of any geographic area or geologic period.

Faunorum ludibria (fazen-o'-rum lu-dib'-re-ah) [L., "sport of the fauns" $]$. An old designation for nightmare and for epilepsy.

Favaginous (fav-aj'-in-zus) [farus, a honeycomb]. Resembling favus; having a honeycombed surface.

Favella ( fav-el'-ah) [ favilla, embers: pl., Favella]. In biology, an irregular mass of spores embedded in a gelatinous material, and constituting a form of sporocarp found in the Florider.

Faveolate $($ fav-e'-o-lāt) [ favus, honeycomb]. Favose, honeycombed; same as alveolate.

Faveolus (fav-e'-o-lus) [ favus, a honeycomb: pl., Faveoli]. In biology, a pit or cell like that of the honeycomb.

Faviform (fav'-if-orm) [favus, honeycomb; forma, form]. Resembling a honeycomb; a designation of certain ulcerated surfaces.

Favous, or Favose (fav'-us or fav-ōs') [ favus, honeycomb]. Resembling a honeycomb ; resembling favus; alveolate; filled with polygonal depressions.

Favulus (fav'-u-lus) [dim. of favus, a honeycomb: $p l .$, Favili]. Any one of the honeycomb-like depressions or alveoli of the gastric mucous membrane.

Favus $\left(f a^{\prime}\right.$-vus $)$ [ favus, honeycomb]. Tinea favosa, Honeycomb Ringruorm, a parasitic skin-disease due to the presence of a vegetable parasite, the Achorion schönleiniz, which, growing in the epidermis, hair, and nails, causes varying grades of inflammation, alterations of structure, and, when occurring upon hairy parts, partial or complete loss of hair. It is characterized by the presence of variously-sized, sulphur-yellow, cup-shaped crusts, having a peculiar musty odor, which are found on microscopic examination to be composed almost entirely of the elements of the fungus. F.-cup, any one of the cup-shaped crusts that characterize favus.

Faxwax (faks'-waks) [fax, hair; Ger., wachsen, to grow]. The ligamentum nuchæ, or the material of which it is composed. It is also called paxwax.

Fear (fêr) [ME., feer]. An emotion of dread; apprehension; the feeling which in its intenser manifestations is called terror or fright.

Feather $\left(f e t h^{\prime}-e r\right)$ [AS., fedher ${ }^{-}$. One of the epidermal appendages of birds. F. Respiration-register. See Anesthetic.

Feature ( $f e^{\prime}$-chür) [factura, a making]. Any single part or lineament of the face.

Febricity (fe-bris'-it-e) [febris, a fever]. Feverishness.

Febricula (fe-brik'-u-lah) [L., dim. of febris, fever]. A term indicating a slight and short fever, most frequently encountered among children. The rash that accompanies it is very similar to that of scarlet fever.

Febrifacient (feb-re-fa'-se-ent) [febris, a fever; facere, to make]. Causing fever.

Febriferous (fe-brif'-er-us) [febris, a fever; ferre, to bear]. Causing or conveying fever.

Febrific (fe-brif'-ik) [febris, a fever]. Febrifacient.

Febrifugal (fe-brif'-u-gal) [febris, fever; fugare, to dispel]. Removing or dispelling fever. 
Febrifuge (feb'-rif- $\overrightarrow{u j}$ ) [febris, fever; fugare, to dispel]. I. Antipyretic; cooling; lessening or relieving fever, 2. An agent that lessens fever.

Febrile (fe'-bril) [febrilis; febris, a fever]. Pertaining to or having the symptoms of a fever.

Febrility (fe-bril'-it-e) [febris, a fever]. The quality of being febrile; feverishness.

Febris (fe'-bris) [L.]. See Fever. F. bullosa. Synonym of Pemphigus. F. catarrhalis. Synonym of Infuenza. F. dysenterica. Synonym of Dysentery. F. famelica. See Famelica. F. flava. See Fever, Yellow. F. nigra. Synonym of Fever, Cerebro-spinal. F. recurrens. Synonym of Fever, Relapsing. F. remittens. See Fever, Remittent.

Fecal ( $\left.f^{\prime}-k a l\right)$ [ fex, sediment]. Pertaining to or consisting of feces.

Fecaline $\left(f e^{\prime}-k_{a l}-\bar{e} n\right)$. Same as Fecaloid.

Fecaloid (fe'-kal-oid) [fiex, feces; eidos, likeness]. Resembling feces.

Feces $\left(f e^{\prime}-s \bar{z} z\right)$ [fex, sediment]. The dregs of a liquor, as wine. Also, the alvine discharges or excretions of the bowels.

Fechner's Law. See Lau'

Fecula $\left(f e k^{\prime}-u-l a h\right)$ [dim. of $f a x$, sediment]. The starchy part of a seed. Also the sediment subsiding from an infusion.

Feculent (fek'-u-lent) [ feculentus, impure]. Abounding in or of the nature of feces; excrementitious; sedimentary; muddy.

Fecundate $\left(f e^{\prime}-k u n-d \bar{a} t\right)$ [fecundare, to fecundate]. To impregnate; to render pregnant.

Fecundation (fe-kun-da'shun) [ fecundatio; fecundus, fruitful]. Fertilization; impregnation; the act of making fruitful. F., Artificial, impregnation by means of artificial intromission of the spermatic fluid into the vagina or uterus.

Fecundity (fe-kun'-dit-e) [fecunditas, fruitfulness]. The capability of reproduction. F., Segregate. See Homogamy.

Fed. See Cross-circulation Experiment.

Feeble $\left(f e^{\prime}-b l\right)$ [ME., feble, weak]. Lacking strength; weak. F.-minded, idiotic.

Feed ( féd) [ME., fedan, to nourish]. 1. To supply with food; to graze; to eat. 2. Food, especially that for lower animals; fodder.

Feeder $\left(f e^{\prime}\right.$-der $)$ [ME., fedan, to nourish]. I. An instrument used in the forcible feeding of insane patients who obstinately refuse to eat. 2, See Crosscirculation Experiment.

Feeding ( $f e^{\prime}$-ding) [ME., fedan, to nourish]. The taking of food or aliment. F., Artificial, the introduction of food into the body by means of artificial devices, such as the stomach-pump or in the form of an enema. Also, the nourishing of a child by food other than the mother's milk. F-bottle, a glass flask armed with a rubber nipple, used in feeding liquid food to infants. F. - cup, a cup used in the forcible feeding of the insane. F., Forcible, the administration of aliment by compulsion to such patients as refuse to take food in the natural manner. F.-gland, a chyle-gland or "salivary gland" of working bees. F.-groove, a narrow trough on the tongue of a worker bee, along which the honey is brought by compression of the honey-sac. F. by the Rectum, the introduction of food into the rectum in the form of an enema or suppository. F.-system. See Rest-cure.

Feel $(f e l)$ [ME., felen, to feel]. To have a sensation of; to try by touch; to have perception by means of the sense of touch.

Feeler (fell-er) [ME., felen, to feel]. See Antenna.

Feeling (fell'ing) [ME., felen, to feel]. The sense of touch; any emotion or sensibility; any conscious state of nervous activity; any sensation.
Feet (fet). The plural of Foot, q.v. F., Frosted. See Chilblain.

Fegaritis ( $\left.f e g-a \dot{r}^{\prime}-i^{\prime}-t i s\right)$ [Sp.; $\iota \tau \iota s$, inflammation]. An old name for a form of gangrenous stomatitis.

Fehling's Method. A method of dressing the umbilical cord. The stump is wrapped in cotton-wool powdered with a mixture of salicylic acid one part, and starch five parts. It becomes mummified. F.'s Solution, a solution for testing for sugar in the urine; as this solution does not keep well, Prof. Holland advises its manufacture as follows: To be kept in two distinct parts. (a) Take copper sulph. 34.64 gms. and water enough to make 500 c.c. M. (b) Pure Rochelle salt 173 gms.; sol. sodium hydrate (sp. gr., I.33), roo c.c., and water enough to make 500 c.c. For use, mix equal volumes, and thus make Fehling's solution. See Copper. F.'s Test for Sugar. See Tests, Table of.

Feigned Disease. See Disease.

Fel [L.]. Bile. F. bovis, or F. bovinum, ox-gall. The biliary liquid of the domestic ox, Bos taurus. It is a dark-green, ropy substance, consisting mainly of sodium glycocholate and sodium taurocholate, together with cholesterin. It is a tonic, antiseptic, and purgative, useful in emulsifying the fatty portions of food. F. b. inspissatum, 100 parts fresh ox-gall, strained and evaporated to 15 parts. Dose gr. v-xv. F. b. purificatum, ox-gall 3, alcohol I part. This should stand 24 hours before straining; then evaporate to the consistence of a pilular mass. Dose gr. $\mathrm{v}-\mathrm{xv}$.

Fell's Method. A method of forced respiration in cases of narcotic poisoning or drowning, by means of an apparatus consisting of a tracheotomy-tube attached to a bellows. F.'s Paste, Caustic, or Cancer-salve, a famous salve formerly used in epithelioma. Its formula was: chlorid of zinc and powdered sanguinaria root, of each one ounce; starch, enough to make a paste; apply on pieces of kid leather or wash-leather.

Fellator (fel'-at-or). See Passizism.

Fellatrice (fel-at-rês') [Fr.]. The female agent in irrumation, who receives the male organ in her mouth and by friction with the lips or tongue produces the orgasm.

Fellic Acid ( $\left.\mathrm{fel}^{\prime}-i k\right)$ [ fel, bile], $\mathrm{C}_{23} \mathrm{H}_{40} \mathrm{O}_{4^{\circ}}$ A constituent of the bile.

Fellmongers' Disease. Anthrax; so called as attacking dealers in fells, or pelts, ard skins.

Fellows' Syrup of Hypophosphites. A proprietary preparation. Each dram contains hypophosph. of iron gr. j, quinin gr. $3 / 4$, strychnin gr. $\frac{1}{64}$, calcium and manganese āa gr. $\mathrm{j}$, potassium q. s. Dose $\mathbf{3}$. Unof.

Felo-de-se ( $f e^{\prime}-20$-de-se) [Sp.]. A suicide. Also, any one who commits an unlawful malicious act, the consequence of which is his own death.

Felon ( fel'-on). See Paronychia.

Felt [feltrum, felt]. A fabric of hair or wool entangled together by beating and rolling. Felt splints are employed in surgery.

Female ( $\left.f e^{\prime}-m \bar{a} l\right)$ [feminca, femella; femina, woman]. Belonging to the sex that conceives and bears young. In surgery, denoting that part of a double-limbed instrument that receives the complementary part. F. Catheter, a catheter having a short tube with a slight curve to correspond to the female urethra.

Feminism ( fem'-in-izm) [fimina, a woman]. Arrested development of the male organs of generation, accompanied by various mental and physical approximations to the characters of the female sex.

Feminity ( $f e m$-in'-it-e), or Femininity ( $f e m-i n-i n^{\prime}$. it-e) [femina, a woman]. The sum of those qualities that distinguish the female sex.

Feminonucleus (fem-in-o-nu'-kle-us) [ femina, woman; nucleus, a kernel]. The embryonic female nucleus, as distinguished from the corresponding male nucleus. 
Femoral (fem'-or-al) [femur, the thigh bone]. Pertaining to the femur. F. Arch, that formed by Poupart's ligament. F. Artery. See Arteries, Table of. F. Canal. See Canal. F. Hernia. See Hernia. F. Ligament of Hey. See Ligament. F. Ring, the abdominal end of the femoral canal, normally

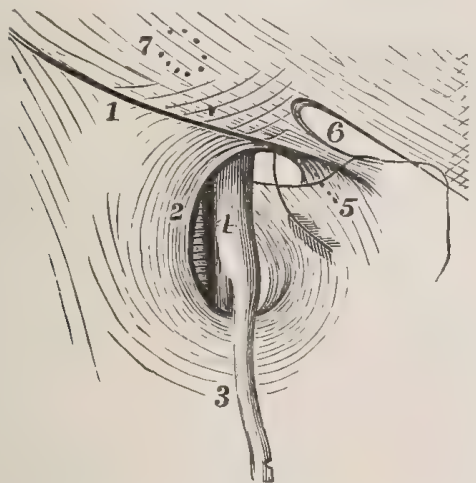

THE FEMORAL RING AND SAPHENOUS OPENING. (After Holden.)

(The arrow is introduced into the femoral ring).

1. Crural arch. 2. Saphenous opening of the fascia lata. 3. Saphena vein. 4. Femoral vein. 5. Gimbernat's ligament. 6. External abdominal ring. 7. Position of internal ring.

closed by the crural septum and the peritoneum. F. Sheath, a continuation downward of the fasciæ that line the abdomen. It contains the femoral vessels. F. Vein, See $V$ in.

Femoren $\left(f e m^{\prime}-o r-e n\right)$ [femur, the thigh-bone]. Belonging to the femur in itself.

Femorocele $\left(\mathrm{fem}^{\prime}-\mathrm{or}-0-\mathrm{se} l\right)$ [femur, femur; $\kappa \dot{n} \lambda \eta$, hernia]. Femoral hernia.

Femoro-rotulian (fem'-or-o-ro-tu'-le-an) [femur, the thigh-bone; rotula, the patella]. Pertaining to the femur and the rotula or patella.

Femoro-tibial (fem'-or-o-tib'-e-al) [femur, the thighbone; tibia, the shin-bone]. Relating to the femur and the tibia.

Femur (fe'-mer) [L., pl., Femora, or Femurs]. The thigh-bone, the longest and heaviest bone of the body, articulating with the acetabulum and the tibia. See Bones, Table of.

Fenestra $\left(f e-n e s^{\prime}-t r a h\right)$ [L., a window]. I. In anatomy, a name given to two apertures of the ear, the $F$. ovalis and $F$. rotunda, 2. The open space in the blade of a forceps. 3. An opening in a bandage or dressing for drainage, etc.

Fenestral, or Fenestrate (fe-nes'-tral, fe'-nes-trāt) [fenestra, a window]. Having apertures or openings.

Fenestrated (fe-nes'-tra-ted) [fenestra, a window]. Perforated. F. Membrane of Henle, the outer membrane of the inner coat of the arteries.

Fenestrella (fe-nes-trel'-ah) [dim. of fenestra, a window: pl., Fenestrella]. In biology, a transparent spet in the wing-cover of certain insects.

Fenestrule ( fe-nes'-trül) [fenestra, a window]. In biology, a small open space, as between the anastomosing branches of the cenecium of a polyzoan.

Fenger's Operations. See Operations, Table of.

Fennel $\left(f e n^{\prime}-e l\right)$ [ME., fenel]. An umbelliferous plant, Foniculum capillaceum, native to the Old World and common in cultivation. Its dried fruit (Foniculum, U. S. P.) is aromatic and carminative, but is chiefly used as a corrigent, as for senna and rhubarb. See Foniculum. Fenner's Guaiac-mixture. See Guaiac-mixture.

Fenugreek (fen'-u-grék) [ fanum, hay; gracum, Greek].
The leguminous plant, Trigonella fonumgracum; also its mucilaginous and oily seed; it is used in plasters and poultices, and is valued in veterinary practice, chiefly as a vehicle for other medicines.

Fenwick's Operation. See Operations, Table of.

Feraconitin (fer-ak-on'-it-in). Same as Pseudaconitin,

$q$.

Feral $\left(f e^{\prime}-r a l\right)$ [feralis, deadly]. Deadly or fatal ; as a feral disease.

Fergusson's Method. See Treatment, Methods of. F.'s Operations. See Operations, Table of.

Ferine $\left(f e^{\prime}-r i n\right)$ [ferinus, wild; fera, a beast]. Noxious, malignant, or violent; as a ferine disease.

Ferment (fer'-ment) [ fermentum, leaven, yeast]. Any microörganism, proteid, or other chemic substance capable of producing fermentation, $i . e .$, the oxidation and disorganization of carbohydrates. Cf. Enzym Zymaze. F., Organized, or Living, one that grows and multiplies at the expense of the substance in which it occurs-this takes place only so long as the ferment is living. Yeast is the representative of this class, causing fermentation by splitting up sugar into $\mathrm{CO}_{2}$ and alcohol. See Fermentation. F., Unorganized, or Non-living, a nitrogenous body produced within the body by the vital activity of the protoplasm of the cells. These ferments are soluble in water and glycerin, and can be precipitated by alcohol. The following is a list of this class: Ptyalin, in saliva, converts starch into maltose. Pepsin, in gastric juice, converts proteids into peptones in an acid medium. There are also in the gastric juice milk-curdling, fat-splitting, and lactic acid ferments, whose functions are indicated by their names. In the pancreatic juice, there are $\mathbf{F}$., Diastatic or Amylopsin, converting starch into maltose; Trypsin, converts proteids into peptones in an alkaline medium; F., Emulsive, emulsify fats; F., Fatsplitting, or Steapsin, splits fats into glycerin and fatty acids, and F., Milk-curdling. In the intestinal juice, there are F., Diastatic, which changes maltose into glucose; F., Proteolytic, which changes fibrin into peptone; Invertase, which changes cane-sugar into grape-sugar; and $F_{2}$, Milk-curdling, and F., Diastatic, are also found in blood, chyle, liver, milk, etc. Pepsin and other ferments are also found in muscle and urine; and, lastly, a Fibrin-forming $F$. is also found in blood.

Fermentation (fer-men-ta'-shun) [fermentum, leaven]. The decomposition of complex molecules under the influence of ferments (organized) or zymazes or enzyms (unorganized), frequently accompanied by the assimilation of one or more molecules of water (hydrolysis). Processes of oxidation and deoxidation sometimes accompany fermentation. The ordinary transformation termed eremacausis or decay, is an oxidation process. Putrefaction is applied especially to those fermentations involving nitrogenous matter and accompanied by the disengagement of offensive gases. In these cases, the growth of one or more species of microbes is correlated with the chemic changes in the medium. F., Acetic, the fermentation whereby weak alcoholic solutions are converted into vinegar, caused by the Bacillus aceti, etc. F., Albuminoid; the agents of this decomposition are the Bacillus albuminis, $B$. catenula, $B$. claviformis, $B$. distortus, $B$. fliformis, $B$. geniculatis, B. scaber, B. tenuis, B. urocephalus, etc. $F$., Ammoniacal; the agent of the ammoniacal fermentation of urine is the Micrococcus uree. F., Butyric, the conversion of butter-fat into butyric acid, due to a microbe, Bacillus butyricus. F., Gluconic; glucose is transformed by the action of the Micrococcus

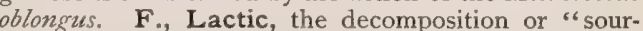
ing" of milk, caused by the microbe, Bacillus lacticus. 
F., Propionic ; the Bacillus cavicida decomposes saccharine solutions, producing propionic acid. F., Putrefactive, the decomposition commonly known as putrefaction, caused by various microbes, especially the Micrococcus pyogenes (albus, aureus, citreus, tenuis, salivarius, etc.). F., Test. See Tests, Table of. F., Viscous, the change produced in the culturemedium by the Micrococcus viscosus, a gummy substance being developed

Fermentemia (fer-men-te'-me-ah) [ fermentum, leaven ; aikn, blood]. The abnormal presence of a ferment in the blood.

Fermentogen (fer-ment'-o-jen) [fermentum, leaven; $\gamma \varepsilon v \nu \tilde{v} v$, to produce]. Any substance (like pepsinogen or trypsinogen) that on the reception of the appropriate stimulus is changed into a ferment.

Fern [ME., ferne]. Any cryptogamous plant of the order Filices. See Aspidium.

Ferntickle (fern'-tik-il) [Prov. Eng.]. A freckle; ephelis.

Ferralum (fer-al'-um) [fermum, iron; alumen, alum]. A proprietary disinfectant, consisting largely of the sulphate of iron and aluminum.

Ferramentum (fer-am-en'-tum) [L., an iron implement: pl., Ferramenta]. A surgical instrument of iron or steel.

Ferran, Peronospora of. See Peronospora.

Ferrein, Canal of. See Canal. F., Pyramids of. See Pyramid. F., Tubule of. See Pyramid.

Ferri- $\left(f e r^{\prime}-i-\right)$ [fermom, iron]. A prefix that indicates the ferric, as distinguished from ferrous compounds. Containing iron as a quadrivalent element.

Ferrier's Snuff. A snuff used in acute rhinitis. Its formula is hydrochlorate of morphin $\mathrm{gr} . \mathrm{ij}$, powdered acacia $3 \mathrm{ij}$, and subnitrate of bismuth, $3 \mathrm{vj}$. See Bismuth.

Ferro- (fer-o-) [ferrum, iron]. A prefix used with the names of certain (ferrous) compounds and salts of iron.

Ferrocyanid (fer-o-si'-an-id) [ferm, iron; cyanogen]. A compound of ferrocyanogen with an element or radical. That of potassium (Potassii ferrocyanidum) is official; that of iron was so formerly. That of zinc (Zinci ferrocyanidum) is sometimes given as a medicine. Dose gr. I-4, in pill. F. of Potassium and Acetic Acid Test. See Tests, Table of.

Ferrocyanogen (fer-o-si-an'-o-jen) [ferrum, iron; cyanogen]. The quadrivalent radical, $\mathrm{Fe}(\mathrm{CN})_{6}$.

Ferrous $($ fer'-us $)$ [ferrum, iron]. Containing iron as a bivalent element. Cf. Ferric.

Ferrozone ( $\left.f e r^{\prime}-o-z o ̈ n\right)$ [ ferrum, iron; $b \zeta \varepsilon \iota v$, to smell]. A material consisting in part of iron protosulphate; it is used as a precipitant for sewage.

Ferruginous (fer-u'-jin-us) [ferrugo, rust; fermm, iron]. Same as Chalybeate.

Ferrule $\left(\right.$ fer $\left.^{\prime}-u l\right)$ [ferm, iron]. A metallic hoop placed around a broken tooth; an instrument used with an attached lever in aligning irregularly placed teeth.

Ferrum $\left(f_{e r}-u m\right)$ [L. : gen., Ferri]. Iron. $F_{e}=56$. Quantivalence II, IV. A metal having a luster varying from silver-white to gray. In pharmacy, a fine non-elastic, soft wire is used. Externally many of the soluble salts of iron make excellent styptic and astringent lotions. F. redactum, Quevenne's Iron, iron by hydrogen, occurs as a fine powder obtained by the reduction of ferric oxid by hydrogen. It is a constituent of the blood, to the red corpuscles of which it gives color. It is an irritant in large or long-continued doses. In small doses it is a stimulant and slightly astringent tonic. It is highly valuable in anemia, but contra-indicated in plethora. Dose gr. j-v. F. redacti, Trochisci (B.P.), each containing gr. I of iron. Ferri acetat., Liq., a 33 per cent solution in water. F. acetat., Liq., fort (B.P.). Dose $m$ j-viij. F. acetat., Tinct., has liq. ferri acetat 50 , alcohol 30 , acetic ether 20 parts. It is styptic and stimulant. Dose $\eta \mathrm{x}-3$ ij. F.bromid., Fe$\mathrm{Br}_{2}$. Dose gr. $\mathrm{v}-\mathrm{xx}$. F. bromidi, Syr., contains Io per cent. of ferric bromid. It is a sedative tonic, recommended in nervous disorders. Dose $m, \mathrm{v}-\mathrm{xxx}$. F. carb. saccharat., contains 15 per cent. of ferrous carbonate. It is a stimulant to digestion. Dose gr. ijx, with food. F . carb., Massa, Vallet's mass; ferrous sulphate I00, sodium carbonate IIO, honey 38 , sugar 25, syrup and distilled water $\bar{a} \bar{a}$ q. s. ad fac. 100 parts. Dose gr. iij to $\mathrm{v}$, after food. F. carb., Pil. (B.P.). Dose gr. $v-x x . \quad F .$, Mist., aromat. (B.P.). Dose 亏 j-ij. F., Mistura, comp., Griffith's mixture; ferrous sulphate 6 , myrrh, sugar, $\bar{a} \bar{a} 18$, potassium carbonate 8 , spt. lavender 50 , rose-water 900 . This is essentially a carbonate of iron. Dose 3 ss. F., Pilulæ, comp., Griffith's pill, containing each, ferrous sulphate gr. $3 / 4$, sodium carb. gx. $3 / 4$, myrrh gr. iss, syrup q. s. Dose gx. ij to vj. F. chloridum, $\mathrm{Fe}_{2} \mathrm{Cl}_{6}, \mathbf{I} 2 \mathrm{H}_{2} \mathrm{O}$, strongly acid, astringent, hemostatic, and styptic. It is never used internally. F. chlorid., Liq. (Liq. fer. perchloridi, B.P.), an aqueous solution containing 38 per cent. of the salt. Dose mij-x; rarely used. Liq. fer. perchlor. fort. (B.P.), a powerful styptic. $\mathrm{Fe}_{2}\left(\mathrm{C}_{6} \mathrm{H}_{5} \mathrm{O}_{7}\right)_{2} 6 \mathrm{H}_{2} \mathrm{O}$. F. chlorid., Tinct., contains liq. ferri chlor. 25 , alcohol q. s. It is very commonly used, and is one of the best tonic preparations. Dose $\eta^{v-x x}$. Tinct. fer. perchloridi (B.P.). Dose $\eta_{x-x x}$. F. citras, soluble in water, insoluble in alcohol; a mild stimulant. Dose gr. ij-v. F. citras, Liq., a solution of ferri citrat., 35 per cent. in strength. Dose $m v-x v$. F. citras, Vinum, ammonio-ferric citrate 4 , tinct. orange peel, syrup, ââ I2, stronger white wine 72 parts. Dose $3 \mathrm{j}$ ij. F. hypophosphis, $\mathrm{Fe}_{2}\left(\mathrm{H}_{2} \mathrm{PO}_{2}\right)_{6}$, ferric hypophosphite, soluble in very dilute hydrochloric acid. Dose gr. v-x. F. iodidum saccharat., soluble in water. It is a tonic. Dose gr. $\mathbf{v - x x v . ~ F . ~ i o d i d . , ~ P i l . ~}$ contains reduced iron, iodin, liquorice, sugar, acacia, and water, coated with balsam of tolu in ether. Dose $j-i j$ pills. F. iodidi, Syr., contains ro per cent. of the iodid. Dose $\eta_{v-x x x}$. F. lactas, $\mathrm{Fe}\left(\mathrm{C}_{3} \mathrm{H}_{5} \mathrm{O}_{3}\right) \cdot 3 \mathrm{H}_{2} \mathrm{O}$, ferrous lactate,- -best solvent, sodium citrate. Dose gr. j-iij. F. nitratis, Liq., aqueous, contains 6 per cent. of the salt; it is styptic and astringent. Dose $m v-x v$. $\mathbf{F}$. oxalas, $\mathrm{FeC}_{2} \mathrm{O}_{4} \cdot \mathrm{H}_{2} \mathrm{O}$. Dose gr. ij in pill. $\mathbf{F}$. oxid. hydratum (Ferri peroxid. hydrat. B.P.), Fe(HO) 6 , ferric hydrate, prepared by adding aq. ammonize 8 parts to a solution of ferric sulphate Io parts. It is an antidote for arsenical poisoning, and should be prepared as needed. Dose $\mathbf{3}$ j. F.oxid. hydrat. cum magnesia, should be prepared as needed from sol. ferric sulphate Iooo gr., water 2000 grains, to which is added magnesia $150 \mathrm{gr}$., water $\overline{3} \times x \times i j$. It is an antidote for arsenic. F., Emplastrum, strengthening-plaster; ferric hydrate 9, olive-oil 5, Burgundy pitch 14, lead-plaster 72. F., Trochisci, have each of ferric hydrate dried gr. $\nabla$, vanilla gr. $\frac{1}{10}$, sugar and mucilage of tragacanth q. s. Dose j-iij each day. F. phosphas, $\mathrm{Fe}_{3} \mathrm{P}_{2} \mathrm{O}_{8} .8 \mathrm{H}_{2} \mathrm{O}$, an adjuvant to laxative pills, gr. $v-x$. F. phosphat., Syr. (B.P.). Dose 3 j. Fox's Pill (B.P.), Blaud's Pill. See Pill. F. pyrophosphas, tasteless and non-astringent. Dose gr. ij-v. F. subchloridi, Syr. (B.P.). Dose 3 ss-j. F. sulphas, $\mathrm{FeSO}_{4} \cdot 7 \mathrm{H}_{2} \mathrm{O}$, copperas, protosulphate of iron, ferrous sulphate, astringent and irritating. It is an ingredient of pil, aloes et ferri, $q . v$. F. sulph, exsiccat., $\mathrm{FeSO}_{4} \cdot \mathrm{H}_{2} \mathrm{O}$. Dose gr. ss-ij in pill. F. sulph. granulatus (Ferri sulphas granulata, B. P.), FeS- 
$\mathrm{O}_{4} \cdot 7 \mathrm{H}_{2} \mathrm{O}$, the foregoing precipitated from its solution by alcohol. Dose gr. ss-ij. F. subsulph., Liq., $\mathrm{Fe}_{4} \mathrm{O}$ $\left(\mathrm{SO}_{4}\right)_{5}$, Monsel's solution, an aqueous solution of basic sulphate of iron, powerfully astringent, styptic and hemostatic; it is rarely given internally. Dose miij-x. F. valerianas, $\mathrm{Fe}_{2}\left(\mathrm{C}_{5} \mathrm{H}_{9} \mathrm{O}_{2}\right)_{6}$, valerianate of iron, soluble in alcohol. Dose gr. $\mathrm{j}$-iij, in pill. F. et ammonii citras, citrate of iron 3 , water of ammonia I part. Dose gr. ij-v. F. et ammonii sulphas, ammonic sulphate of iron, ferric alum. This is the least astringent of the sulphates. Dose gr. ij-v. F. et ammonii tartras (F. tartaratum, B.P.), ammonic tartrate of iron. Dose gr. v-xx. F. et potassii tartras, the least disagreeable of all iron preparations. Dose gr. $\mathrm{V}-\mathrm{x}$. F. et quininæ citras, contains $\mathbf{I} 2$ per cent. of quinin. It is astringent and stimulant. Dose gr. iij-v. F. et quin. cit., Liq., of doubtful value. Dose $m v-x v$. F. et quin. citras solubilis, used in preparing vinum ferri amarum. F., Vinum amarum, bitter wine of iron, contains sol. citrate of iron and quinin 8 , tinct. orange-peel $\mathbf{1} 2$, syrup 36 , stronger white wine 44 . It is a good substitute for the various "elixirs of calisaya and iron." Dose $3 \mathrm{j}-\mathrm{iv}$. F. et strychninz citras, contains I per cent. of strychnin. It is astringent and stimulating. Dose gr. j-iij. F. et ammonii acetat. Liq., Basham's mixture, contains tinct. fer. chlorid 2, acetic acid 3, liq. ammonii acet. 20, elixir aurantii 10, syrup I5, water 50 parts. It is very agreeable, tonic and diuretic. Dose $3 \mathrm{ij}-\mathrm{v}$. Unofficial preparations.-F. albuminas. Dose gr. $\mathrm{x}$-xxx, F. arsenias, $\mathrm{Fe}_{3} \mathrm{As}_{2} \mathrm{O}_{8}$ (not to be confounded with arsenit of iron). Dose gr. $\frac{1}{10}-\frac{1}{6}$. F. dialysatum, dialyzed iron, a ten per cent. oxychlorid in water. It is astringent and styptic, but only feebly chalybeate. Dose $m x-x x x$. Liq. ferri dialyzat. (B.P.). Dose $m x-x x x$. F. et manganesii iodidi, Syr., containing in each fluid ounce 50 grains of iodids in proportion of 3 of iron to $\mathbf{I}$ of manganese. Dose $\mathrm{mx}-\mathrm{xxx}-3 \mathrm{j}$. F. et manganesii phosphat., Syr., syrup of phosphate of iron and manganese. Each dram contains $2 \mathrm{gr}$. phosph. of iron and I grain of manganese. Dose 3 j. F., Mistura, aromat., pale cinchona bark 4 , calumba 2 , cloves $\mathbf{I}$, iron-wire 2 , tinct. cardamom. comp. 12 , tinct. orange-peel 2 , water of peppermint 5o. Dose $\xi^{3}-\mathrm{ij}$. F., Mist., laxans, ferrous sulphate gr. ij, magnesium sulphate $3 j$, dilute sulphuric acid $m$ iij, spt. chloroform $m x x$, water of peppermint ad $\xi_{j}$. F., Mist., salicylat., olei gaultheriæ $m \times x x i j$, tr. ferri chlorid $\mathrm{f} z$ iv, sodii salicylat. $z i v$, acid. citric. gr. $x$, glycerin. $f \xi j, l i q$. ammonii citrat. (B. P.) q. s. ad f $z$ iv ; iron to be added last in mixing. Ferro-salin., Mist., magnesium sulphate $\xi j$, potassium bitartrate $3 \mathrm{j}$, dried sulphate of iron $\mathrm{gr} . \mathrm{x}$, water $\xi \times x x i j$. Dose a wineglassful. F. phosphatum, quininæ et strychninæ, Syr., Easton's syrup, unof. Each 3 j contains gr. j phosph. of iron, gr. $\mathrm{j}$ quinin, and gr. $\frac{1}{36}$ strychnin. F. Salicylas. Dose gr. j-v. F. Tersulphatis, Liq., solution of ferric sulphate, used in making other iron preparations.

Fertile (fer'-til) [ fertilis, fruitful]. Prolific, fruitful. In botany, applied to flowers having a pistil.

Fertilization (fer-til-iz-a - shun) [fertilis, fruitful]. Impregnation; fecundation; the initial act of sexual reproduction; it consists essentially in the union of two cells possessing respectively male and female qualities.

Fertilizing Pouch ( $f\left(r^{\prime}-t i l-\bar{z} z-i n g\right.$ pozech). A folded apparatus connected with the oviduct of queen bees.

Ferula (fer'-u-lah) [L., "a rod"]. I. Giant fennel. A genus of the order Umbelliferæ. See Asafetida, Galbanum, Sumbul, Sagrapenum. 2. A splint.

Fervor (fer"-vor) [L., "heat"]. Fever-heat; it is defined as being more than calor and less than ardor. 30
Fessitude $\left(f e s^{\prime}-i t-\bar{u} d\right)$ [fessus, weary]. A sensation of weariness.

Fester $\left(\right.$ fes'-ter $^{\prime}$ [ME., fester] ، I. Any small or superficial ulceration. 2. To inflame slightly.

Festination (fes-tin- $a^{\prime}-s h u n$ ) [festinare, to hasten]. A symptom of paralysis agitans and other diseases in which the patient shows in walking a tendency to take quicker and quicker steps. Propulsion or retropulsion are coincident symptoms.

Fetal ( fe'-tal) [ fetus, an offspring]. Pertaining to the fetus.

Fetation $\left(f e-t a^{\prime}-s h u n\right)$ [ fetus, a fetus].

I. The formation of a fetus. 2. Pregnancy.

Fetich, Fetish $\left(f e^{\prime}\right.$-tish $)$. Any material object regarded with veneration or awe.

Fetichism, Fetishism (fe'tish-izm) [Fr., fetich]. The term applied by Binet to the sexual perversion exhibited by collectors of napkins, shoes, etc. He maintains that these articles play here the part of the fetish in early theology. The favors given by the women to the knights in the Middle Ages were both tokens of remembrance and sexual excitants of satisfaction. Fetichism is the association of lust with the idea of certain portions of the female person, or with certain articles of female attire. It is designated as dress-f., hair-f., hand-f., glove-f., shoe-f., etc., according to the object worshiped.

Fetichist $\left(f e^{\prime}\right.$-tish-ist $)$ [Fr., fetich $]$. An individual whose sexual interest is confined exclusively to parts of the female body, or to certain portions of female attire.

Feticide ( $f e^{\prime}$-tis-i $\vec{d}$ ) [ fetus, an unborn offspring ; cadere, to kill]. The killing by intent of the fetus in the womb.

Fetid ( $f e^{\prime}$-tid, or $\left.f e t^{\prime}-i d\right)$ [fetere, to become putrid]. Having a foul odor. F. Stomatitis. Synonym of Ulcerative Stomatitis.

Fetiferous (fe-tif'-er-us) [fetus, a fetus ; ferre, to bear]. Pregnant.

Fetiparous (fe-tip'-ar-us) [ fetus, a fetus; parere, to produce]. Giving birth to a fetus.

Fetlock ( fet'-lnk) [ME., fitlokes]. A tuft of hair growing behind the pastern-joint of horses. F.-joint, the joint of a horse's leg next to the foot.

Fetlow $\left(f^{\prime} t^{\prime}-l o\right)$ [E., dial]. A kind of whitlow or felon, seen upon cattle.

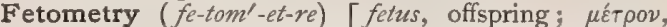
measure]. The measurement of the fetus, especially of its cranial diameters. The measurements usually made are as follows:-

TABLE OF MEASUREMENTS. I. OF THE CHILD.

Length, ............. $50 \quad \mathrm{~cm}_{6}(20$ in

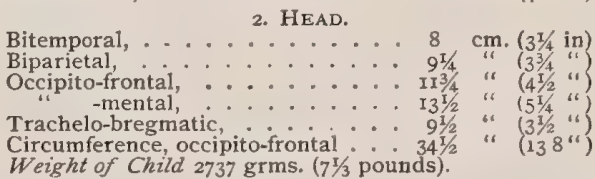

Fetor (fe'tor) [L.]. Stench; offensive odor. F. narium. Synonym of Ozena.

Fetter-bone $\left(f^{\prime} t^{\prime}-e r-\bar{b} n\right)$. In farriery, the same as great pastern. See Pasiern.

Fettered $($ fet'-erd $)$. In biology, applied to animals, as the seal, which have the hind limbs modified so as to unfit them for walking.

Fetus ( $f e^{\prime}$-tus) [fetus, offspring]. The young of viviparous animals in the womb; the embryo in the later stages of development. The following is a table of the development of the embryo and fetus in the 
different months of pregnancy. First Month. Indistinguishable from ovum of other mammals. It is a flattened vesicle. The embryo is nourished by a yelksac which, even at the end of the first month, is larger than the cephalic extremity of the fetus. The

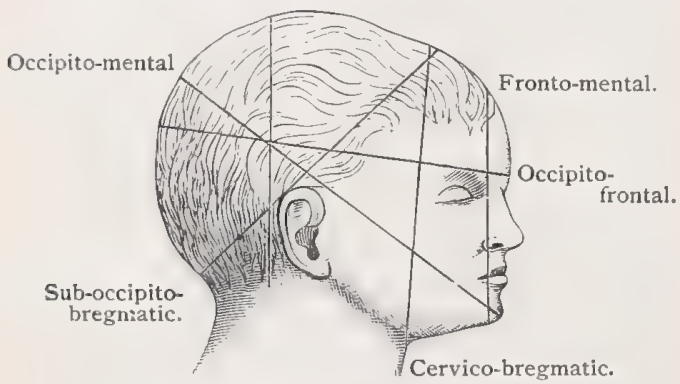

Diameters of the Fetal Head. (Tarnier.)

visceral arches are distinct. The heart, first traces of liver and kidneys, eyes, rudimentary extremities, oral and anal orifices are formed. The spinal canal closes (spina bifida results if this fails to occur at this time). Length, I cm., or .4 inch. Second Month. Grows to $4 \mathrm{~cm}$. in length (I.57 inches), and is about the size of a pigeon's egg. The visceral clefts close, except the first, which forms the external auditory meatus, tympanum, and Eustachian tube. At this time arrest of development results in hare-lip, umbilical hernia, or exomphalos. Eyes, nose, and ears are distinguishable. The first suggestion of hands and feet appears, and these are webbed. External genitals also now develop, but sex is not to be differentiated. Third Month. Maternal blood affords nourishment; $9 \mathrm{~cm}$. long $(3.6$ inches), and about the size of a goose-egg. Fingers and toes lose their webbed character and nails appear as fine membranes. Points of ossification are found in most of the bones. The neck separates the head from the trunk, and sex is determined by the appearance of the uterus. Weight, 30 grms. $=463$ grains. Fourth Month. $16 \mathrm{~cm} .=6$ in. in length. Lanugo is present. Intestines contain meconium. Sex is well defined. Weight, 55 grms. $=848.76$ grains. Fifth Month. $25 \mathrm{~cm}$. = 10 in. Vernix caseosa appears in places. The face is senile in appearance and wrinkled. Eyelids begin to open. Quickening occurs. Heart-sounds are heard. Weight, 273 grms. $=10.8 \mathrm{oz}$. Sixth Month. $30 \mathrm{~cm} .=\mathbf{I} 2 \mathrm{in}$. Hair grows longer. Eyebrows and lashes appear. The testicles approach the inguinal rings. Weight, 715 grms. $=23 \mathrm{oz}$. Seventh Month. $35 \mathrm{~cm}$. = I4 in. Pupillary membrane disappears. Weight, 1213 grms. = $39 \mathrm{oz}$. Eighth Month. $40 \mathrm{~cm} .=16$ in. Down on the face begins to disappear. The left testicle has descended. Ossification begins in the lower epiphysis of the femur. The nails do not project beyond the finger-tips. Weight, I6I7 grms. $=4 \frac{1}{3}$ lbs. Ninth Month. $45 \mathrm{~cm} .=18$ in. Subcutaneous fat increases. Diameters of the head about $\mathbf{I}$ to $\mathbf{I} 1 / 2 \mathrm{~cm}$. less than at term. Weight, 1990 grms. $=5 \frac{1}{3} \mathrm{lbs}$. Mature

ZENGTHS AND WEIGHTS OF THE FETUS AT DIFFERENT STAGES OF ITS DEVELOPMENT.

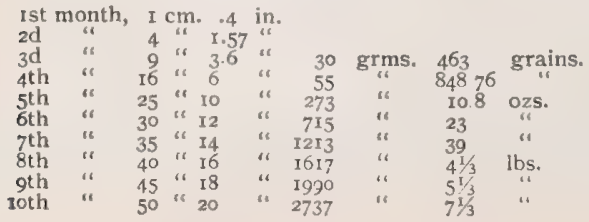

Fetus. $50 \mathrm{~cm}$. long $=20$ inches; weight, 2737 grms. = $71 / 3$ lbs. Skin is rosy; lanugo has disappeared. The nails are perfect and project beyond the finger tips. The eyes are opened. The center of ossification in the lower epiphysis of femur is $5 \mathrm{~mm}$. in diameter, while that of the cuboid bone is just beginning to show. Diameters of head are normal. F., Amorphous. See Anideus. F. Anideus. See Anideus. $F$. in fetu (fetus within the fetus), the name applied to those interesting inclusions in which the stronger fetus in its growth has included within its organism the parts of the weaker fetus. F. papyraceus, the name given to the malformation resulting in a twin-pregnancy, when, owing to an inequality in the circulation of the embryos, the weaker fetus dies, and by the continually increasing pressure of the growing fetus is flattened more and more against the uterine walls, until the mass has a thickness little greater than stout parchment. F., Position of, the position occupied by the fetus in the mother's womb. It may be oblique, transverse, or longitudinal. Also, the position occupied by the fetus with reference to the mother's pelvis. See Table (p. 467). F., Presentation of, that part of the fetus that presents in labor. See Presentation.

Feuillea ( $f u$-ill'-e-ah) [after Louis Fewillet, a French naturalist]. A genus of cucurbitaceous climbing plants. The seeds of F. cordifolia, of Jamaica, are emetic and purgative. F. trilobata, of Brazil, has similar qualities. Unof.

Fever $\left(f e^{\prime}\right.$-ver $)$ [febris, a fever]. A systemic disease or symptom of disease whose distinctive characteristic is elevation of temperature, accompanied also by quickened circulation, increased katabolism or tissuewaste, and disordered secretions. F., Abdominal. See F., Typhoid. F., Adeno-nervous. Synonym of Plague, $q . v$. F., Adeno-typhoid. Synonym of $F$., Mediterranean. F., African. See F., Yellow, and Dengue. Also the same as F., Congo. F. and Ague. See F., Intermittent. F., Amatory. See Amatory. F., Anomalous, one the symptoms of which are irregular. F., Aquamalarial. Same as $F$, Malarial. F., Ardent, a non-specific, continued fever occurring in hot climates, in which the ordinary symptoms of febricula are exaggerated. See Ardent. F., Articular. See Dengue. F., Asthenic, one with a low-fever temperature, weak circulation, and great loss of nervous force. F., Ataxic. See $F_{\text {. }}, T y p h u s$. F., Atypic. See F., Anomalous. F., Ballast, fever on shipboard; said to be due to decaying organic matter in the ballast. F., Barbadoes. Synonym of $F_{\text {, }}$ Yellow. F., Barcelona. Synonym of F., Yellow. F.-bark. See Alstonia. F., Bilious, one accompanying affections of the digestive organs. F., Black. Synonym of Cerebro-spinal meningitis. F., Blackwater, a fever occurring on the west coast of Africa, and characterized by attacking only those who have already suffered from malarial fever. There is a chill followed by lumbar pain, slight jaundice, fever, and the passage of porter-like urine. Bilious vomiting may occur, and death with uremic symptoms. It occurs in paroxysms-in other words, it is a paroxysmal hemoglobinuria. F., Bladdery. 1. A vulgar name for Pemphious. 2. Same as $F$, Catheter. F.-blister, a vesicular or pustular dermal eruption seen near the mouth, after a febrile disturbance, often occurring after a common cold. See Herpes facialis and $H$. labialis. F., Boa Vista. Synonym of $F$, Yellow. F., Bona, a form of malignant malarial fever in Algeria. F., Bouquet. Synonym of Dengue. F., Brain, fever associated with cerebral disturbance, or with inflammation of the cerebral meninges. F., 


\section{TABLE OF THE POSITIONS AND PRESENTATIONS OF THE FETUS.}

\begin{tabular}{|c|c|c|c|c|c|c|c|c|}
\hline \multirow[b]{2}{*}{ 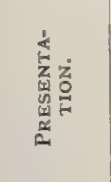 } & \multirow[b]{2}{*}{$\begin{array}{l}y \\
0 \\
z \\
0 \\
0 \\
0 \\
0 \\
0 \\
1 \\
1\end{array}$} & \multirow[b]{2}{*}{ VARIETIES, } & \multirow[b]{2}{*}{ 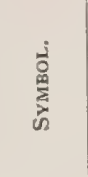 } & \multirow{2}{*}{ 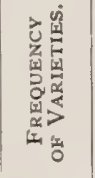 } & \multirow[b]{2}{*}{ Position OF FEtus. } & \multirow[b]{2}{*}{$\begin{array}{l}\text { POSITION OF FETAL } \\
\text { HEART-SOUNDS. }\end{array}$} & \multicolumn{2}{|c|}{ MORTALITY. } \\
\hline & & & & & & & 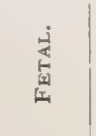 & 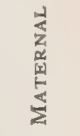 \\
\hline \multirow[t]{4}{*}{ Vertex. } & \multirow[t]{4}{*}{$\begin{array}{l}95 \text { per } \\
\text { cent. of } \\
\text { all cases. }\end{array}$} & $\begin{array}{l}\text { Left occipito- } \\
\text { anterior. }\end{array}$ & L.O.A. & $\begin{array}{l}70 \text { per } \\
\text { cent. }\end{array}$ & $\begin{array}{l}\text { Occiput to left acetabulum, fore- } \\
\text { head to right sacro-iliac joint } \\
\text { back to left; extremities to right, } \\
\text { above. }\end{array}$ & $\begin{array}{l}\text { One inch below, and } \\
\text { to left of umbilicus. }\end{array}$ & $\begin{array}{l}5 \text { per } \\
\text { cent. }\end{array}$ & \multirow[t]{4}{*}{$\begin{array}{l}\text { Less } \\
\text { than I } \\
\text { per } \\
\text { cent. }\end{array}$} \\
\hline & & $\begin{array}{l}\text { Left occipito- } \\
\text { posterior. }\end{array}$ & L.O.P. & & $\begin{array}{l}\text { Occiput to left sacro-iliac joint, } \\
\text { forehead to right acetabulum; } \\
\text { back in left flank; extremities } \\
\text { to right, anteriorly. }\end{array}$ & $\begin{array}{l}\text { In left flank, below a } \\
\text { transverse line } \\
\text { through umbilicus. }\end{array}$ & $\begin{array}{c}\text { Over } 9 \\
\text { per } \\
\text { cent. }\end{array}$ & \\
\hline & & $\begin{array}{l}\text { Right occipito- } \\
\text { anterior. }\end{array}$ & R.O.A. & & $\begin{array}{l}\text { Occiput to right acetabulum, fore- } \\
\text { head to left sacro-iliac joint ; } \\
\text { back to right; extremities to } \\
\text { left, above. }\end{array}$ & $\begin{array}{l}\text { Near median line, be- } \\
\text { low umbilicus. }\end{array}$ & $\begin{array}{c}\text { Over } 9 \\
\text { per } \\
\text { cent. }\end{array}$ & \\
\hline & & $\begin{array}{l}\text { Right occipito- } \\
\text { posterior. }\end{array}$ & R O.P. & $\begin{array}{l}30 \text { per } \\
\text { cent. }\end{array}$ & $\begin{array}{l}\text { Occiput to right sacro-iliac joint, } \\
\text { forehead to left acetabulum; } \\
\text { back in right flank; extremi- } \\
\text { ties to left, anteriorly. }\end{array}$ & $\begin{array}{l}\text { In right flank, below } \\
\text { a transverse line } \\
\text { through umbilicus. }\end{array}$ & $\begin{array}{l}5 \text { per } \\
\text { cent. }\end{array}$ & \\
\hline \multirow[t]{4}{*}{ Face. } & \multirow[t]{4}{*}{$\begin{array}{l}1 / 2 \text { of } I \\
\text { per cent. }\end{array}$} & $\begin{array}{l}\text { Left mento- } \\
\text { anterior. }\end{array}$ & L.M.A. & $\begin{array}{l}\text { Second } \\
\text { in fre- } \\
\text { quency. }\end{array}$ & $\begin{array}{l}\text { Chin to left acetabulum, forehead } \\
\text { to right sacro-iliac joint; back } \\
\text { to right; extremities to left. }\end{array}$ & $\begin{array}{l}\text { Left side of abdomen, } \\
\text { below umbilicus. }\end{array}$ & \multirow[t]{4}{*}{$\begin{array}{l}\text { I3 to } \mathrm{I}_{5} \\
\text { per } \\
\text { cent. }\end{array}$} & \multirow[t]{4}{*}{$\begin{array}{l}6 \text { per } \\
\text { cent. }\end{array}$} \\
\hline & & $\begin{array}{l}\text { Left mento- } \\
\text { posterior. }\end{array}$ & L.M.P. & & $\begin{array}{l}\text { Chin to left sacro-iliac joint, fore- } \\
\text { head to right acetabulum ; back } \\
\text { to right; extremities to left. }\end{array}$ & $\begin{array}{l}\text { Left side of abdomen, } \\
\text { below umbilicus. }\end{array}$ & & \\
\hline & & $\begin{array}{l}\text { Right mento- } \\
\text { anterior. }\end{array}$ & R.M.A. & & $\begin{array}{l}\text { Chin to right acetabulum, fore- } \\
\text { head to left sacro-iliac joint; } \\
\text { back to left; extremities to } \\
\text { right. }\end{array}$ & $\begin{array}{l}\text { Right side of abdomen, } \\
\text { below umbilicus. }\end{array}$ & & \\
\hline & & $\begin{array}{l}\text { Right mento- } \\
\text { posterior. }\end{array}$ & R.M.P. & $\begin{array}{l}\text { Most } \\
\text { com- } \\
\text { mon. }\end{array}$ & $\begin{array}{l}\text { Chin to right sacro-iliac joint, } \\
\text { forehead to left acetabulum; } \\
\text { back to left; extremities to } \\
\text { right. }\end{array}$ & $\begin{array}{l}\text { Right side of abdomen, } \\
\text { below umbilicus. }\end{array}$ & & \\
\hline \multirow[t]{4}{*}{ Brow. } & \multirow[t]{4}{*}{$\begin{array}{ll}1 / 4 & \text { of } I \\
\text { per cent. }\end{array}$} & $\begin{array}{l}\text { Left fronto-an- } \\
\text { terior. }\end{array}$ & L.F.A. & & $\begin{array}{l}\text { Brow to left acetabulum; chin to } \\
\text { right sacro-iliac joint; back to } \\
\text { left; extremities to right, above. }\end{array}$ & $\begin{array}{l}\text { Left side of abdomen, } \\
\text { below umbilicus. }\end{array}$ & \multirow[t]{4}{*}{$\begin{array}{l}30 \text { per } \\
\text { cent. }\end{array}$} & \multirow[t]{4}{*}{$\begin{array}{l}\text { Io per } \\
\text { cent. }\end{array}$} \\
\hline & & $\begin{array}{l}\text { Left fronto- } \\
\text { posterior. }\end{array}$ & L.F.P. & & $\begin{array}{l}\text { Brow to left sacro-iliac joint; chin } \\
\text { to right acetabulum; back to } \\
\text { left; extremities to right, above. }\end{array}$ & $\begin{array}{l}\text { Left side of abdomen, } \\
\text { below umbilicus. }\end{array}$ & & \\
\hline & & $\begin{array}{l}\text { Right fronto- } \\
\text { anterior. }\end{array}$ & R.F.A. & & $\begin{array}{l}\text { Brow to right acetabulum; chin } \\
\text { to left sacro-iliac joint; back to } \\
\text { right; extremities to left, above. }\end{array}$ & $\begin{array}{l}\text { Right side of abdomen, } \\
\text { below umbilicus. }\end{array}$ & & \\
\hline & & $\begin{array}{l}\text { Right fronto- } \\
\text { posterior. }\end{array}$ & R.F.P. & & $\begin{array}{l}\text { Brow to right sacro-iliac joint; } \\
\text { chin to left acetabulum; back to } \\
\text { right; extremities to left, above. }\end{array}$ & $\begin{array}{l}\text { Right side of abdomen, } \\
\text { below umbilicus. }\end{array}$ & & \\
\hline \multirow[t]{4}{*}{ Shoulder. } & \multirow[t]{4}{*}{$\begin{array}{l}1 / 2 \text { of } I \\
\text { per cent. }\end{array}$} & $\begin{array}{l}\text { Left dorso-an- } \\
\text { terior. }\end{array}$ & L.D.A. & $\begin{array}{l}\text { Most } \\
\text { com- } \\
\text { mon. }\end{array}$ & $\begin{array}{l}\text { Head in left iliac fossa, back an- } \\
\text { terior; extremities on right side, } \\
\text { in upper part of abdomen. }\end{array}$ & $\begin{array}{l}\text { Left side of abdomen, } \\
\text { below umbilicus. }\end{array}$ & \multirow[t]{4}{*}{$\begin{array}{c}\text { Almost } \\
\text { 5o per } \\
\text { cent. }\end{array}$} & \multirow[t]{4}{*}{$\begin{array}{l}\text { II per } \\
\text { cent. }\end{array}$} \\
\hline & & $\begin{array}{l}\text { Left dorso- } \\
\text { posterior. }\end{array}$ & L.D.P. & & $\begin{array}{l}\text { Head in left iliac fossa, back pos- } \\
\text { terior; extremities on right side, } \\
\text { in upper part of abdomen. }\end{array}$ & $\begin{array}{l}\text { Frequently cannot be } \\
\text { heard. }\end{array}$ & & \\
\hline & & $\begin{array}{l}\text { Right dorso- } \\
\text { anterior. }\end{array}$ & R.D.A. & & $\begin{array}{l}\text { Head in right iliac fossa, back } \\
\text { anterior; extremities on left } \\
\text { side, in upper part of abdomen. }\end{array}$ & $\begin{array}{l}\text { Right side of abdomen, } \\
\text { below umbilicus. }\end{array}$ & & \\
\hline & & $\begin{array}{l}\text { Right dorso- } \\
\text { posterior. }\end{array}$ & R.D.P. & & $\begin{array}{l}\text { Head in right iliac fossa, back } \\
\text { posterior; extremities on left } \\
\text { side, in upper part of abdomen. }\end{array}$ & $\begin{array}{l}\text { Right side of abdomen, } \\
\text { below umbilicus to- } \\
\text { ward the flank. }\end{array}$ & & \\
\hline \multirow[t]{4}{*}{ Breech. } & \multirow[t]{4}{*}{$\begin{array}{l}3 \text { to } 4 \text { per } \\
\text { cent. of } \\
\text { all cases. }\end{array}$} & $\begin{array}{l}\text { Left sacro-an- } \\
\text { terior. }\end{array}$ & L.S. $\dot{A}$. & $\begin{array}{l}\text { Most } \\
\text { com- } \\
\text { mon. }\end{array}$ & $\begin{array}{l}\text { Sacrum to left acetabulum; back } \\
\text { to left anterior; abdomen to } \\
\text { right posterior. }\end{array}$ & $\begin{array}{l}\text { Left side of abdomen, } \\
\text { above umbilicus. }\end{array}$ & \multirow[t]{4}{*}{$\begin{array}{l}30 \text { per } \\
\text { cent. }\end{array}$} & \multirow[t]{4}{*}{$\begin{array}{l}\text { Less } \\
\text { than I } \\
\text { per } \\
\text { cent. }\end{array}$} \\
\hline & & $\begin{array}{l}\text { Left sacro-pos- } \\
\text { terior. }\end{array}$ & L.S.P. & & $\begin{array}{l}\text { Sacrum to left sacro-iliac joint; } \\
\text { back to left posterior; abdomen } \\
\text { to right anterior. }\end{array}$ & $\begin{array}{l}\text { Left side of abdomen, } \\
\text { above umbilicus and } \\
\text { toward the back. }\end{array}$ & & \\
\hline & & $\begin{array}{l}\text { Right sacro- } \\
\text { anterior. }\end{array}$ & R.S.A. & & $\begin{array}{l}\text { Sacrum to right acetabulum; } \\
\text { back to right anterior; abdomen } \\
\text { to left posterior. }\end{array}$ & $\begin{array}{l}\text { Right side of abdomen, } \\
\text { above umbilicus. }\end{array}$ & & \\
\hline & & $\begin{array}{l}\text { R ig ht sacro- } \\
\text { posterior. }\end{array}$ & R.S.P. & & $\begin{array}{l}\text { Sacrum to right sacro-iliac joint } \\
\text { back to right posterior; abdo- } \\
\text { men to left anterior. }\end{array}$ & $\begin{array}{l}\text { Right side of abdomen, } \\
\text { above umbilicus and } \\
\text { toward the back. }\end{array}$ & & \\
\hline
\end{tabular}


Breslau, a contagious, epidemic disease in Breslau in the middle of the $\mathbf{I} 8$ th century. Its nature is not known. F., Brokenwing. Synonym of Dengue. F., Bucket. Synonym of Dengue. F., Bulam. Synonym of $F$, Yelloze. F., Burdwan, a form of Indian malarial fever. F.-bush. Spice-wood. The bark and fruit of Lindera benzoin, an aromatic stimulant and tonic. Its properties are due to a volatile oil. Dose of the fld. ext. of the bark $3 \mathrm{j}-\mathrm{ij}$; of the berries $m \times x-3 j$. Unof. F.-bush, California. See Garrya. F., Camp. See $F_{\text {. }}$, Typhus. F., Carbuncular. Synonym of Anthrax. F., Catarrhal, one with a catarrhal affection of the air-passages. Synonym of Influenza. F., Catheter, a severe remittent fever sometimes following the passage of the catheter or sound. F., Cerebro-spinal, a malignant epidemic fever characterized by spasmodic contraction of the muscles of the neck, retraction of the head, hyperesthesia, etc., with lesions of the cerebral and spinal membranes; it is due to a specific poison. F., Cesspool. Synonym of F., Typhoid. F. Chagres. Synonym of F., Yellow, or F., Malarial. F., Chickahominy. A synonym of $F$, Typhomalarial. F., Child-bed. See F., Puerperal. F. Colorado. Synonym of Dengue. F., Congestive, a malignant form of a remittent or intermittent malarial fever. Also a synonym of Cerebro-spinal Meningitis. F., Congo, African fever. A form of fever, of mala rial origin, and often of pernicious type, that prevails on parts of the W. African coast. F., Contagious. Synonym of $F_{*}$, Typhus. F., Continued, one in which there is a slowly continuous rise of temperature until a not high acme is reached, whence the fever ends fatally or slowly subsides. F., Country. See F., Florida. F., Cretan. Same as F., Malta. F., New, of Crete. Synonym of F., Mediterranean. F., Dandy. Synonym of Dengue. F., Date. Synonym of Dengue. F., Deccan. Synonym of F., Pernicious Malarial. F., Diary. Synonym of F., Ephemeral. F., Dothienteric. Synonym of F., Typhoid. F., Dynamic. Synonym of F., Relapsing. F., Elephantoid, a name given to the severe febrile symptoms that often attend the onset of Elephantiasis arabum. F., Enteric. See F., Typhoid. F., Epidemic Catarrhal. Synonym of Influenza. F., Epidemic Gastro-rheumatic. Synonym of Dengue. F., Epihippic, influenza in the horse. F., Eruptive, that accompanied or succeeded by an eruption on the skin. Examples are F., Scarlet, Measles, Rötheln, Smallpox, Vaccination, Varicella, Erysipelas, Denoue. F., Eruptive Epidemic, of India. Synonym of Dengue. F., Essential, See $F$, Idiopathic. F., Famine. See F., Relapsing. F., Feco-malarial. See F., Mediterranean. F.-few, the herb Pyrethrum parthenium, a stimulant tonic with emmenagogue and anthelmintic properties. Dose of the fld. ext. $\mathbf{3}$ j-ij. Unof. F., Five-day. Synonym of $F$., Relapsing. F., Florida, Country Fever; a form of fever occurring in tropical or sub-tropical countries, resembling malaria or typhoid fever. It is due to the prolonged action of high temperatures. F., Gastric, a term used indefinitely to indicate any febrile ailment associated with abdominal symptoms. It may be a simple febricula or some graver affection. F., Gastrobilious. See F., Mediterranean. F., Gibraltar. Synonym of F., Mediterranean. F., Hay, a disease of the mucous membranes of the nasal and respiratory passages, also at times involving the conjunctiva and eyeball. It is marked by catarrhal inflammation, coryza, and abundant lachrymation, with well-marked asthmatic attacks and great depression. It is due to the pollen of the grains and other grasses, and to dust, odors, perfumes, and irritating substances acting upon a hypersensitive Schneiderian membrane in those with a marked nervous constitution. It is also attributed to the influence of microbes that float in the air. Climate seems to be a potent factor in the etiology in certain cases. F., Heat. Synonym of Insolation. F.-heat, the heat of fever. F.,Hectic. Synonym of Tabes mesenterica. Also the fever that accompanies pulmonary tuberculosis and other diseases attended with suppuration. F., Hemo-gastric. See F., Yellow. F., Hospital. See F., Typhus. F., Idiopathic, one the cause of which escapes detection. F., Inflammatory. Synonym of Anthrax. F., Intermittent, one in which the symptoms intermit, with intermediate periods of freedom from the febrile attack. This is the common form of malarial fever. F., Italian. Synonym of Infuenza and of F., Mediterranean. F., Jail. Synonym of F., Typhus. F., Jungle, a remittent fever of India. F., Kendal. Synonym of $F$., Yellow. F., Leghorn. Synonym of $F$., Yellow. F., Lent. Synonym of $F$. Typhoid. F., Levant. Synonym of F., Relapsing. F., Low, fever of an asthenic type. F., Lung, acute croupous pneumonia. F., Lying-in. Synonym of $F$. Puerperal. F., Maculated. Synonym of $F$., Typhus. F., Malarial, a febrile condition of periodic character dependent upon the presence of the hematozoa malarix. F., Malarial Typhoid, typhoid fever modified by simultaneous malarial infection. F., Malignant, a severe and fatal form of any fever. F., Malta. See $F$., Mediterranean. F., Marsh. Synonym of $F$., Malarial. F., Mediterranean, Gastrobilious Fever; Feco-malarial Fever; Malta Fever; Italian Fever; Neapolitan Fever; Cretan Fever; Rock Fever; Gibraltar Fever; a specific febrile disease occurring particulary on the Mediterranean coast, and characterized by long, irregular pyrexia, frequent relapses, rheumatic complications, constipation, and the absence of ulceration of Peyer's patches. It has an incubation period of from six to nine days. The temperature may rise to $104^{\circ}$ or $106^{\circ} \mathrm{F}$, and in fatal cases to $110^{\circ} \mathrm{F}$. The course is often prolonged to from three months to a year or more. The mortality rate is about two percent. F. Mesenteric. Synonym of Tabes mesenterica. F., Miasmatic. Synonym of $F$., Malarial. F., Miliary, an affection formerly very common, occurring in an epidemic form, with a prodromal stage of two or three days, during which there is great irritation of the skin, debility, and a feeling of suffocation. This is followed by profuse sweating, high fever, precordial and epigastric distress, and the appearance on the third or fourth day of a rash, first upon the neck and breast, consisting of numerous round or irregular spots, in the center of which vesicles arise that finally burst and form crusts. Desquamation and slow convalescence follow. F., Military. Synonym of $F ., T y$ phus. F., Milk, a form of slight puerperal septicemia, formerly thought to be due to the formation of milk in the mother's breast. F., Mountain. Synonym of $F$., Typhoid. F., Mucous. A synonym of F., Typhoid, q.v. F., Neapolitan. See F., Mediterranean. F., New. Synonym of $F$, Malta, F. Night-soil. Synonym of F., Typhoid. F., Ochlotic. Synonym of F., Typhus. F., Paludal. See $F$., Intermittent. ' F., Panama, an endemic fever on the Isthmus of Panama; pernicious malarial fever. F., Periodic. See F., Intermittent. F., Pernicious, a malignant fatal type of remittent or intermittent malarial fever. F., Peyerian. Synonym of $F$, Typhoid. F., Prison, typhus fever. F., Puerperal, Metria; an acute, heterogenetic, contagious febrile affection of women in child-bed. It is due to the in- 
troduction of germs and septic material into the system, the poisonous agents finding entrance through the wounds and lacerations of the genital tract consequent upon parturition. In some cases these wounds take on an unhealthy condition with the formation over them of a whitish or grayish pellicle; they then form the so-called diphtheric ulcers, although they bear no relation to true diphtheria. In other cases there may start up a gangrenous condition spreading rapidly to the adjoining tissues. Virchow calls this variety Erysipelas Maltgnum Internum, q.v. It may assume a number of other forms, all of which are of a greater or lesser degree of gravity. F., Puking. Synonym of Milk-sickness. F., Pulmonic. A synonym of Croupous Pneumonia. F., Putrid. Synonym of $F_{\text {. }}$. Typhus. F., Pyogenic. Synonym of Sirangles. F., Pythogenic. Synonym of F., Typhoid. F., Quinin, fever produced by large doses of quinin; it is attended with hematuria, dysuria, dyspnea, threatened collapse. F., Red. Synonym of Dengue. F., Relapsing, Famine Fever; an acute specific febrile disease characterized by a short paroxysm of fever, ending in crisis, followed by a well-marked remission, and that by a relapse on or about the fourteenth day. The fever is high and the patient restless; there is no characteristic eruption; but the patient emits a peculiar musty odor like that of burning straw. Epistaxis, often profuse, is present. A crisis is usual on the seventh day and is attended usually by some critical discharge. In seven days, or a little sooner, the relapse occurs, lasting from a few hours to seven days or more. During convalescence there may be a flaky desquamation. There is always in this disease marked enlargement of the spleen; the liveralso is enlarged, as well as the kidneys. The disease is due to the presence in the blood of a specific spirillum, which is only seen during the paroxysms. F., Remittent, a paroxysmal fever with exacerbations and remissions, but not intermissions; usually applied specifically to remittent malarial fever. F., Rheumatic. See Rheumatism. F., Rock. Synonym of F., Mediterranean. F., Scarlet. See Scarlatina. F., Septic, one due to the admission of septic matter into the system. F., Seven-day. Synonym of F., Relapsing. F., Seventeen-day. Synonym of $F$., Relapsing. F., Ship. Synonym of $F$, Typhus. F., Shoddy, an illness occurring among shoddy-grinders. The symptoms are headache, malaise, dryness of the fauces, and difficulty of breathing. The acute symptoms subside in six or eight hours, but cough and expectoration remain as a chronic condition. F., Siam. Synonym of $F$. Yellow. F., Simple Continued, a continued, noncontagious fever, varying in duration from one to twelve days, and usually ending in recovery, F., Solar. Synonym of Dengue. F.-sore, a colloquial name for necrosis of the tibia; also a fever-blister. F., Spirillum. Synonym of $F$, Relapsing. F., Splenic. Synonym of Anthrax. See Pustula maligna. F., Sthenic, fever characterized by abnormal increase of the cardiac and vital activities. F., Stiff-necked. Synonym of Dengue. F., Sudoral. Synonym of $F$., Mediterranean. F., Summer, hay-fever. F., Sun. Synonym of Insolation. F., Three-day. Synonym of Dengue. F., Traumatic, that following traumatism, surgical or accidental. F.-twig. See Climbing Staff-tree and Celastrus. F., Typhoid Enteric Fever; an acute continued fever due to a specific virus, the bacillus typhosis, and characterized by peculiar intestinal lesions, splenic enlargement, maculæ on the skin (rose spots), headache, delirium, diarrhea, prostration, etc. The morbid changes are chiefly in the lower part of the ileum, occasionally in the upper part of the colon, and consist in a necrotic inflammatory infiltration of the follicular structures and neighboring parts, commonly called "Peyer's patches," with a catarrhal inflammation of the rest of the intestinal mucous membrane. The stools are the characteristic liquid ocher-colored passages, resembling pea-soup. Epistaxis is frequently an early symptom. The duration of the disease is usually about four weeks. There may be, however, an abortive form of the disease ending at from the eighth to the fourteenth day. The afebrile form, which is rare, may have a normal or even subnormal temperature through out the entire course. Perforation of the bowel peritonitis, hemorrhage, and tympanites are some of the complications of the disease. Relapses occur in a certain proportion of the cases. The poison of typhoid fever usually enters the system through the drinking-water, or milk, or by inhaling effluvia from drains. Direct contagion from the sick to the healthy plays but a small part in the dissemination of typhoid fever. See Table of Exanthemata. F., Typhoid, Ambulatory, the latent form, with illy-defined symptoms, so that the patient scarcely feels ill enough to go to bed. The prognosis in this form of the disease is often grave. F., Typhoid, Atypical. Synonym of F., Mediterranean. F., Typhoid, Canine, a peculiar form of typhoid fever occurring only among patients who have been previously subject to malaria. The period of invasion is from one to three days, during which the patient complains of general discomfort and constipation. This is followed by a rapid development of the fever, the temperature almost immediately reaching $104^{\circ} \mathrm{F}$. After the third day diarrhea, epistaxis, and intestinal hemorrhage occur. The fever subsides at the end of the first week, though the diarrhea and enlargement of the spleen continue. The pulse is always slow. F., Typhoid, Intermittent. Synonym of F., Mediterranean. F., Typho-malarial, a malarial fever with typhoid symptoms. F., Typhus, an acute, specific, epidemic, contagious, exanthematous fever, probably due to a specific infecting germ, and characterized by a peculiar petechial eruption, depression of the vital powers, profound cerebral manifestations, and absence of any discoverable lesion. It terminates by crisis on or about the fourteenth day, or by death from exhaustion or coma. See Exanthemata, Table of. F., Typhus, Abdominal. Synonym of F., Typhoid. F., Typhus, Walking, typhus fever in which the vital powers are not greatly reduced, so that the patient does not go to bed. F., Urinary, the febrile disturbance that follows the use of the catheter or bougie, or other operation upon the urinary organs, or any distinct impression made upon the urethra or bladder by some other means than these. Urinary fever varies in severity, from a slight chill and moderate rise of temperature to a wellmarked chill with considerable rise of temperatire. F., Vitular. See Collapse, Parturient. F., Vitulary. See Collapse, Parturient. F.-wort. See Triosteum. F., Wound. Synonym of F., Traumatic. F., Yellow, an acute, specific, infectious, contagious, paroxysmal, malignant fever, occurring mainly in subtropical regions, and characterized by three stages - the febrile, the remission, and the collapse. The poison of the disease is destroyed by frost. The period of incubation varies from one to fourteen days. The onset is sudden, the temperature high. There is a tendency to hemorrhage from the nose, mouth, vagina, kidneys, or stomach; the skin and conjunctivæ acquire a yellow tint or even a deep olive or mahogany color. There may be vomiting of altered blood. In fatal cases there is found a granular 
degeneration of the liver-cells. One attack of the disease protects against subsequent seizures; negroes display a peculiar immunity to the disease.

Feverish ( $f e^{\prime}$-ver-ish) [febris, fever]. Somewhat affected with fever; febrile.

Fexism (feks'-izm) [Austrian]. A form of cretinism seen in Styria (Austria); its victims are locally called fexi.

Fiber $\left(f^{\prime}-b e r\right)[f i b r a$, a thread]. A filamentary or threadlike structure. Applied to the thread-like filaments of muscular, cartilaginous, and tendinous tissues. F, Axial, the central or axial band of a nerve-fiber; it is called also the band of Remak and the axiscylinder. F., Beale's, a spinal nerve-fiber seen in sympathetic ganglion-cells. It becomes a medullated nerve. F., Bühlmann's, peculiar lines formed in carious teeth due to the Bacterium lineola. F., Gottstein's, the external ciliated cells and nerve-fibers of the auditory nerve in the cochlea. F. of Corti. See Corti. F. of Gerdy, a transverse band of fibers supporting the hand crosswise and forming the web of the fingers. F. of Müller, a supporting connective tissue that unites the various layers of the retina. F. of Remak, certain pale and nonmedullated nerve-fibers, found mostly in branches of the sympathetic nerve. F. of Sharpey, delicate processes or rods that pass through and rivet together the concentric laminæ of bone. F., Sustentacular. See $F$. of Müller. F. of Tomes, elongated and branched processes of the odontoblasts of the pulp, filling the dentinal tubules of teeth.

Fibra $\left(f^{\prime}-b r a h\right)$ [L.: pl., Fibra]. Same as Fiber.

Fibration (fi-bra'shun) [fibra, fiber]. Fibrous construction; arrangement of fibers.

Fibril, or Fibrilla ( $f l^{\prime}-b r i l$, or $\left.f-b r i l^{\prime}-a \hbar\right)$ [dim. of fibra, a fiber]. A small fiber or component filament of a fiber. A name applied to minute nerve-filaments.

Fibrillar ( $f^{\prime}$-bril-ar) [fibrilla, a small fiber]. Pertaining to fibrillæ. F. Contractions, spontaneous contractions successively taking place in different bundles of muscular fibers; they are characteristically observed in progressive muscular atrophy.

Fibrillary $\left(f^{\prime}-b r i l-a-r e\right)$. Same as Fibrillar.

Fibrillation ( $f-b$ ril- $\left.a^{\prime}-s h u n\right)$ [fibrilla, a small fiber]. The quality of being fibrillar; also a fibrillar contraction; the acquirement of new fibrils. F. of New Tissue, the appearance of fibrillæ in new-formed tissue.

Fibrin $\left(f^{\prime}-b\right.$ rin $)$ [ fibra, a fiber]. A native albumin or proteid, a substance that, becoming solid in shed blood, plasma, and lymph, causes coagulation of these fluids. It then exists in the shape of innumerable, excessively delicate, closely packed, microscopic, doubly refractive fibrils, entangling the blood-corpuscles, as in a spider's web, and with them forming the blood-clot or placenta sanguinis. Fibrin forms about 0.2 percent. of the blood and is insoluble in water and ether. It is changed into syntonin by dilute hydrochloric acid. F.-ferment, a ferment obtainable from blood-serum after clotting has occurred. It does not exist in the living, circulating blood. Its activity is destroyed by heating to $70^{\circ} \mathrm{F}$.

Fibrination (fi-brin-a'-shun) [fbra, a fiber]. The acquirement of an abnormal amount of fibrin.

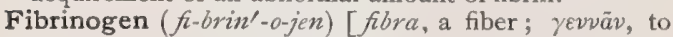
produce]. A native proteid of the globulin class, obtained from blood-plasma, serous transudations, etc. According to Schmidt it is one of the chief elements in the formation of fibrin (the other being Paraglobulin), which occurs dissolved in the plasma, aided by a fibrin-ferment.

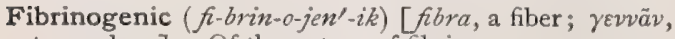
to produce]. Of the nature of fibrinogen.
Fibrinogenous (fi-brin-oj'-en-us) [fibra, a fiber; $\gamma \varepsilon \nu \nu a \tilde{\nu}$, to produce]. Forming or producing fibrin.

Fibrinoplastic (fi-brin-o-plas'-tik) [fibra, a fiber; $\pi \lambda a ́ \sigma \sigma \varepsilon \iota \nu$, to form]. Of the nature of fibrinoplastin.

Fibrinoplastin (fi-brin-o-plas'-tin). See Paraglobulin.

Fibrinous $\left(f^{\prime}-b r i n-u s\right)$ [fibra, a fiber]. Of the nature of or containing fibrin.

Fibrinuria (fi-brin-u'-re-ah) [fibra, a fiber; oṽpov, urine]. The presence of fibrin in the urine to an extent that causes its coagulation after the liquid has been voided. It usually occurs in the course of villous cancers of the bladder, or after the use of cantharides.

Fibro- ( $f^{\prime}$-bro-) [fibra, a fiber]. A prefix used to denote fibrous structure.

Fibro-areolar (fi-bro-ar-é-o-lar) [ fibra, fiber; areola, dim. of area, an open space]. Containing both fibrous and areolar tissues.

Fibroblast $\left(f^{\prime}\right.$-bro-blast $)$ [fibra, fiber; $\beta \lambda \alpha \sigma \tau b s$, germ]. A connective-tissue cell.

Fibro-bronchitis ( $i$-bro-brong-ki'-tis) [ fibra, fiber;

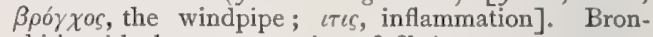
chitis with the expectoration of fibrinous casts.

Fibro-carcinoma $\left(f i-b r o-k a r-\sin -o^{\prime}-m a h\right)$ [ fibra, fiber;

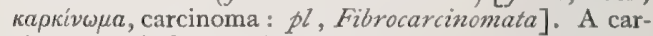
cinoma with fibrous elements.

Fibro-cartilage $\left(f i-b r o-k a r^{\prime}-t i l-\bar{a} j\right)$ [ fibra, a fiber; car tilago, gristle]. Cartilage with more or less copious intermixture of fibrous elements.

Fibro-cartilaginous (fi-bro-kar-til-aj'-in-us) [ fibra, fiber; cartilago, gristle]. Composed of or containing fibro-cartilage.

Fibro-cellular ( fi-bro-sel'-u-lar) [ fibra, fiber; cella, cell]. Both fibrous and cellular; fibro-areolar.

Fibro-chondritis $\left(f i-b r o-k o n-d r^{\prime}-t i s\right) \quad[f i b r a$, fiber ; $\chi \delta \delta \delta \rho o s$, cartilage ; $\iota \tau \iota$, inflammation]. Inflammation of fibro-cartilage.

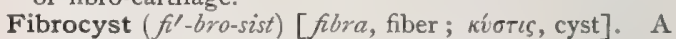
fibroma that has undergone cystic degeneration.

Fibro-elastic ( $f$-bro-e-las'-tik) [ fibra, fiber; $\dot{\varepsilon} \lambda a \sigma \tau \iota \kappa b s$, elastic]. Consisting partly of fibrous elastic tissue.

Fibro-enchondroma ( $f$-bro-en-kon-dro'-mah) [ fibra, fiber; $\varepsilon v$, in ; $\chi \delta \delta \delta \rho o s$, cartilage ; $\delta \mu \alpha$, tumor: $p l$, Fibro-enchondromata ]. An enchondroma containing fibrous elements.

Fibro-glioma (fi-bro-gli-o'-mah) [fibra, fiber; $\gamma \lambda i a$, glue; ö $\mu \alpha$, tumor: pl., Fibrogliomata]. A tumor consisting in part of fibrous and in part of glious elements.

Fibroid ( $f^{\prime}$-broid) [fibra, fiber; eidos, likeness]. A term applied to such structures as possess a fibrous appearance, but cannot be separated into fibers. Also, a fibroid tumor. F. Heart, a chronic form of myocarditis in which there is a development of fibrous connective tissue in the cardiac muscle. F. Induration. See Induration. F. Phthisis, the very chronic form of phthisis, in which the inflammatory products have taken on a fibroid change.

Fibroin ( $i^{\prime}$-bro-in) [fibra, fiber $], \mathrm{C}_{15} \mathrm{H}_{23} \mathrm{~N}_{3} \mathrm{O}_{6}$. An albuminoid; a white, shining substance, the chief constituent of the cocoons of insects and spider-web. See also Fibrorin.

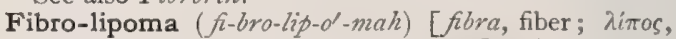
fat; $\tilde{o} \mu a$, tumor: pl., Fibro-lipomata]. A neoplasm constituted of both fibrous and fatty elements.

Fibroma ( $\left.f-b \mathrm{ro}^{\prime}-m a h\right)$ [ fibra, a fiber; ó $\mu \alpha$, a tumor: pl., Fibromata]. I. Any fibrous-tissue tumor; it is called also inoma. 2. See Molluscum fibrosum. F., Concentric, a soft, red, vascular form of uterine fibroma, forming a general enlargement of the uterus, concentrically surrounding the uterine cavity. It contains a relatively greater abundance of muscular tissue than the other varieties of fibromata. F. fungoides. See 
Granuloma fungoides and Mycosis. F. lipomatodes. Same as Xanthoma, q. v. F. molluscum. Synonym of Molluscum fibrosum. F. simplex. Synonym of Molluscum fibrosum.

Fibromyitis ( $\left.f-b r o-m i-i^{\prime}-t i s\right)$ [ fibra, fiber; $\mu \vec{v} s$, muscle; $\iota \tau \iota$, inflammation]. Inflammation of a muscle, leading to its fibrous degeneration.

Fibro-myoma (fi-bro-mi-o'-mah) [ fibra, fiber; $\mu \vec{v} \varsigma$, muscle; $\delta \mu \alpha$, a tumor: pl., Fibro-myomata]. A tumor composed of fibrous and muscular tissue.

Fibromyxoma ( fi-bro-miks-ól-mah) [ fibra, fiber; $\mu$ í $\xi a$, mucus; $\dot{\alpha} \mu a$, a tumor: pl., Fibromyxomata]. A fibro$m a$ that is undergoing a myxoid change.

Fibroplastic (fi-bro-plas'-tik) [ fibra, fiber; $\pi \lambda a ́ \sigma \sigma \varepsilon \iota v$, to form]. Showing a tendency toward the formation of fibers; a term applied to certain cases of spindlecelled sarcoma.

Fibrorin $(f$-brort-in $)$ [fibra, fiber]. In biology, the substance of which the webs of spiders are composed.

Fibro-sarcoma ( $k$-bro-sar-ko'-mah) [ fihra, fiber; $\sigma a ́ \rho \xi$, flesh; ö $\mu$, tumor: pl., Fibro-sarcomata]. A spindlecelled sarcoma, with elements that cause it to resemble a fibroma.

Fibro-serous (fi-bro-se'-rus) [fibra, fiber; serum, whey]. Having the qualities of a fibrous and serous structure. F.-s. Membranes, thin, transparent, glistening structures forming closed sacs, that contain certain organs. They are the peritoneum, the two pleuræ, the pericardium, the tunica vaginalis testis, the arachnoid, and synovial membranes.

Fibrosis $(f$-bro'-sis $)$ [ fibra, fiber]. The development of interstitial fibrous tissue; it occurs as a diseaseprocess in the coats of the smaller blood-vessels at about middle life. F., Arterio-capillary. See Endarteritis.

Fibrous $\left(f^{\prime}\right.$-brus) [fbra, a fiber]. Containing fibers; of the character of a fiber.

Fibula $\left(f b^{\prime}-u\right.$-lah) [L., a buckle]. The smaller or splint-bone at the outer part of the lower leg articulating above with the tibia, and below with the astragalus and tibia. It forms the external malleolus.

Fibular ( $f b^{\prime}$-u-lar) [ fibula, a buckle]. Relating to the fibula.

Fibulare $\left(f b-u-l a^{\prime}-r e\right)$ [L.: pl., Fibularia]. Same as Calcaneum.

Fibulen ( $f b^{\prime}-u$-len) [fibula, a buckle]. Belonging to the fibula in itself.

Fibulo-calcaneal ( $\left.f i b-u-l o-k a l-k a^{\prime}-n e-a l\right)$ [fibula, a buckle; calcaneum, the heel]. Pertaining to or connecting the fibula and the calcaneum.

Ficarin ( $\left.f k^{\prime}-a r-i n\right)$ [ficus, a fig]. A neutral principle obtained from the common ficary ; it is used internally and externally for piles.

Ficary $\left(f k^{\prime}-a r-e\right)$ [ficaria; ficus, a fig; a hemorrhoid]. The Ranunculus ficaria, pilewort, a common European herb, long a popular remedy for piles.

Fick's Angle. See Angle.

Ficoin $\left(f^{\prime}-k o-i n\right)$ [ficus, a fig]. Doliariin, or cradin; a form of papayin, or vegetable pepsin, obtained from various species of Ficus.

Ficosis $\left(f-k o^{\prime}-s i s\right)$. See Sycosis.

Ficus $\left(f^{\prime}-k u s\right)$ [L., a fig-tree]. I. The fig. The fleshy receptacle of $F$. carica, native to Asia Minor, - and cultivated throughout Europe and tropical America. It contains 62 per cent. of grape-sugar when dry. It is somewhat laxative and fairly nutritious, aid is a constituent of Confectio sennce. The genus Ficus contains many species. Forms of papayin (cradin, doliariin) occur in several species. Others afford caoutchouc, lac, etc. 2. A hemorrhoidal or condylomatous tumor.

Fiddle, Scotch $\left(f i d^{\prime}-l\right)$ [ME., fidel]. The itch.

Fiddler's Muscle. See Fidicinal.
Fidgets $\left(f j^{\prime}-e t s\right)$ [dim. of fidge]. Uneasiness; restlessness; dysphoria, $q . v$.

Fidicinal Muscle. See Muscles, Table of.

Fidispinalis ( $f i d$-is-pi-na'-lis) [ fidicinus, for playing on stringed instruments; spina, the back]. The muscle called multifidus spinæ. See Muscles, Table of.

Field $(f \bar{e} l d)$ [ME., feeld]. Any space or area, especially the field of vision. F., Contraction of the, occurs in certain retinal and cerebral affections. F. glass, in an eye-piece, the lens farthest from the eye. F.-hospital, a temporary hospital on a battle-field. F. of Vision, sometimes spoken of simply as the field. The extent of indirect vision with fixation of the visual axis upon one point. Its limit for white light is about $90^{\circ}$ outward, $70^{\circ}$ inward and above, and $60^{\circ}$ downward. The $\mathbf{F}$. for Colors is more restricted; that for blue is nearly as large as that for white, while that for red and green is more narrow. F., Testing the. See Perimeter.

Fifth Nerve. See Trifacial. F. Ventricle. See Ventricle.

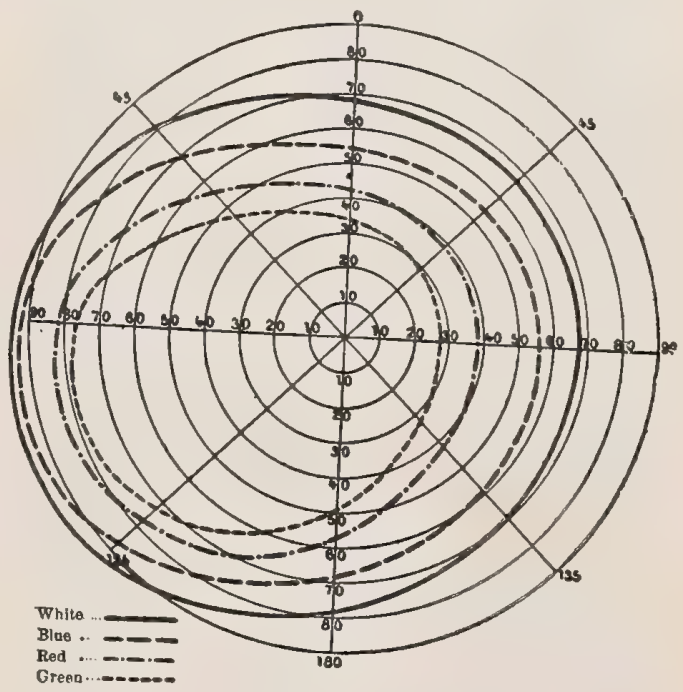

Field OF VISION OF THE LEFT Eye,

Fig [ME., fig, a fig]. See Ficus. F.-wart. See Verruca acuminata. F.-wort, the herb Scrophularia nodosa, an alterative, diuretic, and anodyne. It is sometimes used in the form of an ointment for piles. Dose of the fld. ext. $3 \mathrm{ss}-\mathrm{j}$. Unof.

Figure of Eight. See Bandage.

Fila $\left(f^{\prime}-l a h\right)$ [L. ]. Plural of Filum, q.v.

Filament ( fll'am-ent) [flum, a thread]. A small, thread-like structure or part of an organ, as a muscle, nerve, or tendon. F., Spermatic, the caudal filament of a spermatozoön.

Filamentation [L., fitum, a thread]. Thread formation. A peculiar reaction produced in certain bacteria (bacillus coli communis, proteus, etc.) when they are brought in contact with blood-serum, and consisting in the formation of long interlacing threads. The reaction is best obtained when the bacteria are suspended in serum derived from the same individual from whose body the bacteria were obtained (so-called "homologous" serum).

Filaria $\left(f i-l a^{\prime}-r e-a h\right)$ [flum, a thread]. A genus of nematode or thread-worms of the family Filariida. See Parasites (Animal), Table of. F. bancrofti. See 
Thread-worms and Parasites (Animal), Table of. F. conjunctiva has been taken from the human conjunctiva; it is found chiefly in Africa. F. lentis has been found in cataractous lenses. F. medinensis. See Thread-worms, Guinea-zuorm, and Parasites (Animal), Table of. F. sanguinis hominis, Crawcraw; the embryo of a nematode worm native to the Guinea coast of Africa, which, entering the blood and lymphatics, causes abscesses in the lymphatic glands, certain forms of Elephantiasis, q. v., lymph-scrotum, if the lymphatics of the scrotum are involved, or chyluria, if those of the pelvis are obstructed. See Parasites (Animal), Table of. F. sanguinolenta. See Thread-worms and Parasites (Animal), Table of.

Filariasis $\left(\hat{i}-l a r^{\prime}-i^{\prime}-a s-i s\right)$ [ filum, a thread]. A diseased state due to the presence in human blood of Filaria sanguinis, or of an entozoön of some allied species.

File $(f i l)$ [ME., file, a file]. See Raspatory, Xyster. F.-cutter's Disease, a form of pneumonokoniosis. F., Dental, Odontorine; Scalprum dentarum; Lima dentaria; a tooth-file; an instrument for the removal of a portion of one or more teeth. There are files for separating incisor, bicuspid, and molar teeth, etc.

Filhos, Caustic of. A cauterizing paste composed of quicklime and caustic potash mixed with alcohol.

Filices $\left(f i l^{\prime}-i s-\bar{e} z\right)$ [L., $p l$. of Filix, a fern]. Ferns. See Filix.

Filiform ( $i l^{\prime}$-if-orm) [filum, a thread; forma, form]. Thread-like. F. Bougie. See Bougie. F. Papillæ, the smallest and most numerous of the papillæ of the tongue, occurring over its whole surface. F. Apparatus, in biology, the longitudinally striated, homogeneous, strongly refractive, cellulose cap, often found at the apex of each of the two cells (synergida) forming a part of the germinal apparatus or egg-apparatus of plants.

Filipuncture ( fil-e-punk'-chür) [ flum, thread; punc. tura, a puncture]. The passing into an aneurysmal sac of wire-threads, hairs, or the like, to promote coagulation.

Filix $\left(f^{\prime}-l i k s\right)$ [L.: pl., Filices]. A general name for any fern. F. femina, or feminea, the fern now called Asplenium filix femina, female fern or spleenwort. See Asplenium. F. mas, male fern. See Aspidium.

Filixolin $(f$-liks'-o-lin $)$ [flex, fern; oleum, oil]. The fatty oil of Male Fern.

Filleau's Method. See Treatment, Methods of.

Fillet $\left(f l^{\prime}-e t\right)$ [Fr., filet, a thread]. A loop-shaped bandage; a tape loop passed through the handles of an obstetric forceps, or about some part of the fetus, for the purpose of making traction. Also see Lemniscus. F., Olivary, a fasciculus of nerve-fibers enclosing the olivary body of the medulla. F. Test. See Death, Signs of.

Filling ( fll'-ing) [ME., fillen, to fill]. The material used in closing cavities in carious teeth.

Film [ME, fylme, a film]. A pellicle or thin skin; an opacity of the cornea.

Filoplume $\left(f^{\prime}-l o-p l u m\right)$ [ filum, thread; pluma, a feather]. In biology, an extremely slender, threadlike feather, usually destitute of vane, very abundant on common poultry.

Filo-pressure $\left(f^{\prime}-l o-p r e s h^{\prime}-\bar{u} r^{\prime}\right)$ [ flum, a thread; pressura, a pressing]. Compression of a vessel by means of a wire or a thread.

Filovaricosis (fi-lo-var-ik-o'-sis) [filum, a thread; varix, a dilated vein]. A varicosity of the axiscylinder of a nerve-fiber, or the formation of one.

Filter ( $f l^{\prime}$-ter) [fitrum, felt]. An apparatus for straining and removing from water or other liquid solutions the impurities it may contain. F. Paper, a paper of close, firm mesh, much used by pharmacists for filtration.

Filth [ME., filthe, foulness]. Foul, offensive matter. F.-disease, any disease due to filth. F.-dread. See Mysophobia and Rupophobia.

Filtration $\left(\right.$ fll-trat $a^{\prime}$ hum $)$ [ filtrum, felt]. The operation of straining through bibulous paper. The best white filter-paper should be used for filtering alkaline or alkaloidal solutions.

Filtrum (fil'trum) [L., felt: pl., Filtra]. 1. Felt, q. $v$. 2. A filter or strainer.

Filum $\left(f^{\prime}-\right.$-lum $)[\mathrm{L}$.$] . Any thread-like or filamentous$ structure; in surgery, a thread or wire. F. coronarium, a cord-like ridge that runs along the auricular opening of the heart. F. terminale, the terminal strands of the spinal cord, extending from the first lumbar vertebra through the cauda equina.

Fimbria ( $\left.f m \eta^{\prime}-b r e-a h\right)$ [Lat, a "fringe" : pl., Fimlbria]. Corpus fimbriatum; tænia hippocampi; a zone consisting of alba alone, and forming, as it were, a margin for the hippocamp. There is one in each hemicerebrum between the hippocamp and the rima. F ovarica, one of the fimbriæe of the Fallopian tube nearly double the length of the others, and characterized by the great size of its secondary fringes. It leads toward the ovary.

Fimbrix (fin'-bre-e) [fimbria, a fringe]. Threads; a fringe. F. of Fallopian Tube, the fringe-like processes of the outer extremity of the oviduct.

Fimbrial ( $f m^{\prime}-b r e-a l$ ) [fimbria, a thread]. Relating to the fimbria or to fimbriæ.

Fimbriated (fim'-bre-a-ted) [fimbria, a thread]. Fringed; having a shred-like or fimbrial border.

Fimbriocele $\left(f m^{\prime}-b r e-o-s e l\right)$ [ fimbria, a thread; $\left.\kappa \hat{h}\right\rangle \eta$, hernia]. Hernia enclosing some or all of the fim. briæ of an oviduct.

Fimetarious $\left(f i m-e t-a^{\prime}-r e-u s\right)$ [fimus, dung]. In biology, growing on dung.

Finckler and Prior, Spirillum of. See Bacteria, Synonymatic Table of.

Fine $\left(f_{i n}\right)$ [ME., fin, fine]. Opposed to coarse. F. Adjustment. See Adjustment.

Finger (fing'-ger) [ME., finger]. A digit of the hand. F., Clubbed. See Clubbed Fingers. F., Insane, a finger affected with a variety of chronic whitlow; it is seen in certain cases of confirmed braindisorder. F., Mallet, a deformity of a finger characterized by deficient extension or undue flexion of the terminal phalanx. F.-stall, a rubber covering for a finger. F., Transparent, a small, round plate of glass set in a metal frame, used by Liebreich in place of digital pressure in lupus-examinations. A lens may be used in place of plain glass, thus illuminating the skin. F., Trigger. See Trigger-finger.

Fingers and Toes, Numbering of. Among anatom. ists the rule is almost universally followed of numbering from the thumb and great toe (pollux and hal. lux). Occasionally the index finger is considered number one.

Fining $\left(f^{\prime}\right.$-ning $)$ [ME., fin, fine]. A term applied to the "clearing" of wine. It consists in adding to muddy wine some albuminous or similar substance that will mix with the suspended matter and carry it to the bottom or bring it to the surface. The substances most generally employed are white of egg, oxblood, and milk, or mixtures of these substances.

Finlay's Micrococcus. See Bacteria, Synonymatic Table of.

Finn $(f i n)$. The cysticercus or larva of a tape-worm.

Fiocca, Bacillus of.' See Bacteria, Synonymatic Table of. 
Fir (fur) [ME; fir, the fir-tree]. See Abies. F.-balsam. See Abies balsamea. F.-wool, a fiber prepared in Germany from pine-leaves. It has been recommended as a material for the clothing of invalids. F.-wool Extract, an extract prepared from the leaves of Pinus sylvestris in the process of separating fir-wool. It is used in chronic rheumatism. Unof. F.-wool Oil (Oleum pinisylvestris, B. P.), the fragrant volatile oil distilled from the leaves of Pinus sylvestris, used mainly by inhalation. Dose, for rheumatism, IO-20 drops, four times a day.

Fire (fir) [ME., fire]. The visible heat of burning bodies. F.-damp, the gas contained in coal, often given off in large quantities, and exploding, on ignition, when mixed with atmospheric air. F. measles. Synonym of R'ötheln. F.-weed. See Erechthites and Epilobium.

Firing ( fir $r^{\prime}$-ing) [ME., fire, fire]. The application, either slight or caustic, of a hot metallic cauter. The sterilization of a vessel or flask by the combustion of contained alcohol.

Firming (furm'-ing) [firmus, firm]. Hardening of the flesh of a slaughtered animal. Marked flaccidity of the flesh is a sign of an unhealthy condition of the meat.

First (furst) [ME., first]. Before all others; foremost in rank. F. Intention. See Healing. F. Light Oil, the fraction of coal-tar distilling at a temperature up to $170^{\circ} \mathrm{C}$. It includes a small percentage of ammonia-liquor which is mechanically contained in the tar, and is separated from the tar-oils by being allowed to stand and settle out, when it is drawn off. The specific gravity of this fraction is about .975, and it is made up of benzene, toluene, and higher homologues, with phenol, cresol, naphthalene, etc.

Fischer's Operation. See Operations, Table of. F.'s Test. See Tests, Table of.

Fisetin $\left(f-s e^{\prime}-t i n\right)$. Same as Fustin.

Fish [ME., fisch]. A vertebrate with gills and fins, inhabiting the water. F.-berry. See Cocculus indicus. F.-gelatin. See Glue and Isinglass. F.-roe Bodies. See Fungus Foot. F.-skin Disease. See Ichthyosis.

Fisher's Brain-murmur. See Signs and Symptoms, Table of. F.'s Train-murmur. See Signs and Symptoms, Table of.

Fissate $\left(f i s^{\prime}-\bar{a} t\right)$ [ fissus; findere, to cleave]. In biology, applied to antennæ or other structures having the terminal portion divided or split into two parts.

Fissile $\left(f s^{\prime}-i l\right)$ [findere, to split]. That which may be split or cleft. In biology, formed of plates or scales closely placed together.

Fission ( fish'-un) [fissus; findere, to cleave]. In biology, spontaneous self-division of unicellular organisms or histologic cells, as a process of multiplication.

Fissipalmation ( $f$ s-ip-al-ma'-shun) [ fissus; findere, to cleave; palma, palm]. In biology, applied to animals having the toes incompletely webbed.

Fissipara ( $f i s$-ip'-ar-ah) [fissus; findere, to cleave; parus, produce]. In biology, applied in a general way to all organisms that multiply by spontaneous self-division.

Fissiparation (fis-ip-ar-a'-shun) [findere, to split; parere, to produce]. A form of cell-division. See Cell.

Fissiparous ( $\left.i s-i p^{\prime}-a r-u s\right)$ [ findere, to split; parere, to produce]. Propagating by fission; applied to unicellular organisms or histologic cells that undergo spontaneous self-division in the process of multiplication. See Fission.

Fissural Integer ( fish'-ñr-al in'-te-jer). See Integer. Fissuration ( fish-ür-a'-shun) [findere, to split]. Same as Fission. Also applied to the arrangement of the fissures of various organs, such as the brain.
Fissure (fish'-ür) [fissura; findere, to cleave]. A groove or cleft. A term applied to the clefts or grooves in various organs. F., Abdominal, a sepa. ration of the recti muscles of the abdomen, either above and below the umbilicus, or both. F., Accessory, the inferior end of the cartilaginous portion of the Eustachian tube. F., Adoccipital (of Wilder), an inconstant cerebral fissure, extending across the caudal portion of the precuneus, and forming an acute angle with the occipital fissure. F. Ammon's, during the early fetal period, a pyriform fissure in the lower portion of the sclerotic coat of the eye. F., Amygdaline (of Wilder), a cerebral fissure on the mesal aspect of the tip of the temporal lobe ; it may be identical with the basirrhinal fissure of Owen; it is collocated with the amygdala. F., Anal. See F. of the Anus. F., Anterior (of Burdach), a cerebral fissure, probably the presylvian. F., Anterior (of spinal cord). See F., Anterior Median (of spinal cord). F., Anterior Lateral (of spinal cord), a groove on the ventro-lateral aspect of the spinal cord. F., Anterior Median (of medulla oblongata), the continuation of the ventral fissure of the cord into the oblongata, where it terminates at the pons in the foramen cecum. F., Anterior Median (of spinal cord), a deep longitudinal groove in the median line of the ventral aspect of the spinal cord. F., Anterolateral, a slightly marked depression along the ventrolateral column of the spinal cord, separating the latter into the ventral and lateral columns. F., Anteromedian. See $F_{\text {. }}$, Anterior Median (of spinal cord). F., Antero-parietal. See $F$., Precentral. F., Antitragohelicine, a fissure between the helix and the antitragus of the external ear. F., Antorbital (of Owen), a transverse fissure on the orbital surface of the frontal lobe of the brain near its cephalic margin. F. of the Anus, a linear ulcer at the muco-cutaneous junction of the anus, giving rise to intense suffering on defecation. F., Ape, I. The dorsal extension of an unusually deep occipital fissure. 2. An independent fissure on the lateral aspect of the cerebrum, between the occipital and temporal regions (the exoccipital fissure of Wilder). F., Auricular, an opening situated between the vaginal and mastoid processes of the petrous portion of the temporal bone, through which passes the auricular branch of the pneumogastric nerve. F., Basirrhinal (of Owen), a short fissure near the tip of the temporal lobe of the brain. F., Basisylvian (of Wilder), the stem of the Sylvian fissure on the ventral aspect of the cerebrum. F. of Bichat. See $F$. Cerebral, Transverse. F., Branchial, any one of the visceral clefts. F. of Broca. See $F$., Limbic. F., Burdach's. See F., Anterior, and $F$, Superior. F of Calamus scriptorius, the termination of the mesal fissure of the fourth ventricle at the apex of the calamus. F., Calcarine, a fissure on the mesal aspect of the cerebrum, extending from near the occipital end and joining the occipital fissure; it is collocated with the calcar or hippocampus minor. F., Callosal (of Owen), the space between the dorsal surface of the callosum and the overhanging cortex. F., Calloso-marginal, one on the mesal surface of the cerebral hemisphere, dividing the area between the callosum and the margin into nearly equal parts; opposite to the splenium it turns in a dorsal direction. F., Central, a deep and constant fissure extending from the dorsal margin in a ventro-cephalic direction, at an angle of about $67^{\circ}$ with the meson; it crosses the lateral aspect of the cerebrum at about the middle of its length; the fissure of Rolando. F., Cephalic, in Schizonemertines, a longitudinal fissure on each side of the head. F., Cerebral, Great. See F., Cerebral, 
Transverse (of the brain). F., Cerebral, Inferior. See F., Transwerse, Inferior. F., Cerebral, Small. See $F$, Transverse, Inferior. F., Cerebral, Transverse. See F., Transverse (of brain). F., Cervical, a congenital cleft in the cervical region, produced by a failure of union of the visceral clefts. F., Choroidal. See $F$., Cerebral, Transverse. F., Circuminsular (of Wilder), the groove surrounding the base of the insula. F. of Clevenger. See F., Occipital, Inferior. F., Collateral, a fissure on the mesal aspect of the cerebrum between the subcalcarine and subcollateral gyri; it is collocated with the collateral eminence. F., Collateral, Inferior, in lower animals, a slight depression in the spinal cord corresponding to the ventrolateral fissure in man. F., Collateral, Superior, in lower vertebrates, a groove in the spinal cord corresponding to the postero-lateral groove in man. F., Constant (of Wilder), any fissure of the adult cerebrum that is always present in a given species or group. Among the human constant fissures are: Calcarine, callosal, central, collateral, circuminsular, olfactory, hippocampal, Sylvian, transinsular, occipital, orbital, parietal, postcentral, precentral, subfrontal, supertemporal. F., Coronal (of Owen), on the lateral aspect of the carnivoral cerebrum, the frontal portion of the third arched fissure. F., Cruciate, in nearly all the carnivora, a fissure extending laterad, and forming, with its opposite, a Roman cross with the intercerebral fissure. F., Dentate. See F., Hippocampal. F., Dorsal, in embryology, the dorsal median fissure of the spinal cord. F. of the Ductus venosus, a fissure of the fetal liver, lodging the ductus venosus. It is indistinct in the adult. $\mathbf{F}$. of Ecker. See $F$. Occipital, Transverse. F., Ectoccipital (of Orven), an illy-defined transverse fissure near the tip of the occipital lobe of the brain. F., Ectofrontal (of Oren), a fissure corresponding in position with the anterior fissure of Sylvius. F., Ectorrhinal (of Owen), a furrow just laterad of the base of the olfactory crus. F., Ectosylvian (of Ozen), in Carnivora, the first or lowest arched fissure. F., Ectotentorial (of Owen), the outer fissure on the ventral surface of the occipital lobe. F., Endomesognathica, an occasional fissure in the superior maxilla, between the endognathion and mesognathion. F., Entoccipital (of Oren), an illydefined fissure on the occipital lobe. F., Entolambdoid. See F., Adoccipital. F., Entorbital (of Orven), an inconstant fissure between the olfactory and orbital fissures. F., Entorrhinal. See $F$., Ector rhinal. F., Entotentorial. See $F$., Ectotentorial. F., Episylvian (of Wilder), an inconstant dorsal branch of the Sylvian fissure. F., Ethmoid, the superior meatus of the nares. F., Exoccipital (of Wilder), the ape-fissure, $q . v$. F., Falcial (of Ozven), a fissure on the mesal surface of the frontal lobe. F., Fetal, Ocular, in the embryonic eye, a fissure in the thick wall surrounding the lens. A coloboma results if it be not closed. F., Fimbrial, a small and constant depression between the fasciola and the fimbria. F., Frontal (of Owen), the precentral and supercentral fissures of man. F. Frontal, First. See F., Frontal, Superior. F., Frontal, Inferior, the subfrontal fissure. F., Frontal, Superior, the superfrontal fissure. F., Frontal, Vertical. See $F$. of Rolando. F., Fronto-marginal, an inconstant fissure in the fronto-marginal convolution. F. for the Gall-bladder, a shallow depression on the lower surface of the right lobe of the liver for the accommodation of the gall-bladder. F. of Glaser. See $F$. of Glaserius. F. of Glaserius, a small fissure in the outer wall of the tympanic cavity opening into the glenoid fossa. It lodges the processus gracilis of the malleus, and transmits the laxator tympani muscle and the anterior tympanic artery. F., Glenoid. See F. of Glaserius. F., Hippocampal, a constant fissure of the cerebrum extending from the splenium to near the tip of the temporal lobe; it is collocated with the hippocamp. F., Horizontal. See $F$. Calcarine. F. Horizontal, Great (of brain). See F., Calcarine, F., Hyposylvian (of Wilder), an inconstant ventral branch of the fissure of Sylvius. F., Incisor, a fissure separating the intermaxillary bone from the superior maxillæ. F., Infero-lateral. See $F$., Calcarine, F., Inflected, an inconstant indentation of the dorsal margin of the cerebrum, a little cephalad of the central fissure. F., Infra-orbital. See F., Suborbital, and F., Spheno-maxillary. F., Insular (of Wilder), one of the fissures crossing the insula. F., Intragyral (of Wilder), a small cerebral fissure occasionally developed between the larger fissures. $\mathbf{F}$. Intra-orbital, in the dog's brain, a fissure between the olfactory bulb and the supraorbital fissure. F., Intraparietal. See $F$., Parietal. F., Intraparacentral (of Wilder), a nearly constant depression in the paracentral gyrus. F., Intercerebral (of Wilder), the great longitudinal fissure of the brain. F., Intergyral (of Wilder), a fissure between two cerebral gyri. F., Interhemispheral. See $F$., Longitudinal, Great (of brain). F., Interhemispheric. See F., Longitudinal, Great (of brain). F., Interlamellar, one of the fissures separating the lamellæ of the cerebellum. F., Interlobar (of Wilder), the fissures of the brain separating the lobes. F., Interlobular, the great longitudinal fissure of the cerebrum. F., Interlobular, Great. See $F$. of Sylvius. F., Intermedial (of Jensen), an inconstant fissure near the end of the fissure of Sylvius. F., Interpalpebral. See $F$, Palpebral. F. Interparietal. See F., Parietal. F., Interpeduncular, the depression between the crura cerebri. F., of Jensen. See F., Intermedial. F., Lambdoid. I (of Owen), the occipital fissure, q. $v_{.} ; 2$ (of Wilder), in the fetus, between the third and seventh months, a sharply defined transverse depression in the occipital lobe, collocated with the lambdoid suture. F., Lateral, a straight fissure between the suprasylvian and the longitudinal fissures. F., Lateral (of Owen), an inconstant fissure on the mesal surface of the frontal lobe. F., Lateral (of spinal cord). See $F$., Antero-lateral. F., Lateral, Posterior (of spinal cora). See F., Postero-lateral. F., Limbic (of Broca), the fissure surrounding Broca's great limbic lobe. It includes the supercallosal, precuneal, and part of the collateral fissures. F., Longitudinal (of brain). See $F$., Longiudinal, Great (of brain). F., Longitudinal (of liver), a deep fissure on the under surface of the liver, separating the right and left lobes. F., Longitudinal, Great (of brain), the deep mesal fissure that divides the cerebrum into two hemispheres. F., Longitudinal, Medilateral. See $F$., Intercerebral. F., Longitudinal, Posterior (of spinalcord), a deep, narrow groove, extending the whole length of the spinal cord, in the middle line posteriorly. F. Longitudinal, Superior. See $F$. Intercerebral. F., Marginal (of Owen), a fissure on the mesal surface of the cerebrum, forming the cephalic boundary of the paracentral convolutions. F., Maxillary, a fissure on the internal surface of the superior maxilla for the maxillary process of the palate bone. It extends obliquely downward and forward from the lower portion of the orifice of the antrum. F., Medial, a fissure parallel with and posterior to the fissure of Rolando. F., Median, Posterior (of spinal cord). See F., Longitudinal, Posterior (of spinal cord). F., Me- 
difrontal (of Oiven), an inconstant fissure, subdividing the medifrontal convolutions. F., Meditemporal (of Wilder), inconstant and irregular fissures, ventrad of the supertemporal fissure. F., Meso-exognathic, an occasional fissure in the superior maxilla between the exognathion and mesognathion. F., Midfrontal. See F., Medifrontal. F., Midoccipital. See $F$. Orbital. F., Midorbital. See F., Orbital. F.needle, a spiral needle for bringing together the lips of a wound. F. of Nipple, a linear ulceration radiating from the nipple during lactation. It results from improper care of the breast. F., Occalcarine (of Wilder), the common stem of which the occipital and calcarine fissures are branches. F., Occipital. I (of Owen), the mid-occipital fissure, an illy-defined, inconstant fissure on the dorso-caudal slope of the occipital lobe; 2 (of. Pansch), a deep and constant fissure, situated between the parietal and occipital lobes of the brain; the occipito-parietal, F., Occipital, Anterior (of Schwalbe), a fissure between the occipito-temporal and the inferior temporo-sphenoidal lobes of the brain. F., Occipital, External. See $F$., Ape. F., Occipital, Inferior (of Clevenger), a small fissure between the second and third occipital convolutions. $\mathbf{F}$., Occipital, Transverse (of Ecker), a transverse fissure on the dorsal surface of the occipital lobe of the brain; it is part of the paroccipital fissure. F., Occipito-parietal. See $F$., Occipital. F., Occipitotemporal. See F., Collateral. F., Olfactory, a depression on the ventral aspect of the frontal lobe, lodging the olfactory bulb and crus. F., Orbital, a fissure on the orbital surface of the frontal lobe exter. nal to the olfactory fissure. F., Orbital, Anterior. See $F$., Spheno-maxillary. F., Orbital, Posterior.

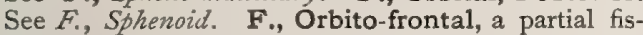
sure on the lateral aspect of the brain, separating the super-frontal and orbital convolutions. F. of Owen. See Fissures, Antorbital, Basirrhinal, Callosal, Coronal, Ectoccipital, Ectofrontal, Octorrhinal, Ectosylvian, Ectotentorial, Entoccipital, Entorbital, Falcial, Frontal, Lambdoid, Marginal, Medifrontal, Occipital, Postfrontal, Posthippocampal, Postoccipital, Postorbital, Postseptal, Postsylvian, Rhinal, Septal, Subfalcial, Subsylvian, Supercallosal, Supersylvian. F., Palpebral, the space between the eyelids extending from the outer to the inner canthus. F. of Pansch. See $F$. Occipital. F. of Pansch and Dalton. See $F$., Parietal. F., Paracentral (of Wilder), a fissure on the mesal surface of the cerebrum, surrounding the paracentral lobule. F., Parallel. See F., Supertemporal. F., Parietal. I (of Wilder), the parietal portion of the intraparietal fissure; 2 (of Pansch and Dalton), a fissure between the parietal lobules, beginning near the ventral end of the central fissure, and running to near the tip of the occipital lobe; it includes the parietal and paroccipital fissures. F., Parieto-occipital. See $F$, Occipital. F., Parietooccipital, External, the lateral portion of the occipital fissure. F., Paroccipital (of Wilder), the occipital portion of the intraparietal fissure. F., Peritoneal, a fissure of the lateral mesoblastic plates of the embryo, constituting the rudiment of the great visceral cavity. F., Perpendicular, External. See $F$, Parieto-occipital, External and F.,Ape. F., Perpendicular, Internal, the portion of the occipital fissure on the mesal surface of the hemisphere. F., Petrosquamosal, or Petro-squamous, a small fissure between the petrosa and internal surface of the squamosa. F., Petro-tympanic, a fissure in the tympanic ring, lodging the long process of the malleus. F., Petroso-angular, a fissure between the apex of the pyramidal portion of the petrosa and the great wing of the sphenoid. F., Petro-basilar, a fissure between the petrosa and the sphenoid and occiput, joining the middle lacerated and jugular foramina. F.-plane, a term employed to designate the entire length and depth of a fissure of the brain. F. Pomatic (of Wilder), in monkeys, a fissure crossing the cerebrum opposite the dorsal end of the occipital fissure; it forms the margin of the poma or occipital operculum. F., Portal. See F., Transverse (of liver). F., Postcalcarine (of Wilder), an inconstant vertical fissure at the occipital end of the cerebrum. F., Postcentral, a fissure just posterior and parallel to the central fissure. F., Postero-intermediary, a slight depression in the dorsal portion of the cervical region of the spinal cord. F., Posterolateral, a groove on the posterior portion of the side of the spinal cord, corresponding to the line of emergence of the posterior roots of the spinal nerves. F., Postero-median (of spinal cord). See $F$. Median, Posterior (of spinal cord). F., Postfrontal (of Owen), the frontal fissure. F., Posthippocampal (of Orven). See $F$., Calcarine. F., Postoccipital (of Orven), an inconstant vertical fissure forming the anterior boundary of the superior occipital convolution. F., Postorbital (of Owen), a portion of the orbital fissure. F., Postparoccipital (of Wilder), an inconstant fissure in the occipital portion of the paroccipital gyrus. F., Postseptal (of Oren), a small vertical fissure on the mesal surface of the posterior portion of the occipital lobe. F., Postsylvian (of Owen), the supertemporal or parallel fissure. F., Precentral, a fissure running parallel with the ventral portion of the central fissure. F. Precuneal, a right-angled fissure in the precuneus. F., Preoccipital, a fissure on the ventral aspect of the brain, separating the occipital and temporal lobes. F., Preorbital, the antorbital fissure. F., Preparoccipital (of Wilder), a fissure in the parietal portion of the paroccipital gyrus. F., Presylvian (of Wilder), the anterior branch of the fissure of Sylvius. F., Pterygoid, the space between the lower ends of the pterygoid plates of the ethmoid. F., Pterygomaxillary, a vertical fissure in the zygomatic fossa, opening above into the spheno-maxillary fossa. F., Pterygopalatine. See $F$, Pterygoid. F., Purselike (of Reil), the vallicula, $q . v$. F. of Reil. See F., Purse-like. F., Reticular. See F., Posicentral. F., Rhinal (of Owen), the fissure separating the olfactory bulb and crus from the cerebrum proper. $F$. of Rolando. See F., Central. F., Rostral, in Ungulates, a fissure on the mesal aspect of the cerebrum. F., Sagittal. See F., Intercerebral. F. of Santorini, two transverse fissures in the cartilaginous auditory meatus. F. of Schwalbe. See F., Occipital, Anterior, and F., Supercentral. F., Semilunar. See $F$., Calcarine. F. Septal (of Oren), an inconstant fissure in the cuneus, posterior to the calcarine. F., Sphenoid, a triangular fissure between the greater and lesser wings of the sphenoid bone. It transmits the third, fourth, sixth, and ophthalmic division of the fifth, cranial nerves, and the ophthalmic vein. F., Sphenomaxillary, a fissure between the orbital plate of the sphenoid and the lateral margin of the superior maxilla. F., Splenial, a fissure in the brain of the dog near the splenius. F., Subcentral (of Wilder), an inconstant fissure at the ventral end of the postcentral fissure, F., Subfalcial (of Owen), a small fissure on the mesal surface of the frontal lobe. F. Subfrontal, a fissure between the middle and inferior frontal convolutions. F., Suboccipital, an inconstant fissure in the occipital convolution of the brain. 
F., Suborbital, a fissure in the superior maxillary portion of the floor of the orbit. It is the upper termination of the infraorbital canal. F., Subseptal, a fissure on the cuneus between the calcarine and the collateral fissures. F., Subsylvian. I (of Ozen), an inconstant fissure on the ventral aspect of the frontal lobe; 2 (of Wilder), the constant horizontal branch of the fissure of Sylvius. F., Subtemporal, an inconstant fissure in the middle temporal and subtemporal convolutions. F., Superior (of Burdach), a fissure of the cerebrum between the lateral surface of the insula and the ental surface of the operculum. F., Supercallosal. I (of Wilder), the cephalic portion of the calloso-mar-
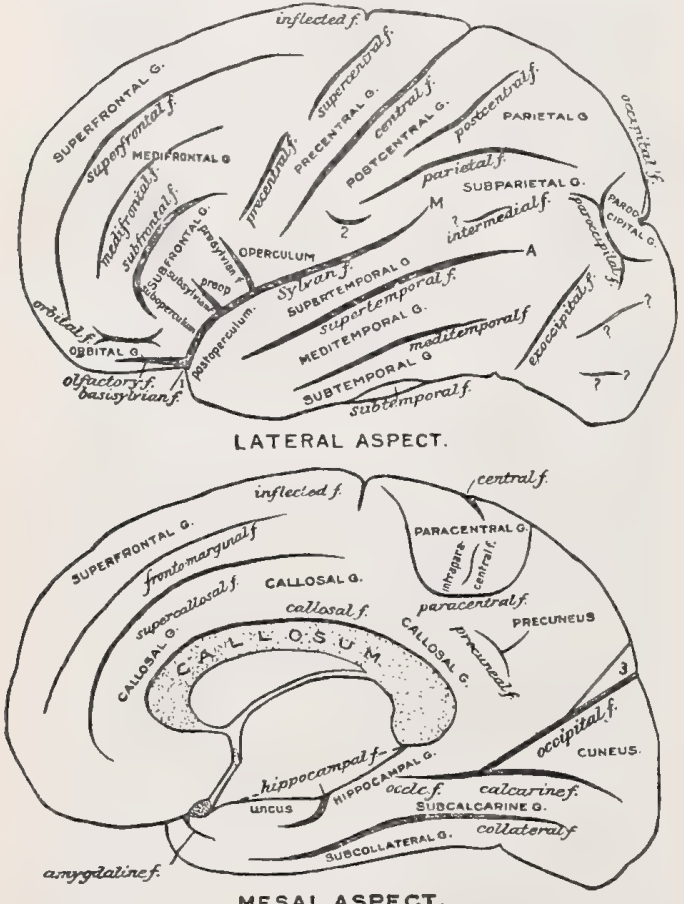

Lateral Aspecr.-Preop. Preoperculum. 2. Subcentra fissure. MEsal AsPeCt,-3. Cuneolus; the fissure cephalad of it is the adoccipital.

ginal fissure; 2 (of Ozen), the calloso-marginal fissure. F., Supercentral (of Schroalbe), the fissure parallel to and cephalad of the dorsal portion of the central fissure. F., Superfrontal, a fissure on the lateral aspect of the frontal lobe, marking off the second frontal convolution. F., Superoccipital, an irregular fissure in the upper portion of the occipital surface of the posterior lobe of the brain. F. Superseptal, a fissure in the cuneus, almost parallel with the occipital fissures. F., Supersylvian (of Owen), in Carnivora, the second arched fissure on the lateral surface of the cerebrum. F., Supertemporal, a constant fissure parallel with the fissure of Sylvius. F., Suprasylvian. See F., Supersylvian. F. of Sylvius, a deep fissure of the brain beginning on the outer side of the anterior perforated space, and extending outward to the surface of the hemisphere. It presents two short cephalic branches, subsylvian and presylvian, and a long caudal branch, which separate the parietal and temporo-sphenoidal lobes. The insula is situated between the divisions. F., Sylvian. See $F$. of Sylvius. F., Temporal, First. See $F$., Super- temporal. F., Temporal, Inferior. See F., Subtemporal. F., Temporo-occipital. See $F$, Collateral. F., Temporosphenoidal, a name applied to both the supertemporal and subtemporal fissures. F., Temporosphenoidal, Superior. See F., Supertemporal. F., Tentorial. See F., Collateral. F.,Transverse (of brain), the transverse fissure separating the anterior from the posterior and middle portions of the brain. It transmits the folds of pia that form the choroid plexus. F., Transverse (of cerebellum). See F., Horizontal (of cerebellum). F., Transverse (of liver), a fissure crossing transversely the lower surface of the right lobe of the liver. It transmits the portal vein, hepatic artery and nerves, and hepatic duct. F., Transverse, Great (of brain). See F., Transverse (of brain). F., Transverse, Inferior, a fissure between the cerebellum and the oblongata. It transmits a fold of the pia to the fourth ventricle. F., Transverse, Superior. See F., Transverse (of brain). F. Transinsular (of Wilder), the deepest of the fissures crossing the insula. F., Transtemporal, one of the inconstant short fissures on the lateral surface of the temporal lobe. F., Triradiate. See F., Orbital. F., Umbilical, the anterior portion of the longitudinal fissure of the liver, separating the left and quadrate lobes. F., Uncinate. See - $F$., Collateral. F., Ventral. See F., Median, Anterior (of spinal cord). F., Wernicke's, an inconstant vertical fissure on the lateral surface of the cerebrum midway between the end of the fissure of Sylvius and the caudal end of the cerebrum; the exoccipital fissure. F. of Wilder. See Fissures, Adoccipital, Amygdaline, Basisylvian, Circuminsular, Constant, Episylvian, Exoccipital, Intercerebral, Insular, Interlobar, Intergyral, Intragyral, Intraparacentral, Lambdoid, Meditemporal, Paracentral, Paroccipital, Pomatic, Postcalcarine, Postparoccipital, Preparoccipital, Presylvian, Subcentral, Subsylvian, Supercallosal, Transinsular, Zygal. F. Zygal (of Wilder), any fissure that presents a pair of branches at either end of a connecting bar. F., Zygomatico-sphenoid, a space between the orbital surface of the great wing of the sphenoid and the malar bone.

Fissured (fish'-ürd) [ fissus; findere, to cleave]. Cleft; split.

Fist [ME., fist, the fist]. x. The firmly-closed hand. 2. Same as Bovista.

Fistula ( $\left.f s^{\prime}-t u-l a h\right)$ [L., a "pipe"]. An abnormal, tube-like passage in the body. F., Aërial, a small opening in the neck communicating with the larynx, following imperfect closure of incised wounds of the throat. The voice is defective in consequence. F., Anal, an abnormal channel of communication between the bowel and the surface in the neighborhood of the anus. F., Biliary, an abnormal channel of communication with a biliary duct or the gall-bladder. F., Blind, a variety of anal, urinary, or other abnormal tract with but one opening. F., Blind, External, an anal fistula with but one opening, and that external. F., Blind, Internal, an anal fissure with but one opening, and that internal. F., Blind, Urinary, a suppurating track opening into the urethra, but without external opening. F., Branchial, an opening that extends from the surface of the neck to the pharynx; it is an unclosed branchial cleft, a relic of fetal life. F., Complete, one having two openings, an internal and external. F., Fecal, an abdominal fistula, communicating with the intestine. F., Gastric, an opening into the stomach, generally artificial, through the abdominal wall. It is sometimes used for feeding a patient who cannot swallow. F., Horseshoe, a variety of fistula in ano, the external opening being on 
one side of the anus and the internal opening on the other. F. in Ano. See F., Anal. F., Incomplete, one with a single opening. F., Mammary, or Milk, a fistula of the mamma or of its ducts. In F. rectolabial, recto-urethral, recto-vaginal, and rectovesical, the gut communicates by a fistulous track with the labia majora, the urethra, the vagina, or the bladder, respectively. F., Thiry's, an artificial intestinal fistula made by dividing the intestine in two places; the loop so cut out is still supplied with blood and nerves from its mesentery; it is emptied of its contents, and one end is closed by sutures, while the other is stitched to the abdominal wound, and the intestinal juice is thus collected. F., True, one that discharges the secretion of an organ. F., Vella's, is the same as Thiry's, except that both ends of the loop are left free and are sutured to the wound in the abdomen. F., Vesical, a fistula of the urinary bladder.

Fistular, Fistulate ( $f s^{\prime}-t u$-lar, -lät) [ fistula, a tube]. Fistulous; of the form or nature of a fistula.

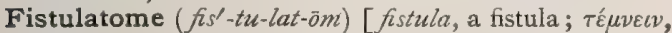
to cut]. A cutting-instrument used in the operative treatment of fistula.

Fistulous $\left(f i s^{\prime}-t u\right.$-lus $)$ [fistula, a tube]. Of the nature of or affected with a fistula.

Fit [ME., fit, a struggle]: A popular name applied to any sudden paroxysm of a disease, but especially to one of epilepsy. F., Nine-days', Tetanus neonatorum.

Fivefinger $\left(f i v-f i n g^{\prime}-e r^{\circ}\right)$. I. The plant Potentilla canadensis (see Potentilla). 2. Ampelopsis quinquefolia (see American Ivy).

Fixation ( $\left.f k s-a^{\prime}-\operatorname{shun}\right)$ [ fixus, fixed]. A making firm or rigid. F., Field of, in optics, the region bounded by the utmost limits of distinct or central vision, and which the eye has under its direct control through its excursions, without movements of the head. F.-forceps, those used for fixing or holding a part in position during a surgical operation.

Fixator $\left(f i k s-a^{\prime}-t o r\right)[L$.$] . A term applied to a muscle$ that holds a part immovable, as the diaphragm.

Fixature ( $\left.f i k s^{\prime}-a t-\bar{u} r\right)$. See Bandolin.

Fixed (fikst) [ fixus, firm]. Firm; immovable. F Idea, a morbid belief, opinion, or conception, entertained constantly by certain insane patients, and more or less permanently dominating the entire mind. F Oils. See Olea fixa.

Fixi dentes $\left(f i k s^{\prime}-i d e n^{\prime}-t e z z\right)$ [L.]. The teeth of the second dentition.

Fixing $\left(f i k s^{\prime}-i n g\right)$ [fixus, fixed]. The first stage in the preparation of tissues for histologic or pathologic examination. The chief fixing agents are-corrosive sublimate, nitric acid, alcohol, osmic acid, Flemming's solution, Fol's solution, Müller's solution, picric acid, picro-sulphuric acid, acetate of copper. See Stains, Table of.

Fixuræ $\left(f k s-u^{\prime}-r e\right)$ [fixura, fixure]. In biology, the fibrils by which lichens and many other thallophytes attach themselves to their substratum.

Flabby $\left(f a b^{\prime}-e\right)$ [E. dial.]. Lax or flaccid; deficient in firmness.

Flabellarium (fab-el-a'-re-um) [fabellum, a fan]. A vibraculum; a whip-like process of a polyzoan.

Flabellate $($ fab-ell-ät) [flabellum, a fan]. In biology, fan-shaped; applied to leaves, antennæ, etc.

Flabellation (fab-el-a -shun) [fabellare, to fan]. In surgery, the act of keeping a wound or fracture cool by fanning.

Flabelliform ( $f a b$-el'-if-orm). Same as Flabellate.

Flabellinerved ( fab-el'-in-urvd) [fabellum, fan; nervus, a nerve]. In biology, applied to leaves, such as those of the Gingko tree, with veins or nerves radiating from a common point.
Flabellum $\left(f a b-e l^{\prime}-u m\right)[\mathrm{L}$, , fan $]$. The set of white fibers radiating from the stria terminalis of the cerebrum into the corpus striatum. See also Epipodite.

Flaccid (flak'-sid) [flaccidus, flaccus, flaccid]. See Flabby.

Flaccidezza (fah-che-det'-sah) [Ital. for flaccidity]. Same as Filacherie.

Flaccidity (flak-sid'-it-e) [ flaccidus, flaccus, flaccid] Flabbiness; lack of normal reaction or firmness.

Flachérie, or Flachery (fash'-er-e) [Fr.]. A disease attacking silk-worms whose digestive apparatus is weakened by disease or heredity. It is said to be caused by a bacterium, Micrococcus bombycis. See Micrococcus bombycis and Bacillus $\beta$ of Hofmann, under Bacteria, Synonymatic Table of.

Flag [ME., flagge]. One of various endogenous plants with ensiform leaves. In biology, a flagellum; a part of the reproductive apparatus of certain gasteropods (Helix) projecting from the vas deferens. F., Blue. See Iris. F., Sweet. See Acorus.

Flagellate (faj'-el-ât) [flagellum, a whip]. In biology, furnished with slender, whip-like processes.

Flagellation (faj-el-a'-shun) [fagellare, to whip]. I. One of the many means used for the purpose of masochistic gratification in the sense of subjection to the woman; the lustful feeling arising from a mechanical irritation of the genito-spinal center. 2. Flogging, formerly used as a local stimulant and counter-irritant, and once employed in the control of the insane Latterly it has been recommended as a check for post partum hemorrhage. See Percussion.

Flagelliform (faj-ell-if-orm) [fagellum, a whip; forma, form.] Having the form of a flagellum or whip-lash.

Flagellula (faj-el'-u-lah) [dim. of flagellum, a whip] A flagellate spore; a zoöspore.

Flagellum (flaj-el'-um) [L. a whip: pl., Flagella]. Any long vibratile cilium. See also Flag. In biology, applied to the various long, slender, lash-like appendages of bacteria, zoöspores, infusoria, etc., and to slender runners, and tendrils of higher plants.

Flagg's Drill-stock. See Drill-stock.

Flail $(f \vec{a} l)$ [ME., flaile]. An arm or leg not under muscular control. F.-joint, a condition of preternatural mobility frequently following resection of a joint.

Flajan's Disease. Synonym of Exophthalmic Goiter.

Flake $(f \bar{a} k)$ [ME., flake, a flake]. A small, scalelike fragment, as of epidermis. F. Manna, the best and purest commercial manna, so called from its form.

Flambage $\left(f a m-b a h z h^{\prime}\right)[\mathrm{Fr}$.$] . The singeing of wounds$ for therapeutic purposes.

Flank (fank) [ME., flank]. The part of the body between the ribs and the upper border of the ilium.

Flannagan Garbage-cart. See Garbage-cart.

Flannel Rash. See Seborrhea corporis.

Flap [ME., flap, a loose, flexible part]. A loose and partly detached portion of the skin or other soft tissue. F. Amputation. See Amputation. F. Extraction. See Extraction of Cataract. F. Operation. See Operations, Table of.

Flapless (flap'-les) [ME., flap, a loose, flexible part; less, a suffix signifying without]. Without flaps. F. Amputation. See Operations, Table of.

Flash-point. The temperature at which a petroleum oil gives off vapors which, mixing with air, cause an explosion or flash of flame, dying out, however, at once.

Flask [ $\phi \lambda a ́ \sigma \kappa \eta$, a flask]. A narrow-necked, globular glass bottle. F., Boiling, a small flask, with a wide neck, provided on the side with an exit-tube; it is employed for determining the boiling-point. F.-clamp, an instrument in the form of a press, employed in vulcanite work for closing flasks after packing. F., 
Moulding. See Moulding-flask. F.-press, a screwpress for closing the sections of a vulcanite flask after packing. F., Vulcanite, in dentistry, an iron, brass, or bronze box for holding the model and teeth in the vulcanized-rubber process. It is generally divided into two sections, one of which is closed by an adjustable lid, the other having a bottom, and is locked by pins or bolts.

Flat [ME., flat]. Lying on one plane. F--ear. See Morel's Ear. F--foot, depression of the plantar arch; it differs from splay-foot or talipes valgus in that the sole is not everted. F.-worm. See Tape-zrorm.

Flatulence (flat'-u-lentz) [ flatulentia; fatus, breath]. A condition marked by the presence of gases in the alimentary canal. It arises mainly from the fermentation of the contents of the stomach and intestines.

Flatulent (fat'-u-lent) [flatus, breath]. Characterized by, or attended with the presence of, flatulence.

Flatus (flat-'us) [L.]. A term applied to gases in the digestive tract.

Flavanilin (Alav-an'-il-in) [flavus, yellow; anilin], $\mathrm{C}_{16} \mathrm{H}_{14} \mathrm{~N}_{2}$. A beautiful yellow dye produced by heat ing acetanilid with zinc chlorid to $270^{\circ} \mathrm{C}$. It forms colorless crystals that become yellow on exposure to the air. See Pigments, Conspectus of.

Flavaurin (Alav-az'-rin). See Pigments, Conspectus of.

Flavescent (fav-es'-ent) [favescere, to become yellow]. Yellowish.

Flavin (flav'-in) [ flavus, yellow]. A yellow dye-stuff prepared from quercitron-bark by the action of $\mathrm{H}_{2} \mathrm{SO}_{4}$

Flavophenin (flav-o-fe'-nin) [ flavus, yellow; phenyl] $\mathrm{C}_{26} \mathrm{H}_{18} \mathrm{~N}_{4} \mathrm{O}_{6}$. A yellow coloring-matter. See Chry samin.

Flavopurpurin (fav-o-pur'-pu-rin) [ favus, yellow; purpura, purple], $\mathrm{C}_{14} \mathrm{H}_{8} \mathrm{O}_{5}$. A coloring-matter occurring in golden-yellcw, acicular crystals. See Pigments, Conspectus of.

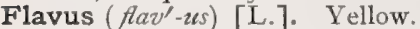

Flaw [ME., flaze, a flake]. A disease in which the skin recedes from the nails.

Flax (flaks) [ME., flax, flax]. The best known and probably the most valuable of the bast-fibers, derived from the flax-plant, Linum usitatissimum. The linen fiber, when cleansed, has a blonde or even white color, a white, silky luster, and great strength. It is less pliant and elastic than cotton, but is a better conductor of heat. Chemically, it is, like cotton, a pure cellulose. F., New Zealand, a fiber obtained from the leaves of Phormium tenax, which acquires a length of one to two meters. The fiber, as prepared by hand-scraping, is soft, white, and of silky luster. Its chief value is for rope-making and for coarse textiles. The rope made from this fiber is, however, weakened when wet by sea-water, and must therefore be kept well-oiled. F.-dresser's Phthisis, a form of pneumonokoniosis. F.-seed. See Linum.

Flay $(A \Omega)$ [ME., fleen, to skin]. To skin.

Flea ( $f e)$ [ME., flee, a flea]. See Pulex, and Parasites (Animal), Table of. F.-bane. See Erigeron. F.bite, the bite of a flea. F.-powder. See Buhach.

Fleam ( $f$ tèm) $[\phi \lambda \hat{\varepsilon} \psi$, a vein]. A phlebotome; a veterinarian's lancet for venesection.

Flechsig, Method of. A method of differentiating nerve-tracts in the brain and spinal cord. It consists in noting the successive periods at which the fibers of the tracts become medullated during the process of development. F., Tract of. See Tract.

Fleck's Disinfectant. A disinfectant solution containing copperas, 70 parts, and chlorinated lime 20 parts, in 1000 parts of water.

Fleece of Stilling. An interlacing of fibers passing from the cortex about the dentatum of the cerebellum.
Fleischl's Law. See Law.

Fleischmann's Bursa. The sublingual bursa.

Fleitmann's Test. See Tests, Table of.

Flema salada ( $f a^{\prime}-m a h$ sal-a'-da) [Sp.]. Synonym. of Acrodynia.

Fleming's Tincture. An alcoholic preparation of aconite, stronger than the official tincture. Dose, two minims.

Flemming's Method. A method of preparing tissue for histologic study. Small bits of tissue are fixed in 0.1 to 0.5 per cent. solution of chromic acid, and the hardening completed with alcohol. F.'s Mixture, a mixture used in histologic investigations. - Its composition is as follows: One per cent. solution of osmic acid, Io parts ; one per cent. solution of chromic acid, 25 parts; two per cent. solution of acetic acid, 5 parts, water 60 parts.

Flesh [ME, flesh, flesh]. The soft tissues of the body, especially the muscles. F.-brush, a brush for rubbing the surface of the body. F., Goose. See Cutis anserina. F.-juice, the juice derived from meat by expression. F., Proud, a colloquial term for the soft and inflamed granulations of the edges of a wound. F.-wound, a slight or superficial wound. F.-worm. See Thread-worms.

Fleshy (flesh'-e) [ME., flesh, flesh]. Mainly composed of muscular tissue.

Fleury's Method. See Treatment, Methods of.

Flexed-toe (Alekst'-to). See Hammer-toe.

Flexibilitas (fleks-ib-ill-it-as) [L.]. Flexibility. F. cerea, a condition of the limbs in catalepsy in which they resist passive movement and seem as if made ofwax.

Flexible $($ fleks $-i b-l)$ [Alexus, bent]. That which may be bent. F. Catheter, a catheter made of flexible substance. F. Collodion. See Pyroxylin. F. Pillar. See Pillar.

Flexile $\left(f l e x^{\prime}-i l\right)$ [flexilis, pliable]. Easily bent.

Flexion (flek'shun) [flexus, bent]. The operation or process of bending; the condition of being bent; the opposite of extension. F., Forcible, in surgery, a mode of treating aneurysm by a forcible bending, as, for example, of the knee, so as to compress the popliteal artery, thereby reducing the volume of blood; also a means of breaking up articular adhesions by mechanical bending. F, and Extension, certain passive Swedish movements used principally for regulating the circulation in certain parts, and for relieving local congestion. F.-stage of Labor, one of the stages of labor, consisting in a bending of the fetal head forward toward the chest.

Flexor (Aleks'-or) [flexus, bent]. Any muscle that bends a limb or part. See Muscles, Table of.

Flexuous (fleks'-u-us) [flectere, to bend]. In biology, alternately curved in opposite directions.

Flexura ( $\left.l e k s-u^{\prime}-r a h\right)$ [L., a bending]. A bending or curve in an organ. In veterinary anatomy, the so-called knee (in fact the wrist) of the horse.

Flexure (fleks'-ür) [flexura, a bending]. A bending. F., Sigmoid. See Sigmoid Flexure.

Flighty $\left(f i^{\prime}-t e\right)$ [Dan, vlugtig, volatile]. Slightly delirious.

Flint's Formula. See Alimentation, Rectal. F.'s Murmur. See Signs and Symptoms, Table of. F.'s Pill, a pill containing half a grain of iron combined with all the inorganic salts found in the blood in the normal proportion, except chlorid of sodium, which is in excess.

Floating (fot'-ing) [ME, floten, to float]. Free to move around. F. Kidney, one that is misplaced or movable; wandering. F. Liver, a movable liver. F. Ribs. See Ribs. F. Spleen, one that is separate from its attachments, and displaced. 
Flocci $\left(f \circ k^{\prime}-i\right)$ [L. ]. Plural of floccus, a tuft. F. volitantes. Same as Muscre volitantes.

Floccillation (fok-sil-a'-shun) [flocillatio]. Same as Carphology.

Floccitation (flok-sit-a'-shun) [floccitatio]. Same as Carphology.

Floccose $\left(f l o k^{\prime}-\bar{s} s\right)$ [ floccus, a flock of wool]. In biology, composed of or bearing tufts of woolly or long and soft hairs.

Floccular (flok'-u-lar) [ flocculus, a little flock of wool]. Pertaining to the flocculus.

Flocculence (flok'-u-lens) [floccus, a lock of wool]. In biology, a soft, waxy excretion, resembling wool, found on certain insects, $e . g$, the woolly Aphis.

Flocculent (flok'-u-lent) [floccus, a flock of wool]. Flaky, downy, or woolly; coalescing in flocky masses.

Flocculus (flok'-u-lus) [dim. of floccus, a tuft of wool]. I. A bilobular mass attached to the medipeduncle of the brain at the peduncular sulcus, and wedged, as it were, between the rounded contiguous angles of the sephalic and caudal regions of the cerebellum. Along with it is the paraflocculus, a single-lobed mass. Their functions and their representatives in other mammals are little known. 2. In biology, a small bunch of stiff hairs.

Floccus $\left(f l o k^{\prime}-u s\right)$ [L., a flock or tuft of wool: $p l$. , Flocci]. In biology, a small tuft of woolly hairs.

Flood's Ligament. See Ligament.

Flooding (fud'-ing) [ME., flood, a flood]. A copious bleeding from the womb during, after, or just at childbirth; any excessive uterine hemorrhage.

Floor (flor) [ME., floor, floor]. The basal limit of any hollow organ or open space; as the floor of a ventricle, of the antrum, of an orbit, or of the pelvis. F.space, the distance apart of beds required to afford proper ventilation in hospitals. It should be not less than $\frac{1}{12}$ of the cubic space.

Flora (flo'-rah) [Flora, the goddess of flowers]. The entire plant-life of any geographic area or geologic period.

Florence Lake. See Pigments, Conspectus of.

Florentine Lake. Same as Florence Lake.

Flores $\left(f l o^{\prime}-r e \bar{z}\right)[\mathrm{L}$.$] . Plural of flos, a flower. 1. The$ flowers or blossoms of any plant used as a medicine. 2. A flocculent or pulverulent form assumed by certain medicines and chemicals after sublimation; as flores sulphuris, flowers of sulphur; flores benzoës, flowers of benzoin, or sublimated benzoic acid.

Florescence (flor-es'-ens) [florescere, to begin to bloom ]. The opening of flowers; blossoming.

Floret $\left(f \circ r^{\prime}-e t\right)$ [flos, flower]. In biology, an individual flower of a head or cluster of flowers; it is also called floscule.

Florid (flor'-id) [floridus, abounding with flowers]. Bright-red in color; rosy; as a florid cheek, or countenance. F. Phthisis. See Galloping Consumption.

Florida (forl-id-ah) [floridus, abounding with flowers]. One of the Southern states of the United States. F. Allspice, the leaves of Calycanthus floridus, a pleasant aromatic stimulant. Dose of the fld. ext., gtt. x-xxx. Unof. F., Fever. See Fever.

Florisugent (flor-is-u'-jent) [flos, flower; sugere, to suck]. Applied to birds and insects that suck the nectar of flowers.

Flos [L., a "flower"]. A flower. Singular of Flores, q. $v$.

Floscule $\left(f l o s^{\prime}-k \overline{u l}\right)$ [dim. of flos, a flower]. See Floret.

Flour (flowr) [old spelling of flower]. A finelyground meal; this may be from either wheat, rye, barley, oats, maize or Indian corn, and rice, although wheat-flour is used in far the largest amount. Wheatflour contains starch, dextrin, cellulose, sugar, albu min, gliadin or gluten, mucin or mucedin, fibrin, cerealin, fat, mineral matter, and water. The first four are carbohydrates, or non-nitrogenous substances, and they form nearly three-fourths of the entire weight of the flour. The nitrogenous matter consists of at least five principles, three of which, gluten (or gliadin), mucin (or mucedin), and fibrin, constitute the bulk of the material known as crude gluten, which is the substance left when flour is kneaded with water and afterwards washed to remove the starch and any soluble substance. The remaining two nitrogenous principles, albumin and cerealin, are soluble in water, and are carried away with the starch in the process of washing. Crude gluten possesses a peculiar adhesiveness, arising from the presence of gliadin, which is a highly tenacious body, and which is not present in the same form in other cereal flours. The vegetable albumin is accompanied also by small amounts of legumin, or vegetable casein, which is also soluble in water. The cerealin is a soluble nitrogenized ferment occurring especially in the husk or bran of wheat and other cereals. It has a powerful fermentative action on starch, rapidly converting it into dextrin and other soluble bodies. The difference in the composition of

\begin{tabular}{|c|c|c|c|c|}
\hline & \multicolumn{2}{|c|}{ Fine White Flour. } & \multicolumn{2}{|c|}{ COARSE WHEAT BRAN. } \\
\hline & $\begin{array}{l}\text { In Ioo } \\
\text { parts. }\end{array}$ & In one pound. & $\begin{array}{l}\text { In roo } \\
\text { parts }\end{array}$ & In one pound. \\
\hline Water, ... & 13.0 & 2 ozs.. 35 grs. & 14.0 & 2 ozs., 105 grs. \\
\hline Fibrin, etc., . & 10.5 & I oz., 297 grs & 15.0 & 2 ozs., I75 grs. \\
\hline Starch, etc., . & $74 \cdot 3$ & I I ozs., 388 grs. & 44.0 & 7 ozs., 17 grs. \\
\hline Fat, .... & 0.8 & o ozs., 57 grs. & 4.0 & o ozs., 280 grs. \\
\hline Cellulose, . . & $\circ 7$ & o ozs., 49 grs. & $I 7.0$ & 2 ozs., 316 grs. \\
\hline $\left.\begin{array}{l}\text { Mineral } \\
\text { matter, }\end{array}\right\}$. & 0.7 & o ozs., 49 grs. & 60 & o ozs., 422 grs. \\
\hline
\end{tabular}

the several parts of the wheat-grain is seen in the foregoing table given by Church. F.-ball, a much used food for infants suffering from summer-complaint. It is made as follows:-Two or three pounds of wheat-flour, tied in a bag, are boiled continuously for 12 hours; the outer shell is then scraped off, and the inner, yellow portion (mainly dextrin) is grated and used to make a thin gruel.

Flourens' Doctrine. A theory that the whole of the cerebrum is concerned in every psychic process.

Flow $(f o)$ [ME., flowen, to flow]. The free discharge of a liquid, as the blood.

Flower (flow'-er) [ME., flowre, flower]. See Flos.

Flower, Angle of. In craniometry, the naso-malar angle.

Fluctuation (fuk-tu-a $\left.a^{\prime}-\operatorname{shu}\right)$ [ fuctuare, to float or roll]. The wave-like motion of contained fluid upon pressure, or by succussion.

Fluid $\left(f u^{\prime}-i d\right)$ [fuere, to flow]. A substance whose molecules move freely upon one another; any liquid constituent, or secretion of the body. See Amniotic, Condy's, Culture, Labarraque's, and other fluids. F. Extract. See Extractum Fluidum. F.-ounce. See Weights. F.-dram. See Weights. F., Scarpa's, the 
endolymph. F. Vein, the name given to the eddies produced in a cavity of the heart by regurgitating blood coming in contact with the current entering the cavity in the normal direction. The oscillation of the particles of blood are attended with a blowing sound or murmur.

Fluigram (floo'-e-gram) [fluidus, fluid; $\gamma \rho a ́ \mu \mu \alpha, ~ a$ small weight]. In medicine and pharmacy the gram and the cubic centimeter are the most important metric units, and to express their close relationship the cubic centimeter has been very appropriately termed a Fluigram.

Fluke or F.-worm $(f \bar{u} k)$ [ME., floke, a fluke]. Any trematode worm; especially Distoma hepaticum, q.v. See Trematodes, and Parasites (Animal), Table of.

Fluor ( $f\left(u^{\prime}-o r\right)$ [L., a flow]. I. A liquid state. 2. The menstrual flux. F. albus, white flow; an old name for Leukorrhea. F. muliebris. Synonym of Lenkorrhea.

Fluoranthene (Au-or-an'-thèn) [fuor, a flow], $\mathrm{C}_{15} \mathrm{H}_{10}$. Idryl; a substance that occurs in the "stubb-fat" obtained from the distillation of the "stubb." It crystallizes from alcohol in needles or plates, melting at IOg- $110^{\circ} \mathrm{C}$, and dissolves readily in hot alcohol, ether, and carbon disulphid.

Fluorene $\left(f u\right.$-or-ēn') [fuor, a flow], $\mathrm{C}_{13} \mathrm{H}_{10^{*}}$ A substance found in coal-tar; it can be obtained by passing diphenylmethane through a combustion-tube heated to redness. It is very soluble in hot alcohol, less so in cold alcohol; it crystallizes in colorless plates having a violet fluorescence, melts at $1 \mathbf{I} 3^{\circ} \mathrm{C}$, and boils at $295^{\circ} \mathrm{C}$.

Fluorescein ( fiu-or-es'-e-in) [fuor, a flow], $\mathrm{C}_{20} \mathrm{H}_{12} \mathrm{O}_{5}$. $+\mathrm{H}_{2} \mathrm{O}$. Resorcinol-phthaleĩn. An anhydrid of resorcin, prepared by heating phthalic anhydrid with resorcinol to $200^{\circ} \mathrm{C}$. It occurs as a yellowish or darkred powder decomposing at about $290^{\circ} \mathrm{C}$. From it are derived the eosin coloring-matters, $q . v$.

Fluorescence (fut-or-es'-ens) [fuere, to flow]. A property possessed by certain substances, consisting in the emission of colors while light is being passed through them. Quinin, fluorspar, and several structures of the eye, possess this power. See also Phosphorescence.

Fluorescent Resorcinol. Same as Resorcin Blue.

Fluorescigenous (fu-or-es-ij'-en-us) [fuere, to flow ;

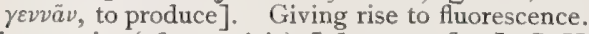

Fluorescin (fu-or-es'-in) [fuere, to flow], $\mathrm{C}_{20} \mathrm{H}_{14} \mathrm{O}_{5}$. A colorless amorphous product of the reduction of fluoresceĩn. On account of its neutral quality and green fluorescence, it has been used to study the movements of the intraocular fluids.

Fluorid $\left(f u^{\prime}-o r-i d\right)$ [fuere, to flow]. A basic salt of fluorin.

Fluorin $\left(f u^{\prime}-o r-i n\right)$ [ fuor, a flow]. $\mathrm{F}=\mathbf{I}$; quantivalence I. One of the elements. It has not been isolated, but is probably a gas. All its salts are highly corrosive and poisonous in their full strength. See Elements, Table of. Ammonium fluorid is recommended by Lucas for hypertrophy of the spleen. Dose $m$ v of a gr. iv to $3 \mathrm{j}$ solution. Unof. Hydrofluoric acid, is an antiseptic and antiferment. Inhalations of the dilute vapor have been recommended in diphtheria and tuberculosis.

Fluorindenes (fu-or-in'-dènz) [fuor, a flow]. A series of dye-stuffs closely allied to the indulins. They are produced by the protracted heating of azophenin or amidophenazin, alone or with orthodiamins. They dissolve in alcohol with beautiful fluorescence and form greenish-blue fluorescent salts.

Fluoroform (fu-or'-o-form) [fluor, a flow; forma, form ?, $\mathrm{CHF}_{3}$. A gas, the fluorin analogue of chloroform.

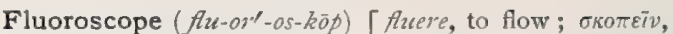
to examine ]: The instrument for holding the fluorescent screen in $\mathrm{X}$-ray examination.

Fluoroscopy (fuc-or-os'-ko-pe) [fuere, to flow; бколвiv, to examine]. The process of inspecting the tissues by means of a fluorescent screen.

Flush [origin obscure]. A temporary redness, as the hectic flush, sometimes due to vasomotor paresis.

Flushing (fush'-ing) [origin obscure]. I. A frequent symptom in the subjects of cardiac palpitation, and especially in Graves' disease. It implies a condition of vaso-motor irritability with a paresis of the arterioles in certain areas. It is often accompanied by local perspiration. It is seldom a marked symptom of organic disease. 2. The process of cleansing by a rapid flow of liquid.

Flux (fluks) [fluxus, flowing]. I. An abnormal flow of any of the excretions of the body, especially the feces. Also, a synonym of Dysentery. 2. In chemistry, any highly-fusible substance or mixture, as the subborate of soda, employed in the fusion of metals. F., Sebaceous. See Seborrhea.

Fluxion (fuk'-shun) [fluxus, a flowing]. A gathering of blood or other fluid in one part of the body; congestion, or hyperemia.

Fluxus (fuks'-us) [L.]. A flow or a flqwing. F. cruentus. Synonym of Dysentery. F. dysentericus. Synonym of Dysentery. F. sebaceus. Synonym of Seborrhea. F. splenicus. Synonym of Melena. F. torminosus. Synonym of Dysentery.

Fly $(f i)$ [ME., flye, a fly]. A dipterous insect. For parasitic flies, see Parasites (Animal), Table of. F.agaric. See Agaricus muscarius. F.-blister, Flying Blister. See Blister. F.-poison. See Amianthium. F.-sickness. See Barcoo.

Focal $\left(\mathrm{fo}^{\prime}-\mathrm{kal}\right)$ [ focus, a point; a fire-place]. Pertaining to or occupying a focus. F. Disease. See Disease. F. Hemorrhage, localized hemorrhage, in contradistinction to diffuse or disseminated hemorrhage. F Meningitis, meningitis involving but a small area of the membranes. F. Myelitis, localized myelitis, in contradistinction to diffuse or disseminated myelitis. F. Sclerosis, the chronic form, sometimes called Sclerotic Myelitis.

Focil $\left(f o^{\prime}\right.$-sil $)$ [focile, a spindle]. Any bone of the forearm or leg. F. majus, the ulna. F. majus cruris, the tibia, F. minus, the radius. F.minus cruris, the fibula.

Focus $\left(f o^{\prime}-k u s\right)$ [ focus, a point: $p l$, foci]. The principal seat of a disease. The point (called principal focus) to which converge the rays of light that pass through a convex lens or are reflected from a concave mirror. F., Equivalent, in microscopy, when the real image of an objective of a certain focal length is of the same size as that produced by a simple converging lens whose focal distance equals that of the objective, it is said to have an equivalent focus. F., Negative, or Virtual, the imaginary focus of an object placed within the principal focus. Conjugate Foci, interdependent foci.

Focusing (fo'-kus-ing) [focus, a point]. The mutual arrangement of an object and the optic parts of a microscope so that a clear image may be seen. F. Down, in microscopy, focusing by moving the objective down or toward the object, but at the risk of damaging it. F. Up, focusing by moving the objective up or away from the object.

Foderé's Test. See Birth.

Fœniculum (fen-ik'-u-lum) [L.: gen., Foniculi]. Fennel. The fruit of $F$. vulgare, with properties due to a volatile oil. It is a mild stimulant and aromatic carminative. F., Aq., 2 parts of the oil in $\mathbf{1 0 0 0}$ of 
water. Dose 3 ss- zj. F., Ol., the volatile oil. Dose mij-v. See also Fennel.

Foerster's Shifting-type. See Signs and Symptoms.

Förster's Method. See Cataract, Artificial Maturation of. F.'s Operation. See Operations, Table of.

Fotal $\left(f e^{\prime}\right.$-tal). See Fetal.

Fcetor (fe'-tor). See Fetor.

Fotus ( $f^{\prime}$-tus ). See Fetus.

Fokker's Method. A method of estimating uric acid in the urine. 200 c.c. of urine are made strongly alkaline by sodium carbonate, and after an hour $20 \mathrm{c}$. c. of a concentrated solution of ammonium chlorid are added. The mixture is allowed to stand at a low temperature for 48 hours, when the precipitate that forms is collected on a weighed filter and washed. The filter is washed with dilute $\mathrm{HCl}$ ( $\mathrm{I}$ in $\mathbf{I O}$ ), and the filtrate collected; this operation is repeated till all the acid urate on the filter is dissolved. The filtrates are mixed, allowed to stand for 6 hours, and the uric acid which then separates is collected on the same filter, washed twice with water, then with alcohol, till all acid reaction disappears, dried at $110^{\circ} \mathrm{C}$., and weighed. To the weight obtained add 0.03 gram, and subtract the weight of the filter ; the remainder is the weight of uric acid in 200 c.c. of urine.

Fol's Fixing-fluid. A modification of Fleming's solution, used, as is the latter, for the fixation of cells undergoing indirect cell-division. See Stains, Table of. F.'s Yellow. See Pigments, Conspectus of.

Fold (fold) [ME, fold, a fold]. A term applied to the plication or doubling together of various parts of the body. F., Aryteno-epiglottidean, a fold of mucous membrane stretched between the sides of the epiglottis and the apex of the arytenoid cartilage. F., Palpebral, the fold formed by the reflection of the conjunctiva from the eyelids on to the eye. There are two folds, the superior and inferior. F., Rectovaginal, the fold of the peritoneum in females descending in front of the rectum and behind the vagina. It corresponds with the recto-vesical fold of males. F., Vater's, the plica transversalis or transverse fold of the duodenum, situated just above the opening of the pancreatic and biliary ducts.

Folders (föl'-derz) [ME., fold, a fold]. English usage for Pince-nez or "eye-glasses."

Folia $\left(f o^{\prime}-l e-a h\right)[p l$. of folium, leaf $]$. I. Leaves; a term much used in pharmaccpeias and dispensatories, and designating the leaves of such plants as are used in medicine. 2. The intervening thin plates between the crevices of greater or less depth (rimule) upon the entire surface of the adult cerebellum.

Foliaceous (fo-le-a'-se-us) [folium, a leaf ]. Leaf-like.

Foliation (fo-le-a'-shun) [foliare, to put forth leaves]. The act of leafing out; frondescence.

Folie $\left(f_{0}-l e^{\prime}\right)$ [Fr.]. Insanity. F. à deux (fo-le'-ah duh'). [Fr.] See Insanity, Communicated. F. Circulaire (fo-le'-ser-ku-lär'). Cyclic insanity. F. du Doute. See Doubt, Insanity of. F., Alternate. Cyclic Insanity, $q . v$.

Foliicolous (fo-le-ik'-o-lus) [folium, a leaf; colere, to dwell]. In biology, growing upon leaves.

Foliole $\left(f_{o^{\prime}}-l e-\bar{o} l\right)$ [ folium, a leaf. $]$ In biology, a leaflet or leaflet-like organ.

Foliose $\left(f o^{\prime}-l e-\bar{o} s\right)$ [foliosus, leafy]. Abounding in leaves, leaflets, or leaf-like appendages.

Folium $\left(f^{\prime}\right.$-le-um $)$ [L., a leaf: pl., Folia $]$. I. In biology, a leaf. At the time of Cæsalpinus it applied equally to sepals, petals, or ordinary leaves. 2. Any lamina or leaflet of gray matter, forming a part of the arbor vitæ of the cerebellum.

Folius, Process of. Process of Rau; a process at the junction of the handle with the neck of the malleus.
It passes anteriorly into the Glaserian fissure. It is about three-and-a-half lines long in the new-born infant. After birth it unites with the under wall of the Glaserian fissure.

Follette (fol-et') [Fr.]. Synonym of Infuenza.

Follicle $\left(\mathrm{fol}^{\prime}-i k-l\right)$ [folliculus, dim. of follis, bellows]. I. In anatomy, a very small secretory cavity or sac, as one of the follicles of Lieberkühn. 2. In biology, a simple pod, splitting only by the ventral suture. F. Graafian, one of the small vesicular bodies in the cortical layer of the ovary, consisting of flattened granular cells with oval nuclei and membrana propria, each about $\frac{1}{100}$ inch in diameter. F., Sebaceous, one of the sacs lying within the skin that secrete the oily fluid with which the skin is softened.

Follicular (fol-ik'-u-lar) [folliculus, a little follicle] Relating or appertaining to a follicle.

Folliculitis (fol-ik-u-li'-tis) [ folliculus, a follicle; $\iota$ Ts , inflammation]. Inflammation of a group of follicles, as of the hair. F. barbæ. See Sycosis. F. decalvans, Quinquaud's Disease : a chronic folliculitis of the hairy parts, especially of the scalp, which leads to a cicatricial alopecia. The patches are about the size of a shilling, irregular in outline, and almost smooth and polished, but with some granular points at the periphery, and red points on the white, atrophied, cicatricially-depressed surface. F. exulcerans. See Hydrosadenitis phlegmonosa.

Folliculium (fol-ik-u'-le-um). The liquor folliculi. See Liquor

Folliculose $\left(f \circ l-i k^{\prime}-u-l \bar{s} s\right)$ [follis, a bellows]. Full of follicles. Having the appearance of follicles.

Fomentation (fo-men-ta'-shun) [ fomentare, to foment]. The application of cloths soaked in hot medicinal solutions, to reduce inflammation or to allay pain. Also, the application of hot dry cloths, Also, the medicament, or other material, so applied.

Fomes $\left(f o^{\prime}-m e \bar{z}\right)$ [L. for "tinder": pl., Fomites]. Any substance (as a garment, carpet, letter) capable of acting as the medium for the transmission of an infectious disease.

Fonifero (fo-nif'-er-o). See Phonophore.

Fons pulsatilis ( fons pul-sat'-il-is) [L.]. See Fontanel.

Fontaine's Chamber. See Anesthetic.

Fontana, Canals of. See Canal. F.'s Markings, or Striæ of. Delicate microscopic transverse folds of nerve-fibers, to which is due the fact of the nonretraction of the fibers when divided. F.'s, Spaces, those between the processes of the ligamentum pectinatum iridis. See Canal.

Fontanel,or Fontanelle ( fon-tan-el') [dim. of fontana, a spring, from the appearance and feeling]. A

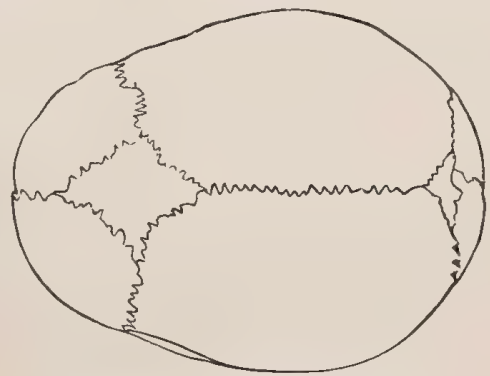

Fontanels of Fetal Skull.

membranous space of the infant's skull, from delayed ossification of the cranial bones. F., Anterior, that at the point of union of the frontal, sagittal, and coronal sutures. See also Bregma. F., Posterior, that at 
the point of junction of the apex of the lambdoid and the sagittal sutures.

Fonticulus (fon-tik'-u-lus) [dim. of fons, fountain]. r. The depression at the root of the neck, just cephalad of the sternum; more fully fonticulus gutturis. 2. A small artificial ulcer or issue.

Food [ME., foode]. Anything used for the nourishment or formation of tissue. The substances ordinarily employed as aliments. F., Albumin-spring, one that diminishes the metabolism of albuminates. F.-accessories, a term given to the various substances used as condiments, which give flavor to food or

ANIMAL FOODS.

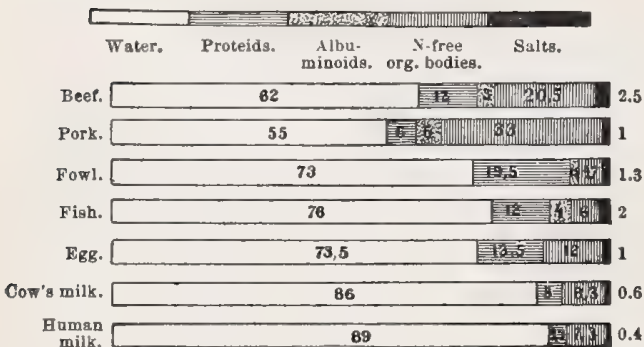

VEGETABLE FOODS.

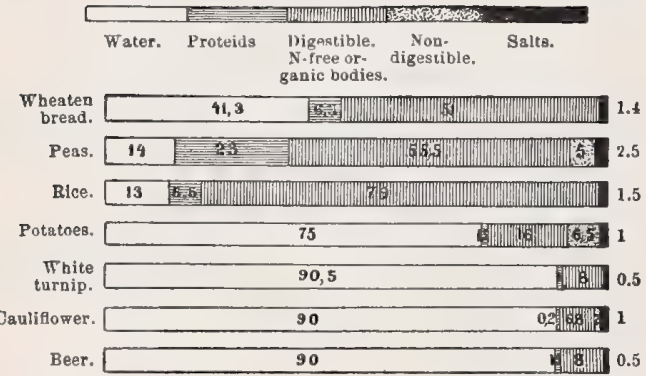

stimulate the digestive secretions, as well as to the wellknown stimulants, tea, coffee, cocoa, alcohol, etc. Foods, Isodynamic. Those producing an equal amount of heat. F., Plastic, proteids. F., Respiratory, fats and carbohydrates. (The nomenclature of the last two rests upon an erroneous theory.) F., Classification of (according to Yeo) :-

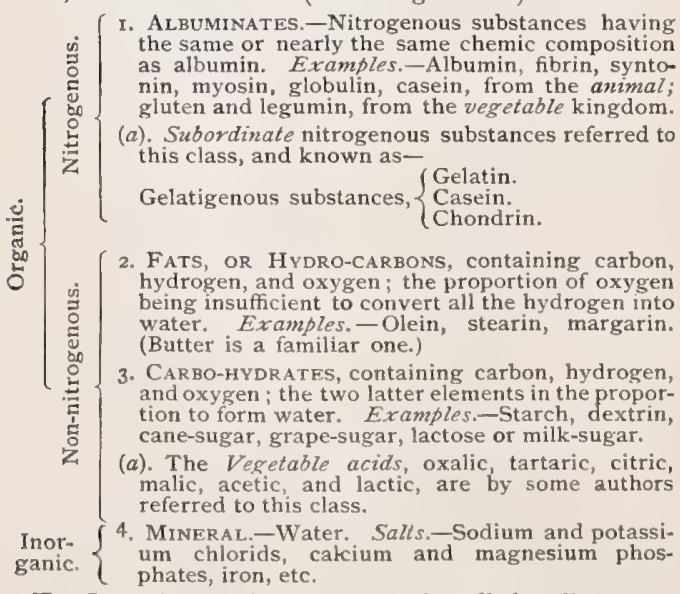

F., Complete, a food that contains all the alimentary substances required for the support and maintenance of animal life. The only complete food afforded by the animal kingdom is eggs. F.-cure, dietetic treatment of disease. F.-stuffs or F.-substances, the materials, from both the animal and vegetable kingdoms, that may be employed for the purpose of supplying nourishment to the body, and providing the elements necessary for the formation of tissue. F.vacuole, a temporary space often noticed in protozoa, containing nutritive matter. F.-yolk, all that portion of the yolk that does not undergo segmentation, but serves to nourish the embryo; nutritive protoplasm; deutoplasm.

Fool's Parsley. See Ethusa.

Foot [ME., foot]. I. The terminal extremity of the leg; one of the organs of locomotion. In bimana and quadrumana it consists of the tarsus, metatarsus, and phalanges, or toes. 2. The base of a microscope. 3. A measure of length equal to twelve inches or 30.479 cm. F.-clonus. See Clonus and Ankle-clonus. F.-bath, a pediluvium. F.-drop, a falling of the foot due to a paralysis of the flexors of the ankle. It is seen in neuritis. See Dropped Foot. F., Fungus. Madura Foot; Mycetoma; Ulcus grave. An endemic disease of India affecting the foot, which increases in size, this increase being attended with the development of mammillated pustules, in each of which is a deep-seated sinus. The sinuses are lined by a distinct membrane, and contain characteristic "fish-roe bodies" of a wh i te, yellowish, reddish, or blackish color. These bodies are composed mainly of fatty and caseous matters, the results of decomposition, encrusted with salts and blood-pigment. The bones are slowly absorbed, and gangrene or exhaustion may carry off the patient. The disease is most common in adult males. A fungus, Chionypha carteri, appears to be the active cause of the disease, F,-halt, a disease of sheep, said to be caused by worms in the foot. F, -mange, a para-

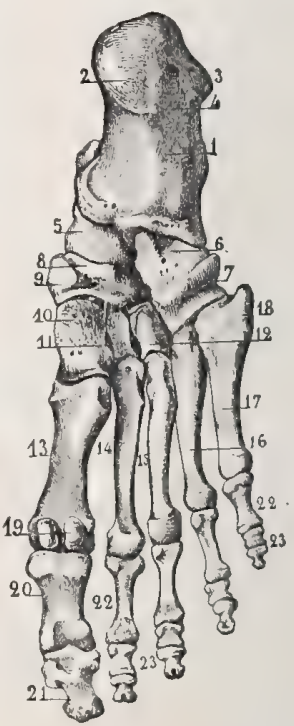

Foot, Plantar Aspect.

. Inferior surface of calcaneum. 2. Inner tuberosity. 3. Outer tuberosity. 4. Angular depression between these tuberosities. 5. Inferior portion of head of astragalus. 6. Plantar surface of cuboid, for attachment of inferior calcaneo-cuboid ligament. 7 . caneo-cuboid ligament. 7 . Tuberosity of cuboid. 8. Sca-
phoid. 9. Tuberosity of scaphoid. 9. Tuberosity of sca-
phoid. yo. Inferior portion of internal cuneiform. II. Apex of middle cuneiform. 12. Apex of internal cuneiform $13,14,15,16,17$. First, form $13,14,15,16,17$. First, metatarsal bones. 18. Tubermetatarsal bones. 18. Tuber-
osity of fifth metatarsal bone. I9 Two sesamoid bones. 20 . First phalanx of great toe. 2I. Last phalanx of great toe. 22, 22. First phalanges of remaining toes. 23, 23. Second and third phalanges of these toes. sitic disease of the heels and lower parts of the legs, especially the hind ones, of a horse, giving rise to great itching and irritation. It is due to an acarus, Symbiotis equi. F.-and-mouth Disease, a rare affection that occurs in sheep, cows, pigs, and horses, and is occasionally transmitted to man. It manifests itself by the appearance of vesicles and bullæ in the mouth and on 
the feet at the margins of the hoofs, and in cows, on the udder and teats. In man, vesicles form in the mouth, on the hands and feet. In two or three days, these rupture, discharging an opaque, yellowish fluid, and leaving dark-red ulcers. There are also fever, anorexia, pain on eating, swelling of the tongue, fetid breath, salivation, and derangement of digestion. See Eczema epizoötica, and Streptocytus of Eczema epizoötica, Schottelius, under Bacteria, Synonymatic Table of. F.-phenomenon. See Ankle-clonus.. F.-pound, the work required to overcome a force equal to raising the weight of a pound through the space of a foot. See Unit. F.poundal, the work done by a poundal acting through one foot. F.-rot, a disease of sheep, said to be due to pasturing in wet ground. One form is contagious; and the disease is said by some to be tuberculous in nature.

Footling (foot'-ling) [ME., foote]. With the foot or feet foremost ; as a footling presentation in obstetrics.

Foramen (fo-ra'-men) [ forare, to pierce]. A passage or opening, especially one in a bone. A Table of Foramina is appended.

\section{TABLE OF FORAMINA.}

\begin{tabular}{|c|c|c|}
\hline NAME. & LOCATION. & TRANSMITS. \\
\hline Accessory transverse. & $\begin{array}{l}\text { Anomalous foramina in the transverse processes of the cervical } \\
\text { vertebræ. }\end{array}$ & $\begin{array}{l}\text { An anomalous and accessory verte- } \\
\text { bral artery. }\end{array}$ \\
\hline Acoustic. & The same as the internal auditory meatus. & The auditory and facial nerves. \\
\hline Alveolar, anterior. & See Dental, inferior. & \\
\hline Alveolar, inferior. & See Dental, inferior. & \\
\hline Alveolar, posterior. & In the superior maxilla. & $\begin{array}{l}\text { Superior posterior dental vessels and } \\
\text { nerves. }\end{array}$ \\
\hline Amplum pelveos. & See Obturator. & \\
\hline Anonymous of Ferrein. & See Hiatus Fallopii. & \\
\hline Anteorbital. & $\begin{array}{l}\text { In mammals, an orifice in the cheek-bone in front of the orbit, } \\
\text { corresponding to the infraorbital foramen of man. }\end{array}$ & $\begin{array}{l}\text { Superior maxillary division of the tri- } \\
\text { facial nerve; occasionally the mas- } \\
\text { seter muscle. }\end{array}$ \\
\hline Antorbital. & See Anteorbital. & \\
\hline Aortic. & An opening in the diaphragm. & The aorta. \\
\hline Arachnoid. & See Foramen of Magendie. & \\
\hline Atlantal. & $\begin{array}{l}\text { In many animals, a hole through the ventral border of the atlas; } \\
\text { only exceptionally present in man. }\end{array}$ & Suboccipital nerve; vertebral artery. \\
\hline $\begin{array}{l}\text { Atrio-ventricular, com- } \\
\text { mon. }\end{array}$ & $\begin{array}{l}\text { In some animals, an auriculo-ventricular opening common to } \\
\text { both auricles and ventricles. }\end{array}$ & Blood. \\
\hline Auditory, external. & The external meatus of the auditory canal. & Sound-waves to tympanic membrane. \\
\hline Auditory, internal. & See Acoustic. & \\
\hline Auricular. & The mouth of the external auditory meatus. & Sound-waves to tympanic membrane. \\
\hline Bartholin's. & See Obturator. & \\
\hline Bichat's. & $\begin{array}{l}\text { A supposed communication between the subarachnoid space } \\
\text { and the cavity of the third ventricle of the brain. }\end{array}$ & \\
\hline Of Botal or Botallo. & $\begin{array}{l}\text { In the fetus, the opening between the two auricles of the heart, } \\
\text { situated at the lower posterior portion of the septum auricu- } \\
\text { larum. }\end{array}$ & Blood. \\
\hline Carotic. & The inferior aperture of the carotid canal. & Carotid vessels. \\
\hline Carotico-clinoid. & $\begin{array}{l}\text { Sphenoid bone; an occasional foramen, formed by the union of } \\
\text { the apices of the anterior and middle clinoid processes. }\end{array}$ & \\
\hline Carotico-tympanic. & See Canal, Carotico-tympanic. & \\
\hline Carotid, external. & The external aperture of the carotid canal. & $\begin{array}{l}\text { Internal carotid artery and carotid } \\
\text { plexus. }\end{array}$ \\
\hline Carotid, internal. & The internal aperture of the carotid canal. & $\begin{array}{l}\text { Internal carotid artery and carotid } \\
\text { plexus. }\end{array}$ \\
\hline Cavernous. & Sphenoid bone; a small passage. & The median vertebral vein. \\
\hline Cecal, anterior. & $\begin{array}{l}\text { Also called prepontile fossa; the depression at the cephalic } \\
\text { margin of the pons. }\end{array}$ & \\
\hline $\begin{array}{l}\text { Cecal (of frontal } \\
\text { bone). }\end{array}$ & $\begin{array}{l}\text { Formed by the frontal bone and the crista galli of the ethmoid; } \\
\text { a small foramen. }\end{array}$ & A vein, occasionally. \\
\hline $\begin{array}{l}\text { Cecal (of medulla ob- } \\
\text { longata). }\end{array}$ & See Cecal, anterior. & \\
\hline
\end{tabular}


TABLE OF FORAMINA.-Continued.

\begin{tabular}{|c|c|c|}
\hline NAME. & LOCATION. & TRANSMITS. \\
\hline Cecal (of pharynx). & $\begin{array}{l}\text { Median line of posterior wall of the pharynx: a depression in } \\
\text { the mucous membrane. }\end{array}$ & \\
\hline Cecal, posterior. & A depression just below the pons. & $\begin{array}{l}\text { The ventral median fissure terminates } \\
\text { in this. }\end{array}$ \\
\hline Cecal (or retina). & See Fovea centralis. & \\
\hline Cecal, retro-anal. & See Foveola coccygea. & \\
\hline $\begin{array}{l}\text { Cecal (of superior } \\
\text { maxilla). }\end{array}$ & See Incisive. & \\
\hline Cecal (of tongue). & Posterior termination of the median raphe of tongue. & A number of small glands open into it. \\
\hline Central. & See Fovea centralis. & \\
\hline$\overline{\text { Central (of the cochlea). }}$ & See Cochlea centrale. & \\
\hline $\begin{array}{l}\text { Central (of Scemmer- } \\
\text { ring). }\end{array}$ & See Central (of the retina). & \\
\hline Cervical. & Transverse processes of the cervical vertebræ. & The vertebral artery and vein. \\
\hline Clinoideo-carotic. & See Carotico-clinoid. & \\
\hline Cochleæ centrale. & The largest of several openings at the base of the modiolus. & \\
\hline Common, anterior. & See Foramen of Monro. & \\
\hline Conarial. & The orifice of the conarial recess. & \\
\hline Condylar, anterior. & See Condyloid, anterior. & \\
\hline Condylar, posterior. & $\begin{array}{l}\text { Behind the condyles of the occipital bone, opening externally } \\
\text { into the occipital fossa. }\end{array}$ & Veins. \\
\hline Condyloid, accessory. & A small foramen near the anterior condyloid foramen. & A vein, occasionally. \\
\hline $\begin{array}{l}\text { Condyloid, anterior } \\
\text { (sometimes double). }\end{array}$ & $\begin{array}{l}\text { Anterior to and to the outer side of each occipital condyle, } \\
\text { passing downward, outward, and forward through the basilar } \\
\text { process }\end{array}$ & $\begin{array}{l}\text { The hypoglossal nerve; occasionally a } \\
\text { meningeal branch of the ascending } \\
\text { pharyngeal artery. }\end{array}$ \\
\hline Condyloid, posterior. & The fossa behind the occipital condyles. & A vein to the lateral sinus. \\
\hline Coraco-scapular. & $\begin{array}{l}\text { In some animals, an orifice formed by the articulation of the } \\
\text { coracoid bone with the scapula. }\end{array}$ & \\
\hline Cordiform. & In reptiles, the obturator foramen. & \\
\hline Costo-trausverse. & $\begin{array}{l}\text { The space between the transverse process of a vertebra and } \\
\text { the neck of its corresponding rib. }\end{array}$ & $\begin{array}{l}\text { Branches of intercostal arteries and } \\
\text { nerves. }\end{array}$ \\
\hline Cotyloid. & A notch in the acetabulum converted into a canal by a ligament. & Vessels and nerves. \\
\hline Cribrosa. & Small openings in the lamina cribrosa of the ethmoid bone. & Filaments of the olfactory nerves. \\
\hline $\begin{array}{l}\text { Cruro-popliteal, ante- } \\
\text { rior. }\end{array}$ & $\begin{array}{l}\text { An aperture in the upper part of the tibio-fibular interosseous } \\
\text { membrane. }\end{array}$ & The anterior tibial vessels. \\
\hline Dental, inferior. & $\begin{array}{l}\text { The external aperture of the inferior dental canal, in the } \\
\text { ramus of the inferior maxilla. }\end{array}$ & Inferior dental vessels and nerves. \\
\hline Dextrum. & See Quadrate. & \\
\hline Diaphragmatic. & Several canals through the diaphragm. & $\begin{array}{l}\text { The esophagus, aorta, vagus nerves, } \\
\text { inferior vena cava, and other struc* } \\
\text { tures. }\end{array}$ \\
\hline $\begin{array}{l}\text { Diaphragmatic, left in- } \\
\text { ferior. }\end{array}$ & See Aortic. & \\
\hline $\begin{array}{l}\text { Diaphragmatic, left su- } \\
\text { perior. }\end{array}$ & See Esophageal. & \\
\hline Diploic. & $\begin{array}{l}\text { Small openings in the inner plate of the cranial bones, leading } \\
\text { from the cranial cavity into the diploë. }\end{array}$ & Veins. \\
\hline Of Duverney. & See Foramen of Winslow. & \\
\hline Emissary. & The skull. & The emissary veins. \\
\hline Epiploic. & See Foramen of Winstow. & \\
\hline Epitrochlear. & $\begin{array}{l}\text { In many animals, on the inner condyle of the humerus; some- } \\
\text { times present or represented in man by a groove. }\end{array}$ & \\
\hline
\end{tabular}


TABLE OF FORAMINA.-Continued.

\begin{tabular}{|c|c|c|}
\hline NAME. & LOCATION. & TRANSMITS. \\
\hline Esophageal. & The diaphragm. & The esophagus. \\
\hline Ethmoid, anterior. & A canal formed between the ethmoid and frontal bones. & $\begin{array}{l}\text { The nasal branch of the ophthalmic } \\
\text { nerve; anterior ethmoid vessels. }\end{array}$ \\
\hline Ethmoid, posterior. & See Canal, Ethmoid, posterior. & Posterior ethmoid artery and vein. \\
\hline Frontal. & $\begin{array}{l}\text { The supra-orbital notch of the frontal bone when it is con- } \\
\text { verted into a canal by an overlying process of bone. }\end{array}$ & Supraorbital vessels and nerves. \\
\hline Fronto-ethmoid. & $\begin{array}{l}\text { The foramen cecum in the suture between the frontal and eth- } \\
\text { moid bones. }\end{array}$ & \\
\hline $\begin{array}{l}\text { Glandulosum Mor- } \\
\text { gagni. }\end{array}$ & See Foramen cecum (of tongue). & \\
\hline Of Huschke. & $\begin{array}{l}\text { A perforation often found near the inner extremity of the tym- } \\
\text { panic plate; it is due to an arrest of development. }\end{array}$ & $\begin{array}{l}\text { Connects the glenoid fossa of the tem- } \\
\text { poral bone with the external auditory } \\
\text { meatus. }\end{array}$ \\
\hline Incisive. & See Incisor & \\
\hline Incisor. & Aperture of the incisor canal in the alveolar margin. & $\begin{array}{l}\text { Nerves and vessels to the incisor } \\
\text { teeth. }\end{array}$ \\
\hline Infra-maxillary. & The inferior dental canal, $q . v .$, under Canal. & \\
\hline Infra-orbital. & $\begin{array}{l}\text { In the superior maxilla, the external aperture of the infra- } \\
\text { orbital canal. }\end{array}$ & The infraorbital nerve and artery. \\
\hline Infra-pubic. & See Obturator. & \\
\hline Innominate. & Temporal bone. & The Vidian nerve. \\
\hline Intercarpal. & The carpus of batrachians. & \\
\hline Interclinoid. & $\begin{array}{l}\text { A canal formed by an anomalous process, connecting the } \\
\text { middle and posterior clinoid processes of the sphenoid. }\end{array}$ & \\
\hline Intermaxillary. & See Incisor. & \\
\hline Interorbital. & In birds, a space in the bony plate separating the orbits. & \\
\hline $\begin{array}{l}\text { Intervertebral, ante- } \\
\text { rior. }\end{array}$ & $\begin{array}{l}\text { The aperture formed by the notches opposite to each other in } \\
\text { the laminæ of adjacent vertebra. }\end{array}$ & The spinal nerves and vessels. \\
\hline $\begin{array}{l}\text { Intervertebral, poste- } \\
\text { rior. }\end{array}$ & $\begin{array}{l}\text { The space between the articular processes of adjacent verte- } \\
\text { bræ, except the first cervical. }\end{array}$ & \\
\hline Ischiadic, major. & See Sacro-sciatic, great. & \\
\hline Ischiadic, middle. & $\begin{array}{l}\text { An open space left between an anomalous and the normal sacro- } \\
\text { spinal ligament. }\end{array}$ & \\
\hline $\begin{array}{l}\text { Ischiadic, minor or } \\
\text { small. }\end{array}$ & See Sacro-sciatic, small. & \\
\hline Ischio-pubic. & See Obturator. & \\
\hline Jugular. & See Lacerated, posterior. & \\
\hline Jugular, spurious. & $\begin{array}{l}\text { An anomalous opening in the squamous portion of the temporal } \\
\text { bone. }\end{array}$ & $\begin{array}{l}\text { A vessel that connects the external jug- } \\
\text { ular vein with an intracranial vessel. }\end{array}$ \\
\hline Lacerated, anterior. & See Sphenoid fissure. & \\
\hline Lacerated, inferior. & See Spheno-maxillary fissure. & \\
\hline Lacerated, jugular. & See Lacerated, posterior. & \\
\hline Lacerated, middle. & $\begin{array}{l}\text { An irregular aperture between the apex of the petrous por- } \\
\text { tion of the temporal bone and the body and great wing of } \\
\text { the sphenoid, and the basilar process of the occipital bone. }\end{array}$ & $\begin{array}{l}\text { The carotid artery and the large } \\
\text { superficial petrosal nerve. }\end{array}$ \\
\hline Lacerated, orbital. & The Sphenoid Fissure, $q \cdot v$. & \\
\hline Lacerated, posterior. & $\begin{array}{l}\text { The space formed by the jugular notches of the occipital and } \\
\text { temporal bones, divided into two portions. }\end{array}$ & $\begin{array}{l}\text { The posterior portion, the internal } \\
\text { jugular vein; the anterior portion, } \\
\text { the gth, Ioth, and IIth cranial nerves, } \\
\text { and the inferior petrosal sinus. }\end{array}$ \\
\hline Lacerated, superior. & See Sphenoid fissure. & \\
\hline Of Magendie. & An orifice in the membranous roof of the fourth ventricle. & \\
\hline Magnum. & See Magnum occipitale. & \\
\hline
\end{tabular}


TABLE OF FORAMINA.-Continued.

\begin{tabular}{|c|c|c|}
\hline NAME. & LOCATION, & TRANSMITS. \\
\hline Magnum ischii. & The Obturator foramen, $q \cdot v$ & \\
\hline Magnum occipitale. & $\begin{array}{l}\text { A large oval aperture, centraliy placed in the lower and } \\
\text { anterior part of the occipital bone. }\end{array}$ & $\begin{array}{l}\text { The spinal cord and its membranes; } \\
\text { the spinal accessory nerves; the ver- } \\
\text { tebral arteries. }\end{array}$ \\
\hline Malar. & The malar bone. & Nerves and vessels. \\
\hline Mandibular. & See Dental, inferior. & \\
\hline Mandibular, anterior. & See Mental. & \\
\hline Mandibular, posterior. & See Dental, inferior. & \\
\hline Mastoid. & A small foramen behind the mastoid process. & $\begin{array}{l}\text { A small artery from the dura; a vein } \\
\text { opening into the lateral sinus. }\end{array}$ \\
\hline Mastoid, posterior. & See Mastoid. & \\
\hline Maxillary, anterior. & See Mental. & \\
\hline Maxillary, inferior. & See Dental, inferior. & \\
\hline Maxillary, posterior. & See Dental, inferior. & \\
\hline Maxillary, superior. & See Canal, Dental, posterior. & \\
\hline Medium. & See Lacerated, middle. & \\
\hline Medullæ spinalis. & See Veriebral. & \\
\hline Medullary. & See Nutrient. & \\
\hline $\begin{array}{l}\text { Medullary (of the ver- } \\
\text { tebral column). }\end{array}$ & See Vertebral. & \\
\hline Of Meibomius. & See Cecum (of the tongue). & \\
\hline Meningeal. & $\begin{array}{l}\text { An anomalous opening in the squamous portion of the temporal } \\
\text { bone. }\end{array}$ & $\begin{array}{l}\text { A branch of the middle meningeal } \\
\text { artery. }\end{array}$ \\
\hline Mental. & $\begin{array}{l}\text { A foramen in the inferior maxilla, external to the incisive fossa, } \\
\text { midway between the upper and lower borders of the bone, } \\
\text { and in the interval between the two bicuspid teeth. }\end{array}$ & Mental nerve and vessels. \\
\hline Of Monro. & $\begin{array}{l}\text { An opening behind the anterior pillars of the fornix through } \\
\text { which the lateral ventricle of the brain communicates with } \\
\text { the third ventricle. }\end{array}$ & The choroid plexus. \\
\hline Monro, anterior of. & See Foramen of Monro. & \\
\hline Monro, primitive. & $\begin{array}{l}\text { The primitive foramen that connects the third with the lateral } \\
\text { ventricle of the brain. }\end{array}$ & \\
\hline Morgagni's. & See Cecum (of tongue). & \\
\hline Nasal. & Small canals that perforate the nasal bones. & Vessels and nerves. \\
\hline Nutrient. & $\begin{array}{l}\text { The canal connecting the medullary cavity of the bone with } \\
\text { its external surface. }\end{array}$ & The nutrient vessels. \\
\hline Nutrient (of femur). & $\begin{array}{l}\text { The aperture near the upper part of the linea aspera of the } \\
\text { femur. }\end{array}$ & Nutrient artery. \\
\hline Nutrient (of humerus). & The aperture slightly below the middle of the humerus. & The nutrient artery. \\
\hline Nutrient (of radius). & The aperture on the anterior surface of the radius. & The nutrient artery. \\
\hline Nutrient (of $u \ln a$ ). & The aperture on the anterior surface of the ulna. & The nutrient artery. \\
\hline Obturator. & $\begin{array}{l}\text { The large ovoid opening between the ischium and the pubis, } \\
\text { internal and inferior to the acetabulum; it is partly closed in } \\
\text { by a fibrous membrane. }\end{array}$ & Obturator vessels and nerves. \\
\hline Occipital. & See Magnum occipitale. & \\
\hline Occipital, superior. & See Superior occipital. & \\
\hline Occipitale, magnum. & See Magnum occipitale. & \\
\hline Oculi. & The pupil. & Rays of light. \\
\hline Olfactory. & Numerous foramina in the cribriform plate of the ethmoid. & Olfactory nerves. \\
\hline Omental, great. & $\begin{array}{l}\text { The communication between the cavities of the greater and } \\
\text { lesser omenta. }\end{array}$ & \\
\hline
\end{tabular}


TABLE OF FORAMINA.-Continued.

\begin{tabular}{|c|c|c|}
\hline NAME. & LOCATION. & TRANSMITS. \\
\hline $\begin{array}{l}\text { Omental, lesser or } \\
\text { small. }\end{array}$ & See Foramen of Winslow. & \\
\hline Oödes. & See Obturator. & \\
\hline Optic. & $\begin{array}{l}\text { The canal at the apex of the orbit, the anterior termination of } \\
\text { the optic groove, just beneath the lesser wing of the sphenoid } \\
\text { bone. }\end{array}$ & Optic nerve; ophthalmic artery. \\
\hline Optic (of the choroid). & The choroid. & $\begin{array}{l}\text { The optic nerve-fibers pass through } \\
\text { this to their expansion in the re- } \\
\text { tina. }\end{array}$ \\
\hline Optic (of the sclera). & The sclerotic coat of the eye. & The optic nerve. \\
\hline $\begin{array}{l}\text { Orbital, anterior inter- } \\
\text { nal. }\end{array}$ & See Ethmoid, anterior. & \\
\hline Orbital, internal. & See Canal, Ethmoid, anterior. & \\
\hline Orbital, superior. & See Supraorbital. & \\
\hline Ossis pubis. & See obturator. & \\
\hline Oval (of the heart). & See Foramen of Botal. & \\
\hline Oval (of the hip). & See Obturator. & \\
\hline Oval (of innominate & See Obturator. & \\
\hline Oval (of the sphenoid). & $\begin{array}{l}\text { An ovoid aperture near the posterior margin of the great } \\
\text { wing of the sphenoid. }\end{array}$ & $\begin{array}{l}\text { The inferior maxillary division of the } \\
\text { trigeminal nerve; the small menin- } \\
\text { geal artery; occasionally, the small } \\
\text { petrosal nerve. }\end{array}$ \\
\hline Pacchionian. & The depressions on the inner surface of the skull. & For the Pacchionian bodies. \\
\hline Palatine, anterior. & See Canal, Incisor. & \\
\hline $\begin{array}{l}\text { Palatine, great poste- } \\
\text { rior. }\end{array}$ & The Posterior palatine canal, $q . v$. & \\
\hline Palato-maxillary. & See Canal, Palato-maxillary. & \\
\hline Of Panizza. & $\begin{array}{l}\text { The communication between the right and left aortic arches of } \\
\text { reptiles. }\end{array}$ & Blood. \\
\hline Papillaria. & $\begin{array}{l}\text { The opening of the uriniferous tubules at the apices of the pyra- } \\
\text { mids of Malpighi. }\end{array}$ & Urine. \\
\hline Parietal. & $\begin{array}{l}\text { Neat the posterior superior angle of the parietal bone; incon- } \\
\text { stant. }\end{array}$ & $\begin{array}{l}\text { An emissary vein of the superior } \\
\text { longitudinal sinus; occasionally a } \\
\text { small branch of the occipital artery. }\end{array}$ \\
\hline Pelvic, large. & See Obturator. & \\
\hline Pneumatic. & $\begin{array}{l}\text { In birds, a large aperture near one end of the long pneumatic } \\
\text { bones communicating with the interior. }\end{array}$ & Permits the entrance of air. \\
\hline Posterior. & See Lacerated, posterior. & \\
\hline Postglenal. & See Postglenoid. & \\
\hline Postglenoid. & $\begin{array}{l}\text { In comparative anatomy, an opening immediately posterior to } \\
\text { the root of the zygoma. }\end{array}$ & \\
\hline Postpalatine. & The Posterior palatine canal, $q . v$. & \\
\hline Pre-acetabular. & $\begin{array}{l}\text { In the Cheiroptera, an opening formed by a process extending } \\
\text { from the ilio-pectineal eminence to the anterior extremity of } \\
\text { the ilium. }\end{array}$ & \\
\hline $\begin{array}{l}\text { Pro sinu petroso infe- } \\
\text { riore. }\end{array}$ & $\begin{array}{l}\text { An anomalous roundish opening formed by adjacent portions } \\
\text { of the petrous portion of the temporal bone and the occipital } \\
\text { bone. }\end{array}$ & The inferior petrosal sinus. \\
\hline Profundum. & See Iter ad infundibulum. & \\
\hline Pterygo-palatine. & The external aperture of the pterygo-palatine canal. & $\begin{array}{l}\text { Pterygo-palatine vessels; pharyngeal } \\
\text { nerve. }\end{array}$ \\
\hline Quadrate. & The diaphragm. & The inferior vena cava. \\
\hline Repugnatoria. & $\begin{array}{l}\text { In Cheilognatha, apertures of cutaneous glands on each side } \\
\text { of the back, in rows. }\end{array}$ & Secrete a defensive corrosive fluid. \\
\hline
\end{tabular}


TABLE OF FORAMINA.-Continued.

\begin{tabular}{l} 
Name. \\
Retina centrale. \\
Of Rivini. \\
\hline Rotundum. \\
\hline Round. \\
\hline Sacral, anterior (four \\
on eilher side). \\
Sacral, posterior (four \\
on either side). \\
\hline Sacro-sciatic, great. \\
\hline Sacro-sciatic, small.
\end{tabular}

Saphenous.

Scapular.

Of Scarpa.

Sclerotic, anterior.

Sclerotic, posterior.

Of Søemmering.

Spheno-frontal.

Sphenoidal, anterior.

Spheno-palatine.

Spheno-spinosum.

Spinal.

Spinosum.

Spöndli.

Of Stensen.

Sternal.

Stylo-mastoid.

Suborbital.

Subsacral.

Supersacral.

Supracondyloid.

Supra-orbital.

Supratrochlear.

Of Tarinus.

Of Thebesius.

Thyreoid.
LOCATION.

See Fovea centralis.

An opening in the tympanum, the existence of which is disputed.

See Round.

A roundish opening in the great wing of the sphenoid bone.

On anterior surface of sacrum, connecting with sacral canal.

The posterior surface of the sacrum, external to the articular processes.

The oval space between the lesser sacro-sciatic ligament and the innominate bone.

The space included between the greater and lesser sacrosciatic ligaments and the portion of the innominate bone between the spine and tuberosity of the ischium.

\section{See Saphenous Opening}

The supra-scapular notch, when it is converted into a foramen by a ligamentous or bony structure.

Bony canals opening into the incisor canal.

The opening in the sclerotic which is filled in by the cornea.

See Optic (of the sclera).

See Fovea centralis, and Central (of the retina).

In the cartilaginous basis of the skull, between the labyrinths of the ethmoid and the alæ parvæ of the sphenoid and the anterior sphenoid.

A rare anomalous opening in the pterygoid process of the sphenoid bone.

The space between the sphenoid and orbital processes of the palate and sphenoid spongy bone; it opens into the nasal cavity.

See Spinosum.

See Vertebral.

The great wing of the sphenoid bone, near its posterior angle. See Spheno-frontal.

See Canal, Incisor.

Near the inferior termination of the sternum; inconstant.

Between the styloid and mastoid processes of the temporal bone, constituting the external aperture of the aqueduct of Fallopius

The orifice at the anterior end of the infraorbital canal.

See Sacral, anterior.

See Sacral, posterior.

See Epitrochlear.

A notch in the superior orbital margin at the junction of the middle with the inner third, sometimes converted into a foramen by a bony process or a ligamentous band. It is the orifice of a groove in the upper wall of the orbit.

The thin plate of bone between the olecranon and the coronoid fossa of the humerus; inconstant.

The Hiatus Fallopii, q. v.

Small depressions on the inner surface of the heart, especially in the right auricle.
TrANSMITS.

The superior division of the fifth nerve.

The anterior branches of sacral nerves.

Posterior branches of sacral nerves.

The pyriformis muscle, the gluteal, sciatic, and pudic vessels and nerves.

Internal obturator muscle; the internal pudic vessels and nerves.

Suprascapular nerve and artery.

The naso-palatine nerves

The internal maxillary artery.

Branches from Meckel's ganglion; the nasal branch of the internal maxillary artery.

\section{Vessel.}

Facial nerve; stylo-mastoid artery.

Infraorbital artery and nerve.

........

nerve.

Some of these are cul-de-sucs; others are the mouths of the venæ minima cordis. 
TABLE OF FORAMINA.-Continued.

\begin{tabular}{|c|c|c|}
\hline NAME. & LOCATION. & TRANSMITS. \\
\hline Thyroid. & $\begin{array}{l}\text { 1. A foramen in the ala of the thyroid cartilage, more or less } \\
\text { completely covered by perichondrium. 2. See Obturator. }\end{array}$ & \\
\hline Trachelian. & See Vertebrarterial. & \\
\hline Transverse. & See Veriebrarterial. & \\
\hline Venæ cavæ. & See Quadrate. & \\
\hline Venæ saphenæ. & See Saphenous Opening. & \\
\hline Venosum. & See Quadrale. & \\
\hline Vertebral. & The space included between the body and arch of a vertebra. & The spinal cord and its appendages. \\
\hline Vertebrarterial. & $\begin{array}{l}\text { The foramina in the transverse processes of the cervical } \\
\text { vertebra. }\end{array}$ & Vertebral artery and vein. \\
\hline Vesalius. & $\begin{array}{l}\text { A minute inconstant aperture at the root of the pterygoid } \\
\text { process of the sphenoid bone. }\end{array}$ & A small vein. \\
\hline Vicq d'Azyr's. & See Foramen cecum, anterior and posterior. & \\
\hline Vidian. & See Canal, Vidian. & \\
\hline Of the vomer. & The posterior aperture of the canal of the vomer. & \\
\hline Of Winslow. & $\begin{array}{l}\text { An aperture situated between the liver and stomach, bounded } \\
\text { in front by the portal vein, hepatic artery and duct, behind, } \\
\text { by the inferior vena cava, below, by the hepatic artery, and } \\
\text { above, by the liver. It is formed by folds of the peritoneum, } \\
\text { and establishes communication between the greater and lesser } \\
\text { cavities of the peritoneum. }\end{array}$ & \\
\hline Zygomatic, anterior. & See Zygomatico-facial. & \\
\hline Zygomatic, external. & See Zygomatico-facial. & \\
\hline Zygomatic, internal. & See Zygomatico-temporal. & \\
\hline Zygomatic, posterior. & See Zygomatico-temporal. & \\
\hline Zygomatic, superior. & See Zygomatico-temporal. & \\
\hline Zygomatic, temporal. & See Zygomatico-temporal. & : \\
\hline Zygomatico-facial. & $\begin{array}{l}\text { The aperture of the malar canal on the facial surface of the } \\
\text { malar bone. }\end{array}$ & $\begin{array}{l}\text { Malar division of temporo-malar } \\
\text { branch of superior maxillary nerve. }\end{array}$ \\
\hline Zygomatico-temporal. & $\begin{array}{l}\text { The external aperture of the malar canal, on the temporal } \\
\text { surface of the malar bone. }\end{array}$ & $\begin{array}{l}\text { Malar division of temporo-malat } \\
\text { branch of superior maxillary nerve. }\end{array}$ \\
\hline
\end{tabular}

Foraminated (fo-ram'-in-a-ted) [foramen, an opening]. Containing foramina.

Foraminiferous (fo-ram-in-if'-er-us). Same as Foraminated.

Forbes, Micrococcus of. See Bacteria, Synonymatic Table of. F., Operation of. See Operations, Table of.

Force (fors) [fortis, strong]. That which produces or arrests motion. The rate of transformation of energy in time. Whatever may be converted into motion (Robert Mayer).

Forced (forst) [fortis, strong]. Accomplished by an unusual exertion of force. F. Feeding. See Sur. alimentation and Feeding.

Forceps (for'-seps) [forceps, a pair of tongs]. An instrument with two blades and handles for purposes of seizing, traction, etc., in surgical, obstetric, and other operations. F., Angular, one bent for introduction into a canal. F., Arterial, one specially adapted for seizing an artery; many varieties are named after inventors. F., Bone, one exceptionally strong, for use in operations upon bones. F., Bull-dog, a forceps with sharp teeth (as for holding an artery). $\mathbf{F}$., Bullet, one of peculiar construction, to extract bullets. F., Cannula, long, slender forceps enclosed in a tube, that opens by protruding the blades. F., Catch, a forceps with a catch on the handle. F., Craniotomy, the halves are crossed and adapted to embryotomy. F., Dental, adapted for extraction of teeth. This was probably among the first, and, perhaps, almost the only instrument employed for the extraction of teeth, until the invention of Garengeot, in the early part of the eighteenth century. But from the time of Celsus, down to this period, the forceps used for the extraction of teeth were so rude in their construction and so illy adapted for the purpose, that for the removal of the molar teeth the employ. ment of the key-instrument became general, both among dentists and physicians. At the present time, however, forceps have been so greatly improved that the key is but little used. F., Duckbill. See Duckbill. F., Ectropion, adapted for seizing the lid in operations for ectropion. F., Gouge, cutting-forceps for operations upon bone. F., Hemostatic, a forceps for controlling hemorrhage. F., Iridectomy, a delicate forceps for seizing the iris. F., Midwifery, or Obstetric, a forceps for grasping the fetal head in difficult labor and by traction aiding its exit; there is a great number of varieties. F., 
Rat-toothed, a form of forceps used in the removal

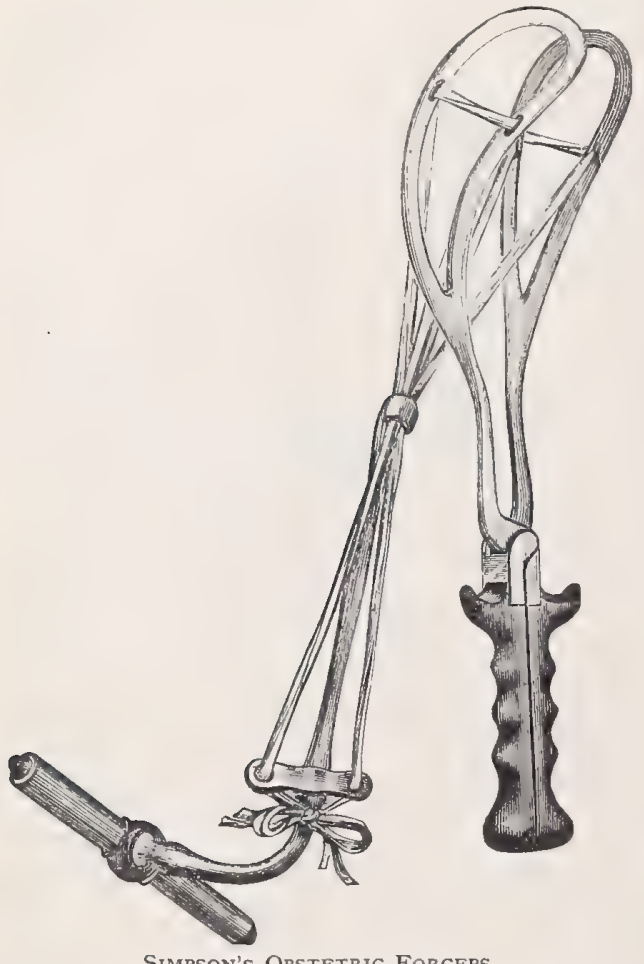

SIMPSON'S OBSTETRIC FORCEPS.

With Poullet Tape-attachment for Axis-traction.

of bullets, or other foreign bodies, from wounds. F., Spring, same as $F$. Catch.

Forcible $\left(\right.$ for $^{\prime}-$ sib-l $)$ [ fortis, strong]. With force or power. F. Extension. See Extension.

Forcipate, Forcipated (for'-sip-ät, -a-ted) [forceps, forceps]. In biology, forceps-like.

Forcipressure (for'-se-presh'-ür) [forceps, a pair of tongs; pressura, a pressing]. The arrest of a minor hemorrhage by catching the end of the divided vessel with a pair of spring-forceps, the pressure being kept up for 24-36 hours.

Fore (for) [ME., fore, before]. Applied to the part that is in front or first. F.-arm, that part of the arm between the wrist and the elbow. F.-brain, the anterior of the encephalic vesicles into which the primary nervous axis of the embryo divides at an early stage ; at a later stage, the prosencephalon. F.-finger, the index finger. F.-foot, the foot of a fore-limb. F.-front, the forehead. F.-gut, the cavity in the raised cephalic end of the embryo, called also headgut. The rudimentary pharynx and duodenum, with the intermediate portions of the future alimentary canal, are included in the foregut. F.-head, that part of the face between the orbits of the eyes, the hair above, and the temples at the sides. F.-limb, the pectoral limb of an animal. F.-milk. I. The colostrum, $q . v$. 2. The first part of the milk taken from the teat at any one milking. It is less rich in butter than is the after-milk, or strippings. F.-skin, the prepuce, $q . v$. ; the term sometimes designates also the dewlap occasionally seen upon the throat of an aged person. F.-waters, a name sometimes given to that portion of the amniotic sac and its contents in advance of the presenting part in labor.
Foreign (for'en) [ME., foren, foreign]. Alien; exotic; not native; irrelevant. F. Body, a substance in a wound, organ, or cavity not normally present.

Forensic (for-en'-sik) [forensis, belonging to the forum ]. Pertaining to a court of law. In medicine, that part of the science connected with judicial inquiry. Also, medical jurisprudence.

Forest's Method. See Artificial Respiration.

Forficate $\left(\right.$ for $\left.^{\prime}-f i k-\bar{a} t\right)$ [forfex, scissors]. In biology, deeply-forked.

Fork [ME., fork, a fork]. A name frequently given to the space between the thighs.

Form [forma, shape]. The external shape or configuration of the body, or of a part of a body.

Formaldehyd (form-al'-de-hìd) [formica, an ant, aldehyd]. Formic aldehyd. See Aldehyd, Formic.

Formalin (for'mal-in) [formica, an ant], $\mathrm{HCOH}$. A proprietary germicide composed of a 40 per cenc. solution of formaldehyd. Unof.

Formanilid (form-an'-il-id) [fornica, an ant; anilin], $\mathrm{C}_{7} \mathrm{H}_{7} \mathrm{NO}$. A substance obtained on digesting anilin with formic acid, or by rapidly heating anilin with oxalic acid. It consists of colorless prisms, readily soluble in water, alcohol, and ether, melting at $46^{\circ} \mathrm{C}$.

Formatio (for-ma'-she-a) [L.]. A formation. F. reticularis, the intercrossing of the fibers of the anterior columns in the medulla.

Formative (form'-at-iv) [ formare, to form]. Plastic; molding. F. Cell, a large spheric, refractive cell beneath the hypoblast.

Formic Acid (for'-mik). See Acid.

Formicant (for'-mik-ant) [ formicare, to crawl like an ant]. Creeping, or moving with a small and feeble action; applied to the pulse when it is unequal and scarcely perceptible.

Formication (for-mik-a'-shun) [formice, an ant]. A sensation like that produced by ants or other insects crawling upon the skin. F., Cocain. See Cocainbug.

Formol (for'-mol) [ formica, an ant], $\mathrm{CH}_{2} \mathrm{O}$. A name given to formic aldehyd or formaldehyd. It is a powerful antiseptic, ranking as one of the best, but its microbicidal power in a given time is very feeble.

Formula (form'-u-lah) [dim. of forma, a form : $p l$., Formula]. A prescribed method. In pharmacy, a list of the names and respective quantities of substances entering into a composition. In chemistry, a method of representing the gravimetric structure of a compound by symbols. F., Constitutional, or Rational, one that indicates only the union of individual atoms, such as are especially characteristic of the compound. F., Empiric. See F., Unitary. F., Graphic. Same as F., Constitutional. F., Rational. Same as F., Constitutional. F., Structural, one that indicates the complete grouping of all of the atoms, representing the whole chemic deportment of a given compound. F., Unitary, or Empiric, one that belongs to an entire series of bodies that are isomeric, yet wholly different, and that affords no hint as to the character of the compound.

Formulary (for'-mu-la-re) [formula; dim. of forma, form]. F., National, a collection of widely-used and well-known preparations, omitted from the U.S. Pharmacopeia, but collected and published by the American Pharmaceutic Association.

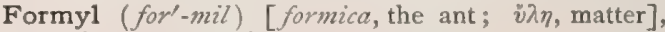
$\mathrm{CHO}$. The radicle of formic acid.

Forne's Method. See Anesthetic.

Forneaux Jordan's Operations. See Operations.

Fornicate (for'-nik-ät) [ fornix, an arch]. In biology, bearing fornices; overarched. To commit fornication. 
Fornication (for-nik-a'-shun) [fornicari, to fornicate]. The illicit sexual intercourse of an unmarried person of either sex with another, whether married or not.

Fornicolumn (for'-ne-kol-um) [ fornix, an arch; columna, a column]. The anterior pillar of the fornix, one in each hemicerebrum. It is a bundle of fibers ascending from the albicans and thalamus, passing just caudad of the precommissure, forming the cephalic boundary of the porta, and ending in the temporal lobe.

Fornicommissure (for-ne-kom'-is-shitr) [fornix, an arch; commissura, a commissure]. A lamina of greater or less thickness uniting the two hemifornices of the brain. It is not a true commissure, nor even fibrous in structure.

Fornicrista (for-ne-kris'-tah). See Crista.

Fornix (for'-niks) [fornix, an arch]. I. An arched portion of the brain composed of the two hippocamps and their respective fimbrias, united across the meson by a thin lamina, the forni commissure. 2. In biology, a vaulted or arched arrangement or appendage, as, for example, the scales in the throat of some corollas, or the hollow beneath the umbo of a bivalve shell. F. descendens. See Bundle of Vicq d'Azyr.

Förster's Method. See Cataract, Artificial Maturation of. F.'s, Operation. See Operations, Tuble of.

Fortification Spectrum (for-tif-ik-a'-shun spek'-trum). Teichopsia; the appearance of a peculiar subjective visual sensation in migraine. The luminous shape of its outer edge assumes a zigzag form, with angles like those of a fortification.

Fosforus ( $f s^{\prime}-$ for-us). A commendable orthography for phosphorus. It has been recommended for adoption by recent spelling-reformers.

Fossa $\left(f \circ s^{\prime}-a h\right)$ [fossa, a ditch: pl., Fossa $]$. A depression, furrow, or sinus. F., Canine, the depression on the external surface of the superior maxillary bone, giving rise to the origin of the levator anguli oris and compressor nasi muscles. F., Condyloid, a fossa behind each condyle of the occipital bone. F. coronaris, the boundary between the disc and corona, in Meduse. F., Cranial, any fossa of the skull. F., Digastric, a deep groove on the inner aspect of the mastoid process for the attachment of the digastric muscle. F., Digital, a deep depression at the base of the inner surface of the great trochanter of the femur. F., Glenoid, the fossa in the temporal bone that receives the condyle of the lower jaw. F., Hyaloid, a depression in the anterior surface of the vitreous body for the crystalline lens. F., Hyoid, a small cavity external to the ary-epiglottic fold on either side of the larynx. It is also called the Sinus pyriformis. F., Iliac, the smooth internal surface of the ilium. F., Incisive, a depression in the superior maxillary bone just above the incisor teeth. F., Infraclavicular. See $F$, Mohrenheim's. F. innominata. Same as $F$. scaphoidea. F., Jugular, a deep excavation in the petrous portion of the temporal bone, forming part of the posterior lacerated foramen. F. lachrymalis, the depression in the frontal bone for the reception of the lachrymal gland. F., Lenticular. Same as $F$., Hyaloid. F., Mohrenheim's, the infraclavicular fossa; a triangular depression beneath the clavicle. F., Myrtiform. Same as F., Incisize. F., Nasal, the nostrils. See Nasal Fossa. F. navicularis, Morgagni's fossa, a fossa within the penis, formed by a dilatation in the spongy portion of the urethral passage. F., Occipital, a fossa behind the condyle of the occipital bone. F., Olfactory, the fossa in the fetus that develops into the nasal fossa. F. ovalis, an oval depression in the right auricle of the heart. F.,
Palatine, the anterior palatine canal passing through the palatine process of the superior maxillary bone. It branches into four compartments, the foramina of Stensen, and the foramina of Scarpa. F. patellaris, a depression on the anterior aspect of the vitreous humor in which rests the posterior surface of the lens. F., Pituitary, a depression below the olivary process of the sphenoid bone lodging the pituitary body. F., Prepontile, the anterior foramen cæcum. See For amina, Iable of. F., Pterygoid, the notch separating the external and internal plates of the pterygoid process of the sphenoid. F. of Rosenmüller, a depression on the posterior wall of the naso-pharynx immediately behind the Eustachian orifice. F. scaphoidea, the curved depression between the helix and antihelix of the external ear. F. sigmoidea, a deep groove on the internal surface of the mastoid portion of the temporal bone into which the mastoid foramen opens. F., Spheno-maxillary, a triangular space at the angle of the spheno-maxillary and pterygo-maxillary fissures. F., Sublingual, a depression on the internal surface of the inferior maxillary bone, for containing the sublingual gland. F., Submaxillary, the oblong depression on the internal surface of the inferior maxillary bone, which contains the submaxillary gland. F., Subscapular, a broad cavity on the internal surface of the scapula. F., Temporal, the fossa on either side of the head filled by the temporal muscle. It is formed by parts of the frontal, sphenoid, parietal, temporal, and malar bones. F., Trochanteric. Same as $F$., Digital. F., Zygomatic, a cavity below and on the inner side of the zygoma.

Fosset, or Fossette (fos-et') [Fr.]. A dimple or small depression.

Fossilin (fos'-it-in) [ fossilis, dug up]. A trade-name for a product resembling vaselin.

Fossula ( fos'-su-lah) [dim. of fossa, a ditch: pl., Fossula]. I. In biology, a small fossa. 2. Any one of the numerous slight depressions on the surface of the cerebrum. F. olfactoriæ, the olfactory depressions of acraspede medusæ.

Fothergill's Disease, or Faceache. See Diseases, Table of. F.'s Sore-throat, a synonym of the angi. noid variety of scarlet fever (Scarlatina anginosa).

Foubert's Test. See Death.

Foudroyancy (foo-droi'-an-se) [Fr.]. The property of being foudroyant.

Foudroyant (foo-droi'-ant) [Fr.]. Sudden and overwhelming; fulminant; fulgurant.

Foul (fowl) [ME., foul, foul]. Filthy; offensive; disgusting. F.-in-the-foot. See $F$-rot. F.-rot, an inflammatory disease of the hoofs of cattle; it is attended with suppuration.

Foulage (foo-lahzh') [Fr., "fulling, or pressing" ']. In massage, a form of manipulation of the tissues. See Fulling.

Foulbrood (fowl'-brood). A contagious zymotic disease of the honey-bee and its larva, due to the presence of the Bacillus alvei. See Bacteria, Synonymatic, Table of.

Foullioy's Operation. See Operations, Table of.

Founder (fown'-der) [fundere, to pour]. Laminitis $\left(q \cdot v_{0}\right)$ of the horse's fore-feet, with the accompanying disorders of related parts. F., Chest, founder in a horse, marked or accompanied by atrophy of the chestmuscles.

Foundling (found'-ling) [Ger., funden, found]. An abandoned infant.

Four (for) [ME., feown , four]. Twice two. F.-drug Ointment. See Basilicon Ointment. F. Masters, Suture of the. See Suture. F.-tailed Bandage. See Bandage. 
Fourchet, or Fourchette (foor-shet') [Fr., a fork]. 1. A fold of mucous membrane at the posterior junc tion of the labia majora. 2. A forked instrument used in division of the frenum lingux

Fournier's Method. See Treatment, Methods of.

Fovea $\left(f o-v e^{\prime}-a h\right)$ [forea, a small pit]. Applied to many depressions in the body or its organs, but more particularly to the fortea centralis retina, a little pit in the macula lutea opposite the visual axis, the spot of distinctest vision, where the retinal cones are massed together and the rods and some other parts are absent. It is opposite the center of the cornea. F. hemielliptica, recessus ellipticus; sinus semiovalis; a small fossa on the inner wall of the labyrinth, between the fovea hemispherica and the orifices of the semicircular canals. F. hemispherica, recessus sphericus; a depression in the forepart of the inner wall of the labyrinth.

Foveate $\left(f^{\prime}-v e-a \bar{t}\right)$ [fovea, a small pit]. In biology, deeply pitted.

Foveola (fo-ve'-o-lah) [dim. of fovea, a small pit]. I. A small pit or depression. 2. The depression at the summit of each papilla of the kidney. F. coccygea, a slight depression-a congenital defect-a little above the anus and at the apex of the coccyx. It is due to imperfect development. F. inguinalis, a somewhat funnel-shaped depression in the external inguinal fossa. It is open in fetal life, and is the abdominal end of the inguinal canal, through which the testis descended. F. radialis. See Anatomist's Snuffor

Fovilla (fo-vil'-ah) [fovere, to warm, to cherish : $p l$., Fovilla]. In biology, the protoplasmic contents of a pollen-grain.

Fowler's Method. A method of estimating the amount of urea in the urine. It consists in mixing one volume of the urine with seven volumes of liquor sodæ chloratæ (U. S. P.) and comparing the specific gravity before and after effervescence. See Urea. F.'s Solution. See Arsenic.

Fox's Apparatus. An apparatus for treating fracture of the clavicle. It consists of a pad in the axilla with a suspensory apparatus from the opposite shoulder.

Fox-glove (foks'-gluv). See Digitalis.

Foxination (foks-in-a'-shun). See Hypnotism.

Fractional (frak'-shun-ac) [fractio, a breaking]. Pertaining to fractions. F. Cultivation, the isolation of one variety of microörganism from a mixture of several, in order to study or cultivate it. This is done by attenuation of the medium so that a drop will probably contain but one organism. Distilled water was first used as the attenuating medium, but gelatinized media are now used. Brefeld and Nägeli suggested the procedure, and Lister isolated the first microbe, the Bacillus lacticus of Cohn. F. Distillation. See Distillation.

Fractionation (frak-shun-a'-shun) [fractio, a breaking]. Chemic separation by successive operations.

Fractura (frak-tūr'-ah) [L.]. A fracture. F. dentis, fracture of a tooth.

Fracture (frak'tur ) [fractura; frangere, to break]. The breaking of a bone, either by external force, or by the action of the muscles of the body. Applied also to the breaking of a cartilage. F., Barton's, an oblique fracture of the lower end of the radius, beginning on the articulating surface. F.-bed, a doublyinclined plane used in the treatment of fractures of the hip. F.-box, a long box with no ends or cover, used in the immobilization of fractured bones. F., Capillary, consisting of only a fine crack or fissure. F., Comminuted, with shattering of the bone. F., Colles', one of the lower end of the radius with displacement back- ward. F., Complete, entirely through the bone. F.,

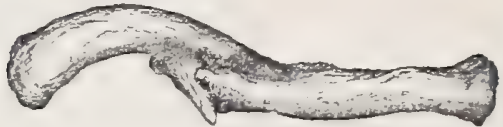

Comminuted Fracture of Clavicle. (Moullin.)

Complicated, with injury of adjacent parts. F., Compound, with a communicating wound of the skin. F., Depressed, with depression of the fractured part below the normal level, as in fracture of the skull. F., Double, one bone is fractured in two places. F., Dupuytren's, fracture of the fibula, with retraction and displacement outward, and with laceration of the ligaments of the foot. F., Epiphyseal, with separation of the epiphysis of a bone. F., Greenstick, one

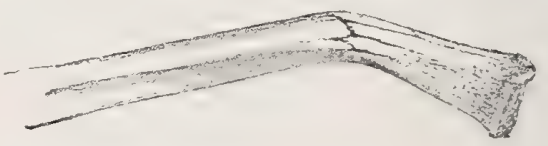

Greenstick Fracture of the Radius. (Moullin.)

side of the bone is broken, the other bent. F., Impacted, with forcible compression of the fragments into each other. F., Moore's, fracture of the lower end of the radius, with laceration of the internal lateral ligament and detachment of the triangular interarticular cartilage, which allows of the dislocation of the head of the ulna and the imprisonment of the styloid process under the annular ligaments. F., Pott's, same as F., Dupuytren's, but without laceration of the inferior tibio-fibular ligaments. F., Shepherd's, a fracture of the astragalus, the outer projecting edge being detached. F., Simple, without rupture of the over. lying skin or mucous membrane. F., Smith's, fracture of the lower end of the radius, from a quarter of an inch to an inch from the articular surface. F., Spontaneous, with but a slight force to cause it, as when there is disease of the bone.

Frænulum (fren'-u-lum). See Frenulum.

Frænum (fre'-num). See Frenum.

Fragilitas (fraj-il'-it-as) [L.]. Brittleness. In physiology, a want of flexile strength. F. crinium, an atrophic condition of the hair in which the individual hairs split into numerous fibrillæ, the cleavage in many cases being recognizable as far as to the roots, the fibrils often curling in several turns away from the axis of the shaft. F. ossium, abnormal brittleness of the bones.

Fragmentation (frag-men-ta'-shun) [fragmentum, a piece]. The subdivision into fragments; the separation of certain forms of bacilli, or other microörganisms, into joints which become new individuals; the division or segmentation of a cell. F. of Calculi, Spontaneous, the exfoliation and breaking up of a calculus by the action of the uric acid or other morbid products in the bladder.

Frambesia (fram-be'-ze-ah) [frambosia, raspberry]. Yaws; Pian; Amboyna Button; Parangi; Coco; Endemic Verrugas. A tropical contagious disease of the skin, of long duration, characterized by dirty or bright-red raspberry-like tubercles, appearing usually on the face, toes, and genital organs. It is most frequent in young colored people.

Frambesial (fram-be'-ze-al) [frambosia, a raspberry]. Resembling, or pertaining to frambesia.

Frambesioid (fram-be'-ze-oid) [ frambasia, a raspberry; Eifos, likeness]. Resembling frambesia, or one of its tubercles. 
Franchimont's Test. See Tests, Table of.

Francis' Test. See Tests, Table of.

Franciscea (fran-sis'-e-ah). See Manaca.

Franck's Pill. A purgative pill containing aloes 4, rhubarb 2, syrup of absinthe, q. s.

Franco's Operations. See Operations, Table of.

Frangible (fran'-jib-l) [frangere, to break]. Liable to fracture; breakable.

Frangula ( frang $-g u$-lah) [origin uncertain]. The bark (one year old) of khamnus frangula, or alder buckthorn. The fresh bark is a violent irritant; the old bark is a non-irritant purgative much used in the constipation of pregnancy. Ext. Rhamni Frang. (B. P.). Dose gr. $x v-3$ j. F., Ext., Fld. Dose 3 ss-ij. Ext. Rham. Frang. Liq. (B. P.). Dose 3 j-iv.

Frangulin ( frang'-gu-lin) [origin uncertain], $\mathrm{C}_{20} \mathrm{H}_{20} \mathrm{O}_{10}$. Rhamnoxanthin; a lemon-yellow, crystalline, odorless, and tasteless glucosid found in Buckthorn.

Frarik [ME., frank, open]. Of a benign or favorable tendency; as a frank inflammation; sometimes also applied to remedies, in a similar sense.

Frank's Operation. See Operations, Table of.

Fränkel's Apparatus. A pneumatic apparatus. F.'s Pneumobacillus. See Bacteria, Synonymatic Table.

Frankenhäuser, Ganglion of. See Ganglia, Table of. F.'s Micrococcus. The micrococcus of pernicious anemia. See Bacteria, Synonymatic Table of.

Frankenia (frang-ke'-ne-ah) [after Johann Franke]. A genus of heath-like herbs and undershrubs. F. grandifora, of California, called Yerba rheuma, is astringent, and is a popular remedy for nasal, urethral and vaginal catarrhs. F. portulacifolia, of St. Helena, has been used as a substitute for tea. Other species of the genus are aromatic and stimulant. Unof.

Frankfort Black. See Pigments, Conspectus of. F. Plane. See Plane.

Frankincense (frangh'-in-sens) [francum incensum, pure incense]. A name given to a variety of resinous aromatic substances, especially the exudation of Abies excelsa; the term was originally, and properly, the same as olibanum. It is the concrete turpentine scraped off the trunks of Pinus australis and P.tada. It is used externally as a slight stimulant and is contained in Emplastrum picis (B. P.).

Frankland's Artificial Human Milk. A nutritious preparation made from cow's milk as follows :-Allow $1 / 3$ of a pint of new milk to stand 12 hours; remove the cream, and mix it with $2 / 3$ of a pint of perfectly fresh cow's milk. Take the milk from which the cream was removed, and put into it a piece of rennet about an inch square (fluid rennet may be employed). Keep the vessel containing it in a warm place, until the milk is fully curdled, an operation requiring from 5 to 15 minutes according to the activity of the rennet. Break up the curd repeatedly, and carefully separate the whole of the whey, which should then be rapidly heated to boiling in a small tin-pan placed over a spirit-lamp or gas-lamp. During the heating a further quantity of casein, technically called "fleetings," separates, and must be removed by straining through clean muslin. Now dissolve I Io grains of powdered sugar of milk in the hot whey, and mix it with $2 / 3$ of a pint of new milk to which the cream from the other fluid has already been added. The artificial milk should be used within 12 hours of its preparation. F.'s Method, a method of estimating the quantity of organic matter present in water. The organic carbon is oxidized and obtained as $\mathrm{CO}_{2}$, and the organic nitrogen is liberated in the free gaseous state and measured.

Franklin (frangk'-lin) [from Benjamin Franklin]. A unit of static or frictional electricity. F. Spectacles. See Bifocal.
Franklinic (frangk-lin'-ik) [from B. Franklin]. Frictional. F. Electricity, static or frictional electricity.

Franklinism (frangk'-lin-izm). Same as Franklinization.

Franklinization (frangk-lin-iz-a'-shun) [after B. Franklin]. The therapeutic use of frictional or static electricity.

Frasera ( $\left.f r a^{\prime}-z e r-a h\right)$. See American Columbo.

Fraserin (fra'-zer-in) [after John Fraser, an English botanist]. A precipitate from a tincture of the root of Frasera carolinensis; it is atonic, stimulant, and mildly astringent. Dose 1 to 3 grains. Unof.

Fraunhofer's Lines. See Alsorption, and LinesTable.

Fraxin (fraks'-in) [fraxinus, an ash-tree], $\mathrm{C}_{21} \mathrm{H}_{22} \mathrm{O}_{13}$. A glucosid from the bark of certain species of ash (Fraxinus excelsior, etc.). It forms fine, white, foursided prisms, of a bitter taste. It has been proposed as a remedy for gout, rheumatism, etc.

Fraxinus (fraks-in'-us) [L., "ash-tree."]. A genus of trees, order Oleacea, to which the various species of the ash belong. F. americana, is useful in dysmenorrhea. A wine (Vinum fraxini americana, N. F.) is prepared from its inner bark. Dose, one fluidrachm. F. excelsior, of Europe, affords a medicinal bark, its leaves, and wood formerly being official. Chinese wax is collected from the branches of F. chinensis ; and manna from $F$. ornus and $F$, rotundifolia.

Freak (frék) [ME., freke, bold]. A popular name for a deformed person.

Freckles (frek'-lz). See Lentigo and Ephelides.

Freestone-hewers' Lung. Synonym of Pneumonokoniosis.

Freezing (frēz'-ing) [ME, freesen, to freeze]. The congelation of liquids, especially of water. F.-fluids, liquid preparations, with boric acid, syrupy or gummy in consistence, in which tissue-specimens are immersed prior to freezing and section-cutting. F.-machine, an apparatus for producing intense cold by the evaporation of condensed gases. F.-microtome, a microtome attached to a contrivance for freezing artificially the tissue to be sectionized. It is used with very soft tissues. F.-mixture, a mixture of salts which absorb heat in undergoing solution. F.-point, the temperature at which a liquid freezes.

Frèire, Micrococcus of. See Bacteria, Table of.

Fremitus (frem'-it-us) [L., a murmur]. A tremor caused by the sympathetic vibration of some part or organ of the body in consonance with some other vibrating body. Also, a murmuring. F., Friction, the vibrations produced by the rubbing together of two dry surfaces of the pleura, and felt by the hand. It is met with frequently in dry pleurisy. F., Rhonchal, vibrations produced by the passage of air through a large bronchial tube containing mucus. It is most often felt in bronchitis. F., Tactile, the vibratory sensation conveyed to the hand applied to the chest of a speaking person. F., Tussive, the thrill felt when the hand is placed upon the chest while the patient coughs. F., Vocal. See Vocal.

Fremontia (fre-mon'-she-ah) [after John C. Fremont, an American explorer]. A genus of malvaceous shrubs. F. californica, Californian slippery elm, is not related botanically to the true elms, but its bark is used in the same way as that of the slippery elm.

French [Francus, a Frank]. Pertaining to France. F. Blue. See Artificial Ultramarine under Pigments, Conspectus of. F. Crust, or F. Distemper. Synonym of Suphilis. F. Green. Same as Schweinfurt Green. F. Measles. Synonym of Rölheln, q. v. F. Method, the manual method of instruction of deaf-mutes. F. Mulberry. See Callicarpa. F. Pox. Synonym of 
Syphilis. F. Purple. Same as Archil. See Pigments, Conspectus of. F. Red. See Pigments, Conspectus of. F. Spirit, Brandy, F. White. Same as White Lead.

Frenetic (fren-et'-ik) [Fr., frénétique]. Relating to mental disorder

Freno-secretory ( fre'-no-se-kre'-tor-e) [ frenum, bridle; secretio, a separation]. Exercising a restraining or inhibitory power over the secretions.

Frenulum (fren'-u-lum) [dim., of frenum, a bridle: pl., Frenula]. A small or minute frenum. The name given to the cephalic portion of the valvula of the mesencephal. In biology, a strong elastic bristle on the upper edge and near the base of the secondary wing of butterflies and moths, which folds the secondaries when at rest; it serves to lock the wings together.

Frenum (fre'-num) [L., a curb]. A ligament, fold of integument, or other part, that checks or limits the movements of any organ. F. dentis, the socket of a tooth. F. labiorum, the fourchet or lower commissure of the labia pudendi. F. linguæe, the bridle of the tongue. F., Macdowel's, the accessory fibers strengthening anteriorly the intermuscular septum of the deep fascia of the arm attached to the great pectoral tendon. F. of Penis, the fold on the lower surface of the glans penis connecting it with the prepuce.

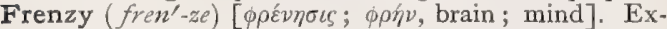
treme and violent mania. F., Transitory, a condition of impaired consciousness characterized by either an intense maniacal frenzy or a confused hallucinatory delirium, the duration of which does not exceed the period of a day or two.

Frère Côme, Arsenical Paste of. Arsenious acid and animal charcoal, each one part; mercuric sulphid, four parts; to be used only over a small area at a time. F. C.'s Operation. See Operations Table.

Fresco Colors. See Pigments, Colors, and Dyestuffs:

Fret [ME., freten, to eat up]. An abrasion; a chafing; herpes ; tetter.

Fretting ( fret'-ing) [ME., freten, to eat up]. A chafing. Synonym of Tormina.

Fretum (fre'-tum) [L., a strait]. A constriction. F. of Haller, in the fetal heart, the constriction between the auricles and the ventricles.

Freund's Operations. See Operations, Table of. F.'s Test. See Tests, Table of.

Frey's White Mass. A substance for injecting tissues. Precipitate from $\mathbf{I} 25$ to $\mathbf{1} 85$ c. c. of a cold, saturated, aqueous solution of barium chlorid by adding $\mathrm{H}_{2} \mathrm{SO}_{4}$, drop by drop. Allow the precipitate to settle for 24 hours, and decant the clear fluid. The remaining mucilaginous mass is mixed with an equal volume of strong gelatin solution.

Friable (fri'-ab-l) [friare, to rub]. Easily broken or crumbled.

Friar's Balsam ( fri'-arz bal'-sam). A name given to the Balsamum traumaticum, N. F., and also to the very similar Tinctura bensoini composita, U. S. P. See Benzoin, and Wade's Balsam.

Fricke's Operation. See Operations, Table of.

Friction (frik'-s/unn) [frictio; fricare, to rub]. I. The act of rubbing. The process, in medicine, called shampooing. Also the inunction of a medicinal substance by rubbing. 2. In massage, firm circular manipulations, always followed by centripetal strokings. Friction may be practised with the thumb, with the tips of the fingers, or with one hand. F。-fremitus. See Fremitus. F.-sound, the sound observed in auscultation, as a result of the rubbing together of adjacent parts, as of the pleural folds, the pericardium, or the peritoneum.
Friedländer, Bacillus of. See Bacteria, Synonymatic Table of. F.'s Hematoxylon Solution. See Stains, Table of. F.'s Method, a method of staining Pneumonia-cocci. See Stains, Table of. F., Microbe of. See Bacteria, Synonymatic Table of.

Friedreich's Ataxia or Disease. Hereditary Ataxia, or Hereditary Ataxic Paraplegia, or Postero-lateral Sclerosis, depending on combined posterior and lateral sclerosis of the cord, and differing from tabes and ataxic paraplegia in the early age of its appearance, its hereditary nature, and some other features. Also applied to Paramyoclonus multiplex. See Diseases, Table of. F.'s Sign. See Signs and Symptoms, Table of.

Fright ( $f r i t)$ [ME, frizt, fright]. Sudden and extreme fear. F. -neuroses, Page's term for certain neuromimetic disorders following injury. This class of cases is generally considered under the name of "traumatic hysteria." Fright-neuroses are frequently encountered in males as the result of railway injuries.

Frigorific (frig-or-if'-ik) [frigus, cold; facere, to make]. 1. Producing extreme cold. 2. That which produces extreme cold. F. Mixture, Arnott's Mix. ture; a mixture used as a local anesthetic. It consists of two parts of ice, and one of salt. These are pulverized separately in a canvas or linen bag, and then thoroughly mixed and surrounded by a piece of gauze. As soon as the mixture begins to melt it should be placed over the part to be anesthetized.

Fringe (frinj) [ME., fringe, a fringe]. See Fimbria. F.-tree, the bark of the root of Chionanthus virginica, a mild diuretic, aperient, and reputed alterative. Dose of the fld. ext. 3 ss-j. Unof. See Chionanthus.

Frog [ME, frogge, a frog]. I. An amphibian of the family Ranida. 2. In farriery, an elastic, horny substance that grows in the middle of the sole of a horse's foot, dividing it into two branches, and running toward the heel in the form of a fork. 3. A popular name for Ranula, $q . v$. It is also called Frog-tongue. F., Cohnheim's. See Cohnheim. F.face, a facial deformity due to the growth of polypi or other tumors in the nasal cavities. A temporary condition of this kind may be due to orbital cellulitis or facial erysipelas. F.-gait, a peculiar hopping progression due to contractions of the flexors and adductors of the thighs, and to paralysis of the adductors. It is one of the results of infantile diplegia. F.headed, the appellation given to anencephalic monsters, from their peculiar contour, which is due to the imperfect development of the orbits and the consequent apparent prominence of the eyes. F.-spawn Matter. See Boiled-sago Matter. F.-tongue. See Frog. Froissement (frwas-mon $(g)$ ) [Fr., bruising]. In massage, a form of "rough attachement," of the skin and superficial tissues. See Attachement.

Frôlement (fröl-mon $(\mathrm{g})$ ) [Fr.]. A brushing.; in massage, a succession of slow, backward-and-forward movements, as from a center to a periphery, and the reverse. It is done with the palmar surface of the fingers, or with the roulet.

Fromage de Brie (fro-makgh du(r)-bre). See Cheese. Frohmann's Lines. See Line.

Frond (frond) [frons, a leafy branch]. In biology, a leaf-like expansion of certain invertebrates, especially such as resemble plants. A thallus, or organ in which the functions of leaf and stem are not fully differentiated.

Frondescence (fron-des'-ens) [frondescere, to put forth leaves]. In biology, the state of bursting into leaf. Cf. Foliation, and Phyllody.

Frondose (fron'-dōs) [frondosus, leafy]. In biology, 
having thin, expanded parts. Thalloid, or like a thallus.

Frons (fronz) [L.: gen., Frontis]. The forehead.

Front (frunt) [frons, the forehead]. The forehead. F. Combination. See Combination. F.-tap Contraction of Gowers. See Contraction, and Reflexes, Table of.

Frontad (frun'-tad) [frons, the forehead; $a d$, to]. Towards the frontal aspect.

Frontadiform ( frun-tad'-if-orm) [ frons, front; forma, form]. In biology, having the body extended in the direction of the forehead.

Frontal (frunt'-al) [frontalis, of the forehead]. I. Pertaining to the anterior part or aspect of an organ or body. 2. More often, belonging to the fröns or forehead. F. Bone, the anterior bone of the skull and superior bone of the face. F. Crest. See Crest. F. Eminence. See Eminence. F. Lobe. See Lobe. F. Section. See Section. F. Sinuses, the cavities, one over each orbit, of the frontal bone. F. Triangle. See Triangles, Table of.

Frontalis Muscle (fron-ta'-lis) [frontalis, of the forehead]. The frontal portion of the occipito-frontal muscle. See Muscles, Table of.

Fronten (frun'ten) [frons, the forehead]. Belonging to the frontal bone in itself.

Frontlet (frunt'-let) [ frons, the forehead]. In biology, applied to the forehead of a bird when distinguished by some peculiarity.

Fronto- (frun'-to-) [frons, the forehead]. A prefix denoting anterior position; or, more often, expressing a relation with the frons, or forehead. F.-alveolar, relating to the frontal and alveolar regions. F.ethmoid, relating to the frontal and ethmoid bones. F.-occipital, relating to both forehead and occiput. F.-triangle. See Triangle. F,-orbital, relating to forehead and orbit.

Frontodymia (frun-to-dim'-e-ah). Same as Cephalopagus and Cephalodymia.

Frost [old Danish, froste, frost]. In farriery, to sharpen the front and hind parts of a horse's shoes. F.-bite, injury to the skin or a part from extreme cold, resulting in inflammation and gangrene; pagoplexia. F.itch, a name for Prurigo hiemalis. F.-wort. See Helianthemum.

Frosted Feet ( fros'-ted fett). See Chilblain.

Froth [ME., frothe, froth]. Foam, as from the mouth. F., Bronchial, that coming from the bronchial tubes, as in asthma.

Frottage (frot-ahzh') [Fr.]. A form of sexual perversion in which the orgasm is induced by simply rubbing against or toying with the clothing of women. An individual so afflicted is called a frotteur.

Frotteur (fro-tairf) [Fr.]. See Frottage.

Frown [ME., frownen, to scowl]. To scowl. A wrinkling of the brow.

Frozen Attitude (fro'-zen $\left.a t^{\prime}-i t-\bar{u} d\right)$. See Attitude.

Fructiculose (fruk-tik'-u-lōs) [fructiculus, dim. of fructus, fruit]. In biology, bearing much fruit.

Fructification (fruk-tif-ik-a $a^{\prime}-\operatorname{shun}$ ) [fructificare, to bear fruit]. In biology, fecundation, fertilization, impregnation ; the act of forming, or the production of fruit, of whatever sort.

Fructose (fruk'-tös) [fructus, fruit], $\mathrm{C}_{6} \mathrm{H}_{12} \mathrm{O}_{6}$. Fruitsugar, formerly called levulose; it is found in almost all sweet fruits. It is formed, together with grape-sugar, in the so-called inversion, or decomposition of cane-sugar, by boiling with acids or by the action of ferments. The mixture of the two is called invert-sugar. Fruit-sugar forms a thick syrup, which at $100^{\circ} \mathrm{C}$. dries to a gummy, deliquescent mass. It may be crystallized in fine, silky needles, fusing at $95^{\circ} \mathrm{C}$. It is more slowly fermented by yeast than grape-sugar. It reduces an alkaline copper-solution in the same proportion as the latter. See also Carbohydrates, Table of.

Fruehjahrkatarrh [Ger.]. See Ophthalmia, Spring

Frugivorous (fru-jiv'-or-us) [ frux, fruit; vorare, to devour]. Fruit-eating.

Frühlingskatarrh (fre'-lings-kat-ar) [Ger.]. See Vernal Conjunctivitis and Ophthalmia, Spring.

Fruit (froot) [ fructus, fruit]. The developed ovary of a plant, and especially the succulent, fleshy parts gathered about the same. Also applied to the offspring of animals. F.-sugar. See Sugar and Fructose. F.-dots. See Sorus.

Frumentaceous (fru-men-t $\alpha^{\prime}-$ she-us) [ firmentum, grain]. Belonging to or resembling grain.

Frumentum (fru-men'-tum) [L.]. Wheat or other grain. Spiritus frumenti, whisky. See Spiritus.

Frutescent ( fru-tes'-ent) [ frutex, a shrub]. In biology, somewhat shrubby.

Frutex (fru'-teks) [L. a shrub, a bush: pl. Frutices]. In biology, a shrub; a woody, perennial plant, generally having several stems and not exceeding twenty feet in height

Fruticose, or Fruticous (fru'-tik-ōs, or -us) [frutex, a shrub]. Shrubby.

Fruticulose (fru-tik'-u-lōs) [fruticulus, dim. of frutex, a shrub]. In biology, resembling a small shrub.

Fryer's Apparatus. A transfusion apparatus made of a single piece of rubber with two bulbs. F.'s Operation. See Operations, Table of.

Fuchsin (fook'-sin) [after Leonhard Fuchs], $\mathrm{C}_{20} \mathrm{H}_{19} \mathrm{~N}_{3}$. $\mathrm{HCl}$. Rosein, Magenta, Eosin, Anilin-red. The hydrochlorid of rosanilin, a lustrous, green, crystalline salt imparting an intense red to solutions. In large doses it produces violent emesis and purging. Injected into a vein it causes staggering and trembling. It is said to be efficient in reducing albuminuria. Dose gr. 1/2-iv. See Pigments, Conspectus of. F.-bodies, the name given by Kussel to certain bodies found in carcinomata to which he attributes the causation of the growths; he refers them to the sprouting fungi. Other observers find similar bodies which they hold to be coccidia, while others consider them as crystals of safranin or other pigments used in the preparation.

Fuchsinophile (fook-sin'-o-ful) [fuchsin; $\phi \iota \lambda \varepsilon \varepsilon \iota v$, to love]. Readily stained by fuchsin.

Fuciphagous (fu-sif'-ag-us). Same as Fucivorous.

Fucivorous ( fu-siv'-or-us) [fucus, a seaweed; vorare, to devour]. In biology, applied to such animals as the dugong, certain marine turtles, etc., that feed on sea-weeds.

Fucus $\left(f u^{\prime}-k u s\right)$ [ $\phi \tilde{v} \kappa o s$, seaweed]. A genus of marine algæ, the rock-weeds. F.vesiculosus, bladder-wrack, sea-wrack; a marine alga abundant on the seashore; it is used as an alterative and tonic. It is employed in goiter and glandular enlargements, but mainly as an empiric remedy for the absorption of fatty tissue in obesity. An extract for such purpose is sold under the name of anti-fat. Dose of the solid extract, gr. $\mathrm{x}$; of the fluid extract, $\mathbf{z} \mathbf{j}-\mathbf{i j}$. Unof.

Fuel $\left(f u^{\prime}-e l\right)$ [ME., fuel, a wood-yard]. Combustible matter. F.-gas, natural gas mixed with air, used largely for manufacturing purposes as a substitute for solid fuel. Artificial gas, of the water-gas type, not enriched with hydrocarbons for rendering it illuminant, is also sold as fuel-gas.

Fugacious (fu-ra'shus) [fugere, to flee]. In biology, falling off, or fading early; fleeting; fugitive.

Fugitive Color ( fu'-jit-iv kul'-or). See Pigments, Colors, and Dye-stuffs.

Fulgurant (full-ju-rant) [ fulgurare, to flash; fulgur, lightning]. Severe and terrific; as fulgurant pains. 
Fulguration ( ful-ju-ra'shun) [ fulguratio, a stroke of lightning]. I. Lightning-stroke. 2, A sensation of swiftly darting pains.

Fuliginous $\left(f u-l i j^{\prime}-i n-u s\right)$ [fuliginosus, full of soot]. Smoke-like ; very dark ; soot-colored; applied to lips that are covered with dry, black crusts, as a "fuliginous coating."

Fuligo $\left(f u-l i^{\prime}-g o\right)[$ L. $]$. Soot ; sordes. F. ligni, the soot of a wood-fire; ointments and tinctures of it are popularly esteemed. It is a good disinfectant. F. kali, a preparation of soot boiled in caustic potash, and used in skin-diseases. Cf. Anthrakokali.

Full [ME., ful, full]. r. Replete; filled, 2. Intoxicated. 3. Entire. F. Bath. See Bath.

Fullers' Earth (ful'-erz urth). A siliceous non-fictile clay, used in the fulling of cloth, on account of its soapy quality; it was formerly used as an absorbent, like bole

Fuller's Lotion. A lotion for rheumatic joints, composed of carbonate of soda, 6 drams; laudanum, I ounce; glycerin, 2 ounces, and water, 9 ounces. Saturate hot cloths with this and apply. F.'s Pill, a purgative pill, containing aloes, senna, asafetida, galbanum, myrrh, sulphate of iron, saffron, mace, oil of amber, honey, and alcohol.

Fulling (full'-ing) [ME., fullynge, fulling]. In massage, a valuable method of kneading, named from the motion used by fullers in rubbing linen between their hands. It consists in holding the limb between the palms of both hands, with the fingers fully extended, and making a rapid to-and-fro movement with each, the result being that the limb is rolled back and forth between the hands.

Fulmar Oil (ful'-mar) [ME., fulmar]. Oil cast up from the stomach of the fulmar (Procellaria glacialis), a sea bird of the N. Atlantic. It has the general qualities of cod-liver oil.

Fulminant, or Fulminating ( ful'-min-ant, or ful'min-a-ting) [fulminare, to lighten]. Sudden, severe, and rapid in course; as fulminant glaucoma. Same as Foudroyant, q. v.

Fulminate ( ful'-min-āt) [fulmen, lightning]. A compound of fulminic acid with a base, usually silver, gold, or mercury, characterized by highly explosive qualities.

Fulminating (ful'-min-a-ting). See Fulminant.

Fulvous (ful'-vus) [ fulvus, deep-yellow, tawny, flamecolored]. Having a tawny-yellow color.

Fumaria (fu-ma'-re-ah). See Fumitory.

Fumarin (fu'-mar-in) [fumus, smoke]. An alkaloid from Fumaria officinalis; recommended as strongly antipyretic. Unof.

Fumigation ( $\left.f u-m i g-a^{\prime}-s h u n\right)$ [funigare, to smoke]. Disinfection by exposure to the fumes of a vaporized disinfectant.

Fumitory $\left(f u^{\prime}\right.$-mit-or-e) [ fumus, smoke ; terra, earth]. The plants Fumaria officinalis, and $F$. bulbosa, herbs native to Europe: formerly esteemed as polychrest remedies, but now neglected; they are actively deobstruent and antifebrile. Unof.

Fumous ( $f u^{\prime}$-mus) [fumus, smoke]. In biology, smoke-colored; fuliginous.

Fumus $\left(f u^{\prime}-m u s\right)\left[L_{0}\right]$. Smoke. F. terre, old name for Fumitory.

Function (fungk'-shun) [fungi, to perform]. The normal or special action of a tissue, organ, or part of the body.

Functional (fungk'-shun-al) [fungi, to perform]. Pertaining to the special action of an organ, whether physiologic or pathologic. F. Disease, one without appreciable organic alterations. F. Spasm, a term applied to any of the so-called Fatigue-diseases.
Functionalization ( funk-shun-al-iz-a $-\operatorname{shun}$ ) [ functio, a function]. Restoration of a lost or diseased function.

Fundal (fun'-dal) [fundus, the bottom]. Relating to a fundus.

Fundament (fun'-dam-ent) [ fundamentum: fundus, bottom ]. I. The foundation or base of a thing. 2 . In embryology, the rudiment. 3. The anus.

Fundamental (fun-dan-ent'-al) [ fundamentum: fundus, bottom]. Pertaining to the foundation. F. Tissue, in biology, unspecialized parenchyma; those tissues of a plant through which the fibro-vascular bundles are distributed.

Fundus (fun'-dus) [fundus, the bottom]. The base of an organ. F. Glands, microscopic tubular glands of the cardiac portion of the gastric mucous membrane. F. oculi, the posterior and interior portion of the eye seen by the ophthalmoscope, comprising chiefly the retina, papilla, retinal vessels, etc. $\mathbf{F}$. uteri, the part of the womb remotest from the cervix, and situated cephalad from the outlets of the oviducts. F. vesicæ, the basis, floor, or bas fond of the urinary bladder.

Fungate (fung'-gāt) [fungus, a toadstool]. To grow up with a fungous form or appearance. Also to grow rapidly like a fungus (applied to certain pathologic growths).

Fungi (fun'-ji). See Fungus.

Fungicide ( fun'-jis-id) [ fungus, a toadstool; cadere, to kill]. I. Destructive to fungi; bactericide. 2. An agent that destroys fungi or bacteria.

Fungiform ( fun'-jif-orm) [ fungus, a mushroom; forma, form $]$. Having the form of a mushroom. F. Papillæ, elevations upon the middle and back part of the tongue.

Fungin (fun'-jin) [fungus, a toadstool]. A peculiar principle found in most of the fungi. It is a whitish, soft, insipid, fleshy substance, insoluble in water, alcohol, ether, or weak $\mathrm{H}_{2} \mathrm{SO}_{4}$, soluble in heated hydrochloric acid.

Fungoid (funs'-goid) [fungus, a toadstool; eidos, likeness]. Resembling a fungus; fungous.

Fungosity (fung-gos'-it-e) [fungus, a toadstool]. A fungous growth; the quality of being fungous.

Fungous (fung'-gus) [fungus, a toadstool]. Having the appearance or qualities of a fungus; excrescent, soft and swiftly-growing. F. Endometritis. See Endometritis.

Fungus (fung'-gus) [fungus, a toadstool: pl., Fungi]. I. An order of plants without stems, leaves or roots, consisting of juxtaposed cells, without chlorophyl. They reproduce by spores. The chief classes are the Hymenomycetes, Basidionycetes, Ascomycetes, Schizomycetes, and Oömycetes. 2. A spongy, morbid excrescence, as proud-flesh. F. of Brain, hernia cerebri. F. of Dura Mater, a tumor of the skull, of malignant nature, originating in the layers of osteal cells. F. Foot. See Foot. F. hæmatodes, a bleeding tumor, generally a soft cancer.

Funic (fu'-nik) [funis, a rope]. Pertaining to the funiculus or umbilical cord.

Funicular ( $f u-n i k^{\prime}-u$-lar) [ funis, a rope]. Relating to the funiculus. F. Souffle, a hissing sound synchronous with that of the fetal heart, heard in auscultating the pregnant abdomen. It is heard in only from I4 to 15 per cent. of cases, and is referable to the umbilical cord.

Funiculitis (fu-nik-u-li'-tis) [ funiculus, the spermatic cord; $\iota$ T/, inflammation]. Inflammation of the spermatic cord.

Funiculus ( $f u-n i k^{\prime}-u$-lus) [L., a cord ; dim. of funis, a rope]. I. In biology, applied to various cord-like structures, as the spermatic cord, the umbilical 
cord of mammals or its analogue in lower animals, the ultimate nerve-bundles, the attachment of the base of the stomach of a polyp with the bottom of its cell, the slender part of the clubbed antenna of an insect, the stalk of an ovule or seed, etc. 2. A bundle of nerve-fibers in a sheath of perineurium. 3. A name, variously qualified, for the diflerent columns of the spinal cord and oblongata; as the $F$ cuneatus, $F$. gracilis, $F$. of Rolando, $F$. teres. F. cuneatus. See Column of Burdach. F. gracilis. See Column of Goll.

Funiform (fil'-nif-orm) [funis, rope; forma, shape]. In biology, resembling a rope or cord.

Funis ( $f u^{\prime}$-nis) [L.]. A cord; applied to the umbilical cord.

Funnel ( fun'-el) [Old Fr., fonel] . I. A wide-mouthed, conic vessel ending in a tube, designed to aid in the speedy and safe transfer of liquids from one vessel to another. It is also used as a support for paper-filters. 2. An infundibulum. F. Mitral, a condition of the mitral valve in mitral stenosis in which the left auricle and the valve-structures are transformed into a hollow cone. This condition is also called Button-hole Mitral. F., Muscular, the funnel-shaped space bounded by the four straight muscles of the eye; its apex is at the optic foramen, the eyeball forms its base, and along its axis runs the optic nerve. F.-shaped Pelvis, a congenital deformity of the pelvis, in which it retains its fetal or funnel shape. F., Vascular, the light-hued depression at the center of the disc of the retina; if exaggerated, it forms a so-called physiologic cup.

Funny Bone $\left(f u n^{\prime}-e b \bar{o} n\right)$. The internal condyle of the humerus. Being crossed superficially by the ulnar nerve, blows upon it give an unpleasant sensation to the hand; whence the name.

Fur [ME, furre, fur]. A coating of morbid matters, including an increased amount of epithelium, seen upon the tongue in various conditions of disease.

Furan (fur'-an) [furfur, bran], $\mathrm{C}_{4} \mathrm{H}_{4} \mathrm{O}$. Furfuran; tetrol ; a product of the destructive distillation of pinewood; it is also produced synthetically by the distillation of pyromucic acid. It is a liquid, insoluble in water, with a peculiar odor, and boiling at $32^{\circ} \mathrm{C}$. It yields bluish-violet dyestuffs with isatin and sulphuric acid, and violet-red with phenanthraquinone.

Fürbringer's Method. A method of cleansing the hands and nails of operators. The hands and forearms having been thoroughly cleansed by scrubbing with soap and warm water and the nails carefully cleansed, the hands and forearms are dipped for at least a minute in absolute alcohol, then immediately into warm bichlorid of mercury solution (I : 1000) and well scrubbed with a nail-brush, the nails receiving particular attention.

Furca $($ fur'-kah) [L., a fork]. A fork. F. orbitalis, the orbital fork; one of the earliest signs of the orbit seen in the embryo; it is a mere trace of bifurcated bony tissue.

Furcate (fur'-kât) [furce, a fork]. In biology, forked; divided into two equal branches.

Furcula (fur'-ku-lah) [L., dim. of furca, a fork]. In biology, applied to various forked structures, as the united clavicles (wish-bone or merry-thought) of a bird, or the bifid processes of certain insects.

Furfur (fur'-fur) [L. ]. Dandruff or perrigo; scurf; the bran of flour. F., Microsporon. See Tinea versicolor. Furfuraceous (fur-fur-a'-she-us) [furfur, bran]. Resembling bran. Applied also to dandruff-covered skin. Furfuran (fur'-fu-ran). See Furan.

Furfurin (fur'-fu-rin) [furfur, bran], $\mathrm{C}_{15} \mathrm{H}_{12} \mathrm{~N}_{2} \mathrm{O}_{3}$. A basic crystalline principle derivable from furfurol; it has been proposed as an antipyretic and tonic remedy.
Furfurol (fur'-fu-rol) [furfur, bran; oleum, oil], $\mathrm{C}_{5} \mathrm{H}_{4} \mathrm{O}_{2}$. The aldehyd of furfuryl alcohol is produced in the distillation of bran with dilute $\mathrm{H}_{2} \mathrm{SO}_{4}$, or of sugar, etc. It is also derived from arabinose or xylose and occurs in the decomposition-products of albuminoid bodies, as meat, cheese, urine, etc. With phenylhydrazin it forms a nearly insoluble compound, furfurol hydrazon. It is a colorless volatile oil, with an aromatic odor. Its specific gravity at $130^{\circ} \mathrm{C}$. is $\mathbf{I}, 163$. It boils at $\mathrm{I} 62^{\circ} \mathrm{C}$. It combines with dimethylanilin to form a green dye-stuff, corresponding to malachite green. It exists in certain new whiskies; but as the spirit becomes older the furfurol gradually disappears.

Furibund ( $\left.f u^{\prime}-r e-b u n d\right)$ [ furibundus, raging]. Raging; maniacal (applied to certain insane patients).

Furor (fu'-ror) [L.]. Madness; fury; a maniacal attack. F. genitalis. Same as Erotomania. F. epilepticus, epileptic insanity. F. transitorius. See Mania, Transitory. F. uterinus. See Nymphomania.

Furred (furd) [ME., furre, fur]. Having an abnormal coating of granular or epithelial scales and other matter; as a furred tongue.

Furrow $\left(f u r^{\prime}-0\right)$ [ME., furze, a groove]. A groove or trench. F., Auriculo-ventricular, the great transverse groove separating the auricles of the heart from the ventricles. F., Digital, one of the transverse lines or furrows on the palmar surface of the fingers. F., Genital, a groove appearing on the genital tubercle of the fetus at the end of the second month. F., Interventricular, two longitudinal grooves separating the two ventricles of the heart. F., Jadelot's. See Jadelot's Lines, or Furrorws.

Furrowing (fur'-o-ing) [ME., furwe, a groove]. In biology, the process of segmentation of the yolk of an egg in some animals, as Amphibia.

Furuncle $\left(f u^{\prime}-r u n g-k l\right)$. See Furunculus.

Furunculosis (fu-rung-ku-lo'-sis) [furunculus, a boil]. The morbid condition that is associated with the production of furuncles.

Furunculous (fu-rung'-ku-lus) [furunculus, a boil]. Characterized by a continuous production of furuncles.

Furunculus ( $\left.f u-r u n g^{\prime}-k u-l u s\right)$ [L.]. A boil. A local inflammatory affection, commonly involving a skingland or hair-follicle, ending in necrosis and central suppuration of adjacent parts. It begins with painful induration, followed by swelling, finally suppurating and sloughing at the "core." F. orientalis, Oriental Boil, Aleppo Boil, Delhi Boil, Biscara Button, Gafsa Button, Kandahar Sore, Pendjeh Sore, Natal Sore. A local disease, marked by the successive formation of papule, tubercle, scab, and sharply circumscribed ulcer on the face, especially the cheeks and angle of the mouth. It is common along the shores of the Mediterranean Sea.

Fuscescent (fus-es'-ent) [fuscus, dusky]. In biology, of a dark-brownish tinge.

Fuscin $\left(\right.$ fus' $^{\prime}$ in) [ fuscus, dark]. Retinal melanin. A pigment found as minute granules imbedded in the cell-substance and processes of the retinal epithelium.

Fuscoferruginous (fus-ko-fer-oo'-jin-us) [ fuscus, dark; ferruginozes, rusty ]. Brownish; rust-colored.

Fuscotestaceous (fus-ko-tes-ta'-she-us) [ fuscus, dark, dusky; testaceus, brick-colored]. Dull reddish-brown.

Fuscous (fus'-kus) [fuscus, dusky]. Grayish-brown.

Fusel Oil $\left(f u^{\prime}-z e l\right)$. See Alcohol.

Fusible $\left(f u^{\prime}-z i b-l\right)$ [fusus, melted]. That which may be fused or melted. F. Calculus. See Calculus.

Fusiform (fu'-sif-orm) [fusus, a spindle; forma, shape]. Spindle-shaped; larger in the middle and diminishing in diameter toward either end; applied to cells, fibers, etc. 
Fusion ( $\left.f u^{\prime}-z h u n\right)$ [fusio; fundere, to pour out]. The process of liquefying a solid by the agency of heat.

Fuso-cellular ( fu'-so-sel'-u-lar) [ fusus, a spindle; cella, a cell]. Spindle-celled; as a fuso-cellular sarcoma.

Fustic (fus'-tik) [Fr., fustoc]. A yellow dye-stuff, the wood of Cholorophora tinctoria, an urticaceous tree of tropical America. The wood of Rhus cotinus, or Venetian sumach, is called young fustic.
Fustigation (fus-tig-a'-shun) [fustigare, to beat]. Flagellation. F., Electric, an application of electricity in which the surface of the body is rapidly tapped with the electrodes of an induced current.

Fustin (fus'-tin) [fustus, a knotted stick], $\mathrm{C}_{15} \mathrm{H}_{10} \mathrm{O}_{6}$. A yellow crystalline coloring-matter obtained from Rhus coinus. See Pigments, Conspectus of.

Fuzzball (fuz'-bazol). See Bovisla.
G. Abbreviation of gram.

Gabbett's Method. A method of detecting tuberclebacilli in cover-glass preparations. See Stains, Table of.

Gabian $\left(g a^{\prime}-b e-a n\right)$ [Fr.]. A variety of naphtha or petroleum from Gabian, a town of France, in Hérault; oleum gabianum.

Gaboon Chocolate (gab-oon' chok'-o.let). See Iba.

Gad-fly (gad'-fi) [gad, a goad; ME., fye, a fly]. A dipterous insect belonging to the genus Tabanus. Also applied to flies of the genus Estris.

Gadinin (gad'-in-in) [from Gadus callarias, haddock], $\mathrm{C}_{7} \mathrm{H}_{17} \mathrm{NO}_{2}$. A ptomaine obtained from decomposing haddock, and also from cultures of the bacteria of human feces. It acts as a decided poison when given in large doses.

Gaduin (gad'-u-in) [gadus, the codfish], $\mathrm{C}_{35} \mathrm{H}_{46} \mathrm{O}_{9} . \quad \mathrm{A}$ fatty principle occurring in cod-liver oil ; it is a darkbrown, brittle substance.

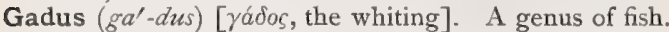
G. morrhua, the cod; a fish from the livers of which cod-liver oil is obtained. See Morrhua.

Gæophagia (je-o-fa'-je-ah). See Geophagy.

Gaertner, Ducts of. See Duct.

Gaftky's Method. A method of staining the bacillus of typhoid fever. See Stains, Table of.

Gafsa Button $\left(g a f^{\prime}-s a h b u t^{\prime}-n\right)$. See Furunculus orientalis.

Gag [gaggen, to suffocate]. An instrument, generally made of flexible rubber, placed between the teeth to prevent closure of the jaws during the administration of nitrous oxid gas, or in operations on the mouth.

Gage's Solution. See Stains, Table of.

Gaiac $\left(g a^{\prime}-y a k\right)$. Same as Guaiacum.

Gaillard's Suture. See Suture.

Gait $(g \bar{a} t)$ [AS.]. The manner of progression by walking. The peculiarities of the gait may assume great diagnostic importance in cases of central nervous disorder. G., Cerebellar, a gait in which the feet are widely spread apart for support, and associated with a staggering movement. It is due to disease, usually tumor, of the middle lobe of the cerebellum. G., Equine, a gait in which the foot hangs down and cannot be moved, progression being accomplished by flexing the thigh on the abdomen. It is seen in peroneal paralysis. G., Frog, the characteristic hoppinggait of infantile paralysis.

Gal. Abbreviation of gallon.

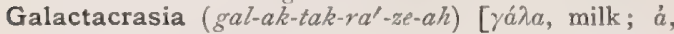
priv.; кра̃ $\iota \iota$, mixture ]. Defect or abnormality in the composition of the milk.

Galactrmia (gal-ak-te'-me-ah), See Galacthemia.

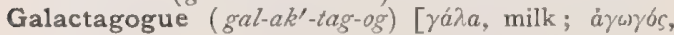
leading]. I. Inducing the secretion of milk. 2. An agent that increases the secretion of milk in the breast.

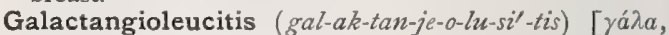
milk; áryeiov, vessel ; $\lambda \varepsilon v \kappa o ́ s$, white]. Lymphangitis associated with lactation.

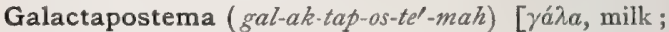

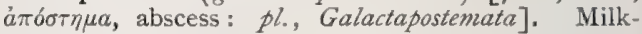
abscess ; mammary abscess associated with lactation.

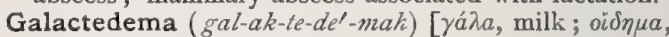
a swelling]. Swelling of the mamma due to accumulation of milk within it.

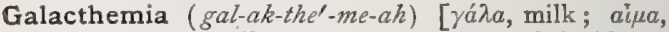
blood]. I. A milky state or appearance of the blood. 2. Bloody milk, or the giving of bloody milk.

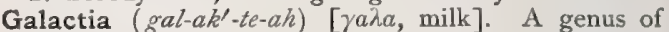
diseases, according to Good's Nosology, embracing defective or abnormal secretion of milk. G. virorum, the secretion of milk by the male.

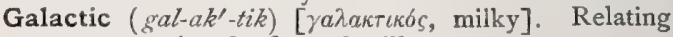
to or promoting the flow of milk.

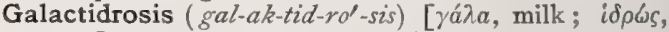
sweat]. The sweating of a milk-like fluid.

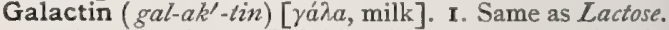
2. An amorphous alkaloid or base, reported to be obtainable from milk. 3. A wax obtained from the sap of the S. American cow-tree, Galactodendron utile; it is used locally in candle-making. 4. $\mathrm{C}_{5} \mathrm{H}_{10} \mathrm{O}_{5}$, a carbohydrate from the seeds of leguminous plants.

Galactirrhea (gal-ak-ter-e'-ah). See Galactorrhea.

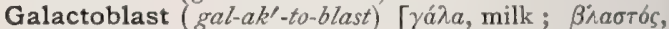
a germ]. A peculiar fat-containing globule found in the acini of the mammary gland.

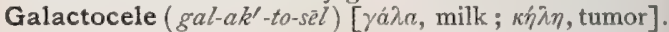
I. A cystic tumor of the female breast due to a collection of milk and resulting from closure of a milk-duct. 2. Hydrocele with milky contents.

Galactodendron (gal-ak-to-den'-dron) [ráìa, milk;

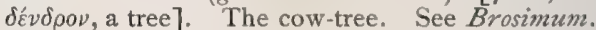

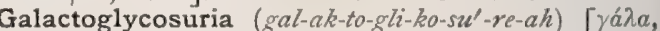

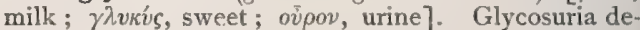
pendent upon lactation.

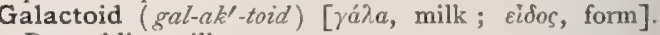
Resembling milk.

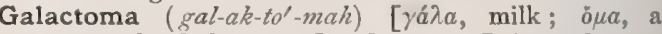
tumor: plo, Galactomata.]. Same as Galactocele.

Galactometer (gal-ak-tom'-et-er). See Lactomeler.

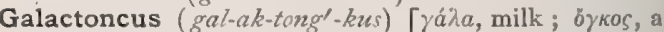
swelling]. Same as Galactocele.

Galactonic Acid ( $a a l-a k-t o n^{\prime}-i k$ ). See Lactonic Acid.

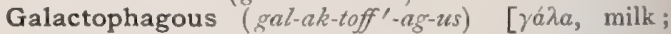
$\phi a \gamma \varepsilon i \nu$, to eat]. Milk-eating.

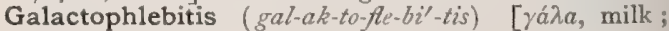
$\phi \lambda \ell \psi$, vein; $\iota \tau \iota$, inflammation]. I. Milk-leg; phleg. 
masia alba dolens; phlebitis associated with lactation. 2. Phlebitis in a suckling child.

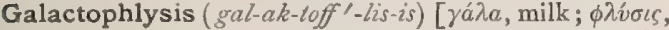
eruption]. A vesicular eruption containing a milk-like fluid, and associated with a suppression of lactation.

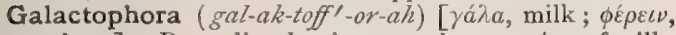
to bear]. Remedies that increase the secretion of milk.

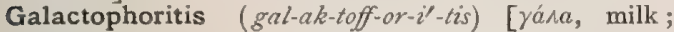
$\phi \varepsilon \hat{\varepsilon \varepsilon \varepsilon \nu}$, to bear ; $\iota \tau \iota$, inflammation]. Inflammation of a milk-duct.

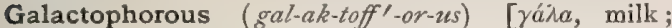
$\phi \varepsilon \varepsilon \varepsilon \varepsilon \nu$, to bear]. Milk-bearing. G. Ducts, the excretory ducts of the mammæ.

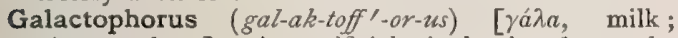
$\phi \varepsilon \varepsilon \rho \varepsilon \imath$, to bear]. An artificial nipple placed over the natural organ in order to facilitate suckling and also to protect the natural nipple when abraded.

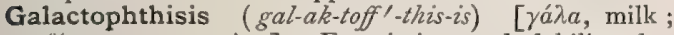
$\phi \theta i \sigma \iota s$, consumption]. Emaciation and debility due to excessive secretion of milk.

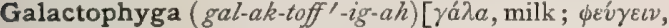
to shun]. Remedies employed to arrest the secretion of milk.

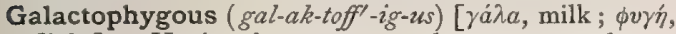
flight]. Having the power to reduce or arrest the secretion of milk.

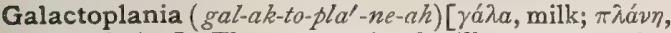
a wandering]. The metastasis of milk; any secretion or discharge of a milky fluid consequent upon a suppression of lactation.

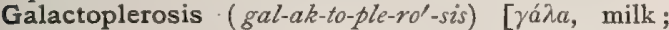
$\pi \dot{n}$ p $\omega \sigma \iota$, a filling]. Distention of the mamma from hypersecretion of milk, or from closure of the milkducts.

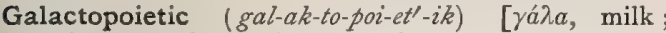
$\pi \circ \iota_{\varepsilon} \varepsilon \nu$, to make]. Inducing the secretion of milk; concerned in the secretion of milk.

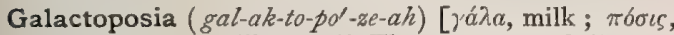
drinking]. "Milk-cure." The treatment of diseases by the use of a milk-diet.

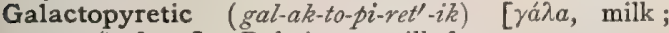
тvрєтós, fever]. Relating to milk-fever.

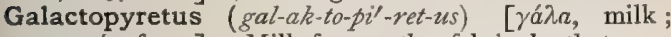
пขрєтб́, fever]. Milk-fever; the febricula that may attend the establishment of lactation; it is a form of septic infection.

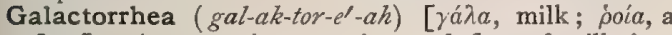
flow]. An excessive secretion and flow of milk in a nursing woman.

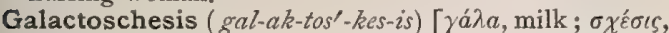
retention]. The retention or suppression of the milk.

Galactoscope (gal-ak'-to-skopp). See Lactoscope.

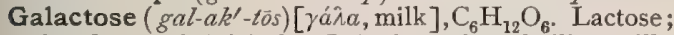
the aldose of dulcitol. It is formed on boiling milksugar with dilute acids, and is obtained from such gums as yield mucic acid when oxidized. It crystallizes in nodules of grouped needles or leaflets, that melt at $166^{\circ} \mathrm{C}$. Its solution is dextro-rotatory. It readily reduces alkaline copper-solutions and is fermentable with yeast. See Carbohydrates, Table of.

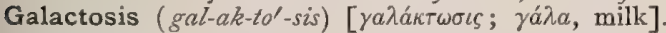
The secretion of milk.

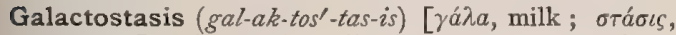
stoppage]. A morbid collection or stoppage of the milk.

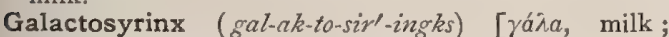
$\sigma \bar{v} \rho \iota \xi \xi$, a pipe]. Lacteal fistula.

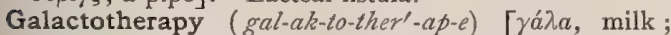
$\forall \varepsilon \rho a \pi \varepsilon i \nu$, treatment]. I. The treatment of disease in suckling infants by the administration of the remedies to the mother or wet-nurse. 2. Milk-cure; galactoposia.
Galactotrophy ( $\left.g a l-a k-t^{\prime} t^{\prime}-r o-f e\right)[\gamma a \dot{\lambda} \alpha$, milk; $\tau \rho \circ \phi \dot{n}$, nourishment]. Nourishing with milk only.

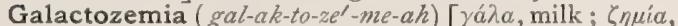
loss]. r. Loss, diminution, or suppression of the milk by failure of secretion. 2. Loss of milk by wastage; oozing of milk from the nipple.

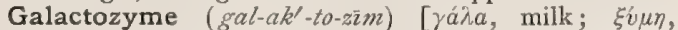
leaven]. I. A drink made by the fermentation of milk, as kefir, or kumiss; also milk fermented with common yeast.

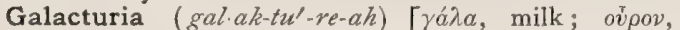
urine]. Milkiness of the urine; chyluria.

Gala-heptose (ga-lah-hep'-toss). See Carbohydrates, Table of.

Galanga, or Galangal (gal-ang'-gah, or gal'-an-gal) [Chin.]. The rhizome of Alpinia officinarum, and of Kampferia galoanga (great galangal), much resembling ginger. It was formerly brought from China and India, but is now little used. Unof.

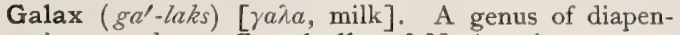
siaceous plants. G. aphylla, of N. America (carpenter's leaf, " galax," beetle-weed), has an astringent root, and the leaves are said to be vulnerary. Unof.

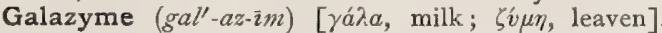
A fermented drink, made on the Continent, from milk by adding to it sugar and a special ferment.

Galbanum (gal'-ban-um) [Heb., khelbenah, white milk]. I. A gum-resin of Ferula galbanifua, and $F$. rubricaulis, native to Asia. It is expectorant, stimulant, and antispasmodic, and is useful in chronic bronchitis and catarrh. Dose gr. $\mathrm{x}-\mathrm{xx}$. G., Pil., Comp., each pill contains galbanum gr. iss, myrrh gr. iss, asafetida gr. ss, and syrup. Dose ij-iij. G., Emplastrum, galbanum 16, turpentine 2, Burgundy pitch 6, leadplaster 76 parts. 2. Locally, in the U. S., Burgundy pitch is popularly called galbanum and is sold under that name.

Galbiati Knife (gal-be-at'-e) [Galbiati, an Italian obstetrician]. A special knife used in the operation of symphysiotomy.

Galbulus (gal'-bu-lus) [L., the nut of the cypress-tree: pl., Galbuli]. In biology, a closed, fleshy, berry-like cone, as the fruit of the juniper.

Gale (gāl) [ME., gawl, gale]. I. A shrub, Myrica gale, sweet gale of cool regions; it has an aromatic odor, and is used locally for external parasites. See Sreet Gale. 2. The fern-gale, or sweet fern. See Sreret Fiern. G. bedouine. See Lichen simplex.

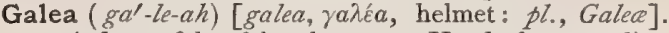
I. A form of head-bandage. 2. Headache extending all over the head. 3. The aponeurotic portion of the occipito-frontal muscle. 4. In biology, applied to various helmet-shaped parts or organs. G. capitis, a fascial investment covering the crown of the head.

Galeamaurosis ( $\left.g a-l e-a m-a w-r o^{\prime}-s i s\right)[\gamma a \lambda \bar{\eta}$, cat, weasel ; áuavpóєเv, to darken]. See Amaurotic Cat's Eye.

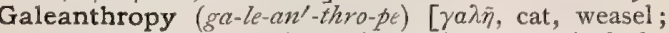
à $v \rho \omega \pi \% s, \operatorname{man}]$. A form of zoanthropy in which the patient believes himself to be transformed into or inhabited by a cat.

Galeati, Glands of. See Crypts of Lieberkühn.

Galen ( $\left.g a^{\prime}-l e n\right)$. An ancient physician, A. D. I30-200. G.'s Anastomosis, that between the superior and inferior laryngeal nerves. G.'s Bandage. See Bandage. G.'s Cerate, a cerate composed of white wax, I; oil of almonds, 4; rose-water, 3. G., Veins of, See Vein.

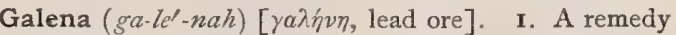
for poison. 2. Native lead sulphid.

Galenic, Galenical ( $\left.g a-l e n^{\prime}-i k,-a l\right)$ [Galen, an ancient physician]. Relating to or consistent with the teachings of Galen. Medicines were said to be galenic 
(a) when they were of vegetable origin, and not chemic or spagyric; (b) when they were designed for the use of human patients, and were not veterinary; (c) the term was often nearly equivalent to officinal, or official, in the modern sense of the latter word.

Galenism ( $\left.g a^{\prime}-l e n-i z m\right)$ [Galen, an ancient physician]. The system or theory of medicine taught by Galen and his followers.

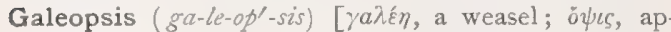
pearance]. A genus of labiate plants; hemp-nettle. G. ladanum, of Europe, is a popular remedy for coughs. The oil of the seeds of G. tetrahit, of Europe and N. America, is said to be a vermifuge. Unof.

Galeropia, or Galeropsia ( $g \alpha$-ler-o'-pe-ah, or ga-ler-op' -

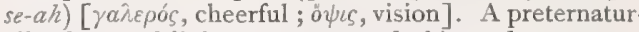
ally clear and light appearance of objects due to some perversion of the visual apparatus

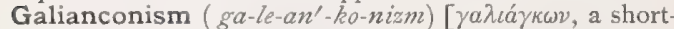
armed person; $\gamma \alpha \lambda \hat{\varepsilon} \eta$, weasel; $\alpha \gamma \kappa \omega \nu$, elbow]. Atrophy of the arm, with shortening.

Galipe's Test. See Tests, Table of.

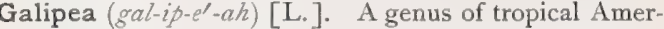
ican rutaceous shrubs and trees. G. cusparia and G. officinalis afford angustura bark, q.v., also called cusparia bark.

Galipein (gal-ip-e'-in) [Galipea $], \mathrm{C}_{20} \mathrm{H}_{21} \mathrm{NO}_{3}$. An alkaloid from cusparia bark.

Galipot $\left(g a l^{\prime}-e-p o t\right)$ [Fr.]. Crude Burgundy pitch. Cf. Gallipot.

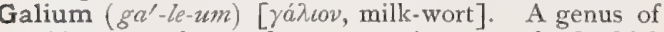
rubiaceous plants of many species, several of which are used in popular medicine. Among them are G. californicum, G. circæzans, G. pilosum, and G. trifedum, in N. America, and G. mollugo, G. cruciatum, and G. verum in Europe. See, also, Ladies' Bedstraze. G. aparine, goose-grass, cleavers, or clivers, a succulent plant, the juice of which is a popular remedy in strumous affections, and is said to be actively diuretic. Dose of the juice $\bar{z} \mathrm{v}$; of the fluid extract $3 \mathrm{j}$-ij. Unof.

Gall (gawl) [ME., galle; $\chi 6 \lambda \eta$, bile]. The bile. The juice normally secreted by the liver. See Galla. G.bladder, the pear-shaped sac in the right lobe of the liver, constituting the reservoir for the bile. See Cholecyst. G.-cyst, the gall-bladder. G-duct. See Duct. G.-fever, a synonym of intermittent fever. G.-stones, the calcareous concretions occasionally formed in the gall-bladder and its ducts. They are usually of small size, but may be as large as a pigeon's egg. They are composed of the bile-pigments and acids, cholesterin, various salts, especially of lime and magnesia. Cholesterin is the chief constituent. They give rise to acute attacks of intense pain, the so-called biliary colic.

Galla (gal'-ah) [L]. Nut-gall. An excrescence on the leaves of dyer's oak, Quercus lusitanica, caused by the deposited ova of an insect. It contains tannic acid from Io-75 per cent., gallic acid 5 per cent. Dose gr. v-xy. G., Tinct., 20 per cent. Dose 3 ss-iij. G., Unguentum, Io per cent. See Acid, Tannic. G., Unguentum, cum opii (B.P.), an astringent and sedative ointment.

Gallacetophenone (gal-as-et-o-fe'-nōn) [galla, gall ; acidum, acid; F., phényle]. A yellow powder with the formula $\mathrm{CH}_{3} \mathrm{CO} . \mathrm{C}_{6} \mathrm{H}_{2}(\mathrm{OH})_{3}$, prepared from pyrogallic acid. It is used as a Io per cent. ointment in dermatology.

Gallein (gal'-e-in), $\mathrm{C}_{18} \mathrm{H}_{14} \mathrm{O}_{7}$. Pyrogallol-phthaleïn; one of the coal-tar colors, obtained on heating pyrogallic acid with phthalic anhydrid to $200^{\circ} \mathrm{C}$. It dissolves with a dark-red color in alcohol, and with a beautiful blue color in alkalies. It is an important dye-stuff, producing tolerably fast shades of purple and violet on cotton, wool, and silk. See Pigments.

Gallic $\left(\mathrm{gal} \mathrm{l}^{\prime}-i k\right)$ [galla, an oak-gall]. Pertaining to the oak-gall or nut-gall. G. Acid. See Acid, Gallic.

Gallipoli Oil (gal-e-po'-le). See Turkey-red Oil.

Gallipot (gal'-e-pot) [OD., gleypot, a gallipot]. An apothecary's pot for holding ointments or confections.

Gallisin (gall-is-in) [grila, an oak-gall], $\mathrm{C}_{12} \mathrm{H}_{24} \mathrm{O}_{10}$. An unfermentable carbohydrate found in starch-sugar. It is prepared by fermenting a 20 per cent. solution of starch-sugar with yeast at $18^{\circ}$ or $20^{\circ} \mathrm{C}$. for five or six days. In the pure state it is a white, amorphous, extremely hygroscopic powder; its taste is at first sweet, but afterward becomes insipid; it is easily decomposed by heat ; is readily soluble in water, nearly insoluble in absolute alcohol. It is dextro-rotatory and reduces copper-solutions.

Gallium (gall-e-um ) [Gallia, Gaul]. A rare metal (symbol Ga., sp. gr. 5.935), extremely fusible, and related in chemic properties to aluminum, like which it is capable of forming a series of alums. Some of its compounds are poisonous. See Elements, Table of.

Gallivorous (gal-iv'-or-us) [galla, a gall-nut; vorare, to eat, devour]. In biology, applied to the larvæ of gall-producing insects that feed on the inside of the nut-gall.

Gallization ( $\left.g a l-i z-a^{\prime}-\operatorname{shun}\right)$. A method of improving wine, by which the must of a bad year is brought up to the standard found to belong to a good must (24 per cent. of sugar, 0.6 per cent. of acid, and 75.4 per cent. of water) by correcting the ratio of acid to sugar. This is done by adding sugar and water in sufficient quantity.

Gallocyanin (gal-o-si'-an-in) [galla, gall (-nut); kíavos, blue], $\mathrm{C}_{15} \mathrm{H}_{12} \mathrm{~N}_{2} \mathrm{O}_{5}$. A compound produced by the action of nitroso-dimethyl-anilin upon gallic acid, catechuic acid, etc. It forms shining green needles, and serves as a beautiful violet-colored lake in calico print. See Pigments, Conspectus of.

Galloflavin (gal-o-fav'-in). See Pigments.

Gallois' Test. See Tests, Table of.

Gallon (gal'-on) [ME., galon, a gallon]. A standard unit of volumetric measurement, having in the United States a capacity of $23 \mathrm{I} \mathrm{cu}$. in., and equivalent to a weight of $58,328.8$ grains of distilled water at maximum density. In Great Britain its capacity is $277.27 \mathrm{cu}$. in. G., Miniature, in water-testing, a name given to 70 c.c.

Gallop Rhythm (gal'-up rithm). A peculiar form of cardiac arrhythmia, in which the sounds resemble the footfall of a horse in cantering. It is expressed by the words "rat-ta-tat." It is most frequently heard in interstitial nephritis and arterio-sclerosis. It is said to be met with also in healthy persons.

Galloping Consumption. The popular term for that very rapidly fatal form of pulmonary tuberculosis, in which there is rapid destruction of the lung-tissue on both sides. It is also called Florid Phthisis, G. Paresis, rapidly progressive general paralysis.

Galton's Whistle. An instrument used for testing the perception of high tones by the ear.

Galvanic (sal-van'-ik) [Galvani, an Italian physician and scientist]. Pertaining to galvanic or chemic electricity. G. Battery. See Battery. G. Belt, a belt composed of alternate plates of copper and zinc, separated by pieces of felt moistened with a dilute acid. It is designed to be worn around the waist for the continuous application of galvanism. G. Cautery. See Cautery. G. Discs, discs of two dissimilar metals arranged alternately, between which a communication is established when moistened and placed on the skin. 
G. Poultice, minute pieces of zinc and copper wrapped in cotton-wool, each pair separated by flannel, all inclosed in a bag, one side of which is made of rubber-cloth and the other of cotton. The cotton side is placed next the skin, perspiration exciting galvanic action.

Galvanism (gal'-van-izm) [Galvani, an Italian physician and scientist]. Primary dynamic or current electricity.

Galvanization (gal-van-iz-a'-shun) [Galvani, an Italian physician]. The transmission of a current of low electro-motive force through any part of the body for the purpose of diagnosticating or curing disease. G., Central, a variety of general galvanization in which the kathode is placed in the epigastrium and the anode is moved over the body. G., General, galvanization of the entire body.

Galvano- (gal-van'-o-) [Galvani, an Italian physician]. A prefix denoting connection with chemic or current electricity. G.-caustic Amputation, an amputation in which the soft parts are divided with the galvaniccautery loop, the bone being sawn through. G.-cauterization, the application of the galvanic cautery. G.-cautery. See Cautery. G.-contractility, muscular contraction produced by the galvanic current. G.-emesis, the production of vomiting by galvanism. G.-faradization, the simultaneous excitation of a nerve or muscle by both a voltaic and a faradic current. G.-hypnotism, a hypnotic state induced by an electric current. G.-magnetism, same as Electromagnetism. G.-puncture, the introduction of fine needles, that complete an electric circuit, into the skin or other tissue. Also, a form of galvano-cautery employing a current of the necessary electro-motive force to heat the needles to whiteness. G.-therapeutics. See Electro-therapeutics.

Galvanometer (gal-van-om'-et-er) [Galvani, an Italian physician; $\mu \dot{\varepsilon} \tau \rho o \nu$, a measure]. An instrument used for the qualitative determination of the presence of an electric current.

Galvanoscope (gal-van'-o-sköp) [Galvani, an Italian

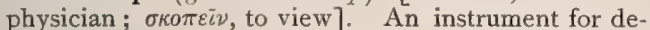
tecting the direction and presence of a galvanic current.

Galvanoscopy (gal-van-os'-ko-pe) [ Galvani, an Italian

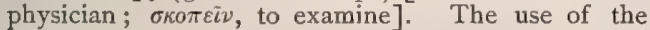
galvanoscope.

Galvanotonus (gal-van-ot'-on-us) [ Galvani, an Italian physician; tóvoৎ, tension]. I. Same as Electrotonus. 2. The "closing tetanus." The continued tetanus of a muscle between the make and break contraction.

Galvanotropism (gal-van-ot'-ro-pizm) [after Galvani; $\tau \rho \varepsilon \varepsilon \varepsilon \iota \nu$, to turn round]. In biology, the turning movements of growing organs under the influence of a current of electricity.

Gambir, Gambier ( gam-bèr') [Malayan]. A kind of catechu produced from the leaves and shoots of $\mathrm{Un}$ caria gambir, a rubiaceous plant of the Malayan region. It has the general properties of official catechu. See also Pigments, Conspectus of. Unof.

Gamboge (gam-bozh'). See Cambogia and Pigments. Game Leg ( $\left.g \bar{a} m^{\prime}-l e g\right)$. A popular term for a lame leg.

Gamenomania (gam-en-o-ma'-ne-ah). See Gamomania.

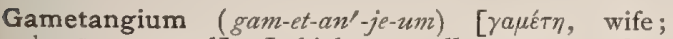
áryeiov, a vessel]. In biology, a cell or organ producing or containing sexual elements, or gametes.

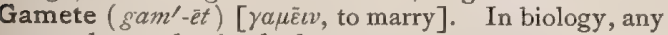
sexual reproductive body.

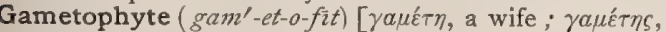
a husband; $\phi v т o v$, a plant]. In biology, the sexual form of such plants as exhibit alternate generation.
Gamgee Tissue (gam'-ge). Absorbent cotton-wool.

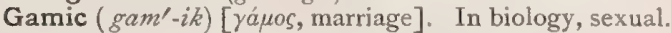

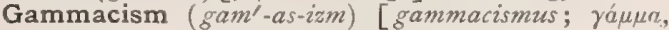
the letter $\mathrm{G}]$. Difficulty in pronouncing any guttural consonant ; guttural stammering.

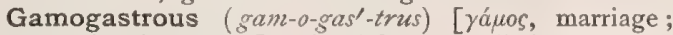
$\gamma \alpha \sigma \tau \eta \hat{p}$, the womb]. In biology, applied to a compound pistil in which the ovaries only are united.

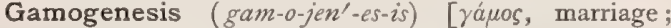

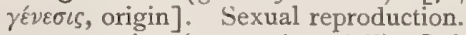

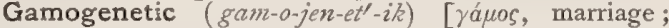

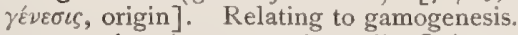

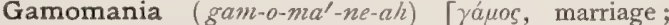
ravia, mania]. Insane desire of marriage.

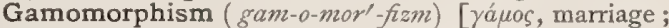
$\mu \circ \rho \phi \eta$, form ]. Puberty; sexual maturity.

Gamopetalous (gam-o-pet'-al-us) [ráuos, marriage ; $\pi \dot{\varepsilon} \tau a \lambda o \nu$, a leaf ]. In biology, sympetalous; having the petals more or less united.

Gamophyllous (gam-o-fil'-us) [yáuss, marriage; $\phi u ́ \lambda \lambda o v$, a leaf ]. In biology, symphyllous; having the floral envelops united into a single perianth-whorl.

Gangliac, Ganglial, Gangliar ( gang'-gle-ak, sang'-leal, gang'-le-ar). Same as Ganglionic.

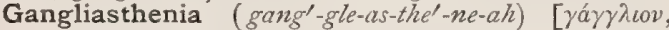

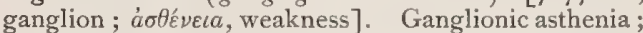
neurasthenia due to defect of ganglionic function.

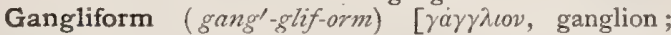
forma, form]. Formed like, or having the nature of, a ganglion.

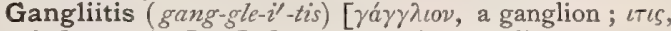
inflammation]. Inflammation of a ganglion.

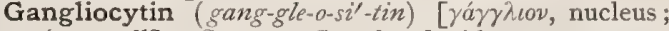
кútos, cell]. Same as Cytophosphatid.

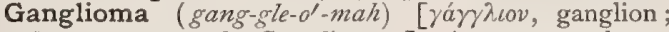
ö $\alpha$, a tumor: pl., Gangliomata $]$. A tumor or enlargement of a lymphatic ganglion.

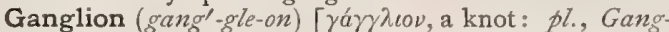
lia]. I. A separate and semi-independent nervous center communicating with other ganglia or nerves, with the central nervous system, and peripheral organs. 2. An enlarged bursa in connection with a tendon. 3. A lymphatic gland. $G_{0}$-capsule, the envelop of a ganglion containing the ganglion-cells or nerve-cells. G.-cell, any one of the nerve-cells characteristic of

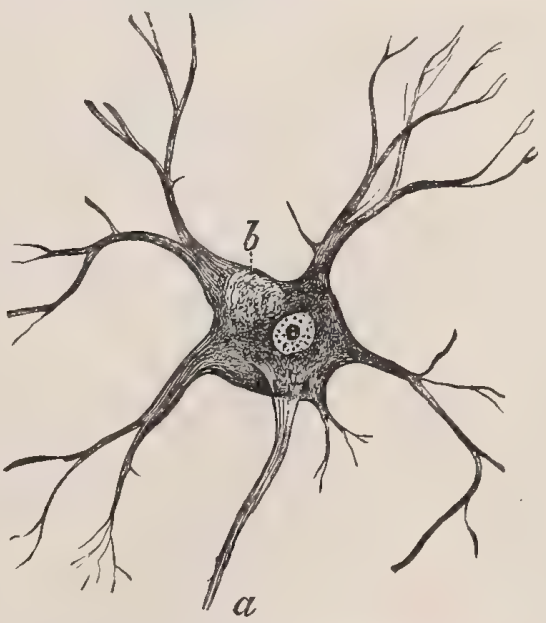

Multipolar Ganglion-Cell. $a$. Axis-cylinder process. b. Pigment.

the ganglia, whether found in a ganglion or not. G.corpuscle, a ganglion-cell. G.-globule, a ganglion- 
cell. An alphabetic table of the principal ganglia is appended, showing their location, roots, and distribution. Ganglia, Basal, the ganglia at the base of the brain, comprising the corpora striata (caudate and lenticular nuclei), thalami, and corpora quadrigemina.

\section{TABLE OF GANGLIA.}

\begin{tabular}{|c|c|c|c|}
\hline NAME. & LOCATION. & Roots. & DISTRIBUTION. \\
\hline Abdominal, maximum. & See Semilunar. & & \\
\hline Acoustic. & $\begin{array}{l}\text { In grasshoppers, the termination of } \\
\text { the acoustic nerve. }\end{array}$ & Ganglionic chain. & Organ of hearing. \\
\hline Andersch's. & See Petrous. & & \\
\hline Anterior (of thalamus). & $\begin{array}{l}\text { The anterior tubercle of the thala- } \\
\text { mus. }\end{array}$ & & \\
\hline Arnold's. & See Otic. & & \\
\hline Auerbach's. & $\begin{array}{l}\text { Several minute ganglia situated in } \\
\text { Auerbach's plexus, } q \cdot v_{\text {. }}\end{array}$ & Sympathetic. & Sympathetic. \\
\hline Auricular. & See Otic. & & \\
\hline Auricular, posterior. & See Temporal. & & \\
\hline Auriculo-ventricular. & See Bidder's. & & \\
\hline Azygous. & See Impar & & \\
\hline Basal. & $\begin{array}{l}\text { At base of cerebrum: they include: } \\
\text { corpora striata, thalami corpora } \\
\text { geniculata, corpora quadrigemina, } \\
\text { locus niger, nuclei tegmenti. }\end{array}$ & & \\
\hline Basal optic. & See Optic, basal. & & \\
\hline Bezold's (Von). & $\begin{array}{l}\text { In the auricular septum of the frog's } \\
\text { heart. }\end{array}$ & Sympathetic. & Heart. \\
\hline Bidder's (2). & $\begin{array}{l}\text { In the auricular septum of the frog's } \\
\text { heart. }\end{array}$ & $\begin{array}{l}\text { Termination of the cardiac branches } \\
\text { of the vagus. }\end{array}$ & Heart. \\
\hline Bochdalek's. & $\begin{array}{l}\text { Above the root of one of the upper } \\
\text { incisor teeth, at the point of commu- } \\
\text { nication between the posterior nasal } \\
\text { branch of Meckel's ganglion and the } \\
\text { anterior dental nerve. }\end{array}$ & Dental nerves. & Dental nerves. \\
\hline Branchial. & In Mollusca, near the branchia. & Ganglionic chain. & Branchia. \\
\hline Buccal. & $\begin{array}{l}\text { In Mollusca, at the point of union of } \\
\text { the esophagus with the buccal mass. }\end{array}$ & Cerebral ganglia. & $\begin{array}{l}\text { Nerves to the mouth } \\
\text { and alimentary canal. }\end{array}$ \\
\hline Cardiac, lesser. & See Cardiac, superior. & & \\
\hline $\begin{array}{l}\text { Cardiac, superior (Wris- } \\
\text { berg). }\end{array}$ & Beneath the arch of the aorta. & Superficial cardiac plexus. & Cardiac plexus. \\
\hline Carotid. & $\begin{array}{l}\text { In the lower part of the cavernous } \\
\text { sinus, beneath the carotid artery. }\end{array}$ & Filaments from the carotid plexus. & Carotif plexus. \\
\hline Carotid, inferior. & Lower portion of the carotid canal. & Carotid plexus. & $\begin{array}{l}\text { Filaments to the } \\
\text { carotid artery. }\end{array}$ \\
\hline Carotid, internal. & See Carotid, superior. & & \\
\hline Carotid, superior. & Upper portion of the carotid canal. & Carotid plexus. & $\begin{array}{l}\text { Filaments to the } \\
\text { carotid artery. }\end{array}$ \\
\hline Casserian. & See Gasserian. & & \\
\hline Celiac, lateral. & Near the spleen. & Splenic plexus. & $\begin{array}{l}\text { Filaments to the } \\
\text { spleen. }\end{array}$ \\
\hline Celiac, left. & The left semilunar ganglion $(q . v$.). & & \\
\hline Celiac, middle. & $\begin{array}{l}\text { In front of the aorta above the celiac } \\
\text { axis. }\end{array}$ & Hepatic plexus. & Filaments to the liver. \\
\hline Celiac, right. & The right semilunar ganglion $(q, v$.). & & \\
\hline Cephalic. & $\begin{array}{l}\text { Sympathetic ganglia of the head. They } \\
\text { include the ciliarv, spheno-palatine, } \\
\text { otic, and submaxillary. }\end{array}$ & & \\
\hline Cerebral. & In Mollusca, above the esophagus. & Ganglionic chain. & To the head. \\
\hline
\end{tabular}


TABLE OF GANGLIA,_Continued.

\section{NAME.}

Cerebral, anterior.

Cervical, first.

Cervical, great.

Cervical, inferior.

Cervical, lower.

Cervical, middle or thyroid.

Cervical, oval.

Cervical (of vagus nerve).

Cervical, second.

Cervical, stellate.

Cervical, superior.

\section{Cervical, third.}

Cervical, upper.

Cervical (of uterus).

Of the chorda tympani.

Ciliary.

Of the circumflex nerve.

Of Cloquet.

Cochlear.

Corti's.

Cranio-cervical.

Diaphragmatic.

Ehrenritter's.

Extraventricular.

Facial.

Of Frankenhäuser.

Frontal.

Fusiform.

Gasser's (A. P.)

Gasserian, or semilunar.

Geniculate.

Great.

Of the habenula.

Hepatic.

\section{LOCATION.}

A name for the corpus striatum.

See Cervical, superior.

See Cervical, superior.

Between the neck of the first rib, and the transverse process of the last cervical vertebra.

See Cervical, inferior.

Opposite the fifth cervical vertebra near the inferior thyroid artery.

See Cervical, superior.

See Inferior (of vagus).

See Cervical, middle.

See Cervical, middle.

Opposite the second and third cervical vertebræ.

\section{See Cervical, inferior.}

See Cervical, superior.

Near the cervix uteri.

In Invertebrata, above the Glaserian fissure.

\section{See Ophthalmic.}

On the branch of the circumflex nerve.

\section{Incisor foramen.}

See Impar.

See Spiral.

See Spiral.

See Cervical, superior.

See Phrenic.

See Jugular.

A name for the lenticular nucleus

\section{See Geniculate.}

See Cervical, uterine.

In Invertebrata, the ganglion from which arises the pharyngeal nerve.

\section{See Cervical, superior.}

See Gasserian.

Fossa on the anterior part of the petrosa, near the apex.

\section{Aqueduct of Fallopius.}

See Cardiac, superior.

A ganglion situated in the trigonum habenula near the thalamus.

Around the hepatic artery.

Three lower cervical, first dorsal.

Fifth and sixth cervical nerves, spinal nerves and ganglia.

Four upper cervical, petrosal,vagus,
glosso-pharyngeal, and hypoglos-
sal nerves.

Superior, inferior, external, internal branches; carotid and cavernous plexuses.

Filaments from the hypogastric plexus, sacral ganglia, and sacral nerves.

\section{Chorda iympani nerve.}

Cardiac nerves and plexus, etc.

Thyroid gland, cardiac nerve, cavernous plexus.

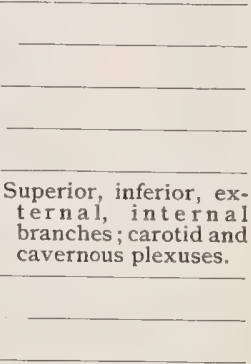

Uterine nerves.

Chorda tympani.

Circumflex nerve. $\quad \begin{aligned} & \text { Filaments to ter es } \\ & \text { minor, deltoid, and } \\ & \text { fascia. }\end{aligned}$

Naso-palatine nerves.

Naso-palatine nerves.

Ganglionic chain.

Pharyngeal nerve.

Fifth cranial nerve, carotid plexus. Large and small superficial petroOphthalmic, superior and inferior maxillary nerves.

Facial.

Hepatic branches of the semilunar ganglion. 
TABLE OF GANGLIA.-Continued.

\begin{tabular}{|c|c|c|c|}
\hline NAME. & LOCATION. & Roots. & DISTRIBUTION. \\
\hline Hirschfeld's. & A name for the hippocampal gyrus. & & \\
\hline Hypogastric. & See Cervical (of uterus). & & \\
\hline Impar, or Coccygeal. & $\begin{array}{l}\text { Anterior surface of the tip of the coc- } \\
\text { cyx, uniting the two sympathetic } \\
\text { nerves. }\end{array}$ & Sympathetic. & Sympathetic. \\
\hline Inferior (of vagus). & Near jugular foramen. & $\begin{array}{l}\text { Hypoglossal and cervical nerves } \\
\text { and various plexuses. }\end{array}$ & Vagus. \\
\hline Infra-esophageal. & In Mollusca, beneath the esophagus. & Ganglionic chain. & Foot. \\
\hline Inframaxillary, anterior. & Near the incisor teeth. & Inferior maxiliary nerve. & Filaments to the teeth. \\
\hline Inframaxillary, posterior. & Near the last molar tooth. & Inferior maxillary nerve. & Filaments to the teeth. \\
\hline Intercarotid. & Bifurcation of the common carotid. & Carotid plexus. & Sympathetic. \\
\hline Interoptic. & $\begin{array}{l}\text { The gray matter of the interoptic } \\
\text { lobes. }\end{array}$ & & \\
\hline Interosseous. & Back of the wrist & Interosseous nerve. & Nerves to the carpus. \\
\hline Intervertebral. & Near the intervertebral foramen. & Spinal cord. & $\begin{array}{l}\text { Dorsal root of spinal } \\
\text { nerve. }\end{array}$ \\
\hline Jugular (Ehrenritter's). & Upper part of the jugular foramen. & Glossopharyngeal. & $\begin{array}{l}\text { Continuation of the } \\
\text { glossopharyngeal. }\end{array}$ \\
\hline Jugular (of vagus). & Jugular foramen. & Vagus. & Vagus. \\
\hline $\begin{array}{l}\text { Lateral (several in num- } \\
\text { ber). }\end{array}$ & Surrounding the subclavian artery. & $\begin{array}{l}\text { Branches of the inferior cervical } \\
\text { ganglion. }\end{array}$ & Subclavian artery. \\
\hline Lenticular. & See Ophthalmic. & & \\
\hline Lingual. & See Submaxillary. & & \\
\hline Ludwig's. & Right auricle of the heart. & Cardiac plexus. & Cardiac plexus. \\
\hline Lumibar ( 4 or 5 ). & $\begin{array}{l}\text { On each side and behind the abdom- } \\
\text { inal aorta. }\end{array}$ & Sympathetic. & Sympathetic. \\
\hline Maxillo-tympanic. & See Otic. & & \\
\hline Meckel's. & See Spheno-palatine. & & \\
\hline Meckelian. & See Spheno-palatine. & & \\
\hline Meissner's. & Intestinal sub-mucosa. & Sympathetic. & Sympathetic. \\
\hline Mesenteric, inferior. & The inferior mesenteric artery. & Inferior mesenteric plexus. & $\begin{array}{l}\text { Mesentery and intes- } \\
\text { tine. }\end{array}$ \\
\hline Mesenteric, lateral. & Left side of the body. & Superior mesenteric plexus. & Mesentery and bowel. \\
\hline Mesenteric, superior. & $\begin{array}{l}\text { Near the origin of the superior mes- } \\
\text { enteric artery. }\end{array}$ & Superior mesenteric plexus. & Sympathetic. \\
\hline Of Meynert. & See Optic, basal. & & \\
\hline Müller's. & See Jugular and Prostatic. & & \\
\hline Nasal. & See Meckels. & & \\
\hline Nephro-aortic. & See Renal. & & \\
\hline Nephro-lumbar. & $\begin{array}{l}\text { Junction of the branches of the lum- } \\
\text { bar and spermatic nerves. }\end{array}$ & Lumbar and spermatic nerves. & $\begin{array}{l}\text { Kidney and lumbar re- } \\
\text { gion. }\end{array}$ \\
\hline Ophthaimic. & Posterior part of the orbit. & $\begin{array}{l}\text { Nasal branch of the ophthalmic, } \\
\text { third, cavernous plexus, and } \\
\text { Meckel's ganglion. }\end{array}$ & Short ciliary. \\
\hline Optic. & See Ophthalmic. & & \\
\hline Optic, basal (of Meynert). & $\begin{array}{l}\text { Beneath the third ventricle, near the } \\
\text { optic tract, }\end{array}$ & Gray matter of the cerebrum. & Optic tract. \\
\hline Optic, inferior. & See Optic, basal. & & \\
\hline Orbital. & See Ophthalmic. & & \\
\hline Otic (Arnold's). & Below the foramen ovale. & $\begin{array}{l}\text { Inferior maxillary, auriculo-tempor- } \\
\text { al, glosso-pharyngeal, facial, sym- } \\
\text { pathetic, and internal pterygoid. }\end{array}$ & $\begin{array}{l}\text { Tensor tympani, ten- } \\
\text { sor palati, chorda } \\
\text { tympani. }\end{array}$ \\
\hline
\end{tabular}


TABLE OF GANGLIA-Continued.

\begin{tabular}{|c|c|c|c|}
\hline NAME. & LOCATION. & Roots. & DISTRIBUTION. \\
\hline Pedal. & See Infra-esophageal. & & \\
\hline Petrosal. & See Petrous. & & \\
\hline Petrous (Andersch's). & $\begin{array}{l}\text { Petrous portion of the temporal bone, } \\
\text { lower border. }\end{array}$ & Glosso-pharyngeal. & $\begin{array}{l}\text { Tympanic, sympathet- } \\
\text { ic, and vagus. }\end{array}$ \\
\hline Pharyngeal. & Near ascending pharyngeal artery. & Carotid plexus. & Carotid plexus. \\
\hline Pharyngeal, soit. & $\begin{array}{l}\text { On the lingual artery, near the } \\
\text { pharyngeal ganglion. }\end{array}$ & Carotid plexus. & Lingual plexus. \\
\hline Phrenic. & $\begin{array}{l}\text { Under the diaphragm at the junction } \\
\text { of the right phrenic nerve and } \\
\text { phrenic plexus. }\end{array}$ & Sympathetic. & $\begin{array}{l}\text { To the diaphragm, in- } \\
\text { ferior vena cava, su- } \\
\text { pra-renal capsule, } \\
\text { hepatic plexus. }\end{array}$ \\
\hline Phrenic, major. & $\begin{array}{l}\text { Point of union of the phrenic nerves } \\
\text { with the spinal and sympathetic sys- } \\
\text { tems. }\end{array}$ & Phrenic, spinal, and sympathetic. & $\begin{array}{l}\text { Filaments to the dia- } \\
\text { phragm. }\end{array}$ \\
\hline Phrenic, secondary. & Near the diaphragm. & $\begin{array}{l}\text { Anterior, superior, transverse } \\
\text { plexus. }\end{array}$ & $\begin{array}{l}\text { Filaments to the dia- } \\
\text { phragm. }\end{array}$ \\
\hline Phrenico-hepatic. & Lower surface of the diaphragm. & The phrenic plexus. & $\begin{array}{l}\text { Filaments to the dia- } \\
\text { phragm and liver. }\end{array}$ \\
\hline Plexiform. & See Gasserian. & & \\
\hline Pneumogastric. & See Vagus. & & \\
\hline Of the portio dura. & See Geniculate. & & \\
\hline Post-esophageal. & In insects, around the gullet. & Cephalic ganglia. & Nerves to the mouth \\
\hline Postoptic. & See Optic, basal. & & \\
\hline Pre-esophageal. & See Cephalic. & & \\
\hline Prostatic (of Müller). & On the prostate. & Prostatic plexus. & $\begin{array}{l}\text { Filaments to seminal } \\
\text { vesicles and caver- } \\
\text { nous tissue of penis. }\end{array}$ \\
\hline Pterygo-palatine. & See Meckels. & & \\
\hline Remak's. & $\begin{array}{l}\text { Tissue of the heart, near the superior } \\
\text { vena cava. }\end{array}$ & Sympathetic. & Sympathetic. \\
\hline Renal. & Around the renal artery. & Renal plexus. & Renal artery. \\
\hline $\begin{array}{l}\text { Renal, anterior communi- } \\
\text { cating. }\end{array}$ & In front of the renal artery. & Renal plexus. & Kidney. \\
\hline Renal, left aortic. & Point of origin of the renal artery. & Renal plexus. & Kidney. \\
\hline $\begin{array}{l}\text { Renal, posterior communi- } \\
\text { cating. }\end{array}$ & Behind the renal artery. & Renal plexus. & Kidney. \\
\hline Reticulate. & Medulla oblongata. & $\begin{array}{l}\text { The gray matter scattered through } \\
\text { the medulla. }\end{array}$ & \\
\hline Rhinic. & See Meckels. & & \\
\hline Of Ribes. & $\begin{array}{l}\text { Anterior communicating artery of the } \\
\text { brain. (It is the upper termination } \\
\text { of the sympathetic.) }\end{array}$ & $\begin{array}{l}\text { Branches from the two superior } \\
\text { ganglia. }\end{array}$ & Sympathetic. \\
\hline Sacral ( 4 or 5$)$ & Ventral surface of the sacrum. & Sympathetic. & Sympathetic. \\
\hline Sacral, accessory (4). & Along the middle sacral artery. & Sympathetic. & Middle sacral artery. \\
\hline Scarpa's. & $\begin{array}{l}\text { Near the internal auditory meatus, at } \\
\text { the point of junction of the facial } \\
\text { nerve and the vestibular branch of } \\
\text { the auditory nerve. }\end{array}$ & Facial and auditory nerves. & Internal ear. \\
\hline Schacher's. & See Ophthalmic. & ; & \\
\hline Schmiedel's. & In the carotid plexus. & Fifth nerve, third branch. & Sympathetic. \\
\hline $\begin{array}{l}\text { Semilunar ( } 2 \text {, right and } \\
\text { left). }\end{array}$ & $\begin{array}{l}\text { Near the supra-renal bodies, in front } \\
\text { of the crura of the diaphragm. }\end{array}$ & $\begin{array}{l}\text { Solar plexus and great splanchnic } \\
\text { nerves. }\end{array}$ & Solar plexus. \\
\hline Semilunar. & See Gasserian. & & \\
\hline Solar. & See Semilunar. & . & \\
\hline
\end{tabular}


TABLE OF GANGLIA.-Continued.

NAME.

Spermatic, inferior.

Spermatic, superior.

Spermatico-renal.

Sphenoid

Spheno-palatine ( $\mathbf{M e c k}$ el's).

Spinal.

Spiral.

Splanchnic.

Stellate.

Stomato-gastric.

Sub-esophageal.

Sub-intestinal.

Sublingual.

Submandibular.

Submaxillary.

Superior.

Superior (of Vagus).

Supra-esophageal.

Supra-maxillary.

Supra-renal.

Temporal.

Thoracic (x2).

Thyroid, inferior.

Thyroid, superior.

Transverse.

Tympanic.

Vagus: (I) of the root, see Jugular; (2) of the trunk (Vagus).

Valentin's.

Ventricular.

Vertebral.

Vesico-vaginal.

Vestibular.

Walter's.

Of Wrisberg.
LOCATION.

Roors.

DISTRIBUTION

On the spermatic artery, near the Sympathetic. internal abdominal ring

Around the spermatic artery.

In a plexus formed by the inferior branches of the renal plexus.

See Meckel's.

Spheno-maxillary fossa, near the spheno-palatine foramen.

See Interveriebral.

Spiral canal of the modiolus.

See Semilunar.

The first thoracic $(q . v$.$) .$

In Mollusca, the upper surface of the stomach.

See Infra-esophageal.

See Meissner's.

See Submaxillary.

See Submaxillary.

Above the submaxillary gland.

See Jugular.

Jugular foramen.

In Mollusca, above the esophagus.

Above the canine tooth.

Junction of the great splanchnic nerves

External carotid artery, near the parotid gland.

Between the transverse processes of the vertebræ and the heads of the ribs.

See Cervical, middle.

See Cervical, superior.

See Semilunar.

Canal between the lower surface of the petrosa and the tympanum.

Below the jugular foramen.

Above the root of the second bicuspid at the junction of the middle and posterior dental nerves.

See Bidier's.

See Cervical, inferior.

Ventral wall of the vagina

Aqueduct of Fallopius.

See Impar.

See Cardiac.

\section{Sympathetic.}

Renal plexus.

Superior maxillary, facial, sympathetic.

Cochlear nerve.

Sympathetic.

Gustatory, chorda tympani, sub-
maxillary, sympathetic.

Superior cervical and petrous ganglia, and spinal accessory.

Ganglionic chain.

Anterior superior dental nerve.

Solar plexus.

Superior cervical ganglion and carotid plexus.

Sympathetic.

Tympanic branch of the glossopharyngeal.

Vagus.

Posterior and middle dental nerves.

V

-

Vesico-vaginal plexus.

Geniculate ganglion.
Cord and testicle.

Sympathetic.

Spermatic artery and kidney.

Anterior, posterior, and external palatine, naso-palatine, superior nasal,Vidian, pharyngeal.

Filaments to the osseous lamina and to the organ of Corti.

Sympathetic.

Mouth, submaxillary gland, and Wharton's duct.

Vagus.

Esophagus.

Anterior superior dental nerve.

Supra-renal plexus.

Temporal region.

Splanchnic nerves and branches to $\mathrm{spinal}$ nerves and plexuses

Tympanum.

Vagus.

Filaments to the teeth

Sympathetic.

Vestibular nerve. 
Ganglionic (gang-gle-on'-ik) [ $\gamma^{\prime} \alpha \gamma \lambda \iota 0 v$, a ganglion]. Pertaining to or of the nature of a ganglion. G. Centers, masses of gray matter of the brain lying between the floor of the lateral ventricles and the decus. sation of the anterior pyramids of the cord. They include the optic thalami, corpora striata, and others. Ganglionitis (gang-gle-on-i'-tis). See Ganglitit.

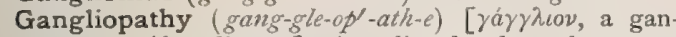
glion; $\pi \alpha ́ \theta 0 s$, disease ]. Any disorder dependent upon a diseased condition of a ganglion; any diseased state of a ganglion.

Gangræna (gang-gre'-nah) [L.]. Gangrene. G. contagiosa. See Gangrene, Hospital. G. nosocomialis. See Gangrene, Hospital. G. oris. See Stomatitis.

Gangrænosis (gang-gre-no'-sis). See Gangrenosis.

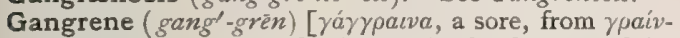
$\varepsilon \iota v$, to gnaw]. Mortification or death of a part of the body from failure in nutrition. The putrefactive fermentation of a dead limb or tissue. G., Circular, a form of mortification occurring usually on some part of the lower extremity, and not exceeding in size a silver half-dollar. It involves the skin and subcutaneous tissues and is accompanied by signs of exhaustion. G., Constitutional, that dependent upon systemic disease, such as diabetes, or circulatory disease. G., Diabetic. See Sphaceloderma. G., Dry, shriveling and desiccation from insufficiency of blood. G., Embolic, that caused by an embolus that cuts off the supply of blood. G., Hospital, a contagious form arising under crowded conditions without antiseptic precautions. G., Moist, a form with abundance of serous exudation and rapid decomposition. G., Nosocomial, hospital gangrene. G., Primary, that without preceding inflammation of the part. G., Pulpy. See G.,Hospital. G., Secondary, a form with preceding inflammation. G., Senile, that attacking the extremities of the aged. G., Symmetric, that attacking corresponding parts of opposite sides. It is called, also, Raynaud's G. See, also, Sphaceloderma. G., White, a moist gangrene of chronic form, in which there is a serous exudate with lymphatic obstruction, followed by complete anemia. It is unaccompanied by the characteristic color-change of other varieties of gangrene.

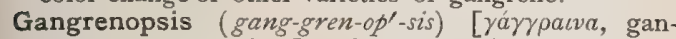
grene; ö $\psi s$, the face]. Synonym of Cancrum oris.

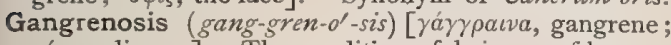
vóoos, disease]. The condition of being or of becoming mortified or gangrenous.

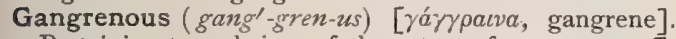
Pertaining to or being of the nature of gangrene. G. Emphysema. See Edema, Malignant.

Ganja (gan'-jah) [Hind.]. Synonym of Cannabis indica.

Gannal's Solution. A preservative fluid containing one part of aluminum acetate in 20 parts of water.

Ganoin (gan'-o-in) [yávos, brightness]. In biology, the dense enamel-like form of bone of the plates of a ganoid fish.

Gant's Line. See Lines, Table of.

Gantelet (gant'-let). See Gauntiet.

Gape (gap, or gapp) [ME., gapen, to yawn]. To yawn; the act of yawning.

Gapes ( $g \bar{a} p s)$ [ME., gapen, to gape]. A disease of young fowls, caused by the presence of a nematode worm, Syngamus trachealis, in the trachea. See Parasites, (Animal) Table of.

Gaping (gap'-ing). See Pandiculation and Yawning.

Gaps, Cranial (gapz) [ME., gapen, to gape]. Certain occasional congenital fissures of the skull.

Garancin (gar-an'-sin) [origin unknown]. The product obtained by the action of concentrated $\mathrm{H}_{2} \mathrm{SO}_{4}$ on pul- verized madder, at a temperature of $100^{\circ} \mathrm{C} .\left(212^{\circ} \mathrm{F}\right.$.). It is a valuable dye. See Pigments Conspectus of

Garbage (gar'-bajj) [ME., garbage, the entrails of fowls]. The refuse materials of kitchen-cookery, etc. G. and Waste. See Servage, Disposal of. G.-cart, Flannagan Automatic, a variety of cart much used for the collection of garbage. G.-furnace, a furnace in use in cities and towns to consume the waste material of the place.

Garbling (gar'-bling) [OF., garbeler, to sift]. The assorting of a drug and its separation into grades of different quality.

Garcinia (gar-sin'-e-ah) [after Laurent Garcin, a French botanist]. A genus of guttiferous trees of Old-world tropical regions. G. hanburii, G. morella, G. pictoria, and G. travancorica afford gamboge. G. mangostana yields the palatable fruit called mangosteen.

Garden Rocket. See Eruca sativa.

Garel, Sign of. See Signs and Symptoms, Table of.

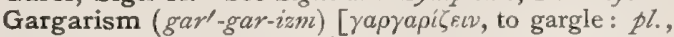
Gargarismata]. A gargle.

Garget (gar'-get) [ME, gargat, the throat]. I. A swelling of the throat in swine or cattle. 2. A hard, knotty condition of the udder in cows, that sometimes follows calving, due to the sudden distention of the bag with milk; it is attended with inflammation. At times it is tuberculous in nature. It is also called "Weed" and Mammitis. G.-root, a name improperly given to the root of Phytolacca decandra (see Phytolacca); so called because it is regarded as a cure for garget in cows.

Gargle (gar'-gl) [Fr., gargouille, the throat]. To rinse or wash the interior of the throat and upper part of the pharynx. Also, a wash for the throat.

Gargling (gar'-gling) [Fr., gargouille, the throat]. Rinsing the throat. G., von Troltsch's Method of, the patient takes a mouthful of fluid, throws back the head, and then, instead of making the customary "gurgle," allows the liquid to pass as far down as possible. The act of deglutition is then performed, without, however, letting the fluid be swallowed.

Garland (gar'-land). See Karyokinesis.

Garlic (gar'-lik). See Allium.

Garnet-brown. See Pigments, Conspectus of.

Garretson's Bandage. See Bandage.

Garrod's Theory. The theory that gout is due to an increase in the uric acid in the blood, either from increased production or diminished elimination. The alkalinity of the blood is also lessened; hence the urates are deposited in the tissues. G.'s Test. See Tests, Table of.

Garrot (gar'-ot) [Fr., garotter, to bind]. An instrument for compression of an artery by twisting a circular bandage about the part.

Garroting (gar'-ot-ing) [Sp., garrote, strangulation by means of an iron collar]. In forensic medicine, a term used in England to signify the forcible compression of a victim's neck by robbers or criminals.

Garrulity (gar-oo'-lit-e) [garrire, to prattle]. Talkativeness. G. of the Vulva. See Vulva.

Garrya ( $\left.g a r^{\prime}-e-a h\right)$ [after Garry, a botanist]. California fever-bush; skunk-bush, or quinin-bush. The leaves of $G$. fremontii, a bitter antiperiodic, popular on the Pacific coast as a remedy for malarial diseases. Dose of the fld. ext. $m x-x x x$. Unof.

Garryin (gar'-e-in) [Garry, a botanist]. An alkaloid said to exist in the leaves of Garrya fremontii.

Gärtner, Canals or Ducts of. See Canal.

Gas (gaz). Any substance that is normally aeriform. Substances normally in a liquid or solid state are usually called vapors when changed to the aerriform 
condition. G.-black. See Pigments, Conspectus of. G., Nitrous Oxid. See Nitrous Oxid.

Gaskell's Clamp. See Clump.

Gasolene (gas'-o-lèn) [gas]. Canadol. A product obtained from petroleum, boiling at $70^{\circ}$ to $90^{\circ} \mathrm{C}$; specific gravity, .660 to .690 , or $80^{\circ}$ to $75^{\circ} \mathrm{B}$. It is used in the extraction of oils from oil-seeds and in carburetting coal-gas.

Gasp [ME., gaspen, to yawn]. To catch for breath. To breathe spasmodically with open mouth.

Gasser's Arteries. See Arteries, Table of. G.'s Ganglion. See Ganglia, Table of. G., Nerve of. See Nerves, Table of.

Gasserian Arteries. See Arteries, Table of. G. Gang. lion. See Ganglia, Table of.

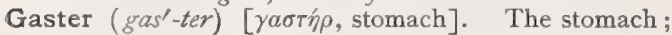
the abdomen. G. basalis, the apical canal, peduncle-tube, or tubus capularis of hydroid polyps. G. buccalis, the esophagus of Medusæ. G. centralis, the central cavity of Medusæ. G. coronaris, the perogaster of Medusæ. G. principales. See Axogaster.

Gasterangiemphraxis (gas-ter-an-je-em-fraks'-is)

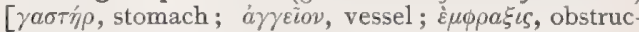
tion]. I. Congestion of the stomachic blood-vessels. 2. Pyloric obstruction.

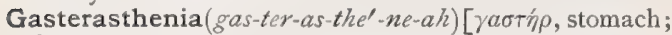

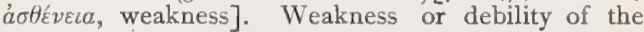
stomach.

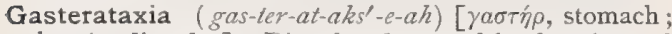
áta $\xi i a$, disorder]. Disordered state of the functions of the stomach; that state of the stomach-walls in which some parts are hardened or thickened, while others are softened or inflamed.

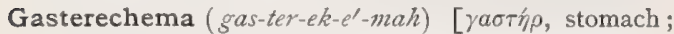
$\eta \eta \chi \eta \mu a$, sound]. A sound heard in the auscultation of the stomach.

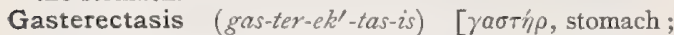
$\tilde{\varepsilon} \kappa \tau a \sigma \iota s$, dilatation]. Dilatation of the stomach; it is usually due to pyloric obstruction, but may also result from muscular weakness, and from over-distention from excessive eating and drinking.

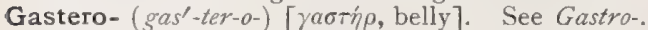

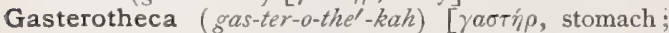
An $\kappa \eta$, case : pl., Gasterotheca]. In biology, the part of the pupa or chrysalis-case that covers the abdomen.

Gasterozoöid, Gastrozoöid (gas-ter-o-zol-oid, gas-tro-

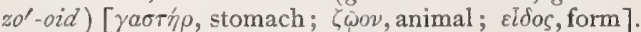
In biology, one of the nutritive zoöids of a polypcolony.

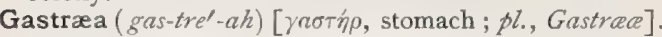
In biology, Hæckel's term for a hypothetic, primeval, two-layered, saccular organism; the supposed ancestral type of the gastrula stage of the present Metazoan.

Gastræmia (gas-tre'-me-ah). See Gastremia.

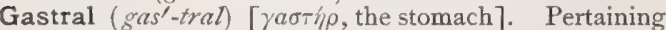
to the gaster or stomach; gastric.

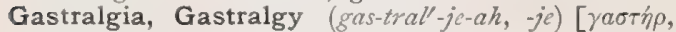
stomach; àyos, pain]. Pain in the stomach. A mild form is sometimes called gastrodynia.

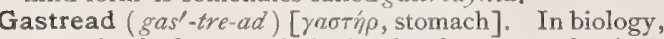
an animal the morphologic development of which stops at the gastrula stage.

Gastrectasia (gas-trek-ta'-ze-ah). See Gastrectasis.

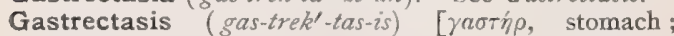

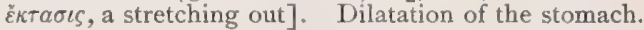

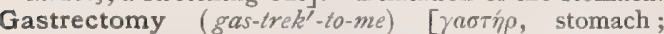

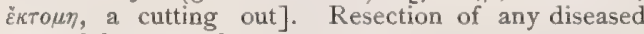
part of the stomach.

Gastrelcobrosis (gas-trel-ko-bro'-sis) [ $\gamma a \sigma T h \rho$, stomach ; $\varepsilon \lambda \kappa o c$, ulcer; $\beta p \omega \sigma \sigma \iota$, an eating]. Ulceration of the stomach.

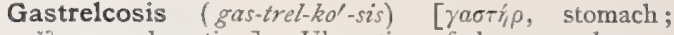
$\bar{\varepsilon} \lambda \kappa \omega \sigma \iota s$, ulceration]. Ulceration of the stomach.

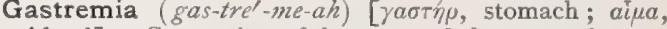
blood]. Congestion of the coats of the stomach.

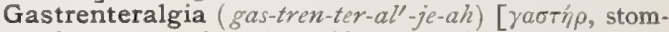

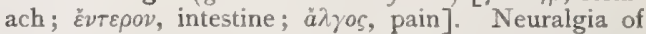
the stomach and bowels.

Gastrenteromalacia (gas-tren-ter-o-mal-a'-se-ah)

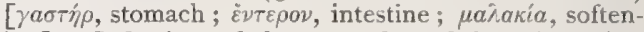
ing]. Softening of the stomach and intestines (asserted by some to be merely a post-mortem condition).

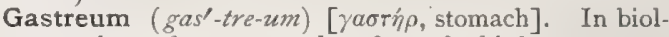
ogy, the under or ventral surface of a bird.

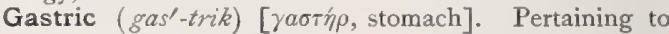
the stomach. G. Artery. See Arteries, Table of. G. Crisis, a severe, paroxysmal attack of pain in the stomach, accompanied by obstinate vomiting, faintness, and occasionally by slowness and irregularity of the pulse. These crises are met with in locomotor ataxia, $q . v$. G. Digestion, that part of the digestion of food performed by the gastric juice ; the conversion of albuminous bodies into peptones. G. Fever. See Ferver. G. Fistula, a perforation or communication other than the normal one between the stomach and peritoneal cavity, or with the outer part of the body. G. Follicles. See Glands, Peptic. G. Insufficiency, a term applied to the early stages of dilatation of the stomach. G. Juice, the normal secretion of the tubular, peptic glands of the stomach. It is a clear, colorless liquid, having an acid reaction, and containing from .5 to 2 per cent. of solid matter in solution. A small amount of hydrochloric acid, .2 to .4 per cent., and a ferment called pepsin, are the essential elements. G. Plexus, a subdivision of the solar plexus distributed to the stomach. It joins branches of the left pneumogastric nerve. See Plexus. G. Veins, two veins of the stomach ; the lesser one is called the pyloric, the greater the coronary. See Vein.

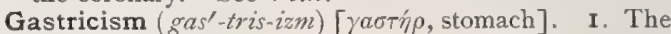
theory that ascribes most diseases to some gastric derangement. 2. A gastric disorder.

Gastrimargia, or Gastrimargism (gas-trim-ar'-je-ah,

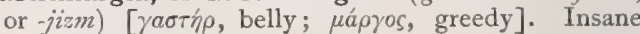
or furious gluttony.

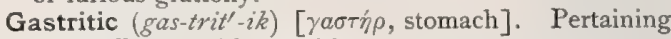
to or affected with gastritis.

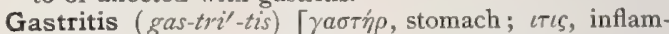
mation]. Inflammation of the coats of the stomach. It may be acute or chronic. G. polyposa, that form associated with a rough, wrinkled, mammillated condition of the gastric mucous membrane.

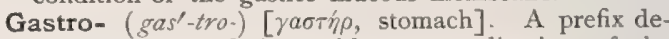
noting some relation with or complication of the stomach.

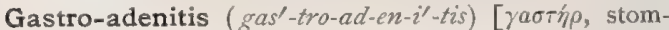
ach; $a \dot{d} \dot{\eta} \nu$, gland; $\iota \tau \iota \zeta$, inflammation]. Inflammation of the glands of the stomach.

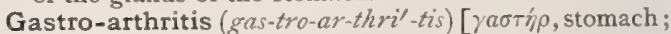
$a \rho \theta \rho \circ v$, a joint; $\iota \tau \iota c$, inflammation]. Gout in the stomach and joints at the same time.

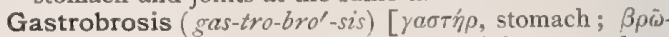
$\sigma \iota s$, a gnawing]. Perforating ulcer of the stomach.

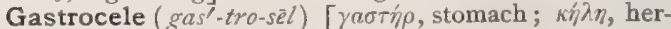
nia]. A hernia of the stomach.

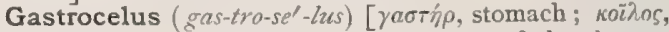
hollow]. In biology, applied to one of the depressions at the base of the second abdominal tergita in certain insects.

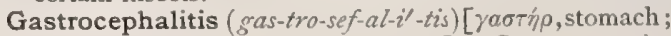

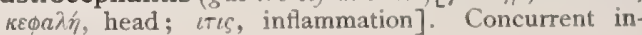
flammation of the stomach and of the brain. 


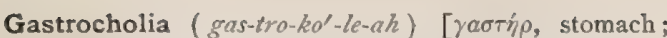
$\chi \hat{\lambda} \lambda \eta$, bile]. Concurrent gastric and bilious disorder.

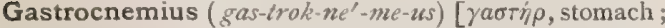
$\kappa v \eta \dot{\mu \eta}, \mathrm{leg}]$. See Muscles, Table of.

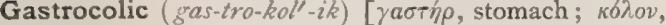
the large intestine]. Pertaining to both the stomach and the colon.

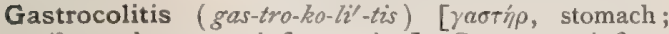
$\kappa o ́ \lambda .0 v$, colon ; $\iota \tau \iota s$, inflammation]. Concurrent inflammation of the stomach and large intestine.

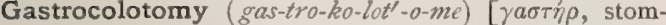

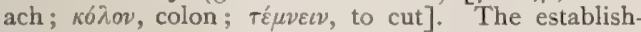
ment of an artificial communication between the stomach and the colon.

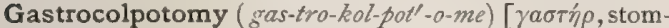
ach; $\kappa \hat{\lambda} \lambda \pi$ os, vagina; $\tau \varepsilon \mu \nu \varepsilon \imath \nu$, to cut ]. The operation of Cesarean section in which the opening is made through the linea alba into the upper part of the vagina.

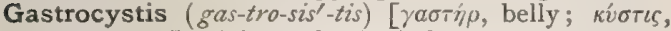
bladder]. In biology, the single-layered blastodermic vesicle of mammals.

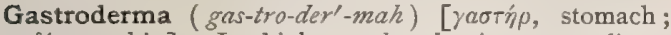
dép $\mu a$, skin]. In biology, the lamina gastralis, or intestinal epithelium.

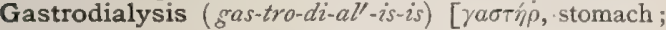
$\lambda \dot{v} \sigma / 5$, a loosening]. A solution of continuity in the gastric wall.

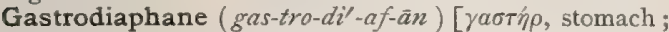
$\delta i a ́$, thruugh ; фaiveıv, to show]. See Gastrodiaphany.

Gastrodiaphanoscopy (gas'-tro-di-af-an-os'-ko-pe)

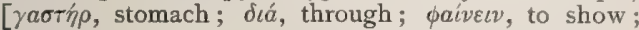

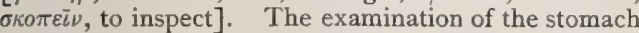
by means of the diaphanoscope.

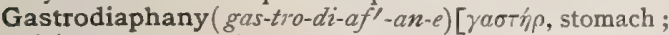

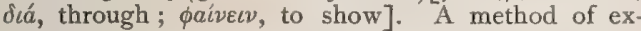
ploration of the stomach by means of the gastrodiaphane. This consists of a soft stomach-tube, at the gastric extremity of which is placed an Edison's hardglass lamp, from which conducting wires, containing a current-interrupter, run to a portable storage-battery. The stomach should be free from food and moderately distended with water. The gastric extremity of the gastrodiaphane, after being lubricated with oil or glycerin, is introduced into that viscus, and the circuit is closed. If no pronounced thickening of the anterior stomach wall exists, trans-illumination in a dark room, with the patient erect, permits the outlines of the stomach to be seen as a zone of reddish hue on the abdominal wall.

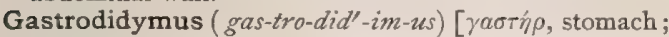

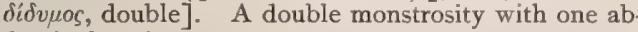
dominal cavity.

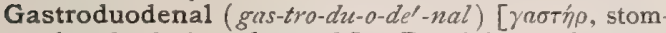
ach ; duodeni, twelve each]. Pertaining to the stomach and the duodenum.

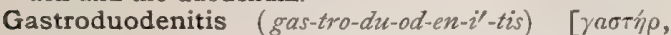
stomach ; duodeni, twelve each ; $\iota \iota \varsigma$, inflammation]. Inflammation of the stomach and duodenum.

Gastroduodenostomy (gas'-tro-du-od-en-os'-to-me)

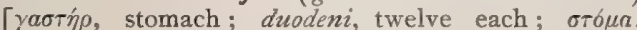
mouth]. A surgical operation upon the stomach and the duodenum, in which a new passage from the one to the other is established.

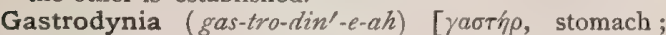
odviv $\eta$ pain]. A mild pain in the stomach. See also Gastralgia.

Gastroectasis (gas-tro-ek'-tas-is). Same as Gastrectasis.

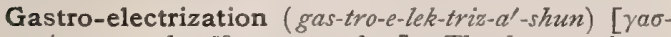
$\tau \dot{\eta} \rho$, stomach ; $\ddot{\eta} \lambda \varepsilon \kappa \tau \rho o \nu$, amber]. The therapeutic application of electricity to the stomach.

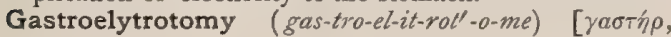

stomach; $\varepsilon \lambda v \tau \rho \circ \nu$, a sheath; $\tau о \mu \eta$, a cutting]. A method of performing Cesarean section. An incision is made into the vagina (after the abdominal section), in stead of into the uterus, and if the child cannot be extracted in this way, an incision is made into the os uteri.

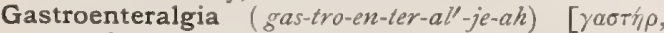

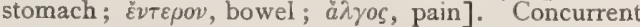
pain in the stomach and bowels.

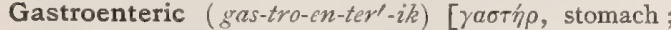
Evข $\rho \circ \nu$, bowel]. Pertaining to both stomach and bowels.

Gastroenteritis (gas-tra-en-ter-i'tis) [yantíp, stom-

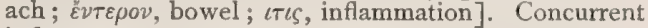
inflammation of stomach and bowels.

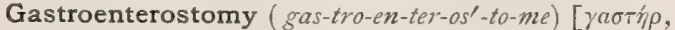

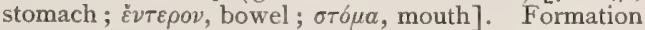
of a fistulous communication between the stomach and the small intestine in obstruction of the pylorus.

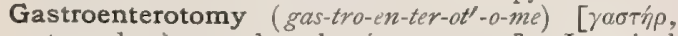
stomach ; $\varepsilon \nu \tau \varepsilon \rho \circ \nu$, bowel ; $\tau \varepsilon \dot{\mu} \mu \varepsilon \varepsilon \nu$, to cut]. Intestinal incision through the abdominal wall.

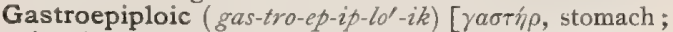
$\varepsilon \pi i \pi \lambda o o \nu$, caul]. Pertaining to stomach and omentum.

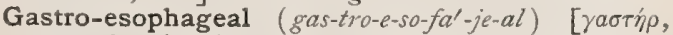
stomach; oiøoфáros, the esophagus]. Pertaining to both the stomach and the esophagus.

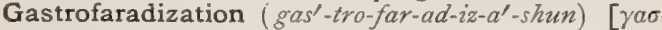
Típ, stomach; Faraday]. The application of faradism to the stomach.

Gastrogalvanization ( $g a s^{\prime}-t r c-g a l-v a n-i z-a^{\prime}-\operatorname{shun}$ )

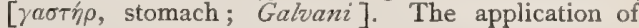
galvanism to the stomach.

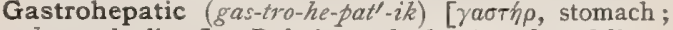
$\eta \pi \alpha \rho$, the liver]. Relating to both stomach and liver.

Gastrohysterectomy (gas'-tro-his-ter-ek'-to-me)

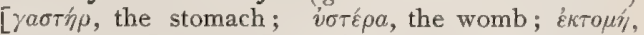
a cutting out]. The Porro-Cesarean operation. See Operations, Table of:

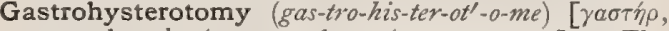

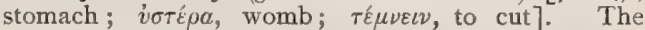
Cesarean section, $q . v$

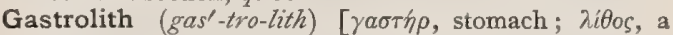
stone]. A calcareous formation in the stomach; gastric calculus; bezoar.

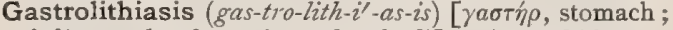
$\lambda \iota \theta i a \sigma \iota s$, the formation of calculi]. A morbid condition associated with the formation of gastroliths.

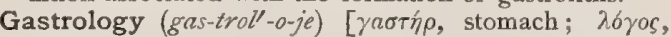
science]. A treatise on the stomach and its functions.

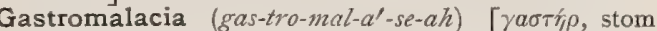
ach ; $\mu a \lambda a \kappa i a$, softening]. An abnormal softening of the structural tissue of the stomach ; it is generally believed to be due to post-mortem acidity.

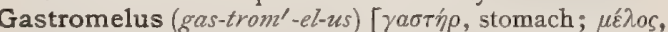
limb]. A monster with accessory limbs attached to the abdomen.

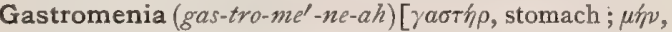
month]. Vicarious menstruation by the stomach.

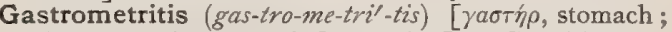
$\mu \eta \dot{\tau} \rho \alpha$, womb; $\iota \tau \iota \zeta$, inflammation]. Gastritis concurrent with metritis.

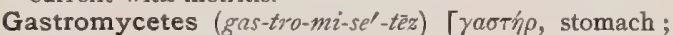
$\mu v \kappa \eta$, mushroom]. A group of fungi, the spores of which are enclosed in a cavity or pouch.

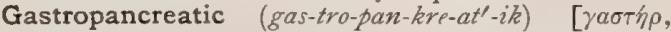
stomach; $\pi a ́ \gamma \kappa \rho \varepsilon \alpha \varsigma$, pancreas]. Both gastric and pancreatic.

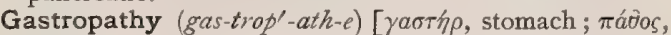
disease]. Any disease or disorder of the stomach.

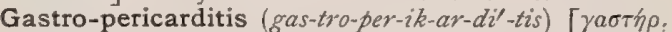

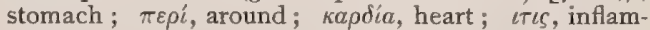
mation]. Gastritis concurrent with pericarditis. 


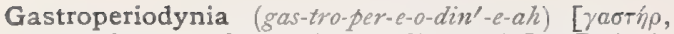

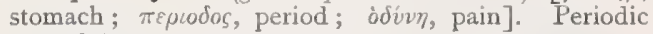
gastralgia.

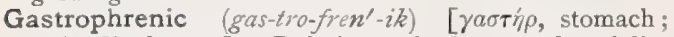
$\phi \rho \dot{\eta} \nu$, diaphragm]. Relating to both stomach and diaphragm.

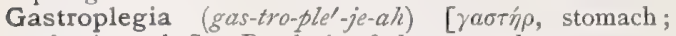
$\pi \lambda \eta \gamma \dot{\eta}$, stroke]. Paralysis of the stomach.

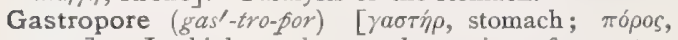
pore]. In biology, the mouth-opening of a gasterozoöid.

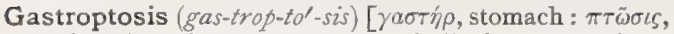
fall]. A prolapse or downward displacement of the stomach.

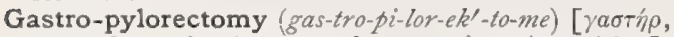

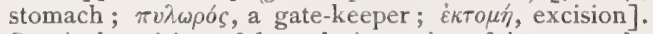
Surgical excision of the pyloric portion of the stomach.

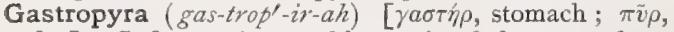
fire]. Inflammation or phlegmasia of the stomach.

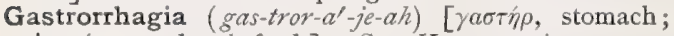
pirvival, to break forth]. See Hematemesis.

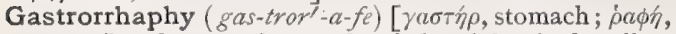
suture ]. Suture of wounds of the abdominal wall or stomach.

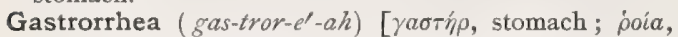
a flow]. Excessive secretion, or regurgitant flow, of gastric mucus or liquid.

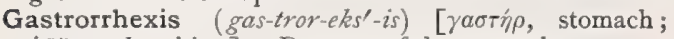
$\dot{\rho} \bar{\eta} \xi_{\iota}$, a breaking]. Rupture of the stomach.

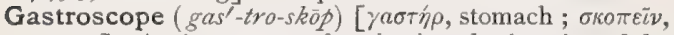
to see]. An instrument for viewing the interior of the stomach. It consists essentially of a tube with an incandescent electric light and reflecting prisms.

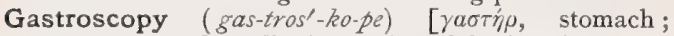
$\sigma \kappa о \pi \varepsilon i \nu$, to see]. The inspection of the interior of the stomach by means of the gastroscope.

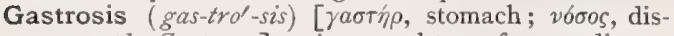
ease: pl., Gastroses]. A general term for any disease of the abdomen or of the stomach only.

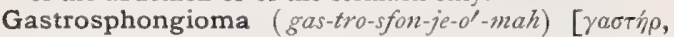
stomach; $\sigma \phi o \gamma \gamma i a ́$, sponge ; o $\mu \alpha$, tumor: pl., Gastrosphongiomata]. A fungosity of the stomach.

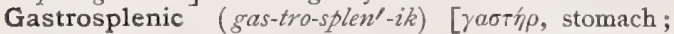
$\sigma \pi \lambda \eta v$, spleen]. Relating both to the stomach and the spleen.

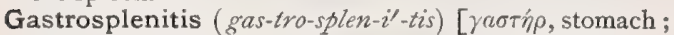
$\sigma \pi \lambda \hat{\eta} \nu$, spleen; $\iota \tau \iota \varsigma$, inflammation]. Inflammation of both stomach and spleen.

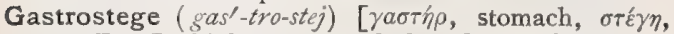
a roof]. In biology, one of the short, wide, transverse scutes or scales that cover the ventral surface of a snake.

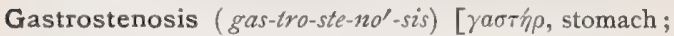

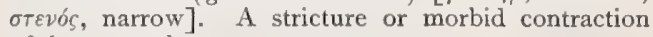
of the stomach.

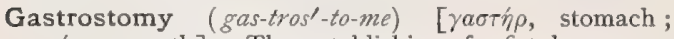
$\sigma \tau b \mu \alpha$, mouth]. The establishing of a fistulous opening into the stomach.

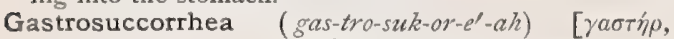
stomach; succus, juice; poía, a flow]. Reichmann's disease; hypersecretion of the gastric juice.

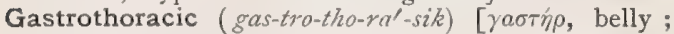
$\forall \omega \rho a \xi$, thorax]. Pertaining both to the abdomen and the thorax.

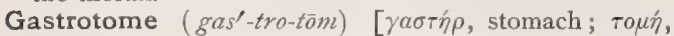
a cutting]. A cutting instrument used in gastrotomy.

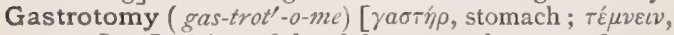
to cut]. Incision of the abdomen or the stomach.

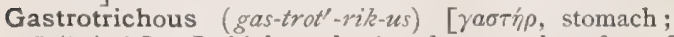
$\theta p i \xi$, hair]. In biology, having the ventral surface of the body ciliated.

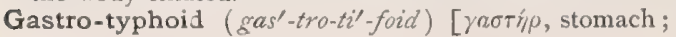

Tr̈фos, smoke]. Typhoid fever with pronounced gastric symptoms.

Gastrovascular (gas-tro-vas'-ku-lar) [yaotíp, stomach; vasculum, a little vessel]. Common to the functions of digestion and circulation, as the body-cavity of some animals.

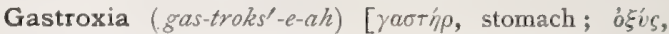
acid]. Abnormal acidity of the contents of the stomach.

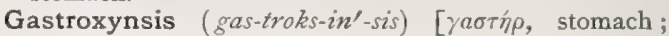
ó vivecv, to irritate]. Rossbach's term for hyperchlorhydria; a periodic form of nervous dyspepsia with hyperacidity of the gastric juice. It is, in fact, a neurosis of secretion that may be quite independent of the time of digestion. It is a rare condition, and is associated either with profound neurasthenia or with locomotor ataxia. It is marked by a gnawing, unpleasant sensation in the stomach, severe headache, and the vomiting of a clear, watery, intensely acid secretion.

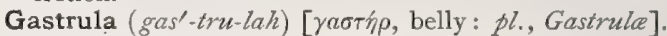
In biology, a stage in the development of Metazoans, in which the germ consists of a two-layered sac, produced by the invagination of the one-layered, hollow germ-sphere, the blastula.

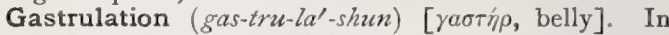
biology, the process of formation of the gastrula by the invagination of the blastula.

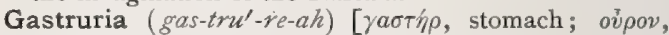
urine]. A supposed passage of urine into the stomach.

Gate-vein ( găt' $\left.\bar{t}^{\prime} v \bar{a} n\right)$. An old name for the portal vein.

Gathering (gath'-er-ing) [ME., gadering, a gathering]. A popular name for an abscess, pustular inflammation, or suppurating sore.

Gattine $\left(\right.$ gat-e $\left.^{\prime}\right)[\mathrm{F}$.$] . A disease of the silk-worm.$

Gaubius' Table. See Dose.

Gaule's Experiment. See Cytozoön.

Gaultheria (gazul-the'-re-ah) [after Ur. Gaultier, a Canadian physician]. Wintergreen, Teaberry. The leaves of wintergreen, $G$. procumbens, an evergreen plant, with properties due to a volatile oil, methyl salicylate, which is also found in black birch and several other plants. It is stimulant, astringent, and antipyretic, and is used in rheumatism and gout, or when salicylic acid is indicated. G., O1., oil of wintergreen, much used as a flavor. Dose, miij-x. G., Spt., oil of wintergreen 5, alcohol 95. Dose, 3 ss-ij. G. fragrans, of India, affords an identical oil.

Gaultherilene (gavel-ther'-il-èn) [after Dr. Gaultier, a Canadian physician], $\mathrm{C}_{10} \mathrm{H}_{16^{\circ}}$ A peculiar hydrocarbon found in the oil of gaultheria. It is a colorless, yellow or reddish liquid, of a peculiar strong and aromatic odor, a sweetish, warm, and aromatic taste, a slightly acid reaction, and a specific gravity of about I. I80. It is readily soluble in alcohol.

Gaulthier's Reagent. See Tests, Table of.

Gauntlet (gahnt'-let, or gazent'-let) [OF., gantelet, dim. of gant, a glove]. A surgical bandage that covers the hand and fingers like a glove. See Bandage.

Gauze (gawz). A thin, open-meshed cloth used for surgical dressings. When impregnated with antiseptic solutions or substances it is called antiseptic gauze, or, according to the substance used, it is spoken of as iodoform-gauze, sublimate-gauze, etc. See Carbasus.

Gavage (gav-ahzh') [Fr.]. I. The regular feeding of an infant with freshly-drawn mother's milk, through a small, soft catheter passed into the stomach at each feeding. 2. The administration of liquid nourishment through the stomach-tube.

Gavard's Muscle. See Muscles, Table of.

Gay-Lussac's Laws. See Law.

Gazeol (gaz'-e-ol) [Fr., gazél]. A mixture of naph. 
thalin, I part ; benzene, Io parts ; acetone, ro parts ; coal-tar, IOo parts; aqua ammonia (20 per cent.), 1000 parts; it is recommended as affording a vapor for inhalation in whooping-cough.

Geber's Glomerules. The convolutions of the terminal branches of the nerves supplying the epithelial lining of the mouth.

Geddes' Fluid Extract. See Abies.

Geissler Tube. A glass tube designed to show the effects of electric discharges through gases at low pressure.

Geissler's Apparatus. An apparatus for estimating the quantity of carbonic acid in a carbonate.

Geissospermin, or Geissin (gi-so-sper'-min, or gi' -

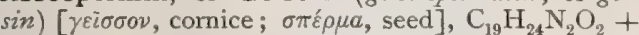
$\mathrm{H}_{2} \mathrm{O}$. An alkaloid from the bark of Geissospermum leve; it is a depressant of the respiration and of the cardiac action.

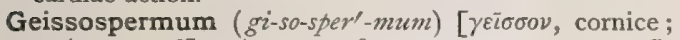
$\sigma \pi \varepsilon \rho \mu a$, seed]. A genus of apocynaceous trees. G. lave and $\mathrm{G}$. vellosii, of Brazil, afford Pao-pereira ("pear-tree") bark, an active febrifuge and astringent. Unof.

Geitonogamy (gi-ton- $\left.\circ g^{\prime}-a m-e\right)$ [ yeít $\omega \nu$, a neighbor;

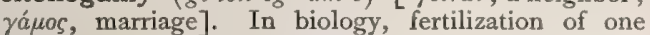
flower by pollen from another flower of the same plant.

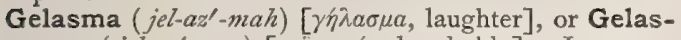

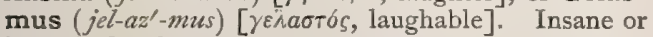
hysteric laughter.

Gelatin (jell-at-in) [gelare, to congeal]. An albuminoid substance of jelly-like consistence, obtained by boiling skin, connective tissue, and bones of animals in water. The glue of commerce is an impure variety. See Glue. G. Bath. See Bath. G., Blasting. See Blasting Gelatin. G. Capsules, capsules of gelatin designed for containing medicines of nauseating taste. G. Culture-medium, a jelly made by a solution of the best commercial food-gelatin in the proportion of 6,8 , or Io parts to Ioo of water, with I or 2 parts of dried peptones or glucose (the latter not to be used if the culture is to be made on slides) for increased nutritive value. Bicarbonate of soda is used to neutralize the acid reaction. This, in bacteriology, is simply known as Gelatin. G.-dynamite. See Blasting Gelatin. G., Liquid, a substance for fastening paper to glass, wood, or paper; its formula is :-

Gelatin or clear glue, ..... 75 to 100 grams (3\%) Commercial acetic acid (No. 8), .... 100 c.c. $\left(3.4^{f 3}\right)$ Water, ........ I00 c.c. $(3.4 \mathrm{f}$ f $)$ 95 per cent Alcohol, . . . . . I00 c c $(3.4 \mathrm{f} 5)$ Glycerin,........... is to 30 c.c. $(1 / 2$ to I $\mathrm{f} 3$ )

Crush the glue and put it into a bottle with the acid; set in a warm place and shake occasionally. After three or more days add the other ingredients. G., Medicated, a soft basis consisting of gelatin 3, zinc oxid 3, glycerin 5, water 9 parts, to which antiseptic or other medicaments may be added. It is preferable to greasy ointments. . All unof. G. Sugar. See Glycin. Gelatinigerous ( $\left.j e l-a t-i n-i j^{\prime}-e r-u s\right)$ [gelatina, gelatin; gerere, to bear]. In biology, applied to such organisms as secrete a gelatinous investment.

Gelatinoid (jell-at-in-oid) [gelare, to freeze; $\varepsilon i \delta o s$, likeness]. I. Resembling gelatin. 2. Any member of a class of nitrogenous substances, including chondrin, collagen, elastin, gelatin, etc.

Gelatinous (jel-at'-in-us) [gelare, to freeze]. Resembling or having the nature of gelatin. G. Tissue. See Animal Tissue.

Gelatio (jel-a'-she-o) [L.]. Synonym of Frostbite.

Gelation (jel-a'shun) [gelatio, a freezing]. I. Freezing; also frost-bite, or chilblain. 2. Catalepsy.

Geld [ME., gelden, to castrate]. 'To castrate.
Gelding (gel'-ding) [ME, gelding, a eunuch]. I. Castration. 2. A castrated person or animal.

Gelidium (jel-id'-e-umz) [gelum, cold]. A genus of seaweed. G. corneum, affords gelosin, and others, as $\mathrm{G}$. spiniform, supply some portion of the agar-agar of commerce.

Gelle's Experiment. A diminution of the bone-conduction of sound resulting from compression of the air in the external auditory canal.

Gellert's Green. Same as Rinmann's Green.

Gelose $\left(j e l-\bar{o} z^{\prime}\right)$ [gelare, to freeze]. I. The gelatinuzing principle of agar-agar. 2. A culture-medium used in bacteriologic investigation. Gelatin liquefies at $23^{\circ}$ or $24^{\circ} \mathrm{C}$, and is thus inferior to gelose for those cultures that require a higher degree of heat for their proper development. Agar-agar contains a considerable proportion of chemic gelose. Of the agaragar a jelly is made, 2 to 3 parts (to Ioo) of dried peptone added; IO to 15 parts of this substance to 50 parts of water, with I to 5 of glycerin, form a nutritive jelly which is called gelose, from its essential ingredient. It is also called Parabin.

Gelosin $\left(j e l^{\prime}-o-\sin \right)$ [gelare, to freeze]. A mucilage resembling gelose, and extracted from some kinds of agar-agar and from various species of algæ. It is soluble in water and alcohol, and is an excellent excipient for powders, tinctures, and salts, and is serviceable in bacterial cultures. Unof.

Gelsemin (jell-sem-in) [gelseminum, jasmine]. I. $\mathrm{C}_{11} \mathrm{H}_{19} \mathrm{NO}_{2}$, a poisonous alkaloid from Gelsemium, $q . v .2$. A precipitate or resinoid from a tincture of the root-bark of Gelsemium sempervirens; it is a febrifuge, antispasmodic, emmenagogue, and narcotic; dose $\frac{1}{8}$ to $I$ grain. Unof.

Gelseminin (jel-sem'-in-in) [gelseminum, jasmine]. An alkaloid of Gelsemium. It is an amorphous yellowish-white, bitter, very poisonous powder, soluble in ether and chloroform, less so in alcohol and water. Dose gr. $\frac{1}{60}-\frac{1}{20}$.

Gelsemium (jel-se'-me-um) [gelseminum, jasmine], $\mathrm{C}_{11} \mathrm{H}_{19} \mathrm{NO}_{2}$. Yellow Jasmine. The root of $G$. sentpervirens, abundant in the southern U. S., with properties mainly due to an alkaloid, gelsemin, a powerful motor depressant, antispasmodic, and diaphoretic. In toxic doses it produces diplopia, extreme muscular weakness, and anesthesia, death occurring from asphyxia. It is useful in exaltation of nerve-action and in cerebro-spinal meningitis, and is especially valuable in remittent and malarial fevers. Dose gx. ij-xx. G., Ext., Alcoholic (B. P.). Dose gr. 1/4-1/2. G., Ext., Fld., alcoholic. Dose $\eta_{\mathrm{ij}-\mathrm{xx}}$ G., Tinct, ${ }_{5}$ per cent. in strength. Dose $m x-3 j$. Gelseminin, the alkaloid. Dose gr. $\frac{1}{60} \frac{1}{20}$. G., Hydrochloras, freely soluble in water. Dose gr. $\frac{1}{60} \frac{1}{20}$. G., Hydrochlorat., Liq., one grain in one dram. Dose $\mathrm{mj}_{\mathrm{j}}$ iij, hypodermatically.

Gely's Suture. See Suture.

Gemellus (jem-el'-us) [dim. of geminus, twin]. Double. In pairs. G. Muscle, the gastrocnemius muscle, on account of its double origin. See Muscles, Table of.

Gemina (jem'-in-ah) [L., twins]. A name for the corpora quadrigemina, or optic lobes. They constitute the larger part of the mesocœlian roof.

Geminate $\left(j e m^{\prime}-i n-\bar{a} t\right)$ [geminus, a twin]. In pairs. In biology, parts that are disposed in pairs.

Geminiflorous (jem-in-if-lo'-rus) [geminus, twin ; flos, flower]. In biology, applied to plants that produce flowers in pairs.

Geminous (jem'-in-us) [geminus, a twin]. Same as Geminate G. or Connate Teeth, twin-formation of two teeth from the occurrence of a double dental germ in a single sac, from which are developed two 
teeth of the same class, when normally there should be but one.

Gemma (jem'-ah) [L., a swelling bud, a germ: $p l$., Gemma]. In biology, one of the various asexual reproductive bud-like processes of cryptogams.

Gemmation (jem-a'-shun) [gemmare, to put forth buds]. In biology, asexual reproduction by budding, as distinguished from fission and free-cell formation. Gemmation occurs in certain cryptogams and in the Calenterata, Polyzoa, and Tunicata among animals, in which the bugl arises as an evagination of the ectoderm only, Cf. Idioplasm, Blastemic, and Budding.

Gemmipara, Gemmiparæ (jem-iph'-ar-ah,-e) [gemma, a bud; parere, to produce]. In biology, organisms that reproduce by budding.

Gemmule $\left(j \mathrm{em}{ }^{\prime}-\bar{u} l\right)$ [gemmula, a little bud; dim. of gemma, a bud]. In biology, $(a)$ one of the small buds produced by a gemmiparous organism. (b) In Darwin's theory of pangenesis, one of the invisible granules or atoms, being given off continually by all the cells of the body, conveyed into the blood and circulated through the body to finally settle down in other cells, especially the germ-cells. Each gemmule is supposed to reproduce the cell from which it is derived, and the gemmules of the different cells become active in the same order as that in which the corresponding cells followed each other in the ontogeny of the parent. Galton accepted the "gemmule hypothesis," but denied the circulation of the gemmules. Brooks attributes to the male germ-cell a particularly strong power of attraction for the gemmules, so that it collects a special mass of them and stores them up. Cf. Anlage, Biophor, Determinant, Id, Idioplasm, Heredity.

Gena $\left(j e^{\prime}-n a h\right)[$ L., the cheek : pl., Gena $]$. In biology, applied to a rather poorly defined region on the side of the head of various animals; the cheek

Genal $\left(j e^{\prime}-n a l\right)[\gamma \varepsilon$ vvs, the cheek]. Relating to the gena, or cheek.

Genepi (jen'-ep-e). See Genipi.

Genera (jen'-er-ah) [L.]. Plural of Genus, q.v.

General (jen'-er-al) [generalis, of a kind]. Common to a class; universal. G. Anatomy, histology, especially comparative histology. G. Anemia, oligemia; also, deficiency of hemoglobin in the blood. G. Paralysis, or Paresis. See Paralysis, General, of the Insane.

Generale $\left(j a-n e-r a l^{\prime}-e\right)$ [Fr.]. Synonym of Infuenza.

Generate (jen'-er-ät) [generare, to beget]. To beget; to produce of the same kind.

Generatio aquivoca (jen-er-a'-she-o e-kwiv'-o-kah) [L.]. See Generation, Equivocal.

Generation (jen-er-a'-shun) [generatio, a begetting]. The begetting or production of offspring. G., Alternate, in biology, the alternation of asexual with sexual generation, the offspring of one process differing from that of the other, e.g., the asexual fern and the sexual prothallium, the asexual hydroid-polyp and the sexual medusa. G., Alternations of. See Altcrnations of Generation. G., Equivocal, spontaneous generation ; birth from parentage of another form; abiogenesis. G., Fissiparous. See Fission. G., Organs of, those that are functional in reproduction; the genitalia. G., Spontaneous, abiogenesis; the generation of living from non-living matter.

Generator (jen'-er-a-tor) [generare, to generate]. One who, or that which, begets or causes. G.-gas, a gas formed from coal, varying in composition according to the kind of coal employed and the manner of working; it is used to gasify coke and for the production of heat and power.
Generic (jen-er-ik) [genus, a kind]. Pertaining to the same genus.

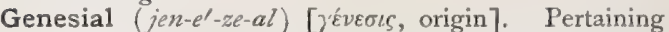
to generation. G. Cycle, the periods of ovarian, uterine, and mammary activity into which the reproductive life of the female is divided; the first extending from puberty to conception, the second from conception to gestation, and the third from gestation through lactation.

Genesiology (jen-e-ze-ol'-o-je) [ $\gamma^{\prime} \varepsilon \varepsilon \varepsilon \sigma \iota$, reproduction; $\lambda \sigma \gamma o s$, science]. The science of reproduction.

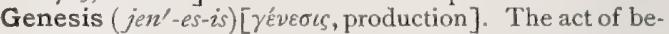
getting; development ; origin ; formation; generation.

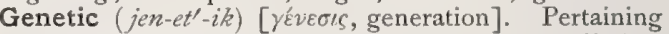
to generation, or to anything inherited. G. Affinity, relationship by direct descent.

Genetous (jen'-et-us) [ $\gamma^{\varepsilon} v \varepsilon \sigma \iota \varsigma$, generation]. Congenital; existing from some point or period in fetal life; as genetous idiocy.

Genévrette (zhen-a-yret') [Fr.]. A drink made by the fermentation of wild fruits with juniper-berries and wine ; it is popular in parts of Switzerland.

Genga's Bandage. See Bandage.

Genial ( $\left.j e^{\prime}-n e-a l\right)[g e n a$, chin]. Pertaining to the chin. G. Tubercles, four prominent tubercles on the internal surface of the lower jaw.

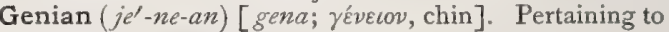
the chin.

Geniculate, Geniculated (jen-ik/-u-lāt, -ed) [geniculare, to bend the knee]. In biology, kneed, or abruptly bent. G. Bodies, the corpora geniculata; two oblong, flattened bodies on the outer side of the corpora quadrigemina and under the back part of the optic thalamus. See Geniculum. G. Ganglion. Same as Intumescentia gangliformis.

Geniculum (jen-ik'-u-lum) [genu, knee]. One of the two eminences on the latero-caudal aspect of the diencephal ; the post-geniculum is mesad and more distinct, and the pre-geniculum, laterad and less distinct.

Genio- $\left(j e^{\prime}-n e-o^{-}\right)[\gamma \varepsilon$ veıov, the chin]. A prefix denoting connection with the chin. G.-hyoglossus Muscle. See Muscles, Table of. G.-hyoid Muscle. See Muscles, Table of.

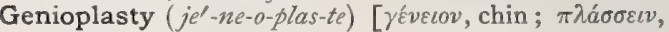
to form]. Plastic surgery, or a plastic operation, upon the chin.

Genipap (jen'-e-pap) [native Guiana, Genipapo]. The agreeable edible fruit of Genipa americana, a rubiaceous tree of tropical America. Cataplasms are made of the unripe fruit.

Genipi $\left(j e n^{\prime}-i p-\ell\right)$ [Fr., génépi]. A green bitter-sweet cordial, or liquor, made from Alpine herbs of the genera Artemisia, Achillea, etc.

Genista (jen-is'-tah) [L.]. A genus of leguminous plants. G. canariensis, affords some part of the socalled oil of rhodium. G. purgans, of W. Europe, is purgative and emetic. G. tinctoria, dyer's broom, is diuretic and purgative. Unof.

Genital (jen'-it-al) [genitalis, pertaining to generation]. Pertaining to the organs of generation or to reproduction. G. Cord, the union of the two ducts of Wolff and of Müller to form a common cord in the embryo. G. Eminence, or Tubercle, an elevation appearing about the sixth week of embryonic life, in front of the cloaca, and from which the penis or clitoris is developed. G. Fissure, a furrow extending from the genital eminence of the embryo to the cloaca. G. Folds, two plications at the side of the orifice of the cloaca. G. Furrow. Same as G. Fissure. G. Sense, the degree of vigorousness of the development of ovisacs.

Genitalia (jen-it-a -le-ah) [genitalis, pertaining to gen- 
eration]. The organs of generation. In the male these consist of two testicles or seminal glands, with their excretory ducts; a musculo-glandular organ, the prostate, which provides a material for the dilution of the semen; an organ of copulation, the penis ; and a canal, the urethra, piercing the prostate and penis, and

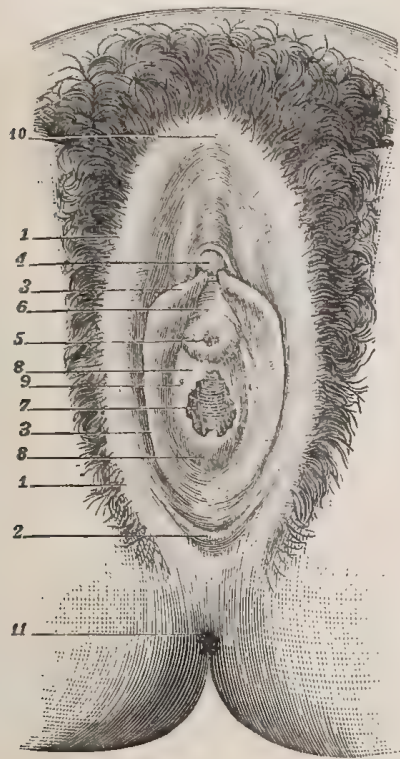

External Genitalia of Female.

I. Labia majora of right side. 2. Fourchet. 3. Labia minora. 4. Clitoris. 5. Urethral orifice. 6. Vestibule. 7. Orifice of the vagina. 8 . Hymen. 9. Orifice of the vulvo-vaginal gland I0. Anterior commissure of the labia majora. II. Orifice of the Anus.

serving for the transit of the generative and urinary secretions. The female genitals include an external part, the vulva, and the vagina, or passage-way leading to the intemal organs; the latter include the ovaries, or organs of ovulation, with their ducts or Fallopian tubes, and the uterus, a musculo-mucous sac in which the ovum undergoes development and by which the fetus is ultimately expelled.

Genitalist (jen'-it-al-ist) [genitalis, pertaining to generation]. One who is a specialist in the treatment of diseases and affections of the genital organs.

Genito- (jen'-it-o-) [genitus, begotten, from gignere, to be born]. A prefix denoting connection or relation to the genital organs. G.-anal, pertaining to the genitals and the anus. G.-crural. See Nerves, Table of. G.-enteric, relating to the genitals and to the intestine. G.-spinal Center. See Center. G.-urinary, relating to the genitals and the urinary organs.

Gennari, Line of. See Lines, Table of.

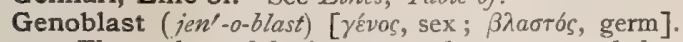
I. The nucleus of the impregnated ovum, regarded as bisexual. 2. An ovum or spermatozoid.

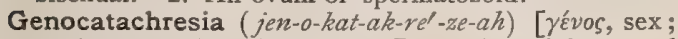
$\kappa \alpha \tau a ́ x \rho \eta \sigma \iota$, misapplication]. Perversion of the sexual instinct.

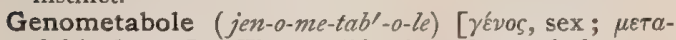
$\beta o \lambda \eta$, change]. The modification of sexual character that may follow the menopause.

Gentele's Green. See Pigments, Conspectus of.

Gentian, or Gentiana (jen'-she-an, or jen-she-a'-nah) [gentiana, gentian]. The root of $G$. lutea, a European, and of $G$. catesbai, an American species, a simple, non-astringent bitter. It is highly esteemed as a stomachic tonic in convalescence from acute diseases and malarial fever. G.-blue. Same as Spirit-blue. G., Ext. Dose gr. j-v; dose of the British extract gr. ij-x. G., Ext., FId. Dose $3^{\mathrm{ss}-j}$. G., Infusum, Comp., unof., gentian Io, bitter-orange peel $2 \mathrm{I} / 2$, coriander $21 / 2$, alcohol 40 , water to make 320 . Dose 3j- $\mathrm{z}^{\mathrm{j}}$. G., Mist., Alkalin., unof., dil. hydrocyanic acid $m$ iij, sodium bicarb. gr. $x v$, infus. gentian. comp. to make $\xi_{j}$. Dose $\xi_{\text {j. }}$ G. et Senna, Mist., unof., infus, of senna $3 \mathrm{iij}$, comp. tinct. cardamom $3 \mathrm{j}$, comp. infus. of gentian 3 vj. Dose $3 \times$. G., Tinct., Comp., contains gentian IO, bitter-orange peel 4 , cardamom I, dil. alcohol to make Ioo. Dose 3 ss-ij.

Gentiogenin (jen-she-oj'-en-in). See Gentiopicrin.

Gentiopicrin (jen-she-o-pik'-rin) [gentiana, gentian; $\pi \iota \kappa \rho o ́ s$, bitter], $\mathrm{C}_{20} \mathrm{H}_{30} \mathrm{O}_{12}$. The principal constituent of Gentian. It is a peculiar, intensely bitter, crystalline glucosid, forming clear, radiate, or clustered needles, soluble in water and dilute alcohol, insoluble in ether. Diluted acids separate it into sugar and gentiogenin, a yellow, bitter, neutral powder.

Gentisin (jen'-tis-in) [gentiana, gentian], $\mathrm{C}_{14} \mathrm{H}_{10} \mathrm{O}_{5}$. A coloring-matter contained in gentian-root; it crystallizes in yellow needles.

Genu $\left(j e^{\prime}-n u\right)[g e n u$, the knee: $p l .$, Genua $]$. I. The knee. 2. Any bent or knee-shaped structure; as the genu of the corpus callosum, or of the optic tract. G. corporis callosi, the cephalic reflected part of the corpus callosum. G.-cubital, relating to the knee and the elbow; as the Genucubital Posture, in surgery. See Postures, Table of. G. extrorsum, out-knee; outward bowing of the knee; bow-leg. G. facialis, the curved portion of the bundle of rootlets emerging from the subnuclei of the Nidus facialis, and causing, together with the underlying nidus of the abducens, the Eminentia facialis on the floor of the fourth ventricle. G.-pectoral, relating to the knee and the chest. G.-p. Posture, the (so-called) Knee-chest Posture. See Postures, Table of. G. recurvatum, the backward curvature of the knee-joint. G. valgum, inward curving of the knee; knock-knee; in-knee. G. varum. Same as $G$. extrorsum.

Genual (jen'-u-al) [genu, the knee]. Pertaining to a knee or to a genu.

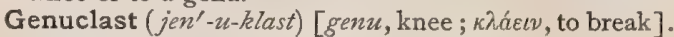
An apparatus for the forcible correction of knee-joint deformities or adhesions.

Genuflex (jen-u-fleks') [genu, knee; flexus, bent]. Bent at, or like, the knee. Also, bent at any joint.

Genuflexion, Genuflection (jen-u-flek'-shun) [genu, knee; flexus, bent]. The bending or flexion of the knee.

Genuflexuous (jen-u-fleks'-u-us) [genu, knee ; fexus, a bending]. In biology, zig-zag, with knee-like bendings.

Genus $\left(j e^{\prime}-n u s\right)[g e n u s$, a family: pl., Genera $]$. A species or a number of species marked by one or more common characteristics that distinguish them from other groups of species.

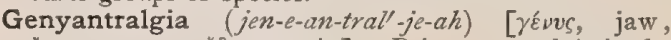

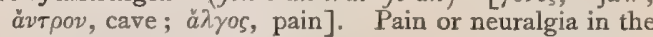
antrum of Highmore.

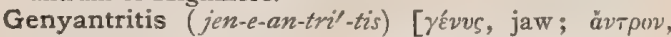
cave; $\iota \tau \iota s$, inflammation]. Inflammation of the genyantrum.

Genyantrum, or Genyantron (jen-e-an'-trum, or -tron)

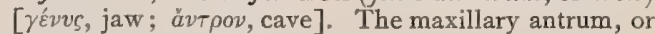
antrum of Highmore.

Genyplasty (jen'-e-plas-te) [yévvs, cheek, chin, jaw ; $\pi \lambda \alpha ́ \sigma \sigma \varepsilon \nu$, to form ]. An operation for reforming or restoring the cheek or jaw, imperfect either from injury or from congenital malformation. 


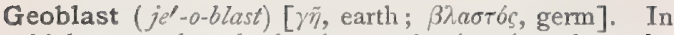
biology, a plumule that in germination rises above the ground, leaving the cotyledons buried, e.g., that of the pea.

Geoffroya (je-off-roi'-yah) [after Geoffroy, a French physician]. A genus of leguminous trees. G. spinulose and $G$. vermifuga are S. American trees with anthelmintic seeds. Unof.

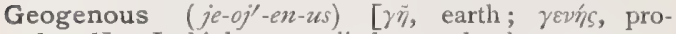
duced]. In biology, applied to such plants as grow on the ground, rather than on other plants; specifically applied to fungi.

Geographic Tongue. An eruption on the dorsum of the tongue, which becomes covered with sinuous, maplike lines. It is very chronic and obstinate in its nature, and most frequently attacks young children. It is probably the expression of a tropho-neurosis.

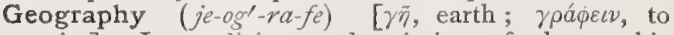
write]. In medicine, a description of the earth's surface with reference to climatology and the distribution of disease, with relation to origin and locality.

Geolin $\left(j e^{\prime}-o-\operatorname{lin}\right)[\gamma \tilde{\eta}$, earth; oleum, oil $]$. A tradename for a petrolatum resembling vaselin.

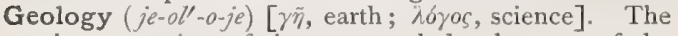
science treating of the structural development of the earth.

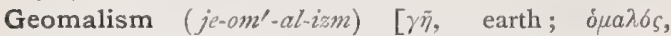
even]. In biology, the tendency of organisms to adjust themselves to the attraction of gravitation by symmetric growth in horizontal planes.

Geomaly (je-om'-al-e). Same as Geomalism.

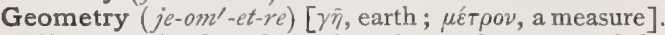
That branch of mathematic science that treats of the relations of magnitudes.

Geophagia (je-o-fa'-je-ah). See Geophagism.

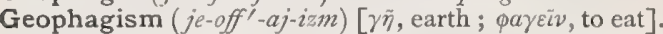
The practice of earth-eating or clay-eating; chthonophagia.

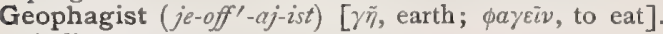
A dirt-eater.

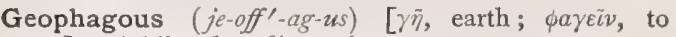
eat]. Addicted to dirt-eating.

Geophagy (je-off'-aj-e). See Geophagism.

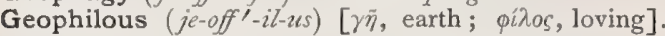
In biology, ground-loving, e.g., certain snails.

Georgia Bark (jorl-je-ah) [after King George, of England]. The bark of Pinckneya pubens, a tree of N. America ; it is said to be febrifuge. Unof.

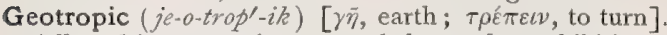
Affected by or turning toward the earth; exhibiting a tendency to grow toward the earth. The roots of plants are geotropic.

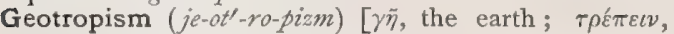
to turn]. In biology, the tendency of roots and other parts to grow downward toward the earth.

Geotropy (je-ot'-ro-pe). Same as Geotropism.

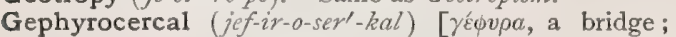
ке́коร, tail]. In biology, applied to fishes in which the aborted tail-fin is replaced by the union of the dorsal and anal fins.

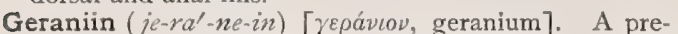
cipitate from the tincture of Cranesbill, Geranium maculatum. It stimulates and contracts the caliber of the capillary vessels of the mucous membranes, etc. Dose I to 3 grains. Unof.

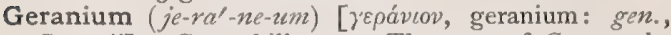
Geranii]. Cranesbill-root. The root of $G$. maculatum, with properties due to tannic and gallic acids. It is useful in diarrhea, infantile colic, etc. G., Ext., F1d. Dose $\eta^{\mathrm{v}-3 \mathrm{j}}$.

Geratic $\left(j e r-a t^{\prime}-i k\right)[\gamma \bar{p} \rho \alpha s$, old age]. Relating to old age.

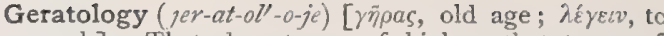
speak]. That department of biology that treats of the decadence and gradual extinction of a group of organisms.

Gerber's Food. A variety of infantile milk-food having the following composition: Water, 6.78 ; fat, 2.21; grape-sugar and milk-sugar, 6.06 ; cane-sugar, 30.50 ; starch, 38.48 ; soluble carbohydrates, 44.76 ; albuminoids, 9.56 ; ash, I.2I.

Gerdy, Fibers of. See Fibers. G., Ligament of. See Ligament.

Gerhardt's Sign. See Signs and Symptoms, Table of. G.'s Test. See Tests, Table of. G., Type Theory of, the molecules were considered as residues that remain unaltered in certain reactions.

Gerlach's Ammonia-carmin. See Stains, Table of. G.'s Carmin Mass, a warm-flowing mass for injecting tissues. Dissolve $5 \mathrm{gm}$. of carmin in a mixture of $4 \mathrm{c}$. c. of water and 0.5 c.c. of ammonia. Allow the solution to stand several days, and mix with 8 parts of a solution of gelatin, $\mathbf{r}$ to 2 . Filter and inject at a temperature of $40^{\circ} \mathrm{C}$. G.'s Network, or Plexus, an exceedingly delicate fibrous network of the finest nerve-fibrils in the gray matter of the cord. G.'s Theory, pertains to the connection of the nerve-fibers and ganglionic cells of the cord. G.'s Tubal Tonsil, a granular condition sometimes noticed at the orifices of the Eustachian tubes in chronic inflammations in this region, and due to swelling of the muciparous glands of the tube. G.'s Valve, the fold of mucous membrane that surrounds the mouth of the vermiform appendix.

Gerlier's Disease. An affection (of farm-hands) characterized by sudden paroxysms of ptosis, vertigo, muscular paresis, and cervico-occipital pain. See Diseases, Epony'mic Table of.

Germ (jerm) [L., germen, sprig, offshoot, embryo]. In biology, $(a)$ a portion of matter potentially vital and having within itself the tendency to assume a definite living form (Harvey); a spore, a seed, an embryo. (b) A microbe or bacterium. G.-area, the germinal area, the germinal disc, area germinativa, the spot on an ovum where the development of the embryo begins. G., Asexual, or Unisexual. See Parthenogenesis, Germ-plasm, Evolution, and Reproduction. G.-band, in embryology, one of the bands that unite to form the primitive streak. G.-cell. I. The germinal vesicle in a non-fertilized ovum. 2. The ovum that has been impregnated, but which is still a single cell ; a cytula, or a blastomere; a simple sphere. See also Heredity. G., Dentinal, a tooth-papilla, or tooth-pulp. G. of Disease, the special virus or spore through which a disease becomes communicable. G.disc. See $G_{\text {-area. G. Epithelium, cylindric cells }}$ on the surface of the median plate of the mesoblast. G.-flesh. See Sarcophyte. G.-gland, a germ-producing gland; an ovary or a testicle. G.-history, ontogeny, $q . v$. G.-layer, in biology, any one of the membranes of a developing germ, as the blastophylla, epiblast, mesoblast, hypoblast, endoderm, ectoderm, mesoderm, somatopleure, splanchnopleure. G.-plasm, in biology, a term introduced by Weissmann to indicate the reproductive or hereditary substance of living organisms. It is held to contain all the primary constituents of the entire organism; it is never produced neogenetically, but is ever passed on from the germ-cell in which an organism originates in direct continuity to the germcells of succeeding generations. It causes the production of the new individual by directing the process of division in ontogeny, in the course of which it becomes changed in a regular manner. It is composed primarily of biophores $(q . v$.$) or bearers of vitality, the$ smallest units that exhibit vital force. (Cf. pangenis 
of De Vries, physiologic units of Herbert Spencer, plastidules of Elsberg, and plasomes of Wiesner.) These biophores unite into groups called determinants (q.v.), each of which is a primary constituent of a cell. Groups of determinants in turn combine to form ids (Cf. ancestral germ-plasms), which correspond to the small granules hitherto called micro-somata $(q . v$.$) .$ The ids again form groups called idants $(q . v$.), which correspond with the chromatosomes $(q . v$.) or rod-like granular masses of chromatin in the nucleus. G.plasma, the protoplasm of the ovum or germ, supposed to determine the character of the resultant offspring; the physical basis of heredity and of the conservation of the species. Its alleged unchangeableness is called "the immortality of the germplasma." See Protoplasm. G.-plasms, Ancestral, Weismann's term for bodies of a highly complex constitution, each containing all the primary constituents that are necessary to the formation of an organism ("Ahnenplasmen"), afterward supplanted by the word $i d, q . v$.). G.-pore, in cryptogamic botany, a simple pit in the coat of a spore or an opening that serves as a place of exit for the tubular outgrowths from the spore at the time of germination (De Bary). G.-sac, the vesicle constituting the blastoderm of mammals. G., Specific, same as Germ. G.-theory, the doctrine of the origin of every organism from a germ or germ-plasm; blastogenesis, as distinguished from neogenesis, or spontaneous generation. Also the doctrine that certain diseases are dependent upon the presence of certain microörganisms. G.-tube, in cryptogamic botany the filamentous growth of a spore upon germination. G.-vesicle. See Germinal Vesicle.

German (jer'-man) [Germanus, German]. Pertaining or belonging to Germany. G. Breast-tea, a decoction of althea, $q . v$. G. Black. Same as Frankfort Black. G. Chamomile. See Matricaria. G. Disease. Synonym of Influenza. G. Ichthyol. See Thiol, G. Measles. See Rubeola. G. Method, the oral method of instruction for deafmutes. G. Tinder. See Amadou.

Germander (jer-man'-der, or jer'-man-der) [ME., germazender, germander]. A popular name for plants of the labiate genus Teucrium. $T$. chamadrys, of Europe, is a popular polychrest remedy. T. narum is diaphoretic, tonic, and emmenagogue. Unof.

Germarium (jer-ma'-re-um) [germen, germ]. In biology, applied to the ovary of certain invertebrates. Germicidal (jer'-nis-i-dal) [ germen, a germ ; cadere, to kill]. Destructive of germs.

Germicide (jer'-mis-ìd) [rermen, germ; cadere, to kill]. A microbicide; an agent that destroys germs. Germiculture (jer'-me-kul-chür) [germen, germ; cultura, culture]. The artificial culture of bacteria.

Germifuge (jer'-mif-uij) [germen, a germ; fugare, to banish]. I. Having the power of expelling germs. 2. An agent that expels germs.

Germinal (jer'-min-al) [germen, a germ]. Pertaining to a germ or the genesis of a tissue or organ. G. Area, the Area germinativa, or embryonal shield, a white round spot upon one side of the vitelline membrane in which the blastoderm becomes double. G. Disc. See Disc. G. Matter. See Protoplasm. G. Membrane, the blastoderm. G. Spot, the nucleolus of the ovule. G. Vesicle; $(a)$ the blastosphere or blastodermic vesicle; $(b)$ a lacuna in the substance of the germ; $(c)$ the imperfectly formed germ-cell in the embryo-sac previous to fertilization. Cf. Gastrocystis. Germination (jer-min-a'-shun) [germinatio, sprouting, budding]. In biology, the development of an embryo from the ovum. Sprouting of a seed or spore.
Germule $(j e r-m \bar{u} l)$ [germen, a germ]. An incipient germ.

Gerocomia, or Gerocomy (jer-o-ko'-me-ah, or jer-ok'

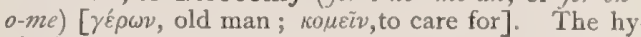
gienic and medical care of old people.

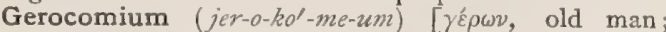

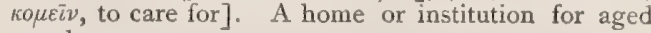
people.

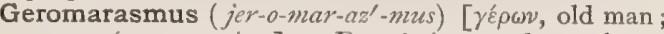
$\mu \alpha \rho a \sigma \mu \delta s$, a wasting]. Emaciation and weakness characteristic of extreme old age.

Geromeninguria (jer-o-men-in-gu'-re-ah) [ $\gamma^{\prime} \varepsilon \omega \nu$, old man; $\mu \tilde{\eta} \nu \iota \gamma \xi$, membrane; ov $\rho \circ \nu$, urine]. That senile condition in which the urine contains membranous shreds.

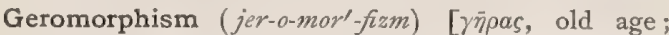
$\mu о \rho \phi \eta$, form ]. Decrepitude of the cutaneous system; appearance of age in a young person.

Geroni speciosa (jer-o'-ne spe-she-o'-sah) [L.]. An Andean plant, having a local reputation as a remedy for syphilis and rheumatism. Unof.

Gerontoxon (jer-on-toks'-on). See Arcus senilis.

Geropigia (jer-o-pij'-e-ah) [Port.]. A strongly sweetened and colored mixture of brandy and grape-juice, used in adulterating and fortifying wines.

Gerst's Method. See Treatment, Methods of.

Gestation (jes-ta'-shun) [gestatio; gestare, to bear]. Same as Pregnancy. G., Abdominal, the form of extra-uterine gestation in which the product of conception is developed in the abdominal cavity. G., Double. I. Twin pregnancy. 2. The coëxistence of uterine and extra-uterine pregnancy. G., Ectopic. Same as G., Extra-uterine. G., Extra-uterine, pregnancy in which the product of conception is not contained in the uterine cavity. G., Dorsal, the hatching of eggs on the back, as occurs in certain batrachians, e. g., the Surinam toad. G., Mammary or Pouch, the completion of growth in a pouch, as in marsupials. G., Oral, applied to the hatching of eggs in the mouth, as occurs in some fishes.

Geum $\left(j e^{\prime}-u m\right)$. See Avens.

Gheel System (gel sis'-tem) [from Gheel, a town in Belgium]. The colony-plan of housing, boarding, and treating the insane, which prevails at Gheel, in Belgium.

Giacomi's Method. A method of staining the bacillus of syphilis. See Stains, Table of.

Giacomini's Method of Preserving the Brain. Immerse the brain in a saturated solution of chlorid of zinc; turn several times daily and inject 600 grms. of the liquid through the carotids. Remove the membranes in 48 hours. Allow the brain to remain in the solution until it begins to sink, then immerse in alcohol for ro days. Immerse in glycerin until it sinks; remove, allow to dry, and varnish.

Giampetro-Löwenberg Method. A method of introducing the Eustachian catheter. The catheter is passed into the pharynx, and the beak is then turned toward the opposite tube and the catheter withdrawn until it catches on the posterior edge of the septum narium, when it is rotated in the opposite direction through an arc of at least $180^{\circ}$ into the tube which it is desired to catheterize.

Giant ( $j i^{\prime}$-ant) [ $\gamma^{\prime}(\gamma a s$, large or ponderous]. An adult of a species excessively developed in stature and proportions. G.-cell. See Cell. G. Pelvis. See Pelvis, Female, Deformities of. G.-powder. See Dualin. G.-swelling. See Angio-neurotic Edema and Urticaria tuberosa. G. Urticaria. See Urticaria cedematosa.

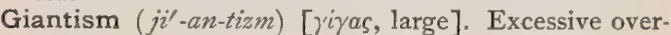
growth; the quality of being gigantic. Gigantism. 
Gianuzzi, Cells or Crescents of. Granular protoplasmic cells found in mucous glands between the mucous cells and the basement-membrane; they play an im portant part in the functional activity of the gland. They are also called demilune cells. See Cell.

Gibbes' Method. A method of staining tubercle-bacilli. See Stains, Table of.

Gibbon's Hydrocele. See Diseases, Table of.

Gibbositas (gib-os'-it-as) [L.]. Gibbosity; the condition of being a hunchback.

Gibbosity (gib-os'-it-e) [ gibber, a hunch, a hump]. In biology, a hump or irregular protuberance.

Gibbous $\left(g i b^{\prime}-a s\right)$ [gibber, hunched]. Swollen, convex, protuberant, especially upon one side.

Gibert's Pityriasis. See Diseases, Table of. G.'s Syrup. See Hydrargyrum.

Giblets (jib'-lets) [OF., gibelet, giblets]. The entrails of fowl

Gibraltar Fever. Synonym of Yellow Fever and of Mediterranean Fever.

Gibson's Bandage. See Bandage.

Gid (gid) [ME., gidie, dizzy]. Staggers in sheep, a disease caused by a cystic worm in the brain, formerly called Conurus cerebralis, q. $\%$. See under Parasites (Animal), Table of.

Giddiness (gid'-e-nes) [ME, gidie, dizzy]. A sensation of whirling or unsteadiness of the body, usually accompanied by more or less nausea. See Gid.

Giesbrecht's Method. A method of mounting serial sections. Make a solution of brown shellac in alcohol; filter and paint on warmed slides; allow to dry. Over this paint a thin layer of creasote and put the sections in place. Then heat the slide on a water-bath for fifteen minutes at the melting-point of paraffin. Allow to cool; dissolve the paraffin in turpentine; mount in balsam. The tissue must have been stained en masse before embedding.

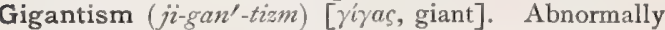
exaggerated size; excessive overgrowth ; great hypertrophy or auxesis. Giantism.

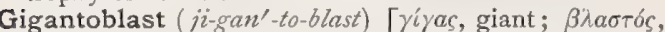
a germ]. A large germ said to exist in the blood in cases of pernicious anemia. It somewhat resembles the larger megalocyte.

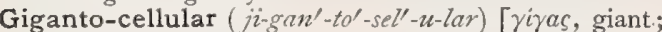
cella, cell]. Characterized by giant-cells; as Gigantocellular Endothelioma.

Gigartina (jig-ar-ti'nah) [L.]. A genus of seaweeds, several species of which are used in the same way as Carragheen, for human food. Some of the agar-agar of commerce is believed to be the product of plants of this genus.

Gigerium ( $\left.j i-j e^{\prime}-r e-u m\right)$ [ gigeria, the entrails of poultry]. In biology, the gizzard of birds, or the thickened muscular portion of the stomach in certain mammals. See Gizzard.

Gigger $\left(j^{\prime} g^{\prime}-e r\right)$. See Pulex.

Gila monster. See Heloderma.

Gill (gil) [ME., gile, gylle, a gill]. One of the respiratory organs of such animals as breathe the air that is mixed with water. The gills first appear in the Polychata. Cf. Branchice. G.-hearts, contractile expansions, with but a single cavity, at the base of the blood-vessels conducting the blood to the branchiæ in the higher crustacea.

Gillenia (jil-e'-ne-ah) [after Dr. Arnold Gill, a German botanist]. A genus of rosaceous herbs. G. stipulacea (Bowman's root, Indian physic) and G. trifoliata, both of N. America, are good, safe, and effective substitutes for ipecac. Unof.

Gillenin (jil'-en-in) [after Dr. Gill, a German botanist]. The active principle of American Ipecac. It is a bitter, slightly odorous, permanent powder with emetic properties.

Gimbernat's Ligament. See Ligament.

Gin (jin) [ME., gynypre, juniper]. Common grainspirit distilled and aromatized with juniper-berries. The finest gin, known as "Holland," is made in the distilleries of Schiedam, whence also the name "Schiedam Schnapps." See Spiritus juniperi. G.drinker's Liver. See Cirrhosis, and Hobnail Liver. G.-liver. See Cirrhosis.

Gingelly Oil (jin-jel'-e oil). See Sesami, Oleum.

Ginger (jin'-jer). See Zingiber.

Gingiva (jin-jiv'-ah) [L. "the gum:" pl., Gingiva]. The vascular tissue surrounding the necks of the teeth and covering the alveoli.

Gingival (jin'-jiv-al) [gingiva, the gum]. Pertaining to the gums. G. Line, a blue or purplish line along the gums where they meet the teeth, indicative of chronic lead-poisoning; also, the reddish line on the gums sometimes seen in tuberculosis, etc. G. Margin, the line or edge of the gums where they meet the teeth; the free edge of the gums.

Gingivalgia (jin-jiv-al'-je-ah) [gingiva, gum; à $\lambda \gamma o s$, pain]. Neuralgia of the gums.

Gingivitis ( $\ddot{2}$ in-jiv-i'-tis) [gingiva, the gums; lTLS, inflammation]. Ulitis; inflammation of the gums. G., Expulsive, osteo-periostitis of a tooth, which is gradually expelled from its socket.

Gingko (ging'-ko) [Jap.]. A genus of taxaceous trees. G. biloba, a native of Eastern Asia, is now common in the U.S. Its edible seeds are astringent and are said to restrain or to slow the secretion of urine. Unof.

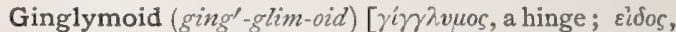
likeness]. Resembling a hinge-joint.

Ginglymus (ging'-glim-us). See Diarthrosis.

Ginseng ( jin' $^{\prime}$-seng) [Chinese, jintsan, ginseng]. The fleshy root of several species of Panax or Aratia. A. ginseng, of Eastern Asia, and $A$. quinquefolia, of the U. S., are the best-known species. Ginseng is an aromatic bitter with tonic properties. Unof.

Giraffe, Girafy (jir-af',-af'-e). See Endemic Colic and Denoue.

Giraldensian Organ or Organ of Giraldès. The parepididymis. It is composed of a number of flat, white bodies, each of which consists of a collection of tubes blind at each end. It is situated at the posterior portion of the epididymis, between the head and the vas deferens.

Girdle $\left(g i r^{\prime}-d l\right)$ [ME., girdel, a waistband]. Any band designed to go around the body. G., Emphy sematous. See Empliysema. G., Neptune's, an abdominal bandage used in applying the wet-pack. G.-pain, a sensation as if a girdle were drawn tightly around the body. When not hysteric, it is characteristic of disease of the myelon, or of the nerveroots. G., Pelvic, the bones (or cartilages) forming the support for the lower limbs of vertebrates. In mammals they consist of the ilia, ischia, and os pubes. G.-sensation. Same as G.-pain. G., Shoulder, the system of bones designed for the support of the upper limbs or arms. In man, the scapulæ and clavicles compose this structure.

Girgensohn's Method. A method of removing proteids from a liquid. Mix the solution with half its volume of a solution of common salt; add tannin in slight excess, and the proteids will be entirely precipitated.

Girmir (gir-mir) [Arab]. Tartar of the teeth.

Giroflé (jir-o-fla'). See Pigments, Conspectus of.

Gizzard (giz'-ard) [OF., gesier; L., gigerium]. The strong muscular stomach of birds; also, the corre- 
sponding organ at the pylorus of certain mammals. G.skin, the lining membrane of a gizzard. Pigeons' gizzard-skins, dried and triturated, are a popular remedy for dyspepsia. See Ingluvin.

Glabella $\left(g l a-b e l^{\prime \prime}-a / 2\right)$ [dim. of glaber, smooth]. The triangular space between the eyebrows. See Craniometric Points.

Glabellad (gla-bel'-ad) [dim. of glaber, smooth; $a d$, to]. Toward the glabellar aspect of the head.

Glabellar (gla-bell-ar) [dim. of glaber, smooth; ad, to]. Pertaining to the glabella.

Glabellen (gla-bel'-en) [dim. of glaber, smooth]. Belonging to the glabella in itself.

Glabello-inial (gla-bel'-o-in'-e-al) [dim. of glaber, smooth; iviov, the nape of the neck]. Included between the glabellum to the inion.

Glabello-obeliac (gla-bel'-o-o-be'-le-ak) [dim. of glaber, smooth ; $\delta \beta \varepsilon \lambda \sigma s$, a spit]. Included between the glabella to the obelion.

Glabello-occipital (gla-bel'-o-ok-siph-it-al) [dim. of slaber, smooth; occiput, the occiput]. Included between the glabellum to the occiput.

Glabellum (gla-bel'-um) [glaber, smooth]. Same as Glabella.

Glabrate (gla'-brät) [glabrare, to make smooth]. In biology, becoming or tending to smoothness or baldness.

Glabrous (gla'-brus) [glaber, smooth]. Smooth. In biology, destitute of hairs or down.

Glacial (gla'-she-al) [glacies, ice]. Icy; resembling ice in appearance, as glacial acetic or phosphoric acid. G. Phosphoric-acid Test. See Tests, Table of .

Glacialin (gla-she- $a^{\prime}$-lin) [ glacies, ice]. An antiseptic substance used for the preservation of foods. It consists of borax, boric acid, sugar, and glycerin.

Glaciation (gla-she- $\Omega^{\prime}-\operatorname{shun}$ ) [glacies, ice]. A condition like that of ice; erosive effect like that of moving ice.

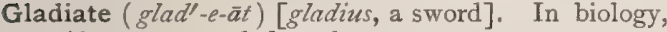
ensiform, or sword-shaped.

Gladiolin (glad-i'-o-lin) [gladius, a sword. An alkaloid from brain-tissue.

Gladiolus ( glad-e-o'-lus) [dim. of gladius, a sword]. I. The middle or second piece of the sternum. 2, A genus of iridaceous flowering-plants. G. segetum, of Europe, is said to be aphrodisiac and emmenagogue. Unof.

Glair (glār) [ME., glayre, the white of egg]. The white of egg; any thin, viscous substance, as a mucous discharge.

Glairidin (glâr'-id-in). Same as Glairin.

Glairin (glār'-in) [ME., glayre, the white of egg]. A peculiar organic, gelatinous substance found on the surface of some thermal waters. It is also called baregin, plombierin, zoögene, glairidin, sulphurain, and zoidin. See Baregin.

Glairy $\left(g l a \bar{r} r^{\prime}-e\right)$ [glayre, the white of egg]. Slimy; also, albuminous.

Glaisher's Factors. A table of figures for calculating the dew-point.

Glama ( $\left.g l a^{\prime}-m a h\right)$ [L.]. Lippitudo. An accumulation of gummy or hard material at the inner canthus of the eye ; the material so accumulated.

Gland [glans, an acorn]. A name given to numerous bodies or organs of the body, both secretive and excretive in function, withdrawing from the blood material for other purposes, or that is injurious or of no use to the economy. In structure they may be simple, saccular, or tubular. Also, the bulbous end of the penis and clitoris. G., Abdominal Salivary, a term for the pancreas. G., Absorbent. See G., Lymphatic. G., Accessory Lachrymal.
See G. of Krause. G., Accessory Lactiferous. See G. of Montgomery. G., Accessory (of Pancreas). See G. Brumner's. G., Accessory (of Parotid). See Socia parotidis. G., Accessory (of Rosenmüller). See G., Rosenmüller's. G., Accessory Supra-renal, a small gland sometimes connected with and resembling the supra-renal capsules. G., Accessory Thyroid, a small mass of gland-tissue connected with the thyroid gland. G., Acinose, one composed of acini. G., Acinous. See G., Racemose, G. Aggregate. See G., Cozoper's. G., Aggregated (of Bruch), a number of follicles in the conjunctiva, at the palpebro-sclerotic reflection. G., Agminated. See G.,Peyer's. G., Albumin, in Cestoda, the gland that secretes the albuminous coating of the ovum. G., Anal, a lymphatic and odoriferous gland situated near the anus. G., Angular. See G., Submaxillary. G., Anomalous. See G., Ductless. G., Anteprostatic. See G., Cowper's. G., Aporic. See $G$., Ductless. G.-area, the depressed area, from the alveolar epithelium of which the mammary gland is developed. G., Arterial, one of a number of small gland-like bodies connected with the arterial system. G., Arytenoid, a small muciparous gland in front of the arytenoid cartilage. G., Atrabiliary, an old name for the Supra-renal Capsule. G., Auricular, Anterior, a lymph-gland anterior to the external auditory meatus. G., Auricular, Posterior. See G., Subauricular. G., Axillary, one of the lymph-glands situated in the axilla. G. of Bartholin. I. A small gland on either side of the vagina, opening through a duct, on the inner side of the nympha. 2. See G., Sublingual. G., Bauhin's. See G., Nuhn's. G. of Benham. See G., Lophophoral. G., Blandin's. See G., Nuhn's. G., Blind. See G., Duct less. G., Blood. See G., Hematopoietic. G., Blood-vascular. See G., Hematopoietic, G. of Boerhaave. See G., Miliary. G., Bowman's, one of the tubular glands of the olfactory region. G., Brachial, one of the lymph-glands of the arm and the fore-arm. G., Branchio-tympanic. See G., Tymtpanic. G., Bronchial. I. One of the lymph-glands of the bronchi and root of the trachea. 2. See G., Thyroid. G. of Bruch. See G., Aggregated. G., Brunner's, one of the granular racemose bodies found in the wall of the duodenum. G., Buccal, one of the glands between the buccinator muscle (of the cheek) and the adjacent mucous membrane. G., Buccal, Inferior. See G., Molar. G., Bulbo-cavernous. See G., Cowper's. G., Bulbo-urethral. See G., Cowper's. G., Byssus. See G., Byssys. G., Byssys, in Lamellibranchiata, a gland near the foot, secreting the substance that forms the byssus. G., Calciferous, in the earth-worm one of several pairs of lateral glandular bodies in the esophagus whose function it is to secrete a calcareous substance. G., Camphor, one of the camphor-secreting glands of the camphortree. G., Cardiac, one of the acinous glands in the mucosa at the distal extremity of the esophagus. G., Cardiac Gastric. See G., Oxyntic. G., Cardiac Lymphatic. See G., Mediastinal, Superior. G., Carotic. See G., Intercarotid. G., Carotid. See $G$., Intercarotid. G., Cecal, one of the lymphglands around the cecum. G., Celiac, one of the lymph-glands on the abdominal aorta, above the superior mesenteric artery. G., Cement. I. One of certain glands in insects whose function it is to secrete the sebum that surrounds the ova prior to their discharge. 2. In Cirripedia, one of the glands in the antennæ secreting a sticky substance. G., Ceruminiparous. See G., Ceruminous. G., Ceruminous, one of the convolute glands secreting the cerumen of 
the ear. G., Cervical, one of the lymph-glands of the neck; these are also called cervical ganglia. G., Cervical, Deep, one of the lymph-glands contained in two groups, superior and inferior, that are deeplyseated in the neck. They empty into the right lymph atic duct, through the jugular lymphatic. G., Cervical, Inferior, Deep, the lower group of deep cervical glands in the supra-clavicular fossa. G., Cervical, Middle, one of the lymph-glands in the neck, corresponding to the lower portion of the larynx. G., Cervical, Posterior, any one of the deep lymphglands situated along the anterior border of the trapezius muscle on either side of the neck. Enlargement of these glands is one of the earliest evidences of the secondary stage of syphilis. G., Cervical, Superficial, one of the superficial lymph-glands in the upper anterior portion of the neck. G., Cervical, Superior, Deep, the upper of the deep cervical lymph-glands, near the bifurcation of the common carotid artery. G., Cervical, Upper, Deep. See $G$, Cervical, Superior, Deep. G., Choroid, in certain Teleostei, a vascular plexus around the optic nerve. G., Choroideal. See G., Choroid. G., Circumanal. See G., Anal. G., Closed. See G., Ductless. G., Coccygeal (or Luschka's). 1. A small arterial gland on the top of the coccyx, ventrally. 2. See G., Uro. pygial. G., Colic. See Crypts of Lieberkühn. G., Colleterial. See Colleterium. G., Compound, one in which the secreting surface is contained in numbers of small pouches. A gland whose duct is branched. G., Concatenate. See G., Cervical, Deep. G., Conglobate. See G., Lymphatic. G., Conglomerate. See G., Racemose. G., Congregate. See G., Peyer's. G., Coniferous, an old name for the discoid tracings in the wood-cells of gymnosperms. G., Convoluted, a tubular gland with a highly convoluted blind termination. G., Cowper's (or Méry's), in the male, one of two small acinous glands, situated between the two layers of the triangular ligament, anteriorly to the prostate gland. G., Cowperian. See $G$., Cowper's. G., Cubital, one of the lymph-glands of the elbow. G., Cubital, Deep, any one of the deep lymph-glands around the elbow-joint. G., Cubital, Superficial, any one of the lymph-glands situated over the inner condyle of the humerus in the subcutaneous connective tissue. G., Cutaneous, any one of the various glands of the skin. They include the hair, sudoriparous and sebaceous glands. G., Cyathiform, in biology, small, fleshy, cup-like glands, secreting a viscid fluid. G., Decidual, any one of the glands of the decidua. G., Dental (of Serres), one of the small, white epithelial bodies on the mucous membrane of the jaw, over the point of emergence of the teeth. G., Diapnogenous. See G., Sudoriparous. G., Digestive, in biology, one of certain glands situated on the leaves or other portions of some insectivorous plants; they secrete a fluid capable of digesting albuminoid substances. G., Dorsal. See $G$., Scapular. G., Ductless, a gland without a duct. G., Duodenal. I. See G.,Brunner's. 2. One of the lymph-glands of the duodenal mesentery. G., Duverney's. See $G$. of Bartholin. G., Ebner's, one of the acinous glands of the tongue situated in the region of the circumvallate papillæ. G., Enteric. See Crypts of Lieberkühn. G., Epiglottic, one of the muciparous glands about the posterior surface of the epiglottis. G., Esophageal, one of the acinous lymph-glands under the mucous membrane of the esophagus. G., Excretory, one of the glands that secrete the excrementitious matters of the body. G., External, in botany, one of the glands on the outer surface of a plant-organ. G., Facial, one of the lymph-glands of the face. G., Facial, Deep, one of the lymph-glands beneath the buccinator muscle. G., Facial, Superficial. See G., Auricular, Anterior. G., Femoral. See G., Inguinal. G.-fever, an infectious constitutional disorder characterized by rapid and painful enlargement of the cervical lymphatic glands, with considerable elevation of temperature. G., Floral. See G., Nectariferous. G., Follicular, one consisting of or beginning in follicles. G., Follicular (of the tongue), one of the lymph-glands in the mucous membrane at the base of the tongue. G., Fundus. See G., Oxyntic. G. of Galeati. See Crypts of Lieberkiihn. G., Gastric, any one of the glands of the stomach, tubular or peptic. Those lining the fundus of the stomach are the true pepsinsecreting glands. G., Gastro-epiploic, Inferior, one of the lymph-glands surrounding the greater curvature of the stomach. G., Gastro-epiploic, Superior, one of the lymph-glands in the gastrophrenic ligament. G., Genal. See G., Buccal. G., Genital. See G., Sexual. G., Globate. See G., Lymphatic. G., Globular (of Mirbel), in biology, one of the spheric glands forming a pulverulent surface upon the calyx, corolla and anthers of many labiate plants. G., Glomerate. See G., Racemose. G., Green, in Crustacea, a gland on the side of the anterior portion of the body. Its duct opens on a cervical eminence, just below the antenna. G., Guerin's. See G., Skene's. G. of Guettard. See G., Miliary. G., Guttural. See G., Pharyngeal. G., Hair, the sebaceous gland of a hair-follicle. G., Harder's. See G., Harderian. G., Harderian, a small gland in the nictitating membrane of many of the lower animals. G. of Havers (also called synovial fringe), one of the fatty bodies lying behind the highly vascular fringe-processes that project from a synovial membrane into the cavity of a joint; these were formerly believed to be the glands that secreted the synovia. G., Haversian. See G. of Havers. G., Hematopoietic, any one of the glands that are supposed to take part in the formation of the blood, as the spleen, thymus, supra-renal capsules, etc. G. of Henle. See G., Aggregated (of Bruch). G., Hepatic, one of the lymph-glands in the ligaments around the liver. G., Hermaphrodite, in hermaphroditic animals, a gland answering both as ovary and testicle. G., Hibernating, in hibernating animals, one of the masses of fatty tissue, supposed to aid in sustaining life during hibernation. G., Honey-comb. See G., Peyer's. G., Hydrophorous. See G., Sudoriparous. G., Hypogastric. See G., Iliac, Internal. G., Iliac, Anterior, one of the lymph-glands anterior to the iliac arteries, and situated between the fifth lumbar vertebra and the femoral ring. They receive the lymphatic and efferent vessels of the inguinal glands. G., Iliac, External. See G., Iliac, Anterior. G., Iliac, Internal, one of the lymph-glands in the course of the hypogastric artery and vein. G., Iliac, Superior, one of the lymph-glands near the crest of the ilium. G., Infraclavicular, one of the small lymph-glands situated below the clavicle, between the deltoid and pectoral muscles. G., Inguinal, Deep, one of the lymph-glands in the crural ring, around the femoral artery and vein. G., Inguinal, Superficial, one of the lymph-glands in the superficial fascia just above Poupart's ligment. G., Infundibular, the infundibulum of the brain. G., Intercarotid, a minute body of glandular structure, of unknown function, situated at the bifurcation of the common carotid artery. G., Intercellular, one of the multicellular vegetable glands, supplying the walls between the cells. G., Intercostal, one of the lymph-glands 
in the posterior portion of the intercostal spaces. G., Internal, in botany, a gland below the surface of a plant-organ. G., Interocular, in comparative anatomy, the ectocranial portion of the epiphysis cerebri. It is regarded as the rudiment. of the third eye. G., Interungulate, in sheep, a muciparous gland between the hoofs. G., Intestinal, Solitary, one of a number of peculiar white isolated lymph-glands distributed through the intestinal mucous membrane. G., Jugular, Inferior. See $G$., Cervical, Deep. G., Jugular, Superficial. See G., Cervical, Superficial. G., Jugular, Superior. See G., Cervical, Superior, Deep. G. of Kölliker. See G., Boruman's. G. of Krause, one of a number of acinous glands in the orbital portion of the conjunctiva. G., Labial, one of several racemose glands near the edges of the lips. G., Lachrymal, a compound racemose gland in the upper and outer portions of the orbit, whose function it is to secrete the tears. G., Lachrymal, Inferior, the lower portion of the lachrymal gland. G., Lachrymal, Superior, the upper portion of the lachrymal gland. G., Lactiferous. See G., Mammary. G., Laryngeal, Anterior, Posterior, one of the acinous lymph-glands in the laryngeal mucous membrane. G., Lateral, in Cestodes, one of the glands situated on either side of the uterus. G., Lenticular. I. In botany, one of the oily or fatty glands found in plants. 2. One of the conglobate glands in the mucous membrane of the stomach. G. of Lieberkiihn. See Lieberkühn, Crypts of: G., Lingual, Anterior. See $G ., N u / n$ 's. G., Lingual, Lateral, one of the acinous glands at the edge of the tongue. G., Lingual, Lymphatic, one of two or three glands on the outer surface of the hyoglossus muscle. G., Lingual, Posterior, one of the acinous lymphglands on the dorsum linguæ near the foramen cecum. G. of Littré (or of Morgagni), one of the small racemose muciparous glands in the mucous membrane of the cavernous portion of the urethra. G., Lobulated. See G., Racemose. G., Lophophoral (of Benham), in biology, a border of glandular tissue, surrounding the lophophore. G., Lumbar, one of a number of lymph-glands, situated in the lumbar region, behind the peritoneum. G., Luschka's. See G., Coccygeal. G., Lymph. See G., Lymphatic. G., Lymphatic, a small oval mass of Iymphoid tissue in the course of a lymphatic vessel. There are supposed to be between 500 and 600 in man. The chyle and lymph pass through them to the blood. G., Lymphatic, Solitary. I. A simple isolated lymph-gland. 2. See G., Intestinal, Solitary. G., Mammary, one of the glands, in mammals, that secrete milk. G., Mastoid. See G., Subauricular. G., Maxillary, Internal. See G., Facial, Deep. G., Mediastinal, one of the lymph-glands in the mediastinum. G. Mediastinal, Anterior, one of several small lymphglands in the lower portion of the anterior mediastinum. G., Mediastinal, Posterior, one of the lymphglands in the posterior mediastinum surrounding the esophagus and thoracic aorta. G., Mediastinal, Superior, one of the lymph-glands in the upper portion of the mediastinum, G., Meibomian, one of the minute sebaceous follicles between the cartilage and conjunctiva of the eyelids. G. of Meibomius. See G., Meibomian. G., Méry's. See G., Corvper's. G., Mesenteric, one of the lymph-glands of the mesentery. G., Meseraic. See G., Mesenteric. G., Mesocolic, one of the lymph-glands in the mesentery of the colon. G., Miliary. I. (of Boerhaave) any one of the sudoriparous glands. 2. (of Mirbel) in biology, one of the minute granules on the green parts of plants. 3. (of Guettard) a stoma.
G. of Mirbel. See G., Miliary, and G., Globular. G., Molar, one of the large buccal glands situated near the molar teeth, between the masseter and buccinator muscles of the cheek. G., Moll's, one of the modified sweat-glands on the free margin of the eyelids opening into the hair-follicles of the eyelashes. G., Montgomery's, one of the microscopic sebaceous glands of the areola of the breast. G. of Morgagni. See G. of Littre. G., Moriform. See G., Racemose. G., Morrenian, in biology, one of certain glands of worms, as the earth-worm, whose function is that of assimilation. G., Mucilaginous, a name given to one of the fringed processes of synovial membranes. See G., Haversian. G., Muciparous. See G., Mucous. G., Mucous, one of the glands in mucous membranes, secreting mucus. G., Mucous, Salivary, a salivary gland mainly secreting mucus. G., Mushroom-shaped, a peculiar accessory male genital organ in certain insects, probably the analogue of the seminal vesicle. G., Musk, the glandular structure in certain animals secreting musk. G. of Naboth (also called follicle of $\mathrm{Naboth}$ ), a pathologic vesicle in the mucous membrane of the uterine cervical canal. G., Nabothian. See G. of Naboth. G., Nasal. I. See G., Supra-orbital. 2, (of Rathke). See Jacobson's Organ. G., Nasal, External, in birds, a gland in the frontal or nasal bone emptying into the nasal cavities. G., Nectar. See G., Nectariferous. G., Nectariferous, in biology, a gland secreting honey or nectar. G., Nerve, the supra-renal capsule. G., Nervous (of the pelvis). See G., Coccygeal. G., Nidamental, in biology, a gland secreting a peculiar viscid material that invests the ova. G., Nuck's. See $G$., Nuhn's. G., Nuhn's, one of the acinous glands near the apex of the tongue. They are also called Nuck's, Bauhin's, and Blondin's glands. G., Occipital, one of the lymph-glands situated over the occipital insertion of the trapezius. G., Odoriferous, one of the glands secreting odoriferous substances, as behind the cervix of the penis, secreting the smegma. G., Oil. See G., Sebaceous. G., Oviducal, in Elasmobranchia, a gland connected with the oviduct. G., Oxyntic, one of the glands of the cardiac region of the stomach, supposed to secrete the acid of the gastric juice. G. of Pacchioni. See Pacchionian Bodies. G., Pacchionian. See Pacchionian Bodies. G., Palatal. See G., Palatine. G., Palatine, a small acinous gland that with others forms a continuous layer beneath the mucous membrane of the hard and soft palate. G., Palpebral. See G., Meibomian. G., Pancreatico-splenic, one of the lymph-glands following the course of the splenic artery and vein. G., Papillary, in biology, a papilla-like gland on the under surface of a leaf of labiate plants. G., Parotic. See G., Parotid. G., Parotid, a large salivary gland situated in front of the ear. G., Parotid, Lymphatic. See G., Auricular, Anterior. G. of Pecklin. See G., Peyer's. G., Pectoral, one of the lymph-glands on the lower portion of the pectoralis major muscle. G., Pepsin. See G., Oxyntic. G., Peptic. See G., Oxyntic. G., Perspiratory. See G., Sudoriparous. G., Petiolar, in botany, a gum-secreting gland occurring on the petiole. G., Peyer's, one of a number of lymphfollicles of the bowel occurring mainly in the ileum. They are especially involved in typhoid fever. G., Peyerian. See G.,Peyer's. G., Pharyngeal, one of the racemose glands in the pharyngeal mucous membrane, G., Phrenic, one of the lymph-glands in the lower portion of the anterior mediastinum. G., Pilous. See G., Hair. G., Pineal. See Pineal Gland. G., Pituitary, a term for the hypophysis of 
the brain. See Pituitary Body. G., Plexiform See G., Peyer's. G., Poison, a gland in venomous insects and snakes that secretes the poisonous substance. G., Popliteal, one of the lymph-glands sur rounding the popliteal vessels. G., Precrural, in comparative anatomy, one of the lymph-glands following the course of the nervus circumflex ilii. G., Prehyoid, an accessory thyroid gland above the hyoid bone. G., Prelaryngeal, a lymph-gland on the crico-thyroid membrane, between the crico-thyroid muscles. G., Prepectoral, in comparative anatomy one of the lymph-glands surrounding the lower portion of the jugular vein. G., Preputial. See G., Tyson's. G., Prescapular, in comparative anatomy, one of the lymphglands situated beneath the elevator humeri muscle. G., Prostate. See Prostate Gland. G., Prostatic. See Prostate Gland. G., Pulmonary, one of the lymphglands in the pulmonary substance. G., Purple, in Gasteropoda, one of the glands secreting the so-called Tyrian purple. G., Pyloric, one of the glands of the stomach mainly situated near the pylorus and secreting the gastric juice. G., Racemose, a compound follicular gland resembling a bunch of grapes. It is composed of a number of acini with a single excretory duct. G. of Rathke. See G., Nasal. G., Renal, the suprarenal capsule. G., Reticulate, a lymphgland containing reticular tissue. G., Retroperitoneal, one of the lymph-glands behind the peritoneum. G., Rivini's. See G., Sublingual. G., Rosenmüller's. I. The inferior lachrymal gland (accessory of Rosenmiiller). It is the fore part of the lachrymal gland, which is separated from the rest of the gland by a fibrous septum. It is also called the palpebral portion of the lachrymal gland. 2. The lymph-gland situated in the crural ring. G., Saccular, a gland formed by a sacculation of a mucous or serous membrane. G., Sacral, one of the lymph-glands on the anterior face of the sacrum. G., Salival. See $G$., Salivary. G., Salivary, a gland whose function it is to secrete saliva. G., Salivary, External. See G., Parotid. G., Scapular, one of the lymph-glands near the axillary border of the scapula. G., Scent. See G., Odoriferous. G., Sebaceous. I. One of the minute saccular glands in the corium of the skin, secreting sebum. 2. See G., Cement. G., Sebiferous. See G., Sebaceous. G., Sebiparous. See G., Sebaceous. G., Secreting. See G., Secretory. G., Secretory, any gland of the body yielding a secretion. It is an arrangement of cells by which certain elements are separated from the blood that circulates in the capillary vessels which are in contact with the cells. G., Seminal, the testicle. G., Septal, in biology, one of the secreting glands in the septa between the loculi of the ovaries of liliaceous plants. G., Serous. See G., Albuminous. G., Serous, Salivary, one of those salivary glands the secretion of which contains a characteristic albuminous substance, with little or no mucin. G. of Serres. See G., Dental. G., Sexual, the ovary or testis. G., Simple, a gland composed of but one secreting sac, with a single and unbranched tube. G., Skene's, one of the two mucous glands just within the meatus urinarius of the female; they are frequently the seat of latent gonorrhea. G., Solitary, one of the glands scattered through the mucous membrane of the small intestine. G., Spinning, one of the tubular glands near the anal or oral orifice of certain spiders and other insects; it secretes a viscid material that hardens on exposure to the air. G., Stalked, in botany, a gland situated upon a stalk. G., Staphyline. See G., Palatine. G.. Sternal, one of the lymph-glands on the upper costal cartilages, near the sternum. G., Subauricular, one of the lymph-glands situated below and behind the ear. G., Sub-caudal, a gland located near the base of the tail, the secretion from which yields the peculiar penetrating odor of the fox and other animals. G., Subconjunctival. See G., Meibomian. G., Sublingual, the smallest of the salivary glands. There is one on either side beneath the tongue. G., Submaxillary, a large salivary gland situated in the submaxillary triangle. G., Submaxillary Lymphatic, one of the lymph-glands in the submaxillary triangle. G., Suboccipital. See G., Occipital. G., Substernal. See G., Sternal. G., Suburethral. Same as $G$. of Cowper. G., Sudoriferous. See G., Sudoriparous. G., Sudoriparous, one of the peculiarly convoluted glands in the subcutaneous connective tissue that secrete the sweat. G., Supraclavicular. See G., Cervical, Inferior, Deep. G., Supra-hyoid, one of the small lymph-glands between the anterior bellies of the digastric muscles. G., Supra-orbital, in biology, a gland in the orbit of birds communicating with the nasal passages. G., Suprarenal, the suprarenal capsules. G., Sweat. See G., Sudoriparous. G., Tarsal. See G., Meibomian. G., Tarso-conjunctival. See G., Meibomian. G., Tartar, one of the hypothetic glands thought to secrete the tartar of the teeth. G., Temporary, the name occasionally given to the Graatian follicle. G., Thoracic, Deep, one of the lymph-glands situated on the outer surface of the serratus magnus muscle. G., Thoracic, Superficial. See G., Pectoral. G., Thymus, a temporary organ lying mainly in the neck, attaining its full growth at two years and practically disappearing at puberty. G., Thyroid, a ductless lobulated gland situated in the lower middle ventral portion of the neck, in front of the trachea and below the thyroid cartilage. G., Tibial, Anterior, a lymph-gland on the anterior surface of the interosseous ligament of the leg. G., Tracheal, one of the minute ovoid acinous glands in the tracheal mucous membrane, especially on its posterior surface. G., Trachoma (of Henle). See G., Aggregated (of Bruch). G., Tubular, a gland composed mainly of a tube-like structure. G. Tubular, Compound, one composed of a number of small tubules with a single duct. G., Tympanic, a swelling upon the tympanic nerve, situated near or within the tympanic canal, and believed to be of the same nature as the coccygeal gland. G., Tyson's, one of the sebaceous glands on the corona of the glans penis and on the prepuce. See G., Odoriferous. G., Urethral. See $G$. of Littré and G., Skene's. G., Uropygial, the oil-secreting gland situated over the coccyx of birds. G., Uterine, one of numerous tubular follicles in the uterine mucous membrane, secreting the so-called uterine milk. G., Utricular. I. In biology, one of the spaces in the epidermis filled with a colorless fluid. 2. See $G$. Uterine. G., Vaginal, one of the acinous glands in the vaginal mucous membrane. G., Venenific. See G., Poison. G., Veneniparous. See G., Poison. G., Vesalius's, one of the pulmonary and bronchial mucous glands. G., Vesicular. See $G$., Utricular (Ist def.). G., Vulvo-vaginal. See $G$. of Bartholin. G., Wax, in insects, one of the glands of the surface secreting a wax-like material. G., Weber's, one of the tubular mucous glands of the tongue situated chiefly near the root. G., Yolk, the vitellarium, q.v. G., Zeiss's, one of the sebaceous glands of the eyelashes. G., Zygomatic. See G., Auricular, Anterior.

Glanderous (g-lan'-der-us), or Glandery (glan'-der-e) [glandula, a gland]. Affected with glanders,

Glanders (glan'-derz). A contagious disease of horses, 
sometimes communicated to man. For staining the microörganism of glanders see Schutz's Method, Kühne's Method, or Laffler's Method, under Stains, Tuble of. See Equinia.

Glandilemma (glan-dil-em'-ah) [glans, gland; $\lambda \varepsilon ́ \mu \mu \sigma$, husk]. The capsular covering of a gland.

Glandula (gland"-u-lah) [L.: pl., Glanduke]. A little gland.

Glandular (gland'-u-lar) [glandula, a gland]. Relating to, or of the nature of, a gland. G. Hypertrophy, a term used to indicate an enlargement of a lymph-gland, without any appreciable cause. G. Pestilence, synonym of the Plague, $q . v$. G. Plague, synonym of the Plague, $q . v$.

Glandule (gland'-ïl) [ glandula, a gland]. A small gland. Glandulin (gland'-u-lin) [glanuula, a gland]. Extract of gland-tissue.

Glans (glanz) [glans, a corn]. 1. The head of the penis or of the clitoris. 2. A gland; an enlarged gland. 3. A suppository or pessary. 4. In botany, a nut. The name applied to fruits like the filbert, acorn, chestnut, etc. G. clitoridis, the small round tubercle of the clitoris analogous to the glans penis of the male. G. penis, the conical-shaped body forming the head of the penis.

Glareose (glārl-e-ōz) [glarea, gravel]. In botany, growing in gravel.

Glaser's Fissure. See Fissure.

Glaserian Artery. See Arteries, Table of. G. Fissure. See Fissure.

Glaserius, Fissure of. See Fissure.

Glasgow Committee. See Anesthetic

Glass (glas) [ME., glas, glass]. A brittle, hard, and transparent substance consisting usually of the fused, amorphous silicates of potassium and calcium, or sodium and calcium, with an excess of silica. When glass of a high refractive index is required, lead silicate is also added. G.-blowers' Cramp. See Cramp. G.-blowers' Disease, a term formerly used to designate any infectious disease of the lips, especially syphilitic eruptions. Also, applied to pulmonary emphysema. G.-blowers' Patch, a condition of the dorsum of the tongue very similar to smokers' patch, and due to an analogous cause. G., Crown, a very hard glass, made from sodium sulphate or lime, without lead. It has a low refractive index, but considerable chromatic dispersion. It is used for making lenses for optic instruments. G., Flint, that composed of lead and potassium silicates. It has a very high refractive index. G. Slides. See Slides. G., Soluble, potassium or sodium silicate.

Glasses (glas'-es) [ME., glas, glass]. A synonym of spectacles or eye-glasses. G., Bifocal, those that have a different refracting power in the upper part from that in the lower. G., Hyperbolic, those ground in the form of an hyperbola. G., Periscopic, those in which the curvature of one surface exceeds that of the other. See Meniscus. G., Prismatic, those formed of prisms; used in insufficiency and paralysis of the ocular muscles. G., Protective, for shielding the eyes against light; they are made of London smoke or blue glass. G., Spheric, those ground in the form of a sphere. G. Stenopaic, those consisting of a blackened disc of metal in which is placed a small round hole or a narrow slit; they are used for examining astigmatic eyes.

Glassy Degeneration. See Degeneration. Swelling, a synonym of amyloid infiltration.

Glauber's Salt. See Sodium.

Glaucedo (glaw-se'-do) [L. ]. Glaucoma

Glaucescence (glarw-ses'-ens) [glaucescens]. A bluishgray or sea-green luster or bloom; the quality of being somewhat glaucous.
Glaucescent (glaw-ses'-ent) [ $\gamma \lambda \alpha v \kappa o ́ s$, silvery]. In biology, slightly glaucous, or bluish-gray.

Glaucin (glaw'-sin) [ $\gamma \lambda a v \kappa o ́ s$, sea-green]. Cow-pox; so-called from the color of the pocks.

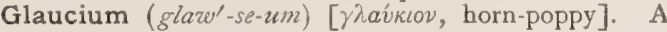
genus of papaveraceous herbs ; horn-poppy. G.luteum and $\mathrm{G}$. corniculatum are acrid herbs, with diuretic and alterative properties. Unof.

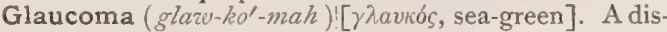
ease of the eye the essential and characteristic symptom of which is an abnormally heightened intraocular tension, resulting in hardness of the globe, excavation of the papilla or optic disc, a restriction of the field of vision, corneal anesthesia, colored halo about lights, and lessening of visual power that may, if unchecked, proceed to blindness. The etiology is obscure. G. absolutum, or consummatum, the completed glaucomatous process, with blindness. G. acutum, the first or the renewed attack, with the characteristic and inflammatory symptoms, generally intermitting after a few days. G, Auricular, a disease of the middle ear characterized by a great increase in the intra-labyrinthine pressure. G. evolutum, the second stage of glaucoma. G. fulminans, an acute attack coming on with great suddenness and violence. G. hæmorrhagicum, or apoplecticum, that associated with retinal hemorrhage. G. malignum, a grave form, attended with violent pain and rapidly leading to blindness. G. Secondary, that consequent upon other ocular diseases. G. simplex, that form without inflammatory symptoms.

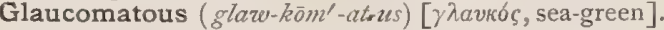
Affected with or pertaining to glaucoma.

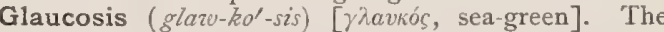
blindness resulting from glaucoma.

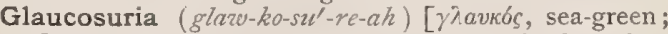
ovpov, urine]. The presence of indican in the urine, which is thereby discolored.

Glaucous (glaw'-kus) [үخavkós, sea-green]. Of a blue-gray or dull sea-green tint; having a blue, or pale-green luster covered with a silvery bloom, as the leaves of the cabbage.

Glaukuria (glaw-ku'-re-ah). See Glaucosuria.

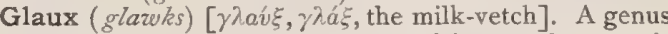
of primulaceous herbs. G. maritima, salt-wort, is said to be an effective galactagogue. Unof.

Glea $\left(g l e^{\prime}-\alpha h\right)\left[\gamma \lambda o^{\prime} \alpha\right.$, glue $]$. A mucilaginous substance secreted by many inferior organisms, and which frequently serves as a matrix in which they lie embedded.

Glean (glèn) [origin obscure]. The afterbirth of a domestic animal.

Gleet (glet) [ME., glet, gleet]. The chronic stage of urethritis, with muco-purulent discharge.

Gleety (gle'-te) [ME., glet, gleet]. Thin and ichorous; resembling the discharge of gleet.

Glénard's Disease. See Diseases, Table of.

Glene $\left(g l e^{\prime}-n e\right)[\gamma \lambda \eta \nu \eta, p i t]$. I. The glenoid cavity. 2. The interior of the eye. Obsolescent.

Gleno-humeral ( $\left.g l l^{\prime}-n o-h u^{\prime}-m e r-a l\right)[\gamma \lambda \eta \dot{v} \eta$, pit; humerus, the humerus]. Pertaining to the glenoid cavity and to the humerus.

Glenoid (gle'-noid) $\left[\gamma \lambda \eta^{\prime} \nu \eta\right.$, a cavity ; $\varepsilon^{\prime} i \delta$ s, form $]$. Having a shallow cavity; pertaining to a shallow cavity. G. Cavity, the articular depression in the head of the scapula. G. Fossa. See Fossa.

Glenoin $\left(g l e-n o^{\prime}-i n\right)$. Same as Trinitrin.

Glenovertebral (gle'-no-ver'-te-bral) $[\gamma \lambda \hat{\eta} \nu \eta$, a cavity ; vertebra, a vertebra]. Pertaining to the glenoid and vertebral borders of the scapula.

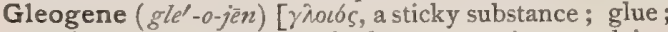

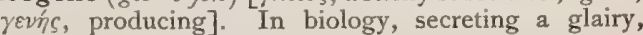
mucilaginous substance. 


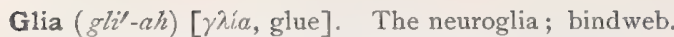
It contains peculiar cells called glia-cells. G.-cells. See Deiters' Cells.

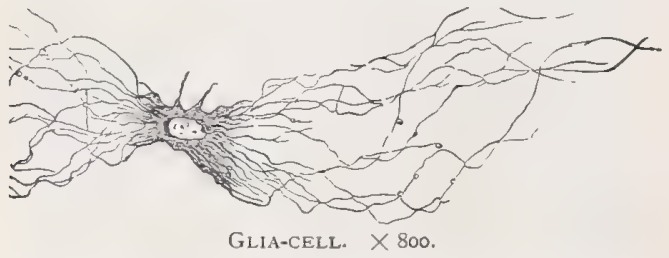

Gliadin $\left(g l i^{\prime}-a d-i n\right)[\gamma \lambda i a$, glue $]$. A proteid obtainable from wheat-gluten; it is tenacious and gelatinous when moist, brittle and glassy when dry. Also a synonym of Hematin. See Gluten.

Gliding Movement ( $g l i^{\prime}$-ding moov'-ment). The most simple kind of movement that can take place in a joint, one surface gliding or moving over another, without any angular or rotary movement.

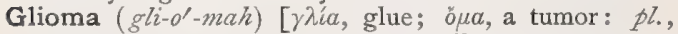
Gliomata]. A variety of round-celled sarcoma, consisting of a tumor of neuroglia-cells, occurring in the central mass of the brain or of the spinal cord. G. of the Retina ("encephaloid of the retina"), a glioma springing from the connective tissue of the retina, usually occurring in the young, and involving the choroid, optic nerve, and extending finally into the brain. G., Pseudo-, of the Retina, metastatic purulent choroiditis, simulating the appearance of retinal glioma.

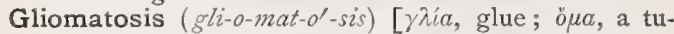
mor: pl., Gliomatoses]. The aggregation of exuberant masses of glioma-like tissue in the spinal cord-a condition thought to precede the development of syringomyelia.

Gliomatous ( $\left.g l i-o^{\prime}-m a t-\imath e s\right)$ [ $\gamma \lambda i a$, glue; $\ddot{\partial} \mu a$, a tumor]. Of the nature of, or affected with, glioma.

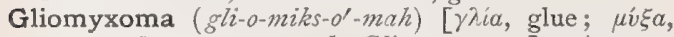
mucus; ö $\mu a$, a tumor: pl., Gliomyxomata]. A tumor having the characters of both glioma and myxoma.

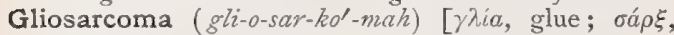
flesh; $\dot{o} \mu a$, a tumor: $p l$., Gliosarcomata]. A tumor with both the neuroglia-cells of glioma and the fusiform cells of sarcoma.

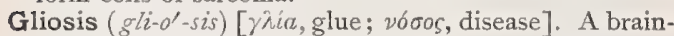
disease marked by foci of sclerosed gray substance, with the formation of lacunar spaces within the foci. It differs from ordinary diffused sclerosis in its histology and symptomatology.

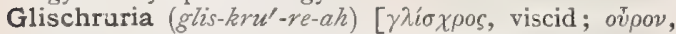
urine]. Mucous degeneration of the urine, supposed to be due to the presence of a microörganism, the Bacterium glischrogenum.

Glisson's Capsule. See Capsule.

Glissonian Cirrhosis. Synonym of Perihepatitis. See also Diseases, Table of.

Glister (glis'-ter). A clyster or enema.

Globe of the Eye. The eyeball.

Globiferous (glo-bif'-er-us) [globus, a ball; ferre, to bear]. In biology, applied to antennæ or similar structures bearing a large globose joint.

Globin $\left(g l 0^{\prime}-b i n\right)[$ globus, a globe $]$. A proteid derivable from hemoglobin. There is also a class of similar proteids grouped together as globins.

Globinometer (glo-bin-om'-et-er) [globus, a globe ; $\mu \varepsilon ́$ $\rho \circ \nu$, a measure]. An instrument devised with special reference to the calculation of the percentage-amount of oxyhemoglobin in a given amount of blood.

Globo-cellular $\left(g l 0^{\prime}-b o-s e l^{\prime \prime}-u\right.$-lar) [globus, a globe; cella, a cell]. Round-celled, as globo-cellular sarcoma.

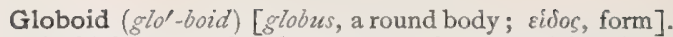
In biology, a globular or amorphous particle of the double phosphate of calcium and magnesium, often found associated with crystalloids in protein-granules.

Globose $(g l o-b \overline{o s})$ [globosus, round as a ball]. Spheric in form, or nearly so.

Globular (glob'-u-lar) [dim. of globus, a globe]. Having the shape of a globe or sphere.

Globularia (glob-u-la'-re-ah) [globulus, a little ball]. A genus of selaginaceous herbs and shrubs. G. alypum, of the old world, affords leaves that are a good substitute for senna. G. puticosa and G. vulgaris have similar properties.

Globule $\left(g l o b^{\prime}-\bar{u} l\right)$ [dim. of globus, a ball]. A small globe; a blood-corpuscle or lymph-corpuscle. In biology, any minute spheric structure. In pharmacy, a small pill or pellet. See also Oil-globule. G. of Donné. See Blood-plates and Hemutoblast. G. in Pulp, a globular mass of dentine within the substance of the dental pulp.

Globulicidal (glob-u-lis-i'-dal) [globutus, a little ball; cadere, to kili]. Destructive to the blood-corpuscles.

Globulicide (glob-u'-lis-ia ) [globulus, a globule; cadere, to kill]. I. Destructive of blood-cells. 2. An agent that destroys blood-cells.

Globulimeter (glob-u-lim'-et-er) [globulus, a little ball; $\mu \varepsilon ́ \tau \rho o \nu$, a measure ]. An instrument for estimating the corpuscular richness of blood.

Globulin (glob'-u-lin) [globulus, a little ball]. I. A general name for various proteids comprising globulin, vitellin, paraglobulin, or serum-globulin, fibrinogen, myosin, and globin, which differ from the albumins in not being soluble in water; one species, existing in the crystalline lens, is specially designated as globulin. They are insoluble in distilled water, but soluble in dilute neutral saline solutions. These solutions are coagulated by heat, and precipitated by a large amount of water. They yield acid-albumin when acted upon by dilute acids, and alkali-albumin when acted upon by dilute alkalies. Vegetable Globulins have been studied, and named vegetable myosin, vitellin, and paraglobulin; they are found in the seeds of plants. 2. A blood-platelet.

Globulinuria (glob-u-lin-u'-re-ah) [globulus, a little ball; ov pov, urine]. The presence of globulin in the urine.

Globulism (glob'-u-lizm) [gtobulus, a little ball]. The administration of medicine in globules; homeopathy.

Globulose ( $\left.g^{\prime} l o b^{\prime}-u-l o ̄ s\right)$ [globulus, a little ball]. Any product of the gastric digestion of a globulin.

Globulus ( $g l o b^{\prime}-u$-lus) [L.]. The Nucleus globuliformis of the cerebellum. It is a mass of gray matter between the fastigatum and the embolus.

Globus ( $\left.g l \sigma^{\prime}-b u s\right)$ [L.]. A ball or globe. G. epididymis. See Epididymis. G. hystericus, the "lump" or choking sensation occurring in hysteria, caused probably by spasmodic contraction of the esophageal and pharyngeal muscles. G. major, the larger end or head of the epididymis. G. minor, the lower end of the epididymis. G. pallidus, the inner and lighter part of the lenticular nucleus.

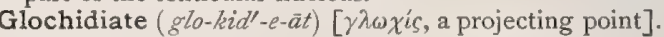
In biology, barbed. Tipped with barbs, or with a doubly-hooked point.

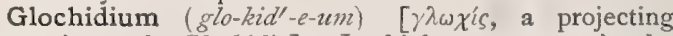
point: pl., Glochidia]. In biology, a stage in the development of lamellibranchiate molluscs [Unio, Anodon], the ova of which develop up to a certain stage in the gill-pouches of the parent, and remain there as glochidia until some fish or wading-bird comes into their vicinity, when the glochidia issue forth, and, swimming as Pectens by the flapping of their valves, 
attach themselves, like external parasites, to the animal whose presence has stimulated their efforts; here they become encysted and transformed into young Unios or Anadons.

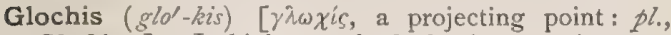
Glochines ]. In biology, a barbed spine or point.

Glome (glom) [glomus, a ball]. Same as Glomerule.

Glomerate $\left(g l o m^{\prime}-e r-a i\right)$ [glomerare, to wind around]. A descriptive term applied to any gland consisting of vessels bunched together like a ball of thread; conglomerate.

Glomerule (glom'-er-ül) [dim. of glomus, a ball of yarn]. In biology, a capitate cyme; a cluster of spores.

Glomerulitis (glom-er-u-li'-tis) [glomemulus, a small ball ; $1 \tau \iota s$, inflammation]. Inflammation of the glomeruli of the kidney.

Glomerulo-nephritis (glom-er'-u-lo-nef-ri'tis) [glom-

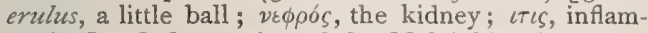
mation]. Inflammation of the Malpighian bodies of the kidney.

Glomerulus, or Glomerule (glom-er'-u-lus, or glom' er-ât) [dim. of glomus, a ball]. A knot or small rounded mass. $\AA$ coil of arterial blood-vessels projecting into the capsular widening of the lumen of each uriniferous tubule and with it composing the Malpighian body peculiar to the vertebrate kidney. G. Malpighii. See Malpighian Bodies. G., Olfactory, a group of nerve-cells, a number of which are embedded in the olfactory nerve-fibers.

Glonoin (glo-no'-in). See Nitroglycerin.

Gloriosa (glo-re-o'-sah) [gloriosus, glorious]. A genus of splendid liliaceous plants with poisonous juices. $G$. superba, of India, is alterative and tonic, and its starch is said to cure hemorrhoids. Unof.

Glossa (glos'-a'́) $[\gamma \lambda \tilde{\omega} \sigma \sigma a$, the tongue]. The tongue ; also the faculty of articulate speech.

Glossagra ( $\left.g-l o s-\alpha^{\prime}-g r a h\right)[\gamma \lambda \tilde{\omega} \sigma \sigma \alpha$, tongue ; $a \gamma \rho \alpha$, seizure]. Gouty pain in the tongue.

Glossal $\left(g l o s^{\prime}-a l\right)$ [ $[\gamma \lambda \tilde{\omega} \sigma \sigma a$, tongue]. Pertaining to the tongue.

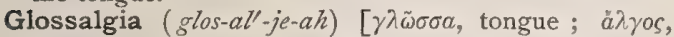
pain]. Any pain in the tongue, especially neuralgia of the tongue.

Glossanthrax (glos-an'-thraks). Synonym of $A n$ thrax.

Glossarium (glos- $\left.a^{\prime}-r e-u m\right)[\gamma \lambda \tilde{\omega} \sigma \sigma \alpha$, a tongue : $p l$, Glossaria]. In biology, the slender, elongated labrum of a dipterous insect, as the mosquito.

Glossate $\left(g l o s^{\prime}-\bar{a} t\right)[\gamma \lambda \tilde{\omega} \sigma \sigma \alpha$, tongue]. In biology, having a tongue or glossa ; applied to suctorial as distinguished from mandibulate insects.

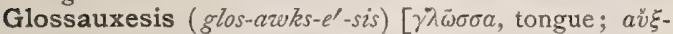
$\eta \sigma \iota \zeta$, increase]. Enlargement of the tongue.

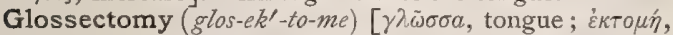
excision]. Amputation or excision of the tongue.

Glossitic $\left(g l o s^{\left.-i t^{\prime}-i k\right)}[\gamma \lambda \tilde{\omega} \sigma \sigma \alpha\right.$, tongue; $\iota \tau \iota s$, inflammation]. Pertaining to or affected with glossitis.

Glossitis (glos-i't-tis) [ $\gamma \lambda \tilde{\omega} \sigma \sigma \alpha$, tongue; $i \tau \iota s$, inflammation]. Inflammation of the tongue. G., Dissecting, a form of chronic superficial glossitis characterized by deep furrows upon the tongue that appear to penetrate into the mucous membrane. G., Idiopathic. Same as G., Parenchymatous. G., Interstitial. Same as G., Parenchymatous. G., Parasitic, an inflammation of the tongue said to be due to parasitic vegetations. It is also called Glossophytia. G., Parenchymatous, an inflammation of the tongue involving its substance as well as the mucous membrane.

Glosso- ( $\left.g l o s^{\prime}-o-\right)[\gamma \lambda \tilde{\omega} \sigma \sigma a$, tongue $]$. A prefix denoting connection with the tongue.

Glossocele $\left(g \operatorname{los}^{\prime}-\alpha-s \bar{e} l\right)$ [ $\gamma \lambda \tilde{\omega} \sigma \sigma \alpha$, tongue; $\kappa \dot{\eta} \lambda \eta$, tumor].
Swelling or edema of the tongue, with consequent extrusion of the organ.

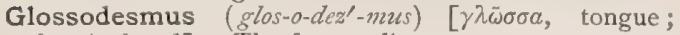
$\delta \varepsilon \sigma \mu \delta$, bond]. The frenum lingux.

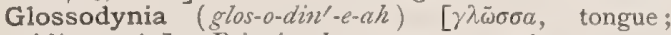
odivn, pain]. Pain in the tongue, sometimes accompanied by exfoliation of its epithelium.

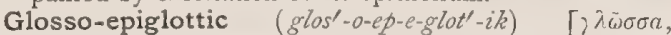
tongue; $\dot{\varepsilon} \pi \gamma_{\lambda} \lambda \tau \tau i \varsigma$, epiglottis]. Pertaining to both tongue and epiglottis.

Glosso-epiglottidean Ligament. See Ligament.

Glossograph (glos'-o-graf) $[\gamma \lambda \tilde{\omega} \sigma \sigma \alpha$, tongue ; $\gamma \rho \alpha \dot{\phi} \phi \varepsilon \iota$, to write]. An instrument for registering the movements of the tongue in speech.

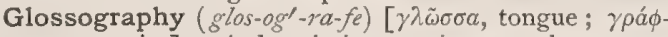
$\varepsilon \iota \nu$, to write]. A descriptive treatise upon the tongue.

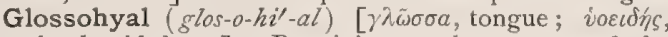
the hyoid bone]. Pertaining to the tongue and the hyoid bone.

Glossoid (glos'-oid) $[\gamma \lambda \tilde{\omega} \sigma \sigma \kappa$, tongue; $\varepsilon i \delta o s$, appearance]. Resembling a tongue.

Glossolalia ( $\left.l o s-o-l a^{\prime}-l e-a h\right)[\gamma \lambda \tilde{\omega} \sigma \sigma a$, tongue ; $\lambda a \lambda \iota a ́$, speech]. The alleged speaking in foreign or unknown tongues by somnambulists.

Glossology (glos-ol'-o-je) $[\gamma \lambda \tilde{\omega} \sigma \sigma \alpha$, tongue; $\lambda 6 \gamma \sigma \varsigma, a$ treatise]. A treatise concerning the tongue.

Glossolysis (glos-oll-is-is) $[\gamma \lambda \tilde{\omega} \sigma \sigma a$, tongue; $\lambda \dot{v} \sigma u s$, a loosening]. Paralysis of the tongue.

Glossomegistus (glos-o-me-jis'-tus). Synonym of Glossitis, Parenchymatous.

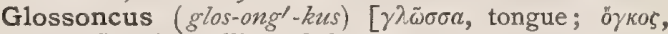
tumor]. A swelling of the tongue.

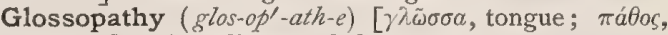
disease]. Any disease of the tongue.

Glosso-pharyngeal (glos'-o-far-in'-je-al) $[\gamma \lambda \hat{\lambda} \omega \sigma \sigma \alpha$, tongue; $\phi a ́ \rho v \gamma \xi$, pharynx $]$. Pertaining to the tongue and the pharynx. See Nerves, Table of.

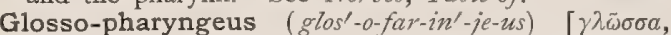
tongue; $\phi a ́ \rho v \gamma \xi$, pharynx ]. A portion of the superior constrictor muscle of the pharynx. See Muscles, Table of.

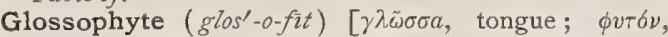
plant]. A parasitic vegetation growing on the tongue.

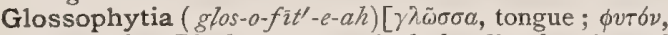
a plant]. Black tongue. A dark discoloration of the tongue, due to accumulations of spores, dead epithelium, and accidental impurities.

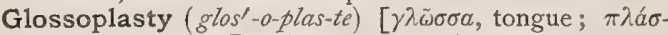
$\sigma \varepsilon \iota v$, to form]. Plastic surgery of the tongue.

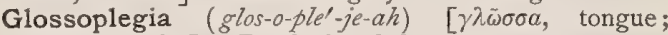
$\pi \lambda \eta \gamma \eta$, stroke]. Paralysis of the tongue.

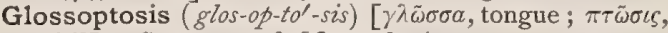
a fall]. Synonym of Macroglossia.

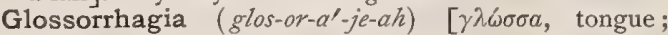
onyvíva, to burst forth]. Hemorrhage from the tongue.

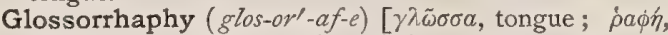
suture]. Surgical suturing of the tongue.

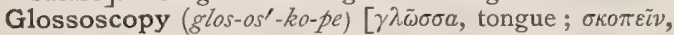
to inspect]. Diagnostic inspection of the tongue.

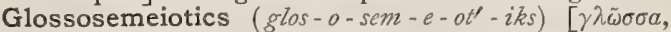
tongue; $\sigma \eta \mu \varepsilon \iota \delta \varepsilon \varepsilon \nu$, to mark]. The study or science of the diagnostic and prognostic signs exhibited by the tongue.

Glossospasm, or Glossospasmus (glos'-o-spazm, or

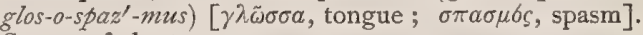
Spasm of the tongue.

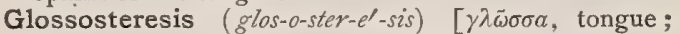
$\sigma \tau \varepsilon$ ' $p$ $\sigma \iota$, privation ]. Surgical excision of the tongue; absence of the tongue.

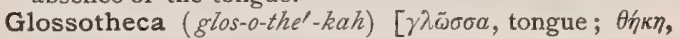


a case : pl., Glossothece]. In biology, that part of a pupa-case inclosing the sucking-organ of an insect.

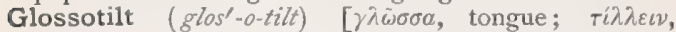
$\tau \iota \lambda T \delta \zeta$, to pull]. An instrument by which the tongue is drawn forward during the process of artificial respiration.

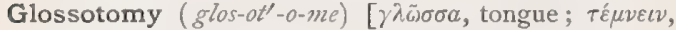
to cut]. The dissection of the tongue. Also, the excision of the tongue.

Glossy Skin, A peculiar neurosis of the skin, charac terized by a smooth, shining, red appearance, accompanied by intense burning pain. See Atrophoderma neuriticum.

Glossypertrophia, or Glossypertrophy (glos-e-per tro'-fe-ah, or - per' -tro-fe $[\gamma \lambda \tilde{\omega} \sigma \sigma \alpha$, tongue ; $v \pi \varepsilon \rho \rho$, over ;

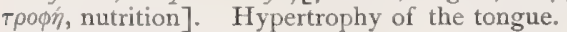

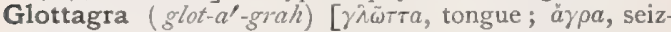
ure]. Glossagra.

Glottal $\left(g l o t^{\prime}-a l\right)$ [ $\gamma \lambda \omega \tau \tau i s$, glottis]. Pertaining to the glottis.

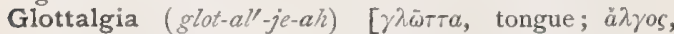
pain ]. Glossalgia.

Glottic $\left(g l o t^{\prime}-i k\right)[\gamma \lambda \tilde{\omega} \tau \tau \alpha$, tongue $]$. I. Pertaining to the tongue. 2. Pertaining to the glottis.

Glottid $\left(g l o t^{\prime}-i d\right)[\gamma \lambda \omega t \tau i \varsigma$, glottis]. An act of the vocal bands whereby the form of the glottis is changed; also, any sound produced by such a change.

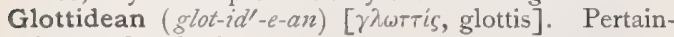
ing to the glottis.

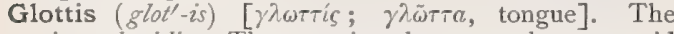
rima glottidis. The opening between the arytenoid cartilages, or the interval between the vocal bands; also, the structures collectively that surround that opening. Over it is the epiglottis, a thin lamella of cartilage covering the larynx during deglutition.

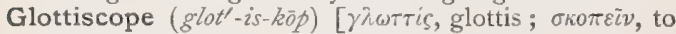
inspect]. A form of laryngoscope.

Glottitis (glot-i'-tis). See Glossitis.

Glottology (glot-ol'-o-je). See Glossology.

Glove (gluv) [ME., glove, a glove]. A protection for the hand, with separate partitions for each finger ; it is used therapeutically in certain skin-diseases of the hand; also as a guard against septic poisoning. G. Alphabet. See Dalganno Alphabet.

Glovers' Stitch (gluv'-erz stitch). The continuous suture in surgery. See Suture.

Glucinum. (glu-si'-num). See Beryllium.

Glucogen ( glu'-ko-jen). See Glycogen.

Glucohemia (glutko-he'-me-ah). See Glycohemia.

Gluco-heptose ( $\left.g l u^{\prime}-k a-h e p^{\prime}-t o s\right)$. See Carbohydrates, Table of.

Glucometer (glu-kom'-et-er). See Glycymeter.

Gluconic Acid (glu-kon'-ik). See Acid.

Glucose $\left(g l u^{\prime}-k \bar{o} s\right)[\gamma \lambda v \kappa u s$, sweet $], \mathrm{C}_{6} \mathrm{H}_{12} \mathrm{O}_{6}$, Grapesugar, Starch-sugar. A substance obtained from starch by the action of the natural ferment, diastase, and by the catalytic action of mineral acids. It is less soluble, and therefore less sweet, than canesugar, but equally nutritious. It is much used as an adulterant of cane-sugar. Its varieties are numerous, dextrose and levulose being the best known. Dextrose differs from levulose in its behavior to the polarized ray of light, which is turned by the former to the right, and by the latter to the left. Glucose crystallizes in nodular masses, melting at $86^{\circ} \mathrm{F}$. See Carbohydrates, Table of. G. Vinegar. See Vinegar.

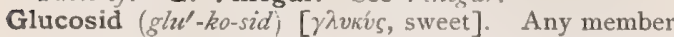
of a series of compounds that may be resolved by the presence of an acid into glucose and another principle.

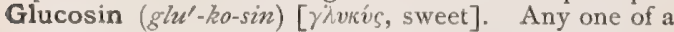
series of ptomaine-bases obtained by the action of ammonia on glucose. One of these, $\mathrm{C}_{14} \mathrm{H}_{10} \mathrm{~N}_{2}(\mathrm{C}=6)$, corresponds in formula and general properties with a remarkable unnamed base formed during the alcoholic fermentation of sugar or molasses,-Morin's base, $\mathrm{C}_{7} \mathrm{H}_{10} \mathrm{~N}_{2}$ : a colorless, strongly refracting, very mobile oil, with a nauseous, pyridin-like odor. It causes stupor, paralysis, impairment of sensibility, dilatation of the pupils, slowing of the pulse and depression of the temperature, coma, and death. Similar alkaloidal bases have also been found in petroleum, paraffin-oil, chloroform, benzole, ether, amyl alcohol, and in most solvents in common use.

Glucosis ( $g$ tu-ko'-sis). Same as Glycosuria.

Glucosuria (glu-ko-su'-re-ah). See Glycosuria.

Glue (glu) [gluere, to draw together]. A decomposition-product of many nitrogenous animal tissues. These lose their organized structure, on heating with water, swell up, and gradually go into solution. The solutions, even when very dilute, gelatinize on cooling, forming a jelly that dries to a horny translucent mass. This mass is glue, or gelatin, as the finer grades are termed. It dissolves in hot water and forms a liquid possessing notable cementing-power. Two proximate principles seem to be present as characteristic in all preparations of glue: glutin, obtained chiefly from the hide and larger bones, and chondrin, from the young bones while yet in the soft state, and the cartilages of the ribs and joints. Of these the former much exceeds the latter in adhesive power. Hide-glue is the variety that shows most strongly the adhesive property. Its color may vary considerably without any impairment of its adhesive power. It is usually of a gray to amber or brownyellow color, and translucent or partially opaque. It should be clear, dry, and hard, and possess a glassy fracture. It should swell up but not dissolve in cold water, but should dissolve in water at $62.5^{\circ} \mathrm{C}$. ( $\left(144.5^{\circ} \mathrm{F}\right.$.). Cologne Glue is manufactured from scrap-hide which, after liming, is carefully bleached in a chlorid-of-lime bath and then thoroughly washed. Russian Glue contains some inorganic admixture. It is of a dirty-white color, and contains from four to eight per cent. of white lead, chalk, zinc-white, or barytes. Size-glue and Parchment-glue are both skin-glues prepared with special care. Bone-glue or Bone-gelatin is a clear product free from offensive odor. It is much used for culinary purposes and for medicinal applications, and for fining or clarifying wines, etc. It is largely used in the manufacture of gelatin capsules, of court-plaster, and of gelatin emulsions with bromid and chlorid of silver for coating photographic dry plates. Patent Glue is a very pure variety of boneglue of deep dark-brown color. It is very glossy and swells up very much in water. Isinglass, or Fish-gelatin, is the finest and best of animal glues. It is pure white, nearly transparent, dry and horny in texture, and free from smell. It dissolves in water at from $35^{\circ}$ to $50^{\circ} \mathrm{C}$. $\left(95^{\circ}\right.$ to $122^{\circ} \mathrm{F}$.) without any residue, and in cooling produces an almost colorless jelly. Liquid Glue. By the action of nitric or acetic acid upon a solution of glue its power to gelatinize may be completely dissipated, while its adhesive power is not at all interfered with.

Gluge's Corpuscles. Compound granular corpuscles ; compound granule-cells. Larger or smaller cells densely crowded with droplets of fat, occurring in tissues that are the seat of fatty degeneration. By transmitted light the globules of fat show as black dots, and the whole corpuscle looks like a mulberry. They are the only pathognomonic evidences of softening of nerve-tissue.

Glumaceous (glu-ma'-she-us) [gluma, a husk]. In biology, possessing chaff-like bracts or glumes. 
Glume $(g-\bar{u} m)$ [gluma, a hull or husk]. In biology, one of the floral envelops in the grasses.

Glumellule (glu-mel'-zill). Same as Lodicule.

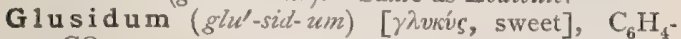
$\langle\mathrm{CO}>\mathrm{NH}$. Saccharin. Benzoyl-sulphonic-imid, a coal-tar derivative. It is an intensely sweet, white powder, 200 times as sweet as cane-sugar. It is antiseptic, and is used to disguise the taste of nauseous medicine. It may be used as a sweetening-agent in diabetes and in the treatment of corpulency.

Glutaric Acid (glu-tar'-ik). See Acid.

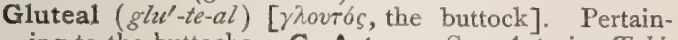
ing to the buttocks. G. Artery. See Arteries, Table of. G. Muscles. See Muscles, Table of. G. Nerve. See Nerves, Table of. G. Reflex. See Reflexes, Table of.

Gluten (glu'-ten) [gluten, glue]. A substance resembling albumin, with which it is probably identical. It occurs abundantly in the seed of cereals, in the form of cubic cells surrounding the starchy fecula of the seed. It consists mainly of gluten-fibrin, glutencasein, gliadin, and mucedin. G.-bread, a variety of non-starch-containing bread for use by diabetics. It is made as follows: Take one quart of sweet milk, or milk and water, one heaping teaspoonful of good butter, one-fifth of a cake of compressed yeast beaten up with a little water, and two eggs well beaten. Stir in the gluten-flour until a soft dough is formed, knead as in making ordinary bread, put in pans to raise, and when light, bake in a hot oven. G.-soap, a bland and soothing variety of soap, containing a considerable proportion of gluten.

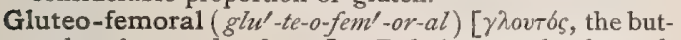
tock; femur, the femur]. Relating to the buttock and the thigh.

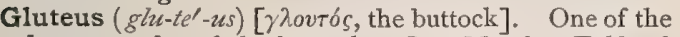
large muscles of the buttock. See Muscles, Table of. Glutin (glu'-tin). See Glue.

Glutition (glu-tish'-un) [glutire, to swallow]. Deglutition.

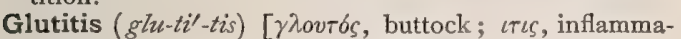
tion]. Inflammation or suppuration of a buttock.

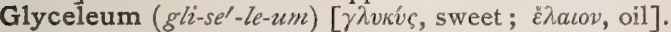
A mixture of glycerin 2 parts, olive oil 6 parts, almond-meal I part; it is used as a base for ointments.

Glycemia ( $\left.g l i-s e^{\prime}-m e-a h\right)$ [ $\gamma \lambda v \kappa v ́ s$, sweet; ai $i \mu$, blood]. The presence of glucose in the blood.

Glycerid ( $g$ lis'-er-id $)[\gamma \lambda v \kappa \varepsilon \rho \delta s$, sweet]. A compound ether of the triatomic alcohol, glycerol or glycerin. Some of the glycerids exist ready-formed, as natural fats, in the bodies of plants and animals, and many more may be produced artificially by the action of an acid upon glycerol.

Glycerin, Glycerinum (glis'-er-in, glis-er-i'-num) $[\gamma \lambda v$ $\kappa \varepsilon \rho o ́ s, ~ s w e e t], \mathrm{C}_{3} \mathrm{H}_{5}(\mathrm{HO})_{3}$. Propenyl hydrate. A viscous, syrupy, colorless substance derived from certain fats-mainly palm-oil-by decomposing them with superheated steam. Pure glycerin is an emollient ; the impure article an irritant to the skin. Dose $3 \mathrm{j}-\mathrm{ij}$. It is an efficient internal remedy in acne and flatulence, and may be used in rectal enemata or in suppositories with soap or gelatin $\left(\frac{1}{10}\right)$, in chronic constipation. See Glycerol. Glycerinum acidi carbolici (B. P.), glycerin 4, carbolic acid I. G. acid. gallici (B. P.), gallic acid I, glycerin 4. G. acid. tannici (B. P.), tannic acid I, glycerin 4. G. aluminis (B. P.), alum I, glycerin 5. G. boracis (B. P.), borax I, glycerin 4, distilled water 2. G. plumbi subacetat. (B. P.), acetate of lead 5, oxid of lead $3 \mathrm{I} / 2$, glycerin 20 , distilled water I2, G. tragacanthæ (B. P.), tragacanth 3 , glycerin I2, distilled water 2. Glycerini, Suppos. (B. P.), each contains 70 per cent. by weight of glycerin. Glycerin-Cupric Test (for sugar); to an inch of potassium hydrate in a test-tube add a few drops of copper sulphate and a few drops of glycerin. Boil and add the suspected urine by small amounts up to less than one inch in the tube. Sugar will throw out the cuprous oxid, red or yellow. G.-Jelly, a valuable preparation for the treatment of eczema. It is made as follows: Gelatin, 4 drams; oxid of zinc, $21 / 2$ drams; glycerin, $1 / 2$ ounce; water, 6 drams. Heat the water, dissolve the gelatin in it, then add the glycerin and zinc, and stir till cold. Before using, the jelly is melted by gentle heat in a water-bath, and applied with a soft brush. See Mounting-media.

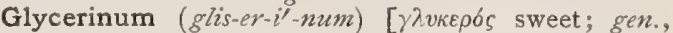
glycerini : pl., Glycerina ]. x. Glycerin, $q . v$. 2. A solution of some medicinal agent in glycerin, $q$. $v$.

Glycerite, or Glyceritum (glis'-er-itt or glis-er-i'tum) $[\gamma \lambda v \kappa \varepsilon \rho o ́ s$, sweet]. A mixture of medicinal substances with glycerin. There are six official glycerites, besides several others in the National Formulary. G. acidi carbolici, carbolic acid 2, glycerin 8 . G. acidi tannici, tannic acid 2, glycerin 8. G. amyli. See Amylum. G. vitelli. See Vitellus.

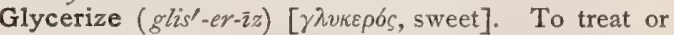
mix with glycerin.

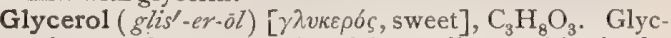
erin; a substance produced in small quantities in the alcoholic fermentation of sugar. It is prepared exclusively from the fats and oils. It is a thick, colorless syrup, of specific gravity 1.265 at $15^{\circ} \mathrm{C}$. It has a pure, sweet taste, hence its name.

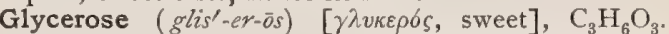
Triose; a substance derived from glycerol. It is the lowest glucose, and is a mixture of glycerol aldehyd and dioxy-acetone. See Carbohydrates, Table of.

Glyceryl (glis'-er-il) [ $\gamma^{\prime} \nu \kappa \varepsilon p o b s$ sweet]. A designation applied to the trivalent group $\mathrm{CH}_{2} \cdot \mathrm{CH} . \mathrm{CH}_{2}$. It is the hypothetic triatomic radicle of glycerol and the glycerids, and is also called propenyl. G. Borate. See Boroglycerin.

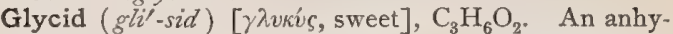
drid of glycerin, not yet isolated. G. Compounds, certain compounds formed from glycerol-derivatives by the loss of $\mathrm{H}_{2} \mathrm{O}$ or $\mathrm{HCl}$. These are again readily converted into glycerol-derivatives.

Glycin (gli'-sin) $[\gamma \lambda v \kappa u ́ s$, sweet $], \mathrm{C}_{2} \mathrm{H}_{5} \mathrm{NO}_{2}$. Also called Glycocol and Glycocin, Amido-acetic Acid, or Gelatin-sugar. It does not occur in the free state in the animal body, but enters into the composition of several important substances, as hippuric and glycocholic acids. It is acid in reaction, and has a sweet taste. It crystallizes in large, colorless, hard rhombohedra, or four-sided prisms, easily soluble in water. See Glycocol.

Glycina (glis-i'-nah). Soya-bean. See Soja.

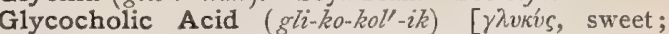
$\chi 0 \lambda \dot{n}$, bile]. An acid found in the bile. See Acid.

Glycocid ( $\left.g^{\prime} l^{\prime}-k o-s i d\right)$. See Glucosid.

Glycocin ( $\left.g l i^{\prime}-k o-\sin \right)$. See Glycin.

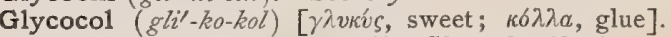
The same as Glycin, q.v. The Glycocols, Alanins, or Amido-fatty Acids are crystalline bodies, usually of a sweet taste, and readily soluble in water.

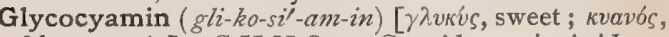
blue; amin $], \mathrm{C}_{3} \mathrm{H}_{7} \mathrm{~N}_{3} \mathrm{O}_{2}$. Guanido-acetic Acid; a substance obtained by the direct union of glycocol with cyanamid. It is soluble in 120 parts of cold water and rather readily in hot water; insoluble in alcohol and in ether. It forms crystalline compounds with acids and bases. 


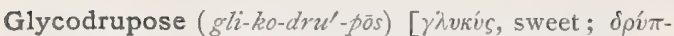
$\pi \alpha$, an over-ripe olive]. The substance forming the stony concretions of pears.

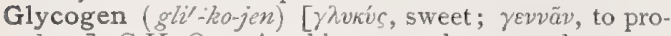
duce ], $\mathrm{C}_{6} \mathrm{H}_{10} \mathrm{O}_{5}$, A white, amorphous powder, tasteless and odorless, forming an opalescent solution with water, and insoluble in alcohol. It is commonly known as animal-starch. It occurs in the blood and the liver, by which it is elaborated, and is changed by diastasic ferments into glucose. See Carbohydrates, Table of.

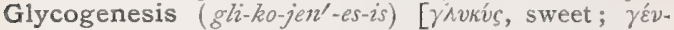
$\varepsilon \sigma \iota s$, production ]. The formation of sugar in the animal economy, whether normal or pathologic.

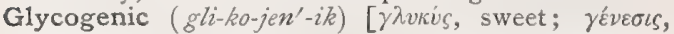
production]. Pertaining to glycogen or to glycogenesis.

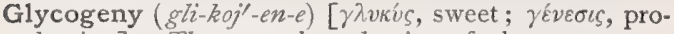
duction]. The normal production of glycogen.

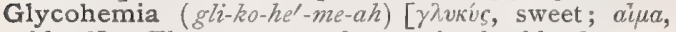
blood]. The presence of sugar in the blood, especially its presence in excessive quantity; glycemia.

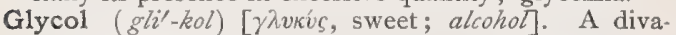
lent alcohol; a compound intermediate in its properties and chemic relations between monohydric alcohol and trihydric glycerol. The glycols are neutral, thick liquids. The solubility of a compound in water increases according to the accumulation of $\mathrm{OH}$ groups in it, and it will be correspondingly less soluble in alcohol and especially in ether. There will also be an appreciable rise in the boiling-temperature, while at the same time the body acquires a sweet taste, inasmuch as there occurs a gradual transition from the hydrocarbons to the sugars. In accord with this, the glycols have a sweetish taste, are readily soluble in water, slightly soluble in ether, and boil at a much higher point ( $100^{\circ} \mathrm{C}$.) than the corresponding monohydric alcohols. They contain two hydroxyl groups united to different carbon atoms.

Glycolamid (gli-kol'-am-id) [ $\gamma \lambda v \kappa i ́ s$, sweet; amid $]$, $\mathrm{C}_{2} \mathrm{H}_{5} \mathrm{NO}_{2}$. A substance crystallizing in needles that melt at $120^{\circ} \mathrm{C}$. ; it possesses a sweet taste, and dissolves easily in water, but with difficulty in alcohol.

Glycollic Acid ( $g\left(i-k o l^{\prime}-i k\right)$. See Acid.

Glycoluric Acid (oli-kol-u'-rik). See Acid.

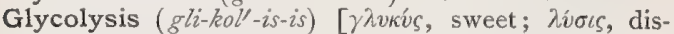
solution]. The process of decomposition into glycols.

Glyconin, Glyconon ( $\left.g l i^{\prime}-k o-n i n,-o n\right)[\gamma \lambda \nu \kappa u s$, sweet]. The Glyceritum vitelli of the U.S. Ph. It is a mixture of yolk of egg 45, and glycerin 55 .

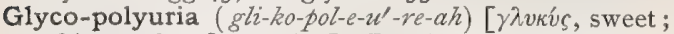
$\pi o \lambda$ ús, much ; ovjpov, urine]. Bouchardat's term for diabetes, attended with a moderate quantity of sugar in the urine and with an increase of lithic acid in the blood.

Glycosamin (gli-kos'-am-in). See Chitin.

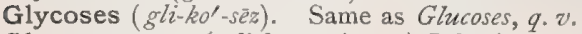

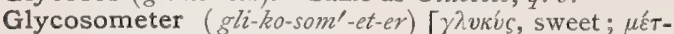
pov, a measure]. An instrument for use in the estimation of the percentage of sugar in diabetic urine.

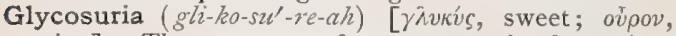
urine]. The presence of grape-sugar in the urine. See Diabetes. G., Tests for. See Boettger's, Fehling's, Glycerin-cupric, Indigo-carmin, Pavy's, Picrosaccharimeter, Phenyl-hydrazin, Roberts' Differential Density, Saccharometer, Trommer's, and others in Tests, Table of. G., Hepatic, a temporary glycosuria due to excessive formation of glycogen in the liver. G., Irritative, that produced by irritation of the diabetic center on the floor of the fourth ventricle. G., Paralytic, that produced by dividing the anterior columns of the spinal cord at the level of the fourth cervical vertebra.

Glycuronic Acid (gli-ku-ron'-ik). See Acid.
Glycyrrhea ( $\left.g l i-s i r-e^{\prime}-a h\right)$ [ $\gamma \lambda v \kappa v s$, sweet ; $\dot{\varepsilon} i v$, to flow]. Any discharge of glucose from the body. Glycyrrhcea urinosa. Synonym of Diabetes mellitus.

Glycyrrhetin (gli-sir-é-tin) [ $\gamma \lambda v \kappa i ́ s$, sweet; $\dot{\rho} i \zeta a$, root], $\mathrm{C}_{18} \mathrm{H}_{26} \mathrm{O}_{4}$. An amorphous bitter substance in liquoriceroct.

Glycyrrhiza ( $\left.g l i-s i \gamma^{\prime}-i^{\prime}-z a h\right)\left[\gamma \lambda v \kappa v_{s}\right.$, sweet; $\dot{\rho} i \zeta a$, root: gen., Glycyrrhize]. Liquorice-root. The root of $G$. glabra, a demulcent and mild laxative, of sweet taste. In combination with other medicaments it is an excellent expectorant, and is much used as an excipient in pills, troches, etc. G., Ext., the liquorice of commerce, occurring in black rolls. G., Ext., Liquid (B.P.). Dose 3 j-ij. G., Ext., Purum, made with aqua ammoniæ and water by percolation and evaporation. G., Ext., Fld., prepared with water and alcohol. G., Mist., Comp., Brown mixture, pure extract, sugar, acacia, āà 3 parts, tinct. opii camph. I2, vin. antimonii 6 , spt. nitrous ether 3 , water 70 . Dose 3 j - ss. G. et Opii, Trochisci, have each ext. of glycyrrhiza, gr. ij, ext. of opium gr. $\frac{1}{20}$, acacia, sugar, oil of anise q. s. Dose j-ij. G., Pulv., Comp., compound licorice-powder, senna 18 , glycyrrhiza 23 , oil of fennel 4, washed sulphur 8 , sugar 50.

Glycyrrhizin (gli-sir-i'-zin). See Glycyrrhizinum.

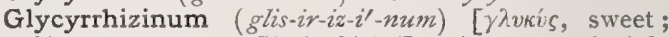

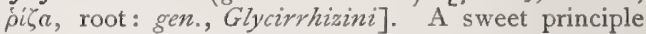
derived from liquorice-root. G. ammoniatum (U. S. P.), ammoniated glycyrrhizin, a sweet preparation used as a substitute for liquorice. Dose gr. $v-x v$.

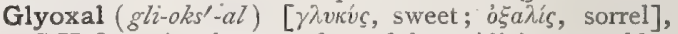
$\mathrm{C}_{2} \mathrm{H}_{2} \mathrm{O}_{2}$, A substance formed by oxidizing acetaldehyd with $\mathrm{HNO}_{3}$. It is an amorphous non-volatile mass that deliquesces in the air, and is soluble in alcohol and in ether.

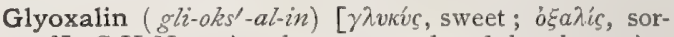
rel], $\mathrm{C}_{3} \mathrm{H}_{4} \mathrm{~N}_{2}$. A substance produced by the action of ammonia upon glyoxal. It is easily soluble in water, alcohol and ether, and crystallizes in brilliant prisms, melting at $89^{\circ} \mathrm{C}$. and boiling at $255^{\circ} \mathrm{C}$.

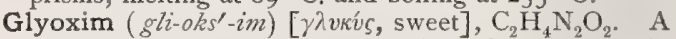
compound produced by the action of hydroxylamin upon trichlorlactic acid. It is soluble in water, alcohol, and ether; crystallizes in rhombic plates; melts at $178^{\circ} \mathrm{C}$; sublimes without difficulty; has a faintly acid reaction, and forms salts with bases.

Glyoxylic Acid (gli-oks-il'-ik). See Acid.

Gmelin's Test. Same as Gmetin-Heintz Reaction.

Gmelin-Heintz Reaction. A test for bile-pigments in the urine. See Tests, Table of.

Gmelina (mel'-in-ah) [after Gmelin, a Russian scientist]. A genus of verbenaceous shrubs and trees. In India, G. arborea, G. asiatica, G. parvifolia, G. villosa, and other species, are employed in catarrhal disorders and in fevers and rheumatism. Unof.

Gnaphalium (naf-a'-le-ım). See Life-everlasting.

Gnat (nat) [ME., gnat, a gnat]. A dipterous insect, the Culex pipiens, differing but slightly from the common mosquito, with which it is popularly confounded. The "bite" consists in a piercing of the skin and the withdrawal of a minute quantity of blood. The gnat has no sting or poison-glands.

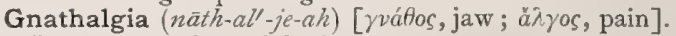
Pain or neuralgia of the jaw.

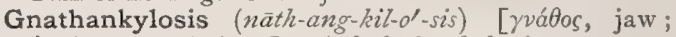

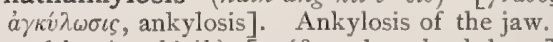

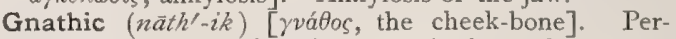
taining to the cheek or jaw. G. Index. See Alveolar and Index.

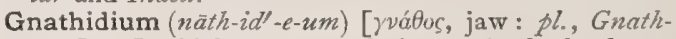
idia]. In biology, one of the rami of the lower mandible of a bird. 
Gnathion (näth'-e-on). See Craniometric Points. Gnathite $\left(n \bar{a} t h^{\prime}-\bar{\imath} t\right)$ [yvatus, the jaw]. In biology, one of the jaw-feet of an arthropod; a gnathopodite.

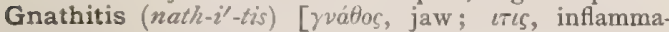
tion]. Inflammation of the jaw or cheek.

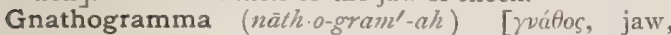
cheek; $\gamma \rho a ́ \mu \mu a$, line]. Jadelot's genal line. See Jadelot's Lines or Furrows.

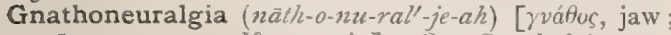

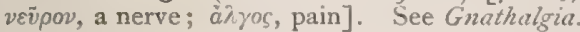

Gnathoparalysis (näth-o-par-al'-is-is) [rvátos, jaw ;

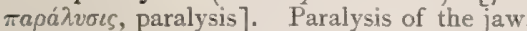

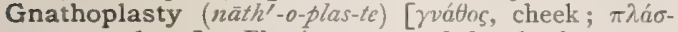
$\sigma \varepsilon \iota \nu$, to shape]. Plastic surgery of the cheek.

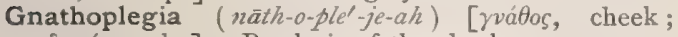
$\pi \lambda \eta \gamma^{\prime}$, stroke]. Paralysis of the cheek.

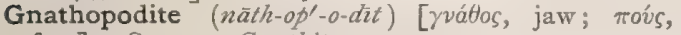
foot]. Same as Gnathite.

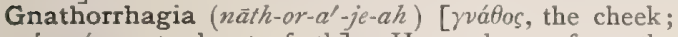
imgrive mucous membrane of the cheek.

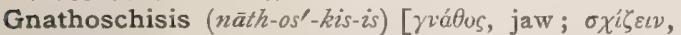
to split]. Cleft-jaw.

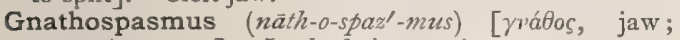
$\sigma \pi \alpha \sigma \mu \delta \varsigma$, spasm]. Locked jaw ; trismus.

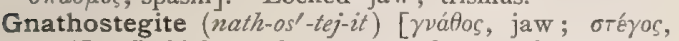
roof ]. In biology, the cover to the mouth-parts of a crustacean formed by the expansion of parts of the third thoracic limbs.

Gnomonic (no-mon'-ik) [ $\gamma \nu \omega \mu \omega \nu$, a carpenter's square]. In biology, bent at right angles.

Gnoscopin (nos'-ko-pin), $\mathrm{C}_{34} \mathrm{H}_{36} \mathrm{~N}_{2} \mathrm{O}_{11}$. A crystalline alkaloid of opium, melting at $233^{\circ} \mathrm{C}$.

Goa Ball, or Goa Stone [Goa, in Portugal]. A mass of drugs made up into a large bolus, from which enough for a dose is scraped as needed; it is said to have originated at Goa. G. Powder. See Araroba.

Goadby's Solution. A solution of salt and corrosive sublimate in water, for preserving meat against putrefaction.

Goanese Ipecacuanha (go-an-ēez $\left.i p-\ell-k a k-u-a n^{\prime}-a h\right)$. See Naregamia.

Goat's-voice (götz'-vois). See Egophony.

Goblet Cells. Chalice-like cells lying between the epithelial cells of the intestinal villi.

Goddard's Astringent Gargle. An astringent gargle composed of alum 2 drams, pomegranate bark $1 / 2$ ounce, red rose petals I dram, honey I ounce, boiling water 6 ounces.

Godfrey's Cordial. A non-official preparation of opium containing from half a grain to a grain and a half of opium to the ounce.

Goggle-eyed ( $\left.g^{\circ} g^{\prime}-l-\bar{\imath} d\right)$ [ME., goggleyed]. A vulgar synonym of Exophthalmos and of Strabismus.

Goggles ( $\left.g \circ g^{\prime}-l z\right)$ [ME., gogelen, to look asquint]. Spectacles with colored lenses and wire or cloth sides, to protect the eyes from excessive light, dust, etc.

Gogo $\left(g o^{\prime}-g o\right)$ [African]. The rhizome of Phrynium beaumetzii, a marantaceous plant indigenous to the western coast of Africa. It is a powerful vermifuge and purgative. It is used in the form of a decoction, $z$ ijss to the $\mathrm{Oj}$. Unof.

Gogul ( $\left.g 0^{\prime}-g u l\right)$ [Beng. or Hind.]. A name for various balsamic resins, the product of Asiatic trees of the genus Balsamodendron; it is sometimes classed as Elemi, and also as Bdellium.

Goiter (goi'-ter) [guttu', throat]. Enlargement, particularly if hypertrophic, of the thyroid gland. It is called, also, Bronchocele and Tracheocele. It generally accompanies cretinism. G., Anemic. Synonym of G., Exophthalmic. G., Exophthalmic, Basedow's
Disease, Graves' Disease. A disease characterized by cardiac palpitation, goiter, exophthalmos, tremor, palpitation usually being the initial symptom; the pulse ranges from 90 to $\mathbf{2} 20$. Occasionally the exophthalmos is so extreme as to produce spontaneous dislocation of one or both eyes. There are present Grafe's lid-sign, namely, inability of the upper lid to follow perfectly the downward movement of the eye ; and, usually, Stellwag's sign, viz., apparent widening of the palpebral aperture, due to retraction of the upper lid. The disease is usually encountered in women; its course is chronic, and the ultimate outcome recovery. Death, however, occasionally results. The etiology is obscure, but the disease occurs frequently in those of the neurotic habit. The theories proposed for the explanation of exophthalmic goiter may be placed in three divisions: I. The cardio-vascular theories, which locate the seat of the disease in the heart itself, the vessels, and the blood. 2. The mechanical theories, which connect the symptoms with compression of vessels or nerves in the neck by a primarily hypertrophied thyroid. 3. The nervous theories, which attribute the disease to disturbance in the vagus nerve, in the sympathetic nerve itself, or in the central nervous system proper. G., Pulsating. Synonym of G., Exophthalmic, G.-stick, the coarse stem of certain kinds of sea-weed (Sargassum bacciferum, etc.), used in various places as a cure for goiter.

Goitrous (goi'-trus) [guttur, throat]. Pertaining to or affected with goiter.

Gokeroo (gook'-er-oo). See Gokhru.

Gokhru $\left(g \circ k^{\prime}-n u\right)$ [E. Indian]. Gokeroo. The fruit of Pedalizm murex, found in the East Indies, much used by the natives for enuresis and spermatorrhea. It is used in infusion of $\xi_{j}$ to $\mathrm{Oj}$ of boiling water. Dose ad lib. Unof.

Gold [ME., gold, gold]. See Aurum. G., Bichlorid of, so-called, has been vaunted in the treatment of drunkenness and the opium-habit. The compounds of chlorin and gold are the monochlorid and the trichlorid. G.-beaters' Cramp. See Cramp. G.-beaters' Skin, a thin membrane prepared from the cecum of the ox for gold-beaters' use. It has a limited use in surgery. G., Annealing of, the softening of gold by means of heat, to reduce the hardness caused by the mechanical forces to which it has been subjected in its manufacture. See Annealing. G.-brown. Same as Phenylene-brown. G. Cinnabar. Same as Minium. G. Crowns, portions of the natural crowns of teeth capped with gold, thereby restoring the contour. G.-foil, Dentists' (aurum foliatum), gold-leaf. Gold-foil, as used by dentists for filling teeth, is gold hammered into a thin leaf, but finer in quality and of much greater thickness than the article ordinarily known as gold-leaf. G.-ochre. Same as Ochre. G.-orange, an anilin dye employed by Unna for staining lepra-bacilli and tuberclebacilli. See Stains, Table of, and Pigments, Conspectus of. G.-plate, for dental uses, may be made by the following formulas:-

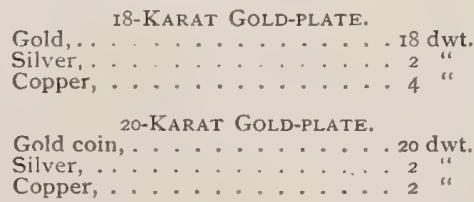

G. of Pleasure. See Camelina. G.-purple. Same as Cassius' Purple. G.-solder, gold alloyed with one or more metals. The following table exhibits the rela- 
tive proportions of the metals most frequently employed :-

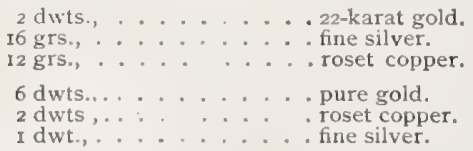

G.-thread. See Coptis.

Golden (gōld'-en) [ME., gold, gold]. Of the nature or color of gold. G. Hair-dye. See Bleach. G.-rod, the leaves of Solidago odora, an aromatic stimulant and carminative. A volatile oil distilled from the plant is used in flatulence. Dose of the fld. ext. $3^{j-i j}$; of the oil $m_{i j-x}$. Unof. G.-seal. See $H y$ drastis. G.-yellow. Same as Martius' Yellow.

Golgi's End-plate. A reticulated ending of nervefibers in tendons, sometimes embedded in granularlooking matter. G.'s Method, a method of staining nerve-cells. See Stains, Table of.

Goll, Columns of. See Column.

Goltz's Balancing-experiment. Animals lose their power of equilibrium with removal of the mid-brain or corpora quadrigemina. G.'s Croaking-experiment, a pithed male frog croaks when the skin of its back or flanks is stroked. G.'s Embrace-experiment, during the breeding-season the body of the male frog between the skull and fourth vertebra embraces every rigid object with which it is brought into contact. G.'s Static-theory, every position of the head causes the endolymph of the semicircular canals to exert the greatest pressure upon some part of the canals, thus in varying degree exciting the nerveterminations of the ampullæ.

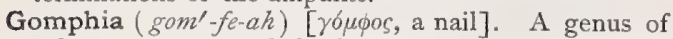
ochnaceous trees and shrubs, partly natives of tropical America and partly of India. The leaves and bark of various species are tonic, astringent, and aromatic. Unof.

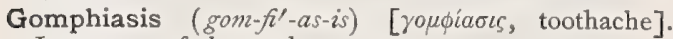
Looseness of the teeth.

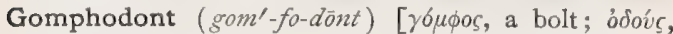
tooth]. In biology, having the teeth set in sockets.

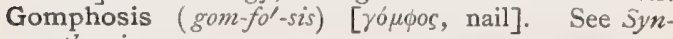
arthrosis.

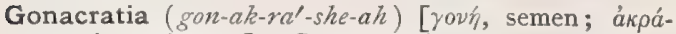
$\tau \varepsilon \iota a$, incontinence]. Spermatorrhea.

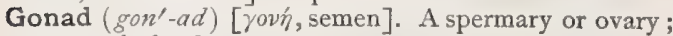
a sexual gland.

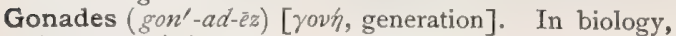
the reproductive organs; genitalia; sexualia.

Gonaduct (gon'-ad-ukt) [gonad, seed; ductus, a duct]. In biology, the excretory duct of a reproductive gland; an oviduct or a sperm-duct.

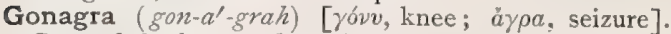
Gout of the knee or knee-joint.

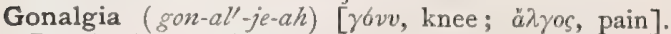
Pain in the knee-joint.

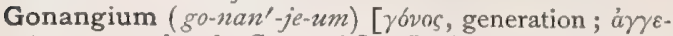
iov, a vessel : $p l$., Gonangia]. In biology, the reproductive capsule of certain hydroids (thecophora), bearing within it a modified hydranth that produces, by budding, many sexual individuals.

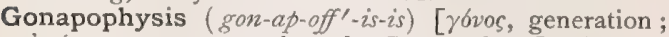

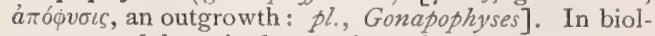
ogy, one of the paired appendages forming the external sexual organs of insects, as the ovipositor, or the clasping-organs.

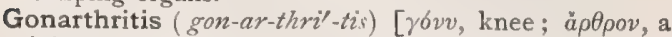
joint ; $\iota \iota \iota$, inflammation ]. Inflammation of the kneejoint.

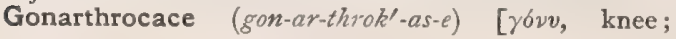

à $\rho \rho \circ \nu$, joint; кák $\eta$, evil]. A cancerous or ulcerated affection of the knee-joint, popularly known as white swelling.

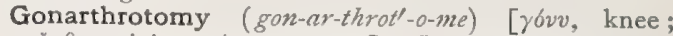
$a \check{\rho} \theta \rho o \nu$, joint ; $\tau \hat{\varepsilon} \mu \nu \varepsilon \iota \nu$, to cut]. Incision into the kneejoint.

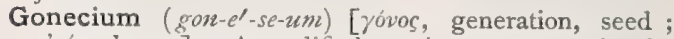
oikia, house]. A modified zoecium set apart in the Polyzoa for reproductive functions.

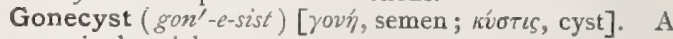
seminal vesicle.

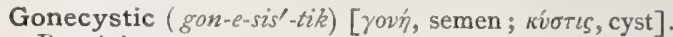
Pertaining to a gonecyst.

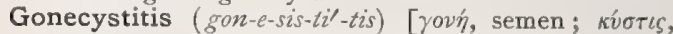
cyst; $\iota \tau \iota$, inflammation]. Inflammation of a gonecyst.

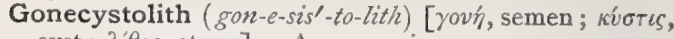
cyst; $\lambda i \theta 0 s$, stone ]. A sympexion, $q . v$.

Gonecystoncus (gon-e-sis-tong'-kus) [yov'́, semen;

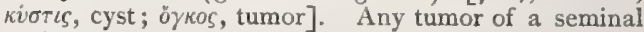
vesicle.

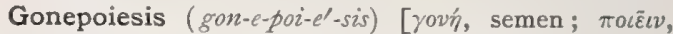
to make]. The secretion or elaboration of semen.

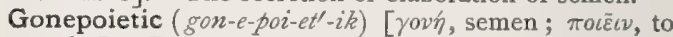
make]. Pertaining to the secretion of semen.

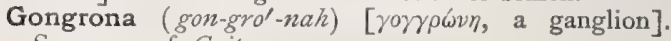
Synonym of Goiter.

Gonic (gon'-ik) [rovıkós, pertaining to semen]. Pertaining to semen or to generation.

Gonid (go-nid'). Same as Gonidium.

Gonidangium (gon-id-an'-je-um) [rov', generation; aryeion, a vessel: pl., Gonidangia]. In biology, a sac or sporangium containing asexually-produced spores.

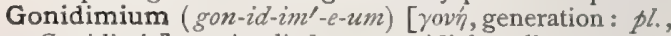
Gonidimia]. Applied to gonidial cells; certain lichens intermediate between gonidia proper and gonimia.

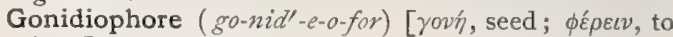
bear]. In biology, the fruiting-organ of certain fungi producing spores asexually.

Gonidium (go-nid'-e-um) [rovh, seed: pl., Gonidia]. In biology, $(a)$ one of the grass-green algal elements of the lichen thallus. (b) Also called Gonid, and applied to various asexually-produced reproductive bodies. Cf. Pseudocyst.

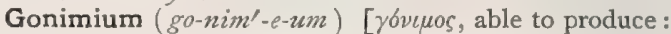
$p l .$, Gonimia]. In biology, glaucous-green or bluishgreen gonidia.

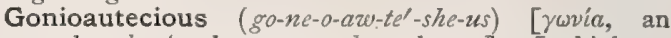
angle; ávrós, the same; оíкs, house]. In biology, applied to plants producing both male and female inflorescences, as mosses with the bud-like male organs growing on a female branch.

Gonion (go'-ne-on) [rwvia, an angle]. See Craniometric Points.

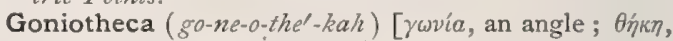
a case : pl., Goniotheca]. See Macrosporangium.

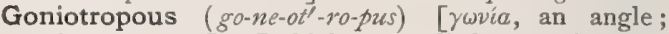
$\tau \rho \varepsilon ́ \pi \varepsilon \iota v$, to turn ]. In biology, applied to certain quadrangular stems, in which two of the angles are anterior and posterior, and the others lateral. Cf. Pleurotropous.

Gonio-zygomatic (go-ne-o-zi-go-mat'-ik) [yovía, an angle; $\xi v \gamma \delta v$, a yolk]. Relating to the gonion and the zygoma.

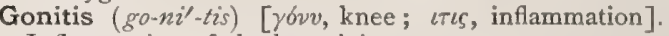
Inflammation of the knee-joint.

Gonoblast (gon'-o-blast) [yóvos, generation; $\beta \lambda \alpha \sigma \tau b s$, germ]. A sperm-cell or germ-cell; any cell concerned directly in reproduction; a spermatozoön; an ovum.

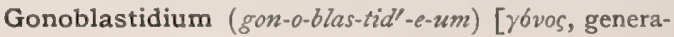


tion, seed; $\beta \lambda$ notós, germ: pl., Gonoblastidia]. A term applied by Huxley to the organs set apart for the production of generative buds in the Physophoride and other Hydrozou. Cf. Blastostyle.

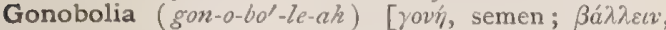
to throw]. I. The ejaculation of semen. 2. Spermatorrhea.

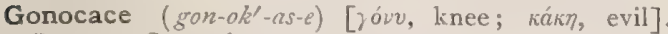
Same as Gunarthrocace.

Gonocalyx (gon-o-ka'-liks) [róvos, generation, seed;

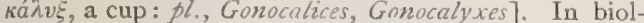
ogy, a term applied by Huxley to the investment of the reproductive organs of many of the Hydrozoa, having more or less the structure of a nectocalyx, but from whose walls those of the actual genital sac, the manubrium of Allman, tend to become independent.

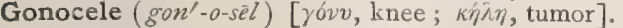
swelling of the knee.

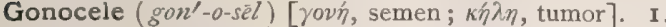
A tumor of a testis, or of a spermatic cord, due to retention of semen. 2. Synonym of Gonorrheal Rhermatism.

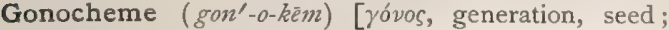
óxeiv, to carry, hold]. In biology, hydroid medusæ bearing genitalia.

Gonochorismus (gon-o-kor-iz'-mus) [ yóvos, generation, sex; $\chi \omega \rho \iota \sigma \mu o ́ s$, separation]. In biology, the specialization of sex; the differentiation of male or female genitalia in a developing embryo; the separation of the sexes in phylogeny.

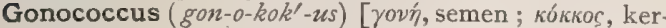
nel]. A microbe thought to be the specific cause of gonorrhea. See Gonorrhea, and Bacteria, Synonymatic Table of.

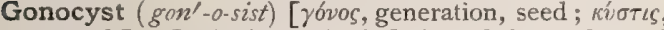
a pouch]. In biology, the inflation of the surface of the zoarium in which the embryos are developed in certain of the Polyzoa, See Gonecyst.

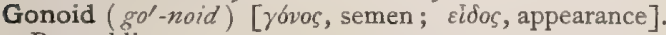
Resembling semen.

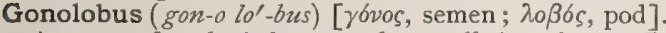
A genus of asclepiadaceous plants, all American. G. macrophyllus, of the U.S., has a cathartic and poisonous root. Unof. Some varieties of condurango are furnished by plants of this genus.

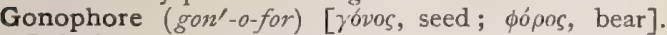
In biology: I, a stipe below stamens. 2. The ultimate generative zoöid of the Hydroid-meduse, that which immediately produces the generative elements. It may be either medusiform or sacciform.

Gonoplasm (gon'-o-plazm) [yówos, seed; $\pi \lambda a ́ \sigma \mu a$, anything formed]. In biology, that portion of the protoplasm of the male fertilizing element in certain cryptogams that penetrates and fertilizes the oösphere.

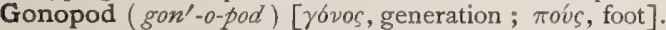
In biology, one of the specialized abdominal feet of certain male crustaceans, functionating as auxiliary reproductive organs.

Gonopoiesis (gon-o-poi-e'-sis). See Gonepoiesis.

Gonopoietic (gon-o-poi-et'-ik) [ yóvos, generation, seed;

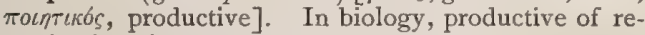
productive elements, as ova or spermatozoa.

Gonorrhea (gon-or-e'-ah) [yovos, semen; joía, a flow]. Etymologically, an involuntary discharge of semen, but generally applied to a specific infectious inflammation of the mucous membrane of the urethra and adjacent cavities. The gonococcus of Neisser is believed to be the specific microbe of gonorrhea. It is a diplococcus, found in clumps of from to to 20 , surrounded by a mucous envelop. G. balani, affects the glans penis. G., Bastard. See G., Mucous. G., Dry, a form unassociated with discharge. G., Mu34 cous, the so-called abortive or slight superficial catarrh. The inflammation never runs high, and subsides in from seven to fourteen days. G. preputialis. See Balanitis. G. sicca. See G., Dry.

Gonorrheal (gon-or-e'-al) [yóvos, semen; poin, a flow]. Relating to gonorrhea. G. Ophthalmia. See Uphthalmia. G. Rheumatism, inflammation of one or more joints as a sequel of gonorrhea. G. Wart. See Venereal Wart.

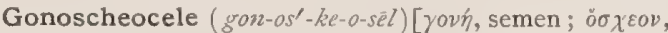

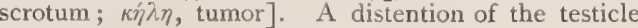
with semen.

Gonosome (gon'-o-söm) [yóvos, generation, seed; $\sigma \tilde{\omega} \mu \alpha$, the body]. In biology, the entire assembly of generative zoöids in a hydroid colony.

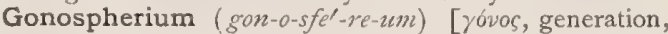
seed; $\sigma \phi a i p a$, sphere: pl., Gonospheria]. In biology, a form of oögonium in which the protoplasm is condensed at the center of the cell and separated by a space from the cell-wall.

Gonostroma (gon-o-stro'-mah) [ rovos, offspring;

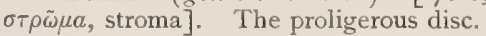

Gonotheca (gon-o-the'-kah) [yóvos, generation, seed; $\theta \dot{\eta} \kappa \eta$, case: pl., Gonotheca]. In biology, the chitinous hull of the reproductive capsules of certain hydrozoans.

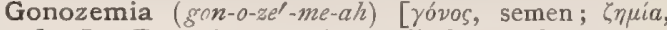
flow]. Excessive secretion or discharge of semen.

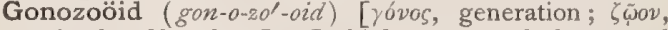
animal; eidos, form]. In biology, one of the sexual zoöids of an ascidian.

Gonyagra (gon-e-a'-grah). See Gonagra.

Gonyalgia (gon-e-al'-je-ah). See Gonalgia.

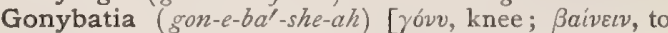
go]. Walking upon the knees; a symptom encountered in some paralytic and paretic cases.

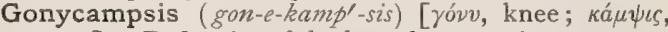
curve]. Deformity of the knee by curvation.

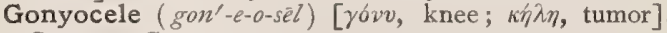
Same as Gonyoncus.

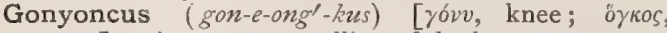
tumor]. A tumor or swelling of the knee.

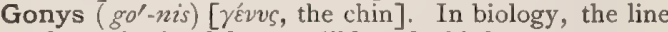
of symphysis of the mandibles of a bird.

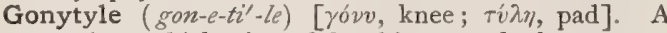
prominent thickening of the skin upon the knee.

Goodyera (good-ye'-rah) [after John Goodyer, an English botanist]. A genus of orchidaceous plants. G. repens of Asia, Europe, and America, is a popular medicine. G. pubescens of N. America (rattlesnake plantain, cancer-plant) is applied to sores, cancers, etc. Unof.

Goose (goos) [ME., goos, a goose]. A bird of the family of Anserines. G.-flesh. See G.-skin. G.foot. See Pes anserinus. G.-grass. See Galium aparine. G.-skin, Cutis ansera, Goose-flesh, a popular name for a well-known condition of the skin marked by prominence about the hair-follicles. See Arrector pili Muscle.

Gore $(g \bar{o} r)$ [ME., gore, gore]. Thick or clotted blood.

Gorged Stomach (gorjd stum'-ak). See Stomach Staggers.

Gorgeret (gor-jer-et') [Fr., gorge, throat]. A surgeon's gorget, especially a small gorget.

Gorget (gor'-jet) [gurges, a chasm]. A channeled instrument similar to a grooved director. It may be blunt, sharp, hooked, etc. In biology, a throatpatch, as the brilliant throat of the humming-bird.

Gorgon's Head. See Caput meduse.

Gosselin's Fracture. A V-shaped fracture of the distal extremity of the tibia, involving the ankle-joint.

Gossypiin (gos-ipp-e-in) [gossypium, the cotton-tree]. 
A precipitate from a tincture of the root-bark of Gossypium herbaceum, recommended as an emmenagogue and diuretic. Dose, I to 5 grains. Unof.

Gossypine (gos'-ip-in) [gossypium, cotton]. In biology, cottony, flocculent.

Gossypium (gos-iph-e-um) [L., cotton-tree: gen., Gossypii]. Cotton. The hairs of the seed of $G$. herbaceum. Freed from impurities and deprived of fatty matter, it becomes the absorbent cotton of surgery. It is soluble in an ammoniacal solution of copper sulphate. The root is thought to have emmenagogue properties. G. purificatum, purified cotton. G. rad., Cortex, cotton-root bark. Dose gr. $x \times x-3$ j. G. rad., Ext., Fld., prepared with glycerin and alcohol. Dose mxxx-3j. G. seminis, Ol., the expressed oil constitutes most of the so-called olive-oil of commerce. G., Tinct., $I$ in 4. Dose $3 \mathrm{j}$. See, also, Pyroxylin. Gothard Worm (goth' -ard veurm). See Anchylostonum. Gothic Palate. An enormously high palatal arch.

Göttinger's Line. See Lines, Table of.

Gottstein's Basal Process. The filiform basal extremity of Corti's organ. It is connected with the fine nerve-filaments of the cochlear nerve. G.'s Curet, a curved curet for the removal of post-nasal growths. G.'s Fibers. See Fiber.

Gouge (gooj or gowj) [Fr.]. An instrument for cutting or removing bone or other hard structures.

Goujeers (goo'-jers) [OF., gouge, a soldier's mistress]. An old name for syphilis.

Goulard's Cerate. See Plumbum. G.'s Extract. See Plumbum.

Gould, Methods of. See Treatment, Methods of.

Gourand's, or Goyrand's, Disease. See Diseases, Table of. G.'s Hernia. See Hernia.

Gourdy (gor'-de or goor'-de) [ME., gourd, a gourd]. In farriery, having swollen legs (said of horses).

Gout (govt) [ME., goute, the gout; gutta, a drop]. A constitutional disease characterized by an excess of uric acid or alkaline urates, especially sodium urate, in the fluids of the body. Sodium urate is first deposited about the articular surfaces of the small joints, but in time the arteries, cardiac valves, and connective tissue of the kidneys may be involved. The metatarso-phalangeal joint of the great toe is, curiously, the favorite point of attack, and the helix of the ear is another favorite seat. Tophi form about the affected part. To diminished solubility of the urates, due to increased acidity of the blood; to increased formation of uric acid, and failure in function of the kidneys; to persistent plethora of the digestive organs, - is variously ascribed the cause of gout. The symptoms of the acute form are malaise, intense pain in the affected part, with swelling and redness, pyrexia, chills, scanty and acid urine, irritability and sleeplessness. The paroxysm usually occurs in the night. Other attacks almost invariably follow at irregular intervals. G., Diaphragmatic, angina pectoris. G., Latent or Masked, a condition ascribed to a gouty diathesis, but not presenting the typical symptoms of gout. $G$., Retrocedent, that form that is manifested by severe internal manifestations, without the customary arthritic symptoms. See DrCosta's Disease. G., Rheumatic. See Arthritis, Rheumatic.

Gouty (gow'-te) [ME., goute, the gout]. Of the nature of gout; affected with gout. G. Kidney. See Bright's Disease.

Goux, System. See Sereage, Disposal of.

Gowers' Column. See Column. G.s' Front-tap Contraction. See Contraction, and Reflexes, Table of. G.'s Method, the method of counting the corpuscles of the blood by the hemocytometer. G.'s Pupil. See Signs and Symptomis, Table of.
Gowland's Cosmetic. Lotion, or Wash. A famous lotion used in the treatment of acne, and said to have contained oxymuriate of mercury in an emulsion of bitter almonds.

Gr. Abbreviation of grain.

Graafian Follicles, or Vesicles. Peculiar vesicular bodies existing in the cortex of the ovary as well as in

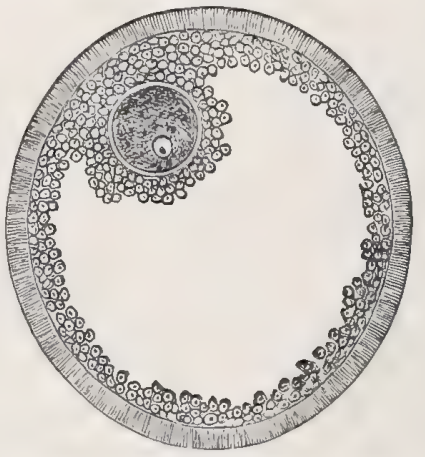

Graafian Follicle and Ovule, with Proligerous Disc. the ovarian stroma. Within them the ova mature. See Vesicle.

Gracilis (gras'-il-is) [L., slender]. See Muscles, Tible of. G. Experiment, an experiment performed upon the gracilis muscle of the frog, showing that pure muscular excitation does not travel backward from the muscle to the nerve.

Gradient ( gra'-de-ent) [gradi, to step, to go]. In biology, walking, rather than creeping or jumping.

Graduate (grad'-u-ät) [gradus, a step]. To take a degree from a college or university. Also, a person on whom a degree has been conferred. Also, in pharmacy, a glass vessel upon which the divisions of liquid measure have been marked.

Graduated (grad'-u-a ted) [gradus, a step]. Arranged in degrees or steps. G. Compress, a compress made of pieces decreasing progressively in size, the apex or smallest piece being applied to the focus of pressure. G. Cones. See Cones. G. Full Bath. See Bath.

Graefe's Collyrium. The celebrated collyrium adstringens luteum. It was made as follows: Camphor, Io grains; alcohol, I ounce; chlorid of ammonium, I5 grains; sulphate of zinc, 30 grains; croci pulv. hispanici, 2 grains ; distilled water, 5 ounces. One drop of this, after filtration, is used morning and evening. G.'s Knife, a knife for the performance of the operation for cataract. G.'s Operations. See Operations, Table of. G.'s Signs or Symptoms. See, Signs and Symptoms, Table of.

Gräfenberg System. See Hydrotherapy.

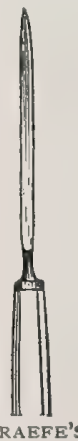
[ME, graffe, graft]. A small portion of skin, bone, periosteum, nerve, etc., inserted into or upon a raw surface or tissue deficient in the special structure desired. G., Sponge, the insertion of antisepticized sponge to act as a framework for the granulations.

Graham Bread. Brown bread; wheaten bread made from unbolted flour.

Grahamism (gra'-am-izm) [after Sylvester Graham, an American reformer]. Vegetarianism; a theory of dietetic and medical reform started in 1839 .

Grahamite $\left(g r a^{\prime}-a m-\bar{\imath} t\right)$ [after Sylvester Graham]. A vegetarian; a follower of the teachings of Sylvester Graham, I794-1851. 
Grahe's Test. See Tests, Table of.

Grain (grān) [ granum, corn]. A general name applied to starch-producing seeds, or to those of the cereals. Also, any small seed. In pharmacy, a small pill. Also, the $\frac{1}{560}$ part of the Troy pound.

Graining-colors. See Pigments, Colors, and Dyestuffs.

Grains of Paradise [Grana paradisi, "grains of paradise"]. The unripe fruit of Amomum meleoueta, and of A. granum paradisi, brought from W. Africa. It is an aromatic stimulant and diuretic, useful in some cases of neuralgia. Unof.

Grallatorial (gral-at-ól-re-al) [grallator, one who walks on stilts]. In biology, applied to wading-birds.

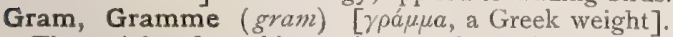
The weight of a cubic centimeter of distilled water at its maximum density. The gravimetric unit of the metric system of weights and measures. See Metric System. G. [Anglo-Indian.] A commercial name for the chick-pea, Cicer arietinum, and for other varieties of pulse.

Gram's Fluid. See Gram's Solution. G.'s Method, I. See Gram's Solution. 2. See Treatment, Methods of. G.'s Solution, a test for amyloid liver, and a mordant in staining for tubercle-bacilli, consisting of iodin I part, potassium iodid 2, water 300 . The preparation is taken from the color-bath, washed and plunged into this solution until it takes a blackish tinge, then washed in alcohol until decolorization is complete. This process is called Gram's Method. See Stains, Table of.

Gramineous (gram-in'-e-us) [gramen, grass]. In biology, grass-like.

Graminifolious (gram-in-if-o'-le-us) [gramen, grass; folium, a leaf]. In biology, having grass-like leaves.

Graminivorous (gram-in-iv'-or-us) [gramen, grass; vorare, to devour]. Feeding upon grass.

Grammatic Acataphasia (gram-at'-ik ak-at-af-a'$z e-a h)$. The faulty use of words, due not to ignorance, but to some central brain-lesion. See Acataphasia.

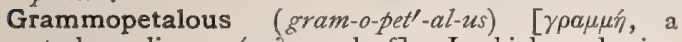

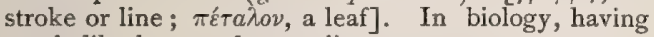
petals like leaves of grass, linear.

Grana paradisi (gran'-ah par-ad-i'-si) [L.]. See Grains of Paradise.

Granatum (gran-a'-tum) [granum, a grain: gen., Granati ]. Pomegranate. The cortex of the root of Punica granatum contains a liquid alkaloid, pelletierin, $\mathrm{C}_{8} \mathrm{H}_{13} \mathrm{NO}$, one of the most efficient anthelmintics against tapeworm, rarely failing to bring away the whole worm. G., Fld. Ext. Dose 3 ss-jss. G., Decoctum, fresh bark 3 xvij, water $\xi$ xvij, boiled to $\zeta$ xij and strained. Dose $\zeta$ iv-vj. Pelletierin tannas, tannate of the alkaloid, $\mathrm{C}_{8} \mathrm{H}_{13} \mathrm{NO} . \mathrm{C}_{14} \mathrm{H}_{10} \mathrm{O}_{9}$. Dose gr. $\nabla-x x$ followed by a quick purgative. P. sulphas, very hygroscopic. Dose $\mathrm{v}-\mathrm{x}$. All unof.

Grancher's Sign. See Signs and Symptoms, Table of.

Grand Mal (grand ma(h)l) [Fr.]. A term for fullydeveloped epilepsy; major epilepsy.

Grandeau's Test. See Tests, Table of.

Grandeur, Delirium of, or Delusions of. Insane exaltation of mind, with false opinions as to one's own greatness and dignity.

Grandidentatus (gran-de-den-ta'-tus) [grandis, large; dens, a tooth]. Having large teeth.

Grandin (gran'-din) [grando, a hailstone]. A peculiar substance found in the urine of pregnant women. It is supposed to produce kyestein by its decomposition.

Grandry's Corpuscles. A variety of sensitive nerveterminations consisting of delicately punctate and sharply defined cells that are flattened and lens-like in form, and have a nucleus, the latter being the so-called
Tactile Cells of Merkel. They occur in the beak and tongue of the duck and goose, in the epidermis of man and mammals, etc. They are the same as the Corpuscles of Krause.

Graniticoline (gran-it-ik'-o-lin) [It., granito, granite; colere, to inhabit]. In biology, applied to such lichens as grow upon granite.

Granny Knot (gran'-e not). A tie of a cord in which in the second loop the end of one cord is over and the other under its fellow, so that the two loops do not lie in the same line. This knot can easily be converted into a slip-knot. See $K$ not.

Granular (gran'-u-lar) [granum, a grain]. Made up of, containing, or bearing granules. G. Casts. See Casts. G. Corpuscles. See Granule-cell. G. Degeneration. See Cloudy Swelling. G. Degeneration of the Cervix. See Erosion. G. Kidney, a kidney affected with diffuse or insterstitial nephritis. G. Lids. See Trachoma. G. Liver, a cirrhosed liver. See Cirrhosis. G. Pharyngitis, follicular pharyngitis.

Granulated (gran'-u-la-ted) [granula, a little grain]. Characterized by the presence of granulations or granules.

Granulation (gran-u-la'-shun) [granula, dim. of granum, a grain]. I. The operation of reducing coarsely crystalline substances to particles of uniform size by solution and rapid evaporation, with constant stirring. Some substances, like ferrous sulphate, are best granulated by filtering a strong solution into alcohol. 2 . The formation of new or cicatricial tissue in the repair of wounds or sores, the surface of which has a granular appearance; also, any one of the elevated points of such a surface or formation. G., Miliary, a miliary tubercle. G.-tissue, new or cicatricial tissue made up of granulations, or by the process of granulation.

Granulative (gran'-u-la-tiv) [granula, a little grain]. Pertaining to or marked by the process of granulation.

Granule (gran'-ül) [granula, a little grain]. In anatomy, any small rounded grain, such as is found in the Malpighian bodies of the spleen. Also a spore or an isolated cell. In pharmacy, a small pill. G., Elementary, irregular protoplasmic bodies in the blood, smaller than ordinary blood-corpuscles. G., Seminal, any one of the solid particles of the semen, consisting of round, granular corpuscles. G.-cell, any one of a variety of round cells found in pathologically softened brain-tissue, and densely filled with fat-globules. G.mass, a giant-cell.

Granulia (pran- $\left.u^{\prime}-l e-a h\right)$ [granula, a little grain]. Empis' name for an acute inflammatory condition distinct from tuberculosis, but, like it, characterized by the development of granulations within organs and on serous surfaces.

Granulistics (gran-u-lis'-tiks) [granula, a little grain]: That branch of physics employed in the estimation of the volume or capacity of a body by means of seed, shot, sand, granules, etc.

Granulitis (gran-u-li'tis) [granula, a little grain ; เтı, inflammation]. Acute miliary tuberculosis.

Granuloma (gran-u-lo'-mah) [granulum, a small grain; ö $\mu \alpha$, a tumor: pl., Granulomata]. A term used by Virchow to include such a neoplasm as does not advance beyond the stage of granulation-tissue. G. fungoides; Mycosis fungoides; Fibroma fungoides ; a rare, chronic inflammatory disorder, probably of specific origin, that affects the superficial and deep layers of the skin, and occasionally the mucous membranes. It is marked by the appearance of urticarial, erythematous, or eczematous patches, of irregular shape and size, with welldefined margins, usually upon the scalp and skin of the trunk. Itching is intense, and frequently the 
patches become hypertrophic, and firm, hard nodules, varying in size from that of a pea to an apple, either sessile or pedunculated, develop on them. These eventually break down, to form deep, unsightly ulcers that contain sensitive, fungating granulation-tissue, and discharge thin pus and serum. Death results from a progressive cachexia. See Mycosis.

Granulomatous (gran-u-lo'-mat-us) [granula, a little grain; ǒ $\mu \alpha$, a tumor]. Pertaining to, of the nature of, or affected with granuloma. G. Inflammation. See Infammation.

Granulose (gran'-u-los) [granula, a grain]. The material that forms the inner portion of starch-granules; it is enclosed by coats of cellulose.

Granum (ra'-num). See Grain.

Granville's Lotion. A compound liniment of ammonia. Grape-cure ( $\left.g r \bar{a} p^{\prime}-k \bar{u} r\right)$. A cure for pulmonary tuber. culosis, consisting in the ingestion of quantities of grapes. Some patients should not take more than an average of two pounds daily, beginning with about a pound, and other patients should not exceed four pounds. The laxative influence of the grapes is also beneficial. Irritation of the gums produced by the treatment should be relieved by rinsing the mouth with cold water to which a little bicarbonate of sodium is added. G.-disease, a vulgar synomyn for tuberculous disease of cattle. G.-sugar. See Glucose and Dextrose.

Grapes (gräps). Same as Grape-disease.

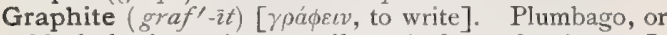
black lead, an impure allotropic form of carbon. It has been applied externally in skin-diseases; its dilutions are also used by homeopathists. Unof.

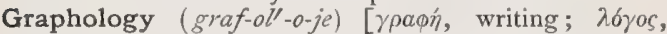
science]. The study of the handwriting or of written sentences, for the purpose of diagnosticating nervedisease or brain-lesion.

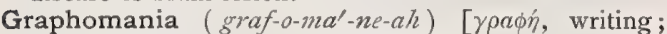

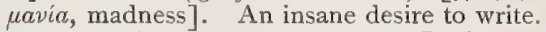

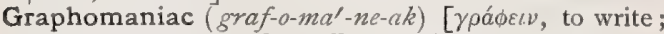
ravia, madness]. One affected with graphomania.

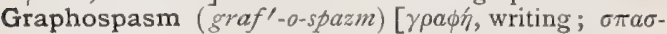
$\mu \delta \varsigma$, spasm]. Writers' cramp.

Grass (gras) [ME., gras, grass]. Herbage. G.-oil. See Anthoxanthum: G.-staggers, indigestion of cattle. G.-tree Resin. See Xanthorrhea.

Grating (gra'ting) [grata, a grating]. A frame or screen composed of bars. Also a sound produced by the friction of very rough surfaces against each other. In optics, a glass ruled with exceedingly fine paralle] lines to produce chromatic dispersion in the rays of light reflected from it.

Gratiola (gra-ti'-o-lah) [gratia, grace]. A genus of scrophulariaceous herbs. G. aurea, G. carolinensis, G. virginiana, and other N. American species are actively medicinal, but are little used. G. officinalis, of Europe, is cathartic, emetic, and diuretic, and is a decided poison. Unof.

Gratiolet's Angle. See Angle. G.'s Bundle, optic radiations running into the occipital cortex.

Gratiolin (gra-ti'-o-lin) [gratia, grace], $\mathrm{C}_{20} \mathrm{H}_{34} \mathrm{O}_{7}, \quad$ A crystalline, bitter glucosid from Gratiola officinalis. It was formerly used as a hydragogue.

Gratiolirrhetin (gra-te-o-lir-et'-in) [gratia, grace;

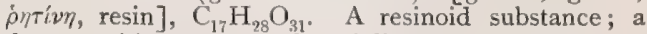
decomposition-product of gratiolin.

Grattage $\left(g r a h-t a(h) z h^{\prime}\right)$ [Fr.]. A method of removing morbid growths, as polypi or trachomatous granulations, by rubbing with a harsh sponge or brush.

Grave (grâv) [ME., grave, a grave]. An excavation in the earth for burying the dead. G.-wax. See Adipocere.
Gravedo (grav-e $\left.e^{\prime}-d o\right)[L$.$] . I. Muscular rheumatism of$ the head. 2. Coryza.

Gravel (grav'-el) [ME., gravel, gravel]. In surgery, a common name for the larger calculi or urinary concretions. Also, difficult or painful micturition. G.plant. See Trailing Arbutus. G.-root, Queen of the Meadow, the root of Eupatorium purpureum, or of Collinsonia canadensis. See Eupatorium and Collinsonia.

Graveolent (grav'-e-o-lent) [gravis, heavy; olere, to smell. Having a strong, unpleasant odor; fetid.

Graves" Disease. See Goiter, Exophthalmic, and Diseases, Table of.

Gravid (grav'-id) [gravare, to load]. With child, pregnant. G. Uterus, the womb during pregnancy or gestation.

Gravida (grav'-id-ah) [gravidus, pregnant]. A pregnant woman.

Gravidin (grav'-id-in) [gravidus, pregnant]. A peculiar substance occurring in white transparent globules on the surface of the urine voided by pregnant women. G.-test, a worthless sign of pregnancy. After the first month of pregnancy the urine of the gravid woman, if allowed to stand from thirty hours to eight days, will have formed upon it a pellicle with a cheesy odor and an appearance like the "fatty scum of cooled broth." Examined microscopically and chemically the pellicle shows fungi, triple phosphates, fat-globules, and sometimes a peculiar form of albumin. It may be found in urine from men, young girls, and very old women, hence is of no value as a test of pregnancy. The test is also called the Kyestern Test.

Gravidism, or Gravidity (gray'-id-izm, or grav-id'it-e) [gravidus, pregnant]. Pregnancy, or the totality of symptoms presented by a pregnant woman.

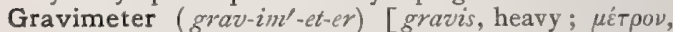
measure]. An instrument used in determining specific gravities; especially a hydrometer, aèrometer, or urinometer.

Gravity (grav'-it-e) [gruvis, heavy]. The property of possessing weight. Also, a condition of serious import. G., Specific, the measured weight of a substance compared with that of an equal volume of another taken as a standard. For gaseous fluids, hydrogen is taken as the standard; for liquids and solids, distilled water at its maximum density.

Grawitz's Theory. A theory as to the immunity conferred by inoculation. The cells of the body and the bacteria take their nutrition from the same places, and it is a true fight for existence between them. If the cells come out victorious, they become habituated to the struggle with the bacteria, and are more able to resist a second attack, and this quality is transmitted to the succeeding generations of body-cells by heredity. This theory is purely hypothetic.

Gray (gra) [ME., gray, gray]. I. Of a color between white and black. 2. Having gray hairs. G. Hepatization. See Hepatization and Pneumonia. G. Induration. See Induration. G. Infiltration. See Infiltration. G. Lanolin Ointment. See G. Oil. G. Matter, the cinerea. See Brain. G. Oil, Oleum cinereum, a semifluid, fatty, mercurial liquid introduced into medicine by Lang, of Vienna, in 1886 . It is used in the treatment of syphilis by injections. It is prepared as follows: A given quantity of lanolin-I or 2 drams-is rubbed up with sufficient chloroform to emulsify it. This mixture is to be thoroughly triturated, during which operation the chloroform will evaporate. While the mixture is still in a fluid state, metallic mercury to the amount of double the quantity of the lanolin is to be added, the trituration being meanwhile continued. As a result, a pomade of mer- 
cury is left, which represents two parts of mercury and one part of lanolin. This is called strong gray lanolin ointment. From this salve-basis a 50 per cent. oleum cinereum, or gray oil, may be obtained by mixing three parts with one part of olive-oil. A mild gray lanolin ointment may be made in the same manner as the strong, by taking equal parts of lanolin and mercury and thoroughly mixing them. From this salvebasis a 30 per cent. gray oil may be made by mixing six parts with four parts of fresh almond-oil or oliveoil. G. Powder, hydrargyrum cum creta. See Hydrargyrum.

Grease (grēs) [ME., grese, grease]. Soft or oily animal fat. In farriery, a swelling and inflammation in a horse's leg, with excretion of oily matter and the formation of cracks in the skin. G.-trap, a contrivance employed to prevent clogging of waste-pipes, as well as to save the grease, which has considerable commercial value.

Great (grät) [ME., gret, great]. Large. G. Laurel, the leaves of Rhododendron maximum, an expectorant, useful in obstinate coughs. Dose of the fld. ext. $\eta^{v-x v}$ Unof. G. Mortality. Synonym of the Plague. G. Pox. Synonym of Syphilis, to distinguish it from smallpox.

Green (green) [ME., grene, green]. I. Verdant; of the color of grass. 2. Unripe; not mature. G. Blindness. Achloropsia, q. . G. Dragon, the corm of Arum dracontium, an expectorant and diaphoretic. Dose of the fld. ext. $m_{\mathrm{lj}}-\mathrm{x}$. Unof. G. Bice. See Bremen Green. G.-blue. Same as Soluble-blue. G. Cinnabar. See Pigments, Conspectus of. G. Gland, one of the excretory organs (kidney) of a decapod crustacean formerly supposed (in Astacus) to be an auditory organ. The secretions contain uric acid and traces of the base guanin. G.-heart. See Bebeeru. G.-man. See Aceras. G. Osier, the bark of Cornus circinata. an astringent, tonic, and febrifuge. Dose of the fld. ext. $m \times x-3 j$. Unof. G., Paris, cupric arsenite. G., Scheele's, cupric arsenite. G., Schweinfurth's, a compound of cupric arsenite and cupric arsenate. G.-sickness. See Chlorosis. G. Smalt. Same as Rinmann's Green. G.-stick Fracture. See Fracture. G. Verditer. See Bremen Green.

Green's Test-types. A slight modification of Snellen's Test-types, q. $v$.

Greenhow's Cholera-mixture. A mixture containing guaiacum, cloves, cinnamon, each I ounce; brandy, 2 pints.

Greffotome (gref'-o-tōm) [Fr., greffe, graft; тouós, cutting]. A knife used in cutting slips for surgical grafting.

Gregarina (greg-ar-e'-nah) [grex, a herd]. A genus of parasitic protozoa, of extremely simple nature. It is not certain that any true Gregarine infest the human subject, most of the supposed protozoan parasites of the human species being now referred to other classes or groups. See Parasites (Animal), Table of.

Gregarinosis (greg-ar-in-a'-sis) [grex, a herd; vóøos, disease]. A morbid condition due to infestation by Gregarine.

Gregarious (gre-ga'-re-us) [grex, a flock, a herd]. In biology, clustered, but not matted together, as the fruit-spots of a parasitic fungus; $e . \sigma^{\circ}$, the cluster-cups.

Gregory's Powder. Compound powder of rhubarb. G.'s Salt, crude hydrochlorate of morphin containing codein.

Grenacher's Alcoholic Carmin. See Stains, Table of. G.'s Alum-carmin. See Stains, Table of. G.'s Purpurin Solution. See Stains, Table of. G.'s Solution. See Stains, Table of.

Grenade (gren-ād'). Synonym of Infuenza.
Grenet Cell. See Cell.

Gressorial (gres-o'-re-al) [gressus, p.p. of gradi, to walk]. In biology, adapted for walking; gradient.

Griesinger's Disease. Cachexia aquosa.

Griffe (grif) [Sp., grifos, frizzled hair]. 1. In biology, the offspring of a mulatto and a negress, or of a mulattress and a negro. See Mulatto. 2. See Main en griffe.

Griffin Hand (grif'-in hand). Same as Claru-hand. Griffith's Mixture. See Ferrum. G.'s Pills. See Ferrum. G.'s Snow-white. Same as Zincolith.

Grin [ME., grinnen, to show the teeth]. To smile, at the same time showing the teeth.

Grindelia (grin-de'-le-ah) [after H. Grindel, a German botanist]. The leaves and flowering top of G. robusta, Wild Sunflower, or Gum-plant, found in California, an anstipasmodic and motor-depressant, in large doses producing mydriasis. It is valuable in asthma, bronchitis, and whooping-cough. Dose of the fld. ext. $m x-$ $3 \mathrm{j}$; of the alcoholic extract, gr. iij. G. squarrosa, common ague-weed, an herb popular in the western $U$. $\mathrm{S}$. as a remedy for ague and malarial diseases. It has proved serviceable in chronic rheumatism. Dose of the fld. ext. $m x v-x x x$. Unof. G. hirsutula and $G$. integrifolia of the Pacific States have similar qualities. These plants are all highly resinous; their tinctures or infusions are said to cure the dermatitis of rhus-poisoning.

Grindelin (grin'-del-in). An alkaloid reported to exist in Grindelia robusta.

Grinder (grin'-der) [ME., gryndere, a miller]. I. See Ouizzer. 2, A molar tooth.

Grinders' Asthma. A chronic affection of the lungs resulting from the inspiration of metallic or siliceous dust, accumulating in the lungs, and producing symptoms similar to those of tuberculosis. It is called also $G$.'s Rot and G.'s Disease. G.'s Disease. See G.'s Asthma. G.'s Phthisis. See G.'s Asthma. G.'s Rot. See G.'s Asthma.

Grinning (grin'-ing) [ME., grinnen, to snarl]. Drawing back the lips, so as to show the teeth. G.-muscle. See Muscles, Table of

Grip or Grippe (grip). See Influenza.

Gripe (grip) [ME., gripen, to seize]. I. To suffer griping pains. 2. A spasmodic pain in the bowels; cramp-colic.

Gripes (grips) [ME., gripen, to seize]. Colic ; tormina.

Grippal (grip'-al) [Fr., gripper, to seize]. Pertaining to influenza.

Grippo-toxin (grip-o-toks'-in) [la grippe, an epidemic form of influenza; toxicum, poison]. A term introduced by Althaus to designate the toxin of influenza.

Griseous (gris'-e-us) [griseus, gray]. Gray or bluish. gray.

Grisolle Sign (gre-zol' $\sin n)$. A sign said to be a certain means of diagnosis of smallpox. If, upon stretching an affected portion of the skin, the papule becomes impalpable to the touch, the eruption is caused by measles; if, on the contrary, the papule is still felt when the skin is drawn out, the eruption is the result of smallpox.

Gristle (gris'-l) [ME., gristel, cartiage]. The popular name for cartilage.

Gristly (gris'-le) [ME., gristel, cartilage]. Cartilaginous; like gristle.

Groan (grön) [ME., gronen, to groan]. To utter a low, moaning sound, as when in pain. The sound so uttered.

Grocers' Itch (gro'-serz ich). Eczema of the hands, due to irritation from flour, sugar, etc. It is said to be due, in some cases, to the presence of sugar-mites upon the hands. 
Groin [origin obscure]. The depression between the belly and the thigh.

Groove (groov) [D., groof, a channel]. A furrow or channel. G., Auriculo-ventricular. See Furroze. G., Bicipital, the deep groove on the anterior surface of the humerus separating the greater and lesser tuberosities. G., Cavernous, a broad groove on the superior surface of the sphenoid bone lodging the internal carotid artery and the cavernous sinus. G., Dental. See Dental Groove. G., Infraorbital, the furrow at the posterior portion of the superior maxillary bone on its orbital surface, which finally develops into a canal of the same name. G., Lachrymal, a groove in front of the opening of the antrum, on the inner surface of the superior maxillary bone. G., Medullary, a long shallow furrow that appears along the dorsal line of the neural tube of the embryo. G., Mylo-hyoid, the groove on the inner surface of the inferior maxillary bone ruming from the submaxillary fossa to the inferior dental foramen. G., Nasal, the groove in the nasal bone for the nasal nerve. G., Occipital, the groove in the mastoid portion of the temporal bone, that lodges the occipital artery. G., Optic, the groove on the superior surface of the sphenoid bone terminating on either side in the optic foramen. G., Sacral, the channel on the back of the sacrum between the spinous and transverse processes. G., Subclavian, the longitudinal groove on the under surface of the clavicle for the attachment of the subclavius muscle. G., Spiral. See Sulcus spiralis. G., Vertebral, the groove running along the spine on each side of the spinous process.

Groping-test (grōp'-ing-test). In ophthalmology, a test for false orientation in paralysis of the ocular muscles. The affected eye does not locate objects in their true place, and if asked to point quickly at an object the patient's finger will be carried to one side of it.

Gros Mal (gro-ma(h)l) [Fr.]. The well-marked form of epilepsy; major epilepsy.

Gross (grōs) [F., gros, great]. Coarse; great. G. Anatomy, anatomy considered without reference to histology or the details of minute structure. G. Appearances, macroscopic appearances.

Grote's Test. See Tests, Table of.

Grough, Grouph (gruf). See Gruff.

Ground (grozend) [ME., ground, ground]. The bottom; soil; earth. G. Ivy, a popular name for Gaultheria procumbens. G. Laurel. See Traiting Arbutus. G.-nut. See Apios. G.-nut Oil, peanut oil. A fixed oil expressed from the embryo of the seed of the peanut, Arachis hypogaca. It resembles olive-oil in general properties, and for which it is often substituted. G.-water. See Subsoil-water.

Groundseltree. See Baccharis.

Grouse (grows) [OF., griesche, gray]. A bird of the genus Tetrio. G.-berry, a popular name for Gaultheria procumbens. G.-disease, a disease that attacks and destroys great numbers of red grouse (Lagopus scoticus) of Europe; it is believed to be due to the overstocking of its haunts and the propagation of the species by depauperized parents. It is said by some writers to be due to the presence of a parasite, Strongylus pergracilis, in the bronchial passages. See Parasites (Animal), Table of.

Grove Cell. See Cell.

Grow (gro) [ME., growen, to grow]. To increase by a natural process of development.

Growing (gro'-ing) [ME., growen, to grow]. Increasing in size. G.-fever, pyrexia associated with rapid growth. G.-pains, a term applied to neuralgic or rheumatic pains in the limbs occurring during youth, apparently of varied origin and character. G.-point, in botany, the tissue immediately about the apical cell; the tip of the stem or other point where cell-division is active; the Punctum vegetationis.

Growth (gröth) [ME., growen, to grow]. I. The augmentation of the body that takes place between infancy and adult age. Also, the increase of any part of the body by addition to the number of its cellular elements, without the production of structural abnormality or differentiation into unlike tissues. 2. Any tumor or adventitious structure.

Grub [ME., grubben, to dig]. I. A dwarf. 2. See Conedo. G.-in-the-head. See Estrus ovis, under Parasites (Animal), Table of. G.-worms. See Comedo.

Gruber's Experiment. An experiment for detecting anomalies of tension in the ear-membrane. A membrane already excessively tense will give no alteration during Valsalva's experiment $(q \cdot v$.$) , but if the mem-$ brane has been previously unduly relaxed, Valsalva's experiment will, according to Gruber, restore its tension, and the vibrating fork will be heard better by airconduction, and worse by bone-conduction than before or after. G.'s Gelatin Bougies, medicated almond-shaped pieces of gelatin for insertion into the auditory meatus. G.'s Method. I. A method of washing out the tympana. Syringe the fluid into one nostril with the other closed, the fluid entering the tympana by way of the Eustachian tubes. 2. A method of inflating the middle ear. The patient is required to phonate at the moment the inflation-bag is compressed. A short word, ending in a guttural consonant, is advised, as " hic" or "hook."

Gruel $\left(g r u^{\prime}-e l\right)$ [dim. of grutum, meal]. A decoction of corn-meal or oat-meal boiled in water to a thick paste.

Gruff (gruf) [D., grof, coarse]. Any crude drug; also the coarse part of a drug that will not pass through a sieve; the term is used also adjectively, as gruff sulphur or saltpeter.

Grume (groom) [grumus, a little heap]. A clot, as of blood; a thick and viscid fluid.

Grumose (gru'-mōs) [grumus, a little heap]. Same as Grumous.

Grumous (gru'-mus) [grumus, a little heap]. Knotted, clotty, or in granular masses. Formed of coarse, clustered grains.

Grutum (gru'-tum) [grutum, grit]. A small, hard tubercle of the skin, usually seen on the face, and due to retention of sebaceous matter. It is also called Miliary Tubercle and Pearly Tubercle. See Milium.

Gruyère Cheese (gru-yār'). See Cheese.

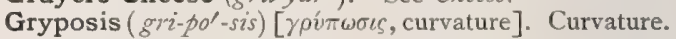
See Arthrogryposis and Onychogryposis.

Gscheidlen's Method. A method of preparing hemoglobin crystals. Take defibrinated blood that has been exposed for 24 hours to the air, and keep it in a closed tube of narrow caliber for several days at $37^{\circ}$ C. When the blood is spread on glass the crystals form rapidly.

Gtt. Abbreviation of gutta, or gutta, drop, or drops.

Guachamaca (gwaw-shaw-maw'-kah) [S. America]. The bark of an apocynaceous tree. G. toxifera, or Malouetia nitida, of $S$. Anerica, furnishes a virulent arrow-poison, somewhat resembling curare; it has been employed in tetanus and hydrophobia. Unof.

Guachata, or Guachacata (g'waze-chaw'-tnh, or gzeazchaw-kat'-ah) [Mex.]. The flowers of a Mexican plant, containing several bitter tonic principles. Unof.

Guacin (gwaw'-sin) [guaco]. A bitter resin from guaco; it is diaphoretic, stimulant, and emetic. Unof. 
Guaco (gvaw'-ko) [S. Amer.]. The leaves of Mikania guaco, much used in S. America for snake-bites. It is thought to be of value in chronic rheumatism. Dose of the fld. ext. $3 \mathrm{ss}-\mathrm{j}$. Unof. Various species of Mikania and Aristolochia are locally known by this name

Guaiac $\left(g w i^{\prime}-a k\right)$ [S. Amer]. See Guaiacum. G.mixture, Fenner's. The Tinctura antucrida $[N$. F.], a tincture of the resin of guaiacum and Canada turpentine, in which each fluidram contains $1 / 3$ of a grain of the corrosive chlorid of mercury. G.test. See Tests, Table of.

Guaiacol (gwi'-ak-ol) [S. Amer.], $\mathrm{C}_{7} \mathrm{H}_{8} \mathrm{O}_{2}$. A substance that occurs in wood-tar, and is also produced on heating pyrocatechin with potassium hydroxid and potassium methyl-sulphate to $180^{\circ} \mathrm{C}$. It is a colorless liquid that boils at $200^{\circ} \mathrm{C}$, and has a specific gravity of I.II7. It is readily soluble in alcohol, ether, and acetic acid, and is recommended instead of creasote in pulmonary tuberculosis. $\quad$ i se $m$ i-ij, or gr. $\frac{1}{12} \frac{1}{6}$. Sciolla (I893) found that topical arplications of guaiacol reduced bodily temperature, and J. Solis-Cohen and $\mathrm{Da}$ Costa (I 894 ) have applied the method successfully in cases of high temperature in typhoid fever and other febrile diseases. The dose is about 30 drops slowly rubbed on the skin of the abdomen or thigh. Unof.

Guaiacum (gwi'-ak-um) [Guaicauans, a tribe of S. A. Indians]. Lignum vitze. The heart of the tree, and also the oleoresin, of $G$. officinale and $G$. sanctum, a prompt diaphoretic, expectorant, and alterative, efficient in tonsillitis, neuralgic dysmenorrhea, amenorrhea, and rheumatism, and formerly much used as an antisyphilitic. Dose gr. $\mathrm{x}-\mathrm{xxx}$. G., Mist. (B. P.) Dose 3 j-iss. G., Resina, the resin of the wood of $G$. officinale. G., Tinct., strength 20 per cent. Dose $\eta^{v-3} j$ in mucilage. G., Tinct., Ammoniat., contains guaiac 20 , and aromatic spirit of ammonia 80 parts. Dose $m v-3 s s$.

Guanin (grwaw'-nin) [Sp., guano, dung], $\mathrm{C}_{5} \mathrm{H}_{5} \mathrm{~N}_{5} \mathrm{O}$. A leukomaine discovered by Unger in $I \checkmark 44$, as a constituent of guano. Since then it has been found in small quantities in the pancreas, liver, and muscle-extract, and has been shown to be one of the decomposition products of nuclein in both animal and vegetable organisms. In the case of the lower animals it is evidently the end-product of katabolic change. It is a white, amorphous powder, insoluble in water, alcohol, ether, and ammonia. Guanin and kreatin appear to mutually replace each other-both being substituted guanidins. Guanin is an intermediate product in the formation of urea. It is non-poisonous and a musclestimulant. See Capranica's Tests.

Guano (grwaze'-no) [Peruv, huanu, dung]. The excrement of sea-fowl found on certain islands in the rainless regions of the Pacific Ocean. It consists essentially of alkaline urates and phosphates. It is used externally in certain skin-diseases. Unof.

Guarana (ywaze-rah'-nah) [the name of a tribe of S. A. Indians]. A dried paste prepared from the seeds of Paullinia cupana, found in Brazil. It contains an alkaloid, guaranin, $\mathrm{C}_{8} \mathrm{H}_{10} \mathrm{~N}_{4} \mathrm{O}_{2} . \mathrm{H}_{2} \mathrm{O}$, identical with caffein. It is employed chiefly in nervous sick-headaches. The commercial preparations are not always trustworthy. Dose of the fld. ext., $\eta_{v-x x x}$; of guaranin gr. j-iij ; of the solid ext. gr. iij- $\mathrm{x}$; of the tincture ( $\mathrm{I}$ in 4 ) $3 \mathrm{ss}-\mathrm{j}$.

Guard (gard) [garder, to keep]. An appliance on a knife to prevent too deep incision. G.-cell, in biology, one of the two semilunar epidermal cells, inclosing the opening of a stoma in plants.

Guardian-cells (gar'-de-an-selz). Same as Guard-cell.

Guarinari's Agar-gelatin. A culture-medium composed of agar-agar 3-4 gms., sodium chlorid 5 gms., peptone 25-30 grms., gelatin $40-60$ gms., water 50 c. c. , meat-infusion 950 c.c.
Guaycuru (grvi-ku-ru') [Sp.]. The S. American name of various plants, as Statica brasiliensis and S. antarctica. The root is a very powerful astringent. Unof.

Gubernaculum testis (gu-ber-nak'-u-lum tes'-tis) [L.]. The conical-shaped cord attached above the lower end of the epididymis and governing the descent of the testes in fetal growth.

Gubler's Tumor. A prominence over the carpus of the dorsum of the hand in chronic wrist-drop from leadpoisoning. See Signs and Symptoms, Table of.

Gudden's Atrophy Method. A method of demonstrating the connection of a nerve-trunk with a center. If a portion of a nerve-trunk is destroyed in a young, growing animal, the peripheral fibers will undergo Wallerian degeneration, while the proximal cells and fibers connected with the destroyed portion will atrophy and disappear. G.'s Commissure, a mass of fibers forming the upper (dorsal) part of the optic tracts. They cannot be demonstrated in man except in cases of complete degeneration of the optic fibers proper. G.'s Ganglion, the cephalo-dorsal ganglion of the mamillary body of the brain. G.'s Law. See Law.

Guérin's Glands. See Gland. G.'s Method. See Treatment, Methods of.

Guernsey Blue. See Pigments, Conspectus of.

Guettard, Glands of. See Gland.

Guidi, Canal of. See Canal.

Guignet's Green. Same as Chrome-green.

Guillotine (gil'-o-tèn) [after Dr. J. I. Guillotin]. A surgical instrument for excision of the tonsils or growths in the larynx, etc.

Guimet Blue. Same as French Blue.

Guinea $\left(g^{\prime} i^{\prime}-e\right)$ [African]. The name of a district on the west coast of Africa. G. Fever, a form of intermittent fever. G.-green. See Pigments, Conspectus of. G. Pepper. See Grains of Paradise. G.-pig, an animal of the genus Cavia, used in bacteriologic investigation. G.-worm, the Filaria medinensis, a nematode worm of tropical countries, that in the human tissues in which it burrows may, unless removed, develop to a length of several feet, producing inflammatory ulceration. See Thread-worm. G.worm Disease, See Dracontiasis.

Gula $\left(g u^{\prime}-l a h\right)[\mathrm{L} .: p l .$, Gulce]. The gullet; the neck and throat, or the pharynx and esophagus. In biology: I. An exoskeletal piece on the under side of the head of certain insects, behind the mentum and between the genæ. 2. The upper portion of the front of the neck of a bird.

Gulancha (goo-lan'-kah) [E. Ind.]. The plant, Tinospora cordifolia, of India. Its stems and roots are diuretic, tonic, and antiperiodic. Unof.

Gular (gu'-lar) [gula, the gullet]. Pertaining to the throat, pharynx, or gula.

Gulinula (su-lin'-u-lah) [gula, throat]. In biology, applied by Hyatt to that stage in the development of an actinozoan in which the actinostome or gullet is formed; it follows the hydroplanula stage.

Gullet (gul'-et). See Esophagus.

Gum [ME., gumme, gum]. A name loosely applied to the concreted juices of plants. Chemically, a sulstance yielding mucic acid when treated with nitric acid. See, also, Gums, and the names of the various gums. G. Arabic, See Acacin. G. Benjamin. See Benzoin. G.-boil, abscess of the gum. G. Dammar. See Dammar. G.-plant. See Grindelia. G.-resins. See Resins. G. Tragacanth. See Tragacanth. G.-wood Tents. See Tupelo.

Gumma (gum'-ah) [Fr., gomme: pl., Gummata]. A soft, elastic tumor resulting from a peculiar kind of caseation of tertiary syphilitic inflammatory deposits. 
Gummatous (gum'-at-zs) [Fr., gomme, gum]. Of the nature of or affected with gummata.

Gummosis (gum-o'-sis) [gummi, gum]. In biology, the transformation of plant-tissue into gum.

Gums (gumz) [ME, gumme, gum]. I. Amorphous, transparent substances widely disseminated in plants. They form sticky masses with water, and are precipitated by alcohol. They are odorless and tasteless. 2. See Gingiva.

Gun-cotton. See Pyroxylin

Gunjah (gun'-jah). See Cannabis.

Gunstock Deformity. A deformity caused by fracture of either condyle of the humerus, in which the long axis of the fully extended forearm deviates outwardly from that of the arm.

Günzburg's Test. See Tests, Table of.

Gurgling Sound. The peculiar sound caused by a gas passing through a liquid. It is heard in breathing, when the bronchi or pulmonary cavities contain fluid, and is observed upon palpation of the abdomen in enteric fever and other conditions in which the bowel is distended with gas and contained liquid.

Gurjun Balsam (ger-jun) [E. Ind.]. Balsamum dipterocarpus, wood-oil. An oleo-resin obtained from several species of Dipterocarpus, trees native to Southern Asia. It is similar to copaiba but more decided in therapeutic effects, and is less unpleasant. It is an admirable expectorant, useful in true leprosy. Dose $m x-z^{i j}$, in emulsion. Unof.

Gussenbauer's Suture. See Suture.

Gustation (gus-la'-shun) [sustare, to taste]. The sense of taste ; the act of tasting. G., Chromatic, the symptom of luminous sensations aroused by the sense of taste of certain substances

Gustative (gus'-tat-iv). See Gustatory.

Gustatory (gus'-tat-o-re) [gustare, to taste]. Pertaining to the special sense of taste and its organs. G. Bud, a taste-bud. G. Cell, a spindle-cell from the interior of a taste-bud. G. Nerve. See Nerve

Gut [ME., gut, intestine]. A common name for intestine. G. Suture. See Catgut. G.-tie, volvulus as occurring in the horse.

Gutta $\left(g u t^{\prime}-a h\right)$ [L. : pl., Gutte]. A drop. Also, freely used as a minim or sixtieth part of a fluid dram. G. nigra, or Black-drop, a dilute acetic acid containing saffron, and flavored with sugar and nutmeg Unof. G. rosacea. See Acne. G. rosea. Synonym of Acne rosacea. G. serena, a synonym of Amaurosis. G.-percha, a substance obtained from the milky juice of different trees of the genus $D i$ chopsis (Isonandra). It forms a fibrous mass, varying in color from nearly white to reddish or brownish, looking like leather-clippings cemented together; it has a specific gravity of.979. Hard and somewhat elastic at the ordinary temperature, at $25^{\circ} \mathrm{C} .\left(77^{\circ} \mathrm{F}\right.$. ) it becomes soft, and at $50^{\circ} \mathrm{C}$. ( $122^{\circ} \mathrm{F}$ ) it can be kneaded or rolled into plates. It is largely used in insulating wires and cables; the best solvents are oil of turpentine, chloroform, and carbon disulphid. G.-p., Liq., a solution in 9I parts of commercial chloroform with 9 parts of lead carbonate. It is employed as a protective application to slight wounds and eruptions. See, also. Traumaticin.

Guttate $\left(g u t^{\prime}-\bar{a} t\right)$ [gulta, a drop]. In biology, spotted as if by drops of something colored.

Guttatim (gut-a'-tim) [gutta, a drop]. A pharmaceutic term signifying drop by drop.

Gutter-water Passages. The liquid stools of a brownish color discharged in typhoid fever.

Guttula $\left(g u t^{\prime}-u-l a h\right)$ [L., dim. of gutta, a drop:pl., Guttula]. In biology, a small spot of color.
Guttulate (gut'-u-lāt) [guttula, a small drop]. In biology, resembling small drops of oil or resin.

Guttur (gut'-er) [outtur, the throat]. The throat with reference to the trachea. G. tumidum. Synonym of Goiter

Guttural (gut'-u-ral) [outturalis, pertaining to the throat]. Pertaining to the throat. G. Pouch, in the horse one of the large air-sacs, diverticula from the Eustachian tubes and lying behind the upper part of the pharynx.

Gutturomycosis (gut-u-ro-mi-ko'-sis) [ guttur, throat; $\mu v ́ \kappa \eta s$, fungus]. An ulcerative affection of the guttural pouches of horses and mules, produced by the parasitic fungus, Gutturomyces equi.

Gutturo-palatine (gut'-us-ro-pal'-at-in) [guttur, the throat; palatum, the palate]. Relating to the pharynx and the palate.

Gutturo-tetany (gut'-u-ro-tet' - an-e) [guttur, throat; tetanus, tetanus]. A form of stuttering in which the pronunciation of such sounds as $g, k, q$, is dificult.

Guyon's Sign. See Signs and Symptoms, Table of.

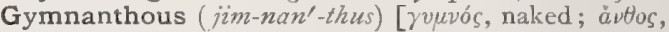
flower]. In biology, applied to flowers wanting in floral envelops.

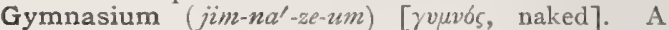
place designed and fitted with appliances for the systematic exercise of the muscles and other organs of the body. Also, in Germany, a high-school.

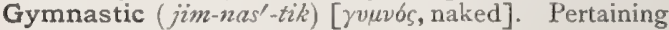
to bodily exercise, or to the science of preserving health by bodily exercise.

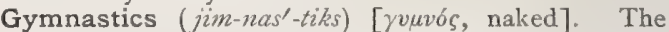
science of preserving (and of restoring) health by bodily exercise. G., Medical, any physical exercise designed to restore or promote health. G., Ocular, regular muscular exercise of the eye to overcome muscular insufficiency. G., Swedish, a system of exercises to restore strength to paretic muscles, and found useful in a great variety of abnormal chronic conditions.

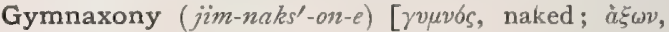
axis]. In biology, a monstrous flower in which the placenta, with its ovules, protrudes from the ovary.

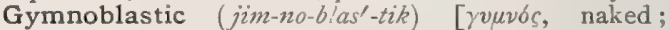
$\beta \lambda a \sigma \tau \delta \varsigma$, germ ]. In biology; applied to those hydroid polyps in which the zoöids are not inclosed in horny receptacles.

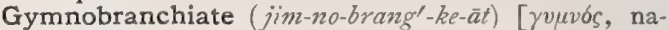
ked; $\beta \rho \alpha \gamma \chi \bar{i} \pi$, gills]. In biology applied to those molluses that have naked gills; nudibranchiate.

Gymnocarpous (jim-no-kar'-pus) [rvuvós, naked; $\kappa \alpha \rho \pi \delta s$, fruit]. In biology, having the fruit naked; applied to lichens and fungi in which the apothecia and hymenia are naked or exposed.

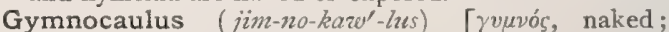
koviós, stalk]. In biology, the immature contractile cord or stalk of a polypid.

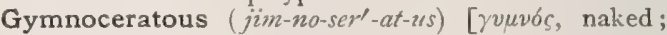
кépas, horn]. In biology, applied to certain insects with prominent antennæe.

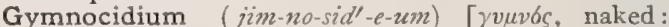
$p l .$, Gimnocidia]. In biology, the swelling at the base of the spore-case in certain mosses.

Gymnocladus (jim-nok'-lad-us). See Chicot.

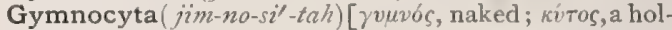
low]. In biology, a naked-celled, unicellular organism.

Gymnocytode (jim-no-si'-tôd) [rvuvós, naked; кútos, a hollow ]. In biology, a naked, non-nucleated, unicellular organism, as a gregarine while in the monerad stage.

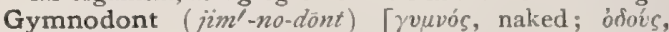
tooth]. In biology, having naked teeth; applied to certain fishes, as the parrot-fish, the globe-fish, etc. 


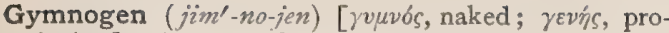
ducing]. Same as Gymnosperm.

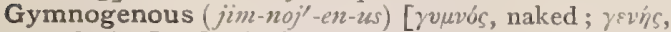
producing]. In biology, applied to birds that are naked when hatched.

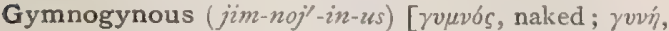
female]. In biology, applied to such plants as have the ovary uncovered.

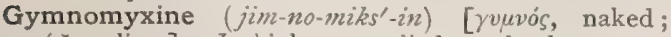
$\mu$ in $\xi a$, slime]. In biology, applied to the lower protozoa.

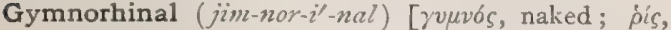
nose]. In biology, applied to birds having the nostrils naked or unfeathered.

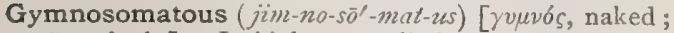
$\sigma \tilde{\omega} \mu \alpha$, body]. In biology, applied to certain molluscs that produce no shell; specifically, naked pteropods.

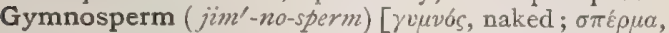
seed]. In biology, a plant characterized by having naked seeds (not inclosed in a pericarp), as in the coniferæ.

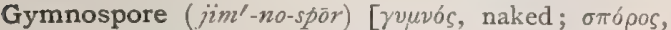
a seed]. In biology, a naked spore.

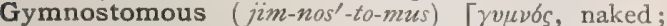
$\sigma \tau b \mu a$, mouth]. In biology, applied to such mosses as have the mouth of the sporangium destitute of a peristome.

Gynæ- $\left(j i n^{\prime}-e\right)$. See Gyne-

Gynæcology (jin-e-kol'-o-je). See Gynecology.

Gynæcomastia (jin-e-ko-mas'-te-ah). See Gynecomastia.

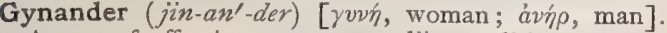
A man of effeminate or woman-like qualities.

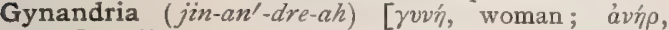
man]. The same as Hermaphroditism.

Gynandrism, or Gynandromorphism (jin-an'-drizm

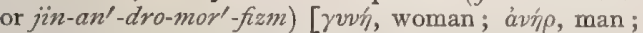
$\mu о \rho \phi \eta ́$, form]. Hermaphroditism.

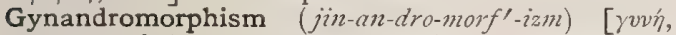
female; ávń $\rho$, male; $\mu \circ \rho \phi \eta ́$, form ]. In biology, applied to such insect-monstrosities as combine both male and female characters.

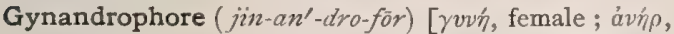
male; $\phi \varepsilon ́ \rho \varepsilon \imath \nu$, to bear]. In biology, a stalk raising the stamens and pistils above the insertion of the corolla.

Gynandrosporous (jin-an-dros'-por-us) [yvvń, female ; áví $\rho$, male; $\sigma \pi 6 \rho \circ \varsigma$, a seed]. In biology, applied to certain algæe that bear both male and female reproductive organs (oögonia and androspores) on the same plant.

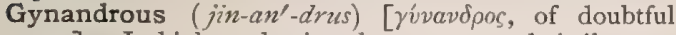
sex]. In biology, having the stamens and pistils more or less intimately united.

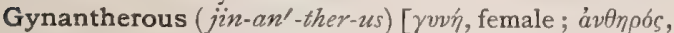
flowering]. In biology, applied to flowers in which the stamens have been converted into pistils.

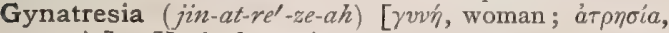
atresia]. Vaginal atresia.

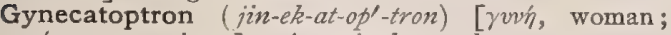

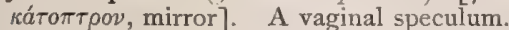

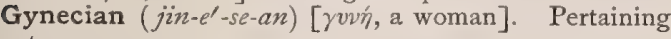
to women.

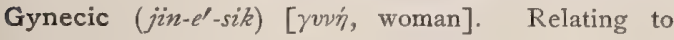
women.

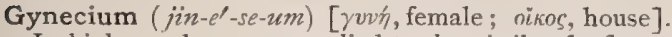
In biology, the name applied to the pistils of a flower taken as a whole.

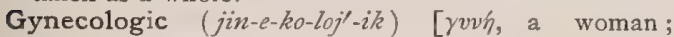
$\lambda$ 'óos, science]. Relating to gynecology.

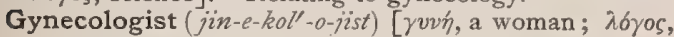
science]. One who practises in gynecology.

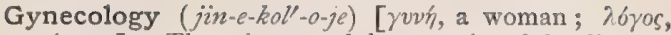
science]. The science and therapeutics of the diseases of women

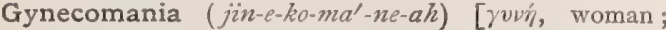
uavía, madness]. Satyriasis.

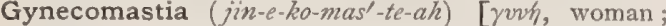

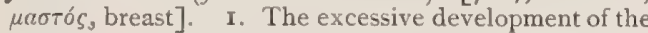
breast of a man, either with or without atrophy of the testicles. 2. The secretion of milk by the male.

Gynecomasty (jin'-e-ko-mas-te). See Gynecomastic.

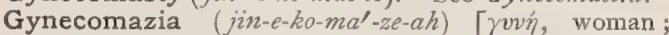

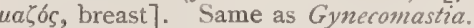

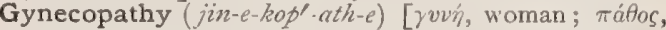
disease ]. Any disease of, or peculiar to, women; the study of diseases of women.

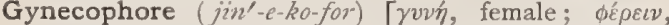
to bear]. In biology, the canal or receptacle in certain male worms, in which the female is retained, as in Bilharzia.

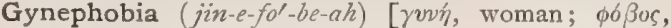
fear]. Morbid aversion to the society of women.

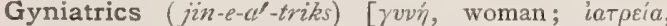
therapy]. Gynecology, or gynecologic therapeutics.

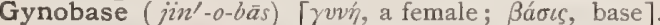
In biology, an elevated portion of the receptacle of a flower, bearing the ovary.

Gynocardia (jin-o-kar'-de-ah). See Chaulmoogra.

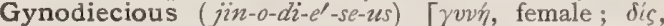
two; olkos, house]. In biology, having pistillate flowers on one set of plants and perfect flowers on another set.

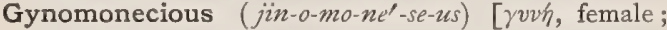

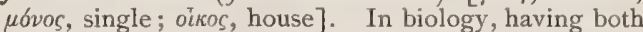
pistillate and perfect flowers upon the same plant.

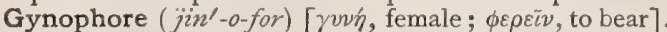
In biology: $(a)$ The stalk of a pistil raising it above the receptacle; $(b)$ The branch of a hydroid gonoblastidium that bears only generative buds containing ova.

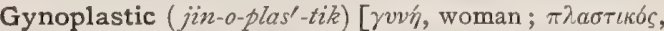
suitable for moulding]. Pertaining to the closing of unnatural openings, or to the dilatation of contracted, narrow openings in the female organs of generation.

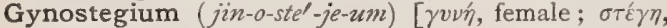
a roof ]. In biology, the sheath or covering of the gynecium, or female portion of a flower taken as a whole.

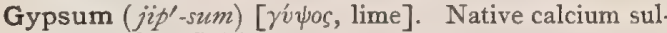
phate. See Calcium.

Gyral ( $\left.j^{\prime \prime}-r a l\right)$ [gyrare, to turn or whirl]. Pertaining to a gyrus or to gyri.

Gyration ( $\left.j i-r a^{\prime}-s h u n\right)$ [gyrare, to turn or whirl]. A turning in a circle; also, giddiness.

Gyre $(j \bar{r} r)$ [gyrus, a circle]. A convolution, and a more commendable word than the polysyllable.

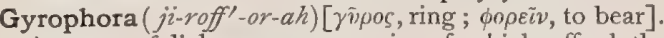
A genus of lichens, some species of which afford the tripe de roche, a rock-tripe of Northern Canada. Though tough, acrid, and unpalatable, these lichens are sometimes eaten when other food is not to be had.

Gyropsoriasis ( $\ddot{j}$-ro-șor-i'-as-is) [yvpós, round;

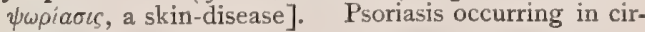
cular patches.

Gyrosa $\left(\ddot{i}-\gamma o^{\prime}-s a h\right)$ [ $\gamma \tilde{v} \rho o s$, a circle]. A variety of gastric vertigo in which, when the patient is standing, everything turns around him, and he must close his eyes to avoid falling

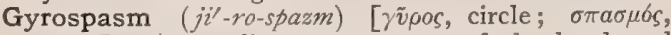
spasm]. A peculiar rotary spasm of the head, and sometimes a nodding spasm.

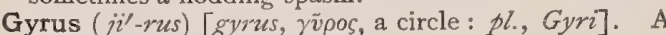
convolution of the brain. See Convolution. 
H. Abbreviation of Hypermetropia. In chemistry, the symbol of hydrogen. In pharmacy, the symbol of Haustus, a draught.

Haarlem Blue. Same as Mineral Blue.

Habena $\left(h a b-e^{\prime}-n a h\right)$ [L., "a rein" $]$. I. A peduncle of the conarium. A slight ridge at the dorsal margin of the mesal surface of the thalamus, with a dorsal convexity, extending from the porta to the supracommissure, which unites it with its opposite. 2. A bandage or strip of plaster for a wound.

Habenal, or Habenar (hab-e'-nal, or hab-e'-nar) [habena, a rein]. Relating to the habena.

Habenula (hab-en'-u-lah) [habena, a rein]. A ribbonlike structure. The superficial gray nucleus of the optic thalamus in front, and superior to the posterior commissure. H. conarii. Same as Habena. H. pectinata, perforativa, and tecta (or arcuata), names of different zones, or portions of the basilar membrane of the internal ear; called also Zona pectinata, etc.

Habenular (hab-en'-u-lar) [habena, a rein]. Pertaining to an habenula.

Habit (hab'-it) [habere, to have]. 1. That condition or quality that one naturally possesses, or that may be acquired. 2. The tendency to repeat an action or condition. 3. In biology, the general aspect of a plant or animal and its mode of growth. H.-chorea. See H.-spasm, H., Full, of a plethoric constitution. H.spasm; Habit-chorea; Convulsive Tic; Gilles de la Tourette's Disease. A choreic disease characterized by simply localized spasmodic movements, or such movements combined with explosive utterances and psychic symptoms (convulsive tic). Habit-spasm is confined chiefly to young girls, and is marked mainly by spasmodic action of the facial muscles or of the head. Convulsive Tic or Gilles de la Tourette's Disease is a psychosis allied to hysteria, and occurring usually in children of a neurotic tendency. It is marked by involuntary muscular movements, usually affecting the facial or brachial muscles, and by explosive utterances that may resemble a bark or an inarticulate cry. A word heard may be mimicked at once and repeated over and over again, usually with the involuntary movements. To this the term Echolalic has been applied. Coprolalia, or the use of bad language, is another symptom, and occasionally actions are mimicked (echokinesis). These may also be associated with curious mental disturbances, the patient becoming the subject of a form of obsession or a fixed idea.

Habitat $\left(h a b^{\prime}-i t-a t\right)$ [habitare, to dwell]. The natural locality, or geographic range of an animal or plant.

Habitation (hab-it-a'-shun) [habitatio, a dwelling]. A dwelling-place. The home, dwelling-place, or natural locality of an animal or a plant.

Habitus (hab'-it-us) [habere, to have]. A habit; general appearance or expression.

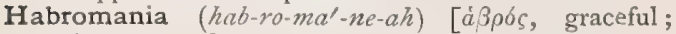
uavia, madness]. Insanity with pleasant or agreeable delusions.

Hachement (hahsh-mon'g)') [Fr., hacking, or chopping]. In massage, a succession of strokes, usually with the ulnar edge of the hand, sometimes with the border of the percutor.

Hackberry (hak'-ber-e). See Celtis.

Hacking (hak'-ing). See Tapotement and Hachement.

Haddock (had'-ok) [ME, haddok, haddock]. A fish, Gadus aglefinus, closely allied to the cod. It is said that the oil of the liver of the haddock is sometimes mixed with cod-liver-oil; but such admixture is probably rare, as it greatly impairs the market value of the oil. Unof.

Hæckel's Law. See Law.

Hæma- (hem'-ah-) [ai Ha $^{\prime}$, blood]. A prefix signifying some relationship with the blood. For words (unless unanglicized) thus beginning, see Hema-.

Hrmal (hem'-al). See Hemal.

Hæmanthin (hem-an'-thin). See Hemanthin.

Hrematoxylin (hem-at-oks'-il-in). See Hematoxylon.

Hæmin $\left(h e m^{\prime}-i n\right)$. See Hemin.

Hæmo- (hem'-o-). For words thus beginning see Hemo-.

Hæmorrhage (hem'-or-ajj). See Hemorrhage.

Hæser and Neubauer's Formula. A formula for estimating from the specific gravity the total amount of solids in the urine; it is sufficiently accurate for clinical purposes. The estimation is made by multiplying the last two figures of the specific gravity by the factor 2.33, the product of which represents the number of grams of solids in $1000 \mathrm{c} . \mathrm{c}$. of the urine; this must be multiplied by the number of c.c. of the urine under examination and divided by 1000 in order to obtain the correct amount of solids.

Hagenia (haj-e'-ne-ah). See Kusso.

Hager's Reagent. A reagent for the detection of sugar in the urine. It consists of the ferrocyanid of iron and caustic potassa.

Hahnemannism (hahn'-e-man-izm). See Homeopathy.

Haidinger's Brushes. A visual phenomenon seen upon directing the eye toward a source of polarized light, due to the doubly-refractive character of the elements of the macula.

Hair (här) [ME., here, hair]. The hirsute appendage of the skin. Each hair consists of a bulb and a shaft. The former is situated in the true skin, but is enveloped in a sheath of epidermis. H.-blanching. See Canities. H.-bulb, a whitish, soft, bulbous enlargement at the proximal extremity of the root of the hair. H.cap Moss, Robin's Rye; the leaves and stems of Polvtrichum juniperum, a powerful diuretic. Dose of the decoction ad lib.; of the fld. ext. $z$ j-ij. Unof. H.-despoiler, an individual who is afflicted with a form of sexual perversion, in which the feelings are aroused during the act of mutilating or cutting-off the hair of the victim. H.-follicle. See Follicle. H.gland, a minute sebaceous gland of the hair-root. H.-knob, Henle's term for a hollow, bulbous hairroot. H.-papilla, the nipple-like process of the corium from which the hair grows. H.-pigment, the coloring-matter of the hair. H.-pith, the medulla of a hair. H.-root, that portion of a hair contained in the follicle. H.-shaft, the part of a hair above the root. (See illustration, page 539.)

Hairy (hâr'-e) [ME., here, hair]. Covered with hair; consisting of hair. H. Heart. See Trichocardia and Cor villosum. H. Tongue. See Nigrities.

Halberd-shaped ( $h a l^{\prime}$-berd-shäpt). Same as Histate. Hale (häl) [ME., heil, in good health]. Sound; healthy; robust.

Half $(h a(h) f)$ [ME., half, half $]$. One of two equal parts. H.-bath. See Bath. H.-breed, a popular term applied to offspring whose parents belong to different races. H.-lying, in massage, reclining at an angle of about $45^{\circ}$. H. Neck-rest, in massage, having one hand supporting the neck posteriorly. H.-wit, a 
weak-minded person; an idiot. H.-witted, idiotic; weak in intellect.

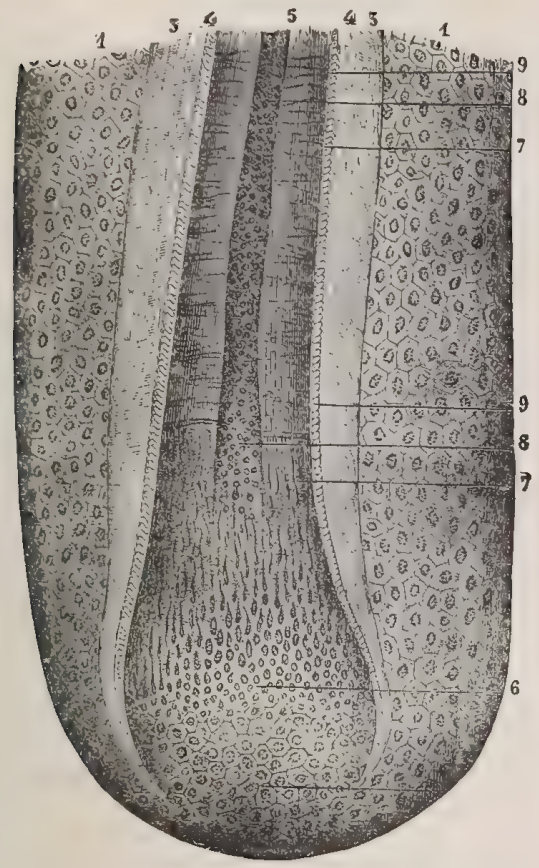

Root of A HAIR AND ITS EPIDERMIC SHEATH.

I, I. External layer of epidermic sheath. 2, 2. Its inferior extremity. 3, 3. Internal layer. 4, 4. External layer of cuticle of hair. 5. Root of hair. 6 Bulb of root. 7,7 . Its peripheral or fibrous portion. 8. Its central or medullary portion. 9.9. Internal layer of cuticle of hair.

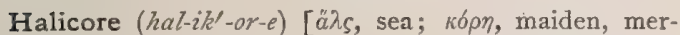
maid]. See Dugong.

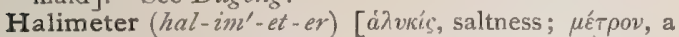
measure]. An instrument for estimating the proportions of water in milk by means of its power to dissolve common salt.

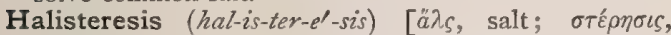
privation]. The loss by fully-formed bones of $1 / 3$ to $1 / 2$ their lime-salts, resulting in osteomalacia.

Halituous (hal-it'-u-us) [halitus, breath]. Moist, as if from having been breathed upon; applied to the skin.

Halitus (hal'-it-us) [L., a vapor]. A vapor. Also, expired breath. H. oris fotidus, tainted or foul breath. H. sanguinis, the characteristic smell of the blood, peculiar to each kind of animal.

Hall's (Marshall) Disease. See Diseases, Table of. H.'s Method. See Artificial Respiration.

Haller, Ansa of. See Ansa. H., Circle of. See Circle and Circulus. H., Cones of, the Coni vasculosa. H., Fretum of. See Fretum. H., Line of. See Lines, Table of. H., Network of, the Rete vasculosum of the testis. H., Passage of, in the embryo the narrow passage joining the auricle and ventricle of the heart.

Hallex (hal'-eks) [L.]. See Hallux.

Hallucal (hal'-u-kal) [hallux, the great toe]. Pertaining to the hallux, or great toe.

Hallucinatio (hal-lere-sin- $\left.a^{\prime}-s h e-o\right)$ [L.]. Hallucination. H. hypochondriaca. Synonym of Hypochondriasis.

Hallucination (hal-lew-sin- $a^{\prime}-\operatorname{shun}$ ) [hallucinari, to wander in mind]. The highest degree of subjective sensation, dependent alone upon morbid stimulation of the sensory cortical centers. There is the perception of non-existent objects or impressions, creations of the imagination. Hallucinations are variousily classed as hypochondriac, hypnagogic, motor, negative, pseudo-sensorial, unilateral, visual, auditory, gustatory, olfactory, tactile, hemiopic, epileptoid, etc.

Hallux, or Hallus (hal'-uks or hal'-us) [L.]. The great toe. The great toe when overriding the second toe. H. dolorosus. See H. Rexus. H. flexus; Hallux rividus; Hallux dolorosus; a condition allied to and perhaps identical with hammer-toe, in which there is flexion of the first phalanx of the great toe. The second phalanx is usually extended upon the first, and there is more or less rigidity of the metatarsophalangeal joint. H. rigidus. See $H$. Rexus. H. valgus, displacement of the great toe toward the other toes. H. varus, displacement of the great toe away from the other toes.

Halo $\left(h \alpha^{\prime}-20\right)$ [ä $\omega s$, a threshing-floor]. I. The brownish circle about the female nipple, called also the areola. 2. The luminous or colored circles seen by the patient about light in glaucoma.

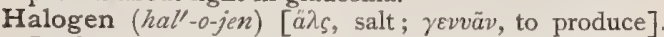
In chemistry, an element that forms a compound of a saline nature by its direct union with a metal. The halogens are chlorin, iodin, bromin, and fluorin, to which cyanogen may be added as a compound halogen.

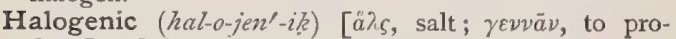
duce ]. Salt-producing; producing haloids.

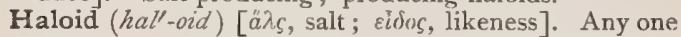
of those compounds that consist of a metal directly united to chlorin, bromin, iodin, fluorin, or cyanogen.

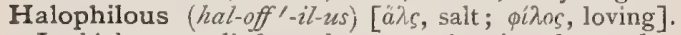
In biology, applied to plants growing in salt marshes and along sea-coasts.

Halstern's Disease. See Diseases, Table of.

Halt (hawlt) [ME., halt, lame]. I. Lame. 2. To limp. 3. A disease in sheep.

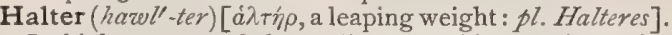
In biology, one of the rudimentary hinder wings of a fly; it is also called poiser or balancer.

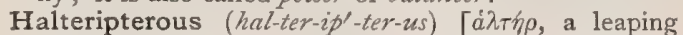
weight ; $\pi \tau \varepsilon p \delta \nu$, wing]. Having halteres; applied to dipterous insects.

Halved (hahvd) [ME., half, half ]. In biology, applind to bilaterally symmetric organs in which one side is wanting, as in certain leaves.

Ham [ME., hamme, the ham]. That part of the leg between the knee-joint and the hip-joint. H.-string, one of the tendons of the posterior muscles of the thigh. Also, to cripple by cutting the tendons of the muscles of the thigh. H., Inner, the tendons of the semimembranosus, sartorius, and semitendinosus muscles. H., Outer, the tendons of the biceps flexor cruris.

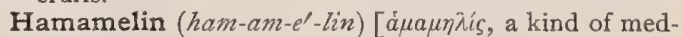
lar or service-tree]. A precipitate from a tincture of the bark of witch-hazel, Hamamelis virginica; it is astringent, tonic, and sedative. Dose gr. j-iij. Unof. Hamamelis (ham-am-e'-lis) $[a \mu \alpha$, together with; $\mu \tilde{n} \lambda o v$, apple-tree: gen., Hamamelidis]. Witchhazel; the leaves of $H$. virginica, with properties not fully known. It is thought to be tonic, styptic, and sedative, and appears to affect the circulation in a manner similar to aconite. It is highly recommended as a hemostatic. A preparation of this drug is sold under the name of Pond's Extract. H., Fld. Ext. Dose $m j-3 j$. H., Tinct. (B. P.) (alc.), I in Io. Dose $\eta_{i j-v}$.

Hamann's Acid Carmin. See Stains, Table or. 


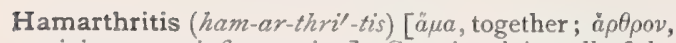
a joint; $\iota T \iota S$, inflammation]. Gout involving all of the joints.

Hamate or Hamose ( $h a^{\prime}-m a \bar{t}$, ha'-mōs) [hamus, a hook ]. In biology, hooked, uncinate.

Hamburg Blue. Same as Berlin Blue. H. White. See Pigments, Conspectus of. H. Yellow. Same as Chrome-yellow.

Hamilton's Bandage. See Bandage.

Hammarsten's Theory of Coagulation. A theory that claims that fibrin is formed from one body only, namely, fibrinogen.

Hammer (ham'-er) [ME., hamer, a hammer]. In anatomy, the malleus. H.-bone, the malleus. H.cramp. See Cramp, Blacksmiths'. H., Thermal. Same as Cautery Button. H.-toe. See Hallux.

Hammerman's Cramp. A spasmodic, and sometimes painless, affection of the muscles of the upper extremity. It is seen in those that use a hammer, and is due to over-use.

Hammock (ham'-ok) [Span., hamaca, a hanging mat]. A couch or bed made of netting or canvas, suspended at the ends. It is much used aboard vessels and in tropical regions; it has been used latterly in the transportation of the sick and wounded. Slings for fractured legs, etc, are sometimes called hammocks.

Hammond's Disease. See Athetosis, and Diseases, Table of.

Hamular (ham'-u-lar) [hamus, a hook]. Pertaining to or shaped like a hook.

Hamulate, Hamulose (ham'-u-lāt, -lōs) [hamus, a hook]. Hooked or hook-shaped.

Hamulus (ham'-u-luss) [dim. of hamus, a hook: pl. and gen., Hamuli]. In anatomy, a hook-shaped process, as of a bone; any unciform process. $\mathbf{H}$. of the Cochlea, the hook-like process of the osseous lamina at the cupola.

Hamus (ha'-mus) [L., a hook: pl., Hami]. In biology, a hooked process found on the wings of certain insects, which, together with the tendo, helps to keep the wings together during flight.

Hamy's Plane, See Plane.

Hanchinol (han'-chinol). See Heimia.

Hancock's Opera tions. See Operations, Table of.

Hand [ME., $h a n d$, hand]. The organ of prehension in bimana and quadrumana, composed of the carpus, the metacarpus and the phalanges. H., Ape. See Main en griffe. H., Claw. See Main en griffe. H., Dropped. See Dropped. H.gout. See Chiragra. H.-litter. See Stretcher. H., Monkey. See Main en griffe.

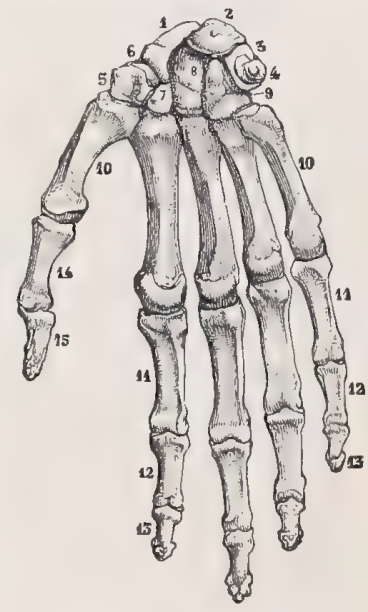

Hand, Palmar Surface.

I. Scaphoid 2. Semilunar. 3 Cuneiform. 4. Pisiform. 5 Trapezium. 6. Groove for tendon of flexor carpi radialis. 7. Trapezoid. 8. Os magnum. 9 Unciform. 10, 10 Metacarpal bones. II, II. First phalanges bones. II, II. First phalanges
of fingers. I2, I2. Second of fingers. 12, I2. Second anges. I4. First phalanx of thumb. 15. Second phalanx.
Handkerchief (hang-ker-chif) [ME., hand, hand; kerchef, a kerchief]. A square piece of cloth for wiping the face or nose. H., Barton's ; a handker- chief is folded in the form of a cravat, and the body is so placed on the point of the heel that the portion on the outer side of the foot is one-third longer than the other portion. The short part is held parallel with the sole of the foot while the long part is carried across the instep, turned round the inner part, carried back under the sole of the foot and looped round its own side. The two ends are then tied together for the purpose of exerting traction.

Handkerchief-Dressing. A form of temporary dressing for wounds and fractures made of handkerchiefs. There are two varieties, viz., cravats, in which the handkerchiefs are folded into rolls like cravats; and triangles, the handkerchiefs being folded diagonally in the form of triangles. The most important cravats are the following: C., Abdomino-inguinal ; two handkerchiefs are folded into cravats and their ends tied together. The body of one is placed beneath the thigh, close up to the nates; the ends are brought to the front, crossed over the groin, then carried round the opposite sides of the body, and tied together on one side rather than behind, so that the knot shall notpress injuriously upon the back. C., Axillo-acromial.

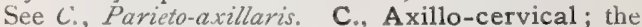
body of the cravat is placed in the axilla, the ends crossed over the shoulder, and tied on the opposite sides of the neck. C., Cervical; a handkerchief is formed into a cravat, the body placed on the front, back, or sides of the neck, according to the part to be dressed, the ends are carried around, crossed on the opposite side and returned, and fastened with pins. C., Compound Bisaxillary; for this two handkerchiefs in cravat form are required. One is tied as an axillo-acromial cravat through one axilla, while the body of the other is placed in the opposite axilla, and its ends, being brought across the chest, one in front and the other behind, are passed through the loop of the first and tied in front of the breast. C., Compound Bis-axillo-scapulary; form two handkerchiefs into cravats. Tie one as a loose ring, or form the axillo-acromial cravat of one side, and, placing the body of the other in front of the opposite shoulder, bring the ends back, one over the shoulder and the other through the axilla; then form these into a single knot, and complete the dressing by passing the ends through the ring or loop of the other cravat, and tying them into a knot. C., Fronto-occipito-labialis ; the handkerchief is formed into a cravat and the middle portion is placed upon the forehead; the ends are carried back, crossed upon the posterior part of the neck, brought forward under the ears and crossed over the upper lip. This is used to approximate lip-wounds. C., Ilio-inguinal, a double cravat, also called the sacro bi-crural cravat of Mayor. The body of a long cravat is placed over the body of the sacrum, the two extremities are brought around the body down in front of each groin and around the thighs, to be fastened on the opposite side of the body. C., Ilio-inguinal, or the cruro-pelvic cravat of Mayor. The body of a large cravat is placed over the inguinal region, the upper extremity is carried around the body, the lower extremity around the thigh, and the two ends knotted in front. C., Metatarso-malleolar; place the body of the cravat obliquely across the dorsum of the foot; carry one end under the foot and up in front of the ankle, and the other around the leg above the malleoli, fastening them together in front of the joint. C., Parieto-axillaris; one handkerchief is formed into a cravat, and its body is placed in the axilla, the ends tied over the shoulder, forming the axillo-acromial cravat. A second handkerchief is made into a triangle, and its body placed over the side of the head, and its ends tied into the first over the shoulder. It is 
used to approximate wounds on the side of the neck and to prevent contraction after burns. C., Simple Bis-axillary; place the body of the cravat in the axilla, cross the ends over the shoulder, and after carrying one across the back and the other across the breast, tie them together at the anterior border of the axilla of the opposite side. C., Simple Bis-axillo-scapulary ; this is a posterior figure-of-eight, and is best formed with a strip of muslin three inches wide and ten yards long. Place the center of the strip in front of the shoulder and the axilla; bring one end back over the top of the shoulder and the
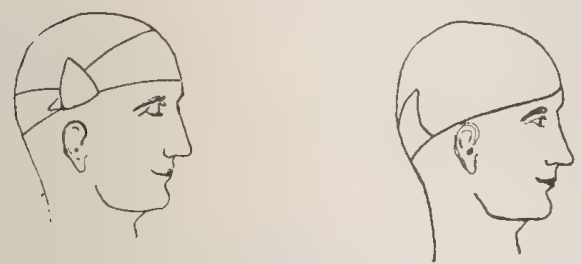

Bi-temporal Triangle.

Fronto-occipital Triangle.

knee, and pinned or tied as they are turned downward. C., Tibial ; place the body of a handkerchief, folded into a cravat, obliquely across the posterior surface of the leg, and carry the extremities around the limb, the one below the knee, and the other above the malleoli. Mayor's Bandage for Fractured Clavicle; the arm is flexed at a right-angle and confined to the side of the chest by a triangular handkerchief, the base being placed above the forearm and the two extremities fastened on the back, the apex hanging down in front. The two folds forming the apex are carried up between the arm and the body and the under one is passed to

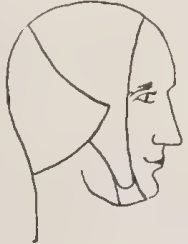

Auriculo-occipital Triangle.

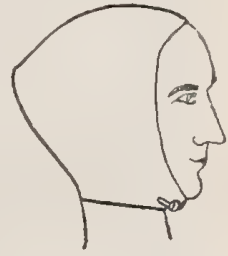

Triangular or Hunter's Cap of the Head.

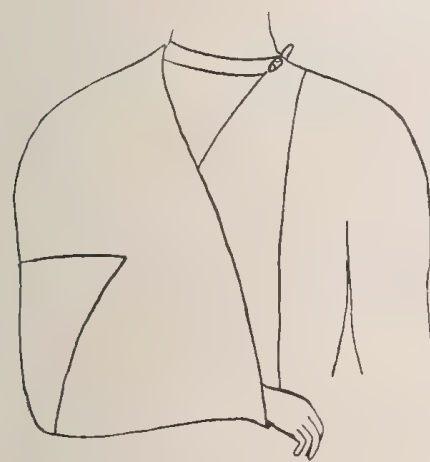

Brachio-cervical Triangle.

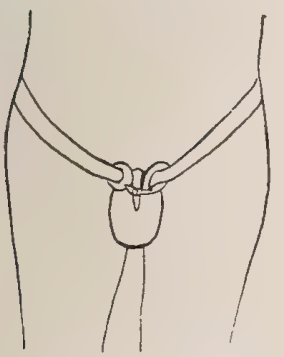

Scroto-lumbar Triangle.

(Suspensory Bandage of the Scrotum).

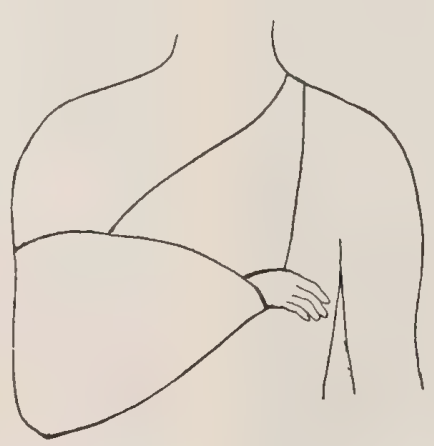

Oblique Triangle of the Arm and Chest.

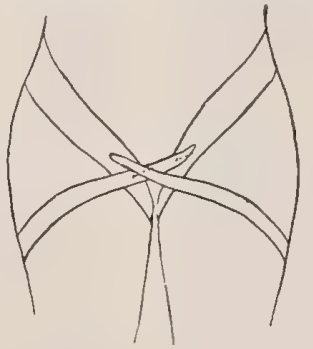

Ilio-inguinal Cravat (double). The Sacro Bi-crural Cravat of Mayor.

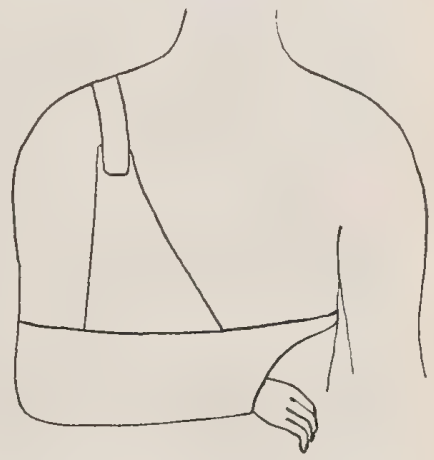

Mayor's Bandage for Fractured Clavicle.

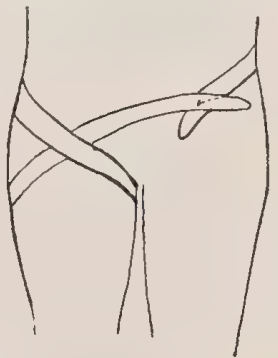

Ilio-inguinal Cravat.

(The Cruro-pelvic Cravat of Mayor) other through the axilla, cross them between the scapulæ, carrying the axillary end over the shoulder of the opposite side and back through the axilla, and the humeral end forward through the axilla, the two overlapping each other; then fasten their ends front and back. This is an extemporaneous dressing for fracture of the clavicle. C., Tarso-patellar; this requires three handkerchiefs, all in cravat-form. One is to be placed about the knee as a figure-of-eight; a second round the foot in front of the ankle; the third is passed through the loop of the latter, the ends being carried on either side through the figure-of-eight of the the sound shoulder, while the upper one is carried to the affected shoulder. A broad piece of bandage is fastened to one apex and carried beneath the handkerchief at the back and is then brought up and fastened to the other apex on the opposite shoulder.

The most important triangles are the following : $\mathbf{T}$., Auriculo-occipital, a variety of handkerchief-dressing for the head, used in keeping an application to the ear in proper place. The base of the handkerchief is placed in front of the ear to be covered, and the apex directed backward. The lower end is next carried under the jaw and up over the face in front of the 
ear on the sound side, where it is made to meet the upper end, the two being tied together. T., Bi-temporal, a form of handkerchief head-dressing, the base being placed over the temporal region upon one side and the apex over the other. The ends are carried round to the opposite temple, crossed, brought back, and secured with pins, and the summit or apex is turned up and pinned above the temporal ridge. T., Fronto-occipital, a variety of handkerchief-dressing in which the base is placed over the forehead, while the summit is allowed to hang down over the occiput. The ends are next carried backward along the sides of the head, above the ears, and either tied behind the occipital protuberance, or crossed, brought forward, and pinned at each side. The apex is then turned forward and pinned to the body of the handkerchief. T., Malleolophalangeal; form the handkerchief into a triangle; place the base under the foot opposite to the instep; fold the summit back over the toes and the dorsum of the foot, and carry the ends round the malleoli, making them fast in front. Tie the ends in front, or cross them over the dorsum and tie under the sole of the foot. T., Mammary; fold a handkerchief into a triangle; place its base under the breast and its apex over the corresponding shoulder; then carry one end under the axilla and the other over the opposite side of the neck, tying the two behind the scapula of the affected side, and pin to these the summit. T., Oblique, of the Arm and Chest; the base of the triangle is placed under the wrist, the apex being allowed to project beyond the elbow. The extremity that is next to the chest is carried over the opposite shoulder, the other extremity being passed through the axilla of the injured side and tied with the first extremity over the sound shoulder. The apex is folded backward around the elbow and fastened. T., Occipito-frontal ; the same as the fronto-occipital, only that the handkerchief is reversed, the base being placed over the occiput. T., Occipito-sternal ; one handkerchief is formed into a triangle and another into a cravat. The latter is tied around the chest, forming the sterno-dorsal cravat. The body of the former is placed over the occiput and its apex over the forehead. The ends are brought down on each side of the face and fastened to the cravat about the chest. The apex is turned backward over the vertex, and pinned. T., Palmar; the base of the handkerchief is placed across the back or the front of the wrist, according as it is designed to dress the palm or dorsum of the hand; the summit is folded back upon the wrist, and secured there by carrying the ends around the same. T., Scroto-lumbar. See $T$., Suspensory. T., Simple Brachio-cervical; the arm being flexed at a right-angle the base of the triangle is placed under the wrist, and the two extremities are tied around the neck, the knot being thrown to one side. The apex is brought round the elbow and pinned in front. T., Suspensory; Scroto-lumbar Triangle; fold one handkerchief into a cravat and tie it around the loins; form another into a triangle, the base of which should be placed under the scrotum, and the extremities brought up, passed beneath the circular cravat and tied in front. The apex is next carried up, passed beneath the abdominal cravat and turned down in front, where it may be fastened with a pin. T., Verticomental, a form of handkerchief head-dressing in which the body of the handkerchief is placed over the vertex, the ends brought down over the ears and crossed under the chin, carried upward and pinned to the descending portion of the handkerchief. The apex is brought round one side of the head, and secured with a pin. The Triangular or Hunter's Cap of the Head; a piece of material is secured, with the side sufficiently long to pass over the head and fasten under the chin. First fold it transversely across until one side is within an inch of the opposite side; the short side is then placed beneath ; the two corners of the folded edge are turned inward, forming a triangle. The two extremities of the triangle are taken in either hand, and while kept tense are twisted and rolled up to the extent of two inches. Lifting the bandage and approximating the hands cause the two sides to separate. It is placed on the head with the thin edge over the forehead and the rolled edge around the back of the neck. The ends are brought under the chin, and tied.

Handwriting (hand'-ri-ting). See Graphology.

Hanging (hang'-ing) [ME., hangynge, banging]. Death by suspension of the body from the neck, by a rope provided with a slip-noose. The immediate cause of death may be asphyxia, cerebral hemorrhage (from strangulation), or dislocation or fracture of the cervical vertebræ.

Hangnail (hang'-nāl) [AS., angnagl, a sore by the nail]. A partly detached piece of epidermis at the root of the nail, the friction against which has caused inflammation of the abraded surface.

Haouwa [E. Ind.]. Synonym, in Bagdad, of Asiatic Cholera.

Hapantismus (hap-an-tiz'-mus) [ã $\pi \alpha \varsigma$, entire]. Complete adhesion between parts or surfaces.

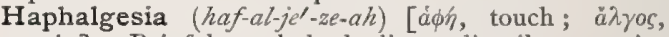
pain]. Painful touch by bodies ordinarily not painful.

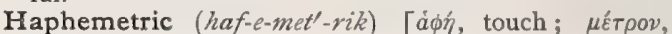
measure]. Relating to esthesiometry. See Esthesiometer.

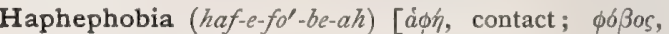
fear]. The morbid dread of touching persons or things; mysophobia.

Haphonosus (haf-on'-o-sus) [åón, touch; voбos, disease]. Any disorder of the sense of touch.

Haplodermitis (hap-lo-der-mi'-tis) [äinbos, simple; $\delta \varepsilon ́ p \mu a$, skin; $\iota \tau \iota \zeta$, inflammation]. A simple or uncomplicated skin-inflammation.

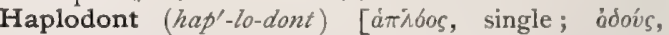

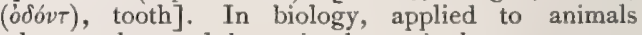
whose molar teeth have simple or single crowns.

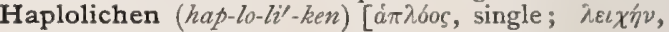
lichen]. Same as Lichen simplex, q. v.

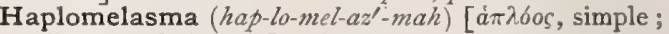
$\mu \varepsilon \dot{\lambda} a \sigma \mu a$, a livid spot]. Simple melasma.

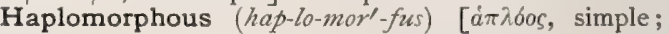
$\mu \circ \rho \phi \eta$, form]. In biology, applied to the simpler forms of certain groups.

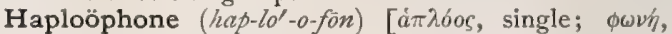
voice]. In biology, applied to the form of the syrinx in certain birds $(e . g .$, Xenicida) which have but one intrinsic syringomyon.

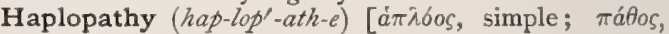
iilness]. Any uncomplicated disease.

Haplopetalous (hap-lo-pet'-al-us) [ảiłóos, single;

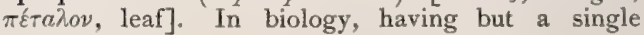
circle of petals.

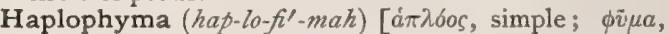
a tumor]. A simple tumor.

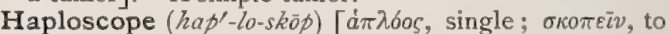
see]. An instrument for measuring the visual axes.

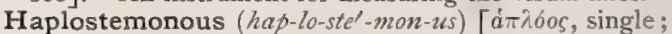
$\sigma \tau \eta \mu \omega v$, a thread]. In biology, having but a single circle of stamens.

Haplotomia, Haplotomy, (hap-lo-to'-me-ah, hap-lot' omme) $[\dot{a} \pi \lambda \sigma o s$, simple; $\tau o \mu \eta$, a cut]. A simple incision.

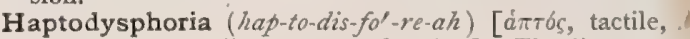
touched; $\delta \dot{v}$, , difficult ; фopós, bearing]. The disagree- 
able sensation aroused by touching certain objects, as velvet, a peach, or a russet apple.

Haramaitism (har-am-a'-it-izm) [Anglo-Indian; from Haram maiti, the name of an Hindu offender in this way]. Child-marriage in India; also, the collective physical evils that result from that system.

Hard [ME., hard, hard]. Solid; firm to the touch. H.-hack, the leaves and twigs of Spiract tomentosa ; it is astringent and tonic, and a popular New England remedy in diarrhea and cholera infantum. Dose gr. $v-x v$, in decoction; of the fld. ext. 3 ss $-\mathrm{j}$. Unof. The shrub Potentilla fruticosa is locally called hardhack; its properties are the same as those of the species named. H. Palate. See Palate. H. Pitch. See Pitch. H. Resins. See Resins. H.tack, a form of biscuit used in the navy and army.

Hardenbergia (har-den-ber'-je-ah) [after Countess Hardenberg]. A genus of Australian leguminous plants. The root of $\mathbf{H}$. monophylla, called lilac, and sarsaparilla, is said to be a good substitute for true sarsaparilla. Unof.

Hardening (hard'-en-ing) [ME, hard, hard]. A stage in the preparation of tissues for microscopic examination. See Alcohol, Ammonium Chromate, Ammonium Bichromate, Potassium Bichromate, Müller's Fluid, Erlicki's Fluid, Chromic Acid, Klein's Fluid, Rabl's Fluid, Corrosive Sublimate, Picric Acid, in Stains, Table of. Alcohol for pieces under I inch square, and the bichromate solutions for larger masses, are best for general use; others in special cases; but in all, full twenty times the bulk of the object should be used. See Stains, Table of.

Harder's Glands. See Gland.

Hare's Method. A method of determining the position on the skull corresponding to the fissure of Rolando. The pre-Rolandic region occupies 55.7 per cent. of the distance from the glabella to the inion.

Hare-eye (har'-i). See Lagophthalmos.

Harelip $\left(h \bar{a} r^{\prime}-l i p\right)$. Congenital fissure of the lip due to arrested facial development. The scheme of the formation of cleft is shown in the annexed illustrations. H., Complicated, with cleft or malformation of the superior maxillary bone also. H., Double, two clefts of the lip, or one of each lip. Twisted or Harelip Suture, a figure-of- 8 suture about a pin thrust through the lips of freshened edges of the cleft. For operations for single harelip see Clemot's, Collis's, Dieffenbach's, Giralués', Graefe's, Hagedorn's, Malgaigne's, Mirault's, Nelaton's, Paré's, Rose's, Stokes' Opera. tions; and for operations for double harelip see Bardeleben's, Blandin's, Butcher's, Desault's, Franco's, Gensoul's, Langenbeck's, Rose's, Sédillot's, Smith's Operations, in Operations, Table of.

Harlequin (har'-le-kwin) [OF., harlequin, a harlequin]. Variegated; party-colored. H. Fetus, a fetus with congenital ichthyosis, general seborrhea, or diffuse keratoma. Such subjects are always born prematurely, and have no external ears, eyelids, or lips.

Harmalin (har'-mal-in) [a $\rho \mu a \lambda a], \mathrm{C}_{13} \mathrm{H}_{14} \mathrm{~N}_{2} \mathrm{O}$. A yellowish crystalline substance used as a dye. See Pigments, Conspectus of.

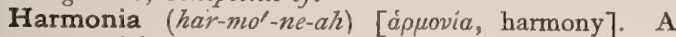
suture (also a mode of suture) between two bones that are apposed closely and immovably upon each other.

Harmonics (har-mon'-iks). See Over-tones.

Harpoon (har-poon') [Fr., harpon, a grappling-iron]. An instrument for the removal of bits of living tissue for microscopic examination.

Harrison's Groove. A transverse curve passing outward from the level of the ensiform cartilage toward the axilla. It may be deepened at each inspiration in certain diseases, e.g., rickets.

Hartig's White Mass. A substance for injecting tissues. Dissolve 125 gms. of lead acetate in enough water to make the whole weigh 500 gms. Dissolve 95 gms. of sodium carbonate in enough water to make the whole weigh 500 gms. One volume of each of these solutions is mixed with two volumes of strong gelatin solution.

Hartmann's Elixir. An elixir containing camphor 50 parts, and saffron $I$ part, in alcohol 350 parts. H.'s 'Tubes, small tubes devised to be passed through a perforated drum-membrane for the purpose of irrigating and draining the middle-ear cavity

Hartshorn (hart'-horn). I. Cornu cervi. 2, A name popularly given to ammonium hydrate. See Ammonium.
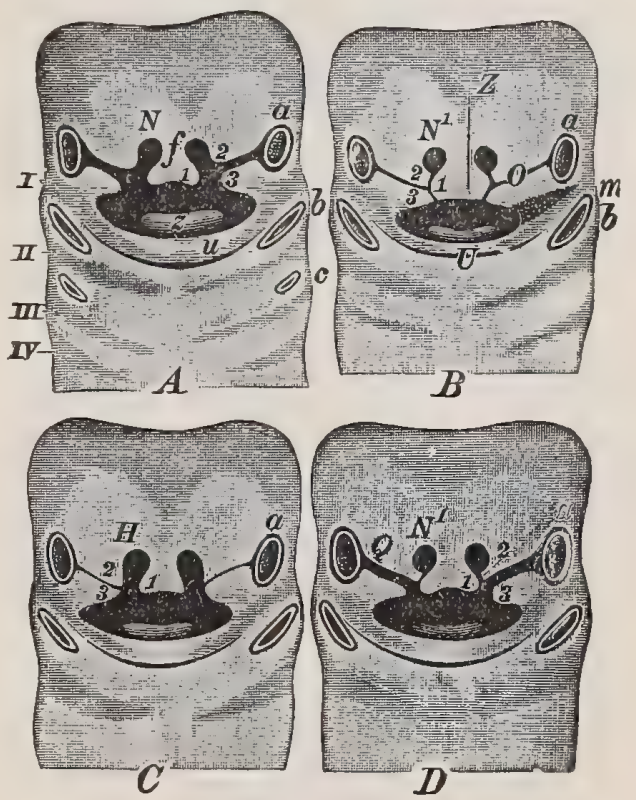

SCHEME OF Formation OF THE FACE AND ARREST OF ITS DEVELOPMENT.

A. First appearance of the face. I, II, III, IV. The four visceral arches. $f$. Frontal process. I. Inner nasal process, 2. Outer nasal process. 3. Superior maxillary process. $u$. Inferior maxillary process. $b, c$. First and second visceral clefts. $a$. Eye. $z$. Tongue. $B$. Normal union of the embryonic parts. $Z$. Intermaxillary bone. $N^{\prime}$. Nasal orifice. $O$. Nasal tear-duct. $U$. Lower jaw $(m$, abnormal dilatation of the mouth, constituting makrostomia). $C$. Arrest of the development, constituting oro-nasal cleft. $D$. Arrest of development showing an "oblique facial cleft" $(Q)$.

Harvest-bug. See Leptus autumnalis.

Hashish (hash'-èsh). See Cannabis.

Hasner's Valve. A fold of the mucous membrane of the nasal duct at the lower orifice. It is not of constant occurrence. See Valve.

Hassa11, Concentric Corpuscles of. Peculiar bodies found in the medulla of the thymus gland. They consist of a central granular part, around which are disposed layers of flattened nucleated endothelial cells arranged concentrically.

Hastate (has'-tât) [hasta, a spear]. In biology, shaped like the head of a spear; halberd-shaped.

Hastifolious (has-tif-o'-le-us) [hasta, a spear ; folium, a leaf]. In biology, having hastate leaves.

Hatters' Disease. A form of constitutional mercurial poisoning occurring in the makers of hats; also a 
skin-disease, arising from the use of mercury and arsenic; also an acute irritation of the respiratory tract caused by the fumes of nitrogen tetroxid; all of these chemicals being used in hat-making. H.'s Consumption, a form of pneumonitis occurring in hatters from inhalation of the fur and dust arising during the process of "finishing and pouncing."

Haunch (haunch or hahnch) [Fr., hanche, haunch]. The part of the body including the hips and the buttocks.

Haustellum (haws-tel"-um) [haustrum, a machine for drawing water: pl., Haustelli]. In biology, the sucking-apparatus of an arthropod.

Haustorium (haws-to'-re-um) [haustus, haurire, to draw: pl., Hausioria]. In biology, the penetrating organs of certain parasitic plants, by means of which they obtain nourishment from their host.

Haustus (hawes'-tus) [haurire, to draw]. In pharmacy, a draft. A portion of medicine in the form of a draft.

Haut Mal (ho-mahl'). See Epilepsy.

Havanna-brown. Sime as Phenyl-brozen.

Havers, Canals of. See Canal. H., Glands of. See Gland. H., Spaces of, large and irregular spaces found in growing bone mainly, though also to a limited extent in adult bones.

Haversian Canal (hav-er'-ghe-un). See Bone and Canal. H. System, a system in bone, consisting of a central opening, or Haversian canal, surrounded by a number of concentric rings.

Haw [ME., haw, an excrescence in the eye]. I. The third eyelid, nictitating membrane, or winker of a horse. 2. A diseased or disordered condition of the third eyelid of the horse.

Hawking (haw'-king) [ME, hauk, to hawk]. Clearing the throat by a peculiar expiratory current of air.

Hawley's Food. A variety of Liebig's foods for infants. Its composition is: Water, 6.60; fat, $0.6 \mathbf{r}$; grape-sugar, 40.57; cane-sugar, 3.44; starch, I0.97; soluble carbohydrates, 76.54; albuminoids, 5.38; ash, I. 50 .

Hay (ha) [ME., hay, hay]. Grass, cut and dried. H.-asthma. See Fever, Hay. H.-cold. Same as Hay-fever. H.-fever. See Fever.

Hay's Method. See Treatment, Methods of. H.'s Reaction. See Strassburg's Test, in Tests, Table of. H.'s Test. See Tests, Table of.

Haya Poison $\left(h a^{\prime}-y a h\right)$ [said to have been named after Mr. John Hay]. A powerful toxic agent from tropical Africa, said by some to be derived from some species of erythrophleum; but this has been disputed. A solution of its impure alkaloid ( $I$ to 2 per cent.) is a powerful local anesthetic, more persistent in its effects than cocain.

Haycraft's Method. A method for the estimation of uric acid in solutions. When uric acid is precipitated by an ammoniacal solution of nitrate of silver in the presence of the ammonio-magnesic mixture (see Salkowski-Ludwig Method), the precipitate is stated to contain one atom of silver to each molecule of uric acid. The uric acid is then determined by dissolving the precipitate in $\mathrm{HNO}_{3}$, in which solution the silver is finally estimated volumetrically with a standard solution of potassium sulphocyanate. See Uric Acid.

Hayden's Viburnum Compound. See Iiburnum.

Hayem's Corpuscles. See Blood-plates. H.'s Fluid, a fluid used in hematology. It consists of distilled water, with the addition of sulphate of sodium, two and one-half per cent.; pure chlorid of sodium, onehalf per cent.; and bichlorid of mercury, one-fourth per cent.

Hayward's Treatment. After the operation of arthrectomy for tuberculous disease, Hayward packed the cavity with lint saturated with dilute sulphuric acid, one-third the official strength, to hasten the separation of diseased tissues, to stimulate granulations, and to secure ankylosis.

Head (hed) [ME., hed, the head]. The anterior or upper part the body. That part of the body containing the brain or central nerve-system. Also, the upper end of a long bone, as the femur. H.-ache, any pain in the head, general or local, arising from any cause whatever. According to Hughlings-Jackson, frontal headaches, such as "sick" and "bilious " headaches, are due to disorders of the digestive system; headache at the vertex, to cerebral troubles; and occipital headache, to anemia. Eye-strain is a frequent source of headache, especially in the frontal region. H.-breeze, Electro-therapeutic, a device for general static cephalic electrization by a head-plate, with numerous insulated pencils for subdividing and accumulating strong currents, and giving more gradual eifects. See Static Breeze. H.-birth, the birth of the fetal head first. H.-drop, a peculiar nervous disease seen in Japan during the spring and early summer, supposed to be miasmatic in origin. It is attended with inability to hold the head erect, paralytic symptoms in the limbs, and optic disorders. One attack predisposes to others. H.-fold, an inflection or tucking-in of the layers in front of and beneath the head of the embryo. H.-gut. See Fore-gut. H.-kidney. Same as Pronephros. H.-light Oil. See Burning Oil. H.-locking, a term in obstetrics denoting the entanglement of the heads of twins at the time of birth. H.-measurements. See Craniometry.

Heal (hêl) [ME., helen, to heal]. To make whole or sound ; to cure. H.-all. See Collinsonia.

Healing (he'-ling) [ME., helen, to heal]. Union and cicatrization of a wound; applied generally to the cure of disease. H. by First Intention, without the granulating process. $\mathrm{H}$. by Second Intention, by the intermediation of granulations. $\mathbf{H}$. by Third Intention, the direct union of two already granulating surfaces.

Health (helth) [ME, helth, health]. That condition of the body and its organs necessary to the proper performance of their normal functions. A hale or whole condition of body. H.-lift, an apparatus for exercising those muscles by which weights are lifted directly upward.

Hear (hèr) [ME., heren, to hear]. To perceive by the ear.

Hearing (hêr'-ing) [ME, heren, to hear]. The special sense by which the sonorous vibrations of the air are communicated to the mind. The cerebral center is excited by the vibration of the fluid contents of the labyrinth, or terminal organs of the auditory nerve. Sound presents three elements, pitch, intensity, and timbre. The first depends upon the number of the aerrial vibrations; the second upon their amplitude; the third upon their form.

Heart (hart) [ME., hart, heart]. The organ giving the initiative and chief impulse to the circulation of the blood. It is enveloped by a membranous tissue called the pericardium. It consists essentially of four cavities, a right auricle and ventricle, and a left auricle and ventricle. The movements of the heart may be recorded by means of the cardiograph, and these tracings, or cardiograms, may be of value in the study of diseased conditions. H., Dilatation of, the abnormal increase in size of any or all of the cavities of the heart. H.-burn, a burning feeling at the epigastrium and lower part of the chest, caused by the acetic or putrefactive fermentation of the gastric contents. H.clot, coagulation of the blood in the cardiac cavities; 
cardiac thrombosis. H.-disease, any functional or organic pathologic condition of the heart. H., Fatty, a name given to two distinct pathologic conditions of the heart-tissue. In the first there is a true fatty degeneration of the muscular fibers of the heart; and in the second there is an increase in the quantity of subpericardial fat-a fatty infiltration. The former and

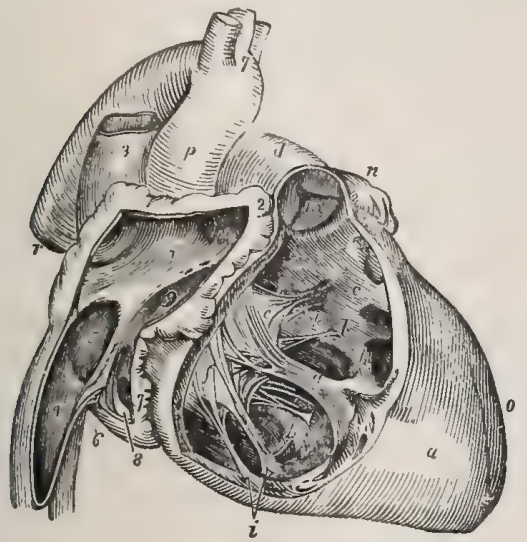

ANATOMY OF the Heart, Right Side.

1. Cavity of right auricle. 2. Appendix auriculae. 3. Superior vena cava. 4. Inferior vena cava. 5. Fossa ovalis; the prominent ridge surrounding it is the anuulus ovalis. 6 . Eustachian valve. 7 . Opening of the coronary vein. 8 , Coronary valve. 9. Entrance of the auriculo-ventricular opening. Between the figures $I$ and 9 , several foramina thebesil are seen. $a$. Right ventricle. $b, c$. Cavity of right ventricle. $e, f$. Tricuspid valve, $g$. Long columna carnea. $h$. The "Iong moderator band." $i$. The two columna carneæ of the right curtain. $k$. Attachment of chordæ tendineæ of the left limb of the anterior curtain. $l, l$. Chordæ tendinez of the "fixed curtain" of the valve. $m$. Valve of the pulmonary artery. 2 . Apex of left appendix auricula. $o$. Left ventricle. $p$. Ascending aorta. $q$. Its transverse portion. $r$. Descending aorta.

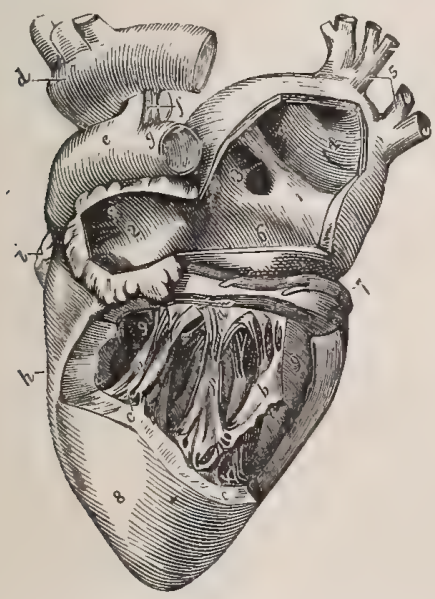

ANatomy of the Heart, Left Side,

I. Cavity of left auricle. 2. Cavity of the appendix auriculæe. 3. Opening of the two right pulmonary veins. 4. The sinus into which the left pulmonary veins open. 5. Left pulmonary veins. 6. Auriculo-ventricular opening. 7. Coronary vein 8. Left ventricle. 9 . Cavity of the left ventricle $a$. Mitral valve, $b, b, b$. Columnæ carnex. $c, c$. Fixed

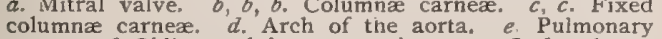
arterv. $f$. Obliterated ductus arteriosus. $g$. Left pulmonary artery. $h$ Right ventricle. $i$. Point of the appendix of right auricle. most serious condition is due to a deficiency in the supply of oxygenated blood to the heart, arising either from local or general causes. It gives rise to asthma, angina pectoris, and a tendency to syncope and sudden death. The second condition is usually associated with general obesity, and may present the same symptoms as the first. H.-hurry, Paroxysmal. See Tachycardia. H., Hypertrophy of, an abnormal increase in the muscular tissue of the heart. See,

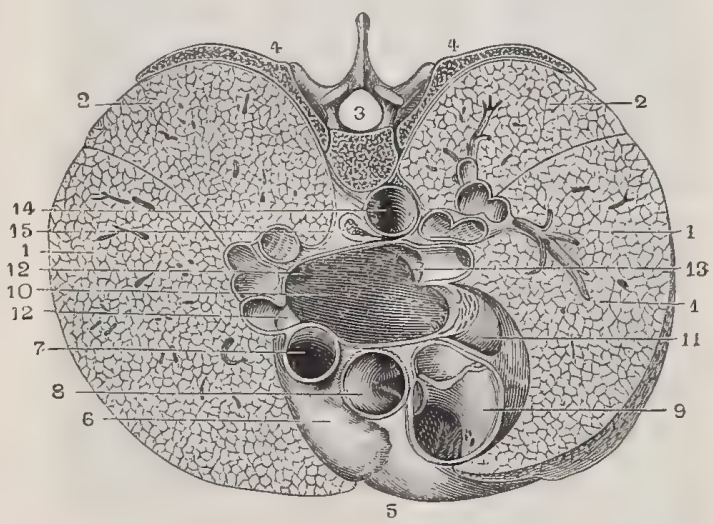

Horizontal Section of Lungs and Heart.

I, I. Upper lobes of lungs, 2, 2. Lower lobes. 3. Dorsal vertebra. 4, 4. Two ribs. 5. Heart. 6. Right auricular appendix. 7. Superior vena cava. 8. Aorta. 9. Pulmonary artery, Io, Left auricle, II. Left auricular appendix I2 Mouths of right pulmonary veins. I3. Mouths of lett monary veins. I4. Thoracic aorta. I5. Esophagus. See also $p p .1 x_{3}$ and 370.$)$

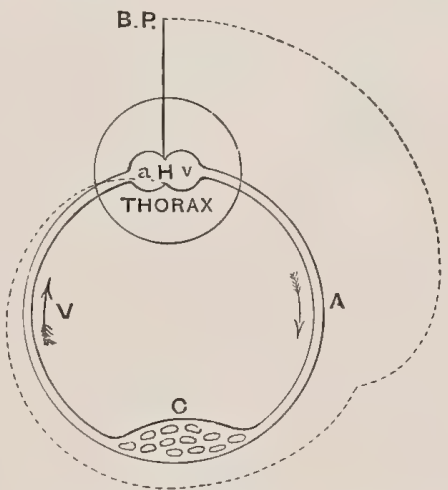

SCHEME OF THE BLOOD-PRESSURE.

H. Heart. a. Auricle. v. Ventricle. A. Arterial ; C, capillary $V$, venous areas. The circle indicates the parts within the thorax. B, P. Pressure in the aorta.

also, Hypertrophy. H.-murmurs. See Murmur. H.-scald. Same as $H_{\text {. }}$-burn. H.-shock, Latham's term for sudden cardiac breakdown during exertion, not due to rupture of a valve. H., Sounds of, the sounds observed in auscultation of the heart, occurring synchronously with systolic contraction and the closure of the valves, etc. H., Valves of. See Valve. H.-starvation, Fothergill's term for a form of cardiac asthenia occurring in adult age, and characterized by feeble circulation, cold extremities, tendency to vertigo, and pseudo-apoplectic attacks, but with absence of arcus senilis. It is due to general ill-nutrition, 
worry, over-work, and loss of sleep. Cardiograms of some pathologic conditions of the heart are appended.
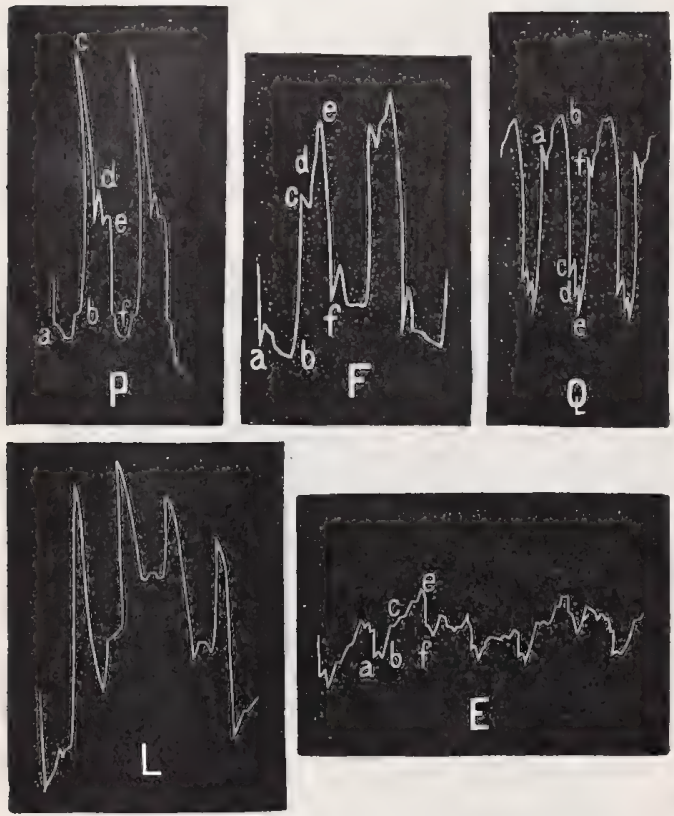

P Q. Hypertrophy and dilatation of the left ventricle. Stenosis of the aortic orifice. F. Mitral insufficiency. L. Exophthalmic goiter.

$(a, b$. Contraction of the auricles. $b, c$. Ventricular systole. $d$, Closure of aortic valve. $e$. Closure of pulmonary valves $e, f$. Diastole of the ventricle,

Heat (hèt) [ME., heete, heat]. A mode or rate of vibration of ethereal, atomic, or molecular, or wavemotion. Within certain limits of intensity it is essential to the development of all organized beings; above a certain degree, it is destructive to all organization and life. As regards the body, heat indicates a temperature above $98.6^{\circ} \mathrm{F}$. $\left(37^{\circ} \mathrm{C}\right.$. $)$. In physiology, the period of sexual excitement in the females of many animals. H., Animal, the heat generated within the bodies of living animals by the liberation of the latent heat contained in the food. H.-apoplexy. See Insolation. H.-asphyxia. Same as Insolation. H.-centers, certain points situated about the mesal and lateral aspects of the corpus striatum, supposed to have the function of regulating or inhibiting the production of body-heat. H.-eruption. Synonym of Eczema. H.-fever. See Insolation. H., Latent, physiologically, the potential energy existing in a complex proteid molecule, and which is liberated by the simplification of the latter, or the katabolic processes of the organism, H., Prickly. See Urticaria. H. Specific. See Specific. H.-spot, a freckle. Also a synonym of Eczema solare. H.-stroke, a nervous affection characterized by sudden syncope, enfeebled circulation and respiration, caused by exposure to intense heat. It is called also Sunstroke. H.-unit, the unit quantity of heat. It is the amount of heat necessary to raise one pound of water through one degree of temperature.

Heaves (hevz) [ME, heven, to raise]. A disease of horses, characterized by difficult and laborious respiration. It is also called "broken wind."

Heavy Oil. See Creasote Oil.

Hebephrenia (he-be-fre'-ne-ah) $[\eta \bar{\beta} \eta$, puberty ; $\phi \rho \dot{\eta} v$, mind]. A special form of mental derangement occurring in young persons at or soon after the age of puberty.

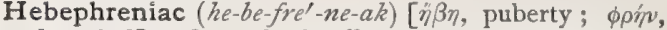
the mind]. One who is affected with hebephrenia.

Hebephrenic (he-be-fren'-ik) $[\eta \beta \eta$, puberty; $\phi \rho \eta \dot{v}$, the mind]. I. Affected with hebephrenia. 2. One who is affected with hebephrenia.

Heberden's Asthma. See Asthma, and Diseases, Table of. H.'s Rheumatism. See Diseases, Table of. H.'s Nodes. See Nodes, and Signs and Symptoms, Table of. H.'s Nodosities. See Signs and Symptoms, Table of.

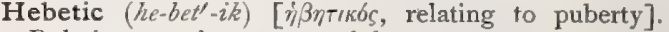
Relating to puberty or to adolescence.

Hebetude (he b'-e-tud ) [hebetudo; hebes, blunt]. Dulness of the senses and intellect. A term applied to the state of partial stupor in affections of the brain.

Hebetudinous (heb-e-tu'-din-us) [hebetudo; hebes, blunt]. Affected with hebetude.

Hebra's Arsenical Paste. A paste also known as Cosme's Paste. It is used in treating lupus vulgaris. It consists of arsenious acid, 10 grains ; artificial cinnabar, $1 / 2$ dram; ointment of rose-water, $1 / 2$ ounce. It is spread on linen and applied accurately by means of a pad and bandage. H.'s Erythema. See Diseases, Table of. H.'s Pityriasis. See Diseases, Table of. H.'s Prurigo. See Diseases, Table of.

Heckle-cell (hek'-l-sel) [ME., hekele, a heckle; cella, a cell]. An epidermal cell having minute, hard, horny projections from its cell-wall.

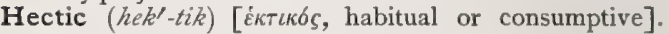
Habitual. A word now commonly used in connection. with certain constant symptoms of pulmonary tuberculosis, as $\mathbf{H}$. Fever, the febrile symptoms concurrent with pulmonary tuberculosis. H. Flush, the flushed cheek accompanying pulmonary tuberculosis. $\mathbf{H}$. Spot. Same as $H$. Flush.

Hectocotylization (hek-to-kot-il-iz-a'-shun) [Ékaróv, a hundred; $\kappa \circ \tau \hat{v} \lambda \eta$, a small cup]. In biology, applied to the peculiar sexual modification of the arm of the male cephalopod, or its use as a fertilizing-organ.

Hectocotylus (hek-to-kot'-il-us) [Ekaróv, a hundred; $\kappa о т \dot{\nu} \lambda \eta$, a cup]. In biology, a specialized arm in certain male cephalopods, which contains the spermcells, and is detached and deposited within the mantlecavity of the female.

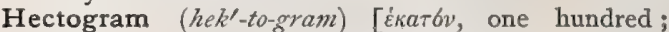

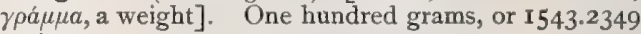
grains.

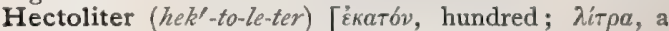
pound]. One hundred liters, equal to 22.009 imperial gallons, or 26.4 U. S. gallons.

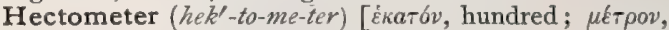
a measure]. One hundred meters, or 328 feet, I inch.

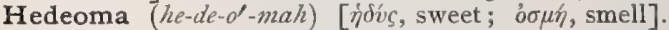
American Pennyroyal. The leaves and tops of $H$. pulegioides, distinguished by their aroma. Its properties are due to a volatile oil. It is stimulant and carminative, and has some value as an emmenagogue. It is useful in the flatulent colic of children. Its odor is extremely repulsive to fleas and mosquitoes. H.,

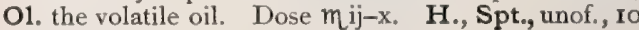
per cent. of the oil in alcohol.

Hedera $\left(h e d^{\prime}-e r-a h\right)$ [L.]. A genus of woody vines. H. helix, the true or European Ivy. Its wood is used in making issue-peas. A decoction of the leaves has been used as an alterative and antibechic. The berries are purgative and emetic. The gum is emetic and stimulant, and is useful in toothache. Unof.

Hederic Acid (hed-er'-ik) [hedera, European Ivy]. An acid derivable from the leaves of Hedera helix, of which it shares the medicinal qualities. Unof. 
Hederin (hed"-er-in) [hedera, European Ivy]. An in tensely bitter alkaloid from the seeds of Hedera helix. It is said to be actively febrifuge. (The gum of ivy has also been called hederin.)

Hedge-hog Crystals. Crystals of urate of soda found as a urinary deposit. The crystals are globular, with spiny projections, and may cause severe vesical irritation.

Hedge-hyssop (hej-his'-up). See Gratiola.

Hedonia (he-do'-ne-ah) [ỉdoví), pleasure]. Abnormal cheerfulness; amenomania.

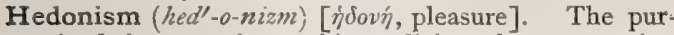
suit of pleasure; in psychic medicine, the unreasoning pursuit of some hobby or whim.

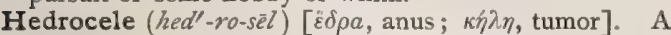
hernia in which the part protrudes through the notch of the ischium. Also, prolapsus of the anus.

Hedrosyrinx (hed-ro-si'-rinks) [ $[\varepsilon \delta \rho \alpha$, anus; fundament; $\sigma \bar{v} \rho \iota \xi \xi$, pipe]. Fistula in ano.

Hedwigia (hed-wij'-e-ah) [after Johann Hedwig]. A genus of amarydaceous trees. $\mathbf{H}$. balsamifera, of the W. Indies, affords a resin, not unlike copaiba in its uses. The bark is antiperiodic, and contains a convulsivant alkaloid, which would appear to be a powerful heart-depressant and antithermic.

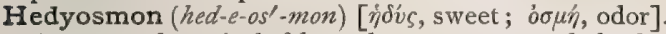
A genus of tropical chloranthaceous trees and shrubs. H. arborescens, a tree of Jamaica, affords a remedy for dyspepsia. H. nutans, a shrub of the W. Indies, has leaves that are good for headaches.

Heel (hèl) [ME., heel, heel]. The hinder part of the foot. H.-bone. See Calcaneum.

Hegar's Sign. See Signs and Symptoms, Table of.

Hegar-Kohrn Method. See Treatment, Method's of.

Heidenhain, Demilune Cells of. See Demilune and Crescent of Gianuzzi. H.'s Method. See Stains, Table of. H., Parietal Cells of. See Delomorphous. H., Rods of. See Rods. H.'s Solution. See Stains, Table of.

Heimia ( $\left.h \bar{\imath} m^{\prime}-\ell-a h\right)$ [after Ludwig Heim, a German botanist]. A genus of lythaceous shrubs of $\mathrm{N}$. and S. America. H. salicifolia (hanchinol), found in Texas and far to the South, is resinous, antisyphilitic, hemostatic, and febrifuge. Unof.

Heintz's Method. A method of estimating uric acid in the urine. Take 100 c.c. of urine. Add to this 5 c.c. of $\mathrm{HCl}$. Lay the mixture aside for 24 hours. Collect the crystals on a weighed filter-paper, wash with dilute $\mathrm{HCl}$; dry at $100^{\circ} \mathrm{C}$, and weigh. The increase in weight will give the percentage of uric acid.

Heisch's Test. See Tests, Table of.

Heister's or Heisterian Valve. A fold of mucous membrane in the cystic duct arranged in a spiral.

Heitzmann's Theory. The theory that the axis-cylinder of a nerve-fiber is ordinary connective tissue modified for the transmission of special impulses.

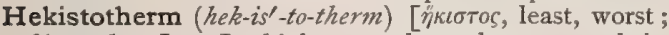
$\theta \dot{\varepsilon} \rho \mu \eta$, heat]. In biology, a plant that can subsist with a minimum of heat, e.g., a member of the Arctic or Antarctic flora.

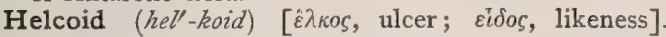
Resembling an ulcer.

Helcology (hel-kol"-o-je) [ $\varepsilon \lambda_{k} o s$, ulcer; $\lambda b \gamma o s$, science]. The pathology and treatment of ulcers.

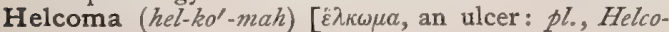
mata]. An ulcer.

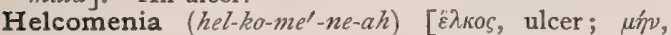
month]. Vicarious menstrual discharge from an ulcer.

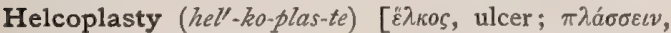
to shape]. The treatment of ulcers by skin-grafting.

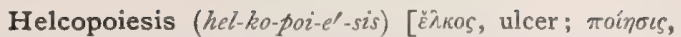
making]. The surgical formation of an issue, for counter-irritation.

Helcosis (hel-ko'-sis) [ $\bar{\varepsilon} \lambda \kappa \omega \sigma \iota \zeta$, ulceration]. The forma tion and development of an ulcer.

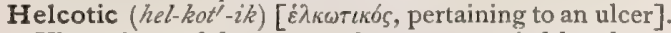
Ulcerative; of the nature of or accompanied by ulceration.

Helenin (hel'-en-in), $\mathrm{C}_{6} \mathrm{H}_{8} \mathrm{O}$. Alant Camphor; Inulol; the active principle of inula. It is a faintly odorous and nearly tasteless, volatile substance, insoluble in water, but soluble in ether, oils, and hot alcohol. It is antiseptic and germicidal, and is recommended for use in diphtheria and tuberculosis. Unof.

Helenium (hel-e'-ne-um) [énévıov, elecampane]. I. Same as Inula, q. v. 2. A genus of composite North American herbs. $H$. autumnale, sneezewort. $H$. nudiflorum, and $\mathbf{H}$. bolanderi are strongly errhine, and are substituted for arnica. $\mathbf{H}$. puberulum is tonic, alterative, and errhine. $\mathbf{H}$. tenuifolium, of the Gulf States, is said to be a destructive cattlepoison. Unof.

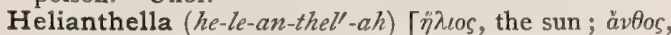
flower]. A genus of North American composite herbs. The root of $H$. tenuifolia is aromatic, expectorant, antispasmodic, and, in large doses, emetic. It is of reputed service in pulmonary complaints. Dose of the fld. ext. $\eta \mathbf{v}-\mathrm{xxx}$, Unof.

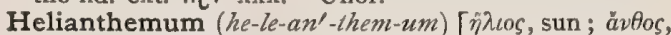
flower]. Frostwort; Rock Rose. The herb $H$. canadensé, astringent, aromatic, tonic, and alterative. It is useful in diarrhea, scrofula, and secondary syphilis. Dose of the fld. ext. $m v-x x$. Unof.

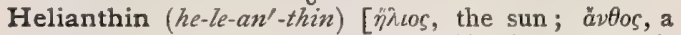
flower], $\mathrm{C}_{6} \mathrm{H}_{4} \mathrm{SO}, \mathrm{Na}, \mathrm{N}: \mathrm{N} . \mathrm{C}_{6} \mathrm{H}_{4} \mathrm{~N}\left(\mathrm{CH}_{3}\right)_{2}$, Methylorange; an orange-yellow powder used as a dye and as a test in analyses. See Pigments, Conspectus of.

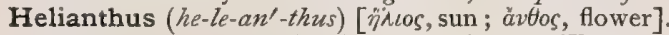
A genus of composite-flowered plants. The sunflower. H. annuus, a commonly cultivated species, affords highly useful, oil-bearing seeds, the seeds of some varieties being also edible. $\mathbf{H}$. tuberosus, the Jerusalem Artichoke, has large tuberous roots, some. times eaten when cooked or pickled. Several of the species are medicinal.

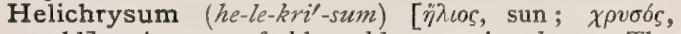
gold]. A genus of old-world composite plants. The European species (as $\mathrm{H}$. arenarium, $\mathrm{H}$. stæchas) are aromatic stimulants, used in domestic practice. Several South African species (H. auriculatum, imbricatum, nudiflorum, etc.) are used as pectoral teas.

Helicin (hell-is-in), $\mathrm{C}_{13} \mathrm{H}_{16} \mathrm{O}_{7}$. A glucosid, produced by oxidizing salicin with $\mathrm{HNO}_{3}$. It dissolves with difficulty in water, crystallizes in small needles, and melts at $175^{\circ} \mathrm{C}$.

Helicine $\left(h e l^{\prime}-i s-i n\right)[\varepsilon \lambda \iota \xi$, a spiral]. I. Tortile, or spiral in structure. 2. Pertaining to the helix. $H$. Arteries, arteries proceeding from the profunda penis branches of the pudic, and from the dorsal arteries of the penis. See Arteries, Table of.

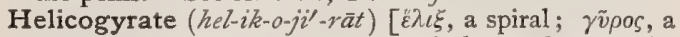
ring]. In biology, having a spiral annulus, as the spore-cases in trichomanes.

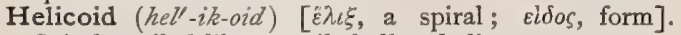
Spiral; coiled like a snail-shell or helix.

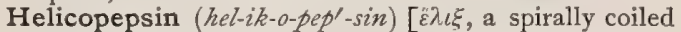
snail; $\pi \varepsilon \dot{\psi} \psi \varsigma$, digestion]. A peptic ferment found by Krukenberg in snails.

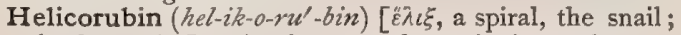
povßivı, ruby]. A pigment of certain invertebrates; the same as Hemochromogen and Enterohematin, q.v. 


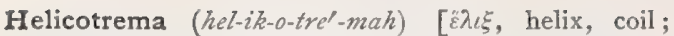
$\tau \rho \tilde{\eta} \mu a$, hole]. The opening connecting the scala tympani and vestibuli of the spiral canal of the cochlea.

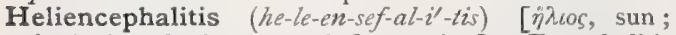

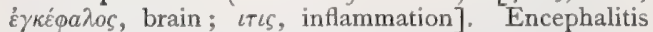
caused by exposure to the sun's rays.

Heliodorus's Bandage. See Bandage.

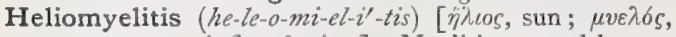

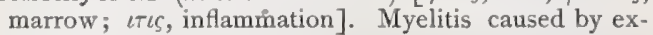
posure to the sun's rays.

Helionosus (he-le-on'-o-sus) [ $\ddot{\eta} \lambda \iota 0 s$, sun; v6бos, disease]. Sunstroke.

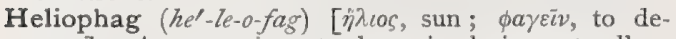
vour]. A name given to the animal pigment-cell, as being a supposed absorber of the radiant energy of the sun's light and heat.

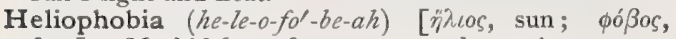
fear]. Morbid fear of exposure to the sun's rays.

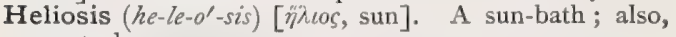
sunstroke.

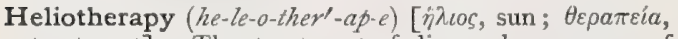
treatment]. The treatment of disease by exposure of the body to sunlight. Sun-bathing

Heliotrope ( $\left.h e^{\prime}-l e-o-t r o \bar{p}\right)$ [ $\dot{\eta} \lambda \cos$, sun; $\tau \rho \hat{\varepsilon} \pi \varepsilon \iota v$, to turn]. Any plant of the boraginaceous genus Heliotropium. $H$. europæum is aperient, and is said to cure warts and ulcers. Unof.

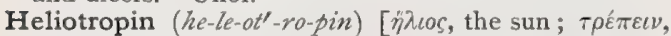
to turn]. I. See Piperonal. 2. A poisonous alkaloid from Heliotropium europaum, a European species of heliotrope. Its action is little known. Unof.

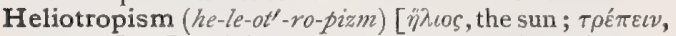
to turn]. In biology, that property of a plant or plant-organ by virtue of which it bends toward or away from the sunlight.

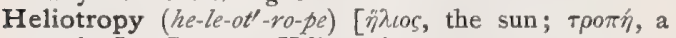
turning]. Same as Heliotropism.

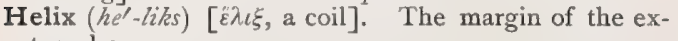
ternal ear.

Hellebore, Black. See Helleborus. H., White. See Veratrum album.

Helleborein (hel-eb-or-e'-in). See Helleborus.

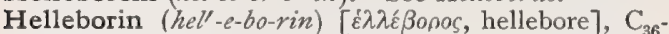
$\mathrm{H}_{42} \mathrm{O}_{6}+{ }_{4} \mathrm{H}_{2} \mathrm{O}$. A crystalline glucosid of Helleborus viridis, insoluble in water. It is a cardiac and nervous poison of great intensity. See Helleborus.

Helleborism (hel'-eb-or-izm) $[\dot{\varepsilon}\rangle, \lambda \varepsilon \beta o p i \zeta \varepsilon v v$, to dose with hellebore]. The treatment of disease with hellebore; the morbid condition induced by the free exhibition of hellebore.

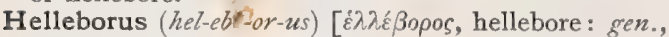
Hellebori]. The root of H. ntger, black hellebore, with properties due to two glucosids, helleborin, $\mathrm{C}_{36}$ $\mathrm{H}_{42} \mathrm{O}_{6}$, and helleborein, $\mathrm{C}_{26} \mathrm{H}_{44} \mathrm{O}_{15}$. It is a drastic hydragogue cathartic, and emmenagogue, and was formerly a popular remedy for insanity, dropsy, and amenorrhea. Helleborein is sometimes used in cardiac affections as a substitute for digitalis, its action being obtained by smaller doses and with less irritation. $\mathbf{H}$. nigri., Ext. Unof. Dose gr. j-x, cautiously. H. nigri., Ext., Fld. Unof. Dose $\eta_{i j}-x v$, Helleborein. Unof. Very soluble in water. Dose gr. $\frac{1}{1}-\frac{1}{10}$.

Heller's Tests. See Tests, Table of.

Hellmund's Ointment. A narcotic ointment composed of acetate of lead, Io parts; extract of conium, 30 parts; balsam of Peru, 30 parts; Sydenham's laudanum, 5 parts; and cerate, 240 parts.

Helmerich's. Ointment. An ointment used in the treatment of scabies. It consists of sublimated sulphur, I dram; potassium carbonate, $1 / 2$ dram; and lard, $61 / 2$ drams. The ointment should remain in contact with the diseased surface for four or five hours.

Helmholtz's Apparatus. A galvanometer consisting of two equal and vertical coils, with a magnetic needle midway between them. H.'s Ligament. See Ligament. H.'s Line. See Lines, Table of.

Helminth (hel'-minth) [ $[\dot{\lambda} \mu \nu \nu$, worm]. A worm; an intestinal or entozoic worm.

Helminthagogue (hel-minth'-ag-og). See Anthelmintic.

Helminthiasis (hel-min-thi'-as-is) [ $\left[\dot{\varepsilon} \mu \iota \nu \theta_{\imath} \tilde{a} v\right.$, to suffer from worms]. A condition marked by the presence of parasites in the body, especially intestinal worms. Also, a disorder or lesion caused by worms.

Helminthicide (hel-minth'-is-id $)$ [ $\hat{\varepsilon} \lambda \mu \iota \nu \varsigma$, a worm; cadere, to kill]. See Vermicide.

Helminthics (hel-min'-thiks). See Anthelmintics.

Helminthochorton (hel-min-tho-kor'-ton) [ $\dot{\varepsilon} \lambda \mu v \mathrm{~s}$, a

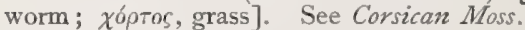

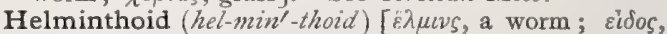
likeness]. Shaped like a worm.

Helminthology (hel-min-thol'-o-je) [ $\tilde{\varepsilon}^{\prime} \mu u v s$, a worm; $\lambda$ óros, science]. A treatise on worms, especially those parasitic within the body

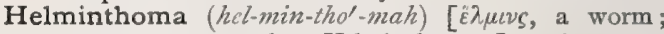
$\ddot{o} \mu a$, a tumor: pl., Helminthomata]. A tumor caused by the presence of a parasitic worm. See Bulam Boil and Guinea-zorm.

Helminthoncus (hel-minth-ong'-kus) [ ô $\gamma \kappa \varsigma$, a tumor]. An old term for a parasitic skin-disease.

Helminthophobia (hel-min-tho-fo'-be-ah) [ $[\tilde{\varepsilon} \lambda \mu \nu s$ $\left(\dot{\varepsilon} \lambda \mu \nu \theta_{-}^{-}\right)$, a worm; $\phi \delta \beta o \varsigma$, fear $]$. A nervous state produced by the-presence or thought of parasitic worms.

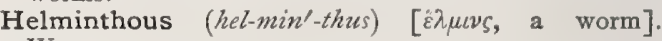
Wormy.

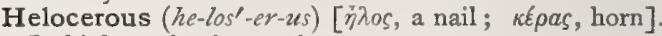
In biology, having capitate antennæ.

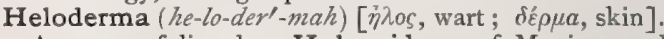
A genus of lizards. H. horridum, of Mexico, and H. suspectum, of Arizona (called Gila Monster), are said to be the only known species of venomous lizards.

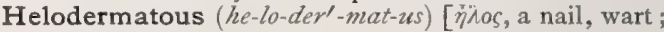
$\delta^{\prime} \rho \mu \alpha$, skin]. In biology, having a warty or tuberculous skin.

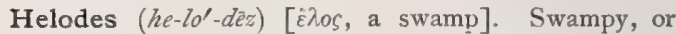
marshy. Also, a fever attended with profuse sweating. Also, marsh-fever.

Helonias (hel-o'-ne-as) [ $\dot{\lambda} \lambda \sigma s$, a marsh]. A genus of monocotyledonous plants. H. dioica. See Chamalivion.

Helonin (hel-o'-nin) [ itate from the tincture of Chanclirion carolinianum. It is prescribed for uterine affections, and is tonic and diuretic. Caution should be observed in its use. Dose, gr. ij-iv. Ungf.

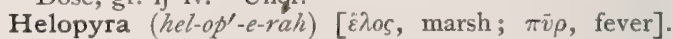
Malarial fever.

Helosis $\left(\right.$ hel-o'-sis) [ $\eta^{\prime} \lambda o s$, nail, bract]. I. A genus of tropical American plants. H. brasiliensis, cayennensis, and jamaicensis, are styptic and vulnerary remedies. Unof. 2. An old name for inversion of the eyelids; strabismus; eye-spasm; plica polonica; the term is now seldom employed.

Helvetia Green. See Pigments, Conspectus of.

Helvolous (hel'-vo-lus) [dim. of helvus, yellow]. Tawny, or reddish-yellow.

Helweg, Triangular Tract of. A tract that appears either in juxtaposition with, or as the most ventral part of, the ventro-lateral tract of the spinal cord.

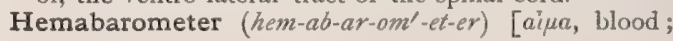




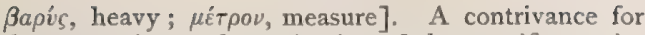
the approximate determination of the specific gravity of the blood.

Hemacelinosis (hem-as-el-en-o'-sis) [aipa, blood; knhis, spot; $\nu 6 \sigma o s$, disease]. A synonym of the disease, Purpura.

Hemachroin (hem-ak-ro'-in) [aina, blood; $\chi \rho \delta ́ a$, color]. Same as Hematosin.

Hemachrome (hem'-ak-rōm) [aiua, blood; $x \rho \tilde{\jmath} \mu \alpha$, color]. The coloring-matter of the blood; hematin.

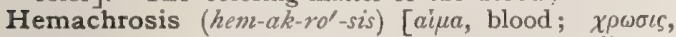
coloring]. I. Redness of the blood. 2. Any disease in which the blood is abnormally colored.

Hemacyanin (hem-as-i'-an-in) [aiux, bilood; kúavos, blue]. A blue coloring-matter found in the blood and the bile.

Hemacytometer (hem-as-i-tom'-et-er). See Hemocytometer.

Hemad (hem'-ad) [aina, blood]. I. Toward the hemal aspect; opposed to neurad. 2. A blood-cell or blood-corpuscle.

Hemadonosos (hem-ad-on'-o-sos) [aiuás, blood-stream ; $\nu 6 \pi \circ$, disease]. A disease of the blood or of the blood-vessels.

Hemadostenosis (hem-ad-o-ste-no'-sis) [airác, blood-

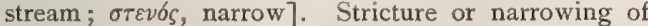
a blood-vessel.

Hemadosteosis (hem-ad-os-te-o'-sis) [airás, bloodstream; botéov, bone]. Ossification or calcification of blood-vessels.

Hemadrometer (hem-ad-rom'-et-er), See Hemadromometer.

Hemadrometry (hem-ad-rom'-et-re). See Hemadromometry.

Hemadromograph (hem-ad-ron'-o-graf) [ai ${ }^{\top} \mu a$, blood; $\delta \rho b \mu o s$, course ; $\gamma \rho \alpha \dot{\phi} \phi \varepsilon v$, to write]. An instrument for registering changes in the velocity of the blood-stream.

Hemadromometer (hem-ad-ro-mom'-et-er) [ai $\mu$,

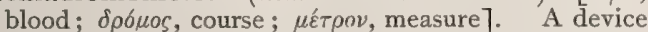
for measuring the velocity of the blood-current.

Hemadromometry (hem-nd-ro-mom'-et-re) [aina, blood; $\delta \rho \delta \mu_{0}$, course; $\mu \varepsilon \dot{\tau} \rho \circ \nu$, measure]. Measurement of the speed of the blood-current.

Hemadynamics (hem-ad-i-nam'-iks) [aipa, blood; Svvaucs, power]. Dynamics of the blood-current.

Hemadynamometer (hem-ad-i-nam-om'-et-er) [ai $\mu a$,

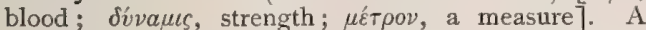
contrivance for measuring the tension or pressure of blood within the arteries. Careful experiments show that, in man, the pressure of blood in the carotid artery is equal to about that of six inches of mercury.

Hemafecal (hem-af-e'-kal) [ri $e_{\alpha}$, blood; fax, dregs]. Characterized by bloody stools. H. Jaundice. See Jaundice.

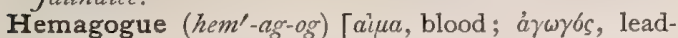
ing]. I. Promoting the menstrual or hemorrhoidal discharge of blood. 2. An agent that promotes the catamenial or hemorrhoidal flow of blood.

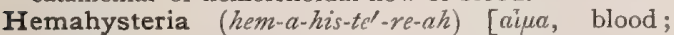

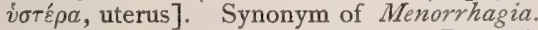

Hemal (hem'-al) [aiua, blood]. I. Pertaining to the blood or the vascular system. 2. See Ventral.

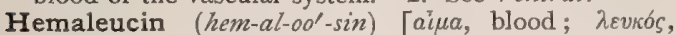
white]. Fibrin; the white portion of a washed bloodclot.

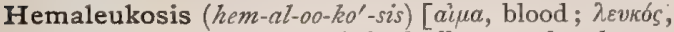
white]. The formation of the buffy coat of a clot.

Hemalopia (hem-al-o'-pe-ah) [ai $\mu \alpha$, blood; $\omega \psi$, the eye]. Effusion of blood in the eye; erythropsia.

Hemameba (hem-am-e'-bah) [ai $\mu \alpha$, blood; a $\mu o \iota \beta \eta ́$, a change]. A white blood-cell so called from its resemblance to an ameba.

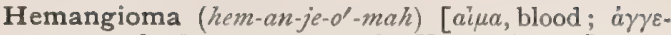
iov, vessel ; ö $\mu a$, a tumor: pl., Hemangiomata]. An angioma made up of blood-vessels, as distinguished from lymphangioma.

Hemanthin (hem-an'-thin) [aira, blood; àv0os, a flower]. An alkaloid from Hemanthus coccineus. it is poisonous, with the general properties of atropin.

Hemanthus (hem-an'-thus) [aiua, blood; àvtoc, flower]. A genus of amaryllidaceous plants; bloodflower. H. coccineus, of S. Africa, affords an arrowpoison, with the general properties of atropin. The plant is a diuretic and cardiant. It affords hemanthin. Unof.

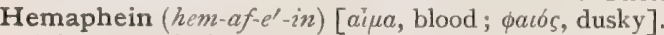
A brown coloring-matter from blood, regarded as a decomposition-product of hematin; it is probably the same as urohematin.

Hemaphobia (hem-af-o'-be-ah). See Hematophobia.

Hemapoiesis (hem-ap-oi-e'-sis). See Hematopoiesis.

Hemapoietic (hem-ap-oi-et'-ik). See Hematopoietic.

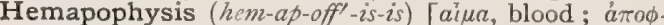
vivi, to put forth]. That part of an ideal or perfect vertebra which forms the antero-lateral part of the hemal arch. In man, all the hemapophyses are either cartilaginous or detached.

Hemaporia (hem-ap-o'-re-ah) [aiua, blood; ámopia, distress]. Any disorder of the blood, $\ell, g$. anemia.

Hemarthron, Hemarthros (hem-ar'-thron, hem-ar' thros) $[$ ai $\mu \alpha$, blood; a $\rho$ to $\rho$, joint $]$. Effusion of blood into the synovial sac of a joint.

Hemarthrosis (hem-ar-thro'-sis) [ai ar $^{\top}$, blood ; à $\rho \theta \omega \sigma \iota$, a joint]. Effusion of blood into a joint.

Hemastatic (hem-as-tat'-ik). See Hemostatic,

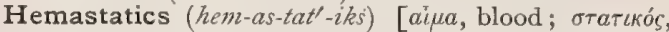
standing]. That branch of physiology treating of the laws of the equilibrium of the blood.

Hemasthenosis (hem-as-then-o'-sis) [aiua, blood;

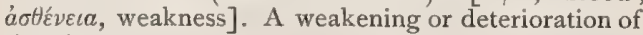
the blood.

Hematachometer (hem-at-ak-om'-et-er). See Hemotachometer.

Hematangionosus (hem-at-an-je-on'-o-sus) [aiua,

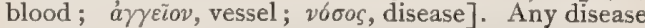
of the blood-vessels.

Hematangiosis (hem-at-an-je-o'-sis) [aiua, blood;

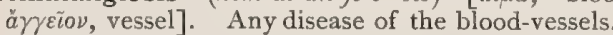

Hemataporia (hem-at-ap-o'-re-ah). See Hemaporia.

Hematapostasis (hem-at-ap-os'-tas-is) [aira, blood; $a \pi b \sigma \tau a \sigma \iota s$, a standing away from]. Unequal distribution or pressure of blood, with congestion or effusion in some part of the body.

Hematapostema (hem-at-ap-os-te'-mah) [aiua, blood ; $a \dot{a} \sigma \sigma \tau \eta \mu a$, abscess : pl., Hemapostemata]. An abscess containing extravasated blood.

Hemataria (hem-at-a'-re-ah) [aija, blood]. The socalled blood-animals.

Hematedema (hem-at-e-de'-mah) [aipa, blood; oľ $\eta \mu a$, a swelling]. Swelling due to the effusion of blood.

Hematein (hem-at-e'-in) [ai $\mu a$, blood], $\mathrm{C}_{16} \mathrm{H}_{12} \mathrm{O}_{6}$. A crystalline principle derivable from, and reconvertible into, hematoxylin.

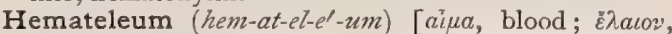
oil]. A yellow or brownish oily fluid obtained by the dry distillation of blood.

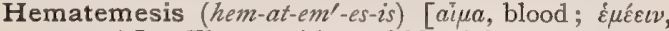
to vomit]. The vomiting of blood from any cause. It may be due to general or constitutional pathologic conditions, or to local conditions.

Hematencephalon (hem-at-en-sef'-al-an) [aika, blood; $\dot{\varepsilon} \gamma \kappa \varepsilon ́ \phi a \lambda o s$, brain ]. A hemorrhage or bleeding within the brain; cerebral apoplexy.

Hemathermous (hem-ath-er'-mus) [ailua, blood; $\theta \varepsilon \rho \mu o ́ s$, hot]. Having warm blood. 
Hemathidrosis (hem-ath-id-r'o'sis). Same as Hematidrosis.

Hemathorax (hem-ah-tho'-raks). See Hemothorax. Hematic (hem-at'-ik) [ai ${ }^{\top} \alpha$, blood]. Bloody; pertaining to, full of, or having the color of, blood. Also, a blood-tonic.

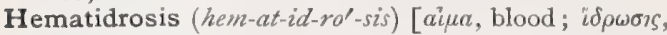
sweat]. Bloody sweat. Ephidrosis cruenta. A sanguineous perspiration caused by the extravasation of blood into the coils and ducts of the sweat-glands, whence it is carried to the surface, mixed with sweat See also Chromidrosis.

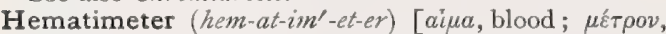
measure]. A device for counting the corpuscles in a given volume of blood.

Hematimetry (hem-at-im'-et-re) [a ${ }^{\top} \mu a$, blood; $\mu \varepsilon \tau \rho o \nu$, measure]. The estimation of the number or proportion of the blood-corpuscles, as by the hemocytometer or hematimeter.

Hematin (hem'-at-in) [ai ${ }^{i} \mu \alpha$, blood], $\mathrm{C}_{31} \mathrm{H}_{35} \mathrm{~N}_{4} \mathrm{FeO}_{5}$. A substance produced by decomposing oxyhemoglobin either by acids or alkalies. It occurs as a scaly but non-crystalline mass of bluish-black color and metallic luster, strongly resembling iodin. It is a very stable substance, and is insoluble in water, alcohol, ether, chloroform, or benzol, but dissolves freely in dilute acids and in alkaline solutions. For test, see Tests, Table of. Also a synonym for Hematoxylon, q. v.

Hematinic (hem-at-in' $i k)$ [ai $\mu \alpha$, blood]. I. Relating to hematin, or serving to increase the proportion of hematin in the blood. 2. An agent, such as iron, which tends to increase the proportion of hematin or coloring-matter in the blood.

Hematinometer (hem-at-in-om'-et-er). Same as Hemoglobinometer.

Hematinuria (hem-at-in- $u^{\prime}-r e-a h$ ) [aiva, blood; ovoov, urine]. Same as Hemoglobinuria. See also Hematuria.

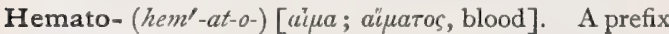
signifying blood.

Hematobious (hem-at-o'-be-us) [aipa, blood; Bios, life]. Living in the blood.

Hematobium (hem -at-o'-be-um) [aija, blood; Bios, life]. I. A blood-corpuscle. 2. A blood-parasite.

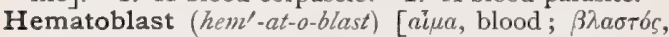
germ]. Blood-plate; a rudimentary or immature red blood-corpuscle.

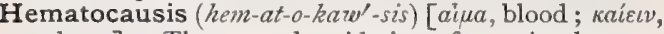
to burn]. The normal oxidation of certain elements of the blood.

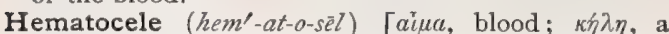
tumor]. A tumor formed by the extravasation and collection of blood in a part. H., Pelvic, an effusion of blood into the pelvis, usually due to rupture of a Fallopian tube, the seat of an extra-uterine pregnancy. It may also be due to the rupture of an ovary, or of a vein in the broad ligament; it may follow an abortion, the blood escaping through the Fallopian tube; or it may be due to retention of the menstrual fluid with escape of the blood. Physical examination, whatever may be the cause, reveals a boggy swelling in Douglas's cul-de-sac.

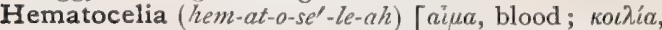
a cavity]. An effusion of blood into the peritoneal cavity.

Hematocephalus (hem-at-o-sef'-al-us) [aiua, blood; $\kappa \varepsilon \phi a \lambda \eta$, head]. An effusion of blood into, or a sanguineous tumor of, the brain. Also a monstrosity characterized by an effusion of blood into the cerebral hemispheres. Also a vascular tumor that is sometimes observed in the pia mater of anencephalic monstrosities.

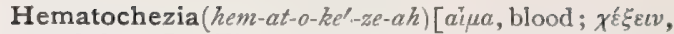
to defecate]. The passage of hemorrhagic stools.

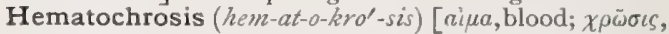
coloring: pl., Hematochroses]. I. Any disease characterized by discoloration of the skin. 2. A discoloration of the skin.

Hematochyluria (hem-at-o-ki-lu'-re-ah) [aiua, blood; $\chi v \lambda$ hós, chyle; ov $\rho o v$, urine]. The presence of blood and chylous material in the urine, due to Filaria sanguinis hominis. It is usually an intermittent condition.

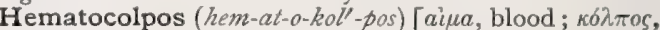
vagina]. Hemorrhage into the vagina. Also a collection of menstrual discharge within the vagina, due to atresia or imperforate hymen.

Hematocrit (hem'-at-o-krit) [aiua, blood; $\rho^{\top} \iota t h s$, judge ; крive $\nu$, to separate, to judge]. An instrument for making volumetric estimation of the blood by separating by centrifugal action the corpuscles from the serum. A volume of blood and one of Müller's liquid (to prevent coagulation) are placed together in each of two small, thick-walled glass tubes, graduated in fifty parts. The tubes rest on brass holders which are fixed on the axes of a revolving apparatus. After some eight thousand revolutions in from five to seven minutes, the process is complete. The corpuscles and the salt-plasma are separated by a narrow band of leukocytes. The instrument is useful in comparing the blood of different individuals. With a little practice the total error is not more than one per cent.

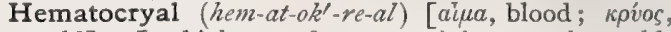
cold]. In biology, of or pertaining to the coldblooded invertebrates.

Hematocrystallin (hem-at-o-kris'-tal-in). Same as Hemoglobin.

Hematocyanosis (hem-at-o-si-an-ol-sis). Synonym of Cyanosis.

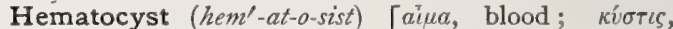
bladder]. A cyst containing blood. Also an effusion of blood into the bladder.

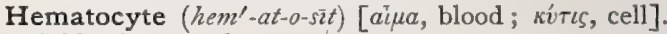
A blood-corpuscle.

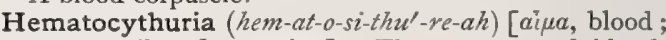
кítos, cell; ov $\rho \circ v$, urine]. The presence of bloodcells in the urine.

Hematocytometer (hem-at-o-si-tom'-et-er). See Hemocytometer.

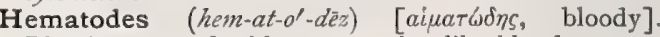
Bloody; gorged with or appearing like blood.

Hematodiarrhea (hem-at-o-di-ar-e'-ah). Synonym of Dysentery.

Hematodynamics (hem-at-o-di-nam'-iks). See Hemadynamics.

Hematodynamometer (hem-at-o-di-nam-om'-et-er). See Hemadynamometer.

Hematodyscrasia (hem-at-o-dis-kra'-se-ah) [ả $\mu a$,

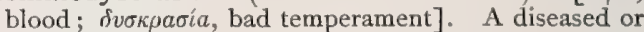
dyscrasic state of the blood.

Hematogenesis (hem-at-o-jen'-es-is) [ailu, blood;

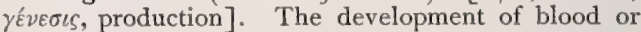
of blood-corpuscles; the making of blood.

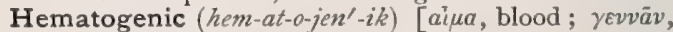
to produce]. Pertaining to the formation of blood.

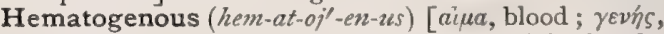
producing]. Derived from, or having origin in, the blood.

Hematoglobin (hem-at-o-glo'-bin). See Hemoglobin.

Hematoglobulin (hem-at-o-glob'-u-lin). Same as Hemoglobin.

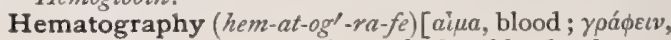
to write]. A description of the blood; hematology. 
Hematohidrosis (hem-at-o-hid-ro'-sis). See Hematidrosis.

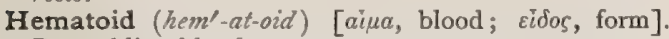
Resembling blood.

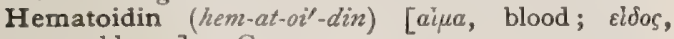
resemblance], $\mathrm{C}_{16}$ $\mathrm{H}_{18} \mathrm{~N}_{2} \mathrm{O}_{3}$. A derivative of hemoglobin, identical with bilirubin, the pigment of the bile. It occurs as reddish or orange rhombohedral crys. tals, in old blood-clots, as of cerebral hemorrhages, in corpora lutea, and in the urine of hematuria.

Hematoin (hem-at-o'-in). Same as Hematoporphyrin.

Hematokrit (hem'-at-o-krit). See Hematocrit.

Hematolin (hem-at'-o-lin) [ai $\mu a$, blood], $\mathrm{C}_{68} \mathrm{H}_{78} \mathrm{~N}_{8} \mathrm{O}_{7}$. An iron-free derivative of hematin.

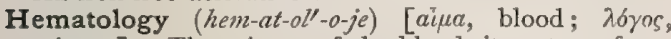
science]. The science of the blood, its nature, functions, and disorders.

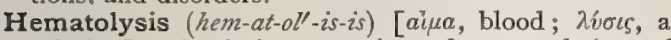
solution]. A solution, or an imperfect coagulation, of the blood; diminished coagulability of the blood; a diseased condition marked by destruction of the corpuscular constituents of the blood; impoverishment of the blood.

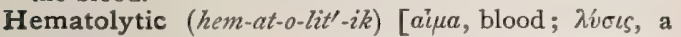
solution]. Marked by or tending to impoverishment of the blood.

Hematoma (hem-at-of-mah) [ai $\mu a$, blood; $\ddot{o} \mu a$, tumor : pl., Hematomata]. A tumor, fungus, or swelling containing blood. H. auris, Insane Ear; an effusion of blood or serum between the cartilage of the ear and its covering, occurring in various forms of insanity. It may be either acute or chronic, if the former reaching the size of a pigeon's egg in a day or two. It is an elastic tumor, generally painless, with some local heat. It may suppurate and burst, or may shrivel up, in either case leaving considerable deformity. In the majority of cases the left ear is involved, and the condition occurs most frequently among men. $H$. of the Dura mater, an effusion beneath the dura mater, forming membranous sheets. H., Pelvic, an effusion of blood into the cellular tissue of the pelvis; it is frequently due to traumatism, or occurs as a complication of pregnancy and the puerperal state, from rupture of dilated veins; it is often the result of rupture of an extra-uterine pregnancy.

Hematomantia (hem-at-o-man'-she-ah) [ai $\mu a$, blood;

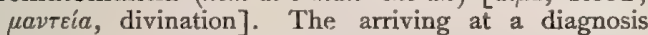
from examination of the blood.

Hematomatous (hem-at-of-mat-us) [ai $\mu a$, blood; ö $\mu a$, a tumor]. Relating to or of the nature of a hematoma.

Hematomediastinum (hem'-at-o-me-de-as-ti'-num) [aika, blood; mediastinum, the mediastinum]. An effusion of blood or bloody serum into the mediastinal cavities.

Hematometer (hem-at-om'-et-er). See Hemoglobinometer.

Hematometra (hem-at-o-me'-trah) [ai $\mu a$, blood; $\mu \hat{\eta} \tau \rho n$, womb]. Hemorrhage in the womb. Also, an accumulation of menstrual discharge within the uterine cavity, as a result of obstruction.

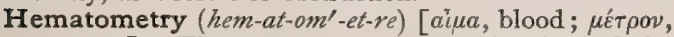
measure]. The measurement, or estimation of the measure, of the blood.

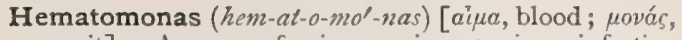
a unit]. A genus of microscopic organisms infesting the blood. See Ague and Plasmodium.

Hematomphalocele (hem-at-om-fal'-o-sèl) [ai $\mu \alpha$, blood; ó $\mu \phi a \lambda o ́ s$, navel; кíñ , tumor]. A tumor or a hernia at the navel, distended with blood.

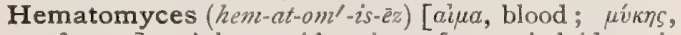
a fungus]. A hematoid variety of encephaloid carci noma ; medullary sarcoma. It is called, also, Fungus hematodes.

Hematomyelia (hem-at-o-mi-e'-le-ah) [aira, blood; $\mu v \varepsilon \lambda$ ós, marrow]. Hemorrhage into the spinal cord; an accumulation of blood in the central canal of the spinal cord. The symptoms vary with the seat, but paralyses, vaso-motor and trophic changes, loss of sensation, etc., are common.

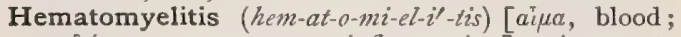
$\mu v \varepsilon \lambda o ́ s$, marrow ; $\iota T \iota s$, inflammation ]. An acute myelitis attended with an effusion of blood into the spinal cord.

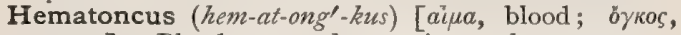
tumor]. Blood-tumor; hemangioma; hematoma.

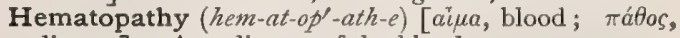
disease]. Any disease of the blood.

Hematopedesis (hem-at-o-ped-el-sis) [aipa, blood; $\pi \hbar \delta \eta \sigma \zeta$, a leaping]. Cutaneous hemorrhage; hematidrosis.

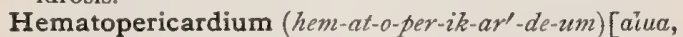

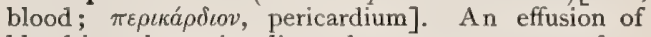
blood into the pericardium, due to rupture or perforation of the walls of the heart.

Hematophagous (hem-at-off'-ag-us) [ailua, blood;

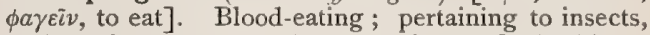
such as the gnat, mosquito, etc., that suck the blood.

Hematophilia (kem-at-o-fil'-e-ah). See Hemophilia.

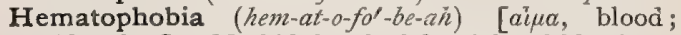
$\phi 6 \beta o s$, fear]. Morbid dread of the sight of blood.

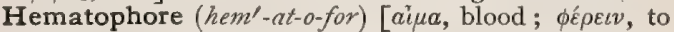
bear]. An instrument used in the transfusion of blood.

Hematophthalmia (hem-at-off-thal'-me-ah). See Hemophthalmia.

Hematophyte (hem'-at-o-fit $)$ [ai $\mu a$, blood; $\phi v \tau b v$, a plant]. A vegetable organism, such as a bacillus, living in the blood.

Hematopinax (hem-at-op'-in-aks) [ai $\mu a$, blood; $\pi i v a \xi$, tablet: $p l$., Hematopinaces]. A blood-plaque.

Hematopisis (hem-at-op'-is-is) [aiju, blood; $\pi i v \varepsilon v$, to drink]. I. The drinking of blood. 2. A morbid collection of blood in any cavity of the body.

Hematopisy (hem-at-op'-is-e). See Hematopisis.

Hematoplanesis (hem-at-o-plan-e'-sis) [ai $\mu a$, blood; $\pi \lambda a ́ v \eta \sigma \iota s$, wandering]. See Hematoplania.

Hematoplania (hem-at-o-pla'-ne-ah) [ai $a^{\prime} a$, blood;

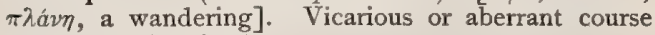
or flow of the blood.

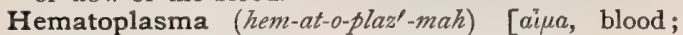
$\pi \lambda a ́ \sigma \mu a$, plasma]. The plasma of the blood.

Hematoplast (hem'-at-o-plast). Same as Hematoblast.

Hematoplastic (hem-at-o-plas'-tik) [aipa, blood; $\pi \lambda \alpha \sigma \tau \iota \kappa \delta$, plastic]. Blood-forming.

Hematoplethora (hem-at-o-pleth'-or-ah). Synonym of Plethora.

Hematopoiesis (hem-at-o-poi-e'-sis) [ai $\mu a$, blood; $\pi \circ \iota_{\varepsilon} \varepsilon \nu$, to make]. The making of blood. See Hematosis.

Hematopoietic (hem-at-o-poi-et'-ik) [aiua, blood; $\pi o \iota_{\varepsilon} \varepsilon \nu$, to make]. Relating to or forwarding the processes of blood-making.

Hematoporphyrin (hem-at-o-por'-fe-rin) [ai $\mu a$, blood; $\pi$ tópvoos, purple], $\mathrm{C}_{68} \mathrm{H}_{74} \mathrm{~N}_{8} \mathrm{O}_{12}$. Iron-free hematin, a metabolitic decomposition-product of hemoglobin. 
It is produced by dissolving hematin in concentrated $\mathrm{H}_{2} \mathrm{SO}_{4}$. It occurs occasionally in urine and in eggshells of certain birds. See Polyperythrin.

Hematoporphyrinuria (hem'-at-o-por'-fe-rin-u'-re-ah)

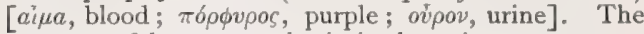
presence of hematoporphyrin in the urine.

Hematoporphyroidin (hem-at-o-por-fir-oid'-in) [aipa, blood; $\pi \delta ́ \rho \varphi v o s$, purple]. A substance similar in origin and character to hematoporphyrin, but less soluble. Like hematoporphyrin, it is sometimes found in the urine.

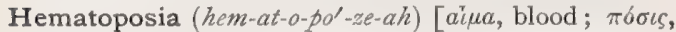
a drinking]. Blood-drinking as a therapeutic measure; hematopisis.

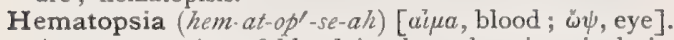
An extravasation of blood in the subconjunctival tissues of the eye.

Hematoptysis (hem-at-oph-tis-is). Same as Hemoptysis,

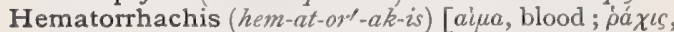
spine]. Hemorrhage within the vertebral canal.

Hematorrhea (hem-at-or-e'-ah) [ai $\mu \alpha$, blood; poia, a flow]. A copious passive flow or discharge of blood; a hemorrhage.

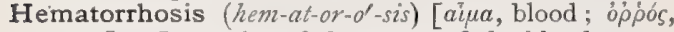
serum]. Separation of the serum of the blood.

Hematosac (hem'-at-o-sak) [airea, blood; saccus, a bag]. A blood-cyst.

Hematosalpinx (hem-at-o-sal'-pinks) [aina, blood; $\sigma \alpha ́ \lambda \pi \iota \gamma \xi$, a trumpet]. A hemorrhagic distention or obstruction of a Fallopian tube.

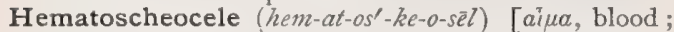
ó $\chi \varepsilon \sigma \nu$, scrotum; $\kappa \dot{\eta} \lambda \eta$, tumor]. A hemorrhagic tumor or distention of the scrotum.

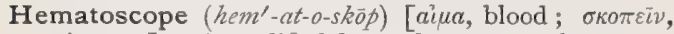
to inspect]. A modified form of, or an attachment to, the spectroscope, for use in examination of blood.

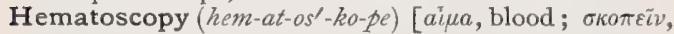
to inspect]. Spectroscopic examination of the blood and blood-discs.

Hematose (hem'-at-ôs) [ai $\mu a$, blood]. Full of blood.

Hematosepsis (hem-at-o-sep'-sis). See Septicemia.

Hematosin (hem-at-o'-sin). See Hematin.

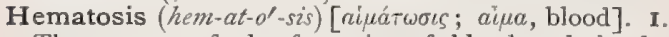
The process of the formation of blood and the development of blood-corpuscles. 2. The arterialization of the blood.

Hematospectroscope (hem-at-o-spek'-tro-skōp) [ai $k^{\top} \alpha$,

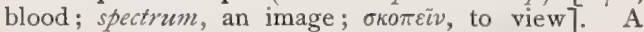
spectroscope adapted for use in the study of the blood.

Hematospermia (hem-at-o-sper'-me-ah) [aina, blood; $\sigma \pi \varepsilon p \mu a$, seed]. The discharge of blondy semen.

Hematospongus (hem-at-o-spun'-gus) [ai $\mu a$, blood; $\sigma \pi \delta \gamma \gamma o s$, sponge]. Medullary sarcoma.

Hematothorax (hem-at-o-tho'-raks). See Hemothorax,

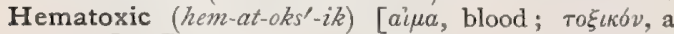
poison]. Pertaining to a poisoned or impure condition of the blood.

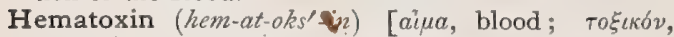
poison]. Any blood-poison or poisonous principle developed in the blood.

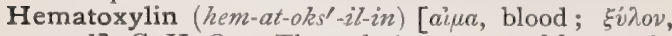
wood], $\mathrm{C}_{16} \mathrm{H}_{14} \mathrm{O}_{6}$. The coloring-matter of logwood; it is very soluble in water and alcohol, and crystallizes in yellowish prisms with $2 \mathrm{H}_{2} \mathrm{O}$. It dissolves in alkalies with a violet-blue color. It is a valuable stain in microscopy. See Pigments, Conspectus of. $\mathbf{H}$., Delafield's. See Stains, Table of. For other hematoxylin stains, including Böhmer's, Kleinenberg's, Mayer's, Friedlander's and Cook's, șee Stains, Table of.

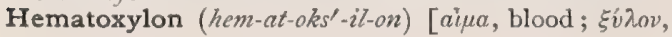

wood]. Logwood. The heart-wood of $H$. campechianum; it occurs as dark brown raspings or a coarse powder, and contains tannic acid and a coloring-principle, hematoxylin, $\mathrm{C}_{16} \mathrm{H}_{14} \mathrm{O}_{6}$, that becomes grayish-red by the action of light. It is a mild astringent. $H$., Ext. Dose gr. v-xx. H., Decoctum, strength I to 17. Dose $3 \mathrm{j}-\mathrm{ij}$. Unof.

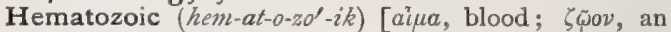
animal]. Pertaining to a hematozoön.

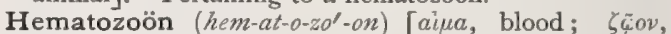
animal: pl., Hematozoa]. Any living organism or animal in the blood.

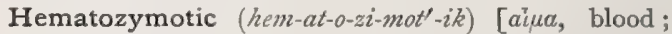

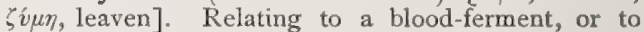
fermentation in the blood of a living organism.

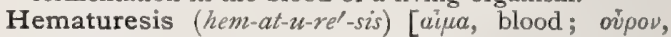
urine]. The passage of bloody urine.

Hematuria (hem-at-u'-re-ah) [aiua, blood; ovjov, urine]. Hematuresis. Blood in the urine. It may be due to injury, local disease, general disorder, or the presence of entozoa. When only the coloring-matter of the blood is found in the urine, it is termed hemoglobinuria or hematinuria. The color of the urine in hematuria varies from bright-red to a dingy, smoky color, or to merely a tinging of the urine. The urine may be examined for blood-corpuscles by means of the microscope; the presence of blood may be demonstrated by the spectroscope. Almen's, or the guaiacum test, or Heller's test may be made. See Tests, Table of. H., Intermittent, that form due to malarial poisoning. H., Paroxysmal. Same as H., Intermittent.

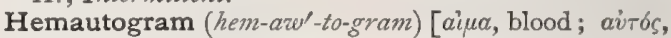
self; $\gamma \rho a ́ \mu \mu \alpha$, a tracing]. The tracing made in hemautography.

Hemautograph (hem-aze'to-graf). Same as Hemautogram.

Hemautography (hem-ave-tog'-ra-fe) [aipa, blood;

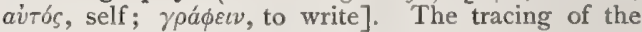
pulse-curve by the jet of blood from a divided artery caught upon paper drawn in front of it.

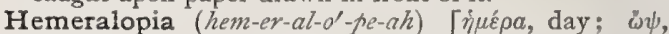
eye]. Day-vision or night-blindness; a symptom of pigmentary degeneration of the retina, failure of general nutrition, etc. Vision is good by day or in a strong light, but fails at night. See also Nyctalopia.

Hemeraphonia (hem-er-af-o'-ne-ah) [ $\dot{\mu} u \dot{\varepsilon} \rho a$, day; $\dot{a}$, priv.; $\nu^{\prime} \eta$. voice]. Loss of voice during the day, with return of the power of phonation at night.

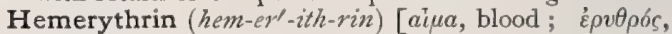
red]. The pigment found by Krukenberg in the blood of Sipunculus nudus.

Hemerythrogen (hem-er-ith'-ro-gen) [aipn, blood;

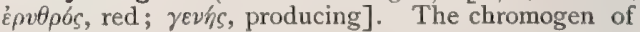
hemerythrin.

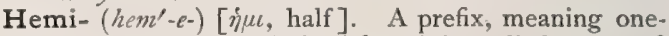
half. In anatomy and physiology it is applied to one of the two lateral halves of the body.

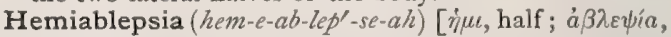
blindness]. See Hemianopsia.

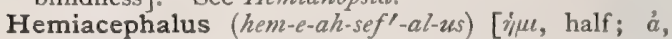
priv.; $\kappa \varepsilon \phi a \lambda \eta$, head]. A variety of omphalositic monsters of the species Paracephalus. It is the lowest grade of development in paracephalus, closely approaching true acephalus.

Hemiachromatopsia (hem-e-ah-kro-mat-op'-se-ah) [jul, half; $\dot{a}$, priv. ; $\chi \rho \bar{\omega} \mu \alpha$, color; ò $\psi \iota$, vision]. Subnormal or absent color-vision in corresponding halves of the field of vision.

Hemialbumin (hem-e-al'-bu-min). See Anti-albumin.

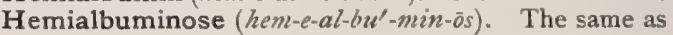
Hemiaibumose. 
Hemialbumose (hem-e-al'-bu-môs) [juc, half; albumen, the white of egg]. The most characteristic and most frequently obtained by-product of proteid zymolysis. It is the forerunner of hemipeptone. It is frequently found in the urine, and occurs normally in the marrow of bones and in cerebro-spinal fluid. See Peplones.

Hemialbumosuria (hem-e-al-bu-mös-u'-re-ah). Same as Propeptonuria.

Hemialgia (hem-e-al'-je-ah) [ju, half; à $\lambda \gamma o s$, pain]. Unilateral neuralgia.

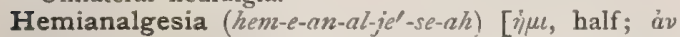
priv.; $\dot{a} \lambda$ yos, pain]. Insensibility to pain throughout one lateral half of the body and limbs.

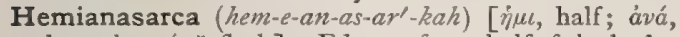
through; $\sigma a ́ \rho \xi$, flesh]. Edema of one-half of the body.

Hemianesthesia (hem-e-an-es-the-ze'-ah) [ijut, half; ávaco0noia, want of feeling]. Partial or complete loss of the sense of feeling in a lateral half of the body.

Hemianopia (hem-e-an-o'-pe-ah). See Hemianopsia.

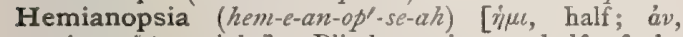
priv.; öwes, sight]. Blindness in one-half of the visual field. It may be bilateral (binocular) or monolateral (monocular or uniocular), according as it affects one or both eyes. H., Binasal, due to anesthesia of the temporal halves of the retina, the nasal fields thereby failing to be visible. H., Bitemporal, the reverse of the last. H., Crossed or Heteronymous, a general term for either binasal or bitemporal hemianopsia. H., Homonymous, right, or left, the most common form, affecting the inner half of one field and the outer of the other. H., Inferior and Superior, the upper or lower halves of the retina are insensitive.

Hemianoptic (hem-e-an-op'-tik) [jut, half; áv, priv. ; $\delta$ w.s, sight]. Affected with hemianopsia.

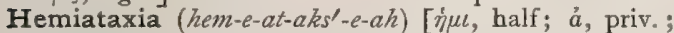
$\tau a ́ \xi \iota \zeta$, order]. Inability to produce orderly or systematic movements on one side of the body.

Hemiathetosis (hem-e-ath-et-o'-sis) [juu, half; ä $\theta \varepsilon \tau o \zeta$, without fixed position]. A term for athetosis or involuntary rhythmic movements of one side of the body only.

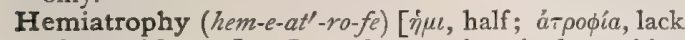
of nourishment]. Imperfect or impaired nutrition confined to one side of the body.

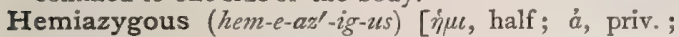

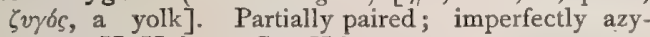
gous. H. Veins. See Vein.

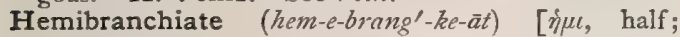
$\beta \rho a ́ \gamma \chi \iota a$, gills]. In biology, having an incomplete branchial apparatus.

Hemic (hem $-i k$ ) [ai $\mu a$, blood]. Pertaining to the blood; hemal.

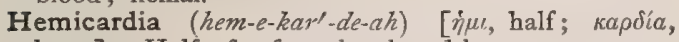
heart]. Half of a four-chambered heart.

Hemicarp (hem'-e-karp) [jur, half; $\kappa \kappa \rho \pi b s$, fruit]. In biology, one of the separable carpels of a dicarpellary fruit.

Hemicatalepsy (hem-e-kat'-al-ep-se) [irut, half; $\kappa a \tau a-$ $\lambda \varepsilon \psi i a$, catalepsy]. Catalepsy affecting only one lateral half of the subject.

Hemicentrum (hem-e-sen'-trum) [iju, half; $\kappa \varepsilon v \tau \rho o v$, center]. Either on of the two lateral elements of the centrum of a vertebra.

Hemicephalia (hem-e-sef-a'-le-ah). Synonym of Hemicrania.

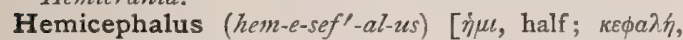
head]. A monster fetus in which the cerebral hemispheres and skull are absent or undeveloped. It is a synonym of Anencephalus.

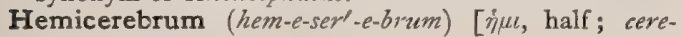
brum, cerebrum]. A cerebral hemisphere.
Hemichordate (hem-e-kor'-dät) [hemi, half; chorda, a string]. In biology, of or pertaining to such animal forms as are intermediate between the Chordata and the Achordata, e.g., Balanoglossus.

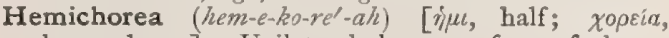
chorea, dance]. Unilateral chorea; a form of chorea in which the convulsive movements are confined to one side of the body only.

Hemicollin (hem-e-kol'-in) [i $\mu \mu$, half; $\kappa \delta \lambda \lambda \alpha$, glue ], $\mathrm{C}_{47} \mathrm{H}_{70} \mathrm{~N}_{14} \mathrm{O}_{19}$. A peptone-like substance derived from collagen. It is soluble in $70-80$ per cent. alcohol, and is not precipitable by platinum tetrachlorid.

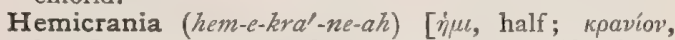
head]. Neuralgia or headache of one-half of the head. See Misraine.

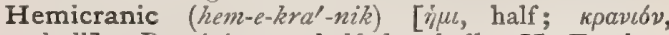
skull]. Pertaining to half the skull. H. Equivalents, a name given to isolated symptoms-flitting scotomata, vomiting, vaso-motor disturbances, etc. in cases of aborted migraine.

Hemicyclic (hem-e-si'-klik) [jue, half; $\kappa \hat{\kappa} \kappa \lambda o s, a$ circle]. In biology, having certain of the floral organs arranged in whorls, and others in a spiral.

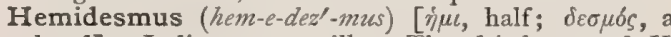
band]. Indian sarsaparilla. The dried root of $H$. indicus, imported from India. It is a tonic, alterative, diaphoretic, and diuretic. H., Syr. (B.P.). Dose $3 \mathrm{j}$.

Hemidiaphoresis (hem-e-di-af-or-e'-sis) [ijul, half; $\delta \iota a \phi \delta p \eta \sigma \iota$, sweating]. Sweating of one lateral half of the body only.

Hemidrosis (hem-id-ro'-sis). See Hematidrosis.

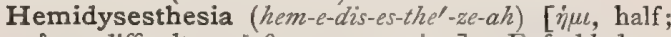
$\delta v \varsigma$, difficult; $a i \sigma \theta \eta \sigma \iota \varsigma$, sensation]. Enfeebled or dulled sensation in a lateral half of the body, or in half of one of the organs of sense.

Hemidystrophia (hem-e-dis-tro'-fe-ah) [i $\mu \iota$, half; $\delta v \sigma$, ill; $\tau \rho \circ \phi \eta$, nourishment]. In biology, the state of being imperfectly nourished.

Hemi-elastin (hem-e-e-las'-tin). See Proto-elastose.

Hemielytrum, Hemielytron (hem-e-ell'-it-rum, -tron) $[\dot{\eta} \mu \iota$, half; $\varepsilon \dot{\lambda} v r \rho o n$, a sheath: pl., Hemielytra]. One of the fore-wings of hemipterous and heteropterous insects, or one of the dorsal scales of certain marine annelids, as in Hermioni.

Hemiencephalon (hem-e-en-sef'-al-on) [ijul, half;

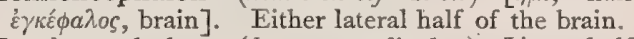

Hemiencephalus (hem-e-en-sef'-al-us) [ijul, half;

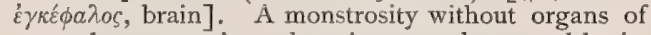
sense, but possessing otherwise a nearly normal brain.

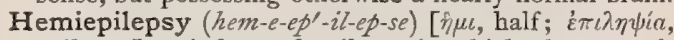
epilepsy]. A form of epilepsy in which the convulsions are confined to one lateral half of the body.

Hemifornix (hem-e-for'-niks) [iंul, half; fornix, an arch, vault]. A name used to designate the irregular, elongated portion of either paracelian floor, composed of hippocamp, fimbria, and fornicolumn.

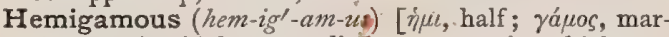
riage]. In biology, applied to grasses in which one floret is neuter and the other male or female.

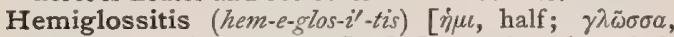
tongue; $\iota \tau \iota s$, inflammation]. Inflammation of one-half of the tongue only. A definite nodule or lump may be present in the substance of the tongue.

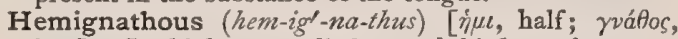
jaw]. In biology, applied to such birds as have one mandible shorter than the other.

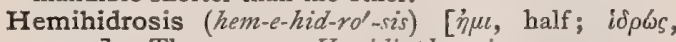
sweat]. The same as Hemidiaphoresis.

Hemihyperesthesia (hem-e-hi-per-es-the'-ze-ah) $[\dot{\eta} \mu \iota$,

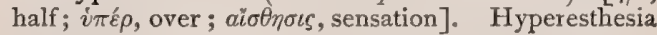
confined to one lateral half of the body. 
Hemihypertrophy (hem-e-hi-per'-tro-fe) [iju, half; $i \pi \varepsilon \rho$, over; $\tau \rho \circ \phi \dot{\eta}$, nourishment]. Hypertrophy of half of the body.

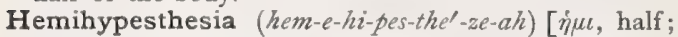

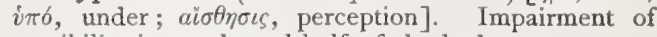
sensibility in one lateral half of the body.

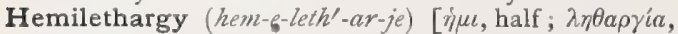
lethargy]. A state of partial lethargy.

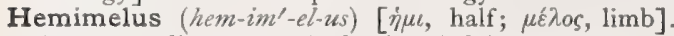
An ectromelic monstrosity having deficient or atrophied forearms, legs, feet, and hands, and normal arms and thighs.

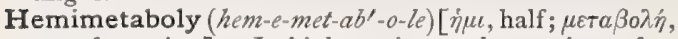
transformation]. In biology, incomplete or imperfect metamorphosis; hemimetamorphosis.

Hemimetamorphosis (hem-e-met-am-or'-fo-sis) [iju, half; $\mu \varepsilon \tau a \mu o ́ \rho \phi \omega \sigma \iota s$, transformation]. In biology, incomplete metamorphosis ; hemimetaboly.

Hemimyasthenia (hem-e-mi-as-the'-ne-ah) [ì $\mu$, balf; $\mu \tilde{v} s$, muscle: $\dot{\alpha} \sigma \theta \varepsilon v i \alpha$, weakness]. Myasthenia of one lateral half of the body.

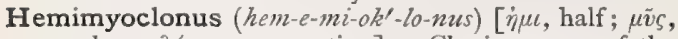
muscle; $\kappa \lambda$ óvos, commotion]. Clonic spasm of the muscles of one lateral half of the body.

Hemin (hem'-in) [aipa, blood], $\mathrm{C}_{34} \mathrm{H}_{35} \mathrm{~N}_{4} \mathrm{FeO}_{5} . \mathrm{HCl}$. Teichmann's crystals, or hydrochlorid of hematin. A doubly-refractive pleochromatic crystalline substance derived from blood. It is obtained by heating under a cover-slip, a drop of fresh blood on a glass-slide with a little glacial acetic acid. In the case of blood that has been dried, or in old blood-clot or stain, the resi-
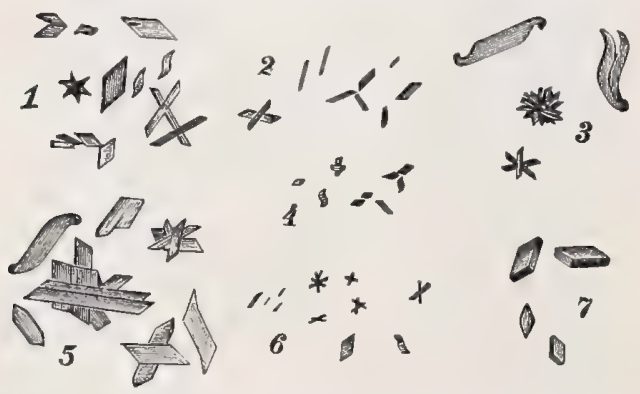

Hemin Crystals. 1. Human. 2. Seal. 3. Calf. $\begin{gathered}\text { Rabit. } \\ \text { Pig. 5. Lamb. 6. Pike. } 7 .\end{gathered}$

due should be powdered as finely as possible with a trace of $\mathrm{NaCl}$. Some of this powder is then placed on a slide and glacial acetic acid added, and heat carefully applied. The crystals are dark-brown or black, elongated rhombic plates and prisms belonging to the triclinic system; they are insoluble in water, alcohol, ether, chloroform, or dilute acids.

Hemineurasthenia (hem-e-nu-ras-the'-ne-ah) [iंu,

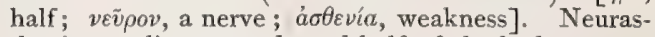
thenia peculiar to one lateral half of the body.

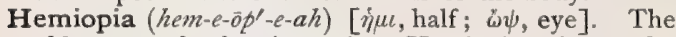
older term for hemianopsia. Hemiopia refers to the seeing-half of the retina, hemianopsia to that part of the field not seen.

Hemiopsia, Hemiopy (hem-e-op'-se-ah, hem'-e-opp-e). See Homiopia.

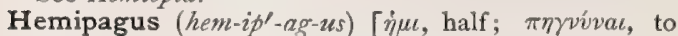
unite]. A monomphalic monstrosity united by the thoraces, and with a common mouth.

Hemiparaplegia (hem-e-par-ap-le'-je-ah) [ijul, half; $\pi a \rho a \pi \lambda \eta \gamma^{\prime} a$, paralysis of the limbs]. Paralysis of a lower limb on one side only.

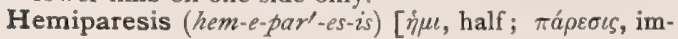

pairment of strength]. Paresis, or weakening of the strength on one side of the body only.

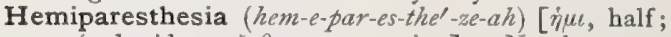

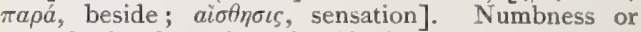
paresthesia of one lateral half of the body.

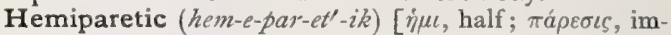
pairment of strength]. Affected with hemiparesis.

Hemi-peptone (hem-e-pep'-tôn). See Peptones.

Hemiphalacrosis (hem-e-fal-ak-ro'-sis) [ijul, half; $\phi a \lambda a ́ \kappa \rho \omega \sigma \iota \varsigma$, baldness]. Baldness affecting one lateral half of the head.

Hemiphonia (hem-e-fo'-ne-ah) [iju, half; $\phi \omega \nu \eta ́$, voice]. Speech having the characteristics of half-voice, halfwhisper; used by patients in great weakness and exhaustion.

Hemipinic Acid (hem-e-pin'-ik). See Acid.

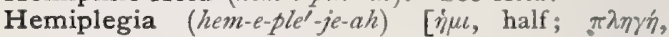
stroke]. Paralysis of one side of the body, due usually to a lesion of some part of the corpus striatum and internal capsule, of the crus cerebri, or of the cortex or subcortex of the opposite side of the brain. H., Alternate, paralysis of the facial muscles upon one side, with paralysis of the trunk and extremities upon the opposite side of the body. H., Bilateral Spastic. See Paraplegia, Infantile Spasmodic. H., Cerebral, the ordinary form first described. H., Crossed. Same as $H$., Alternate. H., Facial, motor paralysis of one side of the face. H., Hephestic, from the use of the hanmer by smiths, a form of occupation neurosis. H., Spastic, a form occurring in infants, in which the affected extremities are subject to convulsive twitchings. H., Spinal, paralysis of one side or of the whole body, with loss of sensation of the opposite side. It is due to disease of the spinal cord.

Hemiplexia (hem-e-pleks'-e-ah). Same as Hemiplegia.

Hemiprosoplegia (hem-e-pro-so-ple'-je-ah) [iju, half; $\pi \rho \sigma \sigma \omega \pi \nu \nu$, face; $\pi \lambda \eta \gamma \eta \dot{n}$, stroke]. Paralysis of one side of the face.

Hemiprotein (hem-e-pro'-te-in). See Antialbumate.

Hemipterous (hem-ip'-ter-us) [ijul, half; $\pi \tau \varepsilon \rho o ́ v$, wing]. In biology, applied to certain insects that have the fore-wings partly membranous and partly coriaceous or chitinous.

Hemirheumatism (hem-e-ru'-mat-izm) [iंul, half;

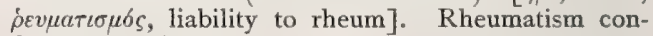
fined to one lateral half of the body.

Hemisection (hem-e-sek'-shun) [ijul, half; sectio, a cutting]. Bisection; chiefly applied to division into two lateral halves. See Medisection.

Hemiseptum (hem-e-sep'-tum) [íu, half; septum, a partition]. The lateral half of a septum, as of the heart; the lateral half of the septum lucidum.

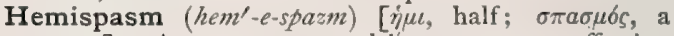
spasm]. A spasm or convulsifve movement affecting only one side of the body.

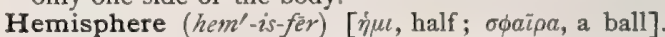
Half a sphere. H., Cerebellar, either lateral half of the cerebellum. H., Cerebral, either lateral half of the cerebrum.

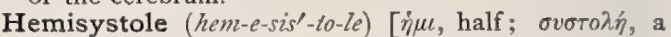
contraction]. A peculiar kind of irregular action of the heart-muscle, in which, with every two beats of the heart, only one beat of the pulse is felt.

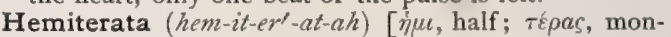
ster]. A class of malformations, including all human bodies presenting any abnormality of development, not grave enough to be called monstrous, nor of the specific character to be classed as heterotaxic or hermaphroditic.

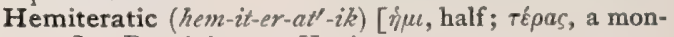
ster]. Pertaining to Heniterata. 


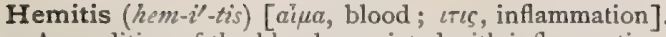
A condition of the blood associated with inflammation.

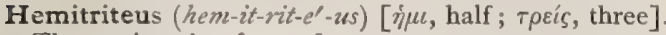
The semi-tertian form of ague.

Hemitropous (hem-it'-ro-pus) [ijue, half; $\tau \rho o \pi h$, a turning over]. In biology, amphitropous; half anatropous; applied to the plant-embryo when much curved.

Hemizonia (hem-iz-o'-ne-ah) [ $\xi \mu \iota$, half ; $\xi \omega v \eta$, girdle]. A genus of composite-flowered herbs and shrubs, of which some I9 species are Californian; they are called tar-weeds and resin-weeds. They are generally strongly fragrant, resinous plants, locally esteemed for their balsamic qualities. Unof.

Hemlock (hem'-lok). See Conium. H.-bark, a bark used in the manufacture of leather. It is taken from Abies canadensis of Canada and the United States, and contains nearly fourteen per cent. of tannin. It is said to produce a leather harder than oak-bark, but which is less pliable and more pervious to water. H.extract, a strongly astringent, solid extract of hemlock-bark, $q . v$. It is principally employed in the arts. H. Spruce. See Abies.

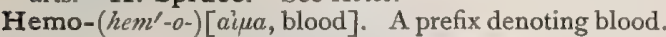

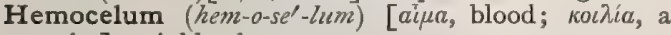
cavity]. A blood-cyst.

Hemochromogen (hem-o-kro'mo-jen) [ai $\mu a$, blood; $\chi \rho \tilde{\omega} \mu u$, color; $\gamma \varepsilon \nu \eta ́ s$, producing]. An excretory pigment of certain invertebrates. In some beetles it has a respiratory function. It is the same as $E n$ terohematin and Helicorubin.

Hemochromometer (hem-okro-mom'-et-er) [ai a $^{\top} a$, blood;

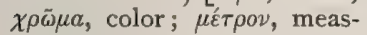
ure]. Colorimeter; an instrument for estimating the amount of oxyhemoglobin in the blood, by comparing a solution of the blood with a standard solution of picrocarminate of ammonia.

Hemochyle (hem'-o-kil $)[\alpha i \mu \alpha$, blood; $\chi v \lambda \hat{s} s$, juice]. The blood-lymph of vertebrates.

Hemocrystallin (hem-o-kris' tal-in). See Hemoglobin.

Hemocyanin (hem-o-si'-an-in) [aǐra, blood; ќ́avos, blue], $\mathrm{C}_{867} \mathrm{H}_{1363} \mathrm{~N}_{223} \mathrm{CuS}_{4} \mathrm{O}_{258}$ (Griffiths). A blue proteid pigment, having a very constant percentage composition. It is analogous to hemoglobin,

but contains copper instead of iron, and forms the chief constituent in the blood of many invertebrates, in which it acts as the carrier of oxygen.

Hemocyne (hem'-o-sin) [aía, blood; кí $\omega v$, кvvós, dog]. The serum of dogs' blood.

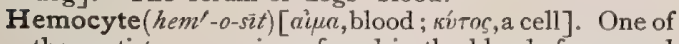
the protistan organisms found in the blood of man and animals, $e_{.} g$., the parasite of malarial fever, as studied by Lavaran, Celli, Machiafava, Golgi, Councilman, Osler, and Pfeiffer. See Parasites (Animal) Table of.

Hemocytolysis (hem-a-si-tol'-is-is) [aiua, blood; кviros, cell; $\lambda \hat{v} \varepsilon \iota v$, to unloose]. The dissolution of bloodcorpuscles by means of heat.

Hemocytometer (hem-o-si-tom'-et-er) [ai ${ }^{3} \mu a$, blood;

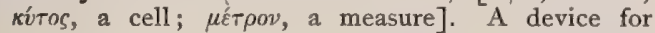
estimating the number of corpuscles in the blood.
The instrument of Gowers, illustrated below, and that of Thoma are those most frequently employed.

Hemocytotrypsis (hem-o-si-to-trip'-sis) [aipa, blood; китоร, cell; $\tau \rho i \beta \varepsilon \iota \nu$, to rub]. The breaking up of blood-corpuscles under strong pressure.

Hemodiapedesis (hem-o-di-ap-ed-ef-sis) [ai $\alpha a$, blood;

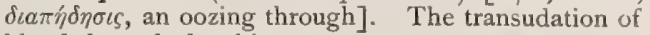
blood through the skin.

Hemodromograph (hem-o-dro'-mo-graf). Same as Hemotachometer.

Hemodromometer (hem-o-dro-mom'-et-er). See Hemadromometer.

Hemodynamometer (hem-o-di-nam-om'-et-er). See Hemadynamometer.

Hemogallol (hem-o-gal'-ol) [ai $\mu a$, blood; galla, gallnut]. A proprietary substance occurring as a brownishred powder, and formed by oxidizing the hemoglobin of the blood by pyrogallol. It is used in anemia in doses of gr. iss-viiss. Unof.

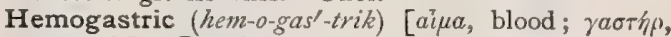
stomach]. Pertaining to blood in the stomach.

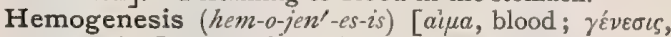
generation]. The formation of blood.

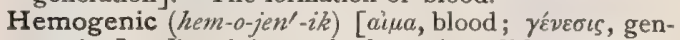
eration]. Pertaining to the formation of blood ; bloodproducing.

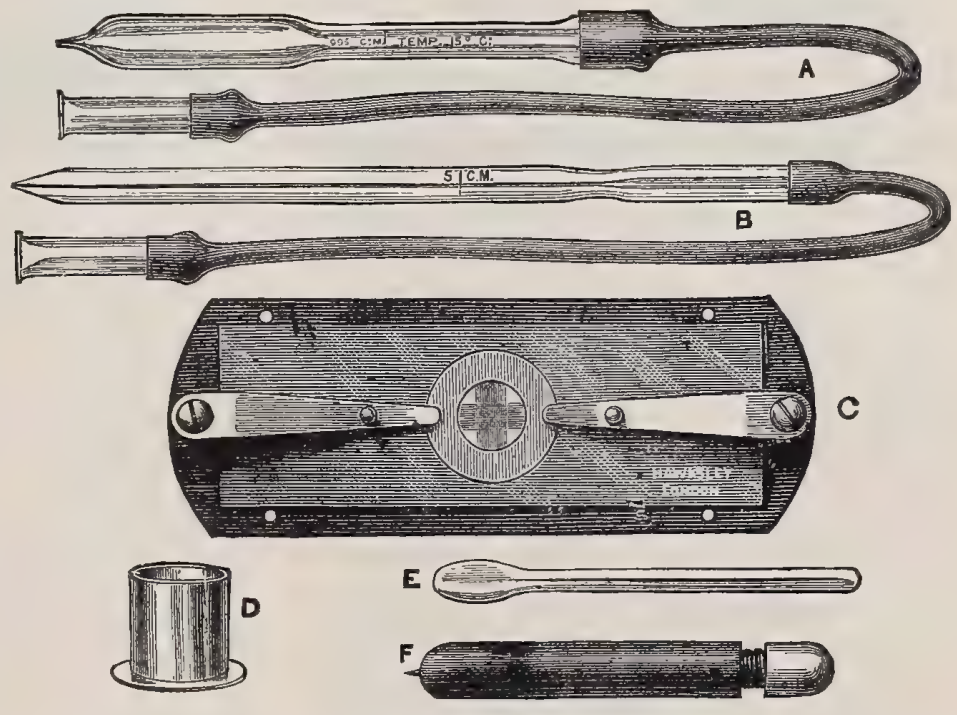

GOWERS' HeMOCYTOMETER.

. Pipet for measuring the diluted solution. B. Capillary tube for measuring the blood. C. Cell with divisions on the floor, mounted on a slide. D. Vessel in which the dilution

Hemoglobin (hem-o-glo'-bin) [ai $\mu \alpha$, blood; globus, a round body]. Hematoglobin, Hemocrystallin. A doubly-refractive, pleochromatic colloid or crystalline matter, existing in the corpuscles of the blood, and to which their red color is due. In man the amount is I3.77 per cent., in woman $\mathbf{1} 2.59$ per cent., reduced by pregnancy to from 9 to 12 per cent. It is an oxygencarrier or respiratory pigment. The crystals of hemoglobin have a dark-red appearance with a strong purple or bluish tint; they are very soluble in water.

Hemoglobinemia (hem-o-glo-bin-e'-me-ah) [aiua, blood; globus, a round body; ai $\mu a$, blood]. A condition in which the hemoglobin is dissolved out of the red corpuscles, probably as the result of the destruc. tion of the latter, and is held in solution in the serum. The blood is "lake" -colored. It occurs in some in- 
fectious diseases, and after injecting certain substances into the blood.

Hemoglobiniferous (hem-o-glo-bin-if'-er-us) [aipa, blood; globus, a round body; ferre, to bear]. Yielding or carrying hemoglobin.

Hemoglobinocholia (hem-o-glo-bin-o-kol-le-ah) [aina,

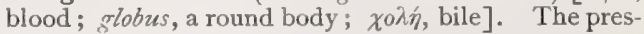
ence of hemoglobin in the bile.

Hemoglobinometer (hem-o-glo-bin-om'-et-er) [ai $[$ a, blood; globus, a round body; $\mu$ ćtpov, a measure]. An instrument for the quantitative estimation of hemo-

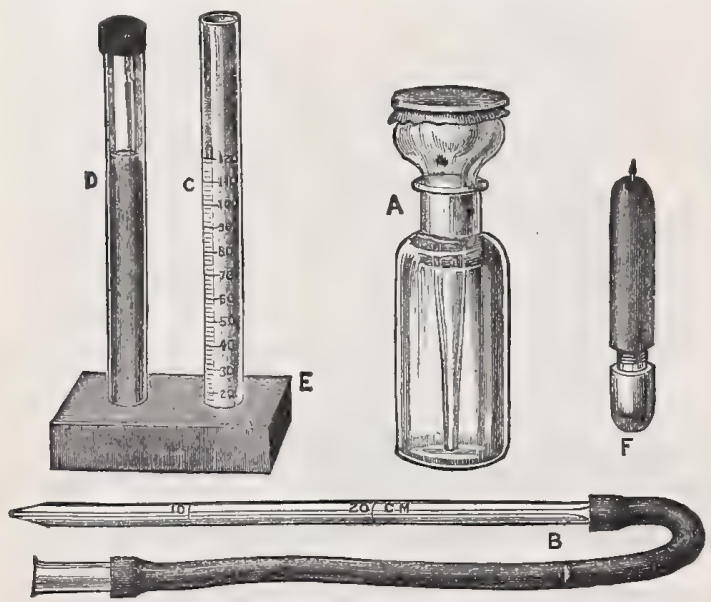

Gowers' HeMogLobinometer.

A. Pipet-bottle for distilled water. B. Capillary pipet. C Graduated tube. D. Closed tube containing standard dilution. F. Lancet for pricking the finger.

globin by comparing the color of a solution of blood of unknown with a color of a known valuation.

Hemoglobinuria (hem-o-glo-bin- $u^{\prime}-r e-a h$ ) [ai $\mu a$, blood; globus, a round body; ovpov, urine]. The presence of hemoglobin, the red coloring-matter of the blood, in the urine, due either to its solution out of the red corpuscles, or to disintegration of the red corpuscles. It occurs after transfusion of blood, during certain stages of septicemia, and after severe burns. It is unattended with the presence of the corpuscular elements of the blood in the urine, thus differing from hematuria. Hemoglobin Test: to a suspected sample add a drop of acetic acid and boil; a red coagulum indicates hemoglobin. See, also, Almen's Test, Hemin, and Heller. H., Epidemic, a condition of the newborn marked by jaundice, cyanosis, and nervous symptoms. H. Intermittent. See $H$., Paroxysmal. H., Paroxysmal, a form characterized by recurring periodic attacks. It is related to cold, and is also closely associated with Raynaud's Disease. H., Toxic, that form occurring in consequence of poisoning by various substances, $e$. $g$., potassium chlorate.

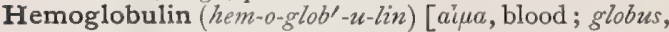
a ball]. Same as Hemoglobin.

Hemoid (hem'-oid) [aipa, blood; eidos, likeness]. Having the appearance of, or resembling, blood.

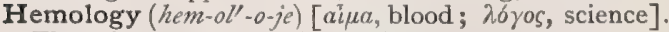
The science treating of the blood.

Hemolutein (hem-o-lu'-te-in) [aina, blood; luteus, yellow]. A yellow coloring-matter obtained from corpora lutea.

Hemolymph (hem'-o-limf) [aina, blood; lympha, clear water]. The blood of the higher invertebrata, containing more albuminoids and less water than the hydrolymph of lower forms. H. Glands, a variety of glands which, according to W. F. Robertson, are a kind of cross between the hemogenic glands $(e, g$. the spleen) and the lymphatic glands. The small prevertebral glands are examples.

Hemolysis (hem-ol'-is-is) [aiua, blood; $\lambda v \sigma \iota s$, solution]. Destruction or breaking-up of the red blood-corpuscles

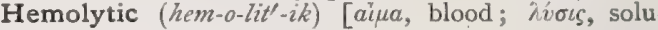
tion]. Pertaining to hemolysis.

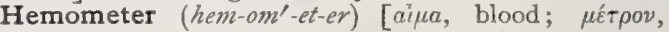
measure]. See Hemoglobinometer. Also, an appa-

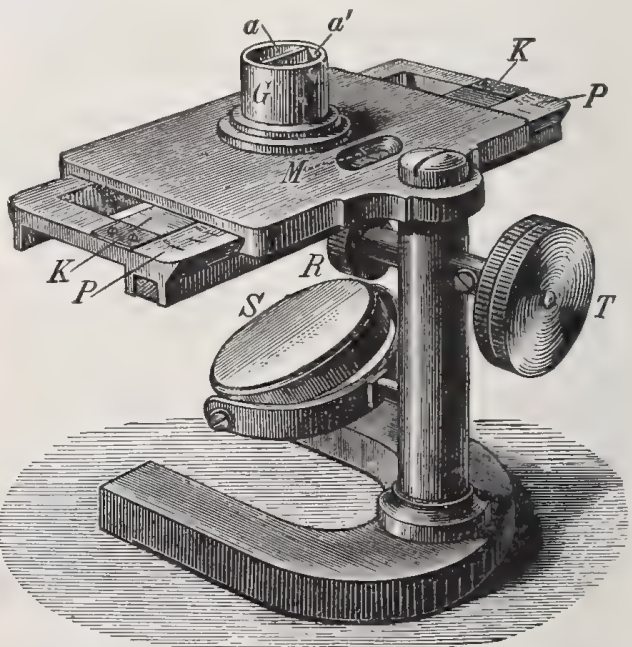

FLEISCHL'S HEMOMETER.

K. Red-colored wedge of glass moved by R. G. Mixing vessel with two compartments $a$ and $a^{\prime}$. M. Table with opening to read off the percentage of hemoglobin on the scale P. T. To move $\mathrm{K}$ through R. S. Reflector of Plaster-of-Paris.

ratus for ascertaining the amount of hemoglobin in normal or diseased blood.

Hemometra (hem-o-me'-trah). See Hematometra.

Hemoöphoritis (hem-o-off-or-i'-tis) [aipa, blood; Gióv,

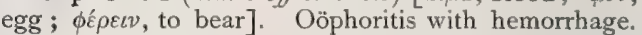

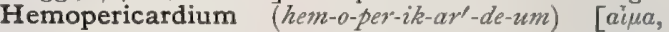
blood; $\pi \varepsilon \rho i$, around; $\kappa a \rho \delta i a$, the heart]. An effusion of blood into the pericardial cavity. It is due usually to the bursting of an aneurysm of the aorta, but may also follow rupture of the heart, or the bursting of an aneurysm of one of the coronary arteries.

Hemophagic (hem-o-faj'-ik) [aipo, blood; фayeiv, to eat]. Feeding upon blood; applied to certain animal parasites.

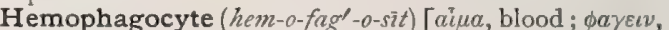
to eat; кútos, a cell]. Any phagocyte of the blood; a white blood-corpuscle.

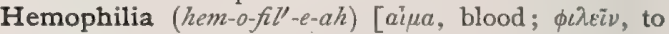
love]. The hemorrhagic diathesis; an abnormal tendency to hemorrhage, or ease of bleeding. It usually first appears at about the period of the second dentition, and is most frequent among males. Heredity plays a prominent part in this affection

Hemophthalmia (hem-off-thal"-me-ah) [aiua, blood; $o \phi A a \lambda \mu \sigma s$, eye]. A hemorrhage into the interior of the eye. It may arise from contusion, from iridectomy, or by rupture of a vessel.

Hemophthalmos (hem-off-thal'-mos) [ailea, blood; $\dot{\sigma} \phi \theta a \lambda \mu \delta s$; the eye]. Blood in the vitreous chamber characterized by a reddish reflex from the pupil.

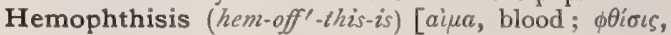
wasting]. Anemia dependent upon undue degeneration of the red blood-corpuscles. 
Hemoplasmodium (hem-o-plaz-mo'-de-um) [ai $\mu a$, blood; $\pi \lambda \dot{a} \sigma \mu a$, a moulded figure; $\varepsilon i \delta o s$, form]. The plasmodium of malaria. See Parasites (Animal), Table of.

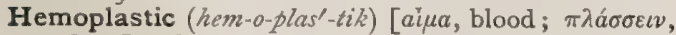
to form]. Same as Hematoplastic.

Hemopneumothorax (hem-o-nu-mo-tho'-raks) [aina, blood; $\pi \nu \varepsilon \tilde{\nu} \mu \alpha$, wind; $\theta \dot{\omega} \rho a \xi$, the chest]. An effusion of air and blood within the pleura.

Hemopoiesis (hem-o-poi-e'-sis). See Hematopoiesis.

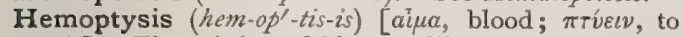
spit]. The spitting of blood. The term is confined usually to the expectoration of blood from the lungs. It may be slight or profuse, and death may result from suffocation. The blood is frothy and bright-red. H., Parasitic. See Distoma ringeri.

Hemorhodin (hem-or-ol-din) [aiua, blood; jófov, a rose]. A rose-colored albuminoid found in the blood of Aplysia depilans; it was discovered by $\mathrm{L}$. Cuénot.

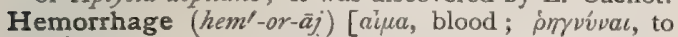
burst forth]. The flowing of blood from wounded or ruptured vessels. H., Accidental, during pregnancy from premature detachment of the placenta when normally situated. H., Capillary, oozing of blood from a wound without a flow from large vessels. H., Collateral, bleeding occurring in the course of acute inflammations. H., Complementary, succeeding upon another hemorrhage that has been cut short. $\mathrm{H}$., Concealed, a variety of accidental hemorrhage in which the bleeding takes place between the ovum and the uterine walls, without escape from the genital tract. H., Consecutive, ensuing some time after injury. H., Critical, occurring at the turning-point of a disease. H., Petechial. See Purpura. H., Postpartum, primary, within 24 hours after labor; secondary, after 24 hours. H., Primary, that immediately following any traumatism. H., Secondary, that occurring some time after the traumatism, and usually due to the sloughing of the tissues. H., Unavoidable, from detachment of a placenta previa. H., Vicarious, suppression of the menses with abnormal discharge of blood from some other part of the body than the vagina.

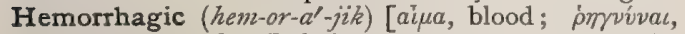
to burst forth]. Relating to or accompanied by hemorrhage $\mathbf{H}$. Diathesis. See Hemophilia. $\mathbf{H}$. Endometritis. See Endometritis. H. Infarct. See Infarct. H. Pneumonia, a form of pneumonia occurring in elderly people and in certain weakened states of the constitution, characterized by the presence of a large amount of blood in the expectoration.

Hemorrhaphilia (hem-or-af-il'-e-ah) [aipoppayia, hemorrhage; $\phi i$ inos, loving]. Synonym of Hemophitia.

Hemorrhea (hem-or-e'-ah) [aika, blood; poia, a flow]. A hemorrhage; a flow of blood. $\mathbf{H}$. ventriculi. See Hematemesis.

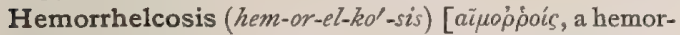
rhoid; $\hat{\varepsilon} \lambda \kappa \omega \sigma \iota s$ ulceration]. The formation of an ulcer upon a hemorrhoid.

Hemorrhinia (hem-or-in'-e-ah) [aija, blood; p'ss, nose]. Epistaxis; nose-bleed.

Hemorrhoid (hem'-or-oid) [aiúppoos, flowing with blood]. Pile. An enlarged and varicose condition of the vessels in the tissues around the anus, sometimes associated with eversion of the rectal mucous membrane. There is always more or less pain and tenderness, with discomfort in sitting. Hemorrhoids are caused by sedentary habits, constipation, obstruction to the portal circulation, or violent purging. $\mathbf{H}$., External, situated without the sphincter ani. H., Internal, within the anal orifice.

Hemorrhoidal (hem-or-oi'-dal) [aiuópoos, flowing with blood]. Pertaining to or affected with hemorrhoids.
Hemoscope (hem'-o-skōp). Same as Hematoscope

Hemosialemesis (hem-o-si-al-em'-es-is) [aina, blood; $\sigma \iota a \lambda o ́ v$, saliva; $\dot{\varepsilon} \mu \varepsilon \varepsilon \varepsilon v$, to vomit]. A form of vomiting sometimes observed in hysterical women with dysmenorrhea, the vomited matter consisting largely of saliva and a small quantity of blood, in addition to the ordinary contents of the stomach.

Hemosiderin (hem-o-sid'-er-in) [aina, blood; ridnpos, iron]. Neumann's name for a pigment often found in extravasations and thrombi with hematoidin, but differing from the latter in containing iron.

Hemospasia (hem-o-spa'-ze-ah) [aica, blood; $\sigma \pi \alpha ́ \varepsilon \iota \nu$, to draw]. The drawing of blood to a part; derivative action; the process of dry-cupping, especially when thoroughly carried out.

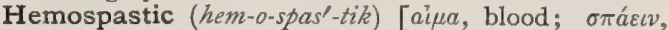
to draw]. Effecting or pertaining to hemospasia.

Hemostasia, or Hemostasis (hem-o-sta'-se-ah, or

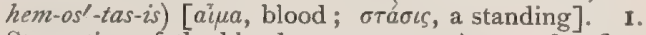
Stagnation of the blood-current, 2. Arrest of a flow of blood.

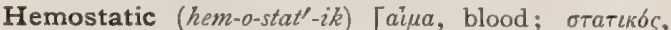
stationary]. Having the power to arrest hemorrhage. Also, an agent or remedy that arrests or restrains bleeding.

Hemostatics (hem-o-stat'-iks). See Hemastatics.

Hemotachometer (hem-o-lak-om'-et-er) [ai ${ }^{i} \mu a$, blood;

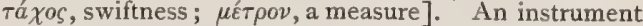
for measuring the rate of flow of arterial blood.

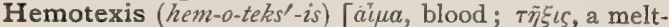
ing]. The dissolution of putrid blood.

Hemothorax (hem-o-tho'-raks) [ai ua, blood; $\theta 6 \rho a \xi$, the chest]. An accumulation of blood in a pleural cavity. It may occur under many varied conditions.

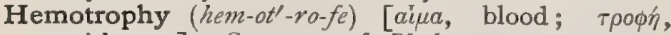
nourishment]. Synonym of Plethora, $q . v$.

Hemp [ME., hemp, hemp]. The hemp-fiber is the product of the Cannabis sativa, which is grown for textile purposes chiefly in Russia and Italy, while the seed is grown in India. It is a bast-fiber similar to that of the flax-plant, but coarser and stronger, and of deeper color, and less luster. It is used chiefly for the manufacture of ropes and cordage, and the fabric woven from it, known as canvas, is used in sail-making. Hemp is a mixture of cellulose and bastose. H., Manila, is a tropical fiber obtained on the Philippine Islands from the leaves of the wild plantain. It furnishes a very superior rope-making fiber, because of its combined lightness and strength, and the finer grades are used for woven goods. The color is yellowish or white, and the white variety has a fine silky luster. H., Suron, is grown in India, and furnishes a fiber of light-yellowish color. It resembles jute, although less lustrous. It is well adapted for cordage and netting. H., Sisal (or henequen), is derived from the fleshy leaves of a species of agave grown in Yucatan and the West Indies. It is used largely in the United States as a substitute for jute in the manufacture of bagging and for cordage, being stronger and lighter than jute. See also Cannabis. H.-nettle. See Galeopsis. H.-seed Calculus, a small rounded urinary concretion composed of oxalate of lime. It may vary in size from a pin's head to that of a hempseed, and is smooth and dark-colored. H.-seed Oil, oleum cannabis, is obtained from the seeds of the Cannabis sativa or common hemp. It has a mild odor, but mawkish taste, and greenish-yellow color, turning brown with age. Its specific gravity at $15^{\circ} \mathrm{C}$. is .9276 . It is freely soluble in boiling alcohol, has weaker drying properties than linseed oil, but is used in paint and varnish manufacture and in making soft soaps. 
Hemuresis (hem-u-re'sis). Synonym of Hematuria. Hen [ME, hen, a hen]. The female of the domestic fowl. H.-bane. See Hyoscyamus. H.-blindness, a popular name for night-blindness. H.-cluck Stertor, a form of stertorous respiration heard in some cases of retropharyngeal abscess.

Henequen (hen'-e-ken). See Hemp, Sisal.

Henle's Ansa. See Ansa. H.'s Canals. See Canal. H.'s Fenestrated Membrane, the layer of longitudinal elastic fibers of the inner coat of the arteries. H.'s Fibers, the elastic fibers forming the fenestrated membrane of Henle. H.'s Glands. See Gland. H.'s Layer, a layer of flat, horny, polygonal, non-nucleated cells situated between the cuticula and the external root-sheath of a hair-bulb. H.'s Loop, a loop in the uriniferous tubules. See Tubuli uriniferi. H.'s Muscle. See Muscles, Table of. H.'s Sheath, a connective-tissue sheath, surrounding terminal nerve-fibers. H.'s Tubular Tumor. See Siphonoma.

Henna (hen'-ah) [Arab., Khanna, henna]. A cosmetic much used in the Orient; it is prepared from the leaves of Lazosonia alba, and is sometimes used externally and internally in leprosy and in skin-diseases. Unof.

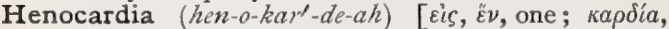
heart]. The condition of having but one auricle and one ventricle in the heart; it is normal in some of the lower animals.

Henoch's Purpura. See Diseases, Table of.

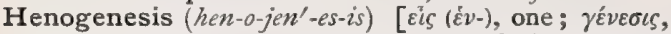
origin]. In biology, the developmental history of an individual organism; ontogenesis.

Henosis (hen-o'sis) [ uniting. 2. Symblepharon.

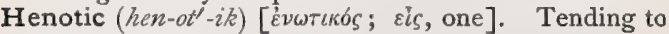
heal or to promote union.

Henry's Law. See Law.

Hensen's Disc. See Engelmann's Middle Disc. H.'s Experiment, an experiment proving that the so-called auditory hairs of the crustacean Mysis vibrate to a particular note. H.'s Prop-cells. See H.'s Supporting Cells. H.'s Stripe, a glistening band in the middle of the under surface of the membrana tectoria of the ear. H.'s Supporting Cells, tall columnar epithelial cells on the outer side of the outermost of Deiters' cells of the ear.

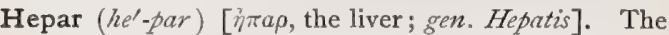
liver; jecur. H. adiposum, a synonym of fatty liver. $\mathbf{H}$. amyloideum, amyloid degeneration of the liver. H. sulphuris, the liver of sulphur; potassium sulphid; formerly much employed in medicine; now used mainly by homeopathists.

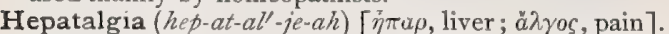
Pain in the liver, but more especially the paroxysmal pain occasionally affecting the right hypochondrium.

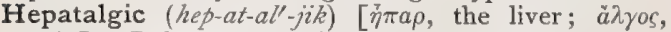
pain ]. Relating to or affected with hepatalgia.

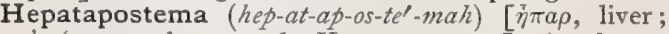
$\dot{a} \sigma \sigma \tau \eta \mu a$, abscess : plo, Hepatapostemata]. An abscess of the liver

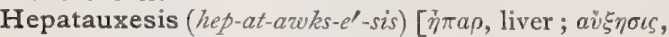
enlargement]. Enlargement of the liver.

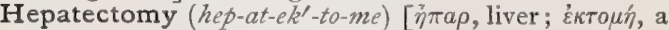
cutting out]. Excision of the liver, wholly or in part.

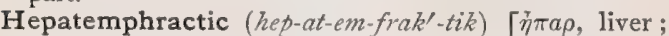
$\dot{\varepsilon} u \phi \rho a \xi \iota 5$, obstruction]. Relating to hepatemphraxis.

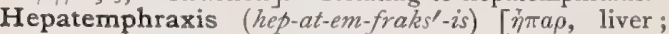
$\varepsilon \mu \phi \rho a \xi \iota \zeta$, obstruction]. Hepatic obstruction.

Hepathelcosis (hep-ath-el-ko'-sis) [ì $\pi a \rho$, liver ; $\varepsilon \lambda_{\kappa \omega \sigma \iota s,}$ ulceration]. Ulceration of the liver.

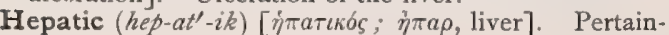

ing or belonging to the liver. $\mathbf{H}$. Aloes. See Aloes. H. Duct. See Duct. H. Lobes, the natural anatomic divisions of the liver, usually designated as right, left, quadrate, spigelian, and caudate lobes. $\mathbf{H}$. Plexus. See Plexus. H. Zones, certain areas in an hepatic lobule. The central area, capillaries and cells form the Hepatic-vein Zone, specially liable to congestive changes; the area next the periphery of the lobule is the Portal-vein Zone; and the area between the two the Hepatic-artery Zone. H. Starch, a synonym of Glycogen.

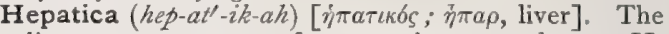
liverwort; a genus of ranunculaceous plants. $\mathbf{H}$. triloba and $\mathbf{H}$. acutiloba were formerly esteemed in hepatic, renal, and pulmonic complaints. Unof.

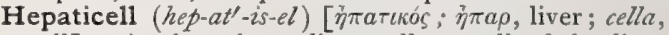
cell]. An hepatic or liver cell; a cell of the liver tissue.

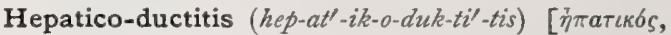
pertaining to the liver; ductus, duct; $\iota \tau \iota$, inflammation]. Inflammation of the hepatic ducts.

He patico-pancreatic (hep-at'-ik-o-pan-kre-at'-ik)

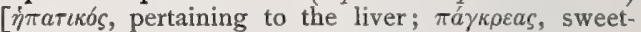
bread]. Relating to the liver and the pancreas.

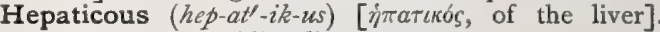
In biology, resembling liver.

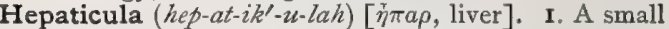
liver. 2. A slight degree of hepatitis.

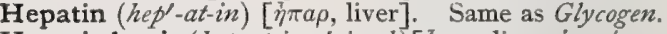

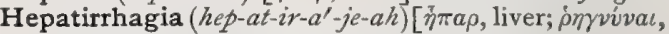
to burst forth]. Hemorrhage from the liver.

Hepatirrhea (hep-at-ir-e'-ah). See Hepatorrhea.

Hepatism (hep'-at-izm) [j $\pi a \rho$, liver]. Derangement of various functions of the body, due or ascribed to some functional or other disorder of the liver.

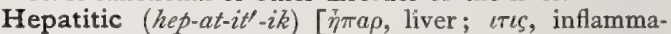
tion]. Affected with, or relating to, hepatitis.

Hepatitis (hep-at-i'-tis) [r $i^{\prime} \pi \rho$, liver; $\iota \tau \iota s$, inflammation.] Inflammation of the liver. H. chronica interstitialis, cirrhosis of the liver. H., Parenchymatous, Acute, acute yellow atrophy of the liver. $H$. suppurativa, abscess of the liver.

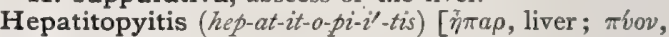
pus; $\iota \tau \iota \varsigma$, inflammation]. Hepatitis characterized by the formation of abscesses.

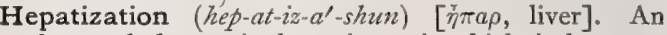
abnormal change in lung-tissue, in which it becomes solid and friable, somewhat resembling the tissue of the liver. H., Gray, the condition of a lung in the third stage of pneumonia. H., Red, that in the second stage of pneumonia. H., White, the condition of the lungs in stillborn syphilitic children. H., Yellow, the condition of the lung in the third stage of pneumonia when tinted by the presence of numerous puscells. See Pneumonia.

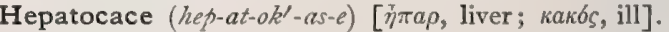
Gangrene of the liver.

Hepatocarcinia (hep-at-o-kar-sin'-e-ah) [iे $\pi \alpha \rho$, liver; каркіро, cancer]. Malignant disease of the liver.

Hepatocele (hep'-at-o-sêl) [ $\eta^{\prime} \pi a \rho$, liver; $\kappa \dot{n} \lambda \eta$, a tumor]. A form of hernia in which the liver protrudes through an opening in the abdominal wall,

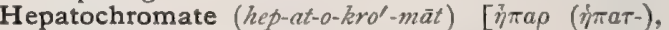
the liver; $\chi \rho \omega \tilde{\omega} \mu$, a color]. Krukenberg's name for Enterochlorophyl.

Hepatocirrhosis (hep-at-o-sir-o'-sis) [iे $\pi a \rho$, liver; $\kappa i \rho \rho b$, yellow]. Cirrhosis of the liver.

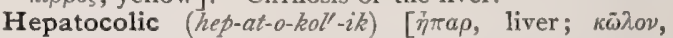
colon]. Relating to the liver and the colon.

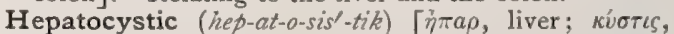
bladder]. Pertaining to the liver and the gallbladder. 


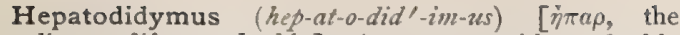

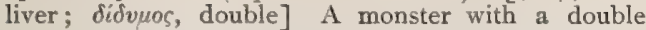
body from the liver up.

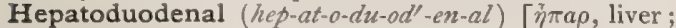
duodeni, twelve each]. Relating to the liver and the duodenum.

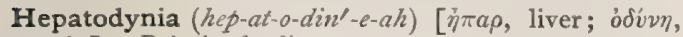
pain ]. Pain in the liver.

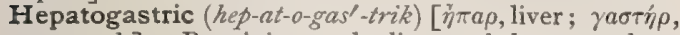
stomach]. Pertaining to the liver and the stomach.

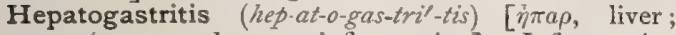

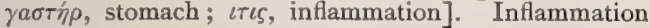
of both liver and stomach.

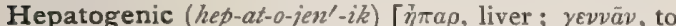
beget]. Produced by or in the liver. H. Icterus, also called absorption-icterus or jaundice, is caused by the absorption of bile already formed in the liver.

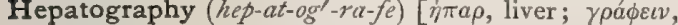
to write]. A description of the liver.

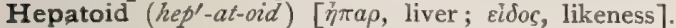
Resembling a liver or liver-substance.

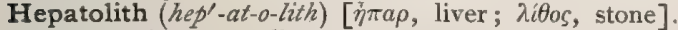
Biliary calculus; gall-stone.

Hepatolithiasis (hep-at-o-lith-i'-as-is) [iे $\pi a \rho$, liver ;

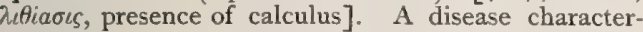
ized by gall-stones or concretions in the liver.

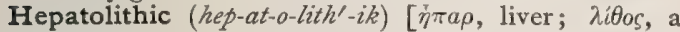
stone]. Affected with biliary calculi.

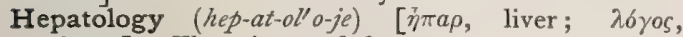
science]. The science of the nature, structure, functions, and diseases of the liver.

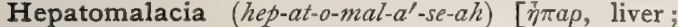

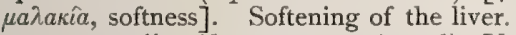

Hepatomegalia (hep-at-o-meg-a $\left.a^{\prime}-l e-a h\right) \quad[\dot{\eta} \pi a \rho$, liver; $\mu \varepsilon \gamma a$, large]. Auxesis of the liver.

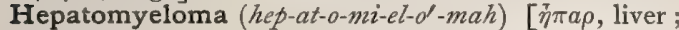
$\mu v \varepsilon \lambda \delta ́ s$, marrow ; ö $\mu a$, a tumor: pl. Hepatomyelomata]. Medullary carcinoma of the liver.

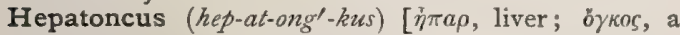
tumor]. A tumor or swelling of the liver.

Hepatonecrosis (hep-at-o-ne-kro'-sis) [i $\pi a \rho$, liver; vékowols, death]. Gangrene of the liver.

Hepatopancreas (hep-at-o-pan'-kre-as) [ $\eta \pi a \rho$, the liver ; $\pi a ́ \gamma \kappa \rho \varepsilon a s$, the pancreas: $p l$. Hepatopancreates]. In biology, a glandular organ of many invertebrates which exercises a digestive action upon starch and albumin, and at the same time secretes matters similar to those found in the bile of vertebrates.

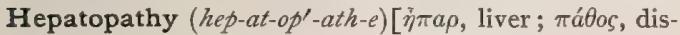
ease]. Any hepatic disease or disorder.

Hepatoperitonitis (hep-at-o-per-it-on-i'-tis) [iे $\pi \alpha \rho$, liver;

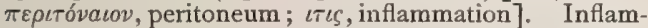
mation of the peritoneal or serous coat of the liver.

Hepatopexia, or Hepatopexy (hep-at-a-peks'-e-ah,

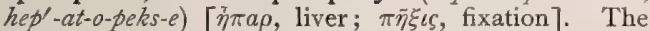
suturing of a floating liver in its proper position.

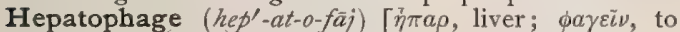
eat]. A giant-cell of a type peculiar to the liver; it is said to absorb and to destroy liver-cells.

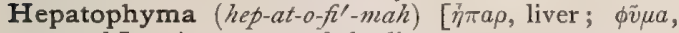
growth]. Any tumor of the liver.

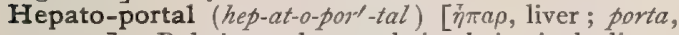
a gate]. Relating to the portal circulation in the liver; portal as distinguished from reniportal.

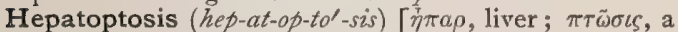
falling]. Synonym of Floating Liver, q. $v$

Hepatorrhagia (hep-at-or-a'-je-ah). Same as Hepatirrhagia.

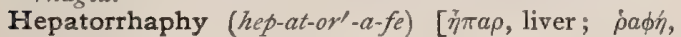
suture]. Suture of the liver.

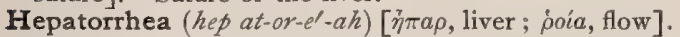
Morbid or excessive secretion of bile by the liver.

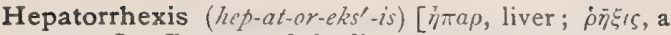
rupture]. Rupture of the liver.

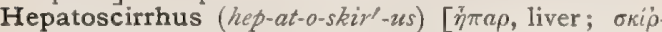
o $o s$, an induration]. Scirrhous carcinoma of the liver.

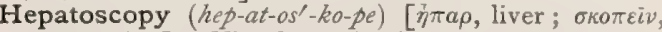
to examine]. Visual examination of the liver.

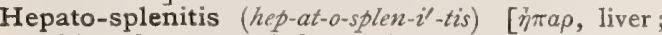
$\sigma \pi \lambda \eta \nu$, spleen ; $\iota \tau \iota \zeta$, inflammation]. Inflammation of both liver and spleen.

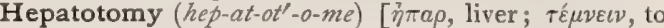
cut]. Incision of the liver.

Hephestic (hef-es'-tik) [Hephestus, Vulcan]. Prevailing or occurring among hammermen. H. Cramp. See Hammermen's Cramp. H. Hemiplegia. See Hemiplegia.

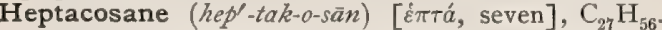
A hydrocarbon contained in beeswax.

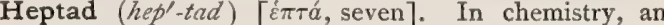
atom whose equivalence is seven atoms of hydrogen, or that can be combined with, substituted for, or replaced by, seven atoms of hydrogen.

Heptagynian (hep-taj-in'-e-an). See Heptagynous.

Heptagynious (hep-taj-in'-e-us). See Heptagynous.

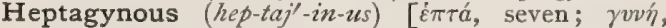
female]. In biology, having seven pistils or styles.

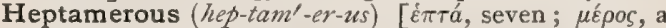
part]. In biology, consisting of seven parts; having the organs in sevens.

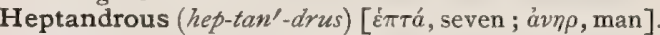
In biology, having seven stamens.

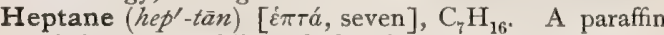
existing as a mobile, colorless liquid. It is contained in petroleum, and is also obtained from the resin of Pinus sabiniana by dry distillation. It is also called abietene, theolin, erasene, and aurantin. See Hydrocarbons, Table of.

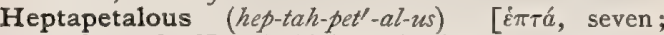

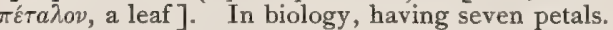

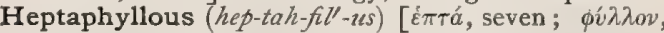
a leaf]. In biology, having seven leaves.

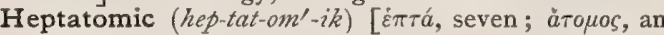
atom]. Same as Heptavalent, q. $v$.

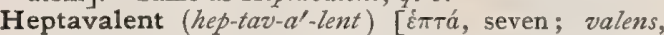
having power]. In chemistry, equal to seven atoms of hydrogen in combining or saturating-power; applied to an atom that can be substituted for, or replaced by, seven atoms of hydrogen.

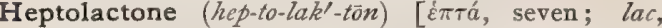
milk], $\mathrm{C}_{7} \mathrm{H}_{12} \mathrm{O}_{2}$. A substance formed from teracrylic acid by reducing with hydrobromic acid. It melts at $\mathrm{II}^{\circ} \mathrm{C}$., and boils at $220^{\circ} \mathrm{C}$.

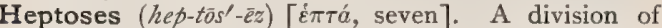
the glucoses, of the composition $\mathrm{C}_{7} \mathrm{H}_{14} \mathrm{O}_{7}$. They are prepared by reducing the corresponding heptonic acids, $\mathrm{C}_{7} \mathrm{H}_{14} \mathrm{O}_{8}$ (their lactones), with sodium amalgam. They have similar properties to the hexoses, and are not fermented by yeast. See Carbohydrates, Table of.

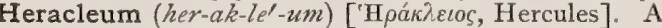
genus of umbelliferous plants, the cow-parsnips. Several species, especially H. lanatum, in North America, and $\mathbf{H}$. tauricum, in Europe, are diuretic and expectorant, and the roots and seeds are recommended for use in epilepsy. Unof.

Herapath's Method. A method for determining the presence of minute quantities of quinin. For a test-fluid use-

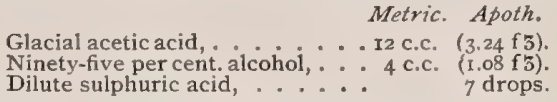

A drop of this is put on the slide, and a very minute amount of the quinin-containing substance added. 
When dissolved, add an extremely minute drop of an alcoholic solution of iodin. The first effect is the production of the yellow, cinnamon-colored compound of iodin and quinin, which forms as a small circular spot; the alcohol separates in little drops, which, by a sort of repulsive movement, drive the fluid away; after a time the acid liquid again flows over the spot, and the polarizing crystals of sulphate of iodoquinin are slowly produced in beautiful rosets. This test succeeds best without the application of heat.

Herapathite (her'-ap-ath-it ] [from Herapath, an English chemist]. An iodid of quinin-sulphate, occurring in rhomboid laminæ. It has been used as a remedy in scrofula and in febrile cases; in microscopy, it is employed in polarizing light.

Herb (erb or herb) [herba, an herb]. An annual, biennial or perennial plant, the stem of which contains but little wood and dies down to the ground at the end of the season. H.-doctor. See Herbalist. H.-juice Cure. See Cure.

Herbaceous (her-ba'-se-us) [herba, grass]. In biology: I. Applied to stems or other organs that have a tender, juicy consistence and perish at the close of the growing-season. 2. Feeding upon herbs.

Herbal (her'-bal) [herba, grass]. An old name for a book on herbs; chiefly designating a book on the medicinal virtues of herbs.

Herbalist (her'-bal-ist) [herba, grass]. An herb-doctor or simpler; a so-called botanic physician.

Herbarium (her-b $a^{\prime}-r e-u m$ ) [herba, grass]. A collection of dried plants arranged for study; a hortus siccus.

Herbicarnivorous (her-be-kar-niv'-or-us) [herba, herbage; caro, flesh: vorare, to eat]. Omnivorous; living upon both animal and vegetable food.

Herbivora (her-biv'-or-ah) [her-ba, grass; vorare, to devour]. A name given to a division of mammalia. Animals that feed on vegetation.

Herbivorous (her-biv'-or-us) [herba, grass; vorare, to devour]. A descriptive term applied to animals that subsist on vegetation.

Herbst's Corpuscles. A variety of sensory end-organs found in the mucous membrane of the tongue of the duck; they resemble small Vater's corpuscles, but their lamellæ are thinner and closer to each other, while the axis-cylinder within the central core is bordered on each side by a row of nuclei.

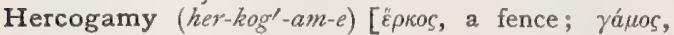
marriage]. In biology, the prevention of impregnation or fertilization by some structural obstacle; applied to flowers.

Herculeus morbus (her-ku-le'-us mor'-bus) [L.]. Synonym of Epilepsy.

Hereditary (he-red'-it-a-re) [heres, an heir]. Acquired by inheritance. H. Disease, one transmitted from parent to offspring. H. Parts. See Determinate. H. Syphilis. See Syphilis.

Heredity (he-red'-it-e) [hereditas, heredity]. The principle or fact of the transmission of physical or mental qualities or tendencies from ancestor to offspring. Darwin's Theory of Heredity, or the Hypothesis of Pangenesis, supposes that each of the different cells of the body gives off gemmules (Plastidules of Els$b e r g)$, or germinal particles, that are capable of reproducing their kind, and which are included in and constitute the generative cells, and thus reproduce all of the peculiarities of the original organism. Weissmann's Theory of the Continuity or "Immortality" of Germ-plasma, is developed from Nussbaum's proposition that germ-substance is directly abstracted from the developing ovum and preserved, without essential alteration, to become, by giving rise to sexual elements, the germ-substance of another generation, by the corollary that the whole nature of the animal or plant depends upon its germinal substance, and that the resemblance of the offspring to the parent is due to every gonoblast containing some germinal matter. According to Nussbaum and Weissmann the cells of the embryo are separated into two kinds: (I) The germ-cells, which become the sexual elements; (2) The somatic cells or body-cells, used as building-material (Somatoplasm) of the individual. Kölliker and others have demonstrated that no sharp distinction exists between germ-cells and somatic cells, so that speculations based on such assumed difference necessarily fall to the ground. Nægele's Theory of Idioplasm and Nutritive Plasma, is a definite theory of germinal continuity ; he assumes the formative force to reside in a specific material substratum, $i . e_{\text {. }}$, idioplasm-essentially identical with Weissmann's germ-plasma. Minot assumes idioplasm to be the nuclear substance, chromatin, the essential factor in the function of heredity, and the nucleus, therefore, the organ of hereditary transmission. De Vries' Theory of Intracellular Pangenesis, suggests that the nuclear substance of the germ-plasm is composed of minute particles, Pangenes, not cells, but the bearers of the properties of the cells. There are also in the nucleus Nuclear Rods, called also Idants, and Chromatin Rods, which are built up of a series of ancestral plasms, called $I d s$, each representing " an individuality." The doubling and multiplication of these idants prior to fertilization is in the interest of variety, or variation of form and character of the subsequent individual. This theory claims the same independence for all constituent parts of the cell-body as Weissmann claimed for those of the nucleus. The entire cell is called the Protoplast, and its various living, independent parts are called Pangenes. The cell is thus likened to a compound organism or colony.

Hering's Experiment. A delicate test of stereoscopic vision in which the perception of degrees of depth is tested by means of falling bodies, seen through a long tube. H.'s 'Theory. See Color-sensation.

Hermann's Difference-theory. See Difference. H.'s Theory, a theory as to the causation of muscular contraction; he claims that the formation of carbonic anhydrid on contraction is not simply due to oxidation, but rather to the decomposition of inogen, with the formation of certain simpler products, of which carbonic anhydrid is one, and sarcolactic acid and myosin the others.

Hermaphrodism, or Hermaphroditism (her-maf'ro-dizm, her-maf'-ro-dit-izm) ['E $\rho \mu \tilde{\eta} s$, Mercury;

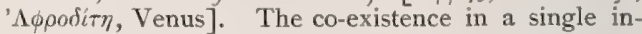
dividual of completely developed ovaries and testicles, or of at least one of each gland. H., Bilateral, an ovary and a testicle on each side. H., Complex, a rare instance of hermaphrodism in which there are present both the internal and external organs of either sex. H., Double. Same as H., Complex. H., Lateral, an instance in which male organs (especially a testicle) are more or less developed on one side, and female organs (especially an ovary) on the opposite side. H., Protandrous, applied to the phenomenon as ex. hibited by most hermaphrodite platode worms, of developing the male sexual products before the female. H., Spurious, doubtful, but not double, sex. H. Transverse, an instance in which the external organs indicate the one sex, and the internal the opposite. H., Unilateral, on one side an ovary and a testicle, on the other an ovary or a testicle. H., Vertical. Same as $H$. Complex.

Hermaphrodite (her-maf'-ro-dit) [ ${ }^{\mathrm{E}} \mathrm{E} \rho \mu \tilde{\eta} \zeta$, Mercury; 
'A $\phi$ podit $\eta$. Venus]. An individual affected with hermaphrodism, q.v.; usually the condition is due to some congenital malformation of the genital organs, such as epispadias, hypospadias, cleft of the scrotum, etc., that makes the determination of sex somewhat doubtful. For varieties, see Hermaphrodism.

Hermaphroditic (her-maf-ro-dit'-ik) ['E $\rho \mu \bar{\eta} s$, Mercury ; Aqproirn, Venus]. Pertaining to hermaphroditism, q. v. See also Teratism.

Hermaphroditism (her-maf'-ro-dit-izm). Same as Hermaphrodism.

Hermetic, Hermetical (her-met'-ik, her-met'-ik-al) ['Epunjs, the god Mercury, the reputed founder of alchemy]. Pertaining to chemistry. Also, having resist ance to chemic action. Also, protected from exposure to air. H. Medicine, alchemistic or spagyric practice. H. Sealing, the closure of an outlet by cementation or fusion, so that it is impervious to air. Also, the closing or covering of a wound by impervious dressings.

Hermodactyl (her-mo-dak'-til) ['E $\rho \mu \tilde{n} s$, Mercury;

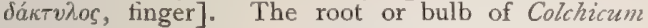
variegatum, or $C$. autumnale; also of Iris tuberosa. It was formerly prized in medicine, but is now little used, except in India. Unof.

Hernia (her'-ne-ah) [hernia, from épvos, sprout]. A tumor formed by the protrusion of the contents of a cavity (usually the abdominal) through its wall. Her nias may be called after their locality, Epigastric, Femoral, Inguinal, Perineal, Scrotal, Umbilical, etc. according to their condition, Encysted, Reducible, Strangulated, Purulent, etc. ; according to their contents, Cerebral, Intestinal, Omental, Vesical, etc. or, lastly, according to their origin, Acquired, Con genital, Infantile, etc. H., Abdominal, a protrusion of a portion of the abdominal viscera through some portion of the parietes. H., Béclard's, a hernia through the saphenous opening. H., Birkett's, a hernia of the synovial membrane of a joint, following laceration of the capsular ligament. $H$. of the Bladder, the protrusion of a part of the bladder through one of the openings of the abdominal cavity, viz. : the femoral ring, or external adominal ring; or it may form part of a ventral hernia after celiotomy or injury, or it may take place through an opening in the floor of the pelvis; the term was also formerly applied to cystocele, $q . v . \quad \mathrm{H}$. of Brain. See Fungus cerebri. H., Bruggiser's. Same as H., Properitoneal. H., Bursal. Same as H., Birkett's. H. carnosa. Synonym of Elephantiasis arabum. H., Cecal, a hernia containing the cecum (with or without other parts of the bowel). H. cerebri. See Fungus cerebri. H., Chronic, an old hernia. $H$. of Cloquet. See $H$., Pectineal-crural and Diseases, Table of. $\mathbf{H}$., Complete, a hernia in which the sac and its contents have passed the hernial orifice. H., Congenital, a form of indirect inguinal hernia in which the vaginal process of the peritoneum having remained patulous, the bowel descends at once into the scrotum, in direct contact with the testicle. See also $H$. of the Cord. H., Cooper's, a variety of femoral hernia with a diverticulum through the superficial fascia. See, also, $D$ iseases, Table of. $\mathbf{H}$. of the Cord, a congenital condition resulting from arrcst of development of the lateral plates, with persistence of the omphalic duct. If the latter does not wither away, the fetal intestines are drawn out into the cord, giving rise to congenital umbilical hernia. H., Crural. See H., Femoral. H., Cruro-properitoneal, a variety in which an additional sac exists between the peritoneum and abdominal wall, in the cellular tiss te of the nelvis, and at the side of the bladder. H., Lystic. Same as Cystocele, $q . v$. H., Dia36 phragmatic, a protrusion of a portion of some of the abdominal viscera into the thorax, through a congenital defect in the diaphragm, or through a dilatation or laceration of one of the natural openings. H., Direct Inguinal. See $H$., Inguinal, Direct. H., Dorsal. Synonym of H., Lumbar. H., Encysted (of Cooper); this form occurs when the ventral orifice closes, but the tunica vaginalis remains patulous, allowing the hernia to descend within the latter, pushing before it the thin septum. H., Epigastric, a hernia in the linea alba, between the ensiform cartilage and the umbilicus. H., External, one appearing upon the external surface of the body. H., Femoral, a protrusion of the abdominal contents through the femoral canal, the tumor appearing on the upper inner aspect of the thigh, below Poupart's ligament. $\mathbf{H}$, of the Foramen ovale. See $H$., Obturator. $\mathbf{H}$. into the Foramen of Winslow, a lodgment of a portion of intestine in the foramen of Winslow. H., Funicular, a hernia into the umbilical cord. See $H$., Infantile. H., Gastric. See Gastrocele. H., Goyrand's or Gourand's. See H., Inguino-interstitial. H., Guttural. Synonym of Goiter. H. of Hesselbach, a femoral hernia with a diverticulum through the cribriform fascia, the hernia presenting a lobulated appearance. See, also, Diseases, Trble of. $\mathbf{H}$. of Holthouse. See H., Inguino-crural. H., Humoral. Synonym of Epididymitis, or Srvelled Testicle. H., Incarcerated, an old irreducible hernia which has become occluded by the accumulation of gas, feces, or undigested food, thus causing obstruction of the bowels. H., Incomplete, one that has not entirely passed through the hernial orifice. H., Infantile, that form of direct inguinal hernia that occurs when the funicular portion of the vaginal process of peritoneum has remained patulous. H., Infantile (of Hey). See H., Encysted. H., Hey's. See H., Encysted. H., Infrapubic. Same as $H$., Obturator. H., Inguinal, a hernia occupying wholly, or in part, the inguinal canal. H., Inguinal, Direct, a protrusion of the abdominal viscera through the parietes at the site of the external abdominal ring, without having traversed the inguinal canal. H., Inguinal, External. See H., Inguinal, Indirect. H., Inguinal, Indirect, one in which the protrusion occurs at the internal ring, and passes along the inguinal canal. $\mathbf{H}$., Inguinal, Internal. See H., Inguinal, Direct. H., Inguinal, Oblique. See H., Inguinal, Indirect. $\mathbf{H}$., Inguino-crural, or $\mathbf{H}$. of Holthouse, a variety of suddenly-developed oblique inguinal hernia, in which, owing to the non-descent of the testicle, or to other causes, the hernia protrudes outward along the fold of the groin. H., Inguino-interstitial, an incomplete inguinal hernia. H., Inguino-labial, a variety of oblique inguinal hernia in the female, corresponding to the inguino-scrotal hernia of the male. $\mathrm{H}$., Inguino-properitoneal, or $\mathrm{H}$. of Krönlein, a hernia, with a prolongation of the hernial sac in various directions, within the abdominal walls. H., Inguinoscrotal, the common form of oblique inguinal hernia in men past middle life. H., Intermuscular. Same as H., Inguino-properitoneal. H., Interparietal. Same as H., Inouino-properitoneal. H., Inveterate. See H., Chronic. H. of Iris, a prolapse of a portion of the iris after iridectomy, trauma, etc. H., Irreducible; a hernia is called irreducible when the protruded viscera cannot be returned to the abdomen by manipulation, with complete disappearance of the symptoms. H., Ischio-rectal. Same as H., Perineal. H., Ischiatic, a protrusion of the bowel through the great sacrosciatic foramen. H.-knife, a probe-pointed knife for incising the constriction of a hernial sac. $\mathbf{H}$. of 
Krönlein. See $H$., Inouino-properitoneal. H., Labial, a protrusion of the bowel between the vagina and the ramus of the ischium into a labium majus. H. of Laugier, a femoral hernia through Gimbernat's ligament. See, also, Diseases, Table of. $\mathbf{H}$. of Littre, a hernia of the bowel in which only a portion of the lumen is constricted in the hernial orifice. There is not, therefore, complete obstruction. $\mathbf{H}$. of the Liver. See Hepatocele. H., Lumbar, a pro- at which the fascia is deficient. H., Obstructed. See $H$., Incarcerated. H., Obturator, a protrusion of bowel through the obturator foramen. H., Omental, a hernia containing omentum. This condition is also called Epiplocele, q. v. H. of Ovary, a hernia including ovary, wholly or in part. H., Parainguinal. Same as H., Properitoneal. H. of Partridge, a femoral hernia, external to the femoral vessels. See, also, Diseases, Table of. H., Pectineal-

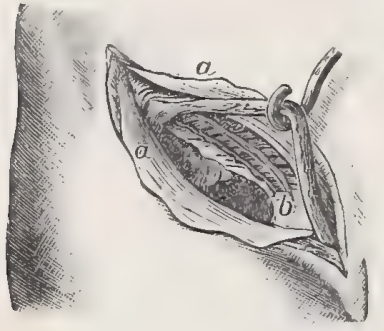

The pillars open, the cord held up.

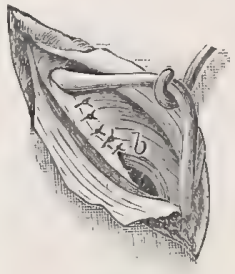

The pillars sutured,
the cord held up.

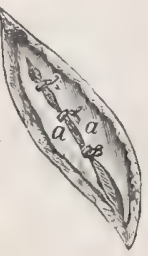

The deep fascia
closed over the cord.

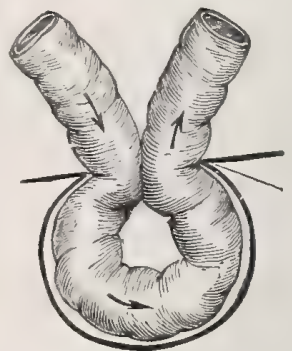

An Unstrangulated HERNIA.

Radical Operation for Inguinal Hernia. (After Bassini.)

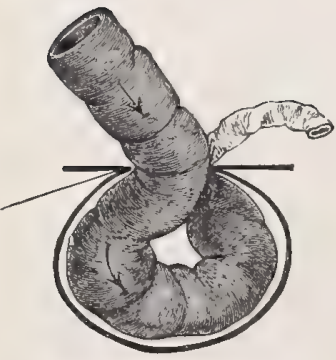

A Strangulated Hernia.

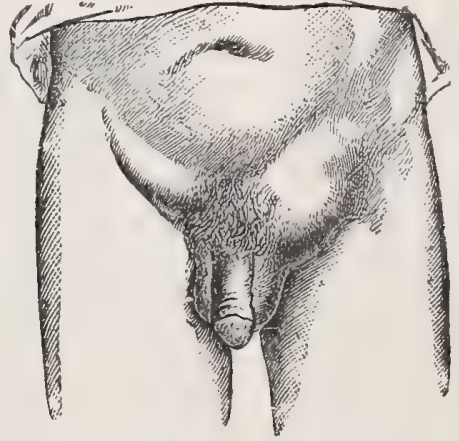

Oblique IngUiNal HeRniA.

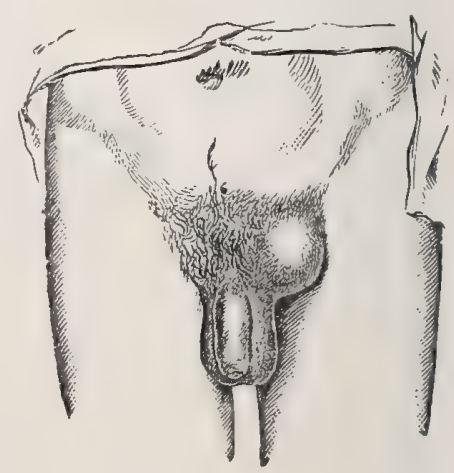

Direct Inguinal HERNIA.

Bubonocele on right side, but passing through external ring on left.

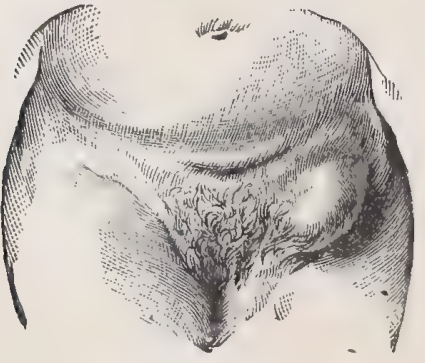

Femoral Hernia.

trusion of the intestine through Petit's triangle-a space bounded by the external oblique and latissimus dorsi muscles and the crest of the ilium. $\mathbf{H}$. of the Lung. See Pneumocele. H., Malgaigne's. Same as H., Congenital. H., Mesenteric (of Cooper); the passage of a portion of gut through an opening in the mesentery. H. of Muscles; occasionally, owing to imperfect healing of the deep fascia after wounds, a limited protrusion of the muscle occurs at the point crural, or $\mathbf{H}$. of Cloquet, a variety in which, after passing the femoral ring, the hernia turns within and behind the femoral vessels, resting on the pectineus muscle. H., Perineal, a protrusion of the abdominal contents between the fibers of the levator ani muscle, in front of or to one side of the anus. H., Petit's. Same as H., Lumbar. H., Pharyngeal. See Pharyngocele. H., Phrenic. Same as H., Diaphragmatic. H., Pleural. See Pleurocele. H., Properitoneal, a hernia occupying a position between the planes of the abdominal wall, in front of the parietal peritoneum. H., Pudendal. Same as H., Labial. H., Reducible, one that may be returned or reduced by manipulation. H., Retroperitoneal ; in this form of hernia the small intestine lodges in the fossa duodeno-jejunalis. H., Sciatic. Same as $H$., Ischiatic. H., Scrotal, that form of inguinal hernia in which the protrusion has entered the scrotum. H. of the Spleen. See Splenocele. H. of the Stomach. Same as Gastrocele. H., Strangulated ; a hernia is said to be strangulated when it is so tightly constricted at its neck as to interfere with its return, with the circulatio : of blood, and the passage of feces. H., Synovial. See H., Bir kett's. H. of Testis, a protrusion of th s seminiferous 
tubules through a fistulous opening following abscess of the testicle. H. of the Tongue. See Glossocele. H. of the Trachea. See Tracheocele. H., Thyroid. See H., Obturator. H., Umbilical, a protrusion of the abdominal contents through the umbilicus. H. of the Uterus. See Hysterocele. H., Vaginal, a protrusion of the abdominal viscera between the uterus and rectum, forming a tumor on the vaginal wall. H.,Velpeau's, a femoral hernia in front of the femoral vessels. H., Ventral, the name applied to protrusions of the abdominal contents through the abdominal walls in situations not usually subject to herniæ; e.g., not at the abdominal rings or the umbilicus. H., Vesical. See $H$. of the Bladder.

Hernial (her'-ne-al) [hernia, a rupture]. Pertaining to hernia. H. Sac, the diverticulum of the peritoneum that accompanies a hernia.

Hernio-celiotomy (her'-ne-o-se-le-ot'-o-me) [hernia, a rupture; $\kappa i \lambda i a$, belly]. Abdominal section for the relief of hernia.

Hernio-enterotomy (her'-ne-o-en-ter-ot'-o-me) [hernia, a rupture ; $\varepsilon \nu \tau \varepsilon \rho \circ \nu$, bowel; $\tau \circ \mu \eta$, a cutting]. Herniotomy combined with enterotomy.

Hernio-laparotomy (her'-ne-o-lap-ar-ot'-o-me) [hernia, a rupture; $\lambda a \pi a ́ \rho a$, the flank; $\tau o \mu n$, a cutting]. Same as Hernio-celiotomy.

Herniology (her-ne-ol'-o-je) [hernia, hernia; hóyos, science]. That department of surgery which treats of the causes, diagnosis, and treatment of hernia.

Herniopuncture (her-ne-o-punk'-chīr) [ hernia, hernia; punctura, a pricking]. The puncture of a hernia.

Herniotome (her'-ne-o-tōm) [hernia, hernia; тo cutting]. A hernia-knife.

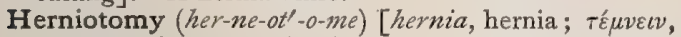
to cut]. Operation for the relief of hernia by section of the constriction.

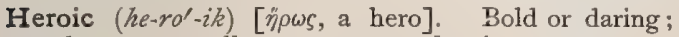
rash or unusually severe; as heroic treatment or measures.

Herophilus, Torcular of. See Torcular.

Herpes (her'-pezz) [" $\tilde{\varepsilon} \rho \pi \eta s$; $\ddot{\varepsilon} \rho \pi \varepsilon \imath v$, to creep]. An acute inflammatory affection, characterized by the development of groups of vesicles on a patch of inflamed skin or mucous membrane. H. catarrhalis, herpetic fever; a form of herpes accompanying the onset or crisis of acute febrile disorders, and frequently following a rigor, of which it may be the sole sequel. It is most common in spring and autumn. Its forms are $H$. facialis and $H$. progenitalis. $\mathbf{H}$. circinatus. See Tinea circinata. H. circinatus bullosus. See Hydroa herpetiforme. H. desquamans. See Tinea imbricata. H. esthiomenos. See Lupus. H. facialis, Herpes labialis; Herpes febrilis, Hydroa febrile; an acute, non-contagious, inflammatory disorder of the skin that appears in the form of one or more groups of vesicles. It is commonly called fever-blisters. Its usual seats are the lips, angles of the mouth, and the face, generally below the forehead. Owing to its relation to digestive derangements the ulcers are often termed "dyspeptic ulcers." H. febrilis. See H. facialis. H. gestationis. See Hydroa herpetiforme. H. iris, a form of erythema in which a vesicle is seated on an erythematous base. It is usually seen on the backs of the hands and feet. H. labialis. See $H$. facialis. H. miliaris. Synonym of Eczema. H. phlyctenodes, Willan's name for Herpes zoster occurring elsewhere than on the trunk. H. preputialis. See $H$. progenitalis. H. progenitalis, Herpes preputialis; a form of $H$. simplex, in which vesicles occur upon the glans and prepuce, from the size of a pin's head to that of a small pea. They number from two or three to a dozen. The condition is most common in males.
H. pyæmicus. See Impetigo herpetiformis. H.simplex. A synonym of $H$. caiarrhalis. $H$. tonsurans. See Tinea tonswrans. H. tonsurans maculosus. See Pityriasis rosea. H. zoster, Zoster ; Zona; Shingles; Ignis sacer; an acute inflammatory disease of the skin, which consists of grouped vesicles on a reddened base, the lesions being distributed in relation to the course of the cutaneous nerves, and, as a rule, unilateral. They are usually seen in the course of the intercostal nerves, but may follow the course of any nerve. The outbreak of the eruption is usually preceded by severe neuralgic pain. The condition occurs most frequently in young people and in the autumn and spring of the year. H.z. ophthalmicus, following the course of the ophthalmic nerve

Herpetic (her-pet'-ik) [ $\hat{\varepsilon} \rho \pi \eta \varsigma$, herpes]. Pertaining to herpes. H. Bridge. See Bridge. H. Fever. See Herpes catarrhalis. H. Sore-throat. See Tonsilitis, Herpetic.

Herpetiform (her-pet'-if-orm) [है $\rho \pi \varepsilon s$, herpes; forma, form]. Having a likeness to herpes.

Herpetism (her'-pet-izm) [ $\hat{\varepsilon} \rho \pi \eta s$, herpes]. The herpetic diathesis; a constitutional predisposition to herpes.

Herpetography (her-pet.og $g g^{\prime}$ ra-fe). Same as Herpetology.

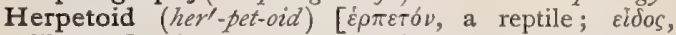
likeness]. In biology, resembling a reptile.

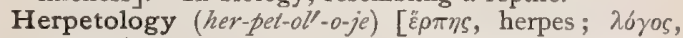
treatise]. The science of skin-diseases, especially those of an herpetic nature.

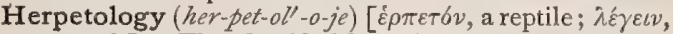
to speak]. The classified knowledge of reptiles.

Hertwig's Theory. A theory of immunity founded upon the chemotactic action of certain chemic substances. The fact of cardinal importance in this theory is that negative chemotropism may, under certain conditions, become positive.

Hesperetinic Acid (hes-per-et-in'-ik). See Acid.

Hesperidin (hes-per'-id in) ["E $\sigma \pi \varepsilon \rho o s$, Hesperus]. $\mathrm{C}_{22} \mathrm{H}_{26} \mathrm{O}_{12}$. A glucosid present in the unripe fruit of oranges, lemons, etc. It separates from alcohol in fine needles, and melts at $25 \mathrm{I}^{\circ} \mathrm{C}$.

Hesperidium (hes-per-id'-e-um) ["E $\sigma \pi \varepsilon \rho \circ$, Hesperus (in allusion to the golden apples of the Hesperides) : $p l$., Hesperidia]. In biology, an orange-like fruit, having a succulent flesh covered with a leathery rind; a variety of berry.

Hesse's Apparatus. An apparatus for air-analysis.

Hesselbach's Hernia. See Hernia, and Diseases, Table of. H.'s Triangle. See Triangles, Table of.

Hessian Crucible (hesh'-yan kru'-sib-l). A crucible made of fine clay and sand, and used for melting gold, silver, and their alloys in the manufacture of gold and silver plates and solders. $\mathbf{H}$. Purple. See Pigments, Conspecius of. $\mathbf{H}$. Violet, and $\mathbf{H}$. Yellow. See Pigments, Conspectus of.

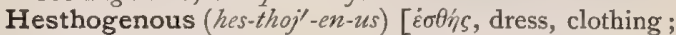
róvos, offspring]. In biology, applied to birds that are hatched with a covering of down; ptilopedic, opposed to gymnogenous, psilopedic.

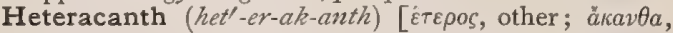
spine]. In biology, applied to fishes in which the dorsal and anal fin-spines are asymmetric.

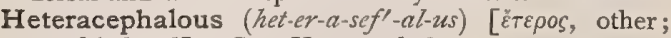
$\kappa \varepsilon \phi a \lambda \eta$, head]. See Heterocephalous.

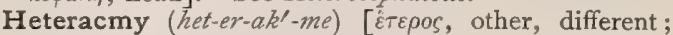
ák $\mu$ '́, prime, maturity]. In biology, applied to plants in which cross-fertilization is secured by the heterochronous maturing of the stamens and pistils.

Heteradelph (het'-er-ad-elf). See Heteradelphus,

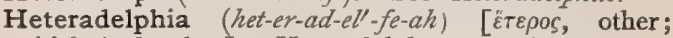
$\dot{a} \delta \varepsilon \lambda \phi \delta \varsigma$, brother]. Heteradelphous teratism. 
Heteradelphous (het-er-ad-el'-fus) [Ẽ $\varepsilon \rho \rho o s$, other;

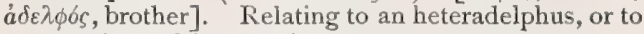
an autosite and its parasite

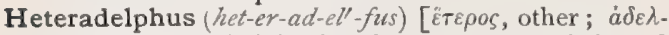
фós, brother]. A joined twin-monster, consisting of an nutosite with an attached parasite, the head of the latter being absent.

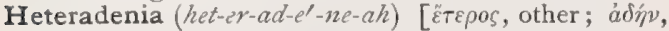
gland]. r. Normal glandular structure occurring in a part normally not provided with glands. 2. Glandular structure departing from the normal type.

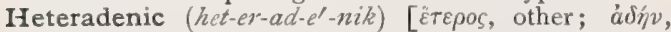
gland]. Pertaining to or consisting of tissue that is unlike normal glandular tissue, though essentially glandular.

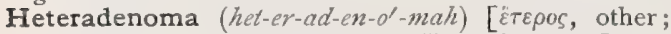
ádív, gland; ö $\mu \alpha$, tumor: pl., Heteradenomata $]$. A tumor formed of heteradenic tissue.

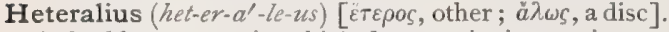
A double monster in which the parasite is very incomplete-usually merely a head-and inserted at a distance from the umbilicus of its host, and with no direct connection with the umbilical cord of the latter

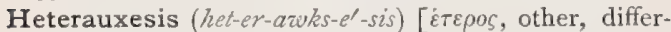

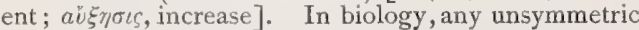
growth, normal or abnormal.

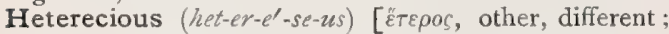
oikos, a house]. In biology, parasitic upon different hosts at different stages of growth.

Hetero- (het'-er-o-) [Eтreos, other]. A Greek prefix denoting diversity or unlikeness.

Hetero-albumose (het'-er-o-al'-bu-mös). See Albumoses.

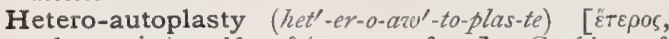
other; aviós, self; $\pi \lambda \alpha$ $\sigma \sigma \varepsilon \varepsilon \nu$, to form]. Grafting of skin from one person upon the body of another.

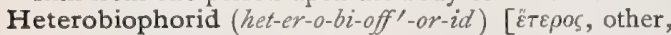
different; biophore, a bearer of vitality, from Bios, life; фépetv, to bear]. In biology, Weismann's name for a primitive organism, the constituent biophores of which have been differentiated, in connection with a division of labor, and combined in various ways to form the body of the organism. See Homeobiophorid.

Heteroblastic (het-er-o-blas'-tik) [ $\varepsilon$ tepos, other, different; $\beta$ haorós, germ, bud]. In biology, arising from a different or abnormal source.

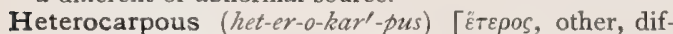
ferent; $\kappa a \rho \pi \delta \varsigma$, fruit]. In biology, having more than one sort of fruit.

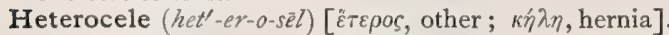
A hernia existing in some prolapsed organ, as in a rectocele.

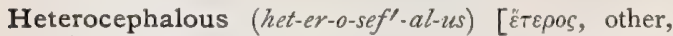
different; $\kappa \varepsilon \phi a \lambda \eta \dot{n}$, head]. In biology, applied to plants bearing flower-heads of more than one kind, as pistillate and staminate.

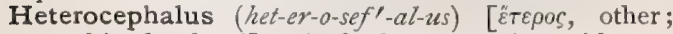
$\kappa \varepsilon \phi a \lambda \eta$, the head]. A fetal monstrosity with two heads of unequal size.

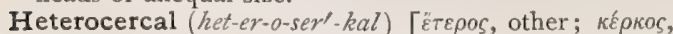
tail]. In biology, having an asymmetric or unequally divided tail-fin.

Heterocerous (het-er-os'-er-us) [ $\tilde{t}+\varepsilon \rho o s$, other, different ; $\kappa \varepsilon \rho a s$, horn]. In biology, applied to a group of insects, the members of which vary as to the form of their antennæe.

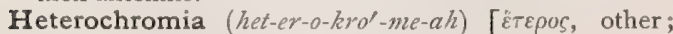
$\chi \rho \tilde{\omega} \mu a$, color]. A difference in color (as between the irides of the two eyes).

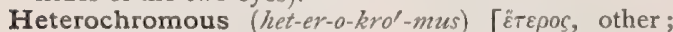
$\chi \rho \tilde{\omega} \mu a$, color]. In biology, having different colors.

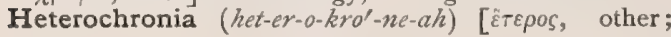

xpóvos, time]. The production of a structure or the occurrence of a phenomenon at an abnormal period of time.

Heterochronic, Heterochronous (het-er-o-kron'-ik,

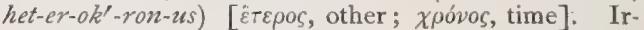
regular in occurrence. Occurring at different times, or at other than the proper time.

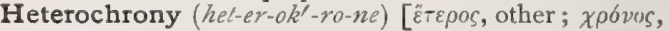
time]. In biology, out of order as to time, as organs, organisms, or hereditary traits that occur out of the true ontogenetic sequence. Cf. Homeochronous.

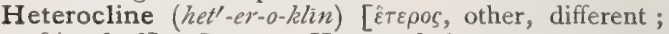
$\kappa \lambda i v \eta$, bed]. Same as Heterocephalus.

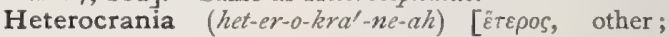
kpaviov, skull]. Headache involving but one side of the head.

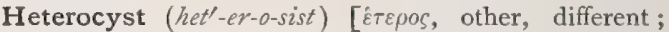

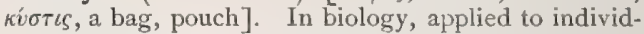
ual cells in the moniliform rows of roundish, chlorophyl-bearing cells of the Nostocacea, which, apparently without any definite law, vary in size and color from those among which they are intercalated; a limiting-cell.

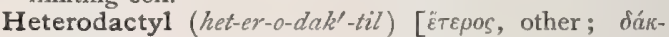
$\tau v$ hos, a finger or toe]. An animal in which the digits are in some way peculiar or irregular.

Heterodermotrophy (het-er-o-der-mot'-ro-fe) [ other; dé $\rho \mu a$, skin; трофй, nutrition]. Disordered or perverted nutrition of the skin.

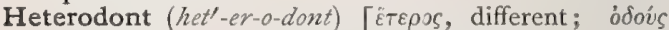
(ojovt-), tooth]. In biology, having more than one sort of teeth, as incisors, canines, molars; the opposite of Homodont.

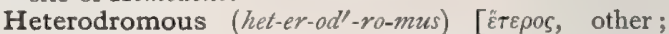
$\delta \rho \alpha \mu \varepsilon i \nu$, to run]. In biology, growing or turning in opposite directions, as a tendril that coils first one way and then the other.

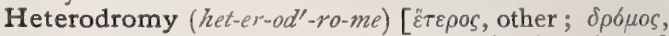
a running]. In biology, a change in the direction of the spiral in the leaves of the branches and stem. Same as Antidromy.

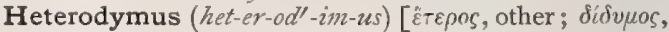
twin]. A double monster, the accessory part being but an imperfect head, with a neck and thorax by which it is implanted in the anterior abdominal wall of its host.

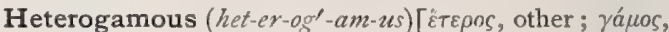
marriage]. In biology, bearing male and female flowers in the same inflorescence or plant.

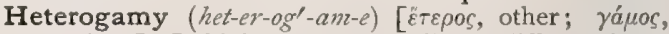
marriage]. In biology, a term applied to different forms of sexual development arising from difference in nutrition or environment. It is typified in the Phylloxera vastatrix, the development of which is far more complex when the insects are bred under ground, on the roots of the grape-vine, compared with that when the insects breed upon the leaves of the vine. In the latter case the successive generations consist of apterous, oviparous females only; in the former the cycle consists of male insects, apterous females for perpetuating, and winged females for spreading the species.

Heterogeneity (het-er-o-jen-e $\left.e^{\prime}-i t-e\right)$ [Ẽ $\tau \varepsilon \rho o s$, other ; yévos, kind]. The condition or quality of being heterogeneous.

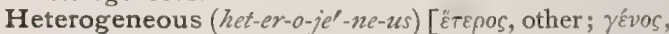
kind]. Differing in kind or nature; composed of different substances; not homogeneous.

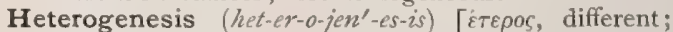
$\gamma^{\varepsilon} v \varepsilon \sigma \iota \zeta$, generation]. I. Organic deviation in the situation or character of organs, etc. 2. In biology, a mode of biogenesis, by which the living parent gives rise to offspring that pass through totally different 
series of states from those exhibited by the parents, and do not return into the cycle of the parents (Huxley). Milne-Edwards has substituted the word Xenogenesis, q. 2 .

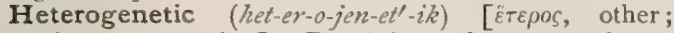

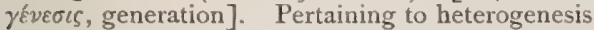

Heterogenist (het-er-oj'-en-ist). See Abiogenesis.

Heterogeny (het-er-oj'-en-e). Same as Heterogenesis.

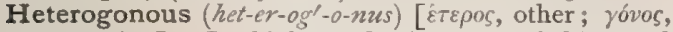
generation]. In biology, having several kinds of flowers as regards the length of the stamens and styles; hetero-styled. Cf. Dimorphous, Trimorphous.

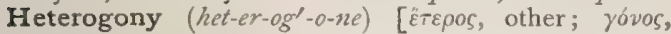
generation]. A form of reproduction that consists in the occurrence, in the cycle of development, of individuals differing in structure from the parent forms and existing under special conditions of nutrition.

Heterogynous (het-er-oj'-in-us) [ërepos, other, different; yov $\eta$, female]. In biology, applied to certain groups of insects among which there are two kinds of females, one sexually perfect, the other not.

Heteroinfection (het-er-o-in-fekl-shunn) [ $\hat{\varepsilon} \tau \varepsilon \rho o s$, other; inficere, to taint]. I. Infection transmitted by a person who is himself not infected. 2. Infection of any organism by a poison not produced within itself; opposed to auto-infection.

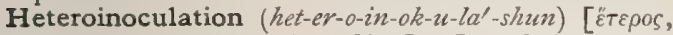
other; inoculatio, an ingrafting]. Inoculation of one person by another.

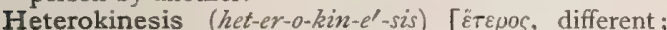
$\kappa \iota \nu \varepsilon i \nu$, to move]. In biology, Weismann's term for that kind of nuclear division in which the two daughternuclei contain different kinds of idioplasm, i.e., nuclear division depending upon a heterogeneous grouping of the primary constituents and resulting in parts containing dissimilar hereditary tendencies. Cf. Homeokinesis.

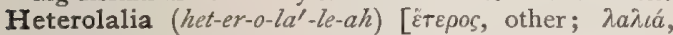
talk]. The utterance of words other than those intended by the speaker; heterophemy.

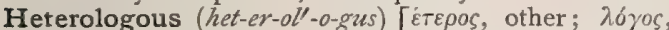
relation]. Differing in structure or form from the normal, H. Series, a series derived from each other by chemic metamorphoses. H. Tissues, morbid tissues that have no structural relation with the normal tissues of the part. H. Tumors, tumors constituted of a different tissue from that of the part in or on which they are situated.

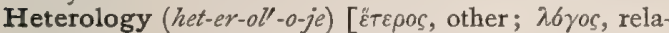
tion]. Abnormality in nature, form, or structure; development of an abnormal structure.

Heterolopia, Heterolopy (het-er-o-lo'-pe-ah, het-er-ol'

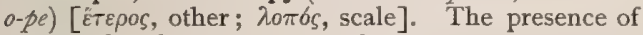
abnormal scales, crusts, or scabs.

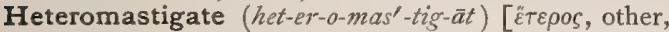
different ; $\mu a ́ \sigma \tau \iota s$, a whip]. In biology, having more than one kind of flagellum.

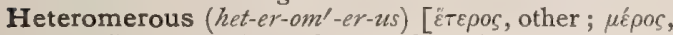
a part]. In biology, having homologous parts diversely composed.

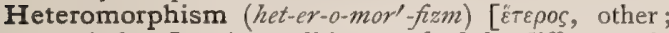
$\mu \rho \rho \phi \eta$, form]. A condition marked by difference in form, as compared with the normal form. In chemistry, the property of crystallizing in different forms. In biology: I. A state of deviation from a type or norm. 2. Exhibiting different forms at different stages in the life-history.

Heteromorphosis (het-er-o-mor-fo'-sis) [ËTepos, other; $\mu o ́ \rho \phi \omega \sigma \iota s$, formation]. Malformation or deformity; any disease characterized by deformity.

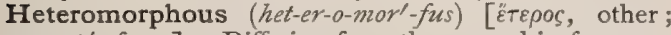
$\mu о \rho \phi \dot{\eta}$, form]. Differing from the normal in form.

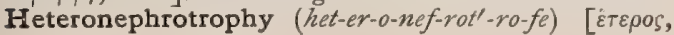

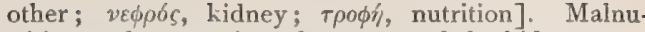
trition or degeneration of any part of the kidney.

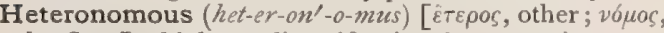
law]. In biology, diversification in any series or set of morphologically related structures through specialization.

Heteronomy (het-er-on'-o-me) [ËTEpos, other; vóros, law]. I. Subordination to a law of adaptive modification. 2. The presence of segmentation. Cf. Autonomy and Homonomy.

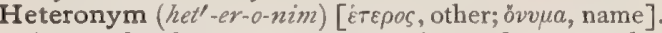
An unrelated synonym; a name in one language that corresponds to the same name in another language, but has no near derivative relationship thereto.

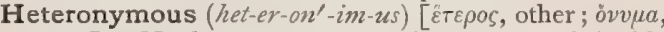
name]. Not homonymous; applied to crossed double visual images, such as are seen when there is a relative divergence of the eyes.

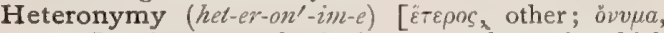
name]. $\Lambda$ system of polyglot nomenclature in which exact synonyms are used in each language to represent corresponding but unrelated words in other languages; compare paronymy.

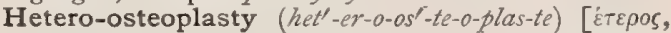

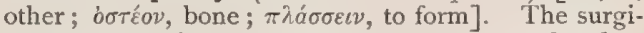
cal grafting of bone, especially with a graft taken from a bone of one of the lower animals.

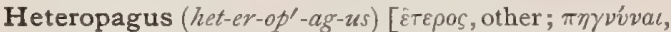
to unite]. A monstrosity with normal head, upper and lower extremities, but with a parasite attached to the anterior abdominal wall. The parasite has a head and extremities.

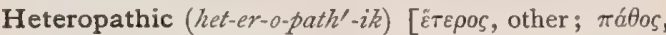
disease]. Pertaining to or making use of heteropathy.

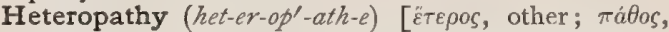
affection]. The treatment of a disease by inducing a different morbid condition to neutralize it. Abnormal reaction to stimulus or irritation.

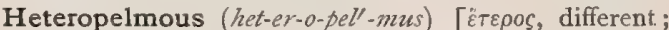
$\pi \hat{\varepsilon} \lambda \mu \alpha$, the sole of the foot]. In biology, applied to birds in which each of the flexor tendons of the sole of the foot splits into two.

Heterophagous (het-er-off'-ag-us) ["̈TEpos, other, different; $\phi a \gamma \varepsilon i \nu$, to eat]. In biology, applied to young animals that require to be fed by the parents; altricial.

Heterophemism (het-er-off'-em-izm). See Heterophemy.

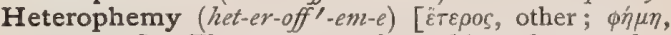
utterance]. The utterance of one thing when another is intended; heterolalia.

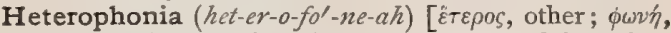
voice]. Abnormal quality or perversion of the voice.

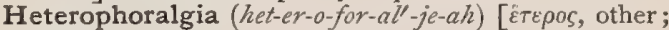
$\phi o \rho \delta s$, tending; àjyos, pain]. Eye-strain or ocular pain caused by heterophoria.

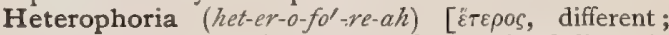
фopós, tending]. A tending of the visual lines in some other way than that of parallelism. It may be Esophoria, a tending of the lines inward; or Exophoria, outward; or Hyperphoria, a tending of the right or left visual line in a direction above its fellow ; Hyperesophoria, a tending of the visual lines upward and inward; Hyperexophoria, upward and outward.

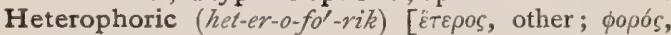
tending]. Due to heterophoria.

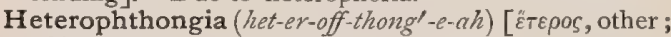
$\phi \theta 6 \gamma y o s$, sound]. Synonym of Ventriloquism.

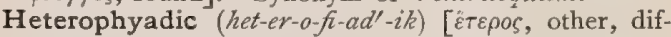

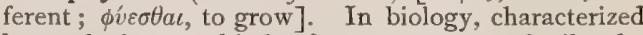
by producing two kinds of stems, $e_{.} g_{\text {. }}$, one fertile, the succeeding one sterile. 


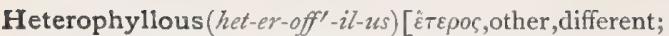
$\phi \hat{v} \lambda \lambda_{0 \nu}$, leaf ]. In biology, producing more than one kind of leaves on the same stem, as in Juniperus sabina, var: procumbens, or having the leaves different in the several species of a genus.

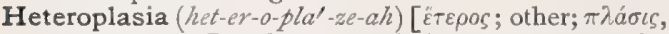
shaping]. I. Development of abnormal tissue; the presence in a part where it does not normally belong, of tissue that may, or may not, be normal. 2. The gradual removal of the material of an engrafted part, and its replacement by material normal to the part in which it is engrafted.

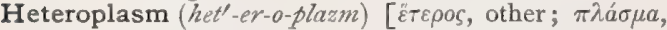
something formed]. Heteroplastic material.

Heteroplastic (het-er-o-plas'-tik) [Ërepos, other; $\pi \lambda a ́ \sigma \sigma \varepsilon \iota \nu$, to form]. I. Relating to heteroplasia. 2. Differing in structure.

Heteroplastid (het-er-o-plas'-tid) [étepos, other; $\pi \lambda a ́ \sigma \sigma \varepsilon \iota v$, to form]. A surgical graft.

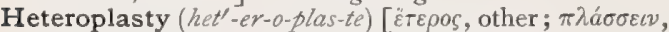
to form ]. I and 2. Same as Heteroplasia, q. v. 3. Surgical grafting, especially of parts taken from another species.

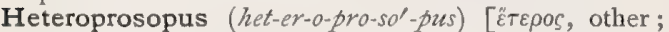
$\pi \rho 6 \sigma \omega \pi \nu \nu$, face ]. A fetus with two faces; janus or janiceps.

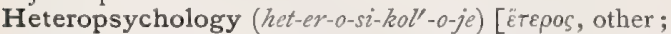
$\psi v \chi \eta \dot{n}$, soul; $\lambda 6 \gamma o s$, treatise $]$. The study or science of psychology, as based upon facts other than those of one's own subjective experiences.

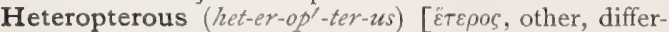
ent; $\pi \tau \varepsilon \rho 6 v$, wing]. In biology, having the wings composed of several distinct parts, as in the bugs.

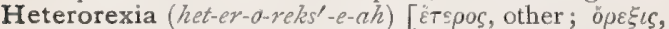
desire]. Perversion of the appetite.

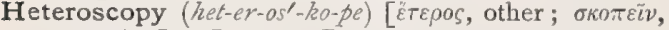
to examine]. Same as Deuteroscopy.

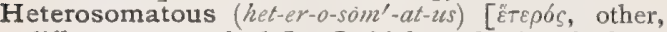
different; $\sigma \tilde{\omega} \mu \alpha$, body]. In biology, having the body bilaterally asymmetric, or otherwise varying from a type.

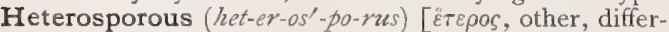
ent; $\sigma \pi \delta \rho o s$, seed]. In biology, bearing spores of more than one kind, as macrospores and microspores.

Heterostrophy (het-er-os'-tro-fe) [ ent; $\sigma \tau \rho \circ \phi \dot{\eta}$, a turning]. In biology, a reversal in the direction of the twist, as in certain spiral shells.

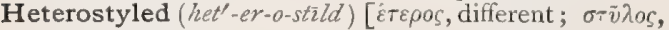
a pillar, style]. See Heterogonous.

Heterotaxia (het-er-o-taks'-e-ah). See Heterotaxis.

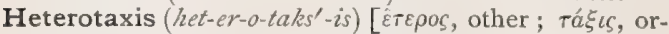
der]. The anomalous disposition or transposition of internal organs; a form of malformation occasionally seen in the human species-situs inversus viscemem. The transposition is most commonly seen in the abdomen. There is no interference with nutrition or function by the abnormal arrangement of the parts. The opposite of Homotaxis.

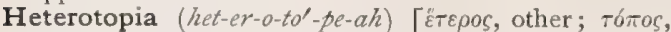
place]. I. Any misplacement of normal tissue, especially a congenital malformation of the brain, in which masses of gray matter are found transplanted into the white. This condition is invariably associated with idiocy. 2. The same as Heterochronia. 3. In biology, a mode of acceleration or change during growth, characterized by the transfer of cells from one part of the organism to the other.

Heterotopic (het-er-o-top'-ik). See Heterotopous.

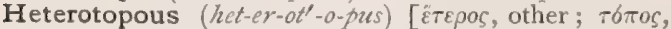
place]. Characterized by heterotopia; misplaced.

Heterotopy (het-er-ot'-o-pe). Same as Heterotopia.

Heterotrophia, or Heterotrophy (het-er-o-tro'fe-ch,

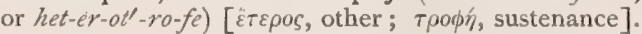

Any perversion or disorder of nutrition, local or general. In biology, obtaining nourishment by some abnormal or unusual arrangement.

Heterotropia (het-er-o-tropp-e-ah). See Strabismus.

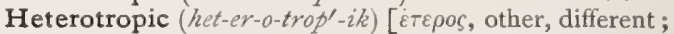
$\tau \rho \delta \pi \%$, a turning]. In biology, applied to plants the different organs of which behave differently under the same form of irritation. Cf. Anisotropic.

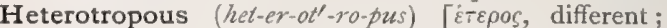
$\tau \rho o ́ \pi o s$, turning]. In biology, applied to any organ or part which is turned in an unusual direction, as an embryo transverse to the axis of the seed; amphitropous.

Heterotypic (het-er-o-tip'-ik), Heterotypical (het-er-o-

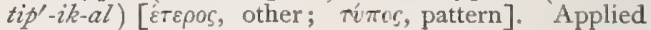
to a monstrosity consisting of a well-developed fetus from which grows an immature secondary fetus.

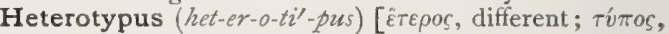
a type]. A double monster having the parasitic fetus hanging from the ventral wall of the principal subject.

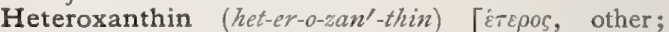

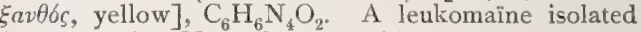
from urine in $\mathbf{1} 884$. In composition it is methyl-xanthin, and it is intermediate between xanthin and paraxanthin or dimethyl-xanthin; it exists in the urine of man in the same proportion as para-xanthin. It occurs in larger amount in the urine of leukemic patients. It is crystalline, soluble in hot water, insoluble in alcohol and ether. It is thought by Solomon to have its origin in the kidney. Its physiologic action is not yet fully known. Xanthin, heteroxanthin, and paraxanthin form normally an homologous series of xanthin-bodies in the urine.

Heubner's Disease. Syphilitic disease of the cerebral arteries. See Diseases, Table of.

Heuchera (hu'-ker-ah). See Alum-root

Heurteloup (her'-tel-ixp) [after Baron Heurteloup, the inventor]. An artificial leech or cupping-apparatus.

Hewitt's Mixture. A mixture used in treating chlorosis. It consists of compound spirit of ether, compound tincture of lavender, and aromatic spirit of ammonia, each 2 drams; water sufficient to make 2 ounces. Of this one dram is given every two or three hours.

Hewson's Dressing. An application for wounds, tumors, etc., consisting of dry earth containing about 50 per cent. of clay. H.'s Experiments, experiments made to prove that the blood-vessels exert a restraining influence on coagulation.

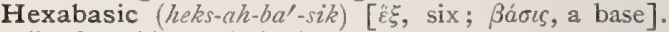
Replaceable by six basic atoms.

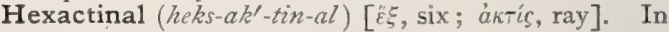
biology, bearing six rays.

Hexad (heks'-ad) [Ěçá, six]. In chemistry, an element the atoms of which have six times the saturating power or equivalence of the hydrogen atom.

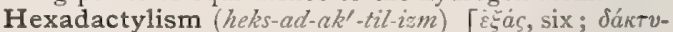
$\lambda o s$, a finger]. Having six fingers or toes.

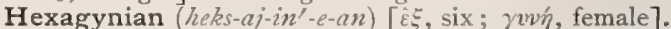
In biology, having six pistils or styles.

Hexahydric Alcohols (heks-ah-hi'-drik). See Alcohol.

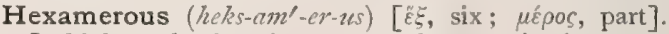
In biology, having six parts, or the parts in sixes.

Hexandrous (heks-an'-drus) [é $\xi$, six; $a v \eta \dot{\eta} \rho$, male]. In biology, having six stamens. It is also called Hexandrious, Hexandrian.

Hexane $\left(h e k s^{\prime}-\bar{a} n\right)$ [éçás, six $], \mathrm{C}_{6} \mathrm{H}_{14^{*}}$. The sixth member of the paraffin series of hydrocarbons. It is a liquid, boiling at about $7 \mathrm{I}^{\circ} \mathrm{C}$, , found in various natural oils. 


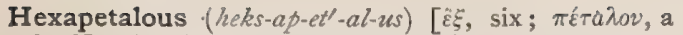
leaf ]. In biology, having six petals.

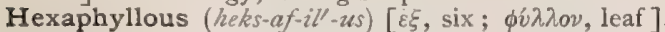
In biology, having six leaves or leaflets.

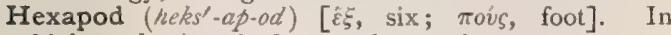
biology, having six feet, as the true insects.

Hexapodan (heks-ap'-o-dan). Same as Hexapod.

Hexapterous (heks-ap'-ter-us) $[\dot{\varepsilon} \xi$, six; $\pi \tau \varepsilon \rho b \nu$, a wing]. In biology, having six wings or wing-like appendages.

Hexastemonous (heks-as-tem'-o-nus) [ $\tilde{\varepsilon} \xi$, six ; $\sigma \tau^{\prime} \eta \omega \omega \nu$, warp, taken as stamen]. Same as Hexandrous.

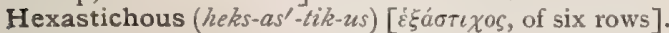
In biology, having the parts or organs arranged in six rows

Hexatomic (heks-at-om'-ik) [ëkás, six; àrouos, an atom]. In chemistry, consisting of six atoms; also applied to atoms that are hexavalent, and to alcohols or other compounds having six replaceable hydrogen atoms.

Hexavalent (heks-av'-al-ent) [ $\tilde{\xi}_{\xi} \dot{a} s$, six ; valens, having power]. In chemistry, having the same saturating or combining-power as six hydrogen atoms, or a valence of six.

Hexicology (heks-ik-ol'-o-je). See Hexiology.

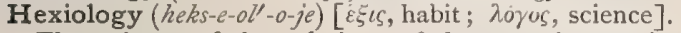
The science of the relations of the organism to its environment.

Hexoses (heks-o'-sëz) [Ékás, six]. The aldehyd or ketone derivatives of the hexahydric alcohols. They occur frequently in plants, especially in ripe fruits. They are formed by the hydrolytic decomposition of all disaccharids and polysaccharids when they are boiled with dilute acids, or acted upon by ferments. They possess feeble reducing-power. They precipitate cuprous oxid from warm alkaline cupric solutions, one molecule of hexose precipitating about five atoms of copper. This is the basis of the method for the volumetric estimation of glucose by means of Fehling's solution. When exposed to Schizomycetes the hexoses readily undergo fermentation. See Carbohydrates, Table of:

Hexylamin (heks-il"-am-in). See Caproylamin.

Hey's Hernia. See Hernia, Encysted. H.'s Ligament. See Ligament.

Hiation (hi-a'-shun) [hiare, to gape]. The act of gaping or yawning. Cf. Pandiculation.

Hiatus (hi-a'tus) [hiare, to gape]. A space or opening. Also, the vulva. $\mathbf{H}$. aorticus. See Aortic Opening. H. of Fallopius, the shallow groove on the petrous portion of the temporal bone. $\mathbf{H}$. sacralis, a slit-like opening on the posterior surface of the sacrum. It is continuous above with the spinal canal. H. semilunaris, a crescentic furrow upon the outer wall of the middle meatus of the nose.

Hibernaculum ( $h i-b e r-n a k^{\prime}-u$-lum) [L., a winter residence : pl., Hibernacula $]$. In biology, an organ fitted to protect delicate parts during the winter; a winter bud.

Hibernation (hi-ber-na'-shun) [hibernus, winter]. The dormant condition or winter-sleep of certain animals, notably bears, hedgehogs, etc., in which animation is almost suspended. Respiration and circulation are greatly reduced, and nutrition is performed mainly at the expense of the fatty tissues of the animal.

Hiccup, or Hiccough $\left(h i k^{\prime}-u p\right)$ [ $h i c$, a mimic word; ME., cough, a cough]. A spasmodic contraction of the diaphragm causing inspiration, followed by a sudden closure of the glottis.

Hickory (hik'-or-e) [an American Indian name]. The bark of shellbark hickory, Hicoria, or Carya alba: it is tonic and anti-intermittent, and useful in malarial

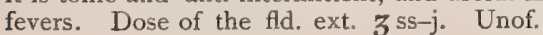

Hicks (Braxton), Method of. In obstetrics a method of performing version. It is the bipolar or combined internal and external method. H., Sign of. See Signs and Symptoms, Table of.

Hidden Seizure. A popular name for various forms of slight or sudden epileptiform attacks.

Hide (hìd) [ME., hide, skin]. The skin of an animal. The skins of the ox, cow, buffalo, horse, etc., that are utilized in the manufacture of leather, are especially so termed. If obtained from younger animals of the same kind, they are called kips. H.-bound Disease. See Scleroderma. H.-bound Skin. See Scleroderma. H.-glue. See Glue.

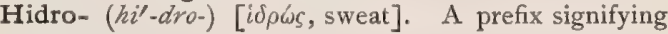
sweat.

Hidroa (hid-ro'-ah) [ $i \delta \rho \omega a$, sweat-spots; sudamina]. Sudamina; any dermal lesion associated with or caused by profuse sweating.

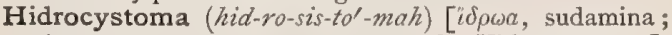

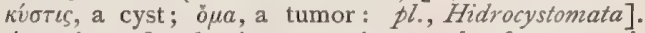
A variety of sudamina appearing on the face, especially in women in middle and advanced life.

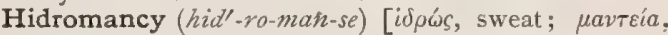
divination ]. The forming of a prognosis from examination of the perspiration.

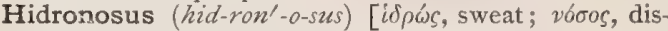
ease]. Any disease of the sweat-glands.

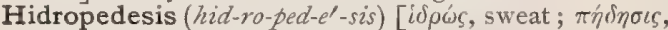
a leaping]. Excessive sweating.

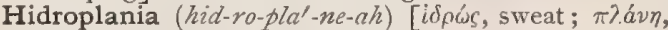
a wandering]. Sweating in an unusual portion of the body.

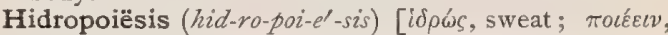
to make]. The process of the formation and excretion of sweat

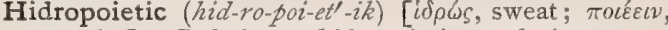
to make]. Relating to hidropoiesis; sudoriparous.

Hidrorrhea (hid-ror-e $-a h)$ [idpós, sweat; poia, a flow]. Excessive flow of sweat.

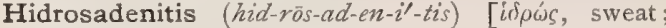
$a ́ \delta \dot{v} v$, gland; $\iota \tau \iota \varsigma$, inflammation]. Inflammation of the sweat-glands.

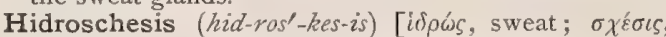
retention]. Retention or suppression of the sweat.

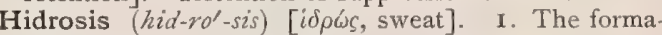
tion and excretion of sweat. 2. Abnormally profuse sweating. 3. Any skin-disease marked by disorder of the sweat-glands.

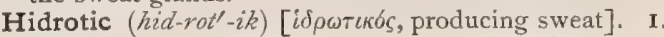
Diaphoretic or sudorific. 2. A medicine that causes sweating.

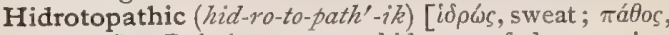
disease]. Relating to a morbid state of the perspiratory function.

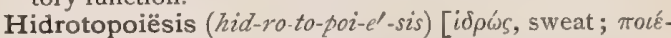
$\varepsilon \iota v]$. Same as Hidropoiesis.

Hidrotopoietic (hid-ro-to-poi-et'-ik). See Hidropoietic.

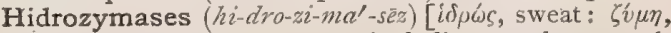
ferment]. Sweat-ferments, including amylase, emul$\sin$, and pepsin.

Hiera picra ( $h i^{\prime}-e r-a h$ pi'-krah) [L., sacred bitters]. Pulvis aloes et canellæ. See Aloes.

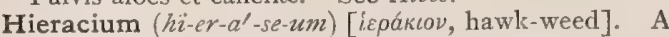
genus of composite-flowered herbs. In the old world, H. murorum and $H$. pilosella, and in the U.S., H. scabrum and $\mathbf{H}$. venosum are popularly esteemed as useful remedies. They have astringent and pectoral qualities. Unof.

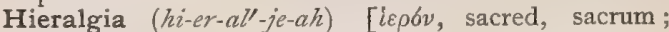
$\bar{a} \hat{\lambda} \gamma^{\prime} \circ s$, pain]. Pain in the sacrum.

High (hi) [ME., high, high]. I. Elevated far above a base. 2. Intensified in physical quality, as temper- 
ature. H. Pelvic Posture. See Postures, Table of H.-ride Sitting, in massage, sitting astride a high stool or narrow bench in order to fix the pelvis.

Highgate Resin (hi'-gät rez'-in). See Copalin.

Highmore, Antrum of. A cavity in the superior maxillary bone. H.'s Antrum of the Testicle. See Antrum.

Highmorianum, Corpus (hi-mor-e-an'-um kor'-pus) [L.]. See Cospus.

Hilar (hi'-lar) [hi/um, a little thing]. In biology, pertaining to the hilum.

Hill Diarrhea. Hill colic. A peculiar type of diarrhea prevailing in certain hili-districts of India, marked by pernicious fever, extreme pain, and often speedy death.

Hill's Stopping. A preparation consisting principally of bleached gutta-percha, carbonate of lime, and quartz, used for filling teeth.

Hilton's Law. See Law. H.'s Line. See Lines, Table of. H.'s Muscle. See Muscles, Table of. H.'s Sac, a laryngeal pouch.

Hilum (hi'-hum) [hilum, a little thing: pl., Hila]. In biology: (a)the point of attachment of an ovule or a seed to its funiculus, or if sessile, to the placenta; $(b)$ a small pit, scar, recess, or opening in an animal structure, especially the notch on the internal or concave border of the kidney.

Hinckes-Bird Method. See Ventilation.

Hind (hind) [ME, hindere, hinder]. Pertaining to the rear or posterior extremity. H.-brain, a division of the brain, developing from a funnel-shaped tube in the embryo to an anterior lobe that becomes the cerebellum, and a posterior lobe that becomes the medulla oblongata. H.-gut, that part of the embryonic intestine from which the extreme aboral part of the large intestine is developed. See Epigaster. H.-head, the occiput. H.-limb, one of the posterior limbs of a quadruped.

Hinge-joint (hin'"joint). See Diarthrosis.

Hinoid ( hin'-oid) [is-(iv.), strength; cidos, form]. In biology, applied to leaves the veins of which are parallel and undivided and set at right angles to the midrib.

Hip [ME., hipe, hip]. I. The upper part of the thigh at its junction with the buttocks. 2. The hip-joint. 3. The coxa or first joint of an insect's leg. 4. To sprain the hip. 5. The fruit of the rose. Confection of hips, confectio rosæcaninæ. H.-bath. See Bath. H.-bone, the ischium. H.-girdle, the pelvic arch. H.-joint, the articulation of the femur with the haunch-bone or innominate bone. H.-joint Disease, an arthritis of the hip-joint; an affection of early life, and according as it begins in the head of the femur, the acetabulum, or in the synovial membrane and proper structures of the joint, divided respectively into Femoral, Acetabular, and Arthritic. Its etiology is obscure, its symptoms pain (coxalgia), swelling, and deformity. Coxalgia is incorrectly used as a synonym.

Hipling (hip'-ling) [ME, hipe, hip]. In obstetrics, a hip-presentation of the fetus.

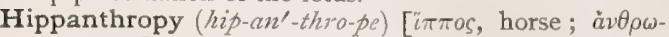
$\pi 0 \varsigma, \operatorname{man}]$. A form of zoanthropy in which the patient believes that he is a horse.

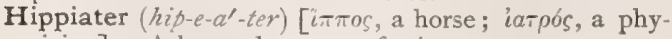
sician]. A horse-doctor; a farrier.

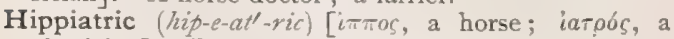
physician]. Pertaining to veterinary surgery.

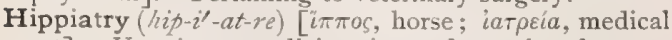
art]. Veterinary medicine, in so far as it relates to the horse; farriery.

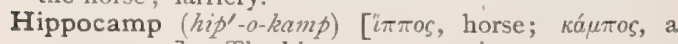
sea-monster]. The hippocampus major.

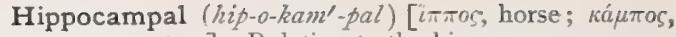
a sea-monster.] Relating to the hippocampus.

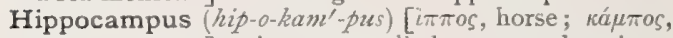
a sea-monster]. A name applied to two elevations, $H$. major and H. minor, the former situated in the inferior, and the latter in the posterior horn of the ventricles of the brain. When the name Hippocampus is used alone, the $H$. major is meant.

Hippocoryza (hip-o-ko-ri'-zah). Synonym of Equinia.

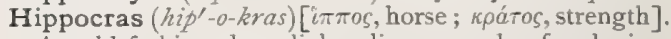
An old-fashioned cordial or liquor, made of red wine, sweetened and flavored.

Hippocrates' Bandage. See Bandage.

Hippocratic (hip-o-krat'-ik) [Hippocrates, a Greek physician of the fourth century]. Pertaining to Hippocrates. H. Expression, an anxious expression of the countenance, described as characteristic of peritonitis. H. Face. See Facies. H. Finger. See $H$. Nait. H. Nail, a peculiar curvation of the nails seen in pulmonary tuberculosis and other lung. diseases. They are curved, longitudinally striated, overlapping the finger like the beak of a parrot. The condition is also called Hippocratic Finger. $\mathbf{H}$. Sound. See Succussion-sound.

Hippocratism (hip-ok'-rat-izm) [Hippocrates, a Greek physician]. Hippocrates' doctrine of imitating nature in the treatment of disease.

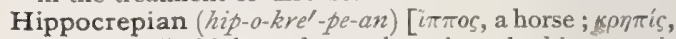
a boot]. In biology, horse-shoe-shaped; hippocrepiform, as a certain deformity of the kidney.

Hippocrepiform (hip-o-kreph-if-orm). See Hippocrepian.

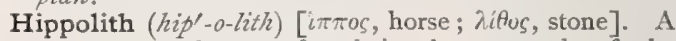
calculus or bezoar found in the stomach of the horse.

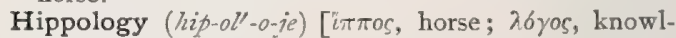
edge]. The anatomy, pathology, etc., of the horse.

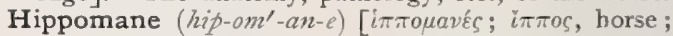
pavia, madness; the ancients believed that horses were madly fond of a plant called by this name]. A genus of euphorbiaceous trees. H. mancinella and H. spinosa, the manchineal trees of tropical America, are extremely acrid and poisonous, even to the touch. They are used locally in medicine, especially in skin-diseases. Unof.

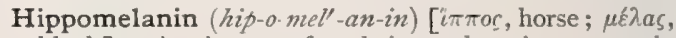
black]. A pigment found in melanotic tumors in horses.

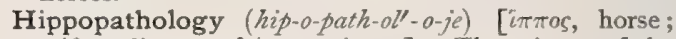

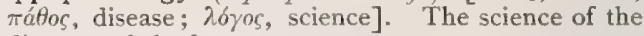
diseases of the horse.

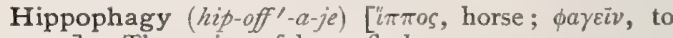
eat]. The eating of horse-flesh.

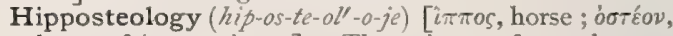
bone; $\bar{x} 6$ yos, science]. The science of osteology as applied to the horse.

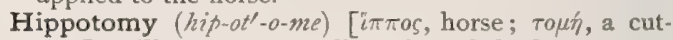
ting]. The anatomy or dissection of the horse.

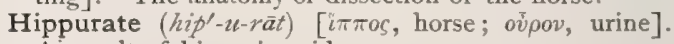
Any salt of hippuric acid, q. $v$.

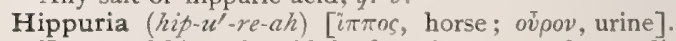
Excess of hippuric acid in the urine, e. go, after medication with benzoic acid.

Hippuric Acid (hip-u'-rik). See Acid.

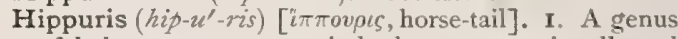
of halorageaceous aquatic herbs, common in all cool regions. $H$. vulgaris is astringent. Unof. 2. The cauda equina, q. $\%$.

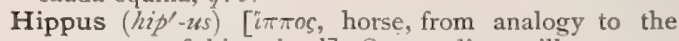
movement of this animal]. Spasmodic pupillary movement, independent of the action of light.

Hircin (her'-sin). See Acid, Hircic. 
Hircinous (her-si'-nus) [hircinus, of a goat]. In biology, having a goat-like odor.

Hircismus (her-siz'-mus) [hircus, a goat]. The goatlike odor sometimes emitted by the human axilla.

Hircus (her'-kus) [L., "goat"]. The tragus.

Hirschfeld's Ganglion. See Ganglia, Table of.

Hirsute (her-sut') [hirsutus, rough, shaggy]. In biology, thickly covered with rough, shaggy hair.

Hirsuties (her-su'-te-erz) [hirsulus, shaggy]. Hypertrichosis; hypertrichiasis; polytrichia; trichauxis; that condition in which the hairs of the body are increased in number or size, or grow in unusual situations, or in normal situations in unusual length or number. H. gestationis, a growth of hair about the chin and lips in women in the course of pregnancy.

Hirsutocinereous (her-su-to-sin-el-re-us) [hirsutus, hairy; cinereous, ashy]. In biology, having a hairy coat of an ashy-gray color.

Hirtellous (her-tel'-zis) [hirtus, hairy]. Minutely hirsute; stiffly pubescent.

Hirudiniculture (hi-ru'-din-e-kul-chür) [hirudo, leech; cultura, culture]. The artificial breeding and rearing of leeches.

Hirudo $\left(h i-r u^{\prime}-d o\right)$ [L. : pl., Hirudines]. The leech, q.v.

His, Bursa of. A dilatation of the end of the archenteron described by His in a human embryo. H.'s Granule-cell, a granular cell resembling a leukocyte, found in the ovarian stroma. H.'s Tissue, a synonym of Adenoid Tissue.

Hispid (his'-pid) [hispidus, bristly]. In biology, bristly. Beset with rigid, spreading hairs or minute spines.

Hispidulous (his-pid'-u-lus) [hispidus, hairy]. In botany, minutely hispid; having short, stiff hairs.

Histioid (his'-te-oid). See Histoid.

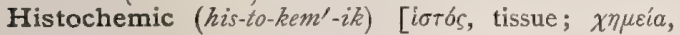
chemistry]. Relating to histochemistry.

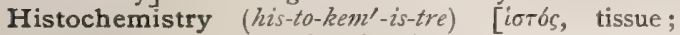

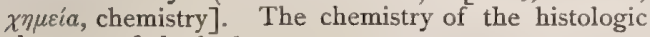
elements of the body.

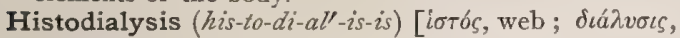
a resolution]. The dissolution of organic tissue.

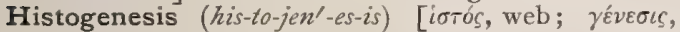
generation]. In biology, the process of formation of cells and cell-products.

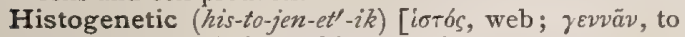
produce]. Relating to histogenesis.

Histogeny (his-toj'-en-e). See Histogenesis.

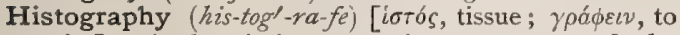
write]. A description or written account of the tissues.

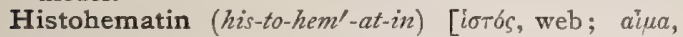
blood]. I. A pigmentary extractive of the suprarenal bodies; it is found also in various other tissues in the lower animals. 2. One of a class of respiratory pigments; the intrinsic coloring-matters of the organs and tissues of invertebrates. The histohematins are of wide-spread occurrence in the tissues of both vertebrates and invertebrates. The best known is that found in muscles, viz., myohematin, $q . v$.

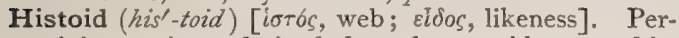
taining to tissue derived from the mesoblast, as a histoid tumor. See Neoplasm.

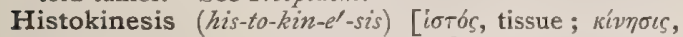
movement]. Movement that takes place in the minute structural elements of the body.

Histologic, Histological (his-to-loj'-ik, his-to-loj'-ik-al)

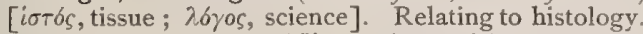

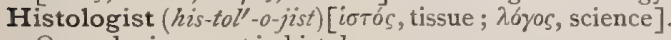
One who is expert in histology.

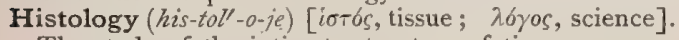
The study of the intimate structure of tissues.

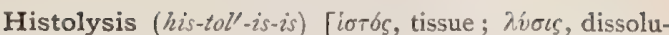
tion]. Disintegration and dissolution of organic tissue.

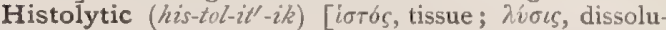
tion]. Pertaining to histolysis.

Histomorphology (his-to-morf-ol'-o-je) [io-ós, tissue; $\mu \cap \rho \phi$, form; hóyos, science]. The morphology of the histologic elements of the body.

Histon (his'-ton) [iorós, tissue]. A proteid prepared from the nuclei of ceils. It belongs to the group of proteids known as albumoses or propeptones.

Histonomy (his-ton'-o-me) [iotós, tissue; vónos, a law]. The laws of the development and arrangement of organic tissue.

Histopathology (his-to-path-ol'-o-je) [iotbs, tissue;

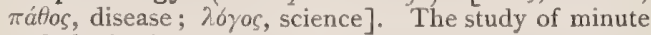
pathologic changes or states.

Histophysiology (his-to-fiz-e-ol'-o-je) [iotos, web, tis

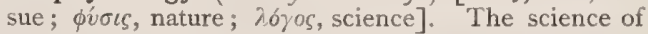
the functions of the various tissues.

History (his'-tor-e) [iotopia, a learning by inquiry]. A narrative ; story. H., Biologic, the life-story of any animal. H., Medical, the account obtained from a patient as to his health, past and present, and the symptoms of his disease.

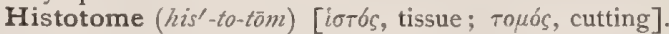
A microtome or other apparatus for cutting tissue for the study of its minute structure.

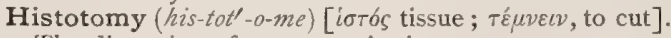
The dissection of any organic tissue.

Histotripsy (his-to-trip'-se) [iorós, web; $\tau \rho i \psi u s$, a crushing]. The crushing of tissues by an ecraseur.

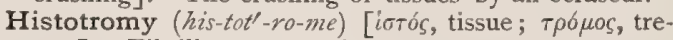
mor]. Fibrillary contraction.

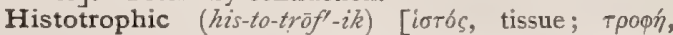
nourishment]. Concerning the nutrition of the tissues.

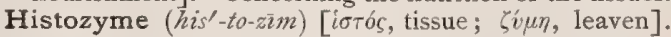
A ferment found by Schmiedeberg in the kidneys of pigs, and concerned in splitting up hippuric acid.

Histrionic (his-tre-on'-ik) [histrio, an actor]. Dramatic. H. Mania, insanity with affectation and lofty manner. H. Muscles, the expressional muscles of the face. H. Spasm, spasm of the histrionic muscles.

Histrionism (his'-tre-on-izm) [histrio, a player]. Dramatic action in insanity or in hysteria.

Hitooch (hit-oosh'). See Hitouch.

Hitouch (hit-oosh') [Heb.]. Hitooch; the first step in the Jewish rite of circumcision. It consists in cutting off the prepuce.

Hives (hivz) [origin uncertain]. A name loosely applied to almost any papular eruption of the skin. In Great Britain, the term is applied to croup, laryngitis, and to chicken-pox; in the United States it is limited to a transitory form of urticaria, $q . v$.

Hive-syrup. See Scilla and Antimonium.

Hoang-nan, or Hwang-nao (hruang-now') [Chinese]. A Chinese preparation obtained from the bark of Strychnos gaultheriana. Its properties are due to a small percentage of strychnin. It is recommended as an alterative in syphilis, leprosy, and similar diseases, and is an alleged preventive of hydrophobia if given in large doses (gr. xv) during the period of incubation. Dose of the powdered drug gr. iij-v; of the aceto-alcoholic extract gr. $1 / 8-1 / 2$; of the tinct. $m j-v$.

Hoar (hor) [ME., hore, hoar]. Gray; old.

Hoarhound (hor'-hozend). See Marrubium.

Hoariness (hor'-e-nes). See Canities.

Hoarse (hors) [ME., hoors, harsh]. Harsh; grating; discordant; applied to the voice.

Hoarseness (hors'-nes) [ME., hoorsnesse, hoarseness]. Harshness of the voice depending on some abnormal condition of the larynx or throat. 
Hob-nail Liver, or Hob-nailed Liver. A liver covered with small bosselations like the heads of hob-nails; it is the result of cirrhosis, or of an old and persistent hyperemia. It is called also Gin-drinkers' Liver.

Hobokenius, Valves of. Crescentic or ring-like ridges on the inner surface of the umbilical vessels, producing constrictions upon their outer surface.

Hock (hok) [Ger., Hochheimer]. White Hochheimer wine; any German white wine.

Hock, Hough (hok) [ME, houz, heel]. The joint on the hind-leg of a quadruped between the knee and the fetlock, corresponding to the ankle-joint in man. In man, the back part of the knee-joint; the ham.

Hodgen's Apparatus. A modification of Smith's anterior splint.

Hodgkin's Disease. See Lymphadenoma and Diseases, Table of.

Hodgson's Dilatation, or Disease. Dilatation of the aorta. It commences with inflammatory and sub-inflammatory changes in the tissues, going on to extreme degeneration, with dilatation of the first part of the aorta. There is sometimes involvement of the aortic valves, with hypertrophy and dilatation of the heart. See Diseases, Table of:

Hoe (ho) [ME., howe, a hoe]. A scraping-instrument used in operations for cleft-palate, or in dentistry.

Hoffmann's Anodyne. See Ether. H.'s Violet. Same as Dahlia. H.'s Method. See Treatment, Methods of.

Hofmeier's Method. A method of expression of the fetal head. It is carried out by pressure on the head alone, by directly pressing from without upon the occiput and the face from both sides.

Hofmeister's Method. A method of removing proteids from a liquid. To the liquid, rendered faintly acid and heated to boiling, add a solution of ferric acetate, made by saturating acetic acid with recently precipitated ferric hydrate. After boiling for a few minutes and filtering, a solution is obtained which contains neither proteids nor iron. This method does not precipitate peptones.

Hog [ME., hog, a gelded hog]. I. A gelded pig; a barrow-pig. 2. A glutton. H.-cholera, a specific, highly contagious fever of swine, attended with inflammation of the lungs, stomach, intestines, and other organs, usually diarrhea, frequently cough, and extravasations of blood in the skin and mucous membranes. It is called also Pneumoenteritis. See Bacillus ex pneumo-enteritide suis, under Bacteria, Table of. H.-gum, a name for various West Indian resins. See Gum. H.'s Potato. See Camass. H.-weed. See Ambrosia.

Hohl's Method. A method of preserving the perineum in labor. It consists in applying resistance to the presenting part, the thumb being applied anteriorly to the occiput and the index and middle fingers posteriorly upon that portion of the head lying nearest the commissure.

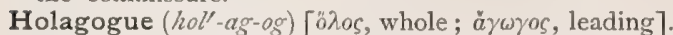
A medicine or remedy that expels or drives out the whole of a morbid substance. A radical remedy.

Holarrhena (hol-ar-e'-nah). See Wrightia.

Holcodont (hol'-ko-dont) [ỏ̀ $\delta$ s, a furrow; ỏdoús

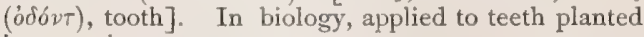
in a continuous groove.

Holden's Line. See Lines, Table of.

Holder (höld'-er) [ME., holdere, a holder]. A device for holding instruments, sponges, etc., in surgical operations.

Holder's Plane. See Plane.

Hold-fast (höld"-fast). A "lumpy-jaw" tumor. See Actinomycosis.
Hollands (hol'-ands). See Gin.

Hollek (hol'-ek). Same as Hollyhock.

Hollow-foot (hol'-o-foot). See Cavnts.

Holly $($ hol'-e). See llex.

Hollyhock (hol'-e-hok) [AS., holihoc, hollyhock]. A name given to the Althea rosea and other species of Althea. See Althea.

Holmgren's Test. The worsted test for color-blindness. One of the worsteds is placed before the person to be tested, and he is asked to match it as nearly as possible.

Holo- (hol'-o-) ["2/os, entire]. A prefix signifying entirety.

Holoblast (hol'-o-blast) [ö $\lambda o s$, whole ; $\beta \lambda a \sigma \tau o ́ s$, germ]. In biology, an ovum that undergoes complete segmentation while germinating.

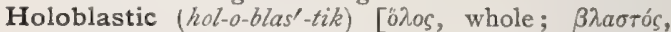
germ]. In biology, applied to eggs in which the entire yolk is included in the process of segmentation; one in which there is no separate food-yolk.

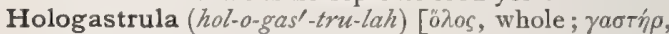
stomach: pl., Hologastrulce]. In biology, the gastrula resulting from the development of a holoblastic ovum.

Holometabolian (hol-o-met-ab-o'-le-an). Same as Holometabolic.

Holometabolic (hol-o-met-ab-ol'-ik) [onos, whole ; $\mu \varepsilon \tau a \beta b \lambda_{o}$, changeable]. In biology, applied to animals that undergo complete metamorphosis or transformation, as insects.

Holonarcosis (hol-o-nar-ko'-sis) [öros, complete;

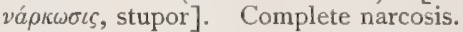

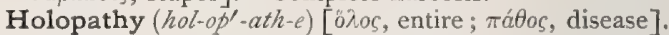
I. A general or constitutional disease of which a local disorder is but a manifestation. 2. The theory that local diseases are manifestations of a general disorder.

Holophanerous (hol-o-fan'-er-us) [öhos, whole; фavepós, visible]. In biology, discernible throughout, as the transformation of insects.

Holophytic (hol-o-fit'-ik) [öhos, whole; $\phi v \tau \delta v$, plant]. In biology, applied to certain protozoa and other animals that, in their mode of nutrition, closely resemble plants.

Holoplexia (hol-o-pleks'-e-rh) ["unos, whole; $\pi \lambda \vec{\eta} \xi \iota s$, a stroke]. Complete or general paralysis.

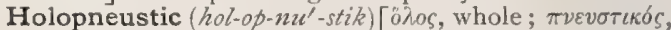
$\pi \nu \varepsilon i \nu$, to breathe]. In biology, applied to such insect larvæ as possess many pairs of open stigmata, as distinguished from those having no open stigmata, apneustic larvæ.

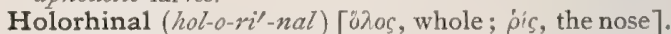
In biology, applied to the Galline and other birds having the anterior margin of the nasal bone concave, with two cornua directed forward, the processes being 'continuous behind with the body of the bone and with one another.

Holoschisis (hol-os'-kis-is) [öhos, whole; oxious, cleavage]. Amitotic or indirect cell-division; amitosis.

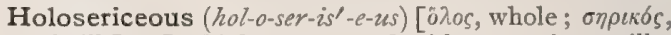
of silk]. In biology, covered with very minute silky hairs.

Holosteous (hol-os'-te-us) [öhos, whole; óctéov, a bone]. In biology, having a completely bony skeleton.

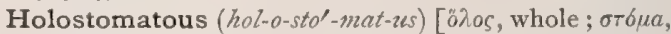
mouth]. In biology, having the mouth entire, neither notched nor with parts missing.

Holostomous (hol-os'-to-mus). Same as Holostomatous.

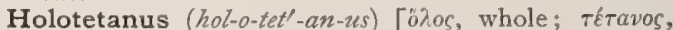
tetanus]. General tetanus; called also Holotonia. 
Holothecal (hol-o-the'-kal) [önos, whole; $\theta \dot{\eta} k \eta$, case]. In biology, booted; applied to birds in which the tarsal envelop is entire.

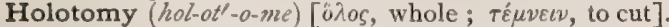
Complete surgical excision of a part or organ.

Holotonia, or Holotony (hol-o-to'-ne-ah, hol-ot'-o-ne) [öhos, entire; reiveıv, to stretch]. Same as Holotetanus.

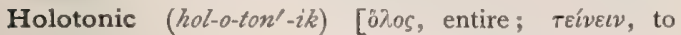
stretch]. Relating to, or characterized by, holotetany.

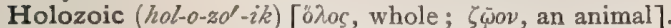
In biology, entirely resembling animals in mode of nutrition.

Holthouse, Hernia of. See Hernia.

Holting (hollt'ing) [after Holt, the inventor of the method]. The divulsion of an urethral stricture by Holt's dilator.

Holtz Machine. A particular form of electro-static induction-machine.

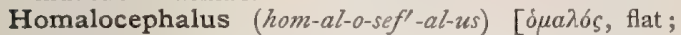
$\kappa \varepsilon \phi a \lambda$, the head]. Lissauer's term for "flatheaded.'"

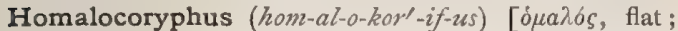
$\kappa о \rho v \phi \dot{n}$, the head]. Lissauer's term for a skull in which the angle formed by two lines drawn from the bregma and the occipital point to the highest point above is between $132^{\circ}$ and $142^{\circ}$.

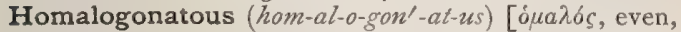
level; $\gamma \delta \nu v, k n e e]$. In biology, applied to such birds as possess an accessory femoro-caudal muscle and a tufted oil-gland and cocca; the opposite of Anomalogonatous, in which this combination is never found.

Homalographic (hom-al-o-graf'-ik) [óuà̀ós, same;

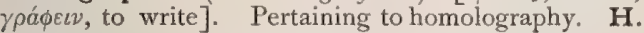
Method, a method of showing the structure of the body by means of plane sections of a frozen body.

Homalography (hom-al-og'-ra-fe) [öuaiós, level; $\gamma \rho a ́ \phi \varepsilon \iota \nu$, to record]. Anatomy by sections; the repre sentation of structure by means of sketches of various sections.

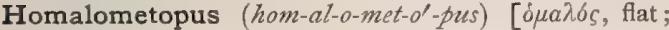
$\mu \varepsilon ́ T \omega \pi \nu \nu$, the space between the eyes]. Lissauer's term for a skull having a frontal angle between $\mathbf{I} 30.5^{\circ}$ and $\mathrm{I}_{4} \mathrm{I}^{\circ}$

Homalopisthocranius (hom-al-o-pis-tho-kra'-ne-us)

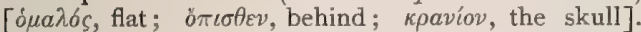
Lissauer's term for a skull in which the angle formed by lines joining the external occipital protuberance and the occipital point with the highest point of the skull is between $140^{\circ}$ and $154^{\circ}$.

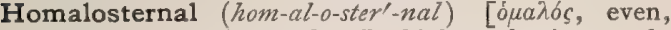

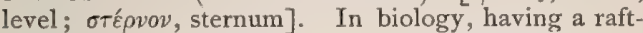
like or keelless sternum; ratite, as certain birds.

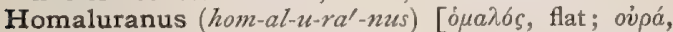
a tail]. Lissauer's term for a skull in which the angle formed by lines joining the occipital point and the bregma with the highest point of the skull is betwen $147.5^{\circ}$ and $163.5^{\circ}$.

Homatropin (höm-at'-ro-pin). See Atropin.

Homeo- (ho'-me-o-) [ouocos, like]. A prefix signifying like or similar.

Homeobiophorid (ho-me-o-bi-off'-or-id) [ouolos, like ; $\beta i o s$, life ; $\phi \varepsilon \rho \varepsilon \iota v$, to bear]. In biology, Weismann's name for the lowest and most primitive undifferentiated organism conceivable, having the form of a single biophore, or of a number of similar biophores, in which multiplication and transmission would occur together, no special apparatus being required for the latter process, as, a reproduction by binary fission must result in two corresponding halves, each containing similar biophores, and each of which, simply by the multipli- cation of its units, is able to give rise to a compact organism like the parent. Cf. Heterobiophorid.

Homeochronous (ho-me-ok'-ro-nus) [öuows, like, similar; xó́vos, time]. In biology, true ontogenetic sequence; appearance in proper order in time; applied to animals, organs, or hereditary traits. H. Heredity, pertaining to the appearance of an organ, trait, tendency or function, whether psychologic, physiologic, or pathologic, at a similar time of life in a series of descendants.

Homeodont ( $\left.h o^{\prime}-m e-o-d o n t\right)$ [ouolos, like; odovs, tooth]. In biology, applied to teeth that are simple cones.

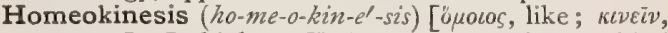
to move]. In biology, Weismann's term for that kind of nuclear division in which the two daughter-nuclei contain similar idioplasm; $i . e$, nuclear division depending upon a perfectly uniform distribution of the primary constituent and resulting in parts containing similar hereditary tendencies. Cf. Heterokinesis.

Homeomerous (ho-me-on'-er-us) [öuowos, like; $\mu$ épos, part]. In biology, having given organs or parts distributed uniformly throughout.

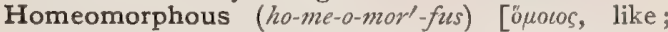
$\mu о \rho \dot{n}$, form]. Like or similar in form and structure.

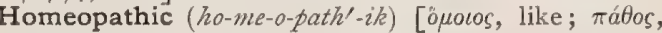
feeling]. Relating to homeopathy.

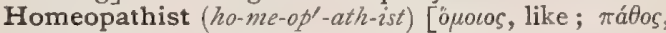
feeling]. A practitioner of homeopathy.

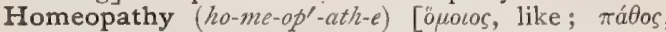
ailment or disease]. A system of treatment of disease by the use of agents that, administered in health, "would produce symptoms similar to those morbid conditions for the relief of which the agent or medicine is given." The hypothesis expressed by the adage, "similia similibus curantur." See Regular and Allopathy.

Homeoplasia (ho-me-o-pla'-ze-ah) [opotos, like; $\pi \lambda a ́ \sigma \sigma \varepsilon \iota \nu$, to shape]. The growth of tissue resembling the normal tissue, or matrix, in its form and properties; also the tissue so formed.

Homeoplastic (ho-me-o-plas'-tik) [opolos, like; $\pi \lambda a ́ \sigma \sigma \varepsilon \iota \nu$, to form]. Pertaining to a neoplasm resembling its matrix-tissue in texture. One differing widely in this respect is heteroplastic. If separated in position, it is said to be heterotopic; in date, heterochronic.

Homeoplasty ( $\left.h o^{\prime}-m e-o-p l a s-t e\right)$. See Homeoplasia.

Homeosis, or Homoiosis (ho-me-o'-sis, or ho-nioi-o' -

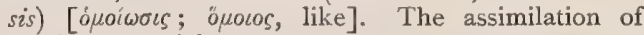
nutrient material.

Homeo-therapeutics (ho-me-o-ther-ap-u'-tiks) [ $0 \mu 0 \mathrm{~s}$, like; $\theta \varepsilon \rho a \pi \varepsilon v \varepsilon \iota \nu$, to serve]. The homeopathic doctrine of therapeutics.

Homeothermal, or Homoiothermal (home-o-ther' mal, ho-moi-o-ther'-mal) ["oporos, like ; $\theta \dot{\varepsilon} \rho \mu \eta$, heat]. Pertaining to animals that are "warm-blooded," or that maintain a uniform temperature despite variations in the surrounding temperature.

Homeozoic (ho-me-o-zol-ik) [ouocos, the same, similar; $\zeta \omega$, life]. In biology, applied to geographic areas, zones, or belts, having similar forms of life.

Homesickness ( $h o m^{\prime}$-sik-nes). Nostalgia. An urgent desire to return to one's home. It may be accompanied by a morbid sluggishness of the functions of the various organs of the body, and may develop into profound melancholy.

Homicidal (hom-is-i'-dal) [homo, a man; coedere, to kill]. Pertaining to homicide. H. Mania, insanity characterized by murderous impulses.

Homicide (hom'-is-id) [homo, a man ; cadere, to kill] The killing of a human being without malice or intent, as distinguished from murder or manslaughter. 
Also, the taking of human life in general by another. Also, one who takes the life of another.

Homiculture (ho'-mik-ul-chur) [homo, man; cultura, culture]. The proposed improvement of the human species by attention to the laws of breeding; stirpiculture.

Hominisection (ho-min-is-ek'-shun) [homo, hominis, man; sectio, a cutting]. Dissection of the human body; anthropotomy.

Homo $\left(h o^{\prime}-m o\right)$ [L.]. Man. The sole genus of the order Bimana

Homoblastic (ho-mo-blas'-tik) [óuós, the same; $\beta \lambda a \sigma \sigma^{\prime} s$, a bud, germ]. In biology, derived from like germs or cells.

Homocarpous (ho-mo-karl-pus) [ojobs, the same; $к а р \pi o ́ s$, fruit]. In biology, bearing fruits all of one kind.

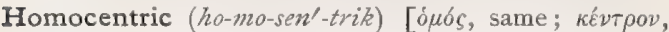
center]. Concentric. Having the same center. $\mathbf{H}$. Rays, a pencil of light-rays either cone-shaped or rod-shaped.

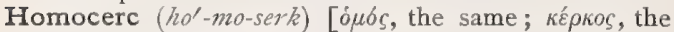
tail]. Same as Homocercal.

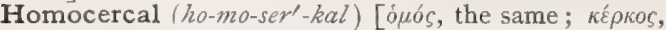
the tail]. In biology, applied to fishes in which the caudal fin-rays are so disposed as to give the tail an appearance of symmetry with respect to the axis of the body,

Homocerebrin (ho-mo-ser'-e-brin) [ópós, like; cerebrum, cerebrum]. A substance derivable from braintissue, closely resembling cerebrin, but more soluble in alcohol.

Homochromous (ho-mo-kro'-mus) [ouós, the same; $\chi \rho \tilde{\omega} \mu a$, color]. In biology, all of one color, as the florets in a flower-head, or an entire organism.

Homocinchonidin (ho-mo-sin-kon'-id-in) [ótos, the same; cinchona], $\mathrm{C}_{19} \mathrm{H}_{22} \mathrm{~N}_{2} \mathrm{O}$. An alkaloid derived from South American Red-bark, one of the Cinchonas.

Homodermic (ho-mo-der'-mik) [o $\mu b_{s}$, the same; $\delta \dot{\varepsilon} p u \alpha$, the skin]. In biology, of similar blastodermic origin; applied to tissues or organs.

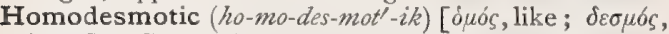
bond]. Connecting centers of equal importance (as a nerve-fiber).

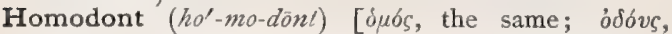
tooth]. In biology, having the teeth alike throughout.

Homodromous (ho-mod'-ro-mus) [ouós, the same; $\delta \rho 6 \mu o s$, a course]. In biology, applied to plants in which the spiral arrangement of the leaves on the stem and branches is alike throughout.

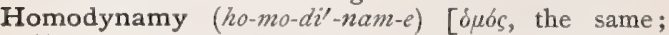
dévaues, power]. In biology, serial homology; applied to homologous parts (somites or metameres) arranged along the long axis of the body.

Homœo- (ho'-me-o-). For words thus beginning, see Homeo-

Homogamous (ho-mogr'-am-us) [ókos, the same; yáuos, marriage]. In biology, having all the florets of the inflorescence alike in sex.

Homogamy (ho-mog'-am-e) [óuós, same; yáuos, marriage]. I. Romanes' term for that method of evolution by physiologic selection of those varieties, the individuals of which are fertile among themselves, but less fertile or sterile with other varieties and with the parent-stock. It is called also Segregate Fecundity by Gulick. See Evolution. 2. In biology, applied to hermaphrodite flowers that mature their stigmas and anthers at the same time.

Homogen (ho'-mo-jen) [ouós, the same; y'v́vos, race]. In biology: I. Derived from the same or similar parents; having a common ancestor. 2. One of two organs or organisms having a common ancestor or ancestral part. H., Ancestral, i. e., homogenetic homologues that do not arise similarly, though probably descended from common ancestral parts, $e . g$., the legs of flies of diverse development. H., Developmental, i. e, homogenetic homologues that arise similarly, whether descending from the same ancestral part or not, e.g., some of the cranial bones of a Teleostean and of a mammal.

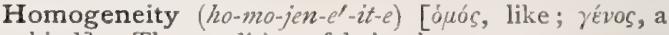
kind]. The condition of being homogeneous.

Homogeneous (ho-mo-jél-ne-us) [ófós, like; ý́vos, kind]. Having the same nature or qualities. Similar or identical in structure. H. Immersion. See Immersion. H. Triplets. See Homogeneous Truins. H. Twins, in embryology, when the cleavage-force is exerted to its fullest effect, the entire embryonal trace is completely divided; each resulting part may be capable of independent develópment, whereby two fetuses are produced remarkable for their great similarity; such offspring are known as homogeneous twins. They are always of the same sex and possess almost perfect identity of physical characteristics. So also may a secondary fission of one of the halves take place, as an extremely rare occurrence, homogeneous triplets resulting from such twofold division of the original area. Such fetuses usually lie within a single chorion, enclosed by a separate or a common amniotic sac, the increased pressure arising from the unusual contents of the limited uterine cavity favoring absorption and disappearance of the amniotic partitions.

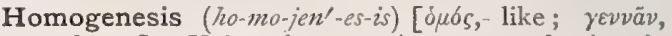
to beget]. Univocal generation; reproduction in which a living parent gives rise to offspring that pass through the same cycle of changes as itself.

Homogenization (ho-mo-jen-iz-a'-shun) [ouós, the

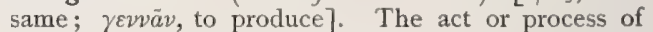
rendering or of becoming homogeneous; reduction to a common standard; the process of rendering the objects of microscopic study transparent and fixed.

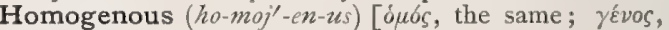
race]. In biology, applied to structures that are genetically related, in so far as they have a single representation in a common ancestor.

Homogentisic Acid (hom-o-jen-tiz'-ik). See Acid.

Homogeny (ho-moj'-en-e) [ouoyevins, of the same race or family]. In biology, an agreement among organisms depending on the inheritance of a common part or having a common ancestor. See Homogrenesis.

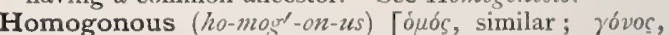
offspring]. In biology, having the stamens and pistils alike in all the flowers of the species; homostyled. C. Heterogonous.

Homoio- $\left(h o^{\prime}-m o i^{\prime}-o^{-}\right)$. For words thus beginning, see Homeo-.

Homoiosis (ho-moi-o'-sis). See Homeosis.

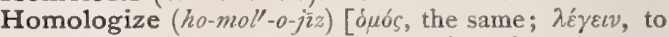
speak]. In biology: I. To recognize as homologous; 2. To exhibit homology; to correspond in structure.

Homologous (ho-mol'-o-gus) [óuós, the same; $\lambda \dot{\varepsilon} \gamma \varepsilon l v$, to speak]. In biology, corresponding in structure, either directly or as referred to a fundamental type. In chemistry, being of the same chemic type or series; differing by a multiple or an arithmetic ratio in certain constituents, while the physical qualities are analogous, with small differences, as if corresponding to a series of parallels. H. Tissues, those identical in type of structure. H. Tumor, a name given by Virchow to a tumor consisting of tissue identical with that of the organ whence it springs. 
Homologue (hom'-o-log) [ókós, same; $\lambda 6 \gamma o s$, proportion]. An homologous organ common to any number of species, classes, or orders of animals; that which has the same relative structure, position, or development as another. The same organ in different organisms under every variety of form and function. We may have: I. Homogenetic Homologues, i.e., parts which, on the evolutionary theory, have a genetic relation, $e . g$, the humerus of a horse and that of an ox. 2. Homoplastic Homologues, $i$, e., parts closely similar as to relative position, but with no genetic affinity, or only a remote one, $e . g$., the ventricle of a bat and that of a bird. 3. Homogenetic Serial Homologues, i. e., different parts of one individual, the correspondence between which is to be accounted for by the influence of external conditions (the "superinduced segmentation" of Mr. Herbert Spencer), e.g., the fore-limbs and hind-limbs of one side of any animal. 4. Vertical Homologues, $i_{\text {. }} e_{\text {e, }}$ different corresponding parts of one individual, of which one part is dorsal, the other ventral, e.g., dorsal and anal fins of certain fishes. 5. Lateral Homologues, $i . e$., different corresponding parts of one individual, of which one part is right and the other left, $e . g$. , the right and left arms of a man. 6. Antero-posterior Homologues, i. e., different corresponding parts of one individual, of which one part is anterior, the other posterior, e.g., the mouth and the cloaca. 7. Radial Homologues, i. $e$., different corresponding parts of one individual which radiate from a central axis, $e . g_{\text {. }}$, any two arms on the same starfish. 8. Homotrophic Homologues, $i . e$, parts of an individual, the correspondences between which are regarded as due to internal modifying influences, $\ell_{.} g_{.}$, the eyes and the ears. 9. Actinologous Homologues, i.e., successive subdivisions, parts, or regions of a part or segmented organ, e.g., two successive joints of an antenna of a lobster, or the vertebral and sternal parts of the same costal element. Io. Special Homologues, i. e., parts of two organisms belonging to the same special skeletal category, $e . g$. the basi-occipital of man and the cod. II. General Homologues, $i$. $e_{\text {, }}$, parts of two organisms belonging to the same general skeletal category, e.g., the vertebral center of man and that of the cod, or the lateral appendages of the lobster and those of the scorpion. (Mivart.)

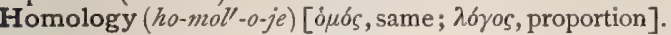
The quality of being homologous; also, the morphologic identity of parts or organs in different animals. In biology, a term introduced by $\mathrm{R}$. Owen to indicate a close resemblance bețween parts, depending upon relations of relative position. (Mivart.)

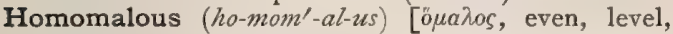
equal]. In biology, applied to parts or organs that are all turned to one side.

Homomorphism (ho-mo-mor'-fizm) [ouós, the same; $\mu \circ \rho \phi \hat{n}$, form]. In biology, superficial resemblance, without true homology; mimicry or adaptive resemblance.

Homomorphous (ho-mo-mor'-fus) [ouós, the same; $\mu о \rho \phi \eta$, form]. In biology, exhibiting superficial resemblance, but not truly homologous.

Homonomous (ho-mon'-o-mus) [ónós, same; vónos, law]. Governed by or under the same law.

Homonym (hom'-o-nim) [ $\dot{\alpha} \omega \sigma \sigma$, same; ov $\nu \mu \alpha$, name]. That which is homonymous.

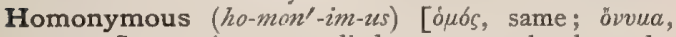
a name]. I. A term applied to names that have the same sound or pronounciation, but different meanings. 2. Coming under the same general designation (thus the two external recti muscles are homonymous); occurring on or within the same lateral half of the body; not heteronomous. H. Diplopia, occurs when the image seen by the right eye seems to be on the right side and that seen by the left eye seems to be on the left side. H. Hemianopia, occurs when all points in the visual field of each eye lying to the right (Right H. H.) or to the left (Left H. H.) of the fixation-point are not seen.

Homophthalic Acid (hom-off-thal'-ik). See Acid.

Homophthalimid (hom-off-thal'-im-id) [ókós, same; ö $\phi \theta a \lambda \mu o s$, eye ; imid], $\mathrm{C}_{9} \mathrm{H}_{7} \mathrm{NO}_{2}$. A substance produced when the ammonium salt of homophthalic acid is heated. It crystallizes in minute needles, melting at $233^{\circ} \mathrm{C}$.

Homophyadic (ho-mo-fi-ad'-ik) [ojós, the same;

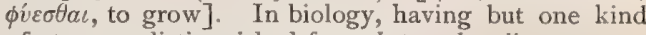
of stem, as distinguished from heterophyadic.

Homophyly (ho-moff'-il-e) [orós, the same; $\phi v \lambda \dot{n}$, race]. In biology, correspondence in genetic relationships.

Homoplasis (ho-mo-pla'-sis) [örós, the same; $\pi \lambda a ́ \sigma \iota s$, formed]. In biology, Lankester's term for structural agreement or modification resulting from the action of identical or nearly similar forces or environments on two or more parts of an organism, or on two organisms, which parts are exactly or nearly alike, or perhaps homogenetic. The same as the "superinduced segmentation" of Spencer.

Homoplasmic (ho-mo-plaz'-nik). Same as Homoplastic.

Homoplasmy (ho'-mo-plaz-me) [o $\mu \delta \varsigma$, the same; $\pi \lambda a \dot{\sigma} \mu a$, a thing moulded]. In biology, homoplastic or homomorphic, $i$. e., showing mimetic resemblances.

Homoplast (ho'-mo-plast) [ojós, the same; $\pi \lambda \alpha \sigma \tau \delta ́$, formed, moulded]. In biology; I. One of any aggregate or fusion of plastids. 2. An organ or part showing mere superficial or mimetic resemblance to another.

Homoplastic (ho-mo-plas'-tik) [ojós, the same; $\pi \lambda a \sigma \tau o ́ s$, formed]. In biology, showing close agreement, dependent upon the common action of evoking causes or moulding environment upon homogeneous parts, or on parts that, for other reasons, offer a likeness of material to begin with. (Lankester.)

Homoplasy (ho'-mo-plaz-e) [ókós, the same; $\pi \lambda a ́ \sigma \iota s$, a forming, moulding]. In biology, agreement in the form, structure, and perhaps function, of organs or parts in the same or separate organisms, dependent upon evoking causes other than genetic affinity.

Homopterous (ho-mop'-ter-us) [óuós, the same; $\pi \tau \varepsilon \rho \sigma o v$, wing, feather]. In biology, applied to insects having wings of the same texture throughout.

Homorgan (hom'-or-gan) [o $\mu o s$, the same; ópyavov, organ]. In biology, an organ resembling another; a homoplast.

Homosexual (ho-mo-seks's-u-al) [juós, same; sexus, sex ]. Pertaining to the same sex.

Homosexuality (ho-mo-seks-u-al'-it-e) [ótós, same; sexualis, of a sex]. That form of sexual perversion, acquired or congenital, in which the individual conceives a violent sexual passion for one of the same sex, and gratifies it either by sodomy, by titillation, or platonically.

Homosporous (ho-mos'-por-us) [ó $\mu \delta \delta s$, similar; $\sigma \pi 6 p o s$, seed]. In biology, producing but one kind of spores; isosporous.

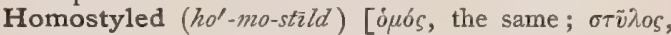
pillar]. See Homogonous.

Homothermic (ho-mo-ther'-mik) [ojos, same; $\theta \varepsilon \rho \mu \eta$, heat]. Having uniformity of temperature or bodily heat.

Homothermous (ho-mo-ther'-mus) [óbs, the same; $\theta \varepsilon \hat{\rho} \mu \eta$, heat]. In biology, applied to animals showing the same degree of bodily heat. 


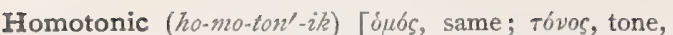
tension]. Having a uniform or even course; applied to diseases.

Homotopia (ho-mo-to'-pe-ah). See Homolopy.

Homotopy (ho-mot'-o-pe) $[\delta \mu \delta s$, the same; $\tau 6 \pi \sigma s$, place]. In biology, the usual or normal mode of acceleration or change of parts during growth, characterized by the exact or modified repetition or multiplication of cells or segments already present; also called repetition. Autonym of Heterotopy.

Homotropal (ho-mot'-ro-pal). Same as Homotropous.

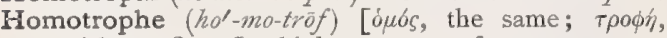
nourishment]. In biology, one of two or more homologous parts or organs the structural correspondences of which are due to corresponding internal, modifying conditions, rather than to external environment. I. Serial Homotrophes, i. e., homotrophic homologues, the correspondence between which is antero-posterior, $e_{0} g$, an extra thumb and an extra great toe on the same side of the body. 2. Vertical Homotrophes, i. e., homotrophic homologues that correspond vertically. 3. Lateral Homotrophes, i. e., homotrophic homologues of the two sides of one individual, e.g., the right and left eyes. 4. Antero-posterior Homotrophes, i. e., homotrophic homologues that correspond antero-posteriorly. (St. Geo. Mivart.)

Homotrophic (homo-trof'-ik) [o $\dot{\delta} \delta s$, the same; $\tau \rho \circ \phi \eta$, nourishment]. In biology, exhibiting homotrophy. Homotrophic Homologues, i. e., parts of an individual, the correspondences between which are regarded as due to internal modifying influences, e.g., the eyes and the ears.

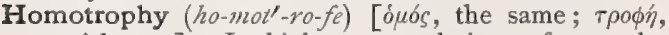
nourishment]. In biology, correlations of growth; homoplasy due to internal conditions rather than external environment.

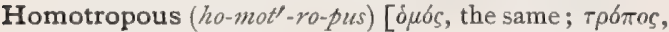
turn]. In botany, said of the embryo when curved the same as the seed containing it.

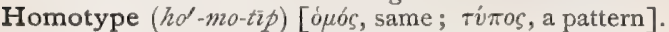
A part corresponding and similar to another part, as the humerus to the femur, a serial homologue, or an antitype.

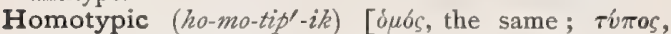
type]. In biology, showing serial correspondence or bilateral symmetry.

Homotypical (ho-mo-tip'-ik-al). Same as Homotypic.

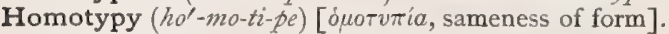
In biology, serial or bilateral homology.

Homunculus (ho-mun'-ku-lus) [L., dim. of homo, man]. The fetus; a dwarf.

Honduras Bark (hon-du'-ras bark). See Cascara amarga.

Honey (hun'-e) [ME, hony, honey]. See Mel. H.berry. See Celtis. H.-comb, the waxy structure formed by bees as a repository for the honey that they produce. H.-comb Glands. See Gland. H.comb Ringworm. See Favus. H.-cyst. See Meliceris. H.-dew, a glutinous liquid exuded by aphides, and frequently to be noticed covering the leaves of the bass-wood, sycamore, oak, maple, plum, apple, box, currant, etc. Its taste is mawkish, its odor unpleasant, and its color often as dark as molasses, especially that found in the oak and sycamore. H.-stone. See Mellitic Acid.

Honorarium (on-or-a'-re-um) [L.]. A professional fee; especially one that is in theory a gift, no formal professional charge having been made.

Hoof (hoof) [ME., hoof, a hoof]. The casing of hard, horny substance that sheathes the ends of the digits or incases the foot in many animals. H.-bound, in far- riery, having a dryness and contraction of the hoof, resulting in pain and lameness. This condition is also called Contracted Heels.

Hook [ME., hok, a hook]. A curved instrument. See Hamus, H., Blunt, an instrument described by its name, for exercising traction upon the fetus in an arrested breech-presentation. H., Tyrrel's, a blunt, slender hook for operations upon the eye.

Hooke's Law. See Lare.

Hooper's Pill. A pill containing aloes, crystallized sulphate of iron, extract of hellebore, myrrh, soap, canella, and ginger.

Hooping-cough (hoop'-ing-kawef). See Pertussis.

Hoose (hooz) [ME, hose, hoarse]. Sheep-cough. A disease of sheep, lambs, etc., due to the presence of Strongylus filaria, a nematode worm, in the lungs and air-passages (see under Parasites, Animal), and characterized by a husky cough, anorexia, dry muzzle, constipation, and dyspnea.

Hoove, Hooven (hoov, hoov'-en) [dial., hooven]. Distention of the stomach of a ruminant animal with gas, caused by the fermentation of food. It is generally due to eating too much green food.

Hop. See Humulus.

Hope's Camphor-mixture. A mixture containing nitric acid, camphor-water, and tincture of opium. It is used in the treatment of serous or choleraic diarrheas. Hopea $\left(h o-p e^{\prime}-a h\right)$ [after John Hope, a Scotch botanist]. A genus of dipterocarpaceous trees of S. Asia. Several species afford resins known in commerce as Dammar. Unof.

Hopein $\left(h \bar{o}-p e^{\prime}-i n\right)$. See Humulus.

Hoppe-Seyler's Method. A method of preparing hemoglobin crystals. Mix defibrinated blood with ten volumes of a 20 per cent. salt-solution, and allow it to stand for two days. Remove the clear upper fluid with a pipet, wash the thick deposit of blood-corpuscles with water, and shake it for a long time with an equal volume of ether, which dissolves the bloodcorpuscles. Remove the ether, filter the lake-colored blood, add to it one-fourth of its volume of cold alcohol $\left(\mathrm{O}^{\circ} \mathrm{C}\right.$.) and allow the mixture to stand in the cold for several days. The crystals can be collected on a filter and pressed between folds of bibulous paper.

Hordeiform (hor-de'-if-orm) [hordeum, barley ; forma, form ]. Shaped like a grain of barley.

Hordein (hor'-de-in) [hordeum, barley]. A mixture of a proteid with starch-cellulose; it exists in barleystarch, but is not soluble.

Hordeolum (hor-de'-o-lum) [hordeum, a grain of barley]. A stye; a furuncular inflammation of the connective tissue of the lids, near a hair-follicle. H., External, H. zeissiantem; one produced by suppuration of one of Zeiss's glands. H., Internal, $H$. meibomianum; one produced by suppuration of one of the Meibomian glands. H. meibomianum. See H., Internal. H. zeissianum. See H., External. Hordeum (hor'-de-um) [L.]. Barley, q. $v$. $\mathbf{H}$. decorticatum, barley deprived of its husk; commonly called pearl barley. H. germinatum, malt. Also, one of several granular elevations described by Spitzka on the floor of the fourth ventricle.

Horehound (hor'-horend). See Marrubium.

Horizon $\left(h o r-i^{\prime}-z o n\right)$ [ópí $\zeta v$, horizon]. I. The line separating the visible from the invisible part of the earth from a single point of view. 2. In craniometry, a line that extends around the skull, touching the lower border of the orbital cavities and passing through the auricular points.

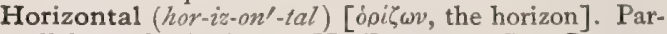
allel to the horizon. H. Posture. See Postures, Table of. 
Horlick's Food. A variety of Liebig's foods for infants. Its composition is: Water, 3.39 ; fat, 0.08 ; grape-sugar, 34.99; cane-sugar, 12.45; no starch; soluble carbohydrates, 87.20 ; albuminoids, 6.71 ; ash, r. 28 .

Hormion (hor'-me-on) [oppí, the first]. See Craniometric Points.

Hormogone, Hormogon (hor'-mo-gön). Same as Hormogonium.

Hormogonium (hor-mo-go'-ne-um) [opuos, a cord, chain; yovos, oftspring: pl., Hormogonia]. In biology, a short, moniliform reproductive body, found in the Nostocs.

Horn [ME., horn, horn]. The hard projection, used as a defensive weapon, growing on the heads of certain animals. Horns may be permanent, as in the ox ; or deciduous, as in the deer. Also, the hardened epithelial substance of which the horn is composed. H., Cutaneous, See Cornu cutaneum. H.-blende, a common mineral, occurring massive or in prismatic crystals, of various colors, from white, through green shades, to black. It is a silicate of lime, magnesia, or iron. It is sometimes used in the manufacture of porcelain teeth for shading the body or enamel. H. distemper, a disease of cattle affecting the core of the horn. H.-pock. See Warty Smallpox. H.-pox, a variety of varicella in which the lesions resemble papules. See also Warty Smallpox.

Horner's Mixture. See Red Mixture. H.'s Muscle. See Muscles, Table of.

Horny (horn'-e) [ME., horn, horn]. Composed of, or resembling, horn. H. Band of Tarinus, a band of white fibers running between the optic thalamus and the corpus striatum. See Band. H. Epithelium. See Trachoma.

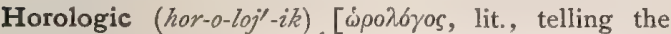
hour]. In biology, applied to such flowers as open or shut at certain hours.

Horological (hor-o-loj'-ik-al). Same as Horologic.

Horopter (hor-op'-ter) ["opos, boundary; ó $\pi \tau \dot{\eta} \rho$, an observer]. The sum of all the points seen singly by the two retinæ while the fixation-point remains stationary. "A circle passing through the center of rotation of each eye and through the apex of the point of fixation of the visual lines." (Mueller.) "A line representing the curve along which both eyes can join in sight.'? (Noyes.)

Horopteric (hor-op-ter'-ik) [ö $\rho \circ \varsigma$, boundary; $\delta \pi \tau \dot{\eta} \rho$, observer]. Pertaining to an horopter.

Horrida cutis (hor'-id-ah ku'-tis) [L.]. Goose-skin. Cutis anserina.

Horripilation (hor-ip-il-a'-shun) [horrere, to stand on end; pilus, the hair]. A sensation as if the hairs of the skin were stiff and erect.

Horripilator (hor-ip-il-a'-tor). Same as Arrector pili.

Horrors (hor'-orz) [horror, a shaking, terror]. A popular name for Delirium tremens, $q . v$.

Horse (hors) [ME., hors, a horse]. A member of the genus Equus; a domestic beast of burden. H.chestnut. See Esculus hippocastanum. H.chestnut bark, the bark of the horse-chestnut (Asculus hippocastanum), said to be used in leather-manufactures for the production of an extract under the simple name of chestnut extract. H.-distemper, influenza. H.-doctor, a farrier; a veterinary surgeon. H.-drench, a dose of physic for a horse. H.-foot. See Talipes equinus. H.-leech, a large leech, the Hæmopis of Southern Europe and Northern Africa; also a horse-doctor. H.-power. See Unit. H.-pox. I. A pustular disease of horses, which, communicated to cows, produces cow-pox. It is also called pustular grease. 2. See Coitus Disease. $H_{\text {.-radish, the fresh }}$ root of Cochlearia armoracia, with properties due to a volatile oil. It is stimulant, diuretic, and externally a rubefacient, and is much used as a condiment. Dose of the fld. ext. $3 \mathrm{j}-\mathrm{ij}$. Armoraciæ, Spt., Comp. (B.P.). Dose 3 j-ij. H.-shoe Fistula, a name applied to a fistulous track surrounding the rectum in a semicircle, either in front or behind. H.-shoe $\mathrm{Hy}$ men. See Hymen. H.-shoe Kidney, the union of the lower ends of the two kidneys, so that they appear to form a single organ of a form somewhat like that of a horse-shoe. H.-sickness. See Anthrax. H.-tail. See Equisetum. H.-weed. See Collinsonia canadensis.

Horsikin (hor'-sik-in) [ME., hors, a horse]. A model used in teaching the anatomy and surgery of the horse.

Horsley's Method. A method of determining the position of the fissure of Rolando. It is carried out by means of an instrument made to encircle the head, and having an arm fixed at an angle of $67^{\circ}$, which indicates the position of the fissure. H.'s Test. See Tests, Table of.

Horst's Eye-water. Collyrium adstringens luteum. An eye-solution prepared as follows: Take of ammonium chlorid, 50 centigrams, and zinc sulphate, 125 centigrams, dissolve in 200 grams of distilled water, and add a solution of 40 centigrams of camphor in 20 grams of dilute alcohol, and 10 centigrams of saffron. Digest for 24 hours with frequent agitation, and filter.

Hospital (hos'-pit-al) [hospitale, a large house]. A building for the care and treatment of sick or infirm people. H. Fever, a feverish condition formerly common in hospitals, due to ill-ventilation and unsanitary conditions. Also, the fever symptomatic of gangrene. Also, a synonym of Typhus Fever. See Fever. H. Gangrene, a contagious, phagedenic gangrene occasionally attacking wounds or open sores. It is confined mainly to military hospitals, and is of microbic origin.

Hospitalism (hos'-pit-al-izm) [hospitale, a large house]. The morbific influence arising from the gathering of diseased persons in a hospital, a condition that seems to have a tendency to produce septic diseases.

Hospitalization (hos-pit-al-iz-a'-shun) [hospitale, a large house]. Confinement in a hospital for treatment.

Hospitalomania (hos-pit-al-o-ma'-ne-ah) [hospitale, a large house; $\mu a v i a$, madness]. A mania for founding or visiting hospitals.

Host (host) [hostis, a stranger, a landlord]. The organic body upon which parasites live.

Hot [ME., hot, hot]. Having or yielding the sensation of heat; stimulating; biting. H.-air Bath. See Bath. H. Bath. See Bath. H.-blanket Pack, a rubber sheet and one or two woolen blankets are placed upon the bed. A heavy woolen blanket is wrung out of water at $\mathbf{I} 10^{\circ} \mathrm{F}$., spread upon the dry blanket, the patient placed upon it and wrapped with it like a mummy. The dry blankets and rubber sheet are wrapped over this, and the patient is allowed to remain in this pack from half an hour to two hours. It is useful in suppression of urine. Hot-box, Japanese, a device for applying dry heat to a part. $\mathbf{H}$. Drops, the Tinctura capsici et myrrha, N. F.; they are useful in many painful conditions of the stomach and bowels, when there is no inflammation or organic disease; it is called also "number six." H. Eye, Hutchinson's term for a persistent hyperemia of the conjunctiva seen in gout. H.-spots. See Temperature-sense. H. Wet-pack, instead of wringing the linen sheet out of cold water, as in the Wet-pack, it 
is dipped into water at $110^{\circ} \mathrm{F}$, well wrung out and spread upon the blanket, as in the cold-pack. The patient is wrapped in this and allowed to remain for an hour. Then he is removed to the side of the bed upon which he is to lie, lightly rubbed over with a rough wash-rag dipped into water at $65^{\circ} \mathrm{F}$, squeezed out by the hand, quickly dried and left alone. This method is useful only in obstinate insomnia. H.-wind Stroke, a form of heat-fever, not unlike sunstroke, but caused by hot winds, and far more fatal than sunstroke; it is common in India.

Hottentot Apron (hot'-n-tot). See Velamen vulve. H. Deformity. See Sieatopygia.

Hottentotism (hot'-n-tot-ism). An extreme form of stammering, sometimes congenital, and often due to or associated with deformity of the vocal organs.

Hough (huf) [AS., hol, the hough]. The lower part of the thigh.

Hound's Tongue (hoiondz tung). The leaves and root of Cynoglossum officinale, an anodyne, demulcent,

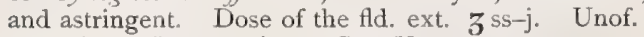

Hour-glass Contraction. See Uterus.

House (hows) [ME., hous, a house]. In biology, a cuticular secretion, representing the cellulose coat of higher ascidians, in which the lowest Tunicata, as represented by Appendicularia, shelter themselves. H.maid's Knee. See Abscess, Bursal. H.-physician, the resident physician in a hospital. H.-refuse, the ashes, dust, food-scraps, both animal and vegetable, waste-paper, and other waste material from a household, and which does not enter the drains. H.-surgeon, the resident surgeon in a hospital.

Houston's Folds, or Valves. Three folds of mucous membrane within the rectum. They are directed obliquely. H.'s Muscle. See Muscles, Table of.

Hove, Hoven (hòv, ho'-ven). See Hoove and Blozen.

Hovius, Canals of. See Canal. H., Plexus of. See Plexuses, Table of.

Howard's Method. See Artificial Respiration.

H swship's Lacunæ, or Pits. Certain deep or shallow depressions, sometimes simple, and at times quite complex, occurring in bones undergoing absorption, at the edges of the bone bordering on vascular surfaces, and seen on making a microscopic examination. These lacunæ are usually filled or lined by larger and smaller granular, frequently multinuclear cells--the socalled osteoclasts.

Hoyer's Alcoholic Carmin. See Stains, Table of. H.'s Carmin. See Stains, Table of. H.'s Solution. See Stains, Table of.

Huanokin (whah'-no-kin) [from Huanuco, a placename]. An alkaloid from Cinchona nitida, said to be strongly febrifugal. Unof.

Hubbell's Wheat Food. A variety of farinaceous food for infants, with the following composition: Water, 7.78 ; fat, $0.4 \mathrm{I}$; grape-sugar, 7.56 ; cane-sugar, 4.87 ; starch, 67.60; soluble carbohydrates, I4.29; albuminoids, 10.13; ash, I.o; gum, cellulose, etc., undecermined.

Huchard's Diet. See Treatment, Methods of.

Huckle-bone (huk'-l-bön) [ME., huccle-bone, the astragalus]. The Astragalus, q.v.

Hudson's Apparatus. An apparatus to support the fingers and hands in the treatment of wrist-drop.

Hueter's Bandage. See Bandage: H.'s Method, a method of inducing premature labor. It consists in applying a bladder filled with water or decoction of ergot to the neck of the womb.

Hüner's Method. A method of obtaining glycocholic acid. A little $\mathrm{HCl}$ is added to fresh bile, the mixture shaken, and the mucinoid material so precipitated is filtered off. Ethyl ether and $\mathrm{HCl}$ are added to the filtrate ; the proportions of the filtrate, acid, and ether are respectively $\mathbf{1 0 0}, 5$, and 30 . The mixture is shaken and allowed to remain some hours, when crystals form, which are then collected on a filter, washed with water holding $\mathrm{HCl}$ and ether in solution, and dried in the air. By recrystallization the crystals are obtained perfectly colorless.

Hufeland's Cerate. A preparation used in treating sore nipples. It consists of zinc oxid and lycopodium each 2 parts, simple cerate 30 parts.

Hughes Bennett's Diuretic. A diuretic mixture employed in chronic nephritis, composed of pulverized potassium acetate, 2 drams; sweet spirit of niter, half an ounce; water sufficient to make two ounces; one dram of this is given three times daily.

Huguier's Canal. See Canal. H.'s Disease. See Diseases, Table of. H.'s Glands, two small glands opening into the vagina.

Huingan (whin'-gan) [S. Amer.]. The seed of a plant (Duvarra dependens) native to the Andes. The infusion is used in urinary affections. Unof.

Human (hu'-man) [humanus, human]. Pertaining to or characteristic of man. H. Dolphin, a monster with complete union of the lower limbs. H. Milk, mother's milk. It derives its origin from an overgrowth of epithelial cells lining the lactiferous ducts, with infiltration with fat, and subsequent rupture. Its specific gravity is IO24-35, its reaction alkaline. Each minute fat-globule is surrounded by a pellicle of serum-albumin. The chemical composition of human milk is as follows :-

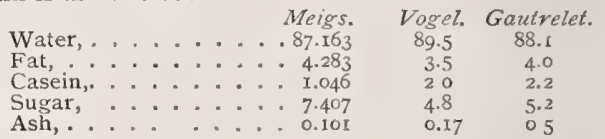

Humation (hu-ma'-shun) [humare, to inter]. Interment; inhumation.

Humboldt Blue. Same as Spirit-blue.

Hume's Test. See Tests, Table of.

Humectant (hu-mek'-tant) [humectare, to make moist]. I. Moistening; like a poultice; diluent. 2. A diluent; a substance used to moisten.

Humeral (hu'-mer-al) [humerus, the shoulder]. Pertaining to the humerus.

Humeren (hu'-mer-en) [humerus, the shoulder]. Belonging to the humerus in itself.

Humero- (hu'-mer-o-) [humerus, the shoulder]. A prefix signifying relationship with the shoulder. H.cubital, relating to the humerus and the ulna. H.-c. Amputation, amputation at the elbow-joint. H.radial, relating to the humerus and the radius. H.scapular, relating to the humerus and the scapula. H.-s. Amputation, amputation at the shoulder-joint. H.-ulnar, relating to the humerus and the ulna. H.-u. Amputation, amputation at the elbow-joint.

Humerus (hu'-mer-us) [L.]. The bone of the upper arm. Also, the shoulder.

Humid (hu'-mid) [humidus, moist]. Moist; damp. H. Tetter. See Eczema.

Humidity (hu-mid'-it-e) [humor, moisture]. The state or quality of being moist. H., Absolute, the actual amount of water present in the air at any moment, regardless of saturation. $H$., Relative, the relative amount of water present in air which is not saturated, as compared to what the air should contain at the existing temperature were its condition that of saturation.

Humifuse ( $h u^{\prime}$-mif-uss) [humus, the ground; fundere, to pour]. In biology, spread over the surface of the ground.

Humming-top Murmur or Sound. See Bruit de diable. 
Humor ( $h u^{\prime}$-mor or $u^{\prime}$-mor) [L.]. Any fluid or semifluid part of the body. H., Aqueous, the transparent fluid that fills the anterior chamber of the eye. H., Crystalline. See Lens, Crystalline. H., Vitreous, the transparent gelatin-like substance filling the posterior chamber of the eye.

Humoral (hu'-mor-al) [humor, moisture]. Pertaining to the natural fluids of the body. H. Pathology, an obsolete theory that all diseases result from a disordered or abnormal condition of the fluids or humors of the body

Humoralism ( $h u^{\prime}-$ mor-al-izm), or Humorism ( $h u^{\prime}$ mor-izm). Same as Humoral Pathology.

Humoralist (hu'-mor-al-ist) [humor, moisture]. The name given to one who was an advocate of the supreme importance of the blood in the processes of health and disease.

Humoro-vitalism ( $h u^{\prime}-m o-r o-v i^{\prime}$-tal-izm) [humor, moisture; vita, life]. The obsolete belief that the fluids of the body are the seat of life.

Humpback (hump $p^{\prime}-b a k$ ). See Kyphosis.

Humulin (hu'-mu-lin) [humulus, hop]. I. The same as Lupulin. 2. A concentrated preparation from the tincture and decoction of hops. Unof

Humulus ( $\left.h u^{\prime}-m u-l u s\right)$ [L. : gen., Humuli]. Hop. The strobiles of $H$. lupulus. It contains various principles, hopein and lupulin being the most important. It is a bitter stomachic tonic and feeble hypnotic, increasing the cardiac action. A poultice of hops is a favorite remedy for painful conditions and in inflammations. H., In-

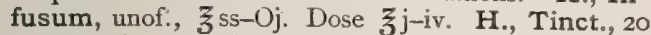
per cent. in strength. Dose $3 j-\mathrm{ij}$. Lupulinum, the glandular powder. Dose gr, $v-x v$. L., Ext. (B.P.) Dose gr. $v-x$. L., Fld. Ext., alcoholic. Dose $m x-$ 3j. L., Oleoresina, ethereal. Dose gr. ij-v. L., Tinct., unof., strength $121 / 2$ per cent. Dose 3 ss-ij.

Humus (hu'-mus) [L., the earth, ground, soil]. Vegetable mold. It contains ulmin and ulmic acid, humin and humic acid. H. Pigments, certain pigmentary bodies of a more or less dark-brown color, produced when carbohydrates are treated with acids or alkalies. When urine is treated with acids in the presence of oxygen, it becomes darker from the formation of some of these humus-pigmented substances by the action of the acids on the carbohydrates.

Hunchback (hunch'-bak). See Kyphosis.

Hungarian (hung-ga'-re-an) [Hungaria, Hungary]. Pertaining to Hungary. H. Balsam, or H. Turpentine, a thin turpentine from the branches of Pinus pumilio. H. Disease. Synonym of Typhus Fever.

Hungary Blue. Same as Cobalt-blue.

Hunger (hung'-ger) [ME, hunger, hunger]. A condition marked by a sensation of emptiness of the stomach, with intense desire for food. H.-cure. See Nestiatria. H.-pest. Synonym of Relapsing Fever, q.v. H.-typhus. Synonym of Relapsing Fever, q. v.

Hunter, Canal of. See Canal. H.'s Line. See Lines, Table of. H.'s Method, a method of treating aneurysm by ligating the artery on the proximal side of the sac.

Hunterian Chancre. See Chancre.

Huntingdon's Chorea. Hereditary Chorea. An affection characterized by irregular movements, disturbance of speech, and gradual dementia. It is frequently hereditary, is associated with psychic troubles, and occurs between the thirtieth and fortieth years. The disease has no connection with Sydenham's Chorea. See Chorea, Hereditary, and Diseases, Table of.

Huntsman's Cup. See Trumpet Plant.

Hunyadi Janos (hun-yah'-de) [from the name of the Hungarian national hero, otherwise called John Cor37 vinus]. An aperient mineral water from Buda-Pesth, in Hungary. It is an effective laxative or cathartic. It should be taken in the quantity of from a half to one wineglassful, fasting.

Hura $\left(h u^{\prime}-r a h\right)$ [S. Amer.]. A genus of poisonous euphorbiaceous trees of tropical America. H. brasiliensis, $H$. crepitans, and $\mathbf{H}$. strepens, are the best-known species. They have the general acrid, pustulant, and cathartic properties of nearly all euphorbiaceous plants. Unof.

Huschke, Auditory Teeth of. Nipple-like projections along the free border of the labium vestibulare of the ear. H., Canal of. See Canal. H., Foramen of. See Foramen. H., Valve of, the fold of mucous membrane at the point where the common canal formed by the junction of the canaliculi enters the lachrymal sac.

Husky (hus'-ke) [E. dial., hasky, rough, dry]. Harsh, rough, as the voice.

Hutchinson's Lotion. A lotion used in the treatment of eczema. It has the following composition: Liquor plumbi subacetatis, $1 / 2$ ounce; liquor carbonis detergentis, $2 \frac{1}{2}$ ounces. Of this one teaspoonful is mixed with a pint of water, and used as a lotion. H.'s Patch. See Signs and Symptoms, Table of. H.'s Teeth, a notched or furrowed condition of the free edges of the permanent teeth, especially the central incisors of the upper jaw, due to inherited syphilis. See Signs and Symptoms, Table of. H.'s Treatment. See Treatment, Method's of. H.'s Trio of Symptoms. See Signs and Symptoms, Table of.

Huttoning (hut'-on-ing) [after Hutton, the inventor]. A method of manipulating a luxated joint, introduced by one Hutton, a bone-setter.

Huxham's Tincture. See Cinchona.

Huxley's Angle. See Angle. H.'s Layer, Membrane, or Sheath, a layer of nucleated, elongated, polygonal cells lying within Henle's layer of the inner root-sheath of hairs. H. Law. See Law.

Huygenian Ocular ( $\left.h i-j e^{\prime}-n e-a n\right)$. See Ocular.

Huygens, Theory of. The undulatory theory of light.

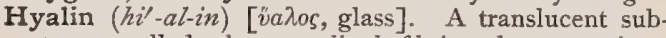
stance, called also canalized fibrin, that sometimes occurs in miliary tubercle. Also, the membrane or sac forming the walls of hydatid cysts. Also, a substance found in echinoderms and other invertebrates. Its centesimal formula is, $\mathrm{C}=45.3$ to $44 . \mathrm{I} ; \mathrm{H}=6.5$ to $6.7 ; \mathrm{N}=5.2$ to $4.5 ; \mathrm{O}=43$ to 44.7 .

Hyaline $\left(h i^{\prime}-a l-i n\right)$ [valos, glass]. Resembling glass in transparency. H. Cartilage. See Cartilage. H. Cast, or Cylinder, a clear, nearly transparent urinary tube-cast. H. Degeneration, a degeneration of fibrous tissue, which becomes transparent, jelly-like, and homogeneous in structure.

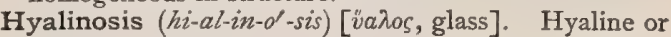
waxy degeneration.

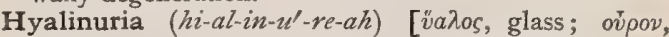
urine]. The presence of hyalin in the urine.

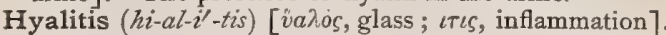
Inflammation of the hyaloid membrane. It is also used as a synonym of inflammation of the vitreous humor.

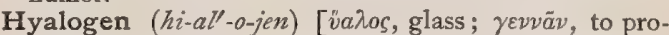
duce]. One of the albuminoids found in cartilage; it is readily changed into hyalin, whence the name.

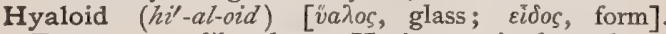
Transparent; like glass. H. Artery, in the embryo, a branch of the arteria centralis retinæ, traversing the vitreous humor to the posterior capsule of the lens. Its hyaloid sheath forms the Canal of Cloquet. Persistence of this artery after birth has been observed. H. Membrane, a delicate, transparent membrane 
surrounding the vitreous humor, except in front, where it becomes fibrous and strong and forms a leaflet of the zonula of Zinn.

Hyaloiditis (hi-al-oid-i'tis). See Hyalitis.

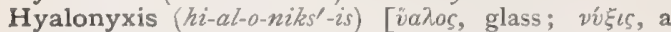
pricking]. Puncture of the vitreous body of the eye.

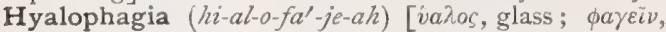
to eat]. The practice of eating glass, sometimes seen among insane persons.

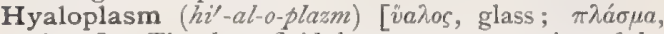
plasm]. The clear, fluid, homogeneous portion of the protoplasm surrounding the spongioplasm of a living cell. The term is also used as a general synonym of protoplasm.

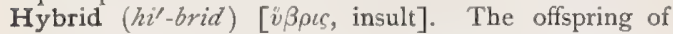
two individuals of distinct but closely related species. Among animals, the mule is the best known hybrid. H. Measles. Synonym of Rötheln, q. v.

Hybridism, or Hybridity (hi'-brid-izm, hi-brid'-it-e) [v $\beta \rho \iota s$, insult]. Cross-breeding; mixture of races; the combination of various diseases.

Hybridization ( $h i-b r i d-i z-a^{\prime}-\operatorname{shun}$ ) [hybrid, a mongrel ; $\hat{v} \beta \rho \iota s$, insult ]. Cross-breeding.

Hydantoic Acid (hi-dan-to'-ik). See Acid, Glycoluric

Hydantoin ( $h i$-dan-to'-in), $\mathrm{C}_{3} \mathrm{H}_{4} \mathrm{~N}_{2} \mathrm{O}_{2}$. Glycolyl urea. A substance that crystallizes from hot water and from alcohol in needles that melt at $206^{\circ} \mathrm{C}$, , and have a neutral reaction and sweet taste.

Hydarthrosis (hi-dar-thro'-sis). See Hydrarthrosis.

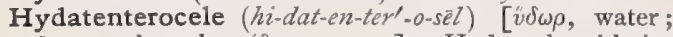
$\varepsilon \dot{v} \tau \varepsilon \rho \circ \nu$, bowel ; $\kappa \eta \lambda \eta$, a tumor]. Hydrocele with intestinal hernia.

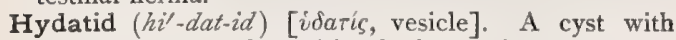
aqueous contents formed by the larva of a tenia, Echinococcus polymorphus, the larva of a small tapeworm, Tenia echinococcus, which, in its adult (strobila) condition is only known to infest the dog and the wolf, while the larvæ (hydatids) are of frequent occurrence in man and other mammals. Three principal forms of hydatids are recognized, viz, exogenous, endogenous, and multilocular. The first is sparingly found in man, but is extremely common in the lower animals, whilst the second is most frequently developed in the human subject, the third kind being found only in man. (Cobbold.) See Parasites (Animal), Table of. The term hydatid is frequently, also, loosely applied to vesicular tumors and cysts of many kinds. Hydatids are most frequent in the liver, but are found in almost any tissue, even in bone. H. Disease, a disease characterized by the presence in various portions of the body of cysts containing the embryo of the Tania echinococcus. The symptoms vary according to the location of the tumor. H. Fremitus, a modified sense of fluctuation occasionally obtained on palpating an hydatid cyst. Placing the palm of one hand upon the tumor, and striking the dorsum with the fingers of the other hand, a tremor or thrill is perceived. This is doubtless due to the physical conditions of a cyst containing fluid, and provided with a tense elastic wall. H. Mole. See Chorion, Cystic Degeneration of, and Mole. H. of Morgagni, one of certain short processes of the tunica vaginalis testis; also a similar structure connected with the fimbriated extremity of the Fallopian tube. These hydatids are the remnants of the Müllerian duct. H. Tapeworm. See Tania echinococcus.

Hydatidiform (hi-dat-idl-if-orm) [vidatis, hydatid; forma, form ]. Having the form of an hydatid. Resembling an hydatid. H. Degeneration of the Chorion, or Vesicular Mole. See Mole and Chorion, Cysicic Degeneration of.

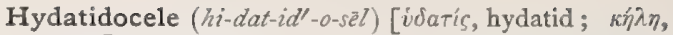
tumor]. Oscheocele with hydatid cysts.

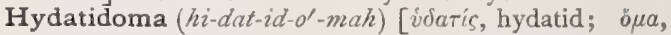
a tumor]. Any hydatid cyst or tumor.

Hydatidosis (hi-dat-id-o'-sis) [idaris, hydatid]. The condition of being affected with hydatids.

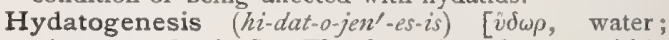

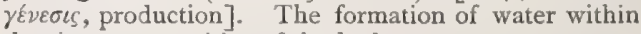
the tissues or cavities of the body.

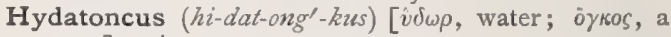
tumor]. Any cyst, or watery tumor.

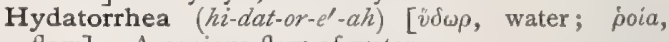
flow]. A copious flow of water.

Hydatotherapy (hi-dat-o-ther'-ap-e). See Hydrotherapy.

Hyderabad Commission. See Anesthetic.

Hydnocarpus (hid-no-kar'-pus) [vivov, mushroom; $\kappa a \rho \pi$ ós, fruit]. A genus of poisonous bixaceous tropical trees. H. (or Gynocardia) anthelminthicus, is anthelmintic and useful in skin-diseases. $\mathbf{H}$. inebrians and $\mathbf{H}$. wightianus have similar uses. Unof.

Hydracetin (hi-dras'-et-in) [ $v \delta \rho a$, a water-serpent], $\mathrm{C}_{6} \mathrm{H}_{5} \mathrm{~N}_{2} \mathrm{H}_{2}\left(\mathrm{C}_{2} \mathrm{H}_{3} \mathrm{O}\right)$. A derivative of coal-tar and a powerful antipyretic and antirheumatic; its use, however, is attended with danger. Dose gr. $\pi / 2$ to $\mathrm{ij}$. An ointment (ro per cent.) is recommended in psoriasis. Unof.

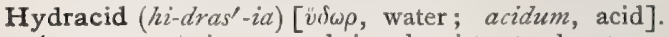
A term sometimes used in chemistry to denote an acid formed by a combination of hydrogen and some acid element or radicle other than oxygen. Hydrochloric acid, $\mathrm{HCl}$, and hydrogen or hydric sulphid, $\mathrm{H}_{2} \mathrm{~S}$, are examples.

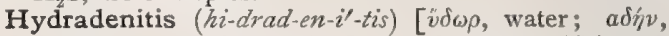
gland; $\iota t \iota s$, inflammation]. I. Same as Hidrosadenitis. 2. Lymphadenitis. H. destruens suppurativa. See Hydrosadenitis phlegmonosa.

Hydradenoma (hi-drad-en-o'-ma). Same as Hidradenoma.

Hydræmia (hi-dre'-me-ah). See Hydremia.

Hydraëropericardium (hi-drah-e-ro-per-ik-ar'-de-um)

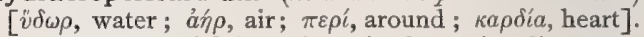
The presence of fluid and gas in the pericardium.

Hydraëropleuria ( $\left.h i-d r a h-e-r o-p l u^{\prime}-r e-a h\right)[v \delta \omega \rho$, water; $\dot{a} \eta \hat{\rho}$, air ; $\pi \lambda \varepsilon v \rho a ́$, side]. Same as Hydropneumothorax.

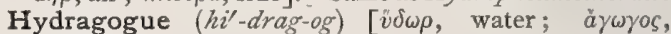
leading]. I. Expelling water. 2. A purgative that causes copious liquil alvine discharges.

Hydramin (hi'-dram-in) [visp, water; amin]. Any one of the oxyethyl bases produced by the action of aqueous ammonia upon ethylene oxid. The hydramins are thick, strongly alkaline liquids, that decompose upon distillation.

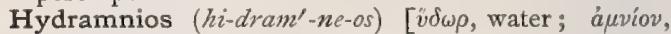
fetal membrane]. An abnormal amount of amniotic fluid.

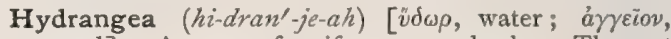
vessel]. A genus of saxifragaceous shrubs. The root of $\mathbf{H}$. arborescensis, much used by the Cherokee Indians for calculi in the bladder, is said to be of some utility. Dose of the liquid extract $3 \mathrm{ss}-\mathrm{ij}$; of a decoction $\zeta_{j}$-ij. Unof.

Hydrangeion (hi-dran'-je-on) [ij $\omega \rho$, water, lymph ; aryeiov, vessel: pl., Hydrangeia]. A lymphatic vessel.

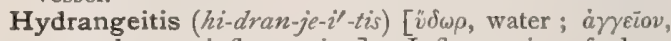
a vessel; $\iota \tau \iota$, inflammation]. Inflammation of a lymphatic vessel; lymphangitis.

Hydrangiology (hi-dran-je-ol'-o-je) [v $\delta \omega \rho$, water; $a \gamma$ -

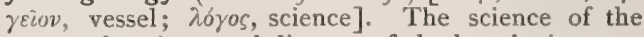
nature, functions, and diseases of the lymphatics. 


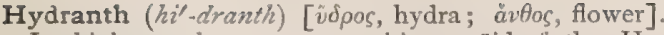
In biology, the proper nutritive zooid of the $\mathrm{Hy}$ drozoa.

Hydrargism (hi-drar'-gizm). See Mercurialism.

Hydrargyria (hi-drar-jir'-e-ah). See Mercurialism.

Hydrargyriasis (hi-drar-jir-i'-as-is). See Mercurialism.

Hydrargyrism (hi-drar'-jir-izm). See Mercurialism.

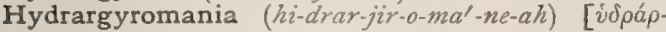
yvoos, mercury; $\mu a v i a$, madness]. Insanity due to the unwise use of mercury.

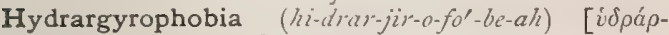
rvoos, mercury; $\varphi 6 \beta 0 s$, fear]. Morbid dread of mercurial medicines.

Hydrargyrophthalmia (hi-drar-jir-off-thal'-me-ah)

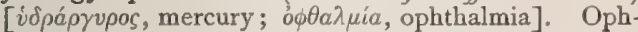
thalmia due to mercurial poisoning.

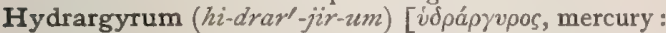
gen., Hydrargyri]. Mercury. Quicksilver. $\mathrm{Hg}=$ 200 ; quantivalence II, IV. The only liquid metallic element, hence the common name, quicksilver. See Elements, Table of. In medicine, the metal, its nitrate, oxids, chlorids, and iodids are the salts most commonly, the sulphid and cyanid less frequently, used. In small doses continued not too long a time it is a tonic, purgative, and alterative. In larger doses, or too long continued, it is likely to produce pytalism. In "biliousness," mercurial purgatives have long been a favorite remedy, blue-mass, and mercurous chlorid or calomel being usually employed. In syphilis, mercuric chlorid and mercuric iodid are generally considered specific. Mercury in the form of calomel is useful in glandular inflammations. Formerly it was much used in the same form in typhoid fever and malarial fevers. The soluble salts of mercury are highly poisonous. $H$. ammoniatum, ammoniated mercury, "white precipitate," mercurammonium chlorid, $\mathrm{NH}_{2} \mathrm{HgCl}$, is used externally. H. ammoniati, Ung., "white precipitate ointment" -ammoniated mercury 10, benzoated lard 90 parts. H. benzoas, $\mathrm{Hg}\left(\mathrm{C}_{6} \mathrm{H}_{5} \mathrm{CO}_{2}\right)_{2}$. Dose, in pill, gr. $\frac{1}{10}$. H. carbolas, easily absorbed. Dose, in pill, gr. $\frac{1}{8}-\frac{1}{2}$. H. chloridum corrosivum, $\mathrm{HgCl}_{2}$ (H. perchloridum, B. P.), corrosive chlorid of mercury, mercuric chlorid, " bichlorid of mercury," "corrosive sublimate." Soluble in water and alcohol; antisyphilitic. Dose gr. $\frac{1}{80} \frac{1}{10}$. Very poisonous. Liq. hydrarg. perchlorid. (B. P.), contains gr. ss of the mercurial salt to the ounce. Dose $3^{\mathrm{ss}-\mathrm{ij}}$. $\mathbf{H}$. chloridum mite, $\mathrm{Hg}_{2} \mathrm{Cl}_{2}$ ( $\mathrm{H}$. subchloridum, $\mathrm{B}$. P.), mild chlorid or subchlorid of mercury, mercurous chlorid, "calomel," -laxative, tonic, and antipyretic. Insoluble in water and alcohol. Dose gr. $\frac{1}{20}-\mathrm{x}$. H. subchlor., Ung. (B. P.), I to $6 \frac{1}{2}$ of benzoated lard. H. cum ammonia, Emplastrum. See $A m$ monium. H. cum creta, mercury with chalk, "chalk-mixture," "gray powder," contains mercury 38 , clarified honey, 10, prepared chalk 57, water q. s. Dose gr. ss- $\mathrm{x}$. H. cyanidum, $\mathrm{Hg}(\mathrm{CN})_{2}$, mercuric cyanid. Soluble in water and alcohol. It is recommended, with aconite, in diphtheria. Dose gr. $\frac{1}{100}-\frac{1}{10}$. Poisonous. H., Emplastrum, mercurial plaster-mercury 30 , oleate of mercury 1.2, leadplaster q. s. H. et arsenii iod., Liq., Donovan's Solution. See Arsenic. H. flav., Lotio, unof, "yellow wash" for syphilitic sores-corrosive sublimate gr. xviij, lime-water 3 x. Gilbert's Syrup, unof., hydrarg. biniodid. gr. iij, potass. iodid. gr. cij, water $3 \mathrm{iij}$, syrup q. s. ad $3 \mathrm{x}$. H. iodid. flavum, $\mathrm{Hg}_{2} \mathrm{I}_{2}$, green iodid of mercury, mercurous iodid. Dose gr. $\frac{1}{10}-\frac{1}{3}$. H. iodid. rubrum, $\mathrm{HgI}_{2}$, red iodid or biniodid of mercury, mercuric iodid. Soluble in a solution of potassium iodid. Poisonous. Dose gr. $\pi-1.4$. iodid. rub. Ung. (B. P.), one in 28. H., Liniment (B. P.), contains one part of mercury in six. H., Massa, "blue mass," "blue pill," has mercury 33 , liquorice 5 , althea 25 , glycerin 3 , confection of rose 34 . It is used mainly as a purgative. Dose gr. ss-xx. H. nigra, Lotio, unof., "black wash" for syphilitic sorescalomel gr. xxx, lime-water $z_{\mathrm{x}}$. H. nitrat., Liq., solution of mercuric nitrate. It is used as an escharotic. H. nitrat. rub., Ung., unof, red ointment of mercuric nitrate, brown citrine ointment ; it is made with cod-liver oil. H. nitrat., Ung., citrine ointment, mercury 7, nitric acid $I 7$, lard-oil $76 . H$. nitrat., Ung., Dil. (B. P.), citrine ointment and soft paraffin, $I$ in 2. $H$. oleat., contains yellow oxid 20 , oleic acid 8o. H. oxid. flav., yellow oxid of mercury. Insoluble in water; soluble in nitric and hydrochloric acids. It is used in the preparation of ointments, etc. H. oxid. flav., Ung., contains ro per cent. of the oxid. H. oxid. rub., red oxid of mercury. Dose gr. $\frac{1}{50}$ 가. H. oxid. rub., Ung., contains Io per cent. of the oxid. H. salicylas, $\mathrm{HgC}_{6} \mathrm{H}_{4} \mathrm{OCOO}$. Dose gr. $\frac{1}{3}$, in pill. $\mathrm{H}$. subsulph. flav., $\mathrm{Hg}(\mathrm{HgO})_{2} \mathrm{SO}_{4}$, yellow subsulphate of mercury, basic mercuric sul. phate, "turpeth mineral." Soluble in nitro-hydrochloric acid. Dose, for emesis, gr, ij-v, H. succinimidum has been recommended for hypodermatic use. H. sulph. rub., red mercuric sulphate, "cinnabar," is used only by fumigation. H., Suppositoria (B. P.), each contains gr. v of mercurial ointment. H. tannas, a green powder, rapidly absorbed. Dose gr. j, in pill. H., Unguent., mercurial ointment, "blue ointment,"-mercury 450 , lard 225, suet 225, comp. tinct. benzoin 40, old mercurial ointment IOO; these are triturated until the globules of mercury disappear under a magnifying glass. It is used to produce the physiologic effects of mercury by inunction.

Hydrarthrosis (hi-drar-thro'-sis) $[v \delta \omega \rho$, water; ă $\rho \theta \rho o v$, joint]. An effusion of fluid into a joint, usually the result of chronic synovitis. It is called also Hydrops articuli, dropsy of the joint, white swelling, etc.

Hydrarthrus (hi-drar'-thrus). See Hydrarthrosis.

Hydrastin (hi-dras'-tin) [ $\hat{v} \delta \omega \rho$, water ; $\delta \rho \bar{a} \nu$, to act], $\mathrm{C}_{22} \mathrm{H}_{23} \mathrm{NO}_{6}$. I. An alkaloid occurring together with berberin $\left(\mathrm{C}_{20} \mathrm{H}_{17} \mathrm{NO}_{4}+4 \frac{1}{2} \mathrm{H}_{2} \mathrm{O}\right)$ in the roots of $H_{y}$ drastis canadensis $(q . v$.) ; I $1-4$ grains may be given per diem, in divided doses. In overdoses it may have poisonous effects. 2. A precipitate from a tincture of the root of Hydrastis canadensis; it is laxative, cholagogue, alterative, tonic, antiseptic, etc. Dose gr. jij. Unof.

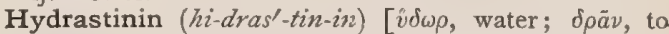
act], $\mathrm{C}_{11} \mathrm{H}_{13} \mathrm{NO}_{3}$. An alkaloid obtained by the oxidation of hydrastin. It is useful in chronic metritis and in salpingitis, controls hemorrhage, and is a good substitute for ergot. It stimulates the cardiac muscle and causes contraction of the lumen of arteries. Dose of the hydrochlorate gr. ij-iv, hypodermatically.

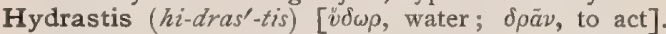
Golden seal. The roots of $H$. canadensis, with properties due to several alkaloids, the principal being hydrastin, $q . v$. It is a simple, bitter tonic, with antiperiodic properties, and arrests the movements of white blood-corpuscles. It is useful in catarrh of the stomach and urinary organs, and as a lotion in gonorrhea and gleet. Dose of the fld, ext., $m_{v-x x x}$; of the tinct. (20 per cent.) 3 ss-ij. H., Ext., Liquid. (B. P.) Dose $\eta_{v-x x x}$. H., Glyceritum, hydrastis Io, glycerin 5, alcohol and water, q. s. H., Tinct., 20 per cent. strength. Dose $m \times x-3 j$. Unof. 
Hydrate $\left(h i^{\prime}-d r \tilde{a} t\right)[v \delta \omega \rho$, water]. A compound of an elementary atom, or of a radical, with the radical hydroxyl $\mathrm{H}-\mathrm{O}-$ or $-\mathrm{O}-\mathrm{H}$, as the hydrogen atom may be positive or negative. Practically a hydrate is con sidered as a molecule of water with its basic atom of hydrogen replaced by another electropositive atom, e.g., potassium hydrate, $\mathrm{K}-\mathrm{O}-\mathrm{H}$, is derived from water, $\mathrm{H}-\mathrm{O}-\mathrm{H}$

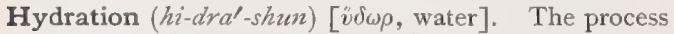
by which a body or substance becomes impregnated or saturated with water.

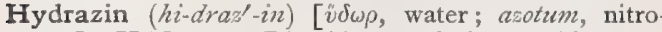
gen $], \mathrm{H}_{4} \mathrm{~N}_{2}$. I. Diamid; a colorless, stable gas, soluble in water, having a peculiar odor and a strong alkaline reaction. Orthin is prepared from it. See Phenyl-hydrazin. 2. One of a class of bodies derived from hydrazin by replacing one or more of its hydrogen atoms by a compound radical.

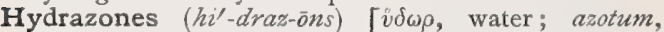
nitrogen]. Phenylhydrazones; a group of chemic bodies produced by the action of phenylhydrazin upon carbonyl compounds. They are usually crystalline compounds, insoluble in water. They are yellow or brown in color, and almost invariably decompose upon fusion.

Hydrecium ( $h i-d r e^{\prime}-s e-u m$ ) [ $v \delta \omega \rho$, water ; oikos, house : $p l$., Hydrecia]. In biology, the sac for the reception of the retracted cenosarc attached to the swimmingbell of certain hydrozoans.

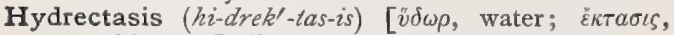
a stretching out]. Distention by water or by a watery fluid.

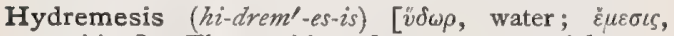
vomiting]. The vomiting of a watery material.

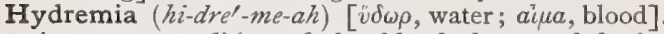
A watery condition of the blood due to defective renal secretion or to imperfect fibrination. It accompanies albuminuria and certain other exhausting diseases.

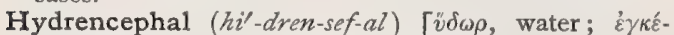
$\phi a \lambda o s$, brain]. A hydrocephalic brain.

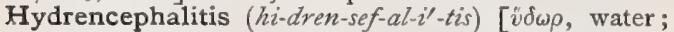
$\dot{\varepsilon} \gamma \kappa \varepsilon \dot{\varepsilon} \phi a \lambda \circ \varsigma$, brain; $\iota \tau \iota \varsigma$, inflammation]. Inflammatory hydrocephalus.

Hydrencephalocele (hi-dren-sef'-al-o-sèl) [ $\tilde{\delta} \delta \omega \rho$, wa-

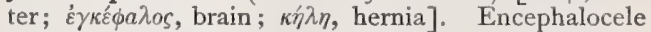
in which the tumor is in part composed of a watery fluid. H. palatina, a variety of hydrencephalocele in which the dura mater, distended with serum, projects into the mouth, forming a tumor possibly as large as a small apple.

Hydrencephalus (hi-dren-sef'-al-us). See Hydrocephalus.

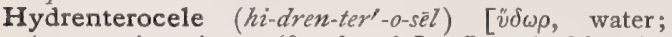
$\varepsilon v \tau \varepsilon \rho \circ \nu$, intestine; $\kappa \dot{\eta} \lambda \eta$, hernia]. Intestinal hernia, the sac of which contains some extravasated fluid.

Hydrenterorrhea (hi-dren-ter-or-e'-ah) [vi $\delta \rho$, water; $\varepsilon \nu \tau \varepsilon \rho \circ \nu$, intestine; $\rho \circ i a$, flow]. A watery diarrhea.

Hydriasis ( $h i$-dri'-as-is). See Hydro-therapeutics.

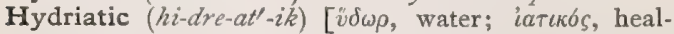
ing]. Pertaining to the cure of disease with water.

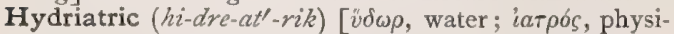
cian]. Relating to the treatment of disease with water.

Hydriatry (hi'-dre-at-re). See Hydro-therapeutics.

Hydric ( $\left.h i^{\prime}-d r i k\right)$ [v $\delta \omega \rho$, water]. Containing water.

Hydrid $\left(h i^{\prime}-d r i d\right)$ [ $v \delta \omega \rho$, water]. A chemic compound containing hydrogen united to an element.

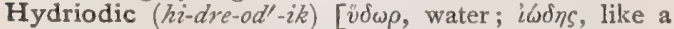
violet]. Containing hydrogen and iodin. H. Acid, HI, a heavy, colorless gas, with a suffocating odor and an acid reaction. It freezes at $-55^{\circ} \mathrm{C}$. The syrup of hydriodic acid contains I per cent. of absolute HI. Dose, 3 j-iv, well diluted.

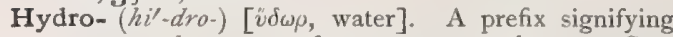
water, or that water forms a structural part. See, also, Hydrate

Hydroa $\left(h i-d r o^{\prime}-a h\right)$ [ $v \delta \omega \rho$, water; $\omega 6 \nu$, egg]. A term including a group of vesicular and bullous skinaffections presenting many points of affinity with vesicating erythemata, herpes, and pemphigus. The group includes the diseases described as Dermatitis herpetiformis, Pemphigus pruriginosus, Urticaria vesicans, and Herpes gestationis, and is by no means uncommon. Hydroa occurs in individuals of the neurotic temperament ; its course is chronic, but with a decided tendency toward ultimate recovery. (Hydroa, as the name of a skin-disease, is much confused in meaning with Hidroa, q. v.) $\mathbf{H}$. bullosa. See $H$. pruriginosum. $\mathbf{H}$. zstivale. See $H$. vacciniforme. $H$. febrile. See Herpes facialis. H. gestationis, that of pregnancy. H. herpetiforme. Also called Dermatitis herpetiformis; Herpes gestationis; Herpes circinatus bullosus; Pempligus circinatus. See Pemphigus pruriginosus. H. pruriginosum. Hydroa bullosa; a very rare form, attended at its development with intense itching, and sometimes preceded by slight febrile symptoms, followed by the formation of small bullee not exceeding the size of a split pea, and commencing as vesicles, without any antecedent lesion. Slight umbilication occurs, followed by desiccation, and the formation of scales or crusts. Successive crops are formed, the bullæ being discrete or grouped irregularly, but never in circles. $\mathbf{H}$. puerorum. See $H$. vacciniforme. $H$. vacciniforme. Hydroa astivale; Hydroa puerorum; Recurrent summer eruption; a recurring summer eruption of boyhood, usually with vesicles that leave scars. The disease generally begins in the first, second, or third year of life, and is often preceded by articular symptoms. The eruption develops chiefly on the uncovered parts, and is generally preceded by burning or pain, fulness of the region attacked, anorexia, and insomnia. Red spots appear, and on these rounded vesicles develop, singly or in groups, varying in size from that of a millet-seed to that of a large pea. They may coalesce into an irregularly outlined flattish bulla. The redness remains as an areola. These bullæ dry up, rupture, or become umbilicated, and form crusts which, on separating, leave slightly depressed scars resembling those of smallpox. The pathology is unknown.

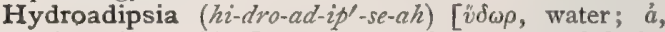
priv. ; di $\psi a$, thirst]. Absence of thirst, or of desire for water.

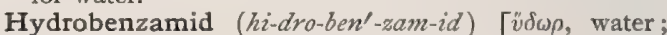
benzoin; amid], $\mathrm{C}_{21} \mathrm{H}_{18} \mathrm{~N}_{2}$. Azobenzoyl hydrid, a crystalline compound, soluble in alcohol.

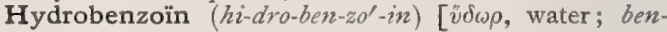
zoin $], \mathrm{C}_{14} \mathrm{H}_{14} \mathrm{O}_{2}$. A compound prepared by the action of sodium amalgam on benzoin. It dissolves with difficulty in water, is readily soluble in alcohol, and crystallizes in large, shining, rhombic plates, melting at $134^{\circ} \mathrm{C}$.

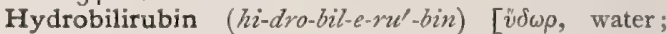
bilis, bile; nuber, red], $\mathrm{C}_{32} \mathrm{H}_{40} \mathrm{~N}_{4} \mathrm{O}_{7}$. A rose-red or brown-red pigment formed by treating a solution of bilirubin or biliverdin in dilute alkali with sodium amalgam. It is slightly soluble in water, easily so in alcohol, ether, and chloroform. It is a coloringmatter of feces, said to be identical with stercobilin, and is sometimes found in urine.

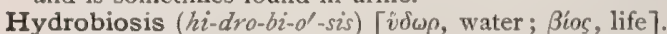
In biology, the origin and maintenance of life in fluid media. 
HY DROBROMATE

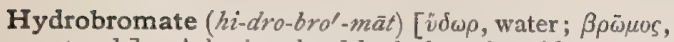
a stench]. A basic salt of hydrobromic acid.

Hydrobromic (hi-dro-bro'-mik) $[\hat{v} \delta \omega \rho$, water; $\beta \rho \bar{\omega} \mu o s$, stench]. Composed of hydrogen and bromin. $\mathrm{H}$. Acid. See Acid, Hydrobromic. H. Ether, $\mathrm{C}_{2} \mathrm{H}_{5} \mathrm{Br}$. Bromid of ethyl. A colorless, translucent liquid, with a neutral reaction, ethereal smell, and a pungent, sweet taste; its specific gravity is I. 4733 ; it boils at IO $4^{\circ} \mathrm{F}$. $\left(40.7^{\circ} \mathrm{C}\right.$ ), and burns with difficulty with a green, smokeless flame. It is prepared by distilling alcohol with either bromin, hydrobromic acid, or bromid of phosphorus. It is only slightly soluble in water, but freely so in ether or alcohol. It is used as an anesthetic. See Anesthetic.

Hydrobromid (hi-dro-bro'-mid). Same as Hydrobromate.

Hydrocaffeic Acid (hi-dro-kaf-e'-ik). See Acid.

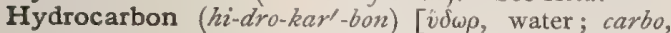
charcoal]. A name applied to any one of a multitude of. compounds composed mainly of hydrogen and carbon, but also under certain conditions containing other elements as substitution-products. The possibilities of the number of such compounds may be seen in the following series, perhaps the simplest, carbon, C, being a tetrad, and requiring four monad atoms to saturate its quantivalence :-

Methane, $\mathrm{CH}_{4}{ }^{\circ}$ ] In either of these one or more Ethane, $\mathrm{C}_{2} \mathrm{H}_{6}$. atoms of hydrogen may be Propane, $\mathrm{C}_{3} \mathrm{H}_{8}$. $\quad$ replaced by other atoms or radiButane, $\mathrm{C}_{4} \mathrm{H}_{10^{\circ}}$ cles without altering the strucPentane, $\mathrm{C}_{5} \mathrm{H}_{12}$. ture of the compound.

It will be noticed that the members of the series differ by $\mathrm{CH}_{2}$ in the present case. The various members of the Fat-series are usually indicated as follows:-

Paraffin Series, $\mathrm{C}_{n} \mathrm{H}_{2 \mathrm{n}}+2$, in which $n$ stands for any Olefins, $\mathrm{C}_{2} \mathrm{H}_{2 \mathrm{n}}$, number of carbon atoms. Acetylenes, $\mathrm{C}_{2} \mathrm{H}_{2 n-2}$, Thus, if $n=3$, the corresponding member of the Paraffin series would be $\mathrm{C}_{3} \mathrm{H}_{8}$, etc. All the hydrocarbons are inflammable. They occur in nature as marsh-gas (fire-damp), natural gas, naphtha, petroleum, asphaltum, ozocerite, etc., in a multitude of forms. They, with their derivatives, form the subject-matter of organic chemistry. A Table of the Hydrocarbons is appended.

\section{TABLE OF HYDROCARBONS.} I. PARAFFINS (ETHANES), $\mathrm{C}_{n} \mathrm{H}_{2 \mathrm{a}}+2$.

\begin{tabular}{|c|c|c|c|c|c|}
\hline NAME. & 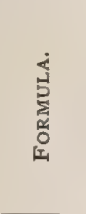 & 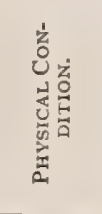 & 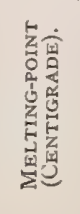 & 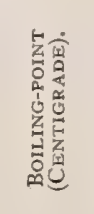 & 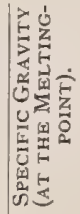 \\
\hline Methane, ... & $\mathrm{CH}_{4}$ & Gas & & & 0.5598 \\
\hline Ethane, .... & $\mathrm{C}_{2} \mathrm{H}_{6}$ & Gas & & & \\
\hline Propane, ... & $\mathrm{C}_{3} \mathrm{H}_{8}$ & Gas & & & \\
\hline Butane, .... & $\mathrm{C}_{4} \mathrm{H}_{10}$ & Gas & & $0^{\circ}$ & \\
\hline Pentane, ... & $\mathrm{C}_{5} \mathrm{H}_{12}$ & Liquid & & $37-39^{\circ}$ & \\
\hline Hexane, ... & $\mathrm{C}_{6} \mathrm{H}_{14}$ & Liquid & & $71.5^{\circ}$ & $0.6 v_{3}$ \\
\hline Heptane, . . & $\mathrm{C}_{7} \mathrm{H}_{16}$ & Liquid & & $99^{\circ}$ & 0.6967 \\
\hline Octane, .... & $\mathrm{C}_{8} \mathrm{H}_{18}$ & Liquid & & $125^{\circ}$ & 0.718 \\
\hline Nonane, ... & $\mathrm{C}_{9} \mathrm{H}_{20}$ & Liquid & $-51^{\circ}$ & $I 49.5^{\circ}$ & 0.7330 \\
\hline
\end{tabular}

TABLE OF HYDROCARBONS,-Continued. x. PARAFFINS (ETHANES).-Continued.

\begin{tabular}{|c|c|c|c|c|c|c|}
\hline NAME. & 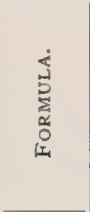 & 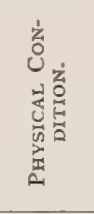 & 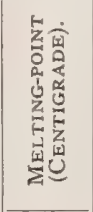 & & 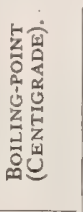 & 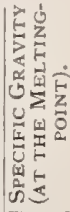 \\
\hline Decane, ... & $\mathrm{C}_{10} \mathrm{H}_{22}$ & Liquid & $-32^{\circ}$ & \multirow{10}{*}{ 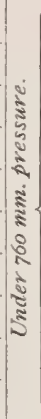 } & $\int 173^{\circ}$ & 0.7456 \\
\hline Undecane, .. & $\mathrm{C}_{11} \mathrm{H}_{24}$ & Liquid & $-26.5^{\circ}$ & & $194.5^{\circ}$ & 0.7745 \\
\hline Dodecane, .. & $\mathrm{C}_{12} \mathrm{H}_{26}$ & Liquid & $-12^{\circ}$ & & $214^{\circ}$ & 0.773 \\
\hline Tridecane, . . & $\mathrm{C}_{13} \mathrm{H}_{28}$ & Liquid & $-6.2^{\circ}$ & & $234^{\circ}$ & 0.775 \\
\hline Tetradecane, & $\mathrm{C}_{14} \mathrm{H}_{80}$ & Liquid & $+4.5^{\circ}$ & & $252.5^{\circ}$ & 0.775 \\
\hline Pentadecane, & $\mathrm{C}_{15} \mathrm{H}_{32}$ & Liq & $+10^{\circ}$ & & $270.5^{\circ}$ & 0.775 \\
\hline Hexdecane, & $\mathrm{C}_{16} \mathrm{H}_{34}$ & Solid & $+18^{\circ}$ & & $\overline{287 \cdot 5^{\circ}}$ & 0.775 \\
\hline Hepdecane, . . & $\mathrm{C}_{17} \mathrm{H}_{36}$ & Solid & $+22.5^{\circ}$ & & $303^{\circ}$ & 0.776 \\
\hline Octdecane, . & $\mathrm{C}_{18} \mathrm{H}_{38}$ & Solid & $28^{\circ}$ & & $317^{\circ}$ & 0.776 \\
\hline Nondecane,. & $\overline{\mathrm{C}_{19} \mathrm{H}_{40}}$ & Solid & $32^{\circ}$ & & $330^{\circ}$ & 0.777 \\
\hline Eicosane,... & $\mathrm{C}_{20} \mathrm{H}_{42}$ & Solid & $36.7^{\circ}$ & \multirow{13}{*}{ 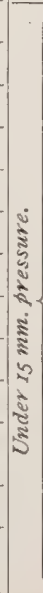 } & $205^{\circ}$ & 0.777 \\
\hline Heneicosane, & $\mathrm{C}_{21} \mathrm{H}_{44}$ & Solid & $40.4^{\circ}$ & & $215^{\circ}$ & $0.77^{8}$ \\
\hline Docosane, :. & $\mathrm{C}_{22} \mathrm{H}_{46}$ & Solid & $44.4^{\circ}$ & & $224.5^{\circ}$ & 0.778 \\
\hline Tricosane, . . & $\mathrm{C}_{23} \mathrm{H}_{48}$ & Solid & $47 \cdot 7^{\circ}$ & & $234^{\circ}$ & $0.77^{8}$ \\
\hline Tetracosane, & $\mathrm{C}_{24} \mathrm{H}_{50}$ & Solid & $5 \mathrm{I} \mathrm{I}^{\circ}$ & & $243^{\circ}$ & $0.77^{8}$ \\
\hline Pentacosane, & $\mathrm{C}_{25} \mathrm{H}_{52}$ & Solid & & & & \\
\hline Hexcosane, . & $\mathrm{C}_{26} \mathrm{H}_{54}$ & Solid & & & & \\
\hline Heptacosane, & $\mathrm{C}_{27} \mathrm{H}_{56}$ & Solid & $595^{\circ}$ & & $270^{\circ}$ & 0.779 \\
\hline Octcosane, . & $\mathrm{C}_{28} \mathrm{H}_{58}$ & Solid & & & & \\
\hline Noncosane, . . & $\mathrm{C}_{29} \mathrm{H}_{60}$ & Solid & & & & \\
\hline $\begin{array}{l}\text { Hentriacon- } \\
\text { tane, }\end{array}$ & $\mathrm{C}_{31} \mathrm{H}_{64}$ & Solid & $68 . \mathrm{I}^{\circ}$ & & $302^{\circ}$ & 0.780 \\
\hline Dotriacontane, & $\mathrm{C}_{32} \mathrm{H}_{66}$ & Solid & $70^{\circ}$ & & $310^{\circ}$ & $0.78 \mathrm{I}$ \\
\hline $\begin{array}{c}\text { Pentatriacon- } \\
\text { tane, .... }\end{array}$ & $\mathrm{C}_{35} \mathrm{H}_{72}$ & Solid & $74 \cdot 7^{\circ}$ & & $33 \mathrm{I}^{\circ}$ & 0.781 \\
\hline Hex & $\overline{\mathrm{C}_{60} \mathrm{H}_{122}}$ & So & $102^{\circ}$ & & & \\
\hline
\end{tabular}

2. ALKYLENS (OLEFINS), $\mathrm{CnH}_{2 n}$.

Methylene, .. $\mathrm{CH}_{2}$ Does not exist in the free state.

\begin{tabular}{|c|c|c|c|c|c|}
\hline Ethylene,... & $\mathrm{C}_{2} \mathrm{H}_{4}$ & Gas & & $-105^{\circ}$ & \\
\hline Propylene, . & $\mathrm{C}_{3} \mathrm{H}_{6}$ & Gas & & & \\
\hline Trimethylene, & $\mathrm{C}_{3} \mathrm{H}_{6}$ & Gas & & & \\
\hline Butylene, . . . & $\mathrm{C}_{4} \mathrm{H}_{8}$ & Gas & & $-5^{\circ}$ & \\
\hline Amylene, ... & $\mathrm{C}_{5} \mathrm{H}_{10}$ & Liquid & & $+37^{\circ}$ & \\
\hline Hexylene, .. & $\mathrm{C}_{6} \mathrm{H}_{12}$ & Liquid & & & \\
\hline Heptylene, .. & $\mathrm{C}_{7} \mathrm{H}_{14}$ & Liquid & & & \\
\hline \multirow[t]{4}{*}{ Cetene, .... } & $\mathrm{C}_{8} \overline{\mathrm{H}_{16}}$ & Liquid & & & \\
\hline & $\mathrm{C}_{9} \mathrm{H}_{18}$ & Liquid & & & \\
\hline & $\overline{\mathrm{C}_{10} \mathrm{H}_{20}}$ & Liquid & & & \\
\hline & $\overline{\mathrm{C}_{11} \mathrm{H}_{22}}$ & Liquid & & & \\
\hline \multirow[t]{2}{*}{ Dodecylene, . } & $\overline{\mathrm{C}_{12} \mathrm{H}_{24}}$ & Liquid & $-31.5^{\circ}$ & $96^{\circ}$ & 0.7954 \\
\hline & $\mathrm{C}_{13} \mathrm{H}_{26}$ & Liquid & & & \\
\hline
\end{tabular}


HYDROCARBON

TABLE OF HYDROCARBONS.-Continued. 2. ALKYLENS (OLEFINS),-Continued.

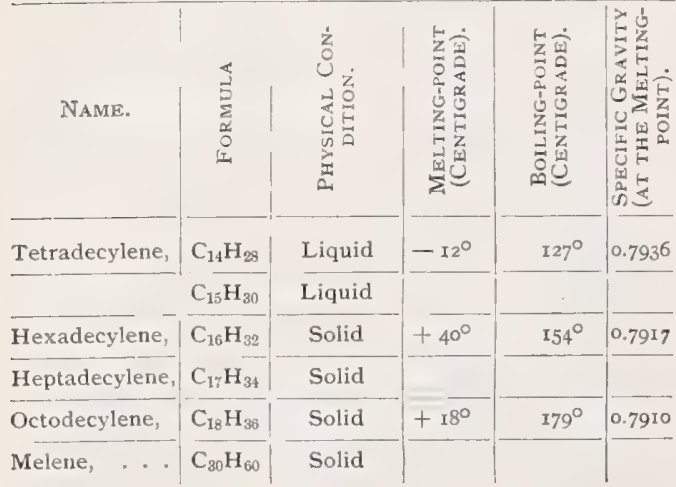

3. ACETYLENE SERIES, $\mathrm{C}_{\mathrm{n}} \mathrm{H}_{2 \mathrm{n}}-2$.

Acetylene, . $\mathrm{C}_{2} \mathrm{H}_{2} \mid$ Gas

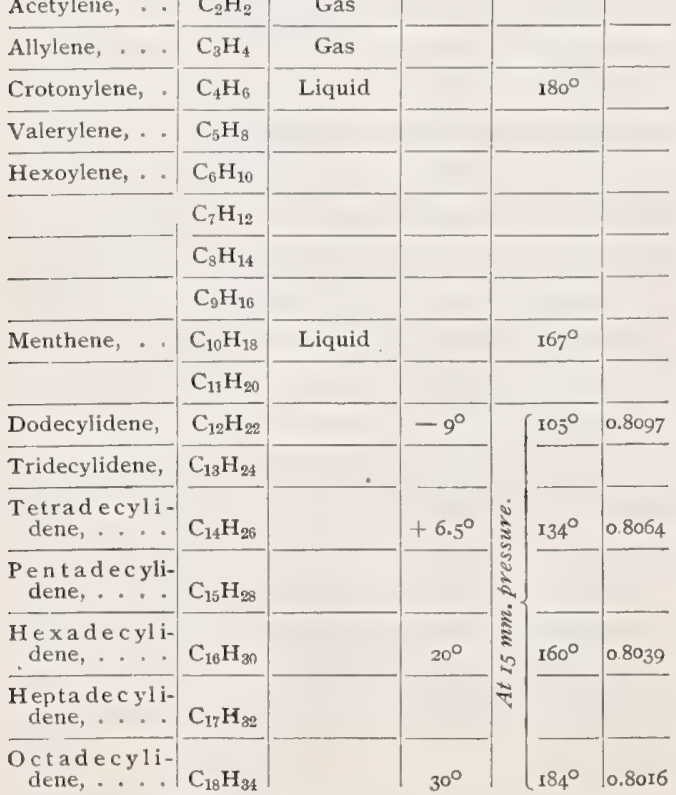

4. HYDROCARBONS, $\mathrm{C}_{2} \mathrm{H}_{2 n-4}$

Vinylacetylene, $\quad \mathrm{C}_{4} \mathrm{H}_{4} \mid$ Not yet isolated.

\begin{tabular}{|c|c|c|c|c|c|}
\hline & & & & & \\
\hline Valylene, ... & $\mathrm{C}_{5} \mathrm{H}_{6}$ & Liquid & & $50^{\circ}$ & \\
\hline Camphene, ... & $\mathrm{C}_{10} \mathrm{H}_{16}$ & Solid & & & \\
\hline Citrene, ... & $\mathrm{C}_{10} \mathrm{H}_{16}$ & Liquid & & $175^{-176^{\circ}}$ & 0.846 \\
\hline Dipentene, ... & $\mathrm{C}_{10} \mathrm{H}_{10}$ & Liquid & & $\times 75^{-176^{\circ}}$ & 0.853 \\
\hline Pinene, ..... & $\mathrm{C}_{10} \mathrm{H}_{16}$ & Liquid & & $175^{\circ}-176^{\circ}$ & \\
\hline Sylvestrene, & $\mathrm{C}_{10} \mathrm{H}_{16}$ & Liquid & & $175^{-1} 78^{\circ}$ & \\
\hline$\overline{\text { Terpinene, ... }}$ & $\overline{\mathrm{C}_{10} \mathrm{H}} \overline{\mathrm{H}_{10}}$ & Liquid & & $180^{\circ}$ & \\
\hline Fichtelite, ... & $\mathrm{C}_{18} \mathrm{H}_{32}$ & Solid & $46^{\circ}$ & & \\
\hline
\end{tabular}

5. HYDROCARBONS, $\mathrm{CnH}_{2 n} \rightarrow 6$.

\begin{tabular}{|c|c|c|c|c|c|}
\hline iacetylene, & $\mathrm{C}_{4} \mathrm{H}_{2}$ & Gas & & & \\
\hline DipropargyI, & $\mathrm{C}_{6} \mathrm{H}_{6}$ & Liquid & & $85^{\circ}$ & $0.8 \mathrm{I}$ \\
\hline Benzene, & $\mathrm{C}_{6} \mathrm{H}_{6}$ & Liquid & $+6^{\circ}$ & $80.5^{\circ}$ & 0.899 \\
\hline & $\mathrm{C}$ & Liquí & & $110.3^{\circ}$ & \\
\hline
\end{tabular}

TABLE OF HYDROCARBONS.-Continued. 5. HYDROCARBONS-Continued.

\begin{tabular}{|c|c|c|c|c|c|}
\hline NAME. & 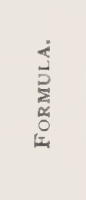 & 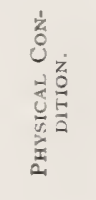 & 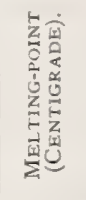 & 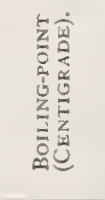 & 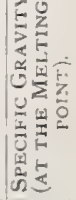 \\
\hline Cumene, ... & $\mathrm{C}_{9} \mathrm{H}_{12}$ & Liquid & 1 & $153^{\circ}$ & \\
\hline Mesitylene, . . & $\overline{\mathrm{C}_{9}} \overline{\mathrm{H}_{12}}$ & Liquid & & $163^{\circ}$ & \\
\hline Pseudocumene, & $\overline{\mathrm{C}_{9} \mathrm{H}_{12}}$ & Liquid & & $166^{\circ}$ & 0.8722 \\
\hline Cymene, ... & $\mathrm{C}_{10} \mathrm{H}_{14}$ & Liquid & & $175-176^{\circ}$ & \\
\hline Durene, ... & $\mathrm{C}_{10} \mathrm{H}_{14}$ & Solid & $79-80^{\circ}$ & $190^{\circ}$ & \\
\hline Prehnitol, .. & $\mathrm{C}_{10} \mathrm{H}_{14}$ & Liquid & & $204^{\circ}$ & \\
\hline
\end{tabular}

6. OTHER HYDROCARBONS.

Methyl, . . . $\mathrm{CH}_{3}$ Does not exist in the free state.

Allyl, . . . . $\mathrm{C}_{3} \mathrm{H}_{5}$ Does not exist in the free state.

Butyl, . . . $\mathrm{C}_{4} \mathrm{H}_{9}$ Does not exist in the free state.

Benzyl, . . . $\mathrm{C}_{7} \mathrm{H}_{7}$ Does not exist in the free state.

\begin{tabular}{llll}
\hline Styrol, . . . & $\mathrm{C}_{8} \mathrm{H}_{8}$ & Liquid & \\
\hline
\end{tabular}

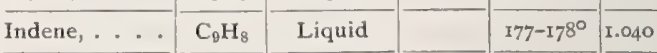

\begin{tabular}{lllll}
\hline Naphthalene, . & $\mathrm{C}_{10} \mathrm{H}_{8}$ & Solid & $79^{\circ}$ & $218^{\circ}$
\end{tabular}

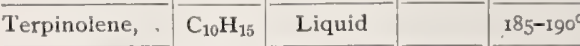

$\begin{array}{llll}\mathrm{C}_{12} \mathrm{H}_{10} & \text { Solid } & 95^{\circ} & 277^{\circ}\end{array}$

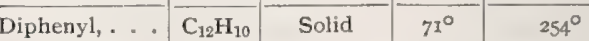

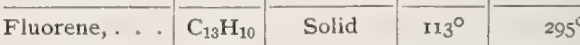

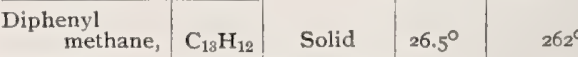

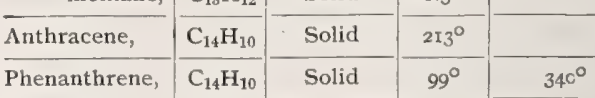

Tolane ....

Stilbene, ... $\mathrm{C}_{14} \mathrm{H}_{12}$ Solid

Dibenzyl, . . $\mathrm{C}_{14} \mathrm{H}_{14} \quad$ Solid $52^{\circ} \quad 284^{\circ}$

Fluoranthene, $\mathrm{C}_{15} \mathrm{H}_{30}$ Solid $109-110^{\circ}$

$\begin{array}{lll}\begin{array}{c}\text { Methyl } \\ \text { anthracene, }\end{array} & \mathrm{C}_{15} \mathrm{H}_{12} & \text { Solid } \\ 190^{\circ}\end{array}$

\begin{tabular}{l|l|l} 
Pyrene, ..... & $\mathrm{C}_{16} \mathrm{H}_{10}$ & Solid \\
$\mathbf{1 4} 48^{\circ}$
\end{tabular}

$\begin{array}{llll}\mathrm{C}_{18} \mathrm{H}_{12} & \text { Solid } & \\ 250^{\circ} & \end{array}{ }_{436^{\circ}}$

\begin{tabular}{lllll}
\hline Retene, . . . & $\mathrm{C}_{18} \mathrm{H}_{18}$ & Solid & $98^{\circ}$ & $390^{\circ}$
\end{tabular}

Tripheny methane, $\mathrm{C}_{19} \mathrm{H}_{16} \quad$ Solic

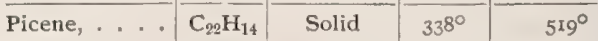

Ceryl, . . . $\mathrm{C}_{27} \mathrm{H}_{55}$ Does not exist in the free state.

Benzene Series. Boiling-point. Specific

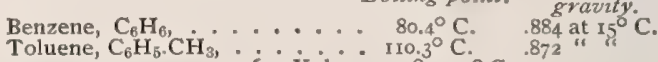

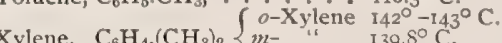

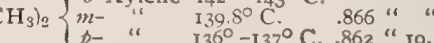

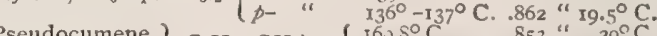

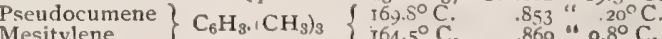

Mesitylene $\left.\mathrm{C}_{6} \mathrm{H}_{3.1} \mathrm{CH}_{3}\right\}_{3}\left\{164.5^{\circ} \mathrm{C}\right.$. 869 " $9.8^{\circ} \mathrm{C}$.

Durene, $\mathrm{C}_{6} \mathrm{H}_{2} \cdot\left(\mathrm{CH}_{3}\right)_{4} . \mathrm{IS}^{\circ}-191^{\circ} \mathrm{C}$

Pentamethylbenzene, $\mathrm{C}_{6} \mathrm{H} .\left(\mathrm{CH}_{3}\right)_{6}, \quad-230^{\circ} \mathrm{C}$

Hexamethylbenzene, $\mathrm{C}_{6}\left(\mathrm{CH}_{3}\right)_{6}, \quad-264^{\circ} \mathrm{C}$. 
Hydrocardia (hi-dro-kar'-de-ah). See Hydropericar. dium.

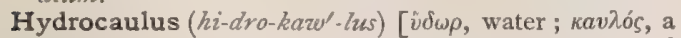
stem: $p l$., Hydrocauli]. In biology, the main stem of a hydrozoan colony.

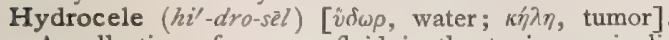
A collection of serous fluid in the tunica vaginalis testis, or in connection with the testicle or cord. The term is applied, also, to a serous tumor in other locations.

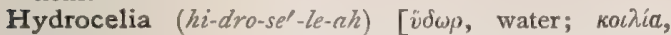
belly]. Dropsy of the belly or abdominal region.

Hydrocellulose (hi-dro-sell'-u-loss) [ $v \delta \omega \rho$, water; cellula, a little cell], $\mathrm{C}_{12} \mathrm{H}_{22} \mathrm{O}_{11}$. A body formed by moistening cellulose with a dilute mineral acid, and then drying. It is used in photography.

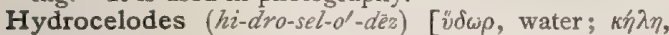
tumor; $\varepsilon i \delta o s$, form ]. A tumor resembling hydrocele, but due to an extravasation of urine.

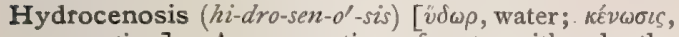
evacuation 1. An evacuation of water either by the use of hydragogue cathartics or by the operation of "tapping" the cavity containing the accumulation of fluid. See Paracentesis.

Hydrocenotic ( $\left.h i-d r o-s e n-o t^{\prime}-i k\right)$ [ $v \delta \omega \rho$, water; $\kappa \dot{v} \nu \omega \sigma \iota$, evacuation]. Relating to or causing hydrocenosis.

Hydrocephalic ( $\left.h i-d r o-s e f-a l^{\prime}-i k\right)$ [ ${ }^{j} \delta \omega \rho$, water; $\kappa \varepsilon \phi a \lambda \dot{\eta}$, head]. Pertaining to or affected with hydrocephalus. H. Cry, the shriek of pain of the hydrocephalic child during the exacerbations.

Hydrocephalitis (hi-dro-sef-al-i'-tis). See Hydrenceph. alitis.

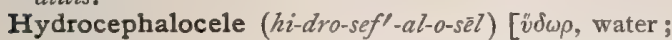
$\kappa \varepsilon \phi \alpha \lambda \eta$, head; $\kappa \hat{\lambda} \lambda \eta$, a tumor]. Congenital hydrocephalus in which the encephalon protrudes through the ununited or undeveloped cranial wall.

Hydrocephaloid (hi-dro-sef'-al-oid) [ij $\omega \rho$, water; $\kappa \varepsilon \phi a \lambda \eta$, head ; $\varepsilon i \delta o \zeta$, form]. Pertaining to or resem. bling hydrocephalus. H. Disease, Marshall Hall's Disease; a disease resembling hydrocephalus, sometimes observed in poorly-nourished infants just after weaning. It is a condition of nervous exhaustion, generally coming on after a prolonged illness, or following premature weaning. There is a stage of irritability and one of torpor. The pulse is irregular, the fontanel flaccid and hollow, and there is no, or but slight, tendency to vomiting. Stimulants and tonics arrest the progress of the condition.

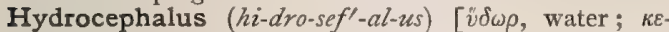
$\phi a \lambda \eta$, head]. A collection of fluid in the cerebral ventricles (internal hydrocephalus) or outside the brainsubstance (external hydrocephalus), preventing closure of the fontanels and causing enlargement of the skull. The head may measure as much as thirty inches in circumference. Wormian bones develop in the sutures and fontanels; the eyeballs are rendered prominent and at the same time their axes are depressed. Often there is a retardation of the mental development, and the patient usually dies within a few years. An acute hydrocephalus occurs in meningeal inflammation. The chronic form is congenital or infantile.

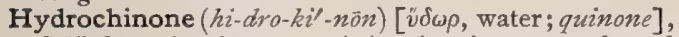
$\mathrm{C}_{6} \mathrm{H}_{6} \mathrm{O}_{2}$. A substance existing in urine as an ethereal compound with $\mathrm{H}_{2} \mathrm{SO}_{4}$; it is largely the cause of the dark color that this excretion assumes after the absorption of phenol on exposure to the air.

Hydrochlorate $\left(h i-d r o-k l l^{\prime}-r \bar{a} t\right)[\hat{v} \delta \omega \rho$, water; $\chi \lambda \omega \rho o s$, green ]. Any salt or compound of hydrochloric acid.

Hydrochloric Acid (hi-dro-klo'-rik). See Acid, Hydrochloric.

Hydrochlorid (hi-dro-chlo'-rid') [ $v \delta \omega \rho$, water; $\chi \lambda$ l $\omega \rho \circ$, green]. Same as Hydrochlorate.

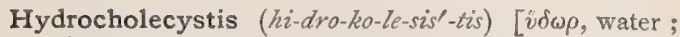

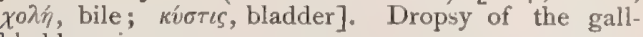
bladder.

Hydrocinnamic Acid ( $\left.h i-d r o-s i n-a m^{\prime}-i k\right)$. See Acid. Hydrocirsocele ( $\left.h i-d r o-s i r^{\prime}-s o-s e l\right)$ [ $[v \delta \omega \rho$, water; $\kappa \iota \rho \sigma \sigma s$, venous enlargement; $\kappa \eta \eta \lambda \eta$, tumor]. Hydrocele accompanied with varicose veins of the spermatic cord.

Hydrocalia (hid-ro-se'-le-ah). See Hydrocelia.

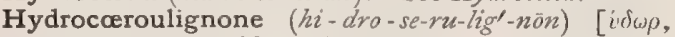
water; ceruleus, blue; lignum, wood], $\mathrm{C}_{16} \mathrm{H}_{18} \mathrm{O}_{6}$. A divalent phenol, crystallizing from alcohol and glacial acetic acid in colorless leaflets, and melting at $190^{\circ} \mathrm{C}$.

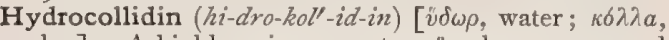
glue]. A highly poisonous ptomaïne-base, so named by Gautier and Etard, and declared by them to be identical with the hydrocollidin obtained by Cahours and Etard from the action of selenium on nicotin. Nencki, on the other hand, asserted its identity with a base (collidin) isolated by him in $\mathbf{1 8 7 6}$, to which he had ascribed the formula $\mathrm{C}_{8} \mathrm{H}_{11} \mathrm{~N}$. The formula of Gautier and Etard's hydrocollidin is $\mathrm{C}_{8} \mathrm{H}_{13} \mathrm{~N}$. This ptomaine was obtained from chloroformic extracts, from putrefying mackerel, and putrefying horse-flesh and ox-flesh. The free base is an almost colorless, alkaline, oily fluid, having a strong, penetrating odor like syringa. So small a dose as 0.0017 gram of the hydrochlorid, injected into birds, produced dizziness, paralysis, and death. The pupils remain normal, and the heart stops in diastole.

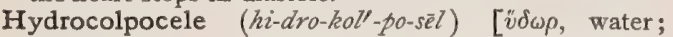

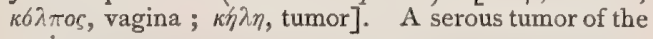
vagina.

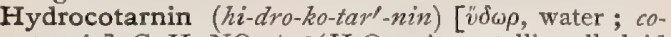
tarnin $], \mathrm{C}_{12} \mathrm{H}_{15} \mathrm{NO}_{3}+1 / 2 \mathrm{H}_{2} \mathrm{O}$. A crystalline alkaloid occurring in small amount in opium. It melts at $50^{\circ}$ $\mathrm{C}$, and is readily soluble in alcohol, ether, and chloroform.

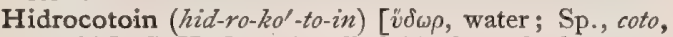
a cubit], $\mathrm{C}_{15} \mathrm{H}_{14} \mathrm{O}_{4}$. An alkaloid of coto-bark, occurring in yellowish crystals without taste.

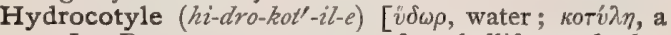
cup]. Pennywort; a genus of umbelliferous herbs. The leaves of $\mathbf{H}$. asiatica serve as a bitter tonic and alterative, and are very serviceable in skin-diseases, syphilitic sores, and leprosy. H. centella, of S. Africa, $H$. umbellata, of America, and $H$. vulgaris, of Europe, have been employed in medicine, but their properties are little known. $\mathbf{H}$. bonariasis, of $\mathbf{S}$. America, is diuretic. All unof.

Hydrocrania (hid-ro-kra'-ne-ah). Same as Hydrocephalus.

Hydrocyanic (hi-dro-se-an'-ik). See Cyanogen, and Acid, Hydrocyanic.

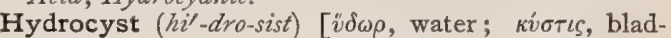
der]. A cyst containing a water-like liquid. Sometimes it is synonymous with hydatid. In biology, Huxley's name for singular organs found in certain of the Hydrozoa (especially the Physophorida). They are pyriform sacs of ectoderm and endoderm, closed at their distal ends, but in free communication with the somatic cavity at their proximal ends; they are arrested polypites in which the mouth has never become developed.

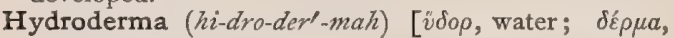
skin]. Dropsy of the skin.

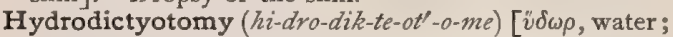

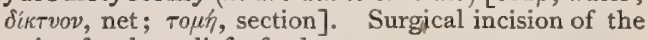
retina for the relief of edema.

Hydrodiuresis (hi-dro-di-u-re'-sis) [ $v \delta \delta \rho$, water; $\delta i a ́$, through; ovjéct, to make water]. A copious flow of watery urine. 


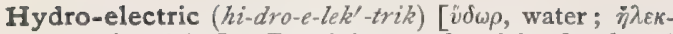
$\tau \rho o \nu$, electricity]. Pertaining to electricity developed by the physical action of fluids or in connection with water. H. Bath, a bath in which the metallic lining of the tub is connected with one pole of a battery, the other being in contact with the person of the patient.

Hydrofluoric Acid (hi-dro-fu-or'-ik). See Acid.

Hydrogaster (hi-dro-gas'-ter). Synonym of Ascites.

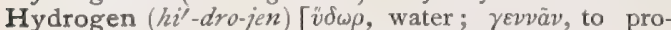
duce]. $H=\mathbf{I}$. Quantivalence $\mathbf{1}$. A gaseous element, one liter of which weighs .0896 gram. It is feebly basic and occurs in nature combined with oxygen in the form of water $\mathrm{H}_{2} \mathrm{O}$. It has been liquefied at a temperature of $-286^{\circ} \mathrm{F}$. under a tension of 650 atmospheres-a pressure of about 4.7 tons per square inch. In combination with carbon, oxygen, and nitrogen, it forms a multitude of radicles formerly known as "organic" compounds, but now often synthetically formed. It is used largely in the qualitative determination of arsenic and antimony, and for combustion with oxygen to produce intense heat. It has also been used by inhalation in pulmonary tuberculosis. See Elements, Table of. H. peroxid, or dioxid, an unstable compound having the composition $\mathrm{H}_{2} \mathrm{O}_{2}$, It is a powerful antiseptic and germicide, and is used as a disinfectant in diphtheria, glandular swellings and suppurative inflammations, and as an antispasmodic to relieve the paroxysms of whooping cough. It is the basis of most hair-bleaching solutions. Dose 3 ss-ij. Unof. H.d., Aqua, solution of hydrogen dioxid; contains 3 per cent. by weight of the pure dioxid. H. sulphid. See Acid Hydrosulphuric.

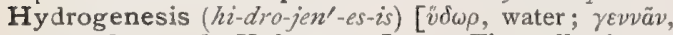
to produce: pi. Hydrogeneses]. I. The collection or formation of a watery fluid. 2. Any disease in which there is a predominance or degeneration of mucous secretion, fat, bile, or milk

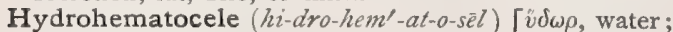
$a^{\top} \mu \alpha$, blood; $\kappa \hat{\eta} \lambda \eta$, tumor]. Hematocele associated with hydrocele.

Hydrohemia (hi-dro-hem'-e-ah). Same as Hyaremia.

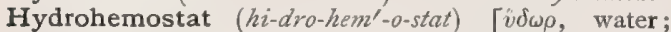

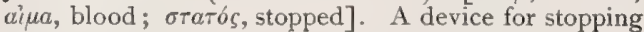
hemorrhage by means of hydrostatic pressure.

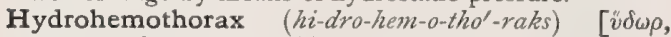
water; ai ${ }^{2} \mu$, blood; $\theta \omega \rho a \xi$, thorax]. An effusion of hemorrhagic fluid into the pleural cavity.

Hydrohymenitis (hi-dro-hi-men-i'-tis). See Hydry. menitis.

Hydrohystera (hi-dro-his'-ter-ah). See Hydrometra.

Hydroid (hil-droid) [ $v \delta \omega \rho$, water; sidos, form]. I. Like water. 2. Living in water.

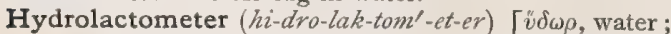
lac, milk; $\mu$ ćrpov, measure]. An instrument used in estimating the percentage of water in any given sample of milk.

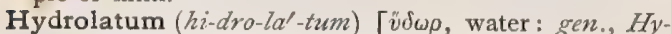
drolati; pl., Hydrolata]. A medicated water.

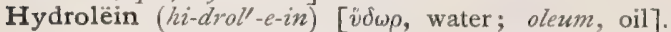
A proprietary remedy consisting of an emulsion of codliver oil with pancreatin and borax.

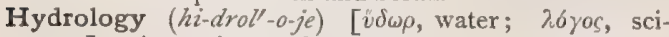
ence]. A treatise on the nature and uses of water.

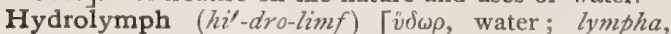
water]. A term applied to the blood of certain animals which is composed largely of the salt or fresh water in which they live, and containing a small amount of corpuscular elements.

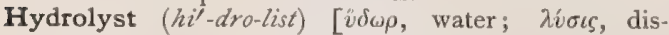
solving]. A substance that, like sulphuric acid, diastase, emulsin, etc., induces hydrolysis; an hydrolytic agent.
Hydrolyte $\left(h i^{\prime}-d r o-l i t\right)$ [ $\tilde{v} \delta \omega \rho$, water; $\lambda \hat{v} \sigma \iota$, dissolving]. The substance hydrolyzed.

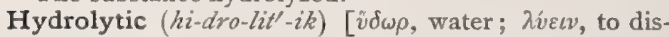
solve]. Pertaining to the decomposition of water, or the liberation of water during a chemic reaction. $\mathbf{H}$. Ferments, those causing a combination with the elements of water in the substances they decompose.

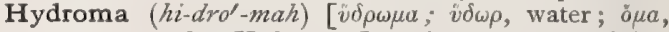
a tumor: pl., Hydromata]. A tumor containing water. A cyst or sac filled with water or serous fluid. Also, an edematous swelling. Also, the cystic dilatation of a lymphatic of the neck.

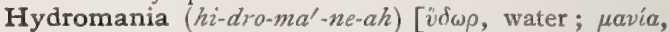
madness]. I. Intense or maddening thirst. 2. Mania with desire for suicide by drowning.

Hydromel ( $i^{\prime}$-dro-mel) [ [ $\delta \omega \rho$, water; $\mu \varepsilon \lambda_{\iota}$, honey]. A fermented mixture of honey and water, whether medicated or not; a kind of mead or metheglin.

Hydromeningitis (hi-dro-men-in- $\left.j i^{\prime}-t i s\right)$ [ $i \delta \omega \rho$, water; $\mu \tilde{\eta} \nu \iota \gamma \xi$, a membrane; $\iota \tau \iota s$, inflammation]. Inflammation of the membranes of the brain or cord, accompanied by effusion of watery fluid.

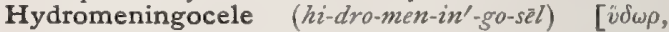
water; $\mu \bar{\eta} \nu \iota \gamma \xi$, membrane; $\kappa \dot{\eta} \lambda \eta$, a tumor]. A cystic tumor of the meninges, protruding through the skull. Also, a cystic tumor in the arachnoid cavity or in the continuation of the subarachnoid space.

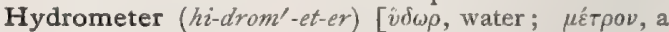
measure]. An instrument for determining the specific gravity of liquids or solutions containing water.

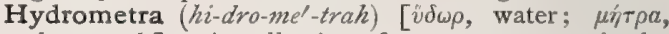
the womb]. A collection of water or mucus in the womb. It may result from congenital atresia in infants, but usually follows an endometritis with stenosis of the cervix.

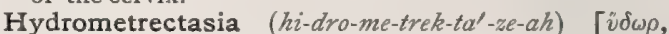

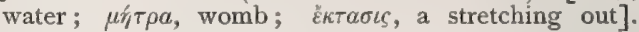
Hydrometra causing distention of the uterus.

Hydromicrencephalia (hi-dro-mi-kren-sef-a'-le-ah) or Hydromicrencephaly ( $\left.h i-d r o-m i-k r e n-s e f^{\prime}-a l-e\right)$

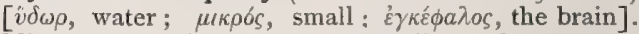
Micrencephaly leading to, or complicated by, a serous effusion within the cranial cavity.

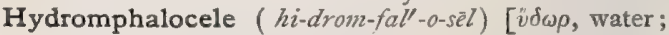
$\grave{\partial} \mu \phi a \lambda \sigma ́ s$, navel; $\kappa \hat{\eta} \lambda \eta$, hernia]. Cystic tumor in the sac of an umbilical hernia.

Hydromphalus (hi-drom'-fal-us) [ $\ddot{\delta} \delta \omega \rho$, water; $b \mu \phi \alpha$ $\lambda \sigma \varsigma$, navel]. A tumor at the navel distended with water. It may arise either from ascites or umbilical hernia.

Hydromyelia (hi-dro-mi-e'-le-ah) or Hydromyelus

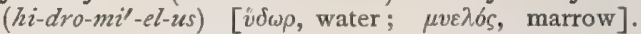
Dilatation of the central canal of the spinal cord with an accumulation of fluid. It may be moderate or extreme.

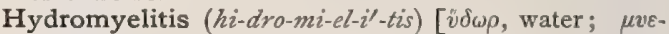
$\lambda \sigma s$, marrow; $\iota \tau \iota \varsigma$, inflammation ]. Same as Hydrorrhachis interna.

Hydromyringa, or Hydromyrinx (hi-dro-mir-in'-gah or hi-dro-mi'-rinks) [ $v \delta \omega \rho$, water; myrinx, the tympanic membrane]. I. The distention of the membrana tympani with water effused within its substance. 2. Less correctly, the same as Hydrotympanum.

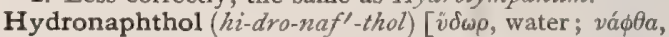
asphalt]. A proprietary preparation recommended as an odorless, non-poisonous, and non-corrosive antiseptic. It is regarded by some as identical with betanaphthol. Dose gr. ij-v. Unof.

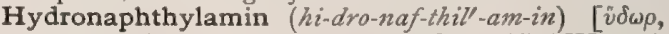
water; vá $\phi \forall a$, asphalt; $a \min ], \mathrm{C}_{10} \mathrm{H}_{7} \cdot \mathrm{H}_{4} \cdot \mathrm{NH}_{2}$. A compound, called also tetrahydrobetanaphthylamin; a solution of I to 5 per cent., whether used topically 
or hypodermatically, causes great dilatation of the pupil.

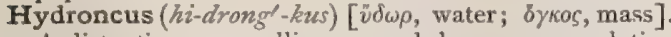
A distention or swelling caused by an accumulation of water. See, also, Edema and Anasarca.

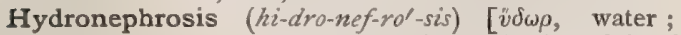
$\nu \varepsilon \phi \rho o ́ s$, kidney]. A collection of urine in the pelvis of the kidney from obstructed outflow. The obstruction may be caused by an impacted calculus, a stenosed ureter, congenital deformities, or new-growths. The cyst may vary in size, being either very small or enormous. Hydronephrosis is marked clinically by the presence of a tumor in the renal region, soft and fluctuating, and usually painless. H., Intermittent, one in which there is from time to time the occurrence of a free discharge of urine, with diminution in the size of the renal tumor; ordinarily the retention is the result of twisting or kinking of a ureter.

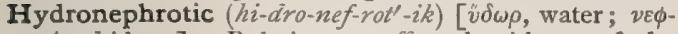
$\rho o ́ s$, kidney]. Relating to, affected with, or of the nature of, hydronephrosis.

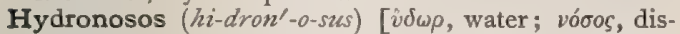
ease]. A disease attended with dropsy.

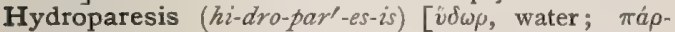
$\varepsilon \sigma \iota \zeta$, paralysis]. A paretic affection characterized by watery effusions, such as are seen in beriberi.

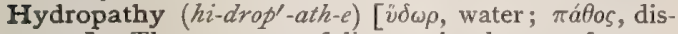
ease]. The treatment of diseases by the use of water, externally and internally.

Hydropedesis ( $h i-d r o-p e d-e^{\prime}-s i s$ ). See Hidropedesis.

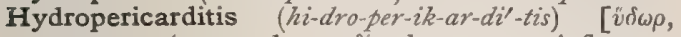
water; $\pi \varepsilon \rho i$, around; $k \alpha \rho \delta i a$, heart; $\iota \tau \iota s$, inflammation]. Pericarditis accompanied by serous effusion into the pericardium.

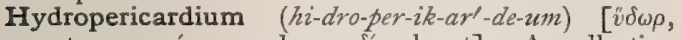
water; $\pi \varepsilon \mu i$, around; $\kappa a \rho \delta i \alpha$, heart]. A collection of water within the pericardium. It may be active, passive, or mechanical, but is generally the result of kidney-disease, valvular lesions of the heart, or chronic affections of the lungs.

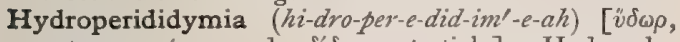
water; $\pi \varepsilon \rho i$, around; $\delta i \delta v \mu o s$, testicle]. Hydrocele.

Hydroperitoneum (hi-dro-per-it-on-e'-um). See $A s-$ cites.

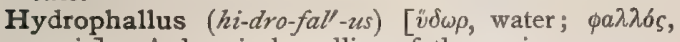
penis]. A dropsical swelling of the penis.

Hydrophilous (hi-droff'-il-us) [ [v $\delta \rho$, water; $\phi i \lambda o s$, loving]. In biology, applied to plants that are fertilized through the agency of water.

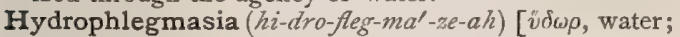
$\phi \lambda \varepsilon \gamma \mu a \sigma i a$, inflammation]. Any phlegmasia or inflammation characterized by serous effusion.

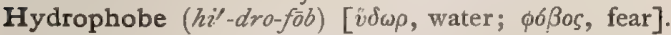
A person who is affected with rabies.

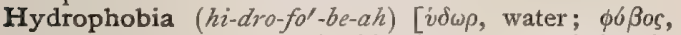
dread]. A symptom of rabies in man, consisting in fear of, or inability to swallow, water. The term is used commonly as a synonym of Rabies, and particularly of the disease in man. H., Pseudo-. See Pseudo-hydrophobia.

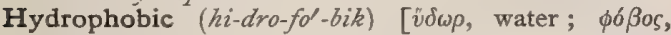
dread]. Pertaining to, or having the nature of, hydrophobia. H. Tetanus. See Kopf-tetanus.

Hydrophobophobia (hi-dro-fo-bo-fol-be-ah) [v $\delta \omega \rho$, water; $\phi 6 \beta \circ s, f e a r]$. A morbid and intense dread of hydrophobia.

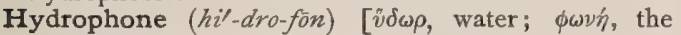
voice]. An instrument used in auscultatory percussion, the sound being conveyed to the ear through a column of water.

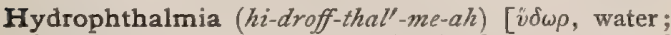
o $\phi \theta a \lambda_{\mu} \delta$ s, eye]. An increase in the fluid contents of the eye, resulting in glaucoma, keratoglobus, staphyloma, etc.

Hydrophthalmos (hi-droff-thal'-mos). See Keratoglobus.

Hydrophyllium ( $\left.h i-d r o-f i l^{\prime}-e-u m\right)[v \delta \omega \rho$, water; $\phi \hat{v} \lambda \lambda o v$, leaf]. In biology, one of the protective envelops of the nutritive zoöids in a colony of hydrozoa.

Hydrophyr (hi'-dro-fer) [ivis, water]. Brücke's name for a variety of peptone insoluble in alcohol. See Peptone.

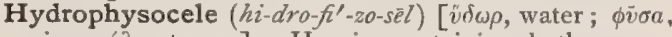
air; $\kappa \dot{\eta} \lambda \eta$, tumor]. Hernia containing both serous fluid and a gas.

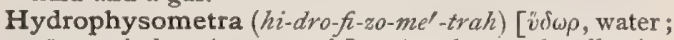
$\dot{\varphi} \sigma \sigma$, wind; $\mu \hat{\eta} \tau \rho a$, womb]. An abnormal collection of water, or other fluid, and gas, in the womb.

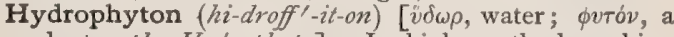
plant: pl., Hydrophyta]. In biology, the branching structure furnishing support to a colony of hydrozoa.

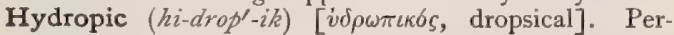
taining to dropsy

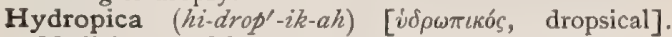
Medicines useful in dropsy; especially diuretic remedies.

Hydroplanula (hi-dro-plan'-u-lah) [hydra, a genus of hydrozoans; planula, a stage of the embryo]. In biology, an embryo hydrozoan between the planula and the tentaculated actinula.

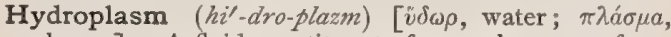
plasma]. A fluid constituent of protoplasm, or of any plasma.

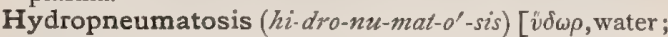
$\pi \nu \varepsilon v \mu a ́ \tau \omega \sigma \iota s$, inflation]. An abnormal or morbid collection of water, or other fluid, and air, within any of the tissues of the body. See, also, Hydropneumonia.

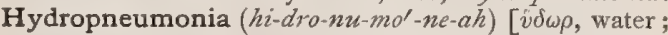
$\pi \nu \varepsilon u \mu \omega \nu$, the lung]. A disease thought to consist of a serous infiltration into the lung; pulmonary edema; also, an effusion within the pleura sometimes accompanying pneumonia.

Hydropneumopericardium (hi-dro-nu-mo-per-ik-ar'

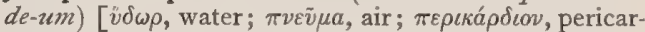
dium]. A morbid collection of air and water within the pericardium. It causes the clacking sound commonly known as the "water-wheel" sound.

Hydropneumothorax (hi-dro-nu-mo-tho'-raks) [viso, water; $\pi \nu \varepsilon \tilde{v} \mu a$, air ; $\theta \omega \rho a \xi$, thorax]. Air (or gas) and water (or serous effusion) in the pleural cavity.

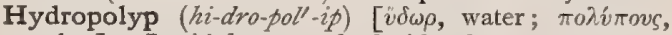
polyp]. In biology, a hydroid polyp; a nutritive zoöid of a hydrozoan colony.

Hydrops ( $\left.h i^{\prime}-d r o p s\right)$ [ $v \delta \rho \omega \psi$, dropsy]. Dropsy; an abnormal collection of fluid in a cavity or part of the body. See Anasarca. H. articuli, a watery effusion into the synovial cavity of a joint. $\mathbf{H}$. cerebri, hydrocephalus. H. fibrinosus, effusion into a joint, with fibrinous deposits. H. oculi. Same as Hydrophthalmia. H. paralyticus, that in paralyzed parts. H. renalis. See Hydronephrosis. H. spurius, from obstruction of the natural outlet of a secreting organ. $\mathrm{H}$. tubæ. Same as Hydrosalpinx, q. $v$. H. tubarum. See Hydrosalpinx. H., Tuberculous, a copious effusion into a joint from tuberculous affection of the synovial membrane. $H$. vesicæ felleæ, dropsy of the gall-bladder.

Hydroptic (hi-drop'-tik). Same as Hydropic.

Hydropyopneumothorax (hi-dro-pi-o-nu-mo-tho'-raks)

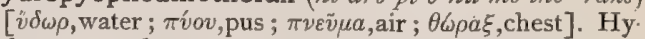
dropneumothorax, associated with the presence of pus.

Hydropyosalpinx ( $\left.h i-d r o-p i-o-s a l^{\prime \prime}-p i n g k s\right)$ [ $i \delta \omega \rho$, water;

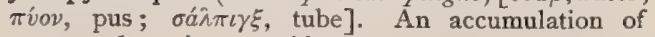
water and pus in an oviduct. 


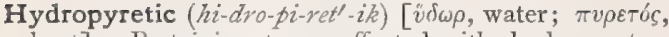
heat]. Pertaining to, or affected with, hydropyretos.

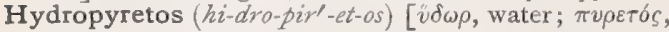
heat]. Sweating fever.

Hydroquinin (hi-dro-kwin'-in) [ $\nu \delta \omega \rho$, water; quina, Peruvian bark], $\mathrm{C}_{20} \mathrm{H}_{26} \mathrm{~N}_{2} \mathrm{O}_{2}$. An alkaloid obtained from cinchona, said to be an admirable antipyretic. Unof.

Hydroquinone (hi-dro-kwin'-ōn) [ $v \delta \omega \rho$, water; quina, Peruvian bark], $\mathrm{C}_{6} \mathrm{H}_{6} \mathrm{O}_{2}$. Quinol, a divalent phenol that results on boiling arbutin with dilute $\mathrm{H}_{2} \mathrm{SO}_{4}$, or from the oxidation of anilin. It crystallizes in monoclinic leaflets and hexagonal prisms, that melt at $169^{\circ}$ C. It is readily soluble in water, alcohol, and ether, and is valuable as an antipyretic, without producing injurious after-effects; it is also used as an antiseptic. Dose gr. xv-xx. Unof.

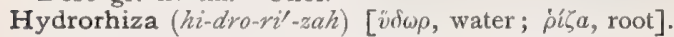
In biology, the disc of attachment of a Hydra or the homologous organs in other Hydrozoa.

Hydrorrhachiocentesis ( $h i-d r o r-a k-e-o-s e n-t e^{\prime}-s i s$ )

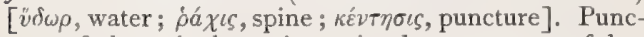
ture of the spinal meninges in the treatment of hydrorrhachis.

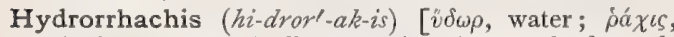
spine]. Dropsical effusion within the vertebral canal. H. interna, syringomyelia, $q . v$.

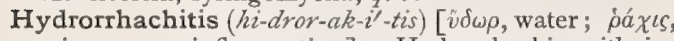
spine; $\iota \tau \iota s$, inflammation]. Hydrorrhachis with inflammation. See Spina bifida.

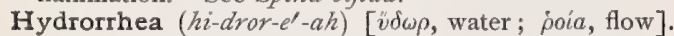
A flow of water. H. gravidarum, a condition occurring occasionally in the pregnant woman, in which there is a periodic discharge from the uterus of thin mucus that accumulates as a result of hypertrophy of the uterine glands with excessive secretion.

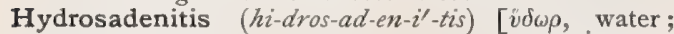

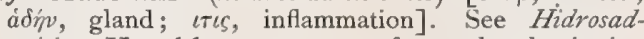
enitis. H. phlegmonosa, a furunculus beginning in a sweat-coil. It is also called Hydradenitis destruens suppurativa (Politzer), Acnitis (Barthélemy), and Folliculitis exulcerans (Lukasiewicz).

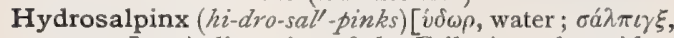
trumpet]. A distention of the Fallopian tube with a fluid substance, and its obstruction at the fimbriated extremity, caused by inflammation. It is frequently a result of gonorrhea.

Hydrosarca (hi-dro-sar'-kah). See Anasarca.

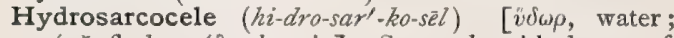
$\sigma a ́ \rho \xi$, flesh; $\kappa \dot{n} \lambda \eta$, hernia]. Sarcocele with dropsy of the tunica vaginalis testis, or with true hydrocele.

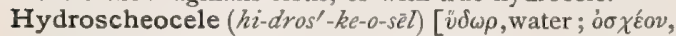
scrotum; $\kappa \eta \lambda \eta$, a tumor]. Dropsical hernia of the scrotum.

Hydrosoma (hi-dro-so'-mah) [ $[\| \delta \omega \rho$, water ; $\sigma \tilde{\omega} \mu \dot{a}$, body: pl., Hydrosomata]. In biology, the entire doublewalled body of a hydrozoön.

Hydrospermatocyst (hi-dro-sper'-mat-o-sist) [ $v \delta \omega \rho$, water; $\sigma \pi \varepsilon \dot{\varepsilon} \mu \alpha$, seed; $\kappa \hat{v} \sigma \tau \iota$, cyst]. A hydrocele whose fluid contains spermatozoa.

Hydrosphygmograph (hi-dro-sfig'-mo-graf) [vidw, water; $\sigma \phi v \gamma \mu \omega \delta$, pulse; $\gamma \rho a ́ \phi \varepsilon \iota \nu$, to write]. A sphygmographic apparatus, in which the registering device is actuated by the fluctuations of a body of water.

Hydrostatic, or Hydrostatics (hi-dro-stat'-ik, or -iks)

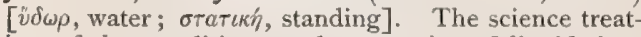
ing of the conditions and properties of liquids in a state of equilibrium. H. Test. See Birth.

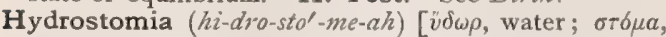
mouth]. Excessive excretion of water from the mouth.

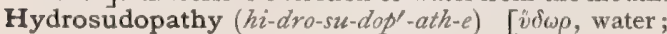

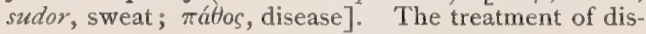

ease by sweating and the use of water internally or externally, or both.

Hydrosulphuric acid (hi-dro-sul-fu'-rik). See Acid.

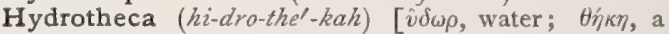
case : pl., Hydrotheca ]. In biology, a polyp-cell; the cuticular investment of a hydroid polyp, forming a cup-like receptacle allowing the protrusion of the distal moiety of the polypite.

Hydrotherapeutics ( $\left.h i-d r o-t h e r-a p-u^{\prime}-t i k s\right)$ [ $v \delta \omega \rho$, water; $\theta \varepsilon \rho a \pi \varepsilon v e w$, to heal]. That part of balneology treating of the hygienic use of water, and of its therapeutic application to the body. See,also, Bath and Aqua.

Hydrotherapy (hi-dro-ther'-ap-e). See Hydrotherapeutics.

Hydrothion (hi-dro-thi'-on) [ $\nu \delta \omega \rho$, water ; $\theta \varepsilon \tilde{\varepsilon} o v$, sulphur]. Hydrogen sulphid.

Hydrothionammonemia (hi-dro-thi-on-am-a-ne'-

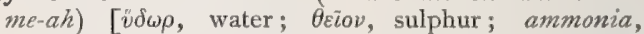
ammonia; $a^{\top} \mu a$, blood]. The presence of hydrosulphid of ammonium in the blood.

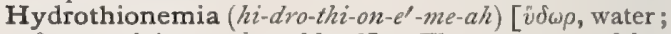
$\theta \varepsilon i o \nu$, sulphur; aipa, blood]. The presence of hydrogen sulphid in the blood; also, the train of morbid symptoms resulting therefrom.

Hydrothionuria (hi-dro-thi-on- $\left.u^{\prime}-r e-a h\right)[v \delta \omega \rho$, water; $\theta \varepsilon i o v$, sulphur; ovpov, urine]. Hydrogen sulphid in the urine.

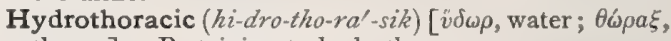
thorax]. Pertaining to hydrothorax.

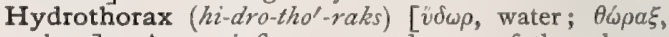
chest]. A non-inflammatory dropsy of the pleura, usually involving both sacs. H. purulentus. Synonym of Empyema.

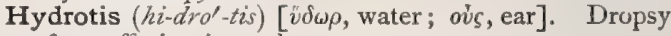
of, or effusion into, the ear.

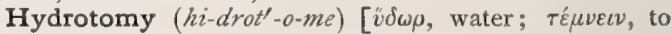
cut]. A method of dissecting certain tissues by the forcible injection of water into the arteries and capillaries, whereby the structures are separated.

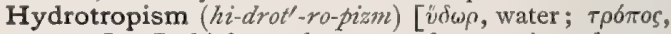
a turn]. In biology, that state of a growing plant or organ which causes it to turn either away from, or toward, moisture.

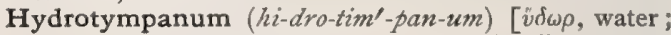
tympanum, the ear-drum]. Dropsical effusion into the cavity of the middle ear.

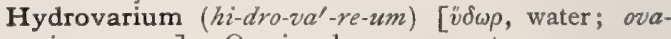
rium, ovary]. Ovarian dropsy, or cystoma.

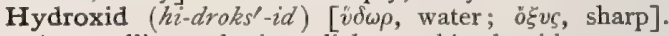
A metallic or basic radicle combined with one or more hydroxyl groups. Hydroxids may be regarded as formed from water $(\mathrm{HOH})$ by the substitution for one of its hydrogen atoms of a metal or basic radicle.

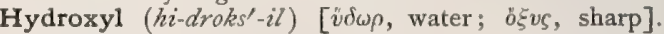
A compound radicle, $\mathrm{OH}$, that has never been isolated, but which is a factor in a vast number of chemic compounds. Thus, the oxygen bases are regarded as compounds of hydroxyl with electropositive atoms or radicles, $e . g$., sodium hydroxid, $\mathrm{NaOH}$. Water may be regarded as hydroxyl hydrid, $\mathrm{HOH}$.

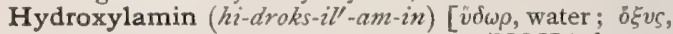
sharp; amin]. A basic substance $\left(\mathrm{NOH}_{3}\right)$ known only in solution in water or in combination with acids. It is prepared by passing nitric-oxid gas through a solution containing nascent hydrogen. The aqueous solution is colorless and odorless, with a strong alkaline reaction. Hydroxylamin hydrochlorid is recommended as a good substitute for chrysarobin in the treatment of skin-diseases.

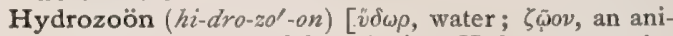
mal]. A cnidarian of the sub-class Hydrozoa, containing the orders Hydrida, Hydromedusa, Siphonophora. 


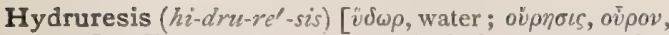
urine]. The passage of a relatively large proportion of water in the urine.

Hydruria (hi-dru'-re-ah) [iv $\omega \rho$, water; ovoov, urine]. Excessive excretion of water by the kidneys, with or without decrease in the amount of the solid constituents of the urine. The urine is pale, limpid, and of low specific gravity. The amount of water discharged in the twenty-four hours is enormously increased. The condition occurs most frequently in men, usually under twenty years of age.

Hydrurilic Acid (hi-dmu-ril'-ik). See Acid.

Hydrymenitis (hi-dri-men-i'-tis) $[\hat{v} \delta \omega \rho$, water; ium, membrane; $\iota \tau \iota \varsigma$, inflammation]. Any inflammation of a serous membrane or surface.

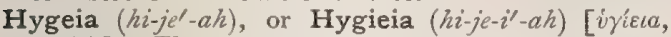
health]. The state or condition of health.

Hygiene $\left(h i^{\prime}-j e-\bar{e} n\right)$ [íyııvós, good for the health]. The science that treats of the laws of health in its broadest sense.

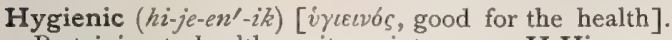
Pertaining to health, or its maintenance. H.Vinegar, a vinegar composed of oils of clove and lavender, each 4.0 ; oil of marjoram, 2.0 ; oil of benzoes, 50.0 ; spiritus vini, 500; concentrated acetic acid, I000.

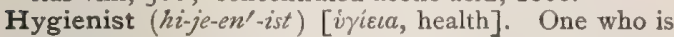
a student of, or an expert in, hygiene.

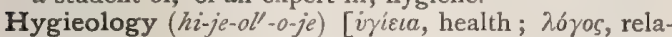
tion]. The science of health; hygiene.

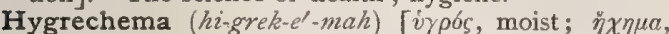
sound: pl., Hygrechemata]. The peculiar sound produced by a liquid, as heard upon mediate or immediate auscultation.

Hygrin ( $h i^{\prime}$-grin) [í $\gamma^{\prime} \rho{ }^{\prime}$, moist ; from its liquid form], $\mathrm{C}_{12} \mathrm{H}_{13} \mathrm{~N}$. A liquid, oily alkaloid, derived from coca $(q \cdot v)$. It has the power of strongly dilating the pupil, but has no anesthetic properties.

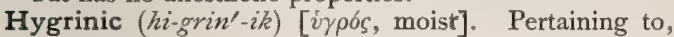
or composed of, hygrin. H. Ether, a substance of uncertain composition, said to have mydriatic properties. Unof.

Hygro- (hi'-gro-) [ v $\rho b \delta$, moist]. A prefix denoting moist or wet.

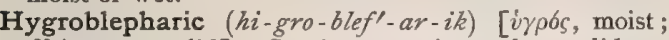
$\beta \lambda \varepsilon \phi a \rho o \nu$, eyelid]. Serving to moisten the eyelid, as a hygroblepharic duct.

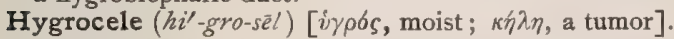
Same as Hydrocele.

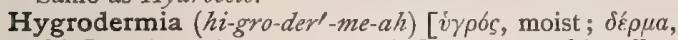
skin]. An edematous non-inflammatory skin-affection.

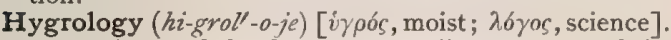
The science of the fluids, or so-called humors, of the body.

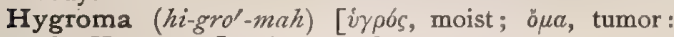
pl., Hygromata]. A serous bursa or cyst.

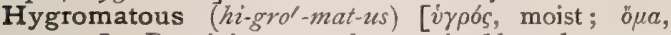
tumor]. Pertaining to, or characterized by, a hygroma.

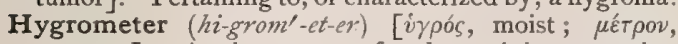
measure]. An instrument for determining quantitatively the amount of moisture in the air. This amount, constantly varying, is expressed in terms of the percentage required to saturate the air at the particular temperature observed.

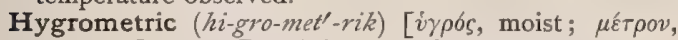
measure ]. I. Pertaining to hygrometry, or the quantitative determination of atmospheric moisture. 2. Readily absorbing water, as a hygrometric salt; hygroscopic.

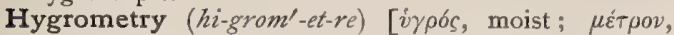
measure]. The measurement of the moisture of the air.

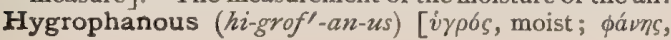

show]. In biology, applied to such plant-structures as are transparent when wet, but opaque when dry.

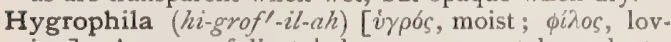
ing]. A genus of dicotyledonous gamopetalous plants. H. spinosa, is a shrub used in Ceylon and India as a diuretic in dropsy. Unof.

Hygrophobia (hi-gro-fo'-be-ah) [ijobss, moist; $\phi 6 \beta 30$, fear]. Insane dislike of water or of moisture.

Hygroplasm, or Hygroplasma ( $h i^{\prime}$-gro-plazm or hi-gro-

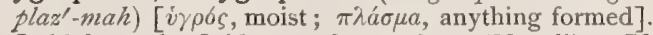
In biology, the fluid part of protoplasm (Nägeli). Cf. Stereoplasma.

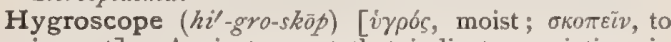
inspect]. An instrument that indicates variations in the moisture of the air.

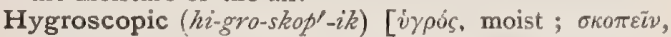
to see]. Having the property of absorbing moisture from the air.

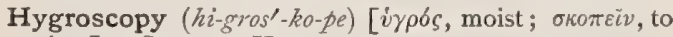
view]. Same as Hygrometry.

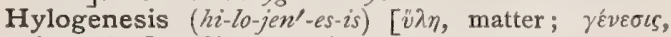
formation]. The formation of matter.

Hylogeny $\left(h i-l o j^{\prime}-e n-e\right)$. Same as Hylogenesis.

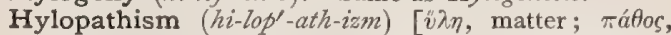
disease]. Any disease arising from defect or disorder of the body-substance.

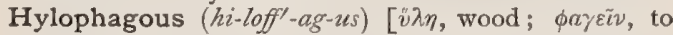
eat]. In biology, applied to certain animals that feed upon wood.

Hymen ( $\left.h i^{\prime}-m e n\right)$ [íu'v, membrane]. The fold of mucous membrane at the vaginal entrance. H., Imperforate, a congenital abnormality, the hymen not having an opening, and thus closing the vaginal outlet or inlet. H., Forms of: I. Bifenestrate, or hymen biforis, with two openings. 2. Bilobate, with two lobes. 3. Circular, with a small foramen. 4. Cribriform, with many holes. 5. Denticular, with a serrate edge. 6. Double (rare). 7. Fimbriate, with fringed edges. 8. Horseshoe, with its convexity downward. 9. Imperforate. Io. Normal. II. Semilunar, same as I0, or normal. 12. Hymen septus, divided across by a slit. 13. Hymen subseptus, covering only the anterior and posterior portions of the passage.

Hymenal ( $\left.h i-m e^{\prime}-n a l\right)$ [i $\mu^{\prime} v$, membrane]. Pertaining to the hymen. H. Tubercles. See Myrtiform Caruncles.

Hymenea (hi-men-e'-ah) [i $\mu h v$, membrane]. A genus of leguminous trees. H. courbaril, locust-tree, indigenous to tropical America; is a good arterial sedative and astringent in hemoptysis, hematuria, dysentery, etc. Dose of the fluid extract gtt. $\mathrm{x}-\mathrm{xx}$. This tree and others of the genus afford copal and animé. Unof.

Hymeniferous (hi-men-if'-er-us) [ín'nv, membrane ; ferre, to bear]. In biology, having a hymenium.

Hymenitis (hi-men-i'-tis) [i $\mu \dot{\eta} v$, membrane; $\iota \tau \iota$, inflammation ]. Inflammation of the hymen, or of any membranous structure.

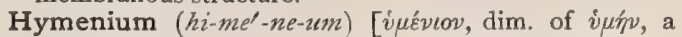
membrane: pl., Hymenia]. In biology, the sporebearing surface in fungi.

Hymenocallis (hi-men-o-kal'-is) [írív, membrane]. A genus of amaryllidaceous plants. H. rotata, grows in the southern U. S. This and other species afford bulbs that may be substituted for squill. Unof.

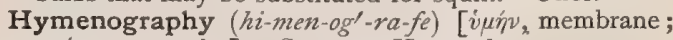

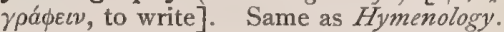

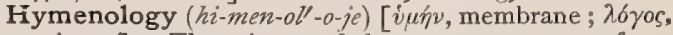
science ]. The science of the nature, structure, functions, and diseases of membranous tissue.

Hymenomalacia (hi-men-o-mal-a -se-ah) [i $[\mu \dot{\eta} \nu$, mem. 
brane; $\mu \alpha \lambda \alpha \kappa i a$, softness]. An abnormal softening of membranous tissues.

Hymenomycetes (hi-men-o-mi-se'-tes) [írín, membrane; $\mu \nu \kappa \eta s$, fungus]. An order of fungi having a hymenium or umbrella. All the edible mushrooms belong to this class.

Hymenoptera (hi-men-op'-ter-ah) [íunv, membrane; $\pi \tau \varepsilon \rho \delta \nu$, wing]. An order of insects distinguished by two pairs of membranous wings. It includes ants, bees, wasps, ichneumons, flies, etc.

Hymenopterous (hi-men-op'-ter-us) [i $\mu \eta \eta v$, membrane ; $\pi \tau \varepsilon \rho \sigma v$, wing]. In biology, applied to insects having membranous wings.

Hymenorrhaphy (hi-nen-or'-a-fe) [ijunv, hymen; $\dot{\rho} \alpha \phi \dot{n}$, suture]. Closure, more or less complete, of the vagina by suture at the hymen.

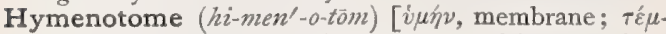
$\nu \varepsilon \varepsilon v$, to cut]. A cutting instrument used in operations upon membranes.

Hymenotomy (hi-men-ot'-o-me) [نuńv, membrane; TÉ $\mu v \varepsilon \nu \nu$, to cut]. I. Surgical incision of the hymen. 2. Dissection or anatomy of membranes.

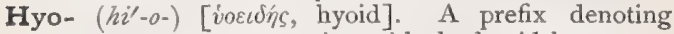
attachment to or connection with the hyoid bone.

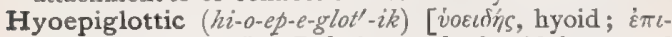
$\gamma \lambda \omega \tau$ is , epiglottis]. Relating to the hyoid bone and the epiglottis.

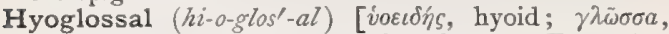
tongue]. Pertaining to the hyoglossus. Extending from the hyoid bone to the tongue.

Hyoglossus (hi-o-glos'-us). See Muscles, Table of.

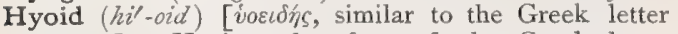
upsilon]. Having the form of the Greek letter upsilon. H. Bone, a bone situated between the root of the tongue and the larynx, supporting the tongue and giving attachment to its muscles. See Bones, Table of. H. Fossa. See Fossa.

Hyoplastron (hi'-o-plas-tron). See Hyosternal.

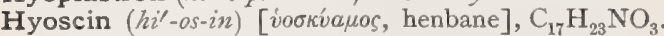
$A$ viscous liquid found in henbane; it is a good soporific and valuable mydriatic. Dose, $\frac{1}{1 \frac{1}{3} 0}$ to $\frac{1}{20}$ of a grain. See Hyoscyamus.

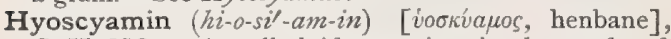
$\mathrm{C}_{17} \mathrm{H}_{23} \mathrm{NO}_{3}$. An alkaloid occurring in the seeds of Hyoscyamus niger, in Atropa belladonna, and in Datura stramonium. It is isomeric with atropin, and identical with daturin and duboisin. It crystallizes in shining needles, and melts at $108.5^{\circ} \mathrm{C}$. It is a mydriatic, narcotic, and sedative. Dose, gr. $\frac{1}{1} \frac{1}{3}$, gradually and cautiously increased, even to I grain. See Hyoscyamus.

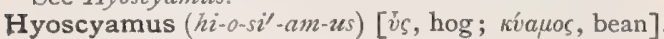
Henbane. The older leaves of $H$. niger. It contains an alkaloid, hyoscyamin, isomeric with and similar to atropin; also, a derivative, hyoscin, $\mathrm{C}_{17} \mathrm{H}_{23} \mathrm{NO}_{3}$. It is an excellent narcotic, calmative, and hypnotic, less irritating than belladonna and stramonium, and is useful in mania and the delirium of fevers. Hyoscyamin is useful whenever atropin is indicated. It is a powerful but uncertain mydriatic. H., Abstract. Dose gr. iij-v. Unof. H., Ext. (B. P.). Dose gr. ij-v. H., Ext., Alcoholic (of uncertain strength), Dose gr. j. H., Ext., Fld. Dose $\eta_{v-x x}$. H., Succus (B. P.) Dose $3 \mathrm{ss}-\mathrm{j}$. H., Tinct., I 5 per cent. in strength. Dose $3 \mathrm{j}-\mathrm{iv}$; as a hypnotic $\bar{\xi} \mathrm{ss}-\mathrm{j}$. Hyoscyamin. sulph. $\left(\mathrm{C}_{17} \mathrm{~N}_{23} \mathrm{NO}_{3}\right) \mathrm{N}_{2} \mathrm{SO}_{4}$. Dose, hypodermatically, gr. $\frac{1}{10}-\frac{1}{65}$; by the mouth gr. $1 / 4-\mathrm{j}$. Injectio hyoscyamin hypodermicæ. Strength I in I20. Dose mj-iv. Hyoscin. hydrobrom. Unof. Dose, gr. $\frac{1}{100} \frac{1}{50}$. Injectio hyoscin. hydrobromat. hypodermicæ. $1 / 2$ per cent. Dose $m j-i j$.

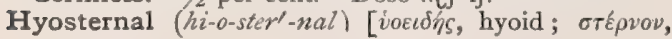

sternum]. I. Relating to the hyoid bone and the sternum. 2. In biology, the second lateral piece of the plastron of a turtle; it is also called Hyoplastron.

Hyp (hip) [iró, under]. A popular name for hypochondriasis, or persistent depression of spirits; hypo.

Hypacousis, Hypacusia, Hypacusis, or Hypakusis

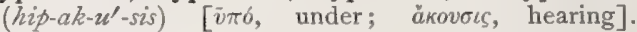
Hardness of hearing from defect of the auditory nerve.

Hypæsthesia (hip-es-the'-ze-ah). See Hypesthesia.

Hypalbuminosis (hip-al-bu-min-o'-sis) [i $[i o$, under; albumen]. Morbid diminution in the proportion of albumin in the blood. It is caused by anything that gives rise to an increased consumption of albumin on the part of the organism.

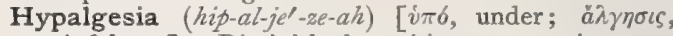
painfulness]. Diminished sensitiveness to pain.

Hypalgia (hip-al'-je-ah) [ijó, under; ă $\lambda$ ros, pain]. Slight or moderate pain; diminished sensibility to pain.

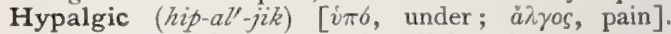
Slightly painful; experiencing slight pain.

Hypanisognathism (hip-an-is-og-nath-izm) [ítro, under; àvioos, unequal, uneven; rvátos, the jaw]. In biology, a lack of correspondence between the teeth of the opposite jaws. Cf. Anisognathism and Epanisognathism.

Hypanisognathous (hip-an-is-og'-na-thus) [ijó, un-

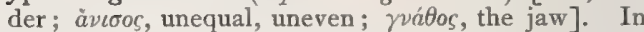
biology, having the upper teeth broader than the lower.

Hypanthium (hip-an'-the-um) [ító, under; $2 v \theta 0 s$, a flower: pl., Hypanthia]. In biology, an enlarged receptacle.

Hypanthodium (hip-an-tho'-de-um [imó, under; ảvOos, a flower; Eidos, form]. See Synconium.

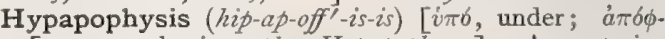
[vous, apophysis : pl., Hypapophyses]. An anterior or ventral apophysis from the centrum of a vertebra in the human skeleton; the atlas is held by some to have an hypophysis, which is blended with the ring of that vertebra.

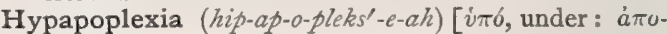
$\pi \lambda \eta \xi i \alpha$, apoplexy]. A slight apoplexy.

Hypatonia (hip-at-o'-ne-ah) [iٓto, under; árovía, atony]. A slight amount of atony.

Hypemia (hip-e'-me-ah). See Hyphemia.

Hyper- (hi'-per-) [írép, above]. A Greek prefix signifying above, beyond, or excessive.

Hyperacidity (hi-per-as-id'-it-e) [ité $\rho$, over; acidum, acid]. Excess of acidity.

Hyperacousis, Hyperacusia, Hyperacusis, or $\mathrm{Hy}$ -

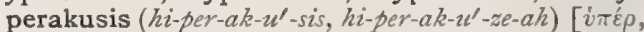
over; ákovous, hearing]. Morbid acuteness of the sense of hearing; auditory hyperesthesia. Also, a highly developed capability of the discernment of pitch and timbre of musical sounds.

Hyperactivity (hi-per-ak-tiv'-it-e) [ijré, over; agere, to do]. Excessive or abnormal activity.

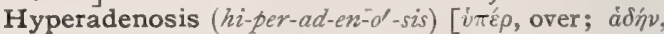
gland; v6ros, disease]. Enlargement of the lymphglands; Hodgkin's disease.

Hyperæmia (hi-per-e-me-ah). See Hyperemia.

Hyperæsthesia (hi-per-es-the'-ze-ah). See Hyperesthesia.

Hyperakusis (hi-per-ak-u'-sis). See Hyperacousis.

Hyperalbuminosis (hi-per-al-bu-min-o'-sis) [iné $\rho$, over; albumen, albumin ]. An increase in the amount of albumin in the blood, which may be either relative or absolute. It is often due to the excessive ingestion of albuminous food, with insufficient exercise.

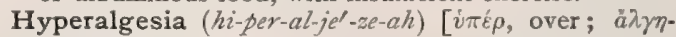
oıs, pain]. Excessive sensibility to pain.

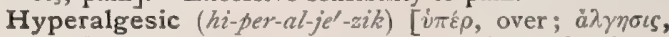
pain]. Exhibiting or appertaining to hyperalgesia. 


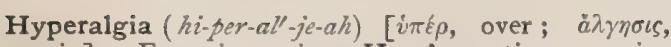
pain]. Excessive pain. H., Acoustic, excessive hyperakusis.

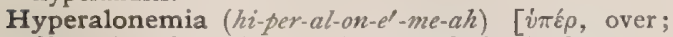
$\hat{a} \lambda s$, salt; aipa, blood]. Excess of blood-salts.

Hyperamnesia (hi-per-am-ne'-zl-ah). See Hypermnesia.

Hyperanabolism (hi-per-an-abl-o-lizm) [ijkp, over; $a \nu a \beta a ́ \lambda \lambda \varepsilon v \nu$, to build up]. Hypertrophy or excess of construction of a tissue or part.

Hyperanthraxis (hi-per-an-thraks'-is). Synonym of Asiatic Cholera.

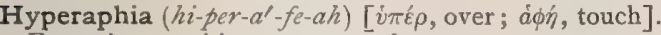
Excessive sensitiveness to touch.

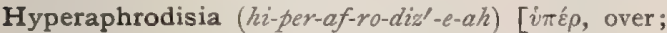

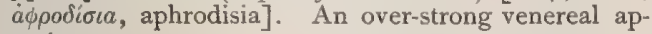
petite.

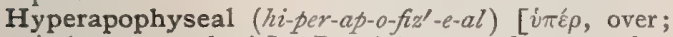

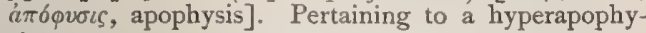
sis.

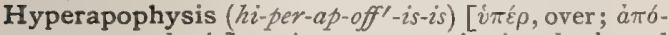
ovoı, apophysis]. A process projecting backward from a neural spine

Hyperarthritis (hi-per-arth-ri'tis) [ijé $\rho$, over; ă $\rho \rho \rho \nu$, joint; $\iota \tau \iota \zeta$, inflammation]. Severe arthritis.

Hyperasthenia (hi-per-as-the'-ne-ah) [ย่ré, over;

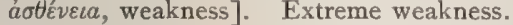

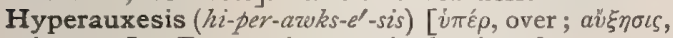
increase]. Extreme increase in the size of a part.

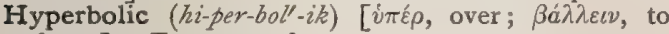
throw]. Exaggerated.

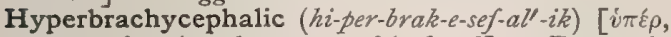
over; $\beta \rho a \chi v ́ s$, short; $\kappa \varepsilon \phi a \lambda \eta$, head]. Extremely brachycephalic.

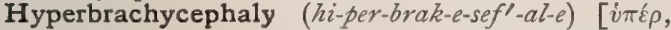

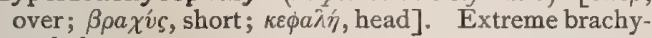
cephaly.

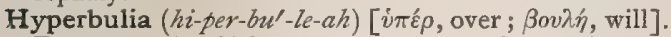
Exaggerated wilfulness or obstinacy; abnormal or insane development of will-power.

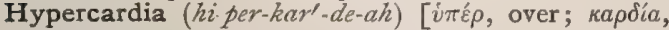
the heart]. Cardiac hypertrophy.

Hypercatabolism (hi-per-kat-ab'-o-lizm) [ijé $\rho$, over;

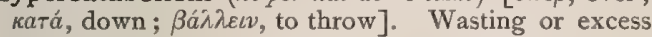
of destruction of a tissue or part.

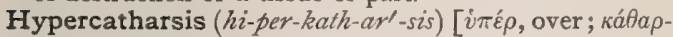

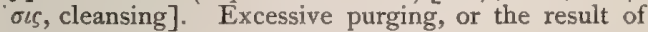
too free use of cathartic medicines.

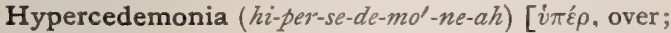
$\kappa \eta \delta \varepsilon \mu o v i \alpha$, anxiety]. 1. Extreme anxiety or grief. 2. Excessive care on the part of the physician.

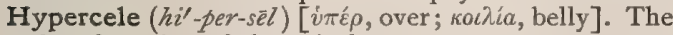
dorsal portion of the epicele.

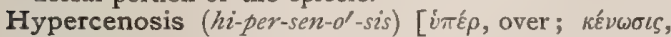
evacuation]. Excessive evacuation, as by purging or bleeding.

Hyperchlorhydria (hi-per-klor-hi'-dre-ah) [vंré , over;

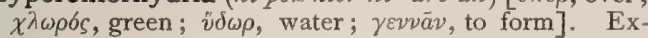
cess of hydrochloric acid in the gastric secretion. Rossbach's Disease. See Diseases, Eponymic, Table of.

Hypercholesteremia (hi-per-ko-les-ter-e'-me-ah) [inḱp, over; $\chi \propto \lambda \eta \dot{n}$, bile; $\sigma \tau \varepsilon \hat{\varepsilon} \alpha \rho$, fat; $\alpha \bar{\imath} \mu a$, blood]. Excess of cholesterin in the blood.

Hypercholia ( $h i$-per-ko'-le-ah) [íté $\rho$, over; $\chi o \lambda \dot{n}$, bile]. An excessive secretion of bile.

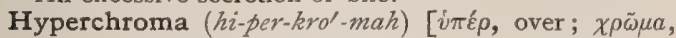
color]. The excessive formation of the pigment of the skin, as in phthiriasis or syphilis.

Hyperchromatemia (hi-per-kro-mat-e'-me-ah) [i $\pi \varepsilon \varepsilon^{\prime}$, over; $\chi \rho \tilde{\omega} \mu a$, color; $a^{\top} \mu a$, blood]. An increase in the color of the blood; excess of coloring-matter in the blood.
Hyperchromatic (hi-per-kro-mat'-ik) [i $\pi \varepsilon \rho^{\prime}$, over : $\chi \rho \tilde{\omega} \mu a$, color]. Exhibiting hyperchroma.

Hyperchromatism (hi-per-kro'-mat-izm). Same as Hyperchroma.

Hyperchromatosis (hi-per-kro-mat-o'-sis) [ité $\rho$, over; $\chi \rho \bar{\omega} \mu \alpha$, color]. Excessive pigmentation, as of the skin. Hypercinesia (hi-per-sin-e'-ze-ah). See Hyperkinesia.

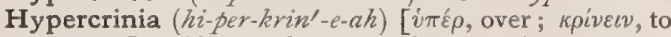
separate]. Abnormal or excessive secretion.

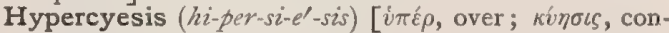
ception]. Superfetation.

Hypercyrtosis (hi-per-sir-to'-sis) [ité $\rho$, over; $\kappa \hat{\imath} \rho \tau \omega \sigma \iota$, curvature]. Extreme curvature, as of the back or a limb.

Hyperdactylia (hi-per-dak-till-e-ah) [ivtép, over;

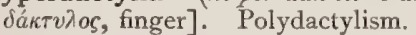

Hyperdermatosis [hi-per-der-mat-o'-sis] [vंtre $\rho$, over; $\delta \varepsilon ́ p \mu \alpha$, skin]. Hypertrophy of the skin.

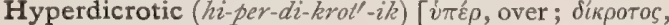
a double beat]. Affected with marked or delayed dicrotism; pertaining to the pulse when the pulsecurve shows the aortic notch below the base-line.

Hyperdicrotism (hi-per-dik'-rot-izm) [ijḱ, over; dikpotos, a double beat]. Strongly marked or excessive dicrotism.

Hyperdistention (hi-per-dis-ten'-shun) [i $\pi \dot{\varepsilon} \rho$, over ; distendere, to stretch]. Forcible or extreme distention.

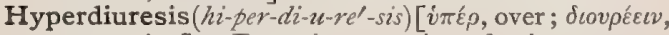
to pass urine]. Excessive secretion of urine.

Hyperdynamia (hi-per-di-nam'-e-ah) [inkp, over; divvaus, energy]. Excessive strength or exaggeration of nervous or muscular function.

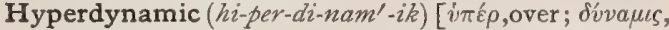
energy]. Pertaining to, or marked by, hyperdynamia.

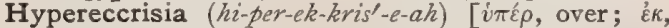
out; крivev, to separate]. Excessive excretion.

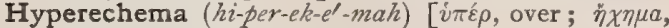
sound: pl., Hyperechemata]. A normal sound abnormally exaggerated.

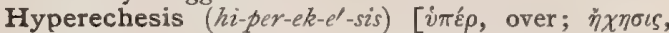
sound]. Abnormal loudness of voice.

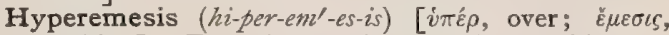
vomiting]. Excessive vomiting. H. gravidarum. See Morning Sickness.

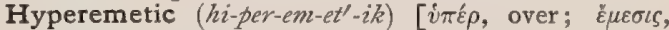
vomiting]. Pertaining to, or characterized by, excessive vomiting.

Hyperemia (hi-per-e'-me.ah) [itre , over; aiua, blood]. A condition of plethora or congestion. H., Active, caused by an excessive supply of blood. H., Passive, caused by an impediment to the removal of the blood. $H$. of the Dental Pulp, a condition due to the overfilling of the vessels of the pulp with blood, the resulting pain being sharp and lancinating, and paroxysmal in character, especially in its earlier stages.

Hyperencephalus (hi-per-en-sef'-al-us) [itré, over;

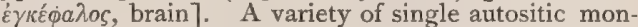
sters of the species exencephalus, in which there is the same deformity as in podencephalus, but in a higher degree. There is often hydrocephalus, and the body is likely to be deformed in other regions.

Hyperenterosis (hi-per-en-ter-o'-sis) [ítép, over; Ev

Hyperephidrosis (hi-per-ef-hid-ro'-sis) [íré, over; $\dot{\varepsilon} \phi i \delta \rho \omega \sigma \iota s$, perspiration ]. Excessive or long-continued sweating.

Hypererethisia, or Hypererethism (hi-per-er-eth-iz'

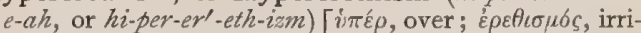
tation]. Excessive nervous or mental irritability.

Hypererythrocythemia (hi-per-er-ith-ro-si-the'-me-ah)

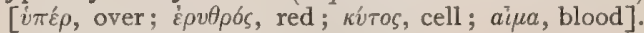
Excess of red corpuscles in the blood. 
Hyperesophoria (hi-per"es-o-fo'-re-ah), See Heterophoria.

Hyperesthesia (hi-per-es-the'-ze-ah) [ivé $\rho$, over; ai $\sigma$ $\theta \eta \sigma \iota s$, sensation]. Excessive or exalted sensibility of the skin. It may be symptomatic or idiopathic.

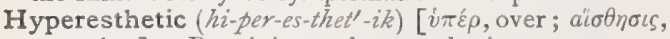
sensation]. Pertaining to hyperesthesia.

Hyperexophoria (hi-per-eks-o-fo'-re-ah). See Heterophoria.

Hyperfecundation ( $\left.h i-p e r-f e \cdot k u n-d a^{\prime}-s h u n\right)$. Same as Superfecundation.

Hyperflexion (hi-per-flek'-shun) [viḱ, over; flexio, a bending]. Overflexion, as of a limb. This is one method of treating aneurysm.

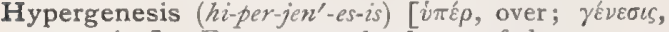
generation]. Excess or redundancy of the parts or organs of the body. It may be normal, as in the increase of the tissue of a muscle; or abnormal, as seen in monstrosities. Also, an excessive production of the elements of a tissue or organ.

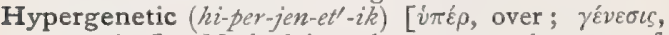
generation]. Marked by enlargement or increase of size. See also Teratism.

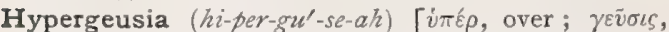
taste]. Abnormal acuteness of the sense of taste.

Hyperglobulia (hi-per-glo-bu'-le-ah) [i $\pi \varepsilon \rho$, over; globus, a ball]. Polycythemic plethora. An abnormal increase of the red blood-corpuscles; hypererythrocythemia.

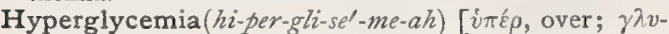
kús, sweet; alpa, blood]. Excess of sugar in the blood.

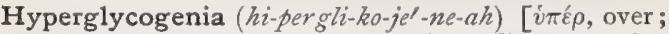

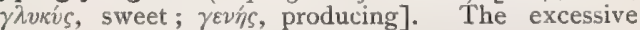
production of glycogen.

Hyperhidrosis, or Hyperidrosis ( $h i-p e r-h i d-r o '-s i s$, or

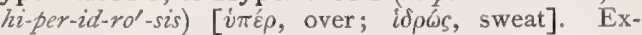
cessive sweating. A functional disorder of the sweatglands marked by excessive secretion. It may be general or local.

Hyperhydremia (hi-per-hi-dre'-me-ah) [ijé $\rho$, over ; $v \delta \omega \rho$, water; ai $\mu a$, blood]. Excess of water in the blood.

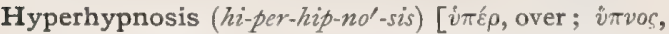
sleep]. Excessive or frequent drowsiness and sleep.

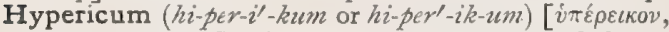
"under heath" "]. St. John's wort; a genus of plants, mostly herbs or shrubs, with a resinous juice. $\mathbf{H}$. perforatum, one of the commonest of the 160 species, has styptic, stimulant, and diuretic properties, but is now used mainly in domestic practice. Dose of the ext., gr. $\mathrm{x}-\mathrm{xx}$; of the fld. ext., $z \mathrm{j}-\mathrm{ij}$. Unof.

Hyperideation ( $h i-p e r-i-d e-a^{\prime}-s h u n$ ) [ $v^{\prime} \varepsilon \dot{\varepsilon} \rho$, over ; idea, idea]. Excessive or morbid mental activity.

Hyperidrosis (hi-per-id-ro'-sis). See Hyperhidrosis

Hyperino-epithelioma ( $h i-p e r^{\prime}-i n-o-e p-i t h-e-l e-o^{\prime}-m a h$ )

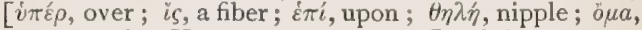
tumor: pl., Hyperino-epitheliomata]. Scirrhous carcinoma with an abundance of fibrous elements.

Hyperinosemia (hi-per-in-o-se'-me-ah) [itrép, over; is, fiber; alua, blood]. An exaggerated tendency to the formation of fibrin in the blood.

Hyperinosis (hi-per-in-o'-sis) [itrep, over; is, muscle]. I. Over-activity of the muscular fiber. 2. Abnormal increase in the fibrin-factors in the blood; hyperinosemia.

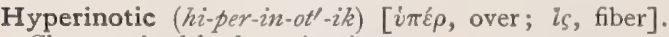
Characterized by hyperinosis.

Hyperinvolution (hi-per-in-vo-lu'-shun) 「int $\rho$, over ; involvere, to roll around]. An extreme diminution in size of the uterus, due to abnormally excessive involution occurring after pregnancy.

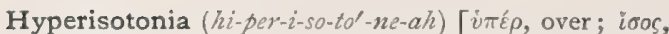
equal; $\tau 6 \nu 0 s$, tone ]. Unusual equality of tone or tension; applied to muscles.

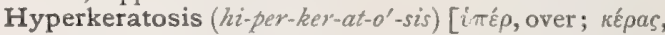
horn, cornea]. Hypertrophy of the cornea either in extent or thickness.

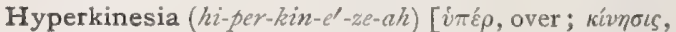
energy]. I. Any exaggerated spasm or muscular contraction. 2. Excessive irritability. 3. Impulsive insanity.

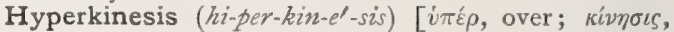
energy]. 1. See Hyperkinesia. 2. A disease or diseased condition marked by hyperkinesia.

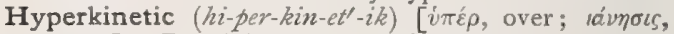
energy]. Pertaining to, or marked by, hyperkinesia. Hyperlactation (hi-per-lak-ta'-shun) [imép, over; lactare, to give milk]. Prolongation of lactation beyond the ninth month. If persisted in, it produces an exhausted physical condition of the mother known as Tabes lactealis. This condition is marked by anemia, with cramp-like pains of the upper extremities when the child is put to the breast.

Hyperleukocythemia ( $\left.h i-p e r-l u-k o-s i-t h e^{\prime}-m e-a h\right)[i \pi \varepsilon \rho$,

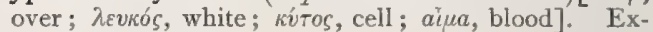
cess in the proportion of white cells in the blood; leukocythemia.

Hyperleukontemia (hi-per-lu-kon-te'-me-ah) [ijép, over; $\lambda \varepsilon v \kappa \delta ́ v$, albumin; aija, blood]. Increase in the albuminous elements of the blood.

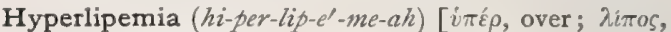
fat; ai $\mu a$, blood]. Excess of fat in the blood; lipemia.

Hyperlithuria (hi-per-lith-u'-re-ah) [ijép, over; $\lambda i \theta o s$, stone; ovoov, urine]. Excess of lithic acid in the urine. Same as Lithuria.

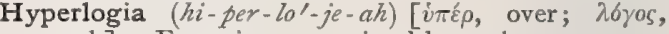
speech]. Excessive or maniacal loquacity.

Hyperlymphia (hi-per-limf'-e-ah) [ijé $\rho$, over; lympha, water]. An increase in the amount of lymph in the body.

Hypermastia ( $h i$-per-mas'-te-ah) [i $\pi \varepsilon \rho$, over; $\mu a \sigma \tau \delta s$, breast]. Excessive development or hypertrophy of the mammary gland, which remains normal in structure.

Hypermetamorphosis (hi-per-met-am-or-fo'-sis) [ijké, over; $\mu \varepsilon \tau \alpha \mu \delta \rho \phi \omega \sigma \iota \varsigma$, a transformation ]. In biology, applied to insects that undergo transformation more completely or having more stages than ordinary.

Hypermetropia (hi-per-me-tro'-pe-ah). Same as $H y$ peropia, $q . v$.

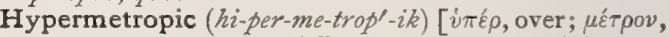
measure; $\omega \psi$, eye]. Affected with, or pertaining to, hypermetropia. H. Disc. See Disc.

Hypermnesia, or Hypermnesis (hi-perm-ne'-ze-ah, or hi-perm-ne'-sis) [i $\pi \varepsilon \hat{\varepsilon} \rho$, over; $\mu \nu \tilde{\eta} \sigma \iota \varsigma$, memory]. Abnormal exaltation of the power of memory.

Hypermotility (hi-per-mo-til'-it-e) [i $\pi \varepsilon \rho$, over; motilis, motile]. Excessive action. H., Gastric, excessive churning action of the gastric walls, often accompanied with hyperacidity due to increased secretion of $\mathrm{HCl}$.

Hypernervia (hi-per-ner'-ve-ah). See Hyperneuria.

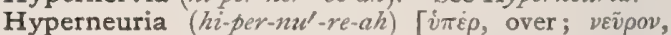
nerve]. Excessive nerve-action.

Hypernidation (hi-per-nid-a'-shun). See Supernidation.

Hypernea (hi-per-ne'-ah) or Hypernoia (hi-per-

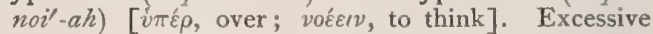
or abnormal mental activity; also, the uncontrolled and incongruous activity of the imagination in some cases of insanity.

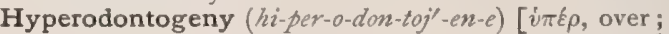
ódoís, tooth; $\gamma \in \nu \nu \tilde{\alpha} \nu$, to beget]. The phenomenon of 
a third dentition late in life. It is supposed to be due to the development of one or more superfluous toothgerms that have remained dormant.

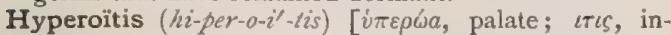
flammation ]. Inflammarion of the palate.

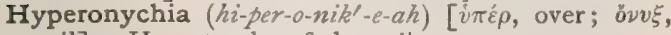
nail]. Hypertrophy of the nails.

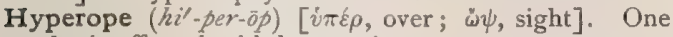
who is affected with hyperopia.

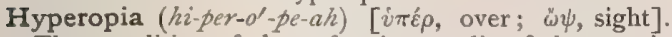
That condition of the refractive media of the eye in which, with suspended accommodation, the focus of parallel rays of light is behind the retina; it is due to an abnormally short antero-posterior diameter of the eye, or to a subnormal refractive power of its media. H., Absolute, that which cannot be corrected completely by accommodation, so that there is indistinct vision even for distance. H., Axial, that due to abnormal shortness of the antero-posterior diameter of the eye, the refractive power being normal. H., Facultative, that which may be corrected by the accommodation, so that there is distinct vision at a distance. H., Latent, that part of the total that cannot be overcome by the accommodation, or the difference between the manifest and the total hyperopia. $\mathbf{H}$., Manifest, that which the accommodation can overcome, or that corrigible by a convex glass aided by the accommodation. H., Relative, a high hyperopia in which distinct vision is possible only when excessive convergence is made. H., Total, the entire hyperopia, both latent and manifest.

Hyperorthognathy (hi-per-or-thog'-na-the) $[i \pi \varepsilon \rho$, over;

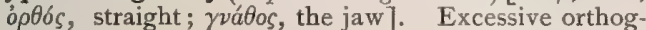
nathy; the condition of having a cranial index greater than $91^{\circ}$

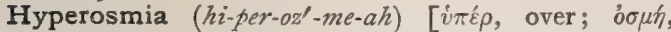
smell]. An abnormal or morbidly acute sense of smell; also, the presence of olfactory illusions.

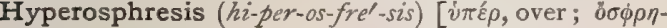

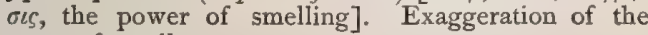
serise of smell.

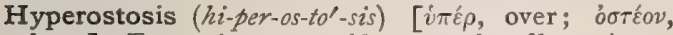
bone]. Exostosis or general hypertrophy of bony tissue.

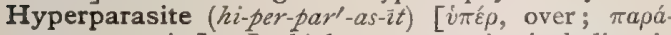

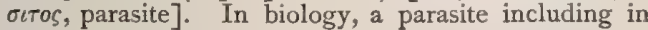
itself another parasite.

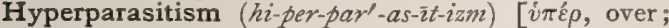

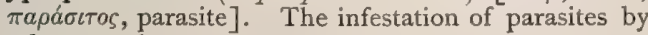
other parasites.

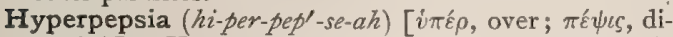
gestion]. Hayem's term for a form of dyspepsia characterized by an excess of chlorids in the gastric juice, without an excess of free hydrochloric acid.

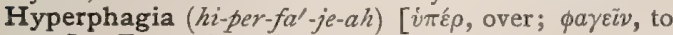
eat]. Excess in eating. See Butimia.

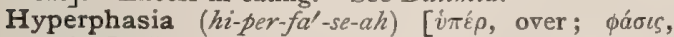
saying]. Hyperlogia; insane volubility; lack of control over the organs of speech.

Hyperphoria (hi-per-fo'-re-ah). See Heterophoria.

Hyperphrasia (hi-per-fra'-ze-ah) [ité $\rho$, over; $\phi \rho a ́ \sigma \iota$, utterance]. The incoherent and exaggerated utterance of an insane person.

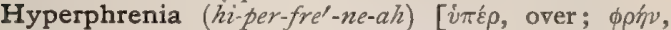
mind]. Passionate mental exaltation of the insane.

Hyperphysemia (hi-per-fi-ze'-me-ah) [i்ḱ $\rho$, over; $\phi \tilde{v} \sigma \alpha$, air; ai $\mu \alpha$, blood]. Excess of gases in the blood, or the abnormal conditions associated with such excess.

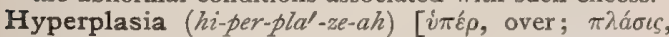
moulding]. The excessive deposit or augmentation of the elements of the tissue composing an organ.

Hyperplastic (hi-per-plas'-tik) [írép, over; $\pi \lambda a \sigma \tau \iota k o ́ s$, fit for moulding]. Pertaining to hyperplasia.
Hyperplerosis ( hi-per-ple-ro'-sis) iviḱ, over; $\pi \lambda \dot{n} \rho \omega \sigma \iota s$, fulness]. Excessive repletion or fulness.

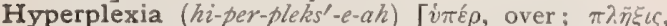
stroke]. I. Ecstacy. 2. Melancholia with stupor.

Hyperpnea, or Hyperpnoia (hi-per-pne'-ah, or hi-per

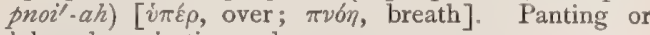
labored respiration; dyspnea.

Hyperporosis (hi-per-po-ro'-sis) [ité $\rho$, over; $\pi \omega \rho \omega \sigma \iota$, cementing or uniting]. An excessive formation of callus in the reunion of fractured bones.

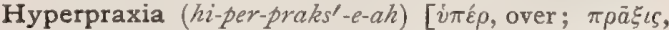
exercise]. The excessive restlessness of movement characterizing certain forms of mania.

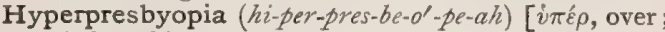

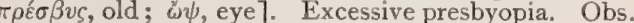

Hyperpselaphesia (hi-per-sel-af-e'-ze-ah) [itép, over; $\psi \eta \lambda a ́ \phi \eta \sigma \iota s, t o u c h]$. Abnormal increase of tactile sensibility.

Hyperpyretic (hi-per-pi-ret'-ik) [ijé $\rho$, over; $\pi \tilde{v} \rho$, fire] Pertaining to hyperpyrexia.

Hyperpyrexia (hi-per-pi-reks'-eحh) [ivép, over; $\pi \vec{v} \rho$, fire; $\chi^{\varepsilon} \iota \nu$, to have]. A condition marked by exces sively high temperature or aggravated febrile symptoms.

Hypersarcoma, or Hypersarcosis (hi-per-sar-ko'-ma,

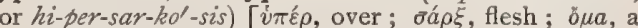
tumor]. I. Excessive granulation, fungesity, or proudflesh. 2. Obesity; hypertrophy.

Hypersecretion (hi-per-se-kre'-shun) [ijép, over; secretio, a secreting]. Excessive secretion.

Hypersomnia (hi-per-som'-ne-ah) [itíp, over; somnus, sleep]. Excessive sleep.

Hyperspasmia (hi-per-spaz'-me-ah). Synonym of Convulsions.

Hypersplenia (hi-per-sple'-ne-ah). See Splenomegalia.

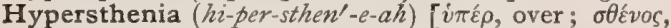
strength]. A condition of exalted strength or tone of the body.

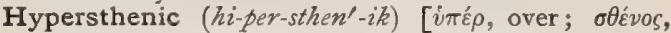
strength]. Characterized by hypersthenia.

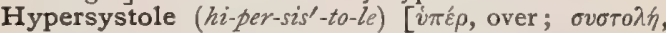
systole]. An excessively strong systole.

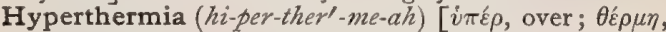
heat]. Excessive elevation of temperature.

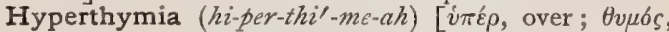
mind]. I. Mental hyperesthesia; morbid over-sensitiveness. 2. Vehement cruelty or foolhardiness as a symptom of mental disease. 3. Moral insanity.

Hypertonia (hi-per-to'-ne-ah) [itrép, over; $\tau 6 v o s$, tone]. I. Excess of muscular tonicity. 2. Increased intraocular tension.

Hypertonic (hi-per-ton'-ik) [ijḱ $\rho$, over; tóvos, tone]. Characterized by hypertonia.

Hypertrichiasis (hi-per-trik-i'-as-is). See Hirsuties.

Hypertrichosis (hi-per-trik-o'-sis). See Hirsuties.

Hypertromos (hi-per'-tro-mos) [i $\tilde{\varepsilon} \varepsilon \rho$, over; $\tau \rho \delta \mu \rho \varsigma$, tremor]. Excessive tremor or fear.

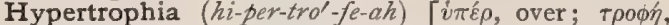
nourishment]. Same as Hypertrophy. H. cordis, hypertrophy of the heart.

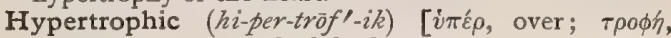
nourishment]. Marked by hypertrophy or excessive size.

Hypertrophy ( $h i$-per'-tro-fe) $[i \pi \varepsilon \rho$, over; $\tau \rho \circ \phi \eta$, nourishment]. This word etymologically denotes simply over-nourishment, but it has unfortunately become synonymous with excessive growth or size of an organ or part (auxesis), whether this is due to over-nourishment, over-use, or to any other condition. H., Cardiac may follow dilatation of the heart, or be caused by valvular disease, diseased condition of the aorta, diseases of the kidneys and other distant organs, by constitutional disease, by excessive use of tobacco 
and of some drugs, or excessive muscular action. It is attended with violent action of the heart, increase in the cardiac area of dulness and increased arterial pressure, headache, vertigo, dyspnea, palpitation, and pain in the heart. H., Compensatory, that following dilatation of the heart, or obstructive or regurgitant valvular disease, and produced by the efforts of that organ to make good the deficiency resulting from failing cardiac power. Let the circulation be restored, and the previous distressing symptoms will disappear. H., Concentric, increase in the thickness of the cardiac walls, without increase in the size of the organ, but with diminution in the capacity of its chambers. H., Excentric, cardiac hypertrophy, with dilatation. $\mathbf{H}$., False, the thickening of the heart-wall is due to some extent to an adventitious fibrous growth. H., Idiopathic, that developing in the absence of other disease of the heart's structure, or of the structure of other organs. H., Numerical, an actual increase in the number of the constituent muscle-cells of the heartwalls. H., Simple, the walls are thicker than usual, the size of the cavities remaining unchanged. $\mathbf{H}$., True, the hypertrophy consists in an increase in the muscular tissue itself.

Hypertropia (hi-per-tro'-pe-ah). See Strabismus.

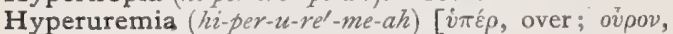
urine; alpa, blood]. Excess of urea in the blood.

Hyperuresis (hi-per-u-re'-sis). Same as Polyuria and Enuresis.

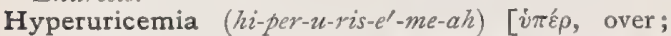

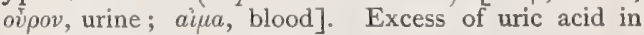
the blood.

Hyperventilation ( $\left.h i-p e r-v e n-t i l-a^{\prime}-\operatorname{shun}\right)[i \pi \varepsilon \rho$, over; ventilare, to fan]. A method of treating some diseases by exposing the body to drafts of air.

Hypesthesia (hip-es-the'-ze-ah) [i $\pi \delta$, under; ai $\sigma$ -

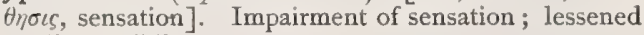
tactile sensibility.

Hypha ( $\left.i^{\prime}-f a h\right)$ [vंभi, a weaving, web: pl., Hypha]. In biology, the filament or thread of a fungus; the matted hyphæ form the mycelium.

Hyphemia ( $\left.h i-f e^{\prime}-m e-a h\right)$ [i $\pi \delta$, under; $a^{\top} \mu \alpha$, blood]. I. Oligemia; deficiency of blood. 2, Hemorrhage within the globe of the eye.

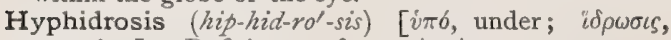
sweating]. Deficiency of perspiration.

Hyphodrome $\left(h i^{\prime}-f o-d r o \bar{m}\right]$ [i $\phi^{\prime}$, a weaving; $\delta \rho b \mu o s$, a running]. In biology, a leaf in which the veins are more or less concealed in the thick mesophyl.

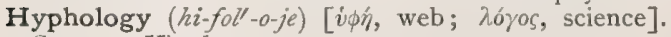
Same as Histology.

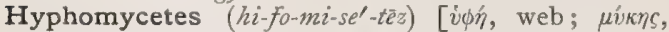
fungus]. A group of fungi having the spores naked, on prominent threads.

Hyphostroma (hi-fo-stro'-mah) $[i \phi \dot{n}$, a web ; $\sigma \tau \rho \tilde{\omega}) \mu a$, a bed]. Same as Mycelium.

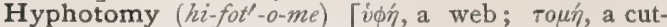
ting]. The dissection of tissues.

Hypinosis (hip-in-o'-sis) [imo, under; is, ivós, fiber]. A deficiency of fibrin in the blood.

Hypinotic (hip-in-ot'-ik) [ijó, under; is, ivós, fiber]. Pertaining to, or affected with, hypinosis.

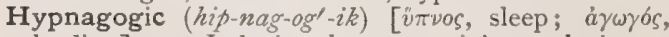
leading]. 1. Inducing sleep; pertaining to the inception of sleep. 2. Induced by sleep.

Hypnal (hip'-nal) [vitvos, sleep]. A drug composed of antipyrin and chloral hydrate, proposed as an hypnotic. It is tasteless, odorless, and crystalline, and soluble in water. Dose gr. xv. Unof.

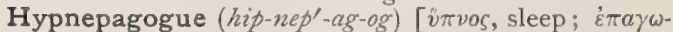
$\gamma 6$, enticing]. A medicine that induces sleep; an hypnotic.

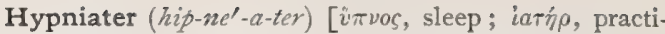
tioner]. A somnambulistic or clairvoyant doctor; a hypnotizer or mesmerist.

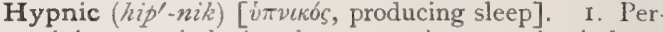
taining to or inducing sleep. 2. An agent that induces or influences sleep.

Hypnobat, or Hypnobate (hip'-no-bāt) [vinvas, sleep; ßatós, walking]. A sleep-walker; somnambulist.

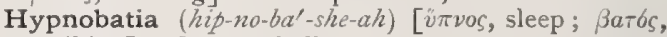
walking]. Somnambulism.

Hypnocyst ( hip'-no-sist) [imvos, sleep; kiorıs, bladder] In biology, an encysted unicellular organism not undergoing sporulation.

Hypnogenetic, Hypnogenic, Hypnogenous (hip-no-

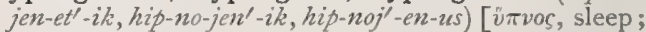

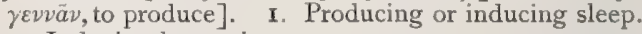
2. Inducing hypnotism.

Hypnography (hip-nog'-ra-fe). Same as Hypnology.

Hypnolepsy (hip'-no-lep-se) [ $v \pi v o s$, sleep; $i \dot{\eta} \psi \iota$, seizure]. Narcolepsy; morbid sleepiness.

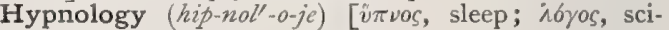
ence]. The science of sleep, its disorders, and its hygienic effects.

Hypnone (hip'-nön). See Acetophenone.

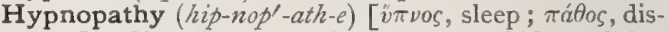
ease?. Sleep due to a diseased or morbid condition of the body, brain, or mind; also, narcolepsy; sleepy disease.

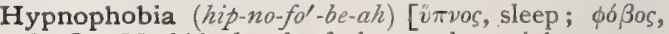
fear]. Morbid dread of sleep; also, nightmare or night-terror.

Hypnosis (hip-no'-sis) [virvos, sleep]. An artificial condition produced by hypnotizing. Also, the gradual approach of sleep. H., African. See African Lethargy.

Hypnosperm (hip'-no-sperm) [vंtvos, sleep; “ $\sigma \pi \varepsilon \rho \mu a$, seed]. In biology, a resting spore. Cf. Hypnospore.

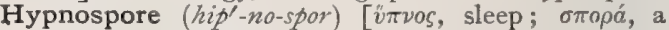
spore]. In biology, a resting spore.

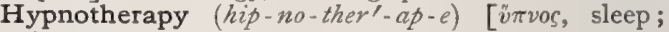
$\theta \varepsilon \rho a \pi \varepsilon i a$, healing]. Hypnotic treatment of disease.

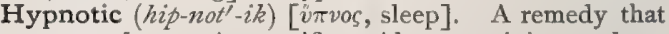
causes sleep. A soporific. Also, pertaining to hypnotism.

Hypnotism (hip'-not-izm) [vivos, sleep]. A state of artificial somnambulism; it may be produced by various means, as, for example, by having the subject look with concentrated attention at any small object so near that effort is required to converge the axes of the eyes. It is characterized by a partial or complete absence of volition, sensation, and self-consciousness, except so much as comes from the hypnotizer or some dominating will or idea. There are four main methods of inducing hypnotism, all originating in France. These are as follows: Charcot's Method; it consists in making gentle pressure over the eyeballs, and, finally, rubbing the top of the head. Luys' Transference Method; the hypnotism is induced by having the patient sit with his back to the light and look steadily at a rapidly revolving mirror placed two or three feet from him, on which the light is directly shining. The constant flash of the light soon wearies the eyes and produces sleep. Nancy Method; in this method hypnotism is induced by means of suggestion entirely, the patient submitting to the will of the operator. Voisin's Method; Braidism; the patient lies upon the broad of his back and gazes steadily at a bright silvered ball, suspended from the ceiling and at a distance of about nine inches from his eyes. The method of fascination is also used, the operator gazing fixedly in the subject's eyes at a distance of about a foot. See, also, Somnambulism. 
Hypnotizable (hip-not-iz'-ab-l) [injvos, sleep]. Susceptible of being hypnotized.

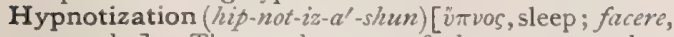
to make]. The employment of the means used to hypnotize a person; the induction of hypnotism.

Hypnotoid (hip'-not-oid) [ivvos, sleep; Eidos, form]. Resembling hypnotism.

Hypo- (hi'-po-) [itó, under]. A prefix denoting deficiency or lack.

Hypo $\left(h i p^{\prime}-o\right)$ [útio, under]. A popular name for hy pochondriasis, lowness of spirits, or imaginary illness, or exaggeration of slight ailments.

Hypormia (hi-po-e'-me-ah). See Hyphemia.

Hypoalbuminosis (hi-po-al-bu-min-o'sis). See Hypalbuminosis and Hypoleukontemia.

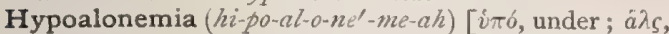
salt, $\dot{a} \lambda \tilde{\omega} \nu$, of salts; aiนa, blood]. A deficiency of the salts of the blood.

Hypoaria ( $\left.h i-p o-a^{\prime}-r e-a h\right)[i \pi \dot{0}$, under; $\omega \alpha a \rho o v, \operatorname{dim}$. of ஸóv, an egg]. In biology, a pair of oval ganglia found on the ventral side of the region of the thalami in most fishes.

Hypoblast ( $\left.h i^{\prime}-p o-b h i s t\right)$ [i $\pi \delta$, under ; $\beta \lambda \alpha \sigma \tau \sigma s$, sprout $]$ The internal layer of the blastoderm, or the ental layer of cells of the embryo of a metazoan; it is called, also, the endoderm, endoblast, entoderm, or epithelioglandular layer; from it is developed the intestinal epithelium (except that of the mouth and anus) and that of the glands opening into the intestines; also, the epithelium of the air-passages.

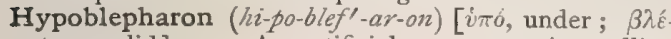
$\phi a \rho o v$, lid]. I. An artificial eye. 2. A swelling under the eyelid.

Hypobromite ( $\left.h i-p o-b r o^{\prime}-m \bar{\imath} t\right)$ [i் $\delta$, under; $\beta \rho \tilde{\omega} \mu \rho \varsigma$, stench]. A salt of hypobromous acid. H. Method, a method of estimating the quantity of urea in urine, based upon the fact that when urea is acted upon by sodium hypobromite (or calcium hypochlorite) it is decomposed into nitrogen, carbon dioxid, and water.

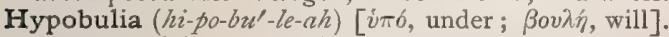
Loss or deficiency of will-power.

Hypocardia (hi-po-kar'-de-ah) [itó, under; rapoia, heart]. Downward displacement of the heart.

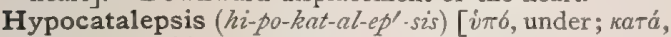
down; $\lambda a \mu \beta a ́ v \varepsilon \iota \nu$, to seize]. Slight catalepsy, or epilepsy.

Hypocatharsis (hi-po-kath-ar'-sis) [ijó, under; $\kappa a \theta-$ aípevv, to purge]. A gentle purgation.

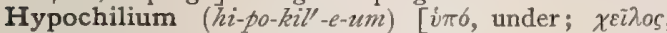
the lip: pl., Hypochitia]. In biology, the lower part of the lip of certain orchids.

Hypochlorhydria (hi-po-klor-hi'-dre-ah) [iró, under; $\chi \lambda \omega \rho \sigma \zeta$, green; $v \delta \omega \rho$, water]. A condition in which there is a diminished amount of $\mathrm{HCl}$ in the gastric juice. It is usually associated with an overproduction of lactic acid, and is often due to a state of lowered general nutrition.

Hypochlorite (hi-po-klo'-nit) [vito, under; $\chi \lambda \omega \rho \sigma s$, green]. Any salt of hypochlorous acid. Calcium hypochlorite is the essential constituent of bleachingpowder.

Hypochlorous Acid ( $\left.h i-p o-k l l^{\prime}-r u s\right)$. See Acid.

Hypocholesteremia (hi-po-ko-les-ter-e'-me-ah) [ijó,

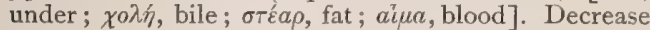
or deficiency of the cholesterin of the blood.

Hypochondria ( $\left.h i-p o-k o n^{\prime}-d r e-a h\right)$ [i $\pi \delta$, under; $\chi x^{\prime} v-$ $\delta \rho \circ \varsigma$, cartilage]. I. The regions below the costal arches on either side. 2. Same as Hypochondriasis.

Hypochondriac ( $\left.h i-p o-k o n^{\prime}-d r e-a k\right)[i \pi \delta$, under; $\chi \dot{b} v$ $\delta \rho \circ$, cartilage]. I. Pertaining to the hypochondrium. 2. A person who is affected with hypochondriasis.

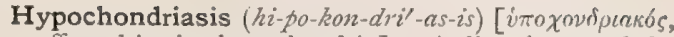
affected in the hypochondria]. A disturbance of the functions of the nervous system similar to that in mel. ancholia, in which the patient believes himself suffering from bodily disease. It is characterized by alternate spells of moodiness and excitability. H. pituitosa. Synonym of Membranous Enteritis.

Hypochondrium ( $\left.h i-p o-k o n^{\prime}-d r e-u m\right)\left[i \pi b\right.$, under; $\chi \delta v^{\prime}$. spos, cartilage: pl., Hypochondria]. The region of the abdomen at each side of the epigastrium. See illustration under Abdominal.

Hypochromatemia (hi-po-kro-mat-e'-me-ah) [ijto, under; $\chi \rho \tilde{\omega} \mu \alpha$, color; ai $\mu a$, blood]. Deficiency of the coloring-matter of the blood.

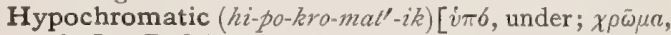
color]. Deficient in coloring-matter.

Hypochromia ( $\left.h i-p o-k r o^{\prime}-m e-a h\right)$ [i่to, under; $\chi p \ddot{\omega} \mu \alpha$, color]. Abnormal pallor or transparency of the skin, occurring in certain skin-diseases.

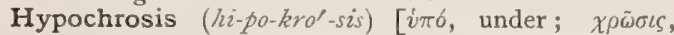
coloring]. Abnormal paleness; lack of normal coloration.

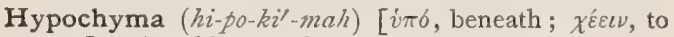
pour]. An old name for cataract.

Hypocist ( $h i^{\prime}$-po-sist) [i $\delta 6$, under; kiotos, cistus]. I. The plant Cytinus hypocistis, of the old world. 2. The dark astringent extract prepared by drying the sap of the foregoing plant and the juice of its berries. It is useful for hemorrhages and diarrhea. Unof.

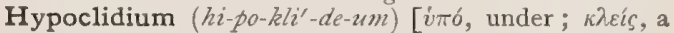
key; the clavicle: $p l$., Hypoclidia]. In biology, the inferomedian process formed at the junction of the clavicles of a bird.

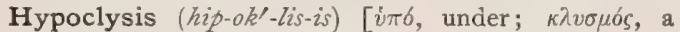
clyster]. The administration of an enema.

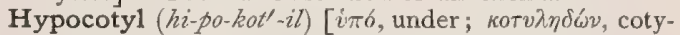
ledon]. A short term for Hypocotyledonous stem.

Hypocotyledonous ( $\left.h i-p o-k o t-i l-e^{\prime}-d o n-u s\right)[i \pi \delta$, under; $\kappa о \tau \nu \lambda \eta \delta \omega \nu$, cotyledon]. In biology, situated below the cotyledons.

Hypocraterimorphous (hi'-po-kra-ter-im-or'-fus) [i ito-

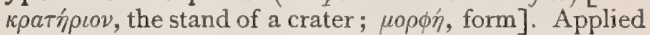
to certain flowers the corolla of which have a flat, spreading limb surmounting a straight tube; salver-shaped.

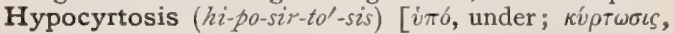
curvature]. A slight amount of curvature.

Hypocystotomy ( $h i-p o-s i s-t o t^{\prime}-o-m e$ ) [ijo, under; $\kappa \dot{\sigma} \sigma-$ $\tau \iota s$, bladder; $\tau o \mu \eta n$, a cut]. Perineal cystotomy.

Hypoderm ( $h i^{\prime}$-po-derm) [i $\pi \delta$, under; $\delta \dot{\varepsilon} \rho \mu a$, skin]. I. Subcutaneous tissue. 2. A hypodermatic injection. 3. In biology, applied to the epithelial membrane lining the cuticular, crustaceous, or chitinous investment of arthropods; also called Hypodermis.

Hypoderma (hi-po-der'-mah) [i $\pi 6$, under; $\delta^{\prime} \rho \mu a$, skin]. In biology: I. A layer of cells, usually collenchyma, just beneath the epidermis of a leaf or stem. 2. A genus of dipterous insects, the bot-flies. See Parasites (Animal), Table of.

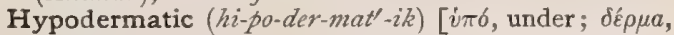
skin]. Pertaining to that which is under the skin, or to the introduction of medicines beneath the skin.

Hypodermatoclysis (hi-po-der-mat-ok'-lis-is), or $\mathbf{H y -}$ podermoclysis (hi-po-der-mok'-lis-is), [ító, under;

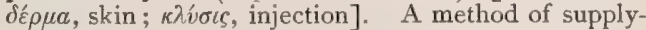
ing fluid to the body to replace that lost through excessive purging, as in cholera, or in cases of hemorrhage. It consists in the introduction into the subcutaneous tissues of certain quantities of normal saline solution.

Hypodermatomy (hi-po-der-mat'-o-me) [int, under; $\delta_{\varepsilon} \rho \mu \alpha$, skin; $\tau \varepsilon \dot{\varepsilon} \mu \nu \varepsilon \nu$, to cut]. Subcutaneous surgical section of parts. 
Hypodermic (hi-po-der'-mik). See Hypodermatic

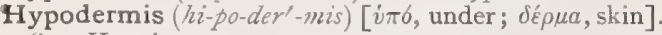
See Hypoderm.

Hypodermoclysm (hi-po-der'-mo-klizm). Same as Hypodermatoclysis

Hypodicrotous (hi-po-dik'-ro-tuss) [ijt6, under; dikpoTos, double beat]. Dicrotic in a small degree.

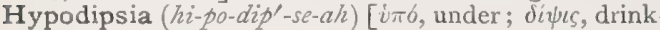
ing]. The drinking of too little water or fluid.

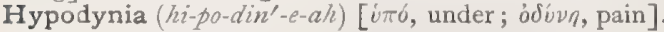
Slight or trifling pain.

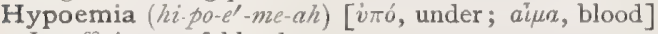
Insufficiency of blood.

Hypoerythrocythemia (hi-po-er-ith-ro-si-the'-me-ah)

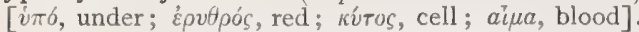
Deficiency in the normal number of red corpuscles in the blood.

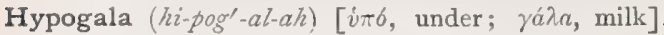
The collection of a milk-like fluid in the eye.

Hypogastralgia (hi-po-gas-tral'-je-ah) [into, under;

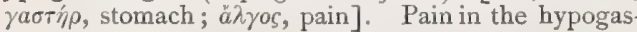
trium.

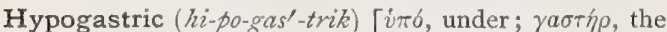
belly]. Pertaining to the hypogastrium. See Abdomen, Artery, Ganglion, and Plexus.

Hypogastriotomy (hi-po-gas-tre-ot'-o-me) [itro, under;

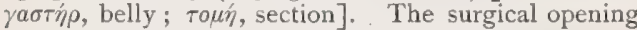
of the abdomen through the hypogastrium.

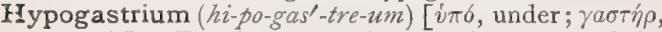
stomach 7 . The lower median anterior region of the abdomen. See Abdomen.

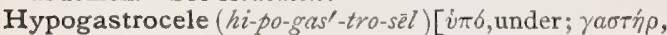
stomach; $\kappa \hat{\lambda} \eta$, hernia]. A hernia in the hypogastric region.

Hypogastrodidymus (hi-po-gas-tro-did'-im-us) [i்t,

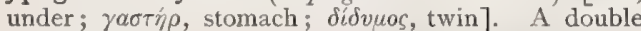
monstrosity in which the two fetuses are united at the hypogastrium.

Hypogastrohemia (hi-po-gas-tro-he'-me-ah) $[i \pi b$,

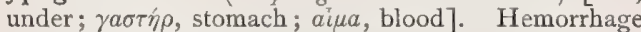
in the hypogastrium

Hypogastrorrhagia ( $h i$-po-gas-tror-a'-je-ah). Same as Hypogastrohemia.

Hypogastrorrhea (hi-po-gas-tror-e'-ah) [ijto, under ;

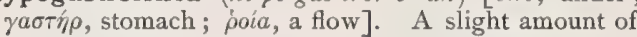
gastrorrhea.

Hypogastrorrhexis (hi-po-gas-tror-eks'-is) [i $\pi 6$, under ;

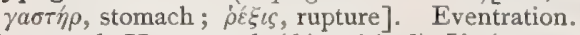

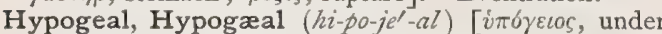
ground]. In biology, growing beneath the surface of the ground. Also, Hypogaan, Hypogaous, Hypogean, Hypoyeous.

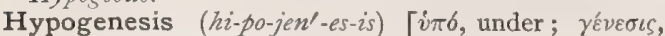
production, generation]. In biology, direct development, without alternation of generations.

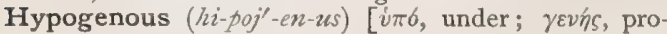
duced]. In biology, growing below the surface or on the under side.

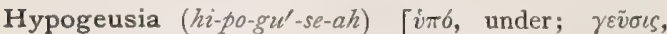
taste]. Diminution in the sense of taste.

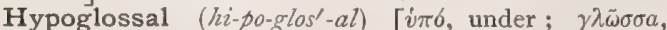
tongue]. Under the tongue. H. Nerve. See Nerves, Table of.

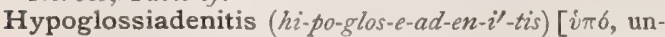
der; $\gamma \lambda \tilde{\omega} \sigma \sigma \alpha$, tongue; ádj́v, gland; $\iota \tau \iota \varsigma$, inflammation]. Inflammation of the sublingual gland.

Hypoglossis (hi-po-glos'-is). See Hypoglottis.

Hypoglossitis (hi-po-glos-i'tis) [ir $\delta$, under; $\gamma \lambda \tilde{\omega} \sigma \sigma a$, tongue; $\iota \tau \iota s$, inflammation]. Inflammation of the tissue under the tongue.

Hypoglossus (hi-po-glos'-us) [int, under; $\gamma \lambda \tilde{\omega} \sigma \sigma a$, tongue]. The hypoglossal nerve.

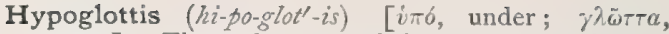
tongite]. The under part of the tongue, attached to the lower jaw. Also, a swelling at the under part of the tongue.

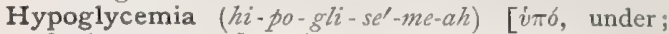

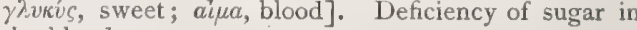
the blood.

Hypognathadenitis (hi-pog-nāth-ad-en-i'-tis) [i்to, un-

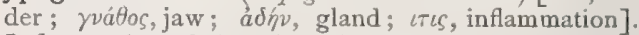
Inflammation of the submaxillary gland.

Hypognathous ( $\left.h i-p \circ g^{\prime}-n a-t h u s\right)$ [i $\pi^{\prime} \delta$, under; yvátos, jaw]. In biology, applied to animals in which the lower mandible is longer than the upper.

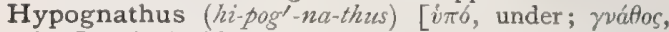
jaw]. A double monstrosity in which the parasite is attached to the inferior maxillary bone.

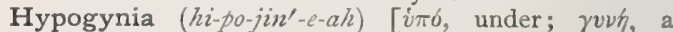
woman]. The state of being hypogynous.

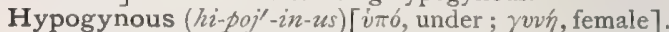
In biology, growing beneath the pistil; applied to stamens or other floral organs that are inserted beneath the pistil.

Hypohæmia (hi-po-he'-me-ah). See Hypohemia.

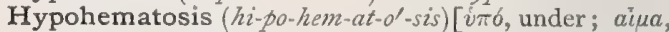
blood]. A diseased condition marked by hyphemia, or deficiency in the amount of blood; also, the production, or process of inducing such a condition.

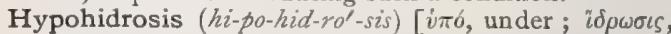
sweating]. Scanty perspiration.

Hypohydremia (hi-po-hi-dre'-me-ah) [imb, under :

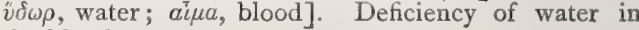
the blood.

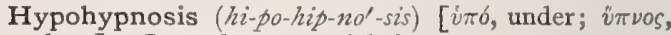
sleep]. Imperfect or partial sleep.

Hypoinosemia (hi-po-in-o-se'-me-ah) [imb, under; is, fiber; aiua, blood.]. Decrease in the tendency to the formation of fibrin in the blood.

Hypokinesia, or Hypokinesis (hi-po-kin-e'-se-ah, or

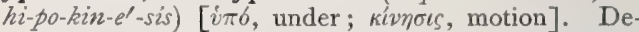
ficiency in motor reaction under stimulation.

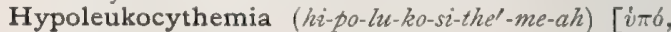

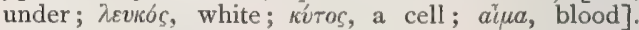
Deficiency of white corpuscles in the blood.

Hypoleukocytosis (hi-po-lu-ko-si-to'-sis) [ $\tilde{v} \pi \hat{b}$, under;

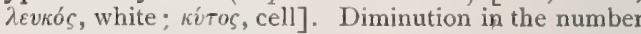
of colorless corpuscles in the blood.

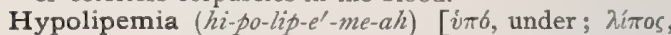
fat; alua, blood]. Deficiency of fat in the blood.

Hypologia (hi-po-lo'-ge-ah) [ijtb, under; $\lambda 6 \gamma o s$, word]. Poverty of speech as a symptom of cerebral disease.

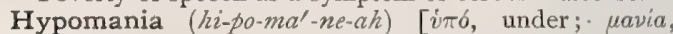
madness]. A moderate degree of maniacal ex altation.

Hypomelancholia ( $\left.h i-p o-m e l-a n-k o^{\prime}-l e-a h\right)[i \pi \delta$, under ; $\mu \varepsilon \lambda a \gamma \chi 0 \lambda i a$, melancholia]. Moderate or reasoning melancholia.

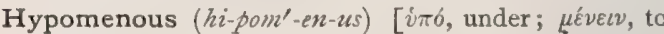
remain]. Same as Hypogenous.

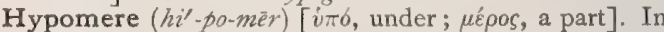
biology, the lower half of certain sponges (rhagon), which consists of all three fundamental layers.

Hypometropia (hi-po-me-tro'pe-ah) [író, under;

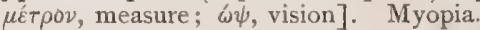

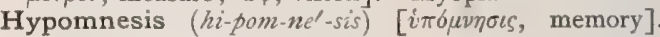
Memory or recollection.

Hypomoria (hi-po-mo'-re-ah) [ito, under; $\mu \omega \rho i a$, folly] Slight mental disorder.

Hypomyosthenia ( $h i-p o-m i-o s-t h e^{\prime}-n e-a h$ ) [ $\dot{v} \pi b$, under ; $\mu \tilde{v} \varsigma$, muscle; $\sigma \theta \dot{v} v o \varsigma$, strength $]$. Deficiency in muscular power.

Hyponasty, or Hyponastic Curvature ( $h i^{\prime}$-po-nas-te)

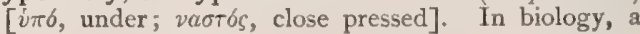


curvature produced by growth on the under side of an extended organ. Cf. Epinasty.

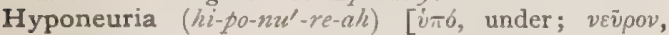
nerve]. Slight or diminished nerve-power.

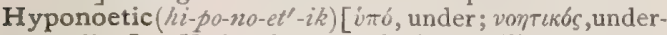
standing]. Under the control of the will.

Hyponome ( $\left.h i^{\prime}-p o-n o \bar{m}\right)[\hat{v} \pi \delta$, under; vé $\mu \varepsilon \iota \nu$, to dwell in, to inhabit]. In biology, the exhalant funnel of a cephalopod.

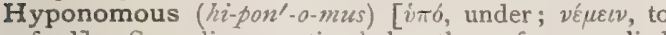
feed]. Spreading or eating below the surface; applied to certain ulcers, etc.

Hypopepsia ( $\left.h i-p o-p e p^{\prime}-s e-a h\right)[\dot{v} \pi b$, under; $\pi \hat{\varepsilon} \psi \iota s$, digestion]. A disorder of digestion in which there is a notable diminution in the functional activity, glandular and chemic, of the stomach.

Hypophemia, Tropical. See Ankylostomiasis.

Hypophlœodic (hi-po-fle-od'-ik) [ijó, under; $\phi \lambda o \iota b s$, bark]. In biology, situated beneath the bark.

Hypophlcous (hi-po-fle'-us): Same as Hypophlocodic. Hypophosphite ( $\left./ i i-p o-f o s^{\prime}-f i t\right)$ [imb, under; phosphorus]. Any salt of hypophosphorous acid. Several hypophosphites (as of calcium, potassium, sodium) are official, and many others are used to a limited extent.

Hypophosphorous Acid (hi-po-fos-fo'-rus). See Acid.

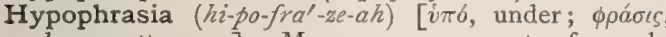
phrase, utterance]. Meagerness or poverty of speech, as a sign of cerebral disease.

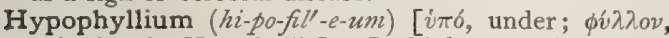
a leaf: pl., Hypophyllia]. In biology, a sheath-like petiole, without laminæ.

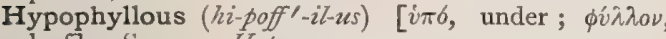
leaf]. - Same as Hypogenous.

Hypophysemia $\left(h i-p o-f i-s e^{\prime}-m e-a h\right) \quad[i \pi \delta, \quad$ under ; $\phi \tilde{v} \sigma a$, air; ai ${ }^{\top} \mu a$, blood]. Deficiency of gaseous elements in the blood.

Hypophysis ( $\left.h i-p o f f^{\prime}-i s-i s\right)$ [vंró, under; $\phi v \varepsilon \varepsilon v$, to grow]. The pituitary body, $q . v$.; sometimes called the $\mathrm{H}$. cerebri.

Hypoplasia ( $\left.h i-p o-p l a^{\prime}-z e-a h\right) \quad[i \pi \delta$, under; $\pi \lambda a ́ \sigma \sigma \varepsilon \iota v$, to mould]. Deficiency or arrested development of any organ or tissue. See Aplasia.

Hypoplastemia (hi-po-plas-te'-me-ah). See Hypoplasticemia.

Hypoplasticemia (hi-po-plas-tis-e'-me-ah) [ijt6, under;

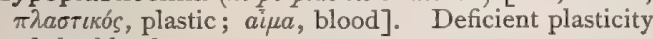
of the blood.

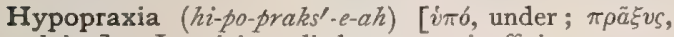
doing]. Inactivity; listlessness; inefficiency as a sign or result of cerebral disorder.

Hypopselaphesia ( $\left.h i-p o p-s e l-a f-e^{\prime}-z e-a h\right)[i \pi b$, under ; $\psi \eta \lambda a ́ \phi \eta \sigma \iota \zeta, ~ t o u c h]$. Diminution of sensitiveness to tactile impressions.

Hypoptilum (hi-pop'-til-um) [ijt, under; $\pi \tau i \lambda o v$, feather: pl., Hypoptila]. In biology, the entire after-shaft of a feather, including the vanes; hyporachis.

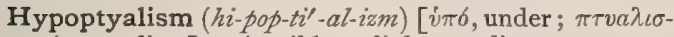
$\mu o ́ s$, ptyalism]. A mild or slight ptyalism.

Hypopygium (hi-po-pij'-e-um) [imb, under; $\pi v \gamma^{\prime}$, the rump: pl., Hypopygia]. In biology, the male clasping-organ of dipterous insects.

Hypopyon ( $\left.h i-p o^{\prime}-p e-o n\right)[i \pi b$, under; $\pi \tilde{v} o v$, pus]. A collection of pus in the anterior chamber of the eye, secondary to inflammation of adjacent tissues.

Hypoquebrachin (hi-po-kwe-brak'-in) [vंtó, under; quebracho], $\mathrm{C}_{21} \mathrm{H}_{26} \mathrm{~N}_{2} \mathrm{O}_{2^{-}}$An alkaloid of Quebracho, occurring in yellow masses, melting at about $80^{\circ} \mathrm{C}$., and soluble in alcohol and ether.

Hyporachis (hi-por'-ak-is) [imó, under; $\dot{p} a \dot{\chi} \iota$, the spine]. In biology, the stem or rachis of the aftershaft; the hypoptilum of a feather.
Hyporadioli (hi-po-ra-di'-o-li) [itó, under; radius, radius]. In biology, the barbules of the after-shaft of a feather.

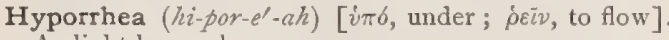
A slight hemorrhage.

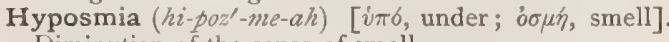
Diminution of the sense of smell.

Hypospadia, or Hypospadias ( $h i-p o-s p a^{\prime}-d e-a h$, $h i-p o-$ $\left.s p a^{\prime}-d e-a s\right)[i \pi b$, under; $\sigma \pi a \tilde{v}$, to draw $]$. An abnormal opening and ending of the urethra upon the under surface of the penis, or in the under wall of the urethra. It is variously classed, according to the position of its opening, as glandular (or balanic), balano-penile, penile, peno-scrotal, scrotal, or perineal. Certain tribes of the Arabs, Africans, and native Australians produce an artificial hypospadias.

Hypostaphylitis (hi-po-staf-il-i'tis) [ijo, under;

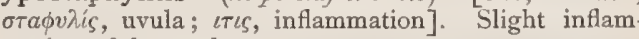
mation of the uvula.

Hypostasis ( $\left.h i-p o s^{\prime}-t a s-i s\right)$ [i $\pi \sigma \sigma \tau a \sigma \iota s$, a standing under]. A word loosely used to denote feces, or any sediment falling from a liquid, especially the sediment of urine. Also, a form of passive hyperemia caused by the dependent position of the part affected.

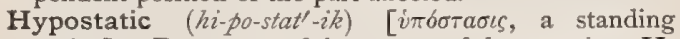
under]. Due to, or of the nature of, hypostasis. $\mathbf{H}$. Congestion. Same as Hypostasis, q.v. H. Pneumonia, Piorry's term for the variety of pneumonia secondary to most of the acute febrile diseases, and occurring in the final stage of many chronic diseases. It is in part due to the mechanic gravitation of blood to the part affected, as to the back, in cases of longcontinued dorsal decubitus.

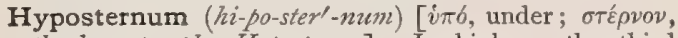
the breast: $p l$. , Hyposterna]. In biology, the third lateral piece of the plastron of a turtle; also called Hypoplastron.

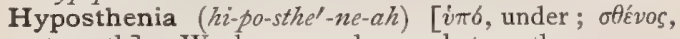
strength]. Weakness; subnormal strength.

Hyposthenic (hi-po-sthen'-ik) [i $\pi 6$, under; of́́vos, strength]. I. Tendency to, or characterized by, hyposthenia; applied to diseases that are more than ordinarily enfeebling. 2. A medicine that reduces the action of the heart without affecting its rhythm.

Hypostoma (hi-pos'-to-mah) [vंro, under; $\sigma \tau \delta \mu a$, mouth: pl., Hypostomata]. In biology, applied (a) by Meigen and Bouché to the clypeus of Diptera, and by Meinert to a curved broad sclerite behind the lamina labialis of the inner stipes in the mouth of Myriopods; (b) to the proboscis of Hydroidea.

Hypostomatous ( $h i$-po-sto'-mat-us) or Hypostomous (hi-pos'-to-mus) [i $\pi \delta$, under; $\sigma \tau \delta \mu \alpha$, mouth ]. In biology, having the mouth inferior or ventral.

Hypostome (hi'-po-stōm). Same as Hypostoma.

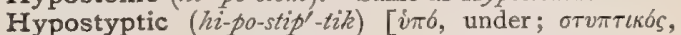
astringent]. I. Moderately or mildly styptic. 2. A mildly styptic medicine.

Hyposynergia ( $h i$-po-sin-er'-je-ah) [itó, under; $\sigma v \nu \varepsilon \rho-$ $\gamma^{\prime} i$, coöperation]. Defective coördination.

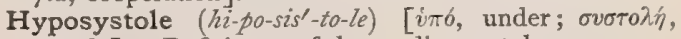
systole]. Deficiency of the cardiac systole.

Hyposystolia (hi-po-sis-to'-le-ah). See Hyposystole.

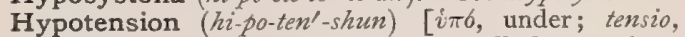
a stretching]. Diminished or abnormally low tension; hypotonia.

Hypothallus (hi-po-thal'-us) [imb, under; $\theta a \lambda \lambda b_{\zeta}$, a young shoot or branch, a frond: $p l$., Hypothalli ]. In biology, a delicate filamentous mass upon which is developed the thallus of a lichen.

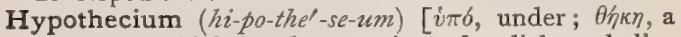
case]. In biology, that portion of a lichen thallus immediately around or beneath the apothecium. 
Hypothenar ( $\left.h i-p o t h^{\prime}-e n-a r\right)$ [ $\dot{v} \pi \delta$, under ; $\theta \dot{\varepsilon} v a \rho$, palm]. The fleshy eminence on the palm of the hand over the metacarpal bone of the little finger. Also, the prominences on the palm at the base of the fingers. Also, the ball of the thumb.

Hypothermal (hi-po-ther'-mal) $[i \pi \delta$, under; $\theta \dot{\varepsilon} \rho \mu$, heat]. Tepid; denoting a temperature placed arbitrarily between $59^{\circ}$ and $68^{\circ} \mathrm{F}$., or $15^{\circ}$ and $25^{\circ} \mathrm{C}$. Also, pertaining to the reduction of the temperature of the body.

Hypothermia (hi-po-ther'-me-ah) or Hypothermy (hi'-po-ther-me) [i $\pi \hat{o}$, under; $\theta \dot{\varepsilon} \rho \mu \eta$, heat]. Deficiency in the heat of the body.

Hypothesis (hi-poth'-es-is) $[i \pi \delta$, under; $\theta \dot{\varepsilon} \sigma \iota \varsigma$, a position]. A supposition set forth for discussion or demonstration. A theory assumed as true

Hypotonia, or Hypotonus ( $h i-p o-t 0^{\prime}-n e-a h$, or hi-pot' o-nius) [i $\pi 6$, under; $\tau$ bvos, tension]. Decrease of normal tonicity; diminution of intraocular pressure.

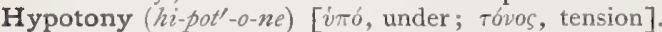
Same as Hypotonia. H., Gastric, the reverse condition of gastric hypermotility, $q . v$.

Hypotreme (hi'-po-trëm) [üro, under; $\tau \rho \tilde{\eta} \mu \alpha$, a hole, (here, a spiracle): pl., Hypotremata]. In entomology, one of a pair of strong fusiform processes extending obliquely across the anterior coxo-sternal foramina to the lower borders of the anterior spiracles in certain insects $(e . g .$, Diptera $)$; they strengthen the anterior part of the thoracic wall. (Lowne.)

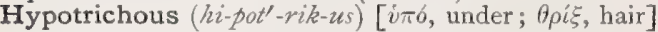
In biology, applied to such infusoria as have the locomotor cilia on the under side of the body.

Hypotrophy ( $\left.h i-p o t^{\prime}-r o-f e\right)[i \pi \delta$, under; $\tau \rho \varepsilon \dot{\phi} \phi \iota v$, to nourish]. Subnormal nutrition. A defect in the constructive or tissue-building powers of the organism. It may be congenital or acquired, and varies much in degree in different individuals, or even in the same individual at different times.

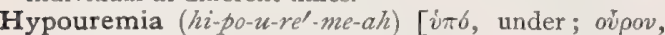
urine; ai $\mu a$, blood]. Diminution of the urea normally present in the blood.

Hypouricemia ( $\left.h i-p o-u-r i s-e^{\prime}-m e-a h\right) \quad[i \pi b$, under; ovpov, urine; aiua, blood]. Decrease in the uric acid of the blood.

Hypourocrinia (hi-po-u-ro-krin'-e-ah) [ító, under ;

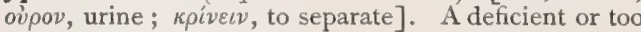
scanty secretion of urine.

Hypoxanthin (hi-po-zan'-thin) [visó, under; $\xi a v \theta o s$, yellow], $\mathrm{C}_{5} \mathrm{H}_{4} \mathrm{~N}_{4} \mathrm{O}$. A leukomaïne, also known as Sarcin or Sarkin. It occurs, accompanying adenin and guanin, in nearly all the animal tissues and organs rich in nucleated cells. In minute quantities it is a normal constituent of urine. It has also been found in plants, seeds, ferments, and wines. It is a crystalline body, soluble in cold and boiling water, insoluble in cold alcohol and ether. Hypoxanthin appears to be one of the products formed by the decomposition and successive oxidation of proteid matter previous to the formation of uric acid and urea. It is produced from adenin by the action of nitrous acid. It is nonpoisonous. See Kossel's Test, and Sarcin.

Hypsicephaly (hip-sis-ef'-al-e) [vं $\psi$, on high; $\kappa \varepsilon \phi a \lambda \dot{n}$, head]. The condition of a skull with a cranial index of over $75.1^{\circ}$.

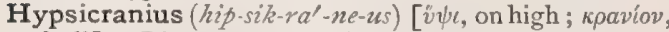
skull]. Lissauer's term for a skull having the ratio between length and height of $82.5^{\circ}$ to $90.4^{\circ}$.

Hypsiliform (hip-sill-if-orm). See Ypsiliform.

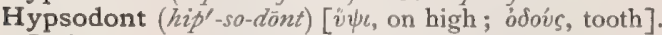
In biology, applied to such animals as have teeth furnished with long crowns and short roots.

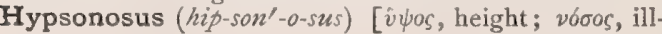

ness]. Mountain-sickness; balloon-sickness; characterized by nausea, headache, epistaxis, etc.

Hypsophobia (hip-so-fo'-be-ah) [vivos, height; ob́ßos, fear]. Morbid dread of being at a great height; aẽrophobia.

Hypsophyl, (hip'-so-fil) [vं $u$, on high ; $\phi \dot{v} \lambda \lambda o v$, a leaf]. In biology, one of the leaf-like or bract-like structures subtending a flower or an inflorescence.

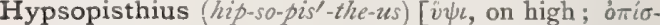
Hcov, occiput]. Lissauer's term for a skull in which the angle included between the radius fixus and the line joining the hormion and lambda is between $33^{\circ}$ and $4 \mathrm{I}^{\circ}$

Hypural (hip-u'-ral) [iлo, under; ovpá, tail]. In biology, located beneath the tail.

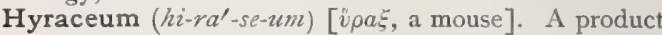
from South Africa, somewhat resembling castoreum, and believed to be an excretion, perhaps fecal, of Hyrax capensis, the so-called South African cony or cliff-badger. Its use is the same as that of castor.

Hyssop $\left(\right.$ his' $\left.^{\prime} \circ p\right)$ [ $v \sigma \sigma \omega \pi \circ$, an aromatic plant]. Hedgehyssop. The leaves and tops of Hyssopus officinalis, an aromatic stimulant, carminative, and tonic, much employed in chronic catarrh of the respiratory tract. Dose of the fld. ext. $3 \mathrm{j}-\mathrm{ij}$. Unof. See also Lophanthus and Gratiola.

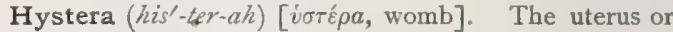
womb. Also, the vulva. Also, the placenta or afterbirth

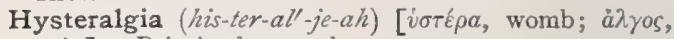
pain]. Pain in the womb.

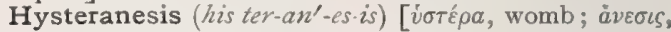
relaxation]. Relaxation and atony of the uterus.

Hysteranthous (his-ter-an'-thus) [votepos, later; avflos, a flower]. In biology, applied to plants in which the leaves do not appear till after the flowers have appeared.

Hysteratresia (his-ter-at-re'-ze-ah) [v่oré $\rho a$, womb; àт $\rho \varepsilon т о \zeta$, imperforate]. An imperforate or impervious condition of the mouth of the womb.

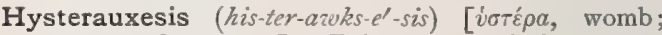
au $\xi \eta \sigma \iota s$, enlargement]. Enlargement of the uterus, normal (as in pregnancy) or abnormal.

Hysterectomy (his-ter-ek'-to-me) [í⿴囗tepa, womb; $\dot{\varepsilon} \kappa \tau о \mu \eta \dot{\eta}$, a cutting out]. Excision or removal of the womb by surgical operation. H., Vaginal, removal of the womb through the vagina.

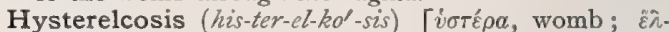
$\kappa \omega \sigma \iota$, ulceration]. Ulceration of the uterus.

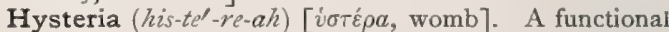
disturbance of the nervous system, supposed by early physicians to be due to a disordered condition of the womb. It is now often considered a neurosis: it is not with certainty known whether it is due to structural alteration in any part of the central nervous system, or to abnormal blood-supply. Paralyses, impairment of vision, convulsions, sensory disturbances, and psychic manifestations, are usually prominent symptoms. Major and minor types are differentiated. The popular significance of the term is that of feigned disease, but the physician usually considers the affection real. It is more frequently encountered in females than in males. H., Epileptiform, a synonym of Hystero-epilepsy. H., Major, hystero-epilepsy. H., Minor, hysteria of a mild form.

Hysteric, Hysterical (his-ter'-ik, his-ter'-ik-al) [vंotkpa, womb]. Pertaining to hysteria, $q . v$. Also, pertaining to the womb. H. Temperature. See Thermal Ataxia. H. Breast, a condition of the breast in neurotic women marked by excessive superficial tenderness, diffuse swelling, constant variation in size and hardness, and by the recurrence of these symptoms at the menstrual epochs. H. Dyspnea, intensely rapid 
breathing, 50 to I 50 respirations per minute, occurring in neurotic individuals, without corresponding alteration of the pulse-rate. H. Somnolence, the early stage or lighter form of $H$. Trance. $\mathrm{H}$. Trance, a peculiar condition in which the patient sinks into a lethargic, corpse-like condition, lasting from a few hours to several days.

Hystericism (his-ter-is-izm) [iَtépa, womb]]. The hysteric diathesis or temperament; proneness to the exhibition of hysteric symptoms.

Hysterics (his-ter'-iks) [ for hysteric or convulsive movements and conditions.

Hysteriencephalitis (his-ter-e-en-sef-al-i'tis) [iotépa, womb; $\dot{\varepsilon} \gamma \kappa \varepsilon \dot{\varepsilon} \phi \lambda \nu \nu$, brain; $\iota T \iota s$, inflammation]. Encephalitis and meningitis following repeated attacks of hysteria.

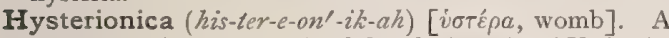
composite-flowered herb of South America (H. baylahuen) of considerable efficacy in the treatment of acute and chronic affections of the respiratory apparatus. It is also a stomachic and intestinal antiseptic of value in the treatment of flatulent dyspepsia. Dose of the fluid extract $m v-x v$. Unof

Hysteritis (his-ter-i'-tis). See Metritis

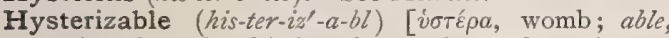
able]. Capable of being thrown into a hysteric condition.

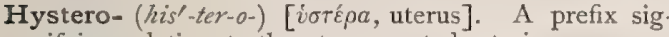
nifying relation to the uterus, or to hysteria.

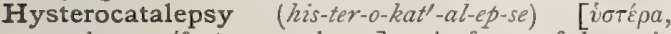

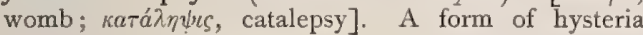
accompanied by catalepsy.

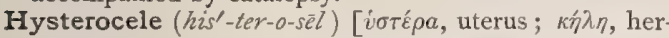
nia]. Hernia containing the uterus, or part of it.

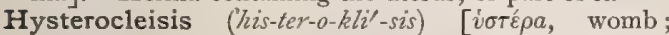

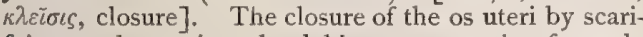
fying and suturing the labia; an operation formerly employed in the treatment of vesico-uterine fistula.

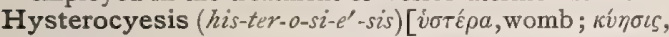
pregnancy]. Uterine pregnancy.

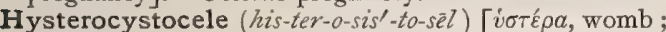
$\kappa \dot{v} \sigma \tau \iota$, bladder; $\kappa \eta \dot{\lambda} \eta$, hernia]. Hysterocele complicated by cystocele; hernia of the womb and the bladder, or parts of them.

Hystero-demonopathy (his-ter-o-de-mon-op'-ath-e)

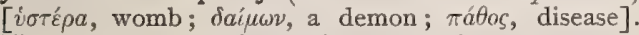
Hysteric demonopathy or demonomania.

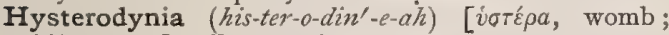
ofvivn, pain]. Pain in the womb.

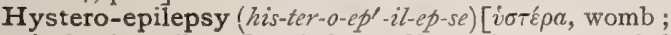
$\varepsilon \pi \imath \eta \psi i a$, epilepsy]. A form of hysteria accompanied by convulsions resembling those of epilepsy. Gowers advises the term hysteroid in reference thereto.

Hystero-epileptogenous (his'-ter-o-ep-il-ep-toj'-en-us)

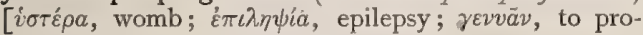
duce]. Producing hysteric epilepsy.

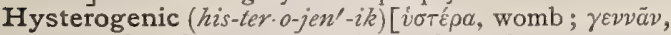
to beget]. Causing or producing hysteria.

Hysterogenic (his-ter-o-jen'-ik) [ produce, bear]. In biology, applied to intercellular spaces or structures appearing late in the life of a plant. Cf. Protogenic.

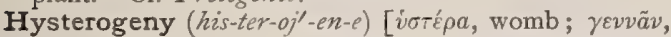
to produce]. The induction of the hysteric state or paroxysm.

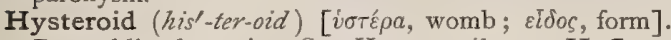
Resembling hysteria. See Hystero-epilepsy. H. Convulsions, convulsive movements with hysteric symptoms in various organic diseases of the brain, in epilepsy, and in hydrophobia.

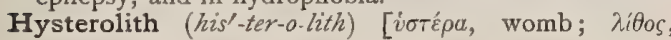
stone]. Calculus or stone in the womb.

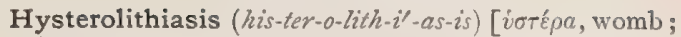
$\lambda_{\iota}$ tiaces, the formation of calculi]. The formation of hysteroliths.

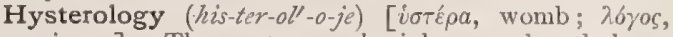
science]. The anatomy, physiology, and pathology, of the uterus.

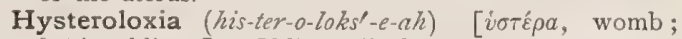
$\lambda_{0} \sigma_{s}$, oblique]. Oblique displacement or position of the uterus.

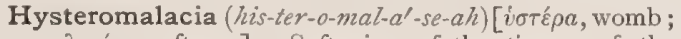

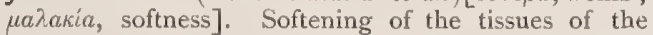
womb.

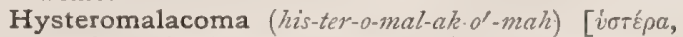

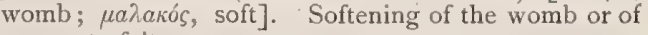
any part of it.

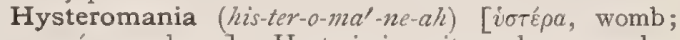
ravia, madness]. Hysteric insanity; also, nymphomania.

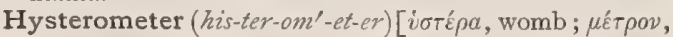
measure]. An instrument for measuring the length of the intra-uterine cavity.

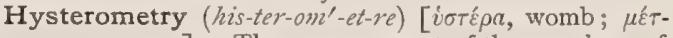
pov, measure]. The measurement of the womb or of its internal space.

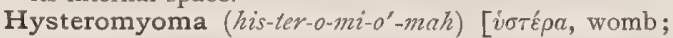
ũ̃s, muscle ; ö $\mu a$, tumor: pl., Hysteromyomata]. Myoma or fibro-myoma of the womb.

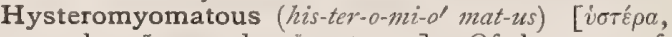
womb; $\mu \tilde{v} s$, muscle; $\ddot{\mu} \mu \alpha$, tumor]. Of the nature of or pertaining to hysteromyoma.

Hysteromyomectomy (his' - ter-o-mi-o-mek' - to - me)

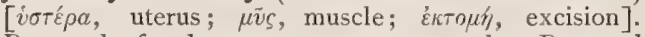
Removal of a hysteromyomatous growth. Removal of the body or supravaginal portion of the uterus for fibroid tumor.

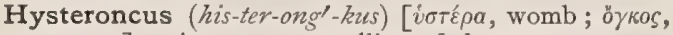
a tumor]. A tumor or swelling of the uterus.

Hysteroneurasthenia (his'-ter-o-nu-ras-the'-ne-ah)

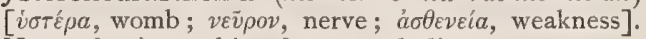
Neurasthenia resulting from womb-disease.

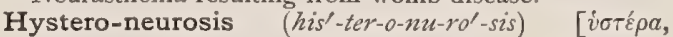

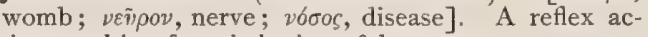
tion resulting from irritation of the uterus.

Hystero-oöphorectomy (his'-ter-o-o-off-or-ek'-to-me)

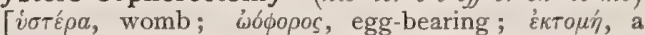
cutting out]. The surgical removal of the uterus and ovaries together.

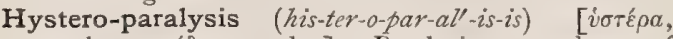

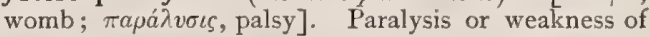
the walls of the womb.

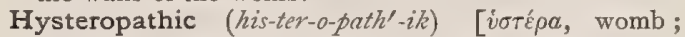
$\pi \alpha ́ \theta o s$, disease]. Of the nature of, or pertaining to, hysteropathy.

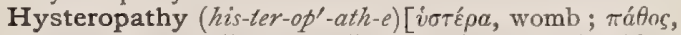
disease ]. Any disease or disorder of the womb. Also, hysteria.

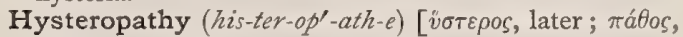
illness]. Same as Deuteropathy.

Hysteropexia, Hysteropexy (his-ter-o-peks'-e-ah, his'.

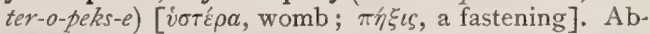
dominal fixation of the uterus by a surgical operation.

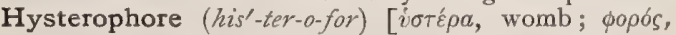
bearing]. A form of uterine pessary.

Hysterophrenic (his-ter-o-fren'-ik) [iotḱpa, womb; $\phi \rho \dot{\eta} v$, the mind]. Opposed to hysterogenic.

Hysteroplegia (his-ter-o-ple'-je-ah) [iorépa, womb; $\pi \lambda \eta \gamma^{\prime}$, a stroke]. Same as Hystero-paralysis.

Hysteropnix (his-ter-oph-niks) [i $\sigma \tau \varepsilon \rho \alpha$, womb; $\pi v i \xi$, suffocation]. Globus hystericus.

Hysteropsophy (his-ter-op'-so-fe) [i $\sigma \tau \varepsilon \rho \rho$, womb ; $\psi b \phi n \varsigma$, sound, utterance]. The escape of air from the uterus with an audible sound. 


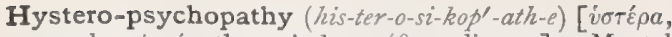

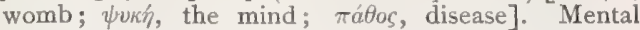
disorder secondary to disease of the uterus.

Hysteropsychosis (his-ter-o-si-ko'sis) [vorépa, womb ; $\psi v \kappa$, the mind]. Mental disorder associated with uterine disease.

Hysteroptosis (his-ter-op-to'-sis) [ivTépa, womb; $\pi \tau \tilde{\omega} \sigma \iota s$, a falling]. Falling of the womb. See Prolapsus.

Hysterorrhaphy (his-ter-or'-ra-fe) [íré $\rho a$, womb; $\dot{\rho} \alpha \phi \eta$, suture]. The closure of a uterine incision or rent by suture.

Hysterorrhea (his-ter-or-e'-ah) [vortépa, womb; ’oia, flow]. A discharge from the uteris.

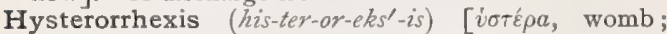
$\dot{\rho} \tilde{\eta} \xi \iota \varsigma$, rupture]. Rupture of the womb.

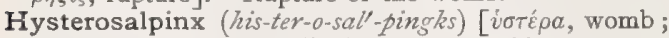
$\sigma a ́ \lambda \pi \iota \gamma \xi$, pipe]. A Fallopian tube or oviduct.

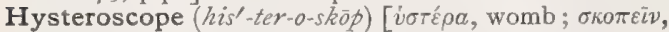
to view]. A uterine speculum, with a reflector.

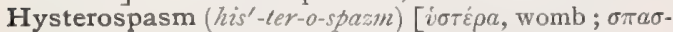
$\mu \sigma ́ s$, spasm]. Uterine spasm.

Hysterostomatome (his-ter-o-sto'-mat-ōm) [írtépa, womb; $\sigma \tau \sigma \mu \alpha$, mouth; $\tau \alpha \mu \eta \dot{n}$, section]. A knife for use in hysterostomatomy.

Hysterostomatomy, or Hysterostomatotomy (hister-o-sto-mat'-o-me, or his-ter-os-to-mat-ot'-o-me) [iv-

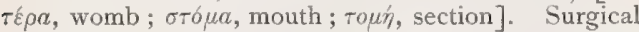
incision of the os uteri, or its enlargement by a cutting operation.

Hysterotokotomy (his-ter-o-to-kot'-o-me) [ỉoté $\rho a$,

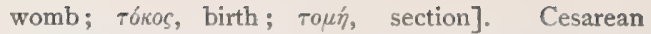
operation, or delivery through an incision into the womb.

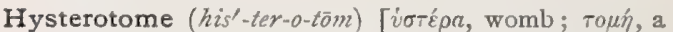
cutting]. A hysterotomy-knife or cutting-instrument for use in hysterotomy.

Hysterotomotocia (his-ter-o-to-mo-to'-se-ah) [ivrépa,

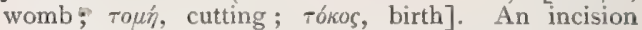
into the womb for the removal of a fetus; hysterotokotomy.

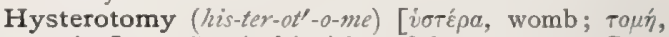
section]. I. Surgical incision of the uterus. 2. Cesarean section. See Cesarean Operation.

Hysterotrachelorrhaphy (his-ter-o-tra-kel-or'-ra-fe)

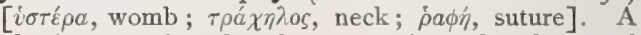
plastic operation for the restoration of a lacerated cervix uteri.

Hysterotrachelotomy (his-ter-o-tra-kel-ot'-o-me) [iv-

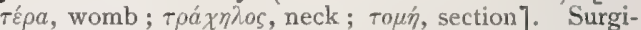
cal incision of the neck of the womb.

Hystero-traumatism (his-ter-o-traze'-mat-izm) [íotépa, womb; $\tau \rho \alpha \tilde{u} \mu c$, wound]. Hysteric symptoms due to or following traumatism.

Hysterotrismus (his-ter-o-triz'-mus) [iotépa, womb ; $\tau \rho \iota \sigma \mu \delta ́ s$, a creaking]. Spasm of the uterus.

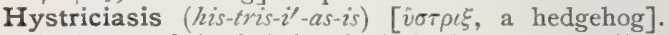
A disease of the hair in which the latter "stares" or stands stiffly out like the hair of the hedgehog.

Hystricismus (his-tris-iz'-mus). See Ichthyosishystrix.

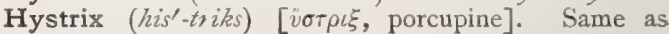
Ichthyosis hystrix.
I. The symbol of Iodin.

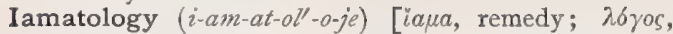
science]. The science of remedies, or of therapeutics; aceology. Obsolete.

Iasis $\left(i-a^{\prime}-s i s\right)$ [iaols, treatment, cure]. Medical or surgical treatment.

Iateria, or Iatoria (i-at-e'-re-ah, or $\left.i-a t-d^{\prime}-p e-a h\right)[i a \tau \eta-$ pía, iaтopía, therapeutics]. Therapeutics; the art or practice of medicine.

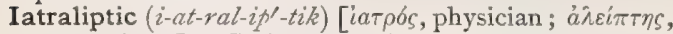
an anointer]. Curing by using ointments and frictions. I. Method. Same as Epidermatic Method.

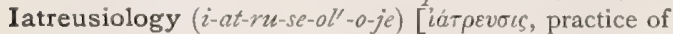
medicine; $\lambda 6 \gamma$ os, science]. The science of medical or surgical treatment; therapeutics. Obsolete.

Iatreusis $\left(i-a t-r u^{\prime}-s i s\right)$ [iát $\rho \varepsilon v \sigma \iota s$, treatment]. Medical or surgical treatment.

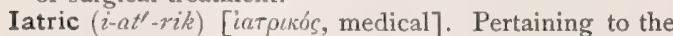
physician or to the science of medicine.

Iatro- $\left(i-a t^{\prime}-r 0^{-}\right)$[iarpos, physician]. A Greek prefix signifying relation to medicine or to physicians.

Iatrochemic, Iatrochemical (i-at-ro-kem'-ik, $i$-at-ro$\left.k e n^{\prime}-i k-a l\right)$ [iatpós, physician; $\chi \eta \mu \varepsilon i a$, chemistry]. Pertaining to the obsolete chemic school of therapeutists; spagiric.

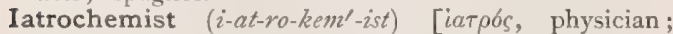

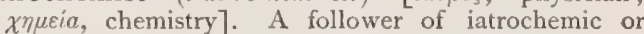
spagiric doctrines.

Iatrol $\left(i^{\prime}\right.$-at-rol) [iatpov, surgery]. Oxy-iodo-methyl- anilid; an odorless and non-toxic antiseptic agent, said to be three times as effective, weight for weight, as iodoform. Unof.

Iatroliptic (i-at-ro-lip'-tik). See Tatraliptic.

Iatrology (i-at-rol's-o-je) [iarobs, physician; $\lambda 6$ yos, science]. The science of medicine; an account of, or treatise on, physicians.

Iatromathematician ( $\left.i-a t-r o-m a t h-e m-a t-i s h^{\prime}-a n\right)$

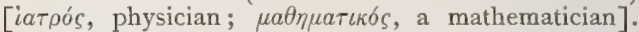
A physician of a 17 th century school (chiefly Italian) which ascribed vital activities to the sizes of pores and particles, to friction and consequent retardation, and to other mechanical causes. He asserted that all vital phenomena are mechanical.

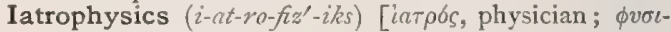
$\kappa \delta s$, pertaining to nature]. The relation of physics to medicine or the application of physics to disease or therapeutics. The materialistic explanation of disease ; applied especially to an obsolete theory of the I 7 th century, that sought to explain physiologic and therapeutic facts by means of the principles of physics (dynamics and statics).

Iatrotechnics (i-at-ro-tek'-niks) [iarpós, physician;

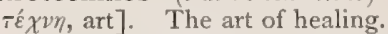

Iba $\left(e^{\prime}-b a h\right)$ [African]. Gaboon chocolate; a substitute for chocolate from Irvingia gabonensis, a simarubaceous tree of W. Africa. Unof.

Icajin $\left(i k^{\prime}-a j-i n\right)$ [African, icaja]. A poisonous alkaloid derived from an African ordeal-drug called icaja. 
It somewhat resembles brucin, and is probably derived from some species of Strophanthus, Unof.

Ice (is) [ME., ise, ice]. Water in its solid state, to which it is reduced by a temperature of $0^{\circ}$ centigrade, or $32^{\circ}$ Fahrenheit. I.-bag, a bag of waterproof material filled with ice, for application to any part of the body. I.-cap, a bladder or rubber cap filled with pounded ice for application to the head in case of congestion. I.-cot, a bed cooled by ice, so as to reduce the temperature of the patient. I.-cradle, a device that consists in the suspension over a febrile patient in bed, by means of iron frames or barrel-hoops, of a number of zinc buckets kept half-filled with ice and enclosed in a light covering. The patient is covered with a muslin sheet and provision is made for the circulation of pure air in the cradle. The temperature of the patient is to be taken at least every four hours, and if it falls to $100^{\circ}$ the apparatus is to be removed. If a sense of chilliness appears hot bottles are to be applied to the feet. I.-poultice, or I.-compress, an application of broken ice used for local refrigeration.

Iceland (is'-land) [ME., ise, ice; ME., land, land]. An island of the Arctic Ocean. I. Moss. See Cetraria. I. Spar, a transparent calcium carbonate, crystallized in rhomboidal prisms. It has the property of dividing and doubly refracting a ray of light.

Ichor $\left(i^{\prime}-k o r\right)$ [ $i \chi \omega \rho$, serum, or pus]. An acrid and thin puriform discharge from an ulcer or wound.

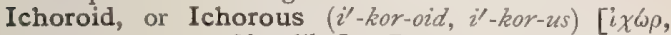
serum, or pus; Eidos, like]. Resembling or relating to pus containing serum and disintegrated tissue.

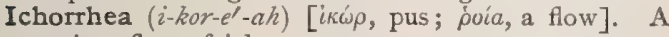
copious flow of ichor.

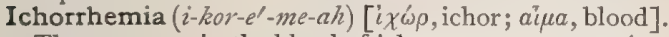
The presence in the blood of ichorous matter; septicemia ; pyemia.

Ichthiasis $\left(i k-t h i^{\prime}-a s-i s\right)$. See Ichthyosis.

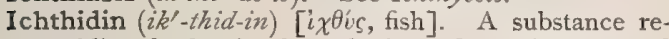
sembling lardacein, but obtained from the eggs of cyprinoid fishes.

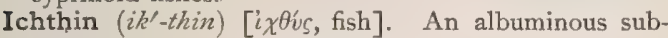
stance obtained from the eggs of some fishes, and also from cartilaginous fishes and frogs.

Ichthulin ( $\left.i k^{\prime}-t h u-l i n\right)$ [i $\chi^{\theta} \dot{v} s$, a fish; $i \lambda \eta$, matter]. A lardaceous substance, with the percentage-composition, $\mathrm{C}_{52 \cdot 5} \mathrm{H}_{8} \mathrm{~N}_{15 \cdot 2} \mathrm{~S}_{1} \mathrm{P}_{0 \cdot 6}$, found in the eggs of fishes and in salmon. It is akin to ichthin and ichthidin.

Ichthyiasis (ik-the-i'-as-is). Same as Ichthyosis.

Ichthyic $\left(i k^{\prime}-t h e-i k\right)$ [i $\chi 0 v i k \delta s$, of a fish, fishy]. Pertaining to, or resembling, a fish; piscine; ichthyoid; ichthyo-morphic; icthyopsidan.

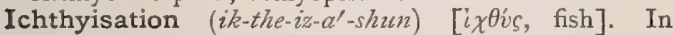
biology the process of intensification of fish-like characters.

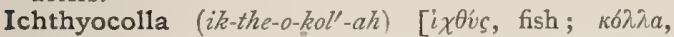
glue]. Isinglass. The air-bladder of the sturgeon, Acipenser huso. It occurs in horny, translucent, white sheets, that form a jelly with hot water. It is the purest form of gelatin, and is used as a food, for clarifying liquids, and as a test for tannic acid. I., Emplastrum, court-plaster ; it consists of isinglass IO, glycerin I, alcohol 40, water and tinct. benzoin q. s., spread upon fine white silk bolting-cloth and dried.

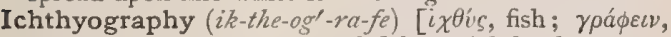
to write ]. A description of fishes; ichthyology.

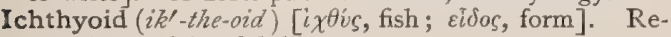
sembling a fish; fish-like.

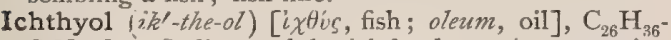
$\mathrm{S}_{3} \mathrm{Na}_{2} \mathrm{O}_{6}$. Sodium sulpho-ichthyolate. A preparation obtained from certain varieties of fossiliferous shale occurring in the Tyrolese Alps. It has a characteristic bituminous odor and taste. It is a good antiphlogistic, and has proved efficient in eczema and psoriasis, and in gynecology. It is used in the form of a 10 to 20 per cent. ointment, as a solution in glycerin, equal parts, or in the pure state. I., German. See Thiol.

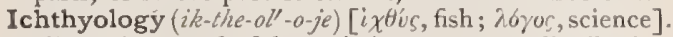
The science of fishes, their anatomy, distribution, and biology.

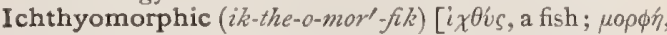
form ]. In biology, having the morphologic characters of a fish; ichthyopsidan.

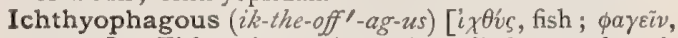
to eat]. Fish-eating. A word applied to such animals as subsist on fish.

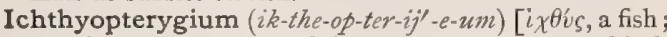
$\pi T \varepsilon \rho$ v'rov, a wing or fin]. The fore-limb or hindlimb of a vertebrate, modified as a fin.

Ichthyosis (ik-the-o'-sis) [' $\chi \theta$ ivs, fish; vooos, disease]. Xeroderma ichthyoides, Ichthyosis vera, fish-skin disease; a congenital skin-disease, usually involving the entire surface of the body, aggravated by cold, and characterized by extreme dryness of the skin and by the development of epidermal plates coarsely resembling the scales of a fish, and forming in some cases verrucous growths, sessile and pedunculated, freely projecting from the surface. I. congenita. See Seborthea squamosa neonatorum. I. follicularis, a form in which the sebum and epithelium are heaped up around the orifices of the hair-follicles; it is especially seen upon the extensor surfaces of the arms and legs. I. hystrix; Hystricismus; a rare skindisease characterized by warty-looking growths, consisting of elongated and hypertrophied papillæ, covered by greatly thickened, dark-brown, horny epidermis, and forming flat-topped or pointed, spinous projections. These are grouped together to form patches, often unilateral and distributed along the course of cutaneous nerves. They are seldom present on the face. Usually they offer no subjective symptoms. 1. linguæ, an acquired affection of the tongue in which it becomes dry and scaly. I. nacrée. See $I$. simplex. I. nigricans. See 1 . simplex, I. nitida. See I. simplex. I. palmæ vel palmaris et plantaris, the exceptional form confined solely to the palms and soles. I. sauroderma. See 1 . simplex. I. scutellata. See $I$. simplex. I. sebacea. Synonym of Seborrhea. I. sebacea cornea. See Darier's Disease. I. serpentina. See $I$. simplex. I. simplex, the common form of ichthyosis in which the whole surface has a tesselated appearance, from being covered with large, angular, dirty-white, finely corrugated, papery scales that are adherent, and therefore slightly depressed in the center ( $I$. scutellata), while the edges are detached, transparent, and shining (I. nacrée or I. nitida). In still higher grades the scales adhere together to form thin plates, and being of a greenish tint, resemble a serpent's skin ( $I$. serpentina); when there are still thicker plates, the appearance of a crocodile hide is produced ( $I$. sauroderna). The older the plates the darker they become, so that they may vary from olive-green to black ( $I$. nig, icans). The hair is dry, harsh, and dull-looking, and the scalp branny; the nails may be pitted and brittle. Itching is frequent. Warmth ameliorates the condition by favoring sweating. I. spinosa, a form of $l$. hystrix, in which the scales are spiny. I. vera. See Ichthyosis.

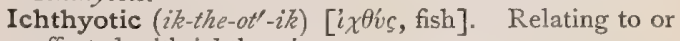
affected with ichthyosis.

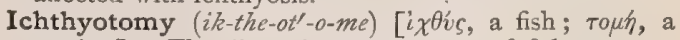
cutting]. The dissection or anatomy of fishes.

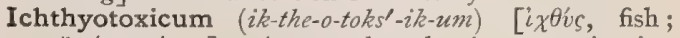
$\tau \circ \xi \iota \kappa b v$, poison]. A name loosely given to poisoning 
from eating the flesh of certain fish, and also to the poisonous principle. It may be a natural poisonous principle, or the result of putrefactive fermentation of the substance of the fish. It is probably a ptomaine.

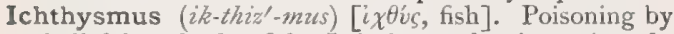
shell-fish and other fish. It is due to the absorption of a poison known as mytilotoxin, that exists chiefly in the liver of the mussel. The symptoms are numbness and coldness, apyrexia, dilated pupils, rapid pulse, and death from collapse, at times within two hours.

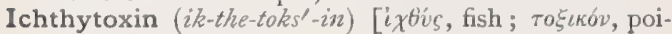
son]. A poisonous substance obtained from the bloodserum of eels.

Icica $\left(i s^{\prime}-i k-a h\right)$ [S. Am.]. A genus of amyridaceous trees, mostly of tropical America. Varieties of elemi, caranna and tacamahac are produced by trees of this genus. Unof.

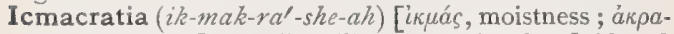
Tia, weakness]. I. Inability to retain the fluids of the body. 2. Depraved or enfeebled state of the bodily fluids or humors. Obsolete.

Icmastic (ik-mas'-tik) [ikuás, fluid]. Relating to the fluids or humors of the body.

Icon ( $\left.i^{\prime}-k o n\right)$ [ $\varepsilon^{\prime} \kappa \omega \nu$, image]. An image or model.

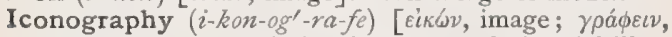
to write]. A description by means of pictorial illustration.

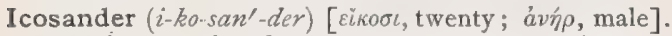
In biology, a plant having twenty or more perigynous stamens.

Icterepatitis $\left(i k-t e r-e p-a t-i^{\prime}-t i s\right)[i \kappa \tau \varepsilon \rho o s$, jaundice; $j \pi a \rho$, liver; $\iota \tau \iota$, inflammation]. Inflammation of the liver attended with jaundice.

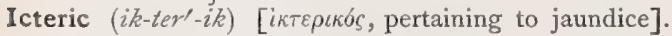
Pertaining to jaundice.

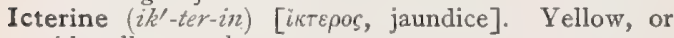
with yellow marks.

Icteritia (ik-ter-ish'-e-ah) [L.]. I. Same as Icterus. 2. Discoloration of the skin.

Icteritious (ik-ter-ish'-us) [icteritia, jaundice]. fected with icterus or icteritia.

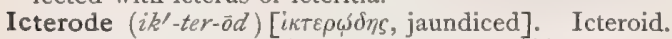

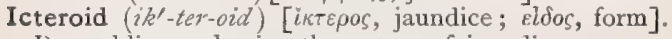
Resembling or having the nature of jaundice.

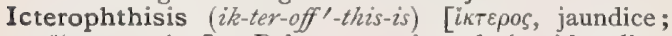
$\phi \theta i \sigma \iota$, wasting]. Pulmonary tuberculosis with yellow discoloration of the skin.

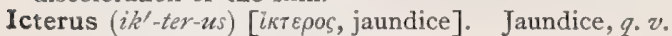
I. gravis, Acute Yellow Atrophy of the Liver. A rare disease of the liver in which there is a rapid wasting of the liver-substance, with marked jaundice, and death. It may be either primary or secondary. Associated with the jaundice are headache and marked cerebral symptoms, hemorrhage from the mucous surfaces, and rise of temperature. The urine contains leucin and tyrosin. The liver is much reduced in weight, fiattened, soft, its capsule wrinkled ; microscopically there is an extensive destruction of the livercells, due to fatty degeneration. The disease occurs most frequently in females, and in early adult life. The primary form of the disease is usually encountered in pregnancy and during the puerperium. The secondary form may follow other morbid conditions of the liver, and phosphorus-poisoning. I., Hematogenic, See Jaundice. I., Hepatogenic. See Hepatogenic. I. neonatorum, that which is sometimes observed in an infant during the first few days after birth; it is possibly an indirect result of tying the umbilical cord, or may be due to a breaking-down of the red blood-corpuscles from exposure to cold. I., Urobilin, a form of jaundice, so called, due to the production in the body of an excess of urobilin by oxidation of the bile-pig- ments. The skin and conjunctivæ are colored yellow, the urine dark-brown, but no true jaundice exists.

Ictus $\left(i k^{\prime}-t u s\right)$ [L., a stroke]. A sudden or unforeseen attack. I. epilepticus, an epileptic fit. I. paralyticus, a paralytic stroke. I. solis, sunstroke.

Id [idus, the dividing or division]. In biology, according to Weismann's theory of the germ-plasm, a vital unit of the third degree, having a definite structure of determinants, which in their turn are made up of biophores; an "ancestral germ-plasm," or unit containing all the primary constituents of the species. Each id represents an individuality, and is probably identical with the "microsome" of the nuclear rod. Cf. Idioplasm; Idant.

-id, or ide (id) [idus, a term]. A suffix used in chemistry to denote a combination of two elementary substances.

Idant $\left(i^{\prime}\right.$-dant $)$ [idus, the dividing or division]. In biology, according to Weismann's theory of the germplasm, a vital unit of the fourth degree; a group of $i d s$, differing from the latter in not being perfectly invariable quantities, but only relatively constant, their constitution being modified from time to time, so that the ids which previously belonged to the idant A may later take part in the composition of the idant B or C. A chromosome (chromatosome) or nuclear rod, composed of vital units or ancestral plasms, termed ids or microsomata (microsomes).

-ide [Eiðos, resembling in form]. A suffix denoting resemblance to the object with the name of which the designated body is combined.

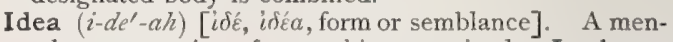
tal representation of something perceived. I.-chase, a condition in acute mania in which disconnected ideas and fancies flow rapidly through the mind. It is a term much used by German authors. I., Fixed, that form of mania in which one dominant idea controls all actions. I., Imperative, a morbid idea or insane suggestion imperiously demanding notice, the patient often being painfully conscious of its domination over his will.

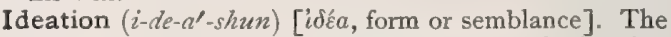
formation of a mental conception; the cerebral action by which, or in accord with which, an idea is formed.

Identical (i-den'-tik-al) [identicus, the same]. The same. I. Points, corresponding points of the two retinæ, or the two positions in normal eyes where the image of an object is focused upon the retinæ.

Identism $(i$-den'-tizm) [idem, the same]. The theory that chancre, chancroid, and gonorrhea are due to one and the same poison or virus.

Identist (i-den'-tist) [idem, the same]. A term applied to one who believes in the identity of certain diseases, e. g., that gonorrhea and hard and soft chancre are due to the same specific virus, or that typhus and typhoid fevers are identical.

Identity (i-den'-tit-e) [idem, the same]. Absolute sameness. I., Personal, one's personal existence; the continuity of one's state as a person; the reality of the existence of any person; in law, the fact of one being the person he is assumed to be; that which is commonly proved by the establishment of similarity or sameness of age, sex, physical characteristics, marks, and peculiar habits.

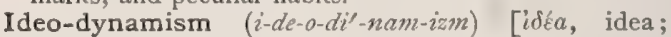
dvvauts, force]. The domination of an idea; the control exercised by a suggested idea over the subsequent acts of a person who is, or has been, hypnotized.

Ideomotion (i-de-o-mo'-shun) [idéa, idea; motio, a moving]. Motion or action due to some idea, and neither purely voluntary nor reflex. 
Ideo-motor (i-de-o-mo'-tor) [idea, a mental image; movere, to move]. Pertaining conjointly to ideation and movement. I. Center, that part of the gray matter which, influenced by ideation, excites muscular movement. I. Movements, unconscious movements, due to impulses of the mind when the attention is otherwise absorbed.

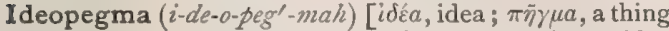
fixed: pl., Ideopegmata]. A fixed or dominant idea that colors all the thoughts of the patient and thus creates a monomania.

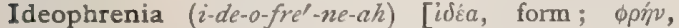
mind]. Insanity with marked perversion of ideas.

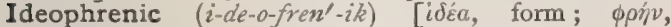
mind]. Relating to, or marked by, ideophrenia.

Ideoplastic (i-de-o-plas'-tik) [idéa, idea; $\pi \lambda a ́ \sigma \sigma \varepsilon \iota v$, to form ]. Giving shape to the ideas; that stage of hypnotism in which the idea impressed on the brain of the subject is translated into action.

Ideosynchysia, or Ideosynchysis (i-de-o-sin-ki'-ze-ah,

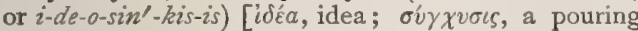
together]. Confusion of ideas; delirium.

-ideus $\left(-i d^{\prime}-e-u / s\right)$ [idcos, one's own]. A suffix having the sense of possession or ownership.

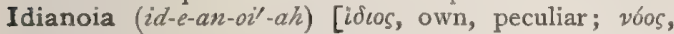
mind]. Same as Idiocy.

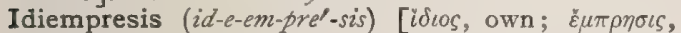
burning]. Spontaneous combustion. Also, spontaneous inflammation.

Idio- $\left(i d^{\prime}-e^{-}-o^{-}\right)[i \delta \iota s$, own]. A prefix signifying individual peculiarity.

Idiobiology $\left(i d-e-0-b i-o l^{\prime}-0-j e\right)$ [idıos, peculiar; ßios, life ;

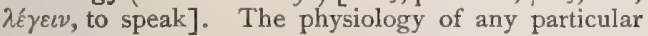
organized body, as opposed to Biontology, q. v. (J. Aitken Meigs.)

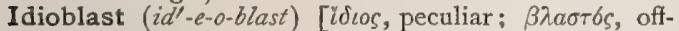
shoot]. In biology, a histologic cell having a character different from that of the surrounding cells, owing to a difference either in its form or its contents, $e_{.} g$., the stellate hair in the interior of the tissue of $N y \mathrm{~m}$ phecece (Sachs).

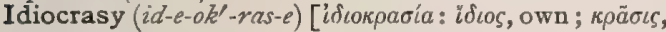
mixture]. Same as Idiosyncrasy.

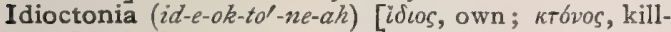
ing]. Self-murder; suicide.

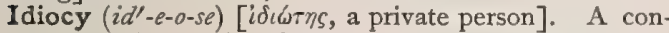
dition of mental deficiency, usually accompanied by physical degeneracy. It is characterized by a peculiar coarse, brutal, and cunning nature, with marked physical peculiarities. It is more common in males than in females. I. of Deprivation, that in which from birth there is a loss of two or more of the senses, with consequent lack of external impressions. I, Eclampsic, that following infantile convulsions. Fourteen per cent. of cases of idiocy are said to be of this origin. I., Epileptic, that associated with epilepsy. Such cases are the subjects of epileptic convulsions through life. I., Ethnic, a characteristic of certain idiocies of the Caucasian race, in which individuals are seen who present a kind of mimicry of various other races of mankind. Among the types of genetous idiocy thus characterized, writers have described the American-Indian type, the Ethiopian or negroid, the Kalmuck, the Malayan, and the highly characterized Mongolian type, which includes about ten per cent. of all cases of idiocy. I., Genetous, those cases in which, although the causation is indefinite, the condition dates from fetal life. I., Hydrocephalic, that dependent upon hydrocephalus. I., Inflammatory. See I., Traumatic. I, Microcephalic, that associated with smallness of the head. A circumference less than eighteen inches implies idiocy. 1., Paralytic, that from paralysis following injury before or after birth. I., Traumatic, that due to injury during labor or in early childhood.

Idioderma (id-e-o-der-mah). Same as Dermatitis $t u$. berusa.

Idiodinic (id-e-o-din'-ik) [iftos, one's own; divos, rotation, a round area, taken in the sense of "pore" "]. In biology, applied to animals that bring forth or reproduce by means of a special genital pore.

Idio-electrics $\left(i d^{\prime}-e-0-e\right.$ lek'-triks) [idıos, own; $\ddot{\eta} \lambda \varepsilon \kappa \tau \rho o \nu$, amber]. A name formerly applied to such bodies as amber, resin, or glass, which are readily electrified by friction, and which were then supposed to be electric in themselves.

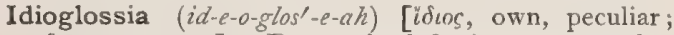
$\gamma \lambda \tilde{\omega} \sigma \sigma \alpha$, tongue]. Extremely defective utterance, but one in which the same sound is used to express the same idea, even though the sounds used belong to no known language.

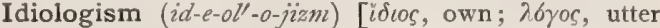
ance]. A characteristic expression or form of utter ance peculiar to any person, especially to an insane person.

Idiometritis (id-e-o-me-tri'-tis) [idıos, own; $\mu$ '́tpa, womb; $\iota \tau / s$, inflammation]. Inflammation of the parenchymatous substance of the womb.

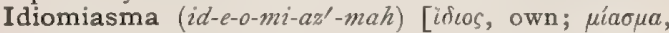
stain, defilement: $p l$., Idiomiasmata]. A term for any noxious exhalation from the body.

Idiomology $(i d-e-o-m o l l-o-j e)$ [idi $\omega \mu \alpha$, a peculiar phraseology, idiom; $\lambda \varepsilon^{\prime} \gamma \varepsilon v$, to speak ]. The study of the peculiarities of speech of various races.

Idio-muscular (id-e-o-mus'-ku-lar) [idıs, own; musculus, muscle]. Peculiar to muscular tissue ; not involving any nerve-stimulus or any function of the organism, except those of the muscle itself. I. Contraction, the contraction of a fatigued or tired muscle under certain conditions of extraneous stimulus.

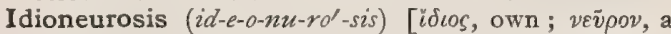
nerve ; $v 6 \sigma o c$, disease]. An affection due to some disturbed or abnormal condition of the nerves supplying the affected part ; a simple and uncomplicated neurosis.

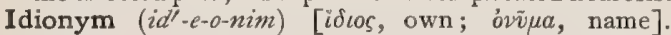
A term restricted in its application to a particular organ.

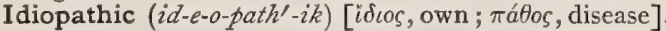
Not consequent or dependent upon another disease or known or recognized cause. The antithesis of sympathetic, deuteropathic. I. Dysmenorrhea, painful menstruation unassociated with organic lesion or displacement.

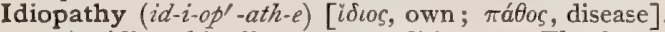
I. An idiopathic disease or condition. 2. The fact or quality of being idiopathic.

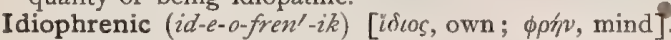
Due to disease of the brain ; a term used to designate certain forms of insanity.

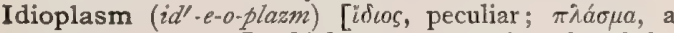
thing formed]. In biology, a term introduced by Nägeli for a special hereditary reproductive substance not contained in the body of the cell, but in the chromosomes of the nucleus, controlling and determining the actual characters of the particular cell, and also those of all of its descendants. Each idioplasm is ccmposed of several or many $i d s\left(q . v_{*}\right)$, which are capable of growth and multiplication by division; although much smaller in bulk than the rest of the living substance of the cell or body (trophoplasm), idioplasm is the active element in the process of formation, and determines the detailed construction of the trophoplasm, which is the passive element. I., Accessory (Neben-idioplasm), a special, minute group of "supple- 
mentary determinants" enclosed within the id in the neighborhood of the determinants which control the cell in question, and rendering the cell capable of regeneration of tissues other than that of which it is a component. I., Bone, that form of idioplasm which contains the determinants of bone-cells. Cf. Germplasm. I., Nägeli's. See Heredity.

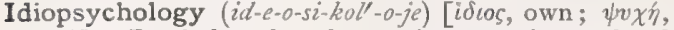
soul]. Psychology based upon introspective study of one's own mental acts. Cf. Heteropsychology.

Idioretinal (ia-e-o-ret'-in-al) [idios, own; retina, retina]. Peculiar or proper to the retina.

Idiospasm (id'-e-o-spazm) [idios, own; $\sigma \pi a \sigma \mu b s$, spasm]. A spasm or cramp confined to one part.

Idiospastic (id-e-o-spas'-tik) [idios, one's own; $\sigma \pi a \sigma \tau t-$ кós, stretching]. Pertaining to ldiospasm.

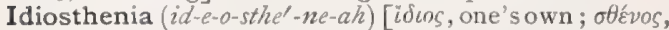
strength]. Having innate or spontaneous strength or power.

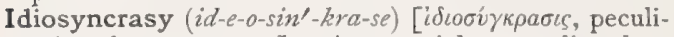
arity of temperament]. Any special or peculiar characteristic or temperament by which a person differs from other persons of ordinary habits. I., Hemorrhagic. See Hemophilia. I., Imaginary, a hysteric aversion to certain foods or medicines. I., Olfactory, a perversion of the sense of smell.

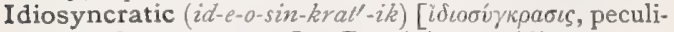
arity of temperament]. Pertaining to idiosyncrasy. I. Coryza, a synonym of Hay-ferver.

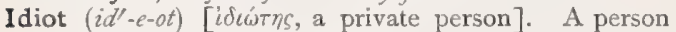
of imperfect, deficient or arrested mental development, either congenital or due to causes arising soon after birth. I. savant, an idiot who has a considerable or even remarkable mental development in certain directions, as in musical art, in mathematics, in memory, or in mechanical ingenuity.

Idiotcy (id'-e-ot-se), Idiotism $\left(i d^{\prime}-e-o t-i z m\right)$, Idiotry

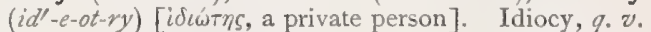

Idiothalamous (id-e-o-thal'-am-us) [idens, one's own; $\theta a ́ \lambda a u o s$, a room]. In biology, applied to such lichens as have certain parts of a different character from the thallus.

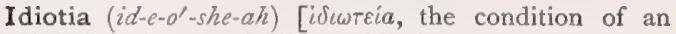
idiot]. A state of idiocy; idiotism.

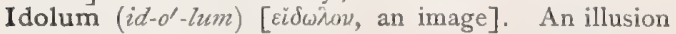
or hallucination.

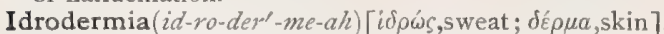
An affection of the sudoriferous glands of the body.

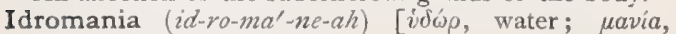
mania]. Hydromania; insane desire for water, or to commit suicide by drowning.

Idrosadenitis (id-ros-ad-en-i'-tis). See Hidrosadenitis.

Idrosis $\left(i d-r o^{\prime}-s i s\right)$. See Hidrosis.

Idryl (id"-ril). See Fluoranthene.

Pasuric Acid (ig-as-u'-rik) [Malay, igasur; ignatia]. An acid occurring in St. Ignatius' bean, and certain other plants containing strychnin.

Igasurin (ig-as-u'-rin) [Malay, igasur; ignatia]. An alkaloid from ignatia, said to be more poisonous than brucin. Its existence as a definite compound has been denied.

Ignatia (ig-na'-she-ah) [from Ignatius, the founder of the Jesuits: gen., Ignatic]. St. Ignatius' bean. The seed of Strychnos ignatii, with properties due to the alkaloids strychnin and brucin, of which the plant contains of each about I per cent. It is said by some to contain igasurin, $q . v$. Its therapeutic effects are similar to those of nux vomica, $q$. $v$. It is recommended in hysteria, and is highly efficient in controlling the functions of the cerebro-spinal axis. I., Abstractum. Dose gr. ss-j. I., Tinct., contains 10 per cent. of the drug. Dose $m_{i j-x}$.
Ignavia (ig-na'-ve-ah) [L.]. Sluggishness; abnormal slowness of function.

Ignipuncture (ig-ne-pun $\left.k^{\prime}-t \bar{u} r\right)$ [ignis, fire; punctura, puncture]. A method of cauterization employed in the treatment of certain forms of hypertrophy by the introduction of platinum needles heated to whiteness by the electric current.

Ignis $\left(i g^{\prime}-n i s\right)$ [L.]. Fire. Combustion distinguished by rapid oxidation. I. actualis, actual cautery. I. fatuus, the phenomenon known as Jack o' Lantern, Will o' the Wisp, etc. I. sacer, an obsolete name for erysipelas. See Anthrax and Herpes zoster. I. sancti Antonii, Saint Anthony's Fire, a common name for erysipelas.

Ignition (ig-nish'-un) [ignis, fire]. The process of heating solids, especially inorganic compounds, until all volatile matter has been driven off.

Ihering's Line. See Lines, Table of.

Ihle's Paste. A modification of Lassar's paste. It is composed of resorcin, gr. Io to 6o; lanolin, vaselin, oxid of zinc, and powdered starch, each, 2 drams. It is used in eczema.

Ikota $\left(i k-o^{\prime}-t a h\right)$ [Siberian], A form of religious and hysteric mania, prevailing among the women of Siberia.

Ileac $\left(i l^{\prime}-e-a k\right)$ [Ei $\lambda \varepsilon \iota \nu$, to roll]. Pertaining to the ileum. I. Passion, an ailment characterized by severe griping pains and vomiting of fecal matter, together with spasm of the abdominal muscles.

Ileadelphus .(il-e-ad-el'-fus) [ $\varepsilon i \lambda \varepsilon L v$, to roll; $a \dot{\delta} \varepsilon \lambda \phi b s$, a brother]. A monstrosity double from the pelvis downward

Ileitic $\left(i l-\ell-i t^{\prime}-i k\right)$ [ $\varepsilon i \lambda \varepsilon \imath \nu$, to roll; $\iota \tau \iota$, inflammation]. Pertaining to or affected with ileitis.

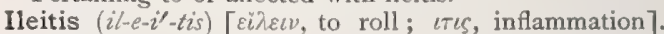
Inflammation of the ileum.

Ileo- $\left(i l^{\prime}-\ell-o-\right)[\varepsilon i \lambda \varepsilon \imath v$, to roll]. A prefix signifying connection or relation to the ileum. I.-cecal, pertaining or belonging to both ileum and cecum. I.-c. Fossa, a depression in the lower part of the small intestine at the base of the vermiform process. I.-c. Valve, a valve consisting of two folds of mucosa that guards the passage between the ileum and cecum. I.-costalis. See Muscles, Table of. I.-lumbar, pertaining to the ileum and the lumbar region. I.-1. Ligament. See Ligament. I.-typhoid, a synonym for typhoid or enteric fever.

Ileo-cleisis $\left(i l-e-o-k l i^{\prime}-s i s\right)$ [ $\varepsilon i \lambda \varepsilon \iota v$, to roll ; $\kappa \lambda \varepsilon i \varepsilon \iota \nu$, to lock]. Obstruction or closure of the ileum.

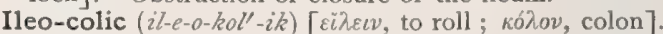
Pertaining conjointly to the ileum and the colon. I.-c. Valve. Same as Ileocecal Valve.

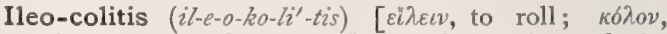
colon; $\iota \tau \iota$, inflammation]. Inflammation of the lower part of the ileum and the colon. It is commonly known as intestinal catarrh.

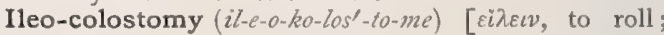
$\kappa 6 \hat{\lambda} \alpha \nu$, colon; $\sigma \tau \dot{\sigma} \mu \alpha$, mouth]. The surgical establishment of an artificial communication between the ileum and the colon.

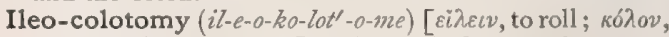
colon; $\tau \dot{\varepsilon} \mu \nu \varepsilon \imath \nu$, to cut]. A surgical operation upon the ileum and the colon.

Ileodicliditis $\left(i l-e-0-d i k-l i d-i^{\prime}-t i s\right)$ [ $\varepsilon i \lambda \varepsilon \iota v$, to roll ; $\delta \iota k \lambda i s$, valve; $\iota$ $\iota$, inflammation ]. Inflammation of the ileocecal valve.

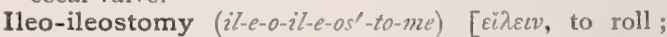

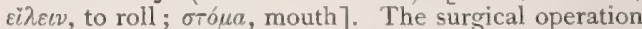
of establishing an artificial communication between two different parts of the ileum.

Ileology $\left(i l-e-o l^{\prime}-o-j e\right)$ [ $\varepsilon i \lambda \varepsilon \iota v$, to roll; $\lambda \sigma \gamma o s$, science]. The anatomy, physiology, and pathology of the ileum. 


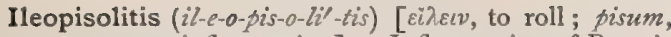
a pea; iTls, inflammation]. Inflammation of Peyer's patches or glands.

Ileoproctostomy (il-e-o-prok-tos'-to-me) [ $\varepsilon i \lambda \varepsilon \imath v$, to roll;

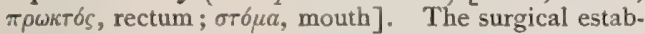
lishment of an artificial communication between the ileum and the rectum.

Ileorectostomy (il-e-0-rek-tos'-to-me). See Ileoproctostomy.

Ileos $\left(i l^{\prime \prime}-e-o s\right)$. See Ileus.

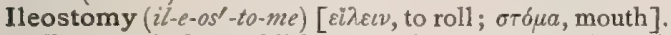
The surgical establishment of a passage through the abdominal wall into the ileum, or from the ileum to some other hollow organ.

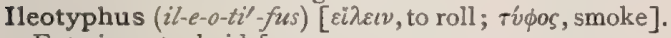
Enteric or typhoid fever.

Ileum $\left(i l^{\prime}-\ell-u m\right)$ [ $\varepsilon i \lambda \varepsilon i \nu$, to roll] . The lower portion of the small intestine. It receives its name from its peristaltic movement.

Ileus (itr-e-us) [ $\varepsilon i \lambda \varepsilon b s$; $\varepsilon i \lambda \varepsilon t v$, to roll]. Same as Ileac or Iliac Passion; volvulus. I. inflammatorius. Synonym of Acute Intestinal Catarrh. I. spasmodicus. Synonym of Enteralgia.

Ilex (i'-leks) [L., the holm-oak]. A genus of aquifoliaceous trees and shrubs of many species; the hollies. I. aquifolium, common European holly; the bark and leaves have medicinal uses. I. cassine. See Cassena. I. opaca, American holly; it has the properties of I. aquifolium. I. glabra, and I. verticillata, of the U. S., are tonic, febrifuge, and astringent. See also Maté. All unof.

Ilia $\left(i l^{\prime}-e-a h\right)$ [L. : $p l$. of Ilium]. The iliac bones; the flanks or loins.

Iliac $\left(i l^{\prime}-e-a k\right)$ [ilia, the flanks]. Pertaining to the ilium or to the flanks. I. Aneurysm, one occurring at the groin. I. Artery. See Arteries, Table of. I. Crest, the upper free margin of the ilium to which the abdominal muscles are attached. I. Fascia. See Fascia. I. Fossa. See Fossa. I. Muscle. See Muscles, Table of. I. Region, one of the regions into which the abdomen is conventionally divided. See Abdomen.

Iliaco- $\left(i l-i^{\prime}-a k-o-\right)$ [ilia, the loins]. A prefix signifying relation to the loins. 1.-femoral, relating to the ilium and the femur. I.-trochanteric, relating to the ilium and the great trochanter of the femur.

Iliacus $\left(i l-i^{\prime}-a k-u s\right)$. See Muscles, Table of.

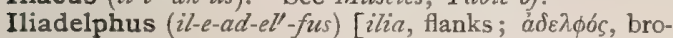
ther]. A monstrosity double from the pelvis upward.

Ilicin (il'-is-in) [ilex, the holm-oak]. A crystalline febrifugal principle from the leaves of Ilex aquifolium.

Ilien $\left(i l^{\prime}-e-e n\right)$ [ilia, the loins]. Belonging to the ilium in itself.

Ilio- $\left(i l^{\prime}-e^{-} 0^{-}\right)$[ilium, the ilium]. A prefix to denote relation to or connection with the ilium. I--capsularis, a muscle occasionally found in man, originating at the anterior inferior spine of the ilium and inserted into the ilio-femoral ligament. See Muscles, Table of. I.-femoral, pertaining conjointly to the ilium and the femur. 1.-f. Crease. See Crease. 1.-f. Ligament, an inverted V-shaped ligament extending obliquely across the hip-joint, from the anterior inferior spine of the ilium to the trochanters of the femur, preventing over-extension of the joint. I.-f. Triangle, a triangle of which the base is a line drawn from the summit of the great trochanter to the anterior superior spine of the ilium, and the apex is formed by lines drawn backward from the anterior superior spine and upward from the summit of the trochanter. See Triangles, Table of. I.-hypogastric, pertaining conjointly to the ilium and the hypogastrium. I.-h. Nerve. See Nerves, Table of. I.-inguinal, pertaining to the ilium and the groin. I.-i. Nerve. See Nerves, Table of. I,-lumbar, pertaining conjointly to the ilium and the loins. I.-1. Artery, a branch of the posterior division of the internal iliac artery, supplying the iliacus, and also the psoas and quadratus lumborum muscles. See Arteries, Table of. I.-1. Muscle, that part of the quadratus lumborum muscle that is inserted into the tips of the processes of the lumbar vertebræ. See Muscles, Table of. I.-pectineal, pertaining conjointly to the ilium and the pubes. I.-p. Ligament, that part of the iliac fascia by which Poupart's ligament and the sheath of the crural vessels are attached to the os pubis. I.-p. Line, the ridge reaching from the spine of the os pubis to the auricular surface of the ilium. See Lines, Table of. I.-pelvic, pertaining conjointly to the ilium and the pelvis. I.-p. Abscess, suppuration sometimes occurring over the iliacus muscle during labor, and commonly due to the laceration of muscular fibers. I.-perineal, relating to the ilium and the perineal region. I.-polymelius, a monstrosity with supernumerary limbs attached to the ilium I.psoas, pertaining conjointly to the ilium and the loins. 1.-p. Muscle. See Muscles, Table of. I.pubic, relating to both ilium and pubes. I.-spinal, relating to the ilium and the spinal column. I.tibial, pertaining to or connecting the ilium and the tibia. I.-t. Band, a thickened portion of the fascia lata extending from the outer tuberosity of the tibia to the iliac crest. I.-trochanteric, pertaining to the ileum and a trochanter.

Ilium $\left(i l^{\prime}-e-u m\right)[\mathrm{L}$.$] . The upper part of the os inno-$ minatum. The haunch-bone.

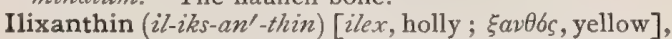
$\mathrm{C}_{17} \mathrm{H}_{22} \mathrm{O}_{11}$. A yellow crystalline coloring-matter found in holly. The crystals melt at $198^{\circ} \mathrm{C}$, and are soluble in hot water and alcohol.

I11 (ii) [ME., ille, ill]. Sick; diseased; unwell.

Illacrimation (il-lak-rim- $\alpha^{\prime}$-shun) [illacrimatio; in, on ; lacrima, a tear]. Same as Epiphora.

Illaqueation (il-lak-we-a'-shun) [illaqueare, to ensnare]. A method of changing the direction of misplaced cilia, by withdrawing them, by a noose, through an opening in the adjacent tissue of the lid.

Illegitimacy (it-e-jit'-im-a-se) [in, not; legitimus, according to law]. The condition of being unlawful, or not legitimate.

Illegitimate (il-e-jit'-im-at) [in, not ; legitimus, according to law]. Not in accordance with statutory law. I. Child, one born out of lawful wedlock; a bastard. Illequation (il-e-kwa'-shun). See Illaqueation.

Illicium $\left(i t-i s^{\prime}-e-u m\right)$ [illicere, to entice]. Star Anise. The fruit of Illicium anisatum, with properties due to a volatile oil identical with oil of anise. Illicium is properly the name of a genus of magnoliaceous trees and shrubs. I. floridanum, of the Gulf States, has poisonous leaves. I. religiosum, of Asia, is said to be highly poisonous. I. verum, is said to yield the star anise of commerce. Unof.

Illness (il'-nes) [ME., ille, ill]. Sickness; disease; an attack of disease.

Illumination (il-oo-min-a'-shun) [illuminare, to make light]. A light produced by a luminous body, and reflected by surrounding objects. In photometry, the unit of intensity of illumination is that given by a standard candle at a distance of one foot. I., Darkground, in microscopsy, a condition in which the object appears self-luminous on a dark back-ground. This occurs when the rays of light are too oblique to enter the front lens of the objective, except such as 
are reflected or refracted from the object itself. I. of Eye, the lighting up of the interior of the eye by means of the ophthalmoscopic mirror. I., Oblique, in microscopy, an illumination produced by throwing the rays of light upon an object at any angle of inclination. In ophthalmology, oblique illumination of the cornea consists in focusing a pencil of rays obliquely upon the part.

Illuminator (il-oo'-min-a-tor) [illuminare, to make light]. In microscopy, an optic apparatus for concentrating light. I., Abbè, an illuminating apparatus for the microscope designed by Professor Abbè. Abbè's Condenser.

Illuminism (il-oo'-min-izm) [illuminare, to make bright]. Insane exaltation; especially exaltation with belief in one's communion or direct intercourse with supernatural or heavenly beings.

Illusion (il-lu'-zhun) [illusio, a mocking]. A false or deceptive mental impression. Illusion differs from hallucination in that it is the false interpretation by the mind of a real sensation. The senses are not at fault in case of illusions, and the defective process is purely psychic. The distinction between illusion and hallucination is, however, by no means a constant one.

Illusional (il-lu'-zhun-al) [illusio, a mocking]. Of the nature of an illusion.

Illutation (il-lu-ta'-shun) [in, in ; lutum, mud]: Treatment of disease by the mud-bath.

Image $\left(i m^{\prime}-\bar{a} j\right)[i m a g o$, a likeness]. The picture of an object formed by the focused rays of light proceeding from it. I., After. See After-image. I., Diffusion of. See Diffusion. I., Direct, or I., Erect, that of the fundus oculi as seen with the ophthalmoscope, the details of the fundus presenting their natural relations. I., Inverted, that obtained by interposing between the ophthalmoscope and the observed eye a high-power lens; it is an aërial image at the focus of the lens used. I., Real, that made by the focused reflected rays. I., Refraction, an image due to the refraction of light upon entering and leaving an object. Two things are involved: $\quad \mathbf{1}$. The form of the object. 2. The relative refractive power of the object and the mounting-medium. I., Subjective, a photism; also a visual hallucination. I., Virtual, that produced by the imaginary focus of the rays, as, $e . g^{\circ}$, behind a mirror.

Imaginal (im-aj'-in-al) [imago, an image]. Pertaining to the Image, $q . v$. I. Discs, in entomology, the name given by Weismann to curious encapsulated groups of embryonal cells, connected with the nerves and nerve-centers of certain insect larvæ (Diptera). They are the rudiments from which the nymph is developed.

Imagination (im-aj-in-a-shun) [imaginatio, imagination]. The picture-making power of the mind. The faculty by which one creates ideas or mental pictures by means of the data derived from experience, ideally revivified, extended, and combined in new forms.

Imago (im- $\left.a^{\prime}-g o\right)$ [L.; gen., Imaginis]. An image. Also, the final, adult, or reproductive stage of an insect.

Imbalance (im-bal'-ans) [in, not; bilancia, a balance]. Lack of balance; lack of the power of keeping the erect position; lack of muscular balance (as between the muscle of the eyes).

Imbecile $\left(i m^{\prime}-b e s-i l\right)$ [imbecillus, weak]. Feeble in mind. Imbecility (im-bes-il'-it-e) [imbecillitas, imbecility]. Mental weakness or defect, similar to that of idiocy, but of less degree.

Imbibe (im-bibj) [imbibere, to drink in]. To drink or suck in.
Imbibition ( $i m-b i b-i s h$-un) [imbibitio, a drinking in] The sucking up, or capillary absorption, of moisture, liquids, or gaseous substances by inorganic, or by dead or torpid organic bodies.

Imbowelling (im-bow'-el-ing). Same as Evisceration.

Imbricate (im'-brik-ât) [imbricare, to cover with tiles]. Applied to that arrangement of scales, feathers, leaves, or floral organs in the bud, in which they overlap like shingles on a roof.

Imbricated (im'-brik-a-ted) [imbrex, a roof-tile]. Distinguished by overlapping. Applied to the position and arrangement of scales in certain squamous diseases of the skin.

Imitation (im-it-a -shun) [imitari, to imitate]. A production that is similar to, or a copy of, another object or process. I., Morbid, the occurrence of a convulsive or mental affection brought about by observing a similar affection in another; mental contagion.

Immaculate (im-akl-u-lät) [in, not; macula, a spot]. Pure; spotless.

Immarginate (im-ar'-jin-ät) [in, not; marginare, to furnish with a border]. In biology, having no welldefined border.

Immature (im-at-ūr') [immaturus, unripe]. Not ripe; not yet of an adult age or growth.

Immediate $\left(i m-m e^{\prime}-d e-\bar{a} t\right)$ [in, not; medio, the middle]. Direct. Without anything intervening, as immediate auscultation or percussion. I. Contagion, that from a direct source. I. Ligature. See Ligature. I. Union, union by first intention, or without suppurative granulation.

Immedicable (im-med'-ik-ab-l) [in, not; medicare, to cure]. That which does not yield to medicine or treatment. Incurable.

Immersion (im-mer'-shun) [in, in; mergere, to dip]. The plunging of a body into a liquid. In medicine, treatment by a continued bath. See Oil-immersion, Water-immersion. I.-bath, the liquid employed for immersion. I.-battery, a form of battery in which, by inclining the cell, the elements are immersed in the liquid. I., Homogeneous, a fluid between the objective of a microscope and the cover-glass, having about the same refractive and dispersive power as the glass. I., Objective, a microscope-objective, usually of high power, the lower lens of which is immersed in a drop of water, glycerin, or oil, placed on the cover-glass of the object under examination.

Immissio $\left(i m-i s h^{\prime}-\ell-0\right)$ [L. ]. Insertion. I. catheteris. See Catheter ism. I. penis, introduction of the penis into the vagina.

Immission (im-mish'-un) [immissio, a letting in]. Introduction, as of a catheter.

Immobilization (imz-mob-il-iz-a -shun) [immobilis, immovable; facere, to make]. The surgical fixation of a part (as a fractured bone) by means that prevent any local motion.

Immortality (im-mor-tal'-it-e) [immortalitas, undyingness]. Exemption from death; unending existence. I. of Germ-cells. See Heredity; also, Germ-plasma.

Immune $\left(i m-m \bar{u} n^{\prime}\right)$ [immunis, safe]. I. Safe from attack; protected by vaccination, or some analogous procedure, or by previous illness. 2. A person who is protected against any special virus. I. Animal. See Control-experiment.

Immunity (im-mūn'-it-e) [immunitas, exemption]. The condition of an organ, or of the body, whereby it resists the development of infectious or morbid processes. The inoculation of attenuated virus and of chemic compounds are examples of methods by which immunity is acquired. It has also been shown that inflam- 
matory action is inhibitive of bacterial development. I., Acquired, that derived from a previous attack of the same disease or from a modified form, as varioloid, or artificially produced by inoculation. I., Artificial, that produced by inoculation with the virus of a disease. I. Natural, the natural resistance of the tissues or system. Immunization may be transient or permanent, relative or absolute.

Immunization (im-mūn-iz-a $\left.a^{\prime}-s h u n\right)$ [immunitas, exemption]. The act or process of endowing with immunity.

Immunize (im'-mün-īz) [immunis, exempt]. To give or to acquire immunity.

Impact $\left(i^{\prime}-p a k t\right)$ [impactus; impingere, to drive into or against]. A forcible striking against.

Impacted (im-pak'-ted) [impactus: impingere, to drive into or against]. Driven against and retained, as a wedge. I. Fracture, one in which the fragments of bone are driven into one another in such a manner as to cause shortening.

Impaction (im-pak'-shun) [impactio, impact]. The state or quality of being impacted; fracture with fixation of the fragments; obstinate constipation; the wedging of the fetal head in the pelvic canal.

Impalement (im-pāl'ment) [in, in; pal, a pale or picket]. The perforation of the body or a part by a rod or stake.

Impalpable (im-pal'-pa-bl) [impalpabilis, impalpable] That which cannot be felt; unappreciable by touch. I. Powder, a powder so fine that its separate particles cannot be felt.

Impalsy (im-pawl'-ze) [in, in; ME., palsey, palsy]. To paralyze.

Impaludism (im-pal'-u-dizm) [in, in ; palus, a marsh]. Chronic malarial poisoning.

Impar (im'-par) [in, not; par, equal]. Odd or unequal. I., Ganglion, a small ganglion on the coccyx. See Ganglia, Table of.

Imparipinnate (im-par-ip-in'-āt) [impar, unequal; pinnatus, feathered]. In biology, unequally pinnate; having an odd leaflet at the apex.

Impatiens (im-pa'-she-enz) [L., impatient]. Touchme-not; jewel-weed or balsamine; a genus of geraniaceous plants. I. balsamina and I. lutea, of the old world, and I. fulva and I. pallida, of the U. S., are diuretic, emetic, and cathartic. Unof.

Impatiinid (im-pa'-te-in-id) [impatiens, impatient]. A resinous emetic principle obtainable from Impatiens lutea. Unof.

Impennate (im-pen'-ät) [in, not; pennatus, winged]. In biology, applied to such birds, as the penguin, as have short wings covered with scale-like feathers.

Impennous (im-pen'-us) [in, not; penna, wing]. In biology, without wings.

Imperative (im-per'-at-iv) [imperativus, imperative]. Peremptory; absolute; binding. I. Idea. See Idea, Imperative.

Imperatoria (im-per-at-o'-re-ah) [imperatorius, belonging to a commander]. A genus of umbelliferous plants; masterworts. I. ostruthium, false pellitory of Spain, is an aromatic stimulant, once prized as a polychrest remedy, but now little used. Unof.

Imperfection (im-per-fek'-shun) [imperfectus, imperfect]. A physical defect.

Imperforate (im-per'-for- $\bar{a} t) \cdot[i n$, not; perforare, to pierce]. Congenitally and abnormally closed; applied to an opening of the body, as the anus, vagina, etc. See Occlusion and Obstruction.

Imperforation (im-per-for-a'-shun) [imperforatio; in, not; perforare, to bore through]. Occlusion; applied especially to the anus, hymen, vagina, etc.

Imperial (im-pe'-re-al) [imperialis, pertaining to an empire]. Sovereign; commanding. I.-blue. Same as Spirit-blue. I. Drink or Draft, potus imperialis, a solution of a half-ounce of potassium bitar trate in three pints of hot water, to which are added four ounces of sugar and half an ounce of fresh lemonpeel. It is a good diuretic and refrigerant drink Unof. I. granum, a farinaceous food for infants. Its composition is: Water 5.49, fat I.OI, a trace each of grape-sugar and cane-sugar, starch 78.93, soluble carbohydrates 3.56 , albuminoids IO.5I, gum, cellulose, etc., 0.50, ash I.16. I.-green. Same as Schreinfurth-green. I.-violet. Same as Rosan. ilin-violet.

Imperialin (im-pe'-re-al-in) [imperialis, pertaining to an empire]. An alkaloid from Fritillaria imperialis, or crown imperial ; it acts upon the heart. Unof.

Impermeable (im-per'-me-a-bl) [in, not; per, through; meare, to go]. Not capable of being traversed.

Impervious (im-per'-ve-us) [in, not; pervius, capable of passage]. Not permitting a passage through.

Impetiginoid (im-pet-ij'-in-oid) [impetiso, impetigo; impetere, to attack; cidos, like]. Same as Impetiginous.

Impetiginous (im-pet-ij'-in-us) [impetigo; impetere, to attack]. Affected with or resembling impetigo.

Impetigo (im-pet-i'-go) [impetigo; impetere, to attack]. An acute inflammatory skin-disease characterized by one or more pea-sized or finger-nail sized, discrete, rounded, and elevated firm pustules, unattended, as a rule, by itching or other subjective symptoms. The pustules are rounded, with thick walls, and are surrounded by areolæ. They appear suddenly, and come out one after another during the first week of the attack, attain full size, and then undergo absorption or crusting. No scar or pigmentation fol lows. The disease is likely to occur in children. I. annua. See Aleppo Boil. I. capitis. Same as Eczema capitis. I. contagiosa, Porrigo contagiosa. an acute, inflammatory, contagious disease, due to the presence of a microörganism, and characterized by the appearance of vesico-pustules or blebs, that dry into flat, straw-colored, granular-looking crusts. The disease occurs usually in children. The vesicles vary in size from minute points to that of a quarter of a dollar, and the contents, at first serous, become seropurulent, and then dry up. The disease is most prone to attack the face and hands. I., Duhring's, differs from the foregoing by being non-infectious. See Diseases, Table of. I. erysipelodes, an old term for Eczema pustulosum, with deeper inflammation than usual. I. granulata. Same as Pediculosis. I. herpetiformis, Herpes pycemicus; a very rare disease of the skin, characterized by the formation of superficial miliary pustules, that may be discrete, but are usually closely set. The contents of the pustules are at first opaque, but become greenish-yellow, and dry up into dirtybrown crusts. The disease spreads until the whole surface is covered with swollen, crusted, and excoriated patches. It develops first on the inner side of the thighs, and about the groins, navel, breasts, and axillæ, and is mainly seen in pregnant women. The termination is fatal, as a rule. I. rodens, an old term for a carcinomatous disease of the skin. I. scabida, an old term for Eczema pustulosum, with unusually thick crusting. 1. sparsa, an old term for small, scattered patches of Ecrema pustulosum. I., Syphilitic. See Syphilid, Impetiginous.

Impetus (im'-pe-tus) [L.]. I. Force or momentum. 2. The onset or attack of a disease, or of a paroxysm.

Implantation (im-plan-ta'shun) [implantatio; in, in ; plantare, to set]. The act of setting in. Also, the transplantation of a tooth from the jaw of one person 
to that of another. Also, the engrafting of epidermis from the skin of one person upon the body of another. The surgical repair of a wounded intestine by uniting the divided ends. I., End-to-end, the approximation of the ends of a divided structure, as of the bowel, or a nerve. I., Hypodermatic, the introduction of a medicine in the form of a soluble solid under the skin for therapeutic purposes. I., Teratologic, a fetal monstrosity consisting of an imperfect, joined to a perfect fetus.

Implexous (im-pleks'-us) [implectere, to entwine, entangle]. In biology, entangled.

Implumous (im-plu'-mus) [in, without; pluma, feathers]. In biology, featherless.

Imponderable (im-pon'-der-a-bl) [in, not; pondera. bilis, that which can be weighed.] That which cannot be weighed. I. Fluids, an obsolete term, formerly applied to light, heat, and electricity.

Importation (im-por-ta'-shun) [in, in; portare, to carry]. Transference from another locality or foreign country. I. of Disease, the carrying of the contagion of disease.

Imposthumate (im-pos'-tu-māt) [corrupt form of apostemate]. To suppurate.

Imposthume (im-pos'-tum) [a corrupt form of apostema]. An abscess.

Impotence (im'-po-tens) [in, not; possum, to be able]. Lack of power, applied especially to male incapacity of procreation. It is variously qualified as atonic, when due to spinal or central exhaustion; paralytic or paretic, when the impulse that leads to the performance of the function is abolished; psychic, when due to fear, bashfulness, or mental disturbance; symptomatic, when due to some drug, or to a disturbance of the health.

Impregnation (im-preg-na'-shun) [impragnatio, the state of being with child]. The state of being pregnant; the act of impregnating; fecundation; fertilization.

Impressio (im-presh'-e-0) [L.]. An impression. I. colica, an impression on the under surface of the right lobe of the liver for the hepatic flexure of the colon. I. renalis, an impression behind the $I$. colica for the right kidney and suprarenal capsule.

Impression (im-presh'-un) [impressio; imprimere, to press upon]. A hollow or depression. I.-cup, in dentistry, a cup or tray of metal, porcelain, guttapercha, or other substance, used for conveying to the mouth and holding in position the material for impressions. I., Digital, the mark made by the pressure of a finger upon an edematous limb, or upon the neck in strangulation. I., Rhomboid, a broad impression on the inferior surface of the clavicle, near the sternal end, for the attachment of the rhomboid ligament.

Impressionable (im-presh'-un-a-bl) [impressio, an impression]. Readily susceptible to impressions. I. Heart, the condition of the heart in which it is very liable to functional disturbance.

Impressorium (im-pres-ó $-r e-u m$ ) [L.]. The seat of impressions; sensorium.

Impuberal (im-pu':ber-al) [impuber, impubes; in, not; pubes, pubes]. Destitute of hair on the pubes. Not of adult age.

Impulse (im'-puls) [impulsus; impellere, to drive against]. Any communicated force. Also, the shock and reverberation on the chest-walls caused by the beating of the heart. Also, a sudden spontaneous emotion of the mind or influence acting upon it. I., Cardiac, the systolic beat of the heart occurring at the apex, and felt in the fifth intercostal space to the left of the sternum. I., Morbid, any strong, unnatural impulse, especially one of an insane character. Morbid impulses are variously qualified, as animal, destructive, homicidal, suicidal, uncontrollable, etc.

Impulsion (im-pul'-shun) [impellere, to impel]. The act of driving or urging onward, either mentally or physically.

Impurity (im-pu'-rit-e) [in, not; purus, pure or clean]. Want of purity or cleanliness. In chemistry, the condition of containing some substance other than that desired. Adulteration. In medicine, a want of clearness in the sounds of the heart, but not sufficient to cause a murmur.

Imputability (im-pu-tab-il'-it-e) [imputabilitas, imputability]. In legal medicine, that degree of mental soundness that makes one responsible for his own acts.

In- [L.]. A prefix signifying in or within. Also, a particle signifying negation.

-in, or -ine (in). A suffix seen in the names of the halogen elements, chlorin, bromin, iodin, and fluorin. Also, a distinctive termination used to distinguish organic bases, particularly the class known as alkaloids. It is also loosely applied to certain organic radicles, and to many glucosids.

Inadequacy (in-ad'-e-qwa-se) [in, not; adaquare, to make equal]. Same as Insufficiency. I., Renal, that state of the kidney in which it is unable to remove from the blood a sufficient proportion of the effete matters that are normally excreted by it.

Inanagenesis (in-an-aj-en'-es-is) [is, fiber; ává, again ; $\gamma^{\prime} \nu \varepsilon \sigma \iota \zeta$, production]. The renewal or regeneration of muscular fiber.

Inanaphysis (in-an-af'-is-is) [is, fiber; ává, again ;

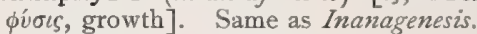

Inanimate $\left(i n-a n^{\prime}-i m-a \bar{t}\right)$ [in, not; animus, life]. Not animate; dead; without life.

Inanition (in-an-ish'-un) [inanire, to make empty]. Emptiness of the organs of digestion from want of food. Also, wasting of the body from starvation or disease. Synonym of Fasting.

Inantherate (in-an'-ther-āt) [in, without; anthera, anther]. In biology, destitute of anthers.

Inantinial (in-an-tin'-e-al) [iviov, the nape of the neck; ávTi, against; iviov, the nape of the neck]. Inio-antinial; pertaining to the inion and the antinion.

Inappendiculate $\left(i n-a p-e n-d i k^{\prime}-u\right.$-lät $)[i n$, without ; appendicula, dim. of appendix, an appendage]. In biology, destitute of appendages.

Inappetence (in-ap'-et-ens) [in, not; appetere, to desire]. Loss or want of appetite.

Inappetentia (in-ap-et-en'-she-ah) [L.]. Synonym of Anorexia.

Inarticulate (in-ar-tik'-u-lāt) [in, not; articulus, a joint]. Not jointed or articulated. Also, vocal sounds not capable of arrangement into syllables, or of being understood.

Inassimilable (in-as-im'-il-a-bl) [in, not; assimulare, to make like]. Incapable of assimilation.

Incandescent (in-kan-des'-ent) [incandescere, to become white-hot]. Emitting luminous heat-rays; heated to the degree of emitting light. I. Electric Light, one consisting of a film of carbon of high resistance enclosed in a vacuous glass globe. The film emits a white light when the current passes through it.

Incapacity (in-kap-as'-it-e). See Doli incapax; also Impotence.

Incarcerated (in-kar-ser-a-ted) [incarcerare, to imprison]. Imprisoned; closely constricted.

Incarceration (in-kar-ser-a'-shun) [incarceratio; in, in; carcerare, to imprison]. The condition of imprisonment or confinement of a part, as of the placenta. See also Hernia.

Incarial Bone (in-ka'-re-al) [Peruvian, Inca, a prince]. The interparietal bone; usually in adult man a part 
of the occipital bone. It is called incarial, because, in the skeletons of ancient Peru, the land of the Incas, it is often persistent as a distinct bone.

Incarnatio (in-kar-na'-she-o) [L.]. Conversion into flesh. I. unguis, the ingrowing of a nail. See Onychogryphosis.

Incarnation (in-kar-na'-shun). I. Granulation; healing process. 2. See Conception.

Incarnification $\left(i n-k a r-n i f-i k-a^{\prime}-s h u n\right)$. Same as Incamation.

Incasement (in-kās'-ment) [in, in; ME., casse, a box] The act of inclosing in a case. Incasement, Encasement, Theory of, the doctrine that the ovum or spermatozoid of the first animal of each species incased the germs of all subsequent individuals of the species. This theory was also called that of Preformation. Cf. Evolution.

Incest (in'-sest) [incestus, not chaste]. Carnal intercourse between persons of near relationship.

Inch [ME., inche, inch]. The twelfth part of a foot. It equals 25.39954 millimeters.

Incidence (in'-sid-ens) [incidere, to fall upon]. . A falling upon. The direction in which one body strikes another. I., Line of, the path of a ray or a projectile. I., Point of, the point upon which the ray or projectile is reflected or strikes.

Incident (in'-sid-ent) [incidere, to fall upon]. Falling upon.

Incineration (in-sin-er-a $\left.a^{\prime}-\operatorname{sh} u\right)$ [in, in ; cineres, ashes]. The prccess of heating organic substances in contact with the air until all organic matter is driven off, and only the mineral ash remains.

Incised (in-sizd') [incidere, to cut]. Cut or notched. I. Wound, one made by a sharp-edged instrument.

Incisiform (in-si'-sif-orm) [incisor, incisor; forma, form]. In biology, resembling an incisor tooth.

Incision (in-sizh'-un) [incisio, or incisura, an incision]. The act of cutting into any tissue of the body.

Incisive (in-si'-siv) [incidere, to cut]. Having the quaiity of cutting. Pertaining to the incisor teeth. I. Canal. See Canal. I. Foramina. See Foramen. I. Fossa. See Fossa. I. Teeth. See Incisor.

Incisor (in-si'-sor) [incidere, to cut]. Any cutting instrument. I. Nerve, the branch of the inferior dental nerve supplying the incisor and canine teeth. See Nerves, Table of. I. Teeth, the four most anterior teeth in each jaw.

Incisura (in-si-su'-rah) [incidere, to cut into]. A notch. Also, an incision. I. cerebelli, one of two notches separating the hemispheres of the cerebellum, the one in front and the other behind. I. intertragica, the deep notch in the pinna of the ear separating the tragus and the anti-tragus. I. santorini, a fissure extending in a vertical direction through the cartilage of the auditory canal.

Incisure (in-sizh'-ur) [incisus, p. p. of incidere, to cut into]. A slit or notch. I.'s of Schmidt and Lantermann, oblique lines running across the white substance of the inter-annular segments of stretched medullated nerve-fibers.

Inclaudent (in-klaw -dent) [in, not ; claudere, to close]. In biology, not closing.

Included (in-klus $\left.d^{\prime}-e d\right)$ [in, in ; claudere, to shut in] Applied to stamens or pistils that do not project beyond the corolla, but are contained within it.

Inclusio fatalis $\left(i n-k l u^{\prime}-z e-o f e-t a^{\prime}\right.$-lis) [L.]. A form of fetal parasitism in which the parasite is more or less included and overgrown by the tissues of the autosite.

Inclusion (in-klu'-zhun) [includere, to enclose or shut in]. The state of being shut in. Also, the act of shutting in; that which is shut in.

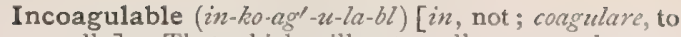
curdle]. That which will not curdle or coagulate.

Incoherence (in-ko-hêr'-ens) [incoharentia; in, not; coharere, to cling together]. The quality of being incoherent ; absence of connection of ideas or of language; incongruity or inconsequence of diction.

Incoherent (in-ko-he'-rent) [in, not; coharere, to stick together]. Not connected or coherent; without ability to preserve that sequence of words or of ideas that is necessary to convey meaning.

Incombustibility (in-com-bus-tib-il'-it-e) [in, not; comburere, to burn up]. The state of being incombustible.

Incombustible (in-com-bus'-tib-l) [in, not; comburere, to burn up]. Incapable of burning.

Income (in'-kum) [ME., income, income]. The amount of food taken per diem.

Incompatibility (in-kom-pat-ib-il'-it-e) [in, not; compatibilis, compatible]. That relation between medicines that renders their admixture unsuitable This incompatibility may be physiologic, chemic, physical, or therapeutic.

Incompatible (in-kom-pat'-ib-l) [in, not; compatibilis, endurable]. Incapable of mixture without undergoing such chemic or physical changes as impair or destroy the usefulness of the compound; physiologically antagonistic, and therefore useless to prescribe.

Incompetence, Incompetency (in-kom'-pet-ens, inkom'-pe-ten-se) [in, not ; competere, to be capable; incompetens, insufficient]. Incapacity; inadequacy. Inability to perform natural functions. I., Mental, a disorder of mind sufficient to produce irresponsibility. I., Aortic, Mitral, Pulmonary, Tricuspid. See Endocarditis. I., Valvular. See Insufficiency.

Incomplete (in-kom-plett) [in, not; completus, complete]. Partial, as an incomplete hernia. I. Copulation. See Coitus reservatus. I. Hernia. See Hernia.

Incongruence (in-kon'-oru-ens) [incongruens, inconsistent]. Lack of congruence. I., Retinal, lack of correspondence in the situation of the percipient elements of the two retinæ.

Incongruity (in-kon-gru'-it-e) [in, not; congmere, to go together]. Absence of agreement or of needful harmony.

Incontinence (in-kon'-tin-ens) [in, not; continere, to contain]. Inability to control the evacuation of the feces or the urine; involuntary evacuation. This term is sometimes used as a synonym of venereal indulgence, lewdness. I., Seminal. See Spermatorrhea.

Incoördination (in-ko-or-din-a'-shun) [in, not ; con, together; ordinare, to order]. In pathology, the inability to produce voluntary movements in proper combination or sequence; lack of harmony between the will and the muscular activity. I, of Ocular Muscles. See Insufficiency.

Incorporation (in-kor-por-a'-shun) [in, in ; corpus, a body]. The process of intimately mixing the particles of different bodies into a practically homogeneous mass.

Incrassate (in-kras'-at) [in, in; crassare, to make thick]. In biology, thickened or swollen.

Incrassation (in-kras-a'-shun) [incrassatio; in, in ; crassus, thick]. The process of making thick, as by inspissation; enlargement of a part, due to fatness.

Incrassative (in-kras'-at-iv) [incrassare, to make thick]. I. Having the power to make thick or thicker. 2. Formerly a medicine supposed to correct a thinness of the humors.

Incremation (in-kre-ma'-shun). See Cremation.

Increment (in'-kre-ment) [incrementum, growth]. In. crease or growth. 
Incremental (in-kre-men'-tal) [incrementum, growth]. Pertaining to increment or growth. I. Lines. See Salter's Lines, in Lines, Table of.

Incrustate (in-krus' $-t \bar{\alpha} t)$ [incrustrure, to incrust]. Forming a crust, or coated with a brittle or granular substance.

Incrustation (in-krus-ta'-shun) [incrustare, to cover with rind]. The formation of a crust. Also, the formation of a calcareous deposit in organic tissue.

Incubation (in-ku-ba'-s/uun) [incubare, to sit on eggs]. I. In medicine, the period between the implanting of the contagium and the development of the disease. For the periods of incubation of some of the most important diseases, see Exanthemata, Table of: 2. The process of sitting upon eggs to favor hatching. See Table under Pregnancy.

Incubator (in'-ku-ba-tor) [incubare, to sit on eggs]. A device for the artificial hatching of eggs or cultivation of microscopic plants; a couveuse $(q . v$.) for the preservation of the life of children prematurely born. I., Crédè's, a copper tube made with double walls, between which water at the desired temperature may be kept, and withdrawn by means of pipes and stop-cocks. I., Tarnier's, an apparatus for the rearing of premature children, consisting of a box with two compartments, one containing the child, the other, and lower compartment, being filled with warm water, so as to keep a uniform temperature of $86^{\circ}-88^{\circ} \mathrm{F}$.

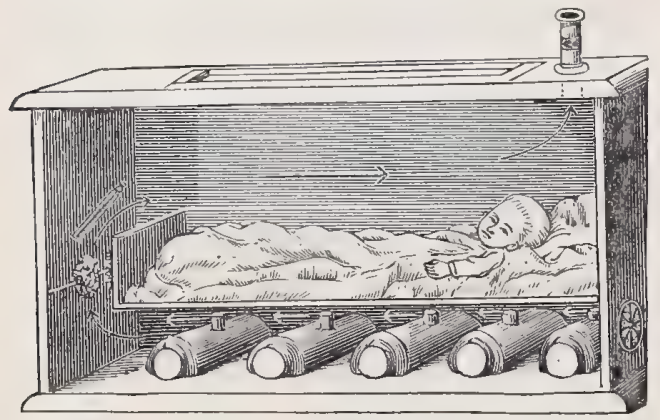

INCUBATOR OR COUVEUSE.

(From Fullevton's "Obstetric Nursing.")

Incubous (in'-ku-bus) [incubus, lying upon]. In biology, with the tip of one leaf lying flat over the base of the next above.

Incubus (in'-ku-bus) [L.]. I. Nightmare; ephialtes. 2. Formerly, a supposed male demon that beset women, just as the succuba was supposed to consort with men. I. vigilantium. See Daymare.

Incudal (ing'-ku-dal) [incus, anvil; incus]. Relating to the incus.

Incudate (ingt-ku-dat $)$ [incus, incus]. In biology, having an incus.

Incudo- (ing -ku-do-) [incus, incus]. In composition, signifying relationship to the incus. I.-malleal, relating to the incus and the malleus. I.-orbicular, relating to the incus and the orbicularis. I.-stapedial, relating to the incus and the stapes. I.-tympanic, relating to the incus and the tympanum.

Incuneation (in-ku-ne-a'-shun) [incuneatio, a wedging]. I. The impaction of a fracture or of the fetal head. 2. The same as Gomphosis.

Incurable $(i n-k \bar{u}, \cdot-a-b l)$ [in, not ; curare, to care for]. That which cannot be cured or restored to wholeness.

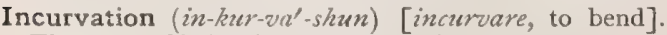
The state of being bent or curved in.

Incus (ing'-kus) [L., an anvil: pl., Incudes]. In biology: $(a)$ The middle one of the chain of bones in the middle ear of a mammal; (b) A portion of the mouth-parts of a rotifer.

Indazole $\left(i^{\prime}-d a-z \bar{o} l\right), \mathrm{C}_{7} \mathrm{H}_{6} \mathrm{~N}_{2}$. A substance formed by heating hydrazin-cinnamic acid. It crystallizes from hot water in colorless needles, melting at $146^{\circ}$ C. , and boiling at $270^{\circ} \mathrm{C}$

Indecent (in-de'-sent) [indecens, unbecoming]. Not decent; obscene. I. Exposure, See Exhibitionism.

Indecision (in-de-sizh'-un) [in, not; decisio; decidere, to decide]. Morbid irresolution; want of firmness or of will; abulia or hypobulia.

Indehiscent (in-de-his'-ent) [in, not; hiscere, to gap]. In biology, not opening spontaneously.

Indene (in-dèn' $), \mathrm{C}_{9} \mathrm{H}_{8^{\circ}}$ A hydrocarbon that occurs with coumarone in that fraction of coal-tar boiling at $\mathbf{1 7} 6^{\circ}-182^{\circ} \mathrm{C}$. It is a clear oil, boiling at $177^{\circ}-178^{\circ}$ C. Its sp. gr. is 1.040 at $15^{\circ} \mathrm{C}$.

Indentation (in-den-ta'-shun) [in, in; dens, a tooth]. A condition of being notched or serrated. 1. of Tongue, the notching of the borders of the tongue made by the teeth, and visible especially during inflammation of the tongue.

Index (in'-deks) [L.]. The first finger. Also, the relation or ratio of one part to another, taken as a standard. I., Altitudinal, the height of a skull multiplied by $\mathbf{I} 00$ and divided by its length. I., Alveolar, the degree of prominence of the jaws, measured by the basi-alveolar length multiplied by 100 and divided by the basi-nasal length. When the alveolar index is less than 98, the skull is orthognathic, when more than 103 , prognathic, when intermediate, mesognathic I., Basilar. Same as I., Alveolar. I. of Breadth. Same as $I$., Cephalic. I., Cephalic, the breadth of a skull multiplied by 100 and divided by its length. When this is below 75 , the skull is called dolichocephatic, when above 80 , it is called brachycephalic, between these limits, mesaticephali: I., Cephalo-orbital, the ratio of the solid contents of the two orbits to the contents of the cranial cavity, multiplied by Ioo. I., Cephalo-spinal, the ratio of the measure of the foramen magnum in square millimeters to that of the cranial cavity in cubic centimeters, multiplied by Ioo. I., Cerebral, the ratio of the greatest transverse to the greatest antero-posterior diameter of the cranial cavity, multiplied by $\mathbf{I} 00$. I.-digit, the forefinger. I., Facial, the ratio of the distance of the ophryon from the alveolar point to the transverse diameter measured from one zygoma to the other, multiplied by Ioo. I.-finger, the forefinger. I., Gnathic, the ratio of the distance between the basion and the alveolar point to the distance between the basion and the nasal point, multiplied by $100 . \mathbf{I}$, Nasal, the greatest nasal width multiplied by 100 , and divided by the nasal length. When the nasal index exceeds 53 , the nose is platyrhine, when less than 48 , it is said to be leptorhine, if between these numbers, mesorhine. I., Orbital, the orbital height multiplied by 100 and divided by the orbital width. If the orbital index be above 89 , it is called megaseme, if under 84 , microseme, if between, mesoseme. I., Refractive, the coefficient of refraction. I., Thoracic, taken at its widest part is Ioo times the sagittal, divided by the transverse measurement. I., Vertical, of Height, the ratio of the vertical diameter of the skull to the maximum antero-posterior diameter, multiplied by $\mathbf{I} 00$.

India $\left(i n^{\prime}-d e-a h\right)$ [Asiatic]. A country of Asia. I. Liver, a condition of hyperemia and enlargement of the liver, associated with general anemia and cachexia, cyanosis, anasarca, and irritable and irregular pulse. I.-rubber, the prepared concrete juice obtained mainly from an Indian tree. Ficus elasticus, and a South American tree, Siphonia elastica. It is valuable 
chiefly for its elasticity and its insolubility in water. It is with difficulty soluble in oil of turpentine, but is highly soluble in carbon disulphid. It melts at $248^{\circ} \mathrm{F}$, and remains unchanged up to $500^{\circ} \mathrm{F}$. It is hardened and used in mechanical dentistry as a base for artificial teeth. It is also called Caoutchouc, $q . v$.

Indian (in'-de-an) [India]. Pertaining to India, the West Indies, or to the aboriginal Americans. I. Basket, a hollow cylinder woven of twigs of the willow, or of strips of other wood, used in applying extension to a dislocated limb. The greater the extension, the more firmly does the device cling to the surface. I.-blue. Same as Indigo. I. Black-root, the root of Pterocaulon pycnostachium. It has reputed alterative properties. Dose of the fluid extract $m x y-x x x$. Unof. I. Corn. See Zea mays. I. Hemp. See Cannabis. I. Liquorice. See Abrus. I. Physic, American Ipecacuanha, the bark of the root of Gillenia trifoliata, a mild emetic and cathartic. Dose of the fluid extract, $m_{\lfloor x-x l}$. Unof. I. Sarsaparilla. See Hemidesmus. I. Tobacco. See Lobelia. I. Turnip. See Dragon Root. I. Madder. Same as Mungeet. I. Meal, corn-meal. I. Ochre. Same as Ochre. I. Plague. Synonym of the Plague, q.v. I. Potato. See Apios. I.-purple. See Pigments, Conspectus of. 1.-red. Same as Colcothar and Ochre. I.-yellow, Same as Purree.

Indican (in'-dik-an) [indicum, indigo], $\mathrm{C}_{26} \mathrm{H}_{31} \mathrm{NO}_{17}$. The natural glucosid by the decomposition of which indigo-blue is produced from the various species of indigo-producing plants. It forms a transparent brown syrup, the aqueous solution of which has a yellow color, bitter taste, and slightly acid reaction. It is occasionally detected in the urine.

Indicant (in'-dik-ant) [indicans; indicare, to indicate]. I. Serving as an index or as an indication. 2. A fact or symptom that indicates a certain treatment ; an indication.

Indicanuria (in-dik-an-u'-re-ah) [indicum, indigo; ovpov, urine]. The morbid excess of indican in the urine.

Indication (in-dik-a'-shun) [indicatio, an indication]. A sign or symptom, especially when it points out the proper course of treatment; the inference drawn from the various symptoms or signs in any particular case.

Indicator (in'-dik-a-tor) [indicare, to point out]. I. The index-finger. 2. The extensor indicis muscle. See Muscles, Table of.

Indicium (in-dish'-e-um) [L. : pl., Indicia ]. A symptom or sign; a discriminating or diagnostic mark.

Indifferent (in-dif'-er-ent) [in, not; differens, different]. I. Not specially differentiated. 2. Not acted upon in a special way by any reagent.

Indifferentism (in-dif'-er-ent-izm) [in, not ; differens, different]. Lack of special differentiation.

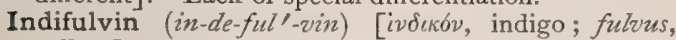
yellow]. A yellowish substance occurring in two varieties, and produced by the action of dilute acids on indican.

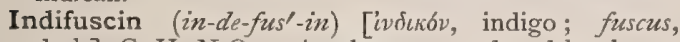
dark ], $\mathrm{C}_{24} \mathrm{H}_{20} \mathrm{~N}_{2} \mathrm{O}_{9}$. A substance produced by the action of dilute acids on indican.

Indigenous (in-dij'-en-us) [indu, in ; gignere, to beget]. Native, and not exotic. Originating or belonging to a certain locality or country.

Indigestion (in-di-jes'-chun) [indigestio; in, not ; digerere, to digest]. Same as Dyspepsia.

Indigitation (in-dij-it-a'-shun) [in, in ; digitus, a finger]. A displacement of a part of the intestine by intussusception.

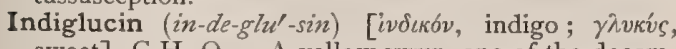
sweet], $\mathrm{C}_{6} \mathrm{H}_{10} \mathrm{O}_{6}$. A yellow syrup, one of the decomposition-products of indican.
Indiglycin (in-de-gli'-sin). Same as Indislucin.

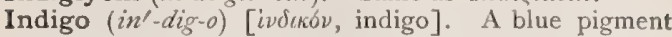
formed during the fermentation of Indigofera anil, $I$. tinctoria, and other species. It is insoluble in alcohol or water, but freely soluble in strong sulphuric acid; it is used mainly in the arts as a dye-stuff. Chemically, it is a mixture of several principles, the chief being a blue coloring-matter, indigotin. Therapeutically, it is an irritant to the mucous membrane of the alimentary tract, producing intense nausea. It has been used advantageously in epilepsy, chorea, and convulsions, in doses varying from $3 \mathrm{ij}-\xi_{\mathrm{ij}}$ daily. Unof. I.-blue, $\mathrm{C}_{16} \mathrm{H}_{10} \mathrm{~N}_{2} \mathrm{O}_{2}$. Indigotin; a chromogen found in ordinary indigo, of which it constitutes the principal ingredient. It is also derived from wood (Isatis tinctoria). It occurs in the plant as a glucosid, indican. Indigo-blue is a dark-blue powder with a reddish glimmer; it becomes metallic and copper-like under pressure. It is insoluble in water, alcohol, and ether, and is odorless and tasteless. It dissolves in hot anilin with a blue color, and crystallizes from hot oil of turpentine in beautiful blue plates. I.-brown, a resinous substance of a brown color, obtained by boiling an aqueous solution of indican with an acid. It is composed of a mixture of indihumin, $\mathrm{C}_{10} \mathrm{H}_{9} \mathrm{NO}_{3}$, and indirhetin, $\mathrm{C}_{18} \mathrm{H}_{17} \mathrm{NO}_{5}$, the former soluble and the latter insoluble in alcohol. I.-carmin, a sodium salt of indigotin-disulphonic acid; it is used as a blue dye, a washing-blue, and is a delicate test for sugar. I.-carmin Test for Sugar; put in 30 minims of water one part each of indigo-carmin and sodium carbonate; heat gently to solution; add one drop of urine, and boil quietly. A change to red or yellow indicates sugar. See Tests, Table of. I. Extract. See Indigo-carmin. I,-red. See Indirubin. I.-white, $\mathrm{C}_{16} \mathrm{H}_{12} \mathrm{~N}_{2} \mathrm{O}_{2}$. Indigogen; a substance obtained by the reduction of indigo-blue. It occurs as a white crystalline powder, soluble in alcohol, ether, and the alkalies, with a yellowish color. It rapidly reoxidizes to indigo-blue by exposure to the air. I., Wild. See Baptisia.

Indigogen (in'-dig-o-jen). See Indigo-zehite and Uroxanthin.

Indigotin (in-dig-o'-tin). See Indigo-blue.

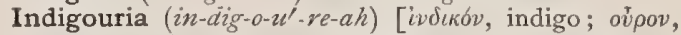
urine]. The presence of indigo in the urine; it is due to a decomposition of indican. See Cyanurin.

Indihumin (in-de-hu'-min). See Indigo-brozen.

Indirect (in-di-rekt') [in, not; dirigere, to be in a straight line]. Not direct. I. Division of Cells. See Karyokinesis. I. Segmentation. See Karyokinesis. I. Vision, that perception of an object in which the image falls on some other spot than the macula.

Indirhetin (in-dir-e'-tin). See Indigo-brozen.

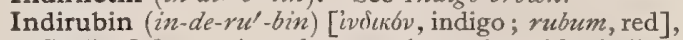
$\mathrm{C}_{16} \mathrm{H}_{10} \mathrm{~N}_{2} \mathrm{O}_{2}$. A substance isomeric with indigoblue, and very similar in its entire character to this substance. It is produced by effecting the condensation of indoxyl with isatin by means of a dilute soda-solution. It is also called indigo-red.

Indisin (in'-dis-in). Same as Mauvein, $q . v$.

Indisposition (in-dis-po-zish'-un) [indispositio, unsuitableness]. Any slight illness or disturbance of the functions of the body.

Indissoluble $\left(i n-d i s^{\prime}-0-l u-b l\right)$. See Insoluble.

Indium $\left(i^{\prime}-d e-u m\right)$ [indicum, indigo, so-called from its indigo-blue spectral line]. A rare metal. Symbol In., atomic weight, II3.7. It is very soft, and resembles lead in its properties. See Elements, Table of.

Individual (in-div-id'-u-al) [in, not; dividere, to divide]. A single being; one of a group or species. 
In biology, the total result of the development of a single ovum. I. Prepotency. See Prepotency.

Indogen (in'-do-jen). Same as Uroxanthin.

Indoin (in'-do-in) [indicum, indigo]. A blue substance produced from propiolic acid on adding metallic iron, zinc, or copper.

Indol (in'-dol) [indicum, indigo], $\mathrm{C}_{8} \mathrm{H}_{7} \mathrm{~N}$. A product of intestinal putrefaction, and occurring in the feces, to which, with skatol, it imparts the unpleasant odor. It is also formed when proteids are heated with alkalies, or by superheating with water to $200^{\circ} \mathrm{C}$. It is a crystalline body melting, when pure, at $53^{\circ} \mathrm{C}$. It is soluble in boiling water, alcohol, and ether.

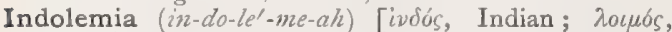
pestilence]. Asiatic cholera.

Indolent (in'-do-lent) [in, not; dolere, to feel pain]. Sluggish. Without pain; applied to ulcers, tumors, etc.

Indophenin (in-do-fe'-nin) [indicum, indigo; phenyl], $\mathrm{C}_{13} \mathrm{H}_{7}$ NOS. A bluish compound formed by the action of a solution of isatin, I part to 30 parts of $\mathrm{H}_{2} \mathrm{SO}_{4}$, on benzene.

Indophenol (in-do-fe'-nol), [indicum, indigo ; phenyl]. Same as Naphthol-blue. I.-blue. See Pioments, Conspectus of.

Indosynclonus (in-do-sin'-klo-nus) [ivdós, Indian;

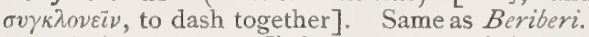

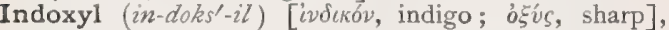
$\mathrm{C}_{8} \mathrm{H}_{7} \mathrm{NO}$. A substance isomeric with oxindol. It results on the elimination of carbon dioxid from indoxylic acid. It is an oil, not volatile in aqueous vapor, readily soluble in water, showing yellow fluorescence.

Indoxylic Acid (in-doks-il'-ik). See Acid.

Induced (in-düsd') [inducere to lead into]. or produced by the agency of any means. rent. See Current.

Induction (in-duk'-shun) [inductio; inducere, to lead in]. The establishment of an abstract law or proposition drawn from specific or particular facts. I.-balance, in physics, an instrument used for the detection of currents too weak to affect the galvanometer. I.-current. See current. I., Faradic. See Faradic. I. of Labor, the bringing on labor by artificial means. I,-coil. See Corl.

Inductorium (in-duk-to'-re-um) [L., a covering]. A magneto-induction apparatus for physiologic purposes.

Indulin-blue. Same as Coupier's Blue.

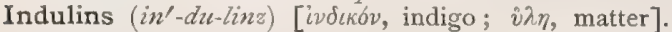
Members of the safranin class of dye-stuffs. They are violet-blue to gray-blue in color, and are formed upon heating various azo-azobenzenes and amido-azobenzenes with anilin hydrochlorids. They are also called nigrosins. They are used to impart a blue color to wool, cotton, and silk. See Pigments, Conspectus of.

Indumentum (in-du-men'-tum) [induere, to put on (clothes)]. In biology, the plumage of a bird or the pubescence of a plant

Induplicate (in-du'-plik-ät) [in, in, on; duplicare, to double]. In biology, applied to leaves, petals, or sepals while in the bud, which have their edges bent or rolled inward.

Indurascent (in-du-ras'-ent) [in, in; durare, to harden]. In biology, gradually hardening.

Indurated (in'-du-ra-ted) [indurare, to harden]. Hardened. I. Bubo, a hard inflammation of the lymphatic glands, usually of syphilitic origin.

Induratio (in-du-ral-she-o) [L.]. Induration. I. telæ cellulosa. See Sclerema neoniztomu.

Induration (in-du-ra'shun) [induratio, an induration]. The hardening of a tissue without alteration of struc- ture ; a hardened mass or lump. I., Black. See $I_{\text {., }}$ Gray. I., Brown, a hardening of lung-tissue, with deposition of pigmentary matter. I. of Chancre, a hard nodule, or a cup-like ring, about the margin of a chancre or syphilitic ulcer. I., Fibroid. See I., Gray, and Cirrhosis. I., Granular. See Cirrhosis. I., Gray, the appearance of the lung in chronic pneumonia, the cut-surface of the lung being smooth, glistening, gray, and dense. It is also called black or fibroid induration. I., Red, a firm, resistant, reddened condition of the lung in chronic pneumonia.

Indusiate (in-du'-ze-ât) [induere, to pui on]. In biology, having an indusium.

Indusium (in-du'-ze-um) [induere, to put on : pl., Indusia ]. I. In biology : $(a)$ that portion of the epidermis of a fern-frond that covers the fruit-dots or sori; (b) the case or covering of an insect larva. 2. The vestigial layer of the cerebral cortex existing with greater or less distinctness upon the dorsal surface of the callosum; it is also seen in many other mammals beside man. It is called also Indusium griseum.

Induvia (in-du'te-e). [L.: pl. Clothes $]$. In biology, persistent withered leaves.

Induviate (in-du'-ve-ât) [induvia, clothes]. In biology, clothed with old or withered parts.

Inebriant (in-e'-bre-ant) [inebrians; inebriare, to make drunk]. I. Intoxicant; causing inebriation. 2. An agent or drug that causes inebriation.

Inebriation (in.e bre-a'-shun) [inebriatio; inebriare, to make drunk]. The condition of drunkenness.

Inebriety $($ in-e-bri'-et-e) [inebrietas, drunkenness]. Inebriation; especially habitual drunkenness.

Inedia $\left(i n-e^{\prime}-d e-a h\right)$ [in, not; edere, to eat]. Synonym of Fasting.

Inein $\left(i n^{\prime}-e-i n\right)$ A crystalline substance obtained from the hairs of the seeds of Strophanthus.

Inenucleable (in-e-nu'-kle-a-bl) [in, not; enucleare, to shell out]. Not removable by enucleation.

Inequivalve (in-e-kri'-valv) [in, not; equre, equal; valve, the leaf of a door]. In biology, applied to shells having unequal valves.

Inerm (in-erm' ) [in, without; arma, arms]. In biology, without hooks, thorns, or prickles; unarmed.

Inertia (in-er'-she-ah) [iners, inactive, unskilled; in, not; ars, skill]. Sluggishness. In physics, the inability of matter to change its condition except by means of an external force. In physiology, inactivity of any organ or function of the body. I. of Drugs, lack of power, from inferior quality, to produce cus. tomary physiologic reactions. 1., Intestinal, torpor of intestinal action, or peristalsis. I., Time. See Time. I., Uterine, the failure or sluggishness of uterine contractions in labor.

In extremis (in eks-tre'-mis) [in, in; extremis, last]. A Latin phrase, meaning at the end; at the point of death or in extreme danger of speedy death.

Infancy (in'-fan-se) [infans, 'a little child]. Early childhood. I., Diseases of, those to which infants are peculiarly liable.

Infant (in' - fant) [infans, a little child]. A babe. According to English law, one not having attained the age of twenty-one. I., Overlaying of, suffocation of an infant by the lying upon it of an adult in sleep. I.-shelter, a day-nursery where the infant-children of working mothers are kept at a moderate expense during the hours of labor. In France, a creche.

Infanticide (in-fant'-is-ìd) [infans, a little child; cadere, to kill]. The murder of an infant.

Infantile (in'-fan-til) [infantilis, of an infant]. Pertaining to infancy. I. Paralysis. See Paralysis.

Infantilism (in-fan'-til-izm) [infans, a little child]. The persistence of the characters of childhood into 
the period of normal adolescence or even into adult life.

Infarct (in-farkt) [infarcire, to fill in]. An obstruction or plug. I., Anemic, a pale wedge-shaped area in an organ due to the occlusion of a blood-vessel by an embolus, the tissues in the distribution of the vessel undergoing coagulation-necrosis. I., Hemorrhagic, a dark-red wedge-shaped area in an organ due to the occlusion of a vessel by an embolus, with the subsequent extravasation of blood into the tissues beyond the point of obstruction. The base of the wedge is toward the periphery, the apex toward the hilum of the organ. The condition is most common in the spleen, the kidney, and the lung. I., Uric Acid, the deposition of crystals of uric acid in the renal tubules of the newborn.

Infarction (in-fark'-shun) [infarcire, to stuff in]. The plugging of a vessel by an embolus; the masses of extravasated blood in the tissues in embolism; obstruction; infarct.

Infarctus (in-fark'-tus). See Infarct.

Infect (in-fekt') [inficere, to put in, or corrupt]. To communicate or transmit the specific virus or germs of disease.

Infection (in-fekl-shun) [infectio, infection]. The communication of disease-germs or virus, by any means, direct or indirect.

Infectious (in-fek'-shus) [infectio, infection]. Having the quality of transmitting disease or the agents that cause disease. See also Contagious. I. Endocarditis, ulcerative endocarditis; malignant endocarditis. I. Pseudo-rheumatism. See Pseudo-rhermatism.

Infective (in-fek-tiv) [infectio, infection]. Infectious. I. Angioma. See Angioma serpiginosum.

Infectivity (in-fek-tiv'-it-e) [inficere, to infect]. Infectiousness; the quality of being infectious.

Infecundity (in-fe-kun'-dit-e) [in, not; fecundus, fruitful]. Sterility, barrenness.

Inferent (in'-fer-ent). Same as Afferent.

Inferior (in-fel-re-or) [comp. of inferus, low]. Lower. Inferius (in-fe'-re-us) [L.]. Inferior.

Infero-lateral (in'-fer-o-lat'-er-al) [inferus, low; latus, side]. Situated below and to one side.

Infero-posterior (in'-fer-o-pos-te'-re-or) [inferus, low ; posterius, posterior]. Situated backward and below.

Infertility (in-fer-til'-it-e) [in, not; fertilis, fertile]. Same as Sterility.

Infibulation (in-fib-u-la'-shun) [in, in ; fibula, a clasp]. An operation formerly employed to prevent the retraction of the prepuce over the glans penis in order to prevent copulation. It consisted in passing a ring through opposite edges of the prepuce. In a similar manner a ring was passed through the labia of the vagina in order to insure the chastity of females.

Infiltrate (in'-fil-trât) [in, in ; filtrare, to strain]. To ooze into the interstitial spaces of a tissue; also, the substance thus having passed.

Infiltration (in-fll-tra'-shun) [infiltratio, infiltration]. The abnormal diffusion of any fluid from without into an organ or tissue, affecting it mechanically so as to destroy its function. I. of Bone, a tuberculous infiltration of bone, consisting either of matter that becomes puriform, or else of gray cancellous matter. 1., Calcareous, deposits of lime or other calcium salts within any tissue of the body. I., Cellular, the primary exudation into a tissue, conveying white corpuscles. I., Fatty, the presence of oil or fatglobules in the interior of a cell. I., Gray, an opaque condition of the lung found after death from acute tuberculosis, the lung being of a dirty ash-gray color, with no appearance of lobulation or of the normal pulmonary structure. I., Plastic, that of a character from which new normal growth may develop. I., Red, a form of infiltration of the lung in acute tuberculosis in which the lung presents a more or less hyperemic appearance, and is soft and granular. I., Sanguineous, an extravasation of blood. An ecchymosis. I., Tuberculous, a confluence of tuberculous granulations.

Infinite $\left(i n^{\prime}-f i n-i t\right)$ [infinitus, boundless]. Immeasurably or innumerably great. I. Distance, a term in optics to denote parallelism of the light rays. Absolute parallelism does not exist, but, practically, rays from an object 20 feet away are so considered and so called.

Infinitesimalism (in-fin-it-es'-im-al-izm) [infinitus, boundless]. The doctrine that favors the infinitesimal dilution of drugs with the view of potentizing them, or developing their power over disease.

Infirm (in-ferm' [infirmus, not strong or firm]. Weak or feeble.

Infirmary (in-fer'-ma-re) [infirmarium, an infirmary]. A hospital. An institution where ill and infirm people are maintained during the period of treatment.

Infirmity (in-fer'-mit-e) [infirmitas, weakness]. Weakness. Feebleness due to disease or senility.

Inflame (in-flām' [inflammare, to set on fire]. To undergo inflammation. To become unduly heated and turgid with blood, owing to a morbid condition.

Inflammatio (in-flam-a -she-o) [L.]. A burning. I. ventriculi. See Gastritis.

Inflammation (in-flam-a'-shun) [inflammatio,-a burning]. A condition of nutritive disturbance characterized by hyperemia, with proliferation of the cells of a tissue or organ, and attended by one or more of the symptoms of pain, heat, swelling, discoloration, and disordered function. I., Adhesive, a synonym of Healing by First Intention. I., Aplastic, and I., Plastic. See Lymph. I., Granulomatous, a chronic form of inflammation occurring usually in scrofulous or syphilitic individuals, with the formation of granulationtissue of low vitality. This tissue breaks down into small abscesses, the latter uniting to form fistulous tracks without any tendency to the formation of cicatrices. I. of the Periosteum of a Tooth, periodontitis. See Odontalgia, and Periostitis, Dental. I., Pyo-gangrenous, a form of rapidly progressive inflammation, with the production of a gangrenous focus, surrounded by a zone of suppuration. I., Regenerative, that form of inflammation which is followed by cicatrization. See also Theories of Inflammation.

Inflammatory (in-fam'-at-o-re) [inflammare, to inflame]. Pertaining to inflammation. I. Blush, synonym of Erythema. I. Corpuscle. See Corpuscle, Gluge's. I. Exudation, the fluid exuded from an inflamed part. I. Fever. See Traumatic Fever. I. Focus, the central or culminating spot of an inflamed part, or that at which suppuration begins. I. Fungoid Neoplasm. See Mycosis. I. Infiltration, the exudation escaping into the interstices of an inflamed tissue and not removed by the lymphatics. I. Zone, the area of gangrenous formation bounded by the line of demarcation between dead and living tissue. Also, the line of demarcation.

Inflation (in-fla'-shun) [inflatio: inflare, to puff up]. Distention with air. In surgery, distention of the bowels with air, to relieve obstruction; or of the lungs, for artificial respiration; or of the Eustachian tube, for therapeutic purposes.

Inflected (in-flek'-ted) [in, in ; flectere, to bend]. In biology, bent inward or downward.

Inflexed (in-flekst') [inflectere, to bend]. In biology, bent. Same as Inflected.

Inflorescence (in-flor-es'-ens) [in, in ; florescere, to begin to blossom]. In biology: (a) blossoming, flowering; (b) a flower-cluster. 
Influenza (in-ftu-en'-zah) [Ital., an influence, formerly thought to be due to the stars]. A specific, contagious, epidemic affection characterized by catarrhal inflammation of the mucous membrane of the respiratory tract, accompanied by a muco-purulent discharge, fever, and prostration. There is a strong tendency to the development of broncho-pneumonia. At times symptoms referable to the gastro-intestinal system predominate; at other times the symptoms are mainly referred to the nervous system. The aged, weak, and young often succumb. The disease is popularly called by its French name, la grippe. See Bacillus of InAuenza, under Bacteria, Synonymatic Table of.

Influx (in'-fluks) [in, in; fuere, to flow]. An inflow. The act of flowing in.

Infossous (in.fos'-us) [in, in ; fodere, to dig]. In biology, sunk in or depressed. Cf. Introvenizm.

Infra- (in'-frah-) [infra, below]. A Latin prefix meaning below or beneath.

Infra-axillary (in'-frah-aks'-it-a-re) [infra, below; axilla, the arm-pit]. Below the arm-pit.

Infra-branchial (in-fra-brang'-ke-al) [infra, below; branchice, gills]. Beneath or below the gills.

Infra-buccal (in-fra-buk'-al) [infra, below; bucca, the cheek]. In molluscs beneath the buccal mass.

Infraclavicular (in-frah-klav-ik'-z-lar) [infra, below; clavicula, the collar-bone]. Below the collarbone.

Infracommissure (in-frah-com'-is-ür) [infra, below; committere, to unite]. The inferior commissure of the brain.

Infraconstrictor (in-frah-kon-strik'-tor) [infra, below; constringere, to bind together]. The inferior constrictor of the pharynx. See Muscles, Table of.

Infracortical (in-frah-kor'-tik-al) [infra, below; cortex, a bark]. Lying beneath the cortical substance of the brain.

Infracostal (in-frah-kos'-tal) [infra, below; costa, a rib]. Below the ribs.

Infracostales (in-frah-kos-ta'-lēz). See Muscles, Table of.

Infraction (in-frak'-shun) [in, in; fractio, breaking]. Incomplete fracture of a bone. Also, an indentation or driving forward.

Infradiaphragmatic (in-frah-di-af-rag-mat'-ik) [infro,

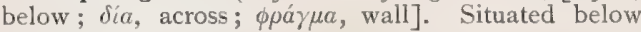
the diaphragm.

Infraglottic (in-frah-glol'-ik) [infra, below; $\gamma \lambda \omega \tau \tau i s$, the glottis]. Below the glottis.

Infrahyoid (in-frah-hi'-oid) [infra, below; voeudís, hyoid]. Situated below the hyoid bone.

Inframammary (in-frah-mam'-ar-e) [infro, below; mamma, the breast]. Below the mammary apparatus.

Inframaxillary (in-frah-maks'-il-a-re) [infra, below; maxilla, the jaw]. Below or under the jaw.

Infraorbital (in-frah-or'-bit-tal) [infra, below; or bita, orbit]. Beneath or below the orbit. I. Artery, the branch of the internal maxillary artery traversing the infraorbital canal. I. Canal, the canal in the superior maxillary bone that transmits the infraorbital vessels and nerve. I. Foramen, the aperture in the superior maxillary bone through which the infraorbital artery passes. I. Groove, the groove in the superior maxillary bone leading to the infraorbital canal. I. Nerve, the name of the superior maxillary nerve at its entrance into the infraorbital canal.

Infrapubian (in-frah-pu'-be-an) [infra, below; pubes, the pubes]. Situated beneath the pubes.

Infrarectus (in.frah-rek'-tus) [infra, below; rectus, straight]. The inferior rectus muscle of the eye. See Muscles, Table of.

Infrascapular (in-frah-skap'-u-lar) [infra, below; scapula, shoulder-blade]. Below the shoulder-blade.
Infraspinatus (in-frah-spi na'-tus). See Muscles, Table of.

Infraspinous (in-frah-spi'-nus) [infra, below ; spina, a spine]. Beneath a spine, as of the scapula or a vertebra. I. Fascia, the dense membranous fascia covering the infraspinous muscle. I. Muscle. See Muscles, Table of.

Infrasternal (in-frah-ster'-nal) [infra, below; sternum, breast-bone]. Below the sternum. I. Depression, the depression of the ensiform cartilage, commonly called the pit of the stomach.

Infratemporal (in-frah-tem'-po-ral) [infra, below ; tempora, the temple]. Situated beneath the temporal bone.

Infrathoracic (in-frah-tho-ra'sik) [infra, below ; $\theta \dot{\omega}$ $\rho a \xi$, thorax ]. Below the thorax.

Infratrochlea (in-frah-trok'-le-ah) [infra, below ; trochlea, a pulley]. Below the trochlea. I. Nerve. See Nerves, Table of.

Infraturbinal (in-frah-tur'-bin-al) [infra, below ; turbo, a wheel, top]. Inferior turbinal. See Bones, Table of.

Infravaginal (in-frah-vaj'-in-al) [infra, below; vagina, sheath]. Situated below the vaginal vault.

Infriction (in-frik'-shun) [infrictio, a rubbing in]. The rubbing of a surface with an ointment or liniment.

Infundibula (in-fun-dib'-u-lah) [L. ]. Plural of Infundibulum, q. $v$. I. of Kidneys, the calices or the divisions of the pelvis of the kidney formed by the confluence of the calices. I. of Lungs, the elongated sacs (set about with air-cells) in which the smallest airpassages terminate. I. subgenitalia. See Demnia.

Infundibular (in-fun-dib'-u-lar) [infundibulum, a funnel]. Of the nature of or belonging to an infundibulum.

Infundibuliform (in-fun-dib-u'-lif-orm) [infundibulum, a funnel; forma, a form]. Funnel-shaped. I. Fascia, the funnel-shaped membranous layer that invests the spermatic cord. I. Process, the cremasteric process of the fascia transversalis.

Infundibulum (in-fun-di $b^{\prime}-u$-lum) [infundere, to pour into]. In biology, a term frequently and variously applied to funnel-shaped organs or parts. I. of Brain, a funnel-shaped mass of gray matter attached to the pituitary body. I. of Cochlea, a small cavity at the end of the modiolus. I. of Heart, the arterial cone from which the pulmonary artery arises. I. of Oviduct, the cavity formed by the fringes at the ovarian end of an oviduct.

Infuscate (in-fus'-kät) [infuscare, to make dark or dusky]. In biology, clouded or darkened.

Infused (in-füzd') [infundere, to pour in]. Extracted; steeped. I. Oils. See Olea infusa.

Infusion (in-fu'-zhun) [infusio, infusum, an infusion]. 1. See Infusum. 2. The slow and gentle injection of water or of a medicated liquid into a vein, or into parenchymatous tissues.

Infusor $\left(i n-f t^{\prime}-z o r\right)[L$.$] . An instrument by means of$ which water or a medicated liquid may be made to flow slowly into a vein, or into the parenchymatous tissues.

Infusoria (in-fu-so'-re-ah) [infusum, an infusion]. A class of microscopic, ciliated Protozon. They are so called because they often develop in great numbers in organic infusions. They reproduce by fission.

Infusum (in-fu'-sum) [L.: gen., Infusi; pl., Infusa]. An infusion. In pharmacy, a preparation made by treating a vegetable substance with hot or with cold water, without boiling. Infusions should, in the absence of specific directions, contain I part of the substance to Io of water. There are four official infusa, and two in the National Formulary, besides a large number in the British Pharmacopeia. 
Ingesta (in-jes'-tah) [ingerere, to carry into]. Substances introduced into the body, especially for purposes of alimentation.

Ingestion (in-jes'-chun) [ingestio, ingestion]. I. The introduction of food or nutrition into the mouth or stomach. 2. The process by which a cell takes up foreign matters, such as bacilli or smaller cells.

Ingluvial (in-glu'-ve-al) [ingluvies, the crop]. Pertaining to the ingluvies.

Ingluvies (in-glu'-ve-ēz) [in, in ; glutire, to swallow]. In biology, the most anterior dilatation of the alimentary canal, as the crop or craw in birds, the paunch or rumen in mammals, the sucking-stomach of insects.

Ingluvin (in'-glu-vin) [ingluvies, crop or craw of a bird]. A preparation obtained from the gizzard of the fowl, Pullus gallinaceus, used as a substitute for pepsin and pancreatin. It is very efficient in the vomiting of pregnancy. Dose gr. $\mathrm{x}-\mathrm{xx}$.

Ingot (ing' -got) [ME., ingot, a mold for molten metal]. A bar of gold, silver, or other metal, cast in a mold.

Ingrassias, Processes, or Wings of. The lesser wings of the sphenoid bone.

Ingravescent (in-grav-es'-ent) [ingravescere, to become heavy]. Increasing in weight or in severity. I. Apoplexy. See Apoplexy.

Ingravidation (in-grav-id-a'-shun). See Impregnation.

Ingredient (in-gre'-de-ent) [ingredi, to step into]. Any substance that enters into the formation of a compound.

Ingrowing Nail. See Onychogryposis.

Inguen (ing'-gwen) [L.]. The groin, $q . v$.

Inguinal (in'-grvin-al) [inguen, the groin]. Pertaining to the groin. I. Arch, the crural arch. I. Canal, the canal transmitting the spermatic cord in the male, and the round ligament in the female. It is situated parallel to and just above Poupart's ligament. I. Glands, the superficial and the deep glands of the groin. I. Hernia. See Hernia. See, also, Ligament, Region, Ring. I. Plague. Synonym of Plague.

Inguino- (in'-gwin-o-) [inguen, the groin]. In composition, pertaining to the groin. I.-abdominal, pertaining conjointly to the groin and the abdomen. I.-crural, relating to the groin and the thigh. I.cutaneous, relating to the integument of the groin.

Ingurgitation (in-gur-jit-a'-shun) [ingurgitatio, a swallowing]. I. The act of swallowing; deglutition. 2. Excess in eating or drinking.

Inhalation (in-ha-la'shun) [inhalatio; inhalare, to draw in]. The in-breathing of air or other vapor. I.-diseases, those due to the inspiration of air containing dust or any finely divided matter. See Grinders? Disease. I. of Medicines, the introduction into the air-passages or lungs of medicinal substances in the form of vapor or fine spray.

Inhale (in-häl') [inhalare, to breathe in]. To inspire or draw air or other vapor into the lungs.

Inhaler (in-ha'-ler) [inhalare, to breathe in]. An instrument for inhaling a gas or the vapor of a liquid medicine. I., Nitrous-oxid, a breathing-tube for the inhalation of nitrous-oxid gas; it is constructed of vulcanized rubber or metal. See Anesthetic.

Inherent (in-he'-rent) [inharere, to cleave to]. Constitutional; innate; natural to the organism; not casual or derivative.

Inheritance (in-her'-it-ans) [F., inheriter, to inherit]. The act of inheriting. I., Particulate, the reappearance of single peculiarities in the offspring. I., Use, the inheritance of acquired characters ; the acquisition by the offspring of changes in the body-cells of the parent.
Inherited (in-her'-it-ed) [in, in, to ; heres, heir]. Derived from an ancestor. I. Disease, a disease that has been transmitted to a child by its parent.

Inhibit (in-hib'-it) [inhibere, to check]. To check, restrain, or suppress.

Inhibition (in-hib-ish'-un) [inhibitio, restraint]. The act of checking, restraining, or suppressing; any influence that controls, retards, or restrains. Inhibitory nerves and centers are those intermediating a modification, stoppage, or suppression of a motor or secretory act already in progress. I., Mental, the involuntary restraint that active mental states exercise over bodily functions, normal or otherwise. I., Vasomotor, an influence exerted on the contractile walls of the bloodvessels, that causes their dilatation by a diminution of their tone. I., Voluntary, the checking or temporary restraint of a reflex by force of will.

Inhibitive (in-hib'-it-iv). See Inhibitory.

Inhibitory (in-hib'-it-o-re) [inhibitorius, inhibitory]. Having the power to restrain or hold in check. I, Center of Setschenow, a cerebral center in the optic lobes of the brain of the frog, the stimulation of which checks spinal reflexes. I. Nerves of the Heart, those of the vagus supplied by the cardio-inhibitory center, through the spinal accessory nerve. I. Nerves of Respiration, certain afferent fibers in the laryngeal branches of the vagus nerve, that exert an inhibitory action on the inspiratory act of respiration. I. Centers, nerve-centers that inhibit, restrain, or even arrest the action of other centers. I. Fibers, centrifugal nerve-fibers that affect other centers so as to moderate or nullify their action.

Inhumation (in-hu-ma'-shun) [inhumare, to put in the ground]. Burial of the dead in the ground. See Humation.

Iniad (in'-e-ad) [iviov, the occiput]. Toward the inial aspect.

Inial (in'-e-al) [iviov, occiput]. Pertaining to the inion. I. Aspect, the posterior aspect of the head.

Inien (in'-e-en) [iviov, occiput]. Belonging to the inion in itself.

Iniencephalus (in-e-en-sef'-al-us) [iviov, occiput ;

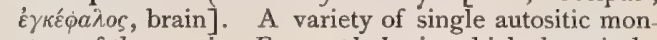
sters of the species Exencephalus in which there is the same deformity of the skull as in notencephalus, with the addition of a spinal fissure involving the cervical and thoracic vertebræ.

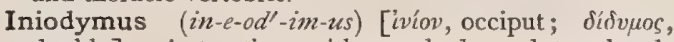
double]. A teratism with one body and two heads joined at the occiput.

Inio-glabellar (in'-e-o-gla-bel'-ar) [iviov, occiput; glaber, smooth]. Relating to or joining the inion and the glabella.

Inion (in'-e-on) [iviov, occiput]. The external protuberance of the occipital bone. SeeCraniometric Points.

Iniops (in'-e-ops) [iviov, occiput; ó $\psi$, face]. A catadidymous monstrosity with the parts below the navel double, the thoraces joined into one, and one head with two faces, the one incomplete.

Inirritative (in-ir'-it-a-tiv) [in, not ; irritare, to irritate]. Not irritant; soothing.

Initial (in-ish'-al) [in, into; ire, to go]. Beginning or commencing. I. Cells, germ-cells. I. Sclerosis, the primary induration of a hard chancre. I. Stage of Labor. See Labor, Stages of.

Initis (in-i'-tis) [is, muscle, fiber; $\iota \tau \iota$, inflammation]. Inflammation of fibrous or muscular tissue.

Inject (in-jekt') [in, into; jacere, to throw]. To effect the introduction of a liquid into any cavity of the body, natural or artificial, by means of a syringe or similar instrument. In pathology, to produce a condition of distention of the capillaries with blood. 
Injecta (in-jek'-tah) [L.]. Things introduced, as into the alimentary canal (correlated with ejecta).

Injection (in-jek'-shun) [injectio, a throwing in]. An aqueous or other solution thrown into the vessels, beneath the skin or into any cavity of the body; the introduction of such a liquid; a condition of capillary distention. I., Anatomic, filling the vessels of a cadaver or of an organ with preservative or coagulating solutions, for purposes of dissection, I., Coagulating, injection of coagulating solutions into the cavity of an aneurysm. I., Hypodermatic, into the subcutaneous connective tissue, by means of a syringe. I., Nutrient, injection of nutritive fluids into the rectum or other cavity of the body. I., Opaque Naked-eye, for anatomic or microscopic purposes, made of plasterof-Paris, tallow, vermilion and gelatin, plumbic acetate and potassium bichromate (yellow injection), or plumbic acetate and sodium carbonate (white). I., Transparent Microscopic, made with carmin for red, potassium ferrocyanid for blue, potassium bichromate for yellow. I.-pneumonia, a condition of the lung somewhat resembling pneumonia, following injections of Koch's tuberculin.

Injector (in-jek'-tor) [injicere, to throw in]. An apparatus, as a syringe, used in injecting any material into the organism, or into any of its cavities.

Injury (in'-ju-re) [injuria; in, not; jus, a right] Any damage or harm to the body or any of its parts.

In-knee $\left(i n^{\prime}-n e\right)$. Knock-knee, or genu valgum, q. $v$.

Inlet $\left(i n^{\prime}-\right.$ let $)$. The place where the air of ventilation is admitted into a room. I. of the Pelvis, the heartshaped space within the brim of the pelvis; the superior pelvic strait.

Inman's Myalgia. See Diseases, Table of.

Innate (in-nāt' or in'-nät) [imnatus, born in]. Congenital ; native to the organism; intrinsic. In biology, applied to anthers that appear to be supported by the very apex of the filament.

Innervation (in-ner-va'-shun) [in, in ; nevous, nerve]. The discharge of nervous impulses from a ganglionic center; the supply of nervous influence bestowed upon any part or organ; the distribution of nerves within a part or organ; the manifestation of nervous force.

Innominata (in-nom-in-al-tah). Plural of Innominatum. The innominate bones.

Innominate $\left(i n-n o m n^{\prime}-i n-\bar{a} t\right)$ [in, without; nomen, a name]. A term applied to several parts of the body to which no other definite name has been given. I. Artery. See Arteries, Table of. 1. Bone, the irregular-shaped bone forming the sides and anterior wall of the pelvic cavity. See Bones, Table of. I. Foramen. See Foramina, Tables of. I. Veins. See Vein.

Innominatum (in-nom-in-a -tum) [L., nameless : pl., Innominata]. The innominate bone.

Innutrition (in-nu-trish'-un) [in, not ; nutrire, to nourish]. Want or deficiency of nutrition or nourishment.

Inoblast (in'-o-blast) [¿s, fiber; $\beta \lambda a \sigma t b s$, germ]. Any one of the cells, or corpuscles, from which connective tissue is derived

Inocarcinoma (in-o-kar-sin-o'-mah) [is, fiber; каркіvos, a crab; ó $\mu a$, tumor: pl., Inocarcinomata]. A carcinoma with a preponderance of fibrous tissue.

Inoccipitia (in-ok-sip-it/-e-ah) [in, negative; occiput, occiput]. Deficiency of the occipital lobe of the brain.

Inochondritis (in-o-kon-dri'-tis) [is, fiber; $\chi o v \delta \rho o s$, cartilage; $t \tau \iota$, inflammation]. Conjoined inflammation of tendons and cartilages.

Inoculability (in-ok-u-la-bil'-it-e) [inoculare, to implant]. The quality of being inoculable.
Inoculable (in-ok'-u-la-bl) [inoculare, to implant]. Susceptible of being inoculated.

Inocular (in-ok'-u-lar) [in, in; oculus, eye]. In biology, applied to those insect antennæe that arise from notches in the inner margins of the compound eyes.

Inoculation (in-ok-u-la'-shun) [inoculatio, an ingrafting]. The introduction into the circulation of the virus of infectious diseases, or of certain medicinal agents. I., Jennerian, vaccination, or the inoculation of cowpox-virus. I. of Smallpox, inoculation with the contagium of smallpox to produce a mild type of the disease. I., Preventive, inoculation with some virus to act as a preventive of a more serious disease or type of the same disease.

Inoculator (in-ok'-u-la-tor) [inoculatio, an ingrafting]. One who or that which inoculates; an instrument used in inoculation.

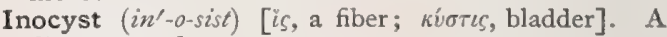
fibrous capsule.

Inoendothelioma (in-o-en-do-the-le-o'-mah) [is, fiber ;

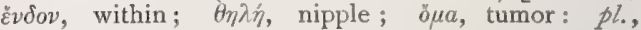
Inoendotheliomata]. Round-celled fibro-sarcoma.

Inoepithelioma (in-o-ep-ith-e-le-o'-mah) [is, fiber; $\dot{\varepsilon} \pi i$,

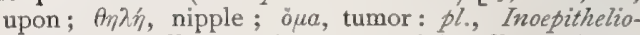
mata ]. Medullary carcinoma containing fibrous tissue.

Inogen (in'-o-jen) [is, (gen. ivos), fiber; yevvãv, to produce]. A hypothetic substance believed to occur in muscular tissue, and to be decomposed, during contraction, into carbon dioxid, sarcolactic acid, and myosin. Because of this behavior it is considered as the energy-producing substance of muscle.

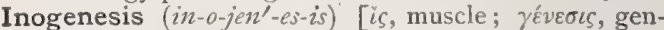
eration]. The formation of fibrous muscular tissue.

Inohymenitis (in-o-hi-men-i'-tis) [is, fiber; $v u^{\prime}{ }^{\prime} v$, membrane; $\iota \tau / s$, inflammation]. Inflammation of any fibrous structure.

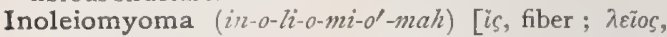
smooth; $\mu \bar{\nu} \varsigma$, muscle; öua, a tumor: pl., Inoleiomyo$\left.m \alpha^{\prime} a\right]$. A -myoma made up of, or containing, unstriped muscular fibers.

Inoma (in-o' $m a h)$ [is, a fiber; ö $\mu a$, a tumor: $p l$. Inomata]. Same as Fibroma.

Inomyxoma (in-o-miks-o'-mah) [is, fiber; $\mu$ v́ka, mucus; ö $\mu a$, tumor: pl., Inomyxomata]. Same as Fibro-1nyxoma.

Inoperculate $($ in-o-per'-ku-lät) [in, without; operculum, a cover, lid]. In biology, having no operculum or lid.

Inopexia, or Inopexy (in-o-peks'-e-ah, or in'-o-peks-e) [is, fiber; $\pi \tilde{\eta} \xi \iota s$, coagulation]. A tendency in the blood toward spontaneous coagulation.

Inophlogosis (in-o-flo-go'-sis) [is, fiber; $\phi \lambda \sigma \gamma \omega \sigma \iota s$, inflammation]. Inflammation of any fibrous tissue.

Inopolypous (in-o-pol'-ip-us) [is, fiber; polypus, polyp]. Of the nature of an inopolypus.

Inopolypus (in-o-pol'-ip-us) [is, fiber; polypus, polyp] A fibrous polypus.

Inorganic (in-or-gan'-ik) [in, not; organum, an instrument]. A term applied to a body or a substance that possesses none of the possibilities of development, yrowth, or life. I. Constituents. See Constituents.

Inorrhabdomyoma (in-or-ab-do-mi-o'-mah) [is, fiber ; $\dot{\rho} a ́ \beta \delta o s, \operatorname{rod} ; \mu \tilde{v} \varsigma$, muscle ; ö $\mu a$, tumor: pl., Inorrhabdomyomata]. A fibrous rhabdomyoma.

Inosclerosis (in-o-skle-ro'sis) [is, fiber; $\sigma \kappa \lambda \eta \rho \sigma^{\prime}$, hard]. Sclerosis or hardening of fibrous tissue.

Inosculate (in-os'-ku-lät) [in, in, on; osculum, dim. of os, mouth]. In biology, to unite by small openings; to anastomose.

Inosculation (in-os-ku-la'-shun) [in, in; osculare, to kiss]. The joining, at their mouths, of the branches of blood-vessels, especially the extremities of the arteries with the origins of veins. 
Inosinic Acid (in-o-sin'-ik). An ammonium derivative from muscle, of unknown constitution.

Inosis $\left(i n-o^{\prime}-\right.$ sis). See Inogenesis.

Inosite $\left(i n^{\prime}-0-s i \iota\right)$ [¿̌, fiber], $\mathrm{C}_{6} \mathrm{H}_{12} \mathrm{O}_{6}+2 \mathrm{H}_{2} \mathrm{O}$. A saccharine substance occurring sparingly in the human body, especially in the muscles. It also occurs in diabetic urine and in the urine of chronic nephritis. It is found in abundance in the vegetable kingdom, particularly in unripe beans. It forms large efflorescent crystals (rhombic tables) ; in microscopic preparations it is usually obtained in tufted lumps of fine crystals. It is readily soluble in water, but insoluble in absolute alcohol and ether.

Inosituria (in-o-sit-u'-re-ah) [is, fiber; ovjpov, urine]. The presence of inosite in the urine.

Inosteatoma (in-o-ste-at-o'-mah) [is, fiber ; $\sigma \tau \varepsilon \dot{c} \alpha \rho$, fat ; $o ̈ \mu a$, tumor: pl., Inosteatomata]. A steatoma with fibrous elements.

Inosuria (in-o-su'-re-ah). See Inosituria.

Inotagmata (in-o-tag'-mat-ah) [is (iv), strength, force ; Tóy $\mu a$, a regular arrangement, as of soldiers]. In biology, Engelmann's name for hypothetic, contractile elements that generate the force of protoplasmic motion; they are held to be uniaxial and doubly refractive; also written Isotagmata.

Inquest (in'-kwest) [inquesita ; in, into ; quarere, to ask]. A judicial inquiry. I., Coroner's, an inquiry concerning the cause of the death of one who has died by violence or in some sudden or unknown way.

Inquiline (in'-kwil-in) [L., inquilinus, an inhabitant of a place that is nothis own]. In biolcgy, a commensal or messmate; an animal inhabiting an abode that it does not produce.

Inquination (in-kwin-a'shun) [inquinatio, pollution]. Pollution; infection; corruption.

Inquisition (in-kwiz-ish'-un) [inquisitio, an inquiry]. The inquiry or hearing before a jury or commission concerning the sanity or lunacy of a criminal or a person charged with crime.

Insaccation (in-sak-a'-shun) [in, in; saccus, sac]. Encystment; enclosure in a sac.

Insalivation (in-sal-iv-a'-shun) [in, in; saliva, the spittle]. The mixture of the food with saliva during mastication.

Insalubrity (in-sal-u'-brit-e) [in, not; salubris, wholesome]. Unwholesomeness of air or of climate.

Insanability (in-san-ab-il'-it-e) [in, not; sanabilis, curable]. Incurableness; the quality or state of being incurable.

Insane (in-sān') [in, not; sanus, sound]. Deranged or diseased in mind. I, Ear. See Hematoma auris.

Insaniola (in-san-i'-o-lah) [dim. of insania, insanity]. A slight or minor degree of insanity.

Insanitary (in-san'-it-a-re) [in, not; sanitas, health]. Not sanitary; not in a proper condition as respects the preservation of health (said of houses, buildings, and their surroundings).

Insanitation (in-san-it-a'-shun) [in, not; sanitas, health]. Lack of proper sanitary conditions; defect of sanitation.

Insanity (in-san'-it-e) [insanitas, insanity]. A derangement or abnormal condition of the mental faculties, with or without loss of volition and of consciousness. Insanity may be due to defective development, to acquired disease, or to natural decay. It is characterized, according to its form, by a variety of symptoms, the most common of which are change of character and habits, moroseness, confusion, elation, melancholy, mania, delusions, and hallucinations. The psychotic tendency is the chief predisposing cause, and on this some one of the many exciting causes will act and result in the final break-down. The vast majority of cases of insanity occur between the ages of twenty-five and forty-five. Melancholia, mania, delusional insanity, and dementia are the four principal types of the affection. According to Krafft-Ebing, insanity may be divided into two great groups, according as the disorder is the result of a disturbance of the developed brain or of an arrest of brain-development. He places insanity ordinarily so-called under the first head; his subdivisions are as follows :-

A. Mental affections of the developed brain.

I. Psychoneuroses.

I. Primary curable conditions.

a. Melancholia

a. Melancholia passiva

B. Melancholia attonita.

b. Mania.

a. Maniacal exaltation.

B. Maniacal frenzy.

c. Stupor

2. Secondary incurable states.

a. Secondary monomania.

b. Termınal dementia.

a. Dementia agitata.

B. Dementia apathetica.

II Psychic degenerative states.

a. Constitutional affective insanity (folie raisonante).

b. Moral insanity.

c. Primary monomania.

a. With delusions.

aa. Of a persecutory tinge.

$\beta \beta$. Of an ambitious tinge.

$\beta$. With imperative conceptions.

$d$. Insanities transformed from the constitutional neuroses.

a. Epileptic

a. Epleptic.

\%. Hypochondriac

Periodic insanity.

III. Brain diseases with predominating mental symptoms.

a. Paralytic dementia.

b. Cerebral syphilis.

c. Chronic alcoholism

d. Senile dementia.

e. Acute delirium.

B. Mental results of arrested brain-development: idiocy and cretinism.

I., Acquired, that arising after a long period of life of mental integrity. I., Alcoholic, that induced by alcoholic excess, usually a result of hereditary tendencies. I., Alternating. See I., Circular. I., Circular, cyclothymia ; alternating insanity; a form of insanity recurring in cycles varying in length from a few days to many months. The arrangement of the cycle varies in different individuals, but is constant in a given case. Thus melancholia may be followed by mania, and this by a lucid interval, the passage from one mental condition to the other being abrupt or gradual. I., Climacteric, insanity occurring at or near the menopause. I., Communicated, that transmitted by association with an insane person. I., Confusional, stuporous insanity; delusional stupor; mania hallucinatoria; surgical insanity; puerperal mania; postfebrile insanity; an acute insanity produced by nervous shock or exhausting disease, without distinct constant emotional depression or exaltation, with marked failure of mental power or complete imbecility, often accompanied by hallucinations and loss of physical power. Recovery is usually complete. 1., Doubting, a form of melancholia according to Régis, but accord. ing to others a psycho-convulsive mental disease closely allied to delusional insanity, which consists in an uncontrollable doubt and indecision regarding the occupations, duties, or events of the day, of religion, etc. I., Epidemic, a form occasionally manifested among a number of people in common association, as in convents or schools. I., Febrile, a maniacal form, occasionally occurring in the course or as a sequel of acute inflammation or fever. I., Hereditary, that trans. mitted from parent to child, and not induced by other 
apparent cause. I., Ideational, a term applied to any form in which there is marked perversion of the reasoning powers. I., Impulsive, a form in which the patient possesses an uncontrollable desire to commit acts of violence. I., Moral, a form marked by perversion and depravity of the moral sense, apparently with out impairment of the reasoning and intellectual fac ulties. I. of Pregnancy, a form occurring during pregnancy, characterized by melancholia, suicidal intent, and abhorrence of friends and relatives. I., Primary, a form, often congenital, that arises with the development of the body. It may also proceed from injury or disease of the brain in early life. I., Puerperal, a term sometimes applied to the delirium of childbirth, but more properly to the mania occurring after delivery. I., Simultaneous, when two or more persons hereditarily inclined become affected at the same time. I., Menstrual. See I., Periodic. I., Periodic, a condition dependent upon original or acquired psychopathy, in which attacks of insanity occur at regular or irregular intervals. If occurring in women at the menstrual epoch it is called Menstrual Insanity. I., Stuporous, the primary acute form of dementia; a disease chiefly met with in youth and early maturity. It is usually due largely to masturbation, and is also called Anergic Stupor. See also I., Confusional. I., Surgical. See I., Confusional. I., Volitional, such forms as are marked by derangement of the will.

Insatiability (in-sa-she-ab-il'-it-e) [in, not; satiare, to satisfy]. The property of being insatiable. See Acoria.

Insatiable (in-sa'-she-ab-l) [insatiabilis, that which cannot be satisfied]. Inordinately greedy; incapable of being satisfied. I. Appetite. See Bulimia.

Inscriptiones tendinea (in-skrip-te-o'-nēz ten-din'-e-e). The lineæ transversæ of the rectus abdominis muscle.

Insculpt (in-skulpt') [insculpere, to cut or carve in]. In biology, applied to lichens that grow in the depressions in rocks.

Insect (in'-sekt) [insectum, an insect]. Any member of the class of animals called Insecta. I.powder, the powdered flowers of several species of Pyrethrum or "buhach," an insecticide in common use. In the United States the flowers of $P$. cinercefolizm are extensively grown for this purpose. See Buhach. I. Wax. See Chinese Wax.

Insected (in-sek'-ted) [insectus, p. p. of insecare, to cut in]. Incised or cut into.

Insecticide (in-sek'-tis-ī $d$ ) [insectum, insect; cadere, to kill]. A substance that is destructive to insects.

Insectiform (in-sek'-tif-orm) [insectum, an insect; forma, form]. Resembling an insect.

Insectivora (in-sek-tiv'-o-rah) [insectum, an insect; vorare, to devour]. An order of plantigrade animals belonging to the Mammalia, and living upon insects.

Insectivorism (in-sek-tiv'-or-izm) [insectum, an insect; vorare, to devour]. In biology, the property of capturing and devouring insects, such as is possessed by certain plants.

Insectivorous (in-sek-tiv'-or-us) [insectum, insect; vorare, to devour]. In biology, feeding upon insects.

Insectology (in-sek-tol'-o-je) [insectum, insect; $\lambda 6 \gamma o s$, science]. The science treating of insects.

Insemination (in-sem-in- $a^{\prime}-\operatorname{shun}$ ) [ inseminare, to plant seed]. The planting of seed. The introduction of semen.

Insenescence (in-sen-es'-ens) [insenescentia; in, not, or upon; senex, old]. I. Vigorous age; old age without its ordinary infirmities. 2. The approach of old age.

Insensibility (in-sens-ib-il'-it-e) [in, not; sentire, to feel]. The condition or state of being insensible; absence of consciousness; anesthesia.
Insensible (in-sen'-sib-l) [in, not; sentire, to feel]. Without the sense of feeling. Incapable of being perceived or recognized by the senses. Unconscious.

Insertion (in-ser'-shun) [insertio; inserere, to set in]. The act of setting or placing in; or, that which is set in; the point at which a muscle is attached to the part that it moves; the place or the mode of attachment of an organ to its support. I., Velamentous, the attachment of the umbilical cord to the margin of the placenta.

Insidious (in-sid'-e-us) [insidia, an ambush]. Deceitful, stealthful. Hidden from external view. I. Dis ease, one, the onset of which is gradual or inappreciable.

Insipid (in-sip'-id) [insipidus, unsavory]. Tasteless.

Insitio dentis (in-sish'-e-o den'-tis) [L.]. Implantation of a tooth.

In situ (in si'-tu) [in, in; situ, position]. A Latin phrase meaning in a given or natural position.

Insolatio (in-so-la'-she-o). See Sunstroke.

Insolation (in-so-la'-shun) [insolatio; in, in ; sol, sun]. I. Exposure to the sun, either as a prophylactic treatment or as a cause of disease. 2. Sunstroke. 3. In pharmacy, the drying or bleaching of substances by exposure to the sun.

Insolubility (in-sol-u-bil'-it-e) [insolubilis, insoluble]. The quality of being insoluble; lack of solubility.

Insoluble (in-sol'-u-bl) [in, not; solubitis, soluble]. Incapable of solution.

Insomnia (in-som'-ne-ah) [in, not; somnus, sleep]. Want of sleep; inability to sleep.

Inspection (in-spek'-shun) [inspectio, or inspectus, a beholding]. In medicine, the examination of the body or any part of it.

Inspergation (in-sper-ga'-shun) [inspergere, to sprinkle into]. The sprinkling or dusting of a part with a fine powder.

Inspiration (in-spir-a'-shun) [inspiratio; in, in ; spir. are, to breathe]. That part of respiration consisting of the drawing in of the breath.

Inspiratory (in-spi'-rat-or-e) $\quad[i n$, in; spirare, to breathe]. Pertaining to the act or function of inspiration. I. Spasm, a rare form of hysteric spasm of the larynx occurring only during inspiration, the vocal bands instead of separating, tending to approach one another.

Inspissant (in-spis'-ant) [inspissans; in, in ; spissare, to thicken]. I. Tending to thicken; thickening the blood or other fluids. 2. An agent that tends to increase the thickness of the blood or some other fluid.

Inspissate (in-spis'-ät) [inspissare, to thicken]. To make thick by evaporation or by absorption of the liquid menstruum.

Instaminate $\left(i n-\operatorname{stan}^{\prime}-i n-\bar{a} t\right)[i n$, not ; stamen, a stamen]. Without stamens.

Instauration (in-statv-ra'-shun) [instauratio, renewal]. The first appearance of a physiologic condition; the establishment of a new function.

Instep (in'-step) [instop, the bend of the foot]. The arch of the foot, or its dorsal aspect.

Instillation (in-stil-a'-shun) [instillatio; instillare, to put in little by little]. The pouring of a liquid guttatim, or little by little. To introduce into a cavity, canal, or sac, drop by drop.

Instinct (in-stingkt') [instinguere, to impel]. In biology, organic habits registered in the nervous system of the race (Grant Allen). An inherited natural impulse, unassociated with a reasoning conception as to cause and effect.

Instinctive (in-sting $k^{\prime}$-tiv) [instinguere, to impel] Prompted or determined by instinct; of the nature of instinct. 
Instipulate (in-stiṕ-u-lät) [in, without; stipula, a stalk]. In biology, without stipules.

Institute $\left(i n^{\prime}\right.$-stit-ül) [insituere, to set up]. A statement of principles. Also, any establishment for the statement or dissemination of principles. Institutes of Medicine, the explanation or philosophy of the laws of the science of medicine, physiology, pathology, therapeutics, and hygiene, or the general and elementary principles of the same. The term is used sometimes as a synonym of physiology.

Instrument (in'-stru-ment) [instrumentum; instruere, to build]. Any mechanical tool or device used in operation or treatment. I., Exploring, for examining teeth to ascertain the work necessary to be done; more especially for determining the presence of caries of the teeth.

Instrumentarium (in-stru-men-ta'-re-um) [L.]. A supply or collection of surgical, dental, or other instruments.

Instrumentation (in-stru-men-ta'-shun) [instrumentum, an instrument]. The care and management of a surgeon's instruments.

Insuccation (in-suk-a'shun) [in, into; succus, juice]. The steeping of a drug for a considerable time in water before using it in any pharmaceutic process.

Insufficiency (in-suf-fish'-en-se) [insufficientia; in, not; sub, under; facere, to make]. Incapacity of normal action, on account of some deficiency, as of size; the quality of not being sufficient for a special function or duty. In ophthalmology, a disturbance of equilibrium of the ocular muscles, that is overcome by the effort of binocular vision, and so does not produce strabismus. It is also called latent or dynamic squint. I., Aortic. See Endocarditis. I. of the Cardiac Valves, imperfect closure, permitting regurgitation. I. of the Externi, or esophoria; the internal recti ocular muscles are more powerful than the externi, or more accurately, the power of adduction, or convergence, is excessive. I. of the Interni, or exophoria ; the external recti are predominant or the power of adduction is subnormal. I. of Muscles, Active, a phenomenon of a muscle acting on two or more joints when the joints over which it passes are so changed that it cannot contract actively any further than to the extent of the shortening from which it begins to be active. I. of Muscles, Passive, the analogue of the phenomena of active insufficiency whereby motion of the part is prevented from the position of the joint, the muscle being too short to act under such circumstances. I. of the Ocular Muscles, heterophoria, or unbalance; high degrees result in strabismus, diplopia, asthenopia, etc. I., Mitral. See Endocarditis. I., Pulmonary. See Endocarditis. I., Tricuspid. See Ednöcarditis.

Insufflation (in-suf-fla-shun) [insufflare; in, in ; sufflare, to puff]. The blowing of any finely divided substance upon a surface or into a cavity, or the filling of any cavity with air, gas, or vapor.

Insufflator (in'-suf-la-tor) [in, in; sufflare, to blow]. A small instrument for blowing fine powders into a cavity or on a surface. Also, one for blowing air into the lungs.

Insula $\left(\right.$ in' $\left.^{\prime}-s u-l a h\right)$ [L. ]. I. In anatomy, the island of Reil. 2. Any detached part or exclave of an organ. 3. A blood-islet, or island. See Islanil.

Insular (in'-su-lar) [insula, an island]. Isolated in condition; also, pertaining to the Island of Reil. I. Sclerosis, Disseminated, Cerehro-spinal, or Multiple Sclerosis. A disease characterized by scattered islets of sclerosis in the brain and cord. It is called sclerose en plaques disseminees by the French, and multiple sclerosis by the Germans. It is distinctly a disease of early adult life, and is of about equal frequency in the two sexes. The causes are obscure. The disease has been observed to follow infectious diseases, exposure to wet and cold, and traumatism. In some cases a neuropathic predisposition has been present. The symptoms vary according to the situation of the islets; the most common are motor derangement, a jerky tremor, paresis or paralysis, and ocular symptoms, as diplopia and amblyopia, with nystagmus, and occasionally atrophy of the discs. The tremor is ordinarily absent during repose, but appears on attempted movement, and is hence designated, intention-tremor. The speech is a characteristic one, very slow, each syllable being pronounced with difficulty; hence it is said to be of a "scanning" nature. Vertigo is also a very fre. quent symptom, and in the advanced stage the mind undergoes deterioration, and dementia may make its appearance. The knee-jerks are exaggerated and ankleclonus is present. The lesions of the disease are small grayish or yellow gelatinous patches scattered through. out the brain and in both the white and gray matter of the cord.

Insulate $\left(i n^{\prime}-s u\right.$-lāt) [insulare, to make like an island]. To isolate or separate from surroundings. In electricity, to surround a conductor with a non-conducting substance or with one having an exceedingly high degree of resistance.

Insulation (in-su-la'-shun) [insulatio; insulare, to make like an island]. The process of insulating; the state or quality of being insulated.

Insult (in'-sult) [insultus; in, upon; saltare, to leap]. The beginning of a paroxysm or of an attack of a disease. I., Apoplectic, an apoplectic stroke.

Insusceptibility (in-sus-sep-tib-ill-it-e) [insusceptibilis, not susceptible]. Absence of contagious quality; it differs from Immunity in being applied to the disease instead of the person.

Integer (in'-te-ger) [L.]. An entity. I., Fissural, a term designating a fissure of the brain, which is independent in some species or individuals, and deepest at or about the middle of its length, corresponding nearly with the place of first appearance.

Integral (in'-te-gral) [integer, whole]. Entire; essential.

Integration (in-te-gra'-shun) [integratio, a renewing]. The blending of separate parts into one, as in the embryo.

Integrity (in-teg'-rit-e) [integritus; integer, whole]. Wholeness; entirety. Also, virginity.

Integument (in-teg'-u-ment) [integumentum; in, upon; tegere, to cover]. A covering, especially the skin. In botany, the envelop surrounding the ovule of phanerogamous plants. I., Fetal, the fetal membranes.

Intellect (in'-tel-ekt) [intellectus; [inter, between; legere, to choose]. The mind or reasoning power. I., Deranged. See Insanity.

Intelligence (in-tel'-ij-ence) [intelligentia, intelligence]. The understanding that comes from the perception of qualities and attributes of the objective world, and is manifested in the purposive employment of means to attain an end.

Intemperance (in-tem'-per-ans) [in, not; temperantia, mildness]. Want of moderation; immoderate indulgence, especially with reference to alcoholic liquors.

Intensity (in-ten'-sit-e) [intensus, stretched, strung]. Concentration of energy or activity. Also, a high degree of energy or power. I., Specific. See Specific. 
Intensive (in-ten'-siv) [intensus, stretched; strung]. Gradually increased in force or energy. Strengthening or increasing the sexual passions. I. Method of Pasteur. See Pasteur.

Intention (in-ten'-shun) [intentio, a stretching out]. See Healing. I.-tremor, a tremor coming on when attempts at voluntary motion are made.

Inter-(in'-ter-) [inter, between]. A Latin prefix signifying between.

Interaccessory (in-ter-ak'-ses-or-e) [inter, between; accedere, to go to]. Situated between accessory processes of the vertebræ. I. Muscles, short lumbar muscles connecting the accessory processes of the vertebræ.

Interarticular (in-ler-ar-tik'-u-lar) [inter, between; articulus, a joint]. Situated between joints. I. Fibro-cartilage, the flattened cartilaginous plates, irregular in shape, between the articular cartilages of certain joints.

Interarytenoid (in-ter-ar-i'ten-oid) [inter, between; áútruva, a pitcher; cidos, likeness]. Between the two arytenoid cartilages. I. Muscle. See Muscles, Table of.

Interauricular (in-ter-aze-rik'-u-lar) [inter, between; auricula, auricle]. Situated between the auricles or auriculæ.

Interbrain (in'-ter-brān). See Diencephalon and Thalamencephalon.

Intercadence (in-ter- $k a^{\prime}$-dens) [inter, between; cadere, to fall]. The irregular beating of the pulse, which seems occasionally to have an additional beat between normal pulsations

Intercadent (in-ter-k $a^{\prime}$-dent) [inter, between; cadere, to fall]. Exhibiting the quality of intercadence.

Intercalary (in-ter'-kal-a-re) [inter, between; calare, to insert]. Placed or inserted between. I. Growth, a growth of new material interstitially deposited.

Intercalatum (in-ter-kal'-at-um) [inter, between; calare, to insert]. Substantia nigra; locus niger; a dark mass of crescentic outline situated between the ventral crusta and the dorsal tegmentum of the crus cerebri.

Intercapillary (in-ter-kaph-il-a-re) [inter, between; capillus, a hair]. Between capillaries.

Intercarotic, Intercarotid (in-ter-kar-ot'-ik, in-ter-karot'-id) [inter, between; $\kappa a \rho \delta \varepsilon \iota \nu$, to produce sleep]. Situated between the external and internal carotids. I. Ganglion. See Ganglia, Table of.

Intercavernous (in-ter-kav-er'-nus) [inter, between; caverna, a cave]. Situated between two antra, or between the two cavernous sinuses.

Intercellular (in-ter-sel'-u-lar) [inter, between; cellula, a small cell]. Among or between cells.

Intercentral (in-ter-sen'-tral) [inter, between; centrum, a center]. Between centers.

Intercerebral (in-ter-ser'-e-bral) [inter, between; cerebrum, cerebrum]. Between the right and left cerebral hemispheres.

Interchondral (in-ter-kon'-dral) [inter, between;

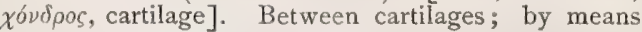
of the interposition of cartilages.

Intercilium (in-ter-sil'-e-um). See Glabella.

Interclavicle (in-ter-klav'-ik-I) [inter, between; clavus, a key]. A membrane-bone which in all vertebrates below the rank of mammals, and also in the monotremes, is developed either ventrad of the sternum, or between the clavicles. In the typical mammalia no true interclavicle exists; but some theorists have given the name to certain extra-sternal structural elements in the true or placental mammals.

Interclavicular (in-ter-klav-ik'-u-lar) [inter, between; clavicula, the collar-bone]. Between the clavicles.

Interclinoid (in-ter-kli'-noid) [inter, between; $\kappa \lambda \iota v \eta$, bed; $\varepsilon i \delta o s$, resemblance]. Between the clinoid processes of the sphenoid bone.

Intercolumnar (in-ter-kol-um'-nar). See Fascia.

Intercondylar, or Intercondyloid (in-ter-kon'-dil-ar,

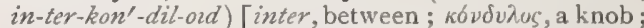

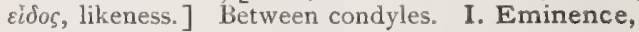
the spine or knob separating the two condylar portions of the tibia. I. Fossa, the notch between the condyles of the femur. I. Line, a transverse line crossing above the intercondyloid fossa, and joining the condyles. I. Notch. Same as I. Fossa.

Intercostal (in-ter-kos'-tal) [inter, between; costa, a rib]. Pertaining to the space between ribs. I. Arteries, the aortic arteries of the intercostal spaces. See Arteries, Table of. I. Muscles. See Muscles, Table of. I. Nerves, the anterior divisions of the dorsospinal nerves. See Nerves, Table of.

Intercosto-humeral (in-ter-kos'-to-hu'-mer-nl) [inter, between ; costa, rib; humerus, the bone of the upper arm]. Pertaining to the arm and the space between the ribs.

Intercourse (in'-ter-kors) [intercursus, commerce]. Communication. I., Carnal, sexual connection; coition. I., Sexual. Same as I., Camal.

Intercoxal (in-ter-koks'-al) [inter, between; coxa, hip]. Situated between the coxæ or hips.

Intercurrent (in-ter-kur'-ent) [inter, between; currere, to run]. Occurring or taking place between. I. Disease, a term loosely applied to diseases occurring sporadically during a period of prevailing endemic or epidemic diseases. Also applied to a disease arising or progressing during the existence of another disease in the same person.

Interdental (in-ter-den'-tal) [inter, between; dens, a tooth]. I. Between the teeth. 2. An interdentium. I. Splint, a splint used in fracture of the jaw, consisting of a metallic frame at the neck of the teeth, held by wire sutures passing between the teeth.

Interdentium (in-ter-den'-she-um) [inter, between; dens, a tooth]. The space between any two of the teeth. Interdiction (in-ter-dik'-shun) [interdictio, a prohibiting]. A judicial or legal process that deprives an insane person or one suspected of insanity of the management of his own affairs or of the affairs of others.

Interdigital (in-ter-dij'-it-al) [inter, between; digitus, a finger]. Between fingers. I. Membrane, the skin between the toes of palmate-footed animals. I. Space, that between adjacent fingers.

Interdigitation (in-ter-dij-it-a'-shun) [inter, between; digitus, a finger]. The locking or dovetailing of similar parts, as the fingers of one hand with those of the other; or of the ends of the obliquus externus muscle with those of the serratus magnus.

Interfascicular (in-ter-fas-ik'-ullar) [inter, between; fasciculus, a bundle]. Situated between fasciculi.

Interfemoral (in-ter-fem'-or-al) [inter, between; femur, the thigh]. Between the femurs or thighs.

Interfere (in-ter-fer') [inter, between; ferire, to strike]. In horses, to strike one hoof or the shoe of one hoof against the opposite leg or fetlock.

Interference (in-ter-fêr'-ens) [inter, between; ferire, to strike]. Interposition. I. of Light, the mutual neutralization of waves of light, as shown in Newton's rings, when the crest of one wave falls upon the trough of another. I. of Sound, the neutralization of two sound-waves, one by the other.

Interfibrillar (in-ter-fí-bril-ar) [inter, between; fibra, a fiber]. In biology, situated between the fibrillæe of tissues.

Interfilar (in-ter-fi-lar) [inter, between; flum; a thread]. In biology, existing between the filaments of a reticulum. 
Interganglionic (in-ter-gang-gle-on'-ik) [inter, between;

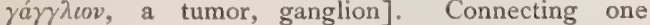
ganglion with another; lying between ganglia.

Interglandular (in-ter-gland'-u-lar) [inter, between ; glandula, a gland]. Situated between glands.

Interglobular (in-ter-glob'-u-lar) [inter, between; globulus, a ball]. Situated between globules. I. Spaces, irregular cavities seen in a section of dentine, after the earthy matter has been removed by putting a tooth in dilute acid. They are so called because surrounded by minute globules of dentine.

Intergyral (in-ter-ji'-ral) [inter, between; gyrus, a gyre]. Situated between two or more gyri.

Interhemicerebral (in-ter-hem-e-ser-e-bral) [inter, between; $\eta \mu$, , half; cerebrum, cerebrum]. Situated between the cerebral hemispheres.

Interhemispheric (in-ter-hem-is-fer'-ik) [inter, between; iju, half; $\sigma \phi a i \rho a$, sphere]. Situated between hemispheres.

Interinhibitive (in-ter-in-hib'-it-iv) [inter, between; inhibere, to inhibit]. Mutually inhibitory.

Interjectional (in-ter-jek'-shun-al) [inter, between; jicere, to throw]. Interjected; thrown between. I. Speech, the expression of emotions by inarticulate sounds.

Interlaminar (in-ter-lam'-in-ar) [inter, between; lamina, a leaf]. In biology, situated between laminx.

Interlobar (in-ter-lo'-bar) [inter, between; lobus, a lobe]. Situated between lobes.

Interlobular (in-ter-1ob'-u-lar) [mter, between; lobulus, a lobule]. Between lobules. See Emphysema.

Intermalar (in-ler-ma'-lar) [inter, between; mala, the cheek-bone]. Situated between the malar bones.

Intermarriage (in-ter-mar'-aj) [inter, between; maritus, a husband]. Marriage between persons related by consanguinity, or between persons of different races.

Intermastoid (in-ter-mas'-toid) [inter, between; $\mu a \sigma r o ́ s$, breast; $\varepsilon \delta \delta o \zeta$, likeness]. Situated between or con. necting the two mastoid processes.

Intermaxilla (in-ter-naks-il'-ah) [inter, between; maxilla, jaw]. The premaxilla; the intermaxillary bone.

Intermaxillary (in-ter-maks'-il-a-re) [inter, between; maxilla, jaw-bone]. Between the maxillary bones. I. Bone, the small bone that receives the incisors, situated between the superior maxillary bones of the fetus. It also occurs in most mammals.

Intermediate (in-ter-me'-de-at) [inter, between; medius, the middle]. Situated between. I. Dysmenorrhea. See Dysmenorrhea. I. Carbon-atoms, those connected with two other carbon-atoms, having two valence-units that may be saturated by two hydrogenatoms (or other elements).

Intermeningeal (in-ter-men-in'-je-al) [inter, between; $\mu \tilde{\eta} v \iota \gamma \xi$, membrane]. Between the dura and the arachnoid; or, between the latter and the pia. I. Hemorrhage, a hemorrhage between the meninges of the brain or spinal cord.

Intermenstrual (in-ter-men'-stru-al) [inter, between; menstruatis, menstrual]. Between the menstrual periods.

Interment (in-ter'-ment) [in, in ; terra, the earth]. The burial of the body.

Intermetacarpal (in-ter-met-ak-ar'-pal) [inter, between; $\mu \varepsilon \tau a ́$, beyond; $\kappa a \rho \pi \delta ́ \varsigma$, the wrist]. Between the metacarpal bones.

Intermetatarsal (in-ter-met-at-ar'sal) [inter, be-

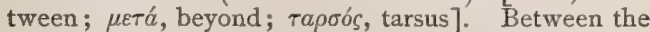
metatarsal bones.

Intermission (in-ter-mish'-un) [intermissio, a breaking off]. The interval between the paroxysms of a fever.
Also, an interval in which the pulse fails to beat in rhythunic time.

Intermittent (in-ter-mit'-ent) [inter, between; mittere, to send or occur]. Occurring at intervals. I. Fever. See Fever. I. Insanity. See Insanity, Cyclic. I. Ligature. See Ligature. I. Pulse, one the rhythm of which is interrupted by pauses at irregular intervals. I. Hemisystole, a very rare condition sometimes encountered in cases of mitral insufficiency, in which with every two beats of the heart only one beat of the pulse is felt.

Intermuscular (in-ter-mus'-ku-lar) [inter, between; musculus, a muscle]. Situated between muscles.

Intern (in-tern') [Fr., interne]. An in-door or resident physician in a hospital; a member of an in-door staff of physicians.

Internal (in-ter'-nal) [internus, inward]. Situated within or on the inside. I. Capsule, the band of white nerve-matter between the thalamus and the interventricular portion of the striatum. I. Capsule, Knee of, the angle formed by the junction of the two divisions of the internal capsule. 1. Cell-formation, free cell-formation; endogenous cell-formation. That mode of cell-division in which new cells are formed within the walls of an old cell, as distinguished from fission and gemmation.

Internarial (in-ter-na'-re-al) [inter, between; nares, nostrils]. Situated between the nostrils.

Interneural (in-ler-nu'-ral) [inter, between; vعṽoov, nerve]. Situated between neural spines.

Internode (in'-ter-nōd) [inter, between; nodus, a knot]. The space between adjacent joints or knots, as the phalanx of a finger or a toe. That part of a nerve-fibril between Ranvier's nodes is called the internodal segment.

Internodium (in-ter-no'-de-um). Same as Internode. Internuclear (in-ter-nu'-kle-ar) [inter, between; nu cleus, a kernel]. Situated between nuclei.

Internuncial (in-ter-nun'-shal) [inter, between; nuncius, a messenger]. Serving as a connecting or announcing medium, $e . g$., the nerves in their relation to the muscles and the will.

Internus (in-ter'-nus). See Internal.

Interoptic (in-ter-op $p^{\prime}$-tik) [inter, between; opticus, optic]. Between the optic lobes, tracts or nerves of the brain.

Interorbital (in-ter-or'-bit-al) [inter, between ; orbita, the orbit]. Situated between the orbits. I. Bone, the median bone of fishes. I. Plate and I. Septum, a structure of the fore-brain, with its extension, found in certain fishes and reptiles.

Interosseous (in-ter-os'-e-us) [inter, between; ossa, a bone]. Between two bones. I. Arteries, a name given to various branches of the dorsal, palmar, plantar, and metatarsal arteries of the hand, foot, and forearm. See Arteries, Table of. I. Muscles, a name given to certain muscles of the hand, foot, and forearm. See Muscles, Table of. I. Nerves, the nerves supplying the interosseous muscles. See Nerves, Table of. Interpalpebral (in-ter-pal'-pe-bral) [inter, between; palpebra, the eyelid]. Between the palpebræ. I. Spot. See Pinguecula. I. Zone, that part of the cornea and of the scleral conjunctiva that ordinarily is not covered by the lids.

Interpapillary (in-ter-pap'-il-a-re) [inter, between; papilla, a papilla]. Between papillæ.

Interparietal (in-ter-par-i'-et-al) [inter, between paries, walls]. Between walls. I. Bone, a term sometimes applied to the upper, squamous, and noncarti'aginous part of the occipital bone. I. Fissure. See Fissure. I. Suture, the sagittal suture, or that formed by the approximation of the parietal bones. 
Interpeduncular (in-ter-pe-dung-ku-lar) [inter, between; pedunculus, a little foot]. Situated between the cerebral or cerebellar peduncles. I. Space, the pons Tarini, or posterior perforated space that forms the posterior portion of the floor of the third ventricle.

Interphalangeal (in-ter-fa-lan'-je-al) [inter, between ; $\phi a ́ \lambda a \gamma \xi$, a finger]. Between the fingers or the toes. 1. Articulations, the ginglymoid articulations of the fingers and of the toes,

Interplacental (in-ter-plas-en'-tal) [inter, between; placenta, a cake]. Between the placental lacunæ.

Interpolation (in-ter-po-la'-shun) [interpolare, to furbish up]. The surgical transfer of tissue to a new part, or from one subject to another.

Interpubic (in-ter-pu'-bik) [inter, between; pubis, pubis]. Situated between the pubic bones. I. Disc, the fibro-cartilaginous mass forming the symphysis of the pubis.

Interradial (in-ter-r $a^{\prime}$-de-al) [inter, between; radius, a ray]. Situated between two rays.

Interramicorn (in-ter-ram'-ik-orn) [inter, between; ramus, a branch; cornu, a horn]. In biology, a portion of the horny sheath of the bill in certain birds.

Interrenal (in-ter-re'-nal) [inter, between; ren, the kidney]. Situated between the kidneys.

Interrupted (in-ter-up'-ted) [intermumpere, to break apart]. Broken; irregular. I. Breathing. See Breath-sounds.

Interrupter (in-ter-up'-ter) [interrumpere, to break apart]. One who, or that which, interrupts; specifically, a device for breaking an electric current.

Interscapular (in-ter-skap'-u-lar) [inter, between; scapula, the shoulder-blade]. Between the shoulderblades. I. Region, the part of the chest between the two shoulder-blades. I. Reflex. See Reflexes, Table of.

Interscapulum (in-ter-skap'-u-lum) [inter, between; scapula, shoulder-blades: pl., Interscapula]. In biology, the region of the back between the shoulderblades.

Interspace (in'-ter-spass) [inter, between; spatium, a space]. An interval between the ribs, or between the fibers or lobules of a tissue or organ.

Interspinal (in-ter-spi'-nal) [inter, between; spina, a spine]. Between spines; specifically, between the spines of the vertebræ. I. Muscles. See Muscles, Table of.

Interspinous (in-ter-spi'-nus) [inter, between; spina, a spine]. Situated between spinous processes, as of the vertebræ.

Interstice (in-ter'-stis) [interstitium, a space between]. A space or interval. Also, a pore.

Interstitial (in-ter-stish'-al) [interstitium, space between: pl., Interstitia $]$. Pertaining to any space or interval between parts or organs, and especially applied to that which is placed between parenchymatous structures. 1. Absorption, the absorption of the partitions of a multiloculated cyst or abscess. Also, any similar absorption. I. Atrophy, a condition observed in certain diseases of the bones (arthritis deformans), in which the mineral matter has been absorbed to such an extent that only reticulated laminx remain. I. Hypertrophy, a condition in certain diseases of the bones in which there is an excessive deposit of mineral matter in the Haversian canals and lacunæ. It is often accompanied by diminution in the size of the bone. I. Keratitis. See Keratitis. I. Pregnancy. See Pregnancy.

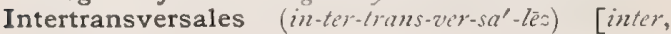
between; transversus, turned across]. A name given to the short bundles of muscular fibers extending between the transverse processes of contiguous vertebra. See Muscles Table of.

Intertriginous (in-ter-trij'-in-us) [inter, between ; terere, to rub]. Of the nature of or affected with intertrigo.

Intertrigo (in-ter-tri'-go) [inter, between; terere, to rub]. An erythematous eruption or lesion of the skin produced by friction of adjacent parts. See Erythema.

Intertrochanteric (in-ter-tro-kan-ter'-ik) [inter, be-

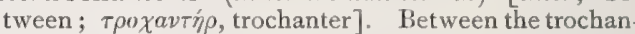
ters. I. Line. See Lines, Table of.

Intertubular (in-ter-tu'-bu-lar) [inter, between tubulus, a tube]. Between tubes. I. Substance, the translucent, granular substance of the dentine of the tooth, containing most of its earthy elements.

Interureteric (in-ter-u-ret-er'-ik) [inter, between;

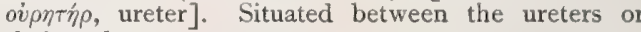
their outlets.

Intervaginal (in-ter-vaj'-in-al) [inter, between; vagina, sheath]. Between sheaths. I. Space, that found within the sheaths of the optic nerve.

Interval (in'-ter-val) [inter, between; vallum, a rampart]. A space or lapse either of time or distance, as the interval between the paroxysms of a fever, or between two organs or parts of the body. I., Focal, the distance between the anterior and posterior focal points. I., Sacro-cotyloid, a space existing between the promontory of the sacrum and the posterior part of the cotyloid cavity or acetabulum.

Intervenium (in-ter-ve' -ne-um) [inter, between; vena, vein: pl., Intervenia $]$. In biology, the space between the veins of leaves.

Interventricular (in-ter-zen-trik'-u-lar) [inter, between; ventriculum, a ventricle]. Between ventricles, e. g., of the heart. I. Septum, the fibrous septum or partition between the ventricles of the heart.

Intervenular (in-ter-ven'-u-lar) [inter, between; venula, a little vein]. In biology, situated between the veins of an insect's wing.

Intervertebral (in-ter-ver'-te-bral) [inter, between; vertebra, a bone of the spine]. Between the vertebræ. I. Discs, the lenticular discs of fibro-cartilage between the adjacent surfaces of the bodies of the vertebræ. I. Foramen. See Foramen. I. Notch, the notch at the base of the pedicle of the laminæe on the sides of the body of each vertebra. I. Substance. Same as $I$. Discs.

Intervillous (in-ter-vil'-us) [inter, between; villus, a tuft of hair]. Situated between villi.

Intestinal (in-tes'-tin-al) [intestinum, the intestine] Pertaining to the intestine. I. Absorption, the absorption of the peptonized products of digestion by the capillaries, veins, and lacteals of the mucous membrane of the intestines. I. Anastomosis. See Anastomosis. I. Arteries, the arteries of the intestines, of which the principal trunks are the celiac axis and the mesenteric branches. The lower part of the rectum is supplied by the hemorrhoidal branches of the iliac and pudic arteries. See Arteries. Table of. I. Canal, the entire intestinal passage from the begining of the duodenum to the anus. I. Cast. Same as I. Mole. I. Concretion. See Enterolith. 1. Fever. Synonym of Tiphoid Fever. I. Fistula, a fistula or unnatural aperture in any part of an intestine. I. Glands, the glands found in the I. Canal. See Gland. I. Juice, the liquid secretion of the intestinal glands. I. Mole, the membranous discharge from the bowel in Pseudomembranous Enteritis. I. Obstruction, arrest of or interference with the progress of the feces. I. Tract, or Tube. Same as I. Canal. 
Intestine (in-tes'-tin) [intestinus, intestine]. The part of the digestive tube extending from the beginning of the duodenum to the anus. I., Large, comprises

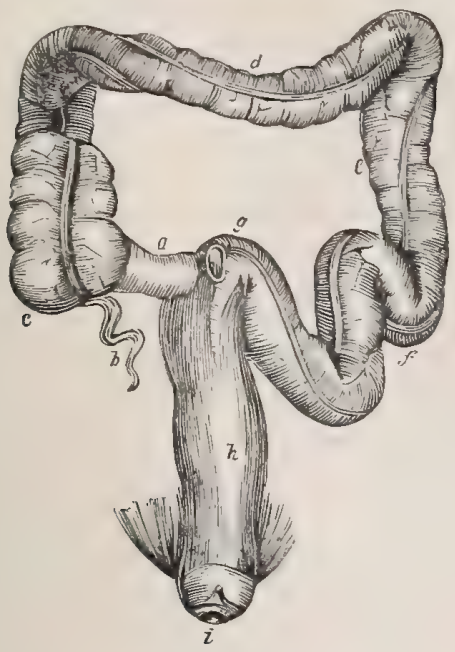

THE LARGE INTESTINE.

a. Entrance of the small intestine. b. Appendix vermiformis. $c$. Caput cæcum coli. d. Transverse colon. e. Descending colon. $f$. Sigmoid flexure. $h$. Rectum. $i$. Anus.

the cecum, colon, and rectum. I., Small, consists of the duodenum, jejunum, and ileum.

Intestinorum inflammatio (in-tes-tin-o'-mu inflam-a'-she-o) [L., "Inflammation of the intestines" ]. See Enteritis.

Intestinulum (in-tes-tin'-u-lum) [L., a small intestine: pl., Intestinula]. I. The small intestine. 2. A cerebral convolution or gyrus. 3. The umbilical cord or navel-string.

Intextine (in-teks'-tin) [intus, within; externus, without]. In biology, a supplementary inner layer of the extine of the pollen-grains of certain plants.

Intima (in'-tim-ah) [intimus, inmost]. A term used instead of tunica intima; the innermost coat, or thin, transparent endothelial lining of the heart and bloodvessels, consisting of a layer of irregular, long, fusiform, nucleated, squamous cells.

Intine (in'-tin) [intus, within]. In biology, the inner coat of the pollen-grain.

Intolerance (in-tol'-er-ans) [intolerans; in, not; tolerere, to bear]. Want of endurance or ability to stand pain. Impatience. Also, the inability to endure the action of a medicine.

Intonation (in-to-na'-shun) [intonere, to thunder]. I. The rumbling or gurgling sound produced by the movement of flatus in the bowels. 2. The tone of the voice.

Intortion (in-tor'-shun) [intortus, p. p. of intorquere, to curl, to twist]. In biology, the winding, bending, or twisting of a part or organ.

Intoxicant (in-toks'-ik-ant) [intoxicare, to intoxicate]. I. Intoxicating; capable of producing intoxication or poisoning. 2. A drug or agent capable of producing intoxication.

Intoxication (in-toks-ik-a $-s h u n$ ) [intoxicare, to poison]. A word popularly used to denote the effect of the excessive use or of an overdose of an alcoholic liquor; in a wider sense, any poisoning; the state resulting from an overpowering dose of any poison. I., Septic. See Septicemia. I., Uremic. See Uremia. Intra- (in'-trah-) [intra, within]. A Latin prefix sig. nifying within. I.-abdominal, within the cavity of the abdomen. I.-arachnoid, within the arachnoid space. I.-articular, within a joint. I.-capsular, within the capsular ligament of a joint.

Intrabiontic (in-trah-bi-on'-tik) [intra, within; $\beta$ ios, life; $\omega \nu$ (ovv), being]. In biology, applied to phenomena occurring within, and determined by, an individual organism. I. Selection, Weismann's term for the principle formulated by Roux, of the struggle of the parts concerned in ontogeny.

Intracardiac (in-trah-kar'-de-ak) [intra, within; $\kappa a \rho-$ dia, heart]. Situated or produced within the heartcavity.

Intracartilaginous (in-trah-kar-til-aj'-in-us) [intra, within; cartilago, cartilage]. Within a cartilage. I. Ossification. See Ossification

Intracellular (in-tra-sel'-u-lar) [intra, within; cellula, a little cell]. In biology, existing or happening within the cell. I. Digestion, also called parenchymatous digestion; digestion as exhibited by unicellular organisms. I. Pangenesis. See Heredity and Pangenesis.

Intracerebral (in-trah-ser'-e-bral) [intra, within ; cerebrum, cerebrum]. Within the cerebrum.

Intracervical (in-trah-ser'-vik-al) [intra, within; cervix, cervix]. Within the cervical canal of the uterus.

Intraciliary (in-trah-sil"-e-a-re) [intra, within; cilium, an eye-lash ]. Situated within the ciliary region.

Intracranial (in-trah-kra'-ne-al) [intra, within; кaaviov, the skull]. Within the skull. I. Hemorrhage, an escape of blood within the cranial cavity; cerebral hemorrhage.

Intracutaneous (in-trah-ku-ta'-ne-us) [intra, within ; cutis, the skin]. Within the skin-substance.

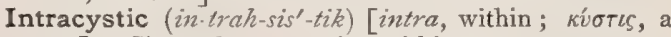
cyst]. Situated or occurring within a cyst.

Intradermic (in-trah-der'-mik) [intra, within; dép $\mu a$, skin]. Same as Intracutaneous.

Intradural (in-trah-du'-ral) [intra, within; durus, hard]. Situated or occurring within the dura.

Intrafetation (in-trah-fe-ta'-shun) [intra, within; fetus, a fetus]. The formation of a fetus within another fetus.

Intragyral (in-trah-ji'-ral) [intra, within; gyrus, a gyre]. Within a gyre of the brain.

Intrahepatic (in-trah-he-pat'-ik) [intra, within; $\eta \pi \pi \rho$, liver]. Within the liver-substance.

Intralamellar (in-trah-lam-el'-ar) [intra, within; lamella, a thin plate]. In biology, within the lamellæ.

Intraligamentous (in-trah-lig-am-en'-tus) [intra, within; ligamentum, a ligament]. Within or between the folds of a ligament, as a cyst.

Intralingual (in-trah-ling'-g7val) [intra, within; lingua, tongue]. Within the substance of the tongue.

Intralobular (in-trah-lob'-u-lar) [intra, within; lobulus, a little lobe]. Within a lobe or lobule. I. Vein, a vein traversing a liver-lobule. I. Plexus, a network of vessels in a liver-lobule.

Intramembranous (in-trah-mem'-bran-us) [intra, within; membrana, a membrane]. Within a membrane.

Intrameningeal (in-trah-men-in'-je-al) [intra, within; $\mu \tilde{\eta} \nu \iota \gamma \xi$, membrane]. Situated within the substance of the membranes of the brain or spinal cord. I. Hemorrhage, an effusion of blood into the sac of the dura mater.

Intramolecular (in-trah-mo-lek'-u-lar) [intra, within; molecula, a molecule]. Within the molecules of a substance.

Intramural (in-trah-nu'-ral) [intra, within; mura, a wall]. Intraparietal. Within the substance of the walls of an organ. 
Intramuscular (in-trah-mus'-ku-lar) [intra, within ; musculus, a muscle]. Within the substance of a muscle.

Intranasal (in-trah-na'-sal) [intra, within; nasus, nose]. Within the cavity of the nose.

Intranuclear (in-trah-mu'kle-ar) [intra, within; nucleus, a kernel]. Within a nucleus.

Intra-ocular (in-trah-ok'-u-lar) [intra, within; oculus, eye]. Within the globe of the eye. I. Hemorrhage, an effusion of blood into the globe of the eye. I. Pressure, or Tension. See Tension.

Intra-orbital (in-trah-or'-bit-al) [intra, within; orbita, orbit]. Within the orbit. I. Aneurysm, an aneurysm within the orbit of the eye, and usually involving a branch of the ophthalmic artery. I. Hemorrhage, a hemorrhage taking place within the orbit, but behind the capsule of Tenon

Intraosseous (in-trah-os'-e-us) [intra, within; os, a bone]. Within the substance of a bone.

Intraovarian (in-trah-o-val-re-an) [intra, within ; ovarium, ovary]. Within the ovarian stroma.

Intraparietal (in-trah-par-i'-et-al) [intra, within; paries, a wall]. I. Within the wall or the substance of the wall of an organ. 2. Within the parietal region of the cerebrum, e.g., the $I$. Fissure.

Intrapelvic (in-trah-pel'-vik) [intra, within; pelvis, basin]. Within the pelvic cavity.

Intraperitoneal (in-tra-per-it-on-e'-al) [intra, within ; $\pi \varepsilon \rho \iota \tau 6 v a \iota 0 v$, the peritoneum]. Within the peritoneum or membranous sac that covers the abdominal viscera.

Intraplacental (in-trah-plas-en'-tal) [intra, within; placenta, cake]. Within the placental tissue.

Intrapleural (in-trah-plu'-ral) [intra, within; $\pi \lambda \varepsilon v \rho a ́$, a rib]. Within the pleural cavity.

Intrapolar (in-trah-po'-lar) [intra, within; polus, pole]. Between the poles or ends of an axis. See, also, Extrapolar.

Intrapulmonary (in-trah-pul'-mo-na-re) [intra, within; pulmo, the lung]. Within the substance of the lung.

Intraretinal (in-trah-ret'-in-al) [intra, within, retina, retina]. Within the substance of the retina.

Intrascleral (in-trah-skle' ral) [intra, within; $\sigma \kappa \lambda \eta \rho \sigma s$, hard]. Situated, occurring, or performed within the sclera.

Intrascrotal (in-trah-skro'tal) [intra, within; scrotum, scrotum]. Within the scrotal sac.

Intraspinal (in-trah-spi'-nal) [intra, within; spina, spine]. Within the spinal canal.

Intratesticular (in-trah-tes-tik'-u-lar) [intra, within ; testiculus, a testicle]. Within the testicle.

Intratubal (in-trah-iu'-bal) [intra, within; tuba, a trumpet]. Within a Fallopian tube.

Intratympanic (in-trall-tim-pan'-ik) [intra, within; tympanum, the ear-drum]. Within the tympanic cavity.

Intraurethral (in-trah-u-rêth'-ral) [intra, within; ov́pí $\theta \rho \alpha$, urethra]. Within the urethra.

Intra-uterine (in-trah-u'-ter-in) [intra, within; uterus, womb]. Within the womb. I. Amputation, a spon. taneous amputation occurring occasionally to some part of the fatus in utero that becomes constricted by the umbilical cord or from other causes. I. Drowning, death of the fatus in utero from efforts at respiration, liquor amnii instead of air being drawn into the air-tubes. The cause of the respiratory efforts is an arrest of fetal circulation in the cord or placenta. I. Fracture, that which occurs to a fotus in utero. 1 . Life, that period of the existence of an animal between conception and birth.

Intravasation (in-trav-as-a'-shun) [intra, within; vas, vessel]. The entrance of extraneous matter, as pus, into a blood-vessel. Cf. Extravasation.
Intravascular (in-trah-vas'-ku-lar) [intra, within ; vasculum, a small vessel]. Within the blood-vessel system.

Intravenous (in-trah-ve'-nus) [intra, within; vena, a vein]. Within, or into the veins. I. Infusion, or Injection, the introduction of a saline solution or other liquid into the veins.

Intravertebral (in-trali-ver'-te-bral) [intra, within; vertebra, a vertebra]. Same as Intraspinal.

Intravesical (in-tra-ves'-ik-al) [intra, within; vesica, bladder]. Occurring or situated within the bladder.

Intrinsic (in-trin'-sik) [intrinsecus, on the inside]. I. inherent, inward. Peculiar to a part-e.g., certain muscles, 2. Relating to the body (or organism) independent of the environment-e.g., Toponymy.

Introcession (in-tro-ses'-shun) [introcedere, to go into]. A depression or sinking in, as of a surface.

Introflexion (in-tro-flek'shun) [intro, within; fexio, a bending]. A bending in; inward flexion.

Introitus (in-tro'-it-us) [intro, within; ire, to go]. Any aperture or opening in the body. I. pelvis, the inlet of the pelvis. I. vaginæ, the external aperture of the vagina.

Intromission (in-tro-mish'-un) [intro, within; mittere, to send]. The introduction of one body within the walls of another, as of the penis into the vagina.

Introrse (in-trors') [intro, within; versus, p. p. of vertere, to turn]. In biology, applied to stamens that turn toward the axis of the flower.

Introspection (in-tro-spek'-shun) [intro, within ; spicere, to look]. The act of looking inward. I., Morbid, the morbid habit of self-examination; insane, or quasi-insane, dwelling upon one's own thoughts, feelings, impulses, fears, or conduct.

Introsusception (in-tro-sus-sep'-shun) [intro, within; suscipere, to receive]. The slipping or telescoping of one part of the intestine upon another part ; intussusception.

Introvenium (in-tro-ve'-ne-um) [intro, within; vena, vein]. In biology, a condition of leaves in which the veins are infossous, or sunk and embedded in the parenchyma.

Introversion (in-tro-ver'-shun) [intro, within ; vertere, to turn]. A turning within, as, introversion of the uterus. I. of the Iris, a bending backward of the iris in such a way that it lies upon the ciliary body.

Introvert (in-tro-vert') [intro, within; vertere, to turn]. In biology, turned in.

Intruse (in-trūs') [intrusus, p.p. of intrudere, to thrust in]. In biology, projecting inward.

Intubation (in-tu-ba'-shun) [in, in ; tubus, a pipe]. The passage of a tube into or past the larynx, to allow the entrance of air into the lungs in croup, diphtheria, etc., or to dilate a stricture, etc.

Intumescence (in-tu-mes'-ens) [intumescentia; intumescere, to swell]. A swelling, of any character whatever. Also, an increase of the volume of any organ or part of the body.

Intumescentia (in-tu-mes-en'-she-ah) [L.]. A swelling. I. gangliformis, the reddish gangliform swelling of the seventh nerve in the aqueductus Fallopii in the petrous portion of the temporal bone.

Intussusception (in-tus-sus-ep'-shun) [intus, within ; suscipiere, to receive]. Invagination or involution of one part of the intestine within another part. It is of frequent occurrence in the young. It is caused by undue peristalsis. The site of the intussusception varies; thus, it may be-I. Ileo-cecal, the ileum with the ileo-cecal valve descending into the cecum and colon; this is the most common variety; 2. Colic, the invagination being limited to the large intestine; 3. Ileal, when the ileum alone is involved; 4. Ileo. 
colic, when the ileum prolapses through the lips of the ileo-cecal valve.

Inula $\left(i n^{\prime}-u-l a h\right)$ [L.]. Elecampane. The root of $I$. helenium. It contains a crystalline substance, helenin, $\mathrm{C}_{6} \mathrm{H}_{8} \mathrm{O}$, the dose of which is gr. $\frac{1}{6}-\frac{1}{3}$, and from 20 to 40 per cent. of a starch, known as inulin. It is a gentle stimulant, and is employed in bronchitis and to hasten the appearance of the skin-symptoms in exanthematous fevers. Dose gr, $\mathrm{xx}-3 \mathrm{j}$ of the root, or $\overline{\mathrm{j}} \mathrm{j}-\mathrm{ij}$ of a decoction, $\xi$ ss to the $\mathrm{Oj}$. The genus Inula contains various coarse composite-flowered herbs of the old world, several of which have properties similar to those of the official species.

Inulin (in'-u-lin) [imula, elecampane], $\mathrm{C}_{6} \mathrm{H}_{10} \mathrm{O}_{5}$. I. A vegetable principle found in the roots of dahlia, in chicory, and other plants. It is a white powder, with which iodin gives a yellow color, and is soluble in hot water. See Carbohydrates, Table of. 2. The precipitate from a tincture of the root of Inula helenium; an aromatic stimulant, tonic, and expectorant. Dose I to 3 grains. Unof.

Inulol (in'-u-lol). See Alantol.

Inunction (in-unk'-shun) [inunctio: inunguere, to anoint]. The act of rubbing an oily or fatty substance into the skin. Also, the substance used for anointment. I. Treatment, a form of treatment of syphilis. It consists in rubbing into the skin metallic mercury or some mercurial preparation, mixed or suspended in a fatty vehicle. It is active, sure, and rapid, but dirty and unpleasant. It is best used in the form of the blue ointment of a strength of fifty per cent. The application should be made upon different portions of the body in successive treatments.

Inustion (in-us'-chun) [inustio, a burning in]. A burning in ; deep or thorough cauterization.

Invagination (in-vaj-in-a'-shun) [invaginatio; invaginare, to ensheathe]. The sheathing or telescoping of a part or organ by a canal-like structure, as the intestine. An operation for obliterating a hernial canal by the inflammation resulting from pushing the skin inward and suturing the parts together.

Invalid (in'-val-id) [invalidus; in, not; valere, to be well]. One who is not well, especially one who is chronically ill or whose convalescence is slow.

Invaliding (in'-val-id-ing) [in, not; valere, to be well]. The placing of a soldier or officer on the list of invalids, and thus excusing him from active duty.

Invalidism $\left(i n^{\prime} \cdot v a l-i d-i z m\right)$ [in, not; valere, to be well]. Chronic ill-health; the state or condition of being an invalid.

Invenose (in-z'e'-nōs) [in, not; vena, a vein]. In biology, destitute of veins.

Invasion (in-va'-zhun) [invasio; in, upon; vadere, to go]. The beginning or attack of a disease. Also, the manner in which the disease begins its attack. I.disease, one due to the presence in the body of some animal parasite, as the tapeworm or the protozoan of malaria.

Invermination (in-ver-min-a $a^{\prime}-\operatorname{sh} u n$ ) [in, in ; vermis, worm ]. A condition of having intestinal worms; illhealth due to parasitic worms; helminthiasis.

Inverse Temperature. A complete reversal of the usual course of the temperature, so that the morning temperature exhibits the maximum, and the evening temperature the minimum. It is not infrequently seen in acute tuberculous affections, and rarely in typhoid fever.

Inversio palpebrarum (in-ver'-she-o pal-pe-bra'-rum). Synonym of Entropion.

Inversion (in-ver'-shun) [inversio; in, not; vertere, to turn ]. A turning or placing in a position the opposite of the normal position. In chemistry, a decomposition of certain sugars and other carbohydrates, induced by the action of a ferment or dilute acid, by which the elements of water are added to a carbohydrate, each molecule of which breaks up into two molecules of a different carbohydrate. I. of Bladder, a condition in which the bladder is in part or completely pushed into the dilated urethra. It occurs in females only. I. of Eyelashes. See Entropion. I. of Uterus, a condition in which the uterus is partially or completely turned inside out

Invert (in-vert') [in, in; vertere, to turn]. To turn in an opposite direction. I.-sugar, an amorphous saccharine substance, the chief constituent of honey, and produced by the action of ferments or dilute acids on cane-sugar. It is regarded as a mixture of equal parts of dextrose and levulose. A solution of canesugar turns the polarized ray of light to the right, while invert-sugar turns it to the left. From this inversion of the action on polarized light the process is called inversion, and the product invert-sugar.

Invertase (in-ver'-tass). Same as Invertin, q. $v$

Invertebrata (in-ver-te-bra'-tah) [in, not; vertebra, backbone]. Animals that have no spinal column.

Invertin (in-ver'-tin) [in, not; vertere, to turn]. A ferment found in the intestinal juice, and produced by several species of yeast-plant; it converts canesugar in solution into invert-sugar. See Ferments.

Investing (in-ves'-ting) [investire, to invest]. Ensheathing. surrounding. In dentistry, embedding a denture in what is known as investing-material, for the purpose of soldering the linings or backings of the teeth to the plate.

Inveterate (in-vet'-er-ât) [inveteratus; vetus, old]. Long established, and obstinately resisting treatment, as an inveterate skin-disease.

Invirility (in-vir-il'-it-e) [in, not; virilis, of a man]. Lack of manly qualities, especially lack of virile power; male impotency.

Inviscation (in ris-ka'-shun) [in, in ; viscum, birdlime]. The mixing of food with the saliva during mastication.

Invital (in-vi'-tal) [in, not; vita, life]. In biology, non-living or dead matter.

In vitro (in vit'-ro) [L.]. In the glass; applied to phenomena that are observed in experiments carried out in the laboratory with microörganisms, digestive ferments, and other agents, but that may not necessarily occur within the living body.

Involucel (in-vol'-u-sel) [dim. of involucrum, involucre]. In biology, a secondary involucre.

Involucre (in'-vo-lu-ker) [involvere, to roll up, to wrapup] In biology, the bracts at the base of a flower-cluster.

Involucrum (in-vo-lu'-kxum) [involvere, to enwrap: pl., Involucra]. The covering of a part. The sheath of bone enveloping a sequestrum in dry necrosis.

Involuntary (in-vol'-un-ta-re) [involuntarius: in, not; volo, velle, to will]. Performed independently of the will; not by an act of the will. A term applied to certain motions and functions of the various organs of the body that are not controlled by, or are not depend. ent on, the will. I. Contraction, muscular contractions not resulting from an act of the will. I. Muscles, those that are not governed by the will.

Involute $\left(i^{\prime}-v o-l \bar{u} t\right)$ [involvere, to roll up, to wrap up] In biology, rolled up, as the edges of certain leaves in the bud.

Involution (in-vo-lu'-shun) [involutio; involvere, to roll upon ]. The retrogressive change to their normal condition that certain organs undergo after fulfilling their functional purposes. I. of the Uterus, the return of the uterus, which after gestation weighs about two pounds, to its normal weight and condition. I.forms, a term applied to microörganisms that deviate 
from a type, or undergo degenerative changes, probably as a result of nutritive variation. They are free in filaments, flat layers, or cube-like packets.

Inward (in'-ward) [ME., inward, inward]. Toward the center. I. Convulsions. Synonym of Laryngismus stridulus.

Iodal $\left(i^{\prime}-0-d a l\right)[i \omega \delta / \zeta$, like a violet $], \mathrm{C}_{2} \mathrm{I}_{3} \mathrm{HO}$. A compound formed on the type of chloral, but containing iodin instead of chlorin. It is reported to resemble chloral in its sedative qualities, but is seldom used as a remedy. Unof.

Iodantipyrin (i-o-dan-tip-i'-rin). See Iodopyrin.

Iodate $\left(i^{\prime}-o-d \bar{a} t\right) \quad[i \omega \hat{\delta} \eta \zeta$, like a violet]. Any salt of iodic acid.

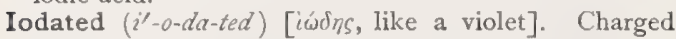
with iodin.

Iodatum $\left(i-0-d \alpha^{\prime}-t u m\right)$ [i $\omega \delta n s$, like a violet]. Charged with iodin. Amylum iodatum, iodized starch.

Iodia $\left(i-o^{\prime}-d e-a h\right)$ [iwdns, like a violet]. A proprietary remedy said to contain stillingia, menispermum, etc., with five grains of potassium iodid and two grains of iron phosphate in each fluidram. Dose as an alterative, $3 \mathrm{j}-\mathrm{ij}$.

Iodic Acid $\left(i-o d^{\prime}-i k\right)$. See Acid.

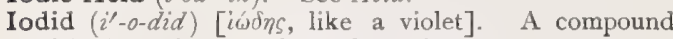
of iodin with a metal or other substance.

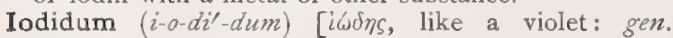
Todidi]. An iodid.

Iodin, or Iodum $\left(i^{\prime}-o-d i n\right.$, or $\left.i-o^{\prime}-d u m\right)[i \omega \delta \eta \eta$, like a violet]. $I=\mathbf{I} 26.53$; quantivalence $\mathbf{I}$; specific gravity $4.948^{\circ}$ at $17^{\circ} \mathrm{C}$. $\left(62.6^{\circ} \mathrm{F}\right.$.) A non-metallic element with metallic luster, volatilizing at a low temperature, and giving off a crimson-purple vapor. It occurs in codliver oil, in most marine plants, and in shell-fish. It is soluble in alcohol, in solution of potassium iodid, and in solution of sodium chlorid. In its elementary state it is an irritant to the skin, and is much used as a tincture to produce counter-irritation. See Elements, Tuble of. Potassium iodid, the principal form for internal use, is an alterative, ranking as a specific in tertiary syphilis, and with mercury, available in all forms of that disease. It is also an excellent remedy in hepatic cirrhosis and chronic bronchitis. Combined with ammonium it is valuable in catarrhal affections. Acidi hydriodici, Syr., contains one per cent. of the absolute acid. Dose 3 j-iv. Ammonii iodidum. See Ammonium. Iodized Phenol, unof, a mixture of iodin and carbolic acid, usually I to 4 . For local use. I., Liniment (B. P.), one part of iodin in nine. I., Liquor (B. P.), one of iodin in 20. Iodi, Liq., Comp., Lugol's solution-iodin 5 , potassium iodid Io, water 85 parts. Dose $m j-x$, diluted. I., Tinct., 8 per cent. in alcohol. Dose $m$ j-v. For local use. I., Trichlorid, unof., recommended by Langenbach as an antiseptic in surgery. I., Ung., iodin 4, potassium iodid $\mathrm{I}$, water 2, benzoated lard 93 parts. I., Vapor (B. P.), for inhalation, $3 \mathrm{j}$ of iodin to $\xi_{\mathrm{j}}$ of water. Amylum iodatum, iodized starch, iodin 5, starch 95 parts, distilled water Ioo parts, triturated and dried. Dose $3 \mathrm{j}$ ろj. Potassii iodidum, KI. Dose gr. $\mathbf{z}-3 \mathrm{j}$. Potass. iodid., Ung., contains potass. iodid. 12, sod. hyposulph. I, boiling water 6 , benzoated lard $8 \mathrm{I}$ parts. Sodii iodidum, NaI, deliquescent. Dose gr. v- 3 ij. I.-green. See Pigments, Conspectus of. I.-scarlet. See Pirments, Conspectus of. I.-violet. See Pigments, Conspectus of.

Iodism $\left(i^{\prime}-0-d i z m\right)$ [i $i \omega \delta \eta s$, like a violet]. A condition arising from the prolonged use of iodin or iodincompounds, marked by redness of the conjunctiva and of the mucous membrane of the respiratory passages, furry throat, and lacrymation, with symptoms resembling those of acute coryza.
Iodized $\left(i^{\prime}-o\right.$-dizd $)$ [i $\omega \delta \eta \zeta$, like a violet]. Impregnatec with iodin, as cotton, glycerin, etc.

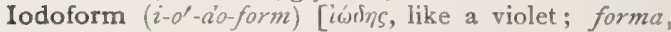
form]. Tri-iodo-methane, $\mathrm{CHI}_{3}$. Iodid of Formyl. A compound containing about $9 \mathbf{I}$ per cent. of iodin. It is an antiseptic and feeble anesthetic, and is highly useful for local application to wounds, abrasions, and indolent sores. Internally it is a tonic. It seems to exerta special influence upon tuberculous processes. Its odor may be disguised by means of thymol or oil of rose. Dose, internally, gr. j-v. I., Suppos. (B.P.), each containing gr. iij of iodoform. I., Unguent., for fetid sores.

Iodoformism $\left(i-o^{\prime}-d o-f o r m-i z m\right)[i \omega \delta \eta \zeta$, like a violet; forma, form]. Poisoning with iodoform.

Iodoformize $\left(i-o^{\prime}-d o-f o r m-\bar{z} z\right)$ [i $\omega \delta \eta \eta$, , like a violet; forma, form]. To impregnate with iodoform.

Iodol $\left(i^{\prime}-0-d o l\right)\left[i \omega \delta \eta s\right.$, like a violet], $\mathrm{C}_{4} \mathrm{I}_{4} \mathrm{NH}$. An iodo-carbamid existing in the form of an amorphous brown powder, soluble in ether and oil. It is more actively antiseptic than iodoform and is free from odor. Locally it is an anesthetic, and favors granulation. It is of reputed service as an application to syphilitic sores, etc. Dose gr. ss-v. Unof.

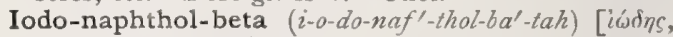
like a violet; vá $\phi \theta a$, naphtha; $\beta \varepsilon r a$, the second Greek letter]. The diiodid of naphthol-beta, sug gested as a substitute for iodoform as an antiseptic dressing. Unof.

Iodophenin (i-o-do-fe'-nin) [i $\omega \delta \eta n s$, like a violet; phenyl]. A compound allied to phenacetin. It is an efficient bactericide, but is objectionable because of its strong evolution of iodin, of which it contains about 50 per cent. It is a crystalline powder, of an iodin-odor and a burning taste, and colors the skin yellow. It melts at $266^{\circ} \mathrm{F}$. $\left(130^{\circ} \mathrm{C}\right.$.) Unof.

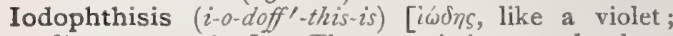
pfiols, a wasting]. The emaciation, or local or general wasting that may result from free use of iodin as a remedy.

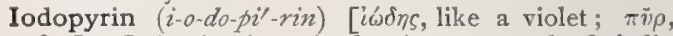
fire]. Iodantipyrin. A chemic compound of iodin and antipyrin, with the composition, $\mathrm{C}_{11} \mathrm{H}_{11} \mathrm{IN}_{2} \mathrm{O}$. It is an antipyretic in doses of from one to five grains. Unof.

Iodo-quinin Sulphate. Same as Herapathite.

Iodosis $\left(i-0 \cdot d o^{\prime}-s i s\right)$. Same as Iodism.

Iodotannin $\left(i-o-d o-\tan ^{\prime}-i n\right)[i \omega \delta \eta$, like a violet; ME. tannen, to $\tan ]$. An aqueous mixture of iodin and tannin.

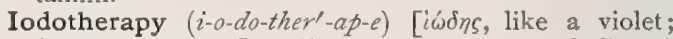
Oe $\rho a \pi \varepsilon i \alpha$, therapy]. The treatment or cure of disease by the use of iodin or its compounds.

Iodum $\left(i-o^{\prime}-d u m\right)$. See Iodin.

Iodure $\left(i^{\prime}-0-d \bar{u} r\right)$ [Fr.]. An iodid.

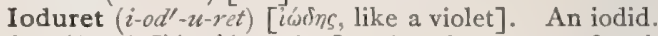

Ion $\left(i^{\prime}-o n\right)[i \omega \nu, i o v$, going]. An element set free by electrolysis, and classified as an anion or kation, according as it is set free at the positive or negative pole. I., Migration of, the transference of an ion from one pole to another.

Ionidium (i-o-nid'-e-um) [iov, a violet]. A genus of violaceous herbs and shrubs. I. ipecacuanha, produces what is called white ipecac; this and several other species are emetic and cathartic. See also Cuichunchulli. None is officinal; but the roots of several species are said to be mixed with commercial ipecac.

Ionthus $\left(i-o n^{\prime}-t / h u s\right)$ [iovtos, acne ]. That form of acne that often accompanies the first appearance of the beard. A general name for acne and the diseases that resemble it. 
Iopterous $\left(i-o p^{\prime}-t e r-u s\right)$ [iov, a violet ; $\pi \tau \varepsilon \rho \sigma \nu$, a feather] In biology, having violet-colored wings.

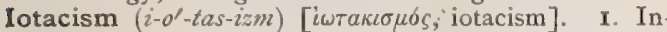
ability to pronounce distinctly the proper sound of the letter $i$. 2. Substitution of the long $e$ sound for the $e$ sounds of other yowels.

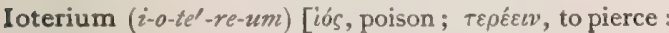
pl., Toteria ]. In biology, a poison-gland.

Ipecac (ip'-e-kak). See Ipecacuanha. I., American. See Gillenia. I., White. See Ionidium.

Ipecacuan (ip-e-kak'-u-an). See Ipecacuanha.

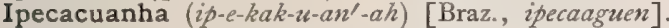
Ipecac. The root of Cephaellis ipecacuanha, found in Brazil. It contains an alkaloid, emetin, $\mathrm{C}_{20} \mathrm{H}_{30} \mathrm{NO}_{5}$, and is an emetic, expectorant, and cholagogue; in very small doses, gr. $1 / 8$, it is a mild tonic. It is used mainly as a safe and prompt emetic, in membranous croup, and in the summer diarrhea of children. Dose as an expectorant gr. $s s-i j$; as an emetic gx. $x v-x x x . ~ I$, , Acetum. (B. P.) Dose $m v-x l$. I., Ext., Fld. Dose $m_{j-\nabla}$. I., Syr., 5 per cent. strength. Dose 3 j- $\bar{z}$ ss. I., Vin., 7 per cent. in strength. Dose $m j-3 j$. I., Trochisci, contain each $1 / 4 \mathrm{gr}$. of the drug. I, et morphinæ, Trochisci, contain each, morphin sulph. gr. $\frac{1}{40}$, ipecac gr. $\frac{1}{12}$, with flavoring-oil and sugar. I. et opii, Pulvis (Pulv, ipec. comp., B. P.) Dover's powder, contains ipecac and opium each Io, sugar of milk 80 parts. Dose gr. ij-xv. I. cum scilla, Pil (B. P.) Dose gr. $\mathrm{v}-\mathrm{X}$. I. et opii, Tinct, deodorized tinct. of opium Ioo, evaporated to 85 , fld. ext. ipecac Io, alcohol q. s. ad I00. Dose $\eta_{\text {v-xxx. }}$ Emetin. Dose as an expectorant gr. $\frac{1}{2} \sigma-\frac{1}{40}$; as an emetic $1 / 8-x / 4$.

Ipomcea (ip-o-me'-ah) (i $\psi$, worm; ö $\mu o \iota s$, like]. A genus of convolvulaceous plants; bindweeds. I. batatas is the sweet potato. I. purga. See Jalap. 1. pandurata, of the U. S., resembles jalap in its action. The seeds of $I$. cœrulia are recommended as a useful intestinal stimulant. I. turpethum affords turpeth-root, $q . v$. Many other species are medicinal. Unof.

Iralgia (i-ral'-je-ah). See Iridalgia.

Irascibility (i-ras-ib-il'-it-e) [iresci, to be angry]. The quality of being choleric, irritable, or of hasty temper. It is a frequent symptom in some varieties of insanity and in neurasthenia, and in some cases it amounts to a species of insanity.

Iridæmia (ir-id-e'-me-ah). See Iridemia.

Iridal $\left(i^{\prime}-r i d-a l\right)$ [ipls, iris]. Relating to the iris.

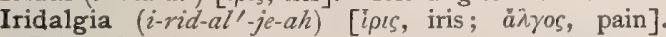
Pain referable to the iris

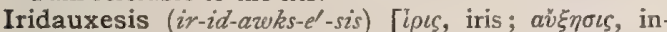
crease]. Auxesis or tumefaction of the iris.

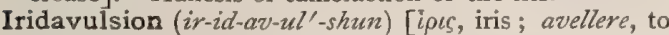
tear away]. Surgical avulsion of the iris.

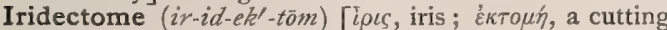
out ]. A cutting instrument used in iridectomy.

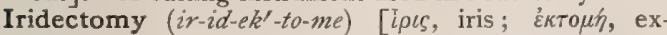
cision]. The cutting out of a part of the iris. I., Antiphlogistic, one performed in inflammatory processes for therapeutic purposes. In Optic I. the piece of iris excised is over a portion of the lens or beneath a portion of cornea clearer than that exposed in the natural pupil, as a result of which additional vision is gained. See Pupil, Artificial. I., Preliminary, is performed in advance of the extraction of cataract, instead of at the same time.

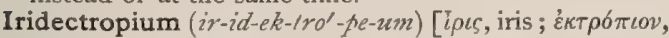
eversion]. Eversion of a part of the iris.

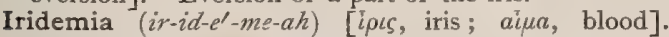
Hemorrhage from the iris.

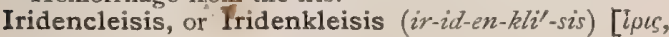
iris; $\dot{\varepsilon} \gamma \kappa \lambda \varepsilon i v$, to lock in]. See Iridodesis.

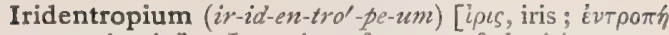
a turning in]. Inversion of a part of the iris

Irideremia $\left(i \gamma^{\prime \prime}-i d-e r-e^{\prime}-m e-a h\right)$ [ipls, iris; $\dot{\varepsilon} \rho \eta \mu i a$, lack]. Absence of one or both irides.

Iridescence (ir-id-es'-ens) [iridescere, to shine with rainbow-colors]. The property of breaking up light into the spectral colors.

Iridesis $\left(i r-i d-e^{\prime}-s i s\right)$. See Iridodesis

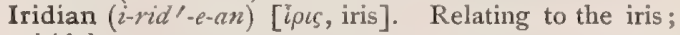
iridal.

Iridicolor (ir-idl-ic-ul-or) [iris, a rainbow; color, color]. In biology, iridescent; exhibiting prismatic colors.

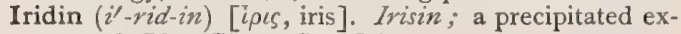
tract of Blue Flag. See Iris.

Iriditis (ir-id-i'-tis). Same as Iritis.

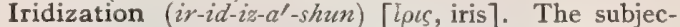
tive appearance, as of an iridescent halo seen by persons affected with glaucoma.

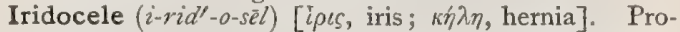
trusion of a part of the iris through a wound or ulcer.

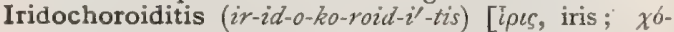

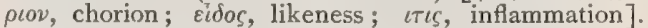
Infiammation of both the iris and the choroid of the eye, the form usually assumed in sympathetic ophthalmia.

Iridocinesis (ir-id-o-sin-e'-sis). See Iridokinesis.

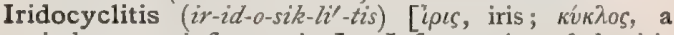
circle; $\iota \tau \iota s$, inflammation]. Inflammation of the iris and the ciliary body. See Cyclitis.

Iridocyclochoroiditis (ir-id-o-sik-lo-ko-roid-i'-tis) [ipls,

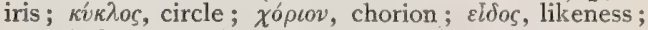
$\iota \tau \iota \varsigma$, inflammation]. Combined inflammation of the iris, the ciliary body, and the choroid.

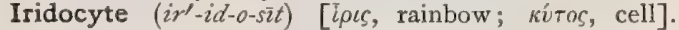
Any cell that produces color, either by means of its structure or its contents.

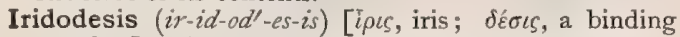
together]. An obsolete method of displacing the normal pupil by ligature, instead of iridectomy.

Iridodialysis $\left(i r-i d-o-d i-a l^{\prime}-i s-i s\right)$. See Coredialysis.

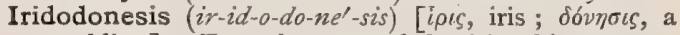
trembling]. Tremulousness of the iris; hippus.

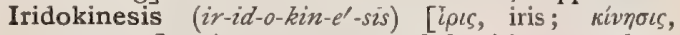
movement]. Any movement of the iris, normal or otherwise.

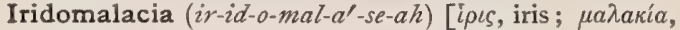
softness]. Morbid softening of the iris.

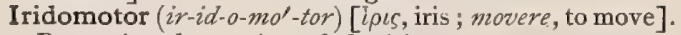
Promoting the motion of the iris.

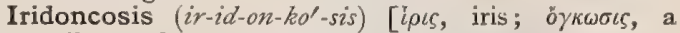
puffing out ]. Thickening of the iris.

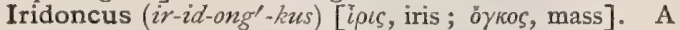
tumor or swelling of the iris.

Iridoparalysis (ir-id-o-par-al'-is-is) [i $\rho \iota s$, iris ; $\pi \alpha \rho a_{-}$ $\lambda v \sigma \iota s$, paralysis]. Paralysis of the iris.

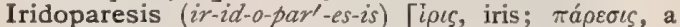
letting go]. A slight or partial paralysis of the iris.

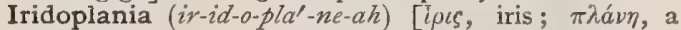
wandering]. Same as Hippus.

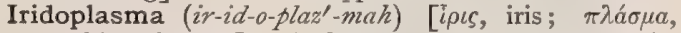
anything formed]. A form of degeneration of the iris.

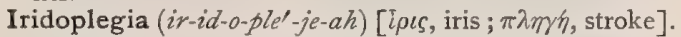
Paralysis of the sphincter of the iris.

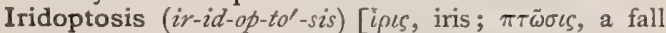
ing]. Prolapse of the iris.

Irido-pupillary (ir-id-o-pu'-pil-a-re) [ipes, iris ; pupilla, the pupil of the eye]. Pertaining to the iris and the pupil.

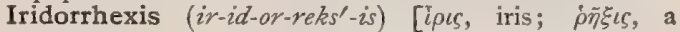
breaking]. Iridectomy with iridavulsion. Rupture of the iris. 
Iridoschisis, or Iridoschisma (ir-id-os'-kis-is or ir-id-

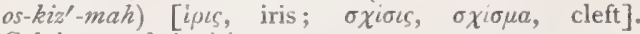
Coloboma of the iris.

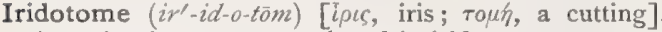
A cutting-instrument employed in iridotomy.

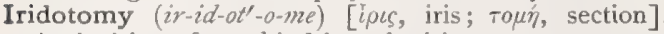
An incision of any kind into the iris.

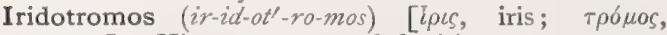
tremor]. Hippus; tremor of the iris.

Iris (i'ris) [ipis, a colored halo or circle]. I. The anterior portion of the vascular tunic of the eye, attached to the pectinate ligament and ciliary body; its central aperture forms the pupil. 2. Blue-flag. The roots of $I$. versicolor. It contains a resinous

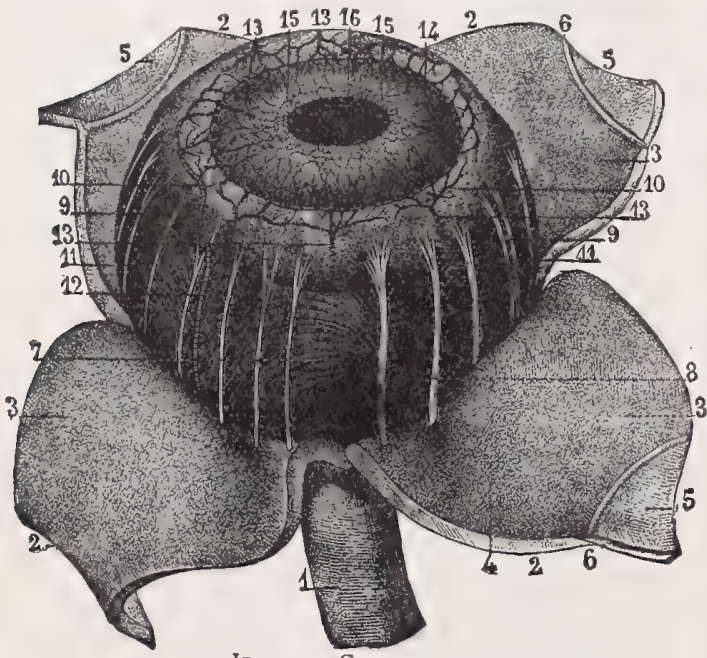

IRIS AND CHOROID.

I. Optic nerve. 2, 2, 2, 2. Sclerotic, divided in four equal parts and turner back. 3,3. Pigmentary granulation of its inner layer. 4. Section of lamina fusca. $5,5,5,5$. Cornea, divided in four equal parts. 6, 6. Canal of Schlemm. 7. Outer surface of choroid. 8. Superior and internal trunk of vasa vorticosa. 9 9. Irregular border limiring the choroid vor posteriorly. Io, ro. Anterior half of this zone; ciliary muscle. II II. Ciliary nerves. I2. Long ciliary artery. ${ }_{13}, 13$ 13, 13. Anterior ciliary arteries. 14. Iris. 15. Small arterial circle of iris. 16. Pupillary orifice.

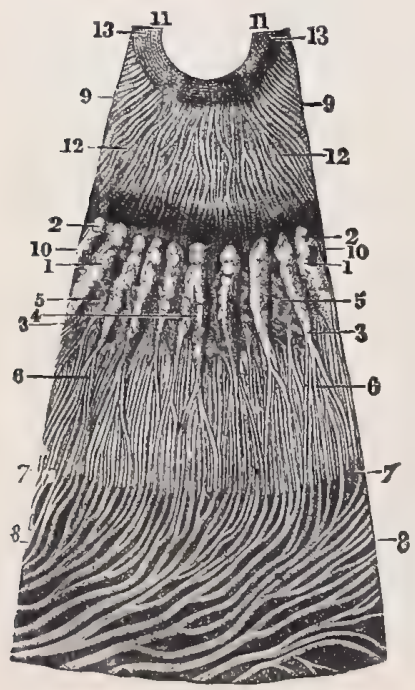

SECTION OF CiLIARY BODY AND IRIS.

I, I. Ciliary processes 2,2 Their bases or rounded extremities. 3, 3. Their apices. 4. furcated extremity 5, 5. Reticulated folds, or ciliary processes of the second order. 6,6 . Venules that emanate from these. 7,7 . Ora serrata of choroid 8 8. Veins of choroid. 9. Section of iris. Io, Io. Circumfer ence of iris. II, II. Small ring of iris 12, 12. Large ring of iris. principle, iridin. The fresh rhizome is purgative, emetic, and diuretic, and is serviceable in catarrh of the duodenum, and in malarial ailments. I., Ext. Dose gr. j-v. I., Ext. Fld. Dose $\eta_{L^{v}-3}$ j. Iridin, the oleoresin, is a cholagogue. Unor, Dose gr. j-v. The genus Iris embraces many other species, some of them purgative, and some reputed to be poisonous. See Orris-root. I., Absence of. See Irideremia. I., Angle of, that formed by the junction of the cornea and the iris. I.-contraction. See Reflexes, Table of. I.-green. Same as Bladder-green. I., Prolapse of (or Hernia of), protrusion of a portion of the iris through an opening in the cornea or sclera; when the iris is adherent the condition is called anterior synechia; when the iris is adherent to the lens behind, the condition is called posterior synechia. I, Tremulous, arises from non-support of the iris in aphakia or dislocation of the crystalline lens.

Irish (i'-rish) [ME., Irish, Irish]. Pertaining to Ireland. I. Ague. Synonym of Typhus Fever, q.v. I. Moss. See Chondrus.

Irisin $\left(i^{\prime}-r i s-i n\right)$ [ipls, iris]. The precipitate from a tincture of the root of Blue-flag, Iris versicolor; it is cholagogue, sialagogue, and diuretic. Dose 2 to 4 grains. Unof.

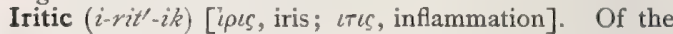
nature of, pertaining to, or affected with, iritis.

Iritis $\left(i-r i^{\prime}-t i s\right)[i \rho \iota$, jris; $\iota \tau \iota s$, inflammation]. Inflammation of the iris, called after its origin, or character, blennorrhagic, rheumatic, diabetic, syphilitic, plastic, serous, primary, secondary. I., Condylomatous, 1. papulosa; that accompanied by the formation of papules or condylomata in the iris. I. gummosa, that in which gummata are formed in the iris. I. papulosa. See I., Condylomatous.

Iritomy (i-rit'-o-me). See Iridotomy.

Iron $\left(i^{\prime}-e r n\right)$ [ME., iron, iron]. See Fermu. I. Bath. See Bath. I. Minium. Same as Colcothar. I. Wood, the heart-wood of Ostrya virginica, a tonic, antiperiodic, and alterative. It has been successfully used in malarial diseases, neuralgia, and strumous affections. Dose of the fld. ext., $3 \mathrm{ss}-\mathrm{j}$. Unof.

Irradiating (ir-r $\left.a^{\prime}-d e-a-t i n g\right)$ [irradiare, to emit rays in every direction]. Radiating from a center, as a pain arising from a definite focus of irritation.

Irradiation (ir-ra-de-a'-shun) [irradiatio; irradiare, to emit rays in every direction]. A phenomenon in which, owing to the difference in the illumination of the field of vision, or its background, objects appear much larger than they really are.

Irreducible (ir-re-dis $\left.s^{\prime}-i b-l\right)$ [in, not; reducere, to lead back]. That which cannot be reduced or restored to its normal condition. In chemistry, applied to a compound that cannot be separated. In surgery, applied to a fracture or dislocation that cannot be replaced. I. Hernia. See Hernia.

Irregular (ir-reg'-u-lar) [in, not; regula, rule $]$. Not regular ; not normal or according to rule; not rhythmic ; not recurring at proper intervals.

Irregularity (ir-reg-u-lar'-it-e) [in, not; regula, a rule]. Lack of regularity; unevenness. I. of the Teeth, deviation of the teeth from their natural arrangement is of frequent occurrence, and is dependent upon a variety of causes. The following are among the most frequent: I. Want of synchronism between the destruction of the roots of the temporary teeth and the growth of the permanent teeth. 2. The premature removal of one or more of the temporary teeth. 3 . Disproportion between the size of the alveolar arch and the teeth. 4. Supernumerary teeth. 5. Mal. formation of the jaws. 
Irrespirable (ir-res-pi'-rab-l) [in, not; respirare, to breathe]. Not capable of being breathed.

Irrigant $\left(i r^{\prime}-i g-a n t\right)$ [irrigare, to lead water to]. A substance or wash used in or by irrigation.

Irrigation (ir-ig-a'-shun) [irrigare, to lead water to]. The application of water, especially a stream, to an inflamed or abnormal tissue for purposes of moistening, antisepsis, cooling, or flushing the part.

Irrigator (ir'-ig-a-tor) [irrigare, to lead water to]. An apparatus, or device, for accomplishing the irrigation of a part, surface, or cavity.

Irritability (ir-it-ab-il'-it-e) [irritabilitas, irritability]. The quality of being susceptible to excitement or irritation. I., Faradic, the muscular contraction caused by a secondary or induced current. I., Galvanic, the muscular contraction caused by the direct current. I., Muscular, the inherent contractile quality of a muscle. I., Nervous, the property of a nerve to transmit impulses upon stimulation. See, also, Irascibility.

Irritable (ir'-it-ab-l) [irritabilis, easily excited]. Easily inflamed. Susceptible to irritation. I. Bladder, a condition of the bladder marked by constant desire to void urine. I. Breast, a neuralgic condition of the mammary gland, usually associated with uterine affections, or with intercostal neuralgia. I. Heart, Da Costa's term for a peculiar condition of the heart characterized by precordial pain, dyspnea on exertion, palpitation, and irregularity of the heart's action. It is induced by over-exertion, masturbation, and neurotic tendencies. Hypertrophy may occasionally develop. I. Spine, a condition of spinal anemia frequently occurring in young hysteric females. There is pain along the spine, with tenderness on pressure, and vertigo, nausea, palpitation, and neuralgias. I. Testicle. See Testicle. I. Tongue, the clean, very red tongue, with enlarged red papillæ about its tip, seen in the dyspepsia of drunkards.

Irritant (ir'-it-ant) [irritare, to excite]. I. Causing, or giving rise to, irritation. 2. An agent or remedy that induces irritation or inflammation. I., Chemic, one acting by virtue of its affinity for the elements or compounds of organic tissue, as nitric acid, or potassic hydrate. I., Mechanical, one causing lesions or inflammations by mechanical operation, as cuts, contusions, pressure, or distention. I., Nervous, one acting through the medium of the nerves.

Irritation (ir-it-a'-shun) [irritatio, excitement]. A condition of undue excitement. Also, an inflamed state. Also, the stimulus necessary to the performance of the functions of an organ.

Irritative (ir'-it-a-tiv) [irritare, to excite]. Exciting or irritating. I. Fever, a febrile condition dependent upon the presence in the body of irritating substances. Also a synonym of Simple Continued Fever.

Irrorate $\left(i r^{\prime}-0 r^{\prime}-\bar{a} t\right)$ [in, upon; rorare, to distil dew]. In biology, minutely dotted, as if with small dewdrops.

Irrumation (ir- $\left.u-m a^{\prime}-s h u n\right)$ [irrumare, to give suck]. Same as Buccul Coitus, q. v. See Nameless Crime.

Isabel, Isabelle $\left(i z^{\prime}-a-b e l\right)$ [Isabelle, a woman's name]. Drab, or yellowish gray.

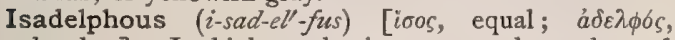
brother]. In biology, having an equal number of stamens in each bundle or brotherhood.

Isambert's Disease. Acute miliary tuberculosis of the larynx and pharynx.

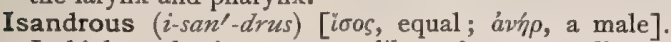
In biology, having stamens alike and corresponding in number to the petals.

Isanthous (i-san'-thus) [ioos, equal; àvflos, a flower]. In biology, having regular flowers.

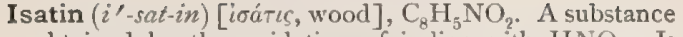
obtained by the oxidation of indigo with $\mathrm{HNO}_{3}$. It crvstallizes in yellowish-red monoclinic prisms, melting at $201^{\circ} \mathrm{C}$. It dissolves in water and in alcohol with a reddish-brown color; it has a disagreeable odor. I.yellow. See Pigments, Conspectus of:

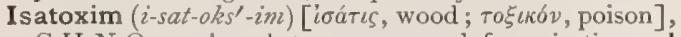
$\mathrm{C}_{8} \mathrm{H}_{6} \mathrm{~N}_{2} \mathrm{O}_{2}$. A substance prepared from isatin and hydroxylamin. It crystallizes from alcohol in yellow needles, and melts at $202^{\circ} \mathrm{C}$

Isatropylcocain (i-sat-ro'-pil-ko-ka'-in), $\mathrm{C}_{19} \mathrm{H}_{22} \mathrm{NO}_{4}$ An amorphous alkaloid from coca leaves. It has no anesthetic properties, but is said to be an active cardiac poison. Unof. See Cocamin.

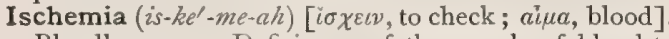
Bloodlessness. Deficiency of the supply of blood to a part. Local anemia.

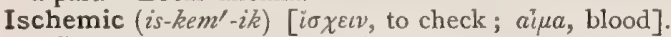
Affected with or relating to ischemia.

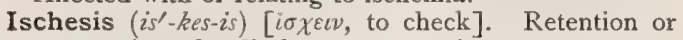
suppression of a discharge or secretion.

Ischiadic (is-ke-ad'-ik). Same as Ischiatic.

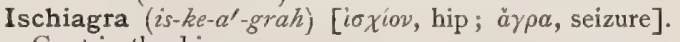
Gout in the hip.

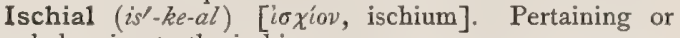
belonging to the ischium.

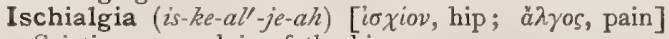
Sciatica; neuralgia of the hip.

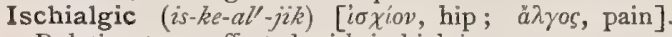
Relating to or affected with ischialgia.

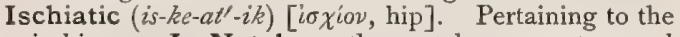
ischium. I. Notches, the notches, greater and lesser, of the ischium. The former transmits the pyriformis muscle, gluteal vessels, and superior gluteal nerve, the latter the tendon of the obturator internus, its nerve, and the pudic vessels and nerve. These notches are called also sacro-sciatic notches. (See illustration on p. 228.)

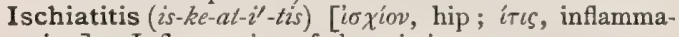
tion]. Inflammation of the sciatic nerve.

Ischiatocele (is-ke-at'-o-sēl). See Ischiocele.

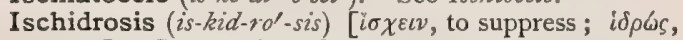
sweat]. Suppression of sweat.

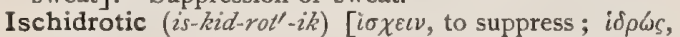
sweat]. Causing a retention or suppression of the sweat.

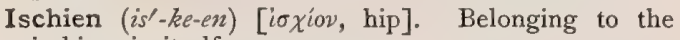
ischium in itself.

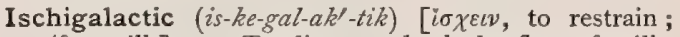
$\gamma a ́ \lambda a$, milk]. I. Tending to check the flow of milk. 2. An antigalactic agent or medicine.

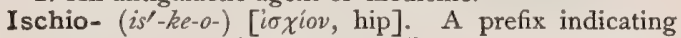
relationship to the ischium. I--anal, pertaining to the ischium and the anus. I.-bulbar, pertaining to the ischium and the bulb of the urethra. 1.-capsular, pertaining to the ischium and the capsular ligament of the hip. I.-cavernosus, the muscle that compresses the veins of the crus penis and assists in the erection of the penis. The I,-clitorianus has a similar relation to the clitoris. See Muscles, Table of. I.-fibular, pertaining both to the ischium and the fibula. I.neuralgia, sciatica. I.-perineal, belonging to or pertaining to both ischium and perineum; pertaining to the space between the anus and the scrotum. I.pubeotomy. See Farabouf's Operation. I.-sacral, relating to the ischium and the sacrum. I.-tibial, relating both to the ischium and the tibia. I.-vertebral, relating to the ischium and the vertebral column.

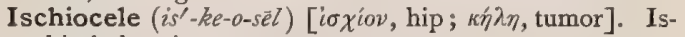
chiatic hernia.

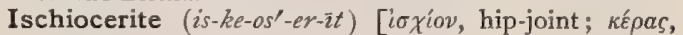
horn]. In biology, the third joint of the developed 
antenna of a crustacean. It is borne upon the basicerite and bears the merocerite.

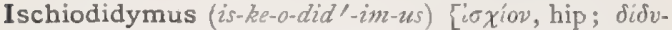
$\mu o s$, double 1. A double monstrosity united at the hips.

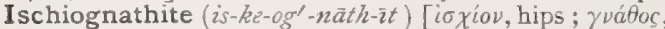
jaw]. The third joint of any one of the mouth-parts of an arthropod.

Ischiomyelitis (is-ke-o-mi-el-i'-tis) [ioxiov, hip, loins; $\mu v \varepsilon \lambda \sigma \varsigma$, marrow; $\iota \tau \iota \varsigma$, inflammation]. Lumbar myelitis ; osphyomyelitis.

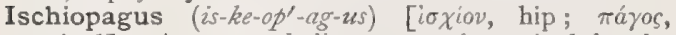
united]. A monomphalic monstrosity united by the coccyges and the sacra.

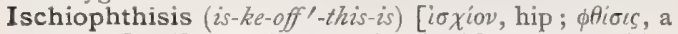
wasting]. Emaciation associated with or due to hipjoint disease.

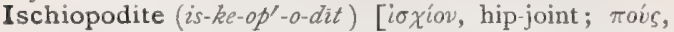
foot]. In biology, the third joint of the inner (endopodite) of the two main divisions of the typical limb of a crustacean.

Ischiorectal (is-ke-o-rek'-tal) [i ${ }^{\prime}$ iov, ischium; rectus, straight]. Pertaining to both ischium and rectum. I. Abscess or I. Cellulitis, an inflammation of the areolar tissue of the ischiorectal fossa involving the rectum and the thigh. Suppuration may occur at any point of the inflammation, but is ordinarily near the anus. I. Fascia. See Fascia. I. Fossa, a deep fossa filled with fatty tissue situated on either side of and between the rectum and the ischium

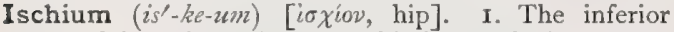
part of the os innominatum or hip-bone; the bone upon which the body rests in a sitting posture. It forms a part, also, of the acetabulum. (See illustration on p. 228.) 2. The third joint of any appendage of a crustacean, e. g., the ischiognathite and the ischiopodite.

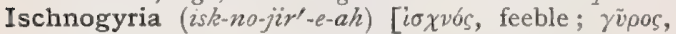
curve]. A condition attended with slight development of the cerebral convolutions.

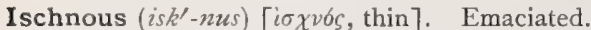

Ischo- $\left(i s^{\prime}-k o-\right)$ [io $\chi \varepsilon \iota v$, to suppress]. A prefix meaning suppressed, stopped, or checked.

Ischoblennia ( $\left.i s-k o-b l e n^{\prime}-e-a h\right)$ [ $i \sigma \chi \varepsilon l \nu$, to suppress; $\beta \bar{\lambda} \varepsilon v \sigma_{\text {s }}$ mucus]. The suppression of a mucous discharge.

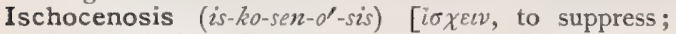
$\kappa \varepsilon ́ v \omega \sigma \iota \zeta$, discharge]. The suppression of any established or normal discharge.

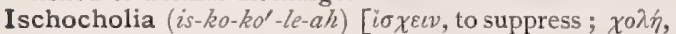
bile]. A suppression of the flow of bile.

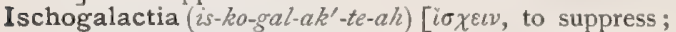
$\gamma a \dot{\lambda} \alpha$, milk]. Suppression of the natural flow of milk.

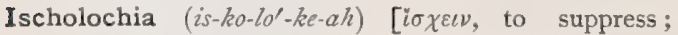
$\lambda o ́ x \iota a$, lochia]. Suppression of the lochial flow.

Ischomenia (is-ko-me'-ne $a h)$ [ $i \sigma \chi \varepsilon \iota v$, to suppress; $\mu \dot{\eta} v$, month, menses]. Suppression of the menstrual flow.

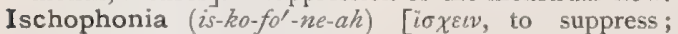
owvin, voice]. Aphonia. An impediment in speech.

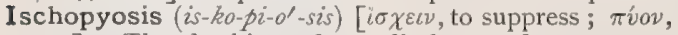
pus]. The checking of any discharge of pus.

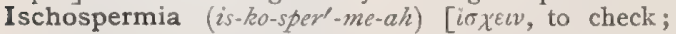
$\sigma \pi \varepsilon \dot{\rho} \mu \alpha$, seed]. Suppression of semen.

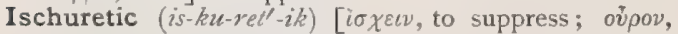
urine]. I. Relating to or relieving ischuria. 2. A remedy or agent that relieves retention or suppression of urine.

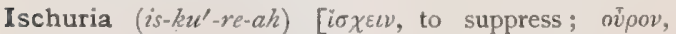
urine]. Retention or suppression of urine. I. paradoxa, the condition in which there is an excessive distention of the bladder, with constant dribbling of urine.

Ischyomyelitis (is-ke-0-mi-el-i'-tis). See Ischiomyelitis.
Isidium (i-sid'-e-2um) [L. : pl., Isidia]. In biology, an excrescence frequently found upon lichens; it corresponds to a soredium.

Isinglass (if-zing-glas). See Ichthyocolla and Glue. I., Vegetable. See Agar-agar.

Island ( $i^{\prime}$-land) [ME., iland, island]. See Insulo and Blood-island. I. of Reil, the central lobe of the hemisphere of the brain, situated at the base, on either side of the fissure of Sylvius. See Insula.

Iso- $\left(i^{\prime}-s o-\right)$ [iøos, equal]. A prefix signifying equality.

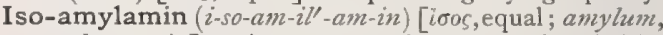
starch; amin]. A ptomainne obtained in the distillation of horn with potassic hydrate; it also occurs in the putrefaction of yeast. It boils at $95^{\circ} \mathrm{C}$., and is non-poisonous. See Ptomaines, Table of.

Iso-apiol (i-so-a'-pi-ol) [iøos, equal ; apium, parsley; oleum, oil]. A substance obtained from apiol, exercising a powerful influence upon the vasomotor system.

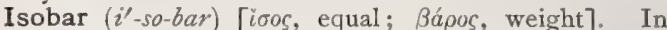
meteorology, a term denoting a line drawn through points having the same synchronous barometric pressure.

Isobrious (i-so'-bre-us) [iбos, equal; $\beta \rho \tilde{a} a v$, to be strong, to make strong]. In biology, applied to dicotyledonous embryos, the two lobes of which grow with equal vigor; isodynamous.

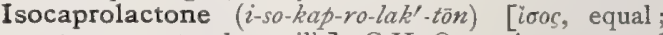
caper, a goat; lac, milk], $\mathrm{C}_{6} \mathrm{H}_{10} \mathrm{O}_{2}$. A compound produced by the distillation of terebic acid. It melts at about $7^{\circ} \mathrm{C}$. ; boils at $206^{\circ} \mathrm{C}$., or $207^{\circ} \mathrm{C}$. ; at $0^{\circ} \mathrm{C}$. it is soluble in double its bulk of water.

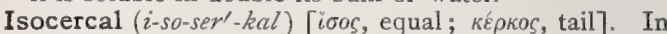
biology, having the tail symmetrically divided by the straight back-bone.

Isocholesterin (i-so-ko-les'-ter-in) [iَos, equal; xoñn, bile; $\sigma \tau \varepsilon \alpha \rho$, fat ], $\mathrm{C}_{26} \mathrm{H}_{44} \mathrm{O}$. A substance isomeric with cholesterin, and found in distilled sheeps' fat ; it melts at $138^{\circ} \mathrm{C}$.

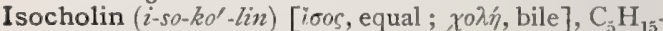
$\mathrm{NO}_{2}$. A body isomeric with cholin; it is found in flyagaric, and may be formed by oxidizing cholin.

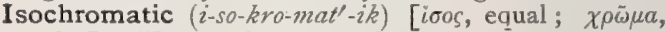
color]. Having the same color.

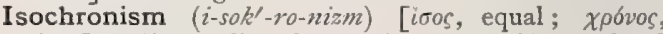
time]. The quality of occurring at equal intervals of time, or lasting for equal periods of time.

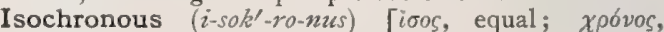
time]. Having, occurring at, or occupying equal intervals of time.

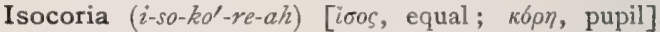
Equality in diameter of the two pupils.

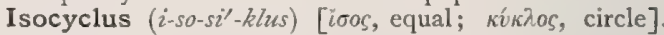
In biology, an organism consisting of a series of similar rings.

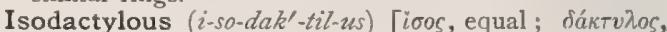
digit]. In biology, having the toes and digits alike.

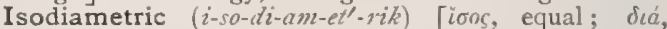

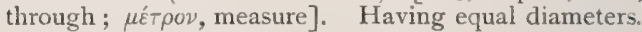

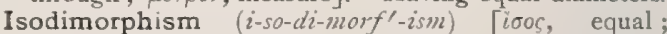
dipopoos, two-formed]. A form of dimorphism, characterized by the appearance of a substance in two similar but incompatible forms.

Isodont (i'-so-dönt) [iَos, equal; ỏdov́s, tooth]. Having teeth of the same size and shape.

Isodulcite $(i$-so-dul'-sit). See Rhamnose.

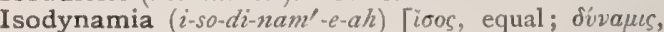
force]. The property of being isodynamic.

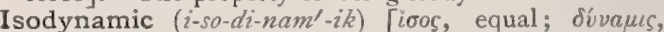
force]. Having equal force. I. Foods, those that produce an equal amount of heat in undergoing the chemic changes of digestion. 


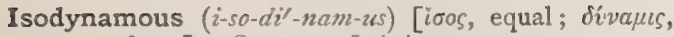
power, force]. Same as Isobrious.

Iso-electric (i-so-e-lek'-tric) [iఠos, equal ; $\ddot{\eta} \lambda \varepsilon \kappa \tau \rho o \nu$, amber]. Equally electric; applied to two bodies or points. I. Curves. See Tension-curves. I. Surfaces. See Tension-planes.

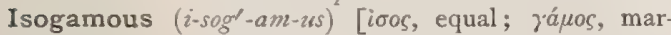
riage]. A term used to designate that mode of reproduction in which the uniting gametes are of equal size. The same as conjugating.

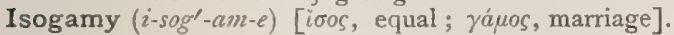
In biology, conjugation of similar gametes.

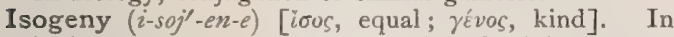
biology, having a general similarity of origin.

Isognathous $\left(i-\operatorname{sog}^{\prime}-n a-t h u s\right)$ [i $\sigma o s$, equal; jvátos, jaw]. In biology, having the molar teeth of both jaws alike.

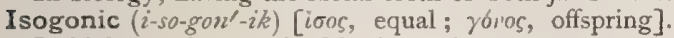
In biology, characterized by isogonism.

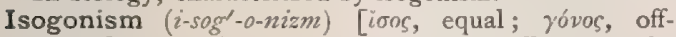
spring]. In biology, the production by different stocks of sexual organisms of identical structure.

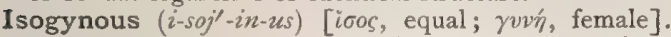
In biology, having the pistils or carpels equal in number to the sepals.

Isolate (is'-so-lāt or $\left.i^{\prime}-s o-l \bar{a} t\right)$ [isola, an island]. To separate one from another. To place apart. In chemistry, to separate an element from its combination. In electricity, to insulate.

Isolation (is-o-la'-shun) [isola, an island]. The act or process of 1solating, or the state of being isolated; separation of those ill of contagious diseases from other persons.

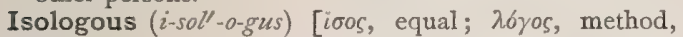
ratio, or system]. Having similar relations or proportions. A qualification applied to compounds containing a like number of carbon-atoms, with a gradually decreasing number of hydrogen-atoms.

Isolophobia (is-a-lo-fo'-be-ah) [isola, an island; $\phi 6 \beta \beta$, fear]. Morbid dread of being alone.

Isomastigate (i-so-mas'-tig-ät) [iбos, equal; $\mu a ́ \sigma \tau \iota \xi$, a whip]. In biology, applied to organisms bearing two or more similar flagella.

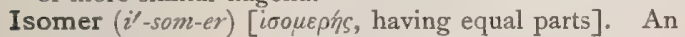
isomeric body. The same as Isomerid.

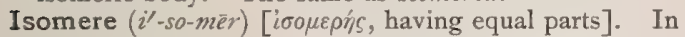
biology, a portion of one organism that is homologous with a portion of another organism.

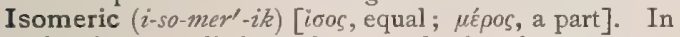
chemistry, applied to substances having the same centesimal composition, but the molecules of which have an essentially different structure and chemic properties; e. g., aldehyd and ethylene oxid, both of which have the formula $\mathrm{C}_{2} \mathrm{H}_{4} \mathrm{O}$. The former, however, has the structure-

$$
\begin{aligned}
& \text { Methyl. Carbonic } \\
& \mathrm{CH}_{3}-\stackrel{\mathrm{CO}}{\mathrm{C}}-\mathrm{H},
\end{aligned}
$$

while the latter is composed of two molecules of ethylene, joined by an atom of oxygen, thus $\left(\mathrm{CH}_{2}\right)-$ $\mathrm{O}-\left(\mathrm{CH}_{2}\right)$. This, the most common type of isomerism, is sometimes called metamerism. The term is also applied to substances having the same centesimal composition, but whose molecular weights are in even multiples, a type of isomerism commonly called polymerism. Also, in crystallography, applied to any substance that crystallizes in more than one form. Also, applied to a substance existing in two or more forms, a type of isomerism called allotropism. I. Theory of Nerve-force; Herbert Spencer's hypothesis that in nervous action the disturbance transmitted is a wave of isomeric change, the alter- nation of isomeric states depending upon both nervefiber and molecular continuity.

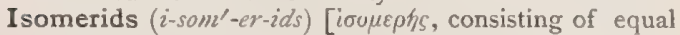

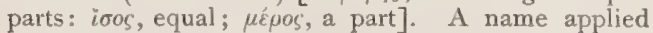
to different substances possessing the same molecular composition. I., Physical, a designation applied to derivations to which one and the same structural formula must be assigned. They have been explained by assuming them to be different aggregations of molecules that were chemically similar. See also Physical Molecules.

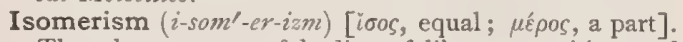
The phenomenon of bodies of like composition and like number of atoms being different in physical or in chemic properties, or in both. I., Geometric. Alloisomerism, q.v. I., Spatial. Same as I., Geometric.

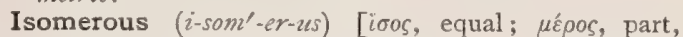
share]. In biology, having an equal number of parts, ridges, or markings.

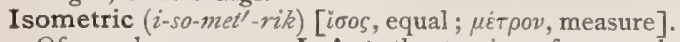
Of equal measure. I. Act, the tension of a muscle when stimulated, its length remaining constant.

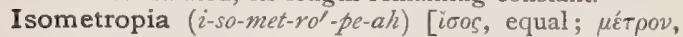
measure; $\mathscr{\omega} \psi$, eye]. Equality of kind and degree in the refraction of the two eyes.

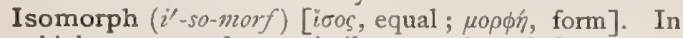
biology, one of two similar organisms belonging to different groups.

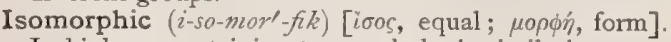
In biology, pertaining to morphologic similarity.

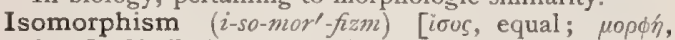
form ]. Similarity in crystalline form. Also, the replacement of one element in a crystalline salt by another, without alteration of form or system. I., Heteromerous, a condition of dissimilarity in molecular composition. I., Isomerous, a condition of similarity in molecular composition. I., Polymeric, the substitution of two or more atoms of one element for one of another, without alteration of crystalline form.

Isonitrosoacetones ( $i$-so-ni-tro-so-as'-et-ōnz). A group of colorless crystalline bodies, readily soluble in ether and in chloroform, and as a rule soluble with difficulty in alcohol. Their aikaline solutions have an intensely yellow color.

Isonitroso-compounds (i-so-ni-tro'-so-kon'-porendz). Compounds that contain the bivalent oximid group $=\mathrm{N} . \mathrm{OH}$ linked to carbon.

Isonomic $\left(i-s o-n o m^{\prime}-i k\right)$ [iбovouckós, having equality of laws]. In chemistry, applied to isomorphism existing between two compounds of like composition.

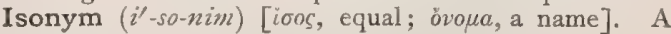
paronym.

Isopathotherapy (i-so-path-o-ther'-ap-e). Same as Isopathy.

Isopathy (i-sop'-ath-e) [iøos, equal; $\pi a \dot{\theta} \theta \phi^{\prime}$, suffering]. A term used to denote the treatment of disease by the administration of one or more of its own products. Thus, smallpox would be treated by the administration internally of the variolous excretions.

Isopelletierin (i-so-pel-et'-e-er-in) [ioos, equal; pelletierin]. A substance found in the root-bark of Punica granatum. It has the same properties as pelletierin.

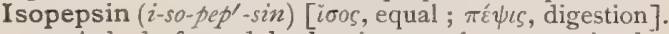
I. A body formed by heating pepsin to a point between $104^{\circ}$ and $140^{\circ} \mathrm{F}$. It changes albumin into parapeptone. 2. Same as Parapeptone.

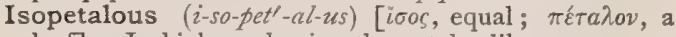
leaf]. In biology, having the petals alike.

Isophoria $\left(i-s o-f o^{\prime}-r e-a / 2\right)$ [i $\sigma o s$, equal ; $\phi 6 \rho o s, a$ tending]. A condition in which the eyes lie in the same horizontal plane, the tension of the vertical muscles of 
each eye being equal, and the visual lines lying in the same plane.

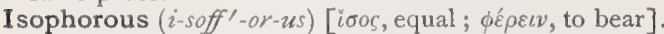
In biology, of equal taxonomic importance, as a species and its abnormal forms.

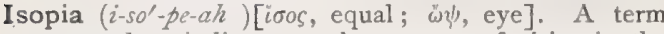
proposed to indicate equal acuteness of vision in the two eyes.

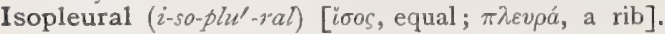
Bilaterally symmetric.

Isopogonous (i-so-pog'-o-nus) [i $\sigma \omega s$, equal; $\pi \omega \gamma \omega \nu$, beard, barb] In biology, applied to feathers, the web of which is alike on both sides of the rachis.

Iso-propylamin (i-so-pro-pil'-am-in). See Propylamin.

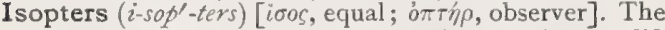
curves of relative visual acuity of the retina at different distances from the macula, both for form and for color.

Isopurpurin (i-so-pur'-pu-rin) [iбos, equal; purpura, purple], $\mathrm{C}_{14} \mathrm{H}_{5} \mathrm{O}_{2}(\mathrm{OH})_{3}$. A coal-tar color used in dyeing, closely allied to alizarin; it is formed by heating beta-anthraquinondisuiphonic acid with sodic hydrate and potassium chlorate. It produces a yellow shade of red. See Pigments, Conspectus of.

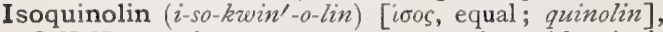
$\mathrm{C}_{4} \mathrm{H}_{7} \mathrm{~N}$. A substance that occurs together with quinaldin and ordinary quinolin in the crude quinolin from coal-tar. It is very similar to quinolin, solidifies at $0^{\circ} \mathrm{C}$. to a crystalline mass, melting at $20-22^{\circ} \mathrm{C}$., and boiling at $237^{\circ} \mathrm{C}$.

Isosaccharic Acid (i-so-sak-a'-rik). See Acid.

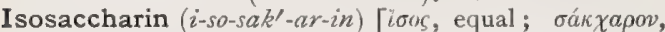
sugar], $\mathrm{C}_{6} \mathrm{H}_{10} \mathrm{O}_{5}$. An isomerid of saccharin. It results from the action of lime upon milk-sugar and maltose.

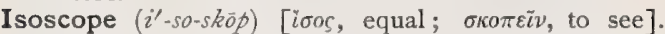
An instrument consisting of two sets of parallel vertical wires, one of which can be superimposed on the other; it is designed to show that the vertical lines of separation of the retina do not correspond exactly to the vertical meridians.

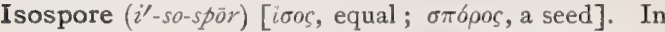
biology, a plant producing but one kind of spore; a zygosperm

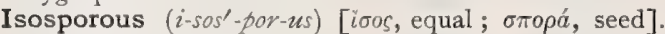
Same as Homosporous.

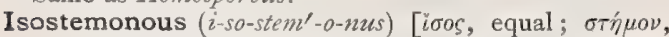
a stamen]. In biology, having the stamens of the same number as the parts of the calyx or corolla

Isotagmata (i-so-tag'-mat-ah). See Inotagmata.

Iso-therapeutics (i-so-ther-ap-u'-tiks). Same as Isopathotherapy.

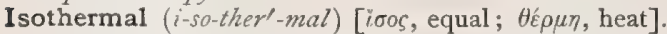
Of equal or uniform temperature. I. Lines, in physical geography, lines drawn through places having the same average temperature for a given period of time. Inasmuch as it frequently happens that two places having the same annual average temperature may have, one a climate of great extremes, the other a very equable climate, it is now customary to display comparative isotherms for the six warm and the six cold months of the extra-tropical regions. I. Zones, zones bounded by isothermal lines.

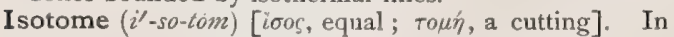
biology, an imaginary line or plane indicating homologous segments or structures.

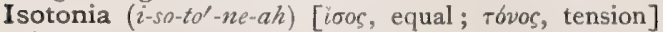
Equality of tension of the blood.

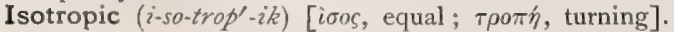
Having the same properties throughout; isotropous; isotropal.

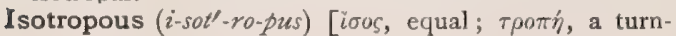

ing]. Having the same shape and appearance, from whatever point observed. A term applied to singlyrefracting bodies.

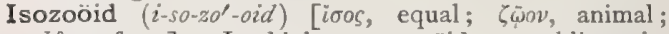

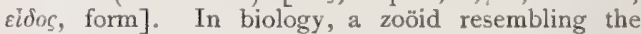
organism producing it. Cf. Allozoöid.

Issue $\left(i s h^{\prime}-u\right)$ [Fr., issue, from exire, to go out]. A discharging ulcer, especially that made artificially for purposes of drainage, or counter-irritation. I.pea, a pea or pea-shaped pellet (as of ivy-wood, or orris-root), inserted into an issue to keep up suppuration. Orange-seeds are also used for the same purpose.

Istarin (is'-tar-in). A nitrogenous, phosphorized substance of complex structure occurring in brain-tissue. Its properties have not been investigated.

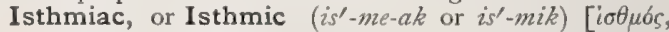
a narrow passage]. Pertaining to any isthmus, as that of the fauces.

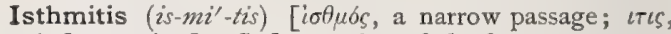
inflammation]. Inflammation of the fauces.

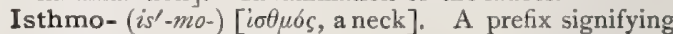
the fauces.

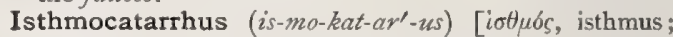

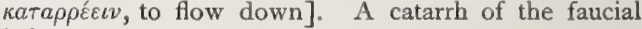
isthmus.

Isthmodynia (is-mo-din'-e-ah) [i $\sigma \theta \mu o ́ s$, neck; óóvin, pain]. Pain in the faucial isthmus.

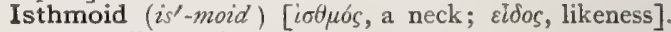
Resembling an isthmus.

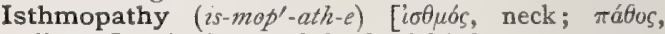
disease]. A disease of the faucial isthmus.

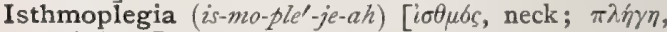
stroke]. Paralysis of the faucial tract.

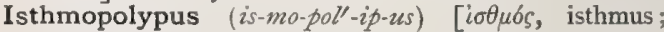
$\pi o \lambda v \pi o v s$, polyp]. A polyp of the fauces.

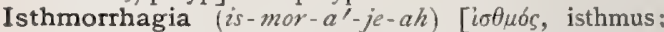
in $\gamma$ vival, to burst forth]. Hemorrhage from the throat.

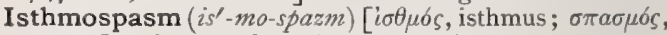
spasm]. Spasm of the isthmus of the fauces.

Isthmus (is'-mus) [i $\sigma \theta \mu o ́ s$, isthmus]. The neck or constricted part of an organ. The part of the brain which, situated axially, serves to unite the forebrain, the cerebellum, and the spinal cord. I., Gyral, a narrow gyrus connecting two adjoining gyri; an annectant convolution or pli de passage. I. of Fauces, the space between the arches of the palate. I. of Thyroid Gland, the transverse cord connecting the lobes of the thyroid body.

Isuretin (i-su-re'-tin) [iَos, equal; ov́pov, urine], $\mathrm{CH}_{4} \mathrm{~N}_{2} \mathrm{O}$. A substance isomeric with urea; it appears on evaporating the alcoholic solution of hydroxylamin and hydrogen cyanid. It crystallizes in rhombic prisms similar to those of urea, and melts at $104-5^{\circ} \mathrm{C}$.

Italian (i-tal'-yan) [Italus, an Italian]. Of or pertaining to Italy. I. Fever. Synonym of Influenza, and also of Mediterranean Fever. I. Leprosy. See Pellagra. I. Method. See Tagliacotian Method.

Itch (ich). See Scabies. I., Army. See Army. I., Bakers'. See Baker. I., Barbers'. See Barber. I., Bricklayers'. See Bricklayer. I., Drunkards', an intense itching frequent in old alcoholics. I., Grocers'. See Grocer. I.-mite. See Acarus scabiei. 1., Norway, an extreme form of general scabies of the body, resulting in fish-scale-like desquamation. Hebra's first case was from Norway. I., Warehousemen's. Same as 1 ., Grocers'.

-ite $(i t)$. A suffix employed in mineralogy denoting a mineral, or of mineral origin. A contraction of $\lambda i \theta 0 s$, a stone.

Iter ( $i^{\prime}$-ter $)$ [iter, a journey]. A passage affording communication between two or more parts. I. ad infundi- 
bulum, the passage between the third ventricle of the brain and the infundibulum. I. a palati ad aurem, the Eustachian tube. I. a tertio ad quartum ventriculum, the aqueduct of Sylvius, extending from the third ventricle to the fourth. I. chordæ anterius, the aperture through which the chorda tympani nerve leaves the tympanum. I. chordæ posterius, the aperture through which the chorda tympani nerve enters the tympanum. I. dentium, the canal of the permanent dental sac opening behind the corresponding temporary tooth and through which the permanent tooth rises.

-itis $\left(i^{\prime}\right.$-tis) [ $\iota \tau \iota \zeta$, inflammation]. A suffix used to denote inflammation.

Ivory $\left(i^{\prime}\right.$-vor-e) [ME., ivory, ivory]. The hard bonelike substance of the tusks of elephants. I.-black. See Carbo animalis, and Pigments, Conspectus of. I.,
Dental. See Dentine. I.-brown. See Pigments, Conspectus of. I. of Tooth. See Dentine.

Ivy $\left(i^{\prime}-2 v e\right)$ [ME., izy, ivy]. See Hedera. I.-pea, an issue-pea made of the wood of the ivy. I., Poison. See Khus.

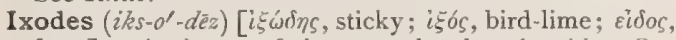
form]. An insect of the natural order Acaridea. See Parasites (Animal), Table of.

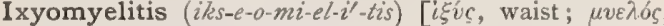
marrow; $\iota \tau \iota$, inflammation]. Myelitis of the dorsal region of the spinal cord; ischiomyelis; osphyomyelitis.

Izal $\left(i^{\prime}-z a l\right)$. Thorncliffe disinfectant; a by-product obtained in the process of coke-formation; it posseses strong disinfectant properties without any irritating quality. It mixes well with water, and has an agreeable odor. Unof.
Jabber (jab'-er) [ME., jaber, to chatter]. To talk rapidly and indistinctly; to chatter.

Jaborandi (jab-or-an'-de) [Braz.]. The leaves of Pilocarpus pennatifolius, a valuable diaphoretic. See Pilocarpus.

Jaborin (jab'-or-in) [Braz., Jaborandi], $\mathrm{C}_{11} \mathrm{H}_{16} \mathrm{~N}_{2} \mathrm{O}_{5}$. An alkaloid derivable from pilocarpin by the action of heat and sulphuric acid. It is an amorphous, strongly basic substance, and has properties resembling those of atropin. Unof.

Jacaranda (jak-ar-an'-dah) [Brazilian]. A genus of bignoniaceous plants of tropical America. J. caroba is antisyphilitic, and is of service in the treatment of urethritis, rheumatism, and skin-diseases. Dose of the fl. ext. gtt. xvi-fl. 3 j. J. lancifoliata, is used by the natives of Brazil in urethritis. Dose of an $\xi i j$ to Oj tincture $m x v$; of the fl. extract, gtt. $x v i-x x x$. Unof.

Jaccoud's Sign. See Signs and Symptoms, Table of.

Jack $(j a k)$ [ME., Jacke, a personal name]. A popular term for horse-flesh salted and subsequently washed in order to deprive it of its peculiar taste. J.-knife Posture. See Postures.

Jacket (jak'-et) [Fr., jacque, a coat of mail]. A short coat. J., Bark, a jacket stuffed with powdered cinchona. J., Cotton, a jacket lined with cotton, sometimes used in the treatment of pneumonia. J., Plaster-of-Paris, a mould of plaster-of-Paris cast upon the body or part, for keeping it rigid and fixed in a desired position, in sprain or dislocation of the spine, etc. J.-poultice, a poultice applied about the whole surface of the thorax; it is sometimes used in the treatment of pneumonia. J., Straight, a system of leather straps used to bind violently insane persons in order to prevent self-inflicted injury.

Jackson's Pectoral Syrup. A cough-medicine containing morphin hydrochlorate, sugar, sassafras pith, gum arabic, and water.

Jacksonian Epilepsy. Focal, cortical, or symptomatic epilepsy. A spasm limited to a single group of muscles in the face, arm, or leg, due generally to irritative lesion of the motor area of the brain; the spasm may also involve other groups of muscles; consciousness is usually retained; there is danger of the convulsions becoming general. See Epilepsy, and Diseases, Table of.

Jacob's Membrane. A name sometimes applied to the layer of rods and cones of the retina. J.'s Ulcer: See Rodent Ulcer, and Diseases, Table of.

Jacobson's Anastomosis. The tympanic plexus. See Plexus. J.'s Canal. See Canal. J.'s Cartilage, a strip of cartilage under Jacobson's organ, firmly adherent to the latter, but distinct from the septal cartilage of the nose, to the outer side of the ventral edge of which it is situated. J.'s Nerve, the nerve of the tympanum. See Nerres, Table of. J.'s Organ, a short, rudimentary canal, extending along the septum of Stensen's duct, and ending in a cul-de-sac.

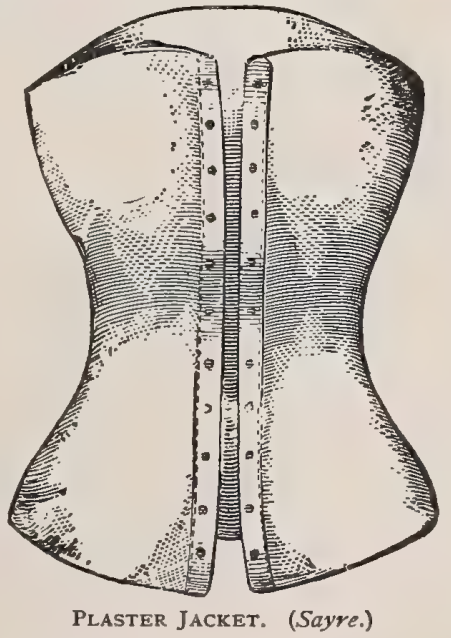

Jacquart, Angle of. See Angle.

Jacquemin's Sign. See Signs and Symptoms, Table of. Jactation ( $\left.j a k-t a^{\prime}-s h u n\right)$. See Jactitation.

Jactitation ( jak-tit-a'-shun) [ jactitare, to pour forth].

The restlessness and tendency to frequent changes of 
position that characterize severe distress in disease. J., Periodic. Synonym of Chorea.

Jadelot's Lines or Furrows. Certain furrows of the face of children in serious illness. Three sets are distinguished: The Genal Furrow, from the mouth almost to the malar bone; this and the nasal furrow are said to indicate disease of the gastro-intestinal tract or abdominal viscera; the Labial Furrow, from the angle of the mouth out ward to the lower part of the face, which "should direct attention to the lungs;" the Nasal Furrow, from the nasal alæ in a semicircle about the mouth; the Oculo-zygomatic Furrow, beginning at the inner canthus of the eye, and passing outward below the lower lid, to be lost on the cheek; it is said to point to disorders of the cerebro-spinal nervous system. See, also, Lines, Table of; and Signs and Symptoms, Table of.

Jæger's Test-types. A series of types of varying size for testing the power of vision.

Jag ( $\mathrm{jag}$ ) [Prov. Eng.]. A popular slang name for a state of drunkenness; also, for enough liquor to produce a state of drunkenness. The term has been adopted into the jargon of certain proprietary cures for the alcohol-habit.

Jaggery $\left(j a g^{\prime}-e r-e\right)$ [E. Ind.]. The name given to a very impure East Indian palm-sugar, sometimes refined in England, but chiefly consumed in the country of its production.

Jail-fever. Synonym of Typhus Fever, $q . v$.

v. Jaksch's Disease. Pseudoleukocythemia of infants. See Diseases, Table of.

Jalap, or Jalapa ( $j a l^{\prime}-a p$ or $j a l^{\prime}-a p-a h$ ) [named from Jalapa, a city of Mexico]. The tuber of Ipomoa jalapa, a plant with properties due to two resins, jalapin and convolvulin. It is an active hydragogue cathartic, especially useful in combination with calomel. J., Abstractum, an ingredient of pil. cathartic comp. Dose gr. j-v. Unof. J., Ext. Dose gr. v-xv. J., Resina, precipitated from the tincture by water. Dose gx. ij-v. J., Pulv., Comp., contains jalap 35, potassium bitartrate 65 . Duse gr. $x-3 j$. J., Tinct. (B. P.) Dose $3^{\mathrm{ss}-\mathrm{j}}$.

Jalapin (jall-ap-in) [from Jalapa, a city of Mexico], $\mathrm{C}_{34} \mathrm{H}_{56} \mathrm{O}_{16}$. I. A glucosid from Convolvulus orizabensis, very similar in properties to convolvulin; it is actively cathartic. 2. The precipitate from a tincture of the root of Ipomea jalapa; an irritant hydragogue cathartic. Dose gr, iij. Unof.

Jamaica (jam-a -kah) [W. Indies]. An island of the West Indies. J. Dogwood. See Piscidia. J. Kino. See Coccoloba.

Jamaicin (jam-a $\left.a^{\prime}-i s-i n\right)$. Same as Berberin.

Jambosa (jam-bo'-sah) [Fr., jambosier]. A genus of myrtaceous S. Asiatic trees. The bark of J. aquea, $\mathrm{J}$. domestica, and $\mathrm{J}$. vulgaris is astringent; the fruit (rose-apple, or jambosa) is edible; the fruit and flowers are refrigerant, and the seeds are aromatic. Unof.

Jambu assu $\left(\mathrm{jam}^{\prime}-b 0 o a s-s o o^{\prime}\right)$ [E. Ind.]. The root of Ottonia jaborandi, a Brazilian tree. It is thought to be stimulant and febrifuge, but its properties are not definitely known. Dose of the fld. ext. $m x-x x x$. Unof.

Jambul $\left(j a m^{\prime}-b u l\right)$ [E. Ind., jambu]. The dried and powdered fruit-stones of Syzygium jambolanum, a shrub of the order of Myrtaceæ, growing in Western India. It is a valuable astringent in the diarrheas of children, and has also been found to lessen the amount of sugar and urine excreted in diabetes. Dose gr. $\mathrm{ij}-\mathrm{x}$; of the fluid extract of the seeds, $\eta_{v-x}$. Unof.

James's Pill. A pill containing equal parts of James's powder, ammoniac, and pil. aloes and myrrh. J.'s Powder. See Antimonium.

Jamestown Weed. See Stramonium.
Janosik's Embryo. A human embryo described by Janosik as having two gill-pouches and three aortic arches.

Janus, or Janiceps ( $j a^{\prime}-n u s$ or $\left.j a n^{\prime}-i s-e p s\right)$ [ Janus, a two-faced divinity; caput, head]. A syncephalic monstrosity with two faces.

Japan (jap-an') [Chin., Jih-pün]. An island on the eastern coast of Asia. J. Colors. See Pigments, Colors, and Dye-stuffs. J.-black. See Pigments, Conspectus of. J. Lacquer. Same as J-black. J. Wax, a wax obtained by boiling the berries of several trees of the genus Rhus, from incisions in the stems of which flows the famous Japan lacquer varnish. It is properly a fat, as it consists almost entirely of glyceryl palmitate. Its specific gravity is .999 and its melting-point $120^{\circ} \mathrm{F} .\left(49^{\circ} \mathrm{C}\right.$. $)$. When freshly broken, the fractured surface is almost white or slightly yellowish-green and the odor tallow-like. It is used for mixing with beeswax in the manufacture of candles and wax matches.

Japanese $\left(j a p-a n-\bar{e} z^{\prime}\right)$ [Japan, an island on the east coast of Asia]. Pertaining to Japan or its inhabitants. J. Method of Resuscitation; it consists in drawing forward the tongue and making rapid passes with paper fans soaked in water and aqua ammoniæ. The object is to get as much of the vapor of ammonia into the lungs as possible. This method is also called Japanese Fanning. J. Fanning. See J. Method of Resuscitation. J. Hot-box, a device for applying dry-heat to a part, as the eyes.

Jar [Pers., jarrah, a little cruse]. A small earthen or glass vessel without handle or spout. J., Leyden, an electric condenser consisting of a glass jar lined, externally and internally, in its lower two-thirds with tin. See Leyden.

Jargon (jarl-gon) [ME., jargoun, chattering]. Confused, unintelligible talk; gibberish; babble ; characteristic of some forms of idiocy and insanity.

Jargonize (jar'-gon-iz) [ME., jargoun, chattering]. To utter unintelligible sounds.

Jarich's Ointment. An ointment containing pyrogallic acid, $3 \mathrm{j}$, and lard, one ounce.

Jarjavay's Muscle. See Muscles, Table of.

Jasmine (jaz'-min) [Pers., yasmīn, jasmine]. See Jasminum. J.-yellow. See Gelsemium.

Jasminum (jaz'-min-um) [Pers., yāsmìn, jasmine]. A genus of oleaceous plants, mostly of tropical old-world origin; jasmine. Many of the species are cultivated for their fragrant flowers, and for their essential oil. Some of the species are vermifuge, others lactifuge, and still others are used in the treatment of skin-diseases. Unof.

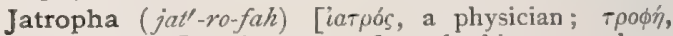
nourishment]. A genus of euphorbiaceous plants having irritant, cathartic, and emetic properties. See Barbadoes Nut and Tapioca. J. macrorhiza, the root of a plant indigenous to Mexico and the Southern United States, possessed of alterative and cholagogue properties; in large doses it is a hydragogue cathartic and emetic. Dose of the fluid extract 3 ss-ij. Unof. $\mathrm{J}$. Oil, the oil of the Barbadoes nut.

Jaundice (jazn'-dis) [Fr., jaunisse, yellowness]. A condition arising from obstruction of the biliary passages. It is characterized by a yellowish coloration of the skin, and may be associated with languor, malaise, nausea, vomiting, itching of the skin, diarrhea or constipation, clay-colored stools, slow pulse, and depression of temperature. Certain of the secretions of the body also are discolored, as the urine. J., Acute Febrile. See Weil's Disease. J , Acute Infective. See Weil's Disease. J., Black, an extreme degree of jaundice. J., Blue, a synonym of Cyanosis. J., Hema- 
togenous, the yellowish discoloration of the skin, resulting from disorganization of the red blood-corpuscles. J., Hemafecal, jaundice associated with bloody stools. J., Hepatogenic. See Hepatogenic. J., Malignant, acute yellow atrophy of the liver. J., White. Synonym of Chlorosis.

Jaune $(z \hbar \bar{o} n)[\mathrm{Fr}$.$] . Yellow. J.-brilliant. Same as$ Cadnium-yellow.

Java Tea. The leaves of Orthosiphon stamincus, the infusion of which is reputed to be diuretic in doses of $3 j$-ij. See Orthosiphon.

Javelle's Water. A solution of potassium or sodium hypochlorite.

Jaw [ME., jarve, jaw]. See Maxilla. J.-bone, a maxilla, especially the inferior maxilla. J.-disease, a term for phosphorus-necrosis. J.-jerk, a tendon reflex obtained by suddenly depressing the lower jaw. See Reflexes, Table of. J.-less, without jaws. J., Lock, or Locked. See Trismus. J., Lumpy, actínomycosis of cattle. J-pocking, a Scottish term for. Wattles, q. v. J.-tooth, a molar tooth.

Jaws (jawz). See Maxillary Bones.

Jealousy (jel'-us-e) [ME., jalous, jealous]. A feeling of resentful suspicion caused by belief in the rivalry of another person in the love or favor of one's husband or wife. When excessive, unreasonable, or abnormal, it may be looked upon as a symptom of insanity.

Jecinorous (jes-in'-or-us) [jecur, jecoris, liver]. Hepatic.

Jecoral (jekl-or-al), Jecorary $\left(j e k^{\prime}-o r-a-r e\right)$, Jecorose (jekl-or-os) [jecur, jecoris, liver]. Hepatic; relating to the liver.

Jecorin (jek'-or-in) [ jecur, jecoris, liver], $\mathrm{C}_{105} \mathrm{H}_{186} \mathrm{~N}_{3}$ $\mathrm{SP}_{3} \mathrm{O}_{46^{\circ}}$ A complex body found by Drechsel in the liver-substance. In its properties it somewhat resembles lecithin, but it reduces Fehling's solution. It occurs also in the spleen, muscle, brain, etc.

Jecur $\left(j e^{\prime}-k e r\right)[\mathrm{L}$.$] . The liver. J. aselli, the liver of$ the cod-fish. J. lardaceum, waxy or lardaceous liver.

Jeffersonia (jef-er-so'-ne-ah) [after Thomas Jefferson, a president of the U. S. ]. A genus of berberidaceous plants. J. diphylla, a N. American berberidaceous plant, useful in rheumatism, and a good substitute for senega. It is tonic and in large doses expectorant; it is also called rheumatism-root and trein-leaf. See Trin-leaf. Unof.

Jeffries, Bacillus of. See Bacteria, Synonymatic Table of.

Jejunal $\left(j e j-u^{\prime}-n a l\right)$ [jejunus, dry]. Pertaining to the jejunum.

Jejunitas (je-ju'-nit-as) [L.]. Fasting.

Jejunitis $\left(j e j-u-n i^{\prime}-t i s\right)$ [jejunus, dry; $\iota \tau \iota \varsigma$, inflammation]. Inflammation of the jejunum.

Jejunium (je-ju'-ne-um) [L., pl., Jejunia]. A fast.

Jejuno-colostomy (jej-u-no-ko-los'-to-me) [jejumus, dry; $\kappa \omega \lambda o \nu$, colon; $\sigma \tau \delta \mu \alpha$, mouth]. The surgical formation of an artificial passage between the jejunum and the colon.

Jejuno-ileitis (jej-u-no-il-e-i'-tis) [jejunus, dry; $\varepsilon i \lambda \varepsilon \iota v$, to roll; $\iota T \iota \zeta$, inflammation]. Inflammation of the jejunum and the ileum.

Jejuno-ileostomy (jej-u-no-il-e-os'-to-me) [jejunus, dry; $\varepsilon i " \lambda \varepsilon v \nu$, to roll; $\sigma \tau \delta \mu \alpha$, mouth]. The surgical formation of an artificial communication between the jejunum and the ileum.

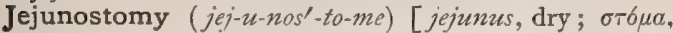
mouth]. The making and maintenance of an artificial opening through the abdominal wall into the jejunum. The operation is designed to permit the introduction of food in cases of carcinoma of the pylorus and similar affections.
Jejuno-typhoid (jej-u-no-ti'-foid) [jejunus, dry; rïфos, smoke; Eidos, likeness]. Typhoid fever with involvement of the jejunum or its glands.

Jejunum ( $\left.j e j-u t^{\prime}-n u m\right)$ [jejunus, dry, empty, because thought to be empty after death]. The two-fifths of

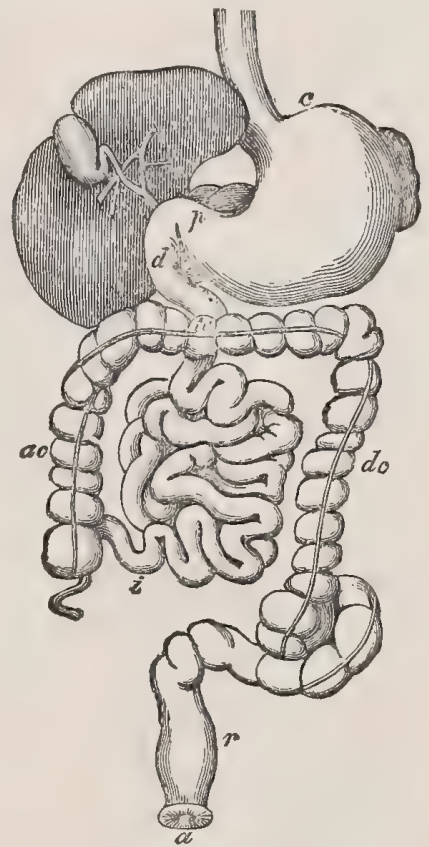

c. Cardiac, p. Pyloric parts of stomach. $d$. Duodenum. i. Jejunum and ileum. $a c$. Ascending, $t c$. transverse, and $d c$. descending colon. $r$. Rectum. $a$. Anus.

the small intestine extending between the duodenum and the ileum. Also a synonym of Fasting.

Jelly $\left(j e l^{\prime}-e\right)$ [ gelare, to freeze]. In pharmacy, a soft, non-viscid, but somewhat elastic substance, of which hydrated gelatin is the best example. Domestic fruitjellies consist of the inspissated juice of the fruit, with one or two parts of sugar, together with the natural mucilage of the seeds of the fruit. Many of the imported jellies sold in the United States contain no fruit-juice, being for the greater part ordinary animal gelatin acidified with tartaric acid, and flavored artificially. J., Glycerin. See Mounting-media; also, Glycerin-jelly. J., Wharton's. See Wharton.

Jennerian (jen-êr'-e-an) [after Jenner, an English physician]. Pertaining to Jenner, or to the theory or practice of vaccination.

Jensen's Fissure. See Fissures, Table of.

Jequiritin (jek-ir'-it-in). A soluble active principle obtained from jequirity seeds. See Abrus.

Jequirity (jek-irl-it-e). See Abrus.

Jerk [origin uncertain]. See Chin-jerk, Elbow-jerk, Jare-jerk, Knee-jerk, Toe-jerk, etc. J.-finger. See Spring-finger.

Jerkers (jerk'-erz). See Jumpers.

Jerks [origin uncertain]. A form of hysteric and almost maniacal agitation, accompanied by sudden distortions of the body. It has been epidemic in certain seasons of unusual religious excitement.

Jersey Tea. See Red-root.

Jervin (jer'-vin) [jerva, green hellebore-root] $\mathrm{C}_{26} \mathrm{H}_{37} \mathrm{NO}_{3}$; a poisonous, crystalline alkaloid found in varieties of veratrum. 
Jesuits' Bark. A name for Cinchona. J. Drops. See Wade's Balsam.

Jetolin (jet'-o-lin). See Pigments, Conspectus of.

Jewel-weed $\left(j u^{\prime}-e l\right.$-wèd). See Impatiens.

Jewlap $\left(j^{\prime}\right.$-lap). See Dewlap.

Jigger Flea. See Pulex.

Jimjams (jim'-jamz) [slang]. A vulgar synonym of delirium tremens.

Jimson (jim'-sun). See Datura stramonium.

Jingko (jing -ko). See Gingko.

Job's Tears. See Coix lacrima.

Jobert's Suture. See Suture.

Joe Pye Weed. See Eupatorium purpureum.

Johnson's Picro-saccharimeter. See P'icro-saccharimeter.

Joint [ME., joynt, a joint]. See Articulation. J.-disease, any morbid affection involving the joints and their surrounding tissues. J., Charcot's, a disease of the joints accompanying tabes dorsalis. It is characterized by a swelling, due to effusion of fluid into the articular cavity and about the surrounding tissues, followed by a lax condition, and ending in distortion or deformity of the joint, sometimes with diminished range of motion, and at other times with excessive range of motion. J.-felon. See J.-ill. J.-ill, a term applied to two very different forms of disease in cattle: 1. To septic arthritis, resulting from septic inflammation of the navel ; 2 . To an acute exudative arthritis, in which large quantities of plastic lymph are thrown into the cavity of the joint, leading to permanent stiffening and deformity. J.-less, without joints. J.-mice. See Corpora libera articulorum. J-oil, the synovia.

Jones's (Bence) Albumin. See Albumin.

Jorissenne's Sign. See Signs and Symptoms, Table of. Joule (jool) [after J. P. Joule, an English physicist]. A heat-unit, equal to one calorie divided by 4200 . See Electric Units. J.'s Law. See Law.

Jowl (jöl or joul) [ME., jolle, jaw]. The cheek.

Judas Tree ( $j u^{\prime}$-das tre). Red-bud. The bark of Cercis canadensis, an astringent, much used in diarrhea, and as an injection in leukorrhea. Dose of the fld. ext., $m \times x v-3 j$. Unof.

Jugal (ju'-gal) [jugum, a yoke]. Connecting or uniting, as by a yoke. J. Bone, the malar bone. J. Points. See Craniometric Points. J. Process. See Zygoma.

Juglandin (jüg-lan'-din) [juglans, a walnut]. A precipitate from a tincture of the root-bark of Butternut, Juglans cinerea; it is alterative, tonic, laxative, detergent, etc. Dose 2 to 5 grains. Unof.

Juglans $\left(j g^{\prime}\right.$-lan 2$)[\mathrm{L} .$, "walnut" $]$. A genus of trees, including the true walnut. J. regia, the European walnut, has stimulant and alterative leaves, which have been found useful in expelling tapeworm. The black walnut, J. nigra, has the same properties. Butternut, the inner bark (collected in autumn) of the roots of J. cinerea, is a mild cathartic, very popular in dysentery and chronic constipation. Dose of the ext., gr. $\mathrm{v} x$.

Juglone (jūg'-lōn) [juglans, walnut], $\mathrm{C}_{10} \mathrm{H}_{5}\left(\mathrm{O}_{2}\right) \cdot \mathrm{OH}$, An active principle existing in the bark of the European walnut; it is also obtained by oxidizing hydrojuglone with ferric chlorid. It is almost insoluble in water, consists of yellow needles, and melts with decomposition at about $150-155^{\circ} \mathrm{C}$. It has the smell of fresh walnuts, and is a powerful sternutatory. Unof.

Jugo-maxillary (ju'-go-maks'-il-a-re) [jugum, a yoke; maxilla, a jaw]. Relating to the jugular vein and the maxilla.

Jug-sound. A term for amphoric resonance.

Jugular (ju'-gu-lar) [jugularis; jugulum, throat].
Pertaining to the throat. J. Fossa. See Fossa. J. Ganglion. See Ganglia, Table. J. Veins. See Vein.

Jugulation (jug-u-la'-shun) [jugulatio, a killing]. The swift and sudden shortening of an attack of disease by therapeutic measures; also, the arrest of an epidemic by prompt and effective measures.

Jugulocephalic (ju-gu-lo-sef-al'-ik) [jugulum, the throat; $\kappa \varepsilon \dot{\phi} a \lambda \dot{\eta}$, head]. Pertaining to the throat and the head.

Jugulum $\left(j \bar{u} g^{\prime}-u\right.$-lum $)\left[L_{0}: p l .\right.$, jugula $]$. The collarbone; also, the throat.

Jugum $\left(j u^{\prime}-g u m\right)[\mathrm{L}$ : $p l ., J u g a]$. A yoke. In biology, a pair of leaflets in a compound leaf. J. penis, a cushioned forceps or compressor applied to the penis to prevent incontinence of urine. J. sphenoidale, the line of fusion of the orbito-sphenoid bones.

Juice (jüs) [jus, broth]. The fluid or liquid contained in the tissue of an animal or plant. Various secretions of the body are known as juices, e. g., the gastric, intestinal, and pancreatic juices. J.-canals, spaces within the connective tissue, constituting the origin of the lymphatic vessels. J., Gastric. See Gastric. J., Intestinal, the intestinal secretion, succus entericus, the secretion of the follicles of Lieberkuihn mainly, but in the duodenum including that of Brunner's glands. J., Pancreatic. See Pancreatic.

Jujube $\left(j u^{\prime}-j u \bar{u} b\right)[j u j u b a$, fruit]. The fruit of the jujube tree, Zizyphus jujuba. J.-paste, a confection, originally containing the pulp of jujubes, but now made of gum-arabic, or of gelatin, variously flavored.

Julaceous $\left(j u-l a^{\prime}-s h e-u s\right)$ [iulus, catkin]. In biology, resembling a catkin.

Julep (ju'-lep) [Pers., jüläb, a sweet drink]. A sweetened and aromatized alcoholic or medicated drink.

Jumbai-bean (jum'-hi-hên) [Negro dial., Jumbai, an evil spirit]. The Leucana glanca Benth, a leguminous tree resembling the locust, found in the West Indies. The eating of the fruit or the foliage by horses and cattle results in the loss of hoofs, horns, and hair of tail and mane.

Jumpers (jum'-perz) [ME., jumpen, to jump]. A name applied to those afflicted with a neurosis characterized by motor incoördination and convulsive movements of any part of the body, but especially of the lower extremities, so that springing movements or jumping movements follow efforts to walk, etc. The name has also been given to hysteric fanatics whose devotional frenzy is accompanied by acts of leaping and distortion; and also to certain persons whose powers of will and control over their movements are in part abolished. See Latah, Myriachit, Palmus, and Saltatoric Spasm.

Jumping ( jump'-ing). See Palmus.

Junctura (junk-tu'-rah) [L.]. A suture, as of bones.

June $(j \bar{u} n)$ [Junius, a Roman name, meaning young]. The sixth month of the year. J.-cold. Synonym of Hay-fever. J. Lobster. See Buckle-shell.

Jungle Fever. See Fever.

Juniper $\left(j u^{\prime}\right.$-nip-er). See Juniperus.

Juniperin (ju-nip'-er-in) [juniperus, the juniper-tree]. A yellow, resin-like powder found in juniper-berries. Juniperus (ju-nip'-er-us) [L..,gen., Juniperi]. I. A genus of berry-bearing coniferous trees. Besides the official species (see Juniperus, 2), there are several other medicinal species. 2. Juniper, the fruit of $J$. communis, its properties are mainly due to a volatile oil, and it is a stomachic tonic, diuretic, and aphrodisiac. The oil is eliminated by the kidneys. It is valuable in chronic pyelitis and cystitis, J., Infusum, unof., consists of juniper-berries $\xi \mathrm{j}$, boiling water $\mathrm{O}$ j. J., Ol., the volatile oil. Dose $m v-x x$. J., Spt., 5 parts of the oil in 95 of alcohol. Dose $3 \mathrm{j}-3 \mathrm{j}$. J., Spt., 
Comp., the gin of commerce; oil of juniper 8 , oil of caraway I, oil of fennel I, alcohol I400, water q. s. ad 5000 parts. Dose $\overline{3} \mathrm{ss}-\mathrm{j}$. J. oxycedrus affords oil of cade, $q . v$. See also Sabina. Oil of Cade, a tar obtained by the distillation of juniper-wood; it is sometimes used externally in eczema and psoriasis. Unof.

Junk [Port., junco, a rush]. In surgery, a quilted cushion forming a sling in which to suspend a fractured limb. It was formerly made of rushes or reeds.

Junker's Inhaler. See Anesthetic.

Junket (junk'-et) [ME., junket, a rush]. Curds and whey; a delicacy for invalids, prepared by taking $1 / 2$ pint of fresh milk heated to an agreeable temperature, adding I teaspoonful of rennet or essence of pepsin, and stirring well. Let the mixture stand till curdled, and serve with sugar and nutmeg.

Junod's Boot. A boot-shaped case, usually of stiff leather, made to enclose the leg so that, the air being exhausted, the blood-vessels and tissues of the limb are dilated by the excess of blood. It has been employed to relieve inflammation and congestion of the viscera.

Jurema ( $\left.j u-r \ell^{\prime}-m a h\right)$ [Braz.]. A leguminous Brazilian tree, Siryphnodendron jurema. Its bark is astringent, and is said to be narcotic. Unof.

Juriballi $\left(j u-r i b-a l^{\prime}-e\right)$ [W. Ind.]. A name for several meliaceous trees and their astringent and antipyretic bark, among which are Trichilia moschata, Soymida febrifuga, and Khaya senegalensis.

Jurisprudence ( $j u$-ris-pru'-dens) [ jus, law; prudentia, skill]. The science of the interpretation and application of the law. J., Medical, the application of medical knowledge to the principles of common law

Jurubeba ( $\left.j u-r u-b e^{\prime}-b a h\right)[\mathrm{Braz}]$. The leaves and juice of a shrub, Solanum insidiosum, indigenous to Brazil. It is an alterative, tonic, diuretic, and drastic cathartic. Dose of the fluid extract gtt. $j-v$. Unof.

Jury $\left(j u^{\prime}-r e\right)$ [jurare, to swear]. A body of men legally appointed to determine the guilt or innocence of a prisoner, or to determine the facts in judicial inquiries. J.-leg, a wooden leg. J. of Matrons, a body of twelve matrons, formerly empaneled in Eng. land to determine if a murderess, for whom such plea was made, were pregnant. J.-mast, a steel shaft with curved iron rods attached, sometimes employed to support the head in disease of the upper vertebræ; it is mainly used in connection with Sayre's treatment of spondylitis. See annexed illustration.

Jus (juss) [L.]. See Juice, and Jusculum.

Jusculum (jus'-ku-lum) [L., a decoction]. A soup or broth; gruel or porridge.

Jusetmond's Arsenical Powder. A preparation of arsenic used in various skin-affections. It consists of sulphuretted antimony, I6 parts; arsenious acid, one part. These are melted in a crucible, and, when cold, the mass is reduced to a powder, and five parts of extract of opium are added.

Justicia (jus-tis'-e-a/h) [named from a Mr. Justice, a botanist]. A genus of acanthaceous herbs and shrubs. $\mathrm{J}$. adhatoda is antispasmodic and febrifuge. J. ecbolium is anti-icteric, diuretic, and deobstruent. J echioides, diuretic. J. gendarussa, diaphoretic. J. pectoralis is bechic and stomachic. Unof.

Justo-major Pelvis (jus'-to-ma'-jor). See Pelvis, Female, Deformities of.

Justo-minor Pelvis. See Pelvis, Female, Deformities of.

Jute (jüt) [Beng., jüt, matted hair]. The bast fiber of two species of the genus Corchorns, grown chiefly in India and Ceylon. The fibers have a length of 2.5 meters, or even more, are of a yellowish-white color, and have a fine luster. Jute contains no free cellulose, but consists of bastose. When treated with iodin and sulphuric acid. it yields a deep-brown color.

Juvantia (ju-van'-she-ah) [L., "aiding"']. Adjuvant remedies or medicines. See Adjuvant.

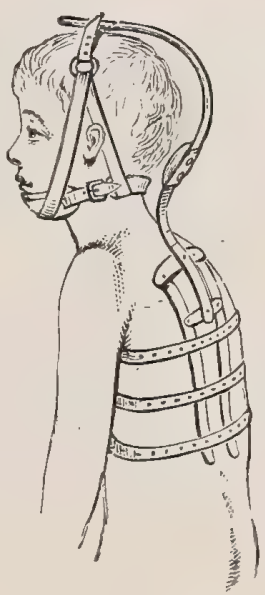

JURY-MAST. (Sayre.)

Juventus (ju-ven'-tus) [juvenis, young]. A term formerly applied to that period of life between the ages of twenty-five and thirty-five years.

Juxtaposition (juks-tah-po-zish'-un) [juxta, near; positio, position]. Situation adjacent to another; the act of placing near; apposition. 
K. The symbol of Kalium, or its more commonly used equivalent, Potassium.

$\mathbf{K}$, or $\mathbf{K a}$. In electrotherapeutics, the abbreviation of Kathode, or of Kathodic

Kaateer's Method. A method of staining tuberclebacilli. See Stains, Table of.

Kabbalistic, Cabalistic (kab-al-is'-tik) [Heb, gabbāläh, reception]. Pertaining to the Kabbala, which included a system of the treatment of diseases by supernatural agencies.

Kaif (kif) [Arab.]. Languor; dreamy enjoyment; sensuous tranquillity, such as follows the use of certain drugs (like opium, or hashish).

Kairin (ki'-rin) [kaıoós, the right time], $\mathrm{C}_{10} \mathrm{H}_{13} \mathrm{NO}$.$\mathrm{HCl} . \mathrm{H}_{2} \mathrm{O}$. An artificial alkaloid prepared from chinolin. It is valuable as a powerful antipyretic; it also produces diaphoresis and emesis; its use is sometimes followed by collapse. Its general properties are similar to those of antipyrin, q.v. Dose gr. iijxxx. Unof.

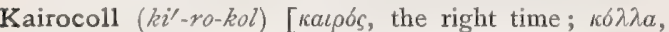
glue], $\mathrm{C}_{11} \mathrm{H}_{11} \mathrm{NO}_{2}$. An artificial alkaloid prepared from chinolin.

Kairolin, or Kairolina (ki'-ro-lin, or ki-ro-li'-nah)

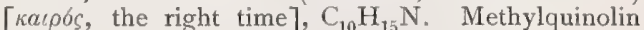
hydrid. An antipyretic resembling kairin, but less efficient. Unof.

Kakké $(k a k \prime-k a)$ [Chinese for "leg-disease" ]. Epidemic and endemic multiple neuritis, or beriberi, as seen in Eastern and Southern Asia.

Kako- (kak'-o-). See Caco-

Kakodyl (kak'-o-dil). See Cacodyl

Kakosmia (kak-oz'-me-ah). See Cacosmia.

Kakotrophia (kak-ot-ro'-fe-ah). See Cacotrophy.

Kaladana (kal-ad-a'-nah) [origin unknown]. An East Indian convolvulaceous plant, Ipomea (Pharbitis) nil. Its seeds are a safe and good cathartic. Dose of the powdered drug, $3 \mathrm{ss}-\overrightarrow{\mathrm{ij}}$; of the resin, gr. iv-viij. Unof.

Kalanchoe (kal-an-kof-e) [Chinese]. An East Indian crassulaceous plant. Its leaves are used in the form of poultices for bites and boils, the juice as an antipyretic. Unof.

Kali ( $k a l^{\prime}-e$, or $\left.k a^{\prime}-l i\right)$ [Ar., qali, potash]. Potassium, q. v. K.-blue. Same as Berlin-blue.

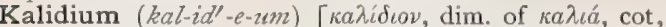
granary: pl., Kalidia ]. In biology, the spore-capsule of certain algæ.

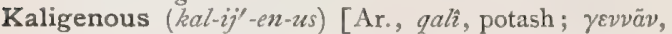
to beget]. Pertaining to the production of potassium.

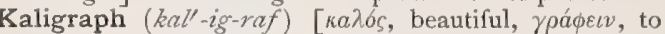
write]. An instrument for the use of those afficted with writers' cramp. It is essentially a pantograph, so arranged that by making the letters very large at one point, they are reproduced of a natural size at another.

Kalimeter (kal-im'-et'-er). See Alkalimeter.

Kalimetry (kal-im'-et-re). See Alkalimetry.

Kaline ( $k a^{\prime}-l i n$ or kal'-in). See Alkaline.

Kalisaya (kal-is-a'-yah). See Calisaya.

Kalium ( $\left.k a^{\prime}-l e-u m\right)$. A synonym of Potassium, $q$. $v$.

Kalmia ( $\left.k a l^{\prime \prime}-m e-a h\right)$ [after Peter Kalm, an explorer] Laurel, Mountain-laurel, Sheep-laurel, Broad-leaved laurel, Calico Bush. The leaves of $K$. latifolia, a well-known evergreen common in the United States, having alterative, cardiac, sedative, and astringent properties. It is a popular cure-all, and has proved valuable in diarrhea and in syphilitic affections. Dose gr. $x x-x x x$; of the fld. ext. $m x x-3$ ss. Unof. $K$. angustifolia, like the foregoing, is poisonous. Its decoction is a popular remedy for sores and ulcers, to which it is applied hot. Unof.

Kalmuck Type. See Idiocy, Ethnic.

Kamala (kam-a'-lah) [Hind., kamīla]. Rottlera. The glands and hairs from the capsules of Mallotus philippinensis (Rottlera tinctoria), native to Southern Asia and Abyssinia. It is a purgative and anthelmintic, much used for the expulsion of lumbricoid and other parasitic worms. Dose $3 j-\xi j$ of an $\bar{j} v j$ to $\xi \times v j$ alcoholic tincture.

Kambi $\left(\mathrm{kam}^{\prime}-\mathrm{be}\right)$ [E. Ind.]. An aromatic gum, like elemi, from Gardenia lucida, a plant of India. Unof.

Kamela $\left(k a m-e^{\prime}-l a h\right)$ or Kamila $\left(k a m-e^{\prime}-l a h\right)$. See Kamala.

Kammerer and Giacomi's Apparatus. An apparatus for air-analysis.

Kanarin (kan'-ar-in), $\mathrm{C}_{3} \mathrm{~N}_{3} \mathrm{HS}_{2}$. A substance obtained from KCNS by electrolysis; it is probably identical with pseudo-cyanogen sulphid, and is employed as a yellow or orange dye for wool, not requiring a mordant.

Kandahar Sore (kan'-da-har). See Furunculus orientalis.

Kandelia (kan-de'-le-ah) [E. Ind, kandel]. A rhizophoreaceous plant found in the Malay Islands. K. rheedii, a small tree found in India, where its bark, mixed with dried ginger, or pepper and rose-water, is used in diabetes. Unof.

Kandol $\left(k a n^{\prime}-d o l\right)$. A volatile constituent of coal-tar, proposed as a local anesthetic. Its rapid evaporation freezes the superficial tissues. It is possibly identical with rhigolene, $q . v$. Unof.

Kangaroo Method (kano-gar-oo'). H. C. Wood's term for the method of treating disease by giving, at short intervals, powerful remedies whose influence is short-lived. K. Tendon, a material derived from the tail of Macropus giganteus, the great kangaroo. It is used in surgery for ligatures. See Ligature.

Kanten (kan'-ten) [Jap.]. A variety of agar-agar, or Japanese sea-weed isinglass, used in the arts, and as a food.

Kaolin (ka'-o-lin) [Chin., kaoling, "high ridge"]. White clay, China clay. The silicate of aluminum, obtained from the decomposition of felspar. It is sometimes used as a protective application in eczema. K., Ung., $\mathbf{I}$ in 3, allays irritation if applied to abraded skin. Unof.

Kaposi's Disease. See Atrophoderma pigmentosum, and Xeroderma pigmentosum; also, Diseases, Table of. K.'s Ointment, an ointment used in the treatment of scabies. It consists of naphthol, 40 grains; green-soap, $21 / 2$ drams; prepared chalk, $1 / 2$ dram; lard, $1 / 2$ ounce. It is also called the compound naphthol-ointment.

Kappeler's Method. See Anesthetic

Karabic Acid (kar'-ab-ic). See Acid, Succinic.

Karakin (kar'-ak-in) [N. Zeal, karaka]. A white crystalline body, apparently a glucosid, obtained from the nuts of the karaka (Corynocarpus levigata). It is an intensely bitter, crystalline body, soluble in water, alcohol, and alkalies, insoluble in ether and chlororoform, and melts at $100^{\circ} \mathrm{C}$.

Kardio- (karl-de-o-). See Cardio-

Karlinski, Bacillus of. See Bacteria, Synonymatic Table of. K., Proteus of. See Bacteria, Synonymatic Table of.

Kartulis, Bacillus of. See Bacteria, Synonymatic Table of. 


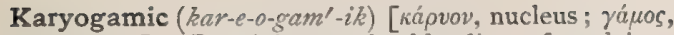
marriage]. Pertaining to the blending of nuclei, as in reproduction.

Karyokinesis (kar-e-o-kin-e'-sis) [kápvov, a nut (nucleus); kimnors, movement, change]. A complicated series of changes accompanying the maturation of the ovum and the extrusion of the polar globule; indirect or nuclear cell-division, characterized by a radiate arrangement of the protoplasm immediately about the "centrosome" and the "sphere of attraction" at one pole, but outside of the nucleus, and following the division of the "sphere of attraction" into two halves of clear protoplasm; also, by changes in the nucleoplasm, the chromatin becoming granular and

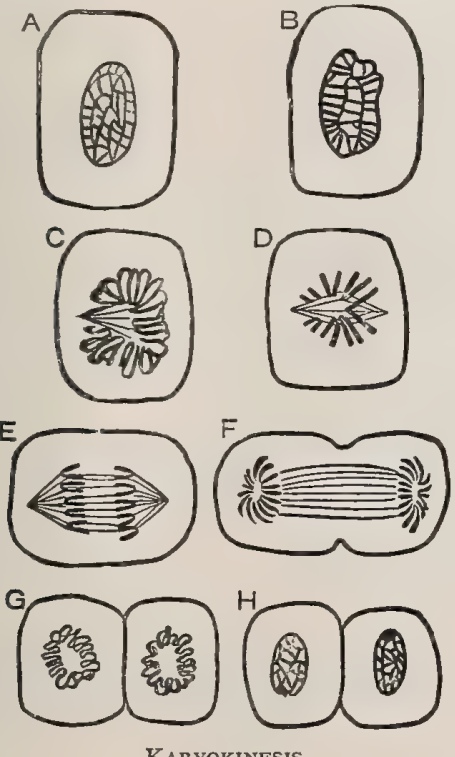

KARYOKINESIS.

A. Nuclear reticulum, resting stage. B. Preparing for division. C. Wreath stage. D. Monaster with achromatic spindle. E. Barrel or pithode stage, or metakinesis, i. e., chromatin-fibrils traveling along the achromatic spindle toward the poles. F. Diaster. G. Daughter-wreath stage. H. Daughter-cells passing to resting-stage,

arranged as a transverse band or disc, while the achromatin is transformed into threads (karyomita), forming a spindle-shaped structure (nuclear, spindle, barrel-form, pithos), stretching between the two astral systems, or suns. The entire arrangement, central disc, spindle, and the two suns, constitutes the socalled amphiaster, or diaster, and, in connection with the production of the polar globules, the archiamphiaster. The groups of the V-shaped chromatin-grains, produced by the division of the central disc, are then translated to the ends of the spindles, and form two polar crowns (Carnoy's couronne polaire, the wreaths, rosets, spirems); the spindle-threads break and are drawn toward the polar crowns, and two daughter-nuclei result.

Karyokinetic (kar-e-o-kin-et'-ik) [kápvov, nucleus ;

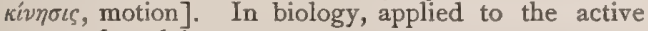
stages of nuclei.

Karyolysis (kar-e-ol'-is-is) [ká loose]. The segmentation of the nucleus of the cell.

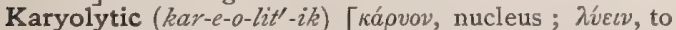
loose]. Relating to karyolysis.

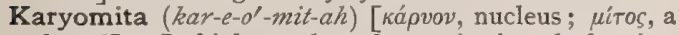
thread]. In biology, the achromatin-threads forming the nuclear spindle in a dividing or active nucleus.

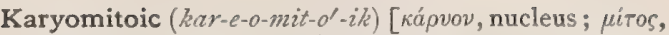
a thread]. Relating to karyomitosis.

Karyomitoma (kar-e-o-mit-o'-mah). See Cell-body.

Karyomiton (kar-e-on'-it-on). See Chromatin.

Karyomitosis (kar-e-o-mit-o'-sis) [kápvov, nucleus; pítos, a thread]. The division or splitting of the nuclear mass of chromatin-fibers.

Karyomitotic (kar-e-o-mit-ot'-ik) [kápvov, nucleus; pitos, a thread]. Relating to karyomitosis.

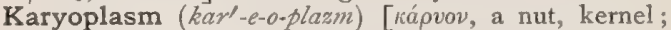
$\pi \lambda a ́ \sigma \mu \alpha$, anything formed]. In biology, the nuclear substance of a cell. See Chromatin.

Karyoplasma (kar-e-o-plaz'mah). Same as Karyoplasm.

Karyosoma (kar-e-o-so'-mah) [kápvov, nucleus ; $\sigma \tilde{\omega} \mu a$, a body, pl., Karyosomata]. A nuclear microsoma; a round body resembling a nucleolus, contained in the segmentation-nucleus of the ovum.

Karyostasis (kar-e-os'-ta-sis) [Kápvov, nucleus; orá$\sigma \iota s$, a stoppage]. The resting-stage of nuclei of cells. It is opposed to karyokinesis.

Karyostatic (kar-e-o-stat'-ik) [kápvov, nucleus; $\sigma \tau a ́ \sigma \iota \varsigma$, a stoppage]. Pertaining to karyostasis.

Karyostenosis (kar-e-o-ste-no'-sis) [kápvov, a nucleus;

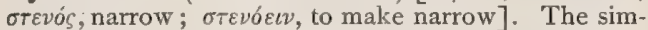
ple division of the nucleus of a cell. This process is called also akinetic, or direct division.

Kassu (kas'-oo) [E. Ind.]. A black astringent substance obtained from areca nuts, and used for the same purpose as true catechu.

Kata- (kat'-ah-). For words thus beginning, and not found under K., see Cata.

Katabolergy (kat-ab-ol'-er-je). See Catabolergy.

Katabolic (kat-ab-ol'-ik). See Catabolic. K. Nerves, thermo-excitory, as distinguished from anabolic, or thermo-inhibitory, nerves.

Katabolism (kat-ab'-o-lizm). See Catabolism.

Katacrotic (kat-ak-rot'-ik). Same as Catadicrotic.

Katadicrotic (kat-ah-di-krot'-ik). See Catadicrotic.

Katadicrotism (kat-ad-ik'-rot-izm). See Catadicrotism.

Katadidymus (kat-ad-id'-im-us). See Catadidymus.

Katalepsy (kat'-al-ep-se). See Catalepsy.

Katalysis (kat-al'-is-is). See Catalysis.

Katantostomus (kat-an-to-sto'-mus). See Catantostomus.

Katanturaniscus (kat-an-tür-an-is'-kus). See Catanturaniscus.

Katanturanus (kat-an-tür'-an-us). See Catanturanus.

Kataplasm (kat'-ap-lazm). See Poultice.

Katastate (kat'-as-tāt). See Catastate.

Katatonia (kat-at-o'-ne-ah). See Catatonia.

Katelectrotonic (kat-el-ek-tro-ton'-ik). See Catelectrotonic. K. Zone. See Zone.

Katelectrotonus (kat-el-ek-trot'-o-nus). See Catelectrotonus.

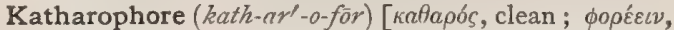
to carry]. An instrument for cleansing the urethra.

Katharsis (kath-ar'-sis). See Catharsis.

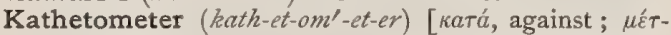
pov, measure]. An instrument for ascertaining the level of fluids.

Kathion (kath'-e-on). See Cation.

Kathode (kath'-od) [kará, down; oøbs, path]. The negative pole of a galvanic battery.

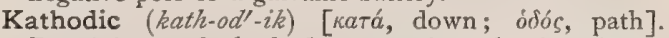
Pertaining to the kathode or negative pole of a galvanic battery. In biology, turned in the opposite direction to that of the genetic spiral. $\mathrm{K}$. Closure-contraction, the muscular contraction occurring when the circuit is closed with the rheophore on a motor point. $\mathbf{K}$. Opening-contraction, the muscular contraction that occurs when the circuit is opened. 
Katin (kat'-in) [Ar., kat, khat, khat]. An alkaloid found in Catha edulis, with properties somewhat like those of calfein.

Kation (kat'-e-on). See Cation and Electrolysis.

Katostomus (kat-os'-to-mus). See Catostomus.

Katouraniscus (kat-o- $\left.u^{\prime}-r a n-i s^{\prime}-k u s\right)$. See Catouran-

Katouranus (kat-o-u'-ran-us). See Catouranus.

Kauri (koze'-re). Same as Cozvdie. K. Gum. See Corudie-gum.

Kava, or Kava-kava(kah'-vah) [Hawaiian]. Ava-kava. The root and also the resin of Piper methysticum, a shrub native to South America and the South Sea Islands. It is a diuretic and motor depressant, producing intoxication when taken in large doses. In small and moderate doses it resembles coca in its action in allaying fatigue. Dose of the fluid extract $3 \mathrm{ss}-\mathrm{j}$. Unof.

Kavain (kah'-va-in) [Hawaiian, kava]. A neutral substance obtained from the roots of kava-kava.

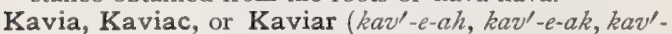
$e-\bar{a} r)$. See Caviar.

Keasbey and Mattison's Food. A variety of Liebig's food for infants. Its composition is: Water 27.95; fat, none ; grape-sugar, 36.75 ; cane-sugar, 7.58 ; no starch; soluble carbohydrates 71.50; no albuminoids ; ash, 0.93 .

Keber's Corpuscles. Oval or lens-shaped bodies present in the ova of fresh-water mussels.

Keel (kél) [AS., ceól, a ship]. In biology, a projecting ridge on a surface, as the two anterior petals of a papilionaceous corolla, or the crest of the breast-bone.

Keen's Sign. See Signs and Symptoms, Table of.

Keeper (ke'-per). See Armature.

Keere nugra. Synonym of Madura Foot.

Kefir $\left(k a^{\prime}-f e ̂ r\right)$. See Kefyr.

Kefyr ( $\left.k a^{\prime}-f \hat{e} r\right)$ [Caucasian]. A nutritious substance obtained by a peculiar fermentation of cows' milk produced by certain fungi. K.-seed, a substance containing the ferment (Bacillus caucasicus) of kefyr. It is used in preparing the genuine kefyr. See Bacteria, Synonymatic Table of.

Kehrer's Operation. See Cesarean Operation, in Operations, Table of.

Keimplasm, Keimplasma (kīm'-plazm, kìm'-plaz$m a h)$ [Ger., Keim, germ, bud; $\pi \lambda a ́ \sigma \mu \alpha$, plasm]. Weissmann's term for the hereditary transmission of a nuclear matter or germ-plasm that he believes to be passed on from generation to generation without alteration. See Germ-plasm.

Kelectome (ke'-lek-tōm) [ $[\kappa \dot{\eta} \lambda \eta$, a tumor; $\varepsilon \kappa$, out; $\tau \varepsilon \dot{ } \mu v \varepsilon v$, to cut]. A cutting instrument introduced into a tumor, by means of a cannula, in order to obtain a part of the substance for examination.

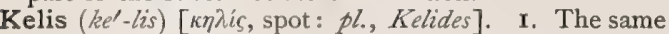
as morphea or scleroderma. 2. See Keloid.

Kellgrenism (kel'-gren-izm) [after J. H. Kellgren, I889]. A system of charlatanry that professes to cure disease by manipulation, which leads to the discharge of a "broach" of gaseous matter passing from the patient through the operator.

Kellin $\left(k e l^{\prime}-i n\right)$. A glucosid from the fruit of Ammi visnaga. It is said to affect the respiration and the pulse, and to have a paralyzant effect upon the lower extremities.

Kellner's Ocular, or Eye-piece. See Ocular.

Keloid (ke'-loid) [ $\chi \eta \lambda \hat{n}$, a claw; cidos, likeness]. Cheloid; Alibert's Keloid; Kelis. A term applied to an overgrowth of scar-tissue, and also to fibrous outgrowths of the skin of a similar character, apparently spontaneous in origin, though many of them are traceable to comparatively trifling lesions of the skin. This is a rather rare disease, and affects the colored races more than the white. It is commonest in middle age; its favorite sites are the sternum, shoulders, and neck. The lesion is crab-like in appearance, hence its name. K. of Addison, forms contractions of the skin and fascix, giving a hide-bound look to the part. It arises spontaneously at the sites of cicatrices and other injuries to the skin. See Diseases, Table of.

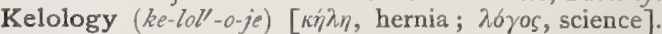
The science of hernias.

Kelotomy (ke-lot'-o-me). See Celotomy and Herniotomy.

Kelp [origin obscure]. I. Burnt sea-weed, from which iodin is obtained. 2. The Fucacea laminaria and other large sea-weeds.

Kelvin (kel'-vin) [in honor of Lord Kelvin]. A commercial unit of electricity; one thousand watt-hours.

Kemperdick's Apparatus. An apparatus for reducing the temperature in fever. It consists of a rubber bag to be introduced into the rectum having an entrancetube and an exit-tube, thus permitting a continuous flow of water.

Kempherid (kem'-fer-id) [after Kampfer, a German traveler], $\mathrm{C}_{16} \mathrm{H}_{12} \mathrm{O}_{6^{*}}$ A yellow, crystalline body obtained from the resin of Kampferia galanga.

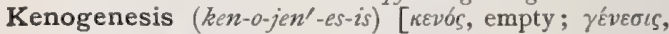
genesis]. Evolution of forms not true to the parental type, but variously adapted or modified. A vitiated individual development in which the phylogenetic evolution is not truly epitomized.

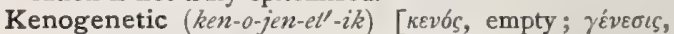
generation]. In biology, having a vitiated germhistory.

Kenogeny (ken-oj'-en-e). See Kenogenesis.

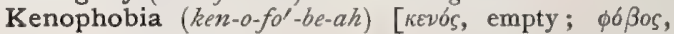
fear]. The morbid fear of open spaces or places. Same as Agoraphobia.

Kenosis (ken-o'-sis). See Cenosis.

Kenospudia (ken-o-spu'-de-ah). See Cenospudia.

Kentish Ointment. The compound resin-ointment made by adding one dram of turpentine to each ounce of the ordinary resin-ointment. It is a useful stimulating application to severe burns.

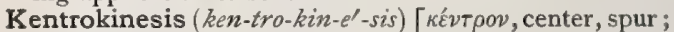
kivnos, motion]. The influence of any motor nervecenter; excito-motor action.

Kentucky Coffee-bean. See Chicot.

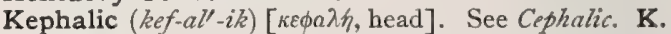
Acid. An acid described by Thudichum as existing in brain-tissue.

Kephalin (kef'-al-in). See Cephalin.

Kephalograph (kef'-al-o-graf). See Cephalograph.

Kephalometer (kef-al-om'-et-er). See Cephalometer.

Kephalo-phosphoric Acid (kef'-al-o-fos-for'-ik). See Acid.

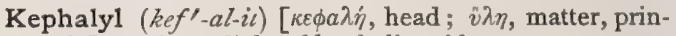
ciple]. The radicle of kephalic acid.

Kephyr (ka'-fër). See Kefyr.

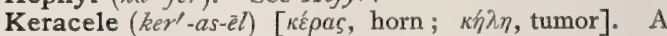
horny tumor on the hoof of horses.

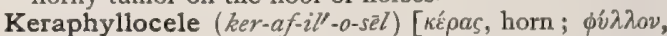
leaf; $\kappa \dot{n} \lambda \eta$, tumor]. A horny growth between the covering of the horse's hoof and the deeper tissues.

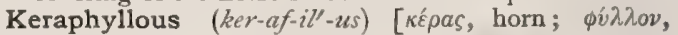
leaf ]. Composed of horny layers.

Kerasene, or Kerasin $\left(k e r^{\prime}-a s-\hat{e} n\right.$ or ker'-as-in) [ [képas, horn ], $\mathrm{C}_{46} \mathrm{H}_{91} \mathrm{NO}_{9}$. A nitrogenous substance; one of the cerebrins obtained from brain-substance.

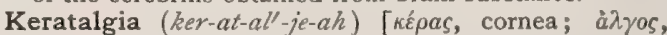
pain]. Pain in the cornea.

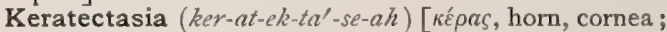

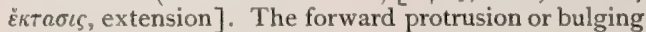
of the cornea. A bulging forward of the deeper layers 
of the cornea, after loss of the superficial lamina. It differs from staphyloma in the absence of perforation, and in the non-involvement of the iris.

Keratectomy (ker-at-ek'-to-me) [képas, horn, cornea; $\dot{\varepsilon} \kappa \tau o \mu \eta ́$, a cutting out]. Surgical excision of a part of the cornea.

Keratiasis (ker-at-i'-as-is) [képas, horn]. A morbid condition characterized by the growth of horny excrescences.

Keratic (ker-at'-ik) [képas, horn]. Horny.

Keratin (ker'-at-in) [képas, horn]. The basis of horny tissues, hair, nails, feathers, etc. It is a mixture of various complex substances. Decomposed, it yields leucin and tyrosin. It is used in pharmacy.

Keratinian (ker-at-in'-e-an) [Képas, horn]. Relating to keratin or to the cornea.

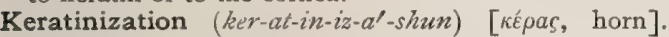
r. The development of a horny quality in a tissue. 2. The coating of pills with keratin.

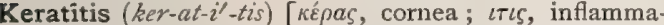
tion]. Inflammation of the cornea. K., Asthenic. See $K$., Phlyctenular. K., Astigmatic, a form of keratitis said to be due to uncorrected astigmatism. K. bullosa, the formation of large or small blebs upon the cornea of an eye, the seat of iridocyclitis, interstitial keratitis, or glaucoma. K., Circumscribed, limited to a part of the cornea. K. contagiosa, a contagious, suppurative variety occurring in cattle. K., Cretaceous, a calcareous infiltration of the corneal epithelium. K., Deep. See $K$. profunda. K., Diffuse. See $K$., Interstitial. K., Dotted. See $K$. punctata. K., Fascicular, a form of phlyctenular keratitis in which one of the ulcers, originally formed at the margin of the cornea, creeps across its surface, followed by a leash of distended blood-vessels. K., Granular, due to conjunctival granulations; pannus. K., Herpetic, characterized by the formation of small vesicles on the cornea, which ulcerate and then heal. Relapses are common. K., Hypopyon, an ulcerative form accompanied by the formation of pus in the anterior chamber. K., Inherited. See $K$., Interstitial. K., Interstitial, a form of keratitis in which the entire cornea is invested with a diffuse haziness, almost completely hiding the iris. The surface of the cornea presents a ground-glass appearance. Later, from ciliary injection, blood-vessels form in the superficial layers of the cornea, and produce a dull-red color, the "salmon patch" of Hutchinson. The entire cornea may become cherryred. The disease is most frequent between the ages of five and fifteen, and occurs in syphilitic individuals. K. maculosa. See $K$. superficialis punctata. K., Marginal, a form of phlyctenular keratitis in which the phlyctenules are arranged around the margin of the cornea. K. marginalis, a rare form of keratitis that must not be confounded with the marginal form of phlyctenular keratitis. It occurs in elderly people, and consists of a yellowish-gray zone of opacity immediately joining the sclera, which pushes into the clear cornea and occupies about one-half the circumference. K. neuroparalytica, keratitis following paralysis of the fifth nerve. It does not usually occur in partial paralysis of the nerve. Its cause is loss of trophic influence, aided by mechanical irritation and drying of the cornea. K. of Reapers, a traumatic form due to irritation of the corneæ of reapers by beards of grain. K. pannosa, a superficial form in which blood-vessels develop beneath and in the epithelium. The latter undergoes hyperplasia and becomes in part opaque. K., Parenchymatous. See $K$., Interstitial. K., Phlegmonous. See $K$. purulenta. K., Phlyctenular, a disease of the eye characterized by the formation upon some portion of the cornea of small papules or pustules, often associated with the formation of a similar lesion upon the conjunctiva. It is marked by much local congestion, lacrymation, and intense photophobia. The papules may develop into ulcers. $\mathbf{K}$. profunda, an unusual form of keratitis characterized by the formation of a gray opacity in the center of the cornea, covered by superficial and stippled corneal layers. K. punctata. I. A secondary affection of the cornea in association with affections of the iris, choroid, and vitreous. It is characterized by the formation of opaque dots, generally arranged in a triangular manner upon the posterior elastic lamina of the cornea. It is sometimes designated as Descemetitis. 2. Also a term given to an inflammatory affection of the cornea in which isolated white spots appear in Descemet's membrane, surrounded by cloudy areas. It occurs in children before puberty, and is probably syphilitic. K. purulenta, accompanied by the formation of pus. K., Pustular. See $K$., Phlyctenular. K., Rheumatic, occurring in a rheumatic subject. K., Ribbon-like, a name applied to the formation of a transverse calcareous film on the cornea, especially in elderly people. It is usually symmetric, and occurs chiefly in men of the gouty diathesis. K. scrofulosa. See $K$., Interstitial. K., Secondary, due to disease of other parts. K., Specific. See $K$., Interstitial. K., Strumous. See $K$. Phlyctenular, and $K$., Interstitial. K. subepithelialis centralis. See $K$. superficialis punctata. K. superficialis punctata, a disease of the cornea associated with severe conjunctivitis and with catarrh of the respiratory tract. In two or three days punctiform or linear spots appear immediately beneath the epithelium, the overlying conjunctiva being slightly hazy. It is also called $K$. subepithelialis centralis, and $K$. macuelosa. K. suppurativa. See $K$. purulenta. K., Sympathetic, that following inflammation of the other eye. K., Syphilitic. See $K$., Interstitial. K. tænulosa. See $K$., Phlyctenular. K., Trachomatous. See Pannus. K., Traumatic, that consequent upon wounds or other injury of the cornea. $\mathbf{K}$. ulcerosa, a form in which one or more ulcers involving part of the cornea are present. $\mathbf{K}$. variolosa, that occurring in smallpox. It is purulent and often arises from a corneal pustule. K., Vascular, a superficial vascularity of the cornea occurring in pannus, etc. K., Vesicular. See $K$., Phlyctenular.

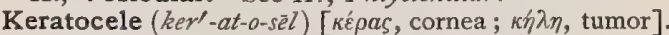
A hernia of Descemet's membrane through the cornea.

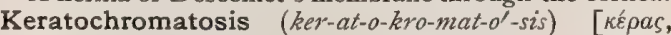
horn; $\chi \rho \tilde{\omega} \mu a$, color]. Discoloration of the cornea.

Kerato-conjunctivitis (ker'-at-o-kon-junk-tiv-i'-tis)

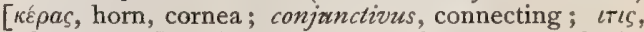
inflammation]. Simultaneous inflammation of the cornea and the conjunctiva.

Kerato-conometer (ker-at-o-ko-nom'-et-er) [ќ́ $\rho a \zeta$,

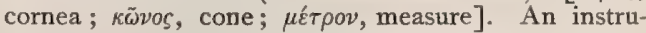
ment for estimating astigmatism by the images reflected from the cornea.

Keratoconus (ker-at-o-ko'-nus). See Keratoglobus.

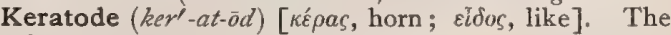
horny substance composing the skeleton of certain sponges.

Keratodeocele (ker-at-od"-e-o-sêt). See Keratocele.

Keratodeonyxis (ker-at-od-e-o-niks'-is). See Keratonyxis.

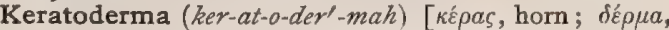
skin]. I. The cornea. 2. A horny condition of the skin.

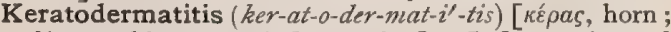
$\delta \varepsilon \rho \mu a$, skin; $\iota \tau \iota \varsigma$, inflammation]. Inflammation of the keratoderma; keratitis. 


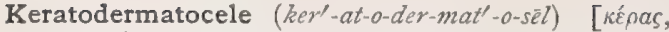
horn; $\delta \dot{\varepsilon} \rho \mu \alpha$, skin; $\kappa \eta \dot{\lambda} \eta$, tumor]. See Keratocele.

Keratodermatomalacia (ker'-at-o-der-mat-o-mal-a'-se-

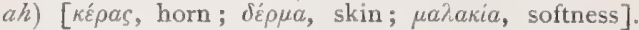
Softening of the cornea.

Keratodermatosis (ker-at-o-der-mat-o'-sis) [ $[\kappa \varepsilon \rho a s$,

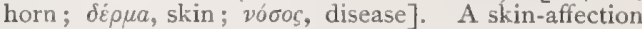
characterized by alteration in the horny elements of the skin.

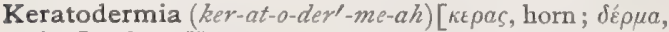
skin]. See Keratoderma. K. erythematosa symmetrica, tylosis of the soles and palms, in which the horny patches show a broken-up surface.

Keratodermites (ker-at-o-der-mi'-tēz) [Képas, horn; $\delta \varepsilon ́ p \mu a$, skin; $\iota \tau \iota s$, inflammation]. A group of inflammatory scaly skin-affections.

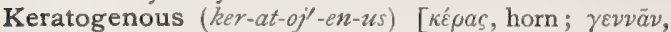
to beget]. Pertaining to the formation of horny growths. K. Membrane, that part of the skin or layer of corium that develops into nails, claws, and hoofs.

Keratoglobus (kcr-at-o-glo'-bus) [képas, cornea; globus, a ball]. Distention and protrusion of the cornea. The sclerotic may also become distended in severe cases. When so extensive as to prevent closure of the lids, it has been called buphthalmos. When the distention is transparent, regular, and cone-shaped, the apex of the cone being the center of the cornea, it is called keratoconus, or conical cornea. When the protrusion is opaque, or connected with synechia of the iris, it is called staphyloma of the cornea, or anterior staphyloma. When due to increase in the fluids of the eye, with increased tension and uniform ectasia, it is called hydrophthalmos. Enlargement of the cornea is also called megalo-cornea.

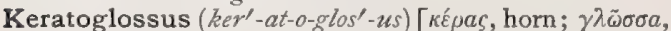
tongue]. See Muscles, Table of.

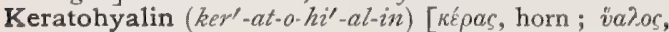
glass]. A peculiar substance occurring in granules in the deeper layers of the skin. These granules are insoluble in ether, alcohol, and water, and are present in the process of cornification of the rete cells. See also Eleidia.

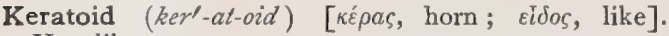
Hornlike.

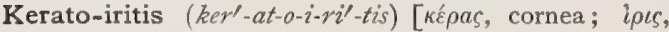
iris ; $\iota \tau \iota s$, inflammation]. Combined inflammation of the cornea and the iris.

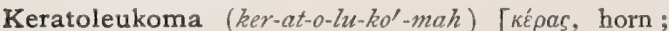
$\lambda \varepsilon v \kappa o ́ s$, white: pl., Keratoleukomata]. A leukoma or whitish opacity of the cornea.

Keratolysis (ker-at-ol'-is-is) [képas, horn; $\lambda \dot{v} \sigma \iota s$, solution]. Deciduous skin; a curious and rare condition of the skin in which the latter, like the serpent's, is cast off periodically, that of the limbs coming off like a glove or a stocking.

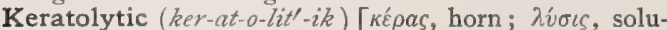
tion]. Pertaining to keratolysis.

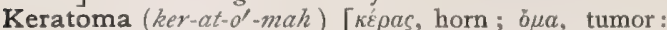
pl., Keratomata]. 1. See Callositas. 2. Congenital ichthyosis; the presence, dating from fetal life, of horny plates upon the integument.

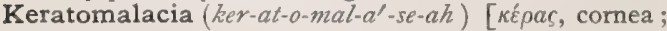

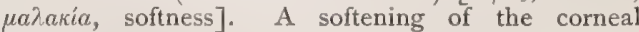
tissue.

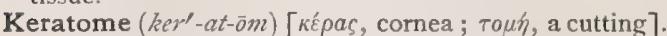
A knife with a peculiar trowel-like blade, used for making the incision into the cornea in the operation of iridectomy.

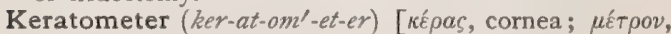
measure]. An instrument for measuring the curves of the cornea.
Keratomycosis (ker-at-o-mi-kó-sis) [képas, cornea;

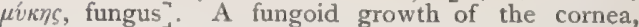
or the diseased condition therewith associated. K. aspergillina, a form characterized by the presence of Aspergillus glaucus.

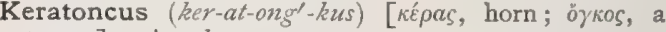
tumor]. Any horny tumor.

Keratonosis (ker-at-on'-o-sis). See Keratosis.

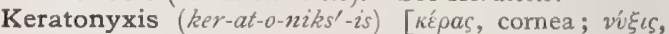
needling]. Tl c needling of a soft cataract by puncture through tha cornea; also, the old operation of couching a cataruct with the needle.

Keratoplasia (ker-at-o-pla'-ze-ah) [ [képas, horn; $\pi \lambda a ́ \sigma-$ $\sigma \varepsilon \imath$, to form $]$. The reparative renewal of the horny layer of the skin.

Keratoplastic (ker-at-o-plas'-tik) [képas, horn; $\pi \lambda a \sigma \tau t-$ $\kappa \delta \varsigma$, formed]. Pertaining to keratoplasty.

Keratoplasty (ker'-at-o-plas-te) [képas, cornea; $\pi \lambda a ́ \sigma-$ $\sigma \varepsilon \iota v$, to form]. Hlastic operation upon the cornea, especially the transplantation of a button or excised portion of cornea from the eye of a lower animal to that of man. This is effected by means of a peculiar trephine, with which the tissue to be transplanted is removed from the animal's eye and the place for its reception is made in the human eye. The operation is sometimes called trephining the cornea.

Keratorrhexis (ker-at-or-eks'-is) [képas, horn; $\dot{\rho} \bar{\eta} \xi \iota$, rupture]. Rupture of the cornea, due to ulceration or traumatism.

Keratoscleritis (ker-at-o-skle-ri'-tis) [Képas, cornea; $\sigma \kappa \lambda \eta \rho \sigma s$, hard ; $\iota \tau / \zeta$, inflammation]. Inflammation of the cornea and the sclera.

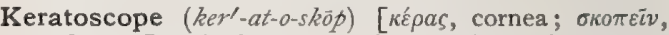
to observe]. An instrument for examining the cornea, and testing the symmetry of its meridians of curvature.

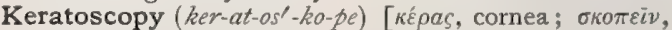
to observe]. Examination of the cornea. See Retinoscopy.

Keratose (ker'-at-ōs) [képac, horn]. Horny.

Keratosis (ker-at-o'-sis) [képas, horn; vóбos, disease]. Any one of a class of skin-diseases characterized by thickened epidermis, and the presence of such callosities as horns, warts, etc. See Callosity. K. follicularis. See Darier's Disease. K. obturans, a condition of the external auditory meatus due to desquamation of the epithelium, the mass being colored by cerumen and containing cholesterin-crystals. K. pilaris, Lichen pilaris; Lichen spinulosus ; Pityriasis pilaris ; a chronic affection of the skin markef by a pin-head-sized conical elevation investing the hair-follicle, and somewhat resembling gooseflesh and ichthyosis. The skin becomes dry and hard, and feels like a nutmeg-grater. The disease appears in workingmen who are uncleanly, and in scrofulous children, and it occurs chiefly on the thighs, arms, and forearms. K. senilis, a cornification of the skin of old people, general or partial, circumscribed or diffuse, and often limited to certain definite regions, as the face and dorsal surfaces of the hands and feet. The lesions consist of light or dark yellowish, brownish, or blackish points, dry, scaling, and horny, or scaling and greasy. These may become the seat of an epitheliomatous process.

Keratotome (ker'-at-o-tom). See Keratome.

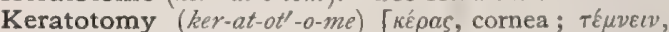
to cut]. Surgical incision of the cornea.

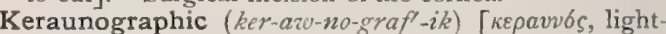
ning; $\gamma \rho a ́ \phi \varepsilon \iota v$, to write]. Pertaining to the pictorial impressions of near objects sometimes seen upon the body of a person who has been struck by lightning.

Keraunoneurosis (ker-aze-no-nu-ro'-sis) [kepavvós, lightning; veṽoov, nerve; vóбos, disease]. Nervous disease due to lightning-stroke. 
Keraunophobia (ker-aw-no-fo'-be-ah) [кعрavvós, lightning; $\phi \delta \beta \circ \varsigma$, dread]. Morbid dread of lightning; astrapaphobia.

Kerectasia (ker-ek-ta'-se-ah). See Keratectasia.

Kerectomy (ker-ek'-to-me). See Keratectomy.

Kerion, or Kerium ( $k e^{\prime}-r e-o n$ or $\left.k e^{\prime}-r e-u m\right)$ [knoiov, honey-comb favus]. Same as Favus.

Kerkring, Valves of. See Valve.

Kermes (ker'-méz) [Pers., qirmiz, crimson]. A red dye-stuff, made up of the dried females of Coccus ilicis, an insect not unlike cochineal, fround on oak-trees in the Orient. K. Mineral, a mixture of the teroxid and tersulphid of antimony, formerly much used in medicine. It is also called red antimony.

Kermesine (ker'-mēz-in) [Pers., qirmiz, crimson]. Pertaining to kermes.

Kermesite (ker'-mēz-ìt) [Pers., qirmiz, crimson]. The native oxysulphid of antimony.

Kermisin (ker'-miz-in) [Pers.', qirmiz, crimson]. Carmin-red.

Kernel (ker'-nel) [ME., kirnel, a little corn or grain]. I. The popular name for the pancreas or sweetbread of animals. 2. The bundle of fat on the fore-shoulder; any swelling or mass of flesh. 3. A nucleus. 4. In the plural, a popular term for enlarged lymphatic glands. 5. In biology, the edible portion of a drupe or an entire seed.

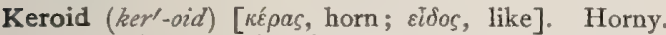
Kerosene (ker'-o-sèn). See Burning oil.

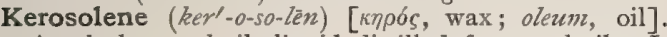
A colorless, volatile liquid distilled from coal-oil. It boils at $58^{\circ} \mathrm{C}$. and has been used as a local anesthetic. Unof.

Kessel's Operation. See Operations, Table of.

Ketin $\left(k e t^{\prime}-i n\right), \mathrm{C}_{6} \mathrm{H}_{8} \mathrm{~N}_{2}$. I. An oily substance, boiling between $170^{\circ}$ and $180^{\circ} \mathrm{C}$. 2. A member of a homologous series, $\mathrm{CnH}_{2} \mathrm{n}-{ }_{4} \mathrm{~N}_{2}$, produced by the action of sodium (or tin) and hydrochloric acid on nitrosoacetone and its homologues. Diethylketin, $\mathrm{C}_{10} \mathrm{H}_{16}$ $\mathrm{N}_{2}$, is an oily substance, boiling at from $215^{\circ}$ to $217^{\circ}$ C. ; it is formed by the reduction of nitrosoethylacetone. Dimethylketin is a crystalline solid, soluble in ether, fusing at $87^{\circ} \mathrm{C}$, and produced by the reduction of nitrosomethylacetone. Dipropylketin, $\mathrm{C}_{12} \mathrm{H}_{20} \mathrm{~N}_{2}$, is an oily substance, boiling between $235^{\circ}$ and $240^{\circ} \mathrm{C}$., and formed in the reduction of nitrosopropylacetone.

Ketols (ke'-tolz). In chemistry, ketone-alcohols, containing both the ketone and alcohol groups.

Ketone $\left(k \ell^{\prime}-t o ̈ n\right)$ [an arbitrary variation of acetone]. In chemistry, an organic compound consisting of the unsaturated radicle $=\mathrm{C}=\mathrm{O}$ united to two alcohol radicles. It may be considered as a derivative of secondary alcohols, bearing the same relation to them as the aldehyds bear to the primary alcohols. The ketones are compounds in which two hydrogen atoms of an intermediate carbon atom are replaced by one atom of oxygen. They are generally volatile liquids, of ethereal odor, insoluble in water. They are the products of the oxidation of the secondary alcohols, or of the union of carboxyl, $\mathrm{CO}$, with two alkyl atoms.

Ketonic $\left(k e-t^{\prime} n^{\prime}-i k\right)$ [ketone]. Pertaining to ketone.

Ketoses (ke-to'-ses). In chemistry, a generic name applied to the ketone alcohols, $\mathrm{CO} . \mathrm{CH}_{2} \cdot \mathrm{OH}$.

Ketoxims (ke-toks'-imz). Same as Acetoxims.

Kettle (ket'-l) [ME., ketel, a kettle]. A vessel made of metal, used for heating liquids. K., Bronchitis. See $K$, Croup. K., Croup, a contrivance for the inhalation of heated moist air, which may be medicated. Shaw's croup-kettle consists of an alcohol-lamp and a vessel fitted with a long tube, by means of which the steam is directed downward when the mouth-piece is introduced far back into the mouth.

Key $(k e)$ [ME, keye, key]. An instrument for opening or fastening a lock. K.-forceps, Elliot's ; two instruments are so called, the one having beaks of forceps and the handle of a key, for the extraction of teeth; the other is designed for the extraction of roots of teeth that present but one side above the alveolus. They are now but little used. K. of Garengeot, an instrument for the extraction of teeth, composed of a shank with a movable clasp and a cross-bar. The clasp is applied to the inner surface of the tooth, and the extraction is accomplished by turning the handle. K., Tooth. See $K$. of Garengeot.

Key and Retzius, Foramina of. Two foramina at the extremities of the lateral recesses of the fourth ventricle behind the upper roots of the glosso-pharyngeal nerves. They connect the cisterna magna with the fourth ventricle.

Kiafer $\left(k i^{\prime}-a f-e r\right)$. See Kefir.

Kibbie's Method. See Treatment, Methods of.

Kibe $(k \bar{i} b)$. See Chilblain.

Kidinga pepo (kid-in'-gah pe'-po) [African]. A name applied in Zanzibar to a disease resembling dengue.

Kidney (kid'-ne) [ME., kid, the belly; nere, kidney]. One of the two large glandular organs situated in the upper and posterior portion of the abdominal cavity,

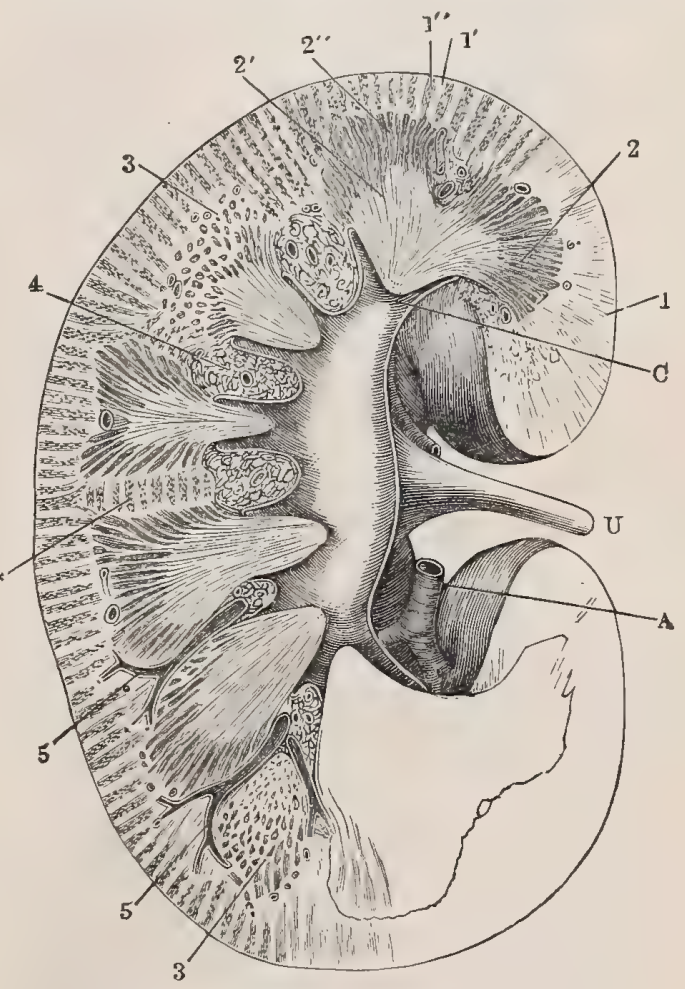

LoNGITUdinal SECTION THROUGH THE KIDNEY. (Tyson, after Henle.)

$2^{\prime \prime}$. Boundary layer of medulla. $2^{\prime}$. Papillary portion of medulla. 3, 3. Transverse section of tubules in boundary layer. 4. Fat of renal sinus. *. Transversely coursing medullary rays. 5, 5. Artery, I'. Labyrinth. I'. Medullary rays. 2. Medulla. I. Cortex, C. Renal calyx. U. Ureter. A. Branch of renal artery.

and especially concerned in the elimination or excretion of water and nitrogenous matter. It consists. 
of an outer cortical substance, and an inner medullary substance. In biology, the term is applied to the "contractile vacuole" of a protozoan, the "segmental organ " or "nephridium" of an annelid, the "glandular organ" of a nematode worm, the "Malpighian tubules " and "shell-gland" of an arthropod, and the "organ of Bojanus" of a mollusc. K., Aching, a mild subacute nephritis characterized by pain, anemia, albuminuria, and irritability of the bladder, with exacerbations at menstrual periods. K., Amyloid, that of amyloid degeneration. K., Arterio-sclerotic, the small, sometimes granular organ characterized by arterio-sclerosis. K., Branny, applied to the branlike appearance of the kidney seen in the early stages of chronic parenchymatous nephritis, due to fatty degeneration occurring in spots. K., Bright's Disease of. See Bright's Disease. K., Calices of, six to twelve membranous canals surrounding the papillæ of the kidney, and opening into the three infundibulæ. K., Cicatricial, the final result of the so-called "surgical kidney." It is produced by the absorption of the ab-

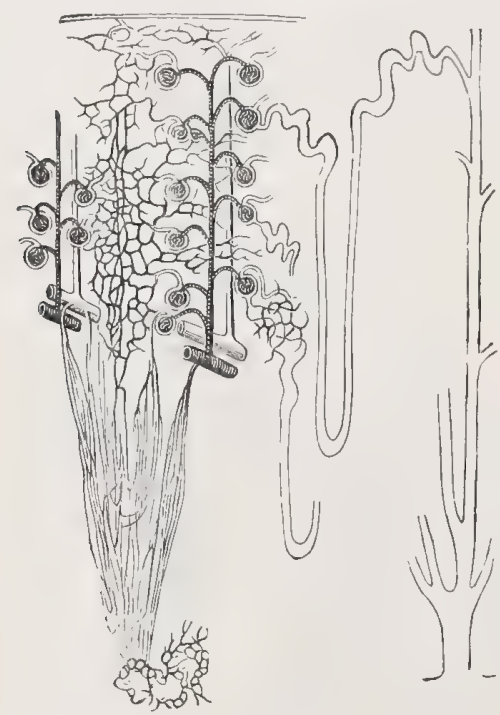

DIAGRAM SHOWING THE RELATION BORNE BY THE BLOODVESSELS TO THE TUBULES OF THE KIDNEY.

The upper half corresponds to the cortical, the lower half to the medullary part of the organ. The plain tubes are shown separately on the right, and the vessels on the left. The darkly shaded arteries send off straight branches to the pyramids and larger interlobular branches to the glomeruli, the efferent vessels of which form the plexus around the convoluted tubes.

scesses and the formation of cicatrices, and by the still further contraction of the increased interstitial tissue. The kidney is small, irregular, and fibrous. K., Cirrhotic. Same as $K$., Anterio-sclerotic, $q . v$. K., Contracted. Same as $K$., Arterio-sclerotic, q. $v$. K., Embolic Contracted, one the seat of a scar the result of an infarct. K., Fatty, one the seat of extensive fatty degeneration. K., Floating, one susceptible of displacement over a considerable extent of the abdomen. This condition is more frequent in females, and in the majority of cases is situated on the right side. It has been suggested that the term "floating kidney" be reserved for those cases in which a distinct mesonephron is present, and that all other cases be designated by the term "movable kidney." K., Gouty. Same as $K$.,
Arterio-sclerotic, q. v. K., Granular. Same as K., Arterio-sclerotic, q. $v$. K., Head, the pronephron. K., Hilum of. See Hilum. K., Hobnail. Same as $K$., Arterio-sclerotic, $q . v$. K., Horseshoe, a congenital deformity in which the two kidneys are joined together, generally at the lower, but occasionally at the upper end, by a connecting band, composed either of true renal substance or of firm fibrous tissue. K., Lardaceous. Same as $K$, Amyloid, q. v. K., Large Mottled, that of parenchymatous nephritis, mottled with gray patches. K., Large Red, the kidney of Bright's Disease extravasated with blood. K., Large White, one affected with lardaceous degeneration; also, that of the advanced stage of chronic parenchymatous nephritis. K., Microcystic, one containing many small cysts. K., Movable. See $K$., Floating. $\mathbf{K}$. of Pregnancy, is described as an anemic kidney with fatty infiltration of the epithelial cells, but without any acute or chronic inflammation, occurring in pregnant women. It is possibly due to a diminution of the blood-supply from tonic contraction of the renal arteries, produced by the presence of effete matter in the blood. Albumin is found in the urine. K., Palpable. See K., Floating. K., Pelvis of, the funnel-shaped expansion or dilated portion of the ureter formed by the junction of the infundibula. K., Pigback, a name proposed for the large congested kidney found in alcoholics. K.-plant, the Baccharis pilularis. K., Primordial, the meso-

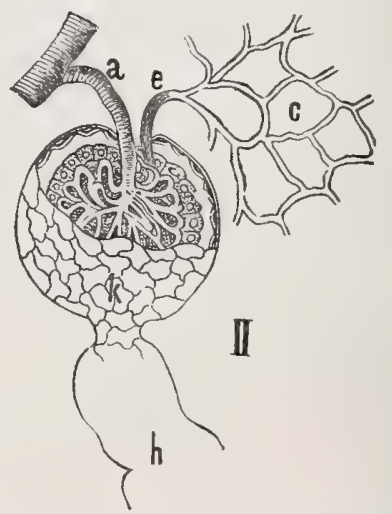

Bowman's CAPSUle and Glomerulus.

a. Vas afferens. e. Vas efferens. $c$ Capillary network of the cortex. $k$. Endothelium of the capsule. $h$. Origin of a convoluted tubule. (Landois.)

nephron. K., Red Contracted. Same as $K$., Arteriosclerotic, q. $v$. K.-root, the root and lower part of the stem of Baccharis pilularis; used in cystitis. Unof. K., Scrofulous, one affected with tuberculous disease, in which the kidney-substance is largely destroyed, nothing being left but a sac with thickened fibrous walls, filled with a yellow creamy or putty-like material containing fatty masses, cholesterin, tuberculous débris, and occasionally calcareous matter. K., Sigmoid, a congenital anomaly intermediate between the horseshoe form and complete fusion. K., Small Red Granular. Same as $\bar{K}$., Arterio-sclerotic, q. $v$. K., Small White, the final stage of the large white kidney after loss of its substance from atrophy or degeneration. K., Spotted. Same as $K$., Large Mottled. K., Surgical, a name sometimes given to pyelonephritis, or distention of the kidney attended with inflammation, abscesses of the cortex, and retention of urine mixed with fetid pus. K., Syphilitic, one presenting either gummata or resulting scars. 
K., Unsymmetric, a term given by Rokitansky to a kidney that is normal in position and conformation, though occasionally rather enlarged, its fellow being deficient. K., Wandering. See $K$., Floating. K., Waxy. Same as $K$, Amyloid. K.-worm. See Thread-worms and Parasites (Animal), Table of.

Kiestine $\left(k i-e s^{\prime}-t i n\right)$. See Gravidin. K. Test. See Gravidin Test.

Kif [African]. An Algerian mixture, the principal ingredient of which is Cannabis indica. Also, the dreamy state induced by the use of hashish.

Kilian's Line. See Lines, Table of. K.'s Pelvis, a halisteretic pelvis; a pelvis the seat of osteomalacia.

Killosis (kil-o'-sis). Synonym of Strabismus.

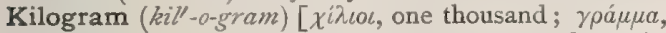
a gram]. One thousand grams, or 2.2 pounds avoirdupois.

Kilogrammeter (kil'-o-gram-êt'-er) $\left[\chi^{i} \lambda \iota\right.$, one thou-

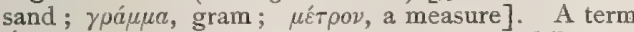
denoting the energy required to raise one kilogram one meter in height; equivalent to 7.233 foot-pounds.

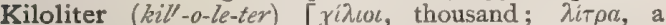
liter]. One thousand liters, or 35.31 cubic feet.

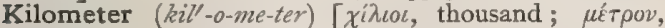
measure]. One thousand meters, or 1093.6 yards.

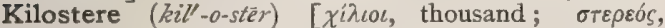
solid]. One thousand cubic meters.

Kilowatt (kill-o-zvot) [ $\chi^{i} \lambda$ col, thousand; zvatt]. One thousand watts of electricity; same as the kelvin.

Kin [ME., kin, kin]. Race; family; breed; kind; relationship.

Kina, or Kino-kina ( $k i^{\prime}-n a h$ or $\left.k i^{\prime}-n o-k i^{\prime}-n a h\right)$. Cinchona bark, $q . v$.

Kinæsthesia (kin-es-the'-ze-ah). See Kinesthesia.

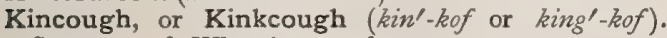
Synonym of Whooping-cough.

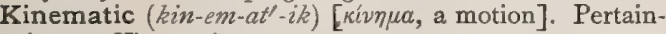
ing to Kinematics.

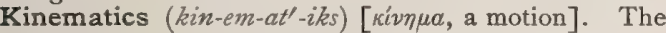
science of motion without reference to its origin or effects.

Kinepock $\left(k i n^{\prime}-p o k\right)$. Synonym of Vaccinia, q. $v$.

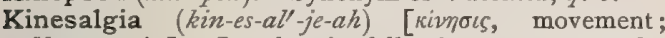
ànyos, pain]. Local pain following upon muscular contraction.

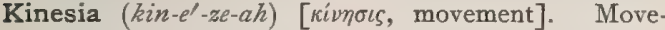
ment-cure; systematic use of motion for therapeutic or hygienic purposes.

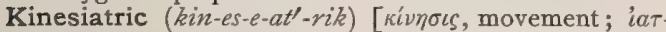
pıkós, therapeutic]. Relating to kinesitherapy.

Kinesiatrics (kin-es-e-at'-riks). Same as Kinesitherapy.

Kinesic $\left(k i n-e z^{\prime}-i k\right)$. See Kinetic.

Kinesiesthesiometer (kin-ez-e-es-the-ze-om'-et-er)

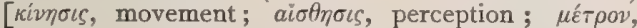
measure ]. An instrument devised by Hitzig for testing the muscular-sense. It consists of seventeen wooden balls of the same diameter, but of different weights.

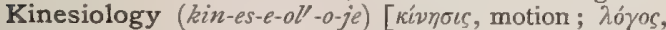
discourse]. The science of movements, considered especially as therapeutic or hygienic agencies.

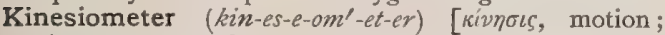
$\mu \varepsilon ́ \tau \rho o \nu$, measure]. An instrument for determining quantitatively the motion of a part.

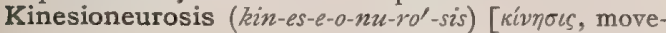

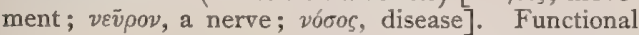
abnormalism of the motor centers or nerves.

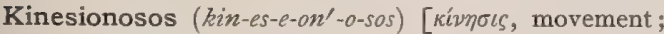
vóoos, disease]. Any disease marked by impairment of the power of motion.

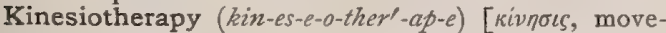
ment; $\theta \varepsilon \rho a \pi \varepsilon i \alpha$, therapy]. The treatment of disease by systematic active or passive movements.

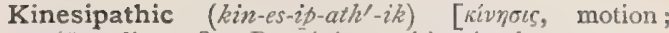
$\pi a ́ t o s$, disease ]. Pertaining to kinesipathy.

Kinesipathist (kin-es-ip'-ath-ist) [kivnors, motion; $\pi a ́ \theta 0 s$, disease]. One who practises the gymnastic treatment of disease.

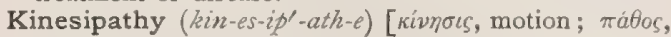
disease]. I. Kinesionosos. 2. (Incorrectly) kinesitherapy.

Kinesis (kin-e'-sis) [kivnous, motion]. The general term for all the physical forms of energy, as opposed to Metakinesis, a term intended to express the psychologic exhibition of coördinates or correlates of kinesis. According to a monistic conception of the universe, both are the double aspects of one underlying reality.

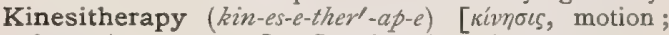
$\theta \varepsilon \rho \alpha \pi \varepsilon i a$, care, cure]. See Sruedish Movements.

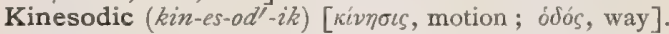
Pertaining to those nerve-fibers conveying motor influences. Also, the motor tracts of the nerve-system.

Kinesotherapy (kin-es-o-ther'-ap-e). Same as Kinesitherapy.

Kinesthesia kin-ez-the'-ze-ah). Same as Kinesthesis.

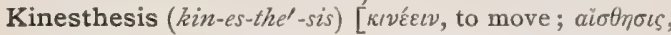
sensation]. That quality of sensations whereby one is aware of one's positions and movements, especially those of the automatic type; it is distinct from the muscular sense.

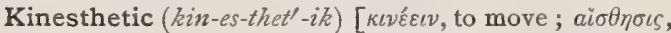
sensation.] Relating to kinesthesia.

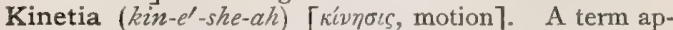
plied to all forms of motion-sickness. It includes such disorders as sea-sickness and car-sickness.

Kinetic $\left(k i n-e t^{\prime}-i k\right)$ [ [ $\iota \eta \eta \tau \iota k \delta s$, producing motion]. That which produces motion. Pertaining to those forces that produce motion.

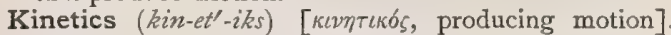
The science of force as developing motion.

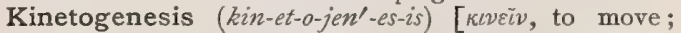

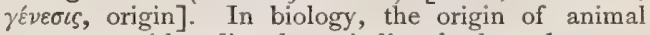
structures, either directly or indirectly through movements.

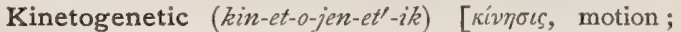

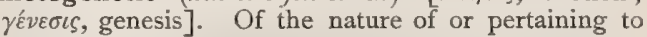
kinetogenesis.

Kinetogenetically (kin-et-o-jen-et'-ik-al-e) [kuveiv, to

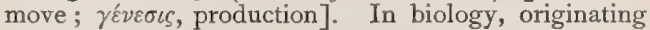
through movement.

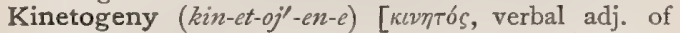

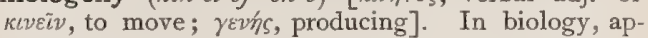
plied to the agency of that energy developed in the motions of organisms and their parts, in the modification of the forms and proportions of their hard parts.

King's Blue. Same as Smalts. K.'s Evil, a name formerly popularly applied to scrofula, on account of a belief that it could be cured by the touch of the king. K.'s Yellow. See Orpiment, and Pigments, Conspectus of.

Kinic Acid (kin'-ik). See Acid, Quinic.

Kink (kingk) [D., kinken, cough]. I. The whoop in whooping-cough, 2. A synonym of whooping-cough. 3. A flexion or a twist. K.-cough, a synonym of whooping-cough. $\mathbf{K}$.-host, a synonym of whoopingcough. See Pertussis.

Kino $\left(k i^{\prime}-n o\right)$ [E. Ind.]. The inspissated juice of Pterocarpus marsupium, found in India, and similar in action to tannic acid ; it is used mainly as a constituent of gargles and diarrhea-mixtures. K., Tinct., Io per cent. of the drug. Dose $m x-3$ ij. K., Pulv., Comp. (B.P.), kino I5, opium I, cinnamon 4. Dose gr. $\mathrm{v}-\mathrm{xx}$. Various similar substances are called by this name. K., Jamaica, is produced by the tree Coccoloba unifera. See Coccoloba. K., Australian, is 
obtained from various species of Eucalyplus. K., Butea, from Butea frondosa. K.-red. See Kinoic Acit. K.-tannic Acid, a variety of tannic acid found in kino.

Kinoic Acid (kin-o'-ik), [E. Ind, kino], $\mathrm{C}_{28} \mathrm{H}_{22} \mathrm{O}_{11}$. A red, amorphous substance, a derivative of kinoin.

Kinoïn $\left(k i-n o^{\prime}-i n\right)$ [E. Ind., kino], $\mathrm{C}_{14} \mathrm{H}_{12} \mathrm{O}_{6}$. A material derived from kino, slightly soluble in water and in alcohol.

Kinometer (kin-om'-et-er) [ [ $\iota v \varepsilon \varepsilon \varepsilon v$, to put in motion; $\mu \varepsilon$ t ${ }^{\prime} \nu$, measure]. An instrument to measure the amount of displacement of the uterus in case of tumor or celiular inflammation of the pelvis.

Kinone (kin'-ön). See Quinone.

Kinovin (kin'-o-vin). See Quinovin.

Kionitis (ki-on-i'-tis). Same as Staphylitis.

Kionorrhaphy $\left(k i-o n-o r^{\prime}-a f-e\right)$. Same as Staphylorrhaphy.

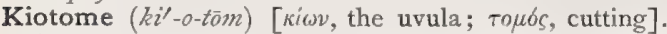
An instrument for amputating the uvula, or for dividing strictures of the bladder or rectum.

Kipp's Apparatus. An apparatus for generating sulphuretted hydrogen by acting upon sulphid of iron with $\mathrm{H}_{2} \mathrm{SO}_{4}$

Kips (kips). See Hides.

Kirchhoff's Laws. See Law. K.'s Lines. See Lines, Table of.

Kirchner's Experiment. See Experimentum mirabile. K., Micrococcus of. See Bacteria, Synonymatic Table of.

Kirkland's Cerate. - A cerate composed of leadplaster, I6 parts; olive-oil, chalk, and vinegar, each 8 parts; Goulard's extract, I part. It is used in the same conditions as is Goulard's cerate.

Kirschley Green. Same as Schweinfurth Green.

Kirschwasser (kirsh'-vos-er) [Ger.]. A spiritous liquor obtained in Germany and Switzerland by the distillation of cherries. It is colorless, of agreeable odor and flavor, which improves by keeping, and is equal in strength to the strongest spirit; it is called, also, Spiritus cerasorum.

Kisch's Method. See Treatment, Methods of.

Kissing Muscle. See Muscles, Table of.

Kissingen Salts (kis'-ing-en) [Ger.]. Effervescing salts from the mineral springs of Kissingen. K. Water, a laxative tonic mineral-water of Bavaria.

Kistotome (kis'-to-tōm). See Cystotome.

Kite-tail Plug. A tampon used in controlling uterine hemorrhage. It is made by tying rolls of cotton to a string at intervals, the whole resembling a kite-tail.

Kitsune-tsuki (kit'-sün-tsu'-ki) [Jap.]. A Japanese form of zoanthropy, or neuropathic delirium, in which the patient (usually a woman or child) believes herself inhabited by a living fox, cat, or badger.

Kiwisch's Method. A method of inducing premature labor by injections of hot water into the vagina.

Kjeldahl's Method. See Nitrogen.

Klærophthalmus (klär-off-thal'-mus). See Embryotoxon.

Klang [Ger.]. See Timbre.

Klaprothium (klap-ro'-the-um). Same as Cadmium, $q . v$.

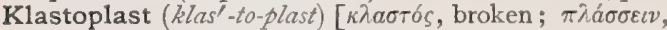
to form]. A cell formed by the partial segmentation of the ovum of Cephalopoda.

Klatsch-preparation (klotch-prep-ar-a'-shun) [Ger., Klatschpräparat]. A cover-glass preparation made by pressing the cover-glass lightly on a bacterial colony in plate-culture.

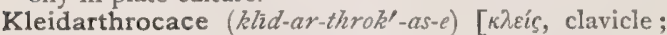

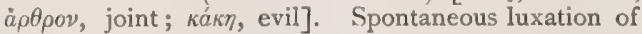
the clavicle.

Klein's Fluid. See Stains, Table of.

Kleinenberg's Fibers. The primary form of nerve, of solely internuncial function. K.'s Hematoxylin Solutions. See Stains, Table of.

Kleinhovia (klin-ho'-ve-ah) [after Kleinhof, director of the Botanic Gardens at Batavia, Java]. A genus of sterculiaceous trees. $K$. hospita, a plant belonging to the Helicterex, found in the islands of the Indian Ocean. The leaves have been used to darken the cornea; their juice causes itching. Unof.

Kleistian Jar (khis'-te-an). Same as Leyden Jar.

Klemperer's Method. A method of ascertaining the condition of gastric peristalsis. It consists in the in troduction, by the tube, into the empty stomach of 100 grams of olive-oil, and removing by aspirating with water what remains after two hours. As oil is not absorbed from the stomach, the difference between the amount introduced and that withdrawn indicates the activity of gastric peristalsis. The oil is taken up from the water with ether, and the ethereal solution placed in a bulb, the weight of which is known. The weight of the oil is calculated after evaporation of the ether.

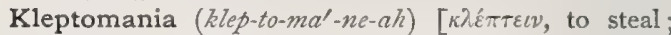
pavia, madness]. A form of emotional insanity manifested by a morbid desire to commit theft. It is sometimes accompanied by impaired intellect, and is often hereditary.

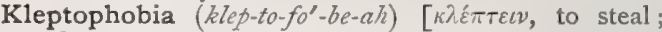
$\phi 6 \beta$ s, fear]. A morbid dread of thieves.

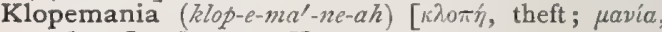
madness]. Same as Kleptomiania.

Klopsophobia (klop-so-fo'-be-ah) $[\kappa \lambda \omega \psi$, thief; $\phi b \beta o s$, fear]. Insane dread of thieves. Same as Kleptophobia.

Klumene $\left(k l u^{\prime}-m e \bar{n} n\right)$. Same as Acetylene.

Knapp's Reagent. A reagent for the detection of sugar in the urine. It consists of cyanid of mercury and an alkali.

Knapweed (nap'-wed). See Centaurea.

Kneading (ne'-ding) [ME., kneden, to knead]. The same as Pétrissage, q.v. See also Malaxation.

Knee (ne) [ME, kne, knee]. The articulation between the femur and the tibia. See also Genu. K.-aching Disorder. Synonym of Densue. K.-cap, the patella. K.-chest Position. See Postures, Table of. K. of Corpus Callosum, the anterior extremity of the corpus callosum. See Genu. K.-elbow Position. See Postures, Table of. K. of Facial Nerve, the point at which the nucleus of its origin winds around that of the abducens nerve. K., Housemaid's. See $A b$ scess, Bursal. K., Hysteric, a painful functional affection of the knee-joint in hysteria. K., In. See Genu valgum. K. of Internal Capsule, the angle of junction of the anterior and posterior limbs of the internal capsule. K.-jerk, Patellar Tendon-reflex, K.-reflex, or K.-phenomenon, a retraction of the quadriceps extensor femoris muscle as a result of a light blow on the patellar tendon. See also Reflexes, Table of. K.-joint, a hinge-joint consisting of the articulation of the condyles of the femur with the upper extremity of the tibia and the posterior surface of the patella. K.-joint Disease. See White Sruelling. K., Knock. See Genu. K., Lawn-tennis, an affection occurring in tennis-players, probably due to a contusion or laceration of the internal semilunar cartilage. K., Out. See Genu varum. K.-pan, the patella.

Kneel (nél) [ME., knelen, to kneel]. To rest upon the knees.

Kneeling (nèl'-ing) [ME., knelen, to kneel]. Resting upon the knees. K.-squatting Position. Sec Postures, Table of.

Knies and Weber's Theory. A theory as to the origin of glaucoma. It claims that glaucoma is due to 
retention of an excess of fluid in the eye, from closure of the canal leading through the pectinate ligament into Schlemm's canal.

Knife (nif) [ME., knif, knife]. An instrument for cutting. In surgery, knives are of various shapes and sizes, according to their use. K.-needle, a needle with a cutting edge, used in the discission of cataracts.

Knitter's Cramp (nit'-erz kramp). See Cramp.

Knitting (nit'-ing) [ME., knitten, to knit]. The union and becoming rigid of a fracture.

Knob (nob) [ME., knobbe, a knob]. A protuberance. K.-root. See Collinsonia canadensis.

Knock-knee (nok'-ne). See Genu valgum.

Knoppern (knop'-em) [Ger.]. Galls from immature acorns of several species of oak, largely used in Austria for tanning. They contain from twenty-eight to thirty-five per cent. of tamnin.

Knot (not) [ME., knotte, a knot]. An interlacement of ends or parts of one or more cords or threads so that they cannot be readily separated. K., Clove-hitch, a knot consisting of two single, contiguous loops, the
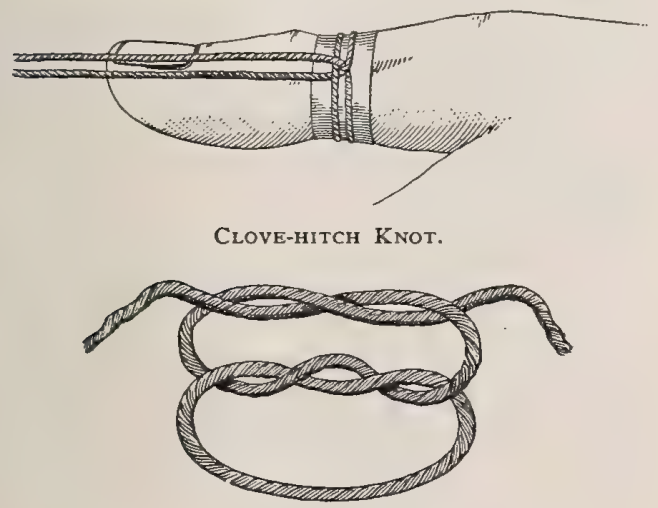

Combined SURgeon's ANd REEF KNot.

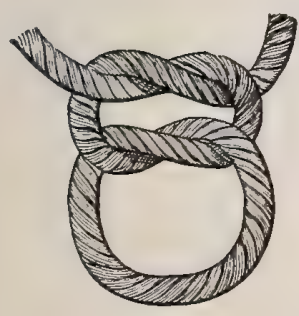

Granny Knot.

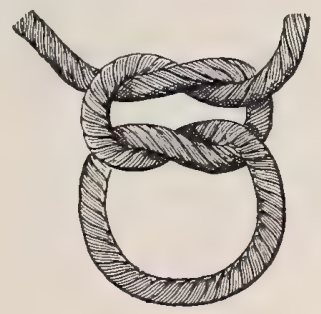

REEF, OR SAILOR'S KNOT. free ends toward each other. It is used for making extension in the reduction of dislocations. K., Double. Same as $K$., Friction. K., False. Same as $K$, Granny. K., Friction, one in which the ends are wound twice around each other before they are tied. K., Gerdy's Extension, resembles the clove-hitch; it is employed in making extension of the leg at the ankle. $\mathbf{K}$., Granny, a tie of a cord in which in the second loop the end of one cord is over, and the other under its fellow, so that the two loops do not lie in the same line. This knot may easily be converted into a slipknot. K.-grass: I. Arrhenatherum odoratum; 2. Avena elatior; 3. Hippuris vulgaris ; 4. Illecebrum; 5. Polygonum; 6. Triticum repens. K., Hensen's, a fixed point in the mammalian blastodermic vesicle at which the formation of the primitive axis and notochordal canal begins. It marks the anterior extremity of the primitive streak. K., Reef, a knot so formed that the ends come out alongside of the standing parts and the knot does not jam. It is also called Square Knot. K., Sailor's. Same as $K$., Reef. K., Square. Same as $K$., Reef. K., Staffordshire, a knot used in ligating the pedicle in ovariotomy. The ligature is passed through the pedicle, and withdrawn so as to leave a loop, which is passed over the tumor, and one of the free ends is then drawn through the loop; both ends are then passed through the pedicle, tightened, and tied. It is also called Tait's Knot. K., Stay, a term applied by Ballance and Edmunds, to a knot formed by two or more ligatures in the following way: On each ligature separately is made the first hitch of a reef-knot, which is tightened so that the loop lies in contact with the vessel, without constricting it; then taking the two ends on one side together in one hand, and the two ends on the other side in the other hand, the vessel is constricted sufficiently to occlude it, after which the reef-knot is completed. The simplest method of completing the knot is to treat the two ends in each hand as a single thread, and to tie them as if

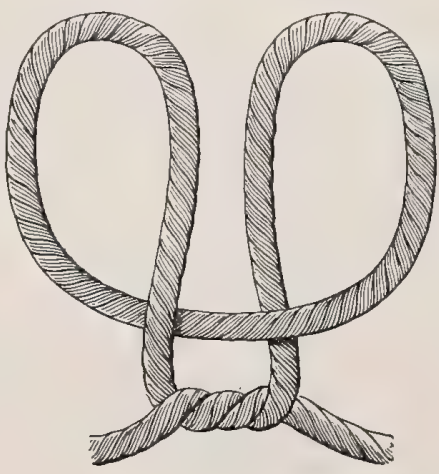

STAFFORDSHIRE KNOT.

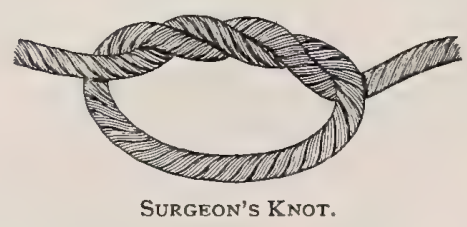

completing a single reef-lknot. K., Surgical, a double knot made by passing the thread twice through the same loop. K., Tait's. See $K$., Staffordshire. K.weed, Centaurea nigra. See also Collinsonia canadensis.

Knuckle (nuk'-l) [ME., knokel, a knuckle or joint]. Any one of the joints of the phalanges with the metacarpal bones or with each other; also a loop of intestine.

Knuckling (nuk'-ling) [ME., knokel, a knuckle or joint]. In farriery, a partial dislocation of the fetlockjoint, in which the relative position of the pasternbone to the cannon and coronet bone is changed, the pastern becoming more nearly perpendicular, with the lower end of the cannon-bone resting behind the center line of the suffraginis, while the lower end of this bone rests behind the center line of the coronet. It is also called Cocked Ankles.

Kobelt's Tubes. Blind tubes of the parovarium.

Koch's Apparatus. An apparatus for air-analysis. K., Bacillus of. See Bacteria, Synonymatic Table of. 
K., Comma-bacillus of. See Bacteria, Synonymatic T'able of. K.'s Dampfapparat. See $K$.' steam Appa ratus. K.'s Eruption, an eruption simulating that of measles or, more rarely, that of scarlet fever, and which occurs at times after the injection of tuberculin. K.'s Lymph. See Tuberculin. K.'s Method,or KochEhrlich Method, for isolated staining of bacteria. See Stains, Table of. K.'s Method of Sterilization, a method of interrupted heating. The culture-media are heated for a short time daily for from three to five successive days. By means of a graduated water-bath temperatures suitable to the various media are maintained. The method is eminently sure, and has not the injurious effects on the media that follow one prolonged heating. K.'s Plates, the casting and solidifying of liquefied inoculated culture-media in plates for the purpose of isolating colonies of microorganisms. K.'s Rules rules formulated by Koch which must be complied with before a given microorganism can be accepted as the cause of an infectious disease. I. The microörganism must be present in every case of the disease, and not in cases of other diseases. 2. It must be isolated and grown on artificial media. 3. Its cultures when injected into an animal body must produce the disease in question. 4. The microörganism must again be found in the body in which the disease was thus produced. K.'s Specific. See Tuberculin. K.'s Steam Apparatus, an apparatus for sterilization by steam. K.'s Treatment. See Treatment, Methods of.

Kochin. Synonym of Tuberculin, $q . v$.

Koberle's Noud. A serre-noud used in the performance of abdominal hysterectomy.

König's Cylinders. An apparatus for testing the perception of high tones by the ear. K.'s Manometric Flames, toothed or zigzag flame-pictures seen in a revolving mirror, and produced by the vibrations of the voice against a thin membrane that separates the gas-chamber supplying a small burner from the airchamber into which one speaks. The form of the flame-picture is characteristic for each vowel, and varies with the pitch. K.'s Rods, steel rods for producing notes of very high pitch. Same as $K$.'s Cylinders.

Kofacker-Sadler's Law. See Law.

Kohlrausch's Fold. See Third Sphincter.

Koino-miasm (koi'-no-mi'-azm) [kotvos, common;

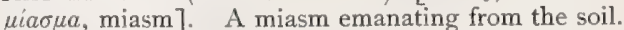

Kola-nut $\left(k o^{\prime}-l a h\right)$ [African]. The seed of Cola acuminata, used in parts of Central Africa as a substitute for tea and coffee. It contains an alkaloid similar to caffein, and is a cerebral stimulant and cardiac tonic. Dose of a twenty per cent. tincture, $3 \mathrm{j}$; of the fluid extract, gtt. $\mathrm{xx}$-xxx. Unof.

Kolla $\left(k o l^{\prime \prime}-a h\right)$ [native name]. An Abyssinian disease resembling malaria.

Kollerism (kol'-er-izm). See Cocainization.

Kölliker's Columns. See Muscle-columns. K., Glands of. See Gland. K., Lamina or Membrane of. See Membrane, Reticular.

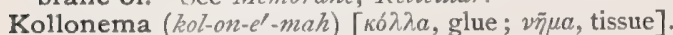
Same as Myxoma, q. v.

Kolossow's Fixing-solution. See Stains, Table of.

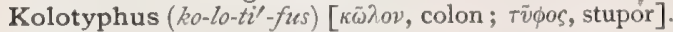
Typhoid fever.

Kolpo- $\left(k_{0} l^{\prime \prime}-p o-\right)$. See Colpo-

Kolpocystotomy (kol-po-sis-tot'-o-me). See Colpocystotomy.

Kolpodesmorrhaphy (kol-po-dez-morl-a-fe) [ $[\kappa \delta \lambda \pi o s$, vagina; $\delta \varepsilon \sigma \mu \delta \varsigma$, bond; $\dot{\rho} \alpha \phi \dot{\eta}$, seam ]. Same as Colporrhaphy, q.v.

Kolpokleisis (kol-po-klis'-is). See Colpokleisis.
Kombé $\left(k o m^{\prime}-b a h\right)$ [African]. An African arrow-poison (kombé inée) extracted from Strophanthus kombé.

Komeceras, Komoceras (ko-mes'-er-as, ko-mos'-er-as)

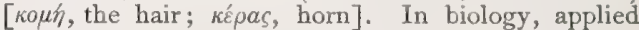
to such a horn as that of the American prong-horn, formed of matted hair.

Kommabacillus (kom-ah-bas-il'-us). See Bacteria, Synonymatic Table of.

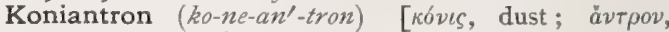
antrum]. An instrument for spraying fluid into the tympanic cavity.

Koosso, or Koosoo (koo'-s0o). See Brayera.

Kopf-tetanus (kopff-tet-an-us) [Ger.]. Cephalic tetanus, due to wounds of the head, chiefly in the region of the fifth nerve. Initial trismus is associated with paralysis of the face on the side of the injury. In some cases there is also pharyngeal spasm, so that the name Hydrophobic Tetanus has also been given to this form of tetanus.

Kopiopia (kop-e-o'-pe-a/z). See Copiopia.

Kopp's Asthma. See Asthma.

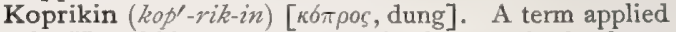
by Hünefeld to undigested animal matter in the feces.

Kore- $\left(k o r^{\prime}-e-\right)$. See Core-.

Koronion (ko-ro'-ne-on). See Craniometric Points.

Koroscopy (ko-ros'-ko-pe). See Retinoscopy.

Kosin $\left(k o^{\prime}-\sin \right)$ [Abyssinian, cusso], $\mathrm{C}_{31} \mathrm{H}_{38} \mathrm{O}_{10^{*}}$ Same as Koussin. See Bravera.

Koso $\left(k o^{\prime}-s o\right)$. Same as Brayera, q. v.

Kossein (kos'-e-in) [Abyssinian, cusso]. A crystalline body contained in koosso. It is soluble in ether, in alcohol, and in acids. It is slightly styptic.

Koubasoff, Bacillus of. See Bacteria, Synonymatic Table of.

Koumiss (koo'-mis) [Tartar, kumiz, fermented mare's milk]. An alcoholic drink made by the fermentation of milk. As made by the fermentation of mare's milk, it has long been a favorite beverage with the Tartars and other Asiatic tribes. Cow's milk has been used chiefly in making it, both in Europe and America. Mare's milk is the more suitable for fermentation because of the larger percentage of milksugar that it contains. The composition of the koumiss as prepared from both mare's milk and cow's milk is shown in the accompanying analyses from various sources:-

ANALYSIS OF KOUMISS.

\begin{tabular}{|c|c|c|c|c|c|c|c|c|}
\hline & $\begin{array}{l}\frac{\alpha}{15} \\
5 \\
5\end{array}$ & 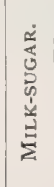 & i & 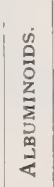 & $\stackrel{4}{a}$ & 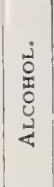 & $\begin{array}{l}0 \\
0 \\
0 \\
0 \\
z \\
0 \\
0 \\
\tilde{\alpha} \\
\tilde{\alpha} \\
\tilde{\alpha}\end{array}$ & $\frac{2}{4}$ \\
\hline $\begin{array}{l}\text { Koumiss from mare's } \\
\text { milk (Fleischmann). . }\end{array}$ & 91.53 & 1.25 & I.OI & I.91 & I. 27 & I. 85 & 0.88 & 0.29 \\
\hline $\begin{array}{l}\text { Koumiss from cow's } \\
\text { milk (Fleischmann), . }\end{array}$ & 88.93 & $3 . I I$ & 0.79 & 2.03 & 0.85 & 2.65 & 1.03 & 0.44 \\
\hline $\begin{array}{c}\text { Koumiss from mare's } \\
\text { milk (König), .... }\end{array}$ & 92.47 & 1.24 & $0.9 \mathrm{I}$ & 197 & I.26 & I. 84 & 0.95 & \\
\hline $\begin{array}{l}\text { Koumiss from mare's } \\
\text { milk (London, I884), }\end{array}$ & 91.87 & 0.79 & 1.04 & 1.91 & 1.19 & 286 & & \\
\hline $\begin{array}{l}\text { Koumiss from cow's } \\
\text { milk (Wiley), }\end{array}$ & 80.32 & $4 \cdot 3^{8}$ & 0.47 & 2.56 & 2.08 & 0.76 & 0.83 & \\
\hline
\end{tabular}

K.-cure, a method of treating pulmonary tuberculosis. Large quantities of koumiss can be easily digested, and its use is frequently attended by a gain in weight. 
The patients rise early and take a glass of koumiss every half hour, except during the two hours preceding dinner and supper. Meat and fats form the chief part of the ordinary food; sweets, fruit and salads are avoided, as well as ices, coffee, and spirits. If the koumiss causes diarrhea, lime-water is used to arrest this. At first a few glasses only are taken daily to gradually accustom the patient to the cure.

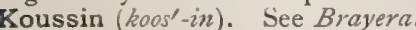

Kousso $\left(\right.$ koos' $\left.^{\prime}-0\right)$. See Brayera .

Kowalevsky, Canal of. See Canal.

Krameria (kra-me'-re-ah) [after J. G. H. Kramer, an Austrian physician]. A genus of polypelatous herbs. Rhatany, the root of $K$. triandra and $K$. tomentosa, shrubs native to South America, possesses the same astringent qualities as tannic acid. It is a popular remedy for fissure of the anus, spongy gums, etc. K., Ext., in water. Dose gr, v-x. K., Ext., Fld. Dose $\eta^{v}-z_{s s}$. K., Infus. (B. P.) Dose $z_{j}$-ij. K., Syr., contains of the fluid extract 45 , syrup 55 . Dose $3^{\text {ss }}-z^{\text {ss. }}$ K., Trochisci, contain each gr. j of the extract. K., Tinct., 20 per cent. Dose $\eta^{v-3 j}$.

Krameric Acid (kra-me'-rik) [after J. G. H. Kramer, an Austrian physician]. An acid contained in Krameria.

Krampton's Muscle. The muscle of the so-called ciliary ligament in the avian eye.

Krarkoff's Method. A method of extracting soluble animal ferments; it consists in precipitating these and the albuminoids by means of ammonium sulphate; subsequent treatment with acids renders the albuminoids insoluble, and the ferments are readily extracted with water.

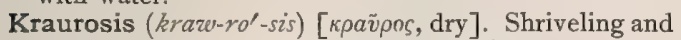
dryness of a part, especially of the vulva.

Krause's Corpuscles. Terminal nerve-corpuscles described by W. Krause (1860) as existing in the conjunctiva, the genitals, and other parts of the human body, and differing from the Pacinian corpuscles only

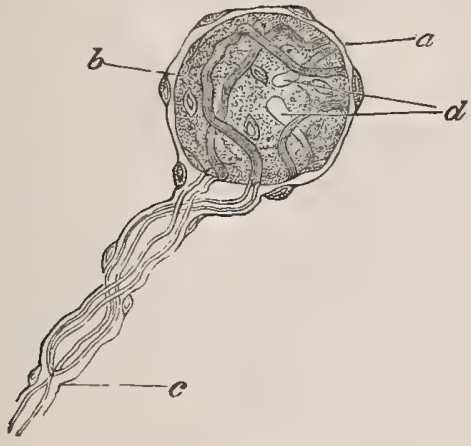

KRAUSE'S END-BULB.

a. Nucleated capsule. b. Core. $c$. Fiber entering and branching, terminating in core at $d$.

in the absence of a thick laminated investment. K.'s Embryo, an embryo of the fourth week, in which there is an absence of the allantoic stalk, the allantois hanging from the posterior extremity of the embryo. K.'s End-bulbs, terminal bodies of sensory nerves in the skin and membranes of all mammals. They are elongated, oval, or round bodies, 0.075 to 0.14 mm. long. K., Glands of. See Gland. K.'s Membrane, a structure that extends from the sarcolemma through the fiber of a muscle, making a complete partition. K.'s Method, a method of inducing premature labor. It consists in passing a flexible bougie into the uterine cavity. K.'s Muscle, the coraco-cervicalis muscle. See Muscles, Table of. K.'s Nerve, a branch of the musculo-spiral nerve which accompanies the ulnar and terminates in the inner head of the triceps. K.'s Process, a process for the separation of the two coloring-matters of chlorophyl. I. Prepare a solution by allowing fresh bruised leaves to be acted upon for a few hours in the dark by warm 65 per cent. alcohol; decant. 2. Shake one volume of this solution with two volumes of benzol; after a time the turbid liquid separates into a benzol layer above having a bluish-green color, and an alcohol layer below tinged yellow. The yellowish pigment is called by Krause xanthophyl, the bluishgreen, kyanophyl. According to Wiesner, kyanophyl is nearly pure chlorophyl freed from its associated yellow pigment xanthophyl. It is believed by many that the yellow pigment separated by this process is identical with that found in plants blanched (etiolated) in darkness, and which has been called etiolin (Goodale).

Kreatin $\left(k r e^{\prime}-a t-i n\right)$. See Creatin.

Kreatinin $\left(k r e-a t^{\prime}-i n-i n\right)$. See Creatinin.

Kremnitz White, Krems White. Same as White Lead.

Kreolin (kre'-o-lin). See Creotin.

Kresol (kre'-sol). See Cresol.

Krinosin (krin'-o-sin). See Crinosin.

Kristeller's Method. A method of hastening tedious labor by fetal expression by means of rhythmic pressure on the fundus uteri. Pressure is made on the fetus while the entire child is still in the genital canal.

Krohn's Glands. A pair of glands in the cephalothorax of certain of the Arachnoidea (Phalangide, Cyphophthalamido).

Kronecker's Center. The inhibitory center of the heart. It may be injured in cardiocentesis.

Krönlein's Hernia. See Hernia, Inguino-properitoneal, and Diseases, Table of.

Krull's Treatment. See Treatment, Methods of.

Krypto- (krip'-to-). See Crypto-.

Kühne's Method. A method of staining bacilli, and $K$ 's Modification of Gram's Method. See Stains, Table of. K.'s Carbol. Methylene-blue, methylene-blue 1.5, absolute alcohol Io. Rub up and gradually add roo parts of a five per cent. solution of carbolic acid. K.'s Motorial End-plates, a peculiar form of nerve-ending. The same as the Hillocks of Doyère. K.'s Pancreas-powder, an extract prepared by the prolonged extraction of fresh pancreas of ox with alcohol and then with ether.

Kuhnt, Cylinder-cone of. See Cylinder.

Kujawah $\left(k u^{\prime}-j a h\right.$-zwaw) [E. Ind. $]$. An apparatus used in India, by means of which wounded persons may be carried on camels.

Kumbecephalic (kum-be-sef-alp-ik) or Kumbokephalic (kum-bo-kef-al'-ik). See Cymbocephalic.

Kumiss (koo'-mis) or Kumyss $\left(k \circ o^{\prime}-m i s\right)$. See Koumiss.

Kümmel (kim'-el) [Ger., "cumin."] A liqueur, or cordial, originating in Germany and Russia, and flavored with fennel, caraway, cumin, or coriander.

Kummerfeld's Lotion. A cosmetic used in dermatology. It consists of spirit of camphor and spirit of lavender, each $1 / 2$ dram; precipitated sulphur 15 grains; cologne-water one dram, distilled water 2 ounces.

Kumysgen (koo-mis'-jen) [Tartar, kumiz, fermented mare's milk; $\gamma \varepsilon v \nu \bar{\alpha} \nu$, to beget]. A preparation used for the production of koumiss.

Kupffer's Cells. Liver-cells which, according to Asp and Kupffer, present exceedingly minute intracellular passages that pass from the bile capillaries into the interior of the cells, where they communicate with 
certain small cavities or vacuoles. K.'s Method. See Stains, I'able of. K.'s Vesicle, a small globular cavity seen near the posterior extremity of the embryo in teleostear fishes.

Kurung Oil (ku'-rung). See Pongamia.

Küssmaul's Coma. A manifestation of diabetes usually associated with the presence of acetone in the uriue, and the patient is comatose. See Diseases, Table of. K.'s Disease, acute atrophic spinal paralysis. See Diseases, Table of.

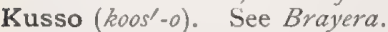

Küster's Sign. See Signs and Symptoms, Table of.

Kutubuth (koo-too-booth') [Arab.]. Melancholia errabunda.

Kvas, or Kwas (kvas or kwas) [Russ.]. A kind of beer made in Russia of rye-flour, oatmeal, or baked bread, sometimes with the addition of various sweet fruits.

Kyanizing ( $k i^{\prime}$-an-izz-ing) [after Kyan, the inventor]. A wood-preserving process having for its object the coagulation of the protein matters in wood-cells, thus retarding putrefaction by impregnating the wood with a solution of mercuric chlorid. Impregnation with a 50 per cent. solution of zinc chlorid is called Burnettizing. See Burnett's Disinfecting-fuid.

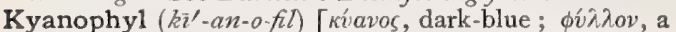
leaf]. The bluish-green pigment of chlorophyl. Same as Cyanophyl.

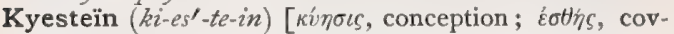
ering]. A filmy deposit upon decomposing urine, at one time thought to be diagnostic of pregnancy.

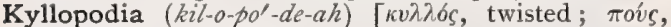
foot]. See $C l u b$-foot.

Kyllosis (kil-o'-sis) [ $\kappa v \lambda \lambda \delta \varsigma$, twisted]. Same as $C l u b$ foot.

Kymograph (ki'-mo-graf), Kymographion (ki-mo-

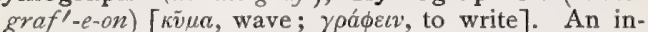
strument for reproducing graphically the variations in the pressure of the blood.

Kymoscope $\left(k i^{\prime}-m o-s k o ̄ p\right)$ [ $\kappa \tilde{v} \mu \alpha$, wave ; $\sigma \kappa o \pi \varepsilon i v$, to inspect]. A device used in the observation and study of the blood-current.

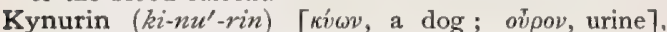
$\mathrm{C}_{18} \mathrm{H}_{14} \mathrm{~N}_{2} \mathrm{O}_{2}$. A crystalline substance obtained from cynurenic acid. It may also be made by oxidizing cinchonin and cinchoninic acid with chromic acid. It crystallizes in needles containing $3 \mathrm{H}_{2} \mathrm{O}$.

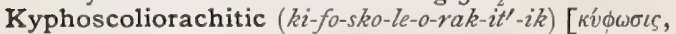

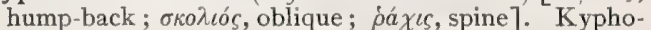
scoliotic.

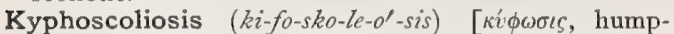

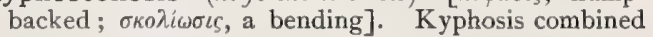
with scoliosis.

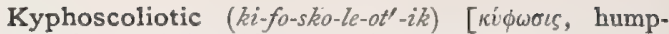

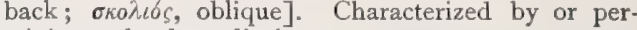
taining to kyphoscoliosis.

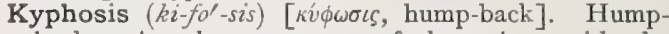
back. Angular curvature of the spine, with the prominence or convexity turned dorsad, K. bicyclistarum, a curvature of the spine, due to error in posture in bicycle-riding.

Kyphotic $\left(k i-f o t^{\prime}-i k\right)$ [ ${ }^{\prime} \phi \omega \sigma \iota$, hump-back]. Relating to, of the nacure of, or affected with, kyphosis.

Kysthoproptosis (kis-tho-prop-to'sis) [Kvotos, a hollow; $\pi \rho \dot{\sigma} \pi \tau \omega \sigma(s$, a falling forward]. Prolapse of the vagina.

Kysto- (kis'-to-). See Cysto-.

Kystoma (kis-to'-mah). See Cystoma.

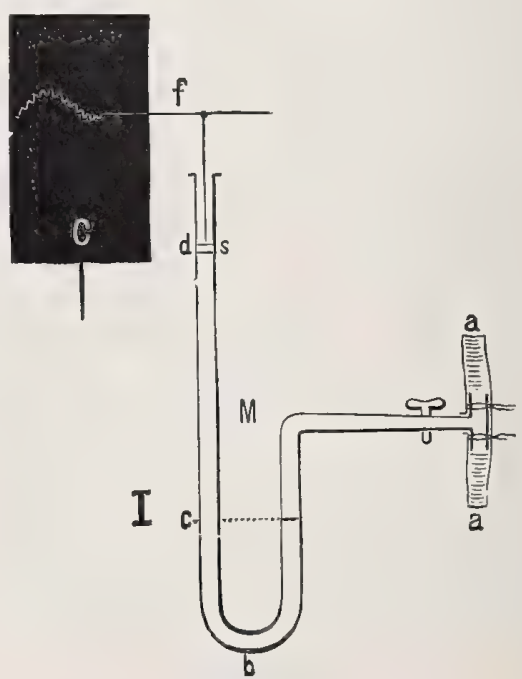

KYMOGRAPH. (Ludwig.)

a a Artery, C. Revolving-cylinder. c. Height of mercury in tube; the difference between this point and dindicates the pressure within the vessel. $d, s$. Float on mercury in tube. f. Writing-style.

Kytharrhagia (kith-ar-a'-je-ah). See Cytharrhagia.

Kythemolytic (ki-them-o-lit'-ik) [кíros, cell ; aija,

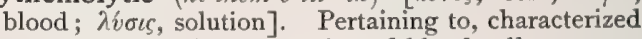
by, or causing, the destruction of blood-cells.

Kytomitom (ki-tom'-it-om) [kítos, cell; $\mu i \tau o s$, thread]. The network in the body of the nucleus of the cell.

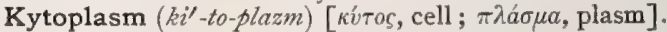
The protoplasm of the cell. 
L. The abbreviation of Left, of Lumbar, of Lithium, and of Libra, a pound.

$\lambda$ denotes wave-length. For instance $\lambda$ 506, means a wave-length equal to 506 millionths of a millimeter. Sometimes the letters W. L. are used instead of $\lambda$.

Lb. Contraction of liber $=$ pound.

Lab, or Lab-ferment. The ferment of rennet producing coagulation of milk. It is separated from the proenzyme, labzymogen, by means of the acids of the gastric juice, and especially by $\mathrm{HCl}$. Labzymogen resists the action of alkalies, which, even in very small amounts, destroys the lab. A temperature of $35^{\circ}$ to $40^{\circ} \mathrm{C}$. is most favorable to the action of lab. At $70^{\circ} \mathrm{C}$. the lab is destroyed, but not the labzymogen.

Labarraque's Liquor. See Liquor. L.'s Solution. See Chlorin.

Labbé, Vein of. See Vein.

Labdacism (lab'-das-izm). Same as Lambdacism.

Labdanum (lab'-dan-um). See Ladanum.

Labellum (la-bel'-um) [dim. of labium, a lip: pl., Labella]. In biology: (a) One of the petals of an orchid, which, properly the upper one, is made the lower by a semi-twist of the ovary. It is larger than the other petals and offers a landing-place for insects; it is carried backward in the form of a spur, and then assumes the functions of a nectary and so attracts visitors (Cheshire); (b) One of the mouth-parts of an insect.

Labes $\left(l a^{\prime}-b \bar{e} z\right)$ [L.]. An old name for the plague; also, for any depravation or lowering of the standard of health.

Labial $\left(l a^{\prime}-b e-a l\right)$ [labium, a lip]. Pertaining to the lips. L. Bone. See Intermaxillary. L. Frenum, frenum of the lips.

Labialism $\left(l a^{\prime}-b e-a l-i z m\right)$ [labium, a lip]. The tendency to pronounce any articulate sounds as if they were labials; the addition of a labial or labio-dental quality to an articulate sound.

Labials $\left(l a^{\prime}-b e-a l z\right)$ [labium, a lip]. The consonantsounds; they are formed mainly by the lips. See Consonants.

Labiate $\left(l a^{\prime}-b e-\bar{a} t\right)$ [labium, a lip]. In biology, lipped. Shaped like, or functioning as, a lip. L. Plants, the Labiate, or mintworts; an order of square-stemmed plants, mostly herbs, with aromatic properties, many of the species being highly charged with volatile oils.

Labiatiform (la-be-at'-if-orm). See Labiate.

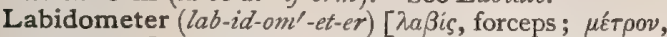
a measure]. A forceps used in measuring the dimensions of the head of a fetus in the pelvis.

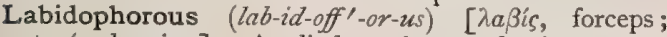
фopós, bearing]. Applied to insects having organs resembling pinchers.

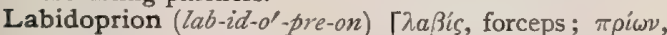
saw]. A forceps-saw.

Labiella (la-be-ell'-ah) [labium, a lip]. In biology, a minute, rounded, median portion of the deutomala in myriapods; it corresponds in a degree to the lingua of hexapods (Packard).

Labile $\left(l a b^{\prime}-i l\right)$ [labilis; labi, to glide]. I. In electrotherapeutics a labile application is the passing of the electrode-usually the negative-along and touching the skin over the track of a nerve. 2. Deciduous.

Labimeter (lab-im'-et-er). Same as Labidometer.

Labio-alveolar ( $\left.l a^{\prime}-b e-o-a l-v e^{\prime}-o-l a r\right)$ [labium, lip; alveolus, a small hollow]. Pertaining to the lip and to one or more dental alveoli.

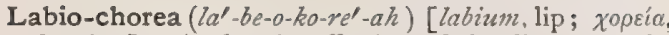
dancing]. A choreic affection of the lips, and the stammering that results from it.

Labio-choreic $\left(l a^{\prime}-b e-o-k o-r e^{\prime}-i k\right)$ [labium, lip; xopeia, dancing]. Relating to lip-stammering.

Labio-dental (la'-be-o-den'-tal) [labium, lip; dens, a tooth]. Pertaining to the lips and the teeth.

Labio-glosso-laryngeal (la'-be-o-glos'-o-lar-in'-je-al) [labium, lip; $\gamma \lambda \omega \sigma \sigma \sigma a$, tongue; $\lambda a \rho v \gamma \xi$, larynx]. Pertaining conjointly to lips, tongue, and larynx. L. Paralysis. See Bulbar Paralysis.

Labio-glosso-pharyngeal (la'-be-o-glos'-o-far-in'-je-

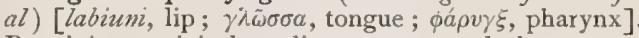
Pertaining conjointly to lips, tongue, and pharynx.

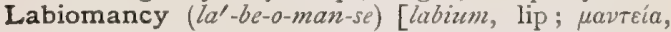
divination]. The power of understanding what is said by observing the motions of the lips in speech.

Labio-mental (la'-be-o-men'-tal) [labium, lip; mentum, chin]. Relating to lip and chin.

Labio-nasal (la'-be-o-na'-sal) [labium, lip; nasus, nose]. Labial and nasal; pertaining to lip and nose.

Labio-palatine (la'-be-o-pal'-at-in) [labium, lip; palatum, palate]. Relating to lip and palate in common.

Labioplastic (la-be-o-plas'-tik) [labium, lip ; $\pi \lambda a ́ \sigma \sigma \varepsilon \imath \nu$, to form]. Pertaining to an operation for restoring the lip, after injury or partial destruction of the same; chiloplastic.

Labiose $\left(l a^{\prime}-b e-\bar{o} s\right)$ [labium, lip]. In biology, resembling a true labiate flower.

Labiotenaculum (la-be-o-ten-ak'-u-lum) [labium, lip tenaculum, a holder]. An instrument for holding the lips in a position required for examination or operation.

Labipalp (la'-be-palp) [labium, a lip; palpare, to stroke, to feel]. In biology, a labial palp or feeler.

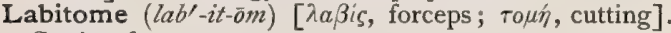
Cutting-forceps.

Labium $\left(l a^{\prime}-b e-u m\right)$ [L. : pl., Labia]. A lip. Also, any structure consisting of a strip or flap of elastic tissue that closes upon an orifice. In biology, applied to various lip-like structures in animals and plants, usually the lower when two are present, the upper being called the labrum. L. austriacum, Austrian lip; the thick, pendent upper lip of the Austrian reigning family. L. cerebri, the margins of the cerebral hemispheres that overlap the corpus callosum. L. duplex, a congenital longitudinai duplication of the mucosa of the upper, and rarely of the lower lip. L. externus pudendi. See $L$ majus. L. internus puaienai. See $L$. minus. L. leopoldinum, a thick, pendent lower lip; named after Emperor Leopold. L. leporinum. See Hare-lip. L. majus, or L. pudendi majus, one of two folds of skin of the female external genital organs, arising just below the mons veneris, surrounding the vulval entrance, and meeting at the anterior part of the perineum. L. minus, L. pudendi minus, or nympha, one of two folds of mucous membrane at the inner surfaces of the labia majora. L. tympanicum, the portion of the lamina spiralis forming the lower border of the sulcus spiralis. L. urethrae, the lateral margins of the external urinary meatus. L. vestibulare, the overhanging extremity of the lamina spiralis that forms the upper part of the sulcus spiralis.

Labor (la'-bor) [L.]. Work. Parturition; bringing forth young. That natural process by which a pregnant woman expels the product of conception at the expiration of the period of pregnancy, normally, 
280 days after conception. L., Abnormal, departing from the normal course. L., Artificial, when effected or aided by other means than the forces of the maternal organism. L., Atonic, labor protracted or rendered incapable of spontaneous termination by atony of the uterus. L., Conduct of, management, hygienic, medical, or surgical, of the parturient woman. L., Difficult. See Dystocia. L., Dry, when there is a deficiency of the liquor amnii, or when there has been a premature rupture of the bag of waters. L., False, or False Pains. See Pains. L., Induced, labor brought on by artificial means. L., Insanity of. See Insanity. L., Instrumental, one requiring manual or instrumental means to extract the child. L., Metastatic, labor in which the true pains cease suddenly, and are succeeded by muscular contractions of neighboring organs, bladder, rectum, or of the muscles of the trunk and limbs. L., Missed, retention of the dead fetus in utero beyond the period of normal gestation. L., Natural, Normal, or Physiologic, when effected by the sole power of the maternal organism. L., Obstructed. See L. Pathologic. L., Pathologic, when deviating from the normal type by reason of weakness of the maternal forces, anomalies of the pelvis, or of the fetus, or of complications, all being causes of Obstructed L. L., Postponed, delayed beyond nine months. L., Premature, taking place before the normal period of gestation, but when the fetus is viable. L., Stages of, arbitrary divisions of the period of labor, - the first begins with dilatation of the os, and ends with complete dilatation, so that the head can pass; the second ends with the expulsion of the child; the third (placental) consists in the expulsion of the placenta. L., Mechanism of, the mechanism by which a fetus and its appendages traverse the birth-canal and are expelled. L.-pains, the pains of, or the contraction of the uterus during, labor. L., Perverse, labor in which there is an abnormal position of the child. L., Precipitate, labor in which the expulsion of the fetus and its appendages takes place with undue celerity. L., Protracted, labor prolonged beyond the usual limit (10-20 hours in primiparæ, 2-6 hours in multiparæ). L., Spontaneous, labor accomplished without artificial aid.

Laboratory (lab'-or-at-a-re) [laboratorium, from laborare, to work]. A room or place designed for experimental work in chemistry, physiology, biology, etc.

Laborde's Method. See Treatment, Methods of. L.'s Sign. See Death

Labrador Tea (lab'-ra-dor). The leaves of Ledum latifolium, demulcent, expectorant, and tonic. Dose of the fld. ext., $3 \mathrm{j}-\mathrm{ij}$. Unof.

Labrose (la'-brōs, or la-brōs's [labrosus, lipped]. Supplied with lips. Large-lipped.

Labrum ( $l a^{\prime}$-brum) [L., a lip-edge, margin: $p l$., Labra]. In biology, a lip-like structure, usually the upper, when two are present, the lower being the labium.

Laburnin (lab-er'-nin) [laburnum, laburnum]. Also called Cytisin. An alkaloid found in Cytisus laburnum.

Laburnum (lab-er'-num) [L.]. The leaves of Cytisus laburnum, the properties of which are due to an alkaloid, cytisin. In small doses it is diuretic and resolvent; in larger doses poisonous, irritating the alimentary tract, and inducing purging, vomiting, and exhaustion. Unof.

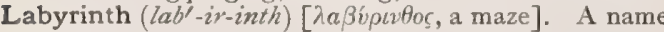
given to the series of cavities of the internal ear comprising the vestibule, cochlea, and the semicircular canals. L., Bony. See L., Osseous. L., Cortical, the intricately arranged collection of uriniferous tubules and blood-vessels filling the intervals in the cortical substance of the kidney. See Kidney. L., Membranous, the membranous cavity within the osseous labyrinth, from which it is partly separated by the perilymph. It comprises two sacs contained within the vestibule, the semicircular canals and the canal of

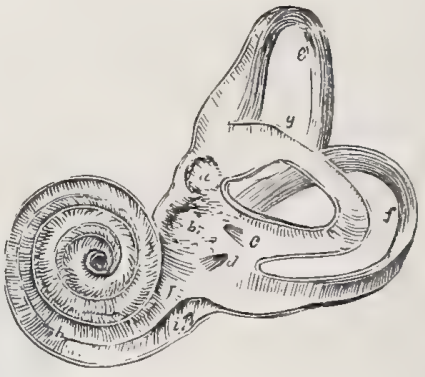

LABYRINTH OF THE EAR LAID OPEN,

a. Fovea elliptica, b. Fovea hemispherica. c. Common entrance of the posterior and superior semicircular canals. $d$. Opening of the aqueduct of the vestibule. $e$. Superior semicircular canal. $f$. Posterior. Inferior semicircular canal. $h$. Spiral canal of cochlea. $i$. Opening of the aqueduct of the cochlea. $j$. Lamina spiralis.

the cochlea. L. of the Kidney. See Labyrinth, Cortical. L., Osseous, the bony capsule of the internal ear, communicating in front with the cochlea and behind with the semicircular canals. L. Pit. See Ear.

Labyrinthal (lab-ir-in'-thal), Labyrinthic (lab-ir-in'thik). See Labyrinthine.

Labyrinthine (lab-ir-in'-thin) [haßínow0os, a maze]. Pertaining to a labyrinth. L. Vertigo. See Ménière's Disease.

Labyrinthus (lab-ir-in'-thus) [L.: pl.,Labyrinthi]. A labyrinth.

Lac $(l a k)$ [Pers., lak, lac]. A resinous incrustation produced on the bark of the twigs and branches of various tropical trees (Urostigma religiosa, Mimosu cinerea, Butea frondosa, Schleichera trijuga, of Ceylon, India, and Burmah, Croton lacciferum, of Ceylon, Croton draco, Acacia gresgii, Larrea mexicana, of Mexico), by the puncture of the female lacinsect Carteria (Coccus) lacca. This crude exudation constitutes the stick-lac of commerce. Shellac is prepared by spreading the resin into thin plates after being melted and strained. In the preparation of the shellac, the resin is freed from the coloring-matter, which is formed into cakes, and is known as lacdye. See Pigments, Conspectus of. Button-lac differs from shellac only in form, appearing in cakes about three inches in diameter and one-sixth of an inch thick. Bleached lac is prepared by dissolving lac in a boiling lye of pearlash or potassic hydrate, filtering and passing chlorin through the solution until all the lac is precipitated. Seed-lac is the residue obtained after dissolving out most of the coloring-matter contained in the resin. The common shellac is used in varnishes, lacquers, and sealing-wax ; the bleached lac in pale varnishes and light-colored sealing-wax. L.-beet, a fruit used in Siam for diarrhea and dyspepsia. L., Stick, lac as taken from the twigs on which it is formed. L. sulphuris, milk of sulphur; sulphur precipitatum (U. S. P.) L., White. See Bleached lac.

Lacca $\left(l a k^{\prime}-a h\right)$. See Lac.

Laccate $\left(\bar{l} a k^{\prime}-\bar{a} t\right)$ [Pers., lak, lac, or sealing-wax]. In biology, appearing as if varnished or lacquered.

Laccin $\left(l a k^{\prime}-i n\right)$ [Pers., lak, lac]. A substance resembling wax, extracted from lac. It is insoluble in water, soluble in alcohol, in ether, in hydrochloric acid, and in potassic hydrate. 


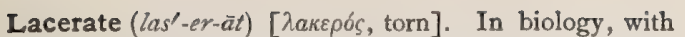
a margin appearing as if torn. L. Foramen. See Foramina, Table of.

Laceration (las-er-a'-shun) [laceratio; lacerare, to tear]. Mechanical rupture by a tearing action, whether accidental or surgical. See Dilaceration. L. of the Infratrochlear Nerve. See Badal's Operation in Operations, Table of. L. of Perineum, a tearing through the wall separating the lower extremity of the vagina and rectum, which occurs occasionally to women in childbirth.

Lacerator (las'-er-a-tor) [lacerare, to tear]. An instrument used in effecting surgical laceration.

Lacertiform (las-er'tif-orm) [lacerta, lizard ; forma, form]. Lizard-shaped.

Lacertoid (las-er'-toid) [lacerta, lizard; eidos, like]. Resembling a lizard.

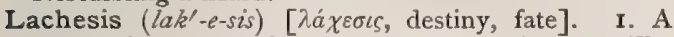
genus of venomous South American reptiles. 2. The venom of $L$. mutus (the bushmaster snake), and also a homeopathic preparation of the poison.

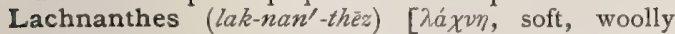
hair; àv 0 os, a flower]. A genus of North American bloodworts. L. tinctoria, red-root, is a plant popular in parts of the United States as an expectorant and alterative in pulmonary tuberculosis. Dose of a Io per cent. tincture, $m x$. Unof.

Lachrymal (lak'-rim-al). See Lacry'mal.

Lacinia (las-in'-e-ah) [L., a lappet, flap, as of a garment: pl., Lacinice]. In biology, one of the fimbriæ at the ovarian extremity of the oviduct; a narrow lobe, as in an incised leaf; or, specifically, the slender apex of the maxilla of a beetle. Cf. Galea.

Laciniate (las-in'-e-ât) [lacinia, a flap]. In biology, fringed; cut into narrow flaps.

Laciniform (las-in'-if-orm) [lacinia, a flap; forma, form]. In biology, fringe-like.

Laciniola (las-in-i'-o-lah) [dim. of Lacinia: pl., Laciniola]. In biology, a small lacinia.

Lacinula (las-in'-u-lah) [dim. of Lacinia, a flap: pl., Lacinula]. In biology, a small lacinia.

Lacmoid (lak'-moid). Same as Resorcin-blue.

Lacmus (lak'-mus). See Litmus.

Lacquer (lakl-er) [Pg., lacre, sealing-wax]. An opaque varnish containing lac. L., Burmese, a natural varnish consisting of a thick, grayish terebinthinous liquid, collected from the Melanorrhoea usitatissima of Burmah. It dissolves in alcohol, turpentine-oil, and benzene, assuming greater fluidity. Locally, it is used in lacquering furniture, temples, idols, and varnishing vessels.

Lacrima (Lak'-rim-ah). See Lacryma.

Lacrimal (lak'-rim-al). See Lacrymal.

Lacryma (lak'-rim-ah) [L.: pl., Lacryma]. A tear.

Lacrymal (lak'-rim-al) [lacryma, a tear]. Having reference to the organs of the secretion, transfer, or excretion of tears. L. Apparatus, the lacrymal gland, ducts, canal, sac, and nasal duct. See Eye. L. Artery, the first branch of the ophthalmic artery, supplying the gland. See Arteries, Table of. L. Bone, a bone upon the nasal side of the orbit, articulating with the frontal, the ethmoid, and superior maxillary bones, in which begin the lacrymal groove and nasal duct. See Bones, Table of. L. Canals, or Canaliculi, superior and inferior, extend from the lacrymal puncta to the sac, and serve to convey the excess of tears from the eye to the nose. See Canal. L. Caruncula. See Caruncle. L. Crest. See Crest. L. Ducts, seven to fourteen in number, extending obliquely from the gland to the fornix conjunctivæ, carrying the tears to the conjunctival surface of the globe. See Duct. L. Gland, the gland secreting the tears, situated in a depression of the frontal bone, the $L$. fossa, at the upper and outer angle of the orbit. See Gland. L. Lake, the inward prolongation of the paipebral fissure of the eyelids. L. Papilla. See Papilla. L. Probe, a probe for exploring or dilating the canaliculi and nasal duct. L. Puncta, the minute orifices of the canaliculi, upon the eyelids near the
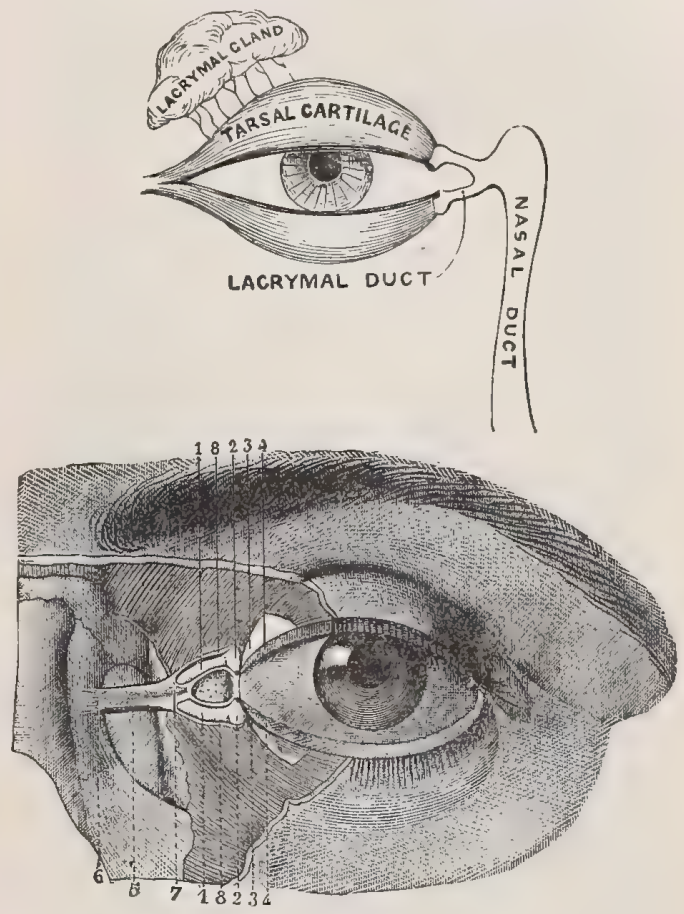

RELATIONS OF THE EYE AND THE LACRYMAL EXCRETORY

1, 1. Canaliculi. 2, 2. Puncta lacrymalia. 3, 3. Inner extremity. of tarsal cartilage. 4, 4. Free borders of lids. 5. Lacrymal sac. 6. Attachment to maxillary bone of superior tendon. 7. Bifurcation of lacrymal sac. 8, 8. Two branches.

inner canthus. L. Sac, a sacciform enlargement of the upper part of the nasal duct, into which the canaliculi empty. L. Style, a probe used in stricture of the nasal duct. L. Tubercle. See Tubercle.

Lacrymation (lak-rim-a'-shun) [lacryma, a tear]. An excessive secretion, or an overflow, of tears, from any cause.

Lacrymatome (lak-rim'-at-öm) [lacryma, tear; тонй, cutting]. A cutting-instrument used in dilating the nasal duct or the canaliculi ; a syringotome.

Lacrymiform (lak-rim'-if-orm) [lacryma, a tear; forma, form ]. In biology, tear-shaped; guttiform.

Lacrymin (lak'-rim-in). See Dacryolin.

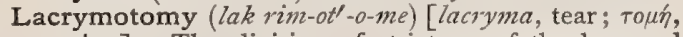
cutting]. The division of strictures of the lacrymal passages.

Lactagogue (lakl-tag-og). See Galactagogue.

Lactalbumin (lakt-al'-bu-min) [lac, milk; albumin]. A proteid contained in milk in small quantities- $1 / 2$ of I per cent. It resembles serum-albumin very closely, differing in specific rotatory power, in its coaguability by heat, and in its precipitation of neutral salts.

Lactamic Acid (lak-tam'-ik). See Alanin.

Lactamid (lak'-tam-id) [lac, milk; amid], $\mathrm{C}_{3} \mathrm{H}_{7}$ $\mathrm{NO}_{2}$. A substance formed by the union of lactid and ammonia. It forms crystals readily soluble in water and in alcohol, and melts at $74^{\circ} \mathrm{C}$. 
Lactamin (lak'tam-in). See Alanin.

Lactant (lak'-tant) [lactare, to suckle]. Suckling.

Lactate $\left(l a k^{\prime}-t a \bar{t}\right)$ [lactare, to suckle]. Any salt of lactic acid.

Lactated Food. A Liebig's food for infants. Its composition is: Water 7.76 ; fat 1.64 ; starch 36.43 ; soluble carbohydrates 39.0 ; albuminoids I1.85; ash $2.6 \mathbf{x}$; milk-sugar 29.65 .

Lactatic (lak-tat'-ik). See Galactagogue.

Lactation (lak-ta'-shun) [lactatio; lactare, to suckle]. Suckling; the period during which the child suckles.

Lacteal (lak'-te-al) [lac, milk]. r. Pertaining to milk. 2. Any one of the lymphatics of the small intestine that take up the chyle.

Lactean (lak'-te-an) [lac, milk]. See Lacteal.

Lacteïn (lak'-te-in) [lac, milk]. Same as Lactolin.

Lacteous (lak'-te-us)'. See Lacteal.

Lactescence (lak-tes'-ens) [lactescere, to turn to milk]. Milkiness (often applied to the chyle).

Lactescent (lak-tes'-ent) [lactescere, to turn to milk]. Milky, or secreting a milky sap or fluid.

Lactic $\left(l a k^{\prime}-t i k\right)$ [lac, milk]. Pertaining to milk or its derivatives. L. Acid. See Acid, Lactic, and Stains, Table of. L. Ether, $\left(\mathrm{C}_{4} \mathrm{H}_{5} \mathrm{O} \cdot \mathrm{C}_{6} \mathrm{H}_{5} \mathrm{O}_{5}\right) \mathrm{C}_{10} \mathrm{H}_{10} \mathrm{O}_{6}$. A colorless substance resulting from the distillation of equal parts of calcium lactate, absolute alcohol, and sulphuric acid. It is soluble in water, in alcohol, and in ether, and boils at $77^{\circ} \mathrm{C}$. L. Fermentation. See Fermentation.

Lactica (lak'-tik-ah) [lac, milk]. An old name for typhoid fever.

Lactid (lak'-tia) [lac, milk], $\mathrm{C}_{6} \mathrm{H}_{8} \mathrm{O}_{4}$. A volatile substance, one of the anhydrids of lactic acid produced by dry distillation of that acid. It crystallizes from alcohol in rhombic plates that melt at $124.5^{\circ} \mathrm{C}$., and boil at $255^{\circ} \mathrm{C}$.; it dissolves slowly in water, with the gradual formation of lactic acid.

Lactiferous (lak-tif'-er-us) [lac, milk; ferre, to carry]. A term applied to vessels that convey milk. L. Ducts, the ducts of the mammary gland. L. Glands, the mammary glands. L. Swelling, a distention of the breast arising from obstruction of a lactiferous duct.

Lactific (lak-tif'-ik) [lac, milk; facere, to make]. Producing milk.

Lactiflorous (lak-tif-lo'-rus) [lac, milk; flos, flower]. In biology, having milk-white flowers.

Lactiform (lak'-tif-orm) [lac, milk; forma, form]. Resembling milk.

Lactifuge (lak'-tif- $\bar{u} j)$ [lac, milk; fugare, to drive away]. A drug or agent that causes a lessening in the secretion of milk.

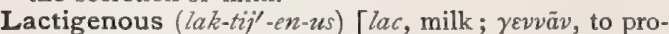
duce]. Milk-producing.

Lactimid (lak'-tim-id) [lac, milk; imid], $\mathrm{C}_{3} \mathrm{H}_{5} \mathrm{NO}$. A substance produced by heating alanin in a current of $\mathrm{HCl}$ to $\mathbf{I} 80-200^{\circ} \mathrm{C}$. It consists of colorless leaflets or needles that melt at $275^{\circ} \mathrm{C}$., and dissolve readily in alcohol and in water.

Lactin (lakl-tin) [lac, milk]. Sugar of milk; lactose.

Lactinated (lak'-tin-a-ted) [lac, mill-]. Containing sugar of milk.

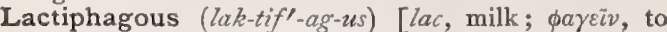
eat]. Consuming milk.

Lactipotous (lak-tip'-o-tus) [lac, milk; potare, to drink ]. Milk-drinking.

Lactis (lak'-tis) [gen. of lac, milk]. Pertaining to milk. L. redundantia, an excessive flow of milk. L. retentio, suppression of the flow of milk.

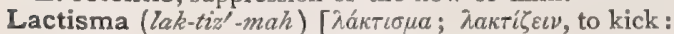
$p l .$, Lactismata]. The kicking or motion of the fetus in utero.
Lactivorous (lak-tiv'-or-us) [lac, milk; vorare, to devour]. Subsisting on milk.

Lacto- (lak'-to-) [lac, milk]. A Latin prefix denoting connection with or relation to milk. L.-pepsin, a preparation of pepsin. According to Heger, its composition is: Pure pepsin 10 parts, pancreatin 7.6 parts, sugar of milk 50 parts, extract of malt 5 parts, lactic acid 2.6 parts, hydrochloric acid (25 per cent.) Io parts, glycerin 20 parts. To this is added enough powdered tragacanth to make a pill-mass. The adult dose is about 15 grains. L.-peptine, a proprietary mixture claimed to contain pepsin, diastase, and pancreatin, acidulated with lactic and hydrochloric acids. One dram should peptonize $\xi$ viij of albumin, casein or fibrin, or emulsionize $\bar{z} x \mathbf{j}$ of cod-liver oil. Dose, gr. v-xv. See Pepsin. Unof. L.-peptone, same as $L$.-peptine. L.-phosphate, any phosphate combined with lactic acid. L.-proteid, any proteid of milk, as caseinogen or lactalbumin. L.-proteïn, a derivative of milk.

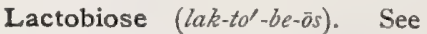
Galactose.

Lactobutyrometer (lak-to-bu-tir-

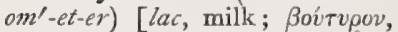
butter; $\mu \varepsilon \tau$ r $\rho \circ$, measure]. An instrument used in estimating the proportion of butter in milk.

Lactocele (lak $\left.k^{\prime}-t o-s e ̂ l\right) ~[l a c$, milk ; $\kappa \hat{\eta} \lambda \eta$, tumor]. A cyst containing a milky fluid. Same as Galactocele.

Lactocrit (lak'-to-krit) [lac, milk ; $\kappa \rho \iota T h$, a judge]. An apparatus for testing the quantity of fatty substance in a sample of milk.

Lactodensimeter(lak-to-den-sim' et-er) [lac, milk ; densus, dense ;

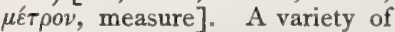
lactometer.

Lacto-globulin (lak-to-glob'-u-lin) [lac, milk; globus, a ball]. One of the native proteids of milk; lactalbumin.

Lactoglucose (lak-to-glu'-kōs) [lac, milk; $\gamma \lambda v \kappa u ́ s$, sweet]. A saccharine substance, produced in the fermentation-fluid along with galactose. It is probably the same as glucose.

Lactokrit (lak'-to-kril). See Lactocrit.

Lactolin (lak'-to-lin) [lac, milk; oleum, oil ]. Condensed milk.

Lactometer (lak-tom'-et-er). An instrument for determining the specific gravity of milk.

Lactone (lak'-ton) [lac, milk], $\mathrm{C}_{10} \mathrm{H}_{8} \mathrm{O}_{4}$. An aromatic, colorless, inflammable fluid, derived from the dry distillation of lactic acid. The lactones are generally liquids, readily soluble in water, of neutral reaction, possessing a faintly aromatic odor, and can be distilled without decomposition.

Lactonic Acid (lac-ton'-ik). See Acid.

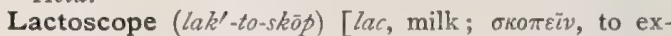
amine]. An instrument for estimating the proportions of water and fat-globules of milk.

Lactose (lakl-tós) [lac, milk], $\mathrm{C}_{12} \mathrm{H}_{22} \mathrm{O}_{11}+\mathrm{H}_{2} \mathrm{O}$. Milksugar; it occurs in the milk of mammals, in the 
amniotic liquor of cows, and in certain pathologic secretions. It crystallizes in white, hard, rhombic prisms, containing one molecule of water. It is soluble in water, has a faint sweet taste, and is insoluble in alcohol. Its aqueous solution is dextro-rotatory. It melts at $205^{\circ} \mathrm{C}$. It is much used in pharmacy for making triturations, and is the vehicle of most homeopathic preparations. See Carbohydrates, Table of.

Lactoserum (lak-to-se'-rum) [lac, milk; serum, whey]. The serum or whey of milk.

Lactosuria (lak-to-su'-re-ah) [lac, milk; ovoov, urine]. The presence of lactose in the urine; a condition oc casionally seen in pregnancy.

Lactotoxin (lak-to-toks'-in) [lac, milk; $\tau 0 \xi \iota \kappa b v$, poison] A poisonous substance found in milk.

Lactous $\left(l a k^{\prime}-\right.$ lus $)$ [lactosus, milky]. Milky.

Lactuca (lak-tu'-kah) [L., "lettuce" ]. A genus of composite-flowered herbs; the lettuces. L. altissima, L. elongata, L. montana, L. sativa (common garden lettuce), and L. virosa, afford lactuca rium; but the $\mathrm{L}$. virosa is the source recognized in the U. S. Pharmacopeia. Lactuca (B. P.) is also a synonym of Lactucarium, $q . v$.

Lactucarium (lak-tu-ka'-re-um) [L.: gen., Lactucarii]. Lettuce. The milky juice of Lactuca virosa, a biennial plant. It contains a crystalline substance, lactucerin, to which its properties are thought to be due. It is a mild hypnotic, with sedative and diuretic properties, somewhat similar to opium, but without depressant after-effects. It is frequently an ingredient of patented cough-mixtures; varieties of commercial lactucarium are produced by other species of Lachuca, $q$. v. L., Ext. (B. P.) Dose gr. $v-x v$. L., Ext., Fld. Dose $m x-3$ j. L., Syr., contains 5 per cent. of the drug. Dose $\xi^{j}-\xi_{j}$. L., Tinct., dose 3 ss $-\zeta_{\mathrm{ij}}$.

Lactucerin (lak-tu'-ser-in) [lactuca, lettuce; cera, wax]. A crystalline substance existing in lactucarium, $q . v$.

Lactucerol (lak-tu'-ser-ōl) [lactuca, lettuce; oleum, oil], $\mathrm{C}_{36} \mathrm{H}_{60} \mathrm{O}_{2}$. A crystalline substance existing in lactucerin; it occurs in two isomeric forms.

Lactucic Acid (lak-tu' -sik) [lactuca, lettuce], $\mathrm{C}_{80} \mathrm{H}_{64} \mathrm{O}_{6}$. A yellow, amorphous body found in lactucarium. It is insoluble in chloroform, ether, benzin, and carbon bisulphid. In some respects it resembles oxalic acid. See Acid.

Lactucin (lak-tu'-sin) [lactuca, lettuce]. A crystalline extractive of lettuce and of lactucarium.

Lactucol (lak'-tu-kol) [lactuca, lettuce], $\mathrm{C}_{13} \mathrm{H}_{20} \mathrm{O}$. A substance crystallizing in needles, formed when lactucerin and potassium hydrate are melted together.

Lactucon (lak-tu'-kon). Same as Lactucin.

Lactucopicric Acid, Lactucopicrin (lak-tu-ko-pik'.

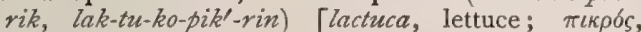
bitter], $\mathrm{C}_{44} \mathrm{H}_{32} \mathrm{O}_{21}$. An amorphous, bitter principle contained in lactucarium.

Lactumen (lak-tu'-men) [lac, milk: pl., Lactumina]. A synonym of Porrigo larvalis. Also, applied to that form of aphthæ in which the spots have a fanciful resemblance to clots of curd.

Lactupicrin (lak-tu-pik'-rin). See Lactucopicric Acid. Lacuna (la-ku'-nah) [lacus, a lake: pl., Lacuna]. A little hollow space. A mucous or lymphatic follicle. L., Absorption. See Howship's Lacune. L. amatorum, the vertical groove in the center of the upper lip. L. Bone. See Bone. L. of Cementum, spaces in the cement of the teeth analogous to those in bone. L. cerebri, the infundibulum of the brain. L. of Cornea, spaces between the laminæ of the cornea. L. graafianæ, Graafian follicles. L., Haversian. See Bone. L., Howship's. I. Depressions on the surface of bone beneath the perios- teum. 2, Carious excavations in bone filled with granulation-tissue. L., Intervillous (of placenta), the spaces in the maternal portion of the placenta filled with blood, and in which the fetal villi hang. L. labii superioris. See $L$. amatorum. L. laterales sinus superioris, depressions along the groove of the superior longitudinal sinus. L. magna, the largest of the orifices of the glands of Littré, situated on the upper surface of the fossa navicularis. L. morgagni, the orifices of the glands of Littré, or the glands themselves. L. pharyngis, a depression at the opening of the Eustachian tube into the pharynx. L. of Tongue, the foramen cecum. See Foramina, Table of. L. of Urethra, follicular depressions in the mucous membrane of the urethra, most abundant along the floor, especially in the region of the bulb. Their mouths are directed forward.

Lacunal (la-ku'-nal), or Lacunar (la-ku'-nar) [lacus, lake]. Pertaining to the lacunæ. L. Spaces, the irregular fissures between the fasciculi of connective tissue, forming the beginnings of the lymphatic vessels.

Lacunose $\left(l a-k u^{\prime}-n \bar{s} s\right)$ [lacuna, a pit, a hollow]. In biology, having pits, depressions, or spaces.

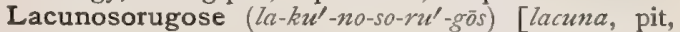
hollow; nuga, a wrinkle]. In biology, deeply pitted or wrinkled, as the stone of a peach.

Lacunula (lak-u'-nu-lah) [dim. of lacuna, a lake: pl., Lacumula]. A small or minute lacuna; an airspace, such as is seen in a gray hair when magnified.

Lacus (la'-kus) [L.]. A small hollow or cavity in a tissue. L. derivationis, one of the venous spaces in the tentorium cerebelli communicating with the superior longitudinal and lateral sinuses. L. lacrymalis, the space at the inner canthus of the eye, near the punctum, in which the tears collect. L. sanguineus, the utero-placental sinus.

Lacustrine (la-kus'-trin) [lacus, a lake]. In biology, inhabiting lakes or ponds.

La Dando (lah $\left.d a n^{\prime}-d o\right)$. Synonym of Influenza.

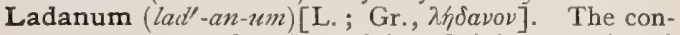
crete gummy and resinous juice of various species of Cistus, growing in the Mediterranean region; as $C$. ladaniferus, C. creticus, C. salvifolius, C. cyprius, $C$. ledon, and $C$. villosus. It is a greenish-gray solid, of bitter taste, formerly in high esteem. It is now chiefly used in making pastils for fumigation.

Ladendo (lad-en'-do). Synonym of Infuenza.

Ladrerie (lah-dra-re') [Fr.]. See Measles.

Ladric (lah'-drik). Pertaining to measles.

Lady Crespigny's Pill. A pill of aloes and cinchona; aloes socotr. $3 \mathrm{j}$, ext. cinchona $3 \mathrm{iij}$, cinnam. $3 \mathrm{j}$, syr. absinth. q. s. It is a stomachic and laxative. Dose gr. $\mathrm{x}-\mathrm{xx}$.

Lady Hesketh's Pill. A pill similar to Lady Crespigny's Pill, q.v.

Lady Webster Pill. See Aloe.

Lady's Bed-straw. Cheese-rennet. The herb Galium verum, a refrigerant and diuretic. Dose, fld. ext. $3 \mathrm{ss}-\mathrm{j}$. Unof. L.'s Slipper. See Cypripedium.

Læmoparalysis (le-mo-par-al'-is-is). See Lemoparalysis.

Laennec's Cirrhosis. Atrophic cirrhosis of the liver; a form of chronic interstitial hepatitis of the liver in which the organ is greatly reduced in size and may be deformed. The weight may be reduced to a pound or a pound and a half; the surface of the organ is granular; and its substance is composed of greenishyellow islands surrounded by grayish-white connective tissue. L.'s Perles and L.'s Râle. See Signs and Symptoms, Table of. L. tubercles, the miliary granulations of tuberculosis.

Lasis (le'-sis). See Lesion. 
Lætificant (le-tif'-ik-ant). See Letificant.

Lævo- (le'-vo-). For words so commencing, see Levo-.

Lævorotatory (le-vo-ro'ta-tor-e). See Levorotatory.

Lævulin (liv'-u-lin). See Levulin.

Lævulose (lev'-u-lôs). See Levulose.

Lafayette Mixture. A mixture employed in gonorrhea. It contains copaiba, cubebs, liquor potassæ, sweet spirit of niter, and is known also as the compound copaiba mixture. See Copaiba.

Lag Tooth. A delayed tooth. A name for the molar or wisdom tooth.

Lagam-balsam ( $\left(a g^{\prime}-a m-b a l^{\prime}-s a m\right)$. A variety of gurjun-balsam brought from Sumatra.

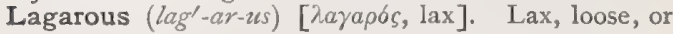
soft.

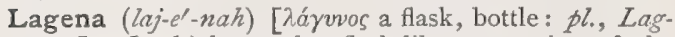
ence]. In biology, the flask-like extremity of the cochlea in certain vertebrates.

Lageniform (laj-en'-if-orm) [lagena, a flask ; forma, form]. Flask-shaped.

Lagentomum (laj-en'-to-mum) [ $\lambda a \gamma \omega s$, hare; $\varepsilon v$, in ;

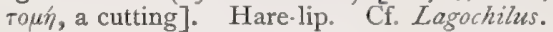

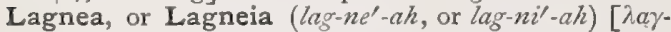
veir, coition, lust]. Same as Satyriasis. Also, coition. Also, the semen.

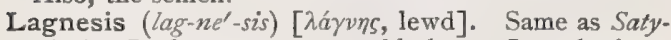
riasis. L. furor, unconquerable lust. L. valacitas, lust capable of control.

Lagnosis (lag-no'-sis). Same as Lagnesis.

Lagochilus (lag-o-ki'-lus), or Lagochilos (lag-o-ki'los) $\left[\lambda a \gamma \omega ́ s\right.$, hare; $\chi \varepsilon \tilde{\varepsilon} \lambda o_{s}$, lip]. Hare-lip. Cf. Lagentomum.

Lagophthalmia (lag-off-thal'-me-ah). Same as Lagophthalmos.

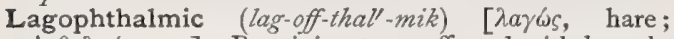
$\dot{o} \phi \theta i \lambda \mu \sigma_{\delta}$, eye]. Pertaining to or affected with lagophthalmos.

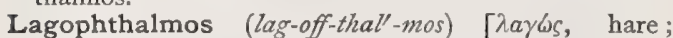
$\dot{a} \phi \theta a \mu \alpha s$, eye; from the popular notion that a hare sleeps with open eyes]. Inability to close the eyes.

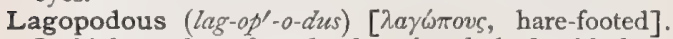
In biology, hare-footed; densely clothed with long and soft entangled hairs.

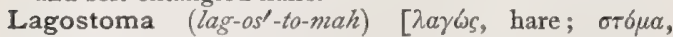
mouth]. See Hare-lip. Cf. Lagochilus and Lagentomum.

Lagrange's Exterminator. An apparatus for destroying the ectoparasites of poultry. It is a wooden box into which the bird is introduced with its feet tied, its head being kept outside by a special opening. In the box a brimstone match is burned; a few minutes of exposure to this vapor suffice to kill the parasites.

La Grippe (lah grip) [Fr.]. Synonym of Influenza.

Laisne's Method. A method of abdominal massage. The masseur lays his hands on either side of the abdomen, and executes a firm but not violent double rubbing movement, one hand ascending as the other descends, the principal pressure being made by the thenar and hypothenar prominences; the movements do not extend higher than the transverse colon, or lower than the ileum.

Laity $\left(i a^{\prime}-i t-e\right)$ [ $\lambda a o_{s}$, the people]. The non-professional public.

Lake (lāk). See Pigments, Colors, and Dye-stuffs, and also Lacus. L.-burn. See Fardel-bound. L.colored, applied to blood in which the hemoglobin, having separated from the stroma, is dissolved in the serum.

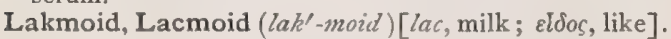
A delicate reagent in alkalimetry, made by acting on resorcin with sodium nitrate.
Lakmus (lak'-mus). See Lacmus.

Laky $\left(l \alpha^{\prime}-k e\right)$. See Lake-colored.

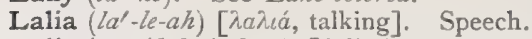

Lallation (lal-a'-shun) [lallatio; lallare, to babble]. Any unintelligible stammering of speech, such as the prattling of a babe. Also, the defect or peculiarity of speech, usually racial, in which $l$ is substituted for $r$.

Lalling (lal'-ing) [lallare, to babble]. Lallation; prattle; baby-talk.

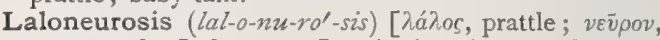
nerve: pl., Laloneuroses]. An impairment of speech arising from spasmodic action of the muscles. It includes stammering and aphthongia.

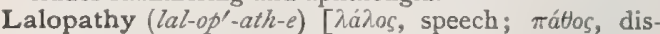
ease]. Any disorder of speech.

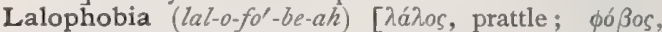
fear]. Stutter-spasm, leading to, or complicated with, a dislike of speaking.

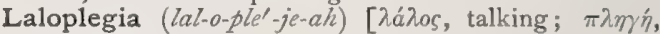
a stroke.] Paralysis of speech, not due, however, to paralysis of the tongue.

Lamarckism or the Lamarckian Theory. The doctrine based upon the teachings of the French naturalist, J. B. P. A. de Monet de Lamarck (1744-1829), who attempted to explain the progressive evolution of nature by virtue of an inherent tendency to development through the appetency and habits of living organisms, the efforts excited by change of conditions reacting upon the structure. It is based on the theory that matter acted upon by heat, light, and electricity may spontaneously generate life of low, homogeneous organisms, and that such organisms would develop qualities of heterogeneity and organs as governed by their surroundings, and especially by their wants or desires. To this preponderating influence of new wants Lamarck ascribes the chief rôle in evolution, while Darwin emphasizes the advantage of accidental variations in the struggle for existence. See $\mathrm{Neo}$ lamarckism.

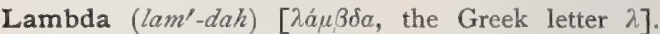
The junction of the sagittal and lambdoid sutures at the apex of the latter. See Cranionetric Points.

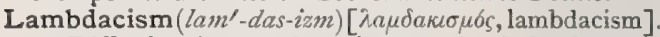
I. Difficulty in uttering the sound of the letter ? 2. Too frequent use of the $l$ sound, or its substitution for the $r$ sound; lallation.

Lambdoid, or Lambdoidal (lam'-doid or lamı-doi'-dal)

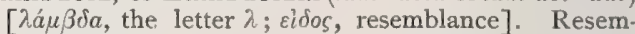
bling the Greek letter $\Lambda$. L. Suture, the suture between the occipital and the two parietal bones.

Lambert's Method. A method of mixing colors by colored wafers and a slip of glass. By means of reflections from the surface of the latter one color may be in part reflected and superimposed on another color.

Lame (Iām) [ME., lame, lame]. Crippled; halting ; limping.

Lamel (lam-el') [lamella, dim. of lamina, a plate]. A medicated disc, made with some soluble basis; it is used in the dosimetric application of drugs to the eye, etc.

Lamella (lam-el'-ah) [dim. of lamina, a plate: $p l$., $L a$ mella]. A descriptive term applied to any foliation or scale-like appearance; a thin lamina, scale, or plate. L. of Bone, the concentric rings surrounding the Haversian canals. L., Bronchial, one of the folds of the mucosa of the gills of fishes and certain molluscs. L. carnosa, that part of the parietal mesoblast from which the muscles of the trunk are developed. L. ceratina, the epiblastic layer giving origin to the skin and its appendages. L. cerebellare, 
one of the laminæ of the cerebellum. L., Concentric, one of the plates of bone surrounding the Haversian canals. L. coriaria, the part of the somatopleure from which the corium and possibly the cutaneous muscles are developed. L., Cribriform. See Lamina cribrosa. L., Fundamental or General, a general term applied to all varieties of osseous lamellæ. L., Haversian. See L., Concentric. L., Homogeneous, the clear, apparently structureless layer of an osseous lamella. L., Intermediate, one of the plates filling the spaces between the concentric layers of bone. L., Interstitial. See L., Intermediate. L., Investing. See L., Concentric. L. medullaris, the epiblastic layer forming the central nervous system and organs of special sense. L., Medullary, the internal lamellæ forming the wall of the medullary cavity of hollow bones. L. mesenterica, that portion of the splanchnopleure from which the mesentery, and the muscular and fibrous parts of the intestines are derived. L. mucosa, that part of the hypoblast from which the epithelia of the gastrointestinal tract and its glands are developed. L. of Nail, an elevation on the corium, dove-tailing into a furrow on the under surface of the nail. L., Perineural, the perineurium. L., Periosteal or Peripheral, a superficial lamella of bone lying under the periosteum. L. renalis, that portion of the mesoblast from which the kidneys and generative organs are developed. L., Special. See L., Concentric. L., Striped, the dark portion of a bonelamella which has a striped appearance. L., Triangular, a fibrous layer connecting the choroid plexuses of the third ventricle of the brain. L., Vascular. See Endochorion.

Lamellar (lam-el'-ar) Lamellate (lam-el'-ät) [lamella, a thin plate]. Having the nature of, or resembling any thin, osseous or membranous tissue ; composed of Iamellæ or thin plates. L. Cataract. See Cataract.

Lamelliferous (lam-el-if'-er-us) [lamella, a thin plate; ferre, to bear]. Composed of lamellæ.

Lamelliform (lam-el'-if-orm) [lamella, a small plate; forma, form]. Having the shape of a lamella.

Lamelligerous (lam-el-ij'-er-us). See Lamelliferous.

Lamelliped (lam-el'-ip-ed) [lamella, a small plate; pes, foot]. Having a flat or lamelliform foot.

Lamellose (lam'-el-ös). See Lamellar.

Lamellule (lam-ell-ül) [lamellula, dim. of lamella, a plate]. A very small plate.

Lameness (lām'-nes) [ME., lame, lame]. The state of being lame. L., Cross, a peculiar gait of horses in which the lameness seems to be in the leg on the opposite side of the one diseased. L., Kennel, a rheumatic affection of dogs. L., Uterine, weakness of the uterus due to disease.

Lamin (l $\Omega^{\prime}-$ min) [laminum, the dead-nettle]. alkaloid said to exist in Lamizm album, $q . v$.

Lamina (lam'-in-ah) [L., a plate or scale: pl., Lamince]. A descriptive term used to designate foliated structure. Also, any thin layer of bone, membrane, or other tissue. L., Arcuate (of the cerebellum), a bundle of fibers uniting the contiguous convolutions of the cerebellum. L., Arcuate (of the cerebrum), a band of fibers uniting adjacent convolutions of the cerebrum. L. ascendens (of the palate bone), the vertical plate of the palate. L. axilis, the primitive streak of the blastoderm. L., Basal (of the placenta), the decidua serotina. L., Bowman's, the structureless membrane between the anterior layers of epithelium and the fibrous tissue of the cornea of the eye. L. cacuminis, a narrow band connecting the posterior superior lobes of the cerebellum. L of Cerebellum, the layers of white matter, covered externally with gray substance, that arise from the central white axis of the cerebellum. L. chrotalis, the dermal plate or covering. L. cinerea, the connecting layer of gray matter between the corpus callosum and the optic chiasma ; the terma. L. cinerea convoluta, the tuber cinereum. L. conarii, the lower lamella of the recess of the pineal gland. L. concharum, the inner surface of the lateral masses of the ethmoid bone. L. connectens, the posterior cerebral commissure. L. connectiva, the colloderma, $q . v$. L. cortis, the membrana tectoria of the internal ear. L. cornea, a thickened band of the ependyma of the lateral ventricle covering the tænia semicircularis, L., Cribriform, the cribriform plate of the ethmoid. See also $L$. cribrosa of the Temporal Bone. L. cribrosa (of the choroid), in lower animals that portion of the choroid which is perforated for the passage of the optic nerve. L. cribrosa (of the fascia lata), the cribriform fascia covering the saphenous opening. L. cribrosa anterior, the anterior perforated space. L. cribrosa anterior inferior, the anterior part of the inferior fossula, through which branches of the cochlear nerve pass. L. cribrosa media, the middle part of the inferior fossula transmitting the branches of the auditory nerve going to the saccule. $\mathbf{L}$. cribrosa posterior, the posterior perforated space. L. cribrosa of the Sclerotic, the perforated lamina through which the optic nerve enters the globe of the eye. L. cribrosa of the Temporal Bone, a small laminated bone forming the boundary of the internal auditory meatus. L. of the Cricoid Cartilage, the flat posterior plate of the cricoid cartilage. L., Crystalline, the anterior part of the capsule of the crystalline lens. L. dentata, the dentate fascia. L. denticulata, the covering of the outer fifth of the vestibular surface of the bony cochlea, from which delicate teeth-like elevations project into the scala vestibuli. $\mathbf{L}$. dorsalis, one of the two ridges bordering the medullary groove, that unite to form a canal which finally develops into the cerebro-spinal canal. See Plates, Medullary. L., External Medullary, the outer of the two white layers of the lenticular nucleus. L., Fibrocutaneous, the parietal mesoblast. L., Fibrointestinal, the visceral mesoblast. L. fusca, the pigmentary tissue of the sclera forming the ectal layer of the perichoroidal sinus. L. gastralis, the gastroderma, q.v. L., Gray. See L. cinerea. L. grisea, the gray matter of the spinal cord. L., Internal Medullary, the inner of the two white layers of the lenticular nucleus. L., Lateral (of the sphenoid bone), the external pterygoid plate. L. lentis, one of the layers of the crystalline lens. L. mastoidea, the basal plate of the mastoid process of the temporal bone. L., Median (of the sphenoid bone), the internal pterygoid plate. L. medullaris media cerebelli, the valve of Vieussens. L. medullaris thalami, a layer of white matter between the optic thalamus and the internal nucleus of the striate body. L. medullaris transversa, a delicate layer of gray matter covering the aqueduct of Sylvius. L. medullaris triangularis, the lyra of the fornix. L.modioli, the bony lamina spiralis of the cochlea. L. muscularis, the myoderma, $q . v$. L. nervea involvens, a delicate layer of nerve-matter covering the ventricular surface of the ependyma. L. neurodermalis, the epiblast. L., Nuclear, the nuclear layer. L. palatina, the horizontal plate of the palate bone. L. papyracea, the os planum of the ethmoid bone L. pedunculorum, one of the layers of which the crura cerebri are composed. L. perforata, either perforated space. L. pigmenti, a delicate layer of 
pigment-cells between the retina and the choroid. L., Posterior Elastic, the posterior layer of the cornea; the membrane of Descemet. L. prima cutis, the epidermis. L. propria (of the tympanic membrane), the middle or fibrous layer of the tympanic membrane. L., Protovertebral, that portion of the mesoblast lying to the side of the chorda dorsalis in which the protovertebræ subsequently form. L. quadrigemina, a layer of gray matter, forming the roof of the aqueduct of Sylvius. L. Quadrilateralis, a term for the Clivus of Blumenbach, $q . v$. L., Reticular, the hyaline membrane of the inner ear, extending between the conjoined head of Corti's rods and Hensen's supporting cells. L. secundaria, one of the secondary germ-layers, $q . v$. L. semicircularis. See Tania semicircularis. L. sphenopetrosa, a small plate of bone near the spinous foramen of the greater wing of the sphenoid bone. L. spiralis, a thin plate in the ear, osseous in the inner part and membranous in the outer, which divides the spiral tube of the cochlea into the scala tympani and the scala vestibuli. L. spiralis ossea, a thin plate of bone that winds spirally around the modiolus of the cochlea. L. superchoroidea, the delicate membrane of the outer surface of the choroid tunic of the eye. L. tectoria. See Lemniscus, Inferior. L., Terminal. I. See $L$. cinerea. 2. The anterior terminal plate of the anterior brain-vesicle. L. terminalis. See Terma. L. triangularis (of the sphenoid bone), the posterior triangular part of the great wing of the sphenoid bone. L. transversa, one of the transverse laminæ of the cerebellum. L., Tympanic, the tympanic plate of the petrous portion of the temporal bone. L., Vascular, the endochorion. L. of Vertebra. See Vertebra. L. ventralis, one of the lateral mesoblastic plates. L. vitra, the inner or vitreous table of the skull. L. visceralis, one of the thickened layers of mesoblastic tissue on each side of the notochord, which by proliferation and splitting form the splanchnopleure and somatopleure. L., Vitreous (of the choroid), a homogeneous membrane covering the inner surface of the choroid; it is also called the membrane of Bruch.

Lamina (lam'-in-e) [lamina, a thin plate]. The sensitive plates of soft tissue, covering the entire anterior surface of the coffin-bone in the horse. See also Lamina.

Laminage (lahm-in-ahzh') [Fr.]. Flattening; the compression or flatwise crushing of the fetal head to facilitate delivery.

Laminal, Laminar (lam'-in-al, lam'-in-ar) [lamina, a layer]. Composed of laminæ; having the form of a lamina. L. Tissue, a synonym of Connective Tissue.

Laminaria (lam-in- $\left.a^{\prime}-r e-a h\right)$ [lamina, a thin plate]. I. A genus of algæ, or seaweeds. Several species are rich in iodin. 2. The cured lower part of the stem of $L$. cloustoni, or $L$. digitata. L. Bougie, a bougie made of the stalk; it is used for urethral dilatation. L. cor nica, L. digitata, devil's-apron, tangle; sea-tangle, sea-girdles, or sea-wand; cairn-tangle, dead-man'stoe, oarweed. A species found in Scotland, very rich in iodin; the stem is used for the manufacture of tents and bougies. L. esculenta, an edible species said to have anti-scorbutic properties. L. Probe, a probe made of the stalk, used to dilate the canaliculi and nasal duct. L. saccharina, ribbon-weed; sea-belt, sweet-tangle, is rich in iodin and potash; it is used as food, and is also purgative. L. Tent, a tent made of the stem of the plant, for dilatation of the cervix uteri.

Laminate, Laminated ( $l a m^{\prime}-i n-\bar{a} t$, la $m^{\prime}$-in-ät-ed). See Laminar.
Lamination (lam-in- $a^{\prime}-\operatorname{sh} u n$ ) [lamina, a layer]. Arrangement in plates or layers. An operation in embryotomy, consisting in cutting the skull in slices.

Laminectomy (lam-in-ek'-to-me) [lamina, a layer; $\dot{\varepsilon} \kappa \tau$ r $\mu$, excision]. The operation of removing the posterior vertebral arches.

Lamineur (lam-in-är $\left.\gamma^{\prime}\right)$ [lamina, a layer]. An instrument for performing laminage, $q . v$.

Laminitis (lam-in-i'-tis). [lamina, plate; $\iota \tau \iota$, inflammation]. Inflammation of the laminæ of a horse's hoof; founder.

Laminose $\left(\right.$ la $\left.^{\prime}-i n-\bar{o} s\right)$ [lamina, a thin plate]. Thin, membranous, or plate-like.

Lamium $\left(l a^{\prime}-m e-u m\right)$ [L., the dead-nettle]. A genus of labiate plants. L. album, the leaves and stems of the plant $L$. album, with properties due to an alkaloid, Lamin. It is useful in menorrhagia. Dose of the tincture $3^{\text {ss-ij. Unof. }}$

Lamnar (lam'-nar) [lamna, a thin plate]. A term applied to nails that are flat, short and broad.

Lamnectomy (lam-nek'-to-me). Same as Laminectomy.

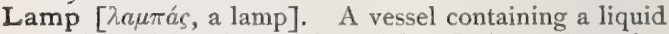
capable of burning, and a wick. It is used to give light. L., Aphlogistic, a lamp devised by Davy in which glowing platinum furnishes the light. L.-black, a fine black substance, almost pure carbon, made by burning coal-oils in an atmosphere deficient in oxygen, or by allowing a gas-flame to impinge on a cold surface. See Pigments, Conspectus of. L., Laryngoscopic, a small incandescent lamp used in laryngoscopy. One form is provided with reflectors and lenses by means of which light can be projected into the mouth, pharynx, and larynx. L., Lee's, a lamp used in mercurial fumigation. L., Mercurial, a lamp consisting of two cups, an upper for holding the mercury, a lower for holding water. The latter is heated by means of a Bunsen burner, the water and mercury being both vaporized. L., Spirit, one in which alcohol is used to produce heat rather than light. L., Van Buren's, a device for mercurial fumigation.

Lampas (lam'-pas) [Fr., lampas, lampas]. A congestive swelling of the fleshy lining of the roof of the mouth, in the horse.

Lampers (lam'-perz). See Lampas.

Lamprophony (lam-proff'-o-ne) [^a $\alpha \pi \rho o ́ s$ sounding; $\phi \omega \nu \dot{\eta}$, voice]. A sonorous, ringing quality of the voice.

Lampsana (lamp-sa'-nah). See Lapsana.

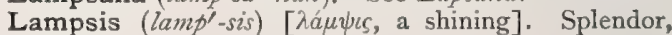
brilliancy

Lana $\left(l a^{\prime}-n a h\right)[\mathrm{L}$.$] . Wool.$

Lanate $\left(\operatorname{lan}^{\prime}-\bar{a} t\right)[\lambda \tilde{\eta} \nu o s$, wool]. Woolly; lanuginous; lanigerous; lanose.

Lancaster Black-drop. Acetum opii; vinegar of opium.

Lance (lans) [lancea, a lance or spear]. I. A lancet. 2. To open, as with a lancet or bistoury. L., Mauriceau's, a lance-shaped knife for opening the fetal head in embryotomy.

Lanceate $\left(\operatorname{lan}^{\prime}-\right.$ se-ät $)$ [lancea, a lance]. See Lanceolate.

Lanceolar (lan'-se-o-lar). See Lanceolate.

Lanceolate ( $\left(a n^{\prime}-s e-0\right.$-lat $)$ [lanceola, a little lance]. In biology, shaped like a lance-head; thin and tapering towards each end.

Lancet $($ lan'-set $)$ [dim. of lancea, a lance]. A two. edged surgical instrument for incising tumors, etc. L., Gum, a small instrument in which the cutting portion has a convex edge and is at right-angles to the shaft. L., Spring, one in which the blade is thrust out by means of a spring, which is controlled by a trigger. L., Thumb, one with a double-edged, broad blade. 
Lanciform (lan'-sif-orm) [lancea, lance ; forma, form]. Lance-shaped.

Lancinate $\left(\operatorname{lan}^{\prime}-\sin -\bar{a} t\right)$ [lancinare, to tear]. To lacerate, to pierce, or tear.

Lancinating ( $a n^{\prime}-\sin$-a-ting) [lancinare, to tear]. Tearing; shooting. L. Pains, rending, tearing, or sharply-cutting pains, common in posterior spinal sclerosis.

Lancing ( lan' $^{\prime}$-sing). See Lance.

Lancisi, Nerves of. The strice longitudinales. The slight ridges of the callosum of the brain bounding the raphé. See Nerves, Table of.

Landmarks (land'-marks) [ME., landmark, the boundary of a country]. Superficial marks (such as eminences, lines, and depressions) that serve as guides to, or indications of, deeper-seated parts. The knowledge of landmarks is of the utmost importance, both to the surgeon and the physician.

Landolphi's or Landolfi's Paste. A caustic application composed of the chlorids of zinc, antimony, bromin, and gold, which is used pure, or weakened by mixing with basilicon ointment in varying proportions. It should be spread on the surface with a spatula, or applied on charpie, and allowed to remain for 24 or 48 hours.

Landolphia (lan-dol'-fe-ah) [after Capt. Landolph, an explorer]. A genus of tropical climbing shrubs, including the African rubber-tree, a source of caoutchouc.

Landolt's Method. A method of determining insufficiency of the internal recti muscles. A small lamp or candle is surrounded by a blackened chimney, a vertical slit in which serves as an object of fixation. The light is then approximated to the eyes, and when the internal recti are no longer able to maintain the necessary convergence, two images of the slit are seen.

Landouzy-Dejerine Type. A type of muscular atrophy. See Diseases, Table of.

Landry's Disease or Paralysis. Acute ascending paralysis; a form of atonic paralysis described by Landry, characterized by loss of motor power in the lower extremities, gradually extending to the upper extremities, and to the centers of circulation and respiration, without characteristic sensory manifestations, trophic changes, or variations in electric reaction. See Diseases, Table of.

Land-scurvy. See Purpura hamorrhagica.

Landzert, Angle of. See Angle.

Lanesin, or Lanessin (lan'-es-in) [lana, wool]. A proprietary preparation of wool-fat similar to lanolin.

Lanfranc's Collyrium. A stimulant application to ulcers, containing aloes and myrrh, each 5 parts ; acetate of copper, Io parts ; trisulphid of arsenic, I 5 parts ; rose-water, 380 parts, and white wine, Iooo parts.

Lang's Oil. See Gray Oil.

Lange's Method. A method of testing for $\mathrm{CO}_{2}$ in the air. It consists in shaking in a bottle full of the air to be tested, a half ounce of clear fresh lime-water. If the air contains 7 parts per 1000 of $\mathrm{CO}_{2}$, a turbidity of the fluid will occur.

Langenbeck's Operation. See Operations, Table of.

Langerhans' Cells. Certain modified epithelial cells forming the simplest nerve-endings. L.'s Granular Layer, the stratum granulosum of the epidermis.

Langier's Apparatus. A form of immovable splint for a limb. It is composed of strips of brown paper impregnated with starch-paste. L.'s Bandage. See Bandage.

Langley, Oxyntic Cells of. See Delomorphous. L.'s Test. See Tests, Table of.

Language (lang'-grwajj) [lingua, the tongue]. The articulate sounds, signs, or symbols whereby thought is communicated. L., Center for. See Aphasia.
Languor (lang'-gwor) [L., faintness]. Lassitude. Disinclination to take bodily exercise, or to exert oneself.

Laniaries or Laniary Teeth $\left(l a^{\prime}-n e-a r^{\prime}-e-\bar{e} z\right)$ [Dentes laniarii; laniare, to rend]. The cuspid teeth; applied more particularly to those of carnivorous animals.

Laniariform (la-ne-ar'-if-orm) [laniare, to rend; forma, shape]. Shaped like the canine teeth of carnivora.

Laniary (la'-ne-a-re) [laniare, to tear, rend]. In biology, applied to well-developed canine or lacerating teeth.

Lanigerous (lan-ij'-er-us) [lana, wool; gevere, to bear]. In biology, producing, or covered with wool or a woolly growth; lanate; lanose; lanuginous.

Lank [ME., lank, lank]. Lean, thin, attenuated.

Lanoleum (lan-o'-le-ztm). See Lanolin.

Lanolin (lan'-o-lin) [lana, wool; oleum, oil]. A cholesterin-fat obtained from sheep's wool, introduced as a basis for ointments. It does not saponify or become rancid, and is characterized by remarkable penetrative powers.

Lanose (la'-noss) [lana, wool]. In biology, woolly; wool-like; lanate.

Lantana ( $\left.l a n-t a^{\prime}-n a h\right)$ [L.]. A genus of verbenaceous shrubs and herbs, principally natives of tropical America. A few grow native in the U. S. L. aculeata is an aromatic stomachic. L. brasiliensis and $\mathbf{L}$. camara are among the antipyretic species. Unof.

Lantanin (lan'-tan-in) [lantana]. An alkaloid extractive of Lantana brasiliensis, called Yerba sagrada. It is asserted to have antiperiodic and antipyretic properties, and has been successfully used in intermittent fevers. Dose, gr. $\mathrm{xv}-\mathrm{xxx}$. Unof.

Lantermann's Notches or Segments. Conico-cylindric segments in the medullary sheath of a nervefiber; they are marked off from one another by the incisures of Schmidt.

Lantern of Aristotle, or Aristotle's Lantern. In biology, the oral skeleton of a sea-urchin. L.-jaws, a colloquialism for a long, thin visage.

Lanthanum (lan'-than-um), or Lanthanium (lan-tha' $n e-u m)$ [ $\lambda a \nu \theta a ́ v \varepsilon \iota \nu$, to conceal ; lanthanum was a substance concealed from the knowledge of chemists] A rare metallic element; symbol $\mathrm{La}$., atomic weight, I38. Little is known of its medicinal properties. See Elements, Table of.

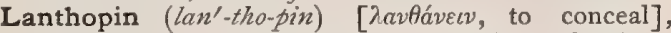
$\mathrm{C}_{33} \mathrm{H}_{25} \mathrm{NO}_{4}$. A finely crystalline alkaloid of opium. It occurs in white crystals fusible at $200^{\circ} \mathrm{C}$.

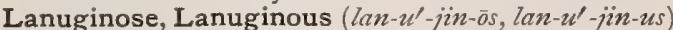
[lanuginosus, wooly]. In biology, woolly, downy, lanate, lanose, lanigerous.

Lanugo $\left(\right.$ lan- $\left.u^{\prime}-g^{\circ}\right)$ [lana, wool]. The down-like hair that appears upon the fetus at about the fifth month of gestation; the downy growth often seen upon the face of women and girls. L. prima, the first growth of beard. L. pudendorium, pubic hair.

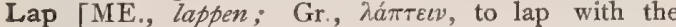
tongue]. I. To lick up. 2. A lick. 3. That part of the body formed by the anterior aspect of the thighs.

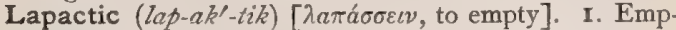
tying; evacuant. 2. Any purgative substance.

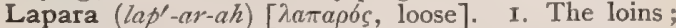
loosely applied to the abdomen. 2. Diarrhea.

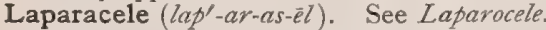

Laparectomy (lap-ar-ek'-to-me). See Enterectomy.

Laparelytrotomy (lap-ar-el-it-rot'-o-me). Same as Laparo-elytrotomy. 
Laparocele ( $\left.l a p^{\prime}-a r-o-s \bar{e} l\right)$ [ $\lambda a \pi a ́ \rho a$, loin; $\kappa \hat{\eta} \lambda \eta$, tumor] Lumbar or abdominal hernia.

Laparocholecystotomy (lap-ar-o-ko-les-is-tot'-o-me)

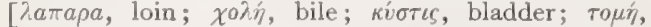
cutting]. Laparotomy conjoined with cholecystotomy.

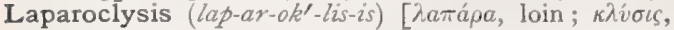
a drenching]. An injection into the peritoneal cavity.

Laparocolectomy (lap-ar-o-ko-lek'-to-me). Same as Colectomy.

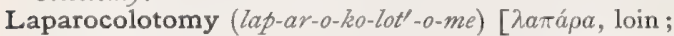

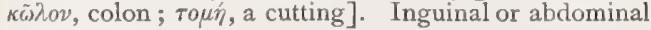
colotomy.

Laparocolpotomy (lap-ar-o-kol-pot'-o-me). See Laparo-elytrotomy.

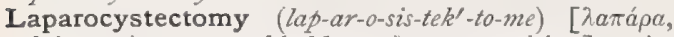

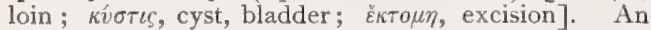
operation performed in advanced extrauterine pregnancy for removal of the fetus and the entire sac. It is performed like an abdominal section for any cystic tumor in the abdominal cavity with dense adhesions. The sac is to be evacuated, or not, as indicated, and adhesions separated, if necessary, after ligation.

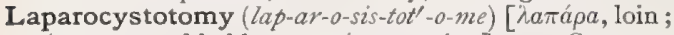

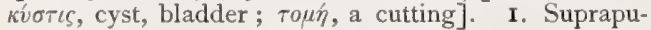
bic cystotomy. 2. An operation in advanced extrauterine pregnancy for the removal of the fetus, the sac being allowed to remain.

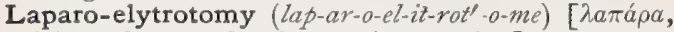
loin; $\varepsilon \lambda v \tau \rho o \nu$, sheath; $\tau o \mu \dot{\eta}$, a cutting]. An operation devised by Jörg as a substitute for the Cesarean operation. It consists in an incision over Poupart's ligament, dissecting up the peritoneum until the vagina is reached, when the latter is incised transversely, the cervix dilated, and the child thus extracted above the inlet. Its mortality is about 50 per cent.

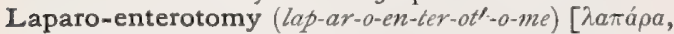
loin; $\varepsilon \tau \tau \varepsilon \rho o v$, intestine; $\tau o \mu \eta \dot{n}$, a cutting]. An opening of the intestine through an abdominal incision.

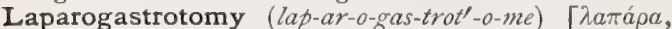

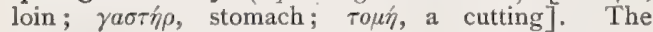
opening of the stomach through an abdominal incision.

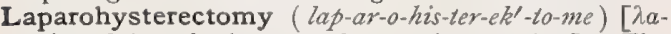

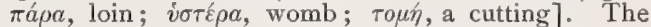
removal of the womb through an incision in the abdominal walls.

Laparo-hystero-oöphorectomy (lap'-ar-o-his'-ter-o-o-

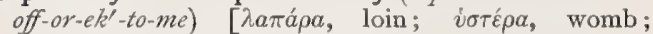

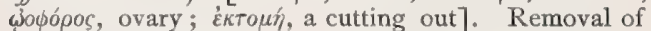
the womb and ovaries through an incision in the abdominal wall.

Laparohysterotomy (lap-ar-o-his-ter-ot'-o-me). See Gastro-enterotomy.

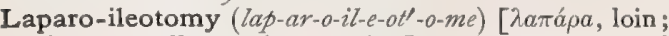
$\varepsilon i \lambda_{\varepsilon} \iota \nu$, to roll; $\tau o \mu \eta$, a cutting]. The formation of an artificial anus in the groin.

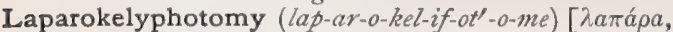

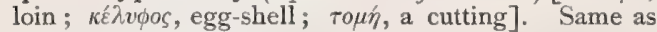
Laparocystotomy.

Laparokolpotomy (lap-ar-o-kol-pot'-o-me). See Laparo-elytrotomy.

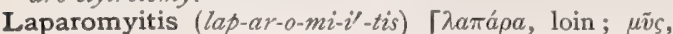
muscle; $\iota \tau \iota \zeta$, inflammation]. Inflammation of the muscular portion of the abdominal wall.

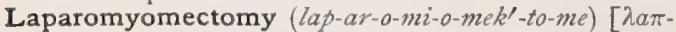
á $\rho a$, loin; $\mu \tilde{v} \varsigma$, muscle; $\dot{\kappa} \kappa о \mu \eta \dot{n}$, a cutting out]. Removal of a myoma through an abdominal incision.

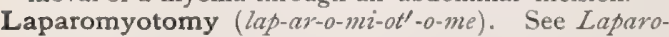
myomectomy.

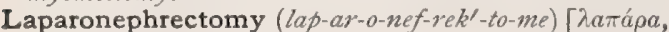

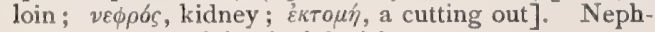
rectomy by an abdominal incision.

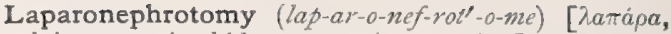

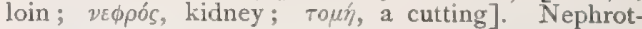
omy through an abdominal incision.

Laparosalpingectomy (lap-ar-o-sal-pin-gek'-to-me)

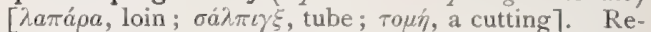
moval of a Fallopian tube through an abdominal incision.

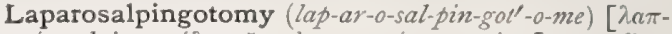
$\alpha \rho \alpha$, loin; $\sigma a ́ \lambda \pi \nu \gamma \xi$, tube; $\tau o \mu \dot{\eta}$, a cutting]. I. Cutting into an oviduct through an abdominal incision. 2. Laparosalpingectomy,

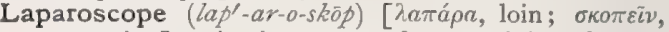
to examine]. An instrument for examining the abdomen.

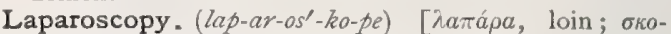
$\pi \varepsilon i \nu$, to examine]. The examination of the abdomen by the stethoscope, plessimeter, or by other instrumental means.

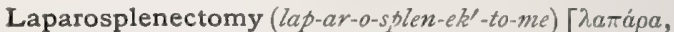
loin; $\sigma \pi \lambda \hat{\nu} \nu$, spleen; $\varepsilon \kappa \tau o \mu \hat{\eta}$, a cutting out]. Removal of the spleen through an abdominal incision.

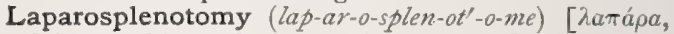
loin; $\sigma \pi \lambda \eta \nu$, spleen; $\tau o \mu \eta \dot{n}$, a cutting]. The surgical incision or entrance upon the spleen through the abdominal walls.

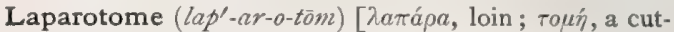
ting]. A cutting-instrument used in laparotomy.

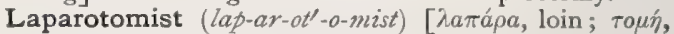
a cutting]. A surgeon who performs laparotomy.

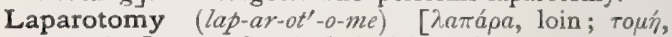
a cutting]. I. Surgical incision through the abdominal wall; celiotomy. 2. Surgical entrance into the abdominal cavity through the loin or flank. (The definition first given is that offered by most lexicographers, and is in accord with common usage; but objection has been made to this use of the word. The second definition is believed to represent the etymologically more correct use of the term.) L., Conservative, abdominal section, with a view either to aspiration of the distended Fallopian tubes, or to breaking down adhesions and freeing the diseased uterine appendages.

Laparotyphlotomy (lap-ar-o-tif-lot'-o-me). Synonym of Typhlotomy.

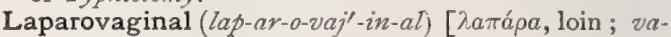
gina, sheath]. Pertaining to the abdomen and the vagina.

Laparysterotomy (lap-ar-is-ter-ot'-o-me). Same as Laparohysterotomy.

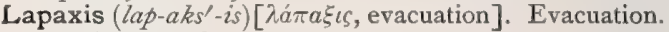
La Perlèche. See Perlèche.

Lapides cancrorum (lapplid-èz kang-kro'-rum) [L.]. See Crab' s-eyes.

Lapidillum (lap-id-il'-um) [dim. of lapis, stone]. A scoop for removing stones from the bladder.

Lapidose (lap'-id-ôs) [lapis, a stone]. In biology, inhabiting stony places.

Lapillation (lap-il-a'-shun) [lapillus, a small stone]. The formation of stones; lithogenesis, $q . v$.

Lapis (la'-pis) [L., a rock]. An alchemic term applied to any non-volatile substance. L. dentium, tartar of the teeth; salivary calculus. L. divinus, aluminated copper; a preparation used in ophthalmology. It is made by fusing together 32 parts each of cupric sulphate, potassium nitrate, and alum, and adding a mixture of 2 parts each of camphor and alum. L. imperialis, silver nitrate. L. lazuli, a beautiful blue stone of complex composition, formerly employed as a purgative and emetic, and in epilepsy. L. lunaris, silver nitrate. L. mitigatus. See $A r$ gentum. L. mutabilis. See Tabasheer. L. nauticus, a lode-stone. 
Laplace's Formulæ. I. For preparing acid sublimate

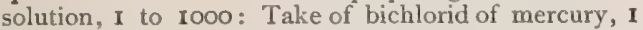
gram; nitric acid, 5 grams; water 1000 grams. 2. For preparing acid sublimate tablets: Take of bichlorid of mercury, I gram; tartaric acid, 5 grams. Make into one tablet. This is to be dissolved in one liter (I000 grams) of water. 3. Acid sublimate gauze is prepared by dipping the gauze in the foregoing solution, wringing it out, and allowing it to dry in a clean atmosphere.

Lappa (lapp-ah) [L.: gen., Lappce]. Burdock. The root of the common burdock, Arctium lappa, contains a bitter principle, a resin, and tannin. It is aperient and diuretic and has some reputation as an alterative in constitutional blood-diseases. A tincture of the seed has been recommended in skin-diseases. The dose of the root is $3 \mathrm{j}-\mathrm{ij}$, in infusion or tincture; of the fluid extract, $m x-3 j$.

Lappaceous (lap-a'-she-us) [lappa, a bur]. In biology, bur-like.

Lappet (lap'-et) [ME., lappet, lappet]. In biology, the wattle of a bird.

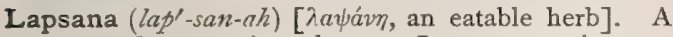
genus of composite plants. L. communis, was formerly used as a laxative and in skin-diseases.

Lapsus (lap'-sus) [labi, to fall]. A fall; ptosis. L. palpebræ superioris, ptosis of the eyelid. L. pilorum, alopecia. L. unguium, falling of the nails.

Larch [ME., larche, larch]. See Larix and Tamarac. Larcher's Sign. See Death.

Lard and Lard-oil [ME., larden, lard]. Adeps. The fat of the pig melted by gentle heat and strained. Crude lard is white, granular, and of the consistency of a salve, of faint odor and sweet, fatty taste. Its specific gravity is $.93^{8}$ to .940 at $15^{\circ} \mathrm{C}$. Exposed to the air it becomes yellowish and rancid. When compressed at $32^{\circ} \mathrm{F}$., it yields 62 parts of colorless lardoil and 38 parts of compact lard. Lard is used in cooking; lard-oil for greasing wool, as a lubricant, and an illuminant.

Lardaceïn (lar-da'-se-in) [ME., larden, lard]. An animal proteid, an indigestible amyloid substance, chiefly occurring as a pathologic infiltration into various organs, as the liver, or spleen.

Lardaceous (lar-da'-she-us) [ME., larden, lard]. See Amyloid. L. Kidney. See Bright's Disease.

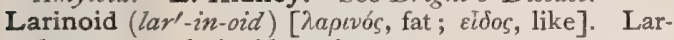
daceous; as larinoid carcinoma.

Larix $\left(l a^{\prime}-r i k s\right)$ [L., gen. Laricis]. Larch. The dried bark of Larix europea, the European larch, similar in action to balsamic and terebinthinate remedies. It is expectorant, stimulant, and astringent. L., Tinct. (B.P.) Dose $\eta_{x x-1 x x x}$ See, also, Tamarac.

Larkspur (lark'-spur). The seed of Delphinium consolida, a diuretic and emmenagogue. Dose of the fld. ext., $m j-x$. Unof.

Larnaude's Disinfecting-fluid. A solution of zinc sulphate containing a little copper sulphate.

Larrey's Amputation. See Operations, Table of. L.'s Apparatus, a form of immovable dressing made by saturating the bandages in a mixture of camphorated spirit, lead-water, and white of egg. L.'s Bandage. See Bandage.

Lartigue's Pills. Pills used in the treatment of gout, containing compound extract of colchicum 20 parts, and extract of digitalis, one part.

Larva (lar'-vah) [larva, a ghost: pl. Lavva]. The young stage of such animals as undergo transformation. The form that insects take in emerging from the egg, commonly known as the caterpillar or " grub" stage. Also, applied to the immature form distinguishing many of the lower vertebrates before maturity. L., Lovèn's, the young of the marine worm polygordius. L., Müller's, the free-swimming young of the polyclad platodes, Thysanozoön and Yungia.

Larvaceous (lar-val'-she-us), Larval (larl-val) [larva, a mask]. Covering the face like a mask.

Larval [larve, a ghost]. I. Pertaining to or existing in the condition of a larva. 2. Same as Larvaceous. L. Paludism. See Dumb Ague. L. Pneumonia. See Pneumonia. L. Scarlatina, a mild case of scarlet fever in which the rash is absent.

Larvate (lar'-vät) [larvatus, masked]. Concealed; masked; applied to diseases and conditions that are hidden by more obvious conditions, or by some peculiarity of their symptoms.

Larviform (lar'-vif-orm) [larva, a larva; forma, shape]. Resembling or being a larva.

Larvigerous (lar-vij'-er-us) [larva, ghost, mask ; gerere, to carry]. In biology, bearing the larval skin.

Larviparous (lar-vip'-ar-us) [larva, larva; parere, to bring forth]. In biology, bringing forth young that have reached the larval state.

Larvivorous (lar-viv'-or-us) [larva, larva; vorare, to devour]. In biology, feeding on larvæ.

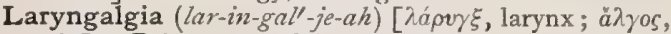
pain ]. Pain or neuralgia of the larynx.

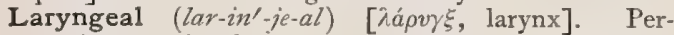
taining to the larynx. L. Artery. See Arteries, 7 able of. L. Cough, an hysteric manifestation in young women. It is a paroxysmal cough, with a peculiar hoarse and muffled sound, like the barking of a dog. L. Crisis, an acute laryngeal spasm, occurring in the course of tabes dorsalis. L. Dilator, an instrument designed to dilate the larynx, when the latter has become constricted by cicatricial tissues, or from other causes. L. Edema, infiltration of a fluid or semi-fluid into the submucous connective tissue of the larynx. It is usually associated with some disease or injury of the larynx, and occurs mainly between the eighteenth and thirty-fifth years. It is characterized by dyspnea and dysphagia. L. Epilepsy, a peculiar neurosis of the larynx characterized by a sense of suffocation during sleep. There is no discoverable lesion. L. Mirror, a small circular, silvered-glass mirror used in laryngoscopy. L. Nerve. See Nerves, Table of. L. Paralysis, a loss of power of some or of all of the muscles of the larynx. L. Pouch. See Pouch. L. Reflex. See Reflexes, Table of. L. Spaces, the upper, middle, and lower parts into which the larynx may be conveniently divided. L. Vertigo. See Vertigo and L. Epilepsy.

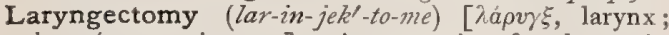

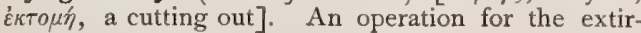
pation of the larynx.

Laryngemphraxis (lar-in-jenn-fraks'-is) [ $[\dot{\alpha} \rho v \gamma \xi$, larynx; $\varepsilon \mu \phi \rho a \xi \iota \varsigma$, stoppage]. Closure or obstruction of the larynx.

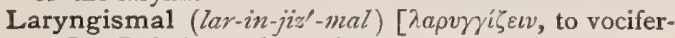
ate]. Relating to laryngismus.

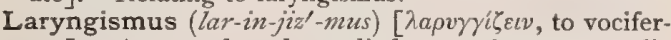
ate]. A term loosely applied to various spasmodic affections of the larynx, such as epileptic spasm. See Laryngeal Epilepsy. L. paralyticus, a paralysis of the recurrent laryngeal nerve in horses, producing the affection called "roaring." L. stridulus, laryngospasm; spasmodic croup; spasm of the glottis. A spasmodic affection of the larynx, mainly confined to the early period of childhood. There is a sudden arrest of respiration, with increasing cyanosis, followed by long, loud crowing inspirations. This affection occurs in rachitic children and especially in such as are of the neurotic tendency. The attack may be severe enough to terminate life. 


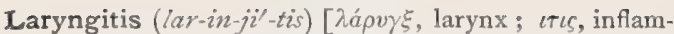
mation]. A catarhal inflammation of the larynx accompanied by sore-throat, hoarseness, and, usually, painful deglutition and cough. In severe cases there may be edema, dyspnea, and suffocation. In infants it is much the same disease as catarrhal croup. It also accompanies malignant affections of the throat and trachea, such as diphtheria, carcinoma, etc. L., Atrophic, a chronic form with atrophy of the mucous membrane. L. catarrhalis, catarrhal inflammation of the larynx. L., Croupous. See Crout. L., Diphtheric. See Croup. L., Dry, a chronic form in which the secretion is small or dries into crusts. L., Edematous. See Laryngeal Edema. L., Fetid, a form with a sticky exudate that decomposes. L., Follicular, a form in which the mucous glands are involved. L., Glandular. See L., follicular. L., Granular. See L., Follicular. L., Hypertrophic, a chronic form with hypertrophy of the tissues. L., Membranous. See Diphtheria. L., Parenchymatous. See $L$., Phlegmonous. L., Phlegmonous. See Laryngeal Edema. L., Polypous, a form characterized by the presence of polyps. L., Pseudo-membranous, an inflammation of the laryngeal mucous membrane characterized by the presence of a pseudo-membrane of a whitish-gray color, of varying consistency, and different degrees of attachment. It is usually met with between the second and seventh years. There is a paroxysmal cough, with hoarseness and increasing dyspnea, with occasional attacks of suffocation. Death frequently results. L., Serous. See Laryngeal Edema. L., Simple, a subacute catarrhal laryngitis. L., Spasmodic, a form in which there is spasm of the glottis. L., Stridulous, laryngitis with stridor. L., Submucous. See L., Phlegmonous and Laryngeal Edema. L., Suffocative, diphtheria. L., Tuberculous, laryngeal tuberculosis. A chronic, usually painful, inflammation of the larynx due to the development of "tubercles." There may be infiltration, ulceration, and destruction of the cartilages. L., Ulcerative, characterized by the presence of ulcers.

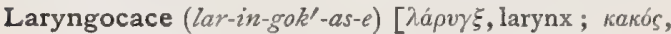
bad]. See Croup.

Laryngocentesis (lar-in-go-sen-te'-sis) [ $\lambda a ́ \rho v \gamma \xi$, larynx;

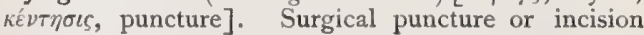
of the larynx.

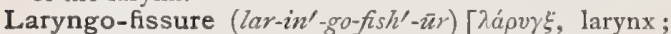
fissura, from findere, to cleave]. Division of the larynx for the removal of tumors or foreign bodies.

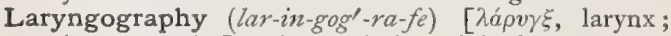

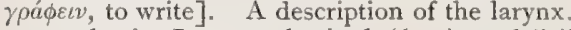

Laryngologic, Laryngological (lar-in-go-loj'-ik, lar-

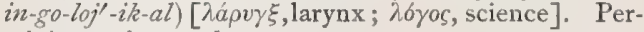
taining to laryngology.

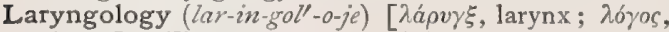
science]. The anatomy, physiology, and pathology of the larynx.

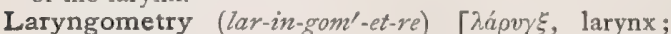

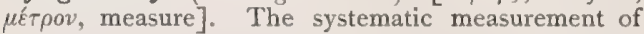
the larynx.

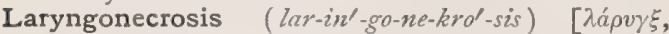

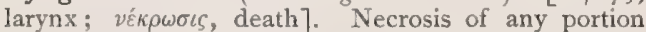
of the larynx.

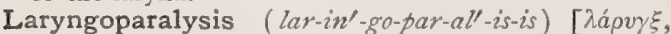
larynx; $\pi \alpha \rho a ́ \lambda v \sigma \iota s$, palsy]. Loss of the voice or paralysis of the vocal bands from nervous affections, and not from local disease.

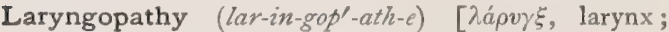
$\pi a ́ \theta 0 s$, a suffering]. Any disease of the larynx.

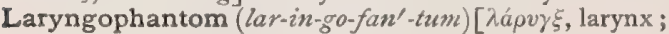

фavrós, visible]. An artificial larynx designed for illustrative purposes.

Laryngo-pharyngeal (lar-in'-go-far-in'-je-al) [ná $\rho v \gamma \xi$, larynx; $\phi a ́ \rho v \gamma \xi$, pharynx]. Pertaining conjointly to larynx and pharynx.

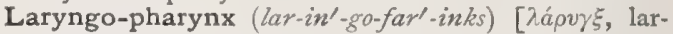
ynx; $\phi a ́ p v \xi$, pharynx]. The inferior portion of the pharynx. It extends from the greater cornua of the hyoid bone to the inferior border of the cricoid cartilage.

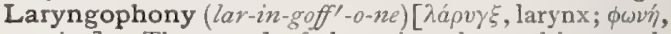
voice]. The sound of the voice observed in auscultation of the larynx with the stethoscope; also, the sound of the voice observed in auscultation of a large cavity in the lung.

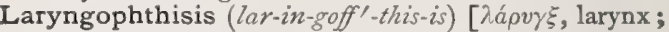
$\phi \forall i$ io $\iota$, wasting]. Laryngeal tuberculosis.

Laryngoplasty $\left(l a r-i n^{\prime}-g o-p l a s-t e\right)\left[\lambda a^{\prime}-\right.$ $\rho v \gamma \xi$, larynx; $\pi \lambda \dot{\alpha} \sigma \sigma \varepsilon \iota \nu$, to shape $]$. Plastic surgery or operation upon the larynx.

Laryngoplegia (lar-in-go-ple'-je-ah)

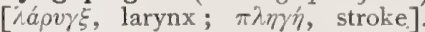
Paralysis of one or more muscles of the larynx.

Laryngorrhagia (lar-in-gor-a'-je-ah)

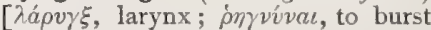
forth]. Hemorrhage from the larynx.

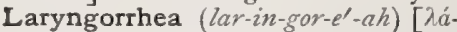
$\rho v \gamma \xi$, larynx; $\rho o i a$, a flow]. Excessive secretion of the laryngeal mucosa, especially on attempting to use the organ.

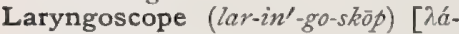
$\rho v \gamma \xi$, larynx; $\sigma \kappa \sigma \pi \varepsilon \dot{\imath} \nu$, to examine]. An instrument for examination of the interior of the larynx.

Laryngoscopist (lar-in-gos'-ko-pist)

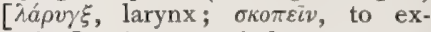
amine]. An expert in laryngoscopy.

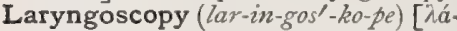
$\rho v \gamma \xi$, larynx; $\sigma \kappa о \pi \varepsilon i v$, to examine]. Examination of the interior of the larynx by means of the laryngoscope.

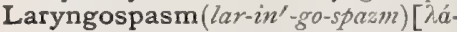
$\rho v \gamma \xi$, larynx ; $\sigma \pi \pi \sigma \mu \delta ́$, spasm]. Spasmodic contraction or closure of the glottis ; spasmodic croup, as distinguished from inflammatory croup.

Laryngospasmopsellismus (lar-in-

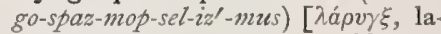
rynx; $\sigma \pi a \sigma \mu \sigma \varsigma$, spasm ; $\psi \varepsilon \lambda \lambda \iota \sigma \mu \sigma \delta$, stammering]. Spasmodic stammering of laryngeal origin, without the utterance of words.

Laryngostasis (lar-in-go-stas'-is) [ $\lambda a^{\prime}-$

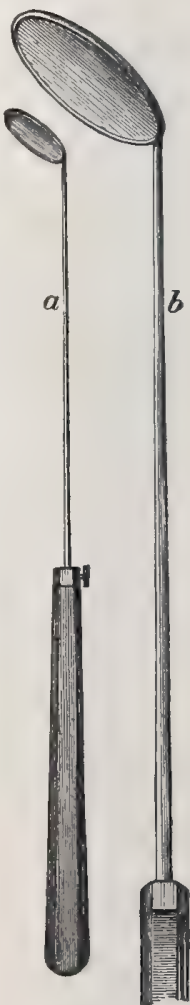

LARYNGOSCOPIC MIRRORS

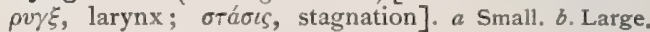
Synonym of Croup.

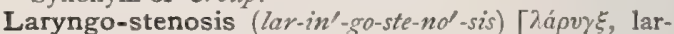
ynx; $\sigma \tau \varepsilon \nu \omega \sigma \iota s$, contraction]. Contraction in size or in caliber of the larynx.

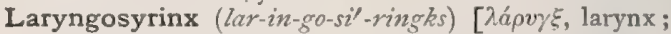
$\sigma \tilde{v} \rho \iota \gamma \xi$, pipe: pl., Laryngosyringes]. A laryngeal tube.

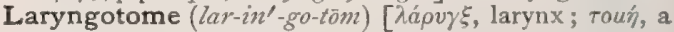
cutting]. A cutting-instrument used in laryngotomy.

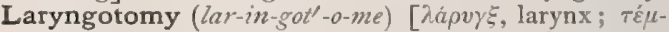
$v \varepsilon(v$, to cut]. The operation of incision of the larynx. L., Complete, incision of the larynx through its whole length. L., Median, incision into the larynx through the thyroid cartilage. L., Subhyoid, incision into the larynx through the thyro-hyoid membrane. L., Superior, and L., Thyro-hyoid, incision into the larynx through the thyro-hyoid membrane. 


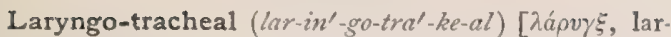
ynx; $\tau \mu a \chi \varepsilon \bar{\imath} a$, the windpipe]. Pertaining conjointly to the larynx and the trachea.

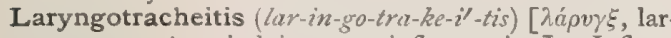

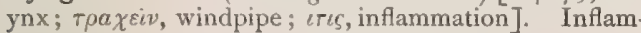
mation of the larynx and the trachea.

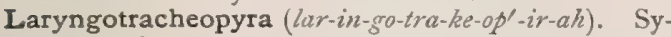
nonym of Croup.

Laryngotracheotomy (lar-in-go-tra-ke-ot'-o-me) [ $\lambda a ́ \rho-$

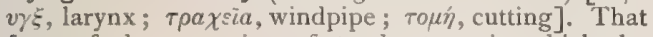
form of the operation of tracheotomy in which the cricoid cartilage, and one or more of the upper rings of the trachea are divided.

Laryngo-typhoid (lar-in'-go-ti'-foid), Laryngoty-

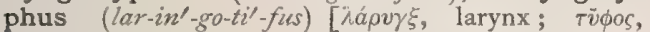
smoke]. Typhoid fever associated with marked laryngeal complications.

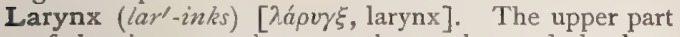
of the air-passage between the trachea and the base of the tongue. It comprises three single cartilages, the

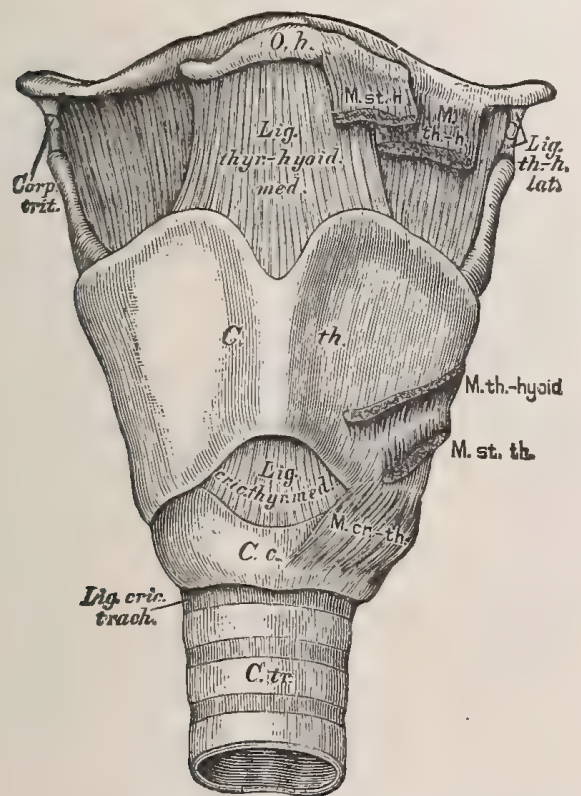

LARYNX, FRONT ViEW, Showing THE Ligaments AND INSERTION OF MUSCLES.

o.h. Os hyoides. C.th. Thyroid cartilage. Corp.trit. Corpus triticeum, or lesser cornu of the hyoid bone. C. $c$. Cricoid cartilage. C.tr. Tracheal cartilage. Lig. thyr.-hyoid med. Middle thyro-hyoid ligament. Lig. th.-h. lat. Lateral thyrohyoid ligament. Lig. cric.thyr. med. Middle crico-thyroid ligament. Lig. cric-trach Crico-tracheal ligament. $M$. st $-h$. Sterno-hyoid muscle. $M$. th-hyoid. Thyro-hyoid muscle.
$M$. st. $t h$. Sterno-thyroid muscle. $M$. $c r_{*}-t h$. Crico-thyroid muscle.

thyroid, the cricoid, and the epiglottis, and three pairs of cartilages, the arytenoids and those of Santorini and Wrisberg. It is lined by an extremely sensitive mucosa, which is thrown into two transverse, lipped folds that constitute the vocal bands.

Lascivious (las-iv'-e-us) [lascivia, wantonness]. Libidinous. Wanton. Having an unlawful desire.

Laser $\left(l a^{\prime}-s e r\right)$ [L.]. I. A gum-resin highly prized by the ancients; probably the same as Asadulcis, q. $v$. 2. The resin of Laserpitium latifolium. Unof.

Laser, Bacillus of. See Bacteria, Synonymatic Table of.

Laserpitium (las-er-pish'-e-um) [L.]. A genus of resinous and umbelliferous old-world herbs, various spe- cies of which have been employed in medicine. L. latifolium, or laserwort, is tonic and stimulant; its root abounds in a cathartic gum-resin. Unof.

Lash [ME., lashe, the flexible end of a whip]. An eye-lash.

Lassaigne's Test. See Semen and Tests, Table of.

Lassar's Paste. A paste used in the treatment of erythema intertrigo. It consists of salicylic acid 30 grains, oxid of zinc and powdered starch each 6 drams, vaselin 2 ounces. This is spread over the involved area. It is curative and affords protection from discharges.

Lassitude (las $\left.s^{\prime}-i t-\bar{u} d\right)$ [lassitudo; lassus, tired]. A state of exhaustion or weakness, arising from causes other than fatigue.

Lasso-cell. One of the peculiar filiferous cell-like structures of celenterates, having the power of throwing out with great rapidity the contained thread, which produces a stinging sensation when brought in contact with the skin; a nettling cell; an urticating organ.

Lata, or Latah $\left(l a^{\prime}-\mathrm{tah}\right)$ [Jav.]. An hysteric neurosis locally prevalent in Java, nearly identical with the disorder of the jumpers in Maine and Canada, and with the myriachit of Siberia. The will and the motor centers appear to lack coördination, and the patient becomes to some extent obedient to the will of others, in spite of his own volitions. See Palmus and Chorea, Automatic.

Latebra (lat'-eb-rah) [latebra, a hiding-place: pl., Latebra]. In biology, the central space of the food-yolk of a meroblastic ovum.

Latebricole (lat-eb'-rik-ol) [latebra, a hiding-place; colere, to dwell]. In biology, inhabiting a hidingplace, as certain spiders, crabs, etc.

Latency $\left(l a^{\prime}\right.$-ten-se) [latere, to be hid]. The condition of being latent or concealed.

Latent (l $a^{\prime}$-tent) [latere, to be hid]. Concealed. Not manifest. In physics, applied to heat that apparently disappears when a liquid is vaporized or a solid melted. L. Period, the time required for the incubation of a disease. L. Squint. See Insufficiency.

Laterad (lat'-er-ad) [latus, the side; $a d$, to]. Toward the lateral aspect.

Lateral (lat'-er-al) [lateralis, belonging to the side]. At, belonging to, or pertaining to the side. Situated on either side of the median vertical plane. See Position and Direction, Table of. L. Column, that column of the spinal cord between the ventral and dorso-lateral fissures. L. Ginglymus, an articulation in which a pivot turns within a ring or a ring around a pivot. $L$. Laparo-nephrectomy, Langenbuch's operation. See Operations, Table of. L. Line, in biology, a very delicate organ of sense, usually tubular, that runs along each side of almost all fishes. According to M. de Sede, it is sensitive to the faintest movements of the water, giving the fish continual information as to the state of the medium in which it lives. L. Operation, that form of operation in lithotomy in which the opening is made on the right or left side of the perineum. L. Organs. See Organs. L. Plates, the part of the mesoblast lying external to the provertebræ. L. Sclerosis, Amyotrophic, a disease of the lateral columns and anterior gray matter of the cord. It is characterized by motor weakness and a spastic condition of the limbs, associated with atrophy of the muscles and final involvement of the nuclei in the medulla oblongata. The cause is unknown, and death may result in from two to three years. L. Sclerosis, Primary, Spasmodic Tabes dorsatis; Spasmodic Spinal Paralysis; Spastic Paraplegia: a sclerotic disease of the crossed pyramidal tracts of the cord characterized by paralysis of the limbs, with rigidity, increased 
tendon-reflexes, and absence of sensory and nutritive disorders. A peculiar characteristic jerking gait is produced, and clonus of the limb may be readily excited. Males are most frequently affected, and the disease occurs usually between the ages of twenty and fifty. Syphilis, exposure, and traumatism are mentioned as causes. The duration is long. L. Sclerosis, Secondary, the descending degeneration that takes place in the lateral columns of the spinal cord after and below lesions of the cerebro-spinal axis. $\mathbf{L}$. Sinuses, the two veins of the dura mater situated in the attached margin of the tentorium cerebelli. L. Ventricles. See Ventricle.

Laterality (lat-er-al'-it-e) [lateralis, belonging to the side]. Excessive development on one side.

Lateralization (lat-er-al-iz-a'-shun) [lateralis, lateral]. The localization of a disease upon one or the other side of the body.

Lateralized (lat'-er-al-izd) [lateralis, lateral]. Localized on one side; directed to one side.

Lateren (lat'-er-en) [latus, side]. Belonging to the lateral aspect in itself.

Latericious, Lateritious (lat-er-ish'-us) [lateritius; later, brick ]. Pertaining to an urinary sediment resembling brick-dust.

Latericorn (lat'-er-ik-orn) [latus, side; cornu, horn]. In biology, one of the lateral pieces of the bill-sheath of certain birds.

Latericumbent (lat-er-ik-um'-bent) [latus, side; cumbere, to lie]. Lying on the side.

Lateriflection, Lateriflexion (lat-er-if-lek'-shun). See Lateroflection.

Laterifolius (lat-er-if-o'-le-us) [latus, side; folium, a leaf]. In biology, growing alongside of a leaf.

Laterigrade (lat'-er-ig-rāl) [latus, side; gradus, step]. Progressing sideways.

Laterinerved (lat'-er-in-ervd) [latus, side; nervus, nerve]. In biology, applied to such leaves as have lateral nerves.

Laterirectus (lat-er-ir-ek'-tus) [latus, side; rectus, straight]. The rectus capitis lateralis muscle. See Muscles, Table of.

Lateriversion (lat-er-iv-er'-shun). See Lateroversion.

Latero-abdominal (lat-er-o-ab-dom'-in-al) [latus, side; abdominalis, pertaining to the abdomen]. Pertaining both to the side and the abdomen. L. Posture, Sims' posture. See Postures, Table of.

Laterocaudal (lat-er-o-kaw'-dal) [latus, side; cauda, tail]. In biology, situated laterally and posteriorly.

Latero-cervical (lat-er-o-ser'-vik-al) [lateralis, lateral ; cervix, the neck]. At or about the side of the neck.

Laterodorsal (lat-er-o-dor'-sal) [latus, side; dorsum, back]. In biology, placed at one side of the upper surface.

Lateroflection, or Lateroflexion (lat-er-o-flek'-shun) [lateralis, lateral; flectere, to bend]. Flexion or bending to one side.

Lateromarginal (lat-er-o-mar'-jin-al) [latus, side; margo, edge]. Placed on the lateral edge.

Lateronuchal (lat-er-o-nu'-kal) [latus, side; nucha, nape]. Situated at the side of the nape of the neck.

Lateropulsion (lat-er-o-pul'-shun) [lateralis, lateral; pellere, to drive]. An involuntary motion or bearing to one side; a symptom in certain central neuroses.

Lateroretroversion (lat-er-o-re-tro-ver'-shun) [lateralis, lateral ; retro, backward; vertere, to turn]. Retroversion (of the uterus), with deviation to one side.

Laterostigmatal (lat-er-o-stig'-mat-al) [latus, side; stigma, a mark]. In entomology, located on the side of the body above the stigmata.

Lateroversion (lat-er-o-ver'-shun) [latus, side; vertere, to turn]. A term applied to the deviation of the uterus from the central position. It may be quite consistent with health and require no treatment.

Latex (la'-teks) [L., liquid: pl., Latices]. The sap or the juice of the tubes or vessels of plants. L.-cells, cells giving rise to latex or milky juice,

Latham's Theory. A theory as to the constitution of the proteid molecule; it claims that the living proteid is composed of a chain of cyanalcohols, or cyanhydrins, as they are sometimes termed, united to a benzene nucleus.

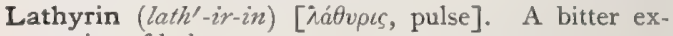
tractive of lathyrus.

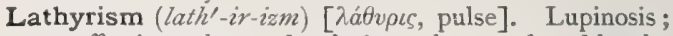
an affection, observed only in males, produced by the use of meal from varieties of vetches, chiefly the Lathyrus satious and $L$. cicera. The grain is popularly known as the chick-pea. It gives rise to a form of spastic paraplegia, with tremor, involving chiefly the legs, and this may proceed to complete paraplegia. There is exaggeration of the knee-jerk and ankle-clonus. The arms are rarely, if ever, affected. It appears to be a slow sclerosis induced by this toxic agent.

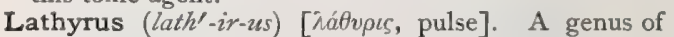
leguminous plants. L. cicera, a species of vetch, commonly known as "chick-pea." L. sativus. See Lathyrism.

Latibulum (la-tib'-u-lum) [L., latere, to lie hid]. A lurking-place for disease, infection, or poison.

Laticiferous (lat-is-if'-er-us) [latex, liquid; ferre, to bear]. In biology, producing or containing latex, or milky juice.

Laticostate (lat-ik-os'-tât) [latus, broad; costa, rib]. Having broad ribs.

Latifia (la-tif-e'-ah) [Cf. Ratafia]. An alcoholic liqueur, or aromatic cordial, with tonic drugs, as gentian, cherry-bark, quassia, and rhubarb; it is called also Dutch bitters.

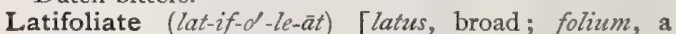
leaf]. Broad-leaved.

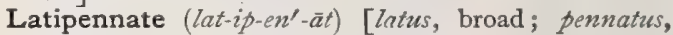
winged]. In biology, broad-winged.

Latipennine (lat-ip-en'-in). Same as Latipennate.

Latissimus (lat-is'-im-us) [superl. of latus, wide]. An adjective signifying widest. It is used as descriptive of certain muscles. L. colli. See Muscles (Platysma myoides), Table of. L. dorsi. See Muscles, Table of.

Latrine (la-trén') [Fr.]. A water-closet or privy, especially one in a public place or institution.

Lattice-work of the Thalamus. The formatio reticularis, $q . v$.

Latus (la'-tus) [L.]. Broad. L. ani, synonym of Levator ani. See Muscles, Table of.

Laudable (lav'-da-bl) [laudabilis, or laudandum, praiseworthy]. Formerly, indicative of a healthy or improving condition; characterizing an active inflammation, as laudable pus. (Obs.).

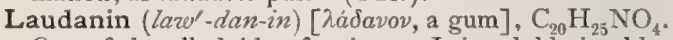
One of the alkaloids of opium. It is soluble in chloroform and in alkaline solutions.

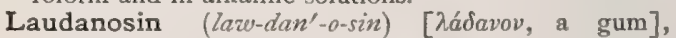
$\mathrm{C}_{21} \mathrm{H}_{27} \mathrm{NO}_{4}$. A crystallizable alkaloid of opium.

Laudanum (lod"-an-um) [derivation undetermined; by some derived from laudatum medicamentum, the praiseworthy drug; by others from laude dignum, worthy of praise; by others, again, from Ladanum]. Tinctura opii. See Opium. L., Liquid. Synonym of Vinum opii. See Opium. L., Rousseau's, a preparation used in Belgium, France, and Mexico, consisting of opium, honey, beer-yeast, water, and alcohol. L., 
Sydenham's. Synonym of Vimum opii, L., Warner's, an ammoniated tincture of opium. Unof.

Laugh (lahf) [ME, laughen, to laugh]. I. To make an audible expression of mirth. 2. The audible expression of mirth. L., Canine, L., Sardonic. Synonyms of Risus sardonicus, $q . v$.

Laughing, or Laughter (lahf'-ing, lahf'-ter) [ME., laughen, to laugh]. A succession of rhythmic, spasmodic expirations with open glottis and vibration of the vocal bands. L. Gas, nitrous oxid, or protoxid of nitrogen. See Nitrous Oxid and Anesthetics. L. Muscle, the risorius. See Muscles, Table of.

Laugier's Hernia. See Hernia and Diseases, Table of.

Laumonier's Ganglion. The superior carotid ganglion.

Laurel (law'-rel, lor'-el) [laurus]. See Cherry-laurel, California Laurel, Great Laurel, Kalmia, Laurus. L.-water, aqua laurocerasi. See Cherny-laurel.

Laurer, Canal of. See Canal.

Laurin (law'-rin) [laurus, laurel], $\mathrm{C}_{22} \mathrm{H}_{30} \mathrm{O}_{3}$. A fatty, crystallizable substance obtainable from the berries of the European laurel, Laurus nobitis.

Lauro-cerasus (law-ro-ser'-as-us) [laurus, laurel; cerasus, cherry-tree]. See Cherry-laurel. Laurocerasi folia, the leaves of the European cherry-laurel.

Laurus (law'-nus) [L.]. A genus of old-world trees and shrubs; the true laurels. Formerly the plants that produce benzoin, camphor, cassia, cinnamon, etc. were assigned to this genus, but at present it is much restricted by botanists. L. nobilis, the noble laurel, is indigenous in the south of Europe. Its fragrant oils (one essential, from the leaves, and the other fixed, from the berries) are chiefly used in liniments. Unof.

Lauryl (law'-ril) [laurus, laurel], $\mathrm{C}_{12} \mathrm{H}_{25}$. A univalent radicle, the hydrid of which is dodecane.

Laurylene (lazo'-ril-èn) [laurus, laurel], $\mathrm{C}_{12} \mathrm{H}_{24^{*}} \quad \mathrm{~A}$ liquid with a high boiling-point, found in certain mineral oils.

Lauth's Ligament. See Ligament. L.'s Violet. See Pigments. Conspectus of.

Lava (lah'-vah) [L., a flood or torrent]. The molten ejecta of a volcano.

Lavage (lav-ahzh') [Fr.]. Irrigation or washing out of an organ, such as the stomach, the bowel, etc.

Lavamentum (lav-am-en'-tum) [lavare, to wash]. An injection.

Lavandula (lav-an'-du-lah). See Lavender.

Lavater, Angle of. See Angle.

Lavatera (lav-at-e'-rah) [after the two Lavaters, physicians of Zurich]. A genus of malvaceous trees, shrubs, and herbs, natives of the old world. L. thuringiaca, L. triloba, and others abound in mucilage, and are used as demulcent remedies. Unof.

Lavation (lav-a'-shun) [lavatio, from lavere, to wash] Lavage. $L$. of the Blood, intravenous injection of water.

Lavatory (lav'-at-or-e) [lavatorium, a place for bathing]. A wash or lotion for a diseased part.

Lave (lāv) [lavare, to wash]. To wash; bathe.

Lavel $\left(l^{\prime}-\right.$ vel $)$ [Prov. Eng.]. A local name for the epiglottis.

Lavement (lāv'-ment) [lavare, to wash]. I. A wash ; the act of washing. 2. A clyster or enema.

Lavender (lav'-en-der) [lavare, to wash]. The flowers of Lavandula vera, having properties due to a volatile oil. It is aromatic, stimulant, and carminative, but is used mainly as a flavor and as an adjuvant to other medicines. Lavandulæ, O1., the volatile oil distilled from the whole herb. Dose $m_{i-\nabla}$. L., O1., Florum, the oil distilled from the fresh flowers; preferable to the preceding. Dose $m \mathrm{j}-\mathrm{v}$. A constituent of Spt. odoratus. L., Spirit of, 5 parts of the oil in 95 of alcohol; a perfume. Dose $3^{\mathrm{ss}-\mathrm{j} .}$ L., Tinct., Comp., oil of lavender 8 , oil of rosemary 2 , cinnamon 18 , cloves 4 , nutmeg 10 , red saunders 8 , alcohol 680 , water 270 , dilute alcohol to make 1000 . Dose 3 ss-ij. A constituent of Fowler's solution. To the labiate genus Lavandula also belong $L$. spica, or broad lavender (which furnishes the oil of spike), and other medicinal species.

Laveran's Corpuscles, or Plasmodia. The Plasmodia malaria, first described by Laveran as $O_{S}$ cillaria malaria. See Parasites (Animal), Table of, and Plasmodium.

Laville's Liquid Mixture, or Antigout Remedy. A mixture used in acute rheumatism. It is said to be a tincture of quinin and colocynthin, but very probably the active principle in it is colocynthin. See Colocynthis.

Lavipedium (lav-ip-e'-de-um) [lavare, to wash; pes, foot]. A foot-bath; a pediluvium.

Law (law) [ME, lawe, a law]. A generalized and epitomized statement of facts. A general rule, or constant mode of action of forces, or phenomena. A rule of action prescribed by authority. See Jurisprudence. L. of Abridged Transmission, the forms assumed by an individual in its ontogeny differ somewhat from the accepted ancestral type. L. of Adaptation, the law that a living organism, under whatsoever conditions, will mould itself into harmony with those conditions, and thus continue its existence, whether in a more perfect or less perfect form. L., Angström's, of Absorption-spectra, the "rays that a substance absorbs are precisely those that it emits when made self-luminous." L., Ampère's. See Ampere. L. of Avogadro, equal volumes of all gases and vapors, at like temperature and like pressure, contain an equal number of molecules. L., Baer's, the principle that the evolution of any animal form is determined, first, by increasing histologic and morphologic differentiation, and secondly, by transition from a more general to a more specific type. L., Bell's, the law that the ventral roots of the spinal nerves are motor, and the dorsal sensory. See also Wallerian Degeneration. L., Berthollet's, when two salts in solution can by double decomposition produce a salt less soluble than either, this salt will be produced. L., Boudin's, that antagonism exists between tuberculosis and malaria. L., Boyle's, at any given temperature the volume of a given mass of gas varies inversely to the pressure that it bears. This is also called Mariotte's Law. L., Brewster's, the angle of polarization of a body is equal to that angle of incidence at which the reflected rays are at right angles to those refracted. L., Charles's, equal increments of temperature add equal amounts to the product of the volume and pressure of a given mass of gas. The increase is $\frac{1}{2} \frac{1}{3}$ of its volume measured at $-273^{\circ} \mathrm{C}$., which is the zero of absolute temperature. L., Colles', a child born of a mother who is without obvious venereal symptoms, and which, without being exposed to any infection subsequent to its birth, presents symptoms of syphilis when a few weeks old, can infect the most healthy nurse, whether she suckle it or merely handle and dress it, while it will not infect its own mother, even though she suckle it while it has venereal ulcers of the lips and tongue. L. of Contemporaneous Transmission, changes in an individual appear at the same time as they appeared in its ancestor. L., Coulomb's, the force of attraction or repulsion between two charges of electricity is proportional to the quantity of electricity acting, and inversely proportional to the square of the distance between them. L., Dalton's, or L., Dalton-Henry's, although the volume of a gas 
absorbed by a liquid remains constant, the weight (volume multiplied by the density) of the absorbed gas rises and falls in proportion to its pressure. L. of Definite Proportions, when two or more chemic substances unite to form a compound, they do so in a fixed and constant proportion. L., Delbcuf's, a congenital variation of a number of individuals in a species, if not advantageous or injurious, and if not balanced by reversion, will produce a variety, the proportion of which to the whole species tends to reach equality. L. of Diffusion of Gases through Membranes. See L., Graham's. L. Donders'. See L., Listing's. L., Dulong and Petit's, the products of the specific heat of elements in the solid state multiplied by their atomic weights are (approximately) the same; $i$. e., the atomic heat of elements is (neariy) a constant. L. of Electrotonus, in anelectrotonus the excitability and rate of nervous conduction are diminished, while the electromotive power is increased; whereas in kathelectrotonus, the excitability and rate of nervous conduction are increased, while the electromotive power is diminished. (Rutherford.) L. of Eccentric Sensations, that wherever excitation occurs, whether in the nerve-cells themselves or anywhere in the course of the nerves leading to the cells, consciousness always refers the sensation to the presence of some external cause of excitement, $i$. $e$., the power of conception always projects every sensation that reaches the consciousness outward, that is, to where the cause of the excitement is normal. (Rosenthal.) L., Faraday's: 1. The quantity of an electrolyte decomposed in a given time is proportional to the strength of the current acting upon it. 2. The quantities of the substances decomposed are proportional to their chemic equivalents. 3. The electrolyte must be a conductor. 4. The strength of the electrolytic force is the same in all parts of the electrolyte. L., Fechner's, the more expanded and accurate statement of Weber's Law as to the relation between the intensity of stimuli and the changes in the resulting sensations, a constant ratio existing between the strength of the stimulus and the intensity of the sensation. With increase of the stimulus the sensation increases only as the logarithm of the stimulus. As there is a lower limit (threshold) or liminal intensity of excitation, so there is an upper or maximal height of sensibility. Between the two is the Range of Sensibility. L., Fleischl's, of Contraction, that the excitability of a nerve varies at different points in its course. L. of Functional Substitution. See L., Vulpian's. L., Gay-Lussac's. See L., Charles's. L., Goodell's, Rule of Ready Practice: "when the cervix uteri is as hard as one's nose, pregnancy does not exist; when it is as soft as one's lips, pregnancy is probable." L., Graham's, the rate of diffusion of gases through porous membranes is in inverse ratio to the square-root of their density. L., Gudden's, lesions of the cortex do not give rise to lesions of the nerves of the periphery. L., Hackel's Fundamental Biologic, the principle that every organism, in its ontogeny, goes through a series of stages, each of which represents a stage in the evolution of that class of organisms to which it belongs; heredity influencing or securing its palingeny, and the environment causing its kenogeny; in other words, "that the ontogeny is a short repetition of the phylogeny." L., Henry's. See L., Dalton's. L., Hilton's, that a nerve-trunk supplying a given joint also supplies the muscles moving that joint and the skin over the insertion of those muscles. L. of Homotopic Transmission, variations or acquired characters appear in the parts of an individual as in those of its pro- genitor. L., Hook and Gravesande's, of Elasticity, that the tension is directly proportionate to the length of the body extended, and to the amount of the extend. ing weights, and that it is also inversely proportionate to the diameter of the extended body. L., Huxley's, the physical differences between man and the higher apes are less marked than those between the higher and the lower apes. L., Joule's, the heating-power of a current is proportional to the product of the resistance, the square of the current-strength, and the time the current flows. L., Kirchhoff's, in electricity: I. The sum of all the positive currents is equal to the sum of all the negative currents, and, hence, if we add these, the result is zero, 2. The sum of all the electromotive forces in any circuit is equal to the sum of all the products obtained by multiplying the separate currents by the resistances through which they are flowing. 3. In optics, the law that a transparent body absorbs from a beam of light passing through it those rays which it emits in the incandescent state. See L., Angström's. L., Kofacker-Sadler's, a law as to the cause of the difference of sex. From a study of 80,000 cases these observers conclude that if the husband is younger than the wife there are as many boys as girls; if both are of the same age there are 1029 boys to 1000 girls; if the husband is older, 1057 boys to 1000 girls. L., Kopp's (of boiling-points), the addition of $\mathrm{CH}_{2}$ to members of certain homologous series of chemic compounds raises the boiling-point about $\mathbf{r} 9.5^{\circ} \mathrm{C}$. L., Lenz's, the law in electro-magnetic induction that the direction of induced currents is such that their reaction arrests the motion that produces them. L., Levert's, that in placenta prævia there is a marginal insertion of the cord. L., Listing's, pertains to the movements of the eye-ball: when moved from the position of rest, the angle of rotation in the second position is the same as if the eye were turned about a fixed axis perpendicular to the first and second positions of the visual line. L., Louis', in adults the lungs usually contain tubercle when it is present elsewhere in the body. L., Magnus's, in thermo-electricity, the law that "in circuits of the same metal throughout, no electromotive force is produced by variation in temperature or of section of the conductor at different parts of the circuit." L., Malaguti's, when two salts are mixed in solution double decomposition occurs and four salts are formed (metathesis), the proportions of each depending on the strength of union of the respective basic and acid radicles. L., Mariotte's, the law of physics that the volume of a gas varies inversely as the pressure to which it is subjected. See L., Boyle's. L. of Molecular Weights, the molecular weight of an element is twice its atomic weight (with the exception of $\mathrm{Hg}$ and $\mathrm{Cd}$ ) ; the molecular weight of a compound is equal to half the sum of the atomic weights of its elements. L. of Multiple Proportions, that two substances uniting to form a series of chemic compounds, do so in proportions that are simple multiples of one another or of one common proportion. L., Newton's, the unit force is that force which, acting for unit time on the unit mass, produces unit velocity. L., Ohm's, the law that the current-strength varies directly as the electromotive force, and inversely as the resistance. It is usually expressed by the formula $\mathrm{C}=\frac{\mathrm{E}}{\mathrm{R}+\boldsymbol{y}}$, in which $\mathrm{C}$ is the current in ampères; $\mathrm{E}$, the electromotive force in volts; $\mathrm{R}$, the resistance of the external, and $\gamma$, that of the internal part of the circuit, in ohms. L. of Organic Balance, excessive development of one part of an organism is counterbalanced by deficient growth of another part. L., Pflüger's, "a given tract of nerve is stimulated by 
the appearance of kathelectrotonus and the disappearance of anelectrotonus-not, however, by the disappearance of kathelectrotonus, or by the appearance of anelectrotonus." L. of Progress, the law of progressive increase in the perfection of organisms in the successive periods of the earth's history. L., Psycho-physical. See L., Fechner's. L. of Reciprocal Proportions, two elements combining with a third do so in proportions that are simple multiples or simple fractions of those in which they combine with each other. L. of Refraction, that rays of light entering a denser medium are deflected toward a perpendicular drawn through the point of incidence, and those entering a rarer medium are deflected away from the same perpendicular. L., Ritter's or RitterValli's, if a nerve be separated from its center, or if the center die, the excitability of the nerve is in creased; the increase of excitability begins at the central end, and travels towards the periphery; the excitability then falls until it disappears entirely. L. of Sexual Transmission, a parent transmits characteristics to children of his or her sex not transmitted to the opposite sex. L., Stokes': I. See L., Angström's. 2. Every muscle in relationship with an inflamed mucous or serous surface becomes paralyzed. L., Tait's, in every disease of the abdomen or pelvis in which the health is destroyed or life is threatened, and in which the condition is evidently not due to malignant disease, an exploration of the cavity by celiotomy should be made. L., Toynbee's, a law concerning intra-cranial disease secondary to otitis. It is that the cerebellum and lateral sinus suffer from disease of the mastoid, while the cerebrum is endangered by caries of the tympanic roof. L., ValliRitter's. See L., Ritter-Valli's. L., Van der Kolk's, the sensory fibers of a mixed nerve are distributed to parts that are moved by muscles that receive the motor fibers of the same nerve. Thus, in nerve-lesions the chief sensory symptoms are always peripheral or distal from the chief motor symptoms. L., Volta's, of Tension, the contact of two different substances produces an electromotive force equal to the algebraic difference of their electric condition, which difference is constant for the same substances. L., Vulpian's, the functions of a destroyed portion of an animal's brain are assumed by the remaining portion. L., Wallerian, of Degeneration; from experiments Waller showed that the trophic centers of the ventral roots of spinal nerves lie in the multipolar nerve-cells of the ventral horns of gray matter, while those of the dorsal roots lie in the ganglia placed upon them. Generalized, the law predicates that the course of the impulses in a nerve may be ascertained by tracing the course of the subsequent degeneration. L., Weber's, the principle that that variation of stimulus that causes the smallest appreciable variation in sensation maintains, approximately, a fixed ratio to the total stimulus. See also $L$. Fechner's.

Lawn-tennis Arm. Displacement of the tendon, or body (or both) of the pronator radii teres. Common in lawn-tennis players. L.-t. Knee. See Knee. L.-t. Leg, tendinous, fascial, or muscular rupture in the calf or sura.

Lawsonia (lare-so'-ne-ah). See Henna.

Lax (laks) [laxus, loose]. Loose; not tense.

Laxarthrus (laks-art-thrus) [laxus, loose; à $\rho$ A $\rho o v$, joint]. Luxation of a joint.

Laxative (laks'-at-iv) [laxativus; laxare, to loosen]. I. Aperient; mildly cathartic. 2. An agent that loosens the bowels; a mild purgative.

Laxator (laks-a'-tor) [laxare, to loosen]. That which loosens or relaxes. A name applied to various muscles. L. tympani. See Muscles, Table of.

Laxitas (laks'-it-as) [L.]. Looseness. L. alvi, diarrhea. L. gingivarum, spongy gums. L. intestinorum, diarrhea. L. ventriculi, atony of the stomach.

Laxity (laks'-it-e) [laxitas, looseness]. Lack or loss of tone or tension; a relaxed, loose, or spongy state of a tissue.

Layer $\left(l a^{\prime}-e r\right)$ [ME., leyer, a layer]. A mass of uniform, or nearly uniform, thickness, spread over or covering a considerable area. L., Bacillar (of the retina), the layer of rods and cones of the retina. L., Basement, basement membrane, $q . v$. L., Bowman's. See Lamina, Bowman's. L., Fibrous (of the pericardium), the outer layer of the pericardium, continuous above with the deep cervical fascia. L., Fundamental, one of the three layers of the blastoderm, $q . v$. L., Ganglionic, a layer of angular cells of the cerebral cortex, best developed in the motor area. L., Germinal. See L., Fundamental. L., Henle's, the outer layer of the inner root-sheath of the hair. L., Huxley's, the inner layer of the inner root-sheath of the hair. L., Horny (of the epiderm), the superficial layer of the skin. L., Inner Molecular, one of the layers of the retina. L., Latticed, the formatio reticularis, $q . v$. L., Malpighian, the rete mucosum of the skin. L., Ollier's. See L., Osteogenetic. L., Osteogenetic, the lower layer of periosteum, connected with the formation of bone. L., Papillary (of the skin), the upper layer of the true skin, having papillary projections fitting into the epidermis. L., Pigmentary (of the retina), the innermost layer of cells of the retina extending also to the choroid, ciliary body, and iris. L., Primitive, or Primordial, the layers of the blastoderm; by some applied to epiblast, hypoblast, and mesoblast; by others to the first two only. L. of Rods and Cones. See L., Bacillar, and Retina. L., Serous, the ental layer of serous membranes, consisting of endothelium.

Layering (la'-er-ing) [ME., leyer, a layer]. The propagation of plants by layers.

Layette (lay-et') [Fr.]. The full outfit of garments, bedding, etc., for a new-born child.

Layman $\left(l a^{\prime}-m a n\right)$ [D., leeman, a layman]. A member of the laity.

Lazar (la'-zar) [from Lazarus, a Biblical name]. An old name for a leper, or for any person having a repulsive disease.

Lazaret Fever. A synonym of Typhus Fever, $q . v$.

Lazaretto (laz-ar-et'-o) [Ital., a pest-house]. A quarantine establishment. Also, a place for fumigation and disinfection.

Lazari malum (laz'-ar-i ma'-lum) [L., "Lazarus' ill']. Synonym of Leprosy.

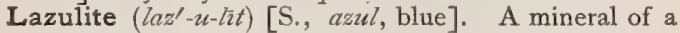
light-blue color, composed of the hydrous phosphate of aluminum, magnesium, and iron.

Leaching (lech'-ing) [ME, leechen, to wet]. In chemistry, removing by percolation.

Lead (led) [ME., leed, lead]. See Plumbum. L., Black. See Graphite. L.-colic. See Colic. L.encephalopathy, a morbid condition of the brain due to chronic lead-poisoning. L.-line, blue line; the line of discoloration on the gums in cases of chronic leadpoisoning. L.-pipe Contraction, Weir Mitchell's term for the marked resistance encountered in attempting to flex the legs in cases of spastic paraplegia of infants, the resistance gradually yielding as the effort to flex is maintained; also the condition of the limbs in the cataleptic state in which they maintain any position that is given them. L.-pipe Paralysis. Same as 
L.-pipe Contraction. L.-poisoning, plumbism ; saturnism ; painters' colic ; lead-palsy ; systemic poisoning. It is due to the introduction of lead into the system. The symptoms are disturbed nutrition, anemia, the gingival line, lead-colic, constipation, pains in the limbs, local muscular paralysis (wrist-drop) and wasting, saturnine encephalopathy, etc. The treatment consists in stopping ingress of lead to the system, its elimination by iodid of potassium, aperients, particularly the sulphates, etc. L., Sugar of. See Plumbi acetas. L., Vinegar of, liquor plumbi subacetatis, q.v. Also applied to alkaline solutions of basic lead salts. L., White, basic lead carbonate $\left(\mathrm{PbCO}_{3}\right)_{2} \mathrm{~Pb}-$ $(\mathrm{OH})_{2}$. L., Pattison's White, the oxychlorid of lead; it is used as a paint.

Leader $\left(l^{\prime}\right.$-der) [ME., leder, a leader]. A sinew or tendon; a main artery; a terminal shoot:

Leaf (lêf) [ME., leef, leaf; $\lambda \hat{\varepsilon} \pi o s$, a scale]. In botany, an expanded plant-organ, produced laterally from the stem or branch, and, regarding only the way in which it originates, applied arbitrarily to the carpels, stamens, floral envelops, cotyledons, and ordinary leaves. See Folia. L.-cup. See Bearsfoot. L.-green. See Chlorophyl.

Leaflet (léf'-let) [ME., leef, a leaf]. A small leaf, or leaf-like organ or appendage.

Lean (len) [ME., lene, lean]. Scant of flesh; thin; spare. Free from fat. L.-faced, having a thin face.

Leanness (lên'-nes) [ME., lene, lean]. A condition of having less than the usual amount of fat or flesh. It may be natural, or the result of disease.

Leap (lep) [ME, lepen, to spring]. To bound; to spring up.

Leaping (leppl-ing) [ME., lepen, to spring]. Springing; jumping. L. Ague, a synonym of Dancing Mania.

Leash $($ lèsh) [ME., leesshe, a leash]. The network of branches into which a nerve-trunk or a vessel may be divided.

Leather (leth'-er) [ME., lether, leather]. A material manufactured from hides or skins by the process of tanning, which may be done by a number of methods. The following are the main varieties of leathers so produced: Sole-leather; this is the heaviest and firmest variety of leather produced. It is made from the heaviest and thickest hides, and is valued for its fine grain and toughness. It retains the whole thickness of the hide. Upper and Harness Leathers; these are made from lighter hides, and are tanned for strength and Hexibility rather than for weight. The black color and finish are put on upper leather by coating it with a mixture of lamp-black, linseed oil, and fish-oil, to which tallow and wax and a little soap have been added. Morocco Leather; the true morocco leathers are manufactured from goat-skins. A cheaper grade, known as French morocco, is produced from sheepskins. Enamelled or Patent Leathers; these are leathers finished with a water-proof and brightly varnished surface, similar to lacquered wood-work. Thin and split hide is used for these. Russia Leather is peculiar in its characteristic odor and its ability to withstand dampness, without any tendency to mold, both of which qualities it owes to the currying with the empyreumatic oil of birch-bark. Chamois Leather is a soft felt-like leather, originally prepared from the skin of the chamois-goat, but now made from other goat-skins and from the "flesh splits" of sheep-skins. Crown Leather is a variety intermediate between oil-tanned and tawed leather, being stronger than the first and more water-resistant than the latter. The leather readily becomes moldy, but seems to be strong and specially adapted for belting. White-tanned or "Tazved" Leather; skins to be tanned with the hair on, as sheep-skin rugs, etc., as well as light calf-kid and glove-leather, are al ways alum-tanned. The gloveleather thus obtained has softness and considerable sirength, but is not thoroughly water-resistant. Parchment and Vellum; the first of these is prepared from the skins of sheep and goats, and the second from the skins of calves. The skins are washed, limed, unhaired, and fleshed, and then stretched thoroughly. They are then again well-scraped and rubbed with pumice-stone, and allowed to dry on a frame in the shade, care being taken to avoid sunshine or frost. Very fine vellums are prepared with the finest pumice-stone. Dégras, a valuable side-product of the leather industry. It is essentially an emulsion of oxidized fish-oil, produced by soluble albuminoids. It is used largely for currying purposes. L.-brown. Same as Phenylene-broum. L.-wood. See Dirca palustris.

Leathery (leth'-er-e) [ME., lether, leather]. Resembling leather; applied to thickened arteries, to various tough tissues in the body, and to the liver, spleen, or lungs.

Leaven $($ lev'-n) [levare, to raise]. A name given to several species of ferments belonging to the class of Saccharomyces, of which the culture known as "sour dough " is a common example.

Leban, Leben (leb'-an, leb'-en) [Ar., leban]. A variety of fermented milk of the Arabs. It is made by adding some of the fermented milk of the previous day to the fresh milk as soon as it is brought in from the milking. It is a slightly acid fluid of the consistence of cream, with small, flaky curds, and with the taste of buttermilk. It is easily digested, and hence is suitable for invalids. It corresponds to the "Matzoon" of the Turks.

Leber's Disease. Congenital malformation of the optic nerve, with atrophy. Hereditary optic atrophy. See Diseases, Table of.

Lecat's Gulf. The dilated bulbous portion of the urethra.

Lecheguana (la-cha-gwan'-ah) [Port.]. A kind of poisonous honey collected in S. America from flowers of the genera Paullinia and Serjania. It produces hilarity, followed by heavy narcotic slumber, and later by melancholic depression. Unof.

Lechopyra (lek-oph-ir-ah) [ $\lambda \varepsilon \chi \omega$, a lying-in woman; $\pi v \tilde{\rho}$, fire, fever]. Puerperal fever.

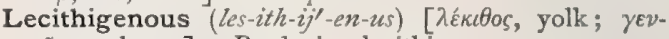
$\nu \tilde{a} \nu$, to beget]. Producing lecithin.

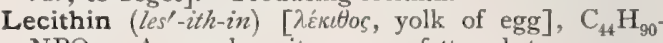
$\mathrm{NPO}_{9}$. A complex nitrogenous fatty substance occurring widely spread throughout the animal body. It is found in the blood, bile, and serous fluids, as well as in the brain, nerves, yolk of egg, semen, pus, and white blood-corpuscles. It is a colorless, slightly crystalline substance, readily soluble in cold, and very much so in hot alcohol. It swells up in water, and throws out curling filamentous processes at the same time. It is easily decomposed. The lecithins, as a class, form a group of substances the type of which is normal lecithin.

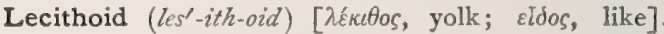
Resembling lecithin.

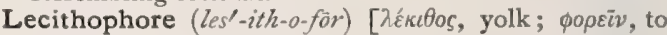
bear]. A layer of cells in the ovum, constituting the floor of the segmentation-cavity.

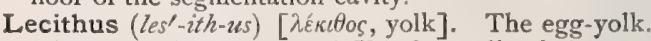

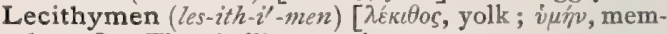
brane]. The vitelline membrane.

Leclanché Cell. See Cell.

Leco $\left(l e^{\prime}-k o\right)[\lambda \eta \kappa \omega$, penis]. The penis.

Lectual (lek'-tu-al) [L., lectus, a bed]. Pertaining to a bed or couch. L. Disease, a disease that confines one to bed. 
Lectulus (lek'-tu-ins) [dim. of lectus, bed]. An old name for various forms of splints, cushions, and pads used in surgery; also, a bed or couch; a couch or mattress containing medicinal substances. L. medicatus, a dry fomentation.

Ledon $\left(l e^{\prime}-d o n\right)[\lambda \hat{\eta} \delta o v$, cistus]. See Ladanum.

Ledoyen's Disinfecting-fluid. A solution of lead nitrate.

Ledran's Suture. See Suture.

Ledum $\left(l e^{\prime}-d u m\right)[\lambda \bar{\eta} \delta o v$, a species of cistus]. A genus of ericaceous shrubs. L. palustre, marsh-tea, the leaves of which have been used as a febrifuge and sedative, and in skin-diseases. Unof.

Ledyson, Powder of. A powder containing Armenian bole, with powdered charcoal, slaked lime, sal ammoniac, and powdered cinnamon.

Leech (lëch) [AS., lace, physician]. I. Hirudo medicinalis, or other worm-shaped aquatic and bloodsucking animals employed in surgery. 2. Formerly a medical practitioner; a physician. 3. To extract blood by leeching. See Hirudo. L., Artificial, an apparatus for cupping. See Heurteloup. Lo--craft, an archaic name for the art of healing. L., Horse. See Horse-leech. L.-tube, a glass tube in which a leech is placed so that its mouth will come in contact with the skin of the part over which the tube is placed.

Leecher (lech'-er) [ME., leeche, a physician]. A person who applies leeches.

Lees (lèz) [AS., les, dregs]. The dregs or solid matter held in suspension by a liquid, that finally settles at the bottom of the vessel. Especially the sediment of vinous liquors. Also, a valuable side-product in the manufacture of wine. It is the deposit formed on the bottom of the casks, and consists of from 30 to 40 per cent. of vegetable matter, the remainder being tartrates, sulphates (in plastered wines), alumina, phosphoric acid, etc.

Leeting $\left(l \bar{e} t^{\prime}-i n g\right)$. The exudation on the surface of the skin in eczema.

Le Fort's Operation. See Operations, Table of.

Left [ME., left, left]. Sinistral; opposite of right. The left-hand side. In man and other mammals, the side containing the larger part of the heart. L.brained, having the speech-center in its normal situation, in the left third frontal, or subfrontal convolution. L.-handed, having more power and dexterity in the left than in the right hand. L. Lateral Recumbent Position. See Postures, Table of.

Leg [ME., leg, leg]. The lower extremity of man, especially that part from the knee to the ankle. An organ of locomotion in man and other animals. L., Bandy, bow-leg. L., Barbadoes, elephantiasis of the leg. L., Black, of Canada, a condition of purpura affecting the legs of Canadian lumbermen. L., Cochin. See L., Barbadoes. L., Crossed, a crossing of the axes of the legs. L., Dentist's, a painful cramp in the leg-muscles of dentists. L., Dover's, a term for hypochondriasis. L.-ill. See Black Leg. L., Lawn-tennis. See Lazun-tennis Leg. L., Milk, phlegmasıa alba dolens. L., Scissors. See L., Crossed. L., Weeping, a leg the seat of eczema madidans. L., White. See L., Milk.

Legal (le'-gal) [lex. legis, law]. Pertaining to law. L. Medicine, medical jurisprudence.

Legal's Disease. Headache due to meningo-tympanic disease. See Diseases, Table of:

Legitimacy (le-jit'-im-as-e) [legitimare, to make lawful]. The condition of being within the bounds of the law. Also, the statutory recognition of a child born within wedlock. or within a period of time necessary to gestation, which may elapse after the death of the father.
Legume $\left(\operatorname{leg}^{\prime}-\hat{u} m\right.$ or leg-umm') [legere, to gather (socalled because it may be gathered by the hand) ]. In biology, the fruit of plants of the pea or pulse family, a pod splitting along both sutures, and formed from a simple pistil.

Legumin (leg-u'-min) [legumen, pulse]. A proteid compound in the seeds of many plants belonging to the natural order of leguminosæ. Vegetable casein. See Casein.

Leguminosæ (leg-u-min-o'-se) [legumen, pulse]. The pulse family ; an important family of plants comprising the bean, the clover, the lentil, the pea. Licorice, indigo, gum arabic, senna, are also obtained from species of this family.

Leguminous (leg-u'-min-us) [legumen, pulse]. Pertaining to or resembling the Leguminosa.

Leicester System. A system of combating smallpox that consists in isolation, quarantine, and disinfection, without vaccination.

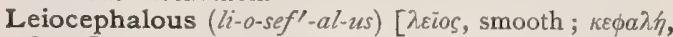
head]. Having a smooth head.

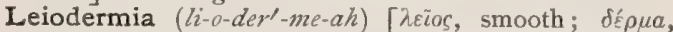
skin]. A disease of the skin marked by abnormal glossiness, and by atrophy.

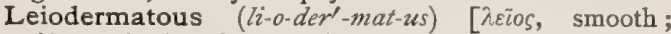
$\delta \varepsilon ́ \rho \mu a$, skin]. Smooth-skinned.

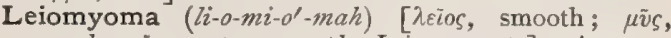
muscle; $b u a$, a tumor: pl., Leiomyomata]. A tumor consisting largely of unstriped muscle-fibers.

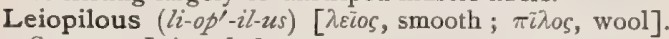
Same as Leiocephalous.

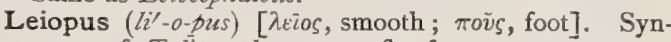
onym of Talipes planum, or flat-foot.

Leiotrichous, Liotrichous ( $\left.l i-o t^{\prime}-r i k-u s\right)$ [ĩeios, smooth; $\theta \rho i \xi$, hair]. Having smooth or straight hair. See Lissotrichous.

Leiphemia ( $\left.l i-f e^{\prime}-m e-a h\right)$ [ $\lambda \varepsilon i \pi \varepsilon \imath \nu$, to fail ; ai $\mu a$, blood]. Failure, poverty, or a depraved state of the blood.

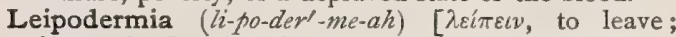

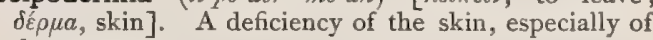
the prepuce.

Leipomeria ( $\left.l i-p o-m e^{\prime}-r e-a h\right)[\lambda \varepsilon i \pi \varepsilon \imath v$, to leave; $\mu \varepsilon \rho o s$, part]. A monstrosity with absence of one or more limbs.

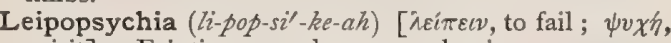
spirit]. Fainting; weakness; asphyxia.

Leipothymia ( $\left(i-p o-t h i^{\prime}-m e-a h\right)[\lambda \varepsilon i \pi \varepsilon \iota v$, to fail ; $\theta v \mu \sigma s$, mind]. A fainting or syncope.

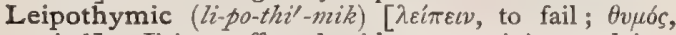
mind]. Faint; affected with or pertaining to leipothymia.

Leipsic Green. Same as Schweinfurth Green. L. Yellow. Same as Chrome-yelloze.

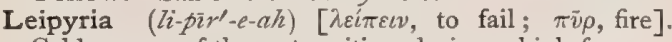
Coldness, as of the extremities, during a high fever.

Leitch's Blue. See Pigments, Conspectus of.

Leiter's Apparatus, Coil, or Tubes. Tubes of soft, flexible metal designed for application about any part of the body. Cold water is passed through the tubes, thereby reducing the temperature of the parts encased.

Leithner's Blue. Same as Cobalt-blue.

Lekene $\left(l e^{\prime}-k \bar{e} n\right)$. The principal constituent of Cau. casian ozokerite ; it melts at $79^{\circ} \mathrm{C}$., and has the composition $\mathrm{C}_{\mathrm{n}} \mathrm{H}_{2 \mathrm{n}+2}$ or $\mathrm{C}_{\mathrm{n}} \mathrm{H}_{2 \mathrm{n}}$.

Lema $\left(l e^{\prime}-m a h\right)[\lambda \dot{\eta} \mu \eta$, rheum]. The collection of dried matter sometimes seen at the canthus of the eye.

Lembert's Suture. See Suture.

Lémery's Powder. A stimulant and digestive powder containing cinnamon, ginger, nutmeg, cloves, mace, musk, and raisins. L.'s Salt, magnesium sulphate.

Lemithochorton (lem-ith-o-kor'-ton). Same as Helminthochorton. 


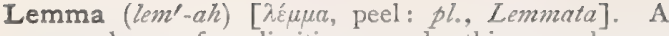
general name for a limiting or ensheathing membrane ; e. $g$., neurilemma, sarcolemma, etc. It is mostly used in composition. In embryology, the outer layer of the germinal vesicle.

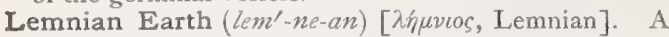
variety of reddish kaolin, originally found in the Isle of Lemnos; a kind of bole $(q . v$.) used as an astringent; also, as a detergent, like fuller's earth; Lemnian bole. See, also, Ocher.

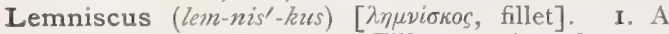
ribbon-like appendage. 2. Fillet; a triangular area on the lateral slope of the mesencephal, in which the fibers run approximately cephalo-dorsad. It is dorsocephalad of the demarcation-line of the pons, and constitutes the most ventral part of the tegmentum. Several divisions are made; $e_{.} g$. , inferior, lateral, and median or superior lemniscus. 3. In biology, the name given by Rudolphi to a glandular, filiform organ, pendent, on either side of the proboscis-sheath, in the anterior body-cavity of Echinorlynchus. Dujardin considers it to be of the nature of a salivary gland.

Lemon (lem'-on): See Limon

Lemonade (lem-on-āal') [limon, lemon]. An acidulous, refrigerant drink made from the juice of lemon. L., Sulphuric Acid, a solution of sugar in water containing sulphuric acid. It is used in lead manufactories to prevent lead-poisoning.

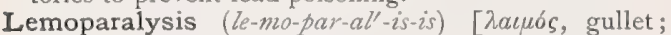
$\pi a \rho a \lambda^{2} v \sigma \iota$, palsy]. Paralysis of the esophagus.

Lemostenosis (le-mo-ste-no'-sis) [haucós, gullet; otḱ$\nu \omega \sigma \iota \zeta$, stricture]. Constriction of the pharynx or esophagus.

Lendigerous (len-dij'-er-us) [lens, a louse's egg ; gerere, to bear]. Bearing or having vesicles.

Lenhossek, Bundle of. The ascending root of the vagus and glosso-pharyngeal nerves.

Leniceps (len'-is-eps) [lenis, mild; capere, to seize]. A form of obstetric forceps, with short handles; it is so called because it was designed to be safer in use than the ordinary forms.

Lenient $\left(l \ell^{\prime}-n e-e n t\right)$ [leniens, softening]. I. Lenitive; emollient. 2. An emollient medicine or application.

Leniment (len'-im-ent) [lenire, to soothe]. A liniment or soothing application.

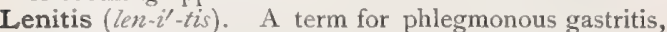
or suppurative inflammation of the areolar tissue of the stomach.

Lenitive (len'-it-iv) [lenitivus, soothing]. Emollient or demulcent ; laxative or aperient. 2. An emollient remedy or application; an aperient or mildly cathartic agent. L. Electuary, confectio sennæ.

Lens (lenz) [L., a lentil]. A regularly-shaped piece of glass or crystal for the refraction of rays of light. The crystalline lens of the eye. L., Achromatic. See Achromatic. L., Apochromatic. See Apochromatic. L., Astigmatic. See L., Cylindric. L., Astigmatic, of Stokes, an apparatus consisting of two plano-cylindric lenses, one concave, the other convex, the two of equal focal distance; it is used in the diagnosis of astigmatism. L., Biconcave (negative or minus (-) lens), a thickedged lens having concave spheric surfaces upon its opposite sides; it is used in spectacles to correct myopia. L., Biconvex (positive or plus ( + ) lens), a thin-edged lens; it has two convex surfaces, and is used to correct hyperopia. L., Bifocal. See Bifocal. L., Cicatricular, a lenticular body in the ovum formed by the junction of the germinal vesicle and the non-germinal layer of the ovum. L., Convergent or Converging, a double convex or planoconvex lens that focuses rays of light. L., Crystalline, the lens of the eye, situated immediately behind the pupil. L., Cylindric (either minus or plus), one ground upon a cylindric tool, $i$. $e$, one with a plane surface in one axis and a concave or convex surface in the axis at right angles to the first. L., Decentered, one in which the optic center is not opposite the pupil of the eye. L., Dispersing, a name for a concave lens. L.-paper, a soft absorbent paper much used for cleaning lenses; it is also known as Japanese filter-paper. L., Periscopic, one with concavo-convex or convexoconcave surfaces, the opposite sides being of different curvatures; it is used to avoid spheric aberration, and to gain a greater field of clear vision; such lenses are called meniscus lenses. L., Plano-concave, Plano-

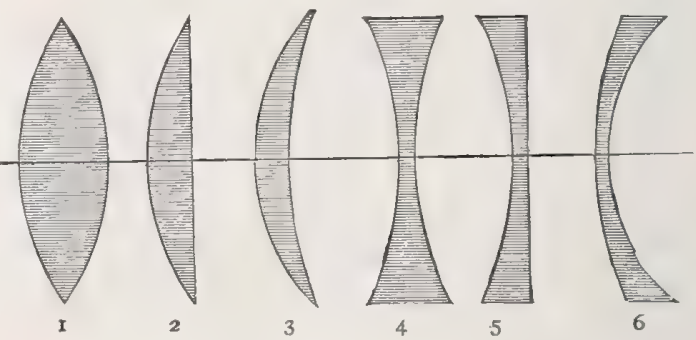

DIFFERENT Forms of SPHERIC LENSES.

I. Biconvex lens. 2. Plano-convex. 3. Concavo-convex, or convergent meniscus. 4. Biconcave 5. Plano-concave. 6. Convexo-concave, or divergent meniscus.

convex, Plano-cylindric, have a plane surface upon one side and a curved surface upon the reverse side. L., Prismatic, a triangular bar of glass. L., Spheric, one whose curved surface, either concave or convex, is a segment of a sphere, in contradistinction to a cylindric lens. L., Sphero-cylindric, one with a spheric surface upon one side, and a cylindric surface upon the reverse, used for the correction of either myopia or hyperopia, associated with astigmatism. See Spectaclelenses. L.-star, the stellate figure seen on the posterior surface of the crystalline lens. L., Test or Trial, one of a set of lenses employed in determining refractive errors.

Lenticel (len'-tis-el) [lenticella; dim. of lens, lentil]. Any one of the little mucous follicles or crypts at the base of the tongue; any lenticular gland. In biology, a lens-shaped collection of cells; applied to the dots on new bark and to certain glands.

Lenticellate (len-tis-el"-ät) [lenticella; dim. of lens, lentil]. Having lenticels.

Lenticonus (len-tik-o'-nus) [lens, a lens; conus, a cone]. A rare, usually congenital, anomaly of the lens in which there is a conical prominence upon its anterior, or more rarely upon its posterior, surface.

Lenticula (len-tik'-u-lah), Lenticule (len'-tik-ül) [L.; dim. of lens, lentil: pl., Lenticula ]. I. Same as Lentigo. 2. A mass of gray matter in the brain situated in the hemicerebral wall, between the caudatum and the cortex. It consists of three zones known as articuli, all more or less striated, the ental the smallest, and the ectal, also called putamen, the largest. The latter is of a deeper reddish-gray color than the two mesal divisions, which together are termee slobus pallidus. 3. In biology: $(a)$ a spore-case: (b) a freckle.

Lenticular (len-tik'-u-lar) [lenticularis; lens, a lentil]. Pertaining to, or resembling, a lens; also a descriptive term applied to an instrument with a curved cut ting-edge for removing the rough edges of bone made by the trephine. L. Ganglion. See Ganglia, Tabis of. L. Nucleus, the lenticula, $q . v$. 
Lentiform (len'-tif-orm). See Lenticular.

Lentigines (len-tijy-in-ēs) [lens, a lentil]. See Lentigo. L. leprosæ, the pigmented spots of macular leprosy.

Lentiginose, Lentiginous (len-tij'-in-ōz, len-tij'-in-us) [lentiginosus, freckled]. Affected with lentigo. Speckled or freckled.

Lentigo (len-ti'-go) [lens, a lentil; pl., Lentigines]. A freckle ; ephelid. A circumscribed spot or patch of pigment, small in size, and occurring mainly on the face and hands. Freckles rarely occur before the age of eight years, and are not common in aged persons. They are most frequent among people of light complexion. Those occurring upon parts of the body not exposed to the sun's rays are called "cold freckles." L. æstiva, summer freckles. L. congenita, pigmented nevus.

Lentil (len'-til) [lenticula, a lentil]. The plant Lens esculenta; also its flat lenticular seed, a kind of pulse, valued as an article of food.

Lentitis (len-ti'-tis). See Phakitis.

Lentoid (len'-toid) [lens, lentil; Eídos, like]. Lensshaped, or lenticular.

Lentor (len'-tor) [lentor; lentus, adhesive]. Viscidity of a liquid; slowness of any function, or process. $\mathbf{L}$. cordis, sluggishness of the heart.

Lentous (len'-tus) [lentus, thick]. Thick, tenacious, or viscid.

Lenus $\left(l e^{\prime}-n u s\right)$ [ $\lambda$ »vós, a depression]. A depression; the torcular herophili, $q . v$.

Lenz's Law. See Law.

Leonard's Tint. A name for methyl-violet, pentamethyltriamido-triphenylcarbinol, used for staining microscopic sections and bacteria.

Leonine (le'-o-nin [leoninus, belonging to a lion]. Lion-like ; resembling a lion.

Leontiasis (le-on-ti'-as-is) [leo, a lion]. A variety of elephantiasis in which the patient's face is said to resemble that of a lion. See Elephantiasis and Leprosy. L. ossea, L. ossium, a form of sclerosis of bone, following osteitis, in which nodular deposits are seen upon the diseased bone. L. vitulina, a congenital disease characterized by a painless enlargement of the face, giving it some resemblance to that of a calf.

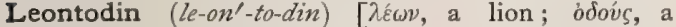
tooth]. The precipitate from a tincture of the root of dandelion, Leontodon taraxacum; it is a tonic, diuretic, aperient, and hepatic excitant. Dose two to four grains. Unof.

Leontodon (le-on'-to-don). See Taraxacum.

Leonurus (le-on- $\left.u^{\prime}-r u s\right)$. See Motherwort.

Leopard's Bane (lep'-ardz bān). See Arnica.

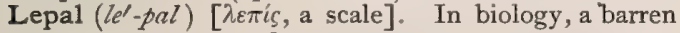
stamen; a stamenode.

Leper $\left(l e p^{\prime}-e r\right)$ [ $\lambda \varepsilon \pi \rho \delta \zeta$, scaly]. One affected with leprosy.

Lepidin (lep'-id-in) [ $\lambda \varepsilon \pi i s$, scale $], \mathrm{C}_{9} \mathrm{H}_{6}\left(\mathrm{CH}_{3}\right) \mathrm{N}$. I. Methyl-quinolin, a substance that occurs with quinolin and quinaldin in coal-tar, and is obtained on distilling cinchonin with potassic hydrate. It possesses an odor like that of quinolin, and boils at $257^{\circ} \mathrm{C}$. 2. A bitter principle from Lepidium iberis; it is reputed to be antipyretic. Unof.

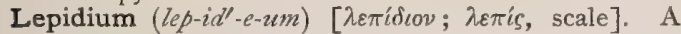
genus of cruciferous herbs; cress, or peppergrass. $L$. iberis, L. latifolium, L. ruderale, L. sativum, and L. virginicum, have been used in medicine. They are antiscorbutic, and stimulant, and are reputed to be antipyretic. Unof.

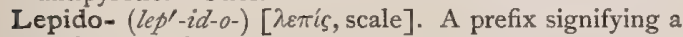
scale, or scaly.

Lepidoid (lepp'-id-oid) [ $\lambda \varepsilon \pi i s$, scale]. Having the appearance of a scale.
Lepidoplastic (lep-id-o-plas'-tik) $[\lambda \varepsilon \pi i s$, scale; $\pi \lambda a ́ \sigma$ $\sigma \varepsilon \iota v$, to form $]$. Forming scales.

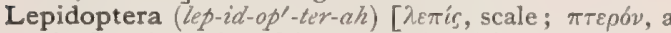
wing]. An order of insects distinguished by featherlike scales and a spirally-coiled suctorial apparatus. The order includes butterflies and moths

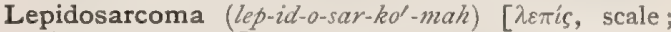
$\sigma a ́ \rho \kappa \omega \mu \alpha$, sarcoma]. A sarcoma covered with scales, occurring in the mouth

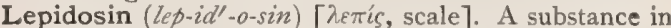
the scales of fishes analogous to dentine.

Lepidosis $\left(l e p-i d-o^{\prime}-s i s\right)[\lambda \varepsilon \pi i s$, scale]. Same as Tchthyosis. Also, a synonym of Lepra and of Pityriasis.

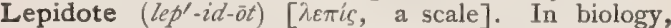
scurfy or covered with small scales.

Le Pita. Synonym of Tinea imbricata.

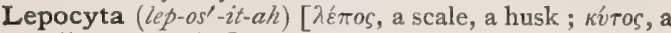
hollow, a cavity]. In biology, a unicellular organism furnished with a limiting membrane. Cf. Gymnocyta.

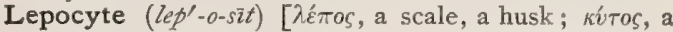
hollow]. In biology, a nucleated cell possessing a cellwall. Cf. Gymnocyte.

Leposteaphyton, or Leposteophytum (lep-os-te-o- $f^{\prime}$.

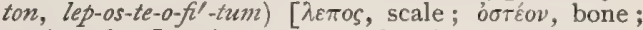
$\phi v \tau \delta v$, plant]. A new growth of bone, scaly in character.

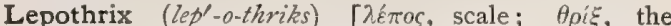
hair]. A condition in which the hairs of the axillæ or scrotum are fringed with feather-like masses along the shaft, or become encased in a sheath of hardened sebaceous matter.

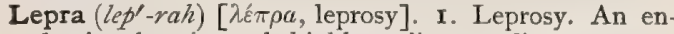
demic, chronic, and highly malignant disease, somewhat analogous to syphilis in pathologic character. It is prevalent in Europe and Asia, especially along the Mediterranean shores, but is rare in North America. It is a constitutional disease preceded by malaise, debility, and languor, followed by characteristic bullous, macular, or tubercular lesions of the skin. Its cause is the Bacillus leprae discovered by Hansen. See Leprosy, and Bacteria, Synonymatic Table of, and also Psoriasis. 2. A so called "false leprosy," apparently a form of psoriasis. L. alba or albida, white leprosy. L. alphos. See Psoriasis. L. anæsthetica. See Leprosy. L. antanea. Same as Leprosy, Tuberculated. L. asturiensis. Synonym of Pellagra, q. $v$. L. fungifera. Synonym of Frambesia. L. ichthyosis. Ichthyosis, q. $v$. L. italica, or mediolanensis, pellagra, $q . v$. L. maculosa, the stage of true leprosy, characterized by the presence of pigment-spots. L. mediolanensis. See L. italica. L. melas, black leprosy. L. mutilans, the final stage of true leprosy, in which there is a loss of members. L. nervorum. See Leprosy, Nerve. L. nervosa. Same as Leprosy, Anesthetic, q. v. L. nodosa, or L., Nodular. See Leprosy. L., Non-tuberculated. See Leprosy. L. of Willan, psoriasis. L. tuberosa. See Leprosy, Tuberculated. L. umbrosa. See Leprosy, Black. L. vera. See Leprosy. L. vulgaris, a synonym of psoriasis.

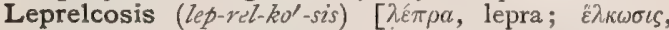
ulceration]. Leprous ulceration.

Lepriasis (lep-ri'-as-is) [ $\lambda \dot{\varepsilon} \pi \rho \alpha$, leprosy]. A synonym of leprosy and of psoriasis; an obsolescent term vaguely used to designate various scaly diseases of the skin.

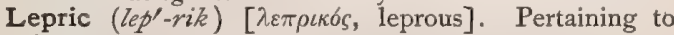
lepra.

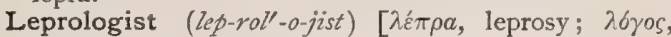
science]. An expert or specialist in leprology.

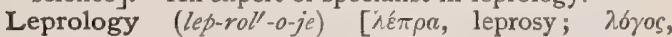
science]. The science of leprosy. 
Lepromorphe (lep-ro-mar'-fe) $[\lambda \dot{\varepsilon} \pi \rho \alpha$, leprosy; $\mu \rho \rho \phi \eta ́$, form]. An advanced stage in leprosy in which the bones are affected.

Leprophobia (lep-ro-fo'-be-ah) [ $\lambda \dot{\varepsilon} \pi \rho a$, leprosy ; $\phi 6 \beta o s$, fear]. Morbid or insane dread of leprosy.

Leprophthalmia (lep-roff-thal'-me-ah) [ $\lambda \dot{\varepsilon} \pi \rho a$, leprosy; $\delta \phi \theta a \lambda \mu o ́ s$, the eye]. Ophthalmia of a leprous character.

Leprosarium (lep-ro-sa'-re-um) [L.]. A leper-house; leprosery.

Leprosery (lep'-ro-ser-e) [Fr., leproserie]. Same as Leprosarium.

Leprosity (lep-ros'-it-e) [leprositas, from $\lambda \dot{\varepsilon} \pi \rho a$, leprosy]. Leprousness; the state of being leprous.

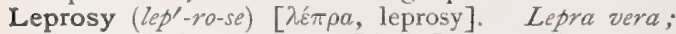
Elephantiasis gracorum; Black Leprosy; Leontiasis; an endemic, chronic, constitutional disease analogous to syphilis, and varying in its morbid manifestations according as the brunt of the disease falls on the skin, the nerves, or other tissues. It occurs in three forms, the tuberculated, non-tuberculated or anesthetic, and the mixed tuberculated. The tuberculated or nodular leprosy is attended at the onset with debility, depression, dyspepsia, diarrhea, drowsiness, chilliness and profuse perspiration, marked vertigo, recurrent epistaxis, fever up to IO $^{\circ}$ F.; after a variable period of days or even months, coming first with edema of the eyelids, the leprous spots appear on the face and ears, and then on the anterior and external surfaces of the limbs. The exanthem is an erythema, varying from a bright-red to a purplish-red or mahogany-red tint, associated with the leprous deposit of well-defined, shiny, slightly raised patches of from one to several inches in diameter. Papules then form in crops, gradually reaching the size of a hen's egg and of a yellowish to a dark-brown color. Tuberculation does not develop until from three to six months after the commencement of the disease. Nodules are most common on the face, limbs, breast, scrotum, and penis. There is also an involvement of the mucous membranes. When the disease is fully developed, the face assumes the characteristic leonine appearance, from thickening of the skin. Ulceration eventually sets in, and the patient dies of exhaustion or complications. Nontuberculated leprosy is the most common tropical form. The prodromal symptoms are marked, and are associated at first with hyperesthesia of the skin. At the end of a year the special eruption breaks out, usually on the back, shoulders, posterior aspect of the arms, nails, thighs, and sometimes in the course of nerves. The spots are one or two inches in diameter, welldefined, not raised, and of a pale-yellow color. They spread peripherally, clearing in the center, which becomes dry, scaly, and anesthetic. Paralysis is usually a late symptom, and ulceration is common. Death results from ulceration, gangrene, marasmus, or general debility. Mixed tuberculated leprosy is the least common form, and its symptoms are a combination of those of the other two varieties. Destruction of the cartilages of the nose and of the soft palate is common. Leprosy is due to the action of a special bacillus, and the disease is almost invariably fatal. L., Anesthetic. See Leprosy, Nerve. L., Articular. Synonym of Lepra mutilans, q.v. L., Black, a form in which the eruption or the crusts are pigmented. L., Cutaneous. See Leprosy. L., Italian. Pellagra, q. v. L., Lombardian. See Pellagra. L., Macular, a form of anesthetic leprosy characterized by the presence of pigmented or white spots. L. of Malabar, elephantiasis arabum. L., Mixed Tuberculated. See Leprosy. L., Nerve, a form of leprosy characterized by the progressive formation of the leprous neoplasm in the peripheral sensory nerves, and to some extent in the motor branches also. The condition is marked by pain along the course of the involved nerves, followed by an eruption of maculx which as they enlarge become anesthetic. L., Nodular. See L., Tubercular, under Leprosy. L., Smooth, anesthetic leprosy. L., Tubercular, and L., Tuberculated. See Leprosy. L., White. See Vitiligo.

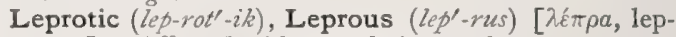
rosy]. Affected with, or relating to, leprosy.

Leprousness (lep'-rus-nes) [leprosus, leprous]. The state of being leprous.

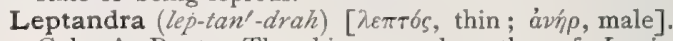
Culver's Root. The rhizome and rootlets of $L$. vir. ginica, now called Veronica virginica. Its properties are thought to be due to a glucosid, leptandrin. It is a tonic, laxative, and cholagogue, and is indicated in indigestion and chronic constipation. Dose of the ext. gr. $\mathrm{j}-\mathrm{iij}$; of the fld. ext. $m \times x x-z j$.

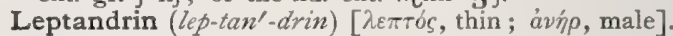
The precipitate from a tincture of the root of Leptandra (Veronica) virginica; alterative, deobstruent, laxative, cholagogue, and tonic. Dose from 2 to 4 grains. Unof.

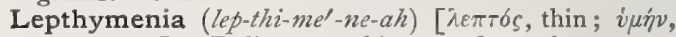
membrane]. Delicacy or thinness of membrane.

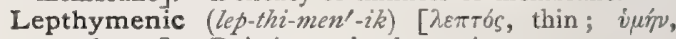
membrane]. Relating to lepthymenia.

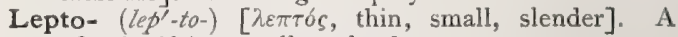
prefix signifying small or slender.

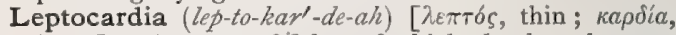
heart]. A group of fishes of which the lancelets are the only representatives.

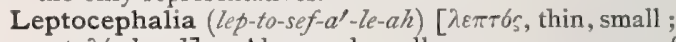
$\kappa \varepsilon \phi a \lambda \dot{\eta}$, head]. Abnormal smallness or narrowness of the skull.

Leptocephalic (lep-to-sef-al'-ik), Leptocephalous (lep-

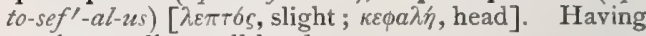
an abnormally small head.

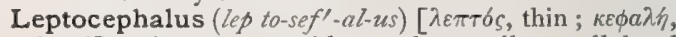
head]. A monster with an abnormally small head from premature union of the frontal and sphenoid bones.

Leptocephaly (lep-to-sef'-al-e). See Leptocephalia.

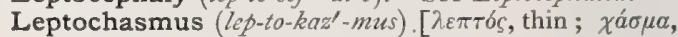
chasm]. Lissauer's term for a skull in which the angle formed by two lines drawn from the punctum alæ vomeris to the posterior nasal spine and the anterior margin of the foramen magnum respectively is between $94^{\circ}$ and $114^{\circ}$.

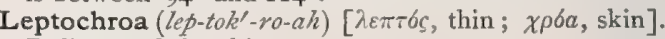
Delicacy of the skin.

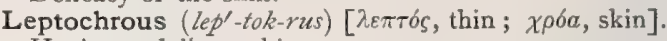
Having a delicate skin.

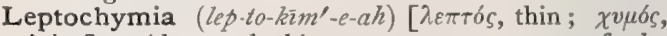
juice]. Abnormal thinness or meagerness of the fluids of the body.

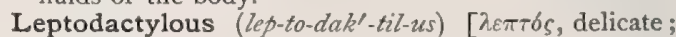
$\delta a ́ k \tau v \lambda o s$, digit]. Characterized by slenderness of the fingers or toes, or both.

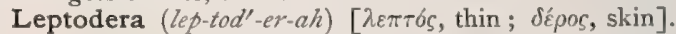
A genus of vinegar eels. L. stercoralis. See Thread-worms, and Parasites (Animal), Table of.

Leptodermic, Leptodermous (lep-to-der'-mik, lep-to-

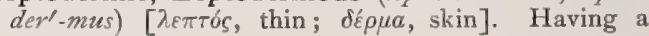
delicate skin.

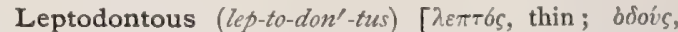
tooth]. Having thin or slender teeth.

Leptomeninges (lep-to-men-in'-jezz) [ $[\lambda \varepsilon \pi \tau b s$, thin; $\mu \bar{\eta} v i \gamma \xi$, a membrane]. The arachnoid and pia, or the pia alone. 


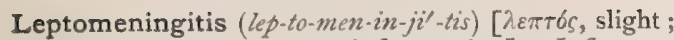
$\mu \tilde{\eta} \nu \iota \gamma \xi$, membrane; $\iota \tau \iota s$, inflammation]. Inflammation of the pia and arachnoid of the brain and the spinal cord, in contradistinction to Pachymeningitis, though meningitis alone usually signifies the same as leptomeningitis. See Meningitis. L. cerebralis, an inflammation confined usually to the pia of the convex surface of an anterior lobe of the cerebrum. L., Cerebro-spinal, an inflammation of the pia of the brain and cord. L. spinalis, an inflammation of the pia of the spinal cord. L., Tuberculous, an in flammation of the pia due to the presence of the tubercle-bacillus.

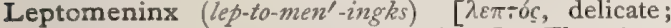
$\mu \bar{\eta} \nu \imath \xi \xi$, membrane: pl., Leptomeninges]. The pia or the arachnoid; in the plural (leptomeninges), usually the arachnoid and pia taken together.

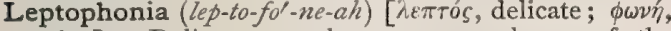
voice]. Delicacy, gentleness, or weakness of the voice.

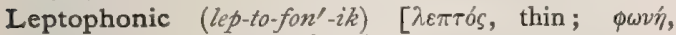
voice]. Having a weak voice.

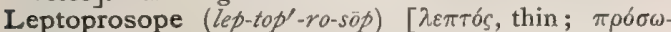
$\pi 0 \nu$, face]. A person, or a head, with a long, narrow face.

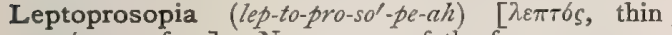
$\pi \rho \sigma \sigma \omega \pi \sigma o v$, face]. Narrowness of the face.

Leptoprosopic, Leptoprosopous (lep-to-pro-sop'-ik,

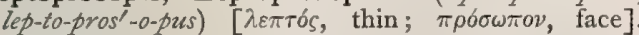
Having a long, narrow face.

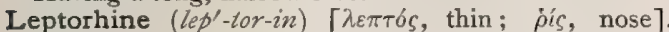
Having a slender nose or proboscis. See Index.

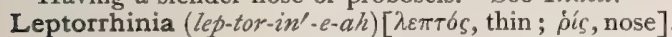
Narrowness of the nasal bones, or smallness of the nasal index.

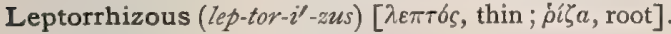
Having a slender root.

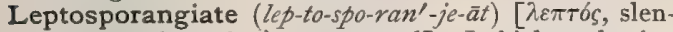

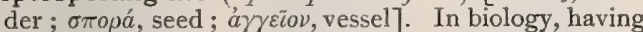
sporangia formed from a single cell.

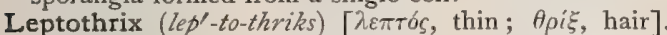
A genus of bacteria, whose elements form straight filaments, often of great length ; possibly indistinguishable from the genus Bacillus. L. buccalis, occasionally found in the mouth, plays a part in the formation of dental tartar and in the production of caries of the teeth. L. gigantea, found in tartar of the teeth. See Bacteria, Synonymatic Table of.

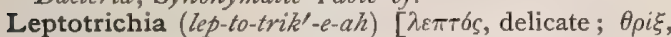
hair]. Abnormal or excessive fineness and delicacy of the hair.

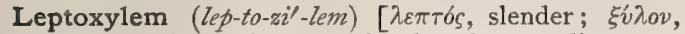
wood]. In biology, undeveloped or rudimentary xylem.

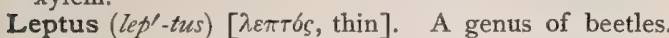
L. autumnalis, harvest bug; mower's mite. A parasite that burrows under the skin, causing lesions similar to those of itch. See Parasites (Animal), Table of.

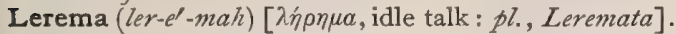
An idle or childish utterance, as in senility, idiocy, or dementia.

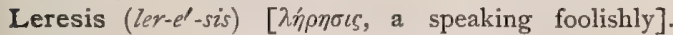
Garrulousness ; insane or senile loquacity.

Leros $\left(l e^{\prime}-r o s\right)[\lambda \tilde{\eta} \rho \circ$, foolish speaking]. Slight delirium, with talkativeness.

Lerp [Australian]. A kind of manna found upon the Eucalyptus dumosa, or mallee, an Australian shrub. L.-amylum, $\mathrm{C}_{6} \mathrm{H}_{10} \mathrm{O}_{5}$, a peculiar carbohydrate found in the thready portion of lerp.

Lesage, Bacillus of. See Bacteria, Synonymatic Table of.

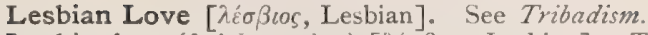

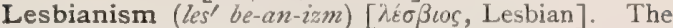
doctrine of Lesbian love.

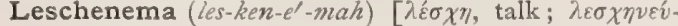
$\varepsilon i \nu$, to chat]. Insane, senile, or hysteric loquacity.

Lesion (le'-zhun) [lasio; ladere, to hurt]. Any injury, hurt, or wound in any part of the body. In pathology, any morbid change. L., Central, one affecting the central nervous system. L. of Continuity, a division or break in any part that is normally continuous. L., Diffuse, one involving all the tissues of an organ. L., Focal, in the nervous system a circumscribed lesion giving rise to distinctive and localizing symptoms. L., Initial, of Syphilis, the chancre. L., Irritative, in the nervous system a lesion exciting the functions of the part wherein it is situated. L. of Nutrition, any pathologic alteration in the capillary system, consisting of increase or decrease in the amount of blood required for assimilation and absorption. L., Organic, a morbid structural change in the tissues of an organ. L., Peripheral, a lesion of the nervetrunks or of their terminations. L., Primary, of the Skin, the change in the skin occurring in the developing stage of a skin-disease. This may be manifested by the macule, the papule, the tubercle, the pomphus, the phyma, the vesicle, the bulla, the pustule. L., Primary, of Syphilis. See L., Initial. L., Secondary. I. In the skin, the change occurring in the primary lesion, due to irritation or other causes. It comprises erosions, ulcers, rhagades, squamæ, cicatrices or scars, crusts, and pigmentation. 2. One of the secondary lesions of syphilis. See Syphitis. L., Systematic or Systemic, in the spinal cord a lesion affecting one or more distinct systems or tracts, as in posterior sclerosis in which the posterior columns or tracts are diseased. L., Traumatic, one due to an injury.

Lesser's Triangle. See Triangles, Table of.

Lethal (le'-thal) [letalis; letum, or lethum, death]. Deadly; pertaining to or producing death.

Lethal (Ze'-thal) [ $\lambda \dot{\eta} \theta \eta$, forgetfulness], $\mathrm{C}_{12} \mathrm{H}_{26} \mathrm{O}$. An alcohol found in spermaceti.

Lethality (le-thal'-it-e) [lethalitas, from letum, death]. Deadliness.

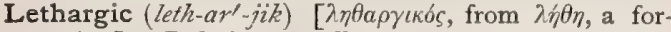
getting]. Relating to, affected with, or of the nature of, lethargy.

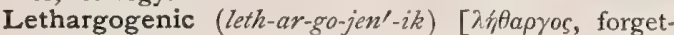

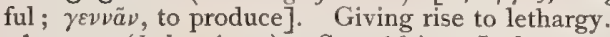

Lethargus (leth-ar'-gus). See African Lethargy.

Lethargy (leth'-ar-je) [ $\lambda \eta \theta a \rho \gamma i a ; \lambda \dot{\eta} \theta \eta$, forgetfulness]. A condition of drowsiness or stupor that cannot be overcome by the will. See, also, Somnambulism. L., African, the African sleeping-sickness. L. of Silkworms. See Flachérie.

Lethe $\left(l e^{\prime}-t h e\right)[\lambda \dot{\eta} \theta \eta$, forgetfulness]. Total loss of memory; amnesia.

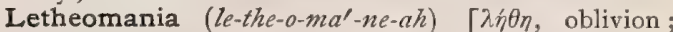
ravia, madness]. Morbid longing for narcotic drugs.

Letheon ( $\left.\ell^{\prime}-t h e-o n\right)$ [ $\lambda \dot{n} \theta \eta$, forgetfulness]. An old trade name for ethylic ether, used as an anesthetic.

Lethiferous (leth-if'-er-us) [ $\lambda \dot{n} \theta \eta$, forgetfulness ; ferre, to bear]. Producing sleep.

Letificant (le-tif'-ik-ant) [latificare, to make glad]. A term applied to any remedy acting as a stimulant tonic in melancholy and languor.

Lettered (let'-erd) [litter $a$, a letter]. In biology, possessing markings that resemble letters.

Letterwort (let'-ter-zvert). Same as Hellebore, q. v.

Lettuce (let'-us). See Lactucarium.

Letzerich, Bacillus of. See Bacteria, Synonymatii Table of. 
Leube and Riegel's Test-dinner. A dinner to ascertain the condition of the secretory function of the stomach. It consists of $400 \mathrm{c}$.c. of beef-soup, 200 grams of beefsteak, 50 grams of white bread, and 200 c.c. of water.

Leube's Pancreatic Meat-emulsion. See Alimentation, Rectal.

Leuc-. For words thus spelled and not found below see Leuk-

Leuca (leu'-kah). Synonym of Leprosy, q.v.

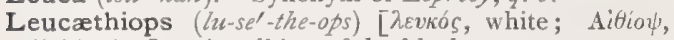
Ethiopian]. An albino of the black race.

Leuce $\left(l^{\prime}-s e\right)[\lambda \varepsilon v \kappa \eta ; \lambda \varepsilon v \kappa o s$, white]. White leprosy; also morphoea alba.

Leucemia ( $h$-se'-me-ah). See Leukemia.

Leuchemia ( $u$-ke'-me-ah). See Leukemia.

Leucin $\left(l u^{\prime}-\sin \right)[\lambda \varepsilon v \kappa o ́ s$, white $], \mathrm{C}_{6} \mathrm{H}_{13} \mathrm{NO}_{2}$. A crystalline substance identical with amido-caproic acid, occurring in the pancreas, spleen, thymus gland, and other parts of the body. It is a product of pancreatic digestion. It may occur in the urine, especially in acute yellow atrophy of the liver and in yellow fever. In the impure form it crystallizes in rounded fatty-looking lumps often aggregated and at times exhibiting radiating striation. When pure, it forms very thin, white, glittering, flat crystals, very soluble in hot water, and oily to the touch. See Scherer's Test in Tests, Table of.

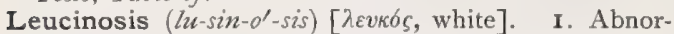
mally excessive proportion or production of leucin, as in the liver. 2, Acute yellow atrophy of the liver.

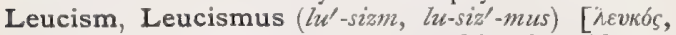
white]. In biology, whiteness resulting from bleaching or etiolation; albinism.

Leucitis (lu-si'-tis). Same as Sclerotitis.

Leuco- $\left(u^{\prime}-k_{0}-\right)$. For words not found under this form see Leuko-.

Leucomain ( $\left(w^{\prime}-k o-m a ̂ n\right)$. See Leukomain.

Leukangeitis (lu-kan-je-i'-tis). Synonym of Lymphangitis, $q . v$.

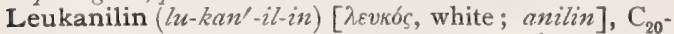
$\mathrm{H}_{21} \mathrm{~N}_{3}$, A substance obtained by digesting the fuchsin salts with ammonium sulphid. It occurs as a white, flocculent precipitate which separates from water in small crystals. It yields rosanilin by oxidation.

Leukasmus ( $u$-kaz'-mus). See Leukoderma. I., Acquired. See Leukoderma. L., Congenital. See Albinismus.

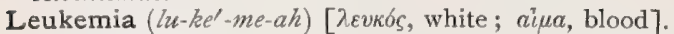
A disease of the blood and the blood-making organs, characterized by a more or less permanent increase in the number of white. blood-corpuscles and the marrow of bone, and by enlargement of the spleen and the lymphatic glands, together or separately. The etiology is obscure; a history of malaria or syphilis has been present in some of the cases. The most characteristic symptom is the increase of white corpuscles in the blood. Instead of the ordinary ratio of white to red-I to $500-1000-i t$ may be $I$ to $20, I$ to $\mathbf{I O}$, or even $\mathbf{I}$ to $\mathbf{I}$. Interesting changes are seen in the relation of the various forms of leukocytes established by Ehrlich (see Leukocyte). In the myelo-splenic form of the disease, the lymphocytes are only slightly, if at all, increased. The eosinophiles are present in much larger numbers than normally. The polynuclear neutrophile forms are not increased. In addition to these, cells not seen in normal blood are found-the myelocytes, large mononuclear leukocytes, filled with neutrophile granules. They are held to originate in the bone-marrow. There is a moderate oligocythemia and a corresponding reduction in the amount of hemoglobin. The liver and the kidney may be the seats of a diffuse lymphatic infiltration; more rarely there are distinct lymphatic tumors. Charcot-Leyden crystals can be found in the blood after death. Fever, dizziness, and hemorrhage, and a peculiar form of retinitis, are often present. The disease is usually fatal.

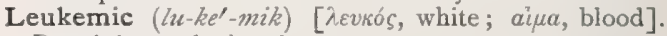
Pertaining to leukemia.

Leuko- $\left(\left\langle u^{\prime}-k o-\right)\right.$ [ $\lambda \varepsilon v \kappa o ́ s$, white]. A prefix signifying white.

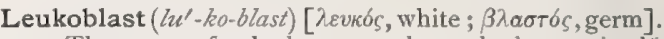
I. The germ of a leukocyte; also, a leukocyte itself. 2. A cell in bone-marrow, of a type that is believed to become developed into a red blood-corpuscle.

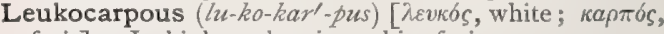
fruit]. In biology, bearing white fruit.

Leukochroos, or Leukochrus (lu-kok'-ro-os, lu-kok'-

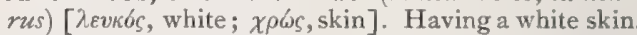

Leukocotin, or Leukocotoin $\left(i u-k o-k o^{\prime}-t i n, l u-k o-k o-\right.$

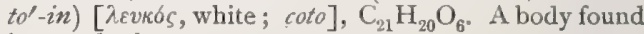
in coto-bark.

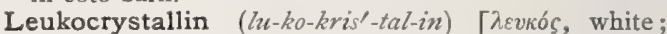

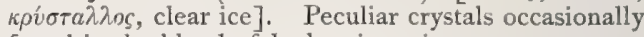
found in the blood of leukemic patients.

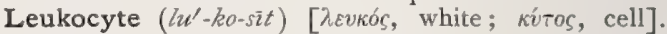
The colorless or white corpuscle of the blood. Leukocytes have ameboid movement and are formed in the lymphadenoid tissue of the spleen, lymphatic glands, intestinal tract, bone-marrow, etc., and probably also in the lymph and blood. Their average diameter is .oI mm. ( $\frac{1}{2500}$ inch). In normal blood Ehrlich distinguishes the following varieties: I. Lymphocytessmall cells with a large nucleus that stains deeply, and a small amount of protoplasm. 2. Large uninuclear leukocytes-large cells with a single large
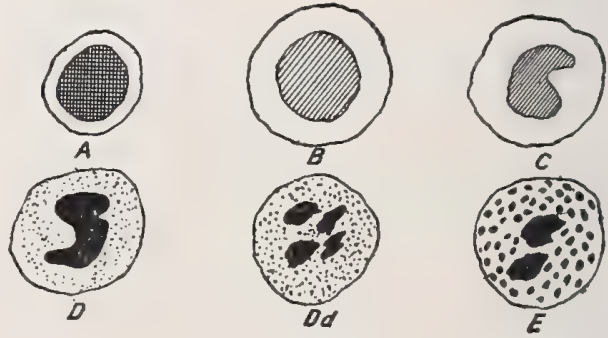

A. Lymphocyte, B. Large uninuclear leukocytes. C. Transitional forms. D.Dd. Multinuclear forms-neutrophile cells. E. Eosinophile cells.

nucleus, staining less deeply, and a large amount of protoplasm. 3. Transitional forms - cells with a single indented nucleus. 4. Multinuclear cells, with neutrophile granules-cells having a polymorphous nucleus or several nuclei. These constitute 70 per cent. of the entire number of white blood-corpuscles. 5. Eosinophile cells. In leukemia another cell, the myelocyte, makes its appearance. This is a large uninuclear cell, with neutrophile granules. Löwit recognizes two classes, leukoblasts and erythroblasts, the latter the antecedents of the red corpuscles. Most authorities reject this division, however. L., Alpha, and L., Beta, two terms used by Heyl, the former to express leukocytes that disintegrate during the coagulation of the blood; the latter, those that do not.

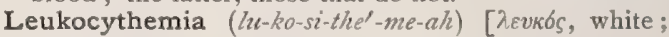
кútos, cell; aiur, blood]. See Lenkemia.

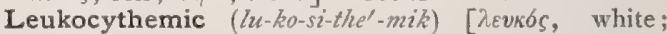
кítos, cell ; aika, blood]. Pertaining to leukemia.

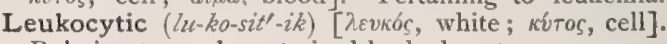
Relating to or characterized by leukocytes. 


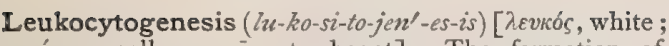

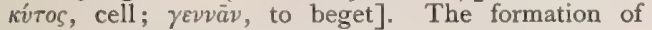
white blood-corpuscles, or leukocytes.

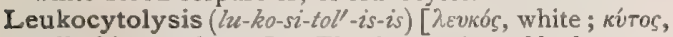
cell; $\lambda i^{\prime} \sigma \varsigma$, solution]. The destruction of leukocytes.

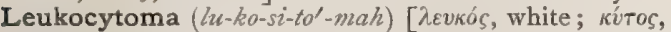
cell; ö $\mu a$, tumor: pl., Leukocytomata]. Any tumor containing cellular growths similar in constitution to the white corpuscles of the blood, such as tubercle, lupus, etc.

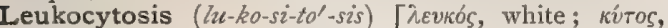
cell]. A moderate and transient increase in the number of colorless blood-corpuscles, not accompanied, as in Ieukemia, by splenic and true glandular enlargement or disease of the bone-marrow

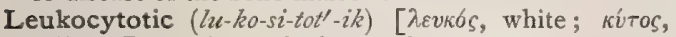
cell]. Pertaining to leukocytosis.

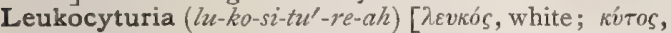
cell; ovpov, urine ]. The presence of colorless bloodcorpuscles in the urine.

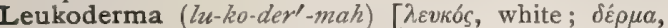
skin]. Leukasmus; achroma cutis; leukopathia; a congenital pigment-anomaly of the skin, in which, at the time of birth or soon after, whitish patches or bands, irregularly outlined and usually isolated, appear upon the skin of the child. See Vitiligo. L., Acquired. See Vitiligo, L., Congenital. See $A l$ binismus. L., Neuritic, L., Neurotic, a localized pigment-atrophy, of nervous origin. L., Syphilitic. See Syphilid, Pigmentary.

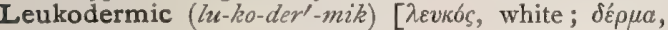
skin]. Exhibiting or pertaining to leukoderma.

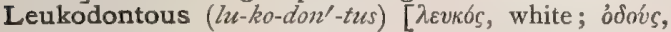
tooth]. Having white teeth.

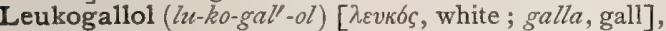
$\mathrm{C}_{18} \mathrm{H}_{10} \mathrm{Cl}_{12} \mathrm{O}_{14}$. A colorless substance, soluble in water, prepared by treating an acetic acid solution of pyrogallol with chlorin and hydrochloric acid

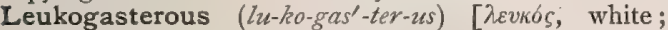

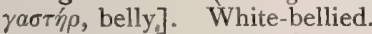

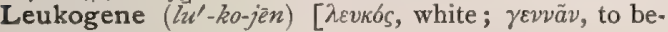
get]. A bleaching-agent.

Leukohemia (lu-ko-hem'-e-ah). See Leukemia.

Leukohemic $\left(h u-k o-h e m^{\prime}-i k\right)$. See Leukemic.

Leukoinoitis ( $\left.l u-k o-i n-o-i^{\prime}-t i s\right)$ [ $\lambda \varepsilon v \kappa o ́ s$, white ; is, fiber; $\iota \tau \iota \varsigma$, inflammation]. Rheumatic inflammation of the white fibrous elements of the bronchi.

Leukol (lu'-kol). See Chinolina

Leukolin ( $\left(u^{\prime}-k o-l i n\right)$. See Chinolina.

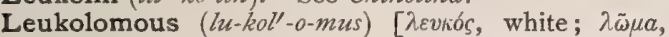
border of a garment]. Having a white border.

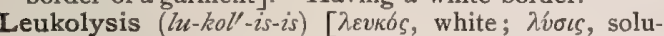
tion]. The process of destruction of the colorless corpuscles of the blood.

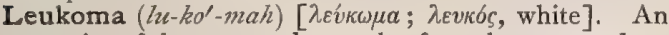
opacity of the cornea the result of an ulcer, wound, or inflammation, and presenting an appearance of ground glass. The term has been used also for albumin. See Leukoplaques. L., Partial, a leukoma circumscribed to a part of the cornea. L., Total, a leukoma involving the entire cornea.

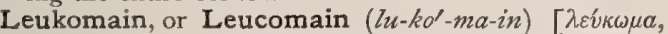
white of egg]. The name applied by Gautier to the nitrogenous bases or alkaloids necessarily and normally developed by the vital functions or metabolic activity of living organisms, as distinguished from the alkaloids developed in dead bodies, and called by Selmi ptomains. From their chemic affinities leukomains may be divided into two groups: the Urid acid group, comprising Adenin, Carnin, Ger. ontin, Guanin, Heteroxanthin, Hypoxanthin, Paraxanthin, Pseudoxanthin, Spermin, Xanthin; and the Kreatinin group, in which are classed Amphi-kreatinin, Cruso-kreatinin, Xantho-kreatinin, and some unnamed bases. The appended table, p. 674, is modi. fied from the work of Vaughan and Novy.

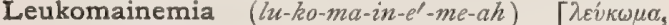
white of egg; aira, blood]. The presence of leukomains in the blood; the retention or imperfect elimination of the various excretory products of the living cells of the organism.

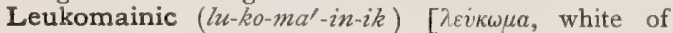
egg]. Pertaining to, or of the nature of, a leukomain.

Leukomatoid (lu-ko'-mat-oid). See Leukomatous.

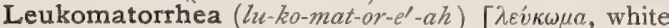
of egg; $\rho$ oia, a flow]. An excessive whitish secretion. L. salivalis, salivation. L. urinalis, albuminuria. L. vaginalis, leukorrhea.

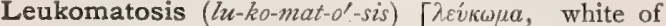
egg ; vóøos, disease]. Abnormal increase of albumin in a part, as in the cornea, the lens, the joints; also amyloid degeneration.

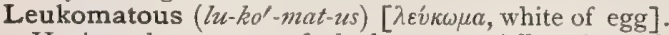
Having the nature of leukoma. Affected with leukoma.

Leukomelanic (lu-ko-mel'-an-ik), Leukomelanous

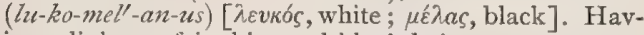
ing a light, or fair skin, and black hair.

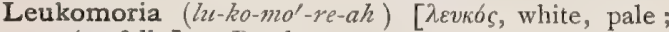
$\mu \omega p i a$, folly]. Restless or wandering melancholy; melancholia errabunda.

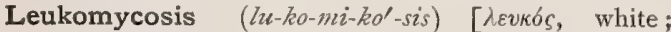

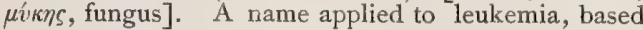
on its supposed infectious origin.

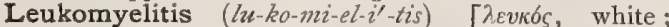
$\mu v \varepsilon \lambda \sigma^{s}$, marrow]. Inflammation of the white or fibrous substance of the spinal cord. L. posterioris chronica, posterior sclerosis; locomotor ataxia.

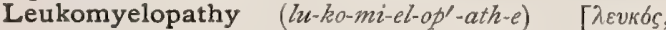

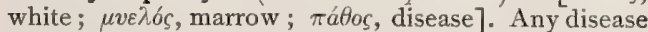
of the white substance of the myelon or spinal cord.

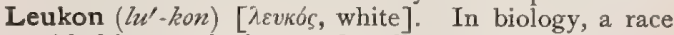
with fair complexions and yellow or red hair. Cf. Xanthochroia.

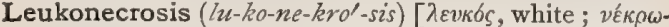
$\sigma \iota s$, death]. A form of dry gangrene, distinguished by light or nearly natural color, instead of the usual dark color of gangrene.

Leukonic Acid ( $u$-kon'-ik). See Acid.

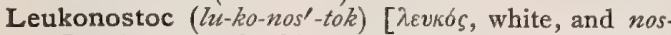
toc]. A genus of schizomycetes, having its elements disposed in chains and enveloped in a sheath of tough jelly. L. mesenteroïdes, is abundant in molasses, beet-root juice, and in sugar-refineries. See Bacteria, Synonymatic Table of:

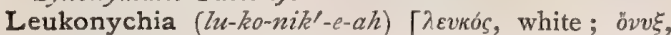
nail 7. A rare and peculiar whitish discoloration of the nails, caused by the presence of air beneath them.

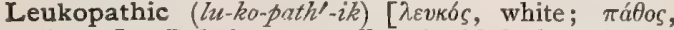
disease]. Relating to or affected with leukopathia.

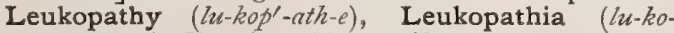

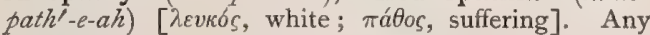
deficiency of coloring-matter; albinism. See Leukoderma. L., Congenital. See Albinism. L., Acquired. See Leukoderma. L., Partial. See Vitiligo. L., Universal. Albinism.

Leukophagium ( $l u-k o-f a j^{\prime}-e-u m$ ), Leukophagum ( $u$ -

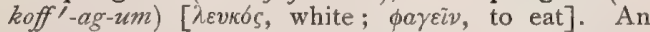
old remedy for pulmonary tuberculosis, consisting of almonds, rose-water, and partridge-flesh.

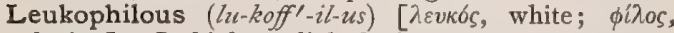
loving]. In biology, light-loving.

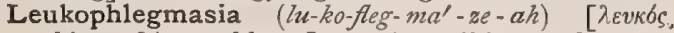

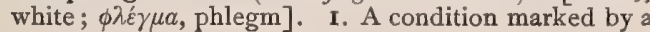


tendency to dropsy, accompanied by a pale, flabby skin, and general edema of the whole body; edema without pitting on pressure. 2. Phlegmasia alba dolens. Also, subcutaneous emphysema. L. Ethiopum, African cachexia. L. dolens puerperarum. Same as Phlegmasia alba dolens, q.v. L., Essential, a form in which there is a rapid and widespread swelling, with fever, chills, and scanty urine. L., Hysteric, a peculiar form occurring in hysteric patients. L., Primary. See L., Essential. L., Urinary, anasarca following suppression of urine.

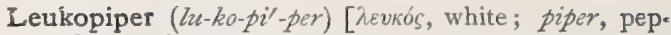
perj. White pepper.

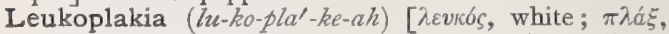
surface]. Whitening of a surface. L. buccalis, a chronic superficial glossitis characterized by the pres. ence of pearly-white or bluish-white patches on the surface of the tongue. This condition is also called Leukoma and lingual psoriasis. It is a rare affection in individuals under twenty, and in women. It is due to some irritant cause, such as the smoking of a pipe and the wearing of tooth-plates.

\section{TABLE OF LEUKOMAINS.}

\begin{tabular}{|c|c|c|c|c|}
\hline NAME. & FORMULA. & DISCOVERER. & SOURCE. & Physiologic Action. \\
\hline Amphi-creatinin. & $\mathrm{C}_{9} \mathrm{H}_{19} \mathrm{~N}_{7} \mathrm{O}_{4}$. & Gautier. & Muscle. & \\
\hline Carnin. & $\mathrm{C}_{7} \mathrm{H}_{8} \mathrm{~N}_{4} \mathrm{O}_{3}$ & Weidel. & Meat-extract. & Non-poisonous. \\
\hline Cruso-creatinin. & $\mathrm{C}_{5} \mathrm{H}_{8} \mathrm{~N}_{4} \mathrm{O}$ & Gautier. & Muscle. & \\
\hline Gerontin. & $\mathrm{C}_{5} \mathrm{H}_{14} \mathrm{~N}_{2}$ & Grandis. & Liver of dog. & $\begin{array}{l}\text { Poisonous; paralyzes } \\
\text { nerve-centers. }\end{array}$ \\
\hline Guanin. & $\mathrm{C}_{6} \mathrm{H}_{5} \mathrm{~N}_{6} \mathrm{O}$ & Unger. & $\begin{array}{l}\text { Animal and vegetable tissues; } \\
\text { guano. }\end{array}$ & Non-poisonous. \\
\hline Heteroxanthin. & $\mathrm{C}_{6} \mathrm{H}_{6} \mathrm{~N}_{4} \mathrm{O}_{2}$ & Salomon. & Urine. & \\
\hline Hypoxanthin. & $\mathrm{C}_{6} \mathrm{H}_{4} \mathrm{~N}_{4} \mathrm{O}$ & Scherer. & $\begin{array}{l}\text { Brain, muscle, kidney, liver, } \\
\text { spleen, certain plants, etc. }\end{array}$ & $\begin{array}{l}\text { Non-poisonous; e x cit o- } \\
\text { motor. }\end{array}$ \\
\hline Methyl-hydantoin. & $\mathrm{C}_{4} \mathrm{H}_{6} \mathrm{~N}_{2} \mathrm{O}_{2}$ & $\begin{array}{l}\text { Guaretchi and } \\
\text { Mosso. }\end{array}$ & Fresh meat. & \\
\hline Parareducin. & $\mathrm{C}_{6} \mathrm{H}_{9} \mathrm{~N}_{3} \mathrm{O}$ & Thudichum. & Urine. & \\
\hline Paraxanthin. & $\mathrm{C}_{7} \mathrm{H}_{8} \mathrm{~N}_{4} \mathrm{O}_{2}$ & $\begin{array}{l}\text { Thudichum, Sal- } \\
\text { omon. }\end{array}$ & Urine. & Poisonous. \\
\hline Protarnin. & 8 & Miescher. & Spawn of salmon. & \\
\hline Pseudoxanthin (?) & $\mathrm{C}_{4} \mathrm{H}_{5} \mathrm{~N}_{5} \mathrm{O}$ & Gautier. & Muscle. & \\
\hline Reducin (?) & $\mathrm{C}_{12} \mathrm{H}_{24} \mathrm{~N}_{6} \mathrm{O}_{9}$ & Thudichum. & Urine. & \\
\hline Salamandarin. & $\mathrm{C}_{34} \mathrm{H}_{60} \mathrm{~N}_{2} \mathrm{O}_{5}$ & Zalesky. & Salamander. & Poisonous. \\
\hline Sarcin or sarkin. & See Hypoxanthin. & & & \\
\hline Spermin. & $\mathrm{C}_{2} \mathrm{H}_{5} \mathrm{~N}(?)$ & Schreiner. & $\begin{array}{l}\text { Semen, testicles; Charcot- } \\
\text { Leyden crystals; tissues in } \\
\text { leukemia. }\end{array}$ & Non-poisonous. \\
\hline Unnamed. & $\mathrm{C}_{3} \mathrm{H}_{5} \mathrm{NO}_{2}$ & Pouchet. & Urine. & \\
\hline Unnamed. & $\mathrm{C}_{7} \mathrm{H}_{12} \mathrm{~N}_{4} \mathrm{O}_{2}$ & Pouchet. & Urine. & \\
\hline Unnamed. & $\mathrm{C}_{11} \mathrm{H}_{24} \mathrm{~N}_{10} \mathrm{O}_{5}$ & Gautier. & Muscle. & \\
\hline Unnamed. & $\mathrm{C}_{12} \mathrm{H}_{25} \mathrm{~N}_{11} \mathrm{O}_{5}$ & Gautier. & Muscle. & \\
\hline Unnamed. & $\mathrm{C}_{13} \mathrm{H}_{24} \mathrm{~N}_{2} \mathrm{O}_{2}\left(\mathrm{C}_{52} \mathrm{H}_{96} \mathrm{~N}_{8} \mathrm{O}_{8} \mathrm{PS}\right)$ & Eliacheff. & Normal urine. & Slightly poisonous. \\
\hline Unnamed. & $\mathrm{C}_{14} \mathrm{H}_{25} \mathrm{~N}_{3} \mathrm{O}_{3}$ & Eliacheff. & Urine in tuberculosis. & Poisonous. \\
\hline Urethrobromin. & See Paraxanthin. & & & \\
\hline Xanthin. & $\mathrm{C}_{5} \mathrm{H}_{4} \mathrm{~N}_{4} \mathrm{O}_{2}$ & Marcet. & $\begin{array}{l}\text { Most animal tissues; certain } \\
\text { plants; certain calculi. }\end{array}$ & $\begin{array}{l}\text { Slightly poisonous; mus- } \\
\text { cle-stimulant. }\end{array}$ \\
\hline Xantho-creatinin. & $\mathrm{C}_{5} \mathrm{H}_{20} \mathrm{~N}_{4} \mathrm{O}$ & Gautier. & Muscle. & Poisonous. \\
\hline
\end{tabular}

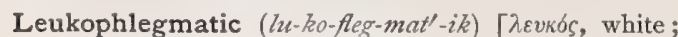
$\phi \lambda \varepsilon \hat{\gamma \mu \alpha}$, phlegm]. Affected with or pertaining to leukophlegmasia.

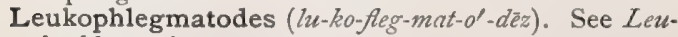
kophlegmatic.

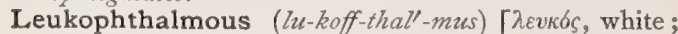
${ }^{\prime} \phi \theta a \lambda \mu \delta s$, eye]. Having unusually white eyes.

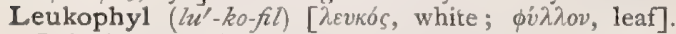
In biology, a chlorophyl-producing chromogen believed to exist in etiolated plants.

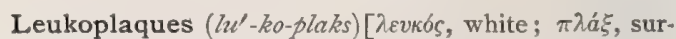
face]. The white patches of Leukoplakia buccalis, q.v. Leukoplasia ( $\left(u-k o-p l a^{\prime}-z e-a h\right)$. See Leukoplakia.

Leukoplast, or Leukoplastid (lu-ko-plast', or lu-ko.

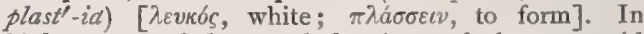
biology, one of the starch-forming, colorless, proteid bodies found in cells not exposed to light; amyloplast.

Leukoplaxia (lu-ko-plaks'-e-ah). See Leukoplakia.

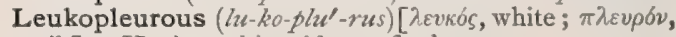
rib]. Having white sides or flanks. 
Leukopodious, Leukopodous ( $m-k o-p o^{\prime}-d e-u s$, $l u-k o p^{\prime}$ -

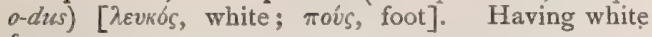
feet.

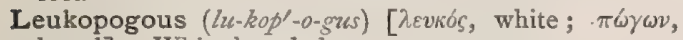
beard]. White-bearded.

Leucopous (lu'-ko-pus). See Leukopodous.

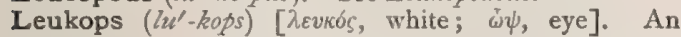
individual having white eyes.

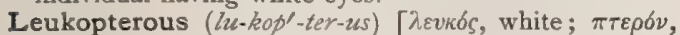
wings]. In biology, possessing white wings.

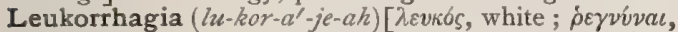
to burst forth]. An excessive leukorrheal flow.

Leukorrhea $\left(h u-k o r-e^{\prime}-a h\right)[\lambda \varepsilon v k o s$, white; poia, a flow]. A whitish muco-purulent discharge from the female genital canal, popularly called "the whites." L., Cervical, that due to disease of the cervix uteri. L., Infantile, a form occurring in female infants, due to lack of cleanliness, to irritant urine, or to worms. L., Menstrual, a variety occurring in young anemic girls at the menstrual period, instead of the menses. L. nabothi, a sero-sanguineous discharge occurring for two or three days before labor. L. masculina syphilitica. Synonym of Gonorrhea, q. $v$. L. of Pregnancy, a vaginal discharge in the pregnant woman. It is more abundant than in the non-pregnant state, and is sometimes confounded with hydrorrhoea gravidarum. L., Periodic, a periodic form coinciding with the menstrual periods. L., Uterine, L., Vaginal, L., Vulval, forms due to uterine, vaginal, and vulval inflammation respectively.

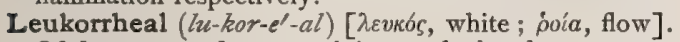
Of the nature of, or pertaining to, leukorrhea.

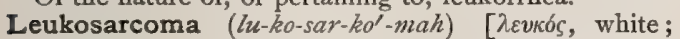
бá non-pigmented sarcoma.

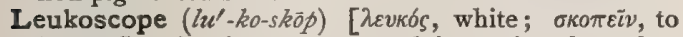
inspect]. An instrument used in testing for colorblindness.

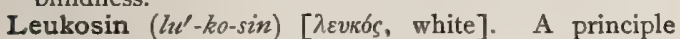
said by some to be present in asthma-crystals, and in crystals found in the blood in certain cases of leukemia.

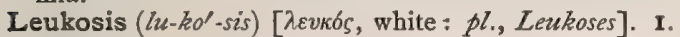
Any disease of the lymphatic system. 2. Abnormal whiteness of the skin. Also, the development and progress of leukoma.

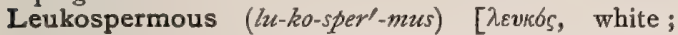
$\sigma \pi \varepsilon \rho \mu a$, seed]. In biology, bearing white seeds.

Leukotic $\left(u-k o t^{\prime}-i k\right) \cdot[\lambda \varepsilon v \kappa o s$, white]. Relating to leukoma.

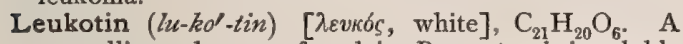
crystalline substance found in Paracoto; it is soluble in alcohol, ether, and chloroform.

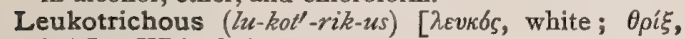
hair]. White-haired.

Leukoturic Acid (lu-kot-uthik). See Oxalantin.

Leukous ( $\left(u^{\prime}-k u s\right)$ [ $\lambda \varepsilon v \kappa \delta s$, white]. White.

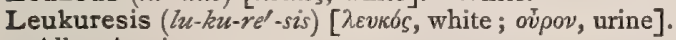
Albuminuria.

Leusin $\left(h^{\prime}-\sin \right)$. See Leucin.

Levant Plague. Synonym of the Plague, q. v. L. Wormseed. See Santonica.

Levantine Plague. Synonym of the Plague, q. v.

Levasseur Sign. See Death.

Levator (le-va'-tor) [L., "a lifter:" pl., Levatores]. I. That which raises or elevates, as certain muscles. See Muscles, Table of. 2. An instrument used for raising a depressed portion of the skull.

Leven (lev'-en). See Leaven.

Lever (le'-ver) [levare, to elevate]. I. A vectis or one-armed tractor, used in obstetrics. 2. A dental instrument, used in lifting out decayed stumps. I..,
Davy's, an aorta-compressor. It is a wooden bar, which is introduced into the rectum.

Levert's Law. See Law.

Levicellular (lev-e-sel'-u-lar) [levis, smooth; cellula, cell]. Smooth-celled, as a levicellular myoma, or a levicellular muscle-fiber.

Levigable (lev'-ig-a-bl) [lavigare, to make smooth]. Susceptible of being levigated, or reduced to fine powder by a mechanical process.

Levigate (lev'-ig-ät) [lavigare, to make smooth]. To reduce to a fine powder by rubbing or grinding; to triturate.

Levigation (lev-ig-a'-shun) [lavigatio, lavigare, to make smooth]. The trituration of a substance made into a paste with water or other liquid. When performed with a muller on a slab of porphyry it is called porphyrization.

Levis's Apparatus. An apparatus for treating fracture of the clavicle, composed of an axillary pad and a sling. L.'s Splints, supporting structures made of light metal, and perforated, for use in the treatment of fractures.

Levitation (lev-it-a'-shun) [levitas, lightness]. I. The pretended elevation of the body into the air without support, a feat professedly performed by various modern thaumaturgists. 2. The subjective sense of being aloft, and without support; a symptom in certain cases of insanity.

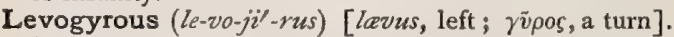
See Levorotatory.

Levorotatory (le-vo-ro'-tat-o-re) [lavus, left ; rotare, to turn]. Causing to turn toward the left hand; a levorotatory crystal is one that turns the rays of polarized light to the left.

Levulan (lev'-u-lan) [lavus, left], $\mathrm{C}_{6} \mathrm{H}_{10} \mathrm{O}_{5}$. An anhydrid of levulose obtained from beet-sugar molasses.

Levulin (lev'-u-lin) [levus, left]. A carbohydrate identical with synanthrose, occurring in immature grain and the tubers of certain composite flowers.

Levulinic Acid (lev-u-lin'-ik). See Acid.

Levulosan (lev-u-lo'-san) [levus, left], $\mathrm{C}_{6} \mathrm{H}_{10} \mathrm{O}_{5}, \quad$ A dehydration-product prepared by heating levulose.

Levulose (lev'-u-lös) [lavus, left], $\mathrm{C}_{6} \mathrm{H}_{12} \mathrm{O}_{6}$. The natural sugar of fruits. It reduces an alkaline solution of copper sulphate. See Sugar, Glucose, and Fructose.

Levulosuria (lev-u-lōs-u'-re-ah) [lavus, left; ov́pov, urine]. The presence of levulose, or fruit-sugar, in the urine.

Lewinin $\left(u^{\prime}-i n-i n\right)$ [from Dr. Lezvin, who described it]. The alpha resin of kava, q. v. ; it is said by Lewin to be as effective a local anesthetic as cocain.

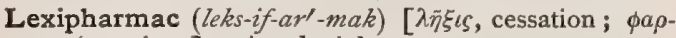
$\mu a \kappa 6 v$, poison]. An alexipharmac.

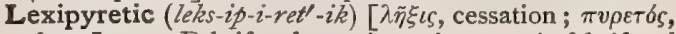
fever]. I. Febrifugal; antipyretic. 2. A febrifugal medicine.

Leyden ( $i^{\prime}$-den) [Dutch]. A town in Holland. L. Battery. A series of Leyden jars connected tandem. L.-blue. Same as Cobalt-blue. L. Jar, glass jar coated within and without with tinfoil, reaching nearly to the neck, and surmounted by a knobbed conductor in connection with the inner coating. It is designed for the temporary "accumulation" of electricity, or rather for the preservation of the high potential to which the inner foil may be charged. It is discharged by connecting the outer foil with the knob. The jar was first made in the town of Leyden, its discovery being due to Cuneus, a pupil of Muschenbrœeck. It is also called Kleistian jar or Kleist's jar. Kleist was a prebendary of Cammin, in Pomerania, and is said to have invented the jar independently of Cuneus, and a year before him, viz., in $\mathbf{1 7 4 5}$. L., 
Periodic Vomit of. Synonym of Angioneurotic Edema.

Leyden's Crystals. See Charcot-Leyden Crystals.

Leydig's Cells. Peculiar goblet-cells found in the epidermis of aquatic vertebrata. L., Duct of. See Duct.

Liatris $\left(i i-a^{\prime}-t\right.$ tris) [origin unknown]. A genus of composite-flowered herbs. L. cylindrica, L. elegans, and L. spicata are diuretic; L. scariosa and L. squarrosa are popularly esteemed as remedies for rattlesnakebite. L. odoratissima, southern vanilla, contains cumarin, the flavoring principle of the tonka bean. Unof.

Libanotus ( $i b$-an-o'-tus) $[\lambda \iota \beta a v \omega \tau \delta s$, from $\lambda i \beta a \nu o s$, frankincense]. An old name for olibanum.

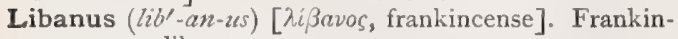
cense, or olibanum.

Libavius, Fuming Liquor of. An old name for anhydrous stannic chlorid.

Liber (le'-ber) [L.]. A book. L. pharmaceuticus, a dispensatory.

Liber (li'-ber) [liber, the inner bark of a tree]. The inner layer of the bark in Gymnosperms and Dicotyledons.

Liberation (lib-er-a'-tion) [liberare, to make free]. The act of freeing. L. of the Arms, in breechpresentations, the bringing down of the arms of the fetus when they have become extended along the sides of the child's head.

Liberomotor (lib-er-o-mo'-tor) [liberare, to disengage; motor, mover]. Setting free or disengaging motor energy.

Libidinous (lib-id'-in-us) [libidinosus, lustful]. Characterized by strong sexual desire.

Libido $\left(l i b-i d^{\prime}-o\right)\left[\mathrm{L}_{0}\right]$. Desire ; lust. L. intestini, desire for defecation. L. sexualis, lust. L. urinæ, desire to urinate.

Liborius, Bacillus of. See Bacteria, Synonymatic Table of.

Libra (le'-brah) [libra, a balance]. A weight of twelve troy ounces, or 5760 grains. Also, applied to the avoirdupois pound of sixteen ounces, or 7000 grains.

Libriform (lib'-rif-orm) [liber, inner bark; forma, form]. In biology, resembling liber or bast. L. Cells, those cells of the wood that are excessively thick-walled and resemble bast or liber-fibers.

Lice (liss). See Louse.

License $\left(l i^{\prime}-\operatorname{sen} s\right)$ [licentia, license]. An official permit or authority conferring on the recipient the right and privilege of exercising his profession.

Licentiate (ii-sen'-she-ät) [licentiatus, one licensed]. A term sometimes applied to a person who practises a profession by the authority of a license.

Lichen $\left(l^{\prime}-k e n\right)[\lambda \varepsilon \iota \chi \dot{\eta} v$, a lichen]. A generic term for a well-defined group of inflammatory affections of the skin, in which the lesions consist of solid papules throughout the entire course of the disease. $\mathbf{L}$. acuminatus, a variety of $L$. ruber in which the papules are acuminate. It is usually a very acute variety, accompanied by grave constitutional symptoms (rigors, pyrexia, sweats, prostration), and by itching. The papules are minute, firm, conic, capped with scales, very closely aggregated, but can generally be recognized as surrounding the hair-follicles. $L$. agrius. See Eczema papulosum. L. annulatus serpiginosus. See Seborrhaea corporis. L. Carrageen, Irish moss. L. circinatus serpiginosus. See $\mathrm{Se}$ borrhea corporis. L. circumscriptus. Same as $L$. circinatus serpiginosus. See also Eczema papulosum. L. confertus, a form characterized by the presence of superficial papules occurring in clusters. L. corneus, a form in which there are elevated horny patches. L. diabeticorum. See Xanthoma diabeticorum.
L. disseminatus, a variety in which the lesions are irregularly scattered over the body. L. ferox or L. ferus. See L. agrius. L. gyratus. See Seborrhea corporis. L. hæmorrhagicus, a petechial papular eruption. L. inveterata, a chronic intractable form, with marked thickening of the skin. L. lividus, a severe form of purpura in which hemorrhage occurs into the lesions around the follicles. L. menti. See Sycosis. L. obtusus, Lichen ruber obtusus; a variety of $L$. planzes in which the lesion consists of medium-sized papules, hemispherically formed, flattened on the top, and marked in the center by a fine indentation, hard, dry, smooth, wax-like, translucent to brownishred, and scaleless. The disease is less acute than $L$. acuminatus, itches less, and is mostly circumscribed. The hair and nails never suffer. L. pilaris, Lichen spinulosus; Lichen spinosus; an inflammatory disease of the hair-follicles, in which a spinous epidermic peg occupies the center of the papule. It is a rather rare disease and occurs mostly in children. The papules appear in crops, each one being the size of a pin's head, red, conic, and containing in its center a horny spine that projects about one-sixteenth of an inch. There is little or no itching. See alsa Keratosis pilaris. L. planus, Lichen ruber planus; Lichen psoriasis; an inflammatory skin-disease, with an eruption made up of papules that are broad and angular at the base, flat and apparently glazed on the summit, slightly umbilicated, and of a dull purplish-red color. These lesions are usually symmetrically disposed, and are generally situated on the flexor surfaces of the forearms, about the wrists, the flanks, around the waist, and the knees, and calves, and also on the nucous membranes. The papules may be discrete or may coalesce, and itching may be slight or severe. L. planus verrucosus, a late stage of $L$. planus, characterized by wart-like enlargements of the papillæ, which are covered with dense horny crusts of a dirty-lilac hue. They are usually seen on the lower part of the leg. L. psoriasis. See $L$. planus. L. ruber, Lichen ruber acuminatus; a very rare skin-disease, with lesions consisting, in the beginning, of discrete, miliary, conic papules, but, as the disease advances, becoming aggregated and forming continuous red, infiltrated, and scaling patches. The whole surface may eventually become involved. The nails of the fingers and toes become affected, being of a dirty-brown color, rough, flaky, and breaking off short. The etiology and pathology of this condition are obscure. L. ruber acuminatus. See Pityriasis rubra pilaris and Lichen ruber. L. ruber moniliformis, a rare variety in which, besides the ordinary papules and plaques, there are thick moniliform bands in the flexures of the limbs, on the abdomen, and on the neck. L. ruber obtusus. See $L$. obtusus. L. ruber planus. See $L$. planus. L. scrofulosorum. See $L$. scrofulosus. L. scrofulosus, $L$. scrofulosorum; a form occurring in strumous children. The eruption is situated on the trunk, especially upon the back, either diffusely or in patches. The papules are very small, pale, conic, and surmounted by fine scales; they cause no itching, and on fading leave a rather persistent yellowish pigmentation. L. simplex, Gale bedouine; the papular stage of eczema. See Eczema papulosum. L. spinosus. See L. pilaris. L. spinulosus. See Keratosis pilaris and Lichen pilaris. L. strophulosus. See Strophulus. L. syphiliticus, the minute papular syphilid. See Syphilid, Follicular. L. tropicus. See Prick,y Heat. L. urticatus. See Urticaria papulosa.

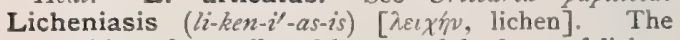
condition of one affected by one of the forms of lichen. L. strophulus. See Lichen strophulus. 


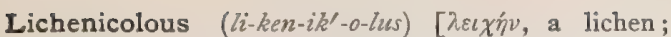
colere, to inhabit]. Growing as a parasite upon lichens.

Licheniform ( $\left.l i-k e n^{\prime}-i f-o r m\right)[\lambda \varepsilon \iota \chi \dot{\eta} v$, lichen, tree-moss ; forma, form]. Shaped like a lichen.

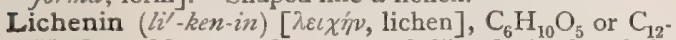
$\mathrm{H}_{20} \mathrm{O}_{10}$. Moss-starch; a starch-like body found in lichens, especially in Cetraria, Ramalina, Usnea, Parmelia, Cladonia, and in Corsican moss (Alsidium helminthochorton). Iodin imparts a dirty-blue color to it. It is insoluble in cold water, but forms a jelly with hot water. See Cetraria; also, Carbohydrates, Table of.

Lichenism $\left(l^{\prime}-k e n-i z m\right)$ [ $\lambda \varepsilon \iota \chi \eta^{\prime} v$, lichen]. In biology, the special form of consortism or symbiosis exhibited by algæ and fungi in lichens. CF. Schwendener's Theory.

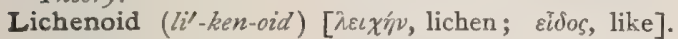
1. Same as Dextrolichenin. 2, See Wandering Rash.

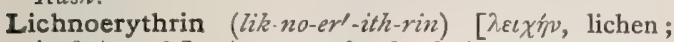

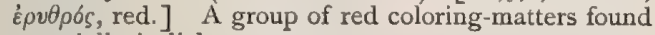
especially in lichens.

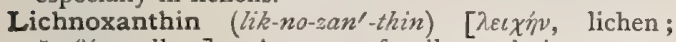

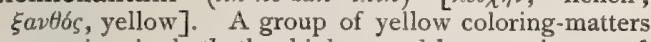
occurring in both the highest and lowest classes of plants, but especially developed in lichens.

Lichtheim's Schema. A diagrammatic representation of the centers and pathways concerned in written and spoken language. In the schema, A represents the center for visual memories, and $O$ that for auditory memories. $\mathrm{M}$ is the center for muscular memories concerned in speech, and W that for muscular memories connected with writing. I is the center for intellectual concepts. Taking the word " bell " as an example, at A will be stored the memory of the appearance of the bell, at $\mathrm{O}$ that of the sound of the word, at $\mathrm{M}$ the memory of the muscular movements necessary to pronounce the word, and at $\mathrm{W}$ those concerned in writing it. I represents the center of the intellectual concept of the object "bell" - the knowledge of its uses and properties. The lines indicate afferent, efferent, and connecting pathways.

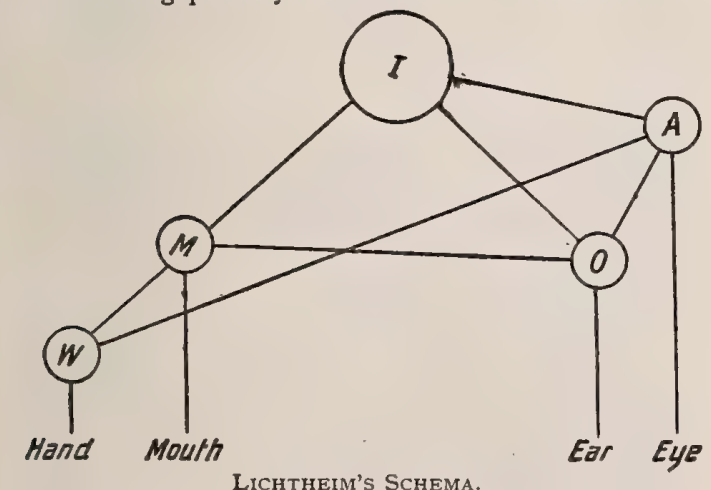

Licinium (li-sin'-e-um) [licium, a thread of a web: gen., Licinii]. Lint; surgeon's lint or charpie.

Lick (lik) [ME., licken, to lick]. To rub with the tongue; to lap.

Licoperdon (li-ko-per'-don). See Lycoperdon.

Licorice (lik'-or-is) [ME., licorice, licorice]. See Glycyrrhiza. L., Indian. See Abrus.

Lid [ME., lid, lid]. See Eyelid. L.-cells, in biology, the "stigmatic cells" which for a time close the neck of the archegonium in cryptogamic plants. L.-clamp. See Blepharostat.
Lie (li) [ME., lien, to lie]. x. To rest in a recumbent position. 2. A popular name for a "gift-spot" or white spot upon a finger nail.

Lieberkühn's Reflector (le'-ber-kèn) [after Lieberkühn, a German physician]. A device attached to a microscope for the purpose of throwing light upon opaque objects. L.'s Ampulla. See Ampulla. L., Crypts of. See Crypt. L., Glands of. See Gland. L.'s Jelly, an insoluble variety of alkali-albumin formed by adding strong potash to undiluted white of egg.

Liebermann's Reaction. See Tests, Table of.

Liebig (le $\left.e^{\prime}-b i g\right)$. A celebrated German chemist and physiologist. L.'s Beef-tea, the soluble extractive matter of lean meat. It is prepared by macerating a pound of lean meat, free from fat and cut into small pieces, in a pint of cold water, in which $m$ xxx of hydrochloric acid and gr. xl of sodium chlorid have been dissolved. The liquid is expressed and strained. L.'s Bouillon. See Bouillon. L.'s Extractum carnis, a proprietary preparation consisting of the soluble fibrin of meat with the natural mineral salts and a flavoring principle, osmazome. L.'s Foods, those infant-foods in which the starch is to a great extent converted into sugar by malting. L.'s Infants' Food, a highly nutritious food made in the following manner: Mix well $1 / 2$ ounce of ground malt with $1 / 2$ ounce of wheat-fiour and $7 \frac{1}{4}$ grains of potassium bicarbonate; add $I$ ounce of water and 5 ounces of fresh cow's milk. Warm over a slow fire, and keep stirring until it begins to thicken. Remove from the fire, stir for five minutes, replace it on the fire, and remove it as soon as thick. As the starch is converted into dextrin and sugar by the diastase of the malt, it will become a thin and sweet liquid. Then, finally, boil it well. Strain through muslin. L.'s Method, a method of estimating the chlorids in the urine, by precipitation by mercuric nitrate. See also Urea.

Liebreich's Bandage. See Bandage. L.'s Solution, a solution of cantharidinate of potassium for hypodermatic injection in the treatment of tuberculosis. Cantharidin 2, hydrate of potassium 4 (or hydrate of sodium 3), distilled water 200. Heat to solution and add distilled water q. s. to 1o,000. Dose by hypodermatic injection, $\pi / 2$ to $I$ c.c. ( 8 to 16 minims). It causes transudation of blood-serum at the seat of the tuberculosis.

Lien $\left(i^{\prime}-e n\right)$ [L.]. The spleen. L. mobile. See Wandering Spleen.

Lienal $\left(l i^{\prime}-e n-a l\right)$ [lien, the spleen]. Relating to the spleen.

Lienculus ( $\left.l i-e n^{\prime}-k u-l u s\right)$ [dim. of lien, spleen: $p l$., Lienculi ]. A detached part or exclave of the spleen.

Lienic $\left(i-e n^{\prime}-i k\right)$ [lien, a spleen]. Pertaining to the spleen.

Lienitis ( $t$-en-i'tis) [lien, spleen; $\iota \tau \iota s$, inflammation]. Splenitis.

Lienocele $\left(l i-e n^{\prime}-o-s e \bar{l}\right)$ [lien, a spleen; $\kappa \dot{n} \lambda \eta$, hernia]. Hernia of some part or of all of the spleen.

Lienomalacia (li-en-o-mal-a'-se-ah) [lien, spleen; $\mu a \lambda a \kappa i a$, softening]. Morbid softening of the tissue of the spleen.

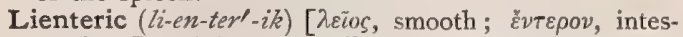
tine]. Pertaining to or affected with lientery.

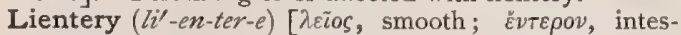
tine]. A kind of diarrhea in which the food passes rapidly through the bowels without undergoing digestion.

Liernur System. See Sezvage, Disposal of.

Lieutaud, Uvula of. A longitudinal mesial ridge in the trigone of the bladder. 
Life (lif) [ME, lif, life]. The force or principle underlying or causing the phenomena of organized beings. The power by which an organism exists and exercises self-movement in response to emotions or sensations and adapts itself to its environment. L. Animal, the functions depending directly on the cerebro-spinal nervous system and the voluntary muscles, as distinguished from $L$., Vegetative; that is, the functions of digestion, respiration, reproduction, etc. ; L., Change of, that period in the life of a female at which menstruation ceases; the climacteric period. L., Duration of, See Probable. L. Everlasting; Cud-weed, the herbs Gnaphalium margaritaceum and $G$. polycephalum, tonic, astringent, and anodyne. They constitute a domestic remedy of some repute in affections of the chest and bowels. Dose of a decoction $a d$ lib.; of the fld. ext. $m \times x v-3 j$. Unof.

L., Expectation of, the average number of years a person is expected to live, as calculated from life-tables. The following table, taken from those constructed by Dr. W. Ogle, of the English RegistrarGeneral's department, shows the average expectation of life at given ages, and also the number of persons of each sex, among every million born at a given time, who may be expected to be alive at the end of each year after that. The figures are based on the death-rates of the years $1871-80$ :-

\begin{tabular}{|c|c|c|c|c|}
\hline \multirow{2}{*}{ 递 } & \multicolumn{2}{|c|}{$\begin{array}{l}\text { Of } 1,000,000 \text { borm, the num- } \\
\text { ber surviving at the end of } \\
\text { each year of life. }\end{array}$} & \multicolumn{2}{|c|}{$\begin{array}{l}\text { Mean after-lifetime } \\
\text { (expectation of life). }\end{array}$} \\
\hline & Males. & Females. & MALES. & FEMALES. \\
\hline 0 & $1,000,000$ & $1,000,000$ & $4 \pi \cdot 35$ & 44.62 \\
\hline I & 841,417 & 871,266 & 48.05 & 50.14 \\
\hline 2 & 790,201 & 820,480 & 50.14 & 52.22 \\
\hline 3 & $763,7,37$ & 793,359 & 50.86 & 52.99 \\
\hline 4 & 746,587 & 775,427 & 51.01 & 53.20 \\
\hline 5 & 734,068 & 762,622 & 50.87 & 53.08 \\
\hline 6 & 726,815 & 755,713 & 50.38 & 52.56 \\
\hline 8 & $\begin{array}{l}721,103 \\
716,309\end{array}$ & $\begin{array}{l}750,276 \\
745,631\end{array}$ & 49.77 & $\begin{array}{l}51.94 \\
51.26\end{array}$ \\
\hline 9 & 712,337 & 741,727 & $\begin{array}{l}49.10 \\
48.37\end{array}$ & $\begin{array}{l}51.20 \\
50.53\end{array}$ \\
\hline Io & 708,990 & 738,382 & 47.60 & 49.76 \\
\hline II & 706,146 & 735,405 & 46.79 & 48. 96 \\
\hline 12 & 703,595 & 732,697 & 45.96 & 48. 13 \\
\hline$I_{3}$ & 701,200 & 730,122 & 45. II & $47 \cdot 30$ \\
\hline 14 & 698,840 & 727,571 & 44.26 & 4647 \\
\hline 15 & 696,419 & 724,956 & $43.4 \mathrm{I}$ & 45.63 \\
\hline 16 & 693,695 & 722,084 & $42.5^{8}$ & $44.8 \mathrm{I}$ \\
\hline 17 & $6,30,746$ & 718,993 & 41.76 & 44.00 \\
\hline 18 & 687,507 & 715,622 & 40.96 & $43.4 \mathrm{I}$ \\
\hline 19 & $683,94 \mathrm{I}$ & 711,946 & 40.17 & $4^{2} .43$ \\
\hline 20 & 680,033 & 707,949 & 39.40 & 41.66 \\
\hline $2 I$ & 675,769 & 703,616 & 38.64 & 40.92 \\
\hline 22 & 671,344 & $699,14 \mathrm{I}$ & 37.89 & 40.18 \\
\hline 23 & 666,754 & $694,52 \mathrm{I}$ & 37.15 & 39.44 \\
\hline 24 & 661,997 & 689,759 & $36.4 \mathrm{I}$ & $38.7 \mathrm{I}$ \\
\hline 25 & 657,077 & 684,858 & 35.68 & 37.98 \\
\hline 26 & 651.998 & 679,822 & 34.96 & 37.26 \\
\hline 27 & 646,757 & $674,66 \mathrm{I}$ & 34.24 & 36.54 \\
\hline 28 & 645,353 & 669,372 & 33.52 & 35.83 \\
\hline 29 & 635,778 & 663.959 & $328 \mathrm{r}$ & $35 \cdot 11$ \\
\hline 30 & 630,038 & 658,418 & 32. Io & $34.4 \mathrm{I}$ \\
\hline $3 \mathrm{I}$ & 624,124 & 652,747 & 31.40 & 3370 \\
\hline 32 & 618,056 & 646,957 & 30.71 & 33.00 \\
\hline 33 & 611,827 & 641,045 & 30.01 & 32.30 \\
\hline 34 & $605,43^{\circ}$ & 635,003 & 29.33 & 31.60 \\
\hline 35 & 598,860 & 628,842 & 28.64 & 3090 \\
\hline 36 & 592,107 & 622,554 & 27.96 & 30.21 \\
\hline 37 & 585,167 & 616,144 & 27.29 & 29.52 \\
\hline 38 & 578 ,019 & 609,599 & 26.62 & 28.83 \\
\hline 39 & 570,656 & 602,924 & 25.96 & 28.15 \\
\hline 40 & 563,077 & $596, \mathrm{II}_{3}$ & $25 \cdot 30$ & 27.46 \\
\hline $4 \mathrm{I}$ & 555,254 & 589,167 & 24.65 & 26.78 \\
\hline 42 & 547,288 & 582,104 & 24.00 & 26.10 \\
\hline 43 & 539,16 I & 574,919 & $23 \cdot 35$ & 25.42 \\
\hline 44 & 530,858 & 567,612 & 22.71 & 24.74 \\
\hline 45 & 522,374 & 560,174 & 22.07 & 24.06 \\
\hline 46 & 513,702 & 552,602 & 21.44 & 23.38 \\
\hline $\begin{array}{l}47 \\
48\end{array}$ & $\begin{array}{l}504,836 \\
495,76 x\end{array}$ & 544,892 & 20.80 & 22.71 \\
\hline & 495,761 & 537,043 & 20.18 & 2203 \\
\hline
\end{tabular}

\begin{tabular}{|c|c|c|c|c|}
\hline \multirow{2}{*}{$\frac{\sqrt{5}}{4}$} & \multicolumn{2}{|c|}{$\begin{array}{l}\text { Of } 1,000,000 \text { born, the num- } \\
\text { ber surviving at the end of } \\
\text { each year of life. }\end{array}$} & \multicolumn{2}{|c|}{$\begin{array}{l}\text { Mean after-lifetime } \\
\text { (expectation of life). }\end{array}$} \\
\hline & Males. & FEMALES & MALES. & Females. \\
\hline 49 & 486,479 & 529,048 & & \\
\hline 50 & 476,980 & 520,901 & 18.93 & 20.68 \\
\hline $5^{I}$ & 467,254 & $512,6 \circ 7$ & 1831 & 20.01 \\
\hline $5^{2}$ & 457,022 & 504,183 & 17.71 & 19.34 \\
\hline 53 & 446,510 & 495,645 & 17.12 & 1866 \\
\hline 54 & 435,729 & $4^{86,973}$ & 16.53 & I7. 98 \\
\hline 55 & 424,677 & 477,440 & 15.95 & 17.33 \\
\hline $5^{6}$ & $4 \mathrm{I} 3,35 \mathrm{I}$ & 467,443 & 15.37 & 16.69 \\
\hline 57 & 401,740 & 456,992 & 14.80 & 1606 \\
\hline $5^{8}$ & 389,827 & 446,079 & 14.24 & 1545 \\
\hline 59 & 377,591 & 434,695 & 13.68 & 1484 \\
\hline 60 & 365,011 & 422,835 & 13.14 & 14.24 \\
\hline $6 I$ & 352,071 & 410,477 & 1260 & 13.65 \\
\hline 62 & 338,820 & 397,644 & I 2.07 & 13.08 \\
\hline 63 & 325,256 & 384,319 & I1. 56 & $32.5 I$ \\
\hline 64 & 311,368 & 370,495 & II.05 & 11.96 \\
\hline 65 & 297,156 & 356,165 & 10.55 & II. 42 \\
\hline 66 & 282,638 & 341,326 & 10.07 & 1090 \\
\hline 67 & 267,829 & 325,988 & 960 & 1039 \\
\hline 68 & 252,763 & 310,170 & 9.14 & 9.89 \\
\hline 69 & 237,487 & 293,899 & 8.70 & $94 \mathrm{I}$ \\
\hline 70 & 222,056 & 277,225 & 8.27 & 8.95 \\
\hline 71 & 206,539 & 260,207 & 7.85 & 8.50 \\
\hline 72 & 190,971 & 242,934 & 7.45 & 8.07 \\
\hline 73 & 175,449 & 225,497 & 7.07 & 7.65 \\
\hline 74 & 160,074 & 208,003 & 6.70 & 725 \\
\hline 75 & 144.960 & 190,566 & 6.34 & 6.87 \\
\hline 76 & $\times 30,227$ & 173,316 & 6.00 & 6.51 \\
\hline 77 & I15,986 & 156,392 & 5.68 & 6.16 \\
\hline 78 & 102,359 & 139,927 & $5 \cdot 37$ & 5.82 \\
\hline 79 & 89,449 & 124,065 & 5.07 & $5 \cdot 50$ \\
\hline 80 & 77,354 & 108,935 & 4.79 & 5.20 \\
\hline 81 & 66,153 & 94,662 & 4.51 & 4.90 \\
\hline 82 & 55,842 & $8 \mathbf{I}, 305$ & 4.26 & 4.63 \\
\hline 83 & 46,489 & 68,966 & 4.OI & 4.37 \\
\hline 84 & 38,132 & 57,723 & 3.58 & 4.12 \\
\hline 85 & 30,785 & 47,631 & 3.56 & 388 \\
\hline 86 & 24,436 & 38,7 10 & 3.36 & 3.66 \\
\hline 87 & 19,054 & $30,95^{8}$ & 3.17 & 3.46 \\
\hline 88 & 14,576 & 24,338 & 2.99 & 3. 26 \\
\hline 89 & ro, 926 & 18,788 & 2.82 & 3.08 \\
\hline 90 & 8,015 & 14,225 & 2.66 & 290 \\
\hline $9 I$ & 5,748 & xo, 553 & $2.5 \mathrm{I}$ & 2.74 \\
\hline 92 & 4,025 & $7,65^{8}$ & 2.37 & 2.58 \\
\hline 93 & 2,749 & 5,429 & 2.24 & 2.44 \\
\hline 94 & 1,828 & 3,756 & 2.12 & $2.3^{\circ}$ \\
\hline 95 & $x, 183$ & 2,533 & 2.01 & 2.17 \\
\hline 96 & 742 & $1,66 \mathrm{I}$ & x. 90 & $2.1 \mathrm{I}$ \\
\hline 97 & 4.52 & & I. $8 \mathrm{I}$ & \\
\hline 98 & 266 & 653 & 1.72 & 1.83 \\
\hline 99 & 151 & 389 & 1.65 & 1.73 \\
\hline 100 & 82 & 225 & $1.6 \mathrm{I}$ & 1.62 \\
\hline
\end{tabular}

L., Extra-uterine, post-natal existence. L., Fetal, life of the fetus. L., Intra-uterine, life within the uterus. L., Mean Duration of, the expectation of life at birth. L., Reproductive, L., Sexual, that period of life during which the individual is capable of begetting or bearing offspring. L.-root, ragwort. The herb Senecio aureus gathered in flower; an expectorant, diuretic, alterative, and tonic. It was formerly used by the Indians as a vulnerary, and is a favorite remedy with eclectic practitioners. Dose of a decoction adlib. ; of the fld. ext. $m \times x \times-3 \mathrm{j}$; of a strong tincture, mviij-xx; of senecin, its resinoid, gr. j-iij. L.-table, a table constructed to show the number and ages of the living, and the number and ages of the dying in a community or society. Halley's Life-table, the earliest English table, was constructed in the second half of the I8th century, and suggested De Mowre's Hypothesis. Price's Northampton Life-table was used by the Equitable Life Assurance Co., of New York, upon its establishment in $\mathbf{1 7 6 2}$. These tables were not constructed by a comparison of the deaths and the living at each age, but from the deaths only; and as births and deaths are not equal, and as migration also disturbs the stability of population, these tables are not correct, as they overstate the mortality of young adults 
and do not dissociate males and females. Dr. Farr constructed three English Life-tables, designated respectively, Nos. I, 2 , and 3 , and various other tables have been made, called the Healthy Districts, the Upper Class Experience, the Healthy Males, the Clerical Experience-tables, etc. The last noteworthy table is the New English Life-table, by Dr. Ogle, which starts with a million males and a million females and shows the number surviving at each age, and the mean expectation of life at each age. See Life, Expectation of. L--time, Mean After. Synonym of Expectation of life. See Life, Expectation of. L. Vegetative. See L., Animal.

Lift-cure (lift-kür). The therapeutic use of the " health lift" $(q . v$.$) , and of other similar devices.$

Ligament (lig'-am-ent), Ligamentum (lig-am-en'tum ) [ligamentum; ligare, to bind]. A band of flexible, compact connective tissue connecting the articular ends of the bones, and sometimes enveloping them in a capsule. L., Accessory. See L., Coraco humeral. L., Acromio-clavicular, a broad ligament covering the acromio-clavicular articulation and extending from the clavicle to the acromial process of the scapula. L., Acromio-clavicular, Inferior, one extending from the clavicle to the acromial process of the scapula, across the lower portion of the acromioclavicular articulation. L., Alar (of knee), one of the two folds of synovial membrane on either side of the mucous ligament. L., Annular (of radius), that surrounding the head of the radius. L., Annular (of stapes), that extending from the base of the stapes to the oval window. L., Annular, Anterior (of ankle), the broad ligament covering the anterior surface of the ankle-joint, L., Annular, Anterior (of wrist), a strong ligament extending from the trapezium to the unciform bone, confining the flexor tendons. L., Annular, External (of ankle), that joining the posterior border of the external malleolus and the external surface of the calcaneum. L., Annular, Internal (of ankle), one joining the internal malleolus and the inner surface of the os calcis. L., Annular, Posterior (of carpus), a strong ligament reaching from the styloid process and lower end of the radius, across the back of the wrist to the styloid process of the ulna. L., Anterior (of ankle), a small ligament in front of the ankle-joint. L., Anterior (of elbozw), that extending from the coronoid process of the ulna to the coronoid fossa of the humerus. L., Anterior (of knee), the ligamentum patellæ. L., Anterior (of malleus), that extending from the spine of the sphenoid to the anterior portion of the head and neck of the malleus. L., Anterior (of uterus), one of the fibrous and peritoneal folds extending from the bladder to the uterus. L., Anterior (of wrist), a strong, broad ligament extending from the anterior surface of the upper row of carpal bones to the lower ends of the ulna and radius. L., Arcuate, one of the arched ligaments extending from the body of the diaphragm to the last rib, and to the transverse process of the first lumbar vertebra. L., Arnold's. See L., Suspensory (of incus). L., Arterial, the fibrous remains of the ductus arteriosus. L., Aryteno-epiglottic, one of the ligamentous folds joining the epiglottis and the arytenoid cartilage. L., Arytenoid, Inferior, one of the false vocal bands. L., Astragalo-calcaneal, External, that joining the external surface of the astragalus and the outer margin of the calcaneum. L., Astragalocalcaneal, Internal, one extending from the os calcis to the posterior margin of the sustentaculum tali. L., Astragalo-calcaneal, Posterior. See L., Calcaneoastragaluid, Posterior. L., Astragalo-navicular, Superior. See L., Astragalo-scaphoid, Sipprior. L.,
Astragalo-scaphoid, Internal, one joining the inner surfaces of the astragalus and the scaphoid. L., Astragalo-scaphoid, Superior, one joining the anterior extremity of the astragalus and the upper surface of the scaphoid. L., Atlanto-axial. See L., Atlo-axoid. L., Atlanto-axial, Deep. See L., Atlo-axoid, Anterior. L., Atlanto-axial, Posterior, one joining the neural arches of the atlas and the axis. L., Atlantoaxial, Superficial. See L., Atlanto-axial, Anterior. L., Atlanto-occipital. See L., Atlo-occipital. L., Atlanto-occipital, Posterior. See L., Occipito-atlantal, Posterior. L., Atlo-axoid, that joining the atlas and the axis. L., Atlo-axoid, Anterior, that joining the ventral margins of the atlas and the axis. L., Atlo-occipital, that joining the atlas and the occiput. L., Auricular, Anterior, a broad ligament extending from the zygoma to the cauda helicis. L., Auricular, Posterior, one reaching from the mastoid process to the posterior surface of the ear. L., Auricular, Superior, a portion of the temporal fascia, inserted into the upper portion of the cartilage of the ear. L. of Barkow, ligamentous fibers in the fatty tissue in the upper portion of the olecranon fossa. L., Bellini's. See L., Tendino-trochanterian. L., Bertin's, the ilio-femoral ligament. L. of Bigelow. See L., Ilio-femoral. L., Broad (of liver), a broad fold of peritoneum extending from the diaphragm to the upper surface of the liver. L., Broad (of lungs), one of the folds of the pleura, connecting the lower surfaces of the lungs with the diaphragm. L., Broad (of uterus), a fold of peritoneum extending laterally from the uterus to the pelvic wall. L., Burns' (Allen). See L., Hey's. L., Calcaneo-astragaloid, Internal. See $L$., $A$ s tragalo-calcaneal, Internal. L., Calcaneo-astragaloid, Interosseous, that uniting the calcaneum and the astragalus. L., Calcaneo-astragaloid, Posterior, one joining the calcaneum and the posterior border of the astragalus. L., Calcaneocuboid, Dorsal. See L., Calcaneo-cuboid, Superior. L., Calcaneo-cuboid, Internal, one joining the inner surfaces of the calcaneum and the cuboid. L., Calcaneo-cuboid, Interosseous. See L., Calcaneocuboid, Internal. L., Calcaneo-cuboid, Long, one running from the under surface of the calcaneum to the under surface of the cuboid. L., Calcaneo-cuboid, Short, a thick ligament extending between the os calcis and the under surface of the cuboid. L., Calcaneo-cuboid, Superior, one attached to the dorsal surface of the calcaneum, and inserted into the dorsal surface of the cuboid. L., Calcaneo-fibular, that joining the apex of the external malleolus to the outer surface of the calcaneum. L., Calcaneonavicular, Inferior. See $L$., Calcaneo-scaphoid, Inferior. L., Calcaneo-scaphoid, Dorsal. See L., Calcaneo-scaphoid,External. L., Calcaneo-scaphoid, External, that extending from the calcaneum at its articulation with the astragalus to the external surface of the scaphoid. L., Calcaneo-scaphoid, Inferior, one joining the anterior and inner end of the calcaneum to the under surface of the scaphoid. L., Calcaneo-scaphoid, Interosseous. See $L$., Calcaneoscaphoid, External. L., Calcaneo-scaphoid, Plantar. See L., Calcaneo-scaphoid, Inferior. L., Calcaneo-scaphoid, Superior. See L., Calcaneo-scaphoid. External. L., Camper's, the deep layer of the perineal fascia covering the bulb of the urethra and the crura of the penis. L., Capsular, a heavy fibrous structure surrounding an articulation, and lined by synovial membrane. L., Carcassonne's. See L., Pubo-vesical, Middle. L., Carpal, Anterior, that covering the palmar surface of the carpus. L., Carpal, Common, the annular ligament of the wrist- 
joint. L., Carpal, Dorsal, short ligaments binding together the dorsal surfaces of the carpal bones. L., Carpal, Posterior. See L., Annular, Posterior (of carpus). L., Carpo-metacarpal, Dorsal, those joining the dorsal surfaces of the carpal and metacarpal bones. L., Carpo-metacarpal, Interosseous, one joining the os magnum and the unciform to the third and fourth metacarpal bones. L., Carpo-metacarpal, Palmar, those joining the palmar surfaces of the metacarpal to the carpal bones. L., Caudal, fibrous tissue uniting posteriorly the two lower vertebræ of the coccyx. L., Check, one controlling the movements of a joint. L., Ciliary. See $L$. pectinatum. L., Cleido-costal. See L., Rhomboid. L., Colles'. See L., Triangular. L., Conoid, the inner portion of the coraco-clavicular ligament. It is attached to the coracoid process of the scapula and the coronoid tubercle of the clavicle. L., Cooper's Suspensory. See L., Suspensory (of Mamma). L., Coraco-acromial, a triangular-shaped ligament extending from the tip of the acromial process to the outer surface of the coracoid process of the scapula. L., Coraco-clavicular, that joining the coracoid process of the scapula and the clavicle. L., Coracohumeral, that joining the coracoid process of the scapula and the upper and posterior portion of the capsule of the shoulder-joint and the upper part of the humerus. L., Coracoid, a fibrous structure forming the scapular foramen, extending from the coracoid process to the supra-scapular notch. L., Corniculopharyngeal, ligamentous fibers extending from the cornicula of the larynx to the walls of the pharynx. L., Coronary (of knee), short fibers binding the semilunar cartilages to the head of the tibia. L., Coronary (of liver), a peritoneal fold extending from the posterior edge of the liver to the diaphragm. L., Coronary (of radius). See L., Annular (of radius). L., Costocentral, ligamentous tissue binding the head of a rib to the vertebral body. L., Costo-central, Anterior, a fan-shaped ligament extending from the vertebræ and the inter-vertebral cartilages to the head of the rib. L., Costo-clavicular. See L., Rhomboid. L., Costo-colic. See L., Phrenico-colic. L., Costocoracoid, that joining the first rib and the coracoid process of the scapula. L., Costo-pericardiac, that joining the upper costo-sternal articulations with the pericardium. L., Costo-sternal, Anterior, a fibrous structure joining the sternum and the anterior edges of the cartilages of the true ribs. L., Costo-sternal, Posterior, one joining the sternum and the posterior surface of the cartilages of the true ribs. L., Costotransverse, one of the ligaments binding the ribs to the adjacent transverse processes of the dorsal vertebræ. L., Costo-transverse, Anterior. See L., Costo-transverse, Superior. L., Costo-transverse Interosseous. See $L$., Costo-transverse, Middle. L., Costo-transverse, Long. See $L$, Costo-transverse, Superior. L., Costo-transverse, Middle, one running between the anterior surface of the transverse process of a dorsal vertebra and the neck of the adjacent rib. L., Costo-transverse, Posterior, one joining the transverse process of a dorsal vertebra and the tubercle of the adjacent rib. L., Costo-transverse, Superior, one extending between the lower margin of the transverse process of a dorsal vertebra, and the crest on the upper margin of the neck of the subjacent rib. L., Costo-vertebral, one of those binding the ribs to the adjacent vertebræ. L., Costovertebral, Interarticular, one of the strong ligaments joining the dorsal intervertebral fibro-cartilages and the crests on the heads of the ribs. L., Costo-xiphoid, fibrous tissue binding the cartilages of the sixth and seventh ribs to the xiphoid cartilage. L., Cotyloid, a ring of fibro-cartilaginous tissue at the margin of the acetabulum. L., Cowper's. Same as L., Pubic. L., Cranio-vertebral, one of those extending between the cranium and the vertebræ. L., Crico-arytenoid, Posterior, one of those joining the cricoid and arytenoid cartilages posteriorly. L., Crico-pharyngeal, that extending between the upper and posterior margin of the cricoid cartilage and the anterior pharyngeal wall. L., Crico-Santorinian, one of those binding together Santorini's cartilages and the cricoid cartilage. L., Crico-thyroid, one of those joining the cricoid and thyroid cartilages. L., Crico-thyroid, Anterior, one on the anterior surfaces of the cricoid and thyroid cartilages. L., Crico-thyroid, Middle, the cricothyroid membrane. L., Crico-tracheal, that joining the cricoid cartilage and the uppermost tracheal ring. L., Crucial (of atlas). See L., Cruciform. L., Crucial (of the fingers), one of the small ligaments running obliquely on the palmar surface of the phalangeal joints. L., Crucial, Anterior, the smaller crucial ligament of the knee, extending from the upper surface of the tibia to the inner surface of the external condyle of the femur. L., Crucial, External. See L., Crucial, Anterior. L., Crucial, Internal. See L., Crucial, Posterior. L., Crucial, Posterior, one extending from the popliteal notch of the tibia, and the external semilunar cartilage, to the anterior portion of the internal condyle of the femur. L., Cruciate, a $\mathrm{Y}$-shaped process of the deep fascia of the leg, situated at the bend of the ankle. It extends from the internal malleolus to the external surface of the anterior portion of the calcaneum. L., Cruciform, a cross-shaped ligament, formed by the transverse ligament of the atlas and a vertical band of fibers extending from the middle of this ligament to the body of the axis. L., Cuneiform, Interosseous. See $L$., Intercuneiform. L., Deltoid. See L., Lateral Internal (of ankle-joint). L., Dentate. See L., Denticulate. L., Denticulate, a band of fibrous connective tissue passing from the arachnoid to the pia in the interval between the anterior and posterior nerve-roots. L., Douglas's, the folds of peritoneum extending between the dorsal surface of the uterus and the ventral surface of the rectum. L., Duodenorenal, a peritoneal fold joining the transverse mesocolon and the parietal peritoneum in the region of the right kidney. It forms the posterior boundary of Winslow's foramen. L. of Ellis. See $L$. of the Rectum. L., External (of malleus), that running from the outer wall of the tympanum to the crista capitis mallei. L., Falciform. a sickle-shaped expansion of the great sacro-ischiatic ligament, extending along the inner margin of the tuberosity and inferior ramus of the ischium. L., Falciform (of liver). See $L$., Broad (of liver). L. of Fallopius. See L., Poupart's. L., False (of bladder), one of the peritoneal folds radiating from the urinary bladder. L., False, Superior (of the bladder), one of the peritoneal folds, running in the median line, from the fundus of the bladder to the umbilicus. L., Femoral. See $L$. Hey's. L., Flood's, the gleno-humeral ligament. L., Gastro-colic, the fold of the great omentum attached to the colon and the stomach. L., Gastro-hepatic, the fold of the great omentum attached to the stomach and the liver. L., Gastrolienal. See L., Gastro-splenic. L., Gastro-pancreatic, a sickle-shaped peritoneal fold joining the posterior surface of the stomach and the anterior surface of the pancreas. L., Gastro-phrenic. See L., Phrenico-gastric. L,, Gastro-splenic, a peritoneal fold joining the gastric cul-de-sac and the 


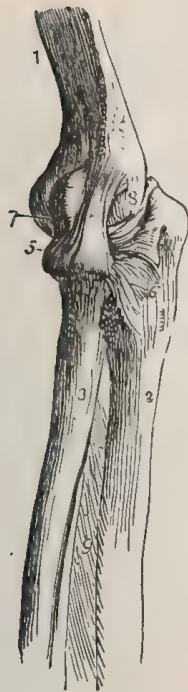

Ligaments of ElbowJOINT.

I. Humerus. 2, Ulna. 3 Radius. 4. External lat eral ligament. 5. Orbicular ligament. 6. Posterior ligament. 7,8. Condyles of humerus. 9. Interosseous membrane.

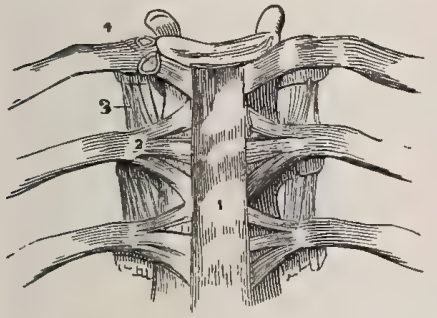

I Anterior common ligament. 2 Anterior costovertebral, or stellate ligament. 3 . Anterior costotransverse li gament.

Ligaments of the Costo-vertebral ARticulations.

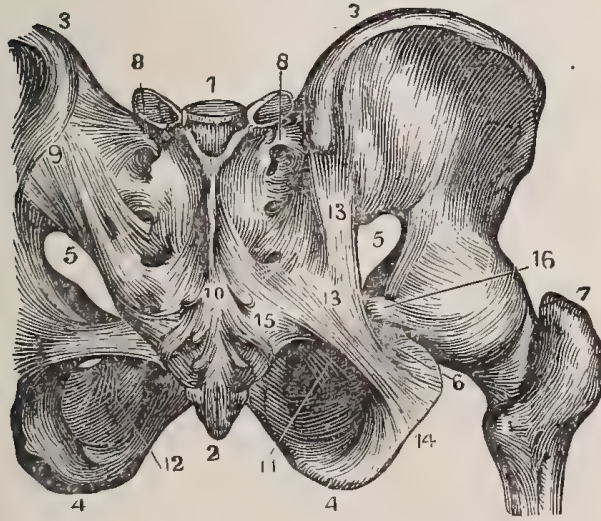

Ligaments of the Pelvis, Posterior View.

r. Articular surface of sacrum for last lumbar vertebra. 2. Coccyx 3. Crest of ilium. 4. Tuberosity of ischium. 5. Great sacro-sciatic foramen. 6. Lesser sacro-sciatic foramen. \%. Great trochanter. 8. Posterior sacro-iliac ligament 9. Posterior inferior spine of ilium. Io. Supra-spinous ligament. II. Obturator membrane. 12. Lesser sacro-sciatic foramen. I3, 14. Great sacro-sciatic ligament. 15. Lesser sacro-sciatic ligament. I6 Spine of ischium.

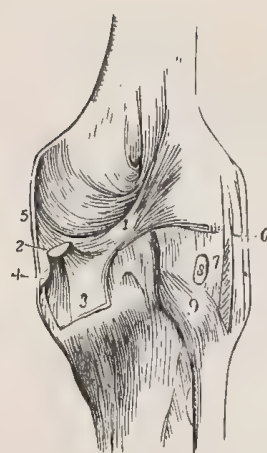

LigamentS OF RIGHT KNEE JOINT, POSTERIOR VIEW

. Posterior ligaments, or ligamentum Winslowii (oblique fasciculus). 2. Tendon of semi-membranous muscle. 3 Tibia, 4. Bursa. 5. Interna lateral ligament. 6. Long external lateral ligament. 7 . Short external lateral ligament. 8 Popliteus muscle. 9. Posterior or internal crucial ligament.

\section{a. Anterior common ligament. b. Anterior occipito-atloid lig- ament. c. Anterior common Anterior atlo-axial ligament. e. Capsular ligament. $f$. Syn- ovial membrane. $g$. Latera occipito-atloid ligament.}

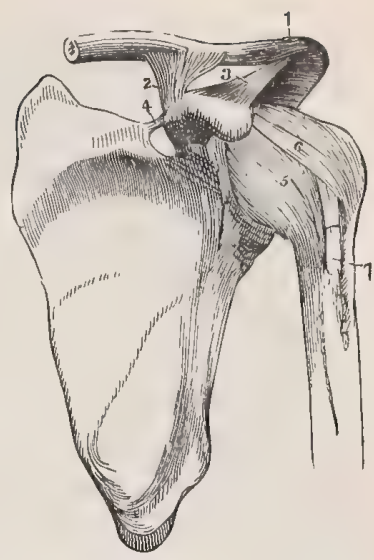

LigAMENTS OF THE SHOULDERJOINT.

I. Superior acromio-clavicular ligament. 2. Coraco-clavicular. 3. Coraco-acromial 4. Transverse. 5. Capsular 6. Coraco-humeral. 7. Tendon of long head of biceps.

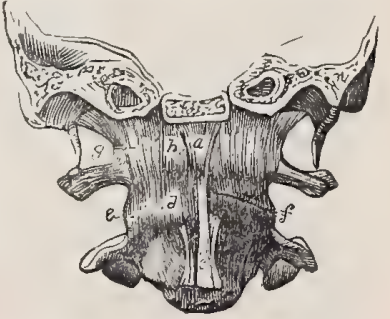

LIGAMENTS OF THE OCCIPITO-ATLOID JOINT.

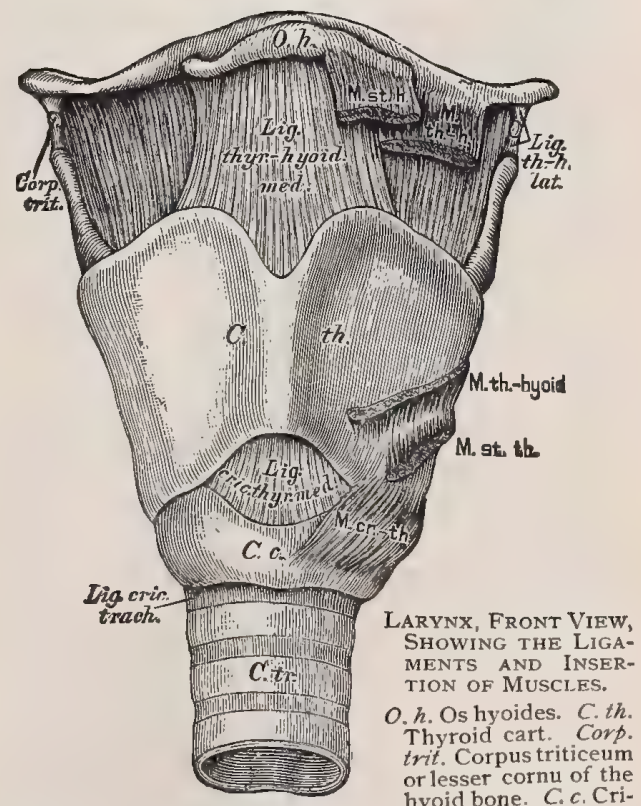

coid cart C.tr. Tracheal cartilage. Lig. thyr-hyoid med. Middle thyro-hyoid ligament. Lig. th. $h$. lat. Lateral thyrohyoid ligament. Lig. cric-thyr, med. Middle crico-thyroid ligament. Lig. cric.-trach. Crico-tracheal ligament. $M$. st. $-h$. Sterno-hyoid muscle. $M$. th. -hyoid. Thyro-hyoid muscle, $M$. st.-th. Sterno-thyroid muscle. $M$. cr.th. Crico-thyroid muscle. 
hilum of the spleen. L. of Gerdy, the suspensory ligament of the axilla, extending from the coracoid process to the skin surrounding the hollow of the axilla. L., Gimbernat's, a triangular expansion of the aponeurosis of the external oblique muscle, connected anteriorly to Poupart's ligament and attached to the ilio-pectineal line. L., Gleno-humeral, a portion of the coraco-humeral ligament, attached to the inner and upper portion of the bicipital groove. L., Glenoid, one of those joining the phalanges (palmar surfaces) and the corresponding metacarpal bones. L., Glenoid (of scapula), a ring of fibro-cartilaginous tissue attached to the rim of the glenoid fossa. L., Glosso-epiglottic, an elastic ligamentous band connecting the epiglottis to the hyoid bone. L., Glosso-epiglottidean. See L., Glosso-epiglottic. L., Helmholtz's, that portion of the anterior ligament of the malleus that is attached to the spina tympanica major. L., Hepatico-colic, a peritoneal fold joining the under surface of the right lobe of the liver and the ascending meso-colon. L., Hepaticoduodenal, a peritoneal fold running from the transverse fissure of the liver to the duodenum. It forms the anterior boundary of Winslow's foramen. L., Hepatico-renal. See L., Hepatico-colic. L., Hey's, also called the femoral ligament; a sickleshaped expansion of the fascia lata. L., Hunter's, a term for the round ligament of the uterus. See $L$, Round (of uterus). L., Hyo-epiglottic, one joining the under surface of the epiglottis and the upper surface of the hyoid bone. L., Ilio-femoral, a strong ligament extending from the anterior inferior iliac spine to the lesser trochanter and the intertrochanteric line. L., Ilio-femoral, Anterior, the anterior portion of the ilio-femoral ligament. L., Iliofemoral, Inferior. See L., Ilio-femoral, Anterior. L., Ilio-femoral, Lateral. See L., Ilio-femoral, Superior. L., Ilio-femoral, Superior, one extending from the anterior inferior spine of the ilium to the proximal end of the anterior intertrochanteric line. L., Ilio-lumbar, a ligament extending from the transverse process of the fifth lumbar vertebra to the iliac crest and the anterior surface of the sacro-iliac synchondrosis. L., Ilio-lumbar, Inferior. See L., Ilio-lumbar, L., Ilio-lumbo-vertebral. See L., Ilio-lumbar. L., Ilio-pectineal, that portion of the pelvic fascia extending from the ilio-pectineal line to the capsular ligament of the hip. L., Ilio-pubic. See L., Poupart's. L., Ilio-sacral, Anterior. See L., Sacro-itiac, Anterior. L., Ilio-sacral, Interosseous. See L., Sacro-iliac, Interosseous. L., Ilio-sacral, Long Posterior. See L., Sacro-iliac, Oblique. L., Ilio-sacral, Short Posterior. See L., Sacro-iliac, Short. L., Ilio-trochanteric. See L., Ilio-femoral, Superior. L., Inferior (of glottis), one of the inferior or true vocal bands. L., Inferior (of malleus), one extending from the handle of the malleus to the outer wall of the tympanum. L., Infundibulo-ovarian, that portion of the free edge of the broad ligament of the uterus extending between the infundibulum and the pelvic end of the ovary. L., Infundibulo-pelvic, that portion of the free edge of the broad ligament of the uterus joining the infundibulum and the pelvic wall. L., Inguinal. See $L$., Poupart's. L., Inguinal, External, the part of Poupart's ligament running from the anterior superior iliac spine to the fascia lata. L., Interarticular of hip). See $L$. teres. L., Interarticular (of ribs). See L., Costo-vertebral, Interarticular. L., Interchondral, one of those joining adjacent costal cartilages. L., Interclavicular, one joining the sternal extremities of the clavicles and the sternum. L.,
Intercostal, one of those joining adjacent ribs. L., Intercostal, External, one of those filling the intercostal spaces externally between the sternum and the intercostal muscles. L., Intercostal, Internal, one of the fibrous bands uniting adjacent ribs. L., Intercrural, one of those connecting the laminæ of the vertebræ. L., Intercuneiform, one of those joining the cuneiform bones of the tarsus. L., Interhyal, one in the embryo joining the malleus and the stylohyal cartilage. L., Interlobular, a prolongation of the pleura, between the lobes of the lungs. L., Intermetacarpal, one of those joining the metacarpal bones. L., Intermetacarpal, Dorsal, one of four ligaments running transversely across the dorsal surfaces of the upper ends of the metacarpal bones. L., Intermetacarpal, Palmar, one of those joining the palmar surfaces of the upper ends of the metacarpal bones. L., Intermetatarsal, one of those joining the metatarsal bones. L., Intermetatarsal, Dorsal, a ligamentous structure joining the dorsal surfaces of the bases of the metatarsal bones. L., Intermetatarsal, Plantar, one of those joining the plantar surfaces of the upper ends of the metatarsal bones. L., Intermuscular, a fascial prolongation between muscles. L., Interosseous, Inferior Tibio-fibular. See $L$., Tibio-fibular Interosseous, Inferior. L., Interspinal. See L., Interspinous. L., Interspinous, one extending between the spinous processes of adjacent vertebra. L., Intertransverse, one extending between the transverse processes of adjacent vertebræ. L., Ischio-capsular, one extending from the ischium, near the acetabulum, to the zona orbicularis. L., Ischio-femoral, one running from the ischium to the great trochanter. L., Jugal (of larynx). See L., Crico-Santorinian. L., Lateral (of liver), one of the peritoneal folds between the sides of the liver and the under surface of the diaphragm. L., Lateral, External (of ankle), that running between the external malleolus and the calcaneum. L., Lateral, External (of carpus), that extending from the scaphoid bone to the styloid process of the radius. L., Lateral, External (of elbow), that extending from the annular ligament of the radius to the external condyle of the humerus. L., Lateral, External (of jazv), that extending from the lower border of the zygoma to the outer surface of the neck of the inferior maxilla. L., Lateral, External (of knee), that joining the head of the fibula and the internal condyle of the tibia. L., Lateral, External (of wrist). See L., Lateral, External (of carpus). L., Lateral, Internal (of anklejoint), one joining the internal malleolus, and the astragalus, calcaneum, and scaphoid. L., Lateral, Internal (of carpus), a ligamentous cord joining the styloid process of the ulna, the pisiform bone, and the anterior annular ligament. L., Lateral, Internal (of elbow), one extending from the coronoid process of the ulna and the inner edge of the sigmoid fossa, to the internal condyle of the humerus. L., Lateral, Internal (of jazw). See L., Lateral, Internal (of Temporo-maxillary articulation). L., Lateral, Internal (of knee), one extending from the internal condyle of the femur to the internal condyle and shaft of the tibia. L., Lateral, Internal (of temporo-maxillary articulation), one extending from the inferior maxilla, near the inferior dental foramen, to the spinous process of the sphenoid bone. L., Lateral, Long Extermal (of knee), one running from the external condyle of the femur to the head of the fibula. L., Lateral, Short External (of knee-joint), one ex tending from the head of the fibula to the external condyle of the femur and posterior portion of the 
capsular ligament. L., Lateral, Short Internal (of knee-joint), one joining the upper portion of the tibia and the internal fibro-cartilage. L., Lauth's, the transverse ligament of the atlas. L., Longitudinal (of liver). See L., Broad (of liver). L., Lumbo-costal, the anterior edge of the lumbo-dorsal fascia. L., Lumbo-iliac. See L., Ilio-lumbar. L., Lumbo-sacral, a part of the ilio-lumbar, extending from the sacrum to the ilium, across the sacro-iliac synchondrosis. L., Mauchart's. Same as L., Odontoid, Alar. L., Metacarpal, Transverse, one joining the distal extremities of the four inner metacarpal bones. L., Metacarpo-phalangeal, Anterior. See L., Glenoid. L., Metacarpophalangeal, Lateral, one joining the lateral surfaces of the phalanges and metacarpal bones. L., Metatarsal, Interosseous, one of those joining adjacent metatarsal bones. L., Metatarsal, Transverse, one uniting the distal extremities of the metatarsal bones. L., Metatarso-phalangeal, Lateral, one joining the lateral surfaces of the phalanges and metatarsal bones. L., Metatarso-phalangeal, Plantar, one of those joining the plantar surfaces of the phalanges and metatarsal bones. L., Mucous (of knee-joint), a fold of synovial membrane extending from the intercondyloid fossa to the lower margin of the patella. L., Naviculo-cuboid, one of those between the scaphoid and cuboid bones. L., Naviculo-cuneiform, one of those joining the scaphoid and cuneiform bones. L., Oblique (of forearm). See-L., Round (of fore$\mathrm{arm}$ ). L., Obturator, the obturator membrane. L., Obturator, External. See L., Occipito-atlantal, Posterior. L., Occipito-atlantal, Lateral, one of those joining the transverse processes of the atlas to the jugular processes of the occipital bone. L., Occipito-atlantal, Posterior, one joining the dorsal arch of the atlas and the posterior margin of the great foramen. L., Occipito-atloid, Anterior, a ligament joining the anterior arch of the atlas to the anierior margin of the great foramen. L., Occipitoaxial. See L., Occipito-axoid. L., Occipito-axoid, a strong ligament attached to the clivus of Blumenbach above and to the body of the axis and adjoining vertebra below. L., Odontoid, any one of the broad, strong ligaments arising on either side of the apex of the odontoid process and connecting the atlas with the skull. L., Odontoid, Alar. See L., Odontoid, Lateral. L., Odontoid, Lateral, one of the ligaments joining the condyles of the occiput and the odontoid process of the axis. L., Odontoid, Middle, one joining the anterior margin of the great foramen and the tip of the odontoid process. L., Omoclavicular. See $L$., Coraco-clavicular. L., Orbicular (of radius). See L., Annular (of radius). L., Ovarian, a band of muscular fibers, extending from the posterior surface of the uterus on either side to the ovary. L., Palmar. See L., Glenoid. L., Palpebral. See L., Tarsal. L., Palpebral, External, that joining the outer margin of the orbit and the tissues of the eye-lid. L., Palpebral, Internal, one extending from the nasal process of the superior maxilla to the lacrymal spine of the lacrymal bone and the inner end of the tarsal cartilage. L. patellæ, a strong fibrous structure, extending from the tubercle of the tibia upward to become the tendon of the quadriceps extensor muscle; it embraces the patella. L., Patellar, Lateral, one of those joining the sides of the condyles of the femur and the patella. L. pectinatum, the spongy tissue at the junction of the cornea and sclera in the sinus of the anterior chamber of the eye. It forms the root of the iris. L., Phalangeal, Anterior, one of the ligaments on the palmar and plantar surfaces of the phalanges. L., Phalan- geal, Lateral, one of those joining the sides of contiguous phalanges. L., Phrenico-colic, a peritoneal fold joining the diaphragm and the splenic flexure of the colon. L., Phrenico-gastric, a peritoneal fold between the diaphragm and the cardiac end of the stomach. L., Phreno-colic. See L., Phrenico-colic. L., Phreno-splenic. See $L$., Suspensory (of spleen). L., Plantar, Deep. See L., Calcaneo-cuboid, Short. L., Plantar, Long. See L., Calcaneo-cuboid Long. L., Plantar, Short. See L., Calcaneo-cuboid, Short. L., Pleuro-colic. See L., Phrenico-colic. L., Posterior (of ankle-joint), a transverse ligament covering the ankle-joint posteriorly. L., Posterior (of elbonv), a ligament covering the elbow posteriorly. L., Posterior (of incus), one joining the horizontal process of the incus and the posterior tympanic wall. L., Posterior (of knee-joint), one bounding the knee posteriorly. L., Posterior (of malleus), the posterior portion of the external ligament of the malleus. L., Posterior (of sacro-coccygeal articulation). See L., Sacro-coccygeal, Posterior. L., Posterior (of zurist), one covering the dorsal surface of the carpus. L., Poupart's, the ligament extending from the anterior superior spine of the ilium to the spine of the pubis and the pectineal line. It is the lower portion of the aponeurosis of the external oblique muscle. L., Pterygo-maxillary, one joining the apex of the internal pterygoid plate of the sphenoid and the posterior extremity of the internal oblique line of the lower jaw. L., Pubic, a portion of the fascia lata attached to the crest of the pubes. L., Pubic, Anterior, a band of fibrous tissue covering the anterior surface of the pubis. L., Pubic, Inferior, a triangular ligament, extending from the symphysis of the pubis to the rami of the pubic bones. L., Pubic, Posterior, one covering the symphysis pubis posteriorly. L., Pubic, Superior, one extending across the upper surface of the symphysis pubis. L., Pubo-femoral, one joining the margin of the obturator foramen, the pectineal eminence and the superior ramus of the pubis with the lesser trochanter of the femur. L., Pubo-prostatic, the anterior true ligament of the bladder. L., Pubo-vesical, Middle, in the female, a ligament between the anterior surface of the bladder, the inferior pubic ligament and the crura of the clitoris. L., Pulmonary. See L., Broad (of lung). L., Pylori-colic, one running from the pyloric end of the stomach to the transverse colon. L., Radiocarpal. See L., Lateral, External (of carpus). L., Radio-ulnar, Anterior, a ligament uniting, anteriorly, the lower end of the ulna and the anterior edge of the sigmoid cavity of the radius. L., Radio-ulnar, Posterior, one joining the posterior surface of the lower end of the ulna, and the posterior margin of the sigmoid cavity of the radius. L., Radio-ulnar, Round. See L., Round (of forearm). L. of the Rectum, that part of the recto-vesical fascia extending to the side of the rectum. L. of Retzius, the outer portion of the anterior annular ligament of the leg. L., Rhomboid, one joining the cartilage of the first rib and the tuberosity of the clavicle. It is a part of the costo-clavicular ligament. L., Round (of forearm), one joining the coronoid process of the ulna and the tuberosity of the radius. L., Round (of hip). See $L$.teres. L., Round (of liver), a fibrous cord running from the umbilicus to the notch in the anterior border of the liver. It represents the remains of the obliterated umbilical vein. L., Round, Posterior, a muscular band extending from the posterior surface of the uterus through the broad ligament to the sub-peritoneal pelvic fascia, L., Round (of superior radioulnar articulation). See $L$., Round (of forearm). 
L., Round (of uterus), a ligament running from the anterior surface of the cornu of the uterus, through the inguinal canal to the mons veneris. L., Sacrococcygeal, Anterior, a two-headed ligament extending from the first vertebra of the coccyx to the last sacral vertebra anteriorly. L., Sacro-coccygeal, Lateral, one of those joining the sides of the sacrum and the transverse processes of the coccygeal vertebræ. L., Sacro-coccygeal, Posterior, one extending from the lower portion of the sacrum over the posterior surface of the coccyx. L., Sacro-iliac, Anterior, a thin fibrous structure covering the pelvic surfaces of the sacrum and ilium. L., Sacro-iliac, Interosseous, one joining the sacrum and ilium. L., Sacro-iliac, Long. See L., Sacro-iliac, Oblique. L., Sacro-iliac, Oblique, a portion of the posterior sacro-iliac ligament, arising from the posterior spine of the ilium. L., Sacro-iliac, Posterior, one extending from the side of the sacrum to the posterior spines of the ilium. L., Sacro-iliac, Short, that extending from the posterior inferior iliac spine to the side of the sacrum. L., Sacro-ischiatic, Great. See L., Sacro-sciatic, Great. L., Sacro-ischiatic, Lesser, one extending from the spine of the ischium to the point of junction of the sacrum and coccyx. L., Sacro-sciatic, Anterior. See L., Sacro-ischiatic, Lesser. L., Sacro-sciatic, Great, a triangular-shaped ligament extending from the sacrum, coccyx, and inferior iliac spine, to the tuberosity of the ischium. L., Sacro-sciatic, Large. See L., Sacro-ischiatic, Great. L., Sacro-sciatic, Lesser. See L., Sacro-ischiatic, Lesser. L., Sacro-sciatic, Posterior. See L., Sacro-ischiatic, Great. L., Sacro-sciatic, Small. See L., Sacro-ischiatic, Lesser. L., Sacro-spinal. See L., Sacro-ischiatic. L., Sacro-spinous. See L., Sacro-ischiatic. L., Sacrovertebral. See $L$., Lumbo-sacral. L. of Schlemm, a ligament of the shoulder-joint. L., Spheno-maxillary. See L., Internal Lateral (of temporo-maxillary articulation). L., Spiral, one attached to the wall of the cochlea. L., Stellate. See L., Costocentral, Anterior. L., Sternal, Anterior, one connecting the manubrium and the gladiolus, anteriorly. L., Sternal, Posterior, one joining the posterior surfaces of the two upper bones of the sternum. L., Sternoclavicilar, Anterior, a fibrous structure extending anteriorly from the sternum to the inner end of the clavicle. L., Sterno-clavicular, Posterior, one joining the clavicle and the sternum posteriorly. L., Sterno-costal, Anterior. See L., Costo-sternal, Anterior. L., Sterno-costal, Posterior. See L, Costo-sternal, Posterior. L., Sterno-xiphoid. See L., Sternal, Anterior. L., Stylo-hyoid, a fibrous cord extending from the apex of the styloid process of the temporal bone, to the lesser cornu of the hyoid bone. L., Stylo-maxillary, a ligament joining the styloid process of the temporal bone and the under surface of the posterior margin of the ramus of the inferior maxilla. L., Stylo-myloid. See L., Stylomaxillary. L., Sub-pubic. See L., Pubic, Inferior. L., Superior (of clitoris), one extending from the clitoris over the bulb of the vagina, and blending with the perineum. L., Superior (of incus). See L., Suspensory (of incus). L., Superior (of malleus), a round ligament extending from the head of the malleus to the upper and outer wall of the tympanic cavity. L., Supra-scapular. See L., Coracoid. L., Supraspinal, one uniting the apices of the spinous processes of the vertebre. L., Supra-spinous. See L., Supraspinal. L., Suspensory (of bladder). See L., False, Superior (of bladder). L., Suspensory (of clitoris), one attaching the clitoris to the lower portion of the symphysis pubis. L., Suspensory (of crystalline lens), the zonule of Zinn. L., Suspensory (of diaphragm), that portion of the prevertebral fascia, attaching the center of the diaphragm to the bodies of the last cervical and first dorsal vertebræ. L., Suspensory (of humerus). See L., Coraco-humeral. L., Suspensory (of incus), Amold's ligament, connecting the body of the incus with the roof of the tympanum. L., Suspensory (of liver). See L., Broad (of liver). L., Suspensory (of malleus). See L., Superior (of malleus). L., Suspensory (of mamma), a fibrous band extending from the fascia above over the anterior surface of the mamma. L., Suspensory (of mesentery'), the root of the mesentery. L., Suspensory (of penis), that attaching the upper portion of the dorsum of the penis to the anterior surface of the symphysis pubis. L., Suspensory (of spleen), a peritoneal fold attaching the spleen to the lower surface of the diaphragm. L., Suspensory (of uterus). See L., Broad (of uterus) and L., Round (of uterus). L., Tarsal, the tarso-orbital fascia. L., Tarso-metatarsal, Dorsal, one of those joining the metatarsal and tarsal bones. L., Tarso-metatarsal Interosseous, External, that joining the external surface of the external cuneiform bone and the third and fourth metatarsal bones. L., Tarso-metatarsal Inter osseous, Internal, one joining the internal cuneiform and second metatarsal bones. L., Tarso-metatarsal Interosseous, Middle, one joining the external cuneiform and second metatarsal bones. L., Tarsometatarsal, Plantar, one of those joining the plantar surfaces of the tarsal and metatarsal bones. L., Tendino-trochanterian, Bellini's ligament, a strong ligament extending from the capsule of the hip-joint to the greater trochanter of the femur. L. teres, a rounded fibrous cord attached to the center of the articular surface of the head of the femur, and extending to the margin of the cotyloid notch of the acetabulum. L., Thyro-arytenoid. See Vocal Bands. L., Thyro-arytenoid, Inferior, one of the inferior or true vocal bands. L., Thyro-arytenoid, Superior, one extending between the inner surface of the upper portion of the thyroid cartilage and the anterior surfaces of the apices of the arytenoid cartilages. L., Thyroepiglottic, one extending from the notch between the wings of the thyroid cartilage to the apex of the epiglottis. L., Thyro-hyoid, the thyro-hyoid membrane. L., Thyro-hyoid, Lateral, one of those joining the tips of the greater cornua of the hyoid bone and the superior cornua of the thyroid cartilage. L., Thyrohyoid, Middle, the center line of the thyro-hyoid membrane. L., Tibio-fibular, Inferior Posterior, one at the lower tibio-fibular articulation, running obliquely downward from the tibia to the fibula. L., Tibio-fibular, Inferior Transverse. See L., Tibiofibular, Transverse. L., Tibio-fibular Interosseous, one extending between the tibia and the fibula. L., Tibio-fibular Interosseous, Inferior, one joining the tibia and the fibula at their lower extremities. L., Tibio-fibular, Posterior Inferior. See L., Posterior (of lower tibio-fibular articulation). L., Tibiofibular, Posterior Superior, one joining the posterior surface of the external tuberosity of the tibia and the head of the fibula, posteriorly. L., Tibio-fibular, Superior Posterior. See L., Tibio-fibular, Posterior Superior. L., Tibio-fibular, Transverse, one extending between the lower posterior border of the tibia and the external malleolus. L., Tibio-tarsal, one extending from the lower anterior margin of the tibia to the upper surface of the astragalus. L., Transverse (of acetabulum). See L., Transverse (of hip-joint). L., Transverse (of atlas), one attached to two small tubercles on the inner surface of 
the atlas, and surrounding the odontoid process of the axis. L., Transverse (of hip-joint), one extending across the cotyloid notch of the acetabulum. L., Transverse (of knee-joint), one extending from the anterior margin of the external semilunar fibro-cartilage to the extremity of the internal semilunar fibrocartilage. L., Transverse, Medial (of tarsus), one extending from the first cuneiform to the bases of the third and fourth metatarsal bones. L., Transverse (of shoulder-joint). See L., Coraco-acromial. L., Transverso-costal. See L., Costo-transverse. L., Trapezoid, the anterior or external portion of the coraco-clavicular ligament, extending from the upper surface of the coracoid process of the scapula, to the under surface of the clavicle. L., Triangular: I. The coraco-acromial liganent, $q . v .2$. That portion of the aponeurosis of the external oblique muscle extending from the outer portion of Poupart's ligament to the linea alba. L., Triangular (of liver). See $L$., Lateral (of liver). L., Triangular, Anterior (of pelvis). See L., Pubic, Inferior. L., Utero-rectal. See L., Utero-sacral. L., Utero-sacral, one of the rectouterine folds of peritoneum. L., Utero-vesical, one of the folds of peritoneum connecting the bladder to the uterus. L,, Vertebral, Posterior, one extending from the axis to the sacrum, along the posterior surface of the bodies of the vertebræ. L., Vesicouterine. See L., Utero-vesical. L., Weitbrecht's. A bundle of fibers upon the anterior aspect of the interosseous ligament of the radio-cubital articulation. L., Winslow's, the posterior ligament of the knee-joint. See L., Posterior (of knee-joint). L., $\mathbf{X}$-shaped (of Bigelore), the Ilio-femoral ligament. L. of Zinn, the tendinous origin of the external, inferior, and internal recti muscles of the eye.

Ligamental (lig-am-en'-tal), Ligamentary (lig-am$e n^{\prime}$-ta-re) [ligare, to bind]. Of the nature of a ligament.

Ligamentous (lig-am-en'-tus) [ligamentum, from ligare, to bind]. Of the nature of, or pertaining to, a ligament.

Ligamentum (lig-am-en'-tum) [L. : pl., Ligamenta]. See Ligament. L. dentis, a name given to that portion of the gum which is attached to the neck of a tooth.

Ligation (li-ga'-shun) [ligatio: ligare, to tie]. The operation of tying, especially of tying arteries. L. of Cord, applying a ligature about the umbilical cord of the new-born child. L., Multiple, the application of several ligatures in the course of a vessel. L. in Continuity, ligation of a vessel in its course for the cure of an aneurysm or to arrest hemorrhage at some distant point.

Ligator (li-ga'-tor) [ligare, to bind]. An instrument used in placing and fastening ligatures.

Ligature (lig'-at-îr $)$ [ligatura; ligare, to tie]. A cord or thread of any material for tying arteries, etc. L., Animal, one made from sheepgut or catgut, or the tendons or sinews of various animals. L., Articulated, the Ecraseur, q.v. L., Aseptic, one rendered free from infective material by soaking in and cleansing with germicidal solutions, or by boiling or heating. L., Buckskin, the first absorbable ligature used by Physick, who employed untanned buckskin. L., Carbolized, a ligature rendered aseptic by carbolic acid. L.,-Catgut, a ligature made from the middle coat of the sheep's intestine, and rendered aseptic and tough by carbolic acid or perchlorid of mercury. L., Chromicised, a ligature hardened by treatment with a solution of chromic acid. L., Deer-skin, a ligature formed of a thin strip cut from prepared deer-skin and rendered aseptic. L., Double, the application of two ligatures to a vessel, between which it is divided. In the case of a pedunculated growth it refers to two ligatures passed through the same opening and tied at opposite sides. L., Elastic, a narrow band or thread of india-rubber applied tightly to a part so as to destroy the tissues and by compression to lead to separation. It is used in the treatment of hemorrhoids, anal fistula, and in the removal of pedunculated growths. Li., Erichsen's, one consisting of a double thread, one-half of which is white, the other half black; it is used in the ligation of nevi. L., Hemp, a thread made from hemp-fibers rendered aseptic. L., Horsehair, an excellent ligature formed by plaiting together a number of strands of horsehair. After immersion in oil for some time it becomes extremely supple, and is capable of slow absorption. L., Immediate, a ligature including the vessel alone. L., Intermittent, a tourniquet applied above a poisoned wound to interrupt the blood-current; it is occasionally relaxed to allow of renewal of the circulation. L., Kangaroo, a ligature made from the smaller tendons of the kangaroo's tail, dried and carbolized. It is stouter than the catgut ligature, and is not absorbed so readily. L., Latera1, partial occlusion of the lumen of a vessel by a loose ligature. L., "Loose," a ligature employed by the younger Cline and South. It consists in the application of a thread around an artery so loosely as not to interfere with the passage of the blood. It was erroneously believed to cause an inflammation that would completely block up the vessel. L., Mediate, one enclosing some of the soft parts as well as the artery. L., Metallic, one made of silver or other metal. L., Momentary, the momentary application of a tight ligature so as to rupture the intima of an artery. L., Ox-aorta, a form of broad ligature introduced by Barwell for the purpose of tying an artery without lacerating its inner and middle coats ; it consists of the middle coat of the aorta of the ox, cut spirally, allowed to dry, and, ten minutes before using, soaked in a five per cent. solution of carbolic acid in water. L., Permanent, one made of non-absorbable material. L., Phlebotomy, the application of a band to a limb to produce distention of the veins to facilitate venesection. L., Provisional, a ligature applied during an operation, with the intention of removing it before the completion of the operation. L., Quadruple, two double ligatures passed at right angles through a growth and tied in four sections; it is used in the strangulation of nevi. L., Scarpa's, one employed in the ligation of arteries; it consists of a small fold of linen which is placed against the vessel and over which the ligature is tied. L., Silk, a thread of silk for ligating vessels. L., Silkwormgut, a material recommended for purposes of ligation

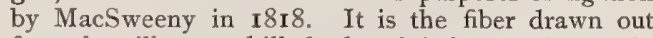
from the silkworm killed when it is just ready to spin its cocoon. L., Soluble, an animal ligature capable of being absorbed. L., Tendon, the tendon, or strips of tendons, of various animals, as those of the kangaroo, deer, and whale, dried and carbolized. L., Wire, a metallic wire for the ligation of arteries and other parts. After its application it is cut short and allowed to become encapsulated.

Light ( $h t$ ) [ME., light, light]. That form of energy which, when impinging upon the retina, gives rise to the sensation of vision. The old theory was the socalled Emission, or Corpuscular Theory, which regarded light as consisting of minute material particles emitted by the luminous body and giving rise to the sensation of vision by impinging upon the retina. The accepted, or Undulatory, Theory regards light as a form of ethereal vibration or undu- 
lation produced by the luminous body and propagated in all directions with a velocity in a vacuum of about I86,500 miles per second. Maxwell's Electromagnetic Theory supposes light to be an "electromagnetic disturbance propagated by vibrations at right angles to the direction of the ray, and taking place in the ether, the strains or vibrations of which serve to propagate electromagnetic induction." L., Axial, lightrays that are parallel to each other and to the optic axis; in microscopy the axial ray of the cone of light must be parallel to the optic axis of the microscope. L.-blue. See Pigments, Conspectus of. L.-brain, a weak-minded person. L., Central. See L., Axial. L., Diffused, that reflected simultaneously from an infinite number of surfaces, or that which has been scattered by means of a concave mirror or lens. L., Dispersion of. See L., Spectrum of. L., Drummond, that produced by heating lime to incandescence, as in the oxy-hydrogen flame. L., Electric, that produced by the passage of electricity through a medium having high resistance, such as the carbon-film of the incandescent light, or the interval of air between the carbons of the arc light, the medium of high resistance being heated to whiteness. L.-green. See Pigments, Conspectus of. L.headed, giddy; flighty ; delirious. L., Incandescent, the incandescence produced as a result of the resistance offered to the passage of an electric current through a delicate film of carbon. L., Incident, or Direct, that falling upon a surface or object. L., Monochromatic, that which, on being analyzed by a prism, consists approximately of waves of one length only. L., Oblique, when parallel rays or the axial ray of a cone of light forms an angle with the optic axis of the microscope. See also Illumination, Oblique. L.red. Same as Ocher. L., Reflected, light thrown upon the object and then thrown back from the object. L., Reflection of, that property by which a ray of light striking an object rebounds, or is sent out again. Rays falling on a plane surface are reflected at an angle equal to that of the incident ray. Objects are perceived by the light reflected by such rays. L., Refraction of, that property by which a ray or pencil of light, when passing through media of different densities, is deflected out of its course. See Law of Refraction. L.-sense, the faculty by which different degrees of light or brightness may be distinguished. L., Spectrum of. See Spectrum, and Wave-lengths. L.-spot, Triangular, the pyramidal spot of light seen on the normal tympanic membrane, having its apex at the umbo, and its base toward the periphery. L., To Feel; quickening; the sensation conveyed to the mother by the movements of the fetus in utero. L., Transmitted, the light passing through an object.

Lighterman's Bottom. Inflammation of the bursa over the tuberosity of the ischium, from much sitting.

Lighting (lit'-ing) [ME., lihtinge, lighting]. The proper arrangement of the optic parts of a microscope, with the mirror so that the field is equally illuminated.

Lightning (lit'-ning) [ME., light, light]. An atmospheric discharge of electricity. In the form commonly known as "chain" or "bolt" lightning, the electricity has an extremely high potential, and a stroke under such circumstances is invariably fatal when the discharge passes through a living body. The form known as "sheet" lightning is a "brush"; discharge of low potential, and is harmless. L. Catarrh. Synonym of Infuenza. L. Pains, the lancinating pains of locomotor ataxia, usually occurring in the thighs, but also at times in the arms, head, and trunk. They are severe and come on in paroxysms, and may or may not follow the course of a nerve or nerves.
Lights (lits) [ME., light, light] because of their light weight.

Lignaloes (lig-nal'-ōz) [lignum aloes]. Same as Agallochum and Eagle-wood, q.v.

Lignatile (lig'-nat-il) [lignum, wood]. Same as Lignicole.

Ligneous (lig'-ne-us) [lignum, wood]. Woody, or having a woody texture.

Lignerolle's Amputation. See Operations, Table of.

Lignicole (lig'-nik-ōl) Lignicoline (lig-nik'-o-lin) [ligmum, wood; colere, to dwell]. In biology, growing upon wood.

Lignification (lig-nif-ik-a'-shun) [lignum, wood; facere, to make]. The process of turning into wood; sometimes also applied to amyloid degeneration, $q . v$.

Ligniform (lig'-nif-orm) [lignum, wood ; forma, form]. Resembling wood.

Lignin (lig'-nin) [lignum, wood], $\mathrm{C}_{19} \mathrm{H}_{24} \mathrm{O}_{10}$ (?). A modification of cellulose, constituting the greater portion of the weight of most dry wood. It has not been isolated. L., Tests for; phloroglucin gives a violet color to lignified cell-walls. Anilin sulphate, in slightly acidulated solution, gives a bright-yellow color.

Lignite (lig'-nit) [lignum, wood]. Brown coal; imperfectly formed coal, or that in which the original form of the wood is so distinctly preserved that it can be readily distinguished by the eye. It is a source of certain members of the paraffin group of hydrocarbons. See Coal.

Lignivorous (lig-niv'-or-us) [lignum, wood; vorare, to eat, to devour]. Applied to such insect larvæ, ants, beetles, etc., as devour wood.

Lignoin (lig'-no-in) [lignum, wood], $\mathrm{C}_{20} \mathrm{H}_{23} \mathrm{NO}_{8}$. An alkaloid found in certain Cinchonas.

Lignose (lig'-nōs). See Cellulose.

Lignum (lig'-num) [L.]. Wood. L. agallochum, aloes wood. L. benedictum, guaiac wood. L. cedrium, cedar wood. L. vitæ. See Guaiacum.

Ligroin (lig'-ro-in) [origin obscure]. A product obtained from petroleum, boiling at from $80^{\circ}$ to $120^{\circ} \mathrm{C}$, and having a specific gravity of from .710 to .730 . It is used in pharmacy for solvent purposes, and for burning in sponge-lamps.

Ligula (lig'-u-lah) [dim. of lingua, a tongue]. A little tongue or tongue-shaped organ; the epiglottis; the clavicle; the tenia of the fourth ventricle, called also ala pontis or ponticulus. Also, a name given to the tongue of an articulate. See Lingula. In biology, applied to various strap-shaped organs or parts, as the corolla-blade in a plant, or the long tongue-like organ of hymenopterous insects. Also called Ligule.

Ligulate (lig'-u-lät) [ligula, from lingua, tongue] Shaped like a small tongue; strap-shaped.

Ligule (lig'-ül) [ligula, a variety of lingula, a little tongue; a strap]. Same as Ligula.

Liguliform (lig-u-lif-orm). See Ligulate.

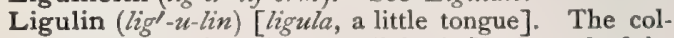
oring-matter of Levisticum officinale, Koch, and of the berries of the common privet (Ligustrum vulgare). With limestone water it strikes a bright-red color changing to blue, whence it has been used as a test for the presence of limestone in water.

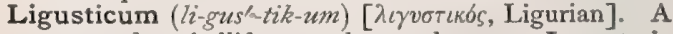
genus of umbelliferous plants: lovage. L. actæifolium is carminative and stimulant, as is also $\mathbf{L}$. apiifolium of $\mathrm{N}$. America. Unof.

Ligustrum (li-gus'-trum) [L.]. A genus of oleaceous shrubs; privets. L. vulgare, the common privet, has astringent leaves and bark, and cathartic berries. Unof.

Lilac $\left(l^{\prime}-l o k\right)[\mathrm{Ar} ., \bar{l} l \bar{a} k$, lilac]. The leaves and fruit of Syringa vulgaris, a bitter tonic, with reputed antiperiodic properties. Unof. 
Lily of the Valley. See Convallaria majalis.

Limb ( $\mathrm{lim}$ ) [ME., lim, a limb]. 1. A member of an animal body, other than the head or trunk; a leg or arm. 2. In biology, the lateral area, border, or margin of an organ or part. An organ of prehension or locomotion. L., Anterior (of the internal capsule), the part of the internal capsule in front of the knee, included between the caudate and the lenticular nucleus. L., Artificial, a mechanical substitute for an arm or a leg. L.-girdle, the bony or cartilaginous junction of a limb and the trunk. L., Pectoral, the upper or fore-limb. L., Pelvic, the lower or hind-limb. L. Plexus, the supposed rearrangement of nerve-strands so as to connect nerves derived from different parts of the spinal cord with -particular groups of muscles. L., Posterior (of the internal capsule), the portion behind the knee, situated between the caudate nucleus and the optic thalamus. L.-root, the part of a skeleton that bears a limb.

Limbate (lim'-batt) [limbus, a border]. Bordered.

Limbation (lim-ba'-shun) [limbus, a border]. In biology, the formation of an extended border; a lateral thickening.

Limbed (limd) [ME., lim, a limb]. Having limbs.

Limbic (lim'-bik) [limbus, a border]. Marginal; pertaining to a border. L. Fissure. See Fìssure. L. Lobe, that surrounding the corpus callosum.

Limburger Cheese. See Cheese.

Limbus (lim'-bus) [L.]. A border. The circumferential edge of any flat organ or part. L. corneæ, the edge of the cornea at its junction with the sclerotic coat. L. laminæ spiralis, the spiral membranous cushion, at the border of the osseous lamina spiralis of the cochlea. L. Iuteus. See Macula lutea. L. vieussenii, that portion of the edge of the septum secundum in the fetal heart of the rabbit that forms part of the boundary of the foramen ovale.

Lime $(l \bar{l} m)$ [Ar., limun , a lemon]. The fruit of several species of Citrus, as C. limetta. L.-juice, the juice of the lime. It should contain, when bottled, a small percentage of sulphurous acid, to prevent fermentation.

Lime $(\hbar \mathrm{m})$ [ME, lim, lime]. The popular name for calcium oxid, $\mathrm{CaO}$ (quicklime), and calcium hydrate, $\mathrm{Ca}(\mathrm{HO})$. Calcium oxid (quicklime) has a great affinity for water and for $\mathrm{CO}_{2}$. On contact with the former, slaked lime is formed, with the evolution of heat. On living tissues it acts as a caustic. L., Burnt, L., Caustic, calcium oxid, quicklime. L., Chlorid of, L., Chlorinated, the chlorid of lime of commerce, is not a distinct chemic compound; its chief constituent, and the one on which its disinfectant properties depend, is calcium hypochlorite, which liberates chlorin. L.secreting Glands. See Morrens' Glands. L., Milk of, a milky fluid consisting of calcium hydrate suspended in water. L., Quick, L., Slaked, common terms for lime. L.-ointment, an ointment consisting of slaked lime 4, lard I, and olive oil 3. L.water, a solution of calcium hydrate in water. It is astringent and alkaline, and prevents the formation of dense coagula if added to milk. It is used in cases of diarrhea and vomiting.

Limen $\left(i^{\prime}-m e n\right)$ [ $\lambda \mu^{\prime}{ }^{\prime}$, a harbor]. Threshold.

Limic ( $\left(i \mathrm{~m}^{\prime}-i k\right)$ [ $[\lambda \iota \kappa \delta$, hunger]. Pertaining to hunger.

Liminal (lim'-in-al) [ $\lambda \iota \mu$ '́ $\nu$, threshold]. Least; lowest; minimal. L. Intensity. See Law, Fechner's.

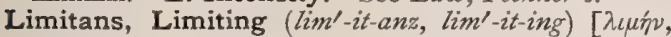
threshold]. Bounding. L. Membrane, the thin membrane on which the epithelial tissue of the various glands rests. L. Membrane, External, the thin layer between the outer nuclear layer of the retina and that of the rods and cones. L. Membrane, Internal, in the eye, the inner layer of the retina.
Limitrophic (lim-it-rōfl-ik) [limitropus, a name given to Roman lands furnishing subsistence to soldiers]. Regulating the processes of nutrition; a qualification sometimes applied to the great ganglionic cord of the sympathetic nerve-system, or to that system at large; pertaining to the sympathetic nerves.

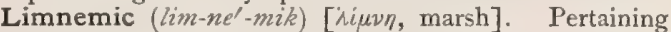
to, or caused by the influence of, a marsh.

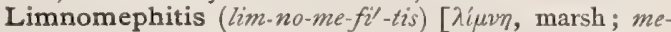
phitis, noxious odor]. Any miasm or noxious odor arising from marshy ground or swamps.

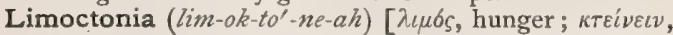
to destroy]. Death from hunger; suicide by hunger.

Limonene $\left(l^{\prime}-m o-n e \bar{n}\right)$ [limo, a lemon]. The same as Citrene, $q . v$.

Limonum (li-mo'-num) [L.: gen., Limonis; from the Arabic limûn]. Lemon. The fruit of Citrus limonum, of the same genus as the orange and the lime. The rind contains a volatile oil, isomeric with oil of turpentine. The pulp yields about 7 per cent. of citric acid, $\mathrm{C}_{6} \mathrm{H}_{8} \mathrm{O}_{7}$, which has about the same properties as acetic acid, but has much value as a refrigerant and antiscorbutic. The expressed juice is largely employed as a refrigerant drink in fevers. L., O1., the volatile oil. Dose $\eta_{j}-v$. L., Spt., "essence of lemon," 6 parts of oil and 4 of peel in 90 parts of alcohol. L., Succus (B. P.), used in preparing syrupus limonis. L., Syr., lemon-juice 40, lemon-peel 2, sugar 6o, water q. s. ad roo. Dose 3 j.

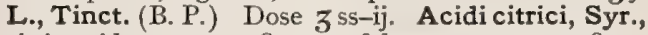
citric acid, water, āã 8 , spt. of lemon 4 , water 980 .

Limophoitos (lim-o-fo'-it-os), Limophoitosis (lim-o-

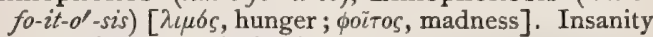
due to hunger or lack of nutrition.

Limophoitosic ( $\left.\mathrm{lim}-o-f o-i t-o^{\prime}-s i k\right)[\lambda \iota \mu \sigma s$, hunger; $\phi o \iota$ Táeıv, to wander]. Insane from hunger or underfeeding.

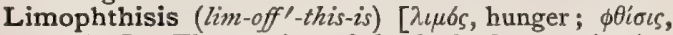
wasting]. The wasting of the body due to privation and lack of food.

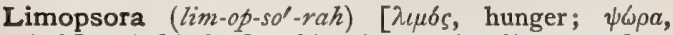
itch]. A kind of scabies (or pruritus?) asserted to attack man and other animals after long deprivation of food.

Limopsorus (lim-op-so'-rus) [ $\lambda \iota \mu b s$, hunger; $\psi \omega \rho a$, itch]. A disease, like scurvy, pellagra, or faminefever, due to poor or insufficient food.

Limoseric (lim-o-ser'-ik) [ $\lambda \iota \mu o ́ s$, hunger]. Pertaining to or caused by hunger.

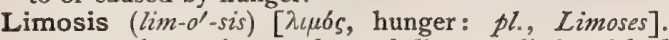
Unnatural appetite; a class of diseases distinguished by depraved appetite.

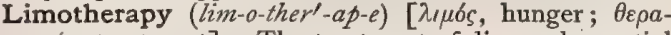
$\pi \varepsilon i a$, treatment]. The treatment of disease by partial or total deprivation of food. This method is useful in certain stages of syphilis, in the treatment of aneurysm, and is recommended in some cases of malignant disease.

Limp [AS., lemp, awkward]. A halting gait. See Claudicatio.

Limprecht's Method. See Nitrogen.

Linagogue (lin'-ag*og), Linagogus (lin-ag-o'-gus) [linum, thread; a $\gamma \omega \gamma b s$, leading]. An instrument used in guiding the course of a suture.

Linament (lin'-am-ent) [linum, flax]. Charpie; lint; a tent for a wound.

Linaria (lin- $\left.a^{\prime}-r e-\alpha h\right)$ [linum, flax]. A genus of herbs. L. vulgaris. See Antirrhinum linaria.

Lincture (iink'-tür) [linctus; lingere, to lick]. A medicine to be taken by licking; an electuary; looch, lohoch, or eclegma. [Old.]

Linctus (link'-tus) [L.]. Same as Lincture. 
Line ( $\mathrm{kn})$ [linea, a line]. In geometry, that extension of dimension which has length, but neither breadth nor thickness. Also, the $\frac{1}{12}$ part of an inch. In anatomy, a boundary or guide-mark. A Table of Lines is appended. L., Atmospheric, those lines of Fraunhofer's spectrum due to absorption of light-rays by the atmosphere. L., Atrope, a name given by Helmholtz to the perpendicular to the plane of the axes of rotation of the eye. L., Colored (of the enamel), one of the concentric striæ of enamel prisms. They may indicate the laminar formation of the enamel.

L.-writing. See Ataxiagram.

\section{TABLE OF LINES OR LINEÆ.}

\begin{tabular}{|c|c|}
\hline NAME. & DEPARTMENT, SIgNIFICANCE, ETC. \\
\hline Abdominal. & See $L . a l b a$. \\
\hline Of accommodation. & In optics. \\
\hline Alba. & In anatomy. \\
\hline Albicantes. & $\begin{array}{l}\text { Distention of the abdomen from preg- } \\
\text { nancy, ascites, or tumors. }\end{array}$ \\
\hline Alveolo-basilar. & Craniometry. \\
\hline Alveolo-nasal. & Craniometry. \\
\hline Aspera. & Anatomy. \\
\hline Atmospheric. & In spectroscopy. \\
\hline Atrope. & Optics. \\
\hline Atrophic. & Distention of the abdomen. \\
\hline Auriculo-bregmatic. & Craniometry. \\
\hline $\begin{array}{l}\text { Axillary, anterior and } \\
\text { posterior. }\end{array}$ & In physical diagnosis. \\
\hline Baillarger's. & See $L .$, Inner and Outer. \\
\hline Base line. & Brain-surgery. \\
\hline Basio-alveolar. & Craniometry. \\
\hline Basio-bregmatic. & Craniometry. \\
\hline Baudelocque's. & Obstetrics. \\
\hline Biauricular. & Craniometry. \\
\hline Blue. & In chronic lead-poisoning. \\
\hline Bryant's. & In surgery. \\
\hline Burton's, & See $L .$, Gingival. \\
\hline Camper's (profile). & Craniometry. \\
\hline Cardiac. & In palmistry. \\
\hline Cephalic. & Craniometry. \\
\hline Of Chaussier. & Anatomy. \\
\hline Clapton's. & Chronic copper-poisoning. \\
\hline $\begin{array}{l}\text { Colored (of the en- } \\
\text { amel). }\end{array}$ & $\begin{array}{l}\text { Nature and significance not } \\
\text { understood. }\end{array}$ \\
\hline
\end{tabular}

DESCRIPTION

Czermak's term for that portion of the visual line in which lie objects that are seen with distinctness, and with a given state or degree of accommodation.

I. A tendinous raphe extending in the median line of the abdomen from the pubes to the ensiform cartilage. It is formed by the blending of the aponeuroses of the oblique and transversalis muscles.

2. Hunter's line, the anterior peduncles of the pineal gland

Glistening white lines in either iliac region of the abdomen.

A line joining the basion and the alveolar point.

A line joining the nasal and the alveolar point.

A rough longitudinal ridge on the posterior surface of the middle third of the femur, dividing below into two and above into three ridges.

2. A ripa; especially the line of rupture of the pia and endyma on the dorsal surface of the thalamus, corresponding with the margin of the fornix and the choroid sulcus of Schwalbe.

That portion of Fraunhofer's lines produced by the absorption of light-rays by atmospheric air.

The line normal to the plane of the axes of rotation of the eye. See $L$. albicantes.

A line passing from the auricular point to the bregma, and dividing the pre-auricular from the post-auricular part of the cranium.

Vertical lines extending downward from the axilla on the side of the trunk.

A line running backward from the infra-orbital ridge through the middle of the external auditory meatus, and prolonged to the middle line of the head posteriorly.

See L., Alveolo-basilar.

The line joining the basion and the bregma.

The external conjugate diameter of the pelvis.

The line separating the anterior from the posterior portion of the skull. It extends from one auditory foramen over the vertex to the other.

A blue-black line at the dental margin of the gums.

See L., Test.

In various diseases.

A line running from the external auditory meatus to a point just below the nasal spine.

The line that runs across the palm of the hand from the radial side to the base of the index finger.

Any line joining certain points on the surface of the skull.

See $L$. media mesolobii.

A green line at the margin of the gums, with a similar green stain extending for some distance on the teeth.

Concentric brown lines or striæ crossing the enamel-prisms of the teeth. 
TABLE OF LINES OR LINEA.-Continued.

\begin{tabular}{|c|c|c|}
\hline NAMF. & DEPARTMENT, SignificanCE, ETC. & DESCRIPTION. \\
\hline Contour. & Microscopic anatomy. & $\begin{array}{l}\text { Lines in dentine more or less parallel with the pulp-cavity, } \\
\text { probably due to the presence of interglobular spaces. }\end{array}$ \\
\hline Corrigan's. & Chronic copper-poisoning. & A purple line at the junction of the teeth and gums. \\
\hline Costo-articular. & In physical diagnosis. & $\begin{array}{l}\text { A line drawn between the sterno-clavicular articulation and the } \\
\text { point of the eleventh rib. }\end{array}$ \\
\hline Costo-clavicular. & In physical diagnosis. & See L., Parasternal. \\
\hline Cruciate ( 4 in number). & In anatomy. & $\begin{array}{l}\text { Ridges upon the ental surface of the occipital bone that } \\
\text { radiate from the internal occipital protuberance. }\end{array}$ \\
\hline Crull's. & Craniometry. & See L., Supraorbital. \\
\hline $\begin{array}{l}\text { Curved, inferior (of } \\
\text { the ilium). }\end{array}$ & In anatomy. & $\begin{array}{l}\text { A line extending from the upper part of the anterior-inferior } \\
\text { spinous process of the ilium, and terminating at the middle of } \\
\text { the great sciatic notch. }\end{array}$ \\
\hline $\begin{array}{l}\text { Curved, inferior (of } \\
\text { the occipital bone). }\end{array}$ & In anatomy. & $\begin{array}{l}\text { A ridge extending transversely across the outer surface of the } \\
\text { occipital bone at about one-third of the distance between its } \\
\text { anterior border and the anterior border of the foramen } \\
\text { magnum. }\end{array}$ \\
\hline $\begin{array}{l}\text { Curved, inferior (of } \\
\text { the parietal bone). }\end{array}$ & In anatomy. & See L., Temporal. \\
\hline $\begin{array}{l}\text { Curved, middle (of } \\
\text { the tilium). }\end{array}$ & In anatomy. & $\begin{array}{l}\text { A line commencing about an inch or an inch and a half behind } \\
\text { the anterior superior spine of the ilium and arching backward } \\
\text { and downward to the upper margin of the great sciatic notch. }\end{array}$ \\
\hline $\begin{array}{l}\text { Curved, superior (of } \\
\text { the ilium). }\end{array}$ & In anatomy. & $\begin{array}{l}\text { A line commencing about two inches in front of the posterior } \\
\text { extremity of the crest of the ilium and curving downward and } \\
\text { forward toward the posterior part of the great sciatic notch. }\end{array}$ \\
\hline $\begin{array}{l}\text { Curved, superior (of } \\
\text { the occipital bone). }\end{array}$ & In anatomy. & $\begin{array}{l}\text { A semicircular line, passing outward and forward from the } \\
\text { external occipital protuberance. }\end{array}$ \\
\hline $\begin{array}{l}\text { Curved, superior (of } \\
\text { the parietal bone). }\end{array}$ & In anatomy. & $\begin{array}{l}\text { A ridge upon the outer surface of the parietal bone, parallel to } \\
\text { and slightly above the temporal line. }\end{array}$ \\
\hline Of Daubenton, & Craniometry. & $\begin{array}{l}\text { A line joining the opisthion and the projection of the lower } \\
\text { border of the orbit. }\end{array}$ \\
\hline Of demarcation. & In surgery. & A line of division between healthy and gangrenous tissues. \\
\hline Of De Salle. & $\begin{array}{l}\text { In abdominal and other wasting } \\
\text { diseases. }\end{array}$ & See L., Nasal. \\
\hline Dobie's. & Microscopic anatomy. & $\begin{array}{l}\text { The thin, dark disc or membrane passing transversely through } \\
\text { and bisecting the clear zone or stria in a striated muscle-fiber. }\end{array}$ \\
\hline $\begin{array}{l}\text { Doornick's horizontal } \\
\text { line. }\end{array}$ & Craniometry. & $\begin{array}{l}\text { A line drawn from the median incisors to the maximum occipital } \\
\text { point. }\end{array}$ \\
\hline Douglas's. & Topographic anatomy. & See $L_{.,}$Semicircular. \\
\hline Eberth's. & Microscopic anatomy. & The lines of junction of the cardiac muscle-cells. \\
\hline Ectental. & Microscopic anatomy. & The line of junction of the ectoderm and endoderm. \\
\hline Ellis's curved line. & In pleurisy. & $\begin{array}{l}\text { The curved line followed by the upper border of a pleuritic } \\
\text { effusion, or of a hydrothorax. It is somewhat like the letter } \\
\mathrm{S} \text {, the highest point being in the axilla, from which it descends } \\
\text { toward the sternum. }\end{array}$ \\
\hline Embryonic. & Embryology. & $\begin{array}{l}\text { The primitive trace in the center of the germinal area of the } \\
\text { ovum. }\end{array}$ \\
\hline $\begin{array}{l}\text { Eminens (of the cri- } \\
\text { coid cartilage). }\end{array}$ & Anatomy. & A mesal ridge of the dorsal half of the cricoid cartilage. \\
\hline $\begin{array}{l}\text { Eminens (of the patel- } \\
\text { la). }\end{array}$ & Anatomy. & $\begin{array}{l}\text { A ridge on the posterior surface of the patella, dividing that } \\
\text { surface into two unequal parts, the outer of which is the } \\
\text { larger. }\end{array}$ \\
\hline $\begin{array}{l}\text { Eminens (of the pos- } \\
\text { terior pyramid, also } \\
\text { of Reil). }\end{array}$ & In anatomy. & $\begin{array}{l}\text { A ridge descending posteriorly from the summit of the pyramis } \\
\text { cerebelli. }\end{array}$ \\
\hline $\begin{array}{l}\text { Eminens transversa (of } \\
\text { the hyoid bone). }\end{array}$ & Anatomy. & $\begin{array}{l}\text { The horizontal ridge crossing the ventral surface of the body } \\
\text { of the hyoid bone. }\end{array}$ \\
\hline Eminentes. & Anatomy. & $\begin{array}{l}\text { The ridges upon the costal surface of the scapula, in the sub- } \\
\text { scapular fossa. }\end{array}$ \\
\hline Facial. & Craniometry. & $\begin{array}{l}\text { I. A straight line tangential to the glabella and some point at } \\
\text { the lower portion of the face. 2. See } L \text {., Camper's. }\end{array}$ \\
\hline
\end{tabular}


TABLE OF LINES OR LINEE.-Continued.

\begin{tabular}{|c|c|}
\hline NAME. & DEPARTMENT, SIGNIFICANCE, ETC. \\
\hline Of fate. & In palmistry. \\
\hline $\begin{array}{l}\text { Festooned (of the car- } \\
\text { diac extremity of the } \\
\text { esophagus). }\end{array}$ & Anatomy. \\
\hline Of fixation. & In optics. \\
\hline Focal. & In optics. \\
\hline Of fortune. & In palmistry. \\
\hline Fraunhofer's. & In spectroscopy. \\
\hline $\begin{array}{l}\text { Fraunhofer's, artifi- } \\
\text { cial. }\end{array}$ & In spectroscopy. \\
\hline Frohmann's. & Microscopic anatomy. \\
\hline Frontal, minimum. & Craniometry. \\
\hline Fusca. & In pregnancy. \\
\hline Gant's (of section). & In surgery. \\
\hline Genal (Jadelot's). & $\begin{array}{l}\text { Supposed to indicate disease of some } \\
\text { abdominal organ. }\end{array}$ \\
\hline \multicolumn{2}{|l|}{ Of Gennari. } \\
\hline Gingival (Burton's). & Characteristic of various diseases. \\
\hline $\begin{array}{l}\text { Gluteal, anterior, in- } \\
\text { ferior, posterior. }\end{array}$ & $\begin{array}{l}\text { See } L ., \text { Curved (of the ilium), Inferior } \\
\text { Middle, Superior. }\end{array}$ \\
\hline Göttingen. & Anatomy. \\
\hline Of Haller. & Anatomy. \\
\hline Of the head. & In palmistry. \\
\hline Of health. & In palmistry. \\
\hline Of the heart. & In palmistry. \\
\hline Of Helmholtz. & In optics. \\
\hline Hepatic. & In palmistry. \\
\hline Hilton's. & In anatomy. \\
\hline Holden's. & $\begin{array}{l}\text { Topographic anatomy. Of value in } \\
\text { amputation of the hip-joint. }\end{array}$ \\
\hline Horizontal. & Microscopic anatomy. \\
\hline Hunter's. & Topographic anatomy. \\
\hline Ihering's. & Craniometry. \\
\hline Iliac. & Anatomy. \\
\hline Ilio-pectineal. & Obstetrics. \\
\hline Ilio-pubic. & Obstetrics. \\
\hline
\end{tabular}

DESCRIPTION:

A line beginning near the wrist and running up the middle of the palm toward the base of the index-finger.

The whitish, dentated border of the mucosa of the esophagus at its junction with the mucosa of the stomach.

An imaginary line drawn from the object viewed through the center of rotation of the eye.

The lines, anterior and posterior, that bound the focal interval.

A line running upward to the base of the ring-finger.

The black lines that cross a very pure solar spectrum. They are produced by the light from lower portions of the solar surface passing through certain incandescent metallic vapors in the luminiferous envelop of the sun, and in the aqueous vapor and permanent gases of the earth's atmosphere.

A black line occupying the position of a luminous line in the spectrum when a metallic vapor is interposed in the ray of light; the position of the line varies with different metals.

Transverse lines or strize appearing on the axis-cylinder of medullated nerve-fibers, near the nodes of Ranvier, after the fibers have been stained with silver nitrate. Their significance is unknown.

The shortest transverse measurement of the forehead.

The pigmentation of the linea alba.

A section of the femur, through an imaginary line below the trochanter major.

A line in a child's face, running downward from the region of the malar bone to join the nasal line.

Same as $L$. of Baillarger.

A reddish streak or margin at the reflected edge of the gums.

A line following the general direction of the upper margin of the zygoma.

See L. splendens.

A line beginning between the thumb and index-finger, and extending across the center of the palm of the hand parallel to the line of the heart.

See L., Hepatic.

See $L$., Cardiac.

See L., Atrope.

A line beginning at the wrist near the line of life and running upward to the base of the little finger.

A white line marking the point of junction of the skin of the perineum with the mucosa of the anus, and also the point of separation of the external from the internal sphincter. It is not always readily detected.

A sulcus below the fold of the oroin, starting from the femoroscrotal furrow, and fading away between the great trochanter and the anterior superior iliac spine. It crosses the middle of the capsule of the hip.

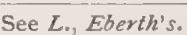

See L. alba.

A line tangential to the lower margin of the orbit, and passing through the auricular point.

The iliac portion of the ilio-pectineal line.

The bony ridge marking the brim of the true pelvis, situated partly on the ilium and partly on the pubis.

See L., Nio-pectineal. 
TABLE OF LINES OR LINEÆ-Continued.

\begin{tabular}{|c|c|c|}
\hline NAME. & DEPARTMENT, Significance, etc. & DEsCRIPTION. \\
\hline Incremental (Salter's). & Microscopic anatomy. & $\begin{array}{l}\text { A curved line in dentine, supposed to indicate the laminar } \\
\text { structure, and to correspond to the successive lamina or } \\
\text { strata of dentine. }\end{array}$ \\
\hline Inner (of Baillarger). & Anatomy. & $\begin{array}{l}\text { A thin, whitish line parallel to the surface, seen with the naked } \\
\text { eye, in a section of the gray matter of the cerebrum. It is the } \\
\text { fifth line from without inward. }\end{array}$ \\
\hline Innominate. & Obstetrics. & See L., Ilio-pectineal. \\
\hline Interauricular. & Craniometry. & A line joining the two auricular points. \\
\hline Intercellular. & Microscopic anatomy. & $\begin{array}{l}\text { The narrow intervals between contiguous cells of epithelium or } \\
\text { endothelium. They are filled by the cell-cement. }\end{array}$ \\
\hline Intercondylar. & Anatomy. & $\begin{array}{l}\text { A transverse ridge joining the condyles of the femur above the } \\
\text { intercondyloid fossa. }\end{array}$ \\
\hline Intercondylean. & Anatomy. & See L., Intercondylar. \\
\hline Interjugal. & Craniometry. & A line joining the jugal points. \\
\hline Intermalar. & Craniometry. & A line joining the malar points. \\
\hline Intermediate. & Microscopic anatomy. & See L., Dobie's. \\
\hline $\begin{array}{l}\text { Intermediate. (of the } \\
\text { ilium). }\end{array}$ & Anatomy. & $\begin{array}{l}\text { The ridge upon the crest of the ilium between its inner and out- } \\
\text { er lip. }\end{array}$ \\
\hline $\begin{array}{l}\text { Intertrochanteric, an* } \\
\text { terior (of the femur). }\end{array}$ & Anatomy. & $\begin{array}{l}\text { A line upon the anterior surface of the femur, separating the } \\
\text { neck and shaft, extending between the tubercle and a point } \\
\text { close to and in front of the lesser trochanter. }\end{array}$ \\
\hline $\begin{array}{l}\text { Intertrochanteric, pos- } \\
\text { terior (of the femur). }\end{array}$ & Anatomy. & $\begin{array}{l}\text { A ridge on the posterior surface of the femur, extending between } \\
\text { the greater and lesser trochanters. }\end{array}$ \\
\hline Intertuberal. & Anatomy. & $\begin{array}{l}\text { A line joining the inner borders of the ischial tuberosities, im- } \\
\text { mediately below the small sciatic notch. }\end{array}$ \\
\hline Jadelot's. & Various diseased conditions. & See L., Genal, Labial, Nasal, and Oculozygomatic. \\
\hline Of Kilian. & Anatomy. & See L.prominens. \\
\hline Kirchoff's. & In spectroscopy. & See $L_{.}$, Fraunhofer's. \\
\hline Labial (of Jadelot). & $\begin{array}{l}\text { Supposed to indicate pulmonary dis- } \\
\text { ease. }\end{array}$ & $\begin{array}{l}\text { A line on an infant's face running downward and backward from } \\
\text { the angle of the mouth. }\end{array}$ \\
\hline Lateral. & Comparative anatomy. & In fishes, the line of openings of ducts on either side of the body. \\
\hline Of life. & In palmistry. & $\begin{array}{l}\text { A line starting near the wrist, skirting the base of the thumb, } \\
\text { and terminating between the thumb and the line of the head. }\end{array}$ \\
\hline Ligar's. & $\begin{array}{l}\text { In anatomy ; the upper point of tri- } \\
\text { section of the first indicates the } \\
\text { emergence of the gluteal artery; the } \\
\text { middle of the second, the spot where } \\
\text { the sciatic axtery leaves the peivis. }\end{array}$ & $\begin{array}{l}\text { Two lines, one joining the posterior iliac spine at a point mid- } \\
\text { way between the tuber ischii and the great trochanter; the } \\
\text { other from the posterior iliac spine to the inner point of trisec- } \\
\text { tion of a line between the tuber ischii and the trochanter. }\end{array}$ \\
\hline Mammillary. & Physical diagnosis. & A vertical line passing through the center of the nipple. \\
\hline Media mesolobii. & Anatomy. & The raphe of the callosum. \\
\hline Media scroti. & Anatomy. & The raphe of the scrotum. \\
\hline Median. & Anatomy. & $\begin{array}{l}\text { A line joining any two points at the periphery of the meson or } \\
\text { median plane of the body. }\end{array}$ \\
\hline Mylo-hyoidean. & Anatomy. & See $L_{.}$, Oblique, Internal (of the inferior maxilla). \\
\hline $\begin{array}{l}\text { Nasal (of Jadelot). Also } \\
\text { called De Salle's line. }\end{array}$ & $\begin{array}{l}\text { Supposed to indicate abdominal dis- } \\
\text { ease and other wasting diseases. }\end{array}$ & $\begin{array}{l}\text { A line on a child's face, starting at the upper margin of the ala } \\
\text { nasi, and, encircling the angle of the mouth, extending down- } \\
\text { ward to the outer edge of the orbicularis muscle. }\end{array}$ \\
\hline Naso-alveolar. & Craniometry. & See $L_{*}$, Alveolo-nasal. \\
\hline Naso-basilar. & Craniometry. & The line drawn through the basion and the nasal point. \\
\hline $\begin{array}{l}\text { Naso-l a mbdoid (of } \\
\text { Poirier). }\end{array}$ & Craniometry. & $\begin{array}{l}\text { A line drawn from the naso-frontal groove to a point one centi- } \\
\text { meter above the lambda. It is of value in determining the } \\
\text { position of the fissure of Rolando. }\end{array}$ \\
\hline Naso-subnasal. & Craniometry. & $\begin{array}{l}\text { The line running from the subnasal spine to the naso-frontal su. } \\
\text { ture. }\end{array}$ \\
\hline Nélaton's. & $\begin{array}{l}\text { In surgery; in dislocation of the fe- } \\
\text { mur backward the trochanter is al- } \\
\text { ways found above this line. }\end{array}$ & $\begin{array}{l}\text { A line drawn from the anterior superior spine of the ilium to the } \\
\text { most prominent part of the tuberosity of the ischium. }\end{array}$ \\
\hline
\end{tabular}


TABLE OF LINES OR LINEÆ.CContinued.

\begin{tabular}{|c|c|c|}
\hline NAME. & DEPARTMENT, SIGNIFICANCE, ETC. & DESCRIPTION. \\
\hline Neutral. & In physics. & The optic axis of a crystal. \\
\hline Nigra. & Obstetrics. & The discoloration of the linea alba in pregnancy. \\
\hline Nuchal, inferior. & Anatomy. & The inferior curved line of the orciput. \\
\hline Nuchal, median. & Anatomy. & The external occipital protubetance. \\
\hline Nuchal, superior. & Anatomy. & The superior curved line of the occiput. \\
\hline Oblique (of the fibula). & Anatomy. & $\begin{array}{l}\text { A prominent ridge on the internal surface of the shaft of the } \\
\text { fibula, commencing above at the inner side of the head, and } \\
\text { terminating in the interosseous ridge at the lower fourth of } \\
\text { the bone. }\end{array}$ \\
\hline Oblique (of the radius). & Anatomy. & $\begin{array}{l}\text { A prominent ridge running from the lower part of the bicipital } \\
\text { tuberosity, downward and outward, to form the anterior bor- } \\
\text { der of the bone. }\end{array}$ \\
\hline $\begin{array}{l}\text { Oblique (of the thyroid } \\
\text { caritilage). }\end{array}$ & Anatomy. & $\begin{array}{l}\text { A line extending downward and outward from the tubercle of } \\
\text { the thyroid cartilage. }\end{array}$ \\
\hline Oblique (of the tibia). & Anatomy. & $\begin{array}{l}\text { A rough ridge that crosses the posterior surface of the tibia ob- } \\
\text { liquely downward from the back part of the articular facet for } \\
\text { the fibula to the internal border. }\end{array}$ \\
\hline $\begin{array}{l}\text { Oblique, external (of } \\
\text { the inferior maxilla). }\end{array}$ & Anatomy. & $\begin{array}{l}\text { A prominent ridge on the external surface of the inferior maxilla } \\
\text { just below the mental foramen, from which it runs outward, } \\
\text { upward, and backward to the anterior margin of the ramus. }\end{array}$ \\
\hline $\begin{array}{l}\text { Oblique, internal (of } \\
\text { the inferior maxilla). }\end{array}$ & Anatomy. & $\begin{array}{l}\text { A ridge on the internal surface of the lower jaw, commencing at } \\
\text { the posterior portion of the sublingual fossa, continuing up- } \\
\text { ward and outward so as to pass just below the last two molar } \\
\text { teeth. }\end{array}$ \\
\hline $\begin{array}{l}\text { Oculoz yg omatic (of } \\
\text { Jadelot). }\end{array}$ & $\begin{array}{l}\text { Supposed to indicate cerebro-spinal } \\
\text { disease. }\end{array}$ & $\begin{array}{l}\text { A line on a child's face running from the inner angle of the eye, } \\
\text { downward and outward, to the malar bone. }\end{array}$ \\
\hline Ogston's. & $\begin{array}{l}\text { Surgery; in section of the internal } \\
\text { condyle from the shaft of the femur. }\end{array}$ & $\begin{array}{l}\text { The line for the tendon of the adductor magnus, running from } \\
\text { the tubercle of the femur to the intercondyloid notch. }\end{array}$ \\
\hline Outer (of Baillarger). & Anatomy. & $\begin{array}{l}\text { A thin, whitish line parallel to the surface, seen with the naked } \\
\text { eye in a section of the gray matter of the cerebrum. It is the } \\
\text { third line from without inward. }\end{array}$ \\
\hline Owen's. & Microscopic anatomy. & See L., Contour. \\
\hline Pacini's. & Comparative anatomy. & $\begin{array}{l}\text { A dark line in the electric plate of Gymnotus, separating the } \\
\text { plate into two parts. }\end{array}$ \\
\hline Pallial. & Comparative anatomy. & $\begin{array}{l}\text { In molluscs, the lines left in the dead shell by the muscular mar- } \\
\text { gin of the mantle. }\end{array}$ \\
\hline Parasternal. & Physical diagnosis. & A line midway between the two nipples. \\
\hline Parturient. & Obstetrics. & The axis of the parturient canal. \\
\hline Pectineal. & Obstetrics and anatomy. & $\begin{array}{l}\text { That portion of the ilio-pectineal line which is formed by the pu- } \\
\text { bic bone. }\end{array}$ \\
\hline Of Poirier. & See L., Naso-lambdoid. & \\
\hline Popliteal. & Anatomy. & See $L$, Oblique (of the tibia). \\
\hline Primitive. & Embryology. & The primitive streak of the embryo. \\
\hline Profile (of Camper). & See $L .$, Camper's. & \\
\hline Profile (of Topinard). & See $L .$, Topinard's. & \\
\hline Prominens (of Kilian). & Anatomy. & The promontory of the sacrum. \\
\hline Quadrate. & Anatomy. & $\begin{array}{l}\text { A well-marked eminence on the femur commencing about the } \\
\text { middle of the posterior intertrochanteric line, and descending } \\
\text { vertically for about two inches along the posterior surface of } \\
\text { the shaft. }\end{array}$ \\
\hline Of Reil. & Anatomy. & See $L$. eminens (of the posterior pyramid). \\
\hline Respiratory. & In sphygmography. & $\begin{array}{l}\text { The line connecting the bases of the upward strokes in a trac- } \\
\text { ing of the pulse. In quiet breathing it is nearly straight, but } \\
\text { in labored respiration and in some diseased conditions it be- } \\
\text { comes a more or less regular curve, due to the influence of the } \\
\text { respiration on the circulation. }\end{array}$ \\
\hline Roser's. & In surgery. & Same as L., Nélaton's. \\
\hline Salter's. & Microscopic anatomy. & See $L$., Incremental. \\
\hline
\end{tabular}


TABLE OF LINES OR LINEF.-Continued.

\begin{tabular}{|c|c|c|}
\hline NAME. & DEPARTMENT, SIGNIFICANCE, ETC, & DESCRIPTION. \\
\hline Scapular. & Physical diagnosis. & $\begin{array}{l}\text { A vertical line downward from the lower angle of the scap- } \\
\text { ula. }\end{array}$ \\
\hline Schreger's. & Microscopic anatomy. & $\begin{array}{l}\text { Lines in dentine, having a general parallelism to the pulp-cavity. } \\
\text { They are caused by a row of the primary or great curvatures } \\
\text { of the dentinal tubules. }\end{array}$ \\
\hline $\begin{array}{l}\text { Semicircular (Doug- } \\
\text { las's). }\end{array}$ & Topographic anatomy. & $\begin{array}{l}\text { The curved lower edge of the internal layer of the aponeurosis } \\
\text { of the internal oblique muscle of the abdomen, where it ceases } \\
\text { to cover the posterior surface of the rectus abdominis. }\end{array}$ \\
\hline $\begin{array}{l}\text { Semilunar (of Spige- } \\
\text { lius). }\end{array}$ & Topographic anatomy. & $\begin{array}{l}\text { A curved tendinous condensation of the aponeurosis of the ex- } \\
\text { ternal oblique muscle of the abdomen, running along the outer } \\
\text { border of the rectus abdominis. }\end{array}$ \\
\hline Of sight. & In optics. & $\begin{array}{l}\text { An imaginary line drawn from the object viewed to the center } \\
\text { of the pupil. }\end{array}$ \\
\hline $\begin{array}{l}\text { Sinuous, inferior (of } \\
\text { the anus). }\end{array}$ & Anatomy. & $\begin{array}{l}\text { The convoluted line at the junction of the mucosa of the rectum } \\
\text { with the integument at the anus. }\end{array}$ \\
\hline Solea. & Anatomy. & Oblique line of the tibia at the attachment of the soleus muscle. \\
\hline Spigel's. & Topographic anatomy. & See L., Semilunar. \\
\hline Of Spigelius. & Topographic anatomy. & See L., Semilunar. \\
\hline Splendens (of Haller). & Anatomy. & $\begin{array}{l}\text { A longitudinal fibrous band extending along the middle line of } \\
\text { the anterior surface of the spinal pia. }\end{array}$ \\
\hline Sternal. & Physical diagnosis. & The median line of the sternum. \\
\hline Sterno-mastoid. & In surgery. & $\begin{array}{l}\text { A line drawn from a point between the two heads of the } \\
\text { sterno-mastoid muscle to the mastoid process. }\end{array}$ \\
\hline $\begin{array}{l}\text { Supracondylar, exter- } \\
\text { nal (of the femur). }\end{array}$ & Anatomy. & $\begin{array}{l}\text { The external, inferior continuation of the linea aspera of the fe- } \\
\text { mur. }\end{array}$ \\
\hline $\begin{array}{l}\text { Supracondylar, inter- } \\
\text { nal (of the femur). }\end{array}$ & Anatomy. & $\begin{array}{l}\text { The inner of the two ridges into which the linea aspera of the } \\
\text { femur divides. }\end{array}$ \\
\hline Supra-orbital. & In craniometry. & $\begin{array}{l}\text { A line extending horizontally across the forehead immediately } \\
\text { above the root of the external angular process of the frontal bone }\end{array}$ \\
\hline Temporal. & Anatomy. & $\begin{array}{l}\text { A curved line on the outer surface of the parietal bone, just be- } \\
\text { low the parietal eminence, forming in part the upper boundary } \\
\text { of the temporal fossa. }\end{array}$ \\
\hline Test (Bryant's). & Surgery. & $\begin{array}{l}\text { A line for detecting fracture or shortening of the neck of the fe- } \\
\text { mur. If two lines are drawn to meet at right angles, one of } \\
\text { them backward from the anterior superior spinous process of } \\
\text { the ilium, and the other upward from the top of the trochanter } \\
\text { major the latter is the test-line. Its length is to be compared } \\
\text { with the same line on the uninjured side. }\end{array}$ \\
\hline Thompson's. & $\begin{array}{l}\text { Frequently noticeable in pulmonary } \\
\text { tuberculosis. }\end{array}$ & A red line of vascular tissue along the margin of the gums. \\
\hline Topinard's profile. & Craniometry. & $\begin{array}{l}\text { A line joining the intersuperciliary point and the most prominent } \\
\text { point of the chin. }\end{array}$ \\
\hline $\begin{array}{l}\text { Transverse (of the } a b \text { - } \\
\text { domen). }\end{array}$ & Anatomy. & $\begin{array}{l}\text { The tendinous intersections in the course of the rectus abdomi- } \\
\text { nis muscle. }\end{array}$ \\
\hline $\begin{array}{l}\text { Transverse (of the } \\
\text { fourth ventricle). }\end{array}$ & Anatomy. & The striæ acusticæ of the fourth ventricle. \\
\hline Transverse (of sacrum). & Anatomy. & Ridges formed by the lines of union of the four sacral vertebra. \\
\hline Trapezoid. & Anatomy. & $\begin{array}{l}\text { The line of attachment of the trapezoid ligament on the inferior } \\
\text { surface of the outer portion of the clavicle. }\end{array}$ \\
\hline Of Vicq d'Azyr. & Anatomy. & See L., Outer (of Baillarger). \\
\hline Virchow's. & Craniometry. & The line extending from the root of the nose to the lambda. \\
\hline Visual. & Optics. & $\begin{array}{l}\text { An imaginary line, drawn from a point looked at, through the } \\
\text { nodal point of the eye, to the macula lutea. }\end{array}$ \\
\hline Vogt's alveolar line. & Craniometry. & $\begin{array}{l}\text { A line extending from the maximum occipital point to the } \\
\text { superior alveolar point. }\end{array}$ \\
\hline L., Zöllner's. & In optics (for test-purposes). & $\begin{array}{l}\text { Draw three parallel horizontal lines one centimeter apart, and } \\
\text { through the upper and lower ones draw short, oblique, parallel } \\
\text { lines in the direction from above and the left to below and the } \\
\text { right; through the middle line draw similar oblique lines, but } \\
\text { in the opposite direction; then the three horizontal lines no } \\
\text { longer appear to be parallel; they are actually so, but some ap- } \\
\text { pear to converge and others to diverge. }\end{array}$ \\
\hline
\end{tabular}


Linea $\left(\operatorname{lin}^{\prime}-e-a h\right)$ [L.]. A line. See Line.

Lineage $\left(\operatorname{lin}^{\prime}-e-\bar{a} j\right)$ [linea, a line]. The line of descent from an ancestor; ancestry.

Lineal (lin'-e-al) [linea, line]. Pertaining to lineage. See also, Linear.

Lineament (lin'-e-am-ent) [lineamentum; linea, a line]. The outline of the face, or of any of its features. Also, the outline of the embryo.

Linear (lin'-e-ar) [linea, a line]. Resembling or pertaining to a line. Applied in biology to an organ that is narrow, many times longer than broad, and that has parallel margins. L. Craniectomy. See Craniectomy. L. Extraction. See Caturact. L. Fracture, one forming a line, and attended with little or no displacement of the fragments.

Lineolate (lin'-e-o-lât) [lineola, a little line]. In biology, minutely lined or scored.

Lineolet (lin'-e-o-let) [lineola, a small line]. In biology, a minute line.

Ling's System. A method of treatment of disease by gymnastic and other rhythmic movements of the body, employed by Ling, a Swedish physician; kinesitherapy. See Swedish System.

Lingam (lin'-gam). See Phallus.

Lingism (ling'-izm). See Ling's System.

Lingua (lin'-greah) [L.: gen. and pl., Lingua]. The tongue. L. frænata, tongue-tie. L. geographica, leukoplakia of the tongue. L., Posterior, the epiglottis. L. propendula, an obsolete synonym of Macroglossia,

Lingual (lin'-gwal) [lingua, tongue]. Shaped like the tongue. Pertaining to the tongue. L. Artery. See Arteries, Table of. L. Bone. See Hyoid Bone. L. Muscle. See Muscles, Table of. L. Nerve. See Nerves, Table of. L. Nerve of Fifth Pair. See Lingual (3), Table of Nerves. L. Nerve of Vagus. See Pneumogastric, Table of Nerves. L. Ribbon. See Odontophore.

Lingualis (ling-gwa'-lis). See Muscles, Table of.

Linguatula (lin-gwat'-u-lah) [lingula, a small tongue]. See Parasiles, Table of.

Linguetta (ling-gwet'-ah) [L., dim. of lingzua, a tongue]. A small tongue. L. laminosa. See Lingula.

Linguiform (ling'-gwif-orm) [lingua, tongue; forma, form]. Shaped like a tongue.

Lingula (lin' $-g u$-lah) [dim. of lingua, a tongue]. A transversely lamellose lobule between the valve of Vieussens and the central lobule of the cerebellum. It is called, also, the linguetta laminosa, the ligula, and the processus petrosus anticus. Also, the line of demarcation between the general, pial surface of the myel and oblongata, and the endymal, metacelian surface. L. mandibularis, the prominent, thin scale of bone partly surrounding the large foramen of the lower jaw ; it serves for the attachment of the sphenomandibular ligament. L. sphenoidalis, a small, tongue-like process of bone projecting backward in the angle between the body and great wing of the sphenoid bone. L. of Wrisberg, connecting fibers of the motor and sensory roots of the trifacial nerve.

Lingulate (ling'-gu-lät) [lingula, dim. of lingua, tongue]. Tongue-shaped.

Linhart's Mixture. See Anesthetic.

Liniment (lin'-im-ent). See Linimentum.

Linimentum (lin-im-en'-tum) [linere, to smear: $p l$., Linimenta]. A liniment. A thin, liquid ointment for external application, usually a solution of a medicinal substance in an excipient of oil or oily mixtures. There are nine official limimenta, and 23 others are given in the U.S. Dispensatory. L. exsiccans. See Pick's Liniment. L., St. John Long's, a powerful counter-irritant containing oil of turpentine, acetic acid, and yolk of egg. L., Stokes', a stimulating liniment containing oil of turpentine IOO, acetic acid 15, rose-water 80 , linseed oil 4 , and the yolk of one egg. L., Swediaur's, a salve for application to carcinomatous ulcers, containing arsenious acid and olive oil.

Linin (li'-nin) [linum, flax]. I. A strongly purgative principle obtainable from Linum catharticum, or purging flax. Unof. 2. In biology, minute threads extending between the individual microsomata (ids) in a cell-nucleus. (O. von Rath.) The achromatin of the nuclear network ; parachromatin, less correctly called nucleo-hyaloplasm

Linitis $\left(l i-n i^{\prime}-t i s\right)$ [ [ivov, web; $\iota t \iota s$, inflammation]. An inflammation of the network of filamentous areolar tissue surrounding the vessels of the stomach. L., Plastic, a term for fibrinous infiltration of the pylorus. L., Suppurative, suppurative or phlegmonous gastritis.

Link (lingk) [ME., lenke, a link]. A loop of a chain.

Linoleic Acid ( $\left(i n-0-l e^{\prime}-i k\right)$. See Acid.

Linolein (lin-o'-le-in) [linum, flax; oleum, oil]. The neutral fat contained in linseed oil, to which the drying property of the oil is due. It is, chemically, a linoleate of glycerin.

Linseed ( $\left.\operatorname{lin}^{\prime}-s \bar{e} d\right)$. See Linum. L. Oil, Oleum lini, is expressed from the seeds of the Linum usitatissimum, or flax-plant. By cold pressure is obtained a pale, tasteless oil, which is used in Russia and Poland in cooking, as a substitute for lard or butter. By warm pressure an amber-colored or dark-yellow oil is obtained. Linseed oil is, when fresh, somewhat viscid, but as a drying-oil it gradually absorbs oxygen, and becomes thick and eventually dry and hard. It is used in the preparation of paints, varnishes, printers' ink, and oil-cloth. L. Poultice, a poultice made of linseed meal.

Lint [linum, flax]. A loosely woven or partly felted mass of broken linen-fibers, made by scraping and "picking" old linen cloth. It is used as a dressing for wounds andraw surfaces. See Charpie. L., Common, lint that is twilled on one side and "woolly" on the other. In the spreading of an ointment the twilled side is used.

Linteum (lin'-te-um) [L.]. Lint. L., Patent, English charpie; lint that is scraped on both sides, a soft finish being thus given to the two surfaces. L., Picked, charpie.

Linum $\left(l^{\prime}\right.$-num $)$ [L.: gen., Lini $]$. Flaxseed. Linseed. The seeds of $L$. usitatissimum, the common flax-plant, containing $30-40$ per cent. of fixed (linseed) oil in the embryo of the seed, and $\mathbf{1 5}$ per cent. of mucilage in the epithelium. It is a demulcent, emollient, and expectorant, useful in all inflammations of mucous membranes. L., Cataplasma (B. P.), made from linseed meal. L. catharticum is an active purga tive and vermifuge. L., Farina (B. P.), flaxseed meal used as a poultice. L., O1., the fixed oil of flaxseed expressed cold; a glycerid of linoleic acid. Dose

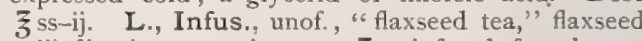
3 iij, licorice root $3 \mathrm{j}$, water $\xi \mathrm{x}$, infused four hours. Dose indefinite. L., Semen, linseed or flaxseed. Carron Oil, linseed oil emulsified in lime-water. The genus Linum contains several other species.

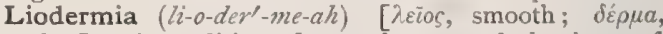
skin]. A condition of smoothness and glossiness of the skin. L. essentialis cum melanosi et telangiectasia. Synonym of Xeroderma pigmentosum.

Liomyoma ( $\left.i i-o-m i-o^{\prime}-m i a h\right) \quad[\lambda \varepsilon \check{o}$, smooth; $\mu v ́ \omega \mu \alpha$, a muscle-tumor]. A tumor composed of unstriped muscular tissue; its most common seat is the uterus, where, on account of the admixture of fibrous tissue, it is known as uterine fibroid. 
Liotrichous (li-ot'-rik-us). See Leiotrichous.

Lip [ME., lip, lip]. Either of the fleshy folds surrounding the orifice of the mouth; or one of the labia majora. See Labium. L.-protector, a shield for protecting the lip during a dental operation. L.reading, German System of, a method of teaching deaf-mutes to speak by imitating the movements of the lips and tongue, while modulation is secured by feeling the vibrations of the teacher's larynx, the pupil in this way attempting to control the natural harshness of the laryngeal sounds. L.-salve, a cosmetic ointment for the lips.

Lipa $\left(l i^{\prime}-p a h\right)$ [L.]. Fat.

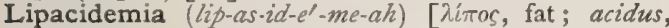
sour; aitua, blood]. The presence of fatty acids in the blood, with diminution of its alkalinity.

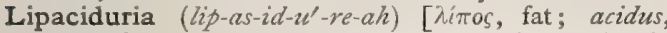
acid; ovpov, urine]. The presence of fatty acids in the urine.

Lipæmia (lip-e'-me-ah). See Lipemia.

Lipanin (lip $\left.p^{\prime}-a n-i n\right)$ [ $\lambda i$ mos, fat]. A substitute for codliver-oil, consisting of pure olive-oil and six per cent. of oleic acid. It speedily emulsifies in weak solutions of soda, has an agreeable taste, and is readily taken. The dose is from 2 to 6 tablespocnfuls daily.

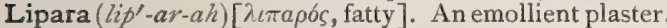

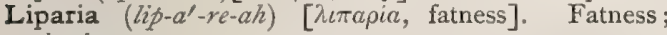
obesity.

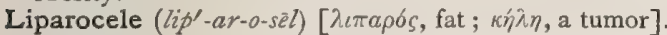
A fatty tumor or cyst; a hernia containing fatty tissue.

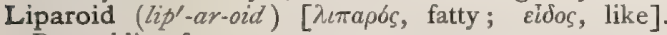
Resembling fat.

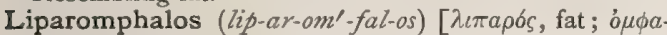
$\lambda o ́ s$, the navel]. A fatty tumor situated at the navel, or involving the umbilical cord.

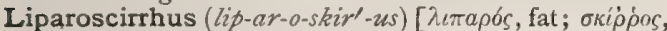
a carcinomatous growth]. A fatty, scirrhous tumor.

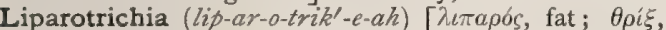
hair]. Abnormal greasiness of the hair.

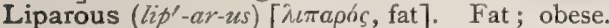

Lipemania (li-pe-ma'-ne-ah). See Lypemania.

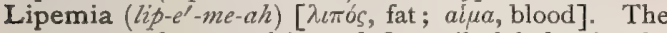
presence of an emulsion of fine oil-globules in the blood, a condition sometimes noted in diabetes. $L$. Intra-ocular, a condition characterized by marked distention of the retinal vessels, and a salmon-colored fundus. L. retinalis. Same as L. Intra-ocular.

Lipocele $\left(l_{i p}^{\prime}-0-s \bar{e} l\right)$. Synonym of Liparocele, $q . v$.

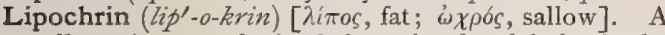
yellow pigment obtained from the fat-globules in the retinal epithelium. It is soluble in chloroform, ether, and benzol. It is probably closely allied to the yellow coloring-matter of many other animal fats. It is slowly bleached by sunlight.

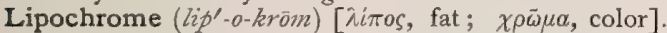
Any one of the very numerous fatty pigments of the animal economy, such as the chromophanes and lutein. They are fatty pigments characterized by exhibiting absorption-bands, which, though varying somewhat in position according to the solvent employed, are usually situated toward the violet end of the spectrum. Under this class of pigments are included the luteins. These fatty pigments are found in the blood and viscera of many invertebrates.

Lipodermatous (lip-o-der'-mat-us) $[\lambda \varepsilon i \pi \varepsilon \iota v$, to leave; ¿Épua, skin]. Affected with lipodermia.

Lipodermia (li-po-der'-me-ah). See Leipodermia.

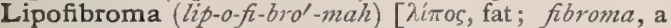
fibrous tumor]. A lipoma with fibrous elements.

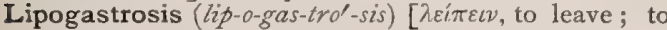

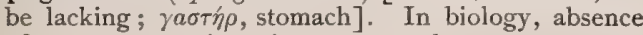
of a proper enteric cavity, or stomach.

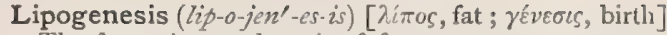
The formation or deposit of fat.

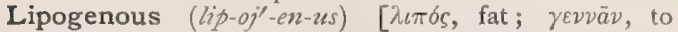
beget]. Fat-producing.

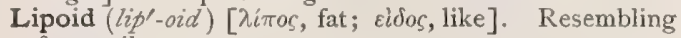
fat or oil.

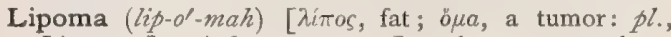
Lipomata]. A fatty tumor. L. arborescens tuberculosum, tuberculous disease of a joint, in which the whole inner surface of the synovial membrane is covered with sessile or pedunculated papillomatous growths, small and rather uniform in size. If these become detached they constitute the so-called ricebodies. L. colloides, myxo-lipoma. L., Cystic, one containing cysts. L., Fibrous. See Lipofibroma. L., Myxo-, a lipoma containing myxomatous tissue. L., Pendulous, Lipoma pendulum. L. pendulum, a lipoma having a pedicle. L., Telangiectatic, one containing many dilated hlood-vessels.

Lipomatoid (lip-o'-mat-oid). See Lipomatous.

Lipomatosis (lip-o-mat-o'-sis) [ $\lambda i \pi \omega \mu a$, a fatty tumor]. A general deposition of fat; obesity.

Lipomatous (lip-o'-mat-us) [ $\lambda i \pi \omega \mu \alpha$, a fatty tumor]. Of the nature of a lipoma; fatty.

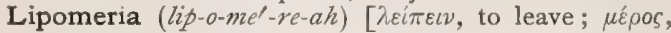
a part]. A monstrosity having one limb absent.

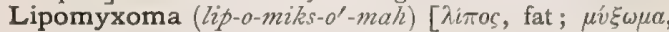
a myxomatous tumor: pl., Lipomyxomata]. A myxoma with fatty elements.

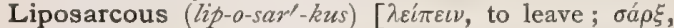
flesh ]. Lean; emaciated.

Liposis (lip-o'-sis). See Lipomatosis.

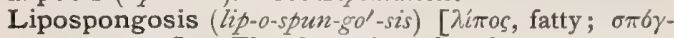
yos, sponge]. The formation of a fatty or spongelike outgrowth.

Lipostomatous (lip-o-sto'-mat-us) $[\lambda \varepsilon i \pi \varepsilon \imath \nu$, to leave; or $\sigma \mu \alpha$, mouth]. Having no mouth.

Lipostomosis (lip-o-sto-mo'-sis) [ $\lambda \varepsilon i \pi \varepsilon \imath v$, to leave; to be lacking; $\sigma \tau \delta \mu a$, mouth ]. In biology, absence of the oral aperture.

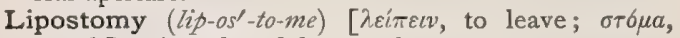
mouth]. Atrophy of the mouth.

Lipothymia (lip-o-thi'-me-ah). See Leipothymia

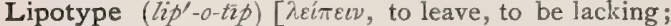

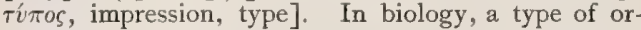
ganism, the absence of which is characteristic of a particular district or region; thus the Bovida and Viverride are lipotypes of the neotropic region.

Lipoxenous ( $h_{\left.i p-o k s^{\prime}-e n-u s\right)}^{\text {[ }} \lambda \varepsilon i \pi \varepsilon c v$, to leave; $\xi^{\prime} v o s$, host]. In biology, applied to a parasite that leaves its host and completes its existence independently.

Lippa (liph'-ah). Lippitudo, q. v.

Lippia (lip'-e-ah) [after Augustus Lippi, a French physician]. A genus of verbenaceous plants. The leaves of L. mexicana, growing in Mexico and the U. S., are demulcent and expectorant, and do not nauseate. Dose of the tincture $3^{55-j}$. L. dulcis and L. graveolens have similar uses. Unof.

Lippich's Polarimeter. A polarimeter for the quantitative determination of sugar in the urine.

Lippiol (lip'-e-öl) [lippia; oleum, oil]. A medicinal camphor derivable from Lippia mexicana. Unof.

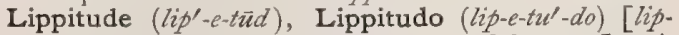
pus, blear-eyed; a watery condition of the eyes]. A condition marked by a moist and raw margin of the eyelids, with a discharge of purulent matter. L. angularis, a chronic inflammation of the lids at the external canthus. L. neonatorum, ophthalmia neonatorum.

Lipsis (lipp'sis) [ $\lambda \varepsilon i \psi \iota s$ a leaving]. Cessation; ending. L. animi, fainting.

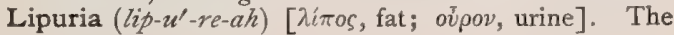
presence of fat in the urine. 


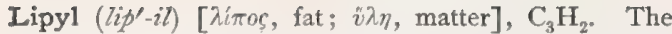
supposed radicle of glycerin; also, an old name for glyceryl, $\mathrm{C}_{3} \mathrm{H}_{5}$

Liquable (lik'-wah-bl) [liquare, to render liquid]. Capable of being liquefied.

Liquamen ( $l i k^{\prime}-$ wam-en) [liquare, to render liquid]. The liquid obtained by melting solids.

Liquation (lik-wa'-shun) [liquare, to render liquid]. The process of melting.

Liquefacient (lik-zue-fa'-se-eni) [liquefaciens, liquefying]. I. Having the power to liquefy or soften. 2. An agent that has the power to liquefy a hard deposit or growth.

Liquefaction (lik-zve-fak'-shun) [liquefactio; liquefacere, to change to liquid form]. The condition of having been changed to a liquid; the process of change into a liquid. L.-necrosis. See Necrosis.

Liquefactive (lik-we-fak'-tiv) [liquefacere, to render liquid]. Pertaining to, causing, or characterized by liquefaction.

Liquescent (lik-wes'-ent) [liquescere, to become liquid]. Becoming, or tending to become, liquid.

Liqueur (lik-ur') [Fr. for "liquor"]. Any cordial or alcoholic drink; especially a compound of alcohol with some flavoring-agent, usually a mixture of aromatic oils; it is often combined with a bitter substance derived from herbs. Formerly the liquors were used as remedies, but now they are mostly served with the meals. Some are employed as vehicles for various remedies.

Liquid (lik'-wid) [liquidus; liquere, to melt]. That form of a substance in which the molecules are in a state intermediate between attraction and repulsion; a substance that flows and takes the shape of the containing-vessel. Water between $0^{\circ}$ and $100^{\circ} \mathrm{C}$. is the best example. L. Acid-green. See Pigments, Conspectus of. L.-blue. Same as Indigo-blue. L. Gelatin. See Gelatin. L. Glue. See Glue, L., Hager's, a substitute for ammonium sulphid or hydrogen sulphid, made by dissolving 0.2 gram of sulphur lotum in $5 \mathrm{cgm}$. of carbon bisulphid, and adding $5 \mathrm{cgm}$. of benzene and $\mathrm{Io} \mathrm{cgm}$. of ether. L. Indigo-blue. Same as Soluble Blue. L., Maynard's Adhesive, collodion. L. of Regnauld. See Anesthetic.

Liquidambar (lik'-vid-am'-bar) [liquidus, liquid; ambar, amber]. A genus of hamamelidaceous trees. L. altingia, of Malaysia, affords a portion of commercial styrax. L. orientale, of Asia, affords Styrax, q. v. L. Styraciflua, of North America (sweet-gum, bilsted, copalm) affords a stimulant gum, and is useful in diarrheas and in coughs and colds. The name of liquidambar has been applied to the sweet-gale or sweet-fern (Comptonia asplenifolia). Unof.

Liquidity (lik-wid'-it-e) [liquidus, liquid]. Fluidity; the state of being liquid.

Liquiform (lik'-wif-orm) [liquor, liquid; forma, form]. Of the nature of a liquid.

Liquor (lik'-or or $l i^{\prime}$-kwor) [L.]. A liquid. In pharmacy, any solution in water of non-volatile substances, except infusions, decoctions, syrups, but including the solution of gutta-percha (in chloroform). There are 20 official liquores; and a large number besides are given in the "U. S. Dispensatory" from the "National Formulary" and the British Pharmacopeia. In anatomy, any fluid of the body. L. acidus halleri, consists of I part of sulphuric acid and 3 parts of alcohol, colored by red-poppy petals. L. amnii, the liquid contained in the amniotic sac in which the fetus lies. Its normal quantity is from one to two pints. At the middle of pregnancy it equals in weight that of the fetus. It serves a number of useful functions, and in labor protects the fetus and cord from pressure, dilates the os and lubricates the genital canal. L. Cotunnii, the perilymph secreted by the fibro-serous membrane of the internal ear. L. entericus, the intestinal juice. L. folliculi, the fluid filling the follicle or space about the developing ovum in the ovary, L. gastricus, the gastric juice. L., Labarraque's, liquor sodæ chloratæ. L. lymphæ, the fluid portion of lymph, analogous to liquor sanguinis. L., Malt, a name given to beer, ale, stout, etc. Malt liquors are made by fermenting an infusion of malt (barley) in the presence of hops and other substances. L. Morgagni, the small quantity of fluid found between the crystalline lens and its capsule. L. pancreaticus, pancreatic juice. L. sanguinis, the blood-plasma; the fluid portion of the blood. $\mathbf{L}$. scarpæ. See Endolymph. L. sedans. See Vibur num. L. seminis, a colorless, transparent, and albuminous liquid, which, along with the spermatozoa and seminal granules, constitutes the semen. L., Spirituous, a distilled alcoholic liquor. L. stypticus, liquor ferri chloridi.

Liquorice (lik'-or-is). See Glycyrrtiza. L., Wild. See Abrus.

Lirate $\left(l l^{\prime}-r \bar{a} t\right)$ [lira, a ridge]. Ridged or furrowed.

Lirella (li-rel' $-a h)$ [lira, a furrow]. In biology, the peculiarly furrowed apothecium of certain lichens.

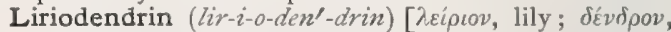
tree]. An alkaloidal precipitate from the bark of Liriodendron tulipifera. It is stimulant, tonic, and diuretic, and is said to have toxic qualities. Unof.

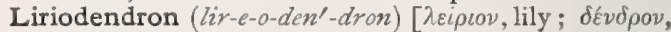
tree]. A genus of magnoliaceous trees. L. tulipifera, of N. America and Asia, is the tulip-tree, miscalled poplar. Its bark is stimulant, tonic, and antipyretic. Dose of the saturated tincture: one fluidram. Unof.

Lisfranc's Operations. See Operations, Table of. L.'s Tubercle, a rough spot on the anterior surface of the first rib near the superior border. It serves for the attachment of the scalenus anticus muscle.

Lisle's Fever-powder. A powder similar to James's Powder, q.v.

Lisp [ME., lispen, to lisp]. To imperfectly pronounce the sibilant letters.

Lisping (lisp'-ing) [ME., lispen, to lisp]. A defect of speech, natural or acquired, in which sibilant letters are sounded like linguals, especially $s$ as $t$. It sometimes arises from too great length of the tongue.

Lissauer's Angles. See Angles. L., Columns of. See Column. L.'s Tract, a group of fine nerve-fibers in the spinal cord lying ventrad and dorsad of the entrance of the dorsal roots. These fibers, which proceed from dorsal roots at a lower level, are supposed to be in relation with the posterior vesicular column.

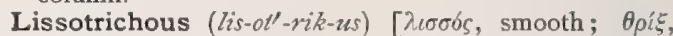
hair]. In biology, having straight, smooth hair; less correctly written leiotrichous and liotrichous.

Listen $\left(l i s^{\prime}-n\right)$ [ME., listnen, to listen]. To give heed to ; to give ear.

Lister's Method. See Listerian Methods, and also, Fractional Cultivation.

Listerian Methods of Dressing Wounds. Carbolic acid was the first antiseptic, but from its volatility and slowness of action as a germicide, it was replaced by corrosive sublimate. But this proved irritating and was precipitated by the albumin of the blood-serum. What might be called the Third Method was the antiseptic dressing called Sero-sublimate Gauze, 
consisting of a gauze charged with a solution of corrosive sublimate in the serum of horses' blood. This was found difficult to manufacture and was harsh and non-absorbent. The Fourth Method consisted in a combination of chlorid of ammonium and bichlorid of mercury, called Sal-alembroth. This was likewise objectionable because of its ready solubility in the blood-serum. Fifth Method, a gauze containing three or four per cent. by weight of the biniodid of mercury. This proved irritating to the skin. A Sixth Method consists in the employment of gauze impregnated with a solution of a double cyanid of zinc and mercury colored with rosanilin. This is said to be non-volatile, unirritating, insoluble in water, and only soluble in 3000 parts of blood-serum. It possesses but little germicidal power, while but I : I 200 keeps animal fluids free from putrefaction. Seventh Method; lately Lister has returned to the use of carbolic acid, preferring it to corrosive sublimate: (I) because it is a more powerful antiseptic; (2) because it has greater penetrating power. He combines it with the use of the double cyanid gauze, preparing the latter with a I to 20 solution of carbolic acid.

Listerine (lis'-ter-in) [after Lister, an English physician]. A proprietary preparation said to contain thyme, eucalyptus, baptisia, gaultheria, and mentha arvensis, with two grains of benzo-boric acid in each dram.

Listerism (lis'-ter-izm) [after Lister, an English physician]. A general name for the antiseptic and aseptic treatment of wounds according to the principles first enunciated by Lister. See Iisterian Methods.

Listing's Law. See Law. L.'s Reduced Eye, in optics, a schematic simplified eye in which there is a mean nodal or principal point lying between the two nodal or principal points, the distance between these two points being so small (only $0.4 \mathrm{~mm}$.) that they may practically be assumed to be one. By this arrangement there is gained but one refractive surface for all the media of the eye. See Eye.

Liter (le'-ter) [litra, a pound]. The unit of capacity in the metric system, equal to 0.88036 of an imperial quart, or I.056 United States quarts ; it is the volume of one kilogram of water at its maximum density.

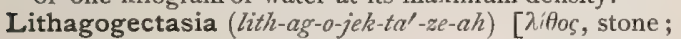

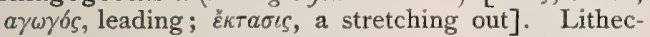
tasy.

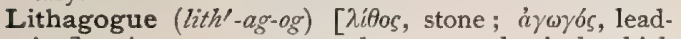
ing]. Any agent or remedy, not mechanical, which tends to expel calculi from the bladder.

Litharge (lith'-arj). See Lead and Pigments, Conspectus of.

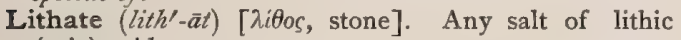
(uric) acid; a urate.

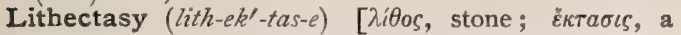
stretching out]. Dilatation of the urethra and neck of the bladder for the removal of calculi.

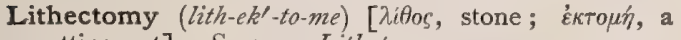
cutting out]. Same as Lithotomy.

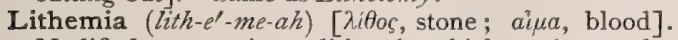
Modified gout. A condition in which, owing to defective metabolism of the nitrogenous elements, the blood becomes charged with deleterious substances, principally, perhaps, of the uric acid group, although their exact chemic nature is not determined.

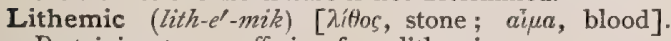
Pertaining to or suffering from lithemia.

Lithenate (lith'-en-āt). See Lithate.

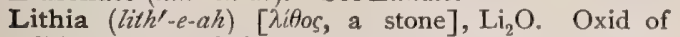
lithium, an alkaline caustic. L. Water, mineral water containing lithium salts in solution. In the United States, are the Buffalo Lithia Water, water from Buffalo Lithia Springs, Mecklenburg County, Va.; Farmville Lithia Water, from Farmville, Va.; Londonderry Lithia Water, from Londonderry N. H. The proportion of bicarbonate of lithia contained in the three waters mentioned is as follows: Londonderry, 8.620, Buffalo, 1.484-2.25, Farmville, 1.99.

Lithiasic Acid (lith-e-as'-ik). Uric acid, q. $v$.

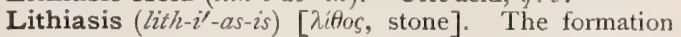
of calculus, especially of urinary calculus, and of gouty concretions in general; also the general state of the body that favors such calculous formation. L. conjunctivæ, an affection of the eyes characterized by calcareous degeneration of the secretion at the mouths of the Meibomian ducts, commonly seen in elderly people, especially such as are rheumatic. On everting the lids the small, yellowish-white concretions, gritty to the touch, may be found.

Lithiate $\left(l i t h^{\prime}-\ell-\bar{a} t\right)$. See Urate.

Lithic (lith'-ik) $\left[\lambda_{\iota} \theta_{l \kappa} b_{s}\right.$, stony]. I. Pertaining to stone, or calculus. 2. Pertaining to lithium. L. Acid. See Acid, Uric.

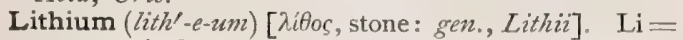
7 ; quantivalence $\mathrm{r}$. One of the rarer alkaline metals, a few of the salts only being used in medicine. See Elements, Table of. Because of its low atomic weight, its high saturating-power makes its salts more highly alkaline than those of sodium and potassium. The carbonate and citrate are used largely in rheumatism and gout. L. benzoas, $\mathrm{LiC}_{7} \mathrm{H}_{5} \mathrm{O}_{2}$. Dose gr. $\mathrm{ij}-\mathrm{x}$. See Benzoic Acid. L. bromidum, LiBr. See Bromin. L. carbonas, $\mathrm{Li}_{2} \mathrm{CO}_{3}$, not deliquescent. Dose gr. ij-xv. L.-carmin Solution. See Stains, Table of. L. citras, $\mathrm{Li}_{3} \mathrm{C}_{6} \mathrm{H}_{5} \mathrm{O}_{7}$, deliquescent. Dose gr. $\mathrm{v}-\mathrm{xxx}$. L. guaiacus, contains 3 parts of guaiacum and $I$ of lithium. Dose gr. v. L. hippuras, used in gout. Dose gr. v-x. L. oxidum. See Lithia. L. salicylas, $2 \mathrm{LiC}_{7} \mathrm{H}_{5} \mathrm{O}_{3} . \mathrm{H}_{2} \mathrm{O}$. See Salix. Liquor lithiæ effervescens (B. P.), useful in gout. Dose $\mathrm{f} \precsim \mathrm{v}-\mathrm{x}$.

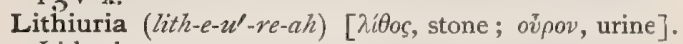
Lithuria, $q . v$.

Lithobexis (lith-o-beks'-is) [ $\lambda i \theta a s$, stone; $\beta \eta \xi \xi$, cough]. Cough with expectoration of calcareous particles.

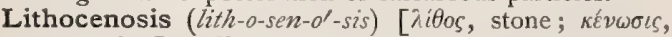
evacuation]. The extraction of the fragments of calculi that have been crushed or mechanically divided.

Lithoclast (lith'-o-klast). See Lithotrite:

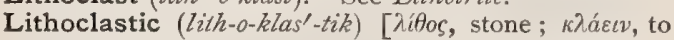
break]. Relating to the surgical crushing of a calculus in the bladder.

Lithoclasty (lith'-o-klas-te). Lithotrity, $q . v$.

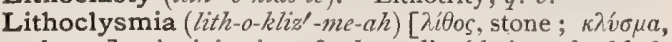
clyster]. An injection of solvent liquids into the bladder for the removal of calculi.

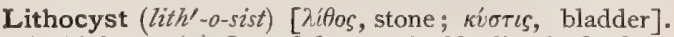
In biology : $(a)$ One of the marginal bodies, in the form of little bags of crystals, found in the covered-eyed Meduse; rudimentary or incipient organs of vision; they are the exclusive seat of spontaneity, so far as the so-called "primary movements" are concerned. (b) One of the "crystal-cells" of plants.

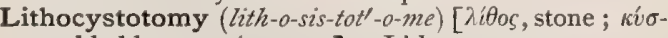

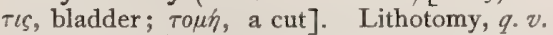

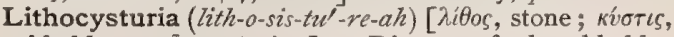
bladder; ovpov, urine]. Disease of the bladder caused by lithuria.

Lithodectasy (lith-o-dek'-tas-e). Lithectasy, q. $v$.

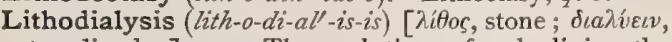
to dissolve]. I. The solution of calculi in the bladder. 2. The surgical operation of breaking or crushing a vesical calculus, previous to its removal by mechanical or other means. 


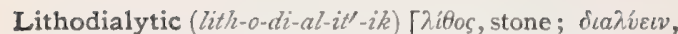
to dissolve]. Relating to or causing lithodialysis.

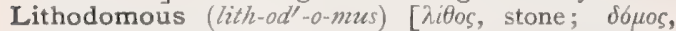
house]. In biology, dwelling in stones.

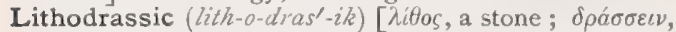
to grasp]. Capable of seizing a stone. L. Forceps, a variety of forceps used in operations for stone in the bladder

Lithodyalisis (lith-o-di-al'-is-is). See Lithoutialysis,

Lithofellic or Lithofellinic Acid (lith-o-fel'-ik, lith-o-

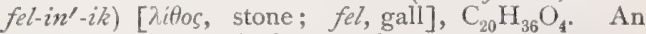
acid found in intestinal concretions.

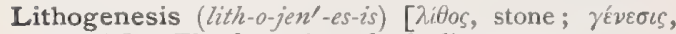
genesis]. The formation of calculi or stones.

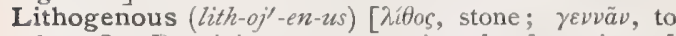
beget]. Pertaining to or causing the formation of calculi or stones.

Lithogeny (lith-oj'-en-e). See Lithogenesis.

Lithoid, Lithoidal (lith'-oid, lith-oid'-al) [ [itHos, stone ; Eidos, like]. Resembling a stone.

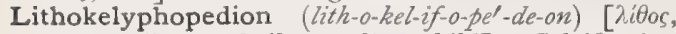
stone; $\kappa \dot{\lambda} \lambda v \phi o s$, shell ; $\pi \alpha \iota \delta i o v$, child]. Calcification of the fetus and the fetal membranes.

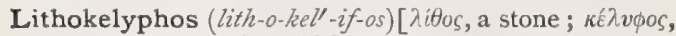
an egg shell]. See Lithopedion.

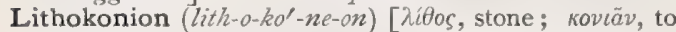
pulverize]. An instrument formerly used in pulverizing vesical calculi.

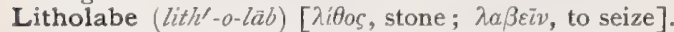
An instrument for grasping and holding a vesical calculus during an operation for its removal.

Litholaby (lith-ol'-a-be). See Lithotrity.

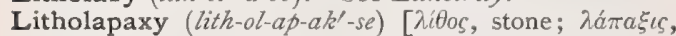
removal]. An operation for crushing stone in the bladder and removing the fragments at the same sitting by irrigation.

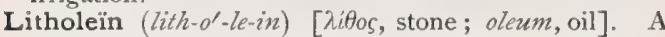
substance similar to vaselin, and, because of its antiseptic and antiparasitic qualities, proposed as a substitute for it. It is oily, of neutral reaction, without smell or taste, and contains no fat.

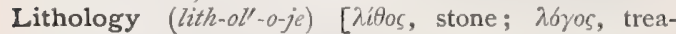
tise]. The science of the nature and treatment of calculi.

Litholysis (lith-ol'-is-is) [ $\lambda i \theta o s$, a stone ; $\lambda \dot{\sigma} \sigma \iota$, solution]. See Lithodialysis. L., Voltaic, electrolytic lithodialysis.

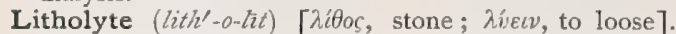
A catheter used in the litholytic treatment of calculi.

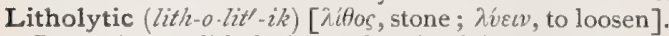
Pertaining to litholysis, or the dissolving of calculi in the bladder.

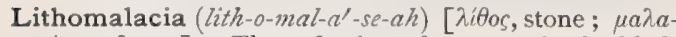
kia, softness]. The softening of a stone in the bladder; the softening of any calculus.

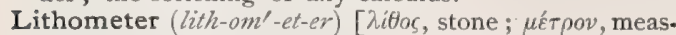
ure]. An instrument for estimating the size of a vesical calculus.

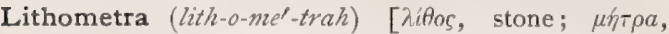
womb]. Ossification or concretion of, or within, the womb.

Lithomyl (lith'-o-mil) [ $\lambda^{\prime}\left(\hat{H}_{0}\right.$, stone; $\mu \dot{\prime} \lambda \eta$, mill]. An instrument for pulverizing a calculus.

Lithomyly (lith-om'-il-e). Same as Lithotrity.

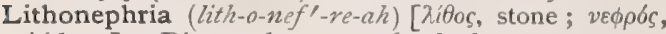
kidney]. Disease due to renal calculus.

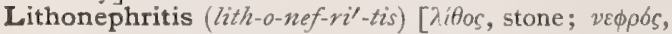
kidney; $\iota \tau \iota \varsigma$, inflammation]. Inflammation of the kidney due to the presence of renal calculi.

Lithonephrotomy (lith-o-nef-rot'-o-me) [ [ittos, stone; $\nu £ \phi \rho o ́ s$, kidney; $\tau o \mu \eta$, a cut]. Surgical incision of the kidney for the removal of a renal calculus.
Lithonlytic, Lithonthryptic (lith-on-lit'-ik, lith-onthrip'-tik). See Lithotriptic

Lithontripsy (lith-on-trip'-se) [ $[\lambda i \theta 0 s$, stone; $\tau \rho i \beta \varepsilon \iota \nu$, to rub]. Synonym of Lithotripsy, q.v.

Lithontriptic (lith-on-lrip'-tik) [ [itos, stone; $\tau \rho i \beta \varepsilon \nu$, to rub]. See Lithotriptic and Antilithic.

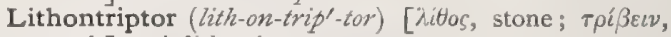
to rub]. A lithotrite.

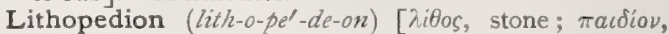
child]. The calcified or mummified remains of a dead fetus carried in the uterus, its appendages, or the abdominal cavity, sometimes long beyond the normal period of gestation.

Lithophagy (lith-off'-aj-e). See Lithotrity.

Lithophan (lith'-o-fan). See Pigments, Conspectus of.

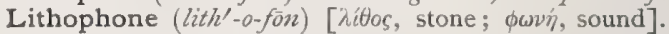
An instrument for detecting by sound the presence of calculi in the bladder.

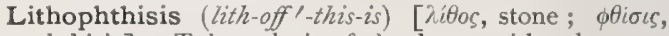
phthisis]. Tuberculosis of the lungs with calcareous concretions.

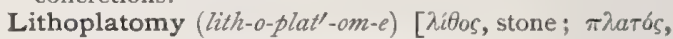
wide]. Removal of a vesical calculus by dilating the urethra.

Lithopriny (lith-op'-rin-e). See Lithotrity.

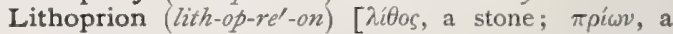
saw]. An instrument for sawing instead of crushing a vesical calculus.

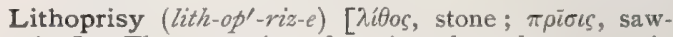
ing]. The operation of sawing through a stone in the bladder.

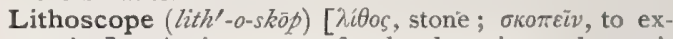
amine]. An instrument for the detection and examination of calculi in the bladder.

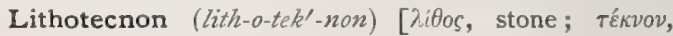
child]. Same as Lithopedion, q. $\%$.

Lithoterethrum, Lithoteretron (lith-o-ter'-eth-mum,

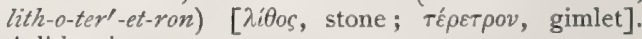
A lithotrite.

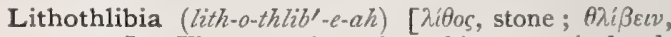
to press]. The operation of crushing a vesical calculus between a sound introduced into the bladder and a finger in the rectum or vagina.

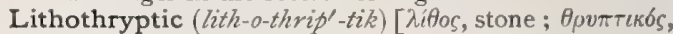
breaking; $\theta \rho v \pi \tau \varepsilon \iota v$, to break]. Same as Lithotritic.

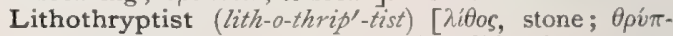
$\tau \varepsilon \iota v$, to break]. One who practises lithotrity.

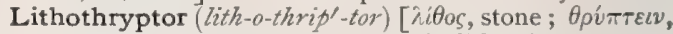
to break]. An instrument used in lithotrity.

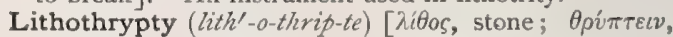
to break]. Lithotrity; the operation of crushing a calculus.

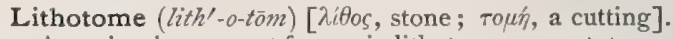
A cutting-instrument for use in lithotomy; a cystotome. L. cache, a lithotome in which the blade is concealed, but is readily made to protrude after the introduction of the instrument.

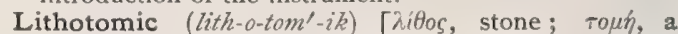
cutting]. Relating to lithotomy. I. Posture, See Postures, Table of.

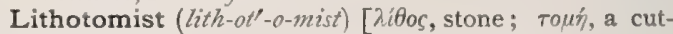
ting]. A surgeon who practises or performs lithotomy.

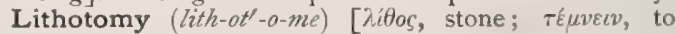
cut]. Incision into the bladder to remove a calculus. L., Bilateral, entrance into the bladder by means of a curved incision into the perineum just in front of the rectum, the lithotome entering by an incision into the urethra at this point. L., Central. See L., Median. L., High, L., Hypogastric, a suprapubic cystotomy for the removal of a stone. L., Lateral, the perineal incision is about $I \frac{1}{2}$ inches in front of the rectum and to the left of the raphe, the cut being 
downward and outward, with the patient on his back and the thighs elevated. L., Median or Marian, the perineal incision is made in the median line one-half inch in front of the anus, by a straight, double-edged bistoury. L., Medio-bilateral, a modification of the bilateral, consisting in a median incision through the perineum, with division of each lateral lobe of the prostate. L., Medio-lateral, a modification of the lateral operation, the perineal incision being made in the median line, and the prostatic incision laterally. L., Perineal, a lithotomy through a perineal incision. L. Position. See Postures, Table of. L., Pre-rectal, a modification of the bilateral, in which after a median incision through the perineum, the anterior wall of the rectum is dissected from the bulb of the urethra, and the membranous urethra is punictured just anterior to the prostate, the latter being divided by the lithotome. L., Recto-vesical, extraction of a vesical stone by an incision through the rectum. L., Renal, Nephrolithotomy. L., Supra-pubic, by an incision above the pubis at a point where the bladder is not covered by peritoneum. L., Urethral, an incision through the membraneous portion of the urethra for removal of a calculus imbedded in the urethra. L., Vaginal, by incision through the vaginal wall.

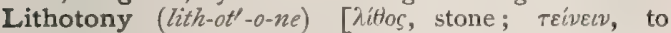
stretch]. Removal of a vesical calculus through an artificial fistula, which is gradually dilated.

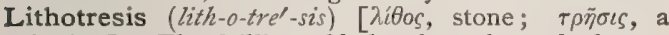
boring]. The drilling of holes through a calculus, as a step in its destruction and removal.

Lithotripsy (lith-o-trip'-se) [ $\lambda i \theta 0 s$, stone; $\tau \rho i \beta \varepsilon v \nu$, to rub]. The operation of crushing calculi of the bladder. See annexed illustration.

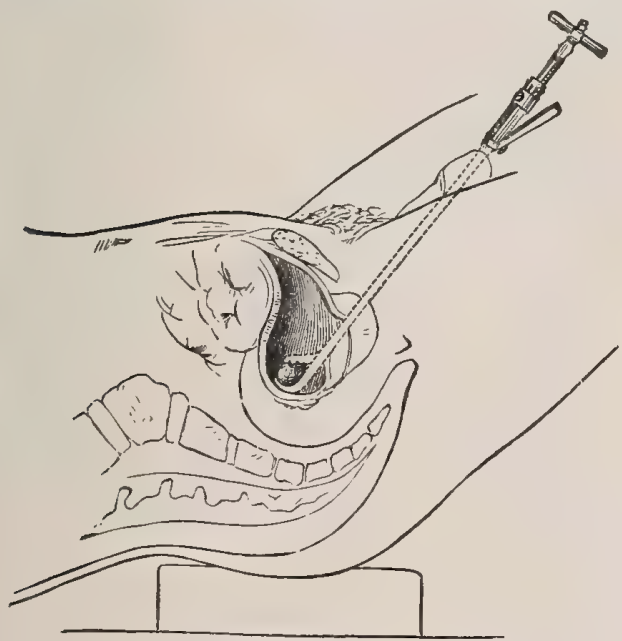

The Lithotrite in Position DURING the Operation OF LITHOTRITY.

Lithotriptic (lith-o-trip'-tik) [ $[\lambda i \theta o s$, stone; $\tau \rho i \beta \varepsilon \iota v$, to rub]. Relating to lithotripsy.

Lithotriptor (lith-o-trip'-tor) [ $\left[\lambda i \theta o s\right.$, stone ; $\tau \rho^{\prime} \beta \varepsilon \varepsilon v$, to rub]. An instrument designed for crushing calculi in the bladder. L., Urethral, an instrument for crushing urethral calculi.

Lithotrite (lith'-o-trit) [ $\lambda i \theta o s$, stone ; terere, to rub]. An instrument for crushing or pulverizing a vesical calculus.

Lithotritic (lith-o-trit'-ik) [ $\lambda i \theta$ os, stone; terere, to rub]. Pertaining to lithotrity.

Lithotrity (lith-ot'-rit-e), Lithotriture (lith-ot' -rit-ür
[ $\lambda i \theta 0 s$, stone; terere, to rub]. The process of crushing a stone in the bladder, by the lithotrite, into fragments small enough to pass through the urethral-canal. L., Electric, lithotrity by means of electrolysis.

Lithotrypsis (lith-o-trip'-sis). Same as Lithotrity, q.v.

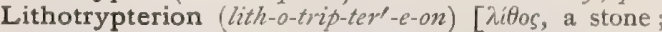
$\tau \rho i \beta \varepsilon \imath$, to rub]. A small lithotrite.

Lithotryptor (lith-o-trip'-tor), Lythotrypter (lith-otrip'-ter). Same as Lithotrite, q. $v$.

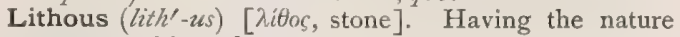
or composition of stone.

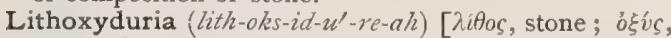
acid; ovpov, urine]. The morbid presence of xanthic oxid in the urine.

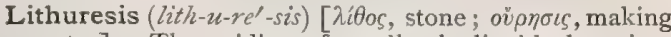
water]. The voiding of small calculi with the urine.

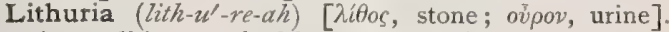
A condition marked by excess of lithic acid, or its salts, in the urine.

Lithurorrhea (lith-u-ror-e'-ah). Same as Lithuresis.

Litigation Symptoms. Various vague manifestations of nervous shock following injury, concerning which the question of malingering arises, and which may become the subject of medico-legal inquiry.

Litmate (lit'-māt) [Dan., lac, lac; moes, pulp]. A salt of litmic acid.

Litmic Acid (lit'-mik) [Dan., lac, lac; moes, pulp]. A constituent of litmus.

Litmus (lit'-mus) [Dan., lac, lac; moes, pulp]. Archil. A blue pigment obtained from Rocella tinctoria, a lichen. It is employed in chemic determinations to detect the presence of acids and alkalies. See Pigments, Conspectus of. L. Paper, Blue, unsized paper steeped in a solution of litmus; it turns red on contact with acid solutions. L. Paper, Red, unsized paper steeped in litmus tincture colored red with acid; it turns blue on contact with alkaline solutions. L. Solution, L. Tincture, a solution of litmus used for the determination of reaction as to acidity or alkalinity.

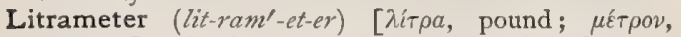
measure]. An instrument for ascertaining the specific gravity of fluids.

Litre (le'-ter). See Liter and Metric System.

Litter (lit'-er) [ME, liter, a litter; lectica, a couch]. An extemporized stretcher or couch, with handles, for carrying the sick or wounded. L., Halsted's, a litter made of two poles, united by two transverse iron bars, and a piece of canvas stretched between the poles. It has four legs, each 14 inches in length. L., Hand, a litter that is carried by hand. L., Schell's, a litter similar to Halsted's, but instead of having stationary legs the handles are hinged, serving as legs.

Little, Disease of. Infantile spasmodic tabes. See Diseases, Table of.

Littoral (lit'-or-al) [litus, litoralis, sea-shore]. Belonging to or inhabiting the shore.

Littre's Glands. See Gland. L.'s Hernia, diverticular hernia. See Diseases, Table of, and Hernia. L.'s Operation. See Operations, Table of. L.'s Suture. See Suture.

Litura (lit-u'-rah) [litura, an erasure, blot, blur: $p l$, Liture]. In biology, a blurred marking.

Liturate (lit'-ut-rāt) [liturare, to erase]. Marked with abrasions of the surface. To abrade.

Live (liv) [ME., liven, to live]. To continue in being. To have life.

Live ( $\hbar v)$ [by apheresis from alive]. Living; animate; manifesting life. L.-birth, birth characterized by "the manifestation of some certain sign or signs of life by the child after it is completely born." L.-blood, the name given to the sensation of fluttering 
in the eyelid, due to spasmodic action of the orbicularis palpebrarum muscle.

Livedo (liv-e'-do) [livere, to grow black]. Same as Livor.

Liver (liv'-er) [ME., liver, liver]. The largest gland in the body, a part of the digestive tract, and situated on the right side of the abdominal cavity, just below the diaphragm. Its functions are: (I) the secretion of bile; (2) the formation of glycogen; (3) the production, at least at a certain period of development, of

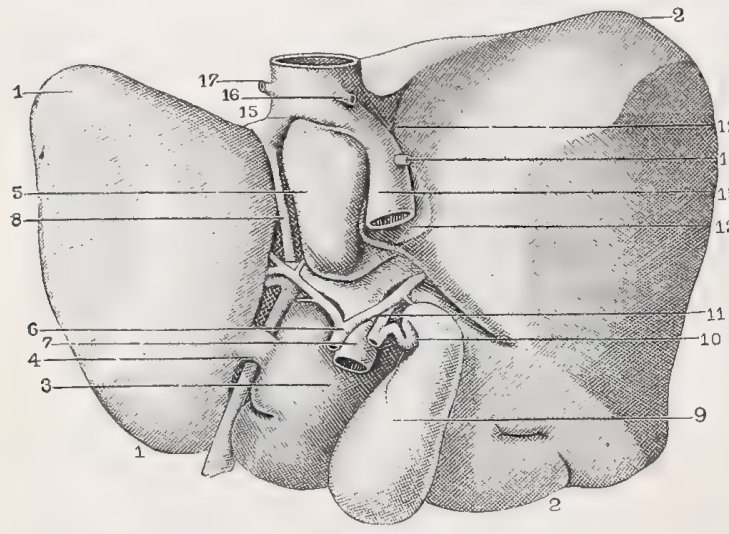

INFERIOR SUIRFACE OF LIVER.

I, I. Left lobe. 2, 2. Right lobe. 3. Quadrate lobe. 4. Caudate lobe. 5. Lobulus spigelii. 6. Hepatic artery. 7. Vena portæ. 8. Fibrous cord from obliteration of the ductus venosus, 9. Gall-bladder. ro. Cystic duct. II. Hepatic duct. 12. Fissure for inferior vena cava. I3. Inferior vena cava. I4. Mouth of capsular vein. 15. Left hepatic vein. I6. Mouth of right diaphragmatic vein. I7. Mouth of left diaphragmatic vein

blood-corpuscles; (4) the destruction of blood-corpuscles ; (5) the formation of a large quantity of urea ; (6) the retention and destruction of certain poisonous substances absorbed from the intestinal tract. Anatomically, it consists of five lobes-the right, the left, the lobus spigelii, the lobus quadratus, and the lobus caudatus. These lobes are made up of lobules or acini, and these again of hepatic cells, capillaries, arteries and veins, lymphatics and biliary channels, each lobule being surrounded by connective tissue. The weight of the liver is between 50 and 60 ounces. L., Albuminoid, or Amyloid, a liver the seat of amyloid degeneration. L., Bacony. Same as L., Amyloid. L., Bastard, the spleen. L., Beavertail, a liver the left lobe of which in form resembles a beaver's tail. L., Biliary Cirrhotic, a liver the seat of chronic inflammation the result of obstruction and distention of the bile-ducts. L.-blotches, liverpatches; a vulgar term for the chloasmata of pregnancy, seen upon the brow and cheeks of the pregnant woman. They may also be present at the menstrual epochs and at the menopause. L., Bronze, a liver discolored by excess of biliary pigment. L., Cirrhotic, a liver the seat of chronic inflammation, with overgrowth of the connective tissue and atrophy of the parenchyma. L.-clapping, in massage, strong percussion of the liver with the full palm of the hand. L.- cough, a reflex cough due to disease of the liver. L., Degraded, the division of the human liver into an unusual number of lobes, such as is normal in the gorilla. L., Drunkard's, usually, a cirrhotic liver. L., Fatty, a liver with marked fatty infiltration and degeneration. L., Floating, a movable condition of the liver, with displacement. L.-fluke. See Trematodes, Distoma, and Parasites (Animal), Table of. L., Hob- nail. See Hobnail Liver. L., Gin-drinkers', or Gin, atrophic cirrhosis of the liver. L., Granulated, or Granular, a cirrhotic liver, with a granular surface, owing to the contraction of the interlobular connective tissue. L., Lænnec's Cirrhosis of, atrophic cirrhosis of the liver. See Diseases, Table of. L.leaf. See Hepatica. L., Leukemic, a liver very much increased in size on account of a diffuse infiltration with leukemic, or lymphoid, tissue. L., Mammillated. See Hobnail Liver. L., Movable. See L., Floating. L., Nutmeg, a condition of the liver met with in heart-disease, fatty infiltration, and amyloid disease. The surface of a section has a peculiar, mottled appearance. The center of the lobules is dark, the periphery lighter in color. L.-pad, a bag or cushion stuffed with medicated materials and worn upon the hypogastric region, for its supposed efficacy in hepatic disease. L.-patches. See L.-blotches. L., Pulsation of. See L.-pulse. L.-pulse, a systolic pulsation over the region of the liver in cases of tricuspid regurgitation. L.-rot, disease in sheep due to the presence in the bile-ducts of the liver of the Distoma hepaticum or Liver-fuke. L.-spot, chloasma; pityriasis versicolor. L.-sugar. Synonym of Glycogen. L. of Sulphur. See Hepar sulphuris. L., Syphilitic, this may be a liver the seat of gummata, which on healing leave scars, or of a diffuse inflammation that may lead to cirrhosis, with atrophy or, especially in hereditary syphilis, to enlargement of the liver. L., Tight-lace, a liver in which the right lobe is thickened vertically from compression, marked by the ribs, and atrophic from constant pressure by tight stays. L., Wandering, a condition occasionally seen in women who have given birth to many children, and in those whose abdominal tissues exhibit unusual laxity. The liver is displaced from its ordinary situation, and falls into the lower portion of the abdomen, where it swings upon its elongated attachments. L., Waxy. See L., Amyloid. L.-wort. See Hepatica.

Livid (liv'-id) [lividus; livere, to be dark]. Discolored from the effects of congestion or contusion; black and blue; pale lead-color.

Lividity (liv-id'-it-e) [lividus, from livere, to be dark]. The state of being livid. L., Cadaveric, or Postmortem, the bluish discoloration in the dependent parts of a corpse, due to the gravitation of the blood. Livor (li'-vor) [livor; livere, to be dark]. Lividity. The discoloration consequent upon severe contusion and congestion of a part; post-mortem sugillation or discoloration of the skin. L. emortualis, change in the color of the skin of a corpse due to putrefaction. L. febris, the lividity occurring during a chill

Lix (liks) [L.: gen., Licis]. Wood-ashes, or the lye therefrom.

Lixivia (liks-iv'-e-ah) [L.]. Same as Lixivium.

Lixivial (liks-iv'-e-al) [lixivia, lye]. Relating to lixiviation.

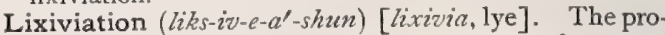
cess of leaching ashes. Also, the process of separating by solution any alkaline salt from the insoluble impurities with which it is mixed.

Lixivious (liks-iv'-e-us) [lixivia, lye]. Lixivial, $q . v$.

Lixivium (liks-iv'-e-um) [lixivia, lye]. The filtrate obtained by leaching ashes; practically a solution of an impure potassium hydrate.

Lizard-tail (liz'-ard-täl). See Saumurus cernums.

Loathing (loth'-ing) [ME., loth, hateful]. Intense disgust, which may excite nausea.

Lobar $\left(10^{\prime}-b a r\right)$ [lobus, a lobe]. Pertaining to a lobe, rather than to a lobule. L. Pneumonia. See Pnewmonia, Croupous. 
Lobate, or Lobed $\left(10^{\prime}-b \bar{a} t\right.$, lobd) [lobus, lobe]. In biology. possessing lobes, or of the form of a lobe.

Lobe $(l o b)[\lambda u \beta o s$, lobus, a lobe $]$. Any one of the parts or divisions into which an organ may be separated by fissures and constrictions; as the lobes of the brain, liver, ear, etc. A more or less rounded part or projection of an organ. Lobes of Brain; each half of the convex cerebral surface is divided by fissures into five lobes, the frontal, parietal, occipital, temporo-sphenoidal, and central, or island of Reil, to which some writers add a fronto-parietal lobe. See Brain and Fissure. Lobes of Liver. See Liver. L., Marginal, the first frontal convolution running along the margin of the longitudinal fissure. Lobes, Optic, the tubercula quadrigemina. L., Slender (of the cerebellum). The fourth of the five lobes on the under surface of either hemisphere of the cerebellum.

Lobelacrin (lo-bel-a'-krin) [from M. de Lobel, a French botanist]. An acrid principle derivable from Lobelia inflata. Unof.

Lobelet $\left(l \bar{b} b^{\prime}-l e t\right)$. Same as Lobulet.

Lobelia $\left(l o-b e^{\prime}-l e-a h\right)$ [from M. de Lobel, a French botanist]. The leaves and tops of $L$. inflata, an expectorant, antispasmodic, and emetic; in larger doses a motor depressant and narcotic. It is valuable in asthma and dry cough, and is the main ingredient of empiric cures for pulmonary tuberculosis. It makes an excellent enema in strangulated hernia. L., Acetum, Io per cent. of the drug. Dose $\eta^{\nabla-3 j}$. L., Fld. Ext. Dose $m j-x$. L., Infus., unof., $z_{j}$ to $\mathrm{Oj}_{\mathrm{j}}$. Dose $3 \mathrm{j}-3 \mathrm{j}$. L., Tinct., 20 per cent. of the drug. Dose $m v-x x x$. L., Tinct., Etherealis (B. P.) Dose $m x-x x x$. The genus Lobelia contains many species, most of them having little-understood medicinal qualities.

Lobelin (lo-be'-lin) [from M. de Lobel, a French botanist]. I. A precipitate from the tincture of Lobelia inflata ; an emetic, nervine, anti-spasmodic, resolvent and relaxant. Dose, as an emetic $I$ to 3 grains in warm water, repeated, if necessary, in ten minutes, until an effect is produced. As a diaphoretic and expectorant from $1 / 4$ to $1 / 2$ grain. Unof. 2. An oily liquid alkaloid, from the plant Lobelia inflata ; actively poisonous. Unof.

Lobopneumonia (lo-bo-nu-mo'-ne-ah). See Pneumonia, Croupous.

Lobstein's Cancer. Retroperitoneal sarcoma. It often attains a considerable size. See Diseases, Table of. $\mathbf{L}$. Disease, idiopathic fragility of the bones without anatomic change.

Lobular (lob'-u-lar) [lobulus, a little lobe]. Like a lobule. Pertaining to any lobule. L. Pneumonia. See Pneumonia, Catarrhal.

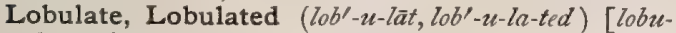
latus, from lobulus, a little lobe]. Consisting of small lobes or lobules.

Lobulation (lob-u-la'shun) [lobulus, small lobe]. Division into lobules. L., Congenital, preservation in adult life of the fetal lobulation of an organ.

Lobule $\left(l o b^{\prime}-\bar{u} l\right)$ [lobus, a lobe]. See Lobulus. L., Oval, the paracentral lobule. L., Paracentral, the superior connecting convolution of the ascending frontal and ascending parietal gyri. L., Pneumogastric, the flocculus of the cerebellum.

Lobulet (lob'-u-let) [dim. of lobulus, a lobule]. A minor lobule, especially of the lung; a group, or series of groups, of five or six air-sacs connected with the dilated end of a bronchiole.

Lobulization $\left(l o b-u-l i z-a^{\prime}-\operatorname{sh} u n\right)$. See Lobulation.

Lobulus $\left(l 0 b^{\prime}-u\right.$-lus) [dim. of lobus, a lobe : pl., Lobuli]. A small lobe or division of an organ. L. caudatus, the tailed lobe, or elevation of the liver that separates the right extremity of the transverse fissure from the commencement of the fissure for the inferior vena cava. L. centralis, the superior vermiform process; the island of Reil. L. corporis striati, the island of Reil; the lenticular nucleus. L. of Ear, the soft mass at the lower part of the pinna of the ear. $\mathbf{L}$. fissuræ sylvii, the island of Reil. L. hepatis anonymus. See Liver, Ouadrate Lobe of. L. paracentralis. See Paracentral Gyrus in Table of Convolutions. L. quadratus, the square lobe upon the inferior surface of the right lobe of the liver. $\mathbf{L}$. spigelii, the lobule projecting from the posterior portion of the inferior surface of the liver. L. tuberis, the nodule of the cerebellum; the supra-marginal gyrus. L. vagi, the flocculus of the cerebellum.

Lobus $\left(l o^{\prime}-b u s\right)$ [L., a lobe]. A lobe. Any well-defined, rounded part of an organ. L. caudatus. See Lobulus. L. opertus, the insula of the brain. L. quadratus. See Lobulus.

Local $\left(l o^{\prime}-k l\right)$ [localis; locus, place]. Not general. Affecting a part or place.

Localization (lo-kal-iz-a'-shun) [locus, a place]. The designation of the seat of any pain, irritation, injury, or

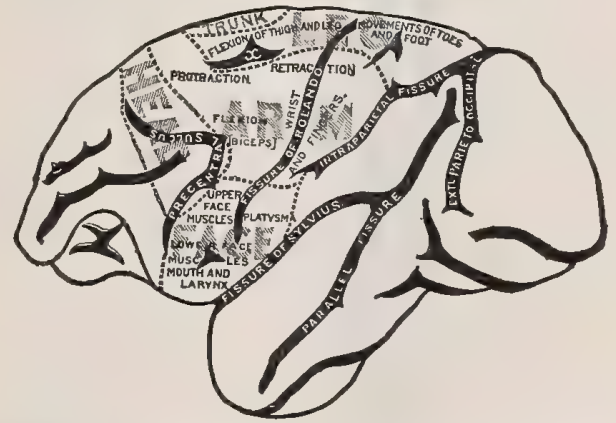

Diagram of THE MOTOR AREAS ON THE OUTER SURface OF A MonKEy's BRAIN. (Horsley and Schäfer.)

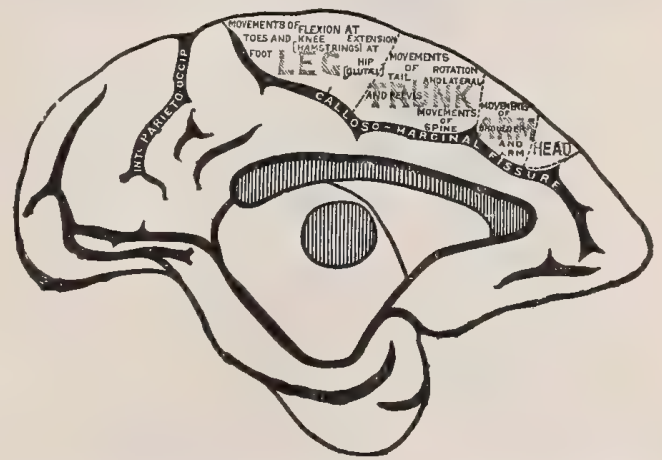

Diagram of the Motor Areas on the Marginal ConvoLUTION OF A MONKEY's BRAIN. (Horsley and Schäfer.)

disease, or the process by which a general condition manifests itself in a particular place. The faculty of locating sensory impressions. L., Cerebral, the determination of the anatomic position of the centers in the brain that preside over certain physiologic acts ; or of the seat of pathologic conditions interfering with the proper function of these centers. See illustrations annexed. L., Spinal-cord; Gowers' table, showing the approximate relations to the spinal nerves of the various functions of the cord, is given herewith. 

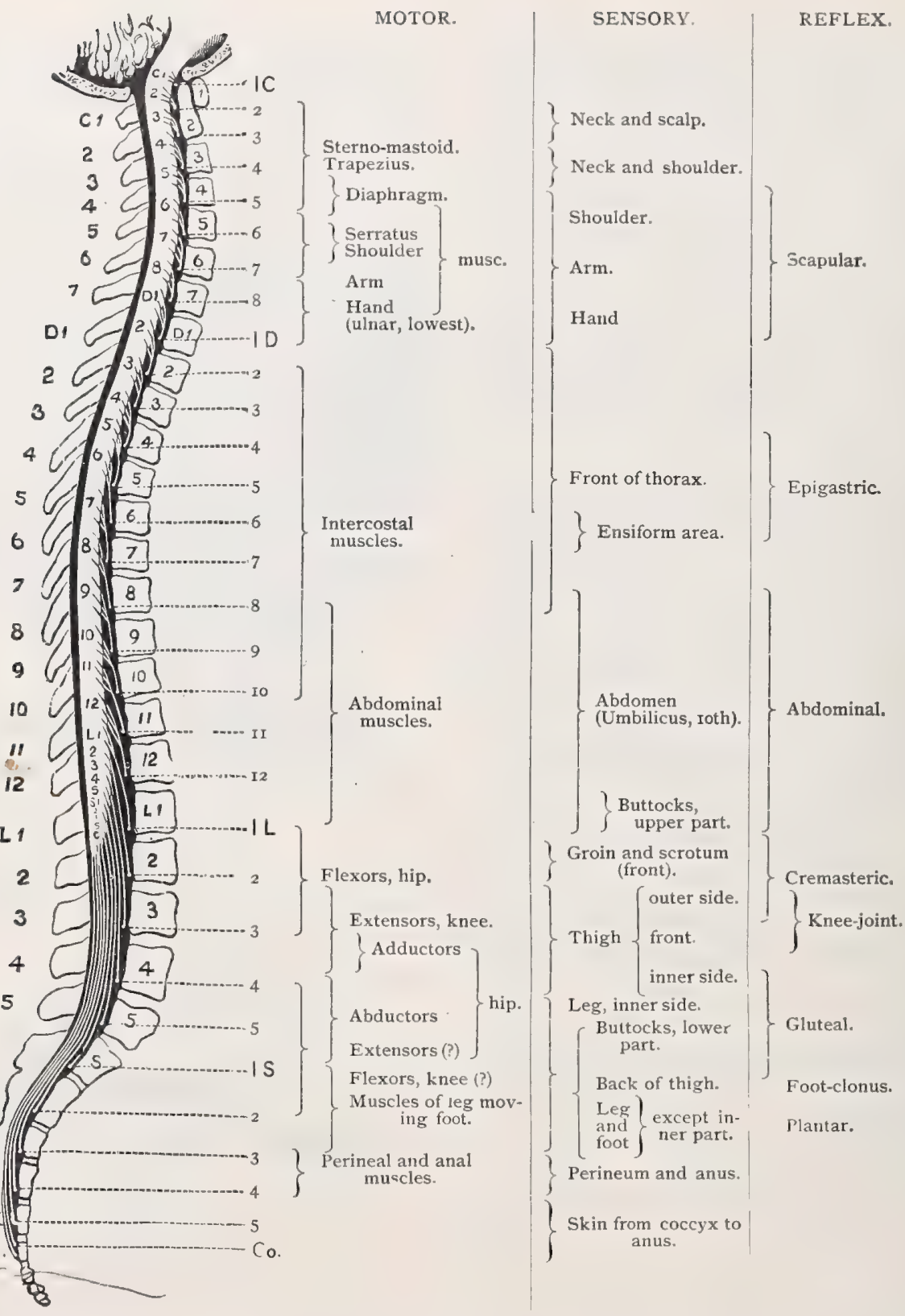

Diagram and Table Showing The Approximate Relation to the Spinal Nerves of the Various Motor, Sensory, AND REFlex FUNCTIONS of THE SPINAL. CoRd. (Arranged by $W . R$. Gowers, from anatomic and pathologic data.)

Localized $\left(l 0^{\prime}-k a l-\bar{\imath} z d\right)$ [locus, a place]. Confined to a particular place.

Locellus (lo-sel'-us) [dim. of loculus, a little place : $p l$., Locelli]. In biology, a subdivision of a loculus.

Loch (lok) [Arab.]. A lincture, or electuary. (Old.)

Lochaditis (lok-ad-i'-tis). Same as Logaditis.

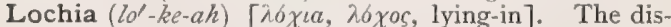
charge from the genital organs during from two to four weeks succeeding labor. L. alba, the whitish flow that takes place from about the seventh day. L. rubra, the sanguineous flow of the first few days. serosa, the serous discharge taking place about the fifth day.

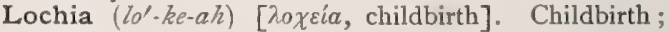
confinement. (Rare.)

Lochial ( $\left.l o^{\prime}-k e-a l\right)[\lambda \sigma \chi \iota \alpha, \lambda \sigma \chi o s$, lying-in]. Pertaining to the lochia.

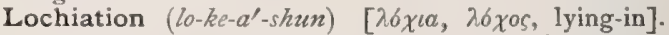
Aveling's term for the excretion of the lochia.

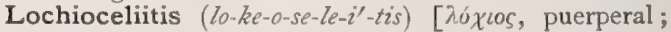

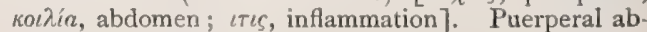
dominal inflammation. 


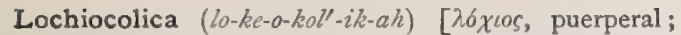

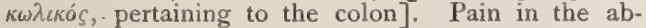
dominal region dependent upon, or associated with, some lochial irregularity.

Lochiodochium (lo-ke-o-do'-ke-um). See Lochodochium.

Lochiometra (lo-ke-o-me'-trah) [ uterus]. A collection of lochia in the uterus.

Lochiopyra (lo-ke-op'-ir-ah) [ióxtos, relating to childbed; $\pi \tilde{v} \rho$, fire, fever]. Puerperal fever. Same as Lochopyra.

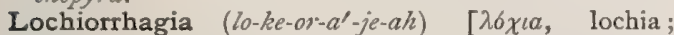
om rvival, to burst forth]. An excessive flow of the lochia.

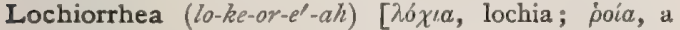
flow]. An abnormal flow of the lochia.

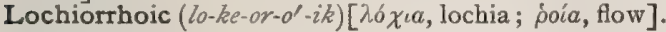
Pertaining to lochiorrhea.

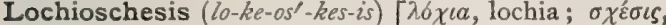
retention]. Suppression or retention of the lochia.

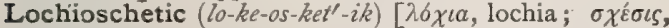
retention]. Pertaining to lochioschesis.

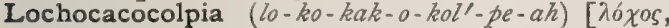

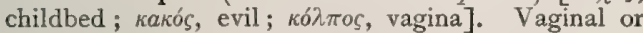
vulval gangrene after childbirth.

Lochoceliitis (lo-ko-se-le-i'tis). See Lochioceliitis.

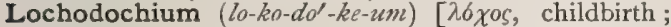
$\delta_{\varepsilon} \chi \varepsilon \sigma \theta a \iota$, to receive]. A lying-in hospital; a maternity.

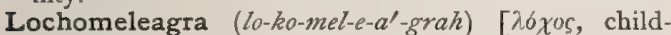
birth; $\mu \varepsilon^{\prime} \lambda o s, \operatorname{limb} ; \dot{a} \gamma \rho a$, seizure]. An attack of pain in the limbs of parturient women.

Lochometritis (lo-ko-me-tri'-tis) [ [óxos, childbirth; $\mu$ ír $\rho a$, womb; $\iota \tau \iota s$, inflammation]. Inflammation of the womb consequent upon delivery; puerperal metritis.

Lochometrophlebitis (lo-ko-me-tro-fle-bi'tis) [ $\lambda 6 \chi^{\prime} 0 s$, childbirth; $\mu \hat{i} \tau \rho \alpha$, womb; $\phi \lambda \hat{\varepsilon} \psi$, vein; $\iota \tau \iota$, inflammation]. Phlebitis of the uterine veins in puerperal women.

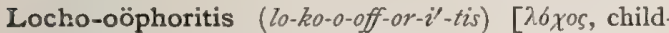

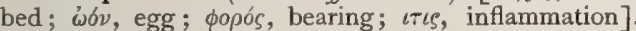
Puerperal inflammation of an ovary.

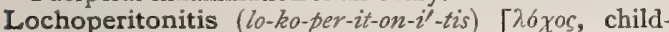

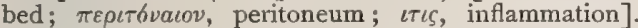
Inflammation of the peritoneum following childbirth.

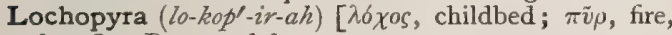
fever]. Puerperal fever.

Lochos $\left(20^{\prime}-k o s\right)$ [ $\lambda \dot{x} \chi o s$, childbirth]. A pregnant woman ; childbed. (Obs.)

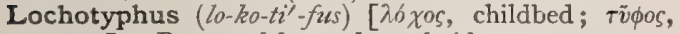
stupor]. Puerperal fever of a typhoid type.

Lock $(l o k)$ [ME., lok, lock]. I. Anything that fastens something else. 2. To fasten by means of a lock; to fasten so as to impede motion. L.-finger, a peculiar and very uncommon affection of the fingers in which they suddenly become fixed in a flexed position. The locking is due to the presence of a small fibrous growth in the sheath of the extensor tendon. L.-hospital, an English hospital for the treatment of venereal diseases; it was originally kept with locked doors, whence the name. L.-jaw, tetanus; trismus. L.-spasm, Weir Mitchell's term for a severe form of writer's cramp, the hand becoming spasmodically firmly contracted, the spasm being followed by complete relaxation.

Locked (lokt) [ME., lok, a lock]. Fastened by means of a lock; immovable. L. Heads. See Head-locking. L. Jaw. See Trismus. L. Joint, Pajet's term for a condition similar to that described as lock-finger, but usually involving a knee-joint.

Loco or L. Plant or L. Weed $\left(10^{\prime}-k_{0}\right)$ [Sp. for "crazy" ]. A name given in parts of the U. S. to various species of Astragalus, Hosackia, Oxytropis, and Sophora, poisonous plants that are believed to cause loco-disease in cattle and horses. L.-disease, a local epizoötic disease of cattle and horses, believed to be liable to follow the eating of any one of the plants called loco.

Locoed $\left(L^{\prime} \cdot k \bar{o} d\right)$ [Sp., loco, crazy]. Suffering from Loco-disease, $q . v$.

Locomobile (lo-ko-mo'-bil) [locus, place; motilis, movable]. Having the power to change place, or to move from a place.

Locomobility (lo-ko-mo-bil'-it-e) [locus, place ; mobilis, movable]. The quality of being locomobile.

Locomotility (lo-ko-mo-til'-it-e) [locus, place; motilitas, motility]. The quality or power of moving from place to place.

Locomotion (Lo-ko-mo'-shun) [locus, place; movere, to move]. Animal movement. L. of an Artery, the straightening out of a curved artery under the impulse of the pulse-wave.

Locomotive (lo-ko-mo'-tiv) [locus, a place; movere, to move]. Moving from place to place; able to change its place; pertaining to locomotion. L. Pulse. See Corrigan's Pulse.

Locomotivity (lo-ko-tno-tiv'-it-e) [locus, place; movere, to move]. The power to move from one place to another.

Locomotor (lo-ko-mo'-tor) [locus, a place; motor, a mover]. I. Pertaining to locomotion. 2. That which moves from place to place. L. Ataxia, or L. Ataxy. See Ataxy and Tabes.

Locomotorium (lo-ko-mo-to'-re-um) [locus, a place; motor, mover: pl., Locomotoria]. In biology, the motive apparatus of an organism; the bones, muscles, and tendons.

Locomotory (lo-ko-mo'-tor-e) [locus, place; movere, to move]. Pertaining to locomotion.

Loculament (lok'-u-lam-ent) [loculamentum, a case, box, cell]. Same as Loculus.

Loculamentum (lok-u-lam-en'-tum). Same as Loculus.

Locular, Loculate (lok'-u-lar, lo $k^{\prime}-u$-lāt $)$ [loculus, a cell]. In biology, possessing one or more cell-like subdivisions; divided into or having loculi.

Locule $\left(l o k^{\prime}+\bar{u} l\right)$. See Loculus.

Loculicidal (lok-u-lis-i'-dal) [loculus, a cell ; cadere, to cut]. In biology, applied to seed-capsules that split open along the dorsal suture.

Loculus (lok'-u-lus) [dim. of locus, a place: $p l$., Loculi]. In biology, a small space or cavity; a small compartment or cell, as the seed-chamber of a fruit.

Locus $\left(l^{\prime}-k u s\right)$ [L. : pl., Loci]. An indefinite term in anatomy, meaning a place or position. L. cinereus, L. coruleus, L. ferrugineus, a bluish-tinted eminence on the fasciculi teretes of the fourth ventricle of the brain. L. luteus, the regio olfactoria of the nose; so called from the yellowish color of the epithelium. L. minoris resistentia, a spot of diminished resistance-a term given to a locality, varying in different individuals, and often accidentally developed, whose resistance to the invasion of disease is less than that of other parts. L. niger, a dark area in the center of a section of the crus cerebri. See Intercalatum. L. perforatus, a name given to the anterior and the posterior perforated space at the base of the brain through which many vessels pass. L. prædilectiorus, the point of election. L. ruber, the red nucleus of the tegmentum.

Locust-tree. See Hymenœa courbaril.

Lodicle $\left(l o d^{\prime}-i k-l\right)$. Same as Lodicule.

Lodicula (lod-ik'-u-lah). Same as Lodicule. 
Lodicule $\left(l o d^{\prime}-i k-\vec{u} l\right)$ [lodicula, dim. of lodix, a coverlet]. In biology, a small scale found between the stamens and palet of many grasses.

Lodoicea (lod-o-is'-e-ah) [after Laodice, daughter of Priam, King of Troy]. A genus of palms. L. sechellarum, the double-cocoanut tree, a palm of the Seychelle Islands. This tree and its double nut are highly esteemed in the East, where magic virtues are ascribed to the fruit. Latterly a fluid extract of the plants has been recommended as a tonic, febrifuge, and alexipharmac. Dose, gtt. $i j-v$. Unof.

Loeb, Bacillus of. See Bacteria, Synon'matic Table of.

Loebisch's Formula. See Christison's Formula.

Löffler's Alkaline Solution. A staining-agent used in the histologic laboratory. See Stains, Table of. L.'s Bacillus, the bacillus of diphtheria. See Bacitlus, Klebs-Löffer's, under Bacteria, Synonymatic Table of. L.'s Blood-serum Mixture, a mixture consisting of one part of neutral meat-infusion bouillon containing Io per cent. of grape-sugar and 3 parts of blood-serum; it is a culture-medium. L.'s Method, a method of staining the flagella of microörganisms. See Stains, Table of.

Lŏhlein's Diameter. In pelvimetry, the internal ascending oblique diameter, measured by the finger in the vagina from the center of the sub-pubic ligament to the upper anterior angle of the great sacro-sciatic foramen. It is $2 \mathrm{~cm}$. Iess than the transverse diameter of the superior strait of the pelvis.

Lœmia (lem'-e-ah). See Loimia.

Lœmic $\left(l e m^{\prime}-i k\right)$. See Loimic

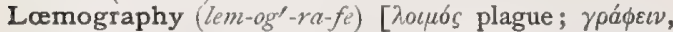
to write]. See Loimology.

Lomoid (lem'-oid). See Loimic.

Lœmology (lem-ol'-o-je). See Loimology.

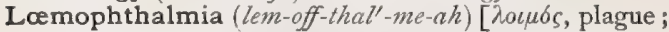
$\dot{\delta} \phi \theta a \lambda u i a$, ophthalmia]. A contagious ophthalmia.

Löwe's Oak-red. See Oak-bark. L.'s Reagent or Test, a solution for the detection of sugar in the urine. It consists of subnitrate of bismuth, glycerin, and soda lye. See Tests, Table of. L.'s Ring, a demonstration of the yellow spot of the retina which, in a strong light, appears surrounded by a bright area, two or three times as large as the spot. Clerk-Maxwell's experiment consists in looking through a solution of chrome-alum, when there is seen an oval, purplish spot due to the pigment of the yellow spot.

Lowenberg, Canal of. See Cunal.

Löwit's Method. See Stains, Table of.

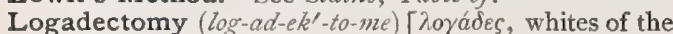
eyes; $\dot{\varepsilon}$ стони, excision]. Excision of a piece of the conjunctiva. (Obs.)

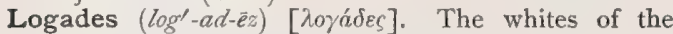
eyes; the sclerotic coats of the eyes. (Obs.)

Logaditis $\left(\log -a d-i^{\prime}-t i s\right)$ [ $\lambda o \gamma a ́ d \varepsilon s$, whites of the eyes; $\iota \tau \iota$, inflammation]. Same as Sclerotitis. (Obs.)

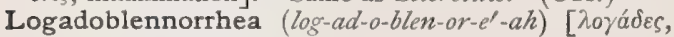
whites of the eyes; $\beta \lambda \varepsilon v v a$, mucus; pnia, flow]. Conjunctival blennorrhea. (Obs.)

Logan Crown. In dentistry, an artificial crown the base of which is deeply recessed, leaving a thin border to be fitted to the natural root. One end of the dowel is baked into the crown during its manufacture. The concavity of the base facilitates the adjustment of the crown to the end of the root, and gives a more permanent form to the cement holding the dowel or post.

Loganin (log'-an-in), $\mathrm{C}_{25} \mathrm{H}_{34} \mathrm{O}_{14}$. A glucosid extracted from strychnos seeds.

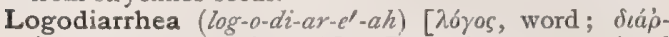
joca, a flowing through]. Excessive or maniacal loquacity.

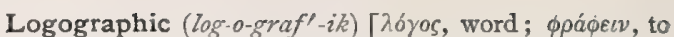
write]. Pertaining to written words. L. Alalia, that in which the thoughts cannot be expressed in writing.

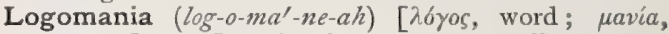
madness]. I. Insanity characterized by talkativeness. 2. Aphasia.

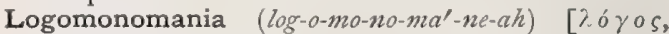

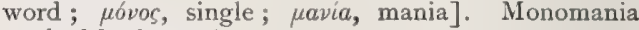
marked by loquacity.

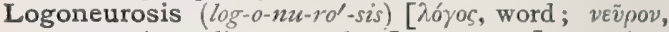
nerve; $v 6 \sigma o s$, disease : pl., Logoneuroses]. I. Any neurosis marked by a speech-defect. 2. Any neurosis attended with impairment of the mental powers.

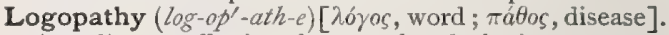
Any disease affecting the speech; dyslogia.

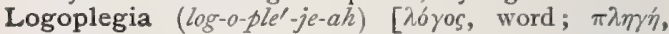
stroke]. An aphasic symptom, consisting in the impossibility of uttering a word, though the memory of its sound is clear.

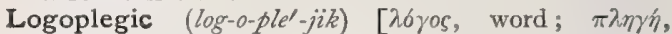
stroke]. Relating to, or characterized by, logoplegia.

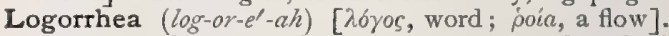
I. Abnormal rapidity of speech; a symptom of cerebral irritation. 2. Same as Logodiarrhea.

Logwood ( $\log ^{\prime}$-roood). See Hematoxylon. L.-black. See Pigments, Conspectus of.

Lohoch $\left(l o^{\prime}-h o k\right)$. Same as Loch.

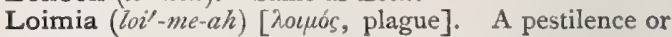
plague.

Loimic $\left(20 i^{\prime}-m i k\right)$ [ ing to the plague or to any pestilence.

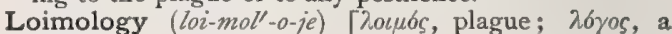
treatise]. The science of contagious epidemic diseases.

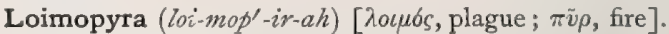
Pestilential fever.

Loin (loin) [ME., loine, loin]. Either of the lumbi, or lower part of the back in the region of the hips.

Loliin (lo'-le-in) [lolium, darnel]. A volatile, poisonous alkaloid contained in the seeds of Lolium temulentum.

Lolium (lo'-le-um) [L., darnel]. A genus of grasses, one of which, L. temulentum, poisonous darnel, is remarkable as one of the few grasses that appear to have poisonous qualities. Its seeds in particular are said to have narcotic qualities. By some writers this poisonous effect has been denied, and by others it has been referred to the presence of ergot; late researches seem to confirm the popular belief. Unof.

Loma $\left(l^{\prime}-m a h\right)[\lambda \bar{\omega} \mu \alpha$, hem, fringe: pl., Lomata $]$. In biology, a flap or fringe along the toe of a bird.

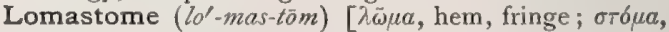
mouth]. In biology, applied to such shells as have a reflected peristome.

Lomatine $\left(10^{\prime}-\right.$ mat-in) $[\lambda \bar{\omega} \mu a$, hem, fringe]. In bio$\operatorname{logy}$, margined or fringed.

Lombardian Leprosy. See Pellagra

Loment $\left(10^{\prime}-m e n t\right)$ [lomentum, a mixture of bean-meal and rice]. In biology, a legume that when ripe breaks transversely into joints.

Lomentum (Lo-men'-tum). Same as Loment.

Lomilomi ( $\left.l 0^{\prime}-m e-l 0^{\prime}-m e\right)$ [Hawaiian]. A kind of shampoo or massage, practised by the Polynesians.

London Paste. A caustic paste containing equal parts of caustic soda and unslaked lime. It must be mixed with water before using. L. White. Same as White Lead.

Long [ME., long, long]. Having great length. L.sight. Synonym of Presbyopia and Hyperopia. L.sightedness. See Hyperopia. L. Thread-worms. See Thread-zorms. 
Longevity (lon-jev'-it-e) [longa, long; vita, life]. Long life.

Longi-(lon'-je-) [longrw, long]. A prefix signifying length or extent.

Longicaudate (lon-je-kaw'-dàt) [longus, long; cauda, a tail]. In biology, having a long tail.

Longiductor (lon-je-duk'-tor) [longrus, long; ductor, leader]. The adductor longus muscle. See Muscles, Table of.

Longimanus (lon-je-ma'-nus) [longus, long; manus, hand]. Long-handed.

Longing (lawng'-ing) [ME., longen, to desire earnestly]. The earnest desire for anything; it is a condition often present in the female during pregnancy.

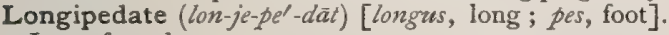
Long-footed.

Longiperoneus (lon-je-per-o-ne'-us) [longzus, long; $\pi \varepsilon \rho o ́ v \eta$ fibula]. The peroneus longus muscle. See Muscles, Table of.

Longipes (lon'-je-pess). See Longipedate.

Longisect (lon-je-sekt') [longus, long; secare, to cut]. To make a longisection, $q . \%$.

Longisection (lon-je-sek'-shun) [longus, long; sectio, cutting]. Longitudinal section; especially used of the body from extremity to extremity. The division of a body into sections parallel with its long axis. See Position and Direction, Table of.

Longissimus (lon-jis'-im-us) [super. of longus, long]. Longest. L. capitis, L. cervicis, the trachelomastoid muscles. See Muscles, Table of. L. dorsi. See Muscles, Table of.

Longitude (lon'-jit-üd) [longitudo, length]. Angular distance from any standard meridian perpendicular to the plane of the axis.

Longitudinal (lon-jit-u'-din-al) [longitudinalis, pertaining to length]. In anatomy, lengthwise, or in a direction the opposite of transverse. L. Fissure, of the cerebrum. See Fissures, Table of. L. Sinus, the triangular subcranial venous channel extending from the crista galli to the tentorium.

Longus (lazeng'-gus) [L., long]. Long. L. colli. See Muscles, Table of. L. capitis, the rectus capitis anticus major muscle. See Muscles, Table of. L. dorsi. The longissimus dorsi muscle. See Muscles, Table of. L. lumborum, an inconstant muscle attached to the bodies of the two upper lumbar vertebræ and the three lower dorsal vertebræ.

Lonsdale's A pparatus. An apparatus for treating fracture of the patella, consisting of movable arms suspended from two upright rods that are attached to a long posterior splint. To these arms are fastened padded plates that hold the fragments together.

Loöch (lo-ok') [Fr.]. Same as Loch.

Loodianah Disease. See Anthrax.

Loofah $\left(l_{0}^{\prime}-f a h\right)$. See Luffa.

Look-at-his-face Disease. Carate; a form of syphilitic skin-disease in Spain, characterized by blotches upon the face.

Loong. See Lung.

Loop [ME., lope, a loop]. A folding of a cord, fiber, tube, or cord-like structure, upon itself. L. of Henle. See Tubuli uriniferi. L., Obstetric, the fillet.

Looped (loopt) [ME., lope, loop]. Doubled upon itself ; containing loops. L. Tubes of Henle. See Tubuli uriniferi.

Loose (luss) [ME., loos, loose]. Lax; wanting power of restraint; as loose bowels. L. Ligature. See Ligature.

Looseness (loos'-nes) [ME., loos, loose]. Popular name for diarrhea. L. of the Teeth, Odontoseisis; Odontosismus; this results from disease of the gums and the gradual destruction of the alveolar processes.
Loosestrife (loos'-strîf). See Lysimachia.

Lophadia (lo-fad'-e-ah). See Lophia.

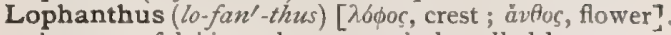
A genus of labiate plants, popularly called hyssops, or hedge-hyssops. L. anisatus, L. nepetoides, and L. urticæfolius of North America have the general properties of the mint-family. Unof.

Lophia $\left(l o^{\prime}-f e-a h\right)[\lambda \sigma \phi o s$, the back of the neck]. The upper part of the back near the first dorsal vertebra.

Lophin $\left(l^{\prime}-f i n\right)[\lambda \sigma \phi o s$, a tuft $], \mathrm{C}_{21} \mathrm{H}_{18} \mathrm{~N}_{2}$. Tripheny] glyoxalin ; a substance produced by distilling amarin. It is not readily soluble in alcohol, crystallizes in long needles, and melts at $275^{\circ} \mathrm{C}$.

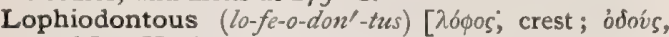
tooth]. Having crested molar teeth.

Lophodont (lo'-fo-dont) [ [ $6 \dot{\phi} \phi \varsigma$, a crest ; ódóvs, tooth]. In biology, applied to that dentition in which the crowns of the molar teeth possess ridges or crests, as distinguished from bunoitont. See Lophiodontous.

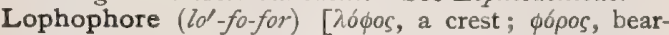
ing]. In biology, the frame or stage surrounding the mouth of a polyzoan and giving support to the tentacles.

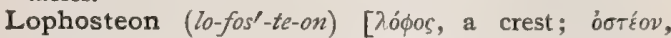
bone: pl., Lophostea ]. In biology, the median one of the five bones that make up the sternum of a carinate bird.

Loquacity (lo-kwas'-it-e) [loquacitos; loquax, talkative]. Volubility of speech; talkativeness; a condition that is frequently excessive in various forms of mental disorder.

Lorate $\left(l^{\prime}-r a \bar{t}\right)$ [lorum, a thong, or lash]. In biology, shaped like a long strap.

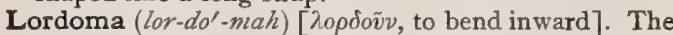
anterior or forward incurvation of the spine.

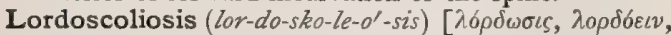
to bend; $\sigma \kappa \omega \lambda i \omega \sigma \iota s$, crookedness]. Lordosis with scoliosis.

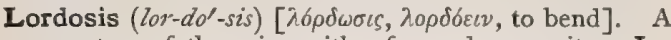
curvature of the spine with a forward convexity. L., Paralytic, lordosis due to paralysis of either the spinal or the abdominal muscles. L. valgorum, genu valgum, q. v.

Lordotic $($ lor-dot'-ik), Lordosic (lor-dos'-ik), Lor-

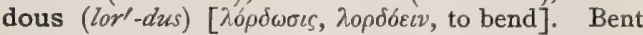
with the convexity turned ventrad; applied to the spinal column.

Lore (lōr) [lorum, a thong, lash, strap]. In biology, the space between the eye and the bill or nostrils in birds and reptiles.

Loreta's Operation. I. The forcible dilatation of the pylorus for the relief of stricture after celiogastrotomy. 2. The treatment of aneurysm by the introduction of metal wire into the sac, through which a current of electricity is then passed. See Operations, Table of.

Lorica (lor-ri'-kah) [L., a corselet, cuirass : pl., Lorica]. In biology, a protective sheath or carapace.

Loricate $\left(l o r^{\prime}-i k-\bar{a} t\right)$ [lorica, a coat of mail]. In biology, covered with a protective coat.

Lorication (lor-ik-a'-shun) [lorica, a leather cuirass] The protection of a glass vessel against heat by a coating of sand and clay.

Loriculate (lor-i $\bar{k}^{\prime}-u$-lät ) [loricula, a small breastplate] Consisting of long divisions.

Lorum $\left(l 0^{\prime}-\right.$ rum $)$ [L., thong, whip, strap: pl., Lora]. Same as Lore.

Lourd, Lourderie (loord, loor'-der-e). See Gid.

Losi-piercing (lo'-se-perr'-sing). See Thoka-losi.

Losophan (lo'-so-fan). Tri-iodo-cresol, an agent said to be strongly parasiticidal, and useful in parasitic dermatoses, whether due to fungous or animal parasites. 
Lostorfer's Corpuscles. The granular masses alleged by Lostorfer to have been found in the blood of syphilitic patients.

Lote (lōt). See Celtis.

Lotio $\left(l 0^{\prime}-\right.$ she-o $)[$ L.]. See Lotion. L. adstringens, Warren's styptic, consisting of five parts of sulphuric acid, and four parts each of turpentine and alcohol. L. nigra. See Hydrargyrum.

Lotion $\left(10^{\prime}-\operatorname{shun}\right)$ [lotio, a wash]. Any medicinal solution intended for external use. L., Black. See $H_{y^{\prime}}$ drargyrum. L., Cold Evaporating, plumbi acet. $\zeta \mathrm{j}$, pulv. opii $\mathbf{3} \mathrm{j}$, aquæ $\mathrm{Oj}$. Or, liq. plumbi subacetat. $\mathrm{f}$ 弓iv, tinct. opii $\mathrm{f} z \mathrm{ij}$, aquæ $\mathrm{Oj}$; for external use. L., Goulard's, liquor plumbi subacetatis. See Plumbum. L. for Mouth, acid pyrolig. $3 \mathrm{j}$, aquæ. $\mathrm{f} z$ viij; use externally. Or, tinct. myrrh $\xi_{\mathrm{ss}}$, potass. chlor. 3 iij, aquæ $f z i v$. L., Red, zinci sulph. gr. x, spts. rosmarin,, tinct. lavand. comp., àă f 3 jss, aq. $\mathrm{f} \xi \mathrm{x}$; use locally.

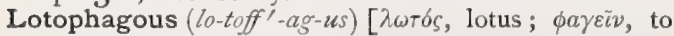
devour]. Lotus-eating.

Lotura $\left(\right.$ lo $\left.t u^{\prime}-r a h\right)$. [L.]. Lotion. L. carnis, L. carnium, a sanguinolent and serous liquid sometimes discharged in cases of dysentery or diarrhea.

Louis's Angina. See Ludwig's Angina. L.'s Angle. See Angle. L.'s Law. See Law.

Louping-ill (loop'-ing-il) [E. dial., loup, to spring]. Leaping-evil: a disease of sheep causing them to spring up in going forward (Scotch). It is due to the presence of a cystic parasite in the spinal canal. See Canums cerebrales, under Parasites (Animal), Table of.

Louse (lows). See Pediculosis.

Lousiness (low'-ze-nes). See Pediculosis.

Lousy (low'-ze) [ME., lows, a louse]. Affected with pediculosis.

Louvred Panes. See Ventilation.

Lovage (luv'-azh) [ME., loveache]. The root of Ligusticum levisticum and Levisticum officinale, stimulant, aromatic, carminative, and emmenagogue drugs. Dose of a fid. ext. $f 3^{j-i j}$. Unof.

Love (luv) [ME., loven, to love]. I. To regard with strong affection. 2. Sexual passion. L.-potion. See Philter.

Low Crown. An artificial crown inserted into the natural root of a tooth; it consists of a gold-backed porcelain facing, to which is attached a combined post and cap, which, from its peculiar form, is called a "step-plug," and which fits into an enlarged rootcanal of a similar form.

Lower, Tubercle of. See Tubercle.

Loxa Bark (loks'-ah bark). Pale cinchona; the bark of Cinchona officinalis.

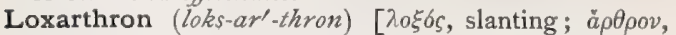
a joint]. Any oblique or abnormal direction of a joint, not caused by spasm or luxation.

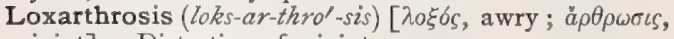
joint]. Distortion of a joint.

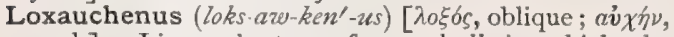
neck]. Lissauer's term for a skull in which the angle formed by the intersection of the radius fixus and a line drawn between the basion and the inion is from $14^{\circ}$ to $20^{\circ}$.

Loxia (loks'-e-ah). See Torticollis.

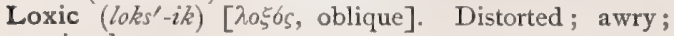
twisted.

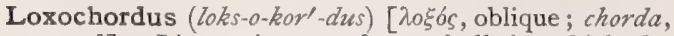
a cord]. Lissauer's term for a skull in which the angle formed between the intersection of the radius fixus and the line drawn from the bregma to the lambda is between $17^{\circ}$ and $29^{\circ}$.

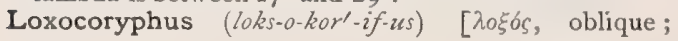

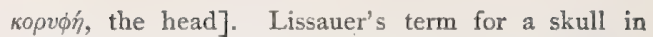
which the angle formed by the intersection of the radius fixus and a line connecting the bregma and the lambda is between $17^{\circ}$ and $28.5^{\circ}$.

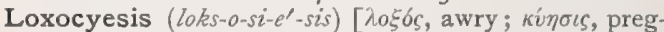
nancy]. Oblique displacement of the gravid uterus,

Loxodont (loks'-o-dont), Loxodontous (loks-o-don'-

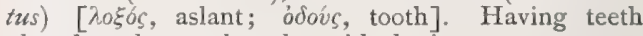
placed at abnormal angles with the jaw.

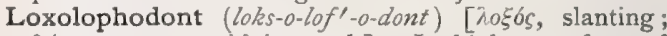
$\lambda$ hoos, a crest; odoís, tooth]. In biology, a form of dentition in which oblique crests connect the anterior internal tubercle of the upper molars with two external tubercles; this is characteristic of a gigantic Ungulate.

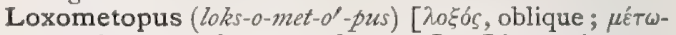
$\pi \circ \nu$, the space between the eyes]. Lissauer's term for a skull in which the angle formed by the intersection of the radius fixus and a line drawn from the bregna to the nasal point is between $43^{\circ}$ and $47^{\circ}$

Loxophthalmos (loks-off-thal'-mos). Synonym of Strabismus, q.v.

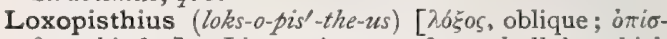
olos, hinder]. Lissauer's term for a skull in which the angle formed by the intersection of the radius fixus and a line drawn through the lambda and the inion is between $95^{\circ}$ and $104^{\circ}$.

Loxopisthocranius (loks-o-pis-tho-kra'-ne-us) [2ogos, oblique ; ó $\iota \iota \theta \varepsilon v$, behind; краviov, skull]. Lissauer's term for a skull in which the angle formed between the radius fixus and a line drawn through the lambda and the opisthion is between $119^{\circ}$ and $130^{\circ}$.

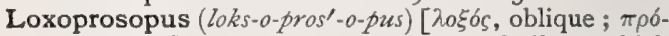
$\sigma \omega \pi \nu \nu$, face]. Lissauer's term for a skull in which the angle formed by the intersection of the radius fixus and a line drawn from the nasion to the alveolar point is between $78.5^{\circ}$ and $89.5^{\circ}$.

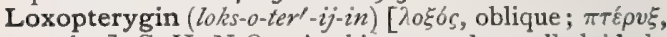
a wing ], $\mathrm{C}_{26} \mathrm{H}_{34} \mathrm{~N}_{2} \mathrm{O}_{2}$. A white amorphous alkaloid obtained from the bark of Loxopterygium lorentzii.

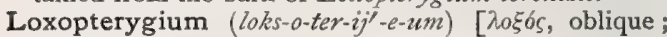
$\pi \tau \varepsilon \hat{\rho} v \xi$, wing]. A genus of anacardiaceous trees. $\mathbf{L}$. lorentzii, L. sagotii, red quebracho, the bark of which is used as a substitute for cinchona. Unof.

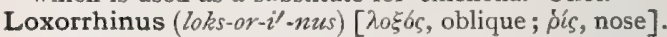
Lissauer's term for a skull in which the angle formed between the radius fixus and a line drawn from the nasion to the subnasal point is between $77.5^{\circ}$ and $87.5^{\circ}$.

Loxotic (loks-ot'-ik). See Loxic.

Loxotmesis (loks-ot-me'-sis). See Loxotomy.

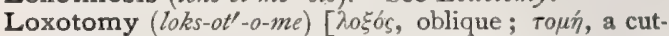
ting]. That form of amputation commonly known as the "oblique section."

Loy's Disease. Horse-pox. See Diseases, Table of.

Lozenge (loz'-enj) [ME., losange, lozenge]. A medicated tablet with sugar as a basis. See Trochiscus.

Lubido ( $h$-bid'-o). See Libido.

Lubricant (lu'-brik-ant) [lubricare, to make smooth]. Making smooth, oily, or slippery.

Lubricating (lu'-brik-a-ting) [lubricare, to make smooth]. Making smooth or slippery. L. Oils, oily products obtained chiefly from petroleum and used for lubricating purposes. Some crude petroleums are natural lubricating oils, requiring little or no treatment to fit them for use. The other petroleum lubricating oils are obtained in one of two ways-either by driving off the light hydrocarbons from the crude oil, yielding what is called a "reduced oil," or they are the oils obtained by distilling the petroleum residuum in tarstills. The lightest of the lubricating oils, varying in gravity from $32^{\circ} \mathrm{B}$. to $38^{\circ} \mathrm{B}$, are frequently called "neutral oils." They are largely used for the purpose of 
mixing with animal or vegetable oils, and it is therefore necessary that they should be thoroughly deodorized, decolorized, and deprived of the blue fluorescence, or "bloom," characteristic of petroleum distillates that contain paraffin. Heavier lubricating oils are called "spindle" oils and "cylinder" oils. The most important characters to be possessed by these oils are high fire-test, low cold-test, and a high degree of viscosity.

Lubrication (hu-brik-a'-shun) [lubricare, to make smooth]. The process of making smooth or slippery by the application of a lubricant.

Lubricity (lu-bris'-it-e) [lubricare, to make slippery]. A synonym of lasciviousness; slipperiness.

Lubricous (lu'-brik-us) [lubricus, lubricare, to make smooth]. Smooth, slippery.

Luca, Horizontal Plane of. See Plane.

Lucent (lu'-sent) [lucere, to shine]. Bright, shining.

Lucernal (hu-ser'-nal) [ucerna, a lamp]. Pertaining to lamp-light.

Lucet, Bacillus of. See Bacteria, Synonymatic Table of.

Lucid $\left(l u^{\prime}-\right.$ sid $)$ [lucidus, clear]. Clear, shining, unobscured. In biology, having a smooth, shining surface. L. Interval, the transitory return of normal mental action and sanity in certain forms and cases of insanity.

Lucidity (lu-sidl-it-e) [lucidus, clear]. Clearness; lucid interval.

Lucidum (lu'-sid-um) [lucidus, clear]. Clear. L., Septum. See Septum.

Luciferase (lu-sif'-er-äz) [lucifer, light-bringing]. The name applied by Dubois to one of the two diastatic substances which become phosphorescent when mixed in the presence of water, and which are found in the mollusc, Pholas dactylifera, the mouth of which is luminous.

Luciferin (lu-sif'-er-in) [lux, lucis, light; ferre, to bear]. A crystalline body obtained from the light-producing organs of certain animals.

Lucifer-match Disease or L.-match Maker's Disease. Necrosis of the jaw due to phosphorus-poisoning.

Luciform (lu'-sif-orm) [lux, light; forma, form]. Resembling light.

Lucifugal (lu-sif'-u-gal) [lux, light; fugere, to flee]. Fleeing from or avoiding light.

Lucifugous (lu-sif'-u-gus) [lux, light; fugere, to flee]. In biology, applied to organisms that avoid light.

Lucilia (lu-sill-e-ah) [L.]. A genus of dipterous insects, the larvæ of which act as facultative parasites, producing various forms of myiasis, $q . v$. See Parasites (Animal), Table of.

Lucilin (lu'-sil-in) [lux, lucis, light]. A commercial mixture of lamp-petroleum and brown coal-oil.

Lucina (lu-si'-nah) [lux, light]. The goddess of childbirth. L. sine coitu. Parthenogenesis, q.v.

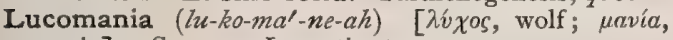
mania]. Same as Lycanthropy, q.v.

Lucuma (lu-ku'-mah) [nat. Peruvian]. A genus of tropical American sapotaceous trees. L. caimito, of S. America (called abi and abiaba) is strongly tonic and antiperiodic, and is useful in diarrhea; other species have similar qualities. Unof.

Lucumin ( $u$-ku-min) [lucuma]. A bitter principle obtained from Lucuma caimito. It is recommended for use in diarrheas and in intermittent fevers. Dose gr. j-viij. Unof.

Ludwig's Angina. A cellulitis of the neck, usually a secondary inflammation in the specific fevers, particularly diphtheria and scarlet fever. It may, however, occur idiopathically or result from trauma. The swelling is marked in the submaxillary region. It is also called Louis's Angina. See Angina, and Diseases, Table of. L.'s Angle (Angulus hudovici), the angle that exists in some cases of emphysema between the manubrium and the body of the sternum. See Angle. L.'s Ganglion. See Ganglia, Table of.

Lücke's Test. See Tests, Table of.

Lues $\left(u^{\prime}\right.$-es) [L.]. Formerly a pestilential disease; at present used as an euphemism for syphilis. L. deifica, L. divina, epilepsy.

Luetic $\left(h-e t^{\prime}-i k\right)$ [lues, a plague]. Affected with or relating to lues; syphilitic.

Luffa (huf'-ah) [Arab.]. A genus of cucurbitaceous plants. L. acutangula, the strainer vine, of India, having an edible fruit, a purgative and emetic root, and oil-bearing seeds. L. amara has similar uses. L. cylindrica, the "wash-rag," "towel gourd," or "vegetable sponge," bears a fruit which when dry contains a sponge-like network of fibers. This is sometimes used as a substitute for a sponge or towel. L. purgans, of S. America, affords a strongly purgative resin. Unof.

Lugol's Caustic. A solution of iodin and potassium iodid, of each one part, in water two parts. L.'s Solution. See Todin.

Lumbaginous (lum-baj'-in-us) [lumbus, loin]. Affected with, or pertaining to, lumbago.

Lumbago (lum-ba'-go) [lumbus, the loin]. Pain in the structures about the loins, whether neuralgic or rheumatic.

Lumbar (lum'-bar) [lumbus, the loin]. Pertaining to the loins, especially to the region about the loins. L. Abscess, an abscess in the lumbar region. L. Arteries. See Arteries, Table of. L. Colotomy. See Lumbo-colotomy. L. Myalgia, lumbago. L. Nephrectomy, nephrectomy through an incision in the lumbar region. L. Nephrotomy, nephrotomy through an incision in the lumbar region. L. Nerves. See Nerves, Table of. L. Reflex. See Reflexes, Table of. L. Region. See Abdomen.

Lumben (lum'.ben) [lumbus, loins]. Belonging to the loin in itself.

Lumberman's Itch. Same as Army Itch.

Lumbifragium (lum-bif-ra'-je-um) [lumbus, loin; frangere, to break]. Lumbar hernia.

Lumbiplex (lum'-be-pleks). The lumbar plexus.

Lumbiplexal (lum-be-pleks'-al) [lumbus, loin; plexus, net]. Pertaining to the lumbiplex.

Lumbo-abdominal (lum'-bo-ab-dom'-in-al) [lumbus, loin; $a b d o m e n$, abdomen]. Pertaining to the loin and the abdomen.

Lumbocolotomy (lum'-bo-ko-lot'-o-me) [lumbus, loin; $\kappa \delta \lambda_{o v}$, colon; $\tau o \mu \eta$, a cutting]. Colotomy performed in the lumbar region.

Lumbo-costal (lum-bo-kos'-tal) [lumbus, loin; costa, rib]. Pertaining to the loins and the ribs.

Lumbodorsal (lum-bo-dor'-sal) [lumbus, loin; dorsum, back]. Pertaining to the lumbar and dorsal regions.

Lumbodynia (lum-bo-din'-e-ah) [lumbus, loin; ódívn, pain]. Same as Lumbago.

Lumbo-inguinal (lum-bo-in'-gzein-al) [lumbus, loin ; inguen, groin]. Pertaining to the lumbar and inguinal regions.

Lumbosacral (lum-bo-sa'-kral) [lumbus, loin; sacrum, sacrum]. Pertaining to the lumbar and sacral regions.

Lumbricales (lum-brik-a'-lēz). See Muscles, Table of.

Lumbricide (hm'-bris-ìd) [lumbricus, earth-worm; ceedere, to kili]. A drug fatal to lumbricoid worms.

Lumbriciform (hm-bris'-if-orm). See Lumbricoid.

Lumbricoid (lum'-brik-oid) [lumbricus, earth-worm;

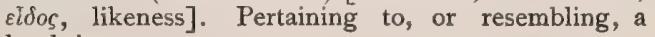
lumbricus. 
Lumbricus (lum'-brik-us) [L.: pl., Lumbrici]. A genus of worms, including the common earth-worm and certain intestinal worms. See Parasites (Animal), Table of.

Lumen (lu'-men) [lumen, light]. The caliber or canal of any tubular vessel; the cavity of a vessel when examined in transverse section.

Luminiferous (lu-min-if'-er-us) [lumen, light; ferre, to bear]. Emitting light.

Luminosity (lu-min-os'-it-e) [luminosus, full of light]. The property of emitting light.

Lumnitzer, Bacillus of. See Bacteria, Synonymatic Table of.

Lump [ME., lompe, a stump]. I. A small mass; a protuberant part. 2. A dull person. 3. In the plural, a popular term for strumous enlargement of the cervical glands.

Lumpy (lum'-pe) [ME., lompe, a stump]. Abounding in, or consisting of, lumps. $L$. Jaw. See Actinomycosis.

Lunacy (lu'-nas-e) [luna, the moon]. A popular name for insanity, so called from the traditional belief that it was influenced by the moon.

Lunar (lu'-nar) [luna, moon]. Pertaining to the moon or to silver (Luna of the alchemists). L. Caustic. See Argentuin and Caustic.

Lunare, or Os lunare $\left(l u-n a^{\prime}-r e\right)$ [luna, moon]. The semilunar bone of the carpus

Lunaria ( $\left.u-n \alpha^{\prime}-r e-a h\right)$ [lunaris, pertaining to the moon]. Menstruation.

Lunate ( $u^{\prime}$-natt) [lunare, bent like a crescent]. In biology, crescent-shaped, or having crescentiform markings.

Lunatic (lu'-nat-ik) [hnaticus; luna, moon] Affected with lunacy or insanity.

Lunatism (lu'-nat-izm) [lunatismus; luna, moon]. An old name for various diseases supposed to be under the controlling influence of the moon.

Lund's Apparatus. A triangular frame of iron used to correct prolapse of the uterus. L.'s Oil, an oil used for anointing catheters. It consists of olive oil and castor oil each one ounce, carbolic acid one dram.

Lune (lim) [luna, moon]. A fit of lunacy or madness.

Lunella (h-nel'-ah) [dim. of luna, moon]. Same as Hypopyon.

Lunet or Lunette (lu-net') [Fr.]. A spectacle-lens. Also, a general term including telescopes, marineglasses, spectacles, and all similar devices to aid vision.

Lung [ME., lunge, lung]. The organ of respiration, in which the impure venous blood is oxidized by the air drawn through the trachea, bronchi, and airvesicles. There are two lungs, a right and a left, the former usually consisting of three, the latter of two lobes. The lungs are situated in the thoracic cavity, and are enveloped by the pleuræ. At the root or hilum the bronchus and its arteries, and the pulmonary artery and nerves enter, and the pulmonary and bronchial veins and lymphatics leave. The lung proper consists of minute air-vesicles held in place by connective-tissue trabeculæ. Capillaries traverse the walls of the air-vesicles and bring the circulating blood in close proximity to the air. The average weight of the adult right lung is 22 ounces; that of the left 20 ounces. L., Black, anthracosis of the lung. L., Coal-miner's, L., Collier's, anthracosis of the lung. L.-fever, croupous pneumonia. L.-grown, having the pleura adherent to the lungs. L., Miner's, anthracosis of the lung. L.-sick, a form of pneumonia prevalent among the oxen of South Africa. L.-struck, suffering from disease of the lungs. L.-tester, a spirometer. L.-worm, a parasitic worm in the lung. L.-wort, the leaves of Pulmonaria officinalis, a demulcent and mucilaginous drug. It is a favorite medicine in lungcomplaints. Dose of the fld. ext. $3^{\text {ss-j. Unof. }}$ 
many of which are poisonous. A large number of the species are American.

Lupinidin (lu-pin'-id'-in) [lupus, a wolf], $\mathrm{C}_{8} \mathrm{H}_{15} \mathrm{~N}$. A liquid alkaloid obtained from Lupinus luteus.

Lupinin (lu'-pin-in) [lupus, a wolf], $\mathrm{C}_{21} \mathrm{H}_{40} \mathrm{~N}_{2} \mathrm{O}_{2}$. An alkaloid, or tertiary amin, from the seeds of Lupinus huteres; also, an alkaloid from the seeds of Lupinus albus; also, a glucosid from the leaves of both species. All three are paralyzants, depressing the motor and sensory centers. The one first named has been proposed as a substitute for quinin.

Lupinosis (lu-pin-o'-sis) [lupus, a wolf]. A disease of cattle said by some to be produced by eating the herbage of certain poisonous species of lupine. See Lathyrism.

Lupinotoxin (lu-pin-o-toks'-in) [lupinus, lupine; $\tau o \xi_{\ell}$ $\kappa o ́ v$, poison]. A resinoid derived from certain poisonous species of lupine, and said to be capable of producing the symptoms of lupinosis.

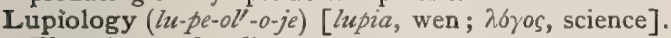
The science of malignant tumors.

Lupoid (lu'-poid) [lupus, wolf; Eidos, like]. Having the nature of lupus.

Lupomania (lu-po-ma'-ne-ah) [lupus, wolf; $\mu a v i a$, madness]. Rabies.

Lupotome (lu'-po-tōm) [lupus, wolf; rouŕ, a cutting]. A cutting or scarifying instrument sometimes used in the treatment of lupus.

Lupous (lu'-pus) [lupus, wolf]. Affected with or pertaining to lupus.

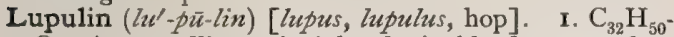
O. A crystalline principle obtainable from powdery glands of the hop-plant. See Humulus. It is said to be strongly narcotic. 2. The yellow, resinous powder of hops, composed mainly of dried glands from the strobiles of the plant; it is the lupulinum of the U. S. P. Its fluid extract and oleoresin are official. Dose of the fld. ext., gtt. IO-I5; of the oleoresin, gr. ij-v. 3. The precipitate from a tincture of the cones of hops, Humulus lupulus, a nervine, hypnotic, febrifuge, antiperiodic, and tonic. Dose from I to 2 grains. Unof.

Lupulina (lu-pu-li'-nah) [L.: gen., Lupulina]. Same as Lupulin.

Lupulinum (lu-pu-li'-num) [L. : gen., Luputini]. Same as Lupulin.

Lupulus (lu'-pu-lus). See Humulus.

Lupus (lu'-pus) [L., a wolf]. Lupus vulgaris; a chronic disease of the skin and some mucous membranes, characterized by the formation in the connective tissue of nodules of granulation-tissue. It passes through a number of clinical phases, and terminates by ulceration or atrophy, with scar-formation. The cause of the disease is the tubercle-bacillus. L., Acne, an obstinate papular eruption of doubtful character occuring in the localities usually selected by Acne vulgaris and sometimes associated with it. L., Acneiform. See $L$. erythematosus sebaceus. L. anatomicus, the anatomic tubercle. L., Cazenave's, lupus erythematosus, $q . v$. See also Diseases, Table of. L., Common, lupus vulgaris. L., Disseminated Follicular, adenoid acne; a variety of acne confined to the face, especially in the situations usually occupied by acne. The papules are from a large pin's head to a pea in size, conic and deep-red. They may coalesce to form a lupuslike tissue. L. disseminatus, a term applied to any case of lupus with multiple patches. L. eczema, a form of $L$. erythematosus resembling eczema. L. endemicus. See Aleppo Boil. L. erythematodes. Synonym of $L$. erythematosus. L. erythematosus, $L$. erythematodes; Cazenave's lupus; a form not due to the tubercle-bacillus. It occurs, as a rule, in multiple patches, with a tendency to symmetric arrange- ment, chiefly about the face and head, occasionally on the extremities, and rarely on the trunk. The patches are sharply defined at the border, flat, very slightly raised, and with a tendency to the formation of crusts. The color is bright-red, and there are no nodules. The disease tends to spread slowly at the periphery, and new patches may form in the neighborhood of the old. Feeble circulation favors the development of the disease. It is most common in females of adult or middle age. L. erythematosus aggregatus. See $L$. erythematosus disseminatus. L. erythematosus circumscriptus, the most common form, attacking chiefly the head and face, especially the nose, cheeks, and ears, often symmetrically. It appears in the early stage as isolated or grouped, small, red spots, about an eighth of an inch in diameter, with a yellowish spot at the center, and a small. closely adherent scale. These slowly extend peripherally and ultimately coalesce into patches of a dirty yellowish-white appearance. Cicatrization occurs in the center. The disease is one of long duration. L. erythematosus corneus, $L$. erythematosus in which the scales are not greasy. L. erythematosus discoides, the asymmetric form of $L$. erythematosus. L. erythematosus discretus, a form of $L$. erythematosus in which irregular patches are scattered over various parts of the body. It is associated with constitutional symptoms-fever and pains in the head, bones, joints, etc. L. erythematosus disseminatus, $L$. erythematosus aggregatus; Lupus-psoriasis; a rare form of Lupus erythematosus, characterized by a wider diffusion of the eruption, an extension by repeated outbreaks, and by the fact that the patches never coalesce. It is a chronic disease usually, but may be acute. L. erythematosus sebaceus, a form with special involvement of the sebaceous glands. L. erythematosus telangiectodes, a variety characterized by marked dilatation of the cutaneous blood-vessels. L., Erythematous, lupus erythematosus. L. exedens. Synonym of $L$, vulgaris. L. exfoliativus. See Lupus maculosus. L. exuberans, a form of lupus, usually $L$. exulcerans, associated with papillary excrescences. L. exulcerans, a term used to distinguish that form in which the destruction of tissue is rapid or intense, or in which the epidermis is lost and a secreting ulcerating surface is disclosed. L. frambosiformis, L. frambcesioides. See L. exuberans. L., Fungous. Synonym of Lupus exuberans. L. hæmorrhagicus, $L$. erythematosus disseminatus associated with hemorrhagic vesicles and blebs that dry and form crusts. L. hypertrophicus, that variety in which new connective-tissue formation predominates over the destructive process, and markedly raised, thick patches result. L. idiopathicus. Synonym of $L$. vulgaris. L. impetiginosus, a form of $L$. erythematosus in its earlier stages resembling impetiginous eczema. L. lymphaticus. See Lymphangioma circumscriptum. L. maculosus, a variety characterized by the eruption of very soft, smooth, brownish-red, semi-translucent miliary nodules, which develop in the connective tissue of otherwise healthy skin without subjective sensations. This eruption constitutes the earliest sign of lupus. When the surface desquamates, the name Lupus exfoliatious is given to it. L. miliaris. See L., Acne. L. mutilans, lupus exedens, causing destruction of tissue and disfigurement. L., Necrogenic, the anatomic tubercle. L. non-exedens, lupus without ulceration. L. papillaris, $L$. papillomatosus, a form characterized by papillary growths that may reach the size of the palm. These are most frequently seen on the extremities and buttocks, and occur only on uicerated surfaces. L. per- 
forans, lupus ulcerating through the skin into a mucous cavity, or through the septum between two mucous cavities. L. phagedænicus, ulcerating lupus associated with phagedena. L. prominens. See Lupus tuberosus. L.-psoriasis. See L. erythematosus disseminatus. L. rodens. See L. exulcerans. L. scrofulosus. See Scrofuloderma tuberculosum. L. sebaceus. Synonym of L. erythematosus. L. seborrhagicus. Synonym of $L$. erythematosus. L. serpiginosus, a term applied to lupus that spreads or creeps on peripherally while cicatrizing centrally. L. solitarius, lupus vulgaris confined to a single patch. L. superficialis. Synonym of L. erythematosus. L., Syphilitic, a form of tubercular syphilid which is likely to ulcerate serpiginously, and closely simulates lupus vulgaris. It is due to the breaking down of superficial gummata. The ulcer is covered with a thick, greenish-brown crust, has a sharply punched-out margin and a circinate or reniform outline. The scar is usually flexible, white, and shining. L. terebrans. Synonym of Lupus perforans. L. tuberculosus. Synonym of $L$. vulgaris. L. tuberosus, a form of lupus with small nodular prominences. L. tumidus, a variety in which edematous infiltration and connective-tissue overgrowth are present, leading to the formation of nodular masses. L. ulcerosus. Synonym of $L$. exulcerans. L. vegetans, L. verrucosus, the formation in the lupus process of a warty-looking patch which is liable to become inflamed from time to time. This form occurs chiefly on the hands and feet, and usually in early life. L. vorax. See $L$, exul. cerans. L. vulgaris. See Lupus. L. vulgaris erythematodes, a variety with lesions resembling those of $L$. vulgaris and $L$. erythematosus. It may invade the scalp and the mucous membrane of the mouth, spreading from the face. L. of the Vulva. See Esthioméne.

Luridity (lu-ridl-it-e) [luridus; luror, yellow color]. A pale-yellow color met with in certain cachectic conditions; also in atrophied paralyzed limbs.

Luschka's Bursa. See L.'s Tonsil. L.'s Cartilage, a nodule of elastic cartilage in the anterior part of the vocal band. L.'s Gland, the coccygeal gland, q. v. A small conglobate body lying near the tip of the coccyx just above the coccygeal attachment of the sphincter ani. Its function is not known. See Gland. L.'s Tonsil, the adenoid tissue that normally exists between the orifices of the Eustachian tubes, analogous in structure to the lymphoid constituents of the tonsil. It is also called "Third tonsil" and "Pharyngeal tonsil." L.'s Villi, minute spheroid, partially vesicular outgrowths from the upper layer of the pia, which eventually become the Pacchionian bodies.

Luscitas (lus'-it-as) [luscus, one-eyed]. I. The state of being blind in one eye. 2. Strabismus, especially when caused by paralysis or rheumatism.

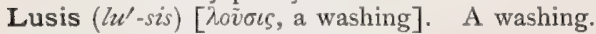

Lussac, Gay, Law of. See Law.

Lust [ME., lust, lust]. Carnal desire; sexual appetite ; concupiscence.

Lustful (lust'-ful) [ME., lust, lust]. Libidinous; having prurient lust.

Lustgarten, Bacillus of. See Bacteria, Synonymatic Table of. L.'s Method, a method of staining the bacillus of syphilis. See Stains, Table of.

Lustramentum (lus-tram-en'-tum) [lustrare, to purify]. A purge.

Lusus $\left(u^{\prime}\right.$-sus $)$ [hudere, to play]. A play; a game. L. naturæ, a freak of nature; any abnormal departure from that which is natural.

Lutation (lu-ta'-shun) [lutum, mud]. The bermetic sealing of a vessel.
Lutein (lu'-te-in) [luteus, yellow]. I. A pigment obtained from corpora lutea by extraction with chloroform. It occurs in minute rhombic prisms or plates that are pleochromatic and insoluble' in water, but readily soluble in alcohol, ether, and chloroform. Lutein is more or less rapidly bleached by the action of light. 2. A red lipochrome pigment found by MacMunn in the blood of Holothusia nigra. L.cells, large cells, containing granules of lutein, characteristic of the metamorphosed clot of ruptured Graafian fol-

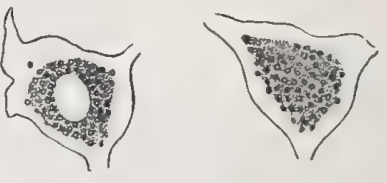

LUTEIN-CELLS. licles, to the margins of which they impart a bright yellow color, whence the name corpora lutea. These cells appear to arise from the theca interna. See illustration.

Luteolin (lu'-te-o-lin) [luteus, yellow]. A yellow coloring-substance obtained from diphenylamin and diazoxylenesulphonic acid; also, a crystalline body, $\mathrm{C}_{20} \mathrm{H}_{14} \mathrm{O}_{8}$, found in Reseda luter. See Pigments, Conspectus of.

Luteolous (lu-te'-o-lus) [luteolus, dim. of luteus, golden-yellow]. In biology, buff, or yellowish.

Luteous (lu'-te-us) [lutum, mud]. Clay-colored, mud colored; saffron, or reddish-yellow.

Lutescent (lu-tes'-ent) [lutum, mud]. In biology, yellowish, or becoming yellow.

Luton's Sugar-test. See Tests, Table of.

Lutose (lu'-tōs) [lutum, mud]. In biology, applied to such organisms as are covered with a substance like mud.

Luxation (luks-a'-s/unn). See Dislocation.

Luxatura (luks-at-u'-rah). See Dislocation.

Luxus $\left(u k s^{\prime}-u s\right)$ [L., "excess,"]. Excess. L.-breathing, the breathing of more air than is actually called for by the needs of the organism. L.-consumption, a term applied by Bidder and Schmidt to the metabolism of certain surplus proteid material, which, though inside the body, does not form a component part of any of its tissues, but constitutes a kind of reservoir of force upon which the organism can draw.

Luys' Body. A lentiform ganglion of a milk-and-coffee color, which lies in the ideal continuation of the lateral part of the ganglion of Scmmering. It represents the boundary between the crusta and the tegmentum. L.'s Transference Method. See Hypnotism.

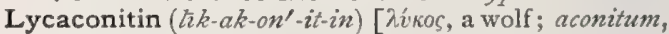
aconite ], $\mathrm{C}_{27} \mathrm{H}_{34} \mathrm{~N}_{2} \mathrm{O}_{6}+\mathrm{H}_{2} \mathrm{O}$. An amorphous alkaloid, soluble in water, alcohol, and chloroform, obtained from Aconitum lycoctonum. In its toxicologic action it resembles curare.

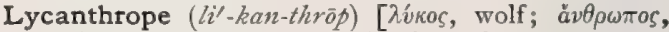
man]. A person affected with lycanthropy.

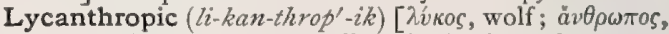
man]. Pertaining to or affected with lycanthropy.

Lycanthropy $\left(l i-k a n^{\prime}-t h r o-p e\right)\left[\lambda v_{\kappa} o s\right.$, a wolf; à $\nu \theta \rho \omega \pi o s$, man]. A form of mania in which a person imagines himself a wild beast. Cf. Zoanthropy.

Lychnidiate $\left(l i k-n i d^{\prime}-e-\bar{a} t\right)$ [ $\lambda \hat{v} \chi \nu o \varsigma$, a lamp]. In biology, luminous, phosphorescent.

Lycin $\left(i^{\prime}-\sin \right)$. See Betazn.

Lycodes $\left(l_{i}-k o^{\prime}-d \bar{e} z\right)[\lambda u ́ k a s$, wolf]. A chronic form of tonsillitis. See Lycoides.

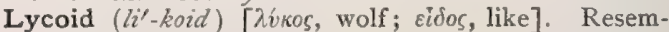
bling a wolf.

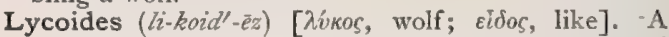
term applied to a form of quinsy popularly attributed to excess of spermatic fluid in the seminal reservoirs and its entrance into the blood. 


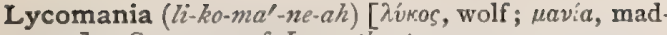
ness]. Synonym of Lycanthropy, q. $v$.

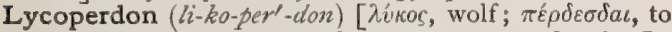
break wind]. A genus of gasteromycetous fungi. L. bovista, fist-ball, puff-ball, devil's snuff-box. This has been used as a styptic, and is now to some extent employed in nervous diseases. The fumes have been used as an anesthetic. L. giganteum, the giant puff-ball; similar to $L$. bovista. L. proteus. See L. giganteum.

Lycopersicon, Lycopersicum (li-ko-perl-sik-on, li-ko-

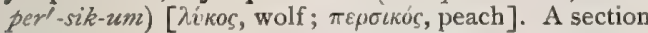
of the Solanacee, of which several species are well known. See Solanum.

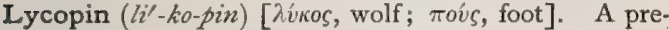
cipitate from a tincture of Lycopus virginicus, an astringent, styptic, sedative, and tonic. Dose from I to 4 grains. Unof.

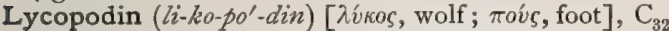
$\mathrm{H}_{52} \mathrm{~N}_{2} \mathrm{O}_{3}$. A bitter alkaloid found in Lycopodium clavatum and $L$. complanatum. It is readily soluble in water, ether, and in alcohol. Unof.

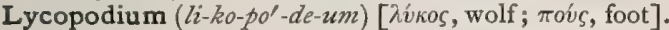
Club-moss, witch-meal, wolf's-claw. In medicine, the sporules of $L$. clavatum and other varieties, in the form of a light, fine, yellowish powder, are used as a desiccant and absorbent on moist and excoriated surfaces; in pharmacy, as an inert powder in which to imbed pills to prevent their adhering to each other. Lycopodium is inflammable and slightly explosive, whence the name "vegetable sulphur." A large number of species are known. L. clavatum, lycopodium. L. complanatum, common club-moss, ground-pine, found in Europe and North America. L. inundatum, marsh club-moss. L. officinale. See L. clavatum. L. phlegmasia, an Asiatic species said to possess aphrodisiac properties. L. recurvum. See $L$. selago. L. rubrum, a species which is actively purgative. It has been employed in South America in elephantiasis. L. saussurus, Brazilian piligon. Its alkaloid, piligonin, is a powerful emetic, purgative, and convulsant. L. selago, fir-moss, fir-club-moss, treemoss; a species found in Europe and North America. It is cathartic and emetic in its action. Unof.

Lycopus ( $l i^{\prime}$-ko-pus). See Bugleweed.

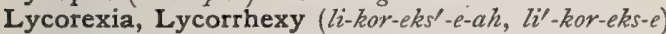

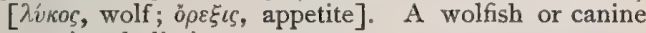
appetite; bulimia.

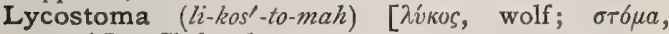
mouth]. Cleft palate.

Lye (li) [ME., ley, lye]. The solution of alkaline hydrates obtained by leaching ashes; any alkaline solution.

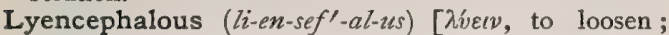
$\dot{\varepsilon} \gamma \kappa \varepsilon \dot{\varepsilon} a \lambda \circ$ s, brain]. Having cerebral hemispheres that are loosely united.

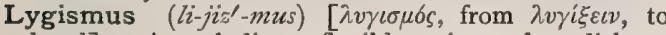
bend]. A melodious, flexible voice; also, dislocation.

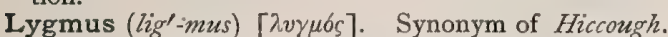

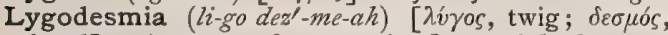
bond]. A genus of composite-flowered herbs. L. spinosa, of Nevada and California, has about its stem, at the ground, a tuft of woolly or silky fiber, useful as a hemostatic. Unof.

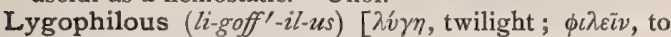
love]. Seeking dark places.

Lying-down, Lying-in. See Puerperal State.

Lyma $\left(l i^{\prime}-m a h\right)[\lambda \tilde{v} \mu a$, washings: pl., Lymata]. I. Filth, or sordes. 2. Lochia.

Lymph (limf) [lympha, water]. The fluid in the lymphatic vessels, the product of the filtration of the liquid portion of the blood through the walls of the capillaries. Applied, also, to certain products of lymph-exudation in wounds, etc. L., Animal, vaccine-lymph obtained from an animal. L., Aplastic, a lymph-product of inflammation that will not form embryonic tissue. It is called, also, Corpuscular or Croupous lymph. L., Bovine, vaccine-material obtained from a cow or a calf. L., Calf, vaccine from the calf. L.-cell, L.-corpuscle, a leukocyte occurring in the lymph. L.-corpuscles, the colorless corpuscles of the lymph. L., Euplastic. See L., Plastic. L., Fibrinous. Same as L., Plastic. L.-follicles, branched lacunar labyrinthine parts composed of adenoid tissue intercalated in the course of the lymphatic vessels. They are not true glands. L.glands. See Lymphatic Glands. L.-hearts, exist in certain cold-blooded animals, the frog, e.g., having two axillary and two sacral hearts for pumping the lymph. L., Humanized, vaccine from a human being. L., Inflammatory, that thrown out as a product of inflammation in wounds, etc. L., Koch's, a term for the fluid called, by Koch, paratoloid, now known as tuberculin. See Tuberculin. It is recommended by Koch for hypodermatic injection in cases of tuberculous disease. L., Plastic, fibrinous lymph; that forming embryonic tissue. L.-scrotum, an anasarcous condition of the scrotum due to the presence of Filaria sanguinis hominis in the blood-stream. See Filaria. L.-spaces, the lacunæ that occur in connective tissue, and contain lymph. L., Vituline. See $L .$, Calf.

Lymphaden (lim-fa'-den) [lympha, water; ádin, gland]. Any lymphatic gland.

Lymphadenectasis (lim-fad-en-ek'-tas-is) [lympha, lymph; $a \delta \not \dot{\nu}$, gland; $\varepsilon \kappa \tau a \sigma \iota \zeta$, distention]. A tumor of a lymph-gland, due to dilatation of its sinuses.

Lymphadenhypertrophy (lim-fad-en-hi-per'-tro-fe) [lympha, lymph; ádńv, gland; $i \pi \hat{\varepsilon} \rho$, over; $\tau \rho \circ \phi \dot{\eta}$, nourishment]. Hypertrophy of the lymphatic glands.

Lymphadenia (lim-fad-e'-ne-ah) [lympha, lymph; $\alpha \delta \eta v$, gland]. A general hyperplasia of the lymphatic tissue with or without leukocytosis.

Lymphadenism (Iim-fad'-en-izm) [lympha, lymph; $a \delta \delta \eta v$, gland]. The general condition of disease that accompanies lymphadenoma.

Lymphadenitis (lim-fad-en-i'-tis) [lympha, lymph ; áfív, gland; $\iota \tau \iota \varsigma$, inflammation]. Inflammation of a lymphatic gland. L., Cutaneous, mycosis fungoides. L., Septic, a form due to the presence of microörganisms. L., Simple, lymphadenitis due to irritation.

Lymphadenoid (lim-fad'-en-oid) [lympha, lymph;

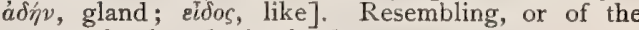
nature of, a lymphatic gland.

Lymphadenoma (lim-fad-en-o'-mah) [lympha, lymph; ádivઢ $\mu \alpha$, a glandular tumor: pl., Lymphadenomata]. Hodgkin's disease; Malignant lymphoma; Pseudoleukemia; Anæmica lymphatica; Adénie [Fr.]. A disease of the lymphatic structures of the body characterized by a hyperplasia, and often a new formation of lymphatic tissue in glands, spleen, and bonemarrow. The cervical glands are usually first involved. The blood, as a rule, presents the characters of anemia without increase in the number of white corpuscles. Pyrexia, often of a remittent type, is common. The disease occurs most frequently in males. The duration is from two to five years, and the disease results fatally. Occasionally Iymphadenoma is converted into a true leukemia. L., Hard, a form characterized by indurated, firm, glandular swellings. L., Leukemic, when associated with leukemia. L., Soft, a form in which the enlarged lymphatic glands are soft. 
Lymphadenosis (lim-fad-en-o'-sis) [lympha, lymph ;

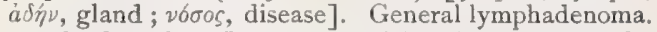

Lymphadermia, Cutaneous (lim-fad-er'-me-ah). Synonym of Granuloma fungoides.

Lymphæduct (lim'-fe-dukt). See Lympheduct.

Lymphæmia (lim-fe'-me-ah). See Lymphemia.

Lymphagogue (lim $-f a g-o g)$ [lympha, lymph; à ${ }^{\prime} \omega \gamma \delta s$, leading]. An agent that increases the production of lymph.

Lymphaneurysma (lim-fan-u-riz'-mah) [lympha, lymph ; ávépvorua, aneurysm: pl., Lymphaneurysmata]. Lymphangiectasis; a tumor caused by dilatation of lymphatic vessels. L., Ganglionar, an endemic form, with multiple localized dilatations of the lymphatic vessels. L., Sporadic, a localized form, usually of traumatic or infectious origin

Lymphangei- (lim'-fan-je-). See Lymphangi-.

Lymphangeiitis (Iim-fan-je-i'tis). See Lymphangitis.

Lymphangiectasis (lim-fan-je-ek'-tas-is) [lympha,

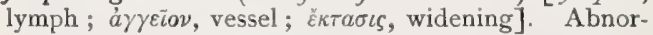
mal dilatation of the lymphatic vessels. See Angiokeratoma. L., Endemic, a form common in the tropics, and generally due to filariasis.

Lymphangiectodes (lim-jan-je-ek-to'-déz). See Lymphangioma circumscriptum.

Lymphangienchysis (lim-fan-je-en'-kis-is) [lympha,

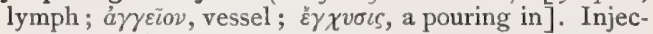
tion of the lymphatic vessels.

Lymphangiography (lim-fan-je-og'-ra-fe) [lympha,

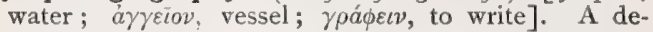
scription of the lymphatics.

Lymphangiology (lim-fan-je-oll-o-je) [lympha, lymph; a $\gamma \gamma \varepsilon i o n$, vessel; $\lambda 6$ jos, treatise ]. The anatomy, physiology, and pathology of the lymphatics.

Lymphangioma (lim-fan-je-o'-mah) [lympha, lymph ;

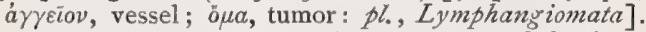
A dilated or varicose condition or tumor of the lymphatic vessels. L. capillare varicosum. Synonym of L. circumscriptum. L. cavernosum. Synonym of L. circumscriptum. L. circumscriptum, Lymphangiectodes; Lupus lymphaticus, a very rare disease of the skin occurring in early life. It is marked by the formation of straw-yellow vesicles, deeply situated in the skin, with thick and tense walls, and connected with the lymphatics. Their usual seats are the shoulders, trunk, face, neck, thighs, and arms. The disease gradually spreads and tends to recur. Its cause is unknown. $\mathbf{L}$. tuberosum multiplex, a very rare disease of the skin, probably congenital, characterized by the formation of large, brownish-red papules or tubercles, the size of lentils, not arranged in groups or clusters, but scattered indiscriminately over the trunk. They dip down into the subcutaneous tissue, and both feel and look solid, but on section they prove to be made up of greatly dilated lymphatics.

Lymphangio-myoma ( $\left(i m-f a n^{\prime}-j e-o-m i-o^{\prime}-m a h\right.$ ). See Myoma.

Lymphangion (lim-fan'-je-on) [lympha, lymph;

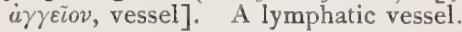

Lymphangiopyra ( $\left.\lim -f a n-j e-o p^{\prime}-i r-a h\right)$ [lympha,

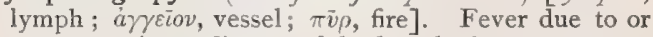
accompanying a disease of the lymphatics.

Lymphangioscopy. (lim - fan-je-os'-ko-pe) [lympha, lymph; $\dot{a} \gamma \gamma \varepsilon i o v$, vessel; $\sigma \kappa o \pi \varepsilon i v$, to inspect]. Inspection or observation of the lymphatics.

Lymphangiotomy ( $\left.\mathrm{lim}-\mathrm{fan}-j e-o t^{\prime}-0-m e\right)\left[l^{\prime} m p h a\right.$,

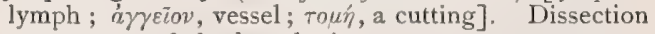
or anatomy of the lymphatics.

Lymphangitis (lim-fan-ji'-tis) [lympha, lymph; à $\gamma \gamma \varepsilon-$ lov, vessel; iT८, inflammation]. Inflammation of a lymphatic vessel. L., Tubular, a form involving the chief lymphatics and attended with the pro- duction of red lines on the skin. L., Wandering, a form occurring usually on the back of the hand, and due to frequent contact with putrefying tissues. It occurs in reticular patches connected by wavy lines.

Lymphangoncus (lim-fan-jon'-kus) [lympha, lymph;

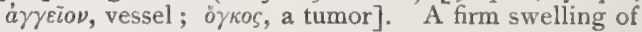
the lymphatic vessels.

Lymphapostema (lim-fap-os-te'-mah) [lympha, lymph;

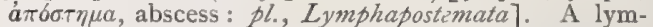
phatic abscess

Lympharia (lim-fa'-re-ah) [lympha, lymph]. A name proposed for lymphatic tissue.

Lymphate (lim'-fät) [lympha, water]. Raving; frightened into madness.

Lymphatic (lim-fat'-ik) [lymphaticus; lympha, lymph]. Pertaining to lymph; containing or characterized by lymph. L. Edema. See Lymphedema. L. Glands, the glands intercalated in the pathway of the lymphatic vessels, through which the lymph is filtered. $\mathbf{L}$. Temperament. See Temperament. L. Vessels. See Lymphatics.

Lymphatico-sanguine (lim-fat'-ik-o-san'-grin) [lympha, lymph; sanguis, blood]. Both lymphatic and sanguine. See Temperament.

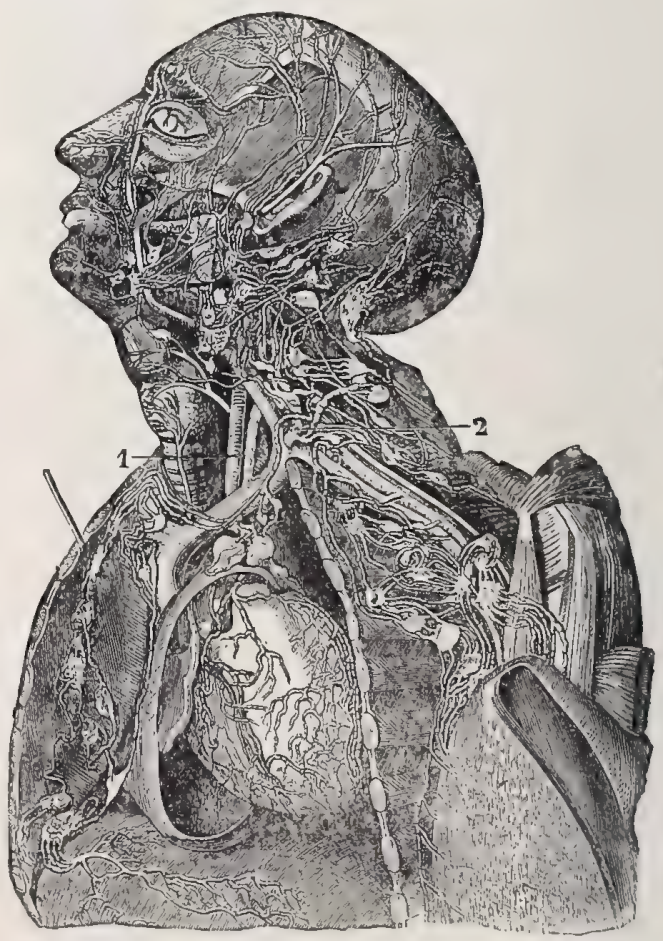

Efferent Lymphatics of Cervical ano Axillary GLANDS.

I. Superior extremity of thoracic duct. 2. Its entrance at the junction of the internal jugular and left subclavian veins.

Lymphatics (lim-fat'-iks) [lympha, lymph]. The lymphatic vessels, including capillaries, afferent and efferent vessels, and ducts or trunks; the lymph-vessels; capillary tubes extending to nearly every part of the body, from which they take up the lymph, forming the principal part of the absorbent system. Afferent or inferent lymphatics, those that convey lymph to the lymphatic glands; efferent lymphatics, those that conduct lymph from the glands. 


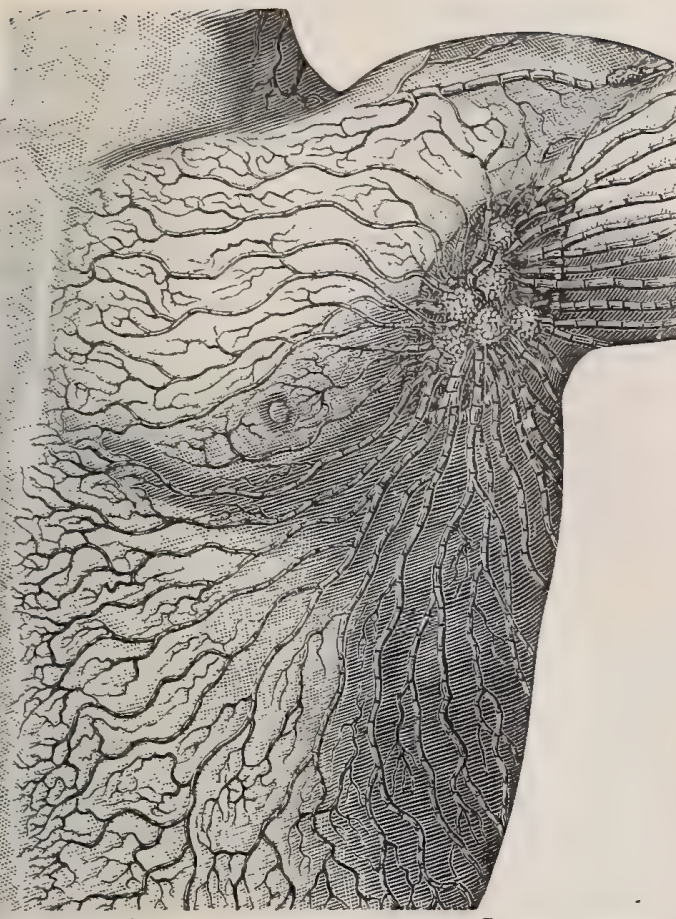

Lymphatic Glands and Vessels of the Cavity of the Axilla.

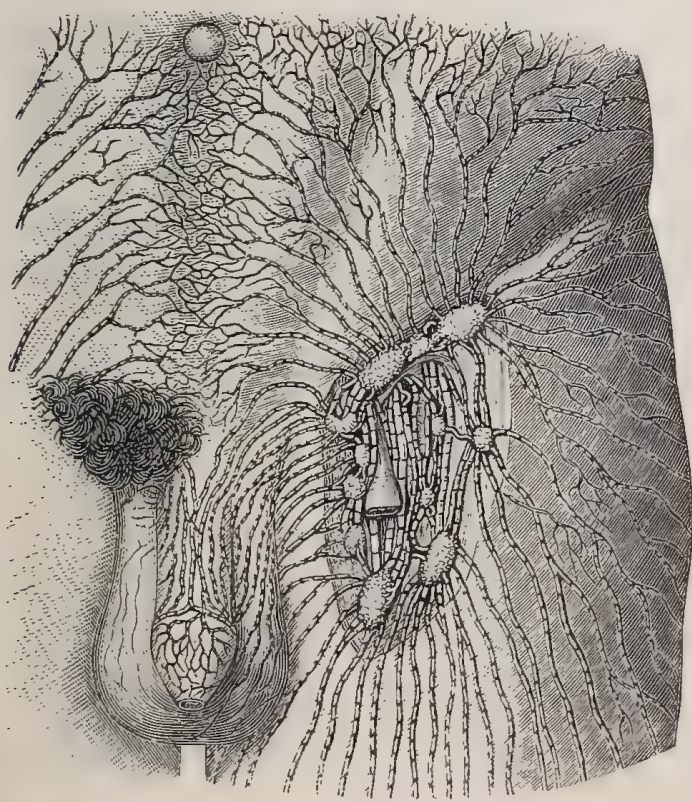

Lymphatic Glands and Vessels of THE INGUINAL REGION.

Lymphatism (lim'-fat-izm) [lymphatismus]. The lymphatic temperament; scrofula.

Lymphatitis (lim-fat-i'-tis). See Lymphangitis.

Lymphatocele (lim-fat'-o-sêl) [lympha, lymph; $\kappa \hat{\eta} \lambda \eta$, tumor]. A tumor composed of dilated lymph-vessels.

Lymphatology (lim-fat-ol'-o-je). See Lymphology.
Lymph-canalicular (limf'-kan-al-ik'-u-lar) [lympha, lymph; canaliculus, small channel]. Pertaining to the ultimate channels of the lymphatic vessels.

Lymphedema (lim-fe-de'-mah) [lympha, lymph; oídnua, edema]. Edema due to accumulation of lymph; serous edema.

Lympheduct ( lim $^{\prime}-f e-d u k t$ ) [lympha, lymph; ducere, to lead]. A lymphatic vessel or duct.

Lymphemia (lim-fe'-me-ah) [lympha, lymph; ailua, blood]. Leukemia characterized by pathologic processes in the lymphatic glands, which become hypertrophied; the kidney or liver sometimes presents what appears to be an element composed of lymphatic tissues.

Lymphenteritis (lim-fen-ter-i'tis) [lympha, lymph; $\varepsilon v \tau \varepsilon \rho \circ \nu$, bowels; $\iota \tau \iota s$, inflammation]. Inflammation of the bowels attended with serous infiltration. 2 . Inflammation of the serous coat of the intestine; peritonitis.

Lymphepatitis (limf-hep-at-i'-tis) [lympha, lymph ; $\eta \pi a \rho$, liver; $\iota \tau \iota \varsigma$, inflammation]. Inflammation of the peritoneal coat of the liver.

Lympheurysma (lim-fu-riz'-nah). See Iymphaneurysma.

Lymphexosmosis (lim-feks-os-mo'-sis) [lympha, lymph; $\dot{\varepsilon} \xi$, out; $\dot{\omega} \sigma \mu \delta \varsigma$, thrust]. Exosmosis of lymph passage of lymph outward, through the coats of the lymph-vessels.

Lymphitis (lim- $f^{\prime}$-tis). See Lymphangitis.

Lymphoblast (lim'-fo-blast) [lympha, lymph; $\beta \lambda a \sigma \tau \sigma s$, germ]. Any cell with a nutritive function.

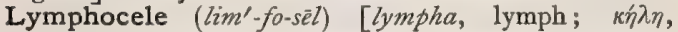
tumor]. A tumor containing an abnormal collection or quantity of lymph.

Lymphocyte (lim'-fo-sit) [lympha, lymph; kítos, a cell]. I. A lymph-cell. 2. One of Ehrlich's classes of leukocytes, comprising those small cells having large nuclei and a very small amount of protoplasm. See Leukocyte.

Lymphocythemia (Iim - fo-si-the'-me-ah) [lympha, lymph ; кv́тos, cell ; aira, blood]. A condition of the blood in which the lymphocytes are increased.

Lymphodermia (lim-fo-der'-me-ah) [lympha, lymph ; $\delta \varepsilon \rho \mu a$, skin]. An affection of the lymphatics of the skin. L. perniciosa, a certain form of Mycosis, or fungoid granuloma.

Lymphoduct (lim'-fo-dukt). See Lympheduct.

Lympho-gastritis (lim-fo-gas-tri'-tis) [lympha, lymph;

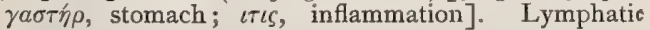
gastritis.

Lymphogenous (lim-foj'-en-us) [lympha, lymph ;

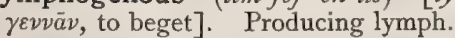

Lymphoid (lim'-foid) [lympha, lymph; Eidos, like]. Having the appearance or character of lymph.

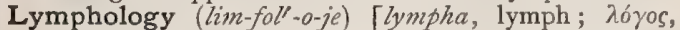
science]. The study of the anatomy and physiology of the lymphatic system.

Lymphoma (lim-fo'-mah) [lympha, lymph; ö $a$, tumor: pl., Lymphomata]. A lymph-tumor; also, lymphadenoma. The term includes formations not strictly tumors but hyperplasias of the tissues proper to lymphatic glands. L., Heteroplastic. Synonym of Lymphadenoma. L., Leukemic. See Lymphadenoma, Leukemic. L., Malignant. Synonym of Lymphadenoma. L., Scrofulous, tuberculous enlargement of lymphatic glands. L., Typhoid, the formation of small lymphatic masses in the intestinal peritoneum and in the liver and kidneys in typhoid fever.

Lymphomatous (lim-fo'-mat-us) [lympha, lymph; ö $\mu \alpha$, tumor]. Of the nature of, affected with, or relating to, lymphoma. 
Lymphoncus (lim-fong-l-kus) [lympha, lymph; ŏ $\gamma к о \varsigma$, tumor]. A hard lymphatic swelling. L. iridis. See Iridauxesis.

Lympho-nephritis (lim-fo-nef-ri'-tis) [lympha, lymph ;

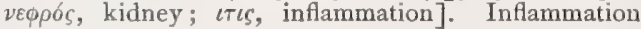
of the serous, or outer, surface of the kidney.

Lymphopathy (lim-fop'-ath-e) [lympha, lymph; $\pi \hat{\theta} \theta 0$, disease]. Any disorder of the lymphatic organs.

Lympho-peritonitis (lim-fo-per-it-on-i'tis) [lympha,

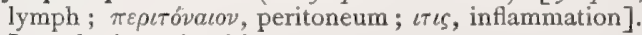
Lymphatic peritonitis.

Lymphopyra (lim-fop'-ir-ah). See Lymphangiopyra.

Lymphorrhagia (lim-for-a'-je-ah) [lympha, lymph pryvival, to burst forth]. An effusion or flow of lymph from a ruptured lymphatic vessel.

Lymphorrhea (lim-for-e'-ah) [lympha, lymph; joía, a flow]. A discharge of lymph from a wound, internally or externally.

Lympho-sarcoma (lim-fo-sar-ko'-mah) [lympha, lymph; $\sigma a ́ \rho \kappa \omega \mu a$, a fleshy mass : pl., Lympho-sarcomata]. Properly, a form of sarcoma having some of the structural elements of a lymphatic gland; also, a sarcoma seated upon, or involving, a lymphatic gland. L. thymicum, a lympho-sarcoma originating in a persistent thymus gland and attended with metastasis to various parts of the body.

Lympho-sarcomatosis (lim' - fo-sar-ko-mat - o'-sis)

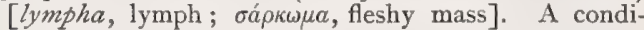
tion or diathesis marked by the development of lympho-sarcoma; also, the process of such development.

Lymphosis (lim-fo'-sis) [lympha, lymph]. The elaboration of lymph.

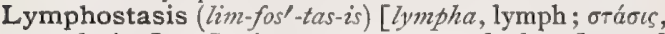
a placing]. Stasis or stoppage of the flow of lymph.

Lymphotomy (lim-fot'-o-me). See Lymphangiotomy.

Lymphotorrhea (lim-fot-or-e'-ah) [lympha, lymph; ov́s, ear; poía, a flow]. A serous or watery discharge from the ear.

Lymphuria (lim-fu'-re-ah) [lympha, lymph; ovjpov, urine]. A condition in which the urine spontaneously coagulates, but contains no fat, as it does in chyluria.

Lynx (links) [ $\lambda \hat{\gamma} \gamma \xi$, a sobbing]. Hiccough; violent sobbing.

Lyon's Apparatus. See Urea and Disinfection.

Lyons Blue. Same as Spirit-blue.

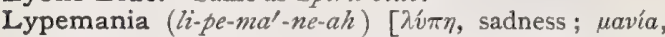
madness]. A form of dementia accompanied by profound mental depression and refusal to take food.

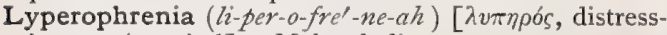
ing; $\phi \rho \eta ́ v$, mind]. Melancholia.

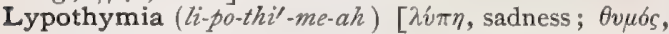
mind]. Melancholia; severe mental prostration from grief. This condition is not to be confounded with Leipothyntia, q. v

Lyra $\left(i^{\prime}-r a h\right)$ [ $\lambda \dot{v} \rho \alpha$, a lyre]. A lyre. L. of Fornix, certain longitudinal, transverse, and oblique lines on the under surface of the fornix, the arrangement of which bears a fanciful resemblance to a harp. L. of
Uterus, the uterine arbor vitæ. vaginal rugæ.

Lyrate (li'-rāt) [lyra, a lyre]. In biology, lyre-shaped.

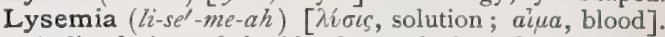
A dissolution of the blood, or a losing of the integral parts of it.

Lysigenetic (lis-ij-en-et'-ik). Same as Lysigenous.

Lysigenic (lis-ij-en'-ik). Same as Lysigenous.

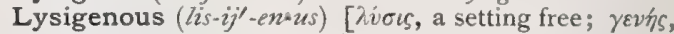
born, produced]. In biology, a term applied to intercellular spaces formed by the breaking down of contiguous cells. Cf. Schizogenic.

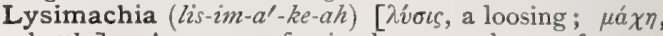
battle]. A genus of primulaceous plants of many species. L. nemorum, L. nummularia, L. vulgaris, of Europe, and L. quadrifolia, and other N. American species are used in domestic medicine. Unof.

Lysinosis (lis-in-o'-sis) [ $\lambda i v \iota s, \lambda v^{\prime} \varepsilon v$, to loose (a ravelling or shred) ]. Hertz's term for a disease of the lungs due to the inhalation of cotton-fibers.

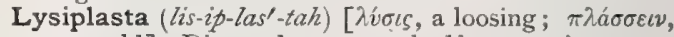
to mould]. Diseased states marked by excessive secretion.

Lysis $\left(l^{\prime}-s i s\right)$ [ $\lambda \dot{v} \sigma \iota, \lambda v_{\varepsilon} \iota v$, to loose]. A term somewhat loosely used, but now applied to the gradual decline of a disease, especially a fever.

Lysol $\left(l^{\prime}-s o l\right)$. A saponified phenol derived from cresols by the action of nascent soap. It is an excellent disinfectant in from one to three per cent. solutions, and has been used in dermatology and gynecology. Unof.

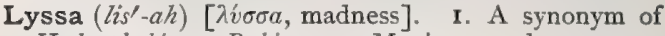
Hydrophobia or Rabies. 2. Mania or madness.

Lyssic $\left(i s^{\prime}-i k\right)$ [ $\lambda \hat{v} \sigma \sigma \alpha$, madness]. Pertaining to rabies ; due to rabies.

Lyssin $\left(l i s^{\prime}-i n\right)$ [ $\lambda \dot{v} \sigma \sigma a$, madness]. The specific virus or germ of hydrophobia.

Lyssodegma (lis-o-deg'-mah). Synonym of Lyssodexis.

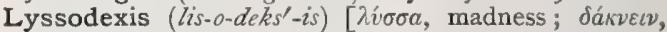
to bite]. The bite of a rabid dog.

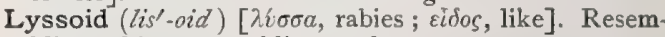
bling rabies; resembling madness.

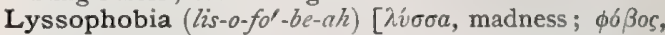
fear]. Morbid dread of rabies; pseudo-hydrophobia.

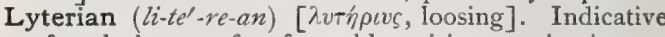
of a lysis, or of a favorable crisis, terminating an attack of disease.

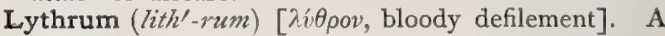
genus of lythraceous plants. L. salicaria, or willowherb, is used as an astringent in leukorrhea, diarrhea, and hemorrhage from the lungs. Unof.

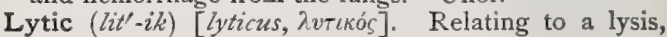
or to a solution.

Lytta (lit'-ah). I. Synonym of Hydrophobia. 2. A long, median, pointed, fibrous or cartilaginous process (glossohyal) in the tongue of carnivora. It is the "worm" of the dog's tongue, commonly held to be a parasite and often extracted by fanciers. L. vesicatoria. See Cantharis. L. vittata, the potato-fly, containing one per cent. or more of cantharidin. 
M. The abbreviation of Musculus, of Meter, of Myopia, of Minim, of Molar, and of Misce, mix; it is also used to represent the number $\mathbf{I} 000$.

$\mathrm{mm}$. An abbreviation for millimeter.

$\mathrm{mmm}$. An abbreviation for Micro-millimeter.

$\mu$ (mu). The abbreviation universally adopted for micron or micro-millimeter.

Ma. An abbreviation of Milliampere.

Maas's Mixture. A mixture employed in the treatment of eczematous diseases of the ear. It is constituted as follows: corrosive sublimate 5 parts, sodium chlorid 500 parts, glycerin 200 parts.

Maba $\left(m a^{\prime}-b a / 2\right)$ [native Tonga-Tabu]. A genus of ebenaceous trees and shrubs of many species. $\mathbf{M}$. ebenus, of the Moluccas, is regarded as a good antisyphilitic and antirheumatic. Unof.

Mac. An abbreviation of Macera, macerate.

Mac., Mc., M'., beginning proper names will be found as if spelled Mac, and in strict alphabetic order.

Macaco Worm (mak-a'-ko zurm) [from a Malagasy name]. The larva of a S. American fly, Dermatobia noxialis, which infests the skin of men and animals. See Parasites (Animal), Table of.

Macallo (mak-al'-o). See Andira.

Macaroni (mak-ar-a'-ne) [Ital.]. 1. Slender tubes made of flour-paste; a favorite dish in Italy and also in the U.S. 2. An active purgative used in lead-colic. Antimony sulphid is one of the ingredients.

McBurney's Point. A localized point of tenderness on deep pressure, supposed to be diagnostic of appendicitis. It is about two inches above the anterior superior spine of the ilium on a line drawn from this point to the umbilicus.

Macdowel's Frenum. See Frenum.

McDowell's Operation. See Operations, Table of. Mace (mās). See Myristica.

Macene $\left(m \bar{a} s-\bar{e} n^{\prime}\right)[$ macis, mace $], \mathrm{C}_{10} \mathrm{H}_{16}$. An essential oil resulting from the distillation of the flowers of nutmeg. The hydrochlorate on distillation yields a camphor.

Maceration (mas-er-a'-shun) [maceratio; macerare, to make soft]. Extraction of the medicinal qualities of a substance by steeping or infusing. Applied, also, to a softening and non-putrefactive decomposition of the dead fetus long carried in the uterus.

Macewen's Method. A method of preparing animal ligatures. To I oz. each of water and glycerin add 12 grs. of chromic acid crystals; in this steep the ligatures ten days, then remove and thoroughly dry; for preservation keep in a 5 per cent. carbolic-acid solution. M.'s Operation. See Operations, Table of.

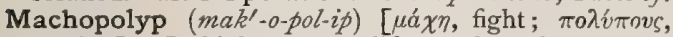
a polyp]. In biology, a modified polyp abundant in the Plumularide, having a defensive function; some animals possess urticating capsules, others, instead, adhesive granules. The name was introduced by Hamann; it is also called Guard-polyp.

Macies (ma'-se-ezz) [macies, a wasting]. Atrophy, leanness, wasting. M. infantum. Synonym of Tabes mesenterica.

Macilent (mas'-il-ent) [macilentus, lean]. Meager; thin; lean.

Macintosh's Cream. A dressing for urticaria. It consists of subnitrate of bismuth 2 drams, oxid of zinc $1 / 2$ dram, glycerin $1 \mathrm{x} / 2$ drams, iiquid carbolic acid from 20 to 30 minims, vaselin 6 ounces.

M'Kinnell's Ventilator. See Ventilation.

Mackintosh (mak'-in-tosh) [after Charles Mackintosh, the inventor]. A fabric of silk or cotton, rendered waterproof and airproof by a coating of india rubber; it is used in antiseptic surgery and in obstetrics.

McLeod's Capsular Rheumatism. A form of rheumatoid arthritis attended with effusion into the synovial capsules and into the synovial sheaths and bursæ about the affected joints. See Diseases, Table of.

Maclurin (mak-lu'-rin) [after W. Maclure], $\mathrm{C}_{15} \mathrm{H}_{12} \mathrm{O}_{8}$. A principle found in yellow-wood (Morustinctoria), from which it may be extracted by hot water. It occurs in the form of a yellow, crystalline powder, soluble in water and alcohol; it is found also in Muclura aurantia, or Osage-orange.

McMunn's Elixir. See Opium.

Macquer's Arsenical Salt. The arseniate of potassium.

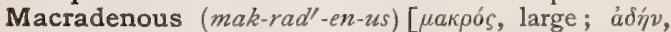
gland]. Having large glands.

Macræsthete (mak'-res-thèt) [ perceived by the senses]. In biology, Moseley's term for one of the more or less fusiform sense-bodies that occupy the cavities of the megalopores of the Chitonide. They terminate in conspicuous obconical plugs of transparent, highly refractive tissue, and are composed of a number of cylindric strands of tissue held closely together. Cf. Eisthete.

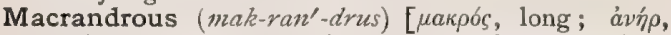
male]. In biology, applied to such plants (alge) as have the male plants large or elongated.

Macrantrus (mak-ran'-trus) [ a cave]. Lissauer's term for a skull in which the vertical line extending from the most prominent point of the frontal torus to the radius fixus is from four to nine $\mathrm{mm}$. in front of that from the nasion to the radius fixus.

Macrauchen (mak-raw'-ken) [ neck ]. A long-necked person.

Macrencephalic (mak-ren-sef-al'-ik), Macrencephal-

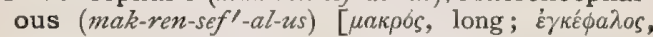
brain]. Having a large or long skull.

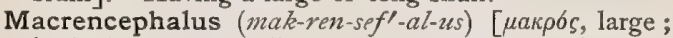

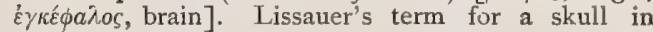
which the angle formed by the junction of the lines drawn from the hormion to the nasion and to the inion is between $156.5^{\circ}$ and $170^{\circ}$.

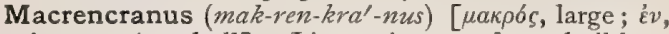
in; крaviov, skull]. Lissauer's term for a skull having a large cerebellar sector (from $20^{\circ}$ to $27.5^{\circ}$ ).

Macritas (mak'-rit-as) [macer, lean]. Emaciation; leanness.

Macro- (mak'-ro-) [накрós, long, great]. A prefix signifying great, long, or extensive.

Macrobiosis (mak-ro-bi-o'-sis) [ $\mu \alpha \kappa \rho o ́ s$, long; ßios, life]. A condition characterized by long life; longevity.

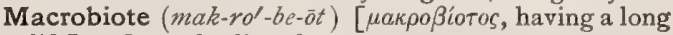
life]. One who lives long.

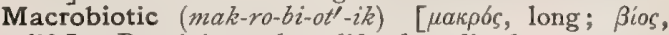
life]. Pertaining to long life; long-lived.

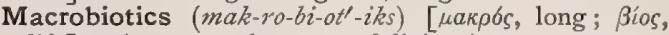
life]. A proposed system of living in a manner conducive to length of life; the art or study of longevity.

Macrobius (mak-ro'-be-us). See Macrobiotic.

Macrocarpin (mak-ro-kar'-pin) [ $\mu a \kappa \rho b s$, large; картós, fruit]. A crystalline neutral principle extracted from the root of Thalictrum macrocarpum.

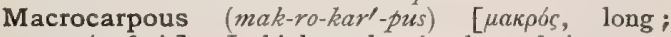
$\kappa a \rho \pi b s$, fruit]. In biology, bearing large fruit.

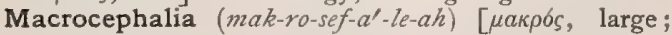

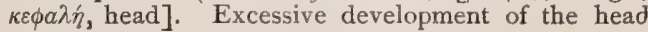


in size. A systematic deviation in a genus or a species distinguished by abnormally large heads.

Macrocephalous (mak-ro-sef'-al-us) [ $\kappa \varepsilon \dot{a} a \lambda \dot{\eta}$, head]. Characterized by an abnormally large head. In biology, applied to plant-embryos that have very large and consolidated cotyledons, such as the horse-chestnut.

Macrocephaly (mak-ro-sef'-al-e). See Macrocephalia.

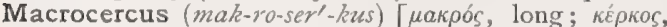
tail]. Long-tailed. In zoölogy, a genus in which the spermatozoa were at one time classed.

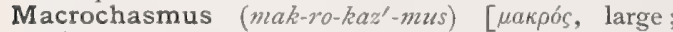

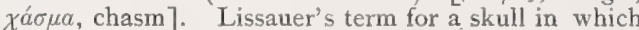
the angle formed by the junction of lines drawn from the wing of the vomer to the posterior nasal spine and to the anterior margin of the foramen magnum is between $94^{\circ}$ and $114^{\circ}$

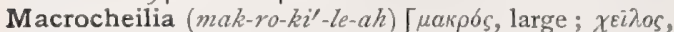
lip]. Excessive size or development of the lips; a characteristic of certain negro and negroid tribes. It occurs aiso in cretinoid states and when the lips and cheeks are the seat of lymphangioma.

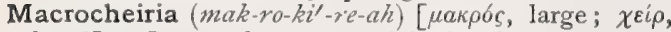
hand]. Great enlargement of the hands.

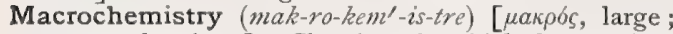
$\chi \eta \mu \varepsilon i a$, chemistry]. Chemistry in which the reactions are observable with the naked eye. Cf. Microchemistry.

Macrococcus (mak-ro-kok'-us) [ a akpós, long or large ; кбккоs, a berry: pl., Macrococci]. A term applied to cocci that are somewhat larger than the average.

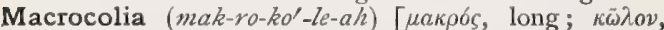
limb]. The possession of long limbs.

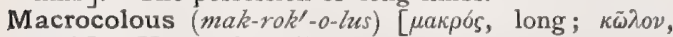
limb]. Having long limbs.

Macrocosm (mak'-ro-kozm) [ world]. The world or cosmos, in contradistinction to man, the microcosm, or little universe.

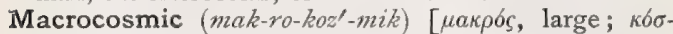
$\mu o s$, world]. Pertaining to the macrocosm.

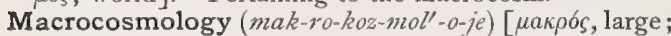
$\kappa 6 \sigma \mu \rho s$, world; $\lambda 6 \gamma o s$, science]. The science of the macrocosm or outer world; mineralogy.

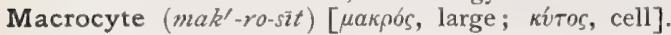
A giant blood-corpuscle found in the blood in pernicious anemia, and leukemia.

Macrocythemia (mak-ro-si-the'-me-ah) [uakposs, long, great; kv́ros, cell; aira, blood]. A condition in which the size of the red blood-corpuscles is increased; it may be due to malaria, anemia, or leadpoisoning

Macrocytosis (mak-ro-si-to'-sis) [ $\mu$ akpós, large ; кv́тos, cell]. The formation of macrocytes.

Macrodactylia (mak-ro-dak-til'-e-ah) [uakpós, long ;

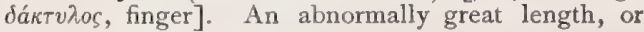
size, of fingers or toes.

Macrodactylism (mak-ro-dak'-til-izm). See Macrodactylia.

Macrodactyly (mak-ro-dak'-til-e). See Macrodactylia.

Macrodont (mak'-ro-dont) [ tooth]. Large-toothed, as applied to the comparative size of the teeth of different races. When the dental length multiplied by 100 divided by the basinasal length exceeds 44 , the skull is considered a macrodont, if under 42 a microdont, if intermediate a mesodont.

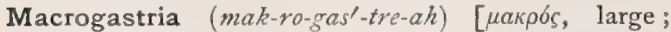

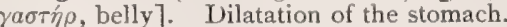

Macrogastrous (mak-ro-gas'-trus) [uakpús, large;

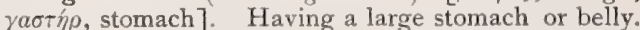

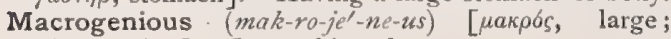

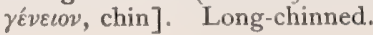

Macroglossia (mak-ro-glos'-e-ah) [uaknbs, great; $\gamma \lambda \bar{\omega} \sigma \sigma \alpha$, tongue]. Hypertrophic development of the tongue, a condition seen in cretins, in whom it is probably due to lymphangioma

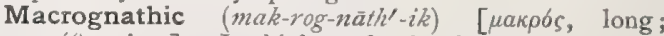
ruátlos, jaw]. In biology, having long jaws; prognathous.

Macrogonidium (mak-ro-go-nid'l-e-um) [uakpós, long, large; yovń, generation, seed: pl., Macrogonidia]. In biology, a gonidium larger than the average.

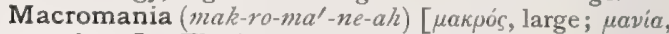
maxlness]. The insane delusion that objects are larger than they really are; or the impression that one's own body or members are much larger than they are.

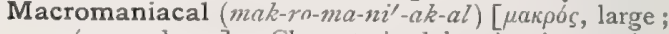
ravia, madness]. Characterized by the insane impression that objects are larger than they really are.

Macromelia, (mak-ro-me'-le-ah), Macromelus (mak-

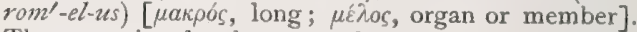
The excessive development of any organ or member.

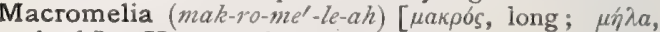
cheek]. Hypertrophy of the cheeks.

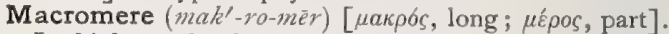
In biology, the larger of the two masses into which the vitellus divides in the development of a lamellibranch, termed by Rabe the "vegetative cell." One of the larger blastomeres in a holoblastic telolecithal germ. M.-plate, a plate of 16 macromeres arranged on the vegetative side of the germ in the Ctenophora.

Macromyelon (mak-ro-mi'-el-on). See Metencephalon.

Macronemous (mak-ro-ne'-mus) [ $\mu a \kappa \rho o ́ s, ~ l o n g ; \nu \tilde{\eta} \mu a$, thread]. Having long tentacles.

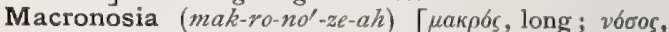
illness]. A protracted or chronic disease.

Macronucleus (mak-ro-nu'-kle-us). See Nucleus.

Macronychous (mak-ro-nik'-us) [ talon]. Having long nails or claws.

Macropanencephalus (mak-ro-pan-en-sef'-al-us) [ $\mu a k$ -

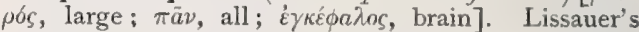
term for a skull in which the angle formed by the junction of the lines joining the hormion to the nasion and to the basion is between $185.5^{\circ}$ and $206^{\circ}$.

Macropetalous (mak-ro-pet'-al-zs) [uakpós, long; $\pi \dot{t} \tau a-$ $2 o v$, a leaf ]. In biology, having large petals.

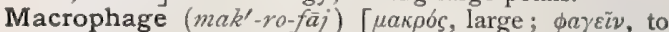
devour]. A large phagocyte. "Metschnikoff's term for certain large leukocytes occurring in structures affected with erysipelas. He believes that they consume and destroy the debris of the dead and dying microphages."

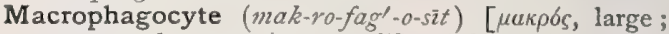
$\phi a \gamma \varepsilon i v$, to devour; кúтos, a cell]. A large-sized phagocyte, possessed of a single nucleus, and derived from some fixed connective-tissue element.

Macrophagus (mak-roff'-ag-us). See Macrophage.

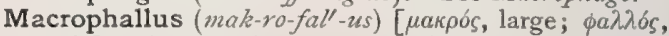
penis]. A penis abnormally large or long.

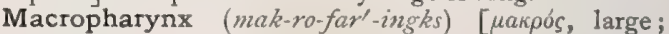
$\phi a ́ p v \gamma \xi$, pharynx]. A large pharynx.

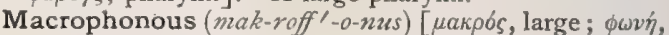
sound]. Loud-voiced.

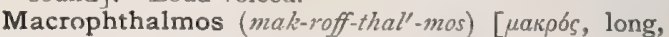
large ; $\dot{\phi} \phi \theta \alpha \lambda \mu \delta \zeta$, eye]. In biology, having large eyes. Macrophylline (mak-ro-fil'-in) [ akoós, long, large;

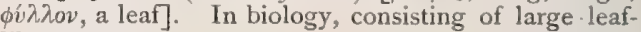
like parts or organs.

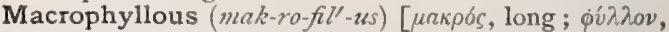
a leaf]. In biology, having large leaves.

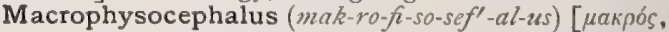
large ; $\phi v \sigma a \tilde{\nu}$, to puff up; $\kappa \varepsilon \phi a \lambda \eta \dot{~, ~ h e a d] . ~ I . ~ E n l a r g e-~}$ ment of the head from emphysema. 2. Caput succedaneum. 
Macropia (mak-ro'-pe-ah). See Megalopsia.

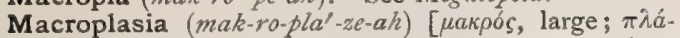
$\sigma \iota \varsigma$, a moulding]. Excessive development of portions of the body.

Macropneuma, Macropnea (mak-ro-nu'-mah, mak-

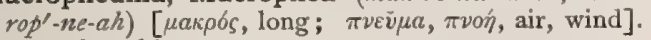
Deep breathing.

Macropodal (mak-rop'-o-dal) [ foot]. Large-footed.

Macropodia (mak-ro-po'-de-ah) [ foot]. Excessive size of the feet.

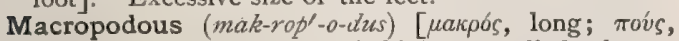
foot]. I. Large-footed. 2. In biology, applied to leaves with long foot-stalks, or to embryos with peculiarly large radicies.

Macropous (mak'-ro-pus). See Macropodal.

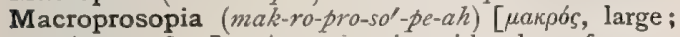
$\pi \rho \sigma \sigma \omega \pi o v$, face]. A monstrosity with a huge face.

Macropsia (mak-rop'-se-ah). See Megalopsia.

Macropterous (mak-rop'-ter-us) [uakpós, long; $\pi \tau \varepsilon \rho b v$, wing]. In biology, having long wings; longipennate.

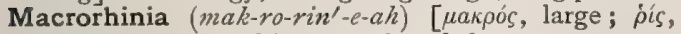
nose]. Congenital hypertrophy of the nose.

Macrorhis (mak'-ro-ris) [ Having a large nose.

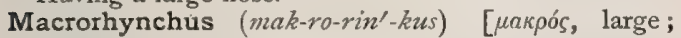
'́vy 0 s, beak]. Large-beaked.

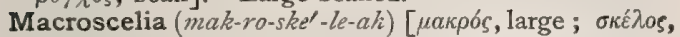
leg]. Excessive development of the legs.

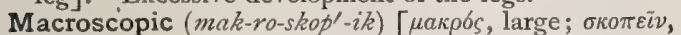
to see]. Large enough to be seen by the naked eye; gross; not microscopic. M. Morbid Anatomy, naked-eye or gross morbid anatomy.

Macroseme (mak'-ro-sèm) [ index]. Having an orbital index in excess of 89 .

Macrosiphon (mak-ro-si'-fon) [ siphon]. In biology, applied to the long, horny funnel of certain cephalopods.

Macrosiphonula (mak-ro-si-fon'-u-lah) [

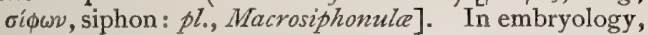
a larval stage of certain cephalopods characterized by the appearance of the macrosiphon.

Macrosis (mak-ro'-sis) [ increase in volume.

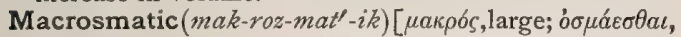
to smell]. Having well-developed olfactory organs.

Macrosomatia (mak-ro-so-ma'-she-ah), Macrosomia

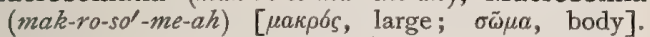

- Great or teratic size of body ; largeness of body suffcient to constitute a monstrosity.

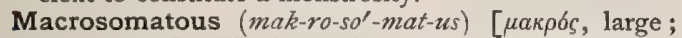
$\sigma \tilde{\omega} \mu \alpha$, body]. Having a large body. Characterized by an abnormally or teratically large body.

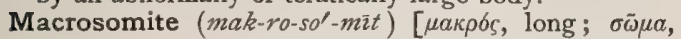
body]. In embryology, one of the larger primitive segments or metameres in the embryos of certain insects.

Macrosporangiophore (mak-ro-spo-ran'-je-o-for) [ $\mu a \kappa-$

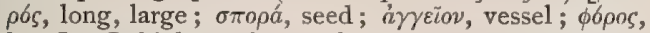
bear]. In biology, the envelop of a macrosporangium.

Macrosporangium (mak-ro-spo-ran'-je-um) [

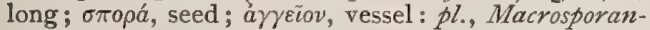
gia]. In biology, a sporangium containing macrospores; a megasporangium, oösporangium, or goniotheca.

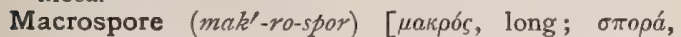
seed]. In biology: (a) a spore of relatively large size; (b) one of the larger anisospores arising in the reproduction of colony-forming Radiolarians.

Macrosporophyl, (mak-ro-spo'-ro-fil) [ large; $\sigma \pi \circ \rho a ́$, seed; $\phi \dot{\nu} \lambda \lambda \nu_{\nu}$, leaf ]. The leaf bearing the macrosporangium in the higher Pteridophyta.

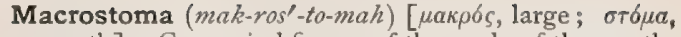
mouth]. Congenital fissure of the angle of the mouth, producing a large opening.

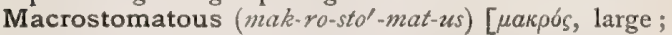
$\sigma \tau \delta \mu \alpha$, mouth]. Large-mouthed.

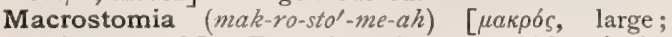
$\sigma \tau b \mu a$, mouth]. Excessive size, or width, of the mouth, or of the oral fissure.

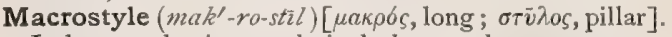
In botany, having a relatively long style.

Macrostylospore (mak-ro-sti'-lo-spor) [

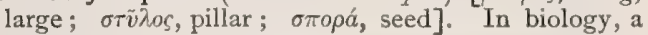
relatively large stylospore.

Macrotes (mak-ró-tēz) [ $\mu a \kappa \rho b ́ s$, large; oús, ear]. One having large ears.

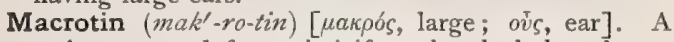
resin extracted from cimicifuga by alcohol, and precipitated by water. See Cimicifuga.

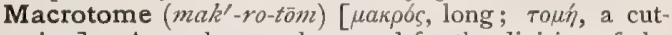
ting]. A saw-box; a box used for the division of the cranium in post-mortem examination of the brain.

Macrozoögonidium (mak-ro-zo-o-go-nid'-e-um) [ $\mu$ akpós,

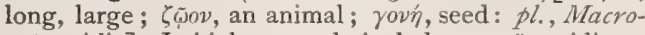
zoögonidia]. In biology, a relatively large zoögonidium.

Macrozoöspore (mak-ro-zo'-o-spor) [ $\mu \alpha \kappa \rho o ́ s, ~ l o n g ~ ; ~ \zeta \bar{\omega} o \nu$,

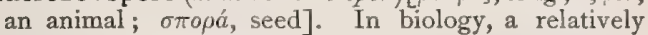
large form of zoöspore.

Macula (mak'-u-lah) [L.: pl., Macule]. A spot or discoloration of the skin, not elevated above the surrounding level. It may be of various sizes, shapes, and tints, and is due to hyperemia, to extravasation of blood and blood coloring-matter, to dilatation of the cutaneous vessels, or to changes in the pigmentation of the skin. M. acusticæ, the terminations of the auditory nerve in the saccule and utricle. $\mathbf{M}$. albida, leukoderma. M. artificialis, a spot produced artificially in order to deceive. M. aurea, the central fovea of the retina. M., Cerebral. See Tâche cérébrale. M. cerulea, a dark spot occurring on a skin infested with parasites. M. corneæ arcuata, the arcus senilis. M. cribrosa, a name given to the perforations of the fovea hemispherica for the passage of the filaments of the auditory nerve. M. flava. See $M$. lutea. M. folliculi, the stigma of the Graafian vesicle. M. fusca, a spot due to diseases characterized by pigmentation, as lentigo and chloasma. M., Germinal, the small spot constituting the germinal vesicle or nucleus of the ovum. M. hepatica, a liver-spot, including pigmentary spots due to various diseases. M. lata plateri, an obscure disease of the skin, sometimes epidemic, characterized by burning, red spots and pustulation. M. lenticularis, a lenticular spot; the roseola of typhoid fever. M. livida, a hemorrhagic or purpuric spot. M. lutea, the yellow spot of the retina, called, sometimes, the spot of Sommering, but usually called simply the macula. The depression in its center is called the fovea centralis. It is the point of clearest vision and is pierced by the visual axis. M. materna, birth-mark, or nevus. M. nigra, a disease of the skin associated with very dark spots of pigmentation. M. ocularis, the eye-spot of the Protozoa, Cnidaria, Platodes, and Crustacea, M., Roberts', a heaping up of pigment in a part of a red corpuscle when a dilute solution of tannic acid is added to the blood. M. solaris, a freckle. M. syphilitica, the coppery stain of the skin left by a syphiloderm.

Macular (mak'-u-lar) [macula, spot]. Exhibiting or characterized by maculæ. Pertaining to the Macula lutea.

Maculate (mak'-u-lät) [maculatus, p.p. of maculare to spot]. In biology, blotched or spotted. 
Maculation (mak-u-la'-shun) [maculatio, a spotting]. The state or quality of being spotted; the formation of maculæ; a spot or macula.

Macule (mak'-ül) [macula, a spot]. See Macula. M., Gonorrheal, Sänger's term for the purplish-red areola resembling a flea-bite, surrounding the orifice of the duct of Bartholin's gland in gonorrheal vaginitis.

Maculiform (mak-u'-lif-orm) [macula, spot; forma, form]. Resembling a macula.

Maculose, Maculous (mak'-u-lōs, mak'-u-lus). See Macular.

Mad [ME., made, mad]. I. Disordered in intellect; insane. 2. Furious from disease; rabid. M.doctor, an alienist. M.-house, an asylum for the insane. M.-man, an insane person. M. Staggers, the enzoötic cerebritis of horses. See Staggers. M. stone, according to popular superstition, a small stone believed to possess the property of absorbing the poison (especially snake-poison) or disease from wounds, made, $e_{.} g$. , by poisoned arrows, or morbid parts. It is called also Snakestone. Galen believed that certain medicines attract poisons as the magnet does iron. Most madstones are an aluminous shale, or other absorptive substance.

Madar (mad-ar'), Mudar (mu-dar') [Hind., madār] The shrubs Calotropis gigantea, and $C$. procera, of India ; also their bark, leaves, flowers, fruits, and juice, which are tonic, alterative, and emetic; it is used in Asia in a wide range of diseases. Unof., except in the Indian Pharmacopeia. C. gigantea yields Madaralban, a colorless crystalline substance soluble in the alkalies; but not in water; and Madar-fuavil, a yellowish, viscid body, soluble in cold alcohol, in ether, and in benzene, insoluble in water, in acids, and in alkalies.

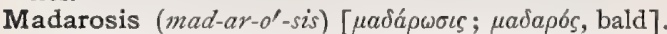
Loss of the eyelashes or hairs of the eyebrows.

Madarotic (mad-ar-ot'-ik), Madarous (mad'-ar-us) [ $\mu a \delta a ́ \rho \omega \sigma \iota s ; \mu a \delta a \rho \delta \delta$, bald]. Affected with or relating to madarosis.

Madder (mad'-er) [ME., moder, madder]. The plant Rubia tinctorum; also its root, well-known as a dyestuff. It was formerly considered emmenagogue and diuretic. Unof. See also Pigments, Conspectus of. M.-brown, M.-carmin, M.-orange, M.-purple. See Pigments, Conspectus of. M.-red. Same as Madder. M.-yellow. See Pigments, Conspectus of.

Maddox Test, or Maddox Glass-rod Test. A test of heterophoria by means of a short cylinder of transparent glass about one-eighth of an inch long, fitted into a slot in an opaque disc to be set in the trial-frame before one eye, with a colored plano lens before the other eye. The rod converts the image of a distant flame into a thin line of light. The relative position of the two images thus formed permits the measure of imbalance of the muscles.

Madefaction (mad-e-fak'-shun) [madefacere, to moisten ]. The act of moistening.

Madeira (mad-a'-rah) [Pg., madeira, wood]. A fine sherry wine from the island of Madeira.

Maderna (mad-er'-nah). Synonym of Madarosis.

Madescent (mad-es'-ent) [madescere, to become wet]. Becoming moist.

Madesis (mad-e'-sis). Synonym of Madarosis.

Madidans (mad'-id-anz) [L.]. Weeping, oozing. See Eczema madidans.

Madisis (mad'-is-is). Synonym of Madarosis.

Madisterion, Madisterium (mad-is-ter'-e-on, mad-is-

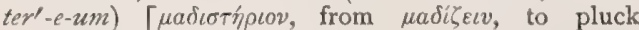
bare]. Epilating-forceps.

Madness (mad'-nes). See Insanity and Mania.
Madrid Colic. See Cotic.

Madura Foot. See Foot, Fungus.

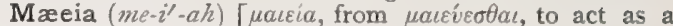
midwife]. An old synonym of Obstetrics.

Mæeleutherosis (me-el-u-ther-o'-sis) [uaı́, midwife: $\dot{\varepsilon} \lambda \varepsilon v \theta \varepsilon \rho \omega \sigma \iota \varsigma$, a freeing]. Delivery by the aid of a midwife. (Obs.)

Mæeuma (me-e- $\left.u^{\prime}-m a h\right)$ [ act as midwife]. The newly-born babe. (Obs.)

Mæeusiomania (me-u-se-o-na'-ne-ah). See Maiusiomania.

Mæeusiophobia (me-u-se-o-fo'-be-ah). See Maiusiophobia.

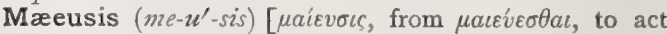
as midwife]. Delivery.

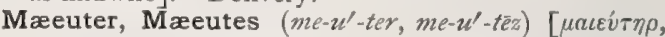

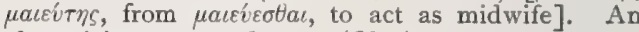
obstetrician; accoucheur. (Obs.)

Mæeutics (me-u'-tiks). See Maiutics.

Mæeutria (me-u'-tre-ah) [ act as midwife]. Midwife. (Obs.)

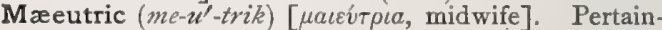
ing to a midwife. (Obs.)

Mæna (me'-nah) [ of herring. The brine from the salted fish has been employed as a dressing for gangrenous ulcers.

Magdala Red (mag-da'-lah). See Naphthalene-red.

Magdaleon (mag-da'-le-on), Magdalia (mag-da'.

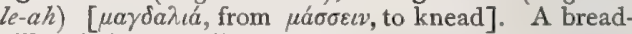
pill or bolus; a roll of plaster.

Magendie, Foramen of. See Foramina, Table of. M.'s Solution, See Morphin.

Magenta (ma-jen'-tah) [from a town in Italy]. A coal-tar dye ; one of the forms of anilin-red; properly, a hydrochlorid of rosanilin. From it fuchsin and a large number of other dyes are prepared. One of the peculiar and somewhat glaring red tints which it produces is also called magenta. See Fuchsin, and Pigments, Conspectus of.

Maggot (mag'-ot) [ME., magot, maggot]. I. The larva of any insect, as a fly, that burrows in wounds or ulcers. Maggots are especially annoying in military practice and in hot countries. 2. A whim or fixed idea dominant in the mind, as of an insane or paranoiac person.

Magistery (maj-is'-ter-e) [magisterium, masterpiece]. Formerly, a preparation considered to have especial virtue as a remedy. $\mathbf{M}$. of bismuth, the subnitrate of bismuth. M. of tin ( $M$. Jovis), precipitated stannous oxid.

Magistral (maj'-is-tral) [Magister, a master]. A term employed to denote those medicines that are prepared on prescription, in distinction from those prepared or sold without the physician's order.

Magma (mag'-mah) [ $\mu a ́ \gamma \mu \alpha$, mass: pl., Magmata]. Sediment, dregs; any pulpy mass.

Magmatic (mag-mat'-ik), Magmoid (mag'-moid)

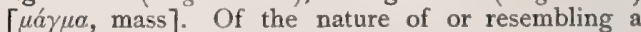
magma.

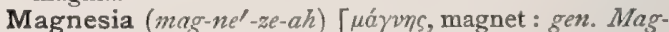
nesia]. Magnesium oxid, MgO. M. White, magnesium carbonate. See Magnesium.

Magnesian (mag-ne'-ze-an). See Magnesic.

Magnesic (mag-ne'-zik) [ magnet]. Pertaining to or containing magnesium.

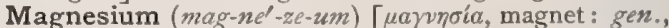
Magnesii]. Mg; atomic weight 24.3; quantivalence II ; spec. gravity I.75. One of the metals of the alkaline earths, widely distributed in inorganic nature and forming also a constituent of animal and vegetable tissues. See Elements, Table of. The physiologic effects of its salts are antacid and laxative. Various salts are 
extensively used in medicine. $\mathbf{M}$. boratis, Liquor (B. P.), contains one part of boric acid in six. It is recommended as a paint in diphtheria. M. carbonas, $\left(\mathrm{Mg} . \mathrm{CO}_{3}\right)_{4} \mathrm{Mg}$. $(\mathrm{HO})_{2} \cdot 5 \mathrm{H}_{2} \mathrm{O}$. Dose gr. $\mathrm{x}-3 \mathrm{j}$. M. carb., Liquor (B.P.) Dose $\xi j-i j$. M. citras effervescens granulatus, a preparation dissolving in water with effervescence. $M$. citras granulatus, " granulated citrate of magnesia," combined with citric acid, sugar, sodium bicarbonate, alcohol, and water. Dose $3^{\mathrm{ij}-z_{j} \text {. }}$ M. citratis, Liq., contains M. carbonate gr. 200 , citric acid gr. 400 , syr. of citric acid gr. I200, potassium bicarbonate gr. 30, water q. s.

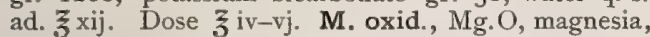
the oxid of the metal, a constituent of several laxative mixtures. Dose gr. $\mathrm{x}-\mathbf{3} \mathrm{j}$. Magnesia ponderosa, heavy or calcined magnesia. Dose gr. $x-z j$. M. sulphas, $\mathrm{Mg} . \mathrm{SO}_{4} \cdot 7 \mathrm{H}_{2} \mathrm{O}$, "Epsom salt," "salts," much used as a popular purgative. Dose $3 \mathrm{j}-\mathbf{z}$. . M. sulphat., Enema (B.P.), composed of sulphate of magnesium one part, olive oil one part, starch mucilage 15 parts. M. sulphis, $\mathrm{MgSO}_{3} \cdot 6 \mathrm{H}_{2} \mathrm{O}$. Dose gr. $\mathrm{x}-\mathrm{xxx}$. M., Trochisci, each contains magnesia gr. iij, nutmeg, gr. $\frac{15}{100}$, sugar, tragacanth, water, q. s.

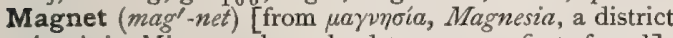
in Asia Minor, where loadstone was first found]. Loadstone, a magnetic oxid of iron. A body having the power to attract the unlike pole of another magnet, or to repel the like pole, and also to attract easilymagnetizable bodies. A body having a magnetic field. M., Electro-, a piece of soft iron temporarily magnetized by induction or by insertion into a helix. M., Gruening's, an instrument consisting of several magnetized steel rods, used for the removal of iron and steel particles from the eye. M., Horse-shoe, an iron magnet having the shape of a horse-shoe. M.operation, the operation of removing foreign bodies of steel from the eye by the aid of a magnet. M., Permanent, one the magnetic properties of which are permanent, in contradistinction to $\mathbf{M}$., Temporary, which derives its magnetism from another magnet or from a galvanic current.

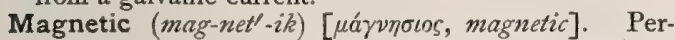
taining, or belonging, to a magnet. Possessed of magnetism. M. Axis, the line joining the poles of a magnet. M. Field, a space traversed by lines of magnetic force.

Magnetism (mag'-net-izm) [ peculiar power possessed by the loadstone or natural magnet, and, under certain conditions, by other mineral substances, to attract or repel other masses. The science that treats of the nature and properties of magnets and the magnetic field. M., Animal, an empiric term for hypnotism. See Somnambulism and Hypnotism.

Magnetization (mag-net-iz-a'-shun) [ $\mu a ́ \gamma v \eta s$, magnet]. The process of rendering a substance magnetic.

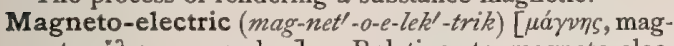
net; $\eta \lambda_{\varepsilon \kappa} \rho \circ o v$, amber]. Relating to magneto-electricity.

Magneto-electricity (mag-net'-o-e-lek-tris'-it-e) [ $\mu a ́$ ' ins, magnet; $\tilde{\eta} \lambda \varepsilon \kappa \tau \rho o \nu$, amber.] Electricity produced by means of a magnet.

Magnetograph (mag-net'-o-graf) [ $\mu \alpha \dot{\gamma} \gamma \eta \eta s$, magnet ;

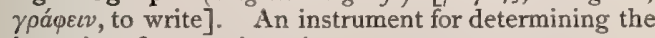
intensity of magnetic action.

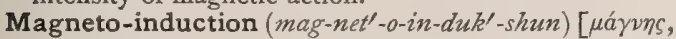
magnet; inductio, induction]. The production of an induced current by the insertion of a magnet within a coil of wire.

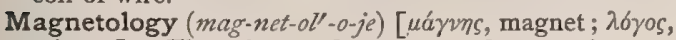
science]. The science of magnets and magnetism.

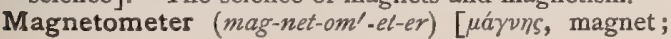

$\mu \varepsilon ́ \tau \rho o \nu$, a measure.] A series of magnets suspended so as to record graphically variations in direction and intensity of magnetic force.

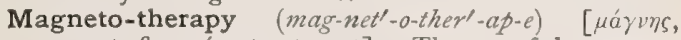
magnet; $\theta \varepsilon \rho a \pi \varepsilon ́ l a$, treatment $]$. The use of the magnet in hypnotic therapeutics.

Magniductor (mag-ne-duk'-tor) [magnus, great; ductor, a leader]. The adductor magnus of the thigh.

Magnification (mag-nif-ik-a'-shun) [magnificare, to magnify]. In microscopy, the result obtained by dividing a linear dimension of the image by the corresponding linear dimension of the object magnified.

Magnify (magl-nif-i) [magnificare, to magnify]. To make greater.

Magnifying (mag'-nif-i-ing) [magnificare, to magnify]. Making greater. M. Power. See Magnification.

Magnium (mag'-ne-um). Synonym of Magnesium.

Magnolia (mag-no'-le-ah) [after Pierre Magnol, a French botanist]. A genus of trees. The bark of $M$. glauca, the common swamp sassafras, and several other species of the same genus are used in medicine. Magnolia is an aromatic, bitter tonic, popular as a remedy in rheumatism and malarial fevers. Dose $3^{\text {ss-j. }}$. Unof.

Magnolin (mag-no'-lin) [after Pierre Magnol, a French botanist]. A crystalline substance found in the fruit of magnolia.

Magnum, or Os magnum [L. for "great bone"]. The largest bone in the distal row of the carpus situated between the unciform and the trapezoid bones.

Magnus's Law. See Law. M.'s Method, in obstetrics, a method of bringing down the arms of the fetus after version. When the arms are about the neck, the hand should be introduced in the ordinary method, two or three fingers being placed on the superior edge of the scapula, which is gently pressed downward. This will cause the arms to move suddenly and to come down without further help. M.'s Sign. See Death.

Máhámari (nah-hah-mah'-re) [E. Ind.]. Synonym of the Plague,q.v. See Pali.

Mahua (mah'-u-ah). See Bassia.

Maid, Maiden (māıl, ma'-den) [ME., maide, maiden, a maid]. A young unmarried woman; a virgin. Maidenhead, popular expression for maidenhood; virginity; also the hymen.

Maidismus (ma-id-iz'-mus) [mays, maidis, maize]. Maize-poisoning, or pellagra.

Maieleutherosis (ma-el-u-ther-o'-sis) [ $\mu a$ ia, midwife; $\varepsilon \dot{\varepsilon} \varepsilon v f \hat{\varepsilon} \rho \omega \sigma$, , delivery]. Delivery by the aid, or with the attendance, of a midwife.

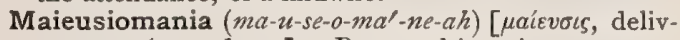
ery; $\mu$ avía, madness]. Puerperal insanity.

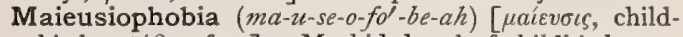
birth; $\phi 6 \beta 0 s$, fear]. Morbid dread of childbirth.

Maieutics (ma- $\left.u^{\prime}-t i k s\right)$ [ $\mu a \iota \varepsilon v ́ v \eta s$, an obstetrician;

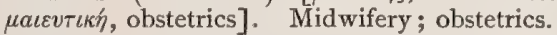

Maignen's Compound. Powdered charcoal and lime supported on asbestos-cloth and used for filtration. It is employed in disinfecting sewage.

Mailed (mâld) [ME., maile, a link]. In biology, provided with some kind of protective or defensive coat, as of scales or plates; loricate; lepidote.

Maim (mām) [ME., maimen, to mutilate]. I. To disable by mutilation. 2. A crippling. 3. See May. hem.

Main de la griffe, Main en griffe. See Atrophy, Progressive Muscular, and Claw-hand.

Maisonneuve's Bandage. See Bandage.

Maissiat's Band. A firm; dense portion of the fascia lata of the thigh passing down to become attached 
to the outer tuberosity of the tibia; the ilio-tibial band. It helps to limit adduction of the thigh.

Maize (māz) [W. Ind., mahiz, maize]. I. Indian corn. See Zea mays. 2. A coal-tar color, used in dyeing silk and wool reddish-yellow in an acid bath. It is the sodium salt of the disulphonic acid of azoxystilbene, and is called Sun-yellow. M.-poisoning. See Pellagra

Maizena (ma-ze'-nah) [W. Ind., mahiz, maize]. A flour made from maize.

Maizenic Acid (mo-zen'-ik). See Acid.

Make (mäk) [ME., maken, to make]. "The make," a colloquialism for designating the making of the electric current by applying the electrode to the conducting surfaces of the body. Interruption of the current is called "the break."

Makrantrus. See Macrantrus.

Makrencephalus. See Macrencephalus.

Makrencranus. See Macrencranus.

Makro-(mak'-ro-). See Macro-.

Makrodaktylia (mak-ro-dak-til'-e-ah). See Macrodactylia.

Makropsia (mak-rop'-se-ah). See Megalopsia.

Makrosomia (mak-ro-so'-me-ah). See Macrosomia.

Mal [malum, evil, disease]. Disease. See Epilepsy. M. de mer. See Sea-sickness. M. de dent, odontalgia.

Mala $\left(m a^{\prime}-l a h\right)$ [L. : pl., Mala $]$. I. The cheekbone or prominence of the cheek. 2. Plural of $\mathrm{Ma}$ lum, the cheek. In biology, one of the inner lobes of the maxilla of certain coleopterous larvæe (Schrödte).

Malabar, Leprosy of. Synonym of Elephantiasis arabum. M. Nut. See Adhatoda vasica. M. Ulcer. See Phagedana tropica.

Malacarne, Antrum of. See Antrum. M.'s Pyramid, the posterior extremity of the pyramid of the cerebellum.

Malachite-green. See Pigments, Conspectus of.

Malacia (mal-a'-se-ah) [ $\mu a \lambda a \kappa i a$, a softening]. Any morbid softening of tissue. Also, a depraved appetite. M., Amphiblestroid, softening of the retina. M. cordis. See Myomalacia. M., Halisteretic, malacia characterized by the absorption of the limesalts of the bones.

Malacismus (mal-as-iz'-mus). See Malacia.

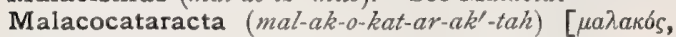
soft; катара́ктᄁs, cataract]. A soft cataract.

Malacogaster (mal-ak-o-gas'-ter) [ $\mu a \lambda a \kappa i a$, a softening;

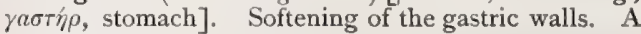
synonym of Gastromalacia.

Malacoid (mal'-ak-oid) [ In biology, applied to organisms, organs, or tissues of soft texture.

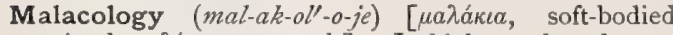
animals; $\lambda \varepsilon \varepsilon_{\varepsilon \varepsilon v}$, to speak]. In biology, that department of science that deals with the Mollusca; conchology.

Malacoma (mal-ak-o'-mah) [ $\mu a \lambda a k b s$, soft : pl., Malacomata]. The softening of any organ or part of the body. Also, a synonym of Molluscum sebaceum.

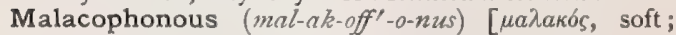
$\phi \omega \nu \eta ́$, voice]. Soft-voiced.

Malacosarcosis (mal-ak-o-sar-ko'-sis) [ $\mu a \lambda a \kappa b ́ s$, soft ; $\sigma a ́ \rho \xi$, flesh ]. Softness of tissues, as of muscle.

Malacosis (mal-ak-o'-sis) [ $\mu a \lambda a \kappa b s$, soft]. The condition distinguished by the abnormal softening of the tissues of any part of the body. Also, the process of malacoma. M. cordis. See Myomalacia.

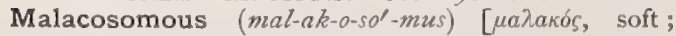
$\sigma \tilde{\omega} \mu \alpha$, body]. Soft-bodied.

Malacosteon (mal-ak-os'-te-on). See Osteo-malacia.

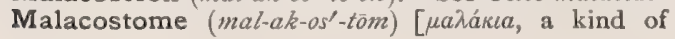

molluse; бró $\mu$, mouth]. In biology, the mouth of a mollusc (L. Agassiz). Cf. Actinostome.

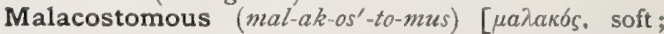
$\sigma \tau \delta \mu a$, mouth]. In biology, applied to animals having a soft or unarmed mouth.

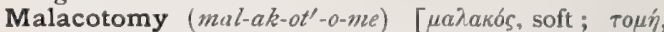
a cutting]. In biology, the anatomy of the mollusca; incision of the abdomen; celiotomy.

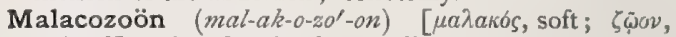
animal]. A soft animal; a mollusc.

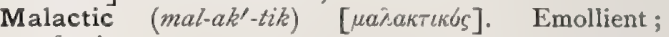
softening.

Malady (mal'-ad-e) [malum, evil]. Any illness or disease. M., Cheyne's English, hypochondriasis. M., Post-boys', aneurysm of the aorta, comparatively common among mounted mail-carriers.

Malagma (mal-ag'-mah) [ $\mu a ́ \lambda a \gamma \mu a$, a poultice: pl., Malagmata]. See Poultice.

Malaguti's Law. See Law.

Malaise (mal-āz $z^{\prime}$ [Fr., malaise]. A general feeling of illness, accompanied by restlessness and discomfort; dysphoria.

Malakin ( $\left.\mathrm{nal}^{\prime}-a k_{-}-i n\right)$. The salicyl-derivative of paraphenetidin. A synthetic product allied to phenacetin, and recommended as an antirheumatic, antipyretic, and antineuralgic. It appears in the form of small, light yellow, fine needles that melt at $197.6^{\circ} \mathrm{F}$., insoluble in water, but fairly soluble in hot alcohol. Dose, from 60 to 90 grains daily. Unof.

Malamid (mal'-am-id) [ $\mu a \tilde{\lambda} \lambda o v$, an apple; amid], $\mathrm{C}_{4} \mathrm{H}_{8} \mathrm{O}_{3} \mathrm{~N}_{2}$; a substance formed by the action of ammonia upon dry ethyl malate. It occurs in large crystals, and when heated with water it breaks up into malic acid and ammonia.

Malandria (mal-an'-dre-ah). See Mallenders.

Malar (ma'-lar) [mala, cheek]. Pertaining to the cheek-bone. M. Bones, the two cheek-bones. M. Foramen. See Foramina, Table of. M. Points. See Craniometric Points.

Malaria (mal-a'-re-ah) [It., mala aria, bad air]. See Malarial Fever. M., Bacillus of. See Bacilhes of Malaria, in Bacteria, Synonymatic Table of. M., Hematozoön of, M., Plasmodium of. See Malarial Fever and Polimitus malaria, under Parasites (Animal), Table of. M., Larval, a masked form of intermittent fever.

Malarial (mal-a'-re-al) [It., mala aria, bad air]. Pertaining to malaria. M. Cachexia, a chronic form of malaria characterized by anemia, general failure of health, a sallow complexion, and enlargement of the spleen. M. Fever, a generic name for a group of diseases associated with the presence in the blood of the Polimitus malaria, and characterized by paroxysmal periodicity, enlargement of the spleen and liver, melanemia, and the presence in the blood, free or within the red corpuscles, of parasites (plasmodia) that exert a deleterious influence upon the red cells. The paroxysms may be intermittent, remittent or irregular. If repeated daily the fever is designated quotidian; if on alternate days, tertion; if with an interval of two days, quartan. If two paroxysms occur daily the fever is designated a double quotidian. There may be a double tertian form, a paroxysm occurring daily, but only those of alternate days being alike; a double quartan form, and others. When the paroxysms succeed one another so closely that the coldstage of one begins before the sweating-stage of its predecessor ends, the fever is designated subintrant. A typical malarial paroxysm consists of a cold stage, a hot stage, and a sweating stage, occurring in the sequence given. Intermittent fever is characterized by the occurrence of a complete intermission of the 
symptoms in the interval between two paroxysms, the temperature becoming normal or subnormal. In remittent fever there is only an amelioration of the symptoms in the intervals. Hemorrhagic malarial fever is a grave form of malarial intoxication in which the height of the paroxysm is characterized by headache, severe pain in the back, nausea, vomiting, decided jaundice, and hemorrhages from various mucous surfaces, particularly from the kidneys. In certain localities in which the malarial organisms are exceedingly numerous or intensely virulent the attack displays a pernicious tendency. Of this type there may be a cerebral form, characterized either by delirium and excitement, or by coma and depression; a thoracic form, in which the respiration is accelerated and there is an urgent sense of the need of air; a gastro-intestinal form, attended with nausea, vomiting, jaundice, and diarrhea; or an asthenic or algid form, in which there is a condition of marked debility and a striking coldness of the surface and of the breath. To the irregular manifestations of malarial poisoning, sometimes acute, but more frequently subacute or chronic, which do not at any time present the classical association of chill, fever and sweat, the designation of "dumb ague" is given. The enlargement of the spleen in a case of chronic malaria or of malarial cachexia is sometimes designated "ague cake." M. Hematuria, the presence of blood in the urine as a result of malarial poisoning. See Malarial Fever. M. Neuralgia, neuralgia due to malarial intoxication. M. Purpura, a purpuric eruption produced by the presence of the malarial poison in the blood. M. Yellow Fever. See Hematuria, Malarial.

Malarious (mal-a'-re-us). See Malarial.

Malaris (ma-lar'-is) [mala, cheek]. A part of the orbicularis palpebrarum muscle, taking its origin from the lower inner margin of the orbit and the adjacent portion of the nose, and inserted near the origin of the zygomaticus major.

Malassez's Disease. Cyst of the testicle. See Diseases, Table of.

Malassimilation (mal-as-im-il-a'-shun) [malus, bad; assimilatio, likeness]. A defective condition of the digestive system in which nutriment is not properly digested and absorbed.

Malate $\left(m a l^{\prime}-\bar{a} t\right)[\mu \tilde{a} \lambda o v$, an apple]. A salt of malic acid.

Malaxation (mal-aks-a'-shun) [malaxatio; malaxare, $\mu a \lambda a ́ \sigma \sigma \varepsilon \iota \nu$, to soften]. I. The kneading of medicine in pharmacy. 2. Massage, as of the eyeball, or of a tumor. See Pétrissage.

Malaxis (mal-aks'-is). Synonym of Malacia.

Malayan Idiocy. See Idiocy, Ethnic.

Male ( $m \bar{l} \bar{l})$ [ME., male, male]. The masculine sex, or that which pertains to that sex. In botany, applied to flowers with stamens, but without ovaries. $\mathbf{M}$. Blade, the sliding blade of a lithotrite; the blade of an obstetric forceps that bears the key. M. Fern, the Aspidium filix mas. M. Organ, the penis. M. Uterus, a term that has been applied to the prostate gland. See Reproductive Organs.

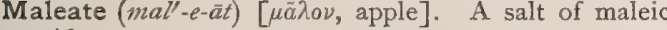
acid.

Maleic Acid ( $\left.m a l^{\prime}-e-i k\right)$ [ $\mu \tilde{a} \lambda o v$, apple], $\mathrm{C}_{4} \mathrm{H}_{4} \mathrm{O}_{4}$. A dibasic acid, obtained from malic acid by distillation.

Malella (mal-el'-ah) [dim. of maln, jaw : pl, Malella ]. In biology, one of two movable toothed appendages of the mouth-parts of a myriapod.

Malen (ma'-len) [mala, cheek]. Belonging to the malar bone in itself.

Malformation (mal-for-ma'-shun) [mal, ill; formatio, a forming]. In embryology and teratology, an abnor46 mal development or formation of the whole or parts of the fetus. Malformations, according to Hirst and Piersol, may be grouped into the following classes: $\mathbf{I}$. Those produced by variations in growth, either excessive or arrested. 2. Those produced by the defective union of component embryonic parts. 3. Those produced by cleavage (either partial or complete) of the primary embryonal cell-masses. M., Congenital, faulty development present at birth.

Malgaigne's Apparatus. An apparatus for correcting forward displacement of the upper fragment in fracture of the thigh. M.'s Hernia. See Hernia, Congenital. M.'s Hooks, an instrument for holding the parts

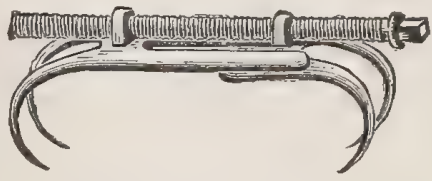

MALGAIGNE'S HOOKS.

of a fractured patella in apposition, for the purpose of aiding union.

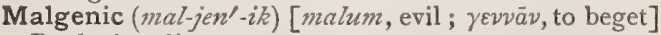
Producing disease.

Malia (mal'-e-ah). Synonym of Equinia.

Maliasmus (mal-e-az'-mus). Synonym of Glanders.

Malic Acid (mal'-ik). See Acid.

Malice Prepense [Fr., malice, evil; prepenser, to premeditate]. In law, a premeditated determination to commit a crime.

Malign (mal-in'). See Malignant.

Malignancy (mal-ig'-nan-se) [malignitas, from malus, evil]. The quality of being malignant.

Malignant (mal-ig'-nant) [malus, evil]. A term applied to diseases that increase in intensity with rapidity, or that proceed to a fatal end. M. Edema. See Edema. M. Fever. Synonym of Typhus Fever. M. Papillary Dermatitis, or Paget's Disease of the Nipple. See Dermatitis, Carcinoma, and Paget's Disease, in Diseases, Table of. M. Pustule. Synonym of Anthrax. M. Tumor; in general, carcinomatous and sarcomatous growths are classed as malignant. M. Vesicle. Synonym of Anthrax.

Malignity (mal-ig'-nit-e). Synonym of Malignancy.

Malingerer (mal-in'-jer-er) [Fr., malinger]. A term applied to one who feigns illness or defect.

Malingering, Malingery (mal-in'-jer-ing, mal-in' jer-e) [Fr., malinger]. The feigning of disease.

Malipedes (mal-ipp-id-êz) [mala, jaw; pes, foot]. In biology, the fourth and fifth pair of cephalic appendages of the Chilopoda, among Myriapods.

Malis ( $\left.m a^{\prime}-l i s\right)$ [ $\left.\mu a \tilde{\lambda} \iota \varsigma\right]$. A name vaguely applied to various diseases, generally of the skin, and especially to such as are due to vermin, or to parasitic worms that burrow in the skin

Malleability (mal-e-ab-il'-it-e) [malleus, hammer]. The quality of being malleable.

Malleable (mal'-e-a-bl) [malleus, hammer]. Capable of being beaten or rolled into thin sheets; applied especially to metals.

Malleal, Mallear (mal'-e-al, mal'-e-ar) [malleus, hammer]. Relating to the malleus.

Malleation (mal-e-a'-shun) [malleatio; malleus, hammer]. A spasmodic action of the hands, consisting in continuously striking any near object. It is a symptom of chorea, and other nervous disorders.

Malledius (mal-ef-de-us) [malleus, hammer; stapes, stirrup]. The tensor tympani muscle.

Malleiform (mal-e'-if-orm) [malleus, hammer; forma, form]. Hammer-shaped. 
Mallein (mal'-e-in) [malleus, farcy]. A fluid obtained from potato-cultures of the Bacillus mallei, the microörganism of glanders. When injected into the circulation of a glandered animal, it causes an elevation of temperature, and on account of this property it has been recommended for use in the early diagnosis of farcy or glanders.

Mallenders (mal'-en-derz) [malandria, blisters on the neck]. A kind of eczema or scab above the fore-foot, and about the knee of the horse.

Malleo-incudal (mal'-e-o-ing'su-dal) [malleus, hammer; incus, anvil]. Relating to the malleus and the incus.

Malleolar (mal-e'-o-lar) [malleolus, little hammer]. Relating to a malleolus.

Malleolus (mal-el-o-lus) [dim. of malleus, hammer: pl., Malleoli]. A part of a process or bone having a hammer-head shape. In biology, a layer or bent-down shoot which emits roots at the notched bend. M., External, a name by which the lower extremity of the fibula is known. M., Internal, the pyramidal process of the internal surface of the lower extremity of the tibia.

Mallet (mal'-et) [OF., mallet, a hammer]. A small wooden hammer. M., Automatic, an instrument operated by the action of a steel spiral spring, and used for condensing gold in filling teeth. M., Electromagnetic, a dental mallet operated by electricity. M.-finger. See Finger. M., Hyde's Pneumatic, a dental mallet with an air-pump attached, which is operated by the foot, revolving a fly-wheel and a drive-wheel. M.-toe, a deformity of a toe characterized by deficient extension or undue flexion of the terminal phalanx.

Malleus (mal'-e-us) [malleus, hammer: pl., Mallei]. I. A bone or ossicle of the internal ear having the shape of a hammer. It is articulated with the incus, Auditory Ossicles. and the tensor tympani muscle I. Head of malleus. 2. arises from it. 2. Synonym of Processus brevis. 3. Equinia. 3. In biology: (a) One 4rocessus gracilis. of the Weberian ossicles that form Long process of ina chain between the air-bladder cus and stapes. 7 . and the auditory apparatus in Stapes.

certain fishes; $(b)$ One of the paired calcareous pharyngeal structures of a rotifer. M. humidus. Synonym of Glanders.

Mallory's Phospho-molybdic Acid Hematoxylin. See Stains, Table of.

Mallow (mal'-o). See Malva.

Malnutrition (mal-nu-trish'-un) [malus, bad; nutrire, to nourish]. Imperfect nutrition or sustenance, due to imperfect assimilation of the food.

Malo-maxillary ( $\left.m a^{\prime}-l o-m a k s^{\prime}-i l-a-r e\right)$ [mala, cheek; maxilla, maxilla]. Relating to the cheek or malar bone and the maxilla.

Malonic Acid (mal-on'-ik). See Acid.

Malpighi, Acini of. The Malpighian bodies. M. Bodies of. See Malpighian Bodies. M., Canals of, renal organs or tubes in certain arthropods. M., Capsule of, the membranous envelop of a renal glomerulus. M., Corpuscles of. See Malpighian Corpuscles. M., Follicles of. See Malpighian Bodies. M., Glomerules of, the Malpighian Bodies, q. v. M., Pyramids of. See Pyramid. M., Tubes or Tubules of. See $M$., Canals of. M., Tuft of. See Malpighian. M., White Canals of. See Canal. M., Yellow Canals of. See Canal.

Malpighian Bodies (mal-pig'-e-an) [from Malpighi, an
Italian anatomist]. The commencement of the uriniferous tubules, consisting of the glomerulus of vessels (the Malpighian tuft) and the membranous envelop

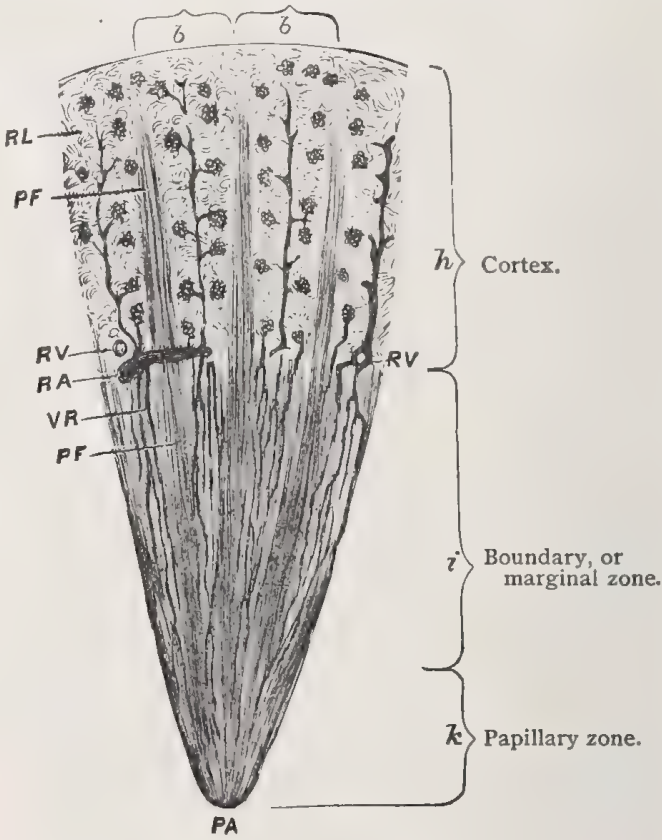

Longitudinal Section of a Malpighian Pyramid

PF. Pyramids of Ferrein. RA. Branch of renal artery. RV. Lumen of renal vein receiving interlobular vein. VR. Vasa recta. PA. Apex of a renal papilla. $b, b$. The bases of the renal lobules.

(the Malpighian capsule). M. Corpuscles, a name given to certain whitish, minute granules in the red substance of the spleen along the course of the blood-vessels. They are composed of lymphadenoid tissue.

Follicles, the $M$ Layer, the rete mucosum of the skin. M. Tuft. See Malpighian Bodies. M.Vessels, tubular, cecal diverticula of the hind-gut of Arthropods, especially characteristic of the Antennata; they arise as in vaginations from the ectodermal proctodeum, and vary in number and in function as excretory organs.

Malposition (mal-po-zish'-un) [malus, bad; positio, from ponere, to place]. The improper or abnormal position of any part or organ, especially of the fetus.

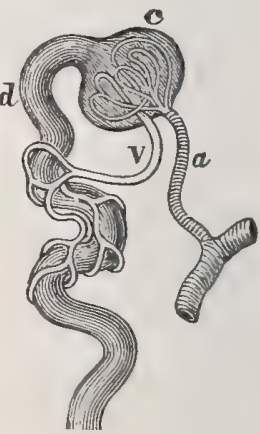

MALPIGHIAN TUFT. Renal artery. $v$. Renal vein. $d$. Tube of Ferrein. c. Capsule of Müller investing the Malpighian tuft.
Malpractice (mal-prak'-tis) [malus, bad; $\pi \rho \bar{a} \xi \iota s$, action]. A term applied to the treatment of a disease that is contrary to that taught by experience, as the improper setting of a fracture or reduction of a dislocation; also, the unlawful production of an abortion.

Malpresentation (mal-pre-sen-ta'-shun) [malus, bad; presentare, to place before]. A position of the child at birth in such form that its delivery is difficult or impossible. 
Malt, Maltum (mazult, mawl' -tum) [L.: gen., Malti] The seed of common barley, Hordeum distichum, germinated until the maximum amount of diastase, the ferment that converts starch into grape-sugar, is developed. It is nutritive, and valuable, also, for the diastase, which aids in the digestion of farinaceous foods. It is employed in wasting diseases, preferably mixed with milk. Mellin's Infant Food, Horlick's Food, popular preparations, consist mainly of granulated extract of malt. Hoff's Malt Extract contains a small percentage of alcohol. M. Ext., the soluble principles of malt, mainly diastase and glucose, in a concentrated form, unfermented. Dose $3 \mathrm{j}$-iv. M., Infus. Dose 3 ij-iv. M. Liquors, fermented and clarified solutions of malt that have been subjected to vinous fermentation, hops being added to prevent acetous fermentation subsequently. Beer is made by a comparatively slow fermentation, and contains about 2.5 per cent. of alcohol. Ale and Porter are fermented more rapidly, and contain about 4.7 per cent. of alcohol. The malt used in making porter is browned, giving the liquor a darker color. Malt liquors contain about 5 per cent. of albuminous matter, 2 of phosphates, and $\mathbf{I}$ of carbon dioxid. M. Vinegar. See Vinegar.

Malta Fever. See Mediterranean Fever.

Maltese Cross. A form of surgical dressing made by taking a square piece of muslin or linen and folding it upon itself twice, the first fold making it oblong, and the second square. Thus prepared, one angle will be found to consist of four layers separable from one another. Let this angle be slit down within two or three inches of the center, and then the piece opened out, when it will be seen to have the form of a Maltese cross. It is used to dress stumps.

Maltha (mal'-thah) [ $\mu a ́ \lambda \theta a$, pitch]. Mineral tar, or pitch; a semi-fluid form of bitumen. In biology, a pudding-tissue containing cells (Hæckel).

Malthaxis (mal-thaks'-is). Synonym of Malaxation.

Malthobiose (mal-tho'-be-ös). Same as Maltose.

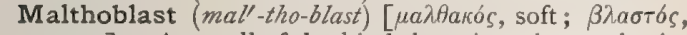
germ ]. Any cell of the kind that gives rise to elastic, adipose, connective, or other soft tissue.

Malthusianism (mal-thu'-se-an-izm) [Malthus, an English economist]. The doctrine that the increase of population is proportionately greater than the increase of subsistence.

Maltine (mazol'-tin) [maltum, malt]. A name given to various proprietary preparations of malted wheat, or barley, useful as food for invalids.

Malting (mazul'ting) [maltum, malt]. The process in the manufacture of beer during which the grainusually barley-is germinated, by means of steeping in water, until it swells and becomes soft. In order to remove the carbon dioxid, which interferes with germination, and to prevent an excessive rise of temperature, so-called pneumatic malting has been devised. Moist, heated air is passed through the germinated grain for this purpose.

Maltodextrin (mazel-to-deks'-trin) [maltum, malt ; dexter, right], $\mathrm{C}_{6} \mathrm{H}_{10} \mathrm{O}_{5}$. A carbohydrate, $q . v$, intermediate between starch and maltose.

Maltose (mazul'-tōs) [maltum, malt], $\mathrm{C}_{12} \mathrm{H}_{22} \mathrm{O}_{11}+\mathrm{H}_{2} \mathrm{O}$. A variety of sugar, formed, together with dextrin, by the action of malt diastase upon starch (in the mash of whiskey and beer). It is capable of direct fermentation. It is obtained in the form of crystalline crusts composed of hard white needles, which lose their water of crystallization at $100^{\circ} \mathrm{C}$. Its properties closely resemble those of grape-sugar. See Carbohydrates, Table of.

Maltum (mawl'-tum) [L. : gen., Malti]. See Malt.
Malulella (mal-u-lel'-ah) [double dim. of mala, jaw: pl., Malulelle $]$. In biology, an appendix to the second pair of jaws of a Myriapod

Malum (mal'-um) [malum, evil]. Disease. M. ægyptiacum, diphtheria. M. articulorum. Synonym of Rheumatism and of Gout. M. articulorum senilis. Synonym of Arthritis deformans. M. caducum, the falling sickness, or epilepsy. M. Cotunnii, sciatica. M. coxæ. Synonym of Hip-disease. M. perforans pedis, perforating ulcer of the foot. M. pilare, trichiosis. M. primarium, a primary or idiopathic disease. M. rustii, a form of cervical Pott's disease described by Rust. $\mathbf{M}$. arteriarum senilis, senile endarteritis deformans. M. venereum. Synonym of Syphilis.

Malusic Acid (mal-u'-sik). Synonym of Malic Acid.

Malva (mal'-vah) [L., mallow]. A genus of malvaceous plants, the true mallows; many of the species are demulcent. M. alcea, $\mathbf{M}$. rotundifolia, and $\mathbf{M}$. silvestris, are valued in domestic practice, and are safe and useful remedies in coughs, ulcerations, and diarrhea. Unof.

Malvaceous (mal-va'-she-us) [malva, mallow]. Belonging to the mallows.

Malwa Sweating-sickness. A disease of Central India resembling cholera, but characterized by profuse sweat ing and periodic remissions. Death is likely to follow.

Mamelon (man'-el-on). See Nipple.

Mamelouc (mam'-el-ük). See Mulatto.

Mamma (mam'-ah) [ $\mu a \mu \mu a$, the child's word for mother ; $\mu a \mu \mu \eta$, breast: gen. and pl., Mamma]. The milk-secreting gland of the mother. The breast.

Mammal (mam'-al) [manmalis, from manma, breast] Having breasts; a member of the Mammalia.

Mammalgia (mam$\left.a l^{\prime}-j e-a h\right) \quad[\mu a ́ \mu \mu \eta$, breast; ằ yos,pain]. Pain in the breast or mammary organ; mastodynia.

Mammalia (mam- $a^{\prime}$ le-ah) [mamma, breast]. A division of the class of vertebrates including all animals that suckle their young.

Mammalogy (mamal'-o-je) [mamma, breast; $\lambda \hat{b}$ ros, science]. The science of the Mammalia.

Mammary (man' $a-r e)$ [ mamma breast]. Pertaining to the mammæ. M. Artery. See Arteries, Table of. I. Lactiferous ducts. 2. Lobuli of Gland. M. Tri- the mammary gland angle. See Triangle.

Mammate (mam'-ät) [mamma, breast]. Having mammæ or breasts.

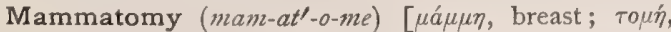
a cutting]. Any surgical cutting operation performed upon the mamma.

Mammea (mam-e'-ah) [Haytian, mamey]. A genus of guttiferous tropical trees. M. americana, the mammee-apple, has large, edible fruits, anthelmintic seeds, antipyretic bark, a diuretic sap, and an antiparasitic gum-resin. Unof. 
Mammifer (mam'-if-er), Mammiferous (man-if'er-us) [mamma, breast; ferre, to bear]. Having mammæ or milk-bearing glands.

Mammiform (mam'-if-orm) [mamma, breast ; forma, shape]. Teat-like in form; shaped like a cone whose apex is rounded.

Mammilla (mam-il'-ah) [dim. of mamma: pl., Mammilla ]. A small prominence or papilla. In biology, a nipple-like structure. M. of Breast, the nipple or teat. M. of Kidney, the conic-shaped apex of the kidney at the point where the urine escapes.

Mammillaplasty (mam-il-ap-las'-te) [mammilla, nipple; $\pi \lambda a ́ \sigma \sigma \varepsilon \imath \nu$, to mold]. A plastic operation for the purpose of elevating a depressed nipple.

Mammillaria (mam-il-a'-re-ah) [mammilla, breast]. I. A genus of cactuses of some 360 species; the nipplecactuses. $M$. lewinii affords the highly poisonous anhaloin, q.v.; other species are used as poultices when crushed. 2. See Tuber cinereum.

Mammillaris maligna (man-il-a'-ris mal-ig'-nah). Same as Paget's Disease of the Nipple.

Mammillary (mam'-il-a-re) [mammilla, dim. of mamma, breast]. Nipple-shaped. M. Bodies, the corpora albicantia. M. Process, the mastoid process of the temporal bone. M. Tubercle, the metapophysis of a lumbar vertebra.

Mammillate (mam'-it-ät), Mammillated (mam'-ita-ted) [mamillatus, from mammilla, dim. of mamma, breast]. Covered upon the surface with mammillæ or teat-like protuberances.

Mammillation (mam-il-a'-shun) [mammilla, dim. of mamma, breast]. A granulation, especially on some mucous surface.

Mammilloid (mam'-il-oid) [manmilla, nipple ; Eifos, like]. Nipple-shaped.

Mammitis (mam-i'tis). Synonym of Mastitis.

Mammose (mam-ōs') [mamma, breast]. Having full or abnormally large breasts.

Mammula (mam'-u-lah) [dim. of mamma, the breast: pl., Mammula]. In biology, a term applied to such nipple-like processes as the spinnerets of spiders.

Man [ME., man, man]. The only genus of the order Bimana, class Mammalia. A term used generally to include the human race. It also denotes the adult male of the genus. M., Descent of, the theory that man has developed, by successive gradations, from lower forms of animal life. See Darwinism. M.hole, an opening into a drain or sewer, boiler or furnace, to permit of inspection or cleaning. M.orchid. See Aceras.

Manaca (man'-ak-ah) [Braz., manacan]. The root of Franciscea uniflora, known in Brazil as "vegetable mercury." It excites the lymphatic system and is in high repute as an antisyphilitic. In small doses it is a resolvent; in larger doses a purgative. Dose of the fld. ext. $m x$. Unof.

Manakin (man'-ak-in). See Manikin.

Manal (ma'-nal) [manus, the hand]. In biology, pertaining to the palmar or metacarpal region of the hand. M. Formula, Harrison Allen's term for the widths of the spaces in bats between the metacarpal bones at the distal ends when the wing is extended, as compared with the length of the forearm.

Manchester-brown. Same as Phenvlene-broien. M.yellow. Same as Martius's Yellow.

Manchineel (man-chin-el'). See Hippomane mancinella.

Mancinism (man'-sin-izm) [mancus, imperfect, maimed]. Left-handedness

Mancona Bark (man-ko'-nah). See Casca Bark.

Mandarin (man'-dar-in) [Pg., mandarim, a mandarin]. A coal-tar color used in dyeing. It is produced from beta-naphthol, and dyes a bright reddish-orange shade. It is also called tropecolin. See Pigments, Conspectus of. M., Oil of, $\mathrm{C}_{10} \mathrm{H}_{16}$, a fine quality of the oil of orange, derived from Citrus nobilis.

Mandelic Acid (man-del' $i k$ ). see $A(i d$.

Mandible (man'-dib-l), Mandibula (man-dib'-u-lah), Mandibulum (man-dib'-u-lum) [mandere, to chew]. A name sometimes applied to the inferior maxillary bone.

Mandibular (man-dib'-u-lar) [mandere, to chew]. Pertaining to the mandible, or lower jaw. M. Tubercle, a small nodule behind the angle of the mouth dependent upon an imperfection in the closure of the mandibular fissure of the face. It is often associated with other congenital anomalies, especially of the ears.

Mandibularis externus (man-dib-u-la'-ris eks-te\%"nus) [L.]. Synonym of the Masseter Muscle. See Muscles, Table of.

Mandibulate (man-dib'-u-lāt) [mandere, to chew]. Having a mandible.

Mandibulo-condylial (man-dib'-u-lo-kon-dill-e-al)

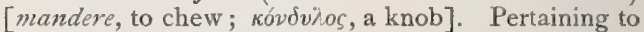
both mandible and condyles. M.-c. Triangle. See Triangles, Table of.

Mandibulo-coronal (man-dib'-u-lo-kor-o'-nal) [mandere, to chew; corona, a crown]. Pertaining to both the mandible and the coronal suture. M.-c. Triangle. See Triangles, Table of.

Mandibulo-facial (man-di $b^{\prime}-u$-lo-fa'-shal) [mandere, to chew; facies, a face]. Pertaining to both mandible and face. M.-f. Index, in craniometry, the vertical projection-measurement of the lower jaw compared with that of the face, the latter being taken as IOO.

Mandibulo-gonial (man-dib'-u-lo-go'-ne-al) [mandere, to chew ; $\gamma \omega v i$ a, an angle]. Pertaining to both mandible and gonion. M.-g. Triangle. See Triangles, Table of.

Mandibulo-infrafacial (man-dib'-u-lo-in'-frah-fa-shal) [mandere, to chew; infra, beneath; facies, a face]. Pertaining to both the mandible and the lower portion of the face. M.-i. Index, the vertical projectionmeasurement of the lower jaw compared with that of the lower face, the latter being taken as roo.

Mandibulo-maxillary (man-dib' $-u$-lo-maks $-i l-a-r p$ ) [mandibula, mandible; maxilla, maxilla]. In biology, related to both the mandibles and the maxillæ.

Mandibulo-suprafacial (mant-dib-u-lo-su'-pra-fa-shal) [mandibula, mandible; supra, above; facies, face]. Pertaining to both the mandible and upper portion of the face. M.-s. Index, the vertical projectionmeasurement of the lower jaw compared with that of the upper face, the latter being taken as 100.

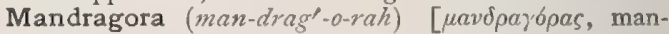
drake]. The mandrake. A genus of solanaceous oldworld plants. M. officinalis, the true mandrake, has long been used as a narcotic and hypnotic. Unof.

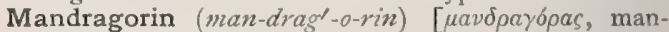
drake], $\mathrm{C}_{17} \mathrm{H}_{23} \mathrm{NO}_{3}$. A poisonous alkaloid from the root of Mandragora officinalis and $M$. autumnalis. It has nearly the same effects as atropin. Unof.

Mandrake (man'-drāk). See Mandragora and Podophyllum.

Mandrin (man'-drin) [Ger.]. The firm guide or stylet (usually of metal) which gives rigidity to a flexible catheter whilst it is being inserted.

Manducation (man-du-ka'-shun) [manducatio, a chewing]. The chewing or mastication of food.

Manducatory (man-du'-kat-or-e) [manducare, to chew]. Pertaining to manducation.

Manec's Paste. A paste used in dermatology. It is composed of arsenious acid gr. I5, black sulphid of 
mercury gr. 75, spongia usta gr. 35. This is made into a thick paste with a few drops of water.

Manfredi, Micrococcus of. See Bacteria, Synonymalic Table of.

Manganese (man'-gan-ēz), Manganum (man-gan'um) [an altered form of Magnesium: gen., Mangani.] $\mathrm{Mn}=54$, quantivalence II, IV. A silver-white metal having the general properties of iron. See Elements, Table of. It is used in medicine and pharmacy in the form of oxids, sulphates, and iodid. In small doses, it is a general tonic; in large doses, a gastro-intestinal irritant. M.-brown. See Pigments, Conspectus of. M. et ferri carbonas saccharatus. Dose gr. v-xx. M. et ferri iodidi, Syr. Unof. Dose $\eta_{\mathrm{x}-\mathrm{xxx}} \quad$ M.-green. See Pigments, Conspectus of. M. iodidi, Syr., unof., contains $3 \mathrm{j}$ of the salt to each $\xi_{j}$ of syrup. Dose $\eta_{x}-x \times x$. M. oxid. nig., $\mathrm{MnO}_{2}$, "black oxid of manganese," used in the manufacture of chlorin-gas. Dose gr. ij-x. M. sulphas, $\mathrm{MnSO}_{4} \cdot 4 \mathrm{H}_{2} \mathrm{O}$, emetic and cholagogue, useful in jaundice and catarrh of the biliary passages. Dose gr. ij- $\mathrm{v}$. Potassii permanganas, $\mathrm{K}_{2} \mathrm{Mn}_{2} \mathrm{O}_{8}$, an excellent antiseptic and germicide, efficient as a local wash, $3 \mathrm{j}$ to $\mathrm{Oj}$, in diphtheria, scarlatina, etc., in carcinoma and foul ulcers, tainted breath, and the fetid odor of the feet. P. permang., Liq. (B. P.) Dose $3 \mathrm{ij}-\mathrm{iv}$; externally $\mathrm{z} \mathrm{j}$ to $\overline{\mathrm{v}} \mathrm{-x}$ of water.

Manganesium (man-gan-e -ze-um). See Manganese.

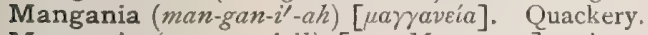

Manganic (man-gan'-ik) [see Manganese]. A term applied to compounds containing manganese.

Manganium (man-gan'-e-um). See Manganese.

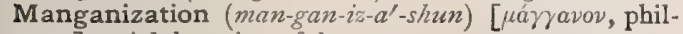
ter]. Adulteration of drugs.

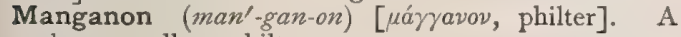
charm, spell, or philter.

Manganous (man'-gan-us) [see Manganese]. Pertaining to those compounds that contain manganese as a bivalent element.

Mange (mānj) [Fr., manger, to eat]. The common name applied indifferently to the various forms of acariasis (Sarcoptinitic, or Demodetic Scabies) produced in mammals by several acaridian parasites. It is known as scabbia, rogna, raspa, in Italy; sarna, roña, in Spain ; itch, scald, juck, mange, in England; gale, in France; Krätze, Krätzauschlag, in Germany. It prevails at times epizoötically, and in most varieties is transmissible to man. See Sarcoptes scabici, De Geer, Psoroptes longirostris, Mégnin, Chorioptes spathiferus, Mégnin, Demodex folliculorum, Owenall under Parasites (Animal), Table of.

Mangifera (man-gif'-er-ah). See Mango.

Mangili's Ganglion. The pedal ganglion of Mollusca.

Mangini's Reagent. A reagent for testing for alkaloids. It consists of potassium iodid 3 parts, bismuth iodid 16 parts, and $\mathrm{HCl} 3$ parts.

Mangle (mang'-gl) [ME., mangelen, to mutilate]. To lacerate; to wound in a jagged or irregular manner.

Mango (man'-go) [Pg., manga, mango]. The fruit of Mangifera indica; the bark yields an unofficial remedy having reputed properties as an astringent and tonic to the mucous membranes. It has been recommended for catarrh of the nasal passages and for purulent discharges from the vagina, and as a wash in skindiseases. Dose of the fluid extract, $m x-3 j$. Unof.

Mangostin (man'-go-stin) [Pg., manga, mango], $\mathrm{C}_{20}$ $\mathrm{H}_{72} \mathrm{O}_{5}$. A crystalline, bitter principle found in the shells of the fruit of Garcinia mangostana.

Manhood (man'-hood) [ME., man, man]. That period in which a man possesses all of his physical and generative faculties; virility.

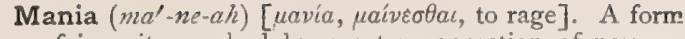
of insanity marked by great exaggeration of nervous action. It may occur suddenly, or follow an attack of melancholia. The patient presents an infinite variety of moods, is the subject of hallucinations and illu. sions, often shows a tendency to destroy what he comes in contact with, and is untidy ; there is a marked change in character, and decided insomnia. There is rapid and progressive emaciation. The brain is found to be in a hyperemic condition, and the disease is probably due to a loss of the inhibitory action of the highest controlling centers of the brain. Mania is most common in young adult life. Heredity is a strong predisposing cause, while mental strain, be reavements, shocks, and alcoholism may act as exciting causes. The great majority of the cases recover. M., Acute. See Mania. M., Acute Delirious, acute mania in which delirium is a prominent feature. M., Alcoholic, acute mania of alcoholic origin. It is to be distinguished from delirium tremens, although sometimes used synonymously with it. M. a potu. See Delirium. M., Bell's, an acute delirium running a rapidly fatal course, with slight fever, and in which post-mortem no lesions are found sufficient to account for the symptoms. There are the wildest hallucinations, insomnia, and intense excitement, followed by a condition called typho-mania, with elevation of temperature, dry tongue, and rapid, feeble pulse. The disease is almost always fatal, ending in from one to three weeks. Its nature is unknown. See Diseases, Table of. M. brevis, transitory mania, q. $v$. M. of Character, reasoning monomania. M. concionabunda, a form characterized by a constant desire to speak publicly. M. crapulosa, dipsomania. M., Dancing, an epidemic of choreic or convulsional movements, especially prevalent in the middle ages. M., Epileptic, a maniacal outburst in an epileptic; it may come on slowly. In many cases it is associated with a destructive tendency. M. errabunda, wandering mania, in which the patient wanders about or rushes forward regardless of obstacles. M., Furious, a violent form of mania; delirium furibundum. M. hallucinatoria. See Insanity, Confusional. M., Homicidal, one in which the individual displays a tendency to kill. M., Hypochondriacal, mania associated with hypochondriacal delusions. M., Hysteric, an outburst resembling mania occurring in an hysteric subject; it is usually associated with erotic manifestations. M., Incendiary. See Pyromania. M., Morphin, morphinomania, $q . v$. M. potatorum. Synonym of M., Alcoholic. M., Preaching, an epidemic, somewhat analogous to dancing mania, that occurred in Sweden in 1841 and 1842 . Those affected, chiefly young girls, passed through a period of trance, then through a stage of violent choreiform movements, and, lastly, into a period of quiet, during which they would preach or speak. M., Puerperal, a form of mania or abnormal mental action sometimes following childbirth. M., Reasoning, simple mania, or mania with delirium-a simple exaltation of the mental faculties. M., Religious, mania in which the central idea is religious in character, or in which a powerful religious emotion has been the exciting cause. M., Senile, a maniacal outburst in old persons. M. sine delirio, mania without delirium. M., Transitory. See Frenzy, Transitory. M., Typho-, acute delirious mania associated with fever, dry, coated tongue, and other symptoms of the typhoid state. M., Wolf. See Lycanthropy.

Maniac (ma'-ne-ak) [ $\mu a v i a$, madness]. An insane person; one affected with mania.

Maniacal (ma-ni'-ak-al) [ $\mu a v i a$, madness]. Having 
the nature of madness or insanity. M. Chorea. See Chorea insaniens. M. Outburst, a sudden development of mania, not uncommon in epilepsy and in general paralysis of the insane.

Maniacocomium ( $\left.m \alpha-n e-a k-o-k o^{\prime}-m e-z m\right)$, Maniacomium (ma-ne-ak-o'-me-um). See Manicocomium.

Manica (man'-ik-ah) [manus, hand]. A protectioncovering, as a sleeve or a glove. M. Hippocratis, Hippocrates' sleeve, a name formerly used to designate the cloth strainer of the apothecary.

Manicate (man'-ik-ât) [manicatus, sleeved]. In biology, having a felted, hairy coating that may be removed entire.

Manicocomium (ma-nkk-o-ko'-me-um), Manicomum

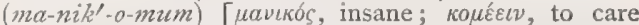
for]. An asylum for the insane.

Manicula (ma-nik'-u-lah) [dim. of $\mu a v i a$, mania]. A mild form of mania.

Maniculum (man-ik'-u-lum) [dim, of manus, hand]. The fore-foot of a mammal.

Manicure (man'-ik-ür) [manus, the hand ; cura, care]. The processes employed in caring for and beautifying the hand. Also, one who professionally attends to the care of the hands and nails; a chiropodist.

Maniform (man'-if-orm) [manus, hand; forma, form]. Hand-shaped.

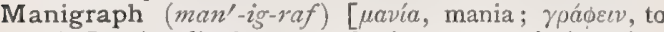
write]. An alienist; one who is an expert in insanity.

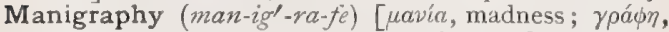
writing]. A treatise on, or the science of, insanity.

Manihot (man'-e-hot) [L.]. A genus of euphorbiaceous plants. M. aipi and M. utilissima afford cassava and tapioca, $q . v$. Unof

Manihotoxin (man-e-ho-toks'-in) [manihot, manihot; $\tau о \xi \iota \kappa \delta v$, poison]. A poisonous, crystalline principle from the root of Manihot utilissima.

Manikin (man'-ik-in) [OF., manequin, a puppet]. A model of plaster, papier machè, etc., designed to show the anatomy or functions of an animal or organ, especially of a human being

Manila Hemp. See Hemp.

Maniluvium (man-il-u'-ve-um) [manus, hand; lavare, to wash]. A hand-bath; a wash or lotion for the hands.

Manioc (man'-e-ok) [Braz.]. The plant Manihot utilissima. M., Sweet (Manihot aipi), used as an esculent vegetable, like potatoes. See Manihot.

Manimetrum (man-im-et'-rum) [manus, hand ; $\mu \varepsilon ́ r \rho o v$, measure]. A hand-measure or cheirometer.

Maniple (man'-ip-l) [manipulus, from manus, hand]. A handful, or pugil.

Maniplies (man-ip-liz'). See Manyplies.

Manipulation (man-ip-u-la'-shun) [manipulus, a handful]. The act of doing with the hands; an operation or experiment in which the hands are particularly employed; dexterity in such acts. A method of reducing dislocations, herniæ, and of treating aneurysms; massage.

Manipulator (man-ip'-u-la-tor) [manipulare, to lead by the hand]. One who manipulates; a masseur or masseuse. M., Amalgam, a dental instrument for introducing amalgam fillings.

Manipulus (man-ip'-te-lus). See Maniple.

Manistupration (man-is-tu-pra'shun). Synonym of Masturbation.

Mann's Reagent. See Tests, Table of.

Manna (man'-ah) [uávva, manna]. The exudation of the flowering ash, Fraxinus ornus, and other trees. Its properties are due to mannite or manna, $\mathrm{C}_{6} \mathrm{H}_{14} \mathrm{O}_{6}$, sugar, dextrin, and a resinous principle. It is a mild laxative, and may be advantageously combined with rhubarb or magnesium citrate. Dose $\xi_{j}-\mathrm{ij}$. Unof.
Manneberg, Streptococcus of. See Bacteria, Synonymatic, Table of.

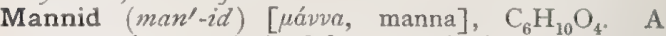
syrupy substance derived from mannite by dehydration.

Manniferous (man-if'-er-us) [uavva, manna; ferre, to bear]. Producing manna.

Mannikin (man'-ik-in). See Manikin.

Manning's Splint. A splint used in the treatment of fracture of the patella.

Manniparous (man-iṕ-ar-us). See Manniferous.

Mannitan (man'-it-an) [ $\mu a ́ v v a$, manna], $\mathrm{C}_{6} \mathrm{H}_{12} \mathrm{O}_{5}$. A sweet, syrupy substance produced by the action of sulphuric acid on mannite.

Mannite (man'-it). See Manna and Mannitol.

Mannitic Acid (man-it'-ik). See Acid.

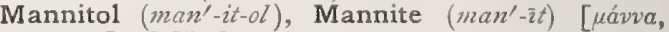
manna], $\mathrm{C}_{6} \mathrm{H}_{4} \mathrm{O}_{6}$. A hexahydric alcohol produced in the vinous fermentation of the different varieties of sugar. It is also obtained by extracting manna with alcohol and allowing the solution to crystallize. It forms delicate, colorless needles or rhombic prisms. It is slightly soluble in water, readily so in boiling alcohol. It possesses a very sweet taste and melts at I66 C. See Manna.

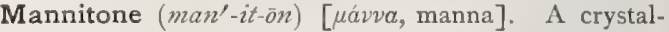
line isomer of mannitan produced when mannite is heated with water in a sealed tube.

Mannitose (man'-it-ōs) [ $\mu a ́ v v a$, manna], $\mathrm{C}_{6} \mathrm{H}_{12} \mathrm{O}_{6}$. An amorphous substance, isomeric with levulose, but optically inactive, obtained from mannite by oxidation.

Manno-heptose (man'-o-hepp-tōs). See Carbohydrates, Table of.

Manno-monose (man'-o-mo'-nöz). See Carbohydrates, Table of.

Mannonic Acid (man-on'-ik). See Acid.

Manno-octose (man'-o-okl-töz). See Carbohydrates, Table of.

Mannose (man'-ōs) [ $\mu$ ávva, manna], $\mathrm{C}_{6} \mathrm{H}_{12} \mathrm{O}_{6^{*}}$ The aldehyd of mannitol. It exists in three forms, dextromannose, levo-mannose, and inactive mannose. See Carbohydrates, Table of.

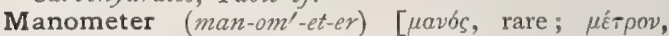
measure]. An instrument, in principle similar to a

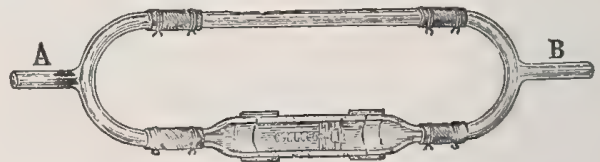

Gaule's Maximum and Minimum Manometer, A, B.

(The extremity $\mathbf{A}$ is connected with the heart, and $B$ with the mercurial manometer.

barometer, by which the tension of a vapor is measured. It consists essentially of a V-tube partly filled with mercury. It is also used to determine bloodpressure.

Manometric (man-o-met'-rik) [uavbs, thin; $\mu \varepsilon t^{\prime} \rho \cap \nu$, measure]. Pertaining to the measurement of atmospheric pressure.

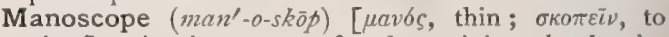
view]. An instrument for determining the density of air.

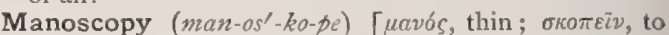
view]. The estimation of the density of the air.

Mansorius (man-so'-re-zs) [L.]. The buccinator muscle. See Muscles, Table of.

Manstupration (man-stu-pra'-shun). Synonym of Masturbation.

Mantle (man'-tl). See Brain-mantle. 
Mantle-cell (man'-tl-sel). Same as Tapetal Cell. Manual (man'-u-al) [manus, hand]. Pertaining to the hand. M.-exercise Bone, a small triangular osseous growth occasionally found in soldiers at the tendinous insertion of the left deltoid muscle. It is also called drill-bone. M. Method. See French Method.

Manubrial (man-u'-bre-al) [manus, hand]. Pertaining to a manubrium.

Manubrium (man-u'-bre-um) [L., a handle]. In biology, variously applied to handle-like or haft-like structures. M. of Malleus, a vertical process of bone forming the handle-shaped attachment of the malleus of the ear. M. manus, the radius. M. of Sternum, the upper piece of the sternum.

Manuduction (man-u-duk'-shun) [manus, hand; ductio, a leading]. The operations performed by the hands in surgical and obstetric practice.

Manuluvium ( $\left.m a n-u-l u^{\prime}-v e-u m\right)$. Synonym of Maniluvium.

Manure (man-ür') [ME., menuren, to manage]. Dung or other substance used to fertilize soil.

Manus ( $\left.m a^{\prime}-n u s\right)$ [L.]. The hand.

Manustupration (man-u-stu-pra'-shun). See Masturbation.

Manyplies (man'-ip-liz) [many;ply]. In biology, the third compartment in the complicated stomach of a ruminant. It is also called the omasum or psalterium.

Manz's Glands. Small flask-shaped depressions occasionally seen on the border of the eyelids in man, and commonly in lower animals.

Manzanita (man-zan-e'-tah) [Sp., small apple]. The leaves of Arctostaphylos glauca, common to California; they are astringent and tonic with reference to the urinary organs. The drug resembles Uva ursi in properties. Dose of the fld. ext $m \times x x-x_{x x}$. Unof.

Maple $\left(m a^{\prime}-p l\right)$ [ME., mapel, maple]. See Acer. M.sugar. See Saccharum.

Maquer's Salt. A compound known as "super-arseniate of potassium."

Maranda (mar-an'-dah) [Ceylonese]. A Ceylonese tree belonging to the Myrtaceae, the leaves of which have been used in syphilis. Unof.

Maransis (mar-an'-sis). Synonym of Marasmus.

Maranta (mar-an'-tah). See Arrowroot.

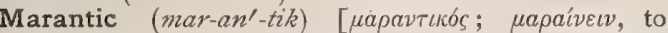
make lean]. Pertaining to marasmus, or to general malnutrition and prostration. M. Clot, a blood-clot produced by slowing of the circulation. M. Thrombosis, primary thrombosis of the cerebral sinuses in connection with general malnutrition.

Maraschino (mar-as-ke/-no) [Sp.]. A liquor made from morello cherries.

Marasmatic (mar-az-mat'-ik). Synonym of Marasmic.

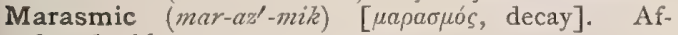
fected with marasmus.

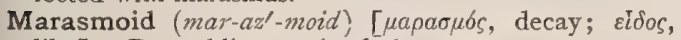
like]. Resembling or simulating marasmus.

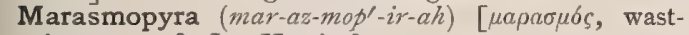
ing; $\pi \tilde{v} \rho$, fire]. Hectic fever.

Marasmous (mar-az'-mus). Synonym of Marasmic.

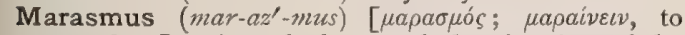
grow lean]. A gradual general deterioration of the mental and physical forces, with marked emaciation. As used popularly it is meant to refer to the wasting of infants. It is generally encountered in hand-raised babes, and is associated with indigestion from improper feeding, congenital syphilis, rickets, or tuberculosis. The children thus affected have a peculiar weazened or senile appearance. In the majority of cases, with proper care the child may be restored to health.

Marble-cutter's Phthisis. See Chalicosis.
Marc (mark) [Fr., dregs]. A side-product in the manufacture of wines, consisting of the stems, skins, and stones of the grapes. It is used for the purpose of making brandy by fermentation; with sheet-copper in the manufacture of verdigris; to start the fermentation in vinegar-making; as cattle-food; when dried, as fuel; or for fertilizing purposes. The refuse of olives, or of oil-seeds, after the removal of the oil, is also called marc.

Marcescent (mar-ses'-ent) [marcescere, to wither, fade, decay]. In biology, withered or shriveled.

March's Disease. Synonym of Exophthalmic Goiter, q. v. Also see Diseases, Table of.

Marchi's Solution. A solution for staining nerve-tissues. See Stains, Trable of.

Marcid (mar'-sid) [marcidus, marcere, to wither]. I. Shrunken; wasted. 2. Accompanied or characterized by wasting.

Marcor (mart-kor). See Marasmus.

Mare [ME., mare, a horse; an incubus]. I. The female of the horse. 2. The substance remaining after the first distillation of spirits. 3. Oppressed sleep; nightmare.

Maremmatic (mar-em-at'-ik) [Maremme, a malarious region of Italy]. Pertaining to very malarious regions, especially of Italy.

Marennin (mar-en'-in) [mare, the sea]. In biology, Lankester's name for the green coloring-principle absorbed by oysters from diatoms (Navicula ostrearia) in the process of greening.

Mareo (mar'-e-o) [Span.]. Mountain sickness. A malady characterized by nausea and violent headache, occasionally overcoming persons who ascend to high altitudes.

Margaric Acid (mar-gar'-ik). See Acids, Table of Fatty. Margarin (mar'-gar-in) [ $\mu a ́ \rho \gamma \alpha \rho o s$, the pearl-oyster]. I. A mixture of olein and palmatin. 2. An artificial substitute for butter.

Margarinic Acid (mar-gar-in'-ik), See Acid, Margaric.

Margaritoma (mar-gar-it-o'-mah) [ $\mu a ́ \rho \gamma a \rho o s$, the pear]oyster; $\delta \mu a$, a tumor]. Virchow's term for a true primary cholesteatoma-formation in the auditory canal.

Margarone (mar'-gar-ön). See Palmitone.

Margarous Acid (mar'-gar-us). A synonym of Acid, Stearic.

Marginal (mar'-jin-al) [marginalis, from margo, margin]. Pertaining to the margin or border. M. Convolution. See Convolutions, Table of. M. Lobe. See Lobe.

Marginate (mar'-jin-ät) [marginare, to furnish with a border]. In biology, applied to structures in which the margin is peculiarly distinct.

Marginoplasty (mar-jin'-o-plas-te) [margo, margin; $\pi \lambda \dot{a} \sigma \sigma \varepsilon \iota \nu$, to shape]. Plastic surgery of the marginal portion of the eyelid.

Margosin (mar'-go-sin) [ $\mu a ́ p \gamma a p o s$, the pearl-oyster]. A bitter alkaloid obtained from Azadirachta indica.

Maricolous (mar-ik'-o-lus) [mare, the sea; colere, to dwell]. In biology, applied to animals or plants inhabiting the sea; pelagic.

Marie's Disease. Akromegaly. See Akromegaly, and Diseases, Table of.

Marigold (mär'-ig-öld). See Calendula.

Marine-blue. See Pigments, Conspectus of.

Mariotte's Experiment, A device for demonstrating the existence of the blind-spot of the eye, consisting in placing a spot upon a paper at such an angle with the visual axis that the image falls upon the papilla. M.'s Blind-spot, M.'s Spot, the point of entrance of the optic nerve into the fundus of the eye. M.'s Law, See Law. 
Mariscous (mar-is'-kus) [marisea, hemorrhoid]. Pertaining to hemorrhoids.

Marito-nucleus (mar-it-o-nu'-kle-us) [maritus, married; nucleus, a little nut]. The nucleus of the ovum after its union with the male pronucleus.

Marjolin's Warty Ulcer. An ulcer resulting from the breaking down of warty cicatricial tissue. It is of slow progress, and finally gives rise to glandular enlargement. See Diseases, Table of.

Marjoram (mar'-jo-ram). See Origanum.

Mark [ME., mark, a mark]. Birth-mark, or mother's mark; nevus. M., Portwine. See Nevus.

Marl [ME., marl, marl]. A clay rich in calcium carbonate.

Marmalade, Marmelade (mar'-mal-ād) [Port., marmello, a quince]. A conserve prepared from the quince, orange, plum, peach, or other fruit, which is sliced and preserved in a saturated syrup.

Marmë's Reagent. See Tests, Table of.

Marmorate (mar'-mo-rāt) [marmor, marble]. In biology, traversed with vein-like markings like those of certain kinds of marble.

Maroon (mar-oon'). See Pigments, Conspectus of. M.oxid. Same as Purple-brown.

Marriageable (mär'-āj-a-bl) [ME., mariage, marriage; maritus, a husband]. Of an age when marriage may be legally performed.

Marriot, Dry Vomit of. An emetic preparation consisting of equal parts of sulphate of copper and tartar emetic.

Marrow (mär $-o$ ) [ME., marow, marrow]. A substance composed of water, fat, and albuminous matter, existing in the cavities of many of the long bones. M.-cell, a cell resembling a white blood-corpuscle, but larger and with a clearer protoplasm and a larger nucleus, and showing ameboid movement. It is found in the marrow of bones. M., Fetal, the juicy, red marrow filling the cavities of the fetal endochondral bones. M., Red, the reddish marrow, quite free from fat, contained near the articular extremities of long bones. M., Spinal, the spinal cord. M., Yellow, the fatty marrow of the shafts of long bones.

Marrubiin (mar-u'-be-in) [marmbium, horehound]. The crystalline, neutral, bitter substance found in Horehound.

Marrubium (mar-u'-be-um) [L.]. Horehound. The leaves and tops of $M$. vulgare. They contain a bitter principle and a volatile oil. In small doses horehound is a mild stomachic tonic; in larger doses a laxative. It exerts a soothing effect in catarrh of the nasal passages, and is therefore an ingredient of various cough-

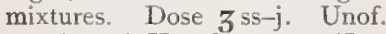

Mars (marz) [L., the war-god]. An old synonym for iron. See Fcrrum. M.-brown. See Pigments, Conspectus of. M.-red. Same as Ocher. M.-violet. Same as Mineral-purple.

Marsala (mahr-sa'-lah) [Ital.]. An Italian wine containing 20 per cent. of alcohol.

Marsden's Mucilage or Paste. A caustic paste consisting of one part of white arsenic to two of gumarabic.

Marsdenia (marz-de'-ne-ah) [after William Marsden, a British orientalist]. A genus of asclepiadaceous plants of which several species yield indigo. M. condurango. See Condurango. M. erecta, a poisonous species from Europe and Asia Minor. Taken internally it produces violent convulsions and death, and applied externally it blisters the skin.

Marsdenin (marz-den'-in) [after William Marsden, a British orientalist]. A bitter crystalline extractive from Marsdenia erecta.

Marsh [ME., mersh, a marsh]. A swamp or bog. M.- fever. See Malaria. M.-gas, Methyl Hydrid, Fire. damp, Methane; a hydrocarbon baving the composition $\mathrm{CH}_{4}$. It occurs in swamps as a product of the decomposition of vegetable tissue. It constitutes a large proportion of common illuminating-gas. M--miasm. See Malaria. M. Rosemary, the root of Statice caroliniana, a bitter astringent, resembling kino in therapeutic properties. It is a popular New England remedy for cancrum oris and for aphthous affections of the mouth. Dose of the fld. ext. 3ss-j. M. Trefoil. See Menyanthes trifoliata. M.-mallow. See Althaa. M.-marigold. See Caltha. Unof.

Marsh's Test. See Tests, Table of.

Marshall's Cerate. A cerate composed of calomel

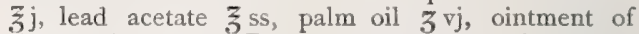
nitrate of mercury $\zeta_{\text {ij. }}$ M., Vein of. See Vein. M.'s Vestigial Fold, a crescentic fold of serous membrane of the pericardium containing the remains of the left superior vena cava.

Marson's Theory. A theory that claims that the degree and duration of vaccinal protection are proportionate to the perfection of the vaccine lesions and to the number of insertions made.

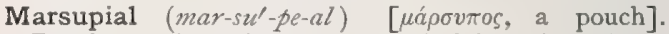
Pouched. In zoölogy, a mammal of the order Marsupialia. See Marsupium and Mastotheca. M. Incisura (Incisura marsupialis), the deep posterior notch between the two halves of the cerebellum, occupied by the falx cerebri.

Marsupiate (mar-su'-pe-ät). See Marsupial

Marsupium (mar-su'-pe-um) [ $\mu a ́ \rho \sigma v \pi o s, a$ pouch, bag]. In biology, the fold of abdominal integument, or " pouch," that serves to support and protect the young of those mammals belonging to the sub-class Metatheria or Didelphia; a Mastotheca, q. v.

Marteno (mar'-te-no). Incorrect form of Martynia, $q . v$. Martial (mar'-shal) [martialis, cf. mars, iron]. Ferruginous or chalybeate ; containing iron.

Martin's Bandages. Long India-rubber bandages, from 5 to 21 feet in length, used in the treatment of chronic ulcers, varicose veins, and joint-disease. M.'s Depilatory, a preparation made by passing $\mathrm{H}_{2} \mathrm{~S}$ through a mixture of slaked lime two parts and water three parts. M.'s Hemostatic, surgeon's agaric saturated with ferric chlorid. M.'s Operation. See Operations, Table of.

Martindale's Mixture. See Anesthetic.

Martineau's Formula. A formula used in the treatment of syphilis, constituted as follows: Bichlorid of mercury $21 / 2$ drams, peptone $1 / 2$ ounce, chlorid of ammonium $1 / 2$ ounce. Fifteen grains of this preparation contain nearly four grains of sublimate. It was diluted with water alone or with a mixture of water and glycerin, and was injected in doses of from $\frac{1}{7}$ of a grain upward. It is not much used now. M.'s Treatment. See Treatment, Methods of.

Martius's Yellow. See Pisments, Conspectus of.

Martynia (mar-tin'-e-ah) [after John Martyn, an American botanist]. A genus of dicotyledonous gamopetalous plants. M. proboscidea, unicorn plant, enaployed as a mucilaginous drink in bladder-troubles.

Maruta (ma-ru'-tah) [L.]. A genus of compositeflowered herbs. M. cotula, mayweed, or dog-fennel, is an ill-scented weed common in Europe and North America. It is antipyretic and insecticide, is a vesicant of some power, and is said to be a good application to bruises and swellings. Unof.

Mas, Masc (mas, mask) [L. abbrev. of masculus, the male, or masculinus, masculine]. I. In biology, employed to designate a male plant or animal. Its symbol is usually $\sigma^{7}$. In old usage it was frequently employed in a fanciful way as the specific name of 
plants. See Aspidium filix mas. 2. The center-pin of a trephine.

Mascarpio (mas-kahr'-pe-o) [mas, male; carpere, to pluck]. A masturbator.

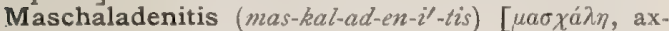
illa; ádŕv, gland; $\iota \tau \iota \zeta$, inflammation]. Inflammation of the glands of the axilla.

Maschaleous (mas-kal'-e-us) [ $\mu a \sigma \chi a ́ \lambda \eta$, axilla]. Pertaining to the axilla.

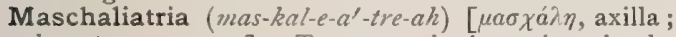
iaTpsia, treatment]. Treatment by inunctions in the axilla.

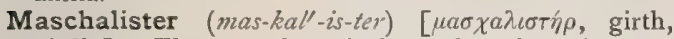
girdle]. The second cervical vertebra, the axis.

Maschaloncus (mas-kal-ong'-kus) [ $\mu a \sigma \chi a ́ \lambda \eta$, axilla; бүкоц, tumor]. An axillary tumor.

Maschalopanus (mas-kal-op'-an-uls). Synonym of Maschaloncus.

Maschalyperidrosis (mas-kal-ip-er-id-ro'-sis) [ $\mu \alpha \sigma-$

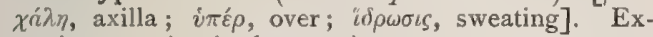
cessive sweating in the armpits.

Masculine (mas'-ku-lin), Masculous (mas'-ku-lus) [dim. of mas, a male]. Of the male sex.

Masesis (mas-e'-sis). Synonym of Mastication.

Maseter (mas'-e-ter). Synonym of Masseter. See Muscles, Table of.

Mash [ME., masche, mash]. A mixture of malt and water prepared in breweries and distilleries for making beers and spirits. Also, the mixture of grains used in feeding animals.

Mask (mask) [Fr., masque, a mask]. I. In biology, a mask-like formation or coloration of the head; a hood or capistrum. 2. In surgery, a bandage applied to the face in case of erysipelas and extensive burns or scalds. 3. Synonym of Chloasma. M., Death, a cast of the face of a dead person made by covering it with plaster-of-Paris or similar material, which is removed when hard. M. of Pregnant Women, the chloasma of pregnancy.

Masked (maskt) [Fr., masque, a mask]. Covered with a mask; concealed. In biology, applied to insects in the larval state, especially such as indicate by lines on the surface the future wings, legs, and other parts of the imago. In botany, the same as Personate. M. Disease, one that is concealed by concomitant symptoms. M. Epilepsy. See Epilepsy. M. Malaria. See Dumb Ague and Malarial Fever. M. Reaction, in chemistry, one that is concealed by a concurrent reaction.

Masochism (mas'-o-kizm) [from Sacher-Masoch, an Austrian novelist]. Sexual perversion in which the pervert takes delight in being subjected to degrading, humiliating, or cruel acts on the part of his or her associate. It is the opposite of Sadism. The victims of this perversion experience peculiar pleasure at the sight of a rival who has obtained the favor of their mistress, and will even receive blows and lashes from the rival with a voluptuous mixture of pain and pleasure. Masochism corresponds to the Passivism of Stefanowski.

Masochist (mas'-o-kist) [ Masoch, from Sacher-Masoch, an Austrian novelist]. One addicted to masochism.

Masochistic (mas-o-kis'-tik) [Sacher-Masoch, an Austrian novelist]. Relating to masochism.

Mason's Lung. A synonym of Pneumonokoniosis. M.'s Method. See Treatment, Methods of.

Masque (mask) [Fr.]. Reaumur's name for a grayishbrown, rounded part of the sexual apparatus of the drone-bee. It is thickly set with short spines having curved points. Also see Mask.

Masrite $\left(\right.$ maz $\left.^{\prime}-n \bar{t}\right)$. See Masrium.

Masrium (maz'-re-um) [Arab., masr, Egypt.]. metal described as a new element, found in Egypt in a mineral first called " Johnsonite," but later mas. rite. The mineral, masrite, has the formula ( $\mathrm{Al}$, $\mathrm{Fe})_{2} \mathrm{O}_{3}$. (MsMnCoFe) O.45O $\mathrm{SO}_{3} \cdot 2 \mathrm{OH}_{2} \mathrm{O}$. See Elements. Table of. Masrium has an atomic weight of 228 . The sulphate, is a white salt, crystallizing poorly from water, but readily from a fifty per cent. alcoholic solution. The reactions of a soluble salt of masrium resemble those of zinc. The free metal has not been obtained; neither has its vapor-density been determined, or spectroscopic examination made.

Mass (mas) [massa, a mass]. Any aggregation of matter. M., Blue. See Hydrargyrum. M., Intermediate Cell, that part of the embryo from which the mesonephros is developed. M., Investing, the tissue that in early embryonic development surrounds the cranial portion of the notochord, and later is transformed into the parachordal cartilages. M., Vallet's, massa ferri carbonatis. See Fernum.

Massa (mas'-ah) [L.]. A mass. In pharmacy, a medicinal substance together with an excipient that gives it the adhesive, plastic quality necessary to form a pill. There are three official masse.

Massage (mas-ahzh') [Fr., from $\mu a ́ \sigma \sigma \varepsilon v \nu$, to knead]. A method of effecting changes in the local and general nutrition, action, and other functions of the body, by rubbing, kneading, and other manipulation of the superficial parts of the body by the hand or an instrument. A male operator is called a masseur, a female operator, a masseuse. M., Friction, superficial rubbing. M. Method of Treating Lacrymal Stenosis. See Gould's Method. under Treatment, Method's of.

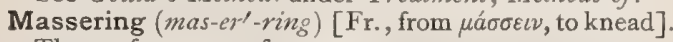
The performance of massage.

Massesis (mas-e'-sis). Synonym of Mastication.

Masset's Test. See Tests, Table of.

Masseter (mas-e'-ter) [ $\mu a \sigma \eta t \eta ́ p$, chewer]. See Muscle.

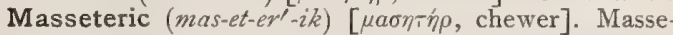
terine; pertaining to the masseter muscle.

Masseterine (mas-et'-er-en) [ $\mu a \sigma \eta \tau \dot{\eta} \rho$, chewer]. Pertaining to the masseter muscle.

Masseur(mas-ur')[Fr.]. A man who practises massage.

Masseuse (mas-u(r)z') [Fr.]. A woman who practises massage.

Massicot (mas'-ik-ot) [Fr.]. PbO. Yellow protoxid of lead; litharge.

Massotherapeutics, Massotherapy (mas-o-ther-ap- $u^{\prime}$ -

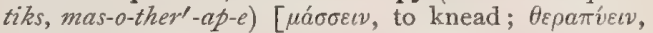
to treat]. The treatment of disease by mears of massage.

Massoy Bark (mas-oi' bark). I. The bark of Cinnamomum kiamis, of the $\mathrm{E}$. Indies; aromatic and antidysenteric; it affords the volatile oil of massoy. 2. The bark of Massoia aromatica, a tree of New Guinea.

Massula (mas'-su-lah) [L., dim. of massa, a lump or mass: pl., Massulce]. In biology: $(a)$ an adherent group of pollen-grains produced by a single mothercell. (b) One of the two or more spheric masses containing microspores, and derived from the mucilage of the microsporangia of Azolla. These masses are sometimes covered with barbed hair-like appendages, called glochids.

Mast-cells. Cells filled with basophile granules, found in the connective tissue and in foci of chronic inflammation.

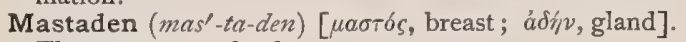
The mammary gland.

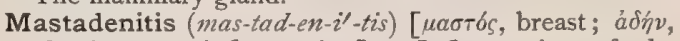
gland; $\iota \tau \iota s$, inflammation]. Inflammation of the mammary gland.

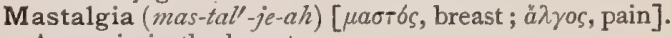
Any pain in the breast. 


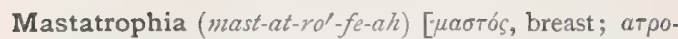
qia, atrophy]. Atrophy of the breast.

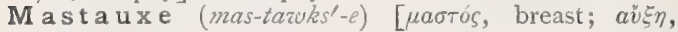
growth]. Increase in size, or excessive size, of the mammary apparatus.

Mastax (mas'-taks) [ $\mu a$ ora $\xi^{\prime}$, the mouth]. In biology, the muscular pharynx, containing the masticatory apparatus of a rotifer or wheel-animalcule.

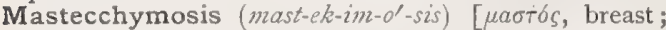
$\dot{\varepsilon} \gamma \chi \dot{v} u \omega \sigma \iota \varsigma$, ecchymosis]. Ecchymosis of the breast.

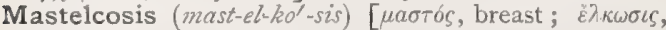
ulceration]. Synonym of Masthelcosis.

Master Tissues. A term applied to the muscular and nervous tissues of the body.

Masterwort (mas'-ter-wert). Cow Parsnip. The root of Heracleum lanatum, a stimulant, carminative, and antispasmodic. Dose of the fld. ext. $3 \mathrm{j}-\mathrm{ij}$. Unof. See also Imperatoria.

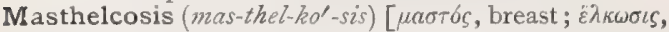
ulceration]. Ulceration of the breast.

Mastic (mas'-tik) [mastiche; $\mu a \sigma \tau i \chi \eta$, mastic]. The resin Howing from the incised bark of the Pistacia lentiscus. It occurs in pale, yellowish, transparent tears, that are brittle, with conchoidal fracture and balsamic odor, and soften between the teeth. It is soluble in alcohol, oil of turpentine, and acetone. It is used in varnish-making, and in dentistry as a temporary filling for teeth that have been prepared for their permanent filling. Internally its action is similar to that of the resin of turpentine. Dose gr. $\mathrm{xx}-\mathrm{xl}$.

Mastication (mas-tik-a'-shun) [masticare, to chew]. The process of chewing and of insalivation.

Masticatory (mas'-tik-at-o-re) [masticare, to chew]. A term applied to remedies or agents designed to be masticated or chewed; also to agents increasing the flow of saliva. M. Spasm, spasm from irritation of the peripheral or of the central tract of the motor portion of the fifth nerve.

Mastiche (mas'-ti-ke). See Mastic.

Masticot (mas'-tik-ot). Synonym of Massicot.

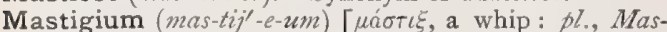
tigia]. In biology, one of the organs provided with defensive lashes, placed on the posterior extremity of certain lepidopterous larvæ.

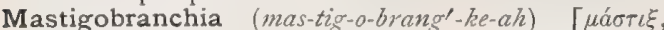
whip; $\beta \rho a ́ \gamma \chi \iota a$, gills]. In biology, the branchial lash of a crustacean. It is synonymous with the epipodite and epignathite of Milne-Edwards, and sometimes with part of the podobranchite of Huxley and with the apodemata of MacCoy, and the flabellum of old authors. (Bate.)

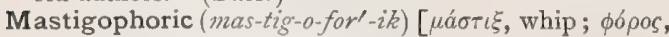
bear]. Same as Mastigophorous.

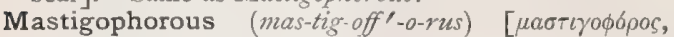
bearing a whip]. In biology, flagellate, as certain infusoria or zoöspores.

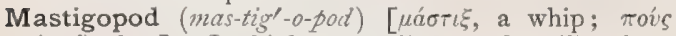
$(\pi \circ \delta)$, foot]. In biology, applied to the ciliated or flagellate stage in the development of certain organisms, as the myxomycetes.

Mastigosis (mas-tig-o'-sis) [ $\mu a \sigma \tau i \gamma \omega \sigma l \zeta$, from $\mu \alpha \sigma \tau \imath \gamma o \tilde{v} \nu$, to whip]. Flagellation as a therapeutic measure.

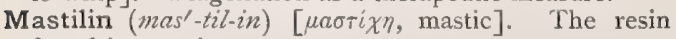
found in mastic.

Mastitis (mas-ti'-tis) [ $\mu a \sigma \tau o ́ s$, breast; $\iota \tau \iota s$, inflammation]. Inflammation of the breast. M. neonatorum, mastitis of infants. M., Parenchymatous, inflammation of the proper glandular substance of the breast. M., Retromammary, M., Submammary, or Paramastitis, inflammation of the connective tissue between the gland and the thorax. M., Supra-mammary, inflammation of the superficial connective tissue of the breast.
Mastix (mas'-tiks). Synonym of Mastic.

Masto-carcinoma (mas-to-kar-sin-o'-mah) [uactbs,

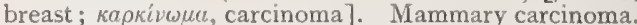

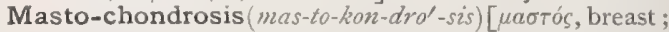
xóvoos, cartilage]. A chondromatous tumor of the mamma.

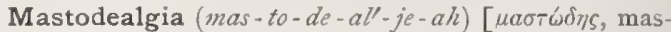
toid; ănjos, pain]. Pain in the mastoid process.

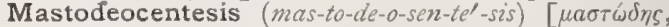

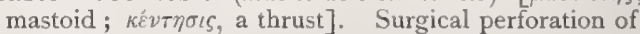
the mastoid process.

Mastodeo-paracentesis (mas-to-de-o-par-as-en-te'-sis). Synonym of Mastodeocentesis.

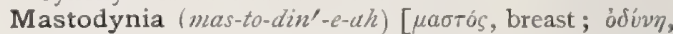
pain]. Pain in the breast.

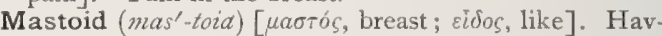
ing the shape of the breast; a descriptive term applied to a process and to a foramen of the temporal bone, and to other parts. M. Abscess, an abscess of the mastoid cells. M. Angle, the postero-inferior angle of the parietal bone. M. Antrum, a cavity in the mastoid portion of the temporal bone. M. Cells, the cells or hollow spaces exhibited in the structure of the mastoid process. M. Disease, inflammation and suppuration of the mastoid cells. M. Foramen. See Foramina, Table of. M. Fossa. See Fossa. M. Process, the protruding part of the temporal bone felt behind the ear

Mastoidal (mas-toi'-dal), Mastoideal (mas-toi-de'-al),

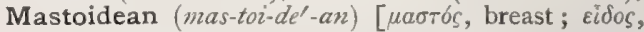
like]. Pertaining to the mastoid process.

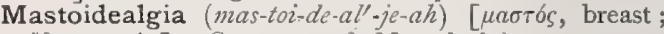
ă $\lambda$ yos, pain]. Synonym of Mastodealgia.

Mastoideocentesis (mas-10i-de-o-sen-te'-sis). See Mastodeocentesis.

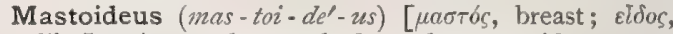
like]. A muscle attached to the mastoid process. See Muscles, Table of.

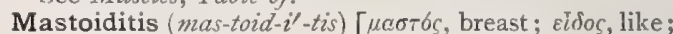
$\iota T \iota$, inflammation]. I. Inflammation of the mastoid colls, and of their lining mucous membrane. 2. Infitimmation of the periosteum of the mastoid process.

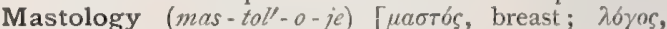
treatise]. A treatise on the mammary apparatus, its anatomy and diseases.

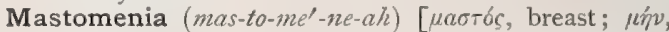
month]. Vicarious menstruation from the breast.

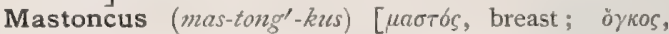
tumor]. Any tumor of the mammary gland or nipple.

Masto-occipital (mas'-to-ok-sip'-it-al) [ $\mu a \sigma \tau \delta s$, breast; occiput, occiput]. Pertaining to the mastoid process and the occipital bone.

Masto-parietal (mas'-to-par-i'-et-al) [uartós, breast; paries, wall]. Pertaining to the mastoid process and the parietal bone.

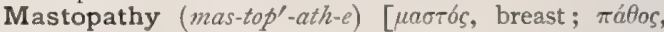
disease]. Any disease or pain of the mammary apparatus.

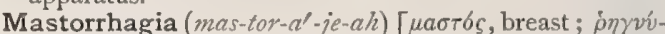
$v a \imath$, to break forth]. Hemorrhage from the breast.

Masto-scirrhus (mas-to-skir'-us) [ $\mu a \sigma \tau o ́ s$, breast; $\sigma \kappa i \rho$ pós, hard]. Scirrhous carcinoma of the mamma.

Mastospargosis (mas-to-spar-go'-sis) [ $\mu a \sigma \tau b s$, breast; $\sigma \pi a ́ \rho \gamma \omega \sigma \iota s$, swelling]. Enlargement or swelling of a mamma, especially that due to excess of milk.

Mastosyrinx (mas-to-si'-rinks) [ $\mu a \sigma \tau o ́ s$, breast ; $\sigma \tilde{v} \rho \iota \gamma \xi$, pipe]. A mammary fistula.

Mastotheca (mas-to-the'-kah) [ $\mu a \sigma \tau o ́ s$, the breast ; Ank $\eta$, a receptacle: $p l$., Mastothecle]. In biology, a pouch in which the nipples of the mammary glands are situated, as in the Marsupialia, whose young are born 
in an exceedingly rudimentary condition, and are never nourished by means of an allantoic placenta, but are transferred to the nipple of the mother, to which they remain firmly attached for a considerable time and are nourished, the milk being injected into the mouth by compression of the muscle covering the mammary gland. Cf. Marsupium.

Mastous (mas'-lus) [ $\mu a \sigma \tau b \varsigma$, breast]. Having large mammi.

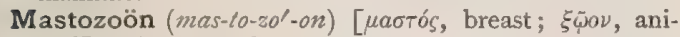
mal]. A mammal.

Mastupration (mas-tu-pra'-shun). Synonym of Maslurbation.

Masturbation (mas-ter-ba'-shun) [masturbari, to pollute one's self ; manus, the hand; stuprare, to ravish]. Production of the venereal orgasm by the hand; secret vice.

Masturbational, Masturbatory (mas-ter-ba'-shun-al, mas-ter-ba'tor-e) [masturbari, to pollute one's self]. Pertaining to masturbation.

Masuri (mas-u'-re) [Ind.]. The name commonly given in India to a parasite of the horse, Amphistoma collinsii. See Parasites (Animal), Table of.

Matchmaker's Disease. See Phosphorus-necrosis.

Matè $($ mah'-ta) [Sp., mate, a vessel]. Paraguay Tea. The leaves of Ilex paraguayensis, an infusion of which is used in South America as a substitute for tea and coffee. Its properties are due to caffein.

Mater (mah'-ler). See Dura Mater and Pia Mater.

Materia (mat-e'-re-ah) [L.]. Matter. M. chirurgica, the instruments, appliances, and general outfit of a surgeon. M. medica, the science that treats of drugs; the things used in medicine.

Material (mat-e'-re-al) [materia, matter]. Pertaining to matter; also, the substance of which anything consists.

Materialism (mat-e'-re-al-izm). See Spiritualism.

Materies morbi (mat-e'-re-ēe mor'-bi) [L., " matter of disease]. I. That material which is essential to the existence of a disease considered as an entity. 2 . A material that is the immediate cause of a disease or of an illness.

Maternal (mat-ur'-nal) [mater, mother]. Pertaining to the mother. M. Impressions. See Impressions.

Maternity (mat-ur'-nit-e). [mater, mother]. I. Motherhood. 2. [Fr., maternité.] A lying-in hospital.

Matica (mat-e'-kah). See Matico.

Maticin (mat'-is-in) [Sp., matico]. A bitter principle that exists in matico.

Matico (mat-e'-ko) [Sp.]. The leaves of Artanthe elongata, an aromatic tonic, stimulant, and aphrodisiac. It is valuable in catarrhal diseases of the mucous membranes; the leaves are efficacious as a

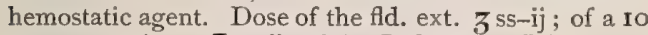

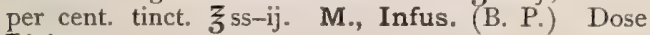
zj-iv.

Matrass (mat'-ras) [Fr., matras, a chemic vessel]. A urinal.

Matricaria (mat-rik-a'-re-ah) [matrix, womb]. German Chamomile; the flower-tops of $M$. chamomila. Matricaria contains a volatile oil and a bitter extractive principle, and is a mild tonic, and in large doses emetic and antispasmodic. It is a popular domestic remedy. among the Germans, and is the chamomilla of the homeopathic pharmacopeia. Dose, of the infusion, indefinite.

Matriculate (mat-rik'-u-lät) [matricula, a register]. To receive admission and to enroll one's self as a member of a college.

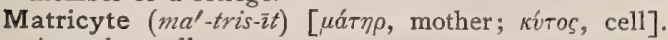
A mother-cell.

Matrix (ma'-triks) [L., a mold in which anything is cast]. I. A mold; the cavity in which anything is formed. 2. That part or tissue into which any organ or process is set, as the matrix of a tooth or of a nail; the intercellular substance. 3. In dentistry, a piece of steel or other metal of suitable form, used in filling proximal cavities. 4. The uterus.

Matrixitis (ma-triks-i'-tis). Same as Onychia.

Matron (ma'-tron) [matrona, a matron]. The principal female nurse or housekeeper of a hospital.

Matted (mat'-ed) [ME., matte, à mat]. Closely adherent; applied to tissues or structures that have been bound together by inflammatory exudate.

Matter (mat'-er) [materies; materia, matter]. The substance, or stuff, of which anything is made; the term is used as the name of certain tissues (as white matter, gray matter); also of certain morbid products (e.g., cheesy matter). Pus is colloquially designated as matter. M., Cheesy, the peculiar yellow cheese-like material, found in scrofulous and tuberculous glands, tissues, and other structures. M., Gray (of Sömmer. ing). The locus niger of the crus cerebri.

Matteuci's Muscular Pile. See Pile.

Mattoid (mat'-oid) [mattus, drunk; sioos, like]. A person half-crazed; a crank, or paranoiac.

Maturant (mat'-u-rant) [maturare, to ripen]. I. Ripening; hastening the process of maturation. 2. Any agent that promotes suppuration or maturation.

Maturation (mat-u-ra'-shun) [maturatio; maturare, to ripen]. I. The period of ripening. The culminating stage of inflammation marked by the collection and excretion of pus in some part of the inflamed tissue. 2. The ripening of the ovum; the stage succeeding the extrusion of the polar bodies. M. of Cataract. See Cataract.

Maturative (mat'-u-ra-tiv). Synonym of Maturant.

Mature (ma-tūr') [maturare, to ripen]. Ripe; also, to ripen.

Maturity (ma-tu'-rit-e) [maturitas; maturare, to ripen]. Full development; the quality or period of complete growth.

Matutinal (ma-tu'-lin-al) [Matuta, goddess of the morning]. Occurring in the morning, as matutinal nausea.

Matzoon. (mat'-zūn). A variety of koumiss, prepared largely in Asiatic Turkey. It is the Turkish equivalent of the Arabian leben, $q . v$.

Mauchart's Ligaments. See Ligament.

Maumène's Test. See Tests, Table of.

Mauriceau's Method. See Treatment, Methods of.

Mauriceau-Lachapelle Method. Same as Mauriceau's Method.

Mauthner, Sheath of. A thin zone of protoplasm situated immediately adjacent to the axis-cylinder of a nerve, and separating it from the medullary sheath.

Mauvanilin (mazvy-an'-il-in) [Fr., mauve, yellow; anilin], $\mathrm{C}_{19} \mathrm{H}_{19} \mathrm{~N}_{3} \mathrm{O}$. A derivative of anilin, occurring as a by-product in the manufacture of rosanilin. It is soluble in alcohol, in benzene, and in acetic ether. See Pigments, Conspectus of.

Mauve (mavev) [Fr.]. A purple dye derived from anilin. It is a salt of mauvein, $q . v$. See also Pigments, Conspectus of.

Mauvein (maw'-ve-in) [Fr. mauve, yellow], $\mathrm{C}_{25} \mathrm{H}_{24} \mathrm{~N}_{4}$. A base derived from anilin; its salts, especially the sulphate, form the anilin-dye mauve. It is a dark, crystalline powder, soluble in alcohol, insoluble in benzene and ether. See Pigments, Conspectus of.

Maw-bound. Constipated. M.-worm. Any intestinal worm that finds its way into the stomach, as Oxyuris vermicularis, or especially Ascaris lumbricis. See Parasites (Animal), Table of. 
Maxilla (maks-il'-ah) [L., the jaw-bone : pl., Maxilla]. The bone of the upper jaw, the supra-maxillary bone proper, but applied also to the bone of the lower jaw ;
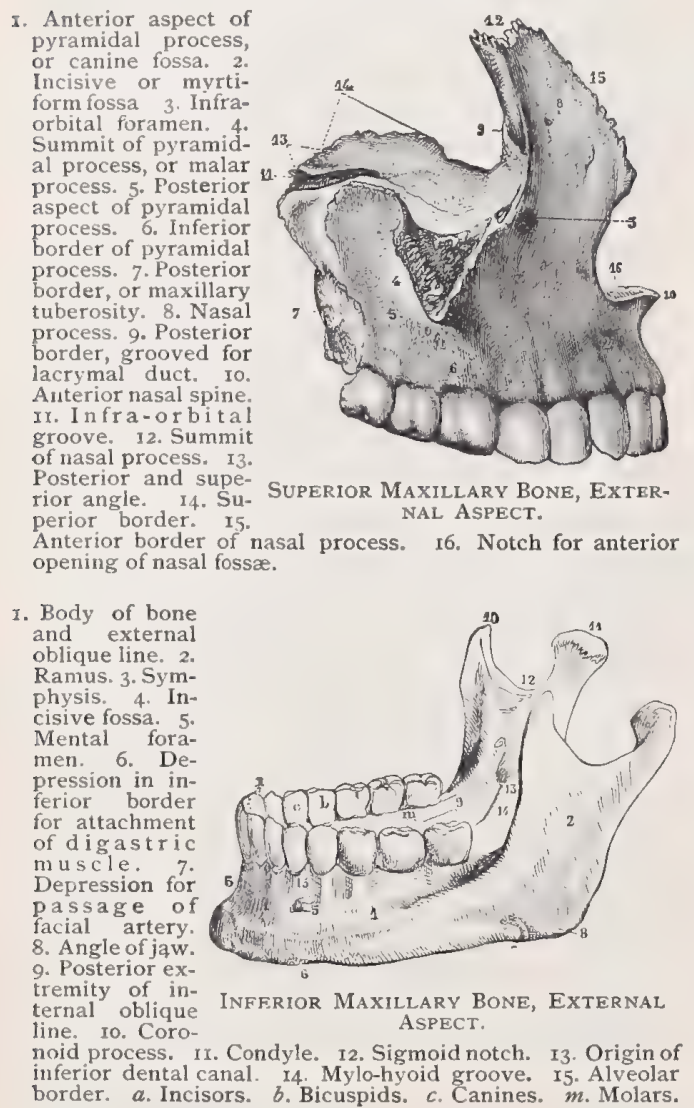

among insects and crustaceans, a member of one of the pairs of gnathites behind and below the mandibles.

Maxillar (maks'-il-ar), Maxillary (maks'-il-a-re) [maxilla, jaw-bone]. Pertaining to the maxillæ or jaws. M. Bones, the bones of the jaws, consisting of an inferior or lower, and a superior or upper jaw. M. Nerve, Inferior. See Nerves, Table of. M. Nerve, Superior. See Nerves, Table of. M. Sinus, the antrum of Highmore.

Maxillen (maks-it-en) [maxilla, jaw-bone]. Belonging to the maxillary bone in itself.

Maxilliform (maks-ill'if-orm) [maxilla, jaw ; forma, form ]. Shaped like a jaw-bone.

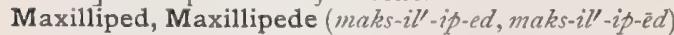
[maxilla, jaw; pes, foot]. In biology, one of the foot-jaws or gnathopodites of a crustacean.

Maxillitis (maks-il-i'-tis) [maxilla, jaw; $\iota \tau \iota s$, inflammation]. Inflammation of a maxillary gland.

Maxillo-dentary (maks-il-o-den'-tar-e) [maxilla, jaw ; dens, tooth]. Pertaining to the jaw and the teeth.

Maxillo-jugal (maks-il-o-ju'-gal) [maxilla, jaw; jugum, yoke]. Pertaining to the jaw and the malar bone.

Maxillo-mandibular (maks-il-o-man-dib-u-lar) [maxilla, jaw; mandibula, lower jaw]. Pertaining to the upper jaw and the lower jaw.

Maxillo-palatine (maks-il-o-pal'-at-in) [maxilla, jaw ; palatum, palate]. Pertaining to the maxilla and the palatine bone.

Maxillo-palpebralis (maks-il-o-pal-pe-bra'-lis). Synonym of Orbicularis palpebrarum. See Muscles, Table of. Maxillo-pharyngeal (maks-il-o-far-in'-je-al) [maxilla, jaw; $\phi a ́ \rho v \gamma \xi$, pharynx]. Pertaining to the jaw and the pharynx.

Maxillo-turbinal (maks-il-o-tur'-bin-al) [maxilla, jaw ; turbo, whirlwind]. Pertaining to the maxilloturbinal bone. M.-t. Bone, the inferior turbinate bone.

Maximal (maks'-im-al) [maximus, the greatest]. Pertaining to the maximum; highest or largest. M. Contraction, the extreme height of the lift or muscular contraction reached by gradually increased stimulus. M. Thermometer, a clinical thermometer with a device (a pin on top of the mercurial column) for preserving a record of the highest temperature to which it may have been subjected since the last observation.

Maximum (maks'-im-um) [L., the greatest]. The greatest or highest degree. M. Dose, the largest dose of a medicament that may be safely given. M. Occipital Point. See Craniometric Points.

Maxwell's Spot. A peculiar figure seen when blue light corresponding to blue glass F, of Rathenow's scale, is made to pass with rapid intermissions before the eye. M.'s Theory. See Light.

May (ma) [Maia, the goddess of growth]. The name of the fifth month. Also, a descriptive term applied to many flowers that mature in that month. M.-apple. See Podophyllum. M.-epidemic, a synonym in Europe for Croupous Pneumonia. M.-flower. See Traiting Arbutus. M.-weed. See Mruta.

Mayer's Alcoholic Carmin. See Stains, Table of. M.'s Cochineal. See Stains, Table of. M.'s Hemalum Staining Fluid. See Stains, Table of. M.'s Reagent. See Tests, Table of. M.'s Solution, a culture-medium for bacteria. It contains di-hydropotassic phosphate, calcic phosphate, and magnesium sulphate, each .I gram, pepsin .23 gram, and I5 per cent. solution of sugar-candy $20 \mathrm{C} . \mathrm{c}$.

Mayet's Formula. See Alimentation, Rectal. M.'s Paste, a caustic paste composed of zinc chlorid 8 parts, zinc oxid I part, wheat flour 7 parts, water I part.

Mayhem (ma'-hem) [OF., mehaigner, to hurt]. A legal term signifying the violent and unauthorized privation by another, of any useful part or organ of the body ; mutilation; maiming.

Maynard's Adhesive Liquid. Same as Collodion.

Mayor's Scarf. A simple dressing for fracture of the clavicle. It is made of a square of muslin, the diagonal being long enough to reach easily around the body. It is folded diagonally, and the forearm placed between the folds and laid horizontally across the chest; the ends of the diagonal are tied together at the back, and the other two ends are drawn snugly up in front so as to support the weight of the arm, and tied together around the neck. See Handkerchief-dressing. Mays (māz) [L.]. The genus Zea, q.v.

Maza $\left(m a^{\prime}-z a h\right)[\mu \tilde{\zeta} \zeta a$, cake]. The placenta.

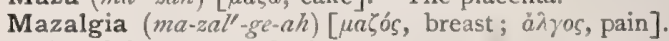
Mastalgia, or mastodynia.

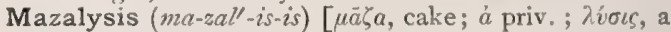
loosing]. Retention of the placenta. Sometimes used as synonym of Mazolysis, q. $v$.

Mazic ( $\left.m a^{\prime}-z i k\right)[\mu \vec{a} \zeta a$, placenta]. Pertaining to tho placenta.

Mazischesis (ma-zis'-kes-is). Synonym of Mazalysis.

Mazocacothesis (ma-zo-kak-oth'-es-is) [ $\mu \tilde{a} \zeta a$, cake ;

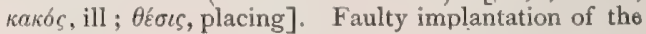
placenta. 


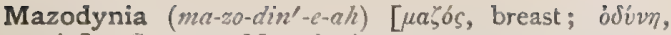
pain]. Same as Mastodynia.

Mazology (ma-zol'-o-je). Same as Mastology.

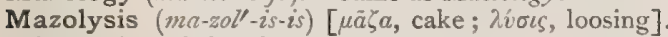
Separation of the placenta.

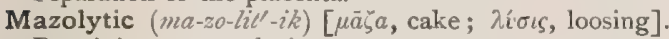
Pertaining to mazolysis.

Mazopathy (ma-zop'-ath-e) [ $\mu \bar{a} \zeta \alpha$, cake, placenta; $\pi a ́ \theta o s$, illness]. I. Any disease of the placenta. 2.

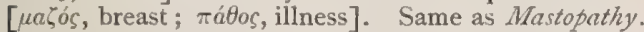

Meable $\left(m e^{\prime}-a-b l\right)$ [meabilis, easily penetrating]. Capable of being readily traversed or passed through.

Mead (méd) [ME., mede, mead]. Dilute, fermented honey or syrup flavored. See Hydromel and Metheglin.

Meadow Anemone. See Pulsatilla. M. Saffron. See Colchicum.

Meal (mél) [ME., mele, meal]. A coarse flour made from leguminous seeds or cereals.

Measle ( $\left.m e \bar{z} z^{\prime}-\mathrm{ll}\right)$ [singular of ME. meseles, measles]. An individual Cysticercus cellulose. M. of Pork. See Cysticercus. M.-worm, cysticercus.

Measles (mēz'-els) [ME, meseles, measles]. I. Rubeola, Morbilli. An acute, infectious disease, characterized by a peculiar eruption and by catarrhal inflammation of the mucous membranes of the conjunctiva and the air-passages. The period of incubation is nearly two weeks. The eruption is of a peculiar reddish color and assumes the form of concentric patches. The disease affects principally the young, is exceedingly contagious, and one attack of it confers almost perpetual immunity. 2. Fr., ladrérie; Ger., Fïnnen. A disease of the pig, the ox, the sheep, the reindeer, the dog, the cat, and man, due to the presence in the muscles, connective tissue, the brain, and other organs, of the finns or larve of various tapeworms; a form of cysticercosis. See Cysticercus, under Parasites (Animal), Table of. M., Anomalous, a form in which the symptoms are irregular, either the fever, catarrh, or eruption being absent. M., Bastard. Synonym of Rötheln. M., Benign, measles running through its ordinary course. M., Black, a very malignant, usually hemorrhagic form of measles. M., Camp, an epidemic form occurring among soldiers. M., Choleriform, a form in which choleraic symptoms supervene. M., Dyspneic, a grave form associated with congestion of the lungs and speedy death. It is most frequent in infants and young soldiers. M., False. Synonym of Rötheln. M., Fire. See Rötheln. M., French. Synonym of Rötheln. M., German. Synonym of Rötheln. M., Hemorrhagic, a form in which the eruption is hemorrhagic in type. M., Malignant, a fatal form with petechix, diarrhea and extreme prostration. M., Putrid, the same as M., Malignant. M., Typhoid, a severe form attended by hyperpyrexia and marked prostration.

Measly ( $\left.m \bar{e} z^{\prime}-l e\right)$ [ME., meseles, measles]. Containing measles (cysticerci); covered with a measles-like eruption.

Measures (mezh'-ürz). See Weights and Measures and Metric System.

Meat (mêt) [ME., mete, meat]. The muscular tissues of an animal, used as food. M.-biscuit, a palatable biscuit, weighing about $1 \frac{1}{4} \mathrm{Hbs}$, and containing from Io to $\mathbf{I} 2$ per cent. of water. It is made by mixing together, cooking, and baking, $\mathbf{I} \mathrm{tb}$. flour, I tb. meat, $\mathrm{I} / 4 \mathrm{tb}$. suet, $\pi / 2 \mathrm{~Tb}$. potatoes, with a little sugar, onion, salt, pepper, and spices. It will keep unchanged for four months. M.-inspection, the examination of meat, by experts, usually at the slaughter-houses, for the purpose of determining the presence or absence of disease, especially of tuberculosis and other infectious diseases, and of trichiniasis. M.-washings. See Dysentery.

Meatometer (me-at-om'-et-er) [meatus, meatus; $\mu \hat{\varepsilon} \tau$ $\rho o v$, measure]. An instrument used in measuring the caliber of the meatus urinarius.

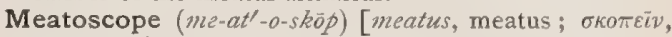
to inspect]. A speculum used in the examination of the distal portion of the male urethra.

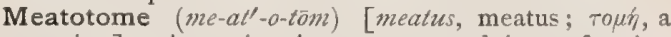
cutting]. A cutting instrument used in performing meatotomy.

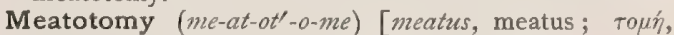
section]. Surgical incision of the meatus urinarius.

Meatus (me- $a^{\prime}$-tus) [meare, to flow or pass]. A passage. M. auditorius externus, the canal extending from the concha to the membrana tympani. M. auditorius internus, the internal auditory canal. M. urethræe, M. urinarius, the orifice of the urethra. $\mathbf{M}$. of Nose, one of the three meati into which the turbinal bones divide the nasal cavity. $\mathbf{M}$. venosus, a short vein, the vitelline, into which the omphalo-mesenteric veins empty.

Mecca Balsam-tree. See Carpobalsamum.

Mechanencephalitis (mek-an-en-sef-al-i'-tis) [ $\mu \eta \chi a v \eta$, instrument; $\dot{\varepsilon} \gamma \kappa \dot{\varepsilon} \phi a \lambda \circ \varsigma$, brain; $\iota \tau \iota s$, inflammation]. Encephalitis due to injury.

Mechanic, Mechanical (me-kan'-ik, me-kan'-ik-al) [ $\mu \eta \chi a v \iota \kappa b s$, pertaining to a machine]. Machine-like; lacking spontaneity; physical ; non-vital ; pertaining to mechanics. M. Dentistry, the art of constructing and applying artificial teeth, artificial palates, obturators and appliances for the correction of irregularity in the arrangement of the natural teeth. M. Parts, the stand of a microscope, excluding the ocular and objective. M. Theory, Virchow's theory of tumor-formation, viz., that tumors are due primarily to local irritation.

Mechanics (me-kan'-iks) [ $\mu \eta \chi a v \iota n^{\prime}$, instrument]. The science that treats of forces and powers and their application, either directly or by the intervention of machinery. It may treat of bodies at rest (statics), or in motion (dynamics).

Mechanism (mek'-an-izm) [mechanismus, from $\mu \eta \chi a v \eta$, instrument]. Any structure having the nature of a machine. The method by which any process is carried on. M. of Accommodation. See Accommodation. M. of Labor. See Labor.

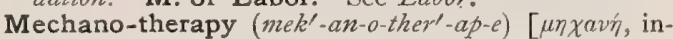
strument; $\theta \varepsilon \rho a \pi \varepsilon i a$, treatment]. The use of mechanical agencies, such as massage, exercise, and the like, in the treatment of disease.

Meckel's Cartilage. The cartilage of the mandibular arch in the embryo. M.'s Cave or Space, the recess of dura mater lodging the Gasserian ganglion. M.'s Diverticulum, a diverticulum of the ileum, arising from one to two feet above the ilio-cecal valve, and representing a portion of the unobliterated omphalomesenteric canal of the fetus. See $D i$ verticulum. M.'s Ganglion. See Ganglia, Table of. M.'s Ligament. See Ligament. M.'s Plane. See Plane.

Meckelian Bar. Same as Meckel's Cartilage. M. Ganglion. See Ganglia, Table of.

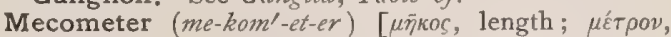
measure]. An instrument used in measuring newborn infants.

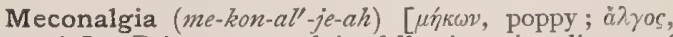
pain]. Pain or neuralgia following the disuse of opium.

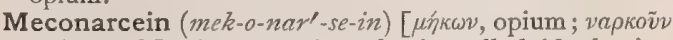
to benumb]. A preparation of opium alkaloids, having sedative properties, but which is free from morphin. 
Meconate (mek $\left.k^{\prime}-o n-\bar{a} t\right)$ [ $\mu \dot{r}_{\kappa} \omega \nu$, opium]. A salt of me conic acid.

Meconeuropathia (mek-on-u-ro-pat-the-ah) [ $\mu \dot{\eta} \kappa \omega v$, opi-

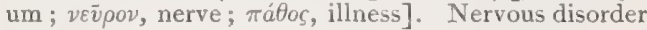
due to the abuse of opium, or its narcotic derivatives.

Meconial Colic (mek-o'-ne-al). See Colic.

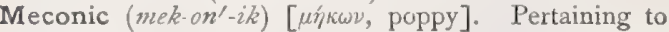
opium. M. Acid. See Acid.

Meconidin (mek-on'-id-in) [ $\mu$ i) $\omega v \nu$, poppy], $\mathrm{C}_{21} \mathrm{H}_{23} \mathrm{NO}_{4}$ An amorphous alkaloid of opium.

Meconidium (mek-on-id'-e-zm) [ $\mu$ ink $\omega \nu$, part of the intestine of a testaceous animal; the ink-bag of a cuttlefish: pl., Meconidia $]$. In biology, one of the generative medusoid buds or zoöids developed on the gonotheca of certain hydroids (Gonothyrea), and that gives rise to ciliated embryos.

Meconin (mek'-on-in) [ $\mu \dot{y} / \kappa \omega v$, poppy], $\mathrm{C}_{10} \mathrm{H}_{10} \mathrm{O}_{4^{*}} \quad \mathrm{~A}$ substance that results from the action of sodium amalgam upon opianic acid. It occurs already formed in opium, and is obtained on boiling narcotin with water. It yields shining crystals, melting at $102^{\circ} \mathrm{C}$, and dissolving with difficulty in water. It is said to be an hypnotic. Unof.

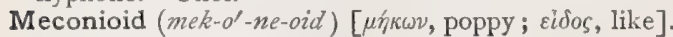
Resembling meconium.

Meconiorrhea (mek-on-e-or-e'-ah) [unkbviov, meconium; poia, flow]. A morbidly free discharge of meconium.

Meconiosin (mek-on-i'-o-sin) [ $\mu \hat{\eta} \kappa \omega \nu$, poppy]. A neutral principle found in opium.

Meconious (mek-o'-ne-us) [ $\mu \hat{\eta} \kappa \omega \nu$, poppy]. Pertaining to meconium.

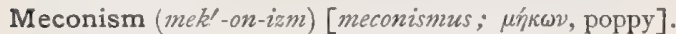
The opium-habit ; opium-poisoning, especially of the chronic kind.

Meconium (mek-o'-ne-um) [ $\mu \eta \kappa \omega v \iota v$, lit., "poppyjuice" ]. The first fecal discharges of the newborn. It is a dark-green, viscid liquid, composed of the secretion of the liver with exfoliated epithelium from the bowel.

Meconoid (mek'-on-oid). Synonym of Meconioid.

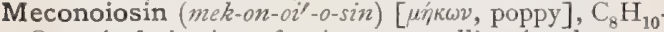
$\mathrm{O}_{2}$. A derivative of opium, crystalline in character and giving a dark-red color with sulphuric acid.

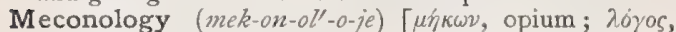
science]. The botany and pharmacology of opium, its allies and derivatives.

Meconophagism (mek-on-off'-aj-izm) [ $\mu \eta^{\prime} \kappa \omega \nu$, opium;

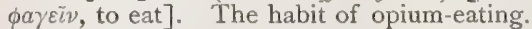

Meconophagist (mek-on-off'-aj-ist) [ $\mu \dot{\eta} \kappa \omega \nu$, opium; $\phi a \gamma \varepsilon[\nu$, to eat]. An opium-eater.

Medeitis (me-de-i'-tis) [ $\mu \dot{\eta} \delta \varepsilon a$, genitals ; $\iota T \iota$, inflammation ]. Inflammation of the genital organs.

Media (me'-de-ah) [fem. of medius, middle: pl. of medium]. The middle coat of an artery, vein, or Iymph-vessel.

Mediad (me'-de-ad) [medius, middle]. Toward the median plane or line.

Medial (me'-de-al). See Median.

Median (me'-de-an) [medius, the middle]. Middle, mesal, or mesial. M. Artery. See Arteries, Table of. M. Line. See Line. M. Nerve. See Nerves, Table of. M. Operation. See Operations, Table of. M. Plane. See Plane.

Mediastinal (me-de-as-tí-nal) [mediastinum, mediastinum]. Pertaining to the mediastinum.

Mediastinitis (me-de-as-tin-i'-tis) [mediastinum, mediastinum; $\iota \tau \iota \varsigma$, inflammation]. Inflammation of the cellular tissue of the mediastinum. It is characterized by constant severe pain beneath the sternum, together with dyspnea. Pus may form and give rise to constitutional symptoms, and, if in large quantity, to a fluctuating tumor in an intercostal space or above the episternal notch.

Mediastino-pericarditis (me-de-as'-tin-o-per-ik-ar-di' tis) [mediastinum, mediastinum; $\pi \varepsilon \rho i$, around; $\kappa \propto \rho \delta i a$, heart; $\iota \tau \iota \varsigma$, inflammation]. Combined inflammation of the mediastinum and the pericardium.

Mediastinum (me-de-as-ti'-num) [in medio stare, to stand in the middle]. A middle portion or septum separating adjacent parts. The pleural folds or septa extending from the spine to the sternum, and dividing the thoracic cavity into right and left chambers. It is divided into the anterior, the middle, and the posterior mediastinum, and otherwise into an upper (or superior) and a lower mediastinum. M. testis, a cavity in the posterior portion of the testicle formed by a projection inward of the tunica albuginea. It occupies about one-third of the transverse, and one-fourth of the longitudinal diameter of the testicle.

Mediate $\left(m e^{\prime}-d e-\bar{a} t\right)$ [medius, the middle]. Indirect. Also applied to the medium interposed between the surface of the body, and the instruments used in percussion and auscultation. M. Ligature. See Liguture. M. Percussion, percussion on a pleximeter.

Medibasilic Vein (me-de-bas-il'-ik). The median basilic vein. See Vein.

Medicable (med'-ik-a-bl) [medicari, to heal]. Amenable to cure.

Medical (med'-ik-al) [medicalis; medicari, to heal]. Pertaining to medicine, or the healing art. M. Ethics, those principles of justice, honor, and courtesy that regulate the intercourse and conduct of physicians. M. Jurisprudence. See Jurisprudence.

Medicament (med-ik'-am-ent) [medicamentum, from medicari, to heal]. A medicinal substance.

Medicamental, Medicamentary (med-ik-am-en'-tal, med-ik-am-en'-ta-re) [medicamentum, from medicari, to heal]. Pertaining to medicine.

Medicamentation (med-ik-am-en-ta'-shun) [medicamentum, a medicine]. Treatment by medicines.

Medicamentous (med-ik-am-en'-tus). See Medicinal.

Medicamentum ( $m e d-i k-a m-e n^{\prime}-t u m$ ). See Medicament. M. arcanum, a proprietary or secret remedy.

Medicaster (med'-ik-as-ter) [medicus, a physician]. An ignorant or unskilful physician or pretender; a quack.

Medicated (med'-ik-a-ted) [medicatus, medicated]. Treated or impregnated with medicine. Also, purified and made fit for medical use.

Medication (med-ik-a'-shun) [medicatio, medication]. Treatment by, or impregnation with, a medicine. M. Hypodermatic, or Hypodermic, treatment by the introduction of medicines beneath the skin, usually by means of a hypodermatic syringe.

Medicephalic (me-de-sef-al'-ik) [ medius, middle; $\kappa \varepsilon \phi a \lambda \dot{n}$, head]. Median cephalic. See Vein.

Medicerebellar (me-de-ser-e-bel'-ar) [medius, middle; cerebellum, little brain]. Pertaining to the intermediate region of the cerebellum.

Medicerebral (me-de-sert - e-bral) [ medius, middle; cerebrum, brain]. Pertaining to the central portion of the cerebrum.

Medicinal (med-is'-in-al) [medicina, medicine]. Pertaining to, or having the nature of, a medicine. $\mathbf{M}$. Rashes, eruptions on the skin following the internal administration of certain drugs, e.g., bromin and the bromids, iodin and the iodids, belladonna, copaiba, chloral, mercury, quinin, the salicylates, antipyrin and arsenic.

Medicine (med"-is-in) [medicina, medicine]. The science and art of preserving health, and preventing and curing disease ; the " healing art," including also the science of obstetrics. In a more restricted sense of the 
word surgery is excluded. On the European continent it is customary to divide medicine into internal and external, the former implying the restricted sense of the term, or the study of diseases of internal organs, the latter referring to surgery or external diseases. The term is applied also to a particular drug or therapeutic application. M., Atomistic, dosimetric medicine. M.-chest, a case or compartment for storing or carrying medicines. M., Clinical, pertaining to the study of disease by the bedside of the patient; internal medicine. M., Conservative, a method of treatment with the object of preserving the vital forces, and not by active measures, that endanger the life of the patient; also used in the ordinary sense of the word as relying upon well understood, or accepted or established methods of treatment, rather than upon new and comparatively untried plans. M. Domestic, the use of domestic remedies. M., Dosimetric. See Dosimetry. M., Eclectic. See Eclectic. M., Empiric. See Empiric. M., Equine, veterinary medicine as applied to the horse. M., Forensic, or M., Legal, the relations of medicine to jurisprudence, involving the diagnosis of insanity, questions in toxicology, surgery, and the like. M., Neurodynamic, the application of heat and cold to the spine in the treatment of certain diseases. M.,-pannier, a pannier used in the United States army for transporting medicines. M. Patent, a mixture or compound of sundry drugs for the sale of which the deviser gets a patent from the government. The ordinary so-called patent medicines, however, are not patented, but have only the name copyrighted. M., Pneumatic, the treatment of disease by means of compressed and rarefied air. See Waldenburg's Apparatus. M., Preventive, that which aims at the prevention of disease, in the community as well as in the individual. M., Proprietary. See Medicine, Patent. M., State, medical jurisprudence. M., Veterinary, the science and treatment of the diseases of domestic animals.

Mediciner (med-is'-in-er) [medicus, a physician]. physician.

Medicinerea (me de-sin-e'-re-ah) [medius, middle, and cinereus, ashen]. The gray matter of the claustrum and lenticula of the brain, lying between the cortex or ectocinerea and the entocinerea.

Medico-chirurgical (med-ik-o-ki-nur'-jik-al) [medicus,

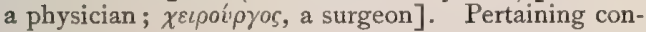
jointly to medicine and surgery.

Medico-legal (med-ik-o-le'-gal) [medicus, physician; lex, law]. Relating both to medicine and law.

Medico-mania (med-ik-o-ma'-ne-ah) [medicus, physician; $\mu a v i a$, madness]. Morbid interest or zeal in medical matters exhibited by non-professional persons.

Medicommissure (me-de-kom'-is-ūr) [medius, middle; commissura, commissure]. The middle commissure of the third ventricle. The junction of the mesal surfaces of the thalami. It is in a direct line between the porta and the aqueduct, and just dorsad of the aulix. It consists mainly of cells, and is so soft as commonly to be torn during the removal of the brain.

Medico-pneumatic (med-ik-o-nu-mat'-ik) [medicus, physician; $\pi v \varepsilon \tilde{v} \mu a$, air]. Relating to pneumatic medicine.

Medico-psychologic (med-ik-o-si-ko-loj'-ik) [medicus, physician; $\psi \mho \chi \chi \eta$, mind; $\lambda 6 \gamma 0 \varsigma$, science]. Pertaining to medico-psychology.

Medico-psychology (med-ik-o-si-kol'-o-je) [medicus,

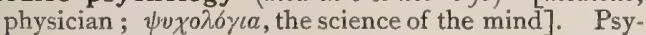
chologic medicine; the study of mental diseases.

Medicornu (me-de-kor'-nu) [medius, middle; cornu, horn]. The middle horn of the lateral ventricle.

Medicus (med'-ik-us) [L.]. A physician.
Medifurca (me-de-fur'-kah) [medius, middle; furca, fork: pl., Medifurce]. In biology, the middle, forked apodeme that projects into the thoracic cauity of an insect from the sternal wall of the somite.

Medina-worm (me-di'-nah-werm), See Filaria medin ensis under Parasites (Animal), Table of.

Medio-bilateral (me-de-o-bi-lat'-er-al) [medius, middle; bis, twice; latus, side]. Pertaining to the middle and to both sides.

Medio-carpal (me-de-o-karl - pal) [medius, middle ; carpus, carpus]. Pertaining to the articulation between the two rows of carpal bones.

Medio-colic (me-de-o-kol'-ik) [medius, middle; $\kappa \tilde{\omega} \lambda \hat{\imath} o v$, colon]. Pertaining to the middle portion of the colon.

Medio-dorsal (ne-de-o-dor'-sul) [medius, middle; dorsum, back]. Both median and dorsal; on the mesial line of the back.

Medio-frontal (me-de-o-frun'-tal) [medius, middle ; frons, forehead]. Pertaining to the middle of the forehead.

Medio-lateral (me-de-o-lat'-er-al) [medius, middle ; latus, side]. Pertaining to the middle and to one side.

Medio-occipital (me-de-o-ok-sip'-it-al) [medius, middle; occiput, occiput]. Pertaining to the middle portion of the occipital region.

Medio-pontine (me-de-o-pon'-tin) [medius, middle; pons, bridge]. Pertaining to the central portion of the pons.

Medio-tarsal (me-de-o-tar'-sal) [medius, middle; tar sus, tarsus]. Pertaining to the middle articulation of the tarsal bones.

Medipectus (me-de-pek'-tus). Same as Mesosternum. Medipeduncle (me-de-pe-dung $g^{\prime}-k l$ ) [medius, middle; pedunculuts, peduncle]. The middle peduncle of the cerebellum; the lateral intermediate continuation of the cerebellum to the pons. It is the largest of the three peduncles of the cerebellum, and is mainly continued from the lateral lobe of the latter.

Mediscalenus (me-de-ska-le'-nus) [medius, middle;

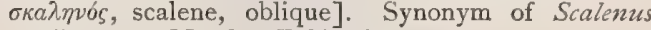
medius; see Muscles, Table of.

Medisect (me-de-sekt') [medius, middle; secare, to cut]. To make a medisection, $q . v$.

Medisection (me-de-sek'-shun) [medius, middle ; sectio, from secare, to cut]. Section of the body, or of any symmetric part, at the median longitudinal antero-posterior plane. See Position and Direction, Table of.

Medisternum (me-de-ster'-num). Synonym of Mesosternum.

Mediterranean Fever. See Fever.

Meditriceps (me-de-tri'-seps) [medius, middle; т.peīs, three; $\kappa \varepsilon \phi \alpha \lambda \eta$, head]. The middle or long head of the triceps muscle.

Medium (me'-de-um) [medius, the middle: $p l$., Media]. That in which anything moves or through which it acts. In medicine, the sum of conditions by which a patient is surrounded, especially those of light, temperature, and ventilation. Also, a person subject to hypnotizing influence. M., Culture. See Media, Nutrient. M. of the Eye, the refracting structures from the anterior surface of the cornea to the retina. M., Fluid, any liquid nutrient substance, such as bouillon, milk, and the like. M., Mounting. See Mounting-media. M., Nutrient, the substances used in bacteriologic studies for the cultivation of microorganisms. See M., Fluid, and M., Solid. M., Solid, any solid nutrient substance for the cultivation of bacteria, as gelatin, agar-agar, potato, and the like.

Mediumism (me'-de-um-izm) [medius, the middle]. Hypnotism.

Medius (me'-de-us) [medius, middle]. The middle. 
Medoblennorrhea (me-do-blen-or-e'-ah). Synonym of Gonorrhea and Glect.

Medorrhea (me-dor-e'-ah) [ $\mu \eta^{\prime} \delta \varepsilon a$, genitals; poía, a flow]. A discharge from the reproductive organs. M. urethralis, gonorrhea. M. virilis, gonorrhea of the male urethra.

Medorrhoic (me-dor-ó-ik) [ $\mu \eta \dot{\delta} \delta \varepsilon a$, genitals ; poía, flow]. Pertaining to medorrhea.

Medulla (me-dul'-ah) [L., marrow]. A fatty substance or marrow occupying certain cavities. Also the central parts of certain organs, as distinguished from the cortex. See Alba. M. of Bone, bone-marrow. M. dorsalis. See $M$. spinalis. M. of Hair, the central portion or core of the hair. M. of Nervefiber, the myelin or white substance of Schwann. $\mathbf{M}$. oblongata, the upper enlarged part of the spinal cord, extending from the cord opposite the foramen magnum to the pons Varolii. M., Renal, the substance of the renal pyramids. M. spinalis, M. vertebralis, the spinal cord or marrow; the myelon.

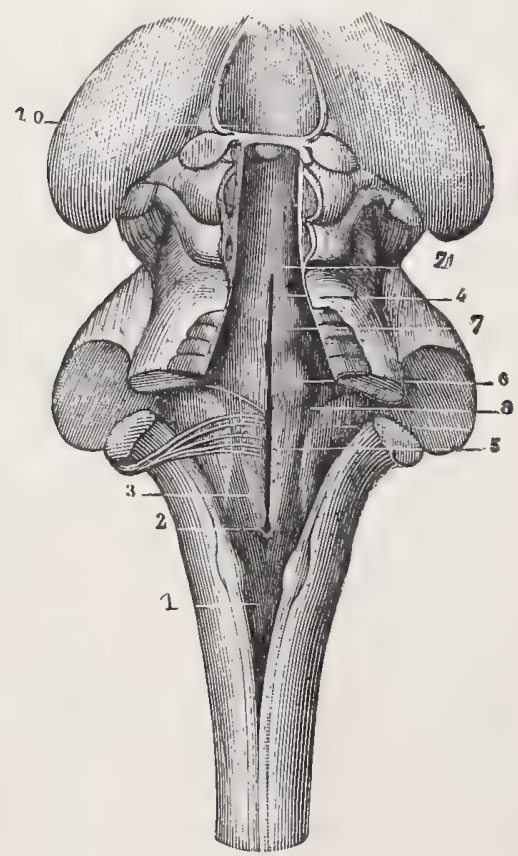

Dorsal Aspect of Medulla Oblongata.

3. Gray matter surrounding central canal. 2. Orifice of this canal. 3. Median fissure. 4. Its upper extremity. 5. Grayish-white matter giving origin to hypoglossal nerve. 6 . Eminentia teres, 7. Prominence corresponding to nucleus of 6 th nerve, $7^{\prime}$. Nucleus of 3 d nerve. 8. Gray column giving origin to mixed nerves. Io. Third ventricle and posterior commissure.

Medullar (me-dul'-ar). Synonym of Medullary.

Medullary (med'-ul-a-re, or med-ul'-a-re) [medulla, marrow]. Pertaining to the medulla or to marrow; resembling marrow. Also, pertaining to the white substance of the brain contained within the cortical envelop of gray matter. M. Canal, the hollow interior of long bones, in which the marrow lies. $\mathbf{M}$. Carcinoma, a soft carcinoma very rich in cells; encephaloid carcinoma. M. Groove, a longitudinal groove at the anterior part of the embryonal shield of the blastoderm. M. Membrane, the areolar envelop of the marrow of the long bones. M. Plates. See Plate. M. Rays. I. Also called Pyramids of
Ferrein; series or bundles of parallel tubules extending from the medulla of the kidney into the cortex. 2. Rays of fundamental tissue that connect the pith with the cortex, and separate the fibrovascular bundles, in the stems of dicotyledons and gymnosperms. M. Sarcoma, a soft, round-celled sarcoma. M. Sheath, I. the semi-fluid, fatty, white matter between the enveloping sheath and the central axis-cylinder, or essential part of a nerve. 2. A sheath composed of spiral ducts and wood-cells surrounding the pith, in dicotyledons and gymnosperms. M. Tube, the closing of the medullary groove, forming a closed medullary or neural tube. M. Velum. See Velum.

Medullated (med'-ul-a-ted) [medulla, marrow]. Containing or covered by medulla or marrow. M. Nerve-fibers, nerve-fibers provided with a medullary sheath, the myelin or white substance of Schwann. Non-M. Nerve-fibers, nerve-fibers not possessing a medullary sheath.

Medullic Acid (med-ul'-ik) [medulla, marrow], $\mathrm{C}_{21}$ $\mathrm{H}_{42} \mathrm{O}_{2}$, A monobasic acid derived from beef-fat.

Medullification (med-ul-if-ik-a'-shun) [medulla, marrow ; facere, to make]. The formation of medulla.

Medullin (med-ul'-in) [medulla, marrow]. I. A variety of cellulose obtained from the pith or medulla of certain plants. 2. An extract derived from the spinal cord.

Medulli-spinal (med-ul-e-spi'-nal) [medulla, marrow ; spinalis, spinal]. Relating to the myelon or spinal marrow; myelonic.

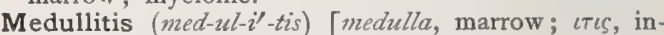
flammation]. I. Inflammation of marrow. 2. Myelitis.

Medullization (med-ul-iz-a'-shun) [medulla, marrow]. Softening of bene-tissue in the course of osteitis.

Medullo-arthritis (med-ul-o-ar-thri'-tis) [medulla, marrow; à $\rho \rho \rho o \nu$, joint; $\iota \iota \zeta$, inflammation]. Inflammation of the marrow-elements of the cancellated articular portion of a bone.

Medullo-cell (med-ul'-o-sel) [medulla, marrow ; cellula, cell]. A marrow-cell.

Medullo-encephalic (med-ul'-o-en-sef-al'-ik) [medulla,

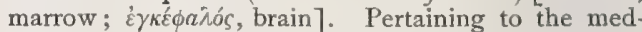
ulla and the encephalon; myelo-encephalic.

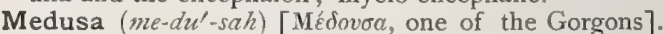
Jelly-fish. M.'s Head. See Medusa Caput. Medus $æ$ Caput, an extensive dilatation of the superficial veins of the abdomen about the umbilicus, seen in certain cases of portal obstruction. The condition largely depends upon the establishment of the venous collateral circulation through an anastomosis of the mesenteric veins and those of the abdominal walls, and, occasionally, also upon a patulousness of the umbilical vein.

Meerschaum (mērl-shazum) [Ger., "sea-foam"], $\mathrm{Mg}_{2} \mathrm{H}_{4} \mathrm{Si}_{3} \mathrm{O}_{9}$. A native hydrated magnesium silicate ; locally used in the same way as bole, or cimolian earth; it is a good absorbent application.

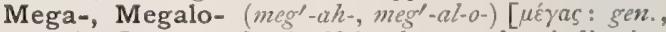
$\mu \varepsilon \gamma a ́ \lambda o v]$. A prefix signifying large; also, indicating a unit one million times as great as the unit to which it is prefixed.

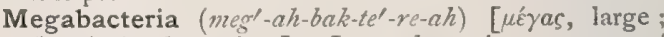
ßaкт́nрiov, bacterium]. Large bacteria; a group of the coccobacteria.

Megacephalia (meg-ah-sef-a'-le-ah) [ $\mu \varepsilon^{\prime} \gamma a s$, large; $\kappa \varepsilon \phi a \lambda \eta \dot{n}$, head]. The megacephalic condition.

Megacephalic (meg-ah-sef-al'-ik), Megacephalous

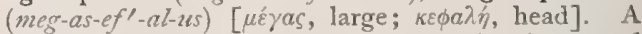
term applied to a skull whose capacity (measured by filling with shot through the foramen magnum) exceeds $1450 \mathrm{c} . c$. If less than $\mathbf{I} 350$ it is called microceshalic: if between these numbers, mesocephalic. 


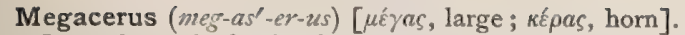
Large-horned; having large antennæe.

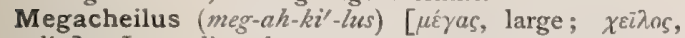
lip]. Large-lipped.

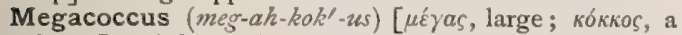
berry]. A large-sized coccus.

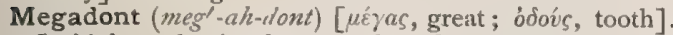
In biology, having large teeth. Cf. Macrodont.

Megadyne (meg'-ah-dìn) [ $\mu \dot{\varepsilon} \gamma a \varsigma$, great ; divuus, power]. A unit equal to a million dynes.

Megaelectrometer (meg-ah-e-lek-trom'-et-er) [ $\mu \dot{\varepsilon} \gamma a \varsigma$,

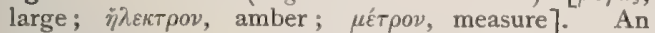
electrometer for measuring strong currents.

Megafarad (meg-ah-far'-ad) [ $\mu \varepsilon^{\prime} \gamma a s$, large; Faraday]. An electric unit equal to a million farads.

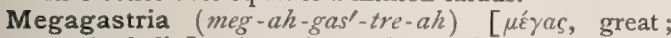

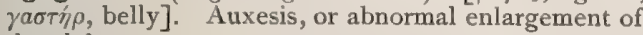
the abdomen.

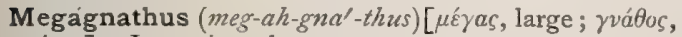
jaw ]. Large-jawed.

Megalerg (meg'-al-erg). See Electric Units.

Megalesthete ( $\mathrm{meg}^{\prime}-a l$-es-that) [ $\mu \varepsilon$ yas, great, large; aiotnrín, one who perceives]. In biology, Moseley's term for peculiar organs of touch characteristic of the Chitonidre; the "papilliform bodies" of Van Bemmelen. It is also written Megalasthete.

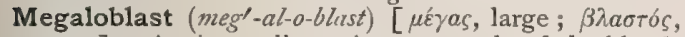
germ]. A giant-cell or giant-corpuscle of the blood. See Corpuscle.

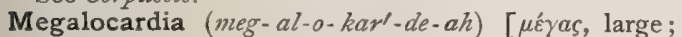
кapdia, heart]. Auxesis, or enlargement of the heart.

Megalocarpous (meg-al-o-kar'-pus) [ $\mu \varepsilon^{\prime} \gamma a_{S}$, great, large; $\kappa a \rho \pi \delta ́ s$, fruit]. In biology, producing large fruit.

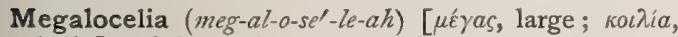
belly]. Colon; also megagastria, $q \cdot v$.

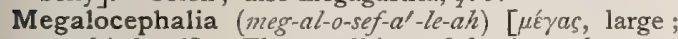
$\kappa \varepsilon \phi \alpha \lambda \eta \dot{n}$, head]. The condition of having a large or megacephalic head.

Megalocephalic (meg-al-o-sef-all-ik). Same as Megacephalic.

Megalocephaly(meg-al-o-sef'-al-e). See Megalocephatia.

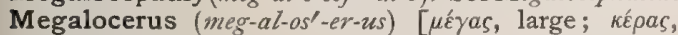
horn]. A monstrosity with horn-like projections on the forehead.

Megalocheirous (meg-al-o-ki'-rus) [ $\mu \varepsilon \gamma_{\alpha}$, large ; $\chi \varepsilon i \rho$, hand]. Large-handed; having large antennæ.

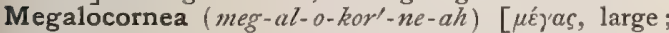
cornea, cornea]. An enlarged condition of the cornea; it may depend upon congenital hypertrophy.

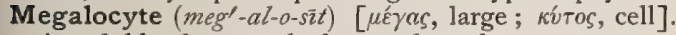
A red blood-corpuscle larger than the average; especially the form that characterizes pernicious anemia. See Corpuscle.

Megalodactylous (meg-al-o-dak'-til-us) [ $\mu \varepsilon^{\prime} \gamma a s$, great;

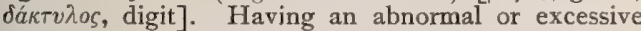
development and size of the fingers or toes.

Megalofrenum (meg-al-a-fre'-mum) [ $\mu \varepsilon^{\prime} \gamma a s$, large; fraenum, frenum]. An enlarged fourchet (Hadra).

Megaloglossia (meg-al-o-glos'-e-ah). Synonym of Macroglossia.

Megalomania (meg-al-o-ma'-ne-ah) [ $\mu \varepsilon ́ \gamma a c$, great; uavia, madness]. Insanity with delusional ideas of one's own greatness or exaltation; applied especially to cases that do not present general paralysis, but a fixed and systematized delusion, or monomania of exaltation.

Megalomelia, Megalomelus (meg-al-o-me'-le-ah, meg-

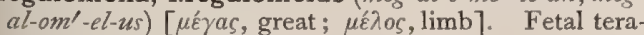
tism characterized by great size of the limbs.

Megalophonic, Megalophonous (meg-al-o-fo'-nik, meg-al-off'-o-nus). Synonym of Macrophonous.
Megalopia (meg-al-o'-pe-ah). Synonym of Megalopsia.

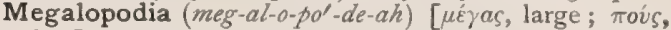
foot]. The condition of having large feet.

Megalopore (meg'-al-o-por) [ $\mu \varepsilon \gamma a_{S}(\mu \varepsilon \gamma a \lambda-)$, large ; $\pi \dot{p}$ os, a pore or passage]. In biology, any large pore; specifically applied by Moseley to the larger of the pores arranged in more or less definite patterns in the tegmenta of the shells of nearly all chitonidæ. Cf. Micropore.

Megalopous (meg-al-op'-us). Synonym of Macropous.

Megalops (meg'-al-ops) [ $\mu \varepsilon \gamma^{\prime} a s,(\mu \varepsilon \gamma a \lambda-)$, large; $\omega \psi$, eye]. In biology, a stage in the development of certain crustaceans, characterized by relatively large eyes.

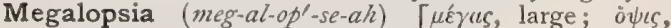
sight]. An apparent increase in the size of objects, ascribed to changes in the retinal end-organs, and to spasm of accommodation.

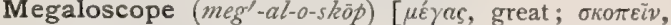
to inspect]. A magnifying endoscope or speculum.

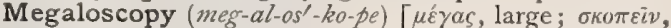
to inspect]. Inspection by means of the megaloscope.

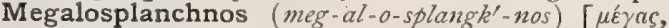
large ; $\sigma \pi \lambda a ́ \gamma \chi \nu o \nu$, viscus]. Possessing large viscera, especially a large liver.

Megalosplenia (meg-al-o-sple'-ne-ah) [ $\mu \varepsilon^{\prime} \gamma a s$, great; $\sigma \pi \lambda \dot{r} \nu$, spleen]. Enlargement of the spleen.

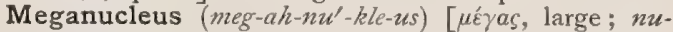
cleus, a kernel]. In biology, Maupas' term for the macronucleus, mucleus, or endoblast, of authors.

Megaphone (meg'-ah-fón) [ $\mu \varepsilon^{\prime} \gamma a \varsigma$, great; $\phi \omega \nu \dot{n}$, sound]. An instrument used for assisting the hearing of the deaf, by means of large reflectors of the sound-waves.

Megasclere (meg'-ah-sklēr) [ $\mu \varepsilon^{\prime} \gamma a s$, great, large ; $\sigma \kappa \lambda \eta \rho o ́ s$, hard]. In biology, one of the large, skeletal spicules of a sponge, as distinguished from a microsclere.

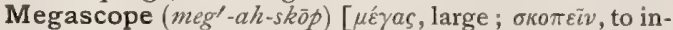
spect]. A microscope for examining objects of comparatively large size.

Megascopic (meg-ah-skop'-ik). See Macroscopic.

Megaseme (meg'-ah-sēm) [ $\mu \hat{\varepsilon} \gamma a \varsigma$, great ; $\sigma \tilde{\eta} \mu \alpha$, sign, index]. See Index.

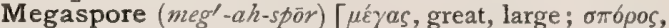
seed]. Same as Macrospore.

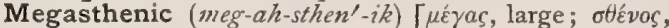
strength]. Powerful; having great bodily strength.

Megastoma (meg-ah-sto'-mah) [ $\mu \hat{\varepsilon} \gamma a c$, large; $\sigma \tau b \mu \alpha$, mouth]. A genus of infusorians. $\mathbf{M}$. entericum, $\mathbf{M}$. intestinale, a species found in the intestinal canal of the cat and of certain mice, and in human feces. It is probably identical with Cercomonas intestinalis.

Megastomatous (meg-ah-sto'-mat-us). Synonym of Macrostomatous.

Megavolt (meg'-ah-volt). See Electric Units.

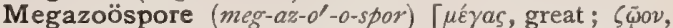
animal; $\sigma \pi 6 \rho o s$, seed]. Same as Macrozoöspore.

Meglin's Pills. Pills used in the treatment of neuralgia. They contain extract of hyoscyamus, oxid of zinc, and extract of valerian, each $3 / 4$ of a grain.

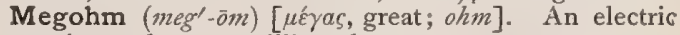
unit equal to one million ohms.

Megrim (me'-grim or meg'-rim) [Fr., migraine; L., hemicrania]. Neuralgia or headache of one-half of the head or upon one side, sometimes attended by aphasic and visual symptoms and sensory disturbance. See Hemicrania and Migraine.

Méhu's Test. See Tests, Table of.

Meibomian (mi-bo'-me-an) [Meibomius, a German physician ]. Pertaining to Heinrich Meibom, or Meibomius, a German physician, I638-1700. M. Cyst, a cyst of the Meibomian gland. M. Glands, the sebaceous glands of the eyelids, each having an excretory duct opening at the free border. Their secretion 
prevents the tears from coming in contact with the skin. There are from 30 to 40 in the upper and from 20 to 30 in the lower lid.

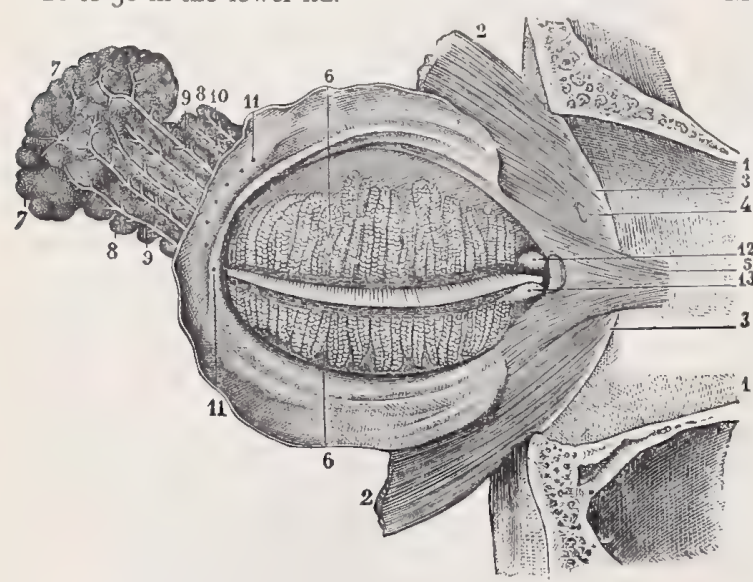

The Lacrymal and Meibomian Glands, and Adjacent ORGANS OF THE EYE.

I, I. Inner wall of orbit. 2, 2. Inner portion of orbicularis palpebrarum. 3, 3. Attachment to circumference of base of orbit. 4. Orifice for transmission of nasal arter:. 5. Muscle orbit. 4. Orifice for transmission of nasal artery. 5. Muscle
of Horner (tensor tarsi). 6, 6. Meibomian glands. 7, 7 . of Horner (tensor tarsi). 6, 6 . Meibomian glands. 7, 7 .
Orbital portion of lacrymal gland. 8, 9, 10. Palpebral portion. II, II. Mouths of excretory ducts. I2, I3. Lacryma puncta.

Meibomius, Cyst of, a cyst of a Meibomian gland. M., Foramen of. See Foramina, Table of. M. Glands of. See Gland.

Meigs's Capillaries. Capillaries penetrating the muscle-fibers of the heart. See Capillary. M.'s Formula or Mixture, an artificial food closely approaching in composition that of human milk. It consists of Io c.c. of cream, 5 c.c. of milk, ro c.c. of lime-water, 15 c.c. of water, and 2.2 grams of milksugar. It is alkaline in reaction, and is composed of 88.42 parts water, II. 58 parts total solids, 4 parts fat, I. I I parts albuminoids, 6.26 parts sugar and 0.21 part ash.

Meio- $\left(m i^{\prime}-o-\right)$. For words thus beginning, see Mio-

Meissner (mis'-ner). A German anatomist. M., Corpuscles of. See Corpuscles, Tactile, of Wagner. M.'s Ganglia. See Ganglia, Table of. M.'s Method, a method of inducing premature labor by puncturing the membranes close up to the fundus of the womb to permit of gradual escape of the liquor amnii. M., Plexus of, a plexus of nerves found in the submucous layer of the small intestine. See Plexus.

Mel [L.]. Honey. The substance deposited in the honeycomb by the common honey-bee, Apis mellifica, and a few other hymenopterous insects. It consists of a solution of cane-sugar and grape-sugar, with coloring and odorous matters. It is emollient, nutritive, and often laxative, its properties depending mainly on the character of the flowers from which it is taken. It is an excellent vehicle for expectorant gargles, etc. M. boracis, honey of borax; 64 grains of borax to the ounce of honey. M. despumatum, clarified honey, prepared by heating, skimming, and straining the natural product. $\mathbf{M}$. rosæ, honey of rose; red rose 8 , clarified honey 92 parts, dilute alcohol, q. s. It is used locally as a gargle.

Melada (mel-a'-dah) [Sp., fem. of melar, candy]. A moist brown sugar, produced like the muscovado, but not drained free of molasses.
Melagra. (mel-a'-grah) [ $\mu \varepsilon^{\prime} \lambda o s, \operatorname{limb} ; \dot{a} \gamma \rho a$, seizure]. Pain or gout in the limbs.

Melain (mel'-a-in) [ $\mu \varepsilon^{\prime} \lambda a \varsigma$, black]. I. The coloringprinciple of sepia. 2. A synonym of Melanin.

Melaleuca (mel-al-u'-kah). See Cajuput.

Melalgia (mel-al'-je-ah) [ $\mu \varepsilon ́ \lambda o s, l i m b ; a ̀ \lambda y o s, p a i n]$. Pain or neuralgia in the extremities.

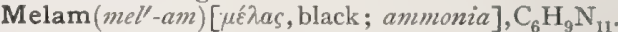
A complex cyanid, formed on rapidly heating $\mathrm{CNSNH}_{4}$ to $200^{\circ} \mathrm{C}$. with ammonium chlorid; it is a granular powder, of a yellow color, insoluble in water.

Melamin (mel'-am-in) [ $\mu \varepsilon^{\prime} \lambda a$, black; amin], $\mathrm{C}_{3} \mathrm{H}_{6} \mathrm{~N}_{6}$. A substance obtained from crude melam by extraction with water. It is nearly insoluble in alcohol and ether, and crystallizes from hot water in shining monoclinic prisms.

Melamphonous (mel-am'-fo-nus) [ $\mu \hat{k}^{\prime} \lambda a \varsigma$, dark; $\phi \omega \nu \eta ́$, voice]. Hoarse-voiced.

Melampodium (mel-am-po'-de-um). See Hellebore, Black.

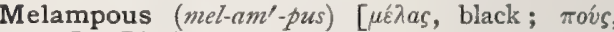
foot]. Black-footed.

Melanæmia (mel-an-e'-me-ah). See Melanemia.

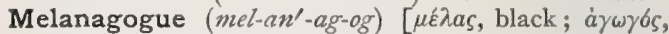
leading]. 1. Causing an expulsion of dark feces, or of bile. 2. A remedy that causes the expulsion of dark stools or of bile; formerly, a medicine of service in the treatment of choler, or melancholy.

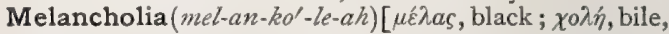
from a former supposition that it was due to excessive biliary secretion]. Melancholy; a form of insanity characterized by depression of spirits and gloominess, without any adequate cause, the central idea being one of personal unworthiness. As the case develops, delusions, associated with illusions and hallucinations, appear, and the patient may at times show suicidal tendencies. The general nutrition suffers, and in females menstruation is usually suppressed. The usual age at which melancholia appears is during middle life. It follows any depressing cause acting in conjunction with a strong hereditary tendency. It usually terminates in recovery, but some cases develop into dementia or mania, while others die from exhaustion, or commit suicide. M. agitans, M. agitata, M., Excited, or M., Motor, melancholia associated with excessive restlessness and mental agony. M. attonita, or M., Stuporous, a form in which the patient is plunged into absolute mental stupor. M., Cataleptic, a form associated with the cataleptic state. M. catatonica. A synonym of Catatonia. M., Delusional, a form in which delusions constitute a prominent feature of the disease. M. erotica, a form caused by disappointment in love. $\mathbf{M}$. errabunda, a form accompanied by great restlessness. M., Homicidal, melancholia with homicidal tendencies. M., Hypochondriac, in which the delusions refer mainly to the state of the patient's viscera. M., Hysteric, that due to hysteria. M., Motor. See $M$. agitans. M., Puerperal, melancholia appearing during the puerperium. M., Resistive, a form in which the extremities are rigid, and this rigidity increases when attempts are made to move them. The patient is obstinate in his nature also. - M., Simple, the ordinary form. M., Stuporous. See $M$. attonita.

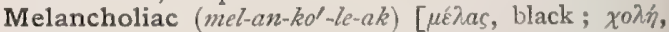
bile]. A person who is affected with melancholia.

Melancholic (mel-an-kol'-ik) [ $\mu \varepsilon^{\prime} \lambda a s$, black; $\chi o \lambda \dot{n}$, bile]. Sad; depressed; affected with melancholy.

Melancholy (mel'-an-kol-e). See Melancholia.

Melanchrous (mel-an'-krus) [ $\mu \varepsilon \hat{\lambda} a s$, black; $\chi \rho \omega s$, color of skin]. Affected with melanism. 


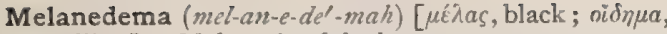
swelling]. Melanosis of the lungs.

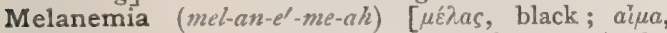
bluod]. The presence in the blood-plasma or in the corpuscles, or in both, of dark pigment-granules due to the disintegration of the hemoglobin. Its most common cause is malaria. If very intense, as in pernicious forms of malaria, it may give rise to embolism of the capillaries of the brain or other organs.

Melanencephaloma (mel-an-en-sef-al-o'-mah) [ $\mu \varepsilon^{\prime} \lambda a s$,

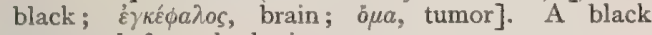
outyrowth from the brain.

Melanephidrosis (mel-an-ef-id-ro'-sis) [ $\mu \varepsilon \hat{\lambda} \alpha_{S}$, black;

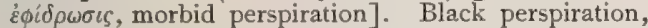
or a disease characterized by black perspiration. See, also, Chromidrosis.

Melangeur (mel-an-jur') [Fr.]. The graduated pipet of the hemocytometer.

Melanic (mel-an'-ik) [ $\mu \varepsilon \lambda a v i a$, blackness]. Characterized by, or pertaining to, a dark color, or to melanosis. M. Acid, $\mathrm{C}_{10} \mathrm{H}_{8} \mathrm{O}_{5}$, a black powder resulting from the oxidation of potassium salicylate. It is insoluble in water, soluble in alcohol, ether, and alkalies.

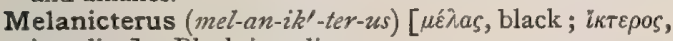
jaundice]. Black jaundice.

Melanidia (mel-an-id'-e-ah). See Miner's Phthisis.

Melanilin (mel-an'-il-in) [ $\mu$ é $\lambda a s$, black; anilin], $\mathrm{C}_{73} \mathrm{H}_{13} \mathrm{~N}_{3}$. A basic substance obtained from cyanogen chlorid and dry anilin.

Melanin (mel'-an-in) [ $\mu \varepsilon^{\prime} \lambda a \varsigma$, black]. I. A black pigmentary matter occurring naturally in the choroid coat of the eye, the skin, the hair, the muscles, and, pathologically, in the skin in Addison's disease and in melanotic tumors. Melanin usually contains sulphur, more rarely iron. From its origin, being a product of cell-activity, it is classed as a metabolic pigment. It is generally soluble in hot alkalies and in hot acids, and its solutions are bleached by chlorin. 2. Specifically applied by Danilewsky to the pigment seen in the hematozoa of men and animals, and formed by these intracellular parasites from the hemoglobin of the red blood-corpuscles which they inhabit.

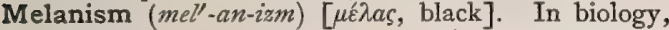
the abnormal development of dark pigments in an organism.

Melano-cancroid (mel-an-o-kang'-kroid). Synonym of Melano-carcinoma.

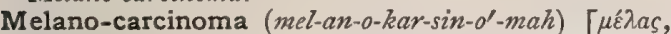

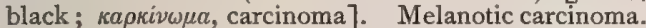

Melano-chlorosis (mel-an-o-klo-ro'-sis) [ $\mu \varepsilon^{\prime} \lambda a s$, black; $\chi \lambda$ wós, green]. Chlorosis in which the skin has a blackish-green hue. Also the same as Melanicterus.

Melanochroic, Melanochroous (mel-an-o-kro'-ik, melan-ok'-ro-us) [ $\mu \varepsilon^{\prime} \lambda a s$, black; $\chi \rho o ́ a$, color]. Having a dark color or complexion.

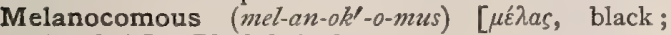
$\kappa o ́ \mu \eta$, hair]. Black-haired.

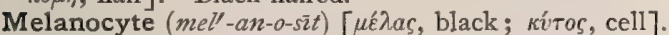
Any wandering lymph-cell that has become discolored by the absorption of dark pigment-granules.

Melanoderma (mel-an-o-der'-mah), Melanodermia

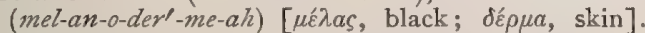
Black pigmentation or discoloration of the skin. M., Parasitic. See Vagabond's Disease.

Melanogen (mel-an'-o-jen) [melanin, from $\mu \hat{\varepsilon} \lambda a s$,

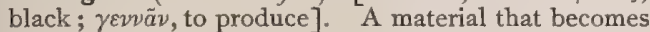
converted into melanin on the reception of the appropriate stimulus.

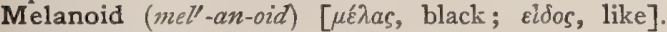
Dark-colored; resembling melanosis.

Melano-leukemia (mel-an-o-lu-ke'-me-ah) [ $\mu \varepsilon^{\prime} \lambda a \varsigma$, black; $\lambda \varepsilon v \kappa o ́ s$, white; aîu, blood]. Melanemia in association with leukemia.

Melanoma (mel-an-o'-mah) [ $\mu \varepsilon \dot{\lambda} a ́ \nu \omega \mu \alpha$, from $\mu \dot{\varepsilon} \lambda a s$, black; ä $\mu \alpha$, tumor: $p l$., Melanomata $]$. I. A disease marked by the development and growth of black or dark-colored tubercles within the tissues of the viscera. 2. Any tumor containing or characterized by dark pigment.

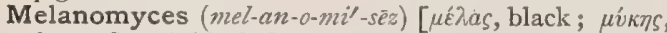
fungus]. A black fungous growth.

Melanopathy (mel-an-op'-ath-e), Melanopathia (mel$\left.a n-o-p a t h^{\prime}-e-a h\right) \quad[\mu \varepsilon \hat{\varepsilon} \lambda a \varsigma$, black; $\pi a ́ \theta o s$, illness]. A disease attended with increase or deepening of the normal pigmentation of a part.

Melanophthalmous (mel-an-off-thal'-mus) [ $\mu \varepsilon \dot{\lambda} \alpha s$, black; $\dot{\phi} \phi \theta a \lambda \mu o ́ s$, eye]. Black-eyed; having a melanoma of the eye

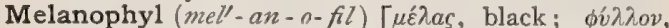
leaf ]. A black substance extracted from green leaves by means of hydrochloric acid and ether.

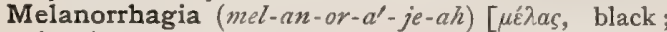
on rvíval, to burst forth]. The copious discharge of blackened feces.

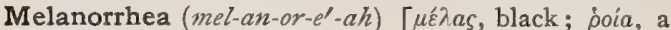
flow]. Synonym of Melena. Also, a genus of the Anacardiacer. M. usitata, M. usitatissima, the black-varnish tree.

Melano-sarcoma (mel-an-o-sar-ko'-mah) $\left[\mu\right.$ ć$^{\prime} \alpha \varsigma$, black ; $\sigma \alpha ́ \rho \xi$, flesh; ö $\mu a$, tumor]. Melanotic sarcoma.

Melano-scirrhus (mel-an-o-skir'-us) [ $\mu \varepsilon \hat{\lambda} \lambda a s$, black ;

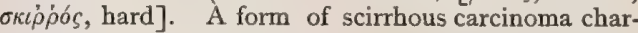
acterized by pigmentation.

Melanose (mel'-an-ōs) [ $\mu \varepsilon \lambda a ́ v \omega \sigma \iota s$, a becoming black]. A disease of grape-vines caused by the fungus Septoria pelina.

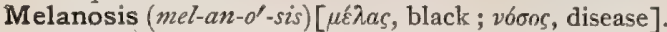
A general tendency to the formation in the blood, and the deposition in the skin, or in organs, of a dark pig. ment. M. lenticularis progressiva. See Xeroderma pigmentosum.

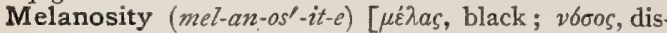
ease]. The condition of being melanous; darkness, as of hair, eyes, or skin.

Melanospongus (mel-an-o-spon'-gus). Synonym of Melanomyces.

Melanothanatos (mel-an-o-than'-at-os). See Plague.

Melanotic (mel-an-ot'-ik) [ $\mu \varepsilon \hat{\lambda} \lambda a s$, black; vóros, disease]. Pertaining to melanosis.

Melanotrichous (mel-an-ot'-rik-us) [ $\mu \varepsilon \dot{\lambda} a s$, black; $\theta \rho i \xi$, hair]. Black-haired.

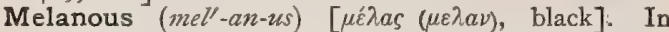
ethnology, applied to races with black hair and darkbrown or blackish skins. One of the two divisions of the Melanochroi according to Huxley's classification. Cf. Xanthomelanous.

Melanuresis (mel-an-u-re'-sis), Melanuria (mel-an-u' re-ah) $\left[\mu \varepsilon^{\prime} \lambda a \varsigma\right.$, black; ovjoov, urine]. The presence of black pigmentary substance in the urine, or the disorder associated with it. Melanotic tumors are in some way related to this condition.

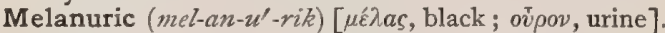
Pertaining to, or characterized by, melanuria.

Melanurin (mel-an-u'-rin) [ $\mu \varepsilon^{\prime} \lambda a s$, black; ov́pov, urine]. A dark pigment found in the urine in melanuria; it is sometimes associated with the presence in the body of melanotic tumors.

Melas (mel'-as) [ $\mu$ ć $\lambda a s$, black]. Black.

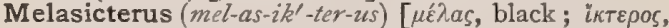
jaundice]. Same as Melanicterus.

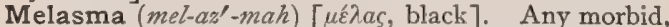
dark discoloration of the skin. M., Suprarenal. Same as Addison's Disease. M. Addisonii, Addi 
son's disease. M. palpebrarum, the pigmentation about the eyelids observed in pregnancy and in certain nervous disorders. M. uterinum, melasma due to uterine disease.

Melasmic (mel-az'-mik) [ $\mu \varepsilon \lambda a s$, black]. Pertaining to or characterized by melasma.

Melastearrhea (mel-as-te-ar-e'-ah). Synonym of Chromidrosis

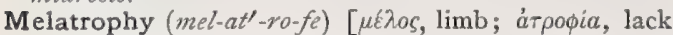
of nutrition]. Wasting of the limbs.

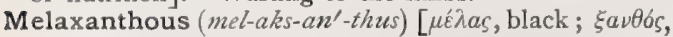
yellow]. Black and yellow.

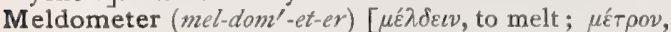
measure]. An instrument for ascertaining the meltingpoints of metals, minerals, and other substances.

Meleagra (mel-e- $\alpha^{\prime}$-grah). - Synonym of Melagra.

Melebiose (mel-ebl-e-os) [ $\mu \varepsilon \lambda_{\ell}$, honey], $\mathrm{C}_{12} \mathrm{H}_{22} \mathrm{O}_{11}$. One of the sugars produced in the hydrolysis of melitriose. See Carbohydrates, Table of.

Meleguetta Pepper. See Grains of Paradise.

Melem (mel'-em) [ $\mu \varepsilon^{\prime} \lambda a \varsigma$, black $], \mathrm{C}_{6} \mathrm{H}_{6} \mathrm{~N}_{10}$. A complex cyanid.

Melena (mel-e'-nah) [ $\mu \varepsilon^{\prime} \lambda \alpha s$, black]. The evacuation of tar-like stools due to the presence therein of altered blood. It is met with in a number of diseases, and often follows a profuse attack of hemoptysis. Also, a name given to the so-called black vomit. M. cholæa, same as Melanicterus. M. neonatorum, an extravasation of blood into the stomach and intestines of the newborn infant, occurring most often in the first few hours of life. It is due to duodenal ulcer, hemophilia, or some congenital defect increasing the intra-abdominal blood-pressure

Melenagogue (mel-en'-ag-og) [melana; $\mu \varepsilon \hat{\imath} \alpha s$, black;

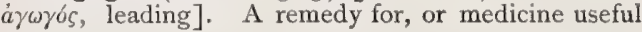
in, melena.

Melene $\left(m e l^{\prime}-\dot{e} n\right)$ [mel, honey], $\mathrm{C}_{30} \mathrm{H}_{60}$. An alkylen or olefin obtained from ordinary wax; it melts at $62^{\circ} \mathrm{C}$.

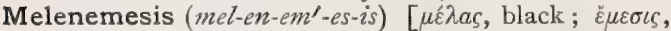
vomiting]. Black vomit.

Melenic (mel-en'-ik) [ $\mu \dot{c} \lambda a s$, black]. Pertaining to melena.

Meleno-diarrhea (mel-en-o-di-ar-e'-ah). Synonym of Melena.

Melenorrhagia (mel-en-or-a'-je-ah). Synonym of Melena.

Melezibiose (mel-ez-ib'-e-ös), Melezitose (mel-ez'-it-ōs) [Fr., melêze, larch], $\mathrm{C}_{18} \mathrm{H}_{32} \mathrm{O}_{16}+2 \mathrm{H}_{2} \mathrm{O}$. A carbohydrate that occurs in the juice of Pinus lavix, and closely resembling cane-sugar. It is distinguished from the latter by its greater rotatory power, and in not being so sweet to the taste. It melts at $148^{\circ} \mathrm{F}$. See Carbohydrates, Table of.

Melia (me'-le-ah). See Azedirach.

Meliasmus (me-le-az'-mus). Synonym of Glanders.

Melibiose (mel-ib'-e-ōs). Synonym of Melebiose.

Melicera, Meliceris (mel-is-e'-rah, mel-is-e - ris)

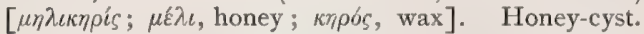
A term loosely applied to any cystic tumor whose contents have a honey-like appearance; a cyst that has undergone colloid degeneration, the contents being changed into a more or less hyaline, thick, honeylike liquid. See Molluscum contagiosum.

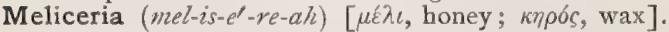
The thick gelatinous substance found in certain tumors.

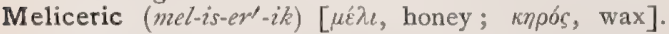
Pertaining to meliceris.

Meliceroma (mel-is-er-o'-mah). Synonym of Meliceris. Melicerous (mel-is'-er-us). Synonym of Meliceric.

Melicerum (mel-is-e'-rum). See Meliceris.

Melichrous (mel'-ik-rus) [ $\mu \hat{\varepsilon} \lambda_{l}$, honey; $\chi \rho \dot{\omega}^{\prime}$, , color]. Honey-colored.
Melilot (mel'-il-ot) [ $\mu \varepsilon^{\prime} \iota$, honey; $\lambda \omega$ tós, Iotus]. Any plant of the genus Melilotus.

Melilotic Acid (mel-il-ot'-ik). See Acid.

Melilotus (mel-il-o'-tus) [ $\mu \dot{\varepsilon} \lambda_{\prime}$, honey; $\lambda \omega \tau \sigma s$, lotus]. A genus of leguminous herbs. M. officinalis, yellow melilot and other species ( $M$. comlea, and other varieties) are official in various European countries. Melilotus is diuretic, anodyne, and expectorant. It contains Coumarin, q.v.; the powdered leaves are used in Switzerland for flavoring Chapziger cheese.

Melinephidrosis (mel-in-ef-id-ro'-sis) [uñ $\iota^{\prime} v o s$, quincecolored; $\dot{\phi} \phi i \delta \rho \omega \sigma \iota$, perspiration]. The excretion of a yellow sweat. It occurs in several infectious fevers in which the blood is profoundly altered, in jaundice, and after the excessive ingestion of rhubarb.

Meliphagous (mel-if'-ag-us) [ $\mu \hat{\varepsilon}^{\prime} \lambda$, honey; $\phi a \gamma \varepsilon \dot{\imath} \nu$, to eat]. In biology, feeding upon honey; mellivorous.

Melissa (mel-is'-ah) [ $\mu \hat{\varepsilon} \lambda \iota \sigma \sigma a$, a bee]. A genus of labiate plants. The leaves and tops of $M$. officinalis, lemon-balm, containing tannin, a bitter extractive, and an essential oil. It is a mild diaphoretic, but is employed chiefly as a flavor.

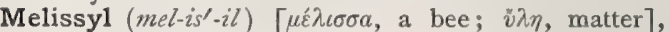
$\mathrm{C}_{30} \mathrm{H}_{6}$. A hypothetic radicle occurring in many waxy compounds. It is also called myricyl

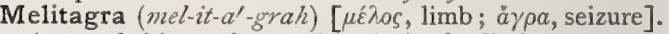
Any arthritic or rheumatic pain in the limbs.

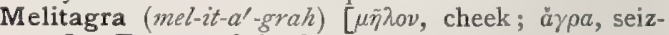
ure]. Eczema of the face.

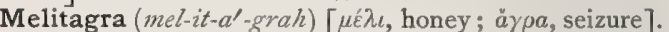
The name given to the honey-like crusts sometimes seen in Impetigo forurata.

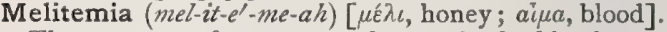
The presence of an excess of sugar in the blood.

Melithemia (mel-ith-e'-me-ah). See Melitemia.

Melithyperuria (mel-ith-ip-er-u'-re-ah) [ $\mu \varepsilon^{\prime} \lambda \iota$, honey; iлćp, over; oư $\rho \nu$, urine]. Diabetes mellitus.

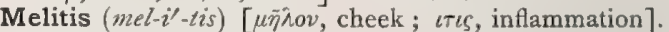
Inflammation of a cheek.

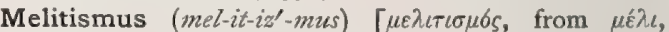
honey]. The use of honey in medicine; an electuary of honey for cough in children.

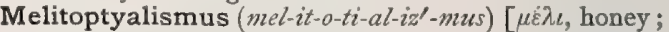
$\pi \tau \hat{\tau} \alpha \lambda_{o \nu}$, saliva]. The production of melitoptyalon.

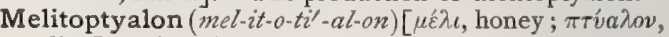
saliva]. A saliva containing glucose said to be secreted by persons suffering from hectic fever.

Melitose (mel'-it-oss) [ $\mu \varepsilon^{\prime} \lambda \iota$, honey], $\mathrm{C}_{18} \mathrm{H}_{32} \mathrm{O}_{16}+5 \mathrm{H}_{2}$ O. Raffinose, melitriose. A carbohydrate occurring in large quantity in Australian manna, flour of cottonseeds, in small amounts in sugar-beets, and in the molasses in sugar-manufacture. It crystallizes in needles, which are more soluble in water and less in alcohol than cane-sugar. It is more strongly dextrorotatory than cane-sugar, and does not reduce Fehling's solution, but is easily fermented by yeast. See Carbohydrates, Table of.

Melitriose (mel-it'-re-oss). See Melitose.

Melituria (mel-it-u'-re-ah) [ $\mu \varepsilon \dot{\lambda} \iota$, honey; oúpov, urine]. Diabetes mellitus. M. inosita, the presence of inosite in the urine.

Melleous (mel'-e-us) [melleus, from mel, honey]. Honey-likè.

Mellifavium (mel-if- $\left.\alpha^{\prime}-v e-u m\right)$. Synonym of Meliceris. Melliferous (mel-if'-er-us) [mel, honey; ferre, to bear]. Producing or carrying honey.

Mellific (mel-if'-ik) [mel, honey; facere, to make] Producing honey.

Melligerous (mel-ij'-er-us). See Mellific.

Mellimid (mel'-im-id). See Paramid.

Mellin's Food. A variety of Liebig's food for infants. Its composition is: Water 5.0, fat 0.15 , grape-sugar 
44.69, cane-sugar 3.51, starch none, soluble carbohydrates 85.44 , albuminoids 5.95 , ash I. 89 .

Mellita (mel-i $\left.i^{\prime}-t a h\right)[\mu \varepsilon \dot{\lambda} \ell$, honey]. Pharmaceutic preparations known as honeys. They consist of honey, either natural, clarified, or flavored. There are three officinal mellita.

Mellitæmia (mel-it-e'-me-ah). See Melitemia.

Mellite (mel'-ît). See Mellitic Acid.

Mellithemia (mel-ith-e'-me-ah), See Melitemia.

Mellitic Acid (mel-it'-ik). See Acid.

Mellituria (mel-it-u'-re-ah). See Melituria.

Mellivorous (mel-iv'-o-rus) [mel, honey; vorare, to devour]. In biology, feeding upon honey; meliphagous.

Mellogen (mell-o-jen) [ $\mu \varepsilon \lambda_{\iota}$, honey ; yevväv, to produce], $\mathrm{C}_{11} \mathrm{H}_{2} \mathrm{O}_{4}$. An amorphous, shiny substance obtained in the electrolysis of distilled water. It is infusible, soluble in hot water and in alkalies, insoluble in most mineral acids and other solvents; it possesses coloring properties.

Mellon (mel'-on), $\mathrm{C}_{3} \mathrm{H}_{3} \mathrm{~N}_{9}$. A complex cyanid produced on igniting ammonium sulphocyanid, melam, and other substances. It is a yellow insoluble powder.

Mellonic Acid (mel-on'-ik). Synonym of Mellon, and also of Hydromellonic Acid.

Mellophanic Acid (mel-o-fan'-ik). See Acid.

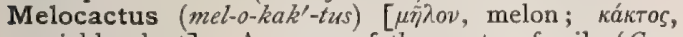
prickly plant]. A genus of the cactus family (Cactacea). M. communis, melon thistle, Turk's cap, Englishman's or Pope's head. A West Indian species possessing edible fruits. It is expectorant and antisyphilitic.

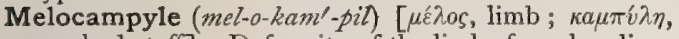
crooked staff]. Deformity of the limbs from bending.

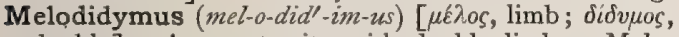
double]. A monstrosity with double limbs. Melodidymi are twins united by the limbs.

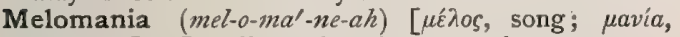
madness]. Inordinate devotion to music.

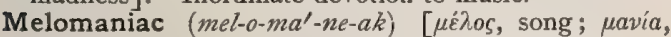
madness]. One who is affected with melomania.

Melomelia (mel-o-me'-le-ah). See Melomelus.

Melomelus (mel-om'-el-us) [ $\left.\mu \varepsilon^{\prime} \lambda o s, l i m b\right] . \quad M e l o m e l i a$; a form of double monster in which rudimentary limbs are attached at the point of junction of the normal limbs.

Meloncus (mel-ong'-kus) [ $\mu \tilde{\eta} \lambda o \nu$, cheek ; ö $\gamma \kappa o s$, tumor]. A tumor of the cheek.

Melon-seed Bodies. Gelatinous bodies, somewhat resembling melon-seeds, found in joints and tendonsheaths. The method of their origin is in dispute. 'They are also known as rice-like bodies.

Meloplastic (mel-o-plas'-tiḱ) [ $\mu \tilde{\eta} \hat{\imath} o \nu$, cheek; $\pi \hat{\lambda} a ́ \sigma \sigma \varepsilon \iota \nu$, to form]. Pertaining to meloplasty.

Meloplasty (mell'-o-plas-te) [ $\mu \tilde{\eta} \lambda o v$, cheek; $\pi \lambda a ́ \sigma \sigma \varepsilon \imath \nu$, to form]. The operation of engrafting or forming a new growth of tissue upon the cheek, in repair of an injury.

Melos (mé-los) [ $\mu \dot{\varepsilon} \lambda \circ s$, a limb]. Limb.

Melosalgia (mel-os-all-je-ah). See Melalgia.

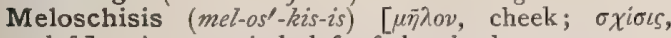
cleft]. A congenital cleft of the cheek.

Melosis (me-lo'-sis) [ $\mu \hat{\eta} \lambda \eta$, probe]. The process of probing.

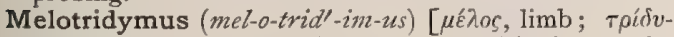
$\mu \circ s$, threefold]. A fetal monstrosity with three pairs of limbs.

Melotris (mel-o'-tris) $[\mu \hbar \lambda \eta$, probe; ov $s$, ear]. An aural probe.

Melt [ME., melten, to melt]. I. To liquefy by means of heat. 2. The spleen of animals. More properly milt, $q . v$.
Melting (melt'-ing) [ME., melten, to melt]. Liquefy. ing by means of heat. M.-point, the degree of temperature at which solids pass into the liquid state.

Melustum (mel-us'-tum) [mel, honey; ustum, from urere, to burn]. Molasses.

Memba Yaw (mem'-bah yaw) [for remember-yaw]. A yaw or frambesial excrescence occurring long after the primary attack of the yaws is over. See Yazes.

Member $\left(m e m^{\prime}-b e r\right)$ [membrum, a limb]. A part of the body, especially a projecting part, having a distinct function, as the legs, the arms, the tail, the penis. M., Abdominal, one of the hind or lower limbs. M., Pelvic, M., Posterior, one of the hind or lower limbs. M., Thoracic, one of the fore or upper limbs. M., Virile, the penis.

Membra (mem'-brah) [L.]. Plural of Membrum.

Membral (mem'-bral) [membrum, limb]. Pertaining to a limb or member.

Membrana (mem-bra'-nah) [L.:pl., Membrana]. A membrane. M. adiposa, the subcutaneous fatty layer. M. adventitia, the adventitia ; also, the decidua reflexa. M. agnina, the amnion. M. anterioris elastica. See Lamina, Elastic. M. basilaris. See Lamina basilaris. M. caduca, the decidua. M. capsularis, a capsular ligament. M. carnosa: I. The platysma myoides. 2. The dartos. M. cellulosa; I. The decidua. 2. Adipose tissue. M. ceratodes, the cornea. M. coronæ ciliaris, zonule of Zinn, M. coronoides, the iris. M. corticalis, the vitelline membrane. M. crassa, the decidua reflexa. M. cribriformis, the decidua. M. cribrosa: $\mathbf{I}$. The decidua vera. 2. The septum crurale. M. decidua. See Decidua. M. dentata, the ligamentum denticulatum. See Ligament. M. dermatodes, the dura. M. externa, the vitelline membrane. M. filamentosa, the decidua reflexa. M. flaccida. See Shrapnell's Membrane. M. foraminalis, the iris. M. germinativa, the blastoderm. M. granulosa, the layer of small polyhedral cells within the theca folliculi of the Graatian follicle. M. intermedia, the mesoblast; also, the layer of gelatinous tissue between the amnion and chorion. $\mathbf{M}$. intestinalis, the allantois, $q . v$. $\mathbf{M}$. Jacobi. See Membrane, Jacob's. M. laminosa, the membrane covering the fetal surface of the placenta after removal of the amnion. It is the atrophied allantois. M. limitans, the limiting layer of the retina. There are two of these, the interna and externa, which are derived from either extremity of the fibers of Müller. M. limitans interna, applied by His to the layer formed in the developing spinal cord by the ental or central ends of the spongioblasts which later become the endyma. M. localis, the pia. M. media, the endochorion, $q . v$. M. media cerebri, the arachnoid. M. medullaris, the endyma. $\mathbf{M}$. mollis, the pia, M. neurium, the epineurium, $q$. v. M. nictans, M. nictitans. See Membrane, Nictitating. M. pellucida, the amnion, q. v. M. pigmenta, the uvea iridis. M. prolifera, the blastodermic membrane. M. proligera. See Discus proligerus. M. propria, the delicate membrane upon which the epithelium of membranes, especially mucous membranes, rests; the basement membrane. M. propria cerebri, the pia. M. pupillaris. See Membrane, Pupillary. M. putaminis, the secondary envelop of a bird's egg; a fibrous membrane secreted in successive laminæ, covering the entire egg and albumen. M. pyogena. See Membrane, Pyogenic. M. quadrangularis, a fibrous membrane extending from the epiglottis to the arytenoid cartilages, as far as the free edge of the ary-epi- 
glottic folds. M. ruyschiana, the middle or capillary layer of the choroid. M. semilunaris conjunctivæ. See Menbrane, Nictitating. M. serotina, that part of the decidua which enters into the formation of the placenta. M. sinuosa, M. spongiosa, the decidua. M. tectoria, a delicate membrane of the internal ear, extending from the upper lip of the limbus above the sulcus spiralis and the organ of Corti as far as the last row of the outer hair-cells. It is also known as Corti's membrane. M. tensa, the tympanic membrane proper, exclusive of Shrapnell's membrane. M. tenuis, the arachnoid. M.tympani. See Menbrane, Tympanic. M. tympani, Artificial. See Membrane, Tympanic. M. tympani secundaria. See Membrane, Secondary Tympanic. M. urinaria, the allantois. M. vasculosa cerebri, the pia. M. vibrans. Synonym of $M$. tensa. M. virginalis, the hymen. M. vocalis, the portion of the laryngeal mucosa investing the vocal bands.

Membranaceous (mem-bran-a'-ce-us) [membranaceus, from membrum, member]. Pertaining to, consisting of, or of the nature of, a membrane.

Membrane (mem'-brān) [membrana, from membrum, member]. In anatomy, a term applied to almost any thin, enveloping or lining substance. In the plural it usually signifies the fetal membranes. M., Adventitious. See Adventitia. M., Albugineous. See Albuginea. M., Amphiblestroid, the retina. M., Animal, a membrane made from animal tissues, used in dialyzing; also, in the plural, the fetal membranes. M., Arachnoid. See Arachnoid. M. of Arnold, the pigmented layer of the iris. M. of Ascherson. See M., Haptogenous. M., Bacillar. See M., Jacob's. M., Basement or Basal, in histology, a delicate membrane, made up of flattened cells, and underlying the epithelium of the mucous surfaces. M.-bone, any bone that originates, not in cartilage, but in membrane, such as some of the cranial and facial bones. M., Bowman's. See Bormman. M. of Bruch, a thin, transparent, homogeneous membrane, the external or vitreous lamina of the choroid of the eye. M., Caducous, the decidua. M., Cell, the membrane surrounding a cell; the cell-wall. M. of Corti. See Membrana tectoria. M., Costo-coracoid, a dense layer of fascia extending between the subclavius muscle and the pectoralis minor, and forming the anterior portion of the sheath of the axillary vessels. M., Crico-thyroid, the triangular membrane connecting the thyroid and cricoid cartilages of the larynx. M., Croupous. See $M$., Diphtheric. M., Debove's, a deep, germinal layer of flattened cells in the mucosa of the trachea and extrapulmonary bronchi. M. of Descemet. See Descemet's Membrane. M., Diphtheric, a fibrinous layer formed on the surface of mucous membranes and extending downward for a variable depth. It is due to a process of coagulation-necrosis. The most common cause of its formation is the bacillus of diphtheria; irritant poisons also may produce it. M., Drum. Synonym of the tympanic membrane. M., Elastic, a membrane largely composed of elastic fibrous tissue. M., Elytroid, the fibers of the cremaster muscle covering the testicle. M., False. See $M$., Diphtheric. M., Fenestrated. See Fenestrated Membrane of Henle. M., Fetal, a name given to the chorion, amnion, and allantois. M., Germinal, the blastoderm. M., Glassy, the hyaloid membrane. M., Granular. See Membrana granulosa. M., Haptogenous, a delicate albuminous pellicle supposed to envelop the fat-globules of milk and of other fluids containing fat and albumin. M., Homogeneous, a delicate layer of connective tissue cover- ing the placental villi. M., Huxley's, a sheath peculiar to hair and surrounding the proximal part of the shaft. M., Hyaloid, a delicate areolar membrane investing the vitreous humor of the eye. M., Inorganic, a membrane used in dialyzing fluids; it is composed of silicic acid. M., Internal, the endyma, $q . v$. M., Interosseous, a thin aponeurosis of parallel fibers extending between contiguous borders of the tibia and fibula, and the ulna and radius. M., Jacob's, the layer of rods and cones of the retina. M., Krause's, a thin, transverse, dark disc bisecting the light substance of the striped muscle-fibers; it divides the fibers into muscular compartments. M., Meconic, a layer within the rectum of the fetus, supposed to invest the meconium. M., Mucous, the continuation of the skin lining those internal cavities and organs exposed to or communicating with the air. It is kept moist by the mucus secreted by the gobletcells and mucous glands. M. of Nasmyth, a delicate but firm membrane covering the ectal surface of the enamel for a short time after birth. M., Nictitating, the plica or third eyelid, a mucous fold at the nasla canthus of the eyes of birds and certain quadrupeds. M., Nuclear, the membrane surrounding the nucleus of a cell. M., Obturator, the fibrous membrane closing the obturator foramen. M., Olfactory. See $M$., Schneiderian. M., Ovular. See M., Vitelline. M., Perforated (of Henle), the ental elastic layer of an artery. M., Perifibril, a special membrane surrounding the skeletal threads of some sponges (Chalinula); it is composed of epithelial cells, either transparent or deeply-colored with granules (Hyatt). M., Periodontal, a fibrous layer covering the cement of teeth. M., Pharyngeal, the oral plate separating the primitive oral and pharyngeal cavities in the embryo. It is formed of an anterior ectodermic and posterior entodermic layer. M., Pituitary. Same as M., Schneiderian. M., Primary, the basement membrane. M., Preformation, a doubtful membrane supposed to cover the dentine papilla. M., Proligerous. See Discus proligerus. M., Pseudo. See M., Diphtheric. M., Pupillary, a delicate, transparent membrane closing the pupil in the fetus. It disappears between the seventh and eighth months. M., Pyogenic, the fibrous membrane forming the lining of abscess-cavities; instead of being a pus-producing membrane, it is really a protective layer, limiting the spread of the abscess, although it may form pus under certain circumstances. M., Pyophylactic, a term suggested by Roswell Park for the so-called "pyogenic membrane." M., Reichert's. See M., Bowman's. M. of Reissner, a delicate membrane stretching across the outer wall of the cochlea. M., Reticular, the membrane covering the space of the outer haircells of the cochlea. M. of Ruysch. See Membrana ruyschiana. M., Schneiderian, the mucosa lining the nasal fossæe. M. of Schwann. See Neurilemma. M., Serous, a delicate membrane covered with flat endothelial cells lining closed cavities of the body, e.g., the peritoneum, the pleura. M., Shell. See Membrana putaminis. M., Shrapnell's, a small portion of the drum-membrane filling the notch of Rivini. It differs from the remainder of the drum-membrane in that it contains none of the fibrous tissue proper to the drum. It is also called Membrana flaccida. M., Synovial, a membrane covering the articular extremities of bones and the inner surface of ligaments entering into the formation of a joint. M., Tectorial. See Membrana tectoria. M., Tenon's. See Tenon's Capsule. M., Thyro-hyoid, the broad membrane joining the thyroid cartilage and the hyoid bone. M., Tubular, 
the neurilemma, q. v. M., Tympanic, the membrane separating the external from the middle ear. It consists of three layers : an ectal or skin layer, a fibrous layer, and an ental layer like that lining the middle ear. M., Undulator, a delicate membrane uniting the spinal filament to the body and tail of the spermatozoön. M., Utero-epichorial, the decidua vera. M., Vascular (of the eve), the choroid, q. $v_{0}$ M., Vestibular. Same as $M$. of Reissner. M., Virginal, the hymen, $q . v$. M., Vitellary, M., Vitelline, the true cell-membrane of the ovum, lying within the zona pellucida. M., Vitreous, the membrane of Descemet; also the basement membrane of a hair-follicle. M., Wachendorf's, the papillary membrane. M., Yolk. Same as M., Vitelline. M., Zinn's. See Zonule of Zinn.

Membraneous (mem-bra'-ne-us). See Membranous.

Membraniform (mem-bran'-if-orm). See Membranous.

Membranine (mem'-bran-in). See Membranous.

Membrano-carneous (mem-bran'-o-kar'-ne-us) [membrana, membrane; caro, flesh]. Of a membranous and fleshy structure.

Membranocranium (mem-bran-o-kra'-ne-um) [membrana, membrane; кpaviov, skull]. The membranous skull of the fetus, prior to ossification.

Membranogenic (mem-bran-o-jen'-ik) [ $\mu \varepsilon \mu \beta \rho a ́ v a$, parchment membrane; $\gamma^{\prime} \varepsilon \nu \bar{\zeta} s$, producing]. In biology, having a tendency to form a membrane or a membranous growth.

Membranoid (mem-bran-oid") [membrana, membrane; Eidos, like]. Resembling membrane.

Membranology (mem-bran-ol'-o-je) [membrana, membrane; $\lambda 6 \gamma 0 s$, science]. The anatomy, physiology, and pathology of the membranes of the body.

Membranosus (mem-bran-o'-sus) [membrana, membrane]. Membranous. M., Semi-, one of the hamstring muscles. See Muscles, Table of.

Membranous (mem'-bran-us) [membranosus, membranous]. Having the nature of, or characterized by, a membrane. In biology, applied to an organ or part that is flattened, thin and flexible. M. Labyrinth. See Labyrinth. M. Urethra, the part of the urethra between the two layers of the triangular ligament.

Membranula, Membranule (mem-bran'-u-lah, membran'-ül) [dim. of membrana, membrane]. A small membrane. In biology, specifically applied to a portion of the wing of certain insects.

Membranulet (mem-bran'-u-let). Same as Membranula.

Membrosus (mem-bro'-sus) [nembrum, limb]. Having a large penis.

Membrum (mem'-brum) [L. : pl., Membra]. Same as Menber. M. muliebre, the clitoris. M. seminale, M. virile, the penis.

Memory (mem'-o-re) [menoria, a recalling]. That faculty of the mind that enables one to recall ideas, events, and the images of objects that have produced sensation. M., Loss of. See Amnesia.

Menagogue $\left(m e n^{\prime}-a g-o g\right)$. Synonym of Emmenagogue.

Menatechenzie (men-at-ek-en'-ze). See Palmus

Mendel's Convolution. See Convolutions, Table of.

Mendelejeff's Classification. See Element.

Mendosus (men-do'-sus) [mendax, false]. False ; applied to certain incomplete parts, as the floating ribs.

Menelcosis (men-el-ko'sis) [ $\mu \tilde{\eta} \nu \varepsilon s$, menses; $\varepsilon \lambda \kappa \omega r \iota s$, ulceration]. Ulceration of the leg, with vicarious menstruation from the sore.

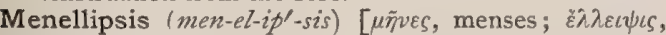
a falling off ]. Menopause.

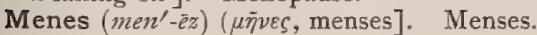

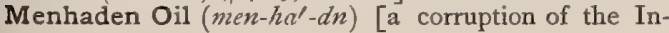

dian munnawhatteang]. An oil obtained from the Alosa menhaden, a kind of herring. It is used in soap-making and in tanning, and, when pure, as a substitute for cod-liver oil.

Menhidrosis, Menidrosis (men-hid-ro'-sis, men-id-

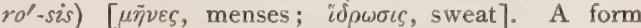
of vicarious menstruation said to consist in monthly excess of sweat, sometimes sanguineous, instead of the menstrual flow.

Ménière's Disease. A disease or injury probably of the semicircular canals, characterized by nausea, vomiting, vertigo, deafness, tinnitus aurium, and other phenomena. It is called also aural or auditory vertigo. See Diseases, Table of.

Meningarthrocace (men-in-gar-throk'-as-e) [ $\mu \bar{\eta} \nu \imath \gamma \xi$, membrane; å $\rho \rho \rho o v$, joint; кakós, evil]. Inflammation of joint-membranes.

Meningeal (men-in'-je-al) [ $\mu \tilde{\eta} \nu \iota \gamma \xi$, membrane]. Pertaining to any membrane of the brain or myel, especially the dura.

Meninges (men-in'-jez) [pl. of $\mu \tilde{\eta} \nu c \gamma \xi$, membrane]. A name applied to the membranes of the brain and myel, the dura, pia, and arachnoid. M., Lepto-, the pia and arachnoid.

Meningina (men-in- $\left.\ddot{i}^{\prime}-n a h\right)$ [ $\mu \tilde{\eta} \nu \iota \xi \xi$ membrane]. The pia and arachnoid considered as the proper meninges, and apart from the dura; the pia-arachnoid.

Meninginitis (men-in-jin-i'tis) $[\mu \tilde{\eta} \nu c \gamma \xi$, membrane; $\iota \tau \iota$, inflammation]. Inflammation of the meningina; leptomeningitis.

Meningitic (men-in-jit'-ik) [ $\mu \tilde{\eta} \nu \iota^{\xi} \xi$, membrane]. Pertaining to, or affected with, meningitis.

Meningitis (men-in-jit'-tis) [ $\mu \bar{\eta} v \iota \gamma \xi$, membrane; $\iota \tau \iota \zeta$, inflammation]. Inflammation of the membranes of the brain or cord; that of the dura is termed pachymeningitis, that of the pia-arachnoid, leptomeningitis. M., Acute. See Teptomeningitis. M., Ascending, a form that begins in the membranes of the lower cord and ascends. M., Basilar. See $M$. Tuberculous. M., Cerebral, M., Cerebro-spinal, a form affecting the membranes of the brain, and those of the cord and brain respectively. It is usually epidemic. M. of the Convexity, simple leptomeningitis. M., Epidemic. Synonym of Fever, Cerebro-spinal. M., Granular, the same as $M$., Tuberculous. M. Malignant. Synonym of Fever, Cerebro-spinal. M., Rhachidian. Synonym of $M$., Spinal. M. Scrofulous. See $M$., Tuberculous. M., Septic, that due to an infectious process. M. siderans, a fulminant, rapidly fatal form of cerebro-spinal fever. M., Simple, that not due to tuberculosis or sepsis. M., Spinal, meningitis of the membranes of the spinal cord. M., Syphilitic, meningitis due to syphilis. M., Traumatic, that following injury to the skull or spinal column. M., Tuberculous, inflammation of the pia of the brain, with effusion of lymph and pus, caused by the deposit of miliary tubercles upon its surface or into its substance. M., Typhoid. Synonym of Fever, Cerebro-spinal.

Meningitophobia (men-in-git-o-fo'-be-ah) [ $\mu \tilde{\eta} \nu \iota \xi$, membrane; $\iota \tau \iota \varsigma$, inflammation; $\phi \hat{b} \beta o \varsigma$, fear]. An exaggerated fear of meningitis when the disease is epidemic, sometimes leading to the development of the symptoms of the disease.

Meningocele (men-in'-go-sêl) $[\mu \tilde{\eta} \nu \iota \gamma \xi$, membrane ; $\kappa \dot{n} \lambda \eta$, tumor]. A tumor composed of cerebral or spinal membranes containing fluid, and perhaps nerve-tissue, protruding from an anomalous opening in the cranium or spinal column, usually covered by skin, but some. times exposed by cutaneous defect.

Meningo-cephalitis (men-in'-go-sef-al-i'tis). See Meningo-encephalitis. 
Meningo-cerebritis (men-in'-go-ser-e-bri'-tis). See Meningo-encephalitis.

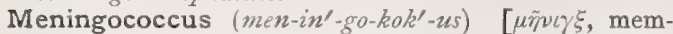
brane; ко́ккоร, coccus]. A name for the supposed coccus, or microbe, of cerebro-spinal fever. See $M i$ crococcus intercellularis meningitidis under Bacteria, Synonymatic Table of.

Meningo-encephalitis (men-in'-go-en-sef-al-i'tis)

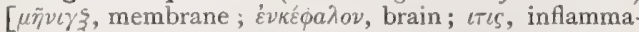
tion]. An inflammation of the brain and its mem. branes.

Meningo-ependymitis (men-in'-go-ep-en-dim-i'-tis) $[\mu \tilde{\eta} \nu \iota \gamma \xi$, membrane ; $\dot{\pi} \pi \dot{\varepsilon} v \delta v \mu \alpha$, ependyma; $\iota \tau \iota s$, inflammation]. Meningitis with inflammation of the ependyma, a condition seen in adult hydrocephalus.

Meningo-gastralgia (men-in'-go-gas-tral'-je-ah) $[\mu \bar{\eta} v-$

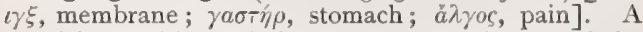
painful condition of the mucous membrane of the stomach.

Meningo-gastric (men-in'-go-gas'-trik) [ $\mu \tilde{\eta} v \imath \gamma \xi$, mem-

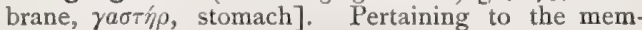
branes of the stomach.

Meningo-gastritic (men-in'-go-gas-trit'-ik) [ $[\mu \bar{\eta} \nu l \gamma \xi$,

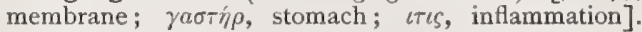
Pertaining to meningo-gastritis.

Meningo-gastritis (men-in'-go-gas-tri'-tis) [ $\mu \tilde{v} v \iota_{\gamma} \xi$,

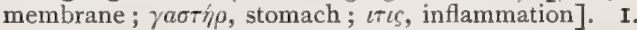
Inflammation of the mucosa of the stomach. 2 . Meningitis associated with gastritis.

Meningo-malacia (men-in'-go-mal-a'-se-ah) [ $\mu \bar{\eta} v \imath \gamma \xi$, membrane; $\mu$ arakia, softness]. A softening of the cerebral or spinal meninges, or other membranes.

Meningomyces (men-in-go-mi'-sẽz) [ $\mu \tilde{\eta} v i \gamma \xi$, membrane; $\mu$ кं $\eta S$, fungus). Fungosity of the meninges.

Meningo-myelitis (men-in'-go-mi-el-i'-tis) [ $\mu i^{\prime} \nu l \xi$, membrane; $\mu v \varepsilon \lambda \sigma \varsigma$, marrow ; $\iota \tau \iota s$, inflammation]. Inflammation of the myel and its meninges.

Meningo-myelocele (men-in'-go-mi'-el-o-sēl) [ $\mu \tilde{m} \nu l \gamma \xi$, membrane; $\mu v \varepsilon \lambda \hat{\delta} \varsigma$, marrow ; $\kappa \hat{n} \lambda \eta$, tumor]. A tumor containing a portion of the myel, with its enveloping meninges.

Meningophylax (men-in-gof'-il-aks) [ $\mu \tilde{\eta} \nu l \gamma \xi$, membrane; $\phi \dot{v} \lambda \alpha \xi$, guard]. An old form of instrument for protecting the brain from injury during operations after trephining.

Meningorrhachidian (men-in'-go-rak-id'-e-an) [ $\mu \tilde{\eta} v \imath \gamma \xi$, membrane; $\dot{\rho} \alpha \dot{\chi \zeta}$, spine]. Relating to the spinal meninges.

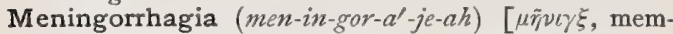

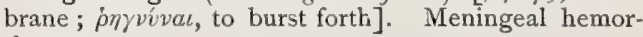
rhage.

Meningorrhea (men-in-gor-e'-ah) $[\mu \ddot{\nu} \nu l \gamma \xi$, membrane; poia, a flow]. Meningeal hemorrhage, or extravasation of blood.

Meningosis (men-in'-go-sis) [ $\mu \bar{\eta} \nu \imath \gamma \xi$, membrane]. The union of bones by a membranous attachment.

Meningo-spinal (men-in'-go-spi'-nal) [ $\mu \bar{\eta} \nu l \gamma \xi$, membrane; spinalis, spinal]. Meningeal and spinal; pertaining to the meninges of the spinal cord.

Meningo-symphysis (men-in'-go-sim'-fis-is) [ $\mu \tilde{\eta} v \imath \gamma \xi$,

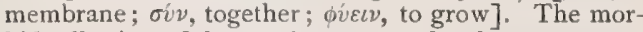
bid adhesion of the meninges to each other.

Meningo-symphytic (men-in'-go-sim-fit'-ik) [ $\mu \tilde{\eta} \nu \iota \gamma_{\xi}^{\prime}$,

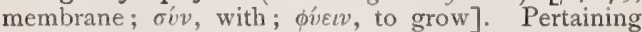
to or characterized by meningo-symphysis.

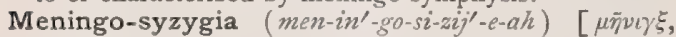

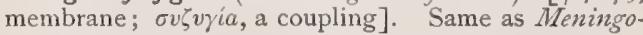
symphysis.

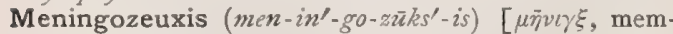
brane; $\zeta \bar{v} \xi_{\xi} \iota \zeta$, a yoking]. Same as Meningo-symphysis.

Meningozeuxitis (men-in'-go-züks-i'tis) $[\mu \bar{\eta} v \imath \gamma \xi$, mem- brane; $\xi \varepsilon \tilde{v} \chi \iota \varsigma$, yoke; $\iota \tau \iota s$, inflammation]. Meningosymphysis with inflammation.

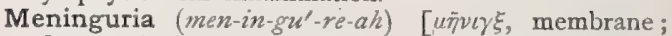
ovpov, urine ]. The passage or presence of membranous shreds in the urine.

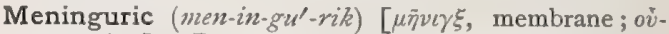
$\rho o v$, urine]. Pertaining to or characterized by meninguria.

Meninx (men'-ingks) [ $\mu \bar{\eta} \nu \iota \gamma \xi$, membrane]. Any one of the meninges, especially the dura.

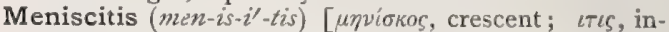
flammation]. An inflammation of the semilunar cartilages of the knee-joint.

Meniscoid (men-is'-koid) [ like]. Resembling a meniscus; crescent-shaped.

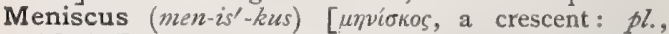
Menisci]. A concavo-convex lens. A concavo-convex articular cartilage, or the semilunar cartilage of the knee-joint. Also, the concavity or convexity produced on the surface of liquids in tubes and vessels by capillary attraction. M., Tactile, a form of nerve-ending with a concave surface turned ectad, each concavity containing a tactile cell.

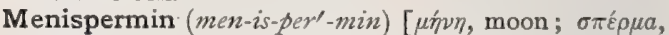
seed]. A precipitate from a tincture of the root of Menispermum canadense; alterative, tonic, laxative, diuretic, stimulant, and resolvent. Dose from I to 4 grains. Unof. 2. $\mathrm{C}_{18} \mathrm{H}_{24} \mathrm{~N}_{2} \mathrm{O}_{2}$. A non-poisonous and inert alkaloid from Anamirta cocculus and Menispermum canadense.

Menispermum (men-is-per'-mum) [ $\mu \dot{u}^{\prime} \nu \eta$, moon; $\sigma \pi \varepsilon \dot{\varepsilon} \mu a$, seed]. The roots of $M$. canadense, or Canadian moon-seed. It is reputed to have tonic properties, and is used for sarsaparilla. Dose gr. $\mathbf{v}-\mathbf{x x}$ in infusion; of a concentrated tinct., gtt. $v=x v$. M., Ext., Fld. Dose $z$ j.

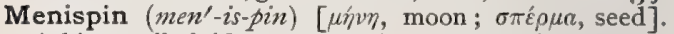
A bitter alkaloid contained in the root of Menispermum canadense. It is readily soluble in alcohol, less so in water, in chloroform, and in ether.

Menocelis (men-o-se'-lis) [ [ $\mu \dot{\eta} \nu$, mouth ; $\kappa \eta \lambda i s$, spot]. A dark spot upon the skin sometimes seen at or near the menstrual period.

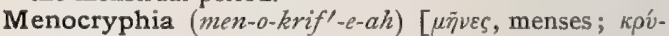
$\phi \iota s$, hidden]. Same as Ischomenia.

Menolipsis (men-o-liph-sis) [ $\mu \bar{\eta} v \varepsilon s$, menses; $\lambda \varepsilon \tilde{i} \psi \iota s$, an omission]. The retention or absence of the menses.

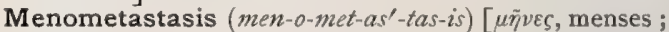
$\mu \varepsilon \tau a ́ \sigma \tau a \sigma \iota s$, metastasis]. Vicarious menstruation.

Menopad (men'-o-pad) [uñves, menses; ME., padde, a pad]. A pad for catching the menstrual blood.

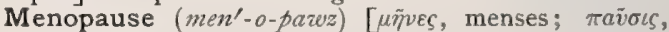
cessation]. The end of menstrual life, usually occurring at the age of from 45 to 50 . It is also called the climacteric, or the change of life.

Menophania (men-o-f $\left.a^{\prime}-n e-a h\right)$ [ $\mu \bar{\eta} \nu \varepsilon s$, menses ; фaivelv, to appear]. The first appearance of the menses.

Menoplania(men-o-pla'-ne-ah) [ $\mu \tilde{\eta} \nu \varepsilon s$, menses ; $\pi \lambda a ́ v \eta$, deviation]. A discharge of blood occurring at the menstrual period, but derived from some other part of the body than the uterus. Also, any deviation or aberration of the menstrual flow.

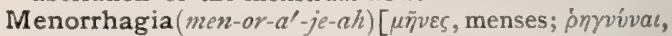
to burst forth]. An excessive menstrual flow.

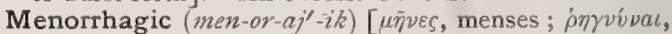
to burst forth]. Relating to, or characterized by, menorrhagia.

Menorrhalgia (men-or-al'-je-ah) [ $\mu \tilde{\eta} \nu \varepsilon s$, the menses; $\dot{\rho} \varepsilon \dot{\varepsilon} \iota \nu$, to flow; $\dot{\lambda} \lambda$ yos, pain]. Painful menstruation. See Dysmenoryhea and Menorrhspasm.

Menorrhea (men-or-e'-ah) [ $\mu \bar{\eta} \nu e s$, menses; poia, a flow]. The normal flow of the menses. Also, excessive menstruation. 
Menorrhspasm (men-or-spaz'-m) [ $\mu \tilde{\eta} \nu \varepsilon s$, menses;

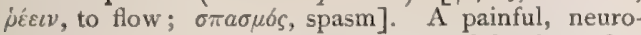
muscular spasm of the uterus, caused by imperfect development and innervation, or by inflammatory processes.

Menoschesis (men-os'-kes-is) [ $\mu \tilde{\nu} \nu \varepsilon s$, menses; $\sigma \chi \varepsilon \delta \iota \varsigma$, retention]. Retention of the menses.

Menoschetic (men-os-ket'-ik) [ $\mu \tilde{\eta} \nu \varepsilon \varsigma$, menses; $\sigma \chi \varepsilon \dot{\sigma} \iota \varsigma$, retention]. Pertaining to, or characterized by, menoschesis.

Menosepsis (men-o-seṕ-sis) [ $\mu \tilde{\eta} \nu \varepsilon \varsigma$, menses; $\sigma \tilde{\eta} \psi \iota$, putridity]. A putrid quality of the menses.

Menoseptic (men-o-seṕ-tic) [ $\mu \bar{\eta} \nu \varepsilon \varsigma$, menses ; $\sigma \tilde{\eta} \psi \iota$, putridity]. Pertaining to, or of the nature of, menosepsis.

Menostasia, Menostasis ( $m e n-o s-t a^{\prime}-z e-a h$, men-os'-tas-

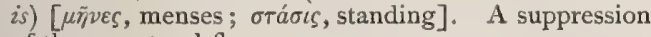
of the menstrual flow.

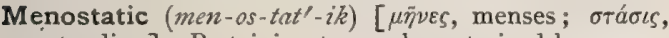
a standing]. Pertaining to, or characterized by, menostasis.

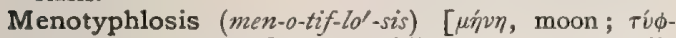
$\lambda \omega \sigma \iota s$, a blinding]. Moon-blindness; a periodic blindness or dimness of vision, formerly ascribed to the influence of the moon, and popularly believed to affect certain horses.

Menoxenia (men-oks-e'-ne-ah) [ $\mu \tilde{\eta} \nu \varepsilon \varsigma$, menses; $\xi \varepsilon ́ v o \zeta$, strange, foreign]. Irregularity of menstruation.

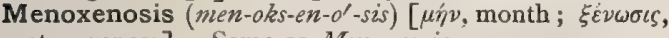
strangeness]. Same as Menoxemia.

Mens (menz) [L. : gen., mentis]. Mind. Compos mentis, of sound mind. Non compos mentis, of unsound mind.

Menses (men'-sēz) [mensis, a month]. The recurrent monthly discharge of blood from the genital canal of the female during sexual life. See Menstruation. M., Excessive, or Immoderate Flow of. See Menorrhagia. M., Obstructive, or Diminution of. See Amenorrhea. M., Suppression of. See Amenorrhea and Menostasis.

Menstrua (men'-stru-ah) [L.: pl., of Menstruus, monthly]. I. The menses. 2. Plural of Menstruum, q. v. M. alba. Synonym of Leukorrhea.

Menstrual (men'-stru-al) [menstrualis: menstruus, monthly]. Pertaining to menstruation. M. Blood, the blood discharged at the menstrual period. $\mathbf{M}$. Colic. See Colic. M. Insanity. See Insanity.

Menstruant (men'-stru-ant) [menstruus, monthly]. I. Subject to, or capable of, menstruating. 2. One who menstruates, or is capable of menstruating.

Menstruate (men'-stru-ät) [menstruare; from menstruus, monthly]. To discharge the menstrual flow.

Menstruation (men-stru-a'-shun) [menstruatio; from menstruus, monthly]. A periodic discharge of a sanguineous fluid from the uterus and Fallopian tubes, occurring during the period of a woman's sexual activity, from puberty to the menopause. The flow is alkaline and composed of blood, shreds of mucous membrane, and vaginal and uterine secretion; it is darker than ordinary blood, and should not clot; its odor is characteristic and disagreeable; the usual quantity is from four to six ounces. M., Vicarious, the discharge of blood in connection with, or at the time of, menstruation, but taking place from some other organ or part than the vagina. Atopomenorrhea.

Menstruous (men'-stru-us) [menstruus, monthly]. Having, or pertaining to, the monthly flow.

Menstruum (men'-stru-um) [menstruus, monthly]. A liquid used for effecting solution. A solvent.

Mensuration (men-su-ra'-shun) [mensurare, to measure]. The estimation of quantity or dimension. In anatomy, the estimation of the dimensions of any organ or part of the body. In physical diagnosis, the measurement of parts of the body.

Mentagra (men-ta'-grah). See Sycosis. M. parasitica. See Tinea sycosis.

Mentagrophyte (men-tag'-ro-fit $)$, Mentagrophyton (men-tag-roff'-it-on) [mentagra, sycosis; pvtóv, plant]. A cryptogamous plant thought to cause sycosis.

Mental (men'-tal) [mens, the mind]. Pertaining to the mind. Also, pertaining to the mentum or chin. M. Point. See Craniometric Points.

Mentality (men-tal'-it-e) [mens, mind]. Mental activity and power; intellect.

Mentation (men-ta'-shun). See Mentality and Ideation.

Mentha (men'-thah) [L., mint]. A genus of labiate plants, including the true or typical mints. M. arvensis, var. piperascens. The source of Menthol, $q . v$. M.-camphor. See Menthol. M. piperita, peppermint. The leaves and tops of $M$. piperita, or common peppermint, having properties due to a volatile oil, in which form it is commonly used. It is an aromatic, stimulant, carminative, and antispasmodic, and is valuable internally to relieve flatulent colic, and externally to relieve superficial neuralgia. It is of reputed value in typhoid fever, and as an antiseptic in parasitic skindiseases. M. pip., Aqua, contains 2 parts of the oil in 1000 of distilled water. Dose indefinite. M. pip., Essentia (B. P.) Dose $\eta x-x x$. M. pip., O1., the volatile oil, consists of a liquid terpene and a camphor, menthol, $q . v$. Dose $\prod_{j}-\mathrm{v} . \quad$ M. pip., Spt., essence of peppermint, contains Io per cent. of the oil and I per cent. of the herb in alcohol. Dose $\eta_{\mathbf{x}-\mathbf{x x x}} \mathbf{M}$. pip., Trochisci, each contains $\frac{15}{100}$ of the oil, with sugar and tragacanth. Dose indefinite. M. pulegium, the true or European pennyroyal. Its odor and properties are much the same as those of American pennyroyal. M: viridis, spearmint. The leaves and tops of common "kitchen" mint, $M$. viridis, having properties due to a volatile oil, differing slightly in taste and odor from oil of peppermint. Its medicinal properties are like those of $M$. piperita. $\mathbf{M}$. virid., Aq., 2 parts of the oil in Iooo of water. M. virid., Ol., the volatile oil. Dose $m_{i j}-v$. M. virid., Spt., alcoholic, contains Io per cent. of the oil and I per cent. of the herb. Dose $m x-x l$.

Menthene (men'-thēn) [mentha, mint], $\mathrm{C}_{10} \mathrm{H}_{18^{\circ}} \mathrm{A}$ liquid hydrocarbon produced when menthol is distilled with $\mathrm{P}_{2} \mathrm{O}_{5}$. It boils at $\mathrm{I} 67^{\circ} \mathrm{C}$.

Menthol (men'-thol) [mentha, mint], $\mathrm{C}_{10} \mathrm{H}_{20} \mathrm{O}$. Japanese peppermint; peppermint camphor; mentha camphor; the chief component of peppermint oil, from which it separates in crystalline form on cooling. It possesses, like borneol, the character of an alicyclic alcohol ; melts at $42^{\circ} \mathrm{C}$, , and boils at $213^{\circ} \mathrm{C}$. It is obtained from Mentha arvensis, var. piperascens, a Chinese and Japanese herb; also from the seeds of Carum copticum, of India. It is used as a local application in neuralgia, sciatica, ringworm, and other painful conditions. Unof. M., Emplast., containing menthol, wax, and resin; has a place in the 1890 addition to the B. P. M. Pencil, a small, pointed cylinder of menthol used as an application to the skin in neuralgia.

Menthone (men'-thon) [mentha, mint], $\mathrm{C}_{10} \mathrm{H}_{18} \mathrm{O}$. The ketone of menthol, a colorless liquid with a high boiling-point $\left(206^{\circ} \mathrm{C}\right.$.). It is soluble in alcohol, in benzene, in carbon disulphid, and in chloroform, but insoluble in water.

Mentiferous (men-tif'-er-us) [mens, mind; ferre, to carry]. Conveying, or supposed to convey, mental impressions; telepathic. M. Ether, a supposed ethereal medium of telepathy, or thought-transfer. 
Mentigo (men-ti'-go). See Mentagra.

Mento-bregmatic (men'-to-breg-mat'-ik) [mentum, chin; $\beta \rho \eta \gamma \gamma \mu a$, bregma]. Extending from the chin to the bregma

Mento-condylean (men'-to-kon-dil'-e-an) [mentum, chin; $\kappa \delta v \delta v \lambda o s$, condyle]. Pertaining to the chin and the occipital condyles. M.-c. Triangle. See Triangles, Table of.

Mento-coronial (men'-to-kor-o'-ne-al) [mentum, chin; corona, crown]. Relating to the chin and the coronal suture. M.-c. Triangle. See Triangles, Table of.

Mento-gonial (men'-to-go'-ne-al) [mentum, chin; $\gamma \omega v i a$, angle]. Extending from the gonion to the gnathion. M.-g. Triangle. See Triangles, Table of.

Mento-hyoid (men'-to-hi'-oid) [mentum, chin; voeufhs, hyoid]. Relating to the chin and the hyoid bone.

Mento-labial (men'-to-la'-be-al) [mentum, chin; labium, lip]. Relating both to the chin and the lip.

Mento-mastoid (men'-to-mas'-toid) [mentum, chin;

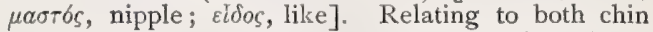
and mastoid process. M.-m. Triangle. See Triangles, Table of.

Mento-meckelian (men'-to-mek-el'-e-an) [mentum, chin; Meckel, a German anatomist]. Pertaining to the distal or mental division of Meckel's cartilage.

Mentula (men'-tu-lah) [L.]. The penis.

Mentulagra (men-tu-la'-grah) [mentulagra; mentula, penis; ă $\gamma p \alpha$, seizure]. Painful priapism; chordee.

Mentulomania (men-tu-lo-ma'-ne-ah). Synonym of Masturbation.

Mentum (men'-tum) [L., the chin: pl., Menta]. The chin. In biology, variously applied to structures below the lip, or labium, as in insects, that part of the labium between the submentum and the ligula; in orchids, an extension of the foot of the column.

Mentzelia (ment-ze'-le-ah) [after C. Mentzel, a German botanist]. A genus of the Loaseæ. M. aspera, M. hispida, is a Mexican species, the root of which has drastic properties, and is also used in gonorrhea and syphilis. Unof.

Menyanthes (men-e-an'-thẽz) [ $\mu \eta v a i ̃ o s$, monthly ; àv $\theta 0 \varsigma$, flower]. A genus of plants of the gentian order. $\mathbf{M}$. trifoliata. See Buckbean.

Menyanthin (men-e-an'-thin) [ $\mu$ mvaīos, monthly ; àv0os, flower $], \mathrm{C}_{30} \mathrm{H}_{46} \mathrm{O}_{14}$. The bitter principle of Buckbean. It is a white, amorphous, bitter glucosid.

Meosis (me-o'-sis). See Miosis.

Mephitic (me-fit'-ik) [Mephitis, a mythologic divinity ]. Foul or noxious; stifling; noisome, as a vapor, or stench. M. Gangrene, moist necrosis of bone, associated with the evolution of offensive odors.

Mephitis (me-f $f^{\prime}$-tis) [L.]. I. A pestilent or noxious exhalation. 2. A genus of American carnivorous mammals, the skunks. They are noted for the fetid secretion of their perineal glands, which has been used as an antasthmatic remedy and in hysteria. Unof.

Mephitism (mef'-it-izm). Synonym of Mephitis (first definition).

Meramaurosis (mer-am-aw-ro'-sis) [ $\mu \varepsilon^{\prime} \rho o s$, part; a’ $\mu$ -

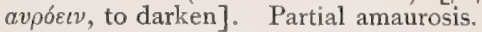

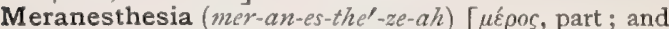

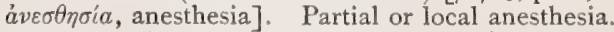

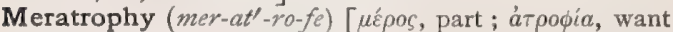
of nourishment]. Partial atrophy.

Mercaptal (mer-kap'-tal) [mercurius, mercury; captans, seizing]. A thio-acetal; a product of the union of a mercaptan and an aldehyd.

Mercaptan (mer-kap'-tan) [mercurius, mercury; captans, seizing]. A thio-alcohol; any one of a certain class of alcohols in which the oxygen is replaced by sulphur. The mercaptans are the sulphur analogues of the alcohols, and are colorless liquids, mostly insoluble in water, and possessed of a disagreeable odor resembling that of garlic.

Mercaptid (mer-kap'-tid) [mercurius, mercury; captans, seizing]. A metallic derivation of a mercaptan.

Mercaptol (mer-kap'-lol) [mercurius, mercury; captans, seizing]. A product of the union of 'a mercaptan and a ketone.

Mercier's Bar. The crescentic ridge of submucous tissue forming the posterior boundary of the trigone of the bladder.

Mercurial (mer-ku'-re-al) [Mercury, a Grecian god] Pertaining to mercury. M. Palsy, a paralysis or an involuntary spasmodic twitching of the voluntary muscles, as a result of mercurial intoxication, and intensified on voluntary motion; it sometimes affects persons habitually exposed to the vapor of mercury. $\mathbf{M}$. Ptyalism. Synonym of Stomatitis, Mercurial. M. Rash, an eczematous eruption arising from the continued use of mercury. M. Tremors. Same as $M$. Palsy. See also Tremor.

Mercurialin (mer-ku'-re-al-in) [Mercury, a Grecian god], $\mathrm{CH}_{5} \mathrm{~N}$, An oily basic principle obtainable from Mercurialis annua and $M$. perennis. It is poisonous, diuretic, and cathartic. Unof.

Mercurialis (mer-ku-re-a'-lis) [Mercury, a Grecian god]. A genus of euphorbiaceous plants, with actively poisonous qualities. M. annua and $\mathbf{M}$. perennis were formerly used in medicine, being strongly purgative, emmenagogue, and diuretic. Unof.

Mercurialism (mer-ku'-re-al-izm) [Mercury, a Grecian god]. A name for the morbid condition arising from the too free or the long continued use of mercury.

Mercurialist (mer-ku'-re-al-ist) [Mercury, a Grecian god]. One who prescribes mercury largely, or one who believes in the treatment of syphilis by mercury.

Mercurialization (mer-ku-re-al-iz-a'-shun) [Mercury, a Grecian god]. Bringing under the influence of mercury.

Mercuric (mer-ku'-rik) [Mercury, a Grecian god] Pertaining to or containing mercury as a bivalent radicle.

Mercuricum (mer-ku'-rik-um) [Mercury, a Grecian god]. A term applied to compounds containing mercury as a bivalent radicle.

Mercurius (mer-ku'-re-us). See Mercury.

Mercurosum (mer-ku-ro'-sum) [Mercury, a Grecian god]. A term given to compounds containing mercury as a univalent radicle.

Mercurous (mer'-ku-rus) [Mercury, a Grecian god]. A term applied to compounds containing mercury as a univalent radicle.

Mercury (mer'-ku-re) [Mercury, a Grecian god]. See Hydrargyrum. M. Weed, the herb Mercurialis annua. See Mercurialis.

Merd [merda, merdus, feces]. Feces. M. diaboli, asafetida.

Merdivomous (mer-div'-o-mus) [merda, feces; vomere, to vomit]. Having stercoraceous vomiting.

Merdivorous (mer-div'-or-us) [merda, feces; vorare, to devour]. Devouring excrement.

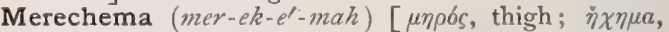
sound: pl., Merechemata]. An auscultatory sound ascribed to the friction of the thighs of the fetus.

Meremphraxis (mer-em-fraks'-is) [ $\mu \varepsilon \rho \rho s$, part; $\varepsilon \mu \phi$ $\rho a \xi \iota$, stoppage]. Partial obstruction.

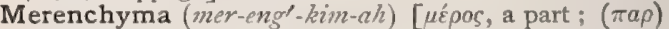
$\varepsilon \gamma \chi v \mu a$, in modern sense "parenchyma"]. In biology, an imperfect parenchyma.

Meretrix (mer'-et-riks) [merere, to earn money]. A prostitute. 


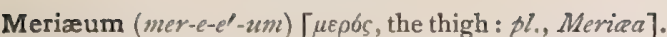
In biology, the anterior surface of the socket of the hind-leg of a beetle.

Meric (mer'-ik) [ $\mu \varepsilon$ pos, part]. Relating to a part.

Mericarp (mer'-ik-arp) [ $\mu \varepsilon \rho o s, a$ part; $\kappa a \rho \pi \delta ́ s$, fruit]. In biology, one of the ripened carpels of a schizocarp; a portion of a fruit separating from the rest.

Mericism (mer'-is-izm). Same as Merycism.

Meride (mer'-id) [ $\mu \varepsilon$ és, part; $\mu \varepsilon i \rho o \mu a \iota$, to share]. In biology, a colony of cells that either remains isolated or multiplies by gemmation to form a larger aggregate.

Meridian (mer-id'-e-an) [meridies, midday]. An imaginary great circle surrounding any globe and intersecting the poles. M. of the Eye, an imaginary circle surrounding the globe of the eye, vertical if supposed to be perpendicular, or horizontal if level. A lens is also described in the same way.

Meridional (mer-id'-e-on-al) [meridies, midday]. Relating to a meridian.

Meridrosis (mer-id-ro'-sis) [ $\mu \varepsilon \rho_{\rho} \rho \varsigma$, part ; $i \delta \rho \omega s$, sweat]. Local perspiration.

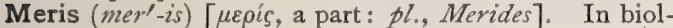
ogy, a cell-colony either permanently isolated. or by budding giving rise to a higher aggregate, the deme.

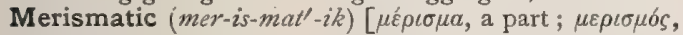
a division; $\mu \varepsilon \rho i \zeta \varepsilon \imath \nu$, to divide]. In biology, characterized by the formation of internal septa.

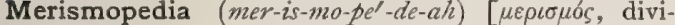
sion; $\pi a^{\prime}$ ' , child]. A bacterium multiplying by two rectangular divisions, thus forming a tablet-like group of four cells in one plane. See Bacteria, Table of.

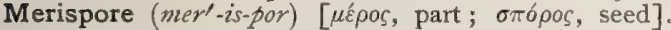
The spores resulting from division of the endospore or exospore of fungi ; one of the secondary spores of a compound spore.

Meristem (mer'-is-tem) [ $\mu \varepsilon \rho \iota \sigma \tau o ́ s$, verbal adj. of $\mu \varepsilon \rho i \zeta \varepsilon \iota \nu$, to divide]. In biology, the actively growing, undifferentiated cell-tissue of the growing tips of plants; the formative tissue of the cambium layer.

Meristematic (mer-is-tem-at'-ik). Synonym of Merismatic.

Meristogenetic (mer-is-to-jen-et'-ik) [ $\mu \varepsilon \rho \iota \sigma \tau o ́ s$, divided; $\gamma \varepsilon \nu \nu \tilde{a} \nu$, to beget]. Developed from meristem.

Merit (mer'-it) [ $\mu \varepsilon \rho i \varsigma$, a part ( $\mu \varepsilon \rho i \tau \eta \varsigma$, a partaker)]. In biology, one of the small bodies or granules containing one or two chromatin-specks, or microsomata, formed by the breaking up of the male and female pronuclei in the process of impregnation. The Spermatomeriten and Ovomeriten of Boehm. Cf Idant.

Merithal (mer'-ith-al) [ $\mu \varepsilon \rho i s$, part ; $\theta a \lambda \lambda \sigma s$, a branch]. Same as Internode.

Merizotropia (mer-iz-o-tro'-pe-ah). See Merotropia.

Merkel's Cells. The tactile corpuscles. M.'s Ganglia, small groups of subepidermic ganglion-cells; the tactile corpuscles. M.'s Muscle. See Muscles, Table of. M.'s Plane. See Plane. M.'s Solution, a fixing-agent used in histologic research. It is composed of equal parts of a one-fourth per cent. solution of platinum chlorid, and a one-fourth per cent. solution of chromic acid. The specimen is placed in this fluid for from two to three hours, and then preserved in alcohol. M., Tactile Cells of. See Grandry's Corpuscles. M.'s Touch-corpuscles. See Grandry's Corpuscles.

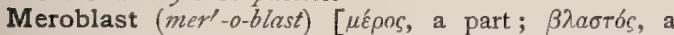
germ ]. In embryology, an ovum that contains beside the formative protoplasm or yolk, more or less foodyolk or nutritive protoplasm.

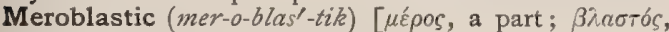
a germ]. In embryology, a term applied to such ova as present some impediment to the segmentation of the protoplasm of the vegetative pole, owing to which this process is more or less confined to one por. tion of the ovum, the protoplasm of the animal pole. The distinction between meroblastic and holoblastic is one of degree, not of kind. "The best known example of a vertebrate meroblastic ovum is undoubtedly the hen's egg." (Minot.)

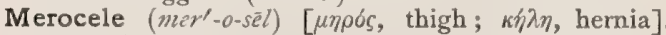
Femoral hernia.

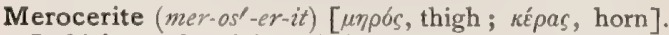
In biology, that joint of the antenna of a crustacean which is borne upon the ischiocerite.

Merocoxalgia (mer-o-koks-al'-je-ah) [ $\mu \eta \rho b s$, thigh;

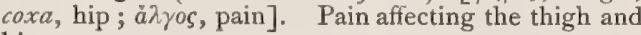
hip.

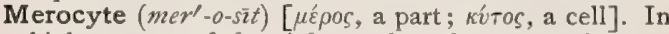
biology, one of the eight nucleated masses of protoplasm of the meroblastic, mesolecithal, or telolecithal germ. (Lang.)

Merodialysis (mer-o-di-al'-is-is) [ $\mu \dot{\varepsilon} \rho o s$, part; $\delta \iota a ́ \lambda v \sigma \iota$, separation]. Partial decomposition.

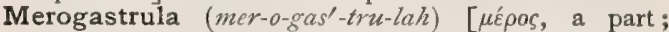

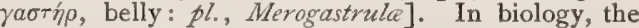
gastrula of a meroblastic ovum.

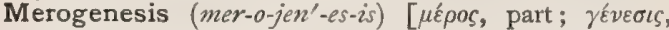
genesis]. Segmentation; the origination of segments.

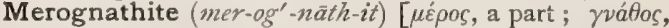
jaw ]. In biology, the fourth joint of one of the gnathites or jaw-feet of a crustacean. (Milne-Edwards.)

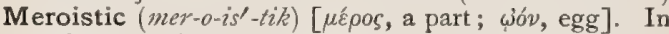
biology, applied to the ovaries of certain insects $(e, g$. aphis) that give rise not only to ova and ovicapsular epithelium, but also to large vitelligenous cells. The latter are connected with the ova and supply nutritive material. Cf. Panoistic.

Merology (mer-ol'-o-je) [ $\mu \varepsilon \rho o s$, share; $\lambda 6 \gamma o s$, science]. General anatomy; the science of elementary tissues.

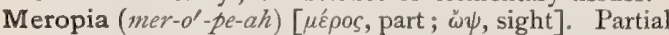
blindness; obscuration of vision.

Meroplanktonic (mer-o-plank-ton'-ik). See Plankton.

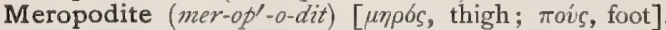
In biology, the fourth joint of a developed endopodite; the inner of the two main divisions of the typical limb. (Milne-Edwards.)

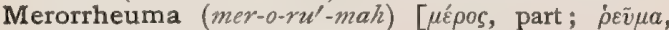
rheum]. Partial rheumatism.

Merorrhexis (mer-or-eks'-is). Synonym of Merocele.

Meros (me'-ros), Merus (me'-rus) [ $\mu \eta \rho b s$, thigh]. In biology, the thigh; the proximal segment of the lower or posterior limb. The fourth joint of any crustacean appendage, as the merognathite or meropodite.

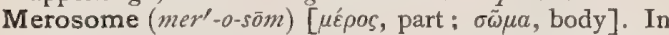
biology, one of the serial parts of a segmented organism ; a somite or metamere.

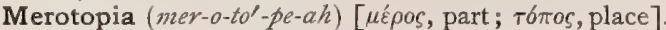
Replacement of a part.

Merotrope (mer'-o-trōp), Merotropia (mer-o-tro'-pe-ah)

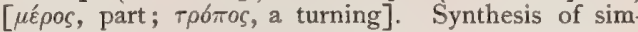
pler bodies that have resulted from more complex compounds which did not combine directly.

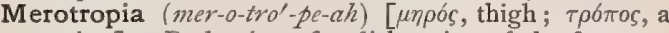
turning]. Reduction of a dislocation of the femur.

Merry-thought (mer'-e-thawt). See Furcula and Wish-bone.

Méry's Glands. - See Gland.

Merycism (mer'-is-izm) [ gurgitation and rechewing of food. Rumination; a phenomenon characteristic of an extremely homogeneous group of Mammalia, i. e., the Pecora, or true ruminants, and sometimes observed in man

Merycology (mer-ik-ol'-o-je) [ $[\mu \varepsilon \rho v i \zeta \varepsilon \iota \nu$, to ruminate; $\lambda \sigma$ yos, science]. The study of rumination. 


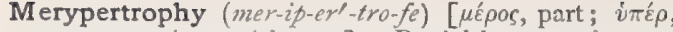
over; tpoф́n, nourishment]. Partial hypertrophy.

Merz System. A system in use for the disposal of garbage and refuse, by which the waste material is subjected to a process akin to desiccation. See Seztage, Disposal of.

Mesad (me'-zad) [ $\mu$ ŕoos, middle; $a d$, to]. Toward the mesial or mesal line or plane; toward the meson.

Mesal (me'-zal) [ $\mu$ ćoov, the middle]. At or in the direction of the meson or median plane of the body. Compare the opposite, lateral. Also, see Position and Direction, Table of.

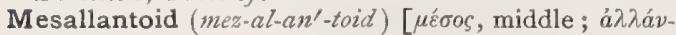
toss, allantois]. An animal having a small allantoic sac

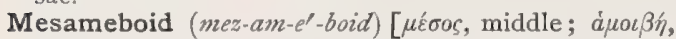
a change; $\varepsilon[\delta o \varsigma$, shape]. In embryology, any one of the leukocytes or wandering-cells, or perhaps the embryonic red blood-cells or the marrow-cells.

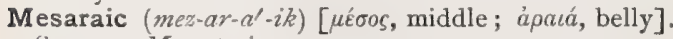
Same as Mesenteric.

Mesaraion (mez-ar-a'-e-on), Mesareum (mez-ar-e'. um) [ $\mu \varepsilon \sigma a ́ p a \iota v$, the mesentery]. The mesentery.

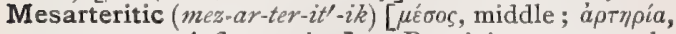
artery ; $\iota \tau \iota$, inflammation]. Pertaining to or resulting from mesarteritis.

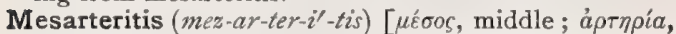
artery; $\iota \tau \iota \zeta$, inflammation]. Inflammation of the middle coat of an artery (usually chronic).

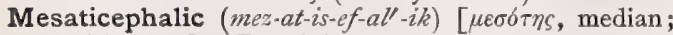
$\kappa \varepsilon \phi a \lambda \eta$, head]. Pertaining to Mesaticephalus. Also, see Index.

Mesaticephalus (mez-at-is-ef'-al-us) [ $\mu \varepsilon \sigma o ́ r \eta s$, median; $\kappa \varepsilon \phi \alpha \lambda \eta$, head]. In craniometry, a term applied to a skull having a cephalic index of between 75 and 79 .

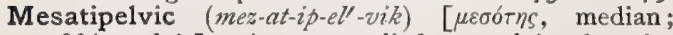
$\pi \varepsilon \lambda \lambda$ í, pelvis]. A term applied to a pelvis whose index ranges between $90^{\circ}$ and $95^{\circ}$.

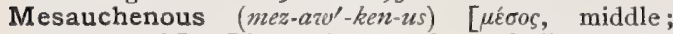
av $\chi \eta \nu$, neck]. Lissauer's term for a skull in which the angle formed between the radius fixus and a line joining the inion and the basion is between $26^{\circ}$ and $38^{\circ}$.

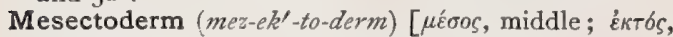
outside; $\delta \varepsilon \dot{\varepsilon} \mu a$, skin $]$. The ectal or ectodermal division of the mesoderm; also, indifferent tissue from which both ectoderm and mesoderm are developed.

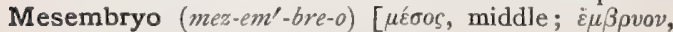
embryo]. The blastula stage of the ova of metazoans.

Mesembryonic (mez-em-bre-on'-ik) [ $\mu$ ḱoos, middle;

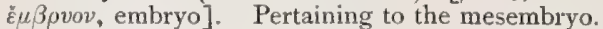

Mesencephal (mez-en-sef'-al). Same as Mesencephalon.

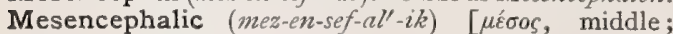
$\dot{\varepsilon} \gamma \kappa \varepsilon \dot{\varepsilon} a \lambda o v$, the brain]. Relating to the mesencephalon.

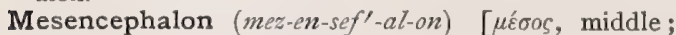

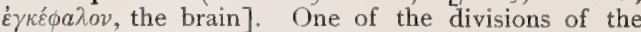
brain, consisting of the corpora quadrigemina, and the crura cerebri.

Mesenchyma (mez-eng'-kim-ah) [ $\mu \varepsilon \sigma o \varsigma$, middle ; है $\gamma \chi v \mu a$, an infusion]. The portion of the mesoderm that produces all the connective tissues of the body, the blood-vessels, and the blood, the entire lymphatic system proper, and the heart. The non-epithelial portions of the mesoderm.

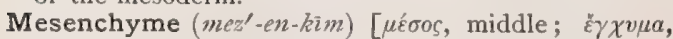
an infusion]. In biology: $(a)$ applied to the mesoderm of certain animals (e.g., sponges); (b) embryonic connective tissue composed of cells thrown off by the mesothelium.

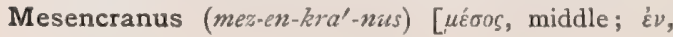

in; крaviov, skull]. Lissauer's term for a skull having a median cerebellar sector of from $15^{\circ}$ to $20^{\circ}$.

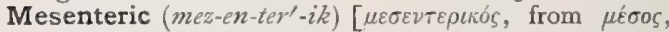

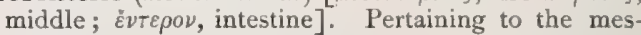
entery.

Mesenterica (mez-en-ter'-ik-ah) [ $\mu$ ćoos, middle; $\dot{\varepsilon} \nu$ $\tau \varepsilon \rho \circ \nu$, intestine]. I. The mycelium of certain molds. 2. A vessel of the mesentery. M., Tabes. See Tabes.

Mesenteriitis (mez-en-ter-e-i'-tis). Same as Mesenteritis.

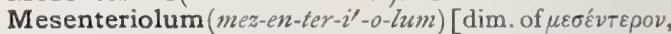
mesentery]. A little mesentery; especially the fold of peritoneum that sometimes connects the appendix vermiformis with the mesentery.

Mesenteriophthisis (mez-en-ter-e-off'-this-is) [ $\mu \varepsilon \sigma \varepsilon$ c $\tau \varepsilon \rho \circ \nu$, mesentery; $\phi \theta i \sigma \iota s$, wasting]. Tabes mesenterica, $q . v$.

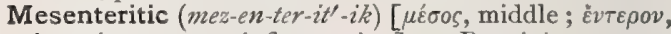
intestine; $\iota \tau \iota$, inflammation]. Pertaining to or affected with mesenteritis.

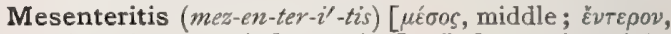
an intestine; $\iota \tau \iota$, inflammation]. Inflammation of the mesentery. M. chronica. Synonym of Tabes mesenterica.

Mesenterium (mez-en-ter'-e-um) [L.: pl., Mesenteria]. A mesentery.

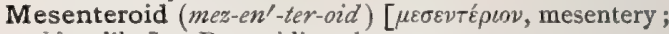
cidos, like]. Resembling the mesentery.

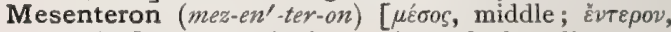
intestine]. The middle portion of the alimentary tract in the embryo.

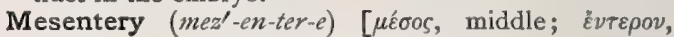
bowel]. I. A fold of the peritoneum that connects certain portions of the intestine with the posterior abdominal wall. 2. A membranous septum dividing the perivisceral cavity into more or less completely separate chambers.

Mesentoderm, Mesendoderm (mez-en'-to-derm, mez-

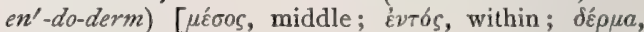
skin]. The ental or entodermal division of the mesoderm; also, the indifferent tissue from which both entoderm and mesoderm are developed.

Mesepimeron (mez-ep-im'-er-on) [ $\mu \varepsilon \sigma o s$, middle; ' $\dot{\varepsilon} \pi$, upon; $\mu h \rho o s$, thigh: $p l$. , Mesepimera]. In biology, the middle lateral piece (epimeron) of the thorax or mesothorax of an arthropod.

Mesepisternum (mez-ep-is-ter'-num) [ $\mu \varepsilon \sigma^{\prime} \sigma o s$, middle ;

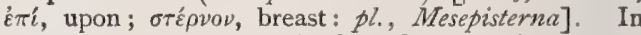
biology, one of the anterior lateral pieces of the mesothorax of an arthropod.

Meseraic (mez-er-a'-ik), See Mesaraic.

Mesethmoid (mez-eth'-moid) [ $\mu \varepsilon ́ \sigma o s$, middle; $\dot{\eta} \theta \mu \delta s$, ethmoid]. The mesal element of the ethmoid bone, forming a separate bone in some of the lower animals.

Mesh [ME., maske, a mesh, or net]. A network, as of vessels or nerves.

Mesiad ( $\left.m e z^{\prime}-\ell-a d\right)$ [ $\mu \varepsilon ́ \sigma o \zeta$, middle]. Same as Mesad. Mesial (mez'-e-al) [ $\mu \varepsilon ́ \sigma o s$, middle]. Same as Median.

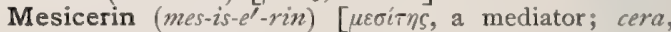
wax $], \mathrm{C}_{6} \mathrm{H}_{3}\left(\mathrm{CH}_{2} . \mathrm{OH}\right)_{3}$. Mesitylene glycerol, produced by the action of tribrom-mesitylene upon boiling water and lead carbonate. It is a thick liquid.

Mesidic Acid (mes-id'-ik). See Uvitic Acid.

Mesien (mez'-e-en) [ $\mu \varepsilon \sigma o \varsigma$, middle]. Belonging to the mesion in itself.

Mesion (mez'-e-on) [ $\mu \varepsilon \tilde{\varepsilon} \sigma \varsigma$, middle]. See Meson.

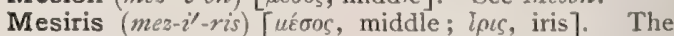
middle layer of the iris, lying between the ectiris and the entiris.

Mesitilol (mez-it'-il-ol). Same as Mesitylene.

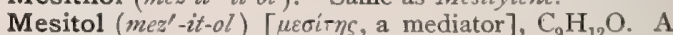
crystalline body, chemically a hydrated mesitylene. 
Mesitylene (mes-it'-il-ēn) [ $\mu \varepsilon \sigma i r \eta s$, a mediator], $\mathrm{C}_{9} \mathrm{H}_{12}$ Trimethyl benzin. It occurs in coal-tar, and is produced by distilling acetone or allylene with $\mathrm{H}_{2} \mathrm{SO}_{4}$. It is an oily, colorless, agreeable-smelling liquid, boiling at $163^{\circ} \mathrm{C}$.

Mesitylenic Acid (mes-it-il-en'-ik). See Acid.

Mesmeric (mez-mer'-ik) [from Mesmer, an investigator of mesmerism]. Pertaining to or induced by mesmerism, as mesmeric sleep. M. Coma, hypnotism, q. v. M. Lucidity, clairvoyance. M. Promise, the same as Hypnotic Suggestion. M. Sleep, hypnotism, $q . v$. M. State, the condition of mesmerism.

Mesmerism (mez'-mer-izm) [Mesmer, an investigator of the phenomena]. The phenomena formerly known as somnambulism, and subsequently as animal magnetism, now better known as hypnotism.

Mesmerist (mez'-mer-ist) [Mesmer, an investigator of the phenomena]. One who induces mesmeric phenomena.

Mesmerization (mez-mer-iz-a $\left.a^{\prime}-s h u n\right)$. Synonym of Hypnotization.

Mesmeromania (nez-mer-o-ma'-ne-ah) [Mesmer, the investigator of mesmerism; $\mu a v i a$, madness]. Insane or delusional pursuit of mesmeric observations.

Meso- (mez'-o-) [ $\mu \varepsilon ́ \sigma o s$, middle]. A prefix signifying middle.

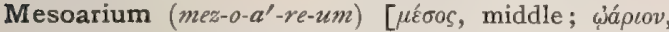
dim. of $\omega \nu^{\prime}$, egg : pl., Mesoaria]. In biology, that fold of the peritoneum in certain animals (e.g., fishes) which forms the mesentery of the ovary. See Mesovarium.

Mesoarteritis (mez-o-ar-ter-i'-tis). Synonym of Mesarteritis.

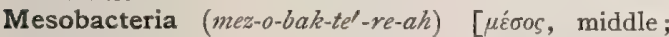
$\beta a \kappa \tau \eta ́ p \iota n$, little rod]. Medium-sized vegetable microorganisms.

Mesoblast (mez'-o-blast) [ $\mu \varepsilon \dot{\sigma o s, ~ m i d d l e ; ~ \beta \lambda a \sigma \tau \delta \varsigma, ~ a ~}$ germ ]. In embryology : $(a)$ a large, granular, single cell, the most posterior in each of the two bands from which the mesoderm arises in a metazoan, and which throws off cells to add to the mesodermal band. It appears to be a derivative of the entoderm; $(b)$ The middle layer of the blastoderm, probably derived from both the ectoderm and entoderm, and from which are developed the vascular, muscular, and skeletal systems, the generative glands, and the kidneys. It is also called mesoderm. Kleinenberg protests against the use of the term mesoblast, at least in a sense imply. ing any possibility of comparison with the primary layers, epiblast and hypoblast, of ccelenterata. M., Parietal, M., Somatic, the outer mesoblastic plates entering into the formation of the body-wall. It is also known as Somatopleure. M., Splanchnic, M., Visceral, the inner mesoblastic plates forming the wall of the digestive tract and its derivatives. It is also known as Splanchnopleure.

Mesoblastema (mez-a-blas-te'-mah) [ $\mu \varepsilon \dot{\sigma o s, ~ m i d d l e ; ~}$ $\beta \lambda a ́ \sigma \tau \eta \mu \alpha$, a shoot; pl., Mesoblastemata]. In embryology, the germinal cells that go to form the mesoderm; the mesoblastic cells.

Mesoblastic (mez-o-blas'-tik) [ $\mu \varepsilon \sigma \sigma \varsigma$, middle; $\beta \lambda a \sigma \tau b \varsigma$, sprout]. Pertaining to the mesoblast.

Mesobranchious (mez-o-brang'-ke-us) [ $\mu$ ćoos, middle; $\beta \rho a ́ \gamma \chi\llcorner a$, gill]. Having the gills or branchiæ in the middle of the body.

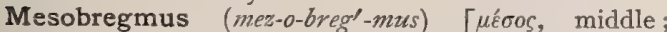
$\beta \rho \varepsilon ́ \gamma \mu a$, the sinciput]. Lissauer's term for a skull in which the angle formed between the radius fixus and the line joining the hormium and the bregma is between $68^{\circ}$ and $82^{\circ}$

Mesobronchitis (mez-o-bron-ki'-tis) [ $\mu \varepsilon \sigma o s$, middle ; $\beta \rho 6 \gamma \times \iota a$, bronchus; $\iota \tau \iota \varsigma$, inflammation]. An inflammation of the middle coat of the bronchial tubes.

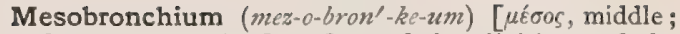
$\beta \rho b \gamma \chi \ell a$, bronchus]. One of the divisions of the trachea in birds.

Mesocæcum (mez-o-se'-kum). See Mesocecrm.

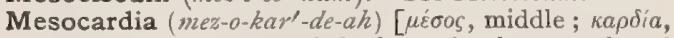
heart]. The position of the heart in the central and anterior part of the chest, a situation that is normal at an early stage of development.

Mesocardium (mez-o-kar'-de-um) [ $\mu$ éoos, middle;

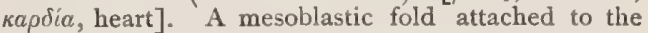
heart.

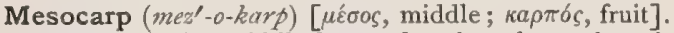
In biology, the middle layer of a three-layered pericarp; the sarcocarp.

Mesocecum (mez-o-se'-kum) [ $\mu \varepsilon^{\prime} \sigma o s$, middle; cacus, blind]. The mesentery that sometimes connects the dorsal part of the cecum with the right iliac fossa.

Mesocele (mez'-o-sél) [ $\mu \dot{\varepsilon} \sigma o s$, middle; $\kappa o \iota \lambda i ́ a$, cavity]. The cavity or ventricle of the mesencephal ; considerable in lower vertebrates but in adult mammals reduced to a slender passage, the aqueduct of Sylvius or iter a tertio ad quartum ventriculum.

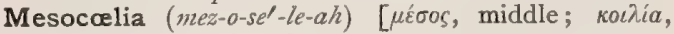
cavity]. See Mesocele.

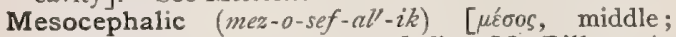
$\kappa \varepsilon \phi a \lambda \eta ́$, head]. See Megacephalic. M. Pillars, in entomology, a pair of strong rods running from the front to the back of the inside of the head of certain insects (e. g., bees), and attached by their extremities just outside and below the antennæ, and at the rear of the head beneath and on each side of the occipital opening. (Cheshire.)

Mesocephalism (mez-o-sef'-al-izm), Mesocephaly

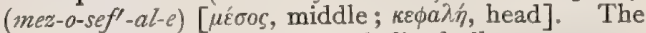
condition of having a mesocephalic skull.

Mesocephalitis (mez-o-sef-al-i'tis) [ $\mu \varepsilon^{\prime} \sigma o \zeta$, middle; $\kappa \varepsilon \phi a \lambda \eta$, head; $\iota \tau \iota$, inflammation]. Inflammation of the mesocephalon or pons Varolii.

Mesocephalon (mez-o-sef'-al-on). See Pons Varolii.

Mesocerebrum (mez-o-ser'-e-brum). See Pons Varolii.

Mesochil (mez-o-kil'), Mesochilium (mez-o-kil'-e-um) [ $\mu \varepsilon$ бos, middle ; $\chi \varepsilon \bar{\imath} \lambda$ os, lip]. In biology, the middle part of the tripartite labellum of certain orchids.

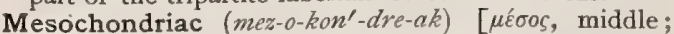
$\chi \delta \delta \delta \rho o s$, cartilage]. Situated between any two contiguous tracheal cartilages.

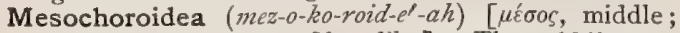

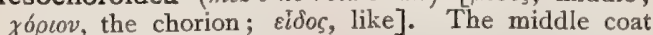
of the choroid.

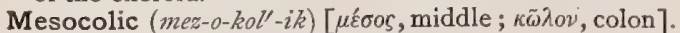
Pertaining to the mesocolon.

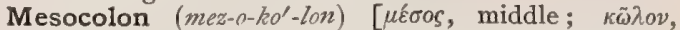
colon]. The mesentery connecting the colon with the posterior abdominal wall. It is divided into ascending, transverse, and descending parts. M., Sigmoid, the fold of the peritoneum connecting the sigmoid flexure with the left iliac fossa.

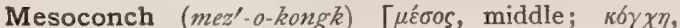
a shell]. Possessing an orbital index of from $80^{\circ}$ to $85^{\circ}$.

Mesocoracoid (mez-o-kor'-ak-oid) [ [ $\kappa \delta \rho \alpha \xi$, a raven; $\varepsilon \delta \delta o s$, form ]. In comparative anatomy, situated between the hypercoracoid and the hypocoracoid; specifically an element in the shouldergirdle of certain bony fishes.

Mesocord (mez'-o-kord) [ $\mu \varepsilon ́ \sigma o s$, middle; chorda, cord]. An abnormality of the umbilical cord in which, instead of being directly inserted into the placenta, it is received into a fold of the amnion arranged analogous to the meso-rectum. This condition does not inter. fere with the health of the child. 
Mesocornea (mez-o-kor'-ne-ah) [ $\mu \varepsilon ́ \sigma o s$, middle ; corneus, horny]. The proper substance of the cornea lying between the ectocornea and the entocornea.

Mesocranium (mez-o-kra'-ne-um). Synonym of Vertex.

Mesocuneiform (mez-o-ku'-ne-if-orm) [ $\mu$ ćos$^{\prime}$, middle; cuners, wedge; forma, form]. The middle cuneiform bone of the tarsus

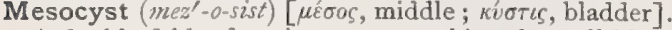
A double fold of peritoneum attaching the gall-bladder to the liver.

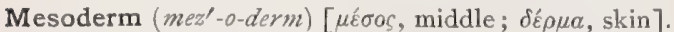
In embryology, the middle of the three blastodermic layers of the germ in the metazoa. "The morphology of the mesoderm is one of the most vexed questions of the day. Scarcely an embryologist can be found who has not published opinions on this question considerably at variance with the opinions of others. It has been maintained that the mesoderm arises from the ectoderm; that it arises from the entoderm, or from both; from neither, but from two special segmentation-spheres; that it has a double origin, part coming from the blastoderm, part from the yolk; and even that there is no mesoderm." (Minot.)

Mesodiastolic (mez-o-di-as-tol'-ik) [ $\mu$ ćøos, middle ;

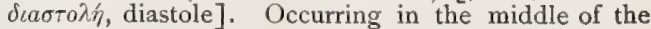
diastolic period.

Mesodme (mez-od'-me) [ $\mu \varepsilon \sigma o \delta \mu \eta]$. See Mediastinum.

Mesodmitis (mez-od-mi'-tis). See Mediastinitis.

Mesodont (mez'-o-dont). See Macrodont.

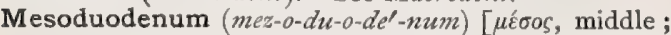
duodeni, twelve each]. That part of the mesentery that sometimes connects the duodenum with the posterior wall of the abdominal cavity. Normally, the true duodenum has no mesentery, at least in its fully developed state.

Mesoepididymis (mez-o-ep-id-id'-im-is) [ dle; $\dot{\varepsilon} \iota \delta i \delta v \mu i s$, epididymis]. The fold of the tunica vaginalis attaching the epididymis to the upper posterior part of the testis.

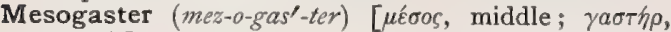
stomach]. The part of the primitive gut giving rise to the duodenum, the liver, the pancreas, the jejunum, and the ileum.

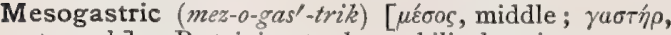
stomach]. Pertaining to the umbilical region.

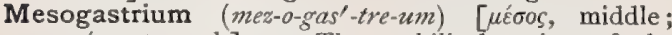
$\gamma \alpha \sigma \tau \eta \dot{p}$, stomach]. I. The umbilical region of the abdomen. 2. A fold of mesentery, which, in early fetal life, connects the stomach with the posterior wall of the abdominal cavity.

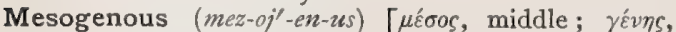
born]. In biology, increasing by growth at or from the middle, as the spores of certain fungi.

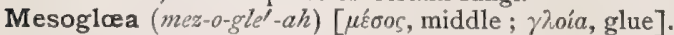
In biology, applied to the intercellular matrix or ground-substance of certain organisms.

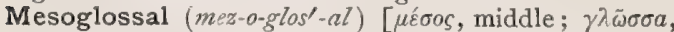
tongue]. Pertaining to the middle of the tongue.

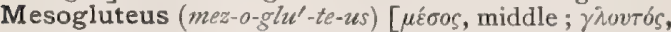
the buttock]. The middle gluteal muscle.

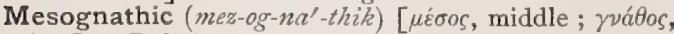
jaw]. Relating to the mesognathion. See, also, Index.

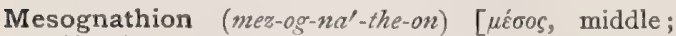
yvátos, jaw ]. The intermaxillary bone.

Mesognathism (mez-or-nāth'-ism) [ $\mu$ ćoos, middle; yvátos, jaw]. The presence of a mesognathion.

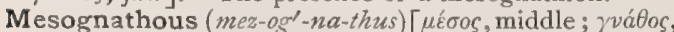
jaw]. Having a gnathic index between 98 and 103 .

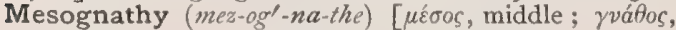
jaw]. The character of having a gnathic index between 98 and 103.

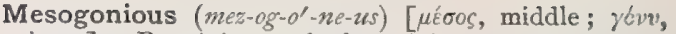
knee]. Pertaining to the knee-joint.

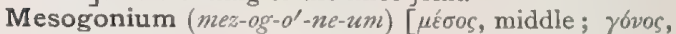
producing: pl, Mesogonia]. In biology, one of the mesenteria of a cnidarian, in which the gonades or reproductive glands are situated.

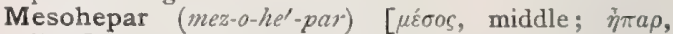
liver]. The peritoneal fold attached to the right hepatic lobe in many animals.

Mesolobe (mez'-o-lob), Mesolobus (mez-ol'-o-bus) $\left[\mu \varepsilon_{\sigma o s}\right.$, middle; $\lambda o \beta o s$, lobe]. The callosum.

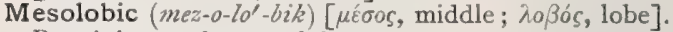
Pertaining to the mesolobe.

Mesology (mez-ol'-o-je) [ $\mu \varepsilon ́ \sigma o s$, middle ; $\lambda 6 \gamma o s$, science]. The science of environment in its relation to life.

Mesomental(mez-o-men'-tal) [ $\mu \varepsilon ́ \sigma o s$, middle; omentum, omentum]. Relating to the middle of the omentum.

Mesomeria (mez-o-me'-re-ah), Mesomerion (mez-ome'-re-on) [ $\mu \varepsilon ́ \sigma o s$, middle; $\mu \eta \sigma^{\prime} s$, thigh]. The perineum.

Mesometrion (mez-o-me'tre-on). Synonym of Mesometrium.

Mesometritis (mez-o-me-tri'-tis) [ $\mu \varepsilon \sigma o s$, middle ; $\mu \eta \dot{r} \tau \rho a$, womb; $\iota$ T $\zeta$, inflammation]. Inflammation of the parenchyma of the womb.

Mesometrium (mez-o-me'-tre-um), Mesometry (mez-o-

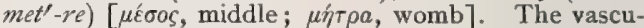
lar membranous tissue connecting the body of the womb with the adjoining parts; the broad ligaments considered as one organ.

Mesomphalion (mez-om- $f a^{\prime}-l e-o n$ ), Mesomphalium (mez-om-fol-le-um), Mesomphalum (mez-om'-fal-um) [ $\mu \varepsilon \sigma \sigma \varsigma$, middle; $\dot{\mu} \mu a \lambda \sigma \varsigma s$, navel]. The middle of the umbilicus, or the umbilicus itself.

Meson ( $\left.\mathrm{mez}^{\prime}-o n\right)$ [ $\mu \varepsilon \sigma o \zeta$, the middle]. The imaginary plane in the body extending from the dorsal to the ventral aspect, and from the caudal to the cephalic extremity, and serving to divide the body into symmetric right and left halves. The middle or median plane.

Mesonasal (mez-o-na'-sal) [ $\mu$ ćos, middle; nasus, nose]. Pertaining to the median region of the nose. Mesonephric (mez-o-nef'-rik), Mesonephritic (mez-o.

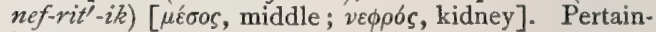
ing to the mesonephron.

Mesonephron (mez-o-nef'-ron), Mesonephros (mez-o-

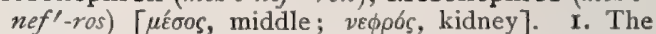
Wolffian body, primitive kidney, archinephron, corps de Wolff, or Urniere ; a body arising from the posterior portion of the Wolffian or nephridial ridge of the vertebrate embryo. It is the chief renal organ throughout life in the anamnia, whereas in the amniuta it disappears during embryonic life, to be replaced by the true kidney, a small portion being retained in connection with the sexual organs. 2. The mesentery for the kidney.

Mesonotal (mez-o-no'-tal) [ $\mu \varepsilon ́ \sigma o \zeta$, middle ; väros, back]. Pertaining to the Mesonotum, q. $v$.

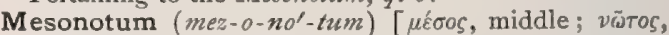
the back]. In biology, the medio-dorsal portion of the thorax of an insect.

Mesopanencephalus (mez-o-pan-en-sef'-al-us) [ $\mu \varepsilon \varepsilon^{\prime} \sigma o s$, middle ; $\pi \tilde{\alpha} \nu$, all ; $\dot{\gamma} \gamma \varepsilon \varepsilon \phi a \lambda o s$, brain]. Lissauer's term for a skull in which the angle between the lines drawn from the nasion and the basion to the punctum alæ vomeris is between $163^{\circ}$ and $165.5^{\circ}$.

Mesoparapteron (mez-o-par-apt'ter-on) [ $\mu \varepsilon \sigma o s$, middle; $\pi a \rho \hat{a}$, beyond; $\pi \tau \varepsilon \rho \delta$, wing]. In biology, the third sclerite of the mesopleuron; the parapteron of the mesothoracic segment.

Mesopatagium (mez-o-pat-a'-je-um) [ $\mu \varepsilon \sigma o s$, middle;

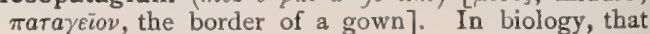


part of the wing-membrane of bats which is limited by the vertical terminal branch of the intercostohumeral line, by the forearm, and the fifth metacarpal bone and phalanges. Cf. Dactylo-patagium, Ectopatagium. (Allen.)

Mesophlebion (mez-o-fleb'-e-on), Mesophlebium (mez$\left.o-f l e b^{\prime}-e-u m\right)$ [ $\mu \varepsilon ́ \sigma o \varsigma$, middle; $\left.\phi \lambda \varepsilon \hat{\beta} \iota \circ \nu, v e i n\right] . \quad$ I. The middle coat of a vein. 2. The space between two veins.

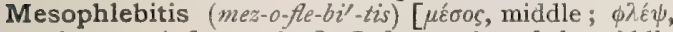
vein; $\iota \tau \iota$, inflammation ]. Inflammation of the middle coat of a vein, or mesophlebion.

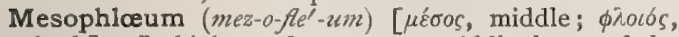
bark]. In biology, the green or middle layer of the bark.

Mesophragm (mez'-o-fram), Mesophragma (mez-o-

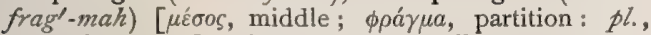
Mesophragmata]. In biology, a stiff plate between the meso-thorax and the meta-thorax in certain insects (e.g., bees), giving attachment to part of the muscles of the organs of flight. (Cheshire.)

Mesophryon (mez-off'-re-on) [ $\mu$ ćoos, middle; ó $\rho \dot{\rho} s$, eyebrow]. The glabella.

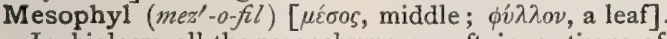
In biology, all the parenchyma or soft inner tissue of a leaf, between the layers of epidermis.

Mesophyllum (mez-o-fil'-um). Same as Mesophyl.

Mesophyte (mez'-o-fit), Mesophytum (mez-off'-it-um)

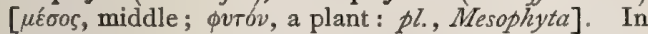
biology, the line of demarcation between the internode and the petiole; the collar.

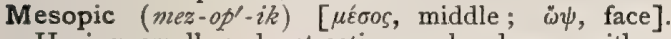
Having small and retreating malar bones, with a naso-malar index of from 107.5 to IIO.

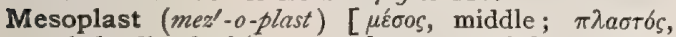
verbal adj. of $\pi \lambda a ́ \sigma \sigma \varepsilon \iota \nu$, to form, to mold]. In biology, the nuclear protoplasm of a cell-nucleus; the endoplast.

Mesoplastron (mez-o-plas'-tron) [ $\mu$ ćбos, middle; Fr., piastron, a breast-plate]. In biology, the median and anterior plate of the plastron.

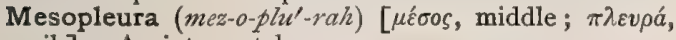
rib]. An intercostal space.

Mesopleurius, Mesopleurus (mez-o-plu'-re-us, mez-o-

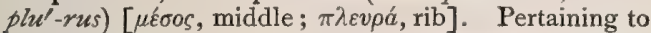
the spaces between the ribs. In the plural, the intercostal spaces.

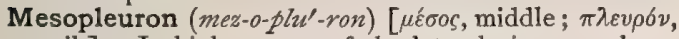
a rib]. In biology, one of the lateral pieces or pleura of the mesothorax of an insect.

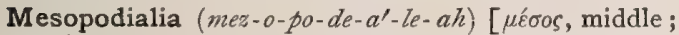

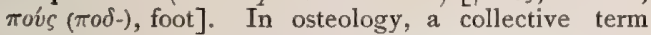
applied to the bones of the carpus and tarsus considered as forming a segment of the fore-limb or hindlimb. Cf. Metapodialia.

Mesopodium (mez-o-po'-de-um) [ $\mu \varepsilon \dot{\sigma} \sigma o s$, middle; $\pi$ oús, foot: $p l$., Mesopodia $]$. In biology, the middle region of the foot of a gasteropod or pteropod, as distinguished from the propodium and metapodium.

Mesoprosopic (mez-o-pros-o'-pik) [ [ $\pi \rho o ́ \sigma \omega \pi \nu \nu$, face]. Having a face of moderate breadth; not chameprosopic or leptoprosopic.

Mesopsyche (mez-op-si'-ke) [ $\mu \varepsilon \varepsilon^{\prime} \sigma o s$, middle; $\psi v \chi \eta$, soul]. Haeckel's term for the mesencephalon.

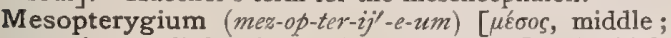
$\pi \tau \varepsilon \rho$ y yov, a little wing: pl., Mesopteryoia]. In biology, the middle, basal cartilage in the pterygium of a fish, between the propterygium and the metapteryoium.

Mesoraic (mez-or-a'-ik). Synonym of Mesenteric.

Mesorchion (mez-or'-ke-on), Mesorchis (mez-or'-kis), Mesorchium (mez-or'-ke-um) [ $\mu \varepsilon \dot{c o s}$, middle; ŏp $\chi \iota \varsigma$, testicle]. A fold of the peritoneum containing the fetal testes at about the fifth month, before their descent.
Mesorcin (mez-or'-sin), Mesorcinol (mez-or'-sin-ol)

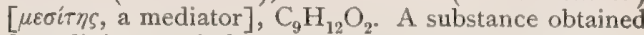
from dinitro-mesitylene. It sublimes in shining leaflets, melts at $150^{\circ} \mathrm{C}$, and distils at $275^{\circ} \mathrm{C}$.

Mesorectum (mez-o-rek'-tum) [ $\mu \varepsilon \sigma o s$, middle; rectus, straight]. The narrow fold of the peritoneum connecting the upper part of the rectum with the sacrum.

Mesoretina (mez-o-ret'-in-ah) [ $\mu$ ćoos, middle; retina, retina]. The middle layer of the retina, composed of the nuclear and the rod-and-cone layer. The mesoretina is also called the mosaic layer.

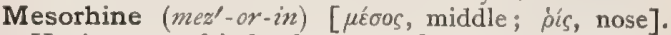
Having a nasal index between $48^{\circ}$ and $52^{\circ}$. See $\mathrm{In}$ dex.

Mesorhinium (mez-o-rin'-e-um) [ $\mu$ éoos, middle; p's, the nose: $p l$. , Mesorhinia]. In biology, the part between the nostrils, as the beak of a bird.

Mesoropter (mez-o-rop'-ter) [ $\mu$ ćos, middle; opos,

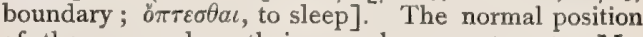
of the eyes when their muscles are at rest. M., Muscular, the angle formed by the visual axes of the eyes when the external ocular muscles are at rest.

Mesorrhine (mez'-or-in). See Mesorhine.

Mesosalpinx (mez-o-sal'-pingks) [ $\mu \varepsilon \sigma o s$, middle ; $\sigma a ́ \lambda \pi t \gamma \xi$, a trumpet]. A falciform, double fold of peritoneum bounded above by the Fallopian tube, internally by the lateral wall of the uterus, externally by the tuboovarian fimbria and the ligamentum infundibulo-ovaricum of Henle, and inferiorly by the ovary and the utero-ovarian ligament.

Mesoscapula (mez-o-skaph'-u-lah) [ $\mu$ ćoos, middle ; scap$u l a$, shoulder-blade ]. The scapular spine.

Mesoscelocele (mez-o-skel'-o-sēl) [ [ $\mu$ ćoos, middle; $\sigma \kappa \varepsilon ́ \lambda o s$, leg; $\kappa \hat{\lambda} \eta$, tumor]. Perineal hernia.

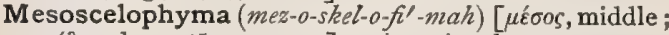
$\sigma \kappa \varepsilon ́ \lambda o s, l e g ; \phi \tilde{v} \mu \alpha$, tumor]. A perineal tumor.

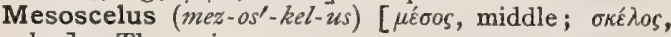
leg]. The perineum.

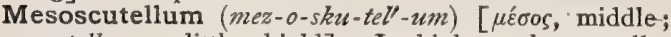
scutellum, a little shield]. In biology, the scutellar sclerite of the mesothorax.

Mesoscutum (mez-o-sku'-tum) [ $\mu$ ćбos, middle ; scutum, a shield]. In biology, the scutum of the mesonotum.

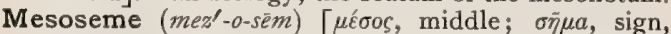
index]. Having a moderate orbital index. See Index.

Mesosigmoid (mez-o-sig'-moid) [ $\mu \varepsilon ́ \sigma o \varsigma$, middle; $\sigma i \gamma \mu \alpha$, sigma; $\varepsilon i \delta o s$, form]. The mesentery of the sigmoid flexure of the colon.

Mesoskeleton (mez-o-skel'-et-on) [ $\mu \varepsilon ́ \sigma o s$, middle ; $\sigma \kappa \varepsilon \lambda$ $\varepsilon \tau \delta \dot{v}$, skeleton]. The internal skeleton of an animal of mesodermic origin.

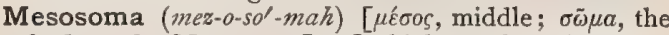
body: $p l .$, Mesosamala]. In biology, the middle region of the body. Especially is the term applied to lamellibranchiate molluscs to distinguish it from the prosoma and the metasoma.

Mesosperm (mez'-o-sperm) [ $\mu$ ḱoos, middle; $\sigma \pi \varepsilon \rho \mu a$, seed]. In biology, the inner coat or integument of the ovule. Cf. Secundine.

Mesospore (mez'-o-spor) [ $\mu \varepsilon \sigma \sigma o s$, middle; $\sigma \pi b \rho o \zeta$, seed]. In biology: I. The middle coat of a spore having three coats. 2. A spore of moderate size.

Mesostaphyline (mez-o-staf'-il-in) [ $\mu \dot{\varepsilon} \sigma o s$, middle; $\sigma \tau a \phi v \lambda \hat{n}$, the uvula]. In craniometry, a term applied to a skull having a palatal index of from $80^{\circ}$ to $85^{\circ}$.

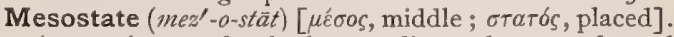
A generic term for the intermediate substances formed in the metabolic processes of secretion, nutrition, or cell-metamorphosis, between the less complex forms of the ingesta up to and through those of the highest complexity and instability (anabolism), and back again 
to the simpler end-products of the katabolic processes. Those metastates formed in the "ascending staircase" - synthetic or anabolic-are called Anastates. Those of the descending staircase-analytic katabolic-are called Catastates. See Anabolin, Katabolin, Metabolin.

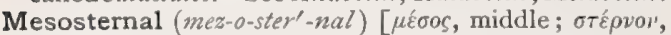
breast-bone]. Pertaining to the mesosternum.

Mesosternebra (mez-o-ster'-neb-rah) [ú́oos, middle; sternebra, sternum]. Any sternebra that helps to make up the mesosternum or its homologue in any lower animal.

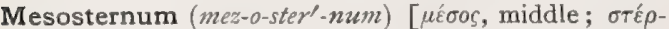
vov, the sternum]. I. In biology, the large ventral sclerite of an insect between the legs of the second thoracic segment. 2. The gladiolus, or second piece of the sternum.

Mesostethium (mez-o-ste'-the-um) [ $\mu \varepsilon^{\prime} \sigma o s$, middle ;

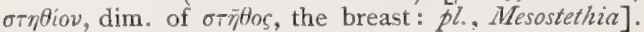
In biology, the large ventral sclerite of an insect between the bases of the middle and posterior legs; the metasternum.

Mesosthenic (mez-o-sthen'-ik) [ $\mu \varepsilon ́ \sigma o s$, middle; $\sigma \theta \varepsilon$ vos, strength]. Having a moderate degree of muscular force.

Mesostomatous (mez-o-sto'-mat-us), Mesostomous

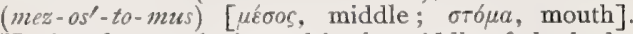
Having the mouth situated in the middle of the body

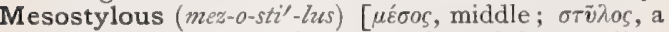
pillar]. In biology, having styles of intermediate length in heterostyled plants.

Mesotarsal (mez-o-tar'-sal). Synonym of Mediotarsal.

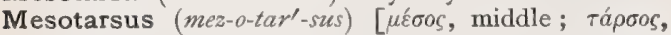
any broad, flat surface : $p l$., Mesotarsi]. In biology, the tarsus of the middle or second leg of a hexapod insect.

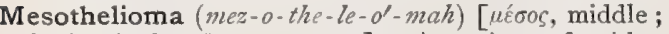
$\theta \eta \lambda \eta$, nipple; ó $\mu a$, a tumor]. A variety of epithelioma supposed to be developed from the mesoblast.

Mesothelium (mez-o-the'-le-um) [ $\mu \varepsilon \sigma^{\prime} \sigma \varsigma$, middle; $\theta \eta \lambda \eta ́ n$, the nipple]. In biology, an epithelial arrangement assumed by the mesodermic cells which bound the cavities formed in the mesoderm of a metazoan embryo ; the peritoneal epithelium.

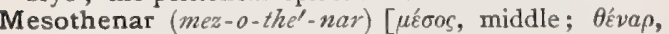
palm]. The muscle drawing the thumb toward the palm of the hand; the adductor pollicis.

Mesothermal (mez-o-ther'-mal) [ [ $\varepsilon \dot{\varepsilon} \sigma o s$, middle ; $\theta \dot{\varepsilon} \rho \mu \eta$, heat]. Of medium warmth.

Mesothoracotheca (mez-o-tho-rak-o-the'-kah) [ $\mu \varepsilon \dot{\sigma} \sigma \varsigma$, middle; $\theta \omega \omega \rho \xi \xi$, chest; $\theta \dot{\eta} \kappa \eta$, a case: pl., Mesothoracotheca]. In entomology, that portion of a pupacase covering the mesothorax.

Mesothorax (mez-o-tho'-raks) [ $\mu \varepsilon \sigma o s$, middle; $\theta \omega \omega a \xi$, chest]. In entomology, the second or intermediate segment of the thorax of an insect; to it are joined the second pair of legs and the first pair of wings.

Mesotic (mez-ot'-ik) [ $\mu \varepsilon \sigma \delta \tau \eta s$, the middle]. Pertaining to, or affecting, the median or parenchymatous tissues.

Mesotocatarrhus (mez-ot-o-kat-ar'-us) [ $\mu$ ćoos, middle ;

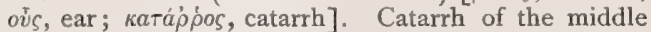
ear.

Mesotœchitis (mez-o-te-ki-tis) [ $\mu \varepsilon \sigma 6 \tau o \iota x o s$, dividing wall ; $\iota t \iota$, inflammation]. Inflammation of the mesotoechium.

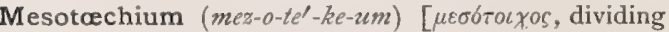
wall]. The mediastinum.

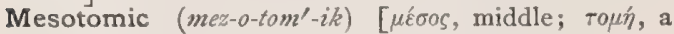
cutting]. Pertaining to mesotomism.

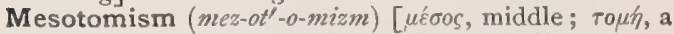
cutting]. The process of separating optically opposite isomers.

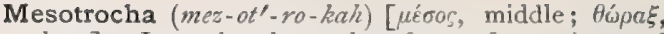
chest]. In embryology, that form of vermian and molluscan larva in which one or two rows of cilia are present in the middle of the body, and the characteristic telotrochal rings are absent. Cf. Atrocha, Monotracha, Telotrocha, Polytrocha, Nototrocha Gasterotrocha, Amphitrocha, Actinotrocha, Trochophora.

Mesoturbinal (mez-o-ter'-bin-al) [ $\mu \varepsilon ́ \sigma o s$, middle; turbo, a wheel]. The lower part of the ectethmoid, overhanging the middle nasal meatus.

Mesotympanic (mez-o-tim-pan'-ik) [ $\mu$ ćoos, middle ; Tó $\mu \pi a v o v$, a drum]. See Symplectic.

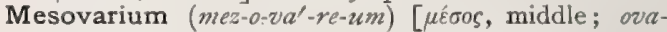
rium, ovary]. A peritoneal fold connecting the ovary to the broad ligament.

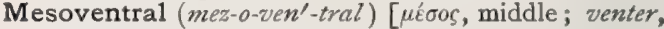
belly]. Both median and ventral.

Mesoxalic Acid (mez-oks-al'-ik) [ $\mu \varepsilon \sigma o s$, middle ; $\dot{\xi} \xi \alpha \lambda i s$, sorrel $], \mathrm{C}_{3} \mathrm{H}_{2} \mathrm{O}_{5}+\mathrm{H}_{2} \mathrm{O}$. A crystalline acid obtained in several ways from alloxan and from amidomalonic acid.

Mesoxalylurea (mez-oks-al-il-u'-re-ah). Same as $A l$ loxan.

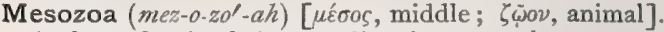
A class of animals intermediate between the protozoa and the metazoa.

Mesquite (mes'-kit). See Mezquite.

Mestica (mes'-tik-ah). Same as Cochineal.

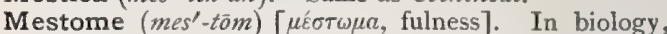
that portion of a fibrovascular bundle which is essentially conductive, as distinguished from the supporting tissue, stereome

Meta-(met'-ah-) [ $\mu \varepsilon \tau^{\prime} a ́$, among or between]. A prefix signifying over, beyond, among, between, change, or transformation. For many meta-organic compounds see the corresponding words without the prefix.

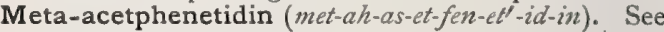
Phenacetin.

Metabasis (met-ab'-as-is) [ $\mu \varepsilon \tau a ́$, over; $\beta a i v e \iota v$, to go] Any radical change in a disease. Also, a change in the treatment of a disease.

Metabole (met-ab'-o-le). Synonym of Metabolism; also of Metabasis.

Metabolia $\left(m e t-a b-o^{\prime}-l e-a h\right)$. Synonym of Metabolism.

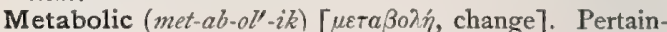
ing to metabolism. M. Equilibrium, the equality between the absorption and assimilation of food, and the excretion of effete or end-products.

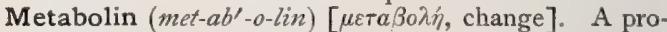
duct of metabolism; a metabolite or mesostate.

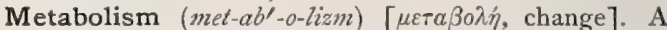
change taking place in the intimate condition of cells whereby their molecule becomes more complex or contains more force-anabolism - or less complexkatabolism. The former process is also called constructive or synthetic metabolism, the latter, destructive metabolism. The power that organized bodies possess of continually using up and renewing the matter composing the body.

Metabolite (met-ab'-o- $\bar{t} t)$ [ $\mu \varepsilon \tau a \beta n \lambda \eta \dot{n}$, change]. Any product of metabolic change; any mesostate.

Metabolize (met-ab'-o-lis) [ $\mu \varepsilon \tau \alpha \beta a \lambda \eta$, change]. To transform by means of metabolism.

Metabolous (met-ab'-o-lus). Synonym of Metabolic.

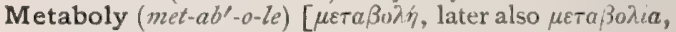
change, exchange]. Same as Metabolism.

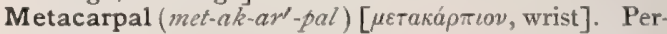
taining to the metacarpus, or to any bone of the metacarpus.

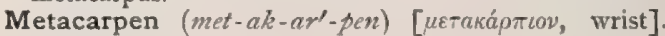
Belonging to the metacarpus in itself. 


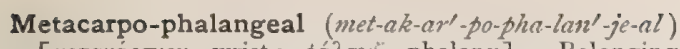
[ to the metacarpus and the phalanges.

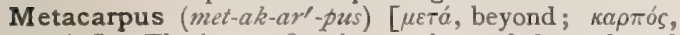
wrist]. The bones, five in number, of the palm of the hand; that part between the carpus and the phalanges.

Metacasein Reaction. The coagulation of milk on boiling, after treatment with pancreatic extracts.

Metacele, Metacelia (met'-as-êl, met-as-e' le-ah) [ $\mu \varepsilon \tau a ́$, beyond; кoìia, cavity]. The caudal or metencephalic portion of the fourth ventricle.

Metacellulose (met-as$\left.e l^{\prime}-u-l o ̄ s\right)$ [ $\mu \varepsilon \tau^{\prime} a ́$, along with; cellula, a cell]. An isomer of cellulose, with which it agrees in being soluble in concentrated sulphuric acid, and from which it differs in being insoluble in cupric ammonia even after the addition of acids. $\mathrm{Cf}$. Paracellulose.

Metacheirisis (met-ak$i^{\prime}$-ris-is), Metacheirismus (met-ak-i-riz'. mus) [ $\mu \varepsilon \tau a ́$, with ; $\chi \varepsilon i \rho$, hand]. Manipulation

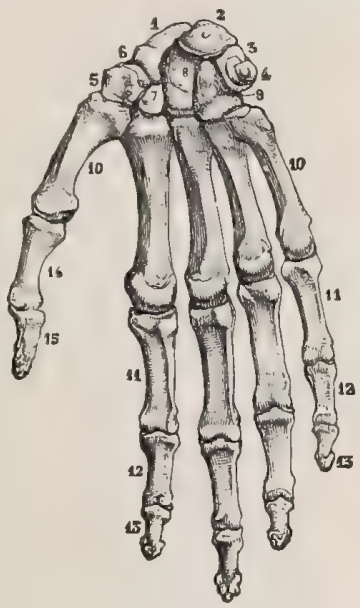

BONES OF THE HAND, SHOWINC THE METACARPUS.

1. Scaphoid. 2. Semilunar. 3. Cuneiform. 4. Pisiform. 5. Trapezium. 6. Groove for tendon of flexor carpi radialis. 7 . Trapezoid. 8. Os magnum. 9. Unciform. Io, 10, Metacarpal bones. II, II. First phalanges bones. II, II. First phalanges
of fingers, I2, I2. Second phaof fingers, 12, 12. Second pha-
langes. I3, I3. Third phalanges. I4. First phalanx of thumb. I5. Second phalanx. in the treatment of disease.

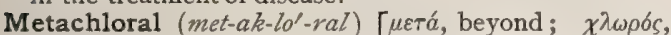
green]. A tasteless, polymeric form of chloral, said to have properties not unlike those of chloral hydrate. Unof.

Metachoresis (met-ak-o'-res-is) [ $\mu \varepsilon \tau a ́$, beyond; $\chi \omega \rho \eta \sigma \iota$, a going]. Metastasis; dislocation.

Metachromasia (met-ak-ro-málze-ah) $[\mu \varepsilon \tau a ́$, beyond : $x \rho \bar{\omega}) \mu a$, color]. The chemico-chromatic changes induced in cells by the staining substances employed in histologic technic.

Metachromatism (met-ak-ro'-mat-izm) [ $\mu \varepsilon \tau a ́$, after; $\chi \rho \tilde{\omega} \mu \alpha$, color]. Change of color, as of the hair.

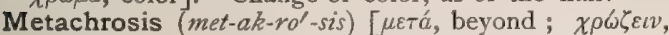
to tinge, to stain]. In biology, applied to the change or play of colors seen in the squid, chameleon, and other animals.

Metachysis (met-akl-is-is) [ $\mu \varepsilon \tau a ́$, beyond; $\chi \chi^{\prime} \sigma \iota s$, effusion]. The transfusion of blood. Also, the introduction of any substance into the blood by mechanical means.

Metacinesis (met-as-in-ésis). Synonym of Metakinesis.

Metacism (met'-as-izm) [ $\mu v \tau a \kappa i \sigma \mu o ́ s$, from $\mu \tilde{v}$, letter m]. Repetition of the letter $\mathrm{m}$.

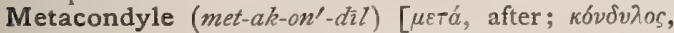
knuckle]. Any distal phalanx of a finger, or the bone thereof.

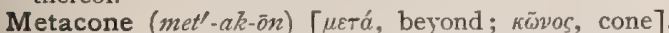
The outer posterior cusp of an upper molar tooth.

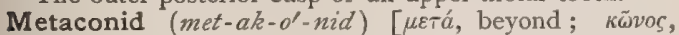
cone]. The inner anterior cusp of a lower molar tooth.

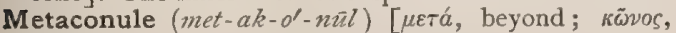
cone]. The posterior intermediate cusp of an upper molar tooth.
Metacroleîn (met-ak-ro'-le-in) [ $\mu \varepsilon \tau a ́$, beyond; acer, sharp; oleum, oil], $\left(\mathrm{C}_{3} \mathrm{H}_{4} \mathrm{O}\right)_{8}$. A product of the burning of the $\mathrm{HCl}$ compound of acrolein with alkalies or potassium carbonate. It crystallizes from alcohol in tablets, fusing at from $45^{\circ}$ to $46^{\circ} \mathrm{C}$., and dissociating at $160^{\circ} \mathrm{C}$.

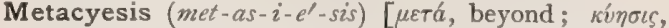
gestation]. Extra-uterine gestation, especially that which is begun in the oviduct and continued in the abdominal cavity

Metadermatosis (met-ad-er-mat-o'-sis) [ $\mu \varepsilon \tau a ́$, beyond; đéo $\mu a$, skin; vó́os, disease]. A pathologic production of epidermis.

Metadrasis (met-ad-ra'-sis) [ $\mu \varepsilon \tau \hat{\alpha}$, over; $\delta \rho a \tilde{\sigma} \iota \zeta$, exertion]. Overwork of body or mind.

Metafacial (met-af-a'-shal) [ $\mu \varepsilon \tau a ́$, beyond; facies, face]. Posterior to the face.

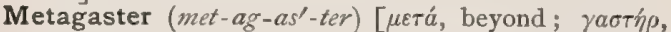
stomach]. The primitive digestive tube from which the respiratory organs are developed.

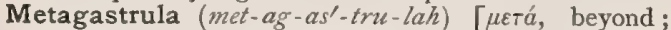
$\gamma \alpha \sigma \tau \eta \dot{n}$, belly]. A modification of segmentation, producing a form of gastrula differing from the simple gastrula of the amphioxus.

Metagenesis (met-aj-en'-es-is) [ $\mu \varepsilon \tau a ́$, beyond, after;

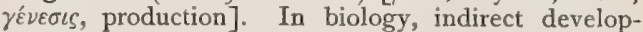
ment, or the alternation of differently-formed generations which multiply in different ways, i.e., sexually or gemmiparously.

Metagenetic, Metagenic (met-aj-en-et'-ik, met-aj-en'-

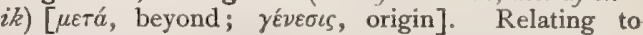
metagenesis.

Metaglycerin (met-ag-lis'-er-in) [ $\mu \varepsilon \tau a ́$, beyond; $\gamma \lambda v$ -

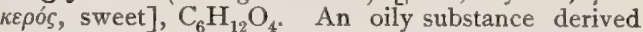
from glycerin by heating a solution of it in water to $100^{\circ} \mathrm{C}$. or by treating glycerin with hydrochloric acid.

Metagnathism (met-ag'-na-thizm) [ $\mu \varepsilon \tau a ́$, beyond ; rvátos, the jaw]. In biology, applied to the crossing of the mandibles, as seen in certain birds, e.g., Loxia curvirostra.

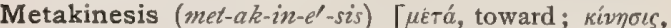
movement, change]. I. In biology, Waldeyer's term for the pithode, or barrel-stage of cell-division, in which the secondary threads or loops tend to pass toward the two poles of the nuclear spindle. 2. Any psychologic exhibition coördinate or correlate of kinesis. See Kinesis.

Metakresol (met-ak-rel-sol) [ $\mu \varepsilon \tau a$, along with; кpḱs , flesh ; oleum, oil ]; $\mathrm{C}_{7} \mathrm{H}_{8} \mathrm{O}_{2}$. A phenol isomeric with kresol. It boils at $20 \mathrm{I}^{\circ} \mathrm{C} .\left(398.8^{\circ} \mathrm{F}\right.$. $)$ and has an odor like that of carbolic acid.

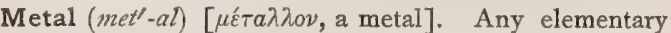
substance distinguished by malleability, ductility, fusibility, and the basic character of its oxid.

Metalbumin (met-al'-bu-min). See Paralbumin.

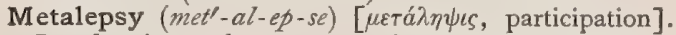
In chemistry, change or variation produced by the displacement of an element or radicle in a compound by its chemic equivalent. It is the same as Substitution, $q . v$.

Metaleptic (met-al-ep'-tik) [ $\mu \varepsilon \tau a ́ \lambda \eta \eta \iota s$, participation]. Relating to metalepsy; also applied to a muscle, associated in its movement with another.

Metallage, Metallaxis (met'-al-ajj, met-al-aks'-is). Synonym of Metabasis, $q . v$.

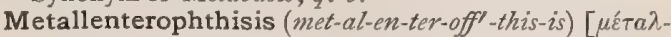
$\lambda o \nu$, metal ; $\varepsilon^{2} \nu \tau \rho o \nu$, intestine ; $\phi \theta i \sigma \iota \zeta$, wasting]. Intestinal wasting or phthisis caused by metallic poisoning.

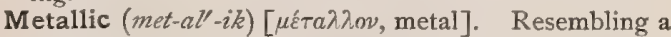
metal. M. Base for Artificial Teeth, a metallic plate adapted to such portion of the alveolar arch as 
is deprived of natural teeth, and is supplied with an artificial substitute. Gold and platinum are the most suitable metals for this purpose, and those usually employed by American dentists ; but silver is also very frequently used. M. Taste, a peculiar taste observed in certain diseases, and also after the ingestion of some of the metallic poisons. M. Tinkling, the peculiar quality given to a sound produced in a cavity in a tuberculous lung, or in a pleural sac containing a liquid exudate and a layer of air above it. M. Tractors, the instruments used by Perkins in his system of metallo-therapy. See Perkinism.

Metalliform (met-al'-if-orm). See Metallic.

Metalline (met'-al-ēn) [ $\mu \dot{\varepsilon} T a \lambda \lambda o v$, metal]. Consisting of metal.

Metallochymia (met-al-o-kim'-e-ah) [ $\mu \varepsilon ́ \tau a \lambda \lambda o \nu$, metal;

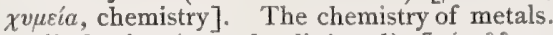

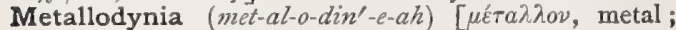
ódviv, pain]. Pain caused by metallic poisoning.

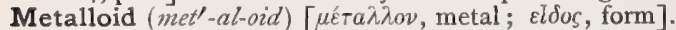
I. Resembling a metal in luster and color. 2. Any non-metallic element.

Metallophagia (met-al-o-fa'-je-ah), Metallophagy (met-al-off'-a-je) [ $\mu \varepsilon \dot{\tau} \tau a \lambda \lambda o v$, metal; $\phi a \gamma \varepsilon i v$, to eat]. The insane impulse to swallow metallic objects.

Metalloscopy (met-al-os'-ko-pe) [ $\mu \dot{\varepsilon} \tau \alpha \lambda \lambda o v$, a metal; $\sigma \kappa \circ \bar{\varepsilon} t \nu$, to examine]. The art of determining by external application what metals or metallic substances act most easily and favorably upon a given person. See also Metallotherapy.

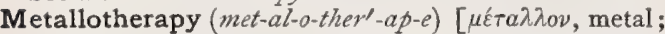
$\theta \varepsilon \rho a \pi \varepsilon i a$, therapy]. A method of treating certain hysteric or paralytic affections by the application of different metals to the affected part. There is usually a transfer of the anesthesia or paralysis to the limb of the other side. This method is called also Burcquism and Metalloscopy. An old method of similar character was called Perkinism.

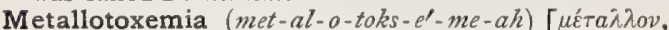
metal; $\tau о \xi \iota \kappa \delta \nu$, poison; $a^{\top} \mu \alpha$, blood]. Toxemia, or blood-poisoning, due to the ingestion of a metal.

Metamere (met'-am-ër) [ Any one of the theoretic segments of a vertebrate animal.

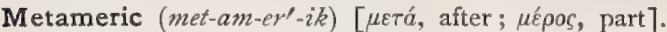
A qualification applied to isomeric bodies containing several different carbon groups held in combination by an atom of higher valence.

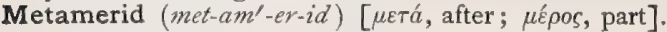
A group of metameric bodies; usually applied to the more complex metameric substances.

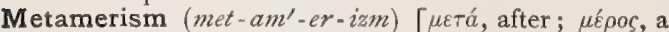
part]. A change in the arrangement of the parts or atoms of a chemic compound; a form of isomerism.

Metamethylphenol (met-am-eth-il-fel-nol). Same as Metakresol.

Metamorphia (met-am-or'-fe-ah). Synonym of Metamorphin.

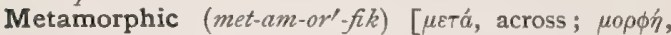
form]. Pertaining to metamorphosis; also synonymous with metamorphous.

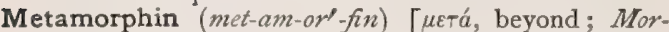
pheus, the god of sleep]. An alkaloidal decomposition-product obtained from the mother-liquor of morphin-manufacture. It is said to be narcotic and sudorific, but is little known and seldom used. Unof.

Metamorphism (met-am-or'-fizm). See Metamorphosis. Metamorphology (met-am-or-fol'-o-je) [ $\mu \varepsilon \tau a \mu \delta \rho \phi \omega \sigma \iota$, a transformation; 26 yos, science]. In biology, the science of the changes of form passed through by individual organisms in the course of their life-histories.
Metamorphopsia (met-am-or-fop'-se-ah), Metamor-

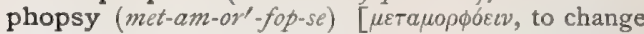
shape ; ó $\psi$ (s, sight]. An apparent distortion or change of form of objects, supposed to be produced by changes in the relative position of the retinal endorgans.

Metamorphosing (met-am-or-fo'-zing) [ $\mu \varepsilon \tau a \mu \sigma \rho \phi \varepsilon \iota \nu$, to change shape]. Altering; changing. M. Breathsound, a variety of breathing related to the existence of a cavity. It occurs only in inspiration, and consists of a very harsh sound, which lasts for about one-third of the period of inspiration, when it is continued as blowing respiration, attended with metallic echo or ordinary râles. It is produced by the air entering the cavity through a narrow opening.

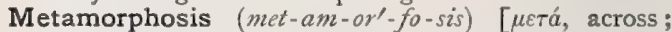
$\mu о \rho \phi o ́ \varepsilon \iota \nu$, to change]. A term denoting the structural changes in form which all organisms undergo during their development from the embryonic to the adult stage. It is applied particularly to that form of sexual reproduction in which the embryo undergoes a series of marked changes of external form (e.g., the chrysalis, the pupa-stage, etc.), and in none of which reproduction is possible until the sexually dereloped form (the imago-stage of butterflies) is produced. In pathology, a degeneration. M., Complete, in insects, the three stages of metamorphosis, larva, pupa, imago. M., Hemimetabolic, a metamorphosis in which the succeeding stages do not differ much, although the first and last stages may present great variations. M., Holometabolic. See M., Complete. M., Regres. sive, M., Retrograde, a disintegrating change; a degeneration; also the change of an organ from a higher to a lower type. M., Viscous, the agglutination of blood-plaques and their conversion into a thrombus.

Metamorphous (met-am-or'-fus) [ $\mu \varepsilon \tau a ́$, across; $\mu \rho \rho \phi-$ $\sigma \varepsilon \imath \nu$, to change]. Amorphous, but with a tendency to crystallize.

Metamorphy (met-am-or'-fe). Synonym of Metamorphosis.

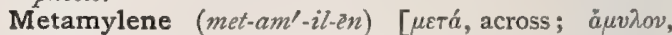
starch $], \mathrm{C}_{20} \mathrm{H}_{40^{\circ}}$ A derivative of the polymers of amylene, produced by heating amylic alcohol with sulphuric or phosphoric acid, or with zinc chlorid.

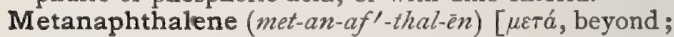
vá $\theta a$, naphtha]. A decomposition-product obtained by the destructive distillation of resin. It is isomeric with naphthalene, and boils at $235^{\circ} \mathrm{C}$.

Metanaphthalin (met-an-af'-thal-in) [ $\mu \varepsilon \tau a ́$, beyond ; $v a ́ \phi \theta a$, naphtha]. A solid hydrocarbon, insoluble in water, soluble in hot alcohol, in ether, and in naphtha, obtained in one stage of the dry distillation of a resin.

Metanauplius (met-an-aud'-ple-us) [ $\mu \varepsilon \tau a ́$, after; nauplius, vav̄s, a ship; $\pi \lambda_{\varepsilon i v}$, a sail: pl., Metanauplii]. In biology, a larval crustacean at a certain stage of development.

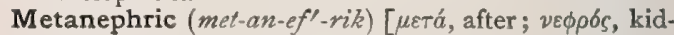
ney]. Pertaining to the metanephros.

Metanephros, Metanephron (met-an-ef'-ros, met-an-

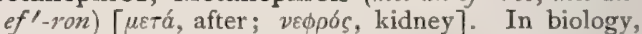
the kidney proper of vertebrates. The posterior of the three segmental bodies of the fetus; it forms the rudiment of the permanent kidney and ureter. It is a special portion of the Wolffian body, that develops late, and only occurs in the amniota as a gland distinct from the mesonephros. Cf. Pronephros, Mesonephros.

Metanil-yellow (met'-an-il-yel-o). Sodium-phenylamido-benzol-meta-sulphonate; a substance used in counter-staining tissues. See Pigments, Conspectus of. 
Metanotum (met-an-o'-tum) [uعтá, behind; vätov, the back: $p l .$, Metanota]. In biology, the third and last segment of the notum, or dorsal part of the metathorax of an insect.

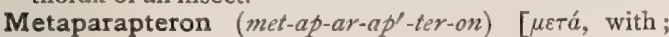
$\pi a \rho a ́$, beside ; $\pi \tau \varepsilon \rho \sigma \nu$, wing : pl., Metaparaptera ]. In biology, the third sclerite in the metapleuron of an insect.

Metapedium (met-ap-e'-de-um). Synonym of Metatarsus.

Metapeptone (met-app-epp-tön) [ $\mu \varepsilon \tau \dot{\alpha}$, beyond; $\pi \dot{\varepsilon} \psi \iota \varsigma$, digestion]. A substance obtained by Meissner from the fluid resulting from the acid peptic digestion of any proteid after the parapeptone had been removed. The latter having been removed by filtration, to the filtrate was added some acid, and a precipitate was secured, to which was given the foregoing name. Meissner further describes a residue insoluble in dilute acids, but soluble in dilute alkalies, that made its appearance during the digestion of casein, and to this he gave the name of dyspeptone. Metapeptone is said to be intermediate between parapeptone and dyspeptone.

Metaphases (met-af-a'-zés) [ $\mu \varepsilon \tau a ́$, after, following ; фá $\iota \varsigma$, a phase]. In biology, the final phase or set of phenomena of karyokinesis, from the division of the nuclear fibrils to the separation of the daughter-nuclei. (Strasburger.) Cf. Anaphases, Prophases.

Metaphenylendiamin (met-af-en-il-en-di'-am-in) [ $\mu \varepsilon \tau \dot{\alpha}$, beyond; phenylendiamin ]. A base similar in action to the toxic ptomains, quickly producing death in animals, preceded by ptyalism, vomiting, diarrhea, and excessive urinary secretion. See Paraphenylendiamin.

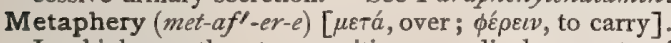
In biology, the transposition or displacement of floral organs.

Metaphlogosis (met-af-lo-go'-sis) [ $\mu \varepsilon \tau a ́$, beyond; $\phi \lambda 6 \gamma \omega \sigma \iota$, a burning]. Severe inflammation with much engorgement, but of short duration.

Metaphosphoric Acid (met-af-os-for'-ik) [ $\mu \varepsilon \tau a ́$, beyond; phosphorus]. See Acid, Phosphoric. M. Test for Albumin. See Tests, Table of.

Metaphrenon (met-af'-ren-on) [ $\mu \varepsilon \tau f^{\prime}$, beyond; $\phi \rho \not ́ v$, diaphragm]. The space between the shoulders.

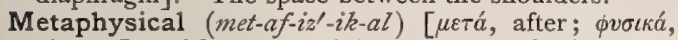
physics]. Of or pertaining to metaphysics. M. Mania, doubting insanity. M. School, a name assumed for an alleged system of medicine; the socalled mind-cure.

Metaphysician (met-af-is-ish'-an) [ $\mu \varepsilon \tau a ́$, after; $\phi v \sigma \iota k a ́$, physics]. A term that has been applied to one who practises the mind-cure.

Metaphysicist (met-af-iz'-is-ist). Same as Metaphysician.

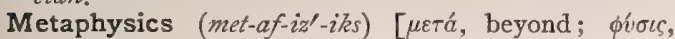
nature]. That science which includes the investigation and discussion of the nature of mind and all supersensible phenomena. M., Medical, the consideration of the essential nature and cause of disease. The philosophy of disease.

Metaphysis (met-af'-is-is). Synonym of Metamorphosis.

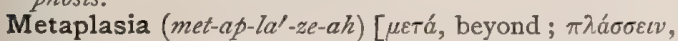
to form]. A transformation of a tissue into another without the intervention of an embryonal tissue. It occurs only among tissues closely related, and is most common in the connective tissues. Fibrous tissue may be transformed directly into bone, myxomatous into adipose tissue. Metaplasia occurs also in epithelium.

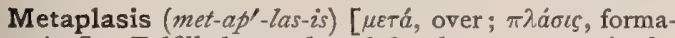
tion]. Fulfilled growth and development seen in the stage between anaplasis and cataplasis.
Metaplasm (met'-ap-lazm) [ $\mu \varepsilon \tau a ́$, beyond ; $\pi \lambda a ́ \sigma u a$, molded material]. In biology, the name given by Hanstein to the granular substances mingled with protoplasm. Properly, protoplasm that has passed beyond its highest stage of perfection; a catastate. The term is used also as a synonym of anastate, and as a general term for both anastates and catastates.

Metaplastic (met-ap-las'-tik) [ $\mu \varepsilon \tau \dot{\alpha}$, beyond; $\pi \lambda a \sigma \iota k o ́ s$, plastic]. Pertaining to metaplasia.

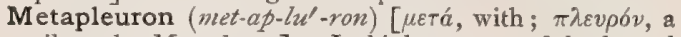
rib: pl., Metapleura]. In biology, one of the lateral divisions of the metathorax of an insect.

Metaplex (mel'-ap-leks), Metaplexus (met-ap-leks'-us) [ $\mu \varepsilon \tau a ́$, behind; plexus, a twining]. The choroid plexus of the fourth ventricle.

Metapneustic (met-ap-nūs'-tik) [ $\mu \varepsilon \tau a ́$, behind; $\pi v \varepsilon v-$ oтєאós, of or for breathing]. In biology, applied to that state of the tracheal system in insect larvæ in which all the stigmata remain closed, except the last pair, through adaptation to parasitism or an aquatic life.

Metapodialia (met-ap-o-de-a'-le-ah) [ $\mu \varepsilon \tau a ́$, behind;

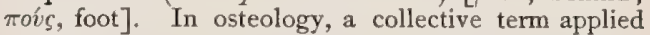
to the bones of the metacarpus and metatarsus considered as a segment of the fore-limb or hind-limb, respectively. Cf. Mesopodialia.

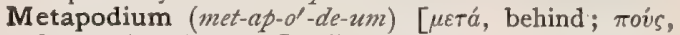
foot: pl., Metapodia]. In biology, the posterior of the three sections into which the foot of some molluscs may be divided. A synonym of Metatarsus. Cf. Mesopodium, Propodium.

Metapophysis (met-app-off'-is-is) [ $\mu \varepsilon \tau a ́$, after ; $a \pi b \phi v \sigma \iota s$, offshoot]. A mammillary process, such as is seen upon the lumbar vertebre.

Metapore (met'-ap-or) [ $\mu \varepsilon \tau a ́$, behind; $\pi b \rho o s$, passage]. The foramen of Magendie; a mesal orifice in the metatela.

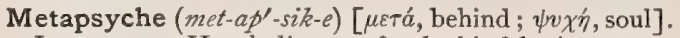
In anatomy, Haeckel's term for the hind-brain or metencephalon.

Metapsychosis (met-ap-si-ko'-sis) [ $\mu \varepsilon \tau \dot{\alpha}$, beyond;

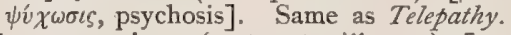

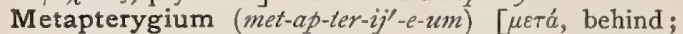
$\pi \tau \varepsilon \rho \dot{\gamma} \gamma\llcorner o \nu$, a little wing : pl., Metapterysia]. In biology, the most posterior of the basal cartilages in the pterygium of a fish.

Metapterygoid (met-ap-ter'-ig-oid) [ $\mu \varepsilon \tau a ́$, beyond; $\pi \tau \varepsilon \hat{\rho} v \xi$, wing]. Placed behind the pterygoid bone.

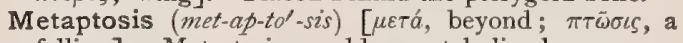
falling]. Metastasis; sudden metabolic change.

Metarrhea (met-ar-e'-ah). Synonym of Metastasis.

Metarrhysis (met-ar'-is-is). Synonym of Metastasis.

Metasaccharic Acid (met-as-ak-ar'-ik). See Acid.

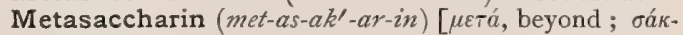
xapov, sugar $], \mathrm{C}_{6} \mathrm{H}_{10} \mathrm{O}_{5}$. An isomerid of saccharin. It crystallizes in plates and melts at $142^{\circ} \mathrm{C}$.

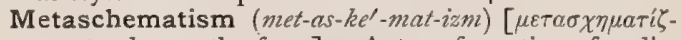
$\varepsilon \iota v$, to change the form]. A transformation of a disease into another form; the change of one substance of the body into another.

Metasoma (met-as-o'-mah) [ $\mu \varepsilon \tau a ́$, after; $\sigma \tilde{\omega} \mu \alpha$, body]. The part of the body of lamellibranchs posterior to the foot; also the posterior part of cephalopods.

Metasomatome (met-as-o'-mat-öm) [ $[\mu \varepsilon \tau a ́$, between; $\sigma \tilde{\omega} \mu \alpha$ the body; $\tau \varepsilon \mu \nu \varepsilon \tilde{\imath} \nu$, to cut]. In biology, Goodsir's term for the interspaces between the primitive vertebræ (Urwirbel). Cf. Somatome.

Metasome (met'-as-ōm) [ $\mu \varepsilon \tau a ́$, after; $\sigma \tilde{\omega} \mu \alpha$, body]. In biology, the posterior part of the body of a mollusc.

Metaspondylum, Metaspondyllum (met-as-pon'-

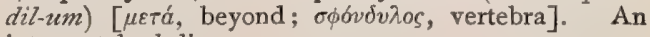
intervertebral disc. 
Metastasis (met-as'-tas-is) [ $\mu \varepsilon \theta$ cotával, to transpose]. r. The change in position, manifestation, or character of a disease; thus, in mumps, the inflammation of the parotid sometimes disappears in a (metastatic) orchitis. Such cases are possibly explained by the transfer of the pathogenic virus from one place to another by the blood-current. 2. In pathology, the reproduction of disease at a distance from the primary seat by the conveyance of the causal agents through the blood or lymph-channels.

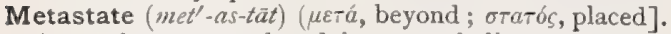
Any substance produced by a metabolic process; an anastate or a catastate. Same as Mesostate.

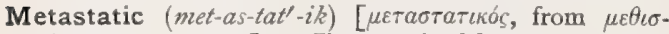
rávaı, to transpose]. Characterized by or pertaining to metastasis. M. Abscess, the secondary abscesses in pyemia. M. Calcification, calcareous infiltration due to an excess of lime-salts in the blood in diseases associated with rapid disintegration of bone.

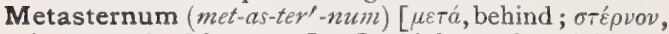
breast: pl., Metasterna]. In biology, the xiphisternum, or in insects the sternite of the metathorax.

Metasthenic (met-as-then'-ik) [ $\mu \varepsilon \tau \dot{a}$, behind; $\sigma \theta \dot{\varepsilon} v o s$, strength, might]. In biology, having a strong, welldeveloped hind-region to the body.

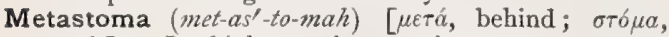
mouth]. In biology, the membranous appendage that lies behind and over the mandibles in crustacea; the posterior lip of some authors.

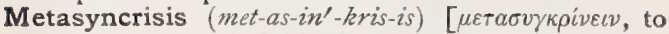
discharge morbid fluids through pores]. I. An induced crisis. 2. The restoration of diseased tissues.

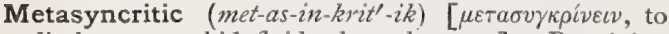
discharge morbid fluids through pores]. Pertaining to metasyncrisis; alterative.

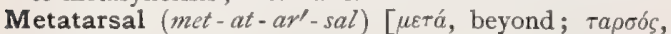
tarsus]. Pertaining to the metatarsus.

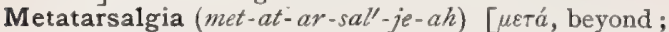

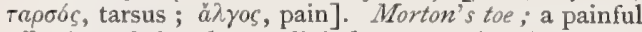
affection of the plantar digital nerves directly caused by pressure upon or pinching of them by certain portions of the metatarso-phalangeal articulations-especially the fourth. See Diseases, Table of.

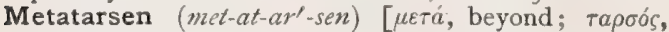
tarsus]. Belonging to the metatarsus in itself.

Metatarso-phalangeal (met-at-ar-so-fa-lan'-je-al)

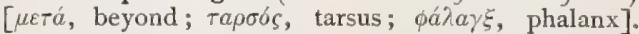
Pertaining to the metatarsus and the phalanges.

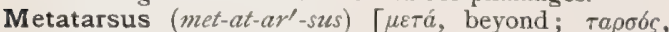
tarsus: pl., Metatarsi]. The bones of the arch of the foot, five in number, situated between the tarsus and the phalanges; the instep. In entomology : $(a)$ the terminal joint or appendage of the tarsus of an insect's leg, called planta empodium, scopula; (b) the entire foot of the hind-leg.

Metatela (met-at-e'-lah) [ $\mu \varepsilon \tau a ́$, behind; tela, tissue]. The tela of the metencephal; the velum medullare posterius, or inferior choroid tela. It constitutes the roof of the metacele.

Metathesis (met-ath'-es-is) [ $\mu \varepsilon \tau a$, beyond ; $\tau \iota \theta \varepsilon \dot{v} a \iota$, to place]. An operation designed to effect a transformation or change in the seat of disease from one part to another. In chemistry, the interchange of two elements in decomposition.

Metathetic (met-ath-et'-ik) [ $\mu \varepsilon \tau a ́$, beyond; $\tau \iota \theta \varepsilon \dot{v} v \iota$, to place]. Of the nature of a metathesis.

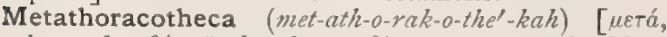
beyond; $\theta \omega \rho \alpha \xi$, the chest; $\theta i j k$, a case : pl., Metathoracothece]. In entomology, that part of the integument covering the metathorax in a pupa.

Metathorax (met-ath-o'-raks) [ $\mu \varepsilon \tau a ́$, beyond; $\theta \omega \rho \alpha \xi$, the chest]. In biology, the third and last segment of the thorax in insects; it bears the third pair of legs and the second pair of wings, and is composed of the metasternum, metapleura, and post-dorsum.

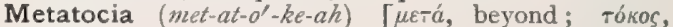
birth]. Birth by any other than the normal process, as by Cesarean section.

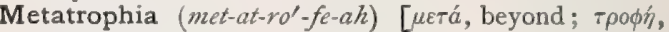
nourishment]. Any morbid condition or process of nutrition.

Metaxin (met-aks'-in) [ $\mu \varepsilon \tau a \xi v$, between]. A proteid found by Schwartz in the plasmatic substratum of chlorophyl-grains. It is easily digested by both pepsin and trypsin.

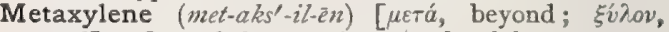
wood]. One of the constituents of xylol.

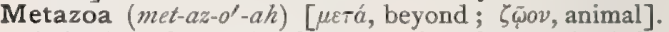
Animals whose development is characterized by segmentation of the ovum. They comprise all animals except the Protozoa.

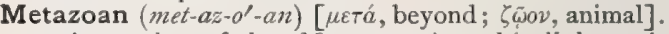
I. A member of the Metazoa. A multicellular animal having a transitional stage (Gastrula) in its development, corresponding to a hypothetic ancestor, the Gastraa, which is held to have arisen from a Protozoan colony in the shape of a hollow sphere, by the formation and gradual deepening of a depression or invagination. 2. Pertaining to the metazoa.

Metecious (met-e'-she-us) [ $\mu \varepsilon \tau a ́$, beyond; oikos, a house]. See Heterecions.

Metembryo (met-em'-bre-o) [ $\mu \varepsilon \tau a ́$, after; $\tilde{\varepsilon} \mu \beta \rho v o \nu$, embryo]. In biology, the gastrula stage of the metazoan embryo,

Metencephal (met-en-sef'-al). Same as Metencephalon.

The Metatarsus AND ADJACENT BONES.

I. Inferior surface of calcaneum. 2. Inner tuberosity. 3. Outer tuberosity. 4. Angular depression between these tuberosities. 5. Inferior portion osities. 5. Inferior portion of head of astragalus. 6.
Plantar surface of cuboid, for attachment of inferior calcaneo-cuboid ligament. 7 . Tuberosity of cuboid. 8 . Scaphoid. Tuberosity of scaphoid. I0. Inferior portion of phoid. I0. Inferior portion of
internal cuneiform. II. Apex internal cuneiform. II. Apex
of middle cuneiform. I2. Apex of internal cuneiform. I3, 14, I5, 16, 17. First, second, third, fourth and fith metatarsal bones. I8. Tuberosity of fifth metatarsal bone. Two sesamoid bones. First phalanx of great toe. $2 \mathbf{x}$. Last phalanx of great toe. 22.22. First phalanges of remaining toes. 23,23. Second and third phalanges of these toes.

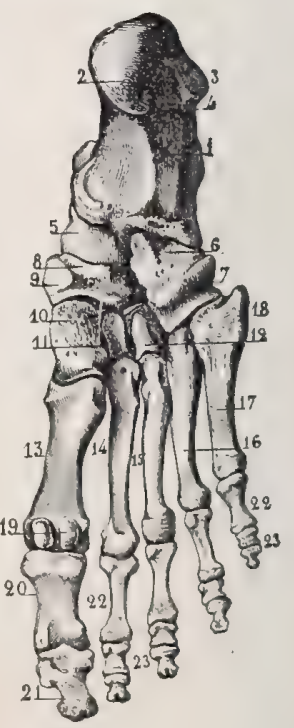

Metencephalic (met-en-sef-al'-ik) [ $\mu \varepsilon \tau a ́$, after ; $\dot{\varepsilon} \gamma \kappa \dot{\varepsilon} \phi a-$ $\lambda \circ s$, brain]. Pertaining to the metencephalon.

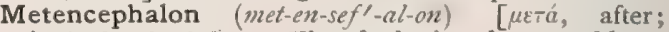

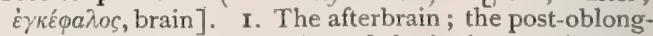
ata, or most caudal portion of the brain. 2. Rarely, the cerebellum and the pons.

Metensomatosis (met-en-so-mat-o'-sis) [ $\mu \varepsilon \tau a ́$, beyond;

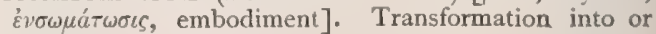
union with another body.

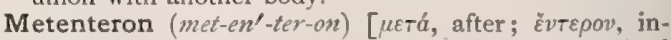
testine]. The enteron in any secondary or specialized state due to modification of the archenteron. 
Meteoric (me-te-or'-ik) [ $\mu \varepsilon \tau \varepsilon \omega \rho i \zeta \varepsilon \iota \nu$, to elevate]. Pertaining to meteorism; also, pertaining to the atmosphere.

Meteorism, Meteorismus (me'-te-or-izm, me-te-or$\left.i z^{\prime}-m u s\right)$ [ $\mu \varepsilon \tau \varepsilon \omega \rho i \zeta \varepsilon \iota v$, to elevate]. Distention of the abdomen with gases; tympanites.

Meteoristic (me-te-or-is'-tik) [ $\mu \varepsilon \tau \varepsilon \omega \rho i \zeta \varepsilon \iota v$, to elevate]. Synonym of Tympanitic.

Meteorization (me-te-or-iz-a $a^{\prime}-\operatorname{shun)}[\mu \varepsilon \tau \varepsilon \omega p i \zeta \varepsilon l \nu$, to elevate]. The formation of gas in the abdomen; the production of meteorism.

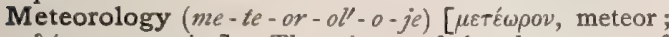
$\lambda$ bros, a treatise]. The science of the phenomena of the atmosphere and the laws of its motions.

Metepencephalon (met-ep-en-sef'-al-on) [ $\mu \varepsilon \tau \boldsymbol{t}^{\prime}$, after ; $\dot{\varepsilon} \pi i$, upon; $\dot{\varepsilon} \gamma \kappa \varepsilon \dot{\phi} \alpha \lambda \circ$ s, brain]. The metencephalon and epencephalon considered together. It includes the cerebrum, the oblongata, and the pons.

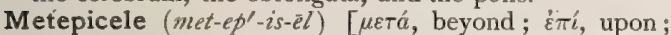
кoinia, belly]. The fourth ventricle of the brain; the ventricle of the metepencephalon; the metacele and epicele taken together.

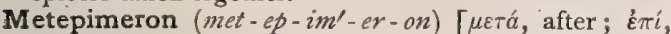
upon; $\mu \eta \rho \delta$ s, a thigh: pl., Metepimera]. In biology, the epimeron or lateral piece of the metathorax of an insect.

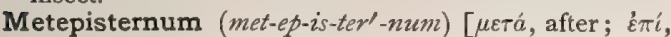
upon; $\sigma \tau \varepsilon \hat{\varepsilon} \rho o v$, breast, breast-bone : pl., Metepisterna]. In biology, one of the episterna of the metathorax of an insect.

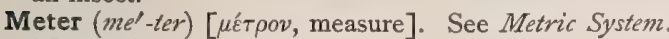
M.-angle. See Angle.

Methacetin (meth-as'-et-in) [ $\mu \varepsilon \tau$ á, beyond; acetum, vinegar], $\mathrm{C}_{9} \mathrm{H}_{11} \mathrm{NO}_{2}$. An analogue of phenacetin, having the same antipyretic qualities as the latter, and more soluble. Dose from 2 to 4 grains exhibited with great caution. Unof.

Methal (meth'-al) [ $\mu \varepsilon \tau a ́$, with ; vं $\eta$, matter], $\mathrm{C}_{14} \mathrm{H}_{30} \mathrm{O}$. Ar alcohol, not yet isolated, occurring in spermaceti.

Methane $\left(m e t h^{\prime}-\bar{a} n\right)\left[\mu \varepsilon \tau \dot{\alpha}\right.$, with ; $v \lambda \eta$, matter], $\mathrm{CH}_{4}$. Marsh-gas. The first member of the homologous series of paraffins, $\mathrm{C}_{n} \mathrm{H}_{2 n+2}$. It occurs in nature wherever decomposition of organic matter is going on, especially in marshes. It is inflammable, and unites readily with the halogens. See Carbohydrates, Table of.

Metheglin (me-theg'-lin) [Welsh, medd, mead; llyn, liquor]. A variety of mead, or hydromel. See Hydromel.

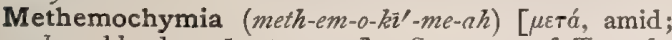
ai $\mu a$, blood; $\chi \varepsilon \tilde{i \nu}$, to pour]. Synonym of Transfusion.

Methemoglobin (met-hem-o-glo'-bin) [ $\mu \varepsilon \tau a ́$, with ; ai $\mu a$, blood; globus, a ball]. A modified form of hemoglobin produced by exposing blood, or solutions of hemoglobin, to the air for some time. It may be obtained in crystalline form as reddish-brown needles that are doubly refracting and readily soluble in water, though less so than oxyhemoglobin. It is the product either of the incomplete decomposition of hemoglobin or of its excessive oxidation; the oxygen is more firmly combined in it than in oxyhemoglobin. In poisoning with potassium chlorate, the nitrites, acetanilid, and some other bodies, the blood contains methemoglobin.

Methemoglobinemia (met - hem - o - glo-bin - $e^{\prime}-$ me-ah) [ $\mu \varepsilon \tau a ́$, with ; ai $\mu a$, blood; globus, a ball; ai $\mu a$, blood]. The presence of free methemoglobin in the blood. See Methemoglobin.

Methemoglobinuria (met-hem-o-glo-bin-u'-re-ah) [ $\mu \varepsilon \tau \dot{a}$, with; ai $\mu \alpha$, blood; globus, a ball ; orjoov, urine]. The presence of free methemoglobin in the urine.

Methexiphrenesis (meth-eks-if-ren-el-sis) [ $\mu \varepsilon \hat{\theta} v$, wine ; $\dot{\varepsilon} \xi \iota$, habit; $\left.\phi \rho \varepsilon v_{\nu}\right)_{\varsigma}$, inflammation of the brain]. Delirium tremens.

Methexomania (meth-eks-o-ma'-ne-ah) [ $\mu \varepsilon \dot{\theta} \theta \eta$ drink; $\tilde{\varepsilon} \xi \iota$, habit; $\mu a v i \alpha$, madness]. See Methomania.

Methilepsia (meth-il-ep'-se-ah) [ $\mu \varepsilon \dot{\theta} \theta \eta$, drink; $\lambda \bar{\eta} \psi \iota s$, seizure]. Irresistible desire for strong drink.

Methobiostatics (meth-o-bi-o-stat'-iks) [ $\mu \varepsilon^{\prime} \theta \eta$, strong drink; $\beta i o s$, life; oratikbs, causing to stand]. The study of the influence of alcoholic excess.

Method (meth'-od) [ $\mu \varepsilon$ bodos, method]. A system or plan of procedure. M. of Definite Mixtures. See Anesthetic. M., Intensive. See Pasteur. M. of Treatment. See Treatment, Methods of.

Methodism (meth'-od-izm) [ $\mu \varepsilon^{\prime} \theta 0 \delta o \varsigma$, way, system]. The system of the treatment of disease according to a strict method, as taught by an ancient school or sect of physicians.

Methodist (meth'-od-ist) [ $\mu \varepsilon^{\prime} \theta 0 \delta o s$, system]. A follower of methodism.

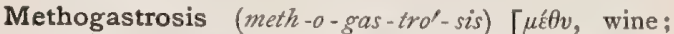
$\gamma \alpha \sigma \tau \eta \hat{\rho}$, stomach; vóбos, disease]. Digestive disturbances consequent upon alcoholic excess.

Methol (meth's $-o l)$ [ $\mu \varepsilon \tau \hat{\alpha}$, with; $i \hat{n} \eta$, matter]. One of the names of methylic alcohol.

Methomania (meth-o-ma'-ne-ah) [ $\mu \varepsilon \dot{\theta} \theta \eta$, drunkenness ; uavia, madness]. I. Same as Mania a potu. 2. (More often) the irresistible desire for strong drink; dipsomania.

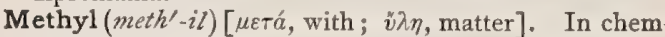
istry, a radicle molecule, having the composition $\mathrm{CH}_{3}$. It is the base of a large number of compounds, including an alcohol, methyl-spirit, and several ptomains. M.-alcohol (wood-spirit), obtained in the destructive distillation of wood. It has a purely spirituous odor, a specific gravity of .7995 at $15^{\circ} \mathrm{C}$., and boils at $55.1^{\circ} \mathrm{C}$. It is miscible in all proportions with water; ordinary alcohol, and ether. M.-alizarin, $\mathrm{C}_{15} \mathrm{H}_{10} \mathrm{O}_{5}$; a substance obtained by fusing methylanthraquinone sulphonic acid with alkalies. It is very similar to alizarin, melting at $250^{\circ}-252^{\circ} \mathrm{C}$, , and readily subliming in red needles. M.-anilin, $\mathrm{C}_{6} \mathrm{H}_{5} \cdot \mathrm{NH}\left(\mathrm{CH}_{3}\right)$; an anilin derivative. Boiling at $190^{\circ}-191^{\circ} \mathrm{C}$, it has an odor resembling that of anilin, and a specific gravity at $15^{\circ} \mathrm{C}$. of 0.976 . The methylated anilins are technically applied in the production of anilin dye-stuffs. They are formed on heating anilin together with $\mathrm{HCl}$ anilin and methyl-alcohol to $200^{\circ} \mathrm{C}$. or better still, by conducting $\mathrm{CH}_{3} \mathrm{Cl}$ into boiling anilin. M.-anthracene, $\mathrm{C}_{15} \mathrm{H}_{12}$; a substance obtained on heating emodin with zinc-dust. It occurs in crude anthracene, and is obtained from oil of turpentine on exposure to a red heat. It resembles anthracene, crystallizes from alcohol in yellow leaflets, and melts at $190^{\circ} \mathrm{C}$. M.arabinose. See Rhamnose. M.-benzene. See Toluene. M.-blue, a basic anilin dye used for staining bacteria. See Pigments, Conspectus of. M.-chlorid, $\mathrm{CH}_{3} \mathrm{Cl}$, a liquefied gas used in the form of a spray as a local anesthetic for the relief of sciatica and similar neuralgic affections. See Anesthetic. M.-ether, $\mathrm{C}_{2}-$ $\mathrm{H}_{6} \mathrm{O}$; dimethyl oxid, an inflammable gas; also, a salt of methyl. M.-glycocoll. See Sarcosin. M.-green, an anilin dye. See Pigments, Conspectus of. M.guanamin, $\mathrm{C}_{4} \mathrm{H}_{7} \mathrm{~N}_{5}$; a crystalline body, readily soluble in hot water and in alcohol. M.-guanidin, $\mathrm{C}_{2} \mathrm{H}_{7} \mathrm{~N}_{3}$; methyluramin; a colorless, highly hygroscopic, and strongly alkaline base, insoluble in alcohol. It is the product of the oxidation of kreatin and kreatinin, and has been obtained from horseflesh after four months' decomposition at low temperature, and from cultures of the comma-bacillus. It is a colorless, easily deliquescing mass, possessing a strong alkaline reaction, and is highly poisonous. The symptoms 
to which toxic doses give rise are dyspnea, muscletremor, and general clonic convulsions. See Ptomains, Table of. M. -heptose. See Carbohydrates, Table of. M.-hexose. See Carbohydrates, Table of. M.-hydantoin, M.-hydrantoin, a crystalline substance, obtained by fusing together sarcosin and urea, or by decomposing kreatinin. It melts at $145^{\circ}$ C. M.hydrid, marsh-gas. M.-indol. See Skatol. M.orange. See Pigments, Conspectus of. M.-phenyl Ether. See Anisol. M.-phenyl-ketone. Same as Hypnone. M. Salicylate, $\mathrm{C}_{8} \mathrm{H}_{8} \mathrm{O}_{3}$; an oily liquid of a peculiar odor, constituting 90 per cent. of the oil of wintergreen; it has been used in rheumatism instead of the alkaline salicylates. M.-spirit. See $M$-alcohol. M--uramin, See $M$-guanidin. M. violet, an anilin dye used for staining bacteria. Under the name of Pyoktanin Stilling recommends it very highly as an effective bactericide. Dose gr. j-v. Unof. See Pioments, Conspectus of.

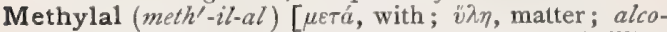
hol ], $\mathrm{C}_{3} \mathrm{H}_{8} \mathrm{O}_{2}$. A substance prepared by distilling methyl-alcohol with sulphuric acid. It is hypnotic and antispasmodic, Dose $3 \mathrm{j}$. Unof.

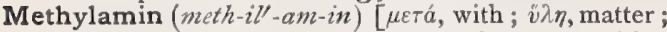
amin]. A colorless gas having the composition $\mathrm{N}\left(\mathrm{CH}_{3}\right) \mathrm{H}_{2}$, easily condensing to a colorless liquid. It is used mainly as a reagent in certain organic tests. It occurs also as a ptomain in certain putrefactions, notably that of fish. It is also found in herring-brine, to which it gives odor.

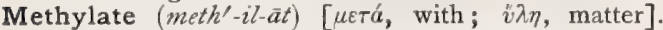
Methyl-alcohol in which a metal substitutes the hydrogen of the hydroxyl.

Methylated (meth'-il-a-ted) [ $\mu \varepsilon \tau a ́$, with; $v \lambda \eta$, matter]. Containing methyl-alcohol. M. Spirits, methyl-alcohol, wood-alcohol. The strongest methylated spirit free from mineral naphtha, can be used in place of 90 per cent. alcohol for hardening and preserving purposes.

Methylation (meth-il-a'-shun) [ $\mu \varepsilon \tau \hat{\alpha}$, with ; $v \lambda \eta$, matter]. The process of mixing a substance with methylalcohol.

Methylene (meth'-il-ēn) [ $\mu \varepsilon \tau a \dot{a}$, with; $v \hat{v} \eta$, matter], $\mathrm{CH}_{2}$. A bivalent hydrocarbon radicle that does not exist free, but occurs in many compounds. See Anesthetic. M.-blue, $\mathrm{C}_{16} \mathrm{H}_{18} \mathrm{~N}_{3} \mathrm{SCl}$; a coal-tar dye prepared from dimethylanilin; it is much used in the arts and as a stain in bacteriology. Its Io per cent. solution is recommended as a local application in diphtheria, tonsillitis, scarlatinal sore-throat, and other inflammatory conditions, and internally administered it has proved serviceable as an antiperiodic and antalgic. Dose gr. jss in capsule. Unof. M. Dichlorid, $\mathrm{CH}_{2} \mathrm{Cl}_{2}$; a general anesthetic, frequently used instead of chloroform. It is asserted by Genther and Eichholz to be more susceptible of management than the latter in protracted operations. Much of the methylene dichlorid contains 5075 per cent. of chloroform. Unof. See Anesthetic.

Methylic (meth-il'-ik) [ $\mu \varepsilon \tau a ́$, with ; $v \lambda \eta$, matter]. Containing methyl. Pertaining to methyl.

Methylized (meth'-il-izd). Synonym of Methylated.

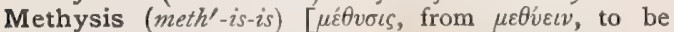
intoxicated]. Intoxication.

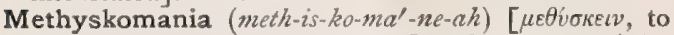
make drunk; $\mu a v i a$, madness]. Same as Methomania; dipsomania.

Methystic (meth-is'-tic) [ $\mu \varepsilon \theta v \sigma \tau \imath \kappa o s$, from $\mu \varepsilon \theta \theta^{\prime} \varepsilon \iota v$, to be intoxicated]. 1. Intoxicant. 2. An intoxicating agent.

Methysticin (meth-is'-tis-in) [ $\mu \varepsilon \theta v \sigma \tau \iota \kappa \delta s$, intoxicating]. A crystalline principle obtained from Kava-kava, closely allied to piperin. It is a neutral, tasteless substance, sparingly soluble in cold, but more freely in hot water, easily soluble in alcohol and ether. It is also called Kavahin.

Metis (ma'-tess) [Fr.]. A half-breed of French and Indian parentage. See Mulatto.

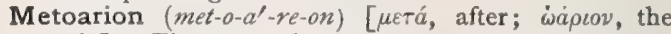
ovule]. The corpus luteum.

Metodontiasis (met-o=don-ti'-as-is) [ $\mu \varepsilon \tau a \dot{a}$, after; odov$\tau \iota \vec{a} \nu$, to cut teeth]. The second dentition; also, abnormality of teething

Metcecesis (met-es-e'-sis) [ $\mu \varepsilon \tau a$, beyond; oiknous, the act of dwelling]. Transposition; displacement.

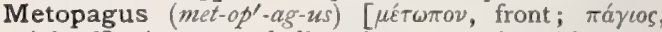
joined]. An ensomphalic twin monstrosity with united foreheads.

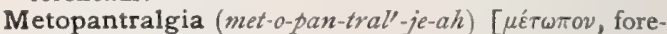

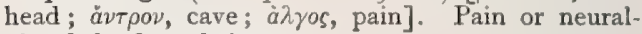
gia of the frontal sinus.

Metopantritis (met-o-pan-tri'-tis) [ $\mu \varepsilon \dot{\varepsilon} \omega \pi \pi \nu$, forehead;

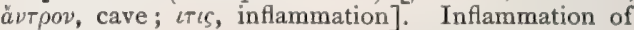
the metopantron.

Metopantron, Metopantrum (met-o-pan'-tron, met-o

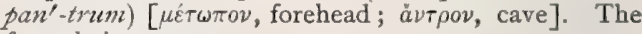
frontal sinus.

Metope $\left(m e t^{\prime}-o-p e\right)$ [ $\mu \varepsilon^{\prime} \tau \omega \pi o v$, face]. In biology, that portion of the frontal surface of a crustacean in which the antennæ are situated. Same as Facies.

Metopic (met-op'-ik) [ $\mu \dot{\varepsilon} \tau \omega \pi o \nu$, forehead]. 1. Relating to the forehead; frontal. 2. A name applied to a cranium having a medio-frontal suture. M. Points. See Craniometric Points.

Metopion (met-o'-pe-on) [ $\mu \dot{\varepsilon} \tau \omega \pi o v$, forehead]. See Craniometric Points.

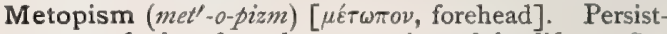
ence of the frontal suture in adult life. See Metopon.

Metopium (met-o'-pe-um). Synonym of Metopon.

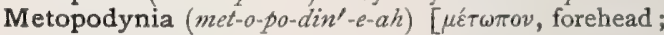
ódiv, pain]. Frontal headache.

Metopon (met'-o-pon) [ $\mu \varepsilon ́ \tau \omega \pi o \nu$, forehead ; from $\mu \varepsilon \tau a ́$, between; $\omega \psi$, eye ]. Forehead; also an old name for galbanum.

Metopopagia (met-o-po-pa'-je-ah). Synonym of Metopagus.

Metoposcopy (met-op-os'-ko-pe) [ $\mu \dot{\varepsilon} \tau \omega \pi o v$, forehead:

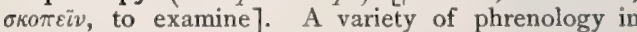
which the character or the future of an individual is supposed to be determined by an inspection of the forehead.

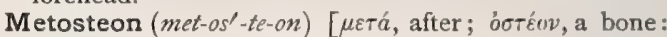
$p l .$, Metostea $]$. In biology, the posterior lateral piece of the sternum of a bird.

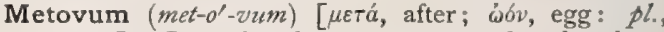
Metova]. In embryology, an ovum that has been modified from its primitive condition as an egg-cell or protovum; an after-egg or deutovum. Cf. Ovicell, Orum.

Metra (me'-trah) [ 'n $^{\prime} \rho a$, uterus]. The uterus.

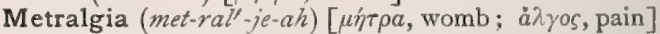
Pain or neuralgia of the uterus.

Metranastrophe (met-ran-as'-tro-fe) [ $\mu$ ír $\rho a$, womb;

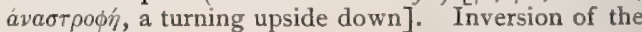
uterus.

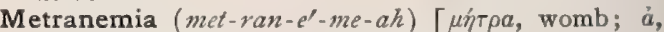
priv.; aipa, blood]. Uterine anemia.

Metraneurysm (met-ran'-u-rizm) [ $\mu$ ŕ $\rho a$, womb; ávev $\rho v \sigma \mu a$, dilatation]. Dilatation of the uterus or vulva.

Metrasia (met-ra'-ze-ah). Synonym of Metratresia.

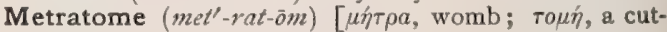
ting]. An instrument for incising the womb. 
Metratonia (met-rat-o'-ne-ah) [ $\mu \dot{\eta} \tau \rho \alpha$, womb ; átovía, atony]. Atony of the uterus.

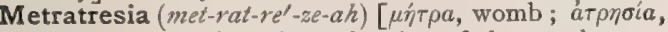
atresia]. Atresia or imperforation of the womb.

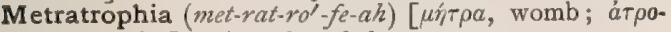
$\phi i a$, atrophy]. Atrophy of the uterus.

Metrauxe (met-rawks'-e) [ $\mu \dot{\eta} \tau \rho a$, womb; $a \dot{v} \xi \eta$, increase]. Hypertrophy or enlargement of the uterus.

Metre (me'-ter). See Metric System.

Metrechoscope (met-rek'-o-skóp) [ $\mu \dot{\varepsilon} \tau \rho o v$, measure;

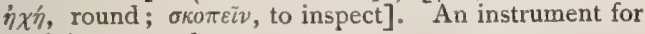
applying metrechoscopy.

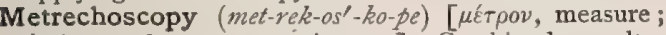

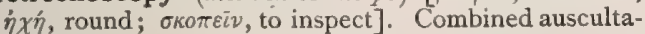
tion and mensuration.

Metrectasia (met-rek-ta'-ze-ah) [ $\mu$ '́ $\tau \rho a$, womb ; $\check{k} \kappa \tau \alpha \sigma \iota$, a stretching]. Dilatation of the womb.

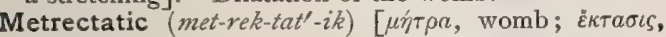
a stretching]. Affected with, or pertaining to, metrectasia.

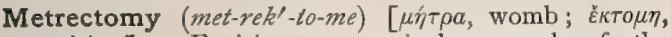
excision]. Excision or surgical removal of the womb.

Metrectopia, Metrectopy (met-rek-to'-pé-ah, met-rek'.

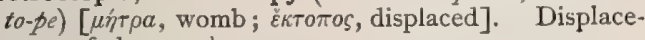
ment of the womb.

Metrelcosis (mel-rel-ko'-sis) [ $\mu \dot{\eta} r \rho \alpha$, womb; $\dot{\varepsilon} \lambda \kappa s$, ulcer]. Uterine ulceration.

Metremia (met-re'-me-ah) [ $\mu \dot{\eta} \tau \rho \alpha$, womb; ai $\mu \alpha$, blood]. Congestion of the uterus.

Metremorrhagia (met-rem-or-a'-je-ah). Synonym of Metrorrhagia.

Metremorrhoid (met-rem'-or-oid) [ $\mu$ í $\rho \alpha$, womb; ai $\mu a$, blood; poía, flow]. A hemorrhoid of the uterus.

Metremphraxis (met-rem-fraks'-is) [ $\mu$ in f $^{\prime} \alpha$, uterus ; $\varepsilon \dot{\varepsilon} \mu \phi \alpha^{\prime} \sigma \varepsilon \varepsilon v$, to obstruct]. Congestion, or infarction, of the uterine tissues.

Metremphysema (met-rem-fis-e'-mah). Synonym of Physometra.

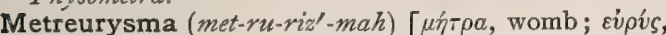
wide]. Morbid dilatation, or width of the womb.

Metria (me'-tre-ah) $\left[\mu \eta^{\prime} \tau \rho\right.$, womb]. Any uterine affection. The term is used also as a synonym of Puerperal Fever.

Metric (met'-rik) [ $\mu \varepsilon \dot{\tau} \rho \rho o v$, a measure]. Pertaining to the system of weights and measures, of which the meter is the basis. M. System, a decimal system of weights and measures employed in France, Germany, and other countries, and used generally in the sciences. The standard is the meter, the quadrant of a meridian circle of the earth. The standard of capacity is the liter, a cubical volume $\frac{1}{10}$ meter in each dimension. The standard of weight is the gram, the weight of $\frac{1}{1000}$ liter (one cubic centimeter) of distilled water at its maximum density. The unit of superficial measure is the are, a square whose side is Io meters or a decameter. As the unit of microscopic measurement the thousandth part of a millimeter has been adopted. It is called micron or microm, micromillimeter; abbreviated, $\mu$. The multiples are expressed by the prefixes deca, hecto, and kilo; the subdivisions by the prefixes deci, centi, and milli.

\begin{tabular}{|c|c|c|c|}
\hline 1000 & meters & $=$ & r kilometer. \\
\hline 100 & meters & $=$ & I hectometer. \\
\hline Io & meters & $=$ & I decameter. \\
\hline .1 & meter & $=$ & I decimeter. \\
\hline .01 & meter & $=$ & I centimeter. \\
\hline .001 & meter & $=$ & I millimeter. \\
\hline 1000 & liters & $=$ & I kiloliter. \\
\hline 100 & liters & $=$ & I hectoliter. \\
\hline ro & liters & $=$ & ecaliter. \\
\hline .I & liter & $=$ & I deciliter. \\
\hline $.0 \mathrm{I}$ & liter & $=$ & I centiliter. \\
\hline $.00 \pi$ & liter & $\Rightarrow$ & I milliliter. \\
\hline
\end{tabular}

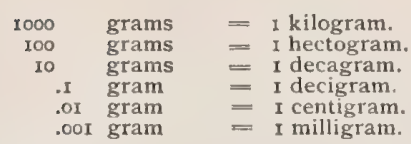

In common practice, however, the following divisions only are used, the others being expressed in figures :-

$$
\begin{aligned}
& \text { I0 millimeters }=\text { I centimeter. } \\
& \text { 100 centimeters }=\text { I meter. } \\
& \text { I000 meters }=\text { I kilometer. } \\
& \text { I000 cubic centimeters }=\text { I liter. } \\
& \text { I000 milligrams }=\text { I gram. } \\
& \text { I000 grams }=\text { I kilogram. }
\end{aligned}
$$

The following are the equivalent values:-

$$
\begin{aligned}
& \text { I meter }=3937 \text { inches } \\
& \text { I liter }=I \text { quart } 1 / 2 \text { gill, U. S. measure. } \\
& \text { I gram }=15.43 \text { grains. } \\
& \text { I minim }=0.06 \mathrm{I} \text { cubic centimeter. }
\end{aligned}
$$

See, also, Weights and Measures.

Metrine (met'-rên) [ $\mu$ ít $\rho a$, womb]. A term given to the germ of puerperal fever. See Bacillus puerperalis, under Bacteria, Synonymatic Table of.

Metritic (met-rit'-ik) [ $\mu$ ' $\tau \rho a$, womb; $\iota \tau \iota s$, inflammation]. Pertaining to, or affected with, metritis.

Metritis (met-ri'-tis) [ $\mu i^{\prime} \tau \alpha$, womb ; $\iota \iota \iota$, inflammation]. Inflammation of the uterus. M., Exanthematous, a form occurring in the course of one of the eruptive fevers. M. gravidarum, metritis occurring in a pregnant woman. M., Puerperal, metritis occurring during the puerperium. M. rheumatica, metritis due to rheumatism or occurring in a rheumatic subject. M., Suppurative, metritis proceeding to suppuration. Metroblennorrhea (met-ro-blen-or-é $-a h)$ [ $\mu \eta \eta \tau \rho$, womb; $\beta \lambda \varepsilon \dot{v v} \alpha$, mucus; poía, a flow]. Uterine blennorrhea.

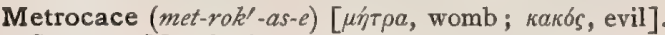
Same as Metrelcosis.

Metrocampsis (met-ro-kamp'-sis) [ $\mu \hat{\eta} \tau \rho a$, womb; кá $\mu$ $\psi(s$, bending]. Obliquity or curvation of the uterus.

Metrocarcinoma (met-ro-kar-sin-o'-mah) [ $\mu \hat{\eta} \tau \rho a$,

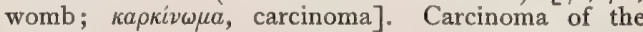
uterus.

Metrocele (met'-ro-sél) [ $\mu \hat{\eta} \tau \rho a$, womb; $\kappa \hat{\eta} \lambda \eta$, hernia]. Hernia of the uterus.

Metrocholosis (met-ro-kol-o'-sis) [ $\mu \hat{\eta} \tau \rho a$, womb; $\chi 6 \hat{\gamma} o_{\text {, }}$, bile]. Puerperal fever with hepatic symptoms; bilious puerperal fever.

Metroclyst (met'-ro-klist) [ $\mu$ inr $\rho a$, womb; $\kappa \lambda \dot{v} \zeta \varepsilon \imath v$, to wash out]. An instrument for giving uterine douches.

Metrocolpocele (met-ro-kol'-po-sél) [ $\mu \hat{\eta} r \rho a$, womb ; $\kappa \delta \lambda$ $\pi \kappa \varsigma$, vagina; $\kappa \eta \lambda \eta$, tumor]. A tumor of the vagina and womb; prolapse of the uterus into the vagina.

Metrocyte (met'-ro-sìt) [ $\mu \eta^{\prime} \tau \rho a$, womb; kv́ros, cell]. A large mononuclear, spheroid cell, of which the protoplasm contains hemoglobin. It is by Engel considered the source of all of the corpuscular elements of the blood. See also Mother-cell.

Metrodynamometer (met-ro-di-nam-om'-et-er) [ $\mu \eta \tilde{\tau} \rho a$,

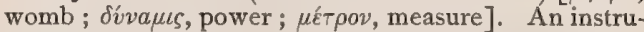
ment for measuring uterine contractions.

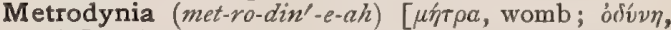
pain]. Any pain of the womb.

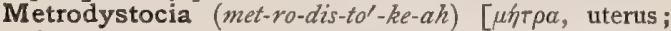

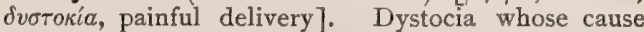
resides in the uterus.

Metroectasia (met-ro-ek-ta'-ze-ah). Synonym of Metrectasia.

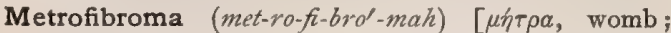
fibroma, fibrous tumor]. Uterine fibroid tumor.

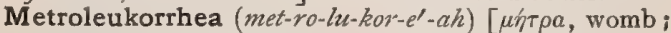
$\lambda \varepsilon v \kappa \delta$ s, white; poí, flow]. Uterine leukorrhea. 


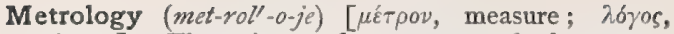
science]. The science of measures and of measurements.

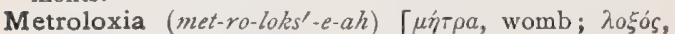
oblique]. Obliquity of the uterus; hysteroloxia.

Metro-lymphangitis (met'-ro-lim-fan-ji'-tis) [ $\mu t^{\prime} \tau \rho a$,

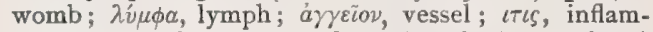
mation]. Inflammation of the lymphatic vessels of the womb. Uterine lymphangitis.

Metromalacoma (met-ro-mal-ak-o'-mah). See Hysteromalacoma.

Metromalacosis (met-ro-mal-ak-o'-sis) [ $\mu \eta \dot{\eta} \tau \rho a$, womb;

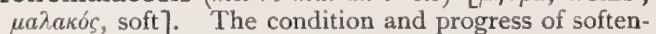
ing of the tissues of the uterus.

Metromania (met-ro-ma'-ne-ah). See Hysteromania and Nymphomania.

Metromania (met-ro-ma'-ne-ah) [ $\mu \dot{\varepsilon} \tau \rho o \nu$, measure;

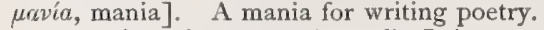

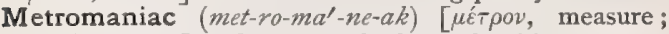
uavia, mania]. One insanely fond of writing verses.

Metromelanorrhea (met-ro-mel-an-or-e'-ah) [ $\mu \dot{n} \tau \rho a$,

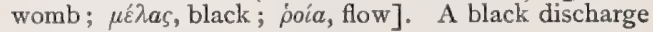
from the uterus.

Metrometer (met-rom'-et-er). See Hysterometer.

Metrometry (met-rom'-et-re). See Hysterometry.

Metronania (met-ro-na'-ne-ah) [ $\mu$ ri $\rho a$, womb; vávos, dwarf ]. Abnormal smallness of the womb.

Metroncus (met-rong $g^{\prime}-k u s$ ). See Hysteroncus.

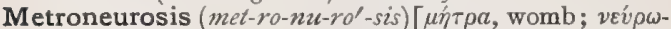
$\sigma \iota s$, neurosis]. Any neurosis caused by uterine disease.

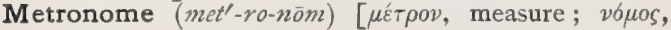
law]. An instrument for measuring time in music; also one for testing the hearing.

Metroparalysis (met-ro-par-al'-is-is) $[\mu \dot{\eta} \tau \rho a$, womb;

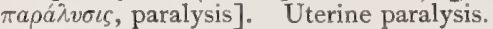

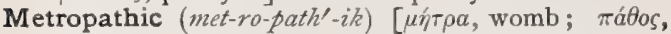
disease]. Pertaining to affections of the womb.

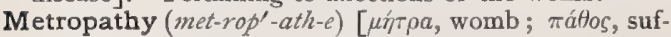
fering]. Any uterine disease.

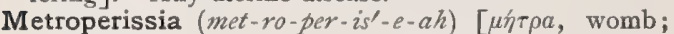
$\pi \varepsilon \rho \iota \sigma \sigma \delta$, full]. Hypertrophy of the uterus.

Metroperitonitis (met-ro-per-it-on-i'-tis) [ $\mu$ in $\rho \alpha$, womb ; $\pi \varepsilon \rho \iota \delta$ va $\iota v$, peritoneum; $\iota \tau \iota \varsigma$, inflammation]. Peritonitis secondary to inflammation of the womb.

Metropexia, Metropexy (met-ro-peks'-e-ah, met'-ropeks-e). See Hysteropexia.

Metrophlebitis (met-ro-fle-bi'-tis) [ $\mu \hat{\eta} \tau \rho a$, womb ; $\phi \lambda \hat{\varepsilon} \psi$, vein; $\iota \tau \iota s$, inflammation]. Inflammation of the veins of the uterus.

Metrophlegmymen (met-ro-fleg-mi'-men) [ $\mu \dot{\eta} \tau \rho a$, womb; $\phi \lambda \hat{\varepsilon} \gamma \mu a$, mucus; $i \mu \eta \dot{v}$, membrane]. The mucosa of the uterus.

Metrophlegmymenitis (met-ro-fleg-mi-men-i'-tis) [ $\mu \eta^{\prime}-$ $\tau \rho a$, womb ; $\phi \lambda \hat{\varepsilon} \gamma \mu a$, mucus; $\dot{v} \mu \eta \hat{v}$, membrane ; $\iota \tau \iota \zeta$, inflammation]. Inflammation of the mucous membrane lining the uterus.

Metrophlogosis (met-ro-flo-go'-sis). Synonym of $\mathrm{Me}$ tritis.

Metrophore (met'-ro-for). See Hysterophore.

Metrophyma (met-ro-fím -mah) [ $\mu \hat{\eta} \tau \rho \alpha$, womb; $\phi \tilde{v} \mu \alpha$, a growth]. A tumor of the womb.

Metroplethora (met-ro-pleth'-or-ah). Synonym of Metremia.

Metropolypus (met-ro-pol'-ip-us) [ $\mu$ ńr $\rho a$, womb ; $\pi 0 \lambda$ útovs, polyp]. Uterine polyp.

Metroproptosis (met-ro-prop-to'-sis), Metroptosis (metrop-to'-sis) [ $\mu \tilde{i} \tau \rho a$, womb; $\pi \tau \bar{\omega} \sigma \iota$, fall]. Prolapse of the uterus.

Metroproptotic (met-ro-prop-tot'-ik), Metroptotic (met$\left.r o p-t o t^{\prime}-i k\right)\left[\mu \dot{r}^{\top} \rho \alpha\right.$, womb; $\pi \tau \tilde{\omega} \sigma \iota$, a fall]. Pertaining to metroptosis.

Metropyophthisis (met-ro-pi-off'-this-is) [ $\mu$ ńtoa, womb;
Tíov, pus; $\phi \theta i \sigma \iota$, wasting]. A purulent wasting, or tabes, of the uterus.

Metrorrhagia (met-ror-a'-je-ah) [ $\mu \dot{\eta} \tau \rho a$, womb; $\dot{n} \eta \gamma$ vival, to burst forth]. Uterine hemorrhage independently of the menstrual discharge.

Metrorrhagic (met-ror-a'-jik) [ $\mu$ in $\rho a$, womb; $\dot{\eta} \gamma v v$ val, to burst forth]. Pertaining to metrorrhagia.

Metrorrhea (met-ror-e'-ah) [ $\mu \hat{i} \tau \rho \alpha$, womb; poía, a flow]. Any morbid uterine discharge.

Metrorrhectic (met-ror-ek'-tik) [ $\mu$ í $\tau \rho a$, womb; $\dot{\rho} \tilde{\eta} \xi \iota$, rupture]. Pertaining to metrorrhexis.

Metrorrheuma (met-ror-ru'-mah) [ $\mu$ ńt $\rho \alpha$, womb; $\dot{\rho} \varepsilon \tilde{v} \mu \alpha$, rheum]. Rheumatism of the uterus.

Metrorrhexis (met-ror-eks'-is) [ $\mu$ in $\rho a$, womb; $\dot{\rho} \tilde{\eta} \xi \iota$, rupture]. Rupture of the womb.

Metrosalpingitis (met-ro-sal-ping-ji'tis) [ $\mu \hat{r} \tau \rho \alpha$, womb; $\sigma a ́ \lambda \pi \iota \gamma \xi$, tube ; $\iota \tau \iota$, inflammation]. Inflammation of the womb and oviducts.

Metrosalpingorrhagia (met-ro-sal-ping - or-a' - je-ah)

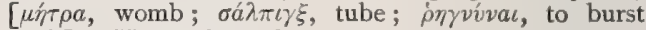
forth]. Hemorrhage from the oviducts.

Metrosalpingorrhexis (met-ro-sal-ping-or - eks'-is) [ $\mu \dot{n} \tau \rho a$, womb; $\sigma a ́ \lambda \pi \iota \gamma \xi$, tube; $\dot{\eta} \xi \xi \varsigma$, rupture]. Rupture of an oviduct.

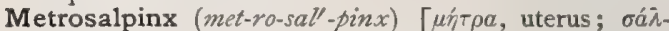
$\pi \iota \gamma \xi$, tube]. An oviduct, or Fallopian tube.

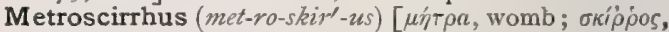
hard]. A scirrhous tumor of the uterus.

Metroscolioma, Metroscoliosis (met-ro-sko-le-o'-mah,

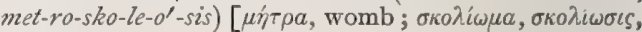
bend]. A flexion of the uterus.

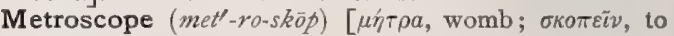
observe]. An instrument for examining the uterus.

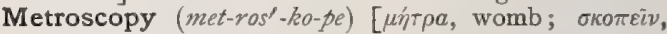
to observe]. The use of the metroscope; inspection of the uterus.

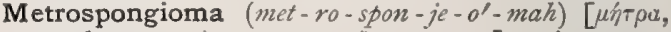

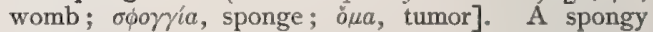
tumor of the uterus.

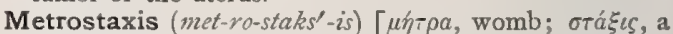
dropping]. Slight but persistent uterine hemorrhage.

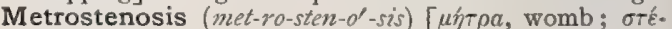
$v \omega \sigma \iota$, contraction]. Contraction of the cavity of the womb.

Metrosteresis (met-ro-ster-e'-sis) [ $\mu \dot{\eta} \tau \rho \alpha$, womb; $\sigma \tau \hat{\varepsilon}$ -

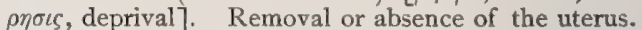

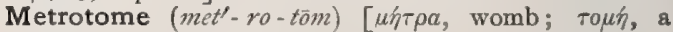
cutting]. Same as Hysterotome.

Metrotomy (met-rot'-o-me) [ $\mu \hat{r} \tau \rho a$, womb; $\tau$ o $\mu$, a cutting]. Same as Hysterotomy.

Metrotuberculum (met-ro- $u$-ber' $-k u-h u m)[\mu \eta j \rho a$, womb; tuberculum, a small nodule]. A fungous excrescence of the uterus.

Metrotyloma (met-ro-ti-lo'-mah). Synonym of Metrotuberculum.

Metrourethrotome (met-ro-u-re'-thro-tōm) [ $\mu$ ŕ $\rho$ ov,

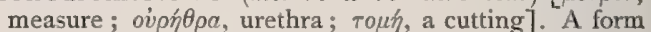
of urethrotome that will cut a stricture to the desired caliber; a graduated urethrotome.

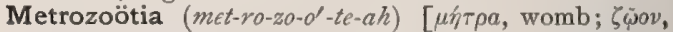
animal]. An epidemic disease of the womb in cattle.

Metrydrorrhea (met-rid-ror-e'-ah). See Hydrorrhea.

Metrymenitis (met-ri-men-i'-tis). Synonym of Metrophlegmymenitis.

Metrypercinesis (met-ri-per-sin-e'-sis) [ $\mu \eta^{\prime} \tau \rho a$, womb;

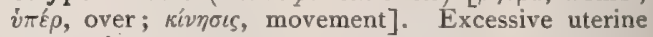
contraction.

Metryperemia (met-ri-per-ef-me-ah). Synonym of Metremia.

Metryperesthesia (met-ri-per-es-the'-ze-ah) [ $\mu \eta^{\prime} \tau a$, womb ; $i \pi \varepsilon \rho$, over; ai $\sigma \theta \eta \sigma \iota s$, perception]. Hyperes. thesia of the uterus. 
Metrypertrophia (met-ri-per-tro'-fe-ah). Synonym of Metrauxe.

Metternich-green. See Pigments, Conspectus of.

Meyer, Method of. A method of determining the vapor density of a substance. A weighed quantity of the substance is vaporized in an enclosed space, when it displaces an equal volume of air, which is measured. M.'s Tissue-paper Test, a test for color-blindness. If a border of gray paper is placed upon red paper, it appears to have the complementary color of its background (that is, green). This is particularly apparent when the whole is covered with a sheet of tissuepaper. A color-blind man cannot see the complementary color correctly.

Meynert's Bundle. See M.'s Fasciculus. M.'s Commissure, a bundle of large-sized nerve-fibers extending from the tuber cinereum and the anterior perforated substance into the optic tract, and terminating in the subthalamic body. M.'s Fasciculus, a fasciculus of white nerve-fibers extending between the habenular and interpeduncular ganglia. M.'s Fountainlike Decussation, a group of nerve-fibers that arise in the roof of the aqueduct and decussate in the dorsal segment of the raphé. M., Ganglion of. See Ganglia, Table of. M.'s Granular Formation, the fourth stratum of the cerebral cortex. M.'s Projection System, a plan of the construction of the nervous system, whereby it is divided into three sections : The first is composed of the fibers from the cortex of the brain through the corona radiata in a radiate direction; the second, of longitudinal bundles of fibers proceeding downward to the ganglionic gray matter reaching from the third ventricle through the aqueduct of Sylvius to the lowest part of the gray matter of the spinal cord; the third, the peripheral nerves, motor and sensory, proceeding from the central tubular gray matter.

Mezcal, Mescal (mez-kahl') [Mex.]. An intoxicant spirit distilled from pulque, the fermented juice of various Mexican species of Agave.

Mezereon, Mezereum (mez-e'-re-on, mez-e'-re-um) [Ar., màzariyunn, the camellia]. The bark of Daphne mezereum, a powerful sialogogue and irritant poison, producing purging and gastro-enteric inflammation. It is used as an antisyphilitic, combined with sarsaparilla, but chiefly as a local irritant to stimulate indolent ulcers. M., Ext., used in the preparation of liniment of mustard. M., Ext., Ether. (B. P.), used externally as a counter-irritant. M., Ext., Fld., used in the preparation of M., Ung., consisting of fld. ext. mezereon 25 , lard 80 , and yellow wax 12 parts.

Mezizah $\left(m e z-i^{\prime}-z a h\right)$ [Heb.]. The fourth act in the Jewish rite of circumcision. It consists in sucking the bleeding surface in order to secure the salutary influence of the saliva.

Mezquit (mes-kèt') [Sp.]. The tree or shrub Prosopis juliflora of the S. W. United States and Mexico. Its gum resembles gum arabic.

Mho $\left(m^{\prime} 0\right)$ [anagram of $\left.0 h m\right]$. The unit of electric conductivity; conductivity at the resistance of one ohm.

Miaria (mi-a'-re-ah) [ $\mu \iota a \rho i \alpha$, defilement]. Synonym of Miasm.

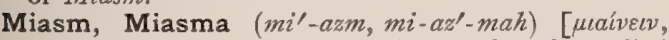
to pollute: pl., Miasmata]. A term loosely applied to the floating germs of any form of microbic life, especially those generating in marshy localities.

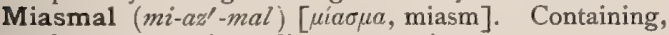
relating to, or depending upon, miasm.

Miasmatic $\left(m i-\alpha z-m a t^{\prime}-i k\right)$ [ $\mu \iota \alpha i v \varepsilon \iota v$, to pollute]. Pextaining to or having the nature of miasma. See Contagious. M., Contagio-, a term applied to those diseases the specific germs of which, after leaving the animal body, undergo a further development before again becoming infectious. Typhoid fever, cholera, yellow fever, and some other diseases, are contagiomiasmatic. M.-contagious. See Contagious, M. Diseases, those diseases produced by infectious causes arising from without the animal body, e.g., malaria.

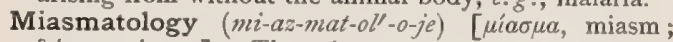
$\lambda$ 'óos, science]. The science or study of miasmata.

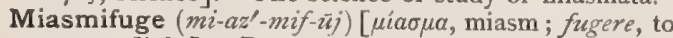
put to flight]. Preventing or banishing miasmatic diseases.

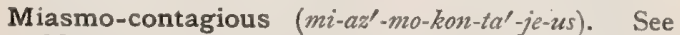
Miasmatic.

Miasmology (mi-az-mol'-o-je). Synonym of Minsmatology.

Mica ( $\left.m i^{\prime}-k a h\right)$ [L., a crumb]. Thin, glossy, transparent scales, composed of aluminum silicate. $\mathbf{M}$. panis, crumb of bread; used in pharmacy.

Micaceous (mi-ka'-she-us) [mica, crumb]. Resembling mica ; composed of crumbs ; friable.

Mication (mi-ka'-shun) [micare, to glitter]. Quick motion; a winking; systolic contraction.

Micella (mi-sel'-ah) [dim. of mica, a crumb, grain ; $p l$, Micelle]. In biology, according to Nägeli's theory, one of the fundamental structural units of organized bodies. He defines it as "a minute crystal, microscopically invisible, consisting of a larger or smaller number of molecules, and, when turgid, surrounded by a layer of water." Weismann does not accept this as corresponding to his "biophore."

Micellar (mi-sel'-ar) [micella, dim. of mica, crumb]. Relating to a micella. M. Aggregate, a number of micellæ united together.

Michel's Diplococcus. The micrococcus found in contagious conjunctivitis. See Bacillus of Conjunctival Catarrh, under Bacteria, Synonymatic Table of. M.'s Paste, a caustic paste composed of asbestos one part, and concentrated sulphuric acid three parts.

Micheli's Placenta. The sporangium of certain fungi, as, for instance, those that give rise to otomycosis.

Michelia (mi-ke'-le-ah) [after P. A. Micheli, an Italian botanist]. A genus of magnoliaceous plants. $\mathbf{M}$. champaca. See Champak.

Michigan Itch. Same as Army Itch. M. Method, a method of Artificial Respiration. The individual is placed on his face, the operator astride of the body. The shoulders are then raised as high as they can go, without the head leaving the floor, and this position is maintained while the operator counts three. The body is then allowed to return to the ground. Pressure is then made downward and inward on the lower ribs while two is counted. The operator then repeats the first series of movements.

Micology (mi-kol'-o-je). See Mycology.

Micracoustic (mi-krah-kow'-stik) [ $\mu \iota \kappa \rho b ́ s$, small ; ákovo$\tau \iota \kappa o ́ s$, pertaining to hearing]. Hearing, or assisting in hearing, very small sounds.

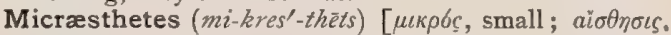
sensation]. In biology, small knob-like sense-organs found by Moseley in the micropores of certain Chitonida.

Micraine (mik'-rān). Synonym of Migraine.

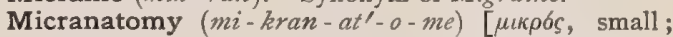
ávaroún, a cutting up]. Minute anatomy; histology. Micrander (mi-kran'-der) [ $\mu \iota \kappa \rho b ́ s$, small; ávíp, male]. In biology, a small male plant.

Micrane (mik'-rān). Synonym of Migraine.

Micrangiopathy (mi-kran-je-op'-ath-e) [ $\mu$ knós, small ;

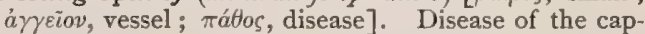
illaries.

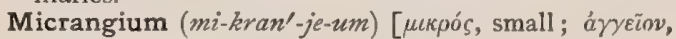
vessel]. Capillary. 


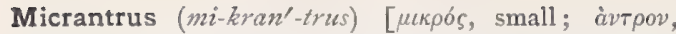
cave]. Lissauer's term for a skull in which a perpendicular from the most prominent point of the frontal torus upon the radius fixus is not more than $4 \mathrm{~mm}$. in front of that from the nasion.

Micrencephalon, Micrencephalium (mi-kren-sef'-al-

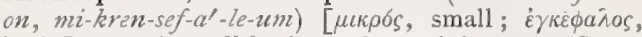
brain]. I. A small brain, as in cretinism. 2, Synonym of Cerebellum.

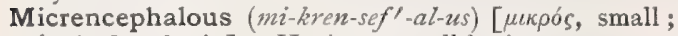

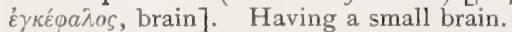

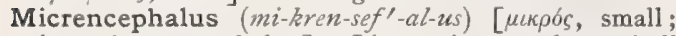

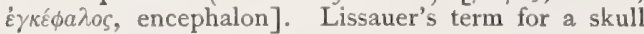
in which the angle formed between lines drawn from the hormion to the nasion and to the inion respectively is between $129^{\circ}$ and $142.5^{\circ}$

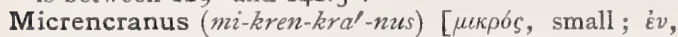
in ; kpaviov, skull]. Lissauer's term for a skull with a cerebellar sector of from $8.5^{\circ}$ to $15^{\circ}$.

Micristology (mi-kris-tol'-o-je). See Histology.

Micro- (mi'-kro-. Mik'-ro-, from an etymologic point of view, would seem preferable to $m i^{\prime}-k r o-$, but the balance of authorities is certainly in favor of the latter pronunciation.) [ $\mu \epsilon \kappa \rho o ́ s$, small]. I. A prefix signifying minute. 2. Also, a prefix occasionally used to signify a unit one-thousandth or one-millionth part of the unit to which it is prefixed.

Microanatomy (mi-kro-an-at'-o-me). See Micranatomy.

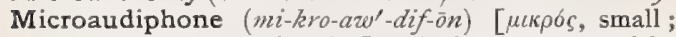
audire, to hear; $\phi o \nu \eta$, voice]. An instrument used for rendering audible sounds that are very slight.

Microbacteria (mi-kro-bak-te'-re-ah). See Bacteria.

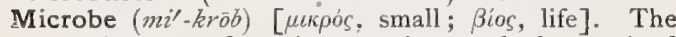
generic name for microörganisms, whether animal or vegetable. In ordinary use the term microbe is equivalent to schizomyces, and designates a vegetable microörganism. See Microörganism.

Microbial, Microbian, Microbic (mi-kro'-be-al, mi-

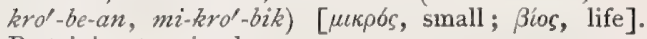
Pertaining to microbes.

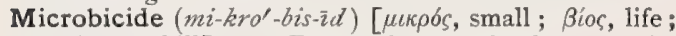
cadere, to kill]. I. Destructive to microbes. 2. An agent that destroys microbes.

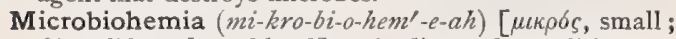
Bíos, life; ai $\mu c$, blood]. A diseased condition resulting from the presence of microörganisms in the blood.

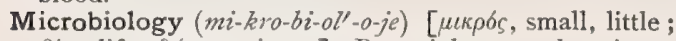
Bios, life; $\lambda \delta$ 'os, science]. Bacteriology, or the science of microörganisms.

Microbion, Microbium (mi-kro'-be-on, mi-kro'-be-um). Same as Microbe.

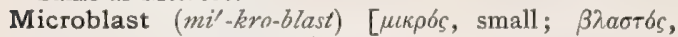
germ]. An immature blood-corpuscle.

Microblepharia, Microblepharon (mi-kro-blef-a'-re-

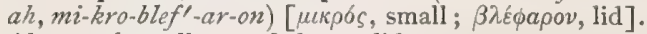
Abnormal smallness of the eyelids.

Microbrachius ( $\left.m i-k r o-b r a^{\prime}-k e-u s\right)$ [ $\mu \varepsilon \kappa \rho b s$, small ;

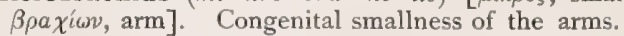

Microbrachycephalia ( $\left.m i-k r o-b r a-k e-s e f-a^{\prime}-l e-a h\right)$ [ cephalia combined with microcephalia.

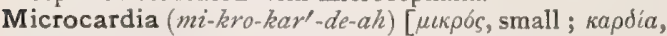
heart]. Congenital smallness of the heart.

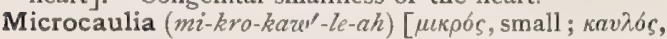
penis]. Abnormal or congenital smallness of the penis.

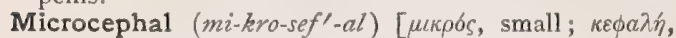
head]. A person affected with microcephaly.

Microcephalia (mi-kro-sef-a'-le-ah). See Microcephaly.

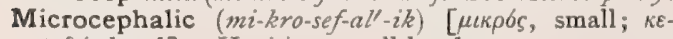
$\phi a \lambda \dot{n}$, head]. Having a small head.
Microcephalism (mi-kro-sef'-al-izm). Synonym of Microcephaly.

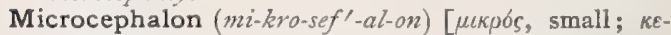
$\phi a \hat{\lambda} \eta \dot{n}$, head]. An abnormally small head.

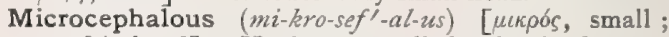
$\kappa \varepsilon \phi a \lambda \dot{n}$, head]. Having a small head; in botany, having flowers arranged in small heads.

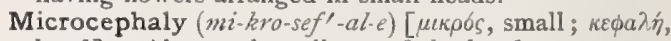
head]. Abnormal smallness of the head.

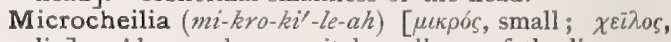
lip]. Abnormal congenital smallness of the lips.

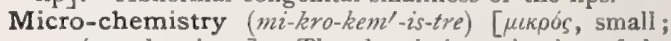
$\chi \eta \mu \varepsilon \varepsilon$, chemistry]. The chemic investigation of the more minute substances of nature. Also, the study of chemic reactions, in which a drop each of the reagent and the substance to be tested are made to coalesce on a porcelain or glass plate, the reaction being observed under a microscopic objective of low power.

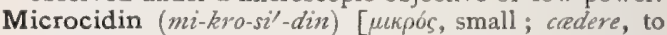
kill]. A fine white powder resulting from heating naphthol- $\beta$ to liquefaction, and adding half its weight of caustic soda. It is said to be a good antiseptic, ten times more powerful than phenol and twenty times more powerful than boric acid, and has but feeble toxic qualities. Internally it may be given in doses of from Io to 30 grains per diem. Unof.

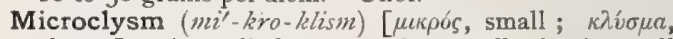
clyster]. A small clyster; a clyster effective in small amounts.

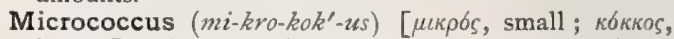
kernel]. A genus of schizomycetous microörganisms, having spheric elements, isolated, united in two's or in larger numbers, or disposed in chaplets, or masses of zoöglea. Sometimes they are united in such a way as to resemble a bunch of grapes and are then called Staphylococci. When united in couples they are called Diplococci. If arranged in strings or chaplets they are called Streptococci. Certain species are pathogenic, others are chromogenic, others have a fermentative action, and some no discoverable function. See Bacteria, Synonymatic Table of.

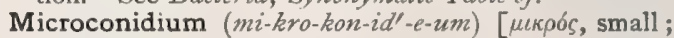
кóvı, dust: pl., Microconidia]. In biology, a relatively small-sized conidium.

Microcoria ( $m i-k r o-k o^{\prime}-r e-a h$ ) [ $\mu \iota \kappa \rho o ́ s$, small; $\kappa b \rho \eta$, pupil]. Same as Miosis.

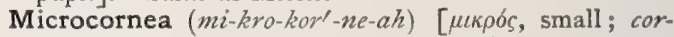
neus, horny]. Abnormal smallness of the cornea.

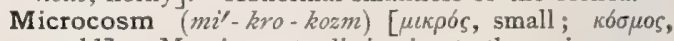
world]. Man in contradistinction to the universe, or the macrocosm; man considered as the epitome of the cosmos.

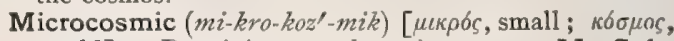
world]. Pertaining to the microcosm. M. Salt, sodium-ammonium-hydrogen phosphate; so called as being derivable from human urine.

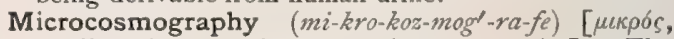

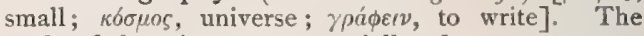
study of the microcosm, especially of man.

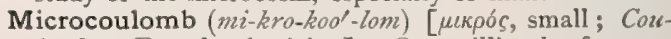
lomb, a French physician]. One millionth of a coulomb. See Coulomb and Electric Units.

Microcoustic (mi-kro-kozes'-tik). Synonym of Micracoustic.

Microcranious (mi-kro-kra'-ne-uss). Synonym of $M i$ crocephalous.

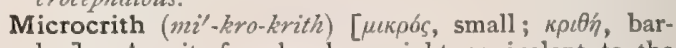
ley]. A unit of molecular weight, equivalent to the weight of an atom of hydrogen.

Microcrystalline (mi-kro-kris'-tal-in) [uıpós, small ; $\kappa \rho v \sigma \tau a ́ \lambda \lambda \iota \nu \circ$, pertaining to a crystal]. Composed of crystals of microscopic size. 


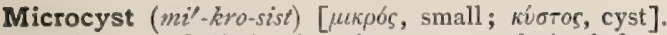
I. A cyst of diminutive size, or one derived from another. 2. The resting swarm-spore of certain fungi.

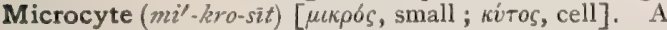
small red blood-corpuscle.

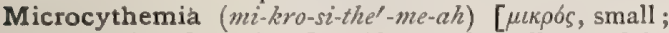

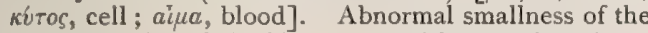
red corpuscles of the blood, caused by certain poisons and diseases.

Microcytosis (mi-kro-si-to'-sis). Same as Microcythemia.

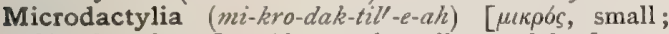
ঠákтvìos, finger]. Abnormal smallness of the fingers.

Microdentism (mi-kro-den'-tizm). See Microdontism.

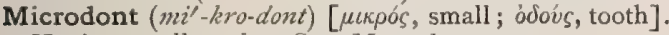
Having small teeth. See Macrodont.

Microdontism (mi-kro-don'-tizm) [ $\mu$ kкós, small ; ódoús, tooth]. Abnormal smallness of the teeth.

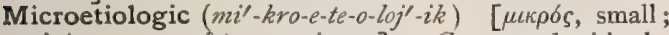
airia, cause; horos, science]. Connected with the study of the causation of microörganismal diseases.

Microfarad (mi-kro-far'-ad). See Farad and Electric Units.

Microform ( $m i^{\prime}$-kro-form) [ $\mu \iota \kappa \rho o ́ s$, small ; forma, form]. A microscopic object.

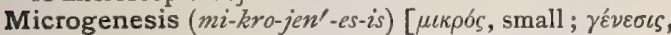
origin]. Abnormally small development of a part.

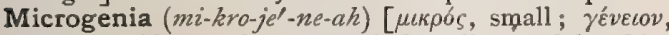
chin]. Abnormal or congenital smallness of the chin.

Microgerm (mi'-kro-jerm) [ $\mu$ kкós, small ; germen, seed, sprig]. A microbe; more properly, the spore of a microörganism.

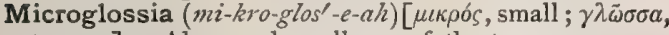
tongue]. Abnormal smallness of the tongue.

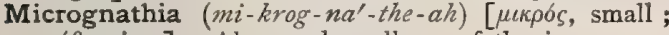

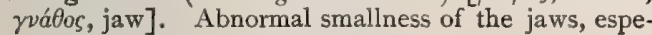
cially of the lower jaw.

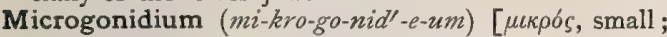
yovn, generation, seed: $p l$., Microgonidia]. In biology, a relatively small-sized gonidium.

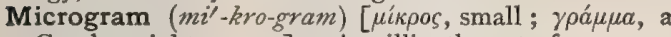
Greek weight; gram]. A millionth part of a gram.

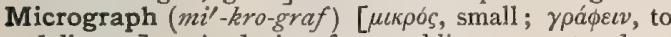
delineate]. A device for enabling one to draw sketches on a very small scale.

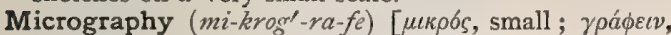
to write]. A description of bodies that are studied under the microscope. See Photo-micrography.

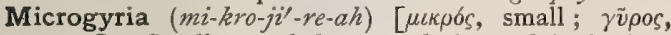
gyrus]. Smallness of the convolutions of the brain.

Microhistology (mi-kro-his-tol'-o-je). Synonym of Micristology.

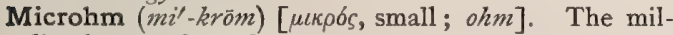
lionth part of an ohm.

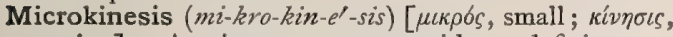
motion]. A minor movement without definite purpose, especially in early infantile life; in children, any spontaneous act; in adults, fidgety movement, restlessness, as in sleep; post-epileptic action.

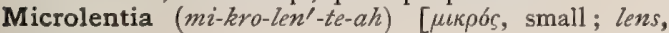
lens]. The state of having an abnormally small crystalline lens.

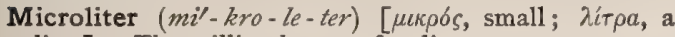
liter]. The millionth part of a liter.

Microlith (mi'-kro-lith) [ $\mu \iota \kappa \rho b s$, small ; $\lambda i \theta o s$, stone]. A microscopic calculus.

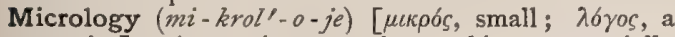
treatise]. A treatise on minute objects, especially microscopic objects.

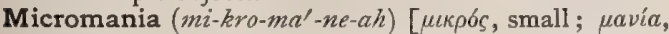
madness]. Delusion of belittlement; the impression that one's body, or some part of it, is or has become small, or that all objects around one are small.

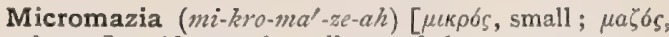
breast]. Abnormal smallness of the mammæ.

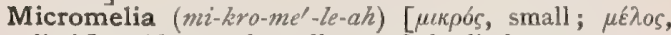
limb]. Abnormal smallness of the limbs.

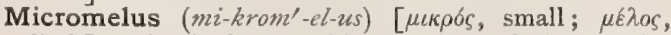
limb]. A single autositic monster of the species ectromelus, characterized by the presence of limbs that are normal in form but abnormally small.

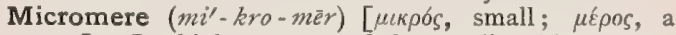
part]. In biology, one of the smaller blastomeres formed in the segmentation of certain ova; specifically, the " animal cell" of Rabl.

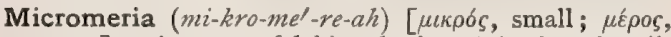
a part]. A genus of labiate herbs. M. douglassii, the Yerba buena of the Pacific U.S., is a fragrant aromatic stimulant and anthelmintic. Unof.

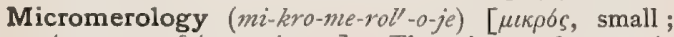

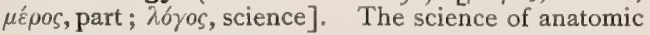
segments.

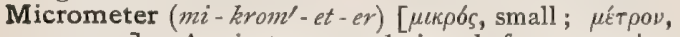
measure]. An instrument designed for measuring exceedingly small dimensions. M., Eye-piece, a micrometer to be used with the eye-piece or ocular. M., Object or Objective. See M., Stage. M., Ocular, a micrometer to be used with the ocular. See Ocular. M., Stage, a finely divided scale or rule on glass or metal for determining the magnification of a compound microscope.

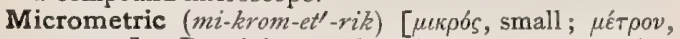
measure]. Pertaining to the micrometer; measuring very minute distances, surfaces, or objects, as a micrometric screw, or hematoscop\&.

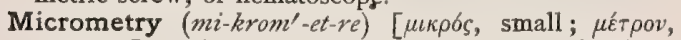
measure]. The determination of the size of objects by the aid of a micrometer. M., Methods of Ocular, are as follows: I. By finding the value of a division of the ocular micrometer for each optic combination and tube-length used, and employing this valuation as a multiplier. Thus, if with a given optic combination and tube-length it required five divisions on the ocular micrometer to include the image of $\frac{2}{10}$ $\mathrm{mm}$. of the stage micrometer, then one space on the ocular would include $\frac{1}{5}$ of $\frac{2}{10} \mathrm{~mm}$., or $\frac{1}{25} \mathrm{~mm}$; and the size of any unknown object would be obtained by multiplying the number of divisions on the ocular micrometer required to include its image by the value of one space. 2. By finding the number of divisions on the ocular micrometer required to include the image of an entire millimeter of the stage micrometer, and using this number as a divisor. If five divisions of the ocular micrometer are required to include the image of $\frac{2}{10} \mathrm{~mm}$. on the stage micrometer, then it would require $5 \div \frac{2}{10}$ $=25$ divisions on the ocular micrometer to include a whole $\mathrm{mm}$. on the stage micrometer; then the number of divisions of the ocular micrometer required to measure an object divided by 25 would give the actual size of the object in millimeters or in a fraction of a millimeter. 3. By having the ocular micrometer ruled in millimeters and divisions of a millimeter, and then getting the size of the real image in millimeters. In employing this method a stage micrometer is used as an object, and the size of the image of one or more divisions is measured by the ocular micrometer. If the stage micrometer is ruled in $\frac{1}{10}$ and $\frac{1}{100} \mathrm{~mm}$., and the ocular micrometer is ruled in millimeters and $\frac{1}{10} \mathrm{~mm}$., take $\frac{2}{10}$ $\mathrm{mm}$, on the stage micrometer as the object, and suppose it to require Io of the $\frac{1}{10}$ spaces, or I $\mathrm{mm}$., to measure the real image; then the real image must be magnified $\frac{10}{10} \div \frac{2}{10}=5$ diameters. M., Methods of Stage: I. By mounting the object upon a stage micrometer, and directly reading off the number of spaces covered by the object. 2. Divide the size of the image by the 
magnification of the microscope. The elliptic nucleated red blood-corpuscle of the Necturus makes a good object. If its long axis is $18 \mathrm{~mm}$., and the magnification of the microscope is 400 diameters, the actual length of the axis would be $18 \mathrm{~mm} . \div 400=.045$ $\mathrm{mm}$. 3. By the use of a stage micrometer and camera lucida. Indicate by means of the camera lucida the outlines of the object to be measured. Replace the object with a stage micrometer. Note how many spaces are required to include the object. As the value of each space is known, the size of the object may be very readily computed.

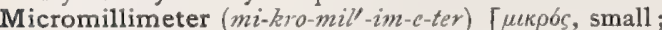
mille, thousand; $\mu \dot{\varepsilon} \tau \rho o \nu$, measure ]. I. The onethousandth part of a millimeter or the one-millionth part of a meter. It is the unit of certain microscopic measurements. It is called also micron. 2. The millionth part of a millimeter.

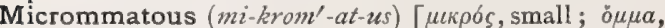
eye]. Small-eyed.

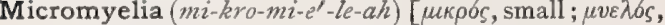
marrow]. Abnormal smallness of the myel, or spinal cord.

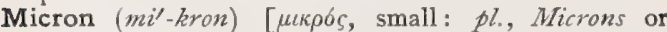
Micra]. The millionth part of a meter or a thousandth of a millimeter, the generally accepted English form of Listing's mikron. It is the equivalent of $5 \frac{1}{4} \sigma 0$ of an English inch, and its symbol is $\mu$.

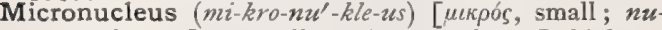
cleus, a kernel]. A small or minute nucleus. In biology, Maupas' term for the paranucleus, or the nucleolus of other authorities.

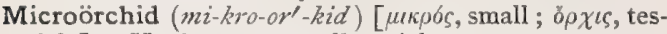
ticle]. Having very small testicles.

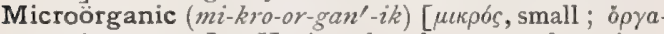
vov, instrument]. Having the character of a microorganism.

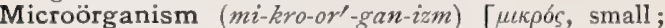
óp yavov, instrument]. A term applied to a microscopic being of the animal or vegetable kingdom ; in a special sense it is restricted to that vegetable group known as bacteria. See Bacteria, Synonymatic Table of.

Micropanencephalus (mi-kro-pan-en-sef'-al-us) [ $[\mu t-$

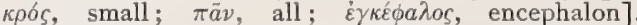
Lissauer's term for a skull in which the angle included between lines drawn from the hormion to the nasion and to the basion, respectively, is between $138^{\circ}$ and $163^{\circ}$.

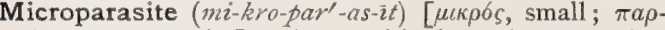
áoıtos, a parasite]. A parasitic bacterium or other microörganism

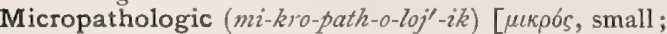

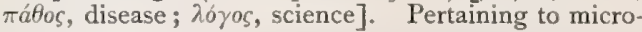
pathology.

Micropathologist (mi-kro-path-ol'-o-jist) [ $\mu \epsilon \kappa o$ s, small;

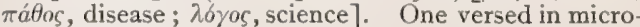
pathology.

Micropathology (mi-kro-path-ol'-o-je) [uєkós, small; $\pi a ́ t o s$, disease; $\lambda o ́ \gamma o s$, science]. The study of minute pathologic changes; also, the scientific study of microorganisms in their relation to disease. Morbid his tology.

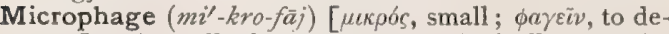
vour]. A small phagocyte. Metschnikoff's term for certain small free leukocytes at the margin of an erysipelatous patch of skin, and which he believes to have the power of destroying the infecting micrococci of the disease. (Power and Sedquick.)

Microphagist (mi-krof'-aj-ist) [ to eat]. In biology, a feeder on microscopic organisms.

Microphagocyte (mi-kro-fag'-o-sit). See Microphage.

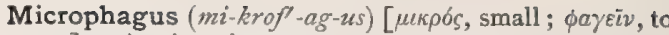
eat]. A microphage.

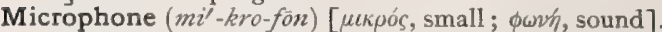
An instrument that amplifies delicate or feeble sounds.

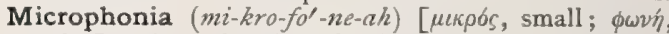
voice]. A weak voice; feebleness of the voice.

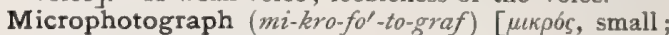
$\phi \bar{\omega} \varsigma$, light; $\gamma \rho a \dot{\phi} \varepsilon \varepsilon \nu$, to write]. A very small or microscopic photograph of an object; in most cases the object is greatly reduced in the photograph, and must be looked at with a microscope. Cf. Photo-micrograph.

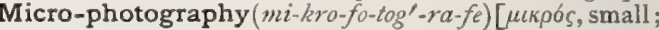

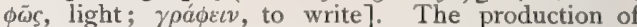
photographs of microscopic size, usually of large objects. These photographs must then be examined with a magnifier or microscope. In French and German this term is also employed for Photo-micrography, q. v.

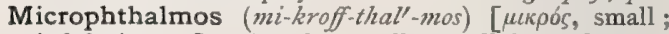
$\dot{\phi} \phi \theta \alpha \lambda \mu \delta \varsigma$, eye]. An abnormally small but otherwise healthy eye.

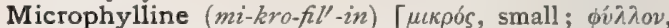
leaf ]. In biology, possessing minute leaflets or scales.

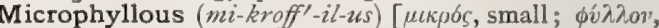
leaf ]. In biology, having small leaves.

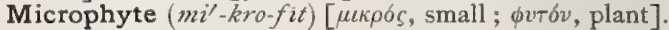
Any microscopic plant, especially one that is parasitic in habits.

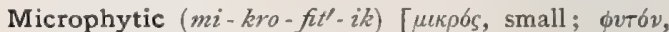
plant]. Pertaining to microscopic vegetable life.

Micropia (mi-kro'-pe-ah). See Micropsia.

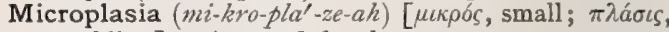
a molding]. Arrested development.

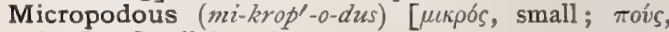
foot]. Small-footed.

Micropolariscope ( $\left.m i-k r o-p o-l a r^{\prime}-i s-k o ̄ p\right)$ [ $\mu \iota \kappa \rho o ́ s, ~ s m a l l$; polaris, polar; $\sigma \kappa o \pi \varepsilon i v$, to view]. A polariscope used in connection with a microscope.

Micropore, Microporus (mi'-kro-por, mi-kro-porl-us)

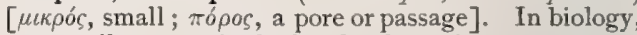
any small pore, as in the heads of certain spermatozoa; specifically applied by Moseley to the smaller pores in the tegmenta of the shells of nearly all Chitonida. Cf. Megalopore.

Microprosopa (mi-kro-pro-so'-pah) [ $\mu \iota k \rho b s$, small; $\pi \rho \sigma \sigma \omega \pi \nu \nu$, face]. Congenital smallness of the face.

Micropsia (mi-krop'-se-ah) [ $\mu \iota \kappa p o ́ s$, small ; õ $\psi s$, sight]. An apparent diminution in the size of objects, supposed to result from changes in the retinal end-organs.

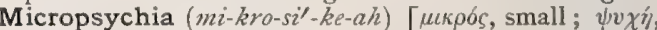
mind]. Weak-mindedness.

Micropsychosis ( $\left.m i-k r o-s i-k o^{\prime}-s i s\right)$ [ $\mu \iota \kappa \rho o ́ s$, small ; $\psi v \chi \dot{\eta}$, mind]. The inchoate thinking of infantile life; the spontaneous, disconnected, and half-suppressed thinking of later life; wandering, dreamy, or uncontrolled mental action.

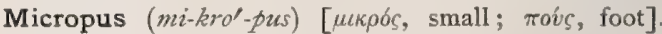
Abnormal smallness of a leg; a congenital defect.

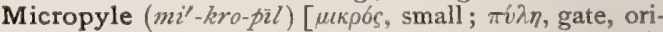
fice]. In biology, the small opening in an ovum or ovule through which the fertilizing particle may penetrate.

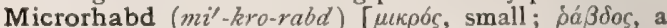
rod, stick, wand]. In biology, a rhabdus-shaped microsclere or flesh-spicule of a sponge.

Microrrheometer (mi-kro-re-om'-et-er) [uikpós, small; $\hat{\rho} \varepsilon i \nu$, to flow; $\mu \varepsilon \varepsilon \tau \rho \nu$, measure]. An instrument for measuring liquids flowing through small tubes.

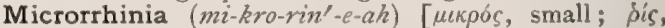
nose]. Congenital atrophy or smallness of the nose.

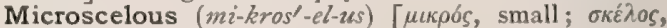
leg]. Short-legged.

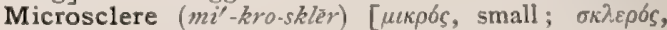
hard]. In biology, a flesh-spicule of a sponge. 


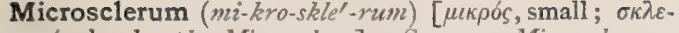
pos, hard: pl., Microsclera $]$. Same as Microsclere.

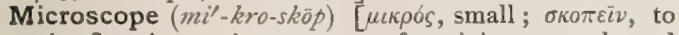
view]. An optic apparatus for giving an enlarged and distinct image of a minute and near object. M., Achromatic, one in which, by proper lenses, the chromatic aberration is corrected. M., Achromatic Triplet, a simple achromatic microscope consisting of one crown-glass and two flint-glass lenses cemented together. M., Binocular, a microscope having divergent oculars, one for each eye, so that the object is seen with both eyes. M., Compound, one that consists of two or more lenses or lens-systems, of which

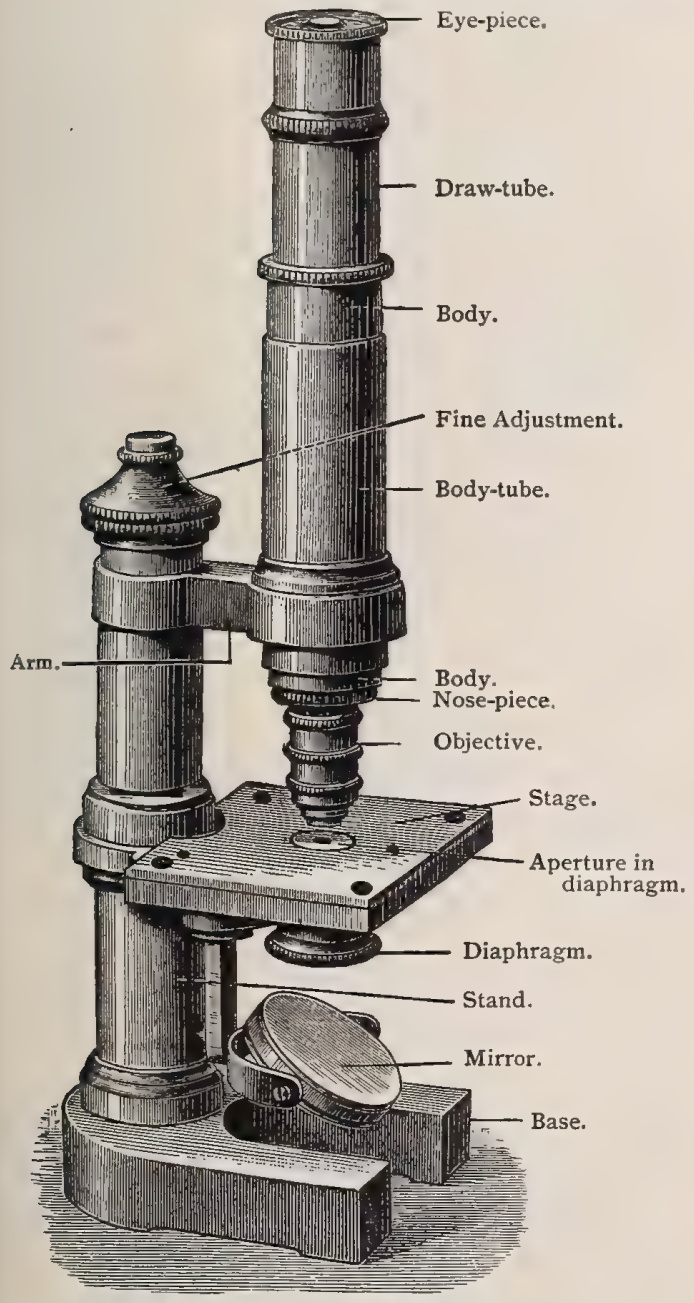

Principal Parts of the Microscope. (Half natural size.)

one, the objective, placed near the object, gives an enlarged and inverted real image. The other, the ocular, acting like a simple microscope, gives an enlarged virtual image of the real image. M., Erecting, one in which the image is made erect by means of a prism placed above the objective. M., Oil-immersion, a compound microscope of which the free surface of the objective is immersed in a drop of oil placed on the cover-glass. M., Polarizing, one with a polariz- ing-prism attached. M., Simple, one consisting of one or more lenses or lens-systems acting as a single lens. The rays of light that enter the eye of the observer, after refraction through these lenses, proceed directly from the object itself. M., Tripod Magnifier, a simple microscope mounted in a frame supported by three legs. M., Water-immersion, one similar to the oil-immersion microscope, except that a drop of water is used instead of oil

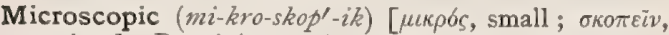
to view ]. Pertaining to the microscope; so small as to be invisible except with the aid of a microscope. M. Slide, M. Slip. See Cover-glass.

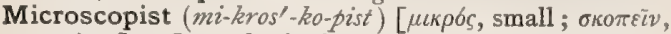
to view]. One who is skilled or expert in the use of the microscope.

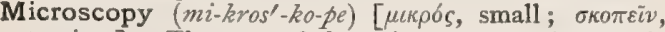
to view]. The use of the microscope; microscopic study or observation.

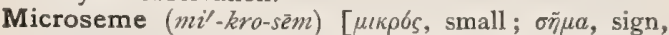
index ]. Having a low index. See Index.

Microsiphonula (mi-kro-si-fon'-u-lah) [uєкós, small; $\sigma i \phi \omega v$, a tube, pipe: pl., Microsiphonula]. In biology, a larval stage of certain cephalopods.

Microskopirlack (mi-kro-sko-pēr'-lak) [Ger.]. See Mounting-media.

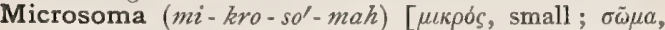
body : pl., Microsomata $]$. In biology, small chromatin-granules in the cell-nuclei; aggregated they form the "merits" of Bohm, and the "ancestral germplasms " or "ids" of Weismann.

Microsomatia (mi-kro-so-ma'-she-ah). Synonym of Microsoma.

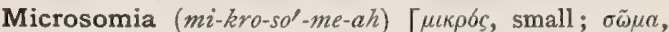
body]. An arrest of growth resulting in a dwarfing of the whole body.

Microspectroscope ( $\left.m i-k r o-s p e k^{\prime}-t r o-s k o ̄ p\right)[\mu l \kappa \rho o ́ s$,

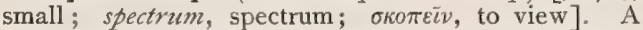
direct-vision spectroscope-prism in connection with the ocular of a microscope, by the use of which it is possible to examine the absorption-bands of a substance in minute quantities. The usual arrangement is a series of glass prisms in a small tube which is attached above the ocular.

Microsphyctous (mi-kro-sfik'-tus) [ $\mu \iota \kappa \rho b s$, small; $\sigma \phi \dot{v} \xi \iota \zeta$, pulse]. Having a small pulse.

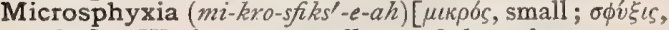
pulse]. Weakness or smallness of the pulse.

Microsplanchnus (mi-kro-splang $\left.k^{\prime}-n u s\right)$ [ $\mu \iota \kappa \rho o ́ s$, small; $\sigma \pi \lambda a ́ \gamma \chi v o v$, viscus]. Having small viscera.

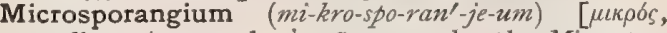

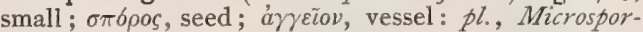
angia]. In biology, a sporangium that produces microspores.

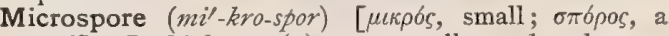
seed]. In biology: $(a)$ an asexually-produced spore of relatively small size, as in the Rhizocarpa, Selaginellce, Isoetit; (b) One form of anisospore among the colonial Radiolarians.

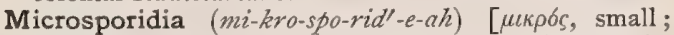
$\sigma \pi b \rho o s$, seed]. A genus of sporidia, a class of the sporozoa. They occur as parasites in the muscles of the frog, the marsh-tortoise, in worms and insects. In silkworms they are held by some to be the cause of Pébrine, q.v.

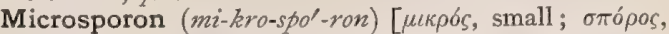
seed]. A fungus to which several diseases of the skin and hair are believed to be due. M. audouini, the cause of Pelade, a disease of the hair-covered skin. M. furfur. See Tinea versicolor. M. malassezii, the specific fungus of pityriasis versicolor, M. mentagrophytes, the cause of mentagra, $q . \%$. M. mi- 
nutissimum, a species found in the groin and axilla, causing an eruption. See Erythrasma.

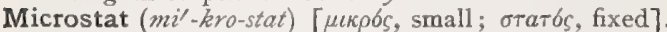
A stage and finder, for attachment to a microscope.

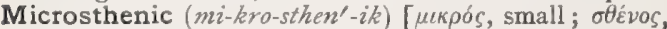
power]. Having feeble muscular power.

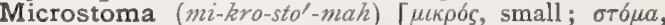
mouth]. Abnormal smallness of the mouth.

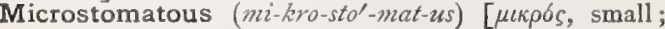
$\sigma-6 \mu \alpha$, mouth]. Small-mouthed.

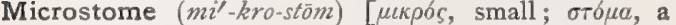
mouth]. In biology, a small mouth or orifice.

Microstomous (mi-kros'-to-mus). Synonym of Microstomatous.

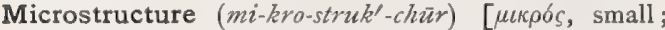
structura, a structure]. Microscopic structure.

Microstylospore (mi-kro-sti'lo-spor) [ $\mu$ ckpós, small ; $\sigma \tau \tilde{v} \lambda o s$, a pillar; $\sigma \pi \dot{\sigma} \rho \sigma_{\text {, }}$ a seed]. In biology, a rela tively small stylospore.

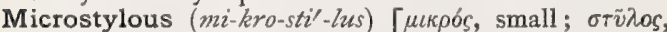
a pillar]. In biology, applied to short-styled flowers; having long stamens.

Microsyphilionthus (mi-kro-sif-il-e-on'-thus) [ $\mu$ ckpós, small; syphilis, syphilis]. A small syphilid.

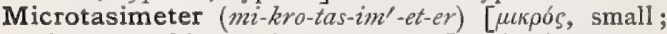

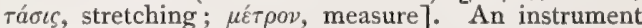
used in ascertaining small pressures.

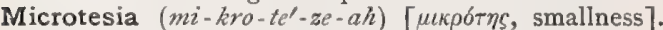
Congenital smallness of part of the body.

Microtia (mi-kro'-she-ah) [ $\mu \kappa \kappa \rho o ́ s$, small; oús, ear]. Abnormal smallness of the external ear.

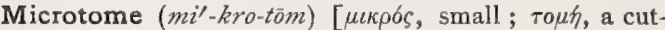
ting]. An instrument for making thin sections for microscopic examination. The microtomes of Schanze, Rutherford, Hamilton, Williams, Lewis, Jung, Leiter, Ryder, Minot, Ranvier, and Cathcart are the most

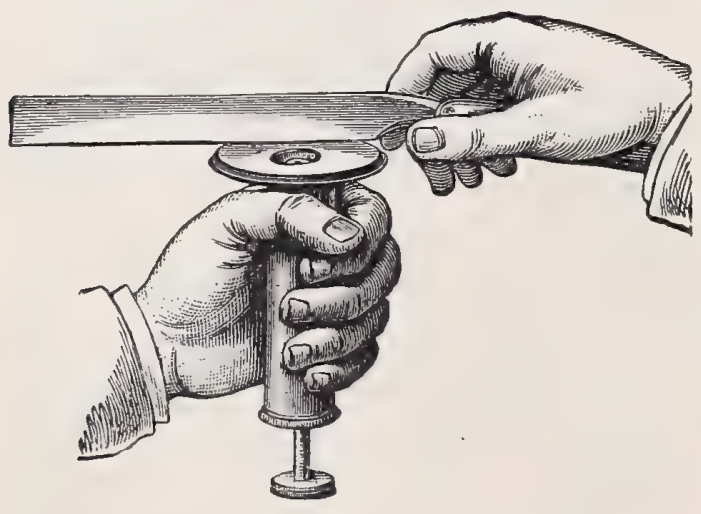

RANVIER'S HAND MICROTOME.

used. M., Freezing, one in which the tissue is frozen, in order to secure the hardness required for properly cutting sections. M., Hand, one consisting of a hollow cylinder in which the specimen is imbedded, and the operation of which is carried out by hand. M., Immersion, one that permits of cutting the sections beneath the surface of alcohol. M., Rocking, for cutting sections in series. M., Sliding, one in which the cutting knife operates by a slidingmovement.

Microtomist (mi-krot'-o-mist) [ [ cutting]. One who cuts sections with the microtome.

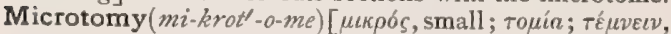
to cut]. In biology, the art of section-cutting, or preparing tissues for histologic investigation.
Microtrophous (mi-krot'-ro-fus) [ $\mu \iota \kappa \rho o ́ s$, small ; $\tau \rho b \phi \eta$, nourishment]. Under-fed; containing little nourishment.

Micro-volt (mi'-kro-vōlt). See Electric Units.

Microzoöid (mi-kro-zo'-oid) [ $\mu \iota \kappa \rho o ́ s, ~ s m a l l ; ~ \zeta \tilde{\omega} o \nu$, an animal; $\varepsilon i \delta o \zeta$, form ]. In biology, applied to certain small, free, swimming zoöids among the Vorticellide.

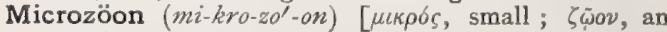
animal: pl., Microzoa $]$. In biology, any microscopic animal; an animalcule.

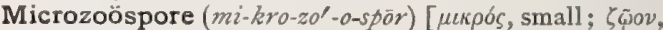
an animal; $\sigma \pi \circ \rho \alpha ́$, seed]. In biology, a relatively small zoöspore.

Microzymatous ( $\left.m i-k r o-z i^{\prime}-m a t-u s\right)$ [ $\mu \iota \kappa \rho b s$, small ;

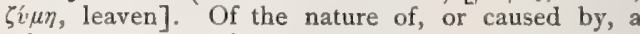
microzyme; zymotic

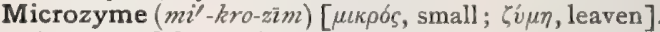
Any one of those microörganisms, or particles of living matter, which according to the theory of Béchamp, are the real agents of the functions of the organism, and the perversion of whose function constitutes disease. They secrete a ferment, Zymase, which in disease is transformed into pathogenic substances.

Miction (mik'-shun) [mictio, urination]. 'The act of voiding the urine.

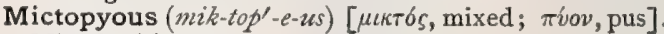
Mixed with pus.

Micturition (mik-tu-rish'-un) [micturitio; micturire, to pass water]. The act of passing urine.

Mid [ME., mid, middle]. Middle. M.-brain. Synonym of Mesencephalon. M.-facial, pertaining to the middle of the face. M.-frontal, pertaining to the middle of the forehead. M.-f. Process, in the embryo, the central one of the three plates forming the fronto-nasal process. M.-gut. See Mesogaster. M.head. See Centriciput.

Middle (mid'-l) [ME., middel, middle]. Mean; equally distant from the extremities. M. Commissure, the medicommissure, q. $v$. M. Oil, the second main fraction in the coal-tar distillation process. It is collected between $170^{\circ} \mathrm{C}$. and $230^{\circ} \mathrm{C}$, yielding upon further treatment two very important and valuable products, namely, liquid and solid carbolic acid and naphthalene.

Midriff. See Diaphragm.

Midwife. A female obstetrician; a female nurse who attends women in childbirth.

Midwifery. See Obstetrics.

Miescher's or Miescherian Sacs, Tubes or Utricules. Sausage-shaped Psorosperm-tubes or saccules, found occasionally in immense numbers in the muscles of pigs, cattle, sheep, mice and fowls, but never in man. See under Parasites (Animal), Table of. See Utricule. M.'s Tubes. See $M$.'s Sacs.

Migraine (me'-grān) [Fr.]. A paroxysmal, usually unilateral headache associated with gastric, vaso-motor, and visual symptoms. There is sharp pain most frequently in the temporo-frontal region of one side, with general hyperesthesia of the affected surface. There is photophobia; nausea and vomiting are common. The face may be pale or flushed. The disease may be hereditary, is often associated with anemia, overwork, dyspepsia, eye-strain, menstrual disorders, and other conditions. By some it is regarded as the sensory analogue of epilepsy. See Hemicrania and Meorim.

Migrainous (me-gra'-nus) [Fr., migraine]. Of the nature of, or associated with, migraine.

Migration (mi-gra'-shun) [migratio; migrare, to wander]. In zoölogy, the periodic departure of certain animals, especially birds, from one to another cli. mate. M., External (of the Ovum), the passage of 
the ovum from an ovary to the tube of the opposite side. M., Internal (of the Ovum), the passage of the ovum through the tube related to the ovary from which the ovule was discharged, into the uterus and across into the opposite tube. M. of Ovum, its passage from the ovary to the Fallopian tube. M. of White Corpuscles, one of the phenomena of inflammation, consisting in the passage of the white corpuscles of the blood through the vessel-wall.

Migratory (mi'-grat-o-re) [migrare, to wander]. Characterized by wandering, or changing locality. M. Pneumonia. See Pneumonia migrans.

Mika Operation ( $\left.m i^{\prime}-k a h\right)$ [African]. A method in vogue among certain African tribes for the purpose of preventing impregnation. It consists in the formation of a permanent urethro-perineal fistula in the male.

Mikrantrus (mi-kran'-trus). See Micrantrus.

Mikrencephalus (mi-kren-sef'-al-us). See Micrencephialus.

Mikrencranus (mi-kren-kra'-nus). See Micrencranus.

Mikro- (mi'-kro-). See Micro-.

Mikron (mil-kron). Same as Micron.

Mikulicz Drain. A method of draining the abdominal cavity after operation. A piece of iodoform-gauze, with a string tied to its center, is placed in the cavity, and into this improvised sac considerably more gauze is packed. Pressure is thus induced while the capillary action of the sac secures drainage.

Mil [mille, a thousand]. The one-thousandth part of an inch. M., Circular, the area of a circle the one-thousandth of an inch in diameter.

Mildew (mil'-du) [ME., mildewe, mildew]. The common name for any one of a number of minute fungi destructive to living plants and dead vegetable substances, as cloth and paper. The name is most properly applied to: (I) The Erysiphe, or powdery mildews, which are parasitic upon living plants of many natural orders. Among the best known and most destructive is the vine mildew, or powdery mildew of the grape, Oidium tuckeri, Berk, a native of America, where alone it produces its perithecial form, described as Erysiphe spiralis, or Uncinula ampelopsidis, the conidial form only being known in Europe. The mildew infesting Compositæ, Plantago, Verbascum, Labiatæ, is Erysiphe lamprocarpa; that of grasses, $E$. graminis; that of Umbelliferæ, clover, lucern, lupines, etc., E. martii; that of Polygonum, Rumex, Convolvulus, Dipsacus, Lathyrus, Delphinium, Aquilegia, Ranunculus, $E$. communis; that of the various species of Prunus, Podosphara kunzei; and that of hops and other plants, $P$. castagnei; (2) The Peronosporea, or downy mildews, among which are a large number of well-known parasites, such as the American downy mildew of the grape, Peronospora viticola; that of the Umbellifera, $P$. nivea; that of Cruciferæ, cabbages, etc., $P$. parasitica; that of onions, $P$. schleideniana; that of violets, $P$. viola: that of "potato rot," Phytophthora infestans, which, according to Bennett and Murray, first appears, as a rule, on the green leaves of the potato-plant in July or August, the sporangiophores emerging through the stomates. Sporanges are formed, under favorable conditions. in a few hours, and are carried by the wind to other potato-leaves, where they produce zoöspoores or germ-tubes, in drops of water formed by dew or rain; the germtubes penetrate the epiderm, setting up fresh growths of mycelium in new plants, and thus the disease is propagated; countless numbers of such propagating cells, each potentially the mother of a number of zoöspores, may thus be set free from a few diseased plants, and the spread of infection and destruction of tissue in warm, moist weather is almost inconceivably rapid. The disease extends to all parts of the plant, including the tubers, in which the mycelium often remains in a resting condition throughout the winter, a fresh start being made in the spring. For treatment, spraying with Bordeaux mixture, alone or in combination with solutions of ammoniacal carbonate of copper, sulphate of copper, sulphate of iron, etc., have been employed.

Milfoil (mil'-foil). See Achillea.

Miliaria (mil-e-a'-re-ah) [milium, millet]. Prickly heat; an acute inflammatory disease of the sweatglands, the lesions consisting of pin-point or largersized vesicles and papules, accompanied by a pricking or tingling sensation. It runs an acute or subacute course, and is followed by slight desquamation. Relapses are common. M. alba. See $M$. crystallina. M. crystallina, a variety of miliaria in which the sweat accumulates under the superficial horny layers of the epidermis to form small, clear, transparent vesicles. It is also called Sudamina crystallina. These lesions are principally found on the neck, chest, back, and abdomen; they form rapidly, but do not increase in size, nor do they coalesce. They are followed by slight desquamation. Sometimes their contents become cloudy, milky, or semi-puriform in character (Miliaria alba). M. lactea, a form occurring in puerperal women. $\mathbf{M}$. papulosa, a variety of $M$. rubra. It is the well-known "prickly heat." M. puerperalis, $\mathbf{M}$. puerperarum, a form occurring in lying-in women, especially in conditions of septic infection. M., Red Gum. See $M$. strophulus. M. rubra, a form of miliaria in which there is an inflammation of the tissues surrounding the sweat-glands, secondary to the retention of sweat. There is redness and itching; the eruption is very copious and thickly set, so that the skin assumes a vividly red color. M. strophulus, a form occurring in nursing infants, due to excessive swathing. $M$. vesiculosa. Same as M. rubra.

Miliariform (mil-e-ar'-if-orm). Synonym of Miliary. Miliary (mill-e-a-re) [milium, millet]. Of the size of a millet-seed. M. Fever. See Fever. M. Tubercles, tubercular nodules of very small size, usually present in large numbers, as in miliary tuberculosis. See, also, Grutum. M. Tuberculosis, See Tuber. culosis.

Military Fever. See Typhus Fever. M. Medicine, or Surgery, the treatment of the diseases and wounds to which soldiers and sailors are liable.

Milium (mil'-e-um) [milium, millet-seed]. Grutum; Strophulus albidus. A skin-disease characterized by the formation of small, roundish, whitish, sebaceous, non-inflammatory elevations, situated just beneath the epidermis. They are found mainly on the face, eyelids, and foreheads of elderly persons, and may exist in immense numbers. They may undergo calcification, giving rise to cutaneons calculi. M., Amyloid. Synonym of Molluscum contagiosum, $q . v$. M., Colloid, a rare skin-disease characterized by the presence, especially on the bridge of the nose, forehead, and cheeks, of minute, shining, flat, or slightly raised lesions of a pale-lemon or bright-lemon color. It is a form of colloid degeneration of the skin, affecting persons of middle or advanced age.

Milk [ME., milk, milk]. The secretion of the mammary glands of Mammalia, consisting of water, casein, albumin, fat, milk-sugar, and salts. Cream consists mainly of the fats that rise to the surface of the milk. Skim-milk is the residue left after the removal of the cream. Buttermilk is cream from which the fatty matter has been removed. The sp. gr, of good 
milk varies from I.027 to 1.034 . It should contain not less than 10 per cent. of cream. The reaction of milk, when first secreted, is alkaline, but it becomes acid on standing, as a result of fermentative processes. The relative proportion of the constituents in milk of different animals may be seen from the appended table of analyses from Wynter Blyth, I882:-

\begin{tabular}{|c|c|c|c|c|c|c|c|}
\hline & $\stackrel{i}{4}$ & $\frac{z_{1}}{\frac{1}{3}}$ & 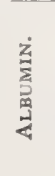 & 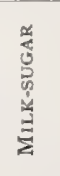 & $\frac{3}{5}$ & 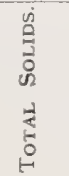 & $\frac{\dot{\alpha}}{z}$ \\
\hline Human milk, & 2.90 & 2.40 & 0.57 & 5.87 & 0.16 & 12.00 & 88.00 \\
\hline Cow's milk, & 3.50 & 3.98 & 0.77 & 4.00 & 0.17 & 13.13 & 86.87 \\
\hline Camel's milk, & 2.90 & & & 5.66 & 0.66 & 13.06 & 86.94 \\
\hline Goat's milk, & $4 \cdot 20$ & 3.00 & 0.62 & 4.00 & $\overline{0.56}$ & 12.46 & $87 \cdot 54$ \\
\hline Ass's milk, & 1.02 & 1.09 & 0.70 & $5 \cdot 50$ & 0.42 & 8.83 & 91.17 \\
\hline Mare's milk, & 2.50 & 2.19 & 0.42 & $5 \cdot 50$ & $\overline{0.50}$ & II. 20 & 88.80 \\
\hline Sheep's milk, & 5.30 & 6.10 & 1.00 & 4.20 & 1.00 & 17.73 & 82.27 \\
\hline
\end{tabular}

Fleischmann gives the computation of the several parts of cow's milk as follows :-

\begin{tabular}{|c|c|c|c|c|c|c|}
\hline & 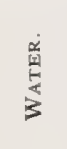 & 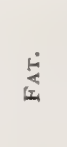 & 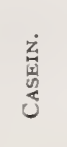 & 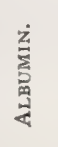 & 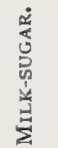 & 焉 \\
\hline Whole milk, & 87.60 & 3.98 & 3.02 & $4 \cdot 40$ & $4 \cdot 30$ & 0.70 \\
\hline Cream, ... & $77 \cdot 30$ & 15.45 & 3.20 & 0.20 & 3.15 & 0.70 \\
\hline Skim-milk, . & 90.34 & 1.00 & 2.87 & 0.45 & 4.63 & 0.71 \\
\hline Butter, ... & 14.89 & 82.02 & 1.97 & 0.28 & 0.28 & 0.56 \\
\hline Buttermilk, & 91.00 & 0.80 & $3.5^{\circ}$ & 0.20 & 3.80 & 0.70 \\
\hline Curd, ... & $59 \cdot 30$ & 6.43 & 24.22 & 3.53 & 5.01 & I.5I \\
\hline Whey, ... & 94.00 & 0.35 & 0.40 & 0.40 & 4.55 & 0.60 \\
\hline
\end{tabular}

M.-abscess, a mammary abscess. M., Artificial Mother's, cow's milk so prepared as to resemble in composition human milk. M.-bath. See Bath. M.-blotch. See Crusta lactea. M., Blue, a change in color of milk due to the development of the Bacillus cyanogenus. See Bacteria, Synonymatic Table of. M., Butter. See Milk. M., Condensed, the milk of cows from which a large part of the water has been evaporated and sugar added. M.-crust, a term for vesicular eczema in children. The same as milkblotch. M.-curdling Ferments. See Ferments. M.-cure, the method of treating certain diseases by an exclusive diet of skim-milk. It is of service in dropsies of all kinds, obstinate intestinal neuralgias, incorrigible dyspepsias with grave disturbances of nutrition, hepatic disorders, asthma due to pulmonary catarrh and emphysema, hysteric and hypochondriac states associated with serious disturbances of nutrition, and in disorders of nutrition dependent on chronic catarh of the stomach and intestine. M.cyst, a peculiar and rare cystic tumor of the mammary gland. It is probably the result of extravasation of milk. The contained milk may become inspissated. M., Deficiency of. See Agalactia. M.-duct, a galactophorous duct. M., Excessive Secretion of. See Galactorrhea. M.-fever, certain phenomena, possibly with a slight rise of temperature, attending the establishment of the secretion of milk. It is due to a slight degree of septic intoxication. The term was formerly applied to all febrile exacerbations following parturition, and was often used synonymously with child-bed or puerperal fever. See, also, Galactopyretus. M.-globule, a globule of oil of the kind seen in freshly drawn milk. M., Green, colostrum. M., Human. See Human. M.-leg. See Phlegmasia alba dolens. M.-maid's Cramp. See Cramp. M., Male, the seminal fluid. M.-molar, any deciduous molar tooth. M.-nurse, a wet-nurse. M.-plasma, the whey, or plasma of milk, seen when the casein and butter have been removed. M.-pump. See Breast-pump. M.-punch, a nutritious preparation made by adding brandy, whiskey, or rum, to milk in the proportion of about one to four or six parts, and flavoring with sugar and nutmeg. M.-rice Culture-medium : to IOO parts by weight of finely powdered rice add 2 IO parts by measure of a 3 to I mixture of milk and bouillon. Beat together and sterilize. M.-scab. Same as $M_{0}$-blotch. M.-scall. See Porrigo larvalis. M.-sickness, an epizootic disease of cattle, communicable to persons who drink their milk or eat their flesh. It is marked by "trembles," or chills, vomiting, and a disordered state of the functions of the alimentary canal. M., Skim. See Milk. M.-spots, small, opaque, white spots of thickened pericardium resulting from a localized inflammation. These spots may sometimes be the result of slow sclerotic changes occurring in old age. M.-sugar. See Lactose. M. Teeth, the teeth of the first dentition; deciduous or temporary teeth. M.-tester, a lactometer. M.-thrush. Synonym of Aphtha. M.-vessel, in biology, one of the tubes in which a milky fluid is secreted. M.-weed, silk-weed. The root of Asclepias cornuti, with properties similar to those of A. tuberosa. It is a popular cure-all. Dose of the $\mathrm{fld}$. ext. $m x-3 j$. Unof. M., Witches', colostrum; also milk secreted by the male breast.

Milker's Cramp, or Spasm. See Cramp.

Millecoulomb (mil-koo'-lôm) [mille, one thousand; Coulomb]. One one-thousandth part of a coulomb.

Miller, Bacillus of, M., Spirillum of. See Bacteria, Synonymatic Table of. M.-Lewis Bacillus. A comma-bacillus found in the human mouth. Cf. Bacillus dentalis viridans, under Bacteria, Synonymatic Table of.

Miller's Asthma. See Laryngismus stridulus and Diseases, Table of.

Millers' Eczema. A form of eczema of the hands, occurring in millers, from the irritation of the flour. M.s' Lung, a form of Pneumonokoniosis.

Millet-seed Rash. Synonym of Miliaria.

Mill-grinders' Phthisis. See Pnezmokoniosis.

Milliampèrage (mil-e-om'-pār-ahzh) [mille, a thousand; Ampere, a French scientist]. The expression of electric current-strength in milliampères.

Milliampère (mil-e-om'-pär) [mille, thousand; Ampère, a French scientist]. One-thousandth of an ampere, = I volt divided by 1000. See also Ampère.

Milliampèremeter (mil-e-om'-parr-me-ter) [mille, thousand; Ampere, a French scientist; $\mu \hat{\varepsilon}$ Tov, measure]. An instrument for measuring the strength of an elec-? tric current.

Milligram (mill-ig-ram). See Metric System.

Milliliter (mil'-il-e-ter). See Metric System.

Millimeter (mill-im-e-ter). See Metric System.

Milliweber (mil'-e-web-er). Same as Milliampere. 
Millon's Reagent. A reagent made by dissolving 10 grams of mercury in 20 grams of nitric acid, diluting the solution with an equal volume of water, and decanting in twenty-four hours. Proteids warmed in contact with the reagent at a temperature of $70^{\circ} \mathrm{C}$. yield a purple-red color. See Tests, Table of.

Millstone-makers' Phthisis. A form of pneumonokoniosis due to the inhalation of fine particles in the manufacture of millstones.

Mill-tooth. A grinder; a molar tooth.

Milman's Drink. A diuretic for use in dropsy. It consists of a solution of $1 / 2$ ounce of potassium bitartrate in two pounds of barley-water, with one or two fluid ounces of brandy added.

Milori Blue. Same as Berlin Blue.

Milphæ (mil'-fe) [ $\mu i \lambda \phi a \iota$, falling of the hair of the eyelids]. Same as Milphosis.

Milphosis (mil-fo'-sis) [ $\mu i \lambda \phi o \sigma \varsigma$, baldness]. Baldness of the eyebrows.

Milt [a corruption of milk]. The spermatic organ or spermatic fluid of fishes, oysters, and other of the lower animals. See also Spleen. M,-waste. See Asplenium.

Miltosis (mil-to'-sis). Same as Milphosis.

Milzbrand (milts'brant) [Ger.]. Synonym of Anthrax, $q . v$.

Mimesis (mim- $\left.e^{\prime}-s i s\right)$ [ $\mu$ i $\mu \eta \sigma \iota$, imitation]. In biology, mimicry ; the simulation by an organism of some other organism or its environment.

Mimetic (mim-et $i k)$ [ $\mu i \mu \eta \sigma \iota$, imitation]. Imitative; mimic.

Mimetism (mim'-et-izm). Same as Mimesis and Mimicry.

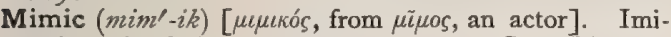
tative simulating. M. Aneurysm. See Phantom Aneurysm. M. Labor, false labor. M. Spasm, habitspasm, or convulsive tic.

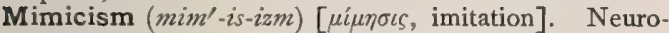
pathic imitation of words, gestures, etc.

Mimicry (mim'-ik-re) [ $\mu \bar{i} \mu \mathrm{s}$, an imitator: pl., Mimicries]. Imitation. In biology, an imitative resemblance of one organism to another. The utilization by an organism of false warning or signaling colors for the repelling of enemies by the deceptive suggestion of some unpleasant or dangerous quality, or for attracting prey by the deceptive appearance of something attractive to them. Even foreign objects commonly associated with some well-defended and aggressive species may be mimicked by a comparatively defenseless form. (Poulton).

Mimmation (mim-a'-shun)[Ar., mim, the name of the letter $m]$. The unduly frequent use of the sound of the letter $m$ in speech.

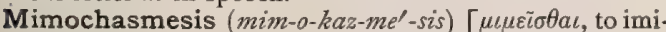

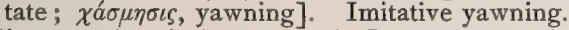

Mimography (mim-og/-ra-fe) [ $\gamma \rho a ́ \phi \varepsilon \iota \nu$, to write]. Sign-language used by deaf-mutes.

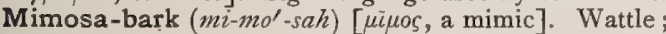
the bark of numerous species of Acacia ( $A$. decurrens and $A$. dealbata) from Australia and Tasmania, containing from 24 to 30 per cent. of mimotannic acid. It is used in leather-manufactures, and makes a red leather. It is generally used in admixture.

Mimosis (mim-o'-sis). Same as Mimesis.

Mimotannic Acid (mim-o-tan'-ik). See Cutch.

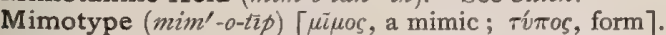
In biology, a form distantly resembling another and fulfilling similar functions; the representative in one country of a type or form found in another.

Mind (mind) [ME., mind, mind]. The understanding. The reasoning and intellectual faculties considered as a whole. M.-blindness, a form of aphasia in which, although the patient is perfectly able to see, no intellectual impression is conveyed to his mind by the object seen. This condition is also called $V$ isual Amnesia. M.-cure, the alleged cure of disease through mental operations. M-curer, one who professes to cure disease by acting directly upon the mind of the patient. M.-deafness, a form of aphasia in which sounds, though heard and perceived as such, awaken no intelligent conceptions. This condition is also called Auditory Amnesia. M.-healer. Same as M.-curer. M.-reading, the perception of another's thoughts and feelings by a direct and occult process. M.-sick, insane.

Mindererus, Spirit of. See Ammonii acetatis, Liq.

Miner's Anemia. A disease of coal-miners due in part to the choke-damp, or ethylene which they breathe. M.'s Asthma. See Anthracosis. M.'s Cachexia. See Ankylostomiasis. M.'s Disease. Same as M.'s Elbow. M.'s Elbow, enlargement of the bursa over the olecranon, due to irritation while working and lying on the side. M.'s Lung. Same as Anthracosis. M.'s Nystagmus. See Nystagmus. M.'s Phthisis, anthracosis; a chronic affection of the lungs due to the constant inhalation of coal-dust; it is attended with cough and dyspnea, and with a black discoloration of the pulmonary tissues. It is designated by various other names. The process often ends in tuberculosis.

Mineral (min'-er-al) [minera, a mine]. Any inorganic chemic compound found in nature. The word is usually limited to the solid inorganic compounds. M.-blue. See Pigments, Conspectus of. M. Colza Oil. See Burning Oil. M.-gray. See Pigments, Conspectus of. M.-green. Same as Paris-green. M.-lake. See Pigments, Conspectus of. M. Oil, petroleum. M.-orange. See Pigments, Conspectus of. M. Pitch, bitumen. M.-purple. See Pigments, Conspectus of. M. Sperm. See Burning Oil. M. Water, water naturally or artificially impregnated with mineral salts or oxids. A classified list of the springs of the United States will be found in the appendix of the author's "Student's Medical Dictionary." The general classes into which the springs are grouped indicate the therapeutic actions of the waters. Analyses of typical examples of each class are there given in full; of the rest, the active ingredients are indicated by the chemic formulæ. Alkaline and carbonated springs are usually hot. Saline and sulphur springs may be either hot or cold. Silicious springs are always hot. M. Wax. See Orocerite. M.-white. Same as Permanent-zuhite. M.-yellow. Same as Cassel Yellow.

Mineralogy (min-er-al'-o-je) [minera, a mine; $\lambda 6$ yos, science]. The science, or a scientific account, of minerals.

Mineromephitis (min-er-o-mef-i'tis) [minera, mine; mephitis, a noxious exhalation]. Mephitic gas, or miasm from mines; choke-damp.

Miniate $\left(\min ^{\prime}-e-\bar{a} t\right)$ [minium, red lead]. Vermilioncolored.

Minim $\left(\min ^{\prime}-i m\right)$ [minimus, dim. of minus, little]. The one-sixtieth of a fluid dram: Symbol, $m$.

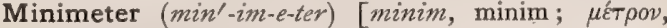
measure]. An apparatus for measuring liquids in minims.

Minimetric (min-im-et'-rik) [minim, minim; $\mu \varepsilon^{\prime} \tau \rho o v$, measure 7. Pertaining to measurement in mining. M. Method, a method of estimating $\mathrm{CO}_{2}$ in the air. See Ventilation.

Minium (min'-e-um) [L., min; or minium, red lead]. Red oxid of lead, $\mathrm{Pb}_{3} \mathrm{O}_{4}$; used formerly in plasters. See also Pigments, Conspectus of. 
Minor (mi'-nor) [L., "less"]. 1. Less; lesser; smaller. 2. An individual under legal age ; one under the authority of parents or guardians. M. Surgery. See Surgery, Minor.

Minoration (mi-nor-a'-shun) [minorare, to make smaller]. Gentle purgation, or emesis.

Minorative (mi'-nor-a-tiv) [minorare, to make smaller]. 1. Effecting minoration. 2. A gently purgative remedy.

Minot's Theory. See Heredity.

Mint. See Mentha. M.-worts. See Labiate Plants.

Minutio (min-u'-she-o) [L.]. Synonym of Minoration. M. morrachi. An old method of reducing the strength of young men by venesection or other derivative means, in order to exert an anaphrodisiac influence.

Minythesis (min-ith-e'-sis) [ $\mu \iota v i \theta \eta \sigma \iota$, decrease]. Lysis; the stage of decrease in an attack of disease.

Mioangioneurosis (mi-o-ant-je-o-nu-ro'-sis) [ $\mu \varepsilon i \omega v$, lesser; ảy A nervous disorder of the smaller blood-vessels; a vaso-motor or vaso-inhibitory disturbance.

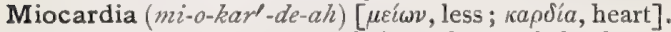
The systolic diminution of the volume of the heart. See Auxocardia.

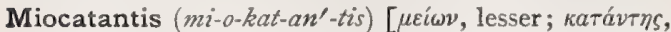
sleep]. Lissauer's term for a skull in which the angle formed between the radius fixus and the line joining the hormion and the staphylion is between $23^{\circ}$ and $45^{\circ}$

Miokatantis (mi-o-kat-an'-tis). See Miocatantis.

Miophylly (mi-off'-il-e) [ $\mu \varepsilon i \omega \nu$, less; $\phi \dot{v} \lambda \lambda o \nu$, a leaf]. In biology, the diminution by suppression of the number of leaves in a whorl.

Miopragia (mi-o-pra'-je-ah) [ $\mu \varepsilon i \omega v$, less; $\pi \rho a ́ \sigma \sigma \varepsilon \iota v$, to do]. Diminished functional activity.

Miopragic (mi-o-praj'-ik) [ $\mu \varepsilon i \omega \nu$, less; $\pi \rho a ́ \sigma \sigma \varepsilon \imath \nu$, to do]. Resulting from too little activity.

Miosis (mi-o'-sis) [ $\mu \varepsilon i \omega \sigma \iota$; $\mu \varepsilon i \omega \nu$, less]. I. Contraction or decrease in the size of an organ, especially of the pupil. 2. A lessening of the intensity of existing symptoms.

Miostemonous (mi-o-stem'-o-nus) [ $\mu \varepsilon i \omega \nu$, less ; $\sigma \tau \dot{\eta} \mu \omega \nu$, stamen]. Having the stamens fewer in number than the petals.

Miot's Operation. See Operations, Table of.

Miotaxy (mi'-o-taks-e) [ $\mu \varepsilon i \omega \nu$, less; $\tau a ́ \xi \iota \varsigma$, arrangement]. In biology, the complete suppression of an entire set of organs, as of the stamens, the petals, or the sepals of a flower.

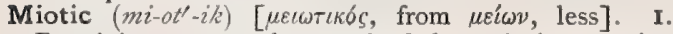
Pertaining to, or characterized by, miosis; causing contraction of the pupil. 2. Any agent or medicine that contracts the pupil.

Miquel's Bulb. An apparatus for air-analysis.

Mirage (mêr ahzh') [Fr., mirer, to look at carefully]. An illusion caused by the reflection of objects against the surface upon which two layers of air of unequal density rest, the lighter on the heavier.

Mirbane, Oil of. A name for nitrobenzene.

Mirbel, Glands of. See Gland.

Mire (mér) [Fr., the sight of a gun; a target]. Figures used upon the perimeter-bar of the ophthalmometer of Javal and Schiötz; by observing the variations of their images, as reflected from different meridians of the cornea, the measurement of corneal astigmatism is effected.

Mirocele (mirl-o-sèll). Same as Merocele.

Mirror (mir'-or) [Fr., miver]. I. A term applied to any polished surface that reflects a large proportion of the light falling upon it, especially a glass silvered on the anterior, or coated with a tin-amalgam on the posterior surface. Mirrors, plane or focusing, are used in the ophthalmoscope, laryngoscope, otoscope, etc., to reflect light into the cavity studied, and thus illuminate it for observation. 2. The movable silvered glass with a plane and a concave face for illuminating the object in microscopic observation. M.-bar, the bar supporting the mirror of a microscope. M., Dentists', a small speculum designed for the examination of the teeth; a mouth-glass. M., Frontal, M., Head, a circular mirror with a central perforation, strapped to the head by a band, and used to throw light on parts to be examined. M.-writing, a peculiarity of penmanship observed in left-handed persons, and characterized by a reversal of the form and arrangement of the letters, which appear as if seen in a mirror.

Miryachit (mér-e'-asch-it) [Rus., "to play the fool "]. A peculiar disease observed in some Oriental tribes, the chief characteristic of which consists in mimicry by the patient of everything said or done by another. The same disease is called Lata by the Javanese. It is also allied to the "Jumpers" of Canada. See Palmus.

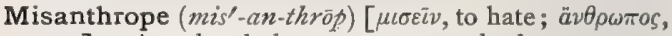
man]. A melancholy person; one who has an aversion to society.

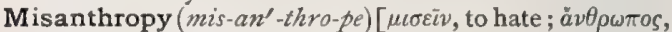
man]. Aversion to human society; a symptom not rare in melancholia.

Misbirth (mis-berth'). Synonym of Abortion.

Miscarriage (mis-kăa $r^{\prime}-\bar{a} j$ ) [ME., mis-, wrong, bad; carriage, burden]. The expulsion of the fetus between the fourth and the sixth month of pregnancy.

Miscarry (mis-kăr'-e) [ME., miscarien, to miscarry]. To give birth to a non-viable fetus.

Miscegenation (mis-ej-en-a'-shun) [miscere, to mix; genus, race]. Mixture of different races by intermarriage.

Miscible $\left(\right.$ mis' $\left.^{\prime}-i b-l\right)$ [miscere, to mix]. Capable of being mixed.

Misemission (mis-e-mish'-un) [ME., mis-, wrong; emittere, to send forth]. A form of sterility in the male in which fertile semen may be secreted and ejaculated, but for some reason fails to be so deposited in the female organs as to come in contact with the ovum and impregnate it. Usually it is due to some malformation of the urethra.

Miserere mei (miz-er-a'-ra ma'-e) [L., "have mercy on me" $]$. An old name for volvulus, or intestinal colic; also for stercoraceous vomiting.

Mislactation (mis-lak-ta'-shun). See Galactia.

Mislocalization (mis-lo-kal-iz-a'-shun) [ME., mis-, wrong; locus, a place]. Failure properly to localize sensory impressions.

Mismenstruation (mis-men-stru- $a^{\prime}-\operatorname{shun}$ ) [ME., mis-, wrong; menstruare, to menstruate]. Any disturbance of menstruation.

Mismicturition (mis-mik-tu-rish'-un) [ME., mis-, wrong; micturire, to pass water]. Any disorder of micturition.

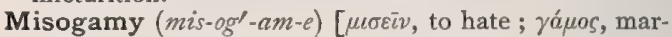
riage]. Morbid and unreasonable aversion to marriage.

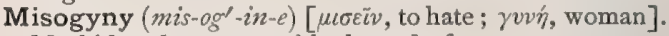
Morbid and unreasonable hatred of women; a symp. tom often seen in insanity and in sexual perversion.

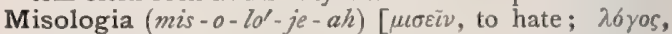
reason]. Unreasoning aversion to intellectual or literary matters.

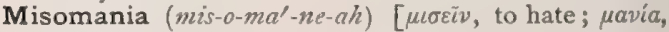
madness]. The delirium of persecution.

Misoneism (mis-on- $\varepsilon^{\prime}-i z m$ ) [ $\mu \iota \sigma \varepsilon i \nu$, to hate; v'os, new]. Fear or horror of novelty. 


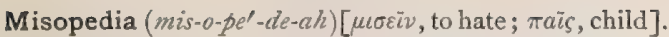
Morbid hatred of children, especially of one's own children.

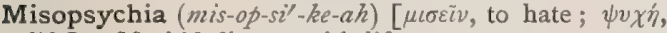
life ]. Morbid disgust with life

Misoptochos, Misoptochus (mis-opp'-to-kos, mis-oppl-tokus) [ $\mu \tau \varepsilon \varepsilon i v$, to hate; $\pi \tau \omega \chi o ́ s$, beggar]. Gout; facetiously so termed because the poor are not so liable to it.

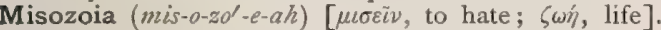
Disgust with life, together with suicidal impulses.

Misplaced (mis-plāst') [ME., mis-, wrong; place, place]. Out of proper position. M. Menstruation, vicarious menstruation.

Missed (mist) [ME., missen, to miss]. Passed; failure of attaining. M. Abortion, the retention of the product of conception in the uterine cavity after its death and with the appearance of some of the symptoms of abortion. M. Labor, a rare accident of pregnancy, in which there is the occurrence of a few labor-pains at term, their subsidence, and the retention of the product of conception in utero for a varying period thereafter. M. Miscarriage. Same as M. Abortion.

Misshapen (mis-sha'-pen) [ME., mis-, wrong; shape, shape]. Deformed; ill-shaped.

Missio (mis'-e-o) [L.]. A letting go. M. sanguinis, blood-letting.

Missoy (mis'-oi). See Massoy Bark.

Mistletoe (mis'-l-to). See Viscum.

Mistura (mis-tu'-rah) [L. : gen. and pl., Mistura). A mixture. In pharmacy an aqueous preparation of an insoluble substance held in suspension, usually by the addition of soluble gum, egg-emulsion, etc. There are four official misture, besides six in the British Pharmacopeia and $\mathbf{I} 8$ in the National Formulary.

Mistus, Mixtus (mis'-tus, miks'-tus) [miscere, p.p. mistus, mixtus, to mix]. In biology, a cross-breed.

Mitchell's (S. Weir) Treatment. See Treatment, Methods of.

Mitchella (mich-el'-ah) [after John Mitchell, a Virginian botanist]. A genus of rubiaceous plants. M. repens, partridge-berry or checker-berry, is diuretic and astringent, and among the Indians has reputed emmenagogue properties. Unof.

Mite (mit) [ME., mite, a mite]. The common name applied indifferently to any of the eight-legged insects of the order Acarina. The fact that the immature forms have but six legs has led to some confusion in the onomy of the group and the formation of spurious species $\left(e . g^{\circ}\right.$, Leptus). The mites are cosmopolitan, and the majority are parasitic upon plants and animals, while others infest organic substances, such as cheese, sugar, flour, old rags, rubbish, etc. For the true ticks see the genus Ixodes; for the garden and harvest "ticks," "mites," or "bugs," and certain ecto-parasites of birds, see the genera Tetranychus (Leptus), Trombidium, Cheyletus, Harpirhynchus, Picobia; and for those forms associated with the various acariases, the itch, mange, etc., of man and domestic animals, consult the genera Chorioptes, Cytodites, Demodex, Dermanyssus, Dermoglyphus, Epidermoptes, Freyana, Hypodectes, Listrophorus, Megninia, Pterolichus, Psoroptes, Sarcoptes, Symbiotes, Symploplectes, under Parasites (Animal), Table of.

Mithradate, Mithridate (mith'-rad-āt, mith'-rid-āt) [M $\iota \theta \rho a \delta a ́ \tau \eta \varsigma, \mathbf{M} \iota \theta \rho \iota a^{\prime} \tau \zeta$, a Grecian king]. An old name for an electuary of many ingredients, used as an antidote and alexipharmac.

Mithradatism, Mithridatism (mith'-rad-ät-izm, mith'-

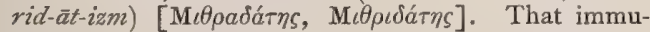
nity from the effects of a poison induced by the administration of gradually increased doses. The selection of the word has reference to the fable concerning
Mithradates, king of Pontus, that he became so charged with the poisons with which he experimented that he acquired an immunity to them all.

Mitigate (mil'-ig-ät) [mitigare, to soften]. To allay; to make milder; to moderate.

Mitigated Stick, or Caustic (mit'-ig-a-ted) [mitigare, to soften]. See Argentum.

Mitigating (mit'-ig-a-ting) [mitigare, to soften]. Assuaging, allaying. Also, a descriptive term applied to anodynes.

Mitigation (mit-ig-a'shun) [mitigare, to soften]. At tenuation; lessening.

Mitis-green. Same as Schweinfurth-green.

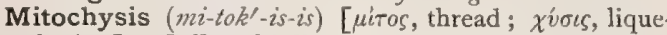
faction]. Cell-multiplication, direct or by mitosis.

Mitom (mi'-tōm). Same as Mitoma.

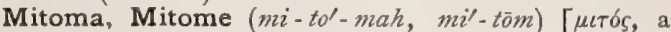
thread]. In biology, Flemming's term for the "filar mass," $i$. e., the threads of the protoplasmic reticulum of a cell, also called Cytomitoma. Cf. Paramitoma, Karyomitoma.

Mitoplastic (mi-to-plas'-tik) [ $\mu i \tau o s$, thread, web ; $\pi \lambda a ́ \sigma \sigma \varepsilon \iota \nu$, to form]. Serving to build up the tissues.

Mitosic (mi-to'-sik). Synonym of Mitotic or Karyokinetic.

Mitosis (mi-to'-sis) [ $\mu$ íos, a thread]. In biology, the splitting of the nuclear chromatin of plant or animal cells while undergoing indirect division ; karyomitosis, karyokinesis.

Mitotic $\left(m i-t^{\prime} t^{\prime}-i k\right)[\mu i \tau o s$, thread]. Pertaining to Mitosis.

Mitra hippocratis (mi'-trah hip-pok'-ra-tis). See Bandage, Capeline.

Mitral (mi'tral) [mitra, miter]. Resembling a miter; mitriform; pertaining to the auriculo-ventricular valve of the left side of the heart. M. Disease, a generic term for organic disease of the mitral valve of the heart. M. Incompetence. See $M$. Regurgitation and Endocarditis. M. Insufficiency. See $M$. Regurgitation and Endocarditis. M. Murmur. See Murmur. M. Obstruction, disease of the mitral valve causing obstruction to the flow of blood through the left auriculo-ventricular opening. M. Regurgitation, disease of the mitral valve preventing its proper closure during the cardiac systole, and permitting blood to be forced back into the left auricle. M. Stenosis. See $M$. Obstruction. M. Valve. See Valves.

Mitrate (mi'-trāt) [mitra, miter]. In biology, bonnetshaped, miter-shaped, mitriform.

Mitriform (mi'-trif-orm) [mitra, miter ; forma, form] See Mitral.

Mitscherlich's Test. See Tests, Table of.

Mittler's Green. See Pigments, Conspectus of.

Mixed Blood. See Mulatto, and Griffe.

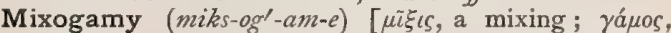
marriage]. In biology, the congregation of males and females, the number of the former being in excess, as exhibited by certain fishes at spawning-time.

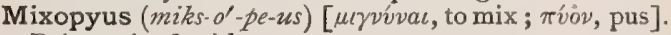
Being mixed with pus.

Mixoscopia (miks - o-sko' - pe-ah) [ $\mu i \xi \iota s$ cohabitation; $\sigma \kappa \varepsilon \pi \tau \varepsilon i v$, to look]. A form of sexual perversion in which the orgasm is excited by the sight of coitus. See Voyeur.

Mixture (miks'-tūr). See Mistura.

Mixtus (miks'-tus). See Mistus.

Mnemonics (ne-mon'-iks) [ $\mu \nu \eta \mu \eta$, the memory]. The science of cultivation of the memory by systematic methods.

Moan (mōn) [ME., monen, to moan]. I. To utter a low, dull sound expressive of suffering. 2. The sound so uttered. 
Mobby $\left(m o b^{\prime}-e\right)$. See Mabby

Mobile (mob'-il) [mobilis, movable]. One that shifts from place to place. M. Spasm, athetosis; slow, irregular movement, as of the paralyzed parts in hemiplegia.

Mobility (mob-il'-it-e) [mobilis, movable]. That property by which the position of a body may be changed. The condition of being movable.

Mochlus (mok'-lus) [ $\mu 0 \chi \lambda \hat{\alpha} s$, lever]. The obstetric lever, or vectis.

Mock Turkey-red. Same as Barwood-red.

Mocmain (mok'-mān) [Chinese for "tree-cotton"']. The cottony hairs of Bombax heptaphyllum, a species of cotton-tree, used in stuffing the pads of trusses.

Modal (mo'-dal) [modus, mode]. A term applied to the order of response of muscles and nerves to the galvanic current.

Model (mod'-el) [modellus, dim. of modus, measure]. A standard for imitation. M., Antagonizing (for artificial teeth), a contrivance for obtaining an exact representation of the manner in which the jaws meet, by which a dentist selects, arranges, and antagonizes artificial teeth.

Moderator (mod'-er-a-tor) [moderare, to regulate]. Reil's band. See Band. M. Band. See Band. M. Centers, M. Nerves. See Inhibitory.

Modification (mod'-if-ik-a'-shun). See Tuberculin.

Modiolus (mo-di'-o-lus) [L., nave]. I. The central pillar or axis of the cochlea, around which the spiral canal makes two and one-half turns. 2. The crown of a trephine.

Modulus (mod'-u-lus) [dim. of modus, measure, mode]. A unit of certain physical forces.

Modus (mo'-dus) [L.]. A mode or method. M. operandi, the method of the performance of an action.

Mœnia (me'-ne-ah) [L., pl.]. Walls. M. dentis, the portions of the jaws that bear the alveoli.

Mogigraphia (mog-ig-raf'-e-ah) [ $\mu$ ó $\gamma \iota s$, with difficulty ;

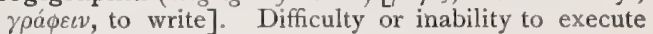
writing movements; writers' cramp.

Mogigraphic (mog-ig-raf'-ik) [ $\mu$ ó $\iota_{\varsigma}$, with difficulty; $\phi \rho a ́ \phi \varepsilon \iota \nu$, to write]. Characterized by mogigraphia.

Mogilalia (mog-il-a'-le-ah) [ $\mu \sigma_{\gamma} \iota \varsigma$, with difficulty; $\lambda a \lambda \iota a ́$, talk]. Stammering, stuttering.

Mogilalism (mog-il-a -lizm). Same as Mooilalia.

Mogiphonia (mog-if-o'-ne-ah) [ $\mu \delta \gamma \iota s$, with difficulty; $\phi \omega \nu \eta \dot{\eta}$, sound]. A difficulty in producing loud vocal sounds with the larynx, ordinary speech remaining unaffected.

Mogographia (mog-o-graf'-e-ah). See Mogigraphia.

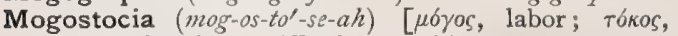
birth ]. Painful or difficult parturition.

Mohr's Method. A volumetric method of estimating the chlorids in the urine. It is carried out by means of precipitation by a standard solution of silver nitrate.

Mohrenheim's Fossa. See Fossa. M.'s Space, the groove on the deltoid muscle between the cephalic vein and the humero-thoracic artery

Moist [ME., moist, damp]. Damp; slightly wet. M. Chamber, a large circular glass with a lid, used in bacteriologic work, especially for growing potato-cultures. The chamber is kept moist by the evaporation of water from a moistened filter-paper which is laid on the bottom of the dish. M. Colors. See Pigments, Colors, and Dyestuffs. M. Filter, a filter-paper which is moistened with water. M. Gangrene, the form of gangrene that occurs in a part filled with blood. See Gangrene. M. Melting, the form of procedure in the extraction of fats, in which the material is melted over direct fire, with the addition of dilute sulphuric acid. This is the process now generally followed. M. Tetter. See Eczema. M. Wart. See Verruca acuminata.

Mola (mo'-lah). See Mole.

Molar (mo'-lar) [moles, mass]. Pertaining to masses, in contradistinction to molecular.

Molar (mo'-lar) [mola, a millstone]. In biology, a tooth that has no deciduous predecessor, but is behind other teeth, the premolars, which (except the first) have deciduous predecessors. M. Glands, the salivary glands of the horse and other mammals; the superior is outside and along the upper border of the buccinator muscle, the inferior is at the inferior border of the buccinator. These glands pour their secretion into the mouth by a series of orifices arranged in line on the buccal membrane, parallel to each molar arch. M. Teeth. See Teeth.

Molariform (mo-lar'-if-orm) [mola, millstone; forma, form]. Having the form of a molar tooth.

Molary (mo'-lar-e) [molaria, belonging to a mill]. In zoölogy, fitted for grinding.

Molasses (mo-las'-sez) [mellaceus, honey-like]. Theriaca; treacle ; the uncrystallized residue of the refining of sugar. It is used in pharmacy.

Mold, Mould (möld) [ME., mould, mold]. I. A minute fungus or other vegetable growth of a low type appearing on moist and decaying bodies. 2. The matrix or prepared and shaped cavity in which anything is cast and receives its form. Anything that serves to regulate the size and form of bodies. Cast; form; shape. A fontanel or space occupied by a cartilaginous membrane in the skull of the fetus and of a newborn child, situated at the angles of the bones that form the skull.

Mole ( $m \bar{o} l)$ [mola, a mass]. I. A proliferative degeneration of the chorionic villi, producing a mass of berrylike vesicles attached to the placenta. It is called Vesicular Mole and Hydatidiform or Myxomatous Degeneration of the Placenta. 2. Also applied to a small, pigmented spot of the skin. M., Blood, a mass of coagulated blood and retained fetal membranes and placenta, sometimes found in the uterus after an abortion. M., Carneous. See $M$., Fleshy. M., Cutaneous, a pigmented spot on the skin. M., Cystic. Same as $M$., Hydatidiform. M., False, a mass of coagulated blood and exfoliated vaginal mucous membrane discharged occasionally in the course of membranous dysmenorrhea, and not due to a retained product of conception. M., Fleshy, the body formed in the uterine cavity when an ovum that has died is retained within the uterus for some time. It may undergo fatty or calcareous degeneration. M., Hairy. See Nerus pilosus. M., Hydatid, M., Hydatidiform, M., Hydatoid. See first definition under Mole. M., Pigmentary. See Navus pigmentosus. M., Sanguineous. Same as M., Fleshy. M., Stone, a fleshy mole that has undergone calcareous degeneration. M., True, one the result of conception. M., Tubal. See Tubal. M., Uterine, a mass of morbid material sometimes contained in the uterus after the death of the product of conception. It is the result of some pathologic process. M., Vesicular. Same as M., Hydatidiform. M., White, a pigmentary nevus that has not yet attained its characteristic color.

Molecular (mo-lek'-u-lar) [dim. of moles, mass]. Pertaining to, or composed of, molecules. M. Death, the changes of cellular or intimate structure that result in the disorganization of the vital cell or somacule, and that render impossible a resumption of its original function. See Somatic Death. M. Débris, heterogeneous microscopic particles of degenerated tissue. M. Heat, the heat-capacity of a moleculs or compound. M. Motion, the movements of the 
molecules of a substance within that substance. M. Weight, the weight of a molecule of any substance as compared with the weight of an atom of hydrogen. It is equal to the sum of the weights of its constituent atoms.

Molecule (mol'-e-kül) [molecula; dim. of moles, mass]. The smallest quantity into which the mass of any substance can be physically divided and retain its characteristic properties; or the smallest quantity that can exist in a free state. A molecule may be chemically separated into two or more atoms. The integrity and properties of a substance reside in its molecules, Ms., Crystal, bodies conceived as existing in solutions of crystalline substances. The presence of such molecules is supposed to be the source of the rotatory power of the solutions. Ms., Organic. See Organic Molecules, Doctrine of. Ms., Physical, the molecules to groups of which rotatory activity has been ascribed.

Moleschott's Potash-solution. A solution for histologic work, consisting of from 35 per cent. to 50 per cent. of potassic hydrate. M.'s Standard Diet, a diet for the healthy adult man per diem: Nitrogen 317 grains, carbon 4750 grains, hydrogen 202 grains, sulphur 24 grains, salts $46 \mathrm{I}$ grains.

Moli (mo'-li) [African]. The tree, Dracena schizantha, of E. Africa. It produces one variety of dragon's blood, $q . v$. See, also, Pterocarpus.

Molilalia (mol-il-a $\left.a^{\prime}-l e-a h\right)$ [ $\mu \sigma \lambda_{\iota \varsigma}$, with toil ; $\lambda a \lambda \iota a ́$, speech]. Difficulty of utterance; stuttering; mogilalia.

Molimen (mo-li'-men) [L., molimen, endeavor: $p l$. Molimina]. Any effort or attempt. M., Menstrual, the menstrual act or function.

Molisch's Test. See Tests, Table of.

Molitor (mol-i'ter). Synonym of Masseter.

Moll's Glands. See Gland.

Mollescence (mol-es'-ens) [mollescere, to soften]. Softening.

Mollification (mol-if-ik-a'-shun). Synonym of Mollescence.

Mollin (mol'-in) [mollis, soft]. A soft soap of potash and cocoanut-oil, proposed as a basis for ointments; it contains an excess of fat. Also a mixture of lard and glycerin, saponified with potassium hydrate and sodium hydrate. Mollin is a kind of soft soap, used in skin-diseases and as a vehicle for various active medicaments. Unof.

Mollinum (mo-li'-num) [mollis, soft : gen., Mollini]. See Mollin. M. hydrargyri, mollin mixed with mercury; it is about twice the mercurial strength of ordinary unguentum hydrargyri.

Mollipilose (mol-ip-i'-los) [mollis, soft; pilus, a hair]. In biology, furnished with a soft downy coat.

Mollisin (mol'-is-in) [mollis, soft]. An ointment composed of yellow wax and spindle-oil.

Mollities (mo-lis $\left.h^{\prime}-e-\bar{e} z\right)$ [mollis, soft]. Softness. M. ossium. See Osteomalacia. M. uteri, softening of the uterus. It is most common in the cervix during pregnancy, but sometimes affects the body of the womb, both in the pregnant and non-pregnant state.

Mollugo (mol-u'-go) [L.]. A genus of herbs. M. spergula, M. verticillata, carpet-weed, Indian chickweed ; a stomachic, antiseptic and laxative. Unof.

Mollusc or Mollusk(mol'-usk) [molluscum, a shell-fish]. Any member of the Mollusca, a class of soft-bodied invertebrates possessing an external and an internal shell. M.-bodies, glistening bodies, about the size of epithelial cells, found in the central and older parts of the growths in Molluscum contagiosum; they are considered by Neisser, Pfeiffer, and others as parasitic (coccidia), a view opposed by Török, Tommasoli, Israel, and Virchow.

Molluscous (mol-us'-kus) [molluscum, a shell-fish]
Pertaining to the Mollusca or second division of the animal kingdom. Also, pertaining to the disease Molluscum.

Molluscum (mol-us'-kum) [L.]. A term applied to several diseases of the skin. M. Acne, M. adenosum. Synonym of $M$. contagiosum. M. atheromatosum, Molluscum contagiosum with cystic tumors. M. cholestericum. Same as Xanthoma, q.v. M. contagiosum, Molluscum epitheliale, a skin-disease characterized by the formation of pinhead-sized to beansized and marble-sized, sessile or pedunculated, yel lowish-white or pinkish tumors, rounded or acuminate. imbedded within or projecting from the skin, and having usually a dark-colored point at the apex, from which, on pressure, can be expressed a milky, curdlike, or inspissated cheesy mass. The lesions may be single or multiple, and occur usually in children or young adults upon the face, neck, and genitals. They may attain a very considerable size. The disease is probably due to a parasitic protozoön of the coccidium type. M. epitheliale. See $M$. contagiosum. M. fibrosum, a disease of the skin characterized by the formation therein of lax fibrous tissue, or of gelatinous tissue in process of becoming fibrous. It begins early in life, and the tumors tend to increase in number and size indefinitely. They are often associated with deficient mental development. The tumors vary in size from a pin's head to an orange, and may be sessile or pedunculated. Their number may reach into the hundreds or thousands. M. giganteum, a variety of $M$. contagiosum in which the tumors attain considerable size. M. pendulum. Synonym of M. fibrosum. M. porcellanum. Synonym of $M$. contagiosum. M. sebaceum. Synonym of $M$. contagiosum. M., Sessile. Synonym of M. contagiosum. M. simplex. Synonym of $M$. fibrosum. M. verrucosum. Synonym of $M$. contagiosum.

Mollusk (mol'-usk). See Mollusc.

Molops (mo'-lops) [ $\mu \omega_{\lambda} \lambda \omega \psi$, weal : pl., Molopes]. A red spot on the skin, such as is seen in certain fevers. The mark of a stroke or stripe upon the skin.

Molt, Moult (mölt) [ME., mouten, to molt]. To shed or cast, as the skin, feathers, or hair.

Molybdamaurosis (mol-ib-dam-aw-ro'-sis) [ $\mu \delta \lambda v \beta \delta o s$,

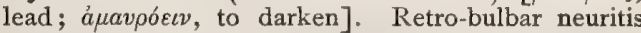
due to lead-poisoning.

Molybdamblyopia (mol-ib-dam-ble-o'-pe-ah) $[\mu b \lambda v \beta \delta o s$, lead; $a \mu \beta \lambda u s$, dulled; $\omega \psi$, eye]. Impairment of vision due to lead-poisoning.

Molybdencephalia (mol-ib-den-sef-a $\left.a^{\prime}-l e-a h\right)[\mu \sigma \lambda \lambda \beta \delta o s$, lead; $\dot{\varepsilon} \gamma \kappa \varepsilon \dot{\varepsilon} \phi \lambda \lambda_{\text {s }}$, brain ]. Brain-disease due to leadpoisoning.

Molybdencephalopathia (mol-ib-den-sef-al-o-path'-e$a h)$, Molybdencephalopathy (mol-ib-den-sef-al-op'-

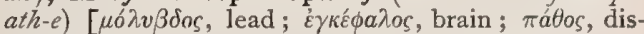
ease]. Brain-disease due to lead-poisoning.

Molybdenterophthisis (mol-ib-den-ter-off'-this - is) [ $\mu \delta \hat{\lambda} v \beta \delta \delta \varsigma$, lead; $\varepsilon v \nu \tau \varepsilon \rho \nu$, intestine ; $\phi \theta i \sigma \iota \varsigma$, wasting]. A wasting enteric disorder due to lead-poisoning.

Molybdenum (mol-ib-de'-num) [ $\mu 0 \lambda \hat{\beta} \beta \delta \alpha \iota v a$, graphite; $\mu \delta \hat{\lambda} v \beta \delta \delta \varsigma$, lead]. A metal somewhat resembling chromium; symbol, Mo; atomic weight, 96. See Elements, Table of.

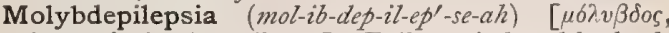
lead; $\dot{\varepsilon} \pi \imath \eta \psi \psi i a$, epilepsy]. Epilepsy induced by leadpoisoning.

Molybdo- $\left(m o l-i b^{\prime}-d o-\right)[\mu o ́ \lambda v \beta \delta o s$, lead]. A prefix denoting reference to or connection with lead. In chemistry, signifying composition with the element molybdenum.

Molybdocachexia (mol-ib-do-kak-ek'-se-ah) $[\mu 6 \lambda v \beta \delta o s$, lead; како́s, bad; $\dot{\varepsilon} \xi \varsigma$, habit]. A depraved state of 
the body due to lead-poisoning ; chronic lead-poisoning; plumbism.

Molybdocardialgia (mol-ib-do-kar-de-all-je-ah)

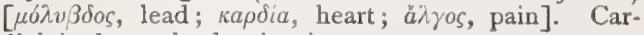
dialgia due to lead-poisoning.

Molybdocolic (mol-ib-do-kol'-ik) [ $\mu 6 \lambda v \beta \delta o s, l e a d ; \kappa \tilde{\omega} \lambda o \nu$, colon]. Lead-colic; painters' colic

Molybdodyspepsia (mol-ib-do-dis-pep'-se-ah) $[\mu \delta \lambda v \beta$. $\delta o \varsigma$, lead; $\delta v \varsigma_{-}^{-}$, ill ; $\pi \varepsilon ́ \pi \tau \varepsilon \iota v$, to digest]. Dyspepsia caused by lead-poisoning.

Molybdonosus (mol-ib-don'-o-sus) $[\mu \delta \hat{\lambda} v \beta \delta o s$, lead; vóos, disease]. Synonym of Plumbism.

Molybdoparesis (mol-ib-do-par'-es-is) [ $\mu 6 \lambda v \beta \delta \delta o s$, lead; $\pi a ́ \rho \varepsilon \sigma \iota s$, paresis]. Partial paralysis, due to leadpoisoning.

Molybdosis (mol-ib-do'-sis) [ $\mu 6 \hat{\lambda} v \beta \delta o s$, lead]. Leadpoisoning; plumbism.

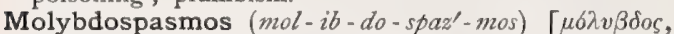
lead; $\sigma \pi \alpha ́ \sigma \mu o s$, spasm]. Spasm or cramp produced by lead-poisoning.

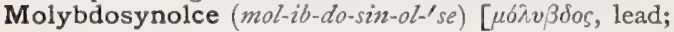

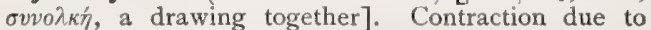
lead-poisoning.

Molybdotromos (mol-ib-dot'-ro-mos) [ $\mu \hat{b} \lambda v \beta \delta o s$, lead; $\tau \rho \delta \mu \rho s$, tremor]. Tremor due to lead-poisoning.

Molyne (mol-i'-ne) [ $i_{0} \lambda \hat{v} v \varepsilon v$, to defile]. The anus.

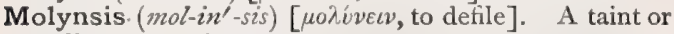
defilement ; miasm.

Momentum (mo-men'-tum) [momen, momentum, a motion]. Amount of force. Also, the quantity of potential energy possessed by a body in motion. It is estimated as the product of its weight, expressed in units of gravity, by its velocity, expressed in units of time. It is usually expressed by the formula $m=w v$, and may be estimated in foot-pounds or kilogrammeters.

Momiscus (mo-mis'-kus) [ $\mu \omega \mu \iota \sigma o s]$. A molar tooth ; the part of a molar tooth that is near the gum.

Momordica (mo-mor'-dik-ah) [mordere, momordi, to bite]. A genus of cucurbitaceous plants, mostly African and Asiatic. M. bucha, a species of cucumber native to Brazil. It is a powerful drastic purgative, useful in dropsy. M. balsamina. See Balsamapple. Unof.

Momordicin (mo-mor'-dis-in). Same as Elaterin.

Mon-(mon-) [uóvos, one]. A prefix denoting one or single.

Monad (mon'-ad) [ [uovás, a unit]. I. Any single-celled microörganism, whether of animal or vegetable character; especially any flagellate infusorium (a microscopic animal). 2. See Quantivalence.

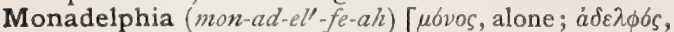
brother]. One brotherhood; a name applied to certain hermaphrodite flowers.

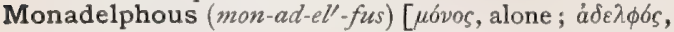
brother]. In biology, in one brotherhood. Applied to stamens that are united by their filaments into one set.

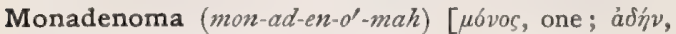
gland; $b \mu a$, tumor]. A uniglandular adenoma.

Monadiform (mon-ad'-if-orm) [ $\mu$ ovás, a unit, a monad; forma, shape]. In biology, resembling a monad.

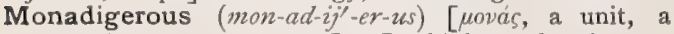
monad; gerere, to carry]. In biology, bearing or composed of monads or monadiform cells.

Monadina (mon-ad-i'-nah) [ $\mu$ ovás, a unit]. The flagellate infusorians, or monadide; a family of animal microörganisms.

Monadine (mon'-ad-in) [ $\mu$ ovás, a unit]. Pertaining to or of the nature of a monad.

Monadinic (mon-ad-in'-ik) [ $\mu$ ovás, a unit]. Belonging to the Monadina.
Monadology (mon-ad-ol'-o-je) [ science]. The doctrine of Leibnitz, Lötze, Zimmermann, and Herbart, according to which the elementary particles of matter are vital forces acting from an internal principle.

Monæ (mon'-e) [L.]. Buttocks.

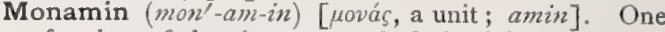
of a class of chemic compounds derived from ammonia by the replacement of the hydrogen by a monovalent alkyl. See Amin.

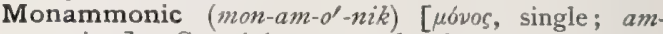
monium]. Containing one molecule of ammonium.

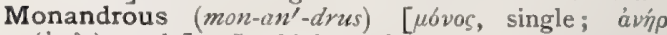
$(a ́ v \delta \rho)$, male]. In biology, having but one male; monarsenous.

Monanthemous (mon-an'-them-us) [uóvos, single; $a \nu \theta \varepsilon \mu o v$, a flower]. In biology, bearing but a single flower; monanthous.

Monantherous (mon-an'-ther-us) [ $\mu$ óvos, single ; àv0os, flower]. In biology, a term applied to a stamen bearing but one anther.

Monanthous (mon-an'-thus) [ $\mu$ ovos, single; ăv0os, flower]. In biology, producing but one flower.

Monarda (mo-nar'-dah) [after N. Monardés, a Spanish physician of the sixteenth century]. A genus of $\mathbf{N}$. American labiate plants. M. fistulosa L., wild bergamot, M. didyma, bee-balm, and M. punctata, horsemint; are diaphoretic, carminative, and stimulant. Unof.

Monardella (mon-ar-del'-ah) [after $N$. Monardés, a Spanish physician of the sixteenth century]. A genus of some eleven species of 'fragrant labiate herbs, all Californian, and having the general properties of the mints, pennyroyal, and basil. Unof.

Monardin (mo-nar'-din) [N. Monardès, a Spanish physician of the sixteenth century], $\mathrm{C}_{10} \mathrm{H}_{14} \mathrm{O}$. A substance much resembling thymol, but derived from the oil of horsemint, Monarda punctata.

Monarsenous (mon-ar'-sen-us) [ubvos, single; à $\sigma \sigma \eta \nu$, male]. In biology, having but one male; monandrous.

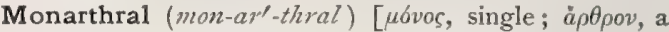
joint]. A term applied to a muscle that passes over but one joint, $e_{0} g$. , the brachialis anticus. Its correlative is disarthral, applied to a muscle passing over two joints, e. $g$. , the biceps.

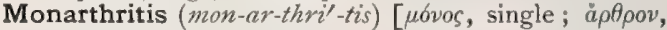
a joint ; $\iota \tau \iota$, inflammation]. Arthritis affecting only a single joint.

Monas (mon'-as) [uovás, unit]. A genus of minute, globose, plastic and free swimming animalcules inhabiting salt and fresh water, especially infusions. In this genus are included the simplest known forms of the typical flagellate infusoria. Early writers consigned to the genus many doubtful or immature microorganisms, some of which have since been found to belong to the Bacteria, or to be zoöspore stages of Algæ, Palmellaceæ, or other protophytic ulants.

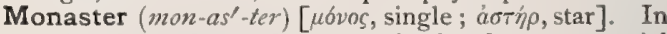
embryology, the mother-star; the fourth, or equatorial stage of karyokinesis. That stage of indirect celldivision or mitosis at which a single star is formed by the arrangement of the chromatin-loops about the equator of the achromatin-spindle.

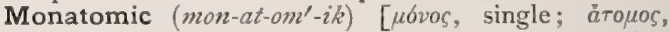
atom]. Having the valence of hydrogen; saturating or saturated by a single monad atom. See Quaniivalence. M. Alcohols, those formed by the substitution in a hydrocarbon of one hydrogen group for one atom of hydrogen.

Monaxial, Monaxonic (mon-aks'-e-al, mon-aks-on'-ik)

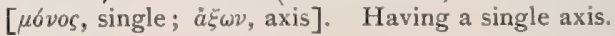


Monecious (mon-e'-shus) [ $\mu$ bvos, single; oikos, house] Having male and female organs united in one animal; of plants, having the male and female organs in separate flowers, but on the same plant, as in the cucurbitaceous plants

Monecism (mon-e'-sizm) [ $\mu$ óvos, single; oikos, house]. Hermaphrodism.

Monembryary (mon-em'-bre-a-re) [ $\mu o ́ v o s$, single ; $\check{\mu} \mu \beta \rho v$ $o v$, an embryo]. In biology, having a single embryo. Moner, Moneron (mo'-ner, mon'-er-on) [ $\mu$ óvos, single]. In biology, a non-nucleated unicellular organism of the simplest possible character.

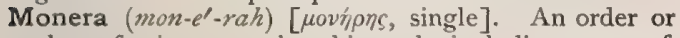
class of minute, marine rhizopods, including some of the lowest forms of animal life.

Moneron (mon'-er-on). See Moner.

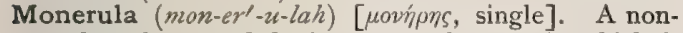
nucleated stage of the impregnated ovum in which it has the form of a simple moner.

Monesia (mo-n $\left.\ell^{\prime}-z \ell-a h\right)$ [origin uncertain]. A vegetable extract from monesia-bark, produced by Chrysophyllum buranhem, a tree of Brazil. It occurs in irregularly-shaped dark-brown pieces, soluble in water, and with a sweetish, astringent taste. It has been used as a stomachic, alterative, and astringent. Dose gr. $\mathrm{v}-\mathrm{x}$. Unof

Monesin (mo-ne'-sin) [monesia]. A principle (said to be identical with saponin) obtained from monesia; it is astringent, and is said to be oxytocic.

Money-counters' Disease. A disease of the hands, head, and conjunctivæ of persons handling banknotes; it is supposed to be due to arsenic-poisoning.

Mongolian Idiocy. See Idiocy, Ethnic.

Mongrel (mung'-grel) [ME., mungrel, mongrel]. "An individual or a breed of animals resulting from repeated crossing or mixture of several varieties; the progeny of varieties, or especially of artificial varieties, as distinguished from the hybrid or cross between two different species."

Monilated (mon'-il-a-ted) [monile, a necklace]. In biology, having a necklace-like arrangement; moniliform.

Monilethrix (mo-nil'-eth-riks) [monile, a necklace; $\theta \rho i \xi$, hair]. An affection of the hair in which nodes can be seen strung regularly or irregularly along the hairshaft, the internodular portions being relatively colorless, atrophied, and thinned. As distinguished from the nodes of trichorrhexis, a fracture occurs through the thinned and apparently non-pigmented portion of the shaft, the pigmented node representing what is thought to be nearly normal hair-tissue.

Moniliform (mon-il'-if-orm) [monile, necklace ; forma, form]. Shaped like a necklace; beaded. Resembling a string of beads. Applied to the shapes of certain hairs, roots, tubers, and other structures. $M$. Bronchiectasis, bead-like dilatations of a bronchial tube, resembling a rosary, the tube between the dilatations retaining its normal size

Monilithrix (mo-nil'-ith-riks). See Monilethrix.

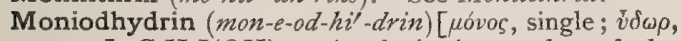
water, $\mathrm{C}_{3} \mathrm{H}_{5} \mathrm{I}(\mathrm{OH})$. A substitution-product of glycerin, occurring in the form of a yellow, syrupy liquid.

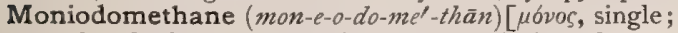
methane, $\mathrm{CH}_{3} \mathrm{I}$. Methylic iodid, a colorless, heavy, ethereal fluid, of the specific gravity of 2.199 at $0^{\circ} \mathrm{C}$., and boiling at $43.8^{\circ} \mathrm{C}$. (II I ${ }^{\circ} \mathrm{F}$.). Its vapor has been used as an anesthetic, but its decomposition is easy, the irritating effects of iodin being produced.

Moniodophenol (mon-e-od-o-fe'-nol) [uóvos, single; $i \omega \delta \eta s$, like a violet; phenol ], $\mathrm{C}_{6} \mathrm{H}_{4} \mathrm{IOH}$. An iodincompound or substitution-product of phenol, existing in three isomeric forms.

Monism (mon'-izm) [ $\mu o ́ v o s$, single]. Any scheme of philosophy, or system of thinking, that aims at deducing all the phenomena of force, matter, life, and action from one principle. In biology, the same as Monogenesis, $q . v$.

Monistic (mon-is'-tik) [ $\mu$ óvos, single]. Of, or pertaining to, or of the nature of, monism.

Monkey-hand (munk'-t-hand). The deformed hand of the early stage of progressive muscular atrophy. The hand presents an appearance of great length; the thumb approaches the index-finger, and is on a line with the other fingers.

Monkshood (munkz'hood) [ME., monk, monk ; ME., hood, hood]. See Aconite. M. Prepuce, a redundant hooded prepuce upon the dorsal aspect of the penis. It is often associated with hypospadias.

Mono- (mon'-o-) [ $\mu$ óvos, single]. A prefix signifying one or single.

Monoathetosis (mon-o-ath-et-o'-sis) [ $\mu$ óvos, single; àdetos, without place]. Athetosis confined to one limb or one-half of the body.

Monobasic (mon-o-ba'-sik) [ $\mu o ́ v o s$, single; basis, base]. Having one base; applied in chemistry to an acid that enters into combination with a univalent basic radicle to form a neutral salt, or a salt containing one equivalent of a base.

Monoblastic (mon-o-blas'-tik) [ $\mu$ bvos, single; $\beta \lambda a \sigma \tau b s$, germ]. In biology, applied to the single germ-layer stage of a metazoic embryo. Cf. Monoplaculir. M. Theory of Disease, Nägeli's theory of the origin of miasmatic-contagious diseases, viz, : that they are due to microphytes, which before they can reproduce the disease must undergo a special stage of development in an abnormal earth substratum.

Monoblepharis (mon-o-blef'-ar-is) [ $\mu 6 v 0 s$, single; $\beta \lambda \varepsilon$. papís, eyelash]. A fungus having only a single posterior flagellum.

Monoblepsia, Monoblepsis (mon-o-blep'-se-ah, mon-o-

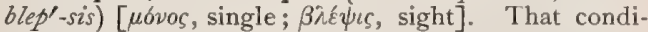
tion in which either eye has a better visual power than both together.

Monobrachius (mon-o-bra'-ke-us) [ $\mu b v o s$, single; $\beta \mu \alpha-$

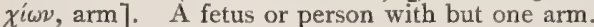

Monobromacetanilid (mon-o-brom-as-et-an'-il-id). Same as Antisepsin.

Monobromated (mon-o-bro'-ma-ted) [ubvos, one; $\beta \rho \tilde{\omega} \mu \rho \varsigma$, stench $]$. Containing one bromin atom; having one component atom of hydrogen replaced by bromin. M. Camphor. See Camphor.

Monocardian (mon-o-kar'-de-an) [ubvos, single; кapdin, heart]. Having a simple heart, single-chambered or not completely divided, as in vertebrates.

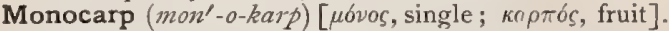
In biology, a plant that bears fruit but once.

Monocarpellary (mon-o-kar'-pel-a-re) [ $\mu$ óvos, single; $\kappa a \rho \pi \delta ́ s$, fruit]. In biology, composed of but one carpel.

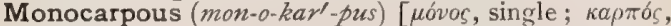
fruit]. In biology: $(a)$ applied to plants that bear fruit once a year, as annuals ; $(b)$ a flower in which but a single ovary, simple or compound, is produced.

Monocelia (mon-o-se'-le-ah) [ cavity]. Vertebrates whose encephalic cavity is single; the lancelets.

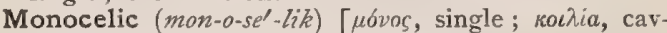
ity]. Having a single hollow cavity.

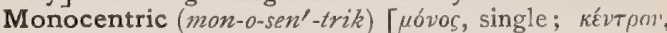
center]. Having but one center; unipolar.

Monocephalous (mon-o-sef'-al-us) [1.01'oc, sirgie; $\kappa \varepsilon \phi \alpha \lambda \dot{\eta}$, head]. In biology, arranged in a single head or head-like cluster.

Monocephalus (mon-o-sef'-al-us) [ $\mu$ óvos, single; $\kappa \varepsilon \phi a \lambda \eta ́ n$, head]. A double monstrosity consisting of a single head with two bodies more or less completely fused. 


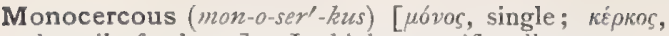
the tail of a beast]. In biology, uniflagellate.

Monocerous (mon-os'-er-us) [ In biology, having but one horn or horn-like process.

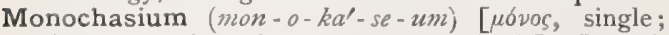

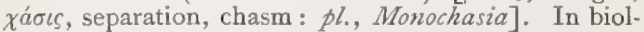
ogy, a cyme with one main axis.

Monochlamydeus (mon-o-klam-id'-e-us) [ $\mu$ óvos, single;

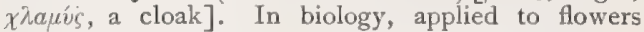
having but one floral envelop or perianth whorl.

Mono-chloral-antipyrin (mon'-o-klo' - ral-an-tip- $i^{\prime}$ rin). See Hypnal.

Monochlormethane (mon-o-klor-meth'-ān). Synonym of Methyl-chlorid.

Monochlorphenol (mon-o-klor-fe'-nol) [ $\mu \delta$ vos, single; $\chi \lambda \omega p o ́ s$, green; phenyl], $\mathrm{C}_{6} \mathrm{H}_{4} \mathrm{ClOH}$. A derivative of carbolic acid. It is a very volatile liquid, giving off vapors that are heavier than air. A mixture of monochlorphenol, alcohol, eugenol, and menthol has been called chlorphenol, and has been used in pulmonary troubles as a bactericide.

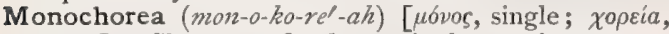
dance]. Chorea confined to a single member or to a part of the body.

Monochroic, Monochroitic (mon-o-kro'-ik, mon-o$\left.k r o-i t^{\prime}-i k\right)$ [ $\mu$ ó ${ }^{\prime}$, single; $\chi \rho \omega ́ s$, color]. Having only one color. Arterial blood is monochroic.

Monochromatic (mon-o-kro-mat'-ik) [ [ 6 ovos, single; $\chi \rho \bar{\omega} \mu a$, color]. Having but one color.

Monochromous (mon-ok'-ro-mus). Synonym of Monochromatic.

Monochrous (mon-ok'-ro-us). Synonym of Monochroic. Monocle (mon'-o-kl) [ $\mu$ óvos, single; oculus, eye]. A single lens or eye-glass.

Monoclinic (mon-o-klin'-ik) [ $\mu 6 v o \varsigma$, single; $\kappa \lambda i v \eta$, bed]. Pertaining to flowers that have the male and female organs in a single perianth. Also, applied to crystals in which the vertical axis is inclined to one, but is at right angles to the other lateral axis.

Monoclinous (mon-o-kli'-nus) [ $\mu 6 \nu o s$, single; $\kappa \lambda i v \eta$, bed]. In biology, having both male and female organs in the same flower.

Monococcus (mon-o-kok'-us) [ $\mu$ b́vos, single ; кб́ккоs, grain]. A single coccus; one not united in chains or pairs.

Monocotyledonous (mon-o-kot-il-e'-don-us) [ $\mu$ óvos,

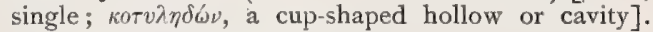
In biology, possessing but one cotyledon or seedleaf.

Monocranus (mon-ok'-ran-us) [ubvos, single; kpaviov, cranium]. A fetal monster with a single cranium, the face in part double, three or four eyes, the brain in part double.

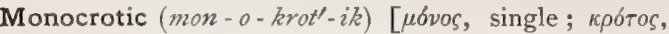
pulse]. Having but a single beat (as the normal pulse) for each cardiac systole; not dicrotic.

Monocrotous (mon-ok'-ro-tus). See Monocrofics.

Monocular (mon-ok'-u-lar). Synonym of Uniocular.

Monoculus (mon-ok'-u-lus) [ $\mu \delta \dot{v o s}$, single; oculus, eye]. In surgery, a bandage for covering one eye.

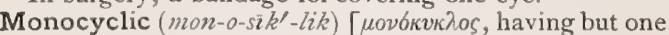
circle ]. In biology, arranged in a single whorl.

Monocyst (mon'-o-sist) [ $\mu b v o s$, single; $\kappa v \sigma \tau \iota s$, cyst $]$. A tumor made up of a single cyst.

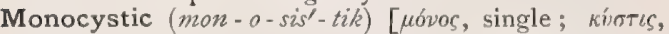
cyst]. Composed of or containing but one cyst.

Monodactylous (mon-o-dak'-til-us) [uovos, single; ઈákтvios, finger]. Having only one finger or toe.

Monodelph, Monodelphon (mon'-o-delf, mon-o-del'-

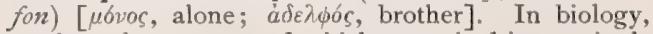
a plant the stamens of which are united into a single group by their filaments.

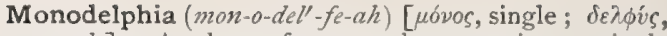
womb]. A class of mammals possessing a single uterus and a single vagina separated from the rectum.

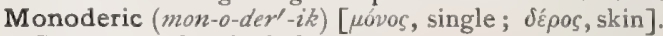
Composed of a single layer.

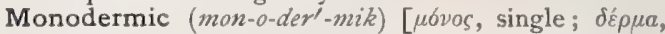
skin]. Having an envelop composed of a single layer.

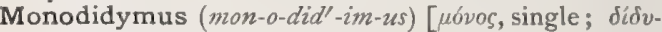
$\mu \circ$, twin]. One of twins.

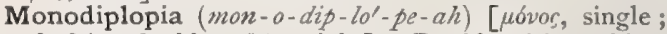
$\delta \iota \pi \lambda o_{o s}$, double; ŏ $\psi \varsigma$, sight]. Double vision with a single eye.

Monodisc strobila. See Strobila.

Monodont (mon'-o-dont) [ $\mu$ ovos, single; ódóvs, tooth]. Having but one tooth.

Monoëmbryony (mon-o-em'-bre-on-e) [ $\mu$ óvos, single ; $\varepsilon \check{\varepsilon} \beta \rho v o \nu$, embryo]. In biology, having but a single embryo, as certain seeds.

Monoflagellate (mon-o-flaj'-el-ät) [ $\mu$ óvos, single ; flagellum, a whip]. Monomastigate; having only one whip-like appendage, as an infusorian.

Monoformin (mon-o-form'-in) [ $\mu$ óvos, single, formica, an ant]. A substitution-compound of glycerin containing the radicle of formic acid. It is a colorless liquid, obtained by the action of oxalic acid and ether upon glycerin.

Monogamous (mon-og'-am-us) [uóvos, single; yáuos, marriage]. Having but one wife or mate; living in pairs. In botany, applied to flowers that have the two kinds of sexual elements isolated from one another or not collected under a single capitulum.

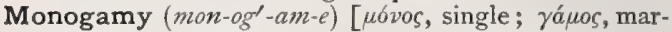
riage]. The marriage of two individuals of opposite sexes.

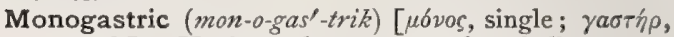
stomach]. Having only one stomach or belly.

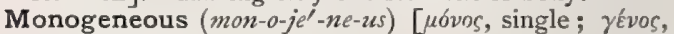
race]. Of one race or family. In botany, having but one surface of increase.

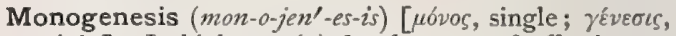
origin]. In biology : (a) development of offspring resembling the parent, as distinguished from metagenesis; (b) development from a single hermaphroditic parent; (c) origin of all organisms from a single cell.

Monogenetic (mon-o-jen-et'-ik) [úbos, single; yeveTh, source, beginning, birth]. In biology, exhibiting direct development without alternation of generations, or heterogeny, as distinguished from digenetic.

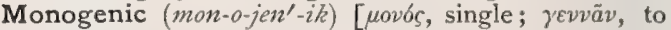
produce]. In biology, producing but one sort of embryo, as distinguished from diphygenic.

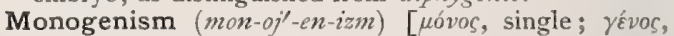
race]. The doctrine that the members of the human race are descended from one pair only.

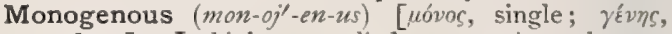
produce]. In biology, applied to organisms that resemble their parents.

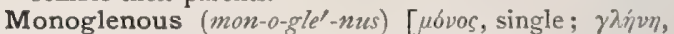
pupil]. Having, or seeing with, but one pupil.

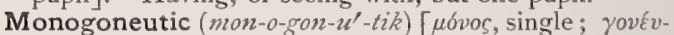
$\varepsilon \imath \nu$, to produce]. In biology, producing but a single brood during the year.

Monogonoporous (mon-o-gon-op'-or-us) [ubvos, single;

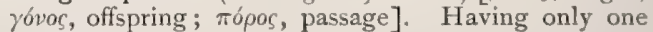
genital outlet.

Monogony (mon-ogl-o-ne) [ubvos, single; yovia, produce]. In biology, generation among animals in which sex is not differentiated.

Monograph (mon'-o-graf) [ write]. A treatise or memoir concerning a single subject. 


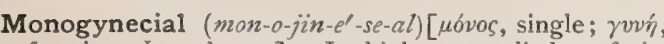
female; oikos, house]. In biology, applied to fruits that are formed from the pistil of one flower.

Monogyny (mon-oj'-in-e) [ $\mu \sigma v o s$, single; $\gamma v v \eta$, female]. In biology, mating with but one female.

Monohemerous (mon-o-hem'-er-us) [ $\dot{\eta} \mu \varepsilon \dot{e} \rho$, a day]. Lasting but a day; ephemeral.

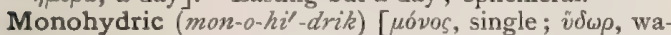
ter]. Containing one atom of hydrogen. Specifically applied to such acids as have a single hydrogen atom replaceable by a basic atom or radicle; and also to alcohols that by oxidation exchange two atoms of hydrogen for one of oxygen, and form acids containing the same number of carbon atoms as the alcohols from which they were derived.

Monoicous (mon-o'-ik-us). Synonym of Monecious.

Monoideism (mon-o-i-de'-izm) [ $\mu$ vós, single; idźa, idea]. The domination of a single idea, as in certain cases of hypnotism and insanity.

Monolein (mon-o'-le-in) [ $\mu$ óvos, single; oleum, oil], $\mathrm{C}_{21} \mathrm{H}_{38} \mathrm{O}_{2}$. A compound of glycerin and oleic acid occurring in crystals.

Monolocular (mon-o-lok'-u-lar) [ $\mu$ óvos, single; loculus a cell or cavity]. Having one cell. Unicellular. Synonym of Unilocular and Monocystic.

Monomania (mon-o-ma'-ne-ah) [ $\mu$ ovos, single; $\mu a v i a$, madness]. A form of mania or madness in which a single delusion or form of delusion is especially dwelt upon. See Paranoia.

Monomaniac (mon-o-ma'-ne-ak) [ $\mu 6 v o s$, single; $\mu a v i a$, madness]. A person who dwells especially upon one delusion or form of delusion.

Monomastigate (mon-o-mas'-tig-ät). Same as Monofagellate.

Monomeniscous (mon-o-men-is'-kus) [ $\mu 60$ os, single; нтиíко, a crescent, or concavo-convex]. In biology, applied to such invertebrate eyes as are provided with a single lens, e.g., the central eyes of scorpions and Limulus, as distinguished from polymeniscous.

Monomerous (mon-om'-er-us) [ $\mu$ óvos, single; $\mu$ épus, part]. In biology, applied to flowers that are constructed on the numerical plan of one ; or to singlejointed parts of certain animals.

Monommatous (mon-om'-at-us) [ $\mu \delta v^{\prime} s$, single; o $\mu \mu \alpha$, eye]. One-eyed.

Monomoria (mon-o-mo'-re-ah) [ $\mu$ óvos, single; $\mu \omega \rho i a$, folly]. Melancholy.

Monomorphic (mon-o-mor'-fik) [ $\mu 6$ vos, single; $\mu \circ \rho \varphi \eta ́$, form ]. In biology : $(a)$ applied to a collection of individuals, exhibiting similarity or identity of form; $(b)$ applied to species in which the same forms recur one after another with comparatively insignificant individual characters; the opposite of pleomorphic.

Monomorpho-cellular (mon-o-mor'-fo-sel'-u-lar) [ $\mu$ óvos, single; $\mu о \rho \phi h$, form; cellula, a little cell]. Having but one form of cell; as a monomorphocellular myxoma.

Monomorphous (mon-o-mor'-fus) [ $\mu \delta$ vos, single ; $\mu \circ \rho \phi \eta ́$, form]. Having but a single form; not polymorphous.

Monomphalia, Monomphalus (mon -om - fa'-le-ah,

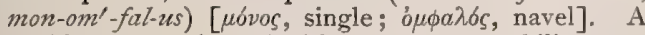
double monstrosity united by a common umbilicus.

Monomyous (mon-a-mi'-us) [ $\mu$ óvos, single; $\mu \tilde{v} s$, muscle]. Having only one muscle; applied to certain bivalves, the shells of which are closed by a single muscle.

Mononeurus (mon-o-nu'-rus) [ $\mu$ óvos, single ; veṽ $\rho \circ \nu$, nerve]. Having only one nervous system.

Mononoia, Mononcea (mon-o-noi'-ah, mon-o-ne'-ah) [ $\mu$ óvos, single; vóos, mind]. Same as Monoideism.

Mononuclear (mon-o-nu'-kle-ar). Synonym of Uninuciear.

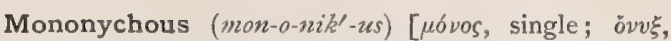
hoof ]. Having an uncleft hoof.

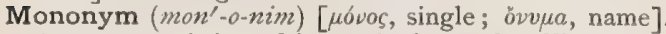
A name consisting of but a single word. Thus callo sum is a mononym for corpus callosum; pia, for pic mater; myel, for spinal cord.

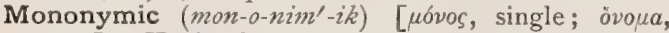
name]. Having but one name.

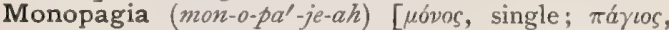
fixed]. Fixed local pain in the head; clavus hystericus.

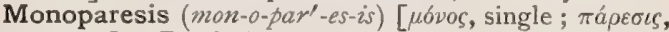
paresis]. Paralysis of a single part of the body, as one limb.

Monopathophobia (mon-o-path-o-fo'-be-ah) [ $\mu$ óvos,

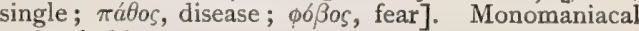
pathophobia.

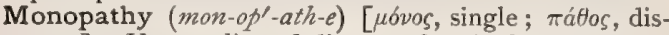
ease]. Uncomplicated disease of a single organ.

Monopegia (mon-o-pe'-je-ah). See Monopagia.

Monopetalous (mon-o-pet'-al-us) [ $\mu$ óvos, single ; $\pi \dot{t} \tau \alpha-$ $\lambda o v$, leaf ]. See Gamopelalous and Sympetalous.

Monophagia (mon-o-fa'-je-ah) [ $\mu \delta v o s$, single; $\phi a \gamma \varepsilon i v$, to eat]. I. Desire for a single article of food. 2. The eating of a single daily meal.

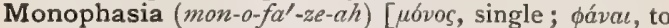
speak ]. A centric disturbance of speech, a form of aphasia, in which speech is limited to a single syllable, word, or sentence.

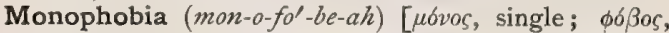
fear]. I. Morbid dread of being alone. 2. Fear in itself, or of everything, as a symptom in neurasthenia ; abnormal timidity.

Monophosphatid (mon-o-fos'-fat-id) [ $\mu 6 v o s$, single; phosphorus]. Any phosphatid which contains only one phosphorus radicle. Several such compounds have been discovered in the brain-substance.

Monophthalmia (mon-off-thal'-me-ah) [ $\mu$ óvos, single; ó $\phi a \lambda \mu \alpha \delta$, eye]. Synonym of Cyclopia.

Monophthalmous (mon-off-thal'-mos) [ $\mu$ ovos, single; $\dot{\delta} \phi \theta a \lambda \mu b s$, eye]. Single-eyed; also, pertaining to a bandage for one eye

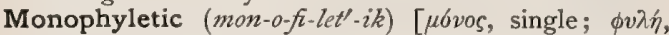
tribe]. In biology, derived from a single prototype. M. Hypothesis, the doctrine of Hreckel, that the various organic lines of animals have descended from a common type.

Monophyllous (mon-o-fil'-us) [ $\mu 6 \nu 0 s$, single; $\phi \dot{v} \lambda \lambda \omega \nu$, leaf ]. In biology, having but one leaf; formed of a single leaf.

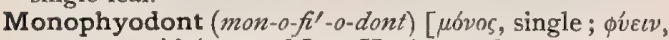
to grow; ódov́s, tooth]. Having only one set of teeth, as is the case with the Cetacea.

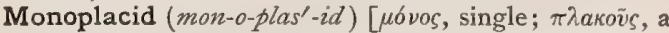
flat cake]. In biology, applied to an echinoderm having but a single madreporic plate, as distinguished from polyplacid.

Monoplacula (mon-o-plak'-u-lah) [ $\mu$ óvos, single ; $\pi \lambda \hat{a} \xi \xi$, plate, tablet: $p l$., Monoplacula $]$. In embryology, a single-layered germ; a monoblastic discoid embryo.

Monoplasmatic (mon-o-plaz-mat'-ik). Synonym of Monoplastic.

Monoplast (mon'-o-plast) [ $\mu$ óvos, single; $\pi \lambda a \sigma \tau o ́ s$, formed, molded]. In biology, any unicellular organism, as a moner or a simple histologic cell.

Monoplastic (mon-o-plas'-tik) [ $\mu \delta \hat{v o s, ~ s i n g l e ; ~} \pi \lambda a ́ \sigma \sigma \varepsilon \iota v$, to mould]. A term applied to cells constituted of only one substance.

Monoplastid (mon-o-plas'-tid) [ $\mu \delta \nu o s$, single; $\pi \lambda \alpha \sigma \tau \sigma o s$, molded]. An organism or structural element composed of only a single cell.

Monoplegia (mon-o-ple'-je-ah) [ $\mu \sigma \nu \circ \varsigma$, single; $\pi \lambda \eta \gamma \dot{\eta}$, stroke]. Paralysis of a single limb or of a single 
muscle or group of muscles. M., Central, that due to a lesion of the brain. M., Peripheral, that due to a lesion of the nerves or of the ganglion-cells of the anterior horns of the spinal cord.

Monopodacephalus (mon-o-po-das-ef'-al-us) [ $\mu$ óvos,

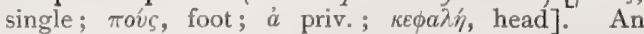
acephalic monstrosity with but a single foot.

Monopodia (mon-o-pol-de-ah). See Monopus.

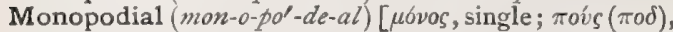
foot]. In biology, applied to that form of ramification in which all of the branches originate as lateral appendages.

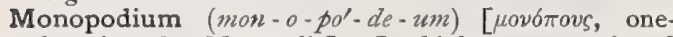
footed: pl., Monopodia]. In biology, an axis of growth that elongates at the apex at the same time that lateral branches are sent out beneath in acropetal succession.

Monoprionidian (mon-o-pri-o-nid'-e-an) [ $\mu$ óvos, single ; $\pi \rho i \omega \nu$, a saw]. In biology, exhibiting a uniserial arrangement of serrations.

Monops (mon'-ops). Synonym of Cyclops.

Monopsia (mon-ops'-e-ah). See Monophthalmia.

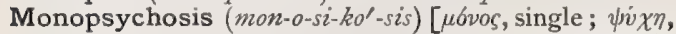
mind : pl., Monopsychoses]. Any kind of monomania or delusional insanity of a fixed type.

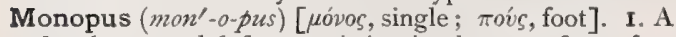
developmental defect consisting in absence of one foot or leg. 2. A one-footed monstrosity.

Monopyrenous (mon-o-pi-re'-nus) [ $\mu$ óvos, single; $\pi v \rho \eta n$, the stone of a fruit]. In biology, having but one kernel or stone.

Monorchid, Monorchis (mon-or'-kid, mon-or'-kis) [ $\mu$ bvos, single; ó $\rho \chi \iota$, testis]. A person who has but one testicle, or in whom one testicle only has descended into the scrotum.

Monorganic (mon-or-gan'-ik) [ $\mu$ óvos, single ; b $\rho \gamma a \nu o \nu$, instrument]. Pertaining to a single organ.

Monorrhinous (mon-or-i'-nus) [ $\mu$ óvos, single; pis, nose]. Having a single median nasal cavity.

Monosaccharid (mon-o-sak'-ar-id). See Polysaccharid.

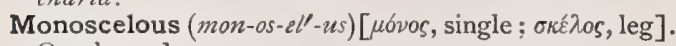
One-legged.

Monose $\left(\operatorname{mon}^{\prime}-\bar{o} s\right)$. See Carbohydrates, Table of

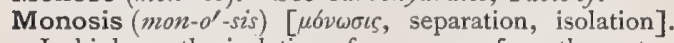
In biology, the isolation of one organ from the rest.

Monositia (mon-o-sit'-e-ah). Synonym of Monophagia.

Monosoma, Monosomia (mon-o-so'-mah, mon-o-so' me-ah) [ $\mu o ́ v o s$, single; $\sigma \tilde{\omega} \mu a$, body : pl., Monosomata]. A double monstrosity with a single body and two heads.

Monosomus (mon-os'-o-mus). See Monosoma.

Monospasm (mon'-o-spazm) [ $\mu \sigma o v o s$, single; $\sigma \pi a \sigma \mu o ́ s$, spasm]. 1. Spasm affecting limited areas, as one side of the face, a single limb, or a single muscle or musclegroup. 2. An epileptiform seizure confined to one lateral half of the body

Monosperm (mon'-o-sperm) [ $\mu 6 \nu o s$, single; $\sigma \pi \varepsilon p \mu a$, seed]. In biology, a one-seeded plant.

Monospheric (mon-o-sfer'-ik) [ $\mu \sigma v o s$, single; $\sigma \phi a i \rho \alpha$, sphere]. Consisting of a single sphere.

Monospondylic (mon-o-spon-dil'-ik) [ $\mu$ óvos, single; $\sigma \pi \sigma v \delta v \lambda_{a}$, a joint of the backbone]. Having a single centrum, as a vertebra.

Monospore (mon'-o-spör) [ $\mu$ óvos, single; $\sigma \pi b \rho o s$, seed]. An unfertilized spore or ovum.

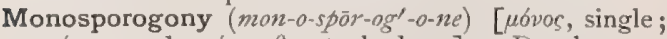

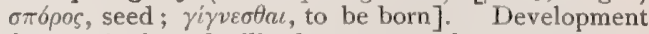
from a single unfertilized spore; parthenogenesis.

Monosporous (mon-o-spör'-us) [ $\mu \hat{b} v o s$, single; $\sigma \pi b \rho o s$, a seed]. In biology, producing but a single spore, as the hyphre or asci of certain Fungi.

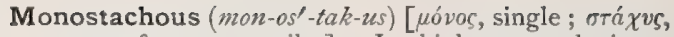
an ear of corn, a spike]. In biology, producing a single spike.

Monostichous (mon-os'-tik-us) [ [uóvos, single; aríxos, a line]. In biology, arranged in a single row, rank, series, or layer; the autonym of diplostichous.

Monostigmatous (mon-o-sigg'-mat-us) [ $\mu$ óvas, single; $\sigma \tau i \gamma \mu \alpha$, stigma]. In biology, having but a single stigma.

Monostomatous (mon-os-to'-mat-us) [

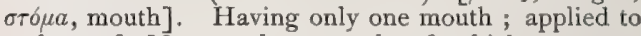
a class of Metazoa the gastrula of which possesses only one ingestive opening.

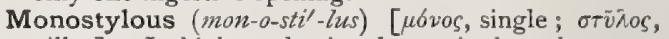
pillar]. In biology, having but a single style.

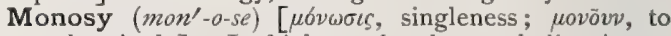
make single]. In biology, the abnormal disunion or isolation of organs ordinarily united partially or completely ; if congenital it is called ademsy, if occurring in parts previously joined dialysis.

Monothalamous (mon-o-thal'-am-us) [

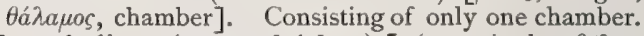

Monothelious (mon-o-the'-le-us) [ $\mu \sigma_{\nu} \sigma s$, single; $\theta \tilde{\eta} \lambda v \varsigma$, female]. In biology, polyandrous; applied to species in which several males serve a single female.

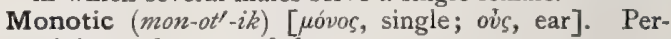
taining to but one of the ears.

Monotocous (mon-ot'-o-kus) [ $\mu$ óvos, single; tókos, birth]. In biology, bearing fruit or producing young but once or but one at a time; uniparous.

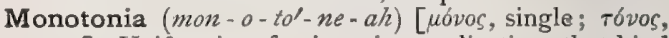
tone]. Uniformity of voice; in vocalization, that kind of uniformity that results from paralysis of the laryngeal tensors.

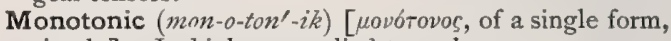
simple]. In biology, applied to such groups or masses of materials or organisms as are homogenous; being characterized by a single species or a single genus, or even a single family or order; the opposite of Poly mixic, q. $v$.

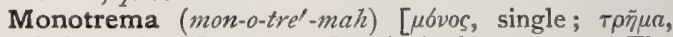
hole: pl., Monotremata]. A single aperture. The Monotremata form a class of animals including the duckbill, in which the intestinal and the genito-urinary tracts open into a common cloaca.

Monotridymus (mon-a-trid'-im-us) [ $\mu$ óvos, single; $\tau \rho i \delta v \mu o s$, triple]. A monstrosity consisting of three bodies or having triplicate parts.

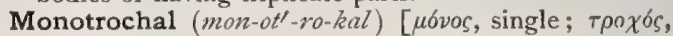
wheel]. In embryology, applied to embryos having but a single ciliated band.

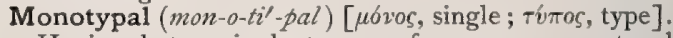
Having but a single type or form, as a monotypal disease or genus.

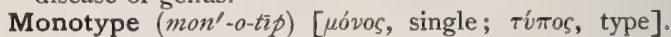
In biology the sole typical representative of its kind. Monovalent (mon-ov'-al-ent). Same as Univalent.

Monoxid (mon-oks'-id) [ubvos, single; óvis, acid]. An oxid containing a single oxygen atom combined either with two univalent atoms or with one bivalent atom.

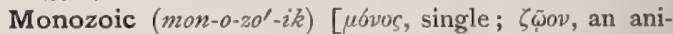
mal]. In biology, applied to certain unsegmented animals, as Amphilina, Caryophyllous, and Archigetes among the Platodes.

Monro, Foramen of. See Foramina, Table of, and Porti. M., Sulcus of, a slight furrow dividing the mesal surface of the thalamus of the brain into a dorsal and a ventral area. Also called Aulix.

Mons (monz) [L.: pl., Montes]. I. A mountain. In anatomy, the Mons pubis or the Mons veneris. M. cerebelli. See Monticulus. M. pubis, the emi- 
nence in front of the body and horizontal ramus of the os pubis; it is called also, in the female, $M$. veneris. $M$, veneris, the mons pubis of the female.

Monsel's Solution, M.'s Salt. See Ferrum.

Monster (mon'-ster). See Monstrosity.

Monstricide (mon'-stris-id) [monstrum, monster; cadere, to kill]. The killing of a monster.

Monstriferous (mon-strif'-er-us) [monstrum, monster; ferre, to bear]. Producing monsters.

Monstrosity (mon-stros'-it-e) [monstrum, a monster]. r. A teratism; a fetus or being with an abnormal development or superfluity or deficiency of parts or some vice of conformation. These may be compound or double, single or simple, according as the monster is composed of the malformations of one or more elementary organisms. 2. Teratism; the abstract quality of being monstrous; congenital deformity. A table of monstrosities is appended. M., Emmenic, Raciborski's term for a female child that menstruates during infancy. M., Parasitic, a compound monstrosity in which a subsidiary part is nourished by the autosite, or principal organism.

\section{TABLE OF MONSTROSITIES.*}

According to Geoffroy Saint-Hilaire, Altered BY HiRst AND PiERSOL.

\section{HEMITERATA.}

\section{ANOMALIES OF VOLUME}

A. Of Stature.

I. General Diminution, as in a dwarf-delayed growth.

2. General Increase, as in a giant-precocious development.

B. OF Volume, strictly speaking

I. Local Diminution. Affecting-

a. Regions, as a limb.

b. Systems, as undeveloped muscles.

c. Organs as small breasts, stenosis of canals, etc.

2. Local increase, affecting-

a. Regions, as the head.

b. Systems, as the adipose tissue.

c. Organs, as large breasts in women, lactiferous breasts in men:

II. ANOMALIES OF FORM. Single Order, includingdeformed heads; anomalies of shape in the stomach; deformed pelves, etc.

III. ANOMALIES OF COLOR.

A. Deficiency, complete, partial or imperfect albinism.

B. Excess, complete, partial or imperfect melanism.

C. Alteration, as in unusual color of the iris.

IV. ANOMALIES OF STRUCTURE.

A. Deficiency in Consistency, as cartilaginous conditions of bones.

B. Excess in Consistency, as anomalous ossification.

\section{ANOMALIES OF DISPOSITION.}

A. BY DisPLACEMFNT.

I. Of the splanchnic organs, as anomalous direction of heart or stomach, hernias, exstrophy of the bladder, etc.

2. Of the non-splanchnic organs, as club-foot, curvature of the spine, misplaced teeth, misplaced blood-vessels, etc.

B. By ChANGE OF CONNECTION.

I. Anomalous anticulations.

2. Anomalous implantations, as teeth out of line.

3. Anomalous attachments, as of muscles and ligaments.

4. Anomalous branches, as of arteries and nerves.

5. Anomalous openings, as of veins into the left auricle, of the ductus choledochus in an unusual situation, of the vagina into the rectum, of the rectim into the male urethra, of the of the rectum into the male ureth
rectum at the umbilicus, cloaca.

* Reproduced with the kind consent of the Publishers, from "Human Monstrosities," By Barton Cooke Hirst, M. D., and George A. Piersol, M. D. Philadelphia: Lea, Brothers \& Co., 1892 .
C. In Continuty.

I. Anomalous imperforations, as of rectum, vulva, vagina, mouth, esophagus.

2. Anomalous union of organs, as of kidneys, tescles, digits, teeth, ribs; adhesion of the tongue to the palate.

D. By Closure, as in complete transverse septum in the vagina.

E. By Disjunction.

1. Anomalous perforations, as persistence of foramen ovale, ductus arteriosus, urachus.

2. Anomalous divisions, as splits, fissures in various organs, hare-lip, hypospadias, fissured tongue, cleft palate, fissured cheek.

VI. ANOMALIES OF NUMBER AND EXISTENCE.

I. By numerical defect, as absence of muscles, vertebræ, ribs, digits, teeth, a lung, a kidney, the womb, the bladder, etc.

2. By numerical excess, as supernumerary digits, ribs, teeth, breasts, a double uterus.

\section{HETEROTAXIS}

I. SPLANChNic INVERSION.

II. GenERAL INVERSION.

\section{HERMAPHRODITES.*}

\section{TRUE HERMAPHRODITES.}

a. Bilateral hermaphrodites.

b. Unilateral hermaphrodites.

c. Lateral hermaphrodites.

I1. PsEudo-hERMAPHRODITES, with double sexual for mation of the external genitals, but with unisexual development of the reproductive glands (ovaries and testicles).

a. Male Pseudo-hermaphrodites (with testicles),

I. Internal pseudo-hermaphrodites. Development of uterus masculinus.

2. Externalpseudo-hermaphrodites. External genitals approach the female type : the monstrosity presents a feminine appearance and build.

3. Complete pseudo-hermaphrodites (internal and external). Uterus masculinus with tubes; separate efferent canals for bladder and uterus.

b. Female pseudo-hermaphrodites (with ovaries). Persistence of male sexual parts.

I. Internal hermaphrodites. Formation of vas def erens and tubes.

2. External hermaphrodites. Approach of the external genitals to the male type.

3. Complete hermaphrodites (internal and external.) Masculine formation of the external genitals and of a part of the sexual tract.

\section{MONSTERS.}

\section{CLASS I.-SINGLE MONSTERS.}

Order I.-Autositic Monsters.

Genus I,
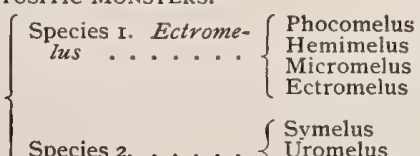

$\int$ Single $\int$ Aspalasoma

Genus II, $\left\{\begin{array}{c}\text { Single species, Cel } \\ \text { osoma, }\end{array}\right.$ osoma, ..... $\begin{aligned} & \text { Schistosoma } \\ & \text { Sleurosoma }\end{aligned}$ Pleurosoma Celosoma

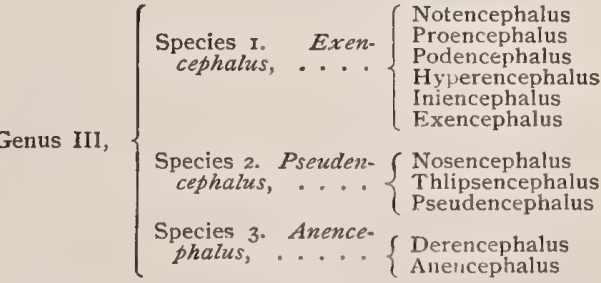

* Klebs' classification of hermaphrodites as given by Ahlfeld, is substituted for that of Geoffroy Saint-Hilaire. 


\begin{tabular}{|c|c|c|}
\hline & $\begin{array}{c}\text { Species I. Cycloceph- } \\
\text { alus, . . . . }\end{array}$ & $\begin{array}{l}\text { Ethmocephalus } \\
\text { Cebocephalus } \\
\text { Rhinocephalus } \\
\text { Cyclocephalus } \\
\text { Stomocephalus }\end{array}$ \\
\hline & $\begin{array}{c}\text { Species 2. Octoceph- } \\
\text { alus. . . . . }\end{array}$ & $\begin{array}{l}\text { Sphenocephalus } \\
\text { Octocephalus } \\
\text { Edocephalus } \\
\text { Opococephalus } \\
\text { Triocephalus }\end{array}$ \\
\hline
\end{tabular}

Order II.-OMphalositic Monsters.

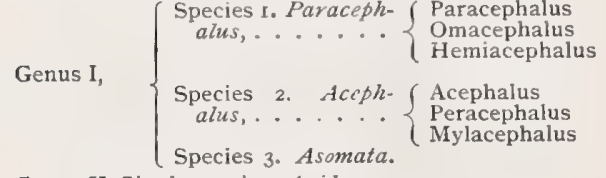

Genus II, Single species, Anideus.

\section{CLASS II.-COMPOSITE MONSTERS.}

Order I.-Double Autositic Monsters.*

A. Terata katadidyma.

Genus I, Diprosopus

Genus II, Dicephalus

Genus III, Ischiopagus

Genus IV, Pygopagus

B. Terata anadidyma.

Genus I, Dipygus

Genus II, Syncephalus

Genus III, Craniopagus

C. Terata anakatadidyma.

Genus I, Prosopothoracopagus

Genus III, Rhaciphagus

Order II.-Double Parasitic Monsters.

\begin{tabular}{|c|c|c|}
\hline Genus I, & $\begin{array}{l}\text { Species I. Hetero- } \\
\text { typus, ...... } \\
\text { Species 2. Heteralius, }\end{array}$ & $\begin{array}{l}\text { Heteropagus } \\
\text { Heterodelphus } \\
\text { Heterodymus } \\
\text { Heterotypus } \\
\text { Heteromorphus } \\
\text { Epicomus }\end{array}$ \\
\hline \multirow[b]{2}{*}{ Genus II, } & $\begin{array}{c}\text { Species 1. Polygna- } \\
\text { thus, ....... }\end{array}$ & $\begin{array}{l}\text { Epignathus } \\
\text { Hypognathus } \\
\text { Paragnathus } \\
\text { Augnathus }\end{array}$ \\
\hline & Species 2. Polymelus, & $\begin{array}{l}\text { Pygomelus } \\
\text { Gastromelus } \\
\text { Notomelus } \\
\text { Cephalomelus } \\
\text { Melomelus }\end{array}$ \\
\hline Genus & Endocyma, & Endo \\
\hline
\end{tabular}

ORder III.-Triple Monsters.

Monstrum (mon'-strum). See Monstrosity.

Monteggia's Dislocation (mon-tej'-e-ah). A form of dislocation of the hip-joint in which the head of the femur is near the anterior superior iliac spine, and the limb is rotated outward.

Monteverde's Sign or Test. See Death, Signs of.

Montgolfier's Formula. A formula for estimating the velocity of air. It is as follows: "The velocity in feet per second is equal to eight times the square root of the height through which the body has fallen." This is expressed by the formula.

$$
\mathbf{v}=\mathbf{1} \frac{x}{2 g\left(x-\frac{x}{1+.002\left(t-t^{\prime}\right)}\right)}
$$

$v=$ The velocity in feet per second.

$g=$ The acceleration due to gravity, 32.18 feet per second.

$x=$ Height of shaft.

$t=$ Internal temperature.

$t^{\prime}=$ External temperature.

$.002=\mathrm{Co}$-efficient of expansion for $\mathrm{I}^{\circ} \mathrm{F}$

* The third order of Geoffroy Saint-Hilaire, single parasitic monsters, under which name he describes dermoid cysts, is omitted. Forster's classification is substituted, with slight modification, for that of Geoffroy Saint-Hilaire.
Montgomery's Cups. The dilated canals of the uterine tubular glands. They appear as minute projections on the external surface of aborted ova. M.'s Glands. Accessory rudimentary milk-glands. (Rein.) See also Gland. M.'s Tubercles. Same as $M$.'s Glands.

Monthier's Blue. Same as Prussian Blue.

Monthlies (munth'-lèz). See Menses.

Monthling (munth'-ling) [ME., month, month]. An infant one month old.

Monthly (munth'-le) [ME., monethly, monthly]. Occurring once a month; lasting for a month. M Courses. See Menses. M. Nurse, a nurse who attends after childbirth.

Monti's Copper Method. A method of staining nervecells. See Stains, Table of.

Monticulus (mon-tik'-u-lus) [L.]. I. A little elevation. 2. Same as $M$. cerebelli. $M$. cerebelli, the small convex projection on the upper part of the median line of the cerebellum; the central portion of the superior vermiform process.

Montpellier Yellow. Same as Cassel Yellow.

Mooltan Sore. Same as Furunculus orientalis.

Moon [ME., moone, moon]. The satellite of the earth. M.-blindness, amblyopia caused by exposure of the eyes to the moon's light during sleep. See also Menotyphlosis. M.-blink, a temporary evening blindness of the tropics, supposed to be due to sleeping in the moonlight. M.-eye; I. An eye supposed to be affected by the moon. 2. A disease of the eye in horses. M.-eyed, dim-eyed; affected with mooneye. M.-face, a full, round face. M.-flaw, an attack of lunacy. M.-madness, lunacy. M.-seed. See Menispermum. M.-sick, crazy. M.-stricken, M.-struck. See Lunatic. M.-stroke, a neurosis supposed to result from exposure to the rays of the moon.

Moonling (moon'-ling) [ME., moone, moon]. A lunatic.

Moore's Figure of Eight. A figure-of-eight bandage made of a folded shawl or strip of muslin, and used as a dressing for fracture of the clavicle. M.'s Method. See Treatment, Methods of. M.'s Reagent and Test. See Tests, Table of.

Moos-pappe (môz-pop-a') [Ger.] An absorbent material consisting of a variety of moss, and prepared for use as a surgical dressing.

Moosewood. See Dirca palustris.

Moral Insanity. See Insanity.

Morand's Disease. Paresis of the extremities. See Diseases, Table of. M.'s Foot, a foot with eight toes. See Diseases, Table of.

Morbi (mor'-bi) [L., plural and genitive of Morbus]. Of a disease. Agens morbi, the cause or agent of disease. Ens morbi, the being or essential quality of disease. Materies morbi, the substance producing a disease.

Morbid (mor-bid) [morbidus, morbus, disease]. Pertaining to disease. M. Anatomy, the anatomy of organs or tissues in a state of disease.

Morbidity (mor-bid'-it-e) [morbus, disease]. The quality of disease or of being diseased. Also the conditions inducing disease. Also the statistics of the diseases in a community at a given period; the sickrate. $\mathbf{M}$. and Mortality, a term expressive of the statistical relations of disease and the death-rate.

Morbiferous (mor-bif'-er-us) [morlins, disease; ferre, to bear]. Conveying or spreading disease.

Morbific (mor-bifl-ik) [morbus, disease; facere, to make]. Causing or inducing disease.

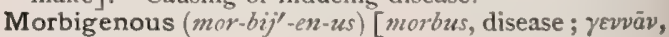
to produce]. Producing disease. 
Morbility (mor-bil'-it-e). Same as Morbidity.

Morbilli (mor-bill-i) [dim. of Morbus, disease].

See Rubeola, Measles.

Morbilliform (mor-bil'-if-orm) [morbilli, measles ; forma, form ]. Resembling measles.

Morbillous (mor-bil'-us) [morbilli, measles]. Pertaining to measles.

Morbose (mor'-bōz) [morbosus, morbus, disease]. Diseased.

Morbosity (mor-bos'-it-e) [morbosus, diseased]. condition of disease.

Morbus (mor'-bus) [L.]. A disease or illness. M. addisonii. See Addison's Disease. M. ætatis, disease peculiar to a certain age. M. anglicus. Synonym of Rachitis. M. ampullaceus. Synonym of Pemphigus. M. animatus, a parasitic disease. M. aphrodisiacus, M. aphrodisia. Synonym of Syphilis. M. apoplectiformis. Synonym of Menière's Disease. M, arietis. Synonym of Influenza. M. articularis. Synonym of Gout. M. attonitus. Synonym of Catalepsy and also of Apoplexy. M. basedowii. See Exophthalmic Goiter. M. brightii. See Bright's Disease. M. bullosus. Synonym of Pemphigus. M. caducus. See Epilepsy. M. carinus, Synonym of Insolation. M. Celsi. Synonym of Catalepsy. M. cerebralis whytii. Synonym of acute internal hydrocephalus. M. ceruleus. See Cyanosis, Congenital. M. comitialis. Synonym of Epilepsy. M. costalis. Synonym of Plezrisy. M. coxarius. See Coxalgia. M. cucullus. Synonym of Whooping-cough. M. deificus. Synonym of Epilepsy. M. divinus, M. divus. Synonym of Epilepsy. M. dominorum. Synonym of Gout. M. elephas. See Elephantiasis arabum. M. erronum, a deep bronze coloration of the skin resulting from prolonged exposure to the sun's rays or to vicissitudes of climate. M. fellifluus. Synonym of Cholera. M. fœdus. Synonym of Epilepsy. M. gallicus. Synonym of Syphilis. M.gesticulatorius. Synonym of Chorea. M. glandulosus. Synonym of Glanders. M. heracleus, M. heraculeus. Synonym of Elephantiasis and of Epilepsy. M. hispanicus. Synonym of Syphilis. M. incurvus. Synonym of Kyphosis. M. indicus. Synonym of Syphilis. M. infantilis. Synonym of Epilepsy. M. insputatus. Synonym of Epilepsy. M. interlunis. Synonym of Epilepsy. M. ischiadicus. Synonym of Sciatica. M. italicus. Synonym of Syphilis. M. Iuteolus. Synonym of Jaundice. M. maculosus dieckerhoffii. A hemorrhagic purpura of horses. M. maculosus werlhofii. See Werlhof's Disease and Purpura hamorrhagica. M. magnus. Synonym of Epilepsy. M. medicorum, the mania of those who seek the advice of physicians forimaginary diseases. Over-much doctoring. M. mucosus, mucous disease ; intestinal catarrh. M. nauticus. Synonym of Sea-sickness. M. neapolitanus. Synonym of Syphilis. M. oryzeus. Synonym of Asiatic Cholera. M. pallidus, M. parthenius. Synonym of Chlorosis. M. pauperum. Synonym of Relapsing fever. M. Paxtonii, a parasitic disease of the hair of the axilla. $\mathbf{M}$. pilaris. Synonym of Trichiasis. M. pleuriticus. Synonym of Pleurisy. M. plumbeus. Synonym of Plumbism. M. psoadicus. Synonym of Psoas Abscess. M. regius. Synonym of Jaundice. M. ruralis. Synonym of Ergotism. M. sacer. Synonym of Epilepsy. M. saltatorius. Synonym of Chorea. M. Sancti Lazari. Synonym of Leprosy. M. Sancti Valentini. Synonym of Epilepsy. M. scrophulosus. Synonym of Scrofula. M. senilis, the physiologic retrogression frequently seen in old age. $\mathbf{M}$. sideratus. Synonym of Epilepsy. M. sonticus.
Synonym of Epilepsy. M. suffocans. Synonym of Diphtheria. M. suffocatorius. Synonym of Diphtheria. M. tyrius. Synonym of Elephantiasis and Leprosy. M. virginens, M. virginum. Synonym of Chlorosis. M. werlhofii. See Werlhof's Disease.

Mordacious (mor-da'-se-us) [mordax, biting]. Biting, pungent.

Mordant (mor'-dant) [mordere, to bite]. A substance that fixes the dyes used in coloring textures, or in staining tissues and bacteria. See Pigments, Colors, and Dyestuffs.

Mordicancy (mor'-dik-an-se) [mordicare, to bite]. Pungency ; biting quality, as of a drug.

Mordicant (mor'-dik-ant). Synonym of Mordacious.

Mordication (mor-dik-a'-shun) [mordicare, to bite] A burning and stinging inflammatory condition of the skin.

Morel's Ear. See Ear, Deformities of, and Diseases, Table of. M.'s Tourniquet, the first tourniquet known, introduced by Morel in 1674 .

Morgagni (mor-gan'-e). A noted Italian anatomist of the eighteenth century. M.'s Caruncle. The middle lobe of the prostate gland. M., Cataract of. See Cataract. M., Columns of. See Column. M., Foramen of. See Foramina, Table of. M.'s Fossa. See Fossa nuvicularis. M.'s Frenum, the projection formed by the union of the ileo-colic and ileo-cecal valves. M., Glands of. See Gland. M.'s Humor, same as M.'s Liquor. M., Hydatid of. See Hydatid. M.'s Lacuna, one of the depressions of the urethral mucosa into which the urethral glands open. Also, the Fossa navicularis. M.'s Liquor, the fluid found within the capsule of the crystalline lens after death. M., Sinus of. See Sinus. M., Ventricle of. See Ventricle.

Morgan's Method. See Treatment, Methods of.

Morgue (morg) [Fr.]. A dead-house, a mortuary. A place where unknown dead are exposed for identification.

Mori, Succus ; Mori, Syrupus. See Morus.

Moria (mo'-re-ah) [ $\mu \omega \rho i a$, folly]. A form of dementia characterized by talkativeness and childish silliness.

Moribund (mor'-ib-und) [moribundus, moriri, to die]. Dying. Ripe for dissolution.

Moric Acid (mo'-rik) [morus, a mulberry tree]. I. A crystalline acid obtained from Morus alba. 2. Morin, $q . v$.

Moriform (mo'-rif-orm) [morus, a mulberry; forma, form]. Shaped like a mulberry. M. Glands. See Gland.

Morin (mo'-rin) [morus, a mulberry tree], $\mathrm{C}_{13} \mathrm{H}_{8} \mathrm{O}_{6}+$ $2 \mathrm{H}_{2} \mathrm{O}$. A coloring-matter found in yellow-wood (Morus tinctoria). It decomposes into phloroglucin and resorcin. See Pigments, Conspectus of.

Morin's Base. See Glucosin.

Morindin (mo-rin'-din) [morus, the mulberry; Indicus, Indian $], \mathrm{C}_{28} \mathrm{H}_{30} \mathrm{O}_{15}$. A crystalline substance found in Morinda citrifolia. On decomposition it is said to yield alizarin.

Morindon (mor-in'-don) [morus, a mulberry; Indicus, Indian ], $\mathrm{C}_{28} \mathrm{H}_{10} \mathrm{O}_{10}$. A beautiful red substance obtained from Morindin.

Moringa (mo-ring'-gah) [native Malabar]. A genus of dicotyledonous polypetalous trees. M. pterygosperma, M. zeylanica, horse-radish tree, found in the West Indies and the East. The oil of the seeds, the root, and the gum, all have been used in a great variety of diseases, both local and general. Unof.

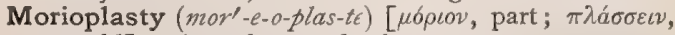
to mold]. Autoplasty; plastic surgery.

Morning (morn'-ing) [ME., morninge, morning]. The first part of the day. M. Sickness. The nausea 
of pregnant women, occurring chiefly in the early months of gestation; also, the imitative or sympathetic nausea sometimes experienced by the husband during the wife's early pregnancy; eonosus. M.tire. A peculiar condition seen in melancholia and neurasthenia, in which the patient awakes in the morning from a sound sleep unrefreshed and, in fact, more fatigued than on retiring

Morocco Leather. See Leather.

Morocomium (mo-ro-ko'-me-um) [ $\mu \omega \rho b s, \operatorname{mad} ; \kappa о \mu \varepsilon i v$, to care for]. An insane asylum.

Morodochium (mo-ro-do'-ke-um) [ $\mu \omega \rho \delta ́ s$, silly ; $\delta \varepsilon \varepsilon \varepsilon \sigma-$ Hal, to receive]. An asylum for the insane.

Morose $\left(\right.$ mor- $\left.\vec{a} z^{\prime}\right)$ [morosus, fretful]. Of a sour temper; sullen.

Morosis (mo-ro'-sis) [ $\mu \omega \rho \omega \sigma \iota s$, foolishness]. Insanity.

Morotrophium (mo-ro-tro'-fe-um). Synonym of Moroconium.

Moroxilic Acid (mor-oks-il'-ik) [morus, mulberry; ósús, acid]. Same as Moric Acid.

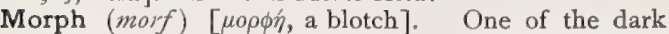
spots that occur on the foreheads of blond women suffering from uterine trouble, or who are pregnant.

Morphea, Morphœa (mor-fe'-ah) [ $\mu \circ \rho \phi \eta$, a blotch]. Circumscribed Scleroderma, Addison's Keloid; the commonest form of scleroderma, occurring usually in young female adults. Its commonest seats are about the breasts and the face and neck, and often it follows the course of the nerve-distribution. It occurs in the form of patches, rounded, ovoid, or irregular in outline ; small or large, soft or firm, smooth or shining, paleyellowish or brownish in color. The lesions are, as a rule, asymmetric. The course of the disease is chronic. The disease may also manifest itself in the form of atrophic, pit-like depressions in the skin, and as lines, streaks, and telangiectases. M. lardacea, a form of Morphea. M. maculosa, a form of morphea characterized by the presence of macules. M. nigra, a pigmented form of Morphea. M. tuberosa, a variety of morphea in which nodules are formed.

Morpheomania (mor-fe-o-ma'-ne-ah). Same as Morphiomania.

Morphetin (mor'-fet-in) [Morpheus, god of sleep]. An amorphous, bitter substance resulting when morphin sulphate is boiled with lead peroxid and dilute sulphuric acid.

Morphew (mor'-fu). See Morphea.

Morphia (mor'-fe-ah). See Morphina.

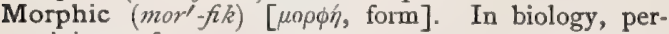
taining to form.

Morphina, Morphin (mor-fin-nah, mor'-fin) [Morpheus, god of sleep; gen., Morphina ], $\mathrm{C}_{17} \mathrm{H}_{19} \mathrm{NO}_{3}$. The name of the principal alkaloid of opium, to which the properties of that drug are chiefly due. It is an anodyne, hypnotic, and narcotic. 1/4 gr. corresponds in activity with one grain of opium of average strength. M. acetas, soluble in water. Dose gr. $\frac{1}{20}$ j. M. acetat., Liq. (B. P.) Dose $m x x-x l$. M. bromid., M. hydrobromat., $\mathrm{C}_{17} \mathrm{H}_{19} \mathrm{NO}_{3} \mathrm{HBr}$. A good sedative narcotic. Dose gr. $\frac{1}{10}-1 / 2$. M. et chloroformi, Tinct. (B. P.) Dose $\eta^{v-x}$. M. hydrochloras, occurs in silky crystals, soluble in water. Dose gr. $\frac{1}{20}$ j. M. hydrochlorat, Liq. (B. P.) Dose $m_{x-x l}$. Injectio morphinæ hypodermica (B. P.), contains one grain of the acetate of morphin in each ten minims of water. M. et ipecacuanhæ, Troch., each contains gr. $\frac{1}{40}$ of morphin. M. Oleatum, contains morphin Io, oleic acid, 90 parts ; for local use. Unof. M., Pulv., Comp., Tully's powder, contains morphin sulphate $\mathbf{I}$, camphor, licorice, and calcium carbonate, $\bar{a} \bar{a}, 20$ parts. Dose gr. v-xv. M. sulph., Liq., Magendie's solution; contains morphin sulph. gr. xvj to each $\mathrm{f}, \xi$. Dose $m_{x-x v}$. Unof. M. sulphas, acicular crystals, soluble in hot water. Dose gr. $1 / 8-\pi / 2$. M., Suppos. (B. P.), each contains gr. ss morphin. M., Suppos., cum sapone (B. P.), each contains gr. ss of morphin. M. tartras, $\mathrm{C}_{4} \mathrm{H}_{6} \mathrm{O}_{6}\left(\mathrm{C}_{17} \mathrm{H}_{19} \mathrm{NO}_{3}\right)_{2}$, used hypoder matically. Dose, gr. $\frac{1}{10}-1 / 2$. M., Trochis. (B. P.) and $M$. et ipecac., Trochis. (B. P.), each containing gr. $\frac{1}{36}$ of morphin. Dose I to 4 .

Morphinia (mor-fin'-e-ah) [Morpheus, god of sleep]. Any disease due to the excessive use of morphin.

Morphinism (mor'-fin-izm) [Morpheus, god of sleep]. The diseased condition caused by the excessive and habitual use of morphin.

Morphinization (mor-fin-iz-a'-shun) [Morpheus, god of sleep]. The production of the physiologic effects of morphin.

Morphinomania (mor-fin-o-ma'-ne-ah) [Morpheus, god of sleep; pavia, madness]. A morbid craving for morphin as a stimulant.

Morphinophagia, Morphiophagy (mor-fin-o-fa'-jeah, mor- $\hat{i}-$ off'-aj-e) [Morpheus, god of sleep; $\phi a \gamma \varepsilon i \nu$, to eat]. Opium-eating.

Morphiomania (mor-fe-o-ma'-ne-ah). Synonym of Morphinomania.

Morphiopathy (mor-fe-op'-ath-e). Synonym of Morphinomania.

Morpho-biologic (mor-fo-bi-o-loj'-ik) [ Bios, life; $\lambda 6 \gamma$ $s$, science]. Pertaining to the form and biology of an organism.

Morphœa (mor-fe'-ah). See Morphea.

Morphogenesis (mor-fo-jen'-es-is) [ $\left[\mu \circ \rho \phi \dot{\eta}\right.$, form; $\gamma^{\prime} v$ $\varepsilon \sigma \iota$, origin]. See Morphogeny.

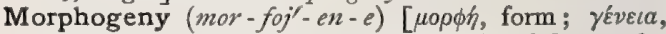
generation]. In biology, the genesis of form; the history of the evolution of form.

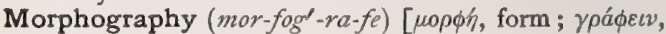
to write]. In biology, systematic investigation of the structure of organisms in the most comprehensive way.

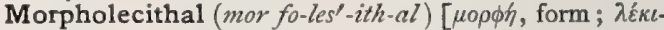
Aos, yolk of an egg]. I. Germinal; formative. 2. Pertaining to the morpholecithus.

Morpholecithus (mor-fo-les'-ith-us) [ $\mu \circ \rho \phi$ ', form; $\lambda \varepsilon \varepsilon \iota \theta 0 s$, yolk of an egg]. The formative yolk of an egg ; the portion of an egg that undergoes segmentation and germination.

Morpholin (mor'-fo-lin) [Morpheus, god of sleep], $\mathrm{C}_{4}$ $\mathrm{H}_{9} \mathrm{NO}$. A compound formed by heating dioxyethylamin to $160^{\circ} \mathrm{C}$. with $\mathrm{HCl}$.

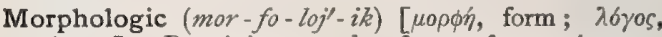
science]. Pertaining to the form of organisms or twin parts.

Morphology (mor-fol $=0-j e$ ) [ $\mu \rho \rho \dot{\phi}$, form; $\lambda \varepsilon \gamma \varepsilon \varepsilon \nu$, to speak]. The department of biology that deals with form and structure.

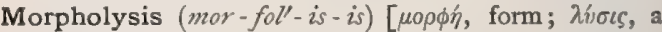
loosing]. Destruction of form.

Morphomania (mor-fo-ma'-ne-ah). See Morphinoma$122 a$.

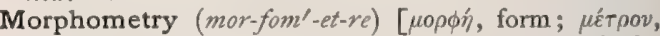
measure]. The measuring or determining of the forms of organisms.

Morphon (mor'-fon) [ $\mu \circ \rho \phi \eta$, form]. In biology, a definite morphologic individual element or organism; one of the following categories: plastid, idorgan (= organ, antimere, metaniere), persona, corm, $q . v$.

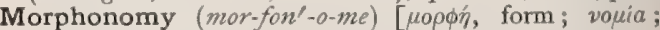

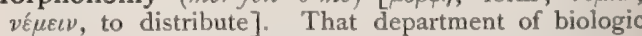
science devoted to the investigation of the principles of organic morphology.

Morphonosus (mor-fon'-o-sus) [ $\mu 0 \rho \phi \hbar$, form; vббos, 
disease]. An anomalous change in the form of organs or parts.

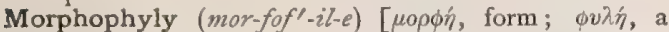
tribe]. The department of phylogeny that deals with form alone.

Morphoplasm (morf'-o-plazm) [ anything formed or molded]. In biology, Weismann's substitute for the word "protoplasm," to distinguish the vital substance of the cell from that of the nucleus; "formative plasm" ; "trophoplasm" (Nägeli) as distinguished from the "hereditary plasm" or "idioplasm."

Morphosis (mor-fo'-sis) [ $\mu \rho \rho \phi \delta \varepsilon \imath \nu$, to form]. Any morbid formation or organic change. In biology, morphogenesis; the assumption of characteristic organic form.

Morphostœchiometry (mor-fo-stek-e-om'-et-re) [ $\mu \circ \rho \phi \eta ́$,

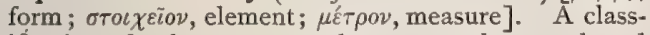
ification of substances, as plants, crystals, etc., based on their external form.

Morphotic (mor-fot'-ik) [ $\mu \circ \rho \phi^{\prime} \dot{y}^{\prime}$ form $]$. Pertaining to, or due to, morphosis; characterized by morphosis; pertaining to anatomic or organic elements. $\mathbf{M}$. Proteids, those that become parts of the living cell or that actually enter into the structure of the tissues.

Morphotomy (mor-fot'-o-me). Synonym of Anatomy.

Morpion (mor'-pe-on) [Fr.]. The crab-louse.

Morren's Glands, Morrenian Glands. Three pairs of glandular lateral sacs that enter the posterior portion of the esophagus of the Lumbricida and related terrestrial Oligochete; they are also called the limesecreting glands. See Gland, Morrenian.

Morrhua (mor'-u-ah) [morua, a cod; gen. Morrhuc]. The principal genus of gadoid fishes, including the cod. M., Oleum, cod-liver oil. The fixed oil from the livers of the cod-fish, Gadus morrhua, and other species of Gadus. The best and only official oil is pale-yellow in color, and is usually obtained from drippings. It is an easily assimilated, nutritive food, indicated in tuberculosis, rickets, nervous debility, and strumous skin-diseases. Black coffee and oil of eucalyptus are the best vehicles for its administration. Dose $3 \mathrm{j}$-ij on a full stomach, or $\xi_{j-i j}$ by inunction. Glyconin Emulsion, contains ol. morrhuæ $३ \mathrm{iv}$, glyceritum vitelli (glyconin) $3 \mathrm{ix}$, spt. ammoniæ arom. $3 \mathrm{j}$, sherry wine $\zeta_{\mathrm{ij}}$, acid. phosphoric dil. 3 iv, essent. amygdal. amar. $3 \mathrm{j}$ to Oss of alcohol. Dose $\mathbf{z}$ ij.

Morrhuic Acid (mor'-u-ik) [morna, a cod], $\mathrm{C}_{9} \mathrm{H}_{13} \mathrm{NO}_{3}$. One of the alkaloids of cod-liver oil. See Morrhuolins.

Morrhuin (mor'-u-in) [morua, cod], $\mathrm{C}_{19} \mathrm{H}_{27} \mathrm{~N}_{3}$. One of the alkaloids of cod-liver oil. See Morrhuolins.

Morrhuol (mor'-u-ol) [morua, cod; oleum, oil]. An alcohblic extractive derivable from cod-liver oil, of complex, and probably of indefinite chemic structure. It has been proposed as a remedial agent in the place of the oil itself. Dose gr. iij-v, in capsules.

Morrhuolins (mor'-u-o-linz) [morua, cod; oleum, oil]. A general name for the alkaloids of cod-liver oil. These are amylamin, $\mathrm{C}_{5} \mathrm{H}_{13} \mathrm{~N}$; dihydrolutidin, $\mathrm{C}_{7} \mathrm{H}_{11} \mathrm{~N}$; oxycollidin, $\mathrm{C}_{8} \mathrm{H}_{11} \mathrm{NO}$; morhuin, $\mathrm{C}_{9} \mathrm{H}_{27} \mathrm{~N}_{3}$; nicomorrhuin, $\mathrm{C}_{20} \mathrm{H}_{28} \mathrm{~N}_{4}$; asellin, $\mathrm{C}_{25} \mathrm{H}_{32} \mathrm{~N}_{4}$; and morrhuic acid, $\mathrm{C}_{9} \mathrm{H}_{13} \mathrm{NO}_{3}$. The most active of these are amylamin, oxycollidin, morrhuin, and nicomorrhuin.

Morrison's Pill. A cathartic pill containing aloes, jalap, extract of colocynth, gamboge, rhubarb, and myrrh.

Mors (morz) [L.]. Death. M. nigris. See Plague. Morsal (mor'-sel) [morsus; mordere, to bite]. Relating to the cutting or grinding portion of a tooth.

Morsulus (mor'-su-lus) [dim. of morsus, bite]. A lozenge or tablet.
Morsus (mor'-sus) [L.]. A bite. M. diaboli, the fimbriated distal extremity of an oviduct, also called the pavilion of the tube. M. stomachi, M. ventriculi. Synonyms of Cartialgia.

Mortal (mor'-tal) [mortalis, from mors, death]. Liable to death or dissolution; terminating in death ; deadly; fatal.

Mortality (mor-tal' -it-e) [mortalitas, mortalis, from mors, death]. The quality of being mortal. Also, the Death-rate. M.-table. See Life-table.

Mortar (mor'-tar) [mortarium, an urn]. An urnshaped vessel for containing substances for pulverization, this being accomplished by means of a pestle. It is usually of iron, porcelain, agate, or glass.

Mortariolum (mor-ta-ri'-o-lum) [dim. of mortarium, an urn]. A small mortar; also an alveolus.

Mortarium (mor-ta'-re-um) [L.]. Same as Mortar; also the trunk of the body from the neck to the hips.

Mortification (mor-tif-ik-a'-shun). See Gangrene.

Mortified (mor'-tif-ìd) [mortificare, to kill]. Gangrenous; dead.

Mortisection (mor-tis-ek'-shun). Synonym of Autopsy. Morton's Affection. Same as M.'s Foot. M.'s Fluid. See M.'s Solution. M.'s Foot, a peculiar and painful disorder pertaining to the metatarso-phalangeal joint of the fourth toe. It consists in a local neuritis, from bruising of one or more branches of the external phalangeal nerve; probably due to highheeled and tight shoes. See Metatarsalgia and Diseases, Table of. M.'s Method. See Treatment, Method's of. M., Plane of. See Plane. M.'s Solution, a solution consisting of potassium iodid gr. $\mathrm{xxx}$, iodin gr. $\mathrm{x}$, glycerin $3 \mathrm{j}$, used for injection in spina bifida. M.'s Toe. Same as M.'s Foot.

Mortuary (mor'-tu-a-re) [mortuarium, a tomb]. I. A house or tomb for temporary burial. 2. Relating to death or burial.

Morula (mor'-u-lah) [dim. of morum, a mulberry : $p l$., Morula]. In embryology, the solid "mulberry germ" or mass of "segmentation cells," "blastomeres" or "cleavage cells", which results from the complete segmentation of the vitellus of an ovum.

Morulation (mor-u-la'-shun) [morula, a little mulberry]. In embryology, the formation of the morula during the process of the segmentation of the egg.

Moruloid (mor'-u-loid) [momula, a little mulberry;

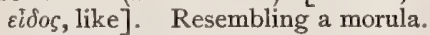

Morus (mo'-rus) [L.: gen, Mori]. Mulberry. Mori, Succus, the juice of the ripe fruit of $M$. nigra. It is refrigerant, and may be given in fevers. M., Syr. (B. P.) Dose $\mathbf{3}^{\mathrm{j}-\mathrm{ij} \text {. }}$

Morvan's Disease. A trophic affection of the skin with pain followed by analgesia, first of one side, then of the other, and then the formation of a succession of whitlows, which are usually painless, and are attended with, or are the result of, necrosis of the phalanges. Muscular atrophy, paresis, contraction of the fingers, and loss of the sensations of heat or cold are other symptoms. Most cases occur between twenty and fifty years of age. See Diseases, Table of.

Morve (morv). See Equinia.

Mosaic (mo-za'-ik) [ made of small pieces inlaid to form a pattern. $\mathbf{M}$. Gold. See Pigments, Conspectus of. M. Layer. See Mesoretina. M. of Muscle-compartments, the mosaic appearance observed in a striped musclefiber when treated with acetic acid.

Moschate $\left(m_{0}^{\prime}-k \bar{a} t\right)[\mu \sigma \sigma \chi o s$, musk]. Having the odor of moschus, or musk.

Moschatin (mos'-kat-in) [ $\mu \sigma \sigma \chi \alpha \varsigma$, musk], $\mathrm{C}_{21} \mathrm{H}_{27} \mathrm{NO}_{7}$. A bitter, brownish substance extracted from Achillea moschata. 
Moschatous (mos'-kat-us). Synonym of Moschate. Moschiferous (mos-kif'-er-us) [ $\mu \sigma \sigma \chi \sigma \varsigma$, musk; ferre, to bear]. Yielding musk.

Moschocaryon (mos-ko-kar'-e-on) [ $\mu \sigma \sigma \chi o s$, musk ; ká $v v o v$, kernel]. Nutmeg.

Moschus (mos'-kus) [ $\mu \delta \sigma \chi 0 s$, musk: gen, Moschi]. Musk. The dried secretion obtained from the follicles of the prepuce of the musk-deer, $M$. moschiferus. It is always liable to adulteration, but the Chinese musk is considered the best. It is a diffusible stimulant acting on the nervous centers, and is used with advantage in the collapse of typhoid fever and in pneumonia. It is used chiefly as a perfume, the odor being somewhat aphrodisiac. Dose gr, ij-x. M., Tinct., ro per cent, in strength. Dose 3 j-jss.

Mosler's Diabetes. See Diabetes.

Mosquito (mus-ke'-to)[Sp., a little gnat]. See Culex. Cf. Parasites (Animal), Table of. M.-culture, a culture of blood that has been drawn by a mosquito from a sick person.

Moss (mares) [ME., mos, moss]. A small herbaceous plant of the natural order Musci. M., Ceylon. See Agar-agar. M., Club. See Lycopodium. M., Corsican. See Corsican Moss. M., Iceland. See Chondruts. M., Irish. See Carragheen. M.-starch. See Lichenin.

Motatorious (mo-tat-o'-re-us) [motare, p. p. motatus, to move]. In biology, vibratory; applied especially to certain longlegged spiders and crane-flies which have a habit of keeping the body in a state of constant vibration.

Moth (mazul/) [ME., mothe, moth]. See Chloasma. M.-patch. Synonym of Chloasma.

Mother (muth'-er) [ME, moder, mother]. A female parent. Also, any residue contained in a solution. M.-cell, a cell before segmentation, afterward splitting up into smaller cells called Daughtercells. See Cell. M.-liquor, the liquid that remains after the contained dissolved substances have been partly or wholly crystallized or precipitated in an amorphous condition. M.'s Mark. See Angioma and Narus maternus. M.-nucleus. See Karyokinesis and Nucleus. M.of-pearl Osteomyelitis. See Osteomyelitis, Conchiolin. M.'s Plaster. See Brozen Plaster. M.'s Salve. See Brown Ointment. M.-skein. See Spirem. M.'s-spot, a nevus. M.-star, a stage in karyokinesis. See Karyokinesis, and Star. M. of Vinegar, the gelatinous deposit found in vinegar, and formed by the filaments of Mycoderma aceti, so-called because, when introduced into a saccharine solution, it converts the solution into vinegar. M.-water, the remaining solution of salts and other substances that fail to crystallize after the spontaneously crystallizable salts have been removed. See $M$.-liquor. M.wort, the herb Leonurus cardiaca, an emmenagogue, nervine, and antispasmodic. It is a popular remedy in amenorrhea and hysteria. Dose of the fld. ext. 3 ss-ij. Unof. M.-wreath. See Aster, and Wreath.

Motile (mo'-til) [movere, to move]. Capable of spontaneous motion, as a motile flagellum.

Motion (mo'-shun) [movere, to move]. Continuous change of position. Also, an evacuation of the bowels. M., Ameboid, the motion of certain low forms of living cells. M., Brownian. See
Brorunian. M., Ciliary, the waving or lashing movement of cells possessed of cilia. M., Involuntary, a movement of an organ or part that is not an act of volition. M., Pendulum, a to-and-fro movement like that of the pendulum, sometimes observed in the arms in obscure nervous diseases. M. Voluntary, any change of position of an organ or part due to an act of the will. See also Movement.

Motive (mo'-tiv) [movere, to move]. Causing motion; a determining impulse. M. Force, M. Power, the moving or impelling force.

Motor (mo'-tor) [movere, to move]. A mover. A term applied to various muscles and to a class of nerves. M. Aphasia. See Aphasia. M. Area, the por-

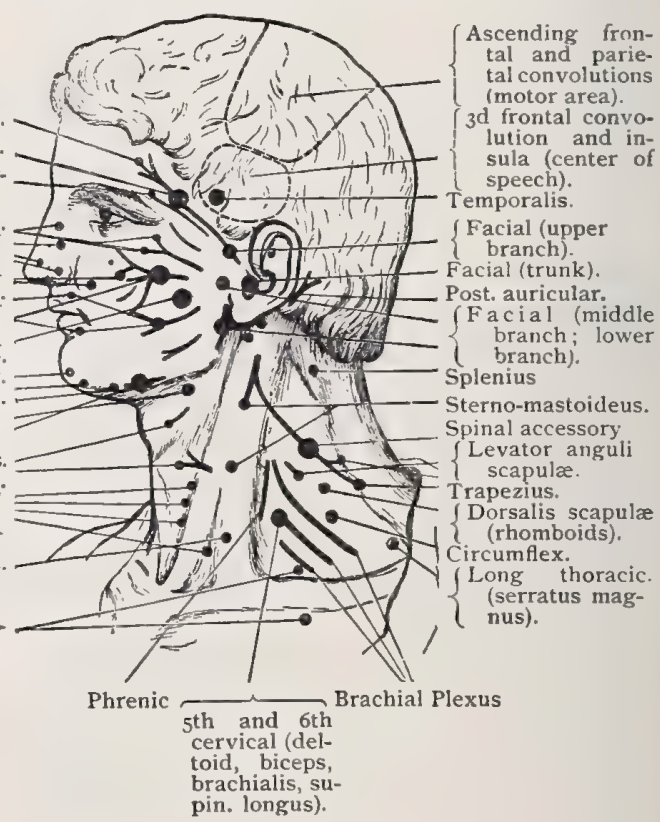

Motor Points of FAcE and Neck.

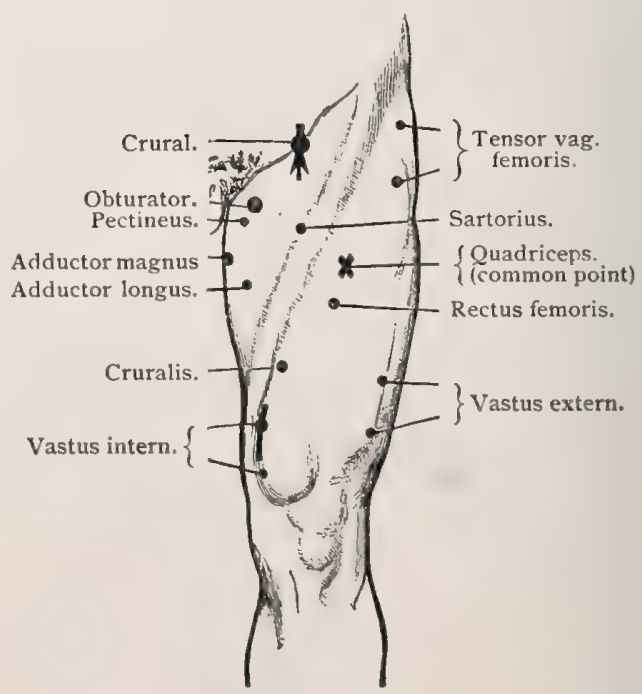

Motor Points of Anterior Aspect of Left Thigh 
tion of the cerebral gyri in each hemisphere surrounding the central fissure, viz.: the precentral and postcentral gyri bordering the fissure, the posterior part of the three frontal gyri, and the paracentral lobule on the mesal surface of the hemisphere. Stimulation of this region by a weak faradic current induces movement in definite parts of the opposite half of the body. $\mathbf{M}$. Ataxia. See Ataxia. M. Cell, a nerve-cell generating motor impulses. M. Centers. See Center. M. Fibers, centrifugal nerve-fibers exciting contraction of muscles. M. Impulse, the nerve-influence that results in action. M. Nerves, those efferent nerves that carry impulses to the muscles. M. oculi. See Nerves, Table of. M. Path, the path traversed by a motor impulse, from the brain to the muscles. M. Points, the points on the surface of the body where the various branches of the motor nerves supplying the muscles may be affected by electricity. See Cuts of Motor-points, pp.784-785. M.Vaso-. See Vaso-motor.

Motorial (mo-to'-re-al) [motorius, motory]. Of or pertaining to motion. M. End-plate, an eminence of protoplasm within the sarcolemma where a nervefiber pierces the latter. It is produced by a spreading out of the axis-cylinder.

Motorium (mo-to'-re-um) [movere, to move]. The motor apparatus of the body, both nervous and muscular, considered as a unit.

Motory (mo'-tor-e) [movere, to move]. Same as Motor. Motosis (mo-to'-sis) [ $\mu 0 \tau \delta \zeta$, lini]. A lint-dressing.

Motricity (mo-tris'-it-e) [movere, to move]. Motor neuricity; the efferent motor impulse sent along a nerve.

Motschutkowski's Method. See Treatment.

Mottle $\left(\right.$ mot' $\left.^{\prime} l\right)$ [ME., motteleye, a mixture of colors]. To mark with spots or blemishes.

Mottled (mot'-ld) [ME., motteleye, a mixture of colors]. Spotted; marked with patches of dark color; variegated. M. Kidney. Same as Large White Kidney.

Mottling (mot'-ling) [ME., mottleye, a mixture of colors]. A spotted condition.

Mouches volantes (mooshvo-lont') [Fr.]. See Musce volitantes.

Mouilla (moo-il'-ah). An excellent liquid potash soap containing a large percentage of glycerin. It is employed in dermatology, and is useful in the treatment of comedones and for cleansing purposes. It does not contain enough fat for use on the face.

Mould, Mold (möld). See Mold and Fungus.

Moulding-flask. A flask invented for obtaining castings from plaster models, which, on account of irregularity of the teeth or projection of the alveolar border, cannot be drawn from a simple impression in sand.

Mounding (mowen'-ding) [ME., mound, a protection]. The rising in a lump of muscle-fibers when struck by a slight, firm blow. It is observed in the thin and feeble, and in certain diseases, as pulmonary tuberculosis and advanced locomotor ataxia. See Myoidema.

Mount (nownt) [ME., mount, a mountain]. In palmistry, a fleshy cushion in the palm of the hand. M. of Jupiter, the name given to the eminence at the root of the index finger. M. of Mars, the name given to the upper part of the hypothenar eminence. M. of Mercury, the name given to the eminence at the root of the little finger. M. of the Moon, the name given to the lower part of the hypothenar eminence. M. of Saturn, the name given to the eminence at the root of the middle finger. $\mathbf{M}$. of the Sun, the name given to the eminence at the root of the ring-finger. M. of Venus, a name given in palmistry to the thenar eminence.

Mountain (mown'-ten) [ME., mountaine, mountain]. A high elevation of land. M. Anemia. See Anky- lostomiasis. M. Balm. See Eriodictyon. M.-blue. Same as Azurite. M.-climbing. See Terrain-cure. M. Fever, a synonym of Typhoid Fever, q. v. M.green. Same as Brunswick Green and Malachite Green. M. Laurel. See Kalmia. M. Sage. See Sierra Salvia. M. Sickness, symptoms consequent upon the ascent to high altitudes, consisting of debility, vomiting, tremulousness, headache, loss of muscular power, etc. See Anoxysmia, Hypsonosus, Mareo. M. Tea, a popular name for Gaultheria procumbens, $q . v$.

Mountaineering Malady. See Mountain Sickness.

Mountebank (mown'-te-bank) [It., montambanco, mountebank]. A quack who prescribes and sells medicines and nostrums in public places. Also called Quacksalver.

Mounting (mown'-ting) [ME., mounten, to mount]. In microscopy, the arrangement of a microscopic object upon some suitable support (slide) and in some suitable medium. M.-cell, in microscopy, a ring of card-board, metal, or rubber, for the support of the cover-glass, or to prevent the mounting-medium from spreading when the object is thick. M.-media, various fluids, or resins in the fluid state, afterward becoming solid, that are employed in the examination and temporary or permanent preservation of microscopic objects. See also Stains, Table of. The most important are as follows: ACETATE OF COPPER, for preserving and mounting green algæ. Acetate of copper I grm, glacial acetic acid I c.c., camphorwater 250 c.c., glycerin 250 c.c., corrosive sublimate 4 grms. The glycerin is sometimes omitted with advantage, as in the case of volvox. ACETATE of Potassium, used in a strongly concentrated solution; it behaves much as glycerin, but does not dry at the edges and is less refractive. BENzOL, employed as a solvent for Canada balsam and in preparing objects for balsam-mounts, but unfit for use as a medium for preliminary examination, on account of its great volatility. BERGAMOT, OIL of. Schiefferdecker first recommended this oil as a clearing-agent and mounting-medium; it clears 95 per cent. alcohol preparations and celloidin preparations, and does not attack anilin colors. CANADA BALSAM. This should be deprived of certain volatile products before using. Solutions free from chloroform are to be preferred, especially for bacteria. Baumgarten recommends equal parts of Canada balsam and oil of cloves. Pure xylol answers equally well. Owing to the high refractive index of Canada balsam (1.53), bacteria are poorly defined in it. CARBOLIC ACID. One of the best agents for clearing and temporary examination of tissues. It is best used in concentrated solution in alcohol, when it clears instantaneously even very watery preparations. For clearing sections imbedded in celloidin, use a mixture of xylol and carbolic acid in equal parts. Caustic Potash. A very useful clearing-agent in moderately strong (5 per cent.) solutions, for the examination of plant-sections. If sections are to be permanently mounted, they should be washed in water, passed through dilute alcohol, and mounted in glycerin. CEDAR-OIL. On account of its refractive index, which resembles that of crown-glass; this is the most widely-used fluid for homogeneous immersion objectives, It is miscible with chloroform-balsam and with castor oil. It clears tissues in 95 per cent. alcohol without shrinkage, and does not extract anilin stains. It is, therefore, one of the most valuable of all media for preliminary examinations. CHLOROFORM, employed in preparing objects for mounting, and sometimes as a solvent for balsam; but it is not to be recommended, as it tends to destroy the staining, 
especially in bacterial preparations. Cloves, OIL OF This has a tendency to form very convex drops, and to render tissues brittle; sometimes this is considered advantageous in minute dissections. It clears objects better than balsam, and may be used in connection with balsam-mounts; but, as it dissolves celloidin, it should not be used for sections imbedded in that medium. It darkens with age, and is commonly adulterated with phenol, which may be detected by Finckiger's test: $i, \ell$, shake the suspected oil with fifty parts of hot water, slowly evaporate the aqueous portion to a small bulk, and test it with a drop of ammonia and a pinch of chlorid of lime. If phenol be present, a green color is developed, which changes to a permanent blue color. COPAL VARnish. Pale copal varnish, of the consistency of oil, is recommended as a substitute for Canada balsam. For very large sections it is very useful, makes no bubbles, and it dries so hard, if slightly warmed, as to stand wiping and dusting with a soft brush. By its use large and expensive cover-glasses may be dispensed with. Creasote (Stieda's Method). $A$ very useful clearing-agent and temporary mount for watery sections. Rinse the sections in water; bring them upon the slide; remove the water by means of blotting-paper; add a drop of creasote at the side; when clear, draw off the creasote in the same way and replace with dammar. CSOKOR'S CEMENT FOR GLYCERIN-MOUnts. Pure Venice turpentine is poured into some melted wax upon a water-bath until a portion taken out on a glass rod becomes stiff at once and does not stick to the hand. DAMMAR, used as a substitute for Canada balsam. Gum dammar dissolved in benzol, or xylol, about $\mathbf{I O O}$ grms. of dammar to 100 c.c. of benzol. DAMMAR AND MAS. TIC, much used as a substitute for Canada balsam. First solution: Gum dammar Ioo grms., oil of turpentine 200 c.c. Dissolve and filter. Second solution: Gum mastic 50 grms., chloroform 200 grms. Mix the two solutions. FarRant's MEdium, recommended because tissues mounted in it preserve their normal appearance, and in that it is more convenient than glycerin, as it dries at the edges and fixes the cover-glass. Tissues may be mounted in it directly from water, but it is better that they be soaked for a time in dilute glycerin. Formula: Dissolve I grm. of arsenious acid in 200 c.c. of distilled water. In this fluid dissolve, at the ordinary temperature, I30 grms. of gum acacia, with frequent stirring; add 100 c.c. of glycerin; mix. Filter the solution through fine Swedish paper upon which has been deposited a thin layer of talc. GLYCERIN. When this is used as a mounting-medium, the best quality should be employed. A mixture of equal parts of water and glycerin is often preferred. As a mounting-medium for plant-tissues, the best preparation is glycerin and acetic acid in equal parts, boiled and filtered. For specimens stained in carmin, the glycerin should be acidulated with one per cent. of formic or acetic acid. Glycerin-Jelly. This is a mixture of glycerin and pure gelatin; it is liquid at the temperature of boiling water, and solidifies on cooling. Specimens should generally be saturated with glycerin before mounting. Goodale gives the following formula: One part of gelatin is soaked in six parts of water for two hours, seven parts of glycerin are added, and one part of carbolic acid is added to the whole. The mass is heated for fifteen minutes with constant stirring, and then filtered through glass-wool in a hot funnel. All of the ingredients must be absolutely pure. Wrap the cork of the bottle containing the jelly in a thin piece of linen which has been dipped in pure carbolic acid. Another formula is the following: Soften $25 \mathrm{grms}$.
(6.4 3) of gelatin in cold water. Warm the gelatin over a water-bath; add $5 \mathrm{c}, \mathrm{c} .(1.3 f 3)$ of white of egg, to clarify. Do not heat above $75^{\circ}$ or $80^{\circ} \mathrm{C}$. (167 or $176^{\circ} \mathrm{F}$.). Pass through a hot filter, mix with an equal volume of glycerin, and add 5 grms. (I.35) of chloral hydrate. GLYCERIN-SOLUTION. Glycerin Io parts, glucose 40 parts, spt. of camphor Io parts, distilled water 140 parts. Mix and filter. The advantage of this medium is that it possesses the refractive index $\mathbf{1} .37$ in the yellow ray. Gold SIzE, employed as a sealing for glycerin and potash mounts. HOYER'S MEDIUM. (a) For anilin preparations: A filtered solution of selected white gum-arabic in a 50 per cent. aqueous solution of acetate of potassiun or acetate of ammonium. (b) For carmin preparations and hematoxylin preparations: The same as the first, but a concentrated solution of chloral hydrate, to which has been added from 5 to Io per cent. of glycerin, is sub. stituted for the solution of potassium or ammonium. It is recommended by Strasburger for plant-tissues. LAVDowsKY's MEDIUM, for mounting sections. It also clears somewhat. It consists of gum-sandarac 30 grms., dissolved in absolute alcohol 50 c.c. A thin solution may also be made by diluting with an equal quantity of absolute alcohol. MASkenlack. An adhesive varnish prepared in Germany for securing the edges of cover-glasses when mounting-media lacking tenacity are used. MiKRosKopirlack. A German varnish employed for securing the edges of coverglasses when mounting-fluids lacking tenacity are used. SHELLAC. This is frequently employed in building up cells or securing the edges of cover-glasses. It may be best used in alcoholic solution, to which a few drops of castor oil are added to prevent brittleness. It may be tinged with the anilin dyes. Smith's (Hamilton) High-INDEX Mounting-Fluid for DiaTOMS. In two (2) fluid drams of glycerin-jelly, made in the usual way, dissolve in the cold ten (IO) drams of chemically-pure stannous chlorid. When the solution is complete, bring to the boil for a few minutes and filter while hot. The fluid must be used hot. This is done by simply heating the slide at the time of mounting. It has a refractive index (approximately) of 2.40 . The color is equal to that of old yellow balsams. Diatoms mounted in it show with wonderful clearness. TURPENTINE, used as a clearingagent, as a solvent for balsam, and as a medium for the temporary examination of sections. Its refractive index is such as to render it a valuable medium. Thickened Turpentine (the verharztes Terpentinol of German writers), which is prepared by exposing rectified turpentine in thin layers to the air for several days, does not shrink alcohol preparations, as does the ordinary spirit. WHITE LEAD (with oil), used in building up cells and sealing mounting-media that lack tenacity. XYLOL, used in preparing objects, and as a solvent for Canada balsam. It is suitable as a medium for preliminary examination, on account of its great solubility. Xylol-Balsam. Canada balsam dissolved in xylol is used as a medium in mounting microscopic objects.

Moussena (moo'-se-nah or moo-se'-nah) [African]. The bark of Albizzia anthelminthica, a good-sized shrub of Abyssinia. It is said to be an efficient teniacide, acting without purging, nauseating, or producing colic. See Acacia.

Moussenin (moo'-sen-in) [moussena]. The alkaloid found in Moussene bark. It was discovered by Theil in Albizzia anthelminthica, and resembles saponin. It is also spelled mussenin.

Moustache (mus'-tash). See Mustache and Mystax. Mouth (mowth) [ME., mouth, mouth]. The proximal 
terminus of the alimentary canal extending from the lips to the pharynx. The cavity in which mastication takes place. Also, the termination of any canal. M.-breather, a person who habitually breathes through the mouth. M.-breathing, respiration through the oro-pharynx instead of, as normally, through the naso-pharynx. M.-protector, an appliance used to protect the lips and cheeks in using the discs with the dental engine. M., Sore. See Aphtha and Stomatitis. M.-wash, a gargle; any liquid preparation for the mouth and fauces.

Mouvement de manége [Fr.]. A form of forced movement in which the animal runs about in a circle; it is seen in certain cases of vivisection in which the semicircular canals of the internal ear have been divided.

Movement (moov'-ment) [movere, to move]. A motion or action. See Motion. M., Acquired, one acquired after much practice and the exercise of voluntary control. M., Ameboid, that resembling the movement of the ameba. It consists of a change in form by the throwing out of processes called pseudopods, the rest of the protoplasm flowing into the processes. It is observed in certain unicellular organisms and in leukocytes. See Motion, Ameboid. M., Associated, an involuntary movement in one part when another is moved voluntarily. M., Brownian, a physical phenomenon observed in aggregations of minute particles, and consisting of a rapid, oscillating movement without change of the relative position of the moving particles. See Brownian. M., Ciliary, the movement of the processes of ciliated cells or of the cilia of organisms. It is a rapid movement, generally in one direction. M., Circus, a type of manége movement $\left[q . v_{0}\right]$, in which the animal executes rapid circular movements or somersauits. It is produced experimentally by injury of the striatum, of the thalamus, or of the crus of one side. M.-cure. See Kinesitherapy. M., Febrile, febrile changes of temperature. M., Fetal, the muscular movements of the fetus in utero. M., Forced, unsymmetric movement of the body from unilateral injury of the motor centers or the conducting paths, as in the following: Index M., when the cephalic part of the body is moved about the stationary caudal part; Rolling M., when the animal rolls on its long axis. M., Molecular. Synonym of Brozenian Movement. M., Sarcodic. Synonym of $M$., Ameboid.

Mower's Mite. See Leptus autumnalis. de Mowre's Hypothesis. See Life.

Moxa (moks'-ah) [Chin. and Jap.]. A term used to designate combustible organic matter which, by burning in contact with the skin, produces a deep-seated eschar. The Chinese moxa consists of bundles of Artemisia. In modern surgery, rolls of cotton half an inch in diameter, impregnated with niter $\bar{j}$ to $\zeta$ viij of water are used. Cobwebs are also employed. Unof. M.-bearer, or Porte-moxa, an instrument for applying the moxa.

Moxiburium (moks-ib-u'-re-um). See Moxihustion.

Moxibustion (moles-ib-us'-chun) [moxa, moxa; urere, toburn]. The application of the actual cautery by means of the moxa. See Byssocausis.

Moxosphyra (moks-os- $\left.\tilde{\imath}^{\prime}-r a h\right)$ [moxa, moxa; $\sigma \phi \tilde{v} \rho n$, hammer]. A hammer heated in boiling water and applied to the skin for purposes of counter-irritation.

Mucago(mu-ka'-go) [mucus, mucus]. Mucus; mucilage.

Mucamid (mu'-kam-id) [mucus, mucus; amid], $\mathrm{C}_{6} \mathrm{H}_{12}$ $\mathrm{N}_{2} \mathrm{O}_{6}$. A crystalline substance isomeric with saccharamid.

Mucate (mu'-kät) [mucus, mucus]. A salt of mucic acid.
Mucedin (mu'-se-din) [mucus, mucus]. A nitrogenous substance obtained by alcohol from gluten-fibrin; when freshly precipitated it is a yellowish-white slimy mass, with a silky luster. It is readily soluble in 6o-7o per cent. alcohol, also in dilute acids and alkalies. See Gluten and Mucin.

Mucedo (mu-se'-do). Synonym of Mucus.

Mucic Acid ( $\left.m u^{\prime}-s i k\right)$. See Acid.

Muciferous (mu-sif'-er-us) [mucus, mucus; ferre, to bear]. Producing or secreting mucus.

Mucific (mu-sif'-ik). Synonym of Muciferous.

Mucifluxus (mu-sif-luks'-us) [mucus, mucus; fluere, to flow]. A mucous discharge.

Muciform (mu'-sif-orm) [mucus, mucus; forma, form]. Resembling mucus.

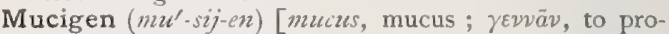
duce]. A hypothetic mucigenous substance of gobletcells.

Mucigenous (mu-sij'-en-us) [muctıs, mucus; yevvãv to produce]. Producing or secreting mucus.

Mucilage (mu'-sil-ij) [mucilago, mucilage]. See Mucilago. M.-cell, one of those plant-cells that secrete mucilage, owing to a change in the contents of the cell, to a disorganization of the cell-wall, or to both causes.

Mucilaginous (mu-sil-aj'-in-us) [mucilago, from mucus, mucus]. Pertaining to mucilage or gum. M. Glands. See Gland.

Mucilago (mu-sil-a'-go) [L.: gen., Mucilaginis: pl., Mucilagines]. A mucilage. In pharmacy, a thick, viscid liquid obtained by extracting the soluble mucilaginous principles of certain plants in water. There are four official mucilagines, besides three in the "National Formulary."

Mucin $\left(m u^{\prime}-\sin \right)$ [mucus, mucus]. A glucosid, a compound of a proteid with a carbohydrate called animal gum, the characteristic substance in mucus, occurring also in saliva, bile, mucous tissue, synovia, etc. Decomposed it yields leucin and tyrosin. It is insoluble in water, and is precipitated by alcohol and acetic acid.

Mucinaginous (mu-sin-aj'-in-us). Same as Mucigenous.

Mucinogen (mu-sin'-o-jen) [mucus, mucus; jevvãv, to produce]. The antecedent principle from which mucin is derived.

Mucinoid (mu'-sin-oid) [mucus, mucus; eidos, like]. Resembling mucin.

Mucinuria (mu-sin-u'-re-ah) [mucus, mucus; ovoov; urine]. The presence of mucin in the urine.

Muciparous (mu-sip'-ar-us) [mucus, mucus; parere, to bring forth]. Secreting or producing mucus.

Mucitis (mu-si'-tis) [mucus, mucus; itıs, inflammation]. Inflammation of any mucous membrane; also, blenorrhea.

Mucocele (mu'-ko-sél) [mucus, mucus; $\kappa \eta ́ \lambda \eta$, tumor]. A mucous tumor or distention of the lacrymal sac.

Muco-colitis (mu-ko-ko-li'tis) [mucus, mucus; $\kappa \bar{\omega} \lambda n v$, colon; $\iota \tau \iota \mathrm{S}$, inflammation]. Inflammation of the mucous membrane of the colon.

Mucocolpos (mue-ko-kol'-pos) [mucus, mucus; $\kappa \delta \lambda \pi o s$, vagina]. A collection of mucus in the vagina.

Mucoderm (mu'-ko-derm) [mucus, mucus; dépua, skin]. The corium of a mucous membrane.

Mucoenteritis (mu-ko-en-ter-i'-tis) [mucus, mucus;

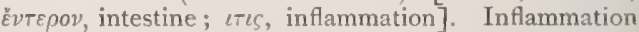
of the mucous membrane of the intestine.

Mucoglobulin (mert-ko-glob'-u-lin) [mucus, mucus; globulus, a ball]. Any one of a certain group of protoplastic substances, of which plastin is an example.

Mucoid (mu'-koid) [mucus, mucus; Eidos, like]. Resembling mucus. 
Muconic Acid (mu-kon'-ik) [mucus, mucus], $\mathrm{C}_{6} \mathrm{H}_{6} \mathrm{O}_{4}$. A crystalline acid obtained from mucic acid.

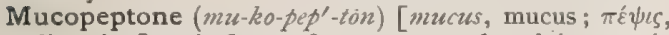
digestion]. A form of peptone produced in gastric digestion when mucus is present together with certain albuminoids.

Muco-purulent (mu-ko-pu'-ru-lent) [mucus, mucus; purulentus, purulent]. Containing mucus mingled with pus.

Muco-pus (mu'-ko-pus) [mucus, mucus; pus, pus]. Mucus mingled with pus; mucus containing many leukocytes.

Mucor (mu'-kor) [L., mold]. I. Moldiness; mustiness. 2. Mucus. 3. A genus of fungi. M. aspergillus, a species yielding dark-brown spores. $\mathbf{M}$. corymbifer, found in the cerumen of the external auditory meatus. M. mucedo, the species that induces alcoholic fermentation. It is said to be found in the blood and sputa of patients suffering from measles. M. vulgaris. Same as $M$. mucedo.

Mucosa (mu-ko'-sah) [mucus, mucus]. The mucous membrane or its corium.

Mucose $\left(m u^{\prime}-k \bar{z}\right)$. Synonym of Mucous.

Mucoserous (mu-ko-se'-rus) [mucus, mucus; serum, serum]. Both mucous and serous; containing mucus and serum.

Mucosin ( $\left.m u^{\prime}-k o-s i n\right)$ [mucus, mucus]. An albuminoid substance derived from mucus-isomerous with keratin ; it is said by some to be simply mucin.

Mucoso-saccharin (mu-ko'so-sak'-ar-in) [mucosus, mucous; saccharum, sugar]. An uncrystallizable sugar.

Mucous (mu'-kus) [mucosus, from mucus, mucus]. Containing or having the nature of mucus. A term applied to those tissues that secrete mucus. M. Casts, a term given to the casts found in the feces in cases of Membranous Enteritis. See also Cylindroids. M. Catarrh, catarrhal inflammation of a mucous membrane. M. Disease, a synonym of entero-colitis, especially in children. M. Fever. See Fever. M. Ligament. See Ligament. M. Membrane. See Membrane. M. Patch, a flattened, indurated, moistened surface, covered with a grayish-white exudation, occurring in syphilis, secondary or congenitak, at points where folds of skin come in contact. M. Râle, a soft, moist crackling heard over the lungs in certain diseased states. See Râles, Table of. M. Tissue, myxomatous tissue.

Mucro $\left(m u^{\prime}-k r o\right)$ [L., a sharp point, especially of a sword: pl., Mucrones]. In biology, an angular prominence, a tip, spine, point, or process, as the apex of a Chiton shell.

Mucronate (mut'-kro-nät) [mucronatus, pointed]. Narrowed to a point. In biology, applied to a leaf that is abruptly tipped with a small, soft point. M. Cartilage, the ensiform cartilage.

Mucroniform (mu-królnif-orm) [mucro, sharp point; forma, form]. Shaped like a mucro.

Mucronule (mu'-kro-nuzl) [dim. of mucro, a sharp point]. In biology, a small mucro.

Muculent (mu'-ku-lent) [mucus, mucus]. Rich in mucus.

Mucuna (mu-ku'-nah) [Braz.]. A genus of leguminous herbs. M. pruriens, cowhage; the hairs of the pods of the plant were formerly much used as a vermifuge for ascarides. It is very irritant to the intestinal mucous membrane, and applied to the skin excites intense itching, inflammation, and pustulation. It was administered in the form of an electuary, of which a teaspoonful or more was given, followed by a brisk purge. Unof.

Mucus (mu'-kus) [I.]. The viscid liquid secretion of mucous membranes, composed essentially of mucin holding in suspension desquamated epithelial cells, leukocytes, etc

Mud [ME., mud, mud]. Moist, soft earth. M.-bath. See Bath. M.-fever, in veterinary medicine, the scratches, 2. v.

Mudar (mu'-dar) [E. Ind.]. The root-bark of various Asiatic species of Calotropis ( $C$. gigantea, $C$. procera, C. hamiltoni); it is alterative, tonic, diuretic, sudorific, and emetic. Unof.

Mudarin (mu'-dar-in) [E. Ind., mudar]. A bitter principle from mudar; it is said to be tonic, emetic, and alterative. Unof.

Muga Silk. See Silk.

Mugrela, Tincture of. A tincture of the seeds of Nigella sativa, formerly used as a carminative.

Muguet (mu-grva') [Fr.]. Thrush; aphtha; parasitic stomatitis.

Mugwort (mug'-wert) [ME., mugworte, mugwort]. The leaves and tops of Artemisia vulgaris, having therapeutic properties similar to those of wormwood. See Absinthium. Dose of the fld. ext. $m x x-3 j$. Unof.

Mühlhäuser's Method. See Sputum, Method's of Examination.

Mulatto (mu-lat'-o) [Sp., muleto; dim. of mule, a mule]. The offspring of a negro mother and a white father, or a white mother and a negro father. The term is also loosely applied to other and all degrees of intermixture. According to the classification adopted and recognized in the French slave-colonies, the people of color were supposed to represent a vethole of 128 parts white and 128 parts black. Nine different varieties of mixed race were recognized; but between each of these there exist a vast number of intermediate shades and interblendings for which no classification was attempted, or could be made, even in theory :-

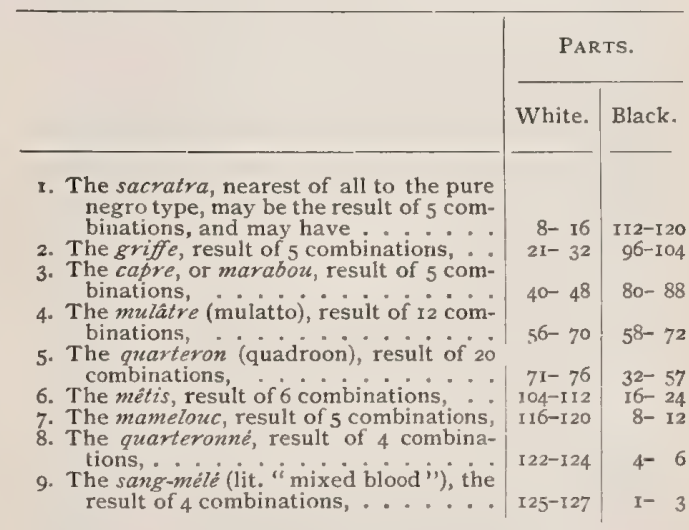

Mulberry (mul'-ber-e) [ME., mulbery, mulberry]. See Morus. M. Calculus, a large, rough urinary calculus of oxalate of lime. It often attains a considerable size, has a rough, irregular surface, and is of a dark color. It is very hard, and on section presents an angular structure, with dark-colored laminæ, which are very compact, and are often marked with fine parallel lines. The nucleus most commonly consists of a mixture of urates, uric acid, and oxalate of lime. M. Mass. See Morula. M. Rash, the eruption of typhus fever. M. Rob. See Rob. M. Tongue. See Strazuberry Tongue.

Mulder's Angle. See Angle. M.'s Hypothesis or Theory, a theory concerning the origin of albumin- 
oids; the theory published in 1838 by Mulder, that albuminous bodies are practically derivatives from one substance, termed by him protein; but it was soon shown that this theory was erroneous, and it has been generally abandoned. Cf. Protein. M.'s Reagent, a reagent for the detection of sugar in the urine. It consists of carmin, indigo, and an alkaline solution. See Tests, Table of.

Muley (mu'-le) [origin uncertain]. Hornless; applied to cattle.

Muliebrity (mu-le-eb'-rit-e) [muliebritas; mulier, woman]. Womanliness; puberty in the female.

Mullein (mul'-en). See Verbascum.

Müller, Canal of. See Duct. M., Duct of. See Duct. M.'s Fibers, the supporting fibers of the retina running transversely to its layers. See also fiber. M.'s Fluid, a fluid used for hardening tissues. Its composition is as follows: Potassium bichromate, 2 to 2.5 parts; sodium sulphate, I part; water, Ioo parts. It should be used in large quantities, renewed at the end of twelve hours, then every third day until the hardening is completed. Then wash well in water and preserve in alcohol. The color which the fluid imparts to tissues that have been preserved in it can be discharged by hydrate of chloral. M.'s Ganglia. See Ganglia, Table of. M.'s Larva, one of the free-swimming embryos of certain polyclad flat-worms (Thysanozoön and Yungia). M.'s (Johannes) Law, the tissue of which a tumor is composed has its type in the tissues of the animal body, either in the adult or in the embryonic condition. M., Lid-muscle of, bundles of non-striped muscle forming the tarsal portion of the fibrous extensions of the tendon of the levator palpebræ. M.'s Muscles. See Muscles, Table of. M.'s Net. See Net. M.'s Ring, the spurious internal os uteri. It marks the termination of the cervical mucous membrane. M.'s Ring-muscle, certain fibers of the ciliary muscle lying near the ciliary border, and abnormally developed in hyperopia. See Muscles, Table of.

Müllerian Cyst. See Cyst.

Mulley (mul'-e) (origin uncertain). A term applied to cattle which are deprived of horns. Cf. Muley.

Mulomedicina (mu-lo-med-is-i'-nah) [mulus, mule; medicina, medicine]. Veterinary medicine.

Multi- (mul'-te-) [pl. of multus, much]. A Latin prefix signifying many.

Multiaxial (mul-te-aks'-e-al) [multus, many; axis, an axis]. In biology, having several lines of growth.

Multicapsular (mul-tik-ap'-su-lar) [multus, many; capsula, a little box]. In biology, composed of many capsules.

Multicellular (mul-tis-el'-u-lar) [multus, many; cellula, cell]. Many-celled.

Multicornate (mul-tik-or'-nāt) [multus, many ; cornua, horn]. Having many horns.

Multicostate (mul-tik-os'-tät) [multus, many; costa, a rib]. In biology, having many ribs.

Multicuspid, Muiticuspidate (mul-tik-us'-pid, multik-us'-pid-ât) [multus, many; cuspis, a point]. Having several cusps. M. Teeth, the molar teeth.

Multidentate (mul-te-den'-tāt) [multus, many; dens, a tooth]. A term applied in biology to parts armed with many teeth or tooth-like processes.

Multidigitate (mul-te-dij'-it-ät) [multus, many ; digitus, a finger]. Having many digits or digitate processes.

Multiembryonate (mul-te-em'-bre-on-ät) [multus, many; $\varepsilon \mu \beta$ puov, embryo]. In biology, having several embryos.

Multifetation (mul-tif-e-ta'-shun) [multus, many; fetatio, fetation]. Pregnancy with more than one or two fetuses.
Multifid (mul'-tif-idd). See Multifidus spine, in Muscles, Table of

Multiflageliate (mul-tif-laj'-el-āt) [multus, many; flagellum, a whip]. In biology, having many flagella.

Multiflorous (mul-tif-lo'-rus) [multus, many; Ros, a flower]. In biology, bearing many flowers.

Multifoliate (mul-tif-o'-le-ât) [multus, many; folium, a leaf ]. In biology, bearing many leaves.

Multiform (mul'-tif-orm). Same as Polymorphous.

Multiganglionate (mul-te-gang'-le-on-āt) [multus, many; ganglion, ganglion]. Having many ganglia.

Multigravida (mul-tig-rav'-id-ah) [mullus, many; gravidus, pregnant]. A pregnant woman who has passed through one or more pregnancies.

Multigyrate (mul-te-ji'-rāt) [multus, many; gyrus, a gyre]. Having many gyres, as the brain.

Multilaminate (mul-til-am'-in-ät) [multus, many; lamina, a thin layer]. Having many laminæ.

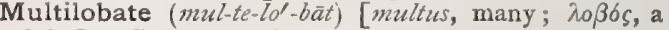
lobe]. Composed of many lobes.

Multilobular (mul-te-lob'-u-lar) [multus, many ; lobus, a lobe]. Many-lobed.

Multilocular (mul-te-lok'-u-lar) [multus, many; loculus, a locule or cell]. Many-celled; polycystic.

Multimammes (mul-tim-am'-ēe). Same as Polymastia.

Multinervate (mul-tin-ur'-vāt) [multus, many; nerva, nerve]. I. Having many nerves. 2. Same as Multicostate.

Multinuclear (mul-tin-u'-kle-ar) [multus, many ; nucleus, kernel]. Having several or many nuclei.

Multiovulate (mul-te-o'-vu-lāt) [multus, many; ovulum, an ovule]. In biology, bearing many ovules.

Multipara (mul-tip'-ar-ah) [multus, many; parere, to bring forth]. One bearing several offspring at a birth; more commonly, a gravid woman who has already borne one or more children.

Multiparient (mul-tip- $a^{\prime}$-re-ent) [multus, many ; parere, to bring forth]. Giving birth to several young.

Multiparity (mul-tip-ar'-it-e) [multus, many; parere, to bring forth]. The condition, state, or fact of being multiparous

Multiparous (mul-tip'-ar-us) [multus, many; parere, to bring forth]. Relating to a multipara.

Multipartite (mul-tip-ar'-tit) [multus, many; partire, to divide]. In biology, composea of many parts, as leaves.

Multipede (mul'-tip-éd) [multus, many; pes, a foot]. In biology, having many feet.

Multipetalous (mul-tip-et'-al-zes). Same as Polypetalous.

Multiple (mul'-tip-l) [multiplus, manifold]. Having many parts or relations. M. Fetation, the presence of two or more fetuses in the uterus. M. Gestation. Same as M. Felation. M. Neuritis. See Neuritis. M. Pregnancy. Same as M. Fetation. M. Sclerosis. See Sclerosis. M. Staining, the staining of tissues with more than one staining-agent.

Multiplicator, Multiplier (mul'-tip-lik-a-tor, mul'-tipli-er) [multiplicare, to multiply]. An instrument for detecting an electric current and for measuring its strength.

Multipolar (mul-tip-o'-lar) [multus, many; polus, a pole]. Having more than one pole; applied also to nerve-cells having more than one process.

Multiradiate (mul-te-ra'-de-ât) [multus, many ; radius, a ray]. In biology, having many rays.

Multisect ( $\mathrm{mul}^{\prime}$-tis-ekt) [mullus, many; secare, to cut]. In biology, divided into many sections.

Multiseptate (mul-tis-ep'-tât) [multus, many; sapire, to fence in]. In biology, having many partitions; multilocular. 
Multistaminate (mul-tis-tam'-in-āt) [multus, many; stamen, stamen]. In biology, bearing many stamens.

Multisulcate (mul-tis-ul'-kāt) [multus, many; sulcus, a furrow]. Having many sulci, as the brain.

Multituberculate (mul-le-tu-ber'-ku-lāt) [multus, many; tuberculum, a tubercle]. Having many tubercles.

Multivalent (mul-tiv'-al-ent) [multus, many; valere, to be worth]. In chemistry, combining with more than two atoms of a univalent element.

Multivorous (mul-tiv'-o-rus) [mullus, many; vorare, to devour]. Voracious.

Mumble (mum'-bl) [ME., momelen, to mumble]. To speak in a low, inarticulate manner.

Mumbo-jumbo (mum'-bo-jum'-bo). See Jumbai Bean.

Mummification (mum-if-ik-a'-shun). See Gangrene, Dry.

Mummified (mum'-if-id ) [ make]. Dried, like a mummy. M. Pulp, the condition of the dental pulp when it is affected by dry gangrene.

Mummy (mum'-e) [ process.

Mumps [D., mompen, to mumble]. Idiopathic parotiditis; an acute infectious disease of chil dren, between the ages of five and fifteen, characterized by swelling of the parotid and other salivary glands, running a definite course, and generally terminating in recovery. The period of invasion is less than twenty-four hours, and the left parotid is usually first involved. When the disease occurs at or near puberty there is often a metastasis to the testes, or to the ovaries or mammæ in the female; rarely atrophy of the testis follows. The disease is most common in males and in the spring of the year. See Parotiditis.

Mundificant (mun-dif'-ik-ant), Mundificative (mundif'-ik-at-iv) [mundus, clean; facere, to make]. I. Having the power to cleanse, purge, or heal. 2. A cleansing or healing agent.

Mungeet (mun-gêt'). See Pigments, Conspectus of.

Mungo (mung'-go). See Shoddy.

Munich (mu'-nik) [Ger.]. The capital of Bavaria. M.-Frankfort Angle, in craniometry, the facial angle having for its base a line joining the lower border of the orbit and the upper border of the external auditory meatus, and for its facial line one tangent to the most prominent portion of the alveolar border of the inferior maxilla. M. Plane. See Plane.

Munjeet (mun-jêt' ${ }^{\prime}$ ). Same as Mungeet.

Munjistin (mun-jis'-tin) [Hind., manjit, a drug used for dyeing red], $\mathrm{C}_{8} \mathrm{H}_{6} \mathrm{O}_{3}$. A coloring-substance obtained from Rubia munjista. It is nearly related in composition to purpurin and alizarin.

Munk's Visual Center. In the dog, the lateral convex portion of the occipital lobe of the cerebrum.

Mural (mu'-ral) [murus, wall]. Pertaining to a wall. M. Gestation, M. Pregnancy, pregnancy in the uterine extremity of a Fallopian tube.

Mures articulorum (mu'-rēz ar-tik-u-lol-rum). See Corpora libera articulorum.

Murexan (mu-reks'-an) [murex, the. purple-fish], $\mathrm{C}_{4} \mathrm{H}_{5} \mathrm{~N}_{3} \mathrm{O}_{3}$. A substance identical with dialuramid, derived from murexid.

Murexid (mu-reks'-id) [murex, the purple-fish], $\mathrm{C}_{8} \mathrm{H}_{8}$ $\mathrm{N}_{6} \mathrm{O}_{6}+\mathrm{H}_{2} \mathrm{O}$. The ammonium salt of purpuric acid, used as a dye-stuff. It occurs in four-sided plates or prisms of a gold-green color. It dissolves in water with a purple-red color, but is insoluble in alcohol and ether. Upon the production of this substance depends the murexid test. See Tests, Table of, and Pimments, Conspectus of.
Murexoin (mu-reks'-o-in [murex, the purple-fish], $\mathrm{C}_{12} \mathrm{H}_{16} \mathrm{~N}_{6} \mathrm{O}_{6}$. A derivative of amalic acid, obtained by treating the acid with water and ammonia.

Muriate (mu'-re-ät)[muria, brine]. An old name for a chlorid.

Muriated (mu'-re-a-ted) [muria, brine]. Containing chlorin or a chlorid. M. Tincture of Iron, tinc tura ferri chloridi. See Ferrum.

Muriatic (mu-re-at'-ik) [muria, brine]. Pertaining to sea-salt. M. Acid. See Acid, Hydrochloric

Muricate (mu'-rik-āt) [muricatus, pointed]. In biology, roughened with short rigid excrescences, spines, or prickles.

Muricatohisped (mu-rik-at-o-his'-pid) [muricatus, pointed; hispidus, hispid]. In biology, covered with rigid hairs or bristles.

Muriform (mu'-rif-orm) [murus, wall; forma, shape]. In biology, wall-like; resembling courses of bricks in a wall. M. Body. Same as Morula.

Murmur (mer'-mer) [L., a murmur]. A mimetic name for the sounds heard on auscultation, and caused by the friction of moving currents or gliding surfaces in the organs of circulation and respiration. See Bruit. M., Accidental. See M., Hemic. M., Anemic. See M., Henic. M., Aneurysmal, the aneurysmal bruit. See Bruit. M., Aortic, one generated at the aortic orifice of the heart. $\mathbf{M}$., Arterial, the sound made by the arterial current. $\mathbf{M}$. aurium. Synonym of Tinnitus aurium. M., Bellows, the bruit de souffet, heard in cardiac hypertrophy and in mitral insufficiency. M., Blood. See $M$. Hemic. M., Brain, a systolic sound heard over the anterior fontanel, especially in young rickety children. M., Cardiac, any one of those adventitious sounds produced by the abnormal passage of blood through the cavities and orifices of the heart or by perverted cardiac action. The names given to these murmurs correspond with the period of the cardiac cycle in which they occur. A murmur that occurs in the period of auricular systole, is termed presystolic or auricular systolic; one that occurs in the period of ventricular systole, systolic ; one that occurs during the diastole of the ventricles, diastolic: and should the murmur immediately follow the first or second sound, post-systolic or post-diastolic respectively. In relation to their seat of generation, cardiac murmurs are designated mitral, aortic, tricuspid, and pulmonary. All murmurs should be timed by the carotid pulse, not by their relation to the apexbeat. Murmurs are most frequently caused by some change in one of the cardiac valves or orifices, allowing of a reflux of the blood, or obstructing its onward progress. A table of organic endocardial murmurs is appended. M., Cardio-pulmonary, an abnormal sound produced outside of the heart, but closely resembling one due to organic valve-disease. Such murmurs are of frequent occurrence, and may be due to displacement of, or pressure upon, the heart, effusion into the pleural cavity, changes in the pleura of the precordial area, changes in the lung overlying the heart, or changes in the pericardium. M., Cephalic, a murmur heard at different parts of the scalp in anemia; it is probably venous in origin. M., Diastolic, a murmur occurring during the diastole of the heart. M., Direct, a murmur produced by obstruction to the blood-current as it is passing in its normal direction. M., Duroziez's, the double murmur,sometimes heard in the femoral artery in aortic regurgitation. See also Signs and Symptoms, Table of. M., Dynamic, one resultine from tumultuous and irregular action of the heart. M., Endocardial, a murmur produced within the cavities of the heart. M., Exocardiac, a murmur connected with the heart, but occurring outside of its 
TABLE OF ORGANIC ENDOCARDIAL MURMURS.

\begin{tabular}{|c|c|c|c|c|c|c|c|}
\hline $\begin{array}{l}\text { NAME, IN ORDER } \\
\text { OF FREQUENCY. }\end{array}$ & TIME. & $\begin{array}{l}\text { SITE of MAXIMUM } \\
\text { INTENSITY. }\end{array}$ & $\begin{array}{l}\text { LINE OF CONDUC- } \\
\text { TION. }\end{array}$ & $\begin{array}{l}\text { DIRECT } \\
\text { OR INDI- } \\
\text { RECT. }\end{array}$ & $\begin{array}{l}\text { BASIC OR } \\
\text { APICAL. }\end{array}$ & LESION. & QUALITY. \\
\hline Mitral regurgitant. & Systolic. & $\begin{array}{l}\text { Center of mitral } \\
\text { area, above and } \\
\text { to left of apex. }\end{array}$ & $\begin{array}{l}\text { At sixth rib oppo- } \\
\text { site apex, a line } \\
\text { drawn from the } \\
\text { anterior fold of } \\
\text { axilla to lower an- } \\
\text { gle of left scapula. }\end{array}$ & $\begin{array}{l}\text { Indirect } \\
\text { mitral. }\end{array}$ & Apical. & $\begin{array}{l}\text { Mitral insuffi- } \\
\text { ciency or in- } \\
\text { competence. }\end{array}$ & $\begin{array}{l}\text { Variable; usually } \\
\text { soft, blowing, bel- } \\
\text { lows; may be dis- } \\
\text { tinctly musical. }\end{array}$ \\
\hline Aortic obstructive. & Systolic. & $\begin{array}{l}\text { Mid-sternum or to } \\
\text { right of it, oppo- } \\
\text { site third rib or } \\
\text { second in ter- } \\
\text { space. }\end{array}$ & $\begin{array}{l}\text { Toward top of ster- } \\
\text { num, and along } \\
\text { aorta a nd its } \\
\text { large branches. }\end{array}$ & $\begin{array}{l}\text { Direct } \\
\text { aortic. }\end{array}$ & Basic. & $\begin{array}{l}\text { Aortic obstruc- } \\
\text { tion or con- } \\
\text { striction. }\end{array}$ & $\begin{array}{l}\text { Usually loud and } \\
\text { harsh. Harsh- } \\
\text { ness is one of } \\
\text { its distinguishing } \\
\text { characteristics. }\end{array}$ \\
\hline Aortic regurgitant. & Diastolic. & $\begin{array}{l}\text { Mid-sternum oppo- } \\
\text { site upperborder } \\
\text { of cartilage of } \\
\text { third rib. }\end{array}$ & $\begin{array}{l}\text { Down sternum to } \\
\text { ensiform cartil- } \\
\text { age. }\end{array}$ & $\begin{array}{l}\text { Indirect } \\
\text { aortic. }\end{array}$ & Basic. & $\begin{array}{l}\text { Aortic insuffi- } \\
\text { ciency or in- } \\
\text { competence. }\end{array}$ & $\begin{array}{l}\text { Soft, blowing, } \\
\text { sometimes rough, } \\
\text { frequently musi- } \\
\text { cal. It has the } \\
\text { greatest area of } \\
\text { diffusion of all } \\
\text { the cardiac mur- } \\
\text { murs. }\end{array}$ \\
\hline Mitral obstructive. & Presystolic. & $\begin{array}{l}\text { Over mitral area } \\
\text { around the apex. }\end{array}$ & $\begin{array}{l}\text { Usually not trans- } \\
\text { mitted. }\end{array}$ & $\begin{array}{l}\text { Direct } \\
\text { mitral. }\end{array}$ & Apical. & $\begin{array}{l}\text { Mitral obstruc- } \\
\text { tion or coll- } \\
\text { striction. }\end{array}$ & $\begin{array}{l}\text { Genera Il y low- } \\
\text { pitched, rough, } \\
\text { churning, grind- } \\
\text { ing, or blubber- } \\
\text { ing. Subject to } \\
\text { great variation of } \\
\text { pitch and quality. }\end{array}$ \\
\hline $\begin{array}{l}\text { Tricuspid regurgi- } \\
\text { tant. }\end{array}$ & Systolic. & $\begin{array}{l}\text { Mid-sternum just } \\
\text { above the ensi- } \\
\text { form cartilage. }\end{array}$ & $\begin{array}{l}\text { Toward the epi- } \\
\text { gastrium. }\end{array}$ & $\begin{array}{l}\text { Indirect } \\
\text { tricuspid. }\end{array}$ & Apical. & $\begin{array}{l}\text { Tricuspid in- } \\
\text { sufficiency or } \\
\text { incompe- } \\
\text { tence. }\end{array}$ & $\begin{array}{l}\text { Lowi-pitched, su- } \\
\text { perficial, blowing, } \\
\text { soft, faint. }\end{array}$ \\
\hline $\begin{array}{l}\text { Tricuspid obstruc- } \\
\text { tive. }\end{array}$ & Presystolic. & $\begin{array}{l}\text { Mid-sternum oppo- } \\
\text { site the cartilage } \\
\text { of fourth rib. }\end{array}$ & Not transmitted. & $\mid \begin{array}{c}\text { Direct } \\
\text { tricuspid. }\end{array}$ & Apical. & $\begin{array}{l}\text { Tricuspid ob- } \\
\text { struction or } \\
\text { constriction. }\end{array}$ & Undetermined. \\
\hline $\begin{array}{l}\text { Pulmonary regur- } \\
\text { gitant. }\end{array}$ & Diastolic. & $\begin{array}{l}\text { Second left inter- } \\
\text { space. }\end{array}$ & $\begin{array}{l}\text { Down left edge of } \\
\text { sternum to ensi- } \\
\text { form cartilage. }\end{array}$ & $\left\{\begin{array}{c}\text { Indirect } \\
\text { pulmon- } \\
\text { ary. }\end{array}\right.$ & Basic. & $\begin{array}{l}\text { Pulmonary in- } \\
\text { sufficiency or } \\
\text { inco m pe - } \\
\text { lence. }\end{array}$ & Soft and blowing. \\
\hline
\end{tabular}

cavities, as the pericardial friction-sounds. M., False. See M., Cardio-pulmonary. M., Flint's, a murmur occasionally heard at the apex in aortic regurgitation. It is sometimes presystolic in time and is probably due to the fact that on account of the extreme ventricular dilatation the valves cannot be forced back against the walls and produce a relative narrowing of the auriculoventricular orifice. See also Signs and Symptoms, Table of. M., Friction, a murmur or sound produced by the rubbing of two inflamed serous surfaces upon each other. M., Functional, a cardiac murmur occurring from excited action of the heart, without any structural change in the valves or orifices. M., Funic. See Souffle, Funic. M., Heart, an abnormal sound produced within the heart or on its surface. M., Hemic, a sound believed to be due to changes in the quality or amount of the blood, and not to lesions of the vessels or valves. M., Indirect, one produced by the blood flowing in a direction contrary to the normal current. M., Inorganic, a murmur not due to valvular lesions; a hemic or a functional murmur. M. Metadiastolic. See M., Post-diastolic. M., Metallic, a murmur sometimes heard in pneumo-pericardium, and having a metallic quality. M., Mitral, a murmur produced at the mitral orifice, M., Musical, a heart-murmur having a musical quality. M., New Leather. See Bruit de cuir neuf. M., Organic, a murmur due to structural changes in the heart. M., Pericardial, a friction-sound produced by the rubbing of the pericardial surfaces upon each other. M., Placental. See Souffle, Uterine. M., Post-diastolic, a murmur heard immediately after the second sound of the heart. M. Pressure, usually a vascular murmur and due to compression of the vessel, as with the stethoscope. M., Presystolic, a murmur heard at the end of the diastolic pause, just before the first sound. It is the common murmur of mitral stenosis. M., Pulmonary, a murmur produced at the pulmonary valve. M., Rasping, a rough murmur. M., Reduplicated, a reduplication of the first or second heart-sound, due usually to an asynchronous action of the two sides of the heart. It occurs in conditions of increased resistance in the systemic or pulmonary circulation-as in chronic nephritis and in emphysema. It is quite frequent in mitral stenosis and in pericarditis. M., Respiratory, the sounds resulting from the passage of the air through the bronchial apparatus during inspiration and expiration. M., Sawing, a long, harsh heart-murmur. M., Scapular, the systolic murmur of mitral regurgitation transmitted to the angle of the left 
scapula. M., Subclavian, a murmur heard over the subclavian arteries; it is not uncommon in pulmonary tuberculosis. M., Systolic, a murmur heard during the systole of the heart. M., Tracheal, a coarse respiratory murmur heard over the trachea. M., Tricuspid, a murnur produced at the tricuspid valve. M., Uterine, M., Utero-placental. See Souffe, Uterine. M., Valvular, a heart-murmur due to some change in a valve. M., Vascular, a hemic murmur heard in the blood-vessels. M., Venous, the hum heard in the veins of the neck, especially in anemia. See Bruit de diable. M., Vesicular. See Vesicular.

Murphy's Button. A mechanical device for coaptating the visceral surfaces in the performance of circular enterorrhaphy, as well as the various intestinal anastomoses. It consists of two brass buttons or plates, each with a peripheral collar and a central hollow stem, the hollow stem of one being slightly smaller than the other, so that it will readly slip within. These buttons may be of various sizes, from three-quarters to one and a quarter inches in diameter, and with central openings of from one-quarter to one-half an inch. In making an anastomosis or enterorrhaphy, a puckering or retaining suture is passed through all the coats around each opening, and after the shoulder of half the button is pushed through each of the openings the suture is drawn taut, so as to prevent the viscus receding from the button. Then the operation is completed by pressing the two halves together, a device on the smaller stem retaining the buttons in apposition, In a few days the buttons will be liberated by pressurenecrosis and carried down the intestinal canal by the natural peristalsis. M.'s Method. See Operations, Table of.

Murr, Murrain (mur, mur'-ān) [ME., murrin, murrain]. Any fatal epizoötic disease of cattle and sheep; also a synonym of foot-and-mouth disease.

Murray's Treatment. See Treatment, Method's of.

Murraya (mur'-a-ah) [after J. A. Murray, a Swedish botanist]. A genus of dicotyledonous trees. $\mathbf{M}$. exotica, Chinese box, yields a perfume and a bitter extract, murrayin.

Murrayetin (mur-a-et'-in) [after J. A. Murray, a Swedish botanist], $\mathrm{C}_{12} \mathrm{H}_{12} \mathrm{O}_{5}+1 / 2 \mathrm{H}_{2} \mathrm{O}$. A glucosid obtained from murrayin by the action of dilute acids.

Murrayin (mur'-a-in) [after J. A. Murray, a Swedish botanist], $\mathrm{C}_{18} \mathrm{H}_{22} \mathrm{O}_{10^{\circ}}$ A glucosid obtained from Murraya exotica.

Murure (mu-ru-ra') [Braz.]. The name given by the natives to a Brazilian tree, the botanic source of which is unknown. The bark presents a brick-red color, with darker patches on the outer surface; internally it is fibrous, grayish and rather hard. Upon incision a reddish, syrupy liquid exudes, which is of acid reaction, I-IOO density, and is called Vegetable mercury. Physiologic investigations show the liquid to be poisonous, injections of the neutralized juice having caused death in various animals.

Musa (mu'-zah) [Ar., mūze, banana]. A genus of monocotyledonous plants. $\mathbf{M}$. paradisiaca, the plantain, $q . v$. M. sapientum, the banana, $q . v$.

Musca (mus'-kah) [ $\mu v \bar{\imath} a$, a fly]. A genus of flies. M. hispaniola. See Cantharis.

Muscæ (mus'-ke) [L.]. Plural of Musca. M., Entohyaloid. See $M$. volitantes. M. volitantes [Fr., Mouches volantes], floating spots, or imperfections in the field of vision due to shadows of vitreous cells.

Muscardine (mus'-kahr-din) [Fr., a peculiar fungus]. See Muskardine.

Muscariform (mus-kar-if-orm) [muscarium, fly-brush; musca, a fly ; forma, form ]. In biology, brush-shaped.
Muscarin (mus'-kar-in) [mescarium, a fly-brush], $\mathrm{C}_{5} \mathrm{H}_{13} \mathrm{NO}_{2}$. An oxycholin found in fly agaric. It is formed by oxidizing cholin with $\mathrm{HNO}_{3}$. It is a powerful respiratory and cardiac depressant, producing myosis, intestinal spasm, dyspnea, and death. Its action may be antagonized by subsequent injection of atropin. See also Pigments, Conspectus of. $\mathbf{M}$. nitras. Dose gr. $\frac{1}{100}$ hypodermatically. Unof.

Muscle (mus'-l) [musculus, a muscle]. An aggregation of tissues, of which muscular tissue is the most important, having the property of contracting and of returning to its original shape. Muscles provide the means of movement in animals, and are of two kinds, the striped and smooth, striated and unstriated, the first being voluntary, the second involuntary, i. e., not as a rule subject to the will. See Table of Muscles, p. 795. M. of Accommodation, the ciliary muscle. Ms, of Animal Life, Striped, Striated or Voluntary Ms., those under the control of the will; they are composed of fasciculi of fibers enclosed in a delicate tissue called the internal perimysium. M.-beater, in massage, an instrument used for flagellation. See Percussion. M.-bundle, a group of muscle-fibers enclosed in an investing membrane. M., Cardiac, the muscular substance of the heart. M.-case, a membranous sac enclosing one of the muscle-compartments of a fiber of muscular tissue. M.-casket, a muscle-compartment. M.-cell. See Myocyte. M., Circular, a muscle surrounding circular openings; a sphincter. M.-clot, the clot formed in the coagulation of muscle-plasm. M.-column, a bundle of muscular fibrils in a muscle-fiber. M.-comma. See Myocomma. M.-compartment, one of the divisions of a muscle-fiber produced by the extension of Krause's membrane from the sarcolemma. M.-corpuscle, a muscle-nucleus. M.-curve, the tracing of a myograph. M., Demipenniform, a muscle with a tendinous portion extending throughout the whole length of its free margin. M.-disc, one of the superimposed discs of a muscie-prism. The same parts were designated by Rollet "chief substance discs." M.-enzyme, a ferment existing in the muscles, retaining its activity until heated to $100^{\circ}$ F. It is not identical with fibrin-ferment. Ms., Extrinsic (of the eye), the recti, oblique, levator palpebræ, and orbicularis palpebrarum muscles. Ms., Extrinsic (of the larynx), the omo-hyoid and sterno-hyoid, the sterno-thyroid, superior, inferior and middle constrictors of the pharynx, the suprahyoid. M., Extrinsic (of the tongue), the hyoglossus, chondro-glossus, genio-hyo-glossus, palato. glossus, and stylo-glossus, and part of the superior pharyngeal constrictor. M.-ferment. See $M$. enzyme. M., Fusiform, a spindle-shaped muscle with a large belly and a narrow origin and insertion. Ms., Hamstring, a name given to the biceps, semi-membranosus, and semi-tendinosus muscles. M., Heart, occupies an intermediate position between the spindleshaped, non-striated involuntary cell and the striped voluntary fiber. It has no sarcolemma, its strix are fainter, the muscle-nuclei are situated within the sarcous substance, and the contractile fibrillæ are peculiarly disposed. The peripheral fibrillæ are arranged in a radiating manner, the central portion being occupied by prismatic bundles of fibrillæ, nuclei, and sarcoplasm. Cardiac muscle-fibers differ in yet another point from ordinary striped muscular tissue-they branch and anastomose with each other. M., Hollow, that surrounding a cavity. M., Inflected, one that passes over a pulley. M., Intrinsic, a muscle confined to a part or organ. M., Involuntary, one not under the control 
of the will, as the non-striated muscles. They vary from 75-225 $\mu$ in length, and from $4-8 \mu$ in width. The cells are surrounded by a delicate hyaline sheath, and possess a rod-shaped nucleus. See $M$., Unstriped. M.-juice. Same as M.-plasma. Ms. of Mastication, the masseters, temporals, and external and internal pterygoid muscles. M., Non-striated, one composed of spindle-shaped involuntary muscle-fibers. M.-nucleus, the nucleus of a muscle-fiber. M., Organic. See Involuntary. Ms. of Organic Life, Unstriped or Involuntary Ms., those composed of spindle-shaped, contractile fibers and nucleated cells collected in bundles. A table arranged alphabetically is appended, showing the principal muscles of the human body, with their origin, insertion, innervation, and function. M., Papillary, the muscular eminences in the ventricles of the heart, from which the chordæ tendineæ arise. M., Pennate, M., Penniform, a muscle with a central axis, from which the fibers radiate on each side. M., Perforated (of Casserius). See M., Coraco-brachialis, in Table. M., Peripenial, a layer of involuntary muscle beneath the skin of the penis. M.-plasma, a liquid obtained from
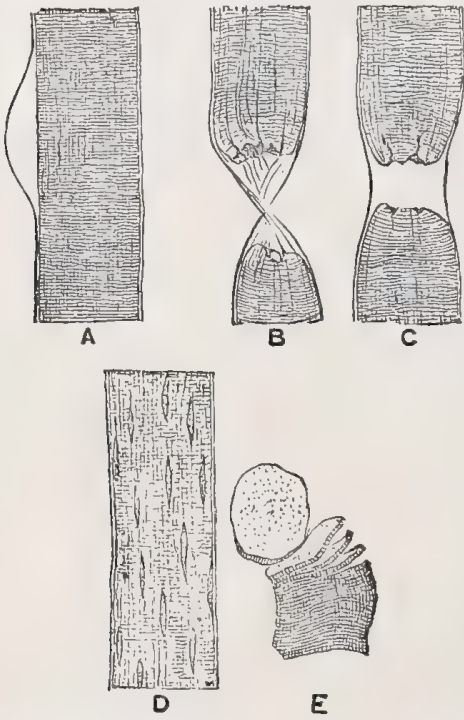

A. Striped muscle of frog, sarcolemma raised in the form of a bleb. B. Ruptured fiber with sarcolemma. C. Fiber ruptured by a hair. D. Effect of acetic acid on a muscle fiber. E. Muscle-discs. (Stirling.)

fresh muscle by expression, preferably after freezing. Its coagulation is the essential condition of rigor mortis, and is comparable to the coagulation of blood. The solid proteid thus separated is called myosin. Two of its proteids, paramyosinogen and myosinogen, go to form the clot, while the other three, myoglobulin, albumin, and myoalbuminose, remain in the muscleserum. M.-plate. See Myocomma, and Myotome. M.-prism, a muscle-rod. M.-reading, the detection of a person's thoughts and emotions by the involuntary action of his muscles. Ms. of Respiration, those involved in the ordinary processes of breathing. Those concerned in inspiration are the diaphragm, the intercostals and the long and short elevators. Other muscles, including the trapezius, scaleni and pectoralis minor, are brought into play during forced inspiration. Ordinary expiration is non-muscular, the act being a purely passive one; forced expiration, however, brings into play most of the abdominal muscles. M.-rod, one of the ultimate divisions of the dim band of a muscle-compartment. M.-serum, the liquid residue left after the separation of the clot by coagulation of muscle-plasma. M., Skeletal, any one of those muscles attached to and acting on the skeleton. M.-sound, the sound produced by the

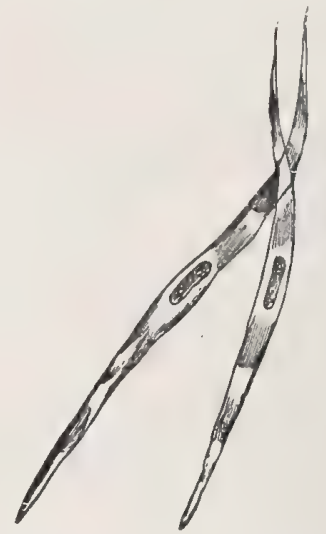

Isolated Smooth MUScular Fibers Nitric acid. $\times 300$, (Stirling.)

contraction of a muscle. M.-spindle, structures described by Kühne and considered by Kirschner as special sensory nerve-endings, and by Kölliker to be transient developmental structures connected with the cleavage of the muscle-fibers (Piersol). M., Stalk, a differentiation of the ectoplasm of the Vorticella, which, in contracting, rolls the stalk up spirally. M. Striated, a muscle constituted of striped muscle-fibers. M., Striped. Same as M., Striated. M.-sugar. See Inosite. M., Tailor's. Synonym of the sartorius muscle. See Table. M.-telegraph, an apparatus arranged by DuBois-Reymond especially for replacing the myograph in experiments during lectures. The muscle is

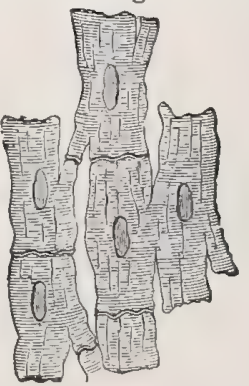

Muscular Fibers of the Human Heart. (Stirling.)

fixed in a vise ; its other end is connected by a hook with a thread running over a reel. The reel supports a long indicating hand to which a colored disc is attached. The muscle, in shortening, turns the wheel and lifts the disc, which is easily seen from a considerable distance. A second thread, slung over the reel, supports a brass vessel, which may be filled with shot, so as to appiy any desired weight to the muscle. M.-tumor, a myoma, q. v. M.. Unstriated, M., Unstriped. See M., Non-striated. M., Visceral, any one of the muscles connected with the viscera; they are not under the command of the will. M. Voluntary. See M., Striped.

Muscoid (mus'-koid) [muscus, moss; eidos, like]. Moss-like. 


\section{TABLE OF MUSCLES (ARRANGed AlPhaBeTICALly).}

\section{NAME.}

ORIGIN.

Outer head of os calcis, plan- Inner portion of lower tar fascia, intermuscular surface of base of great septum ; inner head, internal annular ligament, and rendon of tibialis posticus.

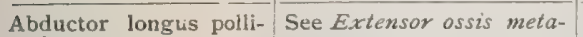
cis.

Abductor minimi digiti manus.

Ahductor minimi digiti pedis.

Abductor ossis metatarsl quinti.

Abductor pollicis manus.

Abductor pollicis pedis.

\section{Accelerator urinæ.}

Accessorius ad accessorium.

Accessorius ad flexorum profundum.

Accessorius orbicularis inferioris.

Accessorius orbicularis superioris.

\section{Accessorius tricipites. \\ Accessory a bd o minal oblique.}

Accessory gluteus minimus.

Accessory to the iliocostal. Accessory palmat ab-
ductor indicis (anomalouss).

Accessory popliteus (anomalous).

\section{Adductor brevis.}

Adductor hallucis.

Adductor longus.

Adductor magnus.

Adductor minimus

Adductor pollicis.

\section{Pisiform bone}

Outer tuberosity of the os calcis and plantar fascia.

Outer tubercle of calcaneum.

Trapezium, scaphoid, annular ligament, palmar fascia.

Inner tuberosity of the os calcis.

Central tendon of perineum and median raphe.

See Flexor accessorius

Internal condyle and coronoid process of humerus

Inferior maxilla, external to levator labii inferioris.

Alveolar border of superior maxilla opposite incisor teeth.

See Dorso-epitrochlearis.

Between the two oblique muscles from the gth, 1oth or IIth rib.

Outer surface of the ilium.

Angles of 7 th to IIth ribs and back of last rib.

Third metacarpal bone.

Usually from a sesamoid bone on the posterior surface of lower end of femur.

\section{Ramus of pubes.}

Tarsal ends of the three middle metatarsal bones.

Front of pubes.

Rami of pubes and ischium.

A name given to the upper portion of the adductor magnus.

Third metacarpal. aspera of femur.
INNERVATION.

FUNCTION

Internal plantar divi- Flexes and abducts first sion of posterior phalanx of great toe toe and inner side of internal sesamoid bone.

carpi pollicis.

First phalanx of the Ulnar. little finger

First phalanx of the little External plantar. toe.

Tuberosity of base of External plantar. 5th metatarsal bone.

First phalanx of thumb. Median.

First phalanx of great Internal plantar. toe.

Bulb, spongy and cav- Perineal. ernous parts of penis.

longus digitorum pedis.

Into the perforating tendons of the flexor profunda.

At angle of mouth, join ing buccinator and other muscles

Angle of mouth; continuous with other muscles inserted at this point.

Crest of ilium.

Anterior border of the great trochanter.

Transverse process of External branches of 7 th cervical vertebra, tubercle of Ist rib. Angles of $2 \mathrm{~d}$ to 5 th ribs.

Base of first phalanx of index finger.

With the popliteus.

Internal popliteal.

Assists in flexing leg.

Upper part of the linea Obturator.

Base of the first phalanx External plantar. of great toe.

Middle of linea aspera of femur.

All of the linea aspera of

Obturator.

Abducts little finger.

Abducts little toe

Abducts little toe

Abducts and flexes first phalanx of thumb.

Abducts great toe.

Ejects urine.

Assists in flexing fingers

Ulnar and anterior inerosseous.

Intercostal, ilio-hypo- Assists in flexing thorax. gastric, ilio-inguinal.

Assists gluteus minimus

Extension of $1 \mathrm{umbar}$ spines on pelvis.

umbar nerves.

ward, and flexes thigh.

Obturator and great Adducts thigh and rosciatic.

tates it outward. 


\section{MUSCLES.}

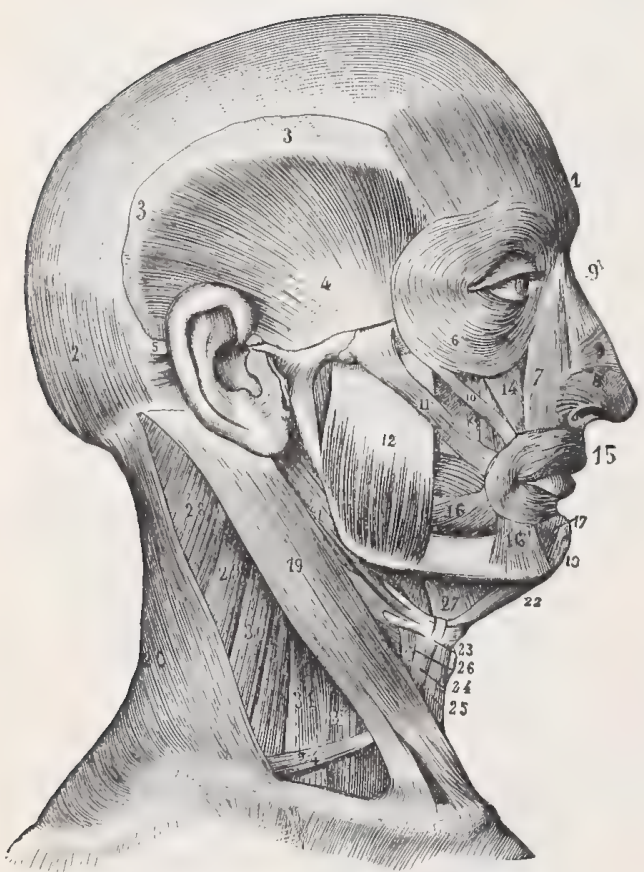

MUSCles OF THE FACE AND NECK.

1. Frontal muscle. 2. Occipital muscle. 3, 3. Epicranial aponeurosis, 4. Temporal muscle. 5. Retrahens aurem. 6. Orbicularis palpebrarum. 7. Levator labii superioris et alæque nasi. 8. Dilator naris. 9. Compressor naris. 9'. Pyramidalis nasi. Io. Zygomatic minor. II. Zygomatic major. 12. Masseter. 13. Levator anguli oris. I4. Levator labii superioris, I5. Orbicularis oris. I6. Buccinator. I6'. Depressor anguli oris. 17. Depressor labii inferioris. 18. Levator labii inferioris. 19. Sterno-mastoid. 20. Trapezius. 2I. Digastric and stylo-hyoid. 22. Anterior belly of digastric. 23. Pulley for tendon of digastric. 24, 24. Omo-hyoid. 25. Sterno-hyoid. 26. Thyro-hyoid. 27. Mylo-hyoid. 28. Splenius capitis. 29. Splenius colli. 30. Levator anguli scapulae. 3I. Scalenus posticus. 32. Scalenus anticus.

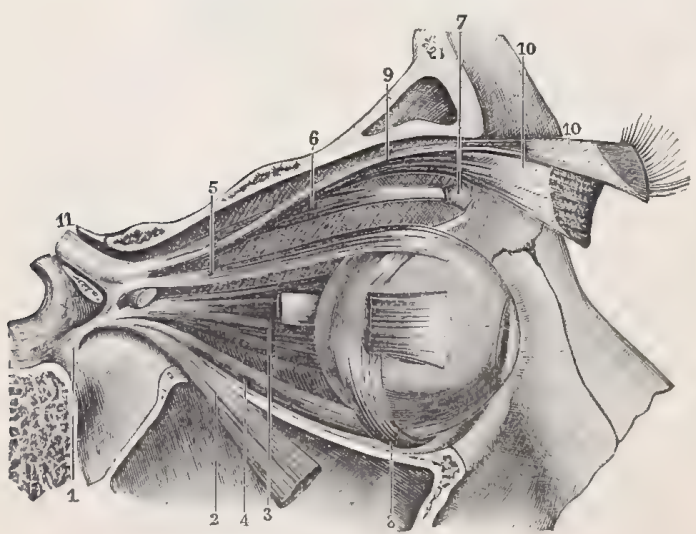

MUSCLES OF THE EYE.

I. Tendon of Zinn. 2. External rectus divided. 3. Internal rectus, 4. Inferior rectus. 5. Superior rectus. 6. Superior oblique. 7. Pulley for superior oblique. 8. Inferior oblique. 9. Levator palpebræ superioris. Io, Io. Its anterior expansion. Lut Optic nerve.

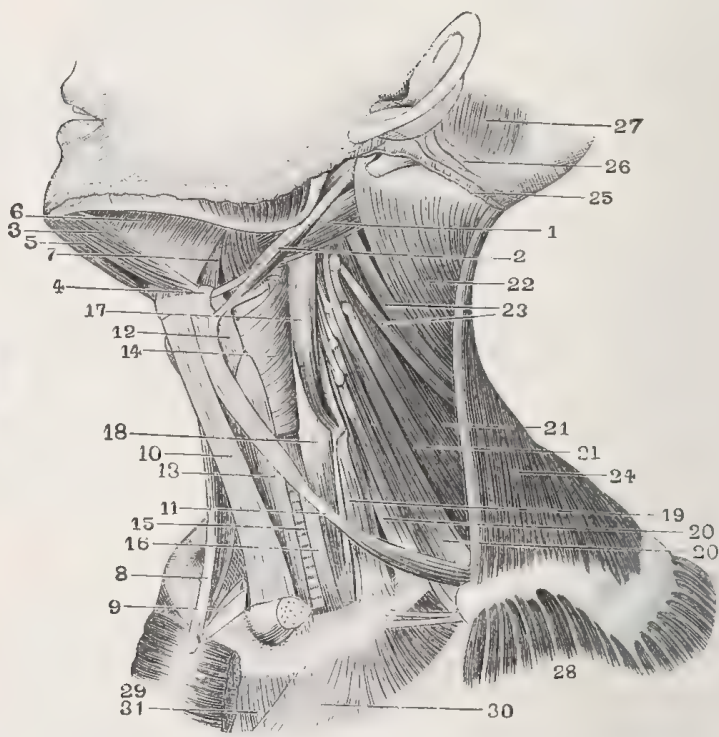

MUSCLES OF SUPRA-HYOID AND INFRA-HYOID REGIONS.

I. Posterior belly of digastric. 2. Stylo-hyoid. 3. Anterior belly of digastric. 4. Tendon and pulley of digastric 5. Anterior belly of right digastric 6. Mylo-hyoid. 7 . Hyoglossus. 8. Sternal fibers of right sterno-mastoid. 9. Sternal fibers of left sterno-mastoid. 10. Sterno-hyoid. II. Tendon of omo-hyoid. 12. Thyro-hyoid. 13. Sterno-thyroid. 14. Inferior constrictor of pharynx. 15. Trachea. 16. Esophagus. 17. Rectus capitis anticus major. 18. Longus colli. I9. Scalenus anticus. 20, 20. Scalenus posticus. 2I, 2I. Levator anguli scapulæ. 22. Splenius capitis. 23, 23. Splenius colli. 24. Trapezius. 25. Attachment of sterno-mastoid. 26. Retrahens aurem. 27. Occipital portion of occipitofrontal. 28. Deltoid. 29. Attachment of pectorales majores to sternum, 30. External intercostal. 3I. Internal intercostal.

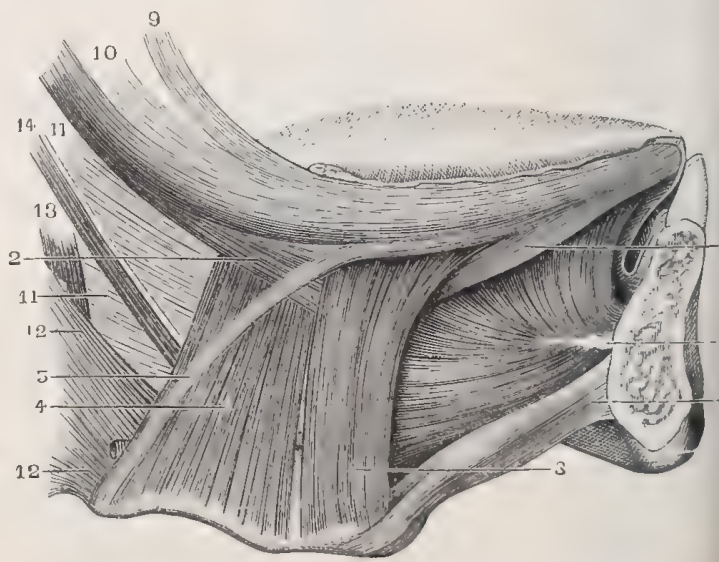

Muscles of the Tongue, Superficial Layer.

1. Stylo-glossus. 2. Inferior fibers of stylo-glossus. 3. Anterior fibers of hvo-glossus or basio-glossus. 4. Posterior fibers. 5. Accessory fibers. 6, Genio-hyoid. 7. Gemio-glossus. 8. Inferior lingual. 9. Palato-glossus, xo. Upper portion of Pharyngo-glossus (from superior constrictor of pharynx). II, II. Inferior portion. I2, 12. Middle constrictor of pha rynx. I3. Stylo-pharyngeus. 14. Stylo-hyoid ligament and stylo-hyoid muscle. 
TABLE OF MUSCLES.-Continued.

\begin{tabular}{|c|c|c|c|c|}
\hline NAME. & ORIGIN. & INSERTION. & INNERVATION. & FunCtION. \\
\hline Adductor quadratus. & See Adductor minimus. & & & \\
\hline Adjutor splenii. & See Rhombo-atloid. & & & \\
\hline Agitator caudæ. & $\begin{array}{l}\text { A name given to the lower } \\
\text { edge of the gluteus maxi- } \\
\text { mus. }\end{array}$ & $\begin{array}{l}\text { The femur or femoral } \\
\text { aponeurosis. }\end{array}$ & & \\
\hline Amygdalo-glossus. & $\begin{array}{l}\text { Pharyngeal aponeurosis } \\
\text { covering the outer sur- } \\
\text { face of the tonsil. }\end{array}$ & $\begin{array}{l}\text { Continuous with the } \\
\text { palato-glossus. }\end{array}$ & & $\begin{array}{l}\text { Aids the stylo-glossus in } \\
\text { raising the margin of } \\
\text { the tongue, rendering } \\
\text { the dorsum concave. }\end{array}$ \\
\hline Anconeus. & $\begin{array}{l}\text { Back of external condyle } \\
\text { of humerus. }\end{array}$ & $\begin{array}{l}\text { Olecranon process and } \\
\text { shaft of ulna. }\end{array}$ & Musculo-spiral. & Extends forearm. \\
\hline Antitragicus. & $\begin{array}{l}\text { Outer surface of antitra- } \\
\text { gus. }\end{array}$ & Caudate process. & $\begin{array}{l}\text { Temporal and poste- } \\
\text { rior auricular. }\end{array}$ & \\
\hline Arrectores pili. & Pars papillaris of the skin. & Hair-follicles. & Sympathetic. & $\begin{array}{l}\text { Elevate the bairs of the } \\
\text { skin. }\end{array}$ \\
\hline $\begin{array}{l}\text { A ryteno-epiglottideus } \\
\text { interioris. }\end{array}$ & Arytenoid (anteriorly). & Epiglottis. & Recurrent laryngeal. & $\begin{array}{l}\text { Compresses saccule of } \\
\text { larynx. }\end{array}$ \\
\hline $\begin{array}{l}\text { A r y te no-epiglottideus } \\
\text { superioris. }\end{array}$ & $\begin{array}{l}\text { Apex of arytenoid car- } \\
\text { tilage. }\end{array}$ & $\begin{array}{l}\text { Aryteno - epiglottidean } \\
\text { folds. }\end{array}$ & Recurrent laryngeal. & $\begin{array}{l}\text { Constricts aperture of } \\
\text { larynx. }\end{array}$ \\
\hline Arytenoideus. & $\begin{array}{l}\text { Posterior and outer border } \\
\text { of one arytenoid. }\end{array}$ & Back of other arytenoid. & $\begin{array}{l}\text { Superior and recur- } \\
\text { rent laryngeal. }\end{array}$ & $\begin{array}{l}\text { Closes back part of glot- } \\
\text { tis. }\end{array}$ \\
\hline Attollens aurem. & $\begin{array}{l}\text { Occipito-frontalis aponeu- } \\
\text { rosis. }\end{array}$ & Pinna. & $\begin{array}{l}\text { Temporal branch of } \\
\text { facia!. }\end{array}$ & Elevates pinna. \\
\hline Attrahens aurem. & $\begin{array}{l}\text { Lateral cranial aponeuro- } \\
\text { sis. }\end{array}$ & Helix. & Facial. & Advances pinna. \\
\hline $\begin{array}{l}\text { Azygos pharyngis (ncca- } \\
\text { sional). }\end{array}$ & $\begin{array}{l}\text { Pharyngeal tubercle of } \\
\text { body of occiput. }\end{array}$ & Raphe of pharynx. & $\begin{array}{l}\text { Gloss o-pharyngeal, } \\
\text { pharyngeal plexus. }\end{array}$ & $\begin{array}{l}\text { Blends with superior } \\
\text { constrictor. }\end{array}$ \\
\hline Azygos uvula. & $\begin{array}{l}\text { Posterior nasal spine of } \\
\text { palate bone. }\end{array}$ & Uvula. & $\begin{array}{l}\text { Facial through spheno- } \\
\text { palatine ganglion. }\end{array}$ & Raises uvula. \\
\hline Basio-glossus. & $\begin{array}{l}\text { The fibers of the hyo-glos- } \\
\text { sus arising from the } \\
\text { hyoid bone. See Hyo- } \\
\text { glossus. }\end{array}$ & & & \\
\hline Biceps. & $\begin{array}{l}\text { 1. Long-Glenoid cavity. } \\
\text { 2. Short-Coracoid pro- } \\
\text { cess. }\end{array}$ & Tuberosity of radius. & Musculo-cutaneous. & $\begin{array}{l}\text { Flexes and supinates } \\
\text { forearm. }\end{array}$ \\
\hline Biceps femoris. & $\begin{array}{l}\text { I. Ischial tuberosity. } 2 \text {. } \\
\text { Linea aspera. }\end{array}$ & $\begin{array}{l}\text { Head of fibula and outer } \\
\text { tuberosity of head of } \\
\text { fibula. }\end{array}$ & $\begin{array}{l}\text { Great sciatic and ex- } \\
\text { ternal popliteal. }\end{array}$ & $\begin{array}{l}\text { Flexes and rotates leg } \\
\text { outward. }\end{array}$ \\
\hline Biventer cervicis. & $\begin{array}{l}\text { Transverse processes, } \\
2-4 \text { upper dorsal. }\end{array}$ & $\begin{array}{l}\text { Superior curved line of } \\
\text { occipital bone. }\end{array}$ & Portion of complexus. & $\begin{array}{l}\text { Retracts and rotates } \\
\text { head. }\end{array}$ \\
\hline Bowman's. & See Ciliary. & & & \\
\hline Brachialis anticus. & $\begin{array}{l}\text { Lower half of the shaft } \\
\text { of humerus. }\end{array}$ & $\begin{array}{l}\text { Coronoid process of } \\
\text { ulna. }\end{array}$ & $\begin{array}{l}\text { Musculo-c ut a ne o us, } \\
\text { musculo-spiral. }\end{array}$ & Flexes forearm. \\
\hline Brachio-capsularis. & See Subscapularis. & & & \\
\hline Brachio-radialis. & See Supinator longus. & & & \\
\hline Briicke's. & See Ciliary. & & & \\
\hline Buccinator. & $\begin{array}{l}\text { Alveolar process of max- } \\
\text { illary bones and pterygo- } \\
\text { maxiliary ligament. }\end{array}$ & Orbicularis oris. & Facial, buccal branch. & $\begin{array}{l}\text { Compresses cheeks, re- } \\
\text { tracts angle of mouth. }\end{array}$ \\
\hline Bulbo-cavernous. & See Accelerator urine. & & & \\
\hline Cephalo-humeral. & See Cleido-occipital. & & & \\
\hline Cephalo-pharyngeus. & See Constrictor of: & pharynx, superior. & & \\
\hline Cervicalis ascendens. & Angles of 5 upper ribs. & $\begin{array}{l}\text { Transverse processes of } \\
4 \text { th, 5th, and 6th cer- } \\
\text { vical vertebra. }\end{array}$ & Branches of cervical. & Keeps head erect. \\
\hline $\begin{array}{l}\text { Chondro-coracoid (an- } \\
\text { omalous). }\end{array}$ & First costal cartilage. & $\begin{array}{l}\text { Coracoid process, super- } \\
\text { ficial to the coraco- } \\
\text { brachialis. }\end{array}$ & & \\
\hline
\end{tabular}




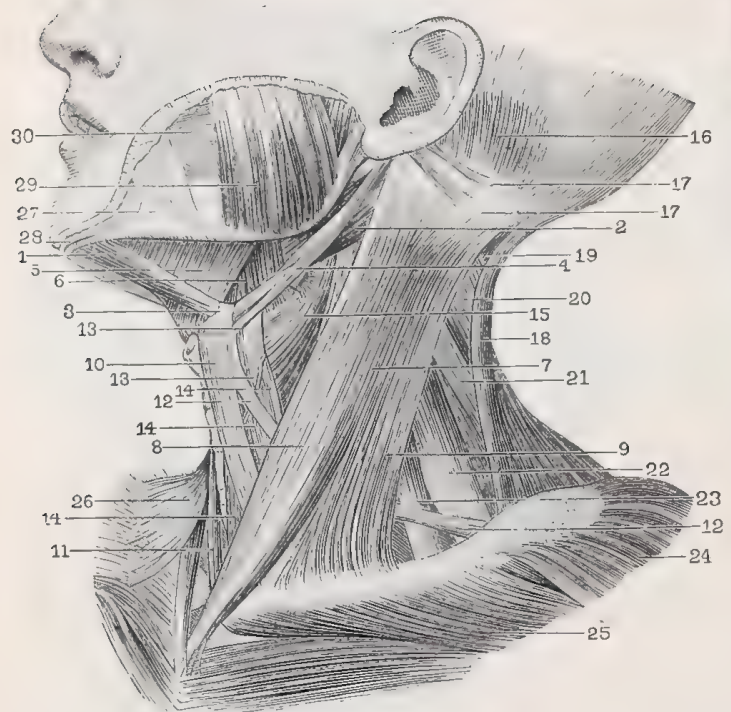

The Sterno-cleido-mastoid Muscle. Muscles of the SUPRA-HYOID AND INFRA-HYOID REGIONS.

I. Anterior belly of digastric. 2. Posterior belly. 3. Tendon and pulley for tendon. 4. Stylo-hyoid. 5. Mylo-hyoid. 6. Hyo-glossus, 7. Sterno-cleido-nastoid. 8. Anterior or sternal portion. 9. Posterior or clavicular portion. Io. Left sterno-hyoid. II. Right sterno-hyoid. I2, I2. Omo-hyoid. 13. Thyro-hyoid. I4, 14. Sterno-thyroid. I5. Anterior portion of inferior constrictor of pharynx. x6. Occipital muscle. I7, 17. Retrahens aurem. 18. Trapezius. 19. Splenius capitis. 20. Splenius colli. 21. Levator anguli scapulæ. 22. Scalenus posticus. 23. Scalenus anticus. 24. Superior portion of deltoid. 25. Superior portion of pectoralis major. 26. Inferior and anterior portion of right platysma myoides. 27. Depressor anguli oris. 28. Depressor labii inferioris. 29. Masseter, 30. Buccinator.

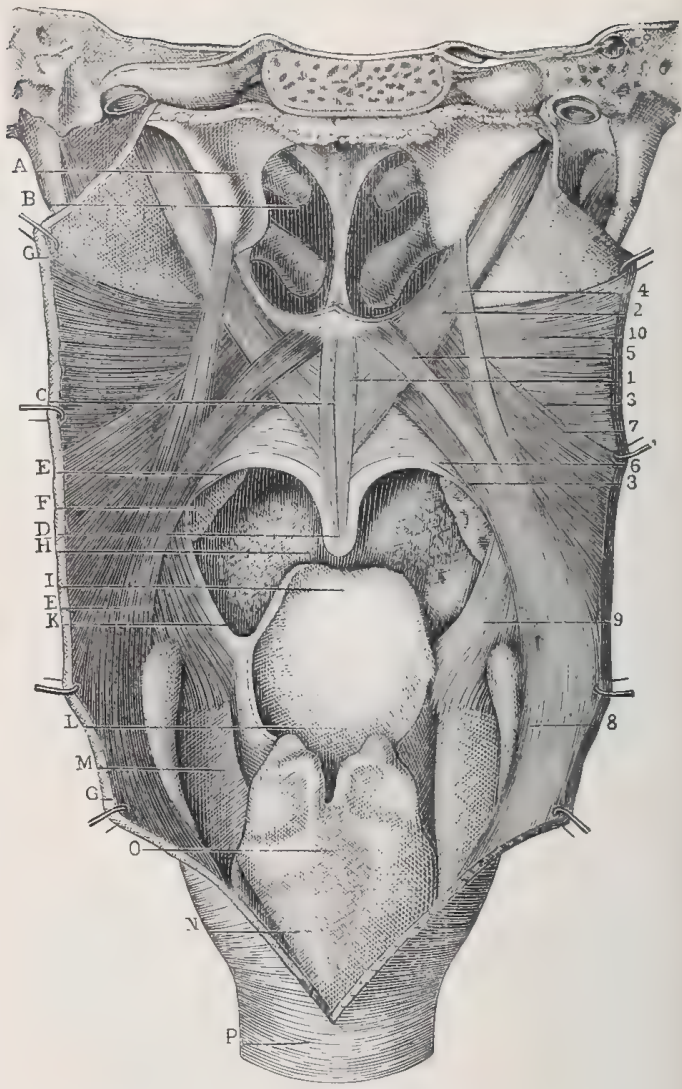

Muscles of the Velum Palati.

A. Cartilaginous portion of Eustachian tube. B. Posterior orifice of nasal fossa. C. Velum palati. D. Uvula. E. Posterior pillar of velum palati. F. Tonsil. G, G. Posterior wall of pharynx, divided in the median line. H. Base of tongue. I. Epiglottis. K. Left lateral prolongation of epiglottis. L. Entrance to larynx. M. Thyroid cartilage. N. Posterior wall of larynx. O. Group of racemose glands. P. Upper part of esophagus. I. Azygos uvulæ. 2, Levator palati. 3. 3. Palato-pharyngeus, 4. External accessory fasciculus. 5. Internal accessory fasciculus. 6. Fibers arising from the median portion of the velum palati and terminating in the palatopharyngeus. 7. Internal fibers of the palato-pharyngeus. 8. Middle and external fibers. 9. Anterior fibers of stylopharyngeus. Io. Superior constrictor of 11 pharynx.

I. External abdominal ring. 2, External pillar. 3, 3. Internal pillar. 4, 4. Gimbernat's ligament. 5, 5. Its attachment. 6. Intercolumnar fibers. 7. Linea alba. 8. Symphysis pubis. 9. Spermatic cord. Io. Crural arch. II, II. Cribriform fascia. I2. Internal saphenous vein.

INEERIOR PORTION OF THE ABDOMINAL APONEUROSIS. 


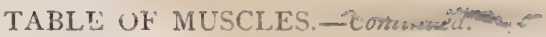

NAME.

ORIGIN.

\section{Chond ro-ep itrochle-} aris (anomalous).

Chondro-glossus.

Choroid.

Ciliary.

\section{Circumflex palati.}

Cleido-cervicalis ( $a n$ omalous).

Cleido-epitrochlearis.

Cleido-hyoid (anomalous).

Cleido-occipitalis ( $\alpha n-$ omalous).

Coccygeus.

\section{Complexus.}

Compressor hemisphericum bulbi.

\section{Compressor narium.}

Compressor narium minor.

Compressor sacculi laryngis.

Compressor urethræ.

\section{Compressor vaginæ.}

Compressor venæe dorsalis penis.

Constrictor isthmi faucium.

Constrictor of pharynx (inferior).

\section{Constrictor of pharynx} (middle).

Constrictor of pharynx (superior)

\section{Constrictor urethræ.}

Constrictor vagina.

Coraco-brachialis.

Coraco-brachialis supe-
rior vel brevis.

\begin{tabular}{|c|c|c|}
\hline INSERTION. & INNERVATION. & Function. \\
\hline $\begin{array}{l}\text { Fascia on inner side of } \\
\text { arm, or internal con- } \\
\text { dyle of hunterus. }\end{array}$ & & \\
\hline Outer layers of choroid. & Ciliary. & $\begin{array}{l}\text { The muscle of visual } \\
\text { accommodation. }\end{array}$ \\
\hline Outer end of clavicle. & & $\begin{array}{l}\text { A supernumerary scalene } \\
\text { muscle. }\end{array}$ \\
\hline $\begin{array}{l}\text { Internal condyle of } \\
\text { humerus. }\end{array}$ & & \\
\hline Body of hyoid. & Hypoglossal. & Depresses hyoid. \\
\hline $\begin{array}{l}\text { Superior nuchal line of } \\
\text { occiput. }\end{array}$ & & \\
\hline $\begin{array}{l}\text { Coccyx, sacrum, and } \\
\text { sacro-coccygeal lig a - } \\
\text { ment. }\end{array}$ & Sacral. & $\begin{array}{l}\text { Supports coccyx, an } \mathrm{d} \\
\text { closes pelvic outlet. }\end{array}$ \\
\hline Occipital bone. & $\begin{array}{l}\text { Sub-occipital, great } \\
\text { occipital, and bran- } \\
\text { ches of cervical. }\end{array}$ & $\begin{array}{l}\text { Retracts and rotates } \\
\text { head. }\end{array}$ \\
\hline $\begin{array}{l}\text { Fellow muscle and } \\
\text { canine fossa. }\end{array}$ & Facial. & Dilates nostril. \\
\hline Skin at end of nose. & Facial. & Dilates nostril. \\
\hline & Recurrent laryngeal. & $\begin{array}{l}\text { Compressor of saccule of } \\
\text { Iarynx. }\end{array}$ \\
\hline Fellow muscle. & Perineal. & $\begin{array}{l}\text { Compresses membran- } \\
\text { ous urethra. }\end{array}$ \\
\hline & Perineal. & Compressor of vagina. \\
\hline $\begin{array}{l}\text { Fascial sheath of penis, } \\
\text { over dorsal vessels. }\end{array}$ & & $\begin{array}{l}\text { Compressor of dorsal } \\
\text { vein. }\end{array}$ \\
\hline Pharyngeal raphe. & $\begin{array}{l}\text { Glosso-pharyngeal, } \\
\text { pharyngeal plexus } \\
\text { and external laryn- } \\
\text { geal. }\end{array}$ & $\begin{array}{l}\text { Contracts caliber of } \\
\text { pharynx. }\end{array}$ \\
\hline Pharyngeal raphe. & $\begin{array}{l}\text { Glosso-pharyngeal } \\
\text { and pharyngeal } \\
\text { plexus. }\end{array}$ & $\begin{array}{l}\text { Contracts caliber of } \\
\text { pharynx. }\end{array}$ \\
\hline Pharyngeal raphe. & $\begin{array}{l}\text { Glosso-p h a ry ng eal } \\
\text { and pharyngeal plex- } \\
\text { us. }\end{array}$ & $\begin{array}{l}\text { Contracts caliber of } \\
\text { pharynx. }\end{array}$ \\
\hline $\begin{array}{l}\text { Inner surface of shaft } \\
\text { of humerus. }\end{array}$ & Musculo-cutaneous. & Adducts and flexes arm. \\
\hline
\end{tabular}



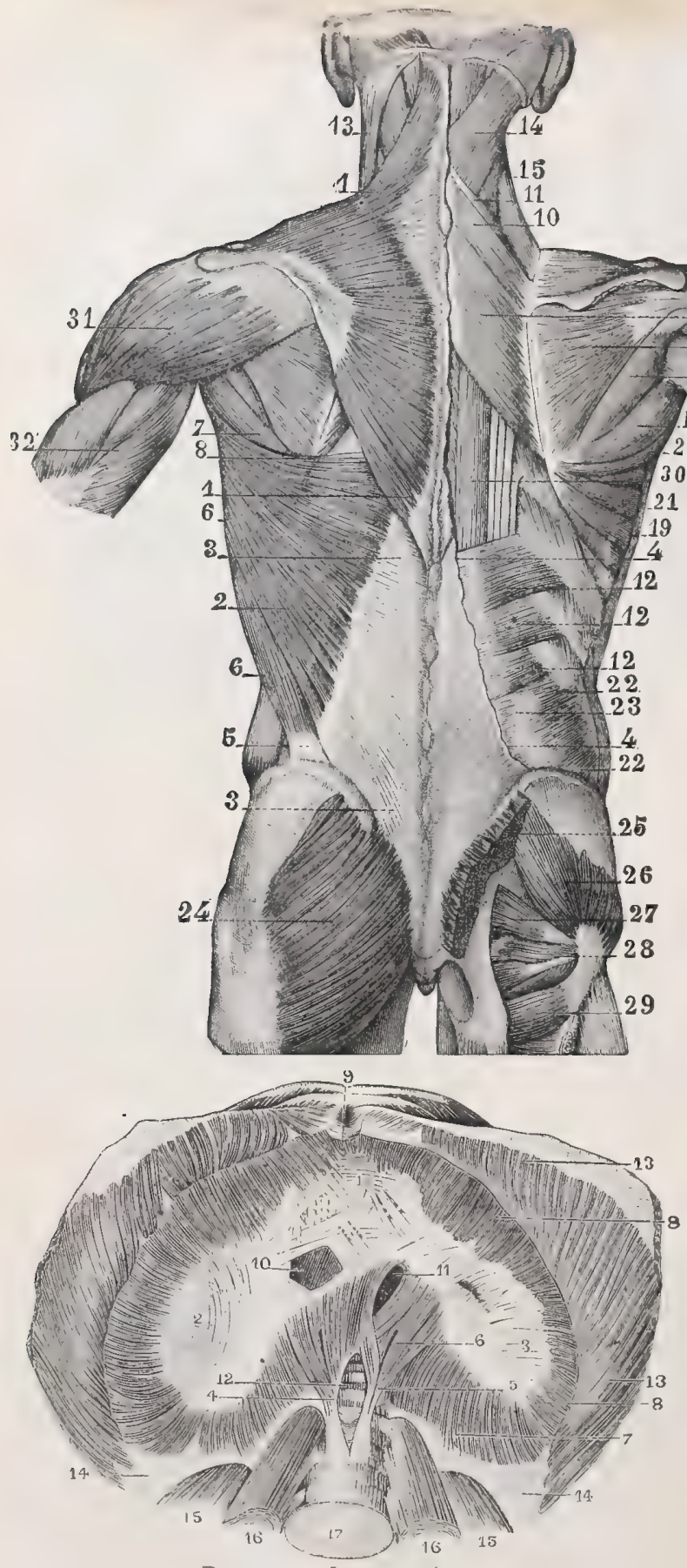

DIAPHRAGM, INFERIOR ASPECT.

I. Middle or anterior leaflet of central tendon. 2. Right leaflet. 3. Left leaflet. 4. Right crus. 5. Left crus, 6, 6. Intervals for phrenic nerves. 7. Muscular fibers from which the ligamenta arcuata originate. $8,8$. Muscular fibers that arise from inner surface of six lower ribs. 9. Fibers that arise from ensiform cartilage. 10. Opening for inferior vena cava. II. Opening for esophagus. 12. Aortic opening. 13, 13. Upper portion of transversalis abdominis, turned upward and outward. 14. Anterior leaflet of transversalis aponeurosis. 15, I5. Quadratus lumborum. 16, 16. Psoas magnus. 17. Third lumbar vertebra.
Superficial and Middle MuscuLAR LAYERS OF THE POSTERIOR ASPECT OF THE TRUNK.

I, x. Trapezius. 2. Latissimus dorsi. 3, 3. Lumbo-sacral aponeur osis. 4, 4. Portion of this aponeurosis to which latissimus dorsi is attached 5. Fasciculus by which latissimus dorsi is attached to crest of ilium. 6. External border of latissimus dorsi. 7. Teres major. 8. Superior border of latissimus dorsi, curving around teres major. 9. Rhomboideus major. Io. Rhomboideus minor. II. Superior border of serratus posticus superioris. 12, 12, 12. Fasciculi of serratus posticus inferioris. ${ }_{13}$. Sterno-mastoid. 14. Splenius. $x_{5}$. Levator anguli scapulæ. I6. Infraspinatus. 17. Teres minor. 18. Teres major. 19. Divided latissimus dorsi. 20. Fasciculus of latissimus dorsi, arising from angle of scapuli. . 21. Inferior portion of serratus magnus. 22, 22. Lower portion of internal oblique. 23. Posterior aponeurosis of internal oblique. 24. Gluteus maximus. 25. oblique. 24. Gluteus maximus. 25. teus medius. 27. Pyramidalis. 28. Tendon of obturator internus and gemelli. 29. Quadratus femoris. 30. Sacronlumbalis and longissimus dorsi. 31. Deltoid. 32. Triceps.

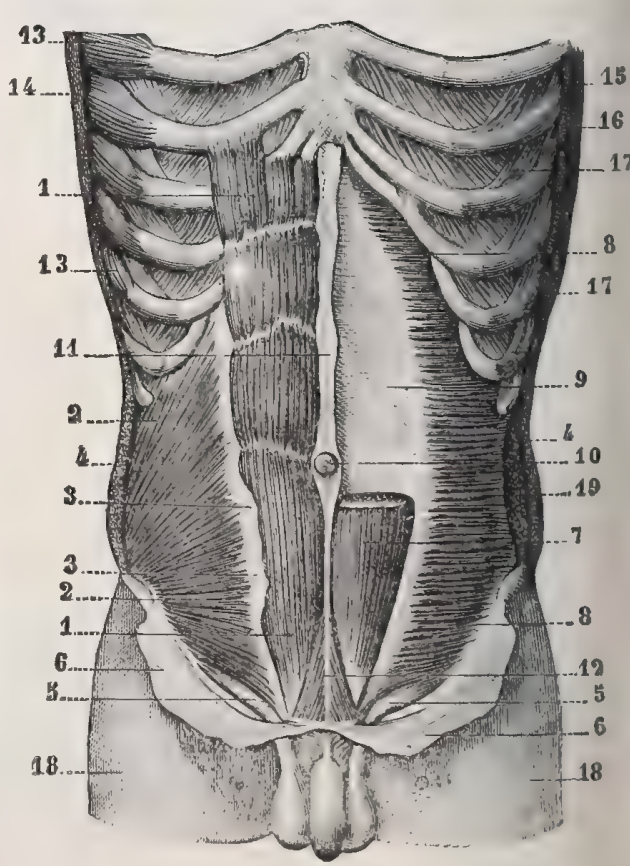

INTERNAL OblyQue and TRANSVERSALIS ABDominis Muscles.

I. I. Rectus abdominis. 2, 2. Internal oblique. 3, 3. Anterior leaflet of aponeurosis of internal oblique. 4, 4. Divided external oblique, 5, 5. Spermatic cords. 6, 6. Inferior portion of aponeurosis of external oblique. 7. Lower portion of left rectus abdominis: upper portion removed. 8, 8. Muscular portion of transversalis abdominis, Aponeurotic portion. ro. Umbilicus. II. Supra-umbilical portion of linea alba. 12. Infra-umbilical portion. 13. Serratus magnus. 14. Divided right latissimus dorsi. 15. Divided left latissimus dorsi. I6. Divided serratus magnus. I7. I7. External intercostals. I8, I8. Femoral aponeurosis. 19. Divided internal oblique. 
TABLE OF MUSCLES.-Continued.

\begin{tabular}{|c|c|c|c|c|}
\hline NAME. & ORIGIN. & INSERTION. & INNERVATION. & FUNCTION. \\
\hline $\begin{array}{l}\text { Coraco-capsularis. } \\
\text { (A name applied to the } \\
\text { upper portion of the } \\
\text { coraco-brachialis). }\end{array}$ & | Coracoid process. & $\begin{array}{l}\text { Below lesser tuberosity } \\
\text { of humerus, or int o } \\
\text { capsule of shoulder- } \\
\text { joint. }\end{array}$ & & \\
\hline Corrugator cutis ani. & $\begin{array}{l}\text { Submucous tissue on inte- } \\
\text { rior of anus. }\end{array}$ & $\begin{array}{l}\text { Subcutaneous tissue on } \\
\text { opposite side of anus }\end{array}$ & Sympathetic. & $\begin{array}{l}\text { Corrugates skin about } \\
\text { anus. }\end{array}$ \\
\hline Corrugator supercilii. & $\begin{array}{l}\text { Superciliary ridge of fron- } \\
\text { tal bone. }\end{array}$ & $\begin{array}{l}\text { Orbicularis palpe- } \\
\text { brarum. }\end{array}$ & Facial. & $\begin{array}{l}\text { Draws eyebrow, down- } \\
\text { ward and inward. }\end{array}$ \\
\hline $\begin{array}{l}\text { Costo-fascialis (anomal- } \\
\text { ous). }\end{array}$ & $\begin{array}{l}\text { Outer border of sterno- } \\
\text { thyroid muscle. }\end{array}$ & $\begin{array}{l}\text { Sheath of carotid ves- } \\
\text { sels. }\end{array}$ & & . \\
\hline Crampton's. & See Ciliary. & . & & \\
\hline Cremaster. & $\begin{array}{l}\text { Upper and deep surface } \\
\text { of middle of Poupart's } \\
\text { ligament. }\end{array}$ & $\begin{array}{l}\text { Spine and crest of pubic } \\
\text { bone and fascia pro- } \\
\text { pria. }\end{array}$ & $\begin{array}{l}\text { Genital branch of } \\
\text { genito-crural. }\end{array}$ & Elevates testicle. \\
\hline $\begin{array}{l}\text { Cremaster, internal, of } \\
\text { Henle. }\end{array}$ & $\begin{array}{l}\text { Fibers of the gubernac- } \\
\text { ulum testis. }\end{array}$ & $\begin{array}{l}\text { Elements of spermatic } \\
\text { cord. }\end{array}$ & & \\
\hline $\begin{array}{l}\text { Crico-arytenoideus lat- } \\
\text { eralis. }\end{array}$ & Side of cricoid cartilage. & $\begin{array}{l}\text { Angle and external sur- } \\
\text { face of arytenoid. }\end{array}$ & Recurrent laryngeal. & Closes glottis. \\
\hline $\begin{array}{l}\text { Crico-arytenoideus } \\
\text { posticus. }\end{array}$ & Back of cricoid cartilage. & $\begin{array}{l}\text { Base of arytenoid carti- } \\
\text { lage. }\end{array}$ & Recurrent laryngea!. & Opens glottis. \\
\hline $\begin{array}{l}\text { Crico-hyoid (a nomal- } \\
\text { ous). }\end{array}$ & $\begin{array}{l}\text { Lower border of side of } \\
\text { cricoid cartilage. }\end{array}$ & $\begin{array}{l}\text { Lower border of hyoid } \\
\text { bone. }\end{array}$ & & \\
\hline Crico-thyroid. & Cricoid cartilage. & $\begin{array}{l}\text { Thyroid cartilage (lower } \\
\text { inner border). }\end{array}$ & Superior laryngeal. & Makes vocal bands tense. \\
\hline Crureus. & See Vastus internus. & & & \\
\hline $\begin{array}{l}\text { Curvator coccygis (an- } \\
\text { omalous). }\end{array}$ & $\begin{array}{l}\text { Anterior surface fifth seg- } \\
\text { ment of sacrum. }\end{array}$ & $\begin{array}{l}\text { Anterior sutface of } \\
\text { coccyx. }\end{array}$ & & Incurvates coccy $x$. \\
\hline Deltoid. & $\begin{array}{l}\text { Clavicle, acromion, and } \\
\text { spine of scapula. }\end{array}$ & Shaft of humerus. & Circumflex. & Abducts humerus. \\
\hline Depressor alæ nasi. & $\begin{array}{l}\text { Incisive fossa of superior } \\
\text { maxillary bone. }\end{array}$ & Septum and ala of nose. & Facial, buccal branch. & Contracts nostril. \\
\hline Depressor anguli oris. & $\begin{array}{l}\text { External oblique line of } \\
\text { inferior maxillary bone. }\end{array}$ & Angle of mouth. & $\begin{array}{l}\text { Facial, supra-maxil- } \\
\text { lary branch. }\end{array}$ & $\begin{array}{l}\text { Depresses angle of } \\
\text { mouth. }\end{array}$ \\
\hline Depressor epiglottidis. & $\begin{array}{l}\text { Those fibers of the thyro- } \\
\text { epiglottideus } \mathrm{th} \text { a } \mathrm{t} \text { a } \mathrm{re} \\
\text { continued forward to the } \\
\text { margin of the epiglot- } \\
\text { tis. }\end{array}$ & & & \\
\hline $\begin{array}{l}\text { Depressor labii inferi- } \\
\text { oris. }\end{array}$ & $\begin{array}{l}\text { External oblique line of } \\
\text { the inferior maxillary } \\
\text { bone. }\end{array}$ & Lower lip. & $\begin{array}{l}\text { Facial, supra-m a x il- } \\
\text { lary branch. }\end{array}$ & Depresses lip. \\
\hline $\begin{array}{l}\text { Depressor thy roid ea } \\
\text { (anomalous). }\end{array}$ & $\begin{array}{l}\text { Lower border first tracheal } \\
\text { ring, near middle line. }\end{array}$ & $\begin{array}{l}\text { Lower border of thyroid } \\
\text { cartilage. }\end{array}$ & & Depresses trachea. \\
\hline Depressor urethræ. & $\begin{array}{l}\text { Ramus of ischium near } \\
\text { deep transversus perinei. }\end{array}$ & $\begin{array}{l}\text { Fibers of constrictor va- } \\
\text { ginæe muscle. }\end{array}$ & & \\
\hline Detrusor urinæ. & Front of pubes. & $\begin{array}{l}\text { Prostate (in ma le), va- } \\
\text { gina (in female). }\end{array}$ & Sympathetic. & Compresses bladder. \\
\hline Diaphragm. & $\begin{array}{l}\text { Ensiform cart, } 6 \text { or } 7 \text { lower } \\
\text { ribs, ligamenta arcuata, } \\
\text { bodies of lumbar verteb. }\end{array}$ & Central tendon. & $\begin{array}{l}\text { Phrenic and sympa- } \\
\text { thetic. }\end{array}$ & $\begin{array}{l}\text { Respiration and expul- } \\
\text { sion. }\end{array}$ \\
\hline $\begin{array}{l}\text { Digastric (anterior } \\
\text { belly). }\end{array}$ & $\begin{array}{l}\text { Inner surface of inferior } \\
\text { maxillary bone, near } \\
\text { symphysis. }\end{array}$ & Hyoid bone. & Inferior dental. & $\begin{array}{l}\text { Elevates byoid and } \\
\text { tongue. }\end{array}$ \\
\hline $\begin{array}{l}\text { Digastric (posterior } \\
\text { belly). }\end{array}$ & $\begin{array}{l}\text { Digastric groove of mas- } \\
\text { toid process. }\end{array}$ & Hyoid bone. & Facial. & $\begin{array}{l}\text { Elevates hyoid and } \\
\text { tongue. }\end{array}$ \\
\hline Dilator naris anterioris. & Alar cartilage. & Border of ala of nose. & $\begin{array}{l}\text { Facial, infraorbital } \\
\text { branch. }\end{array}$ & Dilates nostril. \\
\hline Dilator naris posterioris. & $\begin{array}{l}\text { Nasal notch of superior } \\
\text { maxillary bone. }\end{array}$ & $\begin{array}{l}\text { Skin at margin of nos- } \\
\text { tril. }\end{array}$ & $\begin{array}{l}\text { Facial, infraorbital } \\
\text { branch. }\end{array}$ & Dilates nostril. \\
\hline Dorsal interossei, 4. & Sides of metacarpal bones. & $\begin{array}{l}\text { Bases of corresponding } \\
\text { phalanges. }\end{array}$ & Ulnar. & $\begin{array}{l}\text { Abduct fingers from me- } \\
\text { dian line. }\end{array}$ \\
\hline
\end{tabular}




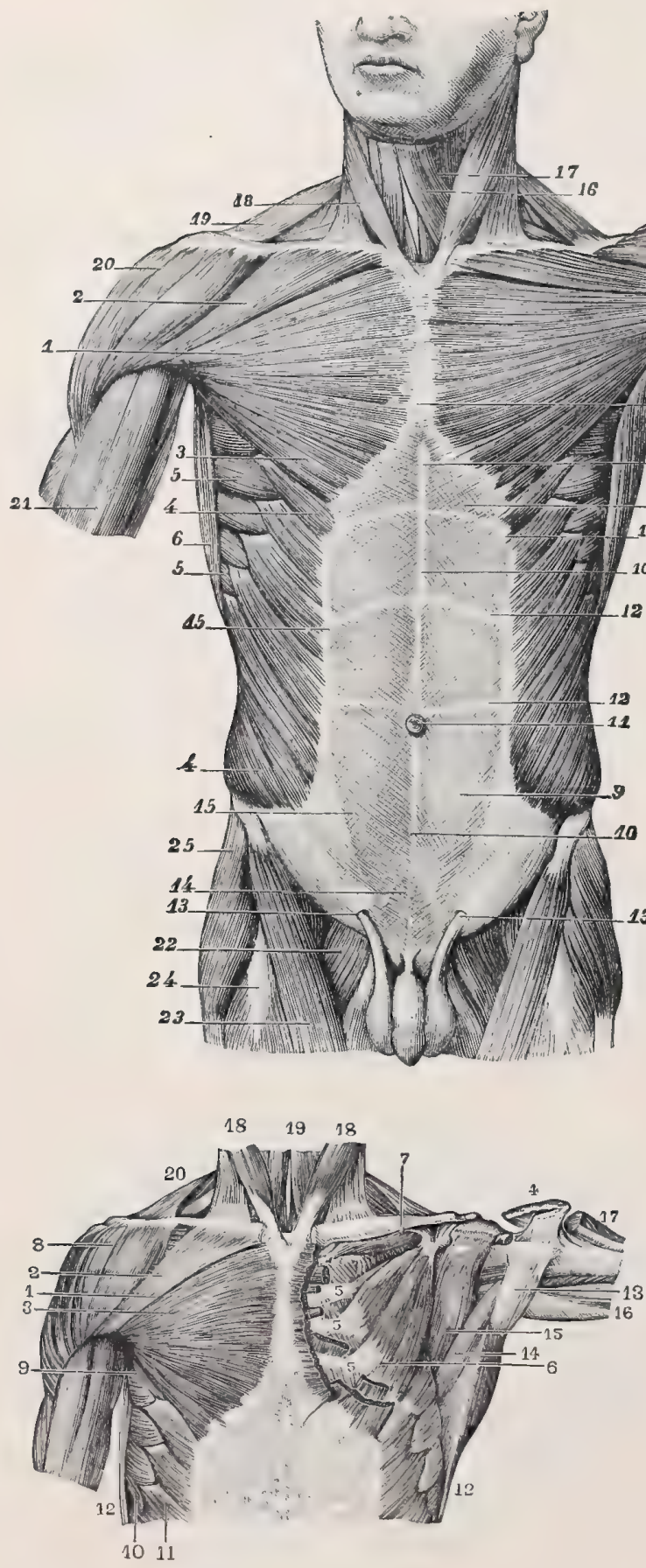

Muscles of Anterior Aspect of Thorax.

I. Pectoralis major. 2. Its clavicular portion. 3. Its sterno-costal portion. 4. Its humeral attachment, divided and displaced upward. 5. 5.5. Its fasciculi of attachment to ribs, 6. Pectoralis minor. 7. Subclavius. 8. Deltoid. 9. Inferior border of pectoralis minor. Io. Digitations of serratus magnus. II. Corresponding digitations of external oblique. 12, 12. Anterior border of latissimus dorsi. 13. Its tendon of attachment to humerus. I4. Teres major. I5. Subscapularis. 16. Long head of triceps. I7. Lower portion of deltoid. I8, 18. Sterno-mastoid. 19. Lower portion of sterno-hyoid. 20. Trapezius.
Muscles of the ANTERIor Aspect OF THE BODY.

I. Pectoralis major. 2. Its clavicular fasciculus. 3. Fasciculus attached to abdominal aponeurosis. 4,4 External oblique. 5, 5. Serratus magnus. 6,6. Anterior border of latissimus dorsi. 7. Decussation of tendinous fibers of pectorales majores. 8. Ensiform cartilage. 9, 9. Abdominal aponeurosis. 10, 10. Linea alba. II. Umbilicus. I2, 12, 12. Tendinous intersections of rectus abdominis. 13, 13. External abdominal ring. 14. Pyramidalis. 15 , 15. External border of rectus abdominis. 16. Sterno-hyoid. 17. Omo. hyoid. 18. Sterno-mastoid. I9. Cervical portion of trapezius. 20. Deltoid. 2I. Biceps brachialis. 22. Pectineus. 23. Sartorius. 24. Rectus femoris, 25. Tensor vaginæ femoris. 
TABLE OF MUSCLES-Continued.

\begin{tabular}{|c|c|c|c|c|}
\hline Name. & ORIGIN. & INSERTION. & INNERVATION. & FUNCTION, \\
\hline Dorsal interossei, 4 . & Sides of metatarsal bones. & $\begin{array}{l}\text { Base of first phalanx of } \\
\text { corresponding toe. }\end{array}$ & Exterual plantar. & Abduct toes. \\
\hline $\begin{array}{l}\text { Dorso - epitrochlearis } \\
\text { (anomalous). }\end{array}$ & $\begin{array}{l}\text { Tendon of latissimus } \\
\text { dorsi. }\end{array}$ & $\begin{array}{l}\text { Long head of triceps, or } \\
\text { fascia of arm. }\end{array}$ & & Aids in climbing. \\
\hline $\begin{array}{l}\text { Epitrochleo-anc one us } \\
\text { (anomalous). }\end{array}$ & $\begin{array}{l}\text { Back of internal condyles } \\
\text { of humerus. }\end{array}$ & Inner side of olecranon. & & \\
\hline Erector clitoridis. & Tuberosity of ischium. & $\begin{array}{l}\text { Each side of crus of cli- } \\
\text { toris. }\end{array}$ & & Erects clitoris. \\
\hline Erector penis. & $\begin{array}{c}\text { Is ch i l l tuberosity, crus } \\
\text { penis, and pubic ramus }\end{array}$ & $\begin{array}{l}\text { Tunica alouginea of cor- } \\
\text { pus cavernosum. }\end{array}$ & Perineal. & To maintain erection. \\
\hline Erector pili. & See Arrectores pili. & & & \\
\hline Erector spina. & $\begin{array}{l}\text { Iliac crest, back of sacrum, } \\
\text { lumbar, and three lower } \\
\text { dorsal spines. }\end{array}$ & $\begin{array}{l}\text { Divides into sacro-lum- } \\
\text { balis, longissimus dor- } \\
\text { si, and spinalis dorsi. }\end{array}$ & $\begin{array}{c}\text { Lumbar nerves, } \\
\text { posterior division. }\end{array}$ & $\begin{array}{l}\text { Extension of } 1 \mathrm{umbar} \\
\text { spines on pelvis. }\end{array}$ \\
\hline $\begin{array}{l}\text { Extensor annularis } \\
\text { (anomalous). }\end{array}$ & $\begin{array}{l}\text { Posterior surface of shaft } \\
\text { of ulna. }\end{array}$ & Tendon of ring-finger. & & \\
\hline $\begin{array}{l}\text { Extensor brevis digito- } \\
\text { rum manus (a noma- } \\
\text { lous). }\end{array}$ & $\begin{array}{l}\text { Ligamentous } t \text { is sues on } \\
\text { back of carpus. }\end{array}$ & $\begin{array}{l}\text { Tendons of third, fourth, } \\
\text { and fifth fingers. }\end{array}$ & & \\
\hline $\begin{array}{l}\text { Extensor brevis digito- } \\
\text { rum pedis. }\end{array}$ & Os calcis, externaily. & $\begin{array}{l}\text { First phalanx of great } \\
\text { toe and tendons of ex- } \\
\text { tensor longus. }\end{array}$ & Anterior tibial. & Extends toes. \\
\hline $\begin{array}{l}\text { Extensor brevis hallu- } \\
\text { cis. }\end{array}$ & $\begin{array}{l}\text { A name applied to that } \\
\text { portion of the extensor } \\
\text { brevis digitorum that } \\
\text { goes to the great toe. }\end{array}$ & & & \\
\hline Extensor brevis pollicis. & See Extensor primi inter & nodii pollicis. & & \\
\hline $\begin{array}{l}\text { Extensor carpi radialis } \\
\text { accessorius ( } a \text { noma- } \\
\text { lous). }\end{array}$ & Shaft of humerus. & $\begin{array}{l}\text { Metacarpal bone of } \\
\text { thumb. }\end{array}$ & & \\
\hline $\begin{array}{l}\text { Extensor carpi radialis } \\
\text { brevior: }\end{array}$ & $\begin{array}{l}\text { External condyloid ridge } \\
\text { of humerus. }\end{array}$ & $\begin{array}{l}\text { Base second and third } \\
\text { metacarpal. }\end{array}$ & Posterior interosseous. & Extends wrist. \\
\hline $\begin{array}{l}\text { Extensor carpi radialis } \\
\text { longior. }\end{array}$ & $\begin{array}{l}\text { Lower } 1 / 3 \text { external condy- } \\
\text { loid ridge of humerus. }\end{array}$ & $\begin{array}{l}\text { Base of second meta- } \\
\text { carpal. }\end{array}$ & Musculo-spiral. & Extends wrist. \\
\hline Extensor carpi ulnaris. & $\begin{array}{l}\text { Ist head, external condyle } \\
\text { of humerus. } 2 d \text { he } d d, \\
\text { posterior border of ulna. }\end{array}$ & Base of fifth metacarpal. & Posterior interosseous. & Extends wrist. \\
\hline Extensor coccygis. & $\begin{array}{l}\text { Last bone of sacrum or } \\
\text { first of coccyx. }\end{array}$ & Lower part of coccy'x. & Sacral branches. & Extends coccyx. \\
\hline $\begin{array}{l}\text { Extensor commu } \mathrm{n} \text { is } \\
\text { digitorum. }\end{array}$ & $\begin{array}{l}\text { External condyle of hu- } \\
\text { merus. }\end{array}$ & $\begin{array}{l}\text { All of the second and } \\
\text { third phalanges. }\end{array}$ & Posterior interosseous. & Extends fingers. \\
\hline $\begin{array}{l}\text { Extensor hallucis } 10 \mathrm{n} \text { - } \\
\text { gus tricaudatus. }\end{array}$ & $\begin{array}{l}\text { The name sometimes ap- } \\
\text { plied to the extensor pro- } \\
\text { prius hallucis, when its } \\
\text { tendon is divided into } \\
\text { three portions. }\end{array}$ & 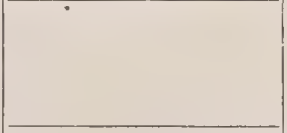 & & \\
\hline Extensor indicis. & Back of ulna. & $\begin{array}{l}\text { Second and third pha- } \\
\text { langes of index finger. }\end{array}$ & Posterior interosseous. & Extends index. \\
\hline $\begin{array}{l}\text { Extensor longus digito- } \\
\text { rum pedis. }\end{array}$ & $\begin{array}{l}\text { Outer tuberosity of tibia } \\
\text { and shaft of fibula. }\end{array}$ & $\begin{array}{l}\text { Second and third pha- } \\
\text { langes of toes. }\end{array}$ & Anterior tibial. & Extends toes. \\
\hline $\begin{array}{l}\text { Extensor longus polli- } \\
\text { cis. }\end{array}$ & See Extensor secundi in & ternodii pollicis. & & \\
\hline $\begin{array}{l}\text { Extensor medii digiti } \\
\text { (anomalous). }\end{array}$ & Back of shaft of ulna. & $\begin{array}{l}\text { Tendon of common ex- } \\
\text { tensor. }\end{array}$ & & \\
\hline Extensor minimi digiti. & $\begin{array}{l}\text { External condyle of hu- } \\
\text { merus. }\end{array}$ & $\begin{array}{l}\text { Second and third pha- } \\
\text { langes of little finger. }\end{array}$ & $\begin{array}{l}\text { Posteriot interos- } \\
\text { seous. }\end{array}$ & Extensor of little finger. \\
\hline $\begin{array}{l}\text { Extensor ossis meta- } \\
\text { carpi pollicis. }\end{array}$ & $\begin{array}{l}\text { Back of radius and ulna and } \\
\text { interosseous membrane. }\end{array}$ & $\begin{array}{l}\text { Base of metacarpal of } \\
\text { thumb and fascia. }\end{array}$ & $\begin{array}{l}\text { Posterior interos- } \\
\text { seous. }\end{array}$ & Extends thumb. \\
\hline $\begin{array}{l}\text { Extensor ossis meta- } \\
\text { tarsi hallucis (anoma- } \\
\text { lous). }\end{array}$ & $\begin{array}{l}\text { Extensor proprius hallu- } \\
\text { cis, or extensor com- } \\
\text { munis digitorum, or tibi- } \\
\text { alis anticus. }\end{array}$ & $\begin{array}{l}\text { Metatarsal bone of hal- } \\
\text { Iux. }\end{array}$ & & \\
\hline
\end{tabular}




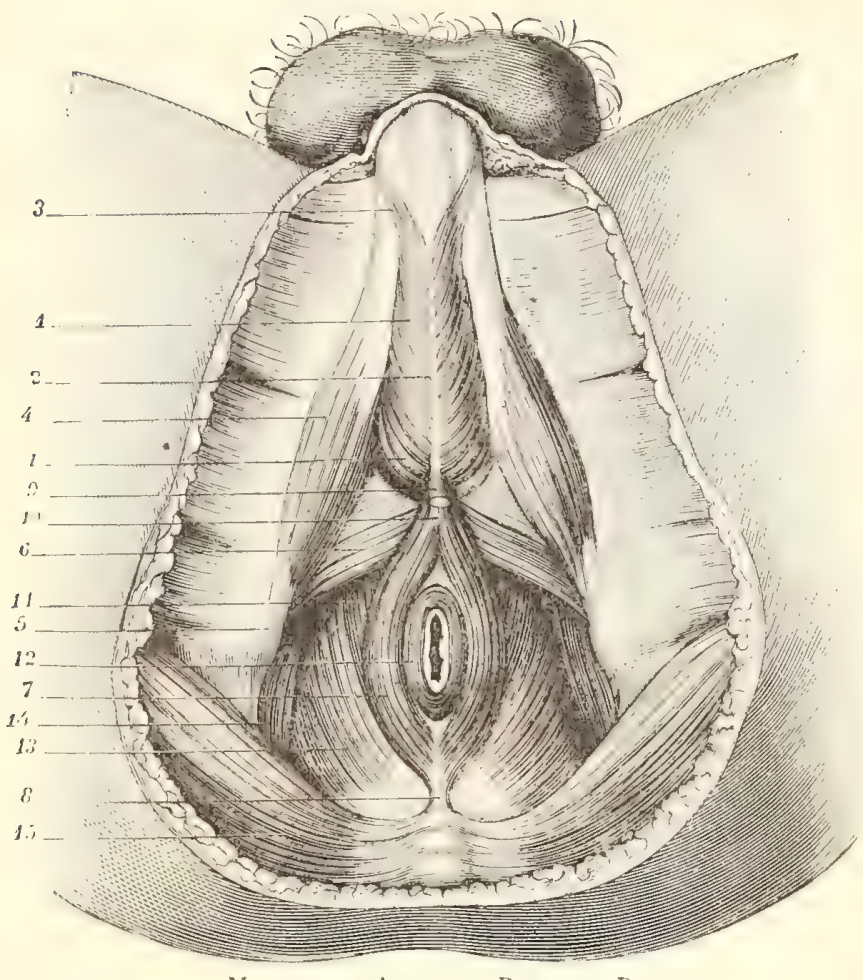

Muscles of anal and Perineal Region.

I. I. Bulbo-cavernosus muscle (accelerator urinæ). 2. Its fibrous raphe, 3 . Its anterior termination. 4 . Ischio-cavernosus (erector penis) muscle. 5 . Tendon of altachment to tuber ischii. 6. Transversus perinei. 7 . Extermal sphincter ani. 8. Aponeurotic insertion into apex of coccyx. 9. Attachment to bulboani. 8. Aponeurotic insertion into apex of coccyx. 9. Attachment to bubo-
cavernous raphe. 10. Fibers of insertion into perineum, divided. II. Upper layer of external sphincter. 12. Internal sphincter. I3. Levator ani. 14. Obturator internus. 15. Internal border of gluteus maximus.

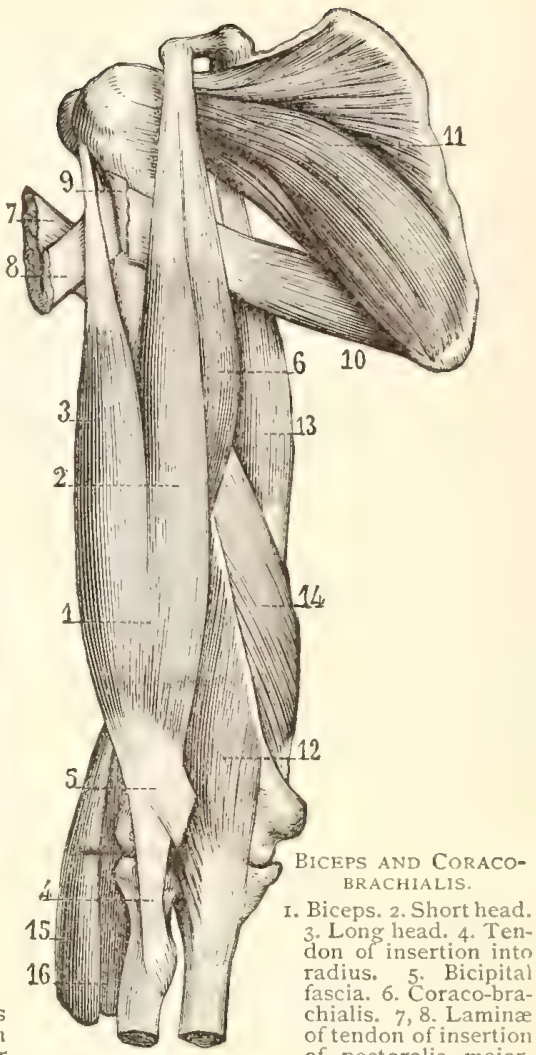
of pectoralis major. 9. Attachment of latissimus dorsi. ro. Teres major. II. Subscapularis. 12. Brachialis anticus. I3. Long, middle, or scapular head of triceps. I4. Internal or short humeral head. 15. Supinator longus. I6. Extensor carpi radialis longior.

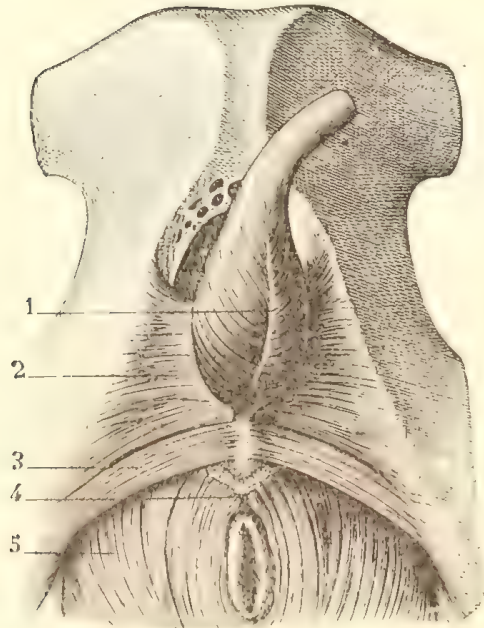

MUSCle OF GUTHRIE. t. Bulbo-cavernosus (erector penis) muscle. 2 Muscle of Guthrie (transversus perinei profundus). 3. Superficial transverse muscle. 4. Ex. ternal sphincter ani. 5. Levator ani.

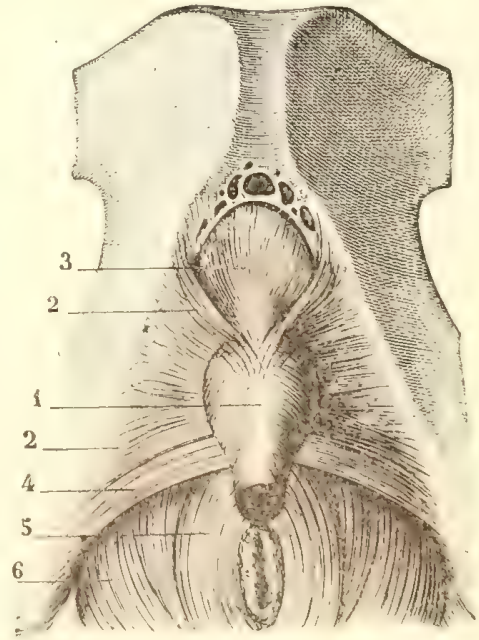

MUSCle OF GUTHRIF AND Wilson.
I. Bulb of urethra. 2, 2. Muscle of Guthrie (transversus perinei profundus). 3 . Muscle of Wilson. 4. Transwersus perinei superficialis, 5, External sphincter ani. 6. Levator ani. 
TABIT OI MUSCLES-Continned.

\begin{tabular}{|c|c|c|c|c|}
\hline NAME. & ORIGIN. & INSERTION. & INNERVATION. & FUNCTION. \\
\hline $\begin{array}{l}\text { Extensor primi inter- } \\
\text { nodii hallucis longus } \\
\text { (anomalous). }\end{array}$ & $\begin{array}{l}\text { Fibula and interosseous } \\
\text { membrane. }\end{array}$ & $\begin{array}{l}\text { Inner part of base of first } \\
\text { phalanx of hallux. }\end{array}$ & & \\
\hline $\begin{array}{l}\text { Extensor primi inter- } \\
\text { nodii pollicis. }\end{array}$ & Back of radius. & $\begin{array}{l}\text { Base of first phalanx of } \\
\text { thumb. }\end{array}$ & $\begin{array}{l}\text { Posterior interos- } \\
\text { seous. }\end{array}$ & Extends thumb. \\
\hline $\begin{array}{l}\text { Extensor primi inter- } \\
\text { nodii pollicis et indicis } \\
\text { (anomalows). }\end{array}$ & $\begin{array}{l}\text { Between extensor indicis } \\
\text { and extensor secundi in- } \\
\text { ternodii pollicis. }\end{array}$ & $\begin{array}{l}\text { First phalanges of thumb } \\
\text { and index tinger. }\end{array}$ & & \\
\hline $\begin{array}{l}\text { Extensor proprius digiti } \\
\text { minimi. }\end{array}$ & $\begin{array}{l}\text { Lower part of ulna, or } \\
\text { posterior Iigament of } \\
\text { wrist-joint. }\end{array}$ & $\begin{array}{l}\text { Base of first phalanx of } \\
\text { little finger. }\end{array}$ & & \\
\hline $\begin{array}{l}\text { Extensor proprius hal- } \\
\text { lucis. }\end{array}$ & Middle of fibula. & $\begin{array}{l}\text { Base of last phalanx of } \\
\text { great toe. }\end{array}$ & Anterior tibial. & Extends great toe. \\
\hline $\begin{array}{l}\text { Extensor secundi inter- } \\
\text { nodii pollicis. }\end{array}$ & Back of ulna. & $\begin{array}{l}\text { Base of last phalanx of } \\
\text { thumb. }\end{array}$ & $\begin{array}{l}\text { Posterior interos- } \\
\text { seous. }\end{array}$ & Extends thumb. \\
\hline $\begin{array}{l}\text { Flexor accessorius digi- } \\
\text { torum pedis ( } 2 \text { heads). }\end{array}$ & $\begin{array}{l}\text { I. Inner; } 2 \text {. Outer surface } \\
\text { of os calcis. }\end{array}$ & $\begin{array}{l}\text { Tendon of flexor longus } \\
\text { digitorum. }\end{array}$ & External plantar. & Accessory flexor of toes. \\
\hline $\begin{array}{l}\text { Flexor accessorius lon- } \\
\text { gus (anomalous). }\end{array}$ & $\begin{array}{l}\text { Fascia over flexor longus } \\
\text { hallucis. }\end{array}$ & $\begin{array}{l}\text { Sesamoid bone in tendon } \\
\text { of peroneus longus. }\end{array}$ & & \\
\hline $\begin{array}{l}\text { Flexor accessorius lon- } \\
\text { gus digitorum pedis. }\end{array}$ & Shaft of tibia or fibula. & $\begin{array}{l}\text { Tubercle of os calcis, } \\
\text { and joins tendon of } \\
\text { long Hexor. }\end{array}$ & External plantar. & Assists in flexing toes. \\
\hline $\begin{array}{l}\text { Flexor brevis digitorum } \\
\text { pedis. }\end{array}$ & $\begin{array}{l}\text { Inner tuberosity of os } \\
\text { calcis and plantar fascia. }\end{array}$ & $\begin{array}{l}\text { Second phalanges of the } \\
\text { lesser toes. }\end{array}$ & Internal plantar. & Flexes lesser toes. \\
\hline Flexor brevis hallucis. & $\begin{array}{l}\text { Under surface of cuboid, } \\
\text { plantar ligaments, and } \\
\text { external cuneiform. }\end{array}$ & $\begin{array}{l}\text { Base of first phalanx of } \\
\text { great toe. }\end{array}$ & Internal plantar. & $\begin{array}{l}\text { Flexes and slightly ad- } \\
\text { ducts first phalanx of } \\
\text { great toe. }\end{array}$ \\
\hline $\begin{array}{l}\text { Flexor brevis minimi } \\
\text { digiti manus. }\end{array}$ & $\begin{array}{l}\text { Unciform bone and annu- } \\
\text { lar ligament. }\end{array}$ & $\begin{array}{l}\text { First phalanx of little } \\
\text { finger. }\end{array}$ & Ulnar. & Flexes little finger. \\
\hline $\begin{array}{l}\text { Flexor brevis minimi } \\
\text { digiti pedis. }\end{array}$ & Base of fifth metatarsal. & $\begin{array}{l}\text { Base of first phalanx of } \\
\text { little toe. }\end{array}$ & External plantar. & Flexes little toe. \\
\hline $\begin{array}{l}\text { Flexor brevis pollicis } \\
\text { manus. }\end{array}$ & $\begin{array}{l}2 \text { heads-onter: lower bor- } \\
\text { der of anterior annular } \\
\text { ligament; ridge of trape- } \\
\text { zium; inner: os mag- } \\
\text { num, and bases of first, } \\
\text { second, and third meta- } \\
\text { carpal bones. }\end{array}$ & $\begin{array}{l}\text { Base of first phalanx of } \\
\text { thumb. }\end{array}$ & $\begin{array}{l}\text { Outer head-median, } \\
\text { palmar branch. In- } \\
\text { ner head-deep ul- } \\
\text { nar. }\end{array}$ & $\begin{array}{l}\text { Flexes metacarpal bone } \\
\text { of thumb. }\end{array}$ \\
\hline $\begin{array}{l}\text { Flexor brevis pollicis } \\
\text { pedis. }\end{array}$ & See Flexor brevis hallucis. & & & \\
\hline Flexor carpi radialis. & $\begin{array}{l}\text { Internal condyle of hu- } \\
\text { merus. }\end{array}$ & $\begin{array}{l}\text { Metacarpal bone of in- } \\
\text { dex finger. }\end{array}$ & Median. & Flexes wrist. \\
\hline $\begin{array}{l}\text { Flexor carpi radialis vel } \\
\text { profundus (anoma- } \\
\text { lous). }\end{array}$ & $\begin{array}{l}\text { Anterior surface of radius, } \\
\text { above the pronator quad- } \\
\text { ratus. }\end{array}$ & $\begin{array}{l}\text { Annular ligament or } \\
\text { trapezium, magnum or } \\
\text { base of second or third } \\
\text { metacarpal bone. }\end{array}$ & & \\
\hline $\begin{array}{l}\text { Flexor carpi ulnaris ( } 2 \\
\text { heads). }\end{array}$ & $\begin{array}{l}\text { I. Internal condyle. } \\
\text { Olecranon and ulna. }\end{array}$ & $\begin{array}{l}\text { 5th metacarpal, annular } \\
\text { lig. and pisiform bone. }\end{array}$ & Uinar. & Flexes wrist. \\
\hline Flexor cruris. & See Biceps femoris. & & & \\
\hline Flexor indicis. & $\begin{array}{l}\text { The name given to the in- } \\
\text { dicial portion of the } \\
\text { flexor profundus digito- } \\
\text { rum, when it is distinct. }\end{array}$ & & & \\
\hline $\begin{array}{l}\text { Flexor longus digito- } \\
\text { rum pedis. }\end{array}$ & Shaft of tibia. & Last phalanges of toes. & Posterior tibial. & $\begin{array}{l}\text { Flexes phalanges and ex- } \\
\text { tends ankle. }\end{array}$ \\
\hline Flexor longus hallucis. & $\begin{array}{l}\text { Lower two-thirds of shaft } \\
\text { of fibula. }\end{array}$ & $\begin{array}{l}\text { Last phalaux of great } \\
\text { toe. }\end{array}$ & Posterior tibial. & Flexes great toe. \\
\hline Flexor longus pollicis. & $\begin{array}{l}\text { Shaft of radius and coro- } \\
\text { noid process of ulna. }\end{array}$ & Last phalanx of thumb. & Anterior interosseous. & Flexes the phalanx. \\
\hline $\begin{array}{l}\text { Flexor ossis metacarpi } \\
\text { pollicis. }\end{array}$ & See Opponens pollicis. & & & \\
\hline Flexor perforatus. & See Flexor brevis digito & rumpedis. & & \\
\hline
\end{tabular}




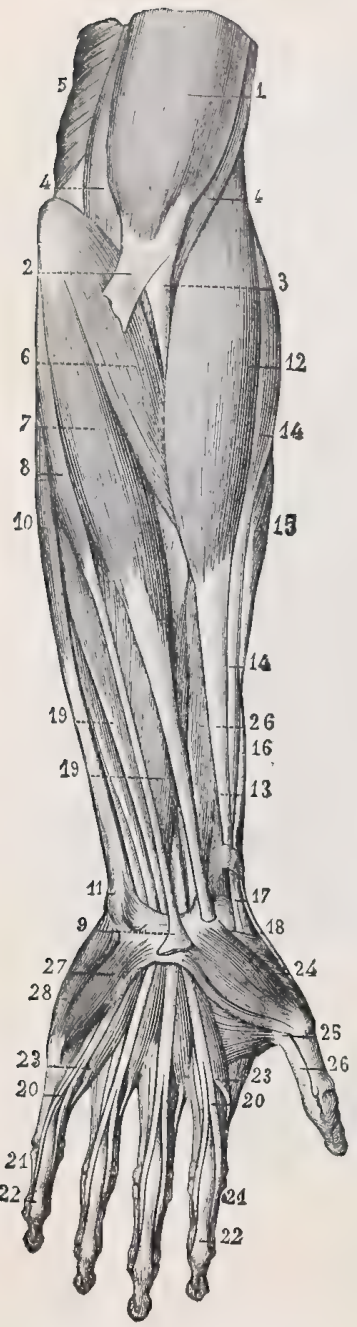

Superficial Muscles of PalMAR ASPECT OF FOREARM.

I. Lower portion of biceps. 2 . Bicipital fascia. 3. Tendon of insertion into radius. 4,4 . Brachialis anticus. 5. Internal head of triceps. 6. Pronator radii teres. 7. Flexor carpi radialis 8. Palmaris longus. 9. Its termination in palmar ligament. Io. Flexor carpi ulnaris. Ir. Its attachment to pisiform bone. 12. Supinator longus. I3. Its attachment to styloid process of radius. I4, 14. Extensor carpi radialis longior. 15. Extensor carpi radialis brevior. 16. Extensor os. sis metacarpi pollicis. 17. Its tendon of insertion into base of first metacarpal bone. I8. Tendon of extensor secundi internodii pollicis. 19, 19. Flexor sublimis digitorum. 20, 20. Tendons of this muscle. 2I, 21. Their attachment to second phalanges

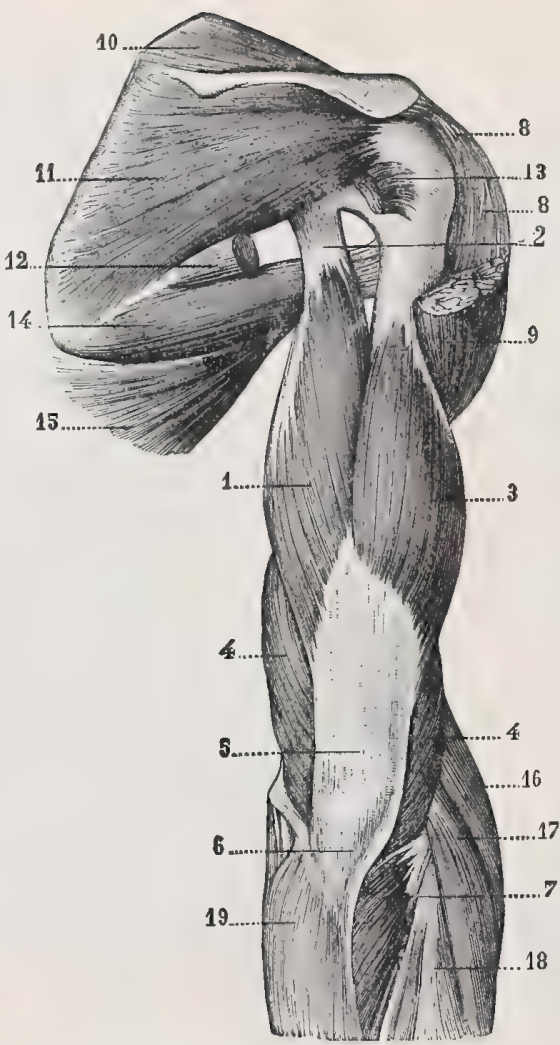

Triceps Brachialis, Posterior Aspect.

I. Long, middle, or scapular head, 2. Its tendon of origin from scapula. 3. External, or long humeral head. 4. Internal, or short humeral head. 5. Common tendon. 6. Attachment to olecranon. 7. Anconeus. 8, 8 . Upper portion of deltoid, posterior half removed. 9. Lower portion. Io. Supraspinatus. II. Infraspinatus. 12. Teres minor, middle portion removed. I3. Insertion of teres minor into humerus. I4. Teres major. 15. Upper extremity of latissimus dorsi. I6 Supinator longus. 17. Extensor carpi radialis longior. I8, Extensor carpi ulnaris. Ig. Flexor carpi ulnaris.

of fingers. 22, 22. Attachment of tendons of flexor profundus digitorum to last phalanges of fingers. 23, 23. Lumbricales. 24. Abductor pollicis. 25. Its insertion into first phalanx of thumb. 26, 26. Flexor longus pollicis. 27. Flexor brevis minimi digiti. 28. Abductor minimi digiti.

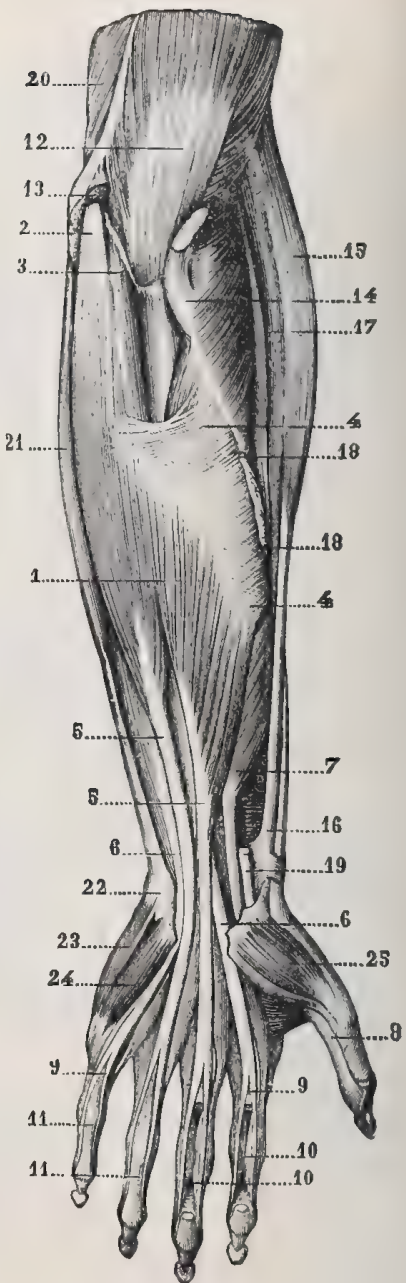

Flexor Sublimis Digitorum.

I. Flexor sublimis digitorum. 2. Its origin from the epitrochlea. 3 . Its origin from coronoid process of ulna. 4, 4. Its aponeurosis of attachment to radius. 5, 5. Superficial tendons, for middle and ring fingers. 6,6 . Deep tendons, for little and index fingers. 7. Flexor longus pollicis. 8. Its tendon. 9,9 . Bífurcation of tendons of flexor sublimis. yo. Intervals between divisions. II, II. Tendons of flexor profundus. 12. Tendon of brachialis anticus. I3. Common tendon of origin of superficial epitrochlear muscles. I4. Tendon of biceps. I5. Supinator longus. I6. Its attachment to styloid process of radius. 17. Extensor carpi radialis longior. 18, 18. Tendon of attachment of pronator radii teres, divided. I9. Tendon of extensor carpi radialis, 20. Triceps. 2I. Flexor carpi ulnaris. 22. Its attachment to pisiform bone. 23. Adductor minimi digiti. 24. Flexor brevis minimi digiti. 25. Adductor brevis pollicis. 
TABLE OF MUSCLES.-Continued.

NAME

ORIGIN.

Shaft of ulna.

Flexor

toru

Fiexnr proprius digit secundi (anomalous).

Flexor sublimis digitorum ( 3 heads).

Frontalis.

Gastrocnemius (z heads).

Gavard's.

Gemellas inf rior.

Gemellus superior

Genio-hyo-glossus.

Genio-hyoid.

Genio-hyoid

Gluteus maximus.

Gluteus medius.

Gluteus minimus.

Gluteus quartus.

Gracilis.

Grinning.

Gubernaculum testis

Gutlirie's.

Helicis major et minor.

Henle's.

Hepatico-diaphraomatic (anomalous)

Hilron's

Horner's.

Houston's.

Hyo-epiglottideus (anomalous)

Hyo-facialis.

H

Hyo-glossus.
Hyo-maxillaris (anom-
aly of Stylo-hyoid).

Shaft of tibia. line of radius. stomach. bone. ischium.

See Cremaster.

See Prevectalis. of diaphragm. tis.

\section{Cornua of hyoid.}

Lower jaw.
1. Inner condyle. 2. Coronoid process. 3 . Oblique

See Occipito-frontalis.

Condyles of femur.

The oblique muscular fibers of the wall of the

Tuberosity of ischium and lesser sacro-sciatic notch

Ischial spine and lesser sacro-sciatic notch.

Superior genial tubercle of inferior maxillary bone.

Inferior genial tubercle of inferior maxillary

Sup. curved iliac line and crest, sacrum, and coccyx.

Ilium between superior and middle curved lines.

llium between middle and inferior curved lines.

See Accessory gluteus

Rami of pubes and

See Levator anguli oris.

See Transversus perinei,

Tubercle on helix.

Left side of central tendon

See Compressor sacculi See Ciliary and Tensor

See Compressor vence dor

Middle of ridge on lingual aspect of epiglot-

A name applied to the anterior portion of the omo-hyoid, when the posterior belly is absent.

Side of tongue.

Hypoglossal.

Base of phalanges of second toe.

Second phalanges by Median. four tendons. lis.

Great trochanter.

Great trochanter.

Hyoid and inferior surface of tongue

Body of hyoid.

Fascia and femur below great trochanter.

Oblique line of great trochanter.

Great trochanter.

minimus.

Tibia, upper and inner part.

deep.

Rim of helix near summit.

Under surface of liver and obliterated ductus venosus and peritoneum.

\section{laryngis.}

tarsi.

salis penis.

Median tubercle on body of hyoid.

Sacral.

Hypoglossal.

Hypoglossal.

Obturator. lar.

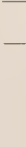

Function.

INNERVATION,

Ulnar and anterior Flexes the phalanges. interosseous. tendous.

Os calcis by tendo Achil- Internal popliteal.

Sacral.

Flexes second phalanges.

Extends foot.

Inferior gluteal and sacral plexus.

Superior gluteal.

Superior gluteal.

Flexes and abducts leg.

Auriculo-temporal and posterior auricu-

External rotator of thigh.

External rotator of thigh.

Retracts and protrudes tongue.

Elevates and advances hyoid.

Extends, abducts, and rotates thigh outward.

Rotates, abducts, and advances thigh.

Rotates, abducts, and draws thigh forward.

See Constrictor of pharynx, middle.

Depresses side of tongue and retracts tongue. 


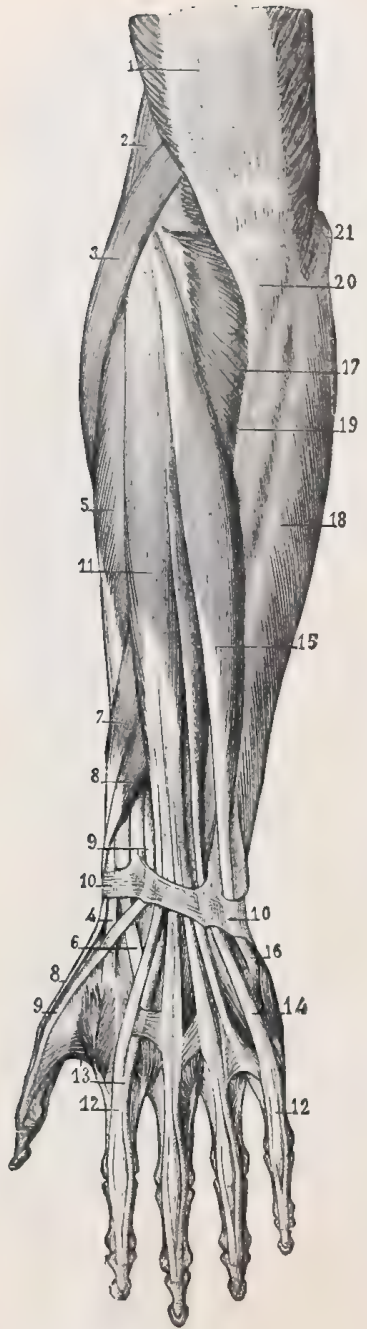

Muscles of Dorsal Aspect of Forearm, SUPERFICIAL LAYER.

2. Tendon of triceps. 2. Upper extremity of supinator longus. 3. Extensor carpi radialis longior. 4 Its attachment to second metacarpal bone. 5. Extensor carpi radialis brevior. 6. Its attachment to third metacarpal bone. 7. Extensor ossis metacarpi pollicis. 8, 8. Extensor primi internodii pollicis. 9, 9. Extensor secundi internodii pollicis. Io, 10. Annular ligament, II. Extensor communis digitorum. 12, I2. Attachment of its four tendons to the second and third phalanges. 13. Tendon of the extensor indicis. I4. Tendon of extensor minimi digiti. I5. Extensor carpi ulnaris. 16. Its attachment to fifth metacarpal bone. 17 . Anconeus. I8. Flexor carpi ulnaris. I9. Posterior border of ulna, 20. Olecranon. internal condyle of humerus.

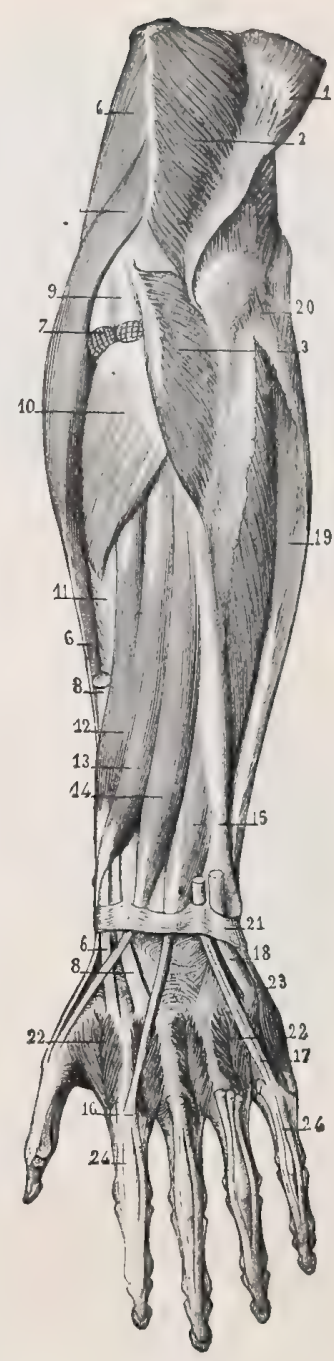

Muscles of DORSAL Aspect of FOREARM DEEP I

$\begin{array}{ll}\text { I. Tendon of triceps } & \text { 2. Internal head }\end{array}$ of triceps. 3. Anconeus. 4. Humeral attachment of supinator longus Humeral attachment of extensor carpi radialis longior. 6,6. Tendon of insertion into second metacar pal bone. 7. Upper extremity of 8. Its tendon of insertion into 8. Its tendon of insertion into mon tendon of the superficial and deep muscles. II. Radial insertion of pronator radi teres. 12. Extensor ossis metacarpi pollicis. I3. Extensor primi interno pollicis. 13. Extensor primi internodii pollicis. I4. Extensor secundi internodii pollicis. 15 . Extensor indicis. 16. Its tendon, uniting with corresponding tendon of common extensor. 17. Tendon of extensor extendigiti. 18. Tendon of extensor carpi ulnaris. 19. Flexor carpi ulnaris, displaced to show flexor profundus digitorum. 20. Fibrous arch extending from epitrochlea to olecranonding forming the upper portion of the and flexor. fexor. 2I. Annular ligament. 22, 22. Dorsal interossei. 23. Abductor minimi digiti. 24, 24. Tendons of extensor conmunis digitorum.
MUSCLES

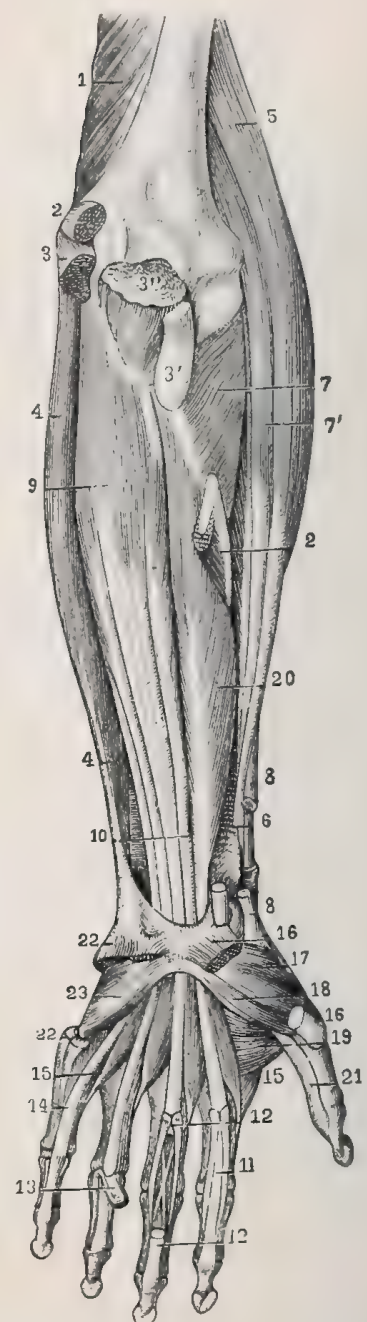

Deep Muscles of Palmar Aspect OF FOREARM.

I. Lower portion of triceps. 2, 2. Attachments of pronator radii teres. Attachment of flexor carpi radialis, palmaris longus, and flexor sublimis digitorum. $3^{\prime}$. Tendon of biceps. $3^{\prime \prime}$ Tendon of brachialis anticus. 4,4 . Flexor carpi ulnaris. 5. Supinator longus, 6. Its distal attachment. 7 Supinator brevis. $7^{\prime}$. Extensor carpi radialis longior. 8, 8. Extensor ossis metacarpi pollicis. 9. Flexor profundus digitorum. Io. Its four tendons. II. Tendon for index finger. 12, 12. Tendon for middle finger. 13. Ten. don of flexor sublimis. 14 Tendon of flexor profundus for little finger. 15, 15. Lumbricales. I6, I6. Attachments of abductor brevis. 17. Opponens pollicis. 18. Flexor brevis pollicis. 19. Adductor pollicis, 20. Flexor longus pollicis. 2r. Its tendon. 22 , 22. Attachments of flexor brevis and adductor minimi digiti. 23. Oppo. nens minimi digiti. 
TABLE OF MUSCLES.-Continued.

\begin{tabular}{|c|c|c|c|c|}
\hline NAME. & ORIGIN. & INSERTION. & INNERVATION. & FunCtION. \\
\hline Iliacus. & $\begin{array}{l}\text { Iliac fossa, crest, base of } \\
\text { sacrum. }\end{array}$ & $\begin{array}{l}\text { Lesser trochanter, up- } \\
\text { per part shaft femur. }\end{array}$ & Anterior crural. & $\begin{array}{l}\text { Flexes and rotates } \\
\text { femur outward. }\end{array}$ \\
\hline $\begin{array}{l}\text { Iliacus minor (anomal- } \\
\text { ouss). }\end{array}$ & $\begin{array}{l}\text { Anterior inferior spine } \\
\text { of ilium. }\end{array}$ & $\begin{array}{l}\text { Inferior part anterior } \\
\text { intertrochanteric line. }\end{array}$ & & \\
\hline $\begin{array}{l}\text { lliacus, superficial (an- } \\
\text { omalous). }\end{array}$ & $\begin{array}{l}\text { Crest of ilium, last lumbar } \\
\text { vertebra or upper border } \\
\text { of sacrum. }\end{array}$ & $\begin{array}{l}\text { lliacus below Poupart's } \\
\text { ligament. }\end{array}$ & & \\
\hline $\begin{array}{l}\text { llio-capsularis (anomal- } \\
\text { ous). }\end{array}$ & See lliacus mumor. & & & \\
\hline Ilio-costal. & See Sacro-lumbar. & & & \\
\hline Incisuræ Santorini. & See Intertragicus. & & . & \\
\hline Infracostals, ro. & Inner surface of ribs. & $\begin{array}{l}\text { Inner surface of two or } \\
\text { three ribs above. }\end{array}$ & Intercostal. & $\begin{array}{l}\text { Expiration, by depress- } \\
\text { ing ribs. }\end{array}$ \\
\hline Infra-spinatus. & Infra-spinous fossa. & $\begin{array}{l}\text { Great tuberosity of } \\
\text { humerus. }\end{array}$ & Supra-scapular. & $\begin{array}{l}\text { Rotates humerus out- } \\
\text { ward. }\end{array}$ \\
\hline Inter-arytenoid. & One arytenoid cartilage. & $\begin{array}{l}\text { The other arytenoid } \\
\text { cartilage. }\end{array}$ & Recurrent laryngeal. & $\begin{array}{l}\text { Approximates arytenoid } \\
\text { cartilages. }\end{array}$ \\
\hline $\begin{array}{l}\text { Interclavicular (anomal- } \\
\text { ous). }\end{array}$ & $\begin{array}{l}\text { Clavicle, anterior to rhom- } \\
\text { boid ligament. }\end{array}$ & $\begin{array}{l}\text { Corresponding point on } \\
\text { opposite clavicle. }\end{array}$ & & \\
\hline $\begin{array}{l}\text { Intercostals, external, } \\
\text { II. }\end{array}$ & $\begin{array}{l}\text { Outer lip of inferior costal } \\
\text { border. }\end{array}$ & $\begin{array}{l}\text { Superior border of ribs } \\
\text { above. }\end{array}$ & Intercostal. & Raise ribs in inspiration. \\
\hline $\begin{array}{l}\text { Intercostals, internal, } \\
11 .\end{array}$ & $\begin{array}{l}\text { Inner lip of inferior costal } \\
\text { border. }\end{array}$ & $\begin{array}{l}\text { Superior border of ribs } \\
\text { below. }\end{array}$ & Intercostal. & $\begin{array}{l}\text { Depress ribs in expira } \\
\text { tion. }\end{array}$ \\
\hline $\begin{array}{l}\text { Interossei of foot, dor- } \\
\text { sal (4). }\end{array}$ & $\begin{array}{l}\text { Adjacent surfaces of meta- } \\
\text { tarsal bones. }\end{array}$ & Bases of first phalanges. & External plantar. & $\begin{array}{l}\text { Flex first phal anges } \\
\text { and extend } 2 d \text { and } 3 d \text {, } \\
\text { aiso abduct } 2 d, 3 d \text {, and } \\
4 \text { th toes. }\end{array}$ \\
\hline $\begin{array}{l}\text { Interossei of foot, plan- } \\
\operatorname{tar}(3) .\end{array}$ & $\begin{array}{c}\text { Inner lower surface of } 3 \\
\text { outer metatarsal bones. }\end{array}$ & $\begin{array}{l}\text { Bases of first phalanges } \\
\text { of three outer toes. }\end{array}$ & External plantar. & $\begin{array}{l}\text { Abduct first phalanges of } \\
\text { three outer toes. }\end{array}$ \\
\hline $\begin{array}{l}\text { Interossei of hand, dor- } \\
\text { sal (4). }\end{array}$ & Five metacarpal bones. & $\begin{array}{l}\text { Sides of aponeurosis of } \\
\text { extensor com } \mathrm{m} \text { u is } \\
\text { and adjacent parts of } \\
\text { first phalanges. }\end{array}$ & Ulnar. & $\begin{array}{l}\text { Abduct index, middle, } \\
\text { and ring fingers, aid in } \\
\text { flexing first phalanges } \\
\text { and extending second } \\
\text { and third. }\end{array}$ \\
\hline $\begin{array}{l}\text { Interossei of haid, } \\
\text { palmar (3). }\end{array}$ & Sides of metacarpal bones. & $\begin{array}{l}\text { Aponeurosis of extensor } \\
\text { tendons, adjacent part } \\
\text { of first phalanges. }\end{array}$ & Ulnar. & $\begin{array}{l}\text { Adduct index, ring, and } \\
\text { little fingers, aid in flex- } \\
\text { ing first phalanges and } \\
\text { in extending second } \\
\text { and third. }\end{array}$ \\
\hline $\begin{array}{c}\begin{array}{c}\text { Interosseus primus } \\
\text { volaris (anomalous). }\end{array} \\
\end{array}$ & $\begin{array}{l}\text { Ulnar side of base of first } \\
\text { metacarpal. }\end{array}$ & $\begin{array}{l}\text { Base of first phalanx of } \\
\text { thumb. }\end{array}$ & & \\
\hline Inter-spinales. & $\begin{array}{l}\text { Upper surface of spines of } \\
\text { vertebra, near tip. }\end{array}$ & $\begin{array}{l}\text { Posterior part of lower } \\
\text { surface of spine above. }\end{array}$ & $\begin{array}{l}\text { Internal divisions of } \\
\text { posterior branches of } \\
\text { spinal nerves. }\end{array}$ & $\begin{array}{l}\text { Extend the vertebra } \\
\text { next above. }\end{array}$ \\
\hline Intertragicus. & $\begin{array}{l}\text { Anterior wall cartilagin- } \\
\text { ous canal of ear. }\end{array}$ & $\begin{array}{l}\text { Opposite side of larger } \\
\text { fissure of ear. }\end{array}$ & Posterior auricular. & Dilates concha. \\
\hline Inter-transversales. & $\begin{array}{l}\text { Between transverse proc. } \\
\text { of contiguous vertebræ. }\end{array}$ & & Spinal nerves. & $\begin{array}{l}\text { Flex laterally the spinal } \\
\text { column. }\end{array}$ \\
\hline $\begin{array}{l}\text { Ischio-calcaneus (anom- } \\
\text { alous). }\end{array}$ & $\begin{array}{l}\text { Long head of biceps } \\
\text { flexor cruris. }\end{array}$ & $\begin{array}{l}\text { Gastrocnemius, external } \\
\text { t u beros ity of tibia, } \\
\text { femoral aponeurosis } \\
\text { or tendo Achillis. }\end{array}$ & & \\
\hline Ischio-cavernosus. & See Erector penis. & & & \\
\hline Ischio-condyloid. & $\begin{array}{l}\text { A name given to the por- } \\
\text { lion of the a d d u t or } \\
\text { magnus inserted into the } \\
\text { internal condyle of femur. }\end{array}$ & & & \\
\hline $\begin{array}{l}\text { Ischio-femoral (anomal- } \\
\text { ous). }\end{array}$ & $\begin{array}{l}\text { Inner edge of great tuber- } \\
\text { osity of ischium. }\end{array}$ & $\begin{array}{l}\text { Lower end of gluteal } \\
\text { ridge of femur. }\end{array}$ & & \\
\hline Jarjavay's. & See Depressor urethra. & & & \\
\hline $\begin{array}{l}\text { Kerato-cricoid (anomal- } \\
\text { ous). }\end{array}$ & $\begin{array}{l}\text { Cricoid cartilage near its } \\
\text { lower border. }\end{array}$ & $\begin{array}{l}\text { Inferior cornu of } \\
\text { thyroid cartilage. }\end{array}$ & & \\
\hline
\end{tabular}




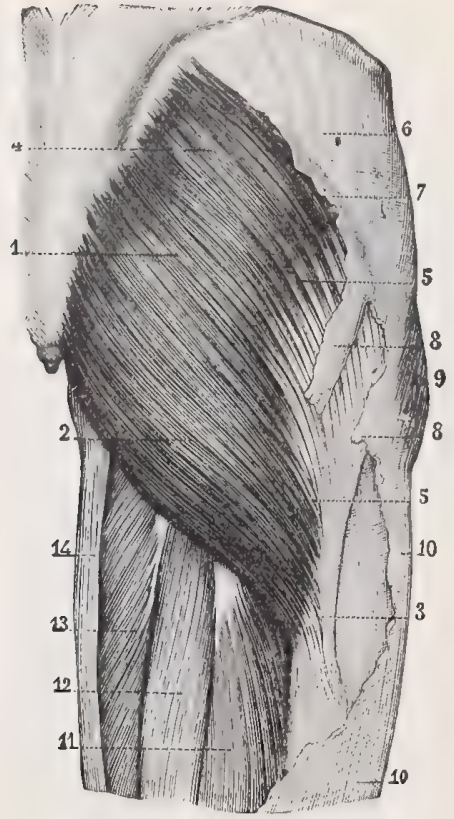

Gluteus Maximus Muscle.

1 Giuteus maximus, 2, Its inferior portion. 3. Fibers of attachment to linea aspera. 4. Superior portion. 5, 5. Tendinous fibers of insertion into linea aspera. 6. Upper portion of femoral aponeurosis, 7. Duplicature of this aponeurosis at superior level of gluteus maximus. 8. Portion of its superficial layer attached to tendinous bands. Portion or its superof tensor vaginæ femoris, Io, 10. Portion of femoral aponeurosis vaginæ femoris. Io, Io. Portion of femoral aponIr. Upper portion of biceps femoris. 12, Upper portion of semitendinosus. 13. Upper portion of semimembranosus. 14. Gracilis.

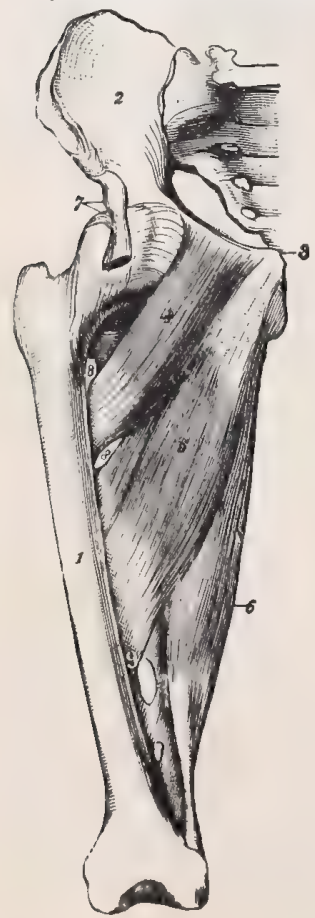

Pectineus and Adductor LONGUS.

x. Femur. 2. Ilium. 3. Pubis. 4. Pectineus. 5. Adductor longus. 6. Lower portion of adductor magnus, 7. Tendon of rectus femoris. 8.8 . Orifices for vessels. 9. Orifices for femoral vessels.

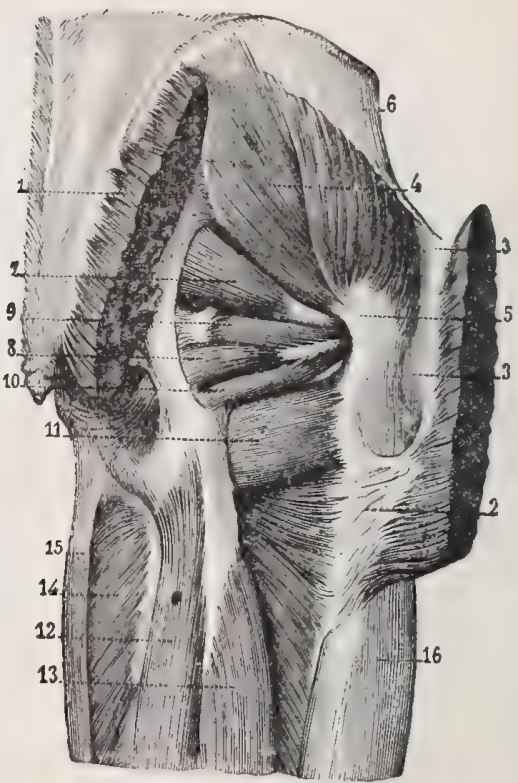

Gluteus Medius Muscle.

I. Inner extremity of gluteus maximus. 2. Attachment of gluteus maximus to linea aspera. 3,3 . Triangular aponeurosis formed by convergence of tendinous fibers of half of gluteus maximus. 4. Gluteus medius. 5. Its tendon of insertion into great trochanter. 6. Upper portion of femoral aponeurosis. 7. Pyramidalis. 8. Obturator internus. 9. Superior gemellus. Io. Inferior gemellus. Ix. Quadratus femoris. 12. Semi-tendinosus. 13. Upper portion of long head of biceps. 14. Adductor magnus. 15. Gracilis. I6. Vastus externus.

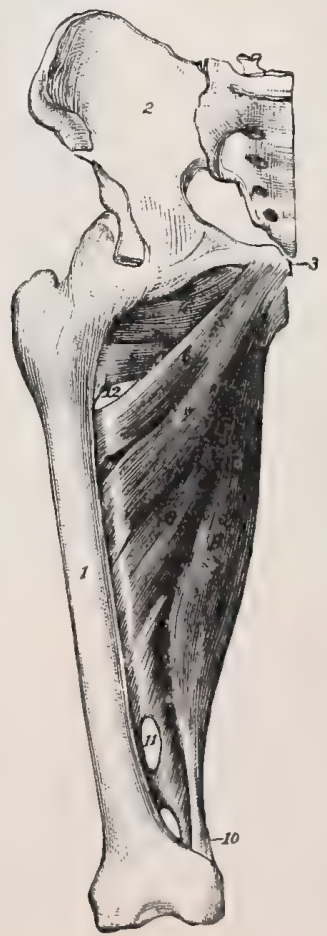

ADDUCTOR BREVIS AND ADDUCTOR MAGNUS.

I. Femur. 2. Ilium 3. Pubis. 4. Obturator externus. 5 Upper portion of adductor magnus. 6. Upper portion of adductor brevis. 7. Inferior portion of adductor brevis. 8. Middle portion of adductor magnus. 9. Inferior portion. Io. Tendon of insertion into internal condyle of femur. II. Orifice for femoral vessels. I2. Orifice for internal circumflex artery and veins. 
TABLE OF MUSCLES.-Continued.

\begin{tabular}{|c|c|c|c|c|}
\hline Name. & ORIGIN. & INSERTION. & INNERVATION. & FUNCTION. \\
\hline Kerato-glossus. & $\begin{array}{l}\text { Those fibers of the hyo- } \\
\text { glossus that arise from } \\
\text { the greater cornu of the } \\
\text { hyoid bone. See Hyo- } \\
\text { glossus. }\end{array}$ & & & \\
\hline $\begin{array}{l}\text { Kerato-thyroid (anomal- } \\
\text { ous). }\end{array}$ & $\begin{array}{l}\text { Lower border of cricoid } \\
\text { cartilage. }\end{array}$ & $\begin{array}{l}\text { Inferior cornu of thy roid } \\
\text { cartilage. }\end{array}$ & & \\
\hline Kissing. & See Orbicularis oris. & & & \\
\hline Laryngo-pharyngeus. & See Constrictor of & pharynx, inferior. & & \\
\hline Lateralis abdominis. & See Accessory abdominal & oblique. & & \\
\hline Latissimus dorsi. & $\begin{array}{l}\text { Spines of } 6 \text { lower dorsal } \\
\text { and lumbar and sacral } \\
\text { vertebra, crest of ilium, } \\
\text { and } 3 \text { or } 4 \text { lower ribs. }\end{array}$ & $\begin{array}{l}\text { Bicipital groove of } \\
\text { humerus. }\end{array}$ & Long subscapular. & $\begin{array}{l}\text { Draws a } \mathrm{r} m \text { backward } \\
\text { and dow } n \text { ward and } \\
\text { rotates it inward. }\end{array}$ \\
\hline$\overline{\text { Laxator tympani major. }}$ & $\begin{array}{l}\text { Spinous process sphenoid } \\
\text { and Eustachian tube. }\end{array}$ & Neck of malleus. & Facial. & $\begin{array}{l}\text { Relaxes membrana tym- } \\
\text { pani. }\end{array}$ \\
\hline Levator anguli oris. & $\begin{array}{l}\text { Canine fossa of superior } \\
\text { maxillary bone. }\end{array}$ & Angle of mouth. & $\begin{array}{l}\text { Facial, in } \mathrm{fr} \text { aor bital } \\
\text { branch. }\end{array}$ & Elevates angle of mouth. \\
\hline Levator anguli scapula. & $\begin{array}{c}\text { Transverse processes of } \\
\text { four upper cervical vert. }\end{array}$ & $\begin{array}{l}\text { Posterior border of } \\
\text { scapula. }\end{array}$ & $\begin{array}{l}\text { Fifth cervical and cer- } \\
\text { vical plexus. }\end{array}$ & $\begin{array}{l}\text { Elevates upper angle of } \\
\text { scapula. }\end{array}$ \\
\hline Levator ani. & $\begin{array}{l}\text { Posterior portion of body } \\
\text { and ramus of pubes, pel- } \\
\text { vic fascia, ischial spine. }\end{array}$ & $\begin{array}{l}\text { Rectum, cocc } y x \text {, and } \\
\text { fibrous raphe. }\end{array}$ & Sacral and perineal. & $\begin{array}{l}\text { Supports rectum and } \\
\text { vagina. }\end{array}$ \\
\hline $\begin{array}{l}\text { Levator claviculæe (an- } \\
\text { omalous). }\end{array}$ & $\begin{array}{l}\text { Transverse processes first } \\
\text { and second cervical ver- } \\
\text { tebræ. }\end{array}$ & Outer half of clavicle. & & \\
\hline $\begin{array}{l}\text { Levator glandula thy- } \\
\text { roidea (anomalous). }\end{array}$ & $\begin{array}{l}\text { Isthmus or pyramidal pro- } \\
\text { cess of thyroid body. }\end{array}$ & $\begin{array}{l}\text { Anterior surface of body } \\
\text { of hyoid. }\end{array}$ & & \\
\hline Levator labii inferioris. & $\begin{array}{l}\text { Incisive fossa of inferior } \\
\text { maxillary bone. }\end{array}$ & Skin of lower lip. & $\begin{array}{l}\text { Facial, supra-m a } \mathrm{x} \text { il- } \\
\text { lary branch. }\end{array}$ & Elevates lower lip. \\
\hline Levator labii superioris. & Lower margin of orbit. & Upper lip. & $\begin{array}{l}\text { Facial, infra or bit al } \\
\text { branch. }\end{array}$ & Elevates upper lip. \\
\hline $\begin{array}{l}\text { Levator labii superioris } \\
\text { alaeque nasi. }\end{array}$ & $\begin{array}{l}\text { Nasal process of superior } \\
\text { maxillary bone. }\end{array}$ & $\begin{array}{l}\text { Alar cartilage and upper } \\
\text { lip. }\end{array}$ & $\begin{array}{l}\text { Facial, infra orbital } \\
\text { branch. }\end{array}$ & $\begin{array}{l}\text { Elevates upper lip, di- } \\
\text { lates nostril. }\end{array}$ \\
\hline Levator menti. & See Levator labii inferio & ris. & & \\
\hline Levator palati. & $\begin{array}{l}\text { Petrous portion of tempo- } \\
\text { ral bone. }\end{array}$ & Soft palate. & $\begin{array}{l}\text { Spheno-palatine gan- } \\
\text { glion (facial). }\end{array}$ & Elevates soft palate. \\
\hline Levator palpebrae sup. & Lesser wing of sphenoid. & Upper tarsal cartilage. & Third. & Lifts upper lid. \\
\hline Levator pharyngis. & See Stylo-pharyngeus. & & & \\
\hline Levator prostatæ. & $\begin{array}{l}\text { A name given to the ante- } \\
\text { rior portion of the leva- } \\
\text { tor ani muscle. }\end{array}$ & & & \\
\hline $\begin{array}{l}\text { Levator thyroidea (an- } \\
\text { omalores). }\end{array}$ & Hyoid bone. & $\begin{array}{l}\text { Left lateral lobe of thy- } \\
\text { roid body. }\end{array}$ & & \\
\hline$\overline{\text { Levatores costarum, r2. }}$ & $\begin{array}{l}\text { Transv. proc. of last cer- } \\
\text { vical and dorsal vertebræ. }\end{array}$ & Each to the rib below. & Intercostal. & Raise ribs. \\
\hline Lingualis. & Under surface of tongue. & & $\begin{array}{l}\text { Chorda tympani and } \\
\text { hypoglossal. }\end{array}$ & $\begin{array}{l}\text { Elevates middle of } \\
\text { tongue. }\end{array}$ \\
\hline Longissimus dorsi. & Erector spinæ. & $\begin{array}{l}\text { Transverse processes of } \\
\text { lumbar and dorsal ver- } \\
\text { tebra and } 7 \text { th-i th ribs. }\end{array}$ & $\begin{array}{l}\text { Branches of lumbar } \\
\text { and dorsal. }\end{array}$ & $\begin{array}{l}\text { Erects spine and bends } \\
\text { trunk backward. }\end{array}$ \\
\hline $\begin{array}{l}\text { Longus colli :- } \\
\text { I. Superior obli que } \\
\text { portion. } \\
\text { 2. Inferior oblique por- } \\
\text { tion. } \\
\text { 3. Vertical portion. }\end{array}$ & $\begin{array}{l}\text { Transverse processes } 3 \mathrm{~d}- \\
5 \text { th cervical. } \\
\text { Bodies of ist-3d dorsal. } \\
\text { Bodies of three dorsal and } \\
\text { two cervical. }\end{array}$ & $\begin{array}{l}\text { Anterior tu bercle of } \\
\text { atlas. } \\
\text { Transverse processes } \\
5 \text { th-6th cervical. } \\
\text { Bodies of } 2 \text { d- } 4 \text { th cervi- } \\
\text { cal. }\end{array}$ & Lower cervical. & $\begin{array}{l}\text { Flexes cervical vertes } \\
\text { bra. }\end{array}$ \\
\hline Lumbricales, 4 , of foot. & $\begin{array}{l}\text { Tendons of flexor longus } \\
\text { digitorum. }\end{array}$ & $\begin{array}{l}\text { First phalanges of the } \\
\text { lesser toes. }\end{array}$ & $\begin{array}{l}\text { Internal and external } \\
\text { plantar. }\end{array}$ & Accessory flexors. \\
\hline
\end{tabular}



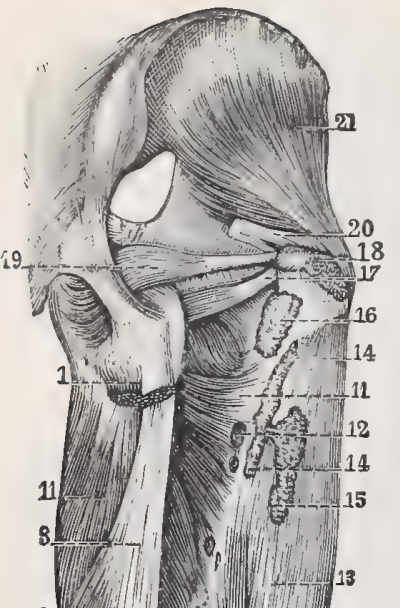

11

11.
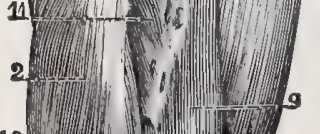

12
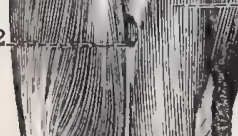

17
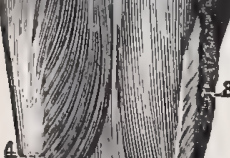

4.
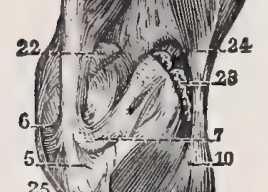

$5-1=-$
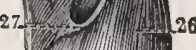

SHORT HEAD OF BICEPS AND SEMIMEMBRANOSUS,

1. Attachment to ischium of long head of biceps and semitendinosus. 2 Semimembranosus. 3. Its superior tendon. 4. Its inferior tendon. 5. Middle portion of tendon. 6. Its anterior portion. 7. Its posterior portion. 8. Section of long head of biceps. 9. Its short head. 10. Its attachment to head of fibula. II, II, II. Adductor magnus, I2, I2, Orifices for passage of perforating arteries and veins. 13. Vastus externus. I4, 14. Insertion of gluteus maximus. I5. Divided expansion of tendon of this muscle, continuous with the aponeurosis of the vastus externus. 16. Attachment of quadratus femoris. I7. Tendon of obturator externus. 18. Attachment of gluteus medius. 19. Obturator internus. 20. Tendon of pyramidalis. 21. Gluteus mini mus. 22. Divided inner head of gastrocnemius. 23. Outer head. 24. Plantaris, 25. Popliteus. 26. Soleus. 27. Fibrous ring for artery, vein and nerve.

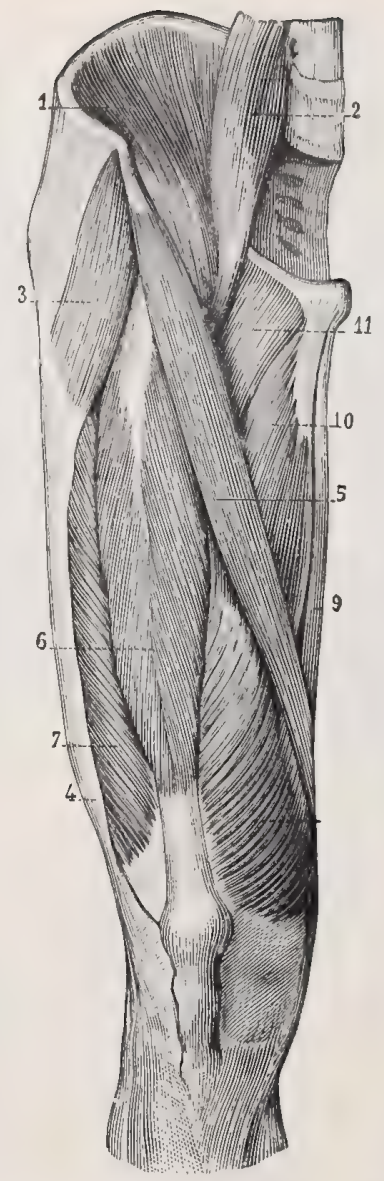

MUSCles of ANTERIOR Aspect of THIGH.

I. Iliacus. 2. Psoas magnus. 3. Tensor vagina femoris. 4. Fibrous band by which this muscle is attached to external tuberosity of tibia. 5. Sartorius. 6. Rectus femoris. 7. Vastus externus. 8. Vastus internus. Gracilis. ro. Adductor longus. 2x. Pectineus.
MUSCLES

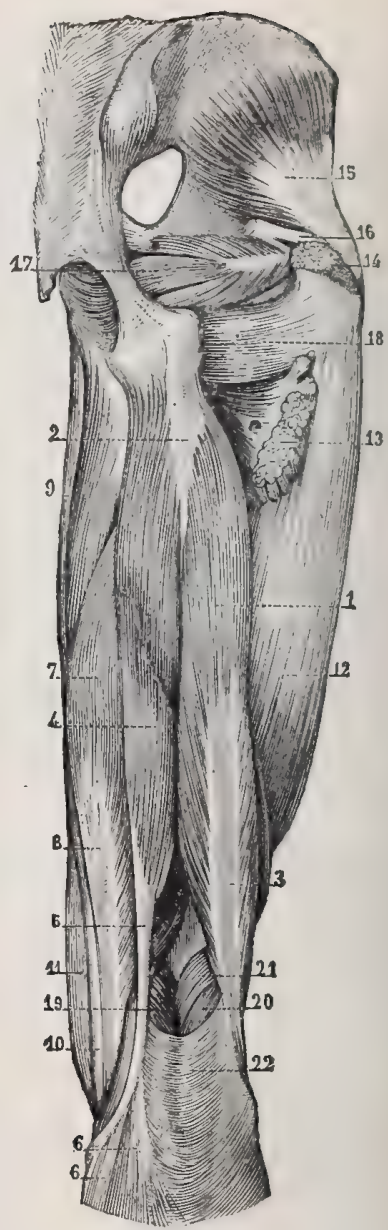

Long Head of Biceps and SemiTENDINOSUS.

r. Long head of biceps. 2. Common tendon of long head of biceps and semitendinosus. 3. Inferior tendon of biceps. 4. Semitendinosus. 5. Its tendon. 6, 6. Its tendinous expansions, continuous with aponeurosis of leg. 7. Semimembranosus. 8. Its inferior tendon. 9. Gracilis. I0. Its tendon. I1. Sartorius. I2. Vastus externus. 13. Femoral attachment of gluteus maximus. 14. Insertion of gluteus medius. 15. Gluteus minimus. I6. Tendon of pyriformis. 17. Obturator internus. 18. Quadratus femoris. 19. Inner head of gastrocnemius. 20. Outer head of gastrocnemius. 2r. Plantaris. 22. Popliteal aponeurosis. 
TABLE OF MUSCLES.-Continued.

\begin{tabular}{|c|c|c|c|c|}
\hline NAME. & ORIGIN." & INSERTION. & INNERVATION. & FUNCTION. \\
\hline Lumbricales, 4 , of hand. & $\begin{array}{l}\text { Tendons of flexor profun- } \\
\text { dus digitorum. }\end{array}$ & $\begin{array}{l}\text { Tendons of common ex- } \\
\text { tensor. }\end{array}$ & Median and ulnar. & Flex first phalanges. \\
\hline Masseter. & Zy'gomatic arch. & Angle and ramus of jaw. & Inferior maxillary. & Muscle of mastication. \\
\hline $\begin{array}{l}\text { Mento-hyoideus (anom- } \\
\text { alous). }\end{array}$ & Body of hyoid bone. & $\begin{array}{l}\text { Symphysis of chin, } \\
\text { superficial to mylo-hy- } \\
\text { oid muscle. }\end{array}$ & $\therefore$ & \\
\hline Merkel's. & See Kerato-cricoid. & & & \\
\hline Midriff. & See Diaphragm. & & & \\
\hline Müller's. & See Ciliary. & & & \\
\hline Müller's (orbital). & $\begin{array}{l}\text { Connected with the orbi- } \\
\text { tal periosteum; it crosses } \\
\text { the spheno-maxillary fis- } \\
\text { sure. }\end{array}$ & & Sympathetic. & \\
\hline $\begin{array}{l}\text { Müller's (superior pal- } \\
\text { pebral). }\end{array}$ & $\begin{array}{c}\text { Connected with the leva- } \\
\text { tor palpebræ superioris. }\end{array}$ & $\begin{array}{l}\text { Along the upper border } \\
\text { of the tarsus. }\end{array}$ & Sympathetic. & Helps raise upper lid. \\
\hline Multifidus spinæ. & $\begin{array}{l}\text { Sacrum, iliac spine, artic- } \\
\text { ular processes l u m ba r } \\
\text { and cervical vertebræ, } \\
\text { and transverse proc. of } \\
\text { dorsal and } 7 \text { th cervical. }\end{array}$ & $\begin{array}{l}\text { Lamina and spines from } \\
\text { last lumbar to second } \\
\text { cervical vertebræ. }\end{array}$ & $\begin{array}{l}\text { Posterior spinal bran- } \\
\text { ches. }\end{array}$ & $\begin{array}{l}\text { Erects and rotates spinal } \\
\text { column. }\end{array}$ \\
\hline $\begin{array}{l}\text { Musculus access or i us } \\
\text { ad sacro-lumbalem. }\end{array}$ & Angles of six lower ribs. & Angles of six upper ribs. & Branches of dorsal. & $\begin{array}{l}\text { Erects spine and bends } \\
\text { trunk backward. }\end{array}$ \\
\hline $\begin{array}{l}\text { Mylo-glossus (anoma- } \\
\text { lous). }\end{array}$ & $\begin{array}{l}\text { Angle of lower jaw, or } \\
\text { stylo-maxillary ligament. }\end{array}$ & $\begin{array}{l}\text { Side of tongue between } \\
\text { "stylo-glossus and hyo- } \\
\text { glossus. }\end{array}$ & & \\
\hline Mylo-hyoid. & $\begin{array}{l}\text { Mylo-hyoid ridge of infe- } \\
\text { rior maxillary bone. }\end{array}$ & $\begin{array}{l}\text { Body of hyoid and } \\
\text { raphe. }\end{array}$ & Inferior dental. & $\begin{array}{l}\text { Elevates and advances } \\
\text { hyoid. Forms the floor } \\
\text { of the mouth. }\end{array}$ \\
\hline Naso-labialis. & Nasal septum. & Upper lip. & & \\
\hline Obliquus auris. & Concha of ear. & Fossa of anti-helix. & $\begin{array}{c}\text { Temporal and pos- } \\
\text { terior annular. }\end{array}$ & \\
\hline $\begin{array}{l}\text { Obliquus capitis infe- } \\
\text { rioris. }\end{array}$ & Spinous process of axis. & $\begin{array}{l}\text { Transverse process of } \\
\text { atlas. }\end{array}$ & $\begin{array}{l}\text { Sub-occipital and } \\
\text { great occipital. }\end{array}$ & $\begin{array}{l}\text { Rotates atlas and crani- } \\
\text { um. }\end{array}$ \\
\hline $\begin{array}{l}\text { Obliquus capitis supe- } \\
\text { rioris. }\end{array}$ & $\begin{array}{l}\text { Transverse process of } \\
\text { atlas. }\end{array}$ & Occipital bone. & $\begin{array}{l}\text { Sub-occipital and } \\
\text { great occipital. }\end{array}$ & Draws head backward. \\
\hline Obliquus externus. - & Eight lower ribs. & $\begin{array}{l}\text { Middle line, iliac crest, } \\
\text { Poupart's ligament. }\end{array}$ & $\begin{array}{l}\text { Intercostal, ilio-hypo- } \\
\text { gastric, ilio-inguinal. }\end{array}$ & $\begin{array}{l}\text { Compresses viscera and } \\
\text { flexes thorax. }\end{array}$ \\
\hline Obliquus inferioris. & $\begin{array}{l}\text { Orbital plate of superior } \\
\text { maxillary bone. }\end{array}$ & Sclerotic. & Third. & $\begin{array}{l}\text { Rotates eyeball upward } \\
\text { and outward. }\end{array}$ \\
\hline Obliquus internus. & $\begin{array}{l}\text { Lumbar fascia, iliac crest, } \\
\text { Poupart's ligament. }\end{array}$ & $\begin{array}{l}\text { Three lower ribs, linea } \\
\text { alba, pubic crest, pec- } \\
\text { tineal line. }\end{array}$ & $\begin{array}{l}\text { Intercostal, ilio-hypo- } \\
\text { gastric, ilio-inguinal. }\end{array}$ & $\begin{array}{l}\text { Compresses viscera, } \\
\text { flexes thorax, and as- } \\
\text { sists in expiration. }\end{array}$ \\
\hline Obliquus superior. & $\begin{array}{l}\text { Above optic foramen, } \\
\text { through pulley. }\end{array}$ & Sclerotic. & Fourth. & $\begin{array}{l}\text { Rotates eyeball down- } \\
\text { ward and inward. }\end{array}$ \\
\hline Obturator externus. & $\begin{array}{l}\text { Obturator foramen and } \\
\text { membrane. }\end{array}$ & $\begin{array}{l}\text { Digital fossa, base of } \\
\text { great trochanter. }\end{array}$ & Obturator. & $\begin{array}{l}\text { External rotator of } \\
\text { thigh. }\end{array}$ \\
\hline Obturator internus. & $\begin{array}{l}\text { Obturator foramen and } \\
\text { membrant. }\end{array}$ & Great trochanter. & Sacral. & $\begin{array}{l}\text { External rotator of } \\
\text { thigh. }\end{array}$ \\
\hline Occipitalis. & See Occipito-frontalis. & & & \\
\hline $\begin{array}{l}\text { Occipitalis minor (an- } \\
\text { omalous). }\end{array}$ & $\begin{array}{l}\text { Fascia over upper end of } \\
\text { trapezius. }\end{array}$ & $\begin{array}{l}\text { Fascia over upper end } \\
\text { of sterno-mastoid. }\end{array}$ & Small occipital. & \\
\hline Occipito-frontalis. & $\begin{array}{l}\text { Superior curved line of } \\
\text { occiput and angular pro- } \\
\text { cess of frontal. }\end{array}$ & Aponeurosis. & $\begin{array}{l}\text { Posterior auricular, } \\
\text { small occipital, facial. }\end{array}$ & $\begin{array}{l}\text { Moves scaip. Facial ex- } \\
\text { pression. }\end{array}$ \\
\hline $\begin{array}{l}\text { Occipito-hyoid (anomal- } \\
\text { ous). }\end{array}$ & $\begin{array}{l}\text { Mastoid process and ad- } \\
\text { jacent portion of superior } \\
\text { oblique line of occiput. }\end{array}$ & $\begin{array}{l}\text { Hyoid bone neat in- } \\
\text { sertion of posterior } \\
\text { belly of digastric. }\end{array}$ & & \\
\hline $\begin{array}{l}\text { Occipito-p hat y ng eus } \\
\text { (anomalous). }\end{array}$ & Basilat process of occiput. & Constrictor of pharynx. & & \\
\hline
\end{tabular}




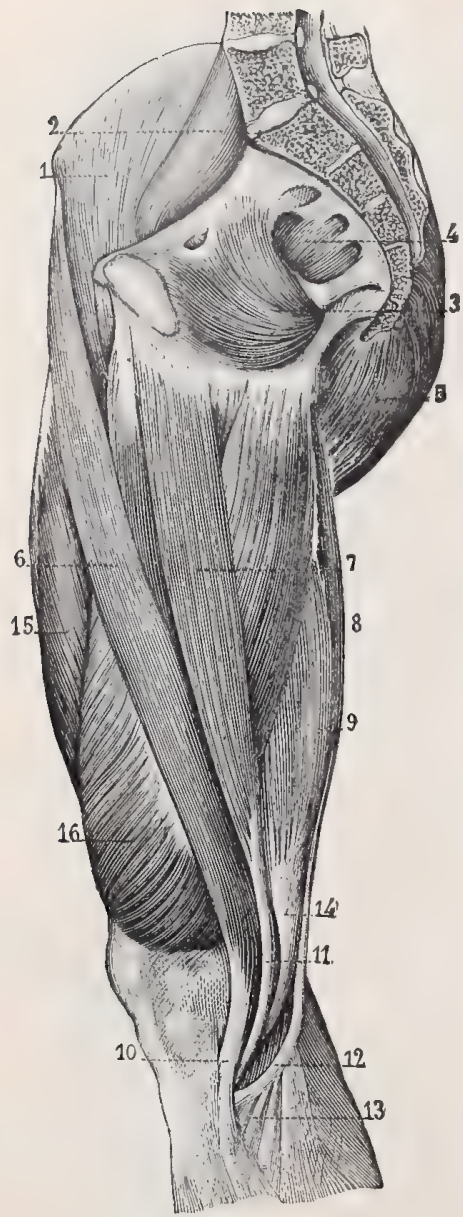

MUSCles OF INNER ASPECT OF THIGH.

1. Iliacus, 2. Psoas magnus. 3. Obturator internus. 4. Pyriformis. 5. Gluteus maximus. 6. Sartorius. 7. Gracilis. 8. Semitendinosus. 9. Semimembranosus. 10. Tendon of sartorius. II. Tendon of gracilis. I2. Tendon of semitendinosus. 13. Its expansions. I4. Tendon of semimembranosus. 15. Rectus femoris. 16. Vastus internus.

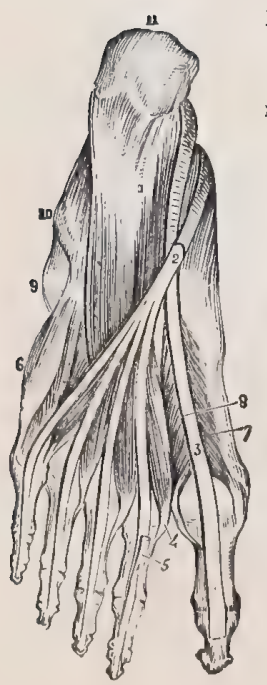

MUSCLES OF THE SOLE OF FOOT, MIDDLE LAYER.

I. Flexor accessorius. 2 Tendon of flexor longus digitorum. 3 Tend on of flexor longus pollicis. 4 First lumbri calis. 5. Tendon of flexo brevis digitorum. 6. Flexor brevis minimi digiti. Inner fascicuinner ffexor brevis pollicis. 8. Outer fasciculus. 9. Tuberosity of fifth metatarsal bone. 10. Fibrous sheath of peroneus longus. xi. Os calcis.

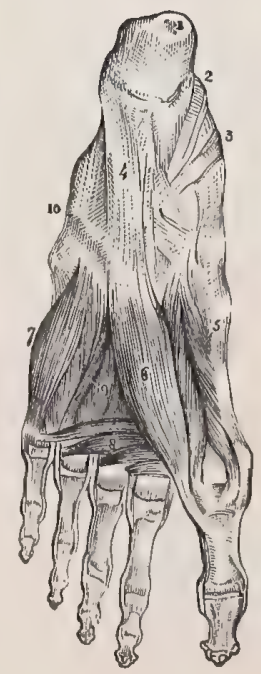

MUSCIES OF THE SOLE OF FOOT, DEEP LAYER.

I. Os calcis. 2 2. Fibrous sheath of flexor longus pol licis. 3. Fibrous sheath of flexor lon. gus digitorum rior calcaneocuboid ligament. 5. Flexor brevis pollicis. 6. Adductor pollicis. 7. Flexor brevis minimi digiti. 8 Transversus pe d i s. 9. Plantar interosseous. 10 Sheath of tendon of peroneus longus.
SHORT PORTION OF BI CEPS AND SEMIMEM BRANOSUS

I. Attachment to ischium of long portion of biceps and semitendinosus. 2. Semimembranosus. 3. Its supe rior tendon. 4. Its inferior telidon. 5 Middle portion of this tendon. 6. Its anterior portion. 7. Its posterior portion 8 . Section of long portion of biceps. 9. Its short portion. 10. Its attachment to the head of fibula. II II, II. Adductor magnus. 12, 12, Series of perforations for the passage of arteries and veins. I3. Vastus externus. I4, I4. Insertion of gluteus maximus. 15 . Section of expansion by which the tendon of this muscle is continuous with the aponeurosis of the vastus exter nus. I6. Attachment of quadratus femoris. r7. Tendon of obtu rator externus, $\quad 18$ Attachment of glu teus medius. 19. Obturator internus. 20. Tendon of pyriformis. 2I. Gluteus minimus. 22. Inner head of gastrocne. mius. 23. Outer head 24. Divided plantaris. 25. Popliteus. 26 Soleus. 27. Tendinous ring in soleus.

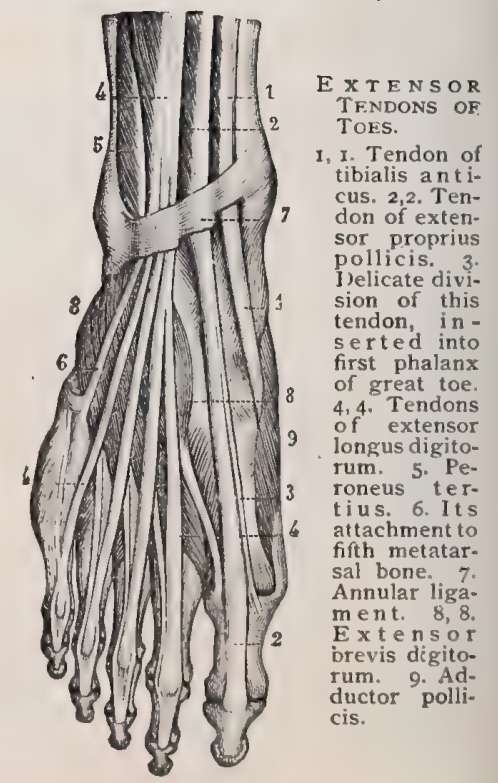


TABLE OF MUSCLES.-Continued.

\begin{tabular}{|c|c|c|c|c|}
\hline NAME. & ORIGIN. & INSERTION. & INNERVATION. & FUNCTION. \\
\hline $\begin{array}{l}\text { Occipito-scapular (an- } \\
\text { omalous). }\end{array}$ & $\begin{array}{l}\text { Occipital bone near sple- } \\
\text { nius capitis muscle. }\end{array}$ & $\begin{array}{l}\text { Dorsal border of scap- } \\
\text { ula at base of spine. }\end{array}$ & & \\
\hline Omo-hyoid. & Upper border of scapula. & Body of hyoid. & $\begin{array}{l}\text { Descendens and com- } \\
\text { municans noni } \\
\text { (hypoglossi). }\end{array}$ & $\begin{array}{l}\text { Depresses and retracts } \\
\text { hyoid. }\end{array}$ \\
\hline $\begin{array}{l}\text { Opponens hallucis (an- } \\
\text { omalous). }\end{array}$ & $\begin{array}{l}\text { Tendon of adductor hal- } \\
\text { lucis muscle. }\end{array}$ & $\begin{array}{l}\text { Base of metatarsal bone } \\
\text { of great toe. }\end{array}$ & & \\
\hline Opponens minimi digiti. & Unciform bone. & Fifth metacarpal. & Ulnar. & Flexes little finger. \\
\hline $\begin{array}{l}\text { Opponens minimi digiti } \\
\text { pedis. }\end{array}$ & See Flexor brevis minimi & digiti. & & \\
\hline Opponens pollicis. & $\begin{array}{l}\text { Trapezium, anterior annu- } \\
\text { lar ligament. }\end{array}$ & $\begin{array}{l}\text { Metacarpal bone of } \\
\text { thumb. }\end{array}$ & $\begin{array}{l}\text { Median, palmar divi- } \\
\text { sion. }\end{array}$ & Flexes thumb. \\
\hline Orbicularis oris. & $\begin{array}{l}\text { Nasal septum and canine } \\
\text { fossa of inferior maxil- } \\
\text { la, by accessory fibers. }\end{array}$ & $\begin{array}{l}\text { Forms lips and sphinc- } \\
\text { ter of mouth. }\end{array}$ & $\begin{array}{l}\text { Facial, buccal and } \\
\text { supramaxillary bran- } \\
\text { ches. }\end{array}$ & Closes inouth. \\
\hline $\begin{array}{l}\text { Orbicularis palpe- } \\
\text { brarum. }\end{array}$ & Mesal margin of orbit. & Lateral margin of orbit. & Facial. & Closes eyelids. \\
\hline Orbital. & See Miuller's. & $\cdot$ & & \\
\hline Orbito-palpebral. & See Palpebral, superior & (Miller's). & & \\
\hline Palato-glossus. & Soft palate. & $\begin{array}{l}\text { Side and dorsum of } \\
\text { tongue. }\end{array}$ & $\begin{array}{l}\text { Spheno-palatine gал- } \\
\text { glion. }\end{array}$ & Constricts the fauces. \\
\hline Palato-pharyngeus. & Soft palate. & $\begin{array}{l}\text { Thyroid cartilage and } \\
\text { pharynx. }\end{array}$ & $\begin{array}{l}\text { Spheno-palatine gan- } \\
\text { glion. }\end{array}$ & Closes posterior nares. \\
\hline Palmaris brevis. & $\begin{array}{l}\text { Annular ligament and } \\
\text { palmar fascia. }\end{array}$ & Skin of palm of hand. & Ulnar. & Corrugates skin of palm. \\
\hline Palmaris interossei. & $\begin{array}{l}\text { Palmar surfaces second, } \\
\text { fourth, and fifth meta- } \\
\text { carpals. }\end{array}$ & $\begin{array}{l}\text { Bases of first phalanges } \\
\text { of corresponding fin- } \\
\text { gers. }\end{array}$ & Ulnar. & Adductors of fingers. \\
\hline Palmaris longus. & Internal condyle. & $\begin{array}{l}\text { Annular ligament and } \\
\text { palmar fascia. }\end{array}$ & Median. & Tenses palmar fascia. \\
\hline Palpebral, superior. & See Miiller's. & & & \\
\hline Pectineus. & $\begin{array}{l}\text { Ilio-pectineal line and } \\
\text { pubes. }\end{array}$ & $\begin{array}{l}\text { Femur below lesser tro- } \\
\text { chanter. }\end{array}$ & $\begin{array}{l}\text { Anterior crura l, ob- } \\
\text { turator. }\end{array}$ & $\begin{array}{l}\text { Flexes and rotates out- } \\
\text { ward the thigh. }\end{array}$ \\
\hline Pectoralis major. & $\begin{array}{l}\text { Clavicle, st ernu } \mathbf{m} \text {, and } \\
\text { costal cartilages. }\end{array}$ & $\begin{array}{l}\text { External bicipital ridge } \\
\text { of humerus. }\end{array}$ & $\begin{array}{c}\text { Anterior thoracic, ex- } \\
\text { ternal and internal. }\end{array}$ & $\begin{array}{l}\text { Draws arm downward } \\
\text { and forward. }\end{array}$ \\
\hline Pectoralis minimus. & $\begin{array}{l}\text { First piece of sternum, } \\
\text { and cartilage of first rib. }\end{array}$ & Coracoid process. & Anterior thoracic. & $\begin{array}{l}\text { Depresses point of } \\
\text { shoulder. }\end{array}$ \\
\hline Pectoralis minor. & $\begin{array}{l}\text { Third, fourth, and fifth } \\
\text { ribs. }\end{array}$ & Coracoid process. & Anterior thoracic. & $\begin{array}{l}\text { Depresses point of } \\
\text { shoulder. }\end{array}$ \\
\hline Peripenial. & $\begin{array}{l}\text { A thin layer of unstriped } \\
\text { muscular tissue forming } \\
\text { the frenum of the penis. }\end{array}$ & & Sympathetic. & \\
\hline $\begin{array}{l}\text { Peroneo-calcaneus in - } \\
\text { ternus (anomalous). }\end{array}$ & $\begin{array}{l}\text { Lower part of posterior } \\
\text { surface of fibula. }\end{array}$ & $\begin{array}{l}\text { Front part, inner sur- } \\
\text { face of calcaneum. }\end{array}$ & & \\
\hline $\begin{array}{l}\text { Peroneo-tibialis (anom- } \\
\text { alous). }\end{array}$ & $\begin{array}{l}\text { Inner side of head of } \\
\text { fibula. }\end{array}$ & $\begin{array}{l}\text { Upper end of oblique } \\
\text { line of tibia. }\end{array}$ & & \\
\hline Peroneus accessorius. & $\begin{array}{l}\text { Fibula between peronei } \\
\text { longus and brevis. }\end{array}$ & $\begin{array}{l}\text { With the peroneus lon- } \\
\text { gus. }\end{array}$ & & \\
\hline Peroneus brevis. & $\begin{array}{l}\text { Middle third of shaft of } \\
\text { fibula, externally. }\end{array}$ & Base of fifth metatarsal. & Musculo-cutaneous. & Extends foot. \\
\hline Peroneus longus. & Head and shaft of fibula. & $\begin{array}{l}\text { First metatarsal of great } \\
\text { toe. }\end{array}$ & Musculo-cutaneous. & Extends and everts foot. \\
\hline $\begin{array}{l}\text { Peroneus quartus (an- } \\
\text { omalous). }\end{array}$ & $\begin{array}{c}\text { Flexor surface of fibula } \\
\text { near peroneus brevis. }\end{array}$ & $\begin{array}{l}\text { Ridge of cuboid or } \\
\text { peroneal tubercle of } \\
\text { calcaneum. }\end{array}$ & & \\
\hline $\begin{array}{l}\text { Peroneus quinti digiti } \\
\text { (anomalous). }\end{array}$ & Lower fourth of fibula. & $\begin{array}{l}\text { Aponeurosis on extensor } \\
\text { surface of little toe. }\end{array}$ & & . \\
\hline Peroneus tertius. & Lower fourth of fibula. & Fifth metatarsal bone. & Anterior tibial. & Flexes tarsus. \\
\hline
\end{tabular}




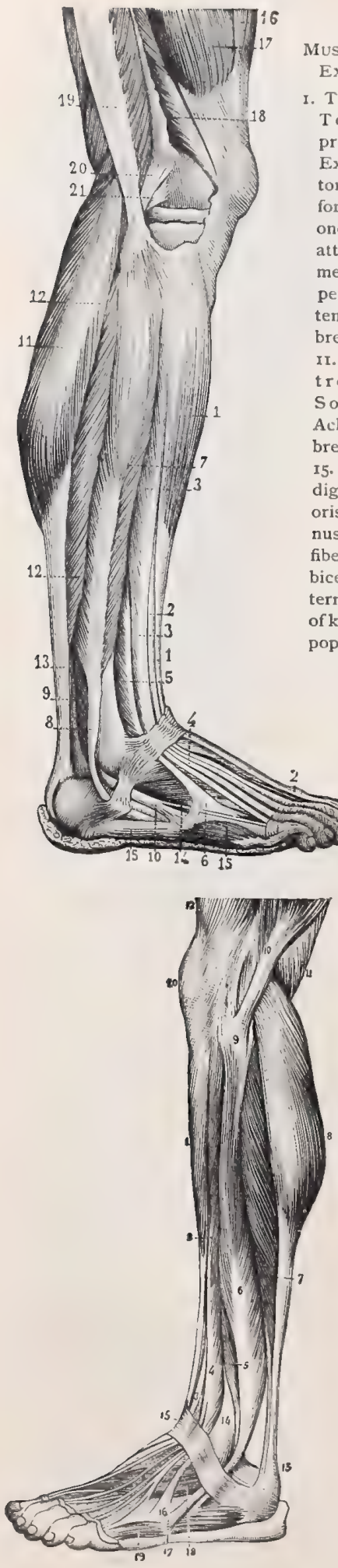

MUSCles OF THE LEG, EXTERNAL ASPECT.

1. Tibialis anticus. 2,2 . Tendon of extensor proprius pollicis. 3,3 . Extensor longus digitorum. 4. Its tendons for four last toes. 5. Peroneus tertius. 6 . Its attachment to last two metacarpal bones. 7 . peroneus longus. 8. Its tendon. 9. Peroneus brevis. Io. Its tendon. II. Outer head of gastrocnemius. I2, I2. Soleus. 13. Tendo Achillis. 14. Extensor brevis digitorum. 15, I5. Abductor min imi digiti. I6. Rectus femoris. 17. Vastus externus. 18. Its inferior fibers. 19. Tendon of biceps femoris. 20. External lateral ligament of knee. 21. Tendon of popliteus.

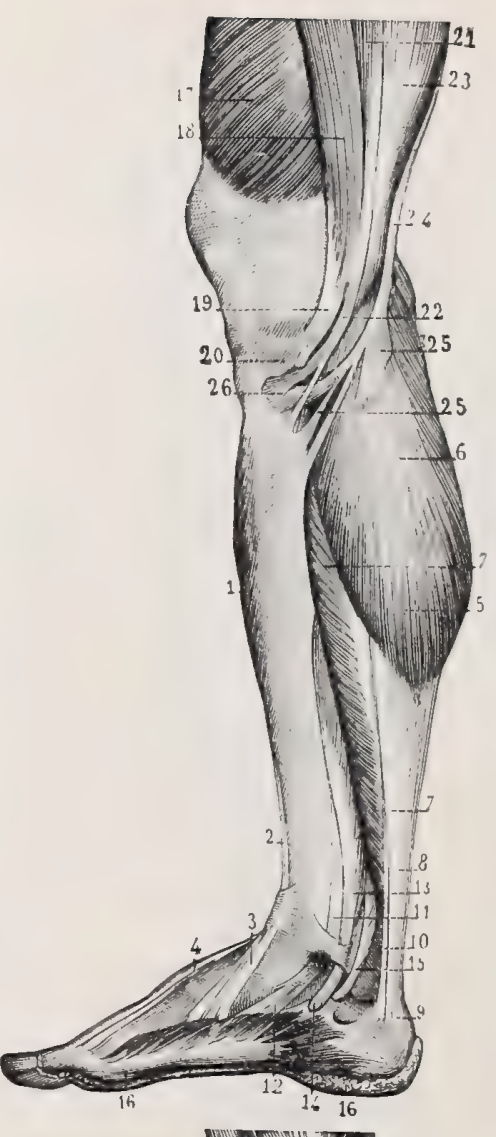

MUSCles OF THE LEG, INTERNAL ASPECT.

1. Tibialis anticus. 2, 3. Its tendon. 4. Tendons of extensor communis digitorum. 5. Inner head of gastrocnemius. 6. Its aponeurosis of origin. 7. Soleus. 8. Tendo Achillis. 9. Its attachment to os calcis. Io. Tendon of plantaris. II. Tendon of tibialis posticus. $₹ 2$. Its attachment to scaphoid bone. 13, 14. Tendon of flexor longus digitorum. I5. Tendon of flexor Iongus pollicis. 16 16. Adductor pollicis. 17. Vastus in. ternus. 18. Sartorius. Ig. Its tendon. 20. Its expansion, largely removed. 21. Gracilis. 22. Its tendon. 23. Tendon of semimembranosus. 24. Tendon of semitendinosus. 25 , 25. Its fibrous expansions. 26. Common tendon of gracilis and semiteudinosus.
Muscles of ExTERnal AsPECT OF LEG.

I. Tibialis anticus. 2. Extensor Iongus digitorum. 3. Tendon of extensor proprius pollicis. 4 Peroneus tertius. 5. Peroneus brevis. 6. Peroneus longus. 7. Soleus. 8. Outer head of gastrocnemius. 9 . Head of fibula. Io. Tendon of biceps femoris. II. Semimembranosus. I2, Tendon of rectus femoris. 13. Tendo Achillis. 14. External malleolus. 15. Annular ligament. I6. Insertion of peroneus tertius. 17. Insertion of peroneus brevis. 18. Extensor brevis digitorum. I9. Abductor minimi digiti. 20 . Patella.

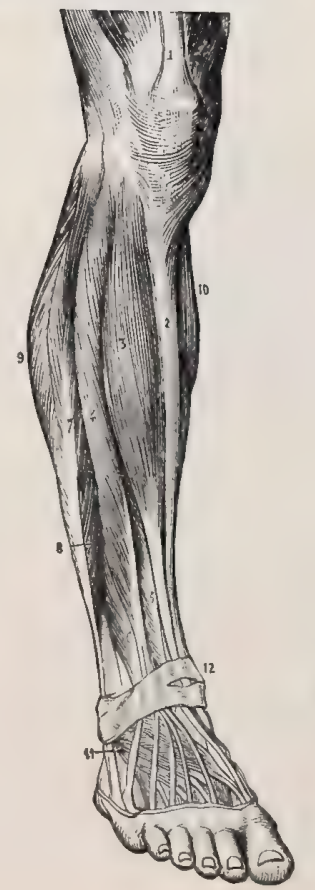

MUSCLES OF ANTERIOR ASPECT OF LEC.

1. Tendon of rectus femoris. 2. Tibia. 3. Tibialis anticus. 4. Extensor longus digitorum. 5. Extensor proprius pollicis. 6 . Peroneus tertius. Peroneus longus. 8. Peroneus brevis. 9 Outer head of gastrocnemius. Io. Inner head. II. Extensor brevis digitorum. 12. Annular ligament. 
TABLE OF MUSCLES.-Continued.

\begin{tabular}{|c|c|c|c|c|}
\hline NAME. & ORIGIN. & INSERTION. & INNERVATION. & FUNCTION. \\
\hline $\begin{array}{l}\text { Petro-pharyngeus (an- } \\
\text { omalous). }\end{array}$ & $\begin{array}{l}\text { Petrous portion of tem- } \\
\text { poral bone. }\end{array}$ & Constrictors of pharynx. & & \\
\hline $\begin{array}{l}\text { Petro-salpingo-staphyli- } \\
\text { nus. }\end{array}$ & See Levator palati. & & & \\
\hline Phillips'. & $\begin{array}{l}\text { External superior tuber- } \\
\text { osity of radius, and ex- } \\
\text { ternal lateral higament of } \\
\text { ulnat articulation. } \\
\end{array}$ & $\begin{array}{l}\text { Proximal portions of } \\
\text { phalanges. }\end{array}$ & Ulnat. & \\
\hline $\begin{array}{l}\text { Pisi-uncinatus (anomal- } \\
\text { ous). }\end{array}$ & Pisiform bone. & $\begin{array}{l}\text { Unciform process of un- } \\
\text { ciform bone. }\end{array}$ & & \\
\hline Plantaris. & $\begin{array}{l}\text { Outer bifurcation of linea } \\
\text { aspera and posterior liga- } \\
\text { ment of knee-joint. }\end{array}$ & $\begin{array}{l}\text { Os calcis by means of } \\
\text { the tendo Achillis. }\end{array}$ & Internal popliteal. & Extends foot. \\
\hline Plantaris interossei. & $\begin{array}{l}\text { Shafts of } 3 d, 4 \text { th, and } 5 \text { th } \\
\text { metatarsal bones. }\end{array}$ & $\begin{array}{c}\text { Bases of first phalanges } \\
\text { of corresponding toes. }\end{array}$ & External plantar. & Adducts toes. \\
\hline Platysma myoides. & $\begin{array}{l}\text { Clavicle, acromion, and } \\
\text { fascia. }\end{array}$ & $\begin{array}{l}\text { Inferior maxillary bone, } \\
\text { angle of mouth. }\end{array}$ & $\begin{array}{l}\text { Facial and superficial } \\
\text { cervical. }\end{array}$ & $\begin{array}{l}\text { Wrinkles skin and de- } \\
\text { presses mouth. }\end{array}$ \\
\hline Popliteus. & $\begin{array}{l}\text { External condyle of fe- } \\
\text { mur. }\end{array}$ & $\begin{array}{l}\text { Shaft of tibia above ob- } \\
\text { lique line. }\end{array}$ & Internal popliteal. & Flexes leg. \\
\hline $\begin{array}{l}\text { Popliteus minor (anom- } \\
\text { alous). }\end{array}$ & $\begin{array}{l}\text { Femur at inner side of } \\
\text { plantaris. }\end{array}$ & $\begin{array}{l}\text { Posterior li g a ment of } \\
\text { knee-joint. }\end{array}$ & & \\
\hline $\begin{array}{l}\text { Prerectalis (of Henle) } \\
\text { (anomalous). }\end{array}$ & $\begin{array}{l}\text { Recto-vesical prolonga- } \\
\text { tion. }\end{array}$ & $\begin{array}{l}\text { Prolongation of recto- } \\
\text { vesical fascia into } \\
\text { perineum. }\end{array}$ & & Sympathetic. \\
\hline Presternal. & See Sternalis. & & & \\
\hline Pronator pedis. & See Flexor accessorius & longus digitorum pedis. & & \\
\hline Pronator quadratus. & Lower fourth of ulna. & Lower $x / 4$ shaft of radius. & Anterior interosseous. & Pronates hand. \\
\hline Pronator radii teres. & $\begin{array}{l}\text { Internal condyle and coro- } \\
\text { noid process. }\end{array}$ & $\begin{array}{l}\text { Outer side of } \mathrm{shaft} \text { of } \\
\text { radius. }\end{array}$ & Median. & Pronates hand. \\
\hline Psoas magnus. & $\begin{array}{c}\text { Bodies and transverse } \\
\text { processes of last dorsal } \\
\text { and all lumbar vertebræ. }\end{array}$ & Lesser trochanter. & Lumbar. & $\begin{array}{l}\text { Flexes and rotates thigh } \\
\text { outward, and flexes } \\
\text { trunk on pelvis. }\end{array}$ \\
\hline Psoas parvus. & $\begin{array}{c}\text { Bodies of last dorsal and } \\
\text { first lumbar vertebræ. }\end{array}$ & $\begin{array}{l}\text { Ilio-pectineal eminence } \\
\text { and iliac fascia. }\end{array}$ & Lumbar. & $\begin{array}{l}\text { Flexes peIvis upon } \\
\text { abdomen. }\end{array}$ \\
\hline Pterygoid (external). & $\begin{array}{l}\text { Two heads: } I \text {, external } \\
\text { pterygoid plate of sphen- } \\
\text { oid bone; } 2 \text {, great wing. }\end{array}$ & Neck of condyle. & Inferior maxillary. & $\begin{array}{l}\text { Draws inferior maxil- } \\
\text { lary bone forward. }\end{array}$ \\
\hline Pterygoid (internal). & $\begin{array}{l}\text { Pterygoid fossa of sphe- } \\
\text { noid bone. }\end{array}$ & $\begin{array}{l}\text { Inner surface of angle } \\
\text { of jaw. }\end{array}$ & Inferior maxillary. & $\begin{array}{l}\text { Raises and draws infe- } \\
\text { rior maxilla forward. }\end{array}$ \\
\hline $\begin{array}{l}\text { Pterygoideus proprius } \\
\text { (anomalous). }\end{array}$ & $\begin{array}{l}\text { Crest on great wing of } \\
\text { sphenoid. }\end{array}$ & $\begin{array}{l}\text { Posterior border of ex- } \\
\text { ternal pterygoid plate, } \\
\text { occasionally the tuber- } \\
\text { osity of superior maxil- } \\
\text { la. }\end{array}$ & & \\
\hline $\begin{array}{l}\text { Pterygo-p hary } n \text { ge us } \\
\text { (anomalous). }\end{array}$ & $\begin{array}{l}\text { Hamular process of } \\
\text { sphenoid bone. }\end{array}$ & Constrictors of pharynx. & & \\
\hline $\begin{array}{l}\text { Pterygo-spinous (anom- } \\
\text { alous). }\end{array}$ & $\begin{array}{l}\text { Alar spine of sphenoid } \\
\text { bone. }\end{array}$ & $\begin{array}{l}\text { Posterior margin of the } \\
\text { external pterygoid. }\end{array}$ & & \\
\hline Pyramidalis. & Pubes. & Linea alba. & Ilio-hypogastric. & Tenses linea alba. \\
\hline Pyramidalis nasi. & Occipito-frontalis. & Compressor naris. & $\begin{array}{l}\text { Facial nerve, infraor- } \\
\text { bital branch. }\end{array}$ & Depresses eyebrow. \\
\hline Pyriformis. & $\begin{array}{l}\text { Front of sacrum, through } \\
\text { great sciatic foramen. }\end{array}$ & Great trochanter. & Sacral branch. & $\begin{array}{l}\text { External rotator of } \\
\text { thigh. }\end{array}$ \\
\hline Quadratus femoris. & Tuberosity of the ischium. & Quadrate line of femur. & $\begin{array}{l}\text { First sacral and fifth } \\
\text { lumbar. }\end{array}$ & $\begin{array}{l}\text { External rotator of } \\
\text { thigh. }\end{array}$ \\
\hline Quadratus lumborum. & $\begin{array}{l}\text { Crest of ilium, transverse } \\
\text { processes of lower three } \\
\text { lumbar vertebræ. }\end{array}$ & $\begin{array}{l}\text { Last rib, transverse pro- } \\
\text { cesses of upper three } \\
\text { lumbar vertebra. }\end{array}$ & $\begin{array}{l}\text { Upper lumbar and } \\
\text { twelfth thoracic. }\end{array}$ & Flexes thorax laterally. \\
\hline Quadratus menti. & See Depressor labii infe & riorus. & & \\
\hline $\begin{array}{l}\text { Quadriceps extensor } \\
\text { femoris. }\end{array}$ & $\begin{array}{l}\text { Includes the rectus, vastus } \\
\text { rounds the patella. }\end{array}$ & internus and externus, & ind crureus muscles. & heir common tendon sur- \\
\hline
\end{tabular}


TABLE OF MUSCLES-Continued.

\begin{tabular}{|c|c|c|c|c|}
\hline NAME. & ORIGIN. & INSERTION. & INNERVATION. & Function. \\
\hline Quadrigeminus capitis. & See Stemo-cleido-mastoid & eus. & & \\
\hline Radio-carpus. & See Flexor carpi radialis & brevis. & & \\
\hline Rectus abdominis. & $\begin{array}{l}\text { Pubic crest and fibrous } \\
\text { tissues in front of sym- } \\
\text { physis. }\end{array}$ & $\begin{array}{l}\text { Cartilages of the fifth to } \\
\text { seventh ribs. }\end{array}$ & $\begin{array}{l}\text { Intercostal, ilio-hypo- } \\
\text { gastric, ilio-inguinal. }\end{array}$ & $\begin{array}{l}\text { Compresses viscera and } \\
\text { flexes thorax. }\end{array}$ \\
\hline $\begin{array}{l}\text { Rectus capitis anticus } \\
\text { major. }\end{array}$ & $\begin{array}{l}\text { Transverse processes } 3 \mathrm{~d}- \\
6 \text { th cervical vertebræ. }\end{array}$ & Basilar process. & $\begin{array}{l}\text { First and second cer- } \\
\text { vical. }\end{array}$ & $\begin{array}{l}\text { Flexes head and slightly } \\
\text { rotates it. }\end{array}$ \\
\hline $\begin{array}{l}\text { Rectus capitis anticus } \\
\text { medius (anomalous). }\end{array}$ & $\begin{array}{l}\text { Middle of anterior sur- } \\
\text { face of body of axis. }\end{array}$ & $\begin{array}{l}\text { Basilar process of occi- } \\
\text { pital bone. }\end{array}$ & - & \\
\hline $\begin{array}{l}\text { Rectus capitis anticus } \\
\text { minor. }\end{array}$ & $\begin{array}{l}\text { Transverse process and } \\
\text { lateral mass of atlas. }\end{array}$ & $\begin{array}{l}\text { Basilar process of occi- } \\
\text { pital bone. }\end{array}$ & First cervical. & Flexes head. \\
\hline Rectus capitis lateralis. & $\begin{array}{c}\text { Ventral cephalic surface } \\
\text { of lateral mass of atlas. }\end{array}$ & $\begin{array}{l}\text { Jugulat process of occi- } \\
\text { pital bone. }\end{array}$ & First cervical. & Flexes head laterally. \\
\hline $\begin{array}{l}\text { Rectus capitis posticus } \\
\text { major. }\end{array}$ & Spine of axis. & $\begin{array}{l}\text { Inferior curved line of } \\
\text { occipital bone. }\end{array}$ & $\begin{array}{l}\text { Sub-occipital and } \\
\text { great occipital. }\end{array}$ & Rotates head. \\
\hline $\begin{array}{l}\text { Rectus capitis posticus } \\
\text { minor. }\end{array}$ & Dorsal arch of atlas. & $\begin{array}{l}\text { Below inferior curved } \\
\text { line of occipital bone. }\end{array}$ & $\left\{\begin{array}{c}\text { Sub-occipital and } \\
\text { great occipital. }\end{array}\right.$ & Draws head backward. \\
\hline Rectus externus. & $\begin{array}{l}\text { Two heads, outer margin } \\
\text { of optic foramen. }\end{array}$ & Sclera. & Sixth. & $\begin{array}{c}\text { Rotates eyeball out- } \\
\text { ward. }\end{array}$ \\
\hline Rectus femoris. & $\begin{array}{l}\text { Anterior inferior iliac } \\
\text { spine, brim acetabulum. }\end{array}$ & $\begin{array}{l}\text { Proximal border of } \\
\text { patella. }\end{array}$ & Anterior crural. & Extends leg. \\
\hline Rectus inferioris. & $\begin{array}{l}\text { Lower margin of optic } \\
\text { foramen. }\end{array}$ & Sclera. & Third. & $\begin{array}{l}\text { Rotates eyeball down- } \\
\text { ward. }\end{array}$ \\
\hline Rectus internus. & $\begin{array}{l}\text { Inner margin of optic } \\
\text { foramen. }\end{array}$ & Sclera. & Third. & Rotates eyeball inward. \\
\hline $\begin{array}{l}\text { Rectus sterna lis (or } \\
\text { sternalis) (anomalous). }\end{array}$ & $\begin{array}{l}\text { Sheath of rectus abdomi- } \\
\text { nis. }\end{array}$ & $\begin{array}{l}\text { Fascia over origin of } \\
\text { sterno-mastoid, or into } \\
\text { aponeurosis of pec- } \\
\text { toralis major. }\end{array}$ & & \\
\hline Rectus superioris. & $\begin{array}{l}\text { Upper margin of optic } \\
\text { foramen. }\end{array}$ & Sclera. & Third. & Rotates eyeball upward. \\
\hline Rectus thoracis. & See Supra-costalis. & & & \\
\hline Retractores uteri. & $\begin{array}{l}\text { A name sometimes given } \\
\text { to the sacro-uterine liga- } \\
\text { ments. }\end{array}$ & & & \\
\hline Retrahens aurem. & Mastoid process. & Concha. & Posterior auricular. & Retracts pinna. \\
\hline $\begin{array}{l}\text { Rhombo-atloid (anom- } \\
\text { alous). }\end{array}$ & $\begin{array}{l}\text { Sixth and seventh cervi- } \\
\text { cal and first thoracic } \\
\text { spinous processes. }\end{array}$ & $\begin{array}{l}\text { Transverse process of } \\
\text { atlas. }\end{array}$ & & \\
\hline Rhomboideus major. & $\begin{array}{l}\text { Spines of first five thor- } \\
\text { acic vertebra. }\end{array}$ & Root of spine of scapula. & Fifth cervical. & $\begin{array}{l}\text { Elevates and retracts } \\
\text { scapula. }\end{array}$ \\
\hline Rhomboideus minor. & $\begin{array}{l}\text { Spines of seventh cervical } \\
\text { and first dorsal vertebra. }\end{array}$ & Root of spine of scapula. & Fifth cervical. & $\begin{array}{l}\text { Retracts and elevates } \\
\text { scapula. }\end{array}$ \\
\hline Rhombo-occipital. & See Occipito-scapular. & & & \\
\hline Riolan's. & $\begin{array}{l}\text { The ciliary portion of the } \\
\text { orbicularis palpebrarum. }\end{array}$ & & & \\
\hline Risorius. & Fascia over masseter. & Angle of mouth. & Facial, buccal branch. & Draws angle laterad. \\
\hline $\begin{array}{l}\text { Rotator humeri (anom- } \\
\text { alous). }\end{array}$ & $\begin{array}{l}\text { Under surface and exter- } \\
\text { nal border of coracoid } \\
\text { process of scapula. }\end{array}$ & $\begin{array}{l}\text { Neck of humerus below } \\
\text { lesser tuberosity. }\end{array}$ & & \\
\hline Rotatores spinze. & $\begin{array}{l}\text { Transverse processes of } \\
\text { from second to twelfth } \\
\text { thoracic vertebra. }\end{array}$ & $\begin{array}{l}\text { Lamina of next vertebra } \\
\text { above. }\end{array}$ & Dorsal branches. & Rotate spinal column. \\
\hline $\begin{array}{l}\text { Sacro-coccygeus anti- } \\
\text { cus. }\end{array}$ & See Curvator coccygis. & & & \\
\hline $\begin{array}{l}\text { Sacro-coccygeus posti- } \\
\text { cus. }\end{array}$ & See Extensor coccygis. & & & \\
\hline Sacro-lumbalis. & Erector spinæ. & Angle of six lower ribs. & Branches of dorsal. & $\begin{array}{l}\text { Erects spine and bends } \\
\text { trunk backward. }\end{array}$ \\
\hline
\end{tabular}


TABLE OF MUSCLES.-Continued.

\begin{tabular}{|c|c|c|c|c|}
\hline NAME. & ORIGIN. & INSERTION. & INNERVATION. & FUNCTION. \\
\hline Salpingo-pharyngeus. & $\begin{array}{l}\text { A portion of the palato- } \\
\text { pharyngeus, } q . v \text {. }\end{array}$ & & & \\
\hline Santorini's. & See Risorius. & & & \\
\hline Sartorius. & $\begin{array}{l}\text { Anterior superior spine } \\
\text { of ilium. }\end{array}$ & $\begin{array}{l}\text { Upper internal portion } \\
\text { of shaft of tibia. }\end{array}$ & Anterior crural. & Flexes and crosses legs. \\
\hline$\overline{\text { Scalenus anticus. }}$ & $\begin{array}{l}\text { Scalene tubercle on first } \\
\text { rib. }\end{array}$ & $\begin{array}{l}\text { Transverse processes } 3 \mathrm{~d} \\
\text {-6th cervical vertebræ. }\end{array}$ & Lower cervical. & Flexes neck laterally. \\
\hline Scalenus medius. & First rib. & $\begin{array}{l}\text { Transverse processes of } \\
\text { six lower cervical ver- } \\
\text { tebra. }\end{array}$ & Lower cervical. & Flexes neck laterally. \\
\hline $\begin{array}{l}\text { Scalenus minimus (an- } \\
\text { omalous). }\end{array}$ & $\begin{array}{l}\text { Transverse processes of } \\
\text { lower cervical vertebra. }\end{array}$ & $\begin{array}{l}\text { First rib, behind sub- } \\
\text { clavian artery. }\end{array}$ & & \\
\hline Scalenus posticus. & Second rib. & $\begin{array}{l}\text { Transverse processes of } \\
\text { three lower cervical } \\
\text { vertebra. }\end{array}$ & Lower cervical. & Bends neck laterally. \\
\hline Scansorius. & See Accessory gluleus & minimus. & & \\
\hline Scapulo-costalis minor. & See Sterno-chondro-scupu & lar. & & \\
\hline Semi-membranosus. & Tuberosity of ischium. & Inner tuberosity of tibia. & Great sciatic. & $\begin{array}{l}\text { Flexes leg and rotates it } \\
\text { inward. }\end{array}$ \\
\hline Semispinalis capitis. & See Complexus. & · & & \\
\hline Semispinalis colli. & $\begin{array}{l}\text { Transverse processes four } \\
\text { upper dorsal and articu- } \\
\text { lar processes four lower } \\
\text { cervical vertebræ. }\end{array}$ & $\begin{array}{l}\text { Spines of second to fifth } \\
\text { cervical vertebræ. }\end{array}$ & Cervical branches. & Erects spinal column. \\
\hline Semispinalis dorsi. & $\begin{array}{l}\text { Transverse processes } 6 \text { th } \\
\text { to roth dorsal vertebræ. }\end{array}$ & $\begin{array}{l}\text { Spines last two cervical } \\
\text { and first four thoracic. }\end{array}$ & Branches of dorsal. & Erects spinal column. \\
\hline Semi-tendinosus. & Tuberosity of ischium. & $\begin{array}{l}\text { Upper and inner surface } \\
\text { of tibia. }\end{array}$ & Great sciatic. & Flexes leg on thigh. \\
\hline Serratus magnus. & Eight upper ribs. & $\begin{array}{l}\text { Inner margin of dorsal } \\
\text { border of scapula. }\end{array}$ & Posterior thoracic. & $\begin{array}{l}\text { Elevates ribs in inspira- } \\
\text { tion. }\end{array}$ \\
\hline $\begin{array}{l}\text { Serratus posticus infe- } \\
\text { rioris. }\end{array}$ & $\begin{array}{l}\text { Spines of last two thoracic } \\
\text { and first three lumbar. }\end{array}$ & Four lower ribs. & $\begin{array}{l}\text { Tenth and eleventh } \\
\text { intercostal. }\end{array}$ & $\begin{array}{l}\text { Depresses ribs in ex- } \\
\text { piration. }\end{array}$ \\
\hline $\begin{array}{l}\text { Serratus posticus supe- } \\
\text { rioris. }\end{array}$ & $\begin{array}{l}\text { Spines of seventh cervical } \\
\text { and first two thoracic } \\
\text { vertebræ. }\end{array}$ & $\begin{array}{l}\text { Second, third, fourth, } \\
\text { and fifth ribs. }\end{array}$ & $\begin{array}{l}\text { Second and third in- } \\
\text { tercostal. }\end{array}$ & $\begin{array}{l}\text { Raises ribs in inspira- } \\
\text { tion. }\end{array}$ \\
\hline Snarling. & See Levator labiii supe & rioris. & & \\
\hline Sneering. & See Levator labii supe & rioris alaqua nasi. & & \\
\hline Soleus. & $\begin{array}{l}\text { Shaft of fibula, oblique line } \\
\text { of tibia. }\end{array}$ & $\begin{array}{l}\text { Os calcis by tendo } \\
\text { Achillis. }\end{array}$ & $\begin{array}{l}\text { Internal popliteal and } \\
\text { posterior tibial. }\end{array}$ & Extends foot. \\
\hline $\begin{array}{l}\text { Spheno-pharyngeus (an- } \\
\text { omalous). }\end{array}$ & Spine of sphenoid bone. & Constrictors of pharynx. & & \\
\hline $\begin{array}{l}\text { Spheno-s a l p ingo-sta- } \\
\text { phylinus. }\end{array}$ & See Circumflexus palati. & & & \\
\hline Sphincter ani, external. & Tip of coccyx. & $\begin{array}{l}\text { Tendinous center of } \\
\text { perineum. }\end{array}$ & $\begin{array}{l}\text { Perineal, pudic, and } \\
\text { fourth sacral. }\end{array}$ & Closes anus. \\
\hline Sphincter ani, internal. & $\begin{array}{l}\text { A thickening of the circu- } \\
\text { lar fibers of the intestine } \\
\text { one inch above the anus. }\end{array}$ & & Hemorrhoidal nerves. & Constricts rectum. \\
\hline Sphincter vaginæ. & $\begin{array}{l}\text { Central tendon of peri- } \\
\text { neum. }\end{array}$ & $\begin{array}{l}\text { Corpora cavernosa and } \\
\text { clitoris. }\end{array}$ & Homologue of accelera & tor urinze in male. \\
\hline $\begin{array}{l}\text { Sphincter vesica inter- } \\
\text { nus. }\end{array}$ & $\begin{array}{l}\text { Near the urethral orifice of } \\
\text { the bladder. }\end{array}$ & & Vesical nerves. & $\begin{array}{l}\text { Constricts internal ori- } \\
\text { fice of urethra. }\end{array}$ \\
\hline $\begin{array}{l}\text { Spinalis cervicis (nor- } \\
\text { mal, but inconstant). }\end{array}$ & $\begin{array}{l}\text { Spines } 5 \text { th, 6th, and } 7 \text { th } \\
\text { cervical and first two } \\
\text { thoracic vertebre. }\end{array}$ & $\begin{array}{l}\text { Spine of axis, some- } \\
\text { times spines of } 3 \mathrm{~d} \text { and } \\
4^{\text {th }} \text { cervical vertebræ. }\end{array}$ & & \\
\hline Spinalis colli. & $\begin{array}{l}\text { Spines of fifth and sixth } \\
\text { cervical vertebrz. }\end{array}$ & $\begin{array}{l}\text { Spine of axis, or third } \\
\text { and fourth cervical } \\
\text { spines. }\end{array}$ & Cervical branches. & Steadies neck. \\
\hline Spinalis dorsi. & $\begin{array}{l}\text { Last two thoracic and first } \\
\text { two lumbar spines. }\end{array}$ & $\begin{array}{l}\text { Remaining thoracic } \\
\text { spines. }\end{array}$ & Dorsal branches. & Erects spinal column. \\
\hline
\end{tabular}


TABLE OF MUSCLES.-Continued.

\begin{tabular}{|c|c|c|c|c|}
\hline NAME. & ORIGIN. & INSERTION. & INNERVATION. & FUNCTION. \\
\hline Splenius accessorius. & See Rhombo-atloid. & & & \\
\hline Splenius capitis. & $\begin{array}{l}\text { Lower two-thirds ligamen- } \\
\text { tum nuchæ, spines of } \\
\text { seventh cervical and first } \\
\text { two thoracic vertebra. }\end{array}$ & $\begin{array}{l}\text { Outer third of middle ob- } \\
\text { lique line of occiput } \\
\text { and outer surface of } \\
\text { mastoid process. }\end{array}$ & $\begin{array}{l}\text { Middle cervical, pos- } \\
\text { terior branches. }\end{array}$ & $\begin{array}{l}\text { Extends head and neck } \\
\text { and rotates and flexes } \\
\text { laterally. }\end{array}$ \\
\hline Splenius colli. & $\begin{array}{l}\text { Spines of third to sixth } \\
\text { thoracic vertebræ. }\end{array}$ & $\begin{array}{l}\text { Dorsal tubercles of } \\
\text { transverse processes of } \\
\text { upper three or four } \\
\text { cervical vertebra. }\end{array}$ & $\begin{array}{l}\text { Posterior divisions of } \\
\text { lower cervical. }\end{array}$ & $\begin{array}{l}\text { Extends, flexes laterally, } \\
\text { and rotates neck. }\end{array}$ \\
\hline Stapedius. & Interior of pyramid. & Neck of stapes. & Facial. & Depresses base of stapes. \\
\hline Sternalis. & See Rectus stemalis. & & & \\
\hline $\begin{array}{l}\text { Sterno - chondro - scap- } \\
\text { ular (anomalous). }\end{array}$ & $\begin{array}{l}\text { Root of coracoid process, } \\
\text { or cephalic border of } \\
\text { scapula. }\end{array}$ & $\begin{array}{l}\text { Costal cartilage of first } \\
\text { rib, first piece of ster- } \\
\text { num, or both. }\end{array}$ & & \\
\hline $\begin{array}{l}\text { Sterno-clavicularis, an- } \\
\text { terior. }\end{array}$ & See Sterno-chondro-scapu & lar. & & \\
\hline Sterno-cleido-mastoid. & $\begin{array}{l}\text { Two heads, sternum and } \\
\text { clavicle. }\end{array}$ & $\begin{array}{l}\text { Mastoid-process and } \\
\text { outer half of superior } \\
\text { oblique line of occiput. }\end{array}$ & $\begin{array}{l}\text { Spinal accessory and } \\
\text { cervical plexus. }\end{array}$ & $\begin{array}{l}\text { Depresses and rotates } \\
\text { head. }\end{array}$ \\
\hline $\begin{array}{l}\text { Sterno-facialis (anomal- } \\
\text { ous). }\end{array}$ & $\begin{array}{c}\text { First piece of sternum, } \\
\text { behind sterno-mastoid. }\end{array}$ & $\begin{array}{l}\text { Fascia of subclavian tri- } \\
\text { angle. }\end{array}$ & & \\
\hline Sterno-hyoid. & Sternum and clavicle. & Hyoid bone. & $\begin{array}{l}\text { Descending and com- } \\
\text { municating branches } \\
\text { of the hypoglossal. }\end{array}$ & Depresses hyoid. \\
\hline Sterno-scapular. & See Sterno-chondro-scapu & lar. & & \\
\hline Sterno-thyroid. & $\begin{array}{l}\text { Sternum and cartilage of } \\
\text { first rib. }\end{array}$ & $\begin{array}{l}\text { Side of thyroid carti- } \\
\text { lage. }\end{array}$ & $\begin{array}{l}\text { Descendens and com- } \\
\text { municans hypoglossi. }\end{array}$ & Depresses larynx. \\
\hline Stylo-auricularis. & $\begin{array}{l}\text { A name given to the stylo- } \\
\text { glossus, when it arises } \\
\text { from the external audi- } \\
\text { tory meatus. }\end{array}$ & & & \\
\hline $\begin{array}{l}\text { Stylo-chondro-hyoideus } \\
\text { (anomalous). }\end{array}$ & Styloid process. & Lesser cornu of hyoid. & & \\
\hline Stylo-glossus. & Styloid process. & Side of tongue. & Hypoglossal. & $\begin{array}{l}\text { Elevates and retracts } \\
\text { tongue. }\end{array}$ \\
\hline Stylo-hyoid. & Styloid process. & Body of hyoid. & Facial. & $\begin{array}{l}\text { Draws hyoid upward } \\
\text { and backward. }\end{array}$ \\
\hline Stylo-hyoideus alter. & See Stylo-chondro-hyoid & eus. & & \\
\hline $\begin{array}{l}\text { Stylo-hyo-t hy roi de us } \\
\text { (anomalous). }\end{array}$ & Styloid process. & $\begin{array}{l}\text { Hyoid bone and tip of } \\
\text { superior cornu of thy- } \\
\text { roid cartilage. }\end{array}$ & & \\
\hline $\begin{array}{l}\text { Stylo-maxillaris (anom- } \\
\text { alous). }\end{array}$ & $\begin{array}{l}\text { The stylo-hyoideus, when } \\
\text { it extends from the sty- } \\
\text { loid process to the angle } \\
\text { of the lower jaw. }\end{array}$ & & & \\
\hline Stylo-pharyngeus. & Styloid process. & Thyroid cartilage. & $\begin{array}{l}\text { Glosso-p h a ryngeal, } \\
\text { and pharyngeal plex- } \\
\text { us. }\end{array}$ & Elevates pharynx. \\
\hline Subanconeus. & $\begin{array}{l}\text { Humerus above olecranon } \\
\text { fossa. }\end{array}$ & $\begin{array}{l}\text { Posterior ligament of } \\
\text { elbow. }\end{array}$ & Musculo-spiral. & Tensor of ligament. \\
\hline Subclavius. & Cartilage of first rib. & $\begin{array}{l}\text { Inferior surface of cla- } \\
\text { vicle. }\end{array}$ & $\begin{array}{l}\text { Fifth and sixth cervi- } \\
\text { cal. }\end{array}$ & $\begin{array}{l}\text { Draws clavicle down- } \\
\text { ward. }\end{array}$ \\
\hline Subclavius posticus. & See Stemo-chondro-scapu & lar. & & \\
\hline Subcostals. & See Infracostals. & & & \\
\hline Subcrureus. & $\begin{array}{l}\text { Anterior distal part of } \\
\text { femur. }\end{array}$ & $\begin{array}{l}\text { Synovial sac behind } \\
\text { patella. }\end{array}$ & Anterior crural. & Draws sac up. \\
\hline Subscapularis. & Ental surface of scapula. & $\begin{array}{l}\text { Humerus, lesser tuber- } \\
\text { osity, and shaft. }\end{array}$ & Subscapular. & $\begin{array}{l}\text { Chief internal rotator of } \\
\text { humerus. }\end{array}$ \\
\hline $\begin{array}{c}\text { Subscapularis minor } \\
\text { (anomalous). }\end{array}$ & Axillary border of scapula. & $\begin{array}{l}\text { Capsule of shoulder- } \\
\text { joint or humerus. }\end{array}$ & & \\
\hline Subscapulo-capsularis. & See Subscapularis minor. & & & \\
\hline
\end{tabular}


TABLE OF MUSCLES.-Continued.

\begin{tabular}{|c|c|c|c|c|}
\hline NAME. & ORIGIN. & INSERTION. & INNERVATION. & FUNCTION. \\
\hline Supinator longus. - & $\begin{array}{l}\text { External condyloid ridge } \\
\text { of humerus. }\end{array}$ & $\begin{array}{l}\text { Styloid process of radi- } \\
\text { us. }\end{array}$ & Musculo-spiral. & Flexes forearm. \\
\hline Supinator radii brevis. & $\begin{array}{l}\text { External condyle of hu- } \\
\text { merus, oblique line of } \\
\text { ulna. }\end{array}$ & $\begin{array}{l}\text { Neck of radius and its } \\
\text { bicipital tuberosity. }\end{array}$ & $\begin{array}{l}\text { Posterior interos- } \\
\text { seous. }\end{array}$ & Supinates hand. \\
\hline $\begin{array}{l}\text { Supra-clavicularis (an- } \\
\text { omalous). }\end{array}$ & Manubrium sterni. & Clavicle. & & \\
\hline $\begin{array}{l}\text { Supra-costalis (anomal- } \\
\text { ous). }\end{array}$ & First rib. & Fourth rib. & & \\
\hline Supra-spinales. & \multicolumn{4}{|c|}{ Lie on spinous processes in cervical region. } \\
\hline Supra-spinatus. & Supra-spinous fossa. & $\begin{array}{l}\text { Great tuberosity of hu- } \\
\text { merus. }\end{array}$ & Supra-scapular. & $\begin{array}{l}\text { Supports shoulder-joint, } \\
\text { raises arm. }\end{array}$ \\
\hline Tailors'. & See Sartorius. & & & \\
\hline Temporal. & Temporal fossa and fascia. & $\begin{array}{l}\text { Coronoid process of } \\
\text { mandible. }\end{array}$ & Inferior maxillary. & Closes mandible. \\
\hline $\begin{array}{l}\text { Temporalis minor (an- } \\
\text { omalous). }\end{array}$ & $\begin{array}{l}\text { Interarticular fibro-carti- } \\
\text { lages of mandible, front } \\
\text { and back borders. }\end{array}$ & $\begin{array}{l}\text { Bottom of sigmoid notch } \\
\text { of lower jaw. }\end{array}$ & & \\
\hline Tensor fasciæ colli. & See Sterno-facialis. & & & \\
\hline $\begin{array}{l}\text { Tensor fascize plantaris } \\
\text { (anomalous). }\end{array}$ & Plantaris. & Plantar fascia. & & \\
\hline Tensor palati. & $\begin{array}{l}\text { Scaphoid fossa and alar } \\
\text { spine of sphenoid. }\end{array}$ & $\begin{array}{l}\text { About hamular process } \\
\text { into soft paiate. }\end{array}$ & Otic ganglion. & Renders palate tense. \\
\hline Tensor tarsi. & Crest of lacrymal bone. & Tarsal cartilages. & $\begin{array}{c}\text { Facial, infraorbital } \\
\text { branch. }\end{array}$ & $\begin{array}{l}\text { Compresses puncta and } \\
\text { lacrymal sac. }\end{array}$ \\
\hline $\begin{array}{l}\text { Tensor trochlea (anom- } \\
\text { alous). }\end{array}$ & Levator palpebræ. & Trochlea. & & \\
\hline Tensor tympani. & $\begin{array}{l}\text { Temporal bone, Eusta- } \\
\text { chian tube and canal, } \\
\text { sphenoid bone. }\end{array}$ & Handle of malleus. & Otic ganglion. & $\begin{array}{l}\text { Renders tense the mem- } \\
\text { brana tympani. }\end{array}$ \\
\hline Tensor vaginæe femoris. & $\begin{array}{l}\text { Iliac crest and anterior } \\
\text { superior spinous process. }\end{array}$ & Fascia lata. & Superior gluteal. & Tensor of fascia. \\
\hline Teres major. & Inferior angle of scapula. & $\begin{array}{l}\text { Internal bicipital ridge } \\
\text { of humerus. }\end{array}$ & Subscapular. & $\begin{array}{l}\text { Draws arm downward } \\
\text { and backward. }\end{array}$ \\
\hline Teres minor. & $\begin{array}{l}\text { Axillary border of scapu- } \\
\text { la. }\end{array}$ & $\begin{array}{l}\text { Great tuberosity of hu- } \\
\text { merus. }\end{array}$ & Circumflex. & $\begin{array}{l}\text { Rotates humerus out- } \\
\text { ward and adducts it. }\end{array}$ \\
\hline Thyro-arytenoideus. & $\begin{array}{l}\text { Thyroid cartilage and cri- } \\
\text { co-thyroid membrane. }\end{array}$ & $\begin{array}{l}\text { Arytenoid, inferior and } \\
\text { anterior surface. }\end{array}$ & Recurrent laryngeal. & Relaxes vocal bands. \\
\hline Thyro-epiglottideus. & $\begin{array}{l}\text { Inner surface of thyroid } \\
\text { cartilage. }\end{array}$ & $\begin{array}{l}\text { Epiglottis and aryteno- } \\
\text { epiglottidean fold. }\end{array}$ & Recurrent laryngeal. & Depresses epiglottis. \\
\hline Thyro-hyoid. & Side of thyroid cartilage. & $\begin{array}{l}\text { Body and greater cornu } \\
\text { of hyoid bone. }\end{array}$ & Hypoglossal. & Elevates larynx. \\
\hline Tibialis anticus. & $\begin{array}{l}\text { Outer tuberosity and up- } \\
\text { per part of shaft of tibia. }\end{array}$ & $\begin{array}{l}\text { Internal cuneiform and } \\
\text { first metatarsal bone. }\end{array}$ & Anterior tibial. & $\begin{array}{l}\text { Flexes tarsus and ele- } \\
\text { vates inner border of } \\
\text { foot. }\end{array}$ \\
\hline Tibialis posticus. & $\begin{array}{l}\text { Shaft of fibula and tibia, } \\
\text { interosseous membrane. }\end{array}$ & $\begin{array}{l}\text { Tuberosity of scaphoid, } \\
\text { internal cuneiform, and } \\
\text { bases of second to } \\
\text { fourth metatarsal. }\end{array}$ & Posterior tibial. & $\begin{array}{l}\text { Extends tarsus and in- } \\
\text { verts foot. }\end{array}$ \\
\hline $\begin{array}{l}\text { Tibialis secundus (an- } \\
\text { omalous). }\end{array}$ & $\begin{array}{l}\text { Back of tibia below flexor } \\
\text { digitorum longus. }\end{array}$ & $\begin{array}{l}\text { Posterior part of cap- } \\
\text { sule of ankle-joint, or } \\
\text { annular ligament. }\end{array}$ & & \\
\hline Tibio-accessorius. & See Flexor accessorius & longus digitorum pedis. & & \\
\hline $\begin{array}{l}\text { Tibio-astragalus anticus } \\
\text { (anomalous). }\end{array}$ & $\begin{array}{l}\text { Tibia and interosseous } \\
\text { membrane behind tibia- } \\
\text { lis anticus. }\end{array}$ & Neck of astragalus. & & \\
\hline $\begin{array}{l}\text { Tibio-fascialis anticus } \\
\text { (anomalous). }\end{array}$ & $\begin{array}{l}\text { Lower third of anterior } \\
\text { border of tibia. }\end{array}$ & $\begin{array}{l}\text { Annular ligament and } \\
\text { deep fascia. }\end{array}$ & & \\
\hline Trachealis. & $\begin{array}{l}\text { A transverse layer of un- } \\
\text { striped muscular fibers } \\
\text { at the dorsal part of } \\
\text { the trachea. }\end{array}$ & & Sympathetic. & \\
\hline
\end{tabular}


TABLE OF MUSCLES.-Continued.

\begin{tabular}{|c|c|c|c|c|}
\hline NAME. & ORIGIN. & INSERTION. & INNERVATION. & FUNCTION. \\
\hline Trachelo-mastoid. & $\begin{array}{l}\text { Trausverse processes of } \\
3 \mathrm{~d}-6 \mathrm{th} \text { thoracic, and ar-* } \\
\text { ticular processes of last } \\
3 \text { or } 4 \text { cervical vertebra. }\end{array}$ & Mastoid process. & Branches of cervical. & Steadies head. \\
\hline Tragicus. & Tragus. & Tragus. & $\begin{array}{l}\text { Temporal and poste- } \\
\text { rior auricular. }\end{array}$ & \\
\hline $\begin{array}{l}\text { Transversalis abdomi- } \\
\text { nis. }\end{array}$ & $\begin{array}{l}\text { Poupart's ligament, iliac } \\
\text { crest, six lower ribs, } \\
\text { lumbar vertebra. }\end{array}$ & $\begin{array}{l}\text { Linea alba, pubic crest, } \\
\text { pectineal line. }\end{array}$ & $\begin{array}{l}\text { Intercostal, ilio-hypo- } \\
\text { gastric, ilio-inguinal. }\end{array}$ & $\begin{array}{l}\text { Compresses viscera and } \\
\text { flexes thorax. }\end{array}$ \\
\hline $\begin{array}{l}\text { Transversalis cervicis } \\
\text { anticus (anomalous). }\end{array}$ & $\begin{array}{l}\text { Anterior tubercles of } \\
\text { transverse processes of } \\
\text { the four lower cervical } \\
\text { vertebra. }\end{array}$ & $\begin{array}{l}\text { Base of transverse pro- } \\
\text { cess of atlas and body } \\
\text { of axis. }\end{array}$ & & \\
\hline $\begin{array}{l}\text { Transversalis cervicis } \\
\text { medius (anomalous). }\end{array}$ & $\begin{array}{l}\text { Transverse processes of } \\
\text { second, third, and fourth } \\
\text { cervical vertebræ. }\end{array}$ & $\begin{array}{l}\text { Sixth and seventh cer- } \\
\text { vical transverse pro- } \\
\text { cesses. }\end{array}$ & & \\
\hline Transversalis coili. & $\begin{array}{l}\text { Transverse processes of } \\
\text { third to sixth thoracic } \\
\text { vertebræ. }\end{array}$ & $\begin{array}{l}\text { Transverse processes of } \\
\text { five lower cervical ver- } \\
\text { tebræ. }\end{array}$ & Cervical branches. & Keeps neck erect. \\
\hline Transversus auris. & Convexity of concha. & $\begin{array}{l}\text { Convexity over groove } \\
\text { of helix. }\end{array}$ & Retracts helix. & $\begin{array}{l}\text { Temporal and posterior } \\
\text { auricular. }\end{array}$ \\
\hline $\begin{array}{l}\text { Transversus menti (an- } \\
\text { omalous). }\end{array}$ & $\begin{array}{l}\text { Inner border of depressor } \\
\text { anguli oris. }\end{array}$ & $\begin{array}{l}\text { Corresponding part of } \\
\text { opposite side of chin. }\end{array}$ & & \\
\hline $\begin{array}{l}\text { Transversus nuchae (an- } \\
\text { omalous). }\end{array}$ & $\begin{array}{l}\text { External occipital protu- } \\
\text { berance. }\end{array}$ & $\begin{array}{l}\text { Aponeurosis of sterno- } \\
\text { mastoid. }\end{array}$ & & \\
\hline $\begin{array}{l}\text { Transversus orbita (an- } \\
\text { omalous). }\end{array}$ & Orbital plate of ethmoid. & Lateral wall of orbit. & & \\
\hline Transversus pedis. & $\begin{array}{l}\text { Head } 5 \text { th metatarsal and } \\
\text { plantar ligaments of meta- } \\
\text { tarso-phalangeal joints. }\end{array}$ & $\begin{array}{l}\text { First phalanx of great } \\
\text { toe. }\end{array}$ & External plantar. & Adducts great toe. \\
\hline $\begin{array}{l}\text { Transversus pedis, } \\
\text { superficial (anomalous). }\end{array}$ & $\begin{array}{c}\text { Bases of first phalanges } \\
\text { of } 2 \mathrm{~d}, 3 \mathrm{~d} \text {, and } 5 \text { th toes. }\end{array}$ & $\begin{array}{l}\text { Base of first phalanx of } \\
\text { great toe. }\end{array}$ & & \\
\hline Transversus perinei. & Ramus of ischium. & Central tendon. & Perineal. & Tensor of central tendon. \\
\hline $\begin{array}{l}\text { Transversus perinei, } \\
\text { deep. }\end{array}$ & See Compressor urethree. & & & \\
\hline Trapezius. & $\begin{array}{l}\text { Superior curved line of } \\
\text { occipital bone, spinous } \\
\text { processes of last cervical } \\
\text { and all the dorsal verte- } \\
\text { bra. }\end{array}$ & $\begin{array}{l}\text { Clavicle and spine of } \\
\text { scapula, and acro- } \\
\text { mion. }\end{array}$ & $\begin{array}{l}\text { Spinal accessory and } \\
\text { cervical plexus. }\end{array}$ & Draws head backward. \\
\hline Triangularis menti. & See Depressor anguli oris. & & & \\
\hline Triangularis sterni. & $\begin{array}{l}\text { Ensiform cartilage, costal } \\
\text { cartilages of } 3 \text { or } 4 \text { lower } \\
\text { true ribs, and sternum. }\end{array}$ & $\begin{array}{l}\text { Border of inner surfaces } \\
2 \mathrm{~d}, 3 \mathrm{~d} \text {, 4th, and } 5 \text { th } \\
\text { costal cartilages. }\end{array}$ & Intercostal. & Expiration. \\
\hline $\begin{array}{l}\text { Triceps }(3 \text { heads) exten- } \\
\text { sor cubiti. }\end{array}$ & $\begin{array}{l}\text { Externaland internalnear } \\
\text { musculo-spiral groove, } \\
\text { shaft of humerus; middle } \\
\text { or long, lower margin } \\
\text { of glenoid cavity. }\end{array}$ & $\begin{array}{l}\text { Olecranon process of } \\
\text { ulna. }\end{array}$ & Musculo-spiral. & Extends forearm. \\
\hline $\begin{array}{l}\text { Triticeo-glossus (anom- } \\
\text { alous). }\end{array}$ & $\begin{array}{l}\text { Cartilago-triticea in the } \\
\text { thyro-hyoid ligament. }\end{array}$ & Side of tongue. & & \\
\hline $\begin{array}{l}\text { Ulnaris quinti (anomal- } \\
\text { ous). }\end{array}$ & $\begin{array}{l}\text { Prolongation of tendon of } \\
\text { extensor carpi ulnaris to } \\
\text { Ist phalanx of little finger. }\end{array}$ & & & \\
\hline $\begin{array}{l}\text { Ulno-carpus (anomal- } \\
\text { ous). }\end{array}$ & Lower surface of ulna. & $\begin{array}{l}\text { Annular ligament or one } \\
\text { of the carpal bones. }\end{array}$ & & \\
\hline Vastus externus. & $\begin{array}{l}\text { Anterior border great tro- } \\
\text { chanter and linea aspera. }\end{array}$ & Tuberosity of tibia. & Anterior crural. & Extends leg. \\
\hline $\begin{array}{l}\text { Vastus internus and } \\
\text { crureus. }\end{array}$ & $\begin{array}{l}\text { Inner lip of linea aspera of } \\
\text { femur. }\end{array}$ & Tuberosity of tibia. & Anterior crural. & Extends leg. \\
\hline Vesico-pubic. & Urachus. & Back of pubic bones. & $\begin{array}{l}\text { Compresses vesical } \\
\text { wall. }\end{array}$ & Sympathetic. \\
\hline Wilson's. & $\begin{array}{l}\text { A portion of the constric- } \\
\text { tor urethræ, } q . v \text {. }\end{array}$ & & & \\
\hline $\begin{array}{l}\text { Zygomaticus major et } \\
\text { minor. }\end{array}$ & Malar bone. & Angle of mouth. & $\begin{array}{l}\text { Facial, infraorbital } \\
\text { branch. }\end{array}$ & Elevates lip outward. \\
\hline
\end{tabular}


Muscular (mus'-ku-ler) [muscularis, of a muscle] Pertaining to, resembling, composed of, or having well-developed, muscles. M. Fiber, a fiber of muscular tissue. It exists in two varieties, striped and unstriped, the latter being associated with involuntary, the former with voluntary motion. M. Force, the energy produced in muscular motion. It is thought to be derived from the oxidation of the fats or carbohydrates of muscular tissue. M. Hypertrophy. See Paralysis, Psendo-hypertrophic. M. Motion, the phenomena attending a self-produced change of position of the body or of any of its parts. It includes voluntary, involuntary, and mixed movements. See Motion. M. Plate. Same as Muscle-plate. M. Rheumatism, rheumatism affecting the muscles. Synonym of Myalgia. M. Sensations, the feelings that accompany the action of muscles. M. Sense, the sense of motion, weight, and position upon which the adjustment of the body to its surroundings depends. Sensory-nerve fibrils probably exist in muscles that convey these sensations. The capacity of experiencing muscular sensations. M. System, all the muscles of the body correlated. The totality of the muscular tissue of the body. M. Tissue, the substance of muscle ; this appears in two principal varieties-the striped, striated, or voluntary, and the unstriped, non-striated, or involuntary. The striped muscular tissue is composed of muscle-fibers, the unstriped of elongated, spindle-shaped cells. A muscle-fiber consists: (I) of sarcolemma; (2) of muscle-nuclei; (3) of muscle-substance. The sarcolemma is an elastic, homogeneous connective-tissue sheath which lightly invests the muscle-fiber. The nuclei are fusiform in shape, are situated immediately beneath the sarcolemma, and run parallel with the axis of the fiber. The muscle-fiber itself consists of two substances-a dark, doubly refracting, or anisotropic contractite substance, and a lighter, semi-fluid, isotropic substance termed sarcoplasm. The contractile substance consists of delicate spindles, the apposition of whose thicker portions produces the dark transverse disc. The spindles terminate in minute beads, the juxtaposition of which gives rise to the intermediate disc or membrane of Krause. The neutral sarcoplasm fills out the spaces left between the-spindles, and, as ordinarily the tapering ends of the spindles are too delicate to be seen, the space between the intermediate and transverse discsthe lateral disc-looks homogeneous. The contractile fibrillæ into which the contractile substance is divided, formed by the end-to-end union of the spindles, is aggregated into bundles-the muscle-columns-surrounded by a layer of sarcolemma. On transverse section these muscle-columns give rise to the appearance known as Colinheim's fields. The muscle-fibers are held together by delicate areolar tissue, the endomysium. Several grouped together form a primary bundle. Primary bundles are surrounded by a sheath termed the endomysium. Fasciculi are aggregations of primary bundles, and are the units of which the complete muscle is composed, the latter being surrounded by the perimysium. M. Tumor. See Myoma.

Muscularis (mus-ku-la'-ris) [musculus, a muscle]. The muscular coat of an organ. M. mucosæ, the layer of unstriped muscular tissue separating the mucosa (of mucous membranes) from the submucosa.

Muscularity (mus-ku-lar'-it-e) [musculus, a muscle]. The quality of being muscular.

Musculation (mus-ku-la'-shun) [musculus, a muscle]. The muscular endowment of the body or a part; also the action of the muscles of the body.

Musculature (mus'-ku-la-tür) [musculus, muscle]. The muscular system of the body, an organ, or part.
Musculi (mus'-ku-li) [L.]. Plural of musculus, a muscle. M. codonoides, the middle bell-muscles of a medusa. M. papillaris. See Muscles, Papillary. M. pectinati [pecten, a comb], small, muscular columns traversing the inner surface of the appendix auriculæ and the adjoining portion of the wall of the auricle. M. proboscidalis, the proboscidal muscles of the Medusa.

Musculin (mus'-ku-lin) [musculus, a muscle]. Ex* tract of muscle-tissue. See Organotherapy.

Musculinteger (mus-ku-lin'-te-jer) [musculus, muscle ; integer, whole]. A combination of several muscles functionally connected and acting as a single muscle.

Musculo- (mus'-ku-lo) [musculus, a muscle]. A prefix to denote connection with or relation to muscular tissue. M.-aponeurotic, composed of muscle and of fibrous connective tissue in the form of a membrane. M.-cutaneous. See Nerves, Table of. M.-membranous, membranous and muscular in character. M.-phrenic, pertaining to the muscular portion of the diaphragm; as the musculo-phrenic artery. See Arteries, Table of. M.-spiral. See Nerves, Table of.

Musculous (mus'-ku-lus) [musculus, muscle]. Containing or composed of muscle-fibers.

Musculus (mus'-ku-lus). See Muscle.

Muscus (mus'-kus) [L.]. Moss; lichen.

Musenin (mus'-en-in). See Moussenin.

Museum (mu-ze'-um) [Moṽ $\sigma \alpha$, a muse]. Formerly, any library or place devoted to the arts and sciences, because these were supposed to be presided over by the Muses. Any systematic collection of objects of nature or of art.

Mush. A thick porridge, or boiled pudding, usually of maize meal, used as an article of diet, and alsa as a poultice.

Mushroom (mush'-rūm). See Agaric and Fungus.

Musicians' Cramp. See Cramp.

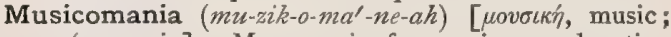
ravia, mania]. Monomania for, or insane devotion to, music.

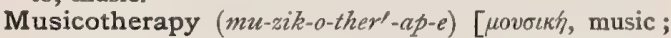
$\theta \varepsilon \rho a \pi \varepsilon i a$, treatment]. The use of music in the treatment of disease, chiefly mental and nervous diseases, and in convalescence.

Musk [ME., musk, musk]. See Moschus. M. Root. See Sumbul.

Muskardine (mus'-kar-din) [F. muscardine, the name of a fungus]. A disease very destructive to silkworms in Europe during the early part of the 19th century, practically disappearing among cultivated worms after 1855 ; it was caused by the fungus Botrytis bassiana, popularly called Muskardine.

Muskeg Moss (mus'-keg) [Chippewa, maskey, swamp]. A plant of the Northwestern United States, recommended as a cheap and excellent absorbent material for surgical dressings. Under this name various species of Sphagnum and Hydnum are confounded.

Musomania (mu-zo-ma'-ne-ah). See Musicomania.

Mussanin (mus'-an-in). See Moussenin.

Mussel-poisoning (mus'-l-poiz'-n-ing). The toxic effects in man sometimes resulting from eating mussels, especially the Mytilus edulis. See Mytilotoxin, and Poisons, Table of.

Mussitation (mus-it-a'-shun) [mussitatio; mussitare, to mutter]. The muttering frequently observed in severe illness, consisting of the movement of the lips without the production of articulate speech.

Must [mustum, new wine]. The juice freshly expressed from grapes by a mechanical process. This must is submitted to the process of spontaneous fermentation, following exposure to the air. 
Mustache, Moustache (mus-tash') [Fr., from $\mu$ v́cta $\xi$, mustache]. The beard worn on the upper lip of men.

Mustard (mus'-tera) [ME., mustarde, mustard]. See Sinapis. M.-bath. See Bath. M.-plaster, a powerful counter-irritant plaster, usually made of equal parts of ground mustard and linseed meal. See Sinapis. M.-poultice. Same as $M$-plaster.

Mutacism (mu'-tas-izm) [ Mytacism; faulty speech; utterance characterized by the too frequent use of the $m$ sound, and its substitution for other sounds.

Mutant (mu'-tant) [mutare, to change]. In biology, applied to any upright part the tip of which is bent over.

Mutation (mu-ta'shun) [mutare, to change]. Change; in obstetrics, a pronounced change in the presentation of the fetus.

Mute (mūt) [mutus, dumb]. Dumb. Unable to use articulate speech

Muticous (mu'-tik-us) [muticus, curtailed]. In biology, unarmed; not provided with a spine, spur, or claw; the autonym of mucronate, cuspidate, aristate, unguiculate, calcarate, dentate.

Mutilation (mu-til-a'-shun) [mutilatio; mutilare, to cut]. The act of being cut or disfigured. Also, the condition of the parts remaining after the excision or amputation of a member or part.

Mutinus (mu-tin'-us) [L.]. An old name for penis.

Mutisia (mu-tiz'-e-ah) [after José Celestino Mutis, a S. American botanist]. The seeds of $M$. vicicefolia, a composite-flowered plant native to Andean regions. Among the natives it has reputed qualities as a cardiac tonic, and is also used in various affections of the respiratory organs. Unof.

Mutisin (mu'-tis-in) [after J. C. Mutis, a S. A. botanist]. The active principle of Mutisia viciafolia.

Mutism (mu'-tizm) [mutus, dumb]. Dumbness. See Mutitas.

Mutitas (mu'-tit-as) [mutus, mute]. Dumbness. M. atonica, dumbness arising from disorder of the nerves of the tongue. $\mathbf{M}$. organica, that from loss of the tongue. M. pathematica, dumbness caused by fright or passion. M. spasmodica, spasmodic dumbness. M. surdorum, dumbness consequent upon congenital deafness.

Mutton $\left(m u t^{\prime}-n\right)$ [montonus, a sheep]. The flesh of sheep.

Mutualism ( $m u^{\prime}$-chu-al-izm) [mutuus, reciprocal]. A form of commensalism; the living together of two organisms of different species for the sake of the advantage that each one derives from the presence of the other. See Symbiosis.

Mutualist (mu'-chu-al-ist) [mutuus, reciprocal]. An organism living with another in a state of mutualism.

Muzzle (muz'-l) [ME, muzle, muzzle]. The projecting jaws and nose of an animal; a snout.

Muzzling (muz'-ling). Same as Infibulation.

Myalgia (mi-al'-je-ah) [ $\mu \tilde{v} s$, muscle; ǎ̀ $\gamma o s$, pain]. Any pain of the muscles; muscular rheumatism. $\mathbf{M}$. rheumatica. Synonym of Myalgia or Muscular Rheumatism.

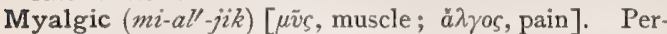
taining to or affected with myalgia.

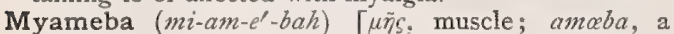
unicellular organism]. In biology, a muscle-cell regarded as an organism. Cf. Neurameba, Osteameba.

Myasis (mi-a'-sis). See Myiosis.

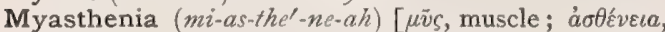
weakness]. Muscular debility.

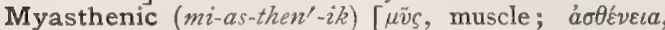
weakness]. Characterized by myasthenia.

Mycele (mi-sell'). Same as Mycelium.

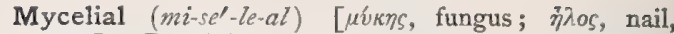
wart]. Pertaining to mycelium.

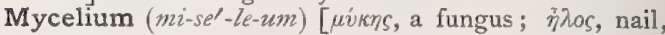
wart, excrescence]. In biology, a collective term for the vegetative hyphæ of fungi, usually forming interwoven masses.

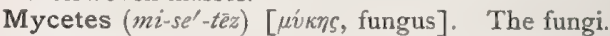

Mycetogenesis (mi-set-o-jen'-es-is) [ [úkns, fungus;

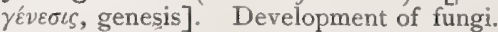

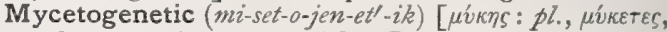

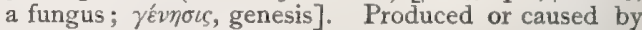
the growth of fungi.

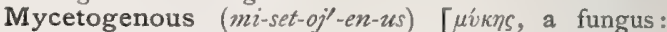
$\gamma \varepsilon \nu \eta ́$, producing]. Same as Mycetogenetic.

Mycetography (mi-set-og'-ra-fe). Synonym of Mycology.

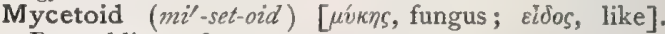
Resembling a fungus.

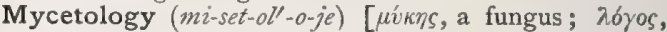
science]. Same as Mycology.

Mycetoma (mi-set-o'-mah), See Fungus Foot.

Mycetophagous (mi-set-off'-ag-us) [ $\mu$ vikns, a fungus ; $\phi a \gamma \varepsilon i v$, eat]. In biology, feeding upon fungi; fungivorous.

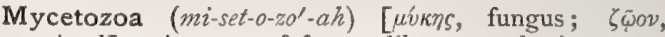
animal]. A group of fungus-like saprophytic organisms, the slime-fungi or slime-molds. Most naturalists class them as fungi or as plant-growths of low type; but by E. R. Lankester and his followers they are grouped with the protozoa or lowest animal forms; while according to a third view they are reckoned as protists or living organisms not decisively classifiable as either plants or animals.

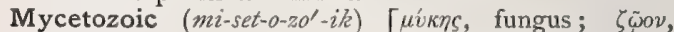
animal]. Of the nature of a slime-fungus or mycetozoön.

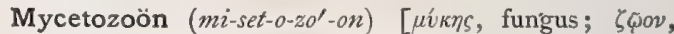
animal]. Any organism belonging to the class mycetozoa.

Mychmus, Mychthismus (mik'-mus, mik-thiz'-mus) $[\mu v \chi \mu \delta \varsigma, \mu v \chi \theta \iota \sigma \mu \delta s$, from $\mu v \zeta \varepsilon \iota v$, to moan]. Sighing.

Mycocellulose (mi-ko-sel'-u-lōz) [ $\mu \tilde{v} \kappa \eta s$, fungus; cellula, a little cell]. Fungin; a variety of cellulose forming the basis of Fungi. See Fungin.

Mycoderm ( $\left.m i^{\prime}-k o-d e r m\right)$ [ $\mu \tilde{v} \kappa o s$, mucus; $\delta \varepsilon \rho \mu a$, skin]. The mucous membrane.

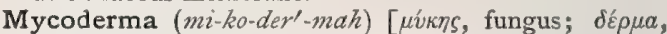
skin]. A genus of fungi forming like a membrane upon or in fermenting liquors. M. aceti, the microorganism of acetous fermentation, constituting the mother of vinegar. M. albicans, Saccharomyces albicans, $q . v$. M. of Beer, acetic skin; a pellicle composed of fungi found on the surface of beer and other liquids deficient in fruit acids. M. sacchari and $\mathbf{M}$. vini, alcoholic ferments. See under Bacteria, Synonymatic Table of.

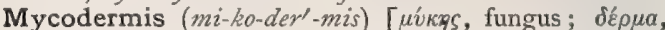
skin]. A genus of microbic or fungoid organisms, species of which have been reported as found in the squamæ of certain skin-diseases, especially favus.

Mycodermitis (mi-ko-der-mi'-tis) [ $\mu v v_{k} o s$, mucus; $\delta \varepsilon p \mu a$, skin; $\iota \tau \iota s$, inflammation]. Inflammation of a mucous surface.

Mycodermosphacelus ( $\left.m i-k o-d e r-m o-s f a s^{\prime}-e l-u s\right)$

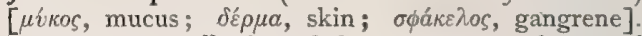
A gangrenous affection of the mucous membrane of any part.

Mycodesmoids (mi-ko-dez'-moids) [u'́rns, fungus; $\delta \varepsilon \delta \sigma \eta$, a bundle; $\varepsilon i \delta o s$, like]. A disease of horses characterized by circumscribed growths in the con. nective tissue. See Micrococcus botryogenus, Rabe, under Bacteria, Synonymatic Table of. 


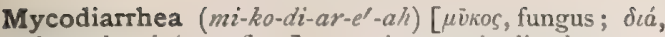
through; $\rho$ oia, a flow ]. I. A mycotic diarrhea. 2. A mucous diarrhea.

Mycodysenteria (mi-ko-dis-en-te'-re-ah) [ $\mu$ íkos, mucus;

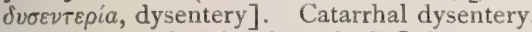

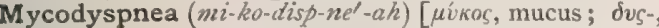
difficult; $\pi \nu \varepsilon \varepsilon \varepsilon \nu$, to breathe]. Dyspnea due to accumulations of mucus in the air-passages.

Mycogastritis (mi-ko-gas-tri'-lis) [ [

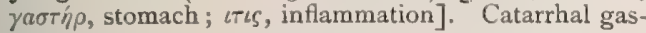
tritis.

Mycography (mi-kog $-r a-f e)$. Synonym of Mycology.

Mycohemia (mi-ko-hem'-e-ah) [uvkns, fungus; aipa, blood]. A generic name for affections caused by the presence of microörganisms in the blood.

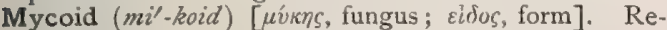
sembling, or appearing like, a fungus ; fungoid.

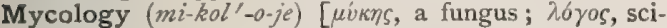
ence]. In biology, the science of fungi.

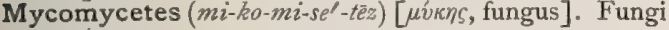
reproducing by oöspores or zygospores.

Myconostoc [mi-ko-nos'-tok) [ $\mu$ ivkns, fungus; nostoc]. A genus of schizomycetes. M. gregarium, a species of microörganisms arranged in interlacing threads and surrounded by a gelatinous capsule; it is probably identical with Cladoihrix dichotoma. See Bacteria, Synonymatic Table of.

Mycophagy (mi-koff'-aj-e) [ $\mu v \kappa \eta \varsigma$, a fungus; $\phi \alpha \gamma^{\prime} a$, from $\phi a \gamma \varepsilon i \nu$, to eat]. In biology, the eating of fungi.

Mycophlyzacium ( $m i-k o-f i z-a^{\prime}-s e-u m$ ) [ $\mu$ v́кos, mucus; $\phi \lambda \nu \zeta \alpha_{\kappa} \iota 0 \nu$, a small blister]. A blister or pustule upon a mucous surface.

Mycophthalmia (mi-koff-thal'-me-ah) [ $\mu$ iv $\eta s$, fungus; $\dot{\phi} \phi \theta \alpha \lambda \mu i a$, ophthalmia]. Ophthalmia due to a fungus.

Mycophthisis (mi-koff'-this-is). Synonym of Bronchorrhea.

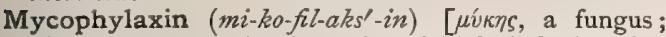
$\phi \dot{v} \lambda a \xi$, a protector]. Any microbicidal phylaxin. See Proteids, Defensive.

Mycopneumonypostasis (mi-ko-nu-mon-ip-os'-tas-is)

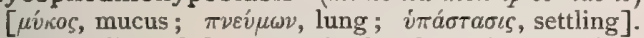
The settling of the mucus in the dependent portions of the lungs.

Mycoprotein (mi-ko-pro'-te-in) [ $\mu$ vik $\zeta$, a fungus; protein (from $\pi \rho \omega \bar{T}$, , first); Mulder's term for the hypothetic substance common to all albuminous bodies], C, 52.32 per cent.; H, 7.55 per cent.; $\mathrm{N}, \mathbf{1} 4.75$ per cent. In biology, the vegetable albuminoid or protoplasmic substance of bacteria, first analyzed and described by Nencki; fungus-protein. It contains no sulphur and no phosphorus, and is not precipitated by alcohol.

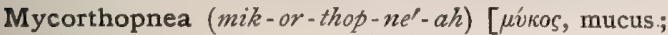
o $\rho \theta b s$, straight ; $\pi \nu$ oia, breathing]. Orthopnea caused by excessive secretion of mucus in the bronchial tubes.

Mycose (mi'-kōz) [ $\mu$ v́kns, fungus], $\mathrm{C}_{12} \mathrm{H}_{22} \mathrm{O}_{11}+2 \mathrm{H}_{2} \mathrm{O}$. Trehalose, a substance that occurs in several species of fungi, in ergot of rye, and in the oriental Trehala. It is distinguished from cane-sugar by its ready solubility in alcohol, greater stability, and stronger rotatory power. It does not reduce copper-solutions. See Carbohydrates, Table of.

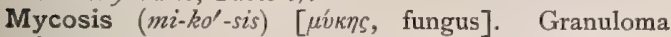
fungoides; Eczema hypertrophicum; Inflammatory fungoid neoplasm; Lymphoderma perniciosa; UIcerative scrofuloderma; Fibroma fungoides. I. Any disease of the skin characterized by soft mammillated tumors, showing an abnormal growth of lymphatic glands, which frequently develop into fungous ulcers. 2. A mucous tumor or polypoid growth. 3. The influence of microphytes upon the health or disease of the body. 4. Any disease caused by the presence of pathogenic microbes in the organism. M., Acute, of the Blood, a name proposed by Neelsen for septic intoxication from the presence of microbes in the blood. M. fungoides. See Granuloma fungoides. M. furfuracea. Synonym of Pityriasis versicolor. M. intestinalis. Synonym of Anthrax. M. microsporina. Synonym of Tinea versicolor. M. oris, the disease caused by Oidium albicans or Leplothrix buccalis, consisting of grayish or black deposits on the tongue and buccal mucosa, usually with constitutional symptoms. M.pulmonum. See Pneumonomycosis. M. pustulosa, parasitic sycosis; also impetigo. $\mathbf{M}$. tonsillaris benigna, the name applied by Fränkel to a peculiar form of pharyngeal disease induced by the undue accumulation of leptothrix upon the pharyngeal structures. The condition is also called by Heryng "Pharyngomykosis leplothricia." M., Toxic, of the Blood, putrid intoxication or sapremia, death being due to poisoning by ptomains.

Mycosozin (mi-ko-so'-zin) [ $\mu \nu \tilde{\kappa} \eta \varsigma$, a fungus ; $\sigma \omega \zeta \varepsilon \iota v$, to save]. Any sozin that acts by the destruction of microbes. See Proteids, Defensive.

Mycothrix (mi-koth'-riks) [ $\mu$ ivkns, fungus; $\theta \rho i \xi$, hair]. The thread-like element in the structure of a micrococcus.

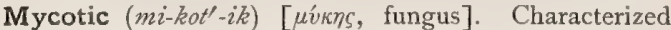
by mycosis; due to the presence of some pathogenic microörganism. M. Endocarditis, that due to microörganismal infection. A synonym of ulcerative or malignant endocarditis.

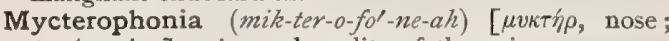
$\phi \omega n \dot{n}$, voice]. A nasal quality of the voice.

Mydalein (mi-da'-le-in) [ $\mu v \delta \alpha \lambda \varepsilon ́ o s$, putrid]. A ptomain obtained from putrefying cadaveric organs. It is present in liver, spleen, etc., after some days of putrefaction, but it is not obtainable before the third or fourth week. It has a specific action as a poison, producing maximum dilatation of the pupil, injection of the ear-vessels, elevation of temperature, peristaltic action of the intestines. Post-mortem examination shows contraction of the bladder and intestines, and the stopping of the heart in diastole. Animals recover from small doses. See Ptomains, Table of.

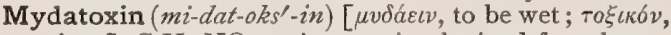
poison ], $\mathrm{C}_{6} \mathrm{H}_{13} \mathrm{NO}_{2}$. A ptomain obtained from horseflesh and human flesh after four months of decomposition. It is toxic, producing lacrymation, diarrhea, and dyspnea in animals, but is not an active poison. A base, $\mathrm{C}_{7} \mathrm{H}_{17} \mathrm{NO}_{2}$, with which it is associated, is, however, a very violent poison, producing effects partly like those of curara and partly like those of mussel-poisoningparalysis a few minutes after injection, with preservation of certain reflexes while the animal cannot move from its place. The same effects are produced by mydatoxin, but more slowly. See Ptomains, Table of.

Mydesis (mi-de'-sis) [ $\mu v \delta \tilde{a} \nu$, to be damp]. Putrefaction; also, a discharge of pus from the eyelids.

Mydin (mi'-din) [ $\mu$ v́os, damp, decay], $\mathrm{C}_{8} \mathrm{H}_{11} \mathrm{NO} . \mathrm{A}$ non-poisonous ptomain obtained by Brieger from the putrefaction of human internal organs. The free base is strongly alkaline, has an ammoniacal odor, and is characterized by its strong reducing-properties. See Ptomain;, Table of.

Mydriasis (mid'-ri'-as-is) [ $\mu v \delta \rho i a \sigma s$, mydriasis]. Abnormal dilatation of the pupil of the eye. The word is also used to denote paralysis of the accommodation, an effect resulting from the use of most mydriatics. M., Paralytic, that due to paralysis of the oculo-motor nerve. M., Spasmodic, M., Spastic, that form caused by over-action of the sympathetic or dilator nerve of the iris. M., Spinal, that produced by irritation of the cilio-spinal center of the cord. 
Mydriatic (mid-re-at'-ik) [ $\mu v \delta \rho i a \sigma \iota$, dilatation of the pupil]. I. Causing mydriasis, or paralysis of the ciliary muscle. 2. A medicine or agent that causes mydriasis, or dilatation of the pupil.

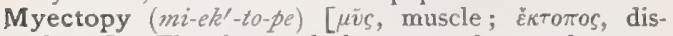
placed]. The abnormal placement of a muscle.

Myedema (mi-e-de'-mah). Synonym of Myoidema

Myel (mi'-el) [ $\mu v \varepsilon \lambda \delta ́ s$, marrow]. The spinal cord

Myelalgia (mi-el-al'-je-ah) [ $\mu v \varepsilon \lambda o ́ s$, marrow; à $\lambda \gamma o s$, pain]. Any pain in the spinal cord.

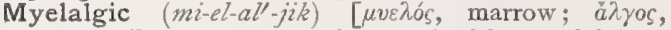
pain]. Pertaining to or characterized by myelalgia.

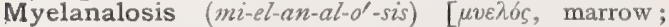

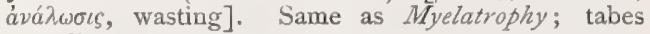
dorsalis.

Myelapoplexy (mi-el-ap'-o-pleks-e) [ $\mu v \varepsilon \lambda \delta s$, myelon; $a \pi \sigma \pi \lambda \eta_{\xi}\llcorner a$, a stupor]. Hemorrhage into the spinal cord.

Myelasthenia (mi-el-as-the'-ne-ah) [ $\mu v \varepsilon \lambda o ́ s$, myelon;

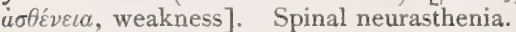

Myelatelia $\left(m i-e l-a t-e^{\prime}-l e-a h\right)$ [ $\mu v \varepsilon \lambda o ́ s$, myelon; $a ̉$ priv. ; $\tau \hat{\varepsilon} \lambda$ os, completion]. Imperfect development of spinal marrow or of bone-marrow.

Myelatrophia, Myelatrophy (mi-el-at-rd-fe-ah, mi-el-

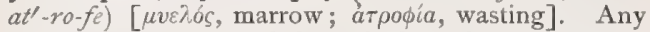
wasting or atrophy of the spinal cord due to spinal disease.

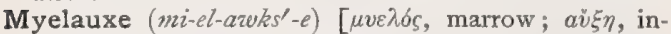
crease]. Morbid enlargement of the myel.

Myelaxis (mi-el-aks'-is) [ $\mu v \varepsilon \lambda o ́ s$, myelon; axis, axis]. The neural, or cerebro-spinal, axis.

Myelemia (mi-el-el-me-ah). Synonym of Myelogenic Leukemia.

Myelencephal (mi-el-en-sef'-al). Same as Myelencephalon.

Myelencephalic (mi-el-en-sef-al'-ik) [ $\mu v \varepsilon \lambda o ́ s$, myelon; $\varepsilon \dot{\varepsilon} \gamma \varepsilon \dot{\varepsilon} \phi \lambda \circ \varsigma$, brain]. Relating to the myelencephalon.

Myelencephalon (mi-el-en-sef'-al-on). I. The cerebrospinal axis. 2. See Metencephalon.

Myeleterosis ( $\left.m i-e l-e t-e r-o^{\prime}-s i s\right)$ [ $\mu v \varepsilon \lambda o ́ s$, marrow ;

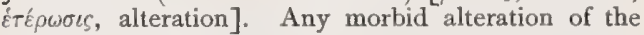
spinal cord.

Myelic (mi-el'-ik) [ $\mu v \varepsilon \lambda \sigma s$, marrow]. Pertaining to the myel.

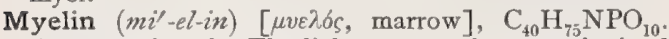
A name given by Thudichum to a substance obtained from the white matter of the brain. It occurs usually as a white, amorphous, ivory-like mass, but crystallizes from an ethereal or alcoholic solution. In a wider sense, any member of the myelin group may be called a myelin. Upomyelin, Paromyelin, Amido-myelin, and Sphingo-myelin differ from myelin mainly in containing one or more additional nitrogenous radicles. The "white substance of Schwann" and the ordinary brain-juice are also called myelin. See Organotherapy.

Myelinic (mi-el-in'-ik) [ $\mu v \varepsilon \lambda \sigma s$, marrow]. Relating to myelin. M. Nerve-fiber, the medullated nerve-fiber.

Myelitic ( $\left.m i-e l-i t^{\prime}-i k\right)$ [ $\mu v \varepsilon \lambda \sigma s$, marrow; $\iota \tau \iota \varsigma$, inflammation]. Pertaining to or affected with myelitis.

Myelitis (mi-el-i'-tis) [ $\mu v \varepsilon \lambda \sigma s$, marrow; $\iota \tau \iota s$, inflammation]. I. Inflammation of the spinal cord. 2. Inflammation of bone-marrow; osteomyelitis. See also Polionvelitis, Leuko-myelitis, and Meningo-myelitis. M., Acute, that due to exposure to cold, injuries, or to acute general diseases; it is attended with sensory disturbances and motor paralysis, complete or incomplete, according to the part of the cord involved and the degree of the inflammation. M., Ascending, a form in which the inflammation travels up the cord. M., Bulbar, that affecting the medulla and manifesting itself in disturbances of the cardio-respiratory appa- ratus, dysphagia, vomiting, and other symptoms. M., Central, myelitis limited chiefly to the gray matter of the cord. M., Chronic, a slowly advancing myelitis, presenting generally the same features as acute myelitis, but extended over a longer period. M., Compression, the term applied to inflammation of the spinal cord secondary to compressing lesions outside of the cord (caries, carcinoma, or exostosis of the vertebræ, aneurysm) or to tumors of the cord itself. M., Concussion, that due to concussion, direct or indirect. M. convulsiva. See Dubini's Disease. M., Cornual, inflammation affecting the anterior or posterior cornua. M., Descending, a form in which the inflammation extends downward, following the pyramidal pathways. M., Diffuse, widely distributed inflammation of the cord involving large areas. M. Disseminated, when there are several foci. M., Focal, when a small area is affected. M., Hemorrhagic, myelitis associated with or dependent upon hemorrhage. M., Meningo-, a combination of meningitis and myelitis. M., Pressure. See $M$., Compression. M. Sclerotic, a form characterized by overgrowth of the interstitial tissue, which undergoes contraction, producing an increase of hardness of the cord. M., Systemic, a variety in which the inflammation is confined to distinct systems or tracts of the cord. M., Transverse, a form in which the inflammatory area extends through a transverse section of the cord. M., Traumatic, myelitis following direct injury. M., Unilateral, a form in which the lesions are confined to one side of the cord.

Myelo- (mi'-el-o-) [ $\mu v \varepsilon \lambda o ́ s$, marrow]. A prefix denoting reference to or connection with the spinal cord, or, more rarely, with some other medullary substance.

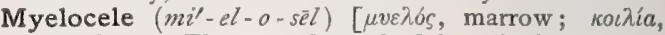
cavity]. I. The central canal of the spinal cord. 2 . $[\kappa \dot{\eta} \lambda \eta$, tumor]. See Spina bifida.

Myelocerebellar (mi-el-o-ser-e-bel'-ar) [ $\mu v \varepsilon \lambda \sigma^{\prime}$, , marrow; cerebellum, cerebellum]. Relating to the spinal cord and the cerebellum.

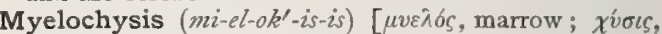
a pouring]. Hydrorrhachis. Protrusion of the spinal marrow.

Myelocalia (mi-el-o-se'-le-ah). See Myelocele.

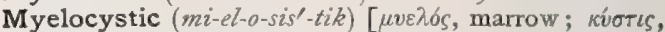
cyst]. Both myeloid and cystic.

Myelocystocele (mi-el-o-sis'-to-sell) [ $\mu v \varepsilon \lambda \delta ́$, marrow;

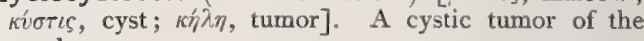
myelon.

Myelocystomeningocele (mi-el-o-sis-to-men-in'-go-sēl)

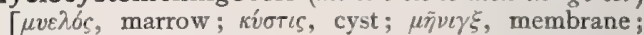
$\kappa \eta \lambda \eta$, tumor]. Spina bifida in which the tumor contains myelic substance, membranes, and fluid.

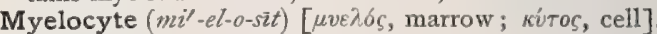
I. Properly, a marrow-cell. 2. Any free nucleus of a central or ganglionic nerve-cell.

Myelodiastasis (mi-el-o- $\lambda i$-as'-tas-is) [ $\mu v \varepsilon \lambda$ ós, marrow;

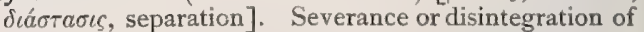
the spinal cord.

Myelodiastema (mi-el-o-di-as-te'-mah). Synonym of Myelodiastasis.

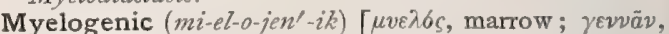
to produce]. Originating in marrow; producing a marrow-like substance. M. Leukemia, leukemia due to disease of the marrow of bones.

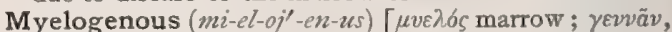
to produce]. Originating in marrow. M. Ossification, ossification taking place from the marrow of bone.

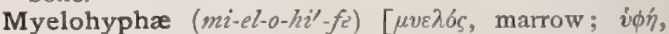
web: prop. myelypha]. In biology, applied to the hyphx of lichens which differ from those of ordin- 
ary fungi in being rigid, elastic, in containing lichenin, in not becoming putrid by maceration, and in lacking the faculty of penetrating.

Myeloid (mi'-el-oid) [ $\mu v \varepsilon \lambda \sigma s$, marrow; $\varepsilon i \delta o s, ~ l i k e]$. Resembling marrow in structure or appearance. Also applied to a form of sarcoma distinguished by the presence of multinucleated cells.

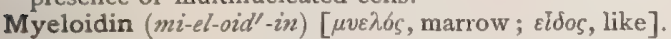
A nitrogenous substance containing phosphorus, found in brain-matter.

Myeloma (mi-el-o'-mah) [ $\mu v \varepsilon \lambda ́ o ́ s$, marrow; ŏ $\mu a$, tumor : pl., Myelomata]. I. A tumor or enlargement of the medullary substance of the brain or cord. 2. A giantcelled sarcoma.

Myelomalacia (mi-el-o-mal-a $-s e-a h)$ [ $\mu v \varepsilon \lambda a ́ s$, marrow; налакí, softening]. A softening of the spinal cord.

Myelomalacosis, Myelomalaxis (mi-el-o-mal-ak-o'sis, mi-el-o-mal-aks'-is). Synonym of Myelomalacia.

Myelomargarin (mi-el-o-mar'-gar-in) [ $\mu v \varepsilon \lambda b s$, mar-

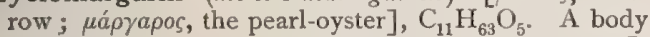
found in the so-called cerebrin of brain-substance. It is soluble in hot water, in ether, and in alcohol.

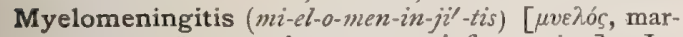
row; $\mu \tilde{\eta} \nu \iota \gamma \xi$, a membrane; $\iota \tau \iota \zeta$, inflammation]. Inflammation of the membranes investing the spinal cord; spinal meningitis.

Myelo-meningocele (mi'-el-o-men-in'-go-sêl). Synonym of Spina bifida.

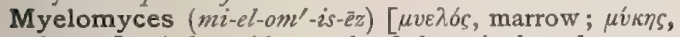
fungus]. A fungoid growth of the spinal cord.

Myelon (mi'-el-on) [ $\mu v \varepsilon \lambda \sigma s$, marrow]. The spinal cord, or Medulla spinalis.

Myelonal, Myelonic ( $\left.m i-e l^{\prime}-o n-a l, m i-e l-o n^{\prime}-i k\right)$ $\left[\mu \nu \varepsilon \lambda \sigma_{s}\right.$, marrow]. Pertaining to the myelon.

Myeloparalysis (mi-el-o-par-al'-is-is) [ $\mu v \varepsilon \lambda \sigma s$, marrow;

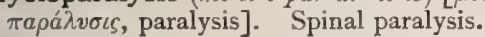

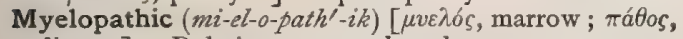
disease]. Relating to a myelopathy.

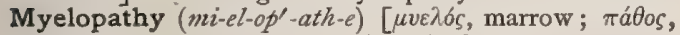
disease]. Any disease of the spinal cord.

Myelophthisis (mi-el-off'-this-is). Synonym of Tabes dorsalis.

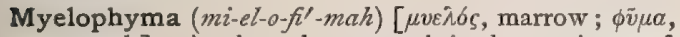
a growth]. A tuberculous growth in the meninges of the spinal cord.

Myeloplacque (mi'-el-o-plak) [ $\mu v \varepsilon \lambda \sigma s$, marrow; $\pi \lambda a ́ \xi$, plate]. A giant-cell of the spinal marrow; an osteoclast; a myeloplax.

Myeloplast (mi'-el-o-plast) [ $\mu v \varepsilon \lambda \sigma \varsigma$, marrow; $\pi \lambda a \sigma \tau \sigma \varsigma$, shaped]. Any giant-cell of the marrow. The myeloplasts are regarded by some as the main seat of the formation of red blood-discs.

Myeloplax (mi'-el-o-plaks) [ $\mu v \varepsilon \lambda \sigma s$, marrow; $\pi \lambda a ́ \xi$, a placque: pl., Myeloplaxes]. In histology, one of the large multinucleated cells frequently found upon the inner surface of bone, and concerned in its destruction; they are the myeloplacques of Robin and other French histologists, and the osteoclasts (bone-destroyers) of Kölliker. Cf. Myeloplacque.

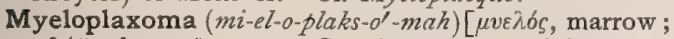
$\pi \lambda a ́ \xi$, plate; $\tilde{\sigma} \mu a$, tumor]. A tumor containing myeloplaxes.

Myeloplegia (mi-el-o-ple'-je-ah)[ $\mu v \varepsilon \lambda \sigma s$, marrow; $\pi \lambda \eta \gamma^{\prime}$, a stroke]. Paralysis of spinal origin.

Myelorrhagia (mi-el-or-a -je-ah) [ $\mu v \varepsilon \lambda b_{s}$, marrow; ívrvivat, to burst forth]. Hemorrhage into the spinal cord.

Myelosarcoma (mi-el-o-sar-ko'-mah). Same as Osteosarcoma.

Myelosclerosis (mi-el-o-skle-ro'-sis) [ $\mu v \varepsilon \lambda .6 s$, marrow ; $\sigma \kappa \lambda \eta \rho \delta s$, hard]. Sclerosis of the spinal cord or of the marrow of bones.
Myelosis (mi-el-o'-sis) [ $\mu v \varepsilon \lambda \sigma^{\prime}$, marrow]. The growth or existence of a myeloma.

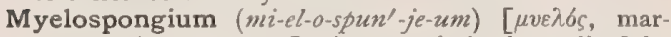
row ; $\sigma \pi 6 \gamma \gamma$ s, sponge]. A network in the wall of the neural canal of the embryo, composed of processes given off by the outer extremities of the columnar cells called spongioblasts.

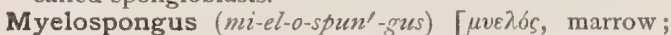
$\sigma \pi 6 \gamma \gamma o s$, a fungus]. An encephaloid growth.

Myelosyringosis ( $\left.m i^{\prime}-e l-o-s i-r i n-g o^{\prime}-s i s\right)$. Synonym of Syringomyelia.

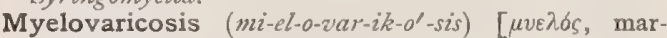
row; varix, varix]. A varicosity of the myelinsheath of a nerve-fiber, or the formation of one.

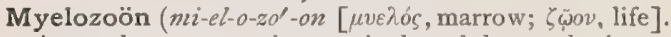
A vertebrate possessing a spinal cord, but no brain.

Myelyperemia (mi-el-ip-er-e'-me-ah) [ $\mu \nu \varepsilon \lambda o ́ s$, marrow ; vík $\rho$ above; aí $\mu$, blood]. Hyperemia of the spinal cord.

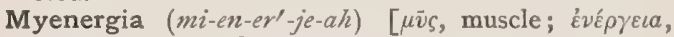
energy]. Muscular energy.

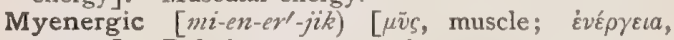
energy]. Relating to myenergia.

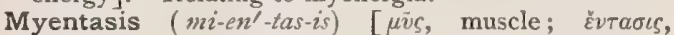
stretch]. The extension or stretching of a muscle.

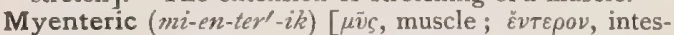
tine]. Relating to the muscular coat of the intestine.

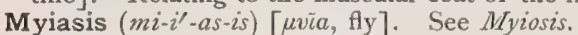

Myiocephalon (mi-i-o-sef'-al-on) [ $\mu v i a$, fly; $\kappa \varepsilon \phi a \lambda \eta \dot{n}$, head]. A minute prolapse of the iris through a corneal perforation, so called from its resemblance to the head of a fly.

Myiodeopsia ( $\left.m i-i-o-d e-o p^{\prime}-s e-a h\right)$, Myiodesopsia

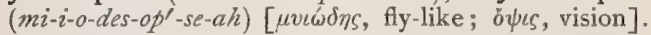
The subjective appearance of muscæ volitantes.

Myiosis (mi'-i-o-sis) [ $\mu v \bar{\imath} \pi$, a fly]. Hugo Summe's term for the diseased condition produced by the presence of parasitic dipterous larvæ, and incorrectly called Myasis by Hope, and Myiasis by Joseph. The presence of larvæ of flies, or maggots, in or on the body, as in the nose or ear, in a wound, or upon mucous membranes. $\mathbf{M}$. aurium, $\mathbf{M}$. narium, $\mathbf{M}$. vulnerum, the presence of maggots in the ears, nose and wounds respectively. The disease is known in the East as Peenash.

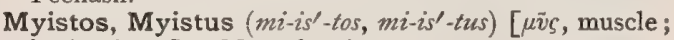
iбтós, tissue]. Muscular tissue.

Myitis (mi-i,tis) [ $\mu \tilde{v} \varsigma$, muscle; $\iota \tau \iota \varsigma$, inflammation]. Inflammation of a muscle.

Mykosis (mi-ko'-sis). See Mycosis.

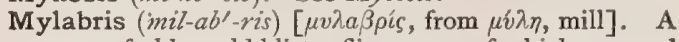
genus of old-world blister-flies, some of which are used like cantharides. Unof.

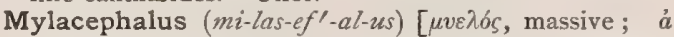

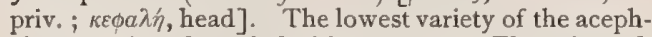
alous species of omphalositic monsters. There is such imperfect development of the fetus that the condition is but a degree above that of fatus amorphus or fotus anideus.

Mylacri (mil'-ak-ri) [ $\mu v \lambda a k \rho i s$, mill-stone]. The molar teeth.

Mylacris (mil'-ak-ris) [ $\mu v \lambda a k \rho i s] . \quad T h e$ patella.

Myle $\left(m i^{\prime}-l e\right)[\mu v ́ \lambda \eta$, mill]. I. Uterine mole. 2. $\mathrm{Pa}-$ tella. 3. Maxilla.

Mylic (mil'-ik) [ $\mu v{ }^{\prime} \lambda \eta$, mill]. Pertaining to the molar teeth; relating to a uterine mole.

Mylo- (mir-lo-) [ $\mu \nu \lambda 6 \varsigma$, mill]. A prefix denoting connection with the lower jaw or the molar teeth.

Mylodus (mi-lo'-dus) [ $[\mu v \lambda \eta$, mill; ódóvs, tooth: $p l$, Mylodontes]. A molar tooth.

Myloglossus (mi-lo-glos'-us) [ $\mu \dot{\lambda} \lambda \eta$, mill; $\gamma \lambda \omega \sigma \sigma \alpha$, tongue]. A portion of the superior constrictor of the 
pharynx-that which arises from the mylo-hyoid ridge of the lower jaw. Also, an anomalous slip joining the styloglossus.

Mylohyoid, Mylohyoidean (mi-lo-hi'-oid, mi-lo-hi-

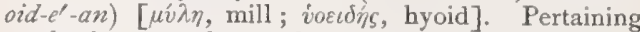
to the lower molar teeth and the hyoid bone. $M$. Muscle. See Muscles, Table of.

Mynsicht's Elixir. Aromatic sulphuric acid.

Myo-(mi'-o-) [uṽs, a muscle]. A prefix signifying muscle. M.-albuminose, one of the proteids of muscle plasma, closely associated with the myosin-ferment. See Muscle-plasma. M.-albumose, Myoproteose; a proteid substance of muscle-plasma closely connected, or identical, with the myosin-ferment, and having the general properties of deutero-albumose. M.-globulin, a substance obtained from muscle, closely resem bling serum-globulin in its properties. Its coagulationtemperature is $63^{\circ} \mathrm{C}$, however, while that of serum globulin is $75^{\circ} \mathrm{C}$.

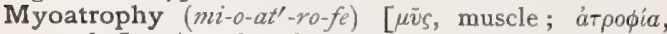
atrophy]. Atrophy of a muscle.

Myoblast (mi'-o-blast) [ $\mu \tilde{v} \varsigma$, muscle ; $\beta \lambda a \sigma \tau b \varsigma$, germ]. In biology, a muscle-forming cell; a descendant of the cells which at an early stage of the metazoan embryo sink below the level of the epithelium to which they belonged. M. epitheliales, epithelial muscular cells neuro-muscular cells, tela muscularis epithelialis. $\mathbf{M}$. mesodermales, mesodermal muscular cells, tela muscularis mesodermalis.

Myoblastic (mi-o-blas'-tik) [ $\mu \tilde{s} s$, muscle; $\beta \lambda a \sigma \tau b s$, germ]. Relating to or of the nature of a myoblast.

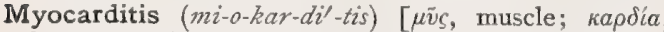
heart ; $\iota \tau \iota \zeta$, inflammation]. Inflammation of the muscular tissue of the heart; it may be parenchymatous or interstitial. M., Segmenting, a form characterized by separation of the muscle-cells from softening of the cement-substance.

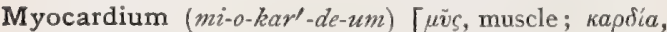
heart ]. The muscular structure of the heart.

Myocele ( $\left.m i^{\prime}-o-s \bar{e} l\right)[\mu \tilde{v} c$, muscle; $\kappa \hat{n} \lambda \eta$, tumor]. The protrusion of a muscle through its ruptured sheath.

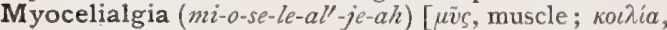
cavity; àjos, pain]. Pain in the muscles of the abdomen.

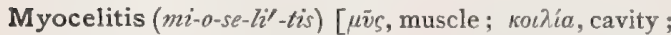
$\iota \tau \iota$, inflammation]. Inflammation of the abdominal muscles

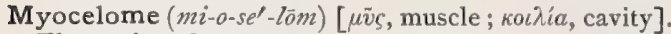
The cavity of a protovertebra or myotome.

Myocephalon (mi-o-sef'-al-on). Synonym of Myiocephalon.

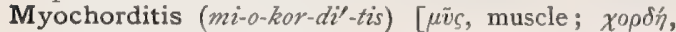
cord; $\imath \tau \iota$, inflammation]. Inflammation of the muscles of the larynx and the vocal bands.

Myochrome ( $\left.m i^{\prime}-o-k r o \bar{m}\right)$ [ $\mu \tilde{v} s$, muscle; $\chi \rho \tilde{\omega} \mu a$, color]. Myohematin, $q . v$.

Myochronoscope (mi-o-kro'-no-skōp) [ $\mu \tilde{v} s$, muscle ;

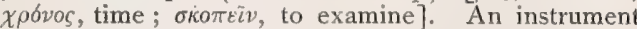
for measuring the rapidity of muscular contraction or the propagation of a nerve-stimulus through a muscle.

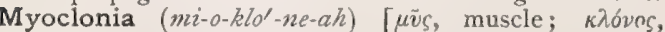
spasm]. Clonic spasm of the muscles.

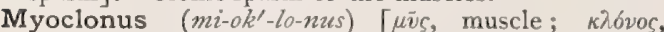
clonus]. Clonic spasm of a muscle, or of various muscles. M. multiplex. See Paramyoclonus multiplex.

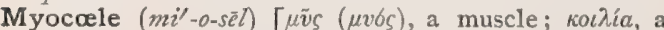
cavity]. Hatschek's term for the thick epithelium of the ental wall of the dorsal segments of the amphioxus larva, which produces the muscles of the entodermal side of the cavity of the segments.

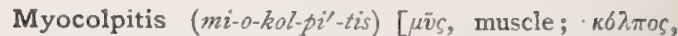
vagina; $\iota \tau \iota$, inflammation]. Inflammation of the muscular coat of the vagina.

Myocomma (mi-o-kom'-ah) [ $\mu \tilde{v} s$, muscle; $\kappa 6 \mu \mu a$, segment: pl., Myocommata]. Any one of the transverse segments into which embryonic muscle-tissue is divided. In adult man, some of the muscles exhibit traces of these primitive myocommata, A myotome, or muscular metamere, a segment of the grand muscle lateral of Cuvier

Myocrismus (mi-o-kriz'-mus) [ $\mu \tilde{v} \varsigma$, muscle; $\kappa \rho i \zeta \varepsilon \iota \nu$, to creak]. A creaking sound heard over muscles during contraction.

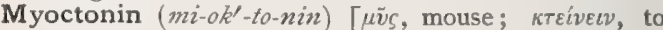
kill]. A bitter extractive of Aconitum lycoctonum, a powerful poison resembling curare in action. Unof.

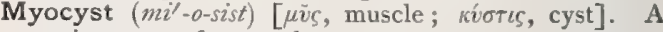
cystic tumor of a muscle.

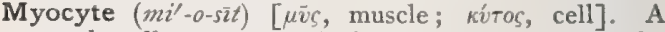
muscle-cell; a structural element conspicuous in the histology of certain of the lower animals.

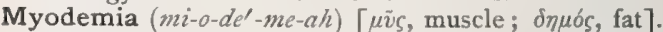
The fatty degeneration of muscle.

Myoderma (mi-o-der'-mah) [ $\mu \bar{v} s$ ( $\mu v o ́ s)$, a muscle;

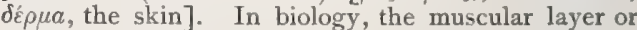
"lamina muscularis" of the invertebrate ectoplasm. Cf. Myophan.

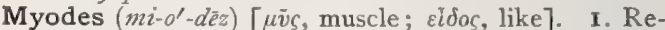
sembling muscle; muscular. 2. The platysma, or fleshy expansion of the neck. See Muscles, Table of.

Myodesopsia (mi-o-dez-ops'-e-ah) See Myiodesopsia.

Myodiastasis (mi-o-di-as'-tas-is) [ $\mu \tilde{v} \varsigma$, muscle; $\delta \iota a ́$, a part; $\sigma \tau \alpha \dot{\sigma} \sigma \zeta$, a standing]. I. The separation that takes place between the ends of a cut muscle. 2. The traumatic injury of a muscle by straining or stretching.

Myodopsia (mi-o-dop'-se-ah). Synonym of Myiodesopsia.

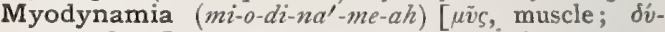
vaurs, force]. Muscular power or strength.

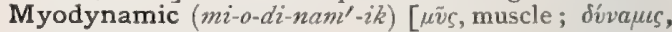
power]. Pertaining to the force of muscular contraction.

Myodynamics (mi-o-di-nam'-iks) [uṽs, muscle; divvauss, power]. The mechanics of muscular action.

Myodynamometer (mi-o-di-nam-om'-et-er) [ $\mu \tilde{v} s$, mus-

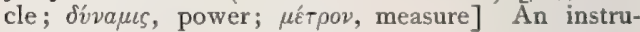
ment for measuring muscular strength.

Myodynia (mi-o-din'-e-ah) [ $\mu \bar{v} \varsigma$, muscle ; óovivn, pain]. Pain in the muscles.

Myoendocarditis [ $\left.m i-o-e n-d o-k a r-d i^{\prime}-t i s\right)$ [ $\mu \nu \bar{\zeta}$, muscle ; Ev $\delta o s$, within; $\kappa a \rho \delta i a$, heart; $\iota \tau \iota s$, inflammation]. Simultaneous inflammation of the endocardium and the myocardium.

Myofibroma (mi-o-fi-bro'-mah) [ $\mu \tilde{v} s$, muscle; fibra, fiber; ǒ $\mu a$, tumor: pl., Myofibromata $]$. A muscular tumor containing fibrous elements. Such tumors are common in the walls of the uterus.

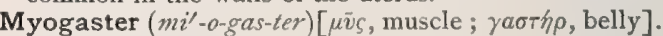
The belly of a muscle.

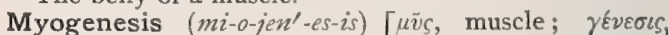
genesis]. The development of muscular tissue.

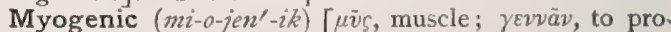
duce]. Of muscular origin.

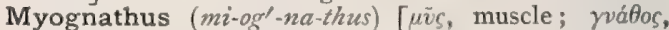
jaw]. A form of double monstrosity in which the accessory head is joined to the autosite by means of muscle and integument only.

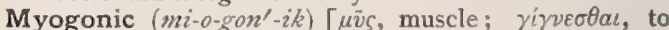
be born]. Inherent in muscle, as contractile power.

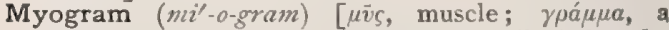
marking]. The muscle-curve as inscribed by the myograph. 


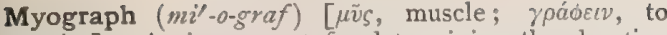
write]. An instrument for determining the duration of each phase of a muscular contraction. M., Cardiac, the cardiograph, $q . v$. M., Palate, an in-

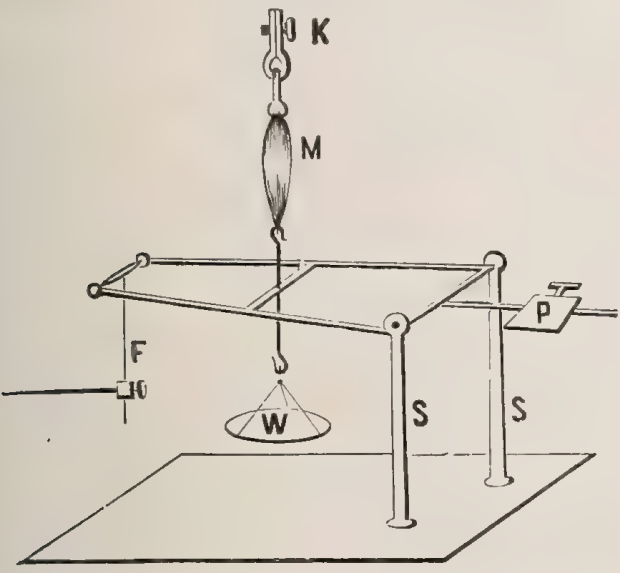

SChEME of v. Helmholtz's MYograph.

M. Muscle fixed in a clamp, K. F. Writing style. P. Weight or counterpoise for the lever. W. Scale-pan for weights. S, S. Supports for the lever.

strument that records the movements of the uvula and soft palate during speaking and swallowing. It consists of a rod which is introduced through the nose and rests against the soft palate, while the other end records the movements on a drum.

Myographer (mi-og'-ra-fer) [ $\mu \tilde{v} \varsigma$, muscle; $\gamma \rho a ́ \phi \varepsilon \iota \nu$, to write]. One versed in myography.

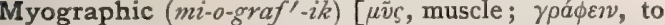
write]. Pertaining to a myograph.

Myographion (mi-o-graf'-e-on) [ $\mu \tilde{v} \varsigma$, muscle; $\gamma \rho a ́ \phi \varepsilon \iota \nu$, to write]. A myograph.

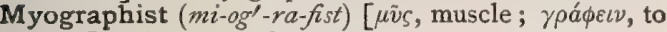
write]. A myographer.

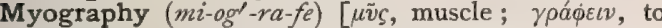
write]. I. A description of the muscles. 2. The employment of the myograph.

Myohematin (mi-o-hem $\left.{ }^{\prime}-a t-i n\right)$ [ $\mu \vec{v} s$, muscle; ai $\mu a$, blood]. A nitrogenous coloring-matter of muscles; the true intrinsic coloring-matter of red muscle, including the histohematin characteristic of invertebrate muscle. It yields a four-banded spectrum. Its solutions when weak are of a reddish-yellow color, but if strong they are pure red.

Myoid (mi'-oid) [ $\mu \bar{v} \varsigma$, muscle; eidos, form]. Having a resemblance to muscular tissue.

Myoidema (mi-oid-e'-mah) [ $\mu \tilde{v} \varsigma$, muscle; o ơ $\eta \mu a$, a swelling]. The wheal brought out by a sharp tap on a muscle in certain conditions of exhaustion.

Myoides (mi-oi'-dez) [ $\mu \tilde{v} \varsigma$, muscle; $\varepsilon i \delta o s$, like]. The platysma. See Muscles, Table of.

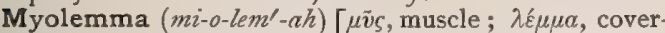
ing]. The thin membrane enveloping the fibrillæ of muscle. Same as Sarcolemma.

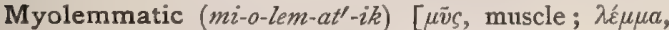
covering]. Pertaining to the myolemma.

Myolin (mi'-o-lin). See Myosin.

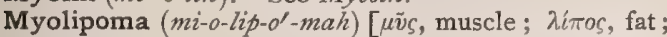
o $\mu a$, tumor: pl., Myolipomata]. A myoma with lipomatous elements.

Myologic (mi-o-loj’-ik) [ $\mu \tilde{v} \varsigma$, muscle ; $\lambda o ́ \gamma o s$, science]. Pertaining to myology.

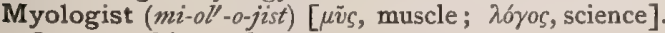
One versed in myology.
Myology (mi-ol’-o-je) [ $\mu \tilde{v} \varsigma$, muscle; $\lambda b \gamma o s$, science]. The science of the nature, structure, functions, and diseases, of muscles.

Myoma (mi-o'-mah) [ $\mu \bar{v} s$, muscle; ö $\mu \alpha$, tumor: $p l$. , Myomata $]$. A muscular tumor. Also, an affection marked by the growth in the skin of small, sessile, freely movable, isolated, reddish tumors consisting of involuntary muscular fibers. If small and multiple, they are called lio-myomata; if there is but a single large tumor, it is called a dartoic myoma; if the tumors contain much fibrous tissue, they are called fibromyomata ; if vascular and erectile, angio-myomata; if the lymphatics are involved, lymphangio-myomata. M., Fibro-. See Myofibroma. M., Lio-, See Liomyoma. M., Rhabdo-. See Rhabdomyoma.

Myomalacia (mi-o-mal-a'-se-ah) [ $\mu \tilde{v} s$, muscle ; $\mu a \lambda a \kappa i ́ a$, softening]. An abnormal softening of the muscles. M. cordis, fatty degeneration and softening of a portion of the heart-muscle, resulting from thrombosis or embolism

Myomatous (mi-o'-mat-us) [ $\mu \breve{v} s$, muscle ; ö $\mu a$, tumor]. Of the nature of a myoma.

Myomectomy (mi-o-mek'-to-me) [ $\mu \tilde{s} \varsigma$, muscle; ö $\mu \alpha$, tumor; éктoù́, excision]. Surgical removal of a uterine or other myoma.

Myomelanosis (mi-o-mel-an-o'-sis) [ $\mu \tilde{v} s$, muscle ; $\mu \varepsilon \lambda$ ávwors, a becoming black]. The presence of a blackish coloration in muscular tissue.

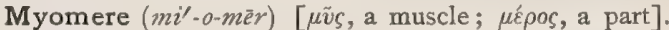
In biology, a muscular flake or metamere; a myocomma or myotome.

Myometer (mi-om'-et-er) [ $\mu \tilde{v} s$, muscle ; $\mu \dot{\varepsilon} \tau \rho o \nu$, measure]. An instrument for measuring the shortening of a muscle in contracting.

Myometritis (mi-o-met-ri'-tis) [ $\mu \vec{v} \varsigma$, muscle; $\mu \dot{r} \tau \rho a$, uterus; $\iota \tau \iota$, inflammation]. Inflammation of the uterine muscular tissue.

Myomotomy (mi-o-mot'-o-me) [ $\mu \tilde{v} \varsigma$, muscle; $\ddot{\partial} \mu a$, tumor; $\tau o \mu \eta$, a cutting]. The operation of excising fibro-myomata of the uterus.

Myon (mi'-on) [ $\mu \nu \omega \nu$, a cluster of muscles]. A unit of musculation; a group of muscles viewed as an integer.

Myonarcosis (mi-o-nar-ko'-sis) [ $\mu \tilde{v} \varsigma$, muscle ; vá $\rho \kappa \omega \sigma \iota$, numbness]. Numbness of the muscles.

Myoneoplasma (mi-o-ne-o-plaz'-mah) [ $\mu \tilde{v} s$, muscle; véos, new ; $\pi \lambda a ́ \sigma \mu a$, formation: pl., Myoneoplasmata]. A myoma or muscular neoplasm.

Myoneuralgia (mi-o-nu-ral' -je-ah) [ $\mu \bar{v} s$, muscle;

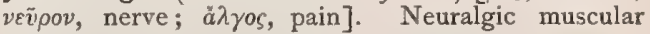
pain.

Myonicity (mi-o-nis'-it-e) [ $\mu \tilde{v} s$, muscle]. The power of living muscle to contract and to relax.

Myonitis (mi-on-i’-tis) [ $\mu \tilde{v} \varsigma$, muscle; $\iota \tau \iota \zeta$, inflammation]. Synonym of Myositis.

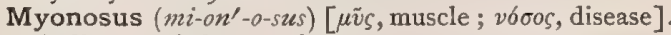
A disease of the muscles.

Myopachynsis (mi-o-pak-in'-sis) [ $\mu \tilde{v} \varsigma$, muscle; $\pi a ́ \chi v \nu \sigma \iota s$, thickening]. Muscular hypertrophy. M. lipomatosa. See Paralysis, Pseudo-hypertrophic.

Myopalmus (mi-o-pal'-mus) [ $\mu \tilde{v} \varsigma$, muscle; $\pi a \lambda \mu \delta \varsigma$, a twitch]. A twitching of the muscles.

Myoparalysis (mi-o-par-all -is-is) [ $\mu \tilde{v} s$, muscle;

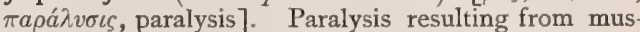
cular abnormality, without affection of the nervous centers or nerves.

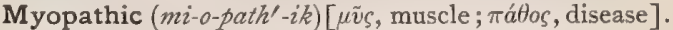
Relating to or of the nature of a myopathy. $\mathbf{M}$. Muscular Atrophy; Erb includes under this head pseudo-hypertrophic muscular paralysis, juvenile muscular atrophy, and infantile paralysis. The three are classed together as Dystrophia muscularis pro- 
gressiva. M. Facies, "facies myopathique;" a peculiar form of expression seen in infantile forms of myopathic muscular atrophy. It is characterized by imperfect movement of the facial muscles, sinking in of the cheeks, and drooping of the lower lip.

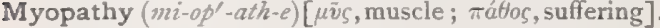
Any disease of a muscle or of the muscular system.

Myope $\left(m i^{\prime}-\bar{o} p\right)$ [ $\left[v^{\prime} \omega \psi\right.$, short-sighted]. A person affected with myopia.

Myopericarditis (mi-o-per-ik-ar-di'-tis) [ $\mu$ ṽs, muscle ;

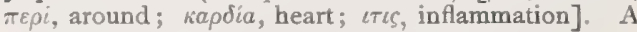
combination of pericarditis with myocarditis.

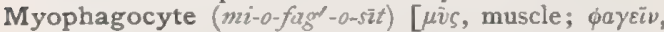
to eat; kv́tos, cell]. Metschnikoff's term for a phagocyte produced from muscular tissue.

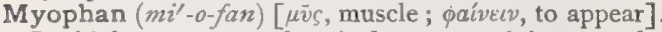
In biology, an ectoplasmic layer containing musclefibrillæ, found in many invertebrates (Infusoria). Cf. Mroderma.

Myophone (mi'-o-fön) [ $\mu \tilde{v} s$, muscle; $\phi \omega \nu \eta ́$, sound]. An instrument for hearing the sounds produced during the contraction of a muscle.

Myophonia ( $\left.m i-o-f o^{\prime}-n e-a h\right) \quad[\mu \bar{s} \varsigma$, muscle; $\phi \omega v \eta ́$, sound]. Muscle-sound.

Myophore (mi'-a-for) [ $\mu \breve{v} \varsigma$, muscle; $\phi \varepsilon ́ \rho \varepsilon \imath$, to bear]. In biology, any specialized apparatus for the attachment of a muscle.

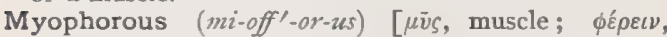
to bear]. Relating to or connected with a muscle, as a myophore.

Myophrisc (mi'-o-frisk) [ $\mu \bar{v} \varsigma$, a muscle; $\phi \rho i \sigma \sigma \varepsilon \iota \nu$, to ruffle or throw into ripples]. In biology, contractile, filamentous processes supposed to perform hydrostatic functions, found arranged on the sarcodyctium in a circle around each skeletal spine of the Acanthometride among the Protozoa.

Myophysical (mi-o-fiz'-ik-al) [ $\mu \bar{v} s$, muscle; $\phi v \sigma \iota \eta^{\prime}$, physics]. Appertaining to the physics of muscular action.

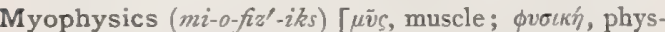
ics]. The physics of muscular action.

Myopia ( $\left.m i-o^{\prime}-p e-a h\right)$ [ $\mu v \varepsilon \varepsilon \iota$, to close ; $\check{\psi} \psi$, eye ; myopes having the habit of partially closing the lids to avoid spheric aberration]. Near-sightedness; an optic defect, usually due to too great length of the antero-posterior diameter of the globe, whereby the focal image is formed in front of the retina. M., High, a degree of

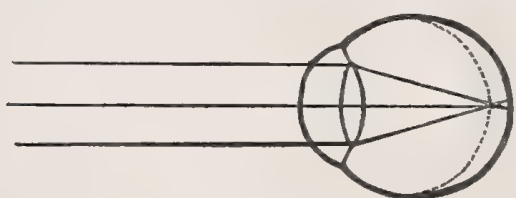

THE FORMATION OF THE IMAGE IN A MYOPIC EYE, IN FRONT OF THE RETINA.

myopia greater than 6.5 diopters. M., Low, one less than two diopters. M., Malignant, rapidly progressing myopia. M., Progressive, continuous increase of myopia, due to increasing elongation of the eyeball.

Myopic (mi-opl-ik) [ $\mu v \varepsilon \varepsilon v$, to close; $\omega \psi$, eye]. Pertaining to or having the nature of myopia. Nearsighted. M. Crescent, a yellowish-white, crescentic area about the papilla, due to atrophy or breaking away of the choroid, and exposure of the sclerotic; it is seen in myopia, but often, also, in other refractive derangements.

Myopiesis (mi-o-pif-es-is) [uṽs, muscle; $\pi i \varepsilon \sigma \iota s$, pressure]. The squeezing or kneading of a muscle as a therapeutic measure.

Myopiosis (mi-o-pi-o'-sis). Synonym of Myopia.
Myoplast (mí-o-plast) [ $\mu \tilde{v} \varsigma$, muscle; $\pi \hat{i} a ́ \sigma \sigma \varepsilon t v$, to mold]. A muscle-producing cell.

Myoplastic (mi-o-plas'-tik) [ $\mu \tilde{v} \varsigma$, muscle; $\pi \lambda a ́ \sigma \sigma \varepsilon t v$, to mold]. Producing muscle; pertaining to a myoplast. M. Bodies, the embryonic cells from which muscular fibers are developed.

Myoplegia (mi-o-ple'-je-ah) [ $\mu \tilde{v} s$, muscle; $\pi \lambda \eta \gamma^{4}$, a stroke]. A condition of diminished muscular power, or of muscular paresis.

Myopodiorthosis (mi-o-po-di-or-tho'-sis). Synonym of Myoporthosis.

Myopolar (mi-o-po'-lar) [ $\mu \bar{v} \varsigma$, muscle; $\pi 6 \lambda \circ \varsigma$, pole]. Pertaining to muscular polarity, electric or other.

Myoporthosis (mi-o-por-tho'-sis) [ $\mu$ viw $\psi$, near-sighted; optos, straight]. The correction of myopia.

Myopresbytia (mi-o-pres-bish'-e-ah) [ sighted; $\pi \rho \varepsilon \sigma \beta v ́ t \eta \zeta$, old-sighted]. Combined myopia and presbyopia.

Myoproteose (mi-o-pro'-te-ōz). See Myoalbumose.

Myopsia (mi-ops'-e-ah). Synonym of Myiodesopsia.

Myopsin (mi-ops'-in). A powerful proteolytic substance said by Defresne to occur in pancreatic juice.

Myopy (mi'-o-pe). Synonym of Myopia.

Myorrheuma (mi-or- $\left.\boldsymbol{u}^{\prime}-m a h\right)$ [ $\mu \tilde{v} s$, a muscle; $\rho \varepsilon \tilde{v} \mu \alpha$, a flow]. A synonym of Muscular Rheumatism or Myalgia.

Myorrhexia, Myorrhexis (mi-or-eks'-e-ah, mi-or$\left.e k s^{\prime}-i s\right)$ [ $\mu \tilde{v} s$, muscle; $\hat{\jmath} \xi \bar{\zeta} \varsigma$, a tearing]. Laceration or rupture of a muscle.

Myosalgia (mi-o-sal'-je-ah). See Myalgia.

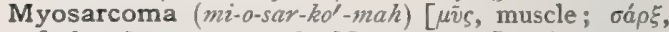
flesh; o $\mu a$, tumor, $p l .$, Myosarcomata $]$. A sarcoma with myomatous elements, or one that has originated in a myoma.

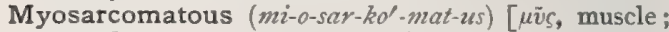
$\sigma a \dot{\rho} \xi$, flesh; $\ddot{\partial} \mu a$, tumor]. Affected with, or of the nature of, myosarcoma.

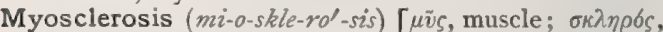
hard]. A temporary hardening of a muscle, often of the sterno-cleido-mastoid, sometimes seen in young infants.

Myosclerotic (mi-o-skle-rot'-ik) [uṽs, muscle; $\sigma \kappa \lambda \eta p o ́ s$, hard]. Pertaining to the hardening of muscles, especially from connective-tissue overgrowth. M. Paralysis. See Paralysis, Pseudo-hypertrophic.

Myoscope (mi'-o-skōp) [ $\mu \tilde{s} s$, muscle; $\sigma \kappa o \pi \varepsilon i \nu$ to inspect]. An apparatus used in observing the contraction-phenomena of muscles.

Myoseism (mi-o-se'-izm), Myoseismia (mi-o-se-iz'-meah) $\left[\mu \tilde{v} \varsigma\right.$, muscle; $\sigma \varepsilon \imath \sigma \sigma_{\zeta}$, a shake]. A symptom that consists in repeated stops in the course of muscular contractions by which the whole movement is rendered jerky. When this jerky movement affects the ocular muscles, it causes an irregularity that may be mistaken for nystagmus. A similar irregularity renders speech and writing jerky and the gait staggering. The patient is unable to maintain his equilibrium with his eyes shut.

Myoseptum (mi-o-seṕ-tum) [ $\mu \bar{v} s$, muscle; septum, septum]. The intermuscular septum between the metameres of muscles of certain animals, as of fishes.

Myosin ( $\left.m i^{\prime}-o-\sin \right)$ [ $\mu v^{\prime} \omega \nu$, muscle]. A proteid of the globulin class, the chief proteid of muscle. Its coagulation in muscle after death causes rigor mortis. $\mathrm{Hy}$. drochloric acid converts it into syntonin. It is soluble in dilute saline and dilute alkaline solutions, and in acids; it is insoluble in water and is precipitated by alcohol. M., Peptone. Synonym of Myosinose. M., Vegetable, a substance resembling myosin, found in almonds, maize, peas, and other vegetables.

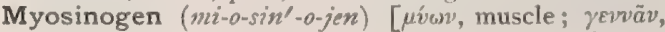
to beget]. One of the proteids of muscle-plasma, 
coagulated at $56^{\circ} \mathrm{C}$. It is the antecedent of myosin, into which it is converted by a suitable stimulus. See

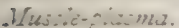

Myosinose (mi-o-sin-äs') [uriwn, muscle]. The substance produced by the peptonization of myosin. Two varieties have been found, protomyosinose and deuteromyosinose.

Myosis $\left(m i-\sigma^{\prime}-s i s\right)$ [úven, to close, or $\mu \bar{s}$, muscle]. I. Abnormal smallness of the pupil of the eye ; the same as Miosis. 2. Myopathy. M., Paralytic, that form due to paralysis of the sympathetic or dilator nerve. M., Spastic, that produced by stimulation of the oculamotor or constrictor nerve. M., Spinal, that dependent on disease of the spinal cord.

Myositic (mi-a-sil'-ik) [uicu, to close; rüs, muscle; [-., inflammation]. Pertaining to, or affected with, myosis, or with myositis.

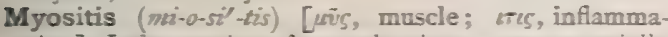
tion]. Intiammation of muscular tissue, more especialiy of the connective tissue of muscles. M., Fibrous, M., Interstitial, an inflammation of the connective tissue of muscle. M. interstitialis lipomatosa progressiva paralytica. Synonym of Psezdahypertrophic Muscular Poralysis. M. ossificans, is characterized by the formation of osseous deposits in the muscles. M., Specific, M., Syphilitic, that due to syphilis. There may be a deposit of gummata in the muscles. M. trichinosa, that due to the presence of trichina spiralis in the muscles.

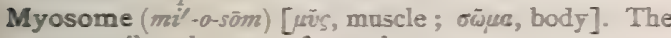
contractile substance of muscle.

Myospasis (mi-os'-pas-is) [ürs, muscle; oráous, a drawing: pl., Myospases]. A muscular contraction.

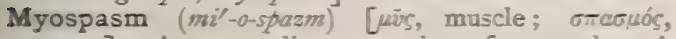
spasm]. A spasmodic contraction of a muscle. A cramp.

Myospectroscope (mi-o-spelk'-tro-skōp) [uv̄s, muscle; spectrum, spectrum; बarotziัy, to see]. An instrument for examining the spectroscopic imaze of a muscle.

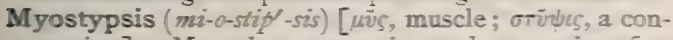
tracting]. YIuscuiar contraction; also any interference with functional morement.

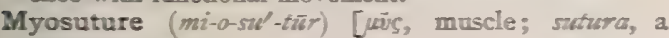
suture]. Suture of a muscle.

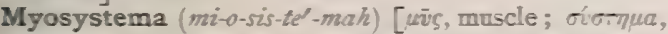
system]. A system of muscles. M. circulare, the circular muscle of the sub-umbrella of meduse. $\mathbf{M}$. radiale, the radial muscles of the sub-umbrella of medusx.

Myotalgia (mi-o-tall-je-ah). Synonym of Mralgia.

Myotasis (mi-ott-as-is) [uis, muscle; teiac, a stretching]. Passive tension of a muscle.

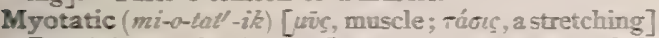
Pertaining to the deep reflexes or contractions of the muscles dependent upon passive tension for their elicitation. M. Irritability, a tern suggested by Gowers to replace the inaccurate one, tendon-relexes, the tendons not being etiologically connected with the phenomenon. "The irritability on which they depend is due to and demonstrative of a muscle reflex action which depends on the spinal cord.

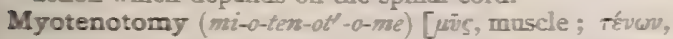
tendon; rouf, a cutting]. The division of a tendon, when the muscle is able to retract.

Myothelium (mi-o-the'-le-uim) [wäs, muscle; Onjy, nipple]. The cellular elements composing a myotome or protovertebra.

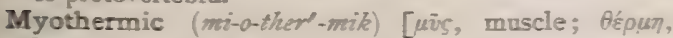
heat]. Pertaining to heat-derelopment in a muscle.

Myotic (mi-ot -ik) [uven, to close]. I. Pertaining to, or cansing, mrosis. 2. An agent causing mrosis, or contraction of the pupil. The one most used by ophthal- mologists is eserin. Morphin, pilocarpin, muscarin and other drugs also cause contraction of the pupil.

Myotility (mi-o-til'-it-e) [uís, muscle]. Muscular contractility, or tonicity.

Myotome (mi'-o-tōm) [ū̌s, muscle; roús, a cutting]. I. A cutting instrument used in myotomy. 2. The same as Iyocomma.

Myotomy (mi-of -o me) [uṽs, muscle; rouj, a cutting]. 1. Surgical division of a muscle. 2. The incision of dissection of muscles. See Tenotomy.

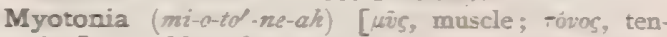
sion]. 1. Muscular spasm. 2. The stretching of a muscle. M. congenita, M. hereditaria. Thom sen's disease; an hereditary neurosis characterized by tonic spasms in the voluntarily mored muscles. See Diseases, Table of.

Myotonic (mi-a-ton'-ik) [uv̄s, muscle ; tóvos, tension]. Pertaining to myotonia, or to myotonus. M. Reaction. See Thomsen's Discase.

Myotonus (mi-oíl-o-mus) [ $\mu \bar{v} \zeta$, muscle; tóvos, stretching]. I. Muscular tone, quality, or tension. Tonic muscular spasm.

Myotyrbe (mi-a-ter/-bz) [uv̄c, muscle; ti $\rho 3 \eta$, disorder] Chorea ; incoördinate muscular movements.

Myrabolan (mi-rab'-o-lan). See Myrobalan.

Myriachit (mir'-e-ak-it). See Palmues.

Myriagram (mirl-e-ag-rame) [uvoioc, ten thousand; jpíupa, gran] ]. Ten thousand grams.

Myriakit (nir -e-cik-it). See Palmus.

Myrialiter (me-re-al-é-ter) [ $u v \rho i o c$, ten thousand; $\lambda_{i} \tau a$, liter]. Ten thousand liters.

Myriameter (me-re-cm-et-ter) [uvpioc, ten thousand; úx-oov, a measure]. Ten thousand meters.

Myrica (mi-rik'-ah) [ of aromatic shrubs of some 35 known species. M. cerifera, of $\mathbf{N}$. America. M. californica, of the Pacific States, M. cordifolia, M. laciniata, and M. zthiopica, of Africa, M. carcasana, and M. microcarpa, of tropical America, are among the wax-bearing species. The species last named has useful medicinal qualities. See Myricin, Gole, and Myrtlewas. M., Oleum, Oil of Mrrica; Oil of Bay is the rolatile oil of the Barberry, or West Indian bayleaf. It is an aromatic, pungent liquid, used chiefly as a perfume and in cosmetics. It is somewhat refreshing in faintness and headaches. M., Spiritus, "bav rum," contains : oil of bay 16 , oil of orange-peel I, oil of pimento I. alcohol I000, water 782 parts, mixed and fitered through carbonate of magnesia.

Myricin ( $\left.m i^{\prime}-r i s-i n\right)$ [uvping, the tamarisk]. A precipitate from a tincture of the root-bark of Myrica cerifera : it is astringent, stimulant, anti-spasmodic, and anti-syphilitic. Dose from $\mathbf{I}$ to 3 grains. Unof.

Myricyl (mi-ris'-il) [ $\mu v p i n$, the tamarisk; $i \lambda \eta$, matter]. See Melissyl. M. alcohol, $\mathrm{C}_{30} \mathrm{H}_{62} \mathrm{O}$. A monatomic alcohol derived from beeswax.

Myringa, Myrinx ( $m i$-rin'-gah, mi'-ringks) [L.]. The membrana tympani.

Myringitis (mi-rin- $\ddot{\imath}$-tis) [myringa, myrinx, mem. brana tympani; $\boldsymbol{T}$ TS, inflammation]. Inflammation of the membrana trmpani.

Myringodectomy "(mi-rin-go-dek"-to-me) [myringa, mrxinga; غ่nouý, excision]. Excision of a part or of the whole of the membrana tympani.

Myringomycosis (mi-rin'-go-mi-ko'-sis) [myringa, membrana tympani; $\mu$ érers, fungus]. A fungous growth within the meatus, or on the miringa: also the diseased condition in which such a growth is seen. $\mathbf{M}$. aspergillina, Wreden's term for Otomycosis, q. $v$

Myringoplastic (mi-rin'-go-plas'-tik) [myringa, men-

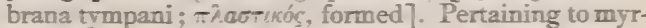
ingoplasty. M. Method, a method for the cure of 
dry perforation of the ear-membrane, recommended by Berthold, and attended with some success. A piece of sticking-plaster is first laid over the perforation and then pulled off in order to cause irritation of the margins. After this a piece of skin from the arm or elsewhere, or the skin of a hen's egg, is applied to the orifice and the ear carefully plugged.

Myringoplasty (mi-rin'-go-plas-te) [myringa, tympanic membrane; $\pi \lambda a ́ \sigma \sigma \varepsilon \iota \nu$, to shape]. Plastic surgery of the membrana tympani.

Myringotome (mi-rin'-go-tōm) [myringa, myringa; roun, a cutting]. A knife-like instrument used in incision or removal of the membrana tympani.

Myringotomy (mi-rin-got'-o-me) [myringa, tympanic membrane; тoнn, a cutting]. Incision of the tympanic membrane.

Myriosporous (mir-e-os'-po-rus) [ $\mu v p i o s$, numberless; $\sigma \pi \delta ́ \rho \circ$, seed]. In biology, producing many spores.

Myrisma (mi-riz'-mah) [ $\mu \nu \rho \iota \sigma \mu a]$. An anointing.

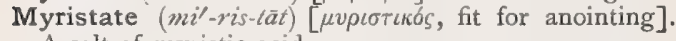
A salt of myristic acid.

Myristic Acid (mi-ris'-tik) [ $\mu v \rho \iota \sigma \tau t k o ́ s$, fit for anointing], $\mathrm{C}_{14} \mathrm{H}_{28} \mathrm{O}_{2}$. A monobasic acid found in Myris. tica fragrans, in cocoanut oil, in spermaceti, etc.

Myristica (mi-ris'-tik-ah) [ $\mu \nu \rho \iota \sigma \tau \iota k o ́ s$, fit for anointing]. Nutmeg. The kernel of the seed of $M$. fragrans, indigenous to the East Indies. Also, the fleshy covering of the fruit called mace. Its properties are due mainly to the volatile oil. It is an aromatic stomachic and tonic, and in large doses a powerful narcotic. The oil is sometimes employed as a rubefacient in paralysis and rheumatism, and is much used as a condiment. Dose gr. v-xx. M. Oleum, the volatile oil. Dose $m_{j}-v$. M., Spiritus, a three per cent. solution in alcohol. Dose $3 \mathrm{j}-\mathrm{ij}$.

Myristicated Liver (mi-ris'-tik-a-ted). Nutmeg liver, q. $v$.

Myristication (mi-ris-tik-a'-shun) [ $\mu v \rho i \zeta \varepsilon \iota v$, to anoint]. The development of a nutmeg condition of the liver.

Myristicin (mi-ris'-tis-in) [ $\mu v \rho i \zeta \varepsilon \ell \nu$, to anoint]. A peculiar fatty body contained in nutmeg.

Myristicol (mi-ris'-tik-ol [ $\mu v \rho i ́ \zeta \varepsilon \iota \nu$, to anoint; oleum, oil], $\mathrm{C}_{10} \mathrm{H}_{16} \mathrm{O}$. An oily substance extracted from oil of nutmeg

Myristin (mi-ris'-tin) [ $\mu v p i \zeta \varepsilon t \nu$, to anoint]. A compound of glycerin and myristic acid.

Myristone (mi-ris'-tōn) [ $\mu v \rho i \zeta \varepsilon \iota \nu$, to anoint]. The ketone of myristic acid.

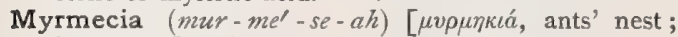
$\mu u \rho \mu \eta \xi$, ant $]$. A warty growth on the palm or sole.

Myrmeciasis (mur-me-si'-as-is) [ $\mu v \rho \mu \eta \xi$, ant]. Formication.

Myrmecismus, Myrmecium (mur-me-siz'-mus, murme'-se-um). Synonym of Myrmeciasis.

Myrmecology (mur-me-kol'-o-je) [ $\mu \dot{v} \rho \mu \eta \xi$, an ant: hóyos, science]. That department of biologic science which treats of ants.

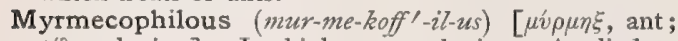
фínos, loving]. In biology, ant-loving. Applied to such plants as are cross-fertilized by means of ants, or to such insects as live in ant-hills.

Myrmecosis (mur-me-ko'-sis). Synonym of Myrmeciasis. Myrobalan (mi-rob'-al-an) [ $\mu$ v́pov, ointment; $\beta a ́ \lambda a v o s$, nut]. Also Myrabolan. The fruit of several species of Terminalia found in India, and other eastern countries, and used in leather-manufactures. The tannin occurs in the pulp that surrounds the kernel. It is generally used in combination with other tanning materials, to modify the objectionable color which some of the latter impart to the leather. By itself it produces a soft and porous tannage. See Myrobalanus. Myrobalan was formerly, and is still locally, much used in medicine. Commercially it is divided into several sorts, citrine, emblic, belleric, etc. Unof. Myrobalanus (mi-ro-bal'-an-us) [ $\mu$ v́pov, ointment; $\beta a ́ \lambda a v o s, n u t]$. The emblic myrobalan; the fruit of Phyllanthus emblica, of Southern Asia. It has a slight laxative followed by an astringent effect, and is highly recommended in dysentery and chronic diarrhea. Botanically, this is not a true myrobalan. Dose $3 \mathrm{ij}-z_{\mathrm{j}}$. Unof.

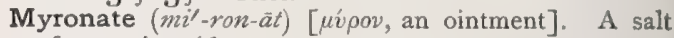
of myronic acid.

Myronic Acid (mi-ron'-ik). See Acid.

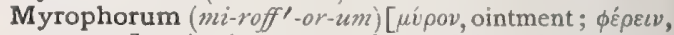
to carry]. An instrument for applying ointments to narrow openings or parts of the body difficult of access.

Myrosin (mi-ro'-sin) [ $\mu \dot{v} \rho o v$, ointment]. An albuminous ferment obtainable from mustard-seed, which liberates the oil of mustard from potassium myronate.

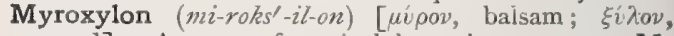
wood]. A genus of tropical leguminous trees. $M$. pereiræ yields balsam of Peru, and $\mathbf{M}$. toluiferum affords the balsam of tolu.

Myrrh (mur) $[\mu \hat{v} \rho \rho \alpha$, myrrh]. The resinous substance obtained from Commiphora myrrha, indigenous to Arabia. In small doses it is a stimulant, in large doses an irritant, to the gastro-intestinal membrane. It is valuable in amenorrhea and bronchial catarrh, and makes an excellent mouth-wash and lotion for spongy gums. It is used chiefly in dentifrices. Dose gr.

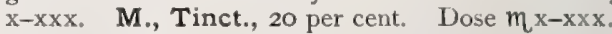

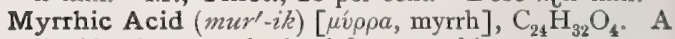
liquid substance obtained from myrrhin.

Myrrhin (mur'-in) [ $\mu$ í $\rho \rho a$, myrrh], $\mathrm{C}_{24} \mathrm{H}_{32} \mathrm{O}_{5}$. A resin contained in myrrh.

Myrrhol (mur'-ōl) [ $\mu$ v́ $\rho \alpha$, myrrh ; oleum, oil], $\mathrm{C}_{22} \mathrm{H}_{32}$ $\mathrm{O}_{2}$. A yellow volatile oil derived from myrrh.

Myrtiform (mur'-tif-orm) [myrtum, a myrtle-berry; forma, form]. Shaped like a myrtle-herry or myrtleleaf. M. Caruncles. See Caruncule. M. Fossa, a shallow pit between the edge of the pyriform aperture of the superior maxilla above, and the sockets of the front teeth of the upper jaw below.

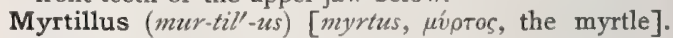
The juice of the common bilberry (Vaccinium myrtillus), used for staining histologic sections.

Myrtle $\left(m u r^{\prime}-t l\right)[m y r t z s, \mu v \rho \tau o s$, the myrtle]. A popular name for several plants of the genera Myrtus, $q . v$. and Myrica, q. v. The wax-myrtles belong to the genus Myrica. M.-wax, a solid fat obtained by pressure from the berries of Myrica cerifera, having a specific gravity of $\mathbf{1} .005$ at $15^{\circ} \mathrm{C}$, and fusing at from $45^{\circ}$ to $46^{\circ} \mathrm{C}$. It is used as a substitute for beeswax in pharmacy and particularly in candle-making. Several other species of this genus (see Myrica) afford myrtle-wax.

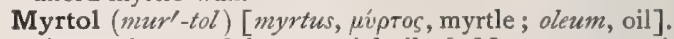
A constituent of the essential oil of Myrtus communis (see Myrtus) ; it is useful in bronchitis, vaginitis, and urethritis, and as a sedative and antiseptic. Dose gtt. iv-xvj, in capsules. Unof.

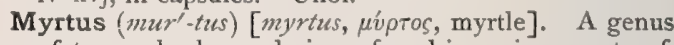
of trees, shrubs, and vines, found in various parts of the world. M. communis, classic myrtle, which has leaves that afford myrtol, $q$. $v$ The plant was formerly much used as an astringent. Unof.

Mysiology (mis-e-ol'-o-je). Synonym of Myology.

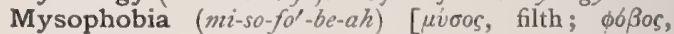
dread]. A form of insanity characterized by a dread of contact, or of dirt; rupophobia.

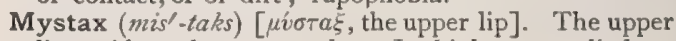
lip. Also, the moustache. In biology, applied to 
the conspicuous tuft of hairs immediately over the mouth in certain diptera (Asilidce).

Mytacism (mit'-as-izm). See Mutacism.

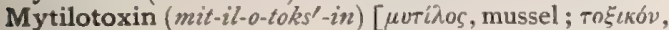
poison], $\mathrm{C}_{6} \mathrm{H}_{15} \mathrm{NO}_{3}$. A poisonous ptomain that has been prepared from the common mussel; it is similar to curara. See Ychthysmus, and Ptomains, Tuble of. Mytilus (mit'-il-us) [ $\mu v \tau i \lambda o \varsigma$, a sea-mussel]. Mussel, a lamellibranchiate mollusc. M. edulis, the edible mussel. Under certain conditions, mussels are very poisonous, either because of some change in their juices, induced by modification of their environment, or because a poisonous species is mixed with a nonpoisonous one. Edible mussels become poisonous in filthy water, while poisonous ones are deprived of their toxicity after a prolonged sojourn in good water.

Mytome (mi'-töm). See Chromatin and Mitome.

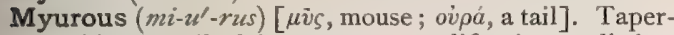
ing like the tail of the mouse; a qualification applied to the pulse when it is progressively growing feeble.

Myxa (miks'-ah) [ $\mu v^{\prime} \xi \alpha$, mucus]. Mucus.

Myxadenitis (miks-ad-en-i'-tis) [ $\mu \hat{v} \xi a$, mucus; ádín, gland; $\iota \tau \iota \varsigma$, inflammation]. Inflammation of a mucous gland.

Myxadenoma (miks-ad-en-o'-mah). Synonym of Myxoadenoma.

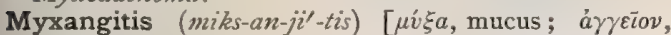
vessel; $\iota \tau \iota \zeta$, inflammation]. Inflammation of the duct of a mucous gland.

Myxedema (miks-e-de'-mah) [ $\mu \dot{v} \xi a$, mucus; oì $\eta \mu a$, edema]. Adult Sporadic Cretinism; Pachydermic Cachexia; Cachexia strumipriva; a disease characterized by the collection of a mucus-like substance in and about the connective tissue of the body, and by atrophy of the thyroid gland. There is a characteristic cretinoid physiognomy; the body is bulky and unwieldy; the skin dry, scaly, and thickened. Speech is slow, monotonous, and guttural; there is marked intellectual torpor, and insanity is likely to develop. The disease is a chronic one, and the tendency is from bad to worse; it is more common in women than in men, and usually occurs between the ages of thirty and sixty-five. Nothing is known positively as to the etiology. It is sometimes induced by surgical interference with or by ablation of the thyroid gland. A similar state has been produced in animals by extirpation of the thyroid gland. Improvement, and, in some cases, cure has been achieved by the therapeutic administration of sheep's thyroids or their extracts.

Myxedematoid (miks-e-de'-mat-oid) [ $\mu$ íga, mucus ;

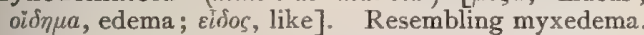

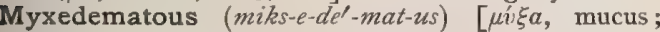
oi $\delta \eta \pi$, edema]. Pertaining to, affected with, or of the nature of, myxedema.

Myxemia (miks-e'-me-ah) [ $\mu \dot{v} \xi a$, mucus ; aí $\mu a$, blood]. An accumulation of mucin in the blood.

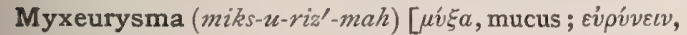
to widen). Cavernous lymphangioma.

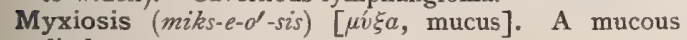
discharge.

Myxoadenoma (mikss-o-ad-en-o'-mah) [ $\mu$ v́za, mucus; $a \delta \eta^{\prime} v$, gland; $\delta \mu a$, tumor]. An adenoma that has in part undergone myxomatous degeneration; an adenoma of a mucous gland.

Myxochondroma (miks-o-kon-dro'-mah) [ $\mu \hat{\prime}, \xi a$, mucus; $\chi o ́ v \delta \rho o s$, cartilage ; ö $\mu a$, tumor: pl., Myxochondromata]. A tumor containing mucous and cartilaginous elements.

Myxochondrosarcoma (miks-a-kon-dro-sar-ko'-mah) [ $\mu \hat{v} \xi a$, mucus ; $\chi 6 \delta \delta \delta o \varsigma$, cartilage; $\sigma a ́ \rho \xi$, flesh; ö $\mu a$, tumor]. A mixed tumor containing myxomatous and cartilaginous tissue and embryonal connective tissue.

Myxocylindroma (miks-o-sil-in-dro'-mah) [ú $\xi a$,

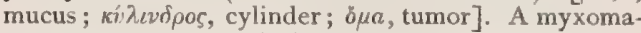
tous sarcoma in which the myxomatous tissue is dis posed in the meshes of the sarcoma.

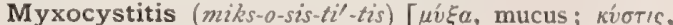
bladder; $\iota \tau \iota$, inflammation]. Inflammation of the mucous membrane of the bladder.

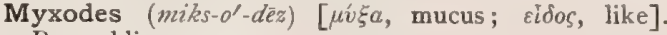
Resembling mucus.

Myxoendothelioma (miks-o-en-do-the-le-o'-mah)

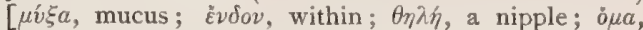
tumor: $p l .$, Myxoendotheliomata $]$. An endothelioma that contains myxomatous tissue.

Myxofibroma (miks-o-fi-bro'-mah) [ $\mu \hat{v} \xi \alpha$, mucus ; fibra, fiber; ö $\mu a$, tumor: $p l .$, Myxofibromata $]$. A fibroma that has in part undergone myxomatous degenera tion.

Myxoglioma (miks-o-gli-o'-mah) [ $\mu \hat{\xi} \xi \alpha$, mucus; $\gamma \lambda i a$, glue; $\partial \mu a$, tumor: $p l .$, Myxogliomata $]$. A glioma with myxomatous elements.

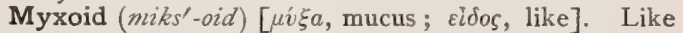
mucus.

Myxoinoma (miks-o-in-o'-mah) [ $\mu v \xi a$, mucus; is, a fiber; $\delta \mu \alpha$, a tumor]. A benign form of inoma, with myxomatous elements.

Myxolipoma (miks-o-lip-o'-mah) [ $\mu v \xi \xi$, mucus; $\lambda i \pi o s$, fat; $\ddot{o} \mu$, tumor: pl., Myxolipomata $]$. A fatty tumor that has in part undergone myxomatous change.

Myxoma (miks-o'-mah) [ $\mu v^{\prime} \xi a$, mucus ; ó $\mu a$, tumor : $p l$. Myxomata]. A connective-tissue tumor the consistency of which is similar to the jelly of Wharton of the umbilical cord. It consists of a gelatinous, mucin-containing intercellular substance, in which are scattered peculiar branched or stellate cells.

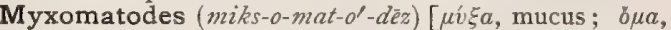
tumor]. Characterized by myxomatous degeneration. Myxomatous (miks-o'-mat-us) [ $\mu v \xi \xi a$, mucus; ŏ $\mu a$, tumor]. Of the nature of, or pertaining to, myxoma. M. Degeneration, the same as mucoid degeneration. It attacks epithelium and connective tissue, giving rise to the production of a gelatinous substance containing mucin. In epithelial tissue the cells only are affected; in connective tissue the intercellular substance. M. Degeneration of the Placenta. See Mole.

Myxomycetes (miks-o-mi-se'-tēz) [ $\mu$ v́ka, mucus ; $\mu \hat{v} \kappa \eta s$, fungus]. A genus of slime-fungi found in decaying wood and moss.

Myxoneuroma (miks-o-nu-ro'-mah) [ $\mu \hat{v} \xi \alpha$, mucus ; veṽpov, nerve ; $\delta \mu a$, tumor: pl., Myxoneuromata]. I. A glioma. 2. A neuroma with mucous elements.

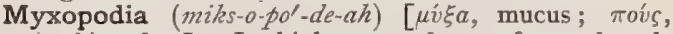
$\left(\pi \circ \delta_{-}\right)$a foot]. In biology, a form of pseudopod, protrusible, retractile, soft, fusing with neighboring pseudopodia into a network, and, in many $R$ hizopoda, often collecting by flowing together outside the body, into small masses at the points where they meet with food. They are characteristic of the Rhizopoda and most Radiolaria, and are to be distinguished from Axopatic.

Myxorrhea (miks-or-e'-ah) [ $\mu$ í $^{\prime} \xi \alpha$, mucus; poia, a flow]. A copious mucous discharge.

Myxosarcoma (miks-o-sar-ko'-mah) [ $\mu$ 'v $\xi \alpha$, mucus; $\sigma a ́ \rho \xi$, flesh; ö $\mu a$, tumor]. A sarcoma that has in part undergone myxomatous degeneration.

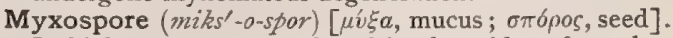
In biology, a spore produced in the midst of a gelatinous mass without a distinct ascus or basidium.

Myxosporidia (miks-o-spor-i $\left.t^{\prime}-e-a h\right)$ [ $\mu \hat{v} \xi a$, mucus; 
$\sigma \pi o ́ p o s$, seed]. A group or order of Sporozoa, found as parasitic bodies in the muscles and epithelia of fishes; they produce a psorospermosis which is frequently wide-spread and destructive.

Myxotheca (miks-o-the'-kah) [ $\mu \dot{\xi} \xi \alpha$, mucus; $\theta \dot{\eta} \kappa \eta$, a sheath: pl., Myxotheca]. In biology, the horny sheath of the tip of the lower mandible of a bird.

Myzesis (mi-ze'-sis) [ $\mu$ í $\zeta \varepsilon i 2$, to suck]. Synonym of sucking.
N. The symbol of nitrogen; also, the sign of the index of refraction.

N. A. Abbreviation for numerical aperture.

N. F. National Formulary; a collection of formulas issued by the American Pharmaceutical Association as a kind of supplement to the U.S. Pharmacopeia.

Na. Symbol of natrium or sodium.

Ni. The symbol for nickel.

Nabalus (nab'-al-zss) [vá $\beta \lambda a$, a harp]. A genus of composite-flowered plants; by some considered a section of Prenanthes. There are many American species, called drop-flower and rattlesnake-root. A poultice of the pounded fresh leaves of $N$. altissimus, or "white lettuce," of N. America, has been used as an application to ulcers, gangrenous sores, etc. Unof.

Naboth, Cysts of, N., Glands of. See Gland. N.'s Menorrhagia, a serous discharge from the vagina in pregnant women.

Nabothian Ovule (na-bo'-the-an). See Ovule.

Nacre (na'-ker) [Ar., nakìr, hollowed out]. Motherof-pearl.

Nacreus (na'-kre-us) [Ar., nakir, hollowed out]. Resembling nacre or mother-of-pearl.

Naegele's Fluids. Fluid culture-media. I. Water IoO c.c., ammonium tartrate I gm., potassium biphosphate 0.1 gm., magnesium sulphate 0.02 gm., calcium chlorid $0.01 \mathrm{gm}$. 2. Water $100 \mathrm{c.c}$, albuminpeptone $1 \mathrm{gm}$., potassium biphosphate $0.2 \mathrm{gm}$., magnesium sulphate $0.04 \mathrm{gm}$., calcium chlorid $0.02 \mathrm{gm}$. 3. Water 100 c.c., cane-sugar 3 gm., ämmonium tartrate $\mathbf{I}$ gm., potassium bitartrate $0.2 \mathrm{I}$ gm., magnesium sulphate $0.04 \mathrm{gm}$., calcium chlorid $0.02 \mathrm{gm}$. Filter and sterilize. N.'s Obliquity of the Head, lateral flexion of the fetal head toward the mother's sacral bone, the left ear approaching the left shoulder, and the right parietal bone presenting in a left occipitoanterior position. It is the third step in the mechanism of delivery. See Obliquity. N.'s Rule, for predicting the date of confinement: "Count back three months from the date of cessation of the last men. strual flow, and add seven days." Hirst modifies this by counting from the date of appearance, believing that the result will be more accurate. N.'s Pelvis. See Pelvis, Female, Deformities of. N.'s Theory. See Heredity.

Nrvoid (ne'-roid). See Neroid.

Nrvose $\left(n e^{\prime}\right.$-vös). See Nevose.

Nævus (ne'-vus). See Nerus.

Nail (nāl) [ME., naile, a nail]. The horny lamina covering the dorsal aspect of the end of each finger and toe. N.-area, a thickening of the epitrichium over the end of the digit, marked out quite definitely by a limiting groove that persists more or less distinctly throughout life. It first appears in the human embryo about the beginning of the third month. N.-bed, the depression in which the nail rests. N.-bone, the lacry-

mal bone or os unguis. N.-brush, a hand brush for cleaning the finger-nails. N.-culture, a term applied in bacteriology to a stab-culture showing a growth along the needle-track, and on the surface a button-like projection, giving the appearance of a nail driven into the gelatin. N.-file, a small single-cut file for trimming the finger-nails. N.-fold, the portion of epi-

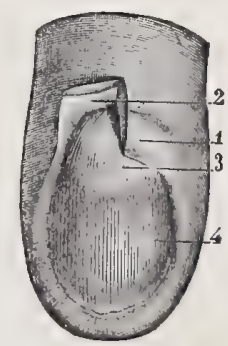

UNGUAL EXTREMITY OF FINGER, SHOWING NaIL.

r. Fold of skin covering root of nail. 2. Incised and turned back. 3. Semilunar portion of subungual skin. 4. Portion corresponding to body of nail.

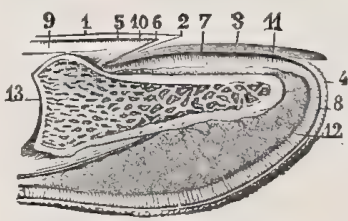

LONGITUDINAL SFCTION OF UNGUAL EXTREMITY OF FINGER, SHOWING NAIL.

dermis that covers the root and

dermis that covers the root and edges of the nail. N.groove, the depression for the insertion of the nail. N., Hang, a little shred of skin hanging from the finger at the side of the nail. Hang-nails are sometimes quite painful, and the little wounds offer entrance to septic matter. N., Infleshed, Ingrowing, or Ingrown, an overlapping of the nail by the flesh, from pressure, attended with ulceration. N.matrix, the proximal end of the $N$.-bed; the structure from which the nail grows. N.-pad. The same as $N$-rampart. N.-plate, the volar side of a claw. N.-rampart, the epidermic border against which the margin of the nail rests. N., Reedy, N., Striated, a nail presenting longitudinal furrows. N.-root, the portion of the nail attached to the $N$-matrix. N., Spring. Same as Hang-nail. N., Turtle-back, a 
name given by S. Weir Mitchell to a nail curved in all directions; it is a condition seen in certain trophic disturbances. N.-wall. The same as $N_{\text {.-rampart. }}$

Nailers' Consumption. See Siderosis.

Nail-smiths' Cramp. See Cramp.

Naked (na'-ked) [ME., naked, naked]. Unclothed; nude. N. Broomrape. See Aphyllon. N. Eye, the eye unaided by a magnifying instrument.

Nakra (na'-krah) [Beng.]. A Bengalese disease resembling influenza.

Nalardofi ( $\left.n a l-a r-d \sigma^{\prime}-f e\right)$ [native Iceland]. In Iceland, an endemic numbness of the hands, probably caused by the milking of ewes.

Namangitis (nam-an-ji'-tis). Synonym of Lymphangitis.

Nameless Crime. The name given to perversion of the genetic instinct, by which sexual gratification is secured in other than the normal way, as by buccal or anal coitus, etc.

Nanander (nan-an'-der) [vävos, a dwarf; ávńp, male]. Same as. Micrander.

Nancy Method. See Hypnotism

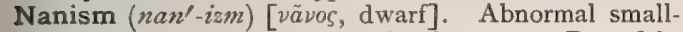
ness of size from arrested development. Dwarfishness.

Nanization (nan-iz-a'-shun) [vãvos, a dwarf]. In biology, artificial dwarfing, as practised by the Japanese on certain trees.

Nanocephalia (nan-o-sef-a'-le-ah) [vãvos, dwarf; $\kappa \varepsilon \phi$ $a \lambda h$, head]. The condition of being nanocephalous.

Nanocephalism (nan-o-sef'-al-izm). See Nanocephalia.

Nanocephalous (nan-o-sef'-al-us) [vävos, dwarf; $\kappa \varepsilon \phi a \lambda \eta \dot{n}$, head]. Possessing a dwarfed or diminutive head.

Nanocephaly (nan-o-sef'-al-e). See Nanocephalia.

Nanocormia, Nanocormus, (nan-o-kor'-me-ah, nan-o-

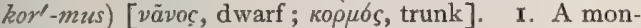
strosity possessing a dwarfed trunk. 2. A dwarfed condition of the trunk.

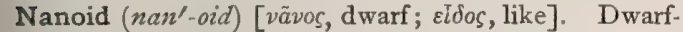
like.

Nanomelia, Nanomelus (nan-o-me'-le-ah, nan-om'-

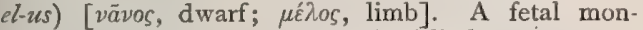
strosity characterized by undersized limbs.

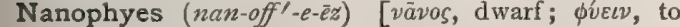
grow]. Dwarfish.

Nanosomia (nan-o-so'-me-ah). See Microsomia.

Nanosomus (nan-o-so'-mus) [vãvos, dwarf; $\sigma \tilde{\omega} \mu a$, body]. One dwarfed in body.

Nanus (nan'-us) [vãvos, a dwarf ]. I. A dwarf. One of less than ordinary stature. 2. Dwarfish; stunted; very small.

Nape (nāp) [ME., nape, nape]. The back part of the neck; the nucha.

Napellin (na-pel'-in) [napellus, dim. of napus, a turnip], $\mathrm{C}_{26} \mathrm{H}_{39} \mathrm{NO}_{11}$. An alkaloid from Aconitum napellus. It is an anodyne and antineuralgic. Dose, gr. $\frac{1}{5}-\frac{1}{2}$. See Aconite.

Napellus (na-pel'-us) [L., dim. of napus, a turnip]. Aconitum napellus, $q . v$.

Naphtha (naf'-thah) [vá $\phi \theta a$, asphaltum]. Danforth's oil ; a product obtained from petroleum, boiling at $80^{\circ}$ to $110^{\circ} \mathrm{C}$. ; specific gravity .690 to .700 or $76^{\circ}$ to $70^{\circ}$ $B$. It is used for burning in vapor-stoves and streetlamps, as a solvent for resins in making varnishes, and in the manufacture of oilcloths.

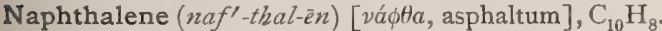
One of the principal constituents of coal-tar, occurring in it in various proportions of from five to ten per cent. ; it is also formed when the vapors of organic substances are passed through tubes heated to redness. The specific gravity of naphthalene when solid is 1.158 ; at its melting-point $\left(79.2^{\circ} \mathrm{C}\right.$. ) the specific gravity is 0.978 ; it boils at $216.6^{\circ} \mathrm{C}$. The odor is pleasant, though characteristic. Naphthalene crystallizes in large, silvery, brilliant, thin, rhombic plates, that are feebly soluble in hot, but insoluble in cold water, though easily soluble in methyl and ethyl alcohols, chloroform, ether, and benzene. It is employed in the manufacture of a large series of coloring-matters; as an enricher of illuminating gas; and when specially refined, as a substitute for ordinary camphor in preventing the ravages of insects in woollen goods. It is an antiseptic, and, internally, an active expectorant ; it is useful as a dressing for indolent sores, and, internally, in pulmonary catarrh. Dose, gr. $\mathrm{ij}-\mathrm{x}$ in emulsion, or in pill, gr. $\frac{2}{5}$, given every hour. In large doses it is toxic, causing emesis and purgation. Unof. N.-red, $\mathrm{C}_{30} \mathrm{H}_{21} \mathrm{~N}_{4} \mathrm{Cl}$; magdala-red; a safranin of naphthalene. It is a dark-brown powder that dissolves very readily in alcohol with a bluish-red coloration. It imparts a beautiful rose-red color to silk. N.-yellow. See Pigments, Conspectus of.

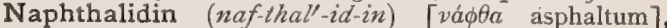
$\mathrm{C}_{10} \mathrm{H}_{9} \mathrm{~N}$. An amin derivative of naphthalene, occurring in two isomeric forms.

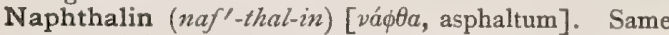
as Naphthalene. N. Dye-stuffs. See Pigments, Conspectus of. N.-red, N.-scarlet, N.-violet. See Pigments, Conspectus of.

Naphthalol (naf'-thal-ol) [vá $\phi \theta a$, asphaltum; oleum, oil ], $\mathrm{C}_{6} \mathrm{H}_{4} \mathrm{OH}$. $\mathrm{COOC}_{10} \mathrm{H}_{7}$. A salicylic-acid derivative of $\beta$-naphthol.

Naphthamein (naf-tham-e'-in). See Pigments, Conspectus of.

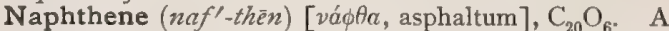
hypothetic substance existing in many naphthalin compounds. The naphthenes are hydrocarbons present in German oils, and are also contained in Caucasian petroleum; they are insoluble in sulphuric acid; octonaphthene, $\mathrm{C}_{8} \mathrm{H}_{16}$, and nono-naphthene, $\mathrm{C}_{9} \mathrm{H}_{18}$, are well known; the naphthenes are considered identical with the benzene hexa-hydrids.

Naphthylamin (naf-thil'-am-in). Same as Naphthalidin

Naphthylcarbamid (naf-thil-kar'-bam-id). See $N a p h-$ thylurea.

Naphthylene (naf'-thil-ēn) [vá $\theta \theta a$, asphaltum]. Synonym of Naphthene. N.-blue, See Pigments, Conspectus of.

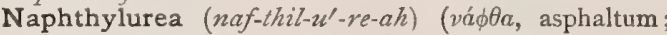
ovpov, urine]. A substance that appears in the urine after free administration of naphthalin; it colors the excretion brown. With acetic acid it gives a rose color; with sulphuric acid it has a green reaction.

Naphtol, or Alpha-naphtol (naf'-tol) [vá $\phi \theta a$, asphaltum], $\mathrm{C}_{10} \mathrm{H}_{7} . \mathrm{OH}$. A substance that results from $a$-naphthylamin by means of the diazo-compound. It is soluble with difficulty in hot water, readily in alcohol and ether, erystallizes in shining needles, and has the odor of phenol. It melts at $95^{\circ} \mathrm{C}$, , and boils at $278^{\circ}-280^{\circ} \mathrm{C}$. It is used in the preparation of alphaoxynaphtoic acid. N., $\beta-$, or Beta-naphtol, $\mathrm{C}_{10} \mathrm{H}_{7} . \mathrm{OH}$, is formed from $\beta$-naphthylamin. It is readily soluble in hot water: it crystallizes in leaflets, melting at $122^{\circ} \mathrm{C}$., and boiling at $286^{\circ} \mathrm{C}$. N. - blue. See Pigments, Conspectus of. N.-camphor, a mixture of $\beta$-naphtol one part, with camphor two parts. It is antiseptic, and is used in diphtheria and pulmonary tuberculosis. Unof. N.-green, N,-violet, N.yellow. See Pigments, Conspectus of.

Napifolious (na-pif-o'-le-us) [napus, a turnip; folium. a leaf]. In biology, having leaves like those of the turnip.

Napiform (na'-pif-orm) [napus, a turnip; forma, form]. Turnip-shaped. 
Napkin (nap'-kin) [ME., napkyn, a napkin]. I. A handkerchief. 2. A diaper. 3. A cloth used by menstruating women. N.-holder, an instrument used by dentists for holding a napkin in position within the mouth while a filling is being inserted in a tooth.

Naples $\left(n a^{\prime}-p l s\right)$ [Ital.]. A city of southern Italy. N. Fever. A synonym of Fever, Typhoid. N. Green. See Pigments, Conspectus of. N. Red. Same as Ocher. N. Yellow. See Pigments, Conspectus of.

Napoleon Blue. See Pigments, Conspectus of.

Narceia (nar-se'-yah). Same as Narcein.

Narceïn (nar'-se-in) [ $v a ́ \rho \kappa \eta$, numbness], $\mathrm{C}_{23} \mathrm{H}_{29} \mathrm{NO}_{9}$. An alkaloid contained in opium. It is sparingly soluble in water and alcohol, and forms fine, silky, inodorous, bitter crystals. It is sometimes used in medicine as a substitute for morphin. Dose gr. $1 / 4$. Unof.

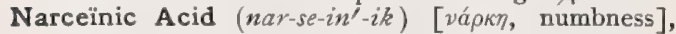
$\mathrm{C}_{15} \mathrm{H}_{15} \mathrm{NO}_{8}+3 \mathrm{H}_{2} \mathrm{O}$. An oxidation-product of narceîn; it is a tribasic acid.

Narcema (nar-se'-mah). Synonym of Narcosis.

Narcesis (nar-se'-sis). Synonym of Narcosis.

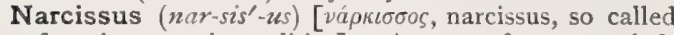
from its narcotic qualities]. A genus of monocotyledonous plants. N. pseudo-narcissus Linn, common daffodil or chalice-flower, used as a diuretic, Unof.

Narcitin (nar'-sit-in). Synonym of Pseudo-narcissin.

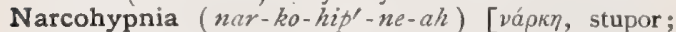
á $\phi \pi \nu \nu \tilde{v} \nu$, to awake]. Waking numbness; a peculiar state in which the patient has a sense of numbness on awaking.

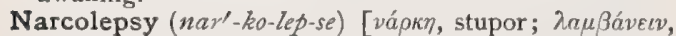
to seize]. A term applied to the sudden but short attacks of deep sleep occasionally accompanying epilepsy, gouty, diabetic, and other affections. See also Nelavan and Filariasis.

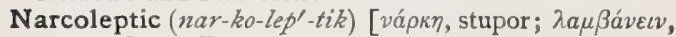
to seize]. Affected with narcolepsy.

Narcoma (nar-ko'-mah) [vá $\rho \kappa \eta$, stupor]. The stupor produced by the use of a narcotic.

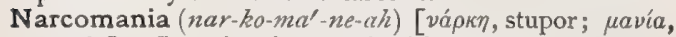
mania]. Insanity characterized by stupor.

Narcomatous (nar-ko'-mat-us) [vá $\kappa \kappa \eta$, stupor]. Pertaining to, affected with, or of the nature of, narcoma.

Narcopepsia, Narcopepsis (nar-ko-pep'-se-ah, nar-ko-

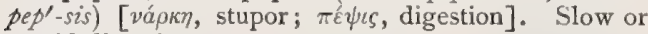
torpid digestion.

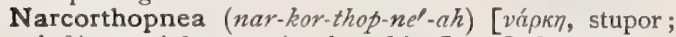
ópfós, straight; $\pi$ voía, breathing]. Orthopnea accompanied by stupor.

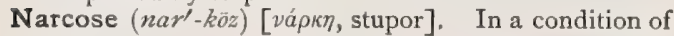
stupor.

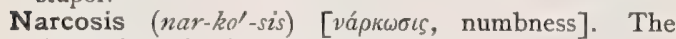
deadening of pain, or the production of incomplete or complete anesthesia by the use of narcotic agents, such as the anesthetics, opium, and other drugs.

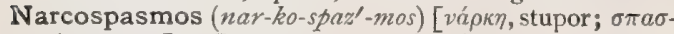
$\mu \delta \varsigma$, spasm]. Spasm accompanied by stupor.

Narcotic $\left(n a r-k o t^{\prime}-i k\right)$ [ numb]. I. Producing stupor. 2, A drug that produces narcosis.

Narcotin (nar'-kot-in) [ $\mathrm{O}_{7}$. An alkaloid of opium, separated from morphin by potassium hydroxid. It crystallizes from alcohol in shining prisms, and melts at $176^{\circ} \mathrm{C}$. It is said to be sudorific and antipyretic, but has no narcotic or hypnotic effects. Dose, gr. j-ij. Unof.

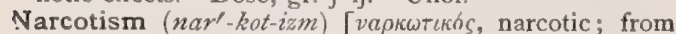
vápкn, stupor]. The condition resulting from the continued use of a narcotic.

Narcurethritis (nar-ku-re-thri'-tis). Synonym of Gleet.

Nard [vápóos, nard]. See Spikenard.
Nardine, Nardy (nar'-din, nar'-de) [vá $\delta o s$, nard]. Pertaining to, or redolent of, nard.

Naregamia (nar-eg-a'-me-ah) [E. Ind.]. Goanese Ipecacuanha; the bark of $N$. alata, having properties due to an alkaloid, naregrmin. It is useful in bilious disorders and rheumatism. The alkaloid has proved valuable in dysentery. Dose gr. xv. Dose of the tincture ( $I$ to 4 ) as an alterative $\eta_{v-x}$; as an emetic, m xv-xxx. Unof.

Naregamin (nar-eg'-am-in) [naregamia]. An alkaloid contained in Naregamia alata.

Narial $\left(n a^{\prime}-r e-a l\right)$. Synonym of Nasal.

Naricorn (na'-rik-orn) [naris, nostril; cornu, horn]. In biology, the horny nasal case or rhinotheca of certain birds.

Nariform (na'-rif-orm) [naris, nostril ; forma, form]. Shaped like a nostril.

Narine (na'-rin) [naris, a nostril]. Narial; pertaining to the nostrils.

Naris $\left(n a^{\prime}-r i s\right)[L .: p l .$, Nares]. The nostril. See $N a s a l$ Fossa. N., Anterior, the nostrils. N., Internal, N., Posterior, the posterior openings of the nasal cavities, through which they connect with the pharyngeal cavity.

Narthex (nar'-theks) [vá $\theta \eta \eta \xi$ narthex]. The genus Terula; also a splint for the leg.

Nasal (na'-zal) [nasus, the nose]. Pertaining to the nose. N. Angle. See Angle. N. Artery. See Arteries, Table of. N. Bones, the two small bones forming the arch of the nose. See Bones, Table of.

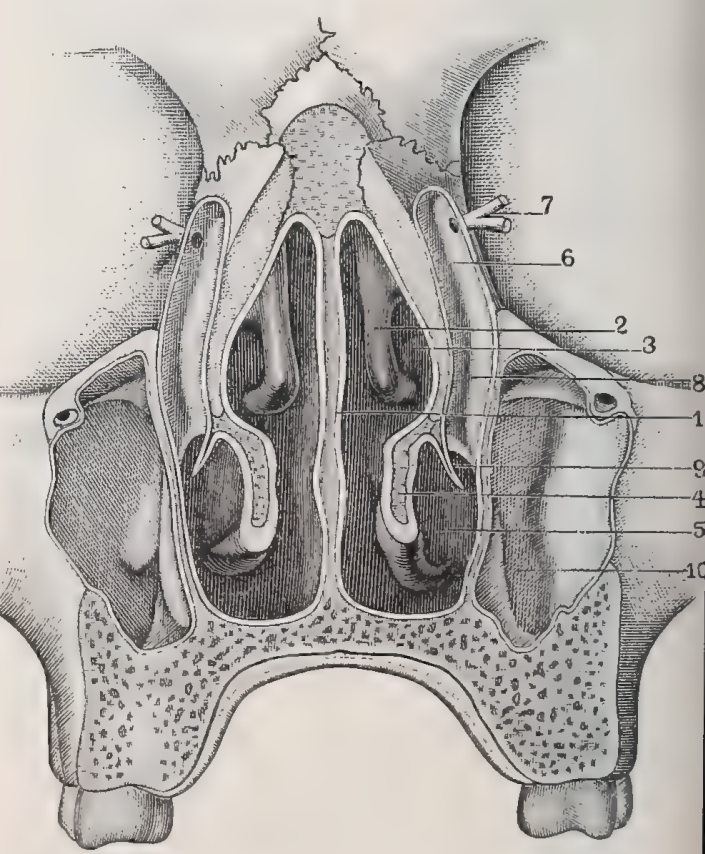

Transverse Section of the Nasal Fosse.

I. Nasal septum. 2. Anteriot extremity of middle turbinated bone. 3. Middle meatus. 4. Section of inferior turbinated bone 5. Inferior meatus. 6. Lacrymal canal. 7. Canaliculi. 8. Nasal canal. 9. Section of reflected mucous membrane. 10. Maxillary sinus or antrum of Highmore.

N. Canal. See Canal. N. Cartilage. See Cartilnge. N. Catarrh, catarrh of the nasal cavities; cold in the head; coryza. N. Cavities, the nasal fossæ, q. $v$. N. Cough, a reflex cough, due to irritation of the mucous membrane of the nasal fossæ. N. Crest. 
See Crest. N. Diplopia. Same as Crossed Diplopia. N. Duct. See Lacrymal Duct. N. Eminence. See Eminence. N. Floor, the floor of the nasal fossæ. N. Fossæ, the nostrils; the cavities in the middle of the face leading to the internal surfaces of the nose. N. Ganglion, the spheno-palatine ganglion. See Ganglia, Table of. N. Groove. See Groove. N. Index. See Index. N. Labyrinth, the irregular cavity formed by the turbinal bones in the nasal passages. $\mathbf{N}$. Line. See Lines, Table of. $\mathbf{N}$. Meatus, one of the nostrils. N. Membrane, the Schneiderian membrane. N. Nerve. See Nerves, Table of. N. Notch. See Notch. N. Passages, the meatuses of the nose. N. Point. See Craniometric Points. $\mathbf{N}$. Process. See Process. N. Reflex. See Reflexes, Table of.

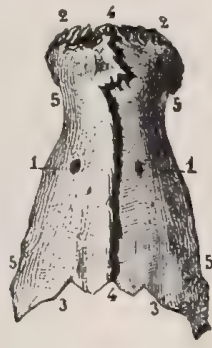

Nasal Bones, ExterNAL ASPECT.

1. The two nasal bones. 2, 2. Superior extremity. 3,3 . Inferior border. 4,4 . Internal border. 4 , 5, 5, 5. External border.

N. Septum. See Septum of the Nose. N. Spine. See Spine. N. Voice, a peculiar muffled twang of the voice, especially marked in cases of perforation of the palate. See Dead Voice.

Nasarium (na-za'-re-um) [nasus, nose]. Nasal mucus.

Nascal (nas'-kl) [nascale]. A pledget or dossil of lint, cotton, or wool, used in the treatment of uterine or vaginal disease.

Nascent (nas'-ent) [nascor, nasci, to be born]. A term applied to gaseous substances at the moment of their liberation from chemic union.

Nasen $\left(n a^{\prime}-z e n\right)$ [naszes, a nose]. Belonging to the nasal bone in itself.

Nasethmoid (na-zeth'-moid) [nasus, nose; $\dot{\eta} \theta \mu b s$, a sieve; $\varepsilon i \delta o s$, like]. Pertaining to the nasal and ethmoid bones.

Nasiform (na'-zif-orm) [nasus, nose; forma, form]. Shaped like the nose.

Nasilabial (na-zil-a $\left.a^{\prime}-b e-a l\right)$. See Nasolabial.

Nasio-alveolar (na'-ze-o-al-ve'-o-lar) [nasus, nose; alveolus, socket]. Relating to or connecting the nasion and the alveolar point.

Nasio-bregmatic (na'-ze-o-breg-mat'-ik) [nasus, nose ; $\beta \rho \rho^{\prime} \gamma \mu a$, bregma]. Pertaining to the nasion and the bregma.

Nasio-inial (na'-ze-o-in'-e-al) [nasus, nose; iviov, occiput]. Pertaining to the nasion and the inion.

Nasio-mental (na'-ze-o-men'-tal) [nasus, nose ; mentum, chin]. Pertaining to or connecting the nasion and the mentum.

Nasion $\left(n a^{\prime}-z e-o n\right)$ [nasus, nose]. The median point of the naso-frontal suture. See Craniometric Points. Nasitis (na-zi'-tis). See Rhinitis.

Nasmyth's Membrane. The epithelial membrane enveloping the enamel of the teeth during their development and sometimes also for a short time after birth; cuticula dentis.

Naso- $\left(n a^{\prime}-z 0^{-}\right)$[nasus, nose]. A prefix to denote connection with or relation to the nose. N.-alveolar. Same as Nasio-alveolar. N.-basal, pertaining to the nose and the base of the skull. N.-basilar, pertaining to the nasal point and the basion. N. - frontal, pertaining to the nasal and frontal bones. N.-labial, pertaining conjointly to the nose and the lips; applied to certain muscles. N.-lacrymal, pertaining to the nose and to the lacrymal apparatus, as the naso-lacrymal duct. N.-maxillary, pertaining to the nasal bone and the upper jaw-bone. N.-opisthiac, pertaining to the nasion and the opisthion. N.-palatal, N.-palatine, pertaining to both nose and palate. Also, the name of the nerve entering the nasal fossa and passing across the roof of the nose to the roof of the mouth, supplying that part of the mucosa behind the incisor teeth. See Nerves, Table of. N.-pharyngeal, pertaining conjointly to the nose and the pharynx. N,-pharyngitis, inflammation of the mucosa lining the nasopharynx. N.-pharynx, the arching space between the posterior nares and a horizontal plane through the lower margin of the soft palate. N.-subnasal, in craniometry, applied to a line connecting the nasal and the subnasal points.

Nasocular (na-zok'-u-lar) [nasus, nose; oculus, eye]. Pertaining to the nose and the eye; nasorbital.

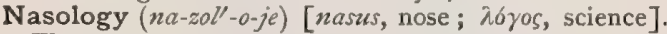
The study of noses.

Nasorbital (na-zor'-bit-al) [nasus, nose ; orbitalis, orbital]. Nasal and orbital.

Nasta (nas'-tah) [vaorós, solid]. A fleshy tumor of the neck about the shoulders.

Nasus $\left(n a^{\prime}-z u s\right)[\mathrm{L}$.$] . The nose.$

Nasute $\left(n a^{\prime}\right.$-süt $)$ [nasus, nose]: Large-nosed.

Nasutiform (na-su'-tif-orm) [nasutus, long-nosed; forma, form]. In biology, applied to nose-like processes of the heads of insects.

Natal $\left(n a^{\prime}-t l\right)$ [natalis, from nasci, to be born]. Native ; connected with one's birth.

Natal $\left(n a^{\prime}-t l\right)$ [natis, rump]. Gluteal; pertaining to the nates.

Natal Sore. See Furunculus orientalis.

Natalitial (na-tal-ish'-al) [natalis, from nasci, to be born]. Pertaining to one's birth.

Natality (na-tal'-it-e) [natalis, of birth]. In State medicine and statistics, the birth-rate.

Nataloin (nat-al'-o-in) [Natal; $a \lambda b \eta n$, the aloe], $\mathrm{C}_{25} \mathrm{H}_{28} \mathrm{O}_{11}$. The aloin derived from Natal aloes.

Natant $\left(n \alpha^{\prime}-\tan t\right)$ [natare, to swim]. Swimming or floating on the surface of a liquid

Nates (na'-téz) [natis, the buttock: pl., Nates]. The buttocks. N. of Brain, the anterior pair of the Corpora quadrigemina.

Natiform (nat'-if-orm) [nates, buttocks; forma, form]. Buttock-shaped.

Native (na'-tiv) [nativus, born]. Coming into existence by birth; of indigenous origin or growth. N. Albumins, a class of animal proteids occurring in a natural condition in animal solids and fluids. They are soluble in water, and are not precipitated by alkaline carbonates, sodium chlorid, or very dilute acids. Their solutions are coagulated by heat at $65^{\circ}$ to $73^{\circ} \mathrm{C}$. Dried at $40^{\circ} \mathrm{C}$. they yield a clear, yellow or ambercolored, friable mass soluble in water, called soluble albumin. The two chief varieties of native albumins are serum-albumin and egg-albumin.

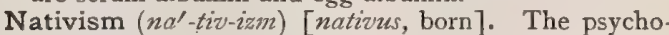
logic theory that assumes that our ideas of form, space, and distance are, at least in part, due to the make-up of the organism or to some native power or endowment, and not entirely to experience.

Nativistic (na-tiv-is'-tik) [nativus, native]. Pertaining to nativism.

Natrium (na'-tre-um). See Sodium.

Natron ( $n a^{\prime}$-tron) [Ar., natrün, native carbonate of sodium]. Native sodium carbonate. Also, sodium or potassium nitrate. This was formerly the exclusive meaning of the word.

Natta (nat'-ah). An old name for a wen, fleshy excres. cence, or tumor. [Obs.]

Natural (nat'-u-ral) [natura, nature]. I. Pertaining to nature. 2. An idiot. N. Gas, the mixture of 
inflammable gases that is found issuing from the earth in various localities. It consists essentially of methane, with small quantities of hydrogen, carbon monoxid and dioxid, and some nitrogen. N. History, a term including a description of all the products and phenomena of nature, but now usually restricted to the sciences of zoölogy and botany. N. Order, one of the divisions in the classification of both animals and plants, varying in its technical meaning according to the system of classification. N. Philosophy, the science treating of the physical properties of matter at rest and in motion. It is now usually called Physics. N. Selection. See Evolution.

Naturalia (nat-u-ra'-le-ah) [natura, nature]. The genitalia.

Naturalism (nat'-u-ral-izm) [natura, nature]. The expectant method of treating disease.

Naturalization (nat-u-ral-iz-a'-shun) [natura, nature]. The process by which a plant or an animal transferred from its natural habitat adapts itself to its new surroundings.

Naturalized (nat'-u-ral-zzd') [natura, nature]. Relating to naturalization.

Nature $\left(n a^{\prime}-t \bar{u} r\right)$ [natura, birth, origin]. The aggregate action and product of many natural laws (Darwin). The energy by which the innumerable phenomena that fall daily under observation are produced. The word is loosely used as covering indiscriminately both biologic and non-living phenomena.

Naturism (na'tür-izm). Synonym of Naturalism.

Naupathia (naw-pa'-the-ah) [vais, ship; $\pi a ́ \theta o s$, sickness]. Seasickness.

Nauplius (naw'-ple-us) [vaṽs, a ship; $\pi \lambda \varepsilon i v$, to saill]. In biology, the earliest recognizable form of the crustacean larva, having an unsegmented ovate body, a median frontal eye, and three pairs of natatory feet, of which the anterior are simple and the other two biramose. N. Eye, the unpaired eye of all larval Crustaceans, and retained in the adult Entomostraca.

Nausea (naze'ze-ah) [nausea, vavoia, seasickness]. Sickness at the stomach, with inclination to vomit. N. marina, N. navalis, seasickness.

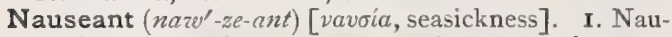
seating; producing nausea. 2, Any agent that produces nausea.

Nauseating (nazv'-ze-a-ting). Synonym of Nauseous.

Nauseous (naz'-ze-us, or nazv'-yus) [vavoia, seasickness]. Producing nausea, or loathing.

Nautomania (nazv-to-ma'-ne-ah) [vav́tys, sailor; ravia, madness]. A kind of homicidal madness said by some writers to exist among sailors.

Navel $\left(n a^{\prime}-v l\right)$ [ME., navel, navel]. See Umbilicus. N.-ill, a disease of calves, in which the navel becomes inflamed and the adjacent parts red and swollen. N.-string, the umbilical cord.

Navicula (na-vik'-u-lah) [dim. of navis, ship]. A genus of diatoms of many species, some of which have the frustules marked with very minute striæ, the definition of which is sometimes taken as a test of the power of microscopes

Navicular (na-vik'-u-lar) [navicula, a little ship]. Boat-shaped. N. Bone. See Scaphoid. N. Fossa, applied to several cavities, especially to a depression between the vaginal aperture and the fourchet, and to a dilatation of the urethra near the glans penis. N. Sheath, the synovial membrane covering the navicular bone in ungulates, as in the horse.

Naviculoid (nav-ik'-u-loid) [navicula, a small boat; Eidos, like]. Scaphoid.

Naviform (na'-vif-orm) [navis, ship; forma, form]. Boat-shaped ; scaphoid.

Navis (na'-vis) [navis, ship]. The vulva.
Navy-blue. Same as Prussian Blue and Soluble Blue.

Neale's Lung. An apparatus devised for the purpose of removing the carbon dioxid and ammonia from the vitiated atmosphere of a room. It is also called Neale's Chemical Lung.

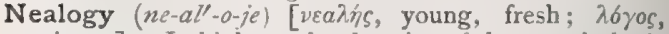
science]. In biology, the doctrine of the morphologic correlations of a young organism.

Neanderthaloid ( $n a$-ahn'-der-tahl-oid) [from Neanderthal in Rhenish Prussia]. Resembling the (prehistoric) Neanderthal skull, a noted skull found near Bonn, in Germany. A term used in craniology and anthropology.

Neapolitan Fever. See Mediterranean Fever. N. Ointment, blue ointment; mercurial ointment.

Near (nèr) [ME., nere, near]. I. Being close by, not distant. 2. Closely akin. 3. The left side of an animal as distinguished from the "off," or the right side. N. Point. See Punctum proximum. N.-sight, N.-sightedness. See Myopia.

Nearthrosis (ne-ar-thro'-sis) [vह́os, new; à $\rho 0 \omega \sigma \iota \zeta$. joint]. A new and abnormally-produced articulation, in the sequence of a fracture, dislocation, or disease of the bone.

Neat (nèt) [ME., neet, an ox or cow]. Cattle of the bovine genus. N.'s-foot Oil, Oleum bubulum, is prepared from ox-feet collected from the slaughterhouses. It is a clear, yellowish oil of specific gravity .916 at $15^{\circ} \mathrm{C}$. It does not congeal until below $32^{\circ} \mathrm{F}$., and is not liable to become rancid. It is of great value as a lubricant, and is used for softening leather and in the grinding of metals. It is recommended as a substitute for cod-liver oil. Unof.

Nebula (neb'-u-lah) [L., a cloud]. A faint, grayish opacity of the cornea. When more pronounced, it is called Leukoma.

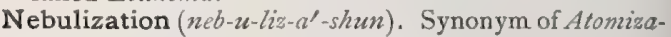
tion.

Nebulizer (neb'-u-li-zer) [nebula, a cloud]. An instrument intended to produce a spray, and then to break this up into a veritable nebula by impact against the wall of the containing vessel or other convenient obstacle. It is a valuable form of inhaler in tuberculosis. See Atomizer.

Nebulose (neb'-u-loz) [nebula, a mist, a cloud]. In biology, having cloudy markings.

Necessity, Triangle of. See Triangle, Carotid, Inferior, in Triangles, Table of.

Neck (nek) [ME., necke, neck]. The constricted portion of the body connecting the head with the trunk; also, the narrow portion of any structure serving to join its parts. See Cervix. N., Anatomic, the constricted portion of the humerus, just below the articular surface, serving for the attachment of the capsular ligament. N., Derbyshire. Synonym of Goiter. N., Nithsdale. Synonym of Goiter. N.rest, in massage, having the hands joined behind the neck. N., Surgical, the constricted part of the humerus just below the condyles. N., Wry-. Synonym of Torticollis.

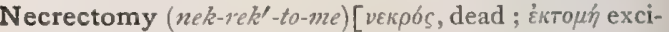
sion]. The excision of the necrotic conductors of sound in chronic purulent otitis media ; in a more general sense, any removal of necrosed material by a cutting operation.

Necrencephalus (nek-ren-sef'-al-us) [vekpós, dead; $\dot{\varepsilon} \gamma \kappa \varepsilon \dot{\varepsilon} \dot{\lambda} 0 \mathrm{~s}$, brain]. Softening of the brain.

Necrobiosis (nek-ro-bi-o'-sis) [veкрós, dead; ßios, life]. Molecular death of a tissue.

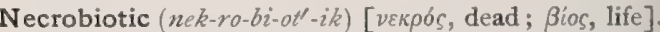
Pertaining to or causing necrobiosis.

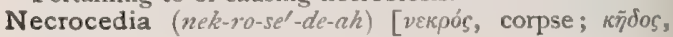
care]. The process of embalming 
Necrocomium (nek-10-ko'-me-um). See Moroue.

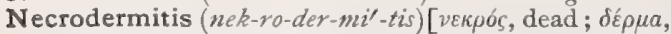
skin; $\iota \tau \iota S$, inflammation]. A gangrenous inflammation of the skin

Necrodochium (nek-ro-do'-ke-um). See Morgue.

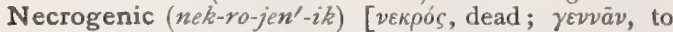
beget]. Originating from dead substances.

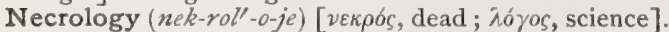
A register containing the statistics concerning the causes and rate of mortality.

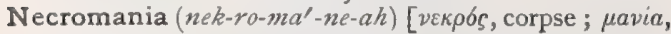
madness]. See Necrophilism.

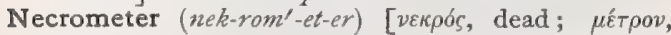
measure]. An instrument for weighing organs at an autopsy.

Necromimesis (nek-ro-mim-é-sis) [vekpós, dead;

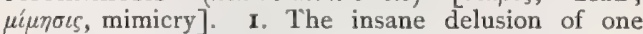
who believes himself to be dead. 2. Simulation of death by a deluded person.

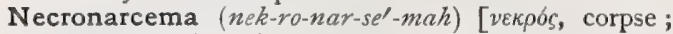

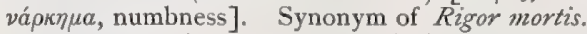

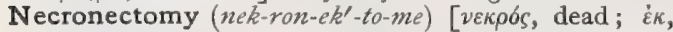
out ; $\tau \varepsilon \mu v \varepsilon \iota \nu$. to cut]. The excision of a necrotic part -applied especially to the excision of the necrotic ossicles of the ear.

Necronium (nek-ro'-ne-um) [vєкрós, dead]. A substance said to be found in the dead body in cases of saponification.

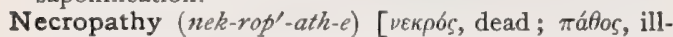
ness]. Any gangrenous or necrotic disease.

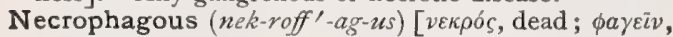
to eat]. A term applied to those animals that feed on dead or putrid flesh. Carrion-eaters.

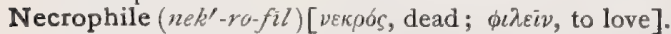
One who violates dead bodies.

Necrophilia (nck-ro-fil'-e-ah). See Necrophilism.

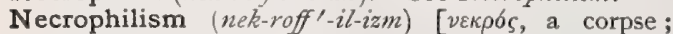
$\phi i \lambda \varepsilon i v$, to love]. A form of sexual perversion in which dead bodies are dug up and violated; insane sexual desire for a corpse.

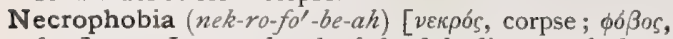
fear]. I. Insane dread of dead bodies, or of phantoms. 2. Thanatophobia; extreme dread of deatb.

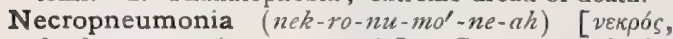
dead; $\pi$ vevuovia, pneumonia]. Gangrene of the lung.

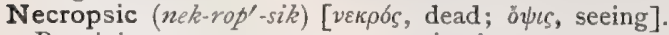
Pertaining to a post-mortem examination.

Necropsy (nek'-rop-se) [veкpós, corpse; ó lus, seeing]. The examination of a dead body.

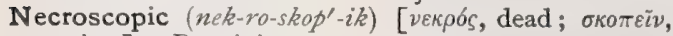
to view]. Pertaining to necroscopy.

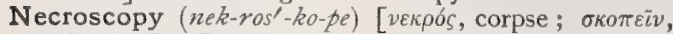
to inspect]. Post-mortem examination of the body.

Necrose $\left(n e k-r o ̄ z^{\prime}\right)[\nu \varepsilon \kappa \rho o ́ s$, dead]. To become affected with necrosis : to cause necrosis.

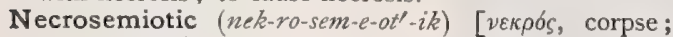

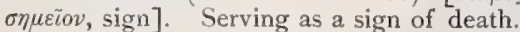

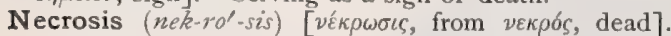
The death of cells surrounded by living tissue. Necrosis proper refers to death in mass, necrobiosis to death of individual cells. Among the causes of necrosis are : (I) direct injury; (2) obstruction of the circulation ; (3) loss of trophic influence. The varieties of necrosis are: (I) coagulative necrosis; (2) liquefactive necrosis; (3) cheesy necrosis ; (4) dry and moist gangrene. See Gangrene. Necrosed tissues may be absorbed, retained, or thrown off. The dead tissue is called sequestrum in case of bone, and sphacelus in case of soft parts. In surgery the term necrosis is often applied specifically to the death of bone. N., Anemic. See $/ n$ farct, $A n$ emic. N.. Caseous. See Cheesy. N., Balser's Fatty, the occurrence of areas of opaque whitish tissue often seen surrounding the lobules of the pancreas in acute pancreatitis, and also occurring in the omentum and mesentery and in the abdominal fatty tissue generally. They are usually about the size of a pin's head, but may reach the size of a hen's egg. On section they have a soft, tallowy consistence. They are constituted of a combination of lime with certain fatty acids, and may be encrusted with lime. They may occur independently of disease of the pancreas. See Diseases, Table of. N., Cheesy, necrosis characterized by the formation of a cheese-like material. Dry and moist cheesy necrosis are the two varieties described. It is usually due to the presence of the tubercle-bacillus, and is most often seen in the lungs. N., Coagulative, a variety characterized by the formation of fibrin. Its most common seat is the blood in thrombi. It also occurs on mucous membranes, where it produces false membrane, chiefly under the influence of the bacillus of diphtheria, but also of other irritant agents. Occasionally it occurs in the interior of organs as the result of embolism or thrombosis, leading to the formation of an anemic infarct $q . v$. N., Colliquative. See $N$., Liquefactive. N., Embolic, coagulative necrosis in an anemic infarct following embolism. N., Hyaline, coagulative necrosis; also a synonym of hyaline degeneration. N. infantilis. Synonym of Cancrum oris. N. laryngis. Synonym of Perichondritis of the Larynx. N., Liquefactive, a process analogous to coagulative necrosis, but instead of fibrin the peculiar reaction of fluids and cells gives rise to the formation of a liquid. Blisters and vesicles, softening of the brain subsequent to embolism, and suppuration are the results of liquefactive necrosis. It may also be the terminal stage of all other forms of necrosis. N, Mercurial, a necrosis of bones due to chronic poisoning with mercury. N., Phosphorus, a necrosis of bone, especially of the lower jaw, occurring in those exposed to the fumes of phosphorus. N. of the Teeth, odonto-necrosis. By the term necrosis, when applied to the teeth, is meant the entire death of the pulp and the loss of vitality of the peridental membrane. $\mathbf{N}$. ustilaginea, dry gangrene from ergotism.

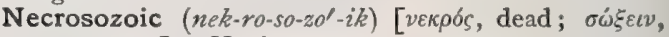
to preserve]. Having power to preserve or to embalm.

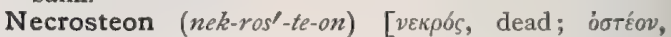
bone]. Necrosis of bone.

Necrotic (nek-rot'-ik) [vekpós, dead]. Pertaining to or characterized by necrosis. N. Pneumonia. See Pneumonia.

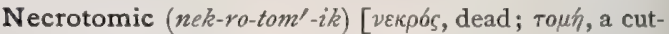
ting]. Pertaining to necrotomy.

Necrotomy (nek-rot'-o-me) [vekpós, a corpse; rouń, a cutting]. The dissection of a dead body.

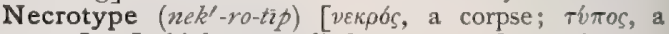
type]. In biology, applied to types of organisms as regards any special region, in which, after having existed, they became extinct.

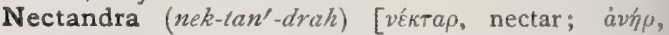
male]. A genus of lauraceous tropical American trees, of some 70 species, of which Bebeeru bark, the bark of $N$. rodici, the green heart, a large tree of $S$. America, is commercially the most important, its timber being of great value. It contains an alkaloid, bebeerin, or buxin, $\mathrm{C}_{20} \mathrm{H}_{23} \mathrm{NO}_{4}$, and is a bitter tonic and febrifuge. Dose of the sulphate of the alkaloid, gr. ij-v. Unof.

Nectandrin (nek-tan'-drin). Same as Buxin.

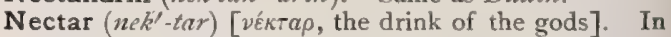
biology, nectar, the sweet liquid in flowers from which 
the bees make honey. It is secreted by certain specialized organs known as nectar-glands. N.-gland, a gland secreting nectar or honey. N.-spots, N.guides, Sprengel's name for the contrasted colors often seen in a single flower and so disposed in spots or lines as to suggest that they bear a direct relation to the point where the nectar is secreted.

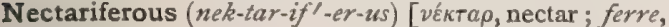
to bear]. In biology, honey-bearing, or having a nectary.

Nectarilyma (nek-tar-il-i'-mah) [nectarium, nectary ; luere, to wash]. In biology, a collection of long hairs found on the inner surface of some flowers.

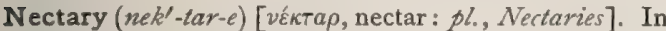
biology, that part of a flower which secretes nectar.

Necteric. See Nekteric.

Nectocalycine (nek-to-kal'-is-in) [ $\kappa a ́ \lambda v \xi$, a cup]. In biology, resembling or pertaining to a nectocalyx or swimming-bell.

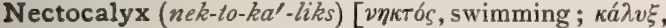
a cup : pl., Nectocalyxes, Nectocalices]. In biology, the swimming-bell or locomotive organ of certain Hydrozoa, which, however moditied, may be reduced to a simple type-that of a cup lined by a muscular membrane, by whose contractions the water is expelled, the animal being consequently urged by its reaction in the opposite direction; a nectophore.

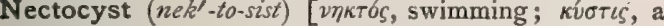
bag]. Same as Nectosac.

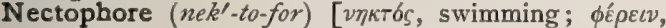
to bear]. In biology, a swimming-bell, or nectocalyx.

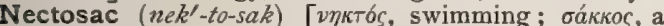
bag or sack]. In biology, the interior of the swimming-bell ; the nectocyst, or nectophore, of a hydrozoan.

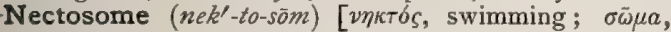
body]. In biology, the upper locomotor portion of a siphonophorous stock, as distinguished from the siphosome or nutrient portion.

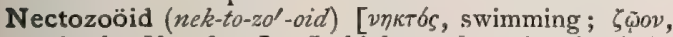
animal ; $\varepsilon\lceil\delta o s$, form ]. In biology, the swimming-bell, or nectocalyx, considered as a specialized zoöid.

Necusia (nek-u'-se-ah) [vékvৎ, corpse]. Poisoning by a dissection-wound.

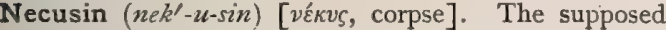
septic principle in necusia.

Needham's Bodies or Filaments. The spermatophores of the cephalopoda. N.'s Receptacle, a cystlike annex of the excretory duct of the seminal vesicle of the cephalopoda.

Needle $\left(n e^{\prime}-d \iota\right)$ [ME., nedle, needle]. An instrument used in surgery for suturing tissues, ligating vessels, and for other purposes. N., Aneurysm, one with a handle, and with the eye at the point, especially adapted for ligating vessels. N., Cataract, one for operating upon the cataractous lens or its capsule. N., Deschamp's, a needle with the eye at the point, and with a handle, for ligating arteries. N., Discission, one for insertion through the cornea, and breaking the capsule and substance of the crystalline lens. N., Exploring, an eyeless needle, grooved to bring away a few drops of the contents of a cavity, a tumor, or an abscess. N.-forceps, a forceps for seizing needles in surgery. N., Hagedorn's, a flat suture-needle curved on its edge, with the eye perforating the side. N., Hare-lip, one provided with a small canula to be left in silu after withdrawal of the needle. N.-holder. a handle for clasping a needle. Also, an insulated handle for holding the needles employed in certain forms of electro-cautery. N., Hutchinson's, a needle for the ligation of hemorrhoids ; it is fixed on a handle and has the eye at the point. N., Hypodermatic, the fine needle-pointed metallic tube attached to the barrel of the hypodermatic syringe. N., Knife, one that has a sharp cutting edge ; it is used in the discission of cataracts. N., Ligature. Synonym of N., Aneurysm. N., Open-eyed, one in which the eye is not completely closed but is in the form of a hook. N.operation. See Extraction of Cataract. See also Acupuncture and Acupressure. N., Spanish. See Spanish Needle. N., Startin's Wire, a hollow needle for carrying silver wire. N., Suture, a needle used for suturing. N., Whitehead's Spiral, a spiral needle with a terminal eye for use in staphylorrhaphy.

Needling (ne'-dling) [ME., nedle, needle]. I. See Extraction of Cataract and Discission. 2. A procedure sometimes employed for the detection of calculi in the biliary passages, gall-bladder, and kidney.

Neef's Hammer. An automatic arrangement for opening and breaking the current in an inductorium.

Neelsen's Carbolic-acid Solution. See Stains, Table of.

Neftgil (neft'-jil). A solid paraffin found free in Baku.

Negative $\left(n e g^{\prime}-a t-i v\right)$ [negare, to deny]. A qualification the opposite of positive; not affirmative. N. Chemotaxis, the absence of the power of attracting leukocytes and wandering cells, or their repulsion. See Chemotaxis. N. Ocular. See Ocular. N. Pole, that pole of a galvanic cell connected with the carbon or least oxidizable plate. Also, that pole of an electric generator toward which the assumed electric current flows.

Negativism (neg'-at-iv-izm) [negare, to deny]. A symptom observed in some cases of so-called Catatonia attonita, in which the patient exhibits no spontaneous movements, although his muscles spontaneously and powerfully antagonize any passive motion.

Negro (ne'-gro) [niger, black]. A race of people distinguished mainly by woolly hair, black skin, thick, protruding lips, and flattened nose. The melanochroi of Huxley's classification. Also, an individual of the race. See Mulatto. N.-cachexy, N.-cachexia, N.-lethargy. See African Lethargy and Cachexia. N.-type of Idiocy. See Idiocy, Ethnic.

Neisser's Method. A method of double-staining of spore-bearing bacilli. Cover-glass preparations are immersed for twenty minutes in fuchsin-anilin-water at $80^{\circ}$ or $90^{\circ} \mathrm{C}$., then rinsed in water or alcohol, and counterstained with an aqueous solution of methyleneblue, rinsed in water, dried, and mounted in balsam; the spores are stained red, other objects blue. N.'s Micrococcus. See Bacteria, Synonymatic Table of: N.'s Oil, a modification of Lang's oil. It consists of mercury, 20 parts; ethereal tincture of benzoin, 5 parts; liquid vaselin, 40 parts ; it is used by injection in the treatment of syphilis.

Neisseria $\left(n \bar{\nu}^{\prime}-\right.$ se-re-ah) [after Neisser, a German physician]. A generic term for a group of schizomycetes. The majority are micrococci. They will be found described under Bacteria, Synonymatic Table of.

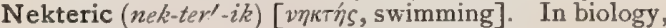
applied by Hæckel to the voluntarily swimming organisms of the ocean, as distinguished from the drifting or ploteric forms.

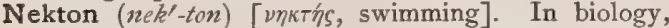
the nekteric or actively swimming portion of the organic life of the ocean (plankton), taken as a whole.

Nelaton's Catheter, the soft rubber catheter. N.'s Dislocation, a form of dislocation of the ankle-joint in which there is a displacement of the astragalus between the lower extremities of the tibia and fibula. N.'s Fibers, the circular muscular fibers of the rectum. N.'s Line. See Lines, Table of. N.'s Method. See Treatment, Methods of. N.'s Operation. See Operations, Table of. N.'s Probe. See Probe. 
Nelavan (nel'-av-an). See African Lethargy.

Nematachometer (nem-at-ak-om'-et-er) [ $\nu \tilde{\eta} \mu \alpha$, thread; Tá Xos, rapidity; $\mu \hat{\varepsilon} \tau \rho o \nu$, measure]. An instrument for measuring the rapidity of transmission of nervous impulses in peripheral nerves.

Nemathece (nem'-ath-ês). Same as Nemathecium.

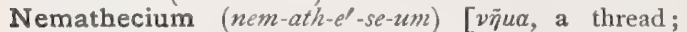
$\theta \eta \kappa i o v, \operatorname{dim}$. of $\theta \dot{\eta} \kappa \eta$, a case or receptacle: pl., Nemathecia]. In biology, a wart-like growth of tetraspores of the thallus of one of the higher algæ (Floridece).

Nemathelminth (nem-ath-el'-minth) [vña, thread; "̇uevs, worm]. Any nematode worm. The Nemathelminthes (the round-worms, or thread-worms), form a class of Vermes, many of which are endoparasitic.

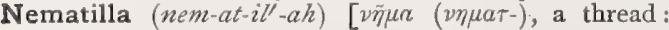
pl., Nematilla]. In biology, one of the urticating organs of a coelenterate; a nematophore, or Organa urticantia.

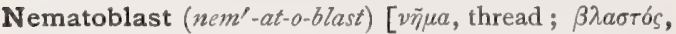
germ]. A spermatoblast. See also Spermatogonia.

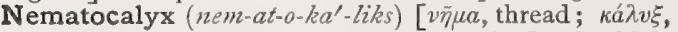
calyx: pl., Nematocalyxes, Nematocalices]. In biol. ogy, a hydrozoan calyx containing nematocysts.

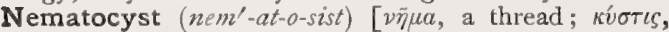
bladder]. In biology, one of the stinging-cells characteristic of the Cnidaria; a thread-cell, lasso-cell, snidocell, cnida, nemocyst.

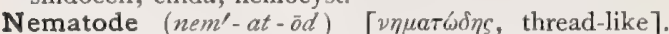
In biology, filiform, thread-like; resembling a thread; it is applied to thread-worms, hair-worms, roundworms, pin-worms.

Nematodes (nem-at-o'-déz). Synonym of Nematoidea.

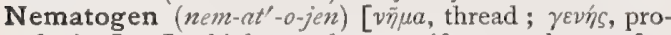
ducing]. In biology, the vermiform embryo of a nematode worm. Cf. Rhombogen.

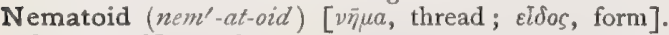
Same as Nematode.

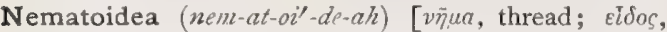
like]. Thread-worms; nemathelminths: The most important nematoidea parasitic upon man and the lower animals belong to the following genera, arranged alphabetically: Anguillula, Ankylostoma, Ascaris, Eustrongylus, Filaria, Nematodium, Oxyuris, Strongylus, Trichina, Trichocephalus. See Parasites (Animal), Table of.

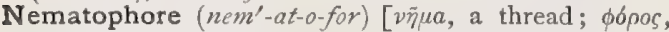
bear]. In biology, a cecal process of the cenosarc of hydrozoans, invested by a continuation of the hard cuticular layer, so as to be quite firm and inflexible, and containing thread-cells. Lendenfeld considers that the expression nematophore should be reserved for the chitinous envelop of the guard-polyp (Machopolyp) ; a nematilla, or urticating organ.

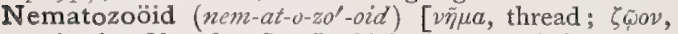

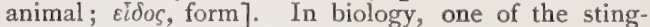
ing tentacles of a siphonophore regarded as a zoöid.

Nemocyst (nem'-o-sist). Same as Nematocyst.

Nemophilous (nem-off'-il-us) [véuos, a wooded pasture, фínos, loving]. In biology, fond of or inhabiting the woods; nemorose.

Nemorose (nem'-or-ōz) [nemus, a grove]. In biology, growing in groves or woodland.

Nemours-blue. See Pigments, Conspectus of.

Neo- $\left(n e^{\prime}-o^{-}\right)$[véos, new]. A prefix signifying new.

Neoarthrosis (ne-o-arth-ro'sis) [véos, new; à $\rho \rho \rho v_{\text {, }}$ a joint ]. A new or false joint.

Neoblastic (ne-o-blas'-tik) [v'́os, new ; $\beta \lambda \alpha \sigma \tau \delta \varsigma$, a germ]. Originating, or of the nature of, new tissue.

Neochmosis (ne-ok-mo'-sis) [veoxuós, new]. A relapse or recurrent attack of a disease.

Neo-Darwinism, Neo-Lamarckism (ne-o-dar'-winizm, ne-o-lam-ark'-izm] [yદ́os, new; Darvin; La- marck]. In biology, the doctrines of Darwin and Lamarck concerning evolution as modified by recent advocates.

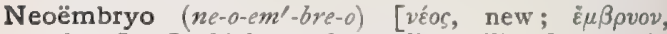
embryo]. In biology, the earliest ciliated stage in the embryonic development of a metazoan.

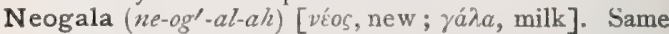
as Colostrum.

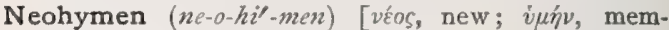
brane]. A new or false membrane.

Neo-Lamarckism (ne-o-lam-ark'-izm) [véos, new; Lamarck]. See Neo-Darwinism.

Neomembrane (ne-o-mem'-brän). See Neohymen.

Neomorphism (ne-o-mor'-fizm) [ form]. In biology, the development of a new form.

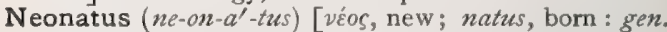
pl., Neonatorum ]. One newly born. Neonatorum, Melæna. See Melena. Neonatorum, Ophthalmia See Ophthalmia. Neonatorum, Trismus. See Trismus.

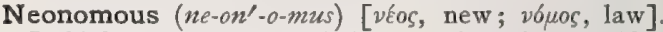
In biology, recently specialized or adapted to modified environment.

Neontology (ne-on-tol'-o-je) [véos, new; $\omega \nu$, being; $\lambda$ byos, science]. In biology, Flourens' term for the study of existing organisms, as opposed to paleontology or the study of fossils.

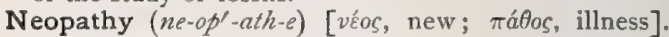
I. A new or newly-discovered form of disease. 2. A recent complication or new condition of disease in a patient.

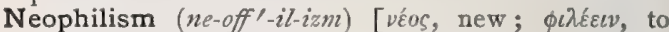
love]. Morbid or undue love of novelty.

Neophobia (ne-o-fo'-be-ah) [v'́os, new; $\phi 6 \beta$ os, fear]. Insane dread of new scenes or of novelties.

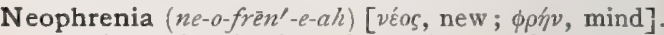
Mental deterioration in early youth.

Neoplasia (ne-o-pla'-ze-ah) [véos, new; $\pi \lambda a ́ \sigma \sigma \varepsilon \iota v$, to mold]. The formation of new tissue or of a tumor.

Neoplasm, Neoplasma (ne'-o-plazm, ne-o-plaz'-mah) [véos, new; $\pi \lambda$ á $\sigma \mu \alpha$, growth]. A new growth of tissue marked by histologic difference from its matrix; a tumor. See Tumors, Table of. N., Inflammatory Fungoid. Synonym of Granuloma fungoides.

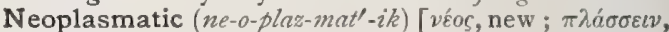
to mold]. Of the nature of neoplasm; neoplastic.

Neoplastic (ne-o-plas'-tik) [véos, new; $\pi \lambda \dot{a} \sigma \sigma \varepsilon \iota v$, to mold]. Pertaining to, or of the nature of, a neoplasm. Applied, also, to plastic operations for restoring lost tissue. See Autoplasty.

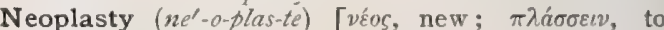
mold]. AA operation for the restoration of lost tissue.

Neoscytechos, Neoscytechus (ne-os-kit'-ek-os, ne-os-

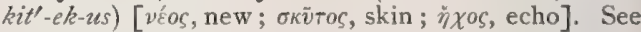
Murmur, New Leather, and Bruit de cuir neuf.

Neosote $\left(n e^{\prime}-o-s \bar{o} t\right)[v \varepsilon \hat{\varepsilon}$, , new ]. A derivative of coaltar having antiseptic properties.

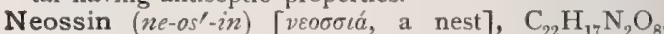
Mulder's term for an insoluble material, the chief component of the edible birdsnest.

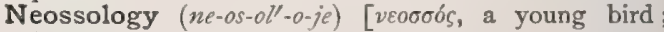
$\lambda o$ oros, science]. In biology, the study of the incubation and rearing of young birds.

Neotenia (ne-o-te'-ne-ah) [ve(s) $\varepsilon \rho \circ$, an innovation or revolutionary movement]. In biology, Kollmann's term for the lengthening (for an indefinite time) of the period during which amphibians are gill-breathers.

Neotocicterus (ne-ot-o-sik'-ter-us) [vєótokos, new-born; iктеоos, jaundice]. Icterus neonatorum.

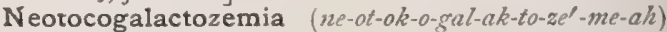

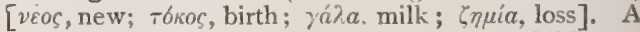
flow of milk from the breast of a new-born child. 
Neotocophthalmia (ne-ot-ok-off-thal'-menah) [veóтoкns, new-born ; ó $\phi a \lambda \mu i a$, ophthalmia]. Ophthalmia neonatorum, q. $v$.

Nep [nepeta, catmint]. The catnip, Nepeta cataria.

Nepal or Nepaul Tumor. A pendulous tumor of the ear, at times reaching the size of a child's head. It is endemic in Nepal, India.

Nepalin (nep'-al-in). Synonym of Pseudaconitin.

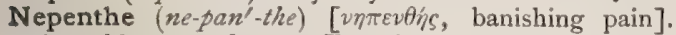
An old name for an Egyptian anodyne, probably opium.

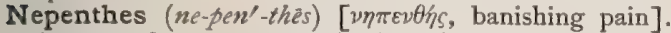
A genus of some 37 recognized species of tropical climbing pitcher-plants. The pitchers contain droserin, $q . v$. and azerin, q.v., and have the power of digesting insects that are drowned in their watery secretion.

Nepeta $\left(n e p^{\prime}-e t-a h\right)$. See Catnip.

Nephablepsia (nef-ab-lep'-se-ah). See Niphablepsia.

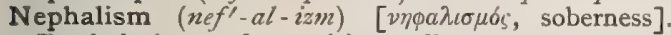
Total abstinence from spirituous liquors.

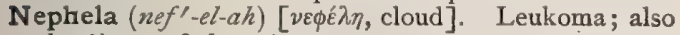
cloudiness of the urine.

Nephelium (nef-el'-e-um). See Nebula.

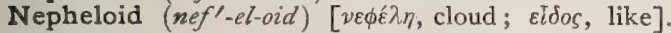
Cloudy or turbid, as the urine under certain conditions.

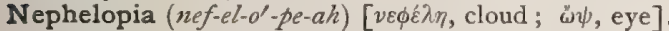
Cloudy or dim vision, due to some diminution of the transparency of the ocular media.

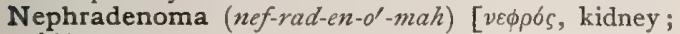
ádńv, gland; ö $\mu a$, tumor: pl., Nephradenomata] Adenoma of the kidney.

Nephralgia, Nephralgy (nef-ral'-je-ah, nef-rall-je)

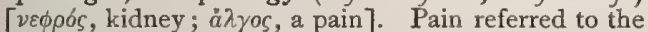
kidney; renal colic.

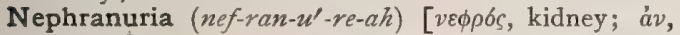
priv.; oṽ $\rho \nu$, urine]. Suppression of the renal secretion.

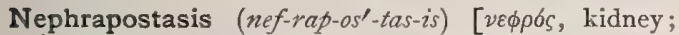
$\dot{a} \pi \sigma \sigma \tau a \sigma \iota \zeta$, suppurative inflammation]. Abscess, or suppurative inflammation, of the kidneys.

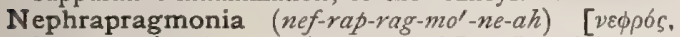
kidney ; á, priv.; $\pi \rho a ́ \gamma \mu \omega \nu$, work]. Inactivity or torpidity of the kidneys.

Nephrarctia (nef-rark'-te-ah) [veфpós, kidney; arctus, from arcere, to find]. Contraction of the kidney.

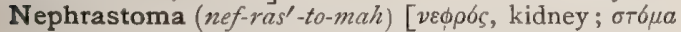

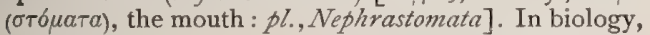
one of the ciliated funnels of the primitive kidney.

Nephratonia (nef-rat-o'-ne-ah), Nephratony (nef-rat'-

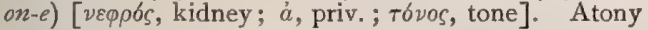
or paralysis of the kidneys.

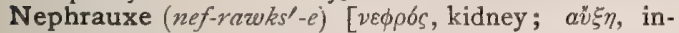
crease]. Enlargement of the kidney.

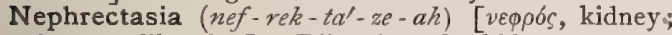
$\varepsilon \kappa \tau a \sigma \iota s$, dilatation ]. Dilatation of a kidney.

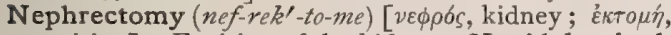
excision ]. Excision of the kidney. N., Abdominal, nephrectomy through an abdominal incision. N., Lumbar, removal of the kidney through an incision in the loin.

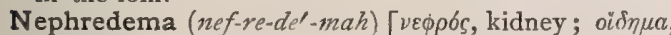
edema]. Edema of the kidneys.

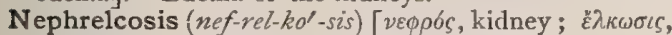
ulceration]. Ulceration of the kidney.

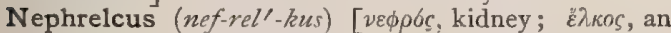
ulcer]. An ulcer of the kidney.

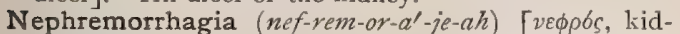
ney; alua, blood; in $\gamma$ viva, to burst forth]. Hemorrhage from the kidney.

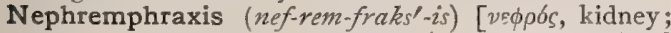
$\varepsilon \mu \phi \rho a \xi \iota s$, obstruction]. Obstruction of the vessels of the kidneys.

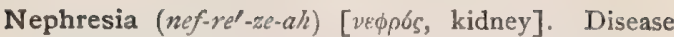
of the kidney.

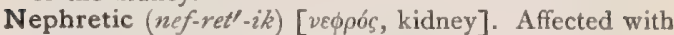
nephresia.

Nephria (nef'-re-ah). See Bright's Disease.

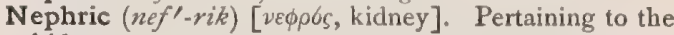
kidney.

Nephridia (nef-rid'-e-ah). Plural of Nephridium.

Nephridial (nef-rid'-e-al) [veфoós, a kidney]. Of or pertaining to a nephridium. N. Ridge, the larger of the two ridges on the dorsal aspect of the body-cavity of a vertebrate embryo. It contains the transverse excretory tubules (segmental tubules, nephridia) which are developed from the nephrotomes. It is also called the Wolffian ridge. N. Row, one of the single or double cell-rows which lie near the neural rows, developed from the polar cells (or nephroblasts) in the embryos of certain worms.

Nephridium, Nephridion (nef-rid'-e-um, nef-rid"-e. on) [dim. of veфoós, kidney: pl., Nephridia]. In biology: 1. The fat about the kidneys. 2. The renalsexual organ (organ of Bojanus) in certain invertebrate animals. Much convoluted cellular tubes functioning as kidneys in the annelida and certain mollusca. They occasionally act as ducts for the transmission of the sexual products. Cf. Nephrogonaduct. I. Provisional or Embryonic Nephridia, those that temporarily appear in the ontogenetic development; $(a)$ those that appear in that region of the embryo or larva that corresponds with the subsequent head-segment and which lie at the anterior extremity of the cell-mass (mesoderm streaks) are called embryonic head nephridia or head kidneys; $(b)$ those that appear in the trunk-segments are called embryonic or provisional trunk nephridia or kidneys. II. Permanent Nephridia, on account of their frequently strict segmental arrangement, are often called segmental organs, or on account of their looped or winding course (in Oligocheta and Hirudinea) looped canals. The anal tubes of the Echiuride are sometimes called nephridia.

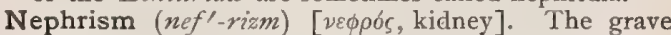
condition of patients suffering from pronounced or advanced disease of the kidney.

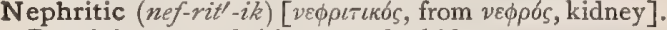
Pertaining to nephritis, or to the kidney.

Nephritis (nef-ri'-tis) [ $\nu \varepsilon \phi \rho \sigma s$, the kidney ; $\iota \tau \iota s$, inflammation]. Inflammation of the kidneys. It occurs in various forms designated as acute, chronic, desquamative, glomerular, interstitial, parenchymatous, and tubal. See Brioht's Disease. N., Acute Albuminous. See $N$., Acute Desquamative. N. apostomatosa, suppurative inflammation of the kidney. N., Cachectic, a synonym of Bright's disease in general. N., Clostridial, a form of chronic nephritis believed by Hopkins (F. V.) to be due to a peculiar microörganism, the "Clostridium renale." The symptoms are nervousness, sleeplessness, flatulent dyspepsia, albuminuria, dropsy, dyspnea, heart-failure, and the presence of the clostridia in the urine, free and attached to casts. N., Consecutive, an inflammatory affection of the kidney secondary to disease of the lower portions of the urinary tract. N., Glomerular. See Glomerulo-nephritis. N., Interstitial, renal inflammation affecting the connective tissue mainly. $\mathbf{N}$., Intertubular. Same as $N$., Interstitial. N., Lardaceous, nephritis associated with amyloid degeneration of the kidney. N. Metastatic, that secondary to disease of another organ. N., Mycotic, that accompany. ing any form of mycosis. N., Parasitic, that dependent upon the presence of renal parasites. N., Parenchymatous, that involving the true renal parenchyma. See Bright's Disease. N., Puerperal, the congested 
kidney of the puerperium, associated with albuminuria. N., Saturnine, that due to chronic lead-poisoning. N., Septic, that caused by germs. N., Toxic, that consequent upon the presence of irritant poisons in the blood. N., Traumatic, that following traumatism of the kidney. N., Tubal. Same as $N$., Paren. chymatous. N., Tuberculous, that due to the presence of tubercle-bacilli. N., Tubular. Same as $N$., Parenchymatous.

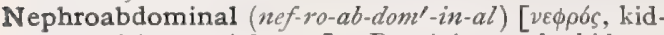
ney; abdomen, abdomen]. Pertaining to the kidneys and the abdomen.

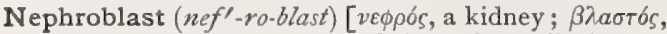
a germ]. In biology, one of the polar cells in embryos of certain worms, that give rise to the nephridial rozes.

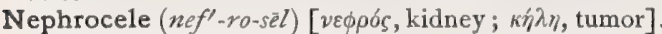
Hernia of the kidney.

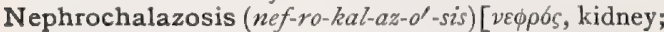
$\chi a \lambda a ́ \zeta u n$, nodule]. Granular kidney.

Nephrococcosis (nef-ro-kok-o'-sis), Synonym of Nephrochalazosis.

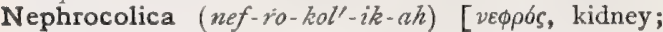
$\kappa \omega \lambda \iota \kappa \delta ́ s$, colic]. Renal colic.

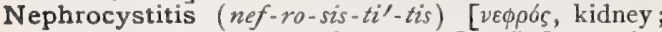
$\kappa v ́ \sigma \tau \iota \varsigma$, bladder; $\iota \tau \iota \varsigma$, inflammation]. Inflammation of both bladder and kidneys.

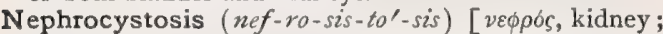

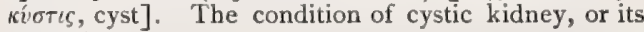
formation.

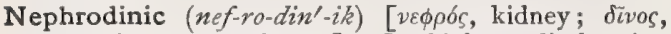
a rotation, a round area]. In biology, discharging the genital products by nephridia or nephrogonaducts.

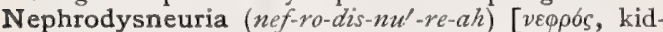
ney; $\delta \bar{v} \zeta$, difficult; veṽpov, nerve]. A morbid state of the renal nerves.

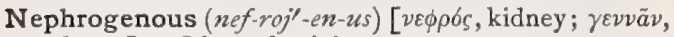
to beget]. Of renal origin.

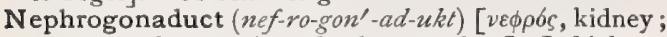
gona luct, from yov'n, seed ; ductus, a duct]. In biology, a rephridium specialized to act as a gonaduct, as in certain molluscs.

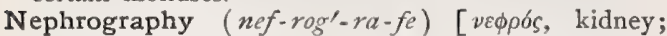
$\gamma \rho \alpha \dot{\phi \varepsilon} \iota \nu$, to write]. A description of the kidneys.

Nephrohydrops (nef-ro-hi'-drops), Nephrydrosis (nef-rid-ro'-sis). See Hydronephrosis.

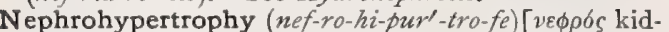
ney; $i \pi \varepsilon \dot{\varepsilon} \rho$, over; т $\rho \circ \emptyset \eta$, nourishment]. Hypertrophy of the kidney.

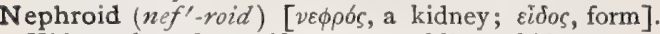
Kidney-shaped; reniform; resembling a kidney.

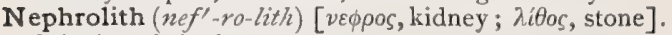
Calculus of the kidney.

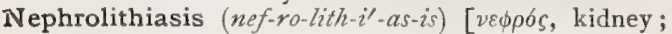
$\lambda$ itiares, lithiasis]. The formation of renal calculi, or the diseased state that leads to their formation.

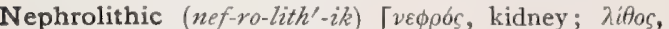
stone]. Pertaining to, or affected with, a nephrolith.

Nephrolithocolica (nef-ro-lith-o-kol'-ik-ah, [veфoós,

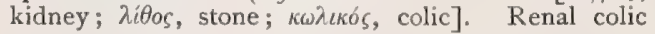
due to stone.

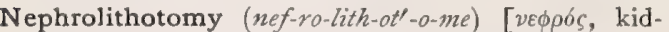

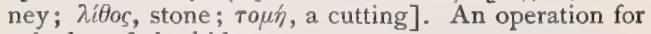
calculus of the kidney.

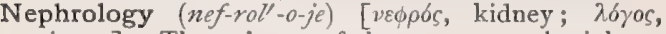
science]. The science of the anatomy, physiology, and diseases of the kidney.

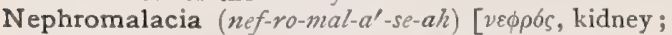

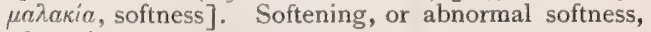
of the kidney.

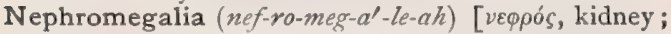
$\mu \varepsilon ́$ yas, large]. Same as Nephrauxe.

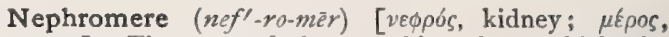
part]. The part of the mesoblast from which the kidney is developed.

Nephromiosis, Nephromeiosis (nef-ro-mi-o'-sis)

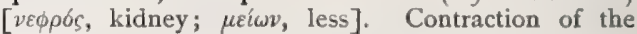
kidney.

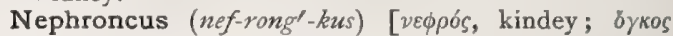
tumor]. Tumor of the kidney.

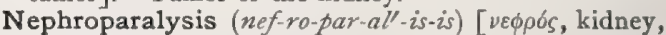

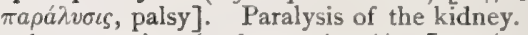

Nephroparesis (nef-ro-par'-es-is) [veøpós, kidney; $\pi a \rho \varepsilon \sigma \iota$, paresis]. Same as Nephroparalysis.

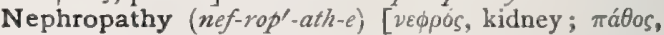
disease]. Any disease of the kidney.

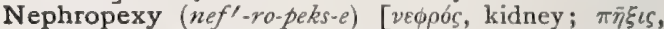
fixation]. Surgical fixation of a floating kidney.

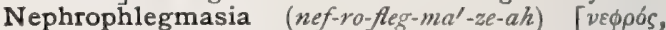
kidney; $\phi \lambda \varepsilon \gamma \mu a \sigma^{\prime} \alpha$, inflammation]. Any inflammation of the kidney.

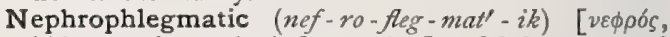
kidney ; $\phi \lambda \varepsilon \gamma \mu \alpha \sigma i \alpha$, inflammation]. Of the nature of or due to nephrophlegmasia.

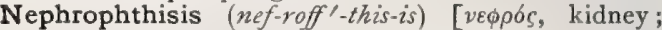

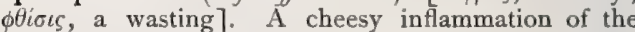
kidney, the process often beginning in the mucous membrane of the bladder, or in the prostate, and extending to the kidney. The urine is generally acid, and small cheesy masses, elastic fibers, and shreds of cast-off connective tissue may be found in it. The disease is most frequent in males, and is due to the presence of the tubercle-bacillus.

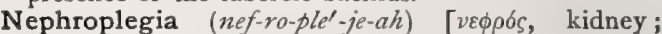
$\pi \lambda \eta \gamma \eta$, stroke]. Paralysis of the kidney.

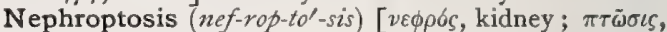
fall]. Downward displacement of the kidney. See Floating Kidney.

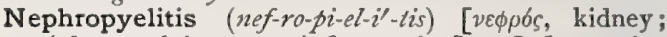
$\pi v \varepsilon \lambda o \zeta$, pelvis; $\iota \tau \iota \varsigma$, inflammation]. Inflammation of the pelvis of the kidney; pyelonephritis.

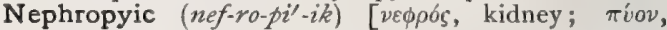
pus]. Relating to suppuration of the kidney.

Nephropyosis (nef-ro-pi-o'-sis). Same as Pyo. nephrosis.

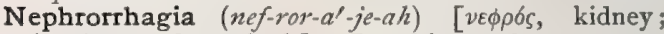

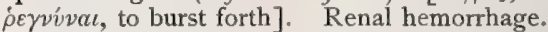

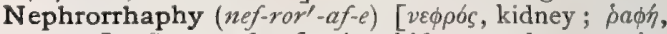
suture]. Suture of a floating kidney to the posterior wall of the abdomen or to the loins. The stitches may be introduced through the capsule or even through the substance of the kidney.

Nephros (nef'-ros) [veфoós, kidney]. The kidney.

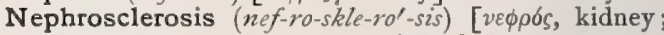
$\sigma \kappa \lambda \eta \rho \delta ́ s$, hard]. Induration of the kidney.

Nephrospastic (nef-ro-spas'-tik) [ $\nu \varepsilon \phi \rho b s$, kidney;

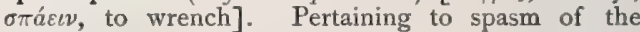
kidney.

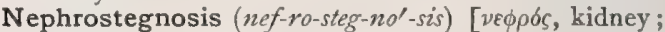

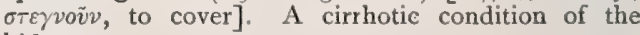
kidney.

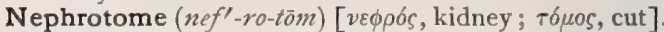
In embryology, one of the two divisions of the primitive segments of the celum in vertebrate embryos; it lies next to the lateral plates or mesothelium of the splanchnocele. It is also called the intermediate mass, Mittelplatte (Kölliker).

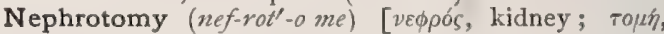
a cutting]. Incision of the kidney. N., Abdominal, nephrotomy through an abdominal incision. $\mathrm{N}$., Lumbar, nephrotomy through an incision in the loin. Nephro-typhoid, Nephro-typhus (nef-ro-ti'foid, nef-

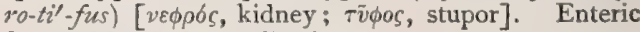
fever with renal complications. 


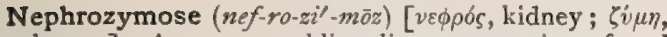
leaven]. A gum resembling diastase sometimes found in urine.

Neptune's Cingulum or Girdle. Cingulum neptuni, a folded sheet. the end of which has been soaked in hot water, wrung out and applied to the abdomen, the larger and dry portion being utilized as a bandage. See Girdle.

Neptunium (nep-tu'-ne-um) [Neptunus, a sea-god]. A doubtful new element obtained from columbite. Atomic weight, 118 .

Nérac, Pian of. An herpetic form of syphilis.

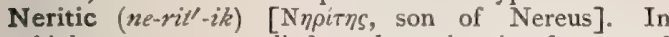
biology, a term applied to the swimming faunas and floras (plankton) of the coast regions of the continents as well as the archipelagoes and islands. Their composition is essentially different from that of the aceanic plankton, and they are quantitatively as well as qualitatively richer.

Nerium (ne'-re-um) [víptov, the oleander]. The leaves and root of $N$. odorum, the common oleander. The extractive principles exert a marked effect on the motor centers, in lethal doses producing paralysis and death from heart-failure. In small doses they act as a cardiac tonic resembling digitalis. Dose of the extract gr. $1 / 3-3 / 4$. The tincture may be given cautiously, in one-drop doses, gradually increased. Unof.

Neroli, Oil of. See Aurantium.

Neronian Phlebotomy. Venesection in which several veins are opened simultaneously.

Nerval (ner'-val) [nervus, a nerve]. Pertaining to a nerve or nerves.

Nervate (ner'-vāt) [nervus, a nerve]. In biology, having nerves, as a leaf.

Nervation (ner-va'-shun) [nervus, a sinew or nerve]. In biology, the arrangement or disposition of the fibrovascular bundles in the blades of leaves, or of the nerves or veins of an insect's wing; innervation.

Nervature (ner'-vat-ür). Same as Nervation.

Nervaura (ner-vaw'-rah) [nervus, nerve; aura, air]. A subtle hypothetic essence emanating from the nervous system, and enveloping the body in a kind of sphere.

Nerve (nerv) [nervus, nerve]. A nerve is an elongated cord or tract of protoplasm made up of aggregations of nerve-fibers and having the property of transmitting impulses. N., Accelerator. Synonym of N., Augmentor. N., Afferent, one that transmits impulses from the periphery to the central nervous system. N., Anabolic, one directly or indirectly bringing about constructive metabolism. N., Arresting. Same as $N$., Inhibitory. N., Augmentor, the cardiac sympathetic nerves, stimulation of which causes acceleration of the heart's action. N.-aura. Same, as Ner vaura. N.-axis, the axis-cylinder. See $N$-fiber. N.-bristles, fine broaches barbed on one side, or with the end bent at right angles, employed for removing devitalized pulps from the canals of the teeth. N.-broach, a wire instrument for extracting the nerve of a tooth. N., Calorific, a nerve, stimulation of which increases the heat of the parts to which it is distributed. The term is applied to the dilator nerves and to those stimulating functional activity of organs. N.-canal, the pulp-cavity of a tooth. N.-canal Reamer, an instrument for enlarging the pulp-canal of a tooth, prior to the filling of the canal. N.-capping, a cap placed over a tooth to protect an exposed nerve. N., Catabolic. See $N$., Katabolic. N.-cell, a mass of protoplasm containing a large vesicular nucleus within which lies a well-marked nucleolus. Nerve-cells have one or more elongated processes, and in accordance with the number of these are designated unipolar, bi- polar, or multipolar. The processes are of two kinds: the axis-cylinder process and the protoplasmic process. The axis-cylinder (Deiter's) process either becomes continuous with the axis-cylinder of a nerve-fiber, or divides within the gray matter into minute branches forming a delicate network. N.-cement, neuroglia. N.-center, a group of ganglion-cells acting together in the performance of some function. $\mathbf{N}$., Centrifugal. Synonym of $N$., Efferent. N., Centripetal. Synonym of $N$., Afferent. N., Cerebral, a cranial nerve, $q . v$. N.-chord. Same as $N$.-cord. N.-cord, a nerve; a cord composed of nervous tissue. N.-corpuscles, nucleated corpuscles lying between the neurilemma and the medullary sheath of medullated nerve-fibers; they are stained by methyl-anilin. N., Cranial, a nerve arising directly from the brain, the oblongata or the cervical part of the cord, and making its exit through one of the foramina in the skull. N.-current, a current, by some thought to pass through the nerves and muscles. N., Depressor, an afferent nerve, irritation of which depresses or inhibits the vaso-motor center. N.-drill, an instrument for enlarging the pulpcavity of a tooth. N., Efferent, one carrying impulses from the central nervous system to the periphery. N.eminence. Same as $N$.-hill. N.-endings, the terminations of nerves at the periphery or in the nervecenters. N. of Expression, the facial nerve. N.fat. Same as Protagon. N.-fiber, a fiber having the property of conducting invisible or molecular waves of stimulation from one part of an organism to another, and so establishing physiologic continuity between such parts, without the necessary passage of waves of contraction (Romanes). There are two kinds of nerve-fibers: the medullated and the non-medullated. A typical medullated fiber consists of: $(a)$ the axiscylinder, which may be surrounded by a sheath, the axilemma; $(b)$ the medullary sheath, or white substance of Schwann; $(c)$ the neurilemma, or sheath of Schwann. The axis-cylinder consists of fine fibrillæ cemented together by a granular interstitial substance, the neuroplasm. The medullary sheath consists of a reticulated framework composed of a material resembling neuro-keratin, and a semifluid substance filling the interstices, called myelin. At regular intervals the medullated sheath is marked by interruptions, the nodes of Ranvier. Each internode, as the portions of fiber included between two Ranvier's nodes are termed, possesses a nerve-corpuscle. Under certain conditions the white substance of Schwann is seen to be composed of elongated pieces, the so-called SchmidtLantermann segments. These may be artifacts. The neurilemma, sheath of Schwann, or primitive sheath, is a delicate elastic membrane, closely investing the medullary substance. On its inner surface are placed the nerve-corpuscles. The non-medullated, pale, or Remak's fibers, do not possess a medullary sheath, but consist only of axis-cylinder and neurilemma. The nerve-corpuscles are more abundant than in medullated nerve-fibers. Medullated nerve-fibers are found in the cerebro-spinal nerves, while non-medullated fibers occur in the sympathetic nerves and tend to form plexuses. Nerve-fibers are aggregated into fasciculi; these in turn unite to form nerve-trunks. The nerve-fibers in a fasciculus are held together by the endoneurium; while each fasciculus is surrounded by a sheath termed the perineurium. The epineurium holds together the several fasciculi composing a nervetrank. N.-fiber, Amyelinic. A synonym of nonmedullated nerve-fiber. See N.-fiber. N.-fiber, Myelinic. A synonym of medullated nerve-fiber. See N.-fiber. N.-fiber, Organic. A synonym of nonmedullated nerve-fiber. See $N$.-fiber. N.-fiber, 
White. A synonym of medullated nerve-fiber. See $N$-fiber. N-fibril, a very fine filament of nervetissue entering into the formation of the axis-cylinder. N.-force, the energy of the nervous system. See Isomeric Theory of. N., Forty-fourth, the sympathetic nerve. N., Frenator, an inhibitory nerve. N., Frigorific, a sympathetic nerve, so-called because its stimulation causes a fall of temperature; the vaso-constrictor nerves are frigorific nerves. N., Ganglionic. A synonym of $N$., Sympathetic. N.-grafting, the transplanting of a portion of healthy nerve from an animal to man, after surgical operations necessitating the removal of a portion of a nerve. N.-head, the optic disc or papilla. N.-hill, N.-hillock, the motor end-plate of a nerve. N., Incident. A synonym of A., Afferent. N., Katabolic, one giving rise to chemic and destructive changes in a muscle or other tissue. $\mathbf{N}$., Krause's Ulnar Collateral, a branch of the mus. culo-spiral, which accompanies the ulnar nerve for some distance and ends in the lower part of the inner

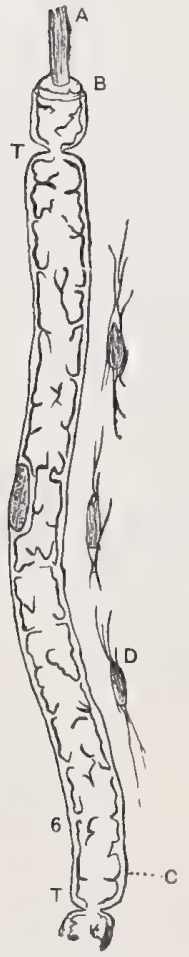

6 Medullated fiber, with Schwann's sheath. c. Neurilemma. $t, t$. Ranvier's Ilodes. $b$. White substance of Schwann. $d$. Cells of the endoneurium. a Axiscylinder.

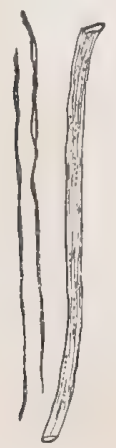

Primitive Fibrilla AND AXIS-CYLINDER.

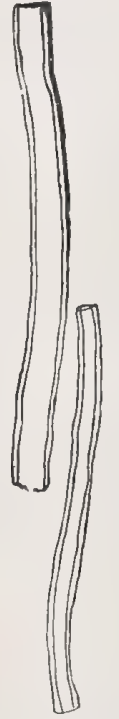

Medullated Fiber, with SCHWANN'S SHEATH.

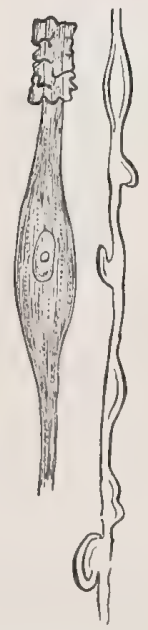

MEdullatFo VARICOSE FIBER.

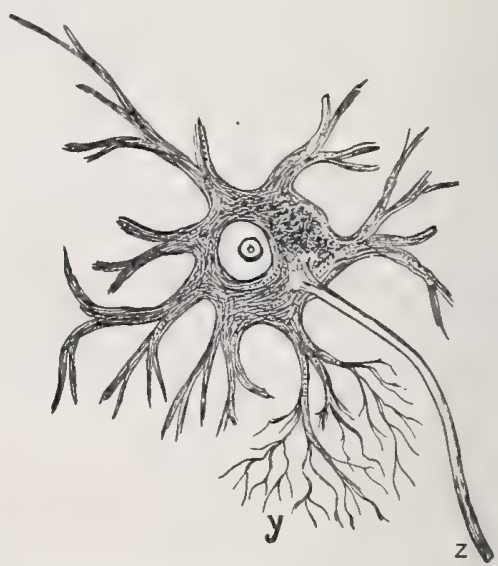

Multipolar Nerve-CELl From the SPINAL Cord.

z. Axis-cylinder process. $y$. Protoplasmic processes.

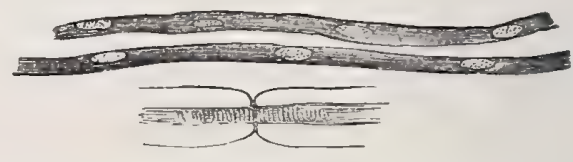

REMAK'S FIBERS.

Nerve-fibers treated with silver nitrate and showing Frohmann's lines.

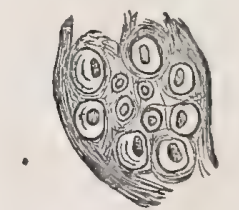

TRANSVERSE SECTION OF A NERVE-FIBER.

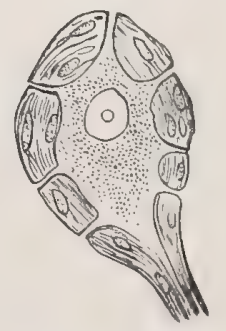

Peripheral Ganglionic Cell, WITh a ConNeCTIVE-TISSUE CAPSULE.

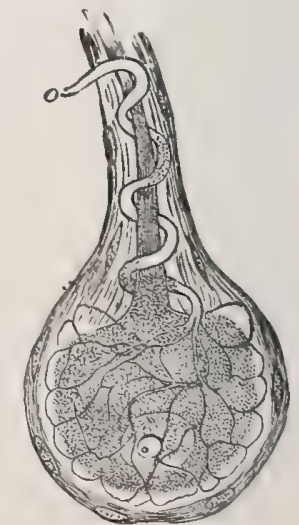

Ganglionic Celi, showing a SPIRAL and a STRAight Process. 
head of the triceps. N.-less, without a nerve. N.like, resembling a nerve. N.-loop, an arched connection between two or more nerves. N.-medulla, the axis-cylinder of a nerve. N., Medullated. See $N$-fiber. N.-mimicry. Same as Neuromimesis. N., Mixed, one made up of both afferent and efferent fibers. N.-motion, the condition of excitement of nerves in the normal, intact body, due to physiologic or normal stimulus; its nature is unknown. N., Motor, one containing only or chiefly motor fibers. N.-needle, in dentistry, an instrument used for broaching out a pulp-cavity. N., Non-medullated. See N.-fiber. N.-paste, a preparation for destroying the nerves of teeth, for the composition of which different formulæ are given. Some are composed of arsenious acid and creasote, others of arsenious acid, creasote, and sulphate of morphin. N.-path, the course pursued by a nervous impulse. N.-plate, a layer of nervous tissue, which may develop into a nerve-tube or nerve-cord. N.-plexus, a grouping of nerves. N.-power, the nervous energy of the body. N., Pressor, an afferent nerve, irritation of which stimulates the vaso-motor center. N.-ring, the ring of nerve-fibers surrounding a hair-follicle below the orifice of the sebaceous glands. N.-root: I. The root of a nerve; the nerve or one of its constituent parts, as it emerges from a central organ. 2. The plant Cypripedium pubescens. N.-rudiment, the rudiment of a nerve. N., Secretory, an efferent nerve, stimulation of which causes increased activity of the gland to which it is distributed. N.-section, the division of a nerve for the relief of neuralgia. N.-shaken, having the nervous system shattered. N., Spinal, one of those arising from the spinal cord and making its exit through an intervertebral foramen. There are $3 \mathbf{I}$ pairs of spinal nerves. N.-storm, a sudden outburst or paroxysm of neurotic disturbance. N.-stretching, mechanical elongation or tension of a nerve, for neuralgia, spasmodic contraction, and other pathologic conditions. N.-substance, the substance of a nerve-cell. N., Sympathetic, one of a system of nerves distributed chiefly to the blood-vessels and to the viscera. They are so-called because they were thought to establish a communication or sympathy between distant organs of the body, especially in diseased states. See Sympathetic. N., Thermic. A synonym of $N$., Calorific. N.-tire, neurasthenia. $\mathbf{N}$-tissue, the intrinsic substance of a nerve or nervefiber. N.-track, same as $N$.-path. N., Trophic, a nerve, the function of which is to preside over the nutrition of the part to which it is distributed. N.trunk, the main division or stem of a nerve. N.-tube, a nerve-fiber ; also a hollow cord of embryonic nervous tissue. N.-tuft, a minute plexus of nerve-fibers. N.tumor. See Neuroma and Tumors, Table of. N.tunic, an investiture by nervous tissue. N.-twig, a minute ramification of a nerve. N., Ulnar Collateral. See N., Krause's. N., Vaso-constrictor. See $N$, Vaso-motor. N., Vaso-dilator. See $N$., Vasomotor. N., Vaso-hypertonic. A synonym of $N$., Vaso-constrictor. N., Vaso-inhibitory. A synonym of $N$., Vaso-dilator. N., Vaso-motor; vaso-motor nerves are of two kinds-those, stimulation of which causes contraction of the vessels, vaso-constrictor nerves, and those, stimulation of which causes active dilatation, vaso-dilator nerves. Ordinarily vaso-motor is synonymous with vaso-constrictor. N.-wave, a wave-motion in a nerve.

Nerved (nervd) [nervus, a fiber]. Having nerves; nervose; innervated.

Nervelessness (nerv'-les-nes) [nervus, a nerve]. Lack of vigor; a nerveless state.
Nervi (nepl-vi) [L.]. Plural of Nervus, a nerve Nerves. N. nervorum, a term applied to the small nerves distributed to the nerve-sheaths.

Nerviduct (ner'-vid-ukt) [nervus, nerve ; ductus, duct]. The channel by which a nerve passes through a bone.

Nerville (ner'-vil) [nervillus, dim. of nervis, nerve]. In biology, a very fine nerve in the blade of a leaf.

Nervimotion (ner'-vim-o-shun) [nervus, a nerve; motio, motion]. In biology, the reflex action of the nervous system, or the power of self-motion, as in leaves.

Nervimotor (ner'-vim-o-tor) [nervus, a nerve; motor, a mover]. 1. Pertaining to or causing nervimotion. 2. That which causes nervimotion.

Nervine (ner'-vin) [nervus, nerve]. I. Pertaining to the nerves. 2. Acting favorably, or decidedly, upon the nerves. 3. A remedy that calms nervous excitement or acts favorably on nervous diseases. 4. The plant Cypripedium pubescens.

Nervose (ner'-vōz) [nervosus, full of fibers]. Nerved; conspicuously nerved.

Nervosism (ner'-vo-sizm) [Fr. nervosisme; nervus, a nerve]. I. Neurasthenia or nervousness. 2. The doctrine that all morbid phenomena are caused by alterations of nerve-force.

Nervous (ner'-vus) [nervus, a nerve]. Pertaining to nerves. Applied to conditions of hyperesthesia and neurasthenia. N. Bladder. See Bladder. N. Breakdown. See Neurasthenia. N. Cough, an hysteric disturbance of the motor functions of the larynx, manifesting itself as an almost constant cough, unassociated with disease of the laryngeal mucosa. N. Fluid, a hypothetic fluid supposed to traverse the nerves from the nerve-centers to the periphery. N. Impulse, the impulse propagated along a stinulated nerve. N. Influence. Same as Nerve-pozer. N. Irritability, a morbid condition of excitability of the nervous system. N. Quinsy. A synonym of Globus hystericus. N. Shock, a functional disturbance of the central nervous system, following fright or other violent emotion. N. System. See Cerebro-spinal. N. Temperament. See Temperament. N. Vomiting, a condition not associated with anatomic changes in the stomach or with any morbid state of its contents, but due to nervous influences acting either directly or indirectly upon the centers presiding over the act of vomiting. It usually occurs in brunet women, and is, as a rule, not of much gravity, although death has occurred.

Nervousness (ner'-vus-nes) [nervus, nerve]. A condition of over-excitability of the nervous system, characterized by great unrest, mental and physical.

Nervule, Nervulet (ner'-vül, ner'-vu-let) [dim. of nervus, nerve]. A small nerve.

Nervulose (ner'-vu-löz) [nervulus, dim. of nervus, a nerve]. In biology, minutely nervose.

Nervure (ner'-vir ) [nervus, a sinew]. In biology, one of the veins or nerves of a leaf or an insect's wing.

Nesis $\left(n e^{\prime}-s i s\right)[\nu \bar{\eta} \sigma \iota \zeta$, suture]. Suture.

Nessler's Reagent and Test. A solution of potassium iodid, mercuric chlorid, and sodium hydroxid, used in estimating the amount of ammonia in water. See Tests, Table of.

Nesslerizing (nes'-ler-i-zing) [after Nessler, a chemist]. The process of using Nessler's reagent.

Nest [ME., nest, a nest]. The home of a bird; the place where its eggs are laid. N.-cell, an aggregation or cluster of cells, as in carcinoma.

Nesteia (nes-ti'-ah) [ 2. The jejunum.

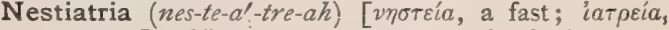
treatment]. Hunger-cure; treatment by fasting. 


\section{The Sympathetic System of Nerves.}

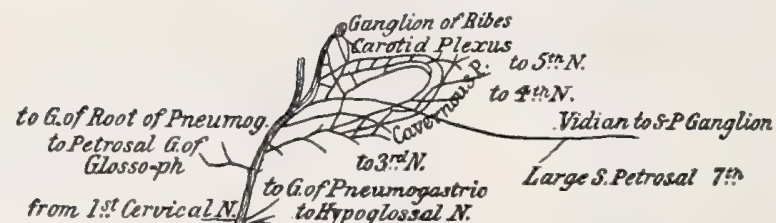

from 1 St Cervical $\boldsymbol{N}$ - to Hypoglossed $\boldsymbol{N}$.

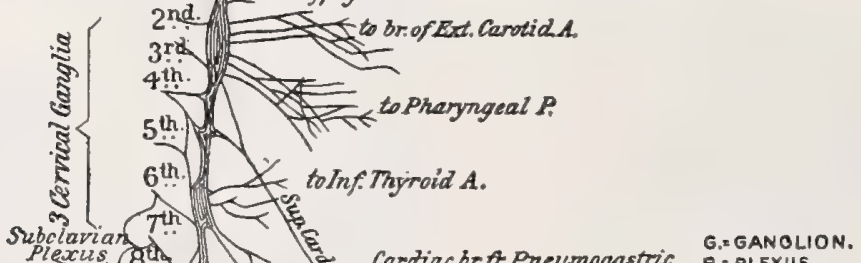

Plexus gth 1 Cardiac beft Pneumogastric G.=GANOLION

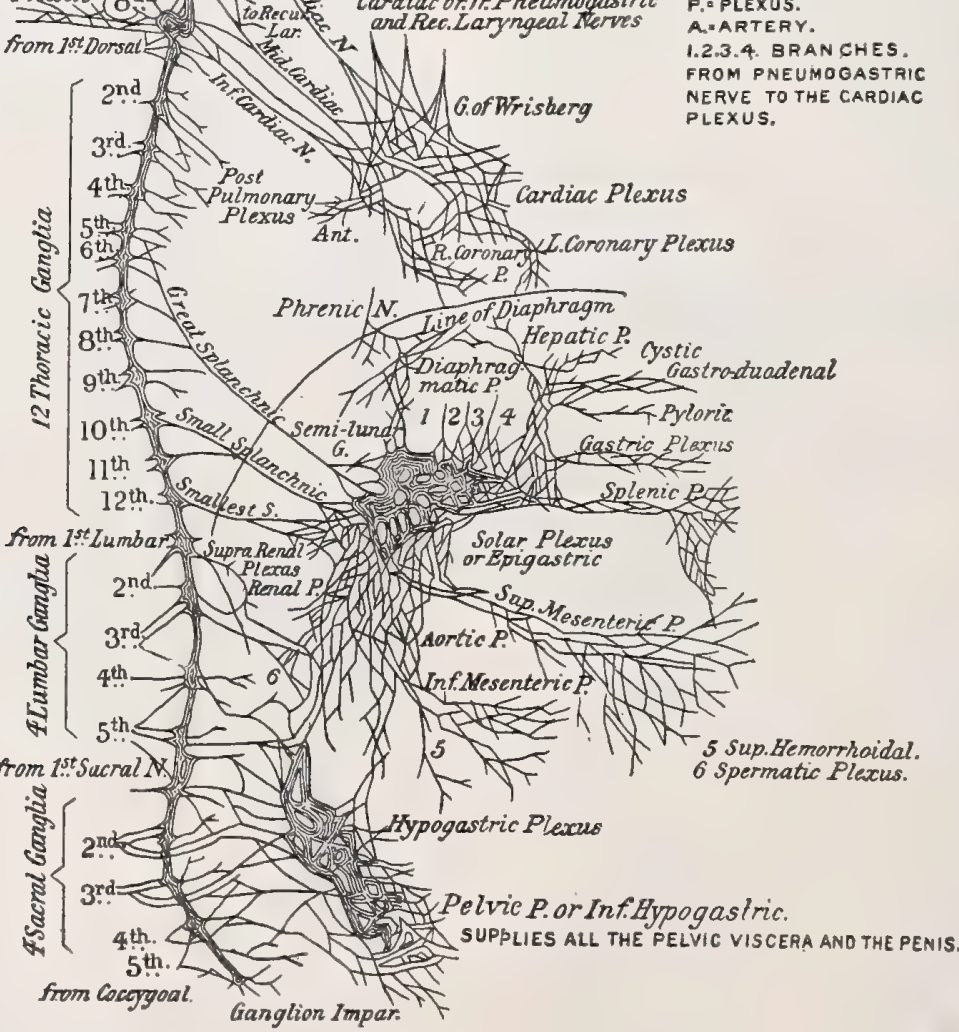



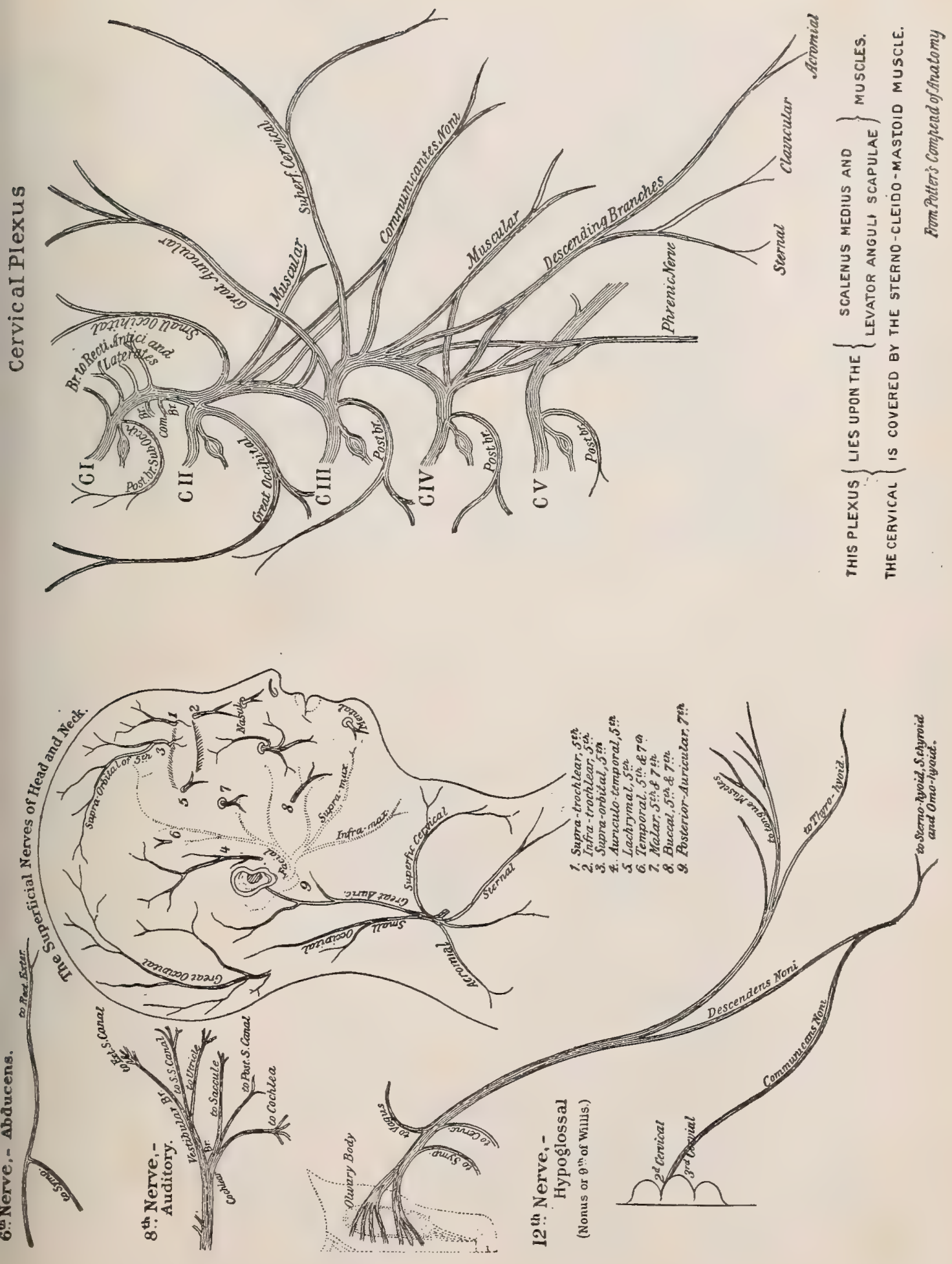


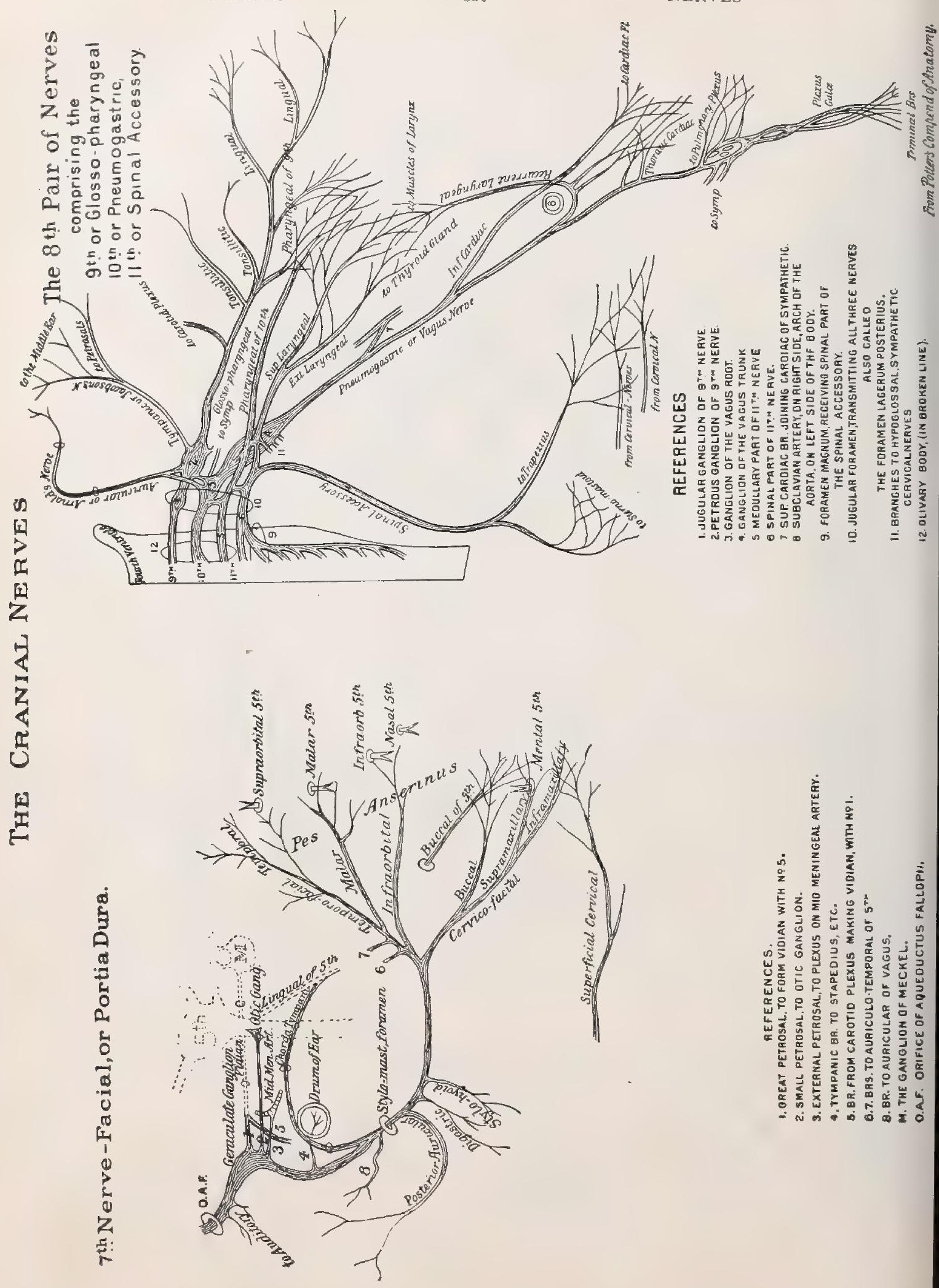




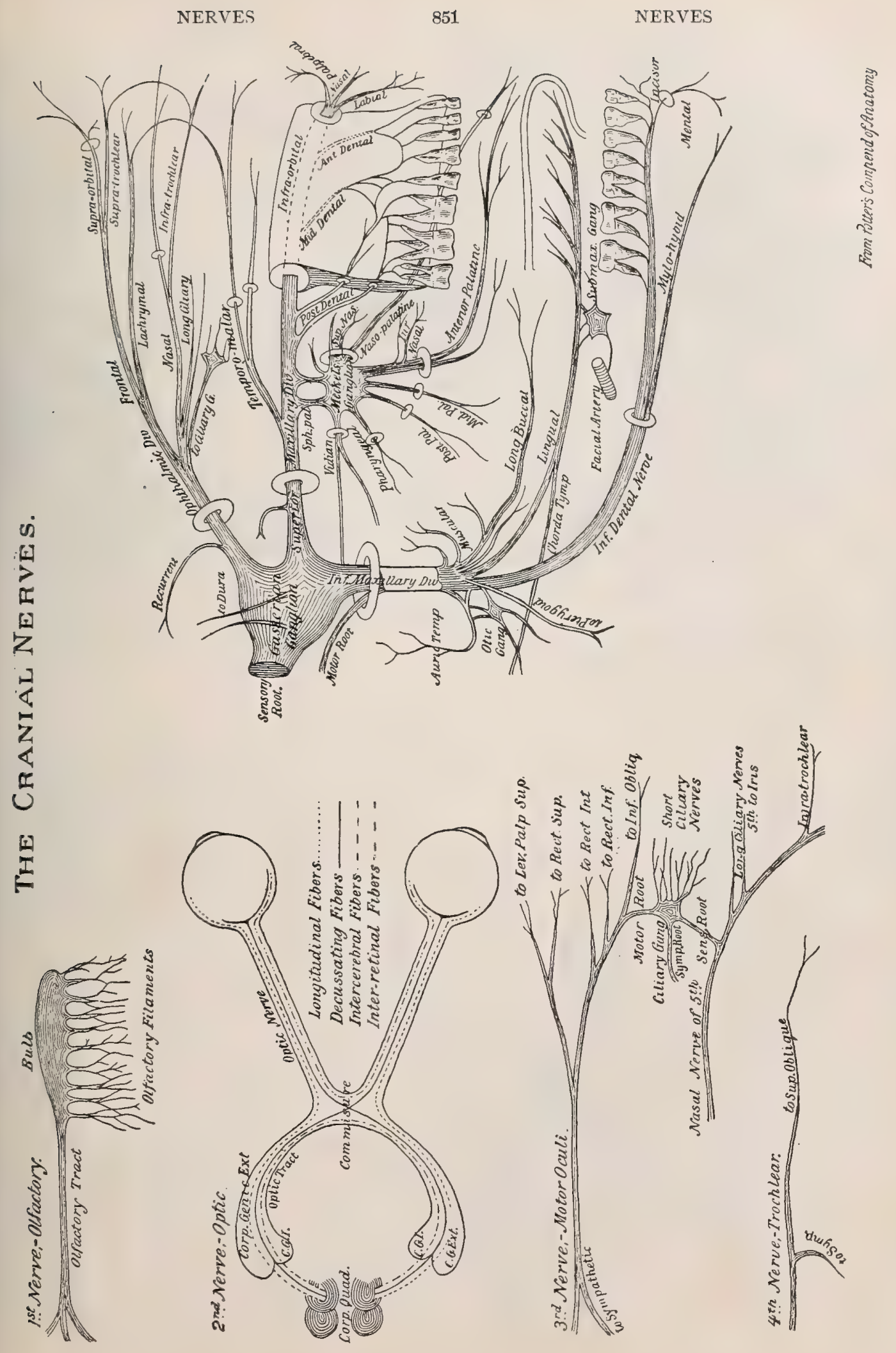




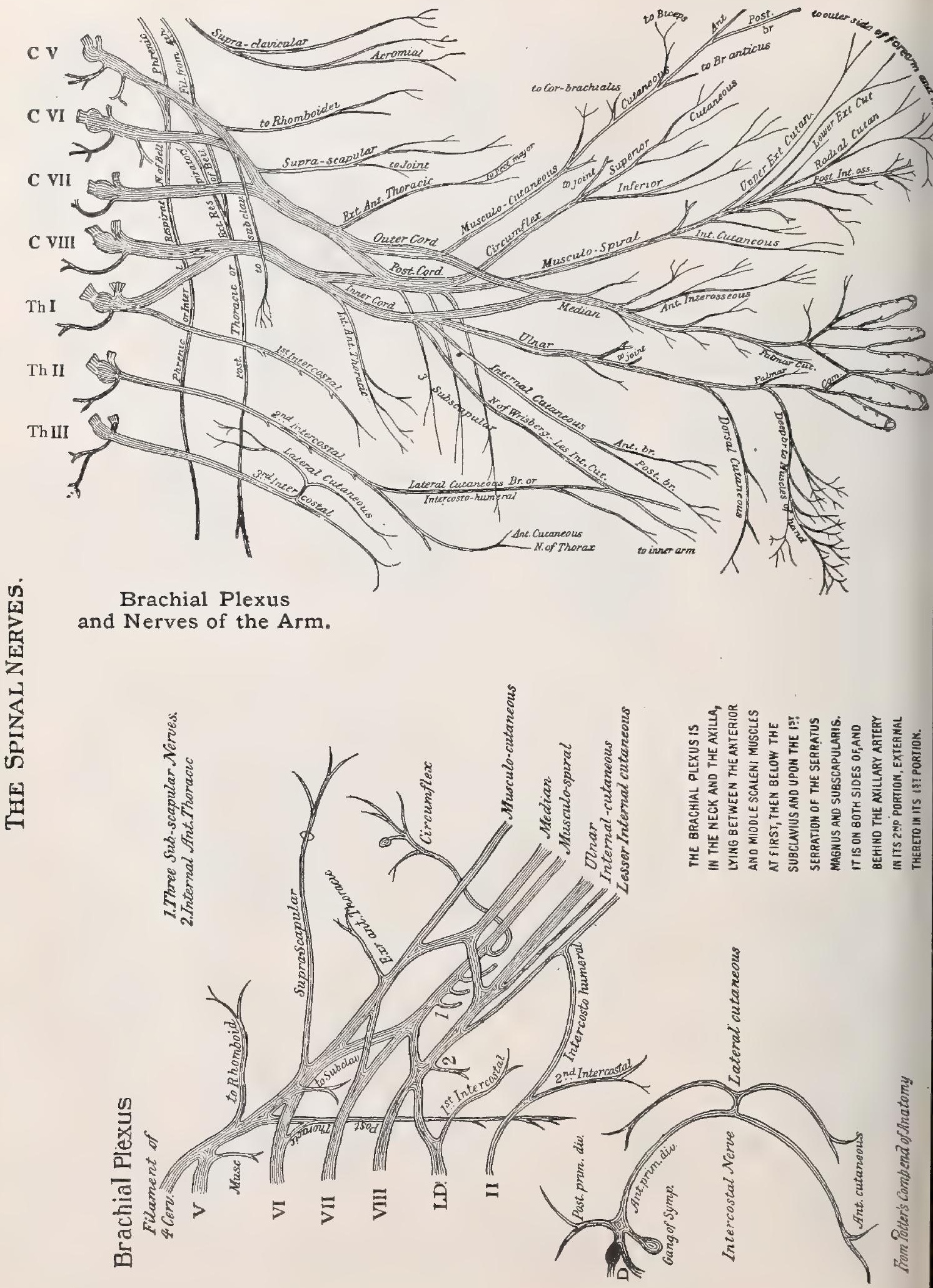




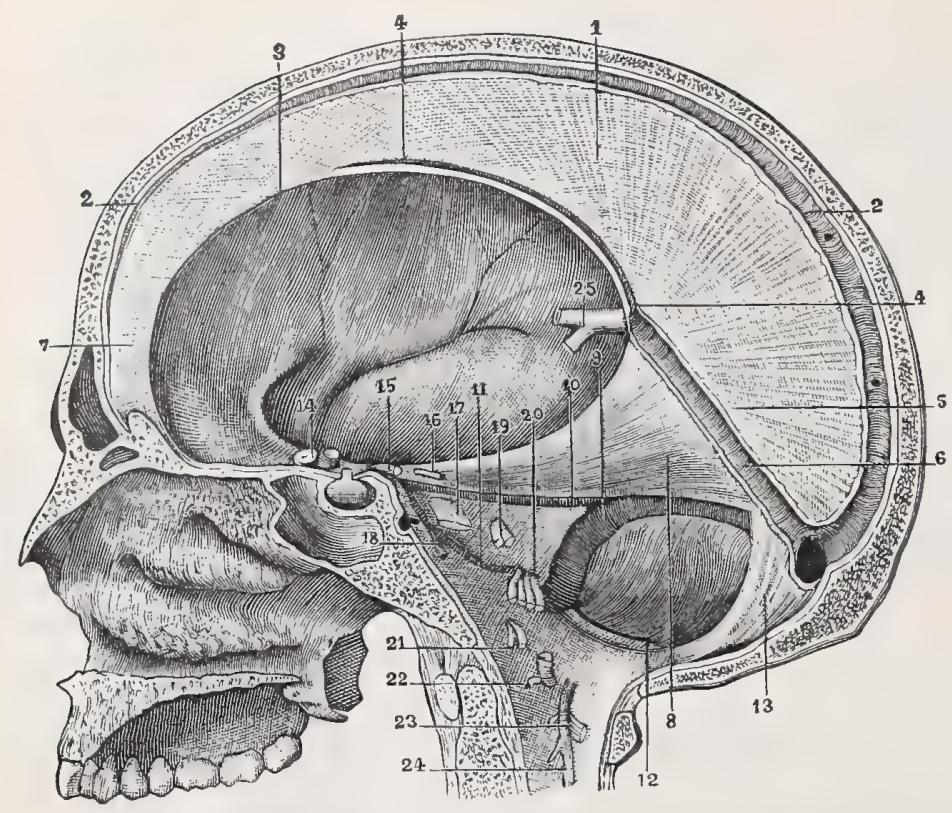

Medisection of Brain. Points of Exit of Nerves.

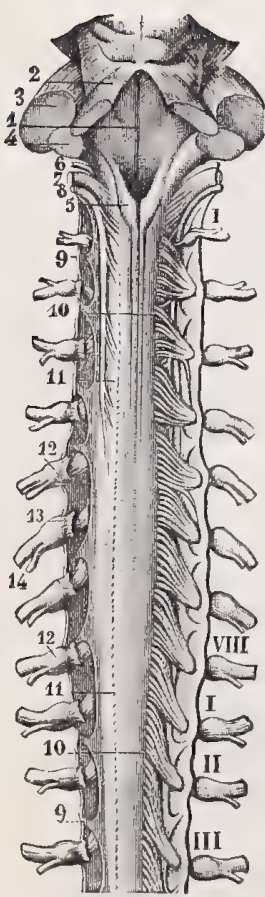

SUPERIOR OR CERVICAI SEGMENT OF SPINAL CORD.

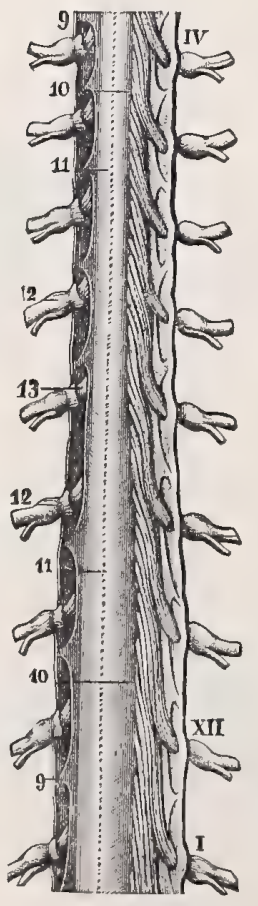

MIDDLE OR DORSAI PORTION OF CORD.
I. Falx cerebri. 2, 2. Its convex border, with the great longitudinal sinus. 3. Its concave border. 4, 4. Inferior longitudinal sinus. 5. Base of falx cerebri. 6. Straight sinus. 7. Apex of falx cerebri. 8. Right half of the tentorium, seen from below. 9. Right lateral sinus. 10. Superior petrosal sinus. II. Inferior petrosal sinus. 12. Posterior occipital sinus. I3, Falx cerebelli. 14. Optic nerve. 15. Motor oculi. I6. Pathetic. 17. Trigeminus. 18. Abducens. I9. Facial and auditory nerves, 20. Glosso-pharyngeal, pneumogastric and spinal accessory nerves. 2r. Hypoglossal nerve. 22 First cervical nerve. 23. Second cervical nerve, 24, 24. Upper extremity of ligamentum denticulatum.

I. Floor of fourth ventricle. 2. Superior cerebellar peduncle. 3. Middle cerebellar peduncle. 4. Inferior cerebellar peduncle. 5. Enlargement at upper extremity of postero-median column. 6. Glosso-pharyngeal nerve. 7. Vagus. 8. Spinal accessory. 9, 9, 9, 9. Ligamentum denticulatum. Io, IO, IO, Io, Posterior roots of spinal nerves. II, II, II, II. Postero-lateral fissure. $12, \mathrm{I} 2, \mathrm{I} 2,12$. Ganglia of posterior roots. 13, I3. Anterior roots. I4. Division of united roots into anterior and posterior nerves. I5. Terminal extremity of cord. I6, I6. Filum terminale. i7, I7. Cauda equina. I, VIII. Cervical nerves. I, XII. Dorsal nerves, I, V. Lumbar nerves. I, V. Sacral nerves. 


\section{TABLE OF NERVES (ALPHABETIC).}

\begin{tabular}{|c|c|c|c|c|}
\hline NAME. & Function. & ORIGIN, & DISTRIBUTION. & BRANCHES. \\
\hline Abdominal. & Sensation and motion. & Vagus. & Surface of stomach. & Filaments. \\
\hline Abducens (sixth cranial). & Motion. & Fourth ventricle. & External rectus of eye. & Filaments. \\
\hline Alveolar. & Sensation. & Inferior dental. & $\begin{array}{l}\text { Molar and bicuspid teeth, } \\
\text { and adjacent gums. }\end{array}$ & Gingivales. \\
\hline Arnold's. & See Auricular. & & & \\
\hline Articular. & Trophic, sensory (?). & Anterior crural. & Knee-joint. & Capsular, synovial. \\
\hline Articular, 2. & Trophic, sensory (?). & Ulnar. & Elbow-joint. & Filaments. \\
\hline Articular, recurrent. & Motion. & External popliteal. & $\begin{array}{l}\text { Knee-joint and anterior } \\
\text { tibial muscle. }\end{array}$ & Filaments. \\
\hline $\begin{array}{c}\text { Auditory (eighth cranial, } \\
\text { portio mollis of } 7 \text { th). }\end{array}$ & Hearing. & Restiform body. & Internal ear. & Vestibular, cochlear. \\
\hline Auricular. & Sensation. & Lesser occipital. & $\begin{array}{l}\text { Integument of post. and } \\
\text { upper portion of pinna. }\end{array}$ & Filaments. \\
\hline Auricular (antevior). & Sensation. & Inferior maxillary. & $\begin{array}{l}\text { Integument of external } \\
\text { ear. }\end{array}$ & Filaments. \\
\hline Auricular (Arnold's). & Sensation. & Vagus. & External ear. & Filaments. \\
\hline Auricular (posterior). & Motion. & Facial. & $\begin{array}{l}\text { Retrahens aurem, attol- } \\
\text { lens a u r e m, occipito- } \\
\text { frontalis. }\end{array}$ & Auricular, occipital. \\
\hline Auricularis magnus. & Sensation. & $\begin{array}{l}\text { Cervical plexus, 2d } \\
\text { and 3d cervical. }\end{array}$ & Parotid gland, face, ear. & $\begin{array}{l}\text { Facial, mastoid and auric } \\
\text { ular. }\end{array}$ \\
\hline Auriculo-temporal. & Sensation. & Inferior maxillary. & Pinna and temple. & $\begin{array}{l}\text { Articular, two branches } \\
\text { to meatus, parotid, ante- } \\
\text { rior auricular, superf } \\
\text { cial temporal. }\end{array}$ \\
\hline Of Bock. & See Pharyngeal. & & & \\
\hline Buccal. & Motion. & Facial. & $\begin{array}{l}\text { Buccinator and orbicularis } \\
\text { oris muscles. }\end{array}$ & Filaments. \\
\hline Buccal, long. & Sensation, motion? & Inferior maxillary. & Cheek. & $\begin{array}{l}\text { Superior and inferior buc- } \\
\text { cinator and externa } \\
\text { pterygoid. }\end{array}$ \\
\hline Calcanean, internal. & Sensation. & Posterior tibial. & $\begin{array}{l}\text { Fascia and integument of } \\
\text { heel and sole. }\end{array}$ & Several small filaments. \\
\hline $\begin{array}{l}\text { Calcaneo-plantar, cuta- } \\
\text { neous. }\end{array}$ & See Calcanean, inter & nal. & & \\
\hline $\begin{array}{l}\text { Cardiac (cervical and } \\
\text { thoracic). }\end{array}$ & Inhibition. & Vagus. & Heart. & $\begin{array}{l}\text { Branches to cardiac plex } \\
\text { uses. }\end{array}$ \\
\hline Of Casser. & See Perforating, and & Musculo-cutaneous. & & \\
\hline Cavernous. & Sensation. & Prostatic plexus. & $\begin{array}{l}\text { Erectile structures of } \\
\text { penis. }\end{array}$ & Filaments. \\
\hline Cervical, eight. & Motion and sensation. & Cord. & $\begin{array}{l}\text { Trunk and upper ex- } \\
\text { tremities. }\end{array}$ & $\begin{array}{l}\text { Ventral and dorsal divi- } \\
\text { sions. See Plexus. }\end{array}$ \\
\hline $\begin{array}{l}\text { Cervical, first (anterior } \\
\text { division). }\end{array}$ & Motion and sensation. & Cord. & $\begin{array}{l}\text { Rectus lateralis and two } \\
\text { anterior recti. }\end{array}$ & $\begin{array}{l}\text { Filaments and communi- } \\
\text { cating to vagus, hypo- } \\
\text { glossal, sympathetic. }\end{array}$ \\
\hline $\begin{array}{l}\text { Cervical, first (posterior } \\
\text { division). }\end{array}$ & Motion and sensation. & Cord. & Recti, obliqui, complexus. & $\begin{array}{l}\text { Communicating and cuta- } \\
\text { neous filaments. }\end{array}$ \\
\hline $\begin{array}{l}\text { Cervical, fourth (ante- } \\
\text { rior division). }\end{array}$ & Motion and sensation. & Cord. & $\begin{array}{l}\text { Shoulder and communi- } \\
\text { cating. }\end{array}$ & $\begin{array}{l}\text { Communicating filaments, } \\
\text { muscular, etc. }\end{array}$ \\
\hline $\begin{array}{l}\text { Cervical, second (ante- } \\
\text { rior division). }\end{array}$ & Motion and sensation. & Cord. & Communicating. & $\begin{array}{l}\text { Ascending, descending, } \\
\text { communicating and fila- } \\
\text { ments. }\end{array}$ \\
\hline $\begin{array}{l}\text { Cervical, second (poste- } \\
\text { rior division). }\end{array}$ & Motion and sensation. & Cord. & $\begin{array}{l}\text { Obliquus inferioris, scalp, } \\
\text { ear, complexus, splenius, } \\
\text { trachelo-mastoid. }\end{array}$ & $\begin{array}{l}\text { Internal or occipitalis } \\
\text { major, and external. }\end{array}$ \\
\hline $\begin{array}{l}\text { Cervical, third (ante- } \\
\text { rior division). }\end{array}$ & Motion and sensation. & Cord. & Communicating. & $\begin{array}{l}\text { Ascending, descending, } \\
\text { and communicating fila- } \\
\text { ments. }\end{array}$ \\
\hline
\end{tabular}




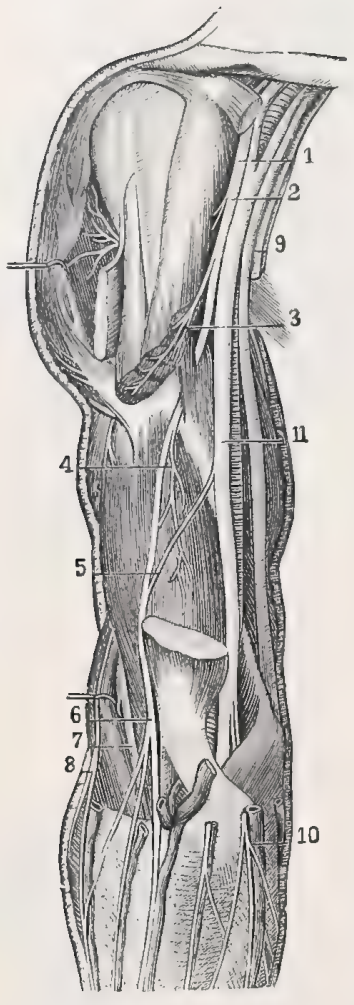

Brachial Portion of MusculoCUTANEOUS, MEDIAN AND UlNAR NERVES.

x. Musculo-cutaneous nerve. 2. Branch to coraco-brachialis 3. Branch to biceps. 4. Branch to brachialis anticus. 5. Anastomotic branch from median. 6. Division of musculo-cutaneous. 7. Radial nerve. 8. Its external cutaneous branch. 9. Internal cutaneous. Io. Its anterior, or ulnar branch. 11. Upper portion of median and ulnar nerves. I2. Their middle portion. 13. Branch to pronator radii teres. 14. Trunk giving rise to anterior muscular branches. 15. Branches to flexor profundus digitorum, 16. Branch to flexor longus proprius pollicis. 17. Interosseous branches. 18. Palmar cutaneous branch. 19. Branch for muscles of thenar eminence. 20. External collateral branch to thumb. 2I. Internal collateral branch. 22. External collateral branch to index finger. 23. Common trunk of internal collateral branch to index finger and external collateral branch to middle finger. 24. Trunk of internal collateral to middle finger and external collateral branch to ring finger. 25. Branch of ulnar nerve to flexor carpi ulnaris. 26. Branches to two inner fasciculi of flexor profundus digitorum. 27. Cutaneous and anastomotic filament. 28. Dorsal branch. 29. Superficial palmar branch. 30. Common trunk of internal collateral branch to ring finger and external collateral branch to little finger. 3I. Internal collateral branch to little finger. 32. Deep palmar branch. 33. Branch of the latter to hypothenar muscles. 34. Branches to muscles of fourth interosseous and to fourth lumbricalis. 35. Branches to muscles of third interosseous space and to third Iumbricalis. 36. Branches to the adductor of the thumb and to the muscles of the first two interosseous spaces.

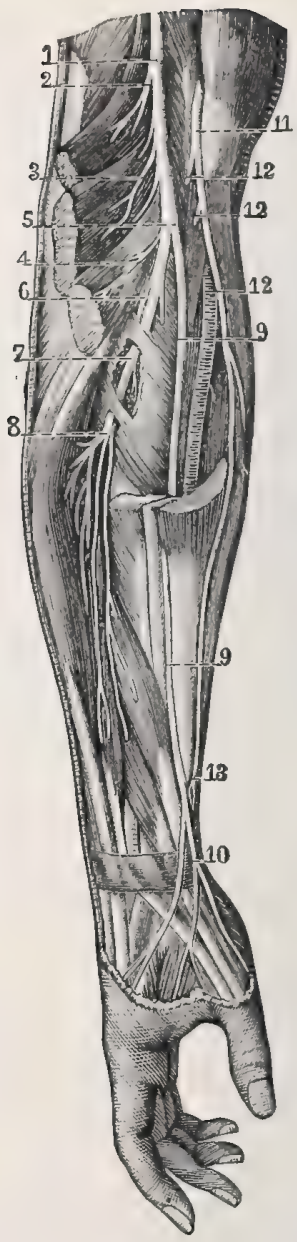

TERMINAL BRANCHES OF THE Radial Nerve.

I. Trunk of radial nerve. 2. Branch to supinator longus. 3. Branch to extensor carpi radialis longior. 4 . Branch to extensor carpi radialis brevior. 5. Bifurcation. 6. Posterior, or muscular division. 7. This division traversing the supinator brevis, to which it furnishes several branches. 8. Its terminal branches. 9, 9. Anterior, or cutaneous division. Io. Terminal branches of this division. II Musculo-cutaneous nerve. 12, 12, 12. Its terminal branches. $1_{3}$. One of its branches descending to the wrist and anastomosing with the cutaneous branch of the radial. 
TABLE OF NERVES.-Continued.

\begin{tabular}{|c|c|c|c|c|}
\hline NAME. & FUNCTION. & ORIGIN. & DISTRIBUTION. & BRANCHES. \\
\hline $\begin{array}{l}\text { Cervical, third (poste- } \\
\text { rior division). }\end{array}$ & Motion and sensation. & Cord. & $\begin{array}{l}\text { Occiput, splenius, com- } \\
\text { plexus. }\end{array}$ & $\begin{array}{l}\text { Internal, external, and fila- } \\
\text { ments. }\end{array}$ \\
\hline $\begin{array}{l}\text { Cervicals, 5th to } 8 \text { th } \\
\text { (anterior divisions). }\end{array}$ & Motion and sensation. & Cord. & Brachial plexus. & Communicating. \\
\hline $\begin{array}{l}\text { Cervicals, } 4 \text { th to } 8 \text { th } \\
\text { (posterior divisions). }\end{array}$ & Motion and sensation. & Cord. & Muscles and skin of neck. & $\begin{array}{l}\text { Internal and external } \\
\text { branches. }\end{array}$ \\
\hline Cervico-facial. & Motion. & Facial. & $\begin{array}{l}\text { Lower part of face and } \\
\text { part of neck. }\end{array}$ & $\begin{array}{l}\text { B uccal, supra-maxillary, } \\
\text { infra-maxillary. }\end{array}$ \\
\hline Chorda tympani. & Motion. & Facial, & $\begin{array}{l}\text { Tongue, tympanum, sub- } \\
\text { maxillary gland. }\end{array}$ & Filaments. \\
\hline Ciliary. & $\begin{array}{l}\text { Sensation, nutrition, } \\
\text { motion. }\end{array}$ & Ciliary ganglion. & Eye-ball. & Filaments. \\
\hline Circumflex. & Motion and sensation. & Brachial plexus. & $\begin{array}{l}\text { Teres minor, deltoid and } \\
\text { skin. }\end{array}$ & $\begin{array}{l}\text { Anterior, posterior and ar- } \\
\text { ticular. }\end{array}$ \\
\hline Coccygeal. & Motion. & Coccygeal plexus. & $\begin{array}{c}\text { Coccygeus and gluteus } \\
\text { maximus. }\end{array}$ & Filaments. \\
\hline Cochlear. & Hearing. & Auditory. & Cochlea. & Filaments. \\
\hline Colli, superficialis. & Sensation. & Cervical plexus. & $\begin{array}{l}\text { Platysma myoides and ven- } \\
\text { tro-lateral parts of neck. }\end{array}$ & $\begin{array}{l}\text { Ascending and descending } \\
\text { branches, filaments. }\end{array}$ \\
\hline $\begin{array}{l}\text { Communicans hypo- } \\
\text { glossi. }\end{array}$ & See Communicans noni. & & & \\
\hline Communicans noni. & Motion and sensation. & $\begin{array}{l}\text { Second cervical, third } \\
\text { cervical. }\end{array}$ & $\begin{array}{l}\text { Descendens noni, depres- } \\
\text { sor muscles of hyoid } \\
\text { bone. }\end{array}$ & $\begin{array}{l}\text { Omo-hyoid and filaments, } \\
\text { ansa hypoglossi. }\end{array}$ \\
\hline Communicating. & Motion and sensation. & Cervical plexus. & Spinal accessory. & Branches. \\
\hline Communicating. & Sensation and motion. & $\begin{array}{l}\text { First and second cer- } \\
\text { vical. }\end{array}$ & $\begin{array}{l}\text { Vagus, hypoglossal, sym- } \\
\text { pathetic. }\end{array}$ & $\begin{array}{l}\text { Three branches and fila- } \\
\text { ments. }\end{array}$ \\
\hline Of Cotunnius. & See $N a$ so-palatine & nerve. & & \\
\hline Crutal. & Sensation. & Genito-crural. & $\begin{array}{l}\text { Skin, upper and central } \\
\text { part ant. aspect of thigh. }\end{array}$ & Filaments. \\
\hline Crural, anterior. & Motion and sensation. & $\begin{array}{l}\text { Lumbar plexus, second, } \\
\text { third and fourth lum- } \\
\text { bar nerves. }\end{array}$ & Thigh. & $\begin{array}{l}\text { Middle and internal cuta- } \\
\text { neous, long saphenous, } \\
\text { muscular, articular. }\end{array}$ \\
\hline Cutaneous. & Sensation. & Musculo-spiral. & $\begin{array}{l}\text { Skin of arm, radial side of } \\
\text { forearm. }\end{array}$ & One internal, two external. \\
\hline Cutaneous. & Sensation. & Ulnar. & Wrist and palm. & Ist and palmar cutaneous. \\
\hline Cutaneous (dorsal). & Sensation. & Ulnar. & Little and ring fingers. & $\begin{array}{l}\text { Filaments and communi- } \\
\text { cating branches. }\end{array}$ \\
\hline Cutaneous (external). & Sensation. & $2 \mathrm{~d}$ and $3 \mathrm{~d}$ lumbar. & Skin of thigh. & Anterior, posterior. \\
\hline Cutaneous (internal). & Sensation. & Brachial plexus. & Forearm. & $\begin{array}{l}\text { Anterior and posterior } \\
\text { branches and filaments. }\end{array}$ \\
\hline $\begin{array}{l}\text { Cutaneous (lesser inter- } \\
\text { nal) (of Wrisberg). }\end{array}$ & Sensation. & Brachial plexus. & Inner side of arm. & Filaments. \\
\hline $\begin{array}{l}\text { Cutaneous (middle and } \\
\text { internal). }\end{array}$ & Sensation. Motion? & Anterior crural. & $\begin{array}{l}\text { Thigh and communica- } \\
\text { ting. }\end{array}$ & $\begin{array}{l}\text { Communicating and fila- } \\
\text { ments. }\end{array}$ \\
\hline Cutaneous, perforating. & Sensation. & Fourth sacral. & $\begin{array}{l}\text { Integument covering glu- } \\
\text { teus maximus. }\end{array}$ & Filaments. \\
\hline Cyon's. & See Depressor. & & & \\
\hline $\begin{array}{l}\text { Dental (inferior or man- } \\
\text { dibular). }\end{array}$ & Sensation. & Inferior maxillary. & Teeth, muscles. & $\begin{array}{l}\text { Mylo-hyoid, incisor, men- } \\
\text { tal, dental. }\end{array}$ \\
\hline Dental, superior. & See Dentals (posterior & and anterior). & & \\
\hline Dentals (post. and ant.). & Sensation. & Superior maxillary. & Teeth. & Filaments. \\
\hline Depressor. & $\begin{array}{l}\text { Lowering of the } \\
\text { blood-pressure. }\end{array}$ & $\begin{array}{l}\text { In the rabbit, from the } \\
\text { vagus. }\end{array}$ & Heart. & Filaments. \\
\hline Descendens hypoglossi. & Motor. & Cervical plexus. & $\begin{array}{l}\text { Omo-hyoid, sterno-hyoid. } \\
\text { sterno-thyroid, thyro-hy- } \\
\text { oid, genio-hyoid, hyo- } \\
\text { glossus and muscles of } \\
\text { tongue. }\end{array}$ & Muscular, tongue. \\
\hline
\end{tabular}




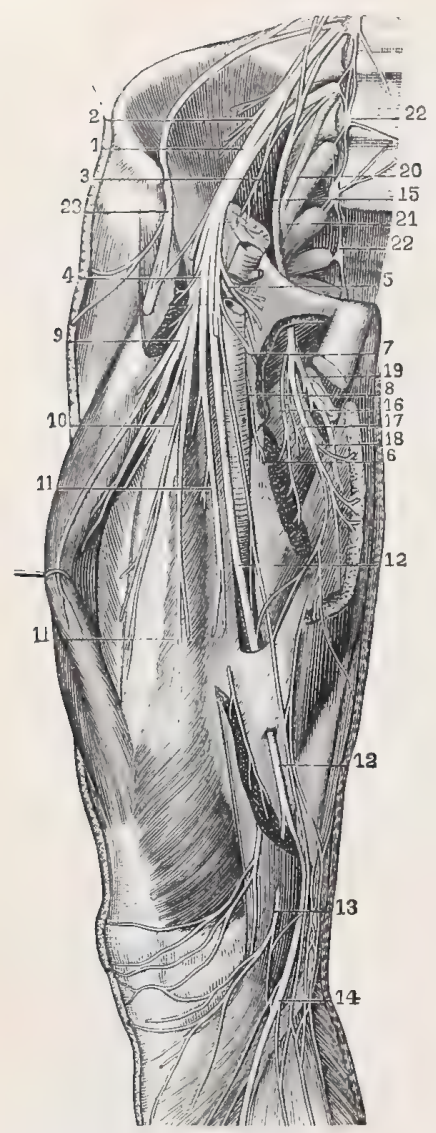

Muscular Nerves of the ANteroINTERNAL ASPECT OF THE THIGH.

I. Anterior crural nerve. 2. Branches to iliacus muscle. 3. Branch to inner part of psoas. 4. Large cutaneous branch. 5,6. Muscular filaments of small musculo-cutaneous branch. 7 Cutaneous branches. 8. Deep, or anastomotic filament of internal cutaneous branch. 9. Branches to rectus femoris. Io. Branches to vastus externus. Ir, II. Branches to vastus internus. 12, 12. Internal saphenous nerve. 13. Its patellar branch. I4 Vertical, or tibial branch. 15, Obturator nerve. I6. Branch to adductor longus. I7. Branch to adductor brevis. I8. Branch to gracilis. I9. Branch to adductor magnus. 20 Lumbo-sacral trunk. 2I. Union of this trunk and the first sacral nerve. 22, 22. Lumbar and sacral portions of sympathetic. 23. External inguinocutaneous branch.

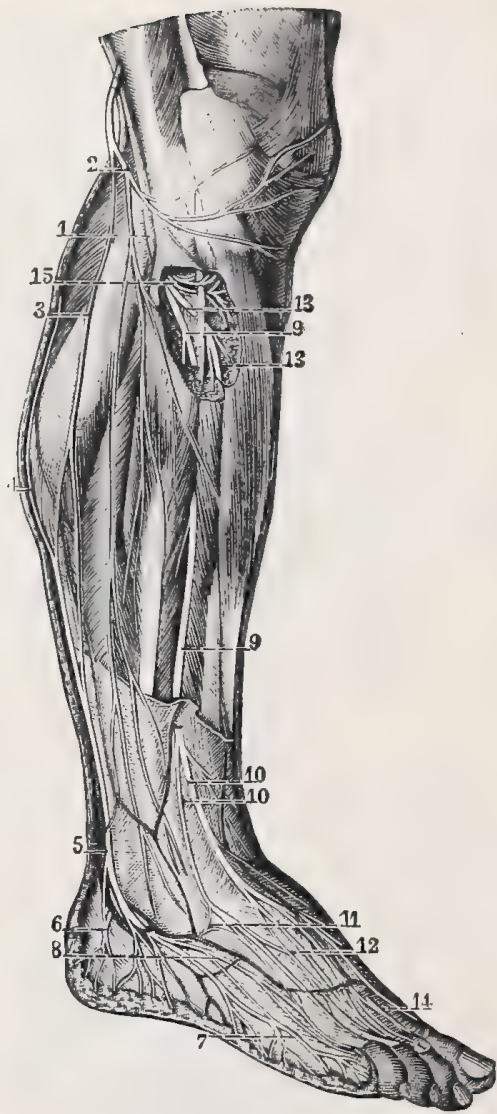

External Popliteal, or Peroneal Nerve.

I. External popliteal nerve. 2. Fibular cutaneous branch. 3. Communicans peroneî. 4. External saphenous nerve. 5. Trunk formed by the union of the last two. 6. Calcanean branches. 7. External terminal branch. 8. Internal branch. 9,9. Musculo-cutaneous nerve. ro, I0. Its terminal branches. II. Anastomosis of its external terminal branch with internal saphenous. I2. Anastomosis of internal terminal branch with external. 13. Anterior tibial nerve. 14. Its terminal portion, anastomosing with the musculo-cutaneous and dividing to form the deep dorsal internal collateral branch to the great toe, and the external collateral branch to the second toe.

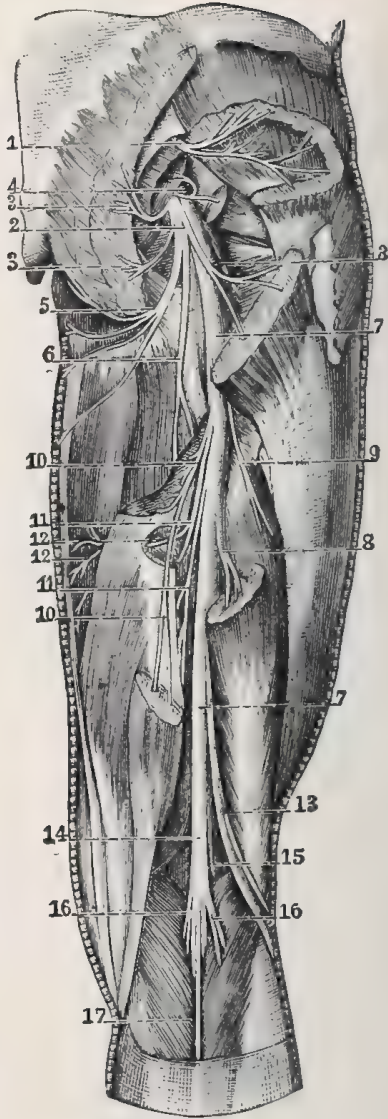

The Great Sciatic Nerve.

I. Superior gluteal nerve. 2. Inferior gluteal, or small sciatic nerve. 3,3 , 3. Branches to gluteus maximus. 4. Branch to pyriformis. 5. Genital branch of small sciatic. 6. Femoropopliteal branch. 7,7. Trunk of great sciatic. 8. Branch to long head of biceps. 9. Branch to short head. ro, ro. Branches to semitendinosus II, II. Branches to semimembranosus. I2, 12. Branches to adductor magnus, I3. External popliteal. I4. Internal popliteal. I5. Filament to plantaris. 16, 16. Branches to gastrocnemius. 77 . Origin of external saphenous. 
TABLE OF NERVES.-Continued.

\begin{tabular}{|c|c|c|c|c|}
\hline Name. & FUNCTION. & ORIGIN. & DISTRIBUTION. & BRANCHES. \\
\hline Descendens noni. & $\begin{array}{l}\text { See Descendens hypo- } \\
\text { glossi. }\end{array}$ & & & \\
\hline Digastric. & Motion. & Facial. & Posterior belly of digastric. & Filaments. \\
\hline $\begin{array}{l}\text { Dorsal, I2 (anterior and } \\
\text { posterior divisions). }\end{array}$ & Motion and sensation. & Cord. & $\begin{array}{l}\text { Muscles and skin of chest } \\
\text { and trunk. }\end{array}$ & $\begin{array}{l}\text { External, internal, cuta- } \\
\text { neous. }\end{array}$ \\
\hline Dorsal (of clitoris). & \multicolumn{2}{|c|}{ Homologue of dorsal of penis. } & & Filaments. \\
\hline Dorsal (of penis). & Sensation. & Pudic. & Penis. & Filaments. \\
\hline Esophageal. & Motion. & Vagus. & $\begin{array}{l}\text { Mucous and muscular } \\
\text { coats of esophagus. }\end{array}$ & Esophageal plexus. \\
\hline Facial. & Sensation. & Great auricular. & Skin over parotid. & Filaments. \\
\hline $\begin{array}{l}\text { Facial (seventh cranial, } \\
\text { portio dura). }\end{array}$ & Motion. & $\begin{array}{l}\text { Floor of fourth ven- } \\
\text { tricle. }\end{array}$ & Face, ear, palate, tongue. & $\begin{array}{l}\text { Petrosals, tympanic, chor- } \\
\text { da tympani, communicat- } \\
\text { ing, post, auricular, digas- } \\
\text { tric, stylo-hyoid, lingual, } \\
\text { temporal, malar, infra- } \\
\text { orbital, buccal, superior } \\
\text { and inferior maxillary. } \\
\end{array}$ \\
\hline Frontal. & Sensation. & Ophthalmic. & Forehead and eyelids. & $\begin{array}{l}\text { Supra-orbital, supra-troch- } \\
\text { lear. }\end{array}$ \\
\hline Gastric. & Motion. & Vagus. & Stomach. & Filaments. \\
\hline Genital. & Motion and sensation. & Genito-crural. & Cremaster muscle. & Filaments. \\
\hline Genito-crural. & Motion and sensation. & $\begin{array}{l}\text { First and second lum- } \\
\text { bar. }\end{array}$ & Cremaster and thigh. & $\begin{array}{l}\text { Genital, crural, communi- } \\
\text { cating. }\end{array}$ \\
\hline $\begin{array}{l}\text { Glosso-phary ngeal } \\
\text { (ninth cranial). }\end{array}$ & Sensation and taste. & Fourth ventricle. & $\begin{array}{l}\text { Tongue, middle ear, ton- } \\
\text { sils, pharynx, meninges. }\end{array}$ & $\begin{array}{l}\text { Tympanic, carotid, } \\
\text { pharyngeal, muscular, } \\
\text { tonsillar, lingual. }\end{array}$ \\
\hline Gluteal (inferior). & Motion. & $\begin{array}{l}\text { Sacral plexus (ad and } \\
\text { 3d sacral nerves). }\end{array}$ & Gluteus maximus. & Filaments. \\
\hline Gluteal (superior). & Motion. & Sacral plexus. & Glutei, tensor vagina fem. & Filaments. \\
\hline Gustatory. & See Lingual. & & & \\
\hline Hemorrhoidal (inferior). & Sensation and motion. & Pudic. & $\begin{array}{l}\text { External sphincter ani, } \\
\text { and adjacent integument. }\end{array}$ & Filaments. \\
\hline Hepatic. & (?) & Vagus. & Liver. & Hepatic plexus. \\
\hline Hirschfeld's. & Motion. & Facial. & $\begin{array}{l}\text { Styloglossus and palato- } \\
\text { glossus. }\end{array}$ & Filaments. \\
\hline Hypogastric. & Sensation. & llio-hypogastric. & $\begin{array}{l}\text { Skin about external ab- } \\
\text { dominal ring. }\end{array}$ & Filaments. \\
\hline $\begin{array}{l}\text { Hypoglossal (t welfth } \\
\text { cranial). }\end{array}$ & Motion. & $\begin{array}{l}\text { Floor of fourth ven- } \\
\text { tricle. }\end{array}$ & $\begin{array}{l}\text { Hyo-glossus and hyoid } \\
\text { muscles. }\end{array}$ & $\begin{array}{l}\text { Descendens noni or hypo- } \\
\text { glossi, muscular, thyro- } \\
\text { hyoid, genio-hyoid and } \\
\text { meningeal. }\end{array}$ \\
\hline Iliac. & Sensation. & Iljo-hypogastric. & $\begin{array}{l}\text { Integument covering fore } \\
\text { part of gluteal region. }\end{array}$ & Filaments. \\
\hline Iliac. & Sensation. & Last dorsal. & $\begin{array}{l}\text { Integument covering fore } \\
\text { part of gluteal region. }\end{array}$ & Filaments. \\
\hline Ilio-hypogastric. & Motion and sensation. & First lumbar. & $\begin{array}{l}\text { Abdominal and gluteal } \\
\text { regions. }\end{array}$ & $\begin{array}{l}\text { Iliac, hypogastric, com- } \\
\text { municating. }\end{array}$ \\
\hline Ilio-inguinal. & Motion and sensation. & First lumbar. & $\begin{array}{l}\text { Inguinal region and scro- } \\
\text { tum. }\end{array}$ & $\begin{array}{l}\text { Muscular, cutaneous and } \\
\text { communicating. }\end{array}$ \\
\hline Incisive. & Sensation. & Inferior dental. & $\begin{array}{l}\text { Canine and incisor teeth } \\
\text { and corresponding gums. }\end{array}$ & Filaments. \\
\hline Infra-mandibular. & See Infra-maxillary. & & & \\
\hline Infra-maxillary. & Motion. & Facial. & Platysma myoides. & Filaments. \\
\hline Infra-orbital. & Sensation and motion. & Facial. & Nose and lip. & Palpebral, nasal, labial. \\
\hline Infra-trochlear. & Sensation. & Nasal. & $\begin{array}{l}\text { Skin and conjunctiva of } \\
\text { inner part of eye, lacry- } \\
\text { mal sac. }\end{array}$ & Filaments. \\
\hline Intercostal. & Motion and sensation. & Spinal cord. & $\begin{array}{l}\text { Muscles and integument } \\
\text { of thorax. }\end{array}$ & $\begin{array}{l}\text { Muscular, anterior and lat- } \\
\text { eral cutaneous. }\end{array}$ \\
\hline
\end{tabular}


TABLE OF NERVES.-Continued.

\begin{tabular}{|c|c|c|c|c|}
\hline NAME. & Function. & ORIGIN. & DISTRIBUTION. & BRANCHES. \\
\hline Intercosto-humeral. & Sensation. & Second intercostal. & $\begin{array}{l}\text { Integument of upper two- } \\
\text { thirds of inner and poste- } \\
\text { rior part of arm. }\end{array}$ & Filaments. \\
\hline Interosseous (anterior). & Motion. & Median. & Deep muscles of forearm. & Filaments. \\
\hline Interosseous (posterior). & Motion and sensation. & Musculo-spiral. & $\begin{array}{l}\text { Carpus and radial and pos- } \\
\text { terior brachial regions. }\end{array}$ & Filaments. \\
\hline Jacobson's. & See Tympanic, of the & glosso-pharyngeal. & & \\
\hline Labial. & Motion and sensation. & Superior maxillary. & $\begin{array}{l}\text { Muscles and mucous mem- } \\
\text { brane of lips. }\end{array}$ & Filaments. \\
\hline Lacrymal. & Sensation. & Ophthalmic. & Gland and conjunctiva. & Filaments. \\
\hline Of Lancisi. & $\begin{array}{l}\text { Longitudinal stria- } \\
\text { tions on upper sur- } \\
\text { face of corpus cal- } \\
\text { losum. }\end{array}$ & & & \\
\hline $\begin{array}{l}\text { Laryngeal (recurrent or } \\
\text { inferior). }\end{array}$ & Motion. & Vagus. & Larynx. & $\begin{array}{l}\text { Branches to all laryngeal } \\
\text { mus. except crico-thyroid. }\end{array}$ \\
\hline Laryngeal (superior). & $\overline{\text { Sensation and motion. }}$ & Vagus. & Larynx. & $\begin{array}{l}\text { External - c r ico-thyroid } \\
\text { muscle and thyroid gland. } \\
\text { Internal - mucous mem- } \\
\text { brane of larynx. }\end{array}$ \\
\hline Lingual. & Motion and sensation. & Facial. & $\begin{array}{l}\text { Mucous membrane of } \\
\text { tongue, palato-glossus } \\
\text { and stylo-glossus mus- } \\
\text { cles. }\end{array}$ & Filaments. \\
\hline Lingual. & Sensation. & Glosso-pharyngeal. & $\begin{array}{l}\text { Circumvallate papiliæ and } \\
\text { glands of tongue. }\end{array}$ & Filaments. \\
\hline Lingual. & Taste and sensation. & Inferior maxillary. & Tongue and mouth. & Filaments. \\
\hline Lumbar (5). & Motion and sensation. & Cord. & $\begin{array}{l}\text { Lumbar and genital tis- } \\
\text { sues. }\end{array}$ & $\begin{array}{l}\text { Anterior and posterior di- } \\
\text { visions, lumbar plexus. }\end{array}$ \\
\hline Malar. & Motion. & Facial. & $\begin{array}{l}\text { Lower part of orbicularis } \\
\text { palpebrarum, and eye- } \\
\text { lids. }\end{array}$ & Filaments. \\
\hline Malar. & Sensation. & Orbital. & Skin over malar bone. & Filaments. \\
\hline Mandibular. & See Maxillary, infe & rior. & & \\
\hline Masseteric. & Motor. & Inferior maxillary. & $\begin{array}{l}\text { Masseter muscle (and tem- } \\
\text { poral?). }\end{array}$ & Filaments. \\
\hline Mastoid. & Sensation. & Great auricular. & Skin over mastoid process. & Filaments. \\
\hline Mastoid. & Motion. & Lesser occipital. & Skin over mastoid process & Filaments. \\
\hline Maxillary (inferior). & $\begin{array}{l}\text { Sensation, motion, } \\
\text { and taste. }\end{array}$ & Trigeminus. & $\begin{array}{l}\text { Muscles of mastication, } \\
\text { ear, cheek, tongue, teeth. }\end{array}$ & $\begin{array}{l}\text { Masseteric, auriculo-tem- } \\
\text { poral, buccal, gustatory, } \\
\text { inferior dental. }\end{array}$ \\
\hline Maxillary (superior). & Sensation. & Trigeminus. & Cheek, face, teeth. & $\begin{array}{l}\text { Orbital, spheno-palatine, } \\
\text { dentals, infra-orbital. }\end{array}$ \\
\hline Median. & Motion and sensation. & Brachial plexus. & $\begin{array}{l}\text { Pronat or radii teres, } \\
\text { flexors, two lumbricales, } \\
\text { fingers, palms. }\end{array}$ & $\begin{array}{l}\text { Muscular, anterior inter- } \\
\text { osseous, palmar cuta- } \\
\text { neous. }\end{array}$ \\
\hline Meningeal. & Sensation. & Glosso-pharyngeal. & Pia and arachnoid. & Filaments. \\
\hline Meningeal. & Sensation. & Hypoglossal. & Dura mater. & Filaments. \\
\hline Meningeal. & Sensation. & Vagus. & Dura around lateral sinus. & Filaments. \\
\hline Meningeal, recurrent. & Sensation. & Inferior maxillary. & Dura and mastoid cells. & Filaments. \\
\hline Mental. & Motion and sensation. & Inferior maxillary. & $\begin{array}{l}\text { Mucous membrane of } \\
\text { lower lip and chin. }\end{array}$ & Filaments. \\
\hline $\begin{array}{l}\text { Motor oculi (third cra- } \\
\text { nial). }\end{array}$ & Motion. & $\begin{array}{l}\text { Floor of aqueduct of } \\
\text { Sylvius. }\end{array}$ & $\begin{array}{l}\text { All muscles of the eye, ex- } \\
\text { cept external rectus, su- } \\
\text { perior oblique, and orbic- } \\
\text { ularis palpebrarum. }\end{array}$ & Filaments. \\
\hline Muscular. & Motion and sensation. & $\begin{array}{l}\text { First and second cer- } \\
\text { vical. }\end{array}$ & $\begin{array}{l}\text { Rec, cap. lat., rec. anterior } \\
\text { major et minor. }\end{array}$ & Filaments. \\
\hline Muscular. & Motion and sensation. & Cervical plexus. & $\begin{array}{l}\text { Sterno-mastoid, lev. ang. } \\
\text { scap., seal. med., trapez. }\end{array}$ & Filaments. \\
\hline
\end{tabular}


TABLE OF NERVES.-Continued.

\begin{tabular}{|c|c|c|c|c|}
\hline NAME. & FUNCTION. & ORIGIN. & DISTRIBUTION. & BRANCHES. \\
\hline Muscular. & Motion. & Brachial plexus. & $\begin{array}{l}\text { Longus colli, scalen i, } \\
\text { rhomboidei, subclavius. }\end{array}$ & Filaments. \\
\hline Muscular. & Motion. & Musculo-spiral. & $\begin{array}{l}\text { Triceps, anconeus, sup- } \\
\text { inat. long., extens. carpi } \\
\text { rad. long., brach. antic. }\end{array}$ & $\begin{array}{l}\text { Internal, posterior, ex. } \\
\text { ternal. }\end{array}$ \\
\hline Muscular. & Motion. & Median. & $\begin{array}{l}\text { Superficial muscles of fore- } \\
\text { arm. }\end{array}$ & Filaments. \\
\hline Muscular. & Motion. & Ulnar. & $\begin{array}{l}\text { Flexor carpi ulnaris, flexor } \\
\text { profundus digitorum. }\end{array}$ & Two branches. \\
\hline Muscular. & Motion. & Great sciatic. & $\begin{array}{l}\text { Biceps, semimembranosus, } \\
\text { semitendinosus, adduc- } \\
\text { tor magnus. }\end{array}$ & Filaments. \\
\hline Muscular. & Motion. & Sacral plexus. & $\begin{array}{l}\text { Pyriformis, obturator int., } \\
\text { gemelli, quad, femoris. }\end{array}$ & Filaments. \\
\hline Muscular. & Motion. & Anterior crural. & $\begin{array}{l}\text { Pectineus and muscles of } \\
\text { thigh. }\end{array}$ & Filaments. \\
\hline Musculo-cutaneous. & Motion and sensation. & Brachial plexus. & $\begin{array}{c}\text { Coraco-brach., biceps, } \\
\text { brach. anticus, forearm. }\end{array}$ & Anterior and posterior. \\
\hline Musculo-cutaneous. & Motion and sensation. & External popliteal. & $\begin{array}{l}\text { Muscles of fibular side of } \\
\text { leg, skin of dorsum of foot. }\end{array}$ & Internal, external. \\
\hline Musculo-spiral. & Motion and sensation. & Brachial plexus. & $\begin{array}{l}\text { Back of arm and forearm, } \\
\text { skin of back of hand. }\end{array}$ & $\begin{array}{l}\text { Musculo-cutaneous, radial, } \\
\text { posterior interosseous. }\end{array}$ \\
\hline Mylo-hyoid. & Motion. & Inferior maxillary. & $\begin{array}{l}\text { Mylo-hyoid and digastric } \\
\text { muscles. }\end{array}$ & Filaments. \\
\hline Nasal. & Sensation. & Dental, anterior. & $\begin{array}{l}\text { Mucous membrane of } \\
\text { inferior meatus. }\end{array}$ & Filaments. \\
\hline Nasal. & Sensation. & Maxillary, superior. & $\begin{array}{l}\text { Integument of lateral as- } \\
\text { pect of nose. }\end{array}$ & Filaments. \\
\hline Nasal. & Sensation. & Ophthalmic. & Iris, ciliary ganglion, nose. & $\begin{array}{l}\text { Ganglionic, ciliary, infra- } \\
\text { trochlear. }\end{array}$ \\
\hline Nasal, inferior. & Sensation. & Anterior palatine. & Mucous membrane of nose. & Filaments. \\
\hline Nasal, superior. & Sensation. & Meckel's ganglion. & $\begin{array}{l}\text { Mucous membrane of nose } \\
\text { and post. ethmoid cells. }\end{array}$ & Filaments. \\
\hline $\begin{array}{l}\text { Naso-palatine (of Cotun- } \\
\text { nius). }\end{array}$ & Sensation. & Meckel's ganglion. & Nasal septum. & Filaments. \\
\hline Obturator. & Motion and sensation. & $\begin{array}{l}\text { Lumbar plexus, third } \\
\text { and fourth nerves. }\end{array}$ & $\begin{array}{l}\text { Obturator externus, ad- } \\
\text { ductors, joint and skin. }\end{array}$ & $\begin{array}{l}\text { Ant and post. articulating } \\
\text { and communicating. }\end{array}$ \\
\hline Obturator (accessory). & Motion and sensation. & Lumbar plexus. & Pectineus and hip-joint. & Filaments. \\
\hline Occipital, smallest or $3 d$. & Sensation. & Third cervical. & Integument of occiput. & Filaments. \\
\hline $\begin{array}{l}\text { Occipitalis, lesser or } \\
\text { minor. }\end{array}$ & Sensation. & Second cervical. & Occipito-frontalis, ear, etc. & $\begin{array}{l}\text { Communicating, auricular, } \\
\text { filaments. }\end{array}$ \\
\hline Occipitalis magnus. & Motion and sensation. & Second cervical. & Complexus, trap. and scalp. & Filaments. \\
\hline Oculo-motor. & See Motor oculi. & & & \\
\hline$\overline{\text { Olfactory (first cranial). }}$ & Smell. & $\begin{array}{l}\text { Frontal lobe, optic } \\
\text { thalamus and insula. }\end{array}$ & $\begin{array}{l}\text { Schneiderian membrane } \\
\text { of nose. }\end{array}$ & Twenty branches. \\
\hline Ophthalmic. & Sensation. & Trigeminus. & Forehead, eyes, nose. & Frontal, lacrymal, nasal. \\
\hline Optic (second cranial). & Sight. & $\begin{array}{l}\text { Cortical center in oc- } \\
\text { cipital lobe. }\end{array}$ & Retina. & None. \\
\hline Orbital. & Sensation. & Meckel's ganglion. & $\begin{array}{l}\text { Mucosa of posterior } \\
\text { ethmoid cells, and } \\
\text { sphenoid sinus. }\end{array}$ & Filaments. \\
\hline Orbital. & Sensation. & Superior maxillary. & Temple and cheek. & Temporal and malar. \\
\hline Orbito-temporal. & See Orbital (of supe & rior maxillary). & & \\
\hline $\begin{array}{l}\text { Palatine, anterior or } \\
\text { great. }\end{array}$ & Sensation. & Meckel's ganglion. & $\begin{array}{l}\text { Hard palate, gums and } \\
\text { nose. }\end{array}$ & Two inferior nasal. \\
\hline Palatine, external. & Serisation. & Meckel's ganglion. & Tonsil and soft palate. & Filaments. \\
\hline $\begin{array}{l}\text { Palatine, posterior or } \\
\text { small. }\end{array}$ & Motor. & Meckel's ganglion. & $\begin{array}{l}\text { Levator palati and azygos } \\
\text { uvula. }\end{array}$ & Filaments. \\
\hline Palmar cutaneous. & Sensation. & Median. & Thumb and palm. & Outer and inner. \\
\hline
\end{tabular}


TABLE OF NERVES. -Continued.

\begin{tabular}{|c|c|c|c|c|}
\hline NAME. & FunCtION. & ORIGIN. & Distribution. & BRANCHES. \\
\hline Paimar (deep). & Motion. & Ulnar. & $\begin{array}{l}\text { Little finger, dorsal and } \\
\text { palmar interosseous, two } \\
\text { inner lumbricales, ab- } \\
\text { ductor pollicis. }\end{array}$ & Filaments. \\
\hline Palmar (superficial). & Sensation and motion. & UInar. & $\begin{array}{l}\text { Palmaris brevis, in } n \text { er } \\
\text { side of hand and little } \\
\text { finger. }\end{array}$ & $\begin{array}{l}\text { Filaments and two digital } \\
\text { branches. }\end{array}$ \\
\hline Palpebral. & Motor. & Superior maxillary. & Integument of lower lid. & Filaments. \\
\hline Parotid. & Sensation. & Auriculo-temporal. & Parotid gland. & Filaments. \\
\hline Patellar. & Sensation. & Long saphenous. & $\begin{array}{l}\text { Integument over patella } \\
\text { and plexus patella. }\end{array}$ & Filaments. \\
\hline Patheticus (4th cranial). & Motion. & Valve of Vieussens. & Superior oblique of eye. & None. \\
\hline Pectineus. & Motion. & Anterior crural. & Pectineus muscle. & Filaments. \\
\hline Perforating (of Casser). & See Musculo-cuta & neous. & & \\
\hline Perineal. & Motion and sensation. & Pudic. & $\begin{array}{l}\text { Perineum, genitalia and } \\
\text { skin of perineal region. }\end{array}$ & Cutaneous and muscular. \\
\hline Perineal. & Motion and sensation. & Fourth sacral. & $\begin{array}{l}\text { External sphincter ani } \\
\text { and integument of anus. }\end{array}$ & Filaments. \\
\hline Petrosals. & Motion. & Facial. & Ganglia and plexus. & $\begin{array}{l}\text { Great, small, external to } \\
\text { Meckel's ganglion, otic } \\
\text { ganglion, and meningeal } \\
\text { plexus, respectively. }\end{array}$ \\
\hline Pharyngeal. & Motion and sensation. & Glosso-pharyngeal. & Pharynx. & $\begin{array}{l}\text { Enters into formation of } \\
\text { pharyngeal plexus. }\end{array}$ \\
\hline Pharyngeal. & Sensation. & Meckel's ganglion. & $\begin{array}{l}\text { Upper part of phary } \mathbf{n} \mathbf{x}_{\text {, }} \\
\text { posterior nares and } \\
\text { sphenoid sinus. }\end{array}$ & Filaments. \\
\hline Pharyngeal. & Motion. & Vagus. & Pharynx. & $\begin{array}{l}\text { Pharyngeal plexus, mus- } \\
\text { cles and mucosa. }\end{array}$ \\
\hline Pharyngeal. & Sensation. & Sympathetic. & Pharynx. & $\begin{array}{l}\text { Helps to form the pharyn- } \\
\text { geal plexus. }\end{array}$ \\
\hline Phrenic. & Motion and sensation. & $\begin{array}{l}\text { Third, fourth, and fifth } \\
\text { cervical. }\end{array}$ & $\begin{array}{l}\text { Diaphragm, pericardium, } \\
\text { pleura. }\end{array}$ & Filaments. \\
\hline Plantar (external). & Motion and sensation. & Posterior tibial. & $\begin{array}{l}\text { Little toe and deep mus- } \\
\text { cles of foot. }\end{array}$ & Superficial and deep. \\
\hline Plantar (internal). & Sensation and motion. & Posterior tibial. & $\begin{array}{l}\text { Sole of foot, adduct. pol- } \\
\text { lic., flexor brev. dig., toes. }\end{array}$ & $\begin{array}{l}\text { Cutaneous, muscular, } \\
\text { articular, digital. }\end{array}$ \\
\hline $\begin{array}{l}\text { Pneumogastric ( } \mathrm{ten} \mathbf{t} \mathbf{h} \\
\text { cranial, "par vagum"). }\end{array}$ & Sensation and motion. & $\begin{array}{l}\text { Floor of fourth ven- } \\
\text { tricle. }\end{array}$ & $\begin{array}{l}\text { Ear, phary ix, larynx, } \\
\text { heart, lungs, esophagus, } \\
\text { stomach. }\end{array}$ & $\begin{array}{l}\text { Auricular, pharyngeal, } \\
\text { s uperior and inferior } \\
\text { laryngeal, recurrent la- } \\
\text { ryngeal, cardiac, pul- } \\
\text { monary, esophageal, gas- } \\
\text { tric, hepatic, communi- } \\
\text { cating, meningeal. }\end{array}$ \\
\hline Popliteal (external). & Sensation and motion. & Great sciatic. & $\begin{array}{l}\text { Extensors of foot, skin, } \\
\text { and fascia. }\end{array}$ & $\begin{array}{l}\text { Anterior tibial, musculo- } \\
\text { cutan eous, articular, } \\
\text { cutaneous. }\end{array}$ \\
\hline Popliteal (internal). & Motion and sensation. & Great sciatic. & $\begin{array}{l}\text { Knee, gastrocnemius, tibi- } \\
\text { alis posticus, plantaris, } \\
\text { soleus, popliteus, skin of } \\
\text { foot. }\end{array}$ & $\begin{array}{l}\text { Articular, muscular, cuta- } \\
\text { neous, external saphen- } \\
\text { ous, plantar, external or } \\
\text { short saphenous. }\end{array}$ \\
\hline Pterygoid, external. & Motion. & Inferior maxillary. & External pterygoid muscle. & Filaments. \\
\hline Pterygoid, internal. & Motion. & Inferior maxillary. & Internal pterygoid muscle. & Filaments. \\
\hline $\begin{array}{l}\text { Pudendal, long (nerve of } \\
\text { Sommering). }\end{array}$ & Sensation. & Small sciatic. & $\begin{array}{l}\text { Integument of genitalia } \\
\text { and inner and proximal } \\
\text { part of thigh. }\end{array}$ & Filaments. \\
\hline Pudic. & Motion and sensation. & Sacral plexus. & Perineum, anus, genitalia. & $\begin{array}{l}\text { Inferior hemorrhoidal, peri- } \\
\text { neal, cutaneous, dorsal of } \\
\text { penis. }\end{array}$ \\
\hline $\begin{array}{l}\text { Pulmonary (anterior } \\
\text { and posterior). }\end{array}$ & (?). & Vagus. & Lungs. & $\begin{array}{l}\text { Branches to pulmonary } \\
\text { plexuses. }\end{array}$ \\
\hline
\end{tabular}


TABLE OF NERVES.-Continued.

\begin{tabular}{|c|c|c|c|c|}
\hline NAME. & Function. & ORIGIN. & DISTRIBUTION. & BRANCHES. \\
\hline Radial. & Sensation. & Musculo-cutaneous. & Thumb and three fingers. & External and internal. \\
\hline Sacral (five). & Motion and sensation. & Cord. & $\begin{array}{l}\text { Multifidus spinæ, skin, } \\
\text { gluteal region. }\end{array}$ & $\begin{array}{l}\text { Filaments and sacral } \\
\text { plexus. }\end{array}$ \\
\hline $\begin{array}{l}\text { Saphenous (external or } \\
\text { short). }\end{array}$ & Sensation. & Internal popliteal. & $\begin{array}{l}\text { Integument of foot and } \\
\text { little toe. }\end{array}$ & Filaments. \\
\hline $\begin{array}{l}\text { Saphenous (long or in- } \\
\text { ternal). }\end{array}$ & Sensation. & Anterior crural. & Knee, ankle. & $\begin{array}{l}\text { Cutaneous, patellar, com } \\
\text { municating, filaments. }\end{array}$ \\
\hline Of Scarpa. & See Naso-palatine. & & & \\
\hline Sciatic (great). & Motion and sensation. & Sacral plexus. & $\begin{array}{l}\text { Skin of leg, muscles of } \\
\text { back of thigh and those } \\
\text { of leg and foot. }\end{array}$ & $\begin{array}{l}\text { Articular, muscular, pop- } \\
\text { liteals. }\end{array}$ \\
\hline Sciatic (small). & Sensation and motion. & Sacral plexus. & $\begin{array}{l}\text { Perineum, back of thigh } \\
\text { and leg, gluteus maximus. }\end{array}$ & $\begin{array}{l}\text { Muscular, cutaneous, long } \\
\text { pudendal. }\end{array}$ \\
\hline Septal. & Sensation. & Meckel's ganglion. & Back part of nasal septum. & Filaments. \\
\hline Of Scmmering. & See Pudendal, Long. & & & \\
\hline Spheno-palatine. & Sensation. & Superior maxillary. & Meckel's ganglion. & See Ganglion. \\
\hline Spinal. & Motion and sensation. & Spinal cord. & Trunk. & Filaments. \\
\hline $\begin{array}{l}\text { Spinal accessory } \\
\text { (eleventh cranial). }\end{array}$ & Motion. & $\begin{array}{l}\text { Floor of fourth ventri- } \\
\text { cle. }\end{array}$ & $\begin{array}{l}\text { Sterno-cleido }-\mathrm{m} \text { as toi } \mathrm{d} \\
\text { trapezius. }\end{array}$ & Filaments. \\
\hline Splanchnic (great). & Sympathetic. & Thoracic ganglia. & $\begin{array}{r}\text { Semilunar ganglion, renal } \\
\text { and supra-renal plexuses. }\end{array}$ & $\begin{array}{l}\text { Communicating and fila- } \\
\text { ments. }\end{array}$ \\
\hline Splanchnic (lesser). & Sympathetic. & $\begin{array}{l}\text { Tenth and eleventh } \\
\text { thor a cic ganglia, } \\
\text { great splanchnic. }\end{array}$ & $\begin{array}{l}\text { Celiac plexus and great } \\
\text { splanchnic. }\end{array}$ & $\begin{array}{l}\text { Communicating and fila- } \\
\text { ments. }\end{array}$ \\
\hline $\begin{array}{l}\text { Splanchnic (renal or } \\
\text { smallest). }\end{array}$ & Sympathetic. & Last thoracic ganglion. & Renal and celiac plexus. & $\begin{array}{l}\text { Communicating and fila- } \\
\text { ments. }\end{array}$ \\
\hline Stapedial. & Motion. & Facial. & Stapedius muscle. & Filaments. \\
\hline Stylo-hyoid. & Motion. & Facial. & Stylo-hyoid muscle. & Filaments. \\
\hline Subscapular (three). & Motion. & Brachial plexus. & $\begin{array}{l}\text { Subscapular, teres major, } \\
\text { and latissimus dorsi. }\end{array}$ & Filaments. \\
\hline Supra-acromial. & Sensation. & Cervical plexus. & Skin over deltoid. & Filaments. \\
\hline $\begin{array}{l}\text { Supra-clavicular (de- } \\
\text { scending). }\end{array}$ & Sensation. & $\begin{array}{l}\text { Third and fourth cer- } \\
\text { vical. }\end{array}$ & $\begin{array}{l}\text { Skin of neck, breast and } \\
\text { shoulder. }\end{array}$ & $\begin{array}{l}\text { Sternal, clavicular, acro- } \\
\text { mial. }\end{array}$ \\
\hline Supra-mandibular. & See Maxillary, supe & rior. & & \\
\hline Supra-maxillary. & See Maxillary, supe & rior. & & \\
\hline Supra-orbital. & Sensation. & Ophthalmic. & Upper lid, forehead. & $\begin{array}{l}\text { Muscular, cutaneous and } \\
\text { pericranial branches. }\end{array}$ \\
\hline Supra-scapular. & Motion and sensation. & Brachial plexus. & Scapular muscles. & Filaments. \\
\hline Supra-sternal. & Sensation. & Cervical plexus. & $\begin{array}{l}\text { Integument over upper } \\
\text { part of sternum. }\end{array}$ & Filaments. \\
\hline Supra-trochlear. & Sensation. & Ophthalmic. & Forehead and upper eyelid. & Muscular and cutaneous. \\
\hline Sympathetic. & See Sympathetic, Gan & glion, and Plexus. & & \\
\hline Temporal. & Motion. & Inferior maxillary. & Temporal muscle. & Filaments. \\
\hline Temporal. & Sensation. & Orbital. & $\begin{array}{l}\text { Integument over temporal } \\
\text { muscle. }\end{array}$ & Filaments. \\
\hline Temporal. & Motion. & Temporo-facial. & $\begin{array}{l}\text { Orbicularis palpebrarum, } \\
\text { occipito-frontalis, attra- } \\
\text { hens and attollens aurem, } \\
\text { corrugator supercilii. }\end{array}$ & Muscular. \\
\hline Temporal, superficial. & Sensation. & Auriculo-temporal. & $\begin{array}{l}\text { Integument over temporal } \\
\text { fascia. }\end{array}$ & Filaments. \\
\hline Temporo-facial. & Motion. & Facial. & Upper part of face. & $\begin{array}{l}\text { Temporal; malar, infra: } \\
\text { orbital. }\end{array}$ \\
\hline Temporo-malar. & See Orbital. & & & \\
\hline
\end{tabular}


TABLE OF NERVES,-Continusd.

\begin{tabular}{|c|c|c|c|c|}
\hline NAME. & FUNCTION. & ORIGIN. & DISTRIBUTION. & BRANCHES. \\
\hline $\begin{array}{l}\text { Thoracic (posterior or } \\
\text { long). External respi- } \\
\text { ratory nerve of Bell. }\end{array}$ & Motion. & Brachial plexus. & Serratus magnus. & Filaments. \\
\hline Thoracic, spinal. & Motion and sensation. & Cord. & Muscles of skin of thorax. & Filaments. \\
\hline Thoracics (ant. and ext.). & Motion. & Brachial plexus. & Pectoralis major et minor. & Filaments. \\
\hline Tibial (anterior). & Motion and sensation. & External popliteal. & $\begin{array}{l}\text { Tibialis antic., extensor } \\
\text { long. digit., peroneus ter., } \\
\text { joints of foot, skin of } \\
\text { great toe. }\end{array}$ & $\begin{array}{l}\text { Muscular, external, inter- } \\
\text { nal. }\end{array}$ \\
\hline Tibial (posterior). & Motion and sensation. & Internal popliteal. & $\begin{array}{l}\text { Tibialis post., flexor long. } \\
\text { digit, flexorlong. pollic., } \\
\text { skin of heel and sole, } \\
\text { knee-joint. }\end{array}$ & $\begin{array}{l}\text { Plantars, muscular, cal. } \\
\text { caneo-plantar, cutaneous } \\
\text { or internal calcanean, ar- } \\
\text { ticular. }\end{array}$ \\
\hline Tonsillar. & Sensation. & Glosso-pharyngeal. & $\begin{array}{l}\text { Tonsil, soft palate, and } \\
\text { fauces. }\end{array}$ & Filaments. \\
\hline $\begin{array}{l}\text { Trigeminus or trifacial } \\
\text { (fifth cranial). }\end{array}$ & $\begin{array}{l}\text { Motion and sensation } \\
\text { (taste). }\end{array}$ & $\begin{array}{l}\text { Medulla and floor of } \\
\text { fourth ventricle. }\end{array}$ & $\begin{array}{l}\text { Skin and structures of } \\
\text { face, tongue and teeth. }\end{array}$ & $\begin{array}{l}\text { Ophthalmic, superior and } \\
\text { inferior max. divisions. }\end{array}$ \\
\hline Trochlear. & See Patheticus. & & & \\
\hline Tympanic. & Motion. & Facial. & $\begin{array}{l}\text { Stapedius and laxat or } \\
\text { tympani muscles. }\end{array}$ & Filaments. \\
\hline Tympanic: & Sensation. & Sympathetic. & Tympanum. & Filaments. \\
\hline $\begin{array}{l}\text { Tympanic (Jacobson's } \\
\text { nerve). }\end{array}$ & Motion. & Glosso-pharyngeal. & Tympanum. & $\begin{array}{c}\text { Tympanic plexus, commu= } \\
\text { nicating, and filaments. }\end{array}$ \\
\hline Ulnar. & Motion and sensation. & Brachial plexus. & $\begin{array}{l}\text { Muscles, shoulder-joint } \\
\text { and wrist-joint, and skin } \\
\text { of little finger. }\end{array}$ & $\begin{array}{l}\text { Two articular, muscular, } \\
\text { palmar cutaneous, dor } \\
\text { sal, superior palmar, deep } \\
\text { palmar. }\end{array}$ \\
\hline Vagus. & See Pneumogastric. & & & \\
\hline Vestibular. & Sensation. & Auditory. & $\begin{array}{l}\text { Utricle and ampullie of } \\
\text { the semicircular canals. }\end{array}$ & Filaments. \\
\hline Vidian. & Sensation. & $\begin{array}{l}\text { Union of large super- } \\
\text { ficial and deep petro- } \\
\text { sal. }\end{array}$ & $\begin{array}{l}\text { Spheno-maxillary fossa, } \\
\text { and posterior part of } \\
\text { upper nasal meatus. }\end{array}$ & Filaments, nasal. \\
\hline Of Willis. & See Spinal accessory. & & & \\
\hline Wrisberg's. & See Cutaneous, lesser & internal. & & \\
\hline
\end{tabular}

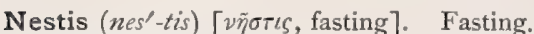

Nestitherapy (nes-tith-er'-ap-e). See Nestiatria.

Nestle's Food. A variety of milk-food for infants. Its composition is: Water, 4.72 ; fat, I.9I ; grapesugar and milk-sugar, 6.02 ; cane-sugar, 32.93 ; starch, 40.10; soluble carbohydrates, 44.88 ; albuminoids, 8.23 ; ash, 1.59

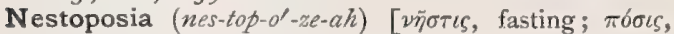
drinking]. Drinking on an empty stomach.

Net [ME., net, net]. A reticulation or cancellation; a web or mesh; a rete; anything formed with interstices or meshes, like a net. N., Bathygraphic, or N., Bathographic Zone, a deep-sea closable net employed in the study of the many different faunal belts overlying one another in the great deep-sea zones, designed by Palumbo, Petersen, Chun, etc. N., Müller's, the "fine pelagic net" of Johannes Müller, a round bag of Muiller gauze or silk mull, the mouth of which is kept open by a circular metallic ring. In ordinary pelagic fishing this ring is fastened to a handle from six to twelve feet long (like the ordinary butterfly net). While the boat moves along the opening of this net is held at the surface in such a way that swimming animals are caught in the bag, in the bottom of which they remain hanging, while the water passes through the narrow meshes of the net. After a time the net is carefully inverted and the tow-stuff (Auftrieb) is emptied into a glass vessel filled with sea-water. If one wishes to fish below the surface, the ring of the net is fastened by means of three strings equally distant from one another, which at a point (about three feet from the opening of the net) are joined to a longer line which is sunk by weights to a definite distance corresponding to the desired depth. (E. Hackel.) N., Palumbo's. See $N_{\text {., Bathygra. }}$ phic. N.-work, the arrangement of fibers in a reticulum. Network, Gerlach's, a network of processes of nerve-cells found in the gray matter of the spinal cord. Network, Haller's, the rete testis.

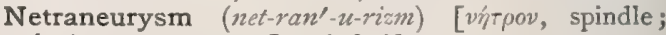

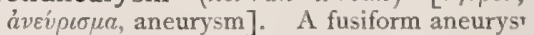

Nettle $\left(\right.$ net' $\left.^{\prime}-l\right)$ [ME., nettle, nettle]. The root of Urtica dioica, the common stinging-nettle, common domestic remedy for renal complaints and hemorrhages. It is astringent, diuretic, and antiscorbutic. Dose of the fld. ext. $m \times x x-x l$. Unof. N.-fever, urticaria, $q . v$. N.-fiber, one of the bast-fibers of the common nettle (Urtica dioica). When cleaned these fibers are soft, of good length and strength, and quite lustrous and white. N.-rash. See Urticaria. 


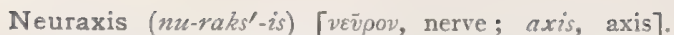
The neural axis; neuron.

Neure (nūr) [veṽ $\rho \circ v$, nerve]. A nerve-cell including all its processes.

Neurectasis, Neurectasy (nu-rek'-tas-is, nu-rek'.

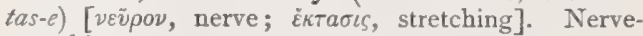
stretching.

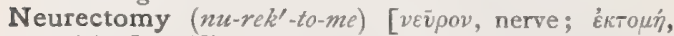
excision]. The operation of excising part of a nerve.

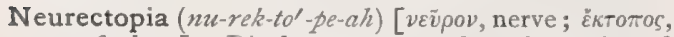
out of place]. Displacement, or other abnormity of the distribution of a nerve

Neuremia (nu-re'-me-ah) [veṽpov, nerve; ai $\mu a$, blood]. A purely functional nervous disorder.

Neurempodism (nu-rem'-po-dizm) [veṽpov, nerve; $\dot{\varepsilon} \mu \pi \sigma \delta \iota \sigma \sigma_{\varsigma}$, hindrance]. Interference with nervous action.

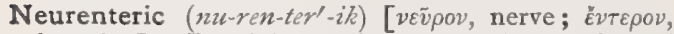
intestine]. Pertaining to the embryonic neural canal and the intestinal tube. N. Canal, the temporary communication existing between the neural canal and the intestinal tube in Tunicates and Vertebrates. It was discovered by Kowalevsky in Ascidians and Amphioxus, and is called also Kowalersky's Canal. See Canal.

Neurepithelium (nu-rep-ith-e'-le-um). See Neuroepithelium.

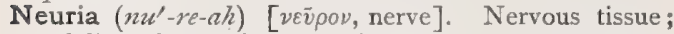
a delicate layer of nerve-substance.

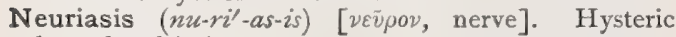
hypochondriasis.

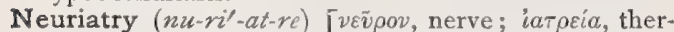
apy]. The study and treatment of nervous diseases.

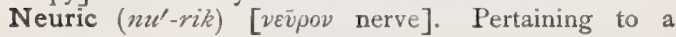
nerve or to nerves.

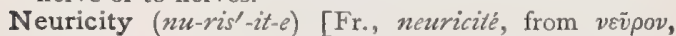
nerve]. Nerve-force; nervous quality, or function.

Neuridin (nu'-rid-in) [veṽoov, a nerve], $\mathrm{C}_{5} \mathrm{H}_{14} \mathrm{~N}_{2}$. A ptomain, the first diamin isolated from animal tissues by Brieger in I884. It is one of the most common products of putrefaction; it has been obtained from putrid human flesh, horseflesh, fish, gelatin and cheese. It can be obtained in the preparation of cholin by heating fresh eggs with baryta, and by heating fresh brain with a two per cent. solution of hydrochloric acid. It is almost invariably associated with cholin in the process of putrefaction; according to the duration of putrefaction, the amount of cholin decreases, with a corresponding increase in the amount of trimethylamin, while the amount of neuridin increases in quantity according to the nature of the decomposing organ. The greatest yield is from gelatinous tissue, such as the intestines; tissues like those of the liver and spleen yield little. Neuridin is isomeric with cadaverin. The free base has an excessively repulsive seminal odor. It is soluble in water, but not in ether and alcohol. Pure neuridin is not poisonous, but when mixed with the products of putrefaction, it has a toxic effect like peptotoxin. This holds true of other non-poisonous bases. See Ptomains, Table of.

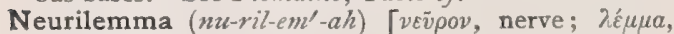
bark]. The sheath encasing a nerve-fiber; the sheath of Schwann. See Nerve-fiber.

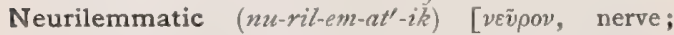
$\lambda \varepsilon$ éua, bark]. Pertaining to the neurilemma.

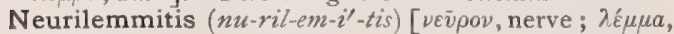
bark; $\iota \tau \iota s$, inflammation ]. Inflammation of the neurilemma.

Neurility (nu-ril"-it-e) [Fr. nevrilite, from vev̈pov, nerve]. The stimulus or power possessed by a nervefiber to cause contraction of a muscle ; neuricity.
Neurilyma (nu-ril-i'-mah). Synonym of Neurilcmma.

Neurin (nu'-rin) [veṽ oov, nerve]. 1. The albuminous basis forming the substance of nerve-tissue. 2. $\mathrm{C}_{5}$ $\mathrm{H}_{13} \mathrm{NO}$; a toxic body, one of the ptomains, the product of decomposition of protagon by caustic baryta. It is a syrupy fluid, with a strongly alkaline reaction, and is extremely soluble in water. See Ptomains, Table of. 3. An extract of nerve-tissue employed therapeutically. See Organotherasy.

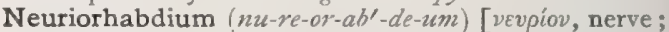
pá $\beta \delta\llcorner o v, \operatorname{rod} ;$ pl. Neuriorhabdia $]$. Any one of the rods of the rod-and-cone layer of the retina.

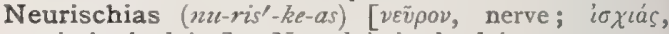
pain in the loins]. Neuralgia in the loins.

Neurism (nu'-rizm) [veṽpov, nerve]. I. Nerve-force; neurility; neuricity. 2. Nervousness.

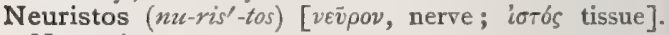
Nerve-tissue.

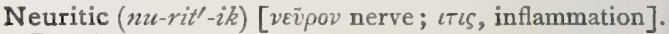
Pertaining to neuritis.

Neuritides (nu-rit-i'-dez). Same as Neuroses.

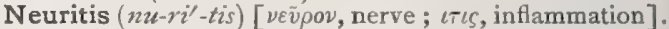
Inflammation of a nerve, especially of a nerve-trunk. The nerve-structure itself is said to be little subject to inflammation, which is usually confined to the coverings, and therefore the condition is more properly termed perineuritis. N., Acute, an acute inflammation of a nerve. N., Adventitial, inflammation affecting especially the connective-tissue sheath of a nerve. N., Alcoholic. See N., Multiple, and Polyneuritis potatorum. N., Ascending, inflammation extending from the periphery of a nerve centrad to the spinal cord or brain. N., Carcinomatous, infiltration of a nerve with carcinomatous tissue. N., Chronic, a form pursuing a protracted course, and with symptoms not actively manifested. N., Degenerative, neuritis in which the nerve-substance proper degenerates. It is the same as $N$., Parenchymatous. N., Descending, neuritis, the result of extension of disease from the spinal cord or the brain toward the periphery. N., Diabetic, a polyneuritis sometimes seen in diabetes, and probably the result of autointoxication with the products of faulty metabolism. N., Eichhorst's. See N. fascians. N., Endemic. A synonym of Beri-beri. N. fascians, that form of neuritis in which the change in the nerve-sheath appears to extend directly to the interstitial tissue of the muscles. It is also called Eichhorst's Neuritis. N., Interstitial, inflammation of the interstitial connective tissue of a nerve-trunk. N., Leprous, a neuritis or perineuritis due to the Bacillus leprae or a toxin produced by it. $\mathbf{N}$. Lipomatous, that form in which the nerve-fibers are completely destroyed and replaced by a fibrous connective tissue in which much fat is sometimes depos. ited. It is also called Leyden's Neuritis. N., Malarial, neuritis, sometimes multiple due to the malarial poison. N., Migrant, Migratory or Wandering, one that changes its position from place to place. N. Multiple, the simultaneous inflammation of several nerve-trunks, usually symmetrically situated on both sides of the body. Its most common cause is alcoholic poisoning ; it may be due to arsenic, malaria, mercury, lead; to diphtheria, pneumonia, typhoid fever, and other infectious diseases. Beri-beri is a form of mul. tiple neuritis. N., Optic, inflammation of the optic nerve. See Prpillitis. N., Parenchymatous, a form in which the medullary substance and the axiscylinders are chiefly involved, the interstitial tissue being but little altered or only affected secondarily. It is also called degenerative neuritis. N., Per ipheral, a form confined to the terminal filaments of nerves. N., Pressure, inflammation of a nerve as a 
result of compression. N., Pressure, Musculospiral, inflammation of the musculo-spiral nerve from pressure usually by the head on the arm rested upon a sharp edge during alcoholic intoxication. N., Rheumatic, that due to rheumatism. N., Terminal. See Erythromelalgia. N., Wandering. See $N$., Migrant.

Neuro- (nu'-ro-) [veṽ pov, nerve]. A prefix signifying connection with or relation to a nerve.

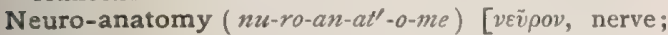
ává, apart: $\tau \varepsilon \dot{\varepsilon} \mu \varepsilon \iota \nu$, to cut]. The anatomy of the nervous system.

Neuroasthenia (nu-ro-as-the'-ne-ah). Same as Neurasthenia.

Neuroasthenic (nu-ro-as-then'-ik). Same as Neurasthenic.

Neuroblacia (nu-ro-bla-se'-ah) [veṽoov, nerve; $\beta \lambda a \kappa \varepsilon i \alpha$, dulness; $\beta \lambda a ́ \xi$, dull]. Paresis; obtundity of nervous sensibility.

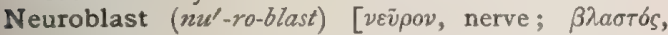
germ]. Any segmentation-sphere whose division gives origin to cells that belong to the nervous system exclusively; a mesodermal nerve-cell or ganglion-cell.

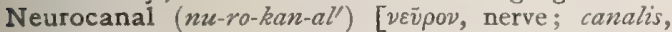
canal]. The central canal of the spinal axis.

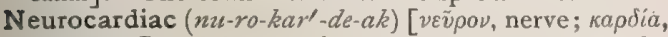
heart]. Pertaining to the nervous system and the heart. N.-c. Disease. Synonym of Exophthalmic Goiter.

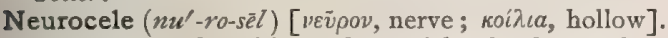
The system of cavities and ventricles in the cerebrospinal axis.

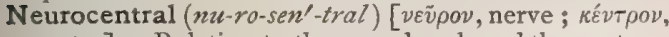
center]. Relating to the neural arch and the centrum of a vertebra.

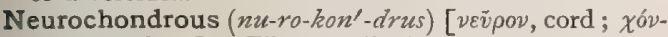
$\delta \rho \circ$, cartilage]. Fibro-cartilaginous.

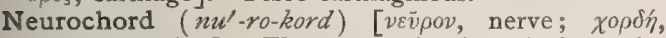
chord or string]. The nerve-chord. N. Strands, or Giant Nerve-tubes, tubes with a wide lumen and wall formed of neurilemma, which run back in varying but always small numbers on the dorsal side of the ventral chord of the Annulata and Thoracostraca.

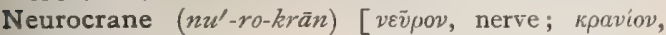
skull]. The brain-case, or cranial portion of the head.

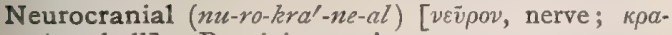
viov, skull]. Pertaining to the neurocrane.

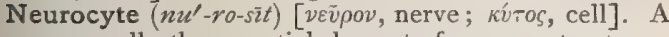
nerve-cell ; the essential element of nervous structures.

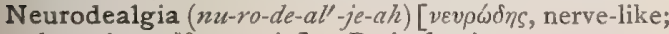
the retina; $a \lambda y o s$, pain]. Retinal pain.

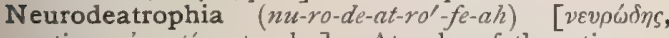
retina; árpoфía, atrophy]. Atrophy of the retina.

Neurodermatosis (nu-ro-der-mat-o'-sis) [vev̈pov, nerve; $\delta \varepsilon ́ \rho \mu \alpha$, skin; vóбos, disease]. A neurotic skin-affection.

Neurodermatrophia (nu-ro-der-mat-ro'-fe-ah) [vEṽ $\rho o v$,

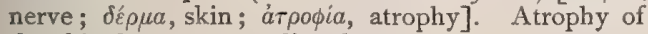
the skin from nervous disturbance.

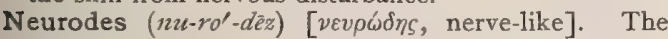
retina, as being made up of nerve-elements.

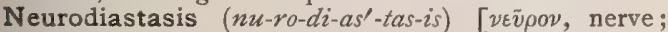

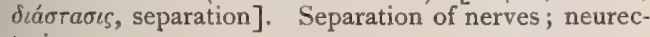
tasis.

Neurodictyitis (nu-ro-dik-te-i'-tis). Synonym of Neuroretinitis.

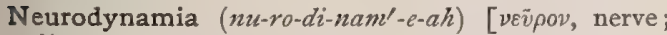
divauts, strength]. Nervous strength or energy.

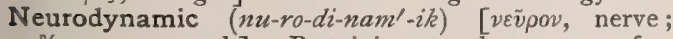
divvaus, strength]. Pertaining to the power of a nerve-current or of the nervous forces of the system.

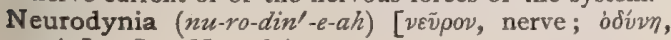
pain]. See Neuralgria.

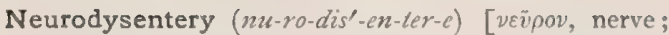

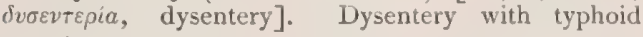
symptoms.

Neuro-enteric $\left(n u-r o-c n-t e r^{\prime}-i k\right)$. Same as Neur. enteric.

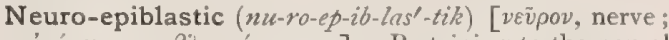

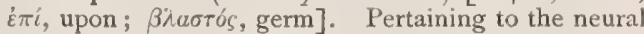
epiblast, $i, e$, that which enters into the formation of the nervous system.

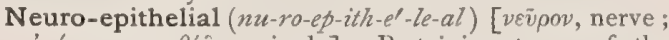
$\dot{\varepsilon} \pi \dot{i}$, upon; $\theta \dot{\prime} \lambda \eta$, nipple]. Pertaining to or of the nature of neuro-epithelium.

Neuro-epithelium $\left(n u-r o-e p-i t h-e^{\prime}-l e-u m\right)[\nu \varepsilon \tilde{v} \rho o v$, nerve; $\varepsilon \pi i$, upon; $\theta \dot{\eta} \lambda \eta$, nipple]. The retinal layer of rods and cones. In a wider sense, that part of any epithelial structure that contains nerve-endings is called by this name. See Epithelium.

Neurofibroma ( $\left.n u-r o-f i-b r o^{\prime}-m a h\right)$ [ veṽ $\rho \circ v$, nerve ; fibra, fiber; $0 \mu a$, tumor]. A tumor of the connective tissue of a nerve, composed of fibrous tissue.

Neurofrontal (nu-ro-frun'-tal) [veṽoov, nerve; frons, frontis, the forehead]. Pertaining to the brain and the frontal bone.

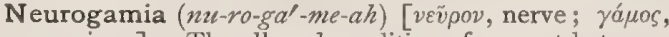
marriage]. The alleged condition of rapport between the animal magnetizer and the mesmerized person, or between the hypnotizer and the hypnotized.

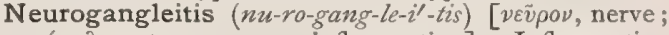
$\gamma a ́ \gamma \gamma \lambda \iota \nu$, tumor; $\iota \tau \iota \zeta$, inflammation]. Inflammation of a ganglion of the nervous system.

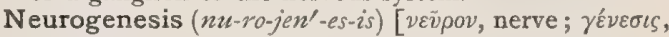
genesis]. The formation of nerves.

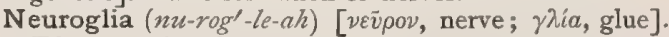
The reticulated framework or skeleton-work of the substance of the brain and spinal cord. The term is sometimes abbreviated to Glia.

Neurogliac, Neurogliar (nu-rog'-le-ak, nu-

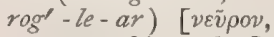
nerve; $\gamma \lambda i a$, glue $]$. Pertaining to or resembling neuroglia.

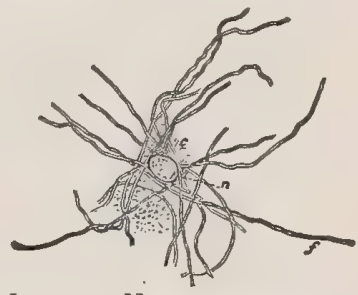

ISOLATED NEUROGLIA-CELL OF SPINAL CORD OF OX. euroglioma ( $n u$-ro- plasm: $f$. Fibers of neuroglia. gli-o'-mah) [veṽpov, (Stirling.)

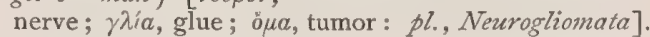
A tumor composed essentially of neurogliar elements ; glioma. N., Ganglionar, a tumor developing in the central nervous system and consisting of hyperplastic neuroglia, ganglion-cells, and nerve-fibers.

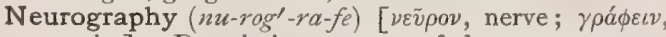
to write]. Descriptive anatomy of the nerves.

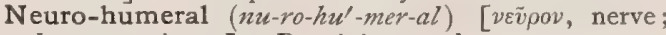
humor, moisture]. Pertaining to the nervous system and to the fluids of the body. N.-h. Theory. See Duckworth's Theory.

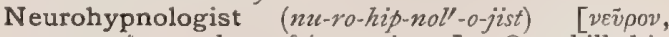

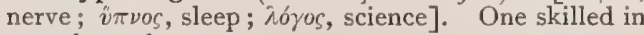
neurohypnology.

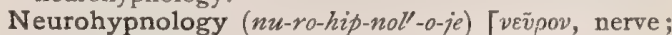

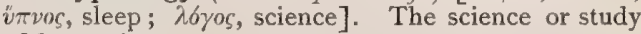
of hypnotism.

Neurohypnotism (nu-ro-hip'-not-izm). Synonym of Hypnotism.

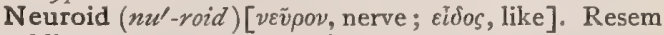
bling a nerve or nerve-substance.

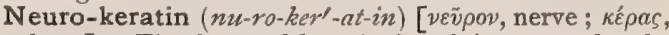
horn]. The form of keratin found in nerve-sheaths and the white substance of Schwann. See Keratin. 
Neurokinesis (nu-ro-kin-e'-sis). A synonym of Nervestretching:

Neurolemma (nu-ro-lem'-ah). Synonym of Retina.

Neurolemmatitis (nu-ro-lem-at-i'tis). A synonym of Retiniti.

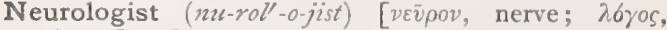
science ]. One versed in neurology.

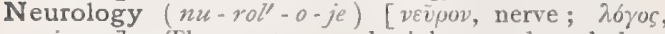
science]. The anatomy, physiology and pathology of the nervous system.

Neurolymph (nu'-ro-limf) [veĩoov, nerve; $\lambda \dot{v} \mu \delta \alpha$, lymph]. The cerebro-spinal fluid.

Neurolysis (nu-rol'-is-is) [veṽpov, nerve; $\lambda$ v́ous a loosing]. I. Relaxation of a nerve. 2. A change in the relation of nerves following the operation of nervestretching.

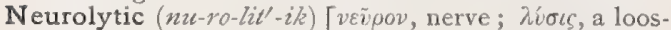
ing]. Pertaining to neurolysis.

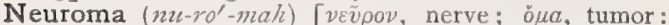
pl., Neuromata]. A tumor of or on a nerve. Most neuromata are really fibromata. N., Amputation, the neuroma of a stump, forming at the end of a divided nerve. N., Amyelinic, a neuroma made up of nonmedullated nerve-fibers. N., Cellular. See $N$., Ganglionic. $\mathbf{N}$. cutis, a tumor of the skin, resembling a myoma, and consisting mainly of firm connective tissue, originating from the neurilemma. It is pathologically considered as a fibro-neuro-myoma. N., Diffuse, a condition characterized by the existence of multiple neuromatous tumors. N., False, a fibromatous tumor forming on a nerve. N., Ganglionic, N., Ganglionated, a neuroma made up of nerve-cells. N., Gliomatous. Synonym of Neurogtiona. N., Medullated, one made up of medullated nerve-fibers. N., Myelinic. Synonym of N., Medullated. N., Myxomatous, a tumor composed of nervous and myxomatous tissues. N., Peripheral, N., Peripheric, one formed near the peripheral termination of a nerve. $\mathbf{N}$., Plexiform, the development of multiple fibromatous tumors along the course of one or more nerves. There is in these cases, however, some hyperplasia of the nerve-fibers, constituting a true neuroma

Neuromalacia, Neuromalaxis (nu-ro-mal-a'-se-ah,

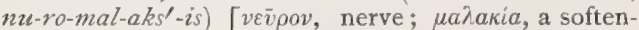
ing]. A softening of nerve-tissue

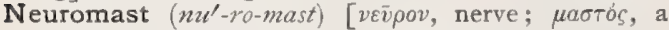
hillock]. In biology, R. Ramsay Wright's term for the "nerve-hillock" and other sense-organs of the same character, whatever their shape ; any neuro-epithelial sense-organ. This name is seldom given to the sense-organs of man, or of the higher vertebrate animals.

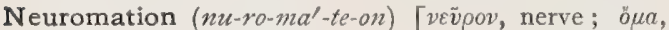
tumor; dim. of neuroma]. A small neuromatous tumor.

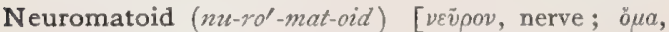
tumor; $\varepsilon i \delta o s$, like]. Resembling a neuroma.

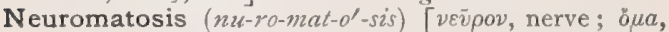

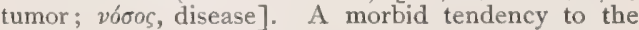
formation of neuromata.

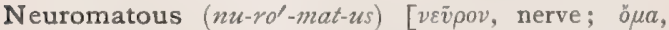
tumor]. Of the nature of a neuroma.

Neuromeninx (nu-ro-men'-inks) [veṽpon, nerve; $\mu \bar{\eta} v \gamma \xi$, a membrane]. A nervous expansion, such as the retina.

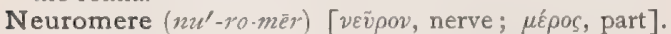
A natural segment of the neuron.

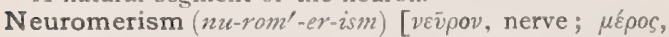
a part]. In biology, neural segmentation.

Neurometabolic (nu-ro-met-ab-ol'-ik) [veṽpov, nerve; $\mu \varepsilon т а \beta о \lambda \varkappa б s$, changeable, metabolic]. Relating to metabolic changes in the nervous system.

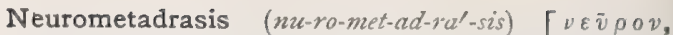

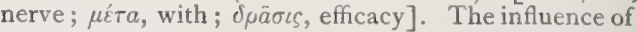
one person, or will, over another, as seen in hypnotism.

Neurometastasis (nu-ro-met-as'-tas-is) [veṽpov, nerve; $\mu \varepsilon \tau a ́ \sigma \tau a \sigma \iota s$, metastasis]. Metastasis to the nervous system.

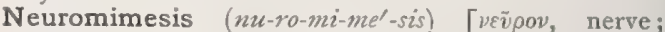
$\mu$ í $\nsim \sigma \iota$, initation ]. Paget's term for hysteric mimicry of organic disease.

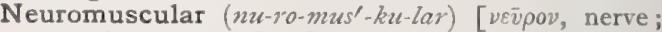
musculus, a muscle]. Pertaining conjointly to nerves and muscles.

Neuromyalgia (nu-ro-mi-al'-je-ah) [vєṽpov, nerve; $\mu \bar{v} \varsigma$, muscle; $\dot{a} \lambda \gamma o \varsigma$, pain]. Neuralgia of a muscle; an association of myalgia and neuralgia.

Neuromyelitis (nu-ro-mi-el-i'-tis) [veṽoov, nerve; $\mu v \varepsilon \lambda \hat{s}$, marrow ; $\iota \tau \iota \zeta$, inflammation]. Inflammation of myelonic substance, or of the medulla spinalis.

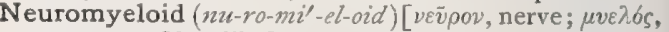

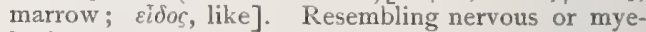
lonic substance.

Neuromyelous ( $\left.n u-r o-m i^{\prime}-e l-u s\right)\left[\nu \varepsilon \tilde{v} \rho o \nu\right.$, nerve; $\mu v \varepsilon \lambda \sigma_{s}$, marrow]. Pertaining to or of the nature of nervous or myelonic substance

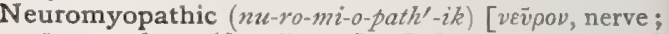
$\mu \tilde{v}$, muscle; $\pi \hat{\theta} \theta o s$, disease]. Relating to disease of both muscles and nerves.

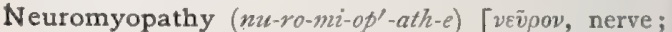

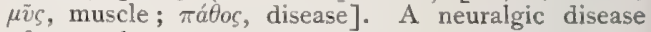
of a muscle.

Neuromyxoma (nu-ro-miks-o'-mah). Synonym of Neuroma, Myxomatous.

Neuron (nu'-ron) [vev̄pov, nerve: pl., Neura]. In biology ; $(a)$ the cerebrospinal cord taken as a whole ; $(b)$ a vein or costa of an insect's wing; (c) same as Neure.

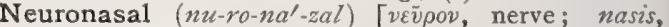
nose]. Relating to the brain and the nasal bone.

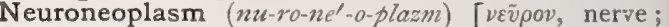

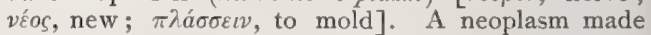
up of or containing nerve-elements ; a neuroma.

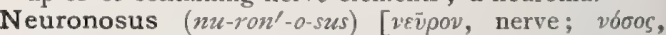
disease]. Synonym of Neurosis. N. of the Skin, neurotic skin-disease.

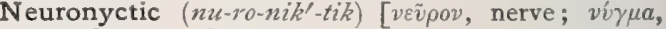

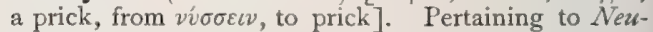
ronyxis.

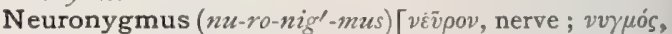
a puncture]. A punctured wound of a nerve.

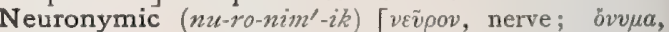
name]. Pertaining to neurologic nomenclature.

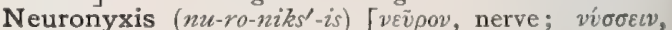
to prick]. The puncturing of nerves.

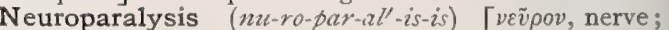

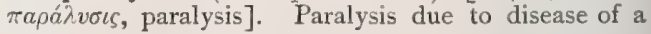
nerve.

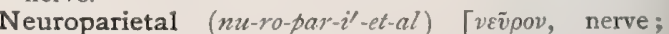
paries, wall]. Relating to the brain and the parietal bones.

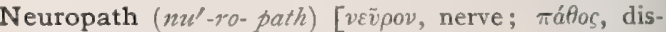
ease]. One who ascribes a nervous origin to disease.

Neuropathic (nu-ro-path'-ik) [veṽpov, nerve; $\pi a ́ \theta 0 s$, disease]. Pertaining to nervous diseases. N. Eschar, a bedsore following disease of the spinal cord.

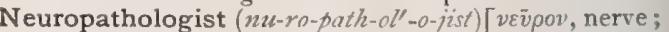

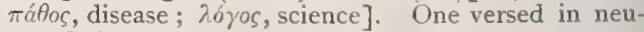
ropathology.

Neuropathology (nu-ro-path-oll-o-je) [vย́z̃pov, nerve:

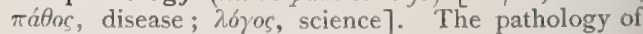
diseases of the nervous system.

Neuropathy, Neuropathia (nu-rop'-ath-e, nu-ro-pa'-

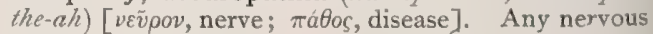
disease. 
Neurophlogosis $\left(m u-r o-f l o-g o^{\prime}-s i s\right)$. Synonym of Neuritis.

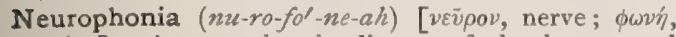
voice]. A rare choreic disease of the larynx and muscles of expiration characterized by the utterance of sharp spasmodic cries resembling the barking of a dog.

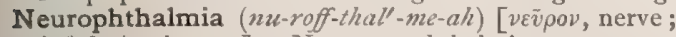
$\dot{\alpha} \dot{\phi} \theta a \dot{\sim} u \dot{s}$, the eye]. Nervous ophthalmia.

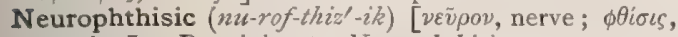
wasting]. Pertaining to Neurophthisis.

Neurophthisis (mu-roff'-this-is) [veṽoov, nerve; $\phi \theta i \sigma \iota s$, wasting]. Wasting of the nerves or nervous tissue.

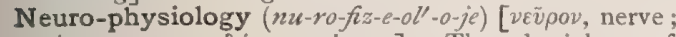

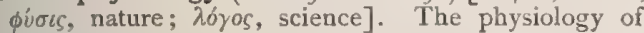
the nervous system.

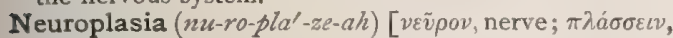
to mold]. The tendency to the formation of neuromata.

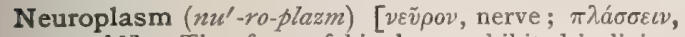
to mold]. That form of bioplasm exhibited in living brain-tissue.

Neuroplasma of Küpffer (nu-ro-plaz'-mah) [veṽoov, nerve; $\pi \hat{\lambda} a ́ \sigma \mu a$, a figure formed or molded]. In biology, a fluid lying between the fibrils of the axiscylinders of medullated nerve-fibers.

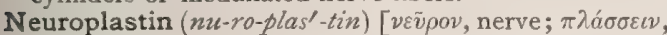
to mold]. A variety of plastin found in the brain and in nerve-tissue.

Neuroplasty ( $n u^{\prime}$-ro-plas-te) [ $\nu \varepsilon \tilde{p} \rho o v$, nerve; $\pi \lambda a ́ \sigma \sigma \varepsilon \dot{\varepsilon} \iota$, to mold]. Plastic surgery of the nerves.

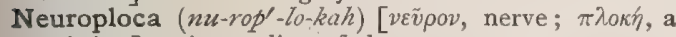
twisting]. A ganglion of the nervous system.

Neuroploconarcosis (nu-ro-plo-ko-nar-ko'-sis) [veṽpov,

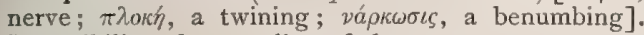
Insensibility of a ganglion of the nervous system.

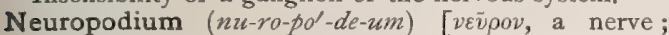
$\pi b v \zeta$, foot: pl., Neuropodia]. In biology, one of the ventral foot-stumps of a worm.

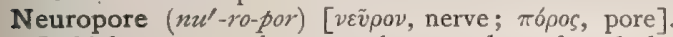
In biology, a pore between the neural canal and the exterior in certain embryos.

Neuro-prosopalgia ( $n u$-ro-pros- - -pal'-je-ah). Synonym of Prosopalgia.

Neuro-psychology (nu-ro-si-kol'-o-je) [veṽoov, nerve; $\psi v \chi^{\prime}$, mind; $\lambda \dot{\gamma} \gamma o s$, science]. A system of psychology based upon neurology.

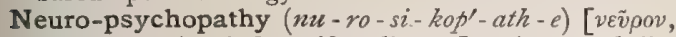
nerve; $\psi v \chi \eta ்$, mind; $\pi a ́ \theta o s$, disease ]. A mental disease based upon, or manifesting itself in, nervous disorders or symptoms.

Neuro-psychosis (nu-ro-si-kol-sis) [veṽpov, nerve; $\psi v \chi \eta ்$, mind; $v \sigma \sigma o s$, disease]. Any psychosis or mental disorder complicated with a nerve-disease; a nervedisease manifesting itself in association with some mental disorder: an association of a neurosis and a psychosis.

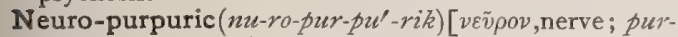
pura, purple]. Pertaining to purpura developed in association with disease of the nervous system. N. Fever. Synonym of Cerebro-spinal Fever.

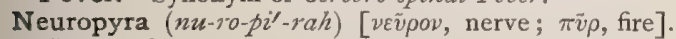
Nervous fever.

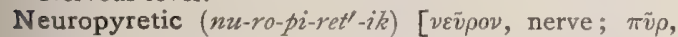
fever]. Pertaining to Neuropyra.

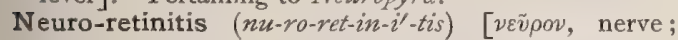
retina, retina; $\iota \tau \iota \varsigma$, inflammation ]. Inflammation of both the optic nerve and the retina.

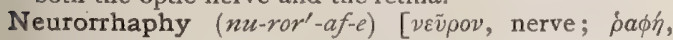
suture]. The operation of uniting a divided nerve by sutures.

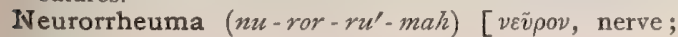
$\dot{\rho} \varepsilon \bar{v} \mu a$, flow]. Nervous force.
Neurosal (nu-ro'-zal) [veṽov, nerve]. Pertaining to, or of the nature of, a neurosis.

Neuro-scirrhus (nu-ro-skir'-us). Synonym of Neuroma.

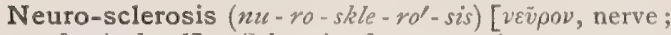

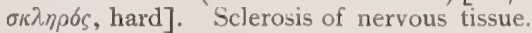

Neurose $\left(n u^{\prime}-r \bar{o} z\right)$ [ $\nu \varepsilon \bar{v} \rho o v$, nerve]. In biology, nerved. Neurosis (nu-ro'-sis) [veṽoov, nerve; vóoos, disease] An abnormal nervous action or an affection of the nerves or nerve-centers of a functional nature. In biology, one of two sets of successive changes incident to all intellectual operations; a change in the physical basis of consciousness. (Huxley.) Cf. Psychosis. N., Acro-, a neurosis of an extremity. N., Cutaneous, a term used to express abnormal functional conditions of the cutaneous nerves. N., Occupation, See N., Professional. N., Professional, one of a class of spasmodic and coördinative disturbances, mainly of functional origin, affecting groups of muscles used in the performance of special movements. N., Psycho-. See Psychoneurosis. N., Reflex, a functional nervous disease whose origin resides in some irritation or part distant from that in which the affection is manifested. Such a neurosis may be succeeded by the development of organic lesions. N., Spasmodic. Maudsley's term for Epilepsy. N., Thyro-exophthalmic. A synonym of Graves' Disease. N., Vascular, a neurosis of the blood-vessels or of their nerves. N., Vasomotor, a neuropathy of the vasomotor nerves.

Neurosism (nu'-ro-sizm). Same as Neurasthenia.

Neurosity (nu-ros'-it-e). A synonym of Neuricity.

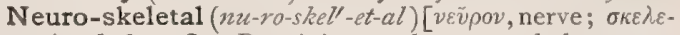
Tov, skeleton]. Pertaining to the neuro-skeleton.

Neuro-skeleton (nu-ro-skell-et-on) [vEv̈pow, nerve; $\sigma \kappa \varepsilon \lambda \varepsilon \tau \delta$, skeleton]. Carus's term for the vertebrate endo-skeleton, or true skeleton; so called from being made up of parts that correspond with and largely serve to protect portions of the central nervous system.

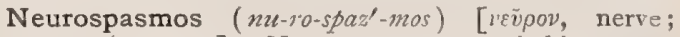
$\sigma \pi \alpha \sigma \mu o ́ s$, spasm]. Nervous spasm or twitching.

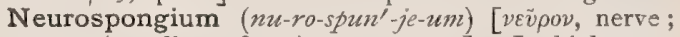
$\sigma \pi 0 \gamma \gamma$ iov, dim. of $\sigma \pi \delta \gamma \gamma o s$, sponge]. In biology, a granular matrix in the periopticon of insects' eyes.

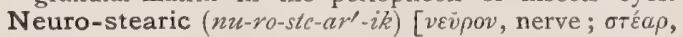
fat]. Pertaining to nervous tissue and fat. N.-s. Acid, an acid isomeric with stearic acid, occurring in the brain. N.-s. Ether, a substance formed by treating phrenosin, an element of brain-tissue, with sulphuric acid and alcohol.

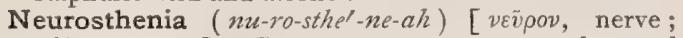
ofćsos, power]. Great nervous power, or abnormal excitation of the nervous centers.

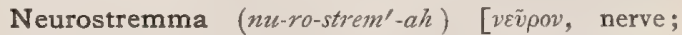
бтре́ $\mu \mu a$, a twist, or knot: pl., Neurostremmata]. A nerve-ganglion.

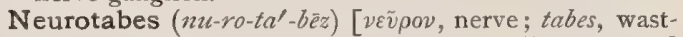
ing]. A complex of symptoms, resembling those of posterior sclerosis, but due to multiple neuritis. N., Peripheric Multiple, peripheral neuritis simulating tabes dorsalis.

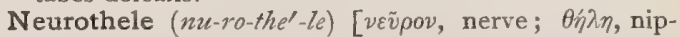
ple]. A nervous papilla.

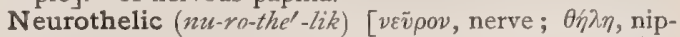
ple]. Pertaining to a neurothele; applied to the skin considered as the organ of tactile sense.

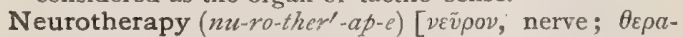
$\pi \varepsilon i a$, treatment]. The treatment of nervous diseases.

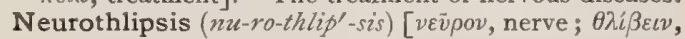
to press]. Pressure on a nerve.

Neurotic $\left(n u-r_{0}^{\prime}-i k\right)$ [ $\nu \varepsilon \bar{v} \rho o \nu$, nerve]. Pertaining to 
the nerves; nervous; also, pertaining to neuroses. In therapeutics, neurotics are such drugs as have a special influence upon the nervous centers and functions. N. Albuminuria, albuminuria due to nervous disturbance. N. Atrophy, atrophy dependent upon changes in some part of the nervous system. N. Dyspepsia. See Dyspepsia. N. Fever, fever following traumatism of the central nervous system. N. Hypertrophy, hypertrophy resulting from excessive nutrition or other trophic abnormality.

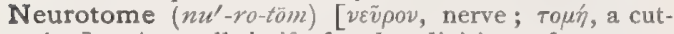
ting]. A small knife for the division of a nerve, especially subcutaneously

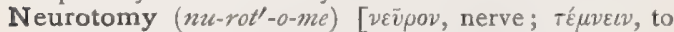
cut]. The division of a nerve.

Neuro-toxicology (nu-ro-toks-ik-ol'-o-je) [veṽoov, nerve ; $\tau u \xi \iota k b \nu$, poison; $\lambda 6 \gamma o s$, science]. The toxicology of the nerves; the science of the nervous disorders of toxic origin.

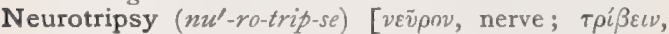
to rub]. The crushing of a nerve.

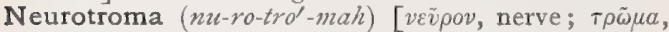
wound]. The wound of a nerve.

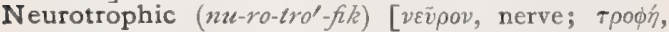
nourishment]. Depending on or attained through the trophic influence exercised by the nerves.

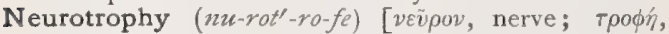
nourishment]. The nourishment of a nerve.

Neurotrosis, Neurotrosmus (nu-rot'-ro-sis, nu-ro-

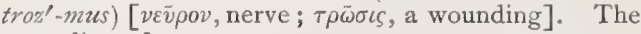
wounding of a nerve.

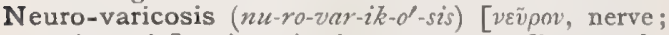
varix, varix]. A varicosity on a nerve-fiber, or the formation of one.

Neurymen (nu-ri'-men). Synonym of Neurilemma.

Neurymenitis (nzt-ri-men-i'tis). Synonym of Neurilemmatitis.

Neurypnology (nu-rip-nol'-o-je). See Neurohypnology

Neuter (nu'-ter) [L.]. Sexually not properly developed; an organism of neither sex.

Neutral (nu'-tral) [neuter, neither]. Neither alkaline nor acid; bland and soothing; having no active effect upon a tissue. N. Blue. See Pigments, Conspectus of. N. Mixture, liquor potassii citratis. See Potassium. N. Oils. See Lubricating Oils. N, Red. See Toluylene-red, and Pigments, Conspectus of. N. Violet. See Pigments, Conspectus of.

Neutraline (nu'-tral-in) [neuter, neither]. A commercial or proprietary name given to a brand of Petrolatum, q. v.

Neutralization (nu-tral-iz-a'-shun) [neuter, neither]. That process or operation that precisely counterbalances or cancels the action of an agent. In medicine, the process of checking the operation of any agent that produces a morbid effect. In chemistry, a change of reaction to that which is neither alkaline nor acid.

Neutralize (mi'-tral-iz $)$ [nenter, neither]. To render neutral ; to render inert.

Neutrophile (nu'-tro-fil) [neuter, neither; $\phi i \lambda o s$, loving]. Stained readily by neutral dyes; applied to certain bacteria and tissue-elements, especially leukocytes. N. Leukocytes, small colorless cells in normal human blood, containing several much-contorted nuclei that are readily stained. The protoplasm of these cells usually contains granules colorable by neutral stains, hence their name. See Leukocyte.

Neuwied-green. Same as Schweinfurth-green.

Nevoid (ne'-void) [ncous, birth-mark; Elios, like]. Resembling a nevus. N. Elephantiasis. See $L_{y m p h-}$ scrotum.
Nevose $\left(n \epsilon^{\prime}-v \bar{o} z\right)$ [n๕evus, a birth-mark]. Freckled; having nevi.

Nevus, Nævus (ne'-vus) [L.: plural Nevi]. A mark or blemish due to the dilatation of the blood-vessels near the surface of the skin or within its texture. $\mathbf{N}$ araneus. See Acne rosaced. N., Capillary, one that involves the capillaries of the skin. $\mathbf{N}$. cerasus, a slightly elevated vascular nevus resembling somewhat the appearance of a cherry. N.,Cutaneous, a nevus of the skin. N. flammeus. See $N$. maternus. N. fragarius, the strawberry mark. N. lipomatodes, a large mole, soft and lax, containing a quantity of fat and loose connective tissue. N. lupus. See Angioma serpiginosum. N. maternus, Mother's mark; the patch of congenital discoloration of the skin due to a dilated condition of the capillaries. If this is diffuse, very slightly, if at all, raised, red, or purplish-red, and on some part of the face, often involving the whole of one side, it is called $N$. fammeus, or "port-zuine mark." This is a relatively common condition. $\mathrm{N}$. morus, the mulberry nevus; a vascular nevus somewhat elevated and with an irregular surface. $\mathbf{N}$. nativus, birth-mark. N. neuroticus, a minor degree of Ichthyosishystrix. N. papillaris, a minor degree of Ichthyosis hystrix. N. papillomatosus, a mole covered with soft, papillary growths. N. pigmentosus, pigmentary mole; navus verrucosus; nevus sigilum; navus pilosus; navus spilus; a circumscribed, congenital pigmentary deposit in the skin, varying in color from a light-fawn to a blackish tint, and often associated with hypertrophy of the hairs as to number, size, and color-elements. It varies in size from a pinhead discoloration to bean-sized or larger flattened and warty elevations, or it may reach the size of a cocoanut or fetal head. N. pilaris, N. pilosus. See $N$. pigmentosus. $\mathbf{N}$. planus, a non-elevated pigmentary nevus. N. sanguineus. See $N$. vascularis. N. sigilum. Synonym of $N$. pignentosus. N., Spider. Synonym of $N$. araneus. N. spilus. See $N$. pigmentosus. N. tuberculosus. Synonym of $N$. verrucosus. $\mathbf{N}$., Varicose. See $N$., Venous. N. vascularis, $N$. zasculosus; $N$. sanguineus: a congenital overgrowth of cutaneous vascular tissue forming the so-called nevi. These may be capillary or cutaneous, and venous or subcutaneous. The former vary in size from a mere point up to large areas, standing on a level with the skin or raised more or less above it, of a bright-red color or of a more or less purplish hue. The venous nevus is generally more raised than the capillary; it is convex, smooth, or lobulated, and of a dark-purple color, compressible, but rapidly filling after the compression has been removed. $N$. vasculosus. See $N$. vascularis. N. verrucosus. See $N$. pigmentosus. N. Venous, a raised, convex, and sometimes lobulated form, consisting of thin-walled veins and sinuses bound together by connective tissue.

New (nu) [ME., nezve, new]. Not old; freshly produced; recent. N. Blue. Same as French Blue. See Pigments, Conspectus of. N.-born, a designation applied to the child for a short period after birth. N. Coccin. See Pigments, Conspectus of. N. Fast Violet. Same as Gallocyanin. N.-formation. See Neoplasm. N. Jersey Tea. See Ceanothus. N. Red. Same as Fuchsin. N. Victoria Green. Same as Brilliant Green. N. White. See Pigments, Conspectus of. N. Yellow. Same as Flavaurin. N. Zealand Flax. See Flax.

Newman's Treatment. See Treatment, Methods of. Newton's Color-rings. The colorings produced when a cover-glass is pressed upon the slide. They are the result of chromatic aberration. N.'s Disc, a circular 
card colored in triangular areas with the colors of the spectrum. On being rapidly revolved it appears white. N.'s Law. See Law. N.'s Metal, a term for Bismuth. N.'s Theory, the Emission theory of light. See Light.

Ngai Camphor. A camphor, $\mathrm{C}_{10} \mathrm{H}_{18} \mathrm{O}$, derived from Blumea balsamifera, a tree of S. E. Asia.

Niata $\left(n i-a^{\prime}-t a h\right)$ [deriv. obscure]. A breed of small "bull-dog" oxen, produced by a sudden variation, in South America, between the sixteenth and eighteenth centuries.

Niatism (ni'-at-izm) [niata, a breed of bull-dog "oxen"]. In biology, a form of sudden variation characterized by dwarfing, at times occurring among animals.

Nibble $\left(n i b^{\prime}-l\right)$ [LG., nibbeln, to nibble]. To gnaw ; to eat in small bits.

Nickel (nik'-ll) [G., nickel, nickel]. Ni $=58$; quantivalence II, IV. A metal of silver-white luster, resembling iron in physical properties. In $\mathbf{I} 889$ it was asserted by Krauss, of Munich, to be a compound body. It is much used for plating metallic surgical appliances. See Elements, Table of. N. Bromid, recommended for epilepsy. Dose gr. v-x. N. Chlorid, a tonic in anemia. N. Sulphate, has been used as a nerve-tonic in tabes dorsalis. Dose gr. iij-v. All unof.

Nicking ( nik' $^{\prime}-i n g$ ) [origin obscure]. The incising of a horse's tail near the root, to cause it to be carried higher.

Nickles' Test. See Tests, Table of.

Nicol (nik'-el) [after William Nicol, of Edinburgh]. An abbreviation for Nicol's prism.

Nicol's Prism (nik-el) [after William Nicol, of Edinburgh]. A polished prism of Iceland spar, cut diagonally across the principal axis, the sections being joined together by means of Canada balsam. It has the property of reflecting the ordinary ray of light out of the field, while the so-called polarized ray is transmitted. See Prism.

Nicomorrhuin (nik-o-mor'-u-in), $\mathrm{C}_{20} \mathrm{H}_{28} \mathrm{~N}_{4}$. One of the alkaloids of cod-liver oil. See Morrhuolins.

Nicotia (nik-o'-she-ah). Synonym of Nicotin.

Nicotian (nik-o'-she-an) [after Jean Nicot]. I. Tobacco. 2. One who uses tobacco. 3. Pertaining to, or derived from, tobacco.

Nicotiana (nik-o-she-a'-nah). See Tabacum.

Nicotianic Acid (nik-o-she-an'-ik). Synonym of Nicotinic Acid.

Nicotianin (nik-o'-she-an-in) [after Jean Nicot, a French ambassador to Portugal]. The solid volatile principle to which tobacco owes its flavor.

Nicotic Acid (nik-ot'-ik). Same as Malonic Acid.

Nicotin (nik'-o-tin) [after Jean Nicot, a French Ambassador to Portugal], $\mathrm{C}_{10} \mathrm{H}_{14} \mathrm{~N}_{2}$. A poisonous alkaloid found in the leaves of the tobacco-plant; it may be obtained by distilling the residue from the aqueous extract with lime. It is an oil, readily soluble in water and alcohol. Its odor is very penetrating. It becomes brown on exposure to the air; its specific gravity at $15^{\circ} \mathrm{C}$. is $\mathbf{I . O I I}$; it boils at $24 \mathrm{I}^{\circ} \mathrm{C}$.

Nicotinic Acid (nik-o-tin'-ik) [after Jean Nicot], $\mathrm{C}_{6} \mathrm{H}_{5}$ $\mathrm{NO}_{2}$. An oxidation-product of nicotin.

Nicotinism (nik'-o-tin-izm) [after Jean Nicot]. The constitutional effects of the continued or excessive use of tobacco.

Nicotism (nik'-o-tizm). Synonym of Nicotinism.

Nictating (nik-ta'-ling) [nictare, to wink]. Winking.

Nictation (nik-ta'-shun). Same as Nictitation.

Nictitating (nik'-tit-n-ting) [nictitare, to wink]. Winking. N. Membrane. See Membrane. N. Spasm, blepharospasm.
Nictitation (nik-tit-a -shun) [nictitare, to wink]. Abnormal frequency of winking.

Nidamentum (nid-am-en'-tum) [nidus, nest]. The decidua; also any covering of the developing ovum; an egg-case.

Nidation (ni-da'-shun) [nidus, nest]. The development of an endometrial epithelium in an inter-menstrual period.

Nidulant (nid'-u-lant) [nidulari, to build a nest]. In biology, lying loose in a nest-like receptacle or pulp, like the seeds or sporangia of certain plants.

Nidularium (nid-u-ln'-re-um) [dim. of nidus, nest]. The mycelium of fungi.

Nidus $\left(n i^{\prime}-d u s\right)$ [L., nest]. I. A central point or focus of infection; a place in which an organism finds conditions suitable for growth and development. 2. A collection of ganglion-cells at the deep origin of a cranial nerve; a nucleus. N. hirundinis, a deep fossa in the cerebellum situated between the velum medullare posterius in front, and the nodulus and uvula behind.

Niemeyer's Pill. A pill of quinin, grain I, digitalis, grain one-half, and opium, grain one-quarter. It is used in pulmonary tuberculosis, and is taken every six hours.

Niepa (ne'-pah) [E. Ind.]. The bark of Samadera indica, a simarubaceous tree of S. Asia; it is intensely bitter, and a good tonic. Unof.

Nigella (ni-jel'-ah) [nigellus, dark]. A ranunculaceous genus of plants represented by several species having medicinal properties. N. sativa, fennel-flower, is diaphoretic and emmenagogue. Unof.

Nigellin $\left(n i-j e l^{\prime}-i n\right)$ [nigellus, dark]. A bitter extractive of Nigella sativa.

Niggl's Test. See Tests, Table of.

Night (nit) [ME., night, night]. The portion of the day during which the sun is below the horizon. N.blindness. See Hemeralopia. N.-blooming Cereus, the flowers of Cereus grandiflorus, a sedative and diuretic plant, useful in functional ailments of the heart, palpitation and angina pectoris. Dose of the fld. ext. (alcoholic) $m x-x x x$. Unof. N. Blue. See Pigments, Conspectus of. N.-cries, a symptom of nervous or physical disorders of children, and especially of the early stage of hip-disease. The child cries out in its sleep from pain produced by reflex spasmodic twitching of the muscles already abnomally irritable. N. Green. See Pigments, Conspectus of. N.-mare, a feeling of distress or suffocation during sleep, attended with fright, hideous dreams and often with inability to stimulate muscular contraction except in a very slight degree. N. -pain, a symptom of hipdisease; pain in the hip or knee occurring during muscular relaxation of the limb in sleep. N.-palsy, a nervous manifestation of no especial significance, consisting simply of a feeling of numbness in one or more extremities of the body when the sleeping patient awakes; the so-called "dead fingers." It principally attacks women at the menopause. N.shade, a popular name for plants of the genus Solanum, and also the genus Atropa. N.-shade, Bittersweet. See Solanum dulcamara. N.-shade, Deadly. See Atropa belladonna. N.-sight. Synonym of Nyctalopia. N.-soil, the contents of privy. vaults (often removed in the night). This material is largely employed as manure. N.-soil Fever, a syno. nym of Typhoid Fever. N.-starting, a jerking of the lower extremity occurring at night in children with hip-disease. N.-sweat, the profuse nocturnal sweating often observed in pulmonary tuberculosis and other wasting disorders. N.-terrors, Pavor nocturnus; consternatio; a sudden terror that attacks young 
children during sleep. N.-walker, a somnambulist. N.-walking, somnambulism.

Nightingale (nit'-in-gall) [after Florence Nightingale]. A sleeved scarf used in the hospital-treatment of the sick and wounded, to protect the shoulders and parts liable to become uncovered in bed.

Nigredo (ni-gre'-do) [niger, black]. A black color; melasma. N. a sole, sunburn. N. nativa, a natural dark coloring of the skin. N. necrotica, the blackness of parts that are becoming gangrenous. $\mathbf{N}$. sordida, dark pigmentation from dirt

Nigrescent (ni-gres'-ent) [nigrescere, to become black]. I'urning black; blackish, dusky.

Nigric Acid (ni'-grik) [niger, black], $\mathrm{C}_{7} \mathrm{H}_{8} \mathrm{O}_{4} \cdot \mathrm{A}$ black powder obtained when ethyl oxalate is treated with potassium.

Nigricant ( $n \bar{\imath}^{\prime}$-grik-ant). Same as Nigrescent.

Nigrismus (ni-griz'-mus) [L.]. Synonym of Nigredo. N. linguæ, black tongue.

Nigritia, Nigrities (ni-yrish'-e-ah, ni'-grit-ēz). Same as Nigrismus, and Glossophytia.

Nigritudo (nig-rit-u $\left.u^{\prime}-u_{G}\right)$. Synonym of Melanosis.

Nigrosin ( $\left.n i^{\prime}-g y^{\prime} 0-s i n\right)$ [niger, black]. A blue-black anilin-dye, useful in staining sections of brain-tissue. For the nigrosins see Indulins. See also Pigments, Conspectus of.

Nile-blue (nīl'blu). See Pigments, Conspectus of.

Nine (nin) [ME, nine, nine]. Thrice three. N.bark. I. The plant Neillia opulifolia, of N. America; it is astringent, tonic, and vulnerary. Unof. 2. The same as Seven-bark. N.-day Fits. Synonym of Tetanus neonatorum.

Niobium $\left(n i-o^{\prime}-b e-z m\right)$ [N'ó $\beta \eta$, the daughter of Tantalus]. A rare metal, akin to bismuth and to antimony; symbol $\mathrm{Nb}$; atomic weight 94 . It is also known as Columbium. Its medicinal properties are little known. See Elements, Table of.

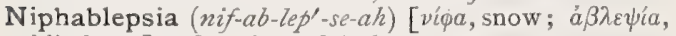
blindness]. See Snoze-blindness.

Niphlotyphlotes (nif-lo-tif-lo'-lêz) [viфa, snow; $\tau v \phi-$ $\lambda \omega \tau \eta s$, blindness]. Snow-blindness.

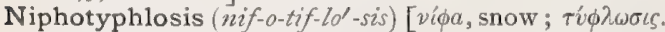
blindness]. Snow-blindness.

Nippers (nip'-erz) [ME., nippen, to nip]. An instru ment for seizing small bodies. N., Bone, an instrument for grasping small bits of bone.

Nipple (nip'-l) [ME., neple, nipple]. The conic elevation in the center of the mammary areola. The mammilla, acromastium, or thele. N.-cactus. See Mammillaria. N., Cracked, a nipple the epidermis of which is broken in places. N.-line, in physical diagnosis, a vertical line drawn on the surface of the chest through the nipple. N.-protector, a device worn by nursing women to protect the nipple. It is called also a Nipple-shield. N., Retracted, a nipple drawn below the surrounding level. protector.

Nirls, Nirles (nerlz) [origin obscure]. A variety of herpes.

Nirlus (nir'-lus) [origin obscure]. An ephemeral papular eruption sometimes following measles or scarlet fever.

Nisbet's Chancre. A lymphatic abscess on the dorsum of the penis proceeding to the formation of a chancre.

Nisus (ni'-sus) [nisus, effort, from niti, to endeavor]. The periodic desire for procreation manifested in the spring season by certain species of animals. Also, the contraction of the diaphragm and abdominal muscles, for the expulsion of the feces or the urine. N.-formations, Blumenbach's, the force of an aggregate organism which constrains the newly-integrated atoms to take a definite form; the "spiritus rector." According to Weismann, this is located in an "accessory idioplasm," consisting of the determinants of the parts to be regenerated.

Nit [ME., nitte, a nit]. A popular name for the larva of several species of pediculus; during incubation it is attached to the hair.

Niter (ni'-ter) [vitpov, natron]. Potassium nitrate. N., Cubic, Sodium nitrate. N., Spirit of, Spiritus atheris nitrosi, sweet spirit of niter.

Nitid (nit'-id) [nitere, to shine]. Shining.

Nitidous (nit'-id-us) [nitidus, shining]. Same as Nitid. Nitor (ni'-tor) [nitere, to shine]. Synonym of Enamel.

Nitrate (ni'-trât) [vítpov, natron]. Any salt of nitric acid. All nitrates are soluble in water. N. Test Reagent. See Acid Phenyl Sulphate.

Nitrated (ni'-tra-ted) [virpov, natron]. Combined with nitric acid.

Nitration (ni-tra'-shun) [vitpov, natron]. The process of combining or treating with nitric acid.

Nitre (ni'-ter). See Niter.

Nitric (ni'-trik) [vitpov, natron]. Pertaining to or containing niter. N. Acid. See Acid, Nitric. N. Acid Test. See Tests, Table of. N. Magnesian Reagent. See Roberts' Reagent.

Nitrification (ni-trif-ik-a'-shun) [vitpov, natron; ficare (facere), to make]. In biology, the oxidation of the nitrogen of organic matter by means of microörganisms. Cf. Bacterioid, and Nitrifying Bacillus of Winogradsky, under Bacteria, Synonymatic Table of.

Nitrify (nit'-rif-i) [vitoov, natron; facere, to make]. To convert into niter.

Nitriles (ni'-trils) [vit $\rho 0$, natron]. Those derivatives of the alcoholic radicles with the cyanogen group, $\mathrm{CN}$, in which the fourth affinity of carbon is limited to the alcohol radicles. They are liquids usually insoluble in water, possessing an ethereal odor, and readily decomposed on heating with acids or alkalies.

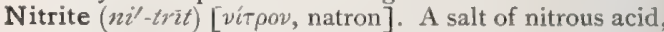
$\mathrm{HNO}_{2}$. Also applied to certain combinations with organic radicles, as nitroglycerin, $\mathrm{C}_{2} \mathrm{H}_{5}\left(\mathrm{NO}_{2}\right)_{3}$, nitrobenzol, amylic nitrite, and other compounds. N., Amyl, $\mathrm{C}_{5} \mathrm{H}_{11} \mathrm{NO}_{22}$, possesses a fruity odor. Inhaled it causes tumultuous action of the heart and a slowing of the respiration. It is useful in angina pectoris, asthma, and occasionally in sea-sickness. Dose, internally, $m^{\mathrm{T} / 4}-\mathrm{j}$, dissolved in alcohol; by inhalation, mij-v. N., Ethyl, $\mathrm{C}_{2} \mathrm{H}_{5} \mathrm{NO}_{2}$, used to make sweet spirit of niter. N., Sodium, $\mathrm{NaNO}_{2}$, acts like amyl nitrite, but is less prompt. It is employed in desquamative nephritis when accompanied by weak action of the heart. Dose, gr. $1 / 2-v$.

Nitro- (ni'-tro-) [vit $\rho o v$, natron]. A prefix denoting combination with nitrogen. Also, denoting combination with the radicle, $\mathrm{NO}_{2}$. N.-amins, a group of chemic compounds containing the nitro-group in union with nitrogen. N.-bacteria, a term given by Winogradsky to those bacteria that convert ammonia into nitrous and nitric acids. N.-benzene $\left(\mathrm{C}_{6} \mathrm{H}_{5} \mathrm{NO}_{2}\right)$, Nitrobenzol; a liquid prepared by adding benzol drop by drop to $\mathrm{HNO}_{3 *}$ It closely resembles oil of bitter almonds in flavor, and is important as a source of anilin in the manufacture of dyes. It is actively poisonous, with the general effects of hydrocyanic acid. N.-benzol. See $N$.benzene. N.-benzol-red. Same as Rosanilin. N.-cellulin, N.-cellulose, a substitution-compound of cellulose, $\mathrm{NO}_{2}$ replacing $\mathrm{H}$. Mononitro-cellulese, $\mathrm{C}_{6} \mathrm{H}_{4}\left(\mathrm{NO} \mathrm{O}_{2}\right) \mathrm{O}_{5}$; Dinitrocillulose. $\mathrm{C}_{6,} \mathrm{H}_{4}\left(\mathrm{NO}_{3}\right) \mathrm{O}_{5}$, or pyroxylin: Trinitrocellulose, $\mathrm{C}_{6} \mathrm{H}_{7}\left(\mathrm{NO}_{2}\right)_{3} \mathrm{O}_{5}$, or gun- 
cotton. N.-compound, a carbon compound that is formed from another by the substitution of the monatomic radicle $\mathrm{NO}_{2}$ for hydrogen, and in which the nitrogen atom is regarded as directly joined to a carbon atom.

Nitroform ( $n i^{\prime}$-tro-form) [vitpov, natron; forma, form], $\mathrm{CH}\left(\mathrm{NO}_{2}\right)_{3}$. An oily acid compound, chemically analugous to chloroform. It is usually obtained by treating biliary acids with nitric acid.

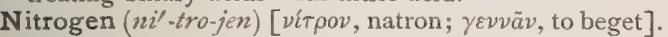
$\mathrm{N}=\mathbf{I} 4$; quantivalence I, III, V. One of the nonmetallic elements, gaseous at ordinary temperatures. It is a component element of albumins, proteids, urea, and other organic substances, of alkaloids, ammonia, and its derivatives, and many other inorganic substances. It forms about 79 per cent. of the air, and is most active in combination with oxygen. The French call it azote. The salts of nitric acid are called nitrates, those of nitrous acid nitrites. See Elements, Table of. A description of various methods for detecting nitrogen is appended: Kjeldahl's Method; the substance is dissolved by heating it with concentrated sulphuric acid. Potassium permanganate (pulverized, or dissolved in sulphuric acid) is then added until a distinctly green color appears. The liquid is diluted with water and the ammonia is expelled by boiling with sodium hydroxid. Limprecht's Method, a method of determining the nitrogen of nitro-compounds and nitroso-compounds indirectly by means of a titrated solution of stannous chlorid. Will and Varrentrap's Method; two parts of calcium hydrate are added to one part of an aqueous solution of pure sodium hydroxid; the mixture is evaporated and gently ignited. The weighed, finely-pulverized substance is mixed with soda-lime (about ten parts) and the mixture is placed in a combustion-tube, about 30 $\mathrm{cm}$. long, which is filled in with soda-lime. In the open extremity of the tube is placed a rubber stopper bearing a bulb-apparatus containing dilute hydrochloric acid. The anterior portion of the bulb is first heated in the furnace; then, that containing the mixture. That all of the ammonia may be carried into the bulb, air is conducted through the tube, after breaking off the point. The ammonium chlorid in the hydrochloric acid is precipitated as ammonio-platinum chlorid by means of platinic chlorid, and the residual platinum is weighed. One atom of platinum corresponds to two molecules of $\mathrm{NH}_{3}$ or two atoms of nitrogen. N., Gaseous Oxid of. See Nitrous Oxid.

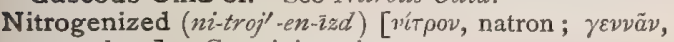
to produce]. Containing nitrogen.

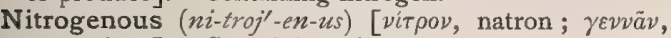
to produce]. Containing nitrogen.

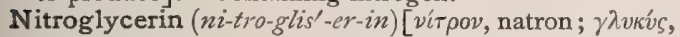
sweet], $\mathrm{C}_{3} \mathrm{H}_{5} \mathrm{~N}_{3} \mathrm{O}_{9}$ Glonoin, Trinitrin, Trinitrite of Glyceryl; Glycerol Nitric Ester; a substance produced by the action of a mixture of sulphuric and nitric acids upon glycerol. It is a colorless oil, with a sweet taste, and is poisonous when taken internally. It is insoluble in water. Heated quickly, or upon percussion, it explodes very violently. Mixed with Kieselguhr it forms dynamite. Therapeutically, it acts like amyl nitrite. Dose gr. $\frac{1}{200}-\frac{1}{50}$. Dose of the tincture, one per cent, in alcohol, $m^{1 / 2}-\mathrm{x}$. N., Liquor (B.P.), contains pure nitroglycerin one part by weight, rectified spirit $q . s$. to produce 100 fluid parts. Dose $\eta$ 1/2-ij. N., Tabellæ (B.P.), tablets of chocolate each containing gr. $\frac{1}{10}$ of pure nitroglycerin. Dose $\mathrm{j}-\mathrm{ij}$. Spiritus glonoini (spirit of nitroglycerin); an alcoholic solution containing one per cent. by weight of glonoin. Nitroleum (ni-tro'-le-um). Synonym of Nitroglycerin. Nitrolin (ni'-tro-lin) [vitoov, natron; oleum, oil]. An explosive compound consisting of a mixture of cellulose, niter, and nitrosaccharose.

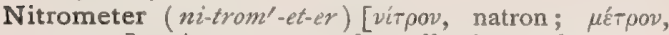
measure]. An apparatus for collecting and measuring nitrogen gas, or for decomposing nitrogen oxids and estimating the resulting gases.

Nitromuriatic Acid (ni-tro-mu-re-at'-ik). See Acid, Nitrohydrochloric.

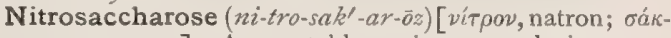
$\chi a \rho o \nu$, sugar]. An unstable, resinous, explosive compound produced by treating saccharose with nitric acid.

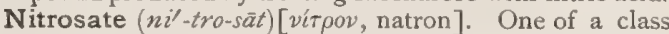
of carbon compounds resulting from the action of nitrogen tetroxid upon the alkylenes.

Nitroso- (ni-tro'so-) [vitpov, natron]. In chemistry, a prefix signifying combination with nitrosyl, the univalent compound radicle, NO. N.-amins, a class of nitroso-compounds in which the nitroso-group is linked to nitrogen. They are mostly oily, yellow liquids, insoluble in water, and may be distilled without suffering decomposition. N.-compounds, a class of chemic compounds containing the group $\mathrm{NO}$ attached to carbon. N.-phenol. See Quinoxim.

Nitrous (ni'-trus) [vitpov, natron]. In chemistry, pertaining to or derived from niter. Nitrous compounds contain less oxygen than do nitric compounds. $\mathbf{N}$. Acid. See Acid, Nitrous. N. Ether, $\mathrm{C}_{2} \mathrm{H}_{5} \mathrm{NO}_{2} ; \mathrm{a}$ very volatile liquid, with properties very similar to those of amyl nitrite. N. Oxid, Laughing gas; a gaseous compound, having the structure $\mathrm{N}_{2} \mathrm{O}_{2}$. Inhaled, it produces cerebral excitement, followed by anesthesia. It is much used in dentistry. See $A n_{t}^{*} s-$ thetic.

Nival (ni'val) [nivalis, snowy]. Living in or near snow.

Njinio-wood [African]. A remedy used in West Africa in the treatment of gastric pains and loss of appetite. Its effects are similar to those of coca. Unof.

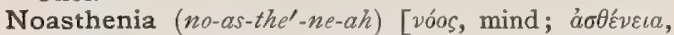
weakness]. Mental feebleness.

Nocard, Bacillus of. See Bacteria, Synonymaiic Table of.

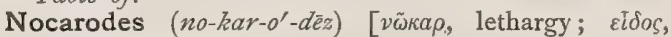
like]. Lethargic.

Nocent (no'-sent) [nocens, from nocere, to harm]. Harmful ; injurious.

Noctambulation (nok-tam-bu-la'-shun) [noctambulatio; nox, night; ambulare, to walk]. Same as Somnambulism.

Noctambulatory (nok-tam'-bu-la-tor-e) [nox, night; ambulare, to walk]. In biology, wandering at night, as many predatory mammals.

Noctambulism (nok-tam'-bu-lizm). See Somnambulism.

Noctidial (nok-tid'-e-al) [nox, night; dies, day]. Lasting for a day and a night, or for twenty-four hours.

Noctisurgium (nok-tis-ur'-je-um). Synonym of Somnambutism.

Nocturnal (nok-tur'-nal) [nocturnus, of the night]. Pertaining to the night-time. N. Blindness. See Hemeralopia. N. Crisis, the nightly exacerbation of symptoms. N. Emission and N. Pollution. See Spermatorrhea. N. Enuresis, incontinence of urine at night during sleep. N. Epilepsy, epilepsy in which the convulsions occur at night. N. Sight. Same as Hemeralopia.

Nocuity (nok-u'-it-e) [nocuus, injurious]. Injuriousness; harmfulness; the quality of being noxious.

Nocuous (nok'-u-us) [nocuus, injurious]. Noxious; hurtful; venomous. N. Meat, meat from animals 
affected with diseases that may be transmitted to man.

Nod [ME., nodden, to shake]. I. To drop the head forward with a quick, involuntary motion. 2. The motion so made.

Nodal (no'-del) [nodus, a node]. Nodated; pertaining to a node. N. Point, the point of intersection of convergent rays of light with the visual axis of the eye. The First $N . P$, is $6.9685 \mathrm{~mm}$. behind the summit of the cornea. The Second $N$. P , is 7.3254 $\mathrm{mm}$. behind the summit of the cornea, or 0.1254 $\mathrm{mm}$. behind the lens.

Nodated (no-da'-ted) [nodus, a node]. Knotted; having nodes.

Nodding (nod'-ing) [ME., nodden, to shake]. I. The act of inclining the head forward. 2. Having a drooping position, as a flower-head. N. Spasm, spasmus nutans; salaam convulsions. See Eclampsia nutans.

Node (nöd) [nodus, a swelling, or node]. A knot or protuberance; an oblong, indurated swelling or tumor that forms upon bones in some forms of periostitis and osteitis. Ns., Heberden's, overgrowths of the natural tubercles of the digital phalangeal bones in rheumatoid arthritis. Ns., Parrot's, bosses of bone on the outer table of the skull, the result of syphilitic periostitis. Ns., Ranvier's, certain constrictions occurring in the course of medullated nerve-fibers, so that the sheath of Schwann lies upon the axis-cylinder. The part of the nerve between the nodes is called an interannular or internodal segment. See Nerve-fiber. Ns., Schmidt's, a term for the medullated interannular segments of a nerve. fiber. N., Syphilitic, the localized sweilings on bones due to syphilitic periostitis.

Nodicorn (nod'-ik-orn) [nodus, a knot; cormu, a horn]. In biology, having nodose antennæ.

Nodiferous [no-dif'-er-us) [nodus, a node; ferre, to bear]. In biology, bearing nodes.

Nodose $\left(n o^{\prime}-d o s\right)$ [nodus, node]. Characterized by nodes or nodosities; jointed or swollen at intervals.

Nodosis (no-do'-sis) [nodus, node]. The condition of having or forming nodes.

Nodosity (no-dos'-it-e). See Node. N., Bouchard's, a nodose condition of the second joints of the fingers, supposed to be indicative of gastrectasis. See Signs and Symptoms, Table of.

Nodous (no'-dus) [vwdós, from $\nu \eta$, negative; ỏdoús, tooth]. Toothless.

Nodular (nod"u-lar). Synonym of Nodose.

Nodule (nod'-ül) [nodulus, dim. of nodus, a node]. A little knot or excrescence; a tubercle; in dermatology, an elevation of the skin varying in size from a split pea to a hazelnut, and due to a cellular infiltration (granuloma of Virchow). N. of Aurantius. See Corpus. N. of Cerebellum, the termination of the inferior vermiform process of the cerebellum situated in front of the uvula. $\mathbf{N}$. of Morgagni. Same as $N$. of Aurantius.

Noduliferous (nod-u-lif'-er-us) [nodulus, a little knot; ferre, to bear]. Having nodules.

Noduliform (nod-u'-lif-orm) [nodulus, a little knot; forma, form $]$. In the form of a nodule.

Nodulo-dermitis (nod'-u-lo-der-mi'-tis) [nodulus, small

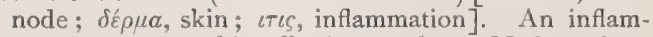
matory nodular skin-affection, such as Madura foot, leprosy, and other skin-diseases.

Nodulose, Nodulous (nod'-u-loz, nod'-u-lus) [nodulus, a little node]. In biology, having little knobs.

Nodulus (nod'-u-lus) [L.: pl., Noduli]. I. See Nodule. 2. The nodule of the cerebellum. N. hystericus. Same as Globus hystericus. Noduli albini, a term given to certain small pathologic knots occasionally found on the free border of the auriculo. ventricular valves.

Nodus $\left(n o^{\prime}-d u s\right)$ [L. : pl., Nodi]. See Node.

Noeggerath's Method. See Treatment, Methods of.

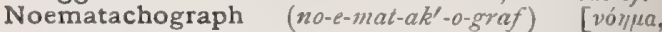

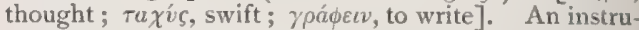
ment for recording the time of mental operations.

Noematachometer. Same as Noematachograph.

Nœud vital (nu(r)d-ve-tahl') [Fr.]. See Center, Respiratory.

Noisome (noi'-sum) [ME., noysome, hurtful]. Hurtful ; noxious.

Noli-me-tangere $\left(n o^{\prime}-l i-m e-t a n^{\prime}-j e r-\ell\right)$ [L.]. 1. See kodent Ulcer. 2. Ecballium officinarum, the squirting cucumber. 3. Impatiens noli-me-tangere, the touch-me-not, an animal of the Balsam family.

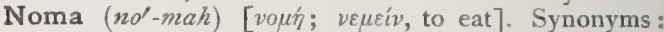
Cancrum oris, Gangræna oris, Gangrenous stomatitis. A grave form of stomatitis, gangrenous in type, and either secondary to ulcerative stomatitis or primary. The process is rapidly progressive, usually fatal, but recovery with great deformity of the face may occur. It is most common between the second and twelfth years. The disease is probably due to microörganisms ; many have been found, but their relations have not been determined.

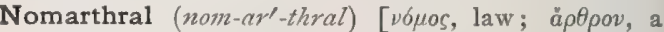
joint]. In biology, normally articulated or jointed the opposite of xenarthral.

Nome (no'-me). Same as Noma.

Nomenclature (no-men'-kla-tūr) [nomen, a name; calare, to call]. A systematic application and arrangement of the distinctive names employed in any science. Cf. Onym, Onymy.

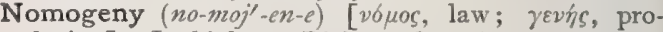
ducing]. In biology, Richard Owen's term for the origin of life through the operation of existing natural law.

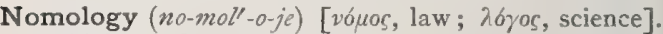
In biology, that department of botany devoted to a study of the laws of variation.

Nomopelmous (nom-o-pel'-mus) [vbuos, law ; $\pi \dot{\varepsilon} \lambda \mu a$, sole]. In biology, applied to birds having the normal arrangement of the flexor tendons of the foot. Cf. antiopelmous, heteropelmous, schizopelmous, sympelmous.

Non- [non, not]. A prefix denoting negation. $\mathbf{N}$. compos mentis [L.]. A legal term denoting an acquired unsoundness of mind, of such character that one is incapable of conducting his own afiairs.

Nona (no'-nah) [L.]. A name given in Italy, Bavaria, and Russia to a supposed new disease, which, however, in all probability is not new, but is typhoid fever with coma, a severe influenza, or a grave form of smallpox.

Non-access (non-r $\left.k^{\prime}-s e s\right)$ [non, not; accessus, an approach]. In medical jurisprudence, the failure to cohabit. The reverse of access, $q$. $v$. A child born under such circumstances is a bastard.

Non-achromatic (non-ak-ro-mat'-ik). See Objective.

Non-adjustable (non-ad-jus'-ta-bl). See Objective.

Nonan (nol-nan) [nomus, ninth]. Applied to a fever that has an exacerbation every ninth day.

Nondecatoic Acid (non-dek-at-o'-ik) [nomus, ninth; ঠદ́кa, ten], $\mathrm{C}_{19} \mathrm{H}_{38} \mathrm{O}_{2}$. A monobasic acid, the nineteenth member of the fatty acid series.

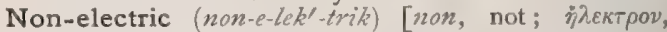
amber]. A term applied to those substances that permit electricity excited in them by friction to escape as fast as it is formed.

Non-identist (non-i-den'-tist) [non, not; identicus, the same]. A designation applied to a person who believes in the non-identity of certain diseases, such as 
typhus and typhoid, chancre and chancroid, membranous croup and laryngeal diphtheria.

Non-medullated (non-med"-ul-la-ted) [non, not; medulla, marrow]. Without marrow. N.-m. Nervefibers. See Nerve-fiber.

Non-motile (non-mo'-til) [non, not; motilis, moving]. Not having the power of spontaneous motion.

Non-naturals, The Six. In the old hygiene, this term designated air, food, exercise, sleep, secretion (and excretion), and mental activity.

Nonose (non'-ōz) [nonus, nine]. One of a group of the glucoses, with the formula $\mathrm{C}_{9} \mathrm{H}_{18} \mathrm{O}_{9}$. See Carbohydrates, Table of.

Non-parous (non-par'-us). Same as Nulliparous.

Non-restraint (non-re-stränt') [non, not; Fr., restraindre, to restrain]. The treatment of insanity without any possible means of compulsion.

Non-sexual (non-seks'-u-al) [non, not; sexus, sex], Same as Asexual.

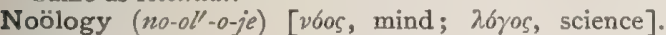
The science of mind, including that of mental disorders.

Noösphales (no-os'-fal-ēe) [vóos, mind; $\phi a ́ \lambda \lambda \varepsilon \iota v$, to overthrow ]. Demented.

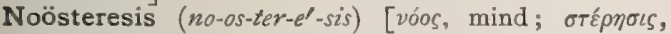
privation]. Dementia; loss of reason.

Nooth's Apparatus. An apparatus for saturating water with carbon dioxid; it consists of three glass vessels united by tubes. The gas is generated in the first, washed in the next, and stored in the third.

Norm [noma, a rule]. Standard.

Norma (nor'-mah) [L., a measure]. In anatomy, a view or aspect-essentially of the skull. N. basilaris, a view or aspect of the skull looking toward the inferior aspect. $\mathbf{N}$. facialis, the aspect looking toward the face. N. lateralis, the aspect looking toward either half; a profile view. $\mathbf{N}$. occipitalis, the aspect looking toward the back of the skull. $\mathbf{N}$. verticalis, the aspect viewed from above, or that directed toward the top of the skull.

Normal (nor'-mal) [norma, rule]. Conforming to natural order or law. N. Position, the typical position to which all vertebrates, especially, are most easily referred for comparison. In it the body axis is straight, the limbs project directly to the right and left; the radius and ulna, tibia and fibula, are parallel with the thumb and great toe on the cephalic (upper) aspect or edge. N. Salt Solution or N. Saline Solution, an aqueous solution of sodium chlorid of a strength similar to that of the body-fluids-usually $0.6-0.75$ per cent. N.-sightedness. See Emmetropia. N. Solution, in chemistry a solution of a salt or an acid containing in 1000 grains of the solvent a quantity of the salt or acid equal in grams to the molecular weight. A decinormal solution is one of one-tenth the strength, and a centinormal solution one of one-hundredth the strength of the normal solution. N. Structure, in organic chemistry, the union of carbon atoms in a simple, open chain.

Normality (nor-mal'-it-e) [norma, rule]. Normal quality; the normal state.

Normalization (nor-inal-iz-a'-shun) [norma, rule]. In biology, a term used to include all processes by which modified or morphologically abnormal forms and relations may be reduced, either actually or ideally, to their known primitive and presumed normal conditions.

Normandy Colic. See Colic.

Normoblast (nor'-mo-blast). See Corpuscle.

Noropianic Acid (nor-o-pe-an'-ik). See Acid.

Norris's Invisible Corpuscles. See Corpuscle.

Norton's Abyssinian Tube-well. A tube or tubes driven into the soil, tapping the subsoil water.
Norway Itch. See Itch, Norway. N. Spruce. See Abies.

Norwegian Itch. A variety of aggravated scabies seen mainly in lepers. See Itch, Norzuay.

Nosacerus (nōz-as'-er-us) [voбakepós, from vóoos, ill ness]. Diseased.

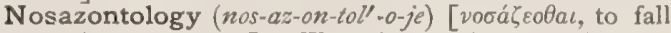
ill; $\lambda 6$ yos, science]. The science of the etiology of diseases.

Nose $(n \bar{o} z)$ [ME., nose, nose]. The special organ of the sense of smell. It is also associated in the performance of phonation and respiration. The anterior or external entrance is termed the anterior nares, and comprises the nostrils. It is lined throughout by a delicate mucosa termed the Schneiderian membrane, in the upper portion of which the terminations of the olfactory nerves are distributed. N.-bleed. See Epistaxis. N., Bottle, an hypertrophied condition of the nose with a varicose condition of its veins, usually associated with alcoholism. N.-brain, the olfactory lobes of the brain; the rhinencephalon.

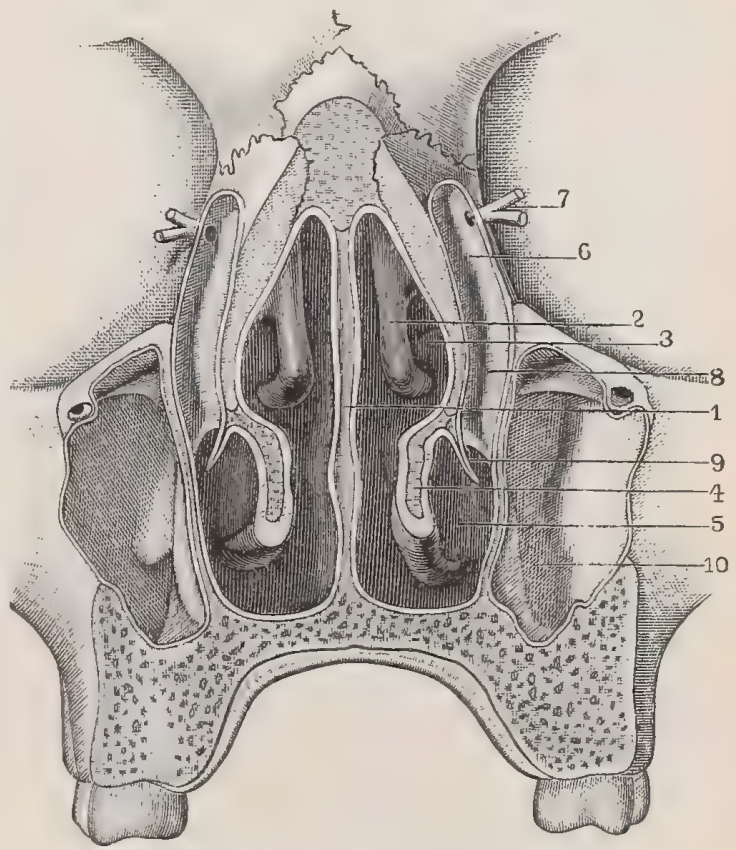

Transverse Section of the Nasal Foss.e.

I. Nasal septum. 2. Anterior extremity of middle turbinated bone. 3. Middle meatus. 4. Section of inferior turbinated bone. 5. Inferior meatus. 6. Lacrymal canal. 7. Canaliculi. 8. Nasal canal. Section of reflected mucous membrane. Io. Maxillary sinus or antrum of Highmore.

N., Bridge of, the prominence formed by the junction of the nasal bones. N.-cavities, the nasal fossæ. N.cough, a reflex trigeminal cough due to irritation of the nasal mucosa. N.-glasses, eye-glasses held on the nose by a spring; a pince-nez. N.-hole, a nostril. N.-piece, a mechanical device to be attached to a microscope for holding two, three, or four objectives. It is screwed into the object-end of the tube of the microscope. N., Tench's, a name for the external os uteri. N.-truss, an instrument for keeping the nasal bones in place after dislocation. N., Wings of, the bulging borders of the nostril, formed by folds of skin enclosing adipose and fibro-connective tissue. 
Nosegay, Riolan's. The entire group of muscles arising from the styloid process of the temporal bone.

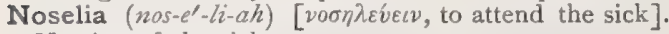
Nursing of the sick.

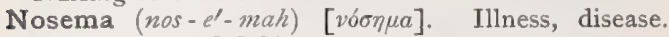
Also a genus of Schizomycetes.

Nosencephalon (nos-en-sef'-al-on). See Nolencephalus.

Nosencephalus (nos-en-sef'-al-us). Same as Notencephalus.

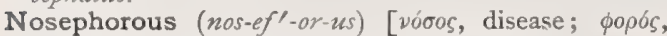
bearing]. Producing disease.

Nosesesthesia (nos-es-es-the'-ze-ah) [voonpos, diseased;

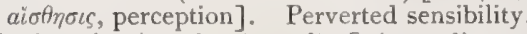

Nosistoria (nos-is-to'-re-ah) [vóros, disease; iotopia, history]. The history of disease or of a disease.

Nosocephalus (no-so-sef'-al-us). See Notencephalus.

Nosocome (nos'-o-kom). Same as Nosocomium.

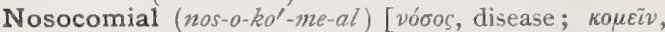
to take care of ]. Pertaining to a hospital, or a nosocomium. N. Gangrene. Synonym of hospital gangrene.

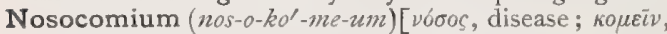
to take care of ]. A place designed for the care of the sick. A hospital.

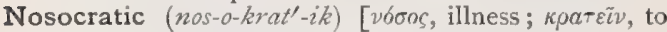
be strong]. Specific (applied to disease).

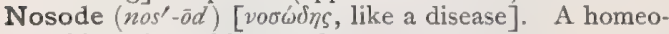
pathic or isopathic remedy.

Nosodochium (nos-o-do'-ke-um). Synonym of Nosocomium.

Nosogenesis (nos-o-jen'-es-is). Synonym of Nosogeny.

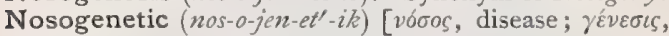
genesis]. Pertaining to nosogenesis.

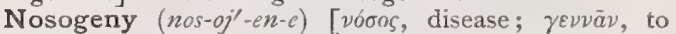
beget]. The development and progress of diseases.

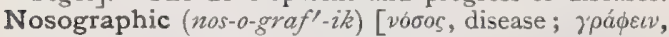
to write]. Pertaining to nosography.

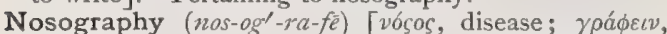
to write]. A descriptive treatise on the character and nature of diseases.

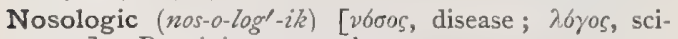
ence]. Pertaining to nosology.

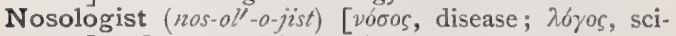
ence]. One versed in nosology.

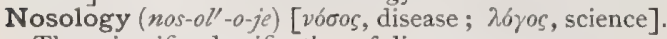
The scientific classification of diseases.

Nosomania (nos-o-ma'-ne-ah) [vóбos, disease; uavíx, mania]. The insane or hypochondriac delusion of a patient that he is suffering from some disease, from which, in point of fact, he may not be entirely free.

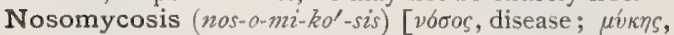
fungus]. Any disease due to the presence of a parasitic fungus, or schizomycete.

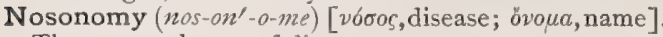
The nomenclature of diseases.

Nosonomy (nos-on'-o-me) [vóøos, disease; vbuos, law]. The study, or science, of the laws of disease.

Nosophobia (nos-o-fo'-be-ah) [vóoos, disease; фóßos, fear]. The insane, or exaggerated, fear of disease; pathophobia.

Nosophthoria (nos-off-thor'-e-ah) [v6oos, disease; $\phi \theta 6 \rho a$, destruction]. The eradication of diseases by prophylactic measures.

Nosophyte (nos'-o-fit) [ $\nu 6 \sigma o s$, disease; $\phi v \tau b v$, plant]. Any pathogenic vegetable microörganism.

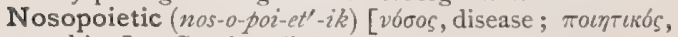
making]. Causing disease.

Nosotaxy (nos'-o-taks-e) [vóoos, disease ; Táłıs, arrangement]. The classification of diseases.

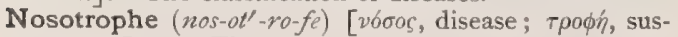
tenance]. I. The nourishment of disease. 2. The care of the sick.
Nosotrophic, Nosotrophous (nos-o-tro'-fik, nos-ol' -ro-

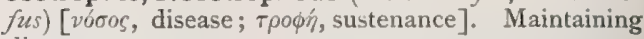
disease.

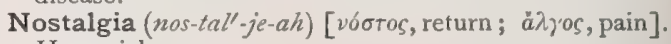
Homesickness.

Nostalgic (nos-tal'-jik) [vóotos, return; ä $\lambda$ yos, pain]. Affected with nostalgia.

Nostoc $\left(n o s^{\prime}-t o k\right)$ [Ger., nostoch, nostoc]. A genus of algous plants, often of a gelatinous nature, such as witches'-butter and star-spittle. Some of the species are edible, $e . g ., N$. edule, being used in soups. Unof.

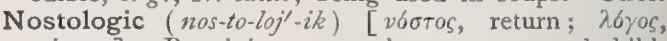
science]. Pertainirg to nostology, or to second childhood; extremely senile.

Nostology (nos-tol'-o-je) [vóstos, return; $\lambda .6 \gamma n s$, science]. In biology, the department devoted to the study of senility.

Nostomania (nos-to-ma'-nc-ah) [vóotos, return; $\mu a v i u$, madness]. Nostalgia amounting to monomania.

Nostrasia (nos-tra'-ze-ah) [nostras, of our country]. Nostalgia.

Nostril (nos'-tril) [A. S. nosu, nose; thyrl, to drill]. One of the external orifices of the nose. N., False, a conic, curved diverticulum or blind pouch, from two to three inches in depth, leaving the nostril of the horse immediately within the opening, and lying in the notch formed between the nasal and premaxillary bones.

Nostromania (nos-tro-ma'-ne-ah). Same as Nostomania.

Nostrum (nos'-trum) [noster, ours]. Any quack medicine or cure-all; any proprietary medicine.

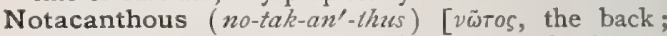

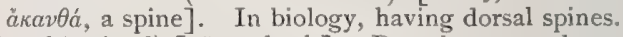

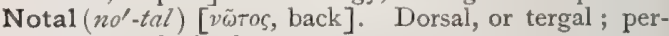
taining to the back.

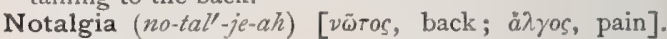
Any pain in the back.

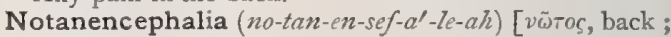

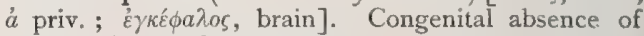
the dorsal part of the cranium.

Notaspis (no-tas'-pis) [v̈̈Tos, the back; áris, shield]. In embryology, the germ-shield or dorsal area of the embryo, in which appears the primitive furrow.

Notate $\left(n o^{\prime}\right.$-tât $)$ [notatus, p.p. of notare, to mark]. In biology, marked, spotted, variegated.

Notch [an assibilated form of nock]. An indentation, especially on the circumferential edge of a bone. N., Acetabular. See Cotyloid. N. of the Cerebellum, the depression between the two hemispheres of the cerebellum, anteriorly and posteriorly. N., Coraco-scapular. See $N$., Supra-scapular. N. Cotyloid. See Cotyloid. N., Ethmoid, the notch separating the two orbital plates of the frontal bone. It is occupied by the cribriform plate of the ethmoid. N., Great Sciatic. See N., Ischiatic. N., Interclavicular. Synonym of N., Suprasternal. N., Intercondyloid. See Intercondyloid Fossa. N., Intervertebral, any one of the depressions on the vertebral pedicles, either on the upper or lower surface. The apposition of two notches of contiguous vertebre, forms the intervertebral foramen. N., Ischiatic, the notch in the ischium that is converted into a foramen by the ischiatic ligaments. N., Jugular, a notch forming the posterior boundary of the jugular foramen. N., Lantermann's, the appearance of the internodal segments of the nerve-sheath under the influence of certain reagents, dividing the same into strips obliquely cut at the ends. N., Lesser Sciatic, a notch below the spine of the ischium over which the tendon of the obturator internus muscle passes. N., Nasal, an uneven interval between the internal angular processes of the frontal bone, which articulates with the nasal 
bone and the nasal process of the superior maxillary bone. N., Popliteal, the depression on the posterior surface of the head of the tibia, separating the two tuberosities. N., Pterygoid. Same as Fossa, Pterygoid. N. of Rivinus, the deficiency in the osseous tympanic ring filled by Shrapnell's membrane, $q . v$. N., Sacro-sciatic, See $N$., Ischiatic. N., Sigmoid, a deep semilunar depression separating the coronoid and condyloid processes of the inferior maxillary bone. N., Spheno-palatine, the notch that separates the orbital and sphenoid processes of the palate bone. N., Supraorbital. See Supraorbital. N., Suprascapular, a notch on the superior border of the scapula at the base of the coracoid process, for the passage of the suprascapular nerve. N., Suprasternal, the depression at the top of the manubrium, between the two sterno-clavicular articulations.

Note $(n \overline{0} t)[n o t a$, a mark]. A sound. N., Percussion, the sound elicited on percussion.

Notencephalia (nöt-en-sef-a'-le-ah). See Notencephalus.

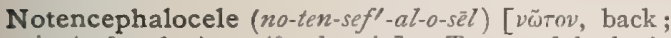

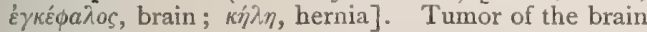
in a notencephalus.

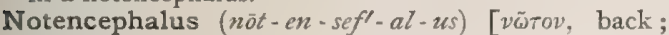
$\dot{\varepsilon} \gamma \kappa \hat{\varepsilon} \phi a \lambda \hat{n} \varsigma$, brain]. A variety of single autositic monsters of the species exencephalus, in which the cranial contents are in large part outside of the skull, resting upon the back of the neck like a huge "waterfall," but not adherent. Hydrocephalus, to some degree, is almost always present. The cranium is misshapen, the forehead sloping backward, and the eyes are directed upward and stand out prominent]y.

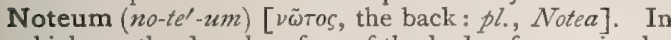
biology, the dorsal surface of the body of an animal.

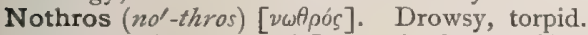

Notochord (no'-to-kord) [ A cellular cord inclosed in a structureless sheath, which in the embryo represents the vertebral column, the chorda dorsalis, or primitive backbone. Also, incorrectly the spinal cord.

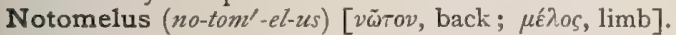
A form of double monster in which the rudimentary limbs are attached to the back.

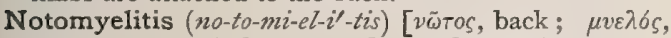
marrow; $\iota \tau / S$, inflammation]. Inflammation of the myelon, or spinal cord.

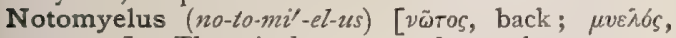
marrow]. The spinal marrow; the myelon.

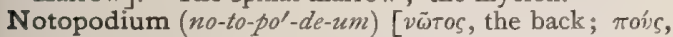
foot]. In biology, one of the dorsal oars or double foot-stumps of certain worms. See Parapodium.

Notopsyche (no-top-si'-ke) [vётos, back; $\psi v \chi^{\prime}$, soul]. Hæckel's term for the spinal cord, or myelon.

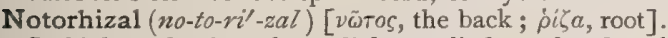
In biology, having the radicle applied to the dorsal part of the cotyledons : incumbent.

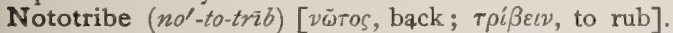
In biology, applied to flowers so arranged that the pollen comes in contact with the back of a visiting insect. Cf. Pleurotribe, Sternotribe.

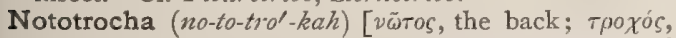
a wheel]. In embryology, a form of segmented chrtopod larva in which the segments of the body bear half-rings of cilia on the dorsal surface.

Nottingham System. See Servage, Disposal of.

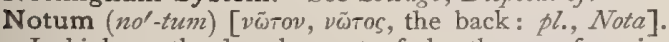
In biology, the dorsal aspect of the thorax of an insect. Cf. Pronotum, Mesonotum, Metanotum.

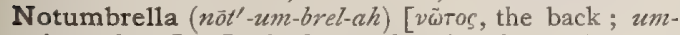
bra, shade]. In biology, the dorsal ectoderm or chrotal epithelium of medusæ.
Novacula (no-vak'-u-lah) [novare, to make new]. A razor; a surgeon's knife.

Noxa $\left(n o k s^{\prime}-a h\right)$ [L.]. An injurious principle; especially a pathogenic microörganism, or other materies mor.bi

Noxious (noks'-yus) [noxius, harmful]. Harmful; poisonous or deleterious. "N. Thing," in forensic medicine anything administered to a person that is harmful in its effects; especially applied to the production of abortion.

Noyes' Method. See Treatment, Methods of.

Nubecula (nu-bek'-u-lah) [dim. of nubes, a cloud]. I. The cloudiness caused by the suspension of insoluble matter in the urine. 2. A cloudiness of the cornea.

Nubile (nu'-bil) [nubilis; nubere, to marry]. Marriageable. Of an age at which there exists the possibility of procreation or child-bearing.

Nubility (nut-bil'-it-e) [nubilitas, from nubere, to marry]. The state of development marked by ability to consummate marriage.

Nucament (nu'-kam-ent) [nucamentum, anything shaped like a nut]. In bjology, an ament or catkin.

Nucellus (nu-sel'-us) [nucella, a little nut: pl., Nucelli ]. In biology, that part of the ovule in which the embryo-sac arises; the equivalent of the macrosporangium of cryptogams.

Nuces $\left(n u^{\prime}-s \bar{e} z\right)$. Plural of $N u x, q . v$.

Nucha $\left(n u^{\prime}-k a h\right)[\mathrm{L}$.$] . The nape of the neck.$

Nuchal $\left(n u^{\prime}-k a l\right)$ [nucha, nape of neck]. Pertaining to the nucha, or nape.

Nuchalalgia (nu-kal-al'-je-ah). Synonym of Nuchalgia.

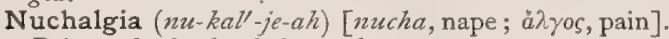
Pain at the back of the neck.

Nuciform (nu'-sif-orm) [nux, a nut; forma, form]. In biology, nut-shaped.

Nucite (nu'-sit), $\mathrm{C}_{6} \mathrm{H}_{12} \mathrm{O}_{6}+4 \mathrm{H}_{2} \mathrm{O}$. A carbohydrate resembling inosite, found in the leaves of Juglans regia.

Nuck, Canal of. See Canal. N.'s Diverticulum. Same as N., Canal of. N.'s Glands. See Gland.

Nucleal, Nuclear (nu'-kle-al, nu'-kle-ar) [nucleus, a cell]. Pertaining to or resembling a nucleus; endoplastic. N. Figures, the peculiar arrangement of the mitome during karyokinesis. N. Layer, a stratum of gray matter in the cortex of the brain. N. Paralysis, paralysis from lesions of nuclei or centers. N. Spindle, delicate striæ appearing in the nucleus undergoing mitosis and arranged in the shape of a double crux with the apices pointing toward the poles of the future nuclei. Its function probably is to guide the movements of the mitome threads. N. Stain, a pigment showing a relatively strong affinity for nuclei. A Direct Nuclear Stain is one that colors nuclei so quickly as to require no subsequent treatment to differentiate them from the plasma. An Indirect Nuclear Stain is one that colors the entire tissue, but in order that the nuclei may be differentiated, the color must be removed from the plasma. The more important nuclear stains are:-Bismarck Brown, Carmin, Cochineal, Fuchsin, Gentian-violet, Hematoxylin, Hoffman's Blue, Methylene-blue, Methyl-green. See Stain, Plasmatic Stain, Specific Stain, Stains, Table of, and Pigments, Conspectus of. N. Substance. See Heredity.

Nucleate, Nucleated ( $\left.n u^{\prime}-k l e-\bar{a} t, n u^{\prime}-k l e-a-t e d\right)$ [nucleus, nucleus]. Having a nucleus.

Nuclei (nu'-kle-i) [L. ]. Plural of Nucleus, q. v. N. of the Thalamus, the three portions into which the cinerea of the thalamus is separated. They are called the anterior, internal, and external nuclei.

Nucleic Acid. Altmann's name for an organic phos- 
phorus-containing acid, the chief product obtained by analysis of nuclein. Kossel's formula is $\mathrm{C}_{30} \mathrm{H}_{52} \mathrm{~N}_{\mathrm{g}}$ $\mathrm{P}_{3} \mathrm{O}_{17}$. Nucleic acid occurs free in the heads of the spermatozoa and contains no sulphur.

Nucleiform (nu'-kle-if-arm) [nucleus, nucleus; forma, form]. Resembling a nucleus.

Nuclein (nu'-kle-in) [nucleus, nucleus]. A compound of proteid substances with nucleic acid, obtained by means of artificial digestion, by Horbaczewski, Miescher, Plosz, Geohegen, Hoppe-Seyler, Lubavin, von Jaksch, Vaughan, and others, from pus-corpuscles, the spermatozoa of various animals, testicles, and thyroid gland, the yolk of hens' eggs, yeast, liver, brain, cows' milk, etc. The results of the analysis of nuclein from different sources are discordant.

\section{From Pils. \\ (Hoppe-Seyler.)}

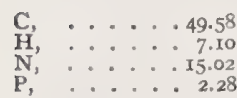

From the

Spermatozoa

(Miescher.)

36. II

5.15

13.09

9.59
From the

Human Brain.

50.06

7.60

I3. 18

1.89
Hoppe-Seyler's classification of nucleins, as modified by Halliburton, is: (I) Nucleins that contain no proteid. They are synonymous with Nucleic acid, $q . v$. (2) Nucleins rich in nucleic acid and in reaction very similar to that substance; they occur in nature in the chromatic fibers of the nucleus. (3) Nucleins that are poorer in nucleic acid; these form numerous links in a chain, which pass insensibly into those of the next group; they occur in nature in the nucleoli (pyrenin) and constitute the chief bulk of the substance called plastin. (4) Nucleins that contain very little nucleic acid; they are chiefly proteid in nature, and pass gradually toward proteids which contain no phosphorus whatever. They occur in the nuclei of cells ; it is difficult to be positive whether the nuclear matrix is composed chiefly of these or of phosphorus-free proteids ; probably both are present. They occur in milk (caseinogen), in egg-yolk (vitellin, itthulin, etc.), in aleurone-grains of plants (plant vitellin), and in cell protoplasm generally (cellnucleo-albumin). The great insolubility in alkalies that characterizes nucleins of the third group is not seen in those of the fourth. According to Horbaczewski, nuclein is the source of uric acid. Nuclein has also been proved to possess germicidal properties.

Nucleo-albumin (nu'-kle-o-al'-bu-min) [nucleus, nucleus; albumen, albumin]. One of the series of nucleins obtainable from cell-protoplasm, poorer in nucleic acid than the plastins of the nucleus. It appears to be the most constant of the proteids obtainable from cellprotoplasm, but is not confined to cells, being the chief constituent of tissue-fibrinogen. The chief proteid of milk (caseinogen), the so-called mucin of bile, and the mucinoid substance in the mucus of urine, are nucleoalbumins. Nucleo-albumin is insoluble in acetic acid, precipitable by magnesium sulphate, not reducible by prolonged heat in the presence of an acid; it is formed by the combination of nuclein and albumin in the process of digestion. It contains phosphorus. The presence of nucleo-albumin in the urine has been observed in cases of leukemia, icterus, diphtheria, and in scarlatinal and other varieties of nephritis.

Nucleochylema (nu-kle-o-ki-le'-mah) [nucleus, nucleus; $\chi v$ zós, juice]. The fluid filling the interstices of the nucleohyaloplasm.

Nucleochyme $\left(n u^{\prime}-k l e-o-k i m\right)$. See Nucleochylema.

Nucleohiston (nu-kle-o-his'-ton) [mucleus, nucleus;

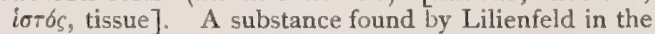
leukocytes of the blood. It is a combination of nu- clein and histon. Nuclein induces coagulation of the blood; histon prevents it. The liquid state of the blood is dependent on the integrity of the compound formed by these two bodies. Liquidity, then, is due to the leukocytes by virtue of the histon contained in them ; as is also coagulation, by reason of the contained nuclein.

Nucleohyaloplasm (nu-kle-o-hi'-al-o-plazm) [nucleus, nucleus; $v a \lambda o s$, transparent substance; $\pi \lambda a ́ \sigma \sigma \varepsilon \iota v$, to mold]. A scarcely tangible substance, which, with chromatin, makes up the threads or mitoma of the cellnucleus. See Linin.

Nucleoid (nu'-kle-oid) [nucleus, nucleus; eidos, like]. Shaped like a nucleus.

Nucleoidioplasm (nu-kle-o-id'-e-o-plazm) [nucleus, nucleus; $i \delta \iota \varsigma$, special; $\pi \lambda a ́ \sigma \sigma \varepsilon \iota \nu$, to mold]. The idio plasm of the nucleus.

Nucleolar (nu-kle'-o-lar) [nucleolus, dim. of nucleus, a nucleus]. Pertaining to the nucleolus.

Nucleolid ( $n u$-kle'-o-lid) [nucleolus, a little nucleus;

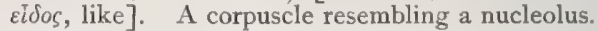

Nucleolin $\left(n u-k l e^{\prime}-o-l i n\right)$ [nucleolinus]. The nucleus of a nucleolus.

Nucleolinus (nu-kle-0.li'-nus) [nucleolus, dim. of nucleus, a little nut: $p l ., N u$ cleotini $]$. In biology, the germinal point within the germinal spot of the nuclei of certain egg-cells.

Nucleolus (nu-kle'-o-lus) [dim. of nucleus, a nucleus]. The small spheric body within the cell-nucleus. It probably plays but a subordinate part in the life-activity of the cell, although its true function has not as yet been established.

Nucleomicrosoma (nu-kle-o-mi-kro-so'-mah) [nucleus, nucleus; $\mu \kappa \kappa \sigma \delta s$, small ; $\sigma \bar{\omega} \mu \alpha$, body : pl., Nucleomicrosomata]. Any one of the many minute tangible bodies that make up each fiber of the nucleoplasm.

Nucleopetal (nu-kle-o-pet'-al) [nucleus, nucleus; petere, to seek]. Seeking the nucleus (said of the movement of the male pronucleus toward the female pronucleus).

Nucleoplasm (mu'-kle-o-plazm) [nucleus, nucleus; $\pi \lambda a \dot{\sigma \sigma \varepsilon} \iota \nu$, to mold]. The formative hyaloplasm of the nucleus; chromatin. E. van Beneden describes the nucleus of the ovum as composed of a membrane within which is a network of chromatin, containing in its meshes a fluid substance. The whole of this mass he calls the nucleoplasm, composed of : $\mathbf{1}$. An achromatic substance in fine moniliform filaments. 2. A chromatic substance permeating the whole. He supposes each fiber to consist of minute bodies, readily stained, called Nucleomicrosomata. Strasburger describes a nucleus as consisting of Nucleoplasm (or Karyoplasma) in which there are two matters, the nucleomicrosomata, taking up pigment, and the nucleohyaloplasm, not stained.

Nucleoplasmatic, Nucleoplasmic (nu-kle-o-plazmat'-ik, mu-kle-o-plaz'-mik) [nucleus, rucleus; $\pi \lambda \dot{a} \sigma$ $\sigma \varepsilon \imath \nu$, to mold]. Relating to nucleoplasm.

Nucleoplastic (nu-kle-o-plas'-tik). Synonym of $N u$ cleoplasmatic.

Nucleus (nu'-kle-us) [nucleus, from nux, nut]. The essential part of a typical cell, usually round in outline, and situated near the center. The center around which the mass of a crystal aggregates; also, the central element in a compound, as the carbon in hydrocarbons. In physiology, the controlling or motor center of a muscle or organ; also, the deep origin (nidus or nidulus) of a nerve. N. ambiguus, N., Anterior, a center near that of the vagus. N. amygdalæ, an irregular aggregation of cinerea situated at the apex of the temporal lobe of the brain, between it and the apex of the middle ventricular hora; it lies ventrad of the lenticula. N., Amygdaloid. 
See $N$. amygdala. N., Anterior (of the thalimus). See Nuclei. N., Arciform, an aggregation of nervecells in the oblongata between the pyramidal tracts and the arciform fibers. N., Arcuate, the largest of the collections of gray matter in the arciform fibers of the pyramidal tracts. N., Balbiani's, a nucleus supposed to be present in all ova, in addition to the germinal vesicle. Its function is to be the separation of the contents of the ovum into a germinal part and a nutritive portion. N. of Bechterew, an ill-defined group of ganglion-cells lying dorsad of Deiters' nucleus, and supposed to give origin to some of the fibers of the middle root of the auditory nerve. It is also called the nucleus vestibularis. N., Burdach's. See $N$. funiculi cuneati. N., Caudal. See $N$. Oculo-motor. N., Caudate. See Caudatum. N., Caudo-ventral. See $N$., Oculo-motor. N. cerebelli, the corpus dentatum, $q . v$. N., Cervical, an accumulation of nerve-cells in the upper part of the spinal cord, opposite the third and fourth cervical nerves, N. cinereus, a term sometimes used to des'ignate the gray substance of the restiform bodies. N., Cleavage. Synonym of $N$., Segmentation. N., Daughter. See Mitosis. N., Deiters'. See $N$. magno-cellularis. N., Dental. the dental papilla. N. dentatus, a nucleus located in the mesal part of the corresponding cerebellar hemisphere, in the direct prolongation of the prepeduncle which enters it, and very close to the roof of the fourth ventricle. It is composed of a folded lamina of cinerea, convoluted like the similar nucleus of the olive, and is open cephalo-mesad. N. de reliquat, a granular body associated with the sickle-shaped rods in coccidia. $\mathbf{N}$. emboliformis, a small mass of gray matter situated in the interval between the $N$. dentatus and $N$. fastigii, and lying nearer the former. It is elongated cephalo-caudad, and is probably an accessory detachment of the $N$. dentatus. N. fastigii, the Fastigatum; a flat expanse of gray matter on each side of the inferior vermis cerebelli, directly over the roof of the fourth ventricle. N. fimbriatus. Synonym of Corpus dentitum. N. funiculi cuneati, a mass of gray matter in the posterior column of the oblongata, lying beneath the funiculus cuneatus. N. funiculi gracilis, an elongated club-shaped mass of gray matter in the mesal portion of the posterior column of the oblongata. N. funiculi teretes, a distinct accumulation of small nerve-elements, closely crowded, found on either side of the sulcus ventriculi of the oblongata. Its relations are unknown. N., Germinal, the nucleus resulting from the union of the male and female pronuclei. N., Gingival, a part of the cerebellum in the fetus (between the third and fourth months), which bears some resemblance to the gums. N., Globic, N. globosus, the globulus, a number of small round or oval masses of cinerea situated in the interval between the $N$. dentatus and $N$. fastigii, lying near to and probably an accessory detachment of the latter. $\mathbf{N}$. gracilis, a column of cinerea in the clava or posterior pyramid of the medulla oblongata. N., Gray, the cinerea of the spinal cord. N., Intraventricular, the caudatum. N., Kölliker's, the cinerea surrounding the canal of the myel (spinal cord). N., Laryngeal, the nucleus of origin of the nerve-fibers of the larynx. N. of Laura, the external auditory nucleus of nervecells. N., Lenticular, N. lentiformis, a cluster of cinerea of the striatum. N. of Luys, an almondshaped mass of cinerea with pigmented ganglion-cells in the regio subthalamica. N. magno-cellularis, Deiters' Nucleus; a nucleus of cinerea in the oblongata, situated mesad of the rostiform column at the level entry of the auditory nerve-roots. It is proba- bly a station for a spinal tract. N., Medullary, any circumscribed collection of white matter in the central nervous system. N., Mother. See Molher-star, under Karyokinesis. N., Motor, a collection of nerve-cells in the central nervous system giving origin to a motor nerve. N., Oculo-motor, the nucleus of the oculo-motor nerve, lying dorsad of the posterior longitudinal bundle, under the aqueduct of Sylvius. N., Olıvary. See Dentoliva. N. of Origin, the collection of ganglion-cells in the central nervous system giving origin to a nerve. $\mathbf{N}$. of Pander, the upper expanded end of the flask-shaped mass of white yolk in the hen's egg. N., Post-pyramidal. See $N$. funiculi gracilis. N. pulposus, the pulpy substance in the center of the intervertebral discs, the remains of the notochord. $\mathbf{N}$. pyramidalis, the inner accessory olivary nucleus. $N$. quintus, the nucleus of the fifth or trigeminal nerve, N., Red. See $N$. tegmenti. N., Restiform, the gray matter of the restiform body. N., Roof. Synonym of $N$. tegmenti. N. ruber. See $N$. tegmenti. N., Segmentation, the nucleus that appears shortly after the fusion of the male and female pronuclei, the last step in the process of fertilization; it is so called because within it cleavage is first established. N., Spermatic. Synonym of the male pronucleus. N., Stilling's. Synonym of $N$. tegmenti. N., Subependymal, the internal nucleus of the eighth or auditory nerve, lying just beneath the ependyma of the metacele. N., Tectorial Cerebellar. Synonym of $N$. tegmenti. N., Tegmental, N. tegmenti, Red Nucleus; a nucleus with a reddish tinge and a round or oval outline, situated in the isthmus at those section-levels where the ganglion of Soemmering has its greatest extent. N., Vesicular, a rather large nucleus, the membrane of which stains deeply, while the central portion re. mains relatively pale. N. vestibularis. See $N$. of Bechterew. N., Vitelline, a nucleus resulting from the fusion of the male and female pronuclei within the vitellus. N., Westphal's, the nucleus of origin of a part of the trochlear fibers; it is situated posteriorly to the trochlear nucleus proper. N., White, the white substance of the dentate body of the olive.

Nuculanium (nu-ku-la'-ne-um) [nucula, a little nut: pl., Nuculania]. In biology, a fruit like the medlar, containing several nut-like seeds or carpels.

Nucule (nu'-kül) [nucula, a little nut]. In biology, the female organ of Characea.

Nude (nüd) [mudus, naked]. Naked; bare. In biology, destitute of hairs, leaves, feathers, and similar dermal appendages.

Nudibrachiate (nu-de-br'a'-ke-āt) [mudus, naked; brachium, the forearm]. In biology, having naked arms, or non-ciliated tentacles.

Nudibranchiate (nu-de-brang'-ke-āt) [nudus, naked; branchia, gills]. See Gymnobranchiate.

Nudicaudate (nu-dik-aw'-dāt) [nudus, naked; cauda, a tail]. In biology, having a bairless tail.

Nudicaul (nu'-dik-awl) [nudus, naked; caulis, stem]. In biology, having leafless stems.

Nudiflorous (mu-dif-lo'-rus) [mudus, bare; flos, a flower]. In biology, having flowers destitute of hairs, glands, etc.

Nudifolious (nu-dif-o'-le-us) [nudus, bare; folium, a leaf. Having smooth leaves.

Nudil ( $\left.n u^{\prime}-d i l\right)$ [origin obscure]. An old name for a medicated pledget, or dossil of wool, lint, or cotton.

Nudiped ( $n u^{\prime}$-dip-ed) [nudus, naked; pes, foot]. In biology, having naked feet.

Nudirostrate (nu-de-ros'-trät) [nudus, naked; rostrum, beak]. In biology, having a naked rostrum, as a hemipterous insect. 
Nudiscutate (nu-dis-ku'-tät) [nudus, naked; scutum a shield]. In biology, having a naked scutellum.

Nuel's Space. In the ear, a triangular space lying between the outer hair-cells and the slanting outer rods of Corti. It is roofed over by the lamina reticulata.

Nuhn's Glands. See Gland.

Nuisance (nu'-sans) [ME., muisance, nuisance]. In medical jurisprudence, that which is noxious, offensive, or troublesome; applied to persons or things.

Nuke $(m u k)$ [Fr., nuque, the neck]. The nape of the neck. N.-bone, the basi-occipital bone.

Nullipara (nul-ip'-ar-ah) [nullus, none; parere, to bring forth]. A woman who has never borne a child.

Nulliparity (nul-ip-ar'-it-e) [mullus, none; parere, to bring forth]. The condition of being nulliparous.

Nulliparous (nul-ip'-ar-us) [nullus, none; parere, to bring forth]. Applied to a woman who has not borne a child.

Numb (num) [ME., nome, taken]. Having impaired sensibility

Number Six. See Hot Drops.

Numbering of Teeth; Fingers and Toes; Series. See Teeth; Fingers and Toes; Series, Numbering of.

Numbness (num'-nes) [ME., nome, taken]. Partial, or local anesthesia with torpor; deficiency of sensation; obdormition.

Nummiform (num'-if-orm) [nummus, a coin; forma, form ]. Having the form of a coin; nummular.

Nummular (num'-u-lar) [nummus, coin]. Resembling a small coin in form; also, resembling rouleaux, or rolls of coins; applied to the red globules of the blood; or the rounded clots of sputum sometimes observed in pulmonary tuberculosis.

Nuptiality (nup-she-all-it-e) [nuptial, nuptial]. The proportion of marriages to the population.

Nurse (ners) [Fr. nourrice, nurse]. The caretaker of an infant. Also, a person caring for the sick. N. Dry, one who does not suckle the infant. N., Hospital, one who cares for the sick in a hospital. N. Monthly, one who attends a woman in confinement. N., Probationer, in hospitals a probationer is one who has entered upon her career as a nurse, and is under observation to determine her fitness for the profession. N., Professional, one who devotes himself or herself to the care of the sick as a life-work or profession. N., Wet, one who suckles the infant. N.'s Contracture, 'Trousseau's term for tetany found in association with debility following lactation.

Nursing (ners'-ing) [Fr., nourrice, a nurse]. A term applied to the babe's taking the breast, and also to the mother's giving the breast. Also, caring for the sick. N.-bottle, a bottle fitted with a rubber tip or nipple for feeding infants not nursed from the breast.

Nursling (ners'ling) [Fr., nourrice, a nurse]. An infant that is nursed.

Nurture (ner-tīr) [ME., norture, nurture]. I. Nourishment; food. 2. The act of supplying with nourishment. 3. To feed or nourish.

Nussbaum's Method. See Anesthetic. N.'s Mixture. See Anesthetic. N.'s Narcosis, the condition of prolonged anesthesia induced when the administration of chloroform is preceded a few minutes by the hypodermatic injection of a full dose of morphin. N.'s Theory of Germinal Continuity, the hypothesis that some of the germ-substance is directly abstracted from the developing ovum and preserved without essential alteration, to become, by giving rise to the sexual elements, the germ-substance of another generation. See Heredity.
Nut [ME., nutte, nut]. See Nux. N.-bone, a sesamoid bone in the foot of a horse. N.-gall. See Galle. N.-meg. See Myristica. N.-meg Liver, a mottled appearance of the liver, the center of the acini being dark, while the periphery is lighter in color. The condition is seen especially in passive congestion and in fatty infiltration.

Nutant $\left(m t^{\prime}-\tan t^{\prime}\right)$ [nutare, to nod with the head]. In biology, drooping, or sloping.

Nutation (nu-tu'-shun) [nutare, to nod]. Nodding or oscillation. In biology, the same as Circummutation. $\mathbf{N}$. of Sacrum, a partial rotation of the sacrum on its transverse axis, whereby the distance between the upper extremity or the lower extremity and the anterior pelvic wall is increased.

Nutator (nu-ta'-tor) [nutare, to nod]. A muscle causing anterior flexion of the head.

Nutatory (mi'-tat-or-e) [nutare, to nod]. In biology, nodding.

Nutriant (nu' tre-ant) [nutrive, to nourish]. A medicine or agent that modifies nutritive processes.

Nutrient (nu'-tre-ent) [nutrire, to nourish]. 1. Affording nutrition. 2. A substance that nourishes; a food.

Nutrility (nu-tril'-it-e) [nutrire, to nourish]. The power of a cell or an organism to take part in the function of nutrition; metabolism.

Nutriment (nu'-trim-ent) [nutrimentum, from nutrire, to nourish]. Anything that nourishes or enters into the formation of living tissue.

Nutrition (nu-trish'-un) [nutrire, to suckle]. The most important of the vital functions, the anabolic process, or the molecular renovation of living protoplasm. N., Centers of, points held by Goodsir to exist in the basement-membrane of mucous membranes.

Nutritious (nu-trish'-us). Synonym of Nutritive.

Nutritive (nu'-trit-iv) [nutrire, to nourish]. Possessing the quality of affording nutrition.

Nutritorium (nu-trit-o'-re-um) [nutrive, to nourish]. The nutritive apparatus, or that part of the organism that is directly concerned with anabolic changes.

Nutritory (nu'-trit-o-re) [nutrive, to nourish]. Concerned in the processes of nutrition.

Nutrix (nu'-triks) [L. : pl., Nutrices]. A female nurse, especially a wet-nurse.

Nuttall's Method. See Sprtum, Methods of Examination

Nux (nuks) [L.]. A nut. N. moschata [L., "musky nut" ]. The nutmeg: myristica. N. vomica, dogbutton; the seed of Strychnos nux vomica. Its properties are due mainly to two alkaloids, strychnin and brucin, and with the properties of which its own properties are identical. In small doses it is a bitter tonic, exciting the secretions and stimulating the functions of the body. In larger doses it exalts the function of the spinal cord, causing tetanic spasms of the extensor muscles. In toxic doses it paralyzes the functions of the spinal cord, arrests respiration and causes death by suffocation. It is valuable as a general tonic in cardiac failure, in hemiplegia, dyspnea and in certain forms of amblyopia. The proportion of strychnin in nux vomica varies from $\frac{1}{5}-\frac{1}{2}$ per cent. N. v., Abstractum. Dose gr. 1/2, gradually increased. Unof. N. v., Ext. Dose gr. 1/8-j. N. v., Ext., Fld. Dose $m_{j}-v$. N. v., Tinct., 2 per cent. of the drug. Dose $\eta_{v} \times x$. Brucina, $\mathrm{C}_{23} \mathrm{H}_{26} \mathrm{~N}_{2}$ $\mathrm{O}_{4}, \frac{2}{2}$ the strength of strychnin and in action onethird as rapid. Dose gr. $\frac{1}{1} \frac{1}{3}$. (Unof.) Liquor brucinz, I per cent. Dose $m x$. Strychnina, strychnin, $\mathrm{C}_{21} \mathrm{H}_{22} \mathrm{~N}_{2} \mathrm{O}_{2}$, the alkaloid, exceedingly bitter; chloroform is its best solvent. Dose gr. $\frac{1}{60}-\frac{1}{2}$. S. Sulphate $\left(\mathrm{C}_{21} \mathrm{H}_{22} \mathrm{~N}_{2} \mathrm{O}_{2}\right)_{2} \mathrm{H}_{2} \mathrm{SO}_{4} 7 \mathrm{H}_{2} \mathrm{O}$, 
O. The chemic symbol of Oxygen. The symbol of Oculus, eye. It is also used in prescriptions as the abbreviation of Octarizes, a pint.

O. D. Abbreviation for oculus dexter, right eye.

Oph. An abbreviation sometimes employed for ophthalmia, ophthalmoscope, and ophthalmoscopy.

Oaf (of) [AS., clf, elf ]. An idiot, or underwitted person.

Oak $(\bar{o} k)$ [ME., oke, oak]. A tree or shrub of the genus Quercus, $q . v$. O.-bark, an important tannincontaining material used in leather-manufactures. It is taken from the common English oak (Quercus robur), and contains from twelve to fifteen per cent. of tannic acid. It produces an excellent quality of leather. Other varieties in use are $Q$. coccifera, of which the bark, known as coppice-oak, is yellowishbrown in hue and very rich in tannin; $Q$. suber (or cork-oak), and $Q$. ilex (or evergreen-oak). The tannin of the several varieties of oak is known as quercitannic acid, $\mathrm{C}_{17} \mathrm{H}_{16} \mathrm{O}_{9}$. In addition to this acid the main constituents of oak-bark are: the first anhydrid of this acid, phlobaphene, $\mathrm{C}_{34} \mathrm{H}_{30} \mathrm{O}_{17}$; its second anhydrid, $\mathrm{C}_{34} \mathrm{H}_{28} \mathrm{O}_{16}$; its third anhydrid, Oser's oak-red, $\mathrm{C}_{34} \mathrm{H}_{26} \mathrm{O}_{15}$; and its fourth anhydrid, Löwe's oak-red, $\mathrm{C}_{34} \mathrm{H}_{24} \mathrm{O}_{14^{*}}$ Of these, the quercitannic acid and the phlobaphene are especially concerned in the tanning process. O.-bark (Quercus alba, U.S. P., Quercus cortex, B.P.) is an astringent tonic mostly employed in washes and decoctions for external use. The official species in the U.S. is Q. alba; in Gr. Britain, Q. robur.

Oakum $\left(o^{\prime}-k u m\right)$ [ME., ocumbe, tow]. The fiber obtained by picking old rope into pieces. Oakum, variously medicated, is used to some extent in surgical dressings.

Oamma $\left(0-a m^{\prime}-a h\right)$ [ $\omega \alpha \mu \mu \alpha$, from oṽs, ear]. Hearing; ear.

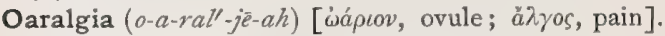
Ovarian neuralgia.

Oaria $\left(o-\alpha^{\prime}-r e-a h\right)$. Plural of Oarium, q.v.

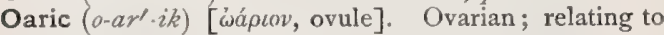
the oaria.

Oariocele $\left(o-a^{\prime}-r e-o-s e ̄ l\right)$ ['́ápıov, ovule ; $\kappa \dot{n} \lambda \eta$, tumor]. Hernia involving an ovary.

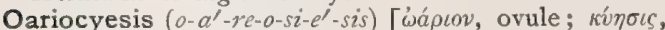
pregnancy]. Ovarian pregnancy.

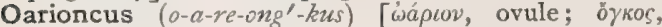
tumor]. An ovarian tumor.

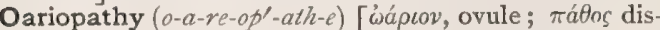
ease]. Any ovarian disease.

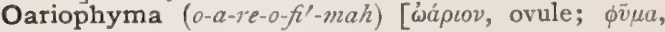
tumor]. Same as Oarioncus.

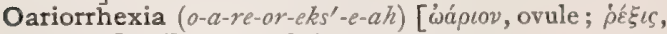
rupture]. Rupture of the ovary.

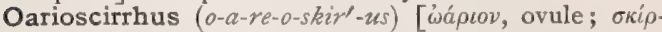
$\rho \circ$, hard]. Scirrhus of the ovary.

Oariosteresis $\left(o-a-r e-o-s t e r-e^{\prime}-\right.$ sis $)$ [ ¿áa

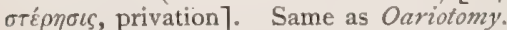

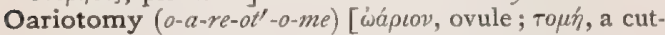
ting]. Surgical removal of an ovary.

Oaritis $\left(0-a-r i^{\prime}-t i s\right)$ [ $\omega a ́ \rho \iota \nu$, ovule; $\iota \tau \iota \zeta$, inflammation]. Inflammation of an ovary.

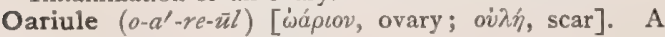
corpus luteum.

Oarium $\left(o-a^{\prime}-r e-u m\right)$ [ஸ́ápıov, ovule: pl., Oaria]. See Ovarium.

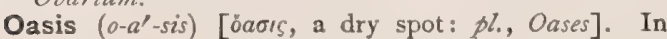

surgery, an isolated spot of healthy tissue surrounded by diseased tissue

Oat (ot) [ME., ote, oat]. A cereal plant, Avena sativa, and $A$. orientalis, or its seed. Oats are used mainly as food for horses, although they are being largely used as food by man in the United States and other countries. See Avena. O.-malt, malt made from oats. O.-meal, the meal made from oats. The proximate analysis of oat-meal gives fat, 7.74 ; starch, 59.88; sugar, 1.27; albumin insoluble in alcohol, I5.66; albumin soluble in alcohol, 4.21 ; cellulose, 2.05 ; mineral matter, 1.94; moisture, 7.25. O.-m. pyrosis, a condition of fermentative dyspepsia, attended with acidity, related to the eating of oat-meal.

Ob- $[o b$, on, against, towards]. A prefix signifying on, against, or towards.

Obalinski's Method. See Anesthetic.

Obconic, Obconical $\left(o b-k o n^{\prime}-i k, o b-k o n^{\prime}-i k-a l\right)[o b$,

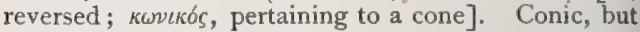
with the point of attachment at the apex.

Obcordate $(o b$-kor'-dat') [ob, reversed; corda, a heart]. In biology, inversely heart-shaped.

Obdeltoid (ob-del'-toid) [ob, reversed; delloides, deltashaped]. In biology, triangular, with the apex downward.

Obdormition (ob-dor-mish'-un) [obdormitio; obdormire, to fall asleep]. The phenomenon known as "sleep" of the limbs; the benumbing of a part due to interference with nervous function.

Obduction $\left(a b-d u k^{\prime}-s h u n\right)[o b$, against; ducere, to lead]. Post-mortem examination. Necropsy.

O'Beirne's Tube. A long flexible tube used in making rectal injections in cases of obstinate constipation.

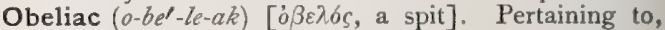
or situated near, the obelion.

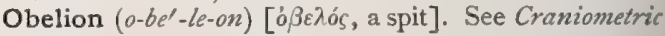
Points.

Oberst Method of Inducing Local Anesthesia. Injection of a I per cent. solution of cocain over the course of a nerve-trunk supplying the area to be attacked.

Obese $\left(o-b \bar{e} s^{\prime}\right)$ [obedere, to eat]. Extremely fat; corpulent.

Obesity $\left(o-b \bar{e} s^{\prime}-i t-e\right)$ [obesitas, from obedere, to eat]. Corpulence; polysarcia. An excessive development of fat throughout the body. Usually it occurs after the prime of life, but it may be congenital or may occur at any period of life. Ebstein's Treatment consists in reducing the quantity of food ingested, and in selecting a diet that the patient may adhere to for the remainder of life. Carbohydrates, including sugar, sweets, and potatoes, are absolutely forbidden. Bread is limited to the smallest possible quantity. All kinds of meat and vegetables are allowed, especially the leguminous vegetables, with tea, coffee, and light wines. Banting's Cure excludes almost all fats, but permits a much larger allowance of albuminous food.

Obex (o'-beks) [L., a barrier: pl., Obices]. A band of white nervous matter at the point of the calamus scriptorius.

Obfuscation (ob-fus-ka'shun) [obfuscare, to make black]. The act of darkening or of producing bewilderment of sight.

Obituary $\left(0-b i t^{\prime}-u-a-r c\right)$ [obitus, death]. Pertaining to death. A notice or account of one who has recently died.

Object $\left(o b^{\prime}-j e k t\right)$ [objectus, a casting before; from objicere, to cast before]. I. Anything that is perceived, 
known, thought of, or signified. 2. A purpose, aim, or end. O.-blindness. See Apraxia.

Objective (ob-jek'-tiv) [objicere, to throw against]. In medicine, a qualification applied to the symptoms observed by the physician, in distinction from those felt only by the patient. In psychology, pertaining to all things lying external to one's self, in contradistinction to subjective, pertaining to the essential ego, or observer. The lens of a compound microscope nearest the object viewed. O., Achromatic, the objective of a microscope in which the lenses, formed of crown-glass and flint-glass, tend to eliminate the color, or chromatic aberration. O., Adjustable, in microscopy, one in which the distance between the systems of lenses may be changed at the will of the observer. O., Aplanatic [à priv.; $\pi \lambda a v \eta$ Tós, wandering], in the microscope, an objective in which both chromatic and spheric aberration are avoided. O., Apochromatic, one in which the lenses, made of a peculiar kind of glass, admit of the combination of the rays from three spectral colors at one focus, instead of two colors, as in the ordinary achromatic objective. O., Dry, in the microscope, one in which the medium between the objective and the coverglass consists of air. O., Endomersion, a form of objective, devised by Zeuger, in which the chromatic aberration is removed by the employment of a liquid (as a mixture of ethereal and fatty oils) placed between the separate lenses. O., Homogeneous Immersion, one between which and the cover-glass a fluid of the same refractive index as glass is placed. Cedar-oil is such a fluid. O., Immersion, one in which some fluid is placed between the front of the objective and the cover-glass. O., Microscopic, the systems of lenses at the lower end of the tube near the object, giving an enlarged and inverted real image. These objectives are of two classes, Dry and Immersion. O., Non-achromatic, an objective which produces an image with a colored border. It also permits spheric aberration. O., Non-adjustable, an objective in which the relative positions of the lenses or lens-systems are fixed. O., Oil-immersion, an objective between which and the object a drop of oil is placed. Cedar-oil is most commonly employed. O., Unadjustable. See O., Non-adjustable. O., Water-immersion, an objective between which and the cover-glass water is placed as a medium.

Oblanceolate $\left(o b-l a n^{\prime}-s e-o-l a \bar{t}\right)[o b$, reversed; lanceola, a little lance]. In biology, lanceolate, with the apex downward.

Obligate $\left(o b^{\prime}-l i g-\bar{a} t\right)$ [obligatus, obligare, to oblige]. In biology, necessary, essential, constrained, bound. O. Aërobic, See Aërobic. O. Anaërobic. See Aërobic. O. Parasite, an organism which is constrained to a parasitic life for the attainment of its development.

Obligatory (ob-lig'-at-or-e) [obligare, to bind]. Compelling; binding. O. Aërobes. See Aërobic.

Oblique ( $a b-l e k^{\prime}$ or $\left.a b-l i k^{\prime}\right)$ [obliquus, oblique, slanting]. Not direct; aslant; slanting. In botany, unequal-sided. In anatomy, an oblique muscle, as the external or internal oblique of the abdomen, or the superior or inferior oblique of the eye.

Obliquity (ab-lik'-zeit-e) [obliquitas, obliqueness]. The state of being oblique. O., Naegele's, in obstetrics the lateral inclination of the fetal head, in consesequence of which the sagittal suture is directed more posteriorly. O., Roederer's, in obstetrics, the extremely flexed position of the fetal head on the body. O., Solayres's, in obstetrics, the entrance of the fetal head into the pelvic inlet in an oblique diameter.
Obliquus (ob-li'-kwus) [L., slanting]. Slanting; oblique. A term applied to various muscles. O. Muscle. See Muscles, Table of. O. Reflex. See ReAlexes, Table of.

Obliterate $\left(o b-l i t^{\prime}-e r-a t^{\prime}\right)$ [obliterare, to erase]. To wipe out. In biology, indistinct; applied to marks, spots, punctures, and strix, in animals.

Obliteration (ob-lit-er-a'-shun) [obliteratio; obliterare, to efface]. Extinction of a part; closure, as of the lumen of a passage.

Oblivion (ob-liv'-e-on) [oblivio, lethargy]. Forgetfulness; lethargy.

Oblongata $\left(o b-l o n g-g a h^{\prime}-t a h\right)$ [L.]. The medulla oblongata.

Oblongatal (ob-long-ga'-tal) [oblongata, the medulla]. Pertaining to the oblongata.

Obmutescence (ab-mu-tes'-ens) [obmutescere, to become dumb]. Aphonia; loss of voice.

Obnubilation (ob-nu-bil-a'-shun) [obnubilare, to becloud]. A beclouded state of the mind or spirit.

Obovate $\left(o b-o^{\prime}-v \bar{a} t\right)$ [ob, reversed; ovatus, egg-shaped]. In biology, inversely ovate.

Obovatifolious (ob-o-va-tif-o'-le-us) [ob, reversed; ovatus, egg-shaped; folium, a leaf ]. In biology, having inversely ovate leaves.

Obovoid $\left(a b-o^{\prime}\right.$-void $)$ [oh, reversed; orn biology, solidly obovate.

Observation $\left(o b-z e r-v a^{\prime}-\operatorname{shu}\right)$ [observatio]. The examination of a thing; a systematic study of phenomena.

Obsession (ab-sesh'-un) [obsessire, to beset]. Besetment. Possession as by evil spirits; an imperative idea; a dominant delusion.

Obsolescence (ob-so-les'-ens) [obsolescere, to grow old]. The state of becoming old or going out of use. Also, the cessation of growth.

Obsolete $\left(a b^{\prime}-s o-l \bar{e} t\right)$ [obsoletus, p. p. of obsolescere, to wear out]. In biology, indistinct, imperfectly developed or rudimentary.

Obstetric (ob-stet'-rik) [obstare, to stand before]. Pertaining to the practice of obstetrics. O. Position. See Postures, Table of.

Obstetrician (ob-stet-rish'-an) [obstare, to stand before]. One who practises obstetrics.

Obstetrics (ob-stet'-riks) [obstare, to stand before]. The care of women in pregnancy, childbirth and the puerperal state.

Obstetrix (ab-stet'-riks) [obstare, to stand before]. A midwife.

Obstipation (ob-stip-a'-shun) [obstipatio; obstipare, to close tightly]. Constipation.

Obstipitas (ob-stip'-it-as) [obstipus, awry, stiff-necked; stipes, a stick]. Wry-neck; torticollis.

Obstruction (ob-struk'-shun) [obstructio; obstruere, to stop up]. Stoppage or blocking up of a canal or opening of the body. See Imperforation, Occlusion.

Obstruent $\left(o b^{\prime}\right.$-stru-ent $)$ [obstruere, to close up]. I. Obstructive; tending to obstruct. 2. In therapeutics or pathology, any remedy or agent closing the lumen or orifice of vessels or ducts.

Obstupefacient (ob-stu-pe-fa'-she-ent) [obstupefacere, to stupefy]. Narcotic or stupefying.

Obstupescentia (ob-stu-pes-en'-she-ah) [L.]. A state of stupefaction, with a look as of astonishment.

Obtected (ob-tek'-ted) [ob, over; tegere, p. p., tectus, to cover]. In biology, concealed under a neighboring part.

Obtund (ob-tund') [obtundere, to dull]. To blunt or dull ; to lessen, as pain.

Obtundent (ob-tun'-dent) [obtundere, to make dull]. Soothing; quieting. In therapeutics, any remedy that relieves or overcomes irritation or pain.

Obtundity $\left(o b-t w n^{\prime}-\right.$ dit-e) [ob'zndere, to make dull]. 
The state of being obtunded, or dulled; diminished sensibility.

Obturator (ob'-tu-ra-tor) [obturator; obturare, to stop up]. That which closes a cavity. In surgery, an instrument for closing an opening caused by a wound or by disease. O. Artery. See Arteries, Table of. O., Dental, an instrument used in the treatment of palatine defect when operative surgical means are not applicable. O. Foramen, a foramen in the anterior part of the os innominatum. See Foramina, Table of. O. Muscle. See Muscles, Table of. O. Nerve. See Nerves, Table of.

Obturbinate $\left(o b-t e r^{\prime}-b i n-\bar{a} t\right)$ [ob, reversed; turbo, a top]. In biology, top-shaped, with the apex or pegend up.

Obtuse (ob-tüs') [obtusus, p. p. of obtundere, to blunt, dull]. Blunt.

Obtusifolious (ob-tu-sif-o'-le-us) [obtusus, blunted; folium, leaf ]. In biology, having blunt leaves.

Obtusilobous (ob-tu-sil-o'-bus) [obtusus, blunted; lobus, a lobe]. In biology, having leaves with obtuse lobes.

Obtusion (ob-tut'-zhun) [obtundere, to blunt]. The blunting or weakening of the normal sharpness or strength of sensation; a symptom of certain diseases.

Obumbrant (ob-um'-brant) [ob, over; umbrare, to shadow, shade]. In biology, overhanging

Obumbrate (ob-um'-brät) [ob, over; umbrare, to shadow ]. In biology, situated under an overhanging part.

Obuncous $\left(a b-u n o^{\prime}-k u s\right)$ [ob, against; uncus, bent in, hooked]. In biology, very crooked or hooked.

Obvallate $\left(o b-v a l^{\prime}-\bar{a} t\right)$ [obvallare, to surround with a wall]. In biology, walled in.

Obvolute $\left(o b^{\prime}-v o-l \bar{u} t\right)$ [obrolvere, to wrap]. In biology, the term applied to that form of vernation in which half of one leaf covers half of another; half-equitant.

Obvolvent (ob-vol"-vent) [obvolvere, to wrap]. In biology, curved downward or inward.

Occipital (ok-sip'-it-al) [occipitalis, occipital]. Pertaining to the occiput. O. Artery. See Arteries, Table of. $\mathrm{O}$. Bone, the bone of the skull situated at its posterior, middle, and inferior part. See Bones, Table of. O. Crest. See Crest. O. Fossa. See Fossa. O. Lobe. See Lobe. O. Nerve. See Nerves, Table of. O. Points. See Craniometric Points. O. Protuberance, the prominence on the inner surface (internal) or on the outer surface (external) of the occipital bone. O. Sinus. See Sinus. O. Triangle. See Triangles, Table of. O. Vertebra, the occipital bone, in the vertebral theory of the skull.

Occipiten (ok-sip'-it-en) [occiput, occiput]. Belonging to the occipital bone in itself.

Occipito- $\left(o k-s i p^{\prime}-i t-o-\right)$ [occiput, occiput]. A prefix to denote connection with or relation to the occipital bone. O.-atloidean, pertaining conjointly to the occipital bone and the atlas. O--axoid, or O--axial, pertaining to both the occipital bone and the axis, or second vertebra. O.-bregmatic, pertaining conjointly to the occipital bone and the bregma. O.-cotyloid, in obstetrics, a term applied to a condition in which the fetus has the occiput directed toward the acetabulum of the mother. O.-frontal, both occipital and frontal. O.-frontal Triangle. See Triangle. O.frontalis. See Muscles, Table of. O.-mastoid, relating to the occiput and the mastoid process. O.-mental, pertaining to chin and occiput. O.odontoid, pertaining to the occipital bone and the odontoid process of the axis. O.-parietal, pertaining conjointly to the occipital and parietal bones of the head. O.-posterior, in obstetrics, a term applied to the condition in which the fetus has the head directed toward the mother's sacrum. O.-sacral. Synonym of O.-posterior. O.-sternal Triangle. See Triangle.
O.-temporal, pertaining to the occiput and the temples.

Occiput $\left(o k^{\prime}-s i p-u t\right)[o b$, against; caput, the head: gen. Occipitis: pl., Occipita]. The back part of the head.

Occludent (ok-lu'-dent) [occludere, to shut up]. In biology, applied to parts that shut up or close.

Occlusio $\left(o k-l u^{\prime}-z e-0\right)$ [L.]. Closure. O. pupillz, obliteration of the pupil. O. pupillæ lymphatica, obliteration of the pupil by a false membrane.

Occlusion (ok-lu'-zhun) [occlusio; occludere, to shut up]. I. A closure, blocking or shutting up of a normally patent aperture, as of the anus or ear. A synonym of Imperforation and Obstruction. 2. In chemistry, the absorption by a metal, of gas in large quantities, as of hydrogen by platinum. 3. The full meeting of the masticating surfaces of the upper and lower teeth, in the position of rest.

Occlusive $\left(o k-l u^{\prime}-z i v\right)$ [occludere, to shut up]. Effecting an occlusion, as an occlusive dressing, in surgery.

Occlusor (ok-lu'-zor) ' [occludere, p. p. occlusus, to close up: pl., Occlusores]. In biology, an organ that closes an opening; or draws parts together.

Occult (ok-kult') [occultus, hidden]. Hidden; concealed; not evident. $O$. disease, any disease the nature of which is not readily determined.

Occupation-diseases. Those caused by or connected with the occupation of the patient, divisible into:a. Irritant, mechanic or chemic effects of materials: b. Toxic, from poisonous matter absorbed into the blood: and $c$. Fatigue, as in scrivener's palsy. 0. neurosis, a neurosis occasioned by one's employment or trade, as writer's cramp. See, also, Anapeiratic.

Ocellar (o-sel'-ar) [ocellus, a little eye]. In biology, pertaining to ocelli.

Ocellatze (os-el-at'-e) [ocellus, a little eye]. In biology, the marginal vesicles in the Leptomeduse. Cf. Ocellicyst.

Ocellate $\left(o s^{\prime}-e l-\bar{a} t\right)$ [ocellatus, having little eyes]. In biology, same as ocellated; having a colored patch like an eye, e.g., certain feathers, flowers, butterfites' wings, or fishes' fins.

Ocellated (os'-el-a-ted) [ocellus, a little eye]. Resembling or having eyes.

Ocelli $\left(o-s e l^{\prime}-i\right)$ [ocellus, dim. of oculus, an eye]. The simple eyes of insects.

Ocelliferous (os-el-if'-er-us) [ocellus, a little eye; ferre, to bear]. Same as Ocellate.

Ocelligerous (os-el-ij'-er-us) [ocellus, little eyes ; gevere, to carry]. Same as Ocellate.

Ocellus $\left(o-s e l^{\prime}-u s\right)$ [a little eye: pl., Ocelli]. In biology: $(a)$ one of the simple eyes or pigment-spots of invertebrate animals. Cf. Stemmatus; (b) one of the elements of a cornpound eye; $(c)$ one of the colored spots on many feathers, flowers, etc.

Ochema $\left(o k-\ell^{\prime}-m \alpha h\right)[\dot{o} \chi \eta \mu \alpha$, from $\dot{\chi} \chi \varepsilon i \nu$, to carry $]$. A vehicle for medicines.

Ocher, Ochre $\left(o^{\prime}-k e r\right)$ [ $\omega \chi 0 o ́ s$, pale yellow]. A name given to clay variously colored by the oxids of iron. See Pigments, Conspectus of. O.-colored Stools, a descriptive term applied to the dejecta of typhoidfever patients.

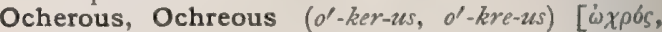
pale, wan]. In biology, brownish-yellow.

Ocheus $\left(o k^{\prime}-\ell-u s\right)$ [o $\chi \varepsilon i \nu$, to carry]. The scrotum.

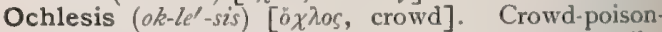
ing ; disease due to over-crowding, and lack of ventilation.

Ochletic $\left(o k-l e t^{\prime}-i k\right)\left[\delta \chi^{\lambda} n s\right.$, crowd]. Pertaining to, or of the nature of, ochlesis.

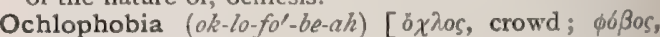
fear]. Morbid dread of crowds. 
Ochlotic $\left(o k-l o t^{\prime}-i k\right)$ [ö $\chi \lambda$ os, crowd]. Same as Ochletic. O. Fever. Synonym of Typhus Fever.

Ochopetalous $\left(0 k-o-p e t^{\prime}-a l-u s\right)$ [ö $\chi O s$, anything that holds; $\pi \varepsilon \dot{\tau} \alpha \lambda o v$, a petal]. In biology, having capacious petals.

Ochraceous $\left(o-k r a^{\prime}-s e-u s\right)$ [ $ఓ \chi \rho a$, ocher]. Ocher-colored; yellowish-brown.

Ochre $\left(o^{\prime}\right.$-ker $)$. See Ocher.

Ochriasis $\left(o-k r i^{\prime}-a s-i s\right)$ ['ंxpós, yellow]. Sallowness of complexion.

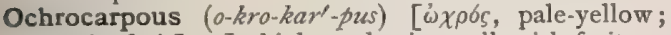
$\kappa a \rho \pi \delta$, fruit]. In biology, having yellowish fruit.

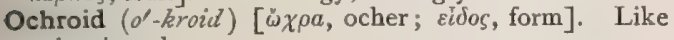
ocher in color.

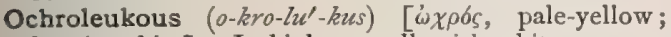
$\lambda \varepsilon$ «кóc, white]. In biology, yellowish-white.

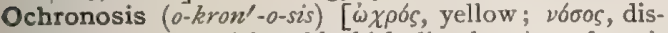
ease]. A brownish or blackish discoloration of cartilage and allied structures; it is probably an intensification of the pigmentation normally present in these structures, occurring in advanced life.

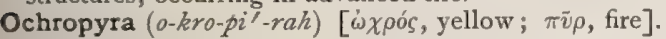
Yellow fever.

Ochthe $\left(o k^{\prime}-t h e\right)[\check{o} \chi \eta \eta$, a bank $]$. The edges of an ulcer.

Ochthiasis (ok-thi'-as-is). Synonym of Molluscum.

Ocrea $\left(o k^{\prime}-r e-a h\right)$ [L., a greave: $p l$., Ocrea]. In biology, a sheath formed about the stem by one or both stipules.

Ocreate $\left(\bar{o} k^{\prime}-r e-\bar{a} t\right)$ [ocrea, a greave]. In biology, having a stipular sheath.

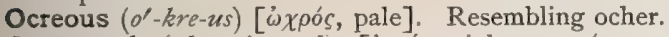

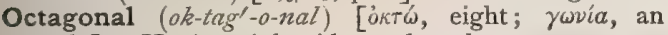
angle]. Having eight sides and angles.

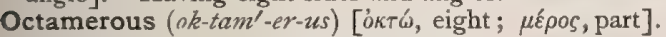
In biology, having the parts in eights.

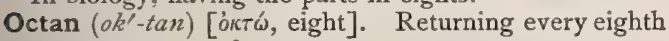
day, as an octan fever.

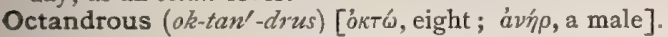
In biology, having eight stamens.

Octane $\left(a k^{\prime}-\tan n\right)$ [okT'́, eight], $\mathrm{C}_{8} \mathrm{H}_{18}$. The eighth member of the paraffin or marsh-gas series. See $H y$ drocarbons, Table of.

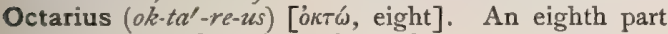
of a gallon. One pint. Symbol $O$.

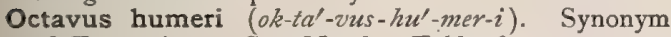
of Teres minor. See Muscles, Table of.

Octo- $\left(o k^{\prime}-t o-\right)$ [óर $\omega$, eight]. A prefix denoting reference to the number eight.

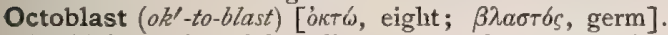
In biology, the eight-celled stage of a segmenting ovum.

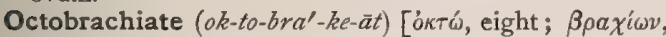
the arm]. In biology, having eight tentacles, rays, arms or brachia.

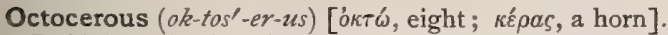
In biology, having eight horns, tentacles, rays or arms.

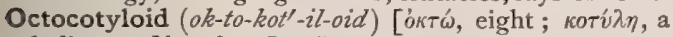
hollow; عidos, form]. In biology, having eight fossettes or bothria.

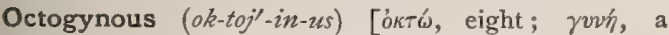
female]. In biology, having eight pistils.

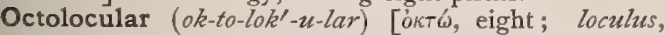
dim. of locus, a place, cell]. In biology, having eight cells.

Octonemal, Octonematous (ok-to-ne'-mal,ok-to-nem'at-us) [okTb, eight; $v \tilde{\eta} \mu c$, thread]. In biology, having eight filamentous organs or appendages.

Octonocular (ok-ton-ak'-u-lar) [okTb, eight; oculus, eye]. In biology, eight-eyed.

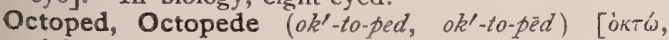
eight; pes, foot]. In biology, an eight-footed creature.

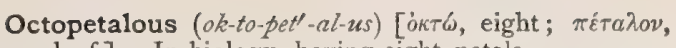
a leaf ]. In biology, having eight petals.

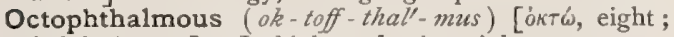
$\dot{o} \phi A a \lambda \mu o ́ s$, eye]. In biology, having eight eyes.

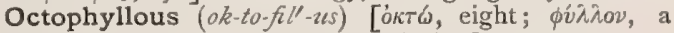
leaf ]. In biology, having eight leaflets.

Octoradial (ok-to-ra'-de-al) [okTw, eight; radius, ray]. Same as Octoradiate.

Octoradiate (ok-to-ra'-de-āt) [ókTh, eight ; radius, ray]. In biology, having eight rays.

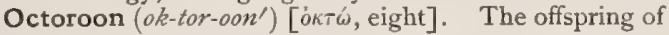
a white person and a quadroon.

Octosepalous (ok-to-sepp'-al-us) [ótw, eight ; sepalum, a sepal]. In biology, having eight sepals.

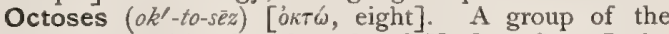
glucoses with the formula $\mathrm{C}_{8} \mathrm{H}_{16} \mathrm{O}_{8}$. See Carbohydrates, Table of.

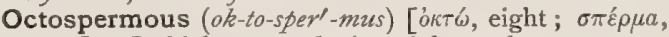
seed]. In biology, producing eight seeds.

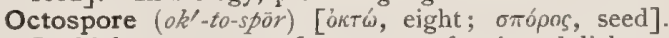
In biology, a spore from many fungi and lichens, the asci of which produce eight spores each.

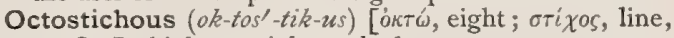
row]. In biology, eight ranked.

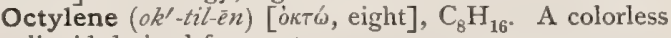
liquid derived from octane.

Ocular $\left(o k^{\prime}-u\right.$-lar $)$ [oculus, the eye]. I. Pertaining to the eye. 2. An optic combination that refracts the diverging rays forming the real object-image so that they may pass through the pupil of the observer's eye ; the eye-piece of a compound miscroscope. Like the simple microscope, it also forms a virtual or magnified image of the real image. O., Campani's. See O., Huygenian. O. Cleft. See Cleft. O., Compensating, an ocular specially constructed for use with the apochromatic objective. It serves to correct or compensate for aberrations in the objective outside the axis. O. Cup. See Optic. O., Erecting, one that is provided with an erecting prism and gives an erect image of the object. $\mathbf{O}$., Huygenian, one that consists of two plano-convex lenses, the convexities being directed toward the objective. The lower and larger lens is the field-lens ; the upper and smaller is the eye-lens. O., Kellner's. See O., Orthoscopic. O., Micrometer, is an ocular with which is connected a micrometer for the purpose of measuring the real image of the object. O. Micrometer Ratio. See Ratio. O. Muscles, External, the six muscles moving the globe of the eye. See Muscles, Table of. $\mathbf{O}$. Muscles, Internal, the ciliary muscle and the iris. O., Negative, an ocular in which the real image formed by the objective lies somewhere between the two lenses or lenssystems forming the ocular. O., Orthoscopic, one that consists of a bi-convex field-glass and an achromatic double meniscus (bi-convex and bi-concave) eye-lens. Os., Parfocal, oculars of different powers which may be interchanged without putting the image wholly out of focus. O., Periscopic $[\pi \varepsilon \rho i$, around; $\sigma \kappa \circ \pi \varepsilon \tilde{\varepsilon}$, to look]; a positive ocular devised by Gundlach; it has a double convex field-lens and a triplet eye-lens. O., Positive, one through which the real image is formed outside of the ocular, and is magnified by the entire system of ocular lenses like a simple microscope. O., Projection, an ocular especially designed for projecting the image formed by an objective on a screen for class-demonstration, or for photography. O., Ramsden's, an ocular consisting of two plano-convex lenses with their convex surfaces facing each other. It has been used in micrometry. O., Searching, an ocular of low power used for finding an object. It consists of a single 
field-lens and a double eye-lens. O. Sheath, the loose sheath-like tissue extending from the apex of the orbit of the eye to the vertical diameter of the globe, the posterior part of which up to the passage of the tendons of the external ocular muscles is called the Capsule of Bonnet, and the anterior portion, the Capsule of Ttnon. O., Solid, an eyepiece devised by Tolles. It consists of a solid piece of glass, with a moderate curvature at one end for a field-lens, and more greatly curved at the other end for use as an eye-lens. For a diaphragm a groove is cut transversely at the proper level and filled with black pigment. O., Spectral, an ocular with a direct-vision spectroscope connected with it. See Micro-spectroscope. O., Spectroscopic. See O., Spectral and Micro-spectroscope. O. Spot, a differentiated pigmented organ having the function of sight, found among the Protozoa, chiefly in the Flagellata, e.g., Euglena (pretty eye); the Colenterates (Sarzia); Actinozoa (Actinia), Asteridea, Echinidea, Rotifera, Trematoda, and Nematoda. O. Vesicle. See Vesicle. O., Working, an ocular used for ordinary microscopic observation, in contradistinction to one of very low power used for finding objects. There are both positive and negative forms.

Oculate $\left(0 k^{\prime}-u\right.$-lāt $)$ [oculus, an eye]. In biology, having eyes or eye-shaped markings

Oculauditory (ok-u-law'-dit-or-e) [oculus, eye; audire, to hear]. In biology, combining the functions of eye and ear, as the marginal bodies or sense-organs of certain invertebrates.

Oculiferous $(o k-u$-lif'-er-us) [oculus, eye ; ferre, to bear]. In biology, eye-bearing; applied to the eyestalks of a crustacean or snail.

Cculiform (ok'-u-lif-orm) [oculus, eye ; forma, shape]. In biology, resembling an eye.

Oculigerous (ok-u-lij'-er-us) [oculus, eye; gerere, to carry]. Same as Oculiferous.

Oculist $\left(o k^{\prime}-u\right.$-list $)$. Synonym of Ophthalmologist.

Oculo- (ok'-u-lo-) [oculus, eye]. A prefix signifying relation with the eye. O.-motor, moving the eye. O.-muscularis, pertaining to the muscles of the eye. O.-pupillary, pertaining to the pupil of the eye. O.zygomatic, pertaining to the eye and the zygoma. See Jadelot's Lines.

Oculomotorius (ok'-u-lo-mo-to'-re-us) [oculus, eye ; movere, to move]. The third, or motor oculi, nerve. See Nerves, Table of.

Oculus $\left(o k^{\prime}-u\right.$-lus) [L., an eye : pl., Oculi]. In biology, an eye or leaf-bud, e.g., in the potato. O. bili. See Tabusheer. O. bovinus, $O$. bovis. Synonym of Hydrophthalmia. 0 . bubulus. Synonym of 0 . bovinus. O. cæsius, glaucoma. O. elephantinus. Synonym of Hydrophthalmia. O. lacrimans, epiphora. O. leporinus, lagophthalmos. O. mundi. See Tabasheer.

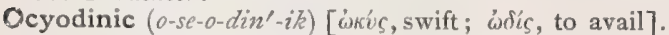
Oxytocic; hastening the delivery of the fetus.

Ocyphonic, Ocyphonous (o-sif-on'-ik, o-sif'-on-us)

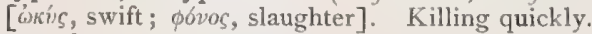

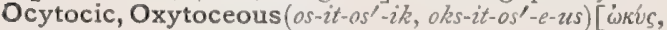
swift; Tokos, birth; labor]. Hastening the process of childbirth; oxytocic

Od ( $\bar{d} d$ or od) [an arbitrary name given by Baron von Reichenbach]. The supposititious force producing the phenomena of mesmerism.

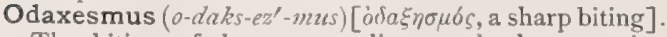
The biting of the tongue, lip, or cheek, occurring during an epileptic fit.

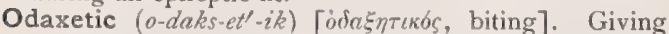
rise to an itching or stinging sensation.

Odd-pinnate (od-pin'-ät) [ME, od, odd; pinna, a wing]. In biology, pinnate, with a terminal odd leaflet ; imparipinnate.

-ode, -odes $\left(-\bar{o} d,-o^{\prime}-d \bar{e} z\right)$ [ $\dot{\omega} \delta \varepsilon$, like]. A suffix denoting likeness.

Odinagogue (o-din'-agoog). Synonym of Oxylocic.

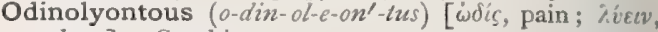
to lose]. Soothing.

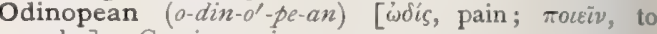
make]. Causing pain.

Odont- $\left(o^{\prime}\right.$-dont- $)$, See Odonto-

Odontagma (o-don-tag'-mah) [ádovs, tooth; áyvival, to break]. Sanie as Odontoclasis.

Odontagra (o-don-ta'-grah) [ódóvs, tooth; árpa, seizure]. Toothache; also, a kind of forceps for the surgical removal of teeth.

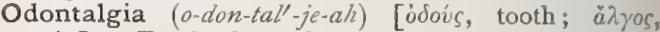
pain]. Toothache. O. nervosa, neuralgic toothache.

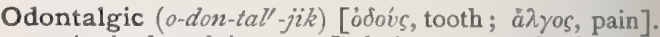
I. Anti-odontalgic. 2. Relating to toothache. 3. A remedy for toothache.

Odontalgy (o-don-tal'-je). Same as Odontalgia.

Odontalite $\left(0-d o n^{\prime}\right.$-tal-ît $)$ [oodoús, a tooth; $\lambda i \theta 0 s$, a stone]. A petrified tooth.

Odontapotribe, Odontapotripsis (o-don-tap'-o-trib,

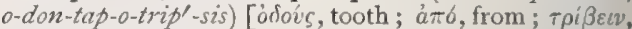
to crush]. Wearing away of the surface of the teeth.

Odontatrophy (o-don-tat'-ro-fe) [ódoís, tooth; átpoфía, atrophy]. Atrophy of the teeth.

Odontelephas (o-don-tel'-ef-as). Synonym of Dentine.

Odonteuros (o-don-tu'-ros) [ódoís, tooth; Evoẃs, decay]. Dental caries.

Odontharpagra (o-don-thar-pa'-grah). Synonym of Dentagra.

Odonthercos (o-don-ther'-kos) [ódoús, tooth; हpкos, fence]. A set of teeth.

Odonthyalophthora (o-dont-hi-al-off'-thor-ah) [odovs, tooth ; virhos, glass; $\phi \theta \varepsilon i \rho \varepsilon \iota \nu$, to destroy]. Destruction of the enamel of the teeth.

Odonthyalus (o-dont-hi'-al-us). Synonym of Enamel.

Odontia (o-don'-she-ah) [ódoús, tooth]. Odontalgia. 0 . deformis, deformity of the teeth, arising either from error of shape, position, or malformation of the jaws or alveolar border. O. incrustans, tartar of the teeth.

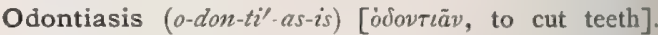
Dentition. The cutting of teeth.

Odontiater (o-don-te-a'-ter) [bjoís, tooth; iatpós, physician]. A dentist.

Odontiatria (o-don-te-a-tre'-ah) [ódoús, tooth ; iarpeia, a healing]. Dental surgery.

Odontic $\left(o-d o n^{\prime}-t i k\right)$ [odoi's, tooth]. Appertaining to the teeth.

Odontinoid (o-don'-tin-oid) [ódov́s, ódovtos, tooth;

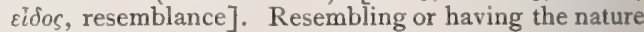
of teeth.

Odontitis (o-don-ti'-tis) [odoves, tooth; $\iota \tau \iota s$, inflammation]. Dentium infammatio; inflammation of the teeth. Formerly a synonym of dental caries, when this affection was supposed to be an inflammation of the dentine.

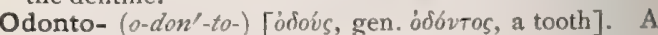
prefix that signifies resemblance to, connection with, or relation to a tooth.

Odontoblast (o-don'-to-blast) [ódoris, tooth; $\beta \lambda a \sigma o b$, germ]. In biology, one of the formative cells of dentine; one of the columnar cells forming the outer layer of the pulp of teeth; they do not enter into the dentine which they have secreted (as do osteoblasts into bone), but they all remain at its base and send into it numerous finely-branched processes, which run parallel to each other in as many little channels of the 
bony substances. The fibers are connected by fine anastomoses. (A. Lang.)

Odontoblastic (o-don-to-blas'-tik) [ódoús, tooth; $\beta \lambda a \sigma-$ Tós, germ]. Of the nature of, or pertaining to, an odontoblast.

Odontobothriitis (o-don-to-both-re-i'-tis) [odoús, tooth; Botpior, a little cavity; $\iota T / S$, inflammation]. Inflammation of the socket of a tooth.

Odontobothrium (o-don-to-both'-re-um) [ojoús, tooth ;

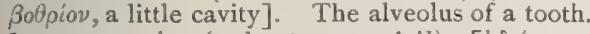

Odontoceramic (o-don-to-ser-am'-ik) [odoús, tooth; ке́papos, clay]. Pertaining to porcelain teeth.

Odontochalix (o-don-tok'-al-iks) [ódov́s, tooth; $\chi a ́ \lambda \iota \xi$, gravel]. Dental cement.

odontochirurgical (o-don-to-ki-rur'-jik-al) [ojóvs, tooth; $\chi \varepsilon \varepsilon \rho \circ o v \gamma i a$, surgery]. Pertaining to dental surgery.

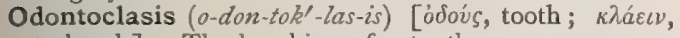
to break]. The breaking of a tooth.

Odontoclast (o-don'-to-klast) [ơdoús, tooth; $\kappa \lambda a ́ \varepsilon t v$, to break]. A multinuclear protoplasmic cell engaged in the process of absorbing the fang of a deciduous tooth. Numbers of these cells exist between the milk-tooth and the permanent tooth.

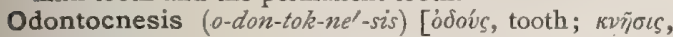
itching]. A painful itching sensation in the gums.

odontodesmium (o-don-to-dez'-me-um) [ódouss, tooth; $\delta \varepsilon \sigma \mu \delta \varsigma$, bond]. A ligament described as holding the teeth in their sockets.

Odontodiarrhea (o-don-to-di-ar-e'-ah) [odovs, tooth;

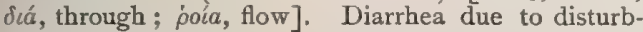
ances of dentition.

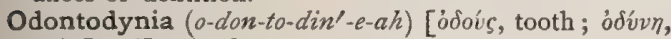
pain]. Toothache.

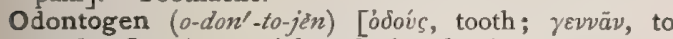
produce]. A material producing dentine.

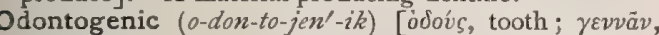
to produce]. Pertaining to the origin and development of teeth.

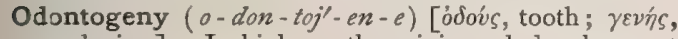
producing]. In biology, the origin and development of teeth.

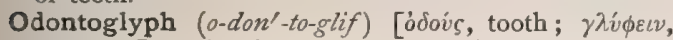
to carve]. An instrument used for scraping the teeth.

Odontoglyphous $\left(a-d o n-\operatorname{tog}^{\prime}-l i f-u s\right)$ [ódovs, tooth; $\gamma \lambda \hat{v} \phi \varepsilon i \nu$, to scrape]. In biology, having furrowed teeth.

Odontography (o-don-tog'-ra-fe) [ódoíc, tooth; $\gamma \rho a ́ \phi \varepsilon \iota v$, to write]. The descriptive anatomy of the teeth.

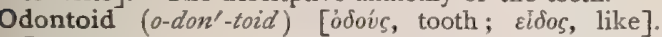
Resembling a tooth. Serrated. O. Ligament. See Ligament. O. Process, the dentate process of the second cervical vertebra.

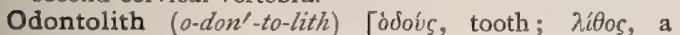
stone]. The calcareous stone-like accretion on the teeth popularly known as "tartar."

Odontologic (o-don-to-loj'-ik) [ódoús, tooth; $\lambda 6$ yos, science]. Pertaining to odontology.

Odontologist (o-don-tol'-o-jist) [odous, tooth; 26 yos, science]. One versed in odontology.

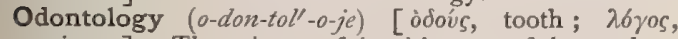
science]. The science of dentition, or of the teeth.

Odontoloxia, Odontoloxy (o-don-to-loks'-e-ah, o-don'to-loks-e) [ódov́s, a tooth; ìo६ós, slanting]. Irregularity or obliquity of the teeth.

Odontoma (o-don-to'-mah) [odoís, tooth; o $\mu a$, tumor: $p l .$, Odontomata $]$. A new formation arising in connection with the teeth and presenting the structure and appearance of teeth.

Odontome (o-don'-tōm). See Odontoma.

Odontomous (o-don'-to-mus) [odoús, teeth; ö $\mu a$, a tumor]. Pertaining to, of the nature of, or affected with, an odontoma,

Odontomys (o-don'-to-mis) [ojoís, tooth; $\mu \tilde{s} s$, mouse]. The dental pulp.

Odontonecrosis (o-don-to-ne-kro'-sis) [ojov́s, tooth;

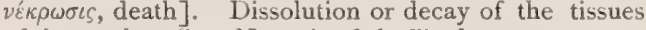
of the teeth. See Necrosis of the T'eeth.

Odontonosology (o-don-to-nos-ol"a-je) [ódoús, tooth;

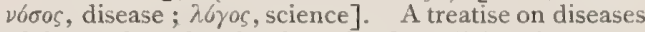
of the teeth; also that branch of medicine that treats of diseases of the teeth.

Odontoparallaxis (o-don-to-par-al-aks'-is) [odoús,

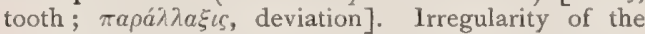
teeth; deviation of one or more of the teeth from the natural position.

Odontopathology (a-don-to-path-ol'-o-je) [odovis, tooth ;

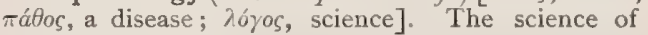
diseases of the teeth.

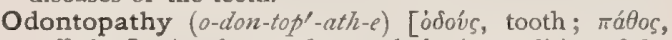
suffering]. An abnormal or pathologic condition of the teeth, or of the organs connected with them; dental disease.

Odontoperiosteum (o-don'-to-per-e-os'-te-um). Synonym of Periodonteum.

Odontophatne (o-don-to-fat'-ne). Synonym of Alveolus.

Odontophatnitis (o-don-to-fat-ni'tis). Synonym of Odontobothriitis.

Odontophore (o-don'-to-for) [ódoús, tooth; фépeıv, to bear]. In biology, a comprehensive name for those mouth-parts of a mollusc known as rasp, radula, radular apparatus, buccal mass, lingual ribbon, or tongue.

Odontophorous (o-don-toff'-or-us) [odoús, tooth ; $\phi \varepsilon \rho \varepsilon v$, to bear]. Bearing or having teeth.

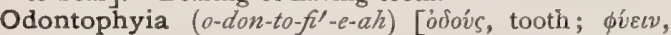
to grow]. Dentition.

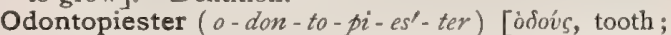
$\pi \iota \varepsilon \sigma \tau \eta \dot{p} \rho$, squeezer]. An instrument for exerting pressure on the teeth; it is used to relieve odontalgia.

Odontoplerosis (o-don-to-ple-ro'-sis) [odous, tooth; $\pi \lambda \dot{n} \rho \omega \sigma \iota$, filling]. The filling of teeth.

Odontoprisis (o-don-to-pri'-sis) [ódov́s, tooth; $\pi \rho i \sigma \iota s$, a sawing]. Stridor dentium, or grinding of the teeth.

Odontorine, Odontorrhine (o-don-to-rin') [idovs, tooth ; fivn, file]. A tooth-file. See File, Dental.

Odontorrhagia $\left(0-d o n-t o r-a^{\prime}-j e-a h\right) \quad[i \delta o v s$, tooth; on $v^{\prime} v v a i$, to burst forth]. Hemorrhage from the socket of a tooth.

Odontorrheumalgia (o-don-to-ru-mal'-je-ah) [ódóvs, tooth; $\rho \dot{\varepsilon} \tilde{v} \mu a$, flow; àdyos, pain]. Rheumatic toothache.

Odontorrhizophthisis (o-don-tor-iz-off'-this-is) [ódov́s, tooth; $\dot{\rho} \iota \xi \alpha$, root; $\phi \theta i \sigma \iota \varsigma$, wasting]. Caries of the root of a tooth.

Odontorthosia (o-don-tor-tho'-ze-ah) [ojoús, tooth ; o $\rho \omega \omega \tau \varsigma$, a straightening]. That part of dental surgery concerned in the straightening of irregularly growing teeth.

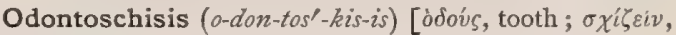
to split]. Splitting of a tooth.

Odontoschism (o-don'-to-skizm) [ódovis, tooth; $\sigma \chi i \zeta \varepsilon \varepsilon \nu$, to split]. A fissure in a tooth.

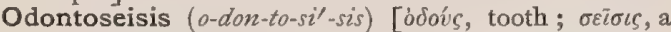
shaking; agitation]. Looseness of the teeth, arising from partial or total destruction of the alveolar processes, caused most frequently by disease of the gums. See Looseness of the Teeth.

Odontosis (o-don-to'-sis) [odovs, tooth]. The formation and development of teeth; dentition.

Odontosisimus (o-don-to-siz'-im-us). See Looseness of the Teeth.

Odontosmegma (o-don-to-smeg'-mah) [ơdors, tooth; 
$\sigma \mu \varepsilon \chi \varepsilon v$, to cleanse]. Anything employed for cleaning teeth; a tooth-powder or tooth-brush.

Odontospasmos (o-don-to-spaz'-mos) [ódov́s, tooth; $\sigma \pi a \sigma \mu \sigma \varsigma, \mathrm{spasm}]$. Convulsions from difficult dentition.

Odontosphacelis, Odontosphacelismus (o-don-tosfas'-el-is, o-den-to-sfas-el-iz'-mus). Synonyms of Dental Caries.

Odontosteophyte, Odontosteophyton (o-don-tos'-te-

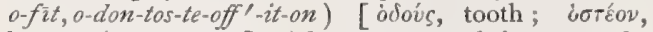
bone; $\phi \dot{v} \varepsilon v$, to grow]. A bony outgrow th from a tooth.

Odontosteresis (o-don-to-ster-e'-sis) [òdoús, tooth;

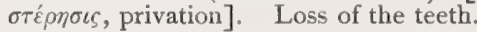

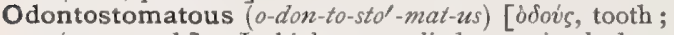
$\sigma \tau \delta \mu a$, mouth]. In biology, applied to animals having jaws that bite like teeth.

Odontostomous (o-don-tos'-to-mus). Same as Odon. tostomatous.

Odontosynerismus (o-don-to-sin-er-iz'mus) [odov́s,

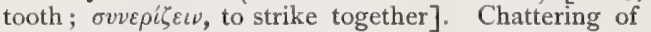
the teeth.

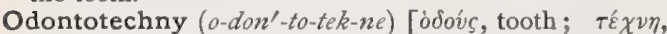
art]. Dental surgery.

Odontotheca (o-don-to-the'-kah) [ódov's, tooth; $\theta \dot{\eta} \kappa \eta$, case]. The follicle of a tooth.

Odontotherapeia (o-don-to-ther-ap-i'-ah) [odovs; tooth, $\theta \varepsilon \rho a \pi \varepsilon v \varepsilon v$, to heal]. See Odontotherapy.

Odontotherapy (o-don-to-ther'-ap-e). Dental therapeutics; the treatment or care of the teeth.

Odontothrypsis (o-don-to-thrip'-sis). See Odontotrip-

odontotrimma ( $o$-don-to-trim'-ah) [boovis, tooth ; $\tau \rho i \mu \mu a$, a pulverized substance: $p l$., Odontotrimmata]. A tooth-powder.

Odontotripsis (o-don-to-trip'-sis) [ódovs, tooth; $\tau \rho i \beta \varepsilon \varepsilon v$, to rub]. The natural abrasion or wearing away of the teeth. See Abrasion of the Teeth.

Odontotryphy, Odontotrypy (o-don-tot'-rif-e, o-don-

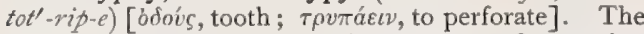
perforation of a tooth for the purpose of removing pus, or diseased pulp.

Odophone (o'-do-fön) [odor, smell, scent, odor]. A scale or gamut of odors arranged by the French chemist, Septimus Piesse.

Odor $\left(o^{\prime}\right.$-dor $)$ [L.]. A scent, smell or perfume. Fragrance.

Odoramentum (o-dor-am-en'-tum) [odoramentum, a perfume; from odorare, to perfume]. A remedy used on account of its odor.

Odoration (o-dor-a'-shun) [odoratio, a smelling]. I. The act of smelling. 2. The sense of smell.

Odoriferous (o-dor-if'-er-us) [odor, odor; ferre, to carry]. Bearing odor or scent. Fragrant.

Odoroscope, Odorscope $\left(o^{\prime}-d o r-0-s k o ̄ p, o^{\prime}\right.$-dor-skōp $)$ [odor, odor; $\sigma \kappa o \pi \varepsilon i \nu$, to examine]. An instrument for testing odors.

Odous $\left(o^{\prime}-d u s\right)[b \delta o v s$, a tooth]. A tooth.

O'Dwyer's Method. See Treatment, Method's of. O'D.'s Tubes, peculiar tubes used for intubation of the larynx.

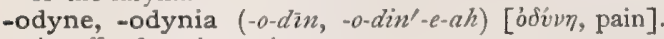
A suffix denoting pain.

Odynephatous (o-din-ef'-at-us). Synonym of Anodyne.

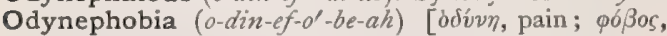
fear]. Morbid dread of pain; algophobia.

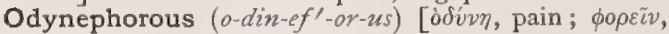
to bear]. Producing pain.

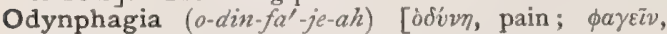
to eat]. Painful deglutition.

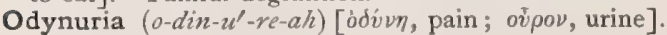
The painful passage of urine.

Eciomania (e-ke-o-ma'-ne-ah). See Oikiomania.
Ecium $\left(e^{\prime}-\right.$ se-um) [oikion, a house: pl., Ecia]. In biology, the special receptacle, attached to the zoocium, in which the ova complete their development into larvæ, in many of the Cheilostomata among Polyzoa. The ovicell.

Ecoid (e'-koid). See Ecoid.

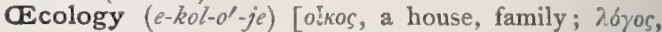
science]. In biology, the science of vegetable and animal economy and activity as shown by their modes of life, e.g., socialism, parasitism. "The terms biology and oecology are not interchangeable, because the latter only forms part of physiology." (Hæckel.)

Ecophobia (e-ko-fo'-be-ah). See Oikophobia.

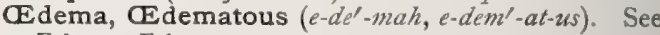
Edema, Edematous.

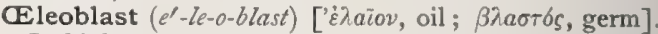
In biology, a mass of large, irregular, non-nucleated, polygonal bodies situated near the cloacal opening of Salpa and other compound Ascidians. The bodies are opaque, coarsely granular and consist of a sort of yolk-material. The function of the celeoblast is undetermined. Vogt called it the statoblast; it is also spelled elocoblast.

Enanthylic (e-nan-thil'-ik). See Enanthylic.

Enomania (e-no-ma'-ne-ah). See Enomania.

Oertel's Method. See Treatment, Methods of.

Oese [Ger.]. In biology, a platinum-wire needle,looped, with a glass handle, employed in bacteriologic investigation.

Esophagism (e-sof'-aj-izm). See Esophagismus.

Esophagitis (e-sof-aj-i'-tis). See Esophagitis.

Esophagus (e-sof'-ag-us). See Esophagus.

Estromania (es-tro-ma'-ne-ah). See Estromania.

Estruation (es-tru-a'-shun). See Estruation.

CEstrum (es'-trum). See Estrum.

Off [ME., off, of: same as preposition of ]. The name commonly applied to the animal on the right hand side of a yoke of oxen or a team of horses, or to the right side and the right fore-foot and hind-foot of a single animal; the antonym of near. O.-set, a short, rooting branch. A short stolon.

Offal (off'-awl) [ME., offal, fallen remnants]. Refuse of any kind.

Official $\left(o f f-i s h^{\prime}-a l\right)$ [officium, an office]. In pharmacy and materia medica, a medicine or preparation emanating from and sanctioned by the pharmacopeia.

Officinal (of-is'-in-al) [officina, a workshop]. For sale in the shops; kept on sale in apothecaries' shops; authorized in pharmacy. O. Preparations, those that are kept for sale in apothecary stores.

Offspring (off'-spring) [ME., of spring, progeny]. Descent; family; progeny.

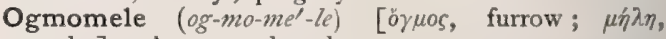
probe]. A grooved probe.

Ogston's Line. See Lines, Table of. O.'s Operation. See Operations, Table of.

Ohio Scratches. Same as Army Itch.

Ohm $(\bar{o} m)$ [after Dr. G. S. Ohm, an electrician]. In electricity, the unit of resistance. Practically, it is the resistance of a pure silver wire, one meter in length and one millimeter in diameter. The theoretic or absolute unit is $\frac{3}{1000000}$ part of the unit practically used. See Electric Units. O.'s Law. See Law.

Ohmad $\left(o^{\prime}\right.$-mad) [after Dr. G. S. Ohm, an electrician]. Same as $\mathrm{Ohm}$.

Ohmic $\left(o^{\prime}-m i k\right)$ [after Dr. G. S. Ohm, an electrician]. Pertaining to an ohm.

-oid (-oid) [ Eldos, like]. A suffix signifying likeness or resemblance.

Oidium $\left(0-i d^{\prime \prime}-\ell-u m\right)$ [dim, of $\omega b v$, egg $]$. A genus of parasitic fungi, Oidium, or Erysiphe tuckeri; the disease of the vine it causes is called white disease on 
Meunier. O, albicans is found in thrush, upon the tongue. O. lactis, the white mold found on milk, bread, etc. $\mathbf{O}$. tuckeri, the conidian stage of Erysyphe tuckeri. See Mildere.

Oidtmann's Purgative. The rectal injection of glycerin, two grams.

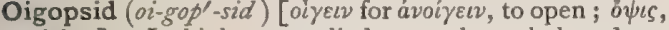
vision]. In biology, applied to such cephalopods as have an opening in the fibrous capsule of the eye, through which the lens projects (Loligophes, Ommastrephes); or, the lens being absent, the capsule of the eye becomes an open cup (Nautilus). The opposite of Myopsid.

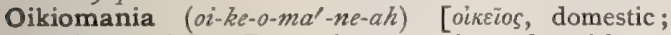
ravia, mania]. Domestic perversity; shrewishness manifested specially in one's own home.

Oikoid (oi'-koid) [oikos, house; Eidos, like]. The stroma of red corpuscles, so called by Brïcke.

Oikophobia (oi-ko-fol-be-ah) [oikos, house; фóßos, dread]. Morbid dread, or dislike of home, or of a house.

Oil [ME., oile, oil]. A greasy liquid not miscible with water, and usually of lighter specific gravity, composed of glyceryl and a fatty acid. In a wider sense the word is applied also to mineral hydrocarbons and to solid fats. The oils are liquid or solid substances characterized by unctuousness to the touch, and inflammability. They may be volatile or they may be non-volatile or fixed. The term is also applied to any oily substance, as oil of vitriol, $q \cdot v$. See also Oleum. 0 . of Allspice, an aromatic oil, and a constituent of bay-rum. Dose $\eta_{i j}-\nabla j$. See Pimenta. O. of Almond, an essential volatile oil from almond kernels, used as a perfume in dermatology, and in making Unguentum aque rosa. See Amygdala. Dose $m^{1} 1 / 4-\mathrm{j}$. O. of Amber, an essential oil. It is a stimulant, antispasmodic, and diuretic internally, and externally an irritant and rubefacient. Dose gtt. $\mathrm{v}-\mathrm{x}$. See Succinum. O. of American Wormwood. See O. of Chenopodium. O. of Anda, an essential oil from Joannesia princeps. It is a purgative. Dose gtt. 1-lxx. O. of Anise, a volatile oil ; it is an ingredient of paregoric. Dose $m j-v$. O. of Asafetida, a volatile oil ; a carminative and antispasmodic. Dose gtt. j-ij. O.bag, in biology, a bag or cyst containing oil. O., Banks, an unrefined cod-liver oil obtained from the livers which are allowed to putrefy in barrels on the ships. It is darker and more offensive than the better oils. O. of Basil, a flavoring agent. O. of Bay, a narcotic volatile oil from the berries of Laurus nobilis. O. of Bayberry, an oil from the leaves of Myrica acris, used in the manufacture of bay-rum. O. of Ben, a fixed oil from the seeds of Moringa pterygosperma; it is used internally as a purgative, and externally in gout and rheumatism. O. of Benzoin, an essential oil used in perfumery. $\mathbf{O}$. of Bergamot, a volatile oil from the fruit of Citrus bergamia, used in the manufacture of perfumes. $O$. of Black Mustard, a fixed oil from the seeds of Sinapis nigra. It is used in pharmacy and as a carminative. Dose $m^{\pi / 8}-1 / 4$. See Sinapis. O. of Black Pepper, a volatile oil from the unripe fruit of Piper nigrum. Externally it is an irritant; internally, a carminative. Dose $m^{1 / 4-j}$. See Piper. O.-blue. See Pigments, Conspectus of. O., Bone, a volatile product obtained by the dry distillation of bones. O., British, a rubefacient liniment. It is a variety of petroleum. O. of Cade, an oil derived from the wood of Juniperus communis, and used in dermatology. See Juniper. O. of Cajuput, a volatile oil distilled from the leaves of Leukadendron cajuputi. Its actions are similar to those of $O$. of Turpentine.
Dose $m$ j-v. O.-cake, a side-product obtained in the manufacture of oils. It is a compacted mass of crushed seeds or nuts, from which the oil has been expressed or extracted. It contains all of the woody fiber and mineral matter of the seed or nut, the residue of oil or fatty matter not extracted, and, that which gives it special value, the proteids or nitrogenous constituents. It is a most valuable cattle-food and is used as a basis for artificial fertilizers. The following table gives the composition of a number of the most important oil-cakes (Sadtler's Industrial Organic Chemistry). O. of Calamus, a volatile oil from the

\begin{tabular}{|c|c|c|c|c|c|c|}
\hline & $\begin{array}{l}\dot{a} \\
\frac{1}{5} \\
\xi\end{array}$ & $\underset{I}{\rightleftarrows}$ & 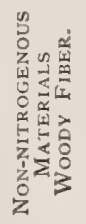 & $\frac{5}{5}$ & 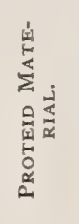 & 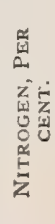 \\
\hline Earth-nut cake, & II.50 & 8.80 & 31.10 & 7.25 & $4 \mathrm{I} \cdot 35$ & 6.80 \\
\hline Cotton-seed cake, & 13.00 & 7.50 & 51.00 & 8.50 & 20.00 & 2.90 \\
\hline Rape-oil cake, & ro.12 & 9.23 & 41.93 & $6.4^{8}$ & 31.88 & 5.00 \\
\hline Colza-oil cake, & II. 35 & 9.00 & 42.82 & 6.28 & 30.55 & 450 \\
\hline Sesame-oil cake, & 10.35 & 10.10 & 38.80 & 9.80 & 31.93 & 5.00 \\
\hline Beech-nut cake, & II. 40 & $8.5^{\circ}$ & 49.80 & $5 \cdot 30$ & 2400 & 3.20 \\
\hline Linseed cake, & 10.56 & 9.83 & 44.61 & 6.50 & 28.50 & 4.25 \\
\hline Camelina cake, & 9.60 & 9.20 & 50.90 & 7.00 & 23.30 & 3.60 \\
\hline Poppy-oil cake, & 9.50 & 8.90 & 37.67 & II. 43 & 32.50 & 5.00 \\
\hline Sunflower-oil cake, & 10.20 & 8.50 & 48.90 & $\mathrm{II} .40$ & 21.00 & 2.40 \\
\hline Hempseed cake, & 10.00 & 8.26 & 48.00 & 12.24 & $21 \cdot 50$ & $3 \cdot 30$ \\
\hline Palm-nut cake, & 9.50 & 8.43 & 40.95 & 10.62 & 30.40 & 4.50 \\
\hline Cocoa-nut cake, & 10.00 & 9.20 & 40.50 & 10.50 & 30.00 & 4.50 \\
\hline
\end{tabular}

root of Acorus crlamus. It is a stomachic. $\mathrm{O}$. of Camomile, from the flowers of Anthemis nobilis. It is a stomachic. O., Camphorated, one impregnated with camphor; a solution of camphor in olive-oil. See Camphor. O. of Camphorwood, an essential oil from Dryobalanops aromatica. Its properties are similar to those of camphor. O., Canadian, oil of winter-green. 0 . of Cananga, an essential oil from the flowers of Cananga odorata, used in the manufacture of perfumery. O. of Caraway, a volatile oil from the fruit of Carum carvi. It is a carminative and flavoring agent. Dose $m j-v$. See Carum. 0 . of Cardamom, a volatile oil from the seeds of Elettaria cardamomum. It is a carminative. O. of Carmaru, a fixed oil from the fruit of Dipteryx eboënsis. It is used in manufacturing perfumes. O., Carron, a useful application to burns, consisting of equal or nearly equal parts of linseed-oil and lime-water. It is named after the Carron iron-works in Scotland, where it was first employed. O. of Cassia, an essential oil from the bark and buds of Cassia lignen, used in making perfumery. O. of Castonha, a fixed oil from Brazil-nuts, used in making perfumery. O., Castor, a fixed oil from the seeds of Ricinus communis, used as a purgative. Dose Zss. See Ricinus. O. of Celery, an essential oil from the fruit and leaves of Apium graveolens. It has emmenagogic properties. See Apium. O., Cedar, a fragrant oil obtained from the red Virginia cedar, used in microscopy as a clarifying agent. 0 ., Chabert, an oil consisting of 
3 parts of oil of turpentine and $\mathbf{I}$ of animal oil. It is used as is $O$. of Turpentine. O. of Chaulmoogra, a fixed oil expressed from the seeds of Gynocardia odorata. It is used in dermatology and rheumatism. Dose gtt. $v-x$. O. of Chenopodium, a volatile oil derived from the fruit of Chenopodium anthelminticum. It is an efficient anthelmintic. Dose $m v-x v$, $O$. of Cinnamon, a volatile oil from the bark of Cinnamomum zeylanicum. It is used in medicine and perfumery. Dose gtt. j-v. O, of Cloves, an essential oil from cloves. It is used in histology, dentistry, and perfumery. O., Cod-liver. See Morrun. O Color. See Pigments, Colors and Dyestuffs. O. of Copaiba, a volatile oil from the Balsamum copaiba. It is used as a diuretic. Dose $\eta_{x-x y}$. O. of Coriander, a volatile oil from the fruit of Coriandrum satioum. It is a carminative. Dose $m_{i j}-v$. O., Croton, a fixed oil from the seeds of Croton tiglii. It is a purgative. Dose $m \frac{1}{2}-\mathrm{ij}$. O. of Cubeb, a volatile oil from the fruit of Piper cubeba. It is a stimulant diuretic. Dose $m \mathrm{v}-\mathrm{xx}$. O., Dead, a heavy oil. O., Drying, one that on drying loses its oily properties and becomes a transparent flexible solid. Such oils are used as bases of paints and varnishes. O., Dugong, an oil from the blubber of dugongs, used sometimes as a substitute for codliver oil. O.-emulsion, an emulsion containing expressed oil of almonds 15 parts; acacia 15 parts, syrup of acacia 20 parts; orange-flower water I 5 parts, and water 100 parts. O. of Ergot, a fixed oil from the ergot of rye. It is an ecbolic. See Ergot. 0. of Erigeron, a volatile oil from the herb Erigeron canadense. Its action is the same as that of oil of turpentine. Dose $m \times-z_{\text {ss. }}$ O., Essential, a volatile oil, so called because it contains the essence or active principle of the plant. O., Ethereal, heavy oil of wine, $q . v$. ; also an essential oil. O. of Eucalyptus, a volatile oil from $E$. globulus, and other species of Eucalyptus. It is an antiseptic and stomachic. Dose $m v-x x x$. $O$. of Eulachon, an oil from the blubber of candle-fish, used as a substitute for cod-liver oil. O. of Euphorbia, a cathartic oil from the seeds of Euphorbia lathyris. O., Fatty, a fixed oil. The fatty oils, as distinguished from the mineral oils and the volatile oils, belong to the class of compound ethers. They are salt-like bodies, composed of characteristic acids (oleic, palmitic, and stearic), known as fatty acids, in combination with an alcohol or base. In most cases the base is the triatomic alcohol, glycerin, so that the oils are said to be glycerids of the several fatty acids. Some few, known as waxes, do not contain glycerin, but, instead, a monatomic alcohol in combination with the fatty acid. Most of the animal and vegetable fats contain three proximate constituents, olein, palmitin and stearin, the combinations of oleic, palmitic, and stearic acids respectively with glycerin. In the more liquid oils the olein predominates, in the more solid, palmitin or stearin. The so-called "drying oils" contain a different acid-linoleic acid-in combination with glycerin. The fish-oils contain a variety of the lower fatty acids and some solid unsaponifiable alcohols like cholesterin. The most satisfactory classification of the oils and fats, is that of A. H. Allen, which is here given in abstract. I. Olive-oil Group.-Vegetable oleins. Vegetable non-drying oils. These are lighter than the oils of groups II, III, and IV, and yield solid elaidins with nitrous acid. The group includes olive, almond, earth-nut, ben, rape-seed, and mustard oils. II. Cottonseed-oil Group.-Intermediate between drying and non-drying oils. These oils undergo more or less dry. ing on exposure and yield little or no elaidin. This group includes cotton-seed, sesamé, sun-flower, hazelnut, and beech-nut oils. III. Linseed-oil Group.Vegetable drying oils that yield no elaidin. They are of less viscosity than the non-drying oils. This group includes linseed, hemp-seed, poppy-seed, nigerseed, and walnut oils. IV. Castor-oil Group.-Medicinal oils. These are very viscous and of high density. The group includes castor and croton oils. V. Palm-oil Group.-Solid vegetable fats, which do not contain notable quantities of glycerids of the lower fatty acids. The group includes palm-oil, cacao-butter, nutmegbutter, and shea-butter. VI. Cocoanut-oil Group.Solid vegetable fats, in part wax-like. Several of these oils contain notable proportions of the glycerids of the lower fatty acids. The group includes cocoanut-oil, palm-nut-oil, laurel-oil, Japan wax, and myrtle-wax. VII. Lard-oil Group.-Animal oleins, which do not dry notably on exposure, and which yield solid elaidins with nitrous acid. The group includes neat's-foot oil, bone-oil, lard-oil, and tallow-oil. VIII. Tallone Group. -Solid animal fats. These are predominantly glycerids of palmitic and stearic acids, although butter contains lower glycerids. The group includes tallow, lard, bone-fat, wool-fat, butter-fat, oleomargarin, and manufactured stearin. IX. Whale-oil Group.-Marine animal oils, characterized by offensive odor and a reddish-brown color when treated with caustic soda. The group includes whale, porpoise, seal, menhaden, cod-liver, and shark-liver oils. X. Sperm-oil Group.-Liquid waxes that are not glycerids but ethers of monatomic alcohols. They yield solid elaidins. The group includes sperm-oil, bottle-nose-oil, and dolphin-oil. XI. Spermaceti Group.-Waxes proper. These are compound ethers of the higher monatomic alcohols, with the higher fatty acids in a free state. The group includes spermaceti, beeswax, Chinese wax, and carnauba wax. O. of Fennel, a volatile oil from the fruit of Faniculum officinale. It is a carminative, and is also used in perfumery. Dose

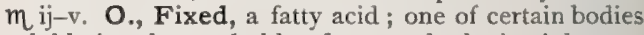
soluble in ether and chloroform, and obtained by expression from various organic substances. See $O$, Fatty. O. of Galanga, a volatile oil from the root of Alpinia officinarum. $\quad 0$. of Garlic, an essential oil formerly used in medicine. It is derived from the bulbs of Allium sativum. O. of Geranium, an essential oil from species of Pelargonium, used in the manufacture of perfumery. O. of Ginger, an essential oil from the roots of Zingiber officinale. It is a carminative and flavoring agent. Dose $m \frac{1}{2}-\mathrm{j}$. O.gland, the uropygial gland of birds, secreting the oil used in dressing their plumage. O.-globules, in microscopy, are prepared by beating a small drop of clove oil with mucilage. In focusing up with central light, the bright center of the globule is clearest last. With oblique light the bright spot will appear on the side toward the mirror. O., Grain, amyl alcohol. O., Gray, an oily substance or ointment made by triturating mercury with oil or liquid paraffin. The quantity of mercury varies from $\mathbf{I}$ to 33 per cent. $O$. of Hazel, a fixed oil from hazel-nuts used in the manufacture of perfumes. O., Heavy, the substances distilled from benzene at between $210^{\circ}$ and $400^{\circ} \mathrm{C}$. O., Heavy (of wine), the product obtained when alcohol is treated with an excess of sulphuric acid. It consists of several ethers and other compounds. $O$. of Hedeoma, oil of pennyroyal, a volatile oil from the leaves and tops of Hedeoma pulegioides. It is a carminative, and is used externally to drive away mosquitoes. Dose $\eta_{i j-x}$. O--immersion, the use of oil as the medium between the objective and the cover-glass. O., Infused, a class of medicated oils, 
(olea infusa, N. F.), prepared by digesting a drug in ammoniated oil and alcohol, the ammona and alcohol being evaporated in the process. O. of Jasmine, an essential oil from Jasminum odoratissimum, used in perfumery. O. of Jatropha, a purgative oil derived from the seeds of Jatropha purgans. O. of Jonquin, an essential oil from the flowers of Narcissus jonquilla, used in perfumery. $\mathbf{0}$. of Juniper, a volatile oil from the berries of Juniperus communis. It is a diuretic and diaphoretic. Dose $\eta^{v-x x}$. O. of Lavender, a volatile oil from species of Lavandula used as a carminative and flavoring agent. Dose $m j-v$. O. of Lemon, a volatile oil from the rind of lemons. It is used in perfumery, and as a flavoring agent. Dose $m j-v$. O., Light, the distillates of benzene at between $I 10^{\circ}$ and $210^{\circ} \mathrm{C}$. O. of Lilies, an essential oil from the flowers of Lilium candidum, used in perfumery. O., Linseed. See Oleum lini. O. of Mace, an essential oil from Myristica officinalis, used as a carminative and flavoring agent, and in perfumery. O. of Marjoram, an essential oil from Origanum majorana used in perfumery. O., Menhaden, an oil from the blubber of menhaden, used as a substitute for cod-liver oil. O., Middle, the distillationproducts of benzene between $170^{\circ}$ and $230^{\circ} \mathrm{C}$. O. of Mignonet, an essential oil from the flowers of Reseda odorata used in perfumery. O., Mineral, refined petroleum. O. of Mint, an essential oil from Mentha viridis, used as a carminative, and in perfumery. Dose $m_{i j-v}$. O. of Mirbane. See Mirbane. O. of Morrhua. See Morrhua. O. of Mustard. See Sinapis. O. of Myrrh, an essential oil from gum myrrh. O. of Myrtle, an essential oil from Myrtus communis, used in perfumery. O., Neatsfoot, a lubricant oil from the feet of neat cattle. O. of Neroli, an essential oil from the flowers of bitter orange, used as a perfume. O., Nobel's Explosive, nitroglycerin. O., Non-drying, a non-oxidizing oil, such as almond oil. O., Olive. See Olive. O. of Orange. See Orange. O. of Orris, an essential oil from the roots of Iris florentina, used as a perfume and flavoring agent. O., Ozonized, an oil containing ozone. Ozonized oil of turpentine is an antidote in phosphorus-poisoning. O., Palm. See Palm. O., Parsley. See Apiol. O. of Pennyroyal, an essential oil from Hedeoma pulegioides. It is a stimulant, emmenagogue, and carminative, and is also used to keep away mosquitoes. Dose gtt. ij-x. O. of Pepper, the volatile oil from the seeds of Piper nigrum. O. of Peppermint, the volatile oil from Mentha piperita. It is a carminative, anodyne, and antiseptic. Dose gtt. j-iij. O., Phosphorated, an oil charged with phosphorus. O. of Pimenta, a volatile oil from the fruit of Pimenta officinalis. It is a carminative. Dose gtt. ij-vj. O., Provence, an olive-oil of superior quality. O., Rock, petroleum. See Petrolatum. O. of Rose, an essential oil from the fresh flowers of Rosa damascena. It is used as a perfume. See Attar of Rose. O. of Rosemary, the essential oil from the flowering tops of Rosmarinus officinalis. It is a carminative and anodyne. Dose gtt. j-ij. O. of Rue, the essential oil derived from Ruta graveolens. It is a vermifuge and emmenagogue. Dose gtt. j-v. $\mathbf{O}$. of Sage, a volatile oil derived from Salvia officinalis. It is used as a mouth-wash in stomatitis. O. of Sandalwood, Oleum santali, distilled from the wood of Santalum album. It is used in gonorrhea. Dose gtt. $x-x x, \quad O$. of Sassafras, a volatile oil from the wood of Sassafras officinale. It is a carminative. Dose gtt. ij-x. O.-seed, castor-bean; the seed of the Ricinus communis. O., Shore, cod-liver oil prepared on shore; it is the finest quality. O. of Spear- mint, an essential oil from Mentha viridis. It is a carminative. Dose gtt. ij-v. O., Sperm, a yellowish oil derived from the Physeter macrocephalus. It is used as a lubricant. O. of Spermaceti, derived from spermaceti. O., Straits, the first oil obtained by the exposure of the livers of cod-fish to the sun in casks, on board the ships. O., Sweet. See Oleum olive. O.-sugar. See Oleo-saccharum. O. of Tansy, an essential oil derived from Tunacetum vulgare. It is used as an emmenagogue and oxytocic. O. of Tar, Oleum picis liquide, obtained from wood-tar. It has been largely used in dermatology. See Pix. O. of Thyme, a volatile oil from $T / 3 y m u s$ vulgaris. It yields Thymol on oxidation. $\mathbf{O}$. of Tobacco, an empyreumatic oil from tobacco, formerly used as an application to ulcers. O.-tube, in biology, a longitudinal canal filled with aromatic oil, found in certain fruits. $\mathbf{O}$., Virgin, the finest variety of olive-oil, made from olives that are not quite ripe. O., Volatile, or essential oil, is one characterized by a pungent, aromatic odor. These oils usually vaporize at ordinary temperatures, and leave no permanent stain on paper. O., Whale. See under $O$., Fatty. O. of Wintergreen, an essential oil from the leaves of Gaultheria procumbens. It is used in chronic cystitis and rheumatism. Dose gtt. $\mathrm{v}-\mathrm{x}$.

Oinomania (oi-no-ma'-ne-ah). See Enomania and Methomania.

Ointment (oint'-ment). See Unguentum. O., Banyer's, an ointment used in chronic eczerna and favus. It is composed of calomel, 2 drams; burnt alum and carbonate of lead, each 4 drams; Venice turpentine, 6 drams; spermaceti ointment, $I \frac{1}{2}$ ounces. $O$. Cyrillo's, used by inunction in syphilis. It con. sists of perchlorid of mercury, 4 parts; lard, 32 parts. O., Maury's, an ointment largely used as an application to chronic ulcers. It contains one dram of nitrate of mercury and half a dram each of powdered opium and rhubarb to an ounce of simple ointment.

Okada, Bacillus of. See Bacteria, Synonymatic Table of

Okenian Bodies [after Lorenz Oken, the naturalist, Jena, I779-185I]. Oken'sche Körper, a name applied by Rathke to the primitive kidneys or Wolffian bodies.

Old (óld) [ME., old, old]. Advanced in life; having many years. O. Age, senility ; senectus.

Olea $\left(\sigma^{\prime}-l e-a h\right)$ [' $\lambda a i^{\prime} n$, the olive-tree]. I. A genus of trees. See Olive. 2. Plural of Oleum, $q . v, \mathbf{O}$, infusa, infused oils.

Oleaginous $\left(o-l e-a j^{\prime}-i n-u s\right)$ [oleum, oil $]$. Oily.

Oleamen $\left(o-l e-a^{\prime}-m e n\right)$ [L.: pl., Oleamina]. An oily, soft ointment or liniment.

Oleander $\left(0-l e-a n^{\prime}-d e r\right)$. See Nerium.

Oleandrin $\left(o-l e-a n^{\prime}-d r i n\right)$ [a corruption from olea, olivetree; laurus, laurel]. $\Lambda$ poisonous alkaloid from Nerium oleander.

Oleate $\left(o^{\prime}-l e-\bar{a} t\right)$ [oleum, oil: pl., Oleata]. A salt formed from oleic acid. A mixture of oleic acid with certain medicinal principles. There are three official oleates in pharmacy, oleatum hydrargyri, oleatum veratrince, and oleatum zinci, neither of which is a definite chemic compound. The oleatum aconitina, oleatum plumbi, and oleatum quinine are recognized in the National Formulary.

Olecranal, Olecranial (o-lek'-ran-al, o-lek-ra'-ne-al)

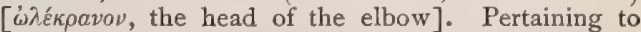
the olecranon.

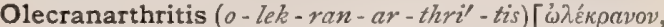
head of elbow; a a $\rho \rho \rho \nu$, joint; $\iota \tau \iota \zeta$, inflammation]. Inflammation of the elbow-joint.

Olecranarthrocace, Olecranocace (o-lek-ran-arth-rok'. 
as-e, o-lek-ran-ok'-as-e) [ $\omega \lambda k^{\prime} \kappa \rho a v o v$, the head of the elbow; à $\theta \rho o \nu$, joint; какбs, evil]. Inflammation of the elbow-joint.

Olecranoid (o-lek'-ran-oid) [ $\omega \lambda \dot{k} \kappa \rho a v o v$, head of the elbow; $\varepsilon i \delta o s$, like]. Resembling the olecranon. $O$. Fossa, the fossa at the dorsal side of the distal end of the humerus for the reception of the olecranon.

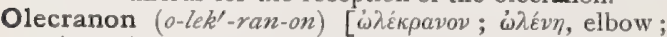
кpáviov, head]. The large process forming the head of the ulna.

Olefiant Gas (o-lef'-e-ant) [oleum, oil ; ficare, to make]. Heavy oil of carbon. See Ethylene.

Olefin $\left(o^{\prime}\right.$-lef-in) [oleum, oil ; ficare, to make]. The name of a series of unsaturated hydrocarbons containing two hydrogen atoms less than the paraffins or ethanes, $\mathrm{C}_{\mathrm{n}} \mathrm{H}_{2 \mathrm{n}}$. They are produced with paraffins in the dry distillation of many complicated carbon compounds; hence their presence in illuminating gas and in tar-oils. The lower members of the series are gases; the intermediate members, ethereal liquids; the higher (from $\mathrm{C}_{16} \mathrm{H}_{32}$ up), solids. They boil at points a few degrees higher than the corresponding paraffins. For Table of Olefins see under Hydrocarbon.

Oleic Acid $\left(o^{\prime}-l e-i k\right)$. See $A c i d$.

Oleiferous (o-le-if'-er-us) [oleum, oil ; ferre, to bear] Producing oil.

Olein $\left(o^{\prime}\right.$-le-in) [oleum, oil $], \mathrm{C}_{57} \mathrm{H}_{104} \mathrm{O}_{6}$. One of the most widely distributed of the natural fats; the trioleic ether of glyceryl. It is a colorless oil at ordinary temperatures, with little odor and a faint sweetish taste, insoluble in water, readily soluble in alcohol and ether.

Oleo- $\left(\sigma^{\prime}-l e-o-\right)$ [oleum, oil]. A prefix to denote connection with or relation to an oil.

Oleomargarin (o-le-o-mar'-gar-in) [oleum, oil; $\mu a ́ \rho-$ rapos, the pearl oyster]. Butterin; an artificial butter made by removing the excess of stearin from tallow or suet (or from lard in winter seasons), and flavoring the residue with the natural flavoring-principle of butter. The fat is melted at a temperature not exceeding $110^{\circ} \mathrm{F}$. - otherwise the product becomes granular and coarse-and in cooling, the excess of stearin is separated by crystallization; the remainder is oleomargarin. When prepared from pure materials, the artificial product is less liable to become rancid than ordinary dairy butter, being free from the bacteria frequently found in the latter. The following analysis of oleomargarin is given by Dr. Bell :-

ANALYSIS OF OLEOMARGARIN OR BUTTERIN.

\begin{tabular}{|c|c|c|c|c|c|c|c|}
\hline 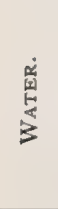 & 点 & 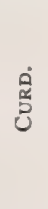 & $\underset{⿱ 亠 䒑}{\overleftrightarrow{L}}$ & 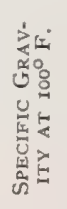 & 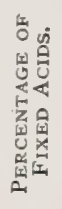 & 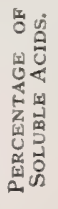 & 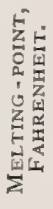 \\
\hline 14.30 & $3.8 \mathrm{I}$ & 0.48 & $8 \mathrm{I} .4 \mathrm{I}$ & 903.84 & 94.34 & $\cdots$ & $82^{\circ}$ \\
\hline II $.2 \mathrm{~J}$ & I. 70 & I. 73 & 85.36 & 902.34 & 94.83 & 0.66 & $78^{\circ}$ \\
\hline 12.33 & 4.00 & 1.09 & $82.5^{8}$ & 903.15 & 95.04 & 0.47 & $79^{\circ}$ \\
\hline $5 \cdot 32$ & 1.09 & 0.67 & 92.92 & 903.79 & 96.29 & 0.23 & $81^{\circ}$ \\
\hline 13.21 & 3.99 & 1.07 & 81.73 & 901.36 & 95.60 & 0.16 & $78^{\circ}$ \\
\hline
\end{tabular}

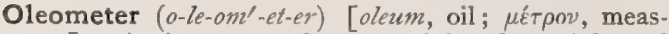
ure]. An instrument for ascertaining the weight and purity of oil.

Oleoresin $\left(o-l e-o-r e z^{\prime}-i n\right)$ [oleum, oil : resin $\alpha$, resin ; pl., Oleoresince]. In pharmacy, a preparation consisting chiefly of a mixture of natural oils and resins extracted from vegetables by percolation with stronger ether. There are six official oleoresince.

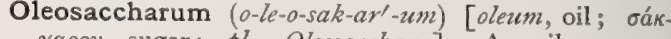

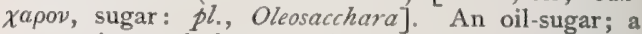
preparation made by saturating thirty grains of sugar with one drop of volatile oil.

Oleose $\left(o^{\prime}-l e-\hat{o} z\right)$ [oleosus, oily]. Oily.

Oleosity $\left(o-l e-o s^{\prime}-i t-e\right)$ [oleosus, oily]. The property of being oily or fatty.

Oleous $\left(o^{\prime}-l e-u s\right)$ [oleosus, oily]. Oily; having the character of oil.

Olera (o-ler'-ah) [olus, a pot-herb]. In biology, the name given by early botanists to the kitchen-herbs.

Oleraceous (o-ler-a $a^{\prime}$-se-us) [olus, a pot-herb; oleraceus, resembling herbs]. Esculent, as a pot-herb.

Oleum $\left(o^{\prime}-l e-u m\right)$ [L.: $p l .$, Olea $]$. See Oil. O. æthereum, ethereal oil, a volatile liquid consisting of equal volumes of heavy oil of wine, and ether. 0 . catharticum, oil of juniper. See Juniper. O. cetaceum, whale-oil. O. cinereum. See Gray Oil. O. fagi, the empyreumatic oil of beech, useful in various skin-diseases. Unof. 0 . phosphoratum. See Oil, Phosphorated, and Phosphorus. O. rusci, Russian oil ; the empyreumatic oil of birch, useful in various skin-diseases. Unof. O. terræ; rock-oil.

Olfaction (ol-fak'-shun) [olfacere, to smell]. The function of smelling.

Olfactive (ol-fak'-tiv) [olfacere, to smell]. Synonym of Olfactory. O. Angle, the angle formed by the line of the olfactory fossa and the os planum of the sphenoid bone.

Olfactometer (ol-fak-tom'-et-er) [olfactus, smell ; $\mu$ ér $\rho \circ \nu$, measure]. An instrument for measuring the power of smell in any given case.

Olfactor (ol-fakl-tor) [olfacere, to smell]. A unit of olfactory sensibility.

Olfactory (ol-fak'-to-re) [olfacere, to smell]. Pertaining to the sense or organ of smell. O. Angle. See Olfactive Angle. O. Bulb. See Bulb. O. Cells. The cells of the nasal fossæ forming the peripheral end-organs of the olfactory apparatus. O.Center, the cerebral center that appreciates smell, supposed by Munk to be in the hippocampal gyrus. $\mathrm{O}$. Cleft, a slit between the tip of the middle turbinated bone and the nasal septum. $O$. Clubs, the claville marginales, or condyli marginales of medusæ. O. Foramina. See Foramina, Table of. O. Fossa. See Fossa. O. Ganglion, the olfactory bulb. O. Glomeruli. See Glomerulus. O. Groove. See O. Sulcus. O. Lobe, the olfactory tubercle, tract, bulb, and roots, considered as a whole. 0 . Membrane, the mucous membrane of the nose. O. Nerve (Stirling). See Nerves, Table of. O. Pit, the primitive ectodermal invagination to become the nasal cavity. O. Plate, one of the two areas of thickened ectoderm immediately above the primitive oral cavity, and in contact with the wall of the fore-brain; it is the earliest indication of the

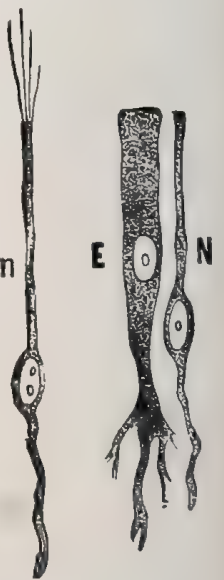

Olfactory Cells. N. From human beE. Supporting cell. ing. n. From frog. nasal mucous membrane. O. Region, the area of distribution of the olfactory nerve. $\mathrm{O}$. Roots, the regions connecting the olfactory tract with the cerebral hemispheres. O. Sulcus, the furrow for the olfactory tract 
and bulb on the cribriform plate of the ethmoid, and on the orbital surface of the cerebral hemispheres. 0 . Tract, the central portion of the olfactory lobe, terminating anteriorly in the olfactory bulb, and posteriorly in the olfactory tubercle. O. Trigone, a triangular gray area forming the base of the $O$. Tuber. 0 . Tuber, O. Tubercle. See Tuber. O. Ventricle, a prolongation of the cavity of the lateral ventricle into the olfactory lobe. It is rarely found in the adult brain, though present in the fetus and in most animals.

Olibanum (o-lib'-an-um) [Ar., al-luban, frankincense]. A gum-resin produced by various Asiatic and E. African trees, mainly of the genus Boswellia; true frankincense. It is now little used, except in certain plasters and as a fumigant. Unof.

Olibene $\left(o l^{\prime}-i b-\bar{e} n\right)$ [Ar, al-lubān, frankincense], $\mathrm{C}_{10^{-}}$ $\mathrm{H}_{16^{\circ}}$ A hydrocarbon found in oil of olibanum.

Oligæmia (ol-ig-e'-me-ah). See Oligenia.

Oligandrous (ol-ig-an'-drus) [ỏilizos, few; ávmo, a male]. In biology, having few stamens.

Oliganthous (ol-ig-an'-thus) [ỏhizos, few; àvflos, a flower]. In biology, having few flowers.

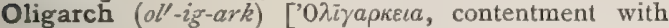
little]. In biology, containing few fibro-vascular bundles; applied also to fibro-vascular bundles that have few rays.

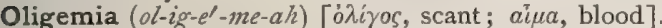
A diminished quantity of the blood. O. hypalbuminosa, diminution in the proteids of the blood. O. sicca, diminution in the volume of blood by loss of water. $\mathbf{O}$. vera, diminution in the quantity of the blood, as a whole.

Oligemydria (ol-ig-em-ī $\left.d^{\prime}-r e-a h\right)$. Synonym of Anhydremia.

Olighydria (ol-ig-hi'-dre-ah) [óhíyos, scanty; $v \delta \omega \rho$, water]. Deficiency of the fluids of the body.

Oligo- $\left(o l^{\prime}-i g-o-\right)[o h i \gamma o s, f e w]$. A prefix that signifies want or deficiency.

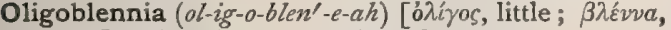
mucus]. A deficient secretion of mucus.

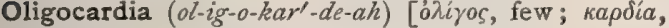
heart]. Abnormal smallness of the heart.

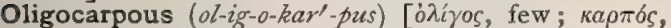
fruit]. In biology, having few fruits.

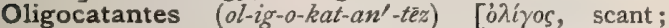

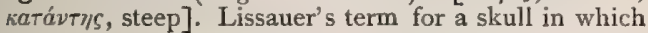
the angle formed between the radius fixus and the line joining the hormion and the staphylion is between $20^{\circ}$ and $23^{\circ}$

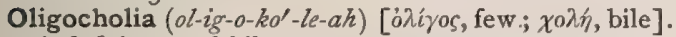
A deficiency of bile.

Oligochromemia (ol-ig-o-kro-me'-me-ah) [o'híos, few ; $\chi \rho \tilde{\omega} \mu a$, color; $a^{i} \mu a$, blood]. Deficiency of hemoglobin in the blood.

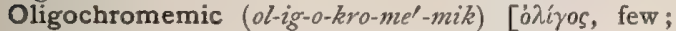
$\chi \rho \omega ̈ \mu a$, color; ai $\mu \alpha$, blood]. Pertaining to, affected with, or of the nature of, oligochromemia.

Oligochrosis (ol-ig-o-kro'-sis) [óniyos, few; $\chi \rho \tilde{\omega} \sigma \iota \varsigma$, a coloring]. Deficiency of hemoglobin in the bloodcorpuscles.

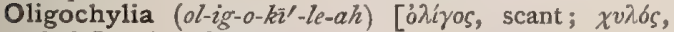
chyle]. A deficiency of chyle.

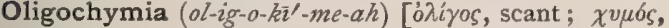
juice]. A deficiency of chyme.

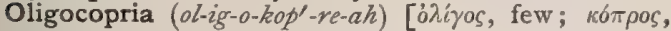
excrement]. Deficiency of excrement.

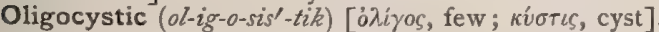
Having few cysts or open spaces.

Oligocythemia $\left(o l-i g-0-s i-t h e^{\prime}-m e-a h\right)$ [a $i$ íos, few ;

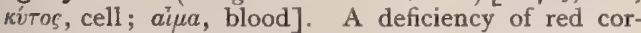
puscles in the blood; a symptom of nearly all forms of anemia, but especially of pernicious anemia.

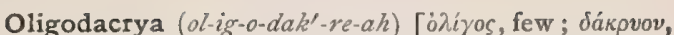
tear]. Deficiency of the tears

Oligodactylia $(o l-i g-0-d a k-t i l l-e-a h)$ [ólíyos, few;

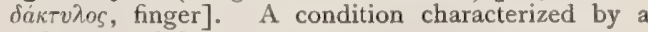
deficiency of fingers.

Oligoerythrocythemia (ol-ig-o-er-ith-ro-si-the'-me-ah)

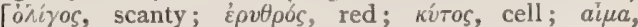
blood]. Deficiency of the coloring-matter of the red corpuscles of the blood.

Oligogalactia (ol-ig-o-gal-ak'-te-ah) [ỉíyos, scant; yá $\lambda a$, milk]. Deficiency in the secretion of milk.

Oligohemia (ol-ig-o-he'-ne-ah). See Oligemia.

Oligohydramnios $\left(o l-i g-o-h i-d r a m^{\prime}-n e-o s\right)$ [óniros, scant; $v \delta \omega \rho$, water; a $\mu v i o v$, the amnion]. A deficiency in the quantity of the amniotic fluid. It is a rare condition, occurring once in 3000 or 4000 pregnancies.

Oligohydria (ol-ig-o-hi'-dre-ah). Same as Olighydria.

Oligokatantes (ol-ig-o-kat-an'-tēz). See Oligocatantes.

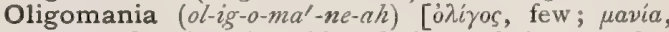
madness]. Insanity with delusions relating to a few subjects. Cf. Oligopsychia.

Oligomenorrhea (ol-ig-o-1nen-or-ef-ah) [ohíos, few; $\mu \eta \dot{v}$, month; poia, flow]. Insufficiency of the menstrual flow.

Oligomerous (ol-ig-om'-er-us) [ỏhígos, few; $\mu$ épos, part]. In biology, having few segments, somites, members, or metameres.

Oligopepsia (ol-ig-o-pep'-se-ah) [óníyos, scant; $\pi \dot{\varepsilon} \psi \iota s$, digestion]. Feebleness of digestion.

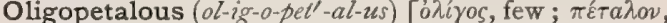
a petal]. In biology, having only a few petals.

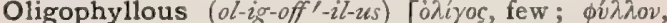
a leaf]. In biology, having few leaves.

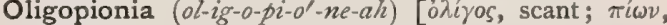
fat]. Wasting; emaciation.

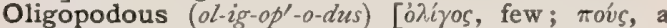
foot]. In biology having only a few feet.

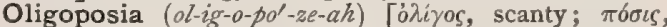
drink ]. Defective desire for drinking.

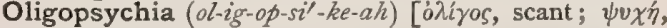
mind]. Fatuity ; imbecility.

Oligopyrenemia (ol-ig-o-pi-ren - $\left.e^{\prime}-m e-a h\right)$ [ólízos, scanty ; $\pi \nu \rho \dot{\eta} v$, a fruit-stone; ai $\mu \alpha$, blood]. Deficiency of red corpuscles in the blood.

Oligoria (ol-ig-o'-re-ah) [óníyos, few, scant; ڤ̈pa, heed, notice]. Susceptibility to but few mental impressions; oligopsychia.

Oligosepalous (ol-ig-o-seṕ-al-us) [òíros, few; sepalum, a sepal]. In biology, having only a few sepals.

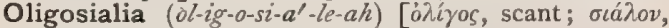
saliva]. Deficiency of saliva.

Oligospermatic (ol-ig-o-sper-mat'-ik) [ỏhiyos, scant; $\sigma \pi \varepsilon \varepsilon^{\prime} \mu a$, seed]. Pertaining to oligospermia.

Oligospermia (ol-ig-o-sper'-me-ah) [òlyos, scant ; $\sigma \pi \varepsilon p \mu \alpha$, seed]. A deficiency in the secretion of semen.

Oligospermism (ol-ig-o-sperm'-izm). See Oligospermia.

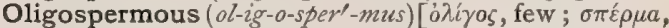
seed]. In biology, having few seeds.

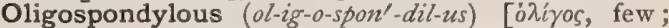
$\sigma \pi \delta v \delta v \lambda$ s, vertebra]. Having fewer vertebræ than normal.

Oligosteatosis (ol-ig-o-ste-at-o'-sis) [ỏifos, scant; $\sigma \tau^{\prime} \alpha \rho$, tallow]. Deficiency of the sebaceous secretion.

Oligostemonous (ol-ig-o-ste'-mon-us) [ólíos, few; $\sigma \tau \eta \mu \omega n$, stamen]. Same as Oligandrous.

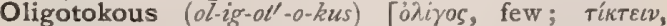

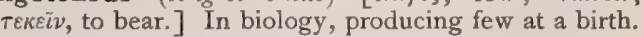

Oligotrichia (ol-ig-o-trik'-e-ah) [òiyos, few, scanto$\theta \rho i \xi$, hair]. Scantiness or thinness of the hair. 


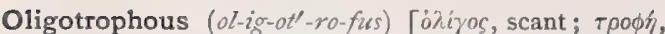
nourishment]. Only slightly nutritious.

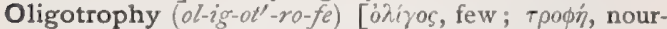
ishment]. Defective or imperfect nutrition.

Oligozoöspermia (ol-ig-o-zo-o-sper-me-ah) [ỏíros,

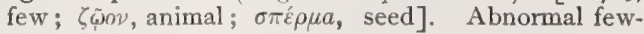
ness of the spermatozoa.

Oliguresis $\left(o l-i g-u-r e^{\prime}-\right.$ sis $)$. See Oliguria.

Oliguria (ol-ig-u'-re-ah) [ónigos, scanty; oṽpov, urine]. A diminution in the quantity of urine excreted.

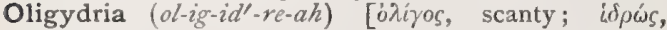
sweat]. Ischidrosis; a deficiency in the sweat.

Olisthema (ol-is-the'-mah) [önotávetv, to slip]. Dislocation.

Oliva $\left(0-l e^{\prime}-v a h\right)[\mathrm{L}$.$] . The olivary body of the brain.$

Olivaceous $\left(o l-i z^{\prime}-a^{\prime}-s e-u s\right) \quad[o l i v a$, olive]. In biology, olive-green.

Olivæ, Oleum $\left(o-l e^{\prime}-v e o^{\prime}-l e-u m\right)$. See Olive-oil.

Olivary $\left(o l^{\prime}-i v-a-r e\right)$ [oliva, olive]. Pertaining to an olive; like an olive. In anatomy, pertaining to the oliva. O. Bodies, the olive-shaped bodies laterad of the anterior pyramids of the medulla oblongata. O. Eminence, the small, rounded, transverse prominence of the body of the sphenoid bone immediately cephalad of the pituitary fossa. O. Fasciculus. See Fasciculus. O. Nucleus, the corpus dentatum of the olivary body. O. Peduncle, the mass of fibers entering the hilum of the olivary body. $O$. Process. See Process.

Olive $\left(o l^{\prime}-i v\right)$ oliva, an olive]. I. The olive-tree. 2. The fruit of the olive-tree. 3. The Olivary Body, q.v. O.-oil, Oleum olivara; Sweet Oil, Salad Oil; the oil expressed from the fruit of Olea europaca. The purest oil is nearly inodorous, pale-yellow, with a pure oily taste, and a specific gravity of .918 at $15^{\circ} \mathrm{C}$. It does not decompose or become rancid easily, and congeals at $32^{\circ} \mathrm{F}$. to a granular solid mass. It is used extensively as an article of food or condiment, in pharmacy, as an illuminant and lubricant, in soap-making, and as a cathartic in the place of castor oil.

Oliver, Sign of. See Signs and Symptoms, Table of. O.'s Test. See Tests, Table of.

Oliverin (ol-iv'-er-in) [oliva, olive]. A body obtained from Olea europaca; it has been used instead of quinin. Unof.

Oliviform (ol-iv'-if-orm) [oliva, an olive; forma, form]. In biology, olive-shaped.

Olivil (olt-iv-il) [oliva, olive; $i \lambda \eta$, matter], $\mathrm{C}_{14} \mathrm{H}_{18} \mathrm{O}_{5}$. A crystalline body found in resin of wild olives.

Ollier's Layer. See Layer, Osteogenetic.

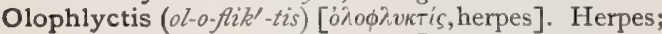
a dark vesicular skin-eruption. [Rare.]

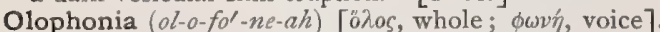
The condition of having a loud and harsh voice.

-oma $\left(-o^{\prime}-m a h\right)[o ̈ \mu a$, tumor: $p l$., -omala $]$. A termination signifying a neoplasm or tumor.

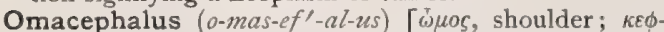
$a \lambda \%$, head]. A variety of omphalositic monsters of the species paracephalus, in which there are present the characteristics of paracephalus except that there is more imperfect development, with absence of the upper extremities.

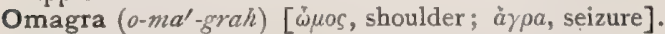
Gout in the shoulder.

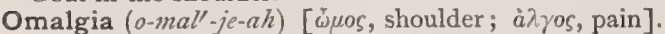
Pain about the shoulder.

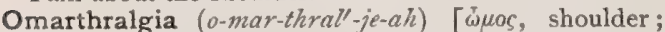
à $\rho$ pov, joint; $\dot{a} \lambda$ yos, pain]. Pain in the shoulder-joint.

Omarthritis (o-mar-thri'-tis) [ $[\dot{\omega} \mu s$, shoulder; à $\rho \rho o v$, joint; $\iota \tau \iota s$, inflammation]. Inflammation of the shoulder-joint.
Omarthrocace (o-mar-throk'-as-e) [ڤuos, shoulder; ápHpov, joint; кสкós, evil]. Disease of the shoulderjoint.

Omasal (o-ma'-sal) [omasum, a paunch]. Pertaining to the omasum.

Omasum $\left(0-m a^{\prime}-s u m\right)$ [omasum, a paunch: pl., Omasa]. The third stomach of a ruminant; it is also called the psalterium, and manyplies. Cf. Abomasum; Reed.

Omatocia (o-mat-o'-se-ah). See Omrotocia.

Omeire $\left(0-m i^{\prime}-r a\right)$ [African]. A vinous and acetous fermented milk used in parts of Africa.

Omelysis $\left(0-m e^{\prime}-l i s-i s\right)$ [ $\omega \mu h \lambda v \sigma \iota$, bruised meal of raw corn]. Barley or wheat-meal used for poultices.

Omental (o-men'-tal) [omentum, the caul]. Pertaining to the omentum. O. Foramen. See Foramina, Table of. O. Hernia. See Epiplocele. O. Sac. See Sac.

Omentitis (o-men-ti'-tis) [omentum, omentum ; $\iota T \iota s$, inflammation]. Inflammation of the omentum or caul.

Omentocele (o-men'-to-sêl) [omentum, omentum; $k \hat{\eta} \lambda \eta$, hernia]. Omental hernia.

Omentulum (o-men'-tu-lum) [dim. of omentum, omentum]. The smaller omentum.

Omentum (o-men'-tum) [L.]. A fold of the peritoneum connecting the abdominal viscera. O. colicum, the part of the great omentum of the fetus that in adult life becomes the hepato-colic ligament. $\mathbf{O}$., Gastric. See O., Greater. O., Gastro-colic, the large peritoneal fold attached to the greater curvature of the

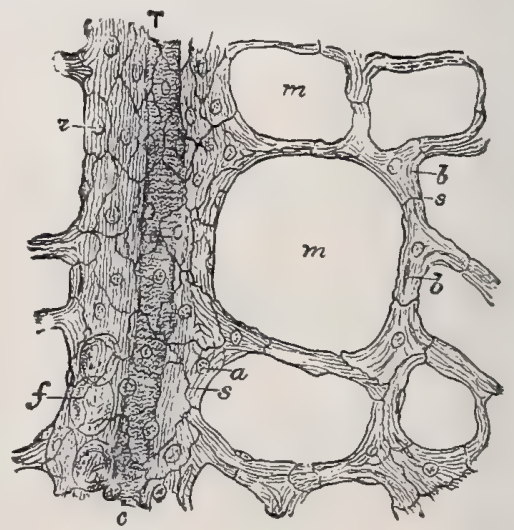

Omentum of Cat, Silvered.

$T=$ Trabecula, with $c$, blood-vessel. $f$. Fat-cells. s. Silverlines, and $a$, nuclei of the endothelium. $m$. Meshes. $b$. Nuclei of the connective-tissue corpuscles. Silver nitrate and hematoxylin. $\times$ 100. (Stirling.)

stomach above and after dipping down over the intestines returning to be attached to the transverse colon. O., Gastro-hepatic, a double fold of peritoneum passing from the lesser curvature of the stomach to the transverse fissure of the liver. On the left side it includes the esophagus; on the right its edges are free and inclose all the structures issuing from or entering the transverse fissure of the liver, the hepatic vessels and nerves, and the bile-duct. Behind it is the foramen of Winslow. O., Gastro-splenic, the fold of peritoneum passing from the stomach to the spleen. O., Greater. See O., Gastro-colic. O., Hepatogastric. See O., Gastro-hepatic. O., Lesser. Synonym of 0. , Gastro-hepatic. O. majus, the greater omentum. $\mathrm{O}$. minus, the gastro-hepatic or lesser omentum.

Omichesis $\left(o-m i k-e^{\prime}-s i s\right)$ [ou ${ }^{\prime} \chi \varepsilon \tilde{\imath} v$, to urinate]. Urination.

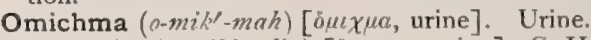
Omicholin $\left(o-m i k^{\prime}-0-l i n\right)[o \mu \chi \mu a$, urine $], \mathrm{C}_{24} \mathrm{H}_{38} \mathrm{NO}_{5}$. 
A resinous substance said to give the fetid odor to putrid urine.

Omission, Death of Children by. In medical jurisprudence, a form of child-murder from neglect or improper attendance at or shortly after birth.

Omitis $\left(0-m i^{\prime}-t i s\right)$ [ $\omega \mu \rho \varsigma$, shoulder; $\iota T \iota \varsigma$, inflammation]. Inflammation of the shoulder.

Ommateal, Ommatidial (om-at-e $-a l, o m-a t-i d^{\prime}-e-a l$ )

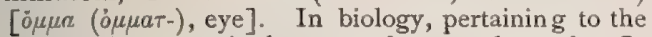
ommatidium or single eye of an arthropod. $O$. Layer, the inner layer of that part of the epidermis from which the optic ganglion originated in decapods, consisting of retinophoræe surrounded by their circles of retinulæ.

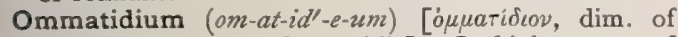
ö $\mu \alpha$, an eye: $p l .$, Ommatidia]. In biology, one of the closely-packed, radially-arranged single eyes composing the compound eye of an arthropod. Each ommatidium has three chief constituents, the retinula, the crystal cone, the hypodermal elements (cornea, etc.).

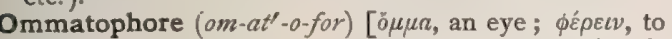
bear]. In biology, one of the eye-stalks, ophthalmites, or eye-bearing tentacles of various invertebrates.

Omnivorous (om-niv'-o-rus) [omnis, all ; vorare, to devour]. Subsisting on all kinds of food.

Omo- $\left(o^{\prime}-m o-\right)\left[\dot{\omega} \mu o_{\varsigma}, \mathrm{raw}\right]$. A prefix signifying raw or crude.

Omo- $\left(\sigma^{\prime}-m o^{-}\right)$[ $\tilde{\omega} \mu \sigma$, scapula]. A prefix that denotes connection with or relation to the scapula or shoulder.

Omo-atlanticus (o-mo-at-lan'-tik-us) [ [̋ $\mu o s$, shoulder; à $T$ as, atlas]. Synonym of the Levator anguli scapule. See Muscles, Table of.

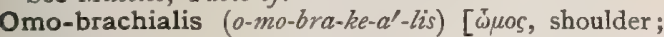

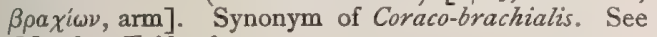
Muscles, Table of.

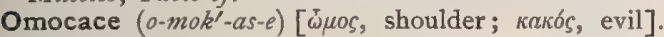
Disease of the shoulder.

Omo-cervicalis (o-mo-ser-vik-a -lis) [ $\omega^{\top} \mu o \zeta$, shoulder; cervix, neck]. Synonym of Levator anguli scapule. See Muscles, Table of.

Omo-clavicular (o-mo-kla-vik'-u-lar) [ $\dot{\omega} \mu o c$, shoulder; clavicula, clavicle]. Pertaining to the shoulder and the clavicle.

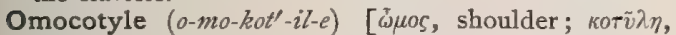
cup]. The glenoid cavity; also, the shoulder-joint.

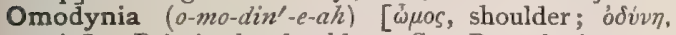
pain]. Pain in the shoulder. See Dorsodynia.

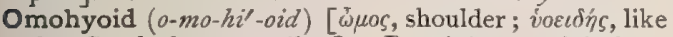
the Greek letter upsilon]. Pertaining conjointly to the scapula and the hyoid bone. O. Muscle. See Muscles, Table of.

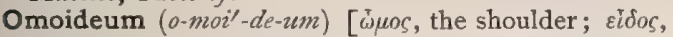
form: $p l .$, Omoidea $]$. In biology, the true pterygoid bone of the skull of a bird.

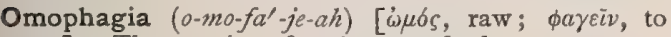
eat]. The practice of eating raw food.

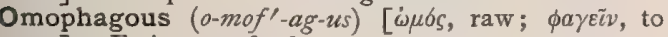
eat]. Eating raw food.

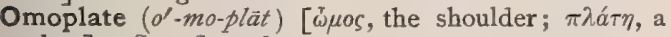
plate]. See Scapula.

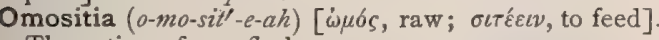
The eating of raw flesh.

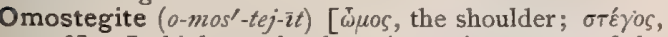
roof ]. In biology, the thoracic portion proper of the carapace of a crustacean.

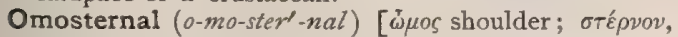
sternum]. Pertaining to the shoulder and the sternum.

Omosternum (o-mo-ster-num) [ڤuos, the shoulder; orépvov, the sternum: $p l .$, Omosterna $]$. In biology, a superior median ossification in the pectoral arch of a batrachian; the homologue of the interclavicle.

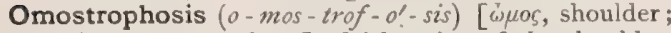
$\sigma \tau \rho \varepsilon ́ \phi \varepsilon \omega$, to turn about]. Dislocation of the shoulder.

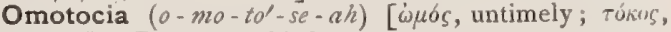
birth]. Premature birth.

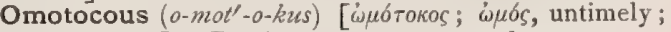
тókos, birth]. Bearing young prematurely.

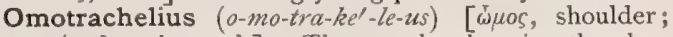
т八á $\chi \eta \lambda$ os, the neck]. The muscle elevating the clavicle in certain animals.

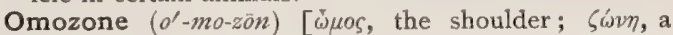
girdle]. A term proposed by Coues and Wilder, 1871, for the shoulder-girdle, including the scapula, clavicle, and coracoid process.

Omphacine $\left(o m^{\prime}-f a s-i n\right)$ [ö $\mu \phi a \xi$, unripe fruit]. Pertaining to unripe fruit. $O$. Oil, the viscous brown juice expressed from unripe olives.

Omphacomel (om-fak'-o-mel) [ö $\mu \phi a \xi$, unripe fruit; $\mu \varepsilon \hat{\imath} \iota$, honey]. An ancient confection; a syrup prepared from unripe grapes and honey.

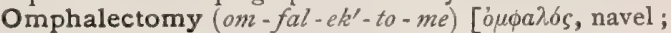
$\dot{\varepsilon} \kappa \tau O \mu \eta \dot{n}$, excision]. Excision of the navel.

Omphalelcosis (om-fal-el-ko'sis) [o $\mu \phi a \lambda \sigma s$, navel; $\hat{\varepsilon} \lambda \kappa \omega \sigma \iota s$, ulceration]. Ulceration of the navel.

Omphalexoche (om-fal-eks'-o-ke) [ó $\mu \phi a \lambda o ́ s$, navel; $\dot{\varepsilon} \xi \circ \chi \hbar$, prominence]. Synonym of Exomphalos.

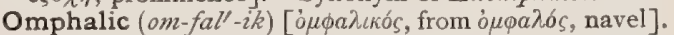
Pertaining to the navel or umbilicus. O. Duct, the vitelline duct; the duct connecting the umbilical vesic!e with the fetal intestines during the first three months of intrauterine life.

Omphalitis (om-fal-i’tis) [ó $\mu \phi a \lambda o ́ s$, navel; $\iota \tau \iota s$, inflammation]. Inflammation of the navel.

Omphalo- (om-fall-o-) [o $\mu \phi a \lambda o ́ s$, navel]. A prefix used to denote relation to the umbilicus or navel.

Omphalocele (om-fal'-o-sêll) [ó $\mu \dot{\phi} a \lambda o s$, navel; $\kappa \dot{\eta} \lambda \eta$, tumor]. Umbilical hernia.

Omphalocraniodidymus (om'-fal-o-kra-ne-o-did'-im-

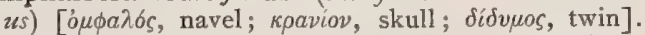
A form of double monstrosity in which the parasite is attached to the cranium of the autosite.

Omphalode $\left(o m^{\prime}-f a l-\bar{o} d\right)[\dot{o} \mu \phi a \lambda \sigma \delta$, navel]. The same as Omphalodium.

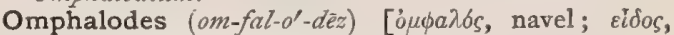
like]. Resembling the navel.

Omphalodium (om-fal-o'-de-um) [o $\alpha \phi a \lambda b s$, a navel : pl., Omphalodia]. In biology, the axial part of the hilum of a seed, containing the vessels that enter the raphe or chalaza.

Omphalo-enteric $\left(o m^{\prime}-f a l-o-e n-t e r^{\prime}-i k\right)$ [ó $\mu \phi a \lambda o ́ s$,

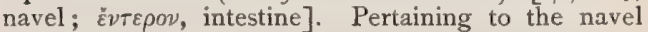
and the intestine.

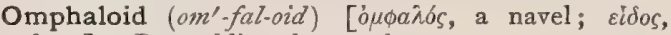
form]. Resembling the navel.

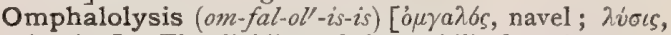
loosing]. The dividing of the umbilical cord.

Omphalomesaraic $\left(o m^{\prime}-f a l-o-m e z-a r^{\prime}-a^{\prime}-i k\right)$. The same as Omphalomesenteric.

Omphalomesenteric (om'-fal-o-mez'-en-ter-ik) [o $\mu \phi a$ -

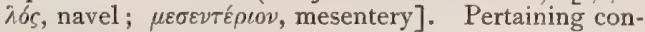
jointly to the navel and the mesentery. O. Duct. See Duct.

Omphalomonodidymi (om-fal-o-mon-o-did'-im-i)

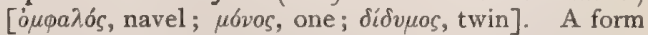
of twin monstrosity in which the fetuses are joined at the umbilicus.

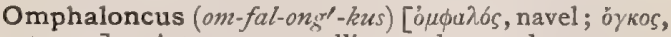
tumor]. A tumor or swelling at the navel.

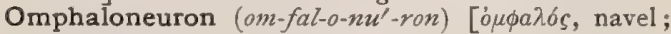
$\nu \varepsilon \bar{v} \rho \circ v$, cord]. The umbilical cord.

Omphaloneurorrhexis (om-fal-o-nu-ror-eks'-is) [o $\mu \phi a-$ 
$\lambda 6 \varsigma$, navel ; veṽ $o v$, cord ; $\dot{\rho} \tilde{\eta} \xi \iota$, rupture]. Laceration of the umbilical cord

Omphaloneurostrepsis (om-fal-o-mu-ro-strep' - sis)

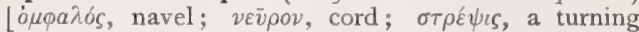
about]. Torsion of the umbilical cord.

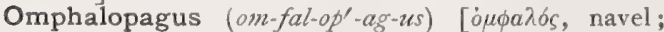
$\pi m \gamma$ vivaı, to make fast]. A better term for the fetal monstrosity known as Xiphopagus, q. v.

Omphalophlebitis (om-fal-o-fle-bi'-tis)[o $\mu \phi a \lambda \sigma s$, navel ; $\phi \lambda \varepsilon \psi$, vein ; $\iota \tau \iota$, inflammation]. Inflammation of the umbilical vein.

Omphalophyma (om-fal-o-fi'-mah). Synonym of $\mathrm{Om}$ phaloncus.

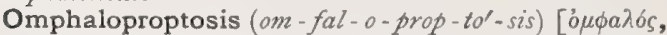
navel; $\pi \rho o ́ \pi \tau \omega \sigma \iota s$, a falling forward]. Abnormal protrusion of the navel

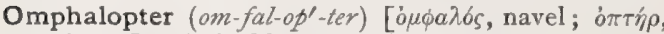
a viewer]. A double convex lens.

Omphaloptic (om-fal-op'-tik) [ó $\mu \phi a \lambda \sigma \varsigma$, navel; ó $\pi \tau \iota k o ́ s$, of seeing]. The same as Omphalopter.

Omphalorrhagia (om-fal-or-a'-je-ah) [o $\mu \phi a \lambda b s$, navel; oprvíva, to burst forth]. Hemorrhage from the umbilicus.

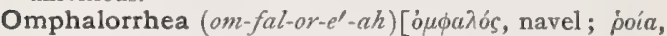
a flow]. An effusion of lymph at the navel.

Omphalorrhexis (om-fal-or-eks'-is) [o $\mu \phi a \lambda \sigma o s$, navel; $\dot{\rho} \tilde{\eta} \xi \iota \zeta$, rupture]. Rupture of the navel, or of the navelstring.

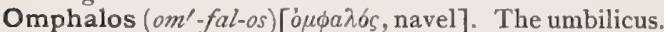

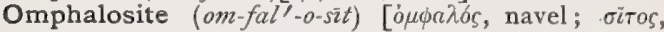
nourishment]. An embryo or fetus dependent for its imperfect growth in the uterus upon another embryo or fetus, usually well-developed, that supplies the circulation of blood for both by means of extensive and intimate anastomoses of the umbilical and placental vessels.

Omphalosoter (om-fal-o-so'-ter) [ó $\mu \phi a \lambda o ́ s$, navel ; $\sigma \omega \tau \eta \hat{\rho}$, preserver]. An instrument for replacing a prolapsed funis.

Omphalotacterium (om-fal-a-tak-te'-re-um) [o $\mu \phi a \lambda o ́ s$,

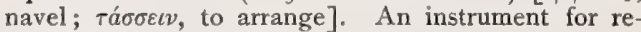
placing a prolapsed umbilical cord.

Omphalotaxis (om- $\left.f a l-a-t a k s^{\prime}-i s\right)$ [ó $\mu \phi a \lambda ́ b$, navel ; $\tau a ́ \sigma \sigma \varepsilon \iota \nu$, to arrange]. Reposition of the prolapsed funis.

Omphalotome (om'-fal-o-tōm) [ỏ $\mu \phi a \lambda b s$, navel; $\tau o \mu h$, a cutting]. An instrument for dividing the umbilical cord.

Omphalotomist (om-fal-ot'-o-mist) [o $0 \mu \alpha a \lambda o ́ s$, navel ; $\tau o \mu \dot{\eta}$, a cutting]. A midwife.

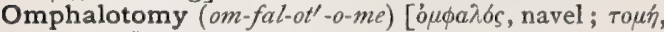
a cutting]. The obstetric separation of the cord at the umbilicus. Also, an obsolete term for obstetrics.

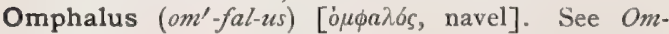
phalos.

Onanism (o'-nan-izm) [from Onan, the son of Judah]. I. Incomplete coitus. 2. Masturbation, or other perversion of the sexual instinct.

Onanist $\left(\sigma^{\prime}\right.$-nan-ist) [from Onan, the son of Judah]. One who practises onanism.

Onchosphæra, Onchosphere (ong'-kos-ef'-rah, ong'-

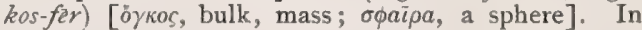
biology, a stage in the development of certain platode worms.

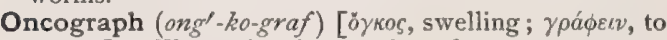
record]. The registering portion of an oncometer; a plethysmograph.

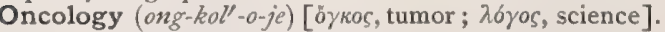
The science or study of tumors.

Oncome $\left(o n^{\prime}-k u m\right)$ [ME., on, on ; ME., cumen, to come]. The oncoming, attack, or onset of a disease or illness.

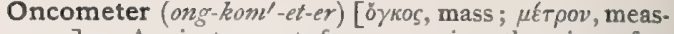
ure]. An instrument for measuring the size of a tumor or the volume of an organ, especially for measuring the size of any variable organ, as the kidney.

Oncosis $\left(o n g-k o^{\prime}-s i s\right)$ [ŏ $\gamma \kappa o s$, tumor]. The presence of a tumor; the diseased state characterized by the growth of tumors

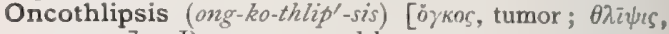
pressure]. Pressure caused by a tumor.

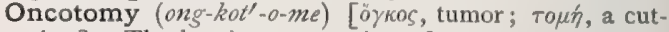
ting]. The lancing or opening of a tumor or abscess.

One (wun) [ME., one, one]. A single unit or individual. O.-eyed, cyclopean, having but one eye. O.-hundred Day Disease, the Japanese term for whooping-cough. O.-sided, developed better upon one side than upon the other. O--year Ulcer, the Arabic synonym of Aleppo Boil.

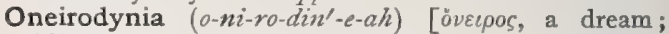
ofuvv, pain]. Disquietude of the mind during sleep; painful dreaming; nightmare. O. activa, somnambulism.

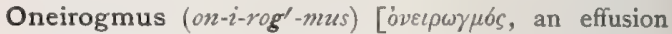
during sleep]. Emission of semen during sleep.

Oneirogonorrhea, Oneirogonos (on-i-rog-on-or-e'-ah, on-i-rog'-on-os). Synonyms of Oneirogmus.

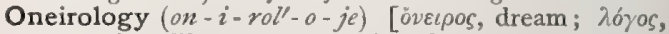
science]. The science or scientific view of dreams.

Oneironosus (on-i-ron'-o-sus) [öveipos, dream; v6oos, disease]. Disorder manifesting itself in dreams; morbid dreaming.

Onion $\left(u n^{\prime}-y u n\right)$ [L., unio, an onion]. A garden plant, Allium cepa; also its esculent bulbous root. Onion-syrup and onion-poultices are much used in domestic medicine; the juice is stimulant, expectorant, and diuretic. Unof.

Onobaio $\left(o n-a-b a^{\prime}-y o\right)$ [Nat. Obock]. An arrow-poison used by the natives of Obock.

Onomatology (on-o-mat-ol'-o-je) [ovo $\mu \alpha$, name; $\lambda 6$ yos, science]. The science of nomenclature; the formation of names.

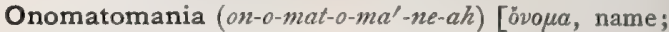
pavia, mania]. Functional derangement of speech, of which five varieties are described: I. A powerful effort to recall some word. 2. An irresistible impulse continually to repeat a word, by which the patient seems perplexed. 3. The patient attaches some peculiar and dreadful meaning to a commonplace word. 4. The patient attaches talismanic significance to certain words, which he repeats as a safeguard. 5. The patient is impelled to spit out some word, like a disgusting morsel. A word is a complexus of images, localized in certain centers of the cerebral cortex, the images being partly auditive, partly visual, partly motor. "Onomatomania is characterized by irregular action of one or several verbal images, resulting from some functional disturbance of the corresponding center." In simple onomatomania, the patient is possessed with the idea of recovering a word that escapes him. The word is familiar; its significance can be given; the place where read or the time when heard can be given, but the word cannot be recalled. Articulate speech may be at fault. The patient knows the word, sees it written before him; but cannot articulate it. He may utter a synonym or a similar word. In associated onomatomania, words acquire a peculiar or preponderant meaning.

Onomatopoiesis (on-o-mat-o-poi-e'-sis) [bovoc, name; $\pi \circ \varepsilon \varepsilon \varepsilon \nu$, to make]. The extemporaneous formation of words by the insane. Words so formed are generally meaningless, or incorrect, but are sometimes quite the reverse. 


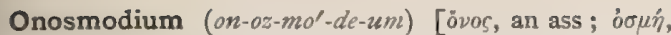
smell; Eidos, form]. A genus of boraginaceous plants. O. hispidum, O. virginianum, a plant of the genus of Boraginacex, growing in the Eastern and Middle States; it has been used in gonorrhea and diseases of the bladder. Unof.

Ontogenesis (on-to-jen' - es - is) [ [ $\nu v$, b̆vros, existing; Y'vEпIS, birth]. The development of the individual cell into the mature being.

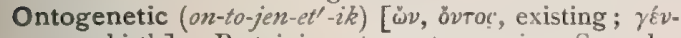
$\varepsilon \sigma \iota s$, birth]. Pertaining to ontogenesis. See also Evolution.

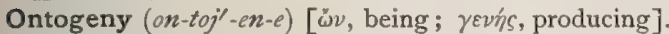
In biology, the history of the development of the individual ; it is a short recapitulation of the history of the race, or phylogeny, $q \cdot v$; that is, every animal passes on to its descendants by inheritance, not only its organization at an adult stage, but also its own course of development. (Lang.)

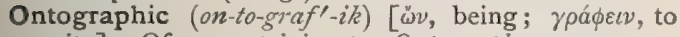
write]. Of, or pertaining to, Ontography.

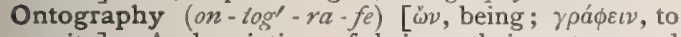
write]. A description of beings, their nature and essence.

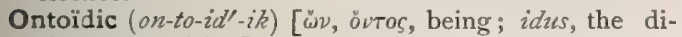
viding or division]. In biology, Weismann's term for the ontogenetic stages of the idioplasm from the hereditary substance or germ-plasm forming the first ontoidic stage and preceding the division of the egg-cell to the natural death of the organism.

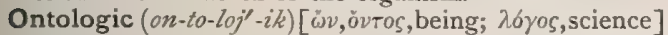
Pertaining to ontology.

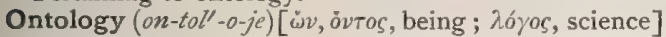
The metaphysical inquiry into the nature and essential quality of beings, or of being in the abstract. According to Flourens, one of the divisions of physiology. A. Biology, the study of life proper. B. Ontology, the study of living beings, which he divides into Neontology and Paleontology. O., Medical, a view which regards diseases as distinct entities.

Onuphin $\left(o n^{\prime}-u-f n\right), \mathrm{C}_{22} \mathrm{H}_{43} \mathrm{NO}_{18^{\circ}}$ A substance obtained from the rings of a species of worm, the Onuphis tubicola. It forms a white mass resembling pipeclay, dissolving easily in water.

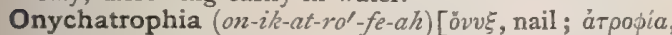
atrophy]. Atrophy of the nails.

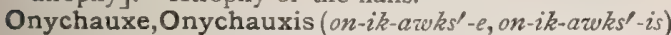

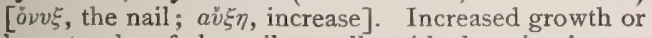
hypertrophy of the nail, usually with alteration in texture, color, and shape.

Onychia $\left(o-n i k^{\prime}-\ell-a h\right)[o ̈ v v \xi$, nail]. Inflammation of the matrix of the nail. See Paronychia. o. maligna. See Onyxitis. O.simplex, onychia without much ulceration, with loss of the nail and its replacement by a new one.

Onychisterion (on-ik-is-te' -

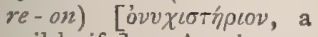
nail-knife]. An instrument used for cutting the nails.

Onychitis (on - ik-i'tis)

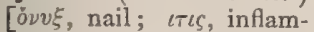
mation]. Inflammation of a nail.

Onychium (o-nik'-e-um) [ơvíxıov, a little claw;

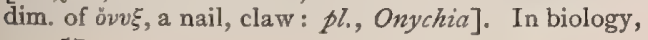

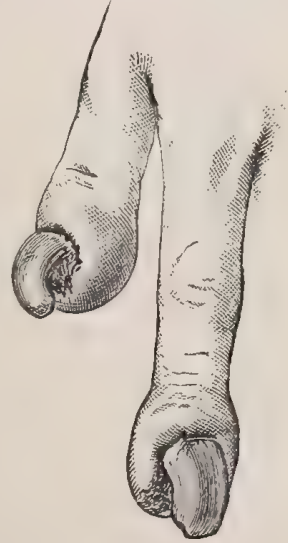

Chronic Onychia. 57 a little claw; specifically the small terminal appendage of the tarsus of many insects, between the two claws proper.

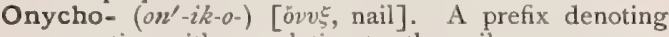
connection with, or relation to, the nails.

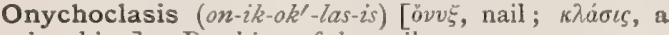
breaking]. Breaking of the nail.

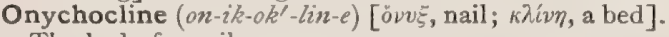
The bed of a nail.

Onychocryptosis (on-ik-o-krip-to'-sis) [övv, nail ; $\kappa \rho v \pi T o ́ s$, hidden]. Ingrowing of a nail.

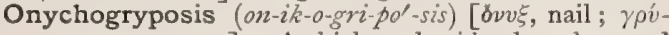
$\pi \omega \sigma \iota$, curvature]. A thickened, ridged, and curved condition of the nail. It sometimes takes the wellknown form of ingrowing nail.

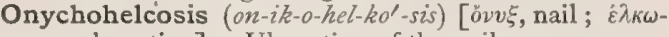
$\sigma \iota s$, ulceration]. Ulceration of the nail.

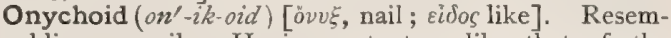
bling a nail. Having a texture like that of the nails.

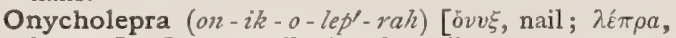
leprosy]. Leprosy affecting the nails.

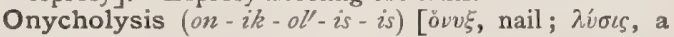
loosening]. Loosening of the nail.

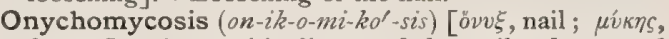
fungus]. A parasitic disease of the nails of men and the hoofs of the horse, mule, etc. In man it is termed dry caries. It is caused by the fungus Achorion keratophagus, or other similar parasite. O. circinata. Same as $O$. trichophytina. $O$. favosa, favus of the nails. O. tonsurans. Same as $O$.trichophytina. O. trichophytina, ringworm of the nails, due to the parasite Trichophyton tonsurans.

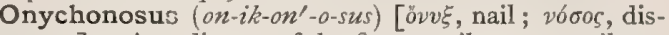
ease]. Any disease of the finger-nails or toe-nails.

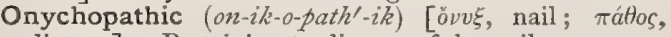
disease]. Pertaining to disease of the nails.

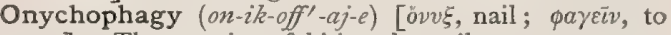
eat]. The practice of biting the nails.

Onychophthora (on-ik-off'-tho-rah), Synonym of Onychosis.

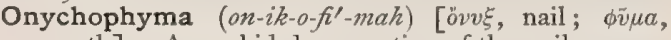
growth]. A morbid degeneration of the nails, sometimes observed in leprosy and in tertiary syphilis.

Onychophyton (on-ik-off'-it-on). Synonym of Onychomycosis.

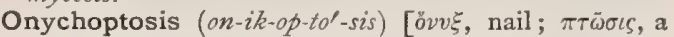
falling]. The falling off of the nails.

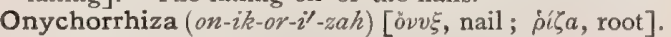
The root of the nail.

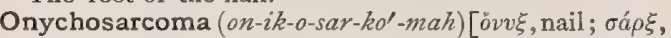
flesh; $\check{\partial} \mu a$, tumor]. A fleshy outgrowth from a nail.

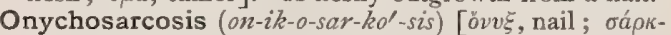
$\omega \sigma \iota \zeta$, the growth of flesh]. The development of an onychosarcoma; an onychosarcoma.

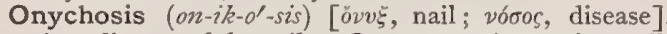
Any disease of the nails. O. arctura, ingrowing nail. O. seline, white spots on the nails. O. tinea, onychomycosis.

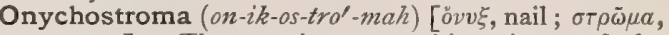
mattress]. The matrix or sensitive tissue of the finger, forming the bed of the nail.

Onychostromelcosis (on-ik-os-trom-el-ko'-sis). Synonym of Onychohelcosis.

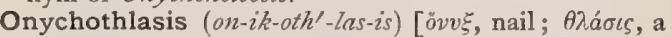
crushing]. Crushing of the nails.

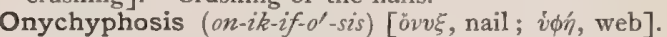
A disease of the toe-nails, consisting of thickened, horny layers of the epidermis accumulated beneath the nail, raising it from its bed, and sometimes altering its growth.

Onym $\left(o n^{\prime}-i m\right)$ [ovopa, a name]. In biology, the 
technical name of a species or other taxonomic division.

Onymal (on'-im-al) [òvou, a name]. In biology, of, or pertaining to, a technical name or technical nomenclature.

Onymatic (on-im-at'-ik) [övo $\mu \alpha$, a name]. In biology, pertaining to technical nomenclature, or scientific taxonomy. Cf. Synonymatic.

Onymize $\left(o n^{\prime}-i m-\bar{i} z\right)$ [ö $\nu o \mu \alpha$, a name]. In biology, to employ onyms, technical names, or nomenclature.

Onymy $\left(o n^{\prime}-i m-e\right)$ [övoua, a name]. In biology, the use of onyms; a system of nomenclature

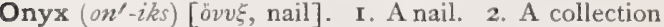
of pus between the corneal lamellæ, at the most dependent part. See Hypopyon.

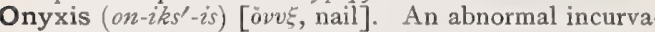
tion or ingrowing of the nails.

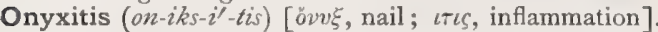
Onychia maligna; an inflammation of the matrix of the nail, occurring most frequently in unhealthy children, after some traumatism.

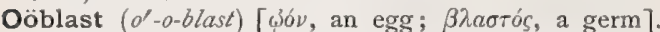
In biology, Ludwig Will's term for the unripe or primitive ovum, the central chromatin-body of which gives rise to the nuclei of the cells forming the egg-follicle by ejecting a large number of chromatinpellets.

Oöblastema (o-o-blas-te'-mah) [认óv, egg; $\beta \lambda a ́ \sigma \tau \eta \mu a$, increase ]. The protoplasm of an ovule.

Oöboo-waioo $\left(o^{\prime}-0-b 00-w a^{\prime}-00\right)$ [Beng. ]. A Bengalese term for Beri-beri.

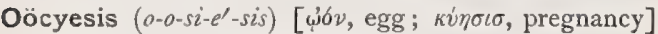
Ovarian pregnancy; oariocyesis.

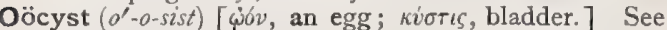
Ecium.

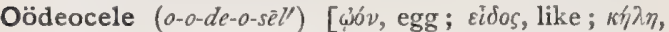
tumor]. Obturator hernia.

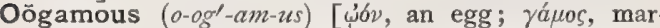
riage]. In biology, exhibiting or reproduced by the conjugation of dissimilar gametes.

Oögamy $\left(o-o g^{\prime}-a m-e\right)$ [ ‘óv, an egg; yáuos, marriage]. In biology, the conjugation of two dissimilar gametes, as distinguished from isogamy.

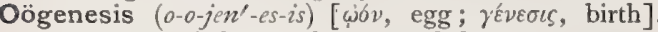
The process of the development of the ovum.

Oögenetic $\left(o-o-j e n-\ell t^{\prime}-i k\right)$ [ $\omega \dot{\omega} v, \mathrm{egg} ; \gamma \varepsilon \nu \nu a \tilde{\nu}$, to beget]. Relating to oögenesis.

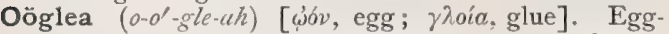
glue; a tough, viscid gelatinous substance enveloping the eggs of certain animals, as crustaceans.

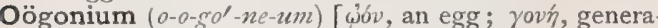
tion: pl., Ooggonia]. In biology, the female sexual organ in the Oosporea before fertilization.

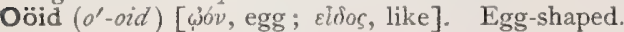

Oökinesis (o-o-kin $\left.e^{\prime}-s i s\right)$ [ [ ment]. The changes occurring in the egg during maturation, fertilization and segmentation.

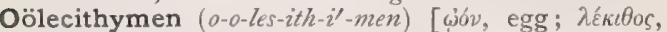
yolk of egg; vunv, membrane]. In biology, the vitelline membrane.

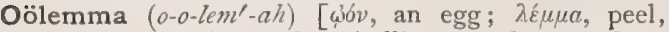
skin]. In biology, the vitelline membrane of an egg.

Oöleukon (o-o-lu'-kon). Synonym of Albumin.

Oölogy $\left(o-o l^{\prime}-o-j e\right)$ [ $\omega \sigma v$, an egg; $\lambda \sigma \gamma o c$, science]. The study of eggs and nidification. Cf. Caliology.

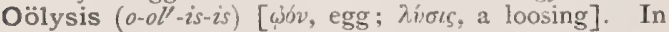
biology, a monstrous ovular development.

Oömetra (o-o-me'-trah) [ఢbv, egg; $\mu$ ír $\rho \pi$, uterus]. In biology, the ovary of phanerogamous plants.

Oömetry $\left(o-o m^{\prime}-e t-r e\right)$ [ $\omega o ́ v$, an egg; $\mu \dot{\varepsilon} T \rho o v$, a measure]. In biology, the measurement of eggs.

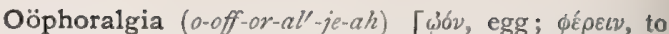
bear; àjos, pain]. Neuralgia of the ovary.

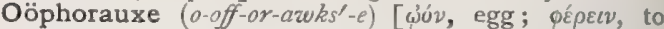
bear; $a v z \xi \eta$ growth]. Hypertrophy of the ovary.

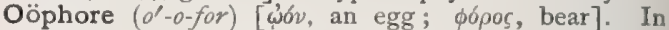
biology, the sexual stage in plants exhibiting alternate generation

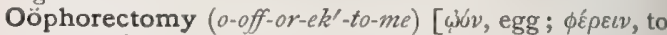

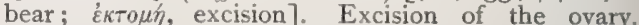
Battey's Operation, the removal of both ovaries to hasten the menopause.

Oöphoridium (o-o-for-id'-e-um) [ఢंóv, an egg; фópos, bear: $p l$., Oophoridia]. See Macrosporangium.

Oöphoritis (o-off-or-i'tis). See Ovaritis.

Oöphoro-epilepsy ( $\left.\alpha^{\prime}-o f f-o r-o-e p^{\prime}-i l-e p-s e\right)[\omega 6 v$, egg; $\phi \varepsilon ́ \rho \varepsilon \iota v$, to bear; $\varepsilon \pi \imath \lambda \eta \psi i \alpha$, epilepsy]. Epileptiform disease due to an ovarian lesion.

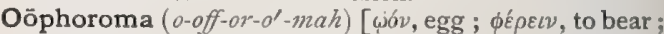
ö $\mu$, a tumor: pl., Oöphoromata]. A dermoid cyst of the ovary, characterized by metastasis.

Oöphoromalacia (o-off-or-o-mal-a'-se-ah) [ڤंbv, egg ;

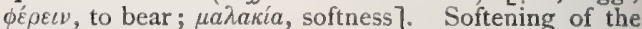
ovary.

Oōphoromania $\left(o-o f f-o r-o-m a^{\prime}-n e-a h\right)[\omega \dot{b} v$, egg; $\phi \varepsilon ́ p \varepsilon v v$, to bear ; $\mu a \nu i a$, mania]. Insanity due to ovarian disorder.

Oöphoromyeloma (o-off-or-o-mi-el-o'-mah) [ $\omega \dot{\omega} v$, egg ; $\phi \varepsilon ́ \rho \varepsilon \iota \nu$, to bear; $\mu v \varepsilon \hat{\lambda} o ́ s$, marrow ; ò $u a$, tumor]. An ovarian encephaloma.

Ö̈phoron, Oöphorum, (o-off'-or-on, o-off'-or-um). See Oöphore, Ovarium, Ovary.

Oöphoropathia (o-off-or-o-pa'-the-ah) [ $\omega 60$, egg ;

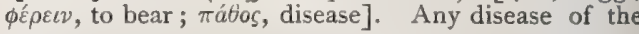
ovary.

Oöphoro-salpingectomy ( $o^{\prime}$-off-or-o-sal-ping-gek'-to-

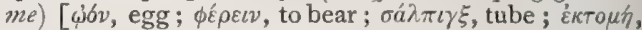
excision]. Surgical removal of an ovary and oviduct.

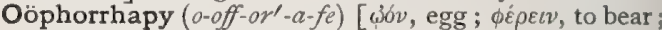
$\dot{\rho} a \phi \eta$, suture]. The surgical fixation, by suture, of a displaced ovary.

Oöphyte $\left(o^{\prime}-o-f i t\right)$ [ $\omega b v$, an egg; $\phi v \tau \delta v$, a plant]. Same as Oöphore.

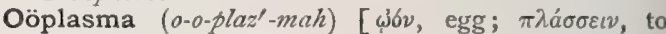
mold]. The vitellus.

Oöplasty (o'-o-plas-te) [ $\omega^{\prime} b v$, egg ; $\pi \lambda a ́ \sigma \sigma \varepsilon \imath \nu$, to form]. The process of fecundation.

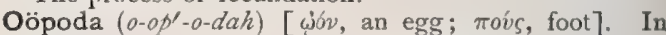
biology, the three pairs of blade-like elements of the sting or modified ovipositor of insects.

Oösperm $\left(o^{\prime}-o\right.$-sperm $)$ [ $\omega \hat{\zeta} \sigma \nu$, egg ; $\sigma \pi \varepsilon \dot{\varepsilon} \sigma a$, seed]. The ovum after union with the male element.

Oöspermospore (o-o-sper'-mo-spor) [ $\omega^{b} \delta \nu$, an egg ; $\sigma \pi \dot{\varepsilon} \rho-$ $\mu a$, seed; $\sigma \pi \delta \rho o s$, seed]. See Oöspore.

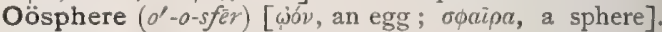
In biology, the unfertilized germ-cell in the oögonium; the female reproductive cell.

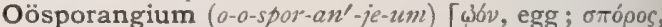
seed; á $\gamma$ riov, vessel]. The sac enclosing the oöspores.

Oöspore $\left(o^{\prime}\right.$-o-spor) [ $\dot{\omega} b v$, an egg; $\sigma \pi b \rho \circ \varsigma$, seed]. In biology, a fertilized and matured oösphere.

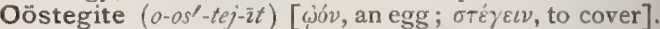
The laminar expansion of some of the limbs of certain crustaceans, beneath which the eggs are retained.

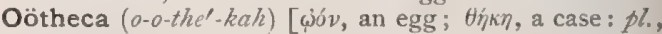
Oöthecce]. In biology, an egg-case or sporangium.

Oötocia $\left(0-0-t 0^{\prime}-k e-a h\right)$ [ $\omega^{\prime} \nu$, an egg; $\tau \varepsilon \kappa \varepsilon i v$, to produce, to lay]. In biology, ovulation; the discharge of the egg from the ovary. Cf. Oviposition.

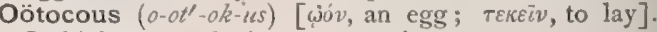
In biology, producing eggs; oviparous.

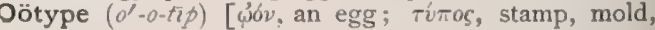
pattern]. In biology, he small part at the beginning 
of the egg-passage in platode worms, which receives the efferent ducts of the shell-glands.

Ooze $(\bar{u} z)$ [ME., wose, mud]. The deposit of calcareous or siliceous shells or frustules, found making up extensive areas of the floor of the ocean and derived from the halobios (benthos and plankton), or organisms living in the sea, i. e., Diatom-ooze, Radiolaria-ooze (about 1000 species are included, the richest regions being the tropical central Pacific), Globigerina-ooze, Pteropod-ooze.

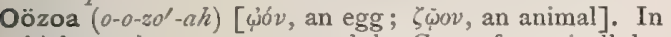
biology, the onym proposed by Carus for unicellular animals, because of their resemblance to ova. Cf. Protista, Protozoa.

Opacity (o-pas'-it-e) [opacus, dull]. The condition of being impervious to light. Non-transparency. Also, an opaque spot, as opacity of the cornea. O. of Lens. See Cataract.

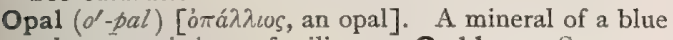
color, consisting of silicon. O.-blue. Same as Spirit-blue.

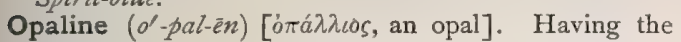
appearance of an opal. O. Patch, the mucous patch of syphilis, forming in the mouth a whitish pellicle.

Opaque $\left(o-p \bar{a} \bar{k}^{\prime}\right)$ [opacus, shaded]. Dark, obscure, not transparent. O. Nerve-fibers, persistence of the medullary sheaths of the optic-nerve fibers beyond the lamina cribrosa, forming brilliant white patches upon the retina as seen by the ophthalmoscope.
Open $\left(o^{\prime}\right.$-pen $)$ [ME., open, open]. Unclosed, unfolded. O. Method. See Anesthetic.

Opening ( $o^{\prime}$-pen-ing) [ME., openyng, opening]. A mouth, or hole; a perforation. O., Aortic. See Aortic. O., Caval, the opening in the diaphragm for the passage of the vena cava. O., Saphenous, an oval opening in the fascia lata at the upper and inner part of the thigh below Poupart's ligament. It transmits the internal saphenous vein and is covered by the cribriform fascia.

Opeocele $\left(o^{\prime}-p e-o-s \bar{e} l\right)$ [ójí, an opening; $\kappa \hat{n} \lambda \eta$, a tumor] Synonym of Hernia.

Operable (op'-er-ab-l) [operari, to labor]. Admitting of an operation.

Operating (opp-er-a-ting) [operari, to work]. Performing; acting; doing some surgical process. O.table, the table on which a patient lies during a surgical operation.

Operation (op-er-a'-shun) [operari, to labor, to do]. An act; especially a surgical act upon the body. A table of many of the most important operations is appended. O., Curative effect of, per se; the improvement or disappearance of symptoms after a simple exploratory incision, with closure of the wound, the supposed condition not being found to exist, or not being amenable to interference. O., Major, a serious and important surgical operation. O., Minor. See Surgery, Minor. O., Plastic. See Surgery.

\section{EPONYMIC TABLE OF OPERATIONS AND METHODS IN SURGERY.}

Abbe's: I. Lateral anastomoszs of the intestines with cat-gut rings. 2. For varicocele; resection of the scrotum, with ligation of the exposed veins. Abernethy's, for ligation of the external itiac artery. In the earlier operation an incision was made in the line of the artery for about three inches, commencing nearly four inches above Poupart's ligament. Later the incision was less nearly vertical and more curved, with the convexity downward and outward, extending from about one inch within and one inch above the anterior superior spine to one and one-half inches above, and external to, the center of Poupart's ligament. Adams' : I. Osteotomy for ankylosis of the hip-joint, the neck of the femur being divided subcutaneously within the capsule. 2. Corectopy; the iris is drawn into a small, corneal incision, in order to change the position of the natural pupil. 3 . For deviated nasal septum; the bent cartilaginous septum is forcibly straightened by means of special flat, parallel-bladed forceps. 4. For Dupuytren's contraction, when the bands extend far down the sides of the finger. It consists in multiple subcutaneous section of the palmar fascia from without inward. 5. For ectropion; a triangular wedge is removed from the whole thickness of the lower lid, and the edges are united by sutures. 6. Iliac colotomy; a modification of Cripps' operation, in which a vertical incision is made external to the epigastric artery. 7. For prolapsus uteri. See 0. , Alexander's. Affieck's, a method of performing embryotomy; also known as Macdonald's method; it consists in rachiotomy followed by forcible podalic version. Agnew's (Cornelius R.) : I. For cataract; it consists in the laceration or removal of the capsule in secondary cataract by means of a stopneedle and hook. 2. For chalazion; incision along the ciliary margin of the lid, followed by curettement or by expression. 3. For destruction of the lacrymal sac; it consists in slitting the canaliculi, vertical incision of the sac, and cauterization of its interior. Agnew's (D. Hayes): 1. For amputations; it is a modification of Vermale's operation by which elliptic tegumentary flaps are made and allowed to retract before the muscles are cut through. 2. For inguinal hernia; a modification of Wutzer's operation, q.v. 3. For salivary fistula; after the introduction of a probe into the duct, a thread is passed from the inside of the mouth, around the duct, the probe is withdrawn, and the thread tied tightly. As it sloughs off, the natural orifice is reestablished. The external opening may be closed subsequently by operation or caustics. 4 . For webbed fingers; a dorsal flap, triangular in shape, is cut from the upper surface of the web. The apex corresponds to the free margin, the base to the interval between the proximal ends of the first phalanges; this is reflected back, and the web is divided as far as necessary; the flap is then folded between the fingers, and the wound closed with sutures. Alanson's, a method of performing amputations; it consists in division of the skin and muscles in the form of a hollow cone. Albert's, for flail knee-joint; excision of the knee to secure ankylosis. Alexander's : I. For the relief of epilepsy; ligation of the vertebral artery to diminish the blood-supply to the brain. 2 . For prolapse and retroflexion of the uterus; shortening of the round ligaments for the purpose of holding the uterus in its normal position. AlexanderAdams'. See Alexander's. Allarton's, for lithotomy; it is the modern median operation for stone in the bladder. Allingham's (H.), for inguinal colotomy; an incision, from one and one-half to three inches long, is made parallel with the outer third of Poupart's ligament, and about one-half inch above. The edges of the peritoneum, in most cases, are stitched to the cut muscles and skin; the intestine is stitched to the edges of the wound, and opening 
of the bowel is deferred, if possible, until the third day. Allingham's (W.): I. For excision of the rectum; the patient in the lithotomy position, an oval incision is made into both ischio-rectal fossæ, around the bowel, and prolonged backward to the coccyx; the bowel is isolated, and separated with the écraseur, scissors, or Paquelin cautery. 2. For hemorrhoids; the pile is dissected off from the muscular tissue with scissors, the pedicle ligated, and the mass cut off. Alonette's, for amputation at the hipjoint; a semicircular external flap is made, extending to the great trochanter, with disarticulation of the head of the femur, and the making of a large internal flap by cutting from within outward. Alquié-Alexander's. The same as Alexander's. V. Ammon's: I. Blepharoplasty; removal of all cicatricial tissue and freeing of the remains of the lid, followed by transplantation of a Hap from the cheek. 2. For destruction of the lacrymal sac; incision into, and excision of, a portion of the anterior wall of the sac ; closure by adhesive inflammation. 3. For ectropion (from caries); an incision is made around the cicatrix, the tissues are dissected free, and after closing the lid the wound is closed over the cicatrix. 4. For symblepharon; the lid is divided, by two converging incisions, into three portions -two lateral and a central wedge-shaped portion; the former are united by sutures, and after union the central, wedge-shaped part is dissected out. Amussat's : I. A method of arresting hemorrhage by torsion of the arteries by means of two forceps. 2. For atresia vagina; dilatation by the use of the finger or a dull instrument, without cutting. 3. For castration; by incision upon the posterior surface of the scrotum. 4. For enterorrhaphy; in cases of completely divided intestine, each end is invaginated and passed over a cork, with a groove at either end, and the intestine is tied in the grooves. 5. For imperforate rectum; the formation of an artificial anus in the perineum, with or without excision of the coccyx. 6. For lumbar colotomy; a transverse incision is made, crossing the outer border of the quadratus lumborum muscle. Anagnostakis': I. For entropion; an incision is made parallel and close to the free margin of the upper lid, a horizontal fold of skin, with the underlying tissue, is excised, and the wound closed by sutures. 2. For trichiasis; the offending cilia are included between two perpendicular incisions and excised. Anderson's, for lengthening tendons; the tendon is split longitudinally, the cut surfaces slid along, and sutured. Anel's : I. For aneurysm; ligation on the cardiac side close to the aneurysm. 2. For stricture of the lacrymal duct; dilatation by means of a gold probe, followed by the injection of an astringent fluid into the sac. Anger's : I. For hypospadias; the formation of a urethra by superimposing a quadrilateral flap from one side and lower border of the penis, over another flap from the other side, which has been turned over a catheter. 2 . For ingronving toe-nail; the lateral-flap operation, with removal of the diseased portion of the matrix. 3. For union of divided tendons; the use of "distance-sutures," when the ends of the tendon are widely apart. Annandale's : 1. For dislocated cartilages; incision into the knee-joint and stitching of the dislocated cartilages into their proper position. 2. For genu valgum; partial excision of both condyles of the femur. 3 . For naso-pharyngeal polypus; division of the alveolar margin and palatal portions of the upper jaw along their center, from before backward, and perforation of the bony septum of the nose, thus permitting separation of the two portions of the bone and exposure of the polypus. 4. For varicocele; a modification of Lee's operation, the veins only being excised, the scrotum being left intact. 5. For webbed-fingers; the longitudinal incisions are made along the sides of each finger. Antal's, for tumor of the bladder-wall; after a supra-pubic incision the tumor is removed with the portion of the bladder from which it springs, and the vesical wound is closed; the peritoneum is rolled up and not opened. Antyllus', for aneurysm; it consists in ligation above and below the sac, followed by opening of the aneurysm and evacuation of its contents. Antyllus-Kuhnts', for paralytic ectropion; excision of a wedge-shaped portion of the conjunctiva and tarsus from the lid, in order to shorten the latter. The base of the wedge is on the free border of the lid. Apostoli's, electrolysis of a uterine fibroid when an electrode cannot be introduced into the womb. One broad abdominal electrode is used, and a spearpointed electrode is thrust through the vaginal wall into the tumor. Appolito's, for enterorrhaphy, by means of a form of right-angle continuous suture, Argyll Robertson's: I. For entropion; a piece of sheet-lead is fastened inside of the lid, so that the pressure will cause absorption of the hypertrophic tissue. 2. For glaucoma; trephining the sclerotic for the relief of pain. 3. For pterygium; the growth is separated and excised; the conjunctiva, previously dissected up, is brought over the wound and sutured. Arlt's : I. For blepharoplasty; a modification of Dieffenbach'soperation, with a downward inclination of the cantho-temporal incision, and a slight deviation of the tempero-genal incision. 2. For cicatricial ectropion; a $V$-shaped incision is made, removing the cicatrix; the wound is closed by interrupted sutures. 3. For entropion; (a) a modification of Gaillard's suture; a thread, with a needle at either end, is passed subcutaneously from the margin of the lid down to the cheek, and the two ends are tied; there results a puckering of the skin and thereby relief of the entropion; (b) a flap-splitting operation upon the lid, with the removal of an oval portion of the skin, and suturing of the latter. 4. For enucleation of the eye; Desmarre's retractors are introduced, and the conjunctiva is divided all around the corneal junction; then the external rectus (if the left eye, the internal if the right eye) is caught by a blunt hook and divided behind it, leaving a stump; then the remaining ocular muscles and the optic nerve are divided by scissors. The internal rectus (if the left eye, the external if the right eye) and the two oblique muscles are divided after luxation of the ball in front of the lids; the conjunctiva is stitched in and out, so as to form a suture like the string of a tobacco-bag, and a pressurebandage is applied. 5. For median tarsorrhaphy; excision with scissors and forceps of a narrow strip of skin from both the upper and lower lids, close to their inner angle, meeting on the inner side of the inner commissure; they are then united by interrupted sutures. 6 . For stricture of the lacrymal duct; incision of the anterior wall of the sac, evacuation of the pus and gradual dilatation of the duct. 7. For symblepharon; dissection of the symblepharon, and suturing of the flap on itself. 8. For trichiasis; known also as the Jaesche-Arlt operation," it is a modification of Jaesche's operation, in which the lid is separated into anterior and posterior flaps by Flarer's incision. Arlt-Jaesche, for distichiasis; the edge of the lid and the contained ciliary bulbs are dissected from the tarsus, a crescentic-shaped piece of skin is removed from the lid above the flap. and the edges of the wound are united, thus transplanting the ciliary. bulbs further away from the edge of the lids. Armsby's, for the radical cure of inguina" hernia; the integument is invaginated, and a single thread is introduced as a seton through the sac of the hernia and the inguinal canal. Ashton's, for $a$ con- 
gesled and bleeding rectum, without distinct hemorrinoidal tumor; cauterize with fuming nitric acid. Assalini's, for iridodialysis; the iris is detached with eye-forceps through a large opening in the cornea. Atlee's, for ovariotomy; the écraseur is applied to the pedicle. Aveling's: 1. For suture of the soft palate; a double loop of suture is passed on one side and the loop drawn out of the mouth; a single suture is then passed through the opposite side and looped into the double one; by pulling the latter back, the single suture is drawn across the cleft. 2. Transfusion by the direct method; this permits measurement of the amount of blood transfused. Avery's, for uranoplasty. Same as Langenbeck's operation. Ayres', for ectopia vesice; closure by means of a flap of skin turned down from the abdomen over the bladder. Bader's: I. For conical cornea; an elliptic piece of the cornea is removed from the apex of the cone, and this is followed by the application of a tight bandage. 2. For the relief of pain in glaucoma; stretching or laceration of the infratrochlear nerve. 3. For sclerotomy; the incision is confined to the scleral margin, without division of the overlying conjunctiva. Baer's $(B . F$.$) : I.$ For perineorrhaphy; the same denudation is made as in Emmet's operation. The needle is passed deeply on the outer side of the denuded sulcus, brought out at the bottom of the sulcus, again introduced on the rectal side and brought out at the top of the opposite side of the sulcus; the crest of the rectocele is then picked up at the upper border of the denudation, the needle is passed down the inner side of the left sulcus and up on the outer side, the entire sweep being made with one suture. The same process is repeated once or twice. 2. For supravaginal hysterectomy; median celiotomy, ligation of the ovarian arteries in the broad ligament; the clamp is applied close to the uterus and the ligament divided between the ligature and the clamp; ligation of the uterine arteries in the broad ligament; formation of anterior and posterior peritoneal flaps; division of the cervix; if necessary, suture of the flaps over the cervical stump. Neither ligature nor suture must pierce or embrace cervical tissue, and nothing whatever is done to the cervical canal. Baker's $\left(M_{\text {. }}\right): \mathbf{I}$. To secure anion of bone; the use of steel pins to keep the bones together after excision of the knee. 2. For carcinoma of the cervix uteri; the cervix is removed by means of a uterotome that makes a funnel-shaped excavation, the base of which is on a line with the internal os, and the apex approaches or meets the fundus. 3. For excision of the tongue; removal through the mouth with the use of the écraseur as a supplemental means. Ball's: I. For itiac colotomy; a modification of Cripps' operation, in which the incision is made in the left linea semilunaris, and the bowel secured above and below the future artificial opening by means of two special clamps, which are removed after suturing and opening of the bowel. 2. For inguinal hernia; the sac is separated up to the abdominal portion of the neck and then twisted around its own axis, after which the fundus is cut away and the stump is secured in the ring. Ballingall's, for excision of the upper jaze. The same as Velperu's operation. Bandl's, for uretero-vaginal fistula; a catheter is passed into the bladder, and through an artificial opening in the bladder into the ureter, and the original opening is closed over the catheter. Banks' $(M$.$) : I. For aneurysm of the third part of the sub-$ clavian artery: ligation of the first part of the artery. 2. For the radical cure of inguinal hernia; the sac is exposed and separated from the surrounding parts; a ligature is then applied close to the ring, and the fundus of the sac is cut away, after which the inguinal ring is closed by sutures. 3. For internal urethrotomy; a special urethrotome is used to divide the stricture from within outward. 4. For removal of the breast; it con sists in removal of the entire breast, the overlying skin, the fascia over the pectoral muscle, and (if suspiciouslooking) the fibers of the muscle. The axilla is always to be cleaned out. 5. For removal of nasal polypi; avulsion with forceps, when the nostrils are in a dependent position, so as to prevent choking by the blood. Bardeleben's, for double harelip; the mucous membrane and periosteum are stripped up behind the pre-maxillary bone; the septum is then divided and the projection reduced, or grasped by forceps and twisted upon itself. Barden's, for angular ankylosis of the knee; removal of a wedge-shaped piece of bone from the shaft of the femur, and fracture of the remaining part. Bardenheuer's: I. For cholecystotomy; performed in two stages: the first operation consists in fixing the gall-bladder to the abdominal incision. After adhesions have formed, the bladder is opened and the operation completed. 2. Exploratory incision; an extraperitoneal exploratory incision, to allow of the palpation of the contents of the abdomen through the parietal peritoneum. 3. For resection of the sacrum: the removal of the entire lower part of the bone at the third sacral foramen. 4. For suprapubic cystotomy; a skin-incision, about the length of a finger, in the middle line, close above, and parallel with, the upper border of the pubis. Barker's $(A . E$.$) : I. For excision of the astragalus$ the incision runs from just above the tip of the external malleolus forward and a little inward, curving toward the dorsum of the foot. 2. For excision of the hip; by an anterior incision, commencing on the front of the thigh, one-half inch below the anterior superior iliac spine, and running downward and inward for three inches. 3. For gastro-enterostomy; the visceral incision is made only through the serous and muscular coats, and the most important part of the suturing is done before the stomach or bowel is opened. 4. For the radical cure of inguinal hernia; a modification of Banks' operation, in which the neck of the sac is ligatured and the sac below the ligature divided, but not dissected out, being used to occlude the internal ring. 5. For spinal abscess; the abscess is opened and scraped, and the débris washed out by the use of the flushing-curet. 6. For ununited fracture of the clavicle; the false joint is exposed by an incision; the two ends of the bone are removed by oblique cuts in the same plane, and held together by silver wire. 7. For varicocele: the application of subcutaneous aseptic silk ligatures at one or two points. Bartisch's, for entropion; removal of the entire ciliary margin of the lid. Barton's (J. Rhen) : I. For bony ankylosis of the knee; the removal of a wedge-shaped piece of bone from the lower end of the femur, to allow of the correction of the deformity. 2. For osteotomy; division of the femur between the two trochanters. Barwell's $\left(R_{.}\right)$: I. For aneurysm; $(a)$ the use of ox aorta in the ligation of aneurysm; $(b)$ passing a needle, armed with a silver wire, subcutaneously around vascular tumors to avoid scars. 2. For aneu$17 y s m$ of the innominate or aorta; ligation of the carotid and subclavian arteries. 3. For ligation of the first part of the subclavian artery; the formation of a triangular flap turned upward and outward, with division of both heads of the sterno-mastoid muscle and the sternothyroid muscle. 4. Osteotomy for genu valgum; division of the lower end of the femur and upper end of the tibia, above and below their respective epiphyses. 5. For varicocele; the subcutaneous applica- 
tion of a silver wire, and twisting of the free ends from day to day. Bassini's, for the radical cure of inguinal hernia; the sac is exposed, twisted, and the neck ligated and removed; the spermatic cord is lifted, and the border of the rectus is stitched to the edge of the internal oblique, the transversalis muscle and the transversalis fascia to Poupart's ligament under the cord. The cord is placed upon this layer and the border of the external oblique is stitched to Poupart's ligament over the cord. Bates', for internal urethrotomy; a special urethrotome is used to divide the stricture from within outward. Battey's (R.), for öphorectomy : also called "normal ovariotomy;" removal of the ovaries in order to eliminate their physiologic influence. Bauden's: I. For amputation through the foot; it is made at the tarso-metatarsal joint, disarticulating the first metatarsal bone, and sawing through the remaining ones on a level with the internal cuneiform bone. 2. For amputation at the knee-joint; by oval anterior and posterior flaps. 3. For excision of the shoulder; by a single anterior vertical or oblique incision. Baum's, for stretching the facial nerve; an incision is made downward and forward from behind the ear, about opposite the meatus, to a point immediately below the lobule, and then prolonged nearly to the angle of the jaw, a small, transverse incision being also made below the pinna. Baynton's, a method of healing leg-ulcers; it is the original method of applying adhesive straps and a bandage in cases of indolent ulcers. Beaufils', for uranoplasty; a single flap is twisted on itself so as to fill up the aperture. Béclard's, for amputation at the hip-joint; a modification of Liston's amputation, by cutting the posterior flap first. Beer's: I. For cataract; extraction by the flap-method. 2. For iridectomy; an incision is made near the margin of the cornea with a lance-knife entered perpendicularly, then made parallel with the plane of the iris, making a section concentric with the cornea, of the desired length. 3. For iridodialysis. The same as Himly's operation. Bégin's, for excision of the knee. Similar to Textor's operation, q.v. Bell's (C.): I. For gastrotomy; a parietal incision is made in a line extending from the umbilicus toward the left false ribs. 2. For ligation of the first part of the lingual artery; the same incision is used as in the operation of election, its center being opposite the body of the hyoid bone. Belmas' (M.), for the radical cure of inguinal hernia; it consists in introducing gold-beaters' skin in the neck of the sac, to excite sufficient inflammation. Benham's, for hemorrhoids; the same as Pollock's operation, q.v. Bennett's $(W . H$.$) , for varicocele; a modification of$ Hozerse's operation, in which the elongated cord is shortened. Benson's, for entropion; a modification of van Millingen's operation, in which a flap of mucous membrane is taken from the lower lip. Bent's, for excision of the shoulder; a flap is taken from the deltoid region, with the base in ward, by means of one vertical and two transverse incisions. Berard's (A.), for naso-pharyngeal tumor; an incision is made either along the median line or the side of the nose, extending down through the upper lip; by means of the cutting-forceps the outer wall of the nasal cavity and of the antrum is removed. Berger's $(P$. $)$, for interscapulothoracic amputation; it is made by two flaps-an antero-inferior or pectoro-axillary flap, and a posterosuperior or cervico-scapular flap. Von Bergmann's $(E$.$) : I. For hydrocele; excision of the parietal part of$ the sac. 2. For mastoid and middle-ear disease : it consists in making a long, crescentic incision from above and in front of the auricle, backward and downward, and then loosening the periosteum from the entire osse- ous auditory canal ; the bony portion between the auditory canal and the middle cranial fossa is penetrated with a chisel as far as the bony annulus tympanicus, and the incision is then carried backward toward the mastoid process, avoiding injury of the facial canal ; there is then inserted a tamponade of iodoform-gauze. 3. For nephrectomy; a lateral lumbar incision is made from the upper end of the twelfth rib obliquely toward the junction of the outer and middle thirds of Poupart's ligament. Berlin's: I. For entropion; incision through the entire thickness of the lid, parallel to the ciliary margin, and excision of a portion of the tarsus and conjunctiva. 2. For excision of the lacrymal sac; the same as Platner's operation, q. v. Berlinghieri's, for entropion and trichiasis; a horizontal incision is made along the margin of the lid, a vertical incision from each end of this, away from the margin, followed by dissection up of the flap, and extirpation of the hair-bulbs; the flap is then replaced. Bernays' (A. C.), for gastrotomy; removal of the growths bulging into the cavity of the stomach by the curet or other instrument, after making an incision through the wall of the stomach. Bernheim's, for circuncision; the operation is performed with the galvano-cautery instead of the knife. Berthold's. See under Myringoplastic. Bigelow's $(H . J$.$) , for vesical calculus; the ordinary$ operation of litholapaxy, q. $v$. Billroth's $\left(T_{.}\right): \mathbf{1}$. For blepharoplasty; a modification of Dieffenbach's operation, $q . v .2$. For ectopia vesica; a modification of Thiersch's operation, in which two broad, lateral, doubly-pedunculated flaps are dissected up. 3. For excision of the tongue; a curved, submental incision is carried backward along the lower border of the jaw on both sides; the bone is then divided in two places, and after excision of the tongue, is replaced. 4. For genu valgum; incomplete linear osteotomy of the tibia. 5. For naso-pharyngeal tumor; an incision from the root of the nose to the tip is carried into the nostril. An incision from either end of this is carried horizontally across the cheek. The nose is separated in the line of the first incision, and the superior maxilla is sawn through in the line of the second and third incisions, and the bone pried out of place, hinging upon the pterygoid process. 6. For ovariotomy; the pedicle is ligated between two forceps, and then divided with the thermo-cautery. 7. For pylorectomy; a parietal incision is made in almost a transverse direction; the divided walls of the stomach and bowel are brought together and united by sutures on the side of the greater curvature of the stomach. 8. For resection of the intestine; when the segments of the intestine are of unequal size, one end is closed by sutures and the other end implanted into a slit made in the long axis of the bowel. Bird's $(G$.) : I. For excision of the knee; the patella is sawn through transversely to reach the joint, and the two fragments are brought together afterward with sutures. 2. For jejunostony; an oblique incision is made in the same position as in pylorectomy; the transverse colon is drawn upward, and the omentum is pushed to the left and the bowel attached to the margin of the parietal wound, and opened after adhesions have formed. 3. Osteotomy for extreme fat-foot; resection of a wedge of bone (the scaphoid alone, or the scaphoid and the head of the astragalus) from the inner side of the foot. 4. For the removal of new-groweths of the tonsil; a modification of Cheever's operation in which the second incision is made through the cheek, from the angle of the mouth to that of the lower jaw. Bischoff's, for laceration of the female perineum; a denudation is made similar to that made in Fremd's operation, except that the tongue of vaginal tissue left in the median line is narrower, and 
the denuded strips on either side are wider and nearer together. The tongue of the posterior vaginal wall is dissected up and brought forward over the median raphe, stitched between the labia and lateral walls, and the perineum is united by deep external sutures beginning behind. Bishop's (Stanmore) : 1. For the radical cure of inguinal hemia; a modification of Maceiven's operation in which the thread is passed through the wall of the sac on each side, so that when drawn upon, the sac is thrown into folds like a purse; Bishop also cuts open the anterior wall of the inguinal canal. 2. For suture of the intestine; an interrupted shoemaker's stitch is introduced on the mucous aspect, each suture loop being tied on alternate sides of the line of junction. Blandin's : I. For deviated nasal septum; the removal of discs from the septum by means of a special punch..2. For double harelip; repression of the pre-maxillary bone after excision of a wedge-shaped piece of the vomerine plate immediately behind it. 3. For excision of the upper jaw; it is done by a median incision. The cheek flap is raised by means of two incisionsthe first carried down from the inner canthus along the side of the nose and into the mouth through the median line of the lip; the other is carried along the lower margin of the orbit. 4. For symblepharon; dissection from above downward, and folding inward of the flap to form the palpebral conjunctiva. Blasius' I. For blepharoplasty; a flap is taken from the forehead to form a lower eyelid. 2. For chiloplasty; two curved incisions are made, each beginning at the center of the lower lip and extending outward and downward to the sides of the cheeks, for the purpose of forming a lower lip. 3. For uranoplasty; a flap is dissected from the forehead, and the long pedicle is twisted so that the flap (the nose being absent) can be brought through the nares into the cleft. Bobbs' (J.S.), for cholecystotomy; the gall-bladder is incised and, after removal of calculi, is closed by one suture. Boeckel's $(E):$. I. For the removal of tumors of the naso-pharynx, an incision is made down to the bone across the bridge of the nose, from one lacrymal sac to the other, and is carried down one nasal furrow to the margin of the nostril, which it opens. The columna is also separated; the bones in the line of the incision are divided, and the septum is separated and the tumor removed; the parts are then to be restored. 2. For $e x$ cision of the verist; it is done by a single dorsal incision on the radial side, with division of the extensor tendons on the same side, and ending by the subperiosteal operation. Boen's, a method of performing embryotomy; it consists in the removal of all of the prolapsed portions of the fetus, followed by thoracic and abdominal evisceration, complete division of the fetus into two parts and separate extraction of the two. Bogue's, for varicocele; ligation with catgut of the veins at different points, after exposing them by means of an incision. Böhm's, for tenotomy'; it is the modern method of performing tenotomy. Bond's, for flat-foot; it consists in making two transverse and two semicircular incisions across the side of the foot with a Paquelin cautery, beginning at the inner malleolus and extending one-third of the distance across the sole of the foot, the semicircular incisions crossing the transverse. The contraction following healing is said to restore the arch. Bonnet's $(M . A$. $)$ : I. For enucleation of the eye; the conjunctiva is divided at the corneal border, and separated from the ball for some distance back; the tendons are next cut, and pressure backward on the lids will usually dislocate the ball forward, when it may be grasped and the enucleation completed. 2. For the radical cure of hernia; after reduction of the hernia, a fold of skin is tucked up, and three or four needles are passed through and allowed to remain; these set up inflammation, which closes the canal. The spermatic cord must be avoided. Bonzel's, for iridodialysis; the iris is detached with a small hook through a corneal incision. Borelli's, for staphylome; the staphyloma is transfixed with two pins introduced at right angles to each other, and encircled behind the pins with a thread. Bose's, for tracheotomy; a vertical incision is made in the middle line for about one-and-a-half or two inches from the center of the thyroid cartilage; a transverse incision is then made along the upper border of the cricoid cartilage to divide the deep cervical fascia. Bosworth's, for deviated nasal septum; removal of the obstructing tissue by means of a delicate saw. Botrel's, for the removal of naso-pharyngeal tumors; in order to preserve the free border of the soft palate, Maisonneuve's incision is made, followed by Nélaton's operation. Bottini's $(E$.$) , for enlarged prostate$ gland; a fresh urethra is bored through the substance of the gland by means of the galvano-cautery. Bouisson's ( $F_{0}$ ), for rhinoplasty ; this is very similar to Thiersch's operation, but the flaps are formed somewhat differently. Boutonnière: I. For external urethrotony; the stricture is divided through an opening made in the urethra just beyond it. 2. For the removal of nasal poiypi; extraction through an incision in the middle line of the soft palate. Bowman's : I. For conical cornea; a circular portion of the apex is removed with a small trephine which is not allowed to penetrate the whole thickness of the cornea. 2. For discission; two needles are passed through the cornea at the same time, one near the inner and the other near the outer margin. The points of the needles are plunged into the center of the membrane and drawn apart by sweeping movements. 3. For ectropion; The same as 7 . Ammon's operation. 4. For excision of the pupil; the puncture and counter-puncture are made with Graefe's linear knife ; the blades of fine scissors are introduced and a triangular piece of the iris, as well as the constrictor pupillæ, removed. 5. For fistula of the lacrymal gland; the establishment by means of a thread of a fistula on the conjunctival surface, to permit of the opening in the skin being permanently closed. 6. For iridodesis; radial incision of the iris from the pupillary margin. 7. For lacrymal obstruction; slitting of the canaliculi. 8. For ptosis; subcutaneous division of the tarsal portion of the orbicular muscle. Boyer's, for excision of the tongue; it is done through the mouth by two converg. ing incisions and two lateral ones, meeting at the same point. Bozeman's $(N$.), for vesico-vaginal fistula; the edges of the fistula are pared and wire sutures are introduced in the usual manner, after which a lead plate or "button" is threaded on the sutures so as to cover the fistula. It is held in place by perforated shot. Brainard's : I. For angular ankylosis of the knee; the shaft of the femur is drilled subcutaneously and then fractured. 2. For ectropion; a flap-transplanting operation. 3. For ununited fracture; drilling of the fragments to excite reparative action. Brandt's, for uranoplasty; in cases of a wide cleft and a deep palate, all the molars of the upper jaw are extracted some months before the operation to produce flattening of the palatal arch. Brasdor's, for aneurysm; ligation immediately beyond the aneurysm. Braun's, for nephrectomy; it is done by means of a transverse incision eight or ten $\mathrm{cm}$. long, parallel with and one $\mathrm{cm}$. below the arch of the ribs. Bribosia's, for cataract; the knife is passed across the anterior chamber and the iris is caused to prolapse upon the knife as the incision is made, so that iridectomy is simultaneously performed, 
the capsule having previously been lacerated by a stopneedle. Briggs': I. For traumatic epilepsy, excision of the painful cicatrix. 2. For varicocele; ligation of the veins at two points with subcutaneous division. Brinton's, for amputation through the knee-joint; the same as Stephen Smith's operation with the exception that the semilunar cartilages are left in situ. Brown's, for nymphomania; amputation of the clitoris. Browne's, for inversion of the uterus ; incision of the fundus, and dilatation of the inverted cervix through the incision. Brüns' $\left(V_{.}\right)$: I. For amputation through the foot; ' a modification of Pirogoff's amputation, in which the sawn surface of the os calcis is made concave and the tibia convex. 2. For arthrectomy; the interior of the ankle-joint is exposed by two anterior and two posterior vertical incisions, and all diseased tissue, including the synovial membrane, ligaments, cartilage and bone, is removed by erasion. 3. Plastic; a quadrilateral gap is closed by displacing a rectangular flap from each side and uniting them in the median line. 4. For removal of a naso-pharyngeal polypies; it is done through the upper jaw by an osteoplastic operation, the whole nose being turned over to one side. 5. For restoration of the lower lip; two quadrilateral flaps are fashioned out of the whole thickness of the cheek and upper lip on each side of the mouth, and so turned downward that their upper borders can be sutured together in the median line. Bryant's $(T)^{\prime}:$ I. For lumbar colotomy; an oblique incision is made midway between the last rib and the iliac crest. The bowel is fixed in position and opened. 2. For splenectomy; the incision is made a little to the outer side of the linea semilunaris. 3. For varicocele; subcutaneous ligation of the veins at two points by means of two needles. Buchanan's: I. For lithotomy; the medio-lateral operation, with the use of an angular staff. 2. For restoration of the lower lip; elevation of an oblique flap from each side of the chin and union of the two flaps in the middle line. 3. For tenotomy for talipes varus in children; division of the tendo Achillis and abductor pollicis muscle, together with the adjoining half of the flexor brevis digitorum muscle, and, in some cases, part of the deep plantar ligament. Buck's : I. For bone-suture; the use of metallic sutures to keep the bones together after excision of the knee. 2. For chiloplasty; to form a lower lip. Pins are inserted into the skin to mark the points of the incisions, and a triangular flap is made from the cheek on either side of the mouth. 3. For genu valgum; a cuneiform osteotomy in which the tibia, fibula, and patella are included. 4. For restoration of the upper lip; (a) for one-sided deficiency, a quadrilateral flap from the lower lip is twisted upward and connected by sutures with the freshened edge of the upper lip; (b) for contracted angle, an incision is made along the red border of the lip skirting the deformed angle; a transverse cut is then made outward, and sutures are introduced. Bumstead's: I. For circumcision; the method formerly employed of grasping the foreskin with forceps and snipping off with a bistoury. 2. For internal urethrotomy; done with a modification of Maisonneuve's or Peter's urethrotome. Burckhardt's, for retropharyngeal abscess: an opening is made on the outside of the neck. Von Burow's : I. For chiloplasty, the large triangular gap is closed by raising flaps on each side after making lateral incisions. 2. For entropion: a deep groove is made parallel to and $3 \mathrm{~mm}$. inside the ciliary margin, with excision of a narrow strip of skin, and closure by sutures. Busch's: I. For Dupurtren's contraction: a triangular flap of skin and subcutaneous tissue is dissected over the palmar cord, the base of the flap being where the finger and palm join, and the apex at the proximal extremity. 2. For entropion; removal of a V-shaped piece of skin from the lower lid, followed by suturing. Butcher's: 1. For dentigerous cysts; cutting away of the expanded bone, followed by the use of the gouge. 2. For double harelip; cutting through the projecting pieces, without dividing the soft parts, or interfering with the vascular supply from behind, previous to bending them back. Buzzi's, for the formation of an artificial pupil; separation of the iris from its peripheral attachment by means of a needle inserted through the cornea. Byrd's: I. For closure of an artificial anus; the same as Dupuytren's operation. 2. For imperforate rectum; the formation of an artificial anus in the perineum, after colotomy. Calignani's, for neurectomy; resection of the inferior dental nerve through an incision made between the lobe of the ear and the angle of the jaw. Callisen's for lumbar colotony; a vertical incision is made following the line of the colon. Carden's $(R):$.$I .$ A method of performing amputations; the formation of a single anterior tegumentary flap. 2. For amputation above the knee-joint; a single rounded flap is removed from the front of the joint, and the operation is completed by a circular incision. Carnochan's : I. For elephantiasis; ligation of the main artery of the limb. 2. For neurectomy; removal of the second division of the fifth nerve, together with the sphenopalatine ganglion as far back as the foramen rotundum. A horizontal incision is made just below the orbit, and this is joined in the middle by a vertical one running downward; this is followed by exposure of the spheno-maxillary fossa by trephining through the antrum. Carpue's, rhinoplasty; repair of the nose by taking a heart-shaped flap from the forehead. Carter's, for the formation of an artifcial pupil; a small incision is made through the cornea, in front of the plane of the iris, followed by iridotomy. Cassel's, for exostoses of the ear; removal through the external orifice of the ear. Celsus': I. A method of performing amputations; division of the skin by the circular method, its retraction, and the cutting to the bone at the level of the retracted skin. 2. For chiloplasty; the removal of tumors of the lower lip by a $\mathrm{V}$-shaped incision; horizontal incisions are carried out from the base to enable the wound to be approximated more easily. 3. A method of performing embryotomy; also called cervical embry otomy ; it is the method of decapitation of the fetus. 4. For lithotomy: localization of the stone by finger in the rectum with perineal incision. 5. For rhinoplasty; flaps are secured from the cheeks, the septum being formed, if necessary, from the upper lip. Cesarean, in case of otherwise impossible labor: incision into the gravid uterus through the abdominal wall, and removal of the fetus. Chalot's, for the removal of naso-pharyngeal polypi; the nasal fossæe are opened by dividing the attachments of the upper lip to the bone. The two upper canine teeth are then rcmoved, and the alveolus and hard palate divided from before back ward from the starting-point. The piece of bone thus isolated is turned down into the mouth, and the polypus is exposed. Chamberlaine's $\left(R_{0}\right): \mathbf{I}$. For ligation of the first part of the axillary artery' the ressel is exposed by means of a curved incision, having its convexity downward, across the supra-clavicular fossa and extending $1 / 2$ inch below the clavicle. 2. For ligation of the brachial artery; an incision is made along the lower margin of the clavicle, and this is joined near its middle by a second incision over the deltoid and pectoral muscles. Championnière's, a method of performing cmbryotomy; it consists in 
evisceration followed by rachiotomy in two or three places and extraction of the fetus in two portions. Charrière's, internal urethrotomy; it is done with a modification of Civiale's urethrotome. Chassaignac's : I. For amputation of a finger; it is done with a single dorsal or palmar flap. 2. For excision of the elboze; a longitudinal posterior incision is made along the outer side of the olecranon process. 3. For excision of the rectum; it is done by means of scissors, knife, and écraseur. 4. For excision of the tongue; it is done with the écraseur by the suprahyoid method. Chauvel's, for restoration of the upper lip; the same as Dieffenbach's operation. Cheever's: I. For the removal of a naso-pharyngeal tumor; (a) single operation; a single incision is made from the inner canthus of the eye to the angle of the mouth on the side on which the tumor is situated; an incisor tooth is then extracted, and the superior maxilla is removed; (b) double operation; an osteoplastic operation is performed on both bones, the facial surfaces are divided by horizontal incisions from the middle meatus outward to a point below the zygoma. The septum and vomer are then divided, and the lower parts of the jaws are depressed. 2. For removal of tonsillar tumors; it is done by an incision through the neck, passing from the lobule of the ear, downward and forward, to the hyoid bone. A second incision is then made along the horizontal ramus of the lower jaw to form a flap. Cheselden's : I. A method of performing amputations; it is the same as Celsus' method, except that the skin-flap is dissected loose from its subjacent attachments, and hence increased in length. 2. For iridotomy; a horizontal incision is made through the iris by means of a sickleshaped needle introduced through the sclerotica. 3. For lithotomy; the lateral operation. See Lithotomy. Cheyne's $(W$.$) , for the radical cure of femoral hernia;$ after reducing the hernia, a flap of the pectineus muscle is raised and made to cover the hernial orifice. Chibret's, for glaucoma; the establishing of corneal drainage. Chiene's, for genu valgum; the removal of an oblique transverse wedge from the body of the condyle of the femur. Chopart's: I. A method of amputation through the foot; the bony structure is divided at the articulation between the astragalus and the calcaneum behind, and the scaphoid and cuboid bones anteriorly. 2. For restoration of the lozver lip; the elevation of a square flap from below. Chrymar's, for ovariotomy; the pedicle is tied in two portions and the ends are left outside. Circular, a method of amputation by a circular sweep of the knife, in contradistinction to the flap-operation. Civiale's $(J$.$) : I.$ For internal urethrotomy; a special urethrotome is used to divide the stricture from within outward. 2. For lithotomy; the medio-bilateral operation. See Lilhotomy. 3. For lithotrity. See Lithotrity. Clark's, for urethroplasty for urethral fistula; the edges of the fistula are pared; then a transverse incision is made through the integuments of the penis about an inch above and below it. The skin-flaps are dissected up and brought together by clamps or quill-suture. Clemot's, for harelip; flaps are turned down on either side, the incision stopping at the red margin of the lip. The cleft is then united from side to side. Cleveland's, for lacerated perineum; denudation of a triangular area, having for its base a line joining the bases of the labia majora and for its apex the crest of the rectocele. The sutures are introduced in loops, each suture having two points of entrance and two of emergence. Cloquet's (J.G.), a method of circumcision; it is done by means of an incision by the side of the frenum. Coates', for internal hemorrhoids; a pile is seized with forceps, Coates' clamp is applied to its base, a few fine catgut sutures are passed beneath the clamp, the pile is excised, bleeding is checked, the clamps are removed, and the sutures are tied. Cock's, a method of external urethrotomy; the urethra is opened behind the stricture without a guide, the knife being carried into the median line of the perineum and the incision extended vertically as far as is necessary. Cohnstein's, a method of performing Cesarean section; it is a modification of the usual operation, consisting in turning the whole uterus out of the abdominal wound and making the opening on its posterior aspect. Colles', for single hare-lip; the inner margin is incompletely pared and hinged back ward on the mucous membrane, to which it is still attached; the outer margin is then transfixed and two flaps are cut, an upper and a lower, which are turned upward and downward respectively, and attached on the opposite side. Colley's, for talipes. See Davies. Colley's operation. Collis', for excision of the tongue. The same as Jaeger's operation. Cooper's (Sir A.): I. For ligation of the abdominal aorta; the intraperitoneal operation. The abdomen is opened by an incision three or four inches in length, made in the linea alba, with the center corresponding to the umbilicus. 2 . For ligature of the external iliac artery; an incision four or five inches long is made parallel with Poupart's ligament, and nearly an inch above it, commencing just outside the center of the ligament and extending outward and upward beyond the anterior superior iliac spine. 3. For tinnitus and deafness in otitis media chronica; excision of a portion of the membrana tympani. 4. For varicocele; excision of a part of the redundant scrotum. Cornuan's, for amputation at the hipjoint; disarticulation by a modified oval method, with the summit of the incision on the outer side. Cotting's $(B . E$.), for ingrozeing toe-nail; all the overlying tissues, together with the sides of the toe, are sliced off freely. The contraction in healing produces a cure. Courvoisier and von Hacker's, a method of performing gastro-enterostomy; the jejunum is connected to the stomach directly after tearing or cutting a passage through the bloodless area of the transverse meso-colon, under the meso-colic arch of Riolan. Cowell's, for glaucoma; paracentesis of the vitreous chamber. Crampton's : I. For entropion; incisions are made in the lid, and healing allowed to take place by granulation. 2. For ligation of the common iliac artery; the incision is commenced at the anterior extremity of the last false rib, and, proceeding directly downward to the ilium, follows the line of the crest to the anterior superior spine. The vessel is reached from behind. Crédè's, a method of performing hysterectomy; it is a modification of Freund's operation, and consists in making a resection of the pubes. Crescent operation, for lacerated perineum, involving the vaginal entrance only; a crescent-shaped denudation is made from the vulvo-vaginal entrance, the angles of which extend into the vulvo-vaginal sulci. Cripps' $(H$.$) : I. For excision of the rectum; dissection of the$ rectum from the adjacent tissues and removal of the diseased portion, the wound being allowed to heal by granulation. 2. For itiac colotomy; an imaginary line from the anterior superior iliac spine to the umbilicus is crossed at right angles, $1 \frac{1}{2}$ inches from the superior spine, by an incision $21 / 2$ inches long. The bowel is fixed in position and opened. 3. A method of trans fusion; it is the same as Aveling's operation, the instrument, however, being supplied with clips instead of taps. Critchett's : I. For cataract-extraction; a slight modification of Graefe's incision. 2. For evisceration of the eyeball; a number of deep stitches are passed through the sclera before removing the staphyloma; 
after the evisceration they are brought together and tied. 3. For iridodesis; drawing of the iris through a corneal incision and its ligation with silk. The ligatured loop sloughs off. 4. For keratoconus; excision of an elliptic portion by a two-edged knife. 5. For staphy. loma; a method of carrying several curved needles through the ciliary region before abscinding the staphyloma. 6. For stillicidium lacrimarum; excision of a portion of the posterior wall of the canaliculus, thus forming a reservoir for the tears. 7. For subconjunctival strabotomy; a small incision is made at the lower edge of the insertion of the internal rectus, close to which the tendon is divided. A small counterpuncture may be made at the upper edge of the tendon for the escape of the effused blood. Croft's : I. For exposing the antrum; an incision is made from the ala nasi to the nasal process of the superior maxillary bone, then along the margin of the orbit; the nasal process is cut through with forceps, the periosteum stripped off and a portion of bone removed. 2 . Plastic; a bridge of sound skin is raised and separated from the subjacent tissues, except at the extremities, by means of oiled silk. After granulation has been established the adjoining contracted (cicatricial) structures are divided and the bridge of skin severed at one end, and made to occupy the gap. Crosby's, for backward dislocation of the first phalanx of the thumb; the phalangeal portion of the thumb is first raised to a right angle with the metacarpal bone; the proximal phalanx is then pressed from behind forward. (An old method, having been practised by Sir C. Bell and by Gerdy.) Curling's, for varicocele; a straight pin is passed between the vas deferens and the veins about two inches above the testicle, and another threequarters of an inch below this point. A figure-of-eight ligature is then applied and the veins are divided subcutaneously between the pins. Cusack's, for hemor. rhoids; removal by the clamp and cautery. Cushing's $(H . W$.$) , for suture of the intestine; a right-angled con-$ tinuous suture is introduced, the needle passing through the serous and muscular coats of the bowel only. Czerny's $(V$.$) : I. For the radical cure of inguinal$ hernia; the sac is exposed and isolated; the neck is tied with a strong catgut ligature, and amputated below this point; the stump is pushed into the abdominal cavity; the borders of the opening are freshened and united by continuous catgut sutures. 2. For the removal of tonsillar tumors; tracheotomy is performed and the larynx or fauces plugged. The growth is then exposed by cutting downward and outward from the angle of the mouth to the anterior border of the masseter, and sawing through the lower jaw, between the second and third molar teeth. 3. For suture of the intestine; a modification of Lembert's suture, in which there is inserted an inner row of interrupted sutures which unite the mucous membrane only. 4 . For vaginal hysterectomy; the uterus is drawn down by Muzeux's forceps and the vaginal vault is completely opened around the cervix. The uterus is separated from the bladder with the finger. A free incision is next made in Douglas's cul-de-sac, when the uterus is turned backward, and brought through the vaginal incision. The peritoneum is now separated anteriorly and the broad ligaments are ligated in from three to six portions on each side. Czerny-Schröder's, hysterectomy. See Crerny's hysterectomy. Dallas', for the radical cure of inguinal and femoral hernia; after a transverse incision through the integument a special instrument is introduced to produce abrasion of the hernial canal; the instrument is then withdrawn, and the external wound sealed with iodoform-collodion, and a compress applied. The canal is obliterated by the resulting inflammatory action. Davat's, for varicoccle: after separating the ras deferens from the veins, an acupressure pin is passed through the scrotum. By means of a perineum needle a thread is carried subcutaneously over the veins through the same skinpunctures as the needle has made. The loop is then slipped over the head of the pin and tied tightly over the needle. A cork is now placed on the point of the pin. Daviel's, for cataract; extraction through a large corneal incision downward, without an iridectomy. Davies-Colley's : I. Osteotomy for ralipes; resection of a wedge of bone from the outer side of the tarsus without regard to the articulation. It always includes portions of the os calcis, cuboid, astragalus and scaphoid bones. 2. For uranoplasty: a triangular muco-periosteal flap is dissected from one side of the cleft, while on the other side a raw surface is prepared by reflecting a longitudinal flap in such a way that it can be turned, as on a hinge, into the cleft. The first flap is then implanted upon the second. Davy's, for osteotomy; the same as the Davies-Colley's operation. Dece's, for zuebbed fingers; a fold of skin is pinched up near the base of the web, and dissected toward the commissure; the fingers are then kept apart. Delagarde's, to improve a stump; stitching of the extensor tendons into the tissues of the sole-flap in Chopart's amputation, to prevent tilting upward of the heel and downward of the scar. Delore's. See Redressement forcé Delpech's: I. For ligation of the first part of the axillary artery: an oblique incision is made downward along the gap that separates the pectoralis major from the deltoid, starting from the clavicle. 2. For urethroplasty; a single flap is raised and carried across the fistula to a new surface prepared for it. Del Toro's, for conical cornea; destroying the apex by means of a white-hot knife. Demarquay's, for nasopharyngeal tumor; an incision is made from the internal angle of the eye along the nasal furrow to the free margin of the nose; it is then carried outward horizontally to the margin of the masseter muscles. Liston's forceps are used to remove sufficient bone to expose the tumor. Denans', for enterorrhaphy: the joining of the serous surfaces of the cut intestines by means of three metallic tubes. Dennis', for ligation of the internal iliac artery; it is done by a celiotomy, the abdomen being opened in the middle line by an incision extending from the symphysis pubis to the umbilicus. Denonvillier's, for rhinoplasty; a triangular flap is raised from the side of the nose above the defective ala, with its pedicle internal, and is then displaced downward into position. Desault's $(P . J$.$) :$ I. For double hare-lip; gradual and continuous backward pressure of the pre-maxillary bone, by means of a bandage: 2. For a preternatural anus; a plug is placed in the two ends of the intestine so that its middle rests on the spur of mesentery; when the latter has been sufficiently obliterated, the plug is removed and an external obturator bandage is applied. 3. For restoration of Stensen's duct; a seton is passed through the cheek into the mouth in the course of the duct. When the patency of the new duct has been established, the seton is removed and the external aperture is closed. 4. For stricture of the lacrymal duct; the application of cauterants by means of threads passed through the duct. Desmarres': I. Iridectomy; after incision of the cornea with eye-forceps, a fold of iris is drawn out and excised. 2. For pterygium; detachment and transplantation of the pterygium. Desprez', for naso-pharyngeal polypus; removal by an osteoplastic operation through the nose. The cartilaginous part of the nose is turned over to one side 
after division of its connections on the opposite side. Dezeanneau's, for naso-pharyngeal tumor: the hard palate is divided in the middle line, from its junction with the soft palate, forward to or beyond the palatomaxillary suture; the section is then carried across at right angles until it approaches the alveolar process, when it is turned and carried backward to the soft palate. Dianoux's, for entropion; the formation of a ciliary and cutaneous flap; separation of the underlying muscle from the tarsus, and suture of both flaps to the margin of the latter. Diday's, for webbed fingers; two narrow longitudinal flaps are dissected up from the palmar and dorsal aspects of the fingers, and each flap is then folded round to cover the denuded surface of the finger to which it is attached. Didot's, for webbed fingers; the same as Diday's operation. Dieffenbach's $(J . F):$. I. For amputation at the hip-joint; an elastic ligature is applied around the $\operatorname{limb}$, a circular incision is made down to the bone, the vessels are secured and the ligature removed; a knife is inserted two inches above the greater trochanter and the incision is carried down the outer aspect of the bone to meet the circular incision; the joint is then disarticulated. 2. For blepharoplasty; a quadrangular flap is taken from the cheek. 3. For chiloplasty; the diseased portion of the lower lip is removed by a wedgeshaped incision; the gap is closed by making horizontal incisions on both sides, and then introducing sutures. 4. For cicatricial entropion; a triangular flap is removed and the gap is closed by displacing and transplanting a large quadrilateral flap and leaving the raw surface to close by granulation. 5. To expose the whole of the upper jaw; an incision is made through the center of the lip, around the ala, and up along the side of the nose to the inner canthus, and then outward just below the margin of the orbit, as far as the malar prominence. 6. For the removal of naso-pharyngeal tumors; an incision, beginning at the lower and outer angle of the nostril, is carried along the base of the nose in the naso-labial fold until the ala of that side can be easily turned upward and inward. If necessary the same can be done on the opposite side. 7. Osteoplasty, for cleft in the hard palate; the edges are pared and both soft tissues and bone divided on each side, the detached portions being prised toward the middle line. 8. For restoration of the upperlip; $(a)$ the formation of a quadrangular flap, attached below, at the level of the mouth, which is turned horizontally in ward to meet a similar one on the other side; this is the reverse of Sédillot's operation; $(b)$ two curved incisions start from the apex of the partial central defect and are carried round the alæ of the nose; the flaps thus marked out are detached and brought together in the median line. 9. For rhinoplasty; $(a)$ repair of the nose by taking a pyriform flap from the forehead; $(b)$ three elongated flaps are raised from the sunken nose and then re-united with sutures, and made to project forward by drawing previously detached portions of the cheeks toward the median line. IO. For single harelip; a modification of Stokes' operation in which additional incisions are made skirting the ala nasi, with the object of securing more tissue. II. For symblepharon; it consists in folding the lid inward and placing the skin against the eyeball. I2. For tenotomy; division of the belly of the muscle. Dittel's, for enlarged prostate; enucleation of the lateral lobes of the prostate by an external incision. Dolbeau's, for lithotomy; a median incision is made into the prostatic urethra, followed by dilatation of the wound by means of metallic dilators; the stone is then crushed and the débris evacuated. Donegana's, for iridodialysis; it is done by means of a special needle; the iris is detached and then incised from its circumference toward the center. Dowell's $(G$.$) , for the radical cure of hernia;$ plugging of the mouth of the sac with its invaginated fundus and securing the fundus to the surrounding tissues by sutures tied over a piece of cork. Drausart's : I. For ptosis; the occipito-frontalis muscle is brought to act on the lid through the medium of cicatricial bands, by means of threads, which are allowed to ulcerate their way through the tracks along which they were passed. 2. For retinal detachment; iridectomy, the recumbent position, a pressure-bandage, and subcutaneous injection of small doses of pilocarpin. Dubrueil's: 1. For amputation of the hand; a single semilunar flap is formed from the dorsal surface of the metacarpal region of the thumb, and when raised, the two ends of its base are joined by a circular incision around the arm at the wrist, followed by disarticulation. 2. For amputation of the toes; disarticulation of the toes en masse at the metatarso-phalangeal joints by a more or less circular incision, a U-shaped flap being cut from the inner side of the great toe. Dudley's, for retroversion of the uterus; the abdomen is opened, and a strip is denuded from the anterior surface of the uterus, and likewise a strip along the inner side of each round ligament, followed by suturing of the three together. Duncan's : $\mathbf{x}$. For lacerated perineum; an incision is made in the median line on the posterior vaginal wall as far as the laceration extends. From the lower end of this an incision is made up along the vulval border of the laceration on either side. The flaps thus outlined are dissected up, and stitched together, and the labia brought together by deep cutaneous sutures. 2 . A method of transfusion; re-infusion of the patient's own blood mixed with a solution of sodium phosphate. Duplay's : I. For epispadias; the urethra is formed at the expense of the corpus spongiosum and corpora cavernosa instead of by flaps. 2. For hypospadias; it is performed in three stages; (I) straightening of the penis and the formation of a meatus; (2) the formation of a canal from the meatus to the hypospadiac opening; (3) junction of the old and new canals. Dupuytren's $(G$.$) : I. Method of performing ampu-$ tations; the double-flap method, the skin-incisions being made by cutting from without inward, and the flaps completed by transfixion. 2. For amputation at the shoulder-joint; two rounded flaps are taken from the outer and inner aspects of the arm; the outer flap is made first by transfixion from behind at a point two inches below the acromion; the bone is then disarticulated and a short inner flap cut from within outward. 3. For atresia vagina, combined incision and dilatation. 4. For chiloplasty; excision of the diseased tissue, the wound being allowed to heal by granulation. 5. For closure of an artificial anus; compression of the spur with the clamp, followed by a plastic operation on the skin. 6. For division of contracted palmar fascia; the open method, both skin and fascia being divided by a simple transverse incision. 7. For excision of the elbow. The same as Moreau's operation. 8. For lithotomy; the bilateral method. See Lithotomy. 9. For stricture of the lacrymal duct; incision of the anterior wall of the sac, and the passage of a fine gold or silver probe through the duct. IO. For suture of the intestine; the edges of the wound are turned inward and the opposed folds of serous membrane brought together by means of an ordinary continuous suture, without involvement of the mucous membrane. II. For wry-neck; tenotomy of the sterno-mastoid muscle. Duval's $\left(M_{0}\right)$ : I. For amputation of the leg; an oblique elliptic incision is made around the limb above the malleoli and the bone divided higher than in Guyon's operation. 2. For ligation of the 
common iliac artery; an incision about five inches in length is commenced one-and-one-quarter inches to the outer side of the spine of the pubes, just above Poupart's ligament; after running parallel with this ligament for one-and-a-half inches, the incision curves sharply upward and is directed toward a point oneand-one-quarter inches to the outer side of the umbilicus. Ely's, for otitis media suppurativa chronica; the grafting of small pieces of skin on the granulating surfaces. Emmet's $\left(T . A_{\text {. }}\right)$ : I. Colporrhaphy; a modification of Sims' colporrhaphy; the sutural approximation of three equidistant, transverse, infracervical denuded spots on the anterior wall of the vagina, and the apposition of the opposing edges of the folds thus formed after abrasion. 2. For cystocele and urethrocele; the buttonhole operation; the removal of a small circular portion of tissue, opening the bladder or urethra, to provide for drainage; this is afterward closed by operation. 3. For lacerated perineum; the crest of the rectocele and the two lower caruncles are drawn together by tenacula, and the tissue thus folded together is denuded as far into the sulci as the folds extend. The $\mathrm{V}$-shaped stitches are passed from the center toward the circumference in the sulci, and the perineum is closed by two or three superficial sutures. 4. For ovariotomy; the pedicle is ligated with silver wire. 5. For procidentia uteri; freshening of the anterior vaginal wall in the middle line and on either side. The two lateral denudations together should correspond in size and shape to the one in the median line. The lateral fresh surfaces are then folded on the central one and stitched. See Emmet's colporrhaphy. 6. For trachelorrhaphy; the edges of the rent are pared and united by sutures. Erichsen's: I. For nerus; ligation of the base with a double ligature which is tied in segments. 2. For varicocele; after separation of the vas deferens from the veins, an incision one-half inch long is made on the anterior and posterior aspects of the scrotum; the veins are then included in a loop of wire without implicating the scrotum. Esmarch's: I. For amputation through the foot; a modification of Pirogoff's amputation; two incisions are made, one across the sole and the other across the dorsum of the foot. 2. For amputation at the hip-joint; the soft parts of the thigh are divided to the bone by a single sweep of the knife five inches below the tip of the trochanter; the bone is then sawn across and a second incision is made to join the first from a point two inches above the trochanter, when the bone is shelled out. 3. For ankylosis of the lower jaze; an incision about two inches long is made along the lower border of the jaw, and a wedge-shaped piece of bone is removed from the horizontal portion. Estlander's: 1. Thoracoplasty for empyema; resection of several ribs to allow the chest-wall to come in contact with the lung. 2. For restoration of the lonver lip; a triangular flap is so fashioned from the upper lip that its base contains the coronary artery, while its apex is situated on the cheek ; this flap is turned downward, with its apex occupying the lower angle of defect. D'Etiolles' (Leroy): I. For the radical cure of inguinal hernia; a scrotal fold is passed in the inguinal canal and held by means of special forceps. 2. For iridectomy; removal of a portion of the iris by an instrument constructed like a tonsillotome. Everbusch's, for ptosis; it consists in shortening the tendinous attachment of the levator palpebre to the tarsus. A horizontal incision is made in the center of the lid; threads armed at each end are used, and, after transfixing the tendon in the wound, the needles are brought out at the free margin of the lid, and the silk tied. Farabeuf's
$(L . H$.$) : I. For amputation at the elbow-joint; (a)$ an elliptic amputation with the highest point of the ellipse over the prominence of the olecranon; (b) a modification of Guerin's operation in which the single external flap is made longer. 2. For amputation of the foot. See subastragaloid amputation of the same surgeon, with which this is identical in all essential points. 3. For amputation of the forefinger; disarticulation at the metacarpo-phalangeal joint by an external palmar flap. 4. For amputation of the great toe; disarticulation at the metatarso-phalangeal joint by an internal plantar flap. 5. For amputation above the knee-joint; a modification of Carden's amputation in which two flaps are formed, the anterior being the longer one. 6. For amputation of the leg; it is done at the "place of election" by a large external flap, being a modification of Sédillot's operation in which the anterior tibial artery is preserved in the entire length of the flap. 7. For amputation of the thigh; a modification of Spencer's amputation in which slightly different flaps are used. 8. For amputation of the thumb; disarticulation at the metacarpo-phalangeal joint by an oblique palmar flap. 9. For subastragaloid amputation; by a large internal and plantar flap. 10. For otherwise impossible labor. See Galbiati's Operation. Fenger's $\left(C_{.}\right)$: I. For gastrostomy; a parietal incision is made parallel with and near to the left costal margin. 2. For troumatic cerebral abscess; exploratory puncture and aspiration, in conjunction with trephining. Fenwick's, for excision of the knee; both femur and tibia are sawn in a curved line so as to make them fit together more accurately. Fergusson's (Sir $W_{\text {. }}$ ) : 1. For amputation through the foot; the same as Pirogoff's operation, except that the malleoli are not interfered with, unless diseased, the retained portion of os calcis being thrust up between them. 2. For amputation at the hipjoint; a modification of Liston's amputation in which the posterior flap is made longer than the anterior. 3. For division of the levator palati muscle; a triangular-bladed knife, set at right angles, is introduced behind the velum and the muscle divided close to its origin. 4. For double hare-lip; removal of the premaxillary bone. 5. For excision of the upper jaz; the same naso-labial incision is made as in Liston's operation, a second cut being made from the angle of the mouth to the malar bone, and, if needed, a third at right angles to the outer extremity of the buccal wound. 6. For lithotomy; lateral lithotomy with the curved staff. 7. Osteoplasty for a cleft in the hard palate; the same as Dieffenbach's operation. Fischer's, for stricture of the lacrymal duct; the same as Schmalz's operation, except that a loop of twilled silk is used on the end of a catgut string. Flajani's, for iridodialysis; the same as Himly's operation. Flap-operation: I. A method of amputation; the formation of definite flaps, embracing the skin only, or all the soft parts. 2. For cataract-extraction; a curved section of the cornea of sufficient extent for the removal of large, hard cataracts. 3. For cicatricial entropion. See Fricke's and Dieffenbach's operations. Flap-splitting. See Tait's Operation. Flarer's, for trichiasis and cicatricial entropion; the lid is split into two portions as far back as the ends of the hairbulbs of the cilia. The anterior flap, containing the bulbs, is then cut away by incision through the skin from above. Forbes' (S.F.), for amputation throught the foot; a modification of Chopart's operation, the three cuneiform bones being disarticulated from the scaphoid and the cuboid bone sawn through in the same line. Forbes' $(W . S$. ), the division of the accessory tendons of the extensor communis digitorum 
muscle, in order to give the ring-finger of musicians (especially pianists) greater freedom of action. Förster's, for a ripening cataract; iridectomy, followed by circular rubbing of the cornea with a blunt instrument. Forster's $(C$.), for gastrostomy ; a parietal incision is made in a vertical direction through the top of the linea semilunaris. Foullioy's, for amputation at the hip-joint; the same as Ravaton's amputation, the common femoral artery being ligated at the fold of the groin as a preliminary step. Franco's : I. For cystotomy; the original supra-pubic method. See Cystotomy. 2. For double hare-lip; complete removal of the pre-maxillary bone as a preliminary step. Frank's, a method of performing Cesarean section; the uterus is turned out of the abdomen before incising; drainage is obtained by passing a tube through the wound and into the vagina; the round ligaments are brought together and sutured. French's, for carbuncle; subcutaneous incision. Frère Côme's, for lithotomy; the high operation. See Lithotomy. Frère Jacques', for lithotomy; a long knife is thrust in the ischio-rectal fossa, penetrating the bladder behind the prostate, then cutting forward; a staff is used, which, however, is not grooved. Freund's : I. For hysterectomy; by abdominal section. 2. For laceration of the female perineum; the bilateral method, with extension of the vaginal triangles or tongues along the cicatrices on either side, and leaving sound vaginal wall about the median line. Fricke's: I. For blepharoplasty; a tongue-shaped flap is taken from the temple or cheek. 2. For cicatricial entropion; a flap-operation similar to Dieffenbach's operation. Fritsch's: 1. For posterior colporrhaphy for extreme degrees of rectocele; a modification of Simon's operation; denudation of the posterior vaginal wall, with a larger perineal denudation. The raw surfaces are closed by vaginal and perineal sutures. 2. For vaginal hysterectomy; the broad ligaments are first operated upon; lateral incisions are made in the vaginal vault, the tissues carefully separated, hemorrhage controlled by sutures, and the incisions united by anterior and posterior incisions; the uterus is turned. forward and brought down. Fritz's, for the radical cure of inguinal hernia; after reduction, pins, protected at each end by ivory or bone discs, are passed in front of and behind the cord in the canal and allowed to remain ten days; ulceration results, which is intended to close the canal and consequently cure the hernia. Fryer's, a method of transfusion; the direct method, with the use of a modified Aveling instrument. Fuchs' $(E$.), for tarsorrhaphy; the lower lid is split into two laminæ to the desired extent by an intermarginal incision; this is converted into a flap by a short incision downward from the inner extremity of the first incision; the same incision as the first is made in the upper lid and then the zone of hairfollicles is ablated; the wound is then sutured. Furnari's: I. For iridectomy; the same as Physick's operation. 2. For pannus; removal of a circular strip of conjunctiva at the circumference of the cornea. Gagnele's, for varicocele; subcutaneous ligation of the varicose veins by silver wire twisted on metal buttons. Gaillard-Arlt's, for entropion. See Arlt's Operation, Galabin's: I. For lacerated perineum; the denudation follows the cicatrix, but extends a little beyond in all directions. 2. A method of transfusion; the direct method; a piece of elastic tubing, supplied at the extremities with cannulæ and springclips, is employed. Galbiati's, for otherwise impossible labor due to contracted pelvis; I. Also called bi-pubeotomy and ischio-pubeotomy, it consists in the division of the ischiatic and horizontal branches of the pubes with the chain-saw, followed by the application of the ob- stetric forceps to the head of the fetus. 2. Symphysiotomy. Galezowski's: I. For calaract; the incision is made as in Wricht's operation, except that the point of the knife is made to divide the capsule. 2. For ptery. gium; turning of the apex under the base. 3. For synectomy; it is done by means of a needle with a cuttingedge. Gant's : I. For excision of the tongue; a moditication of Jaeger's operation. 2. For ankylosis of the hipjoint; division of the shaft of the femur just below the lesser trochanter. Garretson's, for staphylorrhaphy; the same as Fergusson's operation, except that the operator stands behind the patient. Garrigues', a method of transfusion; the indirect method, the blood being defibrinated and filtered before being injected. Gély's, for sulure of the intestine; two straight needles at the ends of a single thread are introduced behind and at the sides of the wound, and made to traverse the outer coats of the bowel in a direction parallel to the edge of the wound for a distance of four or five $\mathrm{mm}$. The needles are then crossed and the procedure repeated as often as necessary. Gensoul's : I. For double hare-lip; forcible repression of the pre-maxillary bone by seizing the projecting tubercle at its extremity and fracturing the bony processes that support it. 2. For excision of the upper jare; one incision is carried vertically downward from the level of the inner canthus through the lip; a second is started at right angles to the first at the level of the floor of the nose; and a third is carried upward in front of the ear to the external angular process of the frontal bone. 3. For stricture of the lacrymal duct. See Laforest's Operation. Gerardin's, for prolapse of the uterus; denudation of the median portion of the ventral and dorsal vaginal walls, or of the ventral lip of the cervix and dorsal vaginal wall, and union by sutures. Gerdy's $(P . N$. $)$ : I. For entropion; also called the scalping operation; removal of the entire margin of the lid. 2. For the radical cure of inguinal hernia; by invagination of the scrotum in the inguinal canal, and its retention there by means of a suture passed by a long needle. 3. For stricture of the lacrymal duct; by two vertical parallel incisions into the duct, with excision of a quadrilateral piece of bone from the inner wall. Gibson's : r. For the formation of an artificial pupil. See Beer's Operation. 2. For cataract; removal of a soft lens through a small corneal incision. Gillespie's, for excision of the wrist; it is done by a single longitudinal dorsal incision between the extensor communis and extensor secundi muscles, without division of the tendons. Gioppi's, for cataract; the lens in its capsule is extracted with a spoon-like instrument through an incision similar to Graefe's incision. Giraldès', for single hare-lip; the mortise operation; two flaps are made, the first with its base attached above to the root of the nose, the second attached below, on the opposite side of the cleft at the muco-cutaneous junction; an incision is then made outward from the ala and the surfaces are approximated by turning the first flap up and the second down. Giraud's, for stricture of the lacrymal duct; a modification of Desault's operation, in which a thread is passed through the duct. Godlee's, for hepatotomy; it is performed in two stages, as in Volkmann's operation, except that stitches are passed deeply into the substance of the liver, and in a double row. Goodsall's, for horseshoe fistula in ano; a single division is made in the posterior median line, to avoid incontinence from repeated division of the sphincter. Gould's (Pearce) : $\mathbf{x}$. For amputation of the penis; complete removal of the organ by dissecting off the crura. 2. For varicocele; the vas deferens is separated from the veins at the upper 
part of the scrotum, and the skin is divided between the two by transfixion; the veins are then secured in a loop of platinum wire attached to a battery. Gouley's : ( J.W.S.) I. For external urethrotony; a small conductor is passed through the stricture, and, guided by this, the stricture is divided and a catheter conducted into the bladder. 2. For extirpation of the penis; a curvilinear incision is made on either side of the root of the penis; the cavernous bodies and the urethra are transfixed with needles, and the organ is amputated $1 / 8$ inch in front of these; a grooved staff is passed into the bladder; a sharp-pointed scalpel is carried through the perineum and lodged in the groove of the staff, and all the tissues are divided from behind forward; the urethra is stitched to the skin ; the crura are removed. 3. For hypospadias; a flap is removed from either side of the normal site of the urethra, and the skin brought forward so that the denuded surfaces are doubled on themselves; they are then secured by stitches. 4. For internal urethrotomy; it is done with a special tunneled urethrotome after Maisonneuve and Voillemier; or, with a special dilating instrument. Goyrand's $\left(N_{0}\right):$ I. For division of the contracted palmar fascia; a longitudinal incision is made in the skin in the long axis of the contracted band, which, when exposed, is divided transversely. 2. For ligation of the internal mammary artery; an oblique incision two incheslong is made at the end of the intercostal space near the edge of the sternum. Von Graefe's : I. For cataract; extraction of the cataract through a scleral incision, with iridectomy and laceration of the capsule. 2. For conical cornea; (a) A small portion of the cornea is removed in the immediate vicinity of the apex of the cone, without perforation, in order to induce cicatricial contraction. (b) The production of an ulcer at the apex of the cornea to give rise to cicatricial contraction. 3. For dacryops; the introduction of a fine thread through the lacrymal duct and anterior wall of the cyst; the ends are tied and the ligature is allowed to slough through, or the tissue may be divided after a few days. 4. For ectropion; the denudation of a wedge-shaped portion of the lid, and the edges brought together by a hare-lip suture, after an incision in the cheek, parallel with the margin of the orbit. 5. For entropion; (a) two vertical incisions are made through the skin of the upper lid, which lid is split into an anterior and a posterior leaf, and the cutaneous margins are entered higher up along the vertical incisions. (b) A horizontal incision is made through the skin of the upper lid, and a triangular piece of skin, with its base downward, is removed; also a triangular portion of the tarsus, base upward, is removed; the wound is then sutured, 6. For evisceration; removal of the cornea and adjacent zone of the sclera; the contents of the eyeball are entirely scooped out with a spoon, and the opening is closed with sutures. 7. For fistula of the lacrymal gland; extirpation of the gland. 8. For prolapse of the lozerer lids; excision of a triangular portion of skin, and closure of the wound vertically. 9. For ptosis; excision of the fibers of the orbicularis muscle. ro. For retinal detachment; incision of the retina by a needle made to penetrate the vitreous chamber through the sclerotic, near the cornea. II. For rhinoplasty; the same as the Tagliacotion method, q. v. 12. For single hare-lip; the edges are prepared by an arch-like incision and brought together with the muco-cutaneous margins even. I3 $_{3}$. For staphyloma; the production of suppurative choroiditis, followed by natural atrophy of the globe of the eye. I4. For strabotomy'; a small incision is made midway between the center and the lower edge of the mus- cle's insertion (internal rectus) near the edge of the cornea; a hook is introduced from below upward and the tendon is divided close to its insertion. I5. For trichiasis; a modification of Arlt's operation; the lid" is split into two flaps, and the flap containing the hair-bulbs is transplanted away from the margin of the lid after two vertical incisions have been made on either side. Graefe-Romberg, for blepharospasm; division of the supraorbital nerve. Green's : 1. For entropion; an operation combining the essential features of the Arlt-Jaesche and Anagnostakis' operations, but the chief feature is that the sutures are made to include the upper border of the tarsus and the tendon of the levator. 2. For readjustment of the levalor palpebre muscle; dissection through the upper border of the upper lid to reach the eyeball, without opening the conjunctival sac, followed by suture of the tendon of the levator. Gritti's $(R$.), for amputation above the knee-joint; the patella is preserved in a long anterior flap, and, having had a thin slice removed from its deep surface, is secured in apposition with the femur, the latter having been deprived of its articular surface by being sawn through the condyles. Gross' (S.D.): I. For amputation of the foot; a modification of Syme's operation; the plantar incision is made further anteriorly, thus affording greater chances of a good bloodsupply. 2. For amputation of the great toe; the operation is performed through the continuity of the metatarsal bone, not at the articulation; there is a dorsal incision. 3. For varicocele; subcutaneous ligation with a stout cord or silver wire and a cork compress. Gross' $(S . W$. ), for internal urethrotomy; a special exploratory urethrotome is used to divide the stricture from within outward. Grossmann's, for retinal detachment; aspiration of the effused sub-retinal fluid and slow injection of a warm saline solution into the vitreous. Gruening's : I. For pannus; curetting of the cornea. 2. For removing steel or iron from the eye; by means of a magnet the foreign body is drawn out through the original wound, or extracted through an incision made in the sclera, when the particle can be drawn to a favorable site. Guérin's : I. For amputation at the elboru-joint; by a single external flap. 2. For carbuncle. See French's operation. 3. For excision of part of the upper jaz"; a curved incision, with its convexity outward, is made from the ala of the nose to the angle of the mouth; the soft parts are dissected up, the nostril opened, and the bone removed by dividing the hard palate in the middle line and its facial aspect outward to the maxillary tuberosity. 4. For ividotomy; a crucial incision of the iris through the cornea. 5. For the removal of a nasopharyngeal polypus; by removal of part of the upper jaw. See Guérin's excision of part of the upper jaz. 6. For subconjunctival strabotomy; a Z-shaped tenotome, introduced between the muscle and the sclera, divides the former when the cutting-edge of the instrument is turned forward, and a slight sawing motion is applied. Guérin and Brodhurst's, for congenital dislocation of the hip; subcutaneous division of the stronger muscles connecting the femur and the pelvis, followed by continuous extension. Guérin and Desmarre's, for corectopy; by means of a punch-like knife a small portion of the cornea is removed, into which opening the iris falls, and is retained by adhesions. Günther's, for amputation at the hip-joint; disarticulation by a modified oval method, with the summit of the incision on the outer side. Gussenbauer's : 1. For suture of the intestine; it combines the Czerny and Lembert sutures in one, but does not traverse the mucosa. 2. For tapping the pericardium; resection of part of the fifth rib, followed by incision of the pericardium. Guthrie's : $\mathbf{x}$. 
For amputation at the hip-joint; antero-posterior flaps are made by cutting from without inward. 2. For amputation at the neck of the humerus; it is dine by the oval method, the incision being commenced beneath the acromion process and carried to the inner side of the arm, then beneath to the outside, where it is met by another incision begun at the same point as the first. 3 . For ligation of the first part of the axillary artery; an incision is made in the course of the artery through the ventral fold of the armpit, with complete division of the soft parts. Guyon's, for amputation of the leg; supra-malleolar division of the bones and covering of the terminal part of the stump with the tissues of the back of the heel. Hagedorn's : I. For double hare-lip; the soft parts covering the premaxillary bone are pared, also the margins of the cleft, and the parts are then brought together by sutures. 2. For single hare-lip; the margins of the gap are isolated by incisions and removed, and the raw surfaces are brought together. Hahn's: 1. For gastrostomy; the parietal incision is made parallel with the lowest rib, and the stomach is opened through the eighth intercostal space. 2. For intubution of the pylorus; gastrotomy is performed and the tube is carried through the stenosed pylorus into the duodenum and left there. 3. For knock-knee; osteotomy on the outer as well as on the inner side of the femur. 4. For nephrorrhaphy; the capsule of the kidney is exposed by an incision in the loin between the ilium and the last rib. In the first operation sutures were carried through the perinephric fat alone; later, they were placed in the capsule proper. Halpin's, for extirpation of the lacrymal gland; a curved incision is made through the middle of the eyebrow, with removal of the gland, and drainage. Halsted's ( $W$. $S$.$) : I. For the radical cure of inguinal hernia; the$ same as Bassini's operation. 2. For suture of the intestine; a modification of Lembert's suture in which each stitch includes not only the whole muscular coat, but also a little of the submucous coat. Hancock's : I. For amputation through the foot; a modification of Pirogoff's operation in which the sawn surface of the os calcis is brought in contact with the transverse section of the astragalus. 2. For glaucoma; intraocular ciliary myotomy. Handyside's, a method of performing ovariotomy; the ligatures of the pedicle are carried through Douglas's pouch into the vagina. Hardie's, for division of a contracted palmar fascia; a modification of Goyrand's open method, in which an incision is made across the hand above the principal transverse fold of the palm and over the tense fascia. Harrison's $(R$.$) : I. For internal urethrotony; a$ special urethrotome is used to divide the stricture from without inward. 2. For puncture of the bladder through the prostate gland; a special straight trocar is introduced in the middle line $3 / 4$ of an inch in front of the anus, and pushed through the prostate into the bladder. Hasner's, for blepharoplasty; two tonguelike flaps are made, one above, and the other below the eye, to supply the deficiency in the lid. Hawkins', for contraction of the palmar fascia ; one transverse incision in the palm, to divide the large fascial bands, and semicircular incisions at the base of the little and ringfingers, to divide the digital prolongations of the fascia. Hay's : I. For stricture of the lacrymal duct; the passage of a special probe, having a hook at one extremity. 2. For strabismus; conjunctival incision and tenotomy. Heart's, for excision of the tongue; the section through the tongue is made with an écraseur. Heath's, for fixity of the lower jaze; division of the ascending ramus beneath the masseter with a saw introduced through the mouth by means of a small incision above the last molar tooth. Heaton's $\left(G_{0}\right)$, for the radical cure of inguinal hernin; the subcutaneous injec tion of an astringent solution to 'produce irrita tion and contraction of the tissue about the rings. Hegar's: I. For Colporrhaphy for lacerated perineum; also called the median operation; it consists in a triangular denudation upon the dorsal wall of the vagina, the base of the triangle being parallel with the lower margin of the vagina, and the apex reaching almost to the cervix, an oval denudation being made upon the skin-perineum. 2. For oophorectomy; the same as Battey's operation. HegarTait's, for öphorectomy; a misnomer for Tait's oper. ation. Heineke's : I. For exostosis of the externat meatus of the ear; removal by means of a mallet and gouge. 2. For pyloric obstruction; the ventral wall of the strictured pylorus is divided in the long axis of the canal, and the incision is carried for the distance of one inch into the healthy tissue; the incision is then sutured in a transverse direction by catching the center of the cut on either side and making traction. Heineke-Mikulicz's, for pyloric obstruction; the same as Heineke's operation. Heisrath's, for trachoma; the excision of a moderately broad piece of the transition-fold of the conjunctiva, the incision to include the subconjunctival tissue and a portion of the tarsus. Heliodorus', for the radical cure of inguinal hernia; after reduction of the hernia the sac is twisted and incised, gentle traction being made so that sufficient of the sac may be removed. Henry's, for varicocele; a modification of Cooper's operation; the application of a specially devised clamp, from above downward, in the line of the raphe, and removal of the redundant skin. Herzenstein's, for trichiasis; this is especially applicable in the partial forms; a ligature is passed subcutaneously around the roots of the offending cilia, and allowed to cut its way out. Herzfeld's, for carcinoma of the uterus; extirpation of the uterus through a sacral opening. Heurteloup's, for varicocele; a modification of Cooper's operation; it consists in resection of the redundant scrotum, together with a portion of the veins behind. Hey's: I. For amputation through the foot; the same as Lisfranc's operation, except that the internal cuneiform bone is sawn through in a line with the articulation of the second metatarsal bone, instead of being disarticulated. 2. For amputation of the leg; the amputation is made in the middle of the leg by a long posterior flap, cut by transfixion, and a slightly shorter anterior one. High Operation: I. Supra-pubic lithotomy. See Lithotomy. 2. Delivery by forceps of a fetus, the instrument being applied at the superior strait. Hill's ( $B$.$) , for internal urethrotomy; it is done with$ a modification of Maisonneuve's urethrotome. Hilton's: I. For amputation of the penis; the spongy body is divided about $1 / 2$ inch in front of the cavernous portion, splitting it longitudinally and uniting the lateral flaps to the skin. 2. For opening an axillary abscess; an incision is made through the skin with a knife; then a grooved director is pushed into the deeper structures until pus escapes. 3. For fissure of the anus; an incision is made from without, a sharp-pointed bistoury being inserted beneath the base and the point made to protrude in the bowel. 4. For obturator hernia; it is done by abdominal section and withdrawing the intestinal loop from within. Himly's: I. For corectopy; the same as Adams' operation. 2. For iridodialysis; the same as Scarpa's operation, except that the needle is introduced through the cornea. 3. For symblepharon; preliminary perforation of the adhesion along the fornix, and the passing of a lead wire along the canal so formed, thus converting a posterior into an anterior symblepharon, 
which can then be operated upon by simply separating the adhesions. Von Hippel's, for transplantation of the cornea; a circular portion of the leukomatous cornea is removed by means of a trephine, the membrane of Descemet being left intact; a piece of the whole thickness of a rabbit's cornea is then excised with the same trephine and transplanted. Hirschberg's, for detachment of the retina; paracentesis of the sclera over the seat of the effusion. Hodgson's : I. For ligation of the axillary artery; a semilunar incision is made just below the clavicle, terminating near the anterior margin of the deltoid muscle. 2. For ligation of the femoral artery; ligation at the apex of Scarpa's triangle. Hoffa's, for congenital dislocation of the hip; the head of the femur is reached through a 3 -inch incision and freed from its attachments; the cotyloid cavity is then gouged out to receive it, and reduction is accomplished under extension. The dressing consists of a plaster-of-Paris bandage, with continuous extension. Hoin's, for amputation at the knee-joint, ; is done by the posteriorflap method. Holmes' (T.) : I. For ectopia vesice; closure by means of reversed and superimposed flaps. 2. For excision of the os calcis; an incision is made from the inner edge of the tendo Achillis along the upper border of the os calcis and the outer border of the foot to the calcaneo-cuboid joint, and this is joined by another incision running across the sole, the peroneal tendons being divided. 3. For varicocele; a small incision is made in the scrotum, and the veins are ligated with kangaroo tendon. Holt's, for internal urethrotomy; rupture of the stricture by rapid dilatation. Horn's, for chiloplasty; removal of the diseased tissue by a V-shaped incision, and filling in of the gap by tissue from the maxillary bones. Horner's : r. For cicatricial ectropion; the lid is dissected loose and a flap from the cheek is used to fill in the gap produced. 2. For salivary fistula; the diseased tissues are cut out with a punch, on a wooden spatula held in the mouth; the external wound is then closed. Horsley's $\left(V_{0}\right)$, for craniectomy; the skull is exposed by raising a flap, and the bone is removed with the trephine and bonecutting forceps. Hotz's: I. For entropion; it is on the same principle as Anagnostakis' operation, but more of the orbicularis muscle is removed, and the sutures are placed higher up. 2. For trichiasis; the skin above the lid-margin is united to the upper border of the tarsal cartilage. Howse's: I. A method of performing gastrostomy; a vertical incision is made in the sheath of the rectus muscle, a little to the inner side of its outer border. 2. For lumbar colotomy; a modification of Bryant's operation in which the operation is carried out in two stages, two pairs of pressureforceps being made to grasp the muscular coats of the colon, and to hold the bowel until the time for establishing the artificial anus. 3. For nephro-lithotomy; an incision is made in a vertical direction, and this is supplemented by a transverse one; the knife is entered close to the edge of the erector spinæ muscle, below the lower border of the twelfth rib, and is carried obliquely downward and forward toward the crest of the ilium. 4. For varicocele; after the vas deferens has been separated from the veins, an incision $11 / 2$ or 2 inches long is made over the varicocele; the veins are then ligated above and below, and the included bundle is excised. Hue's, for performing circumcision; an elastic ligature is made to transfix the dorsal aspect of the prepuce by means of a curved needle; the ligature is then tied in front and allowed to cut through. Hueter's : I. For excision of the elbow; a modification of Ollier'soperation. 2. For excision of the facial nerve; the incision is made in front of the ear, and one of the branches of the nerve is exposed in the parotid gland; this is to be followed back to the trunk. 3. For excision of theshoulder; it is done by a single anterior vertical or oblique incision. 4. For chiloplasty. (lower lip); the margins of the defect are brought together and an incision is made in the cheek horizontally outward from the oral angle, involving the whole thickness on the distorted side; the mucosa on each side of the new wound is reflected a little and then united to the skin by sutures. 5. For rhinoplasty; a quadrilateral flap is taken from the dorsum of the nose to form a new columna. 6. For stretching the facial nerve; an incision two inches long is made in front of the ear, its center being opposite to the upper part of the lobule. Huguier's: 1. A method of performing colotomy; the right lumbar operation. 2. For iridodialysis; the iris is divided from the center to the circumference, and each lip is then detached. 3. For the removal of a naso-pharyngeal tumor; the same as Berard's operation, except that a smaller fragment is removed; the bone is divided horizontally from the maxillary tuberosity to the anterior nares, and the base of the pterygoid process is cut through: the lower part of the jaw is then dislocated downward within the mouth. Hulke's, for fistula of the lacrymal gland; a silk thread armed with a needle at either end is passed from the orifice of the fistula through the conjunctiva and allowed to remain; a triangular portion of the upper lid is thus included in the thread. Humphrey's : 1. For amputation of the penis; a circular skin-flap is made, the urethra is dissected loose from its attachments to the stump of the corpora cavernosa, drawn through a slit made at the base of the scrotum on the under side and attached to the margins of the slit so as to make an artificial meatus in the perineum. 2. For excision of the condyle of the lonver jaw; the condyle is exposed by reflecting a triangular flap upward, and the bone is sawn through the neck, all of the condyle and external pterygoid process being removed. Hunter's $(J \circ h n):$ I. For aneurysm; ligation of the artery on the cardiac side of the aneurysm at some distance from it. 2. For internal urethrotomy; it is done with a special dilating urethrotome. 3. For ligation of the femoral artery; it is done in the aponeurotic canal. 4. For trichiasis; after puncturing the hair-bulb with a fine knife to the depth of $1 / 8$ of an inch, a needle, dipped in some irritant, is introduced and the hair extracted. Hutchinson's: I. A method of performing ovariotomy; application of a clamp to the pedicle. 2. A method of transfusion: the indirect method, with the use of a fountain-syringe devised for the purpose. 3. For varicocele; the open method of deligation. Indian, for rhinoplasty; a flap is taken from the forehead, with its pedicle at the root of the nose; hollow plugs are inserted into the nostrils, and the flap is secured. See Keegan's operation. Invagination Method. See Jobert's operation. Italian Operation: I. For cystotomy. See Allarton's operation. 2. For rhinoplasty; the skin is taken from the arm over the biceps; the flap is cut on three sides, and after the skin has shrunk it is fitted to the fresh margins of the defect, the arm being bandaged in position for at least eight days. Jaboulay's. See Exothyropexy. Jacobs', for trichiasis; scalping of the edge of the lid, including the cilia and the hairbulbs. Jacobson's : I. For amputation of the penis; it is done by the flap-method, the flap being taken from above. 2. For cataract-extraction; scleral section, the flap skirting the lower margin of the cornea ; iridectomy. Jacque's, for excision of the tongue; it is done through an opening made in the cheek. Jaeger's : I. For cataract-extraction: the incision is 
made with a concave knife. 2. For ectropion: detachment of the everted lid, except at the angles, and its adaptation to the eyeball. 3. For ectropion of the up per lid; the incision is made parallel to the edge of the lid, with excision of a portion equal to the difference in the lengths of the lids; the wound is then sutured. 4. For entropion: excision of a portion of the lid with the cilia and hair-bulbs, and healing by granulation. 5. For excision of the elboze; a moditication of Moreau's incision, in which the outer vertical limb of the $H$ is omitted. 6. For excision of the tongue; excision through an opening made in the cheek by a curved incision extending from the angle of the mouth to the anterior edge of the masseter muscle. 7. For trichiasis; paring away of the edge of the lid; removal of the portion of skin over the hair-bulbs. Jaesche's : I. For distichiasis; the margin of the lid is separated except at either end; an incision is made parallel to this, and the intermediate portion of skin is removed; the wound is then closed with sutures. See Arlt's Operation. 2. Plastic; the triangular gap is closed by displacing and transplanting a flap marked out by a curved lateral incision, and sutures are applied. Janin's, for iridotomy; a vertical incision of the iris is made on the inner side of the pupil by a knife or scissors introduced through the cornea. Jeffray's, for excision of the knee; it is done by two vertical lateral incisions. Jenks', for lacerated perineum; denudation of the surface by means of scissors introduced at the lower edge, close to the integument, and made to dissect up the lower surface without being withdrawn. Jobert's $\left(M_{0}\right):$ I. For castration; a curved incision is made upon the scrotum, with its convexity turned downward and inward. 2. For ligation of the upper part of the popliteal artery; an incision, three inches in length, is made parallel with and just posterior to the tendon of the adductor magnus muscle, commencing at the junction of the middle with the lower third of the thigh. 3. For the radical cure of hernia: two cannulated needles are passed and the cannulæ allowed to remain until the requisite amount of inflammation has been produced. 4. For suture of the intestine; the invagination method; the upper segment is transfixed near the divided margin on two opposite sides by a needle and thread; the two ends of the thread hanging down on each side are both armed with needles, and, the intestinal wall of the lower segment being transfixed, the invagination is completed, partly by traction on the sutures, and partly by squeezing. Jones' $(P$.$) , for lumbar colotomy; a$ modification of Bryant's operation in which the lower end of the colon is closed by detaching the mucosa from the upper segment of the bowel and adjusting it by sutures. Jones' $(S$.), a method of performing gastrostomy: the parietal incision is made almost in a vertical direction, in a line drawn from the left nipple to the spine of the pubes. Jones' $(W$.$) ,$ for ectropion; a V-shaped incision is made with its apex directed away from the margin of the lid; when this is united with sutures, after the skin has been freed from the underlying tissues, the wound is $Y$ shaped. Jordan's, for resection of the nose for removal of polypi; osteoplastic resection of the nose and splitting of the upper lip to give more room. Jordan's (Furneaux) : I. For amputation at the hip-joint; the soft parts are divided down to the bone by the circular method, as low down as possible, and the femur is shelled out by a longitudinal incision along the outer side of the thigh. 2. For amputation at the shoulder-joint; the soft parts are divided down to the bone by the circular method, three or four inches below the axilla, and the humerus is shelled out by a longi- tudinal incision along the outer and posterior aspect of the limb, meeting the circular incision at right angles. 3. For excision of the tongue; division of the cheek back to the ramus of the jaw, and removal of the diseased part by two écraseurs, worked simultaneously. The same as Jaeger's operation. 4. For removal of a tumor of the naso-pharynx; an incision beginning at the gingivo-labial fold, just below the posterior margin of the nostril, is carried forward into the nasal cavity, on through the ala of the nose, and along the lateral aspect of the nose; the whole upper lip is then divided, the flaps turned aside, and the anterior nares exposed. Jörg's, for otherwise impossible labor. See Laparo-elytrotomy. Jurine's, for iridotomy; the needle is introduced through the sclerotic, and the iris is punctured from behind forward, and from before backward, and the punctures are united by an incision. Kappeler's, for cholecystenterostomy; it is performed in one stage; the distended gallbladder is emptied by puncture with a trocar, and the margins of the wound, after being enlarged, are united, by means of a double row of sutures, to the highest part of the jejunum. Keegan's, a method of rhinoplasty; the Indian method; the flap being derived mainly from one side of the forehead. Keen's $(W . W$.$) : I. For linear craniotomy; the skull is$ exposed through a slight flap, and the bone is divided by means of a special bone-cutting forceps. 2. For prominent auricles; a large oval piece of skin is removed from the back of the ear, and a $V$-shaped piece of cartilage is excised. 3. For stretching the facial nerve; the use of a weak faradic current to find the nerve, and stretching from the periphery toward the center; the remainder of the operation is the same as Baum's operation. Keetley's (C.B.), for the radical cure of umbilical hernia; after separation and torsion of the sac, it is drawn, by means of a ligature, into a prepared space between the linea alba and the peritoneum, above the umbilical ring. Kehrer's : I. A method of performing Cesarean section; a modification of the usual operation, in which the uterus is opened at the level of the internal os by a transverse incision. 2. For depressed nipple; excision of a ring of skin around the nipple, and healing by granulation. Keith's : I. A method of performing hysterectomy for myoma: either enucleation, or removal of the entire organ and its appendages, with the clamp-treatment of the pedicle. 2 A method of performing ovariotomy; treatment of the pedicle with the cautery and clamp. Kelly's $(H$. $A$.), for retro-positions of the uterus; median celiotomy, followed by stitching of the uterus to the ventral abdominal wall. Kelsey's, for inguinal colotomy; the incision is parallel to and half an inch above Poupart's ligament. Kerr's, for amputation at the hip-joint; the same as Ravaton's amputation. Kessel's : I. For establishing a permanent perforation in the ear-drum; it consists in the removal of the tendinous ring that attaches the drum-membrane to the bone, and in chiseling away a portion of this bone along the posterior circumference. 2. For the mobilization of the stapes, in chronic nonsuppurative middle-ear inflammation; it consists in separating the inflammatory adhesions. Key's, for lithotomy; the lateral operation with the straight staff. See Lithotomy. Keyes' (E. L.), for varicocele; subcutaneous ligation with a special needle, carrying two silk ligatures; it is best performed in the standing position under the use of cocain. Kinloch's, for internal urethrotomy; it is done with a special urethrotome used to divide the stricture from within outward. Klineberger's, for lumbar nephrectomy; a curved incision is made with its convexity upward and outward. Knapp's $(H$.$) : 1. For blepharoplasty; the formation$ 
of a quadrangular flap from the cheek and nose, followed by the insertion of sutures. 2. For cataract-extraction; the formation of de Wecker's corneal flap; a broad iridectomy and peripheral opening of the capsule; the lens is expelled by gentle pressure on the lower part of the cornea. 3. For cleft lobule of the ear; denudation by transfixion, and cutting out and suturing. 4. For coloboma palpebre; a combination of simple union and blepharoplasty. 5. For divergent strabismus; division of the external rectus; insertion of a double suture through the inner margin of the cornea and through the inner canthus. 6. For evisceration; a modification of Critchet's method, in which conjunctival instead of scleral sutures are used. 7. For pterygium; a modification of Desmarre's operation; the corneal portion is excised, and the remainder is divided into two parts, one being transplanted under the conjunctiva above the wound and the other below. 8. For staphyloma: a modification of Critchett's method of closing the wound after operation upon the staphyloma. Critchett inserted stitches in the sclera, Knapp only in the conjunctiva. 9. For symblepharon; a modification of Teale's operation. Knox's, for excision of the tongue; a vertical incision is made through the center of the lower lip, and the inferior maxilla is exposed and sawn through at the symphysis; the tongue is then dealt with as the case demands. Kocher's: I. For excision of the ankle-joint; the incision is made beneath the external malleolus, and is followed by division of the peroneal tendons after being secured with threads, and opening of the joint with removal of the diseased parts; the foot is replaced and the tendons sutured. 2. For excision of the thyroid gland; an incision is made in the median line from the sternal notch to the upper limit of the bronchocele; from this point two lateral incisions are made upward and outward to a point a little below the angle of the jaw. 3. For excision of the tongue; preliminary tracheotomy and packing of the pharynx with sponges; the incision begins below the tip of the ear, extends along the anterior border of the sterno-mastoid muscle to about its middle, then forward to the body of the hyoid bone, then upward along the anterior belly of the digastric muscle to the symphysis menti; the tongue is then removed by the galvano-cautery or scissors through the incision. This operation was devised to avoid pneumonia and septicemia. 4. For varicocele; ligation of the veins at two points, and subcutaneous division. Koeberle's : I. A method of performing oophorectomy; the pedicle is grooved with a specially-devised wire constrictor prior to ligation. 2. For retroflexion uteri; abdominal fixation. Kolomnin's, for hip-joint disease; ignipuncture or cauterization of the diseased tissue. Konig's: I. For nephrectomy; an incision is made vertically downward along the outer border of the erector spinæ muscle to just above the iliac crest, then curving anteriorly, and extending nearly, or quite, to the umbilicus. 2. For single hare-lip; both margins are pared, and two small prolabial flaps are formed by horizontal incisions parallel to the lip-margin. Kraske's: I. For carcinoma of the rectum; resection of the coccyx and of a portion of the sacrum to give access to the rectum high up. 2. For extirpation of the uterus; the operation is made through the same sacral opening as in operating for carcinoma of the rectum. 3. For meloplasty; a flap is taken from the immediate neighborhood, and union follows, even if the pedicle consists of subcutaneous tissue only. Krimer's, for urinoplasty; muco-periosteal flaps are dissected up on either side of the cleft, then reversed from without inward, and united in the middle line by sutures. Kückler's;
1. For cataract-extraction; the incision passes through the cenicr of the cornea. 2. For splenectomy; the incision is made through the linea semilunaris. Kuhnt's: 1. For canthoplasty; a flap of skin is cut from the upper or lower lid, and turned into a wound made at the outer canthus. 2. For ectropion; a modification of Antyllus's operation. 3. For symblepharon; the use of skin-flaps grafted upon the surface, or pedicellate flaps which are thrust in between the eyeball and eyelid through fenestra cut through the latter. Kuister's: I. For performing gastrostomy; the parietal incision is made in the linea alba. 2. For mastoid and middle-ear disense; it consists in making an opening in the posterior wall of the auditory canal as far away from the membrana tympani as possible in cases in which some of the membrana and the ossicles are still retained; if the drum-cavity is filled with granulations the incision should be carried through the bone into the drum-cavity, and the morbid material removed with a spoon. Küster-Dolbeau's, for vesical exploration; paraprostatic section of the urethra and subsequent dilatation to allow of the introduction of the fingers. Labbe's, for gastrotomy; the parietal incision is made parallel to the left costal margin. Lacauchie's, for amputation at the hip-joint; the same as Esmarch's amputation. Lafage's, for castration; by an elliptic incision in the scrotum. Laforest's, for stricture of the lacrymal duct; the injection of an astringent solution through an S-shaped hollow probe. Lallemand's, for circumcision ; dorsal transfixion, followed by excision of the two lateral flaps. Landolt's, for blepharoplasty ; a portion of the upper lid is taken to replace a lost lower lid. Lang enbeck's : 1. A method of performing amputations; the making of musculo-tegumentary flaps by cutting from without inward. 2. For cholecystectomy; the entire gall-bladder is removed, after division of the cystic duct, between two ligatures. 3. For double harelip; the edges of the prominent tubercle and of the maxilla are pared, and, after replacement into position, the parts are transfixed with hare-lip pins. 4. For duodenostomy; the bowel is attached to the wound in the parietes and opened at a later stage of the operation. 5. For ectropion; the same as v. Ammon's operation. 6. For excision of the ankle; a modification of Moreau's operation, in which the outer incision follows the anterior portion of the fibula, curves around and below the malleolus and ascends about one inch along its posterior border. 7. For excision of the elbore; a longitudinal posterior incision is made along the inner side of the olecranon. 8. For excision of the hip; an external incision is made in the long axis of the limb over the outer surface of the great trochanter. 9. For excision of the knee; a vertical incision is made on the antero-internal aspect of the joint. Io. For excision of the shoulder; a single vertical incision is made, having for its starting-point the acromio-clavicular joint. II. For excision of the upper jaz,; a transverse curved incision, with its convexity downward, is carried from the junction of the nasal cartilage with the nasal bone to the middle of the malar bone. 12. For excision of the wurist; the same as Backel's operation. I3. For iridodialysis; impaction is united with detachment; the detached flap of the iris is drawn into the corneal wound, where it is retained by adhesions. 14. For completely lacerated perineum; the edge of the recto-vaginal septum is denuded and then split for some distance ; a flap is cut out of the vaginal side, and, after closure of the rectum, is stitched forward over the new perineum by vaginal sutures; the external sutures are placed from before backward. I5. For the removal of a naso- 
pharyngeal polypus; (a) nasal route; the nasal bone and nasal process of the superior maxilla are exposed and forcibly displaced upward; (b) maxillary route; a tongue-shaped flap is marked out on the face, and a large part of the maxillary bone separated and temporarily displaced inward. 16. For nephrectomy; an incision is made through the abdominal wall at the outer edge of the rectus muscle, in the linea semilunaris, commencing just below the margin of the ribs. 17. For neurectomy; the division of the superior maxillary nerve in the spheno-maxillary fossa by means of a long tenotome passed into the fossa along the outer wall of the orbit. I8. For osteolomy; the subcutaneous method. 19. For restoration of the lower lip; $(a)$ the lower horizontal margin of the defect is prolonged on either side by incisions, which pass along the remainder of the lower lip, around the angles of the mouth and into the upper lip; the portion of the lip. is then mobilized and drawn together by sutures. $(b)$ By a single flap derived from the chin. 20. For rhinoplasty; the Indian method; a single lateral flap is brought from the opposite side, the apex being left attached at the inner angle of the eye on the side of the deficiency, while the base comes from the ala of the sound side. 2I. For uranoplasty; complete closure of the cleft in the palate by dissection of mucoperiosteal flaps obtained from either side, and suturing in the middle line. Langier's, for stricture of the lacrymal duct; perforation of the wall of the duct and the maxillary sinus, to drain the tears into the antrum. Lannelongue's: 1. For craniectomy; $(a)$ The vertex of the skull is exposed by means of a single incision in its long axis and a narrow strip of parietal bone is removed close to the sagittal suture; $(b)$ The bones of the skull are so cut as to produce osseous flaps of various shapes. 2. For cleft-palate; a rectangular flap of mucous membrane is brought down from the side of the septum of the nose; the upper edge of the cleft is then freshened and the two surfaces brought together. Lariche's, for removal of a tumor of the naso-pharynix; a V-shaped incision is made, the ends of which run into either nostril, and the apex is in the middle line one-fourth of an inch below the columna, which is then separated from the upper lip. Larrey's: I. A method of performing amputation; the same as Dupuytren's amputation by the double-flap method. 2. For amputation at the hip-joint; lateral flaps are made by transfixion, the common femoral artery being tied as a preliminary step. 3. For amputation at the shoulder-joint; an incision is made from the acromion to a point $23 / 4$ inches below, from which point anterior and posterior spiral incisions are carried down the arm, meeting on the inner aspect; after disarticulation of the bone the flap is brought up and secured in the space made by the gaping of the first incision. Lateral operation, a method of performing cystotomy; the lateral perineal operation. Lauenstein's, for iliac colotomy; the peritoneum is sutured to the skin; a loop of intestine is then drawn out and the parietal wound closed by sutures passed through the meso-colon of the extruded portion of gut; finally, the serous covering of each limb of the prolapsed loop is stitched to the parietal peritoneum, and the bowel is opened. Lawrence's $\left(\right.$ Sir $\left.W_{.}\right)$: I. For extirpation of the lacrymal gland; an incision is made over the outer third of the orbit, followed by division of the external commissure and extirpation of the gland. 2. For removal of a nasopharyngeal polypus; the nasal bones and nasal processes of the superior maxillæ are cut through; the septum is then divided, and the nasal cavity exposed by turning up the nose. Lawson's, for blepharo- plasty; separation of the adhesions and dissection up of the edges of the wound, followed by grafting. Lebrun's : I. For cataract-extraction: the incision is made farther in the cornea than most operators make it. 2. For entropion; similar to that of Anergnostakis' operation. Ledran's, for suturing the intestines. See Led' ran's Suture. Lee's (Henry): I. For amputation of the leg; a modification of Teale's operation, in which the long fiap is taken from the posterior aspect of the limb. 2. A method of performing embryotomy; brachiotomy, followed by perforation of the thorax and extraction by the crotchet. 3. For traumatic cerebral abscess; the same as Fenger's operation. 4. For varicocele; transfixion by two pins and figure-of-eight turns of a ligature, followed by subcutaneous division of the veins. Le Fort's: I. For amputation of the foot; a modification of Pirogoff's operation, in that the section of the os calcis is more nearly horizontal, all the upper part of the bone being removed. 2. For procidentia uteri; denudation of the anterior and posterior walls of the vagina and the formation of a longitudinal septum. Lembert's, for suture of the intestine; the interrupted suture is used, and a fold of serous, or of serous and muscular, tissue is picked up on one side of the wound; the needle is then carried over to a corresponding point on the other side of the wound, where a similar fold is picked up. Lenoir's, for amputation of the leg; a modified circular operation; a circular incision is made above the malleoli and below the point at which the bones are to be sawn; this is joined by a vertical incision carried up along the inner side of the tibial crest; the skin-flaps are then dissected up and the remaining soft parts are divided down to the bone at the level of the saw-line. Lente's, for stricture of the rectum; incisions are made in the anterior and posterior median lines. Letenneur's, for plastic purposes; the quadrilateral gap is closed by a flap freed from below and displaced upward. Leucke's, a method of performing gastro-enterostomy; in order to expedite the operation the first presenting portion of the small intestine is attached to the stomach. Leveille's, for iridodialysis; it differs from Scarpa's method only in the previous depression of the lens. Levis's: 1 . For the radical cure of hydrocele; the injection of twenty drops of pure carbolic acid into the tunica vaginalis testis after withdrawing the fluid. 2. For varicocele; after ligation of the varicocele the ligature is tied over a piece of rubber tubing so as to maintain the tension of the thread. Liebreich's : 1. For cataract-extraction; the incision is carried farther into the cornea than usual. See also Lebrun's Operation. 2. For strabotomy; the incision is made at the lower edge of the muscle's insertion; the conjunctiva and capsule of Tenon are separated as far as the semilunar fold ; the tendon is divided and the vertical incision is extended upward and downward to the necessary extent. Lignerolle's : I. For amputution of the foot; the astragaius is preserved in situ. 2. For subastragaloid disarticulation; by a short external, and a long internal flap, taking in part of the sole of the foot. Linhart's, for the removal of a tumor of the naso-pharynx; an incision is made from the root of the nose to its tip, and is extended into the nostril of one side: the nasal bone is forcibly turned to one side after having been separated from its fellow. Lisfranc's : I. For amputation of the fingers at the metacarpo-phalangeal joints; it is done by rounded lateral flaps of equal size, the base of each corresponding to the jointline, and the free extremity to the level of the web. 2. For amputation through the foot; disarticulation through the tarso-metatarsal joints. 3. For am- 
putation at the hip-joint; Iateral flaps about four inches long are made by transfixion, the outer one being cut first. 4. For amputation at the shoulder-joint; external and internal flaps are made by transfixion; in operating on the left shoulder the knife is entered near the posterior fold of the axilla, and after passing close to the outer aspect of the joint, is made to emerge between the coracoid process and the clavicle; on the right side the direction of the transfixion is reversed. 5. For excision of the hip; it is done by raising the flap from over the great trochanter. Lister's (Sir Joseph): I. A method of performing amputations; by double rectangular flaps, the difference in length not being so great as in Teale's operation; the angles of the flaps are rounded off, the posterior one consisting of skin and fascia only. 2. For amputation at the lip-joint; disarticulation through an external racket incision; after Ravaton's and Furneaux Jordan's ampulations. 3. For amputation above the knee; a modification of Carden's amputation, in which a short posterior skin-flap is formed. 4. A method of button suture; oval perforated discs of lead are used which are threaded on the ends of wire. 5. For excision of the arrist; the open method, by two dorsal incisions, with division of the extensors of the carpus. 6. For ununited fractures of short bones; the fragments are wired together. Liston's: I. A method of performing amputations; a combination of the double-flap and circular operations, by first dissecting up two semi-oval flaps to serve as covers for the flat-faced stump. 2. For amputation at the hipjoint; disarticulation by antero-posterior flaps, cut by transfixion; the anterior flap is the longer of the two and is made first; the disarticulation is effected before the posterior flap is cut. 3. For chiloplasty; removal of the diseased tissues, and transplantation of a flap from the chin or the cheek. 4. For excision of the elbow; a modification of Moreau's incision, in which the outer vertical limb of the $\mathrm{H}$ is omitted. 5. For excision of the upper jaze; it is done by three incisions: $(a)$ an incision from the external angular process of the frontal bone through the cheek to the angle of the mouth; (b) a short incision along the zygoma to meet the first; $(c)$ an incision along the side of the nose and through the center of the lip. Littrè's: I. For enterotomy; occlusion of the lower end of the intestine, with the formation of an artificial anus. 2. For inguinal colotomy; it is performed on the left side for opening of the sigmoid flexure; an incision from $I 1 / 2$ to 3 inches long is made parallel with the outer part of Poupart's ligament, and about $1 / 2$ inch above it. Lizars' $\left(J_{\text {. }}\right)$, a method of exposing the upper jaw by cutting through the cheek, from the angle of the mouth to the malar bone. Loreta's : I. For aneurysm; the insertion of a small wire into the sac, and the use of electrolysis as well. 2. For stenosis of the orifices of the stomach; digital or instrumental divulsion of the pyloric or cardiac orifice, following gastrotomy. Lossen's, for neurectonny; a modification of Lücke's operation in which the masseter muscle is not divided. Lowdham's, a method of performing amputations; it is done by a single flap. Lubbock's, for lacrymal fistula ; an incision is made into the anterior wall of the lacrymal sac, followed by the introduction of a grooved knife to the bottom of the duct, and the passage of a leaden style. Lucæ's, for strabismus; a semicircularincision is made in the conjunctiva near the cornea, followed by division of the tendon close to the sclerotic. Lucas's: I. For lumbar nephrectomy, an oblique incision is made as for colotomy, supplemented by a vertical incision carried along the outer edge of the quadratus lumborum muscle from the last rib to the iliac crest. 2. For unbilical hernia; excision of the sac and redundant skin, with suture of the ring. Lücke's : 1. For excision of the hip; it is done by an anterior incision in the long axis of the femur, commencing $1 / 2$ inch below and to the inner side of the anterior superior iliac spine. 2. For neurectomy; removal of the second division of the fifth nerve at the point of exit from the skull; the incision is made above the external canthus along the upper border of the zygoma, and the spheno-maxillary fossa is exposed by sawing and breaking through the arch. Luke's: I. A method of performing amputations, the first flap is made by Langenbeck's method, and the second by Vermale's method. 2. For iliac colotomy; a modification of Cripps' operation in which the incision is made in a vertical direction and external to the epigastric artery. Lund's, for talipes; the removal of the astragalus. Luzardi's, for iridodialysis; by means of a special needle a portion of the iris is drawn out through either the cornea or sclerotica, and retained by adhesions. Lydston's, for varicocele; an incision one inch or more in length is made parallel with the spermatic cord and beginning just below the external abdominal ring; the cord and veins are exposed, separated, and the veins ligated with a single silk ligature ; after closure of the wound a clamp is applied and the redundant scrotal tissue removed. Mac Cormac's $(\operatorname{Sir} W$.$) : I. For excision of the shoulder;$ by a posterior vertical incision starting from the angular projection on the inferior margin of the acromion. 2. For genu valgum; division of the femur from the outer side, above and parallel with the articular surface. 3. For ligation of the popliteal artery; it is done from the front at the inner side; the artery is exposed by an incision behind and parallel to the tendon of the adductor magnus. 4. For rhinoplasty; the Italian method, the flap being taken from the inner aspect of the arm. 5. For suture of the intestine; the same as Lembert's method, except that only an external line of sutures is used. Macdonald's, a method of performing embryotomy. See Afleck's operation. Macewen's : I. For aneurysm; a long pin with a tapering point is passed into the aneurysm and the point is made to touch the opposite wall of the sac; the point is then to be moved over the inner surface of the aneurysm for ten minutes for the purpose of causing irritation; in this way each point accessible to the point of the needle is to be treated. 2. For genu valgum; a modification of Chiene's operation, the wedge being removed through the same line of incision as in Ogston's operation. 3. For the radical cure of inguinal hernia; the sac is dissected out and separated from its connections, and then so drawn upward by means of a suture as to form a pad upon the inner surface of the circumference of the ring; the ring and canal are then closed. by means of sutures. 4. For intubation of the larynx, a long, cylindric tube, of the pattern of the gumelastic catheters, is introduced from the mouth into the trachea through the larynx. 5. Osteotomy for genu valgum; supra-condyloid division of the femur from the inner side. Mackenzie's : I. For amputation of the foot; the flap is taken from the inner and plantar surface of the foot and ankle in performing a Syme amputation. 2. For excision of the knee; by raising an anterior U-shaped flap. Macleod's, for amputation at the ankle-joint; a modification of Syme's operation, in which only the malleoli are removed, the cartilage on the under surface of the tibia being preserved. MacNamara's, for calaract-extraction; removal of the lens in its capsule without an iridectomy, through a large corneal incision extending outward. 
Madelung's, for lumbar colotomy; a modification of Bryant's operation in which the lower end of the colon, after being completely detached, is closed by invagination and two rows of sutures, and dropped back into the abdomen. Maisonneuve's: I. A method of performing amputations: it is also called the diaclastic method, and was devised for the purpose of avoiding hemorrhage, infection, and other accidents; the bone is first broken with an osteoclast and the soft parts are divided by means of an écraseur. 2. For excision of the elbow; it is done through a posterior median incision. 3. For excision of the rectum: a circular incision is made around the anus, and several needles, armed with ligatures twelve inches long, are passed into the incision and through the bowel above the growth, and brought out of the anus and made to retrace their course-one free extremity of the thread presenting at the anus, and the other in the wound. A whip-cord is passed through the loops of thread in the anus, when traction on the ends in the wound draws the cord through the bowel after the ligatures. The bowel is divided by allotting each loop of cord to an écraseur. 4. For excision of the tongue; a modification of Jaeger's operation, q. v. 5. For excision of part of the upper jaw; Guerin's operation, slightly modified. 6. For excision of the rurist; it is done by a single median dorsal incision. 7. For internal urethrotomy; a special urethrotome is used to divide the stricture from without inward. 8. For oöphorectomy; the entire pedicle is twisted. 9. For the removal of a naso-pharyngeal polyp; a slight modification of Guerin'soperation; an incision is made in the median line, from the junction of the hard palate down into the body of the uvula as far as is necessary, its free border being preserved. Malgaigne's $(J . F$. : I. A method of performing amputations; it is a variety of oval amputation in which the spiral incisions are continuous above with a single longitudinal one, so that the gaping wound has the form of a racket. 2. For amputation of the arm; a single rounded flap is cut, usually from the flexor surface of the arm. 3. For amputation through the foot; subastragaloid disarticulation by a single, large, internal flap, the astragalus only being left. 4. For amputation at the hip-joint; a modification of Ravaton's amputation, in which the vertical incision is shorter and the circular incision more oblique. 5. For chiloplasty; two lateral incisions are made on either side of the lower lip to restore this portion by the sliding method. 6. For excision of the shoulder; it is done by a single anterior vertical or oblique incision. 7. For hare-lip; the same as Clemot's operation. Manec's, for amputation at the hip-joint; a single long anterior flap is made by transfixion; the joint is then disarticulated, and a circular incision made posteriorly. Manne's, for the removal of a polyp from the naso-pharynx; an incision is made through the soft palate with a bistoury, in the median line, from the tip of the uvula to its junction with the hard palate; after removal of the polyp, the parts are restored by one or more sutures. Margary's, for congenital dislocation of the hip; the formation of an acetabulum in the normal position, reduction of the femur, and the formation of a capsule from the periosteum. Marian's, for lithotomy; the old median perineal operation for stone in the bladder. See Lithotomy. Markoe's, for varicocele; a modification of Vidal's method, in which the pin is dispensed with, and a loop of silver wire is clamped to a lead plate; the wire is gradually tightened. Martin's $(A$.$) : I. For lacerated perineum;$ a modification of Freund's operation, in which the vaginal tongues are denuded more deeply into the vagina, and the vulval denudations are carried higher up. 2. For the radical cure of hydrocele; the injection of tincture of iodin after aspiration. 3. For vaginal hysterectomy; an incision is made around the posterior nargins of the cervix until the peritoneum is reached; the edges of the vaginal wound are then sewn parallel to the incision to bring the peritoneum and raginal wall together and so arrest hemorrhage; the broad ligaments are ligated with silk ligatures in successive portions; the central fissure is now incised, the bladder separated, the cervix freed from the broad ligament on either side, the fundus retroflexed, and the remainder of the broad ligaments ligated and severed; a drainagetube is inserted into Douglas's space. Martino's, for the remedy of a large and prominent ear: a Vshaped piece is removed and the wound closed by sutures. Mason's: I. For osteoplasty; a modification of Dieffenbach's operation in which holes are punched, as a preliminary step, along the line the chisel is subsequently to take. 2. For rhinoplasty; it consists in bringing across the gap two lateral and one superior flap of integument as a base of support for the frontal flap. 3. For uranoplasty; perforation of the bone at several points in the line of the lateral incision before applying the chisel, to prevent comminution. Masslorsky's, a method of performing oöphorectomy; double flaps are made of the pedicle, and these are stitched together. Mastin's, for internal urethrotomy; it is done with a modification of Maisonnewve's urethrotome. Mathews': I. For fistula in ano; after dilating the sinus with a laminaria tent, a urethrotome is introduced to the full depth of the sinus, the knife is protruded, and the instrument withdrawn; the operation is repeated with the knife in the opposite direction. Mathews has devised a special fistulatome for this purpose. 2. For inguinal colotomy; the incision is made two-thirds above and one-third below, and at right angles to a line drawn from the anterior superior spine of the ilium to the umbilicus, one and a half inches from the spine; when the bowel is brought out of the wound, two large pins are passed parallel and close together through one edge of the incision, through the mesentery near the bowel, and out at the other wound-margin ; the operation is completed by stitching the bowel to the skin; the colon is incised at a later period. Mathewson's, for exostosis of the external meatus; removal by a drill. Maunoir's, for ividotomy; incision of the cornea and removal of a triangular flap of the iris, the apex of which is toward the pupil. Maunsell's, for intestinal anastomosis; after dividing the gut, circularly, at the proper points, a longitudinal incision about an inch and a half long is made in the larger segment opposite the mesenteric attachment; a long suture is then passed through all the coats of the two divided ends at the mesenteric attachment and one similarly directly opposite this point; the sutures are then passed in the lumen of the larger segment and out the longitudinal incision, the ends of the gut are invaginated and accurately coaptated by sutures, the invagination is re. duced and the longitudinal incision closed by sutures. Maury's $\left(F_{*}\right)$ : I. For ectopia vesica ; a modification of Roux's operation, in which one flap is taken from the perineum and the scrotum, the other from the abdomen. 2. For gastrostomy; a curved parietal incision is made with its convexity toward the middle line. Maydl's, for iliac colotomy; the peritoneal cavity is opened by Littre's incision; the loop of intestine is drawn out of the wound and held there by a hard rubber cylinder inserted through a slit made in the mesentry close to the gut; the latter is stitched in the abdominal incision, 
and opened from four to six days later. Maynard's, for suture of the bladder; the sutures are placed in two double rows by a special needle before the bladder is opened. McBurney's, for the radical cure of inguinal hernia; after exposing the sac the anterior wall of the canal is incised and the sac ligated and excised at the internal ring; the skin is inverted and stitched to the ligamentous and tendinous structures, the wound healing by granulation. McCreik's, for entropion; the removal of a horizontal strip of the tarsus from the inner surface of the lid. McCurdy's, for amputation at the hip-joint; a modification of Myles' operation, a single needle being inserted at the most prominent point of the great trochanter, passing directly through the thigh in front of the femur to emerge just below the tuber ischii. McDowell's $(E$.$) , for oophorectomy; the first complete operation;$ the pedicle was secured by a single ligature, the ends of which were brought out of the abdominal wound. McGill's, for prostatectomy; it is done by a suprapubic incision, as in supra-pubic lithotomy. McLeod's $(K$.$) : I. A method of performing oöphorec-$ tomy; torsion of the pedicle between two pairs of forceps. 2. For prolapse of the rectum; the upper part of the rectum is stitched to the anterior abdominal parietes, a wound being made through the abdominal wall for the purpose. Mears', for neurectomy; removal of the inferior dental nerve from its canal by traction after exposing the outer surface of the jaw, trephining over the position of the inferior dental foramen, and loosening the nerve at the mental foramen. Median Operation. See Hegar's operation, and also Lithotomy. Méjean's, for stricture of the lacrymal duct; a thread is passed through the canaliculus and duct into the nose, and medicated cotton fibers are drawn through. Mercier's, for prostatotomy; an instrument shaped like a short-beaked lithotrite with sharp edges is used to punch out portions of the floor of the urethra. Meyer's : r. For genu valgum; a cuneiform osteotomy of the tibia below the tuberosity. 2. For hypertrophy of the pharyngeal tonsil; a ring-knife is passed through the nose, and the manipulations are directed by the left forefinger passed into the vault of the pharynx. 3. For sympathetic ophthalmia; an incision is made over the painful portion of the ciliary region with division of the ciliary nerves. Michaelis', a method of performing embryotomy; evisceration followed by rachiotomy and forced evolution. Mika Operation. See Mika. Mikulicz's: I. For the removal of tonsillar tumors; it is done by an incision through the neck, the cut extending from the mastoid process downward and forward as far as the great cornu of the hyoid bone; the ascending ramus of the jaw is then resected and the wall of the pharynx is divided; a preliminary tracheotomy is performed. 2. For tarsectomy; the same as Wladimiroff's operation, but independently designed. Miller's, for amputation of the penis; the flap is cut from below. Milne's, for internal urethrotomy; it is done with a special dilating urethrotome. Miner's, for the removal of an ovarian tumor; enucleation when removal cannot be effected in the usual way, owing to absence or shortness of the pedicle, or to adhesions. Miot's, for chronic non-suppurative middle-ear inflammation; the stapes is exposed, either by excision of the upper posterior part of the mem. brane, or by the use of the electro-cautery, after which methodic mobilization of the exposed stapes is carried out by means of a probe or other instrument. Mirault's : I. For excision of the tongue; excision after ligation of the lingual arteries as a preliminary measure. 2. For hare-lip; a flap is turned down on one side and brought across and attached to the pared opposite side. Mollière's: 1. For amputation through the foot; the foot is treated as though it contained but one bone; if necessary, bone is cut through rather than disarticulation being made. 2. For infantile paralysis; osteoclasis is performed, instead of resection. Moore's : I. For aneurysm; the introduction of a fine wire into the sac through a cannula. 2. For cataract-extraction; extraction several weeks after the performance of a preliminary iridectomy. Mooren's, for cataract; an operation similar to Jacobson's operation, but the iridectomy is made several weeks before the extraction. Moreau's: I. For excision of the ankle; by lateral incisions, the outer one following the posterior border of the fibula and bending forward beneath the malleolus; the inner one is along the inner surface of the tibia in the axis of that bone. 2. For excision of the elbow; a posterior $\mathrm{H}$-shaped incision over the joint. 3. For excision of the knee; by an anterior $\mathrm{H}$-shaped incision. 4. For excision of the shoulder; a flap with its base below is taken from the deltoid region. Morel's, for excision of the shoulder; a rounded flap with its base upward is taken from the deltoid region. Morgan's, for chiloplasty; after the removal of the entire lip, a curvilinear flap is made by an incision below and parallel to the first, allowing the ends to remain attached and securing the flap in the place of the diseased tissue. De Morgan's, to reach the spinal accessory nerve; an incision is made behind the sterno-mastoid muscle. Morris' $(H$.$) : I. For$ excision of the radius; an incision is made parallel to the long axis of the bone between the supinator longus and extensor carpi radialis longior muscles. 2. For lumbar nephrectomy; a transverse or slightly oblique incision is made a short distance below the last rib, and this is joined by a vertical incision running downward from a point near the posterior extremity of the former. 3. For nephrorrhaphy; the sutures are passed through the entire thickness of one lip of the wound, then through the capsule and cortex of the kidney and finally through the other lip of the wound. Mortise Operation. See Giraldes' Operation. Morton's : I. For elephantiasis; the excision of a portion of the nerve-trunk, supplying the affected member. 2. For the reduction of club-foot; tenotomy combined with forcible correction by "Morton's club-foot stretcher." Mosetig Moorhof's, for staphyloplasty; a modification of Schönbein's operation, in which the fistula is allowed to remain at the position of the anterior palatine canal. Mott's: $\mathbf{1}$. For ligation of the common iliac artery; an incision five to eight inches in length is commenced just outside the center of Poupart's ligament, and one and a half inches above it; curving upward and outward toward the ribs, it passes one and a half inches in front of the anterior superior spine of the ilium. 2. For the ligation of the innominate artery; a transverse incision is made above and parallel to the top of the sternum and inner end of the clavicle, and this is joined by another of the same length along the anterior border of the sterno-mastoid muscle. Mulder's, for iridectomy; a crucial incision is made into the iris, with removal of the flaps one by one. Mule's, for evisceration of the cye-ball; evisceration of the globe followed by the insertion of a silver or glass ball within the sclerotic, with the view of rendering the stump better suited to an artificial eye. Müller's: I. For Cesarean section; a modification of Porro's operation, whereby the whole uterus is turned out of the abdomen before it is opened. 2. For vaginal hysterectomy; the uterus is divided into halves longitudinally; one part is brougint down at a time, and the broad ligament is ligated in sections. Murphy's, for intestinal anastomosis; by 
the use of a specially devised apparatus. See Mur phy's Button. Murray's, for ligation of the abdominal aorta; the extra-peritoneal operation; a curved incision, with its concavity forward, and about six inches in length, is made upon the left side of the body, from the anterior extremity of the tenth rib to a point about one inch to the inner side of the anterior superior iliac spine. Mütter's, for chiloplasty; the formation of two quadrilateral flaps to fill the defect caused by removing the diseased tissue. Myles', for amputation at the hip-joint; a stout steel skewer is thrust through the thigh from before backward, the point entering an inch below Poupart's ligament and just to the outer edge of the femoral artery; it passes to the inner side of the neck of the femur and emerges a little above the gluteal fold; an india-rubber cord is passed around the ends in a figure-of-eight. Nall's $(B . R$.), for internal urethrotomy; it is done with a special dilating urethrotome. Nassiloff's, for esophagostomy; the formation of a fistulous opening between the esophagus and the surface of the neck in cases of stricture or tumor of the former. Neal's, for gastrotony; a parietal incision is made in a line extending from the umbilicus toward the left false ribs. Nélaton's: I. For amputation through the foot; subastragaloid disarticulation by dorsal and plantar flaps, larger on the inner than on the outer side. 2. For enterotomy; the abdomen is opened in the right iliac region by an incision parallel to and a little above the outer portion of Poupart's ligament ; the first coil of intestine that presents is drawn into the wound. 3. For epispadias; it is done by reversed flaps, one being obtained from the median line of the anterior abdominal parietes, the other from the anterior surface of the scrotum. 4. For hare-lip; an incision is made around the upper angle of the cleft and the lower edge is turned downward, so that the wound becomes diamond-shaped; the sides are then brought together and sutured. 5. For lithotomy; the pre-rectal method, corresponding with the bilateral operation, with the addition of a careful dissection to obtain more space between the rectum and the bulb of the urethra, to avoid wound ing the latter. See Lithotomy. 6. For the removal of a naso-pharyngeal polypus; it is done through the mouth, by exposing the hard palate and drilling two holes in it, so that the intervening bone can be removed. 7. For proctotomy; the external method; the left index finger is introduced as far as the stricture, and, with this as a guide, the soft parts below the stricture are divided in the median line by a bluntpointed bistoury. 8. For rhinoplasty; two trapezoid flaps are taken from the cheeks, each flap being intended to form the corresponding half of the new nose. 9. For urethroplasty; the edges of the fistula having been pared, the surrounding skin, to the extent of about an inch, is dissected up subcutaneously, through an opening made below the fistula, and the fistula is closed by sutures. Io. For webbed fingers; the same as Didot's operation. Neudörfer's: I. For ectopia vesica; a modification of Trendelenburg's speration, in whith the sacro-iliac synchondroses are not separated, but approximation of the margins is made possible by two lateral incisions through the abdominal wall; the pubic bones are brought together by sutures. 2. For excision of the shoulder; it is done by a curved supra-acromial incision, the acromion being sawn through and the head of the bone thrust out. Neugebauer's, for prolapsus uteri; the same as that subsequently described by $L_{e}$ Fort, and best known by his name. Newman's, for nephrorrhaphy; in addition to stitching the kidney to the abdominal parietes, the fibrous capsule is split and separated from the surface of the kidney; the resulting adhesion thus aids in fixing the kidney. Nicoladoni's, for talipes calcaneus; in cases of paralysis of the calf-muscles, with the peroneal muscles intact, the tendo Achillis is cut and sewn to the peroneal tendons. Norton's, for ruebbed fingers, small triangular flaps are raised between the knuckles on the dorsal and palmar aspects; the webs are then cut through the bases of the flaps, which are stitched together. Noyes': I. For blepharoplasty; (a) The formation of a bucco-temporal flap, sliding the whole cheek, with the shortened lid, inward and upward. (b) The formation of a naso-buccal flap. 2. For inAammatory secondary cataract; the formation of an artificial pupil; a hole is made in the obstructing membrane with a v. Graefe knife, and this is enlarged by tearing. 3. For entropion; cure by a plastic operation. 4. For staphyloma ; incision of the limbus, followed by total avulsion of the iris. 5. For strabismus; advancement of the elongated tendon. Nuël's, for corneo-scleral mipture; the wound in the sclera is reopened by making a section with a knife, and the surrounding conjunctiva is drawn over the opening by means of a special suture. Nunneley's, for excision of the tongue; it is done by a suprahyoid incision and the use of the écraseur. Nussbaum's, a method of performing ovariotomy; the pedicle is tied in sections with catgut and dropped into the pelvic cavity. Oberst's, stomatoplasty; the defects of the mucous membrane of the cheek are covered with tissue removed from the upper or lower lip. Obre's, for the radical cure of obturator hernia; by cutting down on the sac as in other hernix. Odhelius's, for iridotomy; the same as Reichenbach's operation. O'Dwyer's, for intubation of the larynx; the same as Macezven's operation, except that a shorter tube of metal is introduced into the larynx. Oettinger's, for trichiasis; an incision is made in the intermarginal space, and is carried to a point above the upper border of the tarsus, so that all the skin that covers the tarsus can be displaced upward. Ogston's (Alexander) : 1. For extreme flat-foot; excision of the astragalo-scaphoid joint in a wedge-shaped piece, and the fixing of the astragalus and scaphoid together with pegs. 2. Osteotomy for genu valgum; division of the internal condyle of the femur obliquely, from before backward. 3. For opening the frontal sinuses; it is done by trephining in the middle line of the frontal bone. 4. For varicocele; subcutaneous ligation with silk; the same as Keyes' operation. Ollier's : I. For excision of the elbow; by lateral incisions, the main one external and "bayonet" -shaped, the internal one short and vertical. 2. For excision of joints; the subperiosteal method, in which the whole of the periosteum of the involved district and the capsular ligament are preserved. 3. For excision of the knee; by Moreau's incision and the carrying out of the periosteal method. 4. For excision of the scapula; one incision along the spine, and a second along the internal border of the scapula, and the subperiosteal removal of the bone. 5. For excision of the shoulder; by a single anterior vertical or oblique incision and the carrying out of the periosteal method. 6 . For excision of the zurist; the subperiosteal method by two dorsal incisions, after those made by Backel and Lister. 7. For genu valgum; section through the epiphyseal cartilage. 8. For the removal of $a$ naso-pharyngeal polypus; it is done through the nose by an osteoplastic operation; the nasal bones are exposed and sawn through in the upper portion, so that the nose can be turned downward. 9. For rhinoplasty; two diverging incisions are commenced in the median line of the forehead and carried down- 
ward along the border of the nose; the triangular flap is then drawn downward to supply the loss of the lower part of the nose. Olshausen's, for vaginal hysterectomy; a modification of Czerny's operation, the uterus is not turned backward, but the connections are gradually separated, as traction is made on the organ; the broad ligaments are tied with rubber ligatures. Orred's, for excision of the shoulder; it is done by a longitudinal incision from the socket of the shoulder to the insertion of the deltoid. Otis' $\left(F . N_{0}\right)$, for internal urethrotomy, it is done with a special dilating urethrotome. Pagenstecher's: I. For cataract-extraction; extraction of the lens in the closed capsule; a scoop is inserted under the lens and gentle pressure is made on the cornea. 2. For entropion; division of the external canthus; stretching of the horizontal wound to a vertical one, and suture of the opposed surfaces. 3. For iridodesis: a modification of Critchet's operation, the incision being made with a broad needle or narrow knife. 4. For obliteration of the lacrymal sac; slitting of the canaliculi, and the introduction of zinc chlorid paste into the sac. 5. For pterygizm; separation from the cornea and sclerotic and turning back; the edges of the conjunctival wound are brought together with sutures. 6. For ptosis; the fibers of the occipitofrontalis are made to act on the lid. 7. For stricture of the lacrymal duct; the introduction of Bowman's probe No. 3 ; slitting of the canaliculus and sac, and the daily passage of sounds. Paget's, for excision of the tongue; a modification of Nunneley's operation, the tongue being made free by incision of its attachments to the floor. Palasciano's, for tumor of the naso-pharynx; an incision is made through the skin over the lacrymal sac; this is partially dissected out and a puncture is made through the lacrymal bone, thus exposing the superior meatus. Panas': I. For proctotomy; linear proctotomy. 2. For ptosis; the tarsal portion of the lid is raised by sutures and the occipito-frontalis muscle is caused to assume, to a great extent, the function of the levator palpebræ. Pancoast's (Joseph): I. For amputation at the kneejoint; three flaps are made: a short, oval, anterior flap including the patella, and two latero-posterior flaps which join in the middle of the popliteal region. 2. For ectopic vesica; closure by means of two lateral flaps dissected up on either side of the defect, and reversed, but not superimposed. 3. For hernia; a method of operating by injections. 4. For neurectony; the removal of the second division of the fifth nerve at its point of exit from the skull; a square-shaped flap is raised over the ramus of the jaw, and the masseter muscle is elevated; the coronoid process is then resected and the internal maxillary artery is ligated, after which the spheno-maxillary fissure is exposed by separating the two heads of the external pterygoid muscle. 5. For rhinoplasty; the subcutaneous division of the depressed tissues, so that they may be separated from their bony connections. 6. For varicocele; a modification of Levis's operation; a button is introduced between the skin and the rubber. Parés $(A$.), for hare-lip; the edges are united by means of pins and figure-of-eight sutures. Park's: 1. For excision of the elhore: it is done through a posterior median incision. 2. For excision of the knee; it is done by an anterior crucial incision, with its convexity downward. Parker's: I. For the relief of cluronic cystitis in the male; perineal cystotomy. 2. For perityphlitic abscess; incision. 3. Syndesmotomy for talipes varus in children; division of the "astragalo-scaphoid capsule" and the anterior and posterior tibial tendons. Parker's $(R$. Willard) incision, for excision of the hip; employed originally by Dr. Hueter, and later and independently by Parker; the incision commences on the front of the thigh half an inch below the anterior superior spine of the ilium, and runs downward and a little inward for three inches. As the knife sinks into the limb, it passes between the tensor vaginæ femoris and the rectus on the inside, until it reaches the neck of the femur. Pasquier and Le Fort's, for amputation through the foot; ' a modification of Pirogoff's soperation: the section of the os calcis is made horizontally, its upper part being removed. Passavant's : I. For synechia; breaking up of the adhesions with forceps. 2. For staphylo-pharyngorrhaphy; the halves of the velum are stitched to the posterior pharyngeal wall in order to shut off the nose from the mouth. Patruban's, for varicocele; excision of the dilated veins. Paul's, for iliac colotomy; the bowel is divided and the distal end invaginated as in Senn's method; a glass tube is tied into the proximal end of the bowel, which is fixed into the parietal wound by sutures; after three days the projecting bowel is cut away. Péan's: I. For amputation at the hip-joint; the vessels are caught as the operation proceeds. 2. For hysterectomy for fibroid tumor; the extraperitoneal method; after an abdominal incision, the uterus is brought out through the wound, and the stump is transfixed with long heavy needles placed at right angles to each other; beneath these a wire is passed and made tight by means of a serre-noud; the tumor is amputated above the needles, and the abdominal wound is closed around the stump. 3. For the removal of a naso-pharyngeal tumor; an incision is made from the root of the nose down the median line to the lip, through the nostril, and through the median line of the upper lip, which is completely divided; the flaps are separated; a portion of the hard palate is removed after separating the periosteum; the second bicuspid tooth is extracted and the antrum is exposed by bone-forceps. 4. For pylorectomy; a vertical parietal incision is made in the middle line. 5. For vaginal hysterectomy for carcinoma; removal of the affected uterus per vaginam by morcellement, or bit by bit. Peaslee's, for trachelotony; an incision of one or both ora uteri for stenosis by Peaslee's metrotome, followed by dilatation. Percy's, for excision of the hip; it is done by raising a Hap from over the great trochanter. Perièr's, for uterine inversion; removal of the inverted uterus by the elastic ligature. Perrin's $(M$.$) , for amputation through the foot; sub-$ astragaloid disarticulation by the oval operation. Peters', for internal urethrotomy; a special urethrotome is used to divide the stricture from within outward. Petersen's, for lithotomy; the high operation. See Lithotomy. Petit's: I. A method of performing amputations; the same as Cheselden's method. 2. For amputation of the fingers; lateral flaps are cut from within outward. 3. For hernia; the sac is not opened. 4. For stricture of the lacry. mal sac; incision into the sac behind the internal canthal ligament. Pétrequin's, for symblepharon, gradual strangulation by means of a thread. Phelps' $($ A. M. $)$ : I. For club-fnot; a direct open incision is made through the inner and plantar surfaces of the foot. 2. For hare-lip; a loop is passed through the margin of the lip on either side of the cleft ; the incision is curved on both sides, and a V-shaped flap is allowed to remain in the middle line, beneath the septum of the nose; the wound is closed with silk sutures. Physick's, for iridectomy; removal of a circular piece of the iris by the cutting forceps. Pick's, for amputation at the knee-joint; a modification of Stephen Smith's operation by com- 
mencing the anterior incision higher, and removing the patella. Pirogoff's: I. For amputation through the foot; an operation in which the os calcis is sawn through obliquely from above downward and forward, and the posterior portion is brought up and secured against the surface made by sawing off the lower ends of the tibia and fibula. 2. For the radical cure of hernia; after reduction, a bladder of gold-beater's skin is introduced into the canal through a small incision, inflated and allowed to remain. Pitts', for stretching the inferior dental nevve; the nerve is found by a vertical incision within the mouth, along the inner border of the ascending ramus, and is stretched with a blunt hook. Platner's, for excision of the lacrymal sac; incision of the anterior wall, followed by removal of the sac-wall. Poinsot's, cuneiform tarsotomy for talipes varus; a T-shaped incision is made, the horizontal limb of which extends from the external malleolus to the head of the fifth metatarsal bone, while the vertical branch passes across the dorsum toward the scaphoid bone; the periosteum is similarly incised, and a wedge of bone removed. Politzer's: I. Section of the anterior ligament of the malleus. 2. For artificial aperture of the membrana tympani; a crucial incision of the membrane is made, followed by the application of the galvano-cautery. 3. For atrophied tympanic membrane with middle-ear catarrh; incision of the membrane every two or three days with a paracentesis-needle. Pollock's $\left(G_{.}\right): \mathbf{I}$. For amputation at the knee-joint; a long anterior and a short posterior skin-flap, somewhat rectangular in cutline, the patella being left. 2. For division of the levator palati muscle; the knife is passed through the mucous membrane of the velum in front, and to the inner side of the hamular process, and the muscle is fully divided. 3. For hemorrhoids; crushing them with a special clamp, and excising or cauterizing the projecting portion. Pope's: 1. For the formation of an artificial pupil; incision at the sclerocorneal margin, with excision of a portion of the iris without dividing the sphincter pupillæ. 2. For entropion; extirpation of the tarsus. 3. For trichiasis; similar to the Arlt-Jaesche operation: Porro's, for puerperal hysterectomy; Cesarean section, followed by removal of the uterus at the cervical junction, together with the ovaries and oviducts. Porro-Müller's, for otherwise impossible libor; a modification of the Porro operation in which the uterus is brought out of the abdomen before extracting the fetus. Porro-Veit's, for otherwise impossible labor; a modification of the Porro operation; the stump is ligated and dropped. Porta's : I. A method of performing embryotomy; perforation of the thorax in the axillary region, followed by evisceration and podalic version. 2. For varicocele; the injection of a saturated solution of chloral. Post's, for rhinoplasty; a modification of the Tagliacotian operation, the flaps being taken from the patient's finger. Pott's $(P$.$) , for fistula in ano; it consists in a$ simple incision. Power's, for corneal leukoma; rem oal of the opaque portion with a sharp punch, and transplantation of a healthy rabbit's cornea. Pratt's, dilatation of the lower orifices of the body, the anus and the urogenital canal, with the removal of any irritating conditions that may be present. It is based on the belief that many chronic diseases are due to morbid conditions of these orifices. Prévôt's, for mupture of the gravid uterus; removal of the uterus by abdominal incision. Prince's: I. For pterygium; similar to Knapp's modification of Desmarre's operation. 2. For strabismus; advancement of the rectus muscle. Pritchett's, for internal urethrotony; it is done with a modification of Maisonneuve's urethrotome. Purse-string, for cystocele. See Stoltz's operation. Quaglins', for sclerotomy; incision of the sclera with a small knife, and the use of a small spatula to prevent prolapse, should it tend to occur. Ramdohr's, for enterorrhaphy; the insertion of the proximal within the distal end of the intestine, and suturing. Ramsden's, for ligation of the third part of the subclavian artery; a transverse incision three inches in length is made across the base of the posterior triangle of the neck, about one-half inch above the clavicle. Rau's, for the formation of an artificial pupil; perforation of the sclera and iris with a narrow knife, followed by iridectomy. Ravaton's: I. A method of performing amputations; it is done by a circular incision through the soft parts of the bone, with two longitudinal cuts-one in front and the other behindextending from the circular incision upward to the level at which the bone is to be sawn through. 2 . For amputation at the hip-joint; disarticulation through an external racket-incision; a vertical cut is made on the outer side, and this is joined on each side by two oblique crescentic incisions which meet on the inner side of the thigh. Récamièr's, for extirpation of the uterus, vaginal hysterectomy. Reclus', for iliac colotomy; a modification of Maydl's operation, in which the sutures are omitted. Reeves' $(H . A$.$) : I. For inguinal colotomy; the usual$ incision is made, and sutures are passed through the gut to fasten it to the skin. 2. For knock-knee; a modification of Ogston's operation, in which an effort is made not to open the joint. Regnoli's, for excision of the tongue; an incision is made in the median line of the neck from the lower margin of the symphysis to the center of the hyoid bone, and from the upper end of this cut two lateral incisions pass outward along the lower border of the jaw to the anterior borders of the masseter muscles. Reichenbach's, for iridotomy; incision of the cornea and division of the iris from before backward. Reverdin's: I. For blepharoplasty; removal of the cicatricial tissue, suturing of the lid to the opposite one in its normal position, and skingrafting of the raw surface. 2. For skin-grafting; a point of skin is raised on an ordinary sewingneedle, and shaved off with a scalpel or scissors; the graft is then transferred to the fresh surface next to the healthy granulations. 3. For symblepharon; detachment of the lid and transplantation of a small flap from the cheek. Reybard's, for enterorrhaphy; invagination of the upper extremity by passing two sutures through the wall and out of the lumen, and then in the lumen and through the wall of the lower extremity; traction now effects invagination, and sutures are applied. Richard's: I. For ectopia vesica; the same as Roux's operation, following the lines of Nélaton's operation for epispadias. 2. For the removal of naso-pharyngeal polypi; an incision is made in the middle line, from the posterior border of the hard palate, forward to the alveolus; the periosteum is dissected up on either side, and as much of the hard palate as necessary is chiseled away. Richet's: I. For Dupuytren's contraction, or contraction of the palmar fascia; a longitudinal incision is made over the bands and transverse incisions at either extremity of the first; the flaps are dissected back, the bands cut or excised, the wound united, and the finger fixed in extension. 2. For ectropion; the cicatrix (situated at the outer side of the lower lid) is excised, and, after the lids have been stitched together, the gap is filled, and the operation is completed by raising and transplanting two tongue-shaped flaps. 3. For varicocele; cauteriza- 
tion of the scrotum by means of a special apparatus. Richter's: I. For ividotomy; the same as Keichenbach's operation. 2. For stricture of the lacrymal duct; incision of the sac and dilatation of the duct by means of catgut strings. Ricord's: 1. For circumcision; the prepuce is grasped with fenestrated forceps corresponding with the direction of the corona, and the forceps is slid in advance of the glans; the prepuce is cut off in front of the forceps, which are then removed and the mucous membrane is trimmed off, leaving a short stump; stitches are next applied. 2. For varicocele; the introduction of two double ligatures through a single opening in the scrotum, one passing above and the other below the veins; the ends of the ligatures are attached to a yoke provided with a screw, which is tightened from day to day. Riesel's, for the radical cure of inguinal hernia; the external ring is exposed by an incision; the anterior wall of the canal is split up to the internal ring; the neck of the sac is tied as high as possible; part of the anterior wall of the canal is cut away, and deep transverse sutures are then introduced. Rigaud's, for urethroplasty; a quadrilateral flap with its base above is turned over the fistula, and lateral flaps are brought over the first and secured in position by sutures. Riggs', for the radical cure of inguinal hernia; a variety of seton-operation, the peculiarities of which consist in the use of a large-sized mèche and an ingenious stop-needle. Rima's, for castration; a $U$-shaped flap is cut by transfixion from the posterior wall of the scrotum. Rizzoli's: I. For ankylosis of the lower jaw; a linear osteotomy through the mucous membrane, thus avoiding an external scar. 2. For $i m-$ perforate anus (the rectum terminating in the vagina); an incision is made in the perineum, antero-posteriorly -if the anus is absent-followed by dissecting the rectum from the vagina, and after pulling the former down, it is stitched to the skin-incision. Roberts' $(J . B$.$) , for deflected nasal septum; a linear in-$ cision is made with a bistoury along a prominent line of the deflection, so as to enable it to be pressed into its proper position, after which a long steel pin is thrust into the septum in such a manner as to maintain this position. Roberts' $(M . J$.) : 1. Electroosteotomy in knock-knee, bow-legs, and anterior tibial deformities. 2. Cuneiform osteotomy for hallux valgus. Robertson's (A.), for conjunctival entropion; a modification of Snellen's operation, in which the threads are passed through the conjunc tiva at the bottom of the fold, between its palpebral and outer portions. Robson's (Mayo), for ectopia vesica; a modification of Wood's operation, in which, in female subjects, the folds of integument following the labia majora are detached and displaced upward. Rodger's, for ankylosis of the hip; the cuneiform method of osteotomy. Rogers', for internal urethrotomy; it is performed with a special dilating urethrotome. Roonhuysen's, for chiloplasty. See Horn's operation. Rose's : I. For double hare-lip; the central tubercle is pared in a Vshaped manner, and the lateral segments by curved incisions from above downward to the muco-cutaneous junction, and then obliquely upward and inward. 2. For single hare-lip; a semilunar incision is made as far as the red margin of the lip, and an oblique upward cut is made on either side to form the prolabium; the flaps are held in position by means of wire and catgut sutures. 3. For the relief of neuralgia of the fifth nerve; removal of the Gasserian ganglion. Rossbach's, for tumor of the larynx; this consists in introducing a thin knife antero-posteriorly into the median line of the larynx from without, and amputating the tumor while the operation is watched in the laryngeal mirror, held in the usual position. Rotter's, for uranoplasty; a modification of Blasius' operation, in which a long cutaneoperiosteal flap is taken from the forehead, passed through the unclosed hare-lip, and grafted into the cleft of the palate. Rouge's, for access to the nasal cavities; the upper lip is freed from the jaw by an incision through the mucous membrane; the cartilaginous septum and lower lateral cartilages are then detached so that the nose and lips can be raised to the necessary extent. Rouse's, for proctotomy; the making of a deep incision in the fossa beside the sphincter without severing the latter; through this incision the diseased portion of the rectum is pressed out and excised. Routh's, for pyosalpinx; aspiration of the contents of the diseased Fallopian tube. Roux's: I. For amputation of the foot; a modification of Syme's operation, in which the flap is made chiefly from the inner side of the foot. 2. For chiloplasty; after removing the diseased parts and the formation of suitable flaps, the prominent portions of the superior maxillary bones are removed to permit of better adjustment of the flaps. 3. For ectopia vesice; closure by means of flaps, one being dissected from the abdomen above, and another from the scrotum below. 4. For excision of the elbow; a modification of Moreau's incision, in which the inner line of the $\mathrm{H}$ is omitted. 5. For excision of the hip; it is done by raising a flap from over the great trochanter. 6. For excision of the tongue; division of the symphysis menti and removal of the entire tongue. 7. For hysterectomy; temporary resection of the sacrum. 8. For ligation of the axillary artery; the incision is made through the delto-pectoral interval. 9. For removal of a nasopharyngeal polypus; it is done through the upper jaw by an osteoplastic operation, the whole jaw and malar bone with the soft parts being turned upward and outward upon the temple. Io. Plastic; a flap is transferred from a distant part by successive migration. Roux-Sèdillot's, for excision of the tongue. See Roux's operation. Rudtorffer's, for webbed fingers; division of the web after a cicatricial hole has been established through it, at the root of the fingers. Ruysch's, for amputation at the wurist-joint; a semilunar incision is made over the dorsum of the hand; the articulation is opened, and the anterior flap is cut from within outward. Rydygier's, for pylorectomy; a vertical parietal incision is made a little to the right of the middle line. Sabatier's: I. For excision of the shoulder; a V. shaped flap is raised from the deltoid region. 2. For iridectomy; excision through a corneal incision as in cataract-extraction. Sxmisch's, for hypopyon ulcer; the cornea is transfixed and the intervening tissue, including the base of the ulcer, is divided by cutting outward. Saint Germain's : I. For phimosis; dilatation of the foreskin. 2. For tracheotomy for stenosis of the larynx; rapid laryngotracheotomy; the single stroke method; the larynx is fixed between the thumb and finger of the left hand, and a straight sharppointed bistoury is thrust through the crico-thyroid membrane. Salmon's, for fistula in ano ; in cases in which there is much induration an incision from oneeighth to one-fourth of an inch deep is made along the track. This is the well-known "backcut;" it is said to greatly promote healing. Sänger's, a method of performing Cesarean section; a modification of the usual operation in which the uterus is delivered through a long abdominal incision before extraction of the fetus. Sänger-Leopold's, for Cesarean section: improved suture of the uterine wound, a deep and a 
superficial row being introduced, two of the superficial alternating with one of the deep. Sänger-Tait's. See Tait's operation. Sanson's, for excision of the knee; similar to Textor's operation. Sauter's, for colpo-hys terectomy; vaginal hysterectomy, the ovaries and tubes being left in situ. Sauter-Recamièr, for hysterectomy; the same as Sauter's operation. Sayre's: I. For ankylosis of the hip; section of the femur above the lesser trochanter, with removal of a semicircular piece of bone and rounding of the upper shaft-end so as to facilitate the formation of a false joint, 2. For excision of the hip-joint; the subperiosteal method; the incision is made down to the bone, the periosteum is peeled off and the bone is divided above the trochanter minor. 3. Intertrochanteric osteotomy for the formation of a false joint in ankylosis; removal of a disc of bone from between the trochanters, having its upper surface convex and its lower surface flat. Scalping Operation. See Gerdy's operation. Scarpa's : I. For iridodialysis; a needle is plunged through the sclerotica, the point passed through the superior internal border of the iris from behind forward, and with a see-saw motion the iris is detached in one-third of its circumference. 2. For ligation of the femoral artery; it is done at the middle of Scarpa's triangle. 3- For stricture of the lacrymal duct; incision of the anterior wall of the sac and the introduction of a leaden style into the duct. Schäfer's, a method of arterial transfusion; the dorsalis pedis artery is exposed in each subject and the distal ends are ligated; glass cannulæ attached to rubber tubing are then tied into the arteries, both ends being directed toward the heart. Schede's: 1. For carcinoma of the rectum; a modification of Kraske's operation in which the free edge of the peritoneum is secured to the serous surface of the gut; a preliminary inguinal colotomy is performed to avoid the fecal fistula and protracted healing. 2. For genu valgum; osteëctomy of the tibia and a linear complex osteotomy of the fibula. Schmalz's, for stricture of the lacrymal duct; the introduction of a thread through the sac, and as far into the duct as possible. Schmidt's, for iridodialysis; the same as Scarpa's operation. Schmitz's, for genu valgum; the same as Ogston's operation, except that it is done through a larger wound. Schönbein's, for staphyloplasty; a flap of mucous membrane is taken from the posterior pharyngeal wall and is stitched to the velum in order to shut off the nose from the mouth. Schramm's, for carcinoma of the cervix uteri; the injection of antiseptic fluids directly into the carcinomatous tissues; he employs a solution of corrosive sublimate. Schroeder's: I. Colporrhaphy; the removal of a single long and broad strip of the vaginal wall and the approximation of the cut edges by sutures. 2. Hysterectomy; celiotomy and removal of the entire body of the uterus, with intra-peritoneal treatment of the pedicle. 3. Trachelorrhaphy; the whole of the erosion is exsected, and stitches introduced. Schroeder and Löhlein's, for pruritus vulve; excision of the diseased skin. Schicking's, for prolapse of the uterus; vaginal hysteropexia by means of a special needle, the thread being passed through the uterine cavity, out at the fundus, and through the anterior vaginal vault; the two ends are tied together and allowed to slough out. Schueller's, for entropion; two elliptic skin-incisions are made, united at their ends, and the distal margins are sutured together, over the included portion of attached skin. Schultze's, for retrodisplacements of the uterus; it consists in carefully tearing the adhesions from the uterine surface while replacing the uterus. Schwalbe's, for reducible hernia; it consists in the subcutaneous in- jection of alcohol (from 20 to 70 percent.), by means of a Pravaz syringe, into the ring as near as possible to the hernial sac; the amount injected is two or three grams; these injections are repeated in from four to fourteen days, according to the sensitiveness of the patient and the amount of reaction; they are then omitted, and recommenced after a pause of from eight to fourteen days; the ring is eventually closed by fibrous thickening and contraction; the duration of treatment varies from one month to two-and-a-half years or more. Schwartze's, for mastoid and middle-ear disease; opening of the mastoid cells by the use of the hammer and chisel. Schweigger's, for advancement of a rectus muscle; the muscle is transfixed by catgut sutures, a portion of the tendon is removed and the ends are approximated by passing the sutures that have been placed in the muscle. Scoutetten's: $\mathbf{I}$. A method of performing amputation; the oval operation in which a single flap is made on one side of the limb to be received into a corresponding space on the opposite side. 2. For amputation at the hip-joint; disarticulation by the modified oval method, with the summit of the incision on the outer side. Sédillot's : I. A method of performing amputation; the combination of the flap and circular methods; the superficial flaps are formed from within outward, and the deep muscles are divided circularly. 2. For amputation at the ankle-joint; this method resembles Syme's operation, except that the flap is made from the inner and plantar surfaces of the foot and ankle. 3. For amputation of the leg; it is done at the "place of election" by a large external flap cut by transfixion. 4. For amputation of the thigh; it is done by a single long anterior flap, the structures at the back of the limb being divided to the bone by one transverse incision. 5 . Chiloplasty for restoration of the lower lip; vertical flaps are taken from either cheek, and brought together in the median line, to form the lip. 6. Chiloplasty for restoration of the upper lip; the formation of quadrangular flaps extending below the level of the mouth and attached above; it is the reverse of Dieffenbach's operation. 7. For double hare-lip; flaps consisting of the outer margins of the clefts are turned down to form the red border of the completed lip, and are united in the middle line, oblique incisions being made upward and outward to free the outer segments; the central tubercle is then pared, and the raw surfaces are brought together. 8. For excision of the hip; it is done by raising a flap from over the great trochanter. 9. For excision of the knee; it is done by two lateral vertical incisions. IO. For excision of the tongue; a modification of Roux's operation, q.v. II. For gastrostomy; a transverse incision is made below the xiphoid cartilage. 12. For ligation of the innominate artery; an incision is made between the heads of the sternomastoid muscle. 13. For the removal of a nasopharyngeal polyp; a linear incision is made through the soft palate, and extended as far up on the hard palate as the palato-maxillary suture; by means of the periosteal elevator, the palatal processes are denuded first on the oval surfaces, then on the nasal; the horizontal plate of the palatal bone is then exsected by scissors or forceps, and the edges of the wound are to be united by sutures. I4. For staphylorrhaphy; liberating incisions are made on each side of the suture. I5. For strabotomy; an incision is made over the body of the muscle; when the latter is completely exposed, the hook is inserted and division made with the scissors. Semiramidian Operation, castration; a name proposed for castration on the belief that it was first performed by Semiramis. Semon's (Felix), for adenoid vegetations of the naso-pharynx; 
scraping with Gottstein's curet while the patient's head is hanging over the edge of the table, to prevent the blood and fragments from entering the air-passages. Senn's $\left(N_{0}\right)$ : I. For amputation at the hip-joint; by means of a skewer as in Myles' operation. 2. For sastroenterostomy; it is done with the use of perforated boneplates, as in Senn's operation for intestinal anastomosis. 3. For intestinal anastomosis; the diseased tissue is excised and the ends of the bowel entirely and permanently closed, the continuity of the canal being restored by means of " intestinal anastomosis by lateral approximation" with the use of bone-plates. 4. For pancreatic cyst; two stages: (I) the bottom of the wound is packed over the cyst-wall with iodoformgauze; (2) the cyst is opened after six or eight days. 5. For suture of the intestine; a modification of Jobert's operation, in which a soft, pliable rubber ring, made of a rubber band transformed into a ring by fastening the ends together with catgut sutures, is placed within the upper segment of the bowel; the sutures in transfixing the bowel pass through the upper portion of the ring. Serres': I, For blepharoplasty; the same as Knapp's operation. 2. For restoration of the angle of the mouth; two triangles are so fashioned that their bases meet at the site of the new angle of the mouth. Seton Operation, any operation in which a seton is used to give rise to inflammatory adhesions. Sexton's, for otorrhea; it consists in the removal of any traces of the membrana flaccida, of the membrana vibrans and the malleus and incus, if present, and of the granulation and carious tissues. Sharp's, for iridotomy; the same as Cheselden's oper. ation, except that the needle is introduced through the cornea. Sharpe's, a method of performing amputations; the same as Soupart's operation. Sigault's, for otherwise impossible labor; pubic symphysiotomy. Signorini's, for the radical cure of hernia; similar to Gerdy's operation, except that a female catheter takes the place of the finger, and three pins are used instead of sutures. Simon's $(J)$ : 1 . For ectopia vesica; communication between the bladder and the bowel is effected by means of threads passed from the ureters into the rectum. 2. For elongation of the vaginal portion of the cervix; it consists in the removal of a wedge-shaped section of the elongated cervix, the apex of which extends high up into the cervical wall, while the base is formed by the lower portion of the lips. 3. For exploration of the rectum and adjacent parts; it consists in introducing the hand or the hand and arm of the operator into the bowel. 4. For laceration of the perineum; the edges are freshened; then sutures are first passed so as to include all the denuded rectal mucous membrane; each suture commences and ends in the rectum, and is tied as soon as passed; the wound is then closed as usual. 5. For uretero-vaginal fistula; an opening is made into the bladder where the ureter empties into the vagina; through this opening a sound is passed from the bladder into the ureter; the uretero-vaginal wall is slit up from the bladder on the sound; the margins of the wound are daily separated by a sound until cicatrization has taken place; the vaginal fistula is closed at a second operation. 6. For vesico-vaginal fistula; adaptation of the pared margins, the mucous membrane of the bladder being included in the abrasion; the stationary catheter is not retained afterward. Simpson's $(\operatorname{Sir} J$.$) : I. For oüpherectomy;$ acupressure is applied to the pedicle inside of the abdominal wall. 2. For stenosis of the cervix uteri; bilateral incisions through the whole length of the cervical canal. Sims' (Marion): I. For anteflexion of the uterus; incision of the posterior lip of the cervix in the median line up to the point of flexion, to permit of communication between the upper portion of the uterine canal and the posterior vaginal fornix, so that the discharges may escape the curve of flexure. 2. For cholecystotomy; the gall-bladder is stitched to the abdominal wound and a permanent fistula is established. 3. For colporrhaphy; denudation of a Vshaped surface on the anterior wall of the vagina and apposition of its arms by sutures. 4. For lithotomy (in the female); the parts are exposed as for the operation for vesico-vaginal fistula; a curved director is passed through the urethra into the bladder, and made to project on the anterior vaginal wall; this is cut down upon, and the stone extracted; the opening is not to be closed. 5. For supra-vaginal elongation of the cervix; the cervix is amputated with scissors, and the mucous membrane is drawn over the stump and united with four stitches. 6. For trachelotomy; division of the cervix on either side up to the vaginal junction, and division of the cervical canal as high as the internal os; if the cervix is flexed, the lip on the convex side is divided, and the canal is enlarged as before. 7. For vesico-vaginal fistula; coaptation of the pared margins, the abrasion not including the vesical surface; retention of a catheter afterward. Sinclair's, for diseased Fallopian tubes; free incision per vaginam, and subsequent washing out of the empty tubes. Skene's $(A . J . C$.$) , for anteflexion of the uterus with$ imperfect invagination of the cervix into the vagina; transverse division of the anterior vaginal wall after the anterior column of the vagina has been put on the stretch by drawing the cervix backward toward the hollow of the sacrum; the upper and lower edges of the incision are drawn apart by stretching the incised portion, and sutures are introduced from the sides, transforming the transverse incision into a longitudinal incision. Skewer Methods, for amputation through the hip-joint. See Myles', Spence's, and Wyeth's operations. Skey's : I. For tarso-metatarsal amputation; disarticulation through the outer three and inner joints, the base of the second metatarsal bone being sawn through. 2. For rhinoplasty; two lateral flaps made from the side of the nose upon the cheek are brought into the mesial line. Skutsch's, for salpingostomy; after ascertaining by aspiration the nature of the contents of a tube which has been converted into a serous cyst, an oval piece about half an inch wide is excised from the abdominal end, and the nucous and serous surfaces are united with silk sutures around the opening; the new ampulla should be sutured to the ovary. Smith's (Greig): I. For ectopia vesica; a modification of Wood's operation in which the flaps are made larger. 2. For extrene intestinal obstruction; an artificial anus is made, and the intestine is patiently milked to squeeze out the feces. 3. For removal of the uterine appendages; it is done by abdominal incision. Smith's $(G . K$ ), for internal urethrotomy; it is done with a special dilating urethrotome. Smith's $(H$.$) , for hemorrhoids; crushing by means$ of a clamp, and applying the Paquelin cautery to the stump after cutting away the projecting part. Smith's $\left(N_{.}\right):$I. For amputation at the knee-joint; it is done by a large anterior and a smaller posterior skin-flap. 2 . A method of performing ovariotomy : the arteries of the pedicle are tied separately and the ligatures (strips cut from a kid-glove) are cut short, the pedicle being dropped inside. Smith's $\left(S_{0}\right)$ : I. For amputation through the knee-joint; it is done by "lateral hooded skin-flaps," the incision commencing in front about one inch below the tubercle of the tibia, and being carried up to the center of the articulation behind, the patella being preserved. 2. Osteotomy; two partial 
sections of the femur are made just below the trochanter minor, one anteriorly, the other posteriorly; the bone is then fractured. Smith's (T.): I. For double harelip; the outer segments are pared and the parings removed; the prolabial flaps are then turned down from the sides of the central tubercle. 2. For uranoplasty; the utilization of the mucous membrane covering the vomer as a means of bridging the cleft. Smyth's, for ligation of the vertebral artery; the incision is commenced at the clavicle, and is carried upward along the posterior border of the sterno-mastoid muscle for three inches; the process of the sixth cervical vertebra is sought for as a guide. Snellen's : I. For conjunctival ectropion; traction is exerted on the contracted conjunctiva so that it becomes permanently inverted, the sutures being passed through the highest part of the everted mucous membrane. 2. For ectropion; two needles on the same thread are passed parallel to each other some distance apart, from the summit of the everted conjunctiva beneath the skin and out about the margin of the orbit; the two ends are then tied over a roll of gauze. 3. For entropion; a modification of Streatfeld's operation, in which, after grooving the tarsus throughout its whole extent, sutures are used to effect the desired result. 4. For strabotomy; a horizontal incision is made in the conjunctiva over the middle of the tendon; the tendon is then seized with forceps, and a snip is made into it with the scissors; the upper portion of the tendon is divided first, then the lower portion. 5. For trichiasis; a loop of thread is passed, by means of a needle, in the free margin of the lid as near as possible to the offending hair; the hair is caught in the loop and drawn through the needle-tract. Socin's : I. For the radical cure of inguinal hernia; ligature and excision of the sac. 2. For the removal of tumors of the thyroid gland; incision through the normal gland-structure and enucleation of the neoplasm. Sonnenburg's: I. For ectopia vesica; the bladder is extirpated and the ureters united to the dorsal groove of the penis. 2. For resection of the bladder: a supra-pubic operation with removal of a tumor involving the anterior wall of the bladder; the bladderwound is closed by stitching the peritoneum over it. Sotteau's, for the radical cure of inguinal hernia: a double invagination of the scrotum is made to fill the canal. Soupart's, for amputation at the elboze-joint; an elliptic amputation, with the highest point of the ellipse in front, the flap being taken from behind. Spanton's : 1. For fixity of the lower jaw; subcutaneous division of the adhesions between the condyle and the glenoid cavity. 2. For the radical cure of inguinal hernia; the subcutaneous method; after reduction of the rupture a small incision is made over the fundus of the sac and the pillars of the ring are closed with the screw-instrument. Spence's : I. For amputation at the shoulder-joint; this resembles Larrey's operation, except that the longitudinal incision is made on the inner aspect of the arm. 2. For amputation of the thigh; it is done by long anterior and short posterior flaps, the latter being cut from without inward, and commenced two inches below the base of the anterior flap. Sperino's, for cataract; repeated paracentesis of the aqueous humor. Spiegelberg's, for prolapse of the uterus, with marked cystocele; the middle of the lower portion of the anterior vaginal wall is united to the middle of the upper portion of the posterior wall, after each has been denuded, in addition to the repair of the perineum. Squire's, for port-wine marks; multiple parallel incisions. Stacke's, for middle-ear disease; incision through the skin, circumscribing the auricle posteriorly; the membranous meatus is shelled out of the osseous canal; the median upper part of the bony meatus is cut away and the exposed malleus and incus removed; the superior wall is then chiseled to near the drum-insertion; then the posterior wall of the meatus is cut away; thus the attic, tympanum, antrum, and meatus are converted into one large cavity. Star-operation, for transversely lacerated perineum ; after denudation of a transverse strip, a median triangular or bilateral figure is denuded across the transverse strip. Stearns', for internal urethrolomy; it is done with a special dilating urethrotome. Steele's, for deviated nasal septum; a modification of Blandin's operation, q. v. Stellwag's : I. Canthoplasty; an oblique blepharotomy or sphincterotomy. 2. For ceitaract-extraction; a corneal flap-extraction. 3. For trichiasis; re-attaching the raw surface of the tarsus to the ablated zone of hair-follicles, so that the border that bears the cilia looks upward and that which has the raw surface looks downward. Stevens', for ligation of the internal iliac artery; an incision about five inches long is made parallel with the deep epigastric artery and nearly $1 / 2$ inch on the outer side of it. Stevens' (G.T.), for muscular asthenopia; partial or graduated tenotomy of one of the ocular muscles. Stilling's: I. Ovariotomy; the cautery is applied to the pedicle, which should be stitched in the parietal wound. 2. For stricture of the nasal duct; internal incision. Stillman's, for hemorrhoids; the patient is placed in the knee-chest position and each mass is reduced by manipulation as for hernia, after which a pile-bougie is introduced. Stimson's, for fracture of the patella; four small punctures are made deeply through the skin at the margin of the patella, at equal distances from it, : $\mathrm{O}$ : A half-curved Hagedorn needle armed with a heavy silk suture is carried in one lower incision, through the ligamentum patellæ, and out the opposite incision, reëntered at the point of exit and brought out at the upper incision on the same side, inserted again at the same point, made to transfix the quadriceps tendon and emerge at the other upper incision, introduced again at the same point and brought out at the place of starting. The fragments are held together by strong tenacula and the sutures tied tightly and the ends cut short; the incisions are then closed. Stokes' $\left(\operatorname{Sir} W_{0}\right)$ : I. For amputation above the knee; the same as Gritti's operation, except that section of the femur is made above the condyles. 2. For excision of the tongue; a modification of Jaeger's operation. 3. For flat-foot; by removing a wedge-shaped piece of bone from the head and neck of the astragalus. 4. For single hare-lip; the prolabium is formed by tissue from both sides of the cleft by means of incisions skirting the red margin; the upper part of the cleft is incompletely pared and the partially dissected flaps turned back, while the edges of the skin are brought together and the prolabial flaps drawn downward and outward. Stoltz's, for cystocele; it is also called the purse-string and tobacco-pouch operation; denuding a circular patch on the anterior vaginal wall, and running a suture around the margin and tying. Streatfeild's: I. For atresia of the punctum lacrymale; slitting of the canaliculus. 2. For cataractextraction; it is made with a Sichel's knife without counter-puncture, the wound being enlarged by a sawing motion, 3. For entropion; removal of a wedge-shaped strip from the tarsal cartilage. 4. For synechia; the same as Passavant's operation, except that a cutting-hook is used in place of forceps. Streatfeild-Snellen's, for entropion; like Streatfeild's operation, except that the groove in the tarsus is made higher up. Strohmeyer's, for strabotomy; an incis- 
ion is made with a cataract-knife in the line of the tendon; the probe is then passed beneath the muscle and the latter is divided with scissors or knife. Sutton's (R.S.), for trachelorrhaphy; the denudation removes a large amount of diseased tissue, and the patency of the canal is maintained. Syme's (J.): I. A method of performing amputations; the oval tegumentary flap operation; a modification of the mixed amputation. 2. For amputation at the ankle-joint; a single plantar flap is made, from which the os calcis is dissected out, after disarticulation has been accomplished; the malleoli and lower end of the tibia are then removed. 3. For amputation of the thigh; a modification of the circular amputation, in which retraction of the skin is aided by two lateral cuts after the usual circular incision has been made. 4. For excision of the elbow; the same as Moreau's operation. 5. For excision of the shoulder; a large posterior flap is taken from the deltoid region. 6. For excision of the tongue; a modification of Roux's operation, q. v. 7. For external urethrotomy; the stricture is divided through the perineum upon a grooved director. 8. For restoration of the lower lip; two large lateral flaps are dissected from the chin and sides of the face and brought together in the middle line. 9. For rhinoplasty; two flaps from the cheeks, with a conjoint pedicle at the root of the nose, are united in the middle line. Szokalski's, for pterygium; it is removed by means of thread, armed with two needles, so that the growth is strangulated at each end and en masse between. Szymanowski's: 1. For the closure of an artificial anus; it is done by means of a flap of integument without any sacrifice of the intestinal wall. 2. For blepharoplasty; a modification of the cantho-temporal and temporo-genal incisions, the former running obliquely upward and outward and the latter obliquely downward and inward. 3. For ectropion of the lower lid; excision of a triangular piece of skin at the external canthus, removal of a part of the ciliary margin, and suture of the lid in the proper position. 4. For hypospadias; a straight incision is made near one edge of the fistula, and the skin is dissected loose ; on the opposite side of the fistula, a curved flap is raised, and after the epidermis is scraped off, the flap is turned under the first one and secured by sutures. 5. For restoration of the upper lip; lateral flaps of the full breadth of the lip are cut from the cheek on each side, and their inner extremities are brought together in the median line. 6. For urethral fistula; a flap is dissected up on either side of the fistula, and one is slid under the other, the under one having the epidermis removed, except at the point that will lie over the fistula. Tagliacotian, or Italian Method, for restoration of the nose. See Tagliacozzi's operation. Tagliacozzi's, for rhinoplasty; the forming of a new nose from a flap from the arm secured in place, and left attached to the arm until union has occurred. 'Tait's (Lawson) : I. For hepatotomy for hydatid cyst; it is performed in one stage and involves.opening of the abdominal cavity, incision and evacuation of the cyst, and the suturing together of the margins of the hepatic and parietal wounds. 2. For lacerated perineum; the flap-splitting operation; the recto-vaginal septum is split transversely and from the extremities of this incision two lateral incisions are made, running up toward the lower terminus of each nympha and down to a little above the anal orifice; these two flaps are dissected up; the upper one is drawn toward the urethra, the lower one down toward the anus; sutures are passed laterally and the edges are brought together. 3. For oophorectomy; the same as Battey's operation, with inclusion of the Fallopian tube. 4. For öphorectomy; the pedicle is secured with a silk ligature and the "Staffordshire knot." See Knot. Tate's, for uterine inversion; similar to Watts' operation except that one finger is also passed into the bladder to act in conjunction with the fingers in the rectum. Tausini's, for hepatotomy; the cyst is dissected out, and the wound in the liver is closed by a double series of catgut and silk ligatures. Taylor's : I. For cataract-extraction; the incision is made with a broad needle, the capsule is lacerated and an artificial pupil is made, through which the lens is extracted. 2. For genu valgum due to femoral curving; section of the shaft of the femur on the outer side, a short distance above the joint. Teale's: I. For amputation of the arm; the long flap is placed upon the antero-external aspect of the arm; the brachial artery and the median and ulnar nerves are divided with the posterior flap. 2. For amputation of the leg; a rectangular-flap operation, in which a long anterior and a short posterior flap are made, each consisting of both integument and muscle; the length of the anterior flap is equal to half the circumference of the limb, and the posterior flap is one-quarter of the length. 3. For amputation of the thigh; the same procedure as in Teale's amputation of the leg. 4. For cataract-extraction; removal of a soft cataract by suction. 5. For lacrymal stricture; slitting of the lower canaliculus and introduction of different sized olive-pointed probes. 6. For symblepharon; two flaps of the bulbar conjunctiva are taken from either side, one of which is used for covering the inner surface of the lid, while the other serves as a covering for the eye. Teevan's, for internal urethrotomy; it is done with a modification of Maisonneuve's urethrotome. Terrillon's, for hepatotomy for hydatid cyst; the portion of the liver containing the cysts is removed by means of an elastic ligature applied after the performance of celiotomy. Textor's, for excision of the knee; it is done by a curved transverse anterior incision, with its convexity downward. Theobald's, for subconjunctival strabotomy; it is performed after Critchett's method, a "crochet-hook" being used instead of the ordinary blunt one, to prevent the tendon slipping off, Thiersch's: I. For ectopia vesica; closure by means of two large lateral flaps, one to cover the lower half of the defect, and the other the upper half. 2. For rhinoplasty; two lateral flaps from the cheeks are turned over to meet in the middle line, their raw surface being turned out; a flap from the forehead is then brought down and covers all. 3 . For skin-grafting; the graft is made by a to-and-fro motion with a razor, shaving off as long and as broad a section of the upper layers of the skin as is desired. 4. For epispadias; the formation of a meatus and urethra by dissection of various flaps, the entire treatment covering a period of several months. 5 . For uranoplasty; the alveolar process is chiseled away and a flap consisting of the whole thickness of the cheek is turned in to close the hole in the hard palate. Thomas's $(T, G$. ) : I. For hysterectomy; celiotomy with the use of the clamp and the charring of the end of the pedicle with the galvanocautery. 2. For laparo-elytrotomy, removal of the fetus through incisions in the abdominal wall and in the vagina, without opening the peritoneum or wounding the uterus. Thompson's (Sir H.): 1. For cystitis dud to hypertrophied prostate; the establishment of a permanent vesical fistula over the pubes. 2. For internal urethrotomy; it is done with Thompson's modification of Civiale's urethrotome. 3. For vesical tumor; the removal by a median perineal cystotomy, with the use of Thompson's special forceps. Thread-operation, an operation proposed by von Graefe, for regulating the position of the eyeball after tenotomy; the thread is 
passed through the stump of the tendon and is fastened to the skin near the eye. Tiffany's, for zmion of tendon and fap; in amputation of fingers at the joint between the first and second phalanges, the stitch that unites the skin is passed through the tendon and its sheath. Tillaux's, for cholecystenterostomy; it is performed in three stages: (I) the gall-bladder is fixed by sutures to a loop of the jejunum and a biliary fistula is established by uniting the margins of an opening made in the gallbladder to the parietal wound; (2) after about nine days an artificial communication is established between the bowel and the gall-bladder through the fistula; (3) eighteen days later the biliary fistula is closed by a plastic operation. Travers', for cataract-extraction; the capsule is divided and the lens is displaced into the anterior chamber; it is then removed through a small corneal incision. Travignot's, for amputation of the leg; it is done by a large posterior flap and a short anterior one. Trélat's: I. For Dupuy. tren's contraction; division of the attachments between the skin and fibrous bands, followed by division of the bands themselves. 2. For internal urethrotomy; a special urethrotome is used and the stricture is cut both ways. Trendelenburg's: I. For ectopia vesice; narrowing of the defective area by approximating the two innominate bones, after division of the sacro-iliac synchondrosis on either side. 2. For flatfoot; supra-malleolar osteotomy. 3. For staphyloplasty; the same as Schönbein's operation. 'Treves' $(F):$. I. for spinal abscess; a vertical incision, two and a half inches in length, is made in the loin, midway between the last rib and the crest of the ilium, the incision to be parallel with the vertebral side of the outer border of the erector spinæ muscle. 2. For ununited fracture of short bones; the fragments are held in position with a pair of modified Malgaigne's hooks. 3. For varicocele; exposure of the veins, the application of two ligatures and excision of the included portion. Treves' $(W . K$.$) , for excision of the knee;$ it is done by two vertical lateral incisions. Triangular-flap operation, for lacerated perineum. See Duncan's operation. Tripier's : 1. For amputation through the foot; a modification of Chopart'soperation in which the os calcis is sawn through horizontally at the level of the sustentaculum tali and its lower portion is removed. 2. For blepharoplasty; a flap is taken from the upper lid to close a deficiency in the lower lid. Valette's : 1. For the radicul cure of hernia; an attempt is made to close the canal by causing an eschar by means of Vienna paste. 2. For the removal of a naso-pharyngeal tumor; by an operation similar to those of Berard and Hugier, but of less extent; the anterior and inner wall of the maxillary sinus is removed, and the sinus is thus opened into the nasal cavity. Van Best's, for the radical cure of hernia; subcutaneous suturing of the inguinal rings. Van Buren's, for prolapsus ani; a linear cauterization of the mucosa with the Paquelin cautery. Van Millingen's: I. For entropion; the mucosa is transplanted into the wound made by an incision at the lid-margin. 2. For trichiasis; the covering of the wound made in Arlt's operation by mucosa from the patient's lips or from the conjunctiva of a rabbit, instead of with skin. Veit's : I. A method of performing embryotomy; evisceration followed by simultaneous traction on an arm and the breech, the fetus being delivered doubled up. 2. For otherwise impossible labor; the same as Porro-Veit's operation. Veitch's, for amputation at the hip-joint; the same as Esmarch's operation. Velpeau's: I. For excision of the upper jaw; an incision is commenced at the angle of the mouth and is carried in a curved direction, through the cheek to end over the center of the malar bone. 2. For excision of the wrist; by raising a dorsal flap. 3. For iridotomy; a long double-edged knife transfixes the cornea, passes through the iris to the posterior chamber and back to the anterior chamber, through the cornea again, and a flap is cut; this leaves a triangular opening in the iris. 4. For preternatural anus; removal of the adventitious tissue around the preternatural anus, and suturing of the wound. Vermale's: 1. A method of performing amputation; the ordinary double-flap operation, the flaps being cut by transfixion whenever possible. 2. For amputation of the arm; by lateral flaps marked out by a skin-incision, the remaining soft parts being divided by transfixion; the inner flap is cut the longer. 3. For amputation of the thigh; by lateral flaps of the same size and including all the soft parts down to the bone; both flaps are cut by transfixion. Verneuil's: 1. For amputation through the foot; subastragaloid disarticulation, the incision commencing over the outer tuberosity of the os calcis and being carried forward to and over the dorsum of the foot, just behind the base of the metatarsal bones and finally sweeping across the sole to the point of commencement. 2. For iliac colotomy; a nearly vertical incision is made, and a knuckle of gut is transfixed and kept in place by two needles which lie on the parietes; the exposed bowel is then stitched to the margins of the parietal wound and the protruding knuckle is excised. 3. For proctotomy; the rectum is first divided into lateral halves with the écraseur, and the subsequent dissection is done with the galvanocautery knife. 4. For rhinoplasty; two flaps from the cheeks and forehead are superimposed to secure elevation of the sunken nose. 5. For stricture of the rectum; the same as Lenti's operation, except that a posterior incision only is made. Vidal's (de Cassis) : I. For gastrotomy, the parietal incision is made in the middle line. 2. For varicocele; subcutaneous constriction of the veins by means of wire ligatures. Der Villard's (Carron) : I. For ectropion; shortening of the skin of the lid in a transverse direction. 2. For iridotomy; the same as Maunoir's operation. Voillemiér's, for internal urethrotomy; it is done with a modification of Maisonnewve's urethrotome. Volkmann's: I. For amputation at the hip-joint; the same as Esmarch's operation. 2. For excision of the rectum; (a) For a circumscribed growth; dilate the anus; pull down the diseased portion; remove by incision; suture. (b) For disease involving the circumference of the bowel, but not the anus; divide the anus forward in the perineum and backward to the coccyx; remove the growth by a knife or scissors, and the fingers, and stitch the healthy mucosa together; deep drainage; suture. (c) For disease involving the circumference of the bowel, and part or all of the anus; make the anterior and posterior incisions as directed; then carry a circular incision around the sphincter, and dissect out the growth; the healthy mucosa is stitched to the skinborder; drainage; suture. 3. Hepatotomy for hydatid cyst; it is performed in two stages ; in the first, adhesion is secured between the parietal peritoneum and the hepatic peritoneum over the seat of puncture; the second stage consists in incising the adherent cyst after some days. 4. For hydrocele; by a free incision in the tunica vaginalis and stitching the serous membrane to the skin. 5. For lupus; erasion with a curet. Von Graefe's (Alfred). See Graefe's operations. Von Hippel's. See v. Hippel's operations. Von Walther's, for tarsorrhaphy; paring of the borders of the upper and lower lids adjoining the external angle and securing the denuded surfaces together. Waldau's, for cataract-extraction; this differs from the linear 
method of $v$. Graefe only in the smaller incision (less than $1 / 4$ of the circumference of the cornea) and in the use of a special scoop to remove the lens. Walsham and Willett's, for talipes calcaneus; oblique division of the tendo Achillis from above downward and from before backward, and slipping of the ends past each other and suturing. Walton's, for lacrymal stricture; slitting of the upper canaliculus into the sac, and the introduction of pure silver pins. Wardrop's : $\mathbf{r}$. For aneurysm; ligation of a main branch of the artery distal to the aneurysm, leaving a circulation, however, through another branch. 2. For entropion; ligation of a small portion of the skin by a suture passed beneath. Warlomont's : I. For cataract-extraction; a modification of the Graefe incision. 2. For trichiasis; the portion of lid in which the cilia are implanted is detached, shifted upward, and fixed upon the tarsus. Warren's $\left(M_{0}\right)$ : I. For excision of the upper jaw; the same as Velpeau's operation. 2. For the radical cure of hernia ; the tissues of the inguinal rings are injected, by means of a syringe, with a mixture composed of the fluid extract of white oak, reduced to a syrupy consistence, and sulphuric ether and morphin. 3. Uranoplasty; the mucous membrane is dissected up and the soft palate is freed by dividing the posterior pillars, and then sutured in the middle line. Waterman's, for removal of a naso-pharyngeal tumor; similar to Cheever's operation, except that the hard palate is not fractured, but acts as a hinge to the disarticulated superior maxilla, as in Cheever's double operation. Watson's (E.), for amputation through the foot: a modification of Pirogoff's operation, in which the posterior part of the os calcis is sawn off and the cut is extended up behind the ankle-joint; the tibia and fibula are then sawn through from before backward and downward. Watson's $(P . H$.$) : I.$ For tarsectomy; the joints between the astragalus and scaphoid and the os calcis and cuboid are opened and the metatarsal bones are sawn through from below upward. 2. For goiter; extirpation of the goiter. 3. For rhinoplasty; a modification of Fergusson's operation, q. v. Watson's (Spencer): I. For en/ropion; transplanting a bridge of skin from the eyelid through to the conjunctival surface. 2. For trichiasis; the wound is covered by a pedunculated flap. Watts', for uterine inversion; the same as Courty's method, except that the fingers passed into the rectum are used to dilate the inverted cervix. Weber's: I. For cataract-extraction: the incision is made with a curved bistoury. 2. For lacrymal stricture; a modification of Bozuman's operation; slitting of the upper canaliculus, subcutaneous division of the canthal ligament, and dilatation by a conic silver sound and elastic catgut bougies. 3. Plastic; the large elliptic gap is closed by displacing a curved flap; then a second curved flap is displaced into the gap thus made. 4. Rhinoplasty; an oval flap is taken from the center of the upper lip, consisting of only part of its thickness, and turned up and attached to the freshened edges of the defective ala. De Wecker's: I. Blepharoplasty; a modification of Reverdin's operation; it consists in transplanting small pieces of epidermis covered with gold-beater's skin. 2. For cataract-extraction: a modification of the Graefe incision in cataract-extraction, and extraction without iridectomy. 3. For corneal or lenticular opacities; division of the sphincter of the iris by introducing forceps-scissors through the corneal incision. 4. For evisceration; a suture is run through the previously loosened conjunctival and subconjunctival tissue surrounding the cornea, and is carried entirely around by repeated punctures; the protrusion is then cut off and the two ends of continuous suture are drawn together, thus preventing the escape of the vitreous. 5. For glaucoma; trephining of the cornea. 6. For iridectomy : an incision is made with von Graefe's knife through the cornea and iris; the forceps-scissors is then in. troduced, and a $\mathbf{V}$-shaped portion of iris is removed. 7 . For leukomatu of the cornu; tattooing the leukomata. 8. For ptosis; removal of an oval piece of skin from the lid, followed by suturing of the wound. 9. For retinal detachment; a very fine gold wire is introduced through the sclera and choroid and allowed to remain, as a drain. IO. For sclerotony; the cataract-knife is entered into the sclera, without completing the incision; prolapse of the iris is thus prevented. II. For staphyloma; excision and uniting of the conjunctiva over the wound. 12. For strabismus; advancement of Tenon's capsule, and thus of the insertion of the muscle. Wehr's, for resection of the intestine; the end of the narrower part of the bowel is divided obliquely, so that the oblong opening which results shall correspond to the lumen of the other end. Weir's $(R$. $F$.) : I. For lumbar nephrectomy; a vertical lumbar incision three inches from the spine, just below the twelfth rib, is joined at the top by a transverse incision running along the edge of the ribs. 2. Rhinoplasty; a transverse cut is made through the sunken nose, and the tip is drawn down to the desired position, the resulting wedge-shaped gap being filled by transplanting flaps from the cheeks. 3. For varicocele; subcutaneous ligation with carbolized or juniperized catgut. Wells' (Sir S.): 1. Cholecystotomy; a modification of Sims' operation, in which it is proposed to close the incision in the gall-bladder by a continuous suture and return it to the abdominal cavity. 2. Splenectomy; the incision is made through the linea semilunaris. Wells': I. For blepharoplasty of the upper lid; dissection of the cicatrix, replacement of the lid to its normal position, and transplantation of a flap from the temple. 2 . For entropion; splitting of the lid into anterior and posterior leaves, excision of a fold of skin, and removal of a wedge-shaped piece of the tarsus. 3. For strabot. omy ; division of the tendon, subconjunctivally, close to its insertion. Wenzel's : I. For calaract-extraction; in cases of total posterior synechia, a curved incision is directed downward, passing through the iris, and opening the lens. 2. Iridectomy; the same as Velpeau's operation, except that the flap is removed. West's, for excision of the remist; two dorsal incisions are made and the tendons of the thumb and fingers are not divided, but are drawn aside. Westmoreland's, for internal urethrotomy; it is done with a modification of Maisonneuve's urethrotome. Wharton's, for amputation of the foot; a modification of Teale's operation in which only one flap is made and the bone is sawn off at the level to which a short flap, made according to Teale's method, would reach. Wheelhouse's, for extemal urethrotomy; division of the stricture on a grooved probe passed through the stricture from an opening made into the urethra in front of it. White's: I. For excision of the hipjoint ; a semicircular incision is made above and behind the greater trochanter, the joint is exposed and disarticulated, and the section made. 2. For uterine in version; it is replaced by pressure by means of a cup having at its base a short staff terminating in a steel spiral spring which rests against the operator, counterpressure being made above. White's (J. William), for hypertrophy of the prostate; removal of the testicles. White's $(0$.$) , for the radical cure of hernia; invagin-$ ating the sac into the ring and plugging the latter with an instrument devised for the purpose. Whitehead's: I. For excision of hemorrhoids; removal of a circular 
strip of mucous membrane around the anus, including the tumors. 2. For excision of the tongue; removal through the mouth, using only scissors. 3. Tracheoto$m y$; the incision is made in the usual situation, but of greater length than is common. Wickerkiewicz's, for scieritis; the remuval by means of a small sharp spoon of the diseased tissue in stubborn cases. Wickham's, for varicocele; it is done by Heurteloup's modification of Henry's clamp, with removal of a large amount of scrotum. Wilde's : 1. For mastoid or cerebral abscess; the bone is exposed from the base to the apex of the mastoid process, $1 / 2$ inch behind the auricle, and if necessary, the bone is opened with a drill, gouge, or trephine. 2. For staphyloma; very similar to Critchett's operation, $q . \vartheta$. 3. For trichiasis; an incision is made to the roots of the inverted cilia followed by cauterization with silver nitrate and removal of the cilia. Willett's, for talipes calcaneus; the tendo Achillis is divided obliquely and the cut ends are slid past each other until the proper shortening is obtained, when they are stitched in place. Williams', for lacry. mal stricture; a modification of Walton's operation; dilatation by large silver probes. Winckel's, for vaginal hysterectomy; after securing the cervical portion of the uterus an incision is made in the anterior vaginal vault, and is carried spirally around the cervix, ligating the vessels when necessary, and exerting steady traction on the uterus; the peritoneal cavity is thus easily penetrated, and posteriorly the entire supracervical portions of the broad ligament can be plainly seen and ligated in position. Winiwarter's, cholecystenterostomy; it is performed in two stages; in the first the gall-bladder is united to the upper portion of the jejunum and the parts are fixed to the parietal peritoneum; in the second, after about five days, the bowel is incised and a communication is established between the latter and the gall-bladder. Witzel's, for gastrotomy; an incision is made, four inches long, beginning at the middle line and running to the left a finger's breadth below the border of the ribs; the fibers of the rectus muscle are separated by the fingers and not divided; the stomach is brought outside of the wound and opened toward the cardiac extremity, and a rubber tube introduced; the stomach is then returned and sutured to the margin of the abdominal opening. Wladimiroff's, for tarsectomy; the heel portion of the foot, consisting of the astragalus, the calcis, and the soft parts covering them, is removed; the articular surfaces of the tibia, fibula, cuboid, and scaphoid are sawn off and the foot is brought into a straight line with the leg. WladimiroffMikulicz's, for tarsectomy; the same as Mikulicz's operation. Woelfler's, for gastro-enterostomy; the first part of the jejunum is united by sutures to the middle of the anterior surface of the stomach and a communication is established between the two. Wolf's, for mastoid and middle-ear disease; it consists in penetrating the bony partition between the antrum and the external auditory canal by successive layers, after removal of the soft parts. This operation is indicated for subperiosteal removal of exostoses and hyperostoses of the auditory canal, in caries in the upper and back part of the auditory canal, and when the transverse sinus is so far forward as to interfere with other operations. Wolfe's : 1. For ectropion; transplantation of a flap from a distance, without a pedicle. 2. For retinal detachment; a vertical incision is made in the conjunctiva and subconjunctival tissue, and an oblique incision into the sclera, followed by gentle pressure and suture. 3 . For symblepharon; transplantation of the conjunctiva of a rabbit after division of the adhesions of the lid. 4 .
For tympanic granulations ; scraping away of the proliferating granulations by small, sharp spoons of various shapes. Wölfler's, for pyloric stenosis; gastroenterostomy in malignant disease of the pylorus. Wood's (J.): I. For rhinoplasty; a new nose is formed from a broad flap taken from the upper lip. 2 . For ectopia vesica; closure by means of three flaps, a reversed upper or umbilical, and two lateral transplanted flaps which are made to cover over the upper one. 3. For hypospadias; the anterior half of the urethra is formed from the prepuce (if redundant), and the remainder by means of a flap cut from the front of the scrotum. 4. For the radical cure of hernia; (I) the hernial canal is closed by subcutaneous sutures through the tendinous structures forming its boundaries; (2) for small herniæ and herniæ in children, a pair of rectangular pins are used instead of sutures. 5. For varicocele; a modification of Ricora's operation; it consists in the application of a single subcutaneous ligature of annealed iron wire, the ends of which are fastened to a light steel spring, the veins being divided by the constant tension. Woolhouse's, for the formation of an artificial pupil; division of the fibrous deposit binding the iris by means of a needle introduced through the sclerotica. Wright's (G.A.): I. Arthrectomy; the interior of the knee-joint is exposed by an anterior transverse curved incision, and all of the diseased tissues, including the synovial membrane, ligament, cartilage, and bone, are removed by erasion. 2. For cataract-extraction; an incision is made with Beer's knife entirely within the cornea; puncture and counter-puncture are made at the sclerocorneal junction. Wuitzer's, for the radical cure of inguinal hernia; plugging of the hernial canal by an invagination of the scrotum, and its retention by a special instrument, thus exciting adhesive inflammation in the neck of the sac. Wyeth's (J.A.): I. For amputation at the hip-joint; the "bloodless" method; two steel mattress-needles are inserted in the tissues and rubber tubing is passed several times around the limb above the needles. 2. For internal urethrotomy; it is done with a modification of Otis's urethrotome. Wylie's, for retroflexion of the uterus; shortening of the round ligaments after abdominal incision; the ligaments are folded upon themselves and sutured. Zeller's, for webbed fingers; a triangular flap is dissected up on the dorsal aspect of the root of the web, and the latter is divided, after which the apex of the flap is drawn down between the fingers and attached to a prepared raw surface on the palm.

Operative $\left(o p^{\prime}-e r-a-t i v\right)$ [operari, to labor]. Effective; pertaining to an operation. $\mathrm{O}$. Dentistry, the department of dentistry that pertains to the surgical treatment of diseases of the teeth and surrounding parts.

Operator (op'-er-a-tor) [operari, to labor]. A surgeon.

Operatory (op'-er-at-or-e) [operator, a worker]. A laboratory.

Opercle $\left(o-p e r^{\prime}-k l\right)$ [operculum, a lid]. See Operculum.

Opercular (o-per'-ku-lar) [operculum, a lid]. Pertaining to an operculum. Designed for closing a cavity. Having an operculum.

Operculate (o-per'-ku-lāt) [operculum, a lid]. Possessing an operculum.

Operculiferous (o-per-ku-lif'-er-us) [operculum, a lid; ferre, to bear]. In biology, having an operculum.

Operculiform (o-per'-ku-lif-orm) [operculum, a lid ; forma, form]. In biology, resembling an operculum. Operculigenous (o-per-ku-lij'-en-us) [operculum, a lid; gignere, to produce]. In biology, having an operculum.

Operculigerous (o-per-ku-lij'-er-us) [operculum, a lid; gereve, to carry]. Having an operculum. 
Operculum (o-per'-ku-lum) [L.: pl., Opercula]. A lid or cover. In biology, a lid, cap, flap, or cover; applied to various occlusive apparatuses, structures, or organs, in plants and animals, as the cover of the capsule in mosses, the plate for closing the aperture of gasteropod shells, the feathered flaps of the ear of a bird, etc. In ichthyology, an osseous formation which, in part, closes the great opening of the gills. In anatomy, the convolutions covering the insula, consisting of the operculum proper, preoperculum, suboperculum, and postoperculum. O., Burdach's, the O. insula. 0 . cutis, the epidermis. O. ilei, the valve of Bauhin. O. insulæ, the gyri of the brain over the insula. They are the subfrontal, the precentral and postcentral, and the inferior central gyri. O. laryngis, the epiglottis. $O$. oculi, the eyelids. $O$. sellæ, the dura over the pituitary body.

Operimentum (o-per-im-en'-tum). Synonym of the Membrana tympani, $q$. $v$.

Opertorium (o-per-to're-um) [L., a cover]. Same as operculum.

Ophelic Acid (o-fel'-ik), $\mathrm{C}_{13} \mathrm{H}_{20} \mathrm{O}_{10}$. An amorphous sticky substance found in Chiretta. It is soluble in water, in ether, and in alcohol.

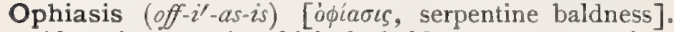
Alopecia areata in which the baldness progresses in a serpentine form. [Old.]

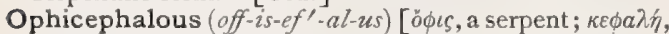
the head]. Having a head like that of a serpent.

Ophidomonas sanguinea (off-id-o'-mo-nas san-grin' $e-a h)$ [L.]. An old name for Beggiatoa roseo-persicina. See Bacteria, Synonymatic Table of.

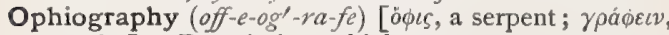
to write]. Descriptive ophiology.

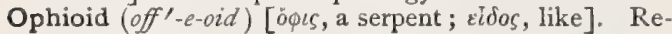
sembling a serpent.

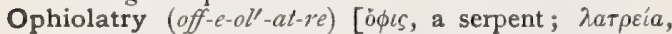
worship]. Serpent-worship.

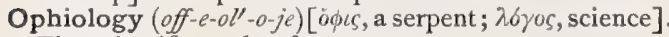
The scientific study of serpents.

Ophiophagous (off-e-off'-ag-us) [ó $\phi \iota s$, a serpent ; $\phi a \gamma \varepsilon i \nu$, to eat]. Feeding upon serpents.

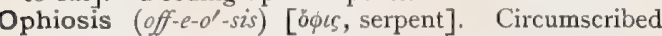
baldness with scaliness.

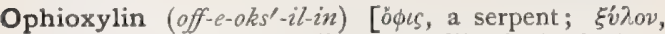
wood], $\mathrm{C}_{16} \mathrm{H}_{13} \mathrm{O}_{6}$. A yellow crystalline body obtained from Ophioxylon serpentinum, a purgative and anthelmintic; its solutions stain first yellow, then brown.

Ophioxylon, Ophioxylum (off-e-oks'-il-on, off-e-oks'-it$u m)[\check{\phi} \phi \iota$, a serpent; $\xi \dot{v} \lambda .0 \nu$, wood]. A genus of apocynaceous plants; serpent-wood. O. serpentinum, East Indian snake-root, used as an oxytocic and as a remedy for snake-bite. Unof.

Ophryitis (off-re-i'tis) [óóós, brow; $\iota \tau \iota s$, inflammation]. Inflammation of the eyebrow.

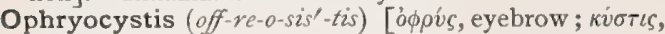
bladder]. A parasitic sporozoön.

Ophryo-iniac (off'-re-o-in'-e-ak) [ó $\phi \rho ́ s$, eyebrow ; iviov, occiput]. Pertaining to the ophryon and the inion.

Ophryon (off'-re-on) [ópús, eyebrow]. In craniometry, the middle of a line drawn across the forehead at the level of the upper margin of the orbits. See Craniometric Points.

Ophryo-opisthiac (off'-re-o-o-pis'-the-ak) [ópós, eyebrow; ótiotlos, hinder]. Pertaining to the ophryon and the opisthion.

Ophryoscolex (off-re-o-sko'-leks) [obpis, hrow ; $\sigma \kappa \omega \lambda \eta \xi$, worm: pl., Ophryoscolices]. A genus of endoparasitic peritrichous infusorians, representatives of which almost constantly inhabit the stomachs of cattle and sheep. See Parasites (Animal), Table of:

Ophryphtheiriasis (off-rif-thi-ri-as-is) [ópovs, eye- brow; $\phi \theta \varepsilon \iota \rho i a \sigma s$, pediculosis]. Pediculosis of the eyebrows and eyelashes.

Ophrys (off'-ris) [òpus, eyebrow]. The eyebrow.

Ophrytic (off-rit'-ik) [opov́s, eyebrow]. Pertaining to the eyebrow.

Ophthalmagra (off-thal-ma'-grah) [o $\phi \theta \alpha \lambda \mu \delta$ s, eye; $\check{a} \gamma \rho \alpha$, a seizure]. Gouty or theumatic pain in the eye.

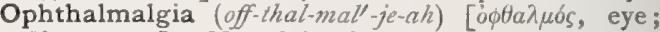

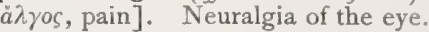

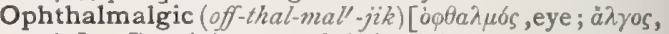
pain]. Pertaining to ophthalmalgia.

Ophthalmanthracosis (off-thal-man-thrak-o' - sis)

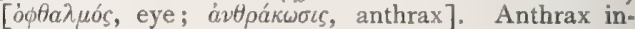
volving the eyelid.

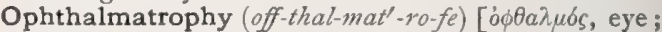

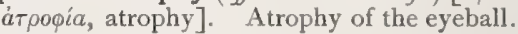

Ophthalmecchymosis (off-thal-mek-im-o'-sis) [ö $\phi a \lambda \mu o ́ s$, eye ; $\dot{\varepsilon} \kappa \chi \dot{v} \mu \omega \sigma \iota s$, ecchymosis]. A conjunctival effusion of blood.

Ophthalmedema (off-thal-me-de'-mah) [o $\phi \theta a \lambda \mu b s$, eye; oífnua, edema]. Conjunctival edema.

Ophthalmencephalon (off-thal-men-sef'-al-on) [o $\phi$ -

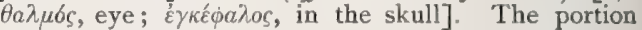
of the eye developed from the neural epiblast.

Ophthalmentozoön (off-thal-men-to-zo'-on) $[\dot{o} \phi \theta a \lambda \mu \delta s$, eye; $\dot{\varepsilon} v \tau o ́ s$, within; $\xi \bar{\omega} o v$, animal]. An intraocular parasite.

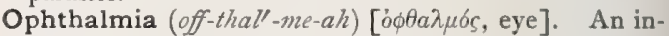
flammation of the superficial tissues of the eye, and especially of the conjunctiva. $\mathbf{O}$. angularis. The same as Canthitis. O., Army, purulent conjunctivitis. O. arthritica. A synonym of Glaucoma. O., Asiatic. See Trachoma. O., Brazilian, a form of xerophthalmia occurring in poorly-nourished children in Brazil; the cornea first dries and is finally destroyed. O., Catarrhal, a synonym of simple conjunctivitis; a hyperemia of the conjunctiva, with a catarrhal or muco-purulent secretion. O., Croupous, a rare disease, characterized by a severe, usually painless, swelling of the lids, a membranous exudation upon the surface of the conjunctiva, and a scanty sero-purulent discharge. It occurs only in children, but no distinct cause is known. O., Diphtheric, a contagious variety of ophthalmia, characterized by a rigid and painful swelling of the lids, a scanty sero-purulent or sanious discharge, and an exudation within the layers of the conjunctiva which leads to the death of the invaded tissues, and tends, by spreading to the ocular conjunctiva and by pressure, to destroy the cornea. The membrane is of a dull, grayish-red appearance and is intimately connected with the conjunctival tissues. O., Dry, a synonym of Xerophthalmia. O., Egyptian. See Trachoma. O., Electric, an ophthalmia sometimes occurring in workmen exposed to the glare of electric light. O., Follicular, an affection of the conjunctiva, associated with the presence of small pinkish prominences in the conjunctiva, chiefiy located in the retrotarsal folds, and usually arranged in parallel rows. The disease is often due to poor hygienic surroundings and may become epidemic. O., Gonorrheal, an acute and severe form of purulent conjunctivitis, caused by infection from urethral discharges containing the gonococcus of Neisser. See Bacteria, Synonymatic Table of. O., Granular. See Trachoma. O., Hoppickers', a form of ophthalmia due to the impaction in the cornea of the spinous hairs from the bracts of the hop. O. humida, conjunctivitis with profuse discharge. O., Lacrymal, a form of chronic conjunctivitis depending upon obstruction of the lacrymal passages. O., Leukorrheal, ophthalmia supposed to be due to infection with leukorrheal dis- 
charges. O., Malignant, an acute form of ophthatmia, usually fatal from extension of the purulent process to the brain. O., Menstrual, a form associated with suppression of the menses, or with the menopause. O., Migratory. See O., Sympathetic. O., Military. See Trachoma. O. neonatorum, a gonorrheal or purulent ophthalmia of the new-born, the eyes having been infected by the mother's uterine or vaginal discharges. O., Neuro-paralytic, ocular disease from lesion of the Gasserian ganglion or of branches of the fifth nerve supplying the eyeball. O., Periodic, an ophthalmia seen in horses and leading to total destruction of vision. O., Phlyctenular, a disease in which phlyctenules or small vesicles are situated in the epithelial layer of the conjunctiva or cornea. O., Plastic, ophthalmia characterized chiefly by the deposition upon the conjunctiva of a false membrane; it is also called Pseudo-membranous Ophthalmia. O., Pseudo-membranous. See O., Plastic. O., Puerperal, a form occurring in the puerperal state. O., Purulent, conjunctivitis with a purulent discharge. O., Pustular. See O., Phlyctenular. O. sicca. The same as Xerophthalmia. O., Spring, Fruehjahrs- or Fruehlings-Catarrh; Phlyctena pallida; a form of conjunctival disease, usually seen in children, characterized by photophobia, stinging pain, considerable mucous secretion, the formation of flat granulations on the conjunctiva, and hypertrophy of this tissue surrounding the limbus of the cornea. It is common in the spring of the year. O., Sympathetic. See Sympathetic. O., Tarsal. See Blepharitis. O. taraxis, a synonym of Conjunctivitis. O., Varicose, a form associated with a varicose condition of the veins of the conjunctiva.

Ophthalmiater (off-thal-me-a'-ter) $[o \phi \theta a \lambda \mu \sigma s$, eye; iarpós, a physician]. An oculist or ophthalmologist.

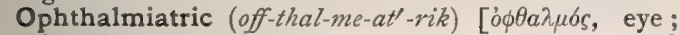
iatpeia, treatment]. Pertaining to the treatment of eye-diseases.

Ophthalmiatrics (off-thal-me-at'-riks) [o $\phi \theta a \lambda \mu \delta^{\prime}$, eye ; iarpei $a$, treatment]. The treatment of eye-diseases.

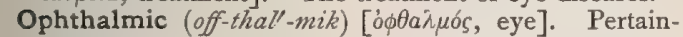
ing to the eye. O. Artery. See Arteries, Table of. O. Ganglion. See Ganglia, Table of. O. Migraine, migraine due to diseased conditions of the eyes. 0 . Nerve. See Nerves, Table of. O. Plexus, a plexus of sympathetic nerves around the ophthalmic artery. o. Vein, the vein returning the blood from the eye; it empties into the sphenoidal sinus.

Ophthalmin (off-thal'-min) [o ${ }^{\dagger} \theta a \lambda \mu b s$, eye]. The name given to the hypothetic contagium of purulent ophthalmia.

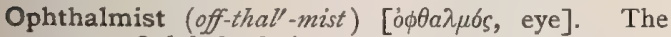
same as Ophthalmologist.

Ophthalmite (off-thal'-mit) $[\dot{o} \phi \theta a \lambda \mu b s$, the eye]. In biology, the eye-bearing stalk of a crustacean; an ommatophore.

Ophthalmitic (off-thal-mit'-ik) [o $\phi \theta a \lambda \mu \delta \varsigma$, eye; $\iota \tau \iota \varsigma$, inflammation]. Pertaining to ophthalmitis. Also pertaining to an ophthalmite.

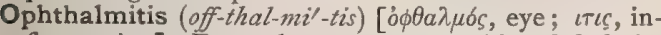
flammation]. Formerly synonymous with ophthalmia, but latterly used as indicating inflammation of some of the deeper tissues of the eye, or restricted to the term Sympathetic Ophthalmia, q. v. Consult also, Panophthalmitis.

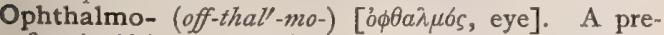
fix signifying connection with or relation to the eye. O.-blennorrhea. See Ophthalmia, Gonorrheal. O.-neuritis, a peripheral neuritis of the ophthalmic branch of the fifth nerve. In part synonymous with Herpes zoster ophthalmicus.

Ophthalmobiotic (off-thal-mo-bi-ot'-ik) [o $\phi \theta a \lambda \mu b s$, eyeball; ßios, life]. Relating to the physiology and development of the eye.

Ophthalmobrachytes (off-thal-mo-brak'-it-ez) [o $\dot{\phi} \theta a \lambda$.

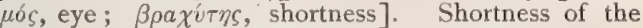
ocular axis; also the shortened axis. [Old.]

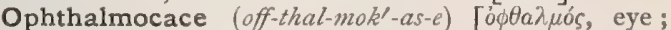
какб́, evil]. Disease of the eye.

Ophthalmocarcinoma (off-thal'-mo-kar-sin-o'-mah)

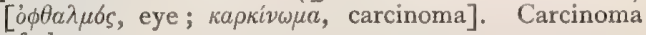
of the eye.

Ophthalmocele (off-thal'-mo-sèl). See Staphyloma and Exophthalmus.

Ophthalmocentesis (off-thal'-mo-sen-te'-sis) [ö $\phi \theta a \lambda \mu o ́ s$, eye; $\kappa \dot{v} v \tau \eta \sigma \iota s$, puncture]. Surgical puncture of the eye.

Ophthalmocholosis (off-thal'-mo-kol-o'-sis) [o $\phi \theta a \lambda \mu b s$, eye; $\chi 6 \lambda\rangle_{0}$, bile]. Ophthalmia due to liver-disease. [Old.]

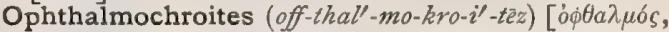
eye; $\chi \rho \omega$ s, color]. The black coloring-matter of theeye.

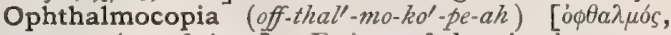
eye ; $\kappa \delta$ tos, fatigue]. Fatigue of the visual powers.

Ophthalmodesmitis (off-thal'-mo-dez-mi'-tis). Synonym of Conjunctivitis.

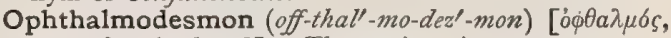
eye; $\delta \varepsilon \sigma \mu \delta s$, bond]. The conjunctiva.

Ophthalmodesmoxerosis (off-thal'-mo-dez-mo-ze-ro' -

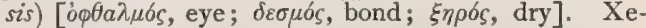
rophthalmia, $q$. $v$.

Ophthalmodiastimeter (off-thal'-mo-di-as-tim'-et-er)

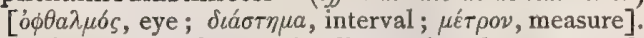
An instrument for use in discovering the proper adjustment of lenses to the axes of the eyes.

Ophthalmodynamometer (off-thal'-mo-di-nam-om'-et-

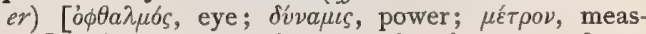
ure]. An instrument for measuring the power of convergence of the eyes.

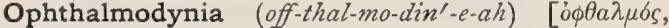
eye; bovv , pain]. Any violent pain in the eye not resulting from inflammation.

Ophthalmography (off-thal-mog'-ra-fe) [ö $\phi \theta a \lambda \mu b s$, eye ; $\gamma \rho \alpha \dot{\phi} \varepsilon v \nu$, to write]. Descriptive anatomy of the eye.

Ophthalmohydrorrhea (off-thal'-mo-hi-dror-e $\left.e^{\prime}-a h\right)$. Synonym of Ophthalmydrorrhea.

Ophthalmokopia (off-thal-mo-kop'-e-ah). See Ophthalmocopia.

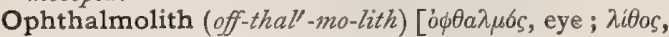
stone]. A calculus of the eye.

Ophthalmologic (off-thal-mo-loj'-ik) $[\dot{o} \phi \theta a \lambda \mu b s$, eye ; $\lambda$ b́os, science]. Pertaining to Ophthalmology.

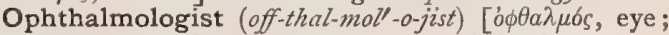
nóyos, science]. One versed in ophthalmology.

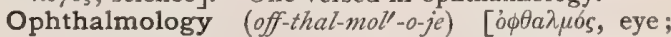
$\lambda 6$ yos, science]. The science of the anatomy and physiology and the diseases of the eye.

Ophthalmolyma (off-thal'-mo- $i^{\prime}-$-mah) $[o \phi \theta a \lambda \mu \sigma s$, eye ; $\lambda v \mu \eta$, destruction]. Destruction of the eye.

Ophthalmomacrosis (off-thal'-mo-mak-ro'-sis) [o $\phi \theta a \lambda$ $\mu b s$, eye; $\mu \alpha \kappa \rho \sigma s$, large ]. Enlargement of the eye.

Ophthalmomalacia (off-thal'-mo-mal-a'-se-ah) $[\dot{o} \phi \theta a \lambda$ $\mu \delta s$, eye; $\mu a \lambda a \kappa i a$, softness]. Abnormal softness of the eye, revealing itself in a diminution of tension.

Ophthalmomelanoma (off-thal'-mo-mel-an-o'-mah)

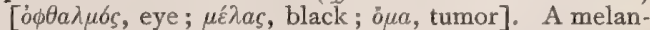
otic tumor, usually sarcoma, of the eye.

Ophthalmomelanosis (off-thal' - mo-mel-an - o' - sis)

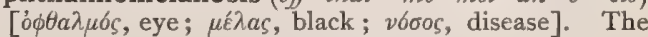
formation of an ophthalmomelanoma; also the growth itself. 


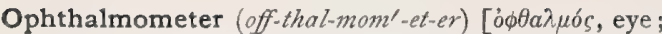
$\mu \varepsilon ́ \tau \rho o \nu$, measure]. I. An instrument for measuring the capacity of the chambers of the eye. 2. An in-

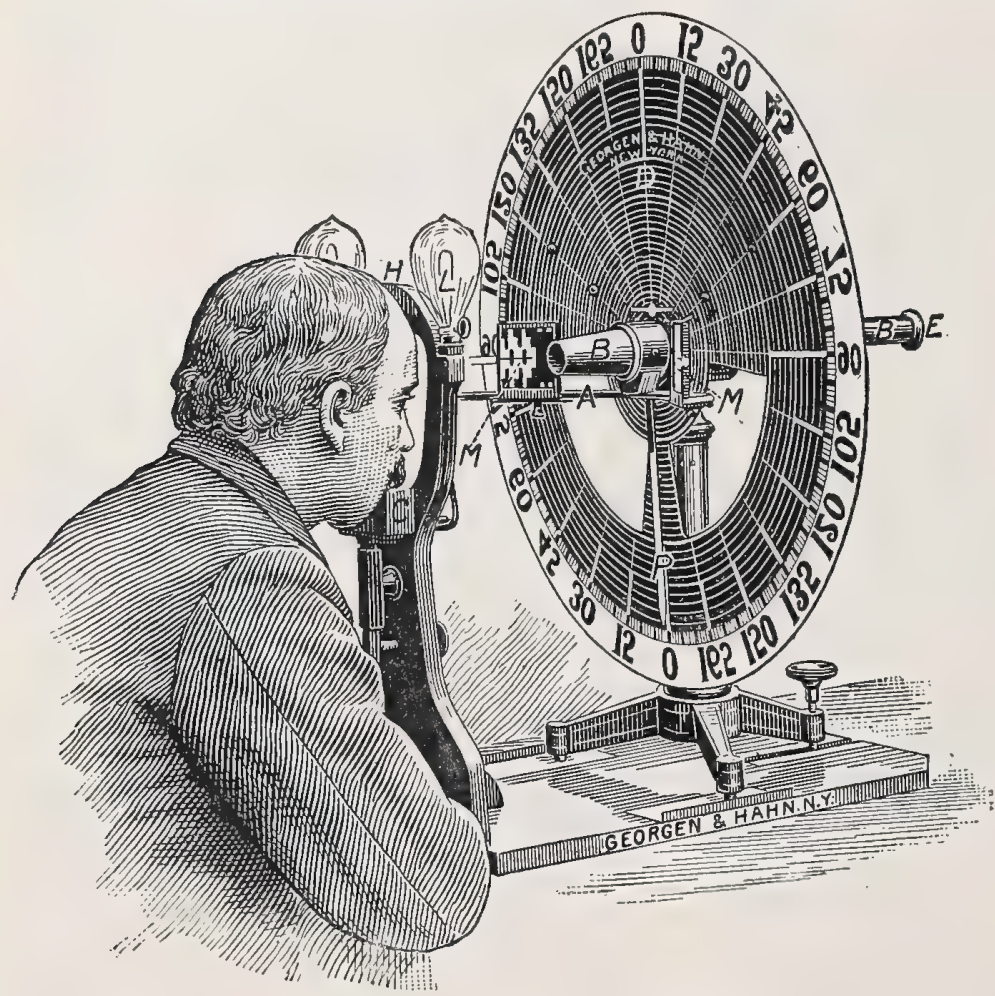

The OPHThalmometer of JaVAl and Schiötz.

A. The perimeter-bar. B, B. Telescope. C. Chin-rest. D. Disc of radiating lines and concentric circles, E. Eye-piece, at which the observer sits. H. Head-rest. L. Lights. M, $M$. The mires, or targets. P. Pointer, indicating the axis by the degree numbers on the peripheral border of the disc.

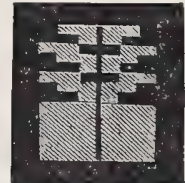

Mires EXACtLy APPROXIMATED.

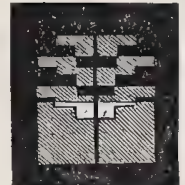

Mires Overlapping One Diopter. strument for measuring refractive errors, especially astigmatism. 3. An instrument for measuring the eye as a whole.

Ophthalmometry (off-thal-mom'-et-re) [ó $\phi \theta a \lambda \mu \delta s$, eye ; $\mu \varepsilon \varepsilon \tau \rho \nu$, measure ]. The use of the ophthalmometer; mensuration of the eyeball, or of the corneal curves.

Ophthalmomicroscope (off-thal' - mo - mi' - kro - sköp)

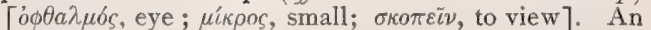
instrument for examining the interior of the eye.

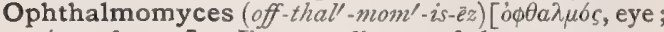
нokns, fungus]. Fungous disease of the eye.

Ophthalmomyitis (off-thal'-mo-mi-i'tis) [ó $\theta a \lambda \mu \delta s$, eye; $\mu \tilde{v} \varsigma$, muscle; $\iota \tau \iota$, inflammation]. Inflammation of the ocular muscles.

Ophthalmomyotomy (off-thal-mo-mi-ot'-o-me) [o $\phi \theta a \lambda$ $\mu \delta \delta$, eye; $\mu \bar{v} \varsigma$, muscle; $\tau o \mu \eta \dot{n}$, a cutting]. Division of the muscles of the eye
Ophthalmoncus (off-thal-mong'-kus) [ó $\phi \theta a \lambda \mu \sigma s$, eye ; ơкоs, tumor]. A tumor or swelling of the eye.

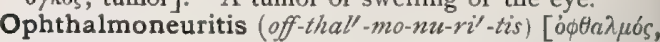

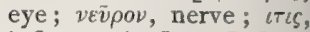
inflammation]. Inflammation of the ophthalmic nerve.

Ophthalmoneuromeninx (off-thal'-no-nu-ro-men' inks). Synonym of $\mathrm{Re}$ tina.

Ophthalmoneurymen (offthal' - mo-nu-ri' - men). Synonym of Retina.

Ophthalmonosology (offthal' - mo-no-zol' $-o-j e)$

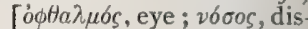
ease; $\lambda \sigma \gamma o s$, science]. The study of the diseases of the eye.

Ophthalmoparacentesis (off - thall' - mo-par-as-en$\left.t e^{\prime}-s i s\right)$. Synonym of $O p h$ thalmocentesis.

Ophthalmoparalysis (of thal'-mo-par-al'-is -is). Synonym of Ophthalmoplegia.

Ophthalmoperipheritis (off-thal'-mo-per-if-er-i' tis) [o $\phi \theta a \lambda \mu \delta s$, eye ; $\pi \varepsilon \rho \iota \phi$. $\varepsilon \rho \varepsilon^{\prime} a$, the periphery ; $\iota T L S$, inflammation]. Inflammation of the tissues around the eyeball.

Ophthalmophantoma (off thal'-mo-fan-to'-mah) $[\dot{\omega} \phi$ -

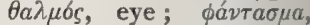
phantom]. A model or mask for practising operations on the eye.

Ophthalmophasmatos copy (off-thal'-mo-faz-

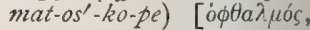
eye ; $\phi a \nu \tau a ́ \zeta \varepsilon \iota \nu$, to make

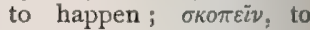
view]. Ophthalmoscopic and spectroscopic examination of the interior of an eye.

Ophthalmophlebotomy (off-thal' -mo-fle-bot'-o-me)

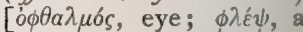
ve in ; $\tau \varepsilon \mu \nu \varepsilon \nu$, to cut]. Blood-letting from a conjunctival vein.

Ophthalmophore (off-thal'-mo-for) [o $\phi \theta a \lambda \mu \sigma \varsigma$, the eye ; $\phi b \rho o s$, bear]. In biology, the eye-stalk or peduncle of a gasteropod; an ommatophore.

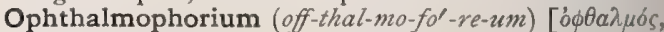
eye; фópos, bear: pl., Ophthalmophoria]. Same as Ophthalmophore.

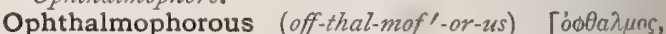
eye; $\phi 6 \rho \circ$, bear]. In biology, supporting the eyes.

Ophthalmophtharsis (off-thal-mo-tars'-is) [óbalús, eye; $\phi \theta a ́ \rho \sigma \iota s$, corruption]. Destructive degeneration of the eye. [Old.]

Ophthalmophthisis (off-thal-mof'-this-is). See Phthisis bulbi; also Ophthalmomalacia.

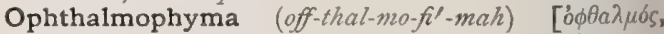
eye; $\phi \tilde{v} \mu \alpha$, growth]. Swelling of the eyeball.

Ophthalmoplastic (off-thal-mo-plas'-tik) [ó $\phi \theta a \lambda \mu \sigma s$, eye; $\pi \lambda a ́ \sigma \sigma \varepsilon \iota \nu$, to mold]. Pertaining to ophthalmoplasty. 
Ophthalmoplasty (off-thal'-mo-plas-te) $[\dot{o} \phi \theta \alpha \lambda \mu \delta \delta$, eye;

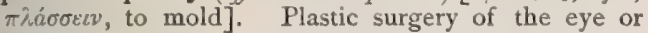
accessory parts.

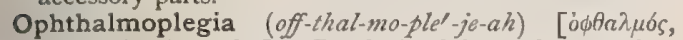
eye; $\pi \lambda \eta \gamma \dot{\eta}$, stroke]. Paralysis of the ocular muscles. O. externa, paralysis of the external muscles. 0 . interna, paralysis of the internal muscles, or combined iridoplegia and cycloplegia. O., Nuclear, ophthalmoplegia due to a lesion of the nuclei of origin of the motor nerves of the eyeball. O., Partial, a form in which only some of the muscles are paralyzed. O., Progressive, a form in which all of the muscles of both eyes gradually become paralyzed. 0 . Total, that form involving the iris and ciliary muscle as well as the external muscles of the eyeball. Ophthalmoplegic (off-thal-mo-ple'-jik) [o $\phi \phi a \lambda \mu \sigma \varsigma$, eye ; $\pi \lambda \eta \gamma^{\prime}$, stroke]. Pertaining to ophthalmoplegia.

Ophthalmoponia (off-thal-mo-po'-ne-ah) [o $\phi \theta a \lambda \mu o ́ s$, eye; $\pi 6 v 0 s$, pain]. Pain in the eye.

Ophthalmoprosopsis (off-thal'-mo-pros-ops'-is) [o $\phi \theta a \lambda$ -

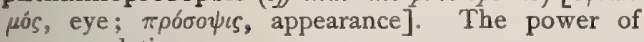
accommodation.

Ophthalmoprostatometer (off-thal'-mo-pros-tat-om'-et-

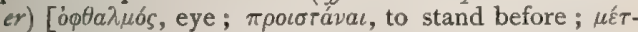
pov, measure]. An instrument for measuring the degree of protrusion of the eyes.

Ophthalmoptoma (off-thal-mop-to'-mah) [o $\phi \theta a \lambda \mu o ́ s$, eye; $\pi \tau \bar{\omega} \mu a$, fall]. Exophthalmos ; protrusion of the eyeball.

Ophthalmoptosis (off-thal-mop-to'-sis) [ó $\phi \theta a \lambda \mu o ́ s$, eye ; $\pi \tau \omega \tilde{\sigma} \iota s$, fall]. The same as Ophthalmoptoma.

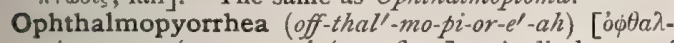

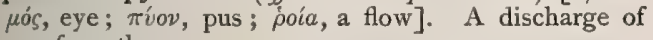
pus from the eye.

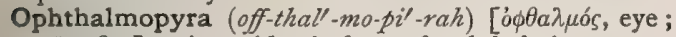
$\pi \tilde{v} \rho$, fire]. An epidemic form of ophthalmia.

Ophthalmorrhagia (off-thal-mor- $\left.a^{\prime}-j e-a h\right) \quad[o \phi \theta a \lambda \mu b s$, eye; im vvival, to burst forth]. A hemorrhage from the eye.

Ophthalmorrhea (off-thal-mor-e'-ah) [ó $\phi \theta a \lambda \mu o ́ s$, eye ; poía, a flow]. A watery or sanguineous discharge from the eye.

Ophthalmorrhexis (off-thal-mor-eks' - is) [ó $\phi \theta 1 a \lambda \mu o ́ s$, eye; $\dot{\rho} \dot{\xi} \xi \varsigma$, rupture]. Rupture of the eyeball.

Ophthalmos (off'-thal-mos) [o $\omega \theta a \lambda \mu \sigma \varsigma$, eye]. The eye.

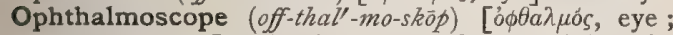
бколєiv, to see]. An instrument for examining the

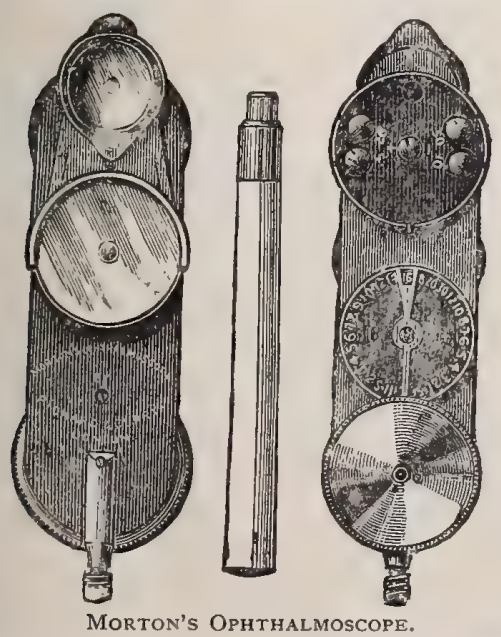

fundus or interior of the eye. It consists essentially of a mirror with a hole in it, through which the ob- server looks, the concavity of the eye being illuminated by light reflected from the mirror into the eye and seen by means of the rays reflected from the eye-ground back through the hole in the mirror. The ophthalmoscope is fitted with lenses of different powers that may be revolved in front of the observing eye, and these neutralize the ametropia of either eye, thus rendering the details of the fundus oculi clear. The autophthalmoscope is so constructed that one may observe the details of his own eye-ground.

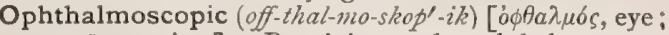

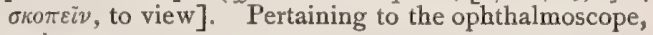
or its use.

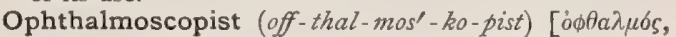
eye; $\sigma \kappa o \pi \varepsilon i \nu$, to view]. One versed in ophthalmoscopy.

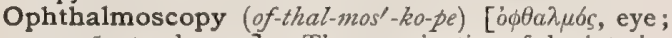
$\sigma \kappa о \pi \varepsilon i v$, to observe]. The examination of the interior of the eye by means of the ophthalmoscope. O., Direct, the method of the erect or upright image, the observer's eye and the ophthalmoscope being brought close to the eye of the patient. O., Indirect, the method of the inverted image; the observer's eye is placed about 16 inches from that of the patient and a $20 \mathrm{D}$. biconvex lens is held about two inches in front of the observed eye, thereby forming an aërial inverted image of the fundus. O., Medical, ophthalmoscopy as an aid to internal medicine in the diagnosis of such diseases as manifest themselves in changes in the fundus of the eye; such diseases are brain-lesions, giving rise to pressure, Bright's disease, syphilis, and leukemia. O., Metric, ophthalmoscopy for purposes of measuring refraction.

Ophthalmospintherism (off-thal-mo-spin'-ther-izm)

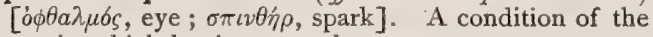
eye in which luminous sparks are seen.

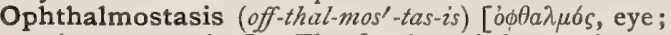
$\sigma \tau a ́ \sigma \iota s, a$ stopping]. The fixation of the eye in any position during a surgical operation upon it.

Ophthalmostat (off-thal' - mo-stat) [ó $\phi \theta a \lambda \mu \delta s$, eye; $\sigma \tau \alpha \tau o ́$, fixed]. An instrument used in ophthalmostasis. See the preferable word, Blepharostat.

Ophthalmostatometer (off-thal'-mo-stat-om'-et-er) [ó $\phi$ -

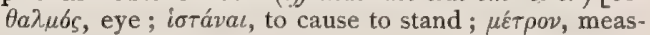
ure]. An instrument for determining the position of the eyes.

Ophthalmostatometry (off-thal'-mo-stat-om'-et-re) [o $\phi$ -

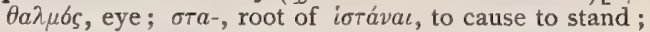
$\mu \varepsilon \dot{\tau} \rho \circ \nu$, measure]. The measurement of the position of the eyes.

Ophthalmosteresis (off-thal'-mo-ster-e'-sis) [o' $\phi \theta a \lambda \mu b s$, eye; $\sigma \tau \varepsilon \dot{\rho} \eta \sigma \iota$, deprival]. Deprival, or absence, of the eyes.

Ophthalmosynchysis (off-thal'-mo-sin'-kis-is) [o $\mu o ́ s$, eye ; $\sigma \hat{v} \gamma \chi v \sigma \iota \zeta$, a mixing together]. Effusion into the interior of the eye.

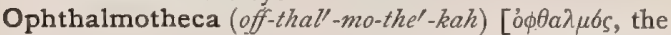
eye; $\theta \dot{\kappa} \kappa \eta$, a case : pl., Ophthalmothece]. In biology, that part of the integument of a pupa which covers the compound eye.

Ophthalmotherapeutics (off-thal'-mo-ther-ap-u'-tiks)

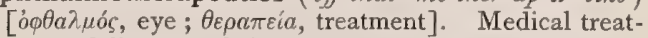
ment of diseases of the eye.

Ophthalmotherapy (off-thal-mo-therl-ap-e) $[\dot{\alpha} \phi \theta a \lambda \mu b s$, eye ; $\theta \varepsilon \rho a \pi \varepsilon i a$, treatment]. The treatment of ophthalmic diseases.

Ophthalmotomy (off-thal-mot'-o-me) [o $\phi \theta a \lambda \mu b s$, eye ;

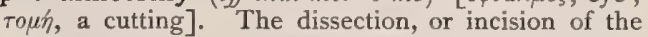
eye.

Ophthalmotonometer (off-thal'-mo-ton-om'-et-er) $[o \phi-$ $\theta a \lambda \mu o ́ s$, eye; $\tau \delta \nu o s$, tone; $\mu \varepsilon ́ \tau \rho o \nu$, measure]. An instrument for measuring intraocular tension. 
Ophthalmotonometry (off-thall-mo-ton-om'-et-re) [o $\phi$

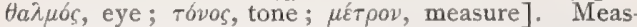
urement of the intraocular tension.

Ophthalmotrope (off-thal'-mo-tröp) [ỏ $\phi \theta a \lambda \mu \delta ́ s$, eye ; $\tau \rho \delta ́ \pi o s, a$ turn]. An instrument intended for the demonstration of the direction and the position that the eye takes under the influence of each of its muscles, and the position of the false image in the case of paralysis of a given muscle.

Ophthalmotropometer (off-thal'-mo-trop-om'-et-er)

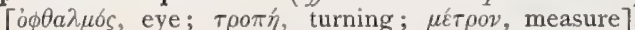
An instrument for measuring the movement of the eyeballs.

Ophthalmotropometry (off-thal'-mo-tro-pom'-et-re)

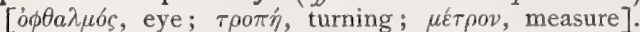
The measurement of the movement of the eyeballs.

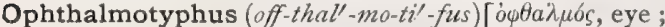
$\tau \tilde{v} \phi o s$, stupor]. A virulent and epidemic form of ophthalmia.

Ophthalmoxerosis (off-thal'-mo-ze-ro'-sis). See Xerophthalmia.

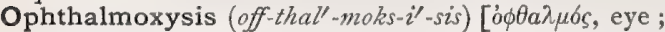
$\xi \tilde{v} \sigma \iota s$, a scraping]. The treatment by scraping or scarification, sometimes employed in certain affections of the conjunctiva.

Ophthalmoxyster (off-thal-moks-is'-ter). The same as Ophthalmoxystrum.

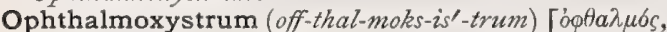

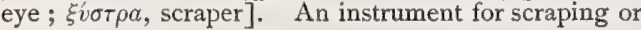
scarifying the conjunctiva.

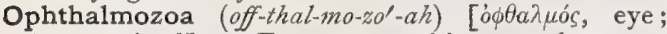
$\zeta$ ஸ̆ov, animal]. I. Entozoa parasitic upon the eye or its appendages. 2. One of Oken's five zoölogic divisions.

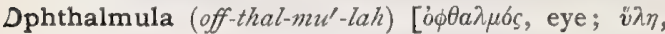
matter]. A scar of the eye.

Ophthalmuria (off-thal-mu'-re-ah) $[\dot{o} \phi \theta a \lambda \mu b s$, eye; ov ${ }^{x} \circ \mathrm{v}$, urine]. A hypothetic metastasis of urine to the eyes.

Ophthalmus (off-thal'-mus). See Ophthalmos.

Ophthalmy (off-thal'-me). The same as Ophthalmia.

Ophthalmyalus (off-thal-mi'-al-us). Synonym of Vitreous Humor.

Ophthalmydrorrhea (off-thal-mid-ror-e'-ah) [o $\phi \theta a \lambda \mu b s$, eye ; $v \delta \omega \rho$, water; $\rho \circ i a$, flow $]$. A watery discharge from the eyes.

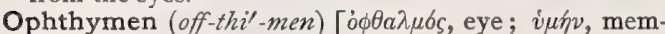
brane]. The retina.

-opia $\left(-o^{\prime}-p e-a h\right)$. See -ops.

Opiane $\left(o^{\prime}-p e-a n\right)$. Same as Narcotin.

Opianic $\left(0-p e-a n^{\prime}-i k\right)$ [ŏ $\pi \iota v$, opium]. Derived from opium. O. Acid. See Acid.

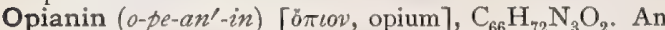
alkaloid obtained from opium by precipitation with ammonia, and extracting the precipitate with alcohol.

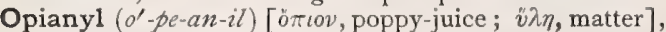
$\mathrm{C}_{10} \mathrm{H}_{10} \mathrm{O}_{4}$. A synonym of Meconin.

Opiate $\left(o^{\prime}-p e-\bar{a} t\right)$ [örıov, poppy-juice]. A preparation of opium.

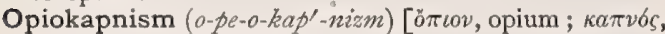
smoke]. Opium-smoking.

Opiologia $\left(o-p e-o l-o^{\prime}-j e-a h\right)[b i \pi \iota v$, opium; $\lambda \varepsilon \dot{\varepsilon} \varepsilon \iota v$, to gather]. The gathering of opium.

Opiology $\left(o-p e-o l^{\prime \prime}-o-j e\right)$ [ö́tıv, opium; $\lambda \sigma \gamma \gamma o s$, science] The pharmacology of opium.

Opionin (o-pe-ó-nin) [ö $\pi \iota v v$, poppy-juice]. A nonnitrogenous crystalline substance extracted from Smyrna opium.

Opiophagia (o-pe-off-a'-je-ah). Synonym of Opiophagism.

Opiophagism (o-pe-off'-aj-ism), Opiophagy (o-pe-off'-

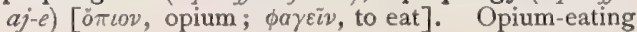

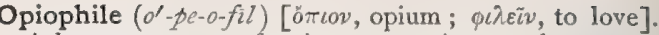
A lover, or eater, of opium; an opium-smoker.

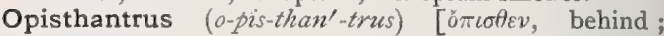

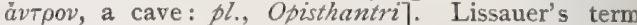
for a skull in which the vertical line dropped from the most prominent part of the torus frontalis to the radius fixus is from I to $6 \mathrm{~mm}$. behind the vertical line from the nasion to the radius fixus.

Opisthen (o-pis'-then) [o $\pi \iota \sigma \theta \varepsilon \nu$, behind]. In biology, the hind part of the body of an animal.

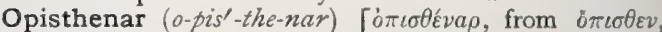
behind; $\theta \dot{\varepsilon} v a \rho$, the palm]. The back of the hand. Cf. Thenar.

Opisthion (o-pis'-the-on) [ómiotlos, hinder]. See Craniometric Points.

Opisthobregmus (o-pis-tho-breg'-mus) [ö $\pi \iota \theta \varepsilon v$, behind; $\beta \rho \varepsilon \gamma u$ ós, the bregma]. Lissauer's term for a skull in which the angle formed between the radius fixus and the line joining the hormion and the bregma is between $55.5^{\circ}$ and $68^{\circ}$.

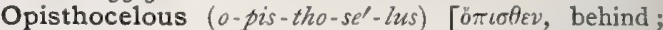

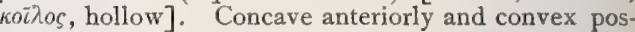
teriorly, as the centrum of a vertebra.

Opisthocephalon (o - pis - tho-sef'-al-on) [ö $\pi \iota \sigma \theta \varepsilon v$, behind; $\kappa \varepsilon \phi a \lambda \eta$, the head]. A synonym of Occiput.

Opisthochasmus (o-pis-tho-kaz'-mus) [ö $\pi \iota \sigma \theta \varepsilon v$, behind; $\chi a ́ \sigma \mu a$, chasm]. Lissauer's term for a skull in which the angle between the radius fixus and the line joining the basion and the staphylion is between $13^{\circ}$ and $26^{\circ}$.

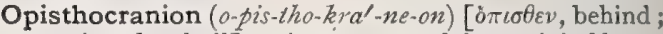
кaaviov, the skull]. A synonym of the occipital bone.

Opisthodont (o-pis'-tho-dont) [ö $\pi \iota \sigma \theta \varepsilon v$, behind; ódoús, tooth]. In biology, possessing back teeth only.

Opisthogastric (o-pis-tho-gas'-trik) [ö $\pi \iota \sigma \theta \varepsilon v$, behind;

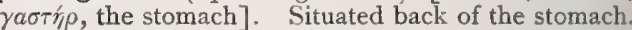

Opisthoglyphic (o-pis-tho-glif'-ik) [ö $\pi \iota 0 \theta \varepsilon v$, behind; $\gamma \lambda u ́ \phi \varepsilon \iota \nu$, to curve]. Grooved posteriorly, e. g., certain teeth.

Opisthognathism (o-pis-thog'-nāth-izm) [ö $\pi \iota \sigma \theta \varepsilon v$, behind; yvátos, jaw]. Recession of the lower jaw.

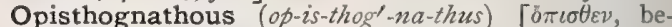
hind; yvátos, jaw]. In biology, having retracting jaws; the antonym of Prognathous.

Opisthokyphosis (o-pis-tho-ki-fo'-sis) [ö $\pi \iota \sigma \theta \varepsilon v$, backward; $\kappa \dot{\omega} \phi \omega \sigma \iota s$, bending]. Curvature of the spinal column, the convexity being forward.

Opisthomelophoros (o-pis-tho-mel-off'-or-os) [oriotios, hinder; $\mu \varepsilon \varepsilon \lambda o s, \operatorname{limb}$; with limbs projecting from the back.

Opisthophalacrosis (o-pis-tho-fal-ak-rol-sis) [ö $/ \sigma \theta \varepsilon v$,

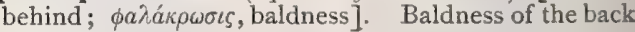
of the head.

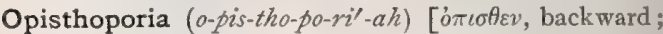
$\pi \circ \rho \varepsilon i a$, going]. Involuntary backward walking in an attempt to go forward.

Opisthorrhexis (o-pis-thor-eks'-is) [ö $\pi \iota \sigma \theta \varepsilon v$, behind; $\rho \tilde{\eta} \xi_{\text {ls }}$, a rupture]. A tearing backward.

Opisthosynechia (o-pis-tho-sin-ek'-e-ah). Synonym of Synechia, Posterior.

Opisthothenar (o-pis-thoth'-en-ar). The Erector spina muscle. See Muscles, Table of.

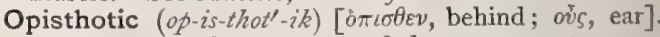
In biology, applied to parts of the ear-apparatus, posterior in position.

Opisthotonic (o-pis-tho-ton'-ik) $[\delta \pi \iota \theta \varepsilon \varepsilon v$, behind; $\tau \delta \nu o s$, tone]. Pertaining to opisthotonos.

Opisthotonoid (o-pis-thot'-on-oid) [ö $\pi i \sigma \theta \varepsilon v$, behind; Tóvos, tone; Eidos, like]. Resembling opisthotonos.

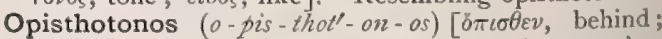
rovos, tone]. A tetanic condition of the muscles, especially of the back, whereby there is an arching 
backward of the trunk, which thus rests upon the head and heels. This condition is seen in tetanus, strychnin-poisoning, hydrophobia, hysteria, and other tetanic conditions.

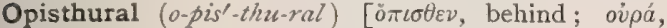
the tail]. Of, or pertaining to, the opisthure.

Opisthure (o-pis'-thūr $)$ [ör $\iota \sigma f \varepsilon v$, behind; oúpá, tail]. In biology, the posterior termination of the caudal axis of certain fishes or their embryos.

Opium $\left(o^{\prime}\right.$-pe $\left.u m\right)$ [örıov, poppy-juice]. The inspissated juice of the unripe capsules of the Papaver somniferum, or poppy, obtained by incising the capsules and collecting the milky juice which is exuded. Most of the opium in the American market comes from Smyrna, Asia Minor. Opium is a very complex substance and contains, besides morphin and codein, a large number of less important alkaloids-narcein, narcotin, thebain, laudanin, papaverin, porphyroxin, cryptopin, meconin, opianin, paramorphin, and meconic, thebolactic, and sulphuric acids, in addition to a variety of extractives. Good opium should yield at least 9 per cent. of morphin. The dominant physiologic action of opium is the relief of pain. It also causes slowing of the respiration and pulse, contraction of the pupils, diaphoresis, constipation; more rarely nausea and vomiting, headache, itching of the skin, erythema; occasionally instead of sleep, wakefulness, delirium, even convulsions. In toxic doses it produces sleep followed by deep coma, with very slow respirations, and pin-point pupils; death is due to paralysis of the centers of respiration. Therapeutically, opium is a most useful drug; it induces sleep, allays excitement, relieves pain and irritation, checks vomiting and diarrhea, and is sudorific. Small doses stimulate ; large doses depress. O., Acetum, vinegar of opium, "black drop," prepared with nutmeg, sugar, and dilute acetic acid. Opium-strength Io per cent. Dose $\eta^{v-x x}$ O., Confectio. $(B . P$. Dose gr. $\mathrm{v}-\mathrm{xx}$. O. denarcotisatum, powdered opium freed from substances soluble in ether; I4 per cent. of morphin and a varying per cent. of narcotin. Dose gx. ss-iij. O., Emplastrum, extract of opium 6, Burgundy pitch, I8, lead-plaster 76 parts. O., Enema $(B . P$.$) , contains 3$ ss of the tincture of opium and $\xi$ ij of starch-mucilage. O. et Glycyrrhizæ, Troch., each contains gr. $\frac{1}{20}$ of opium. Dose j-iv. O. et Ipecacuanhæ, Pulv., Dover's powder, contains ipecac IO, opium IO, sugar of milk 80 parts. Dose gr. $\mathrm{v}-\mathrm{xv}$. O. et Ipecacuanhæ, Tinct., contains deodorized tincture of opium Ioo parts evaporated to 85 , fl. ext. ipecac Io, dilute alcohol q. s. ad Ioo. Dose m v$\mathrm{xv}$. O., Ext., an aqueous extract containing glycerin. Dose gr. $1 / 4-\mathrm{j}$. O., Liniment $\left(B . P_{.}\right)$, contains tinct. opii and soap-liniment. O., Ext., Liq. ( $B . P_{\text {. }}$ ) Dose $\mathrm{m}$ iv-xx. O., Liq., Comp., compound solution of opium, unof., strength Io per cent. Dose $m_{\mathrm{v}-\mathrm{xx} \text {. }}$ O., Pil., each contains I gr. opium with $1 / 4$ gr. soap. Dose j-iij. O., Pulv., powdered opium ; should contain I 2-16 per cent. of morphin. Dose gr. ss-iij. O., Pulv., Comp. $(B . P$.). Dose gr. ij-v. O., Tinct., Ammon. (B.P.) Dose $3^{\mathrm{ss}-\mathrm{j} .}$ O., Tinct., Camph. (Tinct. camphor. comp., B. P.), camphorated tincture of opium, paregoric; contains opium, benzoic acid, camphor, oil of anise àā 4 , glycerin 40 , dil. alcohol ad Iooo parts. Dose, for an infant, gtt. $\mathrm{v}-\mathrm{xx}$; for an adult, $3 \mathrm{j}-\mathrm{iv}$. O., Tinct., Comp., Squibb's diarrhea-mixture, contains laudanum, spt. of camphor, and tinct. capsicum, āā $\bar{\jmath}$, pure chloroform 3 iij, stronger alcohol q. s. ad $3 \mathrm{v}$. Dose gtt. $x-3$ j. O., Tinct., Deodorata, McMunn's elixir, an aqueous extract shaken with ether, the residue being dissolved in water and alcohol. Opium-strength Io per cent.
Dose $m_{v-x x}$ O., Tinct., laudanum, contains ro per cent. of opium. Dose $\eta_{v-x x}$. O., Trochis. (B.P.) Each contains gr. $\frac{1}{10}$ of opium. Dose $\mathrm{j}$-iv. O., Vinum, wine of opium, Sydenham's laudanun, a vinous tincture, with cinnamon and cloves; opiumstrength Io per cent. Dose $\eta_{v-x x}$ O.-eater, one addicted to the use of opium as a stimulant. O.-eating, the habitual use of opium as a stimulant and narcotic. O.-habit. See Morphiomania. O.-lini= ment, an anodyne liniment made of soap-liniment and laudanum. O.-plaster, the Emplastrum opii of the U. S. Pharmacopeia. O-smoking, the inhalation of the fumes of burning opium for the purpose of experiencing the exhilarating effects so produced.

Opiumism $\left(o^{\prime}-p e-u m-i z m\right)$ [ö $\pi \iota \nu$, poppy-juice]. The symptoms of chronic opium-poisoning.

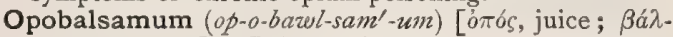

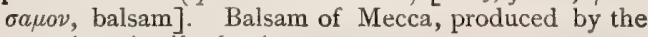
tree Amyris gileadensis.

Opocalpason, Opocalpasum (op-o-kal'pas-on, op-o-

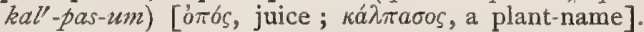
A variety of gum-arabic.

Opocephalus $\left(o p-o-s e f^{\prime}-a l-u s\right)[\ddot{\omega} \psi, \dot{\omega} \pi \delta \zeta$, the eye ; $\kappa \varepsilon \phi$ $a \lambda \dot{\eta}$, head]. A variety of single autositic monsters, of the species otocephalus, in which there is synopsia, with the characteristics of otocephalus, but with the absence of both mouth and proboscis.

Opodeldoc $\left(o p-o-d e l^{\prime}-d o k\right)$ [origin obscure]. Soap-liniment. See Sapo.

Opodidymus $\left(o p-o-d i d^{\prime}-i m-u s\right)$ [ $\omega \psi$, eye ; $\left.\delta i \delta v \mu o s, t w i n\right]$. A monosomic dual monstrosity with the heads united behind, but with two faces; the eyes vary in number.

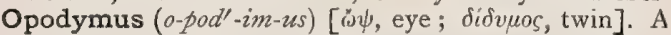
term for a monstrosity with a single body and skull, but with two distinct faces.

Opopanax (o-pop'-an-aks) [ómós, juice; $\pi a ́ v a \xi$, an allhealing plant]. I. A genus of umbelliferous plants. 2. The gum-resin afforded by $O$. chironium, a plant of the Mediterranean region; it is used like asafetida, but is inferior to it. Dose, Io-30 gr. Unof.

Opotomocatheter (o-pot-o-mok-ath'-et-er) [onj, opening; $\tau о \mu \eta \dot{\eta}$, a cutting; $\kappa \alpha \theta \varepsilon \tau \dot{\eta} \rho$, catheter]. An elastic catheter with a stylet.

Oppilation (op-il-a -shun) [oppilatio, closure]. Closure; constipation.

Oppilative $\left(o p^{\prime}-i l-a-t i v\right)$ [oppilatis, closure]. I. Obstruction; closing the pores; causing constipation. 2 . A constipating agent or remedy.

Opponens (op-o'-nenz) [ob, against; ponere, to place]. Opposing; a descriptive term applied to certain muscles that bring the thumb and fingers in juxtaposition.

Opposite (op'-o-zit) [oppositus, placed against]. $\mathbf{r}$. Opposed to. 2. As a noun, the similar part in the remaining half of the body; platytrope; lateral homologue; fellow of the remaining side; and in general, whether referring to the names of parts or to terms of position and direction, the opposite is either member of a symmetrically placed pair, as the right hand is the opposite of the left, the term ventral of dorsal, lateral of mesal, afferent of efferent, etc. O. Standing, in massage, leaning forward and resting the elbows or forearm on some object at about the level of the nipple.

Oppositifolius (op-oz-it-if-o'-le-us) [oppositus, opposite ; folium, leaf]. In biology, situated opposite a leaf.

Oppositipetalous (op-oz-it-ip-et'-al-us) [oppositus, opposite; $\pi \varepsilon ́ \tau a \lambda o \nu$, a leaf]. In biology, placed opposite a petal.

Oppositipinnate (op-oz-it-ip-in'-ät) [oppositus, opposite ; pinna, a feather]. In biology, applied to a pinnate leaf in which the folioles are opposite to each other. 
Oppositisepalous (op-oz-it-is-eppl-nl-us) [opfositus, opposite; sepalum, a sepal]. In biology, placed opposite a sepal.

Oppression (op-resh'-un) [oppressio; opprimere, to bear against]. Any sensation of pressure or weight upon any part, especially the chest

Oprescu and Babes, Bacillus of. See Bacteria, Synonymatic Table of.

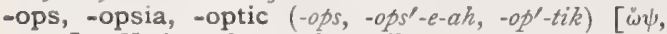
eye]. Variant forms of a suffix denoting connection with or relation to the eye.

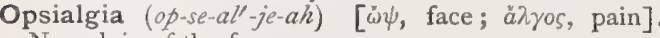
Neuralgia of the face.

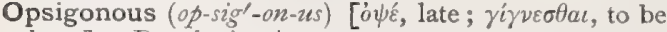
born]. Developing late.

Opsiodont (opp'se-o-dont) [ö $\psi \iota s$, eye ; ódoús, tooth]. An eye-tooth.

Opsiometer (op-se-om'-et-er) [ö $\psi \sigma \iota \varsigma$, sight; $\mu \dot{\tau} \tau p o \nu$, measure]. The same as Optometer.

Opsionosis $(o p$-se-on'-o-sis) [õ $\psi \varsigma$, sight ; vóros, disease]. A disease of the eye, or of vision.

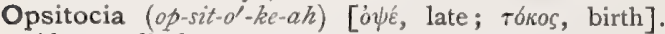
Abnormally long pregnancy.

Opsomania (op-so-ma'-ne-ah) [ö $\psi$ ov, dainty food ; $\mu a v i a$, mania]. Insane desire for dainty food, or for some special food.

Opsomaniac $\left(o p-s o-m a^{\prime}-n e-a k\right)$ [ö $\psi o v$, dainty food; uavia, mania]. One affected with opsomania.

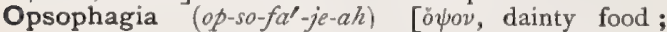

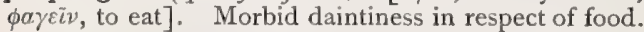

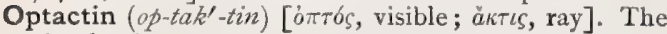
visual axis.

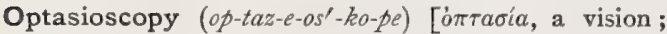
$\sigma \kappa o \pi \varepsilon i v$, to view]. The testing of retinal perception without the action of light, but by pressure or electricity, subjective sensations of light being produced.

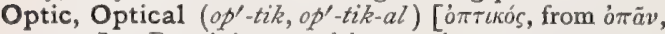
to see]. Pertaining to vision or its organ, or to the science of optics. O. Angle. See Angles, Table of. O. Atrophy, atrophy of the optic nerve. See Atrophy. O. Axis, the axis of the eye. O. Center, the point in the main axis of the crystalline lens at which the rays of light meet. Also applied to the nervous center concerned in the visual function. O. Chiasm. See Commissure, Optic. O. Commissure. See Commissure. O. Cup, the concave area formed by the involution of the distal extremity of the primary optic vesicle. O. Disc. See Disc. O. Foramen. See Foramina, Table of. $\mathbf{O}$. Groove, the groove on the sphenoid bone for the optic chiasm. See Groore. O. Lobes, the corpora quadrigemina. O. Nerve. See Nerves, O. Neuritis. See Papillitis. O. Papilla. See Disc, Optic. O. Radiations, the term given by Gratiolet to the large fasciculus of nerve-fibers joining the corona radiata of the optic thalamus and the occipital lobe of the cerebrum. O. Section. See Section. O. Stalk, a soft process on the head of molluscs supporting an eye; an ommatophore. O. Thalamus. See Thalamus. O. Tract. See Tract. O. Vesicle, in embryology, a diverticulum from each side of the primary anterior vesicle, which forms the basis of the future eye.

Optically $\left(o p^{\prime}-t i k-a l-e\right)$ [órtıkós, from ó $\pi a \tilde{\nu}$, to see]. In accordance with the science of optics; by optic means. O. Active, a qualification applied to many carbon compounds, liquid and solid, capable of rotating the plane of polarized light.

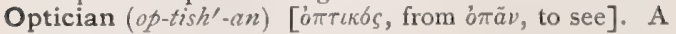
maker of optic instruments.

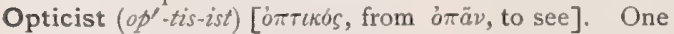
skilled in optics.

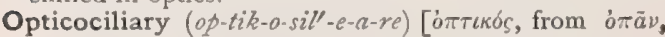

to see; cilium, hair]. Pertaining to the optic and ciliary nerves.

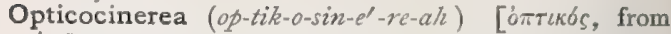
$0 \pi a ̈ \nu$, to see; cinereus, resembling ashes]. The gray matter of the optic lobes.

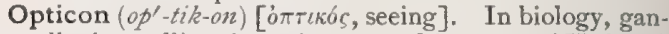
glionic swelling in optic nerve of insects. (Hirkson.) Opticopupillary (op-tik-o-pu'-pil-a-re) [brtikós, from órav, to see; propilla, pupil]. Relating to the pupil and the optic nerve.

Optics (oṕlitis) [ó $\pi \tau \iota k o ́ s$, from ó $\pi \tilde{a} v$, to see]. That branch of physics treating of the laws of light, its refraction and reflection, and of its relation to vision. See Dioptrics.

Optimism (op'-tim-izm) [optimus, best]. Delusional exaltation; delirium of grandeur; amenomania.

Optimum (op'-tim-um) [optimus, best]. In biology, that temperature at which vital processes are carried on with the greatest activity. Midway between the minimum, or lowest endurable, and maximum, or highest endurable, temperatures.

Optocele (oppl-to-sél). See Paraqueduct.

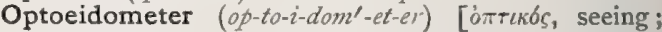

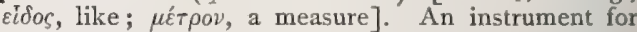
testing the acuity of vision and the refraction of the eye.

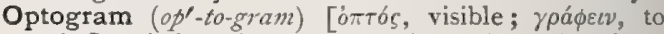
write]. A faint image stamped on the retina for a brief period after death, believed to be that of the last object seen before death.

Optograph (op'-to-graf). See Optogram.

Optomeninx (op-to-men'-inks). Synonym of Retina.

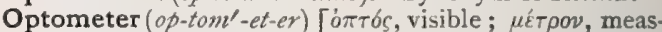
ure]. An instrument for facilitating the measurement of the refraction of the eye.

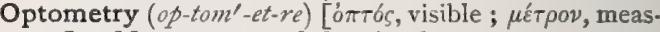
ure]. Measurement of the visual powers.

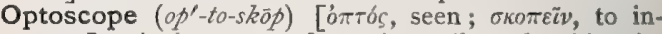
spect]. An instrument for testing unilateral amblyopia.

Optostriate (op-to-stri'-ät) [ómtós, visible; striatum, striped]. Pertaining to the optic thalami and the corpora striata. O. Body, a thalamus and a striatum considered as forming a unit.

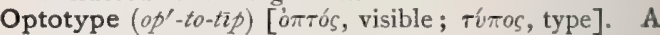
test-type used in testing the acuity of vision.

Opuntia (o-pun'-te-ah) [opuntius, relating to Oprus, a town of Greece]. Prickly pear; a genus of cactaceous plants represented by numerous species, many of which, as $O$. reticulata and $O$, tuna, have slight medicinal properties, the former being anthelmintic, purgative, and locally sedative; the latter has been used for palpitation of the heart. Unof.

Ora $\left(o^{\prime}-r a h\right)[1 .$.$] . Margin. O. serrata, the serrated$ endings of the zonule of Zinn, or ligament of the lens, and the retina.

Orad $\left(o^{\prime}-r a d\right)[o s$, oris, mouth $]$. Toward the mouth, or the oral region.

Oral $\left(o^{\prime}-r a l\right)[o s$, oris, the mouth]. In biology, situated on the same side as the mouth; actinal ; opposed to aboral, abortinal, anal. O. Catarrh. Synonym of Stomatitis catarrhalis. O. Whiff. See Whiff.

Orange $\left(o r^{\prime}\right.$-anj). See Aurantium and Pigments, Conspectus of. O. Colors. See Pigments, Conspectus of. O.-grass, a small North American plant, Hypericum sarothra; pineweed; a popular remedy for colds and catarrhs. Unof. O. Minium. Same as Minium. O. Ocher. Same as Ocher. O.-peas: 1. The seeds of the orange dried and used for issue-peas. 2. Small unripe dried oranges, used in the flavoring of liqueurs. O. Sarcina, See Sarcina. O.-skin, a yellowish tinge of the skin observed in newly-born infants.

Orangeade $\left(o r-a n j-\vec{a} d^{\prime}\right)$ [ME, orenge, orange]. A drink made of orange-juice and sweetened water. 
Orarians (or-ar'-e-ans) [orarius, of, or belonging to, the coast ]. In ethnology, a collective term proposed by Dall for the Aleuts and people of Innuit stock, as indicative of their coastwise distribution and as desig. nating a well-defined race.

Orbicular (or-bik'-u-lar) [orbiculus, dim. of orbis, circle]. Having a circular shape. A term applied to the circular muscles of the eyelids and the mouth. $\mathbf{O}$. Bone. See Bones, Table of.

Orbicularis (or-bik-u-la'-ris). See Muscles, Table of:

Orbiculate (or-bik'-u-lät). Same as Orbicular.

Orbit (or'-bit) [orbita, from orbis, circle]. The bony pyramidal cavity in which the eyeball is suspended. Seven bones enter into its formation, its somewhat indeterminate sides being called the roof, the floor, the inner and outer walls.

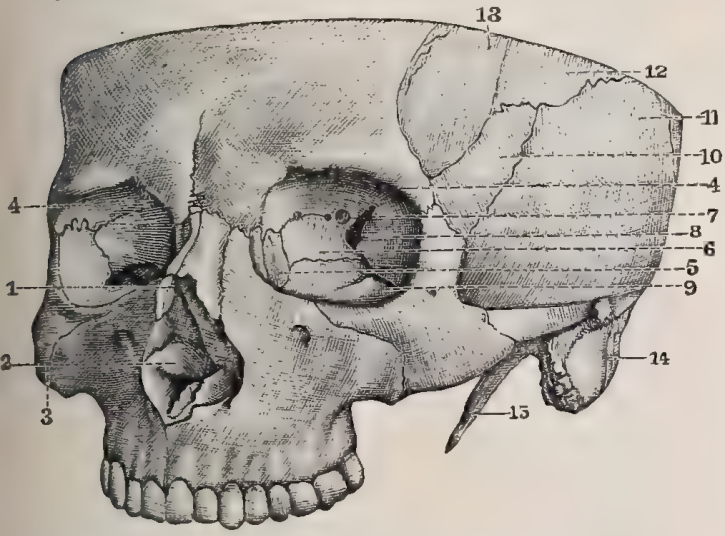

THE ORBITS.

1. Anterior orifice of nasal fossae. 2. Anterior extremity of infericr turbinated bone. 3. Malar bone. 4. Orbital cavity. 5. Lacrymal fossa, at base of which may be seen the line of union of the ascending process of the superior maxilla with the os unguis. 6. Os planum, forming with this bone the internal wall of the orbit. 7. Optic foramen. 8. Sphenoid fissure. 9. Spheno-maxillary fissure, continuous posteriorly fissure. 9. Spheno-maxillary fissure, continuous posteriorly
with the preceding. Io. Upper portion of the great wing of the sphenoid. II. Squamous portion of temporal. I2. Antero-inferior angle of parietal. I3. Part of frontal which contributes to form the temporal fossa. I4. Mastoid process. 15. Styloid process.

Orbita $\left(o r^{\prime}\right.$-bit-ah) [orbis, a circle, orbit: pl., Orbita]. The same as Orbit.

Orbital (or'-bit-al) [orbita, from orbis, circle]. I. Pertaining to the orbit. 2. The orbital portion of the orbicularis palpebrarum. O. Arch, the upper margin of the orbit. O. Breadth, in craniometry, the distance between the middle points of the inner borders of the orbits. O. Fascia, the capsule of Tenon. O. Fissure. See Fissures, Table of. O. Fossa, the cavity of the orbit. 0 . Height, in craniometry, the greatest vertical width of the external opening of the orbit. O. Index. See Index. O. Plane. See Plane. O. Plate: I. That part of the frontal bone helping to form the roof of the orbit. 2. That part of the ethmoid bone helping to form the inner wall of the orbit. $O$. Point, the lowest point on the inferior margin of the orbit. $\mathbf{O}$. Process : $\mathbf{I}$. The orbital portion of the malar bone. 2. The orbital portion of the palate bone. O. Ridge, the free edge of the nasal process of the superior maxilla. $O$. Surface, that portion of the superior maxilla that helps to form the floor of the orbit. O. Vault, the roof of the orbit.

Orbito- $\left(o r^{\prime}-\right.$ bit-o- $)$ [orbita, orbit]. A prefix denoting relation to the orbit. O.-basilar, both orbital and basilar. O.-b. Angle, the angle formed between the line continuing the axis of the orbit and one tangent to the lower border of the inferior maxilla O.-malar, pertaining to both the orbit and the malar bone. $\quad 0 .-m$. Index, in craniometry, the ratio existing between the bizygomatic diameter of the face, and the superior facial diameter, the latter being taken as IOo. O.-nasal, pertaining to both orbit and nose. O.-occipital, pertaining to both orbit and occipital bone. O.-o. Angle, in craniometry, the angle formed between the optic axis and the plane of the foramen magnum. O--ocular, pertaining to both orbit and eye. O.-palpebral, pertaining both to the orbit and the eyelids, O.-sphenoid: I. Pertaining both to the orbit and to the sphenoid bone. 2. The lesser wing of the sphenoid bone; in some animals, and in early human life, it is a separate bone.

Orbitocele (or'-bit-o-sél) [orbita, orbit; $\kappa \eta \dot{\eta} \lambda \eta$, tumor]. I. A tumor of the orbit. 2. The same as Exophthalmos.

Orceic Acid (or'-se-ik). Synonym of Orcein.

Orcein $\left(o r^{\prime}-\right.$ se-in) [Orcus, Pluto, from its dark color], $\mathrm{C}_{7} \mathrm{H}_{7} \mathrm{NO}_{3^{*}}$ A dark-red substance derived from orcin.

Orcheitis $\left(o r-k e-i^{\prime}-t i s\right)$. Synonym of Orchitis.

Orchella (or-kel'-ah). See Orchil.

Orchellin (or-kell-in) [after Oricellari, a chemist]. A purple dye found in Roccella tinctoria.

Orchemphraxis (or-kem-fraks'-is). Same as Orchidemphraxis.

Orcheocele (or'-ke-o-sél). See Orchiocele.

Orcheodesmosarcoma (or'-ke-o-dez'-mo-sar-ko'-mah)

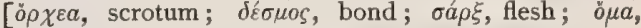
tumor]. Scrotal elephantiasis.

Orcheoplasty (or'-ke-o-plas-te). See Orchioplasty.

Orcheotomy (or-ke-ot'-o-me). See Orchotomy.

Orchestromania (or-kes-tro-ma'-ne-ah) [o $\rho \chi \varepsilon i ̄ \sigma t a \iota$, to dance; $\mu a v i a$, madness]. Dancing mania; chorea, or St. Vitus' dance.

Orchi-, less correctly Orchid- $\left(o \gamma^{\prime}-k e-, o \gamma^{\prime}-k i d-\right)$ [ö $\rho \chi \varsigma$, testicle]. A prefix signifying connection with, or relation to, the testicles.

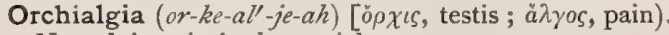
Neuralgic pain in the testicle.

Orchic $\left(o r^{\prime}-k i k\right)$ [o $\rho \chi \iota s$, testicle]. Pertaining to the testicle.

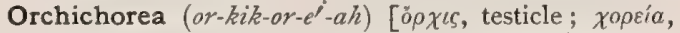
dance]. Irregular movements of the testicle due to contraction of the cremaster muscle.

Orchid $\left(o r^{\prime}-k i d\right)$ [o $\rho \chi \iota \varsigma$, testicle]. Any orchidaceous plant; a plant of the orchis family or order. Orchids are of many species and genera, and are mostly tropical. Salep and vanilla are produced by plants of this order. Faham, cypripedium, and a few others are employed in medicine.

Orchidalgia (or-kid-all-je-ah). Synonym of Orchialgia.

Orchidatonia (or-kid-at-o'-ne-ah) [ $\sigma^{\prime} \rho \chi \iota \zeta$, testicle; árovía, atony]. Atony of the testicle; laxness of the testicle.

Orchidatrophia (or-kid-at-ro'-fe-ah) [oั $\rho \chi \iota \varsigma$, testicle ; átpoфia, atrophy]: Atrophy of the testicle.

Orchidauxe (or-kid-azoks'-e) [o $\rho \chi \iota s$, testicle; av $\xi \eta$, growth]. Hypertrophy of the testicle.

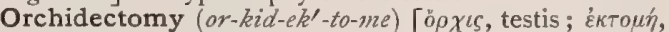
excision]. Surgical removal of a testis; castration.

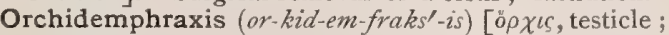
$\varepsilon \check{\varepsilon} \phi \rho a \xi \iota$, stoppage]. Obstruction of the vessels of the testis.

Orchidion (or-kid'-e-on) [dim. of ö $\sigma \chi \varsigma$, testicle]. A small testicle.

Orchiditis (or-kid-i'-tis). Synonym of Orchitis.

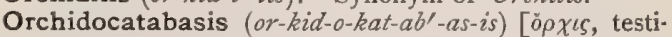

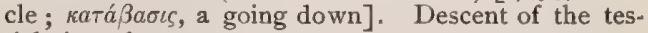
ticle into the scrotum. 
Orchidocele (or-kid'-o-sêl). Synonym of Orchiocele.

Orchidodynia (or-kid-o-din'-e-ah). Synonym of Orchiodynia.

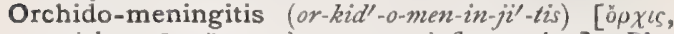
testicle ; $\mu \tilde{\eta} \nu \iota \gamma \xi$, membrane; $\iota \tau \iota$, inflammation]. Blasius' term for the ordinary form of hydrocele.

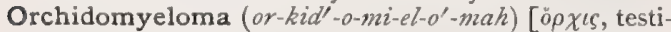

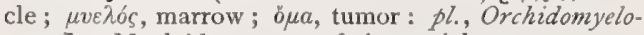
mata]. Myeloid sarcoma of the testicle.

Orchidoncus (or-kid-ong'-kus) [ö $\rho \chi \iota s$, testicle; ő $\gamma \kappa o \zeta$, tumor]. A tumor or tumefaction of the testicle.

Orchidopexia (or-kid-o-peks'-e-ah). See Orchidopexy.

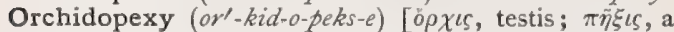
hardening]. I. Hardening of the substance of the testicle. 2. Same as Orchidorraphy.

Orchidorrhaphy (or-kid-or'-a-fe) [o $\rho \chi \iota s$, testicle ; $\rho a ́ \phi \eta$, suture]. Stitching of the testicle to the surrounding tissues.

Orchidoscheocele (or-kid-os'-ke-o-sēl) [ö $\rho \chi \iota s$, testicle ; ŏ $\sigma \chi \eta$, scrotum; $\kappa \dot{\eta} \hat{\lambda} \eta$, tumor]. A scrotal hernia with enlargement of the testicle.

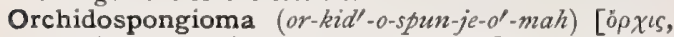
testicle; $\sigma \pi o \gamma \gamma \iota a ́$, sponge; $\ddot{\mu} \mu a$, tumor]. A tuberculous tumor of the testicle.

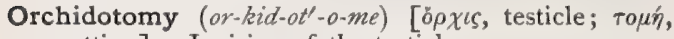
a cutting]. Incision of the testicle.

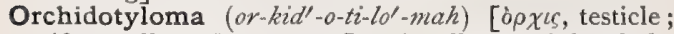
tìnos, callus; ó $\mu a$, tumor]. A callous nodule of the testicle.

Orchiectomy (or-ke-ek'-to-me). Synonym of Orchidectomy.

Orchiepididymitis (or'-ke-ep-id-id-im-i'-tis) [ŏ $\rho \chi \iota s$, testicle ; $\dot{\pi} \pi \iota \delta \delta v \mu i s$, epididymis; $\iota T \iota s$, inflammation]. Inflammation of both testis and epididymis.

Orchil (or'-kil). See Archil. O.-purple. See Pigments, Conspectus of.

Orchilla (or-kil'-ah). See Archil.

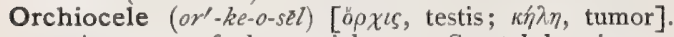
I. A tumor of the testicle. 2. Scrotal hernia. 3. A name loosely applied to several different diseases of the testicles and their envelops.

Orchiococcus (or-ke-o-kok'-us). See Diplococcus of Orchitis under Bacteria, Synonymatic Table of.

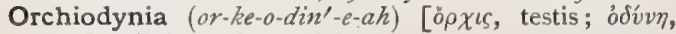
pain]. Pain in the testicles.

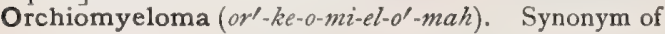
Orchidomyeloma.

Orchioncus (or-ke-ong'-kus). Synonym of Orchidoncus.

Orchioneuralgia (or-ke-o-nu-ral'-je-ah). Synonym of Orchialoia.

Orchioplasty (or'-ke-o-plas-te) [oo $\rho \chi \varsigma$, the testicle; $\pi \lambda a \dot{\sigma \sigma \varepsilon} \varepsilon \nu$, to form $]$. The surgical repair following the loss of any part of the scrotum from disease, by supplying flaps of healthy tissue from an adjacent part.

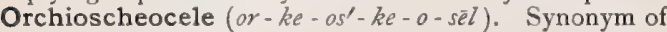
Orchidoscheocele.

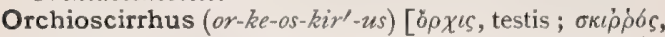
induration]. A hard carcinomatous tumor of the testicle.

Orchiotomy (or-ke-ot'-o-me). Synonym of Orchidotomy.

Orchirrhaphy (or-kirl-af-e). Synonym of Orchidorrhaphy.

Orchis (or'-kis) [ooxıs, testis]. I. The typical genus of the family of orchidaceous plants. 2. The testicle. See Orchid.

Orchitis (or-ki'-tis) [ $\delta \rho \chi \iota \varsigma$, testis; $\iota \tau \iota \varsigma$, inflammation]. Inflammation of the testicle.

Orchitomy (or-kit'-o-me). Synonym of Orchotomy.

Orchocele $\left(o r^{\prime}-k o-s e l\right)$. Synonym of Orchiocele.

Orchos (or'-kos) [ŏ $\rho \chi o \varsigma$, tarsus]. The tarsal cartilage.

Orchotomy (or-kot'-o-me) [o $\rho \chi \iota s$, testis ; touń, a cut ting]. I. Castration. 2. [o $\rho \chi 0 s$, tarsus ; $\tau о \mu \eta \dot{\eta}$, a cutting]. Removal of the tarsal cartilages.

Orcin $\left(o r^{\prime}-\sin \right)$ [Orcus, Pluto, from its dark color], $\mathrm{C}_{7} \mathrm{H}_{6}(\mathrm{OH})_{2}$. Orcinol; a substance found in many lichens of the genera Roccella and Leconora. It crystallizes in colorless, six-sided prisms, containing one molecule of water; it is readily soluble in water, alcohol and ether, and has a sweet taste. It melts at $56^{\circ} \mathrm{C}$, and boils at $290^{\circ} \mathrm{C}$. It yields azo-coloring substances with diazo-compounds. See Pigments, Conspectus of.

Orcinol (or'-sin-ol). See Orcin.

Ord's Theory. A theory of the origin of gout. It is that there is a tendency, inherited or acquired, to a special form of tissue-degeneration.

Ordeal Bark (or'-de-al bark) [ME, ordal, a judgment]. See Casca. O. Bean, O. Nut. See Physostigma. O.-tree. See Cerbera (of Madagascar). Also, the Erythrophlaum guinense.

Order $\left(o r^{\prime}\right.$-der) [ordo, a rule]. Systematic arrangement. In biology, the taxonomic group below a Class and above a Family.

Ordinary (or'-din-a-re) [ordinarius, regular]. Usual; regular. O. Ray. See Ray.

Ordinate (or'-din-ät) [ordinare, to order, ordain]. In biology, placed in regular rows or series.

Ordure $\left(o r^{\prime}-d \bar{u} r\right)[\mathrm{ME}$., ordure, filth]. Dung; excrement ; feces.

Orectic (or-ekl-tik) [o $\rho \varepsilon \xi \xi \varsigma$, appetite]. Stimulating appetite.

Oregon Grape. See Berberis.

Orellin (o-rel'-in) [orellina]. A yellow coloring-matter found in Annatto. See Pigments, Conspectus of.

Orexegen $\left(o-r e k s^{\prime}-e j-i n\right)$. See Orexin.

Orexin (o-reks'-in) [ŏ $\rho \xi \xi \iota$, appetite], $\mathrm{C}_{14} \mathrm{H}_{12} \mathrm{~N}_{2}$. $\mathrm{HCl}$.$2 \mathrm{H}_{2} \mathrm{O}$. Hydrochlorate of phenyl-di-hydro-quinazolin ; a chinolin-preparation, of some repute as a stomachic. It is useful in anorexia not dependent upon gastric disease proper. Dose gr, ij-v in wafer or pill. Unof.

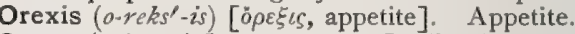

Organ (or'-gan) [opyavov, organ]. In biology, any part of the body having a determinate function; a complex of similar or dissimilar cells or tissues that perform in common one or more vital functions. O., Accessory, an organ that has a subordinate importance in the carrying on of a particular function, but which under certain conditions may act as a substitute for an im. portant organ. O.-albumin, the albumin that constitutes a part of the solid tissues. O. of Bojanus, the renal organ of molluscs, found in the majority of lamellibranchs. O. of Corti. See Corti. O., Cup-shaped, one of the organs of taste in Vermes; widely scattered over them in the integument, but especially numerous at the edge of the mouth. O's., Digestive, the digestive tract and its glands. O. of Eimer, a tactile organ in the nose of the mole, consisting of a group of terminal nerve - fibrils. 0 . Enamel, a club-shaped process of epithelium growing from the dental ridge and forming a cap over the dental papilla. From it the enamel of the tooth is developed. O. of Gegenbauer, one of

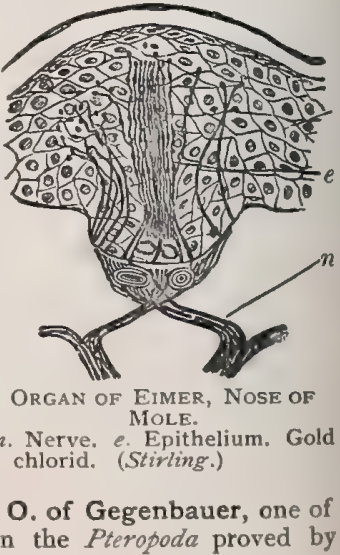


Spengel to have an olfactory function. O. of Giraldès, the paradidymis. O., Goblet-shaped, one of the large rod-shaped end-organs of nerves, observed in the skin of the teleostei and sturgeons. O., Jacobson's, a short cul-de-sac extending along Stensen's duct, lined by epithelium continuous with that of the nasal mucous membrane. It is well developed in some lower animals, in which it is believed to have an olfactory function. O's., Lateral: (a) Segmentally arranged, retractile sensory organs occurring among Vermes only in the Chatopoda. They carry sensory hairs connected on the one hand with transverse musclefibrillæ and on the other with a plexus of ganglion-cells joined by a special nerve to the ventral cord; their function is unknown. (b) A series of nerve end-organs in the "mucous canals" in the head and lateral line of fishes and amphibians. O's., Mayer's, a series of slit-like depressions on the side of the tongue of certain mammals, first discovered by C. Mayer in the African elephant; afterward found in the Uakari monkeys (Pithekia satanis); I5 slits in front of the palato-glossal fold. O's., Pelvic, those organs situated in the pelvis. O's. of Reproduction, the testicles and penis and its glands in the male, the uterus and its appendages and the vagina and its glands, in the female. O's., Respiratory, the nose, pharynx, larynx, trachea, lungs, and glands connected with these different parts. O. of Rosenmüller. See Parovarium. O., Segmental, a mesoblastic embryonic structure consisting of three parts-the pronephros, the mesonephros, or Wolffian body, and the metanephros. O's. of Semper, glandular structures found in gasteropods, well developed at the sides of the mouth in Limax. According to Sochaczewer, they are not olfactory in function. O's. of Special Sense, those parts of the body endowed with highly specialized functions and through which perceptive impressions are received: the eye, ear, skin, mucosa of the mouth and nose are the principal. $O$. of Syrski, the male organ of the eel discovered by Syrski in 1873 .

Organa (or'-gan-ah) [L.]. Plural of Organum. O. palpantia, tactile organs. $O$. urticantia, the nematophores or nematillæ of Calenterates.

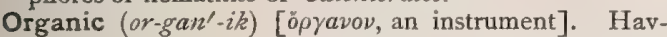
ing, pertaining to, or characterized by, organs; pertaining to the animal and vegetable worlds; exhibiting animal or vegetable characteristics. 0 . Cell, the structural element which is regarded as the basis of the structure of all organized bodies. O. Chemistry, the chemistry of the carbon compounds. O. Constituents. See Constituent. O. Disease, disease of an organ attended with structural changes. $O$. Molecules, Doctrine of, Buffon's hypothesis that life is the indefeasible property of certain indestructible molecules of matter, which exist in all living things, and have inherent activities by which they are distinguished from non-living matter. Each individual living organism is formed by theit temporary combination; they stand to it in the relation of the particles of water to a cascade, or a whirlpool ; or to a mold into which the water is poured. The form of the organism is thus determined by the reaction between external conditions and the inherent activities of the organic molecules of which it is composed; and as the stoppage of a whirlpool destroys nothing but a form and leaves the molecules of the water with all their inherent activities intact. so what we call the death and putrefaction of an animal, or of a plant, are merely the breaking up of a form, or manner of association, of its constituent molecules, which are then set free as infusorial animalcules. It will be perceived that this doctrine is by no means identical with $A b i o$. genesis, with which it is often confounded (Huxley). O. Reflexes, those pertaining to the acts of micturition, erection, ejaculation, defecation, digestion, respiration, etc.

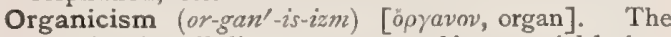
doctrine that all diseases are caused by material lesions of one or more organs.

Organisata (or-gan-is- $\left.a^{\prime}-t a h\right)$ [neut.: pl. of Organisatus, organized]. In biology, any or all organisms.

Organism (or'-gan-izm) [opyavov, organ]. A living being, animal or vegetable, simple or composed of many organs; also the assemblage of organs constituting a living being. O., Micro-, a minute or microscopic body or organism; a schizomycete; a bacterium.

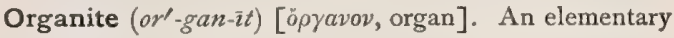
organ.

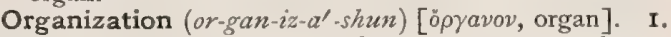
The orderly arrangement of organs or parts; also an organism. 2. The conversion of something into, or its replacement by, living tissue-as the organization of a thrombus.

Organo-chemistry (or'-gan-o-kent'-is-tre). See Organic Chemistry.

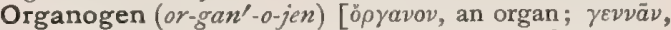
to beget]. A compound containing carbon, hydrogen, oxygen, and nitrogen.

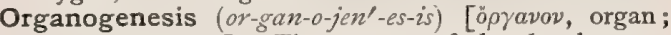
$\gamma \varepsilon \nu v a \tilde{\nu}$, to beget]. The process of the development and growth of an organ. The same as Organogeny.

Organogenetic (or-gan-o-jen-et'-ik) [ö $\rho$ y vov, organ; $\gamma \varepsilon \nu v a \tilde{\nu}$, to beget]. Pertaining to organogenesis.

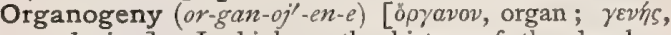
producing]. In biology, the history of the development of organs.

Organographism (or-gan-ogf-raf-izm) [ö $\rho$ yavov, an

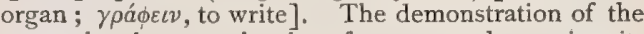
successive increase in size of an organ, by tracing its outlines upon the skin.

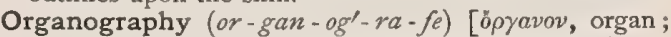
$\gamma \rho a ́ \phi \varepsilon \iota \nu$, to write]. A descriptive treatise of the organs of an animal or plant.

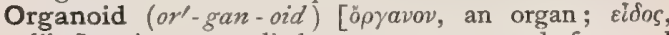
like]. A term applied to tumors composed of several tissues and resembling an organ, as carcinoma, which somewhat resembles an epithelial gland.

Organoleptic (or-gan-o-lep'-tik) [opyavov, organ; $\lambda \eta \pi$ -

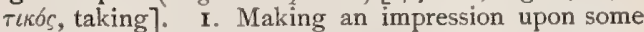
organ, chiefly of special sense. 2. Plastic; capable of receiving organization.

Organologic (or-gan-o-loj'-ik) [ö $\rho \gamma a v o v$, organ; $\lambda 6 \gamma o s$, science]. Pertaining to organology.

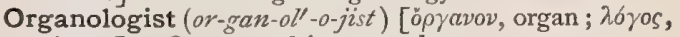
science]. One versed in organology.

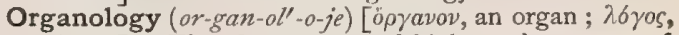
science]. The department of biology that treats of the organs of plants and animals.

Organon (or'-gan-on) [öpyavov, an organ; instrument]. A code of principles.

Organonomy (or-gan-on'-o-me) [ö $\rho \gamma a v o v$, organ; vóuos, law]. The totality of the natural laws of the conduct and functions of organic life.

Organonym (or-gan'-o-nim) [ö $\rho \gamma a \nu o \nu$, an organ; ovvนa, name]. The name of an organ or part.

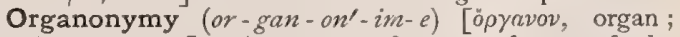
ovv $\mu \alpha$, name]. A system of nomenclature of the organs.

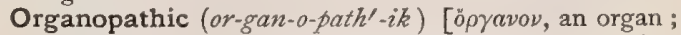
$\pi \alpha$ Áos, disease]. Pertaining to Organopathism and to Organopathy.

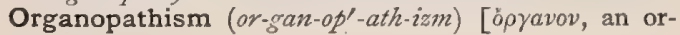


gan ; $\pi \dot{a} \theta 0 \varsigma$, disease]. The doctrine of special study and investigation of the pathology of each and every organ by itself.

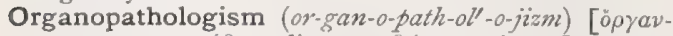

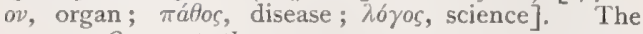
same as Organopathy.

Organopathology (or-gan-o-path-ol'-o-je) [öpyavov, or-

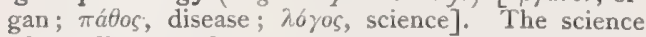
of the diseases of organs.

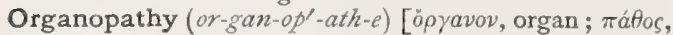
disease]. I. The disease of an organ. 2. A term used by Sharp to express the local action of drugs. 3 . The same as Organopathism.

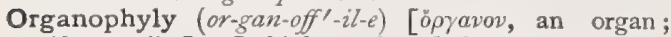

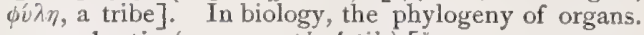

Organoplastic (or-gan-o-plas'-tik) [öpyavov, an organ; $\pi \lambda \alpha \sigma \sigma \varepsilon \varepsilon \nu$, to form, to mold]. In biology, applied to cells or tissues from which organs are developed.

Organoplasty (or'-gan-o-plas-te) [öpyavov, organ; $\pi \lambda a ́ \sigma \sigma \varepsilon \iota \nu$, to form, to mold]. In biology, the origin or development of plant and animal organs.

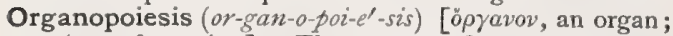

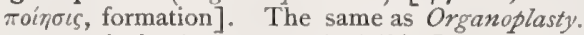

Organopoietic (or-gan-o-poi-et'-ik) [öpavov, organ;

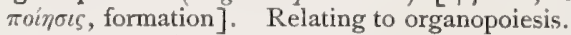

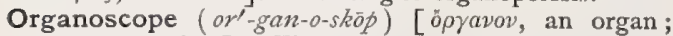
oкotriv, to view]. The same as Endoscope.

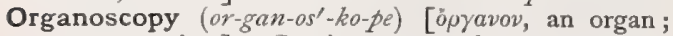

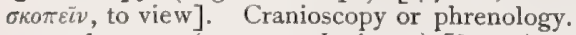

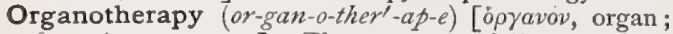
$\theta \varepsilon \rho a \pi \varepsilon \varepsilon a$, treatment]. The treatment of diseases by the administration of animal organs, or extracts prepared from them. Although organotherapy has existed in some form since the most ancient times, the method as now practised, is of recent origin. Brown-Séquard, in 1889 , suggested the employment of testicular juice in the treatment of the mental and physical deterioration incident to old age. Experiments which he had made upon himself had, he reported, yielded the most brilliant results. Physicians in different parts of France subsequently tested the properties of BrownSéquard's extract and found its dynamogenic action beneficial in diseases attended with debility, especially in senile changes, in pulmonary tuberculosis, leprosy, locomotor ataxy, general paralysis and anemia. Paul, in 1892 , under the name of nervous transfusion, advocated the hypodermatic use of an extract of sheeps' brain in conditions of neurasthenia. The method of preparation of the various extracts as employed in France is that suggested by d'Arsonval. The organ is removed with all possible antiseptic precautions, and is cut into small pieces of about one c.c. The segments are covered with pure glycerin and allowed to macerate for twenty-four hours. Before filtering, two or three parts of distilled water are added. Sterilization is accomplished by means of carbonic acid gas under pressure. The first step toward a rational application of the method of organotherapy was the subcutaneous transplantation of pieces of thyroid gland in cases of myxedema and cachexia strumipriva by Horsley and Kocher, and later the employment of extract of sheeps' thyroid in myxedema, the credit of which belongs to G. R. Murray, of Newcastle, England. Since Murray's announcement, in $\mathbf{I} 89 \mathbf{I}$, the method has been extensively tested in England and elsewhere; many cases of myxedema have been reported as improved, and not a few cured. Gratifying results have also been achieved in sporadic cretinism, and in psoriasis and other chronic affections of the skin. Various preparations of the thyroid gland have been employed, e.g., glycerin extracts, dry extracts in powder, and finally the uncooked or partially cooked gland has been used. In the particular case of myxedema neither the kind of preparation nor the mode of administration seems to be of much importance. The results have been practically the same whether a liquid extract was given by bypodermatic injection, or whether a dry extract was administered by the mouth. The fresh gland, slightly fried and seasoned, has also been used, and at present is preferred by many. The success attending thyroid-therapy in myxedema has led to the employment of many other organic extracts in diseases of corresponding organs. Extracts have been prepared from nearly every organ in the animal body ; thus there are on the market cerebrin, from the brain, medullin or myelin, from the cord, cardin, from the heart, musculin, from muscles, ossin, from bones, renin, from the kidneys, gastrin, from the stomach, pancreatin, from pancreas, ovarin, from the ovary, and testin, from the testis. Brainextract has been reported as beneficial in various organic and functional diseases of the nervous system, such as locomotor ataxy, bulbar palsy, general paralysis of the insane; also in epilepsy, neurasthenia, migraine, hysteria, hebephrenia, and other conditions. Heart-extract is recommended for cases of nervous prostration. It is said to raise the blood-pressure, augment the quantity of urine, and increase the number of red blood-corpuscles. In diseases of the muscular system, muscle-extract is also reported as of value. Extract of pancreas, containing the active ferments of the gland has been administered with doubtful success, in certain cases of diabetes mellitus, which disease, as is well known, is sometimes dependent upon morbid changes in the pancreas. Of all the extracts, that from the thyroid gland is still the one most successfully employed. Its use is not confined to the two diseases mentioned, myxedema and cretinism; it has also proved useful in diseases of the skin, in leukemia, and affections of the nervous system, both organic and functional. In exophtbalmic goiter the results have not been encouraging; the symptoms, were as a rule, not ameliorated, in some cases they were even intensified.

Organotrophic (or-gan-o-tro'-fk) [bojavov, organ; $\tau \rho \circ \phi^{\prime}$, nourishment]. Relating or belonging to the nourishment of organized tissue.

Organule $\left(o r^{\prime}-g a n-\bar{u} l\right)$. The same as Organite.

Organum (or'-gan-um) [L.]. See Organ.

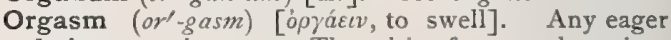
desire or excitement. The crisis of venereal passion. See Estrum.

Orgastic (or-gas'-tik) [o $\rho \gamma a \dot{\varepsilon} \varepsilon \nu$, to swell]. Pertaining to, or characterized by, orgasm.

Orgeat (or-gzah') [Fr. orge, Lat. hordeum, barley]. Pavy's recipe for a demulcent and nutritive drink: Blanch two ounces of sweet almonds and four of bitter almond-seeds; pound them into a paste with a little orange-flower water; rub this up with a pint of milk, diluted with a pint of water, until it forms an emulsion; strain and sweeten with sugar.

Orgosis (or-go'-sis). Synonym of Orgasm.

Oriental (o-re-en'-tal) [oriens, rising]. Pertaining to the Orient or east. O. Boil. See Furunculus orientalis. O. Plague. Synonym of the Plague, q.v. O. Sore, an endemic ulcer probably due to a specific microörganism, prevalent in the Orient. See Furunculus orientalis.

Orientation $\left(o-r i-e n-t a^{\prime}-\operatorname{sh} u n\right)$ [oriri, to rise (in the east)]. In biology: (a) The determination of the east point, and hence of the other points; the direction of a locality. The localization of oneself; the ascription of objects to the place in space where they actually belong, either with respect to each other (objective orienta- 
tion) or with reference to the observer (subjective orientation). False orientation is observed in some cases of monocular squinting paralysis, etc. (b) The homing instinct of animals. (c) The arrangement of tissues in the imbedding-mixture before sectioning.

Orifacial (or-if-a'-shal) [os, oris, mouth ; facies, face]. Pertaining to the mouth and face. 0 . Angle, in craniometry, the angle formed by the junction of the plane passing through the masticating surface of the superior maxilla with the facial line.

Orifice $\left(o r^{\prime}-i f\right.$-is) [orificium; os, oris, mouth ; facere to make]. A mouth or opening. O., Abdominal, the internal abdominal ring. O., Anal, the anus. O., Cardiac. The same as Cardia. O., Esophageal, the perforation in the diaphragm for the esophagus. O., Pyloric. The same as Pylorus. O., Tympanic, the oval opening of the atrium into which the tympanic'membrane is inserted.

Orificial (or-if-ish'-al) [orificium, an orifice]. Pertaining to an orifice of the body. O. Surgery, the surgery of the orifices of the body.

Orificium $\left(o r-i f-i s h^{\prime}-e-u m\right)$ [L.]. Orifice. O. epiploicum, a synonym of Foramen of Winslow. 0. infundibuli, a synonym of Helicotrema.

Oriform (or'-if-orm) [os, oris, mouth; forma, form]. Having the shape of a mouth.

Origanum (o-rig'-an-um) [oo'yavov, marjoram]. Wild marjoram. The leaves and stems of $O$. vulgare, with properties due mainly to a volatile oil. It is a tonic, stimulant, and carminative, and formerly was popularly used as an emmenagogue. Dose $\mathbf{3} \mathrm{j}$-ij in infusion. The oil is esteemed as an ingredient in liniments, especially in veterinary practice. Most of the commercial oil of origanum is in reality oil of thyme (Oleum thymi). The oil is also used in histology as a clearing-fluid for stained specimens.

Origin (or'-ij-in) [origo, originis, beginning]. The beginning or source of a muscle; its more fixed attachment, or that nearest the axis of the body. O., Apparent. See Superficial. O., Deep, or Ental, of a nerve, its origin in the cells of the nerve-center. O., Superficial, or Ectal, of a nerve, the point at which it emerges from the brain or cord.

Orinasal (o-rin-a $\left.a^{\prime}-z a l\right)$ [os, oris, mouth; nasus, nose]. Pertaining to the mouth and nose.

Orist $\left(o^{\prime}-r i s t\right)[o s$, oris, mouth]. A specialist in oristry.

Oristry ( $\sigma^{\prime}$-ris-tre) [os, oris, mouth]. A term proposed to designate the treatment, surgical, dental, or medical, of diseases of the mouth.

Orleans (or-lēnz'). Same as Annatto.

Ormsby's Inhaler. See Anesthetic.

Ornis (or'-nis) [opvis, a bird]. In biology, the avifauna of any region.

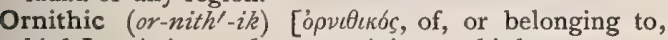
birds]. Avian; of, or pertaining to, birds.

Ornithin (or'-nith-in) [opvec, a bird], $\mathrm{C}_{5} \mathrm{~A}_{12} \mathrm{~N}_{2} \mathrm{O}_{2} . \quad \mathrm{A}$ base found in ornithuric acid.

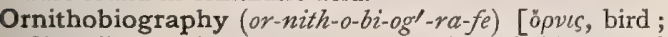

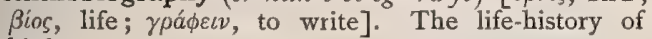
birds.

Ornithocephalous (or-nith-o-sef'-al-us) [opvıs, a bird; $\kappa \varepsilon \phi a \hat{n}$, head]. In biology, shaped like a bird's head.

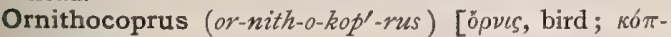
pos, dung]. Guano.

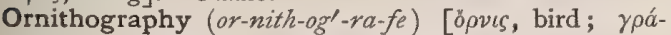
$\phi \varepsilon \iota \nu$, to write]. A description of birds.

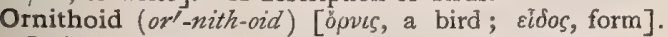
In biology, bird-like.

Ornithologist (or-nith-oll-o-jist) [öpvcs, bird; $\lambda 6 \gamma o s$, science]. One versed in ornithology.

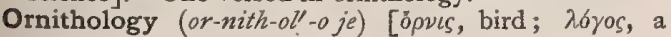

science]. The science of the nature and habits of birds.

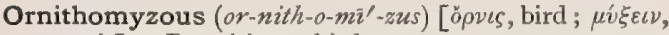
to suck]. Parasitic on birds.

Ornithophilous (or-nith-off'-il-us) [ò $\rho \imath \varsigma$, a bird ; $\phi i \lambda o s$, loving]. In biology, fertilized through the agency of birds.

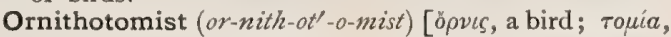
a cut]. One versed in the anatomy of birds.

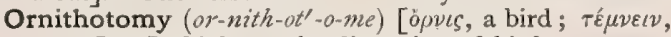
to cut]. In biology, the dissection of birds.

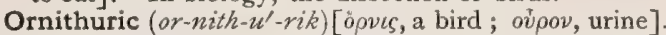
Pertaining to the urine of birds. O. Acid, $\mathrm{C}_{19} \mathrm{H}_{20} \mathrm{~N}_{2}$. $\mathrm{O}_{4}$. An acid found in the dung of birds fed with benzoic acid.

Ornus (or'-nus) [L.]. See Fraxinus.

Oroanal (o-ro-a'-nal) [os, oris, mouth; anus, anus]. Extending from the mouth to the anus.

Orobechos (o-ro-bek'-os) [ö $\rho \circ \beta o s$, a species of pulse;

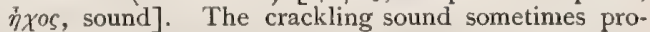
duced by pressure on the inner canthus of the eye.

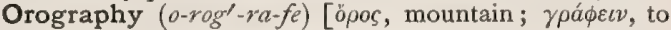
write]. I. A treatise on the distribution and physical geography of mountain-ranges. 2. The same as Orology.

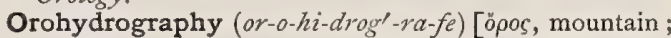
$v \delta \omega \rho$, water; $\gamma \rho a \phi \varepsilon \iota v$, to write]. A treatise on the mutual relation of divides and drainage-basins.

Orolingual (o-ro-lin'-grval) [os, oris, the mouth; lingua, the tongue]. Pertaining to the mouth and the tongue.

Oronasal (o-ro-na'-zal). See Orinasal.

Oronosus (o-ron'-o-sus) [öoos, mountain; vóoos, disease]. A disease prevalent in mountain regions. See Mountain Sickness.

Oropharyngeal (o-ro-far-in'-je-al) [os, oris, mouth;

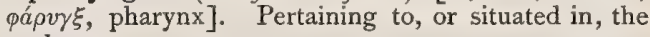
orpharynx.

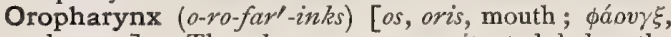
pharynx]. The pharynx proper, situated below the level of the lower border of the soft palate, as dis. tinguished from the naso-pharynx.

Oros $\left(o r^{\prime}-o s\right)$ [o $\rho o s$, a mountain]. 1. The upper part of the foot. 2. A mountain.

Orotherapy (or-o-ther'-ap-e) [óoss, whey; $\theta \varepsilon \rho a \pi \varepsilon i \alpha$, treatment]. See Orrhotherapy.

Oroya Fever (o-roi'-yah) [S. Amer.]. The febrile stage of Verrugas, $q . v$.

Orpiment (or'-pim-ent) [auri pigmentum, golden pigment]. A common name for arsenious sulphid, $\mathrm{As}_{2}$ $\mathrm{S}_{3}$, also known as King's Yellow. It is poisonous. See Pigments, Conspectus of.

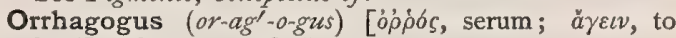
lead]. Synonym of Hydragogue.

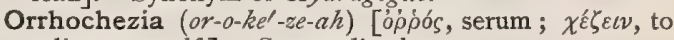
relieve oneself $]$. Serous diarrhea.

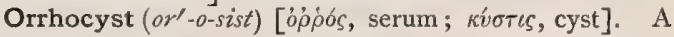
serous cyst.

Orrhoid (or'-oid). Synonym of Serous.

Orrhophallus (or-o-fal'-us) [oopos, the end of the sacrum; $\phi a \lambda \lambda \sigma \varsigma$, the penis]. A monstrosity with a penis protruding from the sacral region.

Orrhoposia (or-op-o'-ze-ah) [ópós, whey; $\pi 6 \sigma \iota s$, drinking]. Whey-drinking.

Orrhorrhagia (or-or-a -je-ah). Synonym of Orrhorrhea.

Orrhorrhea (or-or-e'-ah) [óṕós, serum; $\dot{\rho} \alpha i a$, a flow]. An abnormally great flow of serum. Also, a watery discharge ; rice-water discharges.

Orrhos (or'-ros) [ópóós, serum]. Serum; whey.

Orrhosis $\left(o r-\sigma^{\prime}-s i s\right)$ [óṕbs, serum]. The production of serum. 


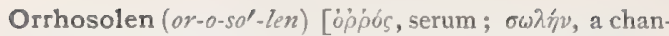
nel]. I. A lymph-duct, 2. Sheath of a tendon.

Orrhosolenitis (or-o-so-len-i'-tis). See Lymphangitis.

Orrhymen (or-i'-men) [öpós, serum; i $\mu \hat{j} \nu$, membrane]. A serous membrane.

Orthymenitis (or-i-men-i'-tis) [ópós, serum; $v \mu \eta \eta \nu$, membrane; $\iota T i s$, inflammation]. Inflammation of a serous surface.

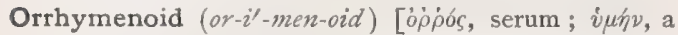
membrane; cioos, like]. Resembling a serous membrane.

Orrhymenous (or-i'-men-us) [óp’ós, serum; $i \mu h v$, a membrane]. Having a serous membrane.

Orris $\left(o r^{\prime}-2 s\right)$ [origin obscure]. The plant yielding orris-root. O.-pea. See Issue-pea. O.-root, the rhizome of Iris florentina, containing a volatile oil and various extractive principles. It is aromatic and astringent, and is much used for flavoring and as a dentifrice. Unof.

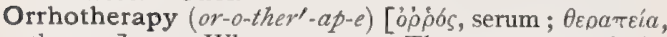
therapy]. I. Whey-cure. 2. The treatment of disease by the use of human or animal blood-serum containing antitoxins.

Orseillin (or-sa'-lin) [Fr., orseille, archil]. A coal-tar color used in dyeing; it is the sodium-sulphonate salt of beta-naphthol-azo-naphthalene. It yields a fast and full red, but is not bright red. It is also called rocellin, mubidin, rauracienne. See Pigments, Conspectus of.

Orsellinic Acid (or-sel-in'-ik). See Acid.

Orthacanthous (orth-ak-an'-thus) [o $\rho \theta b s$, straight : áкav $\theta a$, a thorn]. In biology, having straight thorns.

Ortharthragra (orth-arth-ra'-grah) [opbbs, true,

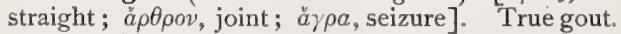

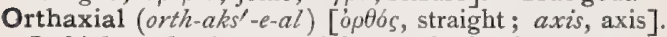
In biology, having a straight vertebral axis.

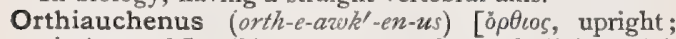
avं $\eta^{\prime}$, neck]. Lissauer's term for a skull in which the angle formed between the radius fixus and the line joining the basion and the inion is between $3^{\circ}$ and $49^{\circ}$

Orthin $\left(o r h^{\prime}-i n\right)[o \rho \theta b s$, straight]. A substance prepared by combining hydrazin with paroxybenzoic acid. Its hydrochlorate has been found actively antipyretic; an overdose causes collapse and profuse sweating. Dose gr. v, twice daily, given with great caution. Unof. See also Hydrazin.

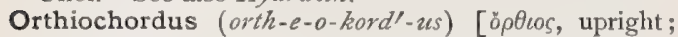
$\chi 0 \rho \delta \dot{n}$, cord]. Lissauer's term for a skull in which the angle formed between the radius fixus and the line joining the hormion and the basion is between $33.2^{\circ}$ and $52^{\circ}$.

Orthiocoryphus (orth-e-o-kor'-if-us) [öptios, upright; корvфиं, head]. Lissauer's term for a skull in which the angle formed between the radius fixus and the line joining the bregma and the lambda is between $29^{\circ}$ and $41^{\circ}$.

Orthiodontus (orth-e-o-don'-tus) [öptlos, upright; ódov́s, a tooth]. Lissauer's term for a skull in which the angle between the radius fixus and the line joining the alveolar and subnasal points is between $88^{\circ}$ and $12 \mathbf{I}^{\circ}$.

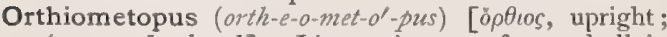
$\mu \varepsilon ́ \tau \omega \pi$, forehead]. Lissauer's term for a skull in which the angle between the radius fixus and the line joining the bregma and the nasal point is between $47^{\circ}$ and $60^{\circ}$

Orthiopisthius (orth-e-o-pis'-the-us) [öptlos, upright *

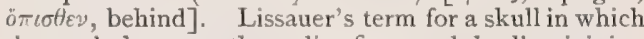
the angle between the radius fixus and the line joining the lambda and the inion is between $84^{\circ}$ and $95^{\circ}$.

Orthiopisthocranius (orth-e-o-pis-tho-kra'-ne-uss) [o $\rho$ $\theta \iota s$, upright ; $\% \iota \sigma \theta \varepsilon v$, behind; крaviov, skull]. Lissauer's term for a skull in which the angle formed be- tween the radius fixus and the line joining the lambda and the opisthion is between $107^{\circ}$ and $119^{\circ}$.

Orthioprosopus (orth-e-o-pros-o'-pus) [opplos, upright ; $\pi \rho \sigma ́ \sigma \omega \pi \sigma \nu$, face]. Lissauer's term for a skull in which the angle formed between the radius fixus and the line joining the nasion and the alveolar point is between $89.4^{\circ}$ and $100^{\circ}$.

Orthiopylus (orth-e-oph-il-us) [öptcos, upright; $\pi \hat{v} \lambda \eta$, gate]. Lissauer's term for a skull in which the angle formed between the radius fixus and the line joining the middle point of the anterior margin of the foramen magnum and the middle point of the posterior margin of the foramen magnum is between $\mathbf{I} 5.5^{\circ}$ and $24^{\circ}$.

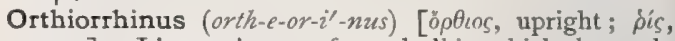
nose]. Lissauer's term for a skull in which the angle formed between the radius fixus and the line joining the nasion and the subnasal point is between $87.5^{\circ}$ and $98^{\circ}$.

Orthiuraniscus (orth-e-u-ran-is'-kus) [ö $\rho \theta t o s, u p r i g h t$; ovpaviokos, canopy]. Lissauer's term for a skull in which the angle formed between the radius fixus and a line joining the posterior border of the incisor foramen and the alveolar point is between $40^{\circ}$ and $60^{\circ}$.

Ortho- (or'-tho-) [o $\rho \theta b s$, right, straight]. A prefix denoting right, straight, normal, or true. In chemistry the prefix indicates the normal compound; among derivatives of the benzol ring it refers to those formed. by the substitution of two adjacent hydrogen atoms.

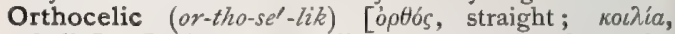
belly]. In biology, applied to birds that have the eight intestinal folds close to and parallel with each other (Tubinares, Steganopodes and Erodii), as distinguished from the Cyclocelic (Pelargi, Raptores and Larida.)

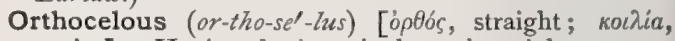
cavity]. Having the intestinal canal straight.

Orthocephalic (or - tho-sef-al'-ik) [ojobos, straight; $\kappa \varepsilon \phi \alpha \lambda \dot{\eta}$, head]. Pertaining to orthocephaly.

Orthocephalism (or-tho-sef'-al-izm). Synonym of Orthocephaly.

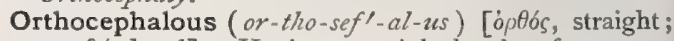
$\kappa \varepsilon \phi a \lambda \dot{\eta}$, head]. Having a straight head or face.

Orthocephaly (or-tho-sef'-al-e) [o $\rho \theta b s$, straight; $\kappa \varepsilon \phi-$ $\alpha \lambda \hat{n}$, head]. The condition of having a skull with a vertical index of from $70 . \mathrm{I}^{\circ}$ to $75^{\circ}$.

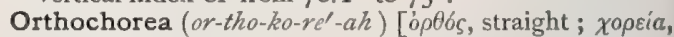
dance]. Choreic movements in the erect posture.

Orthochromatic (or-tho-kro-mat'-ik) [o $0 \theta 6 s$, straight ; $\chi \rho \tilde{3} \mu a$, color]. A term used in photography to denote correctness in the rendering of colors.

Orthocolon (or-tho-ko'-lon) [opoós, straight; $\kappa \bar{\omega} \lambda \alpha v$, limb]. Straightness of a limb from tonic muscular spasm.

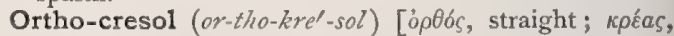
flesh; oleum, oil], $\mathrm{C}_{7} \mathrm{H}_{8} \mathrm{O}$. One of the forms of cresol, $q . v$. It occurs in small amounts in urine.

Orthocyllosis (or-tho-sil-o'-sis) [optoos, straight; $\kappa \hat{\imath} \lambda$ $\lambda \omega \sigma \iota$, crippling]. Ankylosis of a limb in the straight position.

Orthodactylous (or-tho-dak'-til-us) [o $\rho \theta b s$, straight ;

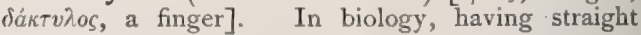
digits.

Orthodolichocephalous (or - tho-do-lik-o-seff-al-zus)

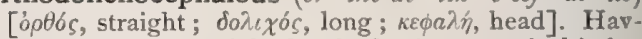
ing a long and straight head; having a vertical index between $70.1^{\circ}$ and $75^{\circ}$, and a transverso-vertical index between $70^{\circ}$ and $74.9^{\circ}$

Orthodontia (or-tho-aon'-she-ah). [óplós, straight; ofoús, tooth]. The correction of irregularities of the teeth.

Orthodontosy (or-tho-don'-to-se) [ojotós, straight i 
odous, a tooth]. That division of dentistry concerned in the straightening of irregular teeth.

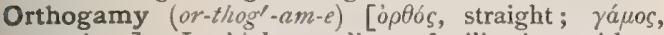
marriage]. In biology, direct fertilization without any mediate agency.

Orthognampsia (or-thoyr-namp'-se-ah) [o $\rho \theta b s$, straight ; $\gamma v \alpha \mu \pi \tau \varepsilon \iota \nu$, to bend]. A bending of the body at the hips. Orthognathic (or-thog-na'-thik). Same as Orthognathous.

Orthognathism (or-thog $\left.{ }^{\prime}-n a-t h i z m\right)$ [óplós, straight ; yvádos, jaw]. The quality of being orthognathous, or of having jaws with little or no forward projection.

Orthognathous (or-thog'-na-thus) [ojotós, straight; rvátos, the jaw]. In biology, straight-jawed; a facial profile having a gnathic angle of from $83^{\circ}$ to $90^{\circ}$; also called Mesognathous. See Index.

Orthognathy (or-thog'-na-the). See Orthognathism.

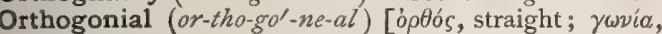
an angle]. Right-angled. O. Cancelli, those cancelli in bone-tissue in which there are two sets of bony structure applied at right angles to each other.

Orthomesocephalous (or-tho-mez-o-sef'-al-us) [o $\rho \theta b s$, straight; $\mu \varepsilon \tilde{\sigma} \sigma \varsigma$, middle; $\kappa \varepsilon \phi a \lambda \eta \dot{n}$, the head]. In craniometry, a term applied to a skull with a transversovertical index between $75.1^{\circ}$ and $79.9^{\circ}$, and a vertical index between $70.1^{\circ}$ and $75^{\circ}$.

Orthometer (or-thom'-et-er) [ojobs, straight; $\mu \dot{\varepsilon} T \rho o \nu$, measure]. An instrument for measuring the relative degree of protrusion of the eyes.

Orthomorphia (or-tho-mor'-fe-ah) [ojotos, straight; $\mu \circ \rho \phi \hbar$, form]. The correction of abnormalism of shape or form by surgical procedure.

Orthomorphic (or-tho-mor'-fik). Same as Orthopedic. Orthomorphosis (or-tho-mor-fo'-sis). Same as Orthomorphia.

Orthomorphotic (or-tho-mor-fot'-ik) [o $\rho \theta b s$, straight ; $\mu о \rho \phi \eta$, form ]. Pertaining to orthomorphosis.

Orthopedia (or-tho-pe'-de-ah) [óptós, straight ; $\pi \alpha u$ s, child]. The surgical and mechanical correction of the deformities of children, and of deformities in general; orthomorphia.

Orthopedic (or-tho-pe'-dik) [o $\rho \theta b s$, straight; $\pi a i s$, child]. Pertaining to orthopedia; intended to correct deformities, congenital or acquired. $\quad 0$. Surgery, the branch of surgery devoted to orthopedia.

Orthopedics (or-tho-pe'-diks). See Orthopedic Surgery.

Orthopedist (or-tho-pel-dist) [optbs, straight; tais, child]. One who practises orthopedic surgery.

Orthopedy (or'-tho-pe-de). See Orthopedia.

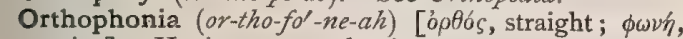
voice]. Having a normal voice.

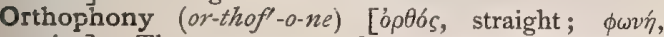
voice]. The treatment and correction of defects of the voice.

Orthophoria (or-tho-fo'-re-ah) [o $\rho \theta b s$, straight; фopos, a tending]. A tending of the visual lines in parallelism.

Orthophosphoric Acid (or-tho-fos-for'-ik). See Acid.

Orthophrenia (or-tho-fre'-ne-ah) [o $00 \hat{o} s$, straight; $\phi \rho^{\prime} \nu$, mind]. Sanity; the correction or cure of insanity.

Orthophrenic (or-tho-fren'-ik) [optoss, straight; $\phi \rho \eta v^{\prime}$, the mind]. Pertaining to Orthophrenia.

Orthophrenismus (or-tho-fren-iz'mus). Same as Orthophrenia.

Orthophreny (or'-tho-fren-e). Synonym of Orthophrenia.

Orthophthalmic (or-thoff-thal'-mik) [ópobs, straight; oyfajusos, the eye]. Relating to the correction of strabismus.

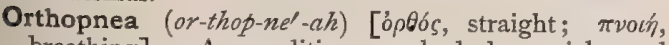
breathing]. A condition marked by quick and labored breathing, in which the patient finds relief only by maintaining an upright position. O. cardiaca. Synonym of Angina pectoris. O. clangosa. Synonym of Whooping-cough. O. cynanchica. Synonym of Croup. O. tussiculosa. Synonym of Whooping-cough

Orthopneic (or-thop-ne'-ik) [optós, straight; $\pi v o i n$, breathing]. Characterized by orthopnea.

Orthopnic (or-thop'-nik) [oofós, straight; $\pi v \varepsilon i v$, to breathe]. One affected with orthopnea.

Orthopraxis, Orthopraxy (or-tho-praks'-is, or'-thopraks-e) [o $\rho \theta 0$ s, straight; $\pi \rho \tilde{a} \xi \iota s$, doing]. The correction of deformities of the body.

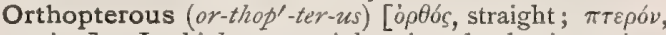
wing]. In biology, straight-winged; having wings that lie straight when folded, e.g., grasshoppers.

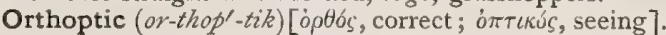
Pertaining to normal binocular vision. O. Training, a method of correcting the monocular or defective vision of those having strabismus or muscular insufficiency, by stereoscopic and other ocular exercises of a gymnastic kind. See Dyerism.

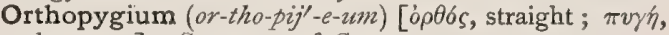
the rump]. Synonym of Coccyx.

Orthoscope (or'-tho-skopp) [o $\rho \theta \phi o s$, straight; $\sigma \kappa o \pi \varepsilon i \nu$, to see]. 1. An instrument for examination of the eye through a layer of water, whereby the curvature, and hence the refraction of the cornea is neutralized and the cornea acts as a plane medium. 2. An instrument for use in drawing the projections of skulls.

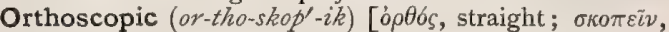
to see]. I. Pertaining to an orthoscope or to orthoscopy. 2. Applied to lenses cut from the periphery of a large lens in such a manner as to act as if decentered. 3. Having normal vision. O. Ocular. See Ocular.

Orthoscopy (or-thos'-ko-pe) [ópobs, straight; бколєiv, to see]. The examination of the eye by the orthoscope; also, the microscopic examination of objects in such a way that they appear as flat bodies without relief; the absence of spheric aberration in the appearance of an object seen through a lens or microscope.

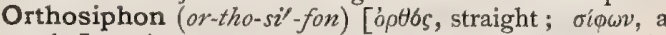
tube]. A genus of cimoideaceous plants. $O$. stamineus, Java tea; a labiate plant of the E. Indies. Its aqueous extract, an infusion of the plant, and a syrup have been employed. It is a safe and efficient remedy in diseases of the bladder. Unof.

Orthosis (or-tho'-sis) [öptwots, a making straight]. The process of straightening a distorted part.

Orthospermous (or-tho-sper'-mus) [ópobs, straight; $\sigma \pi \hat{\varepsilon} \rho \mu a$, seed]. In biology, having straight seeds.

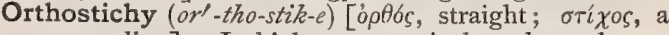
row or line]. In biology, a vertical rank, as leaves on a stem.

Orthostomatous (or-tho-sto'-mat-us) [o $\rho \theta \delta s$, straight; $\sigma \tau 6 \mu \alpha$, a mouth]. In biology, having a straight mouth.

Orthosyne (or-thos'-in-e) [o $\rho \theta 0 \sigma i n \eta]$. Erectility.

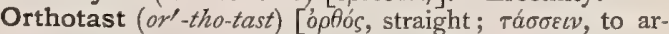
range]. An apparatus for straightening curvatures of long bones. It has also been used as a tourniquet.

Orthoter (or-thot'-er). Synonym of Orthopedist.

Orthoterion, Orthoterium (or-tho-te'-re-on, or-tho-te' $r e-u m)$ [o $\rho \theta b s$, straight]. An apparatus for straightening curved limbs.

Orthotonos, Orthotonus (or-thot'-o-nos, or-thot'-o-mus) [optós, straight; tóvos, tension]. Tetanic cramp in which the body lies rigid and straight.

Orthotropal (or-thot'-ro-pal). Same as Orthotropous.

Orthotrophy (or-thot'-ro-fe) [o $\rho \theta b s$, straight; r $\rho \circ \phi \eta$, nourishment]. Correct or normal nourishment; the normal process of nutrition. 


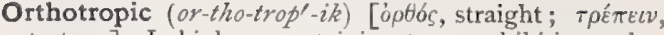
to turn]. In biology, pertaining to, or exhibiting orthotropism.

Orthotropism (or-thot'-ro-pizm) [óptós, straight; $\tau \rho \varepsilon^{\prime}$ $\pi \varepsilon \imath$, to turn ]. In biology, vertical, upward, or downward growth.

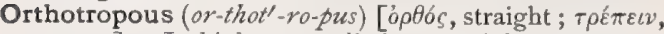
to turn]. In biology, applied to straight, symmetric seeds in which the chalaza is at the base and the micropyle at the apex.

Orthysteroptoma (or - this - ter-op'-to - mah) [o $\rho \theta b s$,

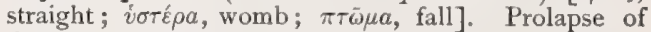
the uterus without inversion.

Orticaria (or-tik-a $\left.a^{\prime}-r e-a h\right)$. Same as Urticaria.

Oryctographic (or-ik-to-graf'-ik) [o $\gamma \rho a ́ \phi \varepsilon \nu \nu$, to write]. Pertaining to oryctography.

Oryctography (or-ik-tog'-ra-fe) [ópvktós, dug out; $\gamma \rho a ́ \phi \varepsilon \imath$, to write]. A description of minerals or of fossils.

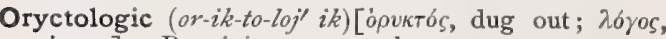
science]. Pertaining to oryctology.

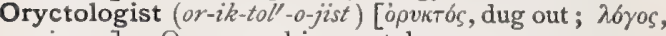
science]. One versed in oryctology.

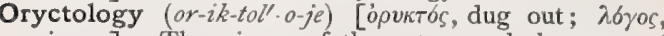
science]. The science of the nature and character of minerals and fossils.

Oryctozoölogic (or-ik-to-zo-o-loj'-ik) [o $\rho v \kappa \tau o ́ s$, fossil ; $\zeta \bar{\varphi} 0 \nu$, an animal]. Same as Paleontologic.

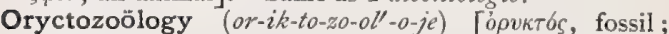
$\zeta \omega o v$, an animal; $\lambda 6 \gamma o s$, science]. The same as Paleontology.

Oryza $\left(o-r i^{\prime}-z a h\right)[\tilde{o} \rho v \zeta \alpha$, rice]. The common rice-plant, $O$. sativa, belonging to the grass family. Its seed consists mainly of starch, and is one of the most nutritious of the various grains. Also, in pathology, the fecal discharges of cholera, which closely resemble ricewater.

Os [L.: gen., Oris; pl., Ora]. The mouth. O. externum, the external opening or entrance to the womb. O. internum, the internal orifice of the womb. 0 tinca ("tench's mouth"), the os uteri, or mouth of the uterus. O. uteri. Same as O. internum.

Os [L.: gen., Ossis; pl., Ossa]. A bone. See Bone. O. innominatum. See Bones, Table of. O. magnum. See Bones, Table of.

Osanore, or Ozanore, Teeth $\left(o z^{\prime}-a n\right.$-or $)$ [os, bone]. A name given by Mr. William Rogers to artificial teeth constructed from the ivory of the tooth of the hippopotamus, and, as he says, submitted to the action of some peculiar chemic agent, by which the pores of the ivory become filled with a siliceous substance.

Osazone $\left(o^{\prime}-z a h-z \bar{o} n\right)$ [ose, systematic termination for members of the starch and sugar-group; $a z$, a syllable indicative of nitrogen ; one, the systematic termination of certain derivatives of the sugar-group]. A compound formed when solutions of sugars are warmed for some time with a solution of phenylhydrazin $\left(\mathrm{C}_{6} \mathrm{H}_{5} \mathrm{NHNH}_{2}\right)$ and dilute acetic acid. They separate either in the amorphous or crystalline state. An intermediate product called a hydrazone is first formed. Each sugar forms a special osazone, lactose, for example, forming phenyl-lactosazone.

Oschea $\left(0 s^{\prime}-k e-\lambda h\right)$. Synonym of Scrotum.

Oscheal $\left(o s^{\prime}-k \epsilon a l\right)$ [o $\sigma \chi \varepsilon o \nu$, scrotum]. Pertaining to the scrotum.

Oscheitis (os-ke-i’-tis) [ $\check{\sigma} \sigma \chi^{\varepsilon o v}$, scrotum ; $\iota \tau \iota s$, inflammation]. Inflammation of the scrotum.

Oschelephantiasis (osk-el-e-fan-ti'-as-is) [ 0 o $\chi \varepsilon o v$, scrotum ; $\dot{\varepsilon} \lambda \varepsilon \dot{\phi} a \nu \operatorname{lia\sigma }^{\prime}$, elephantiasis]. Elephantiasis of the scrotum.

Oschematedema, Oschemedema (os-kem-at-e-de'-

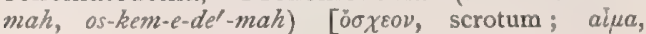

blood; oid $\eta \mu a$, edema]. Effusion of blood into the scrotum; hematoma of the scrotum.

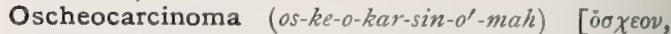

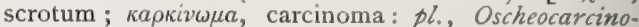
mata]. Carcinoma of the scrotum.

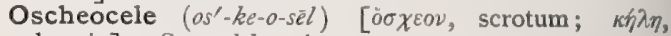
hernia]. Scrotal hernia.

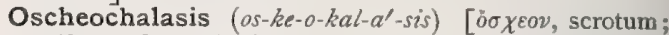

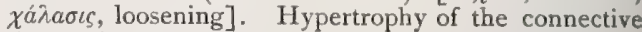
tissue of the scrotum; also, pendulous scrotum.

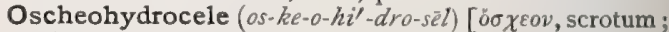
$v \delta \omega \rho$, water; $\kappa \eta \dot{\lambda} \eta$, tumor]. A hydrocele occupying an old hernial sac in the scrotum, after the cure of the hernia.

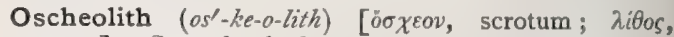
stone]. Scrotal calculus.

Oscheon $\left(o s^{\prime}-k e-o n\right)$ [ö $\sigma \chi \varepsilon \sigma \nu$, scrotum]. The scrotum.

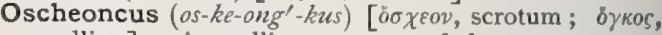
swelling]. A swelling or tumor of the scrotum.

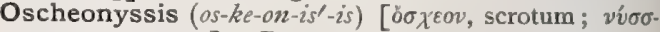
$\varepsilon \iota v$, to puncture]. Paracentesis of the scrotum.

Oscheophlogosis (os-ke-o-flo-go'-sis) [ö $\sigma \chi \varepsilon o v$, scrotum; $\phi \lambda \sigma \gamma \omega \sigma \iota s$, inflammation]. Same as Oscheitis.

Oscheoplastic (os-ke-o-plas'-tik) [ö $\sigma \chi \varepsilon o v$, scrotum; $\pi \lambda a ́ \sigma \sigma \varepsilon \iota v$, to form]. Pertaining io plastic operations upon the scrotum.

Oscheoplasty (os'-ke-o-plas-te) [ö $\sigma x \varepsilon o v$, scrotum; $\pi \lambda a ́ \sigma \sigma \varepsilon \iota \nu$, to form]. Oscheoplastic surgery; plastic surgery of the scrotum.

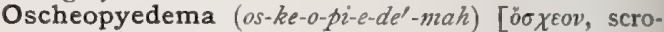
tum ; $\pi \dot{v} o v$, pus ; oí $\eta \mu \alpha$, edema]. Purulent edema of the scrotum.

Oschitis (os-ki'-tis). See Oscheitis.

Oschocarcinoma (os-ko-kar-sin-o'-mah). Synonym of Oscheocarcinoma

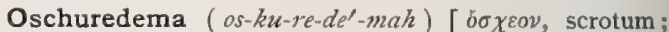

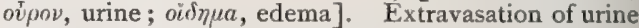
into the scrotur.

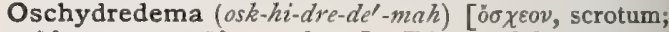
vi $\omega \rho$, water; oid $\eta \mu a$, edema]. Edema of the scrotum.

Oscillation (os-il-a'-shun) [oscillatio; oscillare, to sway to and fro]. A swinging or vibration. Also, any tremulous motion. See Hippus. O., Consecutive. Same as Phenomena of Transfer.

Oscitancy (os'-it-an-se) [oscitare, to yawn]. The disposition to yawn; drowsiness.

Oscitant $\left(o s^{\prime}-i t\right.$-ant $)$ [oscitare, to yawn]. Yawning. O. Fever, fever accompanied by much yawning.

Oscitation (os-it-a'-shun) [oscitatio; oscitare, to yawn]. The act of yawning or gaping.

Osculant (os'-ku-lant) [osculari, to kiss]. In biology, closely connected.

Oscularis (os-ku-la'-ris) [osculans, kissing]. The kissing-muscle, or orbicularis oris. See Muscles, Table of. Osculation (os-ku-la'-shun) [osculatio; osculari, to kiss]. The union or anastomosis of vessels or lymphchannels by their mouths. Also, the act of kissing.

Oscule $\left(o s^{\prime}-k u i l\right)$ [osculum, a little mouth, dim. of os, mouth]. Same as Osculum.

Osculum $\left(o s^{\prime}-k u\right.$-lum $)$ [a little mouth: pl., Oscula]. A small aperture. In biology: (a) the mouth or exhalant aperture of a sponge, either "scattered," " excurrent" or "cloacal." "Cf. Pseudoprod; (b) one of the bothria or fossettes of the head of a platode worm; (c) the opening into the pituitary body.

-ose $(-\bar{o} z)[-o s u s]$. A suffix signifying full of. Also, the systematic termination for the members of the starch and sugar group.

Oser's Oak-red. See Oak-bark.

-osis $\left(\sigma^{\prime}\right.$-sis). A suffix signifying the progress or condition of.

Osite $\left(0 s^{\prime}-i t\right)$ [os, a bone]. The name applied by Leidy 
to a form of guano made up largely of the altered bones of marine animals.

Osler's Method. A method of studying blood-plaques; a drop of osmic acid is placed on the cleansed finger, which is then pricked and the drop transferred to a slide. O.'s Phenomenon, the aggregation of hematoblasts occurring immediately in blood drawn from the body.

Osmate $\left(o z^{\prime}-m \bar{a} t\right)[\dot{o} \sigma \mu \dot{y}$, smell]. A salt of osmic acid. Osmatic $\left(o z-m a \iota^{\prime}-i k\right)[\dot{o} \sigma \mu \dot{\eta}$, smell]. Characterized by a keen sense of smell ; having a highly developed rhinencephalon.

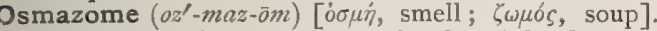
A brownish-yellow substance developed by heat in muscular fibers, and imparting to cooked meats their peculiar flavor. [Old.]

Osmesis (oz-me'-sis) [ö ${ }^{\prime} \mu \eta \iota_{s}$, a smelling]. The act of smelling.

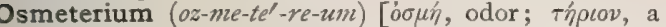
suffix : pl., Osmeteria $]$. In zoölogy, an organ producing scent or odor, especially in the larvæ of certain lepidoptera.

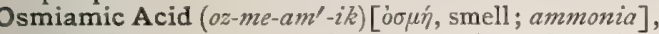
$\mathrm{H}_{2} \mathrm{Os}_{2} \mathrm{~N}_{2} \mathrm{O}_{5}$. A compound of ammonia and osmium tetroxid.

Osmiate $\left(o z^{\prime}-m e-\bar{a} t\right)$. Synonym of Osmate.

Osmic $\left(o z^{\prime}-m i k\right)$ [o $\sigma \mu \dot{y}^{\prime}$, smell]. Pertaining to or obtained from osmium. O. Acid. Osmic acid is used as a fixing and staining agent; it stains fat black. See Acid, and Stains, Table of.

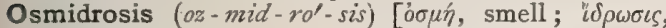
sweat]. The secretion of a malodorous perspiration; bromidrosis, q. $v$.

Osmious $\left(o z^{\prime}-m e-u s\right)$ [ó $\sigma \mu \hat{\eta}$, smell]. Containing osmium as a dyad or tetrad element.

Osmium $\left(o z^{\prime}-m e-u m\right)\left[\dot{o} \sigma \mu \dot{\prime}^{\prime}\right.$, smell]. The heaviest of the known metals (symbol Os, sp. gr. 22.48., at. wt. 190.08); the basis of osmic acid. See Elements, Table of.

Osmodysphoria (oz-mo-dis-fo'-re-ah) [ór $\mu$, smell; $\delta v \varsigma_{-}$, ill ; $\phi \varepsilon \dot{\varepsilon} \varepsilon \iota v$, to bear]. Intolerance of certain odors.

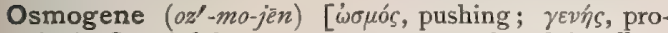
ducing]. A laboratory apparatus employed in effecting osmosis.

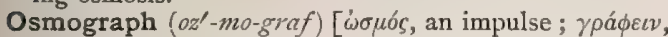
to write]. An apparatus for registering the changes in the level of the liquid in an endosmometer.

Osmology (oz-mol'-o-je). Synonym of Osphresiology.

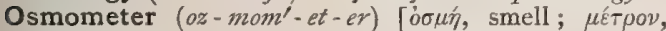
measure]. An instrument for testing the sense of smell.

Osmometric (oz-mo-met'-rik) [ỏ $\sigma \mu \eta \dot{n}$, smell; $\mu$ ćrpov, a measure]. Pertaining to osmometry.

Osmometry $\left(o z-m o m^{\prime}-e t-r e\right)[o ́ \sigma \mu \eta$, smell; $\mu \hat{\varepsilon} \tau \rho o \nu$, measure]. The estimation of the acuteness of the sense of smell.

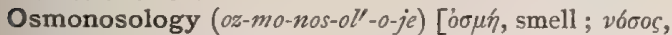
disease; $\lambda 6$ yos, science]. The science of the diseases affecting the sense of smell.

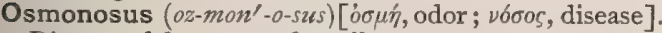
Disease of the sense of smell.

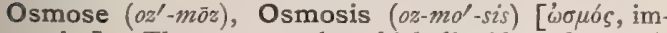
pulse]. That property by which liquids and crystalline substances in solution pass through porous septa; endosmosis and exosmosis.

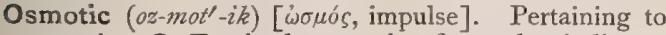
osmosis. O. Equivalent, "that figure that indicates the weight of water which replaces by osmosis one part by weight of the substance subjected to the process." 0 . Pressure, the pressure exerted by the particles of compounds when dissolved, directly ex60 pressed or shown by osmotic phenomena. It is equal to that which would be exerted by an equal amount of the substance if it were converted into gas and occupied the same volume at the same temperature as the solution.

Osmunda $\left(o s-m u n^{\prime}-d a h\right)$ [L.]. A genus of ferns. $\mathbf{O}$. regalis (osmund, royal-fern, flowering-fern, buckhorn) is tonic, astringent, and demulcent, and is vaunted as a cure for rickets. Unof.

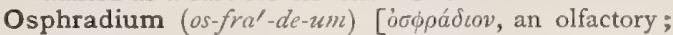
dim. of á $\sigma \rho \rho a$, smell : pl., Osphradiu]. In biology, a special sense-organ in molluscs, supposed to be olfactory in function.

Osphrasia (os-fra'-ze-ah). Synonym of Osphresis.

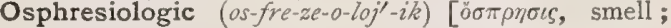
$\lambda$ ófos, science]. Pertaining to osphresiology, or to smell.

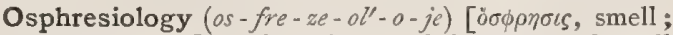
$\lambda \sigma$ yos, science]. The science of the sense of smell and its organs; also of odors and perfumes.

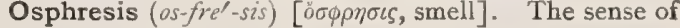
smell ; olfaction.

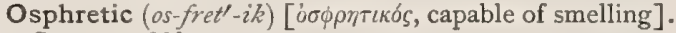
Same as Olfactory.

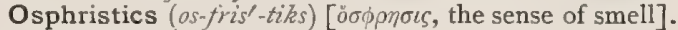
The science of the phenomena of olfaction.

Osphus $\left(o s^{\prime}-f u s\right)$ [óovis, loin]. Loin.

Osphyalgema (os-fi-al-je'-mah). Synonym of Osphyalgia.

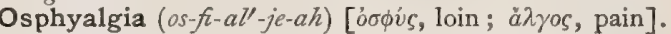
Sciatica. Also, any pain in the hips or loins.

Osphyarthritis (os-fi-arth-ri'-tis). Synonym of Coxitis.

Osphyarthrocace (os - $\left.f-a r t h-r o k^{\prime}-a s-e\right)$ [ódius, the loin ; à $\rho \theta \rho o v$, a joint; kakós, evil]. Synonym of Coxitis or Morbus coxarius.

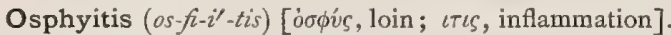
Lumbar inflammation; coxitis.

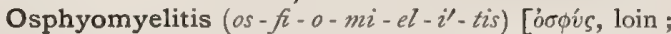
$\mu v \varepsilon \lambda \sigma \sigma$, marrow; $\iota T \iota \varsigma$, inflammation]. Myelitis of the lumbar portion of the spinal cord. See Ischiomyelitis.

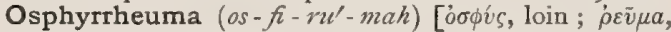
rheum]. Rheumatism of the loins or the hip-joint.

Ossa $\left(o s^{\prime}-a h\right)[\mathrm{L}, p l$. of os, a bone]. Bones. O. innominata, the irregular bones forming the sides and anterior wall of the pelvis. O. lata, the broad or flat bones composing the walls of cavities, as the bones of the cranium, in distinction from $O$. longa, the long bones, as those of the limbs. O. triquetra. See Wormian Bones and Triquetrum. O. wormiana, See Wormian Bones.

Ossature $\left(o s^{\prime}-a t-i \hat{r}\right)$ [os, a bone]. The arrangement of the bones of the body.

Ossein $\left(o s^{\prime}-e-i n\right)$ [os, a bone]. A combination of proteids, mainly collagen and an albuminoid, composing the organic structure of bone; it is called also ostein and bone-cartilage.

Osselet $\left(0 s^{\prime}-e l\right.$-et $)$ [dim. of os, a bone]. A small bone; also a hard nodule on the inner aspect of the horse's knee.

AUDITORY OSSICLES. bone]. Bony; composed of or 2 . Processus breresembling bone.

Ossicle $\left(o s^{\prime}-i k \cdot l\right)$ [ossiculum, dim. of os, a bone]. In biology, a small bone, or in invertebrates a calcareous, bone-like structure. O., Auditory, a chain of small

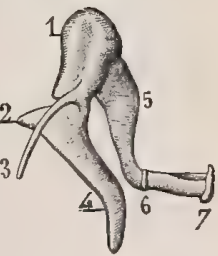
vis. 3. Processus gracilis. 4. Manubrium. 5. Long process of incus. 6 Articulation be tween incus and stapes. 7. Stapes. bones found for the most part in the tympanic cavity of vertebrates. 
Ossicula (os-ik'-u-lah) [L.]. Plural of Ossiculum. O. auditus. See Ossicle.

Ossicular (os-ik'-u-lar) [ossiculum, a small bone]. Resembling small bones.

Ossiculate (os-ik'-u-lāt) [ossiculum, a small bone] Provided with ossicles.

Ossicule $\left(0 s^{\prime}-i k-\bar{z} l\right)$. Same as Ossicle.

Ossiculum $\left(o s-i k^{\prime}-u-l u m\right)$. Synonym of Ossicle.

Ossiculus (os-ik'-u-lus) [masc. dim. of os, a bone]. Same as Pyrene.

Ossiferous (os-if'-er-us) [os, a bone; ferre, to bear]. Bearing or producing bone-tissue.

Ossific $\left(o s-i f^{\prime}-i k\right)[o s$, bone; facere, to make]. Producing bone.

Ossification (os-if-ik-a $\left.a^{\prime}-s h u n\right)$ [os, a bone; facere, to make]. The formation of bone; also a bony formation.

Ossified $\left(0 s^{\prime}-i f-\bar{i} d\right)$ [os, bone; facere, to make]. Transformed into bone.

Ossifluent (os-if'-lu-ent) [os, ossis, a bone; fuere, to flow]. Breaking down and softening the bony tissue; as an ossifluent abscess.

Ossiform $\left(o s^{\prime}-i f\right.$-orm $)$ [os, a bone; forma, form]. Bone-like.

Ossifying (os'-if-i-ing) [os, bone; facere, to make]. Change into bone. O. Chondroma, a chondroma which is changing into hard tissue resembling bone. O. Myositis, inflammation of muscle, attended with, or followed by, the deposition of hard, bone-like masses.

Ossin $\left(o s^{\prime}-i n\right)$ [os, a bone]. An extract made from bonetissue, and used in organotherapy, $q . v$.

Ossiterra (os-it-er'-ah) [os, bone; terra, earth]: The chalk-like substance, composing about two-thirds by weight of adult bone; it is called also bone-earth. The other third consists of bone-cartilage or ossein.

Ossivorous (os-iv'-o-rus) [os, a bone; vorare, to devour]. In biology, feeding upon bones.

Ostæmia (os-te'-me-ah). See Ostemia.

Ostagra (os-ta'-grah) [óotćov, bone; à $\gamma \rho \alpha$, seizure]. A bone-forceps.

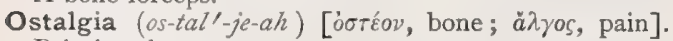
Pain in a bone.

Ostarium $\left(o s-t \alpha^{\prime}-r e-u m\right)$. Synonym of Ossicle.

Ostarthritis (ost-ar-thri'-tis). See Osteoarthritis.

Osteal $\left(o s^{\prime}-t e-a l\right)$ [ootŕov, bone]. Osseous, bony ; pertaining to bone.

Ostealgia (os-te-al'l-je-ah). See Ostalgia.

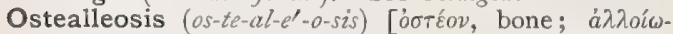
$\sigma \iota$, alteration]. A metamorphosis of the substance of bone, as exemplified in osteosarcoma.

Osteameba (os-te-an-e'-bah) [ooréov, bone; amœba, a rbizopod, from á $\mu \circ \_\not \dot{\eta}$, change]. In biology, a bonecell or osteoblast regarded as an organism. Cf. Neurameba, Myameba.

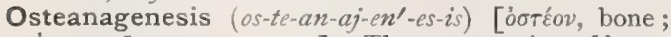

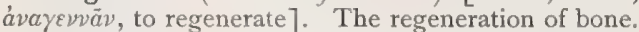

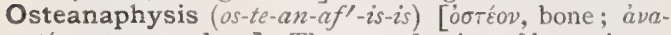
$\phi \varepsilon \varepsilon(\nu$, to reproduce]. The reproduction of bone-tissue. Synonym of Osteanagenesis.

Ostearthrocace (os-te-ar-throk'-ns-e) [óntéov, bone ; a $\rho \theta \rho \circ v$, joint; кaкós, bad]. Malignant caries of the bones of a joint.

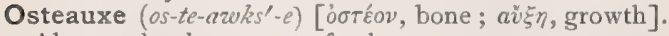
Abnormal enlargement of a bone.

Osteche $\left(o s-t e k^{\prime}-e\right)$. Synonym of Ostechema.

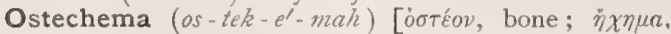
sound]. The sound produced on percussing the frontal bone.

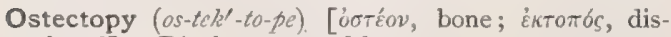
placed]. Displacement of bone.

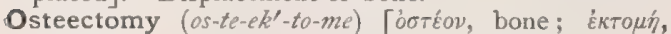
excision]. Excision of a portion of bony tissue.
Osteide $\left(o s^{\prime}-t e-i d\right)$ [óréov, bone]. A small bony mass sometimes found in the pulp-cavity of a tooth.

Ostein $\left(o s^{\prime}-t e-i n\right)$ [ót'́v tuent of bone; ossein. 2. Less frequently, the mineral part of bony substance.

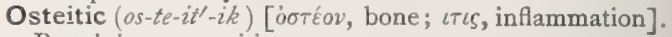
Pertaining to osteitis.

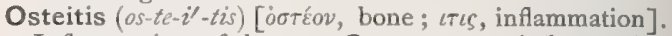
Inflammation of bone. O. carnosa, inflammation of bone, attended with the presence of an excess of fungous granulations. O., Condensing. See Osteosclerosis. O. deformans, the bones yielding to pressure and becoming distorted. O., Gummatous, a chronic form due to syphilis and characterized by the formation of gummata in the cancellous tissue of the epiphysis, in the shaft of the bone, or in the periosteum. O., Ossifying. Synonym of Osteosclerosis. O., Osteoplastic. Synonym of Osteosclerosis. O., Rarefying. See Osteoporosis. O., Suppurative, inflammation of bone attended with suppuration.

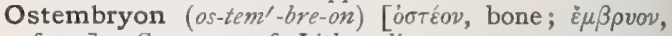
fetus]. Synonym of Lithopedion.

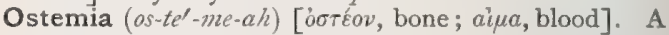
morbid condition of bone, distinguished by its turgescence with blood.

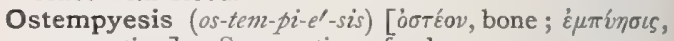
suppuration]. Suppuration of a bone.

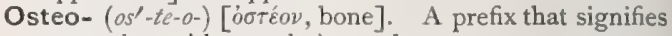
connection with or relation to bone.

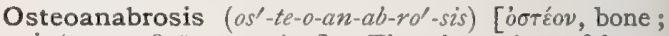
ává, up; $\beta \rho \tilde{\omega} \sigma \iota s$, eating]. The absorption of bone, or its destruction, as by osteoclasts.

Osteo-aneurysm (os'-te-o-an'-u-rizm) [óorḱov, bone;

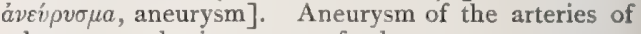
a bone; a pulsating tumor of a bone.

Osteo-arthritis (os'-te-o-ar-thri'-tis) [ootḱov, bone; à $\rho \rho \rho \nu$, joint; $\iota \tau \iota \varsigma$, inflammation ]. A chronic inflammation of the bones forming a joint.

Osteoarthropathy (os'-te-o-ar-throp'-ath-e) [óotéov, bone; à $\rho \theta \rho \circ \nu$, joint; $\pi a ́ \theta 0 \varsigma$, disease ]. Any disease of bony articulations, O., Hypertrophic Pulmonary, a disease first described by Marie, characterized by a bulbous enlargement of the terminal phalanges of the fingers and toes, a thickening of the articular ends of the bones, a peculiar curvation of the nails, and an enlargement of the lower jaw. According to Marie the condition is usually associated with disease of the lungs or pleura, whence the name osteoarthopathie pneumique hypertrophiante, and results from the absorption of toxic products from the diseased foci. The disease is not allied to akromegaly.

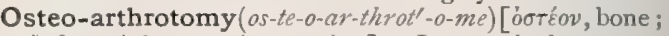

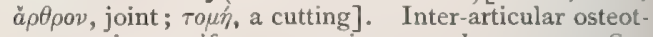
omy, as in cuneiform operations on the tarsus. See the various cuneiform operations in Operations, Table of.

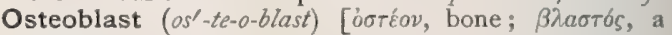
germ ]. In biology, one of the formative cells of bonetissue: a name proposed by Gegenbauer (I864), for the connective-tissue cells that proliferate on one side of bone-substance, in the direction of the supplanted cartilage. Their processes and finally the cells themselves become imbedded in the calcified matrix and become bone-cells. The intercellular threads of protoplasm lead to the development of the canaliculi, the cell-bodies producing the so-called lacunæ.

Osteoblastic (os-te-o-blas'-tik) [óctov, bone; $\beta \lambda a \sigma \tau \delta s$, a germ ]. Pertaining to osteoblasts, or to the formation of bone.

Osteocampsia (os-te-o-kamp'-se-ah) [óotkov, bone ; kák$\pi \tau \varepsilon \iota \nu$, to bend]. Curvature of a bone without fracture, as in osteomalacia. 
Osteocancer (os-te-o-kan'-ser). Synonym of Osteocarcinoma.

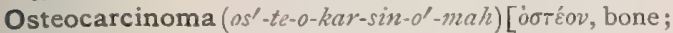
кгркір๘uа, carcinoma: $p l .$, Osteocarcinomata]. Carcinoma of bone; ossifying carcinoma.

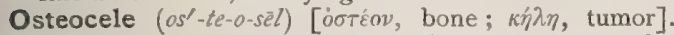
A bone-like substance found in old hernial sacs; also marked hardening of the testicle.

Osteocephaloma $\left(0 s^{\prime}-t e-o-s e f-a l-o^{\prime}-m a h\right)$ [óctíov, bone ; $\kappa \varepsilon \varnothing a \lambda n^{\prime}$, head; $\delta \mu a$, tumor: pl., Osteocephaloniata]. Encephaloma or encephaloid sarcoma of bone.

Osteochondritis $\left(o s^{\prime}-t e-a-k o n-d r i^{\prime}-t i s\right)$ [ótźov, bone; $\chi b \nu \delta \rho o s$, cartilage; $\iota \tau \iota$, , inflammation]. Inflammation involving both bone and cartilage.

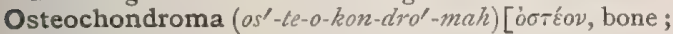

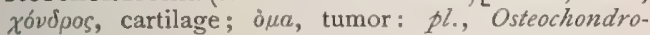
mata]: A tumor that is in part bony, and in part cartilaginous.

Osteoclasia (os-te-o-kla'-ze-ah). See Osteoclasis.

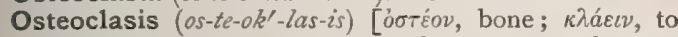
break]. I. Fracture of bones for purposes of remedying deformity. 2. The destruction of bony tissue by osteoclasts.

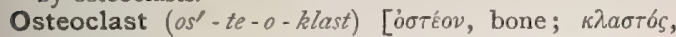
broken]. I. An instrument for performing osteoclasis. 2. One of the large multinucleate cells, derived from mesenchymal cells, and frequently found against the surface of bone in little eroded depressions (Hozeship's lacuna). They are concerned in the removal of bone. They are so called by Kölliker, and are named by Robin and other French histologists Myeloplaxes or Myeloplaques.

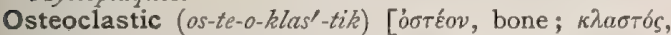
broken]. Of the nature of an osteoclast; concerned in the breaking down and absorption of bone.

Osteoclasy (os'-te-o-kla-ze). See Osteoclasis.

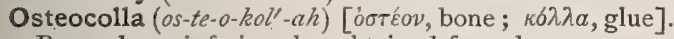
Bone-glue; inferior glue obtained from bones.

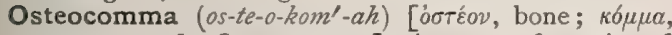
segment : pl., Osteocommata]. Any one of a series of bone-segments ; in the adult skeleton, a vertebra is an example.

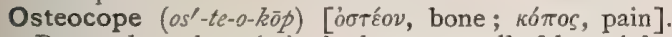
Bone-ache; the pain in the bones, usually felt at night, when the body is warmly covered, that characterizes syphilis.

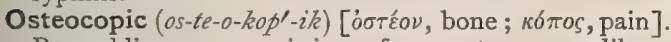
Resembling, or consisting of, an osteocope; like a bone-ache.

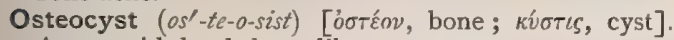
A cyst with hard, bone-like contents.

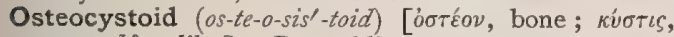
cyst; Eỉos, like]. Resembling an osteocyst.

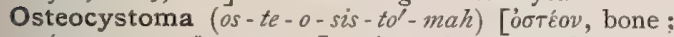

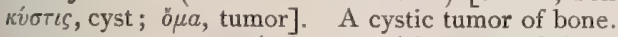

Osteocystosarcoma (os'-te-o-sis'-to-sar-ko'-mah)

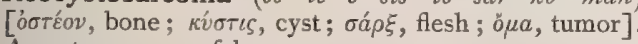
A cystosarcoma of bone.

Osteodentinal (os-te-o-den'-tin-al) [óorźov, bone; dens, tooth]. Made up of osteodentine.

Osteodentine (os-te-o-den'-tin) [órtéov, bone; dens, tooth]. A tissue of the nature of, and intermediate in structure between, bone and dentine.

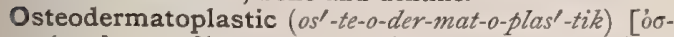

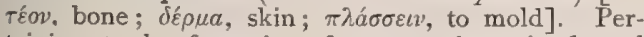
taining to the formation of osseous tissue in dermal structures.

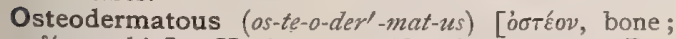

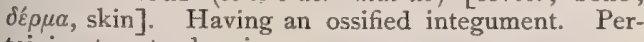
taining to osteodermia.

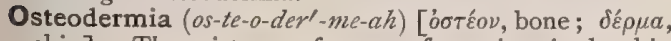
skin]. The existence of osseous formations in the skin or outer covering. It occurs normally in many animals, and occasionally abnormally in man.

Osteodermous (os-te-o-der'-mus). Same as Osteoder. matous.

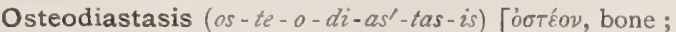
$\delta i \dot{\sigma} \sigma \tau \sigma \iota \zeta$, separation]. Separation of bone (as an epiphysis), without true fracture.

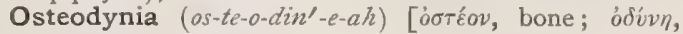
pain]. A chronic pain in the bone.

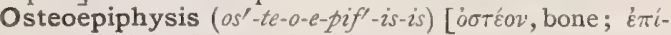
$\phi v \sigma \iota$, epiphysis]. A bony epiphysis.

Osteogangrene $\left(0 s^{\prime}-t e-o-g a n g^{\prime}-g r e ̄ n\right)$ [óotŕov, bone;

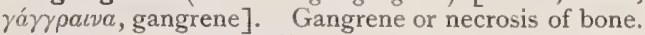

Osteogen $\left(o s^{\prime}-t e-o-j e n\right)$ [órćov, bone; jevvãv, to produce]. The substance of which osteogenic fibers are made up.

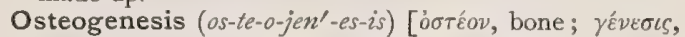
genesis]. The development and formation of bonetissue.

Osteogenesy (os-te-o-jen'-es-e). See Osteogenesis.

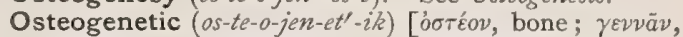
to beget]. Pertaining to, or concerned in, osteogenesis. O. Cell, an osteoblast. O. Fibers, Schäfer's name for the soft and pliant bundles of faintly fibrillated, transparent fibers running out from growing spicules of bone. O. Layer, the deep layer of periosteum from which bone is formed.

Osteogenic (os-te-a-jen'-ik). Synonym of Osteogenetic. Osteogeny (os-te-oj'-en-e). See Osteogenesis.

Osteography (os-te-og'-ra-fe) [óoréov, bone; $\gamma \rho a ́ \phi \varepsilon v$, to write]. Descriptive anatomy of the bones and their articulations.

Osteohalisteresis $\left(0 s^{\prime}-t e-o-h a l-i s-t e r-e^{\prime}-s i s\right)$ [ootźov, bone; $\hat{a} \lambda s$, salt; $\sigma \tau \varepsilon \rho \varepsilon ́ \varepsilon \iota \nu$, to deprive]. A partial loss of the mineral constituents of bone, concomitant with curvature. See Rachitis.

Osteohelcosis (os-te-o-hel-ko'-sis) [órtéov, bone ; $\dot{\varepsilon} \lambda \kappa \omega \sigma \iota \zeta$, ulceration]. Caries of bone.

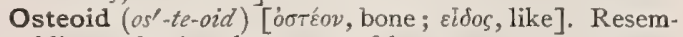
bling or having the nature of bone.

Osteolith $\left(o s^{\prime}\right.$-te-o-lith) [ór'́ov, bone; $\lambda i \theta o s$, stone ]. A petrified bone.

Osteologist (os-te-ol'-o-jist) [öntźov, bone; $\lambda 6 \gamma o s$, science]. One versed in, or expert in, osteology.

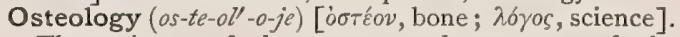
The science of the nature and structure of the bones.

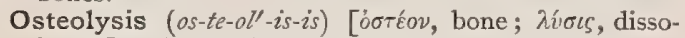
lution]. Absorption and disappearance of bone.

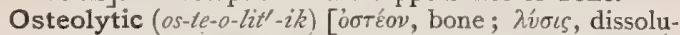
tion]. Pertaining to, or concerned in, osteolysis.

Osteoma (os-te-o'-mah) [oort́ov, bone; ö $\mu a$, tumor: pl., Osteomata ]. A bony tumor; exostosis. O., Dental, dental exostosis or hypercementosis. O. durum, a tumor consisting of very hard, bone-like tissue. 0 . eburneum. Synonym of 0 . durum. O. medullosum, an osteoma formed chiefly of cancellated tissue. O. spongiosum. Synonym of 0 . medullosum.

Osteomalacia (os-te-o-mal-a $a^{\prime}-s e-a h$ ) [ootŕov, bone;

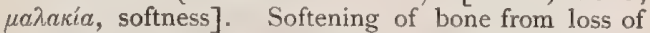
its earthy constituents, occurring in adults, especially in females, and in the course of pregnancy. The true cause of the disease is not known; by some it is considered to be infectious, but this view is not proved. O. infantum. See Rickets.

Osteomalacial, Osteomalacic (os-te-o-mal-a'-se-al,

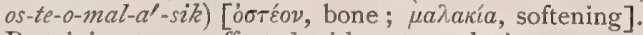
Pertaining to, or affected with, osteomalacia.

Osteomalacosis (os-te-o-mal-ak-o'sis). Synonym of Osteomalacia.

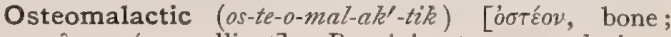

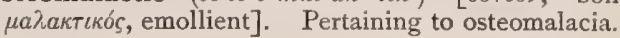




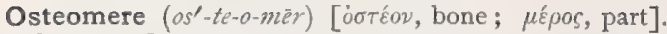
Same as Osteocomma.

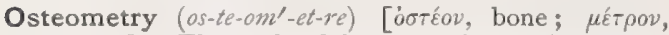
measure]. The study of the proportions and measurements of the skeleton.

Osteomiosis (os-te-o-mi-o'-sis) [óotćov, bone; $\mu \varepsilon i \omega \sigma \iota \zeta$, diminution]. Disintegration of bone.

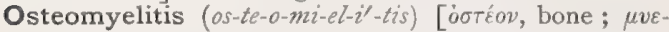
$\lambda 6 s$, marrow; $\iota \tau / \varsigma$, inflammation]. Inflammation of the marrow of bone. O., Conchiolin, Mother-ofpearl Osteomyelitis; a plastic form of inflammation of bone caused by the presence of pearl-dust in the capillary vessels of the epiphyseal extremities of the long bones in persons employed in the manufacture of articles of pearl. O., Gummatous, a form due to the development of gummata in the bone-marrow. $\mathbf{O}$. malleosa, osteomyelitis due to the Bacillus malleus, orglanders-bacillus. See Bacteria, Synonymatic Table of. O., Mother-of-pearl. See O., Conchiolin. O., Scrofulous, probably a chronic inflammation of the bone-marrow of tuberculous character.

Osteomyelon, Osteomyelum (os-te-o-mi'-el-on, os-te-

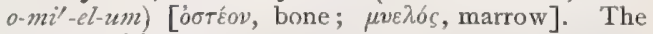
marrow of bone.

Osteonabrosis (os-te-on-ab'-ro-sis). SeeOsteoanabrosis.

Osteonagenesis (os-te-on-aj-en'-es-is). See Osteogenesis.

Osteoncosis, Osteoncus (os-te-on-ko'-sis, os-te-ong' .

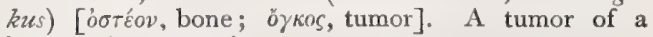
bone. An exostosis.

Osteonecrosis (os-te-o-ne-kro'-sis) [óotźov, bone; $\nu$ ć $^{-}$ $\kappa \rho \omega \sigma \iota$, death]. Necrosis, or death of bone.

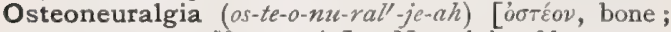
$\nu \varepsilon \tilde{v} \rho \circ \nu$, nerve; $\ddot{\lambda} \lambda$ ys, pain]. Neuralgia of bone.

Osteonosus (os-te-on'-o-sus) [óotḱov, bone; voбos, disease]. Disease of bone.

Osteopalinclasis (os-te-o-pal-in'-klas-is) [ootéov, bone; $\pi a ́ \lambda \iota \nu$, again; $\kappa \lambda a ́ \sigma \iota s$, a breaking]. Rebreaking of a bone for the correction of deformity.

Osteoparectania (os-te-o-par-ek-ta'-ne-ah). Synonym of Osteoparectasis.

Osteoparectasis (os-te-o-par-ek'-tas-is) [ótéov, bone;

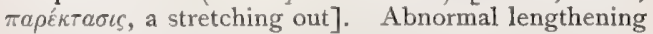
of a bone; over-extension in the treatment of a fracture.

Osteopathy (os-te-op'-ath-e). Disease of bone.

Osteopedion (os-te-o-pe'-de-on). See Lithopedion.

Osteoperiosteal $\left(o s^{\prime}-t e-0-p e r^{\prime \prime}-e-o s^{\prime}-t e-a l\right)$ [óotéov, bone; $\pi \varepsilon \rho i$, around; 'o $\sigma \tau \varepsilon \nu^{\prime}$, bone]. Pertaining to bone and its overlying periosteum.

Osteoperiosteitis $\left(o s^{\prime}-t e-o-p e r-\ell-o s-t e-i^{\prime}-t i s\right)$. Same as Osteoperiostitis.

Osteoperiostitis $\left(o s^{\prime}-t e-o-p e r-e-o s-t i^{\prime}-t i s\right)$ [óotkov, bone ;

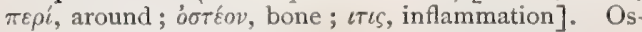
teitis with periostitis

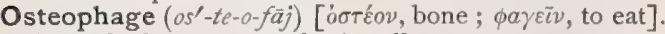
A myeloplax, or osteoclastic cell.

Osteophlebitis (os-te-arfle-bi'-tis) [órtéov, bone; $\phi \lambda \varepsilon ́ \psi$, vein; $\iota \tau \iota s$, inflammation]. Inflammation of the veins of a bone.

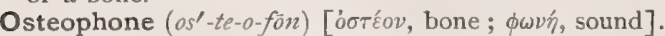
An apparatus for the transmission of sounds through the bones of the face; it is miscalled audiphone.

Osteophony $\left(o s-t e-o f^{\prime}-o-n e\right)$ [óotḱov, bone; $\varphi \omega \nu \eta ́$, sound]. The transmission of sound through bone.

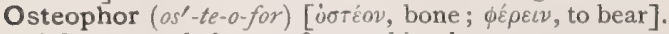
A heavy tooth-forceps for crushing bone.

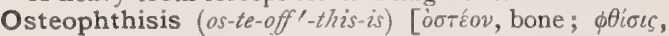
a wasting]. Wasting of the bones.

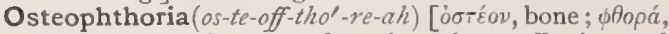
decay]. An old name for tuberculous affections of bones and joints.

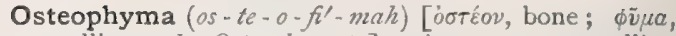
swelling: pl., Osteophymata]. Any tumor or swelling of a bone.

Osteophyte $\left(o s^{\prime}-t e-o-f i t\right)$ [óotéov, bone; $\phi v T o ́ v$, plant]. A bony outgrowth or nodosity.

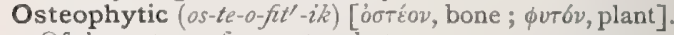
Of the nature of an osteophyte.

Osteophyton (os-te-off'-et-on) [óotéov, bone; фvтóv, a plant: pl., Osteophyta]. Same as Osteophyte.

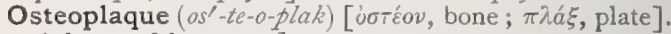
A layer of bone; a flat osteoma.

Osteoplast (os'-te-o-plast) [ $\dot{\sigma} \sigma \tau \varepsilon o \nu$, bone; $\pi \lambda \dot{\alpha} \sigma \sigma \varepsilon \iota \nu$, to form]. Same as Osteoblast.

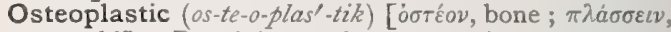
to mold]. Pertaining to plastic operations upon bone; also to the natural or pathologic formation or development of bone. O. Resection, an operation in which a bone or portion of bone, cut loose from all but one of its attachments, is laid back, the underlying diseased structure removed, and the bone replaced.

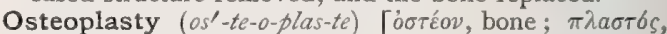
formed]. A plastic operation, as by grafting, etc., performed upon bone; plastic surgery of bone. See Dieffenbach's, Fergusson's, Mason's, and other operations, in Operations, Table of.

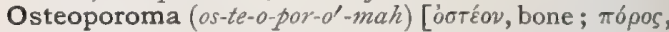
passage]. The changes produced by osteoporosis.

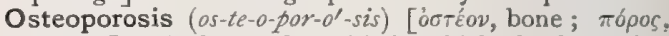
a pore]. A form of osteitis in which the bones become more vascular and are marked by an increase of the spaces filled with granulation-tissue or marrowtissue, with corresponding decrease in their compactness. This is also called Rarefying Osteitis.

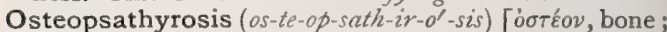
watvpós, friable]. Fragility of bones.

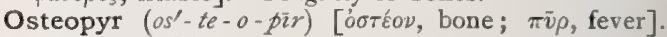
Gangrene of bone.

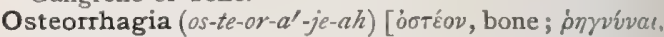
to burst forth]. Hemorrhage from a bone.

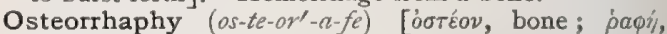
suture]. The suturing of bones.

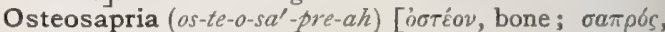
soften]. Caries of bone.

Osteosarcoma (os-te-o-sar-ko'-mah) [óorḱov, bone; $\sigma a ́ \rho \xi$, flesh; ö $\mu a$, tumor: pl., Osteosarcomata]. A sarcoma of bone. O., Central, one arising in the interior of a bone. O., Infiltrated, one infiltrating the entire bone, which becomes softened. O., Internal. Synonym of $O$. , Central. O., Periosteal, one springing from the periosteum. O., Peripheral. Synonym of O., Periosteal.

Osteosarcomatous (os-te-o-sar-ko'-mat-us) [óorḱov, bone; $\sigma a ́ \rho \xi$, flesh; $\dot{\partial} \mu \alpha$, tumor]. Of the nature of sarcoma.

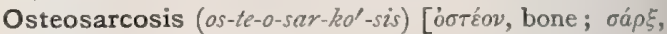
flesh]. The conversion of bone into sarcomatous tissue.

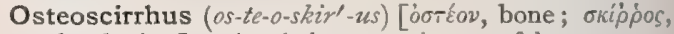
a hardening]. A scirrhous carcinoma of bone.

Osteoscleroma (os-te-o-skle-ro'-mah). Synonym of Osteosclerosis.

Osteosclerosis (os-te-o-skle-ro'sis) [óotkov, bone ;

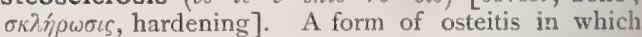
the bone increases in density at the expense of newly formed or pre-existing marrow-cells. It is also called Condensing Osteitis.

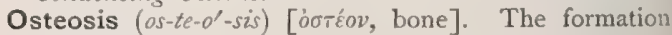
of bone.

Osteospongioma (os-te-o-spun-je-ó-mah) [óotḱov, bone; $\sigma \pi b ́ \gamma$ os, sponge; ¿ $\mu a$, tumor: pl., Osteospongiomata]. A tumor consisting of a spongy or highly cancellous growth of bony tissue. 
Osteospongiosis (os-te-o-spun-je-o'-sis). See Osteophthoria and Osteospongioma.

Osteosteatoma (os-te-o-ste-at-o'-mah) [óoréov, bone; $\sigma \tau \varepsilon a \rho, f a t ; \delta \mu a$, tumor: $p l .$, Osteosteatomata]. Fatty tumor, or growth, of bone.

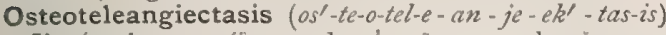

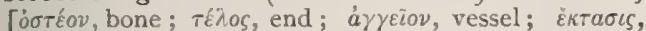
dilatation]. Dilatation of the blood-vessels of a bone; also a telangiectatic osteosarcoma.

Osteothrombosis $\left(0 s^{\prime}-t e-o-t h r o m-b o^{\prime}-s i s\right)$ [ $\sigma \sigma \tau \varepsilon$ rov, bone ;

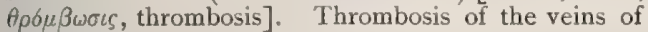
a bone.

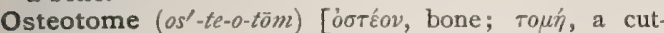
ting]. I. A saw, or other instrument, for cutting bone. 2. An instrument used in cutting the bones of the fetal head in embryotomy.

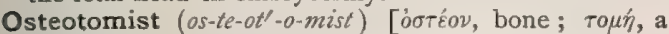
cutting]. One who performs osteotomy.

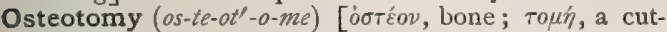
ting]. The cutting or division of a bone. See Adams', Barwell's, Gant's, and other operations, in Operations, Table of. O., Complete, one in which the bone is completely divided. O., Cuneiform, an osteotomy in which a wedge of bone is removed. O., Extra-articular, one not involving a joint. O., Incomplete, one in which the bone is not completely divided. O., Linear, a simple division of a bone, without removal of any part. O., Partial. Synonym of 0. , Incomplete. O., Simple. Synonym of O., Linear. O., Supracondylar, one done just above the condyles of the femur.

Osteotophus (os-te-ot'-o-fus) [órtźov, bone; tophus, sandstone]. A bony outgrowth or excrescence.

Osteotribe $\left(o s^{\prime}-t e-o-t r i \bar{b}\right)$. Same as Osteotrite.

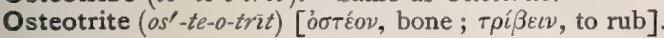
A scraping-instrument for use in operations upon carious bones.

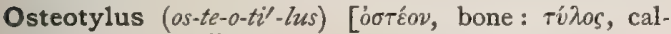
lus]. Bone-callus.

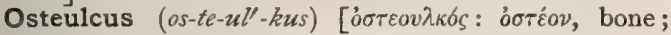
$\varepsilon \dot{\lambda} \kappa \varepsilon \iota \nu$, to draw ]. A bone-forceps.

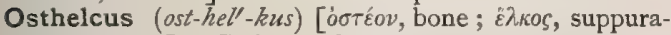
ting around]. Caries of bone.

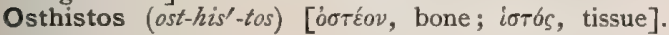
Osseous tissue.

Ostial (os'-te-al) [ostium, a door or mouth]. Pertaining to an opening or orinice.

Ostiole $\left(0 s^{\prime}-t e-\bar{o} l\right)$ [ostium, a door, mouth]. In biology, a small ostium, as the orifices in plants for the discharge of spores, pollen-grains, etc, or in insects for the emission of irritant or foul-smelling fluids

Ostiolum (os-ti'-o-lum) [dim. of $o s$, mouth]. A valve.

Ostitis $\left(o s-t i^{\prime}-t i s\right)$. See Osteitis.

Ostium $\left(0 s^{\prime}-t e-u m\right)$ [L., a door: pl., Ostia]. In biology, a mouth or mouth-like opening ; specifically, one of the slits in the dorsal vessel of certain Crustacea. (Branchippus). O. abdominale, the orifice of the oviduct communicating with the peritoneal cavity. O. œsophageum ventriculi, the opening of the esophageal or cardiac orifice of the stomach. 0 ., Gastric, the mouth by which a radial canal in sponges opens into the paragaster. O. internum, the orifice at the beginning of the oviduct in the uterus. $O$. pharyngeum, the pharyngeal opening of the Eustachian tube. O. tympanicum, the tympanic opening of the Eustachian tube. O., Vaginal, the external orifice of the vagina.

Ostology (os-toll'-o-je). Same as Osteology.

Ostoma (os-to'-mah). Synonym of Osteoma.

Ostosis (os-to'-sis). Same as Osteosis.

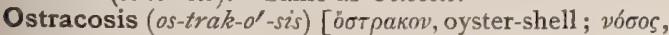
disease]. The degenerative change that sometimes takes place in a portion of bone and causes it to resemble an oyster-shell.

Ostrea $\left(0 s^{\prime}-t r e-a h\right)$ [ö $\sigma \rho \varepsilon o v$, oyster]. Oyster.

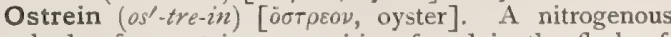
body of uncertain composition found in the flesh of oysters

Ostreios (os-tre-i'-os) [ǒorpeov, oyster; lós, poison]. The poison found in some oysters and mussels

Ostreotoxicum (os-tre-o-toks'-ik-um). Synonym of Ostreios.

Otacoustian, Otacoustic (o-tak-oos'-te-an, o-tak-oos'

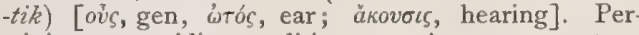
taining to, or aiding, audition. 2. An ear-trumpet.

Otacousticon (o-tak-oos'-tik-on) [ovs, ear; äkovols, hearing]. An otacoustic, or ear-trumpet.

Otagra (o-ta'-grah). Synonym of Otalgia.

Otalgia $\left(o-t a l^{\prime}-j e-a h\right)[o v s$, ear; à $\lambda y o s$, pain]. Earache.

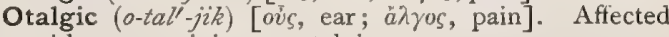
with, or pertaining to, otalgia.

Otalgy (o-tal'-je). Same as Otalgia

Otaphone $\left(o^{\prime}-\operatorname{taf}-\bar{o} n\right)$ [ov̀s, ear; $\phi \omega v \dot{y}$, sound]. A clamp so adjusted as to throw the external ears forward and outward, and thus assist the hearing.

Otechos, Otechus $\left(o^{\prime}-t e k-o s, o^{\prime}-t e k-u s\right)$. Synonym of Tinnitus aurium:

Otemplastrum (o-tem-plas'-trum) [ovs, ear ; $\check{\varepsilon} \mu \pi \lambda a \sigma$. $\tau \rho o \nu$, plaster]. A plaster placed behind the ear. [Old.]

Otenchyte $\left(o^{\prime}\right.$-ten-kit) [ovs, ear ; $\dot{\varepsilon} \gamma \chi^{\prime} v \varepsilon v$, to pour in]. An aural syringe.

Othelcosis $\left(o-t h e l-k o^{\prime}-s i s\right)$ [ovs, ear ; $\dot{\varepsilon} \lambda \kappa \omega \sigma \varsigma$, ulceration]. Ulceration of the ear.

Othematoma (ōt-hem-at-o'-mah) [ov's, ear; ai Ta $^{\top}$, blood; öta, tumor: pl., Othematomata]. Hematoma of the external ear, usually the pinna; hematoma auris. The condition is not rare in insane persons, whence its name "insane ear." It is probably a trophic lesion.

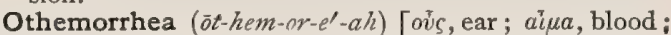
poia, flow]. A sanguineous discharge from the ear.

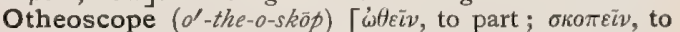
view]. An instrument somewhat like a radiometer.

Othydrops (o-thi'-drops) [ov s, ear; $i \delta \rho \omega \psi$, dropsy]. Dropsy of the tympanic cavity.

Othypersarcoma (o-thi-per-sar-ko'-mah) [oús, ear;

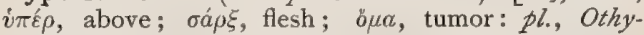
persarcomata]. A fleshy outgrowth from the ear.

Otiater $\left(o^{\prime}\right.$-te-a-ter) [ovs, ear; iath $\rho$, surgeon]. An aural surgeon.

Otiatric (o-te-at'-rik) [ov̌c, ear; $i \alpha \tau \hat{\jmath} \rho$, surgeon]. Pertaining to the treatment of diseases of the ear.

Otiatrics (o-te-at'-riks) [ov̌s, ear; iaríp, surgeon]. The study of diseases of the ear and their treatment.

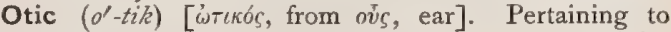
the ear. O. Ganglion. See Ganglion. O. Vesicle. See Vesicle.

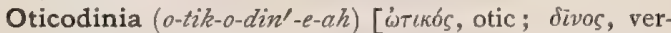
tigo]. Vertigo from disease of the ear; Ménière's disease; also, labyrinthine vertigo, as a symptom of Ménière's disease.

Oticodinosis (o-tik-o-din-ol-sis). See Oticodinia.

Otidium (o-tidl-e-um) [ov́s, ear; pl., Otidia]. In biology, the auditory organ or otocyst of the Mollusca.

Otitis $\left(o-t i^{\prime}-t i s\right)$ [ovs, ear; $\iota \tau \iota s$, inflammation]. Inflammation of the ear. O., Catarrhal, catarrhal inflammation of the middle ear. O., Desquamative, a proliferation and thickening of the epidermic layer of the external auditory canal and the tympanic membrane. The epithelium becomes desquamated and lies in the canal. O., Diphtheric, a pseudo-membranous inflammation of the middle ear, sometimes also of the external canal, due to extension of diphtheria from 
the throat. O. externa; O. interna; O, media; inflammation of the external, internal, and middle ear, respectively. O., Furuncular, the formation of small furuncles in the external auditory canal. $O$. labyrinthica, inflammation of the labyrinth. Its symptoms resemble those of meningitis; it is not fatal, but leads to permanent deafness. O.mycosa. Synonym of 0 . parasitica. $O$. parasitica, inflammation of the external or middle ear from the presence of parasites, Myiasis aurium. O. phlegmonosa, acute otitis with suppuration. O. purulenta chronica, chronic inflammation of the middle ear, with persistent discharge. O., Sclerotic, chronic catarrhal otitis media, with thickening and hardening of the tissues.

Otiyindimba (o-te'-e-in-din $\left.\ell^{\prime}-b a h\right)$ [nat. African]. A pustular dermatitis prevalent in Damaraland.

Oto- $\left(o^{\prime}\right.$-to- $)$ [oùs, gen., $\omega^{\top} t o ́ s$, ear]. A prefix signifying connection with, or relation to, the ear.

Otoblenorrhea $\left(o^{\prime}-t o-b l e n-o r-e^{\prime}-a h\right)[o u ̄ c$, ear; $\beta \lambda \varepsilon ́ v v \alpha$, mucus; poia, flow]. Any abnormal discharge of mucus from the ear.

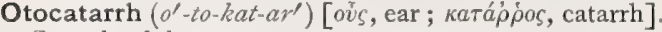
Catarrh of the ear

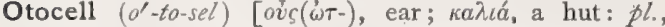
Otocelli]. In biology, an auditory sac or cell, as in the Hydro-medusa.

Otocephalus (o-to-sef'-al-us) [ov̀s, ear; $\kappa \varepsilon \circlearrowleft a \lambda \eta$, head] I. A species of single autositic monsters characterized by an absence or a rudimentary condition of the lower jaw, with ill-development of the mouth, which may be merely a minute orifice, and an approach of the ears to each other, which may touch at their lower parts or even be united. It is a very rare condition in the human species, but is not infrequent among sheep. 2. A variety of the foregoing species in which there is some degree of synopsia, the maxillæ and mouth being distinct, and a proboscis wanting.

Otocerebritis $\left(o^{\prime}-t o-s e r-e-b r i^{\prime}-t i s\right)[o v s$, ear ; cerebrum, brain; $\iota \tau \iota \zeta$, inflammation]. Inflammation of the brain from disease of the ear.

Otocleisis $\left(0-t o-k l i^{\prime}-s i s\right)$ [ov̧, ear; $\kappa \lambda \varepsilon i \sigma \sigma \varsigma$, closure]. Occlusion of the ear.

Otoconia $\left(o-t o-k o^{\prime}-n e-a h\right)$. Plural of Otoconium.

Otoconial $\left(0-t o-k o^{\prime}-n e-a l\right)$ [ov̀s, ear ; kóves, dust]. Pertaining to, or of the nature of, otoconia.

Otoconite $\left(0-t o k^{\prime}-0-n \bar{i} t\right)$. Synonym of Otoconium.

Otoconium (o-to-kof-ne-um) [ov̀s ( $\dot{\omega} \tau-)$, ear ; kóvıs, dust: pl., Otoconia]. In biology, one of the gritty particles or minute otoliths from the membranous labyrinth of higher vertebrates.

Otocrane, Otocranium (o'-to-krän, o-to-kra'-ne-um) [ov's, ear; Koaviov, skull]. The cavity of the skull holding the organ of hearing.

Otocranial, Otocranic (o-to-kra'-ne-al, o-to-kra'-nik) [ov่s, ear; Kpaviov, skull]. Pertaining to the otocrane.

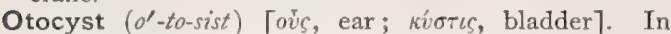
biology, an auditory vesicle, otocell, or otidium in invertebrates, or an otolithic sac in vertebrates.

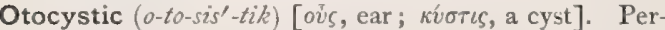
taining to an otocyst.

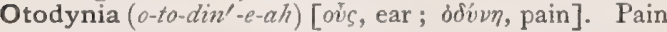
in the ear.

Otoganglion (o-to-gang'-rle-on). See Ganglion, Otic.

Otoglyphis $\left(o-\operatorname{tog}^{\prime}-l i f-i s\right)$ [ovs, ear; jíviev, to scrape]. An ear-spoon.

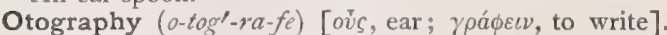
The descriptive anatomy of the ear.

Otoiatry $\left(0-t o-i^{\prime}-a t-r e\right)$. Synonym of Otiatrics.

Otolite $\left(o^{\prime}-t o-l i t\right)$ [ovs, ear; $\lambda i \theta o s$, stone]. Same as Otolith.
Otolith $\left(o^{\prime}\right.$-to-lith $)$ [ov̌s, ear; $\lambda i \theta o s$, stone]. I. A calcareous concretion within the membranous labyrinth of the ear of fishes, in fish-like vertebrates and in the auditory vesicles of invertebrates 2 . One of the otic bones proper. An otostion.

Otolithic, Otolitic (o-to-lith'tik, o-to$\left(i \ell^{\prime}-i k\right)$ [ois, ear ; $\lambda_{i} \theta 0 s$, stone $]$. Pertaining to an otolith.

Otologist (o-toll-ojist) [ovs, ear ; $\lambda$ bos, science]. One versed in otol. ogy ; an aurist.

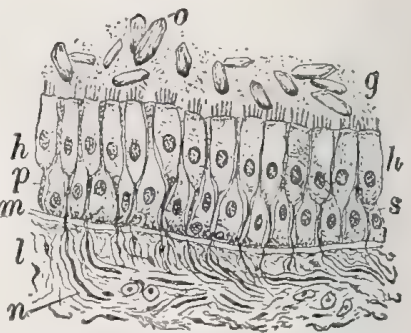

SECTION OF WALl OF UTRICIE OF THE INTERNAL EAR, through macular region, from rabbit, showing otoliths (o), embedded within granular substance $(g)$. h. Ciliated-cells with processes $(p)$, extending between sustentacular elements $(s)$. $n$. Nerve-fibers within fibrous tissue (l) passing toward hair-cells and becoming non-medullated at basement-membrane. (Afler Piersol.)

Otology $\left(o-t_{0} l^{\prime}-o-j e\right)\left[o \bar{s}\right.$, ear; $\lambda b^{\prime} \gamma o s$, science]. The science of the ear, its anatomy, functions, diseases, and treatment.

Otomyces $\left(0-\operatorname{tom}^{\prime}-i s-\bar{e} z\right)$ [ov̀s, ear; $\mu$ v́kns, fungus]. A fungous gruwth within the ear. O. hageni, a fungus, with green conidia, sometimes found in the external canal of the ear. O.purpureus, a dark-red fungous growth in the ear.

Otomycosis $\left(o^{\prime}-t o-m i-k o^{\prime}-s i s\right)$ [ov́s, ear; $\mu$ íkns, fungus]. The growth of fungi within the ear, or the diseased condition associated with such a condition.

Otoncus (o-tong'-kus) [ov̌s, ear; byros, tumor]. A swelling or tumor of the ear.

Otonecronectomy (o'-to-nek-ro-nek'-to-me) [ov's, ear;

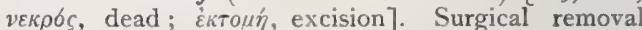
of necrosed sound-conductors from the ear.

Otoneuralgia $\left(o-t o-n u-r a l^{\prime}-j e-a h\right)$. Synonym of Otalgia.

Otopathema (o-to-path-e'-mah) [ov̀s, ear; $\pi a ́ t \eta \mu a$, an attack of sickness]. A disease of the ear.

Otopathic (o-to-path'-ik) [ớ, an ear; $\pi \dot{\top} \theta o \varsigma$, disease]. Pertaining to ear-disease.

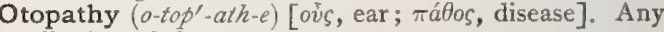
affection of the ear.

Otopharyngeal (o-to-far-in'-je-al) [ov̌s, ear; фá $\rho v \gamma \xi$, pharynx]. Pertaining to the ear and the pharynx. O. Tube, the Eustachian tube.

Otophone $\left(o^{\prime}-t o-f o ̄ n\right)$ [ov́s, ear; $\phi \omega v \dot{n}$, voice]. I. An ear-trumpet, or other device for gathering and intensifying sound-waves. 2. An auscultating tube used in ear-diseases.

Otophthalmic (o-toff-thal'-mik) [ov̀s, ear; $\delta \phi \theta a \lambda \mu \delta s$, eye]. Pertaining to the ear and the eye.

Otopiesis (o-to-pi'-es-is) [ovs, ear; $\pi i \varepsilon \sigma \iota s$, pressure]. Excessive pressure upon the labyrinth, with consequent deafness. Depression of the tympanic membrane by atmospheric pressure, owing to the rarefaction of the air within the tympanic cavity.

Otoplasty $\left(\sigma^{\prime}\right.$-to-plas-te) [ovs, ear; $\pi \lambda a ́ \sigma \sigma \varepsilon \varepsilon v$, to form]. The operation of repairing certain lesions of the external ear by the engrafting of healthy tissue from some other part of the body ; plastic surgery of the ear.

Otoplexiometer $\left(0-t o-p l e k s-\ell-o m^{\prime}-e t^{\prime}-e r\right)$ [ov $s$, ear; $\pi \lambda \bar{\eta} \xi(s$, percussion; $\mu$ ćtpov, measure]. An instrument for examining the concealed portions of the ear by percussion.

Otoporpa (o-to-por'-pah) [ov̀s, ear; $\pi \delta \rho \pi \eta$, a buckle : pl., Otoporpa]. In biology, one of the "auditory clasps" of Medusa. 
Otopyorrhea (o-to-pi-or-e'-ah) [ov's, ear ; $\pi \hat{v} 0 v$, pus ; poia, a flow]. A purulent discharge from the ear. Otopyosis $\left(0-t o-p i^{\prime}-0\right.$-sis) [ovs, ear; $\pi \dot{v} o v$, pus]. Suppuration within the ear.

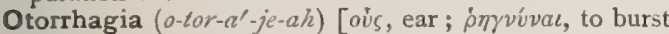
forth]. A discharge of blood from the external auditory meatus.

Otorrhea $\left(o-t o r-e^{\prime}-a h\right)[o v ̌ s$, ear; $\dot{\rho} \circ i a$, a flow]. A discharge from the external auditory meatus.

Otorrheumatismus (o-tor-ru-mat'-iz'-mus) [ovs, ear : $\dot{\rho} \varepsilon \bar{v} \mu n$, rheum]. Pain in the ear due to rheumatism.

Otosalpinx (o-to-sal'-pinks) [ov́s, ear; $\sigma a ́ \lambda \pi \iota \gamma \xi$, tube]. The Eustachian tube.

Otoscleronectomy (o-to-skle-ro-nek'-to-me) [ov̌s, ear

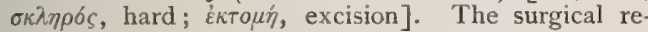
moval of sclerosed and ankylosed conductors of sound in cases of chronic otitis media.

Otoscope $\left(o^{\prime}\right.$-to-skōp $)$ [ov́s, ear; $\sigma \kappa o \pi \varepsilon \bar{v} v$, to examine]. An instrument for examining the ear. What is ordinarily called and used as an otoscope is a rubber tube, one extremity of which is inserted into the ear of the subject, and the other extremity into the ear of the examiner, a current of air being passed by means of a Politzer bag and a Eustachian catheter through the middle ear. In case of tympanic perforation the rushing sound made by the passing air is audible to the examiner.

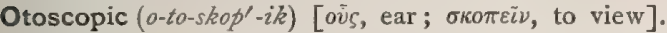
Pertaining to otoscopy.

Otoscopy $\left(o-t o s^{\prime}-k o-p e\right)$ [oủs, ear; $\sigma \kappa o \pi \varepsilon i \tilde{\imath}$, to examine]. The use of the otoscope; clinical examination of the ear.

Otosis $\left(0-t o^{\prime}-s i s\right)$ [ovs, ear]. A mishearing ; a false im pression as to sounds or words heard.

Otosteal $\left(0-t o s^{\prime}-t e-a l\right)$ [ov̀ taining to the bones of the ear.

Otosteon $(0$-tos'-te-on) [ov́s, ear; óoréov, bone : pl., Otostea ]. I. An ossicle, or ear-bone. 2. An otolith.

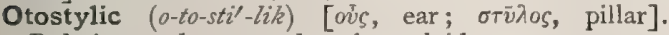
Relating to the ear and to the styloid process.

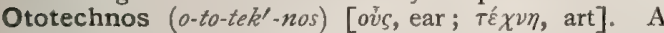
peculiar hammering sensation in the ear.

Ototomy (o-tot'-o-me) [ov̀s, ear; $\tau o \mu$, , a cutting]. Dissection of the ear.

Ottar, Otto (ot'-ar, ot $-o)$. See Attar.

Otto's Restraining Band. A band used in diaphragmatic pleurisy to relieve the pain. It is applied low down to favor thoracic respiration and diminish the abdominal and diaphragmatic movements.

Ouabain (oo-ah-ba'-in) [ouabaio], $\mathrm{C}_{31} \mathrm{H}_{48} \mathrm{O}_{12}$. A highly poisonous glucosid extracted from the wood of a species of Apocynea, the Carissa schimperi. It is a cardiac stimulant. Dose, gr. $\frac{1}{2000}$ to $\frac{1}{2} \frac{1}{50}$, given as a per mille solution.

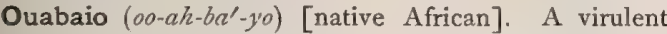
arrow-poison used by certain African tribes.

Oudemann's Method. A method of estimating iron in organic substances, $e . g$. , hemoglobin. A weighed amount of the material is incinerated; the ash is dissolved in $\mathrm{HCl}$, and to the dilute ferric solution, which should not contain more than $\mathrm{O} . \mathrm{I}$ to 0.2 gram $\mathrm{Fe}$ in I00 c. c., nor much free $\mathrm{HCl}$, are added 3 c. c. of a one per cent. solution of cupric sulphate, 2 c. c. of concentrated $\mathrm{HCl}$, and $\mathbf{I}$ c. c. of a one per cent. solution of potassium sulphocyanid. The mixture is slightly warmed, and a standard solution of sodium thiosulphate (I c. c. of a decinormal solution of which corresponds to $0.0056 \mathrm{Fe}$ ) is run in from a buret, until the previously red mixture becomes as colorless as water.

Oulachon (oo'-lak-on). See Euluchon.

Oulitis $\left(00-l i^{\prime}-t i s\right)$. See Vlitis.

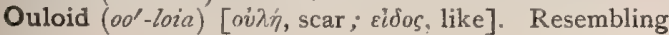

a scar. Also, a form of cicatrix characteristic of lupus, elephantiasis, and syphilis.

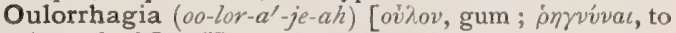
burst forth]. Hemorrhage from the gums.

Ounce (oions) [uncia, a contraction of undecia, a twelfth part]. A twelfth part of the Troy pound, or 480 grains; symbol, 3 . Also, a sixteenth part of the avoirdupois pound, or 437.5 grains. Symbol oz.

Ourari (oo-rah'-re). Same as Curare.

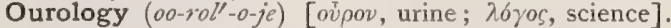
The science of the nature and secretion of urine.

Ouroscopy (oo-ros'-ko-pe). See Uroscopy.

Out (owt) [ME., out, out]. Forth; from within to the exterior. O.-cast Cell, an apoblast ; in the unimpregnated ovum, one of a group of cells that are finally cast off and disappear. See Apoblast. O.knee, bow-leg; valgus.

Outlet. I. The lower aperture of the pelvic canal. 2. The passage that removes the air from a room in ven tilation. O. of Pelvis. See Outlet.

Ova $\left(o^{\prime}-v a h\right)$ [L.]. Plural of ovum, an egg

Oval $\left(o^{\prime}-r a l\right)$ [ovum, egg]. Elliptic; egg-shaped, O. Amputation. See Malgaigne's and Scoutettin's Amputations, in Operations, Table of.

Ovalbumin (o-val'-bu-min) [ovum, egg; albumin] The albumin of the egg.

Ovalescent (o-val-es'-ent) [ovalis, oval]. Somewhat oval.

Ovaliform (o-val'-if-orm) [ovalis, oval ; forma, form]. Oval-shaped.

Ovaloid (o'-val-oid) [ovalis, oval; $\varepsilon i \delta o s$, like]. Resembling an oval.

Ovaralgia (o-var-all-je-ah). See Ovarialgia.

Ovarial $\left(0-v a^{\prime}-r e-a l\right)$. See Ovarian.

Ovarialgia (o-va-re-al'-je-ah) [ovarium, an ovary; $\alpha \lambda \gamma o s$, pain]. Pain in the ovaries.

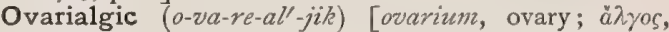
pain]. Pertaining to, or affected with, ovarialgia.

Ovarian (o-va'-re-an) [ovarium, an ovary]. Pertaining to the ovaries. 0 . Center. See Dysmenorrhea. O. Cyst, O. Cystoma, a cystic tumor of an ovary. O. Dysmenorrhea. See Dysmenorrhea. O. Plexus, the pampiniform plexus of the female. O. Pregnancy, extra-uterine pregnancy in which the ovum resides in the ovary. 0 . Vesicle, in biology, the gynophore or female gonophore of a polyp.

Ovaric $\left(o-v a^{\prime}-r i k\right)$. Synonym of Ovarian.

Ovariectomy (o-va-re-ek'-to-me) [ovarium, ovary;

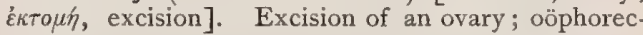
tomy

Ovariocele $\left(o-\tau / \alpha^{\prime}-r e-o-s \bar{e} l\right)$ [ovarium, ovary; $\kappa \eta^{\prime} \lambda \eta$, tumor]. Tumor of the ovary; hernia of an ovary. O., Vaginal, invasion of the vaginal wall by one or both ovaries.

Ovariocentesis (o-va-re-o-sen-te'-sis) [ovarium, ovary; $\kappa \varepsilon ́ v T \eta \sigma \iota \zeta$, puncture]. Puncture of the ovary or of an ovarian cyst.

Ovarioclasis (o-va-re-ok'-las-is) [ovarium, ovary; $\kappa \lambda a ́ \sigma \iota \zeta$, a breaking]. The breaking up of an ovary.

Ovariocyesis (o-va'-re-o-si-e'-sis) [ovarium, ovary;

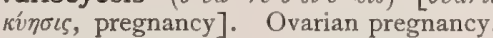

Ovariodysneuria $\left(0-v a^{\prime}-r e-o-d i s-n u^{\prime}-r e-a h\right)$ [ovarium,

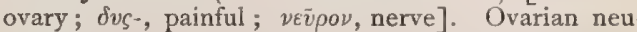
ralgia.

Ovario-hysterectomy (o-va'-re-o-his-ter-ek'-to-me)

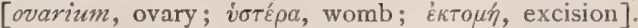
Surgical removal of the ovaries and uterus.

Ovariole $\left(o-v a^{\prime}-r e-\bar{l} l\right)$ [ovariolum, a small ovary]. In biology, a small ovary, or one of the elements of a composite ovary.

Ovariomania (o-va-re-o-ma'-ne-ah). Synonym of Oöphoromania. 
Ovarioncus (o-va-re-ong'-kus) [ovarium, ovary; öykos, tumor]. An ovarian tumor.

Ovariorrhexis $\left(0-v a-r e-o r-e k s^{\prime}-i s\right)$ [ovarium, ovary ; $\hat{\rho} \tilde{\xi} \xi s$, rupture]. Rupture of an ovary.

Ovariosteresis (o-va-re-o-ster-e'-sis) [ovarium, ovary; $\sigma \tau \varepsilon \dot{\rho} \rho \eta \sigma \iota$, deprivation]. Extirpation of an ovary.

Ovariotomist (o-va-re-ot' $-0-m z s t)$ [ovarium, ovary; rouń, a cutting]. One who performs ovariotomy and, by extension, also oöphorectomy.

Ovariotomy (o-va-re-ot'-o-me) [ovarium, ovary; тoún, a cutting]. Literally, incision of an ovary. Improperly, the surgical removal of an ovary; synonymous with oöphorectomy. O., Abdominal, ovariotomy through an abdominal incision. O., Normal, a term for Battey's operation, q. $v$. in Operations, Table of. O., Vaginal, removal of an ovary through an incision in the vault of the vagina.

Ovario-tubal (o-va'-re-o-tu'-bal) [ovarium, ovary ; tuba, tube]. Pertaining to the ovary and the oviduct.

Ovarism $\left(o^{\prime}\right.$-var-izm) [ovarium, ovary]. The theory that every animal organism is developed from an ovum.

Ovarist $\left(o^{\prime}\right.$-var-ist) [ovarium, ovary]. One who believes in ovarism.

Ovaritis $\left(0-v a r-i^{\prime}-t i s\right)$ [ovarium, ovary ; $\iota \tau \iota s$, inflammation]. Inflammation of the substance of an ovary. It may be Parenchymatous or Follicular, or Interstitial. In the former, the contents of the ovarian follicles become turbid and then purulent. This occurs in the acute exanthemata and other diseases, and cannot be recognized clinically. Interstitial ovaritis is usually a sequel of parturition, when it is a part of a general septicemia. It occurs in three forms: (I) serous; (2) suppurative or hemorrhagic; and (3) necrotic, the organ being converted into a brown pulp with entire destruction of its tissue.

Ovarium $\left(o-v a^{\prime}-r e-u m\right)$ [L., ovary: pl., Ovaria]. In biology, an ovary or oöphoron.

Ovariypertrophy (o-var-e-ip-er'-tro-fe). Synonym of Oöphorauxe.

Ovary $\left(o^{\prime}-v a r-e\right)$ [ovarius, an egg-keeper; ovarium, an egg-producing organ; ovum, egg]. The most inportant part of the female reproductive apparatus. A glandular, secreting organ, giving rise to ova. In woman it is a paired organ projecting from the posterior surface of the broad ligament. Its weight is about IOo grains. The right is usually a little larger than the left. It consists of a parenchyma and a cap. sule, or tunica albuginea. In the cortex of the former are numbers of small vesicles called ovisacs or Graafian follicles in which the ova are developed. In biology, among the lower organisms (e.g., Paramecium) the nucleus gives rise to bodies analogous to ovules, while in animals a grade higher, the undifferentiated endoderm or mesoderm is the female germinal layer (e. g., Porifera). Specialization follows localization of function, and the parts of the body set aside for the production of ova gradually take the form of glands (gemaria, ovaria), the products of which may become detached from the spot where they are formed, and pass into the somatic or body-cavity, or into the digestive sac (e.g., Actina, Polyzoa, Brachyopoda), or even directly to the exterior (e.g., Echinidea, Proctucha, Nemertea). Gradually, as the animal scale is ascended, ducts of a complicated character are found to be added to the ovary proper. These ducts are not primitively connected with the germinal glands, but may be regarded as excretory organs which have entered into the service of the genital organ. These ducts (oviducts) become provided with appendages or

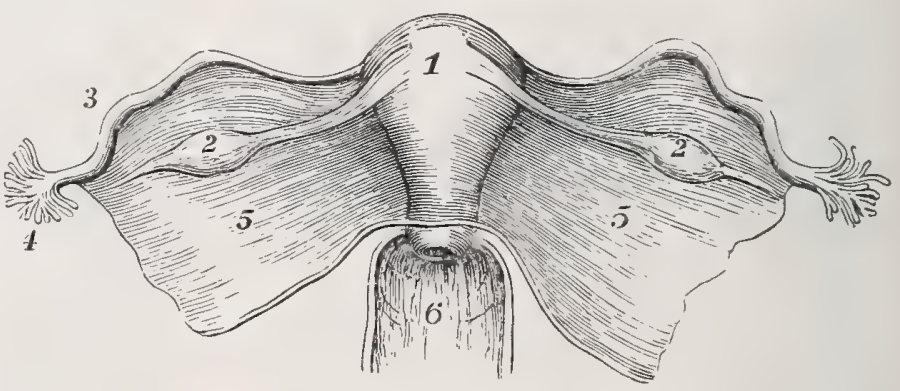

OSterior Aspect of Female Internal, Genitalia.

rus. 2, 2. Ovaries, 3. Left oviduct. 4 Fimbriated extremity of 5. Broad ligaments. 6. Anterior vaginal cul-de-sac

dilatations from which the ova get special envelops ("yelk gland," "shell gland," " oviducal gland," " nidamental gland," "accessory gland"), are fertilized (spermatheca, appendicular gland, fertilizing pouch), or further developed (uterus). The relation of the ovary to the testis varies greatly, and must also be considered from the standpoint of differentiation. In the lower animals, male and female reproductive

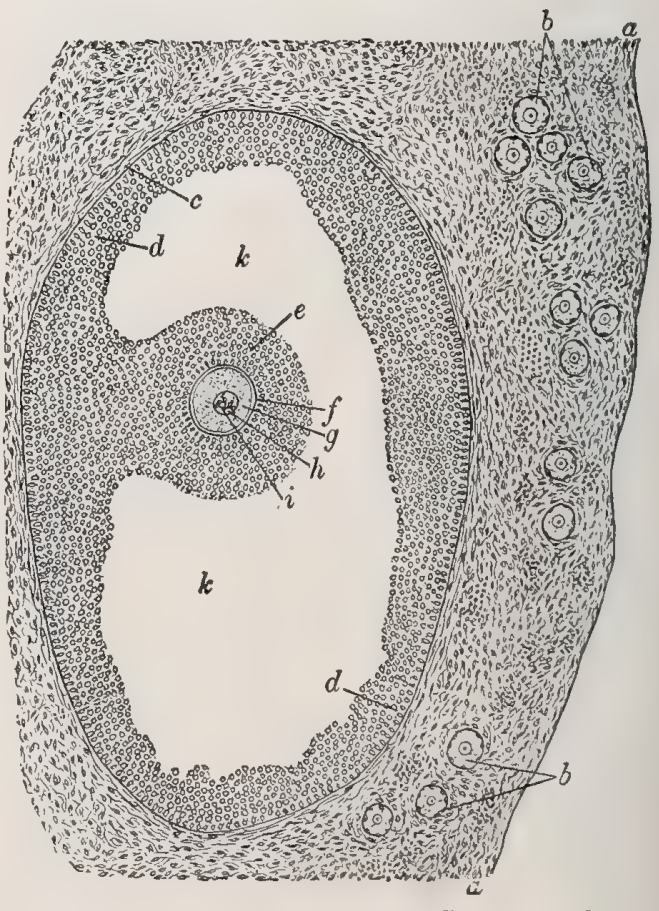

Section of Cortex of Cat's Ovary, Exhibiting Large GRAAFIAN FOLLICLES.

$a$. Peripheral zone of condensed stroma. b. Groups of immature follicles. $c$. Theca of follicle. $d$. Membrana granulosa. $e$. Discus proligerus. $f$. Zona pellucida. $g$. Vitellus. $h$. Germinal vesicle. $i$. Germinal spot. $k$. Cavity of liquor folliculi. (After Piersol.)

glands are so united with one another, that one and the same gland produces both spermatozoa and ova (" hermaphrodite gland," "ovotestis," as in Synapta, Helix, Hyalaa, etc.). Thus, hermaphroditism is the 
primitive condition of the sexual apparatus, the phylogenic and ontogenic precursor of sexual differentiation, which is effected by the abortion or reduction of one kind of sexual apparatus and function taking place at very different stages in the organism, and often when the sexual organs have attained a very high degree of specialization, the human ovary becoming histologically recognizable about the sixth week, and readily distinguished in a three-months embryo. 2. That part of the pistil of a flower which produces and contains the ovules and seeds. The ovarium or germarium. O., Irritable, an ovary the seat of intermittent neuralgic pain.

Ovate $\left(\sigma^{\prime}-v \bar{a} t\right)$ (ovatus, egg-shaped]. Egg-shaped.

Oven $\left(u v^{\prime}-n\right)$ [oven, an oven]. An apparatus used in bacteriologic laboratories for sterilizing culture-media, for maintaining the cultures, etc., at a constant temperature by an automatic mechanism. Those of Koch, Pasteur, d'Arsonval, and Babes are most used.

Over $\left(o^{\prime}\right.$-ver $)$ [ME., over, over]. In a place higher than a given object. O.-crowding, the dwelling together of too many persons in a locality, house, or apartment, with the consequent failure in sanitary and hygienic arrangements, whence result conditions favorable to the development and spread of certain diseases. O.-eat, to surfeit with eating. O.-feed, to feed to excess. O.-grown, grown too large. O.-laid, said of a child suffocated by the parent lying on it. O.-lying of Children, a frequent cause of death in infants from suffocation from one of the parents lying upon the child while in an intoxicated condition or intentionally. O--maximal, beyond the normal maximum, as the over-maximal contraction of a muscle. (Fick.) O.-pressure, applied chiefly to the school-system that forces too long and continuous periods of study upon the pupils, with consequent unhealthy conditions of mind and body. O.-reach, to strike the toe of the hind-foot against the heel or shoe of the fore-foot; said of a horse. O.-riding, overlapping of the broken ends of a fractured bone. O.-sight. See Hypermetropia. O.-strain, to strain to excess; a condition resulting from exhausting effort. O.-toe, a variety of Hallux varus in which the great toe overlies its fellows. O.-tones, the notes represented by the vibrating subdivisions of a string ; harmonics. O.-work, Mental. See Parathymia.

Ovic $\left(o^{\prime}-v i k\right)$ [ $\omega^{\circ} \nu$, ovum, an egg]. Relating to an ovum. O. Cell, in biology, a primitive ovum (the Urei of German authors). Primitive ova exist in great numbers in cord-like ingrowths of the epithelium of the ovary (Pfïger'schen Schläuche) in which each ovic cell finally becomes surrounded by a separate envelop of epithelial cells, forming the primordial follicle.

Ovicapsule (o-vik-ap'-sül) [Giov, ovum, egg; capsula, capsule]. An egg-case, ovisac, or Graafian follicle.

Ovicell $\left(o^{\prime}-v i s-e l\right)$ [ $\omega^{\prime} w$, ovum, an egg; cella, a cell]. r. An unimpregnated ovum. 2. Same as Ovicyst.

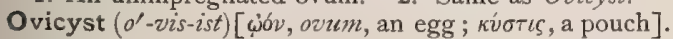
In biology, the incubatory pouch of an ascidian or polyzoan.

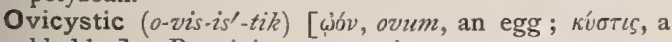
bladder]. Pertaining to an ovicyst.

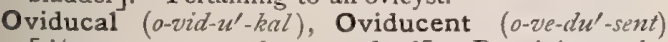
[Góv, ovum, egg; ducere, to lead]. Pertaining to the oviduct, or its functions. O. Gland, an enlargement of the oviduct in Sepin.

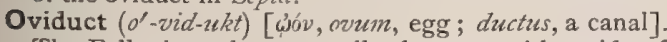
The Fallopian tube; a small tube upon either side of the uterus through which the ovule passes to the uterus. O., Ampulla of, O., Pavilion of, the expanded portion of the abdominal end of the oviduct, the fringed edge of which is called the fimbria.
Oviferous (o-vif'-er-us) [⿳่⿰́v, ovum, an egg ; ferre, to bear]. In biology, bearing eggs or ova.

Ovification (o-vif-ik-a'-shun) [ ‘óv, orım, egg ; facere, to make]. The production of ova.

Oviform (o'-vif-orm $)$ [ $3 \mathrm{ov}$, ovum, egg; forma, form]. Egg-shaped; oval.

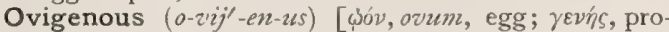
ducing]. Producing ova, as an ovary. O. Layer, the outer layer of the ovary, in which the ovisacs containing the ova are situated.

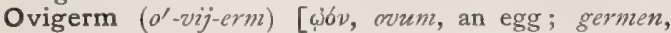
sprout, bud]. In biology, an ovum, or ovicell.

Ovigerous (o-vij'-er-us) [\$ov, ovum, egg; gerere, to carry]. Producing eggs or ova; oviferous, ovigenous, oviparous.

Ovination (o-vin- $a^{\prime}$-shun) [ovis, a sheep]. Inoculation with the virus of sheep-pox. It has been employed like equination and Pasteurism, as a substitute for vaccination.

Oviparous (o-vip'-ar-us) [ $\omega \dot{b} v$, ovum, egg ; pareve, to bring forth]. Producing, or laying, eggs; a term applied to those species of animals, the females of which bring forth their young in the egg-stage of development; incubated outside the body, as distinguished from ovoviviparous, or viviparous.

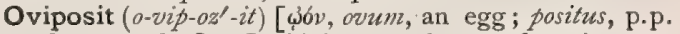
of ponere, lay]. In biology, to lay or deposit eggs, especially with an ovipositor, as an insect.

Oviposition (o-vip-o-zish'-un) [G่óv, ovum, egg; ponere, to place]. In biology, the act of laying or depositing eggs by the females of oviparous animals.

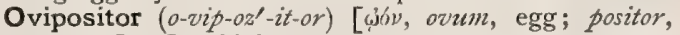
builder]. In biology, an organ, common among insects, composed of several modified rings or somites, forming the end of the abdomen, and employed in depositing the eggs in places fit for development.

Ovis $\left(o^{\prime}-v i s\right)[\mathrm{L}$.$] . Sheep.$

Ovisac $\left(o^{\prime}-v i s-a k\right)$ [ ต่óv, ovum, egg; saccus, sack]. In biology, the capsule, sac, cyst, case, cell, or pod of an individual ovum; a Graafian follicle, an ovicell, ovicyst, ovicapsule.

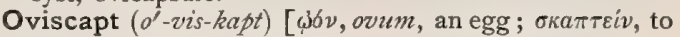
dig]. Same as Ovipositor.

Ovism $\left(o^{\prime}\right.$-vizm $)$ [çov, ovum, egg]. The doctrine that the ovum encloses within itself in an undeveloped form all the organs of the future being; the doctrine of incasement, $q . v$.

Ovispermary (o-vis-per'-mar-e) [ ['ón, ovum, an egg ; spermarium, spermary]. In biology, an ovotestis or sexual organ producing both ova and spermatozoa.

Ovist $\left(o^{\prime}-v i s t\right)$ [ $\$ b v$, ovum, egg]. In biology, an adherent of the doctrine of incasement, $q . v . ;$ an ovulist.

Ovoblast $\left(o^{\prime}-v 0-b l a s t\right)$ [ $\omega \sigma v$, ovum, ovum; $\beta \lambda a \sigma \tau o ́ s$, germ]. The primordial ovum.

Ovococcus (o-vo-kok'-us) [a'óv, ovum, egg; кбккоs, berry : pl., Ovococci]. In biology, the nucleus of the ovicell, or unimpregnated ovum.

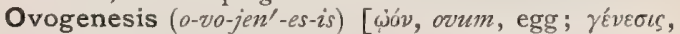
genesis]. The process of the development or production of the ovum.

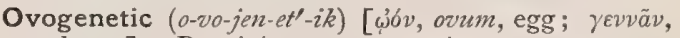
to beget]. Pertaining to ovogenesis.

Ovogenous $\left(0-v o j^{\prime}-e n-u s\right)$. Synonym of Ovogenetic.

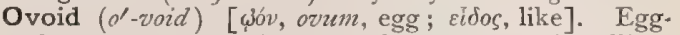
shaped. O., Fetal, the fetal ellipse, or the ellipse formed by the bending of the fetal body in utero.

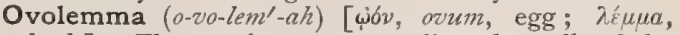
bark]. The membrane surrounding the yolk of the human egg.

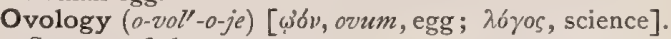
Same as Oölogy.

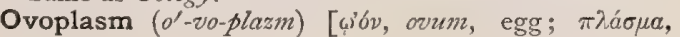


plasm]. The protoplasm of the unimpregnated ovum or ovicell.

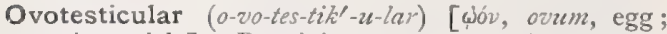
testis, testicle]. Pertaining to an Ovotestis.

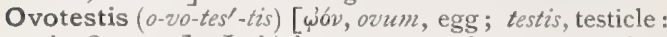
pl., Ovotestes]. In biology, a generative organ producing both male and female products; an ovispermary, as seen in opisthobranchiate Branchiogasteropoda.

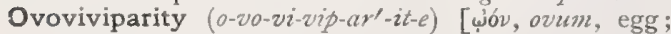
viviparus, bringing forth alive]. The character of being ovoviviparous.

Ovoviviparous (o-vo-vi-vip'-ar-us) [ڤ́óv, ovum, egg ; vivipams, bringing forth alive]. In biology, reproducing by means of eggs incubated within the body, as distinguished from oviparous and viviparous.

Ovula $\left(o^{\prime}-v u\right.$-lah $)$ [L.]. Plural of Ovulum. O. of Naboth. See Orule.

Ovular, Ovulary $\left(o^{\prime}-v u-l a r, o^{\prime}-v u-l a r-e\right)[G i o v$, ovum, egg]. Relating to an ovule or ovum.

Ovulate $\left(o^{\prime}-v u\right.$-lät $)$ [ovulum, a little egg]. In biology, to produce ovules or discharge them from the ovary. Ovuliferous.

Ovulation (o-vu-la'-shun) [ovulum, dim. of ovum, egg]. The maturation and escape of the ovum.

Ovule $\left(\sigma^{\prime}-v \bar{u} l\right)$ [ڤóv, ovum, egg]. In biology: (a) A small ovum or animal egg; $(b)$ a young or rudimentary seed. O., External Migration of, the transfer of an ovule from the right ovary to the left oviduct, or from the left ovary to the right oviduct. O., Membrana granulosa of, the layer of stratified follicular epithelium lining the cavity of the ovisac. The prominence formed at one side is called the cumulus ovigerus, or discus proligerus. O., Migration of, the transfer of the ovule from the ovary to the oviduct. $\mathbf{O}$. of Naboth, one of the small cysts resulting from obstruction of the ducts of the glands of the cervix of the uterus. O., Polar Cells of, certain cells thrown off upon the surface of the vitellus of the unimpregnated ovum. O., or Cell, Primordial, one of the primitive ovules in the substance of the ovary. O., Tunica granulosa of, the layer surrounding the ovum.

Ovuliferous (o-vu-lif'-er-us) [ovulum, a little egg; an ovule; ferre, to bear]. In biology, ovule-bearing.

Ovuligerous (o-vu-lij'-er-us). Same as Ovuliferous.

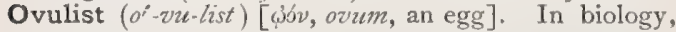
an adherent of the doctrine of incasement, q. $v . ;$ an ovist.

Ovulum $\left(o^{\prime}-v u-h u n\right)$ [L.: pl., Ovula]. An ovule. See Orule.

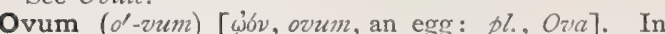
biology, the female reproductive cell of an animal; the egg. It consists of protoplasm (the yolk), and a nucleus (the germinal vesicle) in the unfertilized ovum. It is either naked or covered by one or more membranes and envelops, which either originate from the egg itself, constituting real primary yolk or egr-integuments, or from the surrounding parietal tissues, constituting secondary or accessory ego-envelops. Ova arise in special organs of the metazoan body called ovaria or germaria. The nucleus or rerminal vesicle (vesicula germinativa) is of relatively great size, and central or peripheral in situation. It consists of a distinct membrane and an enclosed nuclear fuid, in which lie one or more solid nucleolior gerninal spots (macula germinativa), which may be connected by an intranaclear network of fine threads. The protoplasm consists of fine, firm particles, forming the threads and meshes of a fine network, the spongioplasm, within which is the more fluid hyaloplasm. This constitutes the formative yolk, besides which there is frequently present nutrient material in the form of drops of fat or oil, and small plates or spheres which form the deuteroplasm, or nutritive yolk. This is rarely absent; usually it is present in considerable quantity. Eggs are distinguished as (A) Alecithal, in which the food-yolk is entirely absent, or present only in very small quantity. (B) Telolecithal, in which the foodyolk and the formative yolk divide the egg into two hemispheres, called respectively the vegetative and the animal; or in which the quantity of the nutritive yolk is greatly in excess, the formative yolk being but a segment or mass at the animal pole, in which lies the germinal vesicle. In both cases a thin layer of protoplasm spreads over the entire surface of the ovum. (C) Centrolecithal, in which the formative yolk is arranged in a regular layer around the whole ovum, as well as in a mass at the center of the ovum in which lies the germinal vesicle. The region between the central and the peripheral formative yolk is more or less completely occupied by deuteroplasm. The distribution of formative yolk and food-yolk affects the germinative phenomena. When the food-yolk is scant and more or less thoroughly intermingled with the formative yolk, germination is accompanied by a practically uniform segmentation and the egg is called holoblastic, e.g., as in all mammals except monotremes, and in some invertebrates, $e . g$., spiders. When the formative yolk and the food-yolk are separated into more or less well-defined masses, the segmentation is less symmetric and uniform and is called meroblastic. The egg envelops are divided into: (I) Primary envelops, yolk. membranes ; these are sometimes double, verforated by numerous pores (zona radiata) and occasionally there is a special opening, the micropyle. (2) Secondary accessory envelops, some of which are formed by the ovum itself. O., Apoplectic, one the seat of a hemorrhagic extravasation. O., Blighted, an impregnated ovum the development of which has been arrested by disease or by hemorrhage into the chorion or amniotic cavity. O.-cycle, an ovum-product. O., Male, certain cells found in diverticula of the seminiferous tubules, considered to be rudimentary or imperfect spermatozoa, O., Meroblastic, an ovum with a large amount of food-yolk which takes no active part in the development of the embryo. O., Permanent, the fully developed ovum capable of being fertilized. O., Primordial. See Egg-cells. O.-product, the whole product of an ovum.

Owen's Fissures. See Fissures, Table of. O.'s Line. See Lines, Table of.

Ox (oks) [ME, oxe, ox]. The adult male of the Bos taurus; a bull. O.-acid. Same as Oxyacid. O.bile. Same as $O$-gall. O.-eyed, having large, full eyes. O.-fly, the bot-fly (Hypoderma bovis), which infests cattle. O.-foot, in farriery, the hind foot of a horse when the horn cleaves just in the middle of the fore part of the hoof from the coronet to the shoe. O.-gall. See $\mathrm{Fcl}$ bovis. O.-warble, a fly troublesome to cattle; also called heel-fly. See Hypoderma bovis under Parasites (Animal), Table of.

Oxalantin (oks-al-an'-tin) [ókvs, acid; Ger., alant, elecampane], $\mathrm{C}_{6} \mathrm{H}_{6} \mathrm{~N}_{4} \mathrm{O}_{6}$. Leukoturic acid; an acid obtained by the action of zinc and $\mathrm{HCl}$ upon oxalyl urea. It occurs in crystalline crusts, sparingly soluble in water.

Oxalate $\left(0 k s^{\prime}-a l-\bar{a} t\right)[\dot{o} \xi a \lambda i s$, sorrel]. Any salt of oxalic acid. In the plural, the term usually refers to calcium oxalate, which is found in the urine under certain conditions.

Oxalemia (oks-al-é-me-ah) [ógahis, sorrel; aima, blood]. Excess of the oxalates, or of oxalic acid, in the blood.

Oxalethylin (oks-al-eth'-il-in) [óśs, acid; aithp, ether; vi $\eta$, matter], $\mathrm{C}_{6} \mathrm{H}_{10} \mathrm{~N}_{2}$. An oily liquid boiling at 
$\lambda \delta \varsigma$, the penis ; poia, a flow]. Acute blennorrhea in the male.

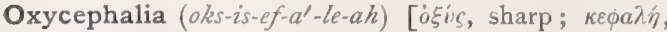
head]. The character of a skull that is high and pointed; hypsicephaly.

Oxycephalus (oks-is-ef'-al-us). See Oxycephalia.

Oxycephaly (oks-is-ef'-al-e). See Oxycephatia.

Oxychilous, Oxycheilous (oks-ik-i'-lus) [ókis, sharp; $\chi \varepsilon i \lambda{ }^{\circ}$, the lip]. In biology, having sharp lips, e. g., certain shells.

Oxychinaseptol (oks-ik-in-as-ep'-tol). See Diaphtherin.

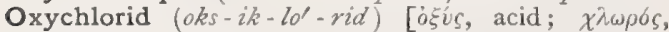
green]. A salt of an element or radicle containing both oxygen and chlorin.

Oxycinchonin (oks-is-in'-ko-nin) [ókis, acid; cinchona $], \mathrm{C}_{20} \mathrm{H}_{24} \mathrm{~N}_{2} \mathrm{O}_{2}$. An isomer of quinin.

Oxycinesis (oks-is-in-ef-sis). Same as Acrocinesis.

Oxycitric Acid (oks-is-it'-rik). See Acid.

Oxycollidin (oks-ik-ol'-id'-in) [óḱv, sharp; $\kappa \delta \lambda \lambda a$ glue], $\mathrm{C}_{8} \mathrm{H}_{11} \mathrm{NO}$. One of the alkaloids of codliver oil. See Morrhuolins.

Oxycoumarin (oks-ik-u'-mar-in). See Umbelliferon.

Oxycyanid (oks-is-i'-an-id) [ókus, sharp; kvavos, blue]. A product of the union of an aldehyd with hydrogen cyanid.

Oxyd $\left(o k s^{\prime}-i d\right)$. Synonym of Oxid.

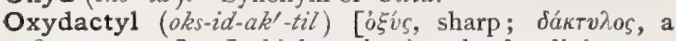
finger or toe]. In biology, having slender digits.

Oxydant $\left(o k s^{\prime}-i d\right.$-ant $)$ [óks, sharp]. An oxidating agent.

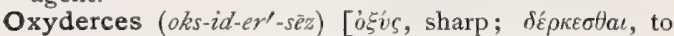
see clearly]. Sharp-sighted; producing keenness of vision.

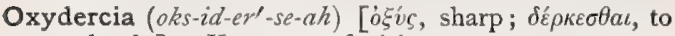
see clearly]. Keenness of vision.

Oxydiabrosis $\left(o k s-i d-i-a b-r o^{\prime}-s i s\right)$ [ókv́s, sharp; diá$\beta \rho \omega \sigma \iota$, ulceration]. A rapidly progressing ulceration.

Oxydimorphin (oks-id-im-or'-fin) [ókis, sharp; Morpheus, the god of sleep], $\mathrm{C}_{34} \mathrm{H}_{36} \mathrm{~N}_{2} \mathrm{O}_{6}$. A finely crystalline derivative of morphin.

Oxydoid (oks'-id-oid) [ókís, sharp; $\varepsilon^{\top} i \delta o s$, like]. Resembling an oxid.

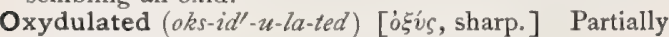
or slightly oxidized.

Oxydum (oks'-id-um). See Oxid.

Oxyecoia (oks-e-ek-oi'-ah). Synonym of Oxyakoia.

Oxyencephalitis (oks-e-en-sef-al-it'-tis) [óvis, acute;

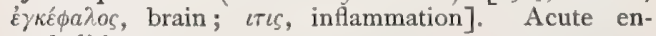
cephalitis.

Oxyendocarditis (oks-e-en-do-kar-di'-tis) [okvs, sharp ;

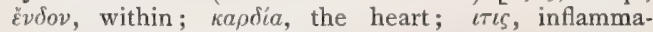
tion]. Acute endocarditis.

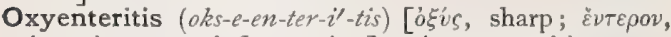
intestine; $\iota \tau \iota$, inflammation]. Acute enteritis.

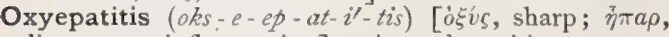
liver; $\iota \tau \iota \zeta$, inflammation]. Acute hepatitis.

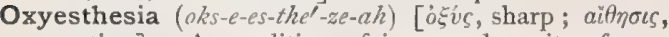
sensation]. A condition of increased acuity of sensibility.

Oxyformobenzoilic Acid (oks-if-or-mno-ben-zo-ill'ik) [ógús, acid; formica, an ant; benzoin], $\mathrm{C}_{8} \mathrm{H}_{8} \mathrm{O}_{4}$. An acid said to be found in the body in acute yellow atrophy of the liver.

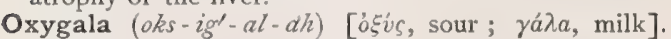
Sour milk.

Oxygastromenia (oks-ig-as-tro-me'-ne-ah) [óg's; sharp;

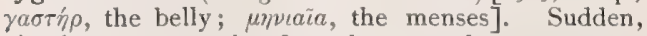
vicarious menstruation from the stomach.

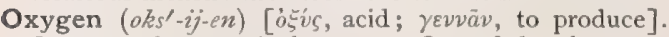
$\mathrm{O}=15.96$; quantivalence II. One of the elements. See Elements, Table of. It is a colorless, tasteless, odorless gas, constituting one-fifth of the atmosphere, eight-ninths of water, three-fourths of organized bodies, and about one-half the crust of the globe. It is characterized by its affinity for the other elements, with every one of which it unites, excepting fluorin. It is an active element in the oxy-acids, and in all the alkaline hydrates. In organic chemistry it unites with radicles and forms alcohols, ethers, and their derivatives. Oxygen is inhaled as a therapeutic agent in diseases of the respiratory organs and blood. It is essential to respiration; its combination with the tissues yields heat and other energy. Combustion is also dependent upon it, consisting of a rapid oxidation, with the evolution of heat and light. It exists also in an allotropic form known as ozone.

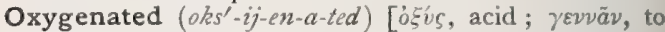
produce]. Containing or provided with oxygen.

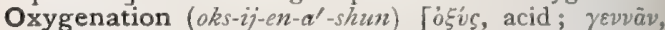
to produce]. The saturation of a substance with oxygen, either by chemic combination or by mixture.

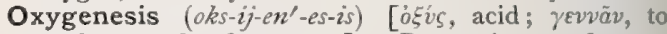
produce: $p l$. , Oxygeneses]. Baumes' name for any disease due to alteration of the normal quantity of oxygen in the blood.

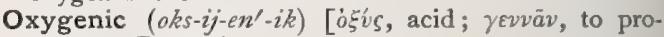
duce]. Producing acids.

Oxygenized $\left(a k s^{\prime}-i j-e n-i z d\right)$. Synonym of Oxygenated.

Oxygenometer (oks-ij-en-om'-et-er). Same as Eudiometer.

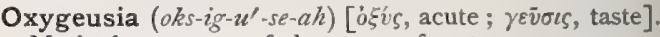
Marked acuteness of the sense of taste.

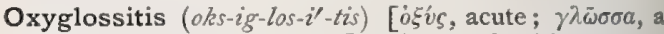
tongue; $\iota \tau \iota s$, inflammation]. Acute glossitis.

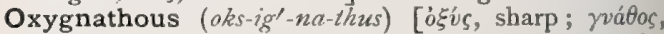
jaw]. In biology, applied to molluscs in which the jaws are smooth or nearly so.

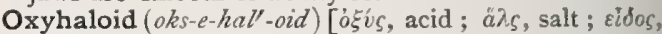
like]. A compound of an element or radicle with oxygen and a halogen.

Oxyhematin (oks-e-hem'-at-in). Synonym of Hematin.

Oxyhemoglobin (oks-e-hem-o-glo'-bin) [óḱv, acid; aina, blood; globus, a round body]. Hemoglobin united, molecule for molecule, with oxygen. It is the characteristic constituent of the red-corpuscles to which the scarlet color of arterial blood is due. It may be obtained in crystalline form, the crystals not being so pleochroic as are those of hemoglobin. Oxyhemoglobin forms from 86 to 94 per cent. of dry, red, human blood-corpuscles.

Oxyhydrogen (oks-e-hi'-dro-jen) [óćss, acid; vidwp, water; $\gamma \varepsilon v \nu a ̄ v$, to produce]. A mixture, in gaseous form, of oxygen and hydrogen. O. Blowpipe, a blowpipe in which the heat is obtained by the combustion of a mixture of oxygen and hydrogen. The heat produced is intense.

Oxyhydroparacoumaric Acid (oks-e-hi'-dro-par-ak-u-

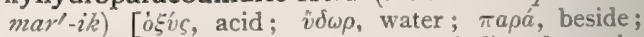
coumarin]. A complex substance believed to be formed in the body by the decomposition of tyrosin.

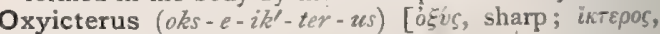
jaundice]. Intense acute jaundice.

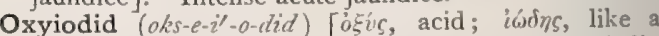
violet]. A salt containing both oxygen and iodin united to an element or radicle.

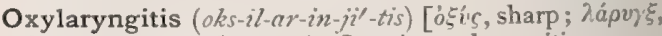
larynx; $\iota \tau \iota s$, inflammation]. Acute laryngitis.

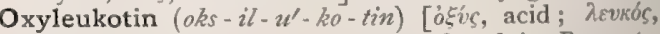
white], $\mathrm{C}_{34} \mathrm{H}_{32} \mathrm{O}_{12}$. A substance found in Paracotobark.

Oxylienitis (oks-il-i-en-i'tis) [óḱvs, sharp; lien, spleen iT $\varsigma_{S}$, inflammation]. Acute inflammation of the spleen. 
Oxylinoleic Acid (oks-il-in-o-le $-i k$ ) [ógús, acid ; linum, flax; oleum, oil], $\mathrm{C}_{16} \mathrm{H}_{26} \mathrm{O}_{5}$. A compound derived from linoleic acid by oxidation.

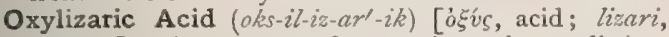
madder]. A synonym of purpurin; also a distinct compound found in madder.

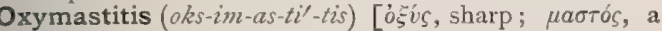
breast; $\iota \tau \iota \zeta$, inflammation]. Acute mastitis.

Oxymel (oks'-im-el) [ózus, sharp; $\mu \varepsilon^{\prime} \lambda \iota$, honey]. Honey mixed with vinegar or dilute acetic acid. $O$. of Squill, the same, prepared with vinegar of squill.

Oxymeter (oks-im'-et-er). Same as Eudiometer.

Oxymetritis $\left(o k s-i m-e t-r i^{\prime}-t i s\right)[\dot{o} \xi \dot{v} s$, sharp; $\mu$ '́r $\rho a$, womb; $\iota \tau \iota \zeta$, inflammation]. Acute metritis.

Oxymetrorrhea (oks - im - et - ror - $\left.e^{\prime}-a h\right)[\dot{b} v s$, sharp; $\mu \hat{\tau} \tau \rho \alpha$, womb; poia, a flow]. Acute metrorrhea.

Oxymorphin (oks-im-or'-fin). Same as Pseudomorphin.

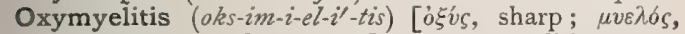
marrow; $\iota \tau \iota \zeta$, inflammation]. Acute myelitis.

Oxymyitis (oks-im-i-i'tis) [ökvs, sharp; $\mu \tilde{v}_{s}$, muscle; $\iota T \zeta$, inflammation]. Acute myitis.

Oxynaphthoic Acid (oks - in - af-tho'-ik). See Acid, Alpha-oxynaphthoic.

Oxynaphthol (oks-in-af'-thol) [ózís, acid ; váptaa, asphaltum], $\mathrm{C}_{10} \mathrm{H}_{8} \mathrm{O}_{2}$. A derivative of naphthol existing in two isomeric forms.

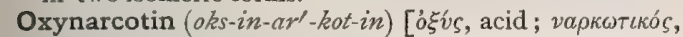
narcotic], $\mathrm{C}_{22} \mathrm{H}_{23} \mathrm{NO}_{8}$. A crystalline alkaloid derived from narcein.

Oxyneurin (oks-in-u'-rin). See Betain.

Oxynosema (oks-in-o-se'-mah) [óḱv, sharp; vóo $\mu a$, a sickness]. Any acute sickness.

Oxynosos $\left(o k s-i n-o^{\prime}-s o s\right)$ [óḱs, sharp; vó $\sigma o s$, disease]. An acute disease.

Oxyntic (oks-in'-tik) [ókvvтós (ókvivecv), to make sharp, to make acid]. Rendering acid. $O$. Cells, the acidfixing cells of Langley; cells of the fundus-glands of the stomach; see Delomorphous Cells of Rollet. 0. Gland, any acid-secreting gland.

Oxynusos (oks-in- $\left.u^{\prime}-s o s\right)$ [o $\dot{\xi} v s$, sharp; voṽoos, disease]. Any acute disease.

Oxynvitic Acid (oks-in-vit'-ik). See Acid.

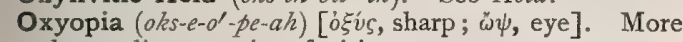
than ordinary acuity of vision.

Oxyopy $\left(o k s^{\prime}-e-o-p e\right)$. Same as Oxyopia.

Oxyosphrasia (oks-e-os-fra'-ze-ah). Same as Oxyosphresio.

Oxyosphresia (oks-e-os-fre'-ze-ah) [ókú, sharp; ö $\sigma$ $\phi \rho \eta \sigma \varsigma$, smell]. Marked or abnormal acuteness of smell.

Oxyphenic Acid (oks-if-en'-ik). Synonym of Pyrocatechin.

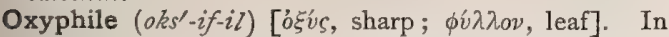
biology, Ehrlich's term for histologic elements that attract acid dyes, ordinarily called eosinophilous. The opposite of basophile or basophilous elements, which attract basic dyes.

Oxyphlegmasia (oks-if-leg-ma'-ze-ah) [ókvs, sharp; $\phi \lambda \varepsilon \gamma \mu a \sigma i \alpha$, inflammation]. An acute inflammation.

Oxyphonia (oks-if-o'-ne-ah) ['óv's, sharp; $\phi \omega v \eta \dot{n}$, voice]. Shriliness of voice.

Oxyphyllous (oks-if-il'-us) [óḱv, sharp; $\phi \dot{v} \lambda \lambda o v$, a leaf]. In biology, having acuminated leaves.

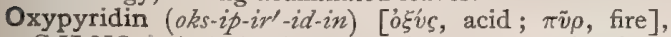
$\mathrm{C}_{5} \mathrm{H}_{5} \mathrm{NO}$. A derivative of pyridin existing in three isomeric forms.

Oxyquinin $\left(o k s-i k-z v i n^{\prime}-i n\right)$ [okvs, acid; S. Amer., quina, bark], $\mathrm{C}_{20} \mathrm{H}_{24} \mathrm{~N}_{2} \mathrm{O}_{3}$. An alkaloid resulting when quinin sulphate is boiled with potassium nitrite.

Oxyquinizin (oks-ik-rin'-iz-in) ['o $\xi v \zeta$, acid: S. Amer., quina, bark], $\mathrm{C}_{9} \mathrm{H}_{8} \mathrm{~N}_{2} \mathrm{O}$. An oxidation-product of quinizin.
Oxyquinolin (oks-ik-zvin'-o-lin). See Carboslyril.

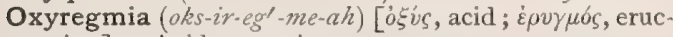
tation]. Acid eructation.

Oxyrhine $\left(0 k s^{\prime}-i r-i n\right)$ [ósis, sharp; ṕs, nose]. In biology, possessing a sharp-pointed nose, or snout; having an acute olfactory sense.

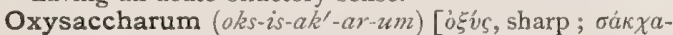
$\rho \mathrm{v}$, sugar]. A mixture of vinegar and sugar.

Oxysepsis (oks-is-ep'-sis) [ókvs, acid; $\sigma \tilde{\eta} \psi \iota s$, putrefac. tion]. Putrefaction during which acids are developed; also, the decomposition following quickly after death.

Oxysitia (oks-is-ish'-e-ah) [ókv́s, acid; oitos, food]. Acidity of the stomach.

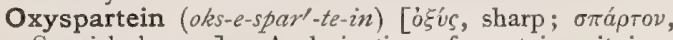
Spanish broom]. A derivative of spartein; it is a cardiac stimulant.

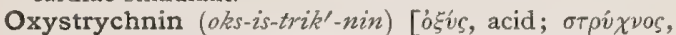
a plant of the nightshade family], $\mathrm{C}_{21} \mathrm{H}_{28} \mathrm{~N}_{2} \mathrm{O}_{7}$. An alkaloid produced by boiling strychnin sulphate with potassium nitrite.

Oxytartarus (oks-it-ar'-tar-us). Synonym of Potassium Acetate.

Oxytes $\left(o k s^{\prime}-i t-\bar{e} z\right)$ [óḱvs, acid]. Acidity.

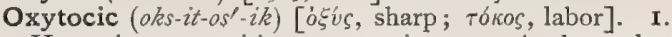
Hastening parturition; ocytocic. 2. A drug that hastens childbirth by stimulating uterine contraction; an ocytocic.

Oxytocous (oks-it-ok'-us). See Oxytocic.

Oxytolyltropin (oks-it-ol-il'tro-pin). Same as Homatropin.

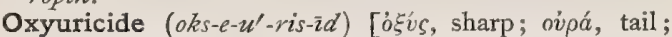
cadere, to kill]. Any anthelmintic that is destructive to worms of the genus Oxyuris, or pinworms.

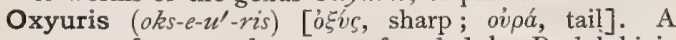
genus of nematode worms founded by Rudolphi in 1809; the pinworms. See Parasites (Animal), Table of.

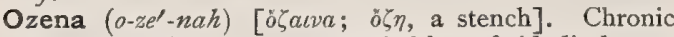
disease of the nose accompanied by a fetid discharge. See Rhinitis, Chronic Atrophic.

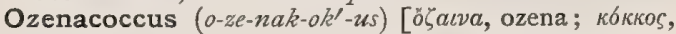
a grain]. The Micrococcus loewenbergii. See Bacteria, Synonymatic Table of.

Ozocerite $\left(0-z o-s e^{\prime}-r i t\right)$. See Ozokerite.

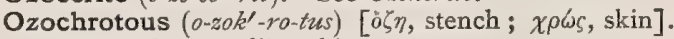
Having a bad-smelling skin.

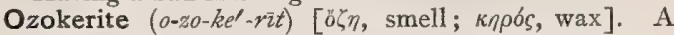
solid paraffin found free in Galicia and Roumania. It is also called mineral wax. It is like resinous wax in consistence and translucency, of a brown or brownish-yellow color, and of a pleasantly aromatic odor.

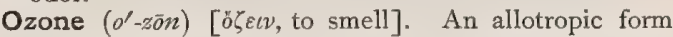
of oxygen, its molecule having the structure $\mathrm{O}_{3}$. It is present in the atmosphere in small quantities, being produced constantly by the evaporation of water, by electric discharges, and in the growth of chlorophylcontaining plants. It is also formed during the slow oxidation of phosphorus, of turpentine and other essential oils. It is an active oxidizing agent, possessing bleaching and antiseptic properties.

Ozonization $\left(0-z o-n i z-a^{\prime}-s h u n\right)$ [o $\zeta \varepsilon \nu$, to smell]. The act of ozonizing, or of impregnating with ozone.

Ozonized $\left(o^{\prime}-z o-n \bar{\imath} z d\right)$ [ $\dot{\sigma} \zeta \varepsilon c \nu$, to smell]. Containing ozone.

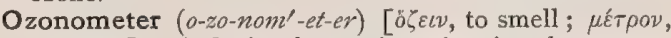
measure]. A device for use in estimating the proportion of ozone in the atmosphere.

Ozostomia $\left(0-z o s-t o^{\prime}-m e-a h\right) \quad[\not \zeta \eta$, stench; $\sigma \tau \sigma \alpha \mu$, mouth]. A foul odor from the mouth, or the breath.

Ozouf's Apparatus. An apparatus for charging water with $\mathrm{CO}_{2}$ by the intermittent method. 
P. Used in chemic nomenclature as the symbol of phosphorus.

Pabular ( $p a b^{\prime}-u$-lar) [pabulum, food]. Of, pertaining to, or of the nature of, pabulum.

Pabulation (pab-u-la'-shun) [pabulari, to graze]. I. The act of feeding. 2. Same as Pabulum.

Pabulin ( $p a b^{\prime}-u$-lin) [pabulum, food]. An albuminous and fatty substance present in the blood immediately after the process of digestion.

Pabulous ( $p a b^{\prime}-u$-lus). Same as Pabular.

Pabulum (pab'-u-lum) [L.]. Food. Anything nutritive.

Pacchionian Bodies, or Pacchioni's Glands ( $p a k-e-$ $o^{\prime}-n e-a n$ ) [after Pacchioni, an Italian anatomist, 1665I726]. A name given to certain granulations, produced by the increased growth of the villi of the arachnoid. See Gland. The bodies are found along the superior longitudinal sinus; along the margin of the fissure of Sylvius; on the surface of the pia; on the posterior and antero-inferior parts of the posterior lobe of the cerebrum; in the interior of the superior longitudinal sinus. They not infrequently contain small, hard, calcareous concretions, called "brain-sand." P. Fossæ, or Depressions, the pit-like depressions on the cerebral surface of the skull, produced by the pressure of the Pacchionian bodies. See Depression.

Pacchionius, Foramina of. See Foramina, Table of.

Pachemia ( $\left.p a k \cdot e^{\prime}-m e-a h\right)$. Synonym of Pachyemia.

Pachismus ( $\left.p a k-i z^{\prime}-m u s\right)$ [ $\pi a \chi v$ s, thick]. Thickening; induration.

Pachulosis (pak-u-lo'-sis). See Pachylosis.

Pachy- $\left(p a k^{\prime}-\ell-\right)\left[\pi \alpha \chi^{\prime} s\right.$, thick $]$. A prefix, denoting thick.

Pachyacria ( $\left.p a k-e-a k^{\prime}-r e-a h\right)\left[\pi a \chi^{\prime} s\right.$, thick ; àkpos, extremity]. Synonym of Akromegaly.

Pachyæmia ( $\left.p a k-e-e^{\prime}-m e-a h\right)$. See Pachyemia.

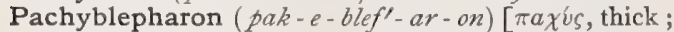

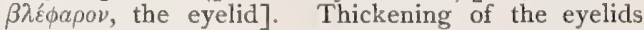
arising from the presence of tubercles or some inflammatory process.

Pachyblepharosis ( $\left.p a k-e-b l e f-a r-o^{\prime}-s i s\right)[\pi a \chi v s$, thick ; $\beta \lambda \varepsilon ́ \dot{q} a \rho o v$, eyelid]. Chronic thickening and induration of the eyelids.

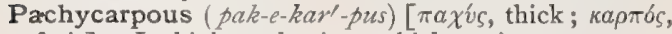
fruit.]. In biology, having a thick pericarp.

Pachycephalia (pak-e-sef-a'-le-ah). See Pachycephaly.

Pachycephalic ( $\left.p a k-e-s e f-a l^{\prime}-i k\right)\left[\pi \alpha \chi^{\prime}{ }^{\prime}\right.$, thick; $\kappa \varepsilon \phi a \lambda \eta \dot{n}$, head]. Having unusual thickness of the skull.

Pachycephalous (pak-e-sef'-al-us). See Pachycephalic.

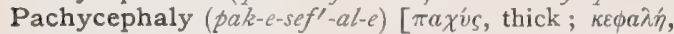
head]. Abnormal thickness of the bones of the skull.

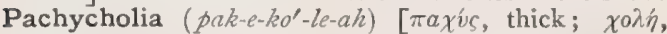
bile]. An inspissated condition of the bile.

Pachychymia ( $\left.p a k-\ell-k i^{\prime}-m e-a h\right)[\pi \alpha \chi v \varsigma$, thick; $\chi v \mu o ́$, juice]. Increased concentration of the bodily fluids.

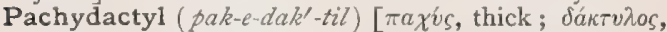
n̂nger]. 4 thick digit.

Pachydact ous (pak-e- $\left.a k^{\prime}-t i l-u s\right)$ [ $\pi \alpha \chi^{\prime} v s$, thick;

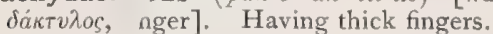

Pachyderm ( $\left.p a k^{\prime}-e-d e r m\right)$ [ $\pi a \chi v ́ s$, thick; $\delta \varepsilon \rho \mu a$, skin]. Thick-skinned.

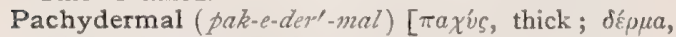
skin]. Same as Pachyderm.

Pachydermatocele $\left(p a k-e-d e r-m a t^{\prime}-o-s e l\right)[\pi a \chi \dot{v} \zeta$,

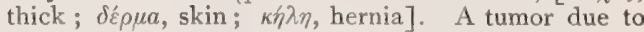
thickening of the skin. The term is applied to Elephantiasis arabum, and to the condition of the skin in Dermatolysis.
Pachydermatoid ( $\left.p a k^{2}-e-d e r^{\prime}-m a t-o i d\right)$ [ $\pi \alpha \chi^{\prime} v_{s}$, thick

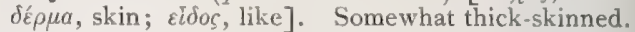

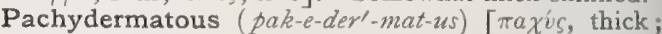
$\delta \varepsilon ́ p \mu a$, skin]. Thick-skinned.

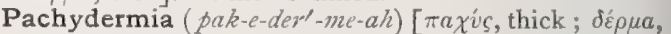
skin]. See Elephantiasis arabum. P. lactiflua, elephantiasis complicated with lymphorrhea, P. laryngis, extensive thickening and induration of the mucosa of the larynx. P. vulgaris, elephantiasis without lymphorrhea.

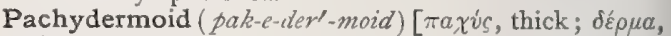
skin; $\varepsilon i \delta o s$, like]. Pachydermatous.

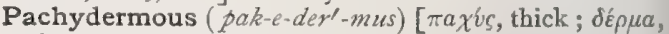
skin]. In biology, thick-coated.

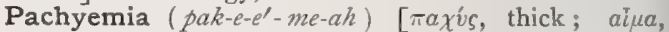
blood]. Abnormal or morbid thickening of the blood.

Pachyglossal, Pachyglossate ( $p a k-\ell-g l o s^{\prime}-a l, p a k-\ell$ $g\left(o s^{\prime}-\bar{a} t\right)[\pi \alpha \chi v \dot{v}$, thick; $\gamma \lambda \bar{\omega} \sigma \sigma \alpha$, tongue]. Having a thick tongue.

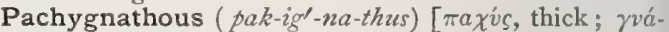
Oos, jaw]. Having thick or heavy jaws.

Pachylosis ( $\left.a a k-i l-\sigma^{\prime}-s i s\right)$ [ $\pi \alpha \chi v \lambda \tilde{\omega} s$, thickly]. An extraordinary development of epidermis, most common about the legs, usually a sequel of chronic eczema or of ulceration.

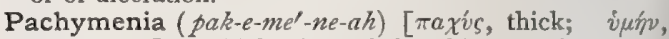
membrane]. Thickening of the skin, or of a membrane.

Pachymenic $\left(p a k-e-m e n^{\prime}-i k\right)\left[\pi a \chi v s\right.$, thick; $v \mu \eta^{\prime} \nu$, membrane]. Affected with pachymenia.

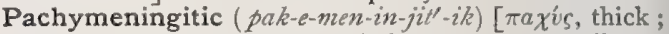
$\mu \tilde{\eta} \nu \imath \gamma \xi$, membrane; $\iota \tau \iota \varsigma$, inflammation]. Affected with, or pertaining to, pachymeningitis.

Pachymeningitis ( $\left.p a k-e-m e n-i n-j i^{\prime}-t i s\right)$ [ $\pi a \chi^{\prime} u$, thick; $\mu \bar{\eta} \nu \iota \gamma \xi$, membrane; $\iota \tau \iota \varsigma$, inflammation]. Inflammation of the dura, especially of the ectal layer. It is usually due to extension from adjacent bone-disease, especially caries; it may be due to syphilis, sunstroke, or injuries. The symptoms are much the same as in leptomeningitis. P., Hemorrhagic, P. hæmorrhagica interna, an effusion of blood on the inner surface of the dura. The quantity may be large and enclosed in a sac - hematoma of the dura-or very small, only a fine rust-colored layer that is easily stripped off. The cause is still sub judice; probably it is a trophic phenomenon in most cases.

Pachymeninx ( $\left.p a k-\ell-n n e^{\prime}-n i n k s\right)[\pi \alpha \chi \dot{\delta} s$, thick; $\mu \tilde{\eta} \nu \ell \xi \xi$ membrane]. The dura.

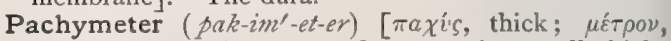
measure]. An instrument for measuring small thicknesses.

Pachynsis ( $\left.p a k-i n^{\prime}-s i s\right)$ [ $\pi a ́ \chi v \nu \sigma \iota s$, thickening], A thickening, as of a membrane.

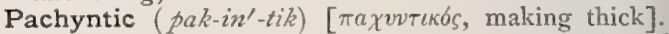
Pertaining to an abnormal thickening or hardening of a part: increasing the thickness.

Pachyodont ( $\left.p a k^{\prime}-\ell-o-d o n t\right)$ [ $[\pi \alpha \chi v$ s, thick; b́doús, tooth]. In biology, having thick or massive teeth.

Pachyopterous (pak-e-op'-ter-us). Same as Pachypterous.

Pachyote $\left(p a k^{\prime}-e-\bar{o} t\right)[\pi \alpha \chi v$ s, thick; ov̀s, ear ]. Having thick ears.

Pachyperitonitis (pak-e-per-it-on-i'-tis) [ $\pi a \chi u^{\prime} s$, thick ;

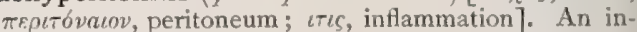
flammation of the peritoneum characterized by thickening of the membrane.

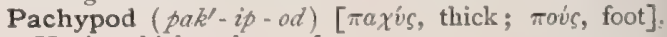
Having thick or heavy feet. 
creased vascularity of the epiphyses of long bones; others believe them to be rheumatic. P.-joy [Ger, Schmerzfreude]. Hysteric enjoyment of suffering; a symptom not uncommon in a certain class of neurasthenic patients. P., Jumping, the pain peculiar to disease of joints when the bone is exposed by ulceration of the cartilage. P., Lancinating. See $P$, Fulgurant. P., Lightning. See P., Fulgurant. P., Osteocopic, bone-tiring pains ; a common symptom of secondary syphilis. P., Shooting. See $P$, Fulgurant, P., Starting. Synonym of $P$., Jumping. Ps., After-, those following labor, and caused by the uterus contracting to expel clots, etc, or to resume its normal proportions. Ps., Bearing-down, pains with a sensation of dragging or bearing down of the pelvic organs, occurring in labor and in various inflammatory affections of the female pelvic organs. Ps., False, those occurring in the latter part of pregnancy, not preceded by the premonitory signs of labor and not directly caused by labor. Ps., Grinding, the laborpains during the stage of dilatation of the os uteri. Ps., Irregular, those not recurring according to the normal periodic or rhythmic nature of uterine contractions. Ps. of Labor, a synonym for uterine contractions, since these are attended by pains, increasing in severity according to the intensity and frequency of the contractions. Ps., Premonitory, so-called painless uterine contractions preceding the onset of true labor.

Painful (pān'-ful) [ME, paine, pain]. Characterized by pain. P. Heel. See Pododynia and Achillodynia. Paint (pānt). See Pigments, Colors, and Dye-stuffs.

Painters' Colic. See Colic.

Pair (pār) [ME., paire, a pair]. Two similar organs, one right and the other left, occupying the same relative position on either side of the body ; as a pair of nerves.

Pajot's Law. The law governing the rotating movements of the child during labor. It is expressed as follows: When a solid body is contained within another, if the receptacle is the seat of alternations of movement and repose, and its surfaces are slippery and but slightly angular, the contained body will tend increasingly to accommodate its form and dimensions to the form and capacity of the receptacle. P.'s $\mathrm{Ma-}$ neuver. Same as $P$ 's Method. P.'s Method, a method of decapitation of the fetus in embryotomy. It consists in passing a strong cord around the child's neck, and by a sawing movement cutting through the parts. The vagina should be protected by a speculum.

Paku-kidang ( $p a^{\prime}-k u$-kid'-ang) [Sumatra]. A drug obtained in Sumatra from several species of ferns. Under the name of Agnus scythicus it was formerly used as a styptic. Unof.

Pal's Method. A method of staining the tissues of the central nervous system. Allow the sections that have been hardened in Miiller's solutions and then in alcohol to remain from five to six hours in Weigert's hematoxylin, and wash in distilled water till no more dye is removed. Then place the sections in potassium permanganate solution ( 0.25 per cent.) for from 15 to 20 seconds to differentiate, then in Pal's solution for from I-2 minutes till the gray and white matter become well defined. Wash for from I5 to 30 minutes in water. If black spots appear at any stage, reverse the steps and then repeat. The medullary sheaths stain bluish-black. To stain nuclei follow with alumcarmin; dehydrate; clear; mount. P.'s Solution. A solution used in Mal's Mcthod. It consists of oxalic acid I part, potassium sulphite I part, distilled water 200 parts.
Pal-Exner Method. A method of staining nerve-centers. Cut the brain or the cord into $1 / 4$-inch squares; fix and harden the segments for two days in ten times the volume of 0.5 per cent. osmic-acid solution; change each day; wash in water; pass up to absolute alcohol, and embed in celloidin. Place the sections as fast as cut in glycerin; treat with 0.25 per cent. aqueous solution of potassium permanganate for from 15-20 seconds; pass through Pal's solution for from $1-2$ minutes; stain the nuclei with alum-carmin; dehydrate; clear; mount (after Squire).

Pala $\left(p a^{\prime}-l a h\right)$ [L., a "spade" ]. I. A thin lamella connecting the fimbria and the tenia of the brain. It has a shape like the blade of a turf-cutter. 2. [Native Hawailan]. The Hawaiian word for syphilis.

Paladina's Palladium Chlorid Method. See Strins, Table of. P.'s Fonifero. See Phoniphore.

Palæo- ( $p a^{\prime}$-le-o-) [ $\pi a \lambda a t o s$, old $]$. A prefix denoting old, early, long ago, etc. For words thus beginning see Paleo-

Palama ( $\left.p a l^{\prime}-a m-a h\right)$ [ $\pi a \hat{a} a \mu_{\eta}$, the palm of the hand: pl., Palame]. In biology, the webbed state of the toes of certain animals, either palmation, semi-palmation, toti-palmation.

Palamosyphilolepis ( $\left.p a l-a m-o-s i f-i l-o-l e p^{\prime}-i s\right)[\pi a \lambda a \mu \eta$, palm of hand; Syphilis, syphilis; $\lambda \in \pi i s$, scale]. A squamous syphiloderm of the palm.

Palatal (pal'-at-al) [ palatum, palate]. Pertaining to the palate; palatine. P. Glands. See GLand, Palatine. P. Reflex. See Reflexes, Table of.

Palate (pal'-at) [palatum, palate]. The roof of the mouth. P., Artificial, a plate of hard material used

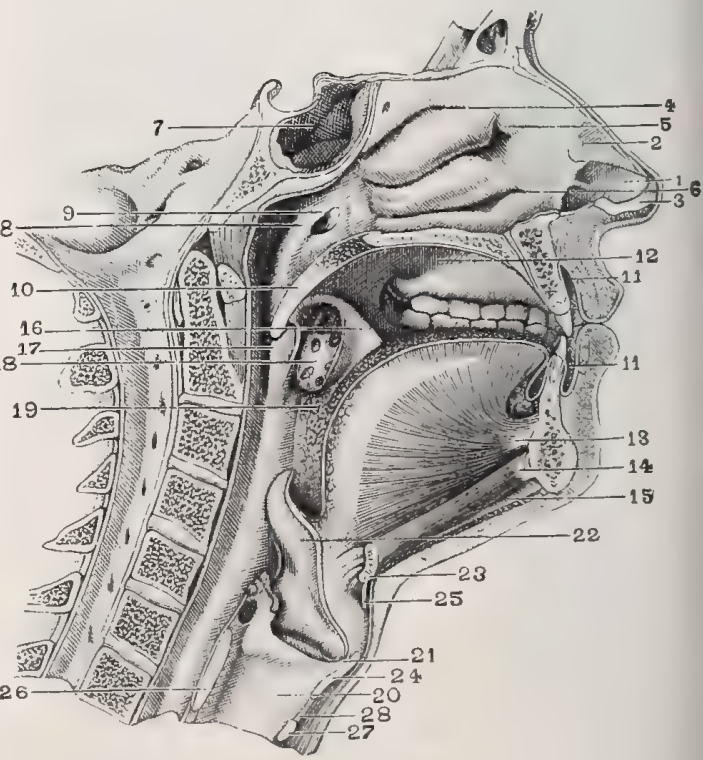

Median Section of Mouth and Nasal Fossae.

I. Left nostril. 2. Upper lateral cartilage. 3. Inner portion of lower cartilage. 4. Superior turbinated bone and meatus 5. Middle turbinated bone and meatus. 6. Inferior turbin ated bone and meatus. $\%$. Sphenoid sinus. 8. Posterior nasal fossa. 9. Internal orifice or pavilion of Eustachia . Velum palati. II, II. Vestibule of mouth is. Palatine vault. 13. Genio-glossus muscle, I4. Genio-hyoic. 15. Mylo-hyoid. 16. Anterior pillar of velum palati. 17 Posterior pillar. 18. Tonsil. 19. Circumvallate papillae of tongue. 20. Cavity of larynx. 21. Ventricle. 22. Epiglottis 23. Hyoid bone. 24. Thyroid cartilage. 25. Thyro-hyoid membrane 26. Posterior portion of cricoid cartilage. 27 Anterior portion. 28. Crico-thyroid membrane. 
as an obturator to close a fissure in the palate. P., Cleft, a congenital deformity characterized by incomplete closure of the lateral halves of the palate. The soft palate and the uvula, the hard palate, or all together may be involved. P., Hard, the bony plate adjacent to the gums and alveolar arches. P.-myograph, an instrument for taking a tracing of the movements of the soft palate. P. Plates, the horizontal portions of the superior maxillx that unite to form the hard palate. P., Soft, the muscular membranelike structure forming an incomplete septum between the mouth and the naso-pharynx. In biology, the convex base of the lower lip of a personate corolla, more or less completely closing the throat. In entomology, the epipharynx.

Palatic $\left(p a l-a t^{\prime}-i k\right)$ [palatum, the palate]. Palatal; palatine.

Palatiform (pal-at'-if-orm) [palatum, palate ; forma, form]. In biology, resembling a palate.

Palatiglossus (pal-at-i-glos'-2is). Same as Palatoglossus.

Palatine ( $p a l^{\prime}-a t$-in) [ palatum, palate]. Pertaining or belonging to the palate. P. Arches, the arches, posterior and anterior, upon each side of the beginning of the pharynx. P. Canals, several canals in the palatal portion of the superior maxilla. P. Fossa. See Fossa. P. Glands. See Gland. P. Orange. See Pigments, Conspectus of.

Palatitensor (pal-at-it-en'-sor) [palatum, palate; tensor, a stretcher]. The tensor palati muscle. See Muscles, Table of.

Palatitis (pal-at-if-tis) [palatum, palate; $\iota \tau \iota s$, inflammation]. Inflammation of the palate.

Palatoglossal ( pal-at-o-glos'-al) [palatum, palate; $\gamma \lambda \tilde{\omega} \sigma \sigma a$, tongue]. Pertaining to the palate and the tongue.

Palatoglossus (pal-at-o-glos'-us). See Muscles, Table of.

Palatognathous ( pal-at-og $g^{\prime}$-na-thus) [palatum, palate; ruátos, jaw]. Affected with palatognathus.

Palatognathus ( $\left.p a l-a t-o g^{\prime}-n a-t h u s\right)$ [palatum, palate ; yválos, jaw]. Cleft palate.

Palato-labial (pal-at-o-la'-be-al) [palatum, palate; labium, lip]. Pertaining to the palate and the lips.

Palato-maxillary (pal-at-o-maks'-il-a-re) [palatum, palate; maxilla, jaw]. Pertaining to the palate and the jaws.

Palato-nasal ( $\left.p a l-a t-o-n a^{\prime}-z e l\right)$ [ palatum, palate ; nasus, nose]. Pertaining to the palate and the nose.

Palato-pharyngeal (pal-at-o-far-in'-je-al) [ palatum, palate; $\phi a ́ \rho v \gamma \xi$, pharynx $]$. Pertaining conjointly to the palate and the pharynx.

Palato-pharyngeus (pal-at-o-far-in'-je-us). See Muscles, Table of.

Palatoplasty ( pall-at-o-plas-te) [palatum, palate; $\pi \lambda a ́ \sigma$ $\sigma \varepsilon \iota \nu$, to form ]. Plastic surgery of the palate.

Palatoplegia (pal-at-o-ple'-je-ah) [palatum, palate; $\pi \lambda \eta \gamma \hat{\eta}$, a stroke]. Paralysis of the soft palate.

Palatopterygoid (pal-at-o-ter'-ig-oid) [ palatum, palate; $\pi \tau \varepsilon \rho \sigma v$, wing; $\varepsilon i \delta o \varsigma$, like]. Pertaining to the palate bone and the pterygoid processes of the sphenoid bone ; pterygopalatine.

Palatoquadrate ( pal-at-o-kwod'-rāt) [ palatum, palate ; quadratum, quadrate bone]. Pertaining to the palate and to the quadrate bone.

Palatorrhaphy (pal-at-or'-a-fe). See Staphylorrhaphy.

Palatoschisis (pal-at-as'-kis-is) [palatum, palate; $\sigma \chi i \sigma \iota$, a cleft]. Cleft palate.

Palatostaphylinus (pal-at-o-staf-il-i'-nus) [palatum,

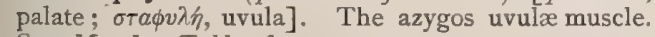
See Muscles, Table of.

Palatum ( $p a l-a^{\prime}$-tum) [I..]. The palate. P. durum, the hard palate. P. fissum, cleft palate. P. mobile,
P. molle, the soft palate. P. pendulum, the soft palate.

Pale, Palea ( $\left.p a \vec{l}, p a^{\prime}-l e-a h\right)$ [ palea, chaff: $p l .$, Palea $]$. I. In biology, one of the inner bracts of the inflorescence of grasses. Also applied to the flattened brown hairs or chaff found on the stems and leaves of ferns. 2. The dewlap or wattle of a bird.

Pale (päl) [Fr. pâle, pale]. Deficient or wanting in the color natural to health. P. Bark. See Cinchona. P. Catechu. See Gambier. P. Rose. See Rosa centifolia.

Paleaceous ( $\left.p a-l e-a^{\prime}-s h e-u s\right)$ [palea, chaff]. In biology, furnished with chaff, or chaffy in texture.

Paleichthyology, Palæichthyology ( $p a-l e-i k$-the-ol).

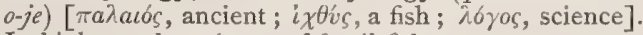
In biology, the science of fossil fishes.

Paleiform ( $p a^{\prime}$-le-if-orm) [palea, chaff; forma, form]. Chaff-like.

Paleness ( $p \bar{a} l^{\prime}$-nes). Same as Pallor.

Paleo-anthropic, Palæo-anthropic ( $a a-l e-o-a n-$

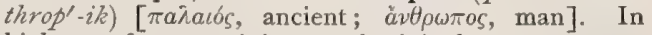
biology, of, or pertaining to, aboriginal man.

Paileobotanic $\left(p a-l e-o-b o t-a n^{\prime}-i k\right)$ [ $\pi a \lambda a t o ́ s$, ancient; ßoтáv $\eta$ herb]. Pertaining to paleobotany.

Paleobotanist ( $\left.p a-l e-o-b o t^{\prime}-a n-i s t\right)$ [ $\pi a \lambda a \imath \delta s$, ancient; ßotávn, herb]. One versed in paleobotany.

Paleobotany, Palæobotany ( $\left.\left.p a-l e-o-b o t^{\prime}-a n-e\right)\right][\pi a \lambda-$

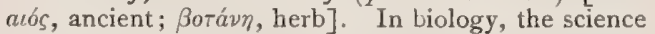
of fossil plants.

Paleo-ethnologic ( $\left.p a-l e-o-e t h-n o-l o j^{\prime}-i k\right)[\pi a \lambda a \iota b s$, ancient; $\theta \nu o s$, race; $\lambda \sigma \gamma o s$, science $]$. Pertaining to paleo-ethnology.

Paleo-ethnologist ( $\left.p a-l e-o-e t h-n o l^{\prime \prime}-o-j i s t\right)[\pi a \lambda a t b s$,

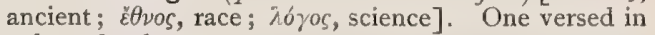
paleo-ethnology.

Paleo-ethnology $\left(p a-l e-o-e t h-n o l^{\prime}-o-j e\right)[\pi a \lambda a t o s$,

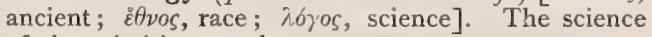
of the primitive peoples.

Paleola (pa-le'-o-lah) [palea, chaff]. In biology, a diminutive palea.

Paleolate $\left(p a^{\prime}-l e-o-l \bar{a} t\right)$ [palea, chaff]. In biology, having paleolæ or palea of a second order.

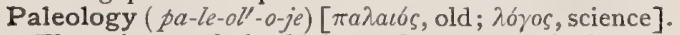
The science of the biology of remote geologic periods, or of antiquities.

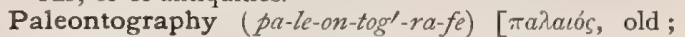

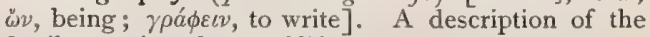
fossil or extinct forms of life.

Paleontologic ( $\left.p a-l e-o n-t o-l o j^{\prime}-i k\right)[\pi a \lambda a \iota b s$, old; $\measuredangle \omega$, being; $\lambda 6 \gamma o s$, science $]$. Pertaining to paleontology.

Paleontologist ( pa-le-on-tol'-o-jist) [ $\pi a \hat{\lambda} a \iota \iota_{s}$, ancient; $\omega v$, being; $\lambda 6 \gamma a s$, science]. One versed in paleontology.

Paleontology ( $\left.p a-l e-o n-t o l^{\prime}-a-j e\right)[\pi \dot{\lambda} \lambda a u ́ s$, old; $\ddot{\omega} v$, being; $\lambda \sigma$ yos, science $]$. The science of the early lifeforms of the earth.

Paleophytology, Palæophytology ( $\left.p a-l e-o-f i-t o l^{\prime}-0-j e\right)$

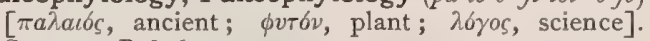
Same as Paleobotany.

Paleornithology, Palæornithology ( $p a-l e-o r-n i t h-$

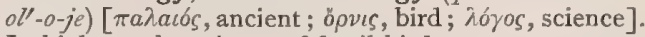
In biology, the science of fossil birds.

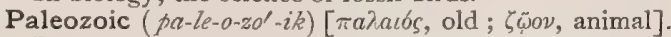
Pertaining to the geologic age preceding that of the carboniferous age, the age in which the first life-forms appeared. Also, pertaining to the life-forms of that age.

Paleozoölogic ( $\left.p a-L e-0-z o-o-l o j^{\prime \prime}-i k\right)$ [ $[\pi a \lambda a \iota o ́ s$, ancient ; $\zeta \tilde{\omega} \circ \nu$, animal; $\lambda 6 \gamma o s$, science $]$. Pertaining to paleozoölogy.

Paleozoölogist ( $\left.p a-l e-0-z o-o l^{\prime}-o-j i s t\right)[\pi a \lambda a u b s$, ancient;

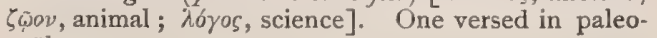
zoölogy. 
Paleozoölogy, Palæozoölogy ( $\left.p a-l e-a-z o-o l^{\prime}-o-j e\right)$

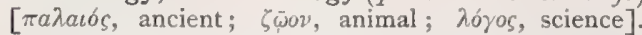
In biology, the science of fossil animals.

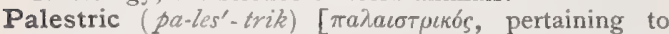
wrestling]. Pertaining to systematic exercise, or physical training; athletic.

Palet $\left(p a l^{\prime}-e t\right)$. See Palette.

Palet $\left(p a l^{\prime}-e t\right)$ [palea, chaff]. English term for Palea.

Palette, Pallet, Palet (pal'-et) [pala, a spade]. In biology, a disc-shaped organ found especially on the front and middle tarsi of the males of certain beetles.

Pali $\left(p a^{\prime}-l e\right)$ [Ind.]. Pali or Indian plague-an infectious febrile disease of India, where it is also known as Mahamurri. P. Plague. Synonym of the Plague,q.v.

Palicourea ( $\left.p a-l i k-o o^{\prime}-r e-a h\right)[\mathrm{L}$.$] . A Brazilian rubia-$ ceous shrub, numbering several species, some of which are poisonous. P. diuretica and $\mathbf{P}$. officinalis, have diuretic properties. 'Unof.

Palillo $\left(p a l-\bar{e} l^{\prime}-y o\right)$ [Sp.]. A Peruvian plant of value in gastric disorders.

Palimptosis (pal-imp-to'-sis) [ $[\pi \hat{\lambda} \iota \nu$, back; $\pi \tau \tilde{\omega} \sigma \iota s$, a fall]. A falling back; properly, a falling back to a former position, whether after a proptosis, or abnormal forward displacement, or after the rectification of backward displacement.

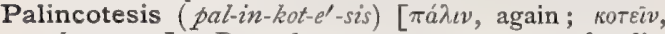
to be angry]. Recrudescence or recurrence of a disease or wound.

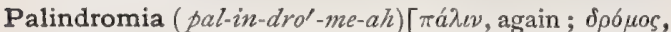
a course]. Recurrence or growing worse of a disease; a relapse.

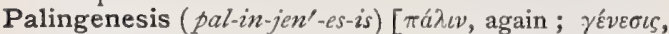
production]. I. In biology, the theory that the developmental history of an individual germ is the brief recapitulation of the development of its ancestors ; unmodified ontogeny, the antonym of Kenogenesis. 2. The transformation or metamorphosis of an insect. 3. The recreation of life after a geologic catastrophe. 4 . The supposed generation of a parasite from its host or from dead matter.

Palingenesy (pal-in-jen'-es-e). Same as Palingenesis.

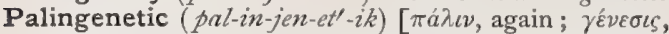
genesis]. Of, or pertaining to, palingenesis; development according to the primitive or original mode.

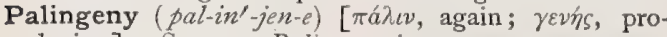
ducing]. Same as Palingenesis.

Palirrhea (pal-ir-é-ah) [ $\pi a ́ \lambda \iota \nu$, again; poía, flow]. The return of a mucous discharge.

Palisade $\left(p a l-i s-\bar{a} d^{\prime}\right)$ [Fr., palisser, to inclose with pales]. A fence made of strong poles or stakes set firmly in the ground. P.-cell, in biology, a constituent cell of palisade-tissue. P.-parenchyma, the same as $P$.-tissue. P.-tissue, in biology, applied to certain cells which are elongated at right angles to the surface, occurring especially on the upper side of leaves. P.-worm. See Parasites (Animal), Table of.

Palladium ( $\left.p a l-a^{\prime}-d e-u m\right)[\pi \alpha \lambda \lambda a ́ \delta \iota o v$, a statue of Pallas]. A rare and valuable metal, in some respects resembling platinum. Symbol, Pd., at. wt., Io6.5, spec. grav. I I.4. It is sometimes used in making instruments of precision, and it has been employed in dentistry. See Elements, Table of.

Pallet (pal'-et). See Palette.

Palliation (pal-e-a'-shun) [palliare, to cloak]. The act of soothing or moderating, without really curing.

Palliative (pall-e-a-tiv) [palliare, to cloak]. A drug relieving or soothing the symptoms of a disease without curing it.

Pallid ( $\left.a l^{\prime}-i d^{\prime}\right)$ [ pallere, to look pale]. Pale.

Palliobranchiate (pal-e-o-brang-ke-ät) [pallium, a cloak; branchice, gills]. In biology, breathing by means of the mantle.
Palliocardiac (pal-e-o-kar'-de-ak) [pallium, a cloak; raprlia, heart]. In biology, pertaining to the mantle and to the pericardial sac of a mollusc.

Palliopedal (pal-e-o-ped"-al) [pallium, cloak; pes, foot]. In biology, pertaining to both the foot and the mantle or pallium of a mollusc.

Pallium (pal'-e-um) [pallium, a mantle, cloak]. In biology, the mantle or enclosing and shell-forming tissue of a mollusc; the stragulum.

Pallor (pal'-or) [L.]. Paleness, especially of the skin and mucous membranes. P. chloroticus, the peculiar paleness of chlorotic persons. P. eximius, abnormal paleness, usually due to anemia. P. pathematicus, the pallor due to terror or fright. P. virginum. Synonym of Chlorosis.

Palm $(p a h m)$ [palma, $\pi a \lambda a ́ \mu a$, palm]. I. The inner or ventral surface of the hand; the flat of the hand. 2 [palma, a palm-tree]. A palm-tree. P.-oil, Oleum palma, is obtained from the fruit of several species of palm. Fresh palm-oil has an orange-yellow tint, a sweetish taste, and an odor resembling that of violets. Its specific gravity is about .968; its consistency is that of butter or lard. It ordinarily becomes rancid rapidly, and hence usually contains free acid. It is used in candle-making and soap-making, and also to color and scent ointments, pomades, soap, and powders. See Oil. P.-wine, the juice of several species of wine-palms which has undergone vinous fermentation. The distilled product is known as arrack.

Palma (pal'-mah) [L.: pl., Palma]. I. In biology: (a) The palm of the hand. (b) The enlarged first joint of the front tarsus of a bee. (c) The dilated and setose tarsus of an insect. 2. A palm-tree. Oleum palmæ. See Palm-oil. Palmæ plicatæ, the arborescent rugæ of the interior of the vagina.

Palmar (pal'-mar) [palma, palm]. Pertaining to the palm of the hand. P. Abscess, an abscess in the palm of the hand, usually situated beneath the palmar fascia. P. Arch, one of the curved arches formed by the anastomosis of the radial and ulnar arteries in the hand. There are two, a superficial and a deep. P. Arteries. See Arteries, Table of. P. Fascia, the sheath investing the muscles of the hand. P. Muscles. See Muscles, Table of. P. Reflex. See Reflexes, Table of. P. Triangle. See Triangle. Palmaris (pal-ma'-ris). See Muscles, Table of.

Palmate (pal'-mât) [ palma, the palm of the hand]. In biology, resembling in some way the open palm, as the webbed foot of a bird or reptile, or a five-lobed leaf.

Palmatifid (pal-mat'-if-ia) [palmatus, palmate; findere, to cleave]. In biology, palmately cleft.

Palmatiform (pal-mat'-if-orm) [palma, the palm of the hand; forma, form]. In biology, having the form of a hand.

Palmatilobate (pal-mat-il-o'-bāt) [ palma, the palm of the hand; lobus, a lobe]. In biology, palmately lobed.

Palmation (pal-ma'-shun) [palma, the palm of the hand]. In biology, the state of being palmate, as the webbed foot of a bird, or a five-lobed leaf.

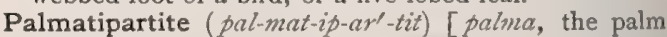
of the hand; partiri, to divide]. In biology, palmately parted.

Palmatisect (pal-mat'-is-ekt) [ palma, the palm of the hand; secare, to cut]. In biology, palmately compound.

Palmature (pal'-mat-ūr $)$ [palma, palm]. Union of the fingers, either congenital or from burns, wounds, or other trauma.

Palmella (pal-mel'-ah) [ $\pi a \lambda \mu o ́ s$, vibration]. A genus of fresh-water algæ believed by Salisbury to be the origin of the spores that produce malarial fever. 
Palmellin ( $\left.p a l-m e l^{\prime}-i n\right)$ [ $\pi a \lambda \mu o ́ s$, vibration]. Phipson's name for the coloring-principle of a fresh-water alga, the Palmella cruenta. It is red in color, resembling hemoglobin, and contains iron in combination with an albuminous substance.

Palmetto (pal-met'-o). See Saw Palmetto.

Palmic (pal'-mik) [palma, palm]. Referring to the palm; palmitic. P. Acid. See Acid, Palmitic.

Palmic ( $\left.p a l^{\prime}-m i k\right)[\pi a \lambda \mu \sigma s$, throb]. Pertaining to the pulse or to palpitation.

Palmicolous (pal-mik'-o-lus) [palma, palm-like; colere, to inhabit]. Growing on the palm-tree.

Palmification (pal-mif-ik-a'-shun) [palma, palm; ficare, facere, to make]. In biology, the artificial fertilization of the flowers of certain trees; originally applied to the date-palm.

Palmiform (pal'-mif-orm) [palma, the palm of the hand; forma, form]. The same as Palmatiform.

Palmigrade (pal'-migr $r \bar{a} d)$ [palma, the palm of the hand; gradi, to walk]. In biology, treading on the soles of the foot; plantigrade.

Palmilla (pal-mil'-ah). Synonym of Palmella.

Palminerved (pal'-min-ervd) [ palma, palm; nervus, nerve]. In biology, palmately nerved.

Palmiped (pal'-mip-ed) [palma, palm; pes, foot]. Having webbed feet.

Palmistry (pal'-mis-tre) [palma, palm of hand]. The comparative study of the lines, marks, and mounds on the palm of the hand; it has been made the basis of a system of fortune-telling.

Palmitamid (pal-mit'-am-id) [palma, palm; amid], $\mathrm{C}_{16} \mathrm{H}_{33} \mathrm{NO}$. A solid substance melting at about $93^{\circ}$ C., formed by the union of the amid radicle of ammonia and the radicle of palmitic acid.

Palmitic Acid ( $\left.p a l-m i t^{\prime}-i k\right)$. See Acid.

Palmitin (pal' - mit-in) [palma, palm-tree]. $\mathrm{C}_{3} \mathrm{H}_{5}$ $\left(\mathrm{C}_{16} \mathrm{H}_{31} \mathrm{O}_{2}\right)_{3}$. A solid crystallizable substance which, with stearin, constitutes the greater proportion of solid fats. It occurs both in animal and in vegetable fats. It is a constituent of palm-oil, from which it derives its name. Chemically, it is the tripalmitate of glyceryl.

Palmitolic Acid (pal-mit-ol'-ik). See Acid.

Palmitone (pal'-mit-ōn) [palma, palm-tree], $\mathrm{C}_{31} \mathrm{H}_{62} \mathrm{O}_{2}$. A ketone of palmitic acid resulting when the latter is distilled with slaked lime.

Palmitoxylic Acid (pal-mit-oks-il'-ik). See Acid.

Palmi-veined (pal'-miv-änd) [palma, a palm; vena, a vein]. In biology, netted-veined, with the veins radiating from the base toward the margin of the leafblade.

Palmodic ( $\left.p a l-m o d^{\prime}-i k\right)$ [ $\pi a \lambda \mu \omega \delta \eta$, like palmus]. Pertaining to, resembling, or affected with, palmus.

Palmo-plantar (pal' - mo-plan' -tar) [palma, palm; planta, the sole of the foot]. Pertaining to both the palms of the hands and the soles of the feet. P.plantar Sign, Filipowicz' Sign; said to be diagnostic of typhoid fever. It consists of an orange or saffron coloration of the prominent parts of the palms of the hands and the soles of the feet. The change in color is attributed to feebleness of the action of the heart, causing incomplete filling of the capillaries, and dryness of the skin. See Signs and Symptoms, Table of.

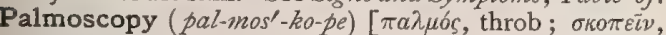
to observe]. The observation of the heart-beat and the pulse.

Palmospasmus (pal-mo-spaz'-mus) $[\pi \alpha \lambda \mu b s$, throb; $\sigma \pi \alpha \sigma \mu \sigma o s$, spasm]. A clonic spasm. P., Electric, a peculiar reaction of the muscles to the electric current in progressive muscular atrophy.

Palmosseus (pal-mos'-e-us) [ palma, palm; osseus, bony]. Any palmar interosseous muscle.
Palmus (pal'-mus) [ $[\pi a \lambda \mu \delta s$, a twitch]. I. Jumpers' disease; lata, or miryachit; a convulsive tic, with echolalia and abulia. 2. Subsultus; palpitation; pulsation; twitching; jerkiness.

Palmus (pal'-mus) [palmus, the palm of the hand]. An old measure of length. P. major, contains twelve fingers. P. minor, four inches.

Palp [palpare, to touch softly, to stroke]. In biology, a tactile organ. See Palpus.

Palpal (pal'-pal) [palpare, to touch softly]. In biology, of, or pertaining to, a palp. P. Organs, the modified recti-palpi of male spiders, functioning as impregnating organs.

Palpate (pal'-pät) [ palpare, to feel]. To examine by touch.

Palpation (pal-pa'-shun) [palpare, to feel]. In phys ical diagnosis, the laying of the hand on a part of the body or the manipulation of a part with the hand or fingers for the purpose of ascertaining its condition or that of underlying organs. P., Abdomino-vaginal, examination of the pelvic contents in women by means of a finger in the vagina and a hand in the suprapubic region pressing downward. P., Bimanual, the use of the two hands in examining an organ; the hands are placed on opposite sides, or one in the vagina and the other on the abdomen, and press toward each other. P., Combined or Conjoined. Synonym of P., Bimanual.

Palpatometry (pal-pat-om'-et-re) [palpare, to feel; $\mu \varepsilon ́ \tau \rho o \nu$, measure]. A measuring of the greatest pressure that can be borne without pain.

Palpebra (pal'-pe-brah) [L.]. The eyelid.

Palpebral (pal'-pe-bral) [palpebra, eyelid]. Pertaining to the eyelid. P. Conjunctiva, the conjunctiva of the eyelids. P. Fissure, the opening between the upper and lower eyelids. P. Folds. See Folds. P. Portion of the Lacrymal Gland. See Gland, Accessory of Rosenmüller.

Palpebralis (pal-pe-bra'-lis) [palpebra, eyelid]. The levator palpebræ superioris muscle. See Muscles, Table of.

Palpebritis (pal-pe-bri'-tis) [palpebra, eyelid; $\iota \tau \iota s$, inflammation]. Synonym of Blepharitis.

Palpicil (pal'-pis-il) [ palpus, a feeler; cilium, a cover, an eyelid]. In biology, a tactile hair.

Palpifer (pal'-pif-er) [palpus, a feeler; ferre, to bear]. In biology, the outer lobe of the maxilla of an insect; the bearer of the palpus.

Palpiform (pal'-pif-orm) [palpus, a feeler; forma, form]. Having the form or function of a palp.

Palpiger (pal'-pij-er) [palpus, a feeler; gerere, to bear]. In biology, an appendage to the labium of certain insects; the bearer of the labial palpus.

Palpitate (pal'-pit-ät) [palpitare, to quiver]. To flutter, to tremble or to beat abnormally fast ; applied especially to the heart.

Palpitation (pal-pit-a'-shun) [palpitatio, a beating]. Any spasmodic fluttering or tremor, especially the abnormally rapid beating of the heart, of which the person is conscious. It is associated often with a choking sensation in the throat. It may be due to organic disease or to functional disturbance of the heart; very often it is caused by disorders of the stomach. P., Arterial, arterial pulsation synchronous with the action of the heart, seen sometimes in the epigastric region in the course of the aorta. It is quite common in hysteric persons. P., Celiac, palpitation of the abdominal aorta. P., Nervous, palpitation of the heart due to reflex disturbances from diseases of other organs. P., Symptomatic, of Andral, the reflex palpitation of the heart sometimes observed when teniæ are present in the intestines. 
Palpocil (pall-po-sil). Same as Palpicil.

Palpon (pal'-pon) [palpus, a feeler]. In biology, a siphonophoran polyp, specialized as a taster or feeler. Cf. person.

Palpulus ( $p a l^{\prime}-p u$-lus) [dim. of palpus, a feeler: $p l$, Palpuli]. In biology, a diminutive palpus.

Palpus (pal'-pus) [palpare, to touch softly: pl., Palpi]. In biology: $(a)$ one of the tactile organs or feelers attached to the maxilla or labium of an insect; $(b)$ one of the fleshy lobes at the side of the mouth of certain molluscs, usually called the labial palpus.

Palsy (pawl/-ze) [ME., palsey, palsy]. Paralysis. P., Bell's. See Diseases, Table of. P., Birth. See Birth. P., Cerebral, a paralysis due to a lesion. in the brain. P., Creeping, an old term for progressive muscular atrophy. P., Crutch, that due to pressure of the crutch in the axilla upon the brachial nerves. P., Dancers', a cramp affecting especially the muscles in the calf of the professional danseuse. P. Erb's: 1. Paralysis of the brachial plexus, 2. Spastic paraplegia. See Diseases, Table of. P., Facial. See Paralysis, Bcll's. P., Pen. See Writers' Cramp. P., Scriveners'. Synonym of Writers' Cramp. P., Shaking. Synonym of Paralysis agitans. P., Wasting, progressive muscular atrophy.

Paludal (pal'-u-dal) [palus, paludis, marsh]. Pertaining to a marsh or the exhalations of marshes. Also a synonym of Malarial. P. Fever. Synonym of Internittent Fever.

Paludicole (pal-u'-dik-ōl). [palus, a marsh; colere, to inhabit]. In biology, inhabiting marshes.

Paludine (pal'-u-din) [palus, a marsh]. Paludal.

Paludinous (pal-u'-din-us) [palus, a marsh]. Pertaining to marshes.

Paludism ( $p a l^{\prime}-u$-dizm) [palus, a marsh]. Malarial poisoning; impaludism.

Paludose ( $p a l^{\prime}-u$-döz) [palus, a marsh]. In biology, growing in marshy places.

Paludous (pal"-u-dus) [palus, a marsh]. Marshy or swampy. Having the nature of, or affected with, marshfever.

Palulus ( $p a l^{\prime}-u$-lus) [dim. of palus, a stake, pale: pl., Paluli.]. A small palus; applied to the columellar rods in actinozoa.

Palumbo's Net. See Net, Bathygraphic.

Palus ( $p a^{\prime}$-lus) [palus, a stake, pale: pl., Pali.]. In biology, one of the plates found in corals between the inner edge of certain septa and the axis of the visceral chamber.

Palustral (pal-us'-tral) [palus, marsh]. Pertaining to, or having the nature of, marsh-fever; paludal.

Palustrine (pal-us'-trin) [palus, a swamp]. The same as Paludal.

Pambotano (pam-bo-tan'-o) [native Mexican]. A Mexican plant, Calliandra houstoni, belonging to the order of Leguminose. It is a bitter and antimalarial of the first order. Dose of the powdered drug, 70 grains in 24 hours. The preparations are the tincture, decoction, elixir, and alcoholic extract. Unof.

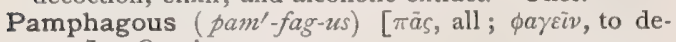
vour]. Omnivorous.

Pamphilus $\left(p a m^{\prime}-f i l-u s\right) \quad[\pi \tilde{a} s$, all; $\phi i \lambda \varepsilon i v$, to love $]$. A plaster.

Pamphobia ( $a m-f 0^{\prime}-b e-a h$ ). See Panophobia.

Pampinary (pam'-pin-a-re) [pampinus, a tendril, or young shoot of a vine]. In biology, of, or pertaining to, a young shoot.

Pampiniform (pam-pin'-if-orm) [pampiniformis: pampinus, tendril; forma, form]. Having the form of a tendril. P. Plexus. See Plexus, Spermatic.

Pampinocele (pam-pin'-o-sēl) [pampinus, tendril; $\kappa \dot{\eta} \lambda \eta$, tumor]. A varicocele of the veins of the pam. piniform plexus.

Pamplegia (pam-ple'-je-ah) [ $\pi \vec{\alpha} S$, all ; $\pi \lambda \eta \gamma^{\prime}$, stroke]. General paralysis.

Pamprodactylous ( pam-pro-dak'-til-us) $[\pi \tilde{a} s$, all ; $\pi \rho \delta$,

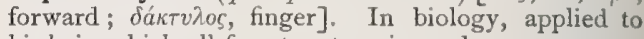
birds in which all four toes turn inward.

Pan- $\left[\pi a \tilde{\nu}\right.$, neuter of $\pi \tilde{a} \zeta\left(g e n . \pi a v T \delta_{\zeta}\right)$, all, everything]. A Greek word signifying all, everything. The form panto- is frequently employed.

Pan [ME., panne, a pan]. A low, flat-bottomed vessel. P., Bed, a large, flat oval pan, usually of china, serving as a receptacle for the fecal discharges and urine of bed-patients. P., Brain, P., Head, the skull. P., Knee, the patella.

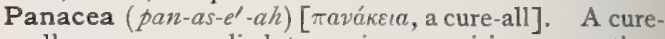
all; a name applied to various empiric preparations alleged to cure a multitude of diseases.

Panache $\left(p a-n a s h^{\prime}\right)$ [penna, feather, plume]. In biology, a tuft of hairs or feathers.

Panacon ( $\left.p a n^{\prime}-a k-o n\right), \mathrm{C}_{22} \mathrm{H}_{19} \mathrm{O}_{8^{\circ}}$. A white, tasteless, crystalline body derived from the root of Aralia quinquefolia.

Panado (pan-a'-do) [Sp. panada, from panis, bread]. Bread softened in water. Also, a bread-poultice.

Panæsthesia (pan-es-the'-ze-ah). See Panesthesia.

Panæsthetism (pan-es'-thet-izm). See Panesthesia.

Panama Fever. I. See Fever. 2. A synonym of Yellow Fever.

Panaquilon (pan-ak'-zvil-on), $\mathrm{C}_{24} \mathrm{H}_{25} \mathrm{O}_{18}$. An amorphous, bitter-sweet principle extracted from the root of Aratia quinquefolia.

Panaricium (pan-ar-is'-e-um). See Panaris.

Panaris (pan- $\left.a^{\prime}-r i s\right)$ [panaricium, a disease of the fingernails]. Phlegmonous inflammation of the finger or toe. Whitlow. See also Paronychia. P., Analgesic. See Morvan's Disease. P., Periosteal, phalangeal periostitis. P., Tendinous, inflammation of the sheath of a digital tendon.

Panaritium (pan-ar-ish'-e-um). See Panaris and Whitlow.

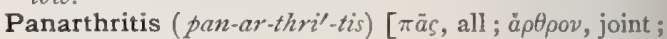
$\iota \tau \iota$, inflammation]. General inflammation of the structures of a joint.

Panas' Solution. A mild antiseptic collyrium, serviceable in conjunctivitis, blepharitis, etc. It contains mercuric iodid I, absolute alcohol 400 , distilled water sufficient to make 20,000 parts.

Panax ( $\left.p a^{\prime}-n a k s\right)$ [ $\pi a ́ v a \xi$, panacea]. Ginseng. The root of $P$. quinquefolium, much used in China as a cure-all. It is a demulcent and mild purgative. Unof.

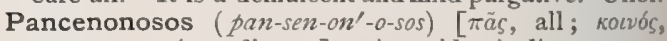
common; v6́бos, disease]. An epidemic disease.

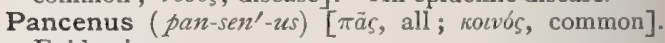
Epidemic.

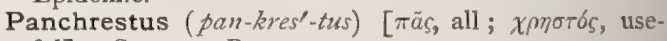
ful]. Same as Prnacea.

Panchymagogue (pan-ki'-magr-og) $[\pi \tilde{a} s$, all; Xijua, juice; $\dot{a} \gamma \omega \gamma \delta \varsigma$, leading]. A drug supposed to deplete all the fluids and humors of the body. [Old.]

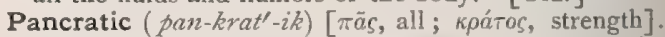
Having a variable magnifying power; applied to the eye-pieces of certain microscopes.

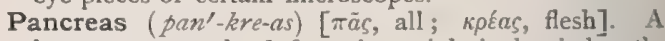
large racemose gland, from six to eight inches in length, lying transversely across the posterior wall of the abdomen. It secretes a limpid, colorless fluid for the digestion of proteids, fats, and carbohydrates. The sweetbread of animals; the abdominal salivary gland of the Germans. It is vulgarly termed "gut bread," or "belly sweetbread," in contradistinction to the thymus or true sweetbread. P., Accessory, a small mass of 
glandular structure similar to the pancreas, and adjacent to it. P.Aselli, a collection of lymph-glands in the mesentery of some mammals, resembling a

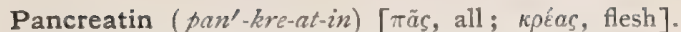
The active elements of the juice of the pancreas ; also the commercial extract of the pancreas. It is added

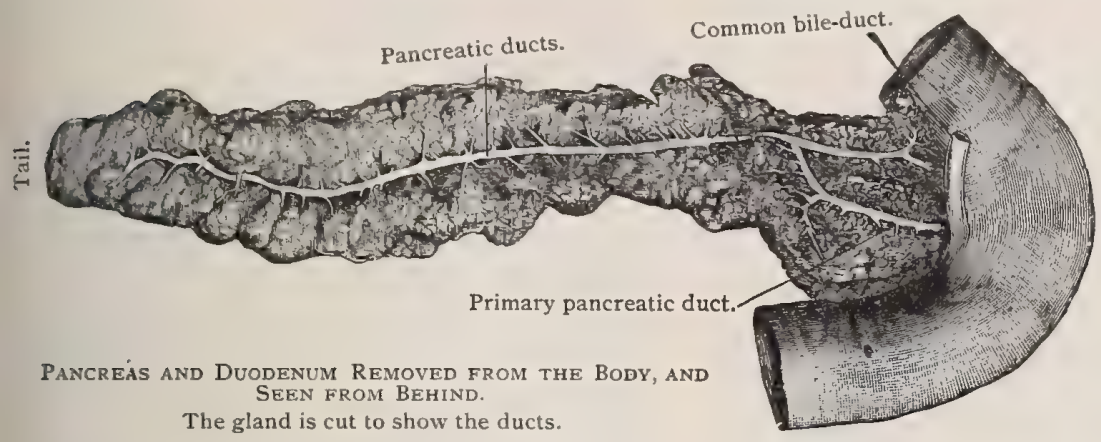

pancreas. P., Lesser, a small partially detached portion of the gland, lying posteriorly to its head and having occasionally a separate duct which opens into the pancreatic duct proper. $\mathbf{P}$., Little. Same as $P$., Lesser. P.-ptyalin, an amylolytic ferment secreted by the pancreas; amylopsin. P., Small, a glandular mass frequently found under the true pancreas, and similar in structure. P. Winslowii. Same as P., Lesser.

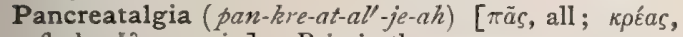
flesh; $\dot{a} \lambda$ yos, pain $]$. Pain in the pancreas.

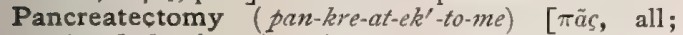

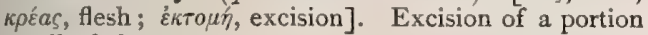
or all of the pancreas.

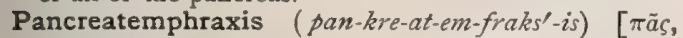

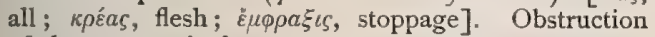
of the pancreatic duct.

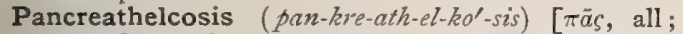

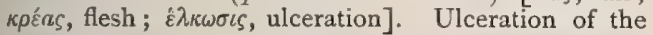
pancreas.

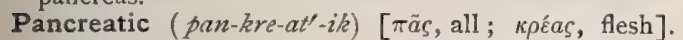
Pertaining to the pancreas. P. Duct, the efferent duct carrying the secretions of the pancreas to the intestines; it is also known as the duct of Wirsung. See Duct. P. Fluid, or Juice, the fluid secreted by the pancreas. It is thick, transparent, colorless, odorless, of a salty taste, and strongly alkaline. By heat it is coagulated into a white mass, from the presence of serum-albumin. Its composition is water 900.8 , and solids 99.2. Of the latter, 90.4 are organic matter, and 8.8 inorganic matter. The ash from rooo parts of juice yields soda $0.5^{8}$; sodium chlorid 7.35 ; potassium chlorid 0.02 ; phosphates of alkaline earths and iron 0.53 ; sodium phosphate 0.01 ; lime and magnesia 0.32 . Traces of leucin and soaps are present in the fresh juice. The ferments or enzymes, four in number, that it contains give to it its important digestive power. Its diastatic action is due to amylopsin; its tryptic or proteolytic action results from the presence of trypsin; its action on fats is due to the presence of steapsin, which causes the fats to split up into glycerin and the corresponding fatty acids; and, finally, it contains a milk-curdling ferment.

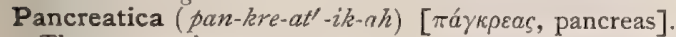
The pancreatic artery.

Pancreatico-duodenal (pan-kre-at'-ik-o-du-od'-en-al)

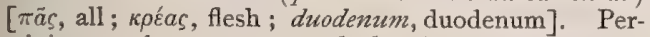
taining to the pancreas and the duodenum. P.-d. Artery. See Arteries, Table of.

Pancreatico-splenic (pan-kre-at'-ik-o-splen'-ik) $[\pi \tilde{a} \varsigma$, all ; $\kappa \rho \varepsilon \varepsilon_{S}$, flesh; $\sigma \pi \lambda \eta \nu$, spleen $]$. Pertaining to the pancreas and the spleen.

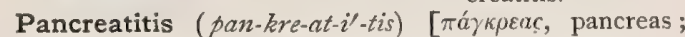
$\iota \tau \iota$, inflammation ]. Inflammation of the pancreas.

Pancreatize $\left(p a n^{\prime}-k r e-a t-i z\right)$ [ $\pi \dot{\alpha} \gamma \kappa \rho \varepsilon a \zeta$, pancreas]. To treat, or digest, with pancreatin.

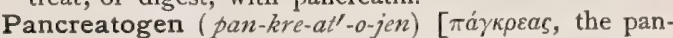
creas ; $\gamma^{\prime} v \varepsilon \sigma \iota \varsigma$, production]. A nutritive element capable of being changed into pancreatin.

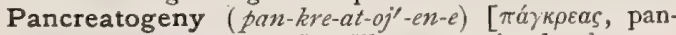
creas; $\gamma^{\prime} \nu \varepsilon \sigma \iota s$, genesis]. The conversion by the pancreas of suitable pabulum into pancreatin.

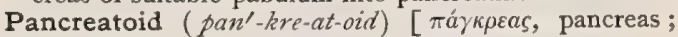
$\varepsilon i \delta$ ¿, like]. Resembling the pancreas.

Pancreatomy (pan-kre-at'-o-me). See Pancreatotomy.

Pancreatoncus (pan-kre-at-ong'-kus) [ $\pi a ́ \gamma \kappa \rho \varepsilon a s$, pancreas; óкко, tumor]. A tumor of the pancreas.

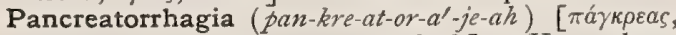
pancreas; ṕqvívae, to burst forth]. Hemorrhage from the pancreas.

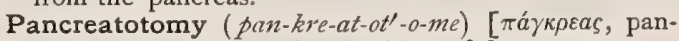
creas; To $\mu^{\prime}$, a cutting]. Incision of the pancreas.

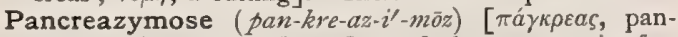
creas; $\zeta^{\prime} \mu \eta$, leaven]. One of the pancreatic ferments.

Pancreectomy (pan-kre-ekl-to-me). See Pancreatectomy.

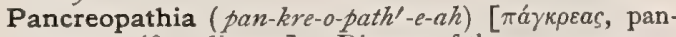
creas; $\pi a ́$ tos, disease]. Disease of the pancreas.

Pandalitium (pan-dal-ish'-e-um). Synonym of Par. onychia.

Pandanus (pan-da'-nus) [Malay, pandang, conspicuous]. A genus of pandaneaceous plants. P. caricosus, a species of screw-pine indigenous in the Molucca Islands, and the leaves of which are used in gastro-intestinal disorders. P. odoratissima, P. utilis, fragrant screw-pine; keora oil-plant, used in dysentery. Unof.

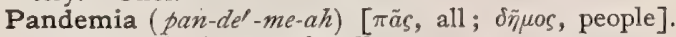
An epidemic that attacks all persons.

Pandemic (pan-dem'-ik) [ $\pi \tilde{a} \varsigma$, all; $\delta \tilde{\eta} \mu o \varsigma$, people]. Epidemic over a wide area.

Pandemy ( $p a n^{\prime}$-dem-e). Same as Pandemia.

Pander, Blood-islands of. Multinucleated areas of the angioblastic cells of the mesoderm, which give rise to the endothelium of the blood-vessels, or are converted into primary blood-corpuscles. P., Nucleus of. See Nucleus.

Pandiculation (pan-dik-2u-la'-shun) [pandiculatio: pandere, to stretch out]. The act of stretching the limbs, especially on waking from sleep. It is sometimes symptomatic of fever, hysteria, and of malarial affections. Also, yawning.

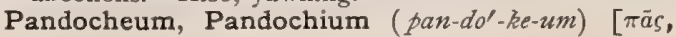


all; $\delta \varepsilon \dot{\varepsilon} \varepsilon \sigma \theta a \iota$, to receive]. A hospital receiving all diseases.

Pandurate ( $\left.p a n^{\prime}-d u-r \bar{a} t\right)$ [ pandura, a musical instrument]. Shaped like a pandura or violin.

Panduriform, Pandurate ( $p a n$-d $u^{\prime}$-rif-orm, pan'-durāt) [pandura, a lyre ; forma, form]. Fiddle-shaped; pandurate. P. Head, a head whose transverse section would show a fiddle-shaped outline.

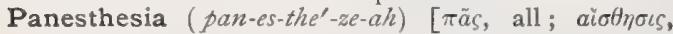
perception]. General or total sensation; cenesthesia.

Panesthetism (pan-es'-thet-izm). Same as Panesthesia.

Pang [ME., pange, a pang]. A momentary sharp pain. P., Breast, angina pectoris.

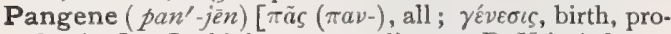
duction]. In biology, according to DeVries' theory of heredity, one of the primary bearers of the individual qualities or characters of the cell, i.e., the constituent qualities of the species; one of the ultimate vital particles. Germ-substance is held to be formed of a num. ber of different kinds of pangenes, of which as many are present as there are qualities in the species; they have no definite arrangement, but are freely miscible. They differ from the "gemmules" of Darwin and correspond to the "biophors" of Weismann. See Heredity.

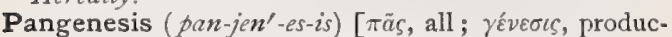
tion]. In biology, Darwin's theory of heredity, which supposes the existence of gemmules separated from the body-cells and segregated from the circulation by the reproductive glands. These preformed constituents of all parts of the fully-formed animal or plant become aggregated in the germ, and give rise by a process of evolution to the new organism. Pangenesis is opposed to the theory of epigenesis, or the origin of the fullyformed organism by a gradual process of differentiation. See Heredity. P., Intracellular, the origin of ultimate vital particles (pangenes, gemmules, biophors) within the cell.

Pangenetic (pan-jen-et'-ǐ) [ $\pi a \tilde{\varsigma}$, all ; $\gamma^{\prime} \varepsilon \varepsilon \sigma \iota \varsigma$, genesis]. Pertaining to pangenesis.

Pangium edule ( $\left.p a n^{\prime}-j e-u m-e-d u^{\prime}-l e\right)$ [L.]. A bixaceous plant of Java. Its oily leaves, though edible after due preparation, contain a powerfully narcotic principle which is readily removed by maceration in cold water. Unof.

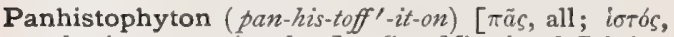
web, tissue; $\phi v t o ́ v$, plant]. See Microbe of Pebrine, under Bacteria. See also Microsporidia.

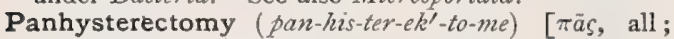

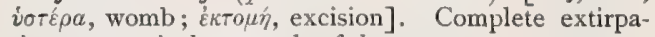
tion, or surgical removal, of the uterus.

Panicle ( $\left.p a n^{\prime}-i k-l\right)$ [ panus, a thread wound upon the bobbin in a shuttle]. In biology, a branched raceme; an inflorescence of varying shape (determinate, indeterminate, cymose, botryose), but typically loose and spreading, with repeatedly branched peduncles, as seen in the grasses or the lilac.

Panicula ( $p a n-i k^{\prime}-\imath$-lah) [L.]. A swelling or tumor.

Paniculate (pan-ik'-u-lat $)$ [ panicula, a panicle]. In biology, arranged in panicles.

Paniculus (pan-ik'-u-lus). See Panniculus.

Panicum (pan'-ik-um) [L.]. Panic-grass, a graminaceous plant widely distributed. P. insulare, a West Indian species, having purgative properties. Unof.

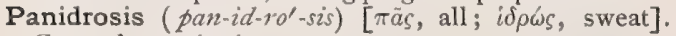
General perspiration.

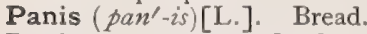

Panizza, Foramen of. See Foramina, Table of.

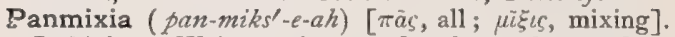
In biology, Weismann's term for the tendency of organic structures to retrogress and disappear when their value to the species becomes nil, as $e . g$, the eyes in cave-animals.

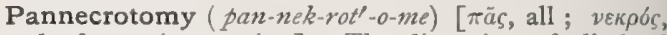
dead; $\tau o \mu \eta \dot{n}$, a cutting]. The dissection of all dead bodies, suggested by Kraus as the best method to prevent burial of living persons.

Pannetier's Green. Same as Mittler's Green.

Panneuritis ( pan-nu-ri'-tis) [ $\pi \tilde{a} s$, all, every; veṽ $\rho o v$, nerve; $\iota \tau \iota$, inflammation]. A synonym of multiple neuritis.

Panniculus (pan-ik'-u-lus) [dim. of pannus, a piece of cloth]. A small piece of cloth. In anatomy, a small membrane. P. adiposus, a compact layer in the subcutaneous stratum of the skin, in which the interfascicular spaces of the reticular framework of fibro-elastic bundles are occupied by adipose tissue. The large, thin muscles by which the lower animals move the skin, represented in man mainly by the platysma and by some of the facial muscles. P. cordis, the pericardium. P. subtilis, the pia mater. P. transversus, the diaphragm.

Pannose ( pan'-ōz) [pannus, cloth, rag]. In biology: (a) Having the texture or appearance of woolen cloth or felt. (b) Covered with a felted coat of hairs.

Pannus $\left(p a n^{\prime}-u s\right)$ [L., a cloth]. Vascularization of the cornea, usually due to the irritation of trachomagranulations. (The cornea is normally non-vascular.) P. carnosus, P. crassus, one that has acquired a considerable thickness. P. siccus, an old pannus composed of connective tissue and poor in vessels.

Panochia (pan-o'-ke-ah). Synonym of Venereal Bubo.

Panococo $\left(p a n-o-k o^{\prime}-k o\right)$ [S. Amer.]. The South American leguminous tree, Szeartzia tomentosa; its. bark is strongly sudorific, and the tree affords a black resin. Unof.

Panoïstic (pan-o-is'-tik) [ $\pi \tilde{a} \varsigma$, all; $\omega^{\prime} \sigma v$, egg]. In biology, applied to ovaries that produce ova only; as distinguished from meroistic ovaries, which produce separate ova and yolk-cells or nutritive cells.

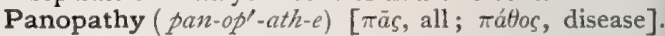
A disease widely prevalent among many people, or affecting all the tissues of one individual.

Panophobia ( $p a n-o-f o^{\prime}-b e-a h$ ). See Pantophobia.

Panophthalmia (pan-off-thal'-me-ah). See Panophthalmitis.

Panophthalmitis (pan off-thal-mi'-tis) $[\pi \tilde{a} s$, all; $\dot{\alpha} \phi \theta a \hat{n}-$ $\mu o s$, eye; $\iota \tau \iota s$, inflammation]. Inflammation of all the tissues of the eyeball.

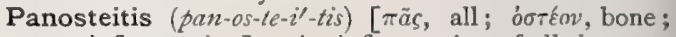
$\iota \tau \iota s$, inflammation]. An inflammation of all the parts of a bone.

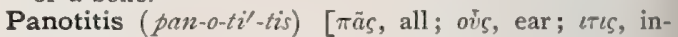
flammation]. An inflammatory affection involving all the structures of the ear, and resulting in complete destruction of its functions, with dangerous bonesequelæ.

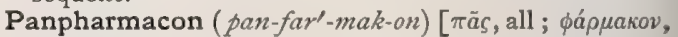
drug]. A panacea.

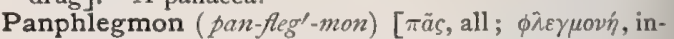
flammation]. Gangrene of rapid course and development, probably microbic in origin.

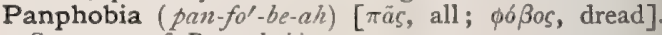
Synonym of Panophobia.

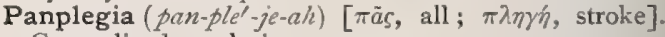
Generalized paralysis.

Pansch, Fissure of. See Fissures, Table of.

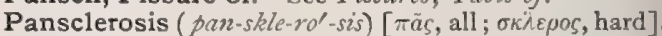
Complete sclerosis or hardening of a part.

Panspermatism (pan-sper'-mat-izm) [ $\pi \bar{a} s$, all ; $\sigma \pi \varepsilon \rho \mu a$, seed]. In biology, Spallanzani's theory that the air is full of invisible germs; the theory of omnipresent germs. 
Panspermia (pan-sper'-me-ah). Same as Panspermatism.

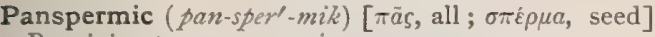
Pertaining to panspermatism.

Panspermism (pan-sper'-mizm). See Panspernatism.

Panspermist ( pin-sper'-nist) $[\pi \bar{\alpha} s$, all ; $\sigma \pi \varepsilon \tilde{\varepsilon} \rho \alpha$, seed] One who believes in spontaneous or equivocal generation. See Abiogenesis.

Panspermium (pan-sper'-me-um) [ $\pi \vec{a} \varsigma$, all ; $\sigma \pi \varepsilon p \mu a$, germ]. The hypothetic ultimate element of matter.

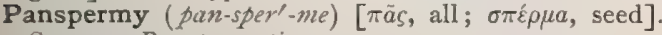
Same as Panspermatism.

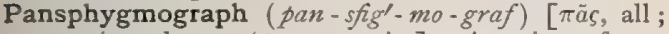

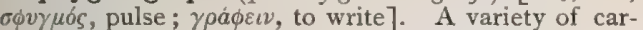
diograph by means of which tracings can be taken simultaneously of the cardiac movements, the arterial pulse, and the respiration.

Pansy $\left(p a n^{\prime}-z e\right)$. See Viola tricolor.

Pant [ME., panten, to pant, gasp]. To breathe hard or quickly.

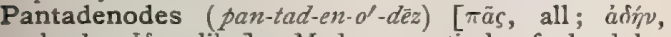
gland; $\varepsilon i \delta o s$, like]. Made up entirely of glandular tissue ; e.g., the pancreas.

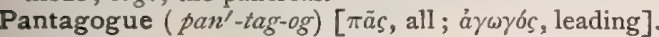
A medicine intended to expel all morbific matters. [Old.]

Pantais. See Pantas.

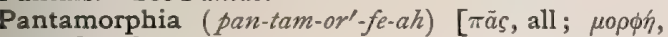
form]. General deformity.

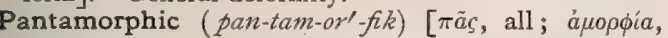
shapelessness]. Completely deformed.

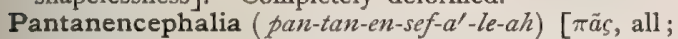

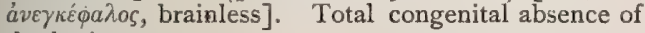
the brain.

Pantanencephalic (pan-tan-en-sef-al'-ik) $[\pi \tilde{a} s$, all ;

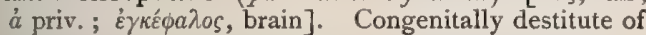
brain.

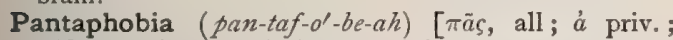
$\phi 6 \beta a s$, fear ]. Total absence of fear.

Pantas (pan'-tas) [pantais, pantois, a disease of hawks]. A pulmonary disease of hawks. Spelled also pantass, pantasse, pantess, pantais.

Pantatrophia, Pantatrophy (pan-tat-ro'-fe-ah, pan-

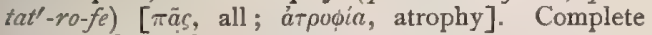
or general atrophy.

Pantephobia (pan-tef-o'-be-ah). Synonym of Hydrophobia.

Pantess (pan'-tes). See Pantas.

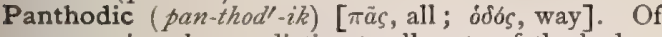
nervous impulses, radiating to all parts of the body.

Panting (pant'-ing) [ME., panten, to pant]. Breathing loudly and rapidly, like a dog that has run fast.

Panto- (pan'-to-). See Pan-.

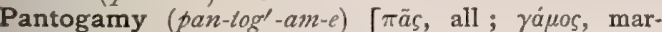
riage]. Reckless, indiscriminate sexual intercourse.

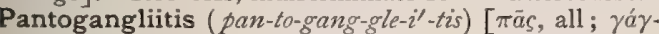
$\gamma \lambda \iota 0 \nu$, ganglion; $\iota \tau \iota$, inflammation]. A synonym of Asiatic Cholera.

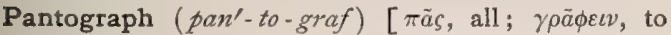
write]. An instrument for the mechanical copying of diagrams, etc., upon the same scale, or upon an enlarged or a reduced scale.

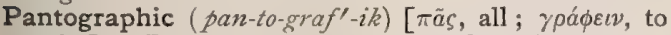
write]. Pertaining to a pantograph and to pantography.

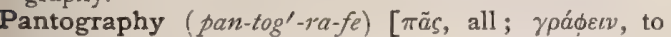
write]. I. General description. 2. The process of copying by a pantograph.

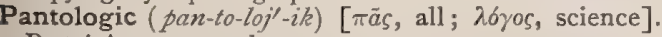
Pertaining to pantology.

Pantologist (pan-tol'-o-jist) [ $\pi \tilde{a} \varsigma$, all ; $\lambda 6 \gamma o s$, science $]$. One versed in pantology.
Pantology (pan-tol' $-o-j e)$ [ $\pi \tilde{s} s$, all; $\lambda 6 \gamma o s$, science]. Universal knowledge.

Pantometer (pan-tom'-et-er) [ $\pi a \tilde{S}$, all ; $\mu \dot{\varepsilon}-p o \nu$, measure]. An instrument for measuring angles of all kinds.

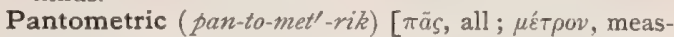
ure]. Pertaining to pantometry.

Pantometry (pan-tom $\left.{ }^{\prime}-e t-r e\right)[\pi \tilde{a} \varsigma$, all; $\mu$ ćtpov, measure]. I. Universal measurement. 2, The use of the pantometer.

Pantomorph (pan'-to-morf) [ $\pi a \tilde{S}$, all ; $\mu \circ \rho \phi \dot{n}$, form $]$. That which assumes, or exists in, all shapes.

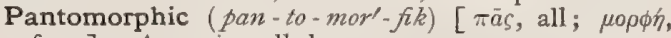
form]. Assuming all shapes.

Pantophagist (pan-toff'-aj-ist) $[\pi \tilde{\alpha} S$, all ; $\phi a \gamma \varepsilon \tilde{\imath} \nu$, to eat]. One who is omnivorous.

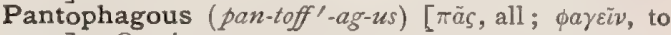
eat]. Omnivorous.

Pantophagy (pan-toff'-aj-e) [ $[\pi \bar{a} \zeta$, all ; $\phi a \gamma \varepsilon i \bar{v}$, to eat $]$. The habit of eating all kinds of food.

Pantophobia ( $\left.p a n-t o-f o^{\prime}-b e-a h\right)$ [ $\pi a \bar{s}$, all ; $\phi o ́ \beta u s$, fear $]$. Insane dread of all things.

Pantophthalmia (pan-toff-thal'-me-ah). Synonym of Panophthalmitis.

Pantoplethora (pan-to-pleth'-or-ah) [ $[\pi \tilde{\varsigma}$, all ; $\pi \lambda \eta \theta \omega \rho \eta$, fulness]. General hyperemia.

Pantoscopic ( $p a n-l o-s k o p^{\prime}-i k$ ). See Bifocal.

Pantostomate (pan-to-sto'-māt). Same as Pantostomatous.

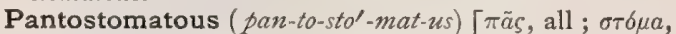
mouth]. In biology, capable of ingesting food at any or every point on the surface of the body, $e_{.} g .$, an ameba.

Pantozoötia (pan-to-zo-o'-she-ah). Synonym of Panzoöty.

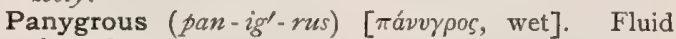
throughout.

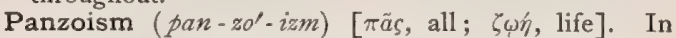
biology, a collective term for the various elements or factors of vitality.

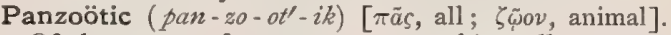
Of the nature of a panzoöty; attacking all, or many animals.

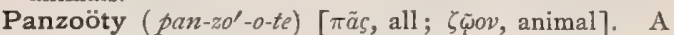
disease attacking all, or a great many, animals at once.

Pap [ME., pap, pap]. A soft, semiliquid food for infants. Also the nipple. P.-pox. Same as Cowpox.

Papain ( $\left.p a^{\prime}-p a-i n\right)$ [Papaiamaram, the native Malabar name of papaya]. A proteolytic ferment obtained from papaw-milk, the juice of Carica papaya, a tree native to South America. It has the digestive properties of pepsin, but is far more active, dissolving fibrin in neutral, acid, or alkaline liquids. It is an excellent solvent of false membranes. Papayotin and Caricin are other names for the ferment. Dose gr. $\mathrm{j}-\mathrm{x}$. Unof.

Papaina (pa-pa-in'-ah) [gen., Papaina]. See Papain.

Papaver ( $\left.p a-p a^{\prime}-v e r\right)$ [papaver, poppy: gen., Papaveris]. The poppy, the juice and extracts of which possess narcotic properties. Opium is obtained from $P$. somniferum. The British Pharmacopeia includes the nearly ripe dried capsules of the foregoing, from which are prepared the following: Papaveris, Decoctum, only used externally. P., Extract. Dose gr. ij-v. P., Syrup. Dose $3 \mathrm{j}$. The action of these preparations is similar to, but much weaker and more uncertain than, that of opium. P. rheas, the red or corn poppy resembling opium in its action, but milder. Rheados, Syr. Dose $3 \mathrm{j}$.

Papaveraldin (pa-pav-er-al'-din) [papaver, poppy], $\mathrm{C}_{20} \mathrm{H}_{19} \mathrm{NO}_{5}$. A crystalline oxidation-product of papaverin. 
Papaverin (pap-av'er-in) [papaver, poppy], $\mathrm{C}_{21} \mathrm{H}_{21}$ $\mathrm{NO}_{4}$. An alkaloid found in opium. It is narcotic, and produces primarily muscular relaxation, later convulsions. Dose gr. $1 / 4$. Unof.

Papaverous (pap-av'-er-us) [papaver, poppy]. Par taking of the character of the poppy.

Papaw (pa-paw') [a name of Malabar origin]. I. The seed of Asimina triloba, a prompt emetic. Dose of the fld. ext. $m x-x x x$. Unof. 2. The tree Carica papaya; also, its edible fruit. See Papain.

Papayotin ( $\left.p a p-a-y o^{\prime}-t i n\right)$. See Papain.

Paper $\left(p a^{\prime}-p e r\right)$ [ $\pi a ́ \pi v \rho o s$, the plant papyrus]. See Charta. P.-shell Lobster. See Buckle-shell.

Papilionaceous ( $\left.p a p-i l-\ell-o n-a^{\prime}-s h e-z s\right)$ [ papilis, butterfly]. Resembling a butterfly.

Papilla (pap-il'-ah) [L., a nipple]. In anatomy, any small, soft, conic eminence, as the nipple. The word is used alone to designate the optic disc or nerve-head as seen by the ophthalmoscope. In pathology, a pimple, or pustule. Cf. Mammilla; Wart. P. Caliciform, $\mathbf{P}$., Circumvallate, one of the large papillie at the root of the tongue, arranged like a $V$ opening forward. P., Clavate. Synonym of $P$., Fungiform. P., Compound, a papilla covered with several perfect secondary papillæ. P., Conic. See P., Filiform. P. Conoidal. Synonym of P., Filiform. P., Dental. See Organ, Enamel. P., Duodenal, the elevation at the point where the ductus choledochus communis enters the

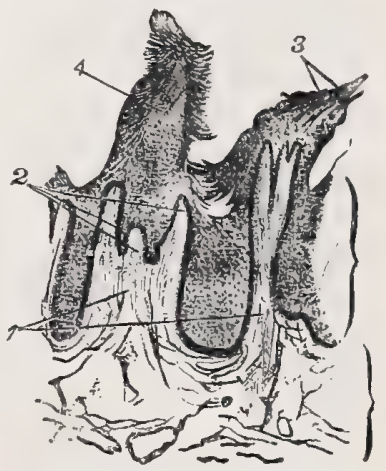

FILIFORM PAPILLfE, $\times 30$ papillæ on its summit. 3. Epithelial process on papilla. 4 . Single process, with entangled epithelial cells. 1. Primary papilla. 2, Secondary

duodenum. P. of Eye. See Disc. P., Filiform, any one of the smallest and most numerous of the lingual papillæ. They are conic and have projecting from their apices filiform processes of a whitish tint. P., Foliate, one of the small folds of mucous membrane at the sides of the tongue ne a $r$ its base, containing tasteorgans. $\mathbf{P}$. Fungiform, any one of the mediumsized papil læ of the to n $\mathrm{g}$ u

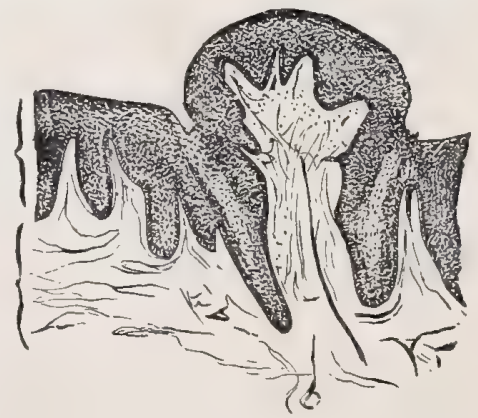

FUNGIFORM PAPILLA. $\times 30$.
They are named from their resemblance to a young mushroom. P., Hair, the projection of the corium into the depression at the end of the hair-bulb. P. of Kidney. See P., Renal. P. Lacrymal, the small elevation at the inner edge of the eyelid containing the opening into the canaliculus. P., Lingual, one of the elevations of the mucous membrane of the dorsum of the tongue; they are covered by stratified epithelium, and are of three varieties, filiform, fungiform, and foliate. See Illustrations. P. mammæ, the nipple. P.

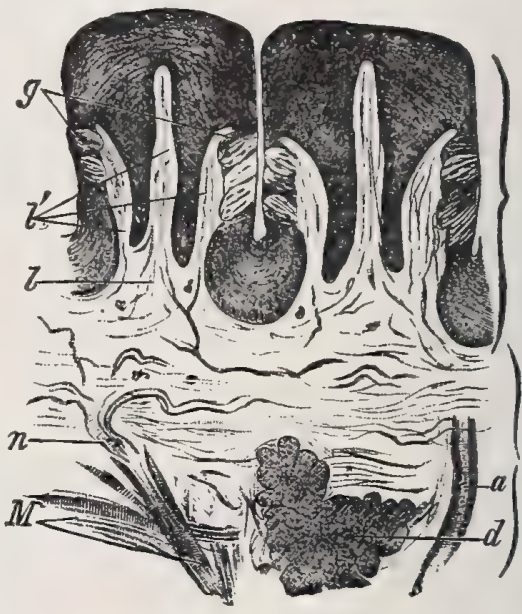

Foliate Papilla in the Rabit. $\times 80$.

l, l'. Primary and secondary septa. $g$. Taste-buds. n. Medul lated nerve, $d$. Serous gland, $a$. Its duct. $M$. Muscular fibers.

Maximal. Same as $P$., Circumvallate. P., Medullary, one of the small eminences on the medulla oblongata. P., Minimal. Same as $P$., Conic. P., Nerve, any one of the skin-papillæ containing tactile corpuscles or nervous plexuses.

P. optica, the optic disc or prominence formed by the fibers of the optic nerve after having entered the cavity of the eyeball. P., Renal, the summit of any one of the renal pyramids projecting into the

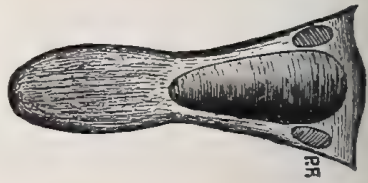

TONGUE OF RABBit, SHOWINC Foliate Papille, P. F. (From Stirling.) renal pelvis. P. of Skin, any one of the minute finger-like projections of the corium. P. spiralis, the same as Organ of Corti. See Corti, Organ of. $\mathbf{P}$. Tactile, one of the papillæ of touch; little eminences of the true skin containing tactile corpuscles and nerve-fibers. P. truncatæ. Synonym of $P$., Cir cumvallate. P., Vallate. See $P$., Circumvallite.

Papillar (pap-il'-ar). Synonym of Papillary.

Papillary $\left(p a p^{\prime}-i l-a-r e\right)$ [papilla, nipple]. Pertaining to a papilla. Also, pertaining to the nipple. Bearing papillæ. P. Wave. See Percussion-zuave.

Papillate $\left(p a p^{\prime}-i l-\bar{a} t\right) \quad[p a p i l l a$, nipple, bud]. In botany, covered with papillz.

Papilliferous ( $\left.p a p-i l-i f^{\prime}-e r-u s\right)$ [papilla, papilla; ferre, to bear]. Papillate; bearing one or more fleshy excrescences.

Papilliform (pap-il'-if-orm) [papilla, nipple; forma, to form]. Shaped like a papilla, or nipple. P. Bodies of Van Bemmelen. See Megalesthete. P. Layer of the Skin, the layer bearing the papillæ. P. Muscles, those conic columnx carnex of the heart to which the chordæ tendinere are attached.

Papillitis (pap-il-i'-tis) [papilla, papilla; $\iota \tau \iota s$, inflammation]. Inflammation of the optic disc or papilla of the eye. The old terms choked disc, descending neuritis, etc., implied unproved theories of causation, and have been replaced by the adoption of the 
better term papillitis. Intracranial diseases, as tu-

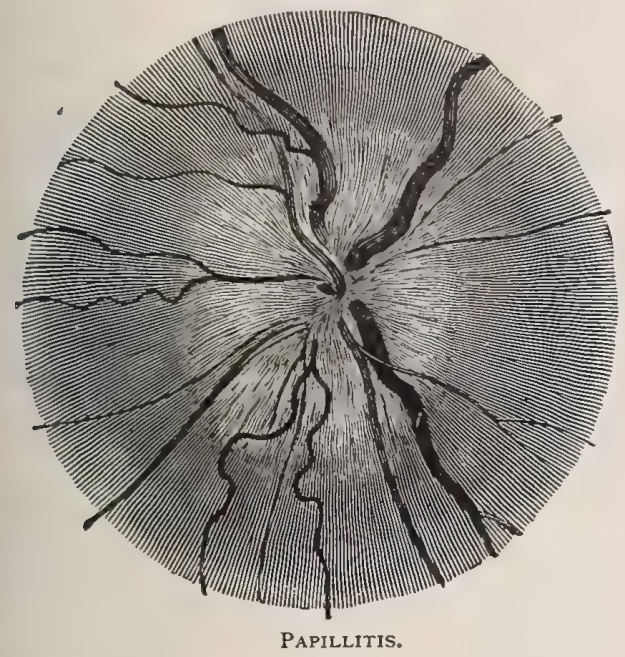

mors, meningitis, abscess, etc., are the most frequent cause.

Papilloma (pap-il-o'-mah) [papilla, papilla; ó $\mu \alpha$. tumor: pl., Papillomata]. A term loosely employed to include corns, warts, horns, and certain nevi. Papillomata stand midway between true tumors and inflammatory growths; a papilloma is any growth on the skin or mucous membrane based upon, or resembling, a normal papilla. P., Hard, a form in which the connective-tissue framework is denser and the cells fewer than usual. It grows chiefly from the skin. P., Soft, one growing from mucous membranes, especially in the uterus, rectum, and bladder.

Papillomatosis (pap-il-o-mat-o'-sis) [papilla, papilla; $\ddot{b} \mu a$, tumor; $v 6 \sigma o \varsigma$, disease]. The widespread formation of papillomata; also the state of being affected with multiple papillomata.

Papillomatous ( $p a p-i l-o^{\prime}$-mat-us) [papilla, papilla; ö $\mu a$, tumor]. Pertaining to a papilloma.

Papilloretinitis ( $p a p-i l-0$-ret-in-i'-tis). Synonym of Neuroretinitis.

Papillose ( $\left.p a p^{\prime}-i l-\bar{o} z\right)$ [fapilla, a nipple]. Bearing papillæ.

Papillulate ( $p a p-i l^{\prime}-u$-lāt $)$ [papillula, papillule]. Papular; covered with papillulæ.

Papillule ( $\left.p a p^{\prime}-i l-\bar{u} l\right)$ [papillula, dim. of papilla, a nipple]. 1. A small papilla or tubercle. 2. Also applied to a small depression, as a variole, when it has a central elevation.

Papoid ( $\left.p a p^{\prime}-o i d^{\prime}\right)$. A proprietary preparation similar to or identical with papain.

Papoose, Pappoose ( $a$ a $p$-oos') [Amer. Ind.]. An Indian babe or young child. P.-root. Synonym of Caulophyllum.

Pappiferous ( $\left.p a p-i f^{\prime}-e r-u s\right)$ [ $\pi \dot{a} \pi \pi o s$, down; ferre, to bear]. Bearing a pappus.

Pappus $\left(p a p^{\prime}-u s\right)[\pi a ́ \pi \pi o \varsigma$, down]. The fine down first appearing on the cheeks and chin. In biology, the modified calyx-limbs of the florets of the Composite.

Papula ( $p a p^{\prime}-u$-lah). See Papule.

Papular (pap'-u-lar) [papula, papule]. Of the nature of a papule.

Papule $\left(p a p^{\prime}-\bar{u} l\right)$ [papula, a pimple]. A small circumscribed, solid elevation of the skin. P., Moist, a name for a broad condyloma. P., Mucous, a mucous patch of syphilis.
Papuliferous (pap-u-lif'-er-us) [papula, a pimple; ferre, to bear]. Pimply; covered with papulæ.

Papulose ( $\left.p a p^{\prime}-u-l a z\right)$. Synonym of Papular.

Papulous ( $p a p^{\prime}-u$-lus). Synonym of Papular.

Papyraceous (pap-ir-a'-se-us) [papyrus, paper]. In biology, of a papery texture.

Papyritious (pap-ir-ish'-us) [papyrus, paper]. In biology, resembling paper, as the nests of certain wasps.

Paquelin's Cautery. See Cautery.

Par [L.]. A pair. P. duodecimum, an old name for the hypoglossal nerve. P. medullæ primum, an old term for the glosso-pharyngeal nerve. $P$. medullæ secundum, the vagus nerve. [Old.] $\mathbf{P}$. nonum, an old name for the hypoglossal nerve. P. piqure. See Culture. P. vagum, the vagus nerve.

Para- $\left(p a \gamma^{\prime}-a h-\right)$ [ $\pi a ̊ \rho a ́$, beyond, beside]. A prefix signifying beyond, beside, near, the opposite of, etc. In chemistry, it denotes close relationship, and is applied, e. g., to a derivation of the benzol ring formed by the substitution of two atoms of hydrogen situated opposite each other. In biology, it indicates comparison with another object, although a distinct difference exists. In pathology, it signifies a condition varying from the normal, though resembling it somewhat.

Para-analgesia ( $\left.p a r-a h-a n-a l-j e^{\prime}-z e-a h\right)$ [ $\pi a \rho a ́$, beside; a $\nu a \lambda \gamma \eta \sigma^{\prime} a$, insensibility to pain]. Analgesia limited to the lower limbs and the lower half of the trunk.

Para-anesthesia (par-ah-an-es-the'-ze-ah) [ $\pi \alpha \rho a ́$, be-

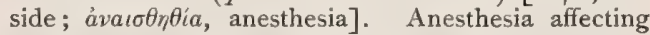
both sides of the body below the waist.

Parabanic Acid (par-ab-a'-nik). See Oxalyurea.

Parabin ( $\left.p a r^{\prime}-a b-i n\right)$. See Gelose.

Parablast (par'-ab-last) [ $\pi \alpha \rho a ́$, beside ; $\beta \lambda a \sigma \tau o ́ s$, germ] In biology, Kupffer's term for peculiar nutritive cells lying under the blastoderm of certain reptilian meroblastic eggs, as distinguished from the archiblast or formative cells. From it are developed the connective tissues, the endothelial cells, the corpuscles of the blood, the blood-plasma, and the lymph.

Parablastic (par-ab-las'-tik) [ $\pi \alpha \rho a ́$, beside; $\beta \lambda a \sigma \tau o ́ s$, germ]. Pertaining to the parablast.

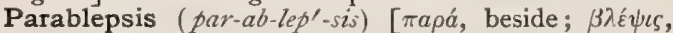
vision]. False or perverted vision.

Paraboulia ( $\left.p a r-a b-o o^{\prime}-l e-a h\right)$. See Parabulia.

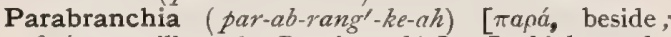

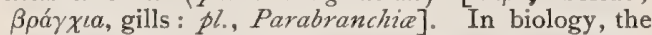
second gill of a gastropodous mollusc.

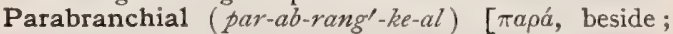
$\beta \rho a ́ \gamma \times \iota \alpha$, gills]. Pertaining to a parabranchia.

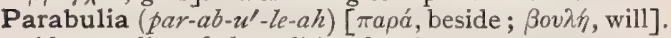
Abnormality of the volitional action.

Parabuxidin (par-ab-uks'-id-in) [ $\pi \alpha \rho a ́$, beside; buxus, the box-tree]. A crystalline alkaloid found in the common garden-box.

Parabuxin ( $\left.p a r-a b-u k s^{\prime}-i n\right)$ [ $\pi a \rho a ́$, beside; buxus, the box-tree], $\mathrm{C}_{24} \mathrm{H}_{48} \mathrm{~N}_{2} \mathrm{O}$. An alkaloid found in common garden-box.

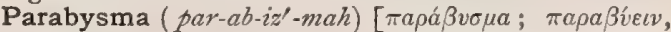
to stuff: pl., Parabysmata] Turgescence, especially of a viscus.

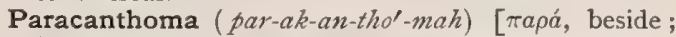

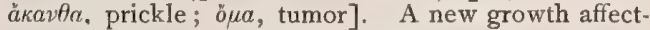
ing the prickle-cell layer of the skin.

Paracanthosis (par-ak-an-tho'-sis) [ $\pi a \rho a ́$, beside;

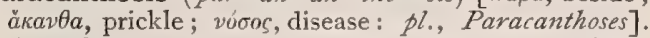
Any skin-disease characterized by some anomaly of the prickle-cell layer.

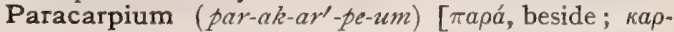
$\pi b s$, fruit]. In biology, an ahortive pistil or ovary.

Paracele ( $\left.p a r^{\prime}-\alpha s-\bar{l} l\right)$ [ $\pi \alpha \rho a ́$, beside; koเnia, a hollow]. A lateral ventricle of the brain. 
Paracenterion ( $\left.p a r-a s-e n-t e^{\prime}-r e-o n\right)$. Synonym of Trocar.

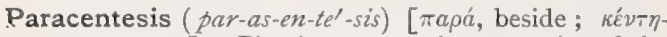
$\sigma \iota s$, puncture]. Piercing or tapping a cavity of the body, such as the chambers of the eye, or the thorax, for the evacuation of fluid.

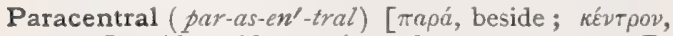
center]. Alongside, or situated near, a center. P. Lobule. See Lobulus.

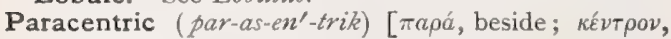
center]. Approaching the center.

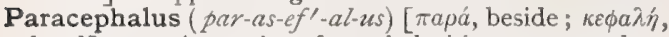
head]. I. A species of omphalositic monsters, characterized by the presence of four extremities, more or less imperfect, especially in the digits, an imperfectlyformed head, a rudimentary condition of the viscera, and, occasionally, absence of the heart. The paracephalus is one of unioval twins; the sex being always the same, and usually female. It is incapable of living. 2. A variety of the foregoing species in which the head is very imperfectly-formed, more or less defective in all its parts, but exhibiting rudiments of the cranium and of the organs of sense, and possessing even an oral orifice and a buccal cavity. The trunk is also defective, and there are no superior extremities.

Parachloralose ( $\left.p a r-a k-l o^{\prime}-r a l-\bar{o} z\right)$ [ $\pi a \rho a ́$, beside ; $\chi \lambda \omega \rho o ́ s$, green]. A product of the action of chloral upon sugar. It is insoluble in water and is practically inert.

Paracholesterin (par-ak-o-les'-ter-in) [ $\pi a \rho a ́$, beside;

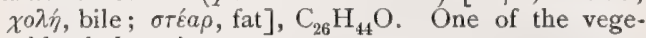
table cholesterins.

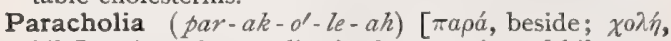
bile]. Any abnormality in the secretion of bile.

Parachordal ( $\left.p a r^{-}-a k-o r^{\prime}-d a l\right)$ [ $\pi a \rho a ́$, beside; $\chi o \rho \delta \dot{\eta}, \mathbf{a}$ string; specifically the chorda or notochord]. In biology: (a) One of two bars of cartilage extending alongside the occipital notochord in the human fetus. (b) Adjoining the cephalochord; situated at the side of the cranial part of the notochord of the embryo. (c) Pertaining to the cartilaginous basis of the cranium in the embryo.

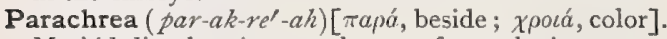
Morbid discoloration, or change of complexion.

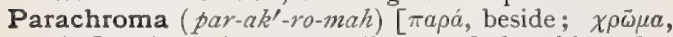
color]. Any pigmentary disease of the skin. See Paracheromatism.

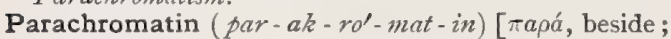
$\chi \rho \omega \tilde{\omega} \mu a$, color $]$. In biology, that portion of the nucleoplasm which goes to form the spindle-threads during mitosis; linin. It is but slightly stainable, whence the name.

Parachromatism ( $\left.p a r-a k-r o^{\prime}-m a t-i z m\right)$ [ $\pi a \rho a ́$, beside; $\chi \rho \tilde{\omega} \mu a$, color $]$. False, or incorrect perception of color. It is not the same as true color-blindness, which it may approach more or less completely.

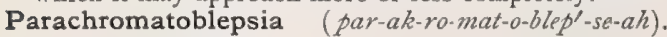
See Parachromatlsm.

Parachromatosis ( par-ak-ro-mat-o'-sis) [ $\pi a \rho a ́$, beside; $\chi \rho \omega \tilde{\omega} \mu$, skin; v6бos, disease $]$. Any one of the pigmentary skin-diseases.

Parachromophore ( $\left.p a r-a k-r o^{\prime}-m o-f o r\right)$ [ $\pi \alpha \rho a ́$, beside ; $\chi \rho \tilde{\omega} \mu \alpha$, color; $\phi o \rho o ́ s$, bearing]. In biology, applied to chromogenic bacteria that produce the pigment as an excretion-product, but retain it in the organism.

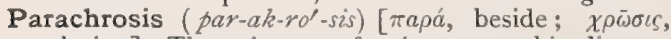
coloring]. The existence of a pigmentary skin-disease.

Parachymosis ( $\left.p a r-a k-i-m o^{\prime}-s i s\right)$ [ $\pi a \rho a ́$, beside; $\chi v \mu b s$, juice]. A morbid state of a secretion or a secreting organ.

Paracinema (par-as-in-e'-mah). Synonym of Dislocation.

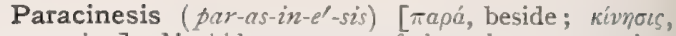
motion]. Morbid movement of the voluntary muscles, arising from a diseased condition of the motor nerves or centers.

Paraclonus ( $\left.p a r-a k^{\prime}-l o-n u s\right)$. Synonym of Paramyoclonus.

Paracmasis (par-ak'-mas-is). Synonym of Paracme.

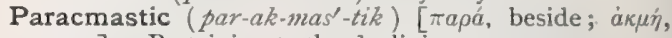
acme]. Pertaining to the declining stage.

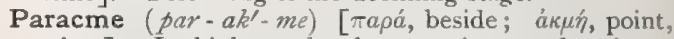
prime]. In biology, the degeneration or decadence of a group of organisms after they have reached their acme of development.

Paracnemion (par-ak-ne'-me-on). Synonym of Fibula.

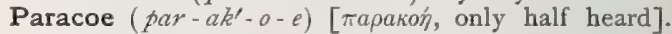
Some perversion of the sense of hearing, in which sounds are not heard distinctly.

Paraccele (par'-as-eेl). See Paracele.

Paraccelia (par-as-e'-le-ah). Same as Paracele.

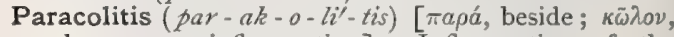

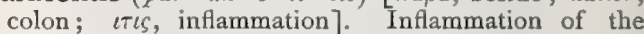
outer coat of the colon.

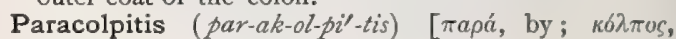
vagina; $\iota \pi \iota$, inflammation]. Inflammation of the connective tissue about the vagina.

Paracondylar, (par-ak-on'-dil-ar) [ $\pi a \rho a ́$, beside : $\kappa b v$ $\delta v \lambda o s$, knuckle; $\varepsilon i \delta o s$, like]. Situated alongside a condyle or a condylar region.

Paracondyloid (par-ak-on'-dil-oid) [ $\pi a \rho a ́$, beside; $\kappa 6 v \delta v \lambda$ s, knuckle; eifos, form]. Adjoining the condyles.

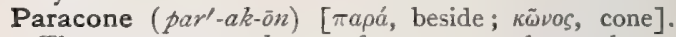
The antero-external cusp of an upper molar tooth.

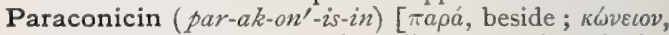
hemlock]. An isomer of coniin, possessing similar physiologic properties.

Paraconid ( $\left.p a r-a k-o^{\prime}-n i d\right)$ [ $\pi \alpha \rho a ́$, beside; $\kappa \tilde{\omega} \nu \circ \varsigma$, cone]. The antero-internal cusp of a lower molar tooth.

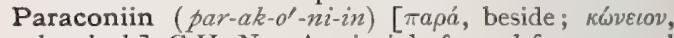
hemlock], $\mathrm{C}_{8} \mathrm{H}_{15} \mathrm{~N}$. A principle formed from normal butyraldehyd and butylidene chlorid upon heating them with alcoholic ammonia. It is a colorless liquid, with a stupefying odor, boiling at $168^{\circ}-170^{\circ} \mathrm{C}$. It is said to have the physiologic properties of coniin, whence the name.

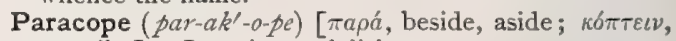
to strike]. Insanity or delirium.

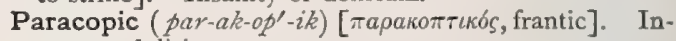
sane or delirious.

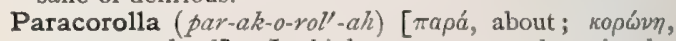
crown, garland]. In biology, an appendage in the throat of the corolla; the crown, as in Narcissus.

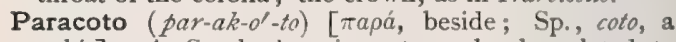
cubit]. A South American tree closely related to Coto. Its bark contains a neutral substance, paracotoin, closely resembling cotoïn, but about half as strong. P. Bark, a variety of bark from Bolivia, of undetermined origin, but much resembling coto. Unof.

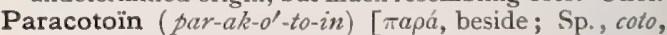
a cubit], $\mathrm{C}_{19} \mathrm{H}_{12} \mathrm{O}_{6}$. An active principle of Paracoto and Paracoto Bark, valuable in cholera. It is similar to, but less active than, cotoin. Dose gr. $1 / 2-j$. Unof.

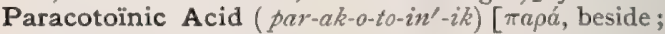
Sp., coto, a cubit], $\mathrm{C}_{19} \mathrm{H}_{12} \mathrm{O}+\mathrm{H}_{22} \mathrm{O}$. An amorphous substance obtained when paracotoin is boiled with potassium hydrate.

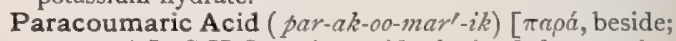
coumarin $], \mathrm{C}_{9} \mathrm{H}_{8} \mathrm{O}_{3}$. An acid obtained by treating aloes with sulphuric acid.

Paracousia, Paracousis ( $a r-a k-00^{\prime}-z e-a h$, par-ak-u sis). See Paracusis.

Paracresotic Acid ( $p a r-a k-r e-s o t^{\prime}-i k$ ). See Acid. 


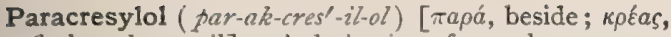
flesh; oleum, oil]. A derivative of cresol.

Paracrusis (par-ak-ru'-sis) [ $\pi a \rho a ́$, beside, aside; roouvetv, to strike]. I. Insanity, delirium. 2. The checking or "driving in" of an eruption or exanthem.

Paracusia, Paracusis ( $p a r-a k-u^{\prime}-z e-a h$, par-ak- $u^{\prime}-s i s$ )

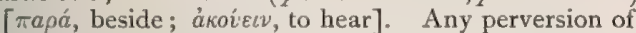
the sense of hearing. P. acris, excessively acute hearing, rendering the person intolerant of sounds. P. duplicata, a condition in which all or only certain sounds are heard double. P. localis, P. loci, Politzer's term for the difficulty in estimating the direction of sounds met with in unilateral deafness, or when the two ears hear unequally. P. obtusa, hardness of hearing. P. perversa, synonym of $P$. zoillisiz. $\mathbf{P}$. willisii. See Deafness, Paradoxic.

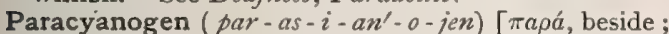

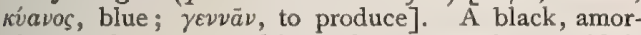
phous substance resulting when mercuric cyanid is heated, with the evolution of cyanogen gas; it is a polymeric form of cyanogen.

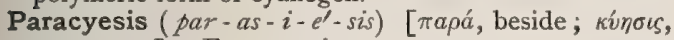
pregnancy]. Extra-uterine pregnancy.

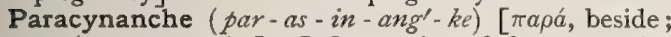
$\kappa v v a ́ \gamma \chi \eta$, cynanche]. Inflammation of the connective tissues about the larynx.

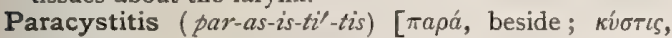
bladder; $\iota \tau \iota s$, inflammation]. Inflammation of the connective tissue that surrounds the bladder.

Paracytic (par-a-si'-tik) [ $\pi \alpha \rho a ́$, beside; kútos, cell]]. Lying among cells.

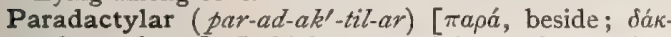
$\tau \imath \lambda o s$, a finger $]$. In biology, pertaining to the paradactylum.

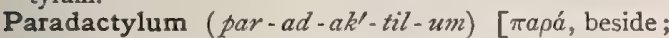

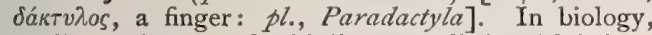
applied to the side of a bird's toe, to distinguish it from the top or sole.

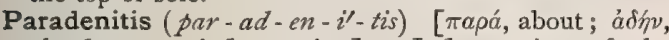
gland; $\iota T / \zeta$, inflammation]. Inflammation of the areolar tissue about a gland.

Paraderm ( $\left.p a r^{\prime}-a d-e r m\right)$ [ $\pi \alpha \rho a ́$, beside ; $\delta \hat{\varepsilon} \rho \mu \alpha$, skin]. In biology, Kupffer's term for a peculiar invagination of the blastoderm of reptilian eggs.

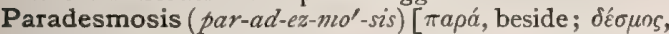
bond]. A disease of the skin characterized by a typical connective-tissue neoplasm.

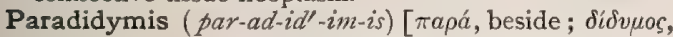
testicle]. The organ of Giraldès; the remains of the urinary part of the Wolffian body of the fetus.

Paradise ( $\left.p a \gamma^{\prime}-a d-i s\right)$ [ $\pi a \rho a ́ \delta \varepsilon \iota \sigma o s$, a park]. I. A park or pleasure-ground. 2. The home of primeval man; the garden of Eden. P., Grains of. See Grains of Paradise. P.-tree, the tree Simaruba glauca, found in America from Florida to Brazil. Its bitter bark is a good tonic. Unof.

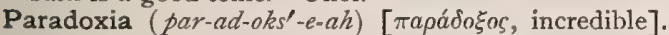
An absurd or contradictory statement or proposition. P. sexualis, sexual excitement occurring independently of the period of the physiologic processes in the generative organs; the abnormal exhibition of sexual instincts in childhood or prior to puberty.

Paradoxic ( $\left.p a r-a d-o k s^{\prime}-i k\right)$ [ $\pi a \rho a ́ d o \xi o s$, incredible]. Of the nature of paradoxia. P.Contraction. See Contraction. P. Deafness. See Deafness. P. Kneejerk. See Reflexes, Table of. P. Muscular Contraction, a slow tonic contraction occurring in a muscle when suddenly relaxed or when its length is suddenly shortened. P. Temperature. See Thermal Ataxia.

Paræsthesia (par-es-the'-ze-ah). See Paresthesia.

Paræsthetic (par-es-thet'-ik). See Paresthetic.
Paraffin (par'-af-in) [parum, little; affinis, related]. I. A white, odorless, translucent, crystalline hydrocarbon obtained from coal-tar, or by the destructive distillation of wood. In a pure state it resembles white wax in physical properties. 2. In chemistry, the term is applied to any member of the paraffin series $\mathrm{C}_{\mathrm{n}} \mathrm{H}_{2 \mathrm{n}+2}$, the lowest representative of which is $\mathrm{CH}_{4}$, methane. In a more limited sense, the high-boiling (beyond $300^{\circ} \mathrm{C}$.) solid hydrocarbons arising from the distillation of the tar obtained from turf, lignite and bituminous shales. Pure paraffins occur as white, translucent, leafy, crystalline masses, soluble in ether and hot alcohol. They melt between $45^{\circ}$ and $70^{\circ} \mathrm{C}$. and are essentially mixtures of hydrocarbons boiling above $300^{\circ} \mathrm{C}$. For Table of Paraffins, see under Hydrocarbons. See also Ethane. P. durum, hard or solid paraffin, a mixture of several of the harder members of the paraffin series of hydrocarbons. It is usually obtained by distillation from shale. P., Liquid, a liquid hydrocarbon of the paraffin series. P. Method, a method of interstitial embedding of tissues, in which there is thorough and complete impregnation of the tissue with the embedding mass. The tissue must be saturated with some fluid with which the paraffin is perfectly miscible, and the fluids usually employed for this purpose are chloroform or turpentine oil. The order of preparation of the tissue is as follows: I. Into 95 per cent. alcohol for from 12 to 24 hours. 2. Into absolute alcohol for from 24 to 48 hours, until complete dehydration has been secured. 3. Into pure chloroform for from 6 to 8 hours, or until the chloroform has replaced the absolute alcohol. 4 . Into a saturated solution of paraffin in chloroform for from 2 to 3 hours. 5. Into pure melted paraffin which has a melting-point of about $50^{\circ} \mathrm{C}$, , and in this the tissue remains until every interstice has been completely filled with the embedding mass and all the chloroform has been drawn off. P. molle, soft paraffin or vaselin. See Vaselin. P.-paper, paper saturated with melted paraffin. P., Scaly, a paraffin that has been resolved into hydrocarbons ranging from heptdecane, $\mathrm{C}_{17} \mathrm{H}_{36}$, to tricosane, $\mathrm{C}_{23} \mathrm{H}_{48}$. P.-treatment. See Diphtheria.

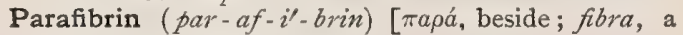
fiber]. A modified fibrin.

Paraflagellate ( $\left.p a r-a f-l a j^{\prime}-e l-\bar{a} t\right)$ [ $\pi \alpha \rho a ́$, beside ; flagellum, a flagellum]. In biology, provided with paraflagella.

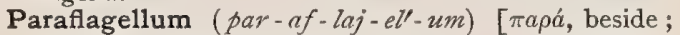
flagellum, a whip: pl., Paraflagella ]. In biology, a small supplementary flagellum.

Paraflocculus ( $p a r-a f-l o k^{\prime}-u$-lus). See Flocculus.

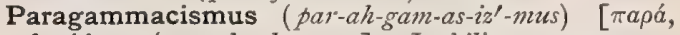
beside; $\gamma a \dot{\mu} \mu \mu$, the letter g]. Inability to pronounce the hard $\mathrm{g}$, and also $\mathrm{k}$, other consonants being substituted, as d or $\mathrm{t}$.

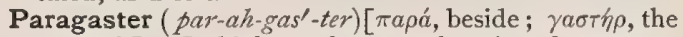
stomach]. In biology, the central cavity of a sponge.

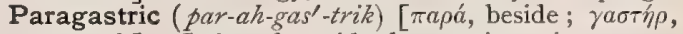
stomach]. Lying alongside the gastric cavity.

Paragastrula ( $\left.p a r-a h-g a s^{\prime}-t r u-l a h\right)$ [ $\pi a \rho a ́$, beside;

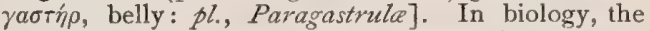
two-layered sac or gastrula formed by the invagination of an amphiblastula.

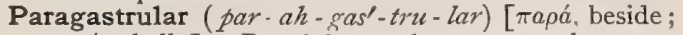

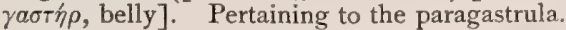

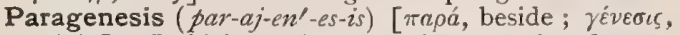
origin]. In biology, the third of Broca's four degrees of fecundity in the union of two species. Cf. Agenesis, Dysgenesis, Eugenesis.

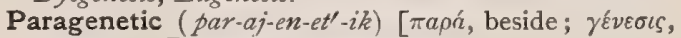
genesis]. Pertaining to paragenesis. 
Parageusia ( $\left.p a r-a g-u \ell^{\prime}-z e-a h\right)$. See Parageusis.

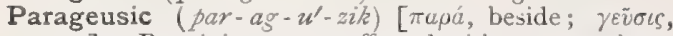
taste]. Pertaining to, or affected with, parageusia.

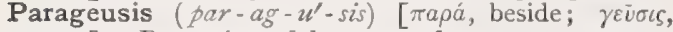
taste]. Perversion of the sense of taste.

Paraglenal ( $\left.p a r-a g-l e^{\prime}-n a l\right) \quad[\pi a \rho a ́$, beside; $\gamma \lambda \eta \dot{\eta} \nu \eta$ the socket of a joint]. In biology, the coracoid of a fish.

Paraglobin (par-ag.lo'-bin). Same as Paraglobulin.

Paraglobularetin ( $\left.p a r-a g-l o b-z-b a r-e t^{\prime}-i n\right)$ [ $\pi a \rho a ́$, beside; globus, a round ball ; ’́viivn, resin $], \mathrm{C}_{12} \mathrm{H}_{16} \mathrm{O}_{4}$. A decomposition-product of globularin obtained when the latter is treated with dilute acids.

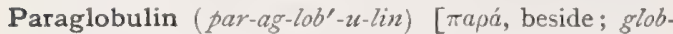
ulus, a little ball]. A native proteid of the globulin class obtained from blood-serum and other fluids of the body. It is called, also, Fibroplastin, Fibrinoplastin, and Serum-globulin. It is precipitated as a white amorphous substance when carbonic acid gas is passed through diluted blood-serum.

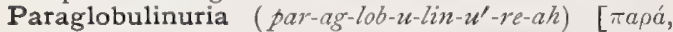
beside; globutus, a little ball; ovpov, urine]. The presence of paraglobulin in the urine.

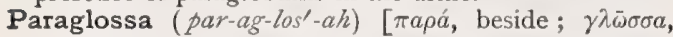
tongue]. Swelling of the tongue. Also an hypertrophy of the tongue, usually congenital. In biology, one of a pair of appendages of the ligula found in many insects on each side of the glossa.

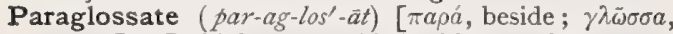
tongue]. In biology, provided with paraglossæ.

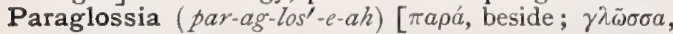
tongue]. Inflammation of the muscles and connective tissues under the tongue.

Paragluconic Acid ( $p a r-a g-l u$-kon'-ik) [ $\pi \alpha \rho a ́$, beside ; $\gamma \lambda v \kappa u ́ s$, sweet]. An isomer of gluconic acid distinguished from the latter by forming with the alkaline metals salts that are crystalline instead of amorphous.

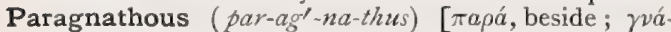
$\theta \circ \varsigma$, jaw]. 1. In biology, having both mandibles of equal length, their tips falling together, as in certain birds. 2. Pertaining to paragnathus.

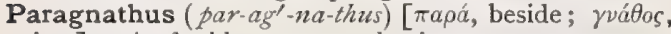
jaw]. A double monster having a supernumerary mandible situated laterally.

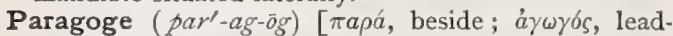
ing]. Reduction of a fracture or luxation.

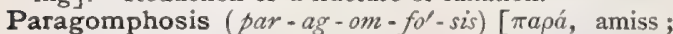

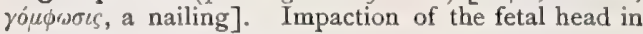
the pelvic canal.

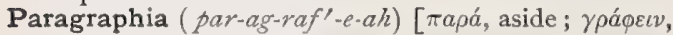
to write]. An aphasic symptom in which there is inability to express words in writing. In literal paragraphia the patient cannot even write the letters of the alphabet; in the verbal form he can write the letters and perhaps some syllables, but not words.

Paraguay Tea. See Mate.

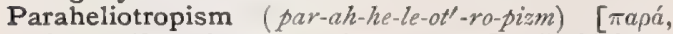

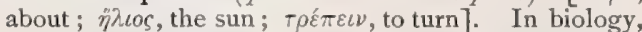
the power possessed by certain leaves of placing their surfaces parallel to the rays of light; diurnal sleep. Cf. Diaheliotropism.

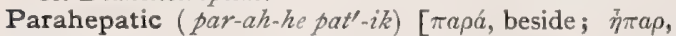
liver]. About or near the liver.

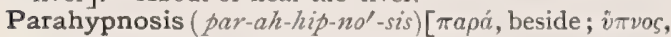
sleep]. Abnormal sleep, like that of hypnotism or of narcosis.

Parakanthosis ( par-ak-an-tho'-sis). See Paracanthosis.

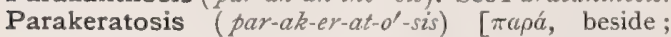
$\kappa \varepsilon \rho a_{\varsigma}$, horn; vбoos, disease]. Any disease of the skin characterized by an abnormal quality of the horny layer. P. variegata, a rare skin-affection characterized by the presence upon the entire surface of the body of a red exanthem leaving small, irregular, sunken patches of normal skin, and giving to the surface a reticulated appearance. The color varies from yellowish-red to bluish-red, and the affected patches are but slightly raised above the surface. Their borders are sharply defined and their surfaces covered with a fine lamellar desquamation under which they appear waxy and bright. There are no subjective symptoms throughout the course of the affection, which is protracted.

Parakinesis ( $a$ ar-ak-in-e'-sis). See Paracinesis.

Parakresol (par-ak-re'-sol). See Kresol.

Paralactic Acid ( $\left.p a r-a l-a k^{\prime}-t i k\right)$. See Acid, Sarcolactic.

Paralalia ( $\left.p a r-a l-a^{\prime}-l e-a h\right) \quad\left[\pi a \rho a ́\right.$, beside; $\lambda a \lambda \iota a^{\prime}$, speech]. I. Inability of correct verbal expression, without loss of the power of thought. 2. A term embracing all abnormalities of speech, from trivial mannerisms to difficulties in the utterance of certain letters, including those painful defects depending upon physical malformations.

Paralambdacism, Paralambdacismus (par-al-am'.

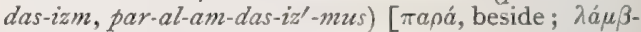
$\delta a$, the letter $\lambda]$. Inability to pronounce the letter 1 , or the substitution of other consonants as $t, r, s$, w for 1 .

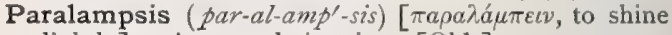
slightly]. A corneal cicatrix. [Old.]

Paralbumin ( $\left.p a r-a l^{\prime}-b u-\min \right)$ [ $\pi a \rho a ́$, beside; albumen, white of egg]. This and metalbumin are two proteid substances found by Scherer in ovarian cysts. They also occur in the ascitic fluid.

Paraldehyd ( $p a r-a l^{\prime}-d e-h \bar{\imath} d$ ) [ [ $a \rho a \dot{a}$, beside; aldehyd], $\mathrm{C}_{6} \mathrm{H}_{12} \mathrm{O}_{3}$. A polymeric form of aldehyd. It is a colorless liquid of repulsive odor and unpleasant taste. It is a powerful hypnotic, and is diuretic. It is valuable in delirium tremens, mania, tetanus, and other nervous affections. P.-habit, morbid addiction to the use of paraldehyd. The following symptoms may be present: Emaciation, anemia, weakness and irregularity of the action of the heart, intermittence and softness of the pulse, palpitation, gastric derangement, costiveness, boulimia, general muscular weakness, general tremulousness, especially in the tongue, facial muscles, and hands, feebleness and unsteadiness of gait, general restlessness, paresthesia, insomnia, mental anxiety and agitation, discontent, unreasonableness, mental confusion, mental excitement, temporary loss of memory, incoherence of speech, hallucinations, delusions. The odor of paraldehyd may be appreciable in the breath.

Paraldol (par-al'-lol) [ $\pi a \rho a ́$, beside ; aldehyd ], $\left(\mathrm{C}_{4} \mathrm{H}_{8}\right.$ $\left.\mathrm{O}_{2}\right)_{\mathrm{n}}$. A polymer of aldol that melts at between $80^{\circ}$ and $90^{\circ} \mathrm{C}$.

Paraleipsis ( $\left.p a r-a l-i p^{\prime}-s i s\right)$ [ $\pi a \rho a ́$, beside; án $\varepsilon \iota \phi \varepsilon i ̄ v$, to anoint]. A disorder of the sebaceous secretion.

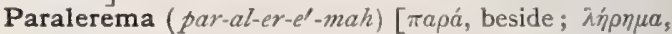
utterance]. Delirium, or delirious utterance.

Paraleresis (par-al-er-é-sis) [ $\pi \alpha \rho \dot{a}$, beside; $\lambda \dot{\eta} \rho \eta \sigma \iota$, speech]. Delirium, or moderate mental disturbance.

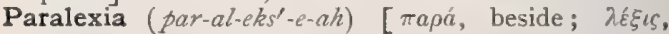
(reading) speech]. A form of aphasia characterized by transposition or substitution of words or syllables in reading.

Paralgesia, Paralgesis ( $p a r-a l-j e^{\prime}-z e-a h$, par-al-je'-sis) [ $\pi$ apú, beside; $\ddot{\alpha} \lambda$ yos, pain]. Anesthesia or analgesia.

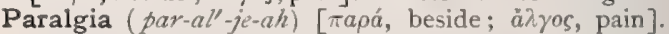
Any perverted and disagreeable cutaneous sensation, as of formication, cold, burning, etc.

Paralinin ( $\left.p a)^{\prime}-a l-i^{\prime}-n i n\right)$ [ $\pi a \rho a$, beside; linin, parachromatin]. In biology, the nuclear sap or matrix, a proteid of the globulin class, similar to those found in the cell-protoplasm. Cf. Paramitom, Paraplasm.

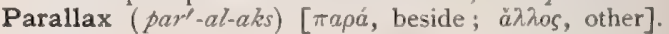
The apparent displacement of an object by a change 
in the position of the observer, or by looking at it alternately with one eye, then with the other ; in the latter case the object seems to move. P., Binocular, the angle of convergence of the visual axes. P., Mental, a slight personal equation in observation due to one's standpoint. See Equation, Personal.

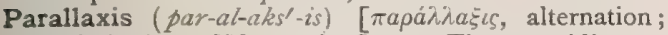
$\pi \alpha \rho a ́$, beside; $a \lambda \lambda o s$, other]. I. The overriding or overlapping of the ends of a fractured bone. 2. Confusion of mind; mental aberration. P., Crossed. Synonym of $P$., Heteronymious. P., Heteronymous, the apparent shifting of an object toward the side of the covered eye. P., Homonymous, the movement of the object toward the side of the uncovered eye.

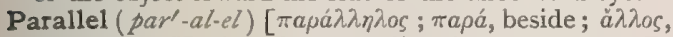
another]. Having the same direction or course. P. Fissure. See Fissures, Table of.

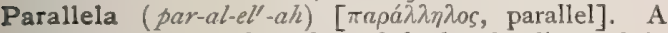
scaly eruption on the palms of the hands, disposed in parallel lines.

Parallelism (par-al-el-izm). See Isopathy.

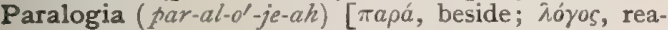
son]. Difficulty in thinking logically. P., Thematic, a condition in which the thought is unduly concentrated on one subject. It characterizes the individual with a hobby.

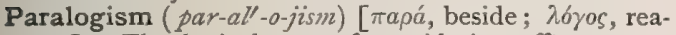
son]. The logical error of considering effects or unrelated phenomena as the causes of a condition.

Paralysant (par-al-i'-zant). See Paralyzant.

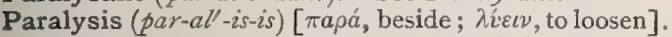
A complete loss or great diminution of the power of motion in one or in a number of muscles, or of sensation in a part, or of both motion and sensation. P., Acute Ascending, Landry's Paralysis; palsy beginning in the feet and ascending to the other muscles of the body, and finally involving the medulla. There is no pain, and no trophic changes; the knee-jerk is usually diminished; the sphincters are uninvolved. The pathology is obscure, and the malady is a very fatal one, usually terminating in death within a week, although it may continue for three or four weeks. Males are more frequently attacked than females, and the affection occurs chiefly between the ages of twenty and forty. See also Landry's Paralysis, and Diseases, Table of. P., Acute Atrophic. See P., Infantile. P., Acute Progressive. Synonym of P., Acute Ascending. P. agitans, Shaking Palsy, Parkinson's Disease; an affection marked by tremor or alternate contraction and relaxation of the muscles of the part involved. The movements are regular and rhythmic (distinction from insular sclerosis), and begin usually in one hand. They almost never affect the head. They persist during rest and are little influenced by voluntary movement. Later in the disease there is a typical gait, known as festination or propulsion. It consists in a progressive increase in the rapidity of the gait until the patient breaks into a run, which grows faster and faster until he either falls or seizes some support. This peculiar gait is ascribed to the bent position of the trunk which throws the head so far forward as to bring the center of gravity beyond the line of the feet. Rarely the movement is backward; this is called retropulsion. It may be to one or the other side-lateropulsion. The speech is slow, monotonous and high-pitched. The face is fixed and expressionless. In advanced stages there is an almost statue-like rigidity of the body. The hand assumes a peculiar position, as if rolling a small body between the thumb and the fingers, but later the position becomes constant, similar to that in which the pen is held-hence the term of writing hand. The knee-jerk may be exaggerated. Flushing and heat are sometimes complained of. The course is of long duration, the disease at times lasting twenty or thirty years. The lesion is probably a diffuse sclerosis of the brain and spinal cord. Paralysis agitans is most common in males over forty years of age. P., Alcoholic, a multiple neuritis due to alcohol. See Neuritis, Multiple. P., Alternate. See Hemiplegia. P., Analgesic, with Whitlow. See Morvan's Disease. P., Anapeiratic. See Fatigue-diseases, and Professional Neuroses. P., Angeioneurotic (of the auditory nerve), a disturbance of the circulation in the internal ear characterized by sudden pallor of the face, nausea, tinnitus aurium, partial deafness, and vertigo, the symptoms disappearing rapidly. P., Anterospinal. Synonym of Poliomyelitis, Anterior. P., Arsenical, a paralysis due to a multiple neuritis caused by arsenical poisoning. P., Association. Synonym of P., Glosso-labio-laryngeal. P., Atrophic (of children). Synonym of P., Infantile. P., Atrophic, Infantile. Synonym of P., Infantile. P., Atrophic, Spinal. See P., Infantile. P., Bell's, a paralysis of the facial muscles arising from a lesion of the seventh, or facial nerve. This lesion may be on the face, in the temporal bone, or within the skull. Very rarely the affection is bilateral. P., Brachial, a paralysis of one or both arms. It may be due to a lesion of the brain-cortex, the spinal cord, or the nerves of the brachial plexus or their roots. P., Brown-Séquard's. See Diseases, Table of. P., Bulbar, Glossolabio-laryngeal paralysis; a form of paralysis due to a degeneration of the nuclei of origin of the nerves (facial, glosso-pharyngeal, vagus, spinal accessory, and hypoglossal) arising in the oblongata. At first only the muscles of the lips, tongue, and pharynx are affected. The disease is marked by difficulty in mastication, deglutition, respiration, phonation, and articulalation, and by wasting of the muscles concerned in the performance of these functions. The condition is sometimes a sequel to exposure to severe cold; it may be caused by morbid growths or by syphilis. It is usually confined to the latter half of life, and its prognosis is bad. P., Caisson. Synonym of Caissondisease. P., Central, a paralysis due to a brain-lesion. P., Centro-capsular, a paralysis due to a lesion of the internal capsule. P., Centrocortical, one caused by a lesion of the cerebral cortex. P., Cerebral, a paralysis due to a brain-lesion. P., Cerebral Infantile, P., Cerebral (of childhood), a spastic paralysis of children due to a lesion of the brain. It is often caused by the use of the forceps at birth. P., Cortical, a paralysis due to a lesion of the cerebral cortex; it is usually a monoplegia or a hemiplegia. P., Crossed : I. A paralysis of the arm and leg of one side, associated with either a facial paralysis or a paralysis of the oculo-motor nerve of the opposite side, due to a lesion involving the pyramidal tracts of the side before they have crossed in the medulla, and a cranial nerve, e.g., the third, the sixth, or the seventh, after its fibers of origin have decussated. 2. Paralysis of the arm on one side and of the leg on the other. P. cruciata. Synonym of P., Crossed. P., Crutch. See Crutch-paralysis. P., Cruveilhier's, progressive muscular atrophy. P., Dental, anterior poliomyelitis occurring in teething children, formerly attributed to disturbed dentition. P., Diphtheric, a form sometimes occurring in patients convalescent from diphtheria. It is primarily a multiple neuritis caused by the toxin of diphtheria. P., Divers'. See Caisson-disease. P., Duchenne's. See Duchenne's Disease in Diseases, Table of. P., Emotional, a hysteric paralysis due to emotional excitement. P., Erb's. See Erb, and Diseases, 
Table of. P., Essential. See P., Infantite. P., Exhaustion, a functional paralysis due to exhaustion of the nerve-centers by overwork. P., Facial, a paralysis of the muscles of the face, usually of one side only. It may be peripheral or central. P. festinans. Synonym of P. agitans. P., Galloping, a swiftly destructive form of general paralysis. P., General (of the Insane), General Paresis; Paralytic Dementia: Paretic Dementia; Progressive Paralysis of the Insane; an organic disease of the brain, characterized by progressive loss of power and by a deterioration of the mental faculties, ending eventually in dementia and death. In the early stages of the disease there are fibrillar tremblings, especially of the tongue and face. Speech is early disturbed. The disease is often associated with posterior spinal sclerosis. In cases presenting this type the knee-jerk is absent. The pupils very early show changes; they may be unequal, irregular in outline, myotic, or may present the Argyll-Robertson phenomenon. Death may result from epileptiform or apoplectiform seizures or from general exhaustion. The affection is most common in males between the ages of thirty and sixty. It is induced by overwork and mental and physical strain, intemperance, syphilis, and lead-poisoning. The lesion is essentially a meningo-encephalitis, with thickening of the cerebral meninges and wasting of the cortical substance. P., General Spinal, Sub. acute and Chronic Atrophic Spinal Paralysis; Subacute and Chronic Anterior Poliomyelitis; Progressive Muscular Atrophy; Wasting Palsy; Chronic Spinal Muscular Atrophy, Amyotrophic Lateral Sclerosis; a chronic disease of the spinal cord, characterized by paralysis followed by atrophy involving first the lower and then the upper extremities. It is due to an atrophy of the ganglionic cells in the anterior gray matter of the cord. The causes of the disease are obscure; it usually occurs between the ages of thirty and fifty. P., Glosso-labio-laryngeal, P., Glosso-labio-pharyngeal, P., Glosso-laryngeal, P., Glosso-pharyngeal. See P., Bulbar. P., Glossoplegic. Synonym of Glossoplegia. P., Gubler's. See Gubler. P., Hemiplegic. See Hemiplegia. P., Hysteric, a paralysis occurring in hysteric subjects and simulating organic disease. It is usually accompanied by impairment or loss of sensation, by peculiar contractions, and the other hysteric stigmata. P., Idiopathic. Synonym of Tetany. P., Indian-bow, paralysis of the thyro-arytenoid muscles. P., Infantile, Acute Anterior Poliomyelitis; Acute Atrophic Paralysis; Atrophic Spinal Paralysis; Essential Paralysis; a disease peculiar to childhood, and characterized by sudden paralysis of one or more limbs or of individual muscle-groups, and followed by rapid wasting of the affected parts, with reaction of degeneration and deformity. It is most common in the first year, and during the warm months. It may be produced by traumatism, exposure to cold, or may follow an exanthem. The tendency is now to consider it infectious. The paralysis is due to changes in the anterior cornua of the gray matter of the spinal cord, with degeneration of the multipolar cells and gradual disappearance of their processes. In accordance with the occurrence of these changes in the lumbar or cervical region the legs or arms are affected. P., Infantile Spastic. See $P$., Cerebral (of childhood). P., Intermittent, a form due to malarial poisoning. P., Intra-peduncular, one involving the muscles of the eye in consequence of a lesion situated between the crura cerebri. P., Ischemic, paralysis of a part due to cutting off of the circulation, e.g., paralysis of the lower limb follow- ing embolism or thrombosis of the femoral artery. P., Klumpke's, an atrophic paralysis of the interossei and thenar and hypothenar muscles, with anes. thesia of the forearm and fingers and contracted pupils. The lesion is probably in the spinal cord, at the level of the first and second thoracic nerve-roots. P., Labio-glosso-laryngeal. See $P$., Bulbar. P., Landry's. Same as $P$., Acute Ascending. P., Laryngeal, a paralysis usually peripheral, of one or more laryngeal muscles, on one or on both sides. P., Lead, a paralysis usually of the extensors of the wrist, causing wrist-drop. It is nearly always bilateral and is due to a peripheral neuritis induced by lead-poisoning. P., Lenticular, one resembling bulbar paralysis, due to hemorrhage into the lenticular nucleus of each side. P., Lingual. Synonym of Glossoplegia. P., Little's. Synonym of P.; Infantile. P., Local, one confined to a single muscle or group of muscles. P., Masticatory, paralysis of one or more of the muscles supplied by the motor trunk of the trigeminal nerve. P., Mimetic, a feigned palsy. P., Motor, paralysis of the voluntary muscles. P., Musculo-spiral, paralysis of the extensors and supinators of the wrist, due to an injury or to inflammation of the musculo-spiral nerve. P., Myogenic. See P., Infantile. P., Myopathic, palsy due to primary disease of the muscles. P., Neural, paralysis due to peripheral neuritis. $\mathbf{P}$. notariorum. See Writers' Cramp. P., Nuclear, one due to a lesion of the nuclei of origin of a cranial nerve. $\mathbf{P} ., \mathrm{Ob}$ stetric, any paralysis of the child resulting from injuries received during delivery. P., Occupation. See Occupation-neurosis. P., Organic, one due to a structural lesion in the nervous system or in the muscles, as opposed to functional. P., Painters'. Synonym of $P_{\text {. }}$, Lead. P., Paraplegic. See Paraplegia. P., Periodic, a non-febrile paralysis of the arms and legs or neck and pharynx occurring in periodic attacks of short duration. P., Peripheral, loss of power due to a lesion of the nervous motor mechanism between the nuclei of origin and the peripheral termination, as distinguished from loss of power due to a lesion between the cortical centers and (including) the nuclei. P., Phonetic, P., Phonic, laryngeal paralysis in which the tensors and adductors of the vocal bands are involved. P., Phosphoric, a paralysis brought about by poisoning with phosphorus. P., Post-febrile, a so-called functional paralysis sometimes occurring during convalescence from certain fevers. P., Pressure, paralysis of a group of muscles supplied by a nerve which has been subjected to prolonged pressure. P. procursoria. Synonym of $P$. agitans. P., Progressive Bulbar. See $P$., Bulbar. P., Pseudo(of rickets). See $P$., Rachitic Pseudo-, P., Pseudobulbar, a symmetric lesion of the halves of the cerebrum producing paralysis of the lips, the tongue, and the larynx or the pharynx. P., Pseudohypertrophic, Lipomatous Muscular Atrophy; Duchenne's Paralysis; a chronic disease characterized by progressive muscular weakness, associated with an apparent hypertrophy of the affected muscles. There is an interstitial fibrous overgrowth of the muscles, frequently accompanied by an accumulation of fat and atrophy of the true muscle-fibers. The disease usually begins in the muscles of the calf, and spreads over the body, the muscles of the hand almost al ways escaping. There is marked lordosis and a characteristic gait with wide separation of the legs and swaying of the body from side to side. The characteristic symptom is the manner in which the patient arises from the floor-he "climbs" up on his legs, on account of the weakened state of the extensor muscles 
of the back. The disease is essentially a chronic one, but the patient becomes absolutely helpless long before death. It is most common in young male children usually under ten years of age. The disease is entirely myopathic, no adequate nerve-lesion having as yet been discovered. P., Puerperal, the paralysis following labor. It may be due to traumatism during delivery, to pressure by the uterus, or from displacement of the pelvic organs, to puerperal sepsis, to phlebitis and phlegmasia alba dolens (these are really septic causes). These causes usually induce inflammation of the lumbar and sacral nerves. There may, however, be myelitis from puerperal septic infection. P., Rachitic Pseudo-, the motor weak ness observed in the lower limbs of marked cases of rickets. There is no true paralysis, the condition being due to changes in the ligaments, softening of the bones, and weakness of the muscles. P., Radial.

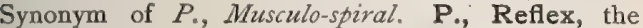
paralysis which sometimes follows immediately upon a wound of a nerve, or the paraplegia that is sometimes due to irritation of an adherent prepuce. Other so-called reflex palsies, as that from renal calculus, are probably due to secondary changes in the spinal cord

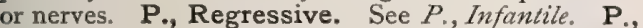
Rheumatic, a paralysis from peripheral neuritis the cause of which is apparently exposure to cold, e. g., in some cases of facial paralysis. P., Saturnine. Synonym of P., Lead. P., Scrivener's. Synonym of Cramp, Writers'. P., Segmental, a paralysis of a segment of a limb produced by hypnotism. P., Sensory, anesthesia. P., Sleep, paralysis of the musculo-spiral nerve from pressure upon it during sleep. P., Spastic, a paralysis associated with rigidity of the muscles and heightened tendon-reflexes. P., Spastic Spinal. Synonym of Lateral Sclerosis. P., Telegraphers', an anapeiratic paralysis sometimes seen in telegraphoperators. P., Toxemic, one due to the presence of a poison in the blood. P., Toxic, a paralysis due to the influence of a mineral or organic poison on some part of the nervous system. P. vacillans. Synonym of Chorea. P., Vasomotor, a paralysis of the vasomotor center or the vasomotor nerves; it leads to dilatation of the blood-vessels. P. venenata. Synonym of $P$., Toxic. P., Writers', paralysis with incoördination of the muscles of the wrist and fingers from overuse.

Paralysma mesentericum. Synonym of Tabes mesenterica.

Paralytic (par-al-it’-ik) [ $\pi a \rho a ́ \lambda v \sigma \iota \varsigma$, paralysis]. Having the nature of paralysis. Affected with paralysis. Also, a person suffering from paralysis; also, one suffering from general paralysis of the insane. P. Chorea, a local choreiform spasm connected with a cerebral hemiplegia or monoplegia. It may precede or follow the onset of the paralysis of the limb. P. dementia. See Paralysis, General (of the Insane). P. Strabismus. See Strabismus. P. Theory of Inflammation. See Theory.

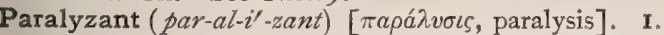
Effecting or causing paralysis. 2. An agent or drug that induces paralysis, P., Motor, a drug paralyzing any part of the motor apparatus; the motor cells of the spinal cord, the motor nerves, or the muscles.

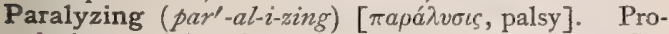
ducing or giving rise to paralysis. P. Vertigo. See Gerlier's Disease

Param (par'-am), $\mathrm{C}_{2} \mathrm{~N}_{4} \mathrm{H}_{4}$. A substance produced by the evaporation of the aqueous solution of cyanamid. It crystallizes in leaflets that melt at $205^{\circ} \mathrm{C}$. ; it is insoluble in ether.

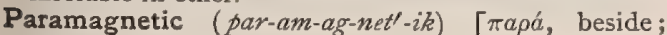

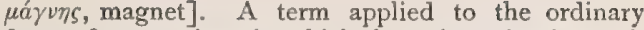
form of magnetism, in which the orientation is north and south, in distinction from diamagnetism.

Paramagnetism (par-am-ag'-net-izm) [ $\pi a \rho a ́$, beside ; $\mu a ́ \gamma \nu \eta s$, magnet]. The phenomena exhibited by paramagnetic substances.

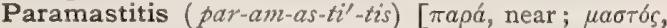
mamma; $\iota \tau \ell \zeta$, inflammation]. Inflammation of the connective tissue about the mammæ.

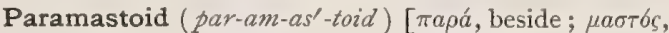
nipple; $\varepsilon i \delta o s$, like]. I. Situated near the mastoid process. 2. The jugular process of the occipital bone,

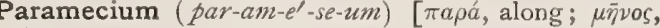
length: $p l$., Paramecia $]$. A longitudinal fissure.

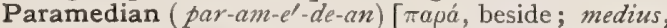
middle]. Situated near the median line. P. Sulcus, a fissure present in the cervical portion of the spinal cord, not far from the posterior median fissure, and separating the column of Goll from the funiculus cuneatus.

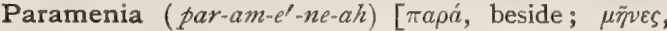
menses]. Difficult or disordered menstruation.

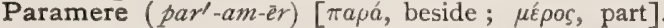
In biology: $(a)$ one of the radial sections composing the body of certain Medusa. (b) Any one of a set of radiated parts. (c) Either half of a bilaterally symmetric organism or somite.

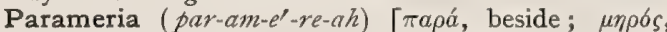
thigh]. The inner surfaces of the thighs.

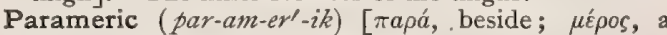
part]. Pertaining to a paramere.

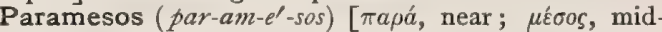
dle]. Synonym of Ring-finger.

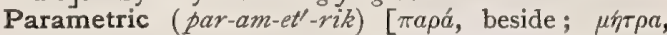
uterus]. Pertaining to the tissues about the uterus.

Parametritic (par-am-et-rit'-ik) [ $\pi a \rho a ́$, beside; $\mu \eta \eta \tau a$, uterus; $\iota \tau \iota s$, inflammation]. Relating to, of the nature of, or affected with, parametritis.

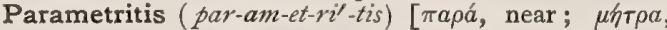
womb; $\iota \tau \iota s$, inflammation]. Pelvic Cellulitis; inflammation of the cellular tissue about the uterus. It is usually due to injury to the cervix and vagina during labor, but may also follow abortion and plastic operations on the cervix. It is marked by pelvic pain, with fever. Suppuration is very prone to take place. The abscess usually points in the inguinal region, but it may point in the thigh, or form a perinephric abscess; it may open into the bowel, bladder, or vagina, or burrow back to the side of the sacrum, or out upon the surface near the trochanter.

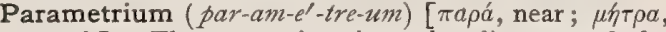
womb]. The connective tissue that lies around the uterus.

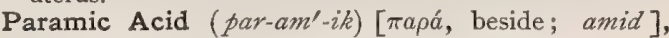
$\mathrm{C}_{12} \mathrm{H}_{5} \mathrm{~N}_{3} \mathrm{O}_{7}$. A crystalline substance obtained when paramid is treated with ammonium and precipitated with hydrochloric acid.

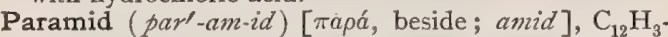
$\mathrm{N}_{3} \mathrm{O}_{6}$. Mellimid; an amid of mellitic acid, produced by the dry distillation of ammonium mellitate. It is a white, amorphous powder, insoluble in water and alcohol.

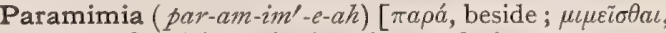
to mimic]. The aphasic misuse of signs or pantomime.

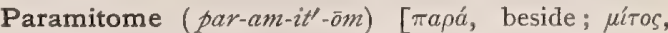
thread]. In biology, Fleming's term for the more fluid portions of the cell-substance, contained in the protoplasmic reticulum. Cf, Paralinin, Paraplasm.

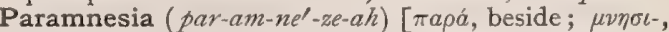
only used in comp., remembering, from $\mu \iota \nu \nu \eta \tilde{\sigma \kappa \varepsilon \iota \nu, ~ t o ~}$ remind]. The name given by $\mathrm{A}$. Lalande to the very 
common illusion of feeling as if one had already undergone the experience which may be passing, already been with just such people, in just such place, saying just such things, etc. The recognition of the situation sometimes goes so far as to lead to a correct expectation of what the next following details are to be. The phenomenon is too wide-spread to be considered pathologic. It is exhibited by both sexes, and all ages and temperaments, in about 30 per cent. of persons interrogated. The explanation is based upon subliminal or "unconscious" telepathic perception, i.e., a double perception, unconscious at first, then conscious.

Paramonobromacetanilid (par-am-o-no-bro-mas-et$\left.a n^{\prime}-i l-i d\right)$. See Antisepsin.

Paramorphia ( $\left.p a r-a n-o r^{\prime}-f e-a h\right)[\pi \alpha \rho a ́$, beside; $\mu \alpha \rho \phi \eta ́ n$, form]. Abnormality of form.

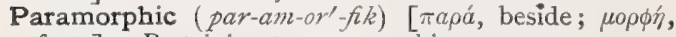
form]. Pertaining to paramorphism.

Paramorphin ( $\left.p a r-a m-o{ }^{\prime}-f n\right)$. See Thebain.

Paramorphism (par-am-orf'-izm) [ $\pi a \rho a ́$, beside; $\mu о \rho \phi \eta \dot{n}$, form]. In chemistry, a variety of pseudomorphism in which there is a change of molecular structure without alteration of external form or chemic constitution.

Paramorphosis (par-am-or-fo'-sis) [ $\pi a \rho a ́$, beside ; $\mu о \rho \phi \dot{\eta}$, form]. Same as Paranorphism.

Paramucic Acid (par-am-ut-sik) [ $\pi \alpha \rho a ́$, beside; $m u$ cus, mucus ], $\mathrm{C}_{6} \mathrm{H}_{10} \mathrm{O}_{8^{*}}$. An isomer of mucic acid, occurring in rectangular crystals.

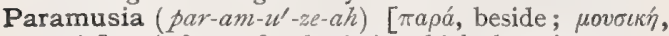
music]. A form of aphasia in which there is perver sion of the musical sense, resulting in the production of improper notes and intervals.

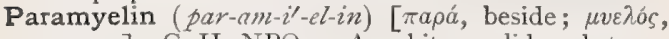
marrow], $\mathrm{C}_{38} \mathrm{H}_{75} \mathrm{NPO}_{9}$. A white, solid substance obtainable from brain-substance and nerve-substance. Other analogous bodies are spoken of as paramyelins.

Paramylum (par-am'-il-um) [ $\pi \alpha \rho a ́$, beside; amylum, starch ], $\mathrm{C}_{6} \mathrm{H}_{10} \mathrm{O}_{5}$. Zoöamylum; a carbohydrate occurring in the infusorian, Euglena viridis, and in all gregarinæ, in the form of granules resembling starch. It is not colored by iodin. See Carbohydrates, Table of.

Paramyoclonus ( $\left.p a-r a h-m i-o k^{\prime}-l o-n u s\right)$ [ $\pi a \rho a ́$, beside;

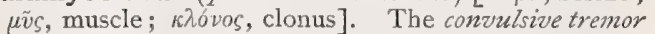
of Friedreich; a functional neurosis marked by the sudden shock-like character of the muscular contractions, their bilateral symmetry, and the freedom of the extremities. There is no ataxia, paralysis, or anesthesia; electric irritability is normal; consciousness is unimpaired; the convulsive movements are usually in abeyance during sleep. The disease generally occurs in males, and manifests itself both in children and in adults. It is supposed to be caused by fright or physical overstrain. P. multiplex, an affection characterized by clonic contractions, chiefly of the muscles of the extremities, occurring either constantly or in paroxysms. It occurs usually in males, and follows emotional disturbance, fright, or straining. The contractions are usually bilateral, and may vary from fifty to one hundred and fifty per minute.

Paramyosinogen (par-am-i-o-sin'-o-jen) [ $\pi \alpha \rho a ́$, beside; $\mu \bar{v} s$, muscle]. Musculin; one of the proteids of muscle-plasma. It coagulates at $47^{\circ} \mathrm{C}$. See Muscleplasma.

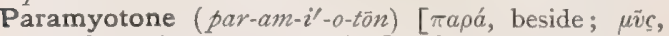
muscle; tovos, tone, tension]. See Paramyotonia. P., Ataxic, a disease much resembling myotonia congenita, but not hereditary.

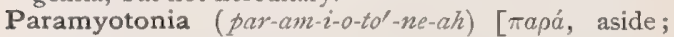
$\mu \tilde{v} \varsigma$, muscle; towos, tone]. Any perversion of muscular tonicity, with liability to spasm on small provo- cation. P. congenita, a rare and obscure family affection, allied to Thomsen's Disease, and by some regarded as identical with it. The chief symptom is tonic spasm, lasting from I5 minutes to several hours, affecting principally the facial muscles, but also those of the extremities; it is directly excited by cold and allayed by warmth.

Paramyotonus (par-am-i-ot'-o-nus). See Paramyotonia.

Paranema (par-an-e'-mah). Same as Paraphysis.

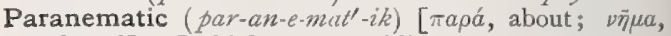
a thread]. In biology, resembling a paranema.

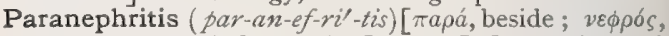
kidney; $\iota \tau \iota$, inflammation $]$. I. Inflammation of the paranephros, or supra-renal capsule. 2. Inflammation of the connective tissue about the kidney.

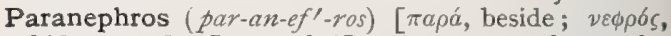
kidney: pl., Paranephri]. A supra-renal capsule, or adrenal.

Paraneurismus ( $\left.p a r-a n-u-r i z^{\prime}-m u s\right)[\pi a \rho a ́$, beside ; $\nu \varepsilon \tilde{v} \rho o v$, nerve]. A nervous disorder, or perversion of nerve-function.

Parangi (par-an'-je). See Frambesia.

Parancea (par-an-e'-ah). See Paranoia.

Paranoia ( $\left.p a r-a n-o i^{\prime}-a h\right)$ [ $\pi a \rho a ́$, beside ; vóos, mind]. Primary monomania; a mental disease characterized by systematized delusions. Heredity usually plays an important rôle.

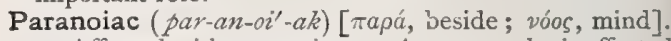
I. Affected with paranoia. 2. A person who is affected with paranoia ; a "crank."

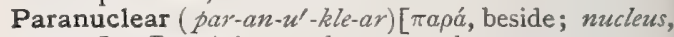
a nut]. Pertaining to the paranucleus.

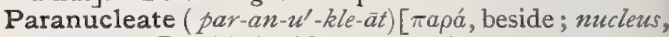
kernel]. Provided with a paranucleus.

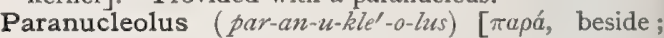
nucleolus, dim. of nucleus, kernel]. The smaller of the nucleoli in a nucleus; also, a synonym of Pseudomucleolus.

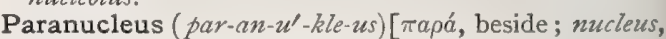
kernel]. A part extruded from the nucleus of the spore-mother-cell, in the zoösphores of algæ, just before division. See Polar Globules.

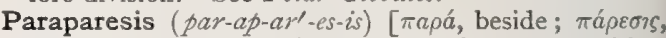
paresis]. Partial loss of power in the lower extremities. Paraparetic ( $\left.p a r-a p-a r-e t^{\prime}-i k\right)$ [ $\pi a \rho a ́$, beside; $\pi a ́ \rho \varepsilon \sigma \iota \zeta$, paresis]. Pertaining to, or affected with, paraparesis.

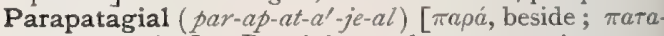
yeiov, a stripe]. Pertaining to the parapatagium.

Parapatagium ( $\left.p a r-a p-a t-a^{\prime}-j e-u m\right)$ [ $\pi a \rho a ́$, beside; $\pi a-$ $\tau a \gamma \varepsilon i o v$, a stripe, border: $p l$., Parapatagia ]. In biology, the fold of skin between the neck and the shoulder of a bird.

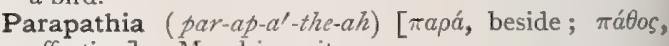
affection]. Moral insanity.

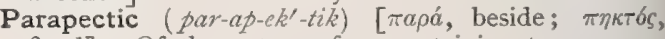
fixed]. Of the nature of, or pertaining to, parapectin. P. Acid, $\mathrm{C}_{24} \mathrm{H}_{34} \mathrm{O}_{23}$, a body derived from pectose during the ripening of fruits.

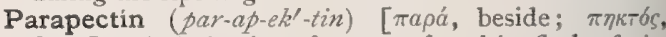
fixed]. A derivative of pectose found in fleshy fruits during the process of ripening.

Parapeptone (par-ap-ep'-ton). See Peptone,

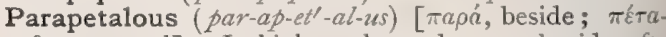
$\lambda_{0 v}$, a petal]. In biology, located on each side of $\varepsilon$ petal. Cf. Antipetalous.

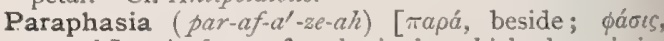
speech]. A form of aphasia in which there is inability to connect ideas with the proper words to ex. press the ideas; conduction-aphasia.

Paraphenetolcarbamid (par-af-en-et-ol-kar'-bam-id). See Dulin. 


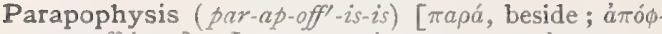
vors, offshoot]. In comparative anatomy, the process homologous to the lower transverse process of a vertebra.

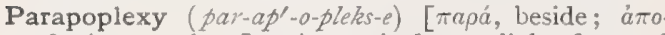
$\pi \lambda \eta \xi^{\prime} i a$, apoplexy]. A masked or slight form of apoplexy

Paraproctitis (par-aṕ-rok-ti'-tis) [ $[\pi a \rho a ́$, beside; $\pi \rho \omega k-$ Tós, anus ; $\iota \tau \iota \zeta$, inflammation]. Inflammation of the connective tissue about the rectum.

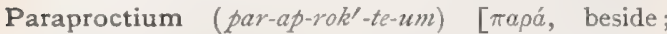
זpwktós, anus]. The connective tissue that surrounds the rectum.

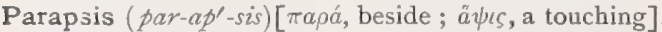
A perverted condition of the sense of touch.

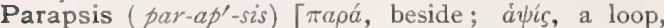
wheel: pl., Parapsi]. In biology, MacLeay's name for the lateral portion of the mesoscutum of the thorax when separate from the dorsal portion; the plaga scapu lares of Haliday and the scapule of Thomson.

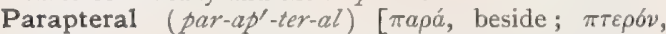
wing. ] Pertaining to the parapterum.

Parapteron (par-aṕt-ter-on). Same as Parapterum.

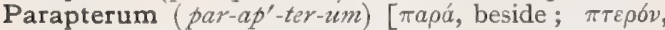
wing: pl., Paraptera]. In biology: (a) The third of the three sclerites into which each lateral segment of each thoracic segment of an insect is divisible; $(b)$ the scapular feathers of a bird's wing.

Paraqueduct ( $\left.p a r-a k^{\prime}-w e-d u k t\right)$ [ $\pi a \rho a ́$, beside; auza, water; ducere, to lead]. The lateral division of the mesocele in the brain of birds and frogs, serially homologous with the paracele or lateral ventricle.

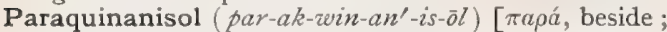
quinanisol ], $\mathrm{C}_{10} \mathrm{H}_{9} \mathrm{NO}$. An artificial alkaloid possessing antipyretic properties.

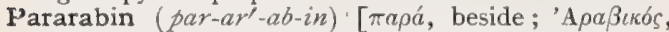
Arabic]. A constituent of sugar-beet. Boiling with alkalies converts it into arabic acid.

Pararectal (par-ar-ek'-tal) [ $\pi a \rho a ́$, beside; rectum, rectum]. Beside or near the rectum. P. Pouch a peritoneal depression behind the broad ligament and beside the rectum.

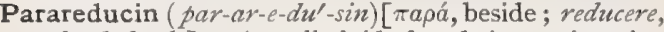
to lead back]. An alkaloid found in conjunction with reducin in the urine.

Pararhotacism (par-ar-o'-tas-izm). See Rhotacism.

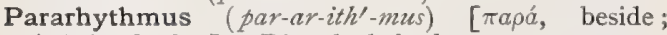
$\hat{\rho} \cup \theta \mu \delta s$, rhythm]. Disturbed rhythm.

Pararthrema, Pararthresis (par-ar-thre'-mah, parar-thre'-sis) [ $\pi a \rho a ́$, beside; a $\rho \theta \rho o v$, joint]. Subluxation.

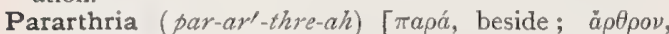
articulation]. A disorder or difficulty in the utterance of articulate speech.
Pararthrosis (par-ar-thro'-sis). Synonym of Pararthria.

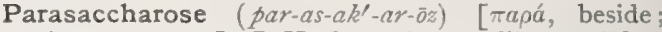

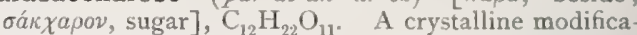
tion of saccharose obtained by allowing a mixture of saccharose and ammonium phosphate in solution to ferment.

Parasalpingitis (par-as-al-pin-jï-tis) [ $\pi \alpha \rho a ́$, near; $\sigma a ́ \lambda \pi \iota \gamma \xi$, tube ; $\iota \tau \iota \zeta$, infiammation]. Intlammation of the tissues around an oviduct.

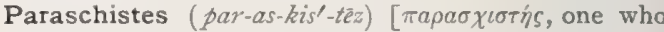
opens corpses to embalm them; from $\pi a \rho \dot{a}$, to ; $\sigma \chi i \zeta \varepsilon \iota \nu$, to rend asunder]. A grade of ancient Egyptian priests who began and carried out the process of embalming; they were also called by the Greeks Tari-

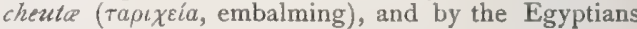
themselves Xar-heb.

Parasecretion (par-as-e-kre'-shun) [ $\pi a \rho a ́$, beside; secernere, to secrete]. Any abnormality of secretion; any substance abnormally secreted.

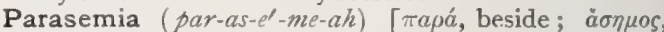
unintelligible]. Simulated asemia. See Asemia.

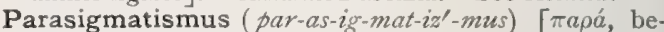
side; $\sigma i \gamma \mu a$, the letter $\left.\varsigma_{\mathrm{a}}\right]$. The inability to pronounce $s$ or $s h$, another letter, as $f$, being substituted.

Parasinoidal (par-as-in-oi'-dai) [ $\pi a \rho a ́$, beside; sinus, sinus]. Lying near or along a cerebral sinus. P. Space, one of the small venous clefts on either side of the superior longitudinal sinus of the dura.

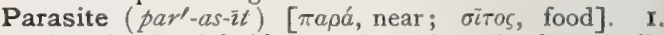
The minor and feebler member of a pair of teratically joined twins. See Autosite. 2. In biology, an organism that inhabits another organism and obtains nourishment from it ; it may be a phytoparasite or a zoöparasite, an ectoparasite or an endoparasite, occasional or constant, temporary or stationary, obligate or facultative, a true parasite or a pseudo-parasite. The term parasite is also applied to such birds as construct no nest and perform none of the duties of incubation, but impose on other birds for this purpose. Parasites that attain their full development upon or within a single host are said to be autecious, or autoxenous; those that pass different stages of development upon or within different hosts are said to be heterecious, or metecious. Among certain invertebrates the degenerated male becomes a permanent parasite of the female. $P_{.}, A c-$ cidental, one which, though ordinarily not parasitic, has found its entrance into the body; e.g., Pentastomia constrictum, $P$. denticulatum, Estrus hom inis, and others. P., Animal, a parasite belonging to the animal kingdom. A table of animal parasites is appended. P., Endophytic, one living within the tissues of its host. P., Epiphytic, a parasite inhabiting the cutaneous or mucous surfaces.

\section{SYNONYMATIC TABLE OF THE ANIMAL PARASITES OF MAN AND OF THE ANIMALS COMMONLY ASSOCIATED WITH HIM.}

Abraxas grossulariata, Linné. The common goose berry-moth; the larva was reported as a human pseudoparasite by Lankester and Norton, of England. -Acanthia ciliata, Acanthia rotundata, two spe cies cited by Cobbold as belonging to Kasam and Reunion Island respectively, which are said to be more blood-thirsty than the common bed-bug.-Acanthia columbaria, Jenyns. The dove-cot bug. It infests doves and poultry, frequently causing sitting bens to abandon their eggs. - Acanthia lectularia. See Cimex lectularius.-Acarus ægyptius, Linné. See Ixodes agyptius, Audouin. - Acarus brachypus, Olfers. See Sarcoptes scabiei, var. hominis, Mégnin.
-Acarus du cheval, Gohier. See Psoroptes communis, var. equi, Fürstenberg.-Acarus domesticus, de Geer. See Glyciphagus cursor, P. Gervais. Acarus dysenteriz, Linné. See Tyroglyphus siro, Latreille.-Acarus elephantiacus, Dubini (1850). See Sarcoptes scabiei, var. Iupi, Mégnin.-Acarus exulcerans, Linné ex Nyander. See Sarcoptes scabiei, var. hominis, Mégnin.-Acarus folliculorum, Simon. See Demodex folliculorum, Owen.-Acarus hordei, Geber. See Tarsonemus monunsuiculosus, R. Blanchard.-Acarus humanus subcutaneus, Linné ex Avelin. See Sarcoptes scabiei, var. hominis, Mégnin. - Acarus marginatus, Fabricius. See 
Argas reflexus, Latreille.-Acarus psoricus, Pallas. See Sarcoptes scabiei, var. hominis, Mégnin.-Acarus reduvius, Schrank. See Boöphilus bovis, Riley, Curtice-Acarus ricinoide, de Geer.-Acarus ricinus, Linné. See Ixodes ricinzs, Linné.-Acarus scabiei. See Sarcoptes scabiei, var. hominis, Mégnin.-Acarus siro, Linné; Acarus siro, var. scabiei, Fabricius. See Sarcoptes scabiei, var, hominis, Mégnin.-Acephalocystis endogena, John Hunter, Owen.-Acephalocystis exogena, Kuhl. - A cephalocystis granulosa, Lrennec, Cloquet. - Acephalocystis macaci, Cobbold. - Acephalocystis ovis tragelaphi, Cobbold.Acephalocystis ovoidea, Lænnec, Cloquet, Deslongchamps, Chiaje. See Echinococcus polymorphus, Diesing.-Acephalocystis plana, Lænnec. See Ovuligera carpi, Dupuytren.-Acephalocystis racemosa, Cloquet. A name including all those grape-like and currant-like hydatigenous formations frequently present in certain morbid affections of the chorion and mistaken for entozoa.-Acephalocystis surculigera, Læennec. See Echinococcus polymorphus, Diesing.-Achylostoma duodenale, Bilharz. See Dochmizes duodenalis, Leuckart. - African Leech. See Hirudo interrupta.Afterbremse, Ger. See Gastrophilus hamorrhoidalis, Linné.- Aftermade. See Oxyuris vermicularis, Bremser.-Agamonema piscium, Diesing. See Filaria piscium, Rudolphi.-Alakurt. See Helmin. thopsylla alakurti, Schimkewitsch.-Algerian Ixode. See Ixodes algeriensis, Mégnin.-Alyselminthus cucumerina, Weinland (1858); Alyselminthus cuniceps, Zeder (1800); Alyselminthus ellipticus, Zeder (1800). See Tania canina, Linné.-Alyselminthus infundibuliformis, Zeder. See Tania infundibuliformis, Goeze.-Alyselminthus litteratus, Zeder. See Trenia pseudo-cucumerina, Baillet. -Alyselminthus lobatus, Zeder. See Tania perfoliata, Goeze.-Alyselminthus plicatus, Zeder. See Trnia plicata, Rudolphi.-Alyselminthus pusillus, Zeder. See Tenia pusilla, Goeze.-Alyselminthus serratus, Zeder. See Trenia crassicollis, Rudolphi.-Alyselminthus setigerus, Zeder. See Tenia setigera, Fröhlich.-Alyselminthus sinuosus, Zeder. See Tania sinuosa, Rudolphi.-Amblyomma americana.-Amblyomma unipunctata, Packard.-American Ixode. See Argas americanus, de Geer--Amoba buccalis, Steinberg. Syn. Amceba dentalis, Grassi. Quiescent below $25^{\circ} \mathrm{C}$.; most active at from $38^{\circ}$ to $40^{\circ} \mathrm{C}$. It is found in the mucus covering the teeth of man.A $\mathrm{m} œ \mathrm{~b}$ a coli, Lösch. Syn. Amaba dysenteria, Councilman and Lafleur. It is found in cases of ulcerative inflammation of the large intestine. Experiments prove this parasite capable of causing violent irritation of the mucous membrane. Moniez hazards the conclusion that this species is identical with Amceba jelaginia of the swamps near St. Petersburg.-Amœba croupogena, Rivolt a. See Coccidium oviforme, Leuckart. - Amœba dentalis, Grassi. See Amreba ouccrlis, Steinberg.- Amcba dysenteriz, Councilman and Lafleur. See Amoba coli, Lösch, Amoba parasitica, Lendenfeld. It is found in a dermatosis of lambs in Australia, attacking the feet, lips, gums, and nostrils. Lendenfeld could not differentiate this parasite morphologically from Amaba princeps, Ehrenberg. It is common in fresh water.-Amceba vaginalis, Baelz. Recorded from Japan as occurring in the human vagina. - Amphistoma collinsii, Cobbold. Brick-red worms found in thousands in the large intestine of the horse in India, where it is known to the natives as Masuri. It is perhaps identical with Amphisloma sonsinoi, Cobbold. Cobbold describes another Amphistoma collinsii, var. stanleyi.-Amphistoma conicum, Rudolphi. Found in the paunch and psalterium of the domestic sheep, ox, goat, deer, and several wild ruminants. It is rosecolored, irregular, length 10 to $13 \mathrm{~mm}$., breadth 2 to $3 \mathrm{~mm}$. It fixes itself between the papillæ of the rumen, especially at the border of the esophagus. It is common in Egypt and Australia, and probably has for its cercaria that found by Sonsino, in Cairo, on the gasteropod Physa alexandrina, and forming cysts on aquatic stones, plants, shells of molluscs, etc.-Amphistoma crumeniferum, Creplin. Found in the rumen of domestic cattle of India, and the zebu (Bos indicus). - Amphistoma explanatum, Creplin. Found by Gurlt, at Berlin, in the gall-bladder and biliary duct of a zebu (Bos indicus).-Amphistoma hawksii, Cobbold. Found at times, and in myriads, adhering to the mucous membrane of the large intestine of the Indian elephant and causing the most frequent disease of that animal, a diarrhea known in India as Litngen; death results from exhaustion following depraved appetite, anemia, and diarrhea.-Amphistoma hominis, Lewis and McConnell. Found in the large intestine and cecum of man.-Amphistoma ornatum, Cobbold. Found in the intestine of the Indian elephant. - Amphistoma papillatum, Cobbold. Found in the large intestine of the Indian elephant. - Amphistoma sonsinoi, Cobbold. Syn., Gastrodiscus polymastos, Leuckart, Cobbold. Possibly Amphistoma collinsii is identical with this species. It is found in the large intestine of the horse.-Amphistoma sp., Cobbold. Found in the stomach of the horse.-Amphistoma truncatum, Rudolphi. Found in the intestine of the domestic cat. Amphistoma tuberculatum, Cobbold. The only trematode found in the intestine of the domestic ox. It is found in India associated with the amphistomes of the rumen.-Analges minor, Nörner. See Dermoglyphus minor, Nörner.-Anchylostoma caninum, Ercolani. Found in the intestine of the dog.-Anchylostoma (Agchylostoma) duodenale, Bilharz, Creplin. See Dochmius duodenalis, Leuckart.-Anchylostoma stenocephalum, Bailliet. See Uncinaria stenocephalus, Bailliet.-Anchylostoma trigonocephalum, Rudolphi. - Anguillula appendiculata, Leidy. See Oxyuris appendiculata, Leidy.Anguilulla intestinalis, Grassi and Parona. See Rhabdonema intestinalis, R. Blanchard.-Anguillula leptodera, Nielley (1882). See Rhabditis niellyi, R. Blanchard (1888). - Anguillula sp., Baillet. Found in the skin of the horse. - Anguillula sp., Grassi and Perroncito. Found in the small intestine of the rabbit; the female only appears to be known.Anguillula stercoralis, Bavay. See Rhabdonema intestinale, Blanchard.-Animal bipede, Bastian. See Sagittula hominis, Lamarck.-Ankylostoma tubæforme, Zeder. See Uncinaria trigonocephala, Rudolphi. - Anthomyia canicularis, Linné.-See Homalomyia canicularis, Linné.-Anthomyia incisurata. See Homalomyia incisurata.-Anthomyia meteorica. See Hydrotca meteorica, Davaine.-Anthomyia pluvialis, A large European (?) fly, the larvæ of 
which have been found by Danthon de Moulin in the human ear and in cutaneous wounds.-Anthomyia scalaris, Fabricius, Judd. See Homalomyia scalaris, Fabricius. - Aphrophora bifasciata. The froghopper, a fly. A case is reported by Cobbold, after Solly and Flower, in which the tly is stated to have been the cause of dysuria in a woman.-Argas americanus, de Geer. Syn., Argas chincha, Goudet ; Amblyomma americanum, Koch; Amblyomma unipunctatr, Packard; Ixodes americanus, Linné; Nisua chinche, the Lone-star Tick. Found in South America. It attacks sleeping men and animals, producing an irritation of the skin so intense as to cause serious symptoms and even death. It is exceedingly troublesome to horses on the prairies of Guatemala.-Argas chincha, Goudet. See Argas americanus, de Geer.-Argas de Fischer. See Argas savignyi, P. Gervais.-Argas hermanni, Audouin. See Argas reflexus, Latreille.-Argas marginatus, A. Railliet (1886). See Argasreflexus, Latreille.-Argas mauritianus, Guérin. A pest upon poultry in Mauritius. It closely resembles Argas reflexus.-Argas mégnini, Dugés. A lyriform species, very abundant in the State of Guanajuato on the horse, ass, and ox, principally upon the ears. It is often found on other animals and on man. Mégnin holds that the Ixodidoe so troublesome to animals, especially horses, in Mexico, ought to be included in this species.-Argas miniatus, Koch. See Argas reflexus, Latreille.-Argas moubouta, Murray. It is found in Angola on man and animals.-Argas persicus, Fischer. Syn., Miana Bus, Mianawanze, Malleh der Perser, Malleh de Minneh. It lives in the dwellings of the Persians, especially in Miana; it is also found in Egypt. It attacks human beings at night, the bite being especially troublesome to strangers.-Argas reflexus, Latreille, I796 (nec Fabricius, I794). Syn., Acarus marginatus, Fabricius (1794); Argas reflexus columbarum, Argas marginatus, Railliet; Argas hermanni, Audouin (I8I2) ; Argas miniatus, Koch (1846); Rhynchoprion columba, Hermann (1808); Saumzecke. The Bordered Argas. It is frequently found in dove-cotes in Italy and France, rarely in Germany and England; it sucks the blood of pigeons, especially the young. It is nocturnal, and is a very troublesome parasite, spreading rapidly, limiting the rearing of pigeons, and wandering into houses, where it attacks human beings, producing painful vesicles, edema, and acute pruritus. Most active measures should be employed to exterminate it, such as hot water, lime, petroleum, insect-powder, soft soap. Zürn recommends washing the legs of the pigeons with an alcoholic solution of balsam of Peru. Hugo Engelmann takes the poison of this mite to be a toxalbumin.-Argas savignyi, P. Gervais. L'argas de Savigny. Found by Savigny in Egypt. Regarded by Audouin as identical with Argas persicus, Fischer.-Argas talaje, Mégnin, Guerin. Syn., Garapates, Telajes. Found in dwellings in Central America. It is nocturnal, and produces painful edema.-Argas tholozani, Laboulbéne and Mégnin. Syn., Argas of Tholozan, Kene der Perser, Sheep-bug. Found on man and sheep in Persia (Djemalabad).-Argas turicata, Dugès. Syn., Turicates. A parasite very troublesome to pigs and man in Guanajuato, Mexico, frequently causing the death of the former and of the fowls which feed on the parasites.-Ascarid of Man. See Ascaris lumbricoides, Linné.-Ascarid of the Pig. See Ascaris suilla, Dujardin. Leuckart, Schneider, and others hold this to be identical with the ascarid of man (Ascaris lumbricoides, Linné).-Ascarid of the Sheep. See Ascaris ovis.-Ascaris brachyoptera, Rudolphi. See Ascaris mystax, Rudolphi. - Ascaris canicutæ,
Schrank (1788). See Ascaris mystax, Rudolphi (I8or). -Ascaris canis, Gmelin (1789). See Ascaris mystax, Rudolphi (I80I).-Ascaris canis aurei, Rudolphi (I8I9). See Ascaris mystax Rudolphi (I80I).-Ascaris canis et martis, Schrank (I788). See Eustrongylus gigas, Diesing (1851).-Ascaris cati, Schrank (1788). See Ascaris mystax, Rudolphi (180I). -Ascaris columbæ, Gmelin. See Heterakis maculosa, Rudolphi.-Ascaris conosoma, Jördens (I802), Lenz, Brera, Bremser, Rudolphi, Diesing. Der Kegelwurn. Found by Bretschneider in the human intestine. According to Brera it is but the larva of Musca domestica.-Ascaris crassa, Deslongchamps. See Heterakis inflexa, Rudolphi.-Ascaris dispar. See Heterakis dispar, Schrank.-Ascaris ensicaudata, Rudolphi. Found in the mouth of the mocking-bird (Mimus polyglottus, Boie).-Ascaris felis, Gmelin. See Ascaris mystax.-Ascaris filiformis caudaratundata, Camper. See Ascaris vituli, Goeze.Ascaris gallinarum, Gmelin. See Heterakis papillosa, Bloch. - Ascaris gallopavonis, Gmelin. See Heterakis inflexa, Rudolphi. - Ascaris gibbosa, Rudolphi. Found in the intestine of the domestic fowl. This is a doubtful species, found only by Zeder in 1788, and described from memory in 1800.-Ascaris gigas, Goeze. See Ascaris lumbricoides.-Ascaris inflexa, Rudolphi. Found in the intestine of domestic fowls, and by Chatin in hens? eggs. Ercolani's statement regarding the descent of this species and Heterakis vesicularis has no foundation.-Ascaris ischnoptera, Creplin. Found in the large intestine of the ostrich.-Ascaris leptoptera, Rudolphi. See Ascaris mystax, Rudolphi.-Ascaris lonchoptera, Diesing. Syn., Ascarides, Jackson; Strongylus elephanti (sic). Rudolphi. Found in the biliary ducts and duodenum of the Elephas indicus, discovered by Mayor in 1822 ; only the female has been described. "The first helminth discovered to infest the elephant, that very species about whose structure and economy we are least informed." (Cobbold.)-As. caris lumbricoides, Linné (1758), Cloquet, Bloch,

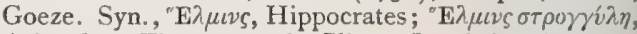
Aristotle; Tinea rotunda, Pliny; Lumbricus longus et rotundus, Sérapion; Lumbricus rotundus, Cælius Aurelianus; Fusaria lumbricoides, Zeder (I800); Lumbricus teres hominis, Celse, Tyson, Redi Valisneri ; Ascaris gigas, Goeze (1782); Nematoideum hominis (ventriculi), Dégland, Leveillé; Nematoideum hominis (viscerum), Pruner, Diesing; Ophiostoma pontieri, Cloquet, Delle Chiaje, Bremser; Spulwurm. Held by some to be identical with the Ascaris megalocephala of the horse and the Ascaris suilla of the hog. This parasite is of cosmopolitan distribution. It is found abundantly in the human intestine, especially in children, and in that of domestic hogs and cattle, in which it reaches a somewhat larger size; a single female is calculated to lay fifty or sixty million eggs. The parasites are erratic, sometimes passing into the ductus choledochus, stomach, nasal fossa, Eustachian tube, larynx, trachea, and, by means of ulceration of the stomach and intestines, at times gaining entrance to the peritoneal cavity. Reflex symptoms of neurasthenic, hysteriform, epileptiform, or choreiform nature, coma, etc., may be directly traced to the presence of these parasites. Therapeusis: Santonin. This should not exceed $1 / 6-1 / 2$ grain (0.0II to 0.032 gram) in each dose, or $11 / 2$ grains ( 0.065 to 0.097 gram) in the day; it is best administered dissolved in castor-oil. Sodium santonate is preferred by many to santonin. Ammonium embellate is highly recommended by Coronadi as less poisonous to the host than other anthelmintics. The alga Alsidium (Cera- 
mium) helminthochorton, $\mathrm{Ktz}$, the so-called Corsican moss, Wurmtang, Wurmmoos, is much used in southern Europe in the shape of an infusion, 30 grains to a pint of water, night and morning; in the same way pinkroot, Spigelia marylandica and Spigelia anthelmia, is employed. In large doses this has narcotic properties. The most popular vermifuge of Europe appears to be worm-seed (Wurmsamen, Littzersamen, Semen flores, Cina, Cyna sina, Santonica, Semen sanctum), Artemesia maritima, var. a Stechmanniana, Bess, the source of santonin, which is administered with sugar or syrup. It owes its activity to the presence of santonin (discovered by Alnus, 1831). The discharged worms should be burned or have boiling water poured over them to prevent the spread of the eggs. -Ascaris maculosa, Rudolphi. See Heterakis maculosa, Rudolphi.-Ascaris marginata, Rudolphi. See Ascaris mystax, Rudolphi.Ascaris maritima, Leuckart (1876). Only one instance is recorded of this worm acting as a human parasite, having been vomited by a child in North Greenland in 1865.-Ascaris megalocephala, Cloquet. The largest species of the genus. Peculiar to the Equida. It is found in the small intestine of the domestic ass, horse, mule, and zebra. No intermediate host is needed; drinking-water appears to be the vehicle of infection. The parasites often exist in great numbers, from 1000 to 1500 , in the small intestine, especially the duodenum, passing at times into the stomach, bile-duct, and pancreatic duct. The manure of animals affected should be destroyed by fire. The presence of the parasite is accompanied by numerous reflex symptoms, $e . g$., chronic intestinal catarrh, slight but obstinate diarrhea, the expulsion of feces being immediately preceded by a discharge of fluid. Treatment :-Arsenious acid with food in increasing doses of $1-3$ grams a day for ten days, tartar emetic in doses of 15-20 grams per day in four doses at intervals of 3-4 hours, with gentian-powder or asafetida, emulsion of oil of turpentine in peanut or cottonseed-oil $80-\mathbf{r} 50$ grams, santonin 80-150 grams. Ferric chlorid and cupric sulphate have been successfully employed, but no specific has been found.-Ascaris microptera, Rudolphi. See Ascaris mystax, Rudolphi.Ascaris mucronata, Fröhlich. See Strongylus nodularis, Rudolphi. - Ascaris mystax, Rudolphi (180I), Bremser, Dujardin, etc. Syn., Lumbricus canis, Werner (1782); Ascaris lumbricoides, Bloch (1782); Ascaris canicula, Schrank (1788); Ascaris canies, Gmelin (1789); Ascaris alata, Bellingham (1839), Dujardin, Diesing; Ascaris cati, Schrank (178); Ascaris felis, Gmelin (1789), Thompson, Pickells; Ascaris marginata, Rudolphi (I793), Zeder (I800); Ascaris teres felis, Goeze (I782); Ascaris triquetra, Schrank; Ascaris leptoptera, Rudolphi; Ascaris microptera, Rudolphi (I8I9); (?) Ascaris brachyoptera, Rudolphi (1819); (?) Fusaria mystax, Zeder (1800); Ascaris canisaurei, Rudolphi (I819). This parasite is found in the small intestine of the domestic cat and dog; also in man. No intermediate host is necessary. Grassi's experiments show its lifehistory to be similar to that of Ascaris lumbricoides; drinking-water is the infecting medium. The form found in the cat appears only to be a larger variety of that found in the dog. It is most frequently found in young animals; by Krabbe, it was found in more than 50 per cent. of cats and 24 per cent. of dogs examined; it inhabits the small intestine and stomach, and causes the vomiting of glairy matter, in which it is to be found; in man it causes intestinal obstruction. Treatment: Santonin in doses of $2-3$ centigrams given in milk, alone or combined with extract of malefern, repeated twice a week, followed by a laxative. Areca-nut is also useful. The investigations of Verloren prove that the eggs of the parasite can retain their vitality for more than a year.-Ascaris ovis, Rudolphi. Found in the intestine of the domestic sheep. It is very rare, only two cases having been reported, by Diesing and Neumann.-Ascaris papillosa, Bloch. See Heterakis papillosa, Bloch.-Ascaris pellucida, Brown. See Filaria equina, Abildgaard.-Ascaris perspicillum. See Heterakis inflexa, Rudolphi.-Ascaris renalis, Gmelin. See Eustrongyhis gigas, Diesing.-Ascaris sp., von Drasche. It is found in the intestine of the domestic sheep.-Ascaris stephanostoma, Jördens (1802); Lenz, Brera, Bremser, Rudolphi, Diesing. It was found in the human intestine by Bretschneider, and asserted by Brera to be the larva of Musca carnaria. - Ascaris suilla, Dujardin. This bears so close a resemblance to the Ascaris lumbricoides that Leuckart, Schneider, and others regard it as identical. Cobbold, Dujardin, Claparède, Moquin-Tandon, hold the two to be distinct. $A$. suilla is found rarely in the small intestine of the pig. Cases of epileptiform seizures in pigs have been referred to reflexes due to the presence of these parasites. Filaria trachealis, Bristow and Rainey ( 1855 ), may be but the larva of this species.-Ascaris teres, Goeze. See Heterakis maculosa, Rudolphi, and Heterakis inflexa, Rudolphi.-Ascaris teres felis, Goeze. See Ascaris mystax, Rudolphi (I801).-Ascaris teres minor (Phasiani Galli et picti), Goeze. See Heterakis papillosa, Bloch.-Ascaris tetraonis, Gmelin. See Heterakis papillosa, Bloch.-Ascaris trichiura, Linné. See Trichocephalus hominis, Schrank (1788).-Ascaris triquetra, Schrank. See Ascaris mystax, Rudolphi.-Ascaris urogalli, Viborg, Rudolphi. See Heterakis papillosa, Bloch.Ascaris vermicularis, Linné (1767). See Oxyuris vermicularis, Bremser (1819).-Ascaris vesicularis, Rudolphi. See Heterakis vesicularis, Fröhlich.Ascaris visceralis aut renalis, Gmelin. See $E u$ strongylus gigas, Diesing.-Ascaris vituli, Gmelin, Goeze, Neumann (1883). Syn., Strongylus vitulorum, Rudolphi; Gordius viviparus, Bloch; Ascaris filiformis cauda rotundata, Camper; Ascaris vituli, Gmelin; Fusaria vituli, Zeder. The Calf-ascarid. Found in the intestine and abomasum of young domestic cattle; it is rare in adults. It is frequently found in the slaughter-houses in France. One case is reported in which 15 liters of these parasites were found in the intestine of the calf. Therapeusis:Give 8-12 grams of a mucilaginous emulsion of empyreumatic oil at night, and follow in the morning with a purgative of sodic sulphate.- Asthmatos ciliaris, Salisbury. Dr. J. H. Salisbury described, in 1873, ciliated cells in the mucous fluid from the eyes, nose, and throat of human beings suffering from infusorial catarrh and asthma, hay-fever or autumn catarrh. He regarded them as parasites belonging to the cilio-flagellate infusoria. Cutter and Reinsch arrived at the conclusion that the organism is a protozoön allied to Actinophrys, but it was, in 1880 , shown by Leidy to be merely detached ciliated epithelial cells from the airpassages, more or less modified by the catarrhal afiection. - Aulacostoma nigrescens, Weigmann et Ruthe; Aulacostomum gulo, Grube. See Aulastoma gulo, Moquin-Tandon.-Aulastoma gulo, Moquin-Tandon. Syn., Aulastoma vorax, Gratiolet; Aulacostoma nigrescens, Weigmann et Ruthe; Aulacostomum gulo, Grube. Hirudo depressa fusca margine laterali. Black-leech, or Voracious aulostoma, incorrectly called Horse-leech in the neighborhood of Paris, 
and thus confused with Hamopis sanguisuga, Bergmann. It is widely distributed over Europe and leaves the water to hide under stones, feeding on earthworms, insect larvæ, and small fishes.-Aulastoma vorax, Gratiolet. See Aulastoma gulo, Moquin-Tandon.-Autumn Ixode. See Ixodes autumnalis, Leach. -Autumnal Breeze-fly. See Tabanus autumnalis, Linné, - Bacon-beetle. See Dermestes lardarius, Linné. - Bacteriöidomonas sporifera, Künstler. See Monocercomonas cavia, Davaine.-Balaninus nucum, Linné. A beetle, the larvæ of which is reported as a facultative parasite of man by Henry, Astley Cooper, and Phillips. - Balantidi u m coli, Stein (1862). Syn., Paramocium coli, Malmsten (1857); Plagiotoma coli, Claparede and Lachmann ( 1858 ); Leucophrys coli, Stein (I860); Holophrya coli, Leuckart (I863).

An infusorian parasite first observed in $\mathbf{1} 856$ by Malmsten, and since found abundantly in the colon of
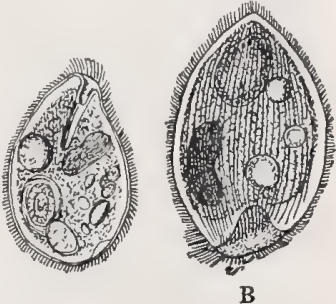

BALANTIDIUM Coli, Stein; (B) with widely opened peristome (dorsal view). (After Leuckart.)

the pig. It has also been found in man in Russia, Sweden, Italy, Cochin-China, and China. In the pig it causes no serious disturbance, but in man it gives rise to profuse and obstinate diarrhea. Calandruccio, Grassi, and Wising maintain that two distinct species are classed under the name. According to Lindner thi parasite is practically limited to northern Europe, where it is not uncommon for the peasantry to live in close and constant association with their swine. Probably its protective cysts or capsules enable it to resist the action of the gastric juice. Diagnosis of its presence in man or swine is readily made by the introduction of a sound into the rectun, the infusoria being found in the mucus and feculent matter brought out on the instrument. Therapeusis:-Malmsten and Henschen recommend enemata of dilute hydrocloric acid, or of vinegar and tannic acid.-Balbiania gigantea, Railliet (1886). A sporozoön parasite of the order Sarcosporidice, which has been found in the connective tissues of the sheep, goat, ox, deer, pig, and eastern buffalo, especially in the muscular layer of the esophagus, base of tongue, muscles of pharynx, cheeks, neck, thorax, abdomen, and thighs. The sudden symptoms of epizoöty, asphyxia, and epileptiform attacks seem to be due to edema of the glottis.-Balbiania rileyi, Stiles. Found in the intermuscular connective tissue of ducks (the shoveler or shovel-bill duck, or spoon-bill duck (Spatula clypeata), and the mallard duck, or tame duck (Anos boschas).-Bed-bug. See Cimex lectularius, Merrett (I667).-Beinwurm. See Dracunculus medinensis, Cobbald. - Benchuate. See Conorhinus nigrovarius. -Bête rouge. The native name in Guiana, the Antilles, and Honduras for Leptus irritans, $q . v .-B e t t-$ wanze. See Cimex lectularius, Merrett (1667).Bewaffneter Bandwurm des Menschen. See Tenia solium, Linné.-Bicho. See Sarcopsylla penetrans, Westwood. - Bicho colorado, of Argentine Republic and Uruguay. See Tetranychus molestissimus, Weyenbergh.-Bilharzia bovis, Sonsino. See Gyncephorus crassa.-Bilharzia capensis, Harley. See Gynacophorus hamatobius (Bilharz), Diesing.Bilharzia crassa. See Gynecophomes crassa.-Bilharzia hæmatobia, Cobbold (1858), - Bilharzia

magna, Cobbold. See Gynacophorus hamatobius, Diesing, - Bird - flea. See Pulex avium, Taschenberg.Biseriated Menopon. See Menopon biseriatum, Piaget. Biting Louse. See Trichodectes scalaris, Nitzsch. - Black Breeze-fly. See Tabanus morio, Latreille.-Black Leech. See Aulastoma gulo, Brown. -Black-mouthed Menopon. Se e Menopon phrostomum, Nitzsch.-Blaps mortisaga, Li nné. Syn., Todtenkäfer, Churchyard-beetle. The larva of this beetle is recorded as a facultative human parasite by Pickells, Thompson, Bellingham, and Bateman. This beetle is common about houses and cellars in Europe from April until harvest - time. - Blaue Fleischfliege. See Calliphora vomitoria, Robineau-Desvoidy. -Blinding Breeze-fly, or

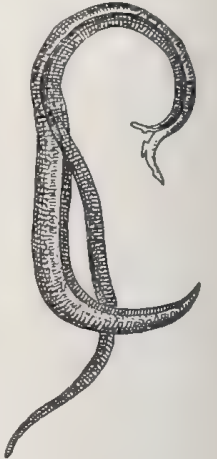

ILHARZIA HFMATOBIA, Cobbold ; male and female, the latter in the canalis gynacophorus of the former. (After Leuckart.)

Blinding Chrysops. See Chrysops cacutiens, Linné. -Blood-sucking Cone-nose. See Conorhinus, Blow-fly. See Calliphora vomitoria, RobineauDesvoidy. - Blue Flesh-fly, Bluebottle-fly. See Calliphora vomitoria, Robineau-Desvoidy.-Bodies of Laveran. See Polimitus malarice, Danilewsky. -Bodo hominis, Saville Kent (1880). See Cercomonas hominis, Davaine (1854). - Bodo intestinalis, Ehrenberg. Observed by Steinberg in the white material found between human teeth. Leuckart regards it of doubtful parasitic nature--Bodo muscæ domesticæ, Burnett. See Herpetomonas musce domestica, Kent-Bodo saltans, Ehrenberg. Found by Wedl in great numbers in unhealthy ulcers in man. Leuckart doubts if it is parasitic. -Bodo socialis, Ehrenberg. This was observed by Steinberg in the white substance obtained from between human teeth. Leuckart doubts its parasitic nature.-Bodo urinarius, Hassal (1859). It is frequently found in the albuminous, alkaline urine of cholera-patients. R. Blanchard considers it as accidentally occurring in the urine and not a parasitic species. - Bodo urinarius, Künstler (1883). See Cystomonas urinaria, R. Blanchard (1885).Body-louse. See Pediculus vestimenti, Leach.Boöphilus bovis (Riley), Curtice. Syn., Hamaphysalis rosea, Koch; Ixodes annulatus, Say; Ixodes bovis, Riley; Ixodes dugesii, P. Gervais (1844); Ixodes indentatus, Gamgee; Ixodes reduvius, De Geer. The cattle-tick; the most widely distributed of all the ticks. occurring in America southward from the northern line of the southern cattle-fever area, to Mexico, Cuba, South America, and also in northern Africa and southern Europe ; it is probably a native of N. Africa. This is the active agent in spreading Texas cattle-fever. Treatment: Almost any oily or greasy material. Bot-fly of Cattle. See Hypoderma bovis, Latreille. -Bot-fly of the Horse. See Gastrophilus equi, Fabricius. - Bothriocefalo largo, Bothriocephale large. See Bothriocephalus latus.-Bothriocephalus canis, Ercolani and Bassi. See Bothriocephalus latus, Bremser (I8I9).-Bothriocephalus cordatus, Leuckart (1863). Syn., Dibothrium cordatum, Diesing. It is found in Iceland and North Greenland in the human body, also in walrus and seal (Phoca barbata) and in dogs. It is smaller than B. latus; Tonia vulgaris, Linné and Pallas, may be identical with 
this species. The larval stage is found in a fish. -
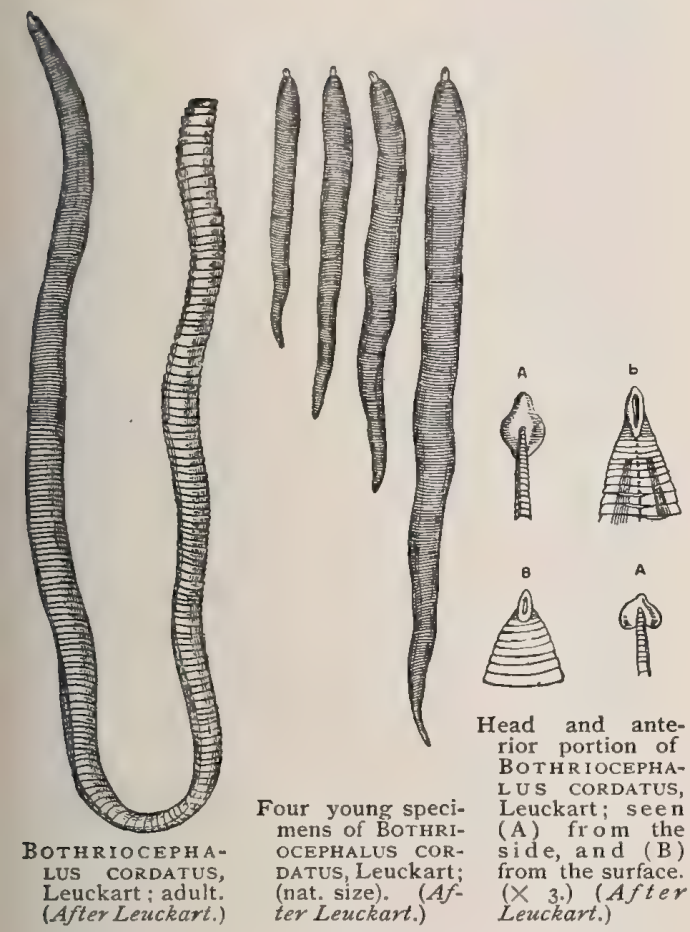

Bothriocephalus cristatus, Davaine (1874). Syn., Bothriocefalo a cresta. It has been found in man in a few cases in Europe. A doubtful variety, possibly a monstrosity, and so considered by Moniez.-Bothriocephalus decipiens, Diesing. This is found in the intestines of several wild Felida, and includes, according to Diesing, Bothriocephalus felis, Creplin (I825), of the domestic cat, $q . v$-Bothriocephalus dubius, Krabbe. This was found by Krabbe in a dog at Reykjavik, and resembles Bothriocephalus fuscus, q. v.-Bothriocephalus felis, Creplin (1825). Syn., Bothriocephalus decipiens, Diesing. This is found in the intestines of domestic cats, and in general features it resembles Bothriocephalus latus, Bremser, except in dimensions. - Bothriocephalus fuscus, Krabbe. Syn., Bothriocephalus reticulatus et dubius, Krabbe. This is found in the intestine of the dog in Iceland.Bothriocephalus hominis, Lamarck. - Bothriocephalus latus (Linné), Bremser (1819), Blainville, Rudolphi. Syn., Bothriocefalo largo; Bothriocephale large; Bothriocephalus canis, Ercolani and Grassi; Bothriocephalus hominis, Lamarck; 'Dibothrium latum, Diesing (1850); The Swiss Tapeworm, Tania latn, Linné (I748), Bloch, Goeze; Tania veterum, Spiegel (1618); Tania sive fascza intestinorum, Spiegel (1618); Ténia de la second espece, Andry (I700); Ténia à épine, Andry (I700); The Broad Tapezvorm, Bradley (1813); Trenia vulgaris, Linné (1748), Werner, Retzius, Gmelin; Tania dentata, Batsch (1786), Gmelin; Tcenia tenella, Pallas (I78I), Retzius; Tania grisea, Schrank; Ténia d̀ article courtes, Bonnet; Tania lata event. grisea, Pallas (1766); Tania prima, Plater (1603); Tania membranacea, Pallas (I78I), Batsch; Tenia humanis inermis, Brera (1802); Breiter Grubenkopfururm, Breiter Bandwurm des Menschen, Grande bothrio-

cefalo; The Broad Tapeworm, Bradley (1813). The largest cestode helminth at present known to infest the human body. Switzerland forms the first center for this parasite, and the Russian and Swedish provinces on the shore of the Baltic the second. It appears to be increasing in Germany and Italy. It is not rare in Denmark. Ijima reports it in Japan, re. ferring to the fish Buchorrhynchus perryi as the host of the larva. Belgium, Holland, England, Scotland, and America are practically free from this para-

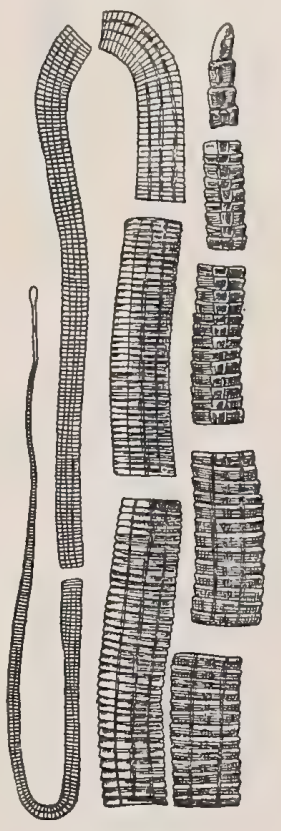

BOTHRIOCEPHALUS LATus, Bremser. (After

site. It appears not to be rare in dogs in Italy and Russia. The larva or finn has been found in a large number of fishes; e. $g$, the perch, turbot, sea-trout, salmon, pike, stint, etc. Its prevalence is due to the custom of eating fish imperfectly cured or cooked. The fish is possibly not the only provisional host, but is infected by eating some mollusc possessing the parasite in a hydatid condition. It is claimed that this parasite gives rise to all the symptoms of pernicious anemia. - Bothriocephalus liguloides, Leuckart (I886). See Bothrioiephalus mansoni, R. Blanchard (I886).Bothriocephalus longicollis, Molin. Found in the intestine of the domestic fowl in Italy. It gives rise to loss of appetite, emaciation, feebleness, diarrhea, and epileptiform attacks. The powdered bark of pomegranate-root-a teaspoonful for every fifty head-mixed with the poultry-food is regarded as the best treatment of teniasis in fowls. - B oth riocepha 1 us mansoni, R. Blanchard (I886). Syn., Bothriocephalus liguloides, Leuckart (1886). Ligula mansoni, Cobbold ( 1883 ). This is found in the human peritoneum, and is known only in the 
larval condition. It has its habitat in the connective tissues of the host, as the conjunctival tissues of the orbit and subcutaneous tissues of the thigh, but it is capable of extensive migrations and has been voided with the urine; the cases are limited to Chinese and Japanese. Bothriocephalus reticulatus, Krabbe. It is found in dogs in Iceland. See Bothriocephalus fuscus, Krabbe. Bothriocephalus serratus, Diesing. This was found by Natterer in the Pampas fox (Canis azare) of Brazil. Diesing holds the form found by von Siebold and others in dogs to be identical. See Bothriocephalus canis Ercolani and B. latus, Bremser. - Bothriocephalus tropicus, Schmidtmüller. See Trenia saginata, Goeze.-Brechfliege. See Calliphora vomitoria, Robineau-Desvoidy. - Breeze. See Gastrophilus equi, Fabricius.Breiter Bandwurm des Menschen, Breiter Grubenkopfwurm. See Bothriocephalus latus, Bremser.-Brummer, See Calliphora vomitoria, Robineau-

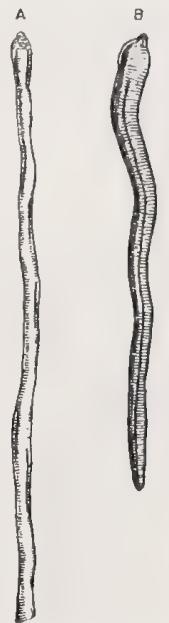

BOTHRIOCEPHALUS chard. (A, after Leuckart; B, after Cobbold.) MANSONI, R. Blan-

Desvoidy.-Buffalo-fly, or Buffalo-gnat. See Simu. lium pecuarium.-Burrowing Flea. See Sarcopsylla penetrans, Westwood.-Bütschlia lanceolata, Fiorentini; Bütschlia neglecta, Schuberg; Bütschlia parva, Schuberg. Three peritrichous infusorian parasites, rarely found in the rumen of the ox.-Cælognathus morsitans. An arachnid discoverd by Hessling and held by Cobbold to be a genuine human parasite. Cæpophagus echinopus, Mégnin (1880). Syn., Tyroglyphus echinopus, Fumouze et Ch Robin (1867). An acaridan, common about liliaceous bulbs, found in the external auditory meatus of a woman suffering from otorrhea, also in a case of "seedy toe" in the horse.Calf Ascarid. See Ascaris vituli, Goeze.-Calliphora anthropophaga, Conil.-Calliphora hominivorax.-Calliphora infesta, Philippi. See Lucilia macellaria-Calliphora limensis. A case of myiasis narium due to the larva of this fly is reported by Aguirre from Santiago de Chile,-Calliphora macellaria, Jörg. See Lucilio macellaria, Fabricius,-Calliphora vomitoria, Robineau-Desvoidy (1830). Syn., Musca vomitoria, Bluebottle-fly, Blue Flesh-fly, Bloze-fly, Mouche bleu de la Viande, blaue Fleischfliege, Schmeissfiege, Brechfiege, Brummer. These flies feed only on fresh meats and rarely deposit their eggs in wounds or in the natural cavities of the body; although Leuckart and Summa cite a case in which the larvæ were passed from the intestines of man, and Summa refers to cases of Myiosis narium due to these larvæ, and Langstein to a case in which he removed large numbers from the bladder of a woman recently confined.-Callodium tenui. See Trichosoma tenuissima, Diesing.-Camel-bot. See Estrus cancli, var. - Camel Ixode. See Ixodes camelinus, G.
Fischer.-Camel Estrus. See Estrus caneli. Camel-tick. See Galeodes araneoides.-Carphoglyphus passularum, Ch. Robin (I869). A mite found on dried fruits, dates, figs, prunes, etc., and occasionally in vomited matter. - Cat-flea. See Pulex serraticeps, Gervais.-Cat-louse. See Trichodectes subrostratus, Nitzsch.-Cattle-louse. See Hamatopinus eurysternus, Nitzsch.-Cattle-worm. See Founza ia ngômbe.-Cayor Fly, Cayor Worm. See Ochromyia anthropophaga, Blanchard.-Cephalomyia ovis, Latreille. See Estrus ovis, Linné,Ceratopsyllus canis. See Pulex serraticeps, Gervais. - Ceratopsyllus gallinæ, Bouché. See Pulex avium, Taschenberg.-Cercaria brunnea, Diesing. According to Diesing this is identical with the cercaria of Distoma echinatum, Zeder, of the duck. - Cercaria cystophora, von Willemoes-Suhm. This was held by Leuckart to be the larva of Distoma lanceolatum, Mehlis, of the sheep, but has since been demonstrated by Creutzburg to belong to $D$ ise toma ovocaudatum of the frog.-Cercaria echinatoides, Fil. Syn., Cercaria echinifera, La Valette, C. spinifera, La Valette, C. brunnea, Diesing (?). It is the larva of Distoma echinatum, Zeder, of the duck. It is found in aquatic molluscs, Limncea, Planorbis, Paludina. - Cercaria echinifera, La Valette. See Cercaria echinatoides, Fil.-Cercaria longicaudata. This is the larva of Distoma lanceolatum, Zeder, of the sheep. It occurs in the pond-snails Helix carthusiana, Müller, and Planorbis marginatus, Draparnaud. - Cercaria spinifera, La Valette. See Cercaria echinatoides, Fil.Cercomonas davainei, Moquin-Tandon (1860). See Cercomonas hominis, Davaine (1854).-Cercomonas gallinæ, Rivolta. Syn., Cercomonas nell intestino dei gallinacei, Perroncito, Cercomonas de l' intestin des gallinacées. It is found in cases of pseudo-croup in fowls and pigeons.-Cercomonas globosus, Per. roncito, Monocer.

comonas cavia,

Davaine, - Cer-

comonas of the

Guinea - pig's

Intestines. See Cercomonas hominis, Davaine: (A), Monocercomonas larger, and (B), smaller variety. cavia, Davaine,

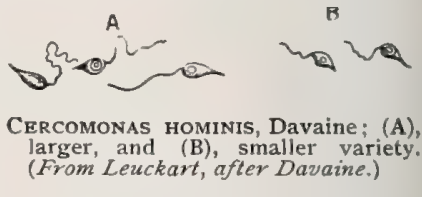

Cercomonas ovalis, Perroncito, Cercomonas pisiformis, Perroncito, Cercomonas globosus, Perroncito, Bacterioidomonas sporifera, Künstler.-Cercomonas hominis, Davaine (1854). Syn., Cercomonas intestinalis, Lambl (1875 nec I859); Cercomonas davainei, MoquinTandon (1860) ; Bodo hominis, Saville Kent (1880); Cercomonas globosus, Perroncito. This infusorian is of frequent and extensive occurrence in the discharges of cholera and typhoid-fever patients, and in various diarrheas, also in healthy persons, e.g., the intestinal mucus of children. It is also found in the hepatic ducts.-Cercomonas intestinalis, Lambl (1859). [The species described by Lambl under this name in 1859 is referred to Megastoma intestinale, Blanchard, 1885 , q. v. ]-Cercomonas intestinalis, Lambl(1875). See Cercomonas hominis, Davaine(1854). -Cercomonas intestinalis, Marchand (1875). See Trichomonas intestinalis, Leuckart (1879). - Cercomonas muscarum, Leidy. Cercomonas muscæ domestica, Stein. See Herpetomonas musca domestice, Saville Kent. - Cercomonas ovalis. This was found by Perroncito in the intestine of the guinea-pig, producing an enteritis; perhaps identical with Monocercomonas cavio, Davaine-Cercomonas pisiformis, Perroncito. See Monocercomonus cavia, Davaine.-Cercosoma. See Eristalis tenax 
and Eristalis pendulum.-Cheiracanthus hispidus, Fedschenko. Syn., Gnathostoma hispida. This is found in the walls of the stomach of the hog and dog.Cheyletus eruditus, Schrank. This is a vagabond species, occasionally found on man and animals as well as among old books, rags, moldy forage, etc. De Mericourt reports a case in the pus from the ear of a sailor, and Picaglia attributed to it a dermatosis observed on the horse, resembling that produced by Dermanyssus avmu, De Geer-Cheyletus heteropalpus, Megnin. This is a mite living at the base of the feathers of pigeons and doves as well as sparrows. It appears to cause no serious inconvenience to its host.-Cheyletus scabiei. See Sarcoptes scabiei. Chicken-louse. See Goniocotes gigas, Taschenberg, Goniocotes hologaster, Nitzsch, and Goniodes dissimilis, Nitzsch.-Chigga, Chigo, Chigoe, Chigger, Chiggre, Chique. See Surcopsylla penetrans, Westwood. Chigo of Fowls. See Sarcopsylla gallinacea, Westwood.-Chinche. See Argas americanus, De Geer. -Chorioptes communis, var. ovis, Verbeyen. "The Foot-scab." See Symbiotes communis, Verheyen. Chorioptes ecaudatus, Mégnin. See Symbiotes auricularum, var. canis, var. cati, Neumann.Chorioptes symbiotes, R. Blanchard (I890), the mange of cattle. See Symbiotes communis, Verheyen. -Chrithoptes monunguiculosus, Geber. This is found among barley; the mites cause urticaria and eczema, accompanied by fever for from one to three days. -Chrysops cæcutiens, Meigen. Syn., Small Blinding Breeze-fly. A common fly, troublesome to man and animals throughout Europe during the summer. Churchyard-beetle. See Blaps mortisaga.-Ciliaris bicaudalis, Salisbury (1868). See Trichomonas vaginalis, Donné (1837).-Cimænomonas caviæ, Grassi. See Trichomonas cavice, Davaine.-Cimex ciliata, Eversmann. This species is native to Russia. -Cimex columbarius, Jenyns, a bug found on the pigeon.-Cimex lectularia, Merrett (I667). Syn., Acanthia lectularia, Fabricius (1794), Cimex columbarius, Jenyns, Cimex hirundinis, Jenyns, Bed-bug, Punaise des lits, Bettwanze, Hauswanze, Wandlaus. This was originally introduced from India, and was known to the Greeks as $\chi o$ ós and to the Romans as Cimex. It was first recorded in Europe in Strasburg, in the IIth century, and was carried to London in the bedsteads of the Huguenots. It is now cosmopolitan. The female lays in March, May, July, and September, about fifty eggs at a time; they take eleven weeks to reach maturity. Adult bugs will withstand severe cold and survive the winter. The bed-bug not only attacks man, but also birds : doves, the swallow, etc. Spirit of turpentine, corrosive sublimate, mercurial ointment, red precipitate, and insect-powder are employed in their destruction, also fumigation (18-24 hours) with sulphurous acid gas. In Europe the pepper-grass (Lepidium ruderale, L.) is used to attract the bugs which are said to gather on the fresh plant to suck the juice, when plant and all can be thrown in the fire-Cirons. See Sarcoptes scabiei, var. hominis, Mègnin.-Clegg. See Hematopota pluvialis.-Clercus formicarius, Linné. This is a beetle; the larva, according to Küchenmeister, was given to von Siebold as a urinary parasite.-Clothes-louse. See Pediculus vestimenti, Leach.-Coccidium bigeminum, Stiles (1891). Syn., Corpuscules geminés, Finck (I854), Cytospermium villorum intestinalium canium, Rivolta, Coccidie gemine, Railliet et Lucet (I890). This is found in the villi of the small intestine, particularly the duodenum of dogs and cats. It appears to cause no ill-effects, being found in healthy animals. Coccidium oviforme, Leuckart (1879). Syn., Corpi oviformes, Vulpian; Amaba croupogena, Rivolta; Psorosperma crouposum, Rivolta; Cytospermium zürnii, Rivolta. This was the first of the psorosperms to be described. It is frequent in the cells of the biliary ducts of rabbits and in man, and the intes. tines of cattle, producing "psorospermnodules," or "coccidium-nodules," which may bring about changes resulting in death. Coccidiosis of rabbits is so common in certain hutches and warrens near London,

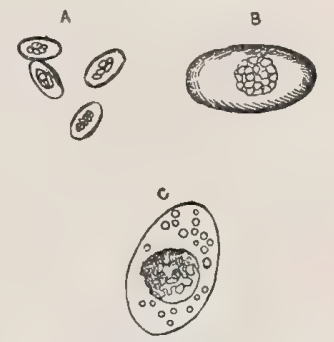

COCCIDIUM OVIFORME, Leuckart; from the human liver. $(A \times 200$, $\mathrm{B}$ and $\mathrm{C} \times 800$. (After Leuckart.)

that the keepers recognize it readily, and distinguish it by the "wet snout" which the affected animals exhibit. It is most fatal in young rabbits, which become affected as soon as they cease to suckle and begin to eat green food; they lose flesh rapidly and suffer from enteritis, dying in from 8 to 15 days. According to Galloway (I) a most important portion of the developmental cycle of this parasite takes place only external to the body, under aërobic circumstances; (2) Influences outside the body delay and even prevent, the external sporulation of the parasite, thus interfering with its infective power; (3) The host cannot be infected by coccidia inoculated directly from an animal already suffering, thus proving that the disease, though infectious, is so only in a very special way; (4) The parasite infects the host by passing into the alimentary canal, where it meets suitable conditions for its future development ; (5) The parasite enters and grows within epithelial cells, without necessarily destroying them and causes great proliferation of the neighboring epithelium. This parasite is also the cause of a cutaneous psorospermosis of fowls, geese, turkeys, and pigeons, forming wart-like nodules on the head, and showing close analogy to the disease of man called Epithelioma contagiosum or Molluscum contagiosum. Treatment consists in cauterization by the hot iron or by chemicals. Oil of turpentine is also effective and prophylactic. - Coccidium perforans, Leuckart (1879). This is found in the intestinal epithelium of the dog, rabbit, cat, and man.-Coccidium rivolta, Grassi (I88I). It is found encysted in the epithelial cells of the intestine in cats, and also free in the intestinal contents and feces. This species closely resembles the Coccidium perforans of the dog. -Cœnurus cerebralis, Rudolphi. This is the cystic larva or finn of Tania canurus, Küchenmeister, of the $\operatorname{dog}, q . v$. It is found in the brain and spinal marrow of cattle, sheep, goats, camels, dromedaries, horses and exceptionally, in man, producing staggers (Hydatidocephalus, Gid). It has also been found in the muscles of the domestic rabbit and in the subcutaneous connective tissue of the calf and sheep. -Conurus serialis, Gervais. This is the cystic finn of Tania serialis. Its usual habitat is the connective tissue of domestic rabbits, hares, and squirrels, occurring on the head, neck, loins, thorax and limbs, and rarelv, in the spinal cord. The fact that the largest number of conures have been collected from wild rabbits would appear to indicate that the Tania which produces them must inhabit the intestine of some carnivorous animal that usually lives in the same localities as the rabbits, and that the development of 
this Tania in the dog must be considered purely accidental. - Cœnurus, sp., Engelmayer. This is found in the liver of the domestic cat-Conurus, sp., Pagenstecher. This was found beneath the skin in the dog.-Colorado, the native name in Cuba for Leptus irritans, q.v.-Colpocephalum longicaudum, Nitzsch. The long-tailed colpocephalus, a louse found on many species of pigeons and doves. Common Scab. See Psoroptes communis, Fürstenberg.Common Tick. See Ixodes ricinus, Linné.-Companion Gonicote. See Gonicote compar, Nitzsch.Compsomyia macellaria, Compsomyia rubifrons, Macquart. See Lucilia macellaria, Robineau - Desvoidy. - Cone-nose. See Conorhinus, sp. This blood-sucking cone-nose has recently been reported from the Yosemite Valley, Cal., where it is found in the beds, biting the face, hands, and feet of the sleeper, causing serious sores in some instances.-Conorhinus nigrovarius, a predaceous bug in the pampas, Cenchucha, which sucks blood like an ordinary tick.Conorhinus sanguisugus, sucks the blood of warmblooded animals.-Corpuscles of Laveran. See Polimitus malaria, Laveran and Danilewsky-Corpuscles of Rainey. See Sarcocystis miescheri, Ray Lankester.-Cousin commun. See Culex pipiens, L.-Crab-louse. See Phthirius inguinalis, Leach. - Crambus pinguinalis. There are three cases cited of this lepidopterous insect (larvæ) acting as facultative human parasites by Linnæus, Church and Angetinus.-Creole Tick. See Ixodes dugesi, Gervais.-Crinons. This is a name given by Chabert in I782 to Sclerostoma armatum, Rudolphi, q.v.,Crithoptis monunguiculosus, Geber (1879). See Tarsonemus monunguiculosus, R. Blanchard (1889). - Crown-tail Strongyle, Cobbold. See Stephanurus dentatus, Diesing.-Cryptocystis tricodectis, Villot. This is the larva of Tania canina, Linné, and was found by Melnikow (I867) in the body-cavity of the Trichodectis latus, Nitzsch, of the dog.- $\mathrm{Cu}$ lex anxifer. The species of mosquito cited by Cobbold as troublesome to man.-Culex ciliatus. This is a large species of mosquito found in the Atlantic States. It bites very severely, but is comparatively rare and does not appear in swarms. - Culex damnosus, Say. The common American mosquito, appears in swarms which invade marshy regions, appearing in the Middle States in four distinct broods, which only swarm at intervals of one month. This troublesome species is reported as becoming common in England.-Culex equinus, Cobbold. This is especially troublesome to horses.-Culex Mosquito. It is found in Southern Asia where, according to Manson, it acts as the host of Filaria sanguinis hominis and is the agent in infecting man with this, the most important of the animal parasites attacking man.-Culex pipiens, Linné. Syn., Zanzara comune, Ital. ; Cousin commun, Fr. ; Gemeine Stechmücke, Ger.; Common Gnat of Europe. This gnat takes the place in Europe of the mosquito of America, being in many regions a veritable scourge to man, especially at night. It is not aggressive toward animals. -Culex pungicus. This is a species found in France and according to Liegard produces serious symptoms in those bitten by it. - Culex rufus, Culex tæniorhynchus. Two American species. Cuterebra cuniculi, Clark (1815); Macquart (1835); Joly (1846). Syn., Estrus cuniculi, Clark (1797); Trypoderma cuniculi, Wildemann (1830). An American species, found on hares and rabbits. - Cuterebra noxialis, J. Goudot (1845). See Dermatobia noxialis, Brauer.-Cyclobdella lumbricoides. The blind leech. A species found in Brazil ; it attacks men and animals indiscriminately.-Cynorhæstes ægyp- tius, Hermann. See Ixodes agyptius, Audouin.-Cynorhæstes ricinus, Hermann. See Ixodes ricinus, Linné.-Cynthostoma tetracanthum, Molin. See Sirongylus tetracanthus, Diesing.-Cyrtoneura stabulans, Macquart. Syn., Musca stabulans, Fallèn; Stallfiege. The larvæ of this fly were first observed as facultative intestinal parasites of man by Laboulbène. It is troublesome about stables, - Cysticercus acanthotrias, Weinland. This is the larva of an undescribed species of Tania, found in the connective tissue and dura mater of man.-Cysticercus albopunctatus. See Cysticercus tenie solii, Leuckart. - Cysticercus alpaca, Sappey. Found in the muscles of the alpaca; it seems to be very abundant in Peru. The adult worm and its host have not been discovered yet.-Cysticercus bailletti, Railliet. Syn., Pleurocercoides bailletti, Railliet, Cysticercus elongatus, Blumberg. This is found in the pleura and peritoneum of the cat, dog, rat, ichneumon and pole-cat.-Cysticercus bicornis, Zeder. See $D i$ ceras rude, Rudolphi.-Cysticercus bothrioplitis, Piana. See Cysticercus tenice bothrioplitis, Piana.Cysticercus bovis, Göze. See Cysticercus tanice saginata, Goeze-Leuckart. - Cysticercus clavatus. See Cysticercus tania marginala, Batsch-Diesing. - Cysticercus conis, Cysticercus cellulosæ. See Cysticercus tenice solii, Leuckart.-Cysticercus coprinus. See Cysticercus tanice marginata, BatschDiesing.-Cysticercus dicysta. A finn found in the cranial cavity of man; its tapeworm is unknown. - Cysticercus elongatus, Blumberg. This name was applied by Blumberg to the finns found in the dog and cat, (see Cysticercus bailletti, Railliet), but it had to be dropped, as it had already been applied by Leuckart to a variety of Cysticercus tenice serrata, ZederGoeze, q. v.-Cysticercus fascicularis, Rudolphi. See Cysticercus tanice crassicollis, Rudolphi,-Cysticercus finna. See Cysticercus tcenia solii, Leuckart; -Cysticercus fischeriana. A finn found by Fischer in the choroid plexus of man; the adult is unknown.-Cysticercus fistularis, Rudolphi. This was found in the peritoneum of the horse by Chabert and Reckleben. The Platode of which this is the finn is as yet unknown.-Cysticercus globosa, Cysticercus lineata. See Cysticercus tania marginata, Batsch-Diesing.-Cysticercus mediocanellata, Davaine. See Cysticercus tanice saginate, Goeze-Leuckart. - Cysticercus melanocephalus, Köberle. Cysticercus multilocularis. See Cysticercus tanice solii, Leuckart.-Cysticercus oviparus, Maddox. This is found in the muscles of the sheep and is regarded by Maddox not only as a new species, but as a sexually mature animal.-Cysticercus ovis, Cobbold. See Cysticercus tonice marginate, Batsch-Diesing. Cf. Tenia tenella, Cobbold. Cobbold found this finn on several occasions in the measles of sheep and held it to be the larvæ of a Tenia of man, the so-called Tania tenella. Chatin demonstrated Cobbold's error, showing that the pretended $T$. tenella, was only a small-sized $T$. solium, and that Cysticercus ovis was but an imperfectly developed Cysticercus tania marginate, BatschDiesing.-Cysticercus phacochceri æthiopici, Cobbold. See Cysticercus tanice marginate, Batsch.Cysticercus pisiformis, Zeder. See Cysticercus tanice serrata, Goeze.-Cysticercus pyriformis, Cysticercus racemosa (us), Zenker. See Cysticercus tanice solii, Leuckart-Cysticercus turbinata, Koberle. A variety in which the head-process is coiled in a regular spiral of sometimes three turns. See Cysticercus tenice solii, Leuckart.-Cysticercus, sp., Baillet. This is found in the peritoneum of the domestic fowl.-Cysticercus, sp., Sappey. This is 
found in the muscles of the llama-Cysticercus suis, Cobbold. See Cysticercus tenia solit, Leuckart. -Cysticercus tæniz bothrioplitis, Piana. This is found in the snails Helix carthusianella, Draparnaud, and Helix maculosa, the mature form occurring in the domestic fowl.-Cysticercus tæniæ cesticillus, Goeze-Molin. Syn., Cysticercus tania infundibuliformis, Goeze. This is found in the house-fly. The adult (Tonice cesticillus, Molin, $q . v_{0}$ ) is found in the intestine of the domestic fowl. According to Grassi and Rovelli the earth-worm Allobophora fotida, Eisen, is its intermediate host.-Cysticercus tæniæ crassicollis, Rudolphi. This is found in the liver of various rats and mice and is remarkable for the elongated form and the smallness of the bladder in which it is coiled up. Von siebold demonstrated (I844) the relation of this finn to Tenice crassicollis, Rudolphi, of the cat.-Cysticercus tæniæ cucumerinz, Bloch. See Cysticercus taniaelliptica, Batsch. Cysticercus tæniæ cuneatæ, von Linstow. Occurs in the worm, Allobophora fatida, Eisen, and the adult in domestic fowls.-Cysticercus tæniæ diminutæ, Rudolphi. This is found in the orthopterous insect Anisolabis annulipes, Lucas; and the beetles Akis spinosa, Latr. and Scaurus striatus, Fabr., also in the meal-moth, Asopia farinalis, L.-Cysticercus tæniæ ellipticæ, Batsch. Syn., Cysticercus tania cucumerine, Bloch. This is found in the fleas (Pulex irritans, L. and Pulex serraticeps, Gervais) and the dog-louse (Trichodectes canis, De Geer).-Cysticercus tæniæ gracilis, Rudolphi. This is found in the perch (Perca fuviatilis) and by Thos. Scott in the ostracod crustacean Candona rostrata, which Blanchard holds to be the intermediate host of Tania gracilis, of the duck. Cysticercus tæniæ infundibuliformis, Goeze. See C. tania cesticillus, Molin-Goeze-Cysticercus tæniæ krabbei, Moniez, occurs in the reindeer (Cervus tarandus, Linné), the mature form being found in the dog.-Cysticercus tæniæ marginatæ, Batsch-Diesing. Syn., Cysticercus clavatus, Cysticercus coprinus, Cysticercus globosa, Cysticercus lineata, Cysticercus tenuicollis, Diesing, Cysticercus phacochori ethiopici, Cobbold, Cysticercus visceralis, Cysticercus ovis, Cobbold. This is the larva of Tania marginata, Batsch ; and is found in the peritoneum and sometimes in the muscles, liver, lungs, and heart of the sheep, goat, ox, camel, reindeer, and pig, and it seems, as the result of the researches of Eschricht and others, occasionally to occur in monkeys and man. It rarely produces serious effects, although at times it grows to the size of a child's head. The size and occurrence have perhaps led to its being confused and ranked with Echinococcus, which has led to error, even as regards its human pathology, it having as a consequence been reckoned among human parasites, especially under the title, Cysticercus visceralis.-Cysticercus tæniæ microstomæ, Dujardin. Syn., Scolex decipiens, Diesing. This occurs in the orthopterous insect Anisolabis annulipes, Lucas; also in the beetle Tenebrio molitor, Fabricius. The mature form occurs in rats and mice.Cysticercus tæniæ proglottidæ, Davaine, occurs in the snails Limax agrestis, Linné, and Limax variegatus, Draparnaud. The mature form is found in the domestic fowl.-Cysticercus tæniæ saginatæ, Goeze-Leuckart. Syn., Cysticercus bovis, Goeze, Cysticercus mediocanellata, Davaine. Leuckart was the first (I86I) to show the relation of this finn to the tenia of the ox, in which animal it often occurs in great numbers, especially in Abyssinia, Russia, and the regions about the Mediterranean. The distribution in the tissues and organs varies. The peritoneum and lymphatic apparatus are rarely free from them; the kidneys, lungs, and liver contain relatively few ; the muscles especially contain great numbers; all other tissues and organs may be infected. In the examination of beeves the finns should especially be looked for in the masseteric region, the internal and external pterygoids, heart and tongue. Owing to the presence of calcareous particles, they assume a white color upon drying, which allows their presence to be made out, e.g., in dried beef; soaking will again render them invisible. E. Gavoy asserts that it has not been proved that the finns of Tania saginata do not exist in man.-Cysticercus tæniæ serratæ, Zeder, Groeze. Syn., Cy'sticercus pisiformis, Goeze, Cysticercus elon gatus, Leuckart, Monostoma leporis, Kuhn. This finn is the most common parasite in the peritoneum of the rabbit. It traverses the liver and, reaching the peritoneum, excites the formation of a cyst, which becomes full of fluid, and about the size of a pea. It occurs in such numbers as to resemble clusters of grapes. The white spot on the surface of each bladder locates the invaginated scolex.-Cysticercus tæniæ sinuosæ, Zeder. Occurs in the crawfish (Astacus fluviatitis, Rondelet), and the mature

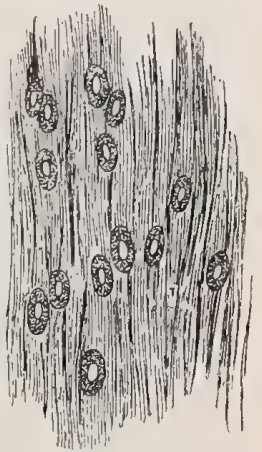

form in the domestic duck. - Cysticercus tæniæ solii, Leuckart. Syn., Tania hydatigena, Pallas; Cysticercus cellulose, Leuckart; Cysticercus albopunctatus, Cysticercus racemosa (us), Zenker; Cysticercus acanthotrias, Weinland (1858); Cysticercus suis, Cobbold; Cysticercus canis, Cysticercus multilocularis, Cysticercus pyriformis, Cysticercus finna. This is the finn of Tania solium.
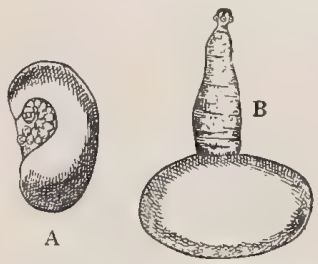

CYSTICERCUS TANIF SOLIY, Leuckart ; or the common bladder-worm of the pig, (A) with invaginated head, and (B) with evaginated head. (After Leuckart.)

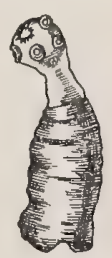

CYSTICERCUS TAEIAE SOLII, Leuckart : or bladder-worm of the pig, after the digestion of the bladder. $(x$ io $)(A f t e r$ Leuckart.
Küchenmeister was the first to point out the relation between this bladder-worm and the hook-bearing Tanice solium. It causes the disease known as measles and is found in swine, dogs, cats, and man, and occurs in all tissues and organs, producing small tumors which are readily recognized when subcutaneous; when in the brain various apoplectiform or epileptiform symptoms, paraplegia, violent cephalalgia, vomiting, vertigo, staggers (tournoiement, tournis), convulsions, narrowing of the field of vision and deafness may ensue. When in the brain the symptoms resemble those of Tabes dorsalis. No treatment has been found for cerebral cysticercosis; some cases recover. The enforced inspection of meats is important in this connection.-Cysticercus tarandi. See Cysticercus tenia krabbei, Moniez.-Cysticercus tenuicollis, Cysticercus visceralis. See Cysticercus tenia marginata, Batsch-Diesing.- Cystomonas urinaria, R. Blan- 
chard (1885). Syn., Trichomonas irregularis, Salisbury (1868); Bodo urinarius, Künstler (1883). A peculiar flagellate infusorian found in human urine and vaginal mucus.-Cystotænia mediocanellata, Leuckart (1862). See Trnia saginata, Goeze, 1782. - Cytodites nudus, Vizioli. Syn., Cytoleichus sarcoptoides, Mégnin; Sarcoptes gerlachi, Rivolta. This is found in the air-sacs of the Gallinacea, especially fowls and pheasants. They even reach the air-canals in the bones, and are supposed to cause enteritis. Cytoleichus sarcoptoides, Mégnin. See Cytodites nudus, Vizioli.-Cytospermium villorum intestinalium canis, Rivolta. Oviform, tetrasporous coccidia found by Railliet and Lucet in the small intestine of the dog and cat. See Coccidium bigeminum, Stiles.-Cytospermium zürnii, Rivolta. This was reported by Pröger and Zürn from the intestine, liver, and glands of calves. It is probably Coccidium perforans, q.v. Cytosporozoōn malariæ, Danilewsky. See Polimitus malarice, Laveran.-Cytozoa pathogena. The hematocystis of man and animals, found in malarial and other fevers. See Polimitus malaria, Laveran. Dactylius aculeatus, Curling. See Euchytraus albidus, Henle.-Dasytricha ruminantium, Schuberg. A holotrichous infusorian of the esophagus and stomach of ruminants.-Deer-tick, Western. See Dermacentor occidentalis, Linné.-Demodex canis, Tulk. See Demodex folliculorum, var. canis. -Demodex folliculorum, Owen. Syn., Acarus folliculorum, Simon (1842); Demodex folliculorum, var. hominis, canis, cati, suis, ovis, capra, equi, Küchenmeister ; Demodex caninus, Tulk; $D$. phylloides, Csokor; Macrogaster platypus, Miescher (1843); Entozoön follicularum, Erasmus Wilson (1845); Steatozoön follicularum, E. Wilson (1847) ; Simonea follicularum, Gervais (1844); Simon et Simonide, Fr. This is found in the hair-follicles and sebaceous glands of several species of mammalia: dog, cat, pig, sheep, goat, ox, deer, fox, rat, mouse, and bat. The dermatosis produced by this parasite has been most frequently and best studied in the dog. Nearly every known parasiticide has been tried for the cure of follicular scabies of the dog, but generally in vain (Neumann). Sulphur baths and applications of creolin or essence of juniper have given fair results.-Demodex phylloides, Csokor. See Demodex folliculorum, var., suis.-Dermacentor americanus, Linné. The American dog-tick. Cf. Ixodes ricinus, Linné. Dermacentor occidentalis, Linné. The western deer-tick of the United States.-Dermanyssus avium, De Geer. Syn., Dermanyssus gallina, Redi ; Dermanyssus gallopavonis, Gervais; Dermanyssus hirundinus, De Geer; Tique, Raspail. Gamasides which live on birds and may be transmitted to domestic mammalia : rabbits, dogs, cats, cows, and man. They are found in dove-cotes and poultry-yards, and are essentially noctambulatory. They frequently enter the nasal cavities or auditory meatus. In nasal or auricular acariasis, olive-oil, to which has been added a little ethereal essence of anise-seed, should be introduced by means of a thin feather. Oily mixtures, sulphuret of carbon and creolin are the most favored remedies for the dermatoses produced by this insect. -Dermanyssus gallinæe, Redi.-Dermanyssus gallopavonis, Gervais.-Dermanyssus hirundinis, De Geer. See Dermanyssus avium, De Geer.-Dermatobia cyanoventris, Moquin-Tandon. This differs from Dermatobia noxialis, Brauer, in the azure hue of the entire abdomen; its habits are the same.-Dermatobia hominis. See Dermatobia noxialis, Brauer. Dermatobia noxialis, Brauer (1860). Syn., Dermatobia hominis; Cstrus guildingi, Hope (1840);
Cuterebra noxialis, J. Goudot (1845). A bot-fly of Central and South America, the eggs of which are not infrequently deposited in the skin of animals and man, producing a swelling like an ordinary boil. In New Grenada this larva is know as Nuche, Gusano, or Macaco Worm, in Cayenne as the Macaw Fly, in Brazil as Ura, in Costa Rica as Torcel, and in Mexico as the Moyoquil Worm. It attacks chiefly the ox and dog, while mules and horses are exempt. In countries in which the parasite is abundant, the skins of slaughtered cattle are frequently so perforated as to be of little value.-Dermatodectes communis, Bourguinon and Delafond.-Dermatodectes equi, Gerlach. See Psoroptes communis, var. equi, Fürstenberg.Dermatokoptes communis, Fürstenberg. See Psoroptes communis, Fürstenberg.-Dermatophagoides scheremetewski, Bogdanow. See Symbiotes communis, Verheyen.-Dermatophagus cuniculi, Zürn, 1872. See Sarcoptes notcedres, Delafond and Bourguinon, 1857.-Dermatophilus penetrans, Guerin. See Sarcopsylla penetrans, Westwood.-Dermestes lardarius, Linné. The larvæ of this beetle, besides devouring dead bodies, skins, leather, etc., develop at times in the old manure of the dove-cote and attack the young pigeons, gnawing the skin of the neck and abdomen. The best preventive measure consists in covering the floor of the dove-cote and the nest with pine sawdust mixed with sand. The larvæ are also reported as facultative parasites of man by Otto and Chichester (England).-Dermestes murinus, Linné. The larva is reported as a facultative parasite of man by Otto and Lister.-Dermofilaria irritans, Rivolta. See Filaria irritans, Rivolta.-Dermoglyphus elongatus, Mégnin. One of the plumicole sarcoptidæ found on the quill of the feathers of the domestic fowl.-Dermoglyphus minor, Nörner. Syn., Analges minor, var. similis, Nörner. This is found in the quill of the feathers of the guinea-fowl. -Dermoglyphus varians, Trouessart. One of the Analgesina observed on the guinea-fowl, in the quill of the beam-feathers of the large wing-covers along with picobia. It is possibly only a variety of Dermoglyphus elongatus of the fowl.-Deutscher Blutegel. See Hirudo medicinalis, Ray.-Diacanpolycephalus, Stiebel, Bremser, Rudolphi, Diesing. Determined by Blumenbach to be a raisin-stalk which had been evacuated per anum. - Dibothrium cordatum, Diesing. See Bothriocephalus cordatus, Leuckart. - Dibothrium latum, Diesing (1805). See Bothriocephalus latus, Bremser. Diceras rude, Rudolphi, Lamarck. Syn., Cysticercus bicornis, Zeder, Ditrachyceras medis, Sultzer, Bremser, Diesing, Eschricht, Lerreboullet. A carpel of the mulberry (Morus nigra), which had been macerated and deprived of its color by digestion.Dicrocœlium buskii, Weinland (1858). See Distoma crassum, Buck, Cobbold, Leuckart. - Dicrocoelium heterophyes, Weinland (1858). See Distoma heterophyes, von Siebold (1852), -Dicrocalium oculi humani, Weinland (1858). See Distoma lanceolatum, Mehlis.-Dimorphus muris, Grassi (1879). See Megastoma intestinale, R. Blanchard (1885).-Dioctophyme, Collet-Meygret. See Eustrongylus gigas, Diesing. - Diplacanthus nanus, Weinland (1858). See Tenia nana, von Siebold (r853).-Diplodinium bursa, Fiorentini. A peritrichous infusorian found in the stomach of ruminants, associated with the following species: Diplodinium cattanei, Fiorentini; Diplodinium caudatum, Fior.; Diplodinium dentatum, Stein; Diplodinium ecauda$t u m$, Fior. (considered by Fiorentini to be only a rarer form of $D$. candatum); Diplodinium maggi, Fior.; 
Diplodinium mammosum, Railliet; Diplodinium ros. tralum, Fior. ; Diplodinium uncinatum, Fior. (found in the large intestine of horses); Diplodinium vortex, Fior-Dipylidium cucumerina, Leuckart (1863). See Tania canina, Linné (I767).-Dipylidium latissima, Riehm.-Dipylidium leuckarti, Riehm. -Dipylidium pectinatum, Riehm. See Tenia pectinata, Goeze.-Diskostoma acephalocystis, Goodsir (1844). See Eichinococcus polymorphus, Diesing (I85I).-Dispharagus nasutus, Rudolphi. Syn., Filaria nasula, Rudolphi ; Spiroptera nasuta, Rudolphi. A filaria-like worm found in the wall of the gizzard of the fowl and sparrow, at times so closely packed together as to form a kind of tissue and giving rise to an epizoöty.-Dispharagus spiralis, Molin. This was found in the esophagus of the fowl and also in the intestine by Fedschenko in Turkestan.-Distoma armatum, Molin, is found in the intestine, cecum, and rectum of the domestic fowl in Italy.Distoma buskii, Wedl, Lankester (1857). See Distoma crassum, Busk.-Distoma campanulatum, Ercolani. See Distoma truncatum, Rudolphi.Distoma capense, J. Harley. See Gynacophorus hamatobius, Diesing; Distoma caria, Sonsino. This was found by Del Chiappa in the biliary ducts of the guinea-pig. It resembles Fasciola hepatica, of which Neumann suggests that it may be but a young form.Distoma columbæ, Mazzizanti. See Mesogonimus commutatus, Sonsino.-Distoma commutatum, Diesing. See Mesogonimus commutatus, Sonsino.Distoma conjunctum, Cobbold (1859). Moniez regards it as not unlikely that this is identical with Distoma sinense, Cobbold, rather than with Distoma truncatum, Rudolphi. See Distoma truncatum, Rudolphi._Distoma conus, Creplin. See Distoma truncatum, Rudolphi._Distoma crassum, Busk (1859), nec von Siebold (1836), Cobbold, Leuckart. Syn., Distoma buskii, Wedl, Lankester (1857) ; Dicrocolium buskii, Weinland (I858). This was found in the human intestine. "No other instance has occurred since the original fourteen specimens were discovered by Mr. Busk in the duodenum of a Lascar" (Cobbold). -Distoma cuneatum, Rudolphi. This was found by Gurlt in the oviduct of the peacock. Rudolphi considers it very similar to Distoma ovatum, Rudolphi. -Distoma dilatatum, Miram. Found in the rectum and cecum of the domestic fowl; rare.-Distoma echinatum, Zeder. Dujardin and von Linstow consider Distoma oxycephalum, Rudolphi, as a variety of this species. It is found in the intestine of the domestic duck and goose, rarely in the fowl. Generali found it in the duodenum of a dog and Nathusius in the black stork. According to the researches of Pagenstecher and Ercolani, the larvæ (Cercaria echinatoides) are the most common distome larvæ found in the aquatic molluscs, Limnoea, Planorbis, and Paludina.-Distoma elegans, Rudolphi, is found in the intestine of the domestic sparrow.Distoma elephantis, Jackson. See Fasciola jacksoni, Cobbold.-Distoma endemicum, Ijima. See Distoma sinense, Cobbold.-Distoma felineum, Rivolta. See Distoma truncatum, Rivolta.-Distoma filum, Dujardin. This is found in the intestine of the domestic sparrow.-Distoma hæmatobium, Bilharz. See Gynacophorus hematobius, Bilharz-Distoma hepaticum, Retzius (1786), Abildgaard, Zeder, Mehlis. See Fasciola hepatica, Linné (I767). Cf. Distoma lanceolatum, Mehlis. Cf. Fasciola jacksoni, Cobbold.-Distoma hepatis endemicum seu perniciosum; Distoma hepatis innocuum, Baelz (1883). See Distoma sinense, Cobbold.-Distoma heterophyes, von Siebold (1852), Küchenmeister,
Bilharz. Syn., Fasciola helerophyes, Moquin-Tandon (I860); Dicrocalium heterophyes, Weinland (1858). -Distoma japonicum, R. Blanchard (1886). See Distoma sinense, Cobbold.-Distoma lanceolatum, Mehlis (1825), Bucholz, Dujardin. Syn., Distoma hepaticum, Zeder (I800), Rudolphi (I8IO), Bremser ; Distoma opthalmobium, Diesing (1850), Küchenmeister; Distoma lentis, von Ammon; Distoma oculi humani, von Ammon (1833), Gescheidt ; Dicrocalium Lanceolatum, Dujardin (I845), Weinland; Dicroca. lium oculi humani, Weinland; Fasciola hepatica, Block (1782), Jördens (1802), Bosc; Fasciola lanceolata, Rudolphi (1803), Moquin-Tandon; Fasciola ocularis, Moquin-Tandon (1862); Festucaria lentis, Moquin-Tandon (1860); Monostoma lentis, Nordmann (I832), Gescheidt, Diesing; Planaria latiuscula, Goze $(\mathbf{1 7 8 2}$ ). This is found in the gall-bladder, bile-ducts, and intestine of sheep, cattle, llama, rabbit, hare, pig, ass, horse, dog, cat, and man. In the last the recorded cases are few and include in all probability the trematodes of the eye described by Gescheidt, von Ammon, and others. The larva, Cercaria longicaudata, is found in Helix carthusiana, Müller, and Planorbis marginatus, Draparnaud. Leuckart believed Cercaria cystophora was the larval form of Distoma lanceolatum. - Distoma lentis, von Ammon. See Distoma lanceolatum, Mehlis.-Distoma lineare, Rudolphi. See Syngamus trachealis, von Siebold.Distoma lineare, Zeder. This is found in the large intestine of the domestic fowl ; rare.-Distoma magnum, Bassi (1875). Syn., Fasciola carnosa, Hassall (July, I89I) ; Fasciola americnna, Hassall (Sept., I89I); Distoma texicanum (Oct., I89I). This parasite occurs in Antilope picta, Bos taurus, Cervus aristoteles, Cervus canadensis, Cervus dama, Cervus elephas, Cariacus (Cervus) viroinianus. It is abundant in Western cattle.-Distoma musculi, Rudolphi. This is found in the intestine of the house-mouse (Mus musculus, Linné).-Distoma oculi humani, von Ammon (I833), Gescheidt. See Distoma lanceolatum, Mehlis.-Distoma ophthalmobium, Diesing (1850). See Distoma lanceolatum, Mehlis.-Distoma ovatum, Rudolphi. Possibly D. cuneatum is identical with this species. This is found in the oviducts and eggs of the domestic fowl, in the intestines of the domestic goose, and in the bursa of Fabricius of numerous young birds, including the fowl.-Distoma oxycephalum, Rudolphi. See Distoma echinatum, Zeder.-Distoma pellucidum, von Linstow. See Mesogonimus pellucidus, Neumann.-Distoma pulmonale, Baelz (1883). See Distoma ringeri, Cobbold (I880).-Distoma rathouisi, Poirier. This was found in the liver of a Chinaman at the mission of Zi-kawei, named after Père Rathouis, and at first sight resembles in size and general form Fasciolo hepatica, Linné,-Distoma ringeri, Cobbold and Manson (ז880). Syn., Distoma pulmonale, Baelz (1883). This is found in the human lungs in the mountainous regions of Formosa, Corea, and Japan. producing a parasitic hemoptysis, the treatment of which has thus far been unsuccessful.-Distoma sinense, Cobbold (1875). Syn., Distoma spathulatum, Leuckart (1876); Distoma hepatis endemicum seu perniciosum, Baelz (1883); Distoma hepatis innocuum, Baelz (1883); Distoma japonicum, Blanchard (1886); Distoma endemicum, Ijima. It is held by Moniez as not unlikely that the Distoma conjunctum of Cobbold belongs here. It is found in the liver, biliary ducts, and intestine of man and the cat in Japan, especially in the region of Okayama.-Distoma spathulatum, Leuckart (1876). See Distoma sinense, Cobbold (1875).-Distoma spiculator, 
Dujardin. This is found in the small intestine of the brown rat (Mus decumanus, Pallas).-Distoma, sp., Duncker. This larva was found by Leunis encapsulated in the muscles of the domestic hog, in the fleshy part of the diaphragm, and in the laryngeal muscles. Distoma texicanum, Francis (Oct., 189r). See Distoma magnum, Bassi (1875).-Distoma truncatum, Rudolphi, Ercolani. Syn., Distoma conus, Creplin; Distona conjunctum, Cobbold (1859); Dis toma felineum, Rivolta; Distoma campanulatum, Ercolani. According to Neumann, this Distoma was first found in the Greenland seal (Otto and Rudolphi), then in the cat (Creplin, Rivolta, Zwaardemaker, Generali), dog (Ercolani, Rivolta, Zwaardemaker, De Jong, Sonsino), American red fox (Cobbold), Indian Pariah dogs (Lewis). It is frequent in $\mathrm{Hol}_{-}$ land and in India. It lodges itself in the bile-ducts and gall-bladder, and gives rise to a cirrhosis, which has been studied by Zwaardemaker and Neumann-. Ditrachyceras rudis, Sultzer. See Diceras rude, Rudolphi.-Dochmius a n chylos toma, Molin (1860). See Dochmius duodenalis, Leuckart.-Dochmius balsami, Pavona. See Uncinaria trigonocephala, Rudolphi.-Dochmius duodenalis, Leuck-
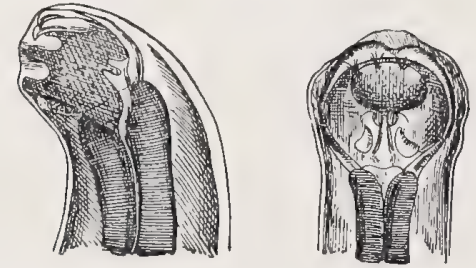

Cephalic extremity of DocHMiUs DUODENALIS, Leuckart profile and front view. (After Leuckart.)

art (1876). Syn., Anchylostoma duodenale, Dubini (1843); Dochmius anchylostoma, Molin (1860); Anchylostomum duodenale, Creplin (1845); Pruner (1847); Dubini (1850); Diesing (1851); Sclerestoma duodenalis, Cobbold; Strongylus duodenalis, Schneider (1866); Strongylus quadridentatus, von Siebold (I85I); Uncincaria duodenalis, Railliet (1885). This nematode occurs in immense numbers in the duodenum of man in many tropical and sub-tropical countries, causing a peculiar anemia known to the Ancient Egyptians as the " $\bar{a} a \bar{a}$ disease" and in modern times as dochmiasis, anchylostomiasis, Egyptian chlorosis, chlorosis agyptiaca, tropical chlorosis, hypocmia intertropicalis, brick-makers' anemia, tunnel anemia, miners' cachexia, anamia vel cachexia montana, jail debility. Oswald Baker reports having found the ova in the evacuations of the dog, and Lutz records the parasite in the gibbon. Giles and Sinclair find the disease known as Beri-beri and the Kala-gar of Assam and Ceylon to be identical with dochmiasis. No intermediate host is necessary, but the eggs are not able to develop in the intestine if swallowed immediately after they have been laid. They must first develop into rhabditiform larvæ in muddy water or upon damp earth, which, after moulting two or three times, reach a stage in which they can develop no more outside the human intestine. The ethereal extract of male fern is a favorite remedy, but Sonsino, Macdonald, and others regard thymol as almost a specific. Perfect cleanliness must, of course, be insisted upon, as this parasite has no intermediate host, it being conveyed directly through dirt or food contaminated with infected feces.-Dochmius sängeri, Cobbold (1882). This is found in the intestine of the Indian elephant. To the naked eye this small worm looks like an ordinary thread-worm, but a hand lens is sufficient to demonstrate its strongyloid character.-Dochmius stenocephalus, Railliet. See Uncinaria stenocephala, Railliet-Dochmius trigonocephala, Dujardin. See Uncinaria trigonocephala, Rudolphi._Dochmius tubæformis, Molin. See Uncinaria trigonocephala, Rudolphi.-Docophorus adustus, Nitzsch. See Docophorus icteroides, Nitzsch.-Docophorus icteroides, Nitzsch. A louse frequent on ducks, relatively rare on geese, on which according to Piaget, it constitutes a mere variety called by Nitzsch Docophorus adustus.-Dog-flea. See Pulex serraticeps, Gervois. - Dog-lice. See Hamatopinus piliferus, Burmeister, and Trichodecles latus, Nitzsch.-Dog-tick. See Ixodes ricinus, Linne, and Dermacentor americanus, Linné.-Domestic Fly. See Musca domestica, Linné.-Douve du foie. See Fasciola hepatica, Linné. Dovecote Bug. See Acanthia columbaria, Jenyns.-Draconcilla Sp.Dracunculus, Lister (I690). See Dracunculus medinensis, Cobbold (1864).- Dracunculus loa, Cobbold (1864). Syn., Dracunculus oculi, Diesing (1860) ; Loa, Guyot, Bajon, Mongin, Guyon, etc. ; Filaria medinensis, Gmelin ; Filaria hominis ovis, Leidy ; Filaria lacrymalis, Dubini (1850, nee Gurlt, 1831); Filaria oculi, Gervais, Van Beneden, Moquin-Tandon; Filaria loa, Guyot (1778). A parasite found beneath the conjunctiva of negroes of the Gaboon and Congo region also reported from $\mathrm{S}$. America, Martinique, San Domingo, etc. The natives state that after a period of several years the worm voluntarily quits the eye.Dracunculus longissimus, Cæsalpinus (1585). See Eustrongylus gigas, Diesing (185I). Dracunculus medinensis, Cobbold (1864). Syn., D. persarum, Kämpfer (1694), Diesing ; Filaria medinensis, Gmelin, (1789), Olfers, Rudolphi ; Filaria dracunculus, Bremser (1819), McClelland, Pruner; Filaria romanorum orientalis, Sarcani ; Furia medinensis, Modeer (1795) ; Gordius medinensis, Linné (1767), Grundler; Vena medinensis, Velsch (I674), Dracunculus, Lister (1690); Vermis medinensis, Grundler (1740); Medinaworm, Guinea-worm, Filaira de médine, Filaire de Guinnée, Ver de Guinée dragoneau, Ver cutanee des marchais, Veine de medine, Fr.; Fadenwurm, Hauawurm, Beinwurm, Pharaohswurm, Guineawurm, Medinazurm, Medinerischer oder guineischer Fadenwurm, Ger.; Draconcillo, Sp.; Kishta, Rus.; Pejunk, Narn, Pers.; Narambo, Narapoo chalandy, Hind.; Hanschoschim Haschrofm, Heb.; $\Delta$ ракбvтіо uikpov, Agatharchidas (Plutarch, Symposiacon viii), a parasite known to the ancients, being the "fiery serpents" which afflicted the children of Israel during their stay in the neighborhood of the Red Sea, which is still the center of the geographic distribution of the worm. It is exclusively confined to hot countries, Arabia Petræa, the border of the Persian Gulf and Caspian Sea, the banks of the Ganges, Upper Egypt, Abyssinia, Guinea, and the Upper Senegal. It also occurs in the West Indies, Guiana, and Brazil. Although chiefly known as a parasite of man, it has been found in the dog, horse, and ox, the disease produced by it being known as dracontiasis. The worm is supposed to have small crustaceans (Copeporla) as its intermediate hosts, and to be taken in drinking-water. Carter suggests the house-fly as its intermediate host. It occurs in the subcutaneous connective tissues, especially of the legs and feet. It is usually removed by gentle and continued traction, but the natives of India hold the plant Amarpattee, or Rádpáná, as a specific in the shape of applications of the bruised leaves.-Dracunculus oculi, Diesing (I860). See Dracunculus loa, Cobbold (1864).- 
Dracunculus persarum, Kæmpfer (I694). See Dracunculus medinensis, Cobbold (I864).-Dracunculus spathulum, Leuckart. See Distomum sinense, Cobbold (I875).-Dragon d'alger, Dragon-leech. See Hirudo troctina, Johnson.-Duck-louse. See Liperurus squalidus, Leach.-Dünndarmbremse. See Gastrophilus nasalis, Linné.-Dyticus marginalis, Linne. A beetle the larva of which is reported as a human pseudo-parasite by Hope.-Earwig. See Forficula auricularia, Linné. - Echinococcifer echinococcus, Weinland (I86I). See Tenia echinococcus, von Siebold, (1853).-Echinococcus altricipariens, Küchenmeister; Echinococcus alveolaris, Bernsteiner; Echinococcus aristis, Blanchard; Echinococcus cerebralis, Perroncito; Echinococcus endogenus, Kubl ; Echinococcus exogenus, Kuhl; Echinococcus gallopavonis, von Siebold; Echinococcus giraffæ, Gervais (1847); Echinococcus granulosus, Rudolphi (I810), Leuckart; Echinococcus hominis, Rudolphi (I81o), Bremser, Chiaje ; Echinococcus hydatidosus, Leuckart; Echinococcus infusorum, Fr.; S. Leuckart (I827); Echinococcus multilocularis, Leuckart. See Echinococcus polymorphus, Diesing.-Echinococcus polymorphus, Diesing (185I), Leidy. Syn., Acephalocystis endogena, Hunter, Owen; Acephalocystis exogena, Kuhl; Acephalocystis granulosa, Lænnec (1804), Cloquet; Acephalocystis macaci, Cobbold; Acephalocystis oris tragelaphi, Cobbold ; Acephalocystis ovoidea, Lænnec (1804), Cloquet, Deslongchamps, Chiaje ; Acephalocystis curculigera, Lænnec (1804), Diskostoma acephalocystis, Goodsir (1844), Echinococcus alveolaris, Bernsteiner; Echinococcus altricipariens, Küchenmeister; Echinococcus arietis, Blanchard ; Echinococcus cerebralis, Perroncito; Echinococcus endogenus, Kuhl; Echinococcus exogenus, Kuhl; Echinococcus gallopavonis, von Siebold; Echinococcus giraffa, Gervais; Echinococcus granulosus, Rudolphi ; Echinococcus hydatidosus, Leuckart; Echinococcus hominis, Rudolphi, Leidy, Bremser, Chiaje; Echinococcus infusorum, Fr., S. Leuckart (I827); Echinococcus multilocularis, Leuckart; Echinococcus scolepariens, Küchenmeister; Echinococcus simice, Rudolphi (I8IO); Echinococcus simplex, Leuckart; Echinococcus veterinorum, Rudolphi (I8Io), Bremser, Gurlt, Blanchard; Hydatigena granulosa, Batsch (1786); Hydatis, Lỉdersen, Rudolphi, Olfers, Bremser; Hydatis erratica, Blumenbach (1810); Polycephalus hominis, Goeze (1782), Jördens (1802); Polycephalus humanus, Zeder (1803); Polycephalus granulosus, Zeder (1803), Cloquet; Polycephalus echinococcus, Zeder (1803), Tschudi; Tania visceralis socialis granulosa, Goeze (1782); Tania granulosa, Gmelin (I790); Vesicaria granulosa, Schrank (I 788). The " hydatids," " acephalocysts," "echinococcus-vesicles," "pill-box vesicles," etc., of medical writers. This parasite is the finn of a small tapeworm (Tania echinococcus, von Siebold, 1853) which infests only the dog and the wolf, occurring in a great variety of animals; it was long regarded as an independent and distinct animal, varying specifically in different hosts and organs. Echinococci have been found in man, monkeys, the dog, cat, ichneumon, rabbit, squirrel, pig, wild boar, ox, argali, sheep, goat, deer, giraffe, camel, dromedary, elan, antelope, horse, zebra, elephant, tapir, kangaroo, and turkey. They are most frequently found in ruminants, the pig and the dog, and are endemic in Iceland and abundant in regions where large numbers of cattle are raised. They are found in all parts of their host, but the liver is the favorite location.-Echinococcus veterinorum, Rudolphi (1810). See Echinococcus polymorphus, Diesing (185I).-Echinorhynchus an- gustatus, Rudolphi. A parasite of fresh water fishes. -Echinorhynchus capræ, Braun (1810). See Linguatula rhinaria, Railliet, I 886.-Echinorhynchus cuniculi, Bellingham. This is found in the small intestine of the domestic rabbit.Echinorhynchus filicollis, Rudolphi. This is found in the intestine of the domestic duck.Echinorhynchus gigas, Goeze (1782). Syn., Echinorhynchus hominis, Lambl (1859); the Giant Echinorhynchus. This parasite is found in the small intestine of the hog, the wild boar, the collared peccary and the striped hyena. It is common in India, North Africa, France, Germany, and Austria, and occurs in the United States and Mexico. Only one case, regarded by Leuckart as accidental, is recorded of its occurrence in man. Kaiser finds that the common rose-chafer (Cetoma aurata, Linné) swallows the larva of this worm from the excrement of the pig, and is probably the intermediate host of the worm. Schneider regards the white worm, the larva of the ordinary May-bug (Melolontha vulgaris, Fabricius) as the intermediate host, and Lespès caused the ova of this parasite to be hatched in the intestine of several species of snails (Helix promatia, Linné; Helix hortensis, Müller; Limax maximus, Linné; Arion rufus, Linné.) - Echinorhynchus hominis, Lambl (1859). See Echinorhynchus gigas, Goeze (I782). - Echinorhynchus miliaris, Zenker. See Echinorhynchus polymorphus, Bremser. -Echinorhynchus moniliformis, Bremser. This parasite,

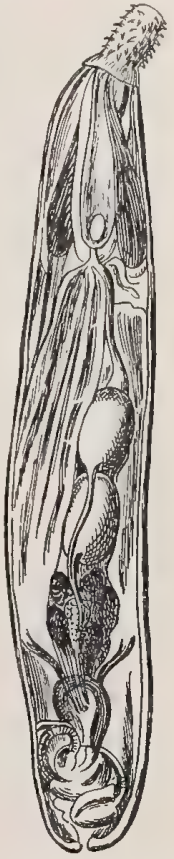

A male EchINORHYNCHUS ANGUSTATUS, Rudolphi. (The internal organs consist of the sheath of sist of the sheath of
the proboscis, with retractor muscles, lemniscus, and sexual organs. An intestine is wanting. (After Leuckart.)

known to occur rarely in the field-mouse (Arvicola arvalis, Selys-Longchamps) and the hamster (Cricetus frumentarius, Pallas), has been proved by Grassi and Calendruccio to occur in the brown or Norway rat (Mus decumanus, Pallas) and in man, the second investigator having himself voided over fifty specimens from his intestine after taking extract of male fern. The common churchyard-beetle (Blaps mortisaga, Linné) is the intermediate host of this parasite.-Echinorhynchus muris, Zeder. This is found in the stomach of the house-mouse (Mus musculus, Linné).-Echinorhynchus polymorphus, Bremser. This is found in the intestine of the tame swan (Cygmus odor, Linné) and the domestic goose (Anser domesticus, Linné). Graeff has recognized the larval form of this parasite in the freshwater shrimp (Gammanuspulex, (L.) De Geer), in which it has been named Echinorhynchus miliaris, Zenker. Von Siebold found it frequently encysted in the intestinal walls of the crayfish (Astacus fruviatilis, Rondelet). - Echinorhynchus sphæzocephalus, Bremser. This is found in the intestine of the domestic duck (Anas domestica, Linné).-Echinorhynchus, sp., Lewis. This is found in the walls of the stomach of the dog.-Egyptian Ixode. See Ixodes agyptius, Linné, and Ixodes savignyi, P., Gervais.-Eimeria falciformis, Eimer. A psorosperm found by Rivolta, d'Arloing, Tripier, and Silvestrini in the liver of the 
rabbit, but previously only found in the intestinal epithelium of the mouse. Artificial psorospermosis was produced by feeding birds with masses of affected flesh.-Eimeria Sp., Blanchard. R. Blanchard refers to this genus as the parasite mentioned by Rivolta in chickens, and which the latter regarded as Sarcosporidia. Probably the parasites of Kübn belong here also.-Elophilus pendulus. See Helophilus pendulus, Méigen,-Emasculating Bot. See Sitomyscalifornicus.-Enchytrœus albidus, Henle. Under the name Dactylius aculeatus, Curling described this setigerous annelid as having been observed in the urine of a girl five years old, undoubtedly introduced designedly, as this worm is not parasitic, but common in garden-earth.-Entodinium bursa, Stein. A peritrichous infusorian found in the rumen of the ox and sheep, as are also the three following species: Entodinium caudatum, Stein; Entodinium minimum, Schuberg; Entodinium rostratum, Fiorentini.Entozoön folliculorum, Wilson (1845). See Demodex folliculorum, Owen (1843).-Epauletted Ixode. See Ixodes scapulatus, Mégnin.-Epidermoptes bifurcatus, Rivolta (I865). Produces a cutaneous acariasis of fowls.-Epidermoptes bilobatus (Rivolta), Railliet and Lucet (1891). Syn., Symbiotes avium, Caparini (1880). Produces a multiple cutaneous acariasis in fowls. - Epidermoptes cysticola, Rivolta. See Symplectoptes cysticola, Railliet.-Eristalis tenax, Linné. Syn. Ver a queue de rat, Rattenschreanzlarve, Rat-tailed larve. The larvæ are reported by Jewell from the human intestine. Under the name Cercosoma, Canali and Brera, Bremser, Rudolphi, Siebold, and Diesing described a larva of this fly, or Helophilus pendulus, which had accidentally got into the urine-Eucolus ærophilus, Creplin. See Trichiosoma arophilum, Creplin.-Eustrongylus gigas, Diesing (1851). Syn., Serpents des rognons des loups, Jean de Clamorgan (1570) ; Dracunculus longissimus casalpineus, $\left(1_{585}\right)$; Ascaris canis et martis, Schrank, (I788); Ascaris visceralis, Gmelin (I789); Ascaris renalis, Gmelin (I789); Fusaria visceralis, Zeder (I800); Fusaria renalis, Zeder (I800); Lumbri. cus in renibus, Blasius; Lumbricus martis et canis renalis, Redi; Lumbricus sanguineus in rene canis, Hartman; Les vers sortis des reins et de l'urèthre, Moublet; Lumbricus gulonis sibirici, Pallas; Dioctophyme, Collet-Meygret (1802); Strongylus gigas, Rudolphi (I802); Strongylus renalis, Moquin-Tandon (1860). This is the largest of the parasitic Nematodes. Its habitat is the kidney, although reported from the liver (Lissizin) and heart (Jones) of the dog. It is met with in man, the horse, ox, dog, wolf, mink, marten, weasel, otter, seal, glutton, raccoon, coati, etc. It is fortunately rare in man; the symptoms arising from its presence resemble those of renal abscess or calculus. The finding of the eggs in the urine is the most important diagnostic consideration. The intermediate host is unknown, though the Filaria cystica or Filaria piscium, Rudolphi, found by Schneider encysted in fishes, is held by some to be the larva of this worm. Oil of turpentine may cause migration of the worm, but extirpation is indicated.-Eustrongylus visceralis. See Eustrongylus gigas, Diesing.-Eutarsus cancriformis. An arachnidan found by Hessling and held by Cobbold to be a genuine human parasite.Eutodinium bursaria, Stein.-Eutodinium caudatum, Stein.-Eutodinium dentatum, Stein (I $85^{8}$ ). Three species of peritrichous infusoria resembiing Ophryoscolex, and described at the same time as endoparasitic in the first and second stomachs of ruminants. - Fadenwurm, Ger. See Dracunculus medinensis, Lister,-Fadenwurm des Augapfels.
See Fillaria conjunctiva, Addario. Falciger rostratus, Bucholz. This is found on pigeons and several other birds, chiefly in the subcutaneous connective tissue around the large veins of the neck and on the surface of the pericardium. The hypopial nympha of this parasite was described by Mégnin as Hypodectes columbe. According to Robertson, wild and tame pigeons are rarely free from these Acarina.-Fasciola americana, Hassall.-Fasciola carnosa, Hassall. See Distoma magnum, Bassi.-Fasciola hepatica, Linné $(\mathbf{I} 767)$, Pallas, Fabricius, Cobbold. Syn., Fasciola humana, Gmelin (1789), Fasciola lanceolatu, Rudolphi (I803), Distoma hepaticum, Retzius (1786), Abildgaard, Zeder, Mehlis; Planaria latizescula, Goeze; Douve du foie, Liverfuke. "The scientific nomenclature of this parasite involves a question of some importance. Amongst naturalists generally, the common liver-fluke is continually described under the Fasciola HEPATICA, combined generic and specific Linné. ( $A f t e r$ title of Distoma hepaticum, but

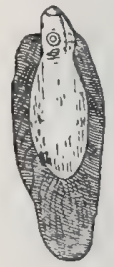
working parasitologists, who are at the same time acquainted with the writings of the earlier scientific observers, know very well that this title is both incorrect and inappropriate. The proper generic appellation of this parasite is Fasciola, as first proposed by the illustrious Linnæus $(1767)$ and subsequently adopted by F. Müller (I787), Brera (I8II), Ramdohr (I8I4), and others. Unfortunately, however, Retzius (I786) and Zeder (1800) changed the generic title without good cause, and the majority of writers, following their authority, obstinately refused to employ the original name, although fair dealing with the posthumous reputation of its distinguished author, and a consideration of the distinctive types of structure displayed by the two genera (Distoma and Fasciola), alike demand the retention of the Linnean title. In later times, M. Emile Blanchard (1847), of Paris, has strongly advocated the final adoption of the original nomenclature, and has also from time to time (in 1854-56-58-60 and I862) demonstrated the propriety of rejecting the commonly received synonym. Another distinguished French naturalist, namely, Prof. Moquin-Tandon, has also employed the term Fasciola, but by placing in the genus several

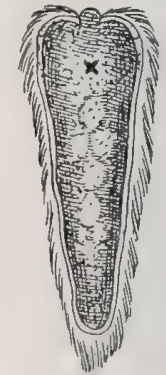

Free embryo of FasCIOLA HEPATICA, Leuckart.) species not properly belonging to it, such as $D$ is toma Ianceolatum and Distoma heterophyes, he has unwittingly rendered "confusion worse confounded (Cobbold)." This is preëminently a parasite of ruminants (ox, sheep, goat, camel), but it is also found in the hog, in the horse and ass (Daubenton), in the hare and rabbit (Cobbold) the squirrel (Tozzetti), kangaroo (Bremser, Diesing), antelopes and deer (Ploskal), beaver (Czermak), and man (Partridge, Giesker, Harris, etc.). It is usually found in the liver, gall-bladder, but sometimes wanders about, reaching the lungs and afterwards the muscles and connective tissue. The egg of the fluke, passing from the biliary duct through the intestine to the ground, gives rise to a ciliated embryo, which attaches itself to and penetrates the water-snail (Limnca minuta, Draparnaud, 
or L. truncalula, Müller, and Limnaa pereger, Draparnaud), in which it lodges in the respiratory cavity, and after encystment gives rise to redex and cercariz; the latter become free and finally infect mammals. Neumann suggests Limnaa humilis, Say, as the intermediate host in North America, and Limncea viator, d' Orbigny, in the Argentine Republic. Prophylaxis consists chiefly in keeping the sheep or cattle in dry pastures. According to Trasbot, the young buds of the maritime pine mixed with bran produce curative effects. Mojkowski obtained encouraging results with naphthalin. The regimen must be strengthening. The liver-fluke is found throughout Europe, except in Iceland. It is rare in Asia and North Africa, but is common in North and South America and Australia and Tasmania. Fascioliasis occurs most frequently in young animals and is increased by wet weather; the epizoöties always follow abundant and prolonged rains. - Fasciola heterophyes, Moquin-Tandon (1860). See Distoma helerophyes, Siebold.-Fasciola humana, Gmelin (1789). See Fasciola hepatica, Linné (1767). - Fasciola jacksoni, Cobbold (1869). Syn., Distoma hepatica, Jackson (1847), Distomum elephantis, Diesing (1858). This is found in the biliary ducts and duodenum of the Indian elephant and is the most important of the whole group of parasites infecting elephants.-Fasciola lanceolata, Rudolphi (I803). Moquin-Tandon.-Fasciola ocularis, Moquin-Tandon (1862). See Distoma lanceolatum, Mehlis (I825); also Fasciola hepatica, Linné (1767).-Fasciola trachea, Montague. See Syngamus trachealis, von Siebold.-Federmilbe der Tauben, Zürn. See Megninia asternalis, Mégnin. -Festucaria lentis, Moquin-Tandon (I860). See Distoma lanceolatum, Mehlis.-Filaire bronchiale, Fr. See Strongylus bronchialis, Cobbold.-Filaire de Guinea, Filaire de Médine. See Dracunculus medinensis, Cobbold (I864).-Filaire de 1'œil, Fr. See Filaria conjunctiva, Addario.-Filaire sousconjonctivale. See Filaria conjunctiva, Addario. -Filaria ægyptiaca, Sonsino. See Filaria sangrinis honinis, Lewis,-Filaria anatis, Rudolphi. Found in the heart of the domestic duck by Paullinus.-Filaria des Auges. See Dracunculus loa, Cobbold, Filaria lacrymatis, Gurlt, and Filaria lentis, Diesing.-Filaria bancrofti, Cobbold (1877). See Filaria sanguinis hominis, Lewis, -Filaria bronchialis, Rudolphi. See Strongylus bronchialis, Cobbold.-Filaria bubali, Rudolphi. See Filaria cervina, Dujardin.-Filaria canis cordis, Leidy. See Filaria immitis, Leidy.-Filaria capræ, von Linstow. This is found in the muscles of the domestic goat. Filaria cervi-elaphi, Rudolphi. See Filaria cervina, Dujardin.-Filaria cervina, Dujardin (I845). Syn., Filaria cervielaphi, Rudolphi ; $F$. papillosa, Rudolphi (ex parte) ; F. labiato-papillosa, Alessandrini ; F. terebra, Diesing (185I); F. bubali, Rudolphi (?); F. tentaculata, Mehlis (?) (1840). This is found in the abdomen, eye, and intestinal wall of domestic cattle and deer. Under the name of Thelozia, Bosc describes it from beneath the eyelids of an ox, but considers it to be an insect larva.-Filaria cincinnati, Perroncito. See Onchocerca reticulata, Diesing.-Filaria clava, WedI. This is found in the peritoneal connective tissue and intestines of the domestic pigeon. Filaria conjunctivæ, Addario (1885). Syn., Filaria palpebralis, Pace (1867) ; Filaria inermis, Grassi ; Filaire sous-conjonctinale, Filaire de l'xil, Fadenzourm des Augapfels. Found beneath the conjunctiva of the eye in man and the domestic ass and horse.-Filaria cygni, Rudolphi. Found by Redi in the intestine and abdomen of the tame swan.-Filaria cystica, Dobson. See Filaria 63 sanguinis hominis, Lewis,-Filaria cystica, Rudolphi. This was found by Schneider encysted in fishes and identified by him as the larva of Eustrongylus gigas, Diesing, though without sufficient reason, ac cording to Leuckart.-Filaria dermathemica, O'Niel (1875); da Silva Aranjo (1875). This was found as the cause of an endemic dermatosis of the negroes of the west coast of Africa. Leuckart reports an analogous disease among foxes, and Semmer in horses.-Filaria dracunculus, Bremser (1819). See Dracunculus medinensis, Cobbold (1864).-Filaria equina, Abildgaard, Emil Blanchard. Syn., Gordius equinus, Abildgaard; Filaria equi, Gmelin; Filaria papillosa, Rudolphi (ex parte Allesandrini); F. pellucida, Kennedy; Ascaris pellucida, Brown; Thelozia rhodesii, Desmarest (1828). This is found in the thoracic cavity, peritoneum, muscles, meninges, and eyes of the domestic horse and ass and mule, and is frequent in Upper India and Bengal, where it is known as sanp, or serpent in the eye. Usually but one eye is affected, the worms swimming about freely in the aqueous humor.-Filaria evansi, Lewis. This was found in the dromedary by Griffith Evans, the larvæ in the general circulation (resembling $F$. sanguinis hominis, Lewis), and the adults in the lungs and mesentery. Filaria hæmatica, Gruby and Delafond. See Filaria immitis, Leidy.-Filaria hæmorrhagica, Railliet. Syn., F. multipapillosa, Condamine and. Drouilly. This was found as the cause of cutaneous hemorrhage (homathydrosis) in horses, especially those of Eastern origin, the steppe breed, and white horses of Tartary.-Filaria hepatica, Cobbold. This was found by Mather encysted in the intestinal mucous membrane and biliary ducts of a dog. Railliet considers it a larval form.-Filaria hominis, Diesing (I85I).-Filaria hominis bronchialis, Rudolphi (I8I9). See Filaria lymphatica, Moquin-Tandon (1860).-Filaria hominis oris, Leidy (1850). Leidy suggested the identity of this worm with Dracunculus medinensis, Cobbold, in which Leuckart agreed. Blanchard and others oppose this view. It may, perhaps, be the Filaria lymphatica, Moquin-Tandon. The single specimen was obtained from the mouth of a child.-Filaria immitis, Leidy. Syn., Filaria hematica, Gruby and Delafond; Filaria canis cordis, Leidy; Filaria papillosa hamatica, Molin. This is found in the heart and blood-vessels of the dog. It is very abundant in Chinese dogs, and is also found in those of Europe, and North and South America. The larvæ are found in the dog-flea (Pulex serraticeps, Gervais) and in the dog-louse (Trichodectes canis, De Geer, and Homatopinus pilifererus Burmeister), and by Manson in the mosquito (Culex mosquito). According to Manson, these insects infest the drinking-water, from which the free-swimming larvæ are taken by dogs in drinking. Grassi disputes this. - Filaria inermis, Grassi (1887). See Filaria conjunctive, Addario - Filaria irritans, Rivolta. Syn., Dermofilaria irritans, Rivolta.-Filaria labialis, Pane (1864). A parasite found in a pustule on the lip of a man in Naples; perhaps it is identical with Filaria lymphatica, Moquin-Tandon.-Filaria labio or Filaria labiato-papilloso, Alessandrini. See Filaria cervina, Dujardin.-Filaria lacrymalis, Dubini (1850). See Dracunculus lon, Cobbold. Filaria lacrymalis, Gurlt (I83I). Syn., Filaria des Auges. This is found in the lacrymal duct and beneath the eyelids of the domestic ox. Baillet distinguishes it from the filaria of the horse $(F$. palpebralis, Wilson), than which it is more common. Its origin is unknown.-Filaria lentis, Diesing (I85I), Gervais, van Beneden, and Cobbold. Syn., Filaria 
oculi, Owen, Moquin-Tandon; Filaria oculi humani, von Nordmann (1832), Gescheidt, Ammon; Filaria des Auges, Ger. This is found in the crystalline lens of the human eye-Filaria leporis pulmonalis, Fröhlich, Diesing. See Strongylus commutatus, Diesing.-Filaria lienalis, Stiles. See Spiroptera reticuLata, Creplin.-Filaria loa, Guyot (I778). See Dra cunculus loa, Cobbold (I864).-Filaria lymphatica, Moquin-Tandon (I860). Syn., Hamularia lymphatica, Treutler (1793); Tentacularia sub-compressa, Zeder (I80o); Hamularia subcompressa, Rudolphi (I8Io); Filaria hominis bronchialis, Rudolphi (I8I9); Filaria hominis, Diesing (I85I); Strongylus bronchialis or Strongylus tracheo-bronchialis, Cobbold (1879); Filaire bronchiale, Fr. A parasite first observed by Bianchi, Treutler, and Brera, and afterward by Zahn and others, in the tracheal and peribronchial lymphatic ganglia of man. Diesing, Weinland, and Cobbold at one time believed this worm to be identical with Strongylus longivaginatus, Diesing, while Leuckart held Treutler's worm to be the male of Ascaris mystax, Rudolphi, and Brass that it was the larva of a fly. The Filaria hominis, Leidy (I850), and Filaria labialis, Pane (1864), may perhaps be identical with this parasite.-Filaria mansoni, Cobbold. This is found in the eye of the domestic fowl in China.Filaria medinensis, Gmelin (1789). See Dracun. culus medinensis, Cobbold (I864). - Filaria megastoma, Rudolphi. See Spiroptera megastoma, Rudolphi.-Filaria microstoma, Schneider. See Spiroptera megastoma, Gurlt and Schneider:-Filaria multipapillosa, Condamine and Drouilly. See Filaria hemorrhagica, Railliet.-Filaria muscæ, Carter. This was found in the horse-fly of India by H. J. Carter, who suggested that it might be the larva of the Guinea-worm (Dracunculus medinensis, Cobbold) of man.-Filaria nasuta, Rudolphi. See Disparagus nasutus, Rudolphi.-Filaria niellyi, Moniez. See Rhabditis niellyi, Blanchard. - Filaria obtusa, Schneider. Syn., Spiroptera obtusa, Rudolphi; Spiroptera murina, Leuckart. This is found in the stomach of the brown rat (Mus. decumanus, Pallas) and of the house mouse (Mus musculus, Linné). Filaria oculi, Owen. See Filaria lentis.-Filaria oculi, Gervais et van Beneden (I859). See Dracunculus loa, Cobbold.-Filaria oculi humani, von Nordmann (1832). See Filaria lentis, Diesing.-Filaria osleri, Cobbold. Syn., Strongylus bronchialis canis, Osler. A parasite found by Blumberg. Rabe, Renault, and Osler in tubercles of the trachea and bronchi in dogs, producing a bronchitis fatal in a large proportion of cases.-Filaria palpebralis, Pace (1867), Wilson. This is found beneath the eyelids or in the lacrymal canal of horses, causing at times severe conjunctivitis, with opacity of the cornea. R. Blanchard holds this to be identical with Filaria conjunctive, Addario (I885).-Filaria papillosa, Rudolphi. A term applied to the filaria of horses and cattle before Alessandrini indicated specific differences. See $F$. cervina and $F$. equina.-Filaria pellucida, Kennedy. This is considered by Neumann as a young form of $F$. equina, Abildgaard. - Filaria peritonei hominis, Babes (1880). This was found encapsulated in the gastrolineal ligament of man by Babes in Budapest. -Filaria piscium, Rudolphi, Siebold, Schneider (q.v.). A parasite held by some to be the larva of Eustrongylus gigas, Diesing. It is a parasite very abundant in many maritime fishes, particularly in the haddock, but never in the human being, in whom it was held to occur by Lawrence and others.-Filaria recondita, Grassi and Calandruccio, a name given to the adult form (yet undiscovered) of Hamatozoön

lezvisii, Grassi.-Filaria restiformis, Leidy (1880) This was found in the human urethra. - Filaria rhytipleuritis, Deslongschamps. This is found in the stomach of the brown rat (Mus decumanus, Pallas). The larva is found in the cockroach (Periplaneta orientalis, Linné).-Filaria romanorum orientalis, Sarcani. See Dracunculus medinensis, Cobbold (1864).-Filaria salisburyi. See $F$. sanguinis hominis, Lewis. Filaria sanguinis, Lewis. See Filaria sanguinis hominis, Lewis.-Filaria sanguinis equi, Sonsino. The name given to the filarial larvæ found in the blood of the horse. The adult form is unknown.-Filaria sanguinis hominis, Lewis

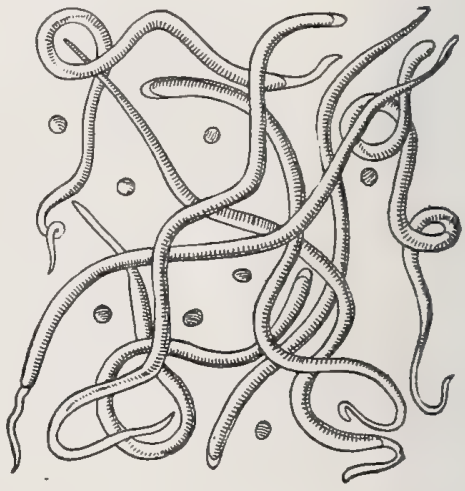

Filaria sanguinis hominis, Lewis. (From Leuckart, afler Lewis.)

(1872), Cobbold. Syn., Filaria bancrofti, Cobbold (1877); Filaria sanguinis hominis agyptiaca, Sonsino (1874); Filaria sanguinis, Bancroft; Filaria salisburyi; Filaria wuchereri, Silva Aranjo (1877); Filaria cystica, Dobson; Filaria dermathemica, da Silva Aranjo (1875); Filaria sanguinis hominum, Hall (1885); Trichina cystica, Salisbury (1868). The female adult worm was discovered by Bancroft of Brisbane, the male by Aranjo and Dos Santos of Brazil and Sibthorp of Madras, and the embryo by Demarquay, Wucherer, and Lewis. Bernard gives the lifehistory of the parasite as follows :-

EMBryo.

t. Parasite man. the blood of

$$
\begin{aligned}
& \text { Larva. } \\
& \text { 2. Parasite of Culex } \\
& \text { mosquito. } \\
& \text { 3. Free in water. } \\
& \text { 4. Parasite of the } \\
& \text { alimentary canal } \\
& \text { of man. }
\end{aligned}
$$

Manson, judging this parasite from the wideness of its distribution and the grave character of the diseases it produces, holds it to be infinitely the most important of the animal parasites attacking man. Filariasis, including lymph-scrotum, chylous dropsy, and hematochyluria, due to this worm is a malady of the tropics up to about the 38 th parallel, N. latitude, but chiefly in the East. Many cases present lymphatic varix of the groin and scrotum, the extirpation of which is strongly recommended by Maitland. Hydrogen is recommended as a therapeutic agent of great efficacy.-Filaria sanguinis hominis ægyptiaca, Sonsino (1874). See Filaria sanguinis hominis, Lewis.-Filaria sanguinolenta, Grassi (1888). See Spiroptera sanguinolenta, Rudolphi.-Filaria scutata oesophagea bovis, Müller. See Myzomimws scutatus, Stiles (1892) -Filaria smithii, Cobbold (1882). This was found in the walls of the stomach of the Indian elephant.Filaria sp., Drechsler. This is found encapsulated 
in the intestine of domestic cattle.-Filaria sp., Megnin. This is found in the connective tissue of the horse.-Filaria tentaculata, Mehls (1846). -Filaria terebra, Diesing (1851). See Filaria cervina, Dujardin (1845). - Filaria trachealis, Bristowe and Rainey (1855). See Sirongylus paradoxus, Mehlis. - Filaria tracheo-bronchialis, Cobbold. See Filaria lymphatica, Moquin-Tandon.-Filaria trispinulosa, Diesing. This was found in the vitreous humor of the dog by Gescheidt; Cobbold holds it to be a larva.-Filaria uncinata, Rudolphi. See Spiroptera uncinata, Rudolphi.-Filaria wucheri, da Silva Lima (1877). See Filaria sanguinis hominis, Lewis. - Filaria zebra, Mongrand. This was found in the left saphena vein of a convict. Robin and Davaine regard this as a fibrinous coagulum. Filzlaus. See Phthiriasis inguinalis, Leach. Fleas. See under Pulex and Sarcopsylla.-Fleischfliege. See Musca camaria, Linné.-Flour-beetle, Flowerworm. See Tenebrio molitor, Linné.-Forest-fly. See Hippobosca equina, Linné.-Forficula auricularia, Linné. Syn., Earwig, Verme antricolare, Ital.; Oorworm, Dutch; Orentrist, Dan.; Ormask, Sw.; Gemeiner Ohrunurm, Ohrbohrer, Ger.; Perceoréille, Fr.; Fura-orelhas, Per.; Gusano del oido, Sp. But few cases are on record in support of the popular notion that this insect acts as a human parasite. See those of Griffin of Ireland.-Forked worm. See Syngamus trachealis, จ. Siebold. - Founza ia ngômbe (cattle-worm). Native name for the larva of a dipterous insect developing beneath the skin of the ox and man in Central Africa. Freyana anatina, Koch. This is an acarine parasite of the duck. Frühlingskäfer. See Geotrupes vernalis, Linné- Fura-orelhas, P. See Forficula auricularia, Linné. -Furia infernalis, Linné. "An altogether fabulous parasite" (Cobbold), believed in by early parasitologists.-Furia medinensis, Modeer (1795). See Dracunculus medinensis, Cobbold (1864).-Fusaria lumbricoides, Zeder. See Ascaris lumbricoides, Linné.-Fusaria mystax, Zeder. See Ascaris mys. tax, Zeder.-Fusaria papillosa, Zeder. See Heterakis papillosa, Bloch.-Fusaria reflexa, Zeder. See Heterakis inflexa, Rudolphi.-Fusaria renalis, Zeder. See Eustrongylus gigas, Diesing.-Fusaria tetraonis, Zeder. See Heterakis papillosa, Bloch.Fusaria vermicularis, Zeder. See Oxyuris vermic. ularis, Bremser. -Fusaria visceralis, Zeder (I803). See Eustrongylus gigas, Gmelin.-Fusaria vituli Zeder. See Ascaris vituli (Gmelin) Goeze.-Gad-fly. See genus Gasterophilus.-Galeodes araneoides, Pallas. Syn., Galeodes arabs, Koch; Galeodes fatalis, Herbst. The Camel Tick, a disgusting and highly venomous species, nearly two inches in length, and very apt to attack man if disturbed. Found in Egypt and the oases of the Sahara, through Southern Russia and Arabia to India. It is a great torment to camels in the countries where it abounds.-Gamasus auris, Leidy. An acarus found by Turnbull in the external auditory canal of the ox, particularly on the tympanum.Gastrodiscus polymastos, Leuckart, Cobbold. See Amphistoma sonsinoi, Cobbold.-Gastrophilus asininus, Brauer. See Gastrophilus flavipes, Olivier. -Gastrophilus elephantis, Cobbold (I882). Syn., Estrus elephantis, Steel (I878). OEstrus of the elephant, Cobbold (1866). The larvæ or bots are found in the stomach of both the African and Indian elephant.-Gastrophilus equi, Fabricius, Leach. Syn., Estrus equi, Clark, Fabricius, Latreille, Olivier, Fallen, Macquart, Westwood, Joly; Estrus intestinalis, De Geer; Estrus hamorrhoidalis, Gmelin, Schrank; Estrus gastricus major, Schwab;
Estrus gastricus vulsaris, Schwab; Estrus bengalensis, var. equi, Macquart; Gastrus equi, Rondani; Common Bot-fy of the Horse; the Breeze or Horse-bee; Pferdemagenfiege or Bremsfiege, grosse Magenbremse. This is a cosmopolitan; from June to July the eggs are laid on the hair, whence they are licked off and transferred to the stomach, to the walls of which the larvæ or grubs adhere and are passed per anum, to bury themselves in the earth until they reach the imago stage.-Gastrophilus flavipes, Olivier. Syn., Estrus favipes, Olivier; Gastrus favipes, Brauer; Gastrophilus asinimus, Brauer. This is found in Southern Europe, North Africa and Asia Minor; larvæ are found in the stomach of the ass.-Gastrophilus hæmorrhoidalis (Linné), Leach, (I8I7). Syn., Estrus ani equorum, Linné, (I746); Estrus hamorrhoidalis, Linné (I76I); L'CEstres du fondement des chevaux, Geoffroy (1764); Estrus equi, var. hamorrh., Fabr. (1794); Gastrus hamorrhoidalis, Meigen (1824) ; Mastdarmbremse, Ger.; Afterbremse, Ger.; Red-tailed Bot-fly, Red-tailed Horse-bot. This is found in Europe and North America, the most common with Gastrophilus equi. The female lays the eggs on the lips of the horse. The larvæ often become attached to the mucous membrane of the pharyngeal region, producing dyspnea and asphyxia ; they may also be found both in the right and left sacs of the stomach and remain for some time in the ectal portions of the rectum before leaving the body, and then they assume a characteristic green tint. They may be seen at the time of defecation, when the rectum is everted, and it is this which gave rise to the error that the bots were developed in the region.Gastrophilus inermis, Brauer (1858). Syn., Gas. trus inermis, Schiner (186I). An Austrian species troublesome to horses, found near Gyois and the Haklasberge; the larva is unknown.-Gastrophilus lativentris, Löw. This is found in Kurland, and infests domestic animals.-Gastrophilus nasalis, Linné (I76I), Schiner (I86I). Syn., Mouche des chevaux, Réaumur (I734); Estrus nasalis, De Geer (1776) ; Cstrus equi, var. (a) nasalis, Fabricius (1794); Estrus veterinus, Clark (I797); Estrus salutiferus, Clark (I8I5); Estrus clarkii, Leach (I8I7); Gastrus salutaris, Gastrus nasalis, Gastrus jumentorum, Gastrus clarkii, Meigen (1824); CEstrus salutaris, Macquart (1835); Estrus duodenalis, Schwab; Gastrus nigritus, Letterst; Gastrus subjacens, Walker; Rasenbremsfiege, Dünndarmbremse, Ger. A European species, most common in Austria and Prussia, the larvæ being found especially in the duodenum, rarely in the stomach of the horse. The female deposits the eggs in the alæ of the nostrils and on the lips of the horse. Brauer considers the form reported from Nova Scotia (Gastrus subjacens, Walker) as belonging here.-Gastrophilus pecorum, Fabricius (1749), Schiner (I86r). Syn., CEstrus bovis, var. $\beta$, Linné (I76I); Estrus pecorum, Fabricius ; Estrus vituli, Fabr. (I794); Estrus equi, var. $\beta$, Clark (I8I5); Gastrus pecorum, Meigen; Gastrus juba. rum, Megerle (I824); Estrus gastricus major, Schwab (1840); Gastrus ferruginatus, Zetterst, Rondani (1843-8); Estrus veterinus, var. Joly (1846); Gastrus selysii, Carlier (1842); Gastrus veterinus, Green; Viehbremse, Horse-bee. This is found throughout Europe, rare in Sweden, abundant in Hungary. The larvæ are fixed for some time in the rectum before emerging to undergo nymphosis.-Gastrus clarkii, Meigen. See Gastrophilus nasalis, Linné,Schiner.Gastrus equi, Rondani. See Gastrophilus equi, Fabricius.-Gastrus ferruginatus, Rondani, Zetterst. See Gastrophilus pecorum, Fabricius. - Gastrus 
flavipes, Brauer. See Gastrophilus favipes. Oliv ier. - Gastrus hæmorrhoidalis, Meigen. See Gastrophilus hamorrhoidalis, Linné. - Gastrus inermis, Brauer. See Gastrophilus inermis, Brauer. - Gastrus jubarum, Meigen. See Gastrophilus pecorum, Fabricius. - Gastrus jumentorum, Meigen. See Gastrophilus nasalis, Linné. - Gastrus lativentris, Brauer, Schiner. See Gastrophilus lativentris, Löw.-Gastrus nasalis, Meigen. See Gas trophilus nasalis, Linné.-Gastrus nigricornis, Löw. Infests domestic animals in the Crimea (Bessarabia).Gastrus nigritus, Zetterst. See Gastrophilus nasalis, (Linné) Schiner.-Gastrus pecorum, Brauer, Meigen, Walker. See Gastrophilus pecorum, Fabricius.Gastrus salutaris, Meigen. See Gastrophilus nasalis (Linné), Schiner. - Gastrus selysii, Carlier. See Gastrophilus pecorum, Fabricius.-Gastrus subjacens, Walker. See Gasirophilus nasalis, (Linné) Schiner.-Gastrus veterinus, Green. See Gastrophilus pecorum, F abricius.-Gauleblutwürmchen. See Drepanidium rananum, R. Lankester.-Gekörnelter Blutegel. See Hirudo granulosa.-Gemeine Räudemilbe. See Psoroptes communis, Fürstenberg. -Gemeiner Blutegel. See Hirudo medicinalis, Ray. - Gemeiner Floh. See Pulex irritans, Linné.Gemeine Kriebelmücke. See Simulium reptans Linné.-Gemeiner Zungenwurm. See Linguatula rhinaria, Railliet.-Geotrupes vernalis, Linné. Syn., Frühlingskäfer. A beetle, the larva of which is reported by Van Bromell as a facultative human parasite.-Gewitterfliege. See Hydrotea meteorica, Linné.-Globidium leuckartii, Flesch. An infusorian found in the wall of the sustaining connective tissue of the villi of the small intestine of the horse. An uncertain form which appears to have analogies with the Sarcosporides (Balbiania mucosa), described by Blanchard, from the kangaroo. Moniez holds it to be but the embryo of the tenia of the horse, encysted in the papillæ, like those of $T$. murina of the rat, described by Grassi.-Globocephalus longemucronatus, Molin. This was found by Wedl in the intestine of the hog.-Glossina morsitans, Westwood. Syn., Tsé-tsé Tzé-tzé, or Zimb. The fly so frequently mentioned in the works of African travelers. It is about the size of the horse-fly. The accounts of the virulence of the bite of this pest are so conflicting as to lead to the conclusion that it is only poisonous when its proboscis is the carrier of a virus with which it has been previously infected.Glyciphagus buski, Murray (I84I). An accidental parasite in the ulcer on a negro's foot.-Glyciphagus cursor, Gervais (184I). Syn., Acarus domesticus, de Geer, 1735. Glyciphagus prunorum, Hering, 1838. Sarcoptes hippopodus, Hering (I838). A mite found in a horse's foot affected with canker. An accidental parasite.-Gnat. See Culex pipiens, Linné.Gnathostoma hispidium. See Cheiracanthus hispidus, Fedschenko.-Goat-louse. See Trichodectes climax, Nitzsch. - Goldfliege. See Lucilia casar, Robineau - Desvoidy. - Gongylonema minimum, Molin. This was found in the stomach and liver of the house-mouse (Mus musculus, Linné). - Goniocotes abdominalis, Piaget. Syn.,Philopterus hologaster [N], Verrill. Goniocotes hologaster (Burmeister), Denny. A louse common to the different varieties of Gallus domesticus, Brisson.-Goniocotes burnetti (Packard) Verrill. See Goniodes burnetti, Packard.-Goniocotes compar, Nitzsch, Denny, Paiget.-Syn., Goniodes compar (N), Verrill. Pediculus bidentatus, Scopoli. Philopterus compar, Burmeister. The louse of the pigeon. A common parasite of all varieties of domestic pigeons. According to Denny it has never been found on the turtle-dove--Goniocotes gigas, Taschenberg. One of the lice of fowls. - Goniocotes hologaster, Nitzsch. Syn., Ricinus galline, De Geer. This is a louse found upon the Bankhiva fowl, but not very abundant. The form described by Denny as Goniocotes hologaster is referred by Piaget to Goniocotes abilominalis, q. v.-Goniocotes rectangulatus, Nitzsch. Syn., Goniocotes rectangulus, Burmeister. This is found upon Guinea-fowls and peacocks.-Goniodes burnetti, Packard. This is found in the domestic fowl and perhaps is identical with Gonziocotes dissimilis, Nitzsch (Piaget, 269).-Goniodes compar (N), Verrill. See Goniocotes compar, Nitzsch. -Goniodes dissimilis, Nitzsch. Syn., Plizlopterm dissimilis (N), Verrill. A louse of the domestic fowl, rather rare.-Goniodes falcicornis, Nitzsch. Syn., Pulex pavonis, Redi ; Pediculus pavonis, Linné, Schrank, Frisch, Panzer; Nirmus tetragonocephalus, Olfers; Ricinus pavonis, Kirby and Spence. The Louse of the Peacock, Albin, Shaw. The common louse of the peacock. - Goniodes minor, Piaget. Syn., Drearf Goniode. This is found on Columbe tigrina, C. risoria, C. bitorquata, and on domestic pigeons. - Goniodes numidianus, Denny. The louse of the Pintado or Guinea-fowl (Numida meleagris, Linné).-Goniodes parviceps, Piaget. Smallheaded Goniode. This is found frequently on peacocks in company with $G$. falcicornis.-Goniodes stylifer, Nitzsch. Syn., Pediculus meleagris, Schrank. Found upon the turkey, - Goose-louse. See Trinotum lituratum (Nitzsch), Piaget. - Gordius aquaticus, Dujardin (1842); Syn., Seta or Vitulus aquaticus, Aldrovandi (1605). A common worm in the mountainous regions of Europe and long considered as an occasional pseudo-parasite of man.-Gordius chilensis, Emil Blanchard (I849); an imperfectly-known species reported by Gay as a pseudo-parasite of man in Chili. Gordius equinus, Abildgaard. See Filaria equina, Abildgaard.-Gordius marinus, Linné. See Filaria piscium, Rudolphi. - Gordius medinensis, Linnè (1767). See Dracunculus medinensis, Cobbold (1864). - Gordius orientalis, von Siebold. This is found in the abdomen of the cockroach (Periplaneta orientalis, Linné).- Gordius sp., Hess (1887). Found in the honey-bee. Cf. Mermis allicans, von Siebold (1857). - Gordius subbifurcus, von Siebold (1848); See Gordius tolosanus, Dujardin (1842).Gordius tolosanus, Dujardin (1842) ; Syn., Ophiostoma pontieri, H. Cloquet (1822), Gordius subbifurcus, von Siebold (1848). A European species reported by Degland (1823), and Fiori (I88I) as a pseudo-parasite of man.-Gordius varius, Leidy (I85I). A common American species, recorded by Diesing after Kirkland as a pseudo-parasite of man. - Gordius viviparous, Bloch. See Ascaris vituli (Gmelin), Goeze. -Grand pou du cheval. See Hamatopinus tenuirostris, Burmeister. -Grande Bothriocefalo. See Bolhriocephalus latus, Bremser. - Gray Carnivorous-fly, Gray Flesh-fly, Graue Fleischfliege. See Sarcophaga carnaria, Meigen. - Gray Leech. See Hirudo medicinalis, Ray.-Gray Simulium. See Simulium cinereum, Meigen. - Great Breeze-fly. See Tabanus bovinus, Linné.-Green Leech. See Hïndo medicinalis, Ray. - Gregarina avium intestinalis. Psorosperms found encysted in the submucous tissue of the intestine of the Gallinacea of the poultry-yards. They are introduced with the food. Symptoms: diarrhea, depression, loss of appetite, death from marasmus. The affection generally occurs in an epizoötic form, which has been termed tuberculo-diphtheria.-Gros pou du boeuf. See Hanatopinus enysternus, Bur. meister.-Gros pou du chien. See Trichodectes latus, 
Nitzsch.-Gros tavin. The name in Burgundy for the Great Breeze-fly. See Tabanus bovinus, Linné. -Grub in the Back. See Hypoderma bovis, Latreille, and Hypoderma lineata, Löw.-Grubentliege. See Homalomyia canicularis, Linné.-Guinea-fowl Goniodes. See Goniodes numidianus, Denny.-Guineaworm, Guineischer Wurm, Ger. See Dracunculus medinensis, Cobbold. - Gusano. See Dermatobia noxialis, Goudot.-Gusano del oido, Sp. See Forficule auricularia.-Gynæcophorus bovis, Sonsino. See Gyncecophorus crassus, Sonsino.-Gynæcophorus crassus, Sonsino. Syn., Bitharzia bovis, Sonsino; Bilharzia crassa, Sonsino. This was found in 1876 at Zagazig, Egypt, in the portal vein, ureters and urinary bladder of domestic sheep and cattle. It has since been found in Italy. Neumann regards it as but a variety of Gynacophorus hamatobius, Diesing, and hence dangerous to man. It gives rise to symptoms similar to those caused by the last-named parasite.Gynæcophorus hæmatobius, Diesing (1858); Syn., Schistoma hamatobium, Weinland (I858); Distoma capense, Harley (1864) ; Distoma hematobium, Bilharz, (I852), Küchenmeister, Moulinie, Leuckart; Thecosoma hematobium, Moquin-Tandon (1860); Bitharzia magna, Cobbold; Bitharsia hamatobia, . Cobbold (1858). A fluke originally found by Bilharz in $\mathbf{1 8 5} \mathbf{I}$ in Egypt in 63 per cen.. of fellahs and copts. It has since been frequently found in the natives and European residents along the entire coast of East Africa, in Arabia, Mauritius, India, and Brazil, producing a grave disorder known as endemic hematuria. It also occurs in an African monkey, the Mangabey (Cercopithecus fuliginosus, Geoffroy). It is most abundant in the vessels of the portal system, and mesentery, and in the hemorrhoidal and vesical veins. It feeds upon the blood; no intermediate host is known, and it is supposed to be introduced into the human system by impure drinking-water, as a swimming embryo. Fouquet of Cairo reports favorably on the use of extract of male fern, and Dight, of Beirut, recommends the injection of large amounts of sulphuretted hydrogen and carbon dioxid into the rectum and bladder.-Gyropus gracilis, Nitzsch. Syn., Pediculus porcelli, Schrank. A louse of the guinea-pig (Cavia cobaya, Shreber).Gyropus ovalis, Nitzsch. A minute louse of the guinea-pig. Cf. Menopon extraneum, Piaget.-Habronema muscæ, Carter. This is found in the head and proboscis of the house-fly,-Hrmadipsa ceylonica, Moquin-Tandon. Syn., Hirudo (Sangzisuga) tagalla, Meyen. Hirudo ceylonica, Moquin-Tandon, Zeylon'scher Blutegel, The Ceylon Leech. A terrestrial leech; according to Hofmeister and Tennant, the most detested of all the plagues which beset the traveler in Ceylon.-Hæmamceba praecox; Hæmamcba vivax; Hæmamœba malariæ; Hæmamcba immaculata, Grassi and Filetti. See Polimitus malaria, Danilewsky.-Hæmaphysalis rosea, Koch. See Boöphilus bovis (Riley), Curtis.-Hæmatobia ferox Davaine; Hæmatobia irritans, Meigen; Hæmatobia serrata, Davaine. - Hæmatobia malariæ, Celli and Guarneri. See Polimitus malaria, (Laveran), Danilewsky. - Hæmatobia stimulans, Meigen. A group of flies recorded by Neumann as troublesome to man, and cattle in pastures. The sawhematobia (Hematobia serrata, Davaine) is particularly spoken of as bloodthirsty, and common in Europe and America. The parasitescollect in swarms at the base of the horns, or on the abdomen, back, flanks or upper parts of the legs. The eggs are deposited in the fresh dung, and they may be destroyed by throwing lime over the dung lying in pastures.-Hæmatomonas evansi. See Trypanosoma evansi (Evans), Balbiani.-Hæma- tomonas malariæ, Osler-Hæmatophyllum malariæ, Metschnilioff (I887). See Polimitus malarice, Danilewsky (I886).-Hæmatopinus acanthopus, Denny, Piaget. Syn., Hiematopinus serratus, Nitzsch, Burmeister, Denny. The louse of the mouse (Mus musculus, Linné),-Hæmatopinus asini, Linné. See Hamatopinus macrocephalus, Burmeister, var. colorata, Piaget.-Hæmatopinus cameli, Redi. The louse of the camel; it resembles that of the hog (Homatopinus urius, Nitzsch).-Hæmotopinus eurysternus, Nitzsch, Burmeister. Syn., Pediculus eurysternus, Nitzsch ; Pediculus vituli, Linné ; P. tenuirostris, Burmeister; Hamatopinus oxyrhynchus, Nitzsch; H. tenuirostris, Burmeister; H. vituli, Stephens; Gros pou du boeuf. One of the lice found upon cattle. Hæmatopinus Iyriocephalus, Burmeister, Denny, Piaget. Syn., Pediculus lyriocephalus, Burmeister. The louse of the hare (Lepus timidus, Linné).Hæmatopinus macrocephalus, Burmeister. Syn., The Horse-louse; Pediculus asini, Linné; Pediculus macrocephalus, Burmeister; Hamatopinus asini, Denny. One of the three lice of the horse.-Hæmatopinus macrocephalus, var. colorata, Piaget. The louse of the ass.-Hæmatopinus oxyrhynchus, Nitzsch. See Hematopinus eurysternus, Burmeister. -Hæmatopinus piliferus, Burmeister, Denny. Syn., Pediculus piliferus, Burmeister; Pediculus canis familiaris, Müller; Pediculus bicolor, Lucas; Petit pouduchien; The dog-louse; not common.-Hrmatopinus serratus, Nitzsch, Burmeister, Denny. See Hamatopinus acanthopus, Denny.-Hæmatopinus spinulosus, Burmeister. Syn., Pediculus spinulosus, Burmeister; $P$. denticulatus, Nitzsch. The louse of the common rat (Mus decumanus, Pallas).-Hæmatopinus stenopsis, Burmeister. Syn., The Goat-louse. -Hrmatopinus suis, Leach. See Hematopinus urius, Nitzsch.-Hæmatopinus tenuirostris, Burmeister. See Hamatopinus eurysternus, Nitzsch.Hæmatopinus tuberculatus, Giebel. The louse of the Eastern buffalo,-Hæmatopinus urius, Nitzsch. Syn., Pediculus suis, Linné; Hamatopinus suis, Leach. The Hog.louse, the largest of the pediculi, and occasionally found in great numbers on swine.Hæmatopinus ventricosis, Denny. The louse of the rabbit (Lepus cuniculus, Linné.) - Hæmatopinus vituli, Stephens; See Homatopinus eurysternus, Nitzsch, Burmeister. - Hæmatopota pluvialis, Meigen. Syn., Small Rain Breeze-fy; Petit taon pluvial, Fr.; Picolo Tafano pluviale, It. The Clegg of the West Highlands of England and Scotland. This is said by Mégnin to be troublesome to man and animals during stormy weather, especially in Lapland, where the reindeer is tormented by it.-Hæmatopota punctulata, Macquart. A breeze-fly found in the Southern United States. - Hæmatozoön lewisi, Grassi. An embryonic nematode found by Gruby, Dellafond, Lewis, Manson, Sonsino, Grassi, etc., in the blood of the dog. The last claimed to have discovered the intermediate host in the cockroach (Periplaneta orientalis, Linné). Sonsino has found the same larvæ in the fleas of dogs (Pulex serraticeps, Gervais), and in their lice (Hamatopinus piliferus, Burmeister). Grassi and Calanduccio have given the name Filaria recondita to the adult form, yet undiscovered, to which these embryo belong. - Hæmatozoön sublatum, Gurlt. See Strongylus sublatus, Cobbold.-Hæmentaria costata, Müller. A Crimean leech employed in medicine.-Hæmentaria ghilianii, de Filippi. A common leech in Brazil especially along the Amazon; it attacks man. Hæmentaria mexicana, de Filippi. Found in Mexico and Central and South America. Its bite produces an acute irritation. Hæmentaria offi- 
cinalis, de Filippi. Found in the lagoons of Mexico; used medicinally.-Hæmogregarina avium, Danilewsky. See Polimitus malaric, Danilewsky.-Hæmopis sanguisorba, Savigny; Hæmopis sanguisuga, Moquin-Tandon; Hæmopis vorax, MoquinTandon. See Hirudo sanguisuga, Bergmann.Hæmoplasmodium malariæ, Marchiafava and Celli. A hemocytozoön found in the blood of malarialfever patients. They are homogenous, protoplasmic bodies from one-tenth to one-third the size of red bloodcorpuscles and within which they occur as pseudovacuoles and also to which they impart a lively movement by their protruded flagella (pseudospirilla). Danilewsky regards this as but a developmental stage of Polimitus malaria, q. v.-Halysis caprina, Zeder (1803). See Linguatula rhinaria, Railliet (1868). - Halysis gracilis, Zeder. See Tania gracilis, Rudolphi.-Halysis infundibuliformis, Zeder. See Tania infundibuliformis, Goeze.Halysis lanceolata, Zeder, Dujardin. See Tenia lanceolata, Bloch.-Halysis lata, Zeder. See Bothriocephalus latus, Bremser.-Halysis lineata, Zeder. See Tania lineata, Goeze.-Halysis litterata, Zeder. See Tania pseudo-cucumerina, Baillet.Halysis marginata, Zeder. See Tania marginata, Batsch.-Halysis membranacea, Zeder (1803). See Bothriocephalus latus, Bremser-Halysis passeris, Zeder. See Tania fringillarum, Rudolphi.Halysis perfoliata, Zeder. See Tenia perfoliata, Goeze.-Halysis plicata, Zeder. See Tania plicata, Rudolphi.-Halysis pusilla, Zeder. See Tenia pusilla, Goeze. Halysis serrata, Zeder. See Tenia crassicollis, Rudolphi, and Tania serrata, Goeze.Halysis setigera, Zeder. See Tania setigera, Frölich.-Halysis sinuosa, Zeder. See Tania sinuosa, Rudolphi.-Halysis solium, Zeder. See Tania solium, Linné.-Halysis torquata, Zeder. See Tania sinuosa, Rudolphi. Halysis trilineata, Zeder. See Tenia trilineata, Batsch.-Hammularia lymphatica, Treutler (1793). See Filaria lymphatica, Moquin-Tandon. - Hammularia subcompressa, Rudolphi. See Filaria bronchialis.-Hanchoschim-Haschrofim, Heb. See Dracunculus medinensis, Lister. Harpirhynchus nidulans, Mégnin. Syn., Sarcoptes nidulans, Nitzsch. The pubescent nymphre have been found in the plumage of pigeons and parrots.-Harvest-bug. See Tetranychus autumnalis, Shaw.-Harvest-mite. See Leptus irritans and Tetranychus autumnatis, also Trombidium americanum.-Harvest-tick. See Leptus irrilans. - Hauswanze. See Cimex lectularia, Merrett. Hautwurm. See Dracunculus medinensis, Cobbold. -Head-louse. See Pediculus capitis, Leach. Heel-fly. See Hypoderma lineata, Löw.-Helminthopsylla alakurti, Schimkewitsch. Syn., Alakurt. A flea, allied to the chigoe, abundant in Turkestan, upon horses, sheep, camels and oxen in the autumn and winter, causing extreme debility.- $\mathrm{He}$ lophilus pendulus, Meigen. A dipterous insect, the "rat-tailed" larvæ of which, according to Cobbold, not infrequently occurs in the digestive canal of the horse. Cf. Eristalistenax, Linné.-Hematopota. See Hamatopota.-Hematozoaires du paludisme, Laveran. See Polimitus malarice (Laveran), Danilewsky.-Hemistoma alatum (Goeze), Diesing. A trematode common in the fox and wolf, and found in the small intestine of the dog by Creplin and Schöne. -Hen-flea. See Pulex avium, Taschenberg.-Henlice. See Goniocotes abdominalis, Piaget; Goniocotes hologaster, Nitzsch; Goniodes dissimilis, Nitzsch; Goniodes burnetti, Packard; Lipeurus heterographus, Nitzsch; Lipeurus variabilis, Nitzsch; Menopon bi- seriatum, Piaget; Menopon pallidum, Nitzsch.Herpetomonas lewisi, Saville, Kent. See Trypanosoma lewisi, Danilewsky, Kent.-Herpetomonas muscæ domesticæ, Saville, Kent. Syn., Monomita muscarum, Grassi; Cercomonas muscarum, Leidy; Bodo muscre domesticr, Burnett. Often found in abundance in the chylific stomach of the house-fly.Heterakis columbx, Gmelin. See Heterakis maculos $\alpha$, Rudolphi.-Heterakis compressa, Schneider. A nematode found in the intestine of the domestic fowl in South Australia.-Heterakis differens, Sonsino. This is found in the posterior portion of the fowl's intestine.-Heterakis dispar, Schrank. Syn, Ascaris dispar. This was found in the intestine and cecum of the domestic goose and duck by Fröhlich, Schrank, and Zeder-Heterakis inflexa, Rudolphi. Syn., Ascaris crassi, Deslongchamps, Ascaris teres, Goeze; Ascaris gallopavonis, Gmelin; Ascaris perspicillum; Rudolphi, Dujardin; Heterakis perspicillum; Fusaria reflexa, Zeder. This is found in the intestine of the domestic fowl, turkey and duck, and is abundant in the latter about Caen. - Heterakis lineata, Schneider. This was found in the intestine of the domestic duck of Turkestan by von Linstow, and in a Brazilian cock by Schneider.-Heterakis maculosa, Rudolphi. Syn., Ascaris maculosa, Rudolphi, Bremser, Bellingham, Dujardin; Ascaris columbe, Gmelin; Ascaris teres, Goeze; Heterakis columber, Gmelin; l'ascaride del piccioni, Ital. This is found in the intestine of the domestic pigeon, producing frequently a fatal disease. Unterberger has shown that the eggs of this nematode require to be kept for about seventeen days under suitable conditions outside the body of the host before they are capable of further development in the intestine. - Heterakis papillosa, Bloch. Syn., Heterakis vesicularis, Fröhlich, Dujardin; Ascaris vesicularis, Rudolphi; Ascaris tetraonis, Gmelin ; Ascaris papillosa, Bloch; Ascaris teres (minor Phasiani et picti), Goeze; Ascaris gallinarum, Gmelin ; Ascaris urogalli, Viborg, Rudolphi; Fusaria tetraonis, Zeder; Fusaria papillosa, Zeder. This is found in the cecum of the fowls, duck, peacock, and turkey.-Heterakis perspicillum, Rudolphi. See Heterakis inflexa, Rudolphi.-Heterakis spumosa, Schneider. This is found in the intestine and cecum of the brown rat (Mus decumanus, Pallas). - Heterakis uncinata, Rudolphi. This is found in the intestine and cecum of the domestic guinea-pig.-Heterakis vesicularis, Fröhlich. See Heterakis papillosa, Bloch. -Heteromita lens, Müller. Syn., Monas lens, Dujardin. Found in the mouth of man by Steinberg. - Hexacotyle venarum, de Blainville. See Hexathyridium venarum, Treutler-Hexamita duodenalis, Davaine. See Megastoma intestinale, Blanchard.-Hexastoma pinguicola, Cuvier. See Hexathyridium pinguicola, Treutler.-Hexastoma venarum, Cuvier. See Hexathyridium venarum, Treutler.-Hexathyridium pinguicola, Treutler, Jördens, Brera. Syn., Hexastoma pinguicola, Cuvier ; Linguatula pinguicola, Lamarck; Polystomum pinguicola, Zeder, Rudolphi, Bremser. A trematode found in the ovaries in women. Van Beneden and Gervais hold this as likely to prove a larval form of Linsuatula rlinaria, Railliet, from which opinion Cobbold differs.-Hexathyridium venarum, Treutler, Jördens, Rudolphi. Syn., Hexastoma venarum, Cuvier; Hexacotrle venarum, de Blainville; Linguatula venarum, Lamarck; Polystoma sanguicola, Delle Chiaje, Frick; Polystoma venarum, Zeder, Rudolphi, Dujardin, Owen. This is found in the veins of man; Rudolphi and others referred this to the fresh-water Planarice, and Davaine 
thought it Distoma lanceolatum, Mehlis, or a young Fasizola hepatica, Linné.-Hippobdella sanguisuga, de Blainville. See Hirudo sanguisuga, Bergmann.Hippobosca canina, Rondani. See Hippobosca equina, Linné. - Hippobosca equina, Linné. Syn., Hippobosca canira, Hippobosca taurina, Rondani: Mouche araignee, Mouche plate, Horse-tick, Forest-fly. An interesting remittent parasitic insect of the family Pupipara, common in the summer on horses, sheep, cattle and dogs, especially about the perineal region; it is very troublesome.-Hippobosca ovina, Linné. See Melophagrus ovinus, Latreille--Hippobosca taurina, Rondani. See Hippobosca equina, Linné.-Hirudine viva. See Hirudo medicinalis, Ray.-Hirudo albopunctata, Diesing. A leech common in Sweden.-Hirudo ceylonica, MoquinTandon. See Hamadipsa ceylonica, Moquin-Tandon.-Hirudo chinensis, Schmarda. A small species used by the Chinese.-Hirudo decora. A North American leech used medicinally.-Hirudo depressa fusea margine laterali. See Aulostoma gulo, Moquin-Tandon.-Hirudo flava, Brossat. See Hirudo medicinalis, Ray. - Hirudo granulosa, Gekör. nelter Blutegel. A leech used in India, and in the Isle of Bourbon and the Mauritius.-Hirudo grisea, Brossat. See Hirudo medicinalis, Ray.-Hirudo interrupta, Moquin-Tandon. Syn., Sanguisuga intermpta, Moquin-Tandon; The Dragon Leech; The African Leech, Blutegel mit unterbrochenen Rückenstreifen. A species found in North Africa.-Hirudo javanica, Wahlberg. Syn., Sanguisuga javanica, Wahlberg. The Javanese leech.-Hirudo medicinalis, Ray (1710), Linné (1746). Syn., Hirudo venasector, Braun; Hirudo fava, Brossat; Hirudo grisea, Brossat; Hirudo officinalis, Savigny; Hirudo provincialis, Braun (1805); Hirudo viridis; Iatrobdella medicinalis, Blainville (1828); The Gray Leech; The Green Leech; The Common Medicinal Leech; The Speckled Leech; Hirudine viva; Sangsue medicinale; Sangsue grise; Sangsue verte; Deutscher Blutegel; Der ungarische Blutegel. A fresh-water species found throughout Europe and the North of Africa; the great color-variation of this species has given rise to the differentiation of some sixty varieties and a confused nomenclature. A large leech will take about fifteen grams of blood, which requires several months to digest.- Hirudo mysomelas, Virey; Senegal'scher, Blutegel. Found in Senegambia and exported to France.-Hirudo obscura. Syn., Sangsue noire. A French species. -Hirudo officinalis, Savigny. See Hirudo medicinalis, Ray.-Hirudo provincialis. See Hirudo medicinalis, Ray.-Hirudo quinquestriata, Schmarda. Syn., Hirudo tristriatc. An Australian species largely exported to Europe.-Hirudo sanguisorba, Lamarck. See Hirudo sanguisuga, Bergmann. - Hirudo sanguisuga, Bergmann (1757). Syn., Hirudo sanguisorba, Lamarck (1818); Homopis sanguisorba, Savigny (1820); Hremopis vorax, Moquin-Tandon (1826); Hippobdella sanguisuga, de Blainville (1827); Hamopis sanguisuga, Moquin-Tandon (1846). The True Horse-leech; Sangsue de cheval, Fr.; Pferdeegel, Ger. Found in Spain and Southern Europe generally, but particularly in the North of Africa, this worm being inadvertently swallowed in an immature condition in drinking-water, not infrequently attaches itself to the mucosa of the nose and pharynx of man, as well as of animals. Strong solutions of salt cause it to loosen its hold.- Hirudo sinica, de Blainville. A Chinese species.-Hirudo tagalla. See Hamadipsa ceylonica, Moquin-Tandon.-Hirudo tesselata. A species found in the United States; it is green with black dots.-Hirudo tristriata, Schmarda. See Hirudo quinquestriata, Schmarda. -Hirudo troctina, Johnson (1816). Syn., Sanguisuga interrupta, Moquin-Tandon (1826); Iatrobdella medicinalis, var. tesselata, de Blainville (1827); Trout Leech; Dragon Leech, Sangsue dragon, Dragon d'Alger, Fr. A native of the North of Africa, but long employed in hospitals throughout Southern Europe and England.-Hirudo venæsector, Braun. See Hindo medicinalis, Ray.- Hirudo verbana. Syn., Blutegel des Lago-Maggiore. An Italian species.-Hirudo viridis. See Hirudo medicinalis, Ray. - Hirudo wiffonia. A Japanese variety, dried, powdered and administered internally to relieve pain.-Hog-louse. See Hamatopinus urius, Nitzsch.-Holophrya coli, Leuckart (1863); See Balantidium coli, Stein (1862).-Holostoma erraticum, Rudolphi, Dujardin. This is found in the intestine of the domestic duck and the tame swan. The larva (Tetracotyle flippi) has been found in the viscera of several molluses and fish, and also as a parasite in the sporocysts of several Distomata. Hom alom y i a canicularis, Linné. Syn., Anthomyia canicularis, Meigen; Kleinstubenfiege: Hundstagfliege. This is common in Europe from spring throughout the summer, and feeds on decaying vegetable matter. The larvæ live in the earth.-Homalomyia incisurata. Syn., Anthomyia incisurata. The larvæ occur in the human intestine, according to Moniez.- Homalomyia scalaris, Fabricius. Syn. Anthomyia scalaris, Fabricius. This is common from spring throughout summer, especially under trees; the larvæ are found on decaying substances, and at times as pseudo-parasites in $\mathrm{man}$, in the intestines nasal passages and ears. Judd (Amer. Nat., I876, p. 374) reports a case of the intestinal discharge of fifty larve of this fly.-Hornfly. See Hamatobia serrata. - Horse-bee. See Gastrophilus equi, Fabricius and Gastrophilus pecorum, Linné.-Horsefly. See Tabanus Sp.-Horse-leech. See Hirudo sanguisuga, Bergmann.-Horse-louse. See Hamatopinus macrocephalus. - Horse-tick. See Hippobosca equina, Linné, - House-fly. See Musca domestica, Linné.-Hunde Haarling. See Trichodectuslatus, Nitzsch.-Hundstagfliege. See Homalomyia canicularis, Linné.-Hydatigena granulosa, Batsch. See Echinococcus polymorphus. - Hydatis erratica, Blumenbach. See Echinococcus polymorphus.-Hydatis Lüdersen, Rudolphi, Olfers, Bremser. See Echinococcus polymorphus, Diesing.-Hydrotæa meteorica, Davaine. Syn., Anthomyia meteorica, L. Meteoric Fly; Storm-fly; Gewitter. fiege. This is so called because at the approach of rain it often forms a kind of cloud about horses' heads. It is common in Europe in summer in damp situations, as forests, its ordinary nourishment consisting of the sap of flowers. The females attack animals and although their soft proboscis cannot pierce the skin, and only allows them to suck up the humors from the surface, they harass and torment most stubbornly. They may produce inflammation of the eyes and ears of domestic animals. The larvæ are found in cow-dung and decaying vegetable matter.- 
Hymenolepis fiavopunctata, Weinland (1858). See Tania favopunctata, Weinland, (1858). Hymenolepis nana, Leuckart, (1863). See Tania nana, von siebold (1853).-Hypodectes columbæ, Mégnin. See Falciger rostratus, Bucholz.-Hypoderma bonassi, Brauer. A grub recorded as being taken from the back of a buffalo in Colorado. Hypoderma bovis, De Geer (Latreille, I825). Syn., Estrus bovis (1776), Fabricius, Herbst, Fischer, Clark, Latreille, Leach, Fallen, Macquart, Westwood, Sells, Saxisen, Walker; Estrus hominis, Gmelin (1788); the Ox-hypoderma, Grub-in-theback, Warble-fly, Bot-fly of Cattle. A cosmopolitan species, the adult Hy having a life of about eight days, occurring during July and August, the larvæ living from ten to eleven months in the skin of the cattle and of man. These parasites cause great damage to hides, and the effect on the carcass is serious, producing what is known as "licked beef " or "butcher's jelly." Squeezing out the maggot is a sure method of getting rid of it, or the warble may be smeared with a thick grease that will choke up its breathing pores.-Hypoderma diana, Brauer (1858). Syn., Estrus hominis, Völkel. The larvæ reported by Joseph Borthen, Völkel, etc., as parasites of the skin in man.-Hypoderma equi, Joly (I849). Syn., Hypoderma silenus, Brauer; Hypoderma loisetti, Joly (1846) ; Estrus cuticole, Loiset; Edemagena equi, Loiset (1844). The larvæ are found in the skin of the horse and ass throughout Europe and S. America.Hypoderma lineata (Villers), Löw (I863). Syn., OEstrus lineatus, Villers (1789); Estrus hamorrhoidalis, var. $\beta$, Clark (1797); Estrus bovis, var. $\beta$ vernalis, Clark; Estrus lineaius, Olivier (I8I1); Estrus ericetorum, Leach(18II); Hypoderma lineatum, Brauer (1858); the Heel-fly of Texas; Grub-in-the-back; Oxwarble. These grubs cause effusion of serum in the connective tissue, giving an appearance in cattle and sheep called the "lick" by ranchmen. It is stated that the only adult warble-flies found in the United States belong to this species, which appears to be cosmopolitan.-Hypoderma loiseti, Joly. See Hypoderma equi, Joly.-Hypoderma silenus, Joly. See Hypoderma equi, Joly.-Hypoderma tarandi, Linné (I76I). Syn., Estrus rangiferinzes, Linné (1736) ; Estrus tarandi, Linné (I76I); Edemagena tarandi, Latreille (I8I6). Larvæ found in the skins of the reindeer; they resemble those of Hypoderma bovis, De Geer, but are smaller-Hystrichis rachycephalus, Molin. This was found in the walls of the crop of the tame swan.-Hystrichis tricolor, Dujardin. Found in the crop of the domestic duck. - Hystrichis tubifex, Diesing. Found in the esophagus of the domestic duck. - Iatrobdella medicinalis, Blainville. See Hirudo medicinalis, Ray.Iatrobdella medicinalis, var. tessellata, de Blainville. See Hirudo troctina, Johnson,-Isotricha intestinalis, Stein. A free-swimming infusorian, with long, dense ciliary clothing, found in the rumen of sheep and cattle.-Isotricha prostoma, Stein, has the same habitat as the preceding.-Ixodes agyptius, Audouin (1812). Syn., Ixodes savignyi, P. Gervais; Acarus agyptius, Linné ; Cynorhestes cogptius, Hermann; Esyptian Ixode. The largest known ixode, very common upon cattle in Africa and upon African cattle in European markets.-Ixodes algeriensis, Mégnin. This is found upon African cattle. Neumann regards this as closely related to the form known in the Guadeloupe as Tique sénésalaise, where it produces farcy on horses, cattle, and mules.-Ixodes americanus, Linné. See Argas americanus, De Geer.-Ixodes annulatus, Say. See Boöphilus bovis, Curtice.-Ixodes autumnalis, Leach. Syn., The Autumn Ixode. A species cited by Neumann as found in France.-Ixodes bovis, Kiley. See Boöphilus bovis, Curtice.-Ixodes brevipes, Murray. A species found in Ceylon.-Ixodes camelinus, Fischer. Found on camels on the Steppes of Asia. Ixodes carapatos, a tick troublesome in Brazil.Ixodes chelifer, Mégnin. This is found on dogs.Ixodes distipes, Murray. Found in Tunis.-Ixodes dugesi, Gervais (Mégnin). See Boöphilus bovis, Curtice.-Ixodes erinaceus, Audouin. This is a common species in Britain, attacking dogs, cattle, foxes, hedgehogs, etc. It is generally known as the dog-tick and mistaken for Ixodes ricinus, Ixodes indentatus, Gamgee.-Ixodes fabricii (Audouin). An acarine parasite found in Southern Europe on cattle and sheep.-Ixodes fodiens, Mégnin. Syn., Ixodes pustularum, Mégnin, Lucas. Found on horses. - Ixodes marginatus, Leach. Syn., Ixodes testudinarius, Murray. A British species troublesome to laborers in hayfields. - Ixodes marmoratus, Risso. Found on sheep in France.-Ixodes megathyreus, Leach. Found on sheep and cattle in Southern Europe.-Ixodes mombata, a troublesome tick in Angola,-Ixodes pustularum, Mégnin. See Ixodes fodiens, Mégnin.Ixodes reduvius, de Geer. This is common in Southern Europe, attacking sheep, cattle, dogs, hares, and man. See Boophilus bovis, Curtis. - Ixodes ricinus, Linné. Syn., Acarus ricinus (1790); Acarus ricinoide, De Geer; Cynorhostes ricinus, Hermann (1808); Ricinus caninus, Ray; Tique des chiens, Geoffroy; Common Tick, Dog-tick. This is frequently found on hunting-dogs, and is the oldest known species.-Ixodes rotundatus, Koch. A South American species.-Ixodes rugica. A species found in Surinam and Brazil.-Ixodes savignyi, Gervais. See Ixodes agyptius, Audouin.-Ixodes scapulatus, Mégnin. A species found on cattle in the South of France.-Ixodes, Sp. (Stiles). Found on cattle in California.-Ixodes testudinarius, Murray. See Ixodes marginatus, Leach. - Ixodes trabeatus, Audouin. A French species.-Jigger. See Sarcopsylla penetrans, Westwood.-Kariophagus hominis, Podwyssozki. Coccidia observed frequently in the white of fowls' eggs and in the hepatic cells of man.-Kegelwurm. See Ascaris conosoma, Jördens( 1802). -Kene der Perser. See Argas tholozani, Laboulbène et Mégnin.-Kleiderlaus. See Pediculus capitis, Leach. -Kleine Stubenfliege. See Homalomyia canicularis, Linné.-Kolumbaczer Mücke. See Simulium columbacschensis, Fabricius.-Kopflaus. See Pediculus capitis, Leach. - Kriebelmücke. See Simulium reptans, Linné.-Kritoptes monunguiculosus, Geber. See Tarsonemus monunguiculosus, R. Blanchard.-Lamblia intestinalis, Blanchard. See Megastoma intestinale, R. Blanchard (1885). - Laminosioptes gallinarum, Mégnin. See Symplecoptes cysticola, Railliet. - Laverania malariæ, Grassi and Feletti. See Polimitus malarice (Laveran), Danilewsky.-Leg-sticker. See Stomoxys calcitrans, Geoffroy. - Leptodera intestinalis, Cobbold. See Rhabdonema intestinale, R. Blanchard. - Leptodera niellyi, Blanchard, Moniez, See Rhabditis niellyi, R. Blanchard.Leptodera stercoralis, Cobbold. See Rhabdonema intestinale, R. Blanchard.-Leptodera teres, Schneider. See Rhabditis terricola, Oerley. - Leptus autumnalis. The larval hexapod of Tetranychus autumnalis, Shaw, q. v.-Leptus irritans. The six-legged stage of a mite, the Tetranychus tlalsahuate, Lemaire, Murray (1876), q. v., (Guiana, Antilles, Honduras); Colorado, (Cuba); Niaibi 
(New Grenada) ; Moqui (Para); Tlalsaliuate? (Mexico). See Tetranychus and Tlalsuhuate, Lemaire. Red Harvest-mite. A widely-dispersed pest, abundant in the Mississippi valley, where it is known as the chigger, being confused in the popular mind with the sandflea or chigoe (Sarcopsylla penetrans, Westwood), which it resembles in its burrowing habits and serious effects.-Leucophrys coli, Stein (1860). See Balantidium coli, Stein (1862). - Ligula mansonii, Cobbold $(\mathbf{I} 883)$. See Bothriocephalus mansoni, R. Blanchard (I886). - Linguatula constricta, Küchenmeister, R. Blanchard (1888). Syn., Pentastoma constricta, von Siebold (I852); Nematoideum hominis, Pruner, Diesing. This is only known in the larval condition. It is found in negroes and in the giraffe. -Linguatula constricta, Pruner; Linguatula denticulata, Lamarck (I8I6); Linguatula ferox, Küchenmeister (1855) ; Linguatula lanceolata, de Blainville (1818). See Linguatula rhinaria (1866).Linguatula pinguicola, Lamarck. See Hexathyridium pinguicola, Treutler-Linguatula rhinaria, Railliet (1886). Syn,, Ténia lanceole ou ver rhinaire, Chabert (1787); Tania caprina, Abildgaard (1789); Trenia rhinaria, Pilger (1802); Halysis caprina, Zeder (1803); Polystcma serrata, Zeder; Polystoma tcenioide, Rudolphi (I810); Echinorhynchus capra, Braun (I81o); Polystoma denticulatum, Rudolphi (1810); Tetragulus cavia, Bosc (1810); Linguatula tanioides, Lamarck (1816); Linguatula denticulata Lamarck (1816); Prionoderma lanceolatum, Cuvier (1817); Prionoderma rhinarium Rudolphi; Linguatula lanceolata, de Blainville (I8I8) ; Pentastoma emarginatum, Rudolphi (I8I9); Pentastoma tanoides, R u dol phi ; Pentastoma fera, Creplin (1829); Linguatula ferox, Küchenmeister (1855); Monostoma settenii, Neumann; Linguatula constricta, Pruner; Linguatula serrata, Fröhlich

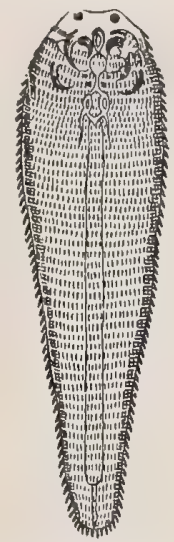

Larva of LinguATULA RHINARIA, Railliet; from the liver of man. (After Leuckart.)

(I789); Gemeiner Zungenzeurm, Ger. An endoparasitic acaridan with elongate, vermiform body, which led to its being classed as a worm. The sexually-mature form inhabits the nasal cavities of dogs and other domestic animals, where the eggs are deposited. These become scattered on the grass and are eaten by herbivorous animals. The larval and encysted stages are found in the mesenteric glands, liver and lungs of the goat, ox, horse, camel, sheep, deer, antelope, peccary, porcupine, rabbit, guinea-pig, brown rat, sometimes in man and according to Creplin in the domestic cat.-Linguatula serrata, Fröhlich (1789); Linguatula tænioides, Lamarck (1816). See Linguatula rhinaria, Railliet (I886).-Linguatula venarum, Lamarck. See Hexathyridium venarum, Treutler. - Liotheum giganteum, Denny, Verrill. See Menopon latum, Piaget.-Liotheum pallidum, Nitzsch, Verrill. See Menopon pallidum, Nitzsch.-Liotheum stramineum, Nitzsch. See Menopon biseriatum, Piaget.Lipeurus anseris, Gurlt. A louse of the goose.Lipeurus baculus, Nitzsch. Syn., Phiopterus baculus (Nitzsch), Verrill; Pulex columba majoris, Redi ; Pediculus columba, Linné ; Nirmus fliformis, Olfers, a common louse of the pigeon found together with Nirmus claviformis and Goniocotes compar.-
Lipeurus cygni, GiebeI. See Ornithobizs bucephalus, Giebel._Lipeurus heterographus, Nitzsch. Syn., Philopterus heterographus, (N) Verrill. A louse found on fowls.-Lipeurus jejunus, Nitzsch. Syn., Pulex anseris, Redi; Pediculus anatis anseris. Linné ; Nir. mus crassicornis, Olfers; Lipeurus jejunus, Rudow. A louse of the goose--Lipeurus numidæ, Denny. Syn., Nirmus numida, Denny. A louse of the guinea-fowl. - Lipeurus polytrapezius, Nitzsch. Syn., Pediculus meliagrides, Linné; Philopterus polytrapezius, Nitzsch, Verrill. The louse of the turkey. -Lipeurus squalidus, Nitzsch. Syn., Philopterus squalidus (Nitzsch), Verrill ; Pediculus anatis, Fabricius. A very common louse of the duck.-Lipeurus variabilis, Nitzsch. Syn., Philopterus variabilis (Nitzsch), Verrill ; Pediculus caponis, Linné. A louse of the fowl.-Listrophorus gibbus, Pagenstecher; Le Listrophore bossu. An acaridan found on domestic rabbits and hares. - Listrophorus mustelæ, Mégnin. An acaridan parasite of the ferret and pole-cat.-Liverfluke. See Fasciola hepatica, Linné.-L'Estre du fondement des chevaux, Geoffroy. See Gastrophilus hamor-hoidalis, Linné,-Lone-star Tick. See Argas americanus, De Geer.-Long-nosed Louse. See Hamatopinus vituli.-Lucilia anthropophagi, Conil. See Lucilia macellaria, Fabricius._Lucilia cæsar, Robineau-Desvoidy. Syn., Musca casar, Linné ; Goldfiege. A fly that commonly deposits its eggs on decomposing organic matter, especially meat, but also in the wounds of man and animals.-Lucilia ferinata, Gerlach. Syn., Lucilia serinata (Perroncito), Gerlach. A species troublesome to sheep in Olanda, the larvæ producing ulceration of the perineal regions. -Lucilia hominivorax, Coquerel. See Lucilia macellaria, Robineau-Desvoidy. - Lucilia macellaria, Robineau-Desvoidy (1830). Syn., Musca macellaria, Fabricius (I794); Lucilia hominivorax, Coquerel (1858); Calliphora infesta, Philippi (I861); Calliphora macellaria, Jorge (1878); Musca anthropophaga; Compsomyia rubrifrons, Macquart; Compsomyia macellaria; Somomyia montevidensis, Bigot; Calliphora anthropophaga, Conil (1878); Lucilia anthropophaga, Conil; Macellaria hominivorax, Macquart; La Lucilie bouchère; Texas Screzu-reorm; Screw-wormis. This fly is widely distributed over America from Canada to the Argentina. It deposits its eggs in the wounds of domestic animals and man, and also in the natural cavities. These larvæ cause serious symptoms. It is said that in Paraguay foals die in great numbers from the effects of larvæ that hatch from eggs deposited upon the navel before it has dried up. The prompt application of a mixture of pine-tar and grease to all raw surfaces, and about the ears, eyes, and nostrils of animals is recommended. Men should avoid sleeping in the open air unprotected by some netting. The myiosis produced is known as Peenash.-Lucilia sericata, Meigen. A fly common in Holland where the larvæ produce a form of myiosis called worm-sickness (worm-ziekte) in young sheep.-Lucilia serinata, Gerlach. See Lucilia ferinata, Gerlach.-Lucilie bouchère. See Lucilia macellaria, Robineau-Desvoidy.-Lumbricus canis, Werner (I782). See Ascaris mystax, Rudolphi (I80I).Lumbricus guloris sibirici, Pallas. See Eustrongylus gigas, Diesing.-Lumbricus in renibus, Blasius. -Lumbricus latus, Plinius; Lumbricus martis et canis renalis, Redi. See Trenia solium, Linné.Lumbricus longus et rotundus, Serapion. See Ascaris lumbricoides, Linné ( $175^{8}$ ).-Lumbricus rotundus, Cælius Aurelianus. See Ascaris lumbricoides, Linné (1758), - Lumbricus sanguineus in rene canis, Hartmann. See Eustrongylus gigas, Diesing. 
-Macaw Fly, Macaco Worm, Macaw Worm. See Dermatobu noxialis, Goudet.-Macellaria hominivorax, Macquart. See Lucilia macellaria, Robineau-Desvoidy.-Macrogaster platypus, Miescher. See Demodex folliculorum, Owen.-Madenwurm. See Oxyuris vermicularis, Bremser.-Mange-mites. See under genera Chorioptes, Demodex, Psoroptes, Sarcoptes, Symbiotes.-Mastdarmbremse, Ger. See Gastrophilus hamorrhoidalis, Linné.-Massuri. See Amphistoma collinsii, Cobbold.-Mastigodes hominis, Zeder (1803); Mastigodes siminæ, Zeder (1803); See Trichocephalus hominis, Schrank (1788). -Maw-worm. See Oxyuris vermicularis, Bremser, and Ascaris lumbricoides, Linné. - Meal-beetle, Mealworm. See Tenebrio molitor, Linné,-Medicinal Leech. See Hirudo medicinatis, Ray.-Medicinischer Blutegel. See Hirudo medicinalis, Ray.Medina-worm; Medinawurm, Ger.; Medinenischer Fadenwurm. See Dracunculus medinensis, Cobbold.-Megastoma entericum, Grassi (I882). See Megrastoma intestinale, Blanchard.-Megastoma intestinale, R. Blanchard (1885). Syn., Cercomonas intestinalis, Lambl 1859 (nec 1875); Lamblia intestinalis, Blanchard; Hexamita duodenalis, Davaine; Dimorphus muris, Grassi(1879); Megastoma entericum, Grassi (1882). This infusorian is found abundantly in the duodenum and jejunum of rats and mice of various species, especially in old individuals. It is frequently transmitted to man by the excrement of rats or mice becoming mixed with food-stuffs.-Megninia asternalis, Mégnin. Syn., Federmilbe der Tauben, Zürn. An acaridan found on domestic fowls.-Megninia cubitalis, Mégnin. Found on the quill-feathers of fowls.-Megninia ginglymura, Mégnin. Found on the turkey.-Megninia velata, Mégnin. Found on the domestic duck.-Mehlkäfer. See Tenebrio molitor, Linné.-Meloe proscarabeus, Linné. Syn., Gemeiner Oelkäfer. A beetle the larva of which is reported as a facultative human parasite by Germar and Otto.-Melon tho sp. A beetle, the iarva of which is reported as a facultative parasite of man by Le Maout, Depalse, and Robineau-Desvoidy. - Melophagus ovinus, Latreille. Syn., Hippobosca ovina, Linné. The Sheep-tick (a misleading name), a wingless fly, spending its entire life on the sheep and multiplying in its fleece. Menopon biseriatum, Piaget. Syn. Liotheum or Menopon stramineum, Nitzsch, Verrill. A louse of domestic fowls and turkeys. - Menopon extraneum, Piaget. A louse found on the guinea-pig. -Menopon giganteum, Denny. See Menopon latum, Piaget. - Menopon latum, Piaget. Syn. Menopon giganteum, Denny; Liotheum gigrnteum, Verrill.-An ectoparasite of the pigeon.-Menopon numidæ, Giebel. An ectoparasite of the guinea-fowl (Numida meleagris, Linné).-Menopon olescuram, Piaget. Found upon the domestic duck.-Menopon pallidum, Nitzsch. Syn., Liotheum pallidum, Nitzsch, Verrill; Pulex capi, Redi ; Nirmus trigonocephalus, Olfers; Pediculus galline, Schrank, Linné. One of the lice infesting domestic fowls.-Menopon phæostomum, Nitzsch. The Black-mouthed Menopon; one of the lice found upon peacocks.-Menopon stramineum, Nitzsch. See Menopon biseriatum, Nitzsch. - Menschenfloh. See Pulex irritans, Linné. - Mermis albicans, von Siebold (1857). Found in the honey-bee (Apis mellifica, Linné) and in many other insects. Hess (I887) describes a species of Gordius as parasitic in the bee.-Mermis blattæ orientalis, Diesing. This is found in the abdomen of the cockroach (Periplaneta orientalis, Linné). Mesocestoides litteratus, Vaillant. See Tania litterati, Batsch. - Mesogonimus commutatus,
Sonsino. Syn., Distoma commutalum, Diesing. A trematode found in the intestine of the common fowl and turkey.-Mesogonimus pellucidus, Neumann. Syn., Distoma pellucidum, von Linstow. A trematode found in the esophagus of the domestic fowl. - Metastrongylus longevaginatus, Molin (1861); See Strongylus lonocvaginatus, Diesing (185I).-Meteoric Fly. See Hydrotea meteorica, Davaine.-Miana Bug; Mianawanze, Ger. See Argas persicus, Fischer.-Microsporidia. Syn., Microbe de la pébrine; Bacterium ovatum, Lebert; Bacillus pasteurianus, Hansen; Micrococcus ovatus; $M$. pasteurianus, Nosema bombycis, Nägeli ; Panhystophyton ovatus, Lebert ; Pleospora herbarum; Cornalia's Corpuscles; Cornalian Bodies; Corpuscles de Cornalia; Cornalia'sche Körperchen, Corpuscles des vers d Soie; Corpuscles piriformes, Granulins, Pasteur ; Psorospermies des Insects (Balbiani); Micrococcus of pébrine, Micrococcus der Fleckenkrankheit. A group of Psorosperms or Sporozoans first discovered by Leydig (I853) in an hemipterous insect (Coccus hesperidum, Linné, the scale-louse of the orange and oleander). They were afterwards found in various arthropods, spiders, bees, crustacea (Daphnia rectirostris). Munk found them in Ascaris mystax (Bischoff mistaking them for seminal corpuscles). Vlacovitch found them in the reptile (Coluber carbonarius) and the cricket (Grillus campestris), and Lebert and Frey in a beetle (Emus oleus). Cornalia, Filippi, Ciccone, Vittdini, Pasteur, etc., found them in the silkworms suffering from pébrine; here they were at first held to be the nucleoli of broken-down blood-corpuscles (Charannes), or hæmatozoa (Guérin-Meneville). While Nägeli believed them to belong to the Schizomycetes, and Lebert to the unicellular algæ, Hallier designated them as the stylospores of a mushroom (Pleospora herbarum). Pasteur finally adopted the idea that they belonged to the so-called "organites." Balbiani was the first to prove the truth of Leydig's supposition and to settle their sporozoan nature. The Microsporidia have within recent years been found in many insects ( $B$ m by $x$ mori, Satturnia pernyi, Bombyx neustria, Liparis chrysorrhce, Tenebrio molitor), the larvæ of flies, of ants, etc., etc. - Miescheria muris, R. Blanchard (I885). Utriculiform psorosperms found in the voluntary muscles of mice by F. Miescher, of Basle, in 1843 . The involuntary muscles remained free from the parasites.-Miescher's, or Miescherian Sacs, Tubes, or Utricles; Miescher'sche Schläuche. See Sarcocystis miescheri, Ray Lankester. - Monas anatis, Davaine. See Monocercomonas anatis, Davaine.-Monas canis, Davaine. See Monocercomonas canis, Davaine.-Monas caviæ, Davaine. See Monocercomonas cavia, Davaine.-Monas crepusculum, Ehrenberg, Müller. A doubtful species observed in the white substance between the teeth by Steinberg-Monas elongata, Dujardin; Monas globulus, Dujardin. Found by Steinberg in the human mouth.-Monas lens. See Heteromyia lens, Müller.-Moniezia alba (Perroncito, I879), R. Blanchard (I89I). Syn., Tenia alba, Perroncito (1879); Moniezia alba, var. dubia Moniez, I89I. A parasite of sheep and cattle.-Moniezia benedeni (Moniez, 1879), R. Blanchard (I89I). Syn., Tenia benedeni, Moniez, 1879; Tenia denticulata. Neumann, I892. This is found in the intestines of domestic sheep and cattle.-Moniezia denticulata (Rudolphi, 18Io), R. Blanchard (I89I). Syn., Tenia denticulata, Rudolphi, I810; Tania denticolata, Perroncito (I882); Alyselminthus denticulatus, Blainville (1853). A parasite of domestic cattle. Moniezia expansa (Ru- 
dolphi, 1810), R. Blanchard (189r). Syn., Tania vasis nutritiis distinctis, Bloch (1782); Tienia ovina, Goeze (1782), Batsch (I786), Schrank (I788), Gmein (1789); Halysis ovina, Zeder (1803); Tania denticulata, Mayer; Alyselminthus expansus, Blainville; Tenia expansa, ex parte Rudolphi, Raillet, Neumann, Perroncito, Curtice. This cestode has for its host, sheep, goats, cattle, and various wild ruminants.Moniezia fimbriata, Moniez (I89I). See Thysanosoma actinioides, Diesing (1834).-Moniezia goezei (Baird, r853), R. Blanchard (I89r). See Tania pectinata, Goeze (1782).-Moniezia leuckarti, Riehm (I88I), R. Blanchard, (I89I). See Tenia pectinata, Goeze (I 782). - Moniezia neumanni, Moniez (I89I). The domestic sheep harbors this platode.-Moniezia nullicollis, Moniez ( $189 \mathbf{I}$ ). Found in sheep in France. - Moniezia ovilla, Moniez (189I). Moniezia ovilla, var. macilenta, Moniez (I89I). See Thysanosoma giardi (Rivolta, I878), Stiles (1803).-Moniezia pectinata, R. Blanchard (I89I). See Tania pectinata, Goeze( 1782 ). - Moniezia planissima, Stiles and Hassall (1892). Syn., Tenia expansa, ex parte Rudolphi. This is found in the small intestine of domestic sheep and cattle.-Moniezia trigonophora, Stiles and Hassall (1893). Syn., Tania expansa, Curtice, ex parte McMurrich, Tania benedeni, Neumann. A species recently described as a pardsite of sheep.-Monocercomonas anatis, Davaine. Syn., Monas anatis, Davaine. A flagellate infusorian found in the cecum of the duck. Monocercomonas canis, Davaine. Syn., Monas canis, Davaine. This is found in the stomach and duodenum of the dog.-Monocercomonas caviæ, Davaine. Syn., Monas cavia, Davaine. A flagellate infusorian found in the large intestine of the guinea pig. It is perhaps identical with the form described by Künstler as Bacterioidomonas sporifera, and those by Perroncito as Cercomonas ovalis, pisiformis, globosus.-Monocercomonas gallinæ, Rivolta. This is found in cases of croupous angina in pullets and young pigeons. - Monocercomonas hepatica, Rivolta. This was found in the diseased liver of a young pigeon.-Monocercomonas hominis, Grassi ( 1883 ) See Cercomonas intestinalis, Lambl.-Monodontus wedli, Molin. See Uncinaria cernua, Creplin.Monomita muscarum, Grassi. See Herpetomonas muscee domestica, Saville Kent.-Monostoma attenuatum, Rudolphi. This was found by Creplin in the intestine and cecum of the domestic goose. Monostoma bijuge, Miescher. See Monostoma faba, Bremser.-Monostoma caryophyllinum, Rudolphi, This is parasitic in the intestine of the stickle-back, but was found by Gwilt in the intestine of the domestic duck.-Monostoma faba, Bremser. Syn., $M$. bijuge, Miescher. Found in tubercles in the skin of the domestic sparrow and of canary birds (Fringilla canaria, Linné).-Monostoma lente, Nordmann, Gescheidt, Diesing, etc. See Distoma lanceolalum, Mehlis.-Monostoma lepore, Kuhn. See Cysticercus tanice serrate, Zeder, Goeze. - Monostoma mutabile, Zeder. Found in the infraorbital space of the domestic goose.-Monostoma setteni, Neumann. See Linguatula rhinaria, Railliet.-Monostoma verrucosum, Fröhlich. Syn., Notocotyle triserialis, Diesing. Found in the large intestine and ceca of the goose, duck, and fowl.-Mordella sp. A beetle, the larvæ reported as a facultative parasite of man by Rosen.-Morpion. See Phthirius inguinalis, Leach.-Mouche araignée. See Hippobosca equina, Linné.-Mouche bleue de la viande. See Calliphora vomitoria, Robineau - Desvoidy.Mouche carnassiere. See Sarcophaga carnaria, Meigen.-Mouche des chevaux, Réaumur. See
Gastrophitus nasalis, Linné.-Mouche domestique. See Musca domestica, Linné.-Mouche ou ver du nez des moutons, Réaumur. See CEstrus ovis, Linné. -Mouche plate. See Hippobosca equina, Linné.Mouqui. The native name in Para for Lepius irritans, q. v.-Mouse-flea. See Pulex musculi, Még nin.-Moyoquil. See Dermatobia noxialis, Goudot, Müller. See Tenebrio molitor, Linné.-Musca anthropophaga. See Lucilia macellaria, RobineauDesvoidy.-Musca bovina, Davaine. A torment to cattle.-Musca cadaverina, Linné. Syn., Pyrellia cadaverina, Robineau-Desvoidy. Aasfiege. A carrion fly, sometimes depositing its eggs in the open wounds of cattle.-Musca carnaria, Linné. Syn., Fleischfiege. A carrion fly, the larva of which was found by Bretschneider in the human intestine; it is described by Jördens and others as Ascaris stcphanostoma. Roulin, Cloquet, Brera, Wahlborn, Cheyne, and Bateman report cases of myiosis from its larva.-Musca carnifex, Davaine. The executioner fy. Torments cattle. - Musca cibaria. Two cases are reported by Good and White (England).-Musca corvina, Fabricius. This is common in Europe in warm, wet weather, and is troublesome to cattle, on which it alights to suck the sweat ; it does not bite.-Musca domestica, Linné. House fy, Domestic fly, Mouche domestique, Stubenfiege. Dubinsky and Senator report cases of the larvæ of the house fly being vomited. It is troublesome to man and animals, sucking their excretions. The Ascaris conosoma of Jördens and others is but the larva of this fly. Musca hortorum, Meigen. Troublesome to domestic animals.-Musca larvarum, one case reported by Pickells (Ireland).-Musca macellaria, Fabricius. See Lucilia macellaria, Robineau-Desvoidy.-Musca nigra, one case of myiosis attributed to this fly reported by Wahlborn (Sweden).-Musca sp. Syn., Warega fly. This is found in Brazil, and deposits its eggs beneath the skin of man and animals, causing painful swellings. - Musca sp. The larva of an unidentified fly, removed by Dr. Kirk from the leg of David Livingston in Africa, also from the shoulder of a negro. The adult fly is said to be not unlike but smaller than our blue-bottle fly (Calliphora vomitoria, Robineau-Desvoidy).- Musca stabulans, Fallen. See Cyrtoneura stabulans, Macquart.-Musca vaccina, Davaine. Troublesome to cattle.-Musca vagatoria, Davaine. The vagabond fly, troublesome to domestic cattle.-Musca vitripennis, Meigen. A torment to cattle.-Musca vomitoria. See Calliphora vomitoria, Robineau - Desvoidy. - Mydæa vomiturationis, Robineau-Desvoidy. See Teichomyza fusca, Macquart.-Myotrichodina. See Tri china spiralis, Owen.- Myzomimus scutatus, Stiles. Syn., Spiroptera scutata, Müller. Filaria scutata asophagea bovis, Müller. Found in the walls of the esophagus of domestic cattle and horses and in the pharynx and tongue of the domestic hog and sheep; it probably belongs to the genus Gongleonema, Molin (I857). - Narambo, Narapoo chalondy, Hind. : Naru, Pers. See Dracunculus medinensis, Cobbold.-Nematoideum bovis tauri, Diesing. Found in the aqueous humor of the eye in domestic cattle.-Nematoideum canis familiaris, Warren. Found in the esophagus of the dog. - Nematoideum equi caballi, Peschel, Diesing. See Sclerostoma tetracanthum, Diesing.-Nematoideum fringillæ domestica, Rudolphi. This is found in the stomach of the domestic sparrow,-Nematoideum ovis pulmonale, Rudolphi, Diesing. See Strongylus rufescens, Leuckart.-Nematoideum sp., Brehm. Found in the pancreas and liver of the vicunna.-Nematoideum sp., Ebertz. This is found in the lungs of the domestic 
sheep, and is probably Strongylus flaria, Rudolphi, or Strongylus rufescens, Leuckart, q. v.-Nematoideum sp., Generali. Found in the house-fly. - Nematoideum sp., Leuckart. Found encapsuled in the lymphatic glands of domestic cattle.-Nematoideum sp., Stiles. Found in lymphatic glands of cattle in capsules.-Nematoideum tracheale, Rainey and Bristowe. See Filaria trachealis, Cobbold. This is possibly but the larval form of Ascaris megalocephala or Ascaris szilla. - Nephrophages sanguinarius, Miyake and Scriba (I893). A mite found in considerable numbers in the urine of a native patient in Tokio. The parasite was held to have its seat in the kidney, and as being the cause of the hematuria. - Nettorhynchus blainvillii, Zenker. According to Raspail, this may have been a partially decomposed Bothriocephalus claviceps or Bothrioceplualus rugosa of the salmon.-Niaibi. The native name in New Grenada for the Leptus irritans, q. v.-Nigua. See Argas americanus, DeGeer, and Sarcopsylla penetrans, Westwood.-Nirmus clavicornis, Denny, Verrill. The louse of the ring-dove and stock-dove. Piaget refers them to Lipeurus baculus, Nitzsch.Nirmus crassicolis, Olfers. See Lipeurus jejunus, Nitzsch.-Nirmus filiformis, Olfers. See Lipeurus baculus, Nitzsch.-Nirmus numidæ, Denny. See Lipeurus numida, Denny,-Nirmus tetragonocephalus, Olfers. See Goniodes falcicornis, Nitzsch.Nirmus trigonocephalus, Olfers. See Menopon pallidum, Nitzsch.-Noctua sp. A lepidopterous insect. One case of the larva acting as a facultative parasite cited by Dumeril (France).-Noisy Breezefly. See Tabanus bromius, Linné. - Notocotyle triserialis. See Monostoma verrucosum, Fröhlich.Nuche. See Dermatobia noxialis, Brauer.-Ochromyia anthropophaga ; Blanchard. Syn., Cayor Fly. A Senegal fly, the larvæ of which are found beneath the skin in man, the dog, cat, and goat.-Edemagena equi, Loiset. See Hypoderma equi, Joly.-CEdemagena tarandi, Latreille. See Hypoderna tarandi, Linné.-Esophagostoma columbianum, Curtice. A worm producing a nodular disease of the intestines of sheep in the Southeastern United States. Esophagostoma dentatum, Rudolphi. Syn., Esophagostona subulatum, Molin; Sclerastomu dentatum, Strongylus dentatus, Rudolphi. This is found in the small intestine, cecum, and colon of the domestic pig, the wild boar, and the white-lipped peccary (Dicotyles (Noctophorus) labiatus).-CEsophagostoma inflatum, Schneider, Railliet. Syn., Strongylus inflectus, Schneider. Found in the large intestine of domestic cattle-Esophagostoma subulatum, Molin. See Esophogostoma dentatum, Rudolphi.Esophagostoma venulosum, Rudolphi. This is found in the goat, sheep, and roe-deer-CEstre du mouton, Geoffroy. See Estrus ovis, Linné.Estrus ani equorum, Linné. See Gastrophilus hamorrhoidalis, Linné.-Estrus bengalensis, var. equi, Macquart. See Gastrophitus equi, Fabricius. CEstrus bovis, Fabricius, Linné (I76I). See Gastrophilus equi, Fabricius.-Estrus bovis, De Geer (I776). See Hypoderma bovis, De Geer-CEstrus cameli, var. pharyngobalus, Steel. Camel-bot. A bot producing great irritation of the nasal cavities and pharynx of camels.-Estrus clarksii, Leach. See Gastrophilus nasalis (Linné), Schiner.-Estrus cuniculi, Clark (1797). See Cuterebra cuniculi, Clark (I815). - Estrus duodenalis, Schwab. See Gastrophilus nasalis ( Linné), Schiner-CEstrus elephantis, Steel. See Gastrophilus elephantis, Cobbold-CEstrus equi, Clark, Fabricius, Latreille, Olivier, Fallen, Macquart, Westwood, Joly. See Gastrophilus equi, Fabri-
cius.-Estrus equi, var. a nasalis, Fabricius. - See Gastrophilus nasalis (Linné), Schiner-WEstrus equi, var., $\beta$ hæmorrhoidalis, Fabricius. See Gastrophilus hamorhoidalis, Linné. - Estrus ericetorum, Leach. See Hypoderma lineata (Villers), Löw.-CEstrus gastricus major, Estrus gastricus vulgaris, Schwab. See Gastrophilus equi, Fabricius.-Estrus guildingi, Hope. See Dermatobia noxialis, Brauer. -CEstrus hæmorrhoidalis, var. $\beta$ Clark, See Hypoderma lineata (Villers), Löw.-CEstrus hæmorrhoidalis, Gmelin, Schrank. See Gastrophilus equi, Fabricius, and Gastrophilus hamorrhoidalis, Linné.Estrus hominis, Völkel. See Hypoderma diana, Brauer.-Estrus intestinalis, DeGeer. See Gastrophilus equi, Fabricius.- Estrus lineatus (Villers), Olivier. See Hypoderma lineata (Villers), Löw.-Estrus nasalis, Linné. See Gastrophitus nasalis (Linné), Schiner.-Estrus nasalis ovinus, Neumann. See Estrus ovis, Linné.-Estrus ovinus, Fischer. See Estrus ovis, Linné.-CEstrus ovis, Linné (1760). Syn., Mouche ou ver du nez des moutons, Réaumur (1734); CEstrus sinus frontalis, Linné (I746); L'estrus de moutons, Geoffroy (1764); Estrus ovinus, Fischer (1787); Cephalomyia ovis, Latreille (1825); Westwood (I840); Joly (1846); Cstrus nasalis ovinus, Neumann (I85I); Sheep Bot-Ay; Sheep Gad-fy, Grub-in-the-head. The larvæ are found in the nostrils and nasal and frontal sinuses of sheep.Estrus rangiferinus, Linné. See Hypoderma tarandi, Linné.-Estrus salutaris, Macquart. - Estrus salutiferus, Clark. See Gastrophilus nasalis (Linné), Schiner-_Estrus tarandi, Linné. See Hypoderma tarandi, Linné. - Estrus veterinus, Clark. See Gastrophilus nasalis (Linné), Schiner.Ohrbohrer ; Ohrwurm, Ger. See Forficula auricularia. - Ollulanus tricuspis, Leuckart. This is found encapsulated in the muscles of the house-mouse (Mus musculues, Linné,) and in the walls of the stomach of domestic cats, wandering into the muscles, connective tissue, and diverse organs.-Onchocerca reticulata, Diesing. Syn., Spiroptera cincinnata, Zün; Filaria cincinnati, Perroncito. Found in the muscles and coats of arteries in the horse.-Oorworm, Dan. See Forficula auricularia.-Ophiostoma pontieri, H. Cloquet (1822). See Gordius tolosanus, Dujardin (1842). - Ophryoscolex inermis, Stein (I858). A peritrichous vorticella-like infusorian found in the rumen and reticulum of various ruminants. The infusoria found in the viscera of sheep by Gruby and Delafond (1843) probably belonged to this genus. Ophryoscolex purkinjei, Stein (I858). Endoparasitic within the first and second stomachs of sheep and cattle.-Orentvist, Dan. See Forficula auricularia. -Ormask, Sw. See Forficula auricularia, Linné.Ornithobius bucephalus, Giebel, Piaget. Syn., Pulex cyoni, Redi; Pediculus cyoni, Linné ; Lipeurus cygni, Giebel; Ornithabius cygni, Denny. The louse of the swan.-Ornithobius cygni, Denny. See $O$. bucephalus, Giebel.-Ovuligera carpi, Dupuytren. Syn., Acephalocystis plana, Lennec. A concretion found between the tendons and muscles and mistaken for an entozoön.-Ox Breeze-fly. See Tabamus bovinus, Linné.-Ox Warble-fly or $\mathrm{Ox}$ Bot-fly. See Hypoderma bovis, Latreille.-Ox Gad-fly. See Tabanus bovinus, Linné.-Ox Warble. See Hypoderma lineata, Villers.-Oxyporus subterraneus. A beetle, the larvæe of which is reported by Paykul as a facultative hunan parasite.-Oxyuris ambigua, Rudolphi. Syn., Passalurus ambiguzes, Dujardin. This is found in the large intestine and cecum of the domestic rabbit and of the hare.-Oxyuris appendiculata, Leidy. Syn., Anguillala appendiculata, Leidy ; 
Oxyuris blatte orientalis, Butschli. This is found in the large and small intestine of the cockroach (Periplaneta orientalis, Linné).-Oxyuris blatta orientalis, Bütschli. See Oxyuris appendiculata, Leidy.Oxyuris blatticola, Galeb. Found in the cockroach (Blatta germanica, Fabricius).-Oxyuris compar, Leidy. This is found in the small intestine of the domestic cat. The female only is known.-Oxyuris curvula, Rudolphi. This is found in the intestine and cecum of the domestic ass, mule, and horse. Oxyuris diesingi, Hammerschmidt. Syn., Angzillula mucrura, Diesing. This is found in the large and small intestine of the cockroach (Periplancta orientalis, Linné).-Oxyuris mastigodes, Nitzsch. This is found in the intestine of the horse.-Oxyuris obvetata, Bremser. Found in the intestine of the house mouse (Mus musculus, Linné) and of the house rat (Mus ratus, Linné) and the brown rat (Mus decumanus, Pallas).-Oxyuris semilanceolata, Molin. See Oxyuris tetraptera, Nitzsch.-Oxyuris tetraptera, Nitzsch. Syn., Oxyuris semilanceolata, Molin. This is found in the large intestine of the house mouse (Mus musculus, Linné).-Oxyuris vermicularis, Bremser (1819), Chiaje, Dugés, etc. . Syn., 'A Hippocrates; Lumbriculus, Aldrovandi ; Ascaris ver. micularis, Linné ( $\mathbf{1} 767)$, Müller, etc. ; Fusaria vermic. ularis, Zeder (1800), Madenwurm; Pfriemenschwanz, Sprinowurm, Aftermade, Ger.; mans worm, threadworm, fin worm, seat worm. This is found in the cecum and lower part of the ileum of man and, according to Zürn, occasionally in the dog. The feeding experiments of Cobb prove that no intermediate host is necessary for the development of this worm. Oxyuris vivipera, Probstmayer and Perroncito. This is found in the cecum and intestine of the domestic ass; according to Railliet this is a Rhabdonema.-Palisade-worm. See Sclerustoma armata, Dujardin, or Eustrongylus gigas, Diesing.-Pampas benchucha. See Conorhinus nigrovarius.-Pangonia neo-caledonica, Mégnin. A gad-fly which is very troublesome in New Caledonia (l'île des Pines), said to have spread an epidemic of anthrax in cattle and men by its bite. To the genus Pangonia is said to belong the "seroot" or "zimb," which, according to Bruce and other African travelers, is so troublesome in Abyssinia; others refer this to Glossina morsitans, Westwood, q.v.-Papilio (Pieris) brassica. One of the cabbage butterflies, the larva of which is reported by Calderwood (Scotland) as a facultative parasite.Paramecium coli, Malmsten(1857). See Balantidium coli, Stein (1862).-Passalurus ambiguous, Dujardin. See Oxyuris ambigza, Rudolphi.-Pediculus anatis, Fabricius. See Lipeurus squalidus, Nitzsch.-Pediculus anatis anseris, Linné. See Lipeurus jejunus, Nitzsch. - Pediculus anseris, Sultzer. See Trinoton conspurcatum, Nitzsch. Pediculus bicolor, Lucas. See Hematopinus piliferus, Burmeister.-Pediculus bidentatus, Scopoli. See Goniocotes compar. Nitzsch.-Pediculus bovis, Linné. See Trichodectes scalaris, Nitzsch. Pediculus canis, O. Fabricius (?). See Trichodectes latus, Nitzsch,-Pediculus canis familiaris, Müller. See Hamatopinus piliferus, Burmeister.-Pediculus capitis, Leach, Nitzsch. Syn., Pediculus ordinarius, Redi; Pediculus cervicalis, Leach; Pediculus corporis humanus, var. I; Linné; Head-louse, Common Louse, Pou human de la tête. De Geer; Le pou ordinaire, Geoffroy; Pou de la tete, Lamarck, Fr.; Kopflaus, Ger. This louse infests by preference the human head, but is frequently found on all parts of the body, and is thus confused with Pediculus vestimenti, Leach. According to Murray the colored races have lice with corresponding colors. Those of the negroes of West Africa and Australia are nearly black, those of the Hindoos dark, those of the Hottentots orange, those of the Chinese and Japanese yellowish-brown, those of the Indians of the Andes dark-brown, those of the California Indian olive, those of the northern Indians, Esquimaux etc., pale. The lice from a negro turn light-colored when placed on the head of a white person. Any simple grease will destroy these parasites, a fact which perhaps explains the universal use of ointments and pomades by all savages and people of dirty habits.-Pediculus caponis, Linné. See Lipeurus variabilis, Nitzsch.Pediculus cervicalis, Leach. See Pediculus capitis, Leach.-Pediculus columbæ, Linné. See Lipeurus baculus, Nitzsch.-Pediculus corporis. See Pediczulus capitis, Leach.-Pediculus cygni, Linné. See Ornithobius bucephalus, Giebel.-Pediculus denticulatus, Nitzsch. See Homatopinus spinulosis.-Pediculus equi, Linné. See Trichodectes pilosus, Giebel. -Pediculus eurysternus, Nitzsch. See Hamatopinus eurysternus, Stephens.-Pediculus gallinæ, Schrank, Linné. See Menopon pallidum, Nitzsch.Pediculus humanus, var. I, Linné. See Pediculus capitis, Leach.-Pediculus humanus, var. 2, Linné. See Pediculus vestamenti.-Pediculus inguinalis, Redi. See Phthirius inguinalis, Leach. - Pediculus lyriocephalus, Burmeister. See Hamatopinus lyriocephalus, Burmeister-Pediculus macrocephalus, Burmeister. See Hamatopinus macrocephalus, Burmeister.-Pediculus meleagris, Schrank. See Goniodes stylifer, Nitzsch.-Pediculus meleagridis, Linné. See Lipeurus polytrapezius, Nitzsch.-Pediculus ordinarius, Redi. See Pediculus capitis. - Pediculus ovis, Linné. See Trichodectes sphorocephalus, Nitzsch, Leach.-Pediculus pavonis, Linné. See Goniodes falcicornis, Nitzsch.-Pediculus piliferus, Burmeister. See $H a$ matopinus piliferus, Burmeister-Pediculus porcelli, Linné, Schrank. See Gyropus gracilis, Nitzsch.Pediculus pubis, Linné See Phthirius inguinalis, Leach. - Pediculus spinulosis, Burmeister. See Hamatopinus spinulosus, Burmeister. - Pediculus setosus, Olfers. See Trichodectes latus, Nitzsch.Pediculus suis, Linné. See Hamatopinus urius, Nitzsch.-Pediculus tabescentium, Alt. See Pediculus vestimenti, Leach. - Pediculus tenuirostris, Burmeister. See Homatopinus eurystermus, Nitzsch, Burmeister.-Pediculus vestimenti, Leach (1864). Syn. Pediculus humanus, var. 2, Linné, Pediculus humanus corporis, De Geer. P. tabescentium, Alt (1824); Clothes louse, Body louse, Kleiderlaus, Pou humain du corps, De Geer; Pou du corps, Lamarck, Pou des malades. This is found on the hairless parts of the body, producing a marked irritation of the skin. The eggs are deposited in the folds of the clothing. These lice at times occur in vast numbers in localities where they were unknown before.-Pediculus vituli, Linné. See Hematopinus eurysternus, Nitzsch, Burmeister. - Peepsa. See Simulium indicum.Peitschenwurm. See Trichocephalus hominis, Schrank. - Pejunk. See Dracunculus medinensis, Cobbold.-Pelodera axei, Cobbold. This is found in the hoof of the horse.-Pelodera pellio, Schneider (I866). See Rhaditis pello, Bütschli (1873).-Pelodera setigera, Bastian (1879). See Rhabditis terricola, Oerly.-Pelodera teres, Schneider (1866). See Rhabditis terricola, Dujardin.-Penetrating Flea. See Sarcopsylla penetrans, Westwood.-Pentastoma coarctata, Virey (1823). See Tania saginata, Goeze. - Pentastoma constricta, von Siebold (1852), Leuckart. See Linguatula constricta, Küch- 
enmeister.- Pentastoma denticulatum, Rudolphi (I819); Pentastoma emarginatum, Rudolphi (I819); Pentastoma fera, Creplin (I829). See Linguatula rhinaria, Railliet (1886).--Pentastoma moniliforme, Diesing, Mégnin refers without good cause, a worm found by Bochefontaine in a dog, to this species, which in the adult state is found in the lung and body-cavity of various serpents (Python, Boo, Crotalus), the crocodile and large lizards.-Pentastoma serratum, Fröhlich ( 1789$)$; Pentastoma settenii, Diesing.-Pentastoma tænioides, Rudolphi (I819). See Linguatula rhinaria, Railliet (1886).Perce-oreille, Fr. See Forfucula auricularia, Linné. Petit pou du bouf. See Trichodectes scalaris, Nitzsch. - Petit pou du cheval. See Trichodectes equi, Denny.-Petit pou de la chèvre. See Trichodectes climax, Nitzsch.-Petit pou du chien. See Hamatopinus piliferus, Denny.-Petit taon pluvial. See Hamatopota pluvialis, Meigen.-Pferdeegel. See Hirudo sanguisuga, Bergmann.-Pfriemenschwanz. See Oxyuris vermicularis, Bremser.-Pharaoh's Worm. See Dracunculus medinensis, Cobbold.Pharyngobolus africanus. A bot found in the pharynx of the African elephant.-Philopterus baculus, Nitzsch. See Lipeurus baculus, Nitzsch.-Philopterus compar, Burmeister. See Goniocotes compar, Nitzsch.-Philopterus dissimilis, Nitzsch, Verrill. See Goniodes dissimilis, Nitzsch, Piaget.-Philopterus heterographus, Nitzsch, Verrill. See Lipeurus heterographus, Nitzsch, Denny.-Philopterus polytrapezius, Nitzsch, Verrill. See Lipeurus polytrapezius, Nitzsch.-Philopterus variabilis (Nitzsch), Verrill. See Lipeurus variabilis, Nitzsch.-Phryganea grandis. A case is reported by Church (England) of the larva of this lepidopterous insect acting as a facultative parasite in man.-Phthirius inguinalis, Denny. Syn., äyolos, Aris totle; Pediculus in guinalis, Redi (1668) ; Pediculus pubis, Linné ; Phthirius pubis, Leach; Pou de pubis, Lat reille, Lamarck; Le morpion, Geoffroy ; Filzlaus, Schamlaus, Crab-louse. Th is infests the pubic re

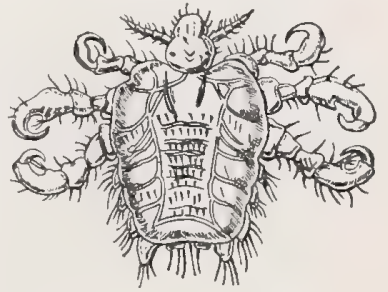

PhthiRius inguinalis, Denny. gion of unclean persons, occasionally spreading over other parts of the body, eyebrows, beard, breast, axilla, etc.-Phthirius pubis, Küchenmeister. See $P$ hthirius inguinalis.-Physaloptera truncata, Schneider; found in the proventriculus of the domestic fowl. -Piccolo tafano pluviale. See Hamatopota pluvialis, Meigen. - Picobia bipectinata, A. Heller; Picobia neeri, G. Haller; Picobia pectinata, A. Heller; Picobia uncinata, Heller. Acaridans found in the quill of the feathers of poultry, guinea-fowls, pigeons, peacocks, and other birds.-Pigeon-flea. See Pulex avium, Taschenberg.-Pigeon-louse. See Lipeurus baculus, Nitzsch, Nirmus claviformis, Denny, Goniocotes compar, Nitzsch.-Piguris reticulata, Schlotthauber. This is found in the intestine and cecum of the mule and horse; Neumann doubts its authenticity.-Pincer Ixode.- See Ixodes chelifer, Mégnin. - Pinworm. See Oxyuris vermicularis, Bremser.-Pique. See Sarcopsylla penetrans, Westwood.-Plagiotoma coli, Claparede and Lachmann (I858). See Balantidium coli, Stein (I862), - Пharẽ $\iota$

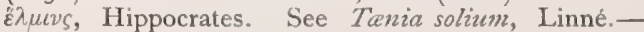
Planaria latiuscula, Goeze. See Distoma lanceo- latum, Mehlis.-Plasmodium malariæe. See Pua imitus malaria.-Pleurocercoides bailleti, Railliet. See Cysticercus bailleti, Railliet.-Pœderus elongatus. A beetle, the larva of which is reported as a facultative parasite by Paykull. - Polimitus malarize (Laveran), Danilewsky (1886). Syn., Bodies of Laveran; Corps spherique aux fulaments mobile (Laveran, I884); Corpuscles of Laveran; Cytameba ; Cytosporozoön malaria, Danilewsky; Cytozoön malaria; Filaments mobile de la malaria; Hamanaba immaculata; Hamameba malaria; Hamanioba pracox; Hamanaba vivax, Grassi and Feletti; Hamatomonas malaria, Osler; Hamatophyllum malaria, Metchnikoff (1887); Hamatazoa of Laveran, Grassi and Felletti; Hamatozocires du paludism (Laveran, 1884); Hamocytozoön (Danilewsky) Hemogragarina avium (Danilewsky); Hamoplasmodium malaria, Marchiafava and Celli (1885); Laverania malaria, Golgi; Plasmodium malaria; Pseudovacuolen; Pseudospirilla malarice (Danilewsky); Pseudovermiculi malaria, Marchiafava and Celli, a species of sporozoön (hæmatozoön or hæmocytozoön) ; occurring as hyaline amceboid bodies in the blood of malarial patients and healthy birds. Morphologically these bodies resemble certain protistans (Polymastix bütschli and Multicella marina). - Polycephalus echinococcus, Zeder, Tschudi. See Echinococcus polymorphus. - Polycephalus granulosus, Zeder, Cloquet. See Echinococcus polymorphus, Diesing.Polycephalus hominis, Goeze, Jördens. See Echinococcus polymorphus, Diesing.-Polycephalus humanus, Zeder. See Echinococcus polymorphus, Diesing.-Polystoma denticulatum, Rudolphi (1810). See Linguatula rhinaria, Railliet (1886).-Polystoma pinguicola, Zeder. See Hexathyridium pinguicola, Treutler.-Polystoma sanguicola, Delle Chiaje, Frick. See Hexathyridium venarum, Treutler. -Polystoma serrata, Zeder.-Polystoma tænioides, Rudolphi (18ro). See Linguatula rhinaria, Railliet (1886).-Polystoma venarum, Zeder. See Hexathyridium venarum, Treutler.-Pou de la tête. See Pediculus capitis, Leach.-Pou de pubis. See Phthirius inguinalis, Leach.-Pou des malades. See Pediculus vestimenti, Leach.-Pou du chat. See Trichodectes subrostratis, Nitzsch.-Pou du corps. See Pediculus vestimenti, Leach.-Pou du porc. See Hamatopinus suis, Denny.-Pou humain de la tête, De Geer. See Pediculus capitis, Leach. - Pou humain du corps, De Geer. See Pediculus vestimenti, Leach.-Pou ordinaire. See Pediculus capitis, Leach.-Prionoderma lanceolatum, Cuvier (I8I7); Prionoderma rhinarium, Rudolphi. See Linguatula rhinaria Railliet, (I886).-Protomyxomyces coprinarius, Cunningham (1880). See Monocercomonas hominis, Grassi (I882).-Pseudalius ovis pulmonalis, Koch. See Nematoideum ovis pulmonale, Dies. ing.-Pseudalius ovis pulmonalis, A. Koch. See Strongylus rufescens, Leuckart.-Pseudalius pubis, Davaine. See Trichina spiralis, Owen.-Pseudalius trichina, Davaine (I862). See Trichina spiralis, Owen (1835).-Pseudo-rhabditis stercoralis, Perroncito. See Rhabdonema intestinale, $\mathrm{R}$. Blanchard. -Pseudospirilla malariæ, Danilewsky; Pseudovermiculi malariæ. See Polimitus malaria (Laveran), Danilewsky.-Psoroptes auricularis canis, Sewell. See Symbiotes auriculium, var. canis, Bendz. -Psoroptes communis, var. bovis, capræ, cuniculi, equi, ovis, Fürstenberg. Syn., Psoroptes longirosth is, Mégnin ; Psoropte à long bec, Acarus du cheval, Gohier; Sarcoptes equi, P. Gervais; Dermatodectes equi, Gerlach; Dermatodectes communis, Bourguinon and Delafond; Dermatokoptes communis, Fürstenberg; 
Saugkrätzmilbe der Hausthiere, Gemeine Raudemilbe, Mange-mite, Scab-mite, Scab-insect, Common Scab. The cause of a special form of mange in the horse, ox, buffalo, sheep, goat, and rabbit.-Psoroptes longirostris, Mégnin. See Psoroptes communis, Fürstenberg.-Psorosperma crouposum, Rivolti. See Coccidium oviforme, Leuckart - Psorospermies des Insects, Balbiani. See Microsporidia.-Pterolichus uncinatus, Mégnin. Found on fowls.-Pterophagus strictus, Mégnin. An acaridan found on the pigeon.Puce chique. See Sarcopsylla penetrans, Westwood. -Puce de l'homme. See Pulex irritans, Gervais.Puce de rats. See Pulex murinus, Mégnin.-Puce de souris. See Pulex musculi, Mégnin.-Puce des pigeons. See Pulex avium, Taschenberg.-Puce du chat, Puce du chien. See Pulex serraticeps, Gervais.-Puce penétrante. See Sarcopsylla penetrans, Westwood.-Pulex anseris, Redi. See Lipeurus jejunus, Nitzsch. - Pulex ater, Linné. See Pulex irritans, Linné.-Pulex avium, Taschenberg. Syn., Pulex columbe, Gervais, Denny; Pulex galline, Schrank ; Ceratopsyllus gallina, Bouché; Ceratopsyllus avium, Taschenberg; Vogelfoh, Puce des pigeons, Birdflea, Hen-flea.-Pulex canis, Curtis. See Pulex serraticeps, Gervais.-Pulex capi, Redi. See Menopon pallidum, Piaget.-Pulex columbx, Denny, Gervais. See Pulex avium, Taschenberg.-Pulex columbæ majoris, Redi. See Lipeurus baculus, Nitzsch.Pulex cygni, Redi. See Ornithobius bucephalus, Giebel.-Pulex felis, Bouché. See Pulex serraticeps, Gervais.-Pulex goniocephalus, Taschenberg. The flea proper of hares and rabbits.-Pulex hominis, Dugés. See Pulex irritans, Linné.-Pulex irritans, Linné (1758). Syn., Pulex ater, Linné (1746); Pulex vulgaris, :De Geer (1778); Pulex hominis (1832); Human Flea, Puce de Thomme, Geneiner Floh, Menschenfloh. This species, common on man, may be conveyed to dogs and cats and rabbits.-Pulex minimus cutem penetrans, Catesby. See Sarcopsylla penetrans, Westwood. - Pulex minutissimus nigricans, Barrère. See Sarcopsylla penetrans, Westwood. Pulex murinus, Mégnin. Syn,. Rat-flea, Puce de rats. A very small species found on rats.Pulex musculi, Mégnin. Syn., Mouse-flea, Puce de souris. A Larva of the flea minute form found on mice, but not transmitted to dogs and cats.

-Pulex pavonis, Redi. See Goniodes falcicornis, Nitzsch.-Pulex penetrans, Linné. See Sarcopsylla penetrans, Westwood.-Pulex serraticeps, Gervais. Syn., Pulex cati, Mégnin; Pulex felis, Künckel, Bouché ; Pulex canis, Curtis ; Ceratopsyllus canis, Dugés; Ceratopsyllus serraticeps, Gervais; Dog-flea, Hundefloh, Puce du chien, Puce de chat, Cat-Rea. This flea abounds on dogs. is less frequent on cats and is transmissible to man, but is not usually troublesome to him; it is occasionally found on rabbits. It acts as the intermediate host for Tania canina, Linné. Verrill and others hold the cat-flea and dog-flea to be different species, the posterior tarsi of the latter having the fifth joint longer than the second, while in the cat-flea the second joint is longer than the fifth.-Pulex vulgaris, De Geer. See Pulex irritans, Linné. - Pyrellia cadaverina, Robin. See Musca cadaverina, Linné.Rain Breeze-fly. See Hamatopota pluvialis, Meigen.-Rainey's Bodies, Rainey's Tubes, Rainey'- sche Körperchen. See Sarcocystis miescheri, Ray Lankester.-Rasenbremsfliege. See Gastrophilus nasalis (Linné), Schiner.-Rat-flea. See Pulex murimus, Mégnin.-Red Flea, Red Harvest-mite, Red Mite. See Tetranychus autumnalis, Shaw.-Redtailed Bot-fly. See Gastrophilus hamorrhoidalis, Leach.-Red-tailed Horse-bot. See Gastrophitus hamorrhoidalis, Linné.-Reduvius amœnus. This is found in Borneo.-Reduvius cruentus, an Indian species.-Reduvius personatus, L. Kothwanze. A common fly-bug in houses throughout Europe, rarely in the open; appears at night to suck the juices of bed bugs, spiders, flies, moths, etc. Cobbold cites it with the other species as a human parasite.-Reduvius pungens, Le Conte. Frequently found in the Eastern United States, about bed-rooms, living upon bed-bugs and other insects. - Reduvius serratus, a predaceous bug of India.. The bugs of the genus Reduvius although included by Blanchard and others among those occasionally attacking man, are on the whole useful. The young stages of these insects cover themselves over with dust, and thus concealed, lurk in dark places for the insects upon which they ordinarily prey.-Red Worm of Game-keepers. See Syngamus trachealis, von Siebold.-Rhabditis cornwalli, Cobbold. See Rhabditis terricola, Oerley.-Rhabditis genitalis, Scheiber. See Rhabditis pellio, Bütschli.-Rhabditis intestinalis. See Rhabdonema intestinale, $\mathrm{R}$. Blanchard-R - Rabditis niellyi, $\mathrm{R}$. Blanchard (1888). Syn., Anguillula leptodera, Nielly (I882); Leptodera niellyi, R. Blanchard (I885); Filaria niellyi, Moniez. It is found in the skin of man, producing a dermatitis occurring in discrete and confluent papules and vesico-papules, covering the arms, forearms, backs of the hands, and dorsal surface of the fingers. The eruption also involves the thighs. From the papules the parasite can easily be expressed. The disease resembles very strongly the African affection termed "Craw-craw." - Rhabditis pellio, Bütschli (1873). Syn., Pelodera pellio, Schneider (1866); Rhabditis genitalis, Scheiber (1880). This was found in the urine of a woman. The history of this case points to the parasite having lived in the vagina rather than in the urinary passages proper. - Rhabditis stercoralis (Normand), Bavay. See Rhabdonema intestinale, R. Blanchard.-Rhabditis teres, Perez, See Rhabditis terricola, Dujardin.Rhabditis terricola, Dujardin (1845), Oerley (I88I). Syn., Pelodera teres, Schneider (I866); Rhabditis teres, Perez (1866) ; Pelodera setigera, Bastian (1879); Rhabditis cornwalli, Cobbold (1879). This is common in garden earth throughout Europe. Found in the body of a boy who died from an epidemic disease on board the British reformatory school ship "Cornwall" in 1879 , producing a trichinosis-scare.-Rhabdonema intestinale, R. Blanchard (1885). Syn., Anguillula stercoralis, Bavay (1877), Normand; Anguillula intestinalis, Bavay (1877), Grassi ; Leptodera stercoralis, Cobbold, (I879): Pseudo-rhabditis stercoralis, Perroncito (I88I); Rhab. ditis stercoralis, Rhabditis intestinalis, Rhabdonema strongyloides, Leuckart (1883); Strongyloides intestinalis, Grassi (I883); Rhabditis strongyloides, Grassi. Found in the human intestine in cases of catarrhal gastro-enteritis. It is said to determine the Cochinchina diarrhea, both of men and of fowls. Grassi first demonstrated that Anguillula stercoralis was but the free state, and Anguillula intestinalis the parasitic stage, of the same worm.-Rhabdonema longum, Grassi and Segrè. Syn., Rhabdonema suis, Lutz.-Rhabdonema strongyloides, Leuckart. See Rhabdonema intestinale, R. Blanchard.-Rhabdone- 
ma suis, Lutz. See Rhalidonema longum, Grassi and Segrè. - Rhophalocephalus carcinomatosis, Korotneff (1893). Found in carcinomatous growths. It is referred to a group of organisms intermediate between the monocystic Gregarine (Monocystide) and the Coccidia (Coccidide). It shows close relationship to Ophryocystisbiutschli, Schneider (1884). Korotneff sum marizes his observations as follows: 1 . "Carcinoma is malignant only in case of the presence of Rhopha locephahes within it." 2. Rhophalocephalus belongs by nature to the Sporozon, and consists of two stages of development: Ameba and Coccidum. 3. The respective conditions of these two stages of development are shown by the two kinds of larva, the zoöid (zoöit) which has no enclosing envelopment (Hiille), and the sporozoöid (sporozoöit), which has an envelop. 4. The zoöid, as also the sporozoöid, can be either a coccidium or an ameba, with this difference, however, that in a coccidium we usually find only one larva (zoöid or sporozoöid), while in the ameba we may find many larvæ together, and of both kinds. 5. The zoöid forms a coccidium by encapsulation, but the sporozoöid changes into an ameba when it loses its envelop. 6. The zoöid, under favorable conditions of nourishment, can enlarge considerably, and assume a gregarina-like form. 7. The disappearance of the nucleus before or at the time of the formation of the larva (multiplication) either in the case of the ameba or coccidium, is a constant occurrence. 8. A regular succession of the stages of development (ameba and coccidium) does not occur in Rhophalocephalus; it is entirely accidental. 9. The coccidia, as well as the larvæ, are entirely passive, and are driven here and there in the organism, while the amebre move about actively. IO. Before the larva is formed within the ameba, the latter becomes encapsulated and degenerates proportionately to the formation of the larva, a circumstance which corresponds with the penetration of the leukocytes into the interior of the cysts. II . Leukocytes are necrophages which have nothing to do with living parasites; their rôle is not beneficial but pernicious, as they form in great numbers around the parasites and change into corpuscles. I2. The zoöid and coccidium are intra-cellular parasites, while the sporozoöid and ameba are ecto-cellular or inter-cellular parasites. 13. After a zoöid has penetrated into a cancer-cell, it may undergo division and form the nucleus (Bildungscentrum) of a cancer-pearl (Krebsperle). I4. The pearls form a necrotic area, which opening outward takes on the character of an abscess." -Rhynchoprion columbæ, Hermann. See Argas refexus, Latreille.-Rhynchoprion penetrans, Owen. See Sarcopsylla penetrans, Westwood.-Ricinus canis, De Geer. See Trichodectes latus, Nitzsch. - Ricinus caninus, Ray. See Ixodes ricinus, Linné. -Ricinus gallinæ, De Geer. See Goniocotes hologaster, Nitzsch. - Rischta, Rees. See Dracunculus medinensis, Cobbold.-Rouget, Le. See Tetranychus autumnalis, Shaw, - Rustic Breeze-fly. See Tabanus rusticus, Fabricius.-Sand-flea, Sandfloh. See Sarcopsylla penetrans, Westwood.-Sagittula hominis, Lamarck, Chiaje, Diesing. Syn., Animal Bipede, Bastiani. According to de Blainville and von Siebold. this is a fragment of the $Y$-shaped first branchial arch of some bird which was passed with the feces.Sangsue-Dragon. See Hirudo troctina, Johnson -Sangsue du cheval. See Hindo sanguisuga, Bergmann.-Sangsue grise. See Hirudo medici nalis, Ray,-Sangsue medicinale. See Hirudo medicinalis, Ray.-Sangsue noire. See Hirudo ob. scura.-Sangsue vert. See Hirudo medicinalis, Ray. -Sanguisuga interrupta, Moquin-Tandon. See
Hirudo troctina, Johnson.-Sanguisuga javanica, Wahlberg. See Hirudo javanica, Wahlberg.-Sanguisuga medicinalis, Savigny. See Hirudo medicinalis, Ray.-Sanguisuga officinalis, Savigny; See Hirudo medicinalis, Ray.-Sanguisuga tagalla, Meyen. See Hamadipsa ceylonica.-Sarcocystis hirsuta, Moulé. See Sarcocystis tenella, Railliet.Sarcocystis miescheri, Ray Lankester (1882). Syn., Synchytrium miescherianum, Kühn (I865), Zopf; Corpuscles of Rainey; Rainey's Bodies; Rainey's Corpuscles: Rainey's Tubes; Utricles of Miescher; Miescher's Tubes," Tubespore spherique. Sausage-like psurosperm tubes or saccules occasionally found in immense numbers in the muscles of pigs, cattle, sheep, mice and fowls, but never in man. - Sarcocystis tenella, Railliet. Syn., Sarcocystis hirsuta, Moulé. The cause of psorospermosis in the muscles of the sheep (Huet, Moulé, von Hessling, Cobbold, Sticker, Brusafeno, Krause), the goat (Pagenstecher, Moulé), the ox (von Hessling, Cobbold, Perroncito, Krause, Manz, Beale, Moulé), and the horse (Siedamgrotzky, Schulze, Pütz, Moulé). - Sarcophaga carnaria, Meigen. Syn., Gray Carnivorous Fly; Mouche carnassiere, Fr.; Graue Fleischfliegre, Ger. Common in Europe in summer and autumn; very rarely deposits its eggs and larvæ in wounds.-Sarcophaga magnifica, Schiner, (I862). Syn., Sarcophaga (Sarcophila) wohlforti, Portschinsky (I875); Sarcophaga muralis, Meigen; Sarcophila meigeni, Portschinsky; The Magnificent Sarcophagus. A fly common to Europe and Russia, rural in habit, never entering houses; found especially about the flowers of Eryngium. The larvæ occur in wounds and folds of the skin of cattle, horses, sheep, dogs, and domestic birds, especially geese. They are especially abundant where collections of sebaceous matter exist, as in the lacunæ of the fourchet of a horse's foot, the cavity of the sheath, or the folds of the pastern, where they produce ulceration. They are especially abundant in the districts of Mohilew, Orscha, and Gorki. Mégnin holds that the majority of cases of myiosis in Europe are due to this fly.-Sarcophaga ruralis, Meigen. See Sarcophaga magnifica, Schiner. - Sarcophaga wohlfarti, Portschinsky. Syn., Sarcophaga magnifica, Schiner.-Sarcophila meigeni, Portschinsky.

See Sarcophaga magnifica, Schiner. - Sarcophila wohlfarti, Portschinsky. See Sarcophaga magnifica, Schiner.-Sarcops y 11 a gallinacea, Westwood. The chigoe of fowls. Found on domestic fowls in Ceylon by Morely and by Green at Colombo. - S a r cops y 11 a penetrans, Westwood $B$ (1840). Syn., Pulex minimus cutem penetrans, Catesby (I743); Pulex minutis simus nigricans, Barrère (1743); Acaries fuscus sub cutem nidulans, P. B row n (1756); Pulex penetrans, Linné (I758); Rhyncho-

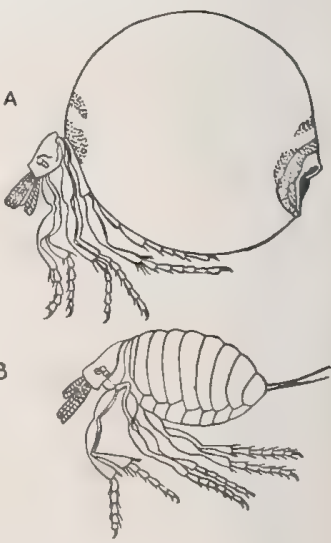

SARCOPSYLLA PENETRANS Westwood: A female: B male. (Afier Lewckart.)

prion penetrans, Oken (I8I5); Sarcopsylla canis, Westwood (1840); Dermatophilus penetrans, GuerinMéneville; Chigo, Chigoe, Chique, Chigga, Chigger, Chiggre, Jigger, Sandflea, Sandfoh, Puce penetrante, Puce-chique, Pique, Tique, Ton, Nigua, Bicholunga, 
Penetrating Flea, Burrozuins Flea. A variety of flea found in Brazil, Guiana, Mexico, West Indies, and recently (1872) introduced into Africa, Congo, Gaboon, from Brazil. It lives in woods, on plants, dry herbage and sand, and attacks man, sheep, goats, cattle, horses, mules, asses, dogs, and especially pigs. Its attacks show preference for the feet, causing gangrenous wounds, arthritis, necrosis, fistulæ, loss of phalanges. Among animals the ears are frequently attacked. Immediate extraction, care being taken not to injure the parasites for fear of perforating the ovigerous $\mathrm{sac}$ and allowing the eggs to escape in the wound, is recommended; also applications of grease. In the western United States, the harvest-mite (Leptus autumnalis) has been confused with this parasite and called chigger.-Sarcoptes auricularum, Lucas and Nicolet. See Symbiotes auricularium, var. canis, Bendz.-Sarcoptes canis, Gerlach. See Sarcoptes scabiei, var. suis, Mégnin; also var. canis, Railliet.-Sarcoptes cati, Hering (1838). See Sarcoptes notodres. - Sarcoptes crustosæ, Fürstenberg. See Sarcoptes scabiei, var. hupi, Mégnin.Sarcoptes cuniculi, Gerlach. See Sarcoptes notodres, Delafond and Bourguinon.-Sarcoptes cynotis, Hering. See Symbiotes auricularium, var. canis, var. cati, Neumann.-Sarcoptes cysticola, Vizioli. See S plectoptes cysticola, Railliet. - Sarcoptes dromedarii, P. Gervais. See Sarcoptes scabiei, var. cameli, Mégnin. - Sarcoptes gerlachi, Rivolta. See Cytodites nutus, Vizioli.-Sarcoptes hippopodos, Hering ( 1838 ). See Glyciphagus cursor, P. Gervais.-Sarcoptes hominis, Raspail. See Sarcoptes scabiei, var. hominis, Mégnin. -Sarcoptes lævis, var. columbæ, Railliet (1855). Found by Railliet and Cadiot at the base of the feathers on pigeons.-Sarcoptes lævis, var. gallinæ, Railliet (1886). Found on fowls.-Sarcoptes minor, Fürstenberg ; Sarcoptes minor, var cati, var. cuniculi, Fürstenberg. See Sarcoptes notodres, Delafond and Bourguinon.-Sarcoptes mutans, Robin. Syn., Kremidokoptes viviparus, Fürstenberg. The cause of the leg scabies of fowls. Reynal and Lanquetin regard it as transmissible to man.-Sarcoptes nidulans, Nitzsch. See Harpirhynchus nidulans, Mégnin.-Sarcoptes notcdres, Delafond and Bourguinon (1857). Syn., Sarcoptes cati, Hering (1838); Sarcoptes cuniculi, Gerlach (1857); Sarcoptes minor, var. cati, var. cuniculi. Fürstenberg (186r); Dermatophagus cuniculi, Zürn (1872). Found on the head of the cat and rabbit by Surmulot and Coati. - Sarcoptes scabiei, var. cameli, Mégnin (1877). Syn., Sarcoptes dromedarii, P. Gervais (184I). The cause of the mange of the camel, llama, giraffe, and certain antelopes. According to Palgrave, Bérenger, Féraud, and Carpot, this form is transmissible to man and constitutes that form of acariasis of the Senegal negroes called larbisch.-Sarcoptes scabiei, var. canis, Railliet, Cadiot, Neumann. Found on mangy dogs ; distinct from the varieties suis and lupi, which are at times found on the dog.-Sarcoptes scabiei, var. capræ, Mégnin (1877). Syn., Sarcoptes capre, Fürstenberg (I86I), Roloff; Sarcoples scabiei, var, ovis, de Geer; Sarcoptes squamiferus ovis, Gerlach. The Head-scab of Sheep. Found on the sheep, goat, mouffion, gazelle, etc. According to Walbraff, transmissible to man and domestic animals. - Sarcoptes scabiei, var. cati, Hering and Fürstenberg, or cuniculi. See Sarcoptes notaderes, Delafond and Bourguinon.- Sarcoptes scabiei communis, Latreille. See Sarcoptes scabiei, var. hominis, Mégnin.Sarcoptes scabiei, var., equi, Mégnin (1877). Syn., Sarcoptes equi, Gerlach (1857). Found on the various species of the horse tribe; transmissible to man according to experiments of Géraud and Gerlach.-
Sarcoptes scabiei, var. hominis, Mégnin (1877). Syn., Acarus scabiei, Linné (1748), De Geer; Acarus exulcerans, Linné ex Nyander (1757); Acarus psoricus, Pallas (1760); Acarus humanus subcutaneus, Linné ex Avelin (I76I); Acarussiro (I76I); Acarus siro, var. scabiei, Fabricius (I775); Sarcoptes scabiei,

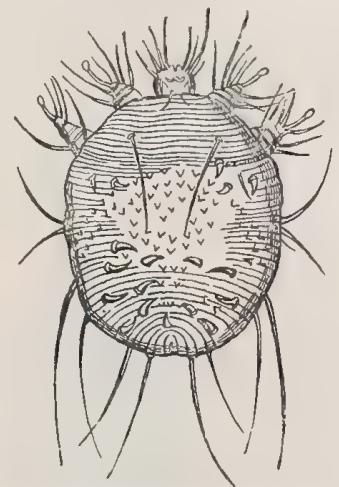

SARCOPTES SCABIEI, var, HOMI Nis, Mégniu. (Áter Leuckart.)

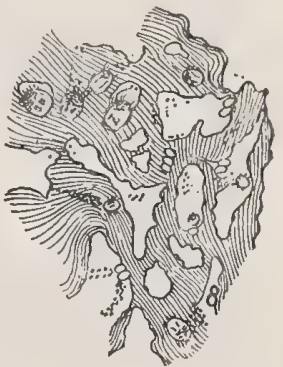

Crust of SCABIES NORVEGICA with the mites (SARCOPTES SCABIES, var. LUPI, Megnin) their botings, eggs and excreta. (After Leuckart.)

Latreille (1806); Acarus brachypus, Olfers (1816); Sarcoptes exulcerans, Nitzsch (1818); Sarcoptes galei, Owen (1853); Sarcoptes hominis, Raspail ; Cheyletus scabiei, Cloquet (I855); Sarcoptes communis, Delafond and Bourguinon (1857). The smallest variety of a form common to man and many mammals - Sarcoptes scabiei, var. lupi, Mégnin (1877). Syn. Acarus elephantiacus, Dubini (1850). Sarcoptes scabiei crustosa, Fürstenberg (I86I). Found on mangy wolves ; most common in Norway; transmissible to man and dogs, causing a crusty form of scabies known as Norwegian itch, Scabies crustosa, or Scabies norvegica. A case has recently been reported from America by Hessler.-Sarcoptes scabiei, var. ovis, de Geer. See Sarcoptes scabiei, var. capra, Mégnin (1877).Sarcoptes scabiei, var. suis, Mégnin (1877). Syn., Sarcoptes suis, Gerlach (1857); Sarcoptes canis, Gerlach (1857); Sarcoptes squamiferus, Fürstenberg (I86I). The sarcopt of the pig.-Sarcoptes squamiferus, Fürstenberg. See Sarcoptes scabiei, var. capra, Mégnin, and Sarcoples scabiei, var. suis, Mégnin.-Sarcoptes suis, Gerlach. See Sarcoptes scabiei, var. suis, Mégnin.-Saugkrätzmilbe der Haustiere. See $P_{s o-}$ ropies communis, Fürstenberg.-Saumzecke. See Argas reflexus.-Scab-insect, Scab-mite. See under genera Chorioptes, Demodex, Psoroptes, Sarcoptes, Symbiotes.-Scatella wimaria, Robineau-Desvoidy, See Trichomyza fusca, Macquart. - Schaff Haarling. See Trichodectes spharocephalus, Nitzsch.-Schamlaus. See Phthirius inguinalis, Leach.-Schistoma, Weinland. See Gynacophorus hamntobius. - Schmeissfliege. See Calliphora vomitoria, Robineau - Desvoidy. - Sclerostoma armata, Dujardin, Molin. Syn., Crinons, Chabert (1782); Strongylus equinus, Mitller, Goeze, Gmelin : Strongylus armatus, Rudolphi, Bremser, Westrumb, Schmalz, Lebland, Gurlt ; Sclerostoma equinum, Blainville; Sclerostoma armatum aneurysmaticum, Rayer, Diesing; Strongylus armatus minor, Rayer; Palisade-worm. The Armed Strongrl. This is found in the adult state in the cecum and colon and the visceral arteries of the horse, ass, mule, and hemione; very common. The larval condition of this worm is passed in water or damp earth, after which development takes place not in the intestine of the host, but in the mesenteric arteries, giving rise to 
aneurysmal dilatations, in which the larvæ remain for a time, finally making their way into the large intestine of the host, where they become sexually mature. Hayem found parasites in the trachea of ducks which he assigned to this species. They more likely belong to Syngamus bronchialis, Mühleg.-Sclerostoma clathratum, Baird. See Strongylus clathratus (Baird), Cobbold.-Sclerostoma dentatum. See $E_{\text {sophagros }}$ toma dentatum, Rudolphi.-Sclerostoma duodenale, Cobbold. See Dochmius duodenalis, Leuckart. Sclerostoma equinum, Blainville. See Sclerostoma armata, Dujardin.-Sclerostoma hypostoma, Dujardin. Syn., Strongylus hypostomus, Rudolphi, Bremser, Creplin, Diesing. Common in the large intestine of the sheep and goat. Probably ingested, in the water drunk, as embryos. Dujardin includes here the Strongylus ammonis, Rudolphi. - Sclerostoma pinguicula, Verrill. See Stephanurus dentatus, Diesing.- Sclerostoma quadridentatum, Dujardin. See Sclerostoma tetracantha, Diesing. - Sclerostoma sipunculiforme, Baird, Cobbold. Found in the large intestine of the Indian elephant.-Sclerostoma struthionis, Horst. Found in the cecum and intestine of the ostrich.-Sclerostoma syngamus, Diesing. See Syngamus trachealis. Siebold.-Sclerostoma tetracantha, Diesing (I85r). Syn., Proles strongyli armati, Rudolphi (I808); Strongylus tetracanthus, Mehlis (I83I); Sclerostoma quadridentatum, Dujardin (I845); Nematoideum equi caballi, Diesing (I85I); Cyathostomum tetracanthum, Molin (1860); Trichonema arcuata, Cobbold (1874-5). Found between the mucous membrane of the cecum and colon of the various members of the horse-tribe, producing tumors, hemorrhagic enteritis, and sometimes fatal colic. Sclerostoma tracheale, Diesing. See Syngamus trachealis, von Siebold.-Scolex decipiens, Diesing. See Cysticercus tenice microstome, Dujardin.-Screwworm. See Lucilia macellaria, Robineau-Desvoidy. -Scrub-tick, a formidable acarine parasite of horses, dogs, and man in the scrub of Australia. Species unidentified.-Seat-worm. See Oxyuris vermicularis, Bremser.-Senegal'scher Blutegel. See Hirudo mysomelas. - Senegal Tick. See Ixodes algeriensis, Mégnin.-Seroot. See Pangonia.-Serpent des rognons des loups, Jean de Clamoyan ( 1570 ). See Eustrongylus gigas, Diesing (I85I).-Seta, Aldrovandi (1605). See Gordius aquaticus, Dujardin (I842).-Sheep Bot-fly. See CEstrus ovis, Linné. -Sheep-bug. See Argas tholozani, Laboulbène and Mégnin. Sheep-tick. See Melophagus ovinus, Latreille.-Short-nosed Louse. See Hamatopinus eurysternus, Burmeister. - Simondsia paradoxa, Cobbold (1864). See Tropidocera paradoxa, Cobbold.- Simonea folliculorum, Gervais. See Demodex folliculorum, Owen.-Simonée, Simonide, Fr. See Demodex folliculorum, Owen. - Simulium boreale, one of the gnat-like flies so troublesome to the reindeer and cattle in Lapland.--Simulium cinereum, Meigen. Gray Simulium. Common in the wooded regions of England and France, attacking horses and producing within their ears a veritable psoriasis gutlata. - Simulium columbacschensis, Fabricius. Syn., Simulium maculatn, Meigen. Kolumbaczer Miicke. A true pest in Central and Southern Europe in April and May, and again in
August; it is especially abundant about the Servian town, Kolumbacz, or Gollabatz, on the right bank of the Danube, where the peasants believe these flies to come from a neighboring cave in which St. George is said to have killed the dragon. Cattle and sheep dying from their bites are considered poisonous. - Simulium indicum, a form common and troublesome in Assam, where it is called Prepsa.-Simulium maculatum, Meigen. See Simulium columbacschensis, Fabricius.Simulium meridionale, the Turkey-gnat. A species found in the Southern U. S. attacking fowls, and especially turkeys, about the head and eyes, often de. stroying them in numbers. - Simulium molestum a species common in the mountainous regions of the Eastern United States, and very troublesome to man and beast.-Simulium pecuarium, Buffalo-fly or Buffalo-gnat. Very injurious by its bite to cattle and horses in the Southern and Western United States. - Simulium reptans, Linné. Syn., Gemeine Kriebelmücke. Common in wooded regions throughout Europe, attacking horses and cattle, especially in the nostrils,-Small Biting Fly. See Stomoxys calcitrans, Geoffroy.-Small Blinding Breeze-fly. See Chrysops cacutiens, Linné, Meigen.-Small Ram Breeze-fly. See Homatopota pluvialis, Meigen. Solium (Syriac, Schuschl-2, the tapeworm, properly "chains" ; Arab., susl or sosl; Middle Age writers, solium, Krehl). The name applied by Andry to a species of tenia, "parce qu'il est toujours seul de son éspèce dans les corps ou il se trouve," hence the term "Ver solitaire," afterward improperly applied to this worm. . The tooth-bearing Tania solium often occurs in groups. Andry's parasite was in reality the modern Tenia saginata, Goeze.Somomyia montevidensis, Bigot. See Lucilia macellaria, Robineau-Desvoidy. Speckkäfer. See Dermestes lardarius, Linné. - Speckled Leech. See Hirudo medicinalis, Ray.-Sphærogyna ventricosa, Moniez. An acaridan normally parasitic upon the larvæ of various insects, but at times troublesome to laborers in the wheat-fields of Europe and America.Sphodrus leucopthalmus, Clairville. A European beetle common in cellars. The larva is reported as parasitic by Paykull.-Spiroptera cincinnata, Ercolani. See Spiroptera reticulata, Creplin.-Spiroptera hamulosa, Diesing. Syn., Chilospirura hamulosa, Diesing. Found on the mucous surface of the gizzard in the domestic fowl in Brazil by Natterer. Spiroptera hominis (Rudolphi), Owen, Dujardin. See Filaria piscium (Rudolphi), Siebold, Schneider. - Spiroptera inflata, Mehlis, Creplin (1840). See Tropidocerca inflata, Diesing (186I), and Tropidocerca paradoxa, Diesing.-Spiroptera leporum, Moniez. Found beneath the gastric mucous membrane of the rabbit and hare.-Spiroptera megastoma, Rudolphi. Syn., Filaria megastoma, Diesing. Forms tumors in the gastric mucous membrane of the horse and ass. -Spiroptera microstoma, Schneider. Found in the stomach of horses and asses.-Spiroptera murina, Leuckart. See Filaria obtusa, Schneider.-Spiroptera nasuta, Rudolphi. See Disparagus nasutus, Rudolphi.-Spiroptera obtusa, Rudolphi. See Filaria obtusa, Schneider.- Spiroptera quadrialata, Molin. Found in the stomach of the house-mouse (Mus musculus, Linné).-Spiroptera ratti, Diesing. This was found in the urinary bladder of the houserat (Mus rattus, Linné).-Spiroptera reticulata, Creplin. Syn., Spiroptera cincinnata, Ercolani, Zürn; Onchocerca reticulata, Diesing; Filaria cincinnats, Perroncito; Filaria lienalis (sic), Stiles. Found in the collateral artery of the cannon and in the arteries adjoining the cervical ligaments, also in the connective 
tissue and muscles of the horse.-Spiroptera rudolphii, Delle Chiaje. See Filaria piscium, Rudolphi.-Spiroptera sanguinolenta, Rudolphi. Syn., Filaria sanguinolenta, Grassi. Usually found lodged in tumors of the stomach and esophagus in the dog, but occasionally in the aorta, lungs, and lymphatic glands. It is common in China and Brazil. The infective agent is the cockroach (Periplaneta orientalis, Linné), which, according to Grassi, Sonsino, etc., is the intermediate host of the parasite, which is not to be regarded as a hematozoön. -Spiroptera scutata œsophagus bovis, Müller. See Myzomimus scutatus, Stiles.-Spiroptera sp., Gerstãcker. Found in the walls of the stomach and the intestines of the house-rat (Mus musculus, Linné) and in the brown rat (Mus decumanus, Pallas).Spiroptera sp., Bokody. Found encapsulated in the wall of 'the intestine of the domestic fowl.-Spiroptera strongylina, Rudolphi. Syn., Filaria strongylina, Rudolphi. Found in the stomach of the hog and wild boar.-Spiroptera uncinata, Rudolphi. See Filaria uncinata, Rudolphi.-Sporozoon in the Intestinal Villi of Cattle, Theobald Smith. The evidence adduced is not sufficient to bring this parasite into any of the known groups, but it at least indicates that it does not belong to the coccidia, and that it has characters which might bring it within the range of the Sarcosporidice-Springwurm. See Oxyuris vermicularis, Bremser.-Spulwurm. See Ascaris lumbricoides, Linné.-Stallfliege. See Cyrtoneura stabulans, Fallèn.-Staphylinus frescipes, Staphylinus politus, Staphylinus punctulatus. Beetles, the larvæ of which are reported as facultative human parasites by Paykull, of Sweden. - Steatozoön folliculare, E. Wilson. See Demodex folliculorum, Owen. Stechmücke. See Culex pipiens, Linné.-Stephanurus dentatus, Diesing. Syn., Sclerostoma pinguicula, Verrill. The Crown-tail Strongyle, Cobbold. The only species of its genus; one of the most important parasites of swine. It is found in pigs in Brazil, the United States, and Australia, in the mesentery and the fat about the viscera and "spare ribs."-Stilesia centripunctata, Rivolta (1874), Railliet (1893). Syn., Tenia centripunctata, Rivolta (1874); Tania centripunteggiata, Perroncito (1882). This is reported as a parasite of sheep and cattle, but there seems to be some doubt of its authenticity.-Stilesia globipunctata, Rivolta (1874), Railliet (1893). Syn., Tenia globipunctata, Rivolta (I874); Tania oripunctata, Rivolta (1874). This is a parasite of sheep and perhaps of cattle.-Stomoxys calcitrans, Geoffroy; Gemeine Stechfiege, Wadenstecher, Leg-sticker. A small biting-fly of wide distribution, closely resembling Musca domestica, but distinguished from it by its palps being as long as the proboscis. Bancroft, of Brisbane, finds it capable of absorbing the embryo of Filaria immitis of the dog, and Mégnin considers it the most active agent in the inoculation of anthrax and septicemia. It is a very troublesome fly, particularly during the showery weather and sultry days, common in May, August, and September, attacking men and beasts. The latter may be protected by washing them with a decoction of walnut leaves, one application a week. - Storm-fly. See Hydrotoea meteorica, Davaine.-Stratyomis sp., a fly. One case (larvæ) reported by Hope (England).Strongyloides intestinalis, Grassi. See Rhabdonema intestina, R. Blanchard.-Strongylus ammonis, Rudolphi. Referred by Dujardin to Sclerostoma hypostoma, Dujardin.-Strongylus anseris, Zeder. See Strongylus nodularis, Rudolphi. - Strongylus armatus, Rudolphi. See Sclerostoma armata,
Dujardin.-Strongylus arnfieldi, Cobbold. Found in the trachea and bronchi of the domestic horse and ass. Cobbold referred the bronchial strongyle of the ass to Strongylus micrurus, Mehlis, of bovine animals, but Railliet has shown its identity with Strongylus arnfieldi.-Strongylus axei, Cobbold. Found in the walls of the stomach in the domestic ass. - Strongylus bronchialis, Cobbold (I860). See Filaria lymphatica, Moquin-Tandon.- Strongylus bronchialis canis, Osler. See Filaria osleri, Cobbold.-Strongylus capreoli, Rudolphi. A doubtful species reported from an old Vienna catalogue as from the kidney of a goat.-Strongylus cernuus, Creplin. See Uncinaria cernua, Creplin. - Strongylus clathratus, Baird. Syn., Sclerostomum clathrum (Baird). Found in the stomach and intestines of Indian and African elephants.-Strongylus commutatus, Diesing. Syn., Filaria leporis pulmonalis, Fröhlich. Found in the trachea and bronchi of hares and wild rabbits and rarely in the domestic rabbit. - Strongylus contortus, Rudolphi. Syn., Strongylus ovinus, Fabricius, Gmelin ; Strongylus fillicolis, Rudolphi. Found in the abomasum of the sheep, goat, argali, chamois, and cattle; producing at times in Europe and the United States an epizoőtic disease (Magenwurmseuche), a kind of pernicious anemia in lambs and yearling sheep.Strongylus convolutus, Ostertag (189o). Syn., Strongylus ostertagi, Stiles (1893). Found frequently in the abomasum of cattle, causing a pernicious anemia and gastric catarrh in young animals. Stiles takes exception to the specific name convolutus as it was once employed for a parasite of the dolphin, now referred to the genus Pseudalus. We prefer to retain the discoverer's name. It may be, as suggested by Neumann, a variety of Strongylus contortus, Rudolphi. -Strongylus dentatus, Rudolphi, Dujardin, Zürn. See Esophagostoma dentatum, Rudolphi.-Strongylus dorcadis, Rudolphi. Vienna catalogue (I82I). See Strongylus filaria, Rudolphi.- Strongylus douglassii, Cobbold. This was found in the crop of the ostrich.-Strongylus duodenalis, Schneider (1866). See Dochmius duodenalis, Leuckart (1876).Strongylus elephanti (sic), Rudolphi (18I9). See Ascaris lonchoptera, Diesing.-Strongylus elongatus, Dujardin. See Strongylus paradoxus, Mehlis.-Strongylus equinus, Müller. See Sclerostoma armata, Dujardin.-Strongylus falcifer, Cobbold (1882). Found in the intestine of the Indian elephant. - Strongylus filaria, Rudolphi. This is found in the trachea and bronchi of the domestic sheep and cattle, goat, Bactrian camel, roebuck, fallow-deer, argali, and gazelle, producing a disease called "Hoose," or "Sheep-cough." Dujardin refers the Strongylus dor. cadis, Rudolphi, from the old Vienna catalogue, to this species.-Strongylus fillicolis, Rudolphi. There is a confusion of this worm with Strongylus contortus, Rudolphi, by early writers. It is found in the abomasum and small intestine of the domestic sheep and goat. According to Curtice it is frequently found in the United States in autumn and winter. The Trichosoma papillosum, Wedl, may be but a young form of this parasite. - Strongylus foliatus, Cobbold. Found in tumors of the stomach of the Indian elephant.-Strongylus gigas, Rudolphi (I802). See Eustrongylus gigas, Diesing (1851).-Strongylus hypostomus, Rudolphi, Bremser, Creplin, Diesing. See Sclerostoma hypostomum, Dujardin.-Strongylus inflatus, Schneider. See Esophagostoma inflatum, Schneider.-Strongylus longevaginatus, Diesing (1851). See Strongylus paradoxus, Mehlis (I830). Diesing, Weinland, Küchenmeister, and Cobbold hold this to be identical with Filaria lymphatica, Moquin. 
Tandon.-Strongylus meleagris gallopavonis, Buckingham. See Syngamus trachealis, von Siebold.Strongylus micrurus, Mehlis. Found in the arterial aneurysms, trachea, and bronchi of domestic cattle. An ovoviviparous species. The strongyle of horses and asses was formerly included in this species, but is now referred to Strongylus arnfieldi by Cobbold and Railliet.-Strongylus minusculus, Neumann. See Strongylus tenuissimus, Mazzanti. - Strongylus minutissimus, Mégnin. This is shown by Railliet to be but a form of Strongylus rufescens, q.v.-Strongylus nodularis, Rudolphi. Syn., Ascaris mucronata, Fröhlich; Strongylus anseris, Zeder. This is found in the esophagus, gizzard, and duodenum of the domestic goose.-Strongylus ostertagi, Stiles (1892). See Strongylus convolutus, Ostertag.-Strongylus ovinus, Fabricius, Gmelin. See Strongylus contortus, Rudolphi._-Strongylus ovis pulmonalis, Diesing, Curtice. See Strongylus rufescens, Leuckart. - Strongylus paradoxus, Mehlis (1830). Syn., Strongylus elongatus (1845); Strongylus longevanginatus, Diesing (185I); Filaria trachealis, Bristowe and Rainey (1855); Metastrongylus longevaginatus, Molin (186I). Discovered at the end of the eighteenth century by Ebel in the lung of a wild boar; afterward by Modeer and Bremser, Rayer, Bellingham, Cobbold, etc., in the bronchial tubes of domestic swine, and by Jortsits (or Jovitsits) in man, and by Koch in sheep.Strongylus pergracilis, the parasite of the Red grouse (Lagopus scoticus) of Europe, causing socalled grouse-disease. - Strongylus pulmonalis, Ercolani, found in the bronchi and lungs of domestic cattle.-Strongylus pusillus, S. Müller. This is found in the bronchi of hares and wild rabbits, rarely in the domestic rabbit, but very frequently in the cat; according to Railliet and Neumann all cases of pulmonary helminthiasis in cats are due to this parasite, which is present in one-fourth of all cats examined.Strongylus quadridentatus, von Siebold (1851). See Dochmius duodenalis, Leuckart (1876).-Strongylus radiatus, Rudolphi. See Uncinaria radiata, Rudolphi. - Strongylus renalis, Moquin-Tandon (1860). See Eustrongylus gigas, Diesing (1850).Strongylus retortæformis, Zeder, Rudolphi, Dujardin. This infests the small intestine of the hare and wild rabbit. This name was incorrectly applied by Bremser to Strongylus strigosus, Dujardin.Strongylus rubidus, Hassall and Stiles. An extremely small species found in the stomachs of pigs in the United States. In some lots of hogs examined the parasite was present in 75 per cent.-Strongylus rufescens, Leuckart. Syn., Nematoideum oris pulmonale, Diesing; Pseudalius ovis pulmonalis, A. Koch; Strongylus ovis pulmonalis, Curtice. This is found in the bronchi and pulmonary follicles of the domestic sheep, goat and roebuck. The Sirongylus minutissimus, Mégnin, which causes the verminous bronchitis of African sheep, is but a variety of this worm, as shown by Railliet. - Strongylus strigosus, Dujardin. Syn., Strongylus retortaformis, Bremser. This is very abundant in warren rabbits, giving rise to a fatal anemia.-Strongylus sublatus, Cobbold. Syn., Hematozoön sublatum, Gurlt. Found in the veins of the dog.-Strongylus tenuis, Eberth. This is found in the intestine and cecum of the domestic goose.Strongylus tenuissimus, Mazzanti (1891). Syn., Strongylus minusculus, Neumann. Found in the mucous membrane of the stomach of the horse.-Strongylus tetracanthus, Diesing. See Sclerostoma tetracantha, Diesing.-Strongylus trachealis, Nathusius. See Syngamus trachealis, von Siebold. - Strongylus trigonocephalus, Rudolphi. See Uncinaria trigonocephala (Rudolphi), Neumann.-Strongylus tubæformis, Zeder. See Ankylostomum tubaforme, Zeder.-Strongylus vasorum, Baillet. The adult worm is found in the right ventricle of the heart and in the lungs, the embryos in the pulmonary arteries of the domestic dog.--Strongylus ventricosus, Rudolphi. This is found in the stomach and small intestine of domestic cattle and European deer.-Strongylus venulosus, Rudolphi. See Uncinaria radiata, Rudolphi.-Strongylus vitulorum, Rudolphi. See Ascaris vituli (Gmelin), Goeze.Strongylus vulpis, Zeder. See Uncinarin trigonocephala, Rudolphi.-Stubenfliege. See Musca domestica, Linné.-Surra Parasite. See Trypanosoma evansii, Balbiani. - Swiss Tapeworm. See Bothriocephalus latus, Bremser. - Symbiotes (I857). A genus of psoric acaridans founded by Gerlach ("Krätze und Räude, entomologisch und klinisch bearbeitet, Berlin," I857). Mégnin's grounds for referring all members of this genus to the genus Chorioptes, Gervais (1859), seem insufficient, as according to Scudder (Nomenclator zoölogicus) the coleopterous genus Symbiotes was not created by Redtenbacher until I 858 (Fauna austrica, "Die Käfer," 2te Auflage, Vienna, 1858 , p. $37 x$ ). We have therefore retained Gerlach's genus. - Symbiotes auricularum, var. canis, var. cati, Neumann (1892). Syn., Sarcoptes cynotis, Hering (1834); Sarcoptes auricularum, Lucas and Nicolet (I849); Symbiotes canis, Bendz (1862); Symbiotes ecaudatus, Mégnin (1876); Chorioptes ecaudatus, Mégnin (I880); Psoroptes auricularis canis, Sewell (I89I). This is found in the ears of dogs and cats, producing that form of otacariasis accompanied by epileptic symptoms, with which packs of hunting-dogs are often attacked.-Symbiotes avium, Caparini, (I880). See Epidermoptes bilobatus, Rivolta.-Symbiotes canis, Bendz. See Symbiotes auricularum, var. canis, Neumann.-Symbiotes communis, Verheyen. Syn., Sarcoptes bovis (?), Hering; Symbiotes bovis, Gerlach ; Symbiotes equi, Gerlach; Dermatophagus bovis, Fürstenberg; Dermatophagoides scheremetervski, Bogdanow (1864); Symbiotes spathiferus, Mégnin (I876); Chorioptes spathiferus, Mégnin (1880); Chorioptes symbiotes, var. bovis, R. Blanchard (I8go) Chorioptes communis, var. ovis, Verheyen; Foot-scab. This parasite lives in colonies, and without excavating sub-epidermic galleries causes a localized scabies; especially on horses and cattle but also on the goat, sheep, and rabbit, and is, according to Bogdanow and Zürn transmissible to man.-Symbiotes ecaudatus, Mégnin. See Symbiotes auricularum, var. canis, var. cati, Neumann.-Symbiotes spathiferus, Mégnin. See Symbiotes communis, Verheyen.Symplectoptes cysticola, Railliet (I885). Syn., Epidermoptes cysticola, Rivolta (1880); Sarcoptes cysticola, Vizioli (1870); Laminosioptes gallinarum, Mégnin (1880). An acaridan peculiar to the Gallinacece, living in the connective tissue of the abdominal viscera, peritoneum, muscles, and beneath the skin of fowls, pheasants, and turkeys, especially old birds. Synchytrium miescherianum, Kuhn. See Sarcocystis miescheri, Ray Lankester.-Syngamus bronchialis, Mühleg (1884). Found in the larynx, trachea, and bronchi of geese by Pezibylka (1853-4) and Mühleg (1884). The specimens found in ducks by Hayem and referred by him to Sclerostoma armatum, Diesing, may belong here.-Syngamus primitivus, Molın. See Syngamus trachealis, Siebold. - Syngamus sclerostomum, Molin. See Syngamus trachealis, v. Siebold. - Syngamus trachealis, von Siebold ( 18,36 '37-'42), Youat (1840), Gurlt (I84I), Dujardin (1845), Ehlers (1872), Perrier (1875), Mégnin (1883), 
Walker (1884), Neumann (1892). Syn., Distoma lineare (tracheale), Rudolphi (1800); Fasciola trachea, Montagu (18II); Strongylus trachealis, Nathusius (1837), v. Siebold (1838), Creplin (1846); Strongylus meleagris gallopavonis, Bellingham (1843); Sclerostomum tracheale, Diesing (I85I); Sclerostoma syngamus, Diesing (185I), Cobbold (I864), Davaine (1877); Syngamus sclerostomum, Molin (1861) ; Syngamus primitivus, Molin (I86I); Forked Worm; Red-worm of Gamekeepers. The cause of gapes in the domestic fowl, peacock, turkey, partridge, black stork, magpie, hooded crow, green woodpecker, starling, swift, robin, etc. The investigations of H. D. Walker indicate the earthworm as the intermediate host of this worm.-Tabanus albifacies, Fabricius $\left(\mathbf{1}_{792-4}\right.$ ). A breeze-fly, very widely spread in Egypt, called by the Arabian fellahs. or bedouins El Debab or Debane (Fly), and falsely blamed by them for a mortality among their horses and camels, but which, according to Piot, is really due to hydatid cysts in the lungs. Tabanus albipes, Fabricius. Syn., The White-footed Breeze-fly.-Tabanus ater, Meigen. See Tabanus morio, Latreille. - Tabanus atratus, Fabricius (1775). Syn., Black Horse-fly. The large, common gad-fly of the United States.-Tabanus autumnalis, Linné. Syn., The Autumnal Breeze-fly'; Taon a' automne. A European species.-Tabanus bovinus, Linné. Syn., The Ox Breeze-fly; Ox Gad-fly; Great Breeze-fly, Gros taon, Taon des baufs, Rinderbremse. A wide-spread and formidable species. The bloodsucking females are equally troublesome to cattle and horses.-Tabanus bromius, Linné. Syn., The Noisy Breeze-fly; Taon bruyant. Common in Europe, especially in wooded regions.-Tabanus fulvus, Meigen. Syn., The Tarony Breeze-fly. A European species.Tabanus lineola, Fabricius. A very common American gad-fly.-Tabanus luridus, Fallen. A European species common in wooded regions.-Tabanus morio, Latreille. Syn., Tabanus ater, Meigen; The Black Breeze-fy; Taon noir. A common European species. - Tabanus rusticus. Syn., The Rustic Breeze-fly; Taon rustique. A common European species.-Tabanus tectus, Riley. A crepuscular species reported from Missouri, by G. M. Dodge, as swarming upon cattle and horses after sunset during June and July, rendering them well nigh frantic in their efforts to escape.-Tabanus tropicus, Linné. A European species common in woods. Tacviai, Aristotle. See Tania solium, Linné. Tænia a articl courtes, Bonnet. See Bothriocephalus latus, Bremser (1819).Tænia á épine, Andry. This name was based upon the belief that the uterine coils of the worm were vertebra. It refers to the modern Bothriocephalus. Tænia abietina, Weinland (1858). See Tenia saginata, Goeze.-Tænia acanthotrias, Weinland (1858), Leuckart. This name was applied by Weinland and Leuckart, to a tapeworm of which only the finn with three rows of hooks has been described under the name Cysticercus acanthotric, Weinland (1858). Küchenmeister, Davaine, Cobbold, and Dallinger, regard it as but a variation of Cysticercus cellulosa.-Tænia aculeata, Perroncito (I882). See Thysanosoma giardi, Rivolta (1878), Stiles (1893). -Tænia acutissima, Pallas. See Tania lanceolata, Bloch.-Tænia æquabiles, Rudolphi (1810). This cestode was found by Rudolphi in the intestine of the swan (Cygnus ferus), and by Bremser in that of Cyomus olor; rare.-Tænia alba, Perroncito (1879). See Moniezia alba, R. Blanchard (1891). Found in the intestine of domestic sheep and cattle.-Tænia albopunctata hominis, Treutler. See Tania solium,
Linné.-Tænia alpaca. Only the finn observed hitherto.-Tænia anatina, Krabbe (1866-67). This cestode is found in the intestine of the domestic duck. - Trnia anatis, $\beta$ lineata, Gmelin. See Tenia trilineata, Batsch.-Tænia anserum, Fischer. See Tania lanceolata, Bloch.-Tænia apri, Gmelin. See Tania marginata, Batsch.-Tænia articulis conoideis, Bloch. See Tania infundibuliformis, Goeze. - Tænia articulus demittens, Dyonis. See Tania solium, Linné,-Tænia avium, Pallas. See Tania fringillarm, Rudolphi.-Tænia benedeni, Moniez (1879). See Moniezia benedeni, R. Blanchard (I89I), and Moniezia trigonophora, Stiles and Hassall (1893). Found in the intestine of the domestic sheep. - Tænia botryoplitis, Piana (188I). Found in the intestine of the domestic fowl. The larva or finn, Cysticercus tania bothryoplitis, occurs in the snails, Helix carthusianella and Helix maculosa.-Tænia bovina, Gmelin. See Tania marginata, Batsch.-Tænia brachydera, Diesing (1854). Found in the small intestine of the brown rat (Mus decumanus, Pallas) by Bellingham, of Ireland.-Tænia canina, Bloch, Carlisle. See Tania serrata, Goeze.-Tænia canina, Linné (I767), Pallas (I78I), Batsch (1786). Syn., Tenia osculis marginalibus oppositis, Linné (1748); Tania monitiformis, Pallas (I78I), Schrank (1788); Tania cucumerina, Bloch (1782); Tenia canina felis, Werner (1782); Tania elliptica, Batsch (I786); Tenia cateniformis, Goeze $(\mathbf{1 7} 87)$; Tenia cateniformis e felis, $\mathrm{Gmelin}$ (1788); Tania (Alyselminthus) cuniceps, Zeder (1800), Rudolphi (1810); Alyselminthus elliptica, Zeder (180o); Tenia (Alyselminthus) cucumerina, W e in 1 and (I858); Tania (Dipylidium) cucumerina, Leuckart (1863). This is found in the small intes- Tenta canina Linne. tine of dogs, cats, and man; in (After Leuckart.) the latter its occurrence is rare and only during childhood. The larva or finn (Cysticercus tenice elliptice, Batsch; Cryptocystis trichodectis, Villot) has for its hosts the fleas of dogs, cats and man (Pulex serraticeps, Gervais, and Pulex irritans, Linné), and the dog-louse (Tricodectes canis, de Geer). -Tænia canina solium, Werner. See Tenia serrata, Goeze. - Tænia canis lagopodis, Rudolphi, Viborg. Syn., Tonia pseudo-cucumerina, Baillet. This is found in the small intestine of the isatis (Canis lagopus, Linné), or arctic fox, and in the cat, the dog, and the house-mouse (Mus musculus, Linné).Tænia cantaniana, Polonio. Found in the intestine of the domestic turkey.-Tænia capensis, Küchenmeister, Moquin-Tandon. See Tania saginata, Goeze.-Tænia capite bonæ spei, Küchenmeister. See Tania saginata, Goeze.-Tænia capræ, Rudolphi (I810); Tænia capreoli, Viborg (I795). Provisional names given to fragments of worms obtained from the intestine of the domestic goat. As a result of recent investigation Stiles concludes that these two species should be entirely ignored.-Tænia caprina, Abildgaard (1789). See Linguatula rhinaria, Railliet (1886). - Tænia caprina, Gmelin. See Tania marginata, Batsch.-Tænia cateniformis, Goeze (1877); Tænia cateniformis, var. E felis, Gmelin (1788). See Trnia canina, Linné ( 1767$)$.Tænia cateniformis, Rudolphi (1810). See Tania echinococcus, von Siebold (I853).-Tænia cateni- 
formis of Glirium, Gmelin. See Tania pumilla, Goeze. - Tænia cateniformis lupi, Goeze. See Tania marginata, Batsch. - Tænia cateniformis vulpis, Borke. See Tania pseudo-cucumerina, Baillet. -Tænia cellulosa, Gmelin. See Tania solium, Linné. Tænia centripunctata, Rivolta (1874). See Stilesia centripunctata, Railliet (1893). Found in sheep. - Tænia centripunteggiata, Perroncito (I882). See Stilesia centripunctata, Railliet (I893).Tænia cesticillus, Molin. Syn., Tania infundibuliformis, Dujardin. A common species found in the intestine of the domestic fowl. The larva (Cysticercus tenice infundibuliformis, Goeze) is found in the house-fly. Mégnin considers Tania cesticillus to be only an incomplete state of Tenia echinobothride. - Tænia cœnurus, Küchenmeister (1853). Found in the small intestine of the dog. The larva (Comurus cerebralis, Rudolphi) is found in the brain, connective tissue, and spinal cord of domestic cattle, sheep, dromedary, and horse. It is the cause of the symptoms known as " gid,", "sturdy," "staggers," or "turnside" in sheep.-Tænia collari nigro, Bloch; Tænia collaris, Bloch. See Tania sinuosa, Rudolphi.-Tænia collo brevissimo, Bloch. See Tenia crassicollis, Rudolphi.-Tænia collo longissimo, Bloch. See Tania gracilis (Zeder), Rudolphi. -Tænia communis, Moquin-Tandon. See Tenia solium, Linné,-Tænia conica, Molin. Found in the intestine of the domestic duck.-Tænia conoidea, Schrank. See Tenia infundibuliformis, Goeze. - Tænia continua, Colin. An anomalous form of Teniu solizm, Linné (q. v.). Tænia coronula, Dujardin. Found in the intestine of the domestic duck. -Tænia crassicollis, Rudolphi (I819), Bremser, Gurlt, Dujardin (1845), Diesing (I850). Syn., Tania cucurbitina, Pallas; Tania collo brevissimo, Bloch ; Tenia serrata felis, Goeze, Batsch, Schrank, Gmelin, Rudolphi ; Tania moniliformis, Batsch, Gmelin; Tenia felis, Carlisle, Gmelin; Alyselminthus serratus, Zeder; Halysis serrata, Zeder; Tenia semiteres, Baird. Found in the small intestine of domestic cats and various wild Felide (Felis catus ferus, Felis concolor, Felis mellivora, Felis onca, Felis par. dalis, Felis macroura, Felis tigrina), giving rise at times to an epizoöty among them, accompanied by epileptiform attacks and chronic enteritis. The larva (Cysticercus fasciolaris, Rudolphi) is found encapsulated in the liver of the brown or Norway rat (Mus decumanus, Pallas), in that of the black rat or house-rat (Mus rattus, Linné), in the house-mouse (Mus musculus, Linné), as well as in moles and water-rats. Baird's specimen is regarded by Neumann as but a monstrous form of this species. R. Blanchard includes Tania crassicollis, Diesing (1851), among the synonyms of Tania echinococcus, von Siebold, of the dog.-Tænia crassula, Rudolphi. Found in the intestine of the pigeon; rare -Tænia cucumerina, Bloch (1782), Weinland (1858), Leuckart (1863). See Tania canina, Linné (1767). This is included among the synonyms of Tania echinococcus, von Siebold, by R. Blanchard. -Tænia cucurbitina, Pallas (1781), Bloch (1782), Goeze (1782), Batsch (1786), Schrank (1788). See Tenia solium, Linné (I767), Rudolphi (1819); Tania saginata, Goeze (I782); Tienia serrata, Goeze (1782); Tania crassicollis, Rudolphi; Tenia marginata, Batsch; and Tania pucilla, Goeze.-Tænia cucurbitina plana pellucida, Goeze. See Trnia solium, Linné.-Tænia cuneata, Batsch, von Linstow. See Trnia infundibuliformis, Goeze. -Tænia cuniceps, Zeder (I800), Rudolphi (I8Io). See Tania canina, Linné (I767). Tænia cysticerci tenuicollis, Leuckart. See Tania marginala,
Batsch.-Tænia degener, Spigel. See Trenia solium, Linné.-Tænia dentata, Batsch (1786), Gmelin (1790), Nicolai (1830). See Bothriocephalus latus, Bremser; Tenia saginata, Goeze (I782); and Tenia solium (Linné), Rudolphi.-Tænia denticolata, Perroncito (1882). See Moniezia denticulata, R. Blanchard (I89I) - Trnia denticulata, Rudolphi (I810), Mayer (after Baird, 1853), Neu mann (1892). See Moniezia benedeni, R. Blanchard (I89I); Moniezia denticulata, R. Blanchard (189I); and Moniezia expansa, R. Blanchard (I89I). This is found in the intestine of domestic cattle.-Trenia diminuta, Rudolphi. See Tania favopunctata, Weinland (1858).-Tænia echinobotrida, Mégnin. Found in the intestine of the domestic fowl. Mégnin considers this to be the complete stage of Tania cesticillus, which has lost its hooks and suckers.-Tænia echinococcus, von Siebold (I853), Leuckart. Syn., Tania cateniformis, Rudolphi (I8Io); Tania cucumerina, Bloch (I8Io); Tenia visceralis socialis granulosa, Goeze; Terratas, Röll (1852) (nec Goeze I782) ; Tania granulosa, Gmelin, Prochaska; Tenia serrata rölli, Küchenmeister; Tania echinococcus scoliopariens, Küchenmeister; Tenia nana, van Beneden (I86I) (nec Bilharz et von Siebold 1853); Echinococcifer echinococcus, Weinland (1861). This worm in its adult or strobila state infests only the small intestine of the dog and the wolf. The well-known larva (Echinococcus polymorphus, Diesing, $q . v$.) is found in the viscera of man, swine, sheep, goat, cattle, dromedary, Bactrian camel, and domestic ass.-Tænia echinococcus scoliopariens, Küchenmeister. See Tania echinococcus, von Siebold (1853).-Tænia elliptica, Batsch (I786): See Tenia canina, Linné ( 1767$)$.-Tænia equina, Pallas, Müller, Chabert. See Tania perfoliata, Goeze; and Tenia plicata, Rudolphi.-Tænia ex cysticerco tenuicolli, Küchenmeister. See Tania marginata, Batsch.-Tænia exilis, Dujardin. Found in the intestines of domestic fowls. - Tænia expansa, Rudolphi (I8Io), Railliet, Neumann, Perroncito, Curtice, McMurrich and various authors. See Moniezia expansa, R. Blanchard (I89I); Moniezia planissima, Stiles and Hassell (1892); and Moniezia trigonophora, Stiles and Hassell (I793). (Tania capra, Rudolphi, probably belongs here). Found in the intestine of domestic sheep, goats, and cattle.-Tænia fasciata, Feuereisen. See Tania setigera, Fröhlich.-Tænia fasciata, Rudolphi. Found in the intestine of the domestic gooseTænia fas ciolaris, Pallas. Syn., Tenia malleus, Goeze. Found in domestic fowls. Tænia felis, Carlisle. See Tania crassicollis, Rudolphi.- Tænia fenestrata, Delle, Chiaje. The name applied to tapeworms exhibiting an anomalous perforated condition, first observed and described by Masars de Cazeles in Tania saginata, afterward by Notta and Marfan in Tenia solium, Linné.-Tænia ferrarum, Gmelin. See Tenia marginata, Batsch.-Trenia fimbriata, Diesing (1850). See Thysanosoma actinioides, Diesing

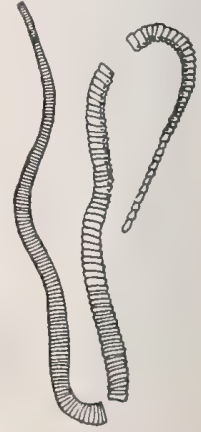

TAENIA FLAVOPUNC. (From Lenckart. after Weinland.) TATA, Weinland. (I834), Stiles (1892). The cause of most of the tapeworm-disease among western (U. S.) sheep, -Tænia finna, Gmelin. See Tania solium, Linné. -Tænia flavopunctata, Weinland (1858). Syn. 
Tania diminuta, Rudolphi ; Tenia lepiocephala, Creplin; Hymenolepis favopunctata, Weinland (I858). This tapeworm bas been found but five times in man, in America (Weinland, Leidy) and Italy (Parona, Grassi). It is not at all uncommon in the intestine of the brown or Norway rat (Mus decumanus, Pallas), in the house-mouse (Mus musculus, Linné), and in the black rat or house-rat (Mus rattus, Linné). The larva or finn (Cysticercus tanice favopunctate, Weinland, Rudolphi) is found in certain insects, e.g., Anisolabris annulipes, Lucas.-Tænia fringillarum, Rudolphi. Syn., Tania avium, Pallas; Tania passeris, Gmelin; Halysis passeris, Zeder. This tapeworm is commonly found in the intestine of the domestic sparrow (Fringilla domestica et canabina, Pallas, F. linaria, $F$. montana, $F$. spinus). -Tænia fusa, Colin. An anomalous form of Tania solium, Linné, q.v.-Tænia giardi, Moniez (1879). See Thysanosoma giardi, Rivolta (I878), Stiles (1893). - Tænia globipunctata, Rivolta. See Stilesia globipunctata, Rivolta (1874), Railliet (1893). A species found in domestic sheep and cattle. - Tænia globosa, Rudolphi. See Tania marginata, Batsch.-Tænia gracilis (Zeder), Rudolphi. Syn., Tania collo longissimo, Bloch; Halysis gracilis, Zeder. This is found in the domestic duck; a cysticercoid found by Scott in the ostracode crustacean (Candona rostrata) is thought to be the finn of this worm.-Tænia grandis saginata, Goeze. See Tania solium, Linné.-Tænia granulosa, Gmelin (1790), Prochaska. See Tania echinococcus, von Siebold (1853), and Echinococcus polymorphus, Diesing (1851). - Tænia grisea, Pallas (1766), or grysea (sic), Schrank (1788). See Bothriocephalus latus, Bremser.-Tænia humanis inermis, Brera (1802). See Bothriocephalus latus, Bremser (1819).Tænia hydatigena, Pallas. See Tania marginata, Batsch. Cf. Cysticercus tonice solii, Leuckart. - Tænia hydatigena anomala, Steinbach; Tænia hydatigena suilla, Fabricius. See Tania solium, Linné. -Tænia hydatula, Linné. See Tania marginata, Batsch.-Tænia imbricata, Diesing (1854). Syn., Tenia pusilla (?), Bellingham. Found in the small intestine of the house-mouse (Mus musculus, Linné). - Tænia imbutiformis, Polonio. Found in the intestine of the domestic duck.-Tænia inermis, Moquin-Tandon (I860); Tænia inermis hominis, Brera (pro parte) (I802). See Tania saginata, Goeze (I782).-Tænia infundibuliformis, Dujardin. See Tania cesticillus, Molin.-Tænia infundibuliformis, Goeze, Batsch, Siebold, von Linstow. Syn., Tania avium, Pallas (ex parte); Tania infundibulum, Bloch ; Tania articulis conoideis, Bloch ; Tania cuneata, Batsch; Tania conoidea, Schrank ; Alyselminthus infundibuliformis, Zeder; Halysis infundibuliformis, Zeder; Tania phasiani cochlici, Rudolphi. This entozoön is found in large numbers in fowls. According to Grassi and Rovelli the cysticercus of this tenia has for its intermediate host an earthworm (Allolobophora fatida, Eisen). Cf Tania simuosa, Rudolphi.-Tænia infundibulum, Bloch. See Tania infundibuliformis, Goeze.-Tænia krabbei, Moniez. An Icelandic species found in the intestine of the domestic dog. The larva or finn occurs in the reindeer (Cervus tarandus, Linné).--Tænia lanceolata, Bloch, Goeze, Batsch, Schrank, Gmelin, Fröhlich, Creplin, Dujardin. Syn., Tania anserum, Frisch (1727); Tania acutissima, Pallas; Halysis lanceolata, Dujardin, Zeder. Most frequently found in the intestine of the domestic goose, often, according to its discoverer Frisch, producing a veritable epizoöty,-Tænia lanceolata, Chabert (1787). See Linguatula rhinaria, Railliet
(1886).- Tænia lata, Linné (1748); Tænia lata event. grisea, Pallas (1776). See Bothriocephalus latus, Bremser.-Tænia lata, Tutscheck, observed by Tumale (Africa). See Tania saginata.-Tænia lata, Pruner (1847), included by R. Blanchard among the synonyms of Tenia saginata, Goeze, and by Cobbold among those of Tania solium (Linné), Rudolphi.-Tænia lata, Reinstein. See Tania solium, Linné, Rudolphi.-Tænia leptocephala, Creplin. See Trnia flavopunctala, Weinland.-Tænia lineata, Bloch. See Tenia trilineata, Batsch.Tænia lineata, Goeze, Batsch, Schrank, Gmelin, Diesing. With this species found in the wild-cat, Hamann (1885) has classed a form expelled by a domestic dog,- Tænia litterata, Batsch. See Tenia pseudo-cucumerina, Baillet.-Tænia litterata, Goeze. See Tania pseudo-elliptica, Baillet.-Tænia longirostris, Fröhlich. See Tenia trilineata, Batsch.Tænia lophosoma, Cobbold. See Tania saginata, Goeze (1872). Cobbold insists that this is a good species despite the criticisms bestowed upon his determination.-Tænia lupina, Schrank, Goeze. See Tania marginata, Batsch.-Tænia madagascariensis, Davaine (1869). Syn., Tania ex cysticerco tenuicolli, Küchenmeister. Found in the human intestine.-Tænia magna, Abildgaard. See Tania plicata, Rudolphi.-Tænia malleus, Goeze. See Tania fasciolaris, Pallas.-Tænia mammillaria, Mehlis, Diesing, Neumann. Found in the intestine of the horse.-Tænia marginata, Batsch, Rudolphi, Dujardin, Diesing, Cobbold. Syn., Tania cucurbiti. na, Pallas, Bloch; Tania cateniformis lupi, Goeze ; Tania lupina, Schrank, Goeze; Tania ex cysticerco tenuicolli, Küchenmeister; Tania tenuicollis, Gunther, Moquin-Tandon; Trenia hydatigena, Pallas, Bloch; Tenia hydatula, Linné; Tania globosa, Rudolphi, Gmelin; Tania simia, Gmelin; Tania ferrarum, Gmelin; Tania caprina, Gmelin; Tania ovilla, Gmelin ; Tania vervicina, Gmelin; Tania bovina, Gmelin; Tania apri, Gmelin; Halysis marginata, Zeder; Tenia cysticerci tenuicollis, Leuckart. This is the largest of the tapeworms infesting the dog and wolf. The finn or larva (Cysticercus tenice marginate, Batsch-Diesing, q.v.), is found in various ruminants, sheep, goats, hogs, horses, squirrels, monkeys, and man.-Tænia mediocanellata, Küchenmeister (1852). The parasite described as new under this name by Küchenmeister being in reality a specimen of Tania solium, the name was unfortunately transferred to the unarmed species, but it should be dropped. "It is surely not only justifiable, but really demanded by the rules of zoölogic nomenclature, that the thoroughly unsuitable designation 'mediocanellata' should be replaced by Goeze's very appropriate name 'saginata,' and since Küchenmeister has himself declared that he was prepared to accept any name more suitable than his own, I have no scruples in using the name Tania saginata" (Leuckart).Tænia megaloön, Weinland. See Tania saginata, Goeze.-Tænia megalops, Nitzsch, Neumann. Found in the intestine of the domestic duck.-Tænia membranacea, Pallas (I78I), Batsch (1786). See Bothriocephalus latus, Bremser (I8I9).-Tænia microstoma, Dujardin, Diesing. This is found in the intestine of the house-mouse (Mus musculus, Linné), and of the house-rat (Mus rattus, Linné). The larva or finn occurs in the insect Anisolabris annulipes, Lucas.-Tænia moniliformis, Batsch, Gmelin. See Tania crassicollis, Rudolphi (1819).-Tænia moniliformis, Pallas (178r), Schrank (1788). See Tania canina, Linné (1767). - Tænia murina, Dujardin. A platode found in the intestine of the 
brown rat (Mus decumanus, Pallas), and of the housemouse (Mus musculus, Linné).-Tænia musculi, Rudolphi, Diesing. Syn., Tania tenella, Pallas. Found in the abdominal cavity of the house-mouse (Mus musculus, I inné); a doubtful species.-Tænia

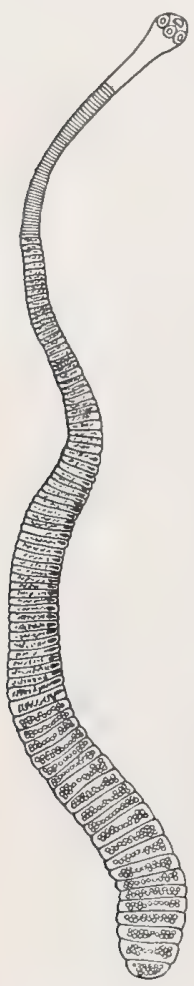

TENIA NANA, von Siebold. (X to. (After Leuckart.) nana, van Beneden (I86I); nec Bilharz et von siebold (1853). See Tania echinococcus, von Siebold (I853). - $\mathbf{T} æ \mathrm{nia}$ nana (Bilharz), von Siebold ( 1853 ). Syn., Diplacanthus nanus, Weinland (1858); Hymenolepis (Tania) nana, Leuckart (1863). A small species found in man, especially in children. Tænia nigra, Laboulbène. A variety characterized by having a pigmented scolex. According to Blanchard it is nothing more than a Tania saginata affected

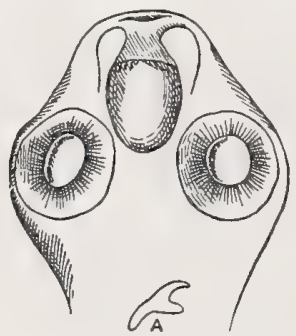

Head of TANIA NANA, von Siebold; with retracted rostellum. ( $x, 75$. Leuckart.)

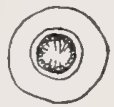

with melanosis.-Tænia osculis marginalibus oppositis, Linné (I748). See Tania canina, Linné ( 1767$)$ - Tænia osculis marginalibus solitariis, Linné (I748), Bradley. See Tania solium, Linné. -Tænia ovilla, Gmelin. See Tania marginata, Batsch.-Tænia ovilla, Rivolta (I878). See Thysanosoma ciardi, Rivolta (I868), Stiles (I893).Tænia ovina, Goeze (I782), Batsch (I786), Schrank (1788), Gmelin (I789). See Moniezia expansa, R. Blanchard (I 89 I).-Tænia ovipunctata, R ivolta (1874). See Stilesia olobipunctata, Railliet (1893).Tænia passeris, Gmelin. See Tania fringillarum, Rudolphi. - Tænia pectinata, Goeze. This tapeworm (possibly the name includes several species) is found in the intestine and stomach of the domestic rabbit. The tapeworms of rabbits and hares, owing to their variable characters, have been grouped by $\mathrm{Riehm}$ into the following species: Tienia rhopalocephala, Riehm; Tania avimerosa, Moniez; Dipylidium latissimum, Riehm; Dipylidium leuckarti, Riehm; Dipylidium pectinatum, Riehm.-Tænia perfoliata, Goeze, Schrank, Rudolphi, Bremser, Gurlt, Dujardin, Diesing, Neumann. Syn., Tania equina, Pallas, Batsch, Gmelin; Tania ouadrilobata, Abildgaard; Alyselminthus lobatus, Zeder: Halysis perfoliata, Zeder. A platode found in the small intestine and colon of the horse.-Tænia phasiani cochlici, Rudolphi. See Tania infundibuliformis, Goeze. - Trnia plana pellucida, Goeze (1782). See Tania solium (Linné), Rudolphi (I810). -Tænia plicata, Rudolphi, Bremser, Gurlt, Dujardin, Diesing, Neumann. Syn., Tania equina, Pallas, Müller, Chabert; Tania magna, Abildgaard; Alyselminthis plicatus, Zeder; Halysis plicata, Zeder. A form found in the small intestine and stomach of the horse. -Tænia prima, Plater (1603). See Bothriocephalus latus, Bremser (I8I9). - Tænia proglottina, Davaine. Found in the intestine of the domestic fowl. The larva or finn occurs in the snails, Limax agrestis, Linné, and Limax variegatus, Draper,-Tænia pseudo-cucumerina, Baillet. Syn., Trenia cateniformis vulpis, Borke apud Goeze, Schrank, Gmelin; Tania litterata, Batsch, Rudolphi, Dujardin, Diesing; Alyselminthus litteratus, Zeder; Halysis litterata, Zeder. Found in the dog in Iceland.-Trnia pseudo-elliptica, Baillet. Syn., Tania litterata, Goeze. Found in the cat. Resembles closely and is perhaps identical with the Tonia pseudo-cucumerina, Baillet, of the dog.-Tænia pusilla, Bellingham. See Tania imbricata, Diesing.-Tænia pusilla, Goeze, Batsch, Schrank, Rudolphi, Dujardin, Diesing. Syn., Tania cucurbitina, Pallas; Tania cateniformis, $\varepsilon$ Gilrium, Gmelin ; Alyselminthus pusillus, Zeder; Halysis pusilla, Zeder. Found in the small intestine of the brown rat (Mus decumanus, $\mathrm{Pal}$ las), and of the house-mouse (Mus musculus, Linné), and of the house-rat (Mus rattus, Linné), and in Mus sylvaticus. - Tænia quadrilobata, Abildgaard. See Tania perfoliata, Goeze.-Tænia ratti, Rudolphi, Diesing. Found in the intestine of the house-rat (Mus rattus, Linné).-Tænia relicta, Zschokke. Found in the intestine of the brown rat (Mus decumanus, Pallas).-Tænia rhinaria, Pilger (1802). See Linguatula rhinaria, Railliet (I886).-Tænia rhopaliocephala, Riehm. Se e Tenia pectinata, Goeze. - Tænia saginata, Goeze $(1782)$. Syn., Tania solium,

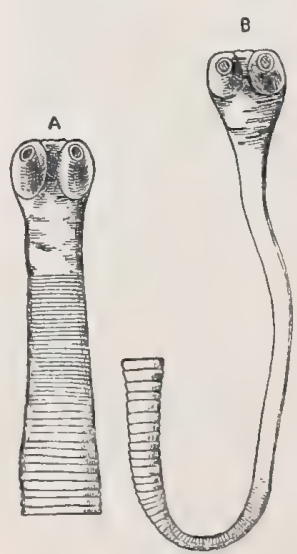

Cephalic end of TAENIA SAGINATA, Goeze: (A) in $\mathrm{rC}$ tracted and (B) extended state. (Afler Leuckart.)

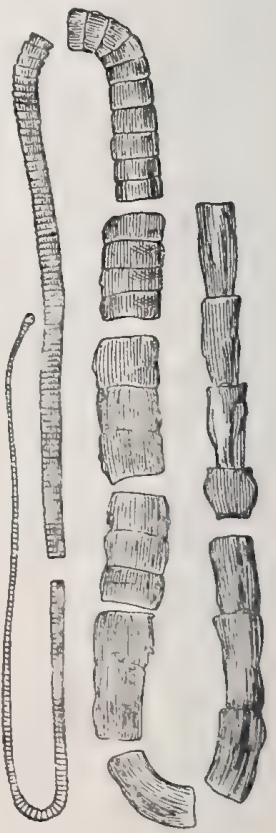

Trenia saginata, Goeze. (After Leuckart.)
Linné, pro parte (I767); Tenia cucurbitina, Pallas, pro parte (178I); Tania inermis hominis, Brera, pro parte (1802); Pentastoma coarctata, Virey (1823); 
Tania dentata, Nicolai (1830); Tania lata, Pruner (I847), Tutschek; Bothriocephalus tropicus, Schmidtmïller (1847); Tania mediocanellata, Kiichenmeister; Tènic sans épine, Andry; Ver solitaire, Andry; Tenia solium, var. mediocanellata, Diesing (1854); Tenia e capite bona spei, Küchenmeister; Tania vom Kap der guten Hoffnung, Küchenmeister (1855); Teniarhynchus mediocanellatus, Weinland (1884); Tania solium, var. abietina, Weinland (1858); Tania megaloön, Weinland; Tania inermis, MoquinTandon (I860); Tenia tropica, Moquin-Tandon (1860); Tania capense, Moquin-Tandon; Ténia algérien, Redon; Tenia fenêtre, Masars de Cazeles; Tenia hybride, Brera; Ténia inerme; Cystotania mediocanellata, Leuckart (1862); Unbewaffneter Bandwurm des Menschen; The Beef Tapeworm, the most prevalent cestode of man. It is frequent in Southern and Western Europe and Russia, and appears to be increasing in Great Britain, France, and Switzerland, and is abundant throughout Asia and Africa. It is rare in North and Central America, but is quite common in Equatorial Brazil, increasing in Peru and Chili. It is least abundant in heavily wooded regions. The finn or larva, a simple scolex known as the beef-measle (Cysticercus tenia saginata, Goeze-Leuckart, q. $v$.), has for its host all the varieties of the ox (Bos taurus).-Tænia saginata, Lewin. See Tania solium, Bremser.-Tænia secunda, Plater. See Tania solium, Rudolphi.-Tænia semiteres, Baird. See Tania crassicollis, Rudolphi.Tænia serialis, Baillet. This species was first found in dogs after feeding them the Conurus serialis, Gervais $\left(q . v_{0}\right)$, from the connective tissue of rodents, es. pecially warren rabbits.-Tænia serrata, Goeze (1782), Batsch, Schrank, Gmelin, Rudolphi, Gurlt, Mehlis, Dujardin, v. Siebold, Diesing, Neumann. Syn., Trenia cucurbitina, Pallas, Batsch, Gmelin; Tania canina, Bloch, Carlisle; Tania canina solium, Werner; Halysis serrata, Zeder. The common tapeworm of the dog which becomes infested by eating hares, rabbits, or mice affected with the finn, Cysticercus tanice serrate (Zeder), Goeze $(q . v)$. - Tænia serrata felis, Goeze, Batsch, Schrank, Gmelin, Rudolphi. See Tania crassicollis, Rudolphi.Tænia serrata rölli, Küchenmeister. See Tania echinococcus, von Siebold (I853).-Tænia setigera, Fröblich, Gmelin, Rudolphi, Siebold, Dujardin, Creplin, Diesing, Neumann. Syn., Tenia fasciate, Feureisen; Alyselminthus setigerus, Zeder; Halysis setigera, Zeder. Found in the intestine of the tame goose and swan, producing at times an epizoötic teniasis.-Tænia simiæ, Gmelin. See Tania marginata, Batsch.-Tænia sinuosa, Rudolphi, Mehlis, Dujardin, Creplin, Diesing. Syn., Tania collari nigro, Bloch; Tinia collaris, Bloch; Tania torquata, Gmelin, Rudolphi ; Alyselminthus sinuosus, Zeder; Halysis torquata, Zeder; Halysis sinuosa, Zeder; Tania infundibuliformis anserum, Goeze, Rudolphi. This cestode is found in wild and domestic ducks and geese (Anas acuta, Anas boschas fera, Anas anser domesticata, Anas anser fera, Anas fulioula, Anas brasiliensis). The larva or finn (Cysticercus tania sinuosce, Zeder), is found in the craw-fish (Astacus fuviatitis, Rondelet).-Tænia sive fascia intestinorum, Spigel (1618). See Bothriocephalus latus, Bremser (I8I9).-Tænia solitaria, Leske. See Tania solium (Linné), Rudolphi.-Tænia solium, Bremser. See Tania saginata.-Tænia solium, Linné ( 1767 ), Hasselquist, Werner, Gmelin, Carlisle, Jördens, Rudolphi (I8Io), Cuvier, Olfers, Frank, Bremser, Gomez, Delle Chiaje, Mehlis, Owen, Creplin, Randel, Lewacher, Nordmann, Wahruch, Dujar-

din, Diesing, Leuckart, Cobbold, Neumann, Perron-

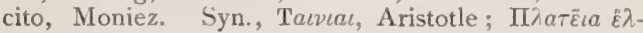
$\mu \iota v s$, Hippocrates ; Lumbriculatus, Plinius ; Tënia de la second espèce, Andry; Tenia à épine, Andry (1700); Tenia secunda, Plater; Vermis cucurbita, Plater; Tenia osculis marginalibus solitariis, Linné, Bradley; Tenia articulos dentittens, Dyonis; Tania cucurbitina, Pallas (1781), Bloch, Goeze (1782), Batsch, Schrank; Tania cucurbitina plana pellucida, Goeze ; Tania vulsaris, Werner (I782); Tania umana armata, Brera (1802); Tania stigmata lateralibus, Bonnet; Tania dentata, Gmelin (1790), Nicolai; Tania lata, Reinstein; Tania fenes trata, Delle Chiaje; Tania de gener, Spigel; Tania solitaria, Leske; Tania communis, Moquin-Tandon; Tania albopunctata hominis, Treutler; Tania hydatigena anomala, Steinbach ; Tania hydatigena suilla, Fabricius: Tania finna, Gmelin; Tania cellulosa, Gmelin, Treutler: Halysis solium, Zeder (1800); Pentastoma coarctata, Vire y (1823); the Tania fusa and Tania continua of Colin are but

anomalous forms of this species. Küchenmeister's Tenia mediocanellata was in reality a Tania solium; Bewaffneter Bandwurm des Menschen; The Armed Tapezerm. This tapeworm has been known as a parasite of man from the earliest times. It has been observed in all parts of Europe, but with remarkable differences in frequency, being relatively rare in Turkey in Europe, the Danubian provinces, Greece, Italy, France, Spain, and Eng

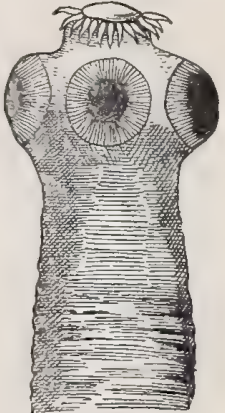

Cephalic end of $T$. NIA soliva Linné. (Afler Leuckart.)

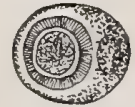

Egg of TAENIA SOLIUM, Linné. $(\times 300$.
(After Leuckart.) land. It is more frequent in Central Europe, in Germany and Austria, the prevalence of the parasite holding direct relation to the quantity of pork consumed. It is rare throughout Asia, Japan, Oceanica, and Africa. In North America it appears to be somewhat on the increase. It is very rare in Mexico and South America. The larva (Cysticercus cellulosa, Cysticercus tanice solii, Leuckart $q . v$.) is found in the tissues of swine, dogs, cats, rats, and man, producing measles ( $\left.q . v_{0}\right)$. Tænia solium, var. abietina, Weinland (1858). See Tania saginata, Gœze.-Tænia solium, var. mediocanellata, Diesing (1854). See Tonia saginata, Goeze (I782),-Tænia stigmata lateralibus, Bonnet. See Tania solium, Linné.-Tænia struthionis, Houltayn. Found in the intestine of the ostrich (Struthio camelus).-Trnia tenella, Cobbold. This name was first applied to Bothriocephalus latus by Pallas and Retzius (178I), afterward by Cobbold to a small-sized Tania solium (according to Chatin), which he held to be a distinct species and derived from a finn which he termed Cisticercus ovis (because found in the pseudo-measles of sheep); this in turn proved to be Cysticercus tanio.-Tænia tenella, Pallas. See T'cnia musculi, Rudolphi.-Tænia tenuicollis, Günther, Moquin-Tandon. See Tania marginata, Batsch.-Tænia tetragona, Molin. Found in the intestine of the domestic fowl.-Tænia torquata, Gmelin. See Tania sinuosa, Rudolphi.Tænia trilineata, Batsch, Rudolphi, Dujardin, Creplin. Syn., Tania lineata, Bloch; Tania anatis, $\beta$ lineato, Gmelin; Tania longirostris, Fröhlich. Halysis trilineata. Zeder. Found in the intestine of 
the domestic duck. - Tænia tropica, Moquin-Tandon (1860). See Tania saginata, Goeze (1782).-Tænia umana armata, Brera (1802-3). See Tenia solium, Linné.-Tænia umbonata, Molin. Found in the intestine of the house-mouse (MTus musculus, Linné). -Tænia vasis nutritiis distinctis, Bloch (1782). See Moniezia expansa, R. Blanchard (I89r).-Tænia vervicina, Gmelin. See Tania marginata, Batsch.Tænia veterum, Spigel (1618). See Bothriocepha. lus latus, Bremser.-Tænia visceralis socialis granulosa, Goeze (1782). See Tenia echinococcus, von Siebold (1853), and Echinococcus polymorphus, Diesing (185I).-Tænia vogti, Moniez (1879). Syn., Anoplocephala vogti, Moniez (I89I). A doubtful species reported as parasitic in sheep.-Tænia vom Kap der guten Hoffnung, Küchenmeister (1855) (the Tania capensis of Moquin-Tandon). See Tania saginata, Goeze.-Tænia vulgaris, Linné (I 748), Werner (1782). See Bothriocephalus latus, Bremser (1819); and Tania solium (Linné), Rudolphi (I8I0).-Tænia wimerosa, Moniez. Found in the wild rabbit. See Tenia pectinata, Goeze.-Tæniarhynchus mediocanellatus, Weinland (1855). See Trenia saginata, Goeze.-Taon bruyant. See Tab. anus bromius, Linné.-Taon d'automne. See Tabanus autumnalis, Linné.-Taon des bœufs. See Tabanus bovinus, Linné.-Taon noir. See Tabanus morio. Latreille.-Taon rustique. See Tabanus rusticus, Fabricius.-Tarsonemus intectus, Karpelles. See Tarsonemus monunguiculosus, R. Blanchard.-Tarsonemus monunguiculosus, R. Blanchard (1889). Syn., Crithoptes monunguiculosus, Geber (1879); Kritoptes monunguiculosus, Geber (1884); Acarus hordei, Geber (1884); Tarsonemus uncinatus, Flemming (1884); Tarsonemus intectus, Karpelles. An acaridan which is frequently very troublesome to workers in barley.-Tarsonemus uncinatus, Flemming. See Tarsonemus monunguiculo sus, R. Blanchard.-Tavin, the common name for the breeze-fly. Cf. Tabanus sp.-Tawny Breeze-fly. See Tabanus fulvus, Meigen.-Trichomyza fusca, Macquart. Syn., Scatella urinaria, Robineau-Desvoidy; Mydea vomiturationis, Robineau-Desvoidy. A fly very common about urinals and water-closets, the larvæ being represented as pseudo-parasites, the possibility of which is not fully settled, but is unlikely. -Tenebrio molitor, Linné. Syn., Ver de farine, Fr.; Mehlkäfer, Müller, Ger.; Meal-beetle, Flourbeetle. The larva or meal-worm is reported as a facultative parasite in the nose, digestive tube, and urinary passages of man, by Bateman, Allen, Shaw, Foresters, Tulpius, Kellie, Pickells, Thomson, Traill, Gleadow, and Acrel.-Ténia á anneaux courts, Bonnet (1750). See Bothriocephalus latus, Bremser (I8I9).-Ténia à épine, Andry (I70o). See Bothriocephalus latus, Bremser.-Ténia algérien, Redon. An anomalous pigmented form of Tenia saginata, Goeze.-Ténia de la second espece, Andry (I 700). See Bothriocephalus latus, Bremser.-Ténia fenêtré, Masars de Cazeles. See Tania saginata, Goeze.Ténia hybrida, Brera. An anomalous form of Tania saginata.-Tenia inerme. See Tania saginata, Goeze.-Ténia lancéole ou ver rhinaire, Chabert (1787). See Linguatula rhinaria, Railliet (1886).- Tentacularia subcompressa, Zeder. See Filaria lymphatica, Moquin-Tandon. - Terratas, Röll (1852). See Tania echinococcus, von Siebold (I853).-Tetracotyle, Filippi. See Holostoma erraticum, Rudolphi.-Tetragulus caviæ, Bosc (I8Io). See Linguatula rhinaria, Railliet (I886). - Tetrameres hxmochrous, Creplin (1846). See Tropidocerca inflata, Diesing (I86I), and Tropidocerca paradoxa, Diesing.-Tetranychus autumnalis, Shaw. Syn., Leptus autumnalis; Trombidium autumnalis. The common "harvest-bug" of England and the rouget of the French, which has been incorrectly referred by Mégnin to Trombidium holosericeum, Fabricius. A minute, scarcely visible, spinning-mite, breeding upon plants, beans, currants, raspberries, gooseberries, etc, which it deserts whenever opportunity offers, to fasten on animals, having a special predilection for human beings, especially women and children. It causes severe itching. The mite is very abundant in England, Scotland, and on the continent of Europe, especially near the seashore. The larval hexapod is the form most often met with.-Tetranychus molestissimus. Syn., Bicho colorado of the Argentine Republic and Uruguay; a small, red Acarus that lives on the under surface of the leaves of Xanthium macrocarpum; it attacks man and other warm-blooded animals, causing insupportable itching. - Tetranychus tlalsahuate, Lemaire, Murray (1867); a mite called by the Indians of Mexico Tlalsahuate. It lives among the herbage and is almost imperceptible to the naked eye. It attacks man and fixes itself upon the eyelids or armpits, etc. It is included by authors under the spurious genus Leptus._-Tetrastoma renalis, Lucarelli and Della Chiaje. A trematode found in the urinary tubules of an Italian woman.-Texas Screwworm. See Lucilia macellaria, Robineau-Desvoidy. -Thecosoma hæmatobium, Moquin-Tandon. See Gynccophorus hamatobius, Diesing. - Thelazia rhodesii, Desmarest. See Filaria equina, Abildgaard. -Threadworm. See Oxyuris vermicularis, Bremser.-Thysanosoma actinioides, Diesing (1834), Stiles (1892). Syn., Tania fimbriata, Diesing (1850); Moniezia fimbriata, Moniez (189I). This is found in sheep and several species of deer. It appears to be the cause of much of the tapeworm-disease of the western United States. - Thysanosoma giardi, Rivolta (1878), Stiles (1893). Syn., Tania ovilla, Rivolta (1878); Tania giardi, Moniez (1879); Tania aculeata, Perroncito (1882); Moniezia ovilla, Moniez (I89I); Moniezia ovilla, var. macilenta, Moniez (I89I). This cestode has sheep and cattle for its hosts.-Tinea rotunda. Plinius. See Ascaris lumbricoides, Linné (1758).- Tipula sp. A fly, the larvæ of which are reported by Kirby (England) as facultative human parasites. - Tique, Raspail. See Dermanyseus avium, de Geer, and Sarcopsylla penetrans, Westwood.-Tique des chiens, Geoffroy. See Ixodes ricinus, Linné. - Tique senegalaise. See Ixodes algeriensis, Mégnin.-Tlalsahuate. See Tetranychus tlalsahuate, Lemaire.-Todtenkäfer. See Blaps mortisaga, Linné.-Ton. See Sarcopsylla penetrans, Westwood. - Torcel. See Dermatobia noxialis, Goudot.-Trichina affinis, Diesing, Herbert, Küchenmeister, Wed!, Leidy. Found encapsulated in the connective tissue and muscles of the hog, cat, dog, mole, badger, gull, buzzard, and crane.-Trichina circumflexa, Polonio. Found encapsulated in the peritoneum of the brown rat (Mus decumanus, Pallas). - Trichina contorta, Botkin. See Tylenchus putrefaciens, Kühn.-Trichina cystica, Salisbury (1868). See Filaria sangrinis hominis, Lewis (1872).Trichina papillosa, Rivolta and Delprato. These nematodes were found encysted in the connective tissue about the esophagus, crop, and gizzard of the fowl. To this species probably belongs the Disparagus spiralis, Molin. - Trichina spiralis, Owen (1835). Syn., Vibrio humana, Lizars (1843); Trichina spiralis, Bischoff $(\mathbf{1} 840)$; Pseudalius trichina, Davaine (1862). The adult parasite is 
found in the intestines, and the larvæ encapsuled in the connective tissue of all warm-blooded animals, especially man, the hog, dog, cat, mouse, and rat.
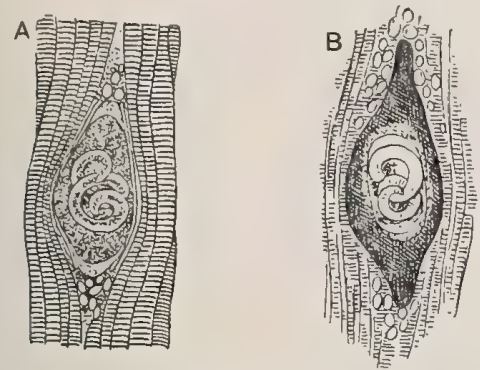

Trichina SPIRALIS, Owen; (A) encapsulated with connective tissue covering (in situ); (B) calcified. (Afier Leuckart.)

Leidy (1846) was the first to discover this parasite in the hog, the source from which man is infected.Trichina spiralis, Bischoff (1840). See Trichina spiralis, Owen (1835).-Trichocephalus, Goze

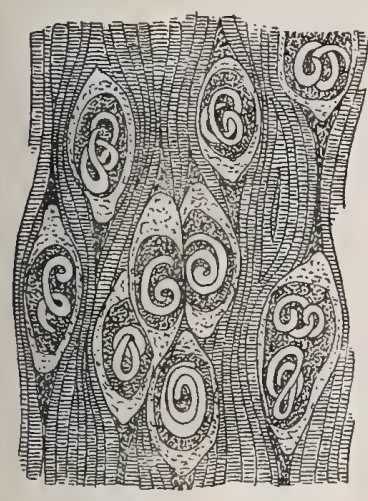

TRICHINOSED PORK. $(X 30$. (After Leuckart.)

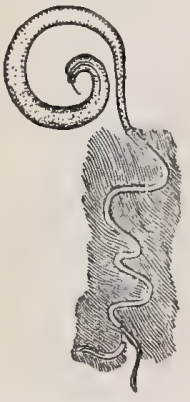

TRICHOCEPHALUS HOMINIS, Schrank (in situ.) (After Leuckart.)
(1782). See Trichocephalus hominis, Schrank (1788). -Trichocephalus affinis, Rudolphi. Found in the large intestine of the domestic sheep, goat, cattle, dromedary, and Bactrian camel.-Trichocephalus campanula, von Linstow. Found in the intestine of the domestic cat.-Trichocephalus crenatus, Rudolphi. Found in the large intestine of the hog. -Trichocephalus depressiusculus, Rudolphi. Found in the cecum of the dog and ferret. - Trichocephalus dispar, Rudolphi (1801). See Trichocephalus hominis, Schrank (I788).-Trichocephalus echinophyllus, Nitzsch. Found in the intestine of the dromedary. - Trichocephalus hominis, Schrank (I788). Syn., Trichuris, Büttner (I76r); Ascaris trichiura, Linné (I77I); Trichocephalus, Gœze (1782); Trichocephalus simice patas, Treutler (I793); Trichocephalus dispar, Rudolphi (1801) ; Mastigodes hominis, Zeder (1803); Mastigodes simia, Zeder (1803); Trichocephalus lemuris, Rudolphi (1819); Trichocephalus palaformis, Rudolphi(I8I9). This parasite of the human intestine is much more common than is generally suspected by physicians, owing to the tenacity with which the worms adhere to the mucous membrane. Recent investigations prove that many cases of obscure and persistent anemia may be traced to its presence by a search for the eggs in the feces.
-Trichocephalus lemuris, Rudolphi (18ro). See Trichocephalus hominis, Schrank (1788). - Trichocephalus nodosus, Rudolphi. Found in the cecum of the house-mouse (Mus musculus, Linné) and of the house-rat (Mus rattus, Linné).-Trichocephalus palæformis, Rudolphi (1819). See Trichocephalus hominis, Schrank (I788).-Trichocephalus serratus, von Linstow. Found in the intestine of the domestic cat.-Trichocephalus simiæ patas, Treutler (1793). See Trichocephalus hominis, Schrank (1788). - Trichocephalus unguiculus, Rudolphi. Found in the intestine, especially the cecum of the wild and domestic rabbit and hare.-Trichodectes canis, de Geer. See Trichodectes Latus, Nitzsch.Trichodectes capræ, Packard, Gurlt. See Trichodectes climax, Nitzsch.-Trichodectes climax, Nitzsch. Syn., Trichodectes capre, Gurlt, Packard; Trichodectessolidus, Rudow; Trichodectes mombricus, Rudow ; Petitpou de la chèrre, Goat-louse. The common goat-louse frequent on the goat (Capra hircus, Linné).- Trichodectes crassipes, Rudow. Syn., Trichodectes penicillatus, Piaget: Found on the Angora goat and kangaroo (Macropus penicillatus).Trichodectes equi, Denny (1842). Syn., Trichodectes parumpilosus, Piaget (1880), varieties ocellata and tarsata.-Trichodectes latus, Nitzsch, Burmeister, Denny, Piaget. Syn., Ricinus canis, de Geer; Trichodectes canis, de Geer; Pediculus setosus, Olfers; Pediculus canis, O. Fabricius (?); Gros pou duchien; Hunde-Haarling; Dog-louse. Found on dogs, especially puppies, mostly on the head and neck. This louse is the host of the finn (Cryptocystis trichodectis, Villot) of the tapeworm of the dog (Tania canina), Linné.-Trichodectes limbatus, Gervais. See Trichodectes climax, Nitzsch. - Trichodectes mombricus, Rudow. See Trichodectes climax, Nitzsch. - Trichodectes ovis. See Trichodecles spharocephalus, Nitzsch.-Trichodectes parumpilosus, Piaget (1880). See Trichodectes equi, Denny (I842).-Trichodectes penicillatus, Piaget. See Trichodectes crassipes, Rudow.-Trichodectes pilosus, Giebel. Syn., Pediculus equi, Linné. The louse of the horse and ass. - Trichodectes pubescens. See Trichodectes equi, Denny.-Trichodectes pubescens, Neumann. Louse of the Horse; Petit pou du cheval. Found on the domestic horse, Burchell's zebra, and the small horses of Java.-Trichodectes quadricornis, Gay (Neumann, I89o). A louse of the horse.-Trichodectes scalaris, Nitsch, Piaget. Syn., Pediculus bovis, Linné ; The Biting Louse; Petit pou du bauf. Found on cattle.-Trichodectes solidus, Rudow. See Trichodectes climax, Nitsch. -Trichodectes sphærocephalus, Nitzsch, Piaget. Syn., Trichodectes ovis, Pediculus ovis, Linné. The Sheep-louse; Schaf-Haarling. The adults lay their eggs at the base of the wool fibers; no other host is known.-Trichodectes subrostratus, Nitzsch, Piaget. Syn., Pou du chat; Cat-louse. The only louse found on the cat. - Trichodes crassicauda, Bellingham. See Trichosoma crassicauda, Bellingham.Trichomonas caudata, Steinberg. An infusorian found in the human mouth.-Trichomonas caviæ, Davaine (1875). Syn., Cimanomonas cavia, Grassi. An infusorian found in the intestine of the guineapig.-Trichomonas columbæ, Railliet. An infusorian intestinal parasite of the pigeon. - Trichomonas eberthi, Neumann. Found by Eberth in the fowl and in the glands of Lieberkuihn of the duck. Neumann holds that the Monocercomonas anatis of Davaine may be identical with this species. - Trichomonas elongatus, Steinberg. Found in the human mouth.-Trichomonas evansi, Crook- 
shank. See Trypanosoma evansi, Balbiana.-Trichomonas flagellata, Steinberg. Found in the human mouth.- Trichomonas intestinalis, Leuckart. Syn., Cercomonas intestinalis, Marchand (1875). This infusorian has been frequently found by Grassi in human dejections in cases of acute and subacute diarrhea, and in cases of typhoid fever and enteritis by Marchand and Zenker. - Trichomonas irregularis, Salisbury (I868). See Cystomonas urinaria, R. Blanchard (I885). -Trichomonas suis, Davaine. A flagellate infusorian parasite in the stomach of the pig.-.Trichomonas vaginalis, Donné. Found abundantly in the acid mucus of the human vagina. Trichonema arcuata, Cobbold. See Sclerostoma tetracantha, Diesing. - Trichosoma ærophilum, Creplin. Syn., Eucoleus arophilus, Creplin. A filiform worm found in the trachea and bronchi of the cat, fox, and marten.-Trichosoma annulatum, Molin. This is found beneath the esophageal membrane of the domestic fowl. - Trichosoma annulosum, Dujardin. This is found in the small intestine and duodenum of the brown rat (Mus decumanus, Pallas), and the house rat (Mus rattus, Linné).-Trichosoma bacillatum, Eberth. This is found in the esophagus of the house-mouse (Mus musculus, Linné).- Trichosoma brevicolle, Rudolphi. This is found in the intestine and cecum of the domestic goose.Trichosoma collare, von Linstow. Occasionally found in great quantities in the intestine of the domestic fowl.-Trichosoma columbæ, Rudolphi. See Trichosoma tenuissima, Diesing.-Trichosoma contortum, Creplin. A nematode found in the intestine of ducks, causing a disease termed by Railliet and Lucet (I890) "ingluvial indigestion." - Trichosoma crassicauda, Bellingham. Syn., Trichodes crassicauda, Bellingham. Found in the urinary bladder and ureter of the brown rat (Mus decumanus). - Trichosoma felis cati, Bellingham. Found in the urinary bladder of house-cats by Wedl, and in wild-cats by Bellingham.-Trichosoma lineare, Leidy (1856). Found in the small intestine of the domestic cat.-Trichosoma longicolle, Rudolphi. Found in the large intestine and cecum of the domestic fowl; not frequent.Trichosoma muris musculi, Creplin. Found in the large intestine of the house-mouse (Mus musculus, Linné).- - Trichosoma papillosum, Polonio. Found in the urinary bladder of the brown rat (Mus decumanus, Pallas).-Trichosoma papillosum, Wedl. Found in the intestine of domestic sheep. Curtice holds it to be the young of Strongylus filicollis, Rudolphi.-Trichosoma plica, Rudolphi. Found in the urinary bladder of the dog, fox, and wolf.-Trichosoma schmidtii, von Linstow. Found in the urinary bladder of the brown rat (Mus decumanus, Pallas).-Trichosoma tenuissima, Diesing. Syn., Trichosoma columber, Rudolphi; Calodium tenue, Dujardin. Found in the large intestine of the domestic dove; it induces extreme anemia. Trichuris, Bütner $(\mathbf{1 7 6 1})$. See Trichocephalus hominis, Schrank (1788).-Trinoton conspurcatum,
Nitzsch, Denny, Piaget. Syn., Pediculus anseris, Sultzer; Trinotum conspurcalum, Burmeister. One of the largest of the lice found on domestic animals, common on the goose and swan, particularly the latter.-Trinoton continuum, Piaget. Probably only a variety of the preceding species.-Trinoton lituratum, Nitzsch, Denny, Piaget. Syn., Ricinus stirna hirundinis, Linné; Trinotum lituratum, Burmeister; Trinoton squalidum, Denny ; Trinotum squalidum, Verrill. Found with other species on geese (Dendrocygna arborea, Anser albifrons, Anas clypeata).-Trinoton luridum, Nitzsch, Denny, Piaget. Found on the domestic duck.-Trinoton squalidum, Denny. See Trinoton lituratum, Nitzsch.Trinotum conspurcatum, Burmeister. See Trinoton conspurcatum, Nitzsch.--Trinotum squalidum, Verrill. See Trinoton lituratum, Nitzsch, Denny, Piaget. - Trombidium americanum. The true American harvest-mite, with eight legs, sometimes confounded with the hexapod stage of a species of Tetranychus, under the name of Leptus irritans. - Trombidium autumnalis. See Tetranychus autumnalis, Shaw.Trombidium cinereum. The hexapod larva of this or some closely allied species is reported as a pseudoparasite of man.-Trombidium holosericum, Fabricius. According to Mégnin it is the larval hexapod of this species which has long been designated as Rouget, Red Flea, Harvest-bug, Lepius autumnalis, etc. This is a mistake, as this hexapod is the larva of Tetranychus autumnalis, Shaw, $q . v$. Tropidocerca fissispina, Diesing (1855), von Linstow (1879). Syn., Tetrameres sp., Leuckart (1860). A nematode found in the mucous membrane of the proventriculus of the duck (Anas boschas domesticus).-Tropidocerca inflata, Diesing (I86I). Syn., Spiroptera inflata, Mehlis, Creplin; Tetrameres hamochrous, Creplin (1846); Tropidocerca paradoxa, Diesing (partime) I85 I). Found in the proventriculus of the domestic duck.-Tropidocerca paradoxa, Diesing (I85I). Syn., Tropisurus paradoxus, Diesing; Spiroptera inflata, Mehlis, Creplin (1846); Tetrameres hamocrous, Creplin (1846). Found in the proventriculus of several birds, among them the domestic duck. The worm discovered by Simonds, and named Simondsia paradoxa by Cobbold ( 1864 ), is referred to this species by some writers, but it seems improbable that this is warranted, as the worm was found in a hog, whereas the entire genus of Tropidocerca seems to be parasitic only in birds. - Trout-leech. See Hirudo troctina, John. son.-Trypanosoma evansi, Balbiani. Syn., Spirochate evansi, Steel ; Trichomonas evansi, Crookshank ; Hamatomonas evansi, Osler; Surra Parasite. The cause of the very serious epizoötic pernicious anemia in horses, mules, and camels, called Surra, prevailing in India and Southern Asia. Rankin recommends large doses of quinin frequently in milk, with iron and arsenic, at the commencement of the disease. Trypanosoma lewisi, Danilewsky (Saville Kent). Syn., Herpetomonas lervisi, Saville Kent. A pale, translucent, motile, flagellate hematozoön found by Lewis in the blood of the rat. Kent suggests, on the grounds of the particular position of the flagellum, that further investigation may demonstrate this to be one of the spermatic elements of minute nematodes, microfilarix, or other endoparasitic forms. Danilewsky calls attention to the similarity between this form and that described by him in the blood of birds. - Trypsoderma cuniculi, Wiedemann (1830). See Cuterebra cuniculi, Clark (1815).-Tsé-tsé, Tse-tsefliege, Ger. ; Tse-tsevlieg, Dutch. See Glossina morsitans, Westwood (it closely resembles Stomoxis calcitrans); abundant in Central Africa. - Tunga. See Sar- 
copsylla penetrans, Westwood. - Turicatas. See Argas turicata, Dugés. - Turkey-gnat. See Simulium meridionale. - Tylenchus contorta, Kühn. Syn., Trichina contorta, Botkin. An occasional parasite of man.-Tyroglyphus echinopus, Fumouze et Robin. See Capophrigzs echinopus, Mégnin.-Tyroglyphus mericourti, Laboulbène. A singular mite with enormous palpi, found on man by Le Roy de Méricourt.-Tyroglyphus siro, Latreille (1806). Syn., Acarus dysenteria, Linné. Common in flour, cheese, etc. Reported as the cause of gastric catarrh in a person who preferred cheese containing these mites. Cases of diarrhea due to them are also recorded. Burke also describes, under the name of Stomatitis pustulosa acarosa, an affection of horses caused by eating bran containing these mites. -Unarmed Tenia of Man, Unbewaffneter Bandwurm des Menschen. See Tania saginata, Goeze-Uncinaria balsami, Parona and Grassi. See Uncinaria trigonocephali, Rudolphi.-Uncinaria cernua, Creplin. Syn., Monodontus wedli, Molin. Found in the small intestine of the domestic sheep.Uncinaria duodenalis, Railliet (I885). See Dochmius duodenalis, Leuckart (1876).-Uncinaria radiata, Rudolphi. Syn., Strongylus radiatus, Rudolphi ; Sirongylus venulosus, Rudolphi. Found in the intestine and duodenum of cattle and goats.-Uncinaria stenocephala, Railliet. Syn., Ankylostomum stenocephalum; Dochmius stenocephalus. Found in dogs, along with Uncinaria trigonocephalus; it appears to play as active a part as its congener in the development of anemia in packs of sporting-dogs (Neumann). -Uncinaria trigonocephala, Rudolphi. Syn., Ankylosiomum trigonocephalum, Rudolphi; Anky. lostomum tubuforme, Zeder; Dochmius trigonocephalus, Rudolphi; Dochmius balsami, Parona; Uncina ria vulpis, Fröhlich; Strongylus vulpis, Zeder. Found in the small intestine of the dog and cat, producing a not uncommon anemia known as "Pernicious Anemia of Packs of Hounds," attended with bleeding at the nose, edematous and indolent engorgement of the limbs, persistent diarrhea, loss of appetite, and emaciation. Greatest care as to cleanliness of kennels and food, and thymol as a vermicide are recommended. This parasite also gives rise to a pernicious anemia of cats, prevalent in Italy.-Uncinaria vulpis, Fröhlich. See Uncinaria trigonocephala, Rudolphi (Neumann). -Ungarische Blutegel. See Hirudo medicinalis, Ray.-Ura. See Dermatobia noxialis, Goudot.Utricules of Miescher. See Sarcocystis miescheri, R. Lankester.-Veine de Medine, Fr. ; Vena medinensis, Veloch (1674). See Dracunculus medinensis, Lister. - Ver cutanée des marchais; Ver de Guinée dragonneau. See Dracunculus medinensis, Cobbold.-Ver de farine. See Tenebrio molitor, Linné. - Ver rhinaire, Chabert. See Linguatula rhinaria, Raillièt.-Ver solitaire, Andry. Applied by Andry to his Solium, which was in reality Tania saginata, $q . v$.-Verme auricolare, Ital. See Forficula auricularia, Linné. - Vermes cucurbitini. See Trenia saginata, Goeze.-Vermis cucurbita, Plater. See Tania solium, Linné.-Vermis medinensis, Grundler (1740). See Dracunculus medinensis, Cobbold.-Vers sortis des reins et de 1'urèthre, Moublet. See Eustrongylus gigas, Bremser. Vesicaria granulosa, Schrank. See Echinococcus polymorphus. - Vibrio humana, Lizars (1843). See Trichina spiralis, Owen (1843).-Viehbremse. See Gastrophilus pecorum, Fabricius.-Vituli aquaticus, Aldrovandi (I605). See Gordius aquaticus, Dujardin (1842).-Vogelfloh. See Pulex avium, Taschenberg.-Wandlaus. See Cimex lectuaria, I.inné.-
Warble - fly. See Hypoderna bovis, Latreille. Warega Fly. See Musca sp. - Western Deertick. See Dermacentor occidentalis, Linné.-Whipworm of Ruminants. See Tricocephalus affinis, Rudolphi. White-footed Breeze-fly. See Tabamus albipes, Fabricius. - Zanzara comune, Ital. See Culex pipiens. - Zeylonischer Blutegel. See Hamadipsa ceylonica.-Zimb. See Glossina morsitans, Westwood; also Pangonia.

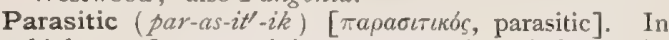
biology, of, or pertaining to, a parasite; holding the position of a parasite. In ornithology, applied to such birds as deposit their eggs in the nests of other birds, to which are left the duties of incubation and care of the young $\left(e, g_{.}\right.$, the European cuckow, Cuculus canorus, Linne, the American Cow Black-bird, Molobrus pecoris) ; also to such birds as obtain their food by systematically robbing other species $(e . g$. , the Parasitic Jaeger, Stercorarius parasiticus and the Bald Eagle, Haliatus leucocephahes). P. Castration, sterility in plant or animal induced by a parasite. P. Disease, one due to the presence of parasites. P. Hemoptysis, hemoptysis associated with cough, due to the presence of a trematode, or fluke, the Distoma ringeri in the bronchial tubes. It is a disease of China, Japan, and Formosa. See Parasites (Animal), Table of. P. Male, applied to the male of certain invertebrates which lives upon, and is nourished by, the female; e.g., the microscopic male of the crustacean Lernca, which becomes practically a spermatophore, and the diminutive Turbellaria-like ciliated male of the vermian Bonellia, which establishes itself upon the sexual organs of the female. P. Plant, a plant deriving its nourishment from another plant or from another organism; a bacterium. P. Twin, an autosite.

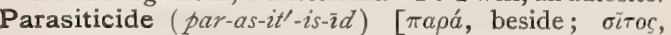
food; cadere, to kill]. Any substance destructive of parasites.

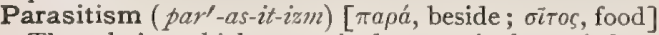
The relation which a parasite bears to its host ; infestation by parasites.

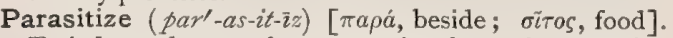
To infest; the act of one organism becoming parasitic within or upon another.

Parasitogenesis ( $\left.p a r-a s-i t-o-j e n^{\prime}-e s-i s\right)$ [ $\pi a \rho a ́$, beside :

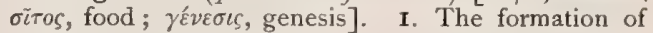
parasites. 2. A bodily condition favoring the development of parasites.

Parasitogeny ( $\left.p a r-a s-i t-o j^{\prime}-e n-e\right)$. Same as Parasitogenesis.

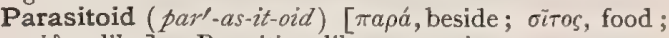
eldos, like]. Parasitic; like a parasite.

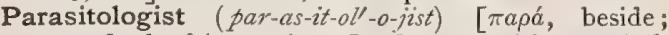

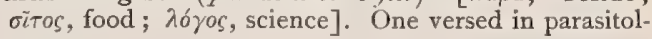
ogy.

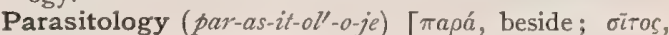
food; $\lambda$ 'ryos, science]. The science, or study, of parasites.

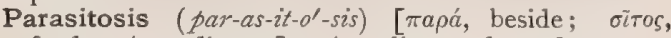
food; vóos, disease]. Any disease dependent upon the presence of parasites. The development of a parasitic disease.

Parasorbic Acid (par-as-or'-bik), $\mathrm{C}_{6} \mathrm{H}_{8} \mathrm{O}_{2}$. An oily liquid, of unpleasant odor, obtained in the production of malic acid from the berries of the mountain-ash.

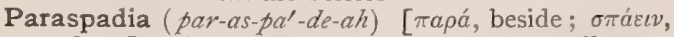
to draw]. An opening of the urethra, usually congenital, on one side of the penis.

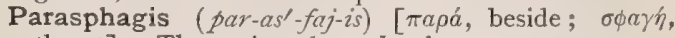
throat]. The region about the throat.

Parasphenoid (par-as-fe'-noid) [ $\pi \alpha \rho a ́$, beside; $\sigma \phi \dot{\eta} v$, wedge ; $\varepsilon i \delta o \varsigma$, form ]. In biology : $(a)$ Located along- 
side or under the sphenoid. (b) A membrane-bone occupying the position of the sphenoid bone proper in the Sauropsida. (c) A mesal bone articulating with the vomer in amphibians and fishes.

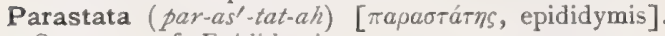
Synonym of Epididymis.

Parastatadenitis (par-as-tat-ad-en-i'-tis). Synonym of Epididymitis.

Parastatitis (par-as-tat-i'-tis). Synonym of Epididy mitis.

Parasteatosis ( par-as-te-at-o'-sis) [ $\pi \alpha \rho \alpha$, beside ; $\sigma \tau \varepsilon \dot{\varepsilon} \alpha \rho$, a hard fat]. Fatty degeneration attended with an altered sebaceous secretion.

Parastemon (par-as-te'-mon) [ $\pi a \rho a ́$, about; $\sigma \tau \eta \dot{\eta} \mu \omega \nu$, the warp of a web]. Same as Staminodeum.

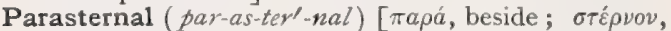
sternum]. Beside or near the sternum. P. Line, the imaginary vertical line midway between the margin of the sternum and the line passing through the nipple. P. Region, the region between the sternal margin and the parasternal line.

Parastichy ( $\left.p a r-a s^{\prime}-t i k-e\right)$ [ $\pi a \rho a ́$, about; $\sigma \tau i \chi o s$, a row, line, rank: pl., Parastichies]. In biology, a whorl or spiral row of organs. Cf. Orthostichy.

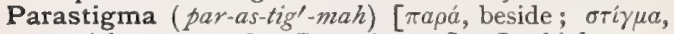
a prick, spot: pl., Parastigmata]. In biology, a chitinous spot on the wings of an insect.

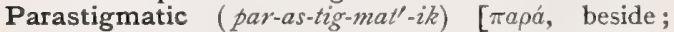
orinua, a spot]. I. Of, or pertaining to, the parastigma. 2. Situated beside the stigma of an insect's wing.

Parastramnia, Parastremma (par-as-tram'-ne-ah, par-

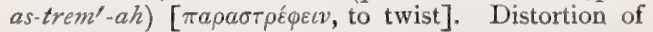
the mouth or face.

Parastrepsis (par-as-trep'-sis). Synonym of Subluxation.

Parastyle ( $\left.p a r^{\prime}-a s-t \bar{l} l\right)$ [ $\pi \alpha \rho a ́$, beside ; $\sigma \tau \tilde{v} \lambda o s$, a pillar]. In biology, an abortive style.

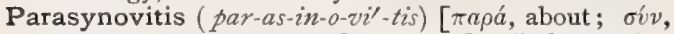
with; ovum, egg; $\iota \tau \iota$, inflammation]. Inflammation of the structures about a joint.

Parasyphilitic (par-as-if-il-it'-ik) [ $\pi a \rho a ́$, beside ; $\sigma \dot{v} \phi l-$ $\lambda \iota s$, syphilis]. Not unlike syphilis, or in some way resembling syphilis.

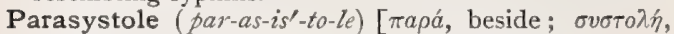
systole]. The interval between the cardiac systole and the diastole.

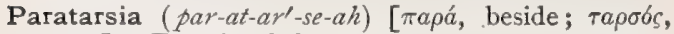
tarsus]. Ectopia of the tarsus.

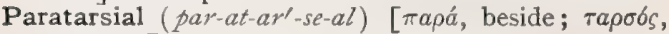
tarsus]. Pertaining to the paratarsium.

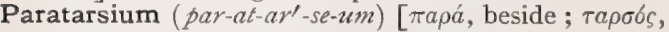
the sole of the foot: pl., Paratarsia]. In biology, applied to the side of the tarsus of a bird to distinguish it from the acrotarsium.

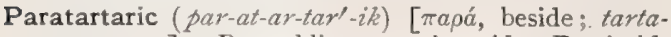
rum, tartar]. Resembling tartaric acid. P. Acid. Synonym of Acid, Racemic.

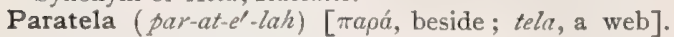
The tela of the lateral ventricle of the brain.

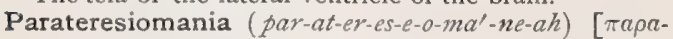

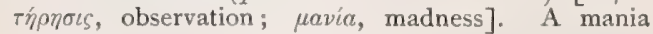
for observing, or seeing new sights.

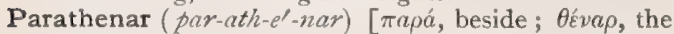
flat of the foot]. Applied to the abductor and flexor brevis muscles of the little toe.

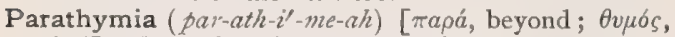
mind]. Mental strain, or overwork.

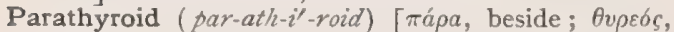
a shield; Eidos, like]. Lying beside the thyroid gland.

Paratoloid (par-at'-o-loid). A synonym of Tuberculin. See Lymph.
Paratoluidin (par-at o-lu'-id-in) [ $\pi \alpha \rho a ́$, beside; toluidin]. A so-called aromatic, or benzyl-compound resembling toluidin, and derived from coal-tar. It has been proposed as a remedy in tuberculosis.

Paratolyl ( $\left.p a r^{-}-a t^{\prime}-0-l i l\right)$. A liquid with a strong odor, inducing, when inhaled, headache and epistaxis. It is also called Phosphene.

Paratomial (par-at-o'-me-al) [ $\pi a \rho a ́$, beside; $\tau a \mu \varepsilon i \nu$, to cut]. Pertaining to the paratomium.

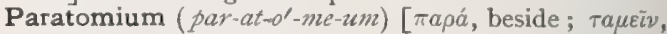
to cut: pl., Paratomia]. In biology, applied to the side of the upper mandible, to distinguish it from the culmen and tomium.

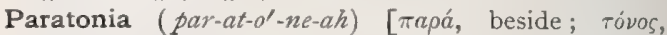
stretching]. In biology, over-extension; excessive tension.

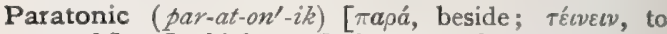
stretch]. In biology, Sachs' term for states of depressed activity in plants.

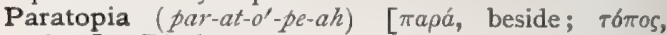
place]. Displacement.

Paratremma (par-at-rem'-ah). Synonym of Paratrimma.

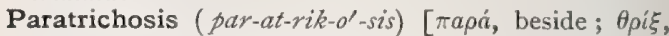
hair]. Trichosis characterized by an excessive growth of imperfect hair, or by growth in abnormal places.

Paratrimma (par-at-rim'-ah) [ $\pi a \rho a ́$, along; $\tau \rho i \beta \varepsilon \imath$, to rub]. Intertrigo. Chafing. See Erythema.

Paratriptic ( $\left.p a r-a t-r i p^{\prime}-t i k\right)$ [ $\pi \alpha \rho a ́$, beside ; $\tau \rho \iota \beta \varepsilon \imath \nu$, to rub]. Rubbing together; increasing waste.

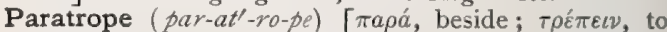
turn]. Twisting of a limb.

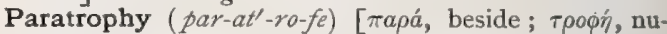
trition]. Perverted or abnormal nutrition.

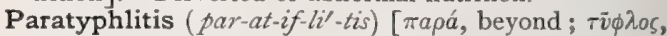
blind; $\iota \tau \iota \zeta$, inflammation]. Inflammation of the extraperitoneal and post-cecal connective tissue. It is always secondary to typhlitis. The tumor in the right iliac fossa is frequently concealed by intestinal folds that are filled with air and mask the dulness on percussion. The term is going out of use, and is being replaced by appendicitis.

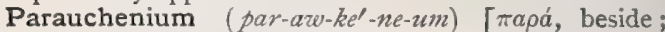
$a \dot{v} \chi \dot{\eta} v$, neck]. In biology, the lateral cervical region.

Paraumbilical ( $\left.p a r-a h-u m-b i l^{\prime}-i k-a l\right)$ [ $\pi a \rho a ́$, beside; $\dot{o} \mu \beta \iota \lambda \iota \kappa o ́ s$, umbilicus]. Near the navel.

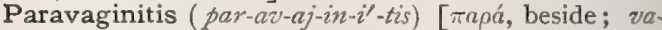
gin $\alpha$, vagina; $\iota T \iota S$, inflammation]. Inflammation of the connective tissue surrounding the vagina.

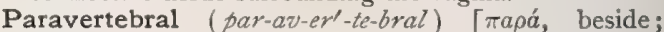
vertebra, vertebra]. Situated near the spinal column.

Paravesical (par-av-es'-ik-al) [ $\pi a \rho a ́$, beside; vesica, bladder ]. Situated near the urinary bladder. P. Pouch, the peritoneal pocket on either side of the bladder.

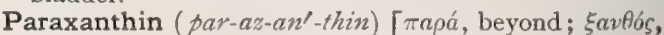
yellow $], \mathrm{C}_{7} \mathrm{H}_{8} \mathrm{~N}_{4} \mathrm{O}_{2}$. A leukomain discovered in $\mathrm{I} 883$, and since shown to be a normal constituent of urine, though present in very small quantities. It was formerly called urotheobromin. Paraxanthin is isomeric with theobromin, also with dioxy-dimethyl-purpurin; it is, therefore, a dimethyl-xanthin. It crystallizes readily in characteristic flat, somewhat irregular, sixsided tables when its solutions are slowly evaporated, or in needles if rapidly evaporated. See Leukomains.

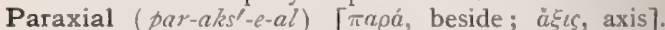
Lying near the axis of the body. A descriptive term applied to certain muscles, which, in the Bimana, are represented by the intercostal and abdominal muscles.

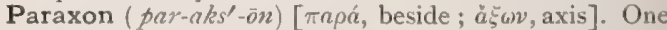
of the first branches of an axis cylinder, a collateral.

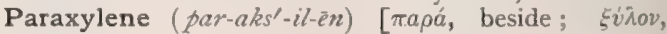


wood]. Paradimethylbenzene; a hydrocarbon found in xylol.

Paraxylorcinol (par-aks-il-or'-sin-ol) [ $\pi a \rho a ́$, beside;

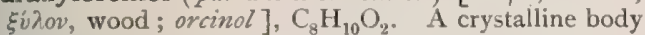
melting at $163^{\circ} \mathrm{C}$; chemically, it is dihydroxylene.

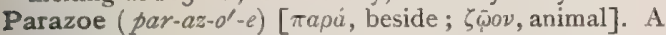
disease characterized by the presence of adult parasites.

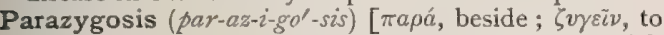
yoke]. The condition of a double monster in which there is union of the trunks above the umbilicus. It includes xiphopagus, thoracopagus, and pleuropagus.

Parchment (parch'-ment) [ME., parchement, parchment]. See Leather. P.-crackling, the peculiar sound elicited by pressure on the cranial bones in children the subjects of rickets and congenital syphilis. It is due to a localized hypertrophy of the bones. P.-glue. See Glue. P.-induration, a form of chancre, or primary lesion of syphilis, in which the induration is parchment-like in feel. P.-skin. See Xeroderma.

Parcidentate (par-sid-en'-tāt) [ parcus, sparing; dens, tooth]. In biology, having relatively few teeth.

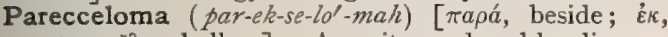
out ; koìnos, hollow]. A cavity produced by disease.

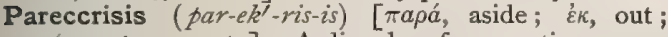
$\kappa \rho i v e i v$, to separate]. A disorder of a secretion.

Parecious, Parœcious (par-e'-she-us) [ $[\pi \alpha \rho a ́$, beside; oikos, house]. In biology, having male and female organs developed side by side.

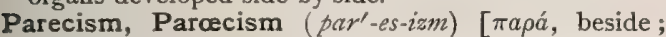
oikos, house]. In biology, the state or condition of being parecious.

Parectama ( $\left.p a-e k^{\prime}-t a m-a h\right)$. Synonym of Parectasis.

Parectasis (par-ek'-tas-is) [ $\pi \alpha \rho \dot{\alpha}$, beyond ; $\varepsilon \kappa \tau \alpha \sigma \iota s$, a stretching out]. Excessive stretching or dilatation.

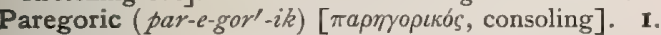
Soothing, or assuaging. 2. A soothing remedy. P., Elixir. See Opii, Tinct., Camphorata.

Pareia $\left(p a r-i^{\prime \prime}-a h\right)$ [ $\pi \alpha \rho \varepsilon \iota^{\prime}$, cheek]. Cheek.

Pareira (par-a'-rah) [native Braz.]. The root of Chondodendron tomentosum, a plant of South America. It is diuretic and laxative, and tonic to the mucous membrane of the genito-urinary organs. It is valuable in cystitis, gonorrhea, and leukorrhea, and is used internally and locally for the bites of poisonous serpents, etc. P., Decoct. (B. P.) Dose $3 \mathrm{j}-\mathrm{ij}$. P., Extract. (B. P.) Dose gr. $x-x x$, P., Ext,, Fld. Dose $3^{\text {ss- }}$ j j. P., Ext., Liq. (B. P.) Dose 3 j-ij. P., Infus, unof. Dose $\xi \mathrm{j}-\mathrm{ij}$. P. brava. Synonym of Pareira.

Pareirin (par-a'-rin). See Pereirin.

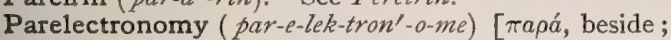

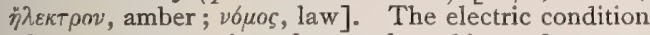
of a transverse section of a muscle and its tendon, compared with that of the natural surface of the muscle. The former is negative, the latter positive.

Paremptosis (par-emp-to'-sis) [ $\pi a \rho a ́$, beside ; $\varepsilon \mu \pi i \pi \tau \varepsilon \iota \nu$, to sink in]. I. Dislocation. 2. A form of amaurosis.

Parencephalis (par-en-sef'-al-is). Synonym of Parencephaton.

Parencephalitis (par-en-sef-al-i'-tis) [ $\pi a \rho a ́$, beside ;

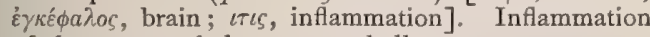
of the parencephalon, or cerebellum.

Parencephalocele (par-en-sef'-al-o-sél) [ $\pi a p a^{\prime}$, beside; $\dot{\varepsilon} \gamma \kappa \varepsilon \dot{\varepsilon} \phi \lambda)^{\circ}$, brain; $\kappa \hat{\eta} \lambda \eta$, hernia]. Hernia of the parencephalon.

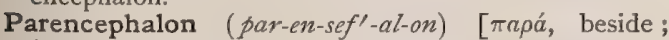

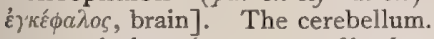

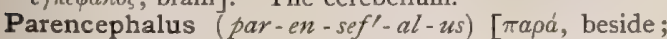

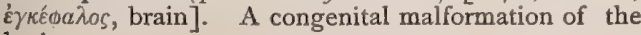
brain.

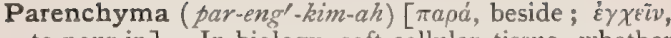
to pour in]. In biology, soft cellular tissue, whether of plants (pith, pulp of leaves, etc.), or of animals, as the solid parts of a gland, any substance lying between ducts, vessels or nerves, connective tissue, corpuscles or amorphous matter. In physiology, the secreting or functionating structure of an organ. P., Digesting, a mass of stellate, branched cells representing the alimentary canal in the so-called Acela among platode worms. Food enters this mass directly through the mouth or esophagus.

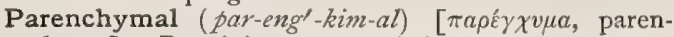
chyma]. Pertaining to, or of the nature of, parenchyma.

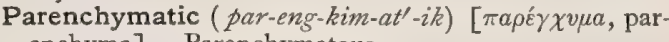
enchyma]. Parenchymatous.

Parenchymatitis (par-eng-kim-at-i't-tis) $[\pi a \rho a ́$, beside ; $\dot{\varepsilon} \gamma \chi \varepsilon \tilde{\imath} \nu$, to pour in; $\iota \tau \iota \varsigma$, inflammation]. Inflammation of parenchyma.

Parenchymatous ( $p a r-e n g-k i n^{\prime}-a t-u s$, or par-eng-ki'mat-us) [ $\pi a \rho \dot{a}$, beside ; $\dot{\varepsilon} \gamma \chi \varepsilon \bar{\varepsilon} \nu$, to pour in]. Pertaining to, or having the nature of, parenchyma. P. Inflammation, inflammation of the parenchyma, as distinguished from that of the interstitial tissue. In reality there can be no inflammation of the parenchyma without the same process in the interstitial tissue.

Parenchyme (par-eng'-kim). Same as Parenchyma.

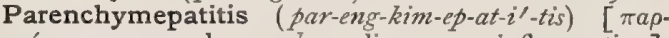
$\xi \gamma \chi v \mu \alpha$, parenchyma; $\eta \pi \alpha \rho$, liver; $i \tau \iota \varsigma$, inflammation]. Inflammation of the parenchyma of the liver.

Parenchymous (par-engl-kim-us). Same as Parenchymatous.

Parenchymula (par-eng-kim'-u-lah) [dim. of parenchyma: pl., Parenchymula]. Hyatt's name for the embryonic stage immediately succeeding that of the closed blastula. Synonym of Metschnikoff's Larva.

Parencranis (par-en-kra'-nis). Synonym of Cerebellum.

Parent ( $\left.p \bar{a} r^{\prime}-e n t\right)$ [parens, a parent]. One who has generated or produced; a father or mother. P.-cell. See Cytula, Mother-cell. P.-form, in biology, a stock; a parent of any kind. P.-hood, the state of being a parent. P.-kernel, the nucleus of a parentcell; a cytococcus.

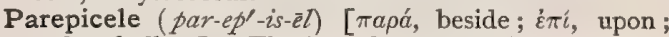
$\kappa \circ i \lambda \circ$, hollow]. The lateral recess of the epicele extending latero-ventrad.

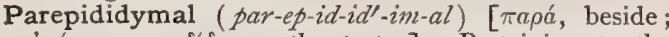

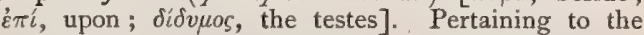
parepididymis.

Parepididymis (par-ep-id-id'-im-is). See Paradidy. mis.

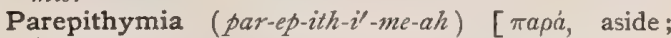
$\dot{\varepsilon} \pi \imath \theta v \mu i a$, desire]. A morbid or depraved desire or habit.

Parerethisis (par-er-eth'-is-is) [ $\pi a \rho a ́$, beyond ; 'e $\rho \iota \theta i \zeta \varepsilon \iota \nu$, to excite]. Abnormal excitement, or stimulus.

Paresis (par'-es-is) [ $\pi a p a ́$, from ; ićval, to let go]. I. Slight paralysis; partial loss of muscular power. 2. Same as general paralysis.

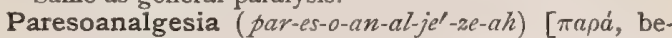

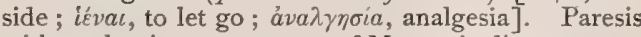
with analgesia; a symptom of Morvan's disease.

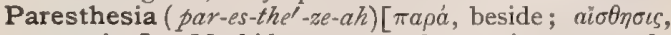
sensation]. Morbid or perverted sensation, as numbness, formication, "pins-and-needles."

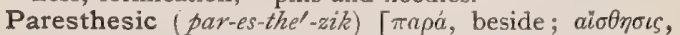
sensation]. Pertaining to paresthesia. P. Neurosis, a peculiar neurosis, in which the patient complains of paresthesiæ as follows: gnawing, boring, "pins and needles," sensations in the extremities, particularly 
the upper, involving the fingers, hands and forearms, often of both sides, but not infrequently of only one. The neurosis appears in the following types: $\mathbf{I}$. The emotional. 2. The mental. 3. The neurasthenic. 4. The toxic. 5. Waking numbness (?). 6. The type that may be called an occupation-paresthesia, as it is often associated with a certain class of occupations. It is more frequent in women.

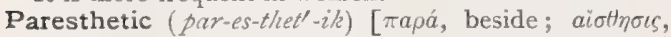
sensation]. Pertaining to, or having the nature of paresthesia.

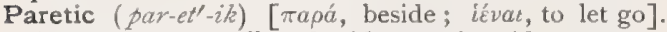
Pertaining to, or affected with, paresis. Also, a person suffering from paresis. P. Dement, a person suffering from paretic dementia. P. Dementia. See General Paralysis of the Insane.

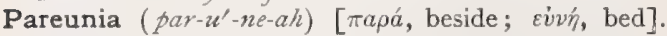
Coitus; sexual congress.

Parfocal Ocular. See Ocular.

Parhidrosis (par-hid-ro'-sis). Same as Paridrosis.

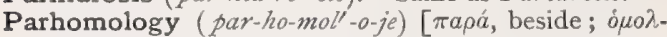
oyia, agreement, conformity]. In biology, apparent homology ; imitative homodynamy.

Paricin (par'-is-in) [par, equal; Cinchona], $\mathrm{C}_{16} \mathrm{H}_{18} \mathrm{~N}_{2} \mathrm{O}$. An amorphous alkaloid of the Cinchonas.

Paridigitate (par-id-ij'-it-ât) [par, equal ; digitatus, having fingers or toes]. In biology, having an even number of digits, as in artiodactyl ungulates.

Paridin (par'-id-in) [par, equal], $\mathrm{C}_{16} \mathrm{H}_{28} \mathrm{O}_{7}$. A glucosid obtained from Paris quadrifolia.

Paridol $\left(p a r^{\prime}-i d-o l\right)$ [par, equal], $\mathrm{C}_{24} \mathrm{H}_{14} \mathrm{O}_{9} . \quad A$ decomposition-product of paridin.

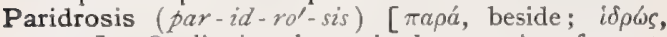
sweat]. Qualitative change in the secretion of sweat.

Paries $\left(p a^{\prime}-r e-\bar{e} z\right)$ [paries, a wall: pl., Parietes]. In biology, an enveloping or investing structure or wall.

Parietal ( $\left.p a r-i^{\prime}-e t-a l\right)$ [parietalis, belonging to walls]. (a) Pertaining to the walls of a body-cavity. $(\vec{b})$ Applied to placentæ that are borne on the walls of the ovary. P. Angle. See Angle. P. Bone, one of the two large, rectangular bones that by their union form che sides and roof of the skull. See Bones, Table of. P. Boss. Same as P. Eminence. P. Cell, one of a variety of cells, also called acid cells, found irregularly distributed among the epithelium of the peptic glands. They communicate with the lumen of the tube by means of intercellular clefts. P. Convolution. See Convolutions, Table of. P. Eminence. See Eminenie. P. Eye. See Pineal Eye. P. Foramen. See Foramen. P. Fossa, the deepest part of the inner surface of the parietal bone. P. Gyrus. See P. Convolution. P. Lobe. See Lobes of Brain. P. Lobules, two lobules of the cerebrum, inferior and superior, separated by the interparietal sulcus. P. Peritoneum, the peritoneum covering the internal surface of the abdominal wall. P. Placenta, in biology, a placenta borne on the ovarian wall. P. Pleura, the pleura lining the thoracic wall. P. Protuberance. Same as $P$. Eminence. P. Segment: I. The second cranial segment, between the occipital and frontal, and including the basisphenoid, alisphenoid, and parietal bones. 2. The posterior segment of the mitral valve. P. Sulcus, the intrapraietal sulcus. P.Vertebra. Same as $P$. Serment.

Parietale (par-i-et-a $-l e)$ [parietalis, belonging to walls]. One of the parietal bones.

Parieten (par-i'-et-en) [paries, wall]. Belonging to the parietal bone in itself.

Parietic Acid. A synonym of Acid, Chrysophanic.

Parieto-frontal (par-i'-et-o-frun'-tal) [paries, a wall ; frons, front]. Of, pertaining to, or representing both the parietal and frontal bones; frontoparietal.
Parieto-mastoid (par-i'-et-o-mas'-toi $\left.i^{\prime}\right)$ [paries, a

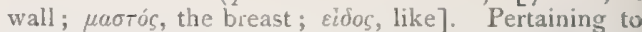
the parietal bone and the mastoid process of the temporal bone; mastoparietal.

Parieto-occipital (par-i'-et-o-ok-sip'-it-al) [paries, a wall; occiput, the back of the head]. Pertaining to the parietal and occipital bones or lobes, as the parieto-occipital fissure, the parieto-occipital convolutions, and the parieto-occipital suture.

Parieto-quadrate ( $\left.p a r-i^{\prime}-e t-0-k w o d^{\prime}-r a \bar{t}\right)$ [paries, the wall; quadratus, square]. Pertaining to the parietal and quadrate bones. P. Arch, an arch in the skull of reptiles.

Parieto-sphenoid (par-i'-et-o-sfe'-noid) [paries, wall ; $\sigma \phi \eta \nu$, wedge; $\varepsilon i \delta o s$, like]. Pertaining to the parietal and sphenoid bones.

Parieto-splanchnic (par-i'-et-o-splangk'-nik) [paries, a wall; $\sigma \pi \lambda a ́ \gamma \chi \nu \nu \nu$, viscera]. Of or pertaining to the walls of the alimentary canal, as the nervous ganglia of certain molluscs.

Parieto-squamosal (par-i'-et-o-skwa-mo'-sal) [ paries, a wall; squama, a scale]. Of or pertaining to the parietal and squamosal bones. P. Suture, a suture between the squamous portion of the temporal bone and the parietal bone.

Parieto-temporal (par-i'-et-o-tem'-po-ral) [paries, a wall; tempora, the temples]. Pertaining to the parietal and temporal bones. P. Suture, the suture between the parietal and temporal bones.

Parieto-vaginal ( $\left.p a r-i^{\prime}-e t-o-v a j^{\prime}-i n-a l\right)$ [ paries, a wall; vagina, a sheath]. Of or pertaining to the ectodermal and endodermal layers of a polyzoan, as the parieto-vaginal muscles.

Parieto-visceral ( $\left.p a r-i^{\prime}-e t-o-v i s^{\prime}-e r-a l\right)$ [ paries, a wall; viscus, a bowel, entrails]. Of or pertaining to the walls of a body-cavity and the contained viscera.

Parietti's Solution. See Stains, Table of.

Parigenin (par-ij'-en-in). See Parillin.

Parillin (par-il'-in) [parilla, dim. of parra, a trained vine]. A glucosid obtained from sarsaparilla. It crystallizes in white scales or needles, permanent in the air, neutral, odorless, at first tasteless, but afterward bitter and acrid, slightly soluble in cold water and alcohol, freely so in hot. If treated by dilute mineral acids it yields parigenin and sugar.

Parin ( $\left.p a r^{\prime}-i n\right)$. Synonym of Paridin.

Pari passu ( $p a r^{\prime}-e p a s^{\prime}-u$ ) [L.]. Coincidently; side by side; with equal progress; in the same degree.

Paripinnate ( $\left.p a r-i p-i n^{\prime}-a t\right)$ [par, equal; pinna, wing, feather]. In biology, abruptly pinnate; $i . \ell$., without an unpaired terminal leaflet.

Paris (par'-is) [par, equal]. I. A genus of liliaceous plants. 2. The capital of France. P. Blue. Same as Cobalt-blue. P. Green. Same as Schaveinfurth Green and Rinmann's Green. See also Copper. P. quadrifolia, a common European herb, the oneberry, true-love, or four-leaved grass, which is actively poisonous. It yields paridin. Unof. P. Red. Same as Colcothar, Mauvein, and Minium. P. Violet. Same as Methyl-violet. P. Yellow. Same as Chromeyellow.

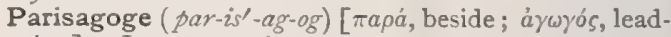
ing]. Intussusception.

Parish (par'-ish) [ME., parishe, a parish]. A place for which a separate poor-rate is or can be made, or for which a separate overseer is or can be appointed. (Brit. Pub. Health Act, I875.)

Parish's Chemical Food. See Phosphorus.

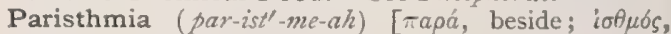
throat]. The tonsils.

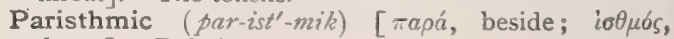
throat]. Relating to the tonsils. 
Paristhmitis (par-ist-mi'-tis) [ $\pi a \rho a ́$, beside; i $\sigma \theta \mu o ́ s$, throat; $\iota \tau \iota \varsigma$, inflammation]. Tonsillitis.

Paristyphnin (par-is-tifl-nin) [par, equal; tī oos, smoke], $\mathrm{C}_{38} \mathrm{H}_{64} \mathrm{O}_{18}$. A glucosid found in the root of Paris quadrifolia.

Parity $\left(p a r^{\prime}-i t-e\right)[p a r$, equal]. Equality.

Parity $\left(\right.$ parl-it-e) $^{2}$ [ parere, to bring forth]. The condition of being able to bear children.

Park's Aneurysm. See Aneurysm, and Diseases, Table of.

Parkinson's Disease. See Paralysis agitans, and Diseases, Table of. P.'s Mask, the immobile, mask-like expression of patients suffering with paralysis agitans. See Signs and Symptoms, Table of.

Parma-blue. Same as Spirit-blue. P.-violet. Same as Rosanilin-violet.

Paroarium, Paroarion ( $p a r-0-a^{\prime}-r e-u m$, par-o-a $a^{\prime}-r e-$

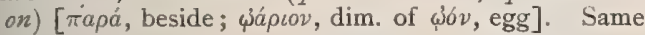
as Purovarium.

Paroccipital (par-ok-siṕ-it-al) [ $\pi a \rho a ́$, beside; occiput, occiput]. I. Literally, beside the occipital region. 2. The mastoid apophysis. See Parieto-occipital.

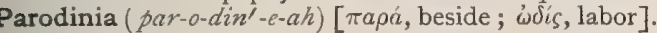
Difficult parturition.

Parodontis (par-o-don'-tis). Synonym of Epulis.

Parodyn (par'-o-din). Synonym of Antipyrin.

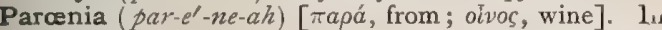
legal medicine, an act committed while intoxicated, or drunken.

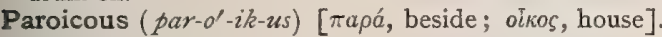
Same as Parecious.

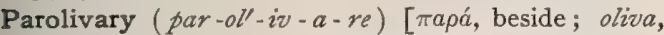
olive]. Situated near the olivary body.

Paromphalocele (par-om-fal'-o-sél) [ [ $\alpha \rho \rho a ́$, near; $\dot{o} \mu$ $\phi a \lambda o ́ s$, navel; $\kappa \eta \dot{\Lambda} \eta$, tumor]. Hernia in the region of the navel.

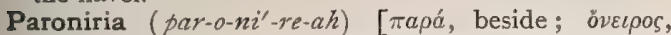
dreami]. Depraved or morbid dreaming. A condition marked by imperfect sleep and by dream-excitement or action of the voluntary muscles. P. ambulans, sleep-walking. P. salax, a restless condition attended with involuntary seminal emissions and lascivious dreams.

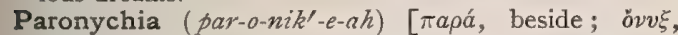
nail]. Inflammation about the finger-nail. It may be phlegmonous and form an abscess. Applied also to inflammation of the flexor-tendons and of their sheaths. Run-around, for the lightest form, and wohitlow, for the severer form, are popular names for these affections. $\mathbf{P}$. gangrænosa, a gangrenous inflammation around the nail, resulting in the loss of the terminal phalanges. P., Syphilitic, an ulcerative form due to syphilis. The swelling is very marked.

Paronychial (par-o-nik'-e-al) [ $\pi a \rho \omega \nu v \chi i a$, a whitlow]. Having the character of paronychia.

Paronychis, Paronychitis ( par-o-nik'-is, par-o-nik-i' tis). Synonym of Paronychia.

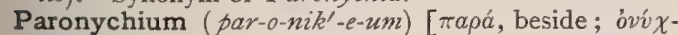
cov, a little claw; dim. of ơv $\xi$, a nail: pl., Paronychia]. In biology, a bristle-like organ between the terminal claws of the foot of an insect.

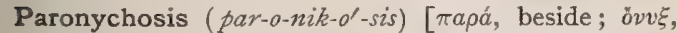
nail ; vóбos, disease $]$. A diseased condition of the structures about the nails; also growth of a nail in unusual places.

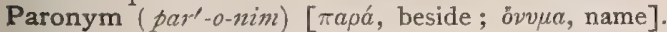
A word that exactly represents a word in another language, differing from it, if at all, only in some slight modification. Thus nerve is a paronym of Latin nervus; muscle of musculus; canal of canalis. A related synonym. Cf. Heteronym.

Paroöphoritis (par-o-off-or-i'-tis) [ $[\pi a \rho a ́$, beside ; $\omega \circ \phi-$ 65 ó $\rho \circ \varsigma$, egg-bearing; $\iota \tau \iota \varsigma$, inflammation]. I. Inflamma. tion of the parovarium. 2. Inflammation of the tis sues about the ovary

Paroöphoron (par-o-off'-o-ron) [ $\pi \alpha \rho a ́$, beside; $\omega \hat{b} v$, an egg; фé $\rho \varepsilon \imath$, to bear: pl., Paroöphora]. In biology, the organ constituted by the persistent tubules of the posterior part of the Wolffian body. It was first described in the male by Giraldés under the name of the corps innomine, and was first described in the female by Waldeyer. See Paradidymis.

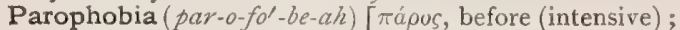
фóßos, fear]. Hydrophobia.

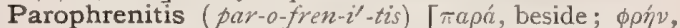
diaphragm; $\iota \tau \iota$, inflammation]. Inflammation about the diaphragm.

Parophthalmia (par-off-thal'-me-ah) [ $\pi a \rho a ́$, beside; o $\phi \theta a \lambda \mu o ́ s$, eye ]. Inflammation about the eye.

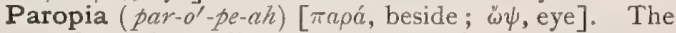
angle of the eyelid toward the temple.

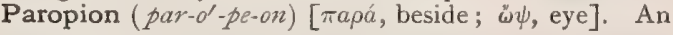
eye-screen.

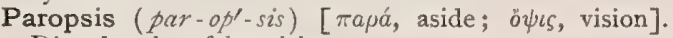
Disordered or false vision.

Paroptesis ( $\left.p a r-o p-t \ell^{\prime}-s i s\right)$ [ $\pi a \rho a ́$, near; ó $\pi \tau \eta \sigma \iota 5$, a roasting]. A hot-air bath.

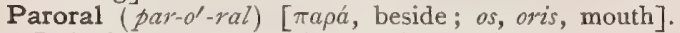
In biology, alongside the mouth or oral aperture.

Parorasis ( $p a \gamma^{\prime}-0-r a^{\prime}$-sis) [ $\pi \alpha \rho a ́$, beside; 'opá $\varepsilon \iota v$, to see]. Any perversion of vision or of color-perception; an hallucination.

Parorchid (par-or'-kil ). Same as Parorchis.

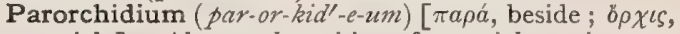
testicle]. Abnormal position of a testicle, or its nondescent.

Parorchido - enterocele ( par-or-kid'-o-en-ter'-o-sèl)

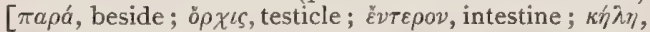
tumor]. Inguinal hernia combined with displacement of the testis.

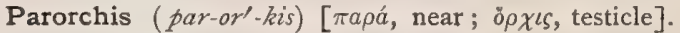
See Epididymis.

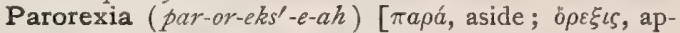
petite]. A perverted appetite.

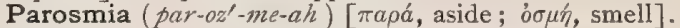
Hallucination of smell, usually unpleasant.

Parosmis (par-oz'-mis). See Parosmia.

Parosphresis (par-os-fre'-sis). Same as Parosmia

Parosteitis (par-os-te-i'tis). Synonym of Parostitis.

Parosteosis (par-os-te-o'-sis). See Parostosis.

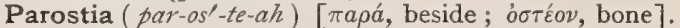
Disorder or defect of ossification.

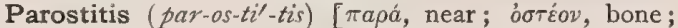
$\iota \tau \iota s$, inflammation]. Inflammation of the outer surface of periosteum.

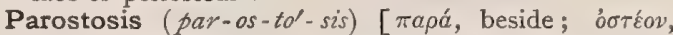
bone]. The abnormal formation of bone outside of the periosteum, or in the connective tissue surrounding the periosteum.

Parotic $\left(p a r-o t^{\prime}-i k\right)$ [ $\pi a \rho a ́$, near; ov̌s, ear]. Situated near or about the ear.

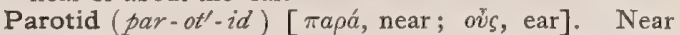
the ear. P. Abscess, an abscess of the parotid gland; also sometimes applied to abscess of the lymphatic gland lying upon the parotid. P. Duct, the excretory duct of the parotid gland. P. Glands. See Salivary Glands.

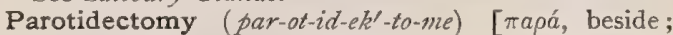
ov's, ear; ékтoufy, excision]. Excision of the parotid gland.

Parotiditis ( $p a r-o t-i d-i^{\prime}$-tis). See Parotitis.

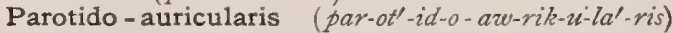
[Tapá, near; ov́s, ear; aura, ear]. A muscle, welldeveloped in lower animals, arising from the surface 
of the parotid gland and inserted into the base of the concha. Its function is to abduct and depress the pinna.

Parotidoncus (par-ot-id-ons'-kus). See Parotitis.

Parotidoscirrhus ( $\left.p a r-o t-i d-o-s k i r^{\prime}-u s\right)$ [ $\pi a \rho a ́$, beside ; ơs, ear; okiṕpós, hard]. Scirrhous carcinoma of the parotid gland.

Parotis (par-o'-tis) [L.]. The parotid gland. P. accessoria, a small lobule near the parotid gland, called the accessory parotid gland.

Parotitic ( $\left.p a r-o-t i t^{\prime}-i k\right)$ [ $[\pi \alpha \rho a ́$, beside; ous, ear ; $\iota \tau \iota \varsigma$, inflammation]. Having the mumps; affected with parotitis.

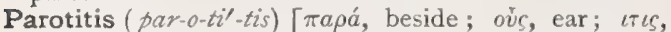
inflammation]. Inflammation of the parotid gland, commonly called the mumps. P. contagiosa, mumps. P., Epidemic, ordinary mumps. P., Idiopathic, mumps. P., Metastatic, mumps secondary to disease elsewhere; it is not uncommon in infectious diseases, and usually goes on to suppuration.

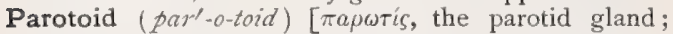
$\varepsilon i \delta o s$, form ]. In biology, applied to certain cutaneous glands near the external ear in some batrachians.

Parous (par'-us) [parerc, to bear]. Having borne one or more children.

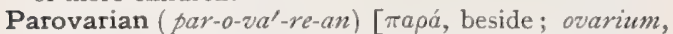
ovary]. Situated in or occurring near the ovary.

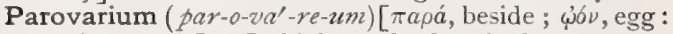
pl., Parovaria]. In biology, the functionless remnant or vestige of the Wolffian body of the female; the organ of Rosenmüller, $q . v$.

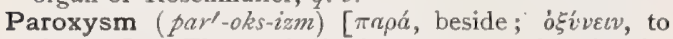
sharpen]. The periodic increase or crisis in the progress of a disease; a fit or sudden attack of pain or convulsion. P., Febrile, an accession of fever.

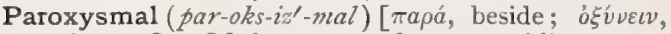
to sharpen]. Of the nature of or resembling a paroxysm; recurring in paroxysms. P. Sleep. See Narcolepsy.

Paroxysmic (par-oks-iz'-mik). Same as Paroxysmal.

Parrot ( par'-ot) [Fr., pierrot, a sparrow]. Any bird of the family Psittacida, having a curved and hooked bill. P.-beak Nails, nails that are curved strongly antero-posteriorly, like the beak of the parrot. P.mouth. A deformity of the mouth of a horse in which the upper incisors project in front of and beyond the lower ones. This results in interference with prehension and mastication, and indirectly with digestion.

Parrot's Disease. Syphilitic pseudo-paralysis. See Diseases, Table of. P.'s Nodes. See Signs and Symptoms, Table of, and also Node. P.'s Sign. See Signs and Symptoms, Table of.

Parry's Disease. Exophthalmic goiter. See Diseases, Table of.

Pars (parz) [L. ]. Part. P. ciliaris retinæ, the part of the retina in front of the ora serrata. $P$. intermedia. I. Same as Portio inter durem et mollem. 2. Also a small plexus of veins establishing communication between the bulbs of the vestibule of the vagina and the clitoris. P. juncturæ, the lock of an obstetric forceps. P. minoris resistentize. Synonym of Locus minoris resistentia.

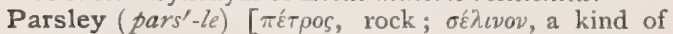
parsley]. A biennial garden herb, Petroselinum sativum. It contains a volatile oil and a camphor (Apiol). P.-camphor. See Apiol.

Parson's Disease. Exophthalmic goiter. See Diseases, Table of. P. Method. See Treatment, Methods of.

Part [pars, a part]. A segment or section; a member or organ.

Parted $\left(p a r t^{\prime}-e d\right)$ [partire, to divide]. In biology, applied to a leaf that is separated into parts almost to the midrib or base.

Parthenicin, Parthenin (par-then'-is-in, par'-then-in)

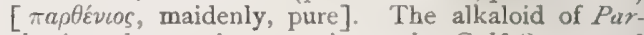
thenium hysterophorus, native to the Gulf States and the West Indies. It has proved efficacious in neuralgia and in intermittent fever. Dose gr. $3 / 4-\mathrm{ij}$; as an antiperiodic, gr. $\mathrm{v}-\mathrm{xv}$. Unof.

Parthenium (par-the'-ne-um) [ pure]. A genus of composite-flowered herbs of America. P. hysterophorus, and P. integrifolium, of $\mathrm{N}$. America, are useful in fever. Unof.

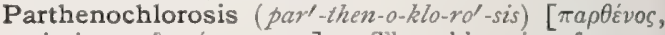
virgin; $\chi \lambda \omega \rho o ́ s$, green $]$. The chlorosis of young maidens.

Parthenogalactozemia ( $p a r^{\prime}$-then-o-gal-ak'-to-ze'-me-

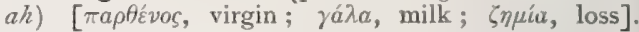
The secretion of milk in the breast of a virgin.

Parthenogenesis (par-then-o-jen'-es-is) [

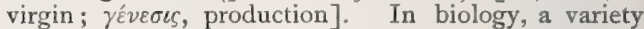
of asexual or virginal reproduction in which the whole development of the embryo is affected without the aid or stimulus of fecundation; the production of young without any previous congress with the male organism, as in various forms of Medusa, Tenia, and Aphida. The common black scale-bug, Lecaneum olece, of the oleander affords an example, all the insects being oviparous females.

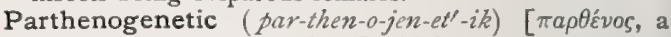
virgin; $\gamma^{\prime} v \varepsilon \sigma \iota s$, genesis]. In biology, of or pertaining to parthenogenesis. P. Eggs, eggs developed without fertilization, as the statoblasts of the freshwater Bryozoa. In these eggs, according to some observers, only one polar body is formed.

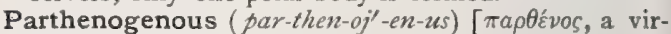
gin; $\gamma \varepsilon v \eta$ s, producing]. Producing spores, eggs, or young, without fertilization.

Parthenogeny (par-then-oj'-en-e) [ $\pi a \rho \theta \varepsilon$ cos, a rirgin; revins, producing]. Same as Parthenogenesis.

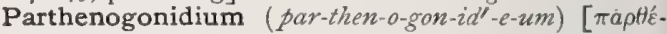
vos, a virgin; yov', generation : pl., Parthenogonidia ]. In biology, an individual of an asexual generation which produces by continuous incomplete fission a colony that separates from the mother-colony.

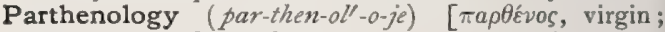
$\lambda 6 \gamma o s$, science]. The study or science of the diseases and conditions peculiar to or characteristic of virginity, or of young girls.

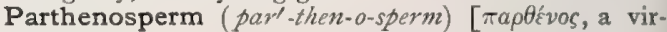
gin; $\sigma \pi \varepsilon \rho \mu a$, seed]. Same as Parthenospore.

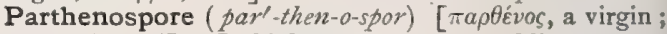
$\sigma \pi \circ \rho a ́$, seed]. In biology, a spore resembling a zygospore, but produced without fertilization, in certain algæ.

Particle (par'-tik-l) [dim. of pars, part]. A small part. The smallest visible portion of any substance.

Particulate (par-tik'-u-lât) [pars, part]. Composed of minute particles; applied to various contagia.

Partite (par'-tīt) [partiri, to divide]. In biology, divided from base to apex.

Partridge-berry (part'-ridj-ber'-e). See Gaultheria procumbens; also Mitchella repens.

Partridge's Hernia. Hernia external to the femoral vessels. See Hernia, and Diseases, Table of.

Parturiate (par-tu'-re-ât) [parturire, to bring forth]. To bring forth young.

Parturiency (par-tu'-re-en-se) [parturive, to bring forth]. The state of being parturient; parturition.

Parturient (par-tu'-re-ent) [parturire, to bring forth]. Being in labor; giving birth. P. Apoplexy. See Collapse, Parturient.

Parturifacient (par-tu-rif-al-se-ent) [parturive, to 
bring forth; fucere, to make]. I. Causing to bring forth. 2. A medicine or agent that induces parturition.

Parturiometer (par-tu-re-om'-et-er) [parturire, to bring forth; $\mu \varepsilon \tau_{\rho}$ ov, measure]. An instrument for measuring the expulsive force of the uterus and indicating the existing stage of labor.

Parturious (par-tu'-re-us) [parturire, to bring forth]. Parturient.

Parturition (par-tu-rish'-un) [parturitio; parturire, to bring forth]. The act of giving birth to young. See Labor.

Parturitive (par-tu'-rit-iv) [ parturire, to bring forth]. Obstetric; relating to parturition.

Partus (par'-tus) [partus; parere, to bring forth]. The bringing forth of offspring; labor. P. cæsarius, Cesarean section. P. difficilis, dystocia. P.immaturus, premature labor. P. maturus, labor at term. P. præcipitatus, precipitate labor. P. siccus, dry labor.

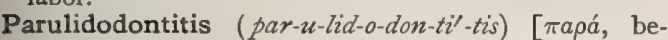

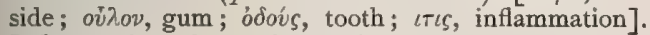
Inflammation of a tooth and the gum.

Parulis (par- $\left.u^{\prime}-l i s\right)$ [ $\pi \alpha \rho a ́$, near; ov $\lambda o v$, the gum]. Alveolar abscess of the gums. Gum-boil.

Parumbilical (par-um-bil'-ik-al) [ $\pi a \rho a ́$, beside; umbilicus, navel]. Situated or occurring near the umbilicus.

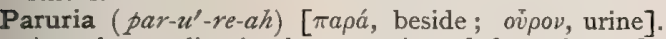
Any abnormality in the excretion of the urine. $\mathbf{P}$. mellita. Synonym of Diabetes mellitus.

Parvipsoas ( $\left.p a r-v i p^{\prime}-s o-a s\right)$ [parvus, small; $\psi b a$, pl. $\psi$ óa, a muscle of the loins]. The psoas parvus muscle. See Muscles, Table of.

Parvirostrate (par-ve-ros'-trāt) [parvus, small ; rostrum, beak]. In biology, having a small bill or beak.

Parvolin (par'-vo-lin). A name given to Gautier and Etard's ptomain-base, $\mathrm{C}_{9} \mathrm{H}_{13} \mathrm{~N}$, obtained (I88I) from decomposing mackerel and horseflesh, and isomeric with Waage's synthetic parvolin. The free base is an oily, amber-colored fluid, having the odor of hawthornblossoms. Its constitution and physiologic action have not yet been definitely settled. See Ptomains, Table of.

Parvule (par'-vül) [Fr.; L., parvulus, small]. A small pill, or pellet of medicine.

Pascual (pas'-ku-al) [ pascuum, a pasture]. Same as Pascuous.

Pascuant (pas'-ku-ant) [pascere, to feed]. In biology, feeding, as in a pasture ; pasturing.

Pascuous (pas'-ku-us) [pascere, to feed]. In biology, growing in pastures.

Pasma ( $\left.p a z^{\prime}-m a h\right)$ [ $\pi \alpha ́ \sigma \mu a ; \pi a ́ \sigma \sigma \varepsilon \imath v$, to sprinkle : pl., Pasmata]. I. A powder for sprinkling on a surface. 2. A powder mixed up into a paste, $q . v$.

Pasque Flower (pask). See Pulsatilla.

Pass (pas) [passus, step]. To go, or to put through, or by ; to discharge from the intestinal canal ; to void.

Passage (pas'-âj) [passare, to pass]. I. A channel. 2. The act of passing from one place to another. 3 . The introduction of an instrument into a cavity or channel. 4. An evacuation of the bowels. P., Lacrymal, the excretory ducts of the lacrymal gland, including the puncta canaliculi, lacrymal sac, and lacrymo-nasal duct. P., Tympanic. See Scala tympani. P., Vestibular. See Scala vestibuli.

Passet's Bacillus. See Bacteria, Synonymatic Table of.

Passifiora (pas-if-lo'-rah) [passio, passion; flos, a flower]. Passion-flower, a genus of climbing plants represented by a number of species several of which have medicinal properties. P. fœtida, is emmenagogue and antispasmodic. Unof.
Passio (pash'-e-o) [L.]. Same as Passion. P. colica. Synonym of Enteralgia. P.hæmoptoica, hemoptysis. P. hysterica. Synonym of Hysteria. P. iliaca. Synonym of Volvulus. P. uterina. Synonym of Hysteria.

Passion (pash'-un) [passio; pati, to suffer]. Pain; suffering. Any intense emotion of the mind. Intense sexual excitement. In pathology, a term formerly used to include all acute diseases. P., Iliac, volvulus. P.-fits, a common name for the spasms occurring in laryngismus stridulus, from the supposition that they are due to anger on the part of the child.

Passive (pas'-iv) [pati, to suffer]. Not active. P. Insufficiency of Muscles. See Insufficiency. P. Motion, the movement of a limb or part of the body by a second person or by external agency, and not by the patient himself.

Passivism (pas'-iv-izm) [pati, to suffer]. The term given by Stefanowski to that variety of sexual perversion which consists in the complete subjugation of the will of one person to the profit of another, with an erotic end. Subjectivism would be a preferable term, as there is an active acquiescence engendering feelings of a positive type. Passivism is the exact opposite of sadism. Passivism in the male may be defined as voluntary subjugation of the male will to the profit of the female, accompanied by an intense desire for abuse and maltreatment by her. In the last factor consists the voluptuous ecstacy of the passivist. Passivism may be physical or moral. Moral passivism consists essentially of humiliations and abasements before women. Here should be included the perverse tastes for female secretions, the cunnilinguists, renifleure, etc. Passivism may accompany sexual inversion, in which case the loved object is a male, and the passivist becomes a fellator. The fellator is the socalled bote, said to be common among the Indians of the N. W. United States.

Passivist (pas'-iv-ist) [pati, to suffer]. One who is the subject of passivism, $q . v$.

Passula (pas'-u-lah) [L.: pl. and gen., Pussula]. A raisin. $\mathbf{P}$. major, the common or large raisin. $\mathbf{P}$. minor, the small raisin, or Greek currant. See Uva passa.

Paste (pāst) [ pasta; $\pi a ́ \sigma \tau \eta$, mess ; $\pi a ́ \sigma \sigma \varepsilon \iota \nu$, to sprinkle. Cf., Pasma]. Any tenacious substance for cementing or uniting parts, especially a semi-solution of starch or flour in water. Also, a confection of gum arabic, sugar, and water, flavored with any aromatic substance. Also, a caustic preparation composed of arsenic acid, cinnabar, and caustic alkali. P., Arsenical, a caustic paste containing arsenic. P., Bonnet's, a caustic paste composed of equal parts of zinc chlorid and flour. P., Canquoin's. See Canquoin. P., Coster's, a solution of iodin in oil of tar. P., Dupuytren's, a caustic paste composed of arsenious acid, calomel, and a solution of gum. P., Esmarch's. See Esmarch. P., Felix's, a caustic paste composed of zinc chlorid, mercuric chlorid, iodol, crotonchloral, bromid of camphor, carbolic acid, starch, and wheat-flour. P., Landolphi's. See Landolphi. P., London, a mixture of equal parts of sodium hydrate and slaked lime, moistened with alcohol. P., Manec's. See Manec. P., Michel's, a caustic paste composed of three parts of strong sulphuric acid and one part of finely powdered asbestos. P., Socin's Antiseptic, a mixture of zinc chlorid one part, and zinc oxid and distilled water each ro parts. It is used as a dressing. P., Vienna, a mixture of potassium hydrate and caustic lime moistened with water. P., Ward's, a paste consisting of black pepper one part; root of Inula helenium, one part; white sugar, two 
parts; fennel-seed, three parts;: to which, before using, two parts of honey are added.

Pastern (pas'-tern) [OF., pasturon, a shackle for a horse at pasture]. That part of a horse's foot between the fetlock-joint and the coronet of the hoof. P.-bone, either of the two proximal phalanges of a borse's foot. P.-joint, the articulation between the proximal phalanx (great pastern-bone) of the horse's foot and the cannon-bone

Pasteur's Fluid or P.'s Liquid. An artificial liquid for the cultivation of bacteria. They flourish in it, but not so well as when proteid elements are also added. It is composed of water 100 parts, crystallized sugar Io parts, carbonate of ammonium and ashes of yeast, each, I part. P.'s Method. I. See Pasteurizing. 2. See Pasteurism. P., Microbe of. See Bacteria, Synonymatic Table of. P.'s Oven. See Oven.

Pasteuring (pas'-tur-ing) [after the French biologist, Louis Pasteur]. See Pasteurizing

Pasteurism (pas'-tur-izm) [after the French biologist, Louis Pasteur]. Prophylactic or protective inoculation; a synonym for the word vaccination.

Pasteurization (pas-tur-iz- $a^{\prime}-s h u n$ ) [after the French biologist, Louis Pasteur]. The preservation of organic fluids by the destruction of the contained ferments or fungi through heating to $60^{\circ}$ or $70^{\circ} \mathrm{C}$.

Pasteurize (pas'-tur-iz $z$ ) [after the French biologist, Louis Pasteur]. To sterilize fermentable fluids, as milk or cream, beer or wine, by heat

Pasteurizing ( $p a s^{\prime}-t u r-i-z i n g$ ) [after the French biologist, Louis Pasteur]. An important process employed for the preservation and protection of wine and other organic fluids against diseases. It consists in heating the substance, either in casks or in bottles, to a temperature of $60^{\circ} \mathrm{C}$., and then preserving it without exposure to the air.

Pastil, Pastille (pas'-til, pas-til') [dim. of pasta, paste or confection]. A lozenge or similarly shaped mass composed of aromatic substances and employed in fumigation. Also, a troche or tablet of medicinal substance.

Pastinaca (pas-tin-a'-kah) [pastinare, to dig]. A former genus of umbelliferous plants. P. sativa, the common parsnip, formerly used as a diuretic and as an antiperiodic. Unof.

Pastophor (pas'-to-for) [ [aotoфópos, a shrine-bearer: pl., Pastophori]. A priest-physician; a clan of priests in Ancient Egypt who united the calling of physician and priest. Thus the High Priest of Sais bore the title of Chief of the Doctors.

Pat [ME., patten, to strike]. To tap; to strike gently with the fingers.

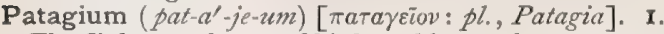
The flight-membrane of birds and bats; also a congenital malformation consisting in a fold of skin passing from the thigh to the leg. 2. In biology, the expansion of the skin of the trunk, limbs, and tail of flying mammals or reptiles. Cf. Ectopatagium, Dactylopatagium.

Patch (pach) [ME., pacche, patch]. An irregular spot or area. Ps., Drab-colored, a name given by Macnamara to certain areas occurring in the livers of persons who during life had been exposed to the influence of a tropical climate. They are thought to be due to a coagulative necrosis. 'P., Mucous. Same as Condyloma. Ps., Peyer's. See Glands, Peyer's.

Patchouly $\left(p a-c h o o^{\prime}-l e\right)$ [E. Ind.]. The labiate herb Pogostemon patchouly, of India, much used in the East as a perfume and insecticide. Unof.

Pate (pät) [ME., pate, the crown of the head]. The crown or top of the head.

Patella (pat-el'-ah) [dim. of patina, dish]. The kneepan or rotula. The small, round sesamoid bone in front of the knee, in the tendon of the quadriceps extensor femoris muscle.

Patellar (pat-el'-ar) [patella, dim. of patina, dish]. Pertaining to the patella or knee-cap. P. Clonus. Same as $P$. Reflex. P. Reflex, or P. Tendon-reflex. See Knee-jerk and Reflexes, Table of.

Patellate (pat-el'-ät) [patella, a patella]. Provided with a patella.

Patelliform (pat-ell-if-orm) [ patella, patella; forma, form]. Having the shape of a patella.

Patelline (pat'-el-in) [patella, patella]. Patelliform.

Patellula (pat-el'-u-lah) [dim. of patella, a pan: pl. Patellula]. In biology, applied to the suctorial fos sets on the lower surface of the tarsi of some insects.

Patellulate $\left(p a t-e l^{\prime}-u-l \bar{a} t\right)$. Same as Patellate.

Patency $\left(p a^{\prime}\right.$-ten-se) [patere, to stand open]. Openness (as of the foramen ovale in fetal life, and in some cases of cyanopathy).

Patent (pat'-ent, $p a^{\prime}$-tent) [patere, to be open]. Open, exposed. P. Glue. See Glue. P. Leather. See Leather. P. Lint. See Lint. P. Medicine. See Medicine. P. Yellow. Same as Cassel Vellow.

Pateriform (pat'-er-if-orm) [ patera, a flat dish; forma, form ]. In biology, saucer-shaped.

Pathema (path-e'-mah) [ $\pi a f \eta \mu \alpha ; \pi a ́ \theta o s$, disease]. Any disease or morbid condition.

Pathematology (path-em-at-ol'-o-je). Same as Pathology.

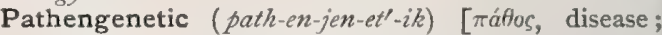
$\dot{\varepsilon} \gamma \gamma \varepsilon v \dot{n} s$, born in, native]. Induced by, or originating in, a disease. $P$. Disease, a disease arising from, or secondary to, another disease.

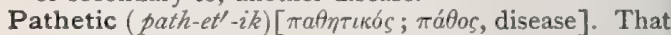
which appeals to or stirs the passions. P. Muscle. See Obliquus superior, in Muscles, Table of. P. Nerve. See Nerve.

Pathetism (path'-et-izm) [ [ádos, disease]. A generic term to express such conditions as hypnotism, telepathy, clairvoyance, etc.

Pathfinder (path'-fin-der) [ME., path, path ; ME., finden, to find]. An instrument for finding the openings of a urethral stricture.

Pathic ( $\left.p a t h^{\prime}-i k\right)$ [ $\pi a \theta \iota \kappa b \varsigma$, passive]. Diseased; pathologic; pertaining to a morbid condition. Also, one who tolerates the commission of an unnatural crime upon the person.

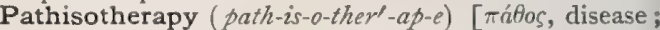
ions, equal ; $\theta \varepsilon \rho a \pi \varepsilon i a$, treatment]. Same as Isopathy.

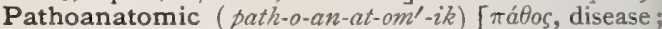
àvioú, a cutting up]. Pertaining to pathologic anatomy.

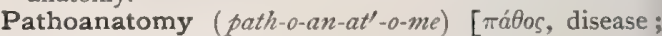
ávatouń, a cutting up]. Pathologic anatomy.

Pathobiologic (path-o-bi-o-loj'-ik). Same as Pathologic.

Pathobiologist (path-o-bi-ol'-o-jist). Same as Pathologist.

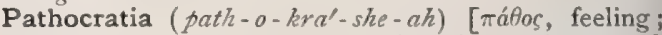
$\kappa \rho a \tau^{\prime} \varepsilon v$, to rule]. The control of the passions; selfrestraint.

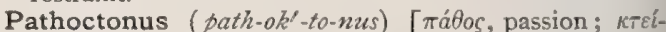
$v \varepsilon w$, to kill]. The killing of the appetites; selfrestraint.

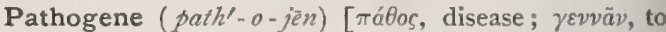
beget]. A disease-producing germ or principle.

Pathogenesis ( $\left.p a t h-o-j e n^{\prime}-e s-i s\right)$ [ $\pi a ́ \theta o s$, disease

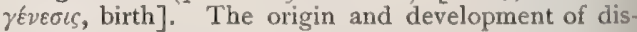
ease.

Pathogenic, Pathogenetic (path-o-jen'-ik, path-o-jen-

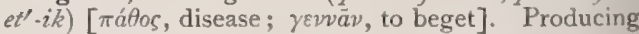
disease. P. Microörganism, any one of the various forms of microbic life which, when introduced into the system, causes disease. 


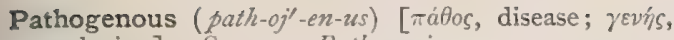
producing]. Same as Pathogrenic.

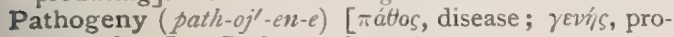
ducing]. See Pathogenesis.

Pathognomonic (path-og-no-mon'-ik) [ $\pi a ́ b o s$, disease; $\gamma \nu \omega, \mu \omega \nu$, judge]. Characteristic of a particular disease, distinguishing it from other diseases.

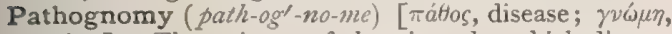
a sign]. The science of the signs by which disease is recognized.

Pathognostic (path-og-nos'-tik). Synonym of Pathognomonic.

Pathogony (path-og'-o-ne). Same as Prthogeny.

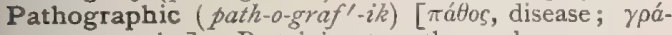
$\phi \varepsilon \iota v$, to write]. Pertaining to pathography.

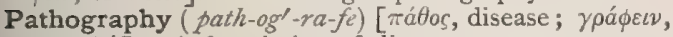
to write]. A description of diseases.

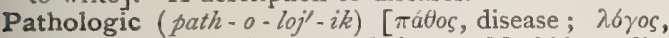
science]. Pertaining to pathology. Morbid or diseased. P. Anatomy. See Anatomy. P. Histology, the microscopic study of diseased tissues.

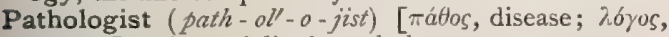
science]. A specialist in pathology.

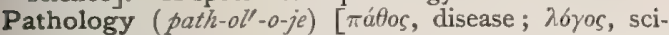
ence]. That branch of medical science which treats of the modifications of function and changes in structure caused by disease. It is divided, especially on the European continent, into P., External, or surgery, and $\mathbf{P}$., Internal, or medicine limited to diseases of internal organs. Of pathology in general three subdivisions are made-morbid anatomy, morbid physiology, and etiology. P., Cellular, pathology that makes the cell the basis of all vital phenomena, and teaches that every cell is derived from a pre-existing parentcell. P., Comparative, a study of pathologic processes in lower animals, for purposes of tracing resemblances and differences among them and between them and those of the human body. P., Experimental, the study of pathologic processes artificially induced in lower animals. P., General, that department of pathology which takes cognizance of those morbid processes that may be observed in various diseases and in any organ, e.g., inflammation and hypertrophy. P., Geographic, pathology in its relation to climatic and geographic conditions. P., Humoral, the old doctrine that all disease is due to abnormal conditions of the blood. It has been revived in recent times in a modified form, and is now based on the theory that both immunity and susceptibility to disease reside in the juices of the body. P., Medical. Synonym of $P_{\text {., Internal. P., Special, the science of such }}$ changes in function and structure as occur in special organs, e.g., pneumonia. P., Surgical. Synonym of P., External.

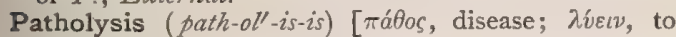
dissolve]. The dissolution of tissues or substances by the influence of disease.

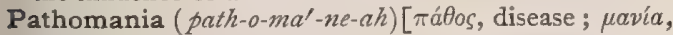
madness]. Moral insanity.

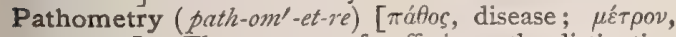
measure]. The measure of suffering; the distinction or diagnosis of different kinds of suffering.

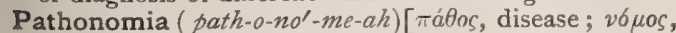
law]. The study of pathologic laws.

Pathopatridalgia (path-o-pat-rid-al'-je-ah) [ $[\pi \alpha$ áos, illness; $\pi \alpha \tau \rho i \zeta$, fatherland; ànyos, pain]. Nostalgia.

Pathopatridomania (path-o-pat-rid-o-ma'-ne-ah). Synonym of Nostromania.

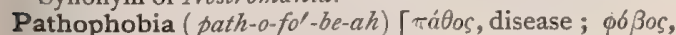
fear]. Exaggerated dread of disease.

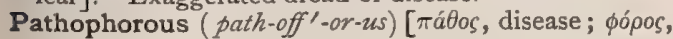
bear]. Pathogenic.

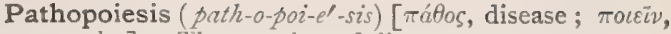
to make]. The creation of disease.

Patience ( $p a^{\prime}$-shens) [patientia]. A species of dock; Rumex patientia, of Europe, sparingly naturalized in N. America; is used in medicine (see Rumex) as an alterative and tonic. Unof.

Patient $\left(p \alpha^{\prime}\right.$-shent $)$ [pati, to suffer]. One who is under the care of a physician. A sick person.

Patten (pat'-en) [Fr., patin, a clog]. An iron support placed under a sound foot to remove pressure from and permit extension of the diseased limb in hip-joint disease.

Patterson's Powder. A mixture of bismuth subnitrate and magnesia.

Pattison's White Lead. See Pigments, Conspectus of.

Patulous ( $p a t^{\prime}-u$-lus) [ patere, to lie open]. In biology, spreading, gaping, open.

Pauci-articulate (paz-se-ar-tik'-u-lāt) [paucus, few ; articulatus, articulate]. In biology, having few joints.

Paucidentate (paw-sid-en'-tăt) [paucus, few; dens, tooth]. In biology, having few teeth.

Pauciflorous (paw-sif-lo'-rus) [ paucus, few; flos, flower]. In biology, having few Howers.

Paucifolious (pare-sif-o'-le-us) [ paucus, few ; folium, a leaf ]. In biology, having few leaves.

Paucinervate (paw-sin-er'-vāt) [paucus, few; nerva, nerve]. In biology, having few nerves.

Pauciradiate (pawe-se-ra'-de-ät) [paucus, few, little; radius, ray]. In biology, having few rays.

Paucispiral (paw-se-spi'-ral) [ paucus, few ; spira, a fold, coil]. In biology, having few spirals, whorls, or turns.

Paul's Sign. See Signs and Symptoms, Table of.

Paullinia (parv-lin'-e-ah). See Guarana.

Paunch (parench) [ME., paunche, paunch]. The abdominal cavity and its contents. In comparative anatomy, the largest stomach of cud-chewing animals. See Farding-bag.

Pausimenia (pare-sin-e'-ne-ah). See Menopause.

Pavasi's (Carlo) Method. A method of masking the taste of cod-liver oil : IOOo parts of the oil, 50 parts of ground coffee, and 25 parts of animal charcoal are placed in a flask and heated for an hour over a waterbath. The mixture is then set aside in a cool place, and stirred occasionally for three days, when the oil is filtered off and is ready for use.

Pavement ( $\left.p \bar{a} v^{\prime}-m e n t\right)$ [pavimentum, a pavement] A floor or paved structure; a formation like pave ment. P. Epithelium. See Epithelium.

Pavilion (pa-vil'yon) [pavilio, a canopy]. A name sometimes given to the expanded portion of a canal or tube; the outer ear; the pinna or auricle of the ear. P. of Oviduct, P. of the Tube, the fimbriæ or fringe-like process of the outer extremity of the oviduct; the center of the ovarian extremity of the oviduct; the morsus diaboli.

Pavimentum (pav-im-en'-tum) [L.]. A floor. P. orbitæ, the floor of the orbit. P. ventriculi, the floor of a ventricle.

Pavitation (pav-it-a'-shun) [pavitatio; pavere, to quake]. Terror, or fear, with trembling.

Pavor $\left(p a^{\prime}-v r^{\prime}\right)$ [L.]. Fright; fear. P. nocturnus. See Night-mare and Night-terrors.

Pavy's Disease. Intermitting or recurrent albuminuria. See Diseases, Table of. P.'s Test, a test for grape-sugar. It consists in the use of ammonia instead of caustic alkali in Fehling's solution. See Tests, Table of.

Paxton's Disease. See Tinea nodosa, Morbus paxtonii, and Diseases, Table of.

Paxwax (paks'-waks) [ME.]. The ligamentum nuchæ in the larger quadrupeds. See Faxwax. 
Payne's Treatment. See Treatment, Method's of. Paytin $\left(p a^{\prime}-i t-i n\right)$ [S.A., Payta], $\mathrm{C}_{21} \mathrm{H}_{24} \mathrm{~N}_{2} \mathrm{O}+\mathrm{H}_{2} \mathrm{O}$. An alkaloid of one of the cinchona barks

Peach (pech) [ME., peche, peach]. The rosaceous tree or shrub, Amygdalus persica, and its valuable fruit. The kernels of the seed are a good substitute for bitter almonds; the decoction of the leaves is laxative and anthelmintic, as well as sedative. Peach-brandy is distilled from the fruit. Unof. P.-black. See Pigments, Conspectus of. P.-brandy, a liquor distilled from peaches. P.-cold. See Hay-fever, and Rhinitis, Hyperesthetic. P.-fever, a morbid condition of the respiratory and cutaneous surfaces, with some consequent systemic disturbances, due to irritation from the pubescence of the skin of the common peach, the Amygdalus persica. It is tolerably frequent among persons employed in the fruit-packing and canning establishments of Maryland and Delaware. The Schneiderian membrane becomes turgid; then follows a copious discharge of serum and mucus; the frontal sinuses, the conjunctivæ, and the larger bronchi also become the seat of catarrh, and asthmatic attacks may be induced. A macular or papular eruption comes out on the wrists, forearms, neck, and forehead; the cutaneous affection may go on to true dermatitis, and the lesions may become pustules. Anderson believes the source of irritation to be some germ whose habitat is the "fuzz" of the peach.

Peacock-sound ( $p e^{\prime}-k \circ k$-sownd). A peculiar sound of the voice supposed to be the result of too close adaptation of the posterior half arches (palato-pharyngeal folds) of the fauces, but according to Harrison Allen due to a faulty method of breathing, neglected catarrh, or a growth in the upper air-passages.

Péan's Operation. See Operations, Table of.

Peanut (pe'-nut) [ME., pease; ME., nutte, nut]. An edible fruit of Arachis hypogaa. P.-oil. See Ground-nut Oil.

Pear [ME., pere, pear]. The tree Pyrus communis, and its fruit. P.-oil, a dilute alcoholic solution of the acetic ester of the amyl alcohol of fermentation; it is used in flavoring, cookery, and in candies.

Pearl (perl) [ME., perle, a pearl]. I. In pharmacy, a small, glass globular body completely filled with liquid medicine. 2. A cataract; an opacity growing on the eye. 3. A peculiar arrangement of the epithelial cells. P.-barley. See Barley. P. Disease, a name for tuberculosis of serous membranes in the lower animals, especially cattle, given to it on account of the most manifest lesion, the pearly nodules or tumors, which are often pendulous. P., Epidermic, P., Epithelial, one of the spheroid concentric masses of epithelial cells often seen in hard papillomata, in squamous epitheliomata and in cholesteatomata; they are also called pearly bodies. See Cell-nests. P.-eye, afflicted with cataract; an opacity of the crystalline lens of the eye. P. Tumor. Synonym of Cholesteatoma. P.-white. Same as Bismuth-rehite and White Lead.

Pearly (perl'-e) [ME., perle, a pearl]. Resembling a pearl; nacreous; clear; translucent. P. Bodies. See Pearls, Epithelial. P. Sputa, a term given by Laennec to the transparent, tough, tenacious masses of mucus of the size of a pea, or smaller, expectorated in the chronic bronchitis of old people, occurring during cold weather. P. Tubercle. See Grutum.

Pearson's Solution. See Arsenic.

Peaslee's Formula. See Alimentation, Rectal.

Peat $(p e t)$ [ME., pete, peat]. The product of the spontaneous decomposition (decay) of plants, especially swamp-plants, in many cases mixed with sand, loam, clay, lime, iron pyrites, ocher, etc. It is largely employed for fuel in some portions of the world, and is extensively used in some countries in mud-baths and for poultices.

Pébrine (peb'-rin) [Fr.]. Syn., gattina, Ital.; gattine, Fr. ; petechia, maladie des corpuscles, maladie des petites, etisie, maladie corpusculeuse. An infectious epidemic disease which has frequently devastated the silkworm establishments (magnanneries) of Europe. The silkworms become infested with Microsporidia (corpuscules de Cornalia, corpuscules vibrants), which have been variously regarded as bacteria, hematozoa, unicellular algae, spores of higher fungi, or "s organites." Cf., Microbe of Pébrine, under Bacteria, Synonymatic Table of, and Microsporidia.

Pebrinous (peb'-rin-us) [Fr., pébrine, pébrine]. Affected with pébrine.

Peccant (pek'-ant) [peccare, to sin]. Pathogenic; morbid; unhealthy; offensive.

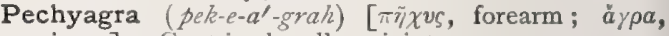
seizure]. Gout in the elbow-joint.

Pechytyrbe (pek-it-er'-be). Synonym of Scurvy.

Pecklin, Glands of. See Gland.

Pecquet, Cistern of. The receptaculum chyli. P., Duct of. See Duct. P., Reservoir of. See P., Cistern of.

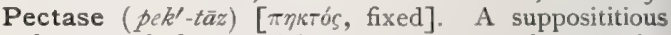
ferment of plants which converts pectose into pectin.

Pecten (pek'-ten) [pecten, a comb: pl., Pectines]. The os pubis. In biology, a comb-like structure or organ.

Pectic (pek'-tik) [ $[\pi \eta \kappa \tau o ́ s$, fixed]. Concealing, curdling. P. Acid, $\mathrm{C}_{32} \mathrm{H}_{48} \mathrm{O}_{32}$, a gelatinous substance obtained when pectin is treated with an alkali and acid successively.

Pectin, Pectine (pek'-tin) [ $\pi \eta \kappa \tau \iota k \delta \zeta$, congealing, curdling]. One of a series of vegetable bodies found combined with lime in fleshy fruits and roots; and also in bark, stems and leaves. According to Braconnot, it is present in all plants. It forms the basis of vegetable jelly. Cf. pectase, pectose, parapectin, metapectin, pectosinic acid, pectinic acid, metapectinic acid, pectinose, arabinose.

Pectinal (pek'-tin-al) [pecten, a comh]. Comb-like.

Pectinate (pek'-tin-ät) [pecten, a comb]. In biology, comb-like; arranged like the teeth of a comb. P. Antenna, in biology, an antenna that resembles a comb, due to a linear projection of each joint on the inner side. P. Ligament, fibers of connective tissue at the angle of the anterior chamber of the eye, between the iris and the cornea. P. Muscles, the musculi pectinati of the heart. P. Zone, the upper surface of the basilar membrane external to Corti's organ.

Pectination (pek-tin- $a^{\prime}-\operatorname{shun}$ ) [pecten, a comb]. In biology: $(a)$ the state of being pectinate; $(b)$ a pecten or comb-like structure.

Pectinato-fimbricate (pek-tin- $\left.a^{\prime}-t o-f i m^{\prime}-b r i k-\bar{t}\right)$ [pecten, a comb; fimbria, a fringe]. In biology, having the pectinations fringed.

Pectineal (pek-tin-é-al) [pecten, a comb]. Pectinal or pectinate. P. Crest. Same as P. Line. P. Fascia, the fascia covering the pectineus and adductor longus muscles. P. Line, a linear prominence on the os innominatum. The same as the ileopectineal line. See Lines, Table of. P. Ridge. Same as $P$. Line.

Pectinella (pek-tin-el'-ah) [dim. of pecten, a comb: pl., Pectinella]. In biology, a pectinated appendage of the protomala of myriapods.

Pectineus (pek-tin-e'-us). See Muscles, Table of.

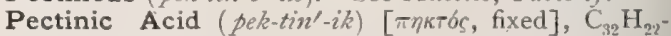
$\mathrm{O}_{30}$, or $\mathrm{C}_{32} \mathrm{H}_{28} \mathrm{O}_{28}$. This equals $4 \mathrm{C}_{8} \mathrm{H}_{5} \mathrm{O}_{3}$, according to Fremy ; $\mathrm{C}_{28} \mathrm{H}_{20} \mathrm{O}_{26}$, according to Chodnew. It is a colorless, transparent jelly, drying up to a horny mass, insoluble in cold water, scarcely soluble in warm water, insoluble in alcohol and ether. 
Pectiniform (pek-tin'-if-orm) [ pecten, a comb ; forma, a form]. Having the form of or resembling a comb. Fimbriated or serrated. P. Septum. See Septum.

Pectinose ( $\left.p e k^{\prime}-t i n-\bar{o} z\right)$. Same as Arabinose.

Pectize ( $\left.p e k^{\prime}-t i z\right)$ [ $\pi \eta \kappa \tau b s$, fixed, congealed]. In biology, to congeal or form jelly. Cf. Pectin.

Pecto-antibrachialis ( $\left.p e k^{\prime}-t o-a n-t e-b r a-k e-a^{\prime}-l i s\right)$ [pectus, breast; antibrachium, the forearm]. In biology, a muscle extending from the sternum to the elbow of certain animals.

Pectocaulis (pek-to-kare'-lis) [pecten, comb; caulis, stem: pl.. Pectocauli]. In biology, the common stalk of the polypides of a polyzoary.

Pectoral (pek'-to-ral) [pectus, breast]. Pertaining to the breast. Of a medicine, useful in diseases of the respiratory tract. P. Fin, the thoraciclimb of a fish. P. Fremitus, vocal fremitus of the chest. P. Glands, lymph-glands along the lower border of the pectoralis major muscle. P. Laminæ, the basal joints of the legs. P. Limb, the anterior or upper limb of a vertebrate animal. P. Muscles. See Muscles, Table of. P. Nerves, the cutaneous branches of the thoracic intercostal nerves. P. Ridge, the anterior or external bicipital ridge of the humerus. P. Species. See Breasttea. $\mathbf{P}$. Tubercle, the impression on the anterior surface of the clavicle for the attachment of the pectoralis major muscle.

Pectoralgia (pek-tor-all-je-ah) [pectus, breast; ànyos, pain]. Neuralgic pain in the breast.

Pectoralis (pek-tor-a'-lis). See Muscles, Table of.

Pectoriloquism (pek-tor-il'-o-kwizm). Same as Pectoriloquy".

Pectoriloquy (pek-tor-ill-o-kwe) [pectus, breast; loqui, to speak]. The distinct transmission of articulate speech to the ear on auscultation. It may be heard over cavities in the lung, over areas of consolidation near a large bronchus, over a pneumothorax when the opening in the lung is patulous; over some pleural effusions. P., Whispering, the transmission of the whispered words to the auscultating ear. The sounds seem to emanate directly from the spot auscultated.

Pectorophony (pek-tor-off'-o-ne) [pectus, breast ; $\phi \omega \nu \eta ́$, sound]. Exaggerated vocal resonance, as heard in auscultating the chest.

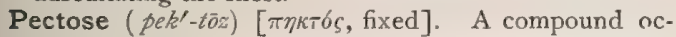
curring in fruits, intermediate between starch and glucose. Its exact composition is not known. Heat and other reagents change it into pectin.

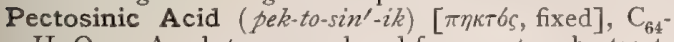
$\mathrm{H}_{46} \mathrm{O}_{62}$. A substance produced from pectose by treatment with dilute watery alkalies. It is amorphous and of an acid reaction, insoluble in cold dilute acids, scarcely soluble in cold water, but easily soluble in warm water. Its salts are jelly-like and amorphous, and soluble in warm dilute acids.

Pectous (pek'-tus) [ $\pi \eta \kappa \tau o ́ s$, fixed, congealed]. In biology, consisting of one or more pectin bodies.

Pectunculate (pek-tung'-ku-lät) [ pectunculus, a little comb]. In biology, furnished with a comb-like arrangement of minute spines or bristles.

Pectunculi (pek-tunk'-u-li) [pecten, comb]. Plural of Pectunculus. Longitudinal striations in the walls of the Sylvian aqueduct.

Pectus (pek'-tus) [pectus, breast: pl., Pectora]. That part of the body between the neck and the abdomen. In biology, the chest, breast, lower surface of the thorax or pectoral region. P. carinatum. Same as Pigeon-breast. P. gallinatum. Same as Chickenbreast. P. gallinaceum. See Chicken-breast.

Pedal ( $\left.p e^{\prime}-d a l\right)$ [pes, pedis, foot]. Pertaining to the foot.

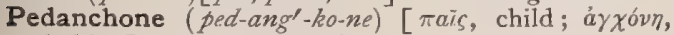
choking]. A synonym of Cynanche maligna.

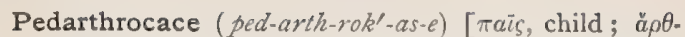
$\rho o \nu$, a joint; kakós, evil]. A necrotic ulceration or caries of the joints of children. The same as Osteophthoria.

Pedate $\left(p e d^{\prime}-\bar{a} t\right)$ [pes, foot]. In biology, resembling a foot in form or arrangement.

Pedatifid (ped-at'-if-id) [pedatus, furnished with feet; findere, to divide, cleave]. In biology, pedately divided or cleft about half-way to the base.

Pedatinerved (ped-at'-in-ervd) [pedatus, furnished with feet; nervus, nerve]. In biology, applied to leaves having no mid-rib, but supplied with two strong lateral nerves, which give rise to others extending toward the apex; pedately veined.

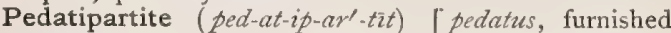
with feet; partire, to part]. In biology, pedately lobed or cleft, with the sinuses extending about halfway to the base.

Pedatisect (ped-at'-is-ekt) [pedatus, furnished with feet; secare, to cut]. In biology, pedately cleft or parted; having the cleft reaching nearly to the mid-rib or base.

Pedatrophia, Pedatrophy (ped-at-ro'-fe-ah, ped-at'-ro$f e)[\pi a i s$, child; $\dot{a} \tau \rho o \phi i ́ a$, atrophy]. I. Any wasting disease of childhood. 2. Synonym of Tabes mesenterica, or Intestinal Catary of Children.

Pederastia, Pederasty (ped-er-as'-te-ah, ped'-er-as-te)

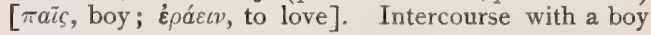
per anum.

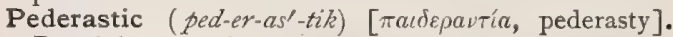
Pertaining to pederasty.

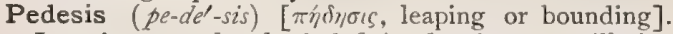
Jevon's name for the indefinite dancing or oscillating motion of the particles of any substance sufficiently powdered and suspended in a suitable liquid. It is a purely physical phenomenon probably due to the fact that the particles are in very delicate equilibrium and hence extremely sensitive to the slightest change of temperature. It is with less propriety termed Molecular Movement, Brownian Movement, and Titubation.

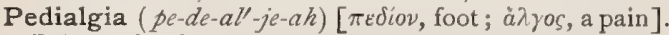
Pain in the foot.

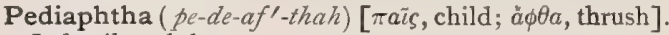
Infantile aphtha.

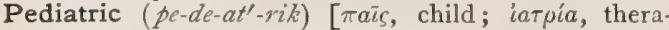
peutics]. Pertaining to pediatrics.

Pediatrics (pe-de-at'-riks) [ $\pi a \bar{s} s$, child; iatoía, therapeutics]. The treatment of the diseases of children.

Pediatry $\left(p e^{\prime}-d e-a t-r e\right)$. See Pediatrics.

Pedicel (ped'-is-el) [pediculus, dim. of pes, a foot]. In biology : $(a)$ a branch of a flower-cluster supporting one or more flowers ; $(b)$ any little foot, foot-stalk, or foot-like organ. P.-cell, in biology, a cell acting as a foot-stalk to some organ; as the flask-shaped cell which supports the antheridium in the Characea.

Pedicellaria (ped-is-el-a'-re-ah) [pedicellus, a pedicel : pl., Pedicellaria]. In biology, one of the tactile organs of the echinoderm, serving to keep off parasites, to retain protective substances (sea-weeds, etc.), and as organs of attachment or aids to locomotion.

Pedicellate (ped-is-el'-ät) [pedicellus, a pedicel]. In biology, having a pedicel.

Pedicellus (ped-is-el'-us) [dim. of pediculus, a little foot: pl., Pedicelli]. In biology: (a) a pedicel; (b) the third joint of the antenna of an insect.

Pedicle (ped'-ik-l) [pediculus, a little foot]. In biology : $(a)$ the stalk of a flower-cluster, whether supporting one flower or more; $(b)$ the bony process giving support to the antlers of a deer: (c) the foot of the neural arch of a vertebra. In pathology, the narrow part of a tumor or morbid growth by which it is attached or which supports it. P. of Invagination, a 
group of cells supporting the hypoblast in a stage of development of certain molluscs (Pisidium), and which subsequently develops into the rectum; the rectal peduncle. P. of a Vertebra, the portion of a vertebra that projects dorsad from the body on each side

Pedicular (ped-ik-u-lar) [from pediculus, dim. of pes, a foot]. Pertaining to a pedicle or little foot-stalk. Peduncular.

Pediculation (ped-ik'-u-la'-shun) [pediculus, dim. of pes, foot]. The state of being lousy.

Pedicule $\left(p e d^{\prime}-i k-\bar{u} l\right)$ [pediculus, a little foot]. In biology, a pedicel, pedicle, or peduncle.

Pediculi (pe-dik'-u-li) [L.]. Plural of Pediculus, $q . v$.

Pediculodermata (pe-dik-u-lo-der'-mat-ah) [pediculus, louse; $\delta \dot{\varepsilon} \rho a$, skin]. The skin-lesion produced by lice.

Pediculophobia (pe-dik-u-lo-fo'-be-ah) [pediculus, louse; $\phi \sigma \beta o s, f e a r]$. Morbid dread of lousiness.

Pediculosis (pe-dik-u-lo'-sis) [pediculus, louse]. Phthiriasis; lousiness; a contagious animal parasitic skin-affection characterized by the presence of pediculi, which occasion peculiar lesions, scratch-marks, and excoriations, accompanied with itching. See Pediculus and Phthiriasis, under Parasites (Animal), Table of.

Pediculus (pe-dik'-u-lus) [pediculus, a louse]. A small parasitic hemipterous insect. See under Parasites (Animal), Table of.

Pedicure (ped'-ik-ür) [pes, foot; cura, care]. A chiropodist; also the care of the feet.

Pediferous (ped-if'-er-us) [pes, foot; ferre, to bear]. Having feet.

Pediform (ped'-if-orm) [pes, foot; forma, form]. In biology, foot-shaped.

Pedigerous (ped-ij'-er-us) [pes, foot; gerere, to bear]. Bearing feet; pediferous.

Pedigree (ped'-ig-re) [possibly from Fr. pied de grue, a crane's foot, from the irregular lines on charts of descent]. An account of genealogy or descent.

Pediluvium (ped-il-u'-ve-um) [pes, foot; lavare, to wash]. A foot-bath.

Pedimana (ped-im'-an-ah) [ pes, foot; manus, hand]. A family of mammals represented by the marsupials, which have the fore limbs so constructed as to serve either as hands or as feet.

Pedimanous (ped-im'-an-us) [pes, foot; manus, hand]. In biology, having hand-like feet.

Pediocle (ped"-e-o-kl) [pes, foot; oculus, eye]. A stalk-eyed crustacean.

Pediococcus (ped-e-o-kok'-us) [pes, a foot; ко́ккоৎ, a berry]. A term formerly given to a genus of micrococci.

Pedion (pe'-de-on) [ $\pi \varepsilon \delta i o v$, sole $]$. Sole of the foot.

Pedion, Pedium ( $\left.p e^{\prime}-d e-o n, p e^{\prime}-d e-u m\right)$ [ $\pi \alpha i \check{s}$, child]. A child; also, a fetus.

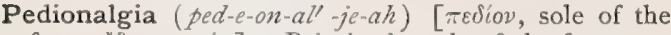
foot; àyos, pain ]. Pain in the sole of the foot.

Pedipalp (ped'-ip-alp) [pes, foot; palpus, feeler]. In biology, a maxillary palpus, so modified as to serve as an efficient limb, tactile or prehensile organ, as in scorpions, chelifers, etc.

Pedipalpous (ped-ip-al'-pus) [pes, foot; palpare, to feel]. Having pedipalps.

Pedipalpus (ped-ip-al'-pus) [ pes, a foot; palpare, to touch: pl., Pedipalpi]. A pedipalp.

Peditis (pe-di'-tis) [pes, foot; $t \tau \iota s$, inflammation]. Williams' term for the serious complication of laminitis of the horse's foot, in which not only the laminæ, but the periosteum and the coffin-bone also, are involved in the inflammatory process.

Pedodynamometer (ped-o-di-nam-om'-et-er $)[$ pes, foot;

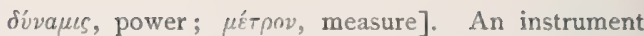
intended to measure the muscular strength of the leg.

Pedogenesis, Pædogenesis (pe-do-jen'-es-is) [ [aic,

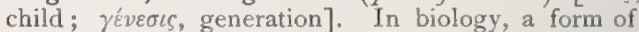
heterogeny, in which an imaginal generation reproducing sexually by means of fertilized eggs alternates with several generations of parthenogenetically reproducing viviparous-larvæ (e.g., in Cecidomyia).

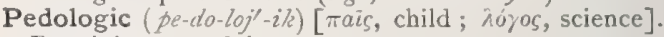
Pertaining to pedology

Pedology (pe-dol'-o-je) [rais, child; $\lambda \sigma \gamma o s$, science]. The science, or sum of knowledge, regarding child. hood, its diseases, hygiene, etc.

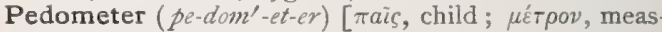
ure]. An instrument for determining the weight and height of a new-born child.

Pedometer (ped-om'-et-er) [pes, foot; $\mu$ éroov, a measure]. An instrument for automatically measuring any distance traveled. As formerly constructed, it registered the number of footsteps.

Pedometry (pe-dom'-et-re) [ $\pi a \tilde{s} s$, a child, or pes, foot : $\mu \varepsilon \tilde{r}$ pov, measure]. I. The measurement of the newborn child. 2. The use of the pedometer.

Pedomorphism (pe-do-morf'-izm) [ $\pi a i s(\pi a i \delta-)$, child ; $\mu \rho \rho \phi \eta$, form]. In biology, Harrison Allen's term for the disposition occasionally exhibited in adult animals for the proportions of different parts of the body to remain as they were in the immature individuals, not due to arrest of growth, but to the fact that certain parts preserve the peculiarities of the young.

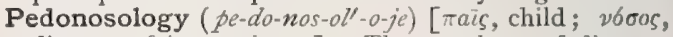
disease; $\lambda$ ó $0 s$, science]. The nosology of diseases peculiar to infancy and childhood. Pediatrics.

Pedonosos, Pedonosus (pe-don'-o-sos, pe-don'-o-sus) [ $\pi$ ris, child; vбoos, disease]. A disease of childhood.

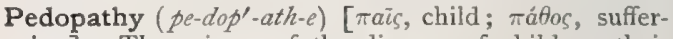
ing]. The science of the diseases of children, their treatment, etc.

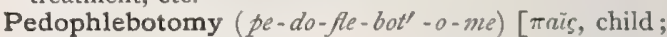

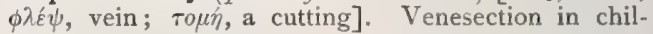
dren.

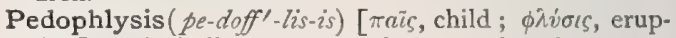
tion]. A bullous or pustular eruption in young children.

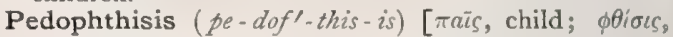
wasting]. Tabetic or other wasting disease of children.

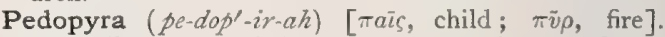
A febrile disease of children. P. americana. Synonym of Cholera infantum.

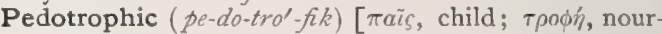
ishment]. Pertaining to the rearing of children.

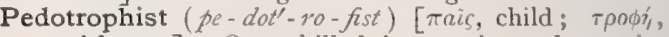
nourishment]. One skilled in, or devoted to, the rearing of children.

Pedotrophium (pe-do-tro'-fe-um) [mais, child; $\tau \rho \varepsilon \dot{\phi} \varepsilon \nu \nu$, to nourish]. A foundling hospital, or one for orphan children.

Pedotrophy ( $\left.p e-d o t^{\prime}-r o-f e\right)[\pi a \bar{s}$, child ; $\tau \rho o \phi \dot{n}$, nourish ment]. The hygiene of childhood; the care, nursing; and regimen of children.

Peduncle ( $\left.p e^{\prime}-d u n g-k l\right)$ [pedunculus, a little foot]. In biology, a foot-stalk, or foot-like part, a pedicel of pedicle, the stalk of a flower-cluster, of a barnacle, or of any organ. In anatomy, any supporting part. P., Anterior Cerebellar. Synonym of $P$., Superior Cerebella". P. of the Cerebellum. See $P$., Inferior, Middle, and Superior Cerehellar. P., Cerebral. Synonym of Crus cerebri. $\mathbf{P}$. of the Cerebrum, the crus cerebri. P. of the Corpus callosum, the 
anterior perforated space. P., Inferior Cerebellar, one of the two bands of white matter passing up from the oblongata, a continuation of the restiform bodies, and connecting the medulla with the cerebellum. It forms the lower lateral wall of the fourth ventricle. P., Middle Cerebellar, one of the bands of white matter joining the pons and the cerebellum. P., Olivary, a band of fibers passing from the olivary nucleus to the lemniscus and the tegmentum. $\mathbf{P}$. of the Pineal Gland, a delicate white band passing forward from each side of the pineal gland along the edge of the third ventricle. P. Posterior Cerebellar. Synonym of $P$., Inferior Cerebellar. P., of the Spinal Cord, the inferior cerebellar peduncle. P. Superior Cerebellar, one of the two bands of white matter that pass from the cerebellum to the testes of the corpora quadrigemina. P., Transverse. Synonym of $P$., Middle Cerebellar.

Peduncled ( $p e^{\prime}$-dung-kld) [pedunculus, a little foot]. Furnished with a peduncle; pedunculate.

Peduncular (pe-dung'-ku-lar) [pedunculus; dim. of pes, foot]. Pertaining to a peduncle.

Pedunculate, Pedunculated ( $p e-d u n g^{\prime}-k u$ - latt, pedung-ku-la-ted) [pedunculus, dim. of pes, foot]. Having a peduncle; stalked.

Pedunculus (pe-dung'-ku-lus). Same as Peduncle.

Peeling ( $\left.p \bar{e} l^{\prime}-i n g\right)$ [pellis, skin]. A term applied to the process of desquamation, as in scarlet fever.

Peenash ( $p e^{\prime}$-nash $)$ [E. Ind.]. The Eastern name for myiosis, produced by Lucitia macellaria. See Parasites (Animal), Table of.

Peeosyne (pe-e-as'-in-e). Synonym of Therapeutics.

Peg [ME., pegge, a spike]. I. A pointed pin of wood, metal, or other material. 2. A wooden leg. P.-leg, a wooden leg of the simplest form. P.-teeth, a name given by Hutchinson to the teeth of children with hereditary syphilis, from the peg-like appearance of the crowns.

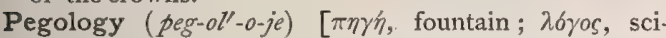
ence]. The science of medicinal springs; balneology.

Peinotherapy ( $\left.p i-n o-t h e \gamma^{\prime}-a p-e\right)[\pi \varepsilon i v a$, hunger; $\theta \varepsilon \rho \alpha-$ $\pi \varepsilon v \varepsilon \iota \nu$, to heal $]$. The cure of disease by the deprivation of food; hunger-cure ; limotherapy.

Pelada (pel'-a-dah) [Fr.]. Alopecia of the scalp; also syphilitic alopecia.

Pelade (pel-ahd')[Fr.]. A synonym of Alopecia areata or Area celsi

Pelage (pel-ahj') [Fr.; $\pi \hat{\varepsilon} \lambda \lambda \alpha$, the hair]. In biology, the hairy system of the body as a whole. The hair, wool, or fur of a mammal.

Pelagian (pel-a'-je-an) [ $\tilde{\varepsilon}^{\prime} \lambda a \gamma o s$, the sea]. Inhabiting the deep sea.

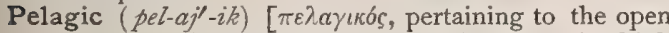
sea; from $\pi \varepsilon \lambda_{a \gamma o s}$, the sea]. Inhabiting the high seas, the deep or open ocean, as contrasted with limnetic, or fresh-water inhabitants or the littoral marine fauna and flora. Cf. Allopelagic, Autopelagic, Bathyplaric, Chimopelagic, Eupelagic, Nyctipelagic, Spanipelagic, under Plankton. P. Fauna and Flora, the animals and plants (passively floating or actively swimming) which remain at the surface of the sea and never leave it, or only for a short time descend to a slight depth. Among such true pelagic animals are the Radiolaria, Peridinia, Noctiluca, Medusa, Siphonophora, Ctenophora, Sagitta, Pteropoda, Heteropoda, a greater part of the Crustacea, the larvæ of Echinodermata, of many Vermes, etc. P. Tow-stuff, the small organisms obtained by towing nets at sea.

Pelargonic Acid (pel-ar-gon'-ik) [ $\pi \varepsilon \lambda n \rho y o ́ s$, a stork], $\mathrm{C}_{4} \mathrm{H}_{18} \mathrm{O}_{2}$. A monobasic crystalline acid obtained from the essential oil of Pelargonium roseum and from other oils. It is employed in the flavoring of wines. see Acid.

Pelargonium (pel-ar-go'-ne-um) [ $\pi \varepsilon \lambda a \rho \gamma \sigma s$, a stork]. A genus of the Pelargonice or stork's-bills, indigenous in Africa and India and cultivated in Europe and America. Several species have medicinal properties. $P$. anceps is an emmenagogue. P. antidysentericum, is used in dysentery. $\mathbf{P}$. roseum, the rosegeranium, contains an oil from which pelargonic acid is obtained. Unof.

Pelican (pell-ik-an) [ $\pi \varepsilon \lambda \varepsilon \kappa a \tilde{\nu}$, to hew with an ax $]$. An old variety of forceps, or key, for the extraction of teeth. In chemistry, a glass vessel for continued distillation.

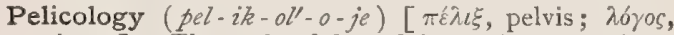
science]. The study of the pelvis and its proportions.

Pelicometer (pel-ik-om'-et-er). Synonym of Pelvimeter.

Pelidnephidrosis (pel-id'nef-id-ro'-sis) [ $\pi \varepsilon \lambda \iota \delta \nu \sigma s$,

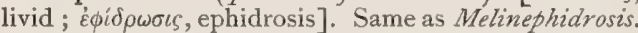

Pelidnoma (pel-id no'-mah). Synonym of Ecchymosis.

Pelidnus (pel-id'-nus) [ $\pi \varepsilon \lambda \iota \delta \nu o ́ s$, livid]. A leadencolored condition of the skin.

Pelioma (pel-e-ó-mah) [ $\pi \varepsilon \lambda i \omega \mu \alpha$, a livid spot: $p l$. Peliomata]. A livid spot, as seen in peliosis, P. typhosum. See Taches bleuatres.

Peliosis (pel-e-o'-sis) [ $\pi \varepsilon \lambda \iota \iota^{\prime} s$, livid]. A livid condition of the skin due to extravasation of blood. P. pemphigoides. See $P$, rheumatica. P. rheumatica, Purpura rheumatica; an acute purpuric skin-disease, more common in persons from fifteen to thirty years old, and characterized by the presence of non-elevated or slightly elevated spots, from the size of a pin's head to a lentil, of a deep-red color, which do not disappear on pressure, and soon become dark-purple. They are usually seen on the legs and feet, often clustered around painful joints; they are also found on the hands and arms, and very rarely on the trunk and face. At times erythematous or urticarial rashes ( $P$. urticans) are present on other parts of the body, and more rarely vesication occurs ( $P$, pemphigoides). $P$. senilis, the minute hemorrhages into the skin seen in marantic senile persons. P. urticans. See $P$. rhemmatica.

Pellada $\left(p e l-a^{\prime}-d a h\right)$. See Pelaile.

Pellagra (pel-a'-grah) [It., pelle, skin ; agra, rough ; or

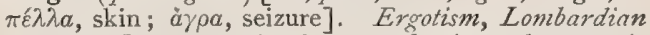
Leprosy, Lepra asturiensis; an endemic trophoneurotic skin disease occurring among the squalid and destitute, due to chronic poisoning with diseased or fermented maize, and affecting chiefly the cerebro-spinal and digestive systems. It usually occurs in those between thirty and fifty years of age. It always begins in spring, and the lesion appears on the parts of the body exposed to the air and light (face, neck, back of hands, and feet). It consists of an intense, rapidly-extending erythema, bright-red, livid or brown in color, with much swelling, and causing violent burning or itching. The spreading edge of the patches is much elevated and generally darker than the central portion. There are marked nervous and general symptoms, insanity, mania, or melancholia being common. P. sine pellagra, [L., pellagra without pellagra]. Pellagra without cutaneous eruption.

Pellagracein (pel-a-gra'-se-in) [It., pelle, skin ; agra, rough; or $\pi \dot{\varepsilon} \lambda \lambda a$, skin ; à $\gamma \rho r$, seizure]. A name given by Lombroso to a poisonous substance found in decomposed corn-meal ; it is probably a mixture of poisonous ptomains, some of which induce narcosis and paralysis; other symptoms are like those of nicotinpoisoning.

Pellagrin (pel'-a-grin) [It., pella, skin; agra, rough; or $\pi \dot{\varepsilon} \lambda \lambda \alpha$, skin; ă $\gamma \rho \alpha$, seizure]. One who is afflicted with pellagra. 


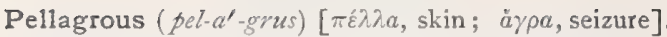
Affected with pellagra; pertaining to pellagra.

Pellet (pel'-et) [pila, ball]. A small pill or tablet.

Pelletierin (pel-et'-e-er-in) [after Bertrand Pelletier, a French chemist, $\mathbf{1 7 6 1 - 9 7 ]}, \mathrm{C}_{8} \mathrm{H}_{13} \mathrm{NO}$. An aromatic oily alkaloid from pomegranate-bark. Its tannate is an effective teniafuge. Dose $1 / 2$ to $\mathbf{I}$ gr., followed by a purgative. Pelletierin is actively poisonous, causing weakness of the legs. Unof

Pellibranchiate (pel-ib-rnng'-ke-ät) [pellis, skin; branchice, gills]. In biology, breathing by means of the skin.

Pellicle ( $\left.p e l^{\prime}-i k-l\right)$ [pellis, skin]. I. A thin membrane, film, scum, or cuticle. 2. The cortical layer of plants. P., Medicated, a medicamentous layer or film left on the skin by the evaporation of collodion which is charged with some drug.

Pellicula (pel-ik'-u-lah) [pellicula, a small skin]. In biology, the cortical layer of a plant, as in lichens and some fleshy fungi.

Pellicular (pel-ik'-u-lar) [pellicula, dim. of pellis, skin]. Of the nature of, or resembling a pellicle; thin-skinned.

Pelliculate (pel-ik'-u-lāt') [pellicula, a small skin]. Covered with a pellicle.

Pellis $\left(p e l^{\prime}-i s\right)[\mathrm{L}$.$] . The skin.$

Pellitory (pel'-it-or-e) [ME., pelleter, pellitory]. See Pyrethrum. P., Persian. See Pyrethrum roseum. See also Parietaria. P., American, Parietaria pennsylvanica.

Pellous (pel'-us) [pellis, skin]. Dark-skinned.

Pellucid (pel-u'sid) [pellucere, to shine through]. Transparent; translucent; not opaque. P. Zone, the zona pellucida, or inclosing membrane of the mammalian ovum. It is also called the zona radiata.

Pellucidity (pel-ut-sid'-it-e). Same as Pellucidness.

Pellucidness (pel-u'-sid-ness) [pellucere, to shine through]. The state of being pellucid.

Pelma (pel'-mah) [ $[\pi \hat{\varepsilon} \lambda \mu a$, sole]. The lower surface of the toes; also the entire sole of the foot.

Pelmatogram (pel-mat'-o-gram) [ $\left[\pi \varepsilon \lambda_{\mu} \mu a\right.$, the sole of

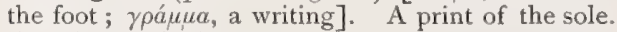

Pelor (pel'or) $[\pi \hat{\varepsilon} \lambda \omega \rho$, a monster $]$. A fetal monstrosity with some parts abnormally large.

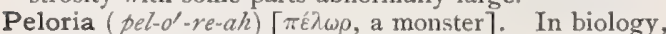
the production of regular flowers upon plants the flowers of which are normally irregular.

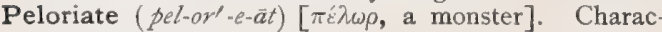
terized by peloria.

Peloric $\left(p e l-o r^{\prime}-i k\right)$ [ [ $\hat{\ell}^{\lambda} \omega \rho$, a monster]. Characterized by peloria.

Pelorisation, Pelorization (pel-or-iz-a $\left.\alpha^{\prime}-s h u n\right)[\pi \varepsilon \hat{\imath} \omega \rho$, a monster]. The becoming affected with peloria.

Pelorism (pel'-or-izm) [ $\pi \dot{\varepsilon} \hat{\omega} \omega \rho$, a monster]. Same as Peloria.

Pelorize (pel'-or-izz) [ $\pi \hat{\varepsilon} \lambda \omega \rho$, a monster]. In biology, to bring about peloria.

Pelosin ( $p \mathrm{l}^{\prime}$-o-zin). See Buxin.

Pelotonnement (pel-o-ton'-mon $(g)$ ) [Fr.]. The folding and the compression of the lower extremities of the fetus against the trunk, preliminary to expulsion in breech-presentations.

Pelt [ME., pelt, pelt]. The skin of a beast with the hair on it.

Peltate (pel'-tāt) [ $\pi \hat{\varepsilon} \lambda \tau \eta$, a light shield]. In biology, shield-shaped.

Peltatifid (pel-tat'-if-id) [ $\pi \dot{\varepsilon} \lambda \tau \eta$, a light shield; findere, to clean]. In biology, peltate and cut into subdivisions.

Pelticleis (pell-tik-lis) [ $\pi \varepsilon \hat{\imath} \lambda \tau \eta$, a shield; $\kappa \lambda \varepsilon i \xi$, bolt] In biology, a tubercle attached to the posterior margin of the carapace of certain crustaceans (Bate).
Peltifolious (pel-tif-o'-le-us) [pelta, a shield; folium, a leaf]. In biology, having peltate leaves.

Peltiform (pel'tif-arm) [pelt:z, a shield ; forma, form]. Peltate.

Peltinerved (pel"-tin-ervd) [pelta, a shield; nerrus, a nerve]. In biology, having nerves radiating from a central point, $e_{\text {. }}$ s., certain leaves.

Pelvangustia (pel-van-gus'-te-ah) [pelvis, pelvis; angustia, narrowing]. A contracted state of the pelvis.

Pelveoperitonitis (pel've-o-per-it-on-i'tis) [ pelvis,

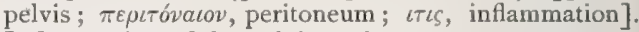
Inflammation of the pelvic peritoneum.

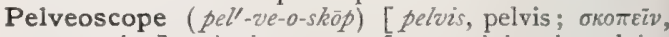
to examine]. An instrument for examining the pelvis; a pelvimeter.

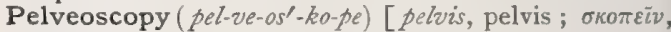
to examine]. The examination of the pelvis; pelvimetry.

Pelviarium (pel-ve-a $a^{\prime}-r e-u m$ ) [L. ]. An artificial pelvis used as a model to demonstrate the anatomy and functions of the pelvic basin.

Pelvic (pel'-vik) [pelvis, a basin]. Pertaining to the pelvis. P. Abscess, a suppurative inflammation of the connective tissue of the pelvic cavity, most common in women, and usually associated with puerperal or gonorrheal infection. P. Aponeurosis, the tendinous lamina having its origin at the brim of the pelvis and lining the pelvic cavity. P. Arch. Same as $P$. Girdle. P. Axis, the curved axial line of the pelvic cavity. P Canal, the birth-canal. P. Cavity, the cavity forming the lower part of the abdomen. P. Cellulitis, inflammation of the connective tissues in the vicinity of the uterus, or between the uterus and perineum. See Parametritis. P.Contraction. See Pelvis, Planes of. P. Diameters. See Pelvis, Diameters of. P. Diaphragm, the muscles forming the pelvic floor. P. Expansion. See Pelvis, Planes of. P. Fascia. See Fascia. P. Girdle, the arch formed by the ilium, ischium and pubis, or in the higher vertebrates by the two innominate bones. P. Hematocele. See Hematocele. P. Hernia, a rare condition in which there is a protrusion of some portion of the pelvic contents through an abnormal opening below the brim of the true pelvis; the chief forms are the perineal, vaginal, sciatic, and pulendal. P. Index, the relation of the antero-posterior to the transverse diameter of the pelvis. P. Inlet, the superior strait. P. Limb, the limb attached to the pelvic girdle. P. Outlet, the inferior strait. P. Peritonitis. See Perimetritis and Pelveoperitonitis. P. Plexus. See Plexuses, Table of. P. Region, the region within the true pelvis.

Pelvicellulitis (pel-vis-el-u-líl -tis) [ pelvis, pelvis; cellula, a little cell; $\iota \tau \iota$, inflammation]. See Pelvic Cellulitis.

Pelvicliseometer (pel-vik-liz-e-om'-et-er) [pelvis, pel-

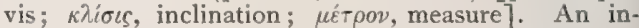
strument for determining the inclination and the diameters of the pelvis.

Pelvicology (pel-vik-oll-o-je). Same as Pelycology.

Pelvicrural (pel-rik-ru'-ral) [pelvis, pelvis; crus, leg]. Pertaining to the pelvis and the thigh.

Pelvicula (pel-vik'-u-lah). Synonym of Orbit.

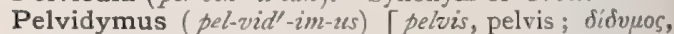
double]. The same as Dipygus.

Pelviform (pel'-7if-orm) [pelvis, a basin; forma, shape]. In biology, shaped like a shallow cup.

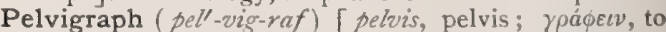
write]. An apparatus that automatically records the outline of the pelvic wall.

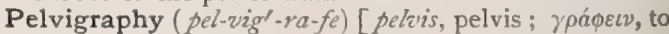
write]. A contour or tracing of the pelvic wall. 
Pelvimeter (pel-vim'-et-er) [pelvis, pelvis; $\mu$ ćrpov, a measure]. An instrument for measuring the pelvic dimensions.

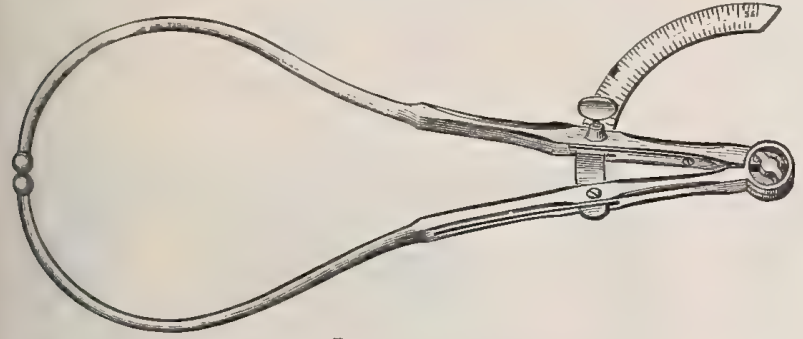

Pelvimeter.

Pelvimetry (pel-vim'-et-re) [pelvis, pelvis; $\mu$ ćtpov, measure]. The estimation of the dimensions of the pelvis. P., Combined, a combination of external and internal pelvimetry. P., Digital, pelvimetry by means of the hand. P., External, measurement of the external diameters of the pelvis, by which to estimate the dimensions of the internal parts. P., Internal, measurement of the internal dimensions of the pelvis by the hand or by the pelvimeter. See Pelvis.

Table of Measurements of the Female Pelvis Covered WITH THE SOFT PARTS.

Between iliac spines, ......... $26 \mathrm{~cm}$

External conjugate diameter, : . . : . $290^{1 / 4}$ "

Internal ".... $123 / 4$ "

True conjugate, estimated,

Right diagonal, estimated, ..... II "... II

Right diagonal, .

Between trochanters, : : : :

Circumference of pelvis, ........ 90 "

Pelvimyon (pel-vim-i'-on) [pelvis, a basin; $\mu v 6 v$, a cluster of muscles]. Any myon of the pelvic arch.

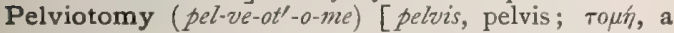
cutting]. Section or cutting of the bones of the pelvis, especially the division of the symphysis pubis in case of difficult labor.'

Pelviperitonitis ( pel-vip-er-it-on-i'-tis). Synonym of Pelveoperitonitis.

Pelvis (pell'-vis) [pelvis, a basin]. The basin-like cavity of the inferior part of the trunk containing the rectum, and the urinary bladder and genital organs,

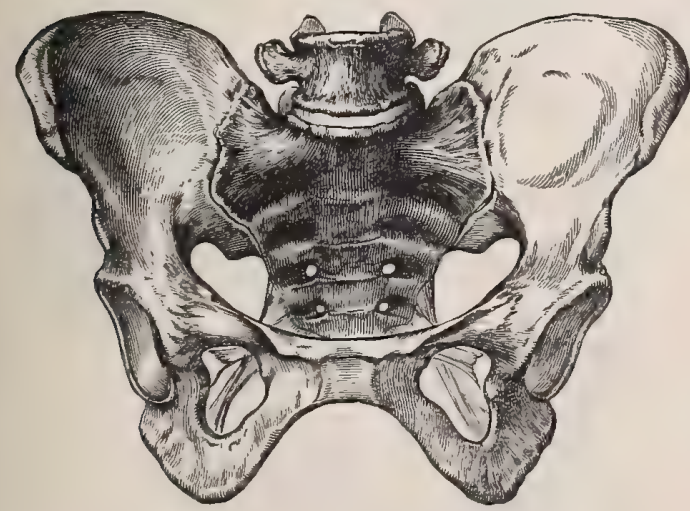

Female Pelvis, seen from the Front.

and bounded anteriorly and laterally by the innominate bones, posteriorly by the sacrum and coccyx, and inferiorly by the floor of the pelvis. P. æquabiliter justo-major, one equally enlarged in all diameters, with preservation of the normal proportions. It complicates labor by rendering it too precipitate. P. æquabiliter justo-minor, a normally proportioned pelvis, but with all its diameters reduced. P., Anatomic. See $P$., Static. P., Axis of (of inlet or outlet), a perpendicular to the middle of the anteroposterior diameter. P., Beaked, one in which the pubic bones are compressed laterally so as to approach each other, and are pushed forward. It is seen in the osteomalacic pelvis P., Bony, the framework of the pelvis. See Pelvis. P., Brim of, the entrance to the pelvic cavity, variously called the inlet, superior strait, margin, or isth-

mus. Capuron, Cardinal Points of, four fixed points of the pelvic inlet, the two ileo-pectineal

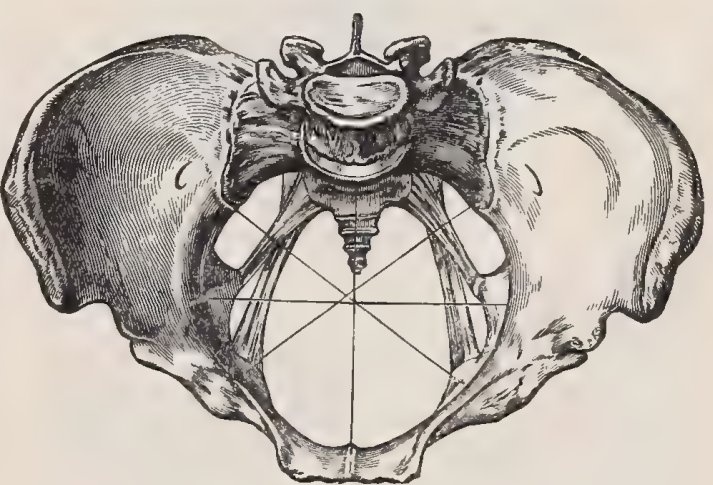

Female Pelvis, viewed in the Axis of the BRIM. Showing the diameters of the superior strait.

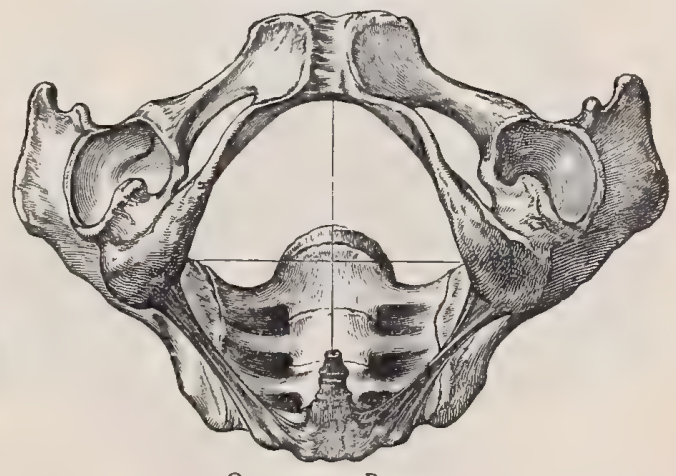

OUtlet of Pelvis.

Antero-posterior and transverse diameters of outlet seen from below.

eminences anteriorly, and the two sacro-iliac joints posteriorly, $\mathbf{P}$. cerea, an osteomalacic pelvis in which the bones are very soft. P., Cordate, one in which the inlet is heart-shaped. P., Cordiform, an abnormal pelvis in which the inlet is shaped like the heart of playing cards. P., Coxalgic, a pelvis deformed as the result of hip-disease. P., Deformities of. See Classification at end of this article. P., Diameters of (of the inlet), the antero-posterior (sacropubic, or conjugate), from the upper edge of the promontory of the sacrum to a point an eighth of an inch below the upper border of the pubic symphysis; it 
measures II cm. ; the transwerse, from side to side at the widest point; it measures $13 \frac{1}{2} \mathrm{~cm}$. ; the oblique (right and left), obliquely between the points of Cap. uron ; it measures $\mathrm{I} 23 / 4 \mathrm{~cm}$; (of the outlet), the anteroposterior, from the tip of the coccyx to the sub-pubic ligament; it measures $9 \mathrm{I} / 2 \mathrm{~cm}$; the transverse, between the ischial tuberosities; it measures II cm. ; the oblique, from the under surface of the sciatic ligaments to the junction of the ischio-pubic rami. P., Dwarf,

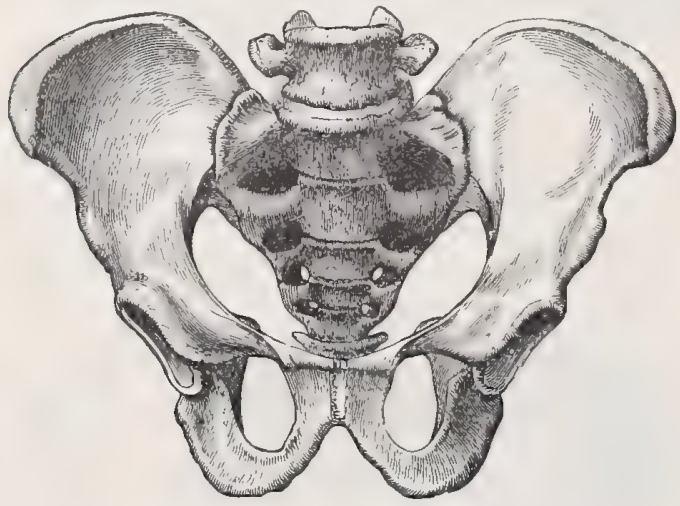

Male Pelvis, seen from the Front.

a justo-minor pelvis of small size, corresponding to the dwarféd state of the body. P., Dynamic, that of the woman in labor. P., Elastic. Synonym of $P$., Osteomalacic. P., False, that part of the pelvis (called, also, the superior or large pelvis) above the ileo-pectineal line. P., Fetal. Same as P., Funnel-shaped. P., Fissured, a form of rachitic pelvis in which the ilia are pushed forward and rendered nearly parallel. Exstrophy of the bladder is a common complication. P. Floor of, the united mass of skin, connective tissue,

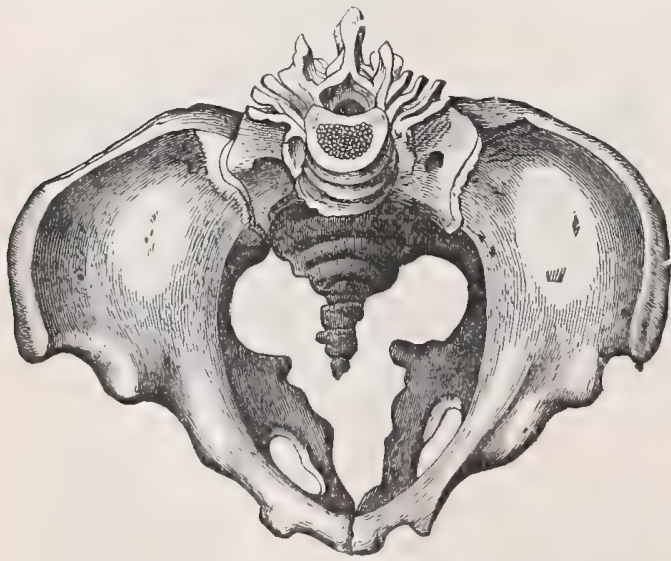

KYPHOTIC PELVIS.

muscles, and fascia forming the inferior boundary of the pelvis. P., Funnel-shaped, one that is narrowed progressively from above downward; called, also, P., Masculine. P., Giant. Same as P., Justomajor. P., Inferior. See $P$., True. P., Inlet of. See Inlet of Pelvis. P., Justo-major. See $P$. cquabiliter justo-major. P., Justo-minor. See $P$., aquabiliter justo-minor. P. of Kidney, the funnelshaped chamber extending into the interior of the kidney and opening into the ureter. P., Kilian's.
Synonym of $P$., Osteomalacic. P., Kyphotic, one with a posterior curvature of the lumbar spinal column with increase of the conjugate diameter of the inlet, but decrease of the transverse diameter of the outlet, through approximation of the tuberosities of the ischium. P., Large. See P., False. P., Lordotic, one with an anterior curvature of the lumbar spinal

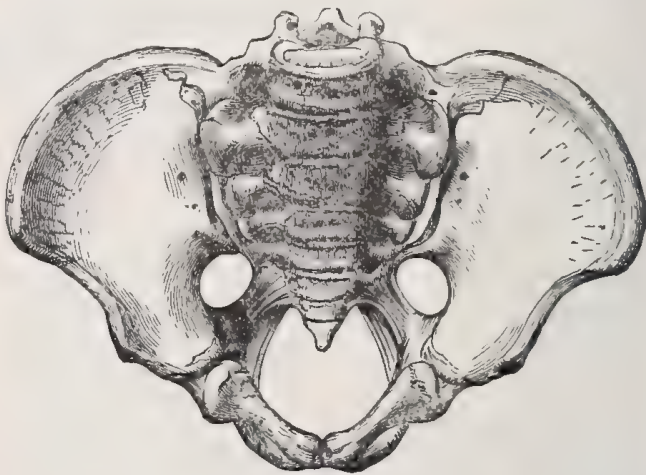

Infantile Pet.vis, viewed in The AXIS OF the BRIM.

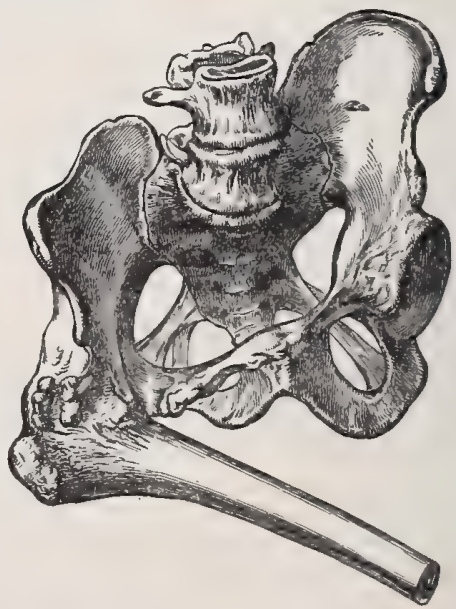

OBLTOUE PELVIS.

From ankylosis of the hip-joint and disuse of the right leg.

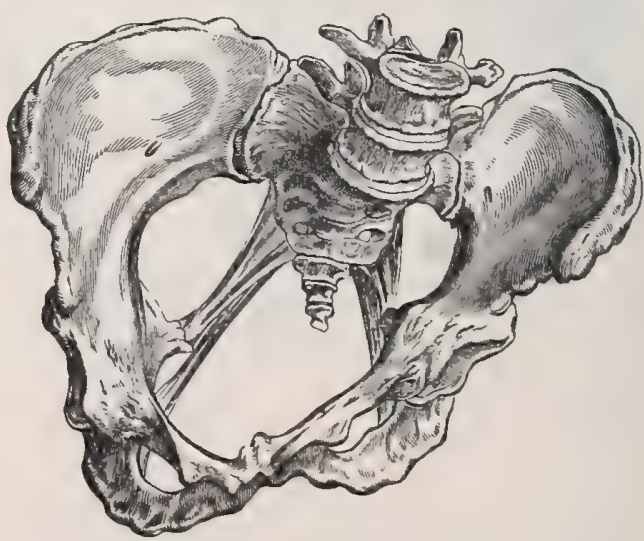

Oblioue Pelvis of Nagele. 
column. P. major, the false pelvis. P., Malacosteon. Synonym of P., Osteomalacic. P., Masculine. See P., Funnel-shaped. P. minor, the true pelvis. P., Nægele's Oblique, a pelvic deformity with ankylosis of one sacro-iliac synchondrosis, lack of development of the associated lateral sacral mass, and other defects that distort the diameters and render the conjugate oblique in direction. P. nana, a dwarf pelvis. P., Obliquely Contracted. Same as $P$.,

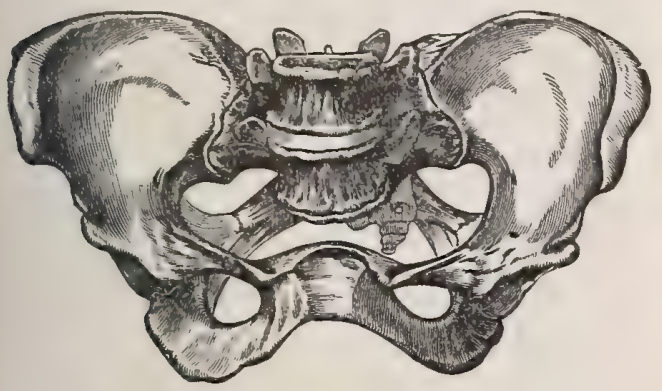

Figure-of-eight Rachitic Pelvis.

Nagele's. P., Obliquity of, called, also, the Inclination, the angle between the axis of the pelvis and that of the body. P., Obstetric, the static pelvis plus the last lumbar vertebra. P., Osteomalacic, a distorted pelvis characterized by a lessening of the transverse and oblique diameters, with great increase of the antero-posterior diameter. It is due to morbid softening of the bones. P., Outlet of. The inferior opening of the pelvic canal. P., Planes of, imaginary surfaces touching all points of the circumference. The plane of pelvic expansion perforates the middle of

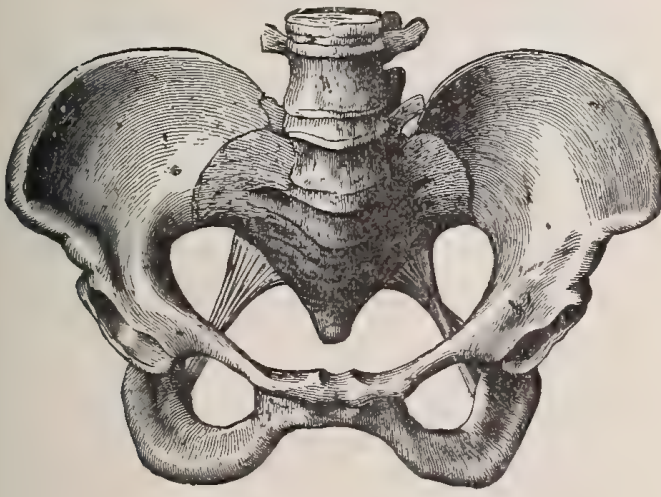

RENIFORM RACHITIC PELVIS.

the symphysis, the tops of the acetabula, and the sacrum between the second and third vertebræ. Its antero-posterior diameter is $123 / 4 \mathrm{~cm}$., its transverse diameter $12 \mathrm{r} / 2 \mathrm{~cm}$. The plane of pelvic contraction passes through the tip of the sacrum, the spines of the ischia and the under surface of the symphysis. Its anteroposterior diameter is II $1 / 2 \mathrm{~cm}$. ; its transverse diameter $101 / 2 \mathrm{~cm}$. P., Pseudo-osteomalacic, a pelvis deformed by rickets, resembling that caused by osteomalacia. P., Rachitic, the distortion produced by rickets, usually consisting in a sinking in and forward of the sacro-vertebral angle, with a flaring outward of the iliac crests and increased separation of the iliac spines. P., Reduced, a generally contracted pelvis ; a justo-minor pelvis. P., Reniform, one in which the inlet is kidney-shaped. P., Robert's, one in which there is an ankylosis of both sacro-iliac joints, with a rudimentary sacrum, both lateral sacral masses being undeveloped, and other malformations, the oblique and transverse diameters being much narrowed.

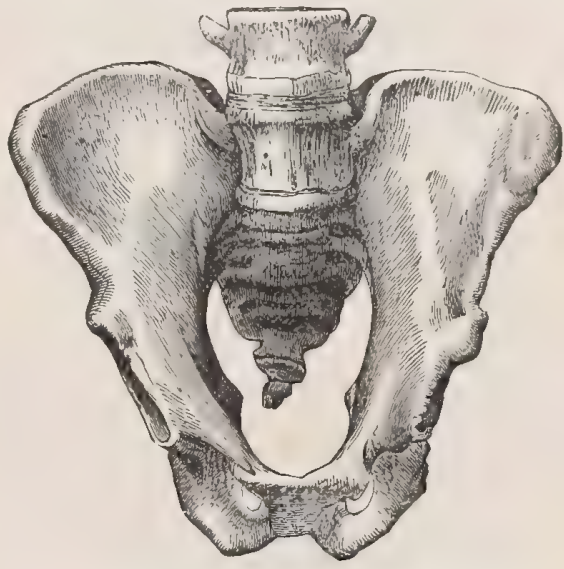

Transversely Contracted Pelvis of Robert.

P., Rostrated. Synonym of P., Beaked. P., Round, one in which the inlet is almost round in outline, owing to a diminution of the difference between the conjugate and the transverse diameter. P., Rubber. Synonym of P., Osteomalacic. P., Scoliotic, a distorted pelvis caused by lateral curvature of the spine. P., Simple Flat, one in which the only do-

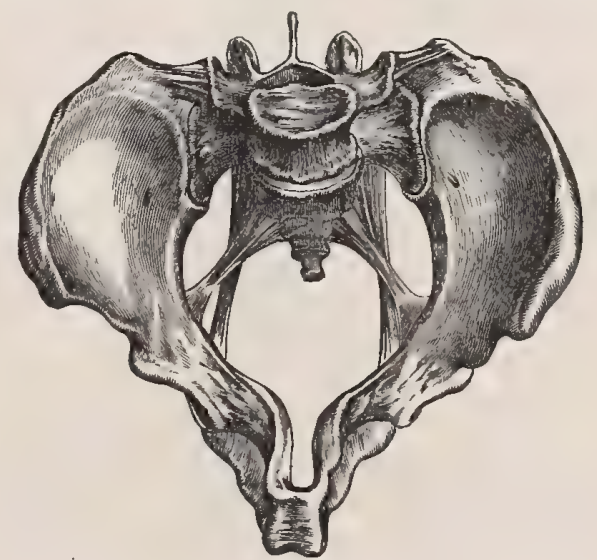

Rostrated Malacosteon Pelvis in Early Stage of DEFORMITY

formity consists in a shortening of the antero-posterior diameter. P., Small. See $P$., True. P. spinosa, a rachitic pelvis in which the crest of the pubis is very sharp, and presents a spine at the insertion of the parvipsoas. P., Split, a form in which there is congenital separation of the pubic bones at the symphysis. It is often associated with exstrophy of the bladder. P., Static, the bony pelvis, called, also, the $P$., Anatomic. P., Straits of, superior and inferior, the planes of the inlet and outlet. P., Superior. See $P$., False. P., Transversely Contracted. Same as $P$., Robert's. P., Triangular, one with a triangular inlet. 
P., Triradiate, a pelvis in which the promontory is pushed forward and the acetabula pressed inward; it is usually due to osteomalacia, and but rarely to rickets. P., True, that below the ilio-pectineal line, called, also, the small, or inferior pelvis, or the pelvic cavity. P., Undeveloped. Same as P., Funnelshaped.

Classification of Deformities of the Female Pelvis, ACCORDING TO SCHAUTA.

A. Anomalies of the Pelvis the Result of Faulty DEVELOPMENT.

r. Simple flat

2. Generally equally contracted (justo-minor)

3. Generally contracted flat (non-rachitic).

4. Narrow funnel-shaped (fetal or undeveloped).

5. Imperfect development of one lateral mass of the sacrum (obliquely contracted or Nagele's pelvis).

6. Imperfect development of both lateral masses (transversely contracted or Robert's pelvis)

7. Generally equally enlarged (jusio-major or giant pelvis). 8. Split pelvis

B. Anomalies due to Disease of the Pelvic Bones.

I. Rachitis.

2. Osteomalacia.

3. New Growths.

4. Fractures.

Atrophy, Caries, and Necrosis.

C. Anomalies in the Conjunction of the Pelvic Bones. I. Too firm union (synostosis).

(I) of symphysis.

2) of one or both sacro-iliac synchondroses.

(3) of sacrum with coccyx.

2. Too loose a union or separation of the joints.

(I) Relaxation and rupture

(2) Luxation of the coccyx.

D. Anomalies due to Disease of The Superimposed SkelETON

I. Spondylolisthesis.

2. Kyphosis.

3. Scoliosis.

4. Kypho-scoliosis.

E. Anomalies due to Disease of the Subjacent SkeleroN

I. Coxalgia.

2. Luxation of one femur.

3. Luxation of both femora.

4. Unilateral or bilateral club-foot

5. Absence or bowing of one or both lower extremities.

Pelvisacral (pel-vis-a'-kral) [pelvis, pelvis; sacrum, sacrum]. Pertaining to the pelvis and the sacrum.

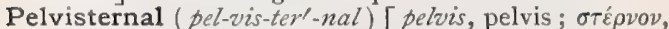
breastplate]. Having the character of a breastbone.

Pelvisternum (pel-vis-ter'-num) [pelvis, pelvis ; oré $\rho$ vov, breastbone]. In biology, an infero-median osseous, cartilaginous, or ligamentous element of the pelvic arch, supposed to correspond to the omosternum of the pectoral arch.

Pelvitomy (pel-vit'-o-me) [pelvis, pelvis; Touń, a cutting]. Synonym of Pelviotomy.

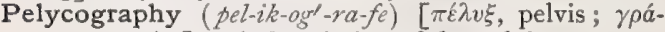
$\phi \varepsilon \iota \nu$, to write $]$. A description of the pelvis.

Pelycology (pel-ik-ol'-o-je) [ $[\pi \varepsilon \lambda v \xi$, pelvis; $\lambda 6 \gamma o s, \mathrm{sci}-$ ence]. A treatise upon the pelvis.

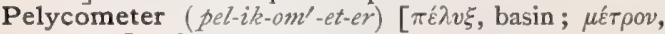
measure]. Same as Pelvimeter.

Pelycometresis (pel-ik-o-met-re'sis). Synonym of Pelvimetry.

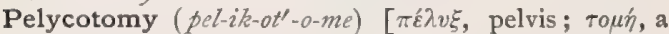
cutting]. Division of the os pubis; symphyseotomy. See Pelviotomy.

Pelyocheirometresis (pel-e-o-ki-ro-met-ré-sis) $[\pi \dot{\varepsilon} \lambda v \xi$, pelvis; $\chi \varepsilon i \rho$, hand ; $\mu \varepsilon ́ \tau \rho o v$, measure $]$. Synonym of Pelvimetry, Digital

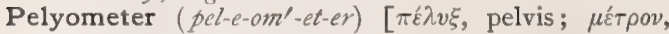
measure]. Same as Pelvimeter.

Pelyometresis (pel-e-o-met-ré-sis) [ $[\pi \varepsilon \lambda v \xi$, pelvis ;

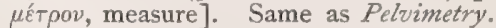

Pemmican (pem'-ik-an) [Amer. Ind.]. A food used by Arctic travelers. It consists of a mixture of the best beef and fat dried together. Sugar is sometimes added, as well as raisins and currants.

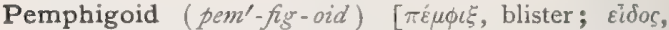
like]. Resembling or having the nature of pemphigus. A term sometimes given to a single bleb running no definite course, and resembling pemphigus.

Pemphigus (pen'-fig-us) [ $\pi \dot{\varepsilon} \mu \dot{\phi} \xi$, a blister $]$. Pompholyx; Bladder-tetter; an inflammatory disease of the skin characterized by the formation of variouslysized blebs that appear in successive crops, occasionally also on the mucous membranes. The acute form is contagious and is most frequent in infants ( $P$. neonatorum); in adults recovery may take place, although there is an acute form that sometimes proves fatal. The acute form of the disease seems to be infectious; microörganisms, especially a diplococcus, have been found in the fluid of the blebs. Some cases of pemphigus appear to be neurotic in origin. P. acutus, the acute form of the disease. P. benignus. See $P$. vulgaris. P. cachecticorum, P. cachecticus, pemphigus occurring in cachectic persons. P. chronicus. See $P$. vulgaris. $P$. circinatus. See $H y$ droa herpetiforme. P. contagiosus, Epidemic Pemphigus; a variety that occurs in epidemics, invariably in children. P. contagiosus tropicus, an epidemic form occurring only in the tropics, and appearing in a diffuse or infantile and an axillary or adult form. $\mathbf{P}$. diphtheriticus, a form in which yellow lymph forms at the bases of the blebs. P. diutinus. See $P$. vulgaris. P., Epidemic. See $P$. contagiosus. P. foliaceus, a rare form in which the blebs are flaccid, with puriform contents, and soon rupture. The disease spreads slowly but surely, and the whole body eventually becomes involved. The mucous membranes may also be affected. The patient usually dies in an exhausted typhoid condition. P. gangrænosus, a variety in which the inflammatory process is intense and superficial, or deep sloughs form. See also $D e r$. matitis gangranosus infantum. P. gyratus, pemphigus in which the blebs are arranged in circular lines. P. hæmorrhagicus, Purpura bullosa; pemphigus attended with hemorrhage into the bullæ, varying in amount from enough to impart a mere pink tint to the serum up to black. P. hystericus. See $P$. pruriginosus. P. leprosus, the bullous eruption of leprosy. P. localis. See $P$ solitarius. P. major. Synonym of $P$. vulgaris. P. malignus. See $P$. pruriginosus. P. medicamentosus, pemphigus due to the administration of a drug. P. neonatorum. See Pemphigus. P.pruriginosus, a form associated with severe itching, purulent contents of the bullæ, and the appearance of wheals. From the scratching, eczema, ecthyma and other forms of dermatitis are produced. The patient becomes exhausted from loss of sleep, and a fatal issue may result. The affection is also called Pemphigus malignus, Hy. droa herpetiforme, Pemphigus hystericus. P. puerperalis, pemphigus occurring in puerperal women. It may be associated with puerperal infection. Some cases have been considered forms of Dubring's disease, dermatitis herpetiformis. P. scorbuticus, the blebs or the blood-stained serum that sometimes appear over hemorrhagic areas in scurvy. P. solitarius, pemphigus localis; a form in which the blebs are single or few in number, localized in distribution, and accompanied by little constitutional disturbance. They occur where the circulation is feeble, as on the toes, fingers, or nose. They are chiefly seen in the aged and debilitated. P. syphiliticus, the bullous eruption of syphilis, most common in the syphilitic newborn. P. vegetans, an extremely rare form, the bullæ on the mucous membrane preceding those on the 
skin by days or even weeks. The latter form most frequently in the axillæ or groins, and on the backs of the hands and feet. After rupture, they leave extensive excoriations, which show little or no tendency to heal, but ulcerate deeply and fungate, discharging offensive, viscid fluid. Death usually results from profound cachexia. P.vulgaris, Pemphigzes benignus; the chronic form of pemphigus; it is a comparatively rare disease, and more frequently attacks children. The eruption may occur on any part of the body except the palms and soles; the seats of election are the abdomen, chest and thighs, face, ears and neck, genitals, and backs of the hands and feet. The lesions are always bilateral and sometimes symmetric. The bullæ may be as large as a walnut or larger; they soon dry up, forming crusts, or burst and form scabs. Successive crops appear, sometimes daily ( $P$. diutinus).

Pen [ pénna, a feather]. A feather; a quill. P.-sac, in biology, the flap or hood-like prolongation of the mantle of a cephalopod which contains the pen, or calamary.

Pencil (pen'-sil) [penicillus, pencil]. In pharmacy, a medicated cylindric stick, as a menthol pencil, which is used for local application. 2. An aggregation of rays meeting in a point. P.-flower. See Stylosanthes.

Penciled (pen'-sild ) [penicillus, a pencil]. In biology : $(a)$ tufted, brushy, penicillate; $(b)$ marked with fine lines.

Penciliform (pen'-sit-if-orm) [penicillus, a pencil; forma, form]. Having the form of a pencil.

Pendent (pen'-dent) [pendere, to hang]. In biology, drooping or hanging.

Pendinski Ulcer. See Furunculus orientalis.

Pendulous (pen'-du-lus) [pendere, to hang]. Hanging or drooping loosely. P. Abdomen. See Abdomen.

Pendulum-motion. See Motion, Pendulous.

Penetrating (pen'-e-tra-ting) [penetrare, to pierce]. Entering beyond the surface. Said of an odor when it is piercing or pungent. P. Wound, one that pierces an organ or one of the larger cavities of the body.

Penetration (pen-e-tra'-shun) [penetratio; penetrare, to pierce]. In medical jurisprudence, the entrance of the penis within the vagina, proof of which is a pre-requisite to establish the crime of rape.

Penial ( $\left.p e^{\prime}-n e-a l\right)$ [penis, penis]. Pertaining to the penis.

Penicil (pen'-is-il) [penicillus, a painter's brush or pencil]. In biology, a brush or bundle of hairs.

Penicillate (pen'-is-il-ät) [penicillus, a pencil]. Shaped liked a pencil of hairs.

Penicilliform (pen-is-ill-if-orm) [penicillus, a pencil ; forma, form ]. Resembling a pencil.

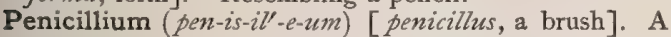
genus of saprophytic hyphomycetes or fungi, of which the P. glaucum, or common blue mold, is a familiar example.

Penile $\left(p e^{\prime}-n i l\right)$. Same as Penial.

Penis $\left(p e^{\prime}-n i s\right)$ [L.]. The male organ of copulation. It consists of the corpus spongiosum (which encloses the urethra) the two corpora cavernosa (which are largely composed of erectile tissue) and the glans. When not erect the organ is pendulous, whence its name. In some animals it contains a slender bone. P. feminis, the clitoris. P. muliebris. Synonym of $P$. feminis.

Penischisis (pen-is'-kis-is) [penis, penis ; $\sigma \chi^{i} \sigma \iota \iota s$, a splitting]. A comprehensive term for epispadias and hypospadias.

Penitis (pe-ni'-tis) [penis, penis; $\iota \tau \iota \varsigma$, inflammation]. Inflammation of the penis.

Penjdeb Sore. See Furunculus orientalis.

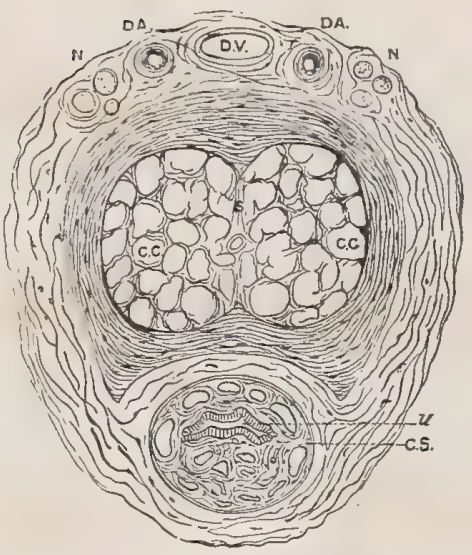

Transverse Section of the Penis of a Monkey.

C.C. Corpora cavernosa. C.S. Corpus spongiosum. S. Septum. $u$. Urethra. D.V. Dorsal vein. D.A. Dorsal arteries. N. Nerves. (From Stirling.)

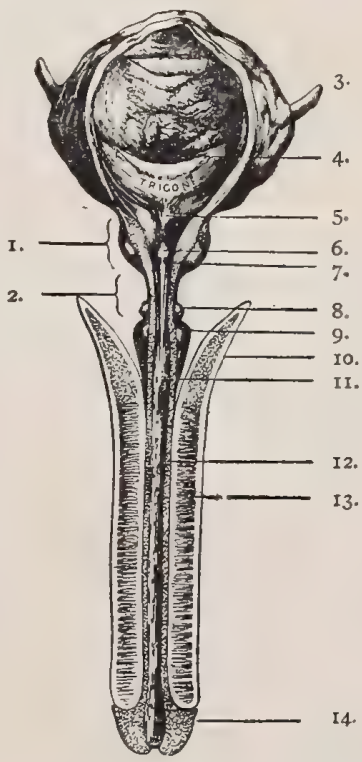

Bladder and URETHRa, LAID OpEn by an Incision Along THE UPPER SURFACE.

I. Prostate gland. 2. Membranous part of the urethra. 3. Ureter. 4. Orifice of ureter. 5. Uvula. 6. Caput gallinaginis. 7. Orifice of seminal duct. 8. Cowper's gland. 9 Bulb of urethra. ro. Crus penis. Ir. Orifice of the duct of Cowper's gland. 12. One of the lacunæ. I3. Corpus cavernosum penis. 14. Glans penis.

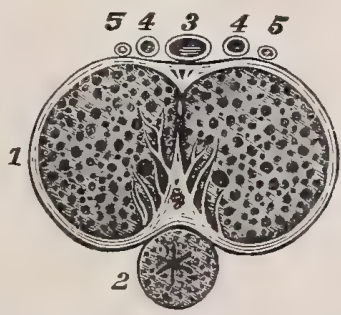

Corpora Cavernosa and Adjacent Parts. (Potter.) I. Corpora cavernosa. 2. Corpus spongiosum. 3. Dorsal vein. 4, 4. Arteries. 5, 5. Nerves. 
Penna (pen'-ah) [L., a feather, wing: pl., Penna]. In biology, a large, stiff feather; a quill-feather or contour-feather.

Pennaceous (pen-a'-se-us) [penna, a feather]. In biology, resembling a quill-feather or the structure resembling the web of such a feather.

Pennate $\left(p e n^{\prime}-\bar{a} t\right)$ [pennatus, winged; penna, a wing]. In biology, winged, feathered.

Penniferous (pen-if'-er-us) [penna, a feather; ferre, to bear]. In biology, provided with feathers.

Penniform (pen'-if-orm) [penna, feather; forma, form ]. Shaped like a feather; said of certain muscles.

Pennigerous (pen-ij'-er-us). Same as Penniferous.

Penninerved (pen'-in-ervd) [ penna, a feather; nervus, nerve]. In biology, feather-nerved or feather-veined; pinnately nerved.

Pennopluma, Pennoplume (pen-o-plu'-mah, pen'-oplum) [penna, a wing; pluma, a feather]. Same as Plumule.

Pennyroyal (pen'-e-roi-al). See Hedeoma and Pulegizum.

Pennyweight (pen'-e-zuāt) [AS., peningzwag, a pennyweight]. A weight of 24 grains, or one-twentieth of the troy ounce. See Weights and Measures.

Pennywort (pen'-e-zert). See Hydrocotile.

Penrose Disc. A solid rubber disc used as a substitute for the Senn bone-plate in intestinal anastomosis.

Pentabasic (pen-tab-a'-sik) [ $\pi \varepsilon \dot{v} \nu \varepsilon$, five ; basis, base]. Having five replaceable hydrogen atoms.

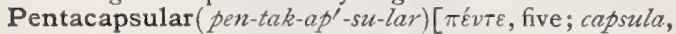
a small box]. In biology, having five capsules or seed-vessels.

Pentacarpellary (pen-tak-ar'-pel-a-re) [ $\pi \varepsilon v \tau \varepsilon$, five ; $\kappa \sim \rho \pi \delta s$, fruit]. In biology, having five carpels.

Pentachlorether (pen-tak-lor-e'-ther) [ [ $e^{\prime} \nu \tau \varepsilon$, five; $\chi^{\lambda} \omega \rho o ́ s$, green ; aitin $\rho$, ether], $\mathrm{C}_{4} \mathrm{H}_{5} \mathrm{Cl}_{5} \mathrm{O}$. A substitution-compound of ether, or diethyl oxid, in which five atoms of $\mathrm{Cl}$ replace five of $\mathrm{H}$.

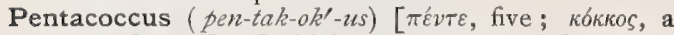
berry, a kernel]. In biology, composed of five cocci, grains, or seeds.

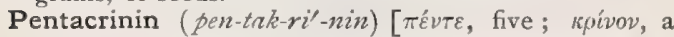
lily]. In biology, a purple pigment discovered by Moseley in Pentacrinus, the sea-lily.

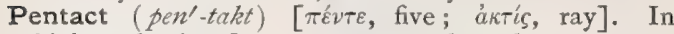
biology, having five rays, arms, or branches.

Pentacyclic (pen-tas-i'-klik) [ $\pi \varepsilon ́ v \tau \varepsilon$, five; ки́к’os, a circle]. In biology, in five whorls.

Pentad (pen'-tad) [ $\pi \varepsilon v^{\prime} v \varepsilon$, five]. A quinquivalent element or radicle.

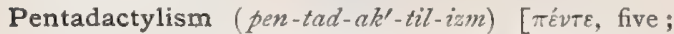
$\delta a ́ k \tau \nu \lambda o s$, finger]. The state of having five digits.

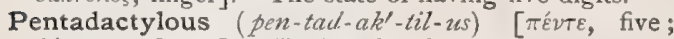

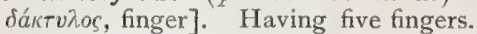

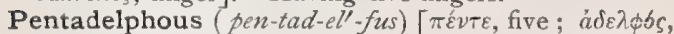
brother]. In biology, arranged in five brotherhoods or sets.

Pentafid (pen'-taf-id) [ $\pi \dot{\varepsilon} \nu \tau \varepsilon$, five ; findere, to cleave]. In biology, cleft into five divisions.

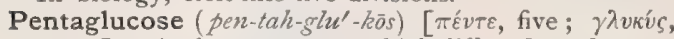
sweet]. A glucose group, which differs from the true carbohydrates by yielding furfurol instead of levulinic acid when treated with hydrochloric acid of a certain concentration, and in certain color-reactions.

Pental (pen'-tal) [ $\pi \dot{\varepsilon} \nu \tau \varepsilon$, five $], \mathrm{C}_{5} \mathrm{H}_{10}$. Trimethylethylene; said by v. Mering to be a safe and effective anesthetic. See Anesthetic.

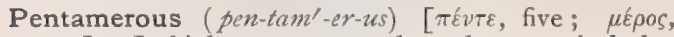
part]. In biology, constructed on the numerical plan of five; five-parted.

Pentamethylendiamin (pen-tam-eth-il-en-di'-am-in). See Ptomains, Table of.

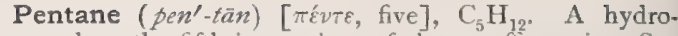
carbon, the fifth in number, of the paraftin series. See Hydrocarbons, Table of.

Pentapetalous (pen-tap-et'-al-us) [ $\pi \dot{\varepsilon} \nu \tau \varepsilon$, five; $\pi \dot{\varepsilon} \tau a \lambda o v$, a leaf]. In biology, having five petals.

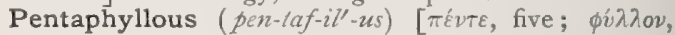
leaf]. In biology, having five leaves.

Pentapterous (pen-tap'-ter-us) [ $[\pi \varepsilon v \tau \varepsilon$, five; $\pi \tau \varepsilon \rho o ́ v$, wing]. In biology, having five wing-like expansions.

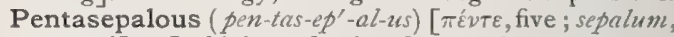
a sepal]. In biology, having five sepals.

Pentaspermous (pen-tas-per'-mus) [ $[\pi \dot{v} \tau \varepsilon$, five; $\sigma \pi \varepsilon \dot{p} \mu a$, seed]. In biology, five-seeded.

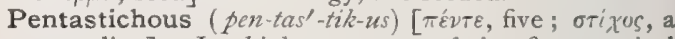
row, line]. In biology, arranged in five vertical ranks.

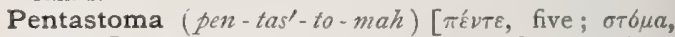
mouth]. A genus of entozoa, worm-like parasites, generally referred to the class Arthropoda. There are many species, several of which have been found encysted in the human liver and lungs. See Linsuatula and Pentasloma under Parasites (Animal), Table of.

Pentatomic $\left(p e n-t a t-o n^{\prime}-i k\right)$ [ $\pi_{\varepsilon} \varepsilon \tau \varepsilon$, five; ă $\tau o \mu o \zeta$, atom]. In chemistry, having five replaceable hydrogen atoms in the molecule.

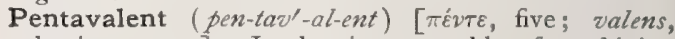
having power]. In chemistry, capable of combining with five univalent elements or radicles.

Pentoic Acid (pen-to'-ik). Synonym of Acid, Valeric.

Pentonville System. See Ventilation.

Pentoses (pen-to'-sēz) [ $[\pi \dot{\varepsilon} v \tau \varepsilon$, five; ose, a characteristic termination of the group of carbohydrates]. In chemistry, bodies containing five carbon atoms and hydrogen and oxygen in the proportion to form water, as $\mathrm{C}_{5} \mathrm{H}_{10} \mathrm{O}_{5}$. Pentoses are produced by the hydrolysis of pentosans, which are found in considerable proportion in plants, See Carbohydrates, Table of.

Pentosuria (pen-tos- $\left.u^{\prime}-r e-a h\right)$ [ $\pi \dot{\varepsilon} \nu \tau \varepsilon$, five; ov่pov, urine]. The presence of pentoses in the urine.

Pentoxid (pen-toks'-id) [ $\pi \varepsilon v \tau \tau$, five ; óvs, sharp]. An oxid containing five oxygenations.

Penzoldt and Faber's Test. A test for the absorptive power of the stomach. Two or three grains of potassium iodid enclosed in a gelatin capsule, which is well wiped to remove all trace of the salt from its exterior, are ingested with a wineglassful of water on an empty stomach. The salt is absorbed from the stomach, and appears normally in the saliva in from six and a half to fifteen minutes. In diseased conditions in which absorption is tardy, e.g., gastric catarrh, dilatation, and carcinoma, the saliva may not contain it for several hours. Its presence is recognized by the patient moistening with the saliva filter-paper which has been first saturated with starch-paste and dried. Touch the moistened spot with fuming $\mathrm{HNO}_{3}$ and a blue coloration shows the presence of iodin.

Penzoldt's Reagent. A reagent for the detection of sugar in the urine. It consists of diazobenzosulphuric acid and caustic potassa. See Tests, Table of. P.'s Test, a test for dilatation of the stomach. The line of dulness over the empty stomach will not extend to the navel. Now let the patient swallow a quart of water, and in cases of dilatation dulness will be found along a line below the navel.

Peony $\left(p e^{\prime}-a-n e\right)$ [ $\pi a l \omega v i a$, the peony $]$. The root of Pronia officinalis, of reputed value in the convulsions of children. Dose, inf., $3 \mathrm{ij}-\zeta_{\mathrm{j}} \mathrm{j}$. Unof. P.-red. Same as Corallin-red.

Peotomy ( $\left.p e-o t^{\prime}-o-m e\right)$ [ $\pi \dot{\varepsilon} o s$, penis; $\tau o \mu \eta \dot{n}$, a cutting]. Amputation of the penis.

Pepastic (pe-pas'-tik) [ $\pi \varepsilon \pi a i v \varepsilon \imath$, to ripen]. Hasten- 
ing the process of ripening, or maturation; promoting suppuration; also, of a medicine, digestive.

Peperomia (pep-er-o'-me-ah) [ $\pi \varepsilon \varepsilon \varepsilon \rho \iota$, pepper]. Pepper elder; a genus of piperaceous plants, widely distributed in South America and the West Indies. Several species have been used medicinally. P. rotundifolia is diaphoretic and antispasmodic. P. um bellata, a Brazilian species, is used as a diuretic. Unof. Peplus (pep'-lus). Synonym of Peritoneum.

Pepo $\left(p e^{\prime}-p o\right)[\pi \varepsilon ́ \pi \omega \nu$, ripe, mellow]. I. In biology, a gourd-like fruit. 2. Pumpkin-seed. The seed of Cucurbita pepo, with properties due to a resin contained in the inner covering of the embryo. It is an excellent teniafuge. Dose of the resin, gr. xv ; of the seeds, $z_{j}$-ij, made into a suitable emulsion.

Pepper (pep'-er) [ME., peper, pepper]. See Piper. P.-mint. See Mentha piperita. P.-mint Camphor See Menthol. P.-mint, Japanese. See Menthol. P., Nellaguetta. See Grains of Paradise. P., Red. See Capsicum. P.-tree, an anacardiaceous tree, Schinus molle, of tropical America, and largely planted in California. Its fruit is diuretic and stimulant, and its gum is purgative and said to remove corneal opacities. Unof.

Pepsin $\left(p e p^{\prime}-\sin \right)[\pi \varepsilon \dot{\varepsilon} \psi s$, digestion]. The chief digestive principle of the gastric juice. It converts albuminous substances into peptones in the presence of an acid. It is prepared by treating the mucous lining of mammalian stomachs with water containing .2 to .3 per cent. of hydrochloric acid. P., Liq., contains saccharated pepsin 40, hydrochloric acid 12, glycerin 400 , water q. s. ad 1000 parts. Dose 3 ij-iv. P. saccharatum, a mixture of pepsin and sugar of milk. Dose gr. $\mathbf{v}-\mathbf{3}$ j. P., Vinum, a solution of the gastric ferments in sherry. Dose $3 \mathrm{j}$-iv. See, also, Lactopeptin, Ingluvin, and Ferments.

Pepsinate $\left(p e p^{\prime}-\sin -\vec{a} t\right)$

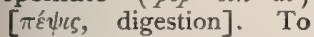
mix, or prepare, with pep$\sin$.

Pepsinogen ( $p e p-\sin ^{\prime}-o$ $j e n)[\pi \varepsilon \dot{\psi} \psi \varsigma$, digestion;

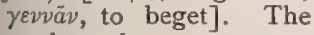
mother-substance, zymogen or propepsin, existing in the cells of the peptic glands of the stomach. It is the antecedent of pepsin, into which it is Peptic Gland From STomchanged by suitable ner-

vous stimuli, by hydro- $a$. Wide mouth and duct which chloric acid, and by so- receive the terminal divisions dium chlorid.

Pepsinum (pep-si'-num). See Pepsin.

Pepsis (peṕ-sis) [ $\pi \varepsilon \dot{\varepsilon} \psi c$,

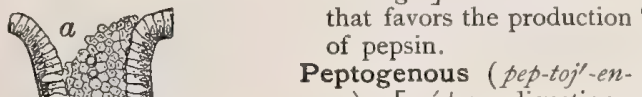

Peptogenous (pep-toj'-enit tube by short lateral branches

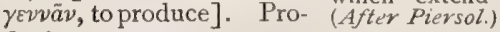
ducing peptones.

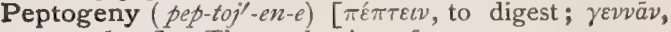
to produce]. The production of peptones.

Peptoglutin Sublimate (pep-to-glu'-tin sub'-lim-āt). Mercuric peptoglutin hydrochlorid. It contains twenty-five per cent. of mercuric chlorid, in combination with a kind of semipeptonized gelatin. It is used hypodermatically in syphilis. Dose gr. $x / 8$, given in a one per cent. solution, a Pravaz syringeful of which is injected.

Peptone (pepp-tôn) [ $[\pi \dot{\varepsilon} \pi \tau \varepsilon \iota v$, to digest]. A proteid body that is not precipitated by heat or by ammonium sulphate, but which yields the biuret-reaction. This is Kühne's peptone. Brücke's peptone is a proteid which is not precipitated by potassium ferrocyanid. but which yields the biuret-reaction. It is probably a mixture of the peptone described by Kuihne and an albumose. Peptones are produced by the action of proteolytic ferments on albuminous substances, $e . g_{.}$, in gastric and pancreatic digestion. They are, unlike the proteids from which they are derived, soluble, non-coagulable, and dialyzable. The largest part of the albumins ingested in the food is converted into peptones; these, however, are not absorbed as such, but are reconverted into albumins in the gastro-intestinal mucosa. Only a small quantity of peptones passes into the blood. Globulin, acidalbumin, para-peptone, propeptone, albumose, and others are intermediate products formed during the conversion of albumins into peptones. Peptone is not present in the urine normally. P., Beef, a sub. stance derived from beef by treating it with an extract of the pancreas. Beef-peptone is extensively used in bacteriologic laboratories in the preparation of media made from meat-infusion. P., Pancreatic, a peptone formed by the action of the pancreatic juice; unlike peptones resulting from digestion with gastric juice, it is precipitated by acids and acid salts.

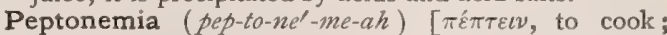
airua, blood]. The presence of peptone in the blood.

Peptonization (pep-to-niz-a $\left.a^{\prime}-s h u n\right)$ [ $\pi \dot{\varepsilon} \pi \tau \varepsilon \iota \nu$, to digest]. The process of converting proteids into peptones.
Peptic (pep'-tik) [ $\pi \hat{\varepsilon} \psi \iota s$, digestion]. Pertaining to pepsin or to digestion. P. Glands, the fundus-glands 66 of Heidenhain situated in the middle and cardiac
thirds of the stomach; they secrete pepsin and hydrothe ordinary round ulcer of the stomach, by some ascribed to erosion of the membrane by the Pepticity (pep-tis' $-i t-e)$
$[\pi \hat{\varepsilon} \pi \tau \varepsilon \iota v$, to digest $]$. The te of being peptic; euPeptogaster (pep-to-gas'-

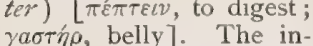
testinal canal, or digesapparatus as a whole. of the gland. $b, c$. Neck and tral or chief cells. $d$. Parietal or acid cells. (After Piersol.)$$
\text { The process of converting proteids into peptones. }
$$ 
Peptonize (peṕl-to nīz) [ $\pi \dot{\varepsilon} \pi \tau \varepsilon \nu$, to digest]. To digest with pepsin; to predigest. Very often an extract of pancreatic juice is used in order to peptonize food; milk especially is thus treated.

Peptonoid (pept-to-noid) [ $\pi \varepsilon \dot{\varepsilon} \pi \varepsilon \iota v$, to digest; $\varepsilon i \delta o s$, like]. A substance resembling or claimed to resemble peptones.

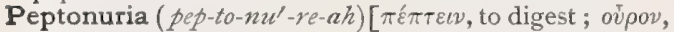
urine]. The presence of peptone in the urine. The proteid body found in the urine in peptonuria is really not a peptone but an albumose, and a better term would be albumosuria. Albumose is characterized by yielding the biuret-reaction; it is not precipitated by heat, but is precipitated by ammonium sulphate. For test, see Tests, Table of. Peptonuria, i. e., albumosuria, occurs in all conditions attended by the destruction of tissue, especially in suppurative processes, purulent pleurisy, purulent peritonitis, abscesses, cerebro-spinal meningitis, pyelonephritis, bronchoblennorrhea, in some cases of pulmonary tuberculosis with cavity-formation, and during the puerperal state. The blood in leukemia may also contain albumose. Propeptonuria is probably only an albumosuria of high degree. P., Enterogenous, peptonuria due to disease of the intestine. P., Hepatogenous, that accompanying certain liver-affections. P., Nephrogenous, peptonuria of renal origin. P., Puerperal, the peptonuria of the puerperal state. P., Pyogenic, that produced by suppuration in the body.

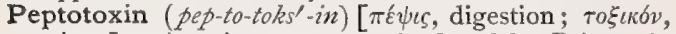
poison]. A poisonous ptomain found by Brieger in some peptones, in digestion of fibrin, and in putrefying albuminous substances, such as fibrin, casein, brain, liver, and muscles. It is a well-known fact that animal tissues, in the early stages of putrefaction, possess strong toxic properties, even before decomposition has advanced far enough to effect the splitting up of the proteid and carbohydrate molecules. An early peptonization of the proteids by ferments in the tissues, which begin their action at once after death, has been offered as an explanation of this toxicity. Peptotoxin has not as yet, however, been definitely isolated. See Ptomains, Table of. P., Cholera, a toxic substance, generated by the cholera-bacillus, and chemically allied to peptone.

Pequet's Reservoir. Synonym of Receptaculum chyli.

Per-[per, through]. A prefix signifying through. Also, more than ordinary.

Pera ( $\left.p e^{\prime}-r a h\right)[\pi \eta p a$, scrotum $]$. The scrotum.

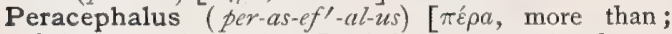
áké $\dot{\alpha} \wedge$ s, without a head]. A fetal monstrosity characterized not only by want of upper extremities, but also by malformation or absence of the thorax.

Peracute (per-ak-üt' $)$ [per, through; acutus, sharp]. More than ordinarily sharp or severe.

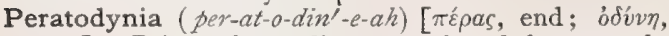
pain]. Pain at the cardiac extremity of the stomach.

Perce-membrane [Fr.]. An instrument for piercing the fetal membranes and evacuating the liquor amnii.

Perception (per-sep'-shun) [per, through; capere, to receive]. The act of receiving impressions or obtaining knowledge of external things through the medium of the senses. P., Differential, the ability to distinguish differences between slight changes in the intensity of stimulation.

Perceptivity (per-sep-tiv'-it-e) [per, through; capere, to receive]. The faculty or capability of receiving impressions.

Perchloric Acid (per-klo'-rik) [per, through; $\chi \lambda \omega \rho o s$, green ], $\mathrm{HClO}_{4}$. A volatile irritant liquid, the highest oxyacid of chlorin. In contact with organic substances it decomposes with explosion.
Percipient (per-siṕ-e-ent) [percipere, to perceive]. Perceiving; seeing.

Perclusion (per-klu'-shun) [ per, through; claudere, to shut up]. Inability to execute any movement.

Percolate (per'-ko-lāt) [ percolare, to strain through]. I. To submit to the process of percolation. 2. The solution obtained by percolation.

Percolation (per-ko-la'-shun) [percolare, to strain through]. The process of extracting the soluble constituents of a substance by allowing the solvent to trickle through the powdered mass placed in a long conic vessel, the percolator; a process similar to lixiviation.

Percolator (per'-ko-la-tor) [ percolare, to strain through]. A long conic vessel with a delivery-tube at the lower extremity, employed for the purpose of extracting the soluble constituents of a substance, packed in a percolator, by means of a liquid poured over it.

Percussion (per-kush'-un) [percutere, to strike through]. A method of physical examination applied by striking upon ariy part of the body, with a view of ascertaining the conditions of the underlying organs by the character of the sounds elicited. In percussing, attention is paid to the resonance, the pitch and the duration of the sound, and to the resistance of the parts. Percussion is sometimes performed by striking with the entire hand. The method, in the case of the chest, serves to distinguish marked degrees of dulness from resonance. In massage, striking or beating the surface. For this purpose the hand or a specially constructed instrument may be used (percussor or muscle-beater). If the palm of the hand is used the operation is called clapping; if the ulnar border is used it is called chopping; if the closed fist is used, or the dorsal surfaces of the two last phalanges of the fingers held rather loosely, the procedure is termed whipping or fagellation. P., Auscultatory, percussion combined with auscultation. The method by which fine shades of difference in the quality of sounds may be detected. It is employed for outlining organs, both those containing and those not containing air. It is best applied by placing a double stetho. scope at a fixed point and percussing gently all around. The stethoscope may be held with one hand while with a finger of the other immediate percussion is made; or, an assistant can percuss. P., Deep, the striking of a firm blow in order to elicit differences in the percussion-note of deep-seated structures. P., Light, used to elicit sound from the parts immediately subjacent, or to outline one of the viscera. P., Finger, percussion with the fingers of one hand as a plexor, and those of the other as a pleximeter; or, in immediate percussion, the use of the fingers as a plexor. P., Immediate, percussion in which the surface is struck directly, without the interposition of a pleximmeter. P., Instrumental, the use of a special hammer as a plexor, either alone or with a plate as a pleximeter. P., Mediate, percussion in which a pleximeter is used. P.-note, the sound elicited on percussion. P., Scholl's Method of. See Scholl. P.wave, the term given to the chief ascending wave of the sphygmographic tracing. Roy and Adami propose to substitute for this name the term papillary wave, on the ground that the elevation is due to the contraction of the papillary muscles. Sanson prefers the term chief ascending wave.

Percusso-punctator (per-kus'-o-pungk-ta'-tor) [ percutere, to beat; punctare, to mark ]. An instrument resembling a plexor or hammer, consisting principally of a group of needles by means of which multiple punctures are made into the tissues in rheumatism, lumbago, and neuralgia. 
Percussor (per-kus'-or) [percutere, to strike through]. He who or that which percusses; a percutor.

Percutaneous (per-ku-la'-ne-us) [per, through ; cutis, the skin]. Done through the skin; as percutaneous ligation.

Percutor (per-ku'-tor) [Fr., percuteur; percutere, to strike]. An instrument used in the percussion of mas. sage and in therapeutic flagellation.

Perditio (per-dish'-e-o) [perdere, to lose]. Abortion.

Pereion (per-i'-on) [ $\pi \varepsilon \rho i$, around; íval, to go: $p l$, Pereia]. In biology, the thorax of a crustacean, as distinguished from the head (cephalon) and abdomen (pleon). (Bate.)

Pereiopod (per-i'-o-pod) [ $\pi \varepsilon \rho \rho^{\prime}$, around; iéval, to go; $\pi$ ous, foot]. In biology, an appendage of the thorax of a crustacean; an ambulatory leg.

Pereira or Pao Pereira (per-a'-rah, $p a h^{\prime}-o$ per- $\left.a^{\prime}-r a h\right)$ [Port., "pear-tree"]. The Geissospermum lave, a large apocynaceous tree of Brazil. Its bark is tonic and febrifuge, retarding the heart-beat and respiration. Unof. See also Pareira.

Pereirin (per-a'-rin) [Port., pereira, "pear-tree], $\mathrm{C}_{19} \mathrm{H}_{24} \mathrm{~N}_{2} \mathrm{O}$. A somewhat poisonous alkaloid from pereira-bark. Its hydrochlorate ( $30 \mathrm{gr}$. per diem) is efficacious in fevers. Unof.

Perelle (per-ell) [parella, the specific name for the lichen]. In biology, a substance obtained from the lichen, Lecanora parella, and employed in the preparation of a red dye.

Perennate (per-en'-ät) [ perennis, lasting through the year]. In biology, to live perennially.

Perennation (per-en-a'-shun) [ perennis, lasting through the year]. In biology, the perennial continuance of life.

Perennial (per-en'-e-al) [per, through; annus, year]. Lasting from year to year.

Perenyi's Solution. A fixing-agent used in histologic research. Its composition is as follows : ten per cent. solution of nitric acid, 4 parts; alcohol, 3 parts; onehalf per cent. solution of chromic acid, 3 parts. After a short time this mixture becomes violet-colored.

Pereterium (per-et-e'-re-um). Synonym of Trephine.

Perfect (per'-fekt) [perfectus, finished]. Complete, without blemish. In biology, having both stamens and pistils; hermaphrodite. P. Yellow. See Pigments, Conspectus of.

Perflation (per-fla'-shun) [perflare, to blow through]. I. A method of ventilation by which a current of air blowing against a dwelling is made to force its way in. 2. Forcing air into a cavity for the purpose of evacuating fluid.

Perfoliate (per-fo'-le-āt) [per, through ; folium, leaf]. In biology: $(a)$ applied to a leaf that is united around the stem at its base; $(b)$ applied to certain insectantennæ consisting of a number of circular plates joined by the shaft running through their centers.

Perforans (per'-fo-ranz) [per, through; forare, to bore]. Penetrating or perforating. Applied to various muscles whose tendons pass through other structures. P., Ulcus. Perforating ulcer. See Ulcer.

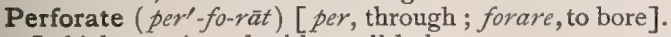
In biology, pierced with small holes.

Perforated (per'-fo-ra-ted') [per, through; forare, to bore]. Pierced through. P. Space. See Space.

Perforation (per-fo-ra'-shun) [per, through; forare, to bore]. The act of piercing. Also, the opening in the wall of a cavity resulting from traumatism or ulceration. In craniotomy, the opening of the fetal head.

Perforator (per'-fo-ra-tor) [per, through; forare, to bore]. An instrument for boring through the fetal skull; also for perforating other bones.

Perforatus (per-fo-ra'-tus). Synonym of Perforated.
Perfrication (per-frik-a'-shun) [ per, through; fricare, to rub]. Inunction.

Perfrigerium (per-frij-e'-re-um) [ perfrigerare, to make very cold]. Numbness due to cold.

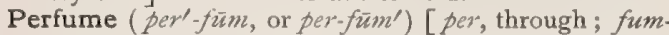
are, to give off a vapor]. The odor of a volatile substance, especially if pleasant or agreeable. Most commercial perfumes belong to the terpene series, and have the uniform composition $\mathrm{C}_{10} \mathrm{H}_{16}$. In a few instances they are manufactured synthetically, but in most they are extracted from the petals of flowers.

Perfusion (per-fu'-zhunj [per, through; fundere, to pour]. The passage of a fluid through spaces.

Pergameneous (per-gam- $\left.e^{\prime}-n e-u s\right)$ [pergameneus, parchment-like]. Resembling parchment, $e_{*} g$., the skin in certain cases of xeroderma.

Pergamentaceous (per-gam-en-ta'-she-us). Same as Pergameneous.

Peri- (per'-e) [ $[\pi \varepsilon \rho i$, around]. A prefix signifying around, or surrounding.

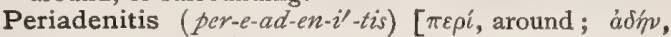
gland; $\iota \tau \iota$, inflammation]. Inflammation of the tissues that surround a gland.

Periadventitial (per-e-ad-ven-tish'-e-al) [ $\pi \varepsilon \rho i$, around ; adventitius, coming from abroad]. Situated, or occurring, around the adventitia, or external coat of a vessel.

Periah (per-i'-ah) [Heb.]. The second act in the Jewish rite of circumcision. It is the act of laceration of the mucous membrane.

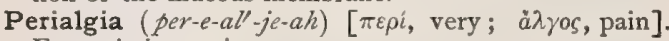
Excruciating pain.

Perianal (per-e-a'-nal) [ $\pi \varepsilon \rho{ }^{\prime}$, around; anus, anus]. Situated, or occurring, around the anus.

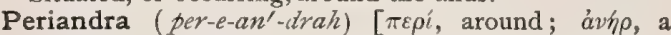
male]. In biology, one of the bracts surrounding the antheridia of mosses.

Periangiocholitis (per-e-an -je - o-ko-li' - tis) [ $\pi \varepsilon \rho i$,

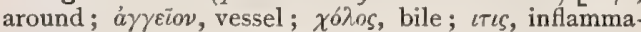
tion]. Inflammation of the connective tissue surrounding the biliary ducts.

Periangioma (per-e-an-je- $\left.o^{\prime}-m a h\right)$ [ $\pi \varepsilon \rho i$, around; ảy $\gamma \varepsilon \bar{i} o v$, vessel ; $0 \mu a$, tumor]. A tumor surrounding a vessel.

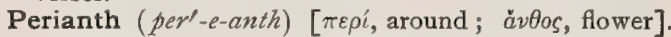
In biology, a collective term for the floral envelops, calyx and corolla, or their representative.

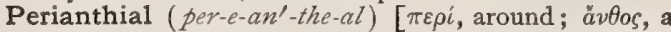
flower]. In biology, pertaining to the perianth. Provided with a perianth.

Perianthium (per-e-an'-the-um). Same as Perianth.

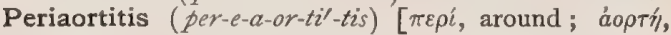
aorta; $\iota \tau \iota \varsigma$, inflammation]. Inflammation of the tissues surrounding the aorta.

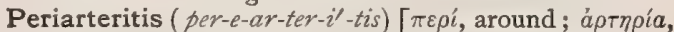
artery; $\iota \tau \iota \zeta$, inflammation]. Inflammation of the external sheath of the arteries. P. nodosa, thickening of the arterial coats in localized areas, producing nodular swellings.

Periarthritis (per-e-ar-thri'-tis) [ $[\pi \varepsilon \rho i$, around; à $\rho \theta \rho o \nu$, joint; $\iota \tau \iota \zeta$, inflammation]. Inflammation of the tissues about a joint.

Periarticular (per-e-ar-tik'-u-lar) $[\pi \varepsilon \rho i$, around ; articulus, joint]. About or around a joint.

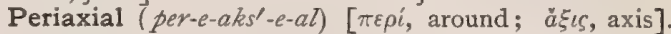
Situated or occurring around an axis or axis-cylinder.

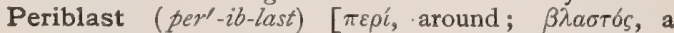
germ ]. In biology, the protoplasm surrounding the nucleus of a cell.

Periblastic (per-ib-las'-tik) [ $\pi \varepsilon \rho i$, around; $\beta \lambda a \sigma \tau b \varsigma$, a germ ]. In biology, pertaining to the periblast. Germinating from the surface of an ovum. 
Periblastula (per-ib-las'-tu-lah) $[\pi \varepsilon \rho i$, around; $\beta \lambda a \sigma-$ $\tau \delta \varsigma$, germ]. A segmenting ovum in which the outer layer of cells is more highly developed than the inner.

Periblem ( $\left.p^{\prime} \gamma^{\prime}-i b-l e m\right)$ [ $\pi \varepsilon \rho i \beta \lambda \eta \mu \alpha$, a covering]. In biology, a zone of meristem lying between the plerome and the dermatogen at the growing end of an axial organ.

Periblepsia, Periblepsis (per-ib-lep'-se-ah, per-ib-lep'sis) $[\pi \varepsilon \rho i$, around; $\beta \lambda \dot{\varepsilon} \pi \varepsilon \iota \nu$, to look $]$. The wild, unnatural look observed in delirium

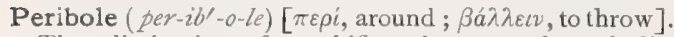
The elimination of morbific substances through diseased conditions of the skin.

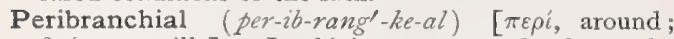
$\beta \rho a ́ \gamma \chi \iota a$, gills]. In biology, arranged about the branchiæ.

Peribronchial (per-ib-rong'-ke-al) [ $\pi \varepsilon \rho i$, around; $\beta \rho o ́ \gamma-$ $\chi \circ \varsigma$, bronchus]. Pertaining to the tissue about the bronchus; surrounding a bronchus. P. Lymphangitis, inflammation of the peribronchial lymphatic vessels.

Peribronchitis (per-ib-rong $\left.-k i^{\prime}-t i s\right)$ [ $\pi \varepsilon \rho i$, around;

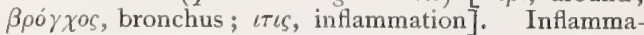
tion of the pulmonary tissue immediately surrounding the bronchi. P., Caseous, a peribronchitis due to tuberculosis, and usually accompanying caseous broncho-pneumonia. P., Purulent, a peribronchial inflammation with the formation of pus. P., Tuberculous, peribronchitis due to the tubercle-bacillus.

Peribrosis (per-ib-ro'-sis) [ $[\pi \varepsilon \rho \hat{\imath}$, around; $\beta \rho \tilde{\omega} \sigma \iota s$, a feeding]. Ulceration at the canthi of the eyelids.

Pericæcal (per-is-é-kal). See Pericecal.

Pericæmentitis (per-is-em-en-ti'-tis). See Pericementitis.

Perical (per'-ik-al). See Fungus-foot.

Pericambium (per-ik-am'-be-um). See Phloëm-sheath.

Pericardiac, Pericardial (per-ik-ar'-de-ak, per-ik-ar'-

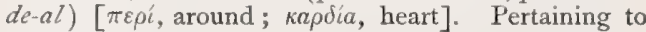
the pericardium.

Pericardiacophrenic (per-ik-ar-de-ak-o-fre'-nik) [ $\pi \varepsilon \rho^{\prime}$,

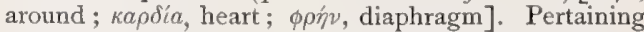
to the pericardium and the diaphragm.

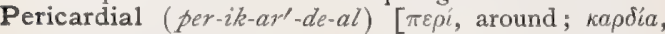
heart]. Pertaining to the pericardium. Surrounding the heart. P. Cavity, the space between the pericardium and the heart. P. Pleura, that part of the pleura attached to the pericardium. P. Space. Same as $P$. Cavity.

Pericardian (per-ik-ar'-de-an). Same as Pericardial.

Pericardiopneumatosis (per-ik-ar'-de-o-nu-mat-o'-sis). Synonym of Pneumopericardizem.

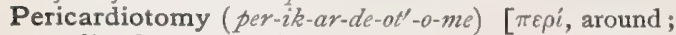

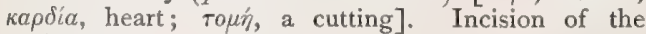
pericardium.

Pericarditic (per-ik-ar-dit'-ik) [ $\pi \varepsilon \rho \dot{\iota}$, around; $\kappa a \rho d i a$, heart; $\iota \tau \iota s$, inflammation]. Pertaining to pericarditis.

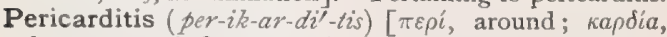
heart; $\iota \tau \iota s$, inflammation]. Inflammation of the pericardium. It may be complicated with myocarditis or endocarditis. It is rarely a primary affection, but is usually secondary to such diseases as rheumatism. chronic nephritis, scarlet fever, measles, pyemia, scorbutus, and hemorrbagic purpura. Many cases are due to extension of inflammation from neighboring organs, as from pleurisy and pleurisy with pneumonia; sometimes, also, to extension of endocardial inflammation. Tuberculosis may affect the pericardium by extension from the lung, but occasionally it appears as a primary disease of the serous membrane. In addition, a pericarditis may follow malignant disease of the pericardium. Actinomycosis may spread to the pericardium from the lung or the mediastinum. Syphilis of the pericardium is usually secondary to myocardial syphilis. It leads to pericardial adhesions. P., Adhesive, pericarditis in which the two layers of pericardium tend to adhere. P., Carcinomatous, pericarditis due to carcinoma of the pericardium. In rare cases pericarditis may accompany carcinoma of a remote organ. P., Dry, pericarditis without effusion. P., External, inflammation of the outer layer of the pericardium ; it is usually accompanied by inflammation of the contiguous pleura. P., Fibrinous, a form in which the membrane is covered with a fibrinous exudate, first soft and buttery in consistence, but later organizing. Tuberculous pericarditis is likely to lead to large deposits of fibrin. P., Hemorrhagic, a form in which the fluid is hemorrhagic. This is the case most often in tuberculous pericarditis; also in scorbutus and in cachectic conditions. P., Internal, inflammation of the serous surface of the pericardium. P., Localized, whitish areas, the so called milk-spots $(q \cdot v$.$) , due to$ circumscribed pericarditis. P., Obliterating, a form leading to adhesion of the two layers of pericardium and obliteration of the cavity. See Pericardium, Adherent. P., Purulent, pericarditis in which the effused fluid becomes purulent. This is not very rare in children. P., Rheumatic, that due to rheumatism. P., Sero-fibrinous, a form in which there is but little lymph or fibrin, but a considerable quantity of serous fluid. P., Tuberculous, pericarditis due to tuberculous infection of the pericardium; it is usu. ally secondary, from extension from neighboring organs, but is sometimes primary. The membrane is covered with thick layers of fibrin, beneath which are miliary tubercles; there may also be larger cheesy masses. The quantity of fluid is usually small, but may be large, and the effusion is generally hemorrhagic.

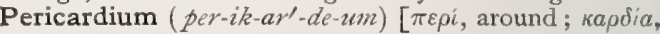
heart]. The closed membranous sac or covering that envelops the heart. Its base is attached to the central tendon of the diaphragm; its apex surrounds for a short distance the great vessels arising from the base of the heart. It consists of an ectal fibrous coat, derived from the cervical fascia, and an ental serous coat. The sac normally contains from half a dram to a dram of clear serous fluid. P., Adherent, a condition resulting from a previous pericarditis, in which the two layers of the pericardium are bound together by newly-formed connective tissue. P., Bread-and-butter, a peculiar appearance produced in fibrinous pericarditis by the rubbing of the two surfaces of the membrane over each other. The surface is rough, like that produced when two pieces of butter-and-bread, that have lain with their spread sides in contact, are pulled apart. P., Calcified, calcification of the pericardium, occurring in spots or diffusely. P., Parietal, the reflection of the pericardium not in direct contact with the heart; the portion in contact with the pleura and the diaphragm. See $P$., Visceral. P., Shaggy, a pericardium upon which, as the result of fibrinous pericarditis, thick, loose, shaggy layers of fibrin are deposited. P., Visceral, the epicardium, i.e., the layer of pericardium attached to the surface of the heart.

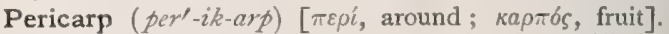
In biology: $(a)$ the shell or cover of a fruit; $(b)$ the wall of a ripened ovary.

Pericarpial (per-ik-arl-pe-al). Same as Pericarpic

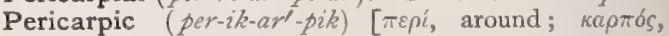
fruit]. Pertaining to the pericarp.

Pericarpium (per-ik-ar'-pe-um). Same as Pericarp.

Pericarpoidal (per-ik-ar-poid'-al) [ $\pi \varepsilon \rho i$, around;

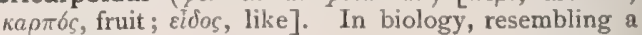
pericarp. 
Pericecal (per-is-él-kal) [ $\pi \varepsilon \rho \hat{\imath}$, around; cacus, blind]. Surrounding the cecum.

Pericellular (per-is-el'-u-lar) [ $\pi \varepsilon \rho i$, around; cellula, a small cell]. Surrounding a cell.

Pericementitis (per-is-em-en-tit-tis) [ $\pi \varepsilon \rho i$, around; camentum, cement; เтৎ, inflammation]. Inflammation of the peridental membrane and tissues around a tooth. P., Phagedenic, a specific infectious inflammation, having its beginning at the gingival or gum margin, and accompanied with destruction of the peridental membrane and alveolar walls. P., Traumatic, inflammation of the peridental membrane resulting from injuries.

Pericementum (per-is-em-en'-tum) [ $\pi \varepsilon \rho i$, around ; camentum, cement]. The layer of true bone covering the fangs of the teeth; it is formed beneath the peridental membrane.

Pericentral (per-is-en'-tral) [ $\pi \varepsilon \rho i$, around; $\kappa \varepsilon ́ v \tau \rho o v$, center]. Situated around a center, or centrum.

Pericerebricity (per-is-er-e-bris'-it-e). See Polyparesis.

Perichæte (per-ik-e'-te). See Perichatium,

Perichætial (per-ik-e'-she-al) [ $[\pi \varepsilon \rho i$, around; $\chi a i \tau \eta$, a long hair]. In biology, pertaining to the perichætium.

Perichætium (per-ik-e'-she-zem) [ $\pi \varepsilon \rho^{\prime}$, around; $\chi a i t \eta$, long hair, foliage: pl., Perichatia]. In biology, the involucre of modified leaves surrounding the reproductive organs in mosses; perichæte, perichete.

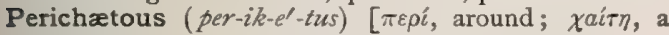
long hair]. Surrounded by bristles.

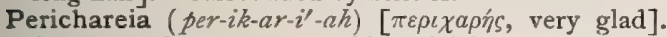
Sudden, vehement, or morbid rejoicing; a symptom in certain insanities.

Perichete (per-ik-el-te). See Perichatium.

Pericholecystitis (per-ik-ol-e-sis-ti'-tis) [ $\pi \varepsilon \rho i$, around;

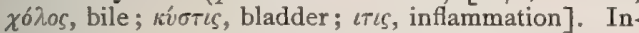
flammation near or around the gall-bladder.

Pericholous ( $\left.p e r-i k^{\prime}-o-l u s\right)$ [ $\pi \varepsilon \rho i$, very; $\chi \delta \hat{\alpha} o s$, bile]. Excessively bilious.

Perichondrial (per-ik-on'-dre-al) [ $\pi \varepsilon \rho^{\prime}$, around; $\chi \delta ́ v$. $\delta \rho o s$, cartilage]. Pertaining to or resembling perichondrium.

Perichondriodynia (per-ik-on-dre-o-din'-e-ah) $[\pi \varepsilon \rho i$,

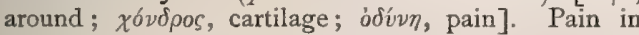
the perichondrium.

Perichondritic (per-ik-on-drit'-ik) [ $\pi \varepsilon p i$, around; $\chi \delta$ vo $\rho \circ \zeta$, cartilage ; $\iota \iota \varsigma$, inflammation ]. Pertaining to or affected with perichondritis.

Perichondritis (per-ik-on-dri'-tis) [ $[\pi \varepsilon \rho i$, around; $\chi \not ́ \nu \delta \rho \circ$, a cartilage; $\iota \tau \iota \zeta$, inflammation]. Inflammation of the perichondrium. P. auriculæ, hæmatoma auris, $q . v$.

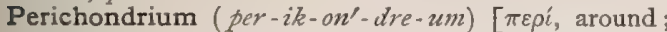
$\chi o ́ v \delta \rho o \zeta$, gristle, cartilage]. An envelop of connective tissue covering the surface of cartilage. It consists of a dense external or fibrous layer, and an inner looser stratum which is intimately concerned in the production of new cartilage and is known as the chondrogenic layer.

Perichondroma (per-ik-on-dro'-mah) [ $[\pi \varepsilon \rho i$, around; $\chi o ́ v \delta \rho o s$, cartilage; $\dot{o} \mu a$, tumor]. A tumor of the perichondrium.

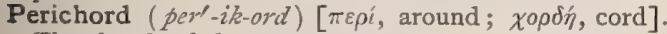
The sheath of the notochord.

Perichordal (per-ik-or'-dal) [ $\pi \varepsilon \rho i$, around; $\chi o \rho \delta \dot{n}$, a cord]. Pertaining to the perichord.

Perichoroid, Perichoroidal (per-ik-o'-roid, per-ik-o-

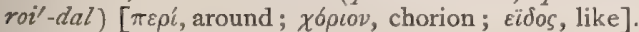
Surrounding the choroid.

Perichrisis (per-ik'-ris-is). Synonym of Inunction.

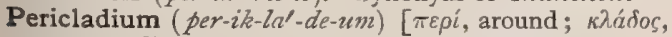
a young slip: $p l .$, Pericladia $]$. A sheathing petiole.
Periclasis (per-ik'-las-is) [ $\pi \varepsilon \rho \iota k \lambda \vec{a} \nu$, to twist around] A comminuted fracture.

Periclinal (per-ik-li'-nal) [ $\pi \varepsilon \rho i$, around; $k \lambda i \nu \varepsilon \iota v$, to bend, to slope]. In biology, applied to layers, cellwalls or lines when parallel to the external surface.

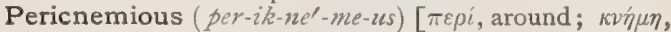
leg]. Surrounding the calf of the leg.

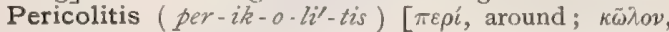
colon; $\iota \tau \iota \varsigma$, inflammation]. Inflammation of the tissues around the colon.

Pericolonitis (per-ik-o-lon-i'tis). Same as Pericolitis.

Pericolpitis (per-ik-ol-pi'-tis) [ $\pi \varepsilon \rho i$, around; $\kappa o ́ \lambda \pi o \varsigma$, vagina; $\iota \tau \iota s$, inflammation]. Inflammation of the areolar tissue surrounding the vagina.

Periconchal (per-ik-ong -kal) [ $\pi \varepsilon \rho i$, around; $\kappa 6 \gamma \gamma \chi \eta$, a shell]. Surrounding the concha of the ear. P. Sulcus, a sulcus separating the helix and the convex hinder surface of the concha.

Pericorneal (per-ik-or'-ne-al) [ $\pi \varepsilon \rho i$, around; corneus, honey]. Surrounding the cornea.

Pericowperitis (per-e-kow-per-i'-tis) [ $\pi \varepsilon \rho i$, around; Cozeper, an anatomist; $\iota T \ell s$, inflammation]. Inflammation of the tissues about Cowper's glands.

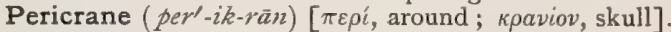
The pericranium; the skull. [Old.]

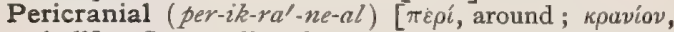
skull]. Surrounding the cranium. Pertaining to the pericranium.

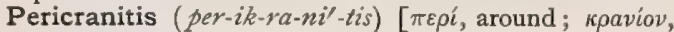
skull; $\iota \tau \iota \varsigma$, inflammation]. Inflammation of the pericranium.

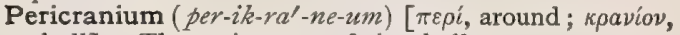
skull]. The periosteum of the skul].

Pericrany ( $\left.p e r^{\prime}-i k-r a-n e\right)$. Same as Pericranium.

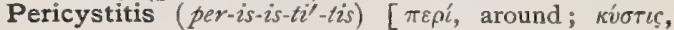
bladder; $\iota \tau \iota s$, inflammation]. Inflammation of the peritoneum or the connective tissue surrounding the bladder.

Pericystomatitis (per-is-is-to-mat-i'-tis) [ $\pi \varepsilon \rho i$, around ;

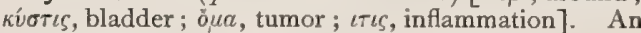
inflammation of the outer envelop of an ovarian cystoma.

Pericytula (per-is-it'-u-lah) [ $\pi \varepsilon \rho \hat{L}$, around; кútos, a cell]. A fecundated ovum before the beginning of superficial segmentation, while the formative yolk encloses the nutritive segmentation.

Peridectomy (per-id-ek'-to-me). Synonym of Peritomy.

Peridental (per-id-en'-tal). Synonym of Periodontal.

Peridentitis (per-id-en-ti'-tis). Synonym of Periodon. titis.

Peridentium (per-id-en'-she-um). See Periodontium.

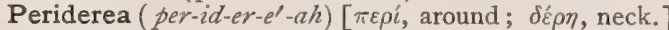
The coiling of the umbilical cord round the fetal neck.

Periderm (per'-id-erm) [ $\pi \varepsilon \rho i$, around; $\delta \varepsilon \hat{\varepsilon} \mu \alpha$, skin]. In biology: (a) a cell-wall or enclosing membrane; (b) the epiphloem; (c) the cortical layer of the cenosarc of a hydrozoan.

Peridermal, Peridermic (per-id-er'-mal, per-id-er'-

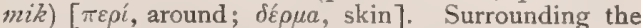
cuticle. Pertaining to the periderm.

Peridesmica (per-id-ez'-mik-ah) [ $\pi \varepsilon \rho \dot{\iota}$, around; $\delta \varepsilon \sigma \mu \delta \zeta$, band]. Retention of urine as a result of stricture of the urethra.

Peridesmitis (per-id-es-mi'-tis) [ $\pi \varepsilon \rho \hat{\imath}$, around ; $\delta \varepsilon \sigma \mu \delta s$, band; $\iota \tau \iota \varsigma$, inflammation]. Inflammation of the peridesmium.

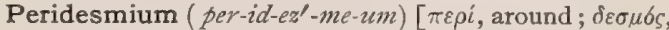
band]. The delicate membrane or covering that invests a ligament.

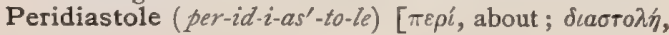


dilatation 1. The short interval that succeeds the diastole in the cycle of the heart's action.

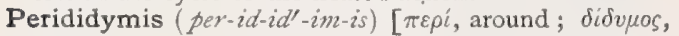
testicle]. The tunica albuginea testis.

Perididymitis ( $\left.p e \gamma^{-}-i d-i d-i m-i^{\prime}-t i s\right)$ [ $[\pi \varepsilon \rho i$, around ; $\delta i \delta v$. $\mu o \varsigma$, testicle; $\iota \tau \iota$, inflammation]. Inflammation of the perididymis.

Perididymium $\left(p e r-i d-i d-i m^{\prime}-e-u m\right)$. Synonym of Perididymis.

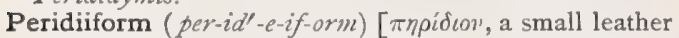
pouch; forma, form ]. In biology, having the form of a peridium.

Peridiodynia (per-id-e-o-din'-e-ah). Synonym of Cardialgia.

Peridiole $($ per-idl-e-ōl). Same as Peridiolum.

Peridiolum (per-id-i'-o-lum) [dim. of $\pi \eta p i \delta \delta c o v$, a little pouch]. In biology, the tunic of the sporangium in the Nidulariacea; a secondary or smaller peridium containing a hymenium.

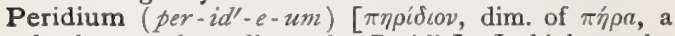
leather pouch, wallet: pl., Peridia $]$. In biology, the covering of a spore-case, as a puff-ball.

Periencephalitis (per-e-en-sef-al-i'-tis) [ $\pi \varepsilon \rho i$, around;

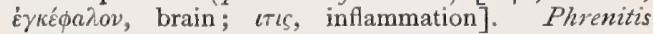
mania gravis; Typhomania, Bell's Disease (Luther Bell). Inflammation of the pia and of the superficies of the brain. The acute form is usually fatal, and is attended by stupor, wild delirium, general disturbance of the psychic functions, restlessness, convulsions, and fever. The chronic form is the so-called General Paralysis of the Insane.

Periendymal (per-e-en'-dim-al). Same as Periependymal.

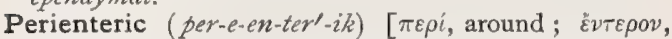
intestine]. Situated around the enteron ; perivisceral.

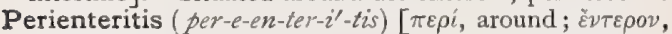
intestine; $\iota \tau \iota \varsigma$, inflammation] Inflammation of the intestinal peritoneum.

Perienteron (per-e-en'-ter-on) [ $\pi \varepsilon \rho i$, around; $\varepsilon \nu \tau \varepsilon \rho o \nu$, intestine]. The primitive perivisceral cavity; the space between the entoderm and the ectoderm, the forerunner of the schizocele or enterocele.

Periependymal (per-e-ep-en'-dim-al) [ [ $\varepsilon \rho i$, around;

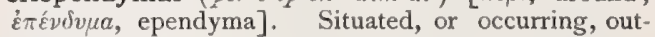
side the ependyma.

Perieresis (per-e-er'-es-is) [ $\pi \varepsilon \rho \iota a \iota \varepsilon \varepsilon \tilde{\nu}$, to take off ]. A circular incision around a tumor or abscess.

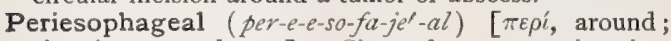
oiøoфáyos, esophagus]. Situated, or occurring, just outside of, or around, the esophagus.

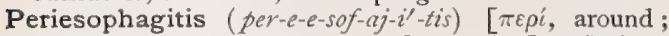
oiøoф́́yos, esophagus; $\iota \tau \iota s$, inflammation]. Inflammation of the tissues that surround the esophagus.

Perifascicular (per-e-fas-ik'-u-lar) [ $\pi \varepsilon \rho i$, around; fasciculus, a fascicle]. Surrounding a fasciculus.

Perifibral, Perifibrous, (per-if-i'-bral, per-if-i'-brus) [ $\pi \varepsilon \rho i$, around; fibra, a fiber]. Surrounding a fiber.

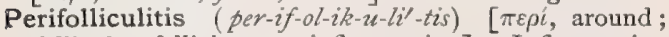
folliculus, follicle; $\iota \tau \iota s$, inflammation]. Inflammation around the hair-follicles. P., Conglomerative Pustular, a rare skin-affection, characterized by an eruption usually on the backs of the hands and on the buttocks, of from one to a dozen oval or roundish patches, from half an inch to two inches in diameter, and raised from about a line to a quarter of an inch. The surface is smooth or slightly mammillated and cribriform, the orifices being filled at first with pus, while the hairs, if any, have generally fallen out. There are also numerous unruptured superficial pustules. There is some itching and heat, but no pain or glandular enlargement. The disease is a local one of short duration and leaves no scar. The etiology is unknown.

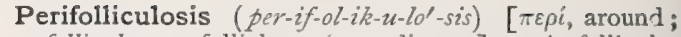
folliculus, a follicle; vóoos, disease $]$. A follicular skin-affection.

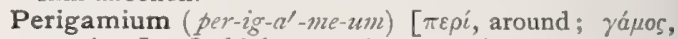
marriage]. In biology, an involucre in certain cryptogams, inclosing both male and female reproductive organs.

Perigangliitis (per-ig-ang-gle-i'-tis) [ $\pi \varepsilon \rho i$, around; $\gamma a ́ \gamma \gamma \lambda \iota 0 v$, ganglion: $\iota \tau \iota \varsigma$, intlammation]. Inflammation of the tissues surrounding a ganglion.

Periganglionic (per-ig-ang-gle-on'-ik) [ $\left[\varepsilon \varepsilon \rho^{\prime}\right.$, around; $\gamma a ́ \gamma \gamma h \iota v$, ganglion]. Situated, or occurring, around a ganglion. P. Glands, tubular glands found in the the spinal ganglia of frogs and other animals. They contain a milky, calcareous fluid.

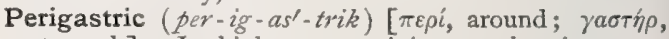
stomach]. In biology, pertaining to the tissues or spaces about the alimentary canal.

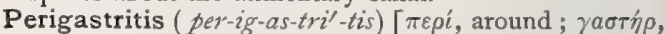
stomach; $\iota \tau \iota$, inflammation]. Inflammation of the peritoneal coat of the stomach.

Perigastrula (per-ig-as'-tru-lah) [ $\pi \varepsilon \rho i$, around; $\gamma a \sigma-$ Típ, belly, stomach : pl., Perigastrula]. In biology, the form of gastrula which results from the surfacecleavage of the egg; a bladder-gastrula, the common form among arthropods.

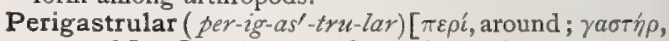
stomach]. Pertaining to the perigastrula.

Perigastrulation (per-ig-as-tru-la'-shun) [ $\pi \varepsilon \rho i$, around;

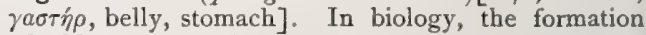
of a bladder-gastrula.

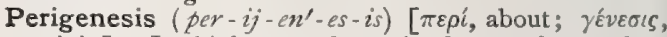
origin]. In biology, a dynamic theory of reproduction proposed by Cope and adopted by Hreckel. It explains inheritance by the transmission of the type of growth-force from one generation to another.

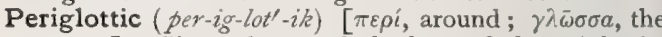
tongue]. Situated around the base of the epiglottis.

Periglottis (per-ig-lot'-is) $\left[\pi \varepsilon \rho \iota^{\prime}\right.$, around; $\gamma \lambda \tilde{\omega} \sigma \sigma a$, the tongue]. The mucous membrane or villous coating of the tongue.

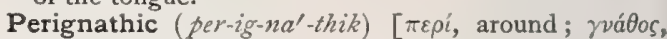
jaw]. Situated about the jaw.

Perigone (per'-ig-ōn) [ $\pi \varepsilon \rho \hat{\imath}$, around; yov'n, seed, generation.] See Perianth.

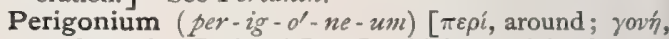
seed: pl., Perigonia $]$. In biology: $(a)$ the sac formed by the ectodermal layers of the gonophore of a hydroid; $(b)$ the leafy envelop surrounding the perianth of the antheridia in mosses.

Perigraph $\left(p e \gamma^{\prime}-i g-r a f\right)$ [ $[\pi \varepsilon \rho \dot{i}$, around; $\gamma \rho a ́ \phi \varepsilon \imath \nu$, to inscribe]. The linea alba and lineæ transversæ of the rectus abdominis muscle.

Perigyne ( per $\left.^{r}-i j-i n\right)$. Same as Perigynium.

Perigynium (per-ij-in'-e-um) [ $\pi \varepsilon \rho \hat{i}$, about; $\gamma v v \dot{\eta}$, a female: $p l .$, Perigynia $]$. In biology, a term applied to the scale-like or bristle-like bodies surrounding the pistils in sedges. Also, the envelop that in liverworts invests the archegonia.

Perigynous (per-ij'-in-us) [ $[\pi \varepsilon \rho i$, around; $\gamma v v \dot{n}$, a female]. In biology, applied to stamens and petals when they are adnate to the throat of the calyx, and therefore borne around the pistil instead of at its base.

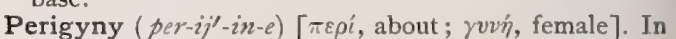
biology, the state or condition of being perigynous.

Perihepatic (per-e-he-pat'-ik) [ $\pi \varepsilon \rho \hat{i}$, around; $\dot{\eta} \pi a p$, liver]. Surrounding, or occurring around, the liver.

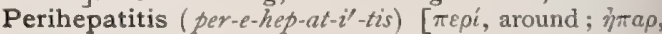
liver; $\iota \tau \iota \zeta$, inflammation]. Inflammation of the serous covering of the liver. It may be local, or a part of a general peritonitis. It is marked by severe pain, 
tenderness, some fever, slight jaundice, and a frictionsound.

Perikeratic (per-ik-er-at'-ik) [ $\pi \varepsilon \rho i$, around; képas, cornea]. Surrounding the cornea.

Perilaryngeal ( $\left.p e r-e-l a)^{-}-i n^{\prime}-j e-a l\right)$ [ $\pi \varepsilon \rho i$, around; $\lambda a ́ \rho v \gamma \xi$, larynx]. Situated, or occurring, around the larynx.

Perilaryngitis (per-il-ar-in-ji'-tis) [ $[\pi \varepsilon \rho$, , around; $\lambda \dot{\alpha} \rho v \gamma \xi$, larynx; $\iota T \iota \zeta$, inflammation]. Inflammation of the areolar tissue surrounding the larynx.

Perilymph (per'-il-imf) [ $\pi \varepsilon \rho i$, around; $\lambda \dot{v} \mu \phi \alpha$, lymph ]. The fluid separating the membranous from the osseous labyrinth. It is secreted by the delicate fibro-serous membrane lining the osseous labyrinth. See Liquor cotunniz.

Perilymphangial (per-il-im-fan'-je-al) [ $\pi \varepsilon \rho i$,

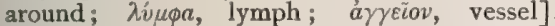
Situated, or occurring, around a lymphatic vessel.

Perilymphangitis (per-il-im-fan- $\ddot{j}^{\prime}$-tis) $[\pi \varepsilon \rho i$,

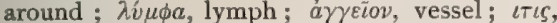
inflammation]. Inflammation of the tissues surrounding a lymphatic vessel.

Perilymphatic (per-il-im-fat'-ik) [ $\pi \varepsilon \rho i$, around; $\lambda_{i} \mu \dot{\phi} \alpha$, lymph]. Pertaining to the perilymph.

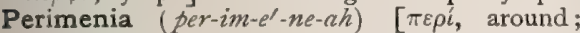
нinuaia, menses]. Hemorrhage around the uterus, occurring usually at the menstrual epoch.

Perimeningitis (per-im-en-in- $\left.\ddot{i}^{\prime}-t i s\right)[\pi \varepsilon \rho i$, around; $\mu \tilde{\eta} \nu \iota \gamma \xi$, membrane; $\iota \tau \iota \varsigma$, inflammation]. Inflammation of the dura, and surrounding tissues.

Perimeningoencephalitis (per-im-en-in'-go-ensef-al-i'-tis). Synonym of Periencephalitis.

Perimeninx (per-im-en'-inks). Synonym of Dura.

Perimeristem (per-im-er'-is-tem) [ $\pi \varepsilon \rho i$, around ;

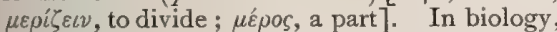
that part of the meristem from which is derived the ectal cortex and the dermatogen.

Perimeter (per-im'-et-er) [ $\pi \varepsilon \rho i ́$, around; $\mu \dot{c} \tau \rho o \nu$, measure]. An instrument for measuring the extent of

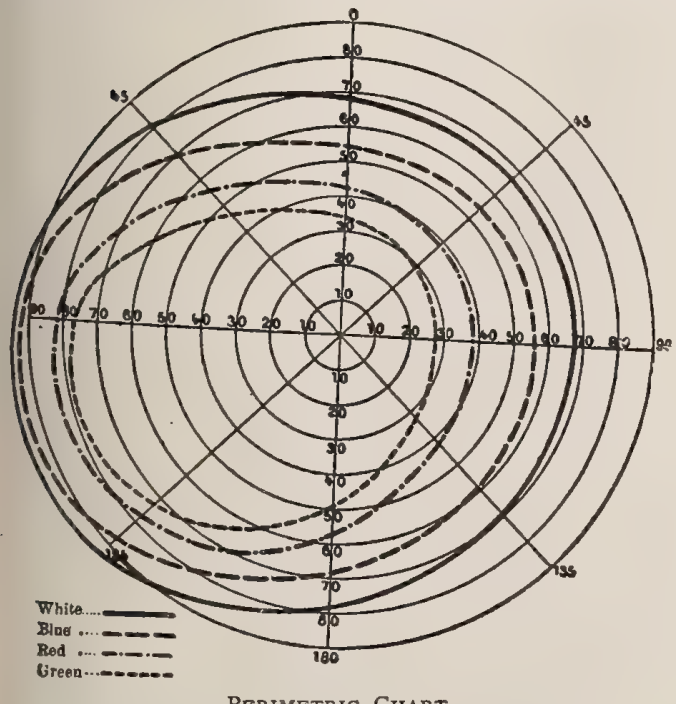

Perimetric Chart.

the field of vision. It consists ordinarily of a flat, narrow metal plate, bent in a semicircle, graduated in degrees, and fixed to an upright at its center by a pivot, on which it is movable. Variously colored

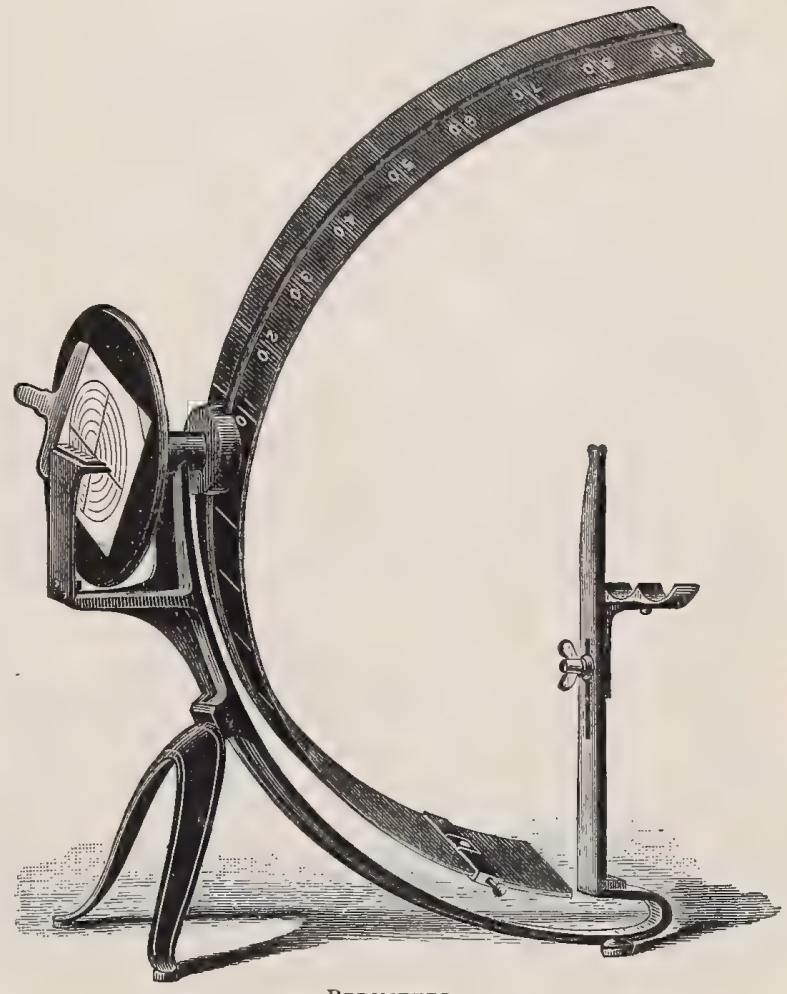

Perimeter.

discs are moved along the metal plate and the degree noted at which the person, looking directly in front of him, distinguishes the color.

Perimetral (per-im-e'-tral). Same as Perimetric.

Perimetric (per-im-et'-rik) $[\pi \varepsilon \rho \hat{i}$, around; $\mu \hat{\eta} \tau \rho \alpha$,

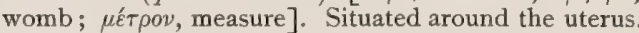
Pertaining to perimetry.

Perimetritic (per-im-et-rit'-ik) [ $\pi \varepsilon \rho i$, around; $\mu \hat{\eta} \tau \rho \alpha$, womb; $\iota \tau \iota s$, inflammation]. Pertaining to perimetritis.

Perimetritis (per-im-et-ri'-tis) [ $\pi \varepsilon \rho i$, around; $\mu \dot{\eta} \tau \rho \alpha$, womb; «Tes, inflammation]. Pelvic Peritonitis; inflammation of the peritoneal covering of the uterus. It is always secondary to inflammatory affections of the uterus, tubes, or ovaries. Three forms are described, viz.: the aulhesive, or most common variety ; the serous, or least common, and the suppurative, or most serious form. Pain, chills and fever are the main symptoms presented.

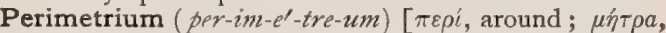
womb]. The serous covering of the uterus.

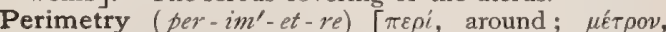
measure]. The measuring of the field of vision.

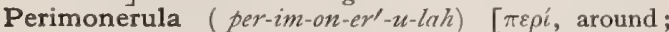

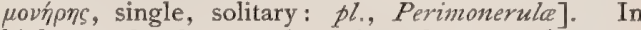
biology, a developmental cytode at the monerula stage, having formative yolk in the ectal wall and deutoplasm in the ental. It is succeeded by a pericytula, perimorula, periblastula, and perigastrula.

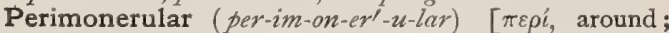
$\mu o v \eta \eta_{\eta} \eta$, single, solitary]. Pertaining to the perimonerula.

Perimorula (per-im-or'-u-lah) [ $\pi \varepsilon \rho i$, around; $\mu 6 \rho \circ \nu$, 
mulberry]. The ovum in the morula stage, in which the nutritive yolk is covered by a layer of cells developed from the formative yolk.

Perimorular (per-im-or'-u-lar) [ $[\pi \varepsilon \rho i$, around; $\mu$ ópov, mulberry]. Pertaining to the perimorula.

Perimyelis (per-im-i'-el-is) [ $[\pi \varepsilon \rho i$, around; $\mu v \varepsilon \lambda \sigma s$, marrow]. The medullary membrane or endosteum; the areolar envelop of the bone-marrow.

Perimyelitis (per-im-i-el-i'-tis) $\left[\pi \varepsilon \rho i\right.$, around; $\mu v \varepsilon \lambda \sigma_{s}$, marrow; $\iota \tau \iota s$, inflammation]. Spinal meningitis.

Perimysial (per-im-iz'-e-al) [ $[\pi \varepsilon \rho i$, around; $\mu \tilde{v} s$, muscle]. Of the nature of, or pertaining to, perimysium; enveloping a muscle.

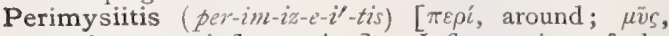
muscle; $\iota \tau \iota \zeta$, inflammation]. Inflammation of the perimysium

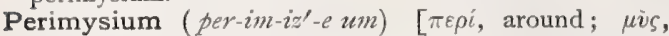
muscle: $p l .$, Perimysia $]$. In biology, the bands of connective tissue that envelop and separate the primary bundles of muscle-fibers from each other, as distinguished from the endomysium, which holds together the individual muscle-fibers, and the epimysium, which invests the entire muscle.

Perin $\left(p e r^{\prime}-i n\right)$ [ $\pi \varepsilon \rho i \nu$, a serous sac]. Perineum; also the scrotum.

Perinæum (per-in-e'-um). See Perineum.

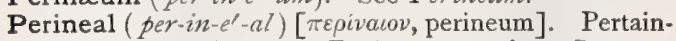
ing to the perineum. P. Aponeurosis. Same as P. Fascia. P. Artery. See Arteries, Table of. P. Body, the peculiar structure in the female, composed of skin, muscle, and fascia, and occupying the interval between the vagina and the rectum. P. Cystotomy, cystotomy performed through a perineal incision. P. Fascia, the fascia of the pelvic outlet. P. Flexure, a sharp bend in the rectum immediately above the anus. P. Fossa, the ischio-rectal fossa, situated between the rectum and the perineal muscles. P. Hernia, a rare form of hernia perforating the perineum by the side of the rectum or between the rectum and the bladder or the vagina. P. Nerve. See Nerves, Table of. P. Region, the perineum. P. Section, incision through the perineum for the relief of urethral stricture, the removal of calculi from the bladder, or the relief of other morbid conditions. P. Spasm. See Vaginodynia. P. Strait, the inferior pelvic strait.

Perineauxesis (per-in-e-awks-e'-sis) [ $\pi \varepsilon \rho i v a \iota 0 v$, perineum; $a v_{\zeta} /, \sigma \iota s$, growth]. The bulging of the perineum during labor.

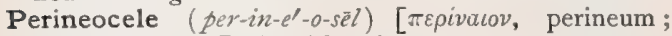
$\kappa \dot{n} \lambda \eta$, tumor]. Perineal hernia.

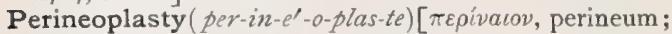
$\pi \lambda a ́ \sigma \sigma \varepsilon \iota$, to form ]. Plastic operation upon the perineum.

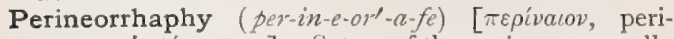
neum; $\dot{\rho} \alpha \phi y$, suture]. Suture of the perineum, usually in repair of a laceration caused during childbirth.

Perineosynthesis (per-in-e-o-sin'-thes-is) [ $\pi \varepsilon \rho i v a l o v$, perineum; $\sigma v \theta_{\varepsilon} \sigma \iota \zeta$, a placing together]. A plastic operation upon the perineum in which a graft of vaginal mucosa is made to cover the wound.

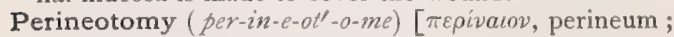
Toun, a cutting]. Incision through the perineum.

Perinephral (per-in-ef'-ral). Same as Perinephric.

Perinephrial (per-in-ef'-re-al) [ $\pi \varepsilon \rho i$, around; veфpós, kidney]. Pertaining to the perinephrium.

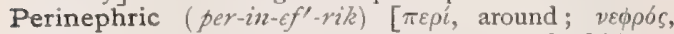
kidney]. Situated, or occurring, around the kidney. P. Abscess, an abscess in the tissues about the kidney.

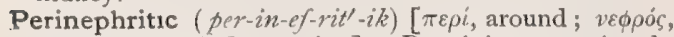
kidney ; $\iota \tau \iota$, inflammation]. Pertaining to perinephritis; improperly, same as perinephric.

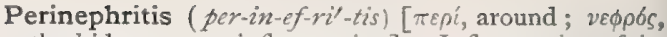
the kidney; $\iota \tau \iota \zeta$, inflammation]. Inflammation of the tissues surrounding the kidney. It may be either primary or secondary, usually the latter. It is marked by pain in one lumbar region, dull, aching in character, with tenderness over that region, slight fever, and slight rigors. If pus forms the symptoms are aggravated, and burrowing may occur in various directions.

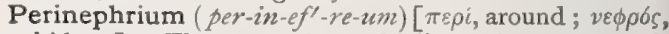
kidney]. The connective and adipose tissue surrounding the kidney.

Perineum (per-in-e -um) [ $\pi \varepsilon \rho i v \varepsilon o v$, or $\pi \varepsilon p i v a \iota \nu]$. That portion of the body included in the outlet of the pelvis, bounded in front by the pubic arch, behind by the coccyx and great sacro-sciatic ligaments, and at the sides by the tuberosities of the ischium. It includes all of the structures between the ischial tuberosities on either side, the anus posteriorly, and the vagina in the female and the scrotum in the male anteriorly. It is separated from the pelvic cavity by the recto-vesical fascia. It is occupied by the terminations of the rectum, the urethra, and the root of the penis, together with their muscles, fascix, vessels, and nerves. In a more restricted sense, the term perineum is applied to the space in advance of the anus (true perineum); in the female it is occupied by the termination of the vagina, the vulva, and the clitoris. The median line of the perineum presents a slight ridge, the raphé.

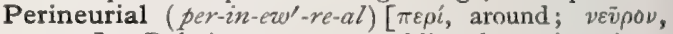
nerve]. Relating to or resembling the perineurium. P. Lymph-channels, lymph-spaces surrounding the nerve-trunks, as in the cornea.

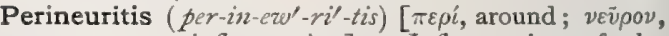
nerve; $t \tau \iota s$, inflammation]. Inflammation of the perineurium.

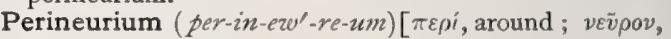
nerve: pl., Perineuria $]$. The connective-tissue sheath investing each funiculus or primary bundle of nerve-fibers; as distinguished from the endoneurium, which extends among and around the individual fibers, and the epineurium, which holds together and envelops the several funiculi of the nerve trunk.

Perinium (per-in'-e-um) [ $\pi \varepsilon \rho i$, around; is (iv), muscle, fibrous tissue in muscle]. In biology, the outer cellwall of the spores of Hepatice, often beautifully sculptured.

Perinuclear ( per-in-ez'-kle-ar) [ $\pi \varepsilon \rho i$, about; nucleus, a kernel]. In biology, of or pertaining to the protoplasm or other substances surrounding the nucleus of a cell. Surrounding the nucleus.

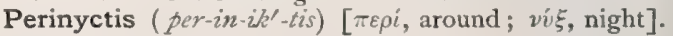
Same as Epinyctis.

Periocular (per-e-ok'-u-lar) [ $\pi \varepsilon \rho i$, around; oculus, eye]. Surrounding the eye. P. Space, the space between the globe of the eye and the orbital walls.

Period ( $\left.p e^{\prime}-r e-o d\right)$ [ $\pi \varepsilon p i o \delta o s$, period]. The space of time during which anything is in progress or at which an event takes place. Also the menses. P., Childbearing, the period, from puberty to the menopause, during which the female is capable of reproducing offspring. P., Dodging, a colloquial term for the menopause. P., Incubation. See Incubation. P., Menstrual, P., Monthly, the act of menstruation. P., Reaction. See Reaction-period. P., Respiratory, the interval between two successive inspirations.

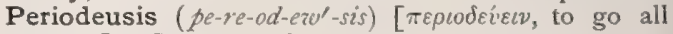
round]. Synonym of Quackery.

Periodic, Periodical (pe-re-od'-ik, pe-re-od'-ik-al)

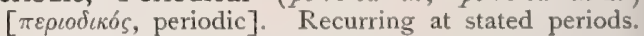
Having periods of recurrence and of intermission. P. Acid, $\mathrm{H}_{2} \mathrm{O}_{4}$. An oxyacid of iodin not yet obtained in the free state. P. Disease, one occurring at stated 
periods or times of the year, or one of which the manifestations recur at regular intervals, e.g., the malarial fevers, relapsing fever. P. Swelling. See Angio-neurotic Edema. P. Vomit of Leyden. See Angio-neurotic Edema.

Periodicity (pe-re-o-dis'-it-e) [ $\pi \varepsilon \rho i o d o s$, a period]. The tendency of certain diseases or morbid phenomena to recur at regular intervals.

Periodontal (per-e-o-don'-tul) [ $\pi \varepsilon \rho i$, around; ódoís, tooth]. I. Surrounding a tooth or its root. 2. The periosteum of an alveolus, or some other membrane or tissue surrounding a tooth.

Periodontitis (per-e-o-don-ti'-tis) [ $\pi \varepsilon \rho i$, about; ódoús, tooth; $\iota \tau \iota \zeta$, inflammation]. Inflammation of the peridental membrane, the lining membrane of the cavity of a tooth. See Pericementitis.

Periodontium (per-e-o-don'-she-um) [ $\pi \varepsilon \rho i$, around; odoús, tooth]. The membrane surrounding a tooth.

Periodoscope (pe-re-od'-o-sköp) [ $\pi \varepsilon p i o \delta o s$, a period; $\sigma \kappa o \pi \varepsilon i \nu$, to inspect]. A kind of dial to show the probable time of confinement.

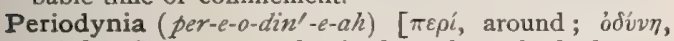
pain]. Severe general pain throughout the body.

Pericesophagitis (per-e-e-sof-aj-i'-tis). See Periesophagitis.

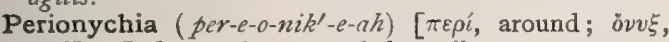
nail]. Inflammation around the nails.

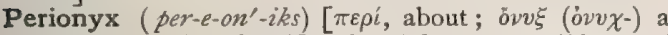
nail, claw, talon, hoof ]. In biology, a small band of the epitrichium (eponychium) which persists across the root of the nail in the development of that organ.

Perionyxis (per-e-o-niks'-is). Synonym of Perionychia.

Perioöphoritis (per-e-o-off-o-ri'-tis) [ $[\pi \varepsilon \rho i$, around;

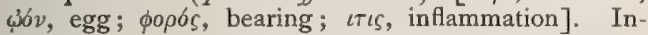
flammation of the peritoneum and connective tissue covering the ovary. It may be acute or chronic, and leads to the formation of adhesions. It is usually due to tubal disease.

Periophthalmitis (per-e-off-thal-mi'-tis) [ $\pi \varepsilon \rho i$, around; $\dot{\partial} \phi \theta a \lambda \mu o ́ s$, eye ; $\iota \tau \iota s$, inflammation]. Inflammation of the tissues surrounding the eye.

Perioptic (per-e-op $\left.p^{\prime}-t i k\right)$ [ $\pi \varepsilon \rho \dot{\prime}$, around; ó $\pi \tau \iota \kappa o ́ s$, seeing]. I. Surrounding the orbit, or the eye. 2. Of, or pertaining to, the tissues about the eye.

Periopticon (per-e-op'-tik-on) [ $\pi \varepsilon \rho i$, about; ó $\pi \tau \iota \kappa \delta s$, of seeing]. In biology, a complex nerve-structure just back of the hasilar membrane in the eyes of insects. (S. J. Hickson.)

Perioptometry (per- $\left.\ell-o p-t o n^{\prime}-e t-r e\right)[\pi \varepsilon \rho i$, around;

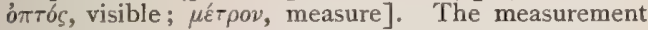
of the limits of the visual field in its several dimensions. It includes, also, the detection and measurement of defects in the field of vision.

Perioral (per-e-o'-ral) [ $[\pi \varepsilon \rho i$, around; os, oris, the mouth]. Surrounding the mouth; circumoral.

Periorbita (per-e-or'-bit-a/l) [ [ $\varepsilon \varepsilon \rho i$, around ; orbita, orbit]. The periosteum of the eye-socket.

Periorbital (per $\left.-e-o r^{\prime}-b i t-a l\right)[\pi \varepsilon \rho i$, around; orbita, orbit]. Pertaining to the periosteum of the socket of the eye or to the tissues about the orbit.

Periorbitis (per-e-or-bi'-tis) [ $\pi \varepsilon \rho i$, around; orbita, orbit; $\iota \tau \iota \zeta$, inflammation]. Inflammation of the periorbita.

Periorchitis (per-e-or-ki'-tis) [ $\pi \varepsilon \rho \rho^{\prime}$, around; ǒ $\rho \chi \iota s$, testicle; $\iota \tau \iota s$, inflammation]. Inflammation of the tissues surrounding the testicle, especially of the tunica vaginalis testis. P. adhæsiva, a form in which adhesions between the two layers of the tunica vaginalis are formed.

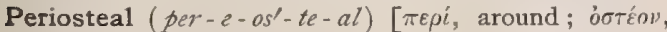
bone]. Pertaining to the periosteum. P. Bone, the bone formed by the cells of the osteogenic layer of the periosteum, as distinguished from the central spongy endochondral bone. P. Reflex. See Reflexes. Table of.

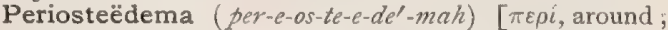

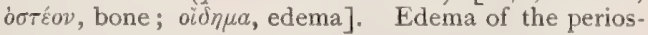
teum.

Periosteitis (per-e-os-te-i'-tis). See Periostitis.

Periosteoma (per-e-os - te- $\left.o^{\prime}-m a h\right)$ [ $\pi \varepsilon \rho i$, around;

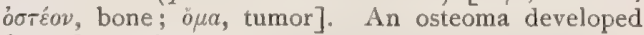
from the periosteum.

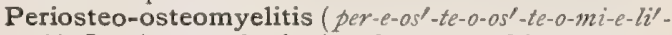

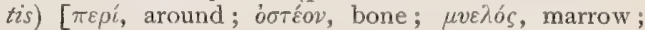
$\iota \tau \iota$, inflammation]. Inflammation of the periosteum and medulla of a bone.

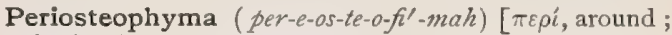
óøtéov, bone; $\phi \tilde{v} u a$, growth]. Swelling of the periosteum; also, a periosteophyte.

Periosteophyte $\left(p e r-e-o s^{\prime}-t e-o-f \bar{i} t\right)[\pi \varepsilon \rho \dot{i}$, around;

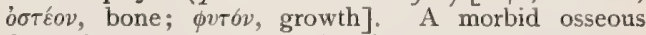
formation upon or proceeding from the periosteum.

Periosteosis (per-e-os-te-o'-sis). Synonym of Periostosis.

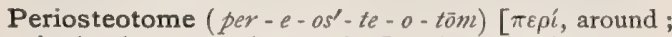

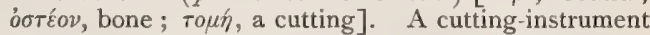
for use in periosteotomy.

Periosteotomy (per-e-os-te-ot'-o-me) [ $\pi \varepsilon \rho i$, around;

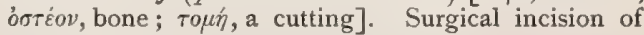
the periosteum.

Periosteous (per-e-os'-te-us). Same as Periosteal.

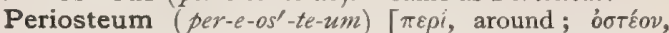
bone]. A fibrous membrane that invests the surfaces of bones, except at the points of tendinous and ligamentous attachment, and on the articular surfaces, where cartilage is substituted. At the attachment of tendons the periosteum blends with the fibers of the tendons. The periosteum consists of two layers, an ectal, fibrous, and an ental, osteogenetic layer. The periosteum serves as a medium for the attachment of tendons, and as the means of nourishment and regeneration of bone.

Periostitic (per-e-os-tit'-ik) [ $\pi \varepsilon \rho i$, around ; ótéov, bone ; $\iota \tau \iota \varsigma$, inflammation]. Pertaining to, resembling, or affected with, periostitis.

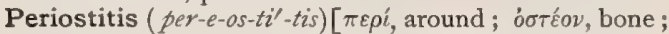
$\iota \tau \iota$, inflammation]. Inflammation of the periosteum. $P$., Dental, inflammation of the investing membrane of the roots of the teeth. P., Diffuse, a serious inflammation usually involving the periosteum of long bones. P., Hemorrhagic, a condition accompanied by bleeding between the periosteum and the bone.

Periostoma (per-e-os-to'-mah) [ $\pi \varepsilon \rho \hat{l}$, around; botŕov, bone; öua, tumor]. Any morbid osseous growth occurring on or surrounding a bone.

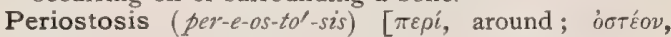
bone]. The formation of periostoma. Inflammatory hypertrophy of bone.

Periostotomy (per-e-os-tot'-o-me). Synonym of Periosteotomy.

Periostracal (per-e-os'-trak-al) [ $\pi \varepsilon \rho \hat{l}$, around; ö $\sigma \tau \rho \alpha-$ $\kappa o v$, a shell]. Pertaining to the periostracum.

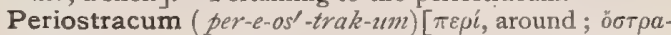
kov, shell]. In biology, the horny epidermis investing the shells of molluscs.

Periotic (per-e-o'-tik) [ $\pi \varepsilon \rho^{\prime}$, around; ov $\varsigma$, ear]. I. Situated or occurring around the ear. A term also applied to the petrous and mastoid parts of the temporal bone. 2. Of or pertaining to the region or tissues immediately about the internal or true ear. P. Capsules, Huxley's name for the independent cartilages that appear very early around the otocysts and later become integral parts of the primitive chondrocranium by coalescing with the occipital cartilage. It 
is not known whether they represent primarily distinct skeletal pieces or merely separate centers of chondrification of a larger mesochymal skeletal piece; probably the latter.

Periovular (per-e-o'-vu-lar) [ $\pi \varepsilon \rho i$, around; ovum, egg]. Surrounding the ovum.

Peripachymeningitis ( $p e r-i p$-ak-im-en-in-ji'tis) $[\pi \varepsilon p i$, around; $\pi a \chi v \dot{v}$, thick; $\mu \tilde{\eta} \nu \iota \gamma \xi$, membrane; $\iota \tau \iota \varsigma$, inflammation]. Inflammation of the connective tissue between the spinal dura and the vertebræ.

Peripancreatitis (per-ip-an-kre-at-i'-tis) [ $\pi \varepsilon \rho i$, around; $\pi \hat{\gamma} \gamma \kappa \rho \varepsilon \alpha \varsigma$, pancreas; $\iota \tau \iota$, inflammation]. Inflammation of the tissue about the pancreas.

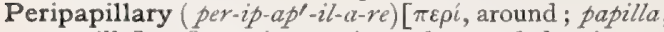
a papilla]. Occurring or situated around the circumference of a papilla, and especially of the optic disc.

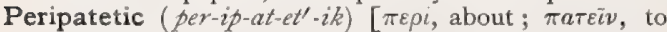
walk]. Walking about, as in "walking typhoid." Also, a disciple of Aristotle, who instructed his pupils while walking.

Peripenial (per-ip-e'-ne-al) [ $\pi \varepsilon \rho i$, around ; penis, penis]. Surrounding the penis.

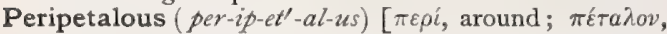
a leaf ]. In biology, situated $(a)$ about the petals of a flower, or $(b)$ about the petaloid ambulacra of a seaurchin.

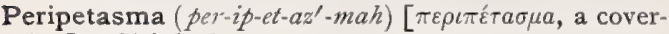
ing]. Sick-bed.

Periphacitis (per-if-a-si'-tis) [ $\pi \varepsilon \rho \dot{c}$, around ; $\phi a \kappa o ́ s$, crystalline lens ; $\iota \tau \iota$, inflammation]. Inflammation of the periphacus.

Periphacus (per-if-a'-kus) [ $\pi \dot{\varepsilon} \rho \dot{i}$, around; $\phi a \kappa o ́ s$, crystalline lens]. The capsule surrounding the crystalline lens.

Peripharyngeal (per-if-ar-in'-je-al) [ $[\pi \varepsilon \rho i$, around ; 'фápvy, the throat]. In biology, surrounding the pharynx.

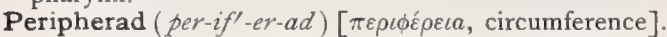
Toward some peripheral part, or the peripheral aspect. See Position and Direction, Table of.

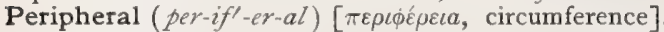
Pertaining to or placed near the periphery. In anat omy, pertaining to the parts, nerves, or blood-vessels located distally, in contradistinction to central. See Position and Direction, Trble of. P. Akinesia, akinesia due to some lesion of the anterior cornua of the gray matter of the cord, the motor nerves, or the muscles. P. Anesthesia, anesthesia due to lesion of the sensory nerves or end-organs. P. Epilepsy, epilepsy due to lesion of the brain-cortex. P. Neuritis, neuritis of the peripheral nerves. P. Organs, in biology, organs distinctly separated from the main part of the body.

Peripheren (per-if'-er-en) [ $\pi \varepsilon \rho \iota \phi \varepsilon \rho \varepsilon \iota a$, circumference]. Belonging to the periphery in itself.

Peripheric (per-if'-er-ik). Synonym of Peripheral.

Peripheritis (per-if-er-i'-tis). Synonym of Periophthalmitis.

Periphery (per-if'-er-e) [ $\pi \varepsilon \rho \iota \phi \varepsilon ́ \rho \varepsilon \iota \alpha ; \pi \varepsilon \rho \dot{i}$, around; $\phi \varepsilon \rho \varepsilon \nu$, to carry]. The line bounding any surface. The ectal part in contradistinction to the ental; the surface of the body.

Periphimosis (per-if-i-mo'-sis). Synonym of Paraphimosis.

Periphlebitic (per-if-leb-it'-ik) [ $\pi \varepsilon \rho i$, around; $\phi \lambda \varepsilon \psi$, vein; $\iota \tau \iota \zeta$, inflammation $]$. Pertaining to, affected with, or of the nature of, periphlebitis.

Periphlebitis (per-if-leb-i'tis) [ $\pi \varepsilon \rho \hat{i}$, around; $\phi \lambda \dot{\varepsilon} \psi$, vein; $\iota \tau \iota s$, inflammation]. Inflammation of the ectal coat of a vein.

Periphoranthium (per-if-or-an'-the-um) [ $\pi \varepsilon \rho \iota \phi o \rho a$, a circuit; ä $\nu \theta 0 \varsigma$, a flower]. See Periclinium.
Periphractolichen (per-if-rak-to-li'-ken) [ $\pi \varepsilon p i \phi \rho a \kappa т o s$, fenced around; $\lambda \iota \chi^{\eta} \eta$, lichen]. Circumscribed lichen.

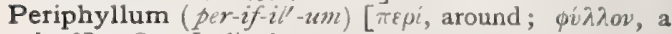
leaf ]. See Lodicule.

Periphyse (per'-if-iz). Same as Periphysis.

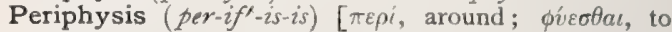
grow: pl., Periphyses]. In biology, one of the filamentous structures arising from the hymenium of a fungus at places where there are no asci, for example, in the region of the neck. Sometimes the periphyses protrude through the osteole. They are always present in greater or less numbers except, according to Fuiisting, in Massaria; while Paraphyses are absent from a number of genera both of fungi and lichens. (Bennett and Murray.)

Periplasm (per'-ip-lazm) [ $\pi \varepsilon p \ell$, around ; $\pi \lambda a ́ \sigma \mu a$, anything formed]. In biology, a peripheral layer of protoplasm, as that surrounding the oösphere, or the gonoplasm of the antherid, in the Oömycetes.

Periplast (per'-ip-last) [ $\pi \varepsilon \rho i$, around; $\pi \lambda a ́ \sigma \sigma \varepsilon \iota v$, to mold, form]. In biology, the periblast or matrix of a part or organ ; the intercellular substance, or stroma.

Periplastic (per-ip-las'-tik) $[\pi \varepsilon \rho i$, around; $\pi \hat{n} \dot{a} \sigma \sigma \varepsilon \iota v$, to mold, to form ]. In biology : (a) Of or pertaining to or resembling the matrix or periplast of a part or organ: (b) The cell-substance about the nucleus or endoplast ; perinuclear protoplasm.

Peripleuritis (per-ip-lu-ri'-tis) [ $\pi \varepsilon \rho i$, around; $\pi \lambda \varepsilon v \rho \delta v$, side ; $\iota \tau \iota$, inflammation]. Inflammation of the tissues surrounding the pleura.

Peripneumonia (per-e-nu-mo'-ne-ah) [ $\pi \varepsilon \rho i$, around ;

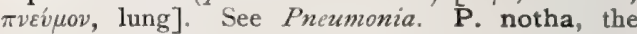
false pneumonia of the older writers; the same as capillary bronchitis. See Bronchitis, Capillary.

Peripneustic (per-e-nüs'-tik) [ $\pi \varepsilon p i$, about; $\pi \nu \varepsilon v \sigma \tau \iota k \delta s$, of or for breathing]. In biology, applied to that state of the tracheal system in the majority of insect larvæ which undergo complete metamorphosis. in which the stigmata of those segments which in the imago carry wings, are closed, the stigmatic strands belonging to these parts being present as rudiments. Cf. amphipneustic, apneustic, holopneustic, metapneustic.

Peripolar (per-ip-ó-lar) [ $[\pi \varepsilon \rho \hat{\imath}$, around; $\pi \dot{\lambda} \lambda o s$, pivot]. Surrounding poles. P. Zone. See Zone.

Periportal (per-ip-or'-tal) [ $\pi \varepsilon \rho i$, around; porta, door]. Surrounding the portal vein. P. Carcinoma, a primary carcinoma developing around the portal vein, beginning at its entrance into the liver, thence extending along the portal vessels to the remotest branches.

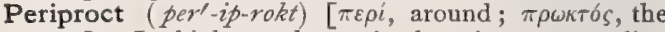
anus]. In biology, the parietal region surrounding the anus in an echinoderm.

Periproctal, Periproctic (per-ip-rok'-tal, per-ip-rok'tik) $[\pi \varepsilon \rho i$, around; $\pi \rho \omega \kappa \tau o ́ s$, anus ]. Surrounding the anus or rectum.

Periproctitis (per-ip-rok-ti'-tis) [ $\pi \varepsilon \rho i$, around; $\pi \rho \omega \kappa \tau \sigma \varsigma$, anus; $\iota \tau \iota s$, inflammation]. Inflammation of the areolar tissue about the rectum or anus.

Periproctous (per-ip-rok'-lus) [ $\pi \varepsilon \rho i$, around; $\pi \rho \omega k \tau o ́ s$, the anus]. In biology, circumanal.

Periprostatic (per-ip-ros-tat'-ik) [ $\pi \varepsilon \rho i$, around; $\pi \rho \circ-$ $\tau a ́ \tau \eta$, one standing before]. Situated or occurring around the prostate.

Periprostatitis (per-ip-ros-tat- $\left.i^{\prime}-t i s\right)$ [ $\pi \varepsilon \rho^{\prime}$, around;

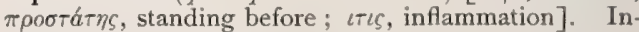
flammation of the tissues situated around the prostate.

Peripsyxis (per-ip-siks'-is) [ $\pi \varepsilon p i$, around; $\psi \tilde{v} \xi \iota s$, a cooling]. The shivering of fever; a general fall of the temperature of the body.

Peripterous (per-iṕ-ter-us) [ $\pi \varepsilon \rho i$, around; $\pi \tau \varepsilon \rho$ on $^{\prime}$, a wing]. In biology, feathered on all sides, or surrounded by a wing-like expansion. 


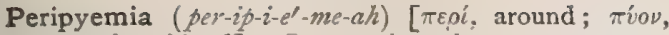
pus; ai $\mu \alpha$, blood]. Suppuration about an organ or tissue.

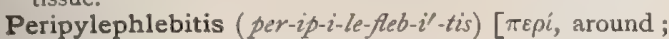
$\pi i \lambda \eta$, gate, porta ; $\phi \lambda \hat{\varepsilon} \psi$, vein; $\iota \tau \iota \varsigma$, inflammation]. Inflammation of the tissues surrounding the portal vein, or of its ectal coat.

Perirectal (per-ir-ek'-tal) [ $\pi \varepsilon \rho i$, around; rectum, rectum]. Surrounding the rectum.

Perirenal (per-ir-e'-nal) [ $\pi \varepsilon p i$, around; ren, kidney]. Around the kidney.

Perirhinal (per-ir-i'nal) [ $\pi \varepsilon \rho i$, around; pis, nose]. Situated about the nose or nasal fossæ.

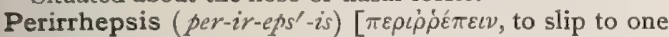
side ]. The slipping of a bandage from its proper place.

Peris (pe'-ris) [ $\pi \eta \rho i c]$. Vagina; scrotum; perineum.

Perisalpingitis (per-is-al-pin-jít-tis) [ $[\pi \varepsilon \rho i$, around; $\sigma a ́ \lambda \pi \iota \gamma \xi$, tube ; $\iota \tau \iota \varsigma$, inflammation]. Inflammation of the peritoneal covering of the oviduct.

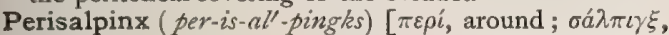
tube]. The peritoneum covering the upper border of the Fallopian tube.

Perisarc $\left(\right.$ per $\left.^{\prime}-i s-a r k\right)$ [ $\pi \varepsilon \rho i$, around; $\sigma a ́ \rho \xi$, flesh]. In biology, the chitinous sheath or horny exoskeleton of a hydrozoan polyp.

Perisarcoma (per-is-ar-ko'-mah). Same as Rhinoscleroma.

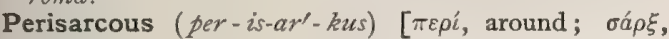
flesh]. In biology, consisting of perisarc; having the character or function of perisarc.

Periscopic (per-is-kop'-ik) [ [ $\pi \varepsilon \rho i$, around; $\sigma \kappa o \pi \varepsilon i v$, to see]. Applied to lenses having a concave surface upon one side and a convex upon the other, either having the smaller radius of curvature, so that the lens may as a whole be positive or negative (concavo-convex, or convexo-concave); it is called, also, meniscus. The object of such lenses is to eliminate spheric aberration, and allow the observer to look more obliquely through them. P. Ocular. See Ocular.

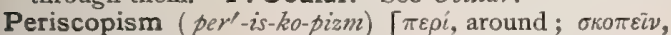
to see]. The power or faculty of periscopic vision.

Periscythismus (per-is-si-thiz'-mus) [ $\pi \varepsilon \rho i$, around; oкvфiov, the skull]. Scalping, -an old operation for headache.

Perisialdochitis (per-is-si-al-do-ki'-tis) [ $\pi \varepsilon \rho \dot{i}$, around;

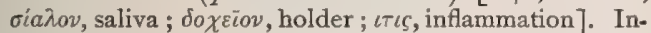
flammation of connective tissue around Stenson's duct.

Perisigmoiditis (per-is-ig-moi-di'-tis) [ $\pi \varepsilon \rho i$, around;

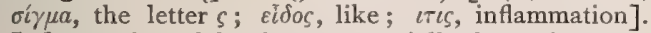
Inflammation of the tissues, especially the peritoneum, covering the sigmoid flexure of the colon.

Perisinusitis (per-e-si-nu-si'-tis) [ $\pi \varepsilon \rho i$, around; sinus, a curve, fold; itıs, inflammation]. Inflammation about a cerebral sinus.

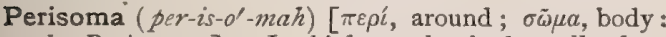
pl., Perisomata]. In biology, the body-wall of an echinoderm.

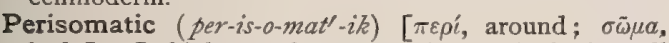
body]. In biology, of or pertaining to the body-wall of an echinoderm. P. Plates, portions of the coriaceous or calcareous exoskeleton of an echinoderm.

Perisome (per'-is-ōm). Same as Perisoma.

Perisomial (per-is-o'-me-al). Same as Perisomatic.

Perisperm (per'-is-perm) [ $\pi \varepsilon \rho^{\prime}$, around; $\sigma \pi \hat{\varepsilon} \rho \mu a$, the seed]. In biology, the albumin of a seed outside the embryo-sac.

Perispermatitis (per-is-per-mat-i'-tis) [ $\pi \varepsilon \rho i$, around ; $\sigma \pi \varepsilon \varepsilon^{\prime} \rho \alpha$, seed ; $\iota \tau \iota s$, inflammation]. Inflammation around the spermatic cord, with an effusion of fluid; a funicular hydrocele.

Perispermic (per-is-per'-mik) [ $\pi \varepsilon \rho \dot{\imath}$, around; $\sigma \pi \varepsilon \dot{\varepsilon} \rho \alpha$, seed]. In biology, characterized by perisperm.
Perisphalsis (per-is-fal"-sis). Synonym of Circumaiction.

Perispheric (per-is-fer'-ik) [ $\pi \varepsilon \rho i$, around; $\sigma \phi a i p a$, sphere]. Having the form of a ball; globular.

Perisphinxis (per-is-finks'-is) [ $\pi \varepsilon \rho i$, around; $\sigma \dot{\phi} i \gamma^{\prime} \xi \iota$, constriction]. Ligation.

Perisplenic (per-is-plen'-ik) [ $\pi \varepsilon \rho i$, around; $\sigma \pi \lambda \hat{n}$, spleen]. Situated or occurring near the spleen.

Perisplenitis (per-is-ple-ni'-tis) [ $\pi \varepsilon p i$, around; $\sigma \pi \lambda \eta \dot{v}$, spleen; $\iota \tau \iota$, inflammation ]. Inflammation of the serous or peritoneal coat of the spleen.

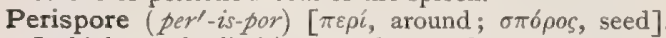
In biology, the limiting membrane of a spore.

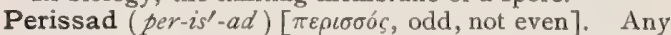
atom or element of uneven quantivalence, e.g.,nitrogen, capable of grasping three or five, boron three, and chlorin one, monad atom. In biology, a perissodactyl.

Perissodactyl (per-is-o-dak'-til) [ $\pi \varepsilon \rho \iota n \sigma o ́ s$, beyond

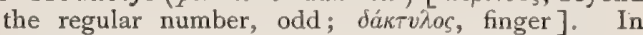
biology, an odd-toed quadruped; a member of welldefined groups of ungulate mammals, the only living representatives of which are the tapirs, rhinoceroses, and horses, which are but the surviving remnants of a very extensive and much varied assemblage of animals which flourished during the tertiary period.

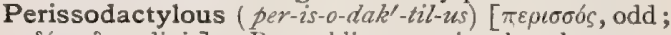

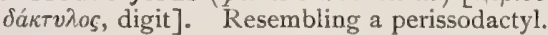

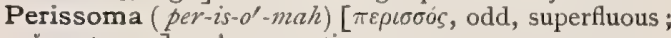
o $\mu \alpha$, tumor]. An excretion.

Peristalsis (per-is-tal'-sis) [ $\pi \varepsilon \rho i$, around ; $\sigma \tau a ́ \lambda \sigma \iota \varsigma$, constriction]. The peculiar movements of the intestine and other tubular organs, consisting in a vermicular shortening and narrowing of the tube, thus propelling the contents onward. It is due to the successive contractions of bundles of longitudinal and circular muscular fibers. See Antiperistalsis, Aperistalsis, Dysperistalsis, Euperistalsis. P., Reversed, peristaltic movement opposite to the normal direction.

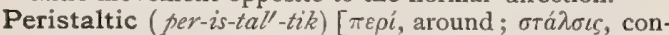
striction]. Pertaining to or resembling peristalsis. P. Movements, vermicular movements of hollow viscera. P. Unrest, an extremely common and distressing symptom of neurasthenia. It consists of increased peristaltic movements of the stomach coming on shortly after eating, with borborygmi and gurgling. $P$. Wave, the wave produced by the rapid advance of the peristaltic movements.

Peristaphyleus (per-is-taf-il-ef-us) [ $\pi \varepsilon \rho i$, around; $\sigma \tau \alpha-$ $\phi v \lambda \dot{n}$, uvula]. A muscle connected with the uvula. $\mathbf{P}$. externus, $\mathbf{P}$. inferior, the abductor of the Eustachian tube. P. internus, P. superior, the levator palati. See Muscles, Table of.

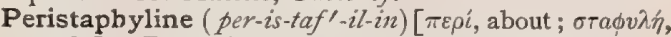
uvula]. Pertaining to or situated near the uvula.

Peristaphylo-pharyngeus (per-is-taf'-il-o-far-in-je'$u s)$ [ $\pi \varepsilon \rho \dot{i}$, around; $\sigma \tau a \phi v \lambda \dot{n}$, uvula ; $\phi a ́ \rho v \gamma \xi$, pharynx]. The palato - pharyngeus muscle. See Muscles, Table of.

Peristem (per'-is-tem). An abbreviation of Perimeristem.

Peristethium (per-is-te'-the-um) [ $\pi \varepsilon \rho^{\prime}$, around; $\sigma \tau \tilde{\eta}$ (tos, the breast : pl., Peristethia]. See Mesosternum.

Peristole $\left(p e r-i s^{\prime}-t o-l e\right)[\pi \varepsilon \rho \iota \sigma \tau o \lambda \eta]$. Peristalsis.

Peristoma (per-is'-to-mah). See Peristome.

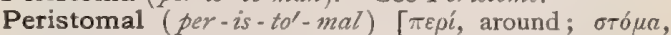
mouth]. Surrounding the mouth.

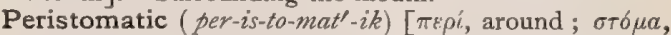
mouth]. In biology, pertaining to the peristome.

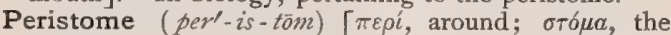
mouth]. In biology: (a) the parietal region surrounding the mouth, as the oral disc of a polyp; (b) the 
fringe of hair-like appendages about the orifice of a moss capsule.

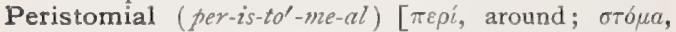
mouth]. In biology: (a) pertaining to a peristome; (b) situated around the mouth

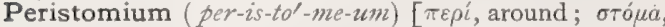
a mouth: pl., Peristomia $]$. In biology, a peristome.

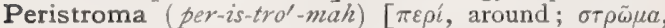
covering]. The internal layer of a tube-like organ. The villous coat of the intestines.

Perisynovial (per-is-i-no'-ve-al) [ $[\pi \varepsilon \rho \dot{\ell}$, around; oiv, with; $b^{\circ} v$, egg]. Situated or occurring around a synovial membrane.

Perisystole (per-is-is'-to-le) [ $[\pi \varepsilon \rho i$, around; $\sigma v \sigma \tau o \lambda \dot{n}$, contraction]. The slight interval between the systole and diastole.

Peritendineum (per-it-en-din'-e-um) [ $[\pi \varepsilon \rho \hat{\imath}$, around; tendo, tendon]. The tissue surrounding the tendons like a sheath.

Periterion (per-it-e'-re-on). Synonym of Trephine.

Peritestis (per-it-es'-tis) [ $\pi \varepsilon p i$, around; testis, testicle]. The tunica albuginea.

Perithece (per'-ith-ës). Same as Perithecium .

Perithecial (per-ith-e $-s e-a l)[\pi \varepsilon \rho i$, around; $A \dot{\eta} \kappa \eta$, cover]. Pertaining to or of the nature of a perithecium.

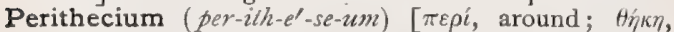
cover: $p l .$, Perithecia $]$. In biology, the envelop covering the fructification of various species of fungus. The flask-shaped organs seen in ergot are perithecia. The receptacle for the asci in Ascomycetes and lichens.

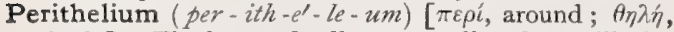
nipple]. The layer of cells surrounding the capillaries and smaller vessels.

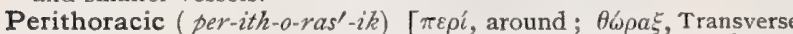
thorax]. Situated or occurring around the thorax.

Perithral Cells (per-ith'-ral). Plasma-cells surround-Mesenter ing the walls of blood-vessels.

Perithyroiditis (per-ith-i-roid-i'-tis) [ $\pi \varepsilon \rho i$, around;

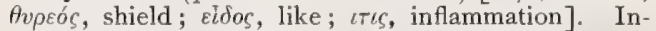
flammation of the capsule of the thyroid gland.

Peritomist (per-it'-o-mist) [ $\pi \varepsilon \rho i$, around; $\tau o \mu \eta^{\prime}$, a cutting]. A circumciser. One who practises peritomy.

Peritomy (per-it'-o-me) [ $\pi \varepsilon \rho i$, around; $\tau o u n$, a cutting]. I. The removal of a riband of conjunctival and subconjunctival tissue from about the cornea, for the relief of pannus. 2. Circumcision.

Peritonæum (per-it-on-e'-um). See Peritoneum.

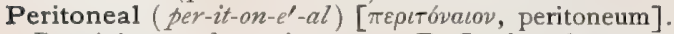
Pertaining to the peritoneum. P. Cavity, the space within the peritoneal folds. P. Fever. Synonym of Peritonitis.

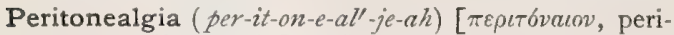
toneum; à $\lambda$ yos, pain $]$. Neuralgia of the peritoneum.

Peritoneoclysis, Peritoneoklysis (per-it-o-ne-ok'-

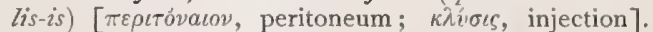
The injection of liquids into the peritoneal cavity.

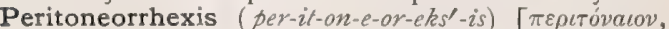
peritoneum; $\dot{\rho} \bar{\eta} \xi \iota$, rupture]. Rupture of the peritoneum.

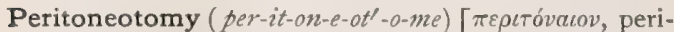

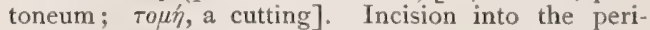
toneum.

Peritoneum (per-it-on-e $\left.e^{\prime}-\imath m\right)$ [ $\pi \varepsilon \rho \iota$, around; $\tau \varepsilon i v \varepsilon \iota \nu$, to stretch]. The serous membrane lining the interior of the abdominal cavity and surrounding the contained viscera. The peritoneum forms a closed sac, but is rendered complex in its arrangement by numerous foldings produced by its reflection upon the viscera. In tracing its extension we may begin at the diaphragm and take two layers. From the diaphragm two layers of peritoneum proceed to the liver, forming its lateral ligaments; they separate to enclose the liver, meet again on its under aspect, and pass on, as the gastro-hepatic omentum, to the lesser curvature of the stomach. Separating here, they embrace the stomach, and, meeting again at its greater curvature, pass down, like an apron, in front of the small intestine, forming the great onentum. At the lower edge of the latter they are reflected upward as far as the transverse colon, which they enclose, meeting again at the back of the colon, and proceeding to the spine as the transverse mesocolon. Here the two layers diverge; the upper ascends in front of the pancreas to the under surface of the diaphragm, the starting-point. The lower layer is reflected from the spine, over the small intestines, and back again to the spine, to form the mesentery. From the root of the mesentery it passes into the pelvis, invests the upper part of the rectum, and is thence reflected on the bladder, forming between the two the recto-vesical pouch. In the female it is reflected from the rectum to the upper part of the vagina, and thence

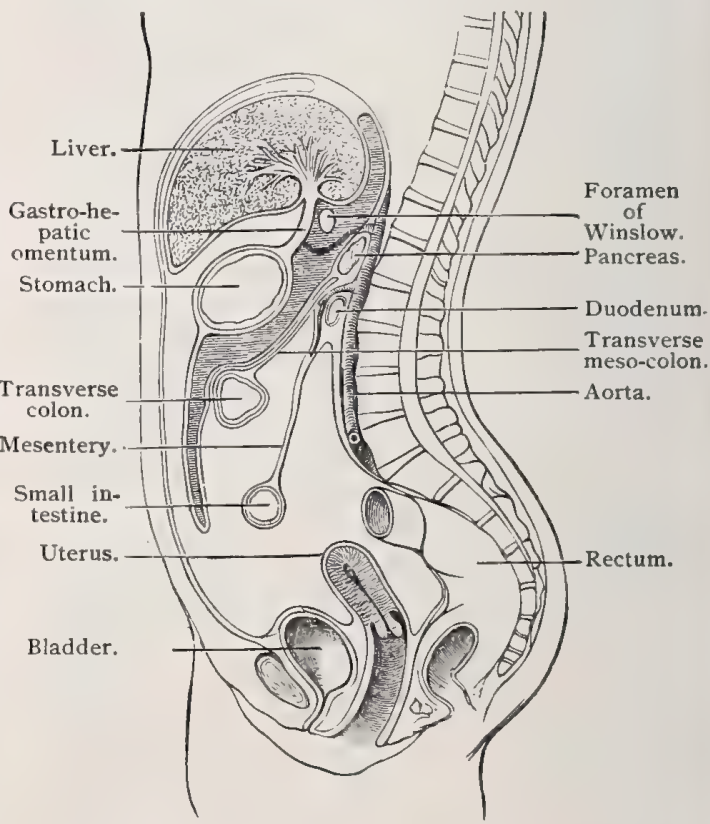

Peritoneum, Vertical Section. (Allen Thomson.)

over the uterus, from which it proceeds to the bladder. Two pouches are thus formed, the recto-uterine, or Douglas's pouch, and the vesico-uterine; between the sides of the uterus and the sides of the pelvic cavity it forms two additional folds, the broad ligaments. From the bladder it passes up the anterior wall of the abdomen to the diaphragm. From the cardiac end of the stomach two layers proceed to the spleen, enclosing it, and forming the gastro-splenic omentum. A few minor folds need yet to be mentioned-the hepato-renal, passing from the right lobe of the liver to the kidney; the gastro-plerenic, from the diaphragm to the cardiac extremity of the stomach the costo-colic, from the diaphragm to the splenic flexure of the colon. The following structures are completely invested by peritoneum:-The stomach, liver, spleen, first portion of the duodenum, the jejunum, the ileum, transverse colon, sigmoid flexure, the upper part of the rectum, and of the uterus, and the ovaries.

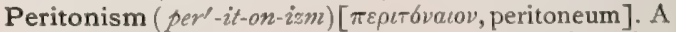
form of pseudo-peritonitis, in which apparently perito- 
nitic symptoms yield readily to treatment. Also, the complexus of symptoms occurring during peritonitis.

Peritonitic (per-il-on-it'-ik) [ $\pi \varepsilon \rho \iota \tau \delta$ valov, peritoneum; $\iota \tau \iota$, inflammation]. Pertaining to or affected with peritonitis.

Peritonitis (per-it-on-i'tis) [ $\pi \varepsilon \rho \iota t o ́ v a \iota o v$, peritoneum; $\iota \tau \iota$, inflammation]. Inflammation of the peritoneum It may be acute or chronic, general or local. P., Acute, is sudden in its onset, with agonizing pain that compels the patient to remain in bed on his back with the shoulders raised and the knees and hips flexed-the characteristic position. The pulse is small, hard, and wiry; there is some fever; and the abdomen becomes tense and tympanitic. Acute peritonitis may terminate in death, recovery, or chronic peritonitis. P., Adhesive, peritonitis with adhesion between the parietal and visceral layers. P., Carcinomatous, that due to carcinoma of the membrane. P., Chronic, a form that has no well-defined symptoms: there is tenderness, pain not so acute, impairment of appetite, and constipation. Fluid may be present in the abdominal cavity and adhesions may form. This chronic form usually follows an acute attack, but may develop insidiously. It is often tuberculous. P., Circumscribed, that limited to a part of the membrane. P. deformans, chronic peritonitis accompanied by thickening and contraction of the mesentery and omentum. P., Diaphragmatic, inflammation of the peritoneum covering the under surface of the diaphragm. P., Diffuse, a form affecting the entire peritoneum. P., Encysted, a collection of serum or pus surrounded by peritoneal adhesions. P., Hemorrhagic, peritonitis with hemorrhages into the membrane; it may lead to the formation of a socalled hematoma. P., Pelvic. See Perimetritis. P., Perforative, peritonitis due to perforation of a hollow viscus, an abscess, or a cyst, and the extrusion of the contents into the cavity of the peritoneum. P., Phlegmonous. Synonym of P., Purulent. P. Puerperal, that following septic infection in the woman in childbed. It rapidly ends in death from asthenia. P., Purulent, peritonitis accompanied by the production of pus. P., Pyemic, peritonitis due to the localization of pyogenic microörganisms in the peritoneum. P., Rheumatic, a peritonitis occurring in the course of acute rheumatic fever. P., Septic, peritonitis due to the microörganisms of suppuration. P., Specific, that due to tuberculosis or syphilis, though the term is usually limited to the latter condition. P., Syphilitic, an indurative form due to syphilis. P., Tuberculous, that form due to the deposit of miliary tubercles upon the peritoneum. According to Fagge, it is more common in children than in adults, and in men than in women. It is insidious in onset, is attended with great emaciation and the effusion of considerable lymph and fluid. The omentum is always much thickened.

Peritonsillar (per-it-on'-sil-ar) [ $\pi \varepsilon p i$, around; tonsilla, tonsil]. Occurring or situated around or near the tonsil.

Peritonsillitis (per-it-on-sil-i'-tis) [ $\pi \varepsilon \rho^{\prime}$, about ; tonsilla, tonsil ; $\iota \tau \iota$, inflammation]. Inflammation of the tissues surrounding the tonsil.

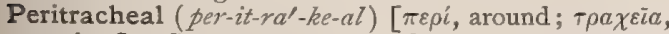
trachea]. Surrounding the trachea.

Peritracheitis (per-it-ra-ke-i'-tis) [ $\pi \varepsilon \rho i$, around; $\tau \rho \alpha \chi \varepsilon i a$, trachea ; $\iota \tau \iota s$, inflammation]. Inflammation of the connective tissue about the trachea.

Peritrema (per-it-re'-mah). Same as Peritreme.

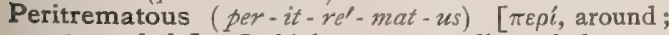
$\tau \rho \bar{\eta} \mu \alpha$, a hole]. In biology, surrounding a hole; pertaining to a peritreme.
Peritreme (per'-it-rèm) [ $\pi \varepsilon \rho i$, around; $\tau \rho \tilde{\eta} \mu \iota$, a hole $]$. In biology, the margin of a spiracle of an insect or of the orifice of a univalve shell.

Peritrichous ( $\left.p e r^{2}-i t^{\prime}-r i k-u s\right)$ [ $\pi \varepsilon \rho i$, around; $\theta \rho i \xi(\tau \rho \iota \chi-)$, a hair]. In biology, having a band of cilia around the body.

Peritroch (per'-it-rok) [ $\pi \varepsilon \rho \dot{\imath}$, around; $\tau \rho o \chi o ́ s$, a wheel] In biology: $(a)$ a circlet of cilia; $(b)$ an embryo bearing such a circlet.

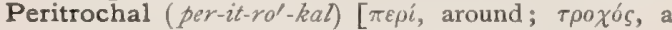
wheel]. Pertaining to a peritroch.

Peritropal (per-it'-ro-pal). Same as Peritropous.

Peritrope (per-it'-ro-pe) [ $\pi \varepsilon \rho i$, around; $\tau \rho \varepsilon \epsilon \varepsilon \iota v$, to turn]. A synonym of Circulation.

Peritropous (per-it'-ro-pus) [ $[\pi \varepsilon \rho \dot{\prime}$, around; $\tau \rho \varepsilon \pi \varepsilon \varepsilon \nu$, to turn]. In biology, horizontal in the pericarp, as a seed.

Perittoma (per-it-to'-mah). Synonym of Perissoma.

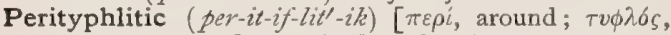
cecum; $\iota \tau \iota s$, inflammation]. Of the nature of or affected with perityphlitis.

Perityphlitis (per-it-if-li'-tis) [ $\left[\pi \varepsilon \rho i\right.$, around; $\tau v \phi \lambda o^{\prime}$, cecum; $\iota \tau \iota$, inflammation]. Inflammation of the peritoneum surrounding the cecum. This is a disease most frequently encountered in the young and in males. It is usually due to some inflammatory disease of the vermiform appendix. It is marked by pain in the right iliac fossa, and a tumor, elongated, sausageshaped, dull on percussion, and very tender, in the same region. It may give rise to general peritonitis from escape of pus into the general peritoneal cavity. The abscess may burst through the abdominal wall, into the bowels, bladder, or pleural cavity.

Periurethritis (per-e-u-re-thri'-tis) [ $\pi \varepsilon \rho \dot{\prime}$, around; ov $\rho \dot{\prime}$ $\theta \rho a$, urethra; $\iota \tau \iota$, inflammation]. Inflammation of the connective tissue about the urethra.

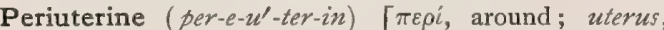
uterus]. Situated or occurring around the uterus.

Perivaginitis (per-iv-aj-in-i'-tis). Synonym of Paracolpitis.

Perivascular (per-iv-as'-ku-lar) [peri, around; vasculum, a vessel]. Surrounding or enclosing a vessel.

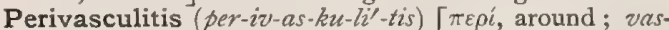
culum, vessel; $\iota \tau \iota$, inflammation]. Inflammation of the vessel-walls, or of the perivascular sheaths.

Perivenous (per-iv-el-nus) [ $\pi \varepsilon \rho i$, around; vena, vein]. Investing or surrounding a vein; occurring around a vein.

Perivesical (per-iv-es'-ik-al) [ $\pi \varepsilon \rho \hat{\imath}$, around; vesica, bladder]. Situated about or surrounding the bladder.

Perivisceral (per-iv-is'-er-al) [ $\pi \varepsilon \rho i$, around; viscus, viscus]. Surrounding a viscus or viscera; occurring about a viscus.

Perivitelline (per-iv-it'-el-in) [ $\pi \varepsilon p i$, around; vitellus, yolk ]. Surrounding the vitellus or yolk. P. Space, the space between the zona pellucida and the vitellus.

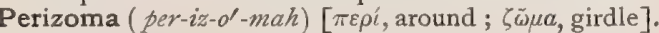
1. A girdle, $q . v$; also, a truss, 2. Herpes zoster.

Perizonium ( per $\left.-i z-o^{\prime}-n e-u m\right)[\pi \varepsilon \rho \ell$, around; $\zeta \omega v \eta$, girdle: pl., Perizonia]. In biology, the thin nonsilicious membrane of a young auxospore in the Diatomacee.

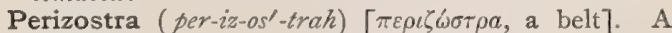
bandage, especially for the head or trunk.

Perkin's Violet. Same as Mauvein.

Perkinism (per'-kin-izm) [after Elisha Perkins, the originator of the method]. Also called Tractoration. A method of empiric treatment devised by a Connecticut physician. It consists in drawing over the affected part the extremities of two rods (" metallic tractors") of different metals. Cf. Metallotherapy.

Perkinist (per'-kin-ist) [after Elisha Perkins, an 
American physician]. A believer in, or practiser of, Perkinism.

Perkinistic (per-kin-is'-tik) [after Elisha Perkins, an American physician]. Pertaining to Perkinism.

Perla (per'-ia/h) [L.: pl., Perla]. Pearl. Perlæ textiles, small pearls sometimes used in pharmacy.

Perlèche (la) (lah pär-lāsh) [Fr.]. A peculiar contagious disease of the mouth occurring in children, and first described by Lemaistre in $\mathbf{I} 886$. It consists in a thickening and peeling off of the epithelium at the angles of the mouth, with occasionally the formation of small fissures, giving rise to a smarting sensation in the lips. The disease is probably microbic in origin, numerous spherobacteria being found in the thickened epithelium. The microörganisms are probably derived from drinking-water.

Perles' Anemia-bodies. Small club-shaped, actively motile bodies, 3-4 $\mu$ in length, found by Perles in the blood in three cases of pernicious anemia.

Perles, Lænnec's, the rounded gelatinous masses of sputum seen in the early stage of an attack of bronchial asthma.

Perlia, Central Nucleus of. The nuclear center for ocular movement.

Permanent (per'-man-ent) [permanens, remaining]. Lasting indefinitely; fixed; enduring. In biology, always present in a species or group. P. Blue. Same as French Blue. P. Teeth, the teeth of the second dentition. See Teeth. P. White. See Pigments, Conspectus of.

Permanganate (per-man'-gan-ät) [per, through ; man. ganese]. A salt of permanganic acid. See Manganese.

Permanganic (per-man-gan'-ik) [per, through ; manganese]. Obtained from manganese. P. Acid, $\mathrm{HMnO}_{4}$; a monobasic acid occurring chiefly as a salt.

Permeable (per'-me-a-bl) [per, through; meare, to pass]. Capable of affording passage. P. Stricture, a stricture that permits the passage of an instrument.

Permutation (per-mu-ta'-shun) [ per, through ; mutare, to change]. The reciprocal substitution between two compounds of one element or radicle for another.

Pernicious (per-nish'-us) [perniciosus, destructive]. That which is highly destructive or mischievous. $\mathbf{P}$. Anemia, a disease of the blood characterized by a great diminution in the number of red corpuscles, and a relatively smaller diminution of the hemoglobin, by the presence in the blood of poikilocytes, macrocytes, microcytes, and nucleated red corpuscles. The diminution in red corpuscles exceeds that met with in any other disease-the number may fall below 400,000 . A case is reported in which the red corpuscles numbered only 143,000 in the $\mathrm{cu}$. $\mathrm{mm}$. As regards the etiology of the disease, two varieties must at present be admitted-a symptomatic and an idiopathic. A symptomatic pernicious anemia, one in which the blood presents characters indistinguishable from those of the idiopathic form, may be produced by parasites in the intestinal canal, such as the Dochmius duodenalis, Trichocephalus hominis, or the Bothriocephalus latus (Cf. Parasites (Animal), Table of), by atrophy of the gastric mucous membrane, and by hemorrhage. The nature of primary pernicious anemia is still obscure. Many believe that the disease is dependent upon increased hemolysis, $i$. $e_{\text {. }}$, blood-destruction. In favor of this view, is the presence in the liver and spleen of cases that have died from the disease, of large quantities of iron, clearly derived from the blood. The hemolytic agent, according to Hunter, is a poison, in all probability of specific origin, absorbed from the intestinal canal. Others ascribe the impoverished state of the blood to imperfect hemogenesis, adducing poikilocytosis and the presence of nucleated corpuscles, in proof. While defective hemogenesis may play a rôle, it is probable that increased hemolysis is the more important factor. The pathologic lesions found, are a yellow color of the skin, fatty degeneration of the liver.and heart, deposits of iron in the spleen and liver, peculiar changes in the spinal cord, hemorrhages into the retina; more rarely hemorrbages into the stomach, serous membranes, and lungs, and occasionally an embryonal state of the bone-marrow. The symptoms of the disease are those of a profound anemia, with the blood-changes noted in the definition; there is not much wasting; the skin is of a lemon-yellow color; febrile movements may occur; also retinal hemorrhages as well as hemorrhages elsewhere; the urine is frequently of a dark color due to an excess of urobilin. The disease, most common in middle life, is usually fatal, although recoveries are reported in several in. stances, under the influence of large doses of arsenic. Intestinal antiseptics are suggested on the ground that the disease is the result of autoinfection from the alimentary tract. P. Malaria. See Malaria.

Pernio (per'-ne-o). Synonym of Chilblain.

Pernoctation (per-nok-ta'-shun) [pernoctatio, wakefulness]. Wakefulness; insomnia.

Pero $\left(p e^{\prime}-r o\right)$ [pero, boot]. The soft ectal layer of the olfactory bulb whence the olfactory nerves arise.

Perobrachia (pe-ro-bra'-ke-ah). See Perobrachizus.

Perobrachius (pe-ro-bra'-ke-us) [ $\pi \eta \rho b s$, maimed: $\beta \rho a \chi i \omega v$, arm]. A developmental defect in which the forearms and hands are malformed or wanting.

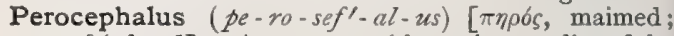
$\kappa \varepsilon \phi a \lambda \dot{n}$, head]. A monster with an abnormality of the conformation of the head.

Perocheirus, Perochirus ( $\left.p e-r o-k i^{\prime}-m u s\right)[\pi \eta \rho b s$, maimed; $\chi \varepsilon i \rho$, hand]. A defect in the development consisting in absence or stunted growth of the hand.

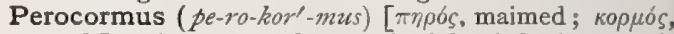
trunk]. A monster characterized by defective development of the trunk.

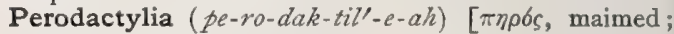
ঠа́ктvіos, finger]. Defective development of the fingers or toes.

Perodactyly (pe-ro-dak'-til-e). Same as Perodactylia.

Perodynia (pe-ro-din'-e-ah) [ $\pi \dot{n} \rho a$, pouch; ódivi, pain ]. Cardialgia.

Perogaster (pe-ro-gas'-ter) [ $\pi \dot{\eta} \rho a$, a pouch or wallet;

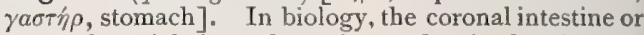
circumferential sinus of gastric pouches in the Peromedusa.

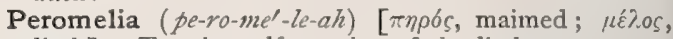
limb]. Teratic malformation of the limbs.

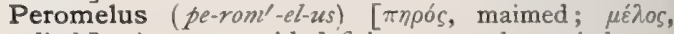
limb]. A monster with deficient, stunted, or misshapen limbs.

Peronæus (per-o-ne'-us). Same as Peroneus.

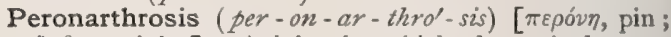
$a \nu \theta \rho o v$, joint]. A joint in which the articular surfaces are both concave and convex, as in the carpometacarpal joint of the thumb.

Peronate (per'-o-nat) [peronatus, rough-booted]. In biology, having the stipe thickly covered with a mealy or woolly substance.

Perone (per'-o-ne) [ $\pi \varepsilon \rho b v \eta$, pin]. The fibula.

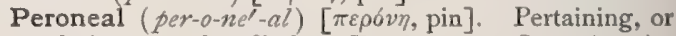
relating, to the fibula. P. Artery. See Arteries, Table of. P. Nerve. See Nerves, Table of. P. Reflex. See Reflexes, Table of.

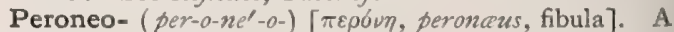
prefix denoting connection with or relation to the fibula.

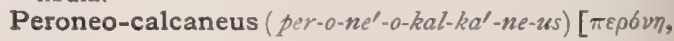


pin; $\operatorname{cal} x$, heel]. Pertaining to the fibula and the os calcis. P. externus anterior. See Muscles, Table of. P. internus. See Muscles, Table of.

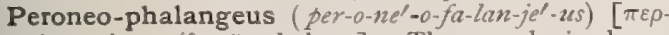
$6 v \eta$, pin; $\phi a ́ \lambda a \gamma \xi \xi$, phalanx]. The muscle in lower animals corresponding to the tibialis anticus in man.

Peroneo-præphalangeus (per-o-ne'-o-pre-fa-lan-je'-zes)

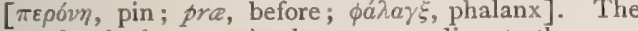
muscles in lower animals corresponding to the peroneus brevis in man.

Peroneo-tibialis (per-o-ne'-o-tib-e-a'-lis). See Muscles, Table of.

Peroneum (per-o-ne'-um). Synonym of Perone.

Peroneus (per-o-ne'-us) [ $\pi \varepsilon \rho o v \eta$, pin]. Pertaining to the fibula. P. Muscle. See Muscles. Table of.

Peronia ( $\left.p e-r o^{\prime}-n e-a h\right)[\pi \eta \rho o \bar{v} v$, to maim]. Mutilation; malformation

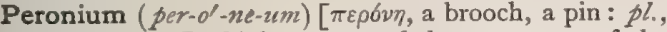
Peronia]. In biology, one of the processes of the urticating-ring of the umbrella-margin in Narcomeduse called the "umbrella-clasp," which divides it into a number of collar lobes.

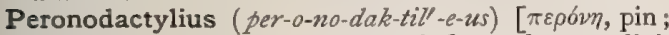
ঠákтvios, finger]. Synonym of flexor longus digitorum muscle. See Muscles, Table of.

Peronospora (per-o-nos'-po-rah) [ $\pi \varepsilon \rho \sigma v \eta$, point; $\sigma \pi \delta$ pos, spore]. A genus of fungi, of which there are some seventy species recognized under the general name of downy mildews ( $q . v$. under Mildew), among which P. viticola, parasitic on the grape, is the most destructive. The cholera-microbe of Ferran has been referred to $\mathbf{P}$. ferrani or $\mathbf{P}$. barcinonæ, and the yellowfever microörganism of Carmona y Valle to P. lutea.

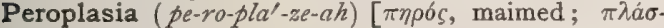
$\sigma \varepsilon \iota \nu$, to mold]. A malformation due to an error of development.

Peropus (pe'-ro-pus) [ $\pi \eta \rho o ́ s$, maimed; $\pi$ oús, foot]. A developmental defect in which the feet are malformed.

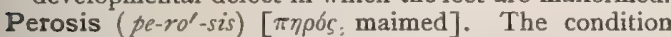
of abnormal or defective formation.

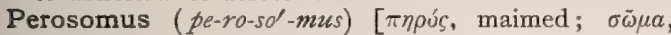
body]. A monster presenting malformation of the entire body.

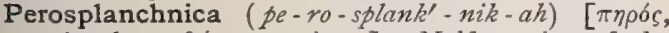
maimed; $\sigma \pi \lambda a ́ \gamma \chi v o \nu$, viscus]. Malformation of the viscera.

Peroxid (per-oks'-id') [ per, through; ók'vs, sharp]. That oxid of any base which contains the most oxygen. P. of Hydrogen. See Hydrogen.

Perpendicular (per-pen-dik'-u-lar) [perpendicularis, vertical]. A term applied to a line or plane, forming a right angle with another line or plane. P. Plate, the mesal vertical plate of the ethmoid bone.

Perplication (per-plik-a'-shun) [per, through; plicare, to fold]. Folding or turning an incised vessel upon or within itself by drawing its end through an incision in its own wall.

Perradial (per-ra'-de-al) [per, through; radius, a ray]. In biology, primarily or fundamentally radial.

Perradius (per-ra'-de-us) [per, through ; radius, ray : $p l .$, Perradii $]$. In biology, one of the primary radial structures of a hydrozoan.

Perrigation (per-rig-a'-shun) [per, through; irrigare, to irrigate]. The name given to the metbod of open drainage in empyema. There is a continuous evacuation of the pus by means of single or double openings in the chest at different or opposite points, selected with the view of securing the advantage of gravity. The tubes, when situated at opposite points, allow of injections of antiseptic fluids to irrigate the whole pleural space.

Perry $($ per'-e) [Fr., poive, pear]. Pear-cider.
Persecution (per-se-ku'-shun) [persecutio, a pursuit]. Persistent or repeated injury of any kind. P., Delusions of, the imaginary belief of an individual that he is being persecuted. P.-mania, monomania characterized by doubt, suspicion, and a belief on the part of the patient that he is subject to, or the victim of, some conspiracy

Persecutory Insanity. See Persecution-mania

Perseïte (per'-se-it $), \mathrm{C}_{7} \mathrm{H}_{16} \mathrm{O}_{7}$. An heptahydric alcohol found in the leaves and seeds of Laurus persea. It crystallizes in needles, melting at $184^{\circ} \mathrm{C}$.

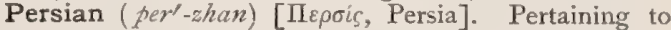
Persia. P. Pellitory. See Pyrethrum roseum. P Red. Same as Ocher.

Persicot (per'-sik-ot) [Fr. ; persicum, peach]. A cor dial, or liqueur, of alcohol flavored with peach-stones and various aromatics.

Persimmon (per-sin' ${ }^{\prime}$ on $)$ [Amer. Ind.]. The tree Diospyros virginiana; also its fruit, edible when fully ripe, but otherwise highly astringent; it is useful in diarrheas. From the fruit a beer is made, and whisky is distilled. Unof.

Persio ( $\left.p e r^{\prime}-s e-0\right)$. See Cudbear

Persistent ( per-zis'-tent) [persistero, to persist]. Constant; not undergoing any diminution or cessation.

Person (per'-son or per'-sn) [ persona, a mask for actors, hence a personage]. In biology, an independent and indivisible organic unit, a complete individual from a morphologic and physiologic standpoint. Among simpler animals we have to do with structures which from their development must be termed individuals, but which are fused into a common stock, forming what is known as a colony, to which they are related physiologically, as organs are to an organism. The individuals of such stocks are, however, generally not similar, but as a consequence of more or less division of labor, dimorphism or polymorphism takes place; we may thus distinguish : (I) sterile nutritive persons, or protective persons, which perform the functions of taking in food, of digestion, of protection, touch, locomotion, etc., e. g. , the so-called " protective," or "bract," the "gastric peduncle," the "tentacle" or capturing filament, the "taster," "feeler," or "palpon," the "swimming bell" or "nectophore" of a siphonophore; (2) Sexual persons or gonophores, to which belong exclusively the function of forming the sexual products. They are male or female. These heteromorphic in dividuals are frequently arranged in groups called cormidia, and then again into siphonanth, $q . v$. On the other hand the same groups of organs or similar parts of the same organ may be repeated in a radial or longitudinal direction; the body thus obtains a segmentation and is divisible into sections (see antimere, metamere, paramere, proglottis, strobila), or segments which may in structure and function appear completely equivalent and represent persons or individuals of a lower order, which on a severance of their mutual connection can acquire independence and remain alive for a longer or shorter period.

Personal (per'-son-al) [persona, a person]. Pertaining to a person. P. Equation, the peculiar difference of each individual in his reaction to various orders of stimuli. P. Identity. See Identity.

Personate (per'-son-ät) [ personatus, assumed, counterfeited, masked]. In biology, masked; applied to labiate flowers in which the throat is closed by a projection of the lower lip called the palate; or to animals having the face colored so as to suggest a mask.

Perspicil (per'-spis-il). Same as Perspicilium.

Perspicilium (per-spis-ill-e-um) [perspicere, to see through]. An eyeglass, a microscope. In the plural spectacles. 
Perspiration (per-spi-ra'-shun) [perspiratio; perspirare, to perspire]. Excretion of liquid from the skin, mainly by sweat-glands; sweating. The liquid so excreted; the sweat.

Perspiratory (per-spi'-ra-to-re) [perspirave, to perspire]. Pertaining to perspiration. Causing perspiration.

Perspire (per-spīr') [perspirare, to perspire]. To sweat; to evacuate the fluids of the body through the emunctories of the skin.

Persultation (per-sul-ta'-shun) [persultare, to leap]. A sudden, profuse sweat.

Perturbation (per-ter-ba'-shun) [ perturbatio; pertur bare, to disturb]. Restlessness or disquietude. The employment of means that arrest or modify the devel opment of a morbid state.

Pertusate (per-tu'-sät) [pertundere, to bore through] In biology, having a perforated apex.

Pertuse (per-tüs's [ per, through; tundere, to strike] In biology, having perforations, holes, or slits.

Pertusorium (per-tus-o'-re-um) [pertundere, to pierce]. An instrument for perforating the fetal membranes.

Pertussal (per-tus'-al) [per, intensive; tussis, a cough]. Pertaining to or of the nature of whooping-cough.

Pertussis (per-tus'-is) [per, through; tussis, cough]. Whooping-cough, a contagious disease, confined usually to childhood and youth, and marked by spasmodic coughing ended by a "whoop," and sometimes by vomiting. Its course lasts usually for a period of six or seven weeks. It is rarely fatal. It is divided into a catarrhal or prodromal stage, and a paroxysmal stage. The period of incubation is about two weeks. During the height of the disease, hemorrhages may occur from the nose, mouth, or ears, or into the subconjunctival tissues, even into the brain or its meninges. Bronchopneumonia is a frequent complication. Affanasiew has found a small bacillus in the expectoration, which he considers the etiologic factor. The presence of this bacillus has been confirmed by others. See Bacillus tussis convulsivce under Bacteria, Synonymatic Table of.

Peru, Balsam of. See Balsam.

Perulate (per'-u-lät) [perula, a scale]. In biology, having scales (perula), such as bud-scales.

Perule $\left(p e r^{\prime}-\bar{u} l\right)$ [ $\pi \dot{y} \rho a$, a purse, wallet]. In biology, a bud-scale.

Peruvian (pe-ru'-ve-an) [Penu]. Pertaining to Peru. P. Bark. See Bark, Peruvian, and Cinchona. P. Wart. See Vermeg peruana and Bacillus of Vermga peruana under Bacteria, Synonymatic Table of.

Peruvin (pe-ru'-vin) [Peru ]. The name given to the cinnamic alcohol derived from balsam of Peru.

Perversion (per-ver'-zhun) [per, through; vertere, to turn]. The state of being turned away from the normal course, as in the modifications of function in disease. P., Sexual, abnormality of the sexual instinct ; desire for unnatural methods of sexual gratification.

Pervert (per'-vert) [per, through; vertere, to turn]. One who has turned from the right way. P., Sexual, a person whose sexual instincts are perverted.

Pervigilium (per-vij-ill-e-um) [ per, through ; vigilium, a watch]. Insomnia; wakefulness.

Pervious (per'-ve-us) [per, through; via, way]. Open; permeable.

Pes $(p \bar{e} z)[\mathrm{L}$.$] . A foot.or foot-like part or organ. P.$ accessorius, the Eminentia collateralis, a smooth, white eminence in the brain, situated at the junction of the posterior and descending cornua of the lateral ventricle. P. anticus. Same as Manus. P. contortus. Synonym of Club-foot. P. depressus. Synonym of Flat-foot. P. equino-varus. Same as Talipes equinovarus. P. equinus. See Talipes equinus. P. hippocampi major, the large, lower portion of the hip- pocampus major. P. hippocampi minor. Same as Hippocampusminor. P. planus. Synonym of Flatfoot. P. valgus. Synonym of Talipesvalgus. P. varus. Synonym of Talipes varus.

Pessary (pes'-ar-e) [ $\pi \varepsilon \sigma \sigma o ́ s$, an oval-shaped stone]. An instrument placed in the vagina to hold the uterus in position.

Pessima (pes'-im-ah) [L.]. A skin-affection characterized by pustular lesions, hard and yellowish and surrounded by areolæe of inflammation, appearing over the whole surface of the body.

Pessimism (pes'-im-izm) [pessimus, worst]. A morbid disposition to put the worst construction upon everything; a symptom common among insane people. Opposite of Optimism.

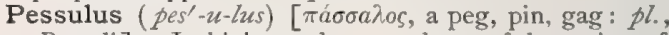
Pessuli ]. In biology, the cross-bone of the syrinx of a bird; the "bolt-bar" or "bar of divarication" across the lower end of the trachea where it divides into the right and left bronchi.

Pest [pestis, a pest]. A plague; pestilence. P.-house, a hospital for persons sick with pestilential diseases.

Pesta (pes'-tah) [L.]. A pest. P. magna. Synonym of Smallpox.

Pestichia, Pesticia (pes-tik'-e-ah, pes-tis'-e-ah). Synonyms of Petechia.

Pestiduct (pes'-tid-ukt) [pestis, pest; ductus, conveyance]. A channel, or means of conveyance, for a contagion; fomites. [Rare.]

Pestiferous (pes-tif'-er-us) [pestis, pest ; ferre, to bear]. Causing pestilence; destructive.

Pestilence (pes'-til-ens) [pestilentia]. Any deadly epidemic disease or the prevalence of such a disease.

Pestilent, Pestilential (pes'-til-ent, pes-til-en'-shal) [pestis, plague]. Having the nature of a pestilence or epidemic disease. P. Fever. Synonym of the Plague, q. v.

Pestilentia (pes-til-en'-she-ah). Synonym of the Playue.

Pestis (pes'-tis) [L.]. A plague. P. americana, yellow fever. $\mathbf{P}$. bubonica, $\mathrm{P}$. inguinaria, $\mathbf{P}$. orientalis, the plague. P. variolosa. Synonym of Variola.

Pestle $\left(\not p e s^{\prime}-l\right)$ [pistillum]. The instrument with which substances are rubbed in a mortar.

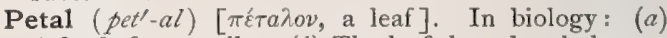
A leaf of a corolla. (b) The leaf-shaped ambulacrum of an echinoderm.

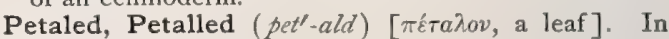
biology, having petals.

Petaliform (pet'-al-if-orm) [ $\pi \dot{\varepsilon} \tau a \lambda o v$, a leaf; forma, form]. In biology, shaped like a petal.

Petaline (pet'-al-in) [petalum, a petal]. In biology, pertaining or attached to a petal.

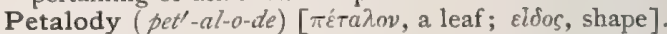
In biology, the assumption of petal-like characters by other parts of a flower.

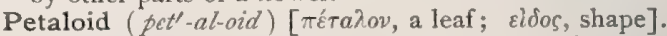
In biology, resembling a petal, either in color, texture or form.

Petalomania (pet-al-o-ma'-ne-ah). Same as Pelalody.

Petalous (pet'-al-us) [ $\pi \varepsilon \tau_{\tau} a \lambda o v$, a leaf ]. In biology, furnished with petals; petaled.

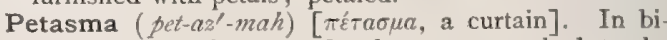
ology, a membranous development attached to the first pair of pleopoda in the male of certain crustaceans. (Bate.)

Petechia (pe-tel-ke-ah) [It., peteche, a flea-bite: pl., Petechice]. A small, round, oval, or irregular spot of ecchymosis beneath the epidermis, varying in size from a flea-bite to an area having a diameter of half an inch or more. It is not raised above the level of the 
skin, but is of a reddish or purple shade, and does not alter on pressure by the finger.

Petechial (pe-te'-ke-al) [It., peteche, flea-bite]. Characterized by or of the nature of petechiæ. P. Fever. Synonym of Fever, Cerebro-spinal, and of Fever, Typhus. P. Scurvy. Synonym of Purpura simplex.

Petechianosis (pe-te-ke-an-o'-sis). Synonym of Petechial Fever.

Petechiate ( $\left.p e-t t^{\prime}-k e-\bar{a} l\right)$ [It., petecchia, a spot]. Having petechire; spotted.

Petersen's Bag. A rubber bag with a capacity of about I5 ounces, to be inserted into the rectum and then distended, so as to elevate the bladder in the operation of supra-pubic cystotomy.

Petiolaceous (pet-e-o-lat-se-uls). Same as Petiolate.

Petiolar (pet'-e-o-lar) [petiolus, a petiole]. In biology, belonging to a petiole or attached to one.

Petiolary $\left(p e t^{\prime}-\varepsilon-o-l a-r e\right)$. Same as Petiolar.

Petiolate (pet'-e-o-lat [ [petiolus, a petiole]. In biology, possessing a petiole; mounted upon a foot-stalk, or peduncle.

Petiole (pet'-e-ōl) [petiolus, a stem, or stalk of fruits]. In biology: (1) A leaf-stalk or foot-stalk. (2) The slender part of a wasp or ant, joining the thorax and abdomen.

Petiolulate $\left(p-t^{\prime}-e-o-l u-l a \bar{t}\right)$ [petiolulus, petiolulus]. In biology, mounted upon a little leaf-stalk of its own; applied to a leaflet or foliole.

Petiolule (pet'-e-o-lül) [petiolulus, dim. of petiolus, petiole]. In biology, a small leaf-stalk, such as those of the leaflets or folioles of compound leaves. P. epiglottidis, the narrow, attached, stalk-like portion of the epiglottis.

Petiolus (pet-i'-o-lus) [petiolus, a stem or stalk of fruit: pl., Petioli ]. In biology, a stem, stalk, or petiole ; as the petiolus of the epiglottis.

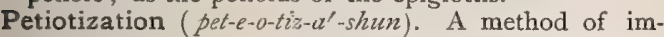
proving wines by adding sugar and water to the marc from which the juice has been separated, and fermenting again. The process may be repeated several times, the different infusions being mixed.

Petit, Canal of $\left(\right.$ pet- $\left.e^{\prime}\right)$. The narrow annular cleft, triangular in section, bounded in front by the zone of Zinn, mesially by the crystalline lens, and behind by the substance of the vitreous body in the eye. See Canal. P.'s Hernia. See Hernia. P.'s Operation, an operation for the relief of strangulated hernia. It consists in a division of the stricture without opening the sac. See Operations, Table of. P., Triangle of. See Triangles, Table of.

Petit Mal (pet-e'-mal) [Fr.]. See Epilepsy.

Petiveria (pet-iv-e'-re-rh) [after J. Petiver, a London apothecary]. A genus of phytolaccaceous plants, growing in tropical America and Africa. P. alliacea, of the West Indies and Guinea, is stimulant, diuretic, sudorific, anodyne, and depurative. P. tetandra, of Brazil, has similar uses. Its tincture has been recommended for external use after baths, and as a local stimulant in paralysis. Unof.

Petri's Capsules, Dishes, Plates, or Saucers. Receptacles for cultures in bacteriologic investigation; shallow cylindric covered glass vessels, in which the colonies may be counted without removing the cover. P.'s Sand-filter, a small filter used in the bacteriologic examination of air. A glass tube, 9 centimeters long, is provided with two portions of sand (previously passed through a sieve with meshes 0.25 millimeter wide) each $3 \mathrm{~cm}$. long, and $0.5 \mathrm{~cm}$. apart, little plates of brass-gauze keeping the portions in position. The tube and its contents, the end having been plugged with cotton, are sterilized in an oven, at $150^{\circ} \mathrm{C}$. A 67 rubber stopper, through which passes a glass tube, is then fitted into one end of the tube, and the apparatus is connected with an aspirator of known capacity.

Petricolous (pet-rik'-o-lus) [ $\pi \varepsilon$ t $\rho a$, rock; colere, to inhabit]. In biology, inhabiting rocks.

Petrifaction (pet-rif-ak'-shun) [ $\pi \dot{\varepsilon} \tau \rho a$, a stone; facere, to make]. The condition resembling stone-calcification. In obstetrics, conversion of the fetus into a lithopedion. Petrifaction of tissues is brought about by the deposit in them of salts of lime and magnesium.

Pétrissage ( $p a$-tre-sahzh') [Fr., kneading]. A form of "soft attachement," in massage, the hand of the operator "climbing" like a caterpillar.

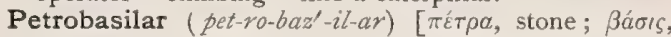
base]. Pertaining to the petrous portion of the temporal bone and the basilar portion of the occipital bone.

Petroccipital (pet-rok-sip'-it-al). Synonym of Petrooccipital.

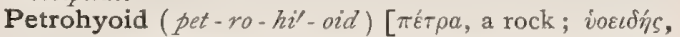
shaped like the letter upsilon]. Related to the hyoid bone and the petrous portion of the temporal bone. P. Muscle, a muscle of some batrachians.

Petrolardium (pet-ro-lar'-de-umn). Synonym of Petrolatum.

Petrolatum (pet-ro-la'-tum) [ $\pi \varepsilon ́ t \rho a$, rock; oleum, oil]]. Petroleum ointment; Cosmolin. A jelly-like preparation obtained from the residium of petroleum, soluble in ether, insoluble in water and alcohol, and known commercially as vaselin and as cosmolin. It is an excellent basis for ointments and a valuable emollient. P. molle, soft petrolatum. P. spissum, hard petrolatum.

Petrolene (pet'-ro-lèn) [ $\pi \dot{\varepsilon} \tau \rho a$, rock; oleum, oil]. A liquid hydrocarbon mixture obtained from petroleum.

Petroleum (pet-ro'-le-um) [ Rock-oil; Naphtha; probably a product of the dry distillation of coal-beds caused by the earth's heat ; or of the dry distillation of the fatty constituents of fossil organisms. In a crude condition, it is a thick, oily liquid, of brownish color, with greenish luster. On exposure to air, its more volatile constituents are lost ; it then thickens and passes into asphaltum. P., American, consists almost exclusively of normal paraffins. In a crude form, it has a specific gravity of from 0.8 to 0.92 , and distils over at from $300^{\circ}$ to $360^{\circ} \mathrm{C}$. and beyond this. P. Benzine (not to be confounded with the benzene of coal-tar), a product of petroleum obtained by fractional distillation; it has a specific gravity of from 0.68 to 0.72 , and distils at from $70^{\circ}$ to $90^{\circ} \mathrm{C}$., and consists of hexane and heptane. P., Caucasian (from Bakex), has a higher specific gravity than American petroleum; it contains less of the light volatile constituents and distils at about $150^{\circ} \mathrm{C}$. P. Ether, a product of petroleum obtained by fractional distillation; it has a specific gravity of from 0.665 to 0.67 , distilling at from $50^{\circ}$ to $60^{\circ} \mathrm{C}$; ; it consists of pentane and hexane. P., Galician ; in composition, intermediate in position between American and Caucasian petroleum. P. gelatum, petrolatum. P., German, contains benzene hydrocarbons, but consists chiefly of the saturated hydrocarbons and naphthenes. P. Oil, Light, a liquid resembling $P$. Benzine, having a specific gravity of 0.70 or 0.71 . P., Refined; Kerosene ; a product of petroleum by fractional distillation; it boils at from $150^{\circ}$ to $300^{\circ} \mathrm{C}$., and has a specific gravity of from 0.78 to 0.82 . P. Spirit. Synonym of Benzine.

Petroliferous (pet-ro-lif'-er-us) [ $\pi \dot{\varepsilon} \tau \rho a$, rock; oleum, oil ; ferre, to bear]. Producing petroleum.

Petrolin (pet'-ro-lin) [ $\pi \varepsilon \tau_{\rho} \rho a$, a rock; oleum, oil]. The commercial name for a combination of hydrocarbons. derived from petroleum. 


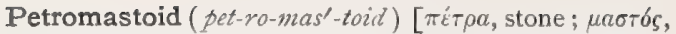
nipple; $\varepsilon i \delta o s$, like]. Pertaining to the petrous and mastoid portions of the temporal bone. P. Bone, a bone of fetal and early infantile life, which in the human species soon becomes merged into the temporal bone. P. Canal, a short passage connecting the mastoid sinuses and the tympanic cavity. P. Foramen, the tympanic orifice of the petro-mastoid canal.

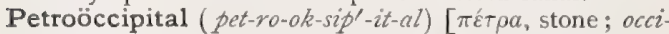
put, occiput]. Pertaining to the petrous portion of the temporal bone and to the occipital bone.

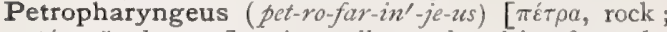
$\phi a ́ \rho v \gamma \xi$, pharyn $x$ ]. A small muscle arising from the lower surface of the petrous portion of the temporal bone, and blending with the constrictors of the pharynx.

Petrosa $($ pet-ro'-sah) $[\pi \varepsilon ́ \tau \rho \alpha$, rock $]$. The petrous portion of the temporal bone.

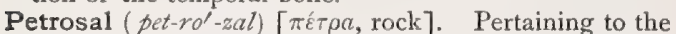
petrous portion of the temporal bone. As a noun, the petrous portion of the temporal bone itself. P. Bone, in biology, one of several portions of the temporal bone in the human fetus and in other animals. $P$. Nerves. See Nerves, Table of. P. Sinus, a name given to two venous sinuses, superior and inferior. The former is situated along the superior border of the petrous portion of the temporal bone; the latter, near the posterior border. P. Vein. Same as $P$. Simus.

Petrosalpingopharyngeus (pet'-ro-sal-ping'-go-far$i^{\prime}$-je-us). Same as Petropharyngeus.

Petrosalpingostaphylinus (pet'-ro-sal-ping'-go-staf-il$i^{\prime}$-nus). Synonym of Levator palati. See Muscles, Table of.

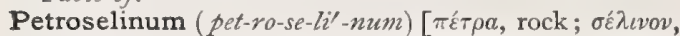
parsley]. A genus of umbelliferous plants including the common parsley.

Petrosomastoid (pet-ro-so-mas'-toid). Synonym of Petromastoid.

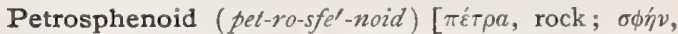
wedge; $\varepsilon i \delta o s$, like ]. Pertaining to the petrous portion of the temporal bone and the sphenoid bone. P. Suture, the suture between the temporal bone and the great wing of the sphenoid bone.

Petrosquamosal, Petrosquamous ( $p e t^{\prime}-r o-s k z a-m o o^{\prime}$. sal, pet-ro-skwa'-mus) [ $\pi \hat{\varepsilon} \tau \rho a$, rock; squama, scale]. Pertaining to the petrous and squamous portions of the temporal bone. P. Fissure. Same as $P$. Suture. P. Sinus, a venous passage formed in the dura at the junction of the petrous and squamous portions of the temporal bone. It opens into the lateral sinus. P. Suture, the line of juncture of the squamous and petrous portions of the temporal bone.

Petrostaphylinus (pet-ro-staf-il-i'-nus). Synonym of Levator palati Muscle. See Muscles, Table of.

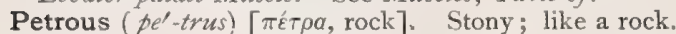
See Petrosal. P. Portion. See Temporal Bone. P. Ganglion. See Ganglia, Table of. P. Sinus. See Petrosal Sinus.

Pettenkofer's Method. A method of estimating $\mathrm{CO}_{2}$ in the air. See Ventilation. P.'s Test. A qualitative test for the presence of biliary acids. A few drops of the suspected liquid, as the urine, are dropped into a fresh solution of sugar and dilute sulphuric acid. If biliary acids be present a purplish-crimson color is produced. See Tests, Table of. P.'s Theory. A theory of the development of cholera. It is that cholera is not communicable from man to man, but requires certain conditions of the soil in order to develop its infectious character. These conditions are, in the main, a low stage of the subsoil water, a certain porosity of the soil, and the presence of substances that can serve as food for low organisms. Pettenkofer succinctly states his theory as follows: The cholera germ, " $\mathrm{X}$," by reason of certain local and chronolugic conditions of the soil, "Y," produces the cholera-poison, " $\mathrm{Z}$," just as the yeast-plant, "X," develops from the sugarsolution, "Y," the poisonous alcohol, "Z Z." The cholera-poison, " $Z$," enters the human body with the inspired air. Pettenkofer's theory is not generally accepted, as it has been proved that the cholerabacillus is the cause of the disease, and enters the body chiefly with the drinking-water.

Petticoat Tube. A device for arresting hemorrhage after lithotomy. It consists of a vulcanite tube, the open end of which is thrust through a small hole in the middle of a piece of linen about four inches square, the linen being firmly tied around the tube about half an inch from the end. This end is lubricated and thrust into the bladder, and the space between the tube and the petticoat is stuffed with strips of lint, thus producing compression.

Peucedanin ( $p u$-sed'-an-in) [ $\pi \varepsilon v \kappa \varepsilon \delta a v o v$, hog-fennel], $\mathrm{C}_{12} \mathrm{H}_{1,2} \mathrm{O}_{3}$. A crystalline body obtained from the root of species of Peucedanum.

Peucedanum (pu-sed'-an-um $)$ [ $\pi \varepsilon v \kappa \varepsilon ́ \delta a v o v$, hog-fennel]. An umbelliferous plant, of which several species have slight medicinal value. It is now rarely used; it yields peucedanin. Unof.

Peumus $\left(p u^{\prime}-m u s\right)$ [native Chilean name]. A genus of apetalous monimiaceous plants. P. boldus. See Boldo. Pexis (peks'-is). Synonym of Concretion.

Peyer's Gland or Peyer's Patch [Johann K. Peyer,

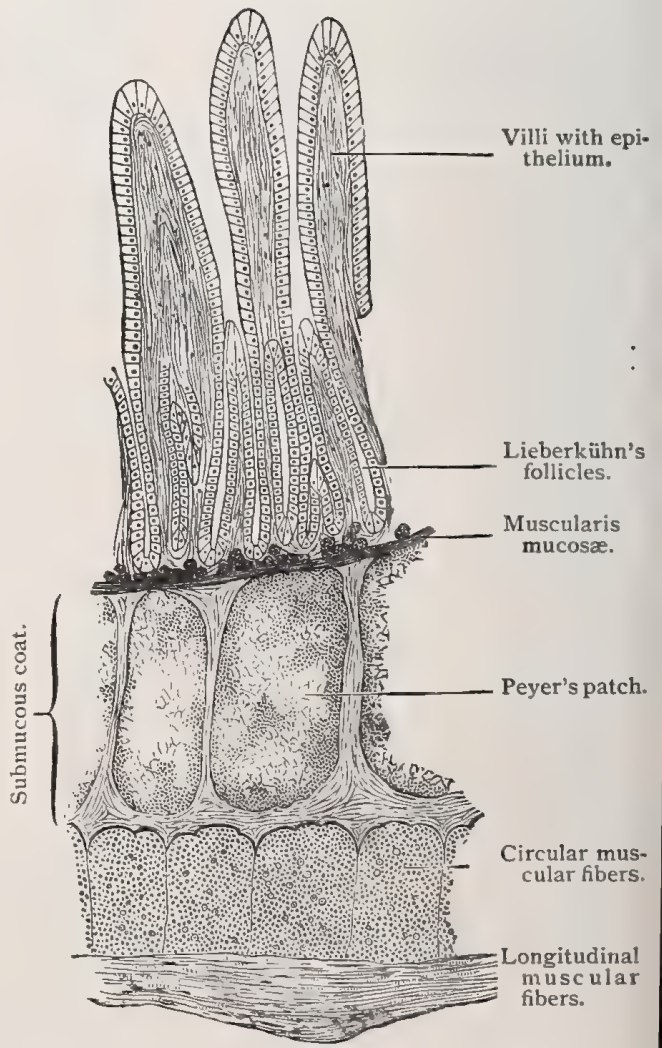

LONGITUdINAL SECTION THROUGH A PEYER'S PATCH OF THE SMall InTESTINe of a Dog. (From Slirling.)

Swiss anatomist $\times 653-1712]$. The agminated glands 
of the small intestine, consisting of large, oval groups of closely aggregated lymph-follicles, bound together by adenoid tissue. The patches vary in size and number; they are usually limited to the lower twothirds of the small intestine, reaching their highest development in the ileum, where they may attain a length of 9-II cm. each; between twenty and thirty patches generally are present; they are relatively better developed in young than in old subjects. (Piersol.)

Peyerian Glands. See Peyer's Gland.

Pfeiffer's Bacillus. See Bacteria, Synonymatic Table of. P.'s Test. See Gout.

Pfluger's Cords, or Loops. Cord-like ingrowths of epithelium into the connective-tissue stroma of the cortex of the ovary, containing the germinal cells. P.'s Law. See Lazu. P.'s Sacs, tubular passages in the fetal ovaries. P.'s Salivary Tubes, the intralobular ducts of the salivary glands. P.'s Tubes, or Tubules. Same as P.'s Sacs.

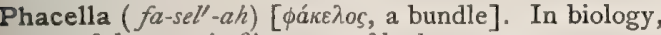
one of the gastric filaments of hydrozoans.

Phacellate ( $\left.f a s^{\prime}-e l-\bar{a} t\right)$ [ $\phi a ́ \kappa \varepsilon \lambda o s, a$ bundle]. In biology, provided with phacellæ.

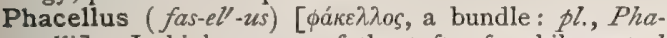
celli ]. In biology, one of the tufts of mobile gastral filaments or mesenterial filaments found in many Cnidarians. Cf. Acontia.

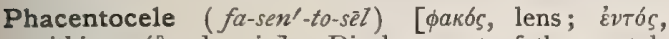
within; $\kappa \eta \hat{\lambda} \eta$, hernia]. Displacement of the crystalline lens into the anterior chamber of the eye.

Phacia $\left(f a^{\prime}-s e-a h\right)$. Synonym of Lentigo.

Phacitis ( $f a$-si'tis). See Phakitis.

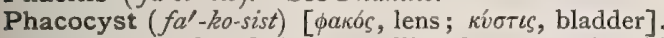
1. The capsule of the crystalline lens. 2. An old term for the often somewhat lenticular nucleus of a plant-cell.

Phacocystectomy (fa-ko-sis-tek'-to-me) [факбs, lens;

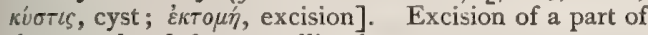
the capsule of the crystalline lens.

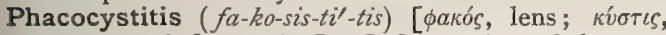
cyst; $t \tau \iota s$, inflammation]. Inflammation of the capsule of the crystalline lens.

Phacoglaucoma ( fa-ko-glaw-ko'-mah) [фakbs, lens; $\gamma \lambda a v k 6 s$, green; $\delta \mu a$, tumor]. Structural changes in the crystalline lens induced by glaucoma.

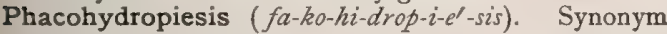
of Cataract, Morgagnian.

Phacohymenitis ( fa-ko- $\left.h i-m e n-i^{\prime}-t i s\right)$ [ $\phi a k o ́ s$, lens;

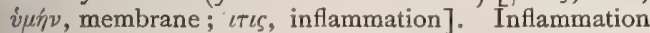
of the capsule of the crystalline lens.

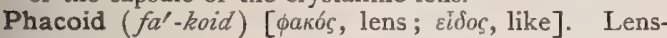
shaped.

Phacoidoscope (fa-koid'-o-scöp). Synonym of Phacoscope.

Phacomalacia (fa-ko-mal-a'-se-ah) [факós, lens ; $\mu \alpha \lambda \alpha \kappa i a$, softness]. Soft cataract.

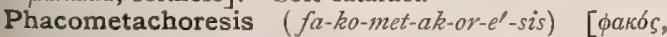
lens; $\mu \varepsilon т \alpha \chi \omega \rho \eta \sigma \zeta^{\circ}$, change of place]. Dislocation of the crystalline lens.

Phacometecesis ( $\left.f a-k o-m e t-e s-e^{\prime}-s i s\right)$. Synonym of Phacometachoresis.

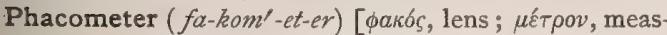
ure]. An instrument for determining the refractive power of lenses.

Phaconin ( $\left.f a^{\prime}-k o-n i n\right)$ [факós, lens]. The albuminoid body of the crystalline lens; it seems to be a globulin.

Phacopalingenesis ( fa-ko-pal-in-jen'-es-is) [фakós, lentil ; $\pi a ́ \lambda \iota \nu$, again; $\gamma^{\prime} v \varepsilon \sigma \iota \varsigma$, genesis]. Reproduction of the crystalline lens.

Phacoplasma (fa-ko-plaz'-mah) [факbs, lentil; $\pi \lambda a ́ \sigma \sigma \varepsilon \nu$, to mold]. A cataplasm made of lentilmeal.
Phacoscleroma ( $\left.f a-k o-s k l e-r o^{\prime}-m a h\right)$. Synonym of Phacosclerosis.

Phacosclerosis $\left(f a-k o-s k l e-r d^{\prime}-s i s\right)$ [фakós, lens; $\sigma \kappa \lambda \eta p o ́ s$, hard]. Hardening of the crystalline lens.

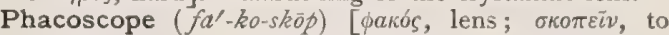
inspect]. An instrument used in observing the accommodative changes of the lens.

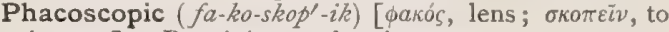
inspect]. Pertaining to the phacoscope.

Phacoscotasmus ( $\left.f a-k o-s k o-t a z^{\prime}-m u s\right)$ [фakós, lens; бќ́тos, darkness]. Clouding of the crystalline lens.

Phacoscotoma ( $\left.f a-k o-s k o-t o^{\prime}-m a h\right)$. Synonym of Cataract.

Phacosis $\left(f a-k o^{\prime}-s i s\right)$ [фakós, lentil]. A freckle or black spot.

Phacydrops, Phacydropsia ( $f a k^{\prime}-i d-r o p s$, fak-id-rop' se-ah). Synonyms of Cataract, Morgagnian.

Phacymenitis (fak-im-en-i'-tis). Synonym of Phacohymenitis.

Phæ- $(f e-)$. See Phe-.

Phænogam, Phænogamic (fen'-o-gam, fen-o-gam'-ik). See Phenogam, Phenogamic.

Phænogamous (fe-nog'-am-us). See Phenogamous.

Phænozygous (fen-o-zi'gus). See Phenozygous.

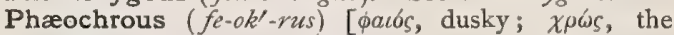
skin]. In biology, dark, dusky.

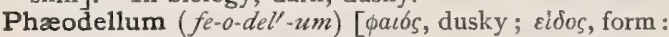
pl., Phaodella $]$. In biology, one of the large pigmentgranules of the Phoodium.

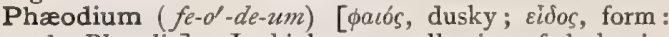
pl., Phaodia]. In biology, a collection of dark pig. ment-bodies in the calymna of certain radiolarians.

Phæophyl, Phæophyll ( $\left.f e^{\prime}-o-f l\right)$ [ $\phi a \iota \delta s$, dusky; $\phi \dot{\prime} \lambda$ $\lambda o v$, leaf]. In biology, Schüt's name for the compound pigment of the Fucacea and Laminariacee. The reddish-brown portion, soluble in water, is called phycophain by Schütt and Millardet. The yellow portion, soluble in alcohol, is called phycoxanthin.

Phagæna ( $\left.f a j-e^{\prime}-n a h\right)$. Synonym of Phagena.

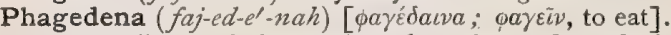
A spreading and destructive ulceration, often obstinately and rapidly disintegrating soft parts. P. gangrænosa. See Gangrene, Hospital. P. nosocomialis, hospital-gangrene. See Gangrene. P. tropica, Aden Ulcer: Malabar Ulcer; a formidable skin-affection of the tropics, attacking chiefly those who live under depressing influences. It is probably due to a microbe that produces a vesicle or bulla that rapidly assumes a sloughing or gangrenous nature. It quickly invades the neighboring tissues, destroying the soft parts and even the bones. The ulcers generally begin on the feet, ankles, or legs, but the thighs or arms may be attacked. Finally, an indurated atonic ulcer is left which, after a variable period of weeks or months, gradually cicatrizes. Death is frequent from exhaustion.

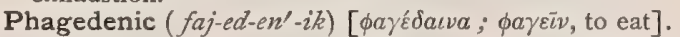
Of the nature of a phagedena. P. Chancre, a syphilitic chancre which has become phagedenic; it is a rare condition. P. Chancroid, a chancroid that spreads rapidly and destroys a large amount of tissue. Nearly the entire penis may be lost in a short time.

Phagedermia, Phagædermia (faj-ed-er'-me-ah) [ $\phi a-$ $\gamma \varepsilon i \nu$, to eat; $\delta \varepsilon p \mu a$, skin]. A phagedenic ulceration of the skin.

Phagedermic, Phagædermic ( faj-ed-er'-mik) [ $\phi a \gamma \varepsilon i v$, to eat; $\delta \varepsilon ́ \rho \mu \alpha$, skin]. Pertaining to phagedermia.

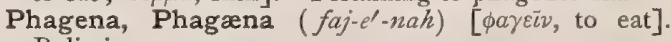
Bulimia.

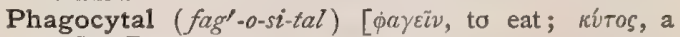
cell]. Pertaining to a phagocyte.

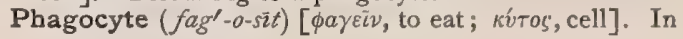


biology, Metschnikoff's name for one of the motile, ameboid, digestive cells of metazoans, moving from place to place in the organism under the influence of thermotaxis, or of what Stahl called positive trophotrop. ism, when it was a question of attraction, and nerative trophotropism, in cases of repulsion. Pfeiffer included the phenomena with that of the attraction of spermatozoids to the female cell, and other forms of sensibility to chemic agents, under the general heading chemiotaxis (positive or negative). Phagocytes are derived from the endodermal or mesodermal tissues in all animals. They are believed to englobe wrecks of larval organs, degradation-products or excretion products, foreign particles, schizomycetes, hematozoa, etc. - their activity varying as the logarithm of the excitation. They digest the soluble parts and reject the insoluble residue. They play an active part in the metamorphosis of tissues and organs, in inflammation, and as prophylactic agents. Phagocytes are fixed-endothelial cells, fixed connective-tissue cells, and free-the wandering cells or leukocytes. In man the colorless blood-cells, as well as other kinds of cells, are credited with playing the rôle of phagocytes. A large phagocytic leukocyte is termed a macrophage, a small one, a microphage.

Phagocytella ( fag-o-si-tel'-ah) [ $\phi a \gamma \varepsilon i v$, to eat, devour; cytella, dim. of кútos, a cell]. In biology, Metschnikoff's term for the simplest, primitive stage of a metazoan, in which it is composed of two layers, the ectal, an enveloping membrane, the other forming, by the ental cells collected into a mass, a kind of parenchyma composed of ameboid elements. This stage readily passes into the gastrula-stage.

Phagocytic (fag-o-sit'-ik) [ $\phi a \gamma \varepsilon i v$, to eat; kítos, cell] In biology, of, pertaining to, or caused by phagocytes; cell-devouring; cytophagous.

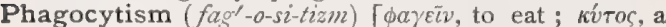
cell]. In biology, the function of a phagocyte. The doctrine that inflammation and other vital processes, normal or abnormal, are due to phagocytes

Phagocytoblast ( fag-o-si'-to-blast) [ $\phi a \gamma \varepsilon i v$, to eat ;

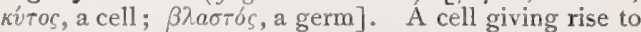
one or more phagocytes.

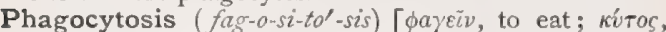
cell]. The destruction or taking up of microörganisms or other solid elements by living cells, as by colorless blood-corpuscles. This theory has been advanced by Metschnikoff and others to explain immunity. It has been found that if microörganisms, such as anthraxbacilli, are introduced into an insusceptible animal, some of them will be found within the bodies of leukocytes, while this does not occur in a susceptible animal. This fact has led to the enunciation of the doctrine that immunity or susceptibility depends on the ability or inability, respectively, of the body-cells to destroy microörganisms. Immunity may be congenital or acquired; in the latter case it is brought about by an adaptation of the cells to the end that they can consume virulent organisms without harm. Several arguments have been advanced against Metschnikoff's views. It has been said that the bacteria sometimes found in leukocytes are probably dead; if a living microörganism enters a colorless blood-corpuscle, the latter is more likely to suffer than the former. Again, the symptoms of infectious diseases are due to peculiar poisons rather than to the bacteria as such. Immunity can be conferred upon an animal by injections of appropriate doses of such poisons, a fact that cannot readily be explained by the phagocytic theory. It has also been demonstrated that the blood-serum possesses bactericidal properties, and that the blood-serum of artificially immune animals is capable of immunizing other ani- mals, and if given in sufficient strength and dose, even of arresting the disease when already established. The tendency at present is to ascribe the causation of immunity to a peculiar property of the body-fluids-whether bactericidal or antitoxic in nature, i.e., counteracting the bacterial poison; this is not fully established.

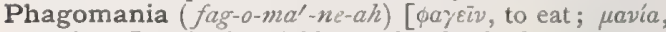
madness]. An insatiable craving for food.

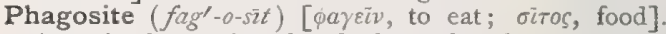
An animal organism that feeds on but does not dwell within or on its host, e.g., the leech, lamprey, cameltick, vampire bat.

Phakitis ( $\left.f a-k i^{\prime}-t i s\right)$ [ $\phi a \kappa b s$, lens ; $\iota \tau \iota$, inflammation]. Hypothetically, inflammation of the crystalline lens of the eye; practically, however, no such condition has been observed.

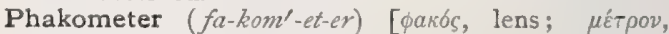
measure]. An instrument for measuring the curvatures and refractive powers of lenses.

Phakosclerosis ( $\left.f a-k o-s k l e-r o^{\prime}-s i s\right)$ [ $\rho b \varsigma$, hard]. Induration or hardness of the crystalline lens.

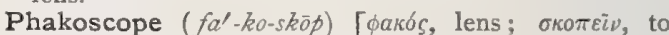
see]. An instrument for observing and estimating the change in the shape of the crystalline lens produced by accommodative influences.

Phalacra, Phalacrosis ( $f a l$ l'-ak-rah, fal-ak-ro'-sis) [øåaкрós, bald]. Baldness.

Phalacroma (fal-ak-ro'-mah). Synonym of Phalacrosis.

Phalangagra ( fa-lang-ga'-grah). Synonym of Phalangarthritis.

Phalangal ( fa-lang $\left.g^{\prime}-g a l\right)$. Same as Phalangeal.

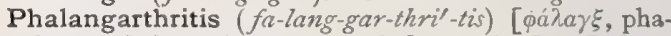
lanx; $a \rho \theta \rho o v$, joint; $\iota \tau \iota$, inflammation ]. Inflammation of phalangeal joints.

Phalange $\left(f a-l a n j^{\prime}\right)$ [ $Q \alpha \dot{\lambda} a \gamma \xi$, the bone of a finger or toe]. In biology : (a) one of the bones of a finger or toe; $(b)$ one of the joints of an insect's tarsus; (c) a bundle of stamens united by their filaments.

Phalangeal (fa-lan'-je-al) [ $\phi a ́ \lambda a \gamma \xi$, phalanx]. Pertaining to a phalanx, or to phalanges. P. Bone, a phalanx. P. Process, in biology : (a) a slender prolongation of Deiter's cells attached to the phalanx of the reticular lamina of the organ of Corti ; $(b)$ the external process of the head of an outer rod of Corti.

Phalangean $\left(f a-l a n^{\prime}-j e-a n\right)$. Same as Phalangeal.

Phalanges (fa-lan'-jêz) [ $\phi a ́ \lambda a \gamma \xi$, phalanx]. Plural of Phalanx. P. of Ear, the minute cuticular fibers in the organ of Corti.

Phalangette, Phalanget ( fal-an-jet') [Fr.]. The third phalanx or terminal bone of the finger.

Phalangial, Phalangian ( $\left.f a-l a n^{\prime}-j e-a l, f a-l a n^{\prime}-j e-a n\right)$. Same as Phalanseal.

Phalangic ( $\left.f a-l a n^{\prime}-j i k\right)$. Synonym of Phalangeal.

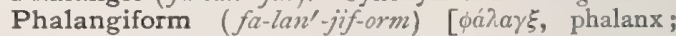
forma, form]. Having the shape of a phalanx.

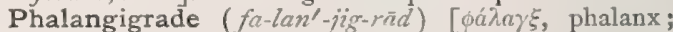
gradi, to go]. In biology, walking on the phalanges. Phalangine $\left(\mathrm{fall}^{\prime}\right.$-an-jin) [Fr.]. The second phalanx or second bone of the finger.

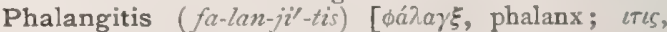
inflammation ]. Inflammation of a phalanx.

Phalango-phalangeal ( fa-lan'-go-fa-lan'-je-al) [ $\phi n^{\prime}-$ $\lambda a \gamma \xi$, phalanx $]$. Pertaining to the successive phalanges of the digits. P. Amputation, removal of a finger or toe at the first or second phalangeal joints.

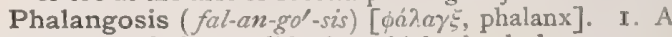
disease of the eyelids in which the lashes are ar ranged in rows. 2. Ptosis.

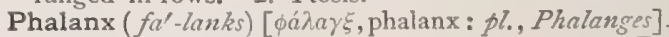
Any one of the bones of the fingers or toes. P. 
Basilar. Synonym of $P$., Proximal. Ps. of Deiters. Synonym of Phalanges of Ear, $q . v$. P., Distal, the phalanx farthest removed from the metacarpus or metatarsus. P., Metacarpal, P., Proximal, of the hand. P., Metatarsal, P., Proximal, of the foot. P., Middle, the middle phalanx of the four fingers or four outer toes. P., Proximal, the one nearest to the metacarpus or metatarsus. P., Terminal. Synonym of $P$., Distal. P., Ungual, P., Unguicular, the distal phalanx, so called because it bears the nail.

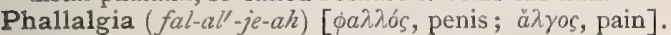
Pain in the penis

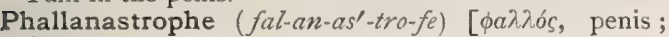

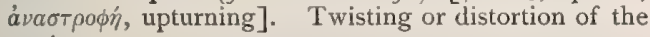
penis.

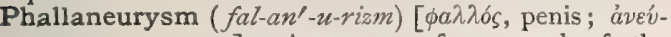
$\rho v \sigma \mu \alpha$, aneurysm]. Aneurysm of a vessel of the penis.

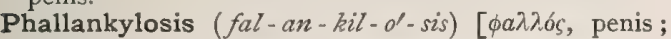

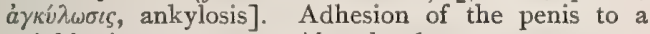
neighboring structure. Also chordee.

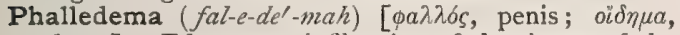
edema]. Edematous infiltration of the tissues of the penis.

Phallic $\left(f a l^{\prime}-i k\right)$ [ $\phi a \lambda \lambda o_{s}$, penis]. Pertaining to the phallus, or penis.

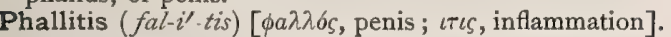
Inflammation of the penis.

Phalloblennorrhea ( fal-o-blen-or-e'-ah) [ $\phi a \lambda \lambda \sigma s$, penis; $\beta \lambda \varepsilon ́ v v a$, mucus; poía, a flow]. A purulent discharge from the urethra.

Phallocampsis ( $\left.f a l-0-k a m p^{\prime}-s i s\right)$ [ $\phi a \lambda \lambda \sigma s$, phallus;

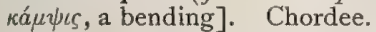

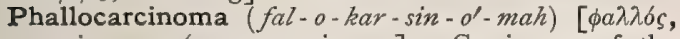

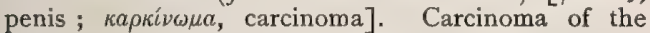
penis; it is usually an epithelioma.

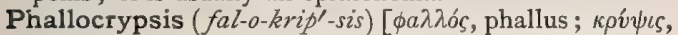
concealment]. Concealment of the penis by retraction.

Phallodynia (fal-o-din'-e-ah) [ $\phi a \lambda \lambda o s$, penis; ódvov, pain]. Pain in the penis.

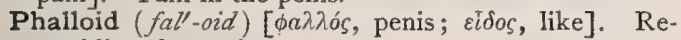
sembling the penis.

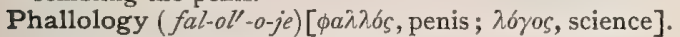
The science treating of the penis.

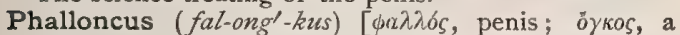
tumor]: Any tumor or swelling of the penis.

Phalloplasty ( fall-o-plas-te) [ $\phi a \lambda \lambda \sigma s$, phallus; $\pi \lambda a ́ \sigma-$ $\sigma \varepsilon \iota \nu$, to mold]. Plastic or restorative surgery of the penis.

Phallopsophia ( fal-op-so'-fe-ah) [ $\phi a \lambda \lambda o ́ s$, penis ; $\psi 6 \phi o s$, noise]. A discharge of gas from the penis.

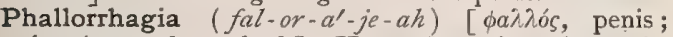
in $\gamma v$ ival, to burst forth]. Hemorrhage from the penis.

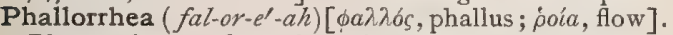
Blennorrhea; a flow of purulent matter from the male urethra.

Phallus $\left(\mathrm{fal}^{\prime}-u s\right)[\phi a \lambda \lambda o ́ s$, penis]. Penis.

Phanakistoscope ( fan- $a k$-is'-to-skōp). See Zoetrope.

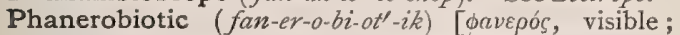
Bios, life]. Presenting evidences of life.

Phanerocodonic ( fan-er-o-ko-don'-ik) [ фavepós, visible; $\kappa \omega \delta \omega \nu$, a bell]. In biology, bell-shaped, campanulate; applied to the gonophores or medusiform buds of hydroid polyps.

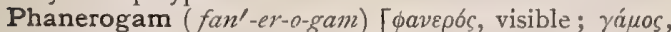
marriage]. In biology, a plant bearing true flowers.

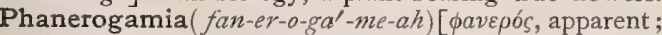

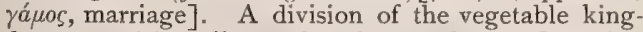
dom comprising all vascular plants, whether flowering or not, with exposed sexual organs. It is subdivided into two classes, endogenous and exogenous. See Cryptogamia.

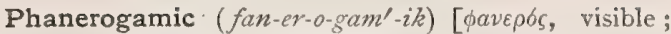
yáuos, marriage]. In biology, flowering.

Phanerogamous (fan-er-og'-am-us) [фavepós, visible;

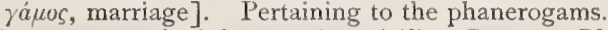

Phanerogenetic (fan-er-o-jen-et'-ik). Same as Phanerogamous.

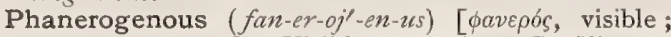
$\gamma \varepsilon v$ '́s, producing]. Visibly producing. P. Tissue, special material forming the pulp of the teeth.

Phaneroscope ( fan'-er-o-sköp) [ $\phi a v \varepsilon \rho o ́ s$, visible; бка$\pi \varepsilon i \nu$, to see]. An instrument devised by Liebreich to render a small patch of skin very translucent and thus to test the color of the blood, condition of anemia, etc.

Phaneroscopy ( fan-er-os'-ko-pe) [ $\phi a v \varepsilon \rho o ́ s$, visible ; $\sigma \kappa o \pi \varepsilon i \nu$, to see]. The use of the phaneroscope.

Phanerozöous (fan-er-o-zo'-us). Synonym of Phanerobiotic.

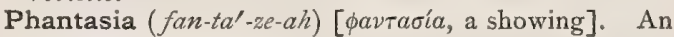
imaginary appearance

Phantasm ( fan'-tazm) [ $\phi a \nu \tau a ́ \zeta \varepsilon \varepsilon v$, to render visible]. An illusive perception of an object that does not exist. A vision or apparition.

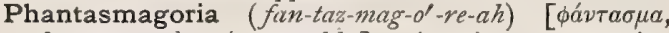
phantasm; ảyopá, assembly]. A series or succession of fantastic and illusory mental pictures.

Phantasmatomoria (fan-taz-mat-o-mo'-re-ah) [ $\phi \alpha^{\prime} \nu$. $\tau \alpha \sigma \mu \alpha$, phantasm; $\mu \omega \rho i ́ a$, folly]. Childishness, or dementia, with absurd fancies.

Phantasmogenesis (fan-taz-mo-jen'-es-is) [ $\phi a ́ v \tau a \sigma \mu \sigma$, phantasm; $\gamma^{\prime} \varepsilon \varepsilon \sigma \iota \varsigma$, genesis]. The origination of phantasms or spectral illusions.

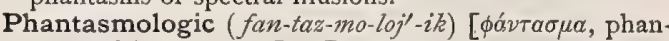
tasm; $\lambda$ ó ${ }^{\circ}$, , science]. Pertaining to phantasmology.

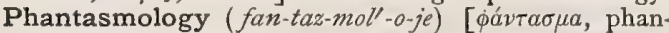
tasm; $\lambda \sigma \gamma o s$, science]. The science of phantasms.

Phantasmophrenosis ( fan-taz-mo-fren-o'-sis) [ $\phi a ́ v \tau a \sigma-$ $\mu \alpha$, phantasm; $\phi \rho \varepsilon v \omega \sigma \iota \zeta$, thought]. The presence of dreamy fancies in the waking state.

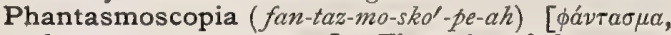
phantasm; $\sigma \kappa o \pi \varepsilon i \tilde{\nu}$, to see]. The seeing of phantasms, in insanity or delirium.

Phantasmoscopy ( $\left.f a n-t a z-m o s^{\prime}-k o-p e\right)$. Synonym of Phantasmoscopia.

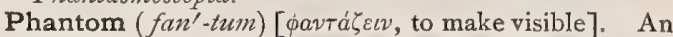
apparition. A model, manikin or effigy upon or by which to illustrate bandaging, surgical, obstetric, and other operations. P. Aneurysm, Mimic Aneurysm; a pulsating tumor simulating subclavian or axillary aneurysm, occasionally met with under the lateral half of the left clavicle. It is associated with thrill, murmur, and dilated veins above, but is apt to disappear suddenly, and return after excitement and after movement of the arms. It is thought to be due to temporary dilatation of the artery from vaso-motor paralysis. P. Brain, a cork and wire model of the brain devised by Aeby. P. Cell, a "shadow," or skeletonized blood-cell. P. Child, a doll used to illustrate the phenomena of labor. P. Face or Head, a metal effigy of a face, with eye-sockets devised to hold animal eyes, wherewith to practice operations in ophthalmic surgery. P. Stricture, erroneous subjective symptoms of the patient who believes he has rectal stricture. P. Tumor, an apparent tumor, usually of the abdomen though occurring elsewhere, which vanishes spontaneously, and which usually consists of a partially and spasmodically contracted muscle. Accumulations of gas and a thickened omentum have simulated ovarian tumor.

Pharaoh's Serpents. Mercury thiocyanate enveloped in a cone of tinfoil and burnt; it is used as a toy. The fumes are said to be poisonous. 


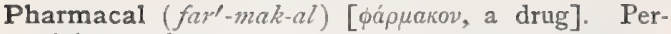
taining to pharmacy.

Pharmaceutic (far-mas-u'-tik) [ $\phi a \rho \mu a \kappa \varepsilon v \varepsilon \iota v$, to administer a drug]. Pertaining to pharmacy.

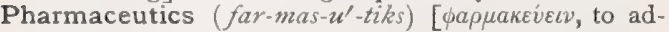
minister a drug]. Pharmacy.

Pharmaceutist (far-mas- $u^{\prime}$-tist). Synonym of Pharmacist.

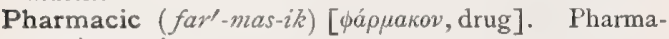
ceutic; poisonous

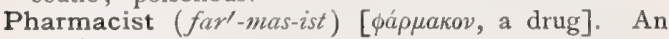
apothecary.

Pharmacocatagraphology (far-mak-o-kat-ag-raf-ol'o-je) [фáp write; $\lambda \hat{\sigma} \gamma o s$, science $]$. The art of prescription-writing.

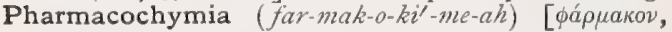
drug; $\chi \eta \mu \varepsilon i a$, chemistry]. Pharmaceutic chemistry.

Pharmacocollocyst (far-mak-o-kol'-o-sist) [фápнакоv, drug, $\kappa \delta \hat{\lambda \lambda a, ~ g l u e ; ~ \kappa v ́ \sigma \tau \iota s, ~ b l a d d e r] . ~ A ~ g e l a t i n o u s ~}$ capsule for receiving medicines.

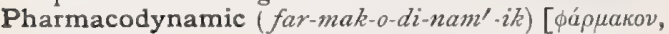
drug; divva $\iota$ s, force]. Pertaining to pharmacodynamics.

Pharmacodynamics ( far-mak-o-di-nam'-iks) [ $\phi a ́ \rho \mu a-$ kov, drug; divaus, force]. The science of the powers and effects of medicines.

Pharmacognosia, Pharmacognosis (far-ma-kog-no'ze-ah, far-na-kog'-no-sis). See I'harmacognosy.

Pharmacognostics ( far-mak-og-nos'-tiks). Synonym of Pharmacognosy.

Pharmacognosy (far-mak-og'-no-ze) [ $\dot{\text { á } \rho \mu \alpha \kappa o v, ~ m e d i-~}$ cine; $\gamma \nu \tilde{\omega} \sigma \iota$, knowledge]. The science or sum of knowledge of drugs.

Pharmacography (far-mak-og'-ra-fe). Synonym of Pharmacognosy.

Pharmacokoniantron ( far-mak-o-kon-e-an' - tron)

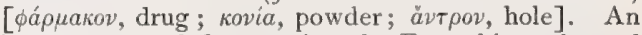
instrument used for spraying the Eustachian tube and middle ear.

Pharmacologic (far-mak-o-loj’-ik) [фа́рнакоv, drug; $\lambda$ óos, science]. Pertaining to pharmacology.

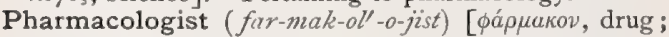
$\lambda 6$ os, science]. One versed in pharmacology.

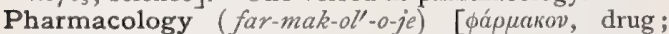
$\lambda 6$ yos, science]. The science of the nature and properties of substances used as medicines; pharmacy and pharmacodynamics.

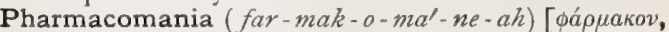
drug; uavia, madness]. A morbid craving for medicines.

Pharmacomaniac ( far-mak-o-ma'-ne-ak) [фа́рнакол', drug; $\mu$ avia, mania]. One excessively fond of the use of drugs.

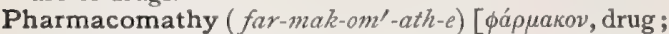
$\mu a ́ \theta \eta$, learning]. Pharmacognostics.

Pharmacometry ( far-mak-om'-et-re) [ $\mu \dot{\tau} T \rho \circ \nu$, measure]. The measuring and weighing of drugs.

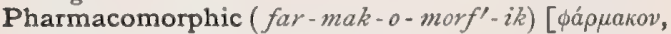
drug; $\mu \rho \rho \phi \eta \dot{n}$, form $]$. Pertaining to the form in which medicines are prepared.

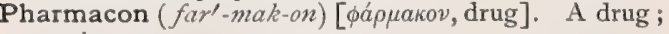
a poison.

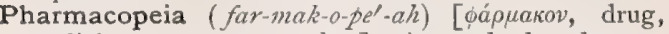
medicine; $\pi$ o $\varepsilon i v$, to make. A standard code containing a selection of medicinal substances, preparations and formulas. The United States (1890), and the British (I885), are among the most comprehensive published. All except the United States pharmacopeia have been issued under government authority.

Pharmacopeial (far-mak-o-pe'-al) [фápuakov, drug;

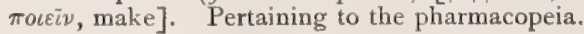

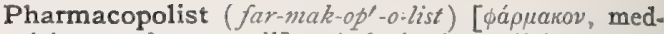
icine; $\pi \omega \lambda \varepsilon i \nu$, to sell]. A dealer in medicines.

Pharmacopolium ( far-mak-o.pol-le-um) [申áppakov, drug; $\pi \omega \lambda \varepsilon i \nu$, to sell]. A drug-store.

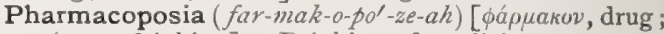

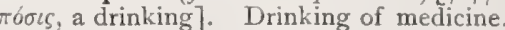

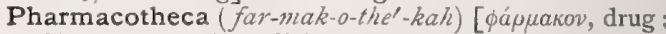
$\theta \dot{\gamma} \kappa \eta$, case]. A medicine-chest.

Pharmacotherapeutic ( far-mak-o-ther-ap-u'-tik) [ $\phi a \rho-$

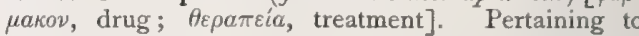
treatment with drugs.

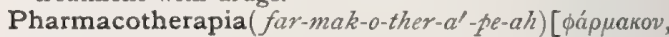
drug; $\theta \varepsilon \rho a \pi \varepsilon i a$, therapy]. Pharmaceutic therapeutics.

Pharmacum ( $f a r^{\prime}-m a k-u m$ ). Same as Pharmacon.

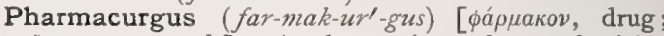
$\varepsilon$ e $\gamma \varepsilon \iota$, to work]. A pharmacist; also a physician who relies entirely on drugs in the treatment of disease.

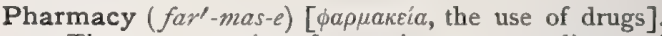
I. The art or practice of preparing, compounding, and dispensing medicines, 2. The occupation of a pharmacist. 3. A drug-store; an apothecary's shop.

Pharus (far'-us). Synonym of Pharynx.

Pharyngalgia (far-in-gal'-je-ah) [фá $\rho v \gamma \xi$, pharynx;

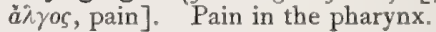

Pharyngeal (far-in'-je-al) [ $\phi a ́ p v \gamma \xi$, pharynx]. Pertaining to the pharynx. P. Aponeurosis, the connective tissue layer of the pharynx, under the mucous surface. P. Arches, the post-oral arches, q. $v$. P. Arteries, two in number; the superior and the inferior. See Arteries, Table of. P. Bones, in biology, the bones behind the last branchial arch in fishes. P. Bursa, a small sac situated in the dorsal wall of the naso-pharynx. P. Cavity, the space within the pharyngeal walls. P. Choke, in farriery, lodgment of a foreign body in the upper portion of the esophagus of a horse, attended with symptoms of great distress. P. Clefts. Same as P. Slits. P. Fascia, the fascia covering the walls of the pharnyx. P. Ganglion. See Ganglia, Table of. P. Glands. See Gland. P. Jaws, jaw-like organs in the pharynx, as in certain worms. P. Nerve, a branch of the vagus. See Nerves, Table of. P. Plexus. See Plexuses, Table of. P. Reflex. See Reflexes, Table of. P. Sac, a sac in the head of a butterfly, at the base of the spiral tongue. By its alternate contraction and expansion the insect is able to suck up the nectar. P. Slits, the post-oral visceral clefts or gill-slits of vertebrates and chordate animals. They are also called Visceral Clefts. P. Spine. Same as $P$. Tubercle. P. Teeth, the teeth on the pharyngeal bones. P. Tonsil. See Luschka's Tonsil. P. Tubercle, a small elevation near the middle of the under surface of the basilar process of the occipital bone. The fibrous raphe of the pharynx is attached to it. P. Vault. See Naso-pharynx. P. Veins, branches of the pharyngeal plexus of veins, emptying into the internal jugular vein. P. Voice, the falsetto voice.

Pharyngectomy (far-in-gek'-to-me) [ $\phi a ́ \rho v \gamma \xi$, pharynx; $\varepsilon \kappa \tau o \mu \eta$, excision]. Excision of a part of the pharynx.

Pharyngemphraxis (far-in-gem-fraks'-is) [ $\phi a ́ \rho v \gamma \xi$, pharynx; $\mu \phi \rho \xi_{\xi} \iota$, obstruction]. Obstruction of the pharynx.

Pharyngeurisma ( $\left.f a r-i n-g u-r i z^{\prime}-m a h\right)$. Synonym of Pharyngocele.

Pharyngeus (far-in-je'-us). See Petro-pharyngeus, etc., under Muscles. Table of.

Pharyngismus ( far-in-jiz'-mus) [фá $\rho v \gamma \xi$, pharynx]. Spasm of the pharynx.

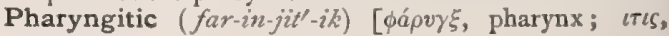


inflammation]. Pertaining to, affected with, or of the nature of, pharyngitis.

Pharyngitis ( $f a r-i n-j i^{\prime \prime}-t i s$ ) [ $\phi a ́ \rho v \gamma \xi \xi$, pharynx; $\iota \tau \iota \zeta$, inflammation]. Inflammation of the pharynx. It may be acute or chronic. In the former there is a frequent desire to swallow, with pain and the sensation of a foreign body in the throat. Malaise, stiffness of the neck, anorexia, fever, and fulness of the head are other symptoms. The chronic form is not so severe as the acute, but there is a more annoying accumulation of viscid mucus, with frequent hawking. P., Apostematous, inflammation of the pharynx attended with the formation of an abscess. P., Atrophic, a form in which there is atrophy of the mucous mem. brane. P., Catarrhal, inflammation of the pharynx, accompanied by abundant secretion. P., Diphtheric, pharyngitis, due to the Klebs-Loeffler Bacillus. P., Follicular, inflammation of the mucous glands of the pharynx. P., Gangrenous, a form of inflammation of the mucous membrane of the pharynx, tonsils, and palatine folds, ending in the formation of gangrenous patches. Fatal hemorrhage may result from erosion of blood-vessels. It is also called Putrid Sore-throat. P., Granular, Clergymens' Sore-throat, a chronic form of pharyngitis, characterized by granular bodies on the mucous membrane of the pharynx. It is common among public speakers, and is due to improper use of the voice. P., Hypertrophic, chronic pharyngitis, with overgrowth, local or general, of the mucous membrane. P. maligna. Synonym of P., Gangrenous. P., Membranous, pharyngitis characterized by the formation of false membrane; it is generally due to the diphtheria-bacillus. P., Phlegmonous, acute infectious phlegmon of the pharynx. A serious form of inflammation of the pharyngeal tissues, with grave constitutional symptoms, the inflammation rapidly passing on to suppuration. P. sicca, chronic pharyngitis, with a dry and glistening state of the mucous membrane, and, generally, with enlargement of the lymph-follicles. P., Ulcerative, a form that may be a simple ulceration of the follicles; or it may be syphilitic, tuberculous, diphtheric, or carcinomatous; or it may be due to such infectious diseases as typhoid fever, or to extension of lupus.

Pharyngo- $\left(f a r-i n^{\prime}-g o^{-}\right)$[фá $v v \gamma \xi$, pharynx]. A prefix signifying connection with or relation to the pharynx.

Pharyngocace ( far-in-gok'-as-e). Synonym of Pharyngilis, Gangrenous.

Pharyngocele ( far-in'-go-sēl) [ $\phi a ́ \rho v \gamma \xi$, pharynx; $\kappa \hat{\eta} \lambda \eta$, tumor]. A tumor or pouch of the pharynx.

Pharyngocenterium (far-in-go-sen-te'-re-um) [ $\phi a ́ \rho v \gamma \xi$,

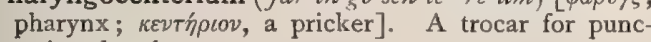
turing the pharynx.

Pharyngocephale (far-in-go-sef'-al-e). A synonym of Pharynx.

Pharyngo-cynanche (far-in-go-sin-an'-ke) [фá $\rho v \gamma \xi$,

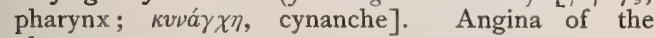
pharynx.

Pharyngodynia ( far-in-go-din'-e-ah) [ $\phi a ́ \rho v \gamma \xi$, pharynx; ófinn, pain]. Pain referred to the pharynx.

Pharyngo-epiglottic $\left(f a r-i n^{\prime}-g o-e p-i g-l o t^{\prime}-i k\right)[\phi a ́ p v \gamma \xi$,

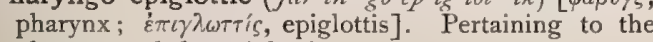
pharyn $x$ and the epiglottis.

Pharyngo-epiglotticus ( $f a r-i n^{\prime}-g o-e p-i g-l o t^{\prime}-i k-u s$ )

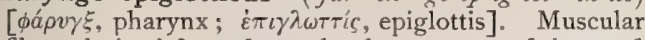
fibers derived from the stylo-pharyngeus and inserted into the side of the epiglottis and the pharyngo-epiglottic ligament.

Pharyngo-esophageal ( $\left.f a r-i n^{\prime}-g o-\ell-s o f-a j^{\prime}-\ell-a l\right)[\phi a ́-$ $\rho v \gamma \xi$, pharynx ; niøoфá $\gamma o s$, gullet]. Pertaining to the pharynx and esophagus.

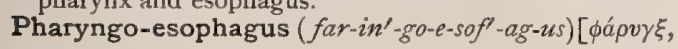

pharynx; oiøoфáyos, esophagus]. The pharynx and esophagus considered as one organ.

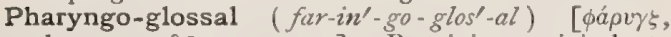
pharynx; $\gamma \lambda \bar{\omega} \sigma \sigma a$, tongue]. Pertaining conjointly to the pharynx and the tongue.

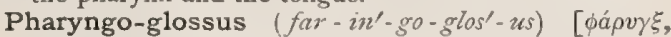
pharynx; $\gamma \lambda \vec{\omega} \sigma \sigma \alpha$, tongue]. A muscle of lower animals corresponding to the palato-glossus of man.

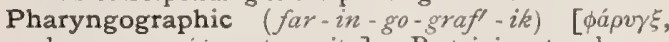
pharynx; $\gamma \rho a \dot{\phi} \varepsilon \iota \nu$, to write]. Pertaining to pharyngography.

Pharyngography ( far-in-gog\% $\bullet r a-f e)$ [ $\phi a ́ \rho v \gamma \xi$, pharynx; $\gamma \rho a ́ \phi \varepsilon \imath$, to write]. A description of the pharynx.

Pharyngo-laryngeal ( $\left.f a r^{\prime}-i n^{\prime}-g o-l a r-i n^{\prime}-j e-a l\right)[\phi a ́ \rho v \gamma \xi$,

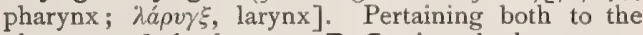
pharynx and the larynx. P. Cavity, the lowest portion of the pharynx. P. Sinus, the pyriform sinus.

Pharyngo-laryngitis ( $\left.f a r-i n^{\prime}-g o-l a r-i n-j i^{\prime}-t i s\right)[\phi a ́ p v \gamma \xi$, pharynx; $\lambda a ́ \rho v \gamma \xi$, larynx; $\iota \tau \iota \varsigma$, inflammation]. Inflammation of both larynx and pharynx at the same time.

Pharyngolith ( far-in'-go-lith) [ $\phi a ́ p v \gamma \xi$, pharynx; $\lambda$ ítos, stone]. A calcareous concretion in the walls of the pharynx.

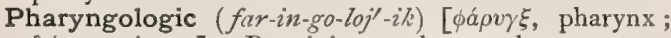
$\lambda \hat{\delta}$ yos, science ]. Pertaining to pharyngology.

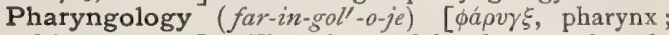
$\lambda o ́$ os, science]. The science of the pharyngeal mechanism, functions and diseases.

Pharyngolysis (far-in-gol'-is-is) [ $\phi a ́ \rho v \gamma \xi$, pharynx ; $\lambda$ vo $\iota$, a loosing]. Paralysis of the pharyngeal muscles.

Pharyngomycosis (far-in'-go-mi-ko'sis) [ $\phi a ́ p v \gamma \xi$, pharynx; $\mu$ v́kns, fungus]. Fungous growths in the pharynx. P. leptothricia. See Mycosis tonsillaris benigna.

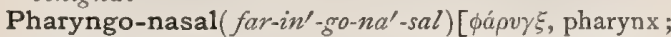
nasus, nose]. Pertaining to the pharynx and the nose. P. Cavity, the upper portion of the pharynx; the naso-pharynx.

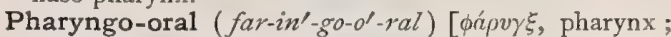
os, oris, mouth]. Oropharyngeal ; pertaining to both pharynx and mouth. P. Cavity, the oropharynx; the middle portion of the pharynx, communicating with the mouth.

Pharyngopalatinus (far-in'-go-pal-at-i'-nus). Synonym of Palatopharyngeus. See Muscles, Table of.

Pharyngopathy (far-in-gop'-ath-e) [ $\phi a ́ p v \gamma \xi$, pharynx; $\pi a ́ f o s$, disease]. Any disease of the pharynx.

Pharyngoperistole (far-in'-go-per-is'-to-le). Synonym of Pharyngostenia.

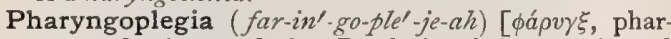
nyx; $\pi \lambda \eta \gamma^{\prime}$, a stroke]. Paralysis of the muscles of the pharynx.

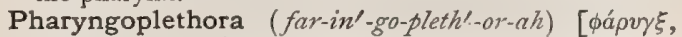
pharynx; $\pi \lambda \eta \theta \omega \rho \eta$, fulness]. Fulness of the vessels of the pharynx.

Pharyngorhinitis (far-in'-go-ri-ni'-tis) $[\phi \rho a ́ v \gamma \xi$, pharynx; ’́ı, nose; $\iota \tau \iota s$, inflammation]. Pharyngitis with rhinitis; inflammation of the pharynx and the nose.

Pharyngorhinoscopy ( far-in'-go-ri-nos'-ko-pe). Synonym of Rhinoscopy, Posterior.

Pharyngorrhagia (far-in-gor-a'-je-ah) [ $\phi a ́ \rho v \gamma \xi$,

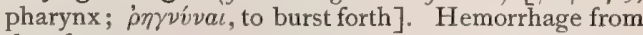
the pharynx.

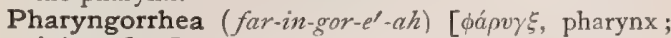
poía, a flow]. A mucous discharge from the pharynx.

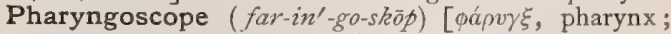
$\sigma \kappa о \pi \varepsilon \bar{\imath} \nu$, to inspect]. An instrument for use in the visual examination of the pharynx.

Pharyngoscopy ( far-in-gos'-ko-pe) [ $\phi a ́ \rho v \gamma \xi$, pharynx; $\sigma \kappa o \pi \varepsilon i \nu$, to examine]. Examination of the pharynx.

Pharyngospasm ( far-in'-go-spazm) [ $\phi a ́ \rho v \gamma \xi$, pharynx; 
$\sigma \pi \alpha \sigma \mu \sigma_{s}$, spasm]. Spasmodic contraction of the pharyngeal muscles.

Pharyngostaphyleus, Pharyngostaphylinus (far in'-g'o-staf-il-e'-us, far-in'-go-staf-il-i'-nus). Synonym of Palatopharyngeus. See Muscles, Table of

Pharyngostenia ( far-in-go-sté-ne-ah) [ á $\rho v \gamma \xi$, phar-

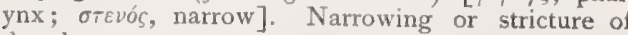
the pharynx.

Pharyngotome (far-in'-go-tōm) [ $\phi a ́ \rho v \gamma \xi$, pharynx; roun, a cutting]. A cutting-instrument used for incising the pharynx.

Pharyngotomy (far-in-got'-o-me) [ $\phi a ́ \rho v \gamma \xi$, pharynx; roun, a cutting]. Incision into the pharynx. P., Inferior, a form in which the tissues between the hyoid bone and the cricoid cartilage are divided. P., Lateral, incision into one side of the pharynx. P., Subhyoidean, pharyngotomy through the thyrohyoid membrane. P., Superior, pharyngotomy in which the incision is made between the anterior border of the sterno-cleido-mastoid muscle and the trachea.

Pharyngotonsillitis ( far-in'-go-ton-sil-i'tis) [ $\phi a ́ p v \gamma \xi$, pharynx ; tonsilla, tonsil ; $\iota \tau \iota$, inflammation]. Inflammation of the pharynx and the tonsil.

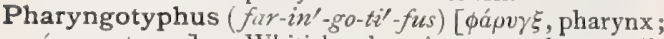
rúos, stupor]. Whitish elevations on the tonsils which tend to ulcerate, seen sometimes in typhoid fever and probably due to localization of the typhoid poison in the tonsils.

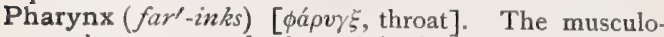
membranous pouch situated back of the nasal cavities, mouth, and larynx, extending from the base of the skull to a point opposite the sixth cervical vertebra,
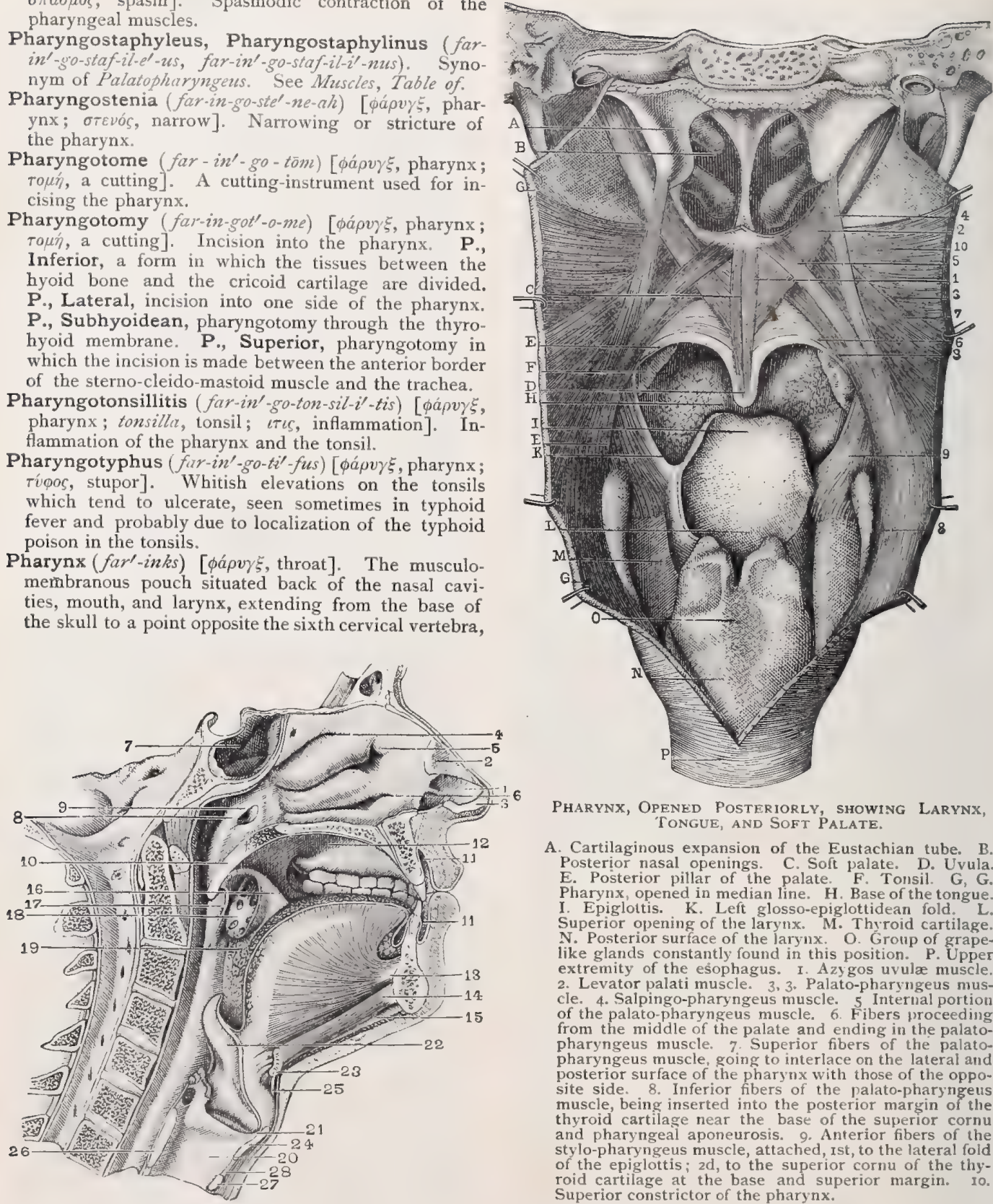

PharynX, Opened POSTERIORLy, SHOWING LARYNX, TONGUE, AND SOFT PALATE.

A. Cartilaginous expansion of the Eustachian tube, B. Posterior nasal openings. C. Soft palate, D. Uvula E. Posterior pillar of the palate. F. Tonsil. G, G. Pharynx, opened in median line. H. Base of the tongue I. Epigloltis. K. Left glosso-epiglottidean fold. L Superior opening of the larynx. M. Thyroid cartilage. N. Posterior surface of the larymx. O. Group of grapelike glands constantly found in this position. $P$. Upper extremity of the esophagus. I. Azygos uvulæ muscle. 2. Levator palati muscle. 3.3. Palato-pharyngeus muscle. 4. Salpingo-pharyngeus muscle. 5 Internal portion of the palato-pharyngeus muscle. 6. Fibers uroceeding from the middle of the palate and ending in the palatopharyngeus muscle. 7. Superior fibers of the palatopharyngeus muscle, going to interlace on the lateral and posterior surface of the pharynx with those of the oppo. site side. 8. Inferior fibers of the palato-pharyngeus site side. 8. Inferior fibers of the palato-pharyngetis
muscle, being inserted into the posterior maryin of the thyroid cartilage near the base of the superior cornu and pharyngeal aponeurosis. 9. Anterior fibers of the stylo-pharyngeus muscle, attached, $x$ st, to the lateral fold of the epiglottis: $2 d$, to the superior cornu of the thyroid cartilage at the base and superior margin. Io. Superior constrictor of the pharynx.

Median Section of Mouth, Pharymx and Larynx.

I. Left nostril. 2. Upper lateral cartilage. 3. Inner portion of lower cartilage. 4. Superior turbinated bone and meatus. 5. Middle turbinated bone and meatus. 6. Inferior turbinated bone and meatus. 7. Sphenoid sinus. 8 Posterior nasal fossa. 9. Internal orifice or pavilion of Eustachian tube. 1o. Velum palati. II, II. Vestibule of mouth. I2 Palatine vault. 13. Genio-glossus muscle. 14. Genio-hyoid. 15. Mylo-byoid. 16. Anterior pillar of velum palati. Posterior pillar. 18. Tonsil. I9. Circumvallate papilla of tongue. 20. Cavity of larynx. 2I. Ventricle. 22. Epiglottis. 23. Hyoid bone. 24. Thyroid cartilage. 25. Thyro-hyoid membrane. 26. Posterior portion of cricoid cartilage. 27 membrane. 26. Posterior portion of cricoid ca
Anterior portion. 28. Crico-thyroid membrane.

where it becomes continuous with the esophagus. It is about five inches long and is narrowed at its termination. It has four coats-an external fascia ; a muscular layer, consisting of the three constrictors, together with the stylo-pharyngeal and palato-pharyngeal muscles; a fibrous connective-tissue layer; and a mucous membrane extending to the base of the uvula, that is covered in its upper part with columnar ciliated epithelium, in its lower part with stratified epithelium. Mucous glands and lymphatic follicles are abundant in the mucous membrane. A group of follicles extends across the 
back of the pharynx between the orifices of the Eustachian tubes.

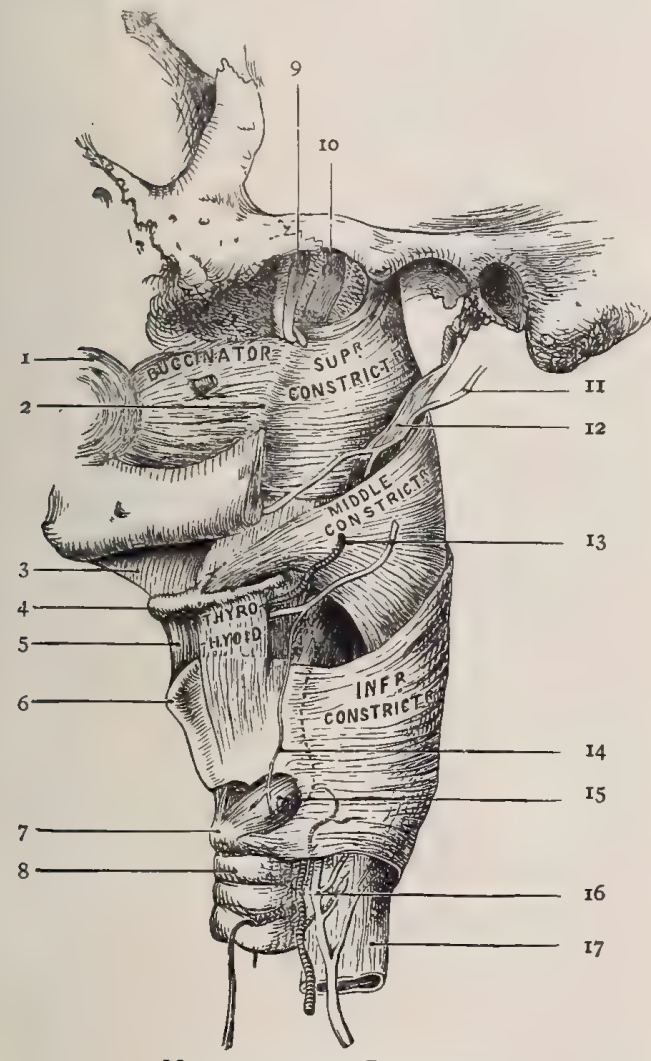

Muscles of the Pharynx.

I. Orbicularis oris. 2. Pterygo-maxillary ligament. 3. Mylohyoideus. 4. Os hyoides. 5. Thyro-hyoid ligament. 6. Pomum Adami. 7. Cricoid cartilage. 8. Trachea. 9. Tensor palati. 10. Levator palati. II. Glosso-pharyngeal nerve. I2. Stylo-pharyngeus. I3. Superior laryngeal nerve and artery. I4. External laryngeal nerve. I5. Crico-thyroideus. I6. Inferior laryngeal nerve. 17. Esophagus.

Phase $(f \bar{a} z)$ [ $\phi a ́ \sigma \iota s$, appearance]. The condition or stage of a disease or physiologic function at a given time.

Phaseomannite ( $\left.f a-z e-o-m a n^{\prime}-\bar{i} t\right)$. See Inosite.

Phasura ( $\left.f a-z u^{\prime}-r a h\right)$. Synonym of Phantasm.

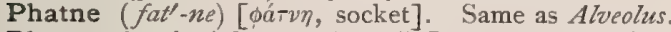

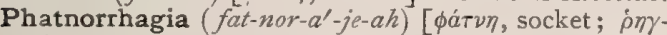
vival, to burst forth]. Hemorrhage from a toothsocket.

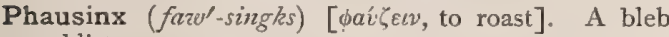
or blister.

Pheduretin (fe-du-re'tin) [phenol (фoĩv $\xi$, purple-

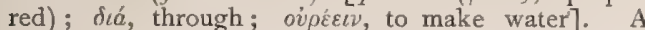
phenol-derivative, occurring in fine, white, silky, acicular crystals, tasteless, hardly soluble in cold water, readily soluble in hot water. It is said to be a powerful diuretic. Dose gr. vij-xv. Unof.

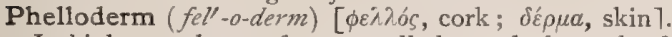
In biology, a layer of green cells beneath the cork of certain stems (Ribes, Lonicera, Spiraa, Deutzia, etc.). It is formed from the ental layer of the phellogen.

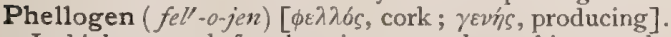
In biology, cork-forming tissue ; cork-cambium, corkmeristem; the ental layers of cork-tissue, possessing cellular activity.
Phellogenetic (fel-o-jen-et'-ik) [ $\phi \varepsilon \lambda \lambda o ́ s$, cork; $\gamma \varepsilon v \eta ́ s$, producing]. In biology, relating to the formation of phellogen.

Phenacetein, see Phenacetolin.

Phenacetin ( $\left.f e-n a s^{\prime} \cdot e l-i n\right)$ [ phenol ( acetum, vinegar $], \mathrm{C}_{10} \mathrm{H}_{13} \mathrm{NO}_{2}$. Acelphenetidin; a compound derived from carbolic acid, having antipyretic and antineuralgic properties. It is crystalline, tasteless, and almost insoluble in water. Dose gr. iv-xxx. Unof.

Phenacetolin ( $f e$-nas'-et-o-lin), $\mathrm{C}_{16} \mathrm{H}_{12} \mathrm{O}_{2}$. A some what irregularly formed name of a compound produced by the interaction of phenol, acetic acid, and zinc chlorid. It is used as an indicator in determining acidity and alkalinity. It is also called phenacetein.

Phenanthrene $\left(f_{e}-n a n^{\prime}-t h r e \bar{n}\right)$ [ phenol ( red) ; a $\nu \theta \rho a \xi, c o a l], \mathrm{C}_{14} \mathrm{H}_{10}, \mathrm{~A}$ hydrocarbon isomeric with anthracene, and found with it in the last fraction of coal-tar. It crystallizes in colorless, shining plates, melting at $100^{\circ} \mathrm{C}$. and boiling at $340^{\circ} \mathrm{C}$.; it is insoluble in water, but soluble in fifty parts of alcohol in the cold, and in ten parts on boiling; it is easily soluble in ether and benzene. P.-red. See Pigments, Conspectus of.

Phenate $\left(f e^{\prime}-n a \bar{t}\right)$ [phenol ( oivi $\xi$, purple-red)]. Any salt-like compound of carbolic acid; a carbolate.

Phenazin ( $f e^{\prime}$-naz-in) [phenol ( $\mathrm{C}_{12} \mathrm{H}_{8} \mathrm{~N}_{2}$. A substance prepared by conducting anilin vapors through a tube heated to redness. It crystallizes and sublimes in bright-yellow needles, melting at $17 \mathbf{I}^{\circ} \mathrm{C}$. The phenazins are chromogenic parentsubstances that yield dyes by the entrance of saltforming groups (especially the amido-group). The eurhodins and safranins are included in this series.

Phenazonum ( $\left.f e-n a z-o^{\prime}-n u m\right)$. See Antipyrin.

Phenetidin (fe-net'-id-in) [phenol ( ooivı $\xi$, purple-red)], $\mathrm{C}_{8} \mathrm{H}_{11} \mathrm{NO}$. The body from which phenacetin is prepared by substitution.

Phenetol ( $\left.f e^{\prime}-n e t-o l\right)$ [phenol ( oleum, oil ], $\mathrm{C}_{2} \mathrm{H}_{5} \mathrm{~S} \mathrm{OC}_{6} \mathrm{H}_{5}$. A volatile aromatic-smelling liquid. P.-red. See Coccinin and Pigments, Conspectus of.

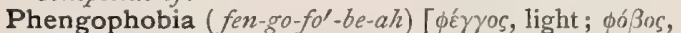
fear]. See Photophobia.

Phenic $\left(f^{\prime}-n i k\right)$ [phenol $(\phi o i v t \xi$, purple-red)]. Obtained from coal-tar. P. Acid. See Acid, Carbolic, and Phenol.

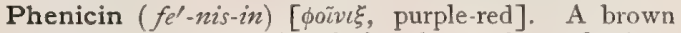
coloring-matter produced by the action of nitrosulphuric acid on carbolic acid. Same as Phenylbrozon. See Pigments, Conspectus of.

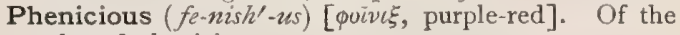
color of phenicin.

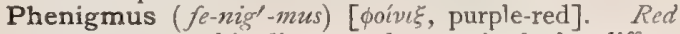
Jaundice; a skin-disease, characterized by diffuse redness, without fever.

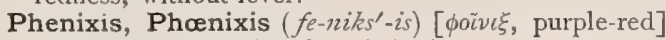
Red color of the skin from irritation.

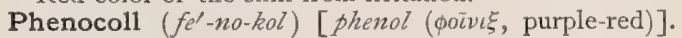
$\left.\mathrm{C}_{6} \mathrm{H}_{4} / \mathrm{OC}_{2} \mathrm{H}_{5}, \mathrm{NH}_{2}\right) \mathrm{CH}_{2} . \mathrm{C}_{10} \mathrm{H}_{14} \mathrm{~N}_{2} \mathrm{O}_{2}$. The hydrochlorate of phenol-glycocoll, a rapid and powerful antipyretic and a valuable nervine. Dose gr, viij$\mathrm{xv}$, repeated at hourly intervals. It is also used as the hydrochlorid. Phenocoll appears as a white crystalline powder soluble in water and alcohol. Unof.

Phenogamous (fen-og'-am-us). Synonym of Phanerogamous.

Phenol ( $\left.f e^{\prime}-n o l\right)$ [фог̈ $\xi$, purple-red], $\mathrm{C}_{6} \mathrm{H}_{5} . \mathrm{OH}$. Benzene Phenol, Carbolic Acid, Creasote; a substance obtained from amidobenzene, etc, , and occurring already formed in Castoreum and in the urine of herbivora. It is a colorless, crystalline mass, which gradually 
acquires a reddish color, and deliquesces on exposure to the air. It melts at $42^{\circ} \mathrm{C}$. and boils at $18 j^{\circ} \mathrm{C}$; its sp. gr. at $0^{\circ}$ is 1.084 . It possesses a characteristic odor, burning taste, and poisonous and antiseptic properties. It is slowly soluble in water, readily so in alcohol and ether. In a general sense the word is applied to the homologous series of which phenol or carbolic acid is the first member. The phenols are compounds formed from benzene and its homologues by the substitution of hydroxyl for hydrogen in the benzene nucleus. They correspond to tertiary alcohols, as they contain the group $\mathrm{COH}$, and all have weak acid properties. They may be monatomic, such as ordinary phenol, cresol, etc.; diatomic, as pyrocatechin, resorcin, hydroquinone; or triatomic, as pyrogallol, phorglucol. P.-blue, $\mathrm{C}_{14} \mathrm{H}_{14} \mathrm{~N}_{2} \mathrm{O}$, a paste-like substance of blue color. See Pigments, Conspectus of. P.-camphor, camphor combined with carbolic acid. P. Colors. See Pigments, Conspectus of. P. Sodique, an antiseptic substance said to be composed of carbolic acid, gr. 188; caustic soda, gr. 3I; distilled water, $z$ iv.

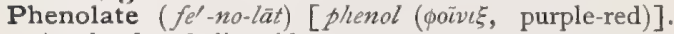
A salt of carbolic acid.

Phenologic (fe-no-loj'-ik) [ $\phi a i \nu \varepsilon t \nu$, to bring to light; $\lambda$ jó $_{0}$, science]. Pertaining to phenology.

Phenologist (fe-nol'-o-jist) [ [aive v, to bring to light; $\lambda 6 \gamma o s$, science]. One versed in phenology.

Phenology (fe-nol'-o-je) [ $\phi a i v \varepsilon l v$, to bring to light; $\lambda 6$ ros, science]. In biology, the science of the behavior of plants and animals to the periodic changes in meteorologic conditions.

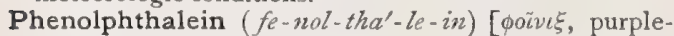
red]. A substance derived from phenol and phthalic acid and used as a delicate test for acids and alkalies. One gram is dissolved in one liter of 50 per cent. alcohol. It is very delicate.

Phenolsulphonic Acid (fe-nol-sul-fon'-ik) [phenol (фoiv $\xi$, purple-red); sulphur]. The "phenol-forming substance" found sometimes in urine from which phenol is obtained.

Phenolsulphuric Acid (fe-nol-sul-fu'-rik) [phenol (фoivı $\xi$, purple-red); sulphur]. An acid that exists in the urine in very small amount.

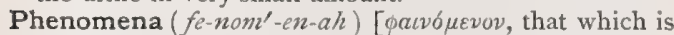
seen]. Plural of Phenomenon, $\%$. Phenomena of Transfer. Peculiar phenomena observed in hysterical patients. It has been found, in some cases, that the laying of a metal plate upon an anesthetic portion of the skin restores to this its sensibility, while simultaneously a corresponding area on the opposite side of the body, previously normal, becomes anesthetic. Frequently the sensibility oscillates from one side to the other. If the metal is placed first on an area possessing normal sensibility, this becomes anesthetic, while a corresponding zone on the anesthetic side regains its sensibility. Other hysterical symptoms may present these same transfer-phenomena. Nor is their production confined to metallic plates; other so-called esthesiogenic substances produce the same effect-thus, large magnets, weak galvanic currents, static electricity, vibrating tuning-forks, mustardplasters, and others. As to the nature of the curious phenomena, it is generally believed that they are due to suggestion.

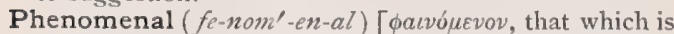
seen ]. Pertaining to phenomena. Also extraordinary, startling, or exceptional to the ordinary course of events in nature.

Phenomenogenia ( $\left.f e-n o m-e n-o-j e^{\prime}-n e-a h\right)[\phi a i v \varepsilon \imath$, to

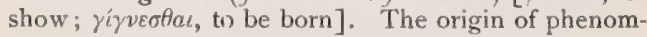
ena.
Phenomenon (fe-nom'-en-on) [onıvórevov, that which is seen; from $\dot{\varphi} u \iota \varepsilon \iota v$, to shine: $p l$. Phenomena ]. An event or manifestation, generally of an unusual character. P., Cheyne-Stokes'. Synonym of Cheyne-Stokes' Respiration. P., Knee. Synonym of Patellar Tendon-reflex. P., Porret's, a wave-like motion seen in a muscle through which a galvanic current passes in a longitudinal direction. P., Westphal's. Synonym of Patellar Tendon-reflex.

Phenomenoscopia (fe-nom-en-o-sko'-pe-ah) [ $\phi a i v \varepsilon \iota v$,

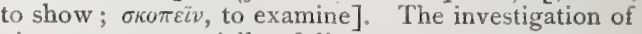
phenomena, especially of disease.

Phenone $\left(f e^{\prime}-n \bar{n}\right)$ [phenol ( ketone formed by the union of phenyl and a hydrocarbon of the marsh-gas series.

Phenophobia $\left(f e-n o-f o^{\prime}-b e-a h\right)$. Synonym of Photophobia.

Phenoquinone (fe-no-kwin'-ōn) [ phenol $(\phi o i v c \xi$, purplered); quinone ], $\mathrm{C}_{18} \mathrm{H}_{14} \mathrm{O}_{4}$. An oxidation-product of phenol.

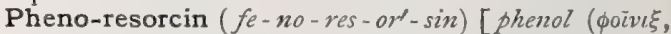
purple-red); resorcin]. A mixture containing carbolic acid 67 , resorcin 33 per cent. Unof.

Phenosafranin (fe-no-saf'-ran-in) [phenol (申oĩv purple-red) ; Fr., safran, saffron], $\mathrm{C}_{18} \mathrm{H}_{15} \mathrm{~N}_{4} \mathrm{Cl}$. The lowest member of the safranins, formed from phenylene, diamin, and anilin. It consists of needles, green in color and having a metallic luster. It dissolves in water and alcohol with a beautiful red color. See Pigments, Conspectus of.

Phenose $\left(f e^{\prime}-n \bar{o} z\right)$ [phenol ( $(\mathrm{OH})_{6}$. A substance obtained by the action of a soda solution upon hexahydrobenzene. It is an amorphous, readily soluble substance, deliquescing in the air. It has a sweet taste, and reduces Febling's solution, but is not capable of fermentation.

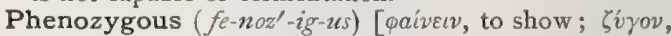
yoke]. In craniometry, "having the zygomatic arches visible directly from above; having the bizygomatic diameter greater than the maximum transverse frontal diameter, and the angle of Quatrefages positive."

Phenyl ( $\left.f e^{\prime}-n i l\right)$ [ A univalent organic radical. P.-acetic Acid. See Acid. P.-amid, a compound formed by the substitution of one or more amido-groups for the hydrogen of benzene; anilin is a phenylamid. P.-amin. Synonym of Anilin. P.-auramin. See Pigments, Conspectus of. P. Bisulphate. See Acid, Sulphocarbolic. P.-brown. See Pigments, Conspectus of. P.-carbamate of Ethyl. See Phenylurethane, P.-endiamin $\mathrm{C}_{6} \mathrm{H}_{4}\left(\mathrm{NH}_{2}\right)_{2}$. Preferably diamidobenzene; a chemic substance of which there are three isomeric forms, distinguished by the prefixes ortho-, meta-, para-. P.ethylene. See Styrol. P.-glucosazone, $\mathrm{C}_{18} \mathrm{H}_{22} \mathrm{~N}_{4} \mathrm{O}_{4}$; a compound of dextrose with phenyl-hydrazin. It crystallizes in yellow needles, is almost insoluble in water, very slightly soluble in hot alcohol, melts at about $205^{\circ}$ C., and is levo-rotatory when dissolved in glacial acetic acid. P.-glycerol. See Stycerin. P.-glycuronic Acid, a levo-rotatory, crystalline body occurring in the urine after the administration of carbolic acid. Dilute acid decomposes it into carbolic and glycuronic acids. P.-hydrazin, $\mathrm{C}_{6} \mathrm{H}_{8} \mathrm{~N}_{2}$, a substance obtained from benzene diazochlorid by reduction with sodium sulphite or stannous chlorid. It is a colorless, peculiarsmelling oil, solidifying, when cooled, to plate-like crystals, melting at $23^{\circ} \mathrm{C}$; ; sp. gr. I.09I at $2 \mathrm{I}^{\circ} \mathrm{C}$. It boils at $24 \mathbf{I}-242^{\circ} \mathrm{C}$. It dissolves with great diffculty in cold water, but readily in alcohol and ether. P.-h. Test (for sugar). Into a test-tube put $1 / 2$ in. dry phenyl-hydrazin hydrochlorate; add pulverized sodium acetate an equal volume; and fill one-half of the tube 
with urine. Agitate until the sodium acetate is dissolved, gently heating up to the boiling-point and boil for 30 seconds. Examine the sediment with the microscope for yellow, branching, needle-shaped crystals of phenyl-glucosazone. See Tests, Table of. $\mathbf{P}$. Hydrid, $\mathrm{C}_{6} \mathrm{H}_{6}$, benzene. $\mathrm{P}$--lactosazone, $\mathrm{C}_{24} \mathrm{H}_{32} \mathrm{~N}_{4}$ $\mathrm{O}_{9}$, a compound of lactose with phenyl-hydrazin; it is soluble in $80-90$ parts of boiling water, and melts at about $200^{\circ} \mathrm{C}$. It crystallizes readily in the form of yellow needles usually aggregated into clusters. P.-maltosazone, $\mathrm{C}_{24} \mathrm{H}_{32} \mathrm{~N}_{4} \mathrm{O}_{9}$, a compound of maltose obtained by the action of phenyl-hydrazin upon it in the presence of acetic acids. It crystallizes readily in minute yellow needles, is soluble in about 75 parts of boiling water, and still more soluble in hot alcohol. Its melting-point is $206^{\circ} \mathrm{C}$. P.-mercaptan. See Thiophenol. P.-methane, $\left(\mathrm{CH}_{2}\left(\mathrm{C}_{6} \mathrm{H}_{5}\right)_{2}\right.$, a crystalline hydrocarbon with the odor of oranges. It has the effects of antipyrin, in half the dose, being antirheumatic and analgesic, as well as antipyretic. Dose from 3 to $7 \mathrm{gr}$, in wine. P.-propionic Acid, $\mathrm{C}_{9} \mathrm{H}_{6} \mathrm{O}_{2}$, a crystalline body which, when injected subcutaneously, causes albuminuria, glycosuria, vomiting, diarrhea, and sometimes death. If the sodium salt is given, large amounts of indican appear in the discharges. P. Salicylate. See Salol. P.-urethane, $\mathrm{C}_{9} \mathrm{H}_{11} \mathrm{NO}_{2}$, a white, crystalline substance made by the action of chlorocarbonic acid on carbanilic ether. It is also known chemically as phenylcarbamate of ethyl and euphorin. It has the flavor of benzine, with an acrid after-taste; it is almost insoluble in cold water, but is soluble in boiling water, alcohol and ether; I-500 hinders alcoholic fermentation. See Euphorin. P.-violet. Same as Rosanilin-violet.

Phenylene $\left(f e^{\prime}-n i l-\bar{e} n\right)$ [ $\phi o i v \iota \xi$, purple-red], $\mathrm{C}_{6} \mathrm{H}_{4}$. A bivalent organic radicle. P.-blue. See Pigments, Conspectus of. P.-brown. See Pigments, Conspectus of.

Phenylia ( $\left.f e-n i l^{\prime}-e-a h\right)$. Same as Anilin.

Phenylic $\left(f e-n i l^{\prime}-i k\right)$ [ $\phi \circ i \nu l \xi$, purple-red]. Pertaining to phenyl. Same as Phenic. P. Acid. Synonym of Carbolic Acid. P. Alcohol. Synonym of Carbolic Acid.

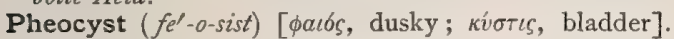
Decaisne's term for the nucleus of a vegetable cell.

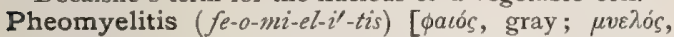
marrow; iTı, inflammation]. Inflammation of the gray matter of the spinal cord.

Phial $\left(f^{\prime}-a l\right)$ [ $\phi \iota^{\prime} \lambda \eta$, a saucer]. A small glass bottle.

Phialine $\left(f^{\prime}-a l-i n\right)$ [ $\phi i \dot{\alpha} \lambda \eta$, a saucer, or patera]. In biology, saucer-shaped.

Philanthrope ( $f l^{\prime}$-an-thrōp $)$ [ $\phi \imath \lambda a ́ v \theta \rho \omega \pi o \varsigma$, humane]. A philanthropist

Philanthropic ( fil-an-throp'-ik) [ $\phi \iota \lambda a ́ v \theta \rho \omega \pi o s$, humane]. Pertaining to philanthropy; benevolent.

Philanthropism (fil-an'-thro-pizm). Same as Philanthropy.

Philanthropist ( $\left.f l-a n^{\prime}-t h r o-p i s t\right)[\phi \iota \lambda a ́ v \theta \rho \omega \pi o s, \mathrm{hu}-$ mane]. One who loves mankind.

Philanthropy ( $f l$-an'-thro-pe) [ $\phi i \lambda a ́ v \theta \rho \omega \pi o s$, humane]. The love of mankind; benevolence; charity.

Philermum ( $f l$-ur'-mum). Synonym of Mercaptan.

Philetron ( $f$-le'tron). Synonym of Philtrum.

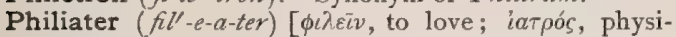
cian]. An amateur student of medical science; a non-professional observer of disease-phenomena.

Phillips' Muscle. See Muscles, Table of.

Philœnia ( $\left.f l-e^{\prime}-n e-a h\right)[\phi i \lambda \varepsilon i v$, to love ; oivos, wine]. Morbid addiction to strong drink.

Philogynist $\left(f l-o j^{\prime}-i n-i s t\right)[\phi \iota \lambda \varepsilon i v$, to love; $\gamma v v \dot{\eta}$, women]. A lover of women; the opposite of misogynist.
Philogyny $\left(f l-o j^{\prime}-i n-\ell\right)$ [ $\phi i \lambda \varepsilon i \nu$, to love; jvví, women]. Admiration for women; the opposite of misogyny.

Philomimesia $\left(f i l-0-m i-m e^{\prime}-z e-a h\right) \quad[\phi i \lambda \varepsilon i \nu$, to love $\mu i \mu \eta \sigma \varsigma$, imitation]. A morbid or insane love of mimicry.

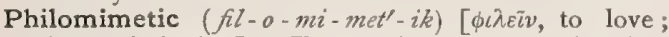

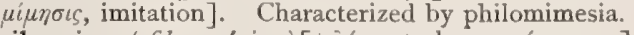

Philoneism ( $\left.f l l-o-n e^{\prime}-i z m\right)$ [ $\phi i \lambda \varepsilon \varepsilon \varepsilon \nu$, to love; véos, new]. Abnormal love of novelty; the reverse of misoneism.

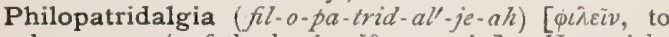
love; $\pi a \tau \rho i s$, fatherland; àyos, pain]. Homesickness, or nostalgia.

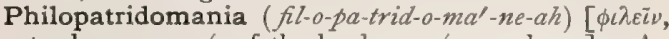
to love; $\pi \alpha \tau \rho i s$, fatherland; $\mu \alpha v i \alpha$, madness]. An insane desire to return home; excessive nostalgia, or homesickness.

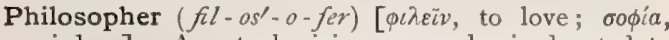
wisdom]. A metaphysician; one who is devoted to philosophy.

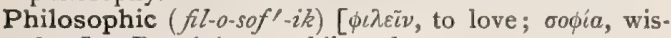
dom]. Pertaining to philosophy.

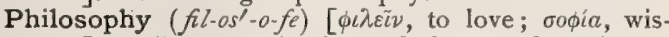
dom]. The coördination of human knowledge. Science in its widest sense; also, any important branch of science. P., Natural. See Physics. P., Positive, Comteism, or the philosophy of Auguste Comte.

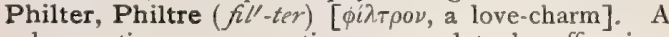
love-potion; a preparation supposed to be efficacious in exciting sexual passion.

Philtrum ( $f l^{\prime}$-trum) [ $\phi i \lambda \tau \rho o \nu$, a love-charm]. The depression on the surface of the skin of the upper lip immediately below the septum of the nose. Also, the same as Filter.

Philydrous ( $\left.f l-i^{\prime}-d r u s\right)$ [ $\phi i \lambda \varepsilon i v$, to love; $v \delta \omega \rho$, water]. In biology, living in or frequenting water.

Philypostrophous ( $\left.f l-i p-0 s^{\prime}-t r o-f u s\right)[\phi i \lambda \varepsilon i \nu$, to love ;

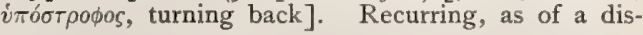
ease.

Phimosientomy ( $f$-mo-se-en'-to-me) $[\phi(\mu o \tilde{\nu} \nu$, to con-

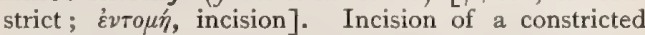
prepuce.

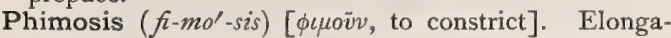
tion of the prepuce and constriction of the orifice, so that the foreskin cannot be retracted to uncover the glans penis. P. oris, narrowing of the opening of the mouth. P. palpebrarum. Synonym of Blepharophimosis. P. vaginalis, atresia of the vagina.

Phlasma (faz'-mah) [ $\phi \lambda a ́ \sigma \mu a$, bruise]. Synonym of Contusion.

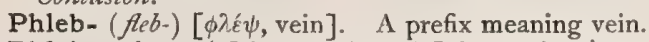

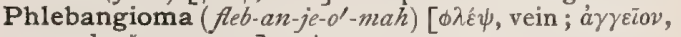
vessel; $\check{\partial} \mu a$, tumor]. A venous aneurysm.

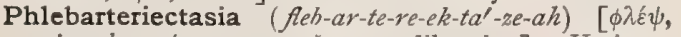

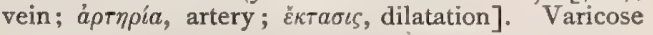
aneurysm.

Phlebarteriodialysis (feb-ar-te-re-o-di-al'-is-is) [ $\phi \lambda c^{\prime} \psi$, vein; á $\rho \tau \eta \rho i a$, artery; $\delta \iota \dot{\gamma} v \sigma \iota$, , separation]. Arteriovenous aneurysm.

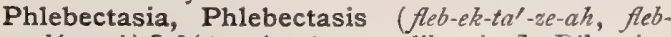

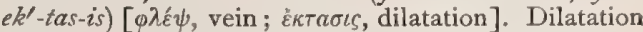
of a vein or veins. See Varix. P. hæmorrhoidalis. Synonym of Hemorrhoid.

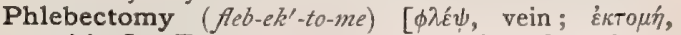
excision]. Excision of a vein or portion of a vein.

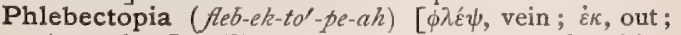
Tótos, place]. The displacement or abnormal position of a vein.

Phlebemphraxis (fleb-em-fraks'-is) [ $\phi \lambda \varepsilon \dot{\psi} \psi$, vein ; $\check{\varepsilon} \mu \phi-$ $\rho a \xi \iota$, obstruction]. Plugging of a vein.

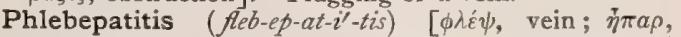
liver; $\iota \tau \iota s$, inflammation]. Inflammation of the portal or hepatic veins. 
Phlebeurisma (Aeb-u-riz'-mah). Synonym of Varix. Phlebic ( leb $\left.^{\prime}-i k\right)\left[\phi \lambda \varepsilon \psi^{\prime}\right.$, vein]. Venous.

Phlebin (Aeb'-in) $[\phi \lambda \varepsilon \psi$, vein]. Hoppe-Seyler's term for the venous blood-pigment as contained in the red corpuscles. See Pigments, Conspectus of.

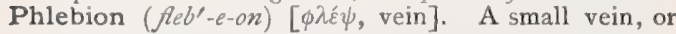
venule.

Phlebismus ( $\left.A e b-i z^{\prime}-m u s\right)[\phi \lambda \hat{\varepsilon} \psi$, vein]. Undue prominence or swelling of a vein.

Phlebitic $\left(\mathcal{A}_{e} b-i t^{\prime}-i k\right)$ [ $\phi \lambda \varepsilon \dot{\psi}$, vein ; $\iota \tau \iota \zeta$, inflammation] Pertaining to, of the nature of, or affected with phlebitis.

Phlebitis ( $\left.A l b-i^{\prime}-t i s\right)$ [ $\phi \lambda \varepsilon \psi$, vein; $\iota \tau \iota s$, inflammation] Inflammation of a vein. P., Crural, inflammation of the veins of the lower limb. See Phlegmasia alba dolens. P., Gouty, that dependent on gout. P., Hyperplastic. Synonym of P., Proliferative. P., Obstructive, phlebitis leading to occlusion of the vein. P., Portal. Synonym of Pylephlebitis. P., Proliferative, inflammation of a vein characterized by hyperplasia of the connective tissue of the vessel. It may be due to thrombosis-thrombophlebitis, or to inflammation of the surrounding tissue -periphlebitis. P., Puerperal, inflammation of the uterine veins following parturition. It generally follows thrombosis and is nearly always septic in origin. P., Sclerotic, diffuse or localized thickening of the intima of a vein, analogous to arteriosclerosis. P., Simple, phlebitis not due to microorganisms. P., Sinus, inflammation of a cerebral venous sinus. P., Suppurative, phlebitis going on to suppuration; this is a dangerous form on account of the distribution of septic emboli to distant organs that may take place. P., Syphilitic, phlebitis due to syphilis, generally seen in the portal radicles and umbilical veins of syphilitic new-born children. $\mathbf{P}$., Tuberculous, a round-celled infiltration in the walls of a vein, due to the presence of the tubercle-bacillus. It may proceed to induration of the wall or to caseation; it may also burst through the intima into the blood-stream. P., Uterine. See P., Puerperal. P., Varicose, inflammation of a varicose vein.

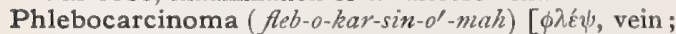
каркіршна, carcinoma]. Extension of carcinoma to the walls of a vein.

Phlebocholosis ( Aleb-o-ko-lo'-sis) [ $\phi \lambda \varepsilon \dot{\psi} \psi$, a vein; $\chi \omega \lambda \omega \sigma \iota s$, lameness]. Paralysis of the veins.

Phlebodes $\left(A e b-o^{\prime}-d \bar{e} z\right)[\phi \lambda \hat{\psi} \psi$, vein; $\varepsilon i \delta o s$, like $] . \operatorname{Re}-$ sembling a vein; made up of veins.

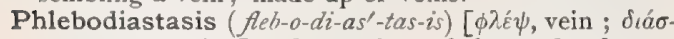

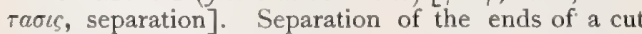
vein; also, separation of two normally contiguous veins,

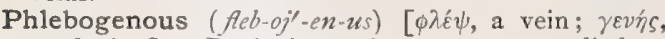
producing]. Producing veins; a term applied to certain angiomatous tumors.

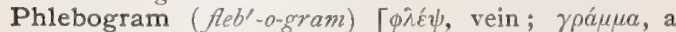
marking]. A tracing of the pulsation of a vein by the sphygmograph.

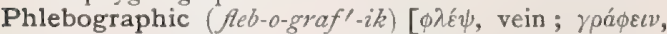
to unite]. Pertaining to phlebography.

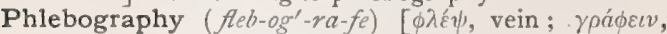
to write]. The anatomy and physiology of the veins.

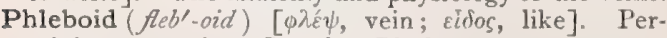
taining to a vein. See also Phlebodes.

Phleboidal ( $\left\{e b-o i^{\prime}-\lambda a l\right)$ [ $[\lambda \dot{\varepsilon} \psi$, vein ; $\varepsilon i \delta o s$, form $]$. In biology, resembling veins.

Phlebolite, Phlebolith ( $\left.f e b^{\prime}-0-\hbar i t, f e b^{\prime}-0-l i t h\right)[\phi \lambda \varepsilon \psi$, vein; $\lambda i \theta 0 s$, stone $]$. Vein-stone, a hard concretion sometimes found in veins, and produced by calcareous infiltration of a thrombus.

Phlebolithiasis (Alb-o-lith-i'-as-is) $[\phi \lambda \hat{\varepsilon} \psi$, vein ; $\lambda i \theta o s$, stone]. The formation of phleboliths.
Phlebolitic ( $\left.A_{e} b-o-l i t^{\prime}-i k\right)$ [ $\phi \lambda \hat{\varepsilon} \psi$, a vein ; $\lambda i \theta o s$, a stone]. Of the nature of, containing, or characterized by, phlebolites.

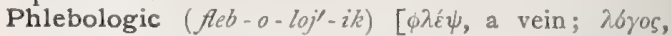
science]. Pertaining to phlebology.

Phlebology ( fleb-ol'-o-je) [ $\phi \lambda \dot{\varepsilon} \psi$, vein; $\lambda o ́ \gamma o s$, science]. The science of the anatomy and physiology of the veins.

Phlebometritis (Aeb-o-met-ri'-tis). Synonym of Phlebitis, Uterine.

Phlebopaly $\left(A e b-o p^{\prime}-a l-e\right)[\phi \lambda \dot{\varepsilon} \psi$, vein; $\pi a ́ \lambda \lambda \varepsilon \imath \nu$, to beat]. Venous pulsation.

Phlebophlogosis ( $\left.A e b-0-f l o-g o^{\prime}-s i s\right)$. Synonym of Phlebitis.

Phlebophthalmotomy (fleb-off-thal-mot'-o-me) [ $\phi \lambda \varepsilon ́ \psi$,

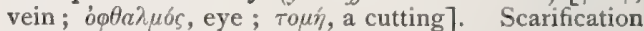
of the conjunctival vein.

Phleboplerosis (fleb-o-ple-ro'-sis) $[\phi \lambda \varepsilon \dot{\psi} \psi$, a vein ; $\pi \lambda \eta$ $\rho \omega \sigma \iota$, a filling]. Distention of the veins.

Phleborrhage (Aeb'-or-ajj). See Phleborrhagia.

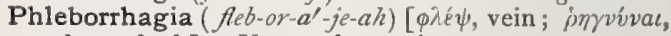
to burst forth]. Venous hemorrhage.

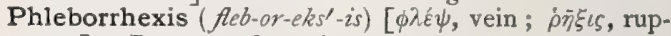
ture]. Rupture of a vein.

Phlebosclerosis (fleb-o-skle-ro'-sis). Synonym of Phlebitis, Sclerotic.

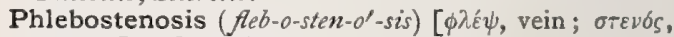
narrow]. Constriction of a vein.

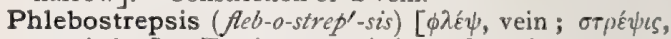
a twisting]. Torsion, or twisting, of a vein.

Phlebothrombosis (feb-o-throm-bo'-sis) [ $\phi \lambda \dot{\varepsilon} \psi$, vein; $\theta \rho b \mu \beta o s$, lump]. The formation of a thrombus in a vein.

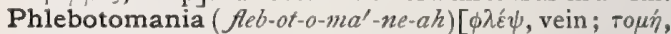
a cutting ; $\mu a v i a$, madness]. A rage for blood-letting; excessive fondness for phlebotomy.

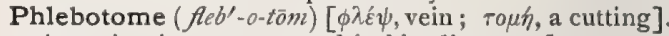
A cutting-instrument used in bleeding; a fleam.

Phlebotomic ( fleb-o-tom'-ik) [ $\phi \lambda \hat{\varepsilon} \psi$, a vein ; $\tau o \mu \hat{n}$, a cutting]. Pertaining to phlebotomy.

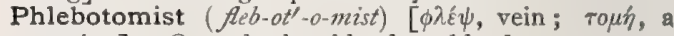
cutting]. One who lets blood; a bleeder.

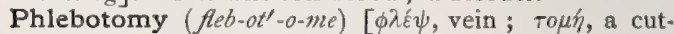
ting]. Blood-letting from a vein. It was formerly performed with a spring-lancet; at present a straight bistoury or a scalpel is used. The vein most often selected is the median cephalic at the bend of the elbow.

Phlebs (flebs) [ $\phi \lambda \varepsilon \psi$, a vein: $p l .$, Phlebes $]$. Vein.

Phlebypectasia ( $\left.f e b-i p-e k-t a^{\prime}-z e-a h\right)[\phi \lambda \hat{\varepsilon} \psi$, vein ; $i \pi \delta$,

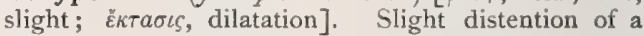
vein.

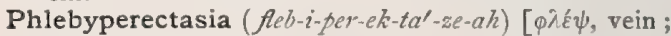
$i \pi \varepsilon \rho$, excessive; $\varepsilon \kappa \tau a \sigma \iota s$, dilation]. Great distention of the veins.

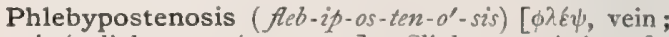

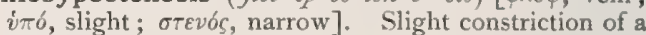
vein.

Phledonia ( $\left.f e-d o^{\prime}-n e-a h\right)$ [ $\phi \lambda \varepsilon \delta o v \varepsilon i a$, babble]. Delirium, or delirious utterance.

Phlegm ( $\mathrm{fcm})$ [ $\phi \lambda \varepsilon \gamma \mu a$, phlegm]. A viscid, stringy mucus, secreted by the mucosa of the upper air-passages and which is expectorated or vomited; also, one of the four humors of old writers.

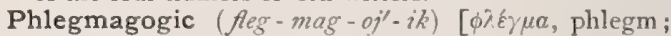
a ${ }^{\prime} \omega \gamma \sigma$ s, leading]. Having the qualities of a phlegmagogue; tending to expel phlegm.

Phlegmagogue (fleg'-mag-og) [ $\phi \lambda \hat{\gamma} \gamma \mu a$, phlegm; áywoós, leading]. I. Expelling phlegm. 2. A medicine that expels phlegm.

Phlegmasia ( $\left.\operatorname{ceg}-m a^{\prime}-z e-a h\right)$ [ $\phi \lambda \ell \gamma \varepsilon \iota \nu$, to burn]. Inflammation. P. alba dolens., popularly called milk-leg. 'A painful swelling of the leg, beginning 
either at the ankle and ascending, or at the groin and extending down the thigh. Its usual cause is septic infection of the genital region after labor. Two forms are described: The most common and most dangerous is a thrombosis of the veins of the thigh; the other involves the connective tissues and lymphatic vessels. The dangers of the first form are embolism, general infection, or the extension of the thrombus into the inferior cava. P. malabarica. Synonym of Elephantiosis arabum.

Phlegmasic ( fleg-ma'-zik) [ $\phi \lambda \dot{\varepsilon} \gamma \varepsilon \iota v$, to burn]. Char acterized by or pertaining to phlegmasia. P. Affection, Gouley's term for a morbid process, one of the local nutritional changes, which, when visible and tangible, is ordinarily characterized by heat, redness, swelling, and pain, and which is now believed to be generally caused by microbic invasion.

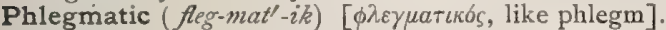
Unfeeling, indifferent, apathetic. Abounding in phlegm. P. Temperament, the lymphatic temperament.

Phlegmatoid (Reg'-mat-oid). Synonym of Phlegmatous.

Phlegmatorrhagia (Aleg-mat-or- $\left.\alpha^{\prime}-j e-c h\right)[\phi \lambda \varepsilon y \mu \alpha$, inflammation; ímyvíva/, to burst forth]. Coryza.

Phlegmatorrhea (fleg-mat-or-e'-ah). Synonym of Phlegmatorrhagia.

Phlegmatous (fleg'-mat-us) [ $\phi \lambda \dot{\varepsilon} \gamma \mu r$, inflammation] Pertaining to or having the nature of phlegm.

Phlegmon ( $\left.f e g^{\prime}-m o n\right)$ [ $\phi \lambda \varepsilon \gamma \mu o \nu \eta ́$, inflammation]. An inflammation characterized by the spreading of a purulent or fibrino-purulent exudate within the tissues.

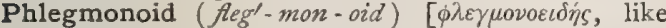
phlegmon]. Resembling phlegmon.

Phlegmonous (fleg'-mon-us) [ $\phi \lambda \varepsilon \gamma \mu o v \dot{n}$, inflammation] Of the nature of or pertaining to phlegmon.

Phlegmorrhagia ( $\left.f e g-m o r-a^{\prime}-j e-a h\right)$. Synonym of Philegmorrhea.

Phlegmorrhea (fleg-mor- $\left.e^{\prime}-a h\right)[\phi \lambda \hat{\varepsilon} \gamma \mu a$, phlegin; $\rho$ oía, a flow]. A profuse discharge of mucus.

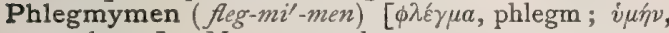
membrane]. Mucous membrane

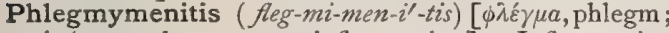
$i \mu{ }^{\prime} \nu$, membrane; $\iota \tau \iota s$, inflammation]. Inflammation of a mucous membrane.

Phlobaphene ( $f o^{\prime}-b a f-\bar{e} n$ ), $\mathrm{C}_{50} \mathrm{H}_{46} \mathrm{O}_{25}$. A dark-red amorphous substance derived from hops, from the bark of various trees, and from sugar by the action of various chemicals. See Oak-bark, and Pigments, Conspectus of.

Phloëm ( $\left.f o^{\prime}-\mathrm{em}\right)\left[\phi \lambda o \iota \sigma_{s}, \mathrm{bark}\right]$. In biology, that portion of a fibro-vascular bundle which consists of basttissue and sieve-tissue ; leptome. Cf. Xylem. P.-ray, a plate of phloëm-tissue between two medullary rays. P.-sheath, in biology, a layer of thin-walled cells surrounding the phloëm-tissue; bast-sheath; periphloëm; vascular-bundle sheath. P.-tissue, phloëm.

Phlogia ( $\left./ 0^{\prime}-j e-a h\right)[\phi \lambda o \gamma i a, a$ burning]. Inflammation.

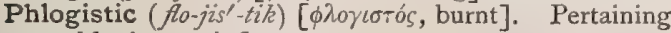
to phlogiston; inflammatory.

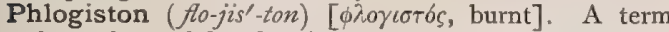
formerly used by chemists to denote the inflammable element which was contained in combustible substances, and which was separated from them during combustion. The term disappeared with the discovery of oxygen.

Phlogmocausus (flog-mo-kaw'-sus) [ $\phi \lambda \circ \gamma \mu o ́ s$, flame; xaṽos, burning heat]. Inflammatory fever.

Phlogochroma (flog-o-kro'-mah) [ $\phi \lambda o \gamma o ́ s$, burning ; $\chi \rho \tilde{\omega} \mu \alpha$, color]. The color due to inflammation.

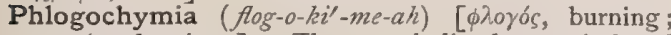
$\kappa v \mu \varepsilon i a$, chemistry]. The metabolic changes induced by inflammation.

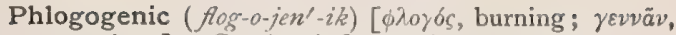
to produce]. Causing inflammation.

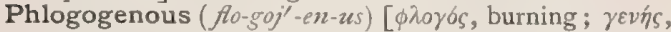
producing]. Producing inflammation.

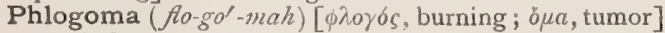
An inflammatory swelling.

Phlogopyra (flo-gop'-ir-ah). Synonym of Phloga cazusus.

Phlogosin (flo-go'-zin) [ $\phi \lambda \sigma \xi(\phi \lambda o \gamma-)$, flame; $\phi \lambda \delta \gamma^{\prime} \omega \sigma \iota \zeta$, inflammation]. In biology, the name given by Leber to the crystalline body isolated from cultures of pyogenic staphylococci. It induces suppuration when injected hypodermatically

Phlogosis ( flo-go'-sis) [ $\phi \lambda \sigma \gamma \omega \sigma \iota \zeta$, a burning]. Inflammation; also erysipelatous inflammation.

Phlogotic (flo-got $-i k$ ) [ $\phi \lambda a \gamma o ́ s$, burning]. Pertaining to or marked by phologosis, or inflammation.

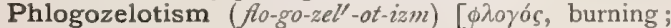
$\zeta \eta \lambda o \tilde{\nu}$, to be eager]. A mania for ascribing to every disease an inflammatory origin.

Phloraglucin (flo-rag-lu'-sin). See Phloroglucin.

Phloretin (flor-e'-tin) [ $\phi \lambda o \iota o s$, bark; $\dot{\rho} i \zeta a$, root]. A product of the treatment of phloridzin by dilute acids. Like that of phloridzin, its administration in suitable doses is followed by glycosuria or true diabetes.

Phloretinic Acid (for-et-in'-ik). See Acid.

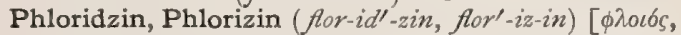
bark; $\rho \dot{i} \zeta \alpha$, root], $\mathrm{C}_{21} \mathrm{H}_{24} \mathrm{O}_{10} \cdot 2 \mathrm{H}_{2} \mathrm{O}$. A bitter crys. talline glucosid occurring in the root and trunk of the apple, pear, and similar fruit-trees. It has reputed value in intermittent fevers and in glycosuria. Its exhibition is, however, very liable to cause glycosuria or true diabetes. In dogs large doses also produce marked fatty infiltration of the liver. Dose gr. I0-20. Unof

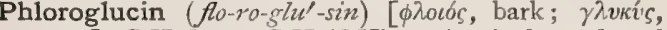
sweet], $\mathrm{C}_{6} \mathrm{H}_{6} \mathrm{O}_{3}$, or $\mathrm{C}_{6} \mathrm{H}_{3}(\mathrm{OH})_{3}$. A trivalent phenol found in many plants, especially in the bark of the cherry, pear, apple, and plum, and the leaves of the apple. It may also be obtained from different resins (catechu, kino) on fusion with caustic potash, or by fusing resorcinol with caustic soda. It crystallizes from water in hard, orthorhombic, yellowish crystals, sweeter than ordinary sugar, melting at $22^{\circ} \mathrm{C}$, and subliming unaltered. It is employed as a test for lignin, giving a violet or purple coloration to lignified cell-walls previously acted on by hydrochloric acid. It is also employed as a decalcifying agent. See Stains, Table of, and Tests, Table of.

Phloroglucinol, Phloroglucol (flo-ro-glu'-sin-ol, floro-glu'-kol). Synonym of Phloroglucin.

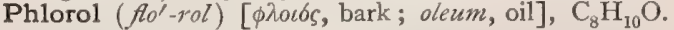
A phenol found in creasote.

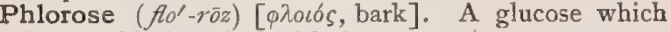
is probably identical with dextrose.

Phlorrhizin (for'-iz-in). Synonym of Phloridzin.

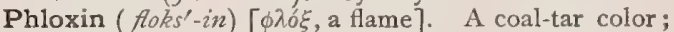
the potassium salt of tetra-brom-di-chlor-fluorescein. It is similar to eosin. See Pigments, Conspectus of.

Phlyctena ( $\left.A i k-t e^{\prime}-n a h\right)[\phi \lambda \hat{i} \kappa \tau \alpha \iota v a$, blister]. An elevation of the skin formed by an effusion of serum under the epidermis; blister; vesicle. P. pallida. See Ophthalmia, Spring.

Phlyctenar (Aik'-ten-ar) [ $\phi \lambda \hat{\imath} \tau a \iota v a$, blister $]$. Affected with phlyctena; pertaining to phlyctena.

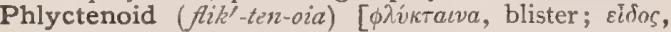
like]. Resembling phlyctena. (Applied to a variety of herpes.)

Phlyctenophthalmia (fik-ten-off-thal'-me-ah). Synonym of Conjunctivitis, Phlyctenular.

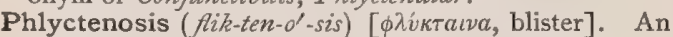
eruption characterized by vesicles. P. aggregata, an 
herpetic eruption in which the vesicles are situated closely together. P. labialis. Synonym of Herpes labialis, P. sparsa, a form in which the vesicles are few and at considerable distances from each other.

Phlyctenous ( Aik-te'-nus) [ $\phi \lambda \hat{\kappa} \kappa \tau a \iota v a$, a blister]. Pertaining to, affected with, or of the nature of, a phlyctena.

Phlyctenula (fik-ten'-u-lah) [dim. of $\phi \lambda u \kappa \tau a \iota v a$, blister]. A little vesicle or blister.

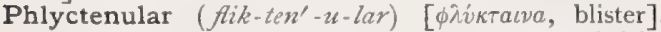
Having the nature of phlyctenula. P. Conjunctivitis, P. Ophthalmia. See Conjunctivitis, Phlyctenular.

Phlyctenule (Aik-ten'-ül). Synonym of Phlyctenula.

Phlyctis (fik'-tis). Synonym of Phlyctenula.

Phlysis ( $\left.A i^{\prime}-s i s\right)[\phi \lambda \hat{v} \sigma \iota$, , eruption $]$. I. A phlyctenula 2. A whitlow.

Phlyzacion, Phlyzacium ( $f i-z a^{\prime}-s e-o n, f i-z a^{\prime}-s e-u m$ )

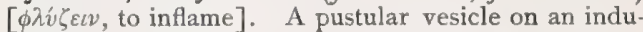
rated base. P. acutum. Synonym of Ecthyma acutum.

Phobanthropy (fo-ban'-thro-pe). See Anthropophobia.

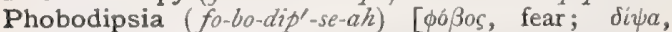
thirst]. Hydrophobia.

Phobodypson (fo-bo-dip'-son). Synonym of Hydrophobia.

Phobophobia $\left(f_{0}-b o-f o^{\prime}-b e-a h\right)$ [ $\phi o ́ \beta o s$, fear; $\phi b \beta o s$, fear]. Dread of being afraid.

Phocenin $\left(f^{\prime}-\operatorname{sen}-i n\right)$. Synonym of Trivalerin.

Phocomelia (fo-ko-me'-le-ah). See Phocomelus.

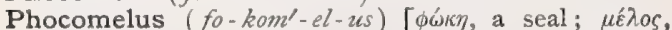
limb]. A monster with shortened or rudimentary arms and thighs, the hands and feet being attached almost directly to the trunk.

Phœeniceous $\left(f e^{\prime}-n i s-\ell-u s\right)$ [ $\phi o i \nu l_{\xi}$, purple-red]. Same as Phenicious

Phœnicin ( $\left.f e n^{\prime}-i s-i n\right)[\phi o \tilde{\nu} t \xi$, purple-red]. A name sometimes given to the coloring-matter of the blood.

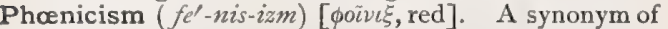
Measles.

Phœenigmus ( $\left.f e-n i g^{\prime}-m u s\right)$ [ $\phi o i \nu \imath \xi$, purple-red]. See Phenigmus.

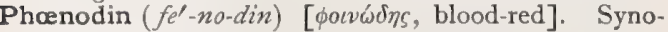
nym of Hematin.

Pholis $\left(f^{\prime}\right.$-lis) $[\phi o \lambda i s$, a scale]. A horny scale.

Phonal (fo'-nal) [ $\phi o \nu \eta$, voice]. Pertaining to the voice or to sound.

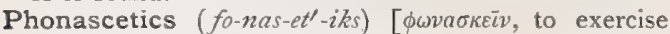
the voice]. Systematic exercise for the restoration or improvement of the voice.

Phonate $\left(f o^{\prime}-n \bar{a} t\right)$ [ $\phi \omega \nu \eta \dot{\eta}$, voice $]$. To utter vocal sounds.

Phonation $\left(f \circ-n a^{\prime}-\operatorname{shz} n\right)$ [ $\phi \omega v \dot{n}$, voice, or sound]. The production of vocal sound. The larynx is the organ of phonation.

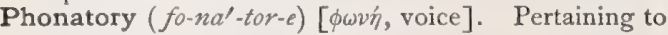
phonation.

Phonautogram ( fo-nazv'-to-gram) [ $\phi \omega \nu \eta ́$, voice; av̉rós,

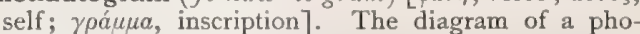
nautograph.

Phonautograph (fo-naw'-to-graf) [ $\phi \omega \nu \eta ́$, voice; avंtó,

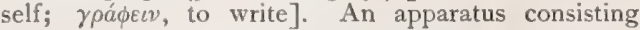
essentially of a membranous diaphragm, a lever, and a revolving drum, by means of which the vibrations of the air produced by the voice are recorded.

Phonautographic (fo-nazv-to-graf'-ik) [ $\phi \omega \nu \eta ́$, voice;

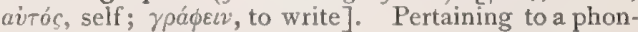
autograph.

Phone (fon) [ $\phi \omega v \eta$, sound, voice]. A vocal sound.

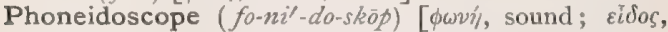
form: $\sigma \kappa о \pi \varepsilon i \nu$, to see]. An instrument for showing "the lights and shadows of musical sounds."

Phoneidoscopic $\left(f o-n i-d o-s k o p^{\prime}-i k\right)[\phi \omega \nu \eta$, , sound;

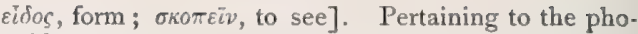
neidoscope.

Phonetic $\left(f_{0}-n e t^{\prime}-i k\right)$ [ $\phi \omega \nu \eta ́$, voice]. Pertaining to sound.

Phonetics (fo-net'-iks) [ $\phi \omega \nu \eta$, voice]. The science of the voice.

Phonic $\left(f \circ n^{\prime}-i k\right)$ [ $\phi \omega \nu \eta$, voice]. Pertaining to the voice or to articulate sounds of the voice. P. Spasm, a rare form of laryngeal spasm occurring on attempts to speak, generally in those of a neurotic habit, or from over-exertion of the voice.

Phonics (fon'-iks). Synonym of Phonetics.

Phonism ( fo'-nizm) [ $\phi \omega \nu \eta ́$, voice].c A sensation, of sound or hearing, due to the effect of sight, touch, taste, or smell, or even to the thought of some object, person, or general conception.

Phonocamptic ( fo-no-kamp'-tik) [ $\phi \omega \nu \eta ́$, voice; $\kappa \pi \mu \pi$ -

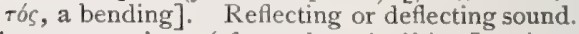

Phonocamptics (fo-no-kamp'-tiks) [ $\phi \omega v \eta$, sound; $\kappa a \mu \pi \tau$ ós, bending]. That branch of physics treating of the reflection of sound.

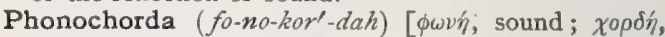
cord : pl., Phonochorde]. A vocal band.

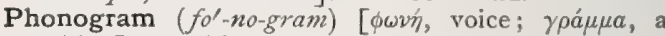
writing]. I. The record of a phonograph. 2. A graphic character representing a vocal sound.

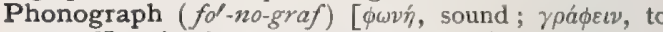
record]. An instrument consisting of a wax-coated cylinder revolving under a stylus attached to a diaphragm. The vibrations of the diaphragm, set in motion by the voice, cause the cylinder to be indented by the stylus. When the cylinder is again revolved the movement of the stylus upon the cylinder throws the diaphragm into vibration and reproduces the original sounds of the voice.

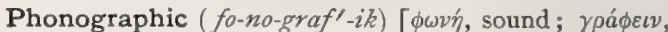
to write] Pertaining to the phonograph.

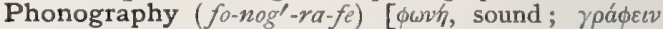
to write]. A scheme of short-hand writing in which the words are spelled according to their sounds.

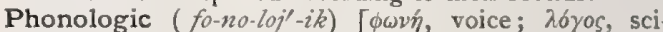
ence]. Pertaining to phonology.

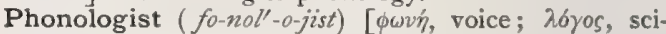
ence]. One versed in phonology.

Phonology ( fo-nol'-o-je) [ $\phi \omega \nu \eta ́$, voice; $\lambda \delta$ yos, science]. The science of vocal sounds.

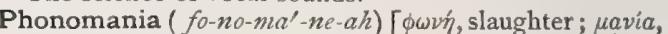
madness]. Homicidal mania.

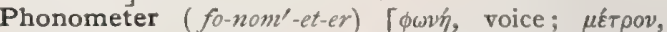
measure]. An instrument for measuring the intensity of the voice, or current of air expired during phonation.

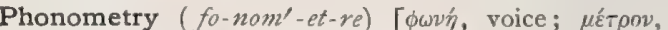
measure]. The measurement of the quality of the voice in thoracic disease.

Phononosus (fo-non'-o-sus). Synonym of Phonopathy.

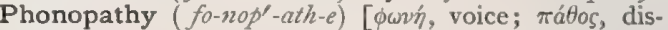
ease]. Any disorder or disease of the voice.

Phonophobia ( fo-no-fo'-be-ah) [ $\phi \omega \nu \eta \eta n$, sound; фóßos, fear]. A fear of speaking, in paresthesia of the lar$y n x$, because of the painful sensation produced during phonation.

Phonophore ( fo'-no-för) [ $\phi \omega \nu \eta$, sound ; фopós, bearing: pl., Phonophori]. An auditory ossicle, viewed as a transmitter of sound. See P., Paladino's. P., Paladino's, an instrument to facilitate hearing, consisting in a rod which connects the larynx of the speaker with the teeth of the listener.

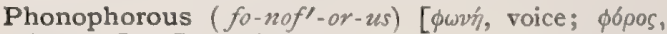
bearing]. Conveying sound.

Phonopore $\left(f o^{\prime}-n 0\right.$-por). Same as Phonophore.

Phonopsia ( fo-nop'-se-ah) [ $\phi \omega \nu \eta \hat{n}$, sound; bucs, vision]. 
The perception of photisms or subjective color-sensations, due to the actual sensation of hearing.

Phonospasm ( $f^{\prime}-$ no-spazm). Synonym of Phonic Spasm.

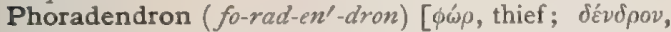
tree]. A genus of apetalous plants including the mistletoe. P. flavescens, American Mistletoe, parasitic on the elm and hickory. It is poisonous, producing gastro-enteritis; it is also said to possess oxytocic and hemostatic properties.

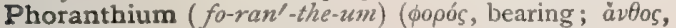
flower: pl., Phoranthia]. Same as Clinanthium.

Phormia (for'-me-ah). Same as Psendomorphin.

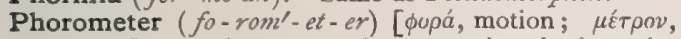
measure]. An instrument for measuring the intensity of light; also one for measuring the relative strengths of the ocular muscles.

Phorone ( $\left.f o^{\prime}-r o \bar{n} r\right), \mathrm{C}_{9} \mathrm{H}_{14} \mathrm{O}$. A substance prepared by saturating acetone with $\mathrm{HCl}$ and permitting it to stand. It crystallizes in large, yellow prisms, melting at $28^{\circ}$ C. and boiling at $196^{\circ} \mathrm{C}$.

Phoronomia, Phoronomics (for-o-no'-me-ah, for-o. nom'-iks). Same as Phoronomy.

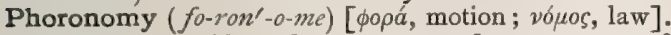
Kinematics. Also, the sequence of movements of the presenting part in the passage of the fetus through the parturient canal.

Phosgen, Phosgene (fos'-jen, fos'-jèn) [ $\phi \vec{\omega} s$, light;

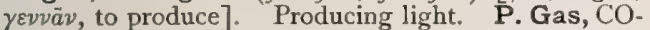
$\mathrm{Cl}_{2}$, carbonyl chlorid; a compound formed by the action of light on a mixture of carbonic oxid and chlorin; it is a colorless gas with a suffocative odor; on cooling it condenses to a liquid that boils at $+8^{\circ} \mathrm{C}$.

Phosphammonium ( fos - fam - $o^{\prime}-n e-u m$ ) [ $\phi \omega \sigma \phi b \rho o s$, phosphorus; ammonium ]. A compound of the radicles phosphonium and ammonium.

Phosphane Biscuits. A chemic food prepared in England from oat-meal.

Phosphanilin ( fos-fan'-il-in) [ $\phi \omega \sigma \phi o ́ \rho o s$, phosphorus; anilin ], $\mathrm{C}_{6} \mathrm{H}_{5} . \mathrm{PH}_{2}$. Phenylphosphin; a substance obtained by the action of hydriodic acid upon phosphenyl chlorid. It is a liquid, boiling at $160^{\circ} \mathrm{C}$. in a current of hydrogen, and possessing an extremely disagreeable odor. It sinks in water.

Phosphate ( $\left.f \circ s^{\prime}-f \bar{a} t\right)$ [ $\phi \omega \sigma \phi b p o s$, phosphorus]. A salt of phosphoric acid. As phosphoric acid has three replaceable hydrogen atoms, we have three kinds of salts: (I) P., Normal, in which the three hydrogen atoms, or the six of two molecules, are substituted by metals, e. g., $\mathrm{Na}_{3} \mathrm{PO}_{4}, \mathrm{Ca}_{3}\left(\mathrm{PO}_{4}\right)_{2}$ (2) P., Dibasic, or P. Monohydric, in which two hydrogen atoms are replaced by a base, as $\mathrm{Na}_{2} \mathrm{HPO}_{4}$. (3) P., Monobasic, or P., Dihydric, in which only one hydrogen atom of the acid molecule is replaced by a metal or radicle, $e$. g., $\mathrm{NaH}_{2} \mathrm{PO}_{4}$. P. Acid, a dihydric or monohydric phosphate. P., Acid Sodium, the salt to which the acidity of urine is chiefly due. P., Alkaline, a normal or acid phosphate of the alkaline metals. P., Ammonio-magnesium, a double salt of ammonium and magnesium combined with phosphoric acid. $\mathbf{P}$., Bone, $\mathrm{Ca}_{3}\left(\mathrm{PO}_{4}\right)_{2}$, the normal calcium ortho-phosphate found in bone. P., Disodic, the phosphate of the blood. P., Earthy, a phosphate, normal or acid, of one of the alkaline earths, calcium or magnesium. Earthy phosphates, as well as the alkaline, occur in the urine, the ratio being about one part of the former to two of the latter. For test, see Tests, Table of. P., Triple, ammonio-magnesium phosphate, occurring in the urine, often in the form of crystals, generally in the shape of a coffin, hip-roof, or envelop. See Urinary Sediments, Table of.

Phosphatic (fos-fat'-ik) [ $\phi(\omega \sigma \phi \sigma o \rho s$, phosphorus]. Re- lating to or having the nature of phosphates. P. Calculus. See Urinary Calculi, Table of. P. Diabetes. See Diabetes mellitus. P. Diathesis, that condition of the body favoring the deposition of phos phates in the urine.

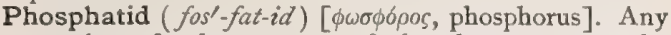
member of a large group of phosphorus-compounds, found in brain-substance, and resembling the phosphates. They contain phosphoric acid in which one, two, or three molecules of hydroxyl are replaced by various radicles. The phosphatids differ widely from each other in physical properties.

Phosphaturia (fos-fat- $u^{\prime}-r e-a h$ ) [ $\phi \omega \sigma \phi b \rho o \zeta, ~ p h o s p h o r u s ;$ ovpov, urine]. A condition in which an excess of phosphates is passed in the urine. It can be diagnosticated by a quantitative analysis of the urine for phosphates by the uranium method.

Phosphene ( $\left.f o s^{\prime}-f e n\right)$ [ $\phi \bar{\omega} s$, light; $\phi a^{\prime}(\nu \varepsilon \iota \nu$, to show]. A subjective luminous circle or sensation of light caused by pressure upon the eyeball. See also Paratolyl. P. of Accommodation, a phosphene produced by the effort of accommodation. P., Pressure. See Phosphene.

Phosphenylic Acid (fos-fen-il'-ik) [ $\phi \omega \sigma \phi b \rho \circ s$, phosphorus; фoĩv $\xi$, purple-red ], $\mathrm{C}_{6} \mathrm{H}_{5} \mathrm{H}_{2} \mathrm{PO}_{3}$. A compound of phenyl and phosphorous acid.

Phosphid ( $f \circ s^{\prime}-f i d$ ) [ $\phi \omega \sigma \phi o \rho o s$, phosphorus]. I. Any compound of phosphorus with a single element or radicle. 2. A substitution compound of phosphin.

Phosphin ( fos'-fin) [ $\phi \omega \sigma \phi \sigma \rho o s$, phosphorus]. 1. Hydrogen phosphid, $\mathrm{PH}_{3}$. 2. A substitution-compound of $\mathrm{PH}_{3}$, bearing to it the same relation that an amin does to ammonia. The phosphins are colorless, stronglyrefracting, volatile liquids, possessing an extremely powerful odor. They are nearly insoluble in water. On exposure to air they are energetically oxidized, and usually inflame spontaneously. They readily combine with sulphur and carbon disulphid. They form salts with acids. 3. A yellow substance occurring as a by-product in the preparation of fuchsin.

Phosphite ( $\left.f \circ s^{\prime}-f i t\right)$ [ $\phi \omega \sigma \phi \delta \rho o s$, phosphorus]. Any salt of phosphorous acid. On account of the three replaceable hydrogen atoms, we have normal, dibasic or monohydric, and monobasic or dihydric phosphites, of which the first are least known.

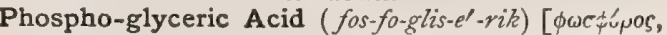
phosphorus; $\gamma \lambda v \kappa v$ s, sweet], $\mathrm{C}_{3} \mathrm{H}_{9} \mathrm{PO}_{6}$. A liquid body obtained from lecithin.

Phosphonium (fos-fo'-ne-um) [ $\phi \omega \sigma \phi b \rho \sigma^{\prime}$, phosphorus]. The hypothetic, univalent radicle, $\mathrm{PH}_{4}$; it is analogous to ammonium, $\mathrm{NH}_{4}$.

Phosphorated (fos'-for-a-ted) [ $\phi \omega \sigma \phi b o o s$, phosphorus]. Synonym of Phosphorized. P. Oil, a one per cent. solution of phosphorus in expressed oil of almonds, with the addition of a small quantity of ether.

Phosphorenesis (fos-for-en'-es-is) [ phorus: pl., Phosphoreneses]. Baumer's name designating any disease due to excess or deficiency of calcium phosphate in the system.

Phosphorescence (fos-for-es'-ens) [ $\phi \omega \sigma \phi 6 \rho \circ$, phosphorus]. The spontaneous luminosity of certain substances, like that of phosphorus, in the dark. It is observed in decomposing organic matter, such as dead fish, wood, etc. ; in the bodies of certain plants and animals, such as the marigold, fire-fly; in the excreta of some animals; in the growth of several species of bacteria; in natural or artificial media. The process is accompanied by oxidation. Several bacteria are known to produce phosphorescence. Thus, the Bacillus phosphorescens (Fischer) is found in the sea-water of the West Indies. Another phosphorescent organism was found by Fischer in the harbor of Kiel. The 
most common is the Baclerium phosphorescens (Fischer), which occurs on the decomposing flesh of fishes, on beef, or fat. The Photobacterium sarcophilum also has the property of producing phosphorescence. See Photogenic

Phosphoreted (fos'-for-et-ed) [ $\phi \omega \sigma \phi 6 \rho o s$, phosphorus]. Combined with phosphorus.

Phosphorhidrosis (fos-for-hid-ro'-sis) [ $\phi \ddot{\omega} \varsigma$, light;

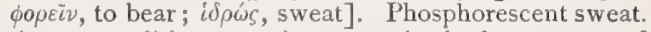
A rare condition sometimes seen in the later stages of pulmonary tuberculosis and in malaria.

Phosphoric (fos-for'-ik) [ $\phi \bar{\omega} s$, light; $\phi o \rho o ́ s, ~ b e a r i n g]$. Pertaining to phosphorus. P. Acid. See Acids and Stains, Table of.

Phosphoridrosis (for-for-id-ro'-sis). See Phosphorhidrosis.

Phosphorism (fos'-for-izm) [ $\phi \omega \sigma \phi \sigma \rho o s$, phosphorus]. Chronic phosphorus-poisoning.

Phosphorized (fos'-for-iz $z d$ ) [ $\phi \omega \sigma \phi 6 \rho o s$, phosphorus]. Containing phosphorus.

Phosphorogenic (fos-for-o-jen'-ik) [ $\phi \omega \sigma \phi o ́ p o s$, phos-

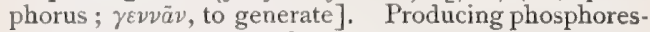
cence, as certain rays of the spectrum.

Phosphorous Acid (fos-for'-us). See Acid.

Phosphoruria ( fos-for- $u^{\prime}-r e-a / 2$ ) [ $\phi \omega \sigma \phi o ́ p o s$, phosphorus; ovpov, urine]. Phosphorescence of the urine. Also, urine containing an excess of phosphates.

Phosphorus (fos'-for-us) [ $\phi \tilde{\omega} s$, light ; $\phi о \rho \varepsilon i v$, to bear]. A non-metallic element, having a quantivalence of 3 or 5 , and an atomic weight of 3I. Symbol P. See Elements, Table of. Phosphorus does not occur in the free state, but is widely distributed in rocks, in fertile soils, in animal and vegetable tissues, in urine and in guano. The human body contains a large quantity of calcium phosphate, in the form of complex organic compounds. Phosphorus is an important constituent of nervous tissue. In commerce it is prepared from bone-ash, or from sombrerite, an impure calcium phosphate found in West Indian guano. Phosphorus may be obtained in several allotropic forms. Ordinary phosphorus is a yellowish-white, waxy solid, of a specific gravity of 1.837 . It melts at $44.2^{\circ} \mathrm{C}$, and boils at $290^{\circ} \mathrm{C}$. It is insoluble in water, soluble to a slight extent in olive-oil and in ether, freely in carbon disulphid. Red or amorphous phosphorus is formed when ordinary phosphorus is heated to $240^{\circ} \mathrm{C}$. in an atmosphere free from oxygen; also by the addition of a trace of iodin at $200^{\circ} \mathrm{C}$. It is a dark-red powder, having a specific gravity of $2 . \mathbf{I}$, insoluble in carbon disulphid, noninflammable, non-Iuminous, non-poisonous. Metallic rhombohedral phosphom is an allotropic form produced by heating phosphorus in a sealed tube with melted lead. Its specific gravity is 2.34 . Other modifications have been described. Phosphorus combines with other elements to form phosphids, with hydrogen and oxygen to form a series of acids, known chiefly through their salts. Medicinally, phosphorus is used as an alterative in osteomalacia and in rickets. It is also employed in sexual impotence, in threatened cerebral degeneration, and in neuralgia. Dose $\frac{1}{100}$ to $\frac{1}{2}$ grain. Ordinary phosphorus is exceedingly poisonous; it causes a wide-spread fatty degeneration, most marked in the liver. Vomiting is one of the earliest symptoms, the material ejected being generally luminous in the dark. Jaundice appears usually within 36 hours, sometimes, however, much later. The liver is at first enlarged, but subsequently diminishes in size. Cerebral symptoms of an intense type occur-wild delirium, convulsions, coma. Death is generally due to failure of respiration and circulation. The urine in phosphorus-poisoning is albuminous, contains bile acids and pigments, and leucin and tyrosin. The treatment of phosphorus-poisoning consists in the administration of emetics and purgatives and of the antidote-copper sulphate or French oil of turpentine. P., Amorphous. See Phosphorus. P., Baldwin's, calcium nitrate. P., Black, a so-called allotropic form of phosphorus described by Thenard. It is believed to consist of a phosphid of mercury or another metal. P., Bolognian, P., Bononian, barium sulphate ignited with combustible substances such as charcoal. P., Brand's, ordinary phosphorus, sonamed after its discoverer. P., Canton's, calcium sulpinid. P., Elixir, spirit of phosphorus 210 c.c., oil of anise 2 c.c., glycerin 550 c.c., aromatic elixir q. s. P., English, ordinary phosphorus. P., Homberg's, calcium chlorid. P., Kunkel's, ordinary phosphorus. P.-necrosis, a necrosis, chiefly of the jawbone, which affects workmen exposed to the fumes of phosphorus. P. oxychlorid, $\mathbf{P O C l}_{3}$. A fuming liquid of pungent odor. P. pentabromid, a yellow, crystalline substance of pungent odor. P. pentachlorid, $\mathrm{PCl}_{5}$; a white, crystalline, unstable powder, with an unpleasant, pungent odor. P. pentafluorid, $\mathrm{PF}_{5}$; a colorless irritant gas. $\mathrm{P}$. pentasulphid, $\mathrm{P}_{2} \mathrm{~S}_{5}$. an unstable crystalline compound. $\mathbf{P}$. pentoxid, $\mathrm{P}_{2} \mathrm{O}_{5}$; a colorless, amorphous substance produced by the combustion of oxygen. On account of its affinity for water it is used as a desiccating agent. P., Red. See under Phosphorus. P., Spt., phosphorus I.2 grams, absolute alcohol q. s. ad IOooc.c. P., Thompson's Solution of. Synonym of $P$., Tinct. P. tribromid, P. trichlorid, $\mathrm{P}$. tri-iodid, $\mathrm{PBr}_{3}, \mathrm{PCl}_{3}, \mathrm{PI}_{3}$; halogen compounds of phosphorus; the first two are pungent liquids, the last a solid. Calcii hypophosphis, $\mathrm{Ca}_{4}\left(\mathrm{PO}_{2}\right)_{3^{*}}$ Dose gr. $\mathrm{x}-\mathrm{xxx}$. Calcii lactophosphat., Syr., of the preceding 22 , lactic acid 33 , orange-flower water 80 , sugar 600 , hydrochloric acid, water of ammonia and water āā q. s. ad rooo. Dose $3 \mathrm{j}-3_{\mathrm{j}}$. Calcii phosphas præcipitat., $\mathrm{Ca}_{3}\left(\mathrm{PO}_{4}\right)_{2}$. Dose gr. ij-x. Ferri hypophosphis, $\mathrm{Fe}_{2}\left(\mathrm{H}_{2} \mathrm{PO}_{2}\right)_{6}$, soluble in sodium citrate. Dose gr. $\mathrm{v}-\mathrm{x}$. Ferri, quininæ et strychninæ phosphat., Syr., phosphates of iron and quinin $\bar{a} \bar{a} I_{3} 3$, strychnin 4, phosphoric acid 800 , sugar 6000 , distilled water q. s. ad 10,000 parts. Dose $3 \mathrm{j}-\mathrm{ij}$. Hypophosphitum cum ferro, Syr., ferrous lactate IO, potass. citrate IO, syr. of hypophosphites q. s. ad rooo. Dose 3 j- 3 j. Hypophosphitum, Syr., calcium hypophosphite 45 , potassium hypophosphite I5, sodium hypophosphite I5, dilute hypophosphorous acid 2 , sugar 500 , spirit of lemon 5 , water q. $s$. Dose $3 \mathrm{j}-3 \mathrm{j}$. Phosphatum, Syr., Comp., Parish's Chemical Food, unof., has in each $3 j$ phosphate of iron gr. ijss, phosphate of calcium gr. j. Dose $\mathbf{3} \mathrm{j}$-ij. Oleum phosphoratum, phosphorated oil, contains phosphorus I, stronger ether 8, expressed oil of almond q. s. ad Ioo. Dose $m$ j-v. P., Pil., each contains gr. $\frac{1}{100}$ of the drug. Dose j-v. P., Tinct. (Bellevue Hosp.), unof., contains phosphorus gr. xxxij, absolute alcohol $\xi$ xlvj, essence of vanilla $\xi \mathrm{j}$, oil of orange-peel,

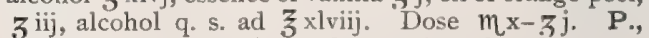
Tinct. (Thompson's), unof., contains phosphorus gr. j, absolute alcohol $3 \mathrm{v}$, glycerin $う$ jss, spt. peppermint $m x x$. Dose $m x x-z j$. Potassii hypophosphis, $\mathrm{KH}_{2} \mathrm{PO}_{2}$. Dose gr. v-x. Sodii hypophosphis, $\mathrm{NaH}_{2} \mathrm{PO}_{2} \mathrm{H}_{2} \mathrm{O}$. Dose gr. $\mathrm{v} \sim \mathrm{x}$. Sodii phosphas, $\mathrm{Na}_{2} \mathrm{HPO}_{4}, \mathrm{I}_{2} \mathrm{H}_{2} \mathrm{O}$. Dose $3 \mathrm{j}-\overline{3} \mathrm{j}$. Sodii pyrophosphas, $\mathrm{Na}_{4} \mathrm{P}_{2} \mathrm{O}_{7}, \mathrm{IOH}_{2} \mathrm{O}$. Dose 3 ss- 3 ss. Zinci phosphidum, $\mathrm{Zn}_{3} \mathrm{P}_{2}$, soluble in hydrochloric acid, irritant and poisonous. Dose gr. $\frac{\frac{3}{50}-\frac{1}{20}}{50}$

Phosphotage (fos'-fo-tahj) [Fr.]. A method of improving wines by adding dicalcic phosphate instead of gypsum, as in the process of "plastering." This does not increase the percentage of sulphuric acid nor decrease that of phosphoric acid. 
Phosphotungstic Acid (fos-fo-tung -stik), $\mathrm{H}_{11} \mathrm{PW}_{10^{-}}$ $\mathrm{O}_{38}+\left(\mathrm{H}_{2} \mathrm{O}\right)$. A crystalline compound of phosphoric acid and tungstic acid used as a test for alkaloids and peptones. See Tests, Table of.

Phosphuret (fos'-fu-ret) [ $\phi \omega \sigma \phi o ́ \rho o s$, phosphorus]. A phosphid.

Phosphureted (fos'-fu-ret-ed). Synonym of Phosphoreted.

Phosphuria (fos- $\left.f u^{\prime}-r e-a h\right)$. Synonym of Phosphaturia.

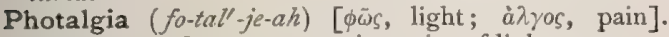
Pain arising from too great intensity of light.

Photastrography (fo-tas-trog'-ra-fe) [ $\phi \tilde{\omega} s$, light; ă $\sigma \tau_{\rho} \nu \nu$, a star; $\gamma \rho \alpha \dot{\phi} \varepsilon \iota v$, to write]. Astronomic photography.

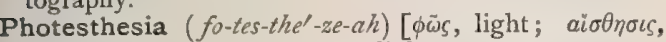
sensation]. Sensitiveness to light.

Photics ( $f o^{\prime}$-tiks). Synonym of Optics.

Photism ( $\left.f o^{\prime}-t i z m\right)$ [ $\phi \omega ́ \tau \iota \sigma \mu a$, a lighting]. A sensation, as of color or light, produced by hearing, taste, smell, touch, or temperature, or even by the thought of some object, person, or general conception. Cf. Phonism.

Photo- $\left(f o^{\prime}-t_{0}\right)\left[\phi \omega_{s}\right.$, light $]$. A prefix denoting connection with or relation to light.

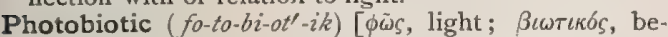
longing to life]. In biology, living habitually in the light.

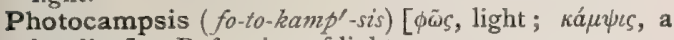
bending]. Refraction of light.

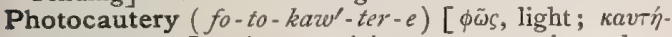
$\rho \iota \mathrm{N}$, cautery]. A cauterizing agency whose heat is derived from the rays of the sun by means of concentration by lenses.

Photo-chemic (fo-to-kem'-ik) [ $\phi \tilde{\omega} \varsigma$, light; $\chi \eta \mu \varepsilon i a$, chemistry]. Pertaining to the chemic action of light, as manifested in its action on silver salts and certain other compounds.

Photochemist (fo-to-kem'-ist) [ $\phi \tilde{\omega} s$, light; $\chi \eta \mu \varepsilon i a$, chemistry]. One versed in photochemistry.

Photochemistry ( fo-to-kem' chemistry]. That branch of chemistry treating of the chemic action of light.

Photochromatic ( fo-to-kro-mat'-i/) $[\phi \tilde{\omega} s$, light; $\chi \rho \bar{\omega} \mu \alpha$, color]. Pertaining to colored light. P. Treatment, treatment of disease by colored light.

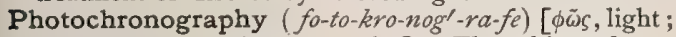
$\chi \rho \delta \nu o s$, time; $\gamma \rho a ́ \phi \varepsilon \imath \nu$, to write]. The taking of successive photographs of moving objects.

Photodermatic (fo-to-der-mat'-ik) [ $\phi \bar{\omega} s$, light; $\delta \dot{\varepsilon} \rho \mu \alpha$, skin]. In biology, having a luminous skin or exterior; phosphorescent.

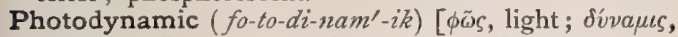
power]. Pertaining to the energy of light.

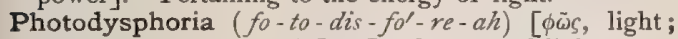

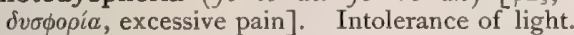

Photo-epinastic ( fo-to-ep-in- $\left.a s^{\prime}-t i k\right)$ [ $\phi \bar{\omega} s$, light; $\varepsilon \pi_{i}$, upon; vaotós, solid]. Pertaining to photo-epinasty.

Photo-epinasty (fo-to-ep'-in-as-te) [ $\phi \tilde{\omega} s$, light; $\dot{\varepsilon} \pi i$, upon; vaбтós, pressed close, solid]. In biology, downward curvature due to exposure to light.

Photogene $\left(f^{\prime}-t o-j \bar{e} n\right)[\phi \bar{\omega} \zeta$, light; $\gamma \varepsilon \nu \nu \bar{a} \nu$, to produce]. I. A retinal picture, or impression. 2. Shale-naphtha, a substance derived from bituminous shales, having a specific gravity of .800 to .810 , boiling at $145^{\circ}$ to $150^{\circ}$ C., with a slight ethereal odor and peppery taste. It dissolves sulphur, phosphorus, iodin, fats, resins, caoutchouc, etc. It is sometimes used for illuminating purposes and for dissolving the fat from bones, and bleaching them, in the preparation of artificial ivory.

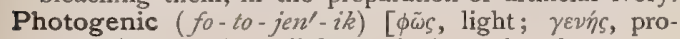
ducing]. In biology, light-producing; phosphorescent, as certain Schizonycetes. See under Bacteria, Synonymatic Table of.

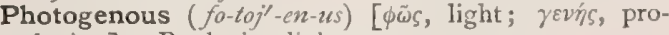
ducing]. Producing light.

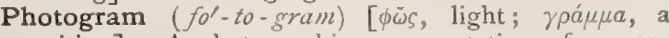
writing]. A photographic representation of an enlargement obtained by the microscope.

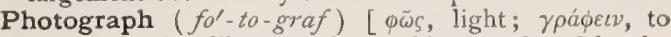
record]. The likeness of any object produced by the chemic action of light reflected from the object upon a surface coated with a chemically sensitive material.

Photographers' Cramp. See Cramp.

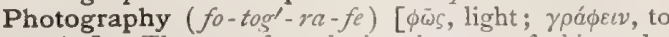
write]. The art of producing images of objects by throwing the rays of light reflected from them upon a surface coated with a film of a chemically sensitive substance such as a silver salt.

Photohemotachometer ( fo'-to-hent'-o-tak-om'-et-er)

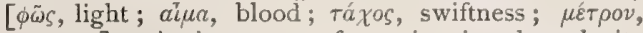
measure]. An instrument for estimating the velocity of the blood and at the same time photographing the changes in the level of the blood produced by the movements of the heart and of respiration.

Photohyponastic (fo-to-hi-po-nas'-tik) [ $\phi \tilde{\omega} s$, light ; $v \pi \delta$, under; vaбtós, solid]. Pertaining to photohyponasty.

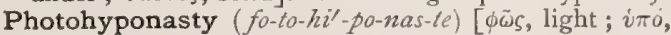
under; vaбrós, closely pressed, solid]. In biology, upward curvature due to exposure to intense light.

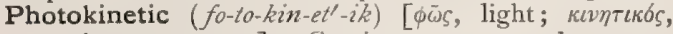
causing movement]. Causing movement by means of the luminous rays of light.

Photo-laryngoscopy ( fo-to-lar-in-gos'-ko-pe) [ $\phi \tilde{\omega} s$,

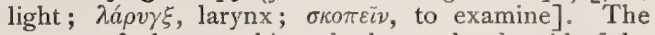
process of photographing the larynx by the aid of the laryngoscope.

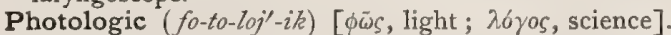
Pertaining to photology.

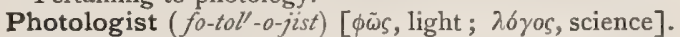
One versed in photology.

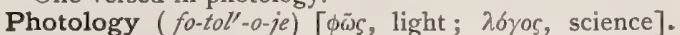
The science of the nature and laws of light; optics.

Photolysis ( fo-tol'-is-is) $[\phi \bar{\omega} s$, light; $\lambda \dot{v} \sigma \iota$, a loosing, setting free]. In biology, the movements of protoplasm under the influence of light. P., Apostrophe, when the chlorophyl-grains collect on the cell-walls which are parallel to the plane of incident light. $\mathbf{P}$., Epistrophe, when the chlorophyl-grains collect on the cell-walls which are at right angles to the plane of incident light.

Photomagnetic (fo-to-mag-net'-ik) [ $\phi \bar{\omega} s$, light; $\mu a \gamma-$ vंrins, magnet]. Pertaining to the power of certain rays of the spectrum to render magnetic a steel needle.

Photomagnetism (fo-to-mag $\left.g^{\prime}-n e t-i z m\right)$. [ $\phi \bar{\omega} s$, light;

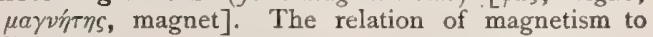
light.

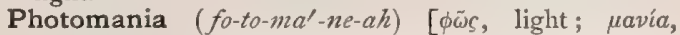
madness]. The increase of maniacal symptoms under the influence of light.

Photometer (fo-tom'-et-er) [ $\phi \bar{\omega} s$, light; $\mu \dot{\varepsilon} \tau \rho o \nu$, measure]. An instrument for measuring the intensity of light.

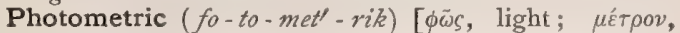
measure]. Pertaining to photometry or the measurement of light.

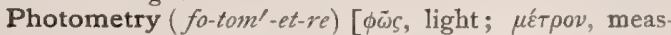
ure]. The measurement of light, its rapidity, intensity, etc.

Photomicrograph (fo-10-mi'-kro-graf) [ $\phi \tilde{\omega} \zeta$, light ;

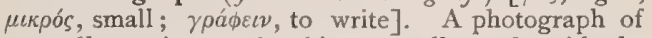
a small or microscopic object, usually made with the aid of a microscope, and of sufficient size for observation with the naked eye. Compare Microphotograph. 


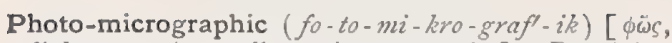

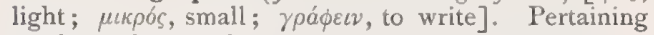
to photomicrography.

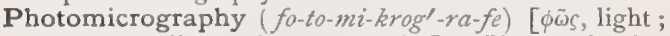

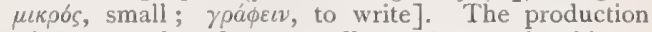
of photographs of very small or microscopic objects, usually by the aid of a microscope, the photographs being of sufficient size for observation with the naked eye. In English this correct form is now almost invariably used, but in French and German the term microphotograply $(q . v$.$) is more commonly used$ with the meaning given.

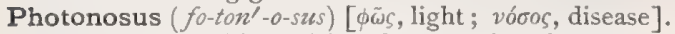
A diseased condition arising from continued exposure to intense or glaring light, $e . g$., snow-blindness, etc.

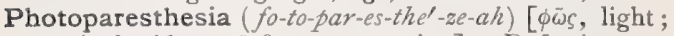

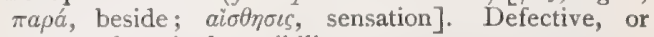
perverted, retinal sensibility.

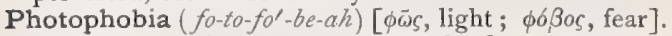
Intolerance of light; a symptom of inflammatory conditions of the eye, of certain diseases of the brain, and of hysteria.

Photophobic (fo-to-fol-bik) [ $\phi \tilde{\omega} \varsigma$, light; $\phi \delta \beta o s$, fear]. Affected with, or pertaining to, photophobia.

Photophobophthalmia (fo-to-fo-boff-thal' - me - ah) Synonym of Nyctalopia.

Photophone ( $\left.f \sigma^{\prime}-t o-f o ̂ n\right) ~[\phi \omega \tilde{s}$, light; $\phi \omega \nu \eta ́$, sound]. 1. An apparatus for the graphic representation of the character of sound-waves by means of a sensitive flame. 2. An instrument for the transmission of sounds to a long distance by means of rays of light.

Photophysical ( fo-to-fiz'-ik-al) [ $\phi \tilde{\omega} s$, light; $\phi v \sigma \iota \kappa o ́ s$, natural]. Pertaining to the physical effect of light; opposed to Photochemic.

Photophore (fol-to-for) [ $\phi \tilde{\omega} s$, light; $\phi o p \varepsilon i v$, to bear]. An instrument for examination of the cavities of the body by means of the electric light.

Photopsia (fo-top'-se-ah) [ $\phi \tilde{\omega} \varsigma$, light; ö $\iota_{\varsigma}$, sight]. Subjective sensations of light, as sparks or flashes of fire, occurring in certain morbid conditions of the optic nerve, the retina, or the brain. It may be produced by sudden mechanical irritation of the eyebali.

Photopsy ( fo'-top-se). Same as Photopsia.

Photoptometer (fo-top-tom'-et-er) [ $\phi \tilde{\omega} s$, light; $\omega \psi$, eye; $\mu$ ćт $\rho \circ$, measure]. An instrument for determining visual acuity.

Photoptometry (fo-top-tom'-et-re) [ $\phi \tilde{\omega} \varsigma$, light; $\delta \psi$,

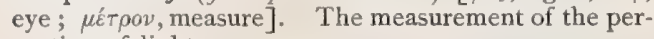
ception of light.

Photorrhexis ( fo-tor-eks'-is). Synonym of Photocampsis.

Photosantonin, or Photosantoninic Acid ( fo-to-san' -

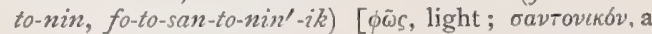
kind of wormwood], $\mathrm{C}_{23} \mathrm{H}_{34} \mathrm{O}_{6}$. Sestini's name for one of the products of the decomposition of santonin as the result of exposure to sunlight. It occurs as quadrate plates, which melt at $64-65^{\circ} \mathrm{C}$., and boil at $305^{\circ} \mathrm{C}$. It is insoluble in cold water, slightly soluble in hot water, and easily soluble in alcohol and ether.

Phototactic (fo-to-ta $\left.k^{\prime}-t i k\right)[\phi \bar{\omega} s$, light; $\tau a ́ \xi \iota s$, arrangement]. In biology, pertaining to phototaxis.

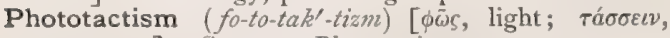
to arrange]. Same as Phototaxis.

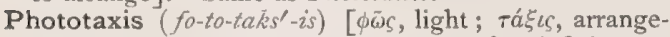
ment]. In biology, the assumption of a definite position with reference to the direction of the rays of incident light, as noticed in the compass-plant (Silphium laciniatum), and in the zoöspores of certain plants (Protococcoidea, Ulotrichacea, Desmideacea).

Phototherapeutics (fo-to-ther-ap-u'-tiks) [ $\phi \tilde{\omega} c$, light ;

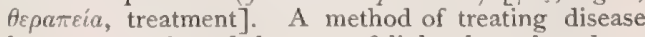
by concentration of the rays of light through a lens.
Local excitement, proportional to the degree of the exciting cause, $i, e$, from a slight excitement to cauterization, may be produced in this way.

Phototonic (fo-to-ton' $-i k)$ [ $\phi \tilde{\omega} s$, light ; tóvos, tension]. In biology, exhibiting increased vital activity under the stimulus of light; the opposite of paratonic.

Phototonus (fo-tot'-o-nus) [ $\phi \bar{\omega} s$, light ; tovos, tension]. In biology, a condition of increased vital irritability or motility due to exposure to light, in contrast with the rigidity or quiescence produced by darkness.

Photoxylin, Photoxylon (fo-toks'-il-in, fo-toks'-il-on) $[\phi \tilde{\omega} s$, light; $\xi \hat{\nu} \lambda o v$, wood]. A substance derived from wood-pulp by the action of sulphuric acid and potassium nitrate. It serves as a substitute for collodion in minor surgery, and as a medium for mounting microscopic specimens.

Photuria $\left(f o-t u^{\prime}-r e-a h\right)[\phi \tilde{\omega} \zeta$, light; ovjpov, urine]. Phosphorescence of the urine.

Phoxos (foks'-os) [ $\phi o \xi o s$, pointed]. An individual with a pointed or peaked head.

Phragma ( frag'-mah) [ $\phi \rho a ́ \gamma \mu \alpha$, a fence, partition: $p l$., Phragmata]. In biology: (I) a false dissepiment in a pericarp or other organ ; (2) any partition, septum, dissepiment, or diaphragm.

Phragmidiothrix (frag-mid-e-o'-thriks) [ $\phi \rho a ́ \gamma \mu a$, fence; idios, one's own; $\theta \rho i \xi$, hair]. A name given to a genus of Schizomycetes resembling the Beggriatoa. See under Bacteria, Synonymatic Table of.

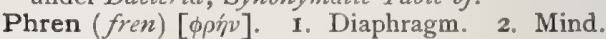

Phrenalgia (fren-al'-je-ah) $[\phi \rho \gamma v$, mind ; ă $\lambda \gamma o s$, pain $]$ Melancholia; psychalgia.

Phrenasthenia (fren-as-the'-ne-ah) $[\phi \rho \eta v$, diaphragm

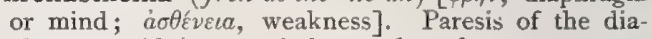
phragm. Also congenital mental weakness.

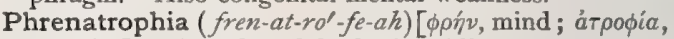
atrophy]. Atrophy of the brain; idiocy.

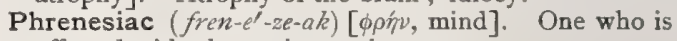
affected with phrenesis; an insane person.

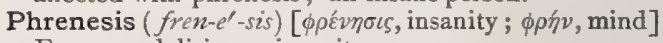
Frenzy; delirium; insanity.

Phrenetic (fren-et'-ik) [ $\phi \rho \dot{\prime} v$, mind]. Maniacal; delirious.

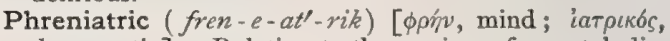
therapeutic]. Relating to the curing of mental dis orders.

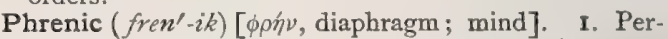
taining to the diaphragm. 2. Pertaining to the mind. 3. A mental disease; or a remedy for mental disease. P. Artery. See Arteries, Table of. P. Nerve. See Nerves, Table of.

Phrenicocolic (fren-ik-o-kol'-ik). Same as Phrenocolic. Phrenicogastric (fren-ik-o-gas'-trik). Same as Phrenogastric.

Phrenicosplenic (fren-ik-o-splen'-ik). Same as Phrenosplenic.

Phrenicula (fren-ik'-u-lah) [ $\phi \rho \eta \dot{v}$, mind]. Brain-fever.

Phrenismus (fren-iz'-mus). Synonym of Encephalitis.

Phrenitic (fren-it'-ik) [ $\phi \rho \eta ́ v$, mind, diaphragm; $\iota \tau \iota s$, inflammation]. Pertaining to, or affected with phrenitis.

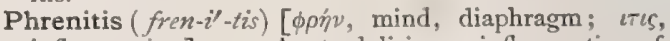
inflammation]. I. Acute delirium; inflammation of the brain, or its meninges. 2. Inflammation of the diaphragm, P. aphrodisiaca, erotomania. P. calentura, insolation. $\mathbf{P}$. potatorum, delirium tremens. P. mania gravis. See Periencephalitis. P. typhodes. Synonym of Fever, Cerebro-spinal.

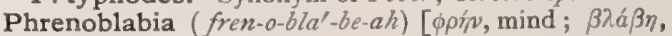
hurt]. Any disorder of the mind.

Phrenocolic (fren-o-kol'-ik) [ $\phi \rho \hat{\nu}$, diaphragm; $\kappa \bar{\omega} \lambda o v$, colon]. Pertaining to the diaphragm and the colon. 
Pbrenocostal (fren-o-kos'-tal) [ $\phi \rho \hat{\eta} \nu$, midriff; costa, rib]. Pertaining to the diaphragm and the ribs.

Phrenogastric (fren-o-gas'-trik) [ $\phi \rho \dot{\eta} v$, diaphragm; yooth $\rho$, stomach]. Pertaining conjointly to the stomach and the diaphragm.

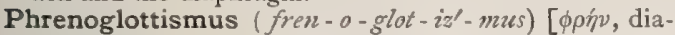
phragm; $\gamma \lambda \hat{\omega} \tau T a$, tongue]. Spasm of the glottis ascribed to disease of the diaphragm.

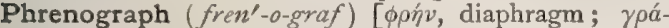
$\phi \varepsilon \varepsilon v$, to record]. An instrument for registering the movements of the diaphragm.

Phrenography (fren-og'-ra-fe). Synonym of Psychology.

Phrenoin ( fren'-o-in). Synonym of Phrenosin.

Phrenolepsia (fren-o-lep'-se-ah) [ $\phi \rho \eta \dot{\nu}$, mind; $\lambda \tilde{\eta} \psi \iota \varsigma$, seizure]. Insanity.

Phrenologic (fren-o-loj/-ik) [ $\phi \rho \eta \dot{\nu}$, mind; $\lambda 6 \gamma o s$, science]. Pertaining to phrenology.

Phrenologist (fren-ol'-o-jist) [ $\phi \rho \hat{\eta} \nu$, mind; $\lambda 6 \gamma o s$, science]. One versed in phrenology

Phrenology (fren-ol'-o-je) $[\phi \rho \eta \nu$, mind; $\lambda 6 \gamma o s$, science]. The theory that the various faculties of the mind occupy distinct and separate areas in the braincortex, and that the predominance of certain faculties can be predicated from modifications of the parts of the skull overlying the areas where these faculties are located.

Phreno-magnetism (fren-o-mag'-net - izm) [ $[\phi \rho \eta j \nu$, mind; $\mu a \gamma \nu \eta$ Tns, magnet]. Excitement of the organs of the brain by mesmeric passes.

Phreno-mesmerism (fren-o-mez-mer-izm). Synonym of Phreno-magnetism.

Phrenonarcosis (fren-o-nar-ko'-sis) [ $\phi \rho \eta \dot{\nu}$, mind ; $\nu a ́ \rho$ $\kappa \omega \sigma \iota \zeta$, stupor]. A dulling of the intellect.

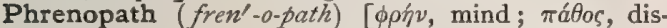
ease ]. One who devotes himself to phrenopathy; an alienist.

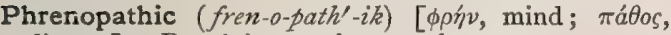
disease]. Pertaining to phrenopathy.

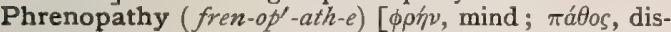
ease]. Mental disease; psychopathy.

Phrenoplegia (fren-o-ple'-je-ah) [ $\phi \rho \dot{\eta} v$, mind ; $\pi \lambda \eta \gamma \dot{\eta}$, stroke]. A sudden failure of mental power.

Phrenoplexia (fren-o-pleks'-e-ah) [ $\phi \rho \eta \dot{\nu}$, mind; $\pi \lambda \vec{\eta} \xi \iota \varsigma$, stroke]. Guislain's name for ecstasy, the patient being motionless, the muscles tense, and the physiognomy expressive of strong emotion.

Phrenosin (fren'-o-zin) [ $\phi \rho \eta \nu$, mind $], \mathrm{C}_{34} \mathrm{H}_{67} \mathrm{NO}_{8}$; a nitrogenous substance, one of the cerebrins, obtained from brain-substance.

Phrenosis (fren-o'-sis). Synonym of Phrenopathy.

Phrenosplenic (fren-o-splen'-ik) [ $\phi \rho \eta \dot{v}$, diaphragm ; $\sigma \pi \lambda \hat{\eta} \nu$, spleen ]. Pertaining to the diaphragm and the spleen.

Phrenotherapy (fren-o-ther'-ap-e) [ [ $\rho^{\prime \prime} \nu$, mind; $\theta \varepsilon \rho \alpha-$ $\pi \varepsilon i a$, therapy]. Guislain's term for psychiatry.

Phrensic (fren'-zik). Same as Phrenetic.

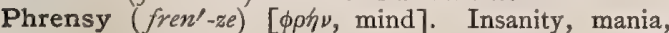
frenzy.

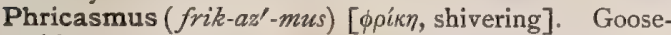
skin.

Phriciasis (frik-i'-as-is). Synonym of Phricasmus.

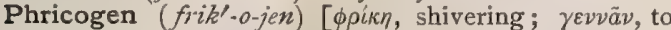
produce]. A hypothetic principle of cold.

Phronemophobia (fron -e - $\left.m o-f o^{\prime}-b e-a h\right)[\phi \rho b \nu \eta \mu a$, a thought; $\phi 6 \beta$ os, fear]. Morbid dread of thinking.

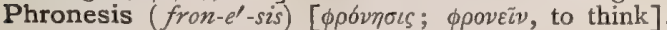
Soundness of mind, or of judgment.

Phrynin (frin'-in). See Bufidin.

Phthalate $\left(t h a l^{\prime}-\bar{a} t\right)$. Any salt of phthalic acid. P. of Morphin, used by subcutaneous injection. Dose, gr. $1 / 3$ in 2 per cent. solution.
Phthaleins (thal'-e-inz). The derivatives of phthalin, containing two phenol residues. They are dyes of great technical value, and are generally colorless, crystalline bodies.

Phthalic Acid (thal'-ik). See Acid.

Phthalin (thal'-in). A colorless body produced by the reduction of phthalein by means of nascent hydrogen.

Phthaluric Acid (thal-u'-rik), $\mathrm{C}_{10} \mathrm{H}_{7} \mathrm{NO}_{4}$. A colorless crystalline substance, fusible at $192^{\circ} \mathrm{C}$.

Phtharma (thar'-mah) [ $\phi \theta \varepsilon i \rho \varepsilon \varepsilon \nu$, to corrupt]. A morbid alteration of structure.

Phtharsis (thar'-sis) [ $\phi \theta a ́ \rho \sigma \iota s$, corruption]. Decom position.

Phtheiræmia (thi-re'-me-ah). Synonym of Phthiremia.

Phtheiriasic (thi-ri-az'-ik). Synonym of Phthiriasic.

Phthinodes $\left(t h i-n o^{\prime}-d \bar{e} z\right)$ [ $\phi \theta i v \varepsilon i \nu$, to waste; $\varepsilon i \delta o s$, like]. Hectic; phthisical or tuberculous.

Phthinoplasm (thi'-no-plazm) [ $\phi \theta i v \varepsilon \iota v$, to waste ; $\pi \lambda a ́ \sigma \mu a$, plasm]. Degraded bioplasm; a proposed name for the irritant material that causes degeneration of the lung-tissue, as opposed to that caused by tubercle.

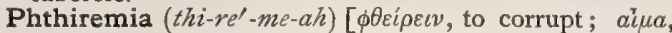
blood]. A depraved state of the blood, with diminished plasticity.

Phthiriasic $\left(t h i-r i-a s^{\prime}-i k\right)[\phi \theta \varepsilon i \rho$, louse $]$. Produced by lice.

Phthiriasis $\left(t h i-r i^{\prime}-a s-i s\right)[\phi \theta \varepsilon i \rho$, louse]. Lousy disease ; morbus pediculosus. See Pediculosis.

Phthirius $($ thi'-re-us) [ $\phi \theta \varepsilon i \rho$, a louse]. A genus of Pediculida or true lice. See Parasites (Animal), Table of.

Phthisic $\left(t i z^{\prime}-i k\right) \quad[\phi \theta \imath \sigma \iota k \delta s$, consumptive]. I. Consumptive or tuberculous; affected with phthisis or tuberculosis. 2. A popular name for asthma.

Phthisical (tiz'-ik-al) [ $\phi \theta i \sigma \iota \varsigma$, a wasting]. I. Pertaining to or affected with phthisis or tuberculosis. 2. Popularly, same as Asthmatic. P. Frame, P. Habit, a long, narrow, flat chest, with depressed sternum, acute costal angle, a fair, transparent skin, light complexion, blue eyes, winged scapulæ, slender limbs. As to internal organs, the heart is relatively small, the arteries narrow, the pulmonary artery relatively wider than the aorta, and the lung-volume rather large.

Phthisiogenesis (tiz-e-o-jen'-es-is) [ $\phi \theta i \sigma \iota s$, wasting;

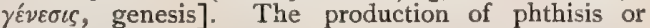
wasting.

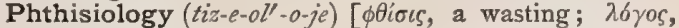
science]. The study or science of phthisis or tuberculosis; its causes, pathology, hygiene, and therapeutics.

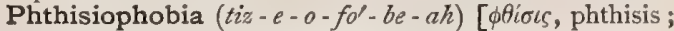
$\phi 6 \beta 0 \varsigma$, dread]. Morbid dread of pulmonary consumption or tuberculosis

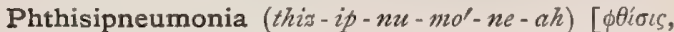
phthisis; $\pi \nu \varepsilon v \mu \omega \nu$, lungs]. Phthisis or pulmonary tuberculosis.

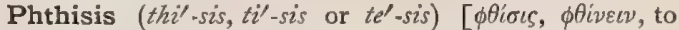
waste]. Formerly any dyscrasia producing emaciation and death; a wasting or consumption. The term has been restricted to designate all puImonary lesions followed by disorganization of lung-tissue, the formation of cavities, loss of function of the lungs, loss of health, and death. It is usually tuberculous in nature, due to the action of a specific vegetable microörganism, the bacillus of tuberculosis. The onset of phthisis is usually very insidious, with gradual loss of strength and flesh, and with cough and expectoration and loss of appetite; it may commence with a bronchitic attack or with one or more attacks of pleurisy; very rarely it follows an acute croupous pneumonia. The 
most important symptoms of the fully-developed disease are cough, at first hacking, later loud, hollow, and paroxysmal; expectoration, frothy and viscid at first, later profuse, purulent, and nummular; fever of hectic type; emaciation often very rapid, hemoptysis, dyspnea, pain, night-sweats, anorexia, and digestive disorders. The physical signs are flattening and retraction of the supra-clavicular and infra-clavicular regions, restricted movement of these regions, dulness on percussion over one or both apices extending to other parts of the lungs, altered rhythm of the respiratory sounds, adventitious sounds on auscultation, such as the presence of râles of various kinds according to the progress of the disease. The duration of the disease varies from the rapidly fatal, in which death may occur in a few weeks, to the very chronic, lasting for years. The pathology usually consists in a deposit of tuberculous nodules, especially in and around the walls of the smallest bronchi; these nodules coalesce and eventually undergo caseation and softening. More rarely a fibrous change takes place, with the production of the more chronic form of the disease, fibroid phthisis. Phthisis may occur at any age, and especially attacks those in whom there is an inberited predisposition or those who have been weakened by previous disease, poor food, poor hygienic surroundings, frequent pregnancies and prolonged lactation or the inhalation of poisonous vapors or irritating particles. Those in whom there is a strong family history of phthisis generally develop the disease before the twenty-fifth year. It may occur in those of middle age, however, or in old age. The usual seat for the primary lesion is in one of the apices, the right a little more frequently than the left. After one apex has been attacked, the disease usually extends, first to the apex of the lower lobe of the same side, then to the other apex. The base is rarely primarily affected. P., Abdominal. See Tabes mesenterica. P., Acute. See P., Acute Pneumonic. P., Acute Pneumonic, a variety that occurs in two forms: $(a)$ the pneumonic or lobar and $(b)$ the broncho-pneumonic or lobular. In the former $(a)$, a lobe or an entire lung may be converted into a dry, opaque, white or yellowish-white, cheesy substance, in which tubercles are scattered here and there. Very often there exists a cavity at the apex. The bronchial glands may be tuberculous. The cases usually begin with a chill and for a time run a course like that of croupous pneumonia. The crisis, however, does not occur; the fever becomes irregular, the sputum mucopurulent, soon presenting tubercle-bacilli and elastic tissue. Death may occur in a few weeks or in two or three months. (b) Acute tuberculous broncho-pneumonia is most common in children and forms most cases of so-called phthisis forida. The smaller bronchi and air-cells become filled with a caseous material, constituting small grayish-white areas. These may coalesce and produce a lobar caseous broncho-pneumonia; but usually some unaffected tissue can be seen among the caseous areas. The symptoms of the disease are similar to those of catarrhal pneumonia; the temperature, however, is high; there is rapid loss of flesh and strength; evidences of softening become manifest; tubercle-bacilli appear in the sputum. Death may occur within three weeks or the disease may lead to chronic phthisis. In children the disease commonly follows one of the infectious fevers, particularly measles and whooping-cough. P., Amphiblestroid, atrophy of the retina. P., Bacillary, phthisis due to a bacillus. P., Basic, phthisis affecting primarily the base of the lung. P., Black, anthracosis. P., Bronchial, tuberculosis of the bronchial glands. P. bulbi, progressive shrinkage and atrophy of the eye. ball. P. calculosa, pulmonary tuberculosis in which the exudates in the smallest lobules become infiltrated with lime. P., Cerebral, tuberculosis of the brain or its membranes. P., Chronic, phthisis running a slow course. P. combinata. Synonym of P., Acute Pneumonic. P., Diabetic, pulmonary tuberculosis in a diabetic patient, manifesting itself as a caseous broncho-pueumonia. P., Embolic, degeneration of areas in the lung, the seat of emboli from other organs. P. enterica, tuberculosis of the intestines. P., Fibroid, P., Fibrous ; I. Interstitial pneumonia. 2. Chronic tuberculosis of the lungs attended with the formation of fibrous tissue, which contracts, causes shrinking of the affected lobe, and sometimes bronchiectasis by eccentric traction on the bronchi. The pleura is usually very much thickened and the layers may adhere so tightly that it is impossible to separate them. P., Flaxdressers', tabacosis occurring in flax-dressers. P. forida, acute phthisis speedily fatal-also known as galloping consumption. P., Galloping. Synonym of P. florida. P., Glandular, tuberculosis of lymphatic glands. P., Gouty, a chronic inflammation of the bronchial tubes supposed to be due to gout. P., Granular. Synonym of Tuberculosis, Acute Miliary. P., Grinders'. See Grinders' Asthma. P. ab hæmaptoë, pulmonary tuberculosis apparently following hemorrhage from the lungs. It is not now believed that pulmonary hemorrhage can be the starting-point of tuberculosis, but it is looked upon rather as a possible very early sign, or as accidental and having no connection with the tuberculosis subsequently developed. P., Hemorrhagic, pulmonary tuberculosis in which extravasated blood is believed to have undergone caseous degeneration. Its existence is questionable. P., Hepatic, tuberculosis of the liver; formerly, also the term meant abscess of the liver. $\mathbf{P}$. ex inanitione, phthisis depending on inanition. P. intestinalis. Synonym of $P$. enterica. P., Knife-grinders'. Synonym of $P$., Grinders'. P. laryngea. Synonym of Tuberculosis, Laryngeal. P., Latent. Synonym of Tuberculosis, Latent. P. lienalis, tuberculosis of the spleen; also splenic abscess. P. mammæ, disorganization of the mammary gland, from suppuration. P. medullæ spinalis. Synonym of Tabes dorsalis, P. mesaraica, P. mesenterica. Synonym of Tabes mesenterica. P., Miners'. See Miners' Phthisis. P., Mucous. Synonym of Tuberculosis, Miliary. P., Neurotic, phthisis occurring in the course of neurasthenia. P., Neuro-vascular, phthisis associated with neurovascular disease. P. nodosa, miliary tuberculosis of the lungs. P., Non-bacillary, pulmonary destruction not due to bacilli. Miners' phthisis and grinders' phthisis are due to fibroid changes in the lung induced by the irritation of the dust inhaled. Ulcerative phthisis is probably always bacillary. P. oculi, atrophy of the eye. P. pancreatica, marked emaciation and general cachexia from disease of the pancreas. P. pharyngea, tuberculosis of the pharynx. P., Phlegmatic, phthisis occurring in persons who in the earlier stages do not present emaciation. P. pituitosa. Synonym of P., Mucous. P. prostatica, tuberculosis of the prostate gland. P. psoasum, psoas abscess due to tuberculous infection. P. pulmonalis, pulmonary tuberculosis. P., Pulmonary. See Phthisis. P. pulmonum. Synonym of $P$., Pulmonary. P. renalis, tuberculosis of the kidneys. P., Rheumatic, phthisis said to be dependent upon a rheumatic diathesis. P., Senile, pulmonary tuberculosis in the aged. P., Specific, breaking down of the lungs due to the bacillus of tuberculosis. 
splenica. Synonym of $P$. lienalis. P., Stonemasons'. See Grinders' Asthma. P., Syphilitic, syphilis of the lung is quite rare. See Syphilis of the Lung. P. of teeth, a condition of the teeth characterized by especial clearness and transparency, with frailness of structure, caries being favored by constitutional weakness. P. testis, tuberculosis of the testicle. P. trachealis, tuberculosis of the trachea. P., Traumatic, pulmonary tuberculosis developing in a lung, shortly after a chest-injury without any external wound. P., Tuberculous, phthisis due to the bacillus of tuberculosis. P. ventriculi, atrophy of the mucous membrane and thinning of the coats of the stomach, with retention or even increase of the size of the organ.

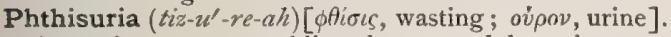
A wasting state resembling that caused by pulmonary tuberculosis, but due to renal disease.

Phthoë (tho'-e). Synonym of Phthisis.

Phthoicus (tho'-ik-us). Synonym of Phthisical.

Phthois $\left(t h 0^{\prime}-i s\right)[\phi \theta o \iota s$, a pill]. Bolus, pill.

Phthongodysphoria (thong-go-dis-fo'-re-ah) [ $\phi \theta 6$ ryos,

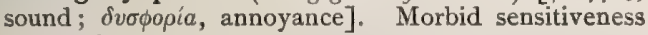
to sounds.

Phthongometer (thong-gom'-et-er) [ $\phi \theta 6 \gamma \gamma o s$, voice ; $\mu \varepsilon ́ \tau \rho \circ \nu$, measure]. An instrument used for measuring vocal sounds.

Phthora $\left(t h o^{\prime}-r a h\right)$ [ $\phi \theta 0 \rho a ́$, decomposition]. I. Corruption. 2. Synonym of the Plague. 3. Abortion.

Phthoric (thor $-i k$ ) [ $\phi$ fopá, decomposition]. Causing decomposition. P.Acid. Synonym of Hydroftuoric Acid. See Acid.

Phthoroctonos (thor-ok'-to-nos) [ $\phi \theta o \rho a ́$, decomposition; $\chi \tau \varepsilon i v \varepsilon(\nu$, to kill]. Feticide.

Phulluah ( ful'-u-ah) [E. Ind.]. An oleaginous substance obtained from a wild East Indian plant. It is largely used by the hill-tribes for the cure of frost-bite and chilblains, and has been used with benefit in rheumatism, sprains, sciatica, etc. Unof.

Phycinic Acid $\left(f-\sin ^{\prime}-i k\right)$ [ $\phi \bar{v} \kappa o s$, seaweed]. The name given by Lamy to the crystalline acid found by him in the Alga Protoccocus vulgaris. It occurs as white, opaque, tasteless, odorless needles, melting at $136^{\circ} \mathrm{C}$; insoluble in water, but soluble in alcohol, ether and oils. It forms crystalline salts with alkalies. Its silver salt is white and insoluble. Analysis gives C, 70.22 per cent. ; H, II.76 per cent. ; N, 3.72 per cent. ; $0,14.30$ per cent.

Phycit $\left(f^{\prime}\right.$-sit) [ $\phi \tilde{v}$ kos, seaweed], $\mathrm{C}_{12} \mathrm{H}_{30} \mathrm{O}_{12}$. A substance found by Lamy along with phycinic acid in the alga Protococcus vulgaris. Wagner suspects its identity with Erythrit or Erythroglucin, and Lamy's later investigations confirm this view. It crystallizes in colorless, right-angled prisms, has a sweet, fresh taste, and neutral reaction. It melts at $120^{\circ} \mathrm{C}$. Cf. Erythrol.

Phycochrome $\left(f^{\prime}-k o-k r o ̄ m\right)[\phi \tilde{v} \kappa s$, seaweed; $\chi \rho \tilde{\omega} \mu a$, color]. In biology, the complex blue-green pigment that masks the pure green of the chlorophyl in certain Alge (Cyanophycee). It is composed of phycocyanin, scytonemin, etc.

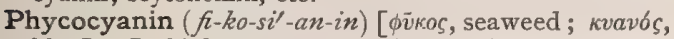
blue]. In biology, a beautiful blue pigment, characteristic of the Cyanophycee among Algee.

Phycocystitis ( $\left.\hat{i}-k o-s i s-t i^{\prime}-t i s\right)$. Synonym of Capsulitis. Phycoerythrin ( $f$-ko-erl-ith-rin) [ $\phi \bar{v} \kappa o s$, seaweed;

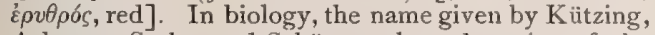
Askenay, Sorby and Schiitt to the red portion of the compound pigment of the red Alge (Floridece), which is soluble in water. Kramer, who first described it, called it rhodospermin. The entire pigment is called by Schüt rhodophyl and the part soluble in alcohol, Floridea green.

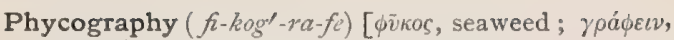
to write]. A description of $A l g a$.

Phycohematin $\left(f-k o-h e m^{\prime}-a t-i n\right)$ [ $\delta \tilde{v} \kappa o s$, seaweed aifátıvos, of blood, bloody]. In biology, the name given by Kuitzing to the peculiar blood-red pigment obtained from the marine alga Rytiplaea tinctoria. It is precipitated in flakes by alcohol from the cold watery solution which has been evaporated to a syrupy consistency.

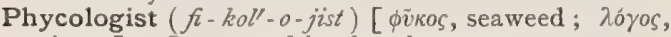
science]. One versed in phycology.

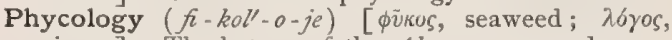
science]. The botany of the Alge or seaweeds.

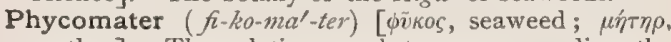
mother]. The gelatinous substance surrounding the sporules of $A \lg a$.

Phycomyces $\left(f i-k o m^{\prime}-i s-\bar{e} z\right)[\phi \tilde{v} \kappa o s$, seaweed; $\mu$ v́kns, fungus]. A genus of Mucosini.

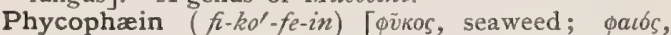
dusky, dun]. In biology, that reddish-brown pigment, soluble in water, which forms part of the coloring-matter (phaophyl) of the Fucacece and Phaosporee among Alge. Cf. Phycoxanthin, Fucoxanthin.

Phycoxanthin $(f i$-koks - an'-thin ) [ $\phi \tilde{v} \kappa o s$, seaweed;

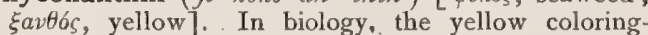
matter, soluble in alcohol, forming part of the compound pigment (phreophyl; diatomin) of certain Alge (Fucacee, Phoosporea, Diatomacea).

Phyganthropia $(f i$-gan-thro'-pe-ah) [ $\phi v y \dot{\eta}$, flight; à $\nu \rho \rho \omega \pi$ s, men]. Morbid dread of human society.

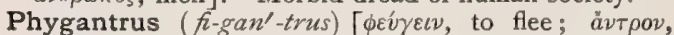
cave]. Lissauer's term for a skull in which the distance between the perpendicular drawn from the most prominent point of the torus frontalis to the radius fixus, and that from the nasion to the same line is between 6 and $12 \mathrm{~mm}$.

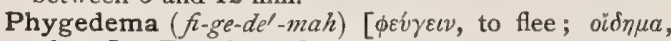
edema]. Transient edema.

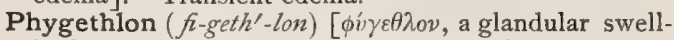
ing]. An inflammatory nodule of the skin.

Phygogalactic $\left(f i-g o-g a l-a k^{\prime}-t i k\right)$ [ $\phi v \gamma \varepsilon i v$, to avoid; $\gamma a ́ \lambda \alpha$, milk]. I. Stopping the secretion of milk. 2. An agent that checks the secretion of milk.

Phygometopus ( $\left.f-g o-m e t-o^{\prime}-p u s\right)[\phi \varepsilon v \gamma \varepsilon \varepsilon v$, to flee ;

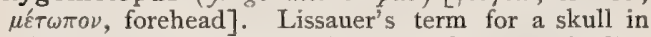
which the angle between the radius fixus and the line joining the bregma and the nasal point is between $8^{\circ}$ and $33.5^{\circ}$.

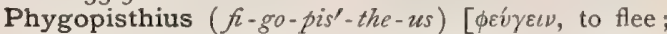
$o ̈ \pi \iota \sigma \theta \varepsilon$, behind]. Lissauer's term for a skull in which the angle formed between the radius fixus and the line joining the lambda and the inion is between $106^{\circ}$ and $127^{\circ}$.

Phygoprosopus ( $f$-go-pros'-o-pus) [ $\phi \varepsilon v y \varepsilon v v$, to flee ;

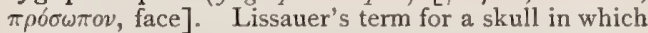
the angle formed between the radius fixus and the line joining the nasion and the alveolar point is between $3^{\circ}$ and $66.5^{\circ}$.

Phygorrhinus (fi-gor-i'-nus) [ $\phi \varepsilon \dot{v} \gamma \varepsilon \omega v$, to flee; $i^{\prime} \iota_{\text {, }}$ nose]. Lissauer's term for a skull in which the angle formed between the radius fixus and the line joining the nasion and the subnasal point is between $36^{\circ}$ and $66.5^{\circ}$.

Phylacterion ( $f$-lak-te'-re-on) [ $\phi \dot{v} \lambda a \xi$, guard]. The same as Phylactery.

Phylactery $\left(f i-l a k^{\prime}-t e r-e\right)[\phi v i \alpha \xi$, guard]. A charm or amulet.

Phylaxin $(f$-laks'-in) [ $\phi \dot{v} \lambda a \xi$, a guardian, protector]. In biology, the name given by Hankin to an antitox. in or defensive proteid-called alexin by Buchnerfound in animals that have acquired an artificial immunity to a given infectious disease; as distinguished 
from a sozin, $i$.e., a defensive proteid that occurs naturally in normal animals. Hankin recognizes two forms of phylaxin: (I) a Mycophylaxin, or defensive proteid produced in the body of an animal which has an acquired immunity to a given infectious disease, which has the power of destroying the pathogenic bacteria to which the disease is due; (2) a Toxophy. laxin, or defensive proteid produced in the body of an animal which has an acquired immunity to a given infectious disease, which has the power of destroying the toxic products of the pathogenic bacteria to which the disease is due. (Sternberg.)

Phyletic $\left(f-l e t^{\prime}-i k\right)$ [ $\phi v \lambda \eta \dot{n}$, a tribe]. In biology, phylogenic; relating to the tribal or ancestral history of an organism

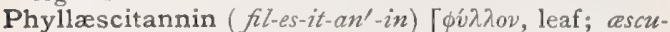
lus, the genus of trees of which the horse-chestnut is a species; tannin, tannin], $\mathrm{C}_{26} \mathrm{H}_{24} \mathrm{O}_{13} \mathrm{H}_{2} \mathrm{O}$. A tannin found by Rochleder in the young leaves of the leafbuds of the horse-chestnut.

Phyllanthus ( $f l l$-an'-lhus ) [ $\phi \dot{v} \lambda \lambda o v$, leaf; àv $\theta 0 \varsigma$, flower]. A genus of euphorbiaceous plants of some 450 species. P. emblica affords the so-called emblic myrobalans. (See Myrobalan.) $\mathbf{P}$. niruri and $\mathbf{P}$. urinaria are strongly diuretic. Unof.

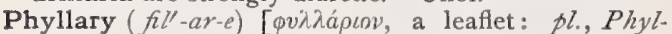
laries]. In biology, a leaflet of the involucre of a composite flower-head.

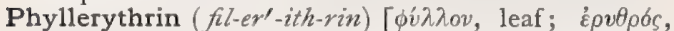
red]. The red coloring-matter of plants, especially that of the leaves in autumn. See Erythrophyl.

Phyllidium $\left(f l l-i d^{\prime}-e-u m\right)[\phi v \lambda \lambda o v$, leaf; dim. suffixidiov: pl., Phyllidia]. In biology, a rudimentary ctenidium, as of a limpet; a capito-pedal body.

Phylline $\left(f l^{\prime \prime}-i n\right)\left[\phi \dot{u}_{\lambda} \lambda \nu^{\prime}\right.$, leaf]. Leaf-like; partaking of the characteristics of a leaf.

Phyllobranchia (fll-o-brang'-ke-ah) [ $\phi \dot{u} \lambda \lambda o v$, a leaf; $\beta p a ́ \gamma \chi \iota a$, branchia, gill]. In biology, a gill in which the folia are arranged in rows upon a stem, as in crabs.

Phylloclade ( $\left.f l^{\prime}-o-k l a \bar{d}\right)$. Same as Phyllocladium.

Phyllocladium ( $\left.f l l-o-k l a^{\prime}-d e-u m\right)[\phi i \lambda \lambda o v$, leaf; $\kappa \lambda a ́ \delta o \varsigma$, branch: $p l$., Phyllocladia $]$. In biology, a leaf-like branch, as in the Cactacea, Ruscus, or Psilotum.

Phyllocyanic Acid ( $\left.f l l-o-s i-a n^{\prime}-i k\right)$. Same as Phyllocyanin.

Phyllocyanin ( fil-o-si'-an-in) [ $\phi \dot{v} \lambda \lambda o \nu$, a leaf; kíaovs, blue]. The bright-blue pigment of flowers, obtained from chlorophyl by the action of alkalies and of alkaline earths.

Phyllocyst ( $\left.f l^{\prime}-0-s i s t\right)$ [ $\phi \dot{v} \lambda \lambda o v$, leaf; $\kappa i \sigma \tau \iota \varsigma$, bladder]. In biology, the cavity of a hydrophyllium.

Phyllode $\left(f l^{\prime}-\bar{o} d\right)$. Same as Phyllodium.

Phyllodium ( fil-o'-de-um) [ $\phi \dot{v} \lambda \lambda$ ov, leaf ; $\varepsilon i \delta o s$, form : pl., Phyllodia]. In biology, a dilated or flattened petiole taking on the character of a blade.

Phyllodoce ( $\left.f l-o d^{\prime}-o-s e\right)$ [L., a sea-nymph]. I. A genus of oceanic hydrozoans. 2. A genus of polychetous annelids. P.-green, a green pigment found in Phyllodoce viridis, not referable to any class of animal pigments, and not chlorophyl. See Pigments, Conspectus of.

Phyllody ( $\left.f l^{\prime \prime}-o \cdot d e\right)[\phi v \lambda \lambda \omega \delta \eta s$, like leaves]. In biology, the reversion of floral organs to leaves; frondescence; phyllomorphy.

Phyllogen ( $\left.f i l^{\prime}-o-j e n\right)$ [ $\phi \dot{v} \lambda \lambda o v$, leaf; $\gamma \varepsilon v \hat{h} s$, producing]. Same as Phyllophore.

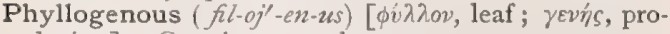
ducing]. Growing upon leaves.

Phylloid ( $\left.f l^{\prime}-o i d\right)$ [ $\phi \dot{v} \lambda \lambda o v$, leaf; $\varepsilon i \delta o s$, form]. In biology, leaf-like.

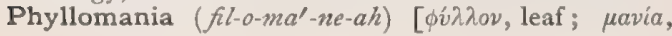

madness]. In biology, an abnormal condition, as to the abundance or position of leaves. Cf. Pleiopliylly. Phyllome $\left(f l^{\prime}-\bar{o} m\right)$ [ $\phi \dot{v} \lambda \lambda \alpha^{\prime} \nu$, leaf]. In biology, any organ that may be regarded morphologically as a leaf.

Phyllomic ( fil-om'-ik) [ $\phi i \lambda \lambda$ ov, leaf]. In biology, of the nature of or resembling a phyllome.

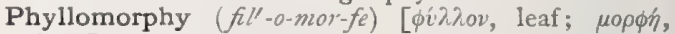
form]. Same as Phyllody, also Phyllomorphosis.

Phyllophagous ( fit-off'-ag-us) [ $\phi \dot{v} \lambda \lambda o v$, a leaf; $\phi a \gamma \varepsilon i v$, to eat]. In biology, feeding on leaves.

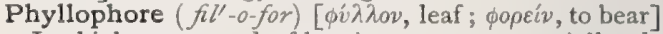
In biology, any leaf-bearing organ, especially the budding summit of a stem, as the palm.

Phyllophorous ( $\left\{l-o f^{\prime}-o-r u s\right)$ [ $\phi \dot{\lambda} \lambda \hat{\lambda} o v$, leaf; $\phi \varepsilon \varepsilon \varepsilon v v$, to bear]. In biology, producing leaves, or leaf-like or foliaceous parts or organs.

Phyllopode $\left(f l^{\prime}-o-p \bar{o} d\right)$ [ $\phi \dot{v} \lambda \lambda o v$, leaf; $\pi$ ov́s, foot]. In biology, the dilated sheathing base of the frond of certain plants (Isaëtes).

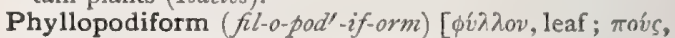
foot; forma, form ]. In biology, resembling a phyllode.

Phylloptosis ( $\left.f l-o p \cdot t 0^{\prime}-s i s\right)$ [ $\phi \dot{\imath} \lambda \lambda o \nu$, leaf ; $\pi \tau \tilde{\omega} \sigma \iota c$, a falling]. In biology, the fall of the leaf.

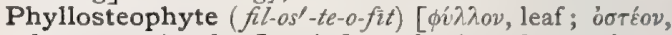
bone; $\phi v \tau \sigma v$, plant]. A flat or laminated osteophyte.

Phyllostomatous (fil-o-sto'-mat-us) [ $\phi \dot{v} \lambda \lambda o v$, a leaf; oroua, mouth]. Leaf-nosed, as a bat.

Phyllotactic ( $\left.f l-o-t a k^{\prime}-t i k\right)$ [ $\phi i \lambda \lambda o v$, leaf ; Tá $\iota \iota$, order]. In biology, pertaining to phyllotaxis.

Phyllotaonin ( $\left.f l-o-t a^{\prime}-0-n i n\right)$ [ $\phi \dot{v} \lambda \lambda o v$, leaf]. A crystalline product obtained by the decomposition of chlorophyl.

Phyllotaxis (fil-o-taks'-is) [ [

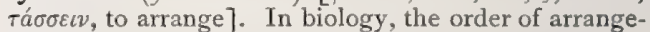
ment of the leaves upon the stem.

Phyllotaxy ( fil'-a-taks-e). Same as Phyllotaxis.

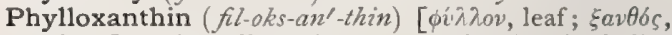
yellow]. The yellow pigment associated with phyllocyanin in chlorophyl.

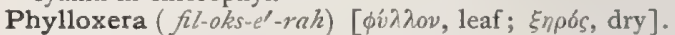
A genus of plant-lice (Aphidida), nearly all the species of which are natives of North America. The grape-vine phylloxera or ine-pest (Phylloxera vastatrix, Planchon) has caused great damage to all varieties of grapes. P.-mite, an acaridan (Rhizoglyphus phylloxera) frequently found in association with the Phylloxera of the vine, feeding, in its young state, on the juices of roots injured by the phylloxera, and, when older-according to Riley and Planchon-preying on the root-inhabiting type of that insect. This is denied by Foumouse and others.

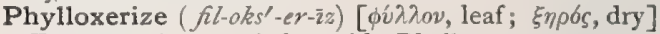
To contaminate or infest with Phylloxere.

Phyllula ( $f l^{\prime}$-u-lah) [diminutive of $\phi \hat{\lambda} \lambda \lambda_{\sigma} v$, a leaf]. In biology, the stage in the embryo of vascular plants at which the first leaf and root have appeared. (T. J. Parker.)

Phylogenesis $\left(f-l o-j e n^{\prime}-e s-i s\right)[\phi \tilde{\lambda} \lambda o v, \phi v \lambda \eta ́ n$, race, tribe;

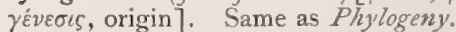

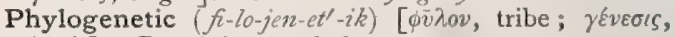
birth]. Pertaining to phylogeny.

Phylogenic $\left(f-l o-j e n^{\prime}-i k\right)$ [ $\phi \bar{v} \lambda o v$, tribe; $\gamma \varepsilon v \dot{n} s$, producing]. Pertaining to phylogeny.

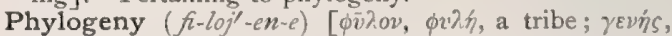
producing]. In biology, the evolution of the phylum, race, group, or species; paleontologic evolution, as distinguished from ontology or individual evolution. According to Weismann's theory each phyletic variation is due to a variation in the structure of the " $i d$ " of germ-plasm.

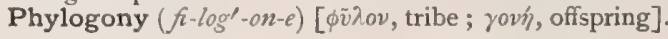


The branch of embryology dealing with the origin of species by evolution.

Phylum $\left(f^{\prime}-l u m\right)$ [ $\phi \tilde{v} \hat{n} o v, \phi v \lambda \eta^{\prime}$ a tribe: $p l .$, Phyla]. In biology, a primary division of the animal or vegetable kingdom.

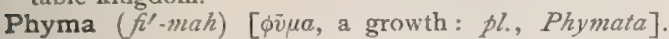
A circumscribed suppurative swelling of the skin. The word was formerly also used to designate any one of a class of diseases including erysipelas, edema, emphysema, scirrhus, etc. Also, a genus of diseases including hordeolum, sycosis, and anthrax. The term now denotes a localized plastic exudate larger than a tubercle.

Phymacerite $\left(f-m a s^{\prime}-e r-i t\right)[\phi \tilde{v} \mu a$, a tumor; $\kappa e ́ p a \varsigma$, horn]. In biology, the tubercle at the base of the second antenna, containing the external orifice of the green gland in Crustacea. (Bate.)

Phymatoid ( $f^{\prime}$-mat-oid $)$ [ $\phi \tilde{v} \mu a$, growth; $\left.\varepsilon i \delta o s, ~ l i k e\right]$. Resémbling a phyma or tubercle; a term describing a condition of carcinomatous growth distinguished by a dull-yellow color and a consistence resembling that of tubercle.

Phymatorhusin $\left(f-m a t-o r-u^{\prime}-\sin \right)[\phi \vec{v} \mu a$, growth $]$. A pigment found by Nencki in the metastatic deposits of a melanotic sarcoma of the skin. It contains sulphur, is insoluble in alcohol, in water, and in ether, but dissolves readily in ammonia, and in alkaline carbonates. It is free from iron.

Phymatosis ( $f$-mat-ó-sis) [ $\phi \bar{v} \mu \alpha$, tubercle; $v \sigma \sigma o s$, disease: $p l .$, Phymatoses]. Any tuberculous or scrofulous disease.

Phymocnidosis ( $f$-mok-nid-o'-sis). Synonym of Erythema nodosum.

Phymolepra ( $f$-mo-lep'-rah). Synonym of Leprosy, Tuberculous.

Phymosis $\left(f i-m o^{\prime}-s i s\right)$. Synonym of Phimosis.

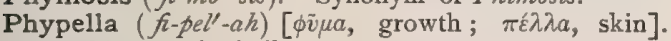
An old name for boil.

Phyraliphore $(f i$-ral'-if-or $)$. One of certain cells containing vesicles or cavities called by Virchow Physalides, and supposed to take part in endogenous cellformation (Von Korsinsky). See Physalis.

Physa $\left(f^{\prime}-s a h\right)[\phi \tilde{v} \sigma a$, air $]$. Bulla or pustule.

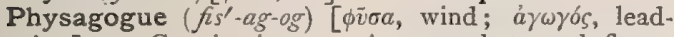
ing]. I. Carminative. 2. An agent that expels flatus.

Physalide ( $\left.f s^{\prime}-a l-i d\right)$ [ $\dot{v} \sigma a \lambda \lambda i s$, bladder]. The vesicular tuft of the chorion as seen in the vesicular mole. Synonym of Physalis.

Physalidocnidosis ( $\left.f i s-a l-i d-o k-n i d-o^{\prime}-s i s\right)$. Synonym of Urticaria bullosa.

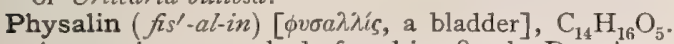
A non-nitrogenous body found in 1852 by Dessaigues and Chautard in Physalis alkekengi; it has been used in place of quinin.

Physalis $\left(f i s^{\prime}-a l-i s\right)$ [ $\phi v \sigma a \lambda \lambda i s$, a bladder]. A genus of solanaceous herbs, mostly American. P.alkekengi, the strawberry tomato, Jerusalem cherry, or Judenkirsche of Europe, and P. viscosa, of N. America, are diuretic. Unof.

Physalis ( $\left.f s^{\prime}-a l-i s\right)$ [ $\phi v \sigma a \lambda \lambda i s$, bladder: pl., Physalides]. A name given by Virchow to the large giant epithelial cell of giant-cell carcinoma.

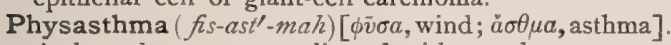
Asthma due to, or complicated with, emphysena.

Physconia ( $\left.f i s-k o^{\prime}-n e-a h\right)$ [ $\phi \dot{v} \sigma \kappa \omega v$, paunch]. Any abdominal enlargement, especially from tympanites. $\mathbf{P}$. adiposa, corpulency. $\mathbf{P}$. aquosa, ascites. $\mathbf{P}$. biliosa, distention of the gall-bladder. P. mesenterica. Synonym of Tubes mesenterica.

Physechema ( $\left.f s-e k-e^{\prime}-m a h\right)$. Synonym of Sound, Bellowes.

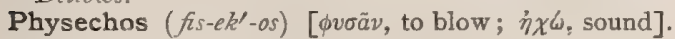
Vesicular murmur.

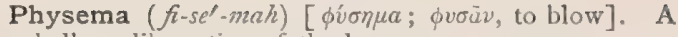
bellows-like action of the lungs.

Physesis $\left(f i-s e^{\prime}-s i s\right)$. Synonym of Physema.

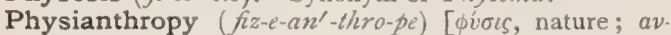
$\theta \rho \omega \pi \%$, man]. The study of the human constitution and of the diseases of man.

Physiatrics ( $\left.f i z-\ell-a t^{\prime}-r i k s\right)$ [ $\phi i j \sigma \iota$, nature; iatpeia, treatment]. The power of nature in curing disease: vis medicatrix nature.

Physiautocracy $\left(f z-\ell-a v-t o k^{\prime}-r a-c \ell\right)$ [ $\phi v ́ \sigma \iota s$, nature ; aitós, self; кpattiv, to rule]. The power of nature.

Physiautotherapia ( $\left.f i z-e-a w-t o-t h e r-a^{\prime}-p e-a h\right)$ [ $\phi i \sigma \iota s$, nature ; av่tós, self; $\theta \varepsilon \rho a \pi \varepsilon v \varepsilon \varepsilon v$, to cure]. Strictiy expectant treatment.

Physic $\left(f i z^{\prime}-i k\right)$ [ $\phi \dot{v} \sigma \iota s$, nature]. The science of medicine. Also, a medicine, especially a cathartic. Also, stannic tetrachlorid, a mordant used in dyeing. P. Nut. See Barbadoes Nut. P.-root. See Leptandra.

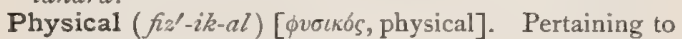
nature or to physics. Also, pertaining to the body or material things, in contradistinction to the mind, or metaphysical things. P. Diagnosis, the investigation of disease by the direct aid of the senses, sight, touch, hearing. P. Education, the training of the body by means of gymnastics, etc. P. Examination, examination of the patient's body to determine the condition of the various organs and parts. P. Signs, the phenomena observed on inspection, palpation, percussion, auscultation, mensuration, or combinations of these methods, etc.

Physicalist $\left(f z^{\prime}-i k-a l-i s t\right)$ [ $\phi \dot{v} \sigma \zeta$, nature]. One who maintains that the physical constitution dominates the intellectual and moral nature.

Physician ( $\left.f z-i s h^{\prime}-a n\right)$ [ $\dot{v} \sigma \iota \varsigma$, nature]. One who practices medicine. Formerly, a natural philosopher. P.-ship, the office of physician.

Physicist ( $\left.f z^{\prime}-i s-i s t\right)$ [ $\dot{v} \sigma \iota \zeta$, nature $]$. In biology, one who holds that vital phenomena are purely physical and chemic. One learned in the science of physics.

Physick's Encysted Rectum. A rare disease of advanced age consisting in an hypertrophy, and sometimes of an inflammation, of the natural rectal sacs, which become dilated also. It is attended with burning pain at the anus and adjacent parts and an increased mucous secretion. See Diseases, Table of. P.'s Splint. A long splint, a modification of Desault's splint for fracture of the femur.

Physico-chemic ( $\left.f z^{\prime}-i k-o-k e n \iota^{\prime}-i k\right)$ [ $\chi \eta \mu \varepsilon i a$, chemistry]. Being both physical and chemic.

Physicomental ( $\left.f z^{\prime}-i k-0-m e n^{\prime}-t a l\right)$ [ $\phi \dot{v} \sigma \iota \zeta$, nature; mens, mind]. Pertaining to physical and mental phenomena and their interdependence.

Physics $\left(f z^{\prime}-i k s\right)$ [ $\phi \dot{v} \sigma \iota$, , nature]. The science that treats of the properties of matter, and of the laws governing it in conditions of rest and motion, and in its fluid, solid, and gaseous states. P., Chemic, that branch of physics which is used by chemists to define substances. P., Medical, that part of physics having bearing upon medicine in any of its branches.

Physiogenesis ( fiz-e-o-jen'-es-is). See Physiogeny.

Physiogenetic $\left(f z-e-o-j e n-e t^{\prime}-i k\right)$. See Physiogenic.

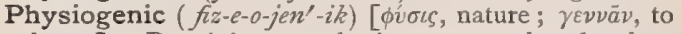
beget]. Pertaining to physiogeny, or the development of functions.

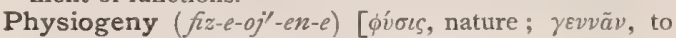
produce]. In biology, the science of the development, genesis, or evolution of functions.

Physiognomic ( $\left.f z-\iota-o g-n o m^{\prime}-i k\right)$ [ $\phi \hat{v} \sigma \iota \zeta$, nature; $\gamma \nu \omega \mu \eta$, knowledge]. Pertaining to physiognomy.

Physiognomist $\left(f i z-e-o g^{\prime}-n o-m i s t\right)$ [ $\phi v \sigma \iota s$, nature;

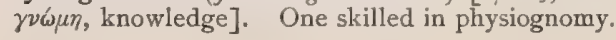


Physiognomonic $\left(f i z-e-o g-n o-n o n^{\prime}-i k\right)$. Same as Physiognomic.

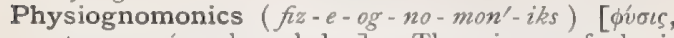

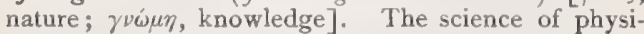
ognomy.

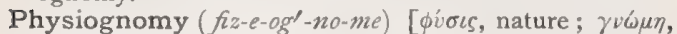
knowledge]. I. The art of reading character by a study of the face. 2. The countenance itself.

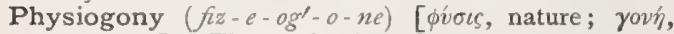
generation]. The production of nature.

Physiologic, Physiological ( $f i z-e-0-l o j^{\prime}-i k$, fiz-e-o-loj' $i k-a l)[\phi v \sigma \iota s$, nature; $\lambda o ́ \gamma o s$, science]. Pertaining to physiology; pertaining to natural or normal processes, as opposed to those that are pathologic. P. Antidote, an antidote that neutralizes not by its chemic power, but through its effects on the system. P. Excavation, the funnel-shaped depression at the center of the optic papilla, at the bottom of which the retinal vessels enter; it varies in size and form, but always has sloping walls, which distinguish it from a pathologic excavation, exhibiting vertical or overhanging walls. P. Selection. See Evolution. P. Units of Herbert Spencer, in biology, hypothetic, complex, protean units, intermediate between chemic units and morphologic units or cells. They are supposed to possess a polarity or aptitude to aggregate in the form of the particular species of organism to which they belong, just as the molecules of a salt possess the intrinsic aptitude to crystallize in a particular way. The entire body is supposed to be composed of these units, making regeneration of lost parts possible, while the germcells are supposed to contain small groups of them, giving each germ-cell the power of reproducing the whole. The theory is one of epigenesis. See $i d$, idant, idioplasm, plasome, microsomata, heredity, epigenesis, pangenesis, etc.

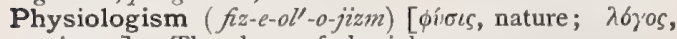
science]. The abuse of physiology.

Physiologist $\left(f i z-e-o l^{\prime}-o-j i s t\right)$ [ $\phi v \sigma \iota \zeta$, nature ; $\lambda 6 \gamma o \varsigma$, science]. One who is expert in physiology.

Physiology $\left(f z-e-o l^{\prime}-o-j e\right)$ [ $\phi^{\prime} \sigma \iota s$, nature; $\lambda 6 \gamma o s$, science]. The science that treats of the functions of organic beings, as distinguished from morphology, etiology, etc. P., Animal, the physiology of animals. P., Cellular, the physiology of cells. P., Comparative, the comparative study of the physiology of different animals and of animals and plants. P., Morbid, the study of diseased functions or of functions modified by disease. P., Pathogenetic, P., Pathologic, pathology. P., Special, the physiology of special organs. P., Vegetable, the physiology of plants.

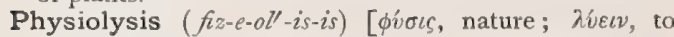
dissolve]. The disintegration of dead tissue by the natural processes of decomposition.

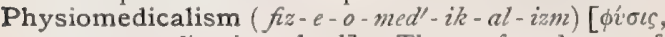
nature; medicari, to heal]. The professed use of natural remedies only, poisons and minerals being rejected.

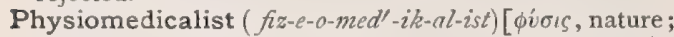
medicari, to heal]. One who professes physiomedicalism.

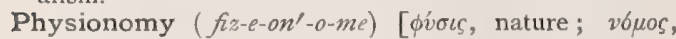
law]. The science of the laws of nature.

Physiophilosophy ( $\left.f i z^{\prime}-e-o f l l-o s^{\prime}-o-f e\right)$. Synonym of Physics.

Physiophyly (fiz-e-off'-il-e) [ $\phi \dot{v} \sigma \iota \varsigma$, nature; $\phi \tilde{v} \lambda o v$, a tribe]. In biology, the tribal history or paleontologic evolution of function, without reference to form.

Physique $\left(f z-\bar{e} k^{\prime}\right)$ [Fr.]. Physical structure or organization

Physocele $\left(f^{\prime}-s o-s \bar{e} l\right)[\phi \tilde{v} \sigma \alpha$, air; $\kappa \hat{h} \lambda \eta$, tumor]. A swelling or tumor containing air or flatus ; emphysema of the scrotum; a hernia filled with flatus.

Physocelia $\left(f i-s o-s e^{\prime}-l e-a h\right)$. Synonym of Tympanites. Physocephalus ( $f i$-so-sef'-al-us) [ $\bar{\omega} \sigma \alpha$, air; $\kappa \varepsilon \phi a \lambda \dot{\eta}$, head]. Emphysematous swelling of the head.

Physocolic $\left(f i-s o-k o l^{\prime}-i k\right)$ [ $\phi \tilde{\sigma} \sigma a$, air; $\kappa \omega \lambda \iota \kappa n$, colic]. Colic caused by flatus.

Physode $\left(f^{\prime}-\operatorname{sod}\right)$ [ $\phi \bar{v} \sigma \iota \gamma \xi$, a bladder]. In biology, the name applied by Crato to minute, refractive, bladder-like formations, found gliding about within the watery fluid in the lamellar systems of certain vegetable cells. In the brown Alga the physodes contain substances analogous to phenol.

Physodin ( $f^{\prime}$-so-din) [physodes, from $\phi v \sigma a$, air; $\phi v \tilde{\sigma} \iota \xi \xi$, a bladder]. A substance found by Gerding associated with Ceratophyllin, in the lichen Parmelia ceratophylla var. physodes, Ach.

Physodyspnea $\left(f^{\prime}-s o-d i s p-n e^{\prime}-a h\right)\left[\phi \tilde{v} \sigma \alpha\right.$, air ; $\delta \varsigma^{-}$, difficult ; $\pi \nu \varepsilon \varepsilon \varepsilon \nu$, to breathe]. Dyspnea due to emphysema.

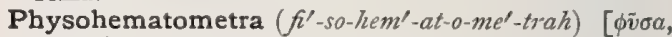
air; ai $\mu a$, blood; $\mu$ í $\tau \rho a$, uterus ]. An accumulation of gas, or air, and blood in the uterus, as in decomposition of retained menses, or placental tissue.

Physohydrometra $\left(f^{\prime}-s o-h i^{\prime}-d r o-m \ell^{\prime}-t r a h\right)[\phi \tilde{v} \sigma a$, air ; in $\omega \rho$, water; $\mu \dot{\eta} \tau \rho a$, womb]. An accumulation of gas and water in the uterus.

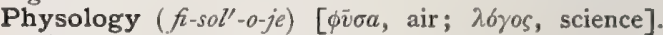
The study of flatulence.

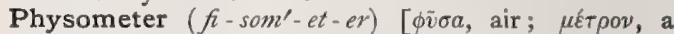
measure]. An instrument for determining variations in the volume of a confined body of air.

Physometra ( $f$-so-me'-trah) [ $\phi \tilde{v} \sigma a$, air; $\mu \hat{\eta} \tau \rho a$, womb]. A distention of the womb with gas, produced by the decomposition of its contents.

Physomycetes $\left(f i-s o-m i-s e^{\prime}-t \bar{e} z\right)[\phi \bar{v} \sigma a$, bellows; $\mu \hat{k} \kappa \eta s$, fungus]. A class of Fungi characterized by a total absence of hymenium.

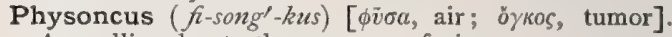
A swelling due to the presence of air.

Physoscheocele $(f i$-sos'-ke-o-sèl) $[\phi \tilde{v} \sigma \alpha$, air; $\check{\sigma} \sigma \chi \varepsilon 0 \nu$, scrotum; $\kappa \hat{n} \lambda \eta$, tumor]. Emphysema of the scrotum.

Physospasmus $\left(f i-s o-s p a z^{\prime}-m u e s\right)[\phi \tilde{v} \sigma a$, air, flatus ; $\sigma \pi a ́ \sigma-$ $\mu \delta s$, spasm]. Flatulent colic.

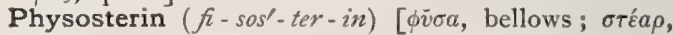
fat]. An inert fatty or cholesterin-like substance occurring in the Calabar bean.

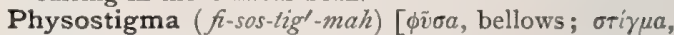
stigma]. Calabar Bean, Ordeal Nut. The seed of $P$. venenosum, native of West Africa. The properties of the drug depend upon two alkaloids, physostigmin or eserin, $\mathrm{C}_{15} \mathrm{H}_{21} \mathrm{~N}_{3} \mathrm{O}_{2}$, which paralyzes the motor functions of the spinal cord and stimulates muscle-fiber, and calabarin, which acts similarly to strychnin. Locally applied to the eye, physostigmin causes contraction of the pupil and diminishes intraocular tension. On account of its action on muscles it causes increased peristaltic movements of the intestines. In toxic doses, death is produced by failure of respiration. Its therapeutic uses are: In diseases of the eye, as in glaucoma, in iritis, to contract the pupil, and, alternated with atropin, to break up adhesions after iritis; in convulsive diseases, as tetanus and strychnin-poisoning ; in constipation from atony of the intestines; in bronchitis and dyspnea, from weakness of the bronchial muscles. It is also used as an antidote to atropin and to strychnin. For poisoning, give an emetic and inject atropin. P., Ext., Alcoholic. Dose gr. 1/6-j. P., Injectio, Hypodermica; Io grains of the extract in $1 / 2$ ounce. Dose miij-xij. P., Tinct., 15 per cent, in strength. Dose $\eta_{v-x x}$ Eserina (Physostigmina, B. P.), unof. 
A myotic. Dose gr. $\frac{1}{6}-\frac{1}{12}$. Lamellæ Physostigminæ (B. P.), each contains $\frac{1}{1000}$ grain of physostigmin. Physostigminz Salicylas. Dose gr. $\frac{1}{10} \frac{1}{60}$. Injectio P. salicylat. hypodermica; $I$ in $\mathbf{r} 60$. Dose $m$ j-vj. Physostigminæ Sulphas, very soluble. Dose gr. $\frac{1}{0} \frac{1}{6} \frac{1}{6}$. Injectio P. Sulphat. hypoderm., 4 grains to one ounce. Dose $m j$-iv.

Physostigmin $(f i$-so-stig'-min). Synonym of Eserin.

Physothorax ( $f$-so-tho'-raks). Synonym of Pneumothorax.

Phytalbumose $\left(f i-t a l^{\prime}-b u-m o ̄ z\right)$ [ $\phi v \tau o ́ v$, plant; albumen]. A vegetable peptone or albumose, found in seeds of the Leguminose, in flour, and in papaw juice. a-phytalbumose agrees with the hemialbumose of Vines, being soluble in cold and boiling water; yielding also the biuret reaction, and a precipitate by saturation with sodium chlorid only in an acid solution. $\beta$-phytalbumose is soluble in cold but not in boiling distilled water; hence it is precipitated by heat. It is also readily thrown down by saturation with sodium chlorid, and gives a faint biuret reaction.

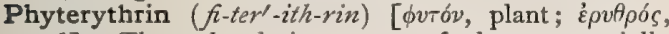
red]. The red coloring-matter of plants, especially of leaves, in autumn.

Phythelminthus $(f-$ thel-min'-thus $)$. Synonym of Bothriocephalus.

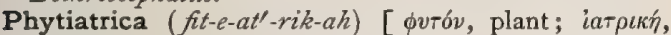
medicine]. Treatment by means of medicinal herbs; botanic medicine.

Phytiform ( $f^{\prime}$-tif-orm) [ $\phi v \tau o ́ v$, plant ; forma, form]. Resembling a plant.

Phytivorous (fi-tiv'-or-us). Same as Phytophagous.

Phyto- $\left(f^{\prime}-t_{0-}\right)$ [ $\phi v \tau o ́ v$, plant]. A prefix signifying connection with or relation to vegetable organisms.

Phyto-alopecia ( $f$-to-al-o-pe'-she-ah). Synonym of Alopecia areata.

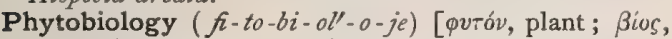
life; $\lambda 6 \gamma u \varsigma$, science $]$. The science of plant-life.

Phytoblast $\left(f^{\prime}\right.$-to-blast $)$ [ $\phi v \tau o ́ v$, plant; $\beta \lambda a \sigma \tau b s$, germ] The living protoplasm constituting a cell.

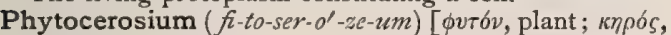
wax]. Vegetable wax.

Phytochemic, Phytochemical ( $f i$-to-kem'-ik, $f_{i}$-to$\left.k e m^{\prime}-i k-a l\right)$ [ $\phi v \tau \delta v$, plant ; $\chi \eta \mu \varepsilon i \alpha$, chemistry]. Pertaining to vegetable chemistry or to changes of vegetable origin, the plants acting by chemic force, or effecting a chemic change. Ferment-fungi are phytochemic, and so are the poisonous or pathogenic principles associated with the presence and growth of microbes in the body.

Phytochemistry $\left(f-t o-k e n^{\prime}-i s-t r e\right)$ [ $\phi v \tau o ́ v$, plant; $\chi \eta \mu \varepsilon i \alpha$, chemistry]. Vegetable chemistry.

Phytochimy ( $f^{\prime}$-to-kim-e). Same as Phytochemistry.

Phytochlore ( $f^{\prime}$-to-klor) [ $\phi v \tau o ́ v$, plant; $\chi \lambda \omega \rho o ́ s$, palegreen]. In biology, same as chlorophyl.

Phytochrome ( $\left.f^{\prime}-t o-k r o ̄ m\right)$ [ $\phi v \tau \sigma v$, plant; $\chi \rho \tilde{\omega} \mu \alpha$, color]. In biology, a general term for those vegetable pigments necessary to the fundamental processes of vegetable assimilation, and for the synthesis of protoplasm and amylum. Cf. chlorophyl, erythrin, pheodin, phyllocyanin, phylloxanthin.

Phytocolla $\left(f i-t o-k o l^{\prime}-a h\right)$ [ $\phi v \tau o ́ v$, plant; $\kappa \delta \hat{\lambda} \lambda a$, glue]. Same as Gliadin.

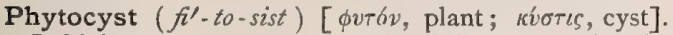
In biology, a cyst or envelop of cellulose containing the phytoblast.

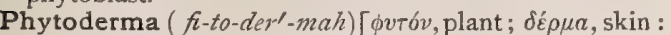
pl., phytodermata]. Any cutaneous disease produced by microscopic vegetation, or by dermatophytes.

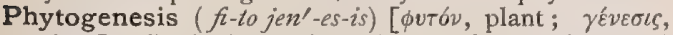
origin]. In biology, the science of the origin and development of plants.

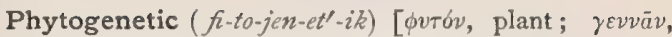
genesis]. Pertaining to phytogenesis.

Phytogeny $\left(f i-t_{0 j}^{\prime \prime}-e n-\ell\right)$. Same as Phytogenesis.

Phytogeographic ( $\left.f^{\prime}-t o-j e-o-g r a f^{\prime}-i k\right)$ [ $\phi v \tau o ́ v$, plant;

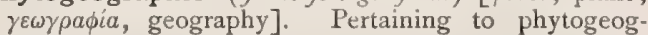
raphy.

Phytogeography $\left(f^{\prime}-t o-j e-o g^{\prime}-r a-f e\right)[\phi v \tau b v$, plant ;

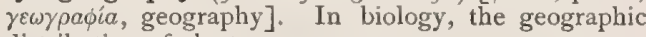
distribution of plants.

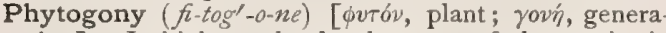
tion]. In biology, the development of the species in plants.

Phytographer ( $f$-tog $\left.{ }^{\prime}-r a-f e r\right)[\phi v \tau o ́ v$, plant ; $\gamma \rho a ́ \phi \varepsilon \iota v$, to write]. One who describes and classifies plants.

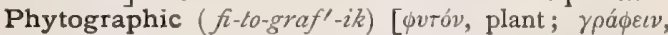
to write]. Pertaining to phytography.

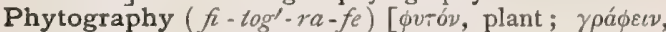
to write]. Botany. Also, a treatise on the geographic distribution of plants.

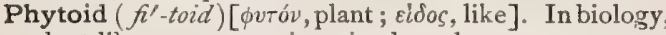
plant-like; $e . g$. , certain animals and organs.

Phytolacca $\left(f i-t o-l a k^{\prime}-a h\right)$ [ $\phi v \tau^{\prime} v$, plant; lacca, lac: gen., Phytolacce]. Poke. The root and the frut of $P$. decandra. It is an emetic, cathartic, and motor depressant. Toxic doses cause death by paralysis of the organs of respiration. Its action is antagonized by alcohol, opium, and digitalis. It is serviceable in malignant tumors, eczema, and similar skin-affections. Dose of the root as an emetic gr. $\mathrm{x}-\mathrm{xxx}$; as an alter. ative gr. j-v. P. bacca (U. S. P.), the berry or fruit of Phytolacca decandra. Dose of a saturated tincture, a fluidram three times a day; serviceable in rheumatism. P. radix (U. S. P.), the root of Phytolacca decandra. P., Ext., Fld., Rad. Dose $m_{\mathrm{v}-3 \mathrm{j} .}$ P., Tinct., unof. Dose $\eta_{\mathrm{x}} \mathrm{x}-\mathbf{3} \mathrm{j}$.

Phytolaccic Acid ( $f$-to-lak'-sik) [ $\phi v \tau b v$, plant ; lacca, lac]. Oxalic acid as found in Phytolacca.

Phytolaccin ( $f$-to-la $\left.k^{\prime}-\sin \right)$ [ $\phi v т o ́ v$, plant ; lacca, lac] The precipitate from a tincture of the root of Phytolacca decandra. It is alterative, anti-syphilitic, laxative, etc. Dose $I$ to 3 grains. Unof.

Phytolithology $\left(f i-t o-l i t h-o l^{\prime}-o-j e\right)$ [ $\phi v \tau o ́ v$, plant; $\lambda i \theta o s$, stone; $\lambda o ́ \gamma o s$, science]. The science of fossil plants.

Phytologic $\left(f-t o-l o j^{\prime}-i k\right)$ [ $\phi v \tau o ́ v$, plant; $\lambda 6 \gamma o s$, science]. Pertaining to phytology.

Phytologist $\left(f i-t o l^{\prime}-o-j i s t\right)[\phi v \tau o ́ v$, plant; $\lambda 6 \gamma o s$, science 1. One versed in phytology.

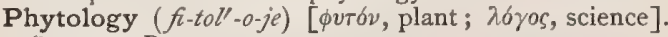
Same as Botany.

Phytolysis ( $f i$-toll-is-is) [ $\phi v \tau o ́ v$, plant; $\lambda v^{\prime} \varepsilon v v$, to loose]. In biology, the change in position occurring in the pigment in a living cell in consequence of changes in the intensity of the light, - such as the changes in the chlorophyl coincident with the alternation of day and night.

Phytomentagra ( $f$-to-men-ta'-grah). Synonym of Sycosis.

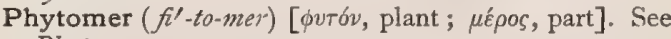
Phyton.

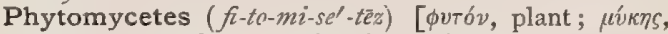
fungus]. Molds occurring in putrid urine.

Phyton ( $f^{\prime}$-ton) [ $\phi v \tau o ́ v$, plant ; $\phi v \varepsilon \varepsilon v$, to produce]. In biology, Gaudichaud's name for the pieces which by their repetition make up a plant, on the theory that the plant is a compound individual. Compare the use of person by zoölogists.

Phytonomatotechny $\left(f-t o-n o-m a t^{\prime}-o-t e k-n e\right)[\phi v \tau b v$,

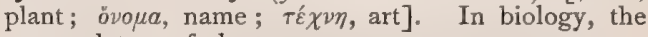
nomenclature of plants.

Phytonomy (fu-ton'-o-me) [ $\phi v \tau \delta$, plant; vó $\mu$ s, law]. In biology, the laws of plant-life.

Phytoparasite $(f i$-to-par'-as-it $)$ [ $\phi u \tau \delta v$, a plant; $\pi a \rho a ́-$ 


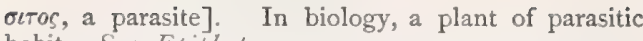
habit. See Epiphyte.

Phytoparasitic $\left(f i-t o-p a \gamma-a s-i t^{\prime}-i k\right)[\phi v \tau \sigma v$, plant ; $\pi \alpha \rho a ́$, beside; бĩTos, food]. Pertaining to phytoparasites.

Phytopathologic $\left(f-t o-p a t h-0-l o j^{\prime}-i k\right)[\phi v \tau \delta v$, plant; $\pi a ́ t o s$, disease; $\lambda 6 \gamma o s$, science]. Pertaining to phytopathology

Phytopathologist $\left(f i-t o-p a t h-o l^{\prime}-o-j i s t\right)[\phi v \tau b v$, plant;

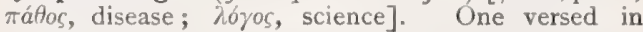
phytopathology.

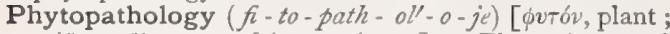
$\pi a ́ t a s$, disease; $\lambda 6$ yos, science]. The science of plant-disease, or of diseases due to vegetable organisms; also, the science of the diseases of plants; vegetable pathology

Phytophagous ( $f$-toff'-ag-us) [ $\phi v \tau \delta v$, a plant; $\phi a \gamma \varepsilon \check{\nu} \nu$, to eat]. In biology, herbivorous; feeding on plants. Phytophagy ( $f$-toff'-aj-e) [ $\phi v \tau \delta v$, a plant; $\phi \alpha \gamma \varepsilon i v$, to eat]. The habit of feeding on plants.

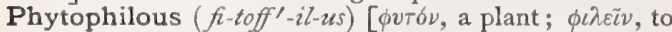
love]. In biology, applied to animals that are fond of plants.

Phytophysiology $\left(f i-t o-f z-e-o l^{\prime}-o-j e\right)$. Synonym of Physiology, Vegetable.

Phytoplasm ( $f^{\prime}$-to-plazm) [ $\phi v \tau o ́ v$, plant; $\pi \lambda a ́ \sigma \mu \alpha$, plasma]. The vegetable protoplasm.

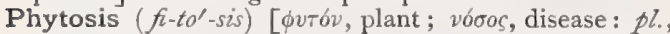
Phytoses]. I. Any disease due to the presence of vegetable parasites. 2. The production of disease by vegetable parasites. 3. The presence of vegetable parasites.

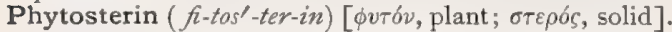
A substance, present in plant-seeds and sprouts, very similar to cholesterin.

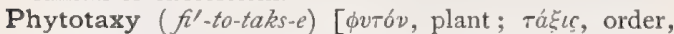
arrangement]. In biology, systematic botany.

Phytotechny $\left(f^{\prime}-t o-t e k-n e\right)$ [ $\phi v \tau \sigma v$, plant ; $\tau \dot{\varepsilon} \chi v \eta$, art]. Industrial botany.

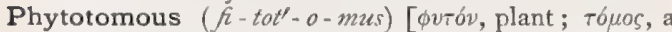
cutting]. In biology, leaf-cutting, or plant-cutting, e. g., certain birds or insects.

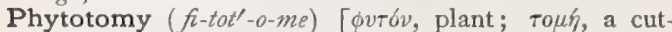
ting]. The anatomy of plants.

Phytovitellin ( $f$-to-vit-el'-in) [ $\phi v \tau \delta$, plant; vitellus, yolk]. The vegetable analogue of vitellin.

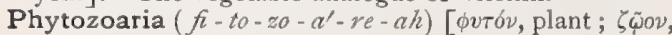
animal]. Same as Infusoria.

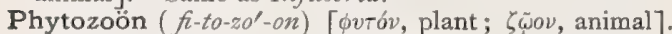
A plant-like animal; a zoöphyte.

Pia $\left(p i^{\prime}-a h\right)$ [native Polynesian]. The plant Tacca pinnatifida, from which a variety of arrowroot is prepared ; it is said to be of special value in the treatment of certain cases of diarrhea and dysentery. Unof.

Pia, or, more fully, Pia Mater ( $p e^{\prime}-a h$ mah'-ter or $p i^{\prime}$ $a h$-ma'-ter) [L., "pious, or tender, mother." ] The vascular membrane, consisting of a plexus of bloodvessels held by a fine areolar tissue, enveloping the entire surface of the brain and spinal cord. It dips into the fissures of the brain and forms the velum interpositum and the choroid plexus of the fourth ventricle. P., Cerebral, the pia mater covering the brain. P., External, that which covers the external portion of the brain. P., Internal, that which passes into the ventricles. $\mathbf{P}$. intima, the inner layer of the spinal pia mater. P., Spinal, the pia of the spinal cord. P. of Testis. See Tunica.

Pia-arachnitis ( $\left.p i^{\prime}-a h-a r^{\prime}-a k-n i^{\prime}-t i s\right)$ [pia, pia; á $\rho a^{\prime} \chi \nu \eta$, spiders' web; $\iota$ T/S, inflammation]. Inflammation of the pia-arachnoid; leptomeningitis.

Pia-arachnoid ( $\left.p i^{\prime}-a h-a r-a k^{\prime}-n o i d\right)$ [pia, pia ; ápá $\chi \nu \eta$, a spider's web; $\varepsilon i \delta o s, l i k e]$. The pia and arachnoid considered as one structure.
Pial $\left(p i^{\prime} \cdot a l\right)$ [pia, pia]. Pertaining to the pia mater.

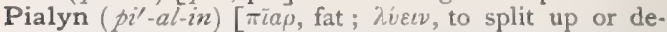
compose]. An enzyme contained in both the pancreatic substance and fluid; which has not as yet been isolated. It is capable of effecting a hydrolytic decomposition of neutral fats into glycerin and free fatty acids. It is most actively present in the substance of the fresh gland or its secretion, and its activity is greatest at about $40^{\circ} \mathrm{C}$

Pia-matral ( $\left.p i^{\prime}-a h-m a^{\prime}-t^{\prime} r a l\right)$. See Pial.

Pian ( $\left.i^{\prime}-a n\right)$. See Frambesia.

Pianists' Cramp. See Cramp.

Piano-players' Cramp. See Cramp.

Piarachnoid ( $p i-a r-a k^{\prime}-n o i d$ ) [ pia, pia ; á $\rho a ́ \chi v \eta$, spiders' web; cilos, like]. The pia mater and arachnoid considered as one membrane.

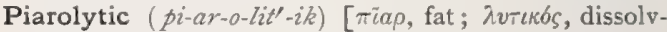
ing]. Forming emulsions with fat.

Piarrhemia ( $\left.i-a r-e^{\prime}-m e-a h\right)$ [ $\pi i \alpha \rho$, fat; $\alpha^{\top} \mu a$, blood]. See Lipemia.

Pica ( $\left.p i i^{\prime}-k a h\right)$ [L., "magpie"']. The craving for unnatural and strange articles of food; a symptom present in certain forms of insanity, in hysteria, and chlorosis, and during pregnancy.

Picacismus (pik-as-iz'-mus) [pix, pitch]. Depilation by means of pitch-plaster.

Picamar (pik-am'-ahr) [pix, pitch; amarus, bitter]. A bitter, oily substance obtained in the distillation of wood-tar.

Picea $\left(p i^{\prime}-s e-a h\right)$ [L., the pitch-pine]. A genus of coniferous trees. P. alba, the white spruce. P. excelsa, the common fir or pitch-pine. It yields resin and turpentine. P. nigra, the black spruce. P. vulgaris. Synonym of $P$. excelsa.

Picene $\left(p i^{\prime}-\operatorname{sen} n\right)$ [picea, the pitch-pine], $\mathrm{C}_{22} \mathrm{H}_{14^{\prime}} \quad$ A hydrocarbon formed by the distillation of lignite, coaltar and petroleum residues. It is very sparingly soluble in most of the solvents, but most readily in crude cumene ; it crystallizes in blue, fluorescent leaflets, melting at $338^{\circ} \mathrm{C}$, and boiling at $519^{\circ} \mathrm{C}$.

Piceous (pish'-e-us) [pix, pitch]. In biology, having the nature of pitch. Viscous. Pitch-black; black with a faint reddish tinge.

Pichi ( $\left.p e^{\prime}-c h e\right)$ [native Chilean]. The stems and leaves of Fabiana imbricata, growing in Chile. It is a terebinthin having tonic properties, and is of repute in the treatment of catarrhal inflammations of the genito-urinary tract. Dose of the fld. ext. $3 \mathrm{j}$; of the extract gr, $\mathrm{v}-\mathrm{x}$. Unof.

Pick (pik) [ME.,picken, to pick]. To pluck with the fingers; a symptom in certain typhoid states. See Carphology.

Pick's Liniment. Linimentum exsiccans; a liniment used in the treatment of eczema. Its formula is: Tragacanth, 75 grains; glycerin, 30 minims; water, $25 \mathrm{I} / 2$ drams. It is of service in the dry forms of eczema. P.'s Salicylated Soap-plaster, a preparation used in the treatment of eczema. It is composed as follows: Emplast. saponis liq., $21 / 2$ ounces; oliveoil, 5 drams. ; salicylic acid, 37 grains. It is applied on strips of muslin.

Picolin (pik'-o-lin) [picea, the pitch-pine ; oleum, oil], $\mathrm{C}_{6} \mathrm{H}_{7} \mathrm{~N}$. Methyl-pyridin, a liquid alkaloid: a product of acroleîn-ammonia.

Picolinic Acid (pik-o-lin'-ik) [picea, the pitch-pine; oleum, oil], $\mathrm{C}_{6} \mathrm{H}_{5} \mathrm{NO}_{2}$. A monobasic acid made from picolin and other pyridin-derivatives.

Picotement $\left(p e-k \bar{o} t^{\prime}-\operatorname{mon}(g)\right)$ [Fr. ]. A pricking sensation; tingling; formication.

Picra (pik'-rah). Same as Fiera picra.

Picræna (pik-re'-nah). See Quassia.

Picramic Acid (pik-ram'-ik) [ $[\pi \iota k \rho \delta s$, bitter; amin $], \mathrm{C}_{6}{ }^{*}$ 
$\mathrm{H}_{5} \mathrm{~N}_{3} \mathrm{O}_{5}$. Picric acid in which one $\mathrm{NO}_{2}$ radicle has been replaced by $\mathrm{NH}_{2}$.

Picramid (pik'-ram-id) [ [ amid of picric acid; trinitranilin.

Picranisic Acid (pik-ran-iz'-ik). Synonym of Picric Acid.

Picrate $\left(p_{i} i k^{\prime}-r \bar{a} t\right)$ [ $\pi \iota \kappa \rho o ́ s$, bitter]. Any salt of picric acid. See Ammonium Picrate.

Picric (pik'-rik) $[\pi(k \rho b s$, bitter]. Same as Carbazotic. P. Acid. See Acid and Pigments, Conspectus of. P. Acid Test. See Tests, Table of.

Picroaconitin (pik-ro-ak-on'-it-in) [ $\pi \iota k \rho \delta s$, bitter ; aconitum $], \mathrm{C}_{31} \mathrm{H}_{45} \mathrm{NO}_{10}$. An amorphous substance extracted from the bulbs of Aconitum napellus. It is slightly poisonous.

Picrocarmin ( pik-ro-kar'-min) [ $\pi \iota k \rho b s$, bitter ; carmin, carmin]. A preparation for staining microscopic specimens. Its composition is as follows: carmin I.0; ammonia 5.0; distilled water 50.0. After solution, add saturated watery solution of picric acid 50.0. Allow to stand in a wide-mouthed bottle until the ammonia has evaporated ; then filter. See Stains, Table of:

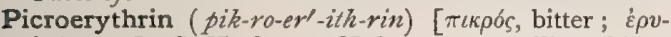
opós, red], $\mathrm{C}_{12} \mathrm{H}_{16} \mathrm{O}_{7}+3 \mathrm{H}_{2} \mathrm{O}$. A crystalline, bitter substance, soluble in hot water, insoluble in absolute alcohol, and melting at $15^{\circ} \mathrm{C}$.

Picroglycin, Picroglycion (pik-ro-gli'-sin, pik-ro-gli' -

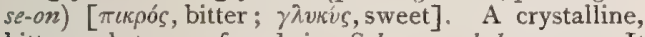
bitter substance, found in Solanum dulcamara. It may be impure solanin.

Picrolithium - carmin (pik-ro-lith'-e-um-kar'-min). A solution used in staining microscopic sections. It is composed of carmin 2.5-5.0; saturated watery solution of lithium carbonate 100.0; to which is added saturated watery solution of picric acid 2.0.

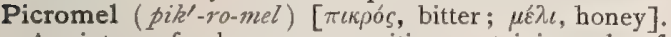
A mixture of unknown composition containing salts of glycocholic and taurocholic acids.

Picronitric Acid (pik-ro-ni'-trik). Synonym of Picric Acid.

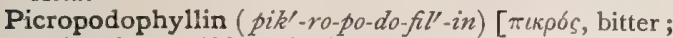

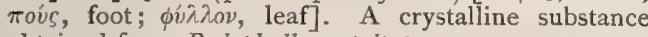
obtained from Podophyllum peltatum.

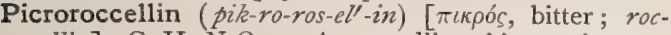
cellin], $\mathrm{C}_{27} \mathrm{H}_{29} \mathrm{~N}_{3} \mathrm{O}_{5}$. A crystalline, bitter substance obtained from Roccella tinctoria, or one of its varieties.

Picro-saccharimeter ( $\left.p i k^{\prime}-r o-s a k-a r-i m l^{\prime}-e t-e r^{\circ}\right)[\pi \iota \kappa \rho b s$,

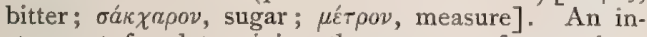
strument for determining the amount of sugar in a given sample of urine by comparison with the color of a permanent standard solution of perchlorid of ironthat of a picric acid reduction of the urine brought to a similar tint as the standard by dilution with waterthe amount of the latter required indicating the amount of sugar present.

Picro-saccharometer ( $p i k^{\prime}-r o-s a k$-ar-om'-et-er). See Picro-saccharimeter.

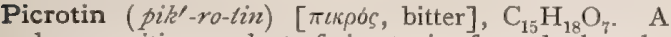
decomposition-product of picrotoxin, formed when the latter is treated with benzene.

Picrotoxic Acid (pik-ro-toks'-ik). Synonym of Picrotoxin.

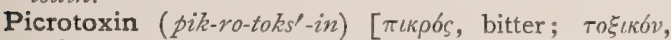
poison; Picrotoxinum, U. S. P. ; gen. Picrotoxini]. A neutral principle prepared from Anamirta paniculata (Cocculus indicus). Picrotoxin stimulates the motor and inhibitory centers in the medulla, especially the respiratory and vagus centers; it causes epileptiform spasms by irritation of the motor centers of the cerebrum or cord and medulla, the spasms often having the character of manege movements. Its action is much like that of strychnin. It has been used in an ointment (Io grains to one oz. of lard) in tinea capitis and in pediculosis. It is useful for the night-sweats of phthisis, and in the complex of symptoms known as vaso-motor ataxia, q. 2\%. Dose gr. $\frac{1}{60}$ to $\frac{1}{20}$. It has been tried in epilepsy, but has proved useless. Cocculi, Ext., Fld. Dose $m_{\text {j-iij. }}$ C., Tinct., tincture of cocculus, $12 \frac{1}{2}$ per cent. in strength. Dose

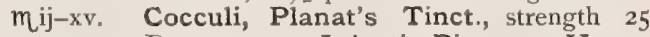
per cent. Dose $m-v$. Injectio Picrotox. Hypodermica, $x$ grain in 240 minims of water. Dose $m_{i j-}$ viij.

Picrotoxinin (pik-ro-toks'-in-in). See Picrotoxin.

Pictet Liquid (pik'-tet) [pix, pitch]. A liquid consisting of a mixture of sulphurous acid gas and carbon dioxid liquefied under pressure. It has been used in the treatment of pulmonary tuberculosis. A small quantity allowed to escape into a closed room quickly resumes the gaseous state, and is inhaled by the tuberculous patient. It appears to give good results.

Pictura (pik-tu'-rah) [pictura, painting, picture]. In biology, the pattern or coloration of a particular part (as a feather) or of an entire animal.

Piddle ( $\left.p i d^{\prime}-l\right)$ [origin obscure]. To urinate (a childish word).

Piebald ( $p i^{\prime}$-bawld) [ME., pyebald, piebald]. Of various colors. P. Iris, an iris which has spots of different colors, generally small dark spots on a lighter background. P.Skin. See Leukoderma, and Vitiligo.

Piedra (pe-a'-drah) [S. Amer.]. A disease of the hair marked by the formation of hard, pin-head-sized nodules on the shaft of the hair, thought to be due to the presence of a species of micrococcus. It occurs in the Andean plateau.

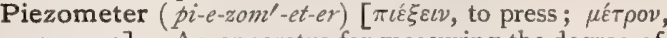
measure]. An apparatus for measuring the degree of compression of gases.

Pigback Kidney. See Kidney.

Pigeon (pij'-un) [ME., pigeon, pigeon]. A bird of the family Columbidce. P.-breast. Synonym of Pectus carinatum; it occurs in rickety children and in mouth-breathers. P.-breasted, affected with pigeonbreast. P.-toe. See Hallux varus. P.-toed, having the toes directed inward.

Pigment (pig'-ment) [ pigmentum, pingere, to paint]. In biology, a pigment is any organic coloring-matter in the tissues of plants or animals, e.g., the coloringmatter occurring in the iris, retina, hair, and in the rete mucosum of the skin. It may be of mimetic value, or concerned in assimilation and metabolism, or in respiration. P., Color, and Dye-stuff ; a pigment is any substance that is employed in the arts for the purpose of imparting color to bodies. The term is properly restricted to the dry coloring-matter, which when mixed with a vehicle becomes a print. $\mathrm{O}$. N. Witt assumes the presence of certain characteristic groups-chromophorous groups-in all dyestuffs, which, by introduction into colorless bodies, give rise to the basisstructure of dyestuffs-chromogenous groups. When these chromogenous groups are joined to salt-forming groups, such as hydroxyl or amidogen, dyestuffs are formed. Color is applied to any hue, especially a pure tint, other than black or white. A dye-stuff is any dyewood, lichen, powder, or dyecake used in dyeing and staining dress-materials. A fast color is one which resists the weather, light, soap-lye, dilute alkalies, and very dilute acids; a fugitive color is one which is dissipated under similar circumstances. A substantive coloring-matter is one which passes into an insoluble state upon the fiber without the intervention of a mordant; examples, all the mineral coloringmatters, indigo, turmeric, annatto, safflower, and most 
of the coal-tar colors. An adjective coloring-matter is one which requires a mordant or mediating agent in order to become insoluble upon the fiber. A mordant is a substance which has an affinity for or which can at least penetrate the tissue to be colored, and which possesses also the property of combining with the coloring-matter employed, and of forming with it an insoluble compound within or about the fibers. Mordants may be iron salts (copperas, ferrous acetate, iron pyrolignite, ferric sulphate, and nitrates), nickel (nickel-ammonium chlorid, nickel nitro-acetate), chromium (chromium sulphate, fluorid, chlorate, potas sium di-chromate and chromate), tin (stannous and stannic chlorid, " pink salt," sodium stannate), manganese $\left(\mathrm{MnCl}_{2}, \mathrm{KMnO}_{4}\right)$, lead, copper (nitrate), antimony (tartar emetic), or tannin. Raising is the process or method of intensifying colors by means of mordants. Dunging is a term applied to the mordanting of goods by passing them through a dung-bath, which is a bath composed of water in which a small proportion of cows' or pigs' dung, or some substitute for it, has been dissolved, with a certain amount of chalk to remove the acetic acid from the printed material. A discharge is some compound, such as the chlorid of lime, which has the property of bleach-

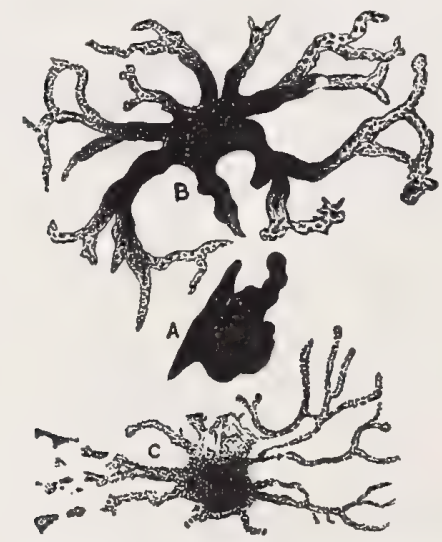

Pigment-cells of Frog. A, Contracted ; B, C, Partially relaxed pigment-cells. (From Stirling.)

ing or taking away the color already communicated to a fabric, by which means white patterns are produced on colored grounds. A lake is a pigment formed by the absorption of animal, vegetable, or coal-tar coloring-matter from an aqueous solution by means of metallic bases. Application-colors. See Spirit-colors. Coaltar colors is a name given to a numerous class of colors derived from coal-tar by various complex chemic processes. Distemper, or fresco, colors are colors ground in water to a creamy consistency, with the addition of a sizing of glue or white of egg to make them adhere to the surface to which they are applied, They are generally used for decorating plasstered walls or ceilings. Graining-color's are colors ground in linseed-oil with the addition of a small amount of wax to prevent their spreading when manipulated with a graining-comb to imitate the graining of various woods. Japan-colors are those ground in the medium called japan. An oil-color is a pigment of any kind ground in linseed-oil or poppy-oil. Spiritcolors (also called "spirits," or application-colors) are certain colors obtained in calico-printing, so-called from the use of "spirits," the technical name for the acid solutions of tin, in applying the colors. Water- colors are pigments ground in water containing a small amount of glue, glycerin, honey, or molasses, to cause them to bind and adhere to the surface to which they are applied. When pressed into molds and dried, they are called cake-colors; but when sold in the form of stiff pastes, they are called moist colors. Very many of the materials used for dyeing purposes are extremely poisonous, and have been productive of eczema and other skin-diseases, or even of systemic poisoning. Recently the use of dyes as staining reagents in bacteriologic, physiologic, and biologic researches has assunied such marked importance that it has been deemed advisable to introduce the following conspectus (pages I085 et seq.), which contains the more important pigments and dye-stuffs. P., Bile. See under Bile. P., Blood, hemoglobin and its derivatives. P., Brown. Same as Soudan Brown. P.cell, a cell specialized for the secretion or retention of a pigment ; a chromatophore. P.-granule, a minute, structureless mass of pigment. P., Hematogenous, any pigment derived from the blood. Hematogenous pigments are hemoglobin, hematoidin, hemosiderin; the bile-pigments, which are indirectly derived from the blood-pigment; ferrous sulphid, which stains the abdominal walls and the serous coat of the abdominal organs after death, is also derived from hemoglobin. P.-liver, a coloration of the liver occurring in the course of malarial fevers, and in the morbid condition of the blood described as melanemia. The liver is also deeply pigmented in pernicious anemia and in chronic valvular heart-disease, with long-continued congestion of the organ. $\mathbf{P}_{\text {., }}$ Metabolic, a pigment formed by the metabolic action of cells. Melanin is the type of metabolic pigments. P.-molecule. Same as P.-granule. P., Respiratory, a pigment resulting from oxidation of the tissues, or a pigment by means of which oxygen is absorbed. Hemoglobin may be considered a respiratory pigment. P.-spot, in biology, a small mass of pigment in the spores of certain plants and protozoans. P., Urinary, urobilin, urochrome, uroerythrin, and others. P., Uveal. See under Uvea.

Pigmental, Pigmentary ( $\left.p i g-m e n^{\prime}-t a l, p_{i g}{ }^{\prime}-m e n-t a-r e\right)$ [pingere, to paint]. Pertaining to or containing pigment. P. Atrophy, atrophy of adipose tissue with deposit of pigment in the fat-cells. P. Layer, the external layer of the retina. See Retina. P. Mole. See Nerus pigmentosus.

Pigmentation (pig-men-ta'-shun) [pingere, to paint]. Deposition of or discoloration by pigment. See also Chromatosis.

Pigodidymus ( $\left.p i-g o-d i d^{\prime \prime}-i m-u s\right)$ [ $\pi v \gamma^{\prime}$, buttock; didvuos, double]. A double monster united at the buttocks.

Pitis (pi-i'-tis) [pia, pia ; $\iota \iota s$, inflammation]. Inflammation of the pia; leptomeningitis.

Pike ( $p i k)$ [ME., pike, a sharp point]. In biology, a thorn or prickle.

Pilar, Pilary (pil-lar, pi'-lar-e) [pilaris; pilus, hair]. Pertaining to the hair.

Pilastered (pi-las'-terd) [pila, a small supplemental pillar]. In anatomy, flanged so as to have a fluted appearance; arranged in pilasters or columns. P. Femur, a condition observed in the femur of individuals of certain races in which the backward concavity of the femoral shaft is exaggerated, and the linea aspera prominent. This exaggeration of structure causes the pilastered appearance.

Pilastri (pi-las'-tre) [ pl. of Pilastrum, a small pillar]. In biology, strong gelatinous columns placed between the subgenital openings in Midusce.

Pilatio (pi-la'-she-o) [pilus, hair]. A cranial fissure. 


\section{CONSPECTUS OF PIGMENTS.}

\section{INORGANIC,}

\begin{tabular}{|c|c|c|c|}
\hline NAME. & FORMULA. & Composition, Preparation, Etc. & Color. \\
\hline $\begin{array}{l}\text { Antimonial cinnabar (antimonial vermilion, } \\
\text { redlead). }\end{array}$ & $\mathrm{Sb}_{6} \mathrm{~S}_{6} \mathrm{O}_{3}$ & $\begin{array}{l}\text { Action of sodium calcium dithionze on } \\
\text { antimonious chlorid. }\end{array}$ & Red. \\
\hline $\begin{array}{l}\text { Artificial ultramarine (French blue, Guimet } \\
\text { blue, new blue, permanent blue). }\end{array}$ & & $\begin{array}{l}\text { Mixture of clay, sodium carbonate, sul- } \\
\text { phur, and rosin. }\end{array}$ & Blue. \\
\hline $\begin{array}{l}\text { Azurite (azure malachite, blue malachite, } \\
\text { copper lazulite, mountain-blue). }\end{array}$ & $2 \mathrm{CuCO}_{3} \cdot \mathrm{Cu}(\mathrm{OH})_{2}$ & Copper hydroxycarbonate. & Blue. \\
\hline $\begin{array}{l}\text { Berlin blue (Erlangen blue, Hamburg blue, } \\
\text { kaliblue, Milori blue, royal blue, steel blue, } \\
\text { Tumbull's blue). }\end{array}$ & & $\begin{array}{l}\text { Action of potassium ferocyanid on ferrous } \\
\text { salts. }\end{array}$ & Blue. \\
\hline Bismuth-white (pearl white, Spanish white). & $\mathrm{BiOCl}$. & Bismuth oxychlorid. & White. \\
\hline Bloodstone. & $\mathrm{Fe}_{2} \mathrm{O}_{3}$ & Found in nature; a hematite. & Red. \\
\hline Blue ocher (native Prussian blue). & & Iron hydroxyphosphate. & Dull-blue. \\
\hline Blue vitriol (blue stone, Cyprus vitriol). & $\mathrm{CuSO}_{4}$ & Copper sulphate; found in nature. & Blue. \\
\hline Bremen blue (blue verditer). & $\mathrm{Cu}(\mathrm{HO})_{2}$ & $\begin{array}{l}\text { Copper hydroxid; action of lime on cop- } \\
\text { per nitrate. }\end{array}$ & Blue. \\
\hline $\begin{array}{l}\text { Bremen green (Erlaw green, green bice, } \\
\text { green verditer). }\end{array}$ & & Copper hydroxid. & Green. \\
\hline Brunswick green (mountain-green). & ${ }_{3} \mathrm{CuO} \cdot \mathrm{CuCl}_{2}$ & Copper oxychlorid. & Light-green. \\
\hline Cadmium-red. & CdS. & Cadmium sulphid. & Orange-red. \\
\hline Cadmium-yellow (Jaune brilliant). & CdS. & Cadmium sulphid. & Orange-yellow. \\
\hline Caledonia brown. & & Natural ore. & Russet-brown. \\
\hline Cappagh brown. & & From bog-earth containing manganese. & Brown. \\
\hline Casall green. & $\mathrm{C}_{2} \mathrm{O}_{3}$ & Chromic oxid. & Green. \\
\hline $\begin{array}{l}\text { Cassel yellow (mineral yellow, Montpellier } \\
\text { yellow, patent yellow, Turner's yellow). }\end{array}$ & $\mathrm{PbCl}_{2.7} \mathrm{PbO}$ & Lead oxychlorid. & Yellow. \\
\hline Casselmann's green. & & $\begin{array}{l}\text { Copper sulphate with potassium or sodium } \\
\text { acetate. }\end{array}$ & Green. \\
\hline Cassius' purple (gold purple). & & Gold and tin. & Purple. \\
\hline Cerulean blue. & & Cobaltous-stannic oxid. & Blue. \\
\hline China clay (kaolin). & & Aluminum hydroxysilicate. & White. \\
\hline Chrome-alum. & $\begin{array}{l}\mathrm{K}_{2} \mathrm{SO}_{4} \cdot \mathrm{Cr}_{2}\left(\mathrm{SO}_{4}\right)_{3},- \\
24 \mathrm{H}_{2} \mathrm{O}\end{array}$ & Potassium and chromium sulphate. & Violet. \\
\hline Chrome chlorid. & $\mathrm{Cr}_{2} \mathrm{Cl}_{6}$ & Action of chlorin on chromium sulphid. & Violet. \\
\hline $\begin{array}{l}\text { Chrome-green (chromium-green, cinnabar- } \\
\text { green, emerald green, Guignet's green, } \\
\text { Victoria green). }\end{array}$ & $\mathrm{Cr}_{2} \mathrm{O}_{3}$ & Chromic oxid. & Bright-green. \\
\hline $\begin{array}{l}\text { Chrome-red (chrome-carmin, chrome-garnet, } \\
\text { chrome-orange, chrome-vermilion). }\end{array}$ & $\mathrm{PbCrO}_{4} \cdot \mathrm{PbO}$ & Lead oxychromate. & Red. \\
\hline $\begin{array}{l}\text { Chrome-yellow (crown-yellow, Hamburg } \\
\text { yellow, Leipsic yellow, Paris yellow). }\end{array}$ & $\mathrm{PbCrO}_{4}$ & Lead chromate. & Brilliant yellow. \\
\hline $\begin{array}{l}\text { Cobalt-blue (azure-blue, cobalt-ultramarine, } \\
\text { Hungary blue, Leithner's blue, Leyden } \\
\text { blue, Paris blue, Thénard's blue). }\end{array}$ & & Aluminum cobaltate. & Blue. \\
\hline Cobalt-red. & & Cobalt phosphate. & Red. \\
\hline Cobalt-yellow. & & Potassium-cobalt nitrite. & Bright-yellow. \\
\hline $\begin{array}{l}\text { Colcothar (English red, Indian red, iron } \\
\text { minium, Paris red, polishing red, red } \\
\text { vitriol). }\end{array}$ & $\mathrm{Fe}_{2} \mathrm{O}_{3}$ & Ferric oxid; from iron sulphate. & Red. \\
\hline Copperas-black. & & $\begin{array}{l}\text { Mordanting with ferrous and copper sul- } \\
\text { phate and dyeing with logwood. }\end{array}$ & Black. \\
\hline Cyanin-blue (Leitch's blue). & & $\begin{array}{l}\text { Compound of Prussian blue and cobalt } \\
\text { blue. }\end{array}$ & Blue. \\
\hline
\end{tabular}


CONSPECTUS OF PIGMENTS.-Continued.

\begin{tabular}{|c|c|c|c|}
\hline NAME. & FORMULA. & Composition, Preparation, EtC. & COLOR. \\
\hline Dingler's green. & & Chromium-calcium phosphate. & Green. \\
\hline $\begin{array}{l}\text { Egyptian blue (Alexandria blue, copper- } \\
\text { glass). }\end{array}$ & & Copper-calcium silicate. & Blue. \\
\hline Fol's yellow. & & $\begin{array}{l}\text { Heating together phenol and arsenous } \\
\text { oxid. }\end{array}$ & Yellow. \\
\hline Gentele's green. & & $\begin{array}{l}\text { Action of sodium stannate on copper sul- } \\
\text { phate. }\end{array}$ & Green. \\
\hline Green cinnabar (Naples green). & & Chrome-yellow and Prussian blue. & Green. \\
\hline $\begin{array}{l}\text { Hamburg white (Dutch white, Tyrol white, } \\
\text { Venice white). }\end{array}$ & & White lead with heavy spar. & White. \\
\hline Iodin-scarlet (pure scarlet). & $\mathrm{HgI}_{2}$ & Mercuric iodid. & Brilliant red. \\
\hline King's yellow (Chinese yellow). & $\mathrm{As}_{2} \mathrm{~S}_{3}$ & $\begin{array}{l}\text { Sublimating a mixture of sulphur and ar- } \\
\text { senous oxid. }\end{array}$ & Yellow. \\
\hline Litharge (Massicot). & $\mathrm{PbO}$. & Lead oxid; found in nature. & Yellow. \\
\hline Lithophan. & $\mathrm{BaSO}_{4} \cdot \mathrm{ZnS}$ & Barium sulphate and zinc sulphid. & White. \\
\hline $\begin{array}{l}\text { Malachite-green (copper-green, mountain- } \\
\text { green). }\end{array}$ & $\mathrm{CuCO}_{3}$ & Copper carbonate. & Green. \\
\hline Manganese-brown. & & $\begin{array}{l}\text { Action of sodium hypochlorite and caustic } \\
\text { soda on manganous chlorid. }\end{array}$ & Brown. \\
\hline $\begin{array}{l}\text { Manganese-green (baryta-green, Cassel } \\
\text { green, Rosenstrehl'sgreen). }\end{array}$ & $\mathrm{BaMnO}_{4}$ & Barium manganate. & Green. \\
\hline Mars' brown. & & $\begin{array}{l}\text { Calcining ferrous sulphate with alum, and } \\
\text { potash. }\end{array}$ & Brown. \\
\hline Mineral blue (Antwerp blue, Haarlem blue). & & Prussian blue mixed with clay. & Green-blue. \\
\hline Mineral gray. & & From lapis lazuli. & Pale blue-gray. \\
\hline Mineral lake. & & Glass flux colored with tin chromate. & Pink. \\
\hline Mineral purple (Mars' violet, purple ocher). & & Artificially prepared iron oxid. & Dark-red. \\
\hline $\begin{array}{l}\text { Minium (gold cinnabar, mineral orange, } \\
\text { orange-minium, Paris red, redlead, Saturn } \\
\text { cinnabar, satumine red). }\end{array}$ & $\mathrm{Pb}_{3} \mathrm{O}_{4}$ & Red oxid of lead. & Red. \\
\hline $\begin{array}{l}\text { Mittler's green (Amandon green, emerald } \\
\text { green, Matthiew Plessy's green, Pan- } \\
\text { netier's green, Schnitzer green). }\end{array}$ & $\mathrm{Cr}_{2}(\mathrm{HO})_{6}$ & Chiefly chromium hydroxid. & Green. \\
\hline Mosaic gold. & $\mathrm{SnS}_{2}$ & Stannic sulphid. & Yellow. \\
\hline Naples yellow. & & Lead antimonate. & $\begin{array}{l}\text { Pale orange-yel- } \\
\text { low. }\end{array}$ \\
\hline Napoleon blue (Raymond's blue). & & $\begin{array}{l}\text { Action of basic ferric sulphate and potas- } \\
\text { sium ferrocyanid. }\end{array}$ & Blue. \\
\hline $\begin{array}{l}\text { Ocher (Indian ocher, Indian red, light red, } \\
\text { Mars' red, Naples red, Persian red, Pom- } \\
\text { peian red,red bole, ruddle, scarlet ocher, } \\
\text { terra di sienna). }\end{array}$ & & $\begin{array}{l}\text { Ferruginous clays, especially those con- } \\
\text { taining ferric hydroxid. }\end{array}$ & Red. \\
\hline $\begin{array}{l}\text { Ocher (burnt ocher, Chinese yellow, gold } \\
\text { ocher, Lemnian earth, orange ocher, } \\
\text { Roman ocher). }\end{array}$ & & Clay containing ferric hydroxid. & Orange-yellow. \\
\hline Oil-blue (copper indigo). & Cus. & Copper sulphid. & Blue. \\
\hline Orpiment. & $\mathrm{As}_{2} \mathrm{~S}_{3}$ & Natural ore; arsenious sulphid. & Yellow. \\
\hline Pattison's white lead. & $\mathrm{PbCl}_{2}, \mathrm{PbH}_{2} \mathrm{O}_{2}$ & $\begin{array}{l}\text { Adding saturated lime-water to a hot solu- } \\
\text { tion of lead chlorid. }\end{array}$ & White. \\
\hline Perfect yellow. & $\mathrm{ZnCrO}_{4}$ & Zinc chromate. & $\begin{array}{l}\text { Bright light-yel- } \\
\text { low. }\end{array}$ \\
\hline $\begin{array}{l}\text { Permanent white (blane fixe, mineral white, } \\
\text { new white). }\end{array}$ & $\mathrm{BaSO}_{4}$ & Barium sulphate. & White. \\
\hline Pink salt (pink crystals). & $\mathrm{SnCl}_{4} \cdot 2 \mathrm{NH}_{4} \mathrm{Cl}$ & & Pink. \\
\hline $\begin{array}{l}\text { Prussian blue (ball-blue, Monthier's blue, } \\
\text { navy blue, royal blue, soluble blue). }\end{array}$ & & $\begin{array}{l}\text { Precipitating ferric sulphate with potas- } \\
\text { sium ferrocyanid. }\end{array}$ & Biue. \\
\hline
\end{tabular}


CONSPECTUS OF PIGMENTS.-Continued.

\begin{tabular}{|c|c|c|c|}
\hline NAME. & FORMULA. & Composition, Preparation, ETC. & Color. \\
\hline Prussian brown. & & A compound of ferric oxid and alumina. & Orange-brown. \\
\hline Prussian green. & & Imperfect iron ferrocyanid. & Green. \\
\hline Purple-brown (maroon oxid). & $\mathrm{Fe}_{2} \mathrm{O}_{3}$ & Ferric oxid. & Purplish-brown. \\
\hline Realgar. & $\mathrm{As}_{2} \mathrm{~S}_{2}$ & Natural ore; arsenium disulphid. & Red. \\
\hline $\begin{array}{l}\text { Rinmann's green (cobalt green, Gellert's } \\
\text { green, green smalt, mineral green, Paris } \\
\text { green, Saxony green, Scheele's green, } \\
\text { Swedish green, zinc-green). }\end{array}$ & $\mathrm{CuHAsO}$ & Copper arsenite. & Bright-green. \\
\hline Satin white. & & Lime, zinc oxid, and a little indigo. & White. \\
\hline Schweinfurth blue (Reboulleau's blue). & & $\begin{array}{l}\text { Fusion of copper arsenate, potassium } \\
\text { arsenate, and niter. }\end{array}$ & Blue. \\
\hline $\begin{array}{l}\text { Schweinfurth green (Bâle green, emerald } \\
\text { green, French green, imperial green, } \\
\text { Kirschberg green, Leipsic green, Mitis } \\
\text { green, Newvied green, Paris green, royal } \\
\text { green, Viennagreen). }\end{array}$ & & Copper aceto-arsenite. & Vivid light-green. \\
\hline Siderine yellow. & & Ferrous chromate. & Yellow. \\
\hline Sienna. & & Ferruginous ocherous earth. & Orange-yellow. \\
\hline $\begin{array}{l}\text { Smalts (Dumont's blue, enamel blue, Eschel } \\
\text { blue, King's blue, royal blue). }\end{array}$ & & Glass tinged by cobaltous oxid. & Blue. \\
\hline Spanish brown. & & Highly adulterated dark ferric oxid. & Dark brown. \\
\hline Strontian yellow. & $\mathrm{SrCrO}_{4}$ & $\begin{array}{l}\text { Addition of potassium chromate to a solu- } \\
\text { tion of a strontium sait. }\end{array}$ & Yellow. \\
\hline $\begin{array}{l}\text { Ultramarine (Armenian blue, azure-blue, } \\
\text { lazulite blue). }\end{array}$ & & From lapis lazuli. & Blue. \\
\hline Ultramarine green. & & $\begin{array}{l}\text { Mixture of alumina, soda, silica, sulphur, } \\
\text { iron, calcium, etc. }\end{array}$ & Green. \\
\hline Ultramarine yellow (barium yellow). & $\mathrm{BaCrO}_{4}$. & Barium chromate. & Yellow. \\
\hline Umber. & & Clayey, brown iron ore. & Red. \\
\hline Umber (colognese, lignite). & & & Red. \\
\hline Vanadium bronze. & & An acid derivative of vanadium. & Fine yellow. \\
\hline $\begin{array}{l}\text { Venetian red (English red, Prussian red, } \\
\text { Spanish red). }\end{array}$ & $\mathrm{Fe}_{2} \mathrm{O}_{3} \cdot \mathrm{CaSO}_{4}$ & $\begin{array}{l}\text { Calcining a mixture of lime and iron sul- } \\
\text { phate. }\end{array}$ & Red. \\
\hline Verdigris. & $\begin{array}{l}\mathrm{Cu}_{2}(\mathrm{HO})\left(\mathrm{C}_{2} \mathrm{H}_{3} \mathrm{O}_{2}\right) \\
\mathrm{H}_{2} \mathrm{O}\end{array}$ & Copper hydroxyacetate or subacetate. & Green. \\
\hline Vermilion (Chinese red, cinnabar). & $\mathrm{HgS}$. & Sulphid of mercury. & Red. \\
\hline Verona brown. & & A calcined ferruginous earth. & Reddish-brown. \\
\hline $\begin{array}{l}\text { Veronese green (French Veronese green, } \\
\text { viridian). }\end{array}$ & $\mathrm{Cr}_{2}(\mathrm{HO})_{6}$ & Chromic hydroxid. & Blue-green. \\
\hline Vienna white (Bologna lime, Vienna lime). & $\mathrm{CaCO}_{3}$ & Prepared chalk. & White. \\
\hline $\begin{array}{l}\text { White lead (blanc d'argent, China white, } \\
\text { Clichy white, Cremnitz white, French } \\
\text { ahite, Kremnitz white, Krem's white, } \\
\text { London white, pearl white, Roman white, } \\
\text { silver white). }\end{array}$ & $2 \mathrm{PbCO}_{3} \mathrm{~Pb}(\mathrm{HO})_{2}$ & Lead carbonates. & White. \\
\hline White lead substitute. & $\mathrm{Sb}_{2} \mathrm{O}_{3}$ & Antimonous oxid. & White, \\
\hline White vitriol. & $\mathrm{ZnSO}_{4}+7 \mathrm{H}_{2} \mathrm{O}$ & Zinc sulphate. & White. \\
\hline Zinc carbonate. & $2 \mathrm{ZnCO}_{3} \mathrm{Zn}(\mathrm{HO})_{2}$ & & White. \\
\hline Zinc-green. & & Zinc-yellow and Prussian blue. & Green. \\
\hline Zincolith (Griffith's snow-white). & $\mathrm{BaSO}_{4} \cdot \mathrm{ZnS}$ & Zinc sulphid and barium sulphate. & White. \\
\hline Zinc-white (Chinese white, snow-white). & $\mathrm{ZnO}$ & Zinc oxid. & White. \\
\hline Zinc-yellow. & $\mathrm{ZnCrO}_{4}$ & Zinc chromate. & Yellow. \\
\hline
\end{tabular}


CONSPEC'TUS OF PIGMENTS.-Continued.

\section{ORGANIC.}

\section{ANIMAL PIGMENTS.}

\section{NAME.}

Actiniochrome.

Actiniohematin.

Animal black (animal charcoal, bone-black).

Bilicyanin (Cholecyanin, choleverdin).

Biliflavin.

Bilifuscin.

Biliphein (Cholophein).

Biliprasin.

Bilipurpurin.

Bilirubin.

Biliverdin.

Bone-brown.

Bonellein.

Chlorocruorin.

\section{Chlorofucin.}

\section{Chlorophan.}

Cholepyrrhin (bilepyrhin).

Cholohematin.

Chromophan.

Cochineal (carmin-red, cochenille, mestica).

Cyanein.

\section{Echinochrome.}

Enterochlorophyl.

Enterohematin. Synonymous with hemochromogen and helicorubin Krukenberg.

Frankfort black (German black).

Helicorubin.

Hemacyanin.

Hemaphein.

Hematin.

Hematoidin.

Hematoporphyrin.

Hemerythrin.

Hemocyanin.

Hemochromagen.

Hemoglohin.
Composition, Preparation, Etc.

Color.

Found in certain invertebrates $(e . g$., in the tentacles Violet. of Anthea cerus).

Found in certain Actinozoa (Anthea cerus).

Calcination of bones in closed vessels.

Obtained from bilirubin.

Obtained from biliverdin.

Obtained from bile and gall-stones.

Obtained from bile.

Found in gall-stones, icteric urine, and bile.

Obtained from biliverdin.

The chief pigment of the bile.

Obtained from bile, icteric urine, and gall-stones.

Roasting bones until brown throughout.

Found in certain Annelids: e.g., Bonellia vividis.

Found in the blood of certain invertebrates $(e, g$. Sabella venlvilabrum, Siphonostoma sp.).

Found in Anthea cereus, Bunodes ballii, and Sagar. tia bellis, and other invertebrates containing symbiotic algae.

A chromophan found in certain invertebrates, and in the retinal cones of vertebrates.

Obtained from bile.

Found in the bile of ruminants.

Found in the retinal cones of certain animals, and in certain invertebrates. Cf. Chlorophan, Rhodophan, Xanthophan.

From the female insect-Coccus cacti.

Found in certain invertebrates (e.g., Rhizostoma, Cyanea, Velella).

A respiratory pigment of certain Echinoderms.

Found in the liver in many invertebrates; pancreatic or hepatic tissues.

Found in the pancreas or liver of many invertebrates.

Better grade of bone-black.

One of the enterohematins of invertebrates.

Found in the blood and bile of vertebrates.

A decomposition-product of hematin.

Obtained from blood

Found in old blood-clots, corpora lutea, hematuria, etc. Cf. Bilimubin and Hemolutein.

A metabolite of myohematin, enterohematin, histohematin and other intrinsic coloring-matters of invertebrates.

Found in the blood of many invertebrates; $e g .$, Si- . Burgundy-red. punculus balanorophus, Phaseolosoma elongatum.

A proteid found in the blood of many invertebrates, worms, molluscs, crustaceans.

One of the enterohematins of invertebrates.

The coloring-matter of vertebrate blood-corpuscles.
Red.

Black.

Blue.

Yellow.

Browi.

Gray.

Brownish-green.

Purple.

Red.

Green.

Brown.

Green.

Green.

Yellow.

Green.

Brown.

Red.

Red, green, yellow.

Crimson.

Blue.

Brown.

Red to green.

Red.

Black.

Red.

Blue.

Brown.

Bluish-black.

Red to orange.

Red.

Blue.

Red.

Red to purple. 
CONSPECTUS OF PIGMENTS.-Continued.

\begin{tabular}{|c|c|c|}
\hline NAME. & COMPOSITION, PREPARATION, ETC. & COLOR. \\
\hline Hemolutein. & Obtained from corpora lutea. Cf. Hematoidin. & Yellow. \\
\hline Hemorhodin. & $\begin{array}{l}\text { An albuminoid giving color to the blood of certain in- } \\
\text { vertebrates, as Aplysia depilans. }\end{array}$ & Rose. \\
\hline Hemosiderin. & Obtained from extravasations and thrombi. & Red. \\
\hline Histohematin. & $\begin{array}{l}\text { Found in various tissues and organs of invertebrate } \\
\text { animals. }\end{array}$ & Red. \\
\hline Indian purple. & $\begin{array}{l}\text { Precipitation of cochineal extract with copper sul- } \\
\text { phate. }\end{array}$ & Deep purpie. \\
\hline Ivory-black. & Calcination of ivory-dust. & Black. \\
\hline Ivory-brown. & Roasting ivory until brown throughout. & Brown. \\
\hline Lac-dye. & Resinous substance from lac-insect-Carteria lacca. & Scarlet. \\
\hline Lutein. & $\begin{array}{l}\text { A lipochrome found in the digestive gland of certain } \\
\text { invertebrates }\left(e_{.} g_{.}, \text {Holothuria nigra). }\right.\end{array}$ & Red. \\
\hline Melanin. & $\begin{array}{l}\text { Found normally in epidermal structures, and patho- } \\
\text { logically in the skin and certain tumors, also in the } \\
\text { hematozoa of men and animals. }\end{array}$ & Black. \\
\hline $\begin{array}{l}\text { Murexid (purple-carmin, ammonium purpur- } \\
\text { ate). }\end{array}$ & $\begin{array}{l}\text { From uric acid by the action of nitric acid and am- } \\
\text { monium hydroxid. }\end{array}$ & Purple. \\
\hline Myohematin. & $\begin{array}{l}\text { The true intrinsic coloring-matter of invertebrate } \\
\text { muscle. It occurs }(e \cdot g .,) \text { in all the Pulmo-gastero- } \\
\text { poda. }\end{array}$ & Red. \\
\hline Pentacrinin. & $\begin{array}{l}\text { Found in certain invertebrates }(e, g, \text {, Pentacrinus } \\
\text { caput medusce). }\end{array}$ & Purple. \\
\hline Phlebin. & $\begin{array}{l}\text { The venous blood-pigment contained in red blood- } \\
\text { corpuscles. }\end{array}$ & Blue. \\
\hline Phoenicin. & $\begin{array}{l}\text { A name sometimes given to the coloring-matter of } \\
\text { the blood. }\end{array}$ & Red. \\
\hline Phyllodoce-green. & Found by MacMunn in the worm Phyllodoce vividis. & Green. \\
\hline Polyperythrin. & Discovered by Moseley in various Colenteratce. & Red. \\
\hline Purree (euxanthin, Indian yellow). & $\begin{array}{l}\text { Impure magnesium euxanthate, obtained from urine } \\
\text { of cows fed on mango-leaves. }\end{array}$ & Bright yellow. \\
\hline Rhodophan. & A chromophan found in the retina of certain animals. & Red. \\
\hline Tetronerythrin. & $\begin{array}{l}\text { A series of lipochrome pigments found in many in- } \\
\text { vertebrates. }\end{array}$ & Red to green. \\
\hline Turacin. & From the feathers of the cape lory. & Crimson. \\
\hline Tyrian purple (purple of mollusca). & $\begin{array}{l}\text { From the juice of the shell-fish, murex or conchyl- } \\
\text { ium, of the genus Purpura. }\end{array}$ & Crimson. \\
\hline Urobilin. & Found in urine. & Red or reddish-yellow. \\
\hline Urochrome. & Found in urine. & Yellow. \\
\hline Uroerythrin. & Found in urine. & Red. \\
\hline Urohematin. & Found in urine. & Red. \\
\hline Uromelanin. & Found in urine. & Dark-red. \\
\hline a. The Alizarins. & $\begin{array}{l}\text { Found in urine. } \\
\text { 2. TAR COLORS. } \\
\text { thracene Colors (from anthracene, } \mathrm{C}_{14} \mathrm{H}_{10} \text { ). } \\
\end{array}$ & Garnet-red. \\
\hline Alizarin-blue (anthracene-blue). & $\begin{array}{l}\text { Heating nitro-alizarin with glycerol and sulphuric } \\
\text { acid. }\end{array}$ & Blue. \\
\hline Alizarin-blue $\mathbf{S}$. & Sodium salt of alizarin-blue. & Blue. \\
\hline Alizarin-brown. & Alizarin-red with potassium ferrocyanid. & Brown. \\
\hline Alizarin-carmin (alizarin $W S$ ). & Sodium alizarin monosulphonate. & Carmin. \\
\hline $\begin{array}{l}\text { Alizarin-green (anthracene-green, ceru- } \\
\text { lein). }\end{array}$ & Action of strong sulphuric acid on gallein. & Olive-green. \\
\hline
\end{tabular}


CONSPECTUS OF PIGMENTS._Contimued.

\section{NAME.}

\begin{tabular}{l} 
Alizarin-orange (alizarin $\mathrm{N}$ ). \\
Alizarin-purple. \\
Alizarin-red. \\
\hline Alizarin-violet (anthracene-violet, gallein). \\
3. Purpurin. \\
Flavo-purpurin.
\end{tabular}

Acid yellow (fast yellow).

Anilin-yellow (spirit-yellow).

Azarin.

Azo-blue.

Benzo-purpurin.

Biebrich scarlet (Ponceau B).

Brilliant yellow.

Buffalo rubin.

Carmin-naphtha.

Chrysamin.

Chrysoidin.

Chrysolin.

Chrysophanin.

Claret-red.

Congo G R.

Congo-red.

Crocein-scarlet.

Double brilliant scarlet $\mathbf{G}$.

Double scarlet $\mathbf{S}$.

Fast brown G.

Fast red (orseillin, rauracienne, roccellin, nubidin).

Fast red B (Bordeaux $B)$.

French red.

Hessian purple $\mathrm{N}$.

Hessian purple P.

Hessian violet.

Hessian yellow.

Metanil-yellow.
Composition, Preparation, Etc.

Color.

Action of nitric acid on alizarin.

Treating alizarin with ferrous sulphate.

Action of phthalic anhydrid on pyrogallol.

Oxidation of alizarin.

Similar to alizarin.

\section{b. Azo-dyes.}

Treating amidoazotoluene hydrochlorid with fuming sulphuric acid

Heating diamidoazobenzene with anilin hydro-Yellow. chlorid.

Compound of naphthol-azo-dichlorphenol and ammonium acid sulphite.

Action of tetraza-ditolyl chlorid on potassium $\beta$-naphthol-sulphonate.

Formed from orthotolidin and two molecules of naphthionic acid.

Action of diazoazobenzene upon $\beta$-naphthol.

Formed from one molecule of diamidostilbenedisulphonic acid with two molecules of phenol.

Derived from $\alpha$-naphthylamin and naphthol.

Derived from a-naphthylamin and naphthol.

Action of tetrazodiphenyl chlorid on sodium salicylate.

Diamidoazobenzene hydrochlorid.

Sodium benzyl-fluorescein.

By ethylating brilliant yellow.

Sodium $\alpha$-azonaphthalene, $\beta$-naphthol disulphonate.

From benzidin, amidobenzolsulphonic acid, and naphthionsulphuric acid.

Sodium benzidin and naphthionate.

Diazotizing amidoazobenzolmonosulphonic acid with hydrochloric acid and sodium nitrite.

From the diazo-compound of $\beta$-naphthylamin-monosulphonic acid and $\beta$-naphthol.

From the diazo-compound of $\beta$-naphthylamin-monosulphonic acid and $a$-naphtholmonosulphonic acid.

Sodium a-naphtholdisazo, p-azobenzenesulphonate.

Sodium $\beta$-naphtholazonaphthalene sulphonate.

Derived from $\alpha$-naphthylamin and naphthol.

Mixture of claret-red and naphthol-orange.

One molecule of diamidostilbenedisulphonic acid with two molecules of $\beta$-naphthylamin.

One molecule of diamidostilbenedisulphonic acid with two molecules of naphthionic acid.

One molecule of diamidostilbenedisulphonic acid - with one molecule of a-naphthylamin and one molecule of $\beta$-naphthol.

One molecule of diamidostilbenedisulphonic acid with two molecules of salicylic acid.

Sodium phenylamidoazobenzene-m-sulphonate.
Brilliant red.

Dark-blue.

Scarlet.

Scarlet.

Yellow.

Red.

Carmin.

Sulphur-yellow.

Bright yellow.

Yellow.

Orange-yellow.

Red.

Red.

Red.

Scarlet.

Scarlet.

Scarlet.

Brown.

Garnet-red.

Red.

Red.

Purple.

Purple.

Violet.

Yellow.

Yellow. 
CONSPECTUS OF PIGMENTS.-Continued.

NAME.

New coccin R (coccinin, phenetol-red).

Orange I (a-naphthol orange, chrysoin, resorcinol-yellow, tropacolin 000 No. I).

Orange II ( $\beta$-naphthol orange, chrysamin, gold orange, mandarin, tropeeolin 000 No. 2).

Orange III (gold orange, helianthin, methylorange, tropacolin $D)$.

Orange IV (diphenylamin-orange, orange $N$, iropeolin oo)

Orange G.

Palatin orange.

Ponceau 2 R (Hylidin red).

Ponceau $3 \mathrm{R}$ (Cumidin red).

Soudan brown (Pigment-brown).

Wool-black,

a. Anilin or Amin colors.

Anilin-black (Collin's black, jetolin).

Nigrosin (one of the indulins).

Anilin blue.

Alkali blue (fast blue, Guernsey blue, Nicholson blue).

Alkali blue D.

Bâle blue.

Bavarian blue (spirit diphenylamin blue)

Bavarian blue D S F.

China blue.

Coupier's blue (acetin-blue, anilin-gray, azodiphenyl-blue, bengaline, fast blue, indulin-blue, printing blue, Roubaix blue).

Ethyl-blue.

Light blue.

Marine blue.

Methyl-blue.

Neutral blue.

Night-blue (Victoria blue).

Soluble blue (Blackley blue, cotton blue, green-blue, liquid indigo-blue, navyblue).

Spirit-blue (basic blue, gentian-blue, Humboldt blue, imperial blue, Lyons blue, opal-blue, Parma blue, rosanilin. blue).

Water-blue.

Anilin-brown.
Color.

Composition, Preparation, Etc.

Derived from $\alpha$-naphthylamin and naphthol.

Sodium $a$-naphthol-azobenzene.

Sodium $\beta$-naphthol-azobenzene.

Ammonium dimethyl-anilin-azobenzene sulphonate.

Potassium phenylated acid yellow.

Sodium benzene-azo- $\beta$-naphthol- $\beta$-disulphonate.

Ammonium tetranitrodiphenol.

Action of hydrochlorid of diazo-m-xylene upon $\beta_{\text {. }}$ naphthol-disulphonic acid.

Action of diazo-m-cumene hydrochlorid upon $\beta$-naphthol-disulphonic acid.

Derived from a-naphthylamin and naphthol.

Combining paratolyl- $\beta$-naphthylamin with diazotized azobenzoldisulphonic acid.

\section{c. Benzene Colors (from benzene, $\mathrm{C}_{6} \mathrm{H}_{6}$ ).}

Oxidation of anilin hydrochlorid with potassium dichromate.

Heating amidoazobenzene with anilin hydrochlorid.

Rosanilin heated with anilin and benzoic acid.

Sodium triphenylrosanilin-monosulphonate.

Sodium triphenylpararosanilin-monosulphonate.

From nitrosodimethylanilin with ditolylnaphthylendiamin.

Sodium triphenylpararosanilin disulphonate.

Similar to soluble blue.

Heating amidoazobenzene with anilin hydrochlorid.

Treating spirit-blue with ethyl chlorid.

Treating spirit-blue with methyl chlorid,

From nitrosodimethylanilin with phenylnaphthylamin.

Heating spirit-blue with sulphuric acid and the product with oxalic acid.

Triphenylrosanilin and triphenylpararosanilin hydrochlorids.

Similar to soluble blue.

Blue.

Brown.
Red.

Reddish-orange.

Bright reddish-orange.

Fiery orange.

Orange-yellow.

Bright orange.

Orange-yellow.

Red.

Red.

Brown.

Blue-black.

Black.

Black.

Blue.

Bright blue.

Blue.

Blue.

Blue.

Blue.

Blue.

Blue.

Pure blue.

Blue.

Blue.

Blue.

Blue.

Blue.

Blue.

Blue. 
CONSPECTUS OF PIGMENTS-Continued.

\begin{tabular}{|c|c|c|}
\hline NAME. & Composition, Preparation, ETC. & Color. \\
\hline $\begin{array}{l}\text { Phenylene-brown ( } B \text { ismarck-brown, } \\
\text { Canelle-brown, cinnamon-brown, gold- } \\
\text { brown, leather-brown, Manchester } \\
\text { brown, Veswin). }\end{array}$ & Triamidoazobenzene hydrochlorid. & Brown. \\
\hline Anilin-green. & & Green. \\
\hline $\begin{array}{l}\text { Acid green (Guinea green, Helvetia } \\
\text { green, light-green } S F \text { ). }\end{array}$ & $\begin{array}{l}\text { Sodium diethyldibenzyl diamidotriphenyl carbinol- } \\
\text { trisulphonate. }\end{array}$ & Bright green. \\
\hline Aldehyd green. & Action of aidehyd on magenta with sulphuric acid. & Green. \\
\hline Alkali green. & Derived from diphenylamin. & Green. \\
\hline $\begin{array}{l}\text { Brilliant green (emerald green, new } \\
\text { Victoriagreen). }\end{array}$ & $\begin{array}{l}\text { Tetramethyl-diparamidotriphenylcarbinol hydro- } \\
\text { chlorid with zinc or iron chlorid. }\end{array}$ & Green. \\
\hline $\begin{array}{l}\text { Ethyl-green (new Victoria green, solid } \\
\text { green). }\end{array}$ & Tetrethyldiparamidotriphenylcarbinol sulphonate. & Green. \\
\hline Fast green. & $\begin{array}{l}\text { Sodium tetramethyl dibenzyl pseudrosanilin disul- } \\
\text { phonate. }\end{array}$ & Green. \\
\hline lodin-green (crystallized green). & $\begin{array}{l}\text { Chlormethylhexmethylrosanilin hydrochlorid and } \\
\text { zinc chlorid. }\end{array}$ & Green. \\
\hline Light green. & $\begin{array}{l}\text { Zinc chlorid and chlormethylhexamethylpararosani- } \\
\text { lin hydrochlorid. }\end{array}$ & Green. \\
\hline Liquid acid green. & 10-20 per cent. solution of acid green. & Green. \\
\hline $\begin{array}{l}\text { Malachite-green (benzol-green, benz- } \\
\text { aldehyd-green, benzoyl-green, bitter- } \\
\text { almond green, fast green, solid green, } \\
\text { Victoria green). }\end{array}$ & $\begin{array}{l}\text { Tetramethyldiamidotriphenylcarbinol hydrochlorid. } \\
\text { Made by the action of benzaldehyd upon dimethyl- } \\
\text { anilin. }\end{array}$ & Green. \\
\hline Methyl-green. & $\begin{array}{l}\text { Chlormethylhexamethylpararosanilin hydrochlorid } \\
\text { with zinc chlorid. }\end{array}$ & Green. \\
\hline Metternich green. & $\begin{array}{l}\text { Chlormethylhexamethylrosanilin hydrochlorid with } \\
\text { zinc chlorid. }\end{array}$ & Green. \\
\hline Night-green. & $\begin{array}{l}\text { Chlormethylhexamethylrosanilin hydrochlorid with } \\
\text { zinc chlorid. }\end{array}$ & Green. \\
\hline Paris green. & $\begin{array}{l}\text { Chlormethylhexamethylpararosanilin hydrochlorid } \\
\text { with zinc chlorid. }\end{array}$ & Green. \\
\hline Anilin-red. & & Red. \\
\hline Acid magenta (magenta $S$, mobin $S$ ). & $\begin{array}{l}\text { Mixture of rosanilin monosulphonic and disulphonic } \\
\text { acids. }\end{array}$ & Red. \\
\hline Azalein. & Rosanilin nitrate. & Red. \\
\hline Cerise. & & Cherry color. \\
\hline Fuchsin (magenta, new red, rubin). & Rosanilin hydrochlorid. & Deep red. \\
\hline Magenta (harmalin, rosein). & Pararosanilin and rosanilin hydrochlorids. & Deep red. \\
\hline Maroon. & From resinous residue after extraction of magenta. & Dark red. \\
\hline Phenosaffranin (saffranin $B$ extra). & & Red. \\
\hline $\begin{array}{l}\text { Rosanilin (anilin-red, Britining's red, } \\
\text { Coupier red, nitrobenzol-red). }\end{array}$ & A derivative of anilin. & Red. \\
\hline Rosein. & Rosanilin acetate. & Red. \\
\hline Saffranin (anilin-rose). & Mixture of tolusafranin and phenotolusafranin. & Red. \\
\hline Anilin-violet (Tyrolin). & & Violet. \\
\hline Acid violet. & Sodium dimethylrosanilintrisulphonate. & Violet. \\
\hline Crystal violet (violet $\sigma B$ ). & Hexamethylpararosanilin hydrochlorid. & Violet. \\
\hline Dahlin (Frofmann's violet, primula). & The ethyl and methyl derivatives of rosanilin. & Violet. \\
\hline Ethyl-purple. & Hexa-ethyl-pararosanilin. & Blue violet. \\
\hline Iodin-violet. & & Violet. \\
\hline Mauvanilin. & $\begin{array}{l}\text { From residue from arsenic acid-process of making } \\
\text { magenta. }\end{array}$ & Violet. \\
\hline
\end{tabular}


CONSPECTUS OF PIGMENTS.-Continued.

NAME.

Mauvein (anilin-purple, anilin-violet, indisin, mauve, Paris red, Perkins violet).

Methyl-violet (Paris violet).

Methyl-violet $6 \mathrm{~B}$ (benzyl-violel).

Red violet.

Rosanilin-violet (imperial violet, Parma violet, phenyl-violel, regina-purple, spinit-violet).

Violanilin.

Violet R.

Anilin-yellow.

Acid yellow (fast yellow).

Chrysanilin.

Flavanilin.

b. The Auramins.

Auramin.

Aurantia (imperial yellow).

Dimethylphenylene-green (Bindscheidler's green).

Ethylene-blue.

Gallocyanin (new fast violet, solid violet).

Girofie.

Indophenol.

Indophenol-blue (naphthol-blue).

Lauth's violet (thionin).

Methylene-blue (fast blue).

Muscarin.

Neutral red.

Neutral violet.

New blue (cotton-blue $R$ fast blue for cot ton, naphthylenene-blue).

Nile blue.

Phenylauramin.

Phenylene-blue.

Prune.

Toluylene-blue.

c. Fluorescein colors. The Eosins (ท่w's, morning redness).

Cyanosin.

Cyanosin B.

Eosin.

Eosin A extra.

Eosin B.

Eosin-orange.

Eosin-scarlet (daphnin, eosin $B N$, lutecienne, rose des Alpes, safrosin).
Composition, Preparation, Etc.

Oxidation of anilin containing toluidin.

Pentamethylpararosanilin hydrochlorid.

Pentamethylbenzylpararosanilin hydrochlorid.

Monophenylrosanilin and diphenylrosanilin hydrochlorids.

One of the indulins.

Sodium amidoazobenzene sulphonate.

Action of steam on the residue left after extraction of rosanilin.

Heating acetanilid with zinc chlorid.

Tetramethyldiamidobenzophenonimid hydrochlorid.

Ammonium hexanitrodiphenylamin.

Oxidizing dimethyl paraphenylene diamin with dimethylanilin.

Formed from nitrosodimethylanilin.

Formed from nitrosodimethylanilin with gallic acid.

Formed from nitrosodimetbylanilin.

Simultaneous oxidation of a phenol and a paradiamin Action of nitrosodimethylanilin on $\alpha$-naphthol.

Oxidation of paraphenylendiamin in an acid solution containing hydrogen sulphid.

Tetramethylthionin hydrochlorid with zinc chlorid.

A derivative of nitrosodimethylanilin.

Dimethyldiamidotoluphenazin hydrochlorid.

Dimethyldiamidophenazin hydrochlorid.

Action of muscarin on a-naphthylamin.

Heating auramin with anilin.

Oxidation of phenylenediamin with anilin.

Obtained from gallic methyl ether.

Oxidation of toluylene diamin.

Formed by methylating phloxin.

Formed by ethylating tetrabromtetrachlorfluorescein.

Tetrabromfluoresceinn.

Sodium tetrabromfluoresceïn.

Sodium or ammonium tetrabromfluoresceïn.

Sodium dibromfiuorescein.

Sodium, potassium, or ammonium dibromdinitrofluorescein
Color.

Purple.

Violet.

Violet.

Violet.

DuIl violet.

Gray-violet.

Violet.

Yellow.

Yellow.

Yellow.

Yellow.

Brilliant yellow.

Orange-yellow.

Yellow-green.

Blue.

Blue-violet.

Blue.

Indigo-blue.

Indigo-blue

Violet.

Green-blue.

Blue.

Red.

Violet.

Blue.

Blue.

Orange-yellow.

Green-blue.

Blue.

Blue.

Blue.

Red.

Garnet-red.

Red.

Orange-red.

Scarlet. 
CONSPECTUS OF PIGMENTS.-Continued.

NAME.

Erythrosin (dianthin $B$, eosin bleuâtre, eosin $J$, iodeosin $B$, pyrosin $B$, rose $B d$ l'eau, soluble primrose).

Erythrosin G (dianthin $G$, iodeosin $G$ ).

Phloxin P.

Phloxin $\mathbf{T}$.

Primrose (eosin $S$, ethyl eosin, rose $J B d$ l'alcool, spirit eosin).

Rose Bengale (Bengal red).

Rose Bengale B.

Soluble eosin.

d. Resorcin colors.

Resorcin-blue (fuorescent resorcinal b̆lue, lacmoid).

Resorcin-brown.

Resorcin-violet.

Solid green.

Brilliant yellow

Martius' yellow (golden yellow, naphthalene-yellow, naphthol-yellow, Manchester yellow, saffron-yellow).

Napthalene-red (magdala-red, naphthalinscarlet, Soudan-red).

Naphthalene-violet (naphthamein).

Naphthol-blue (indophenol, naphthol-violet). Naphthol-green B.

Naphthol-yellow S (acid yellow $S$ ).

Phenanthrene-red.

Sungold.

Aurin (rosolic acid).

Azulin (azurin, rosolic blue).

Corallin-red (aurin $R$, peonin, peony-red).

Corallin-yellow.

Flavaurin (new yellow).

Garnet-brown (grenate brown).

Phenol-blue.

Phenyl-brown (Havana brown, leather brown, phenicin, rothein).

Picric Acid.

Quinolin colors.

Quinolin-blue (cyanin).

Quinolin-green.

Quinolin-red.

Quinolin-yellow.
Composition, Preparation, Etc.

Color.

Sodium, potassium and ammonium tetraiodofluorescein.

Salts of di-iodofluoresceïn.

Potassium tetrabromdichlorfluoresceīn.

Formed by bromizing tetrachlorfluorescein.

Potassium ethyltetrabromfluoresceïn.

Formed by jodizing dichlorfluorescein.

Formed by iodizing tetrachlorfluorescein.

Sodium or ammonium tetrabromfluoresceinn.

Formed by heating resorcin with sodium nitrite.

Combining resorcin with a diazo-compound.

Action of resorcin on tetramethyldiamidobenzophenon.

Dinitroresorcin.

\section{d. Naphthalene Pigments.}

Treating a-llaphtholdisulphonic acid with nitric acid.|Yellow. Sodium, ammonium, or calcium dinitro-a-naphthol. Yellow.

Diamido-naphthyl napthazonium chlorid.

Formed by oxidizing $\alpha$-naphthylamin,

Action of nitrosodimethylanilin on a-naphthol.

Treating $\beta$-naphtholmonosulphonic acid $S$ with witric acid.

Treating $a$-naphtholtrisulphonic acid with nitric acid.

\section{e. Phenol Pigments.}

Heating phenol with sulphuric and oxalic acids.

Heating rosolic acid with anilin.

Heating aurin with ammonium hydroxid.

Formed from aurin.

Ammonium dinitrophenolparasulphonate.

Potassium or ammonium cresylpurpurate.

Action of dimethyl phenylenediamin on phenol.

Action of sulphuric and nitric acids on phenol.

Trinitrophenol.

Reaction of amyl iodid, quinolin and methylquinolin. Tetramethyldiamidodiphenylquinolol hydrochorid.

Heating benzotrichlorid with quinaldin and isoquinolin in the presence of zinc chlorid.

Heating quinaldin with phthalic anhydrid and zinc chlorid.

Scarlet.

Violet.

Indigo-blue.

Green.

Yellow.

Red.

Yellow.

Orange-red.

Blue.

Red

Orange-yellow.

Yellow.

Brown.

Green-blue.

Brown.

Yellow.

Blue.

Green.

Red.

Yellow.
Light brick-red to brownred.

Red.

Red.

Red.

Bright-red.

Blue-red.

Blue-red.

Reddish-brown.

Blue.

Brown.

Violet.

Green. 
CONSPECTUS OF PIGMENTS.-Continued.

\section{NAME.}

Sriticylic acid colors.

Salicy]-orange.

Salicyl-yellow.

Victoria yellow (anilin-orange, saffron-sub stitute, Victoria orange).

Adansonia-red.

Ethylpurpurin.

Alder-red.

Alizarin.

Alkanna-green.

Alkanna-red (Alkanet, Anchusin, Pseudalkannin, "Acid anchusique," Pelletier).

Anthocyan (Flower-blue).

\section{Anthoxanthin (Flower-yellow)}

\section{Antwerp-brown.}

Archil (French purple, orchil, orchil-purple).

Arnatto (annatto, annotto, orleans).

\section{Azale (pincoffin)}

Azolitmin.

Bacterio-purpurin.

Barwood-red (mock Turkey red).

Bezette (turnesol rag).

Bioxyalizarin.

Bixin (orellin, orlean-red).

Bladder-green (ivis-green, sap-green).

Brasilin (brazilin).

\section{Brown madder.}

Brown pink (stil de grain).

Canarin.

\section{Capsicum-red.}

Capucine madder.

\section{Carotin.}

Carthamin (rouge végétal, safflower-carmin).

Catechu (cashoo).
Composition, Preparation, Etc.

Color.

Orange-yellow.

Monobromsalicylic acid or its sodium salt.

Yellow.

Orange-yellow.

3. VEGETABLE PIGMENTS.

Obtained by Walz from the bark of Adansonia digi- Blood-red. tata, L

Obtained by Schützenberger and Schiffert from purpurin.

Obtained from the wood of Alnus glutinosa. Gaert.

Discovered in 1826 by Colin and Robiquet in madder (Rubia tinctoria); named from Ali-zari, the Oriental commercial name for madder.

Obtained from madder-root.

\section{Green. \\ Red. \\ Red. \\ Red.}

Obtained from the roots of Anchusa tinctoria or Al- Red. kanna tinctovia of southern Europe.

The coloring-matter, according to Marquart, of many blue, red, and violet flowers, the tint depending on the amount of acid present. Cf. Cyanin.

Obtained by Marquart from yellow flowers. $C$. the Xanthin of Cloez, and Xanthëin of Fremy.

Asphaltum mixed with a drying-oil.

From Roccella tinctoria and $R$. fuciformis.

The fruit-pulp of Bixin ovellana, L. Empioyed by silk-dyers and varnish-makers; also for coloring cheese, cream, chocolate, confectionery, etc. See Bixin.

Crude alizarin.

From litmus.

Obtained from the protoplasm of Beggiatoa roseopersicina.

\section{Wood of Baphia nitida.}

Juice of Croton tinctorium.

Obtained from Alsatian madder by treatment with alcohol and benzol.

Obtained from Bixa orellanna.

From berries of Rhamnus catharticus.

Obtained by Chevreul and Bolley from the wood of Casalpinia sappan, L.; C. brasiliensis, S. W.; C echinata, Lam.

Lake from madder-root.

From Rhamnus infectorius, or from quercitrin bark.

Oxidation of potassium sulphocyanid with potassium chlorate in the presence of sulphuric and hydro chioric acids.

First obtained by Braconnot from Capsicum annuum, L.

Lake from madder-root.

The coloring-matter of the root of the cultivated carrot, Daucus carota, discovered, in 1832 , by Wackenroder.

Obtained from saffron (Carthamus tinclorius), $\mathbf{L}$.

Extract from Acacia catechu.
Blue.

Yellow.

Brown.

Violet, mauve-purple.

Yellowish-red.

Red.

Deep blood-red.

Peach-color.

Orange-red.

Blue.

Orange-red.

Cinnabar-red.

Green.

Golden-yellow.

Rich brown.

Dark-pink.

Orange-yellow.

Red.

Reddish-orange.

Deep-red to golden-red.

Dark brownish-red to yellowish-red and purple, according to mordant.

Brown. 
CONSPECTUS OF PIGMENTS.Continued.

\begin{tabular}{l}
\hline \multicolumn{1}{c}{ NAME. } \\
\hline Cerulein (azulene). \\
\hline Chelidoxanthin. \\
\hline Chemic black. \\
\hline Chica-red (carajura, chico-red). \\
\hline Chinese green (laokao). \\
Chlorogenin. \\
Chlorophyl (Leaf-green).
\end{tabular}

Chlorrubiadin.

Chlorrubian.

Chrome-black.

\section{Chrysophan.}

Chrysophanic acid.

Chrysorhamnin.
$\begin{aligned} & \text { Cinchona-red (Chinaroth, rosso di China, } \\ & \text { cinchofulvic acid). }\end{aligned}$
Cissotannic-acid.

Colorin.

Common black.

Cork black.

Crocin (Polycroit).

Cudbear.

Curcumin (Curcuma-yellow, Turmeric).

Cyanin (Flower-blue).

Dragon's blood.

Dutch-pink.

Dyer's broom.

Erythrin.

Erythrophyl (Leaf-red).

\section{Etiolin.}

Filix-red.

Florence lake (Florentine lake).

Floridea-green.

Fucoxanthin.

Fustin (fisetin).
Composition, Preparation, Etc.

A vegetable principle.

Obtained by Probst from Chelidonium majus, L.

Gall-nuts with ferric nitrate and pyroligneous acid.

Leaves of Bignonia chica.

From Rhamnus chlorophorus and $R$. utilis.

Obtained from madder-root by Schunck.

From the leaves or other green parts of plants, and certain invertebrates. A complex coloring-matter composed of varying mixtures of phyllocyanin, and phylloxanthin. Cf. phycoxanthin, phycophäin.

Obtained by Schunck from madder-root.

Obtained by Schunck from madder-root.

Produced by mordanting with potassium dichromate and dyeing with logwood.

Obtained from the roots of rhubarb (Rheum palmatum).

Discovered by Schrader (1819); found in the lichens, Parmelia parietina, Parmelia caparata, Squamaria elegans, and Cassia bijuga, Andira araroba, (Goa powder), Rheum palmatum.

Obtained from the fruit of Rhamnus amygdalenus, $R$. infectorius, and $R$. saxatilis.

A phlobophene discovered by Reuss (1812) in cinchona bark.

Obtained by Wittstein from reddened autumn leaves and from strawberries.

Dry alcoholic extract of garancin.

From logwood, sumac, and fustic, by adding a mixture of green and blue vitriol.

Burning cork in closed vessels.

Obtained from Crocus sativus, Gardenia grandifolia, and Fabiana imbricata.

From Lecanora tartarea and other lichens.

Obtained from the roots of Curcuma longa, and other species; cultivated throughout Eastern tropics: used in cookery, and for test-paper.

Found by Fremy and Cloez in blue flowers, $e . g$. corn-flower, violets, etc. This appears to be a pure form of the anthocyan of Marquart. The scarletred of some flowers appear to be a mixture of $c y$. anin and $x$ anthin.

Resin from Dracana draco.

From Reseda luteola. See Luteolin.

From Genista tinctoria.

Obtained from Roccella fuciformis.

Obtained by Berzelius from reddened autumn leave (e. $g_{*}$, cherry, currant).

The yellow pigment of etiolated leaves. Cf. xanthophyl, phylloxanthin.

Obtained from the rhizomes of Aspidium filix mas.

Lake from logwood.

That portion of the compound pigment (Rhodophyl) of the red alga which is soluble in alcohol.

Sorby's name for the principal coloring-matter of the olive-green sea-weeds (Fucacece and Laminarascea). Obtained from the root of Rhus cotinus.
Color.

Blue.

Yellow.

Black.

Orange-red.

Green.

Green.

Green.

Yellow.

Yellow.

Black.

Gold or sulphur-yellow

Yellow.

Golden yellow.

Red.

Brown-red or red-brown.

Red.

Black.

Black.

Yellow.

Purple or violet.

Yellow.

Blue.

Red.

Pink.

Vellow.

Red.

Red.

Yellow.

Dark brick-red.

Deep brown-red.

Green.

Amber.

Yellow. 
CONSPECTUS OF PIGMENTS._Continued.

NAME.

Galloflavin.

Gambier (gambir, pale catechu, terra japonica).

Gamboge.

Garanceux.

\section{Garancin.}

Gas-black (hydrocarbon-black).

Glaucotin.

Guaiac-yellow.

\section{Harmal-red (Harmalin).}

Hemateîn.

Henatoxylin.

Hooker's green.

llixanthin.

Indigo (Indian blue).

Indigo-brown.

Indigo-carmin.

Indigo-extract (disulphonic acid, indigotin).

Indigo-red (indigo-purple, indirubin).

Indigotin (Indigo-blue, liquid blue, Saxony blue, oat-blue).

\section{Indigo-white (indigogen).}

Isatrin-yellow.

Japan black (asphaltum, Brunswick black, Japan lacquer).

Kyanophyl.

Lamp-black (soot).

Ligulin.

Lithospermum-red.

Litmus.

Logwood-black.
Composition, Preparation, Etc.

Color.

Oxidation of gallic acid in alkaline solution.

Extract from leaves of Uncaria gambier.

Gum-resin from Garcinia hanburyi.

From the waste madder of the dye-houses.

Action of conc. sulphuric acid on pulv. madder.

Burning natural gas against a revolving iron cylinder.

Obtained by Probst from the flowers of Glaucium luteum, Scop.

Obtained by Pelletier and Hadelich from the resin of Guaiacum officinale, $\mathbf{L}$

Obtained by Göbel as an oxidation-product of harmalin from Ruta graveolens, and other species of Rutacece.

Obtained from hematoxylin by the action of ammonia.

From logwood, Hamatoxylon campechianum.

Mixture of Prussian blue and gamboge.

Obtained by Moldenhauer from Mex aquifolium.

From leguminous plants of the genus Indigofera.

Mixture of Indihumin and indiretin.

Sodium salt of indigo-extract.

Solution of indigo in strong sulphuric acid.

Decomposition of Indican by oxalic or tartaric acid.

A pigment known to the ancients, and obtained from many plants, Indigofera tinctoria, L. : Indigofera anil, L. : Indigofera argentea, L.; Indigofera disperma $\mathrm{L}$ Isatis tinctoria, Isatis lusitanica (see Woad) Nerium tinctorium, or Wrightia tinctoria, Polygonum tinctorium, Polygonum fagopyrum, Polygonum chinense, Marsdenia tinctoria, Asclepias tingens, Galega tinctoria, Mercurialis perennis, Melampyrum arvena, Melampyrum cristatum, Polygola bracteolata, Croton tinctorium, Croton verbascifolium, Phytolacca decandra, Phytolacca mexicana, Monotropa hypopitys, Tephrosia apollinea, T. toxicaria, Randia aculeata, Amorpha fruticosa; T. toxicania, Randia aculeata, Amorpha fruticosa;
also found in animal fluids, urine, sweat, milk, pus. This pigment is not a direct product of the plantjuices or animal fluids, but a decomposition-product, the result of the action of bacteria upon indican or other glucosids. Cf. Bacillus indigoferus, Classen, and Bacillus indigogenus, Alvarez, under Bacteria, Synonymatic Table of.

Action of reducing agents on commercial indigo.

Action of phenylhydrazinparasulphonic acid on dioxi- Yellow. tartaric acid.

Cooking asphaltum with linseed-oil and adding turpentine.

Wiesner's name for nearly pure chlorophyl freed from its yellow pigment, xanthophyl. Cf. Phyllocyanin.

Imperfect combustion of resin, oils, gas, tar, etc.

Black.

Obtained by Nicklès and Reinsch from the berries of Ligustrum vulgare. Cf. Oppholin.

First obtained by Ludwig and Kromayer from the bark of the root of Lithospermum arvense.

From Roccella tinctoria, and other lichens.

Mordanting with iron salts and dyeing with logwood.
Blue.

Yellow.

Yellowish-brown.

Brownish-yellow.

Red, deep-brown, lilac, black.

Red.

Black.

Yellow.

Yellow.

Red.

Black-violet.

Red, blue, purple.

Green.

Yellow.

Blue.

Brown.

Blue-red.

Blue.

Reddish-purple.

Blue.

Black.

Blue-green.

Carmin-red.

Red.

Blue.

Black. 
CONSPECTUS OF PIGMENTS.-Continued.

\begin{tabular}{|c|}
\hline NAME. \\
\hline Lutein (Egg-yellow). \\
\hline Luteolin. \\
\hline $\begin{array}{l}\text { Madder (Adrianople red, madder-red, Turkey } \\
\text { red). }\end{array}$ \\
\hline Madder-brown. \\
\hline Madder-carmin. \\
\hline Madder-orange. \\
\hline $\begin{array}{l}\text { Madder-purple (Field's purple, purple rubi- } \\
\text { ate). }\end{array}$ \\
\hline Madder-yellow. \\
\hline
\end{tabular}

Marennin.

Morin.

Morindin.

Munjistin (Indian madder, mungeet, munjeet).

Nemours blue.

Nitropurpurein.

Enolin (cenolinic acid, Berry-blue, Berryred).

Orcin (arcinol).

Orellin.

Orlean-red.

Oxyrubian.

Peach.black.

Pheophyl (Phaophyl).

Phlobaphene (Bark-pigment).

Phycochrome.

Phycocyanin.

Phycoerythrin

Phycohematin.

Phycopheïn.

Phycoxanthin.

Phyllerythrin.
Composition, Preparation, Etc.

A red lipochrome obtained by Thudicum from many kinds of yellow flowers, seeds, the flesh of berries, and the yellow bodies in the ovaries of inammals, egg-yolks, and other animal substances.

Discovered by Chevreul in 1830 . The yellow coloringmatter of Reseda luteola, L. (Ash of Jerusalem, Dyers' Rocket, Dyers' Weed, Dyers' Yellow-weed, Gyers' Rocket, Dyers' Weed, Dyers' Yellow-weed, Wolds, Woulds, Woold, Yellow Rocket, Yellow Weed, Yellows): chiefly used for paper-hangings. The color called Dutch pink is also obtained from it.

From the roots of Rubia tinctorum.

From catechu worked with madder-colors.

Lake from madder-root with an aluminum base.

Lake from madder-root.

Lake from madder-root.

Lake from madder-root.

The green coloring-principle absorbed by oysters from diatoms (Navicula ostrearia) in "greening." Cf. Diatomin.

From the Heart-wood of mulberry (Morus tinctoria).

Discovered by Anderson, in 1849, in the bark of the root of Morinda citrifolia.

Obtained from the East India madder (Rubia munjista, or Rubia cordifolia).

Dyeing with sandal-wood and afterward with indigo.

Obtained by Stenhouse from Purpurein by the action of nitric acid.

Obtained by Mulder and Glénard from grapes, whortleberries, bilberries, blackberries, mulberries, elderberries, etc. Cf. Ligulin.

From orchella weed and other lichens.

From Bixa orellana, L. See Bixin.

Obtained from Bixa orellana. See Bixin.

Obtained by Schunck from madder-root.

Calcination of peach-stones.

The compound pigment of the Fucacer and Phoosporea. Cf. Phycophain and Phycoxanthin.

Obtained from the bark of various trees and shrubs, by Stahelin, Hofstetter, Hesse, Hlasiwetz, Grabowski, etc.

A complex pigment of the Cyanophycea, or Phycachromacea. Cf. Phycocyanin.

Obtained from various phycochromaceous alga and from certain invertebrates (Chatopterus). C. Scytonemin.

That portion of the compound pigment (Rhodophyl) of the red Alg $\propto$ which is soluble in water. $\mathrm{Cf}$. Floridea-green.

Obtained from the sea-weed Rhytiplcea linctoria.

Obtained fintn the Fucacece and Phaosporea. Schutt confines the name to that part of pheophyl which is soluble in water.

That portion of the pheophvl of the Fucacece and Phecosparea which is soluble in alcohol.

A general term for the red pigment of leaves.
Color.

Yellow.

Green, yellow, or blue, ac cording to the mordants employed.

Red.

Brown.

Carmin.

Orange.

Deep-purple.

Bright yellow.

Green.

Yellow.

Sulphur-yellow to red, according to mordant.

Golden-yellow to red, according to mordant.

Blue.

Scarlet.

Blue-black, violet-red to red-brown.

Blood-red.

Red.

Red.

Brown.

Black.

Olive or brown.

Brown-red.

Blue-green.

Blue in transmitted light blood-red in reflected light.

Red.

Blood-red.

Reddish-brown.

Yellow.

Red. 
CONSPECTUS OF PIGMENTS.-Continued.

NAME.

Phyllocyanin (Cyanophyl).

Phylloxanthin (Xanthophyl).

Phymatorhusin.

Phyterythrin.

Pink madder.

Pittacal.

Pseudopurpurin.

Puccoon

\section{Purple-madder.}

Purpurein.

Purpurin (Oxyalizarin, Madder purple, Field's purple, Purple rubiate).

Quercetin (Meletin).

\section{Quercitrin.}

\section{Quinora-red.}

Rhodophyl.

\section{Rhodospermin}

Rose-lake.

Rottlera-red.

\section{Ruben's madder.}

Ruberythrinic acid.

Rubiacinic acid.

Rubiadin.

Rubiadipin.

Rubiafin.

Rubiagin.

Rubian.

\section{Rubianic acid.}

Rubianin.

Rubidehydran and Rubihydran.
Composition, Preparation, Etc.

The acid constituent of chlorophyl. Cf. Phylloxanthin

One of the constituents of Chlorophyl. Cf Phyllo cyanin.

From metastatic deposits in the skin.

Same as Erythrophyl.

Lake from madder-root.

From beechwood tar.

Obtained from Alsatian madder by treatment with alcohol and benzol.

The Indian term for the dye obtained from various North American herbs, e.g., Lithospermum hirtum, Lithospermum canesciens, Sanguinaria canadensis, etc.

Lake from madder-root.

From Purpurin by the action of ammonium hydroxid.

Obtained by the action of yeast on Alsatian or Avignon madder.

Obtained from the heart-wood of Rhus cotinus, the berries of Hippophaea rhamnoides, the green parts of Calluna vulgaris, the flowers of Cornus mascula horsechestnut leaves and flowers, etc.

Discovered by Chevreul and Brandt. It occurs in the bark of the black-oak (Quercus tinctoria, Mich.), as well as other species of oak, also in tea-leaves, and as querascitrin in the leaves, flowers, and cotyledons of the horsechestnut.

Obtained from cinchona bark by Pelletier and Caven$\operatorname{ton}(1820)$.

The compound pigment of the red $A l g \&$. Cf. Phycoerythrin and Floridece-green.

The red coloring-matter of the Floridece, obtained by Rosanoff, Cramer, Askenasy, Sorby, and others. C. Phycoerythrin.

From logwood.

Lake from madder-root.

Obtained from the dust-like hairs of the capsules of Rottleva tinctoria, Pixby, and used in India as a dye for silk.

\section{Lake from madder-root.}

An acid glucosid, isolated by Rochleder, in $18_{5} I$, from the madder Rubia tinctoria, L., of which it appears to be the primary chromogen.

Obtained from Rubiafin by Schunck.

Obtained by Schunck from madder-root.

Obtained from madder-root by Schunck.

Obtained from madder-root by Schunck.

Obtained by Schunck from madder-root.

Obtained by Schunck from madder-root (Rubia tinctoria).

Obtained by Schunck from Rubian, and held by him to be identical with Rochleder's Ruberythrinic acid.

Obtained by Schunck from madder-root.

Obtained by Schunck from madder-root.
Color.

Blue or greenish-blue.

Yellow.

Red.

Pink.

Blue.

Red.

Red to yellow.

Purple.

Carmin-red.

Cherry-red to purple, according to mordant.

Citron-yellow.

Sulphur-yellow to chromeyellow.

Red.

Carmin-red in transmitted light, green or reddish-yellow in reflected light.

Red.

Deep brown-red.

Rose.

Red, orange, or, by special process, scarlet.

Brown.

Brick-red, cherry-red.

Citron-yellow.

Golden-yellow.

Yellowish-brown; it yields a blood-red color with alkalies.

Yellow.

Citron-yellow.

Dark-yellow ; it yields with an alum mordant a bright orange, with iron a clear brown.

Citron-yellow.

Bright-yellow.

Dark-yellow. 
CONSPECTUS OF PIGMENTS.-Continued.

NAME.

Rubiretin

Saffron-yellow.

Santalin.

Sawwort.

Sedan black.

Spanish black.

Spiræin (Spircea yellow).

Spirit-brown.

Styrogallol.

Tallochlor

Tartrazin.

Thujetin.

Thujin.

Vandyke-brown (Cassel-brown).

Verantin.

Woad.

Wongshy.

Xanthëin (Fremy), Xanthin (Cloez) (Flower-yellow).

Xanthin.

Xanthophyl (Leaf-yellow).

Xanthorhamnin.

Xanthotannic acid.

Xylochloric acid (Wood-green).

Yellow carmin.
Composition, Preparation, Etc

COLOR

Obtained by Schunck by treating Rubian, Rubidehydran, and Rubihydran with dilute acids and alkalies, or by the action of eryihrozym on rubian.

Obtained from saffron (Carthamus tinctorius, L.), Brown-yellow. by lead acetate and ammonium hydroxid.

From hard red-woods-Bar-wood, Callialura wood, Cam-2wood, Santal-wood.

From foliage of Serratula tincioria

Ferrous sulphate on wood, logwood, and sumac. Burnt cork.

Obtained by Löwig and Weidmann from Spircea ulmaria, $\mathbf{L}$

Dyeing with quercitrin and then with peachwood, logwood, and alum.

By the union of cinnamic and gallic acids.

Obtained from thistle-heads, artichokes, and flowerbuds, by Verdeil, and from various lichens by Schnedermaun and Knop.

Action of phenylhydrazinparasulphonic acid on dioxitartaric acid.

Obtained from Thujin; perhaps identical with Quercetin.

Obtained from the green portions of the common Arbor vitæ (Thuja occidentalis).

Species of peat or lignite.

Obtained by Schunck from madder-root (Rubia tinctoria).

Leaves of Isatis tinctoria. Cf. Luteolin.
From seed-pods of Gardenia florida.
Obtained by Fremy and Cloez from yellow flowers
(e. $g$., sunflowers and yellow dahlias). Cf. Antho-
xanthin.

Otained by Higgin............

Obtained by Higgin and Kuhlmann from madderroot. Schunck holds this to be an impure Rubian, and Rochleder an impure Ruberythrinic acid.

Obtained by Berzelius from yellow autumn leaves, and other parts of plants. Krauss uses it as synonymous with Phylloxanthin.

Fruit of Rhamnus amygdalinus, $R$. infectorius, and $R$. saxatilis.

Obtained by Ferrein from the reddened autumn leaves of the elm.

Isolated from old wood by Bley, Jr.

Lake from Persian berries or quercitrin bark.
Dark reddish-brown

Red.

Yellow.

Intense black.

Black.

Yellow.

Brown.

Pale green

Green.

Yellow.

Yellow.

Citron-yellow.

Reddish-brown.

Reddish-brown.

Blue.

Yellow.

Yellow.

Yellow.

Yellow.

Olive-yellow.

Yellow.

Green.

Yellow.
Pile ( $p \bar{l} l)$ [pilus, hair]. The hair, or hairs collectively, of any part of the integument; a hemorrhoid; a battery. P., Matteuci's Muscular, a voltaic battery or pile, the elements of which are formed of longitudinal and transverse sections of muscle connected alternately.

Pileate $\left(p i l^{\prime}-\imath-\bar{a} t\right)$ [ pileus, a cap]. In biology, having a pileus, or cap, as certain fungi.

Pileiform (pill-e-if-orm) [pileus, a cap; forma, form]. In biology, pileate; having the form of a pileus.

Pileolus (pil-e'-o-lus) [dim. of pileus, a cap: pl., Pileoli] In biology, a little pileus.

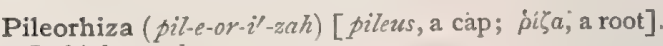
In biology, the root-cap.

Pileous (pill-e-us) [ pilus, hair]. Pertaining to hair.

Piles (pilz). See Hemorrhoids.

Pileum (pil'-e-um) [pileum, a cap : pl., Pilea]. In biology, the cap or whole top of the head of a bird, from bill to nape, including the forehead, vertex, and occiput.

Pileus (pill-e-us) [ pilcus also pileum, a cap: pl., Pilei]. In biology, a term first introduced by Rondelet (1554) to designate the disc of the Meduse, for which many writers have substituted the name umbrclla or disc. It 
is also applied to the cap-like or umbrella-like summit of the stipe of many fungi. The hymenium-bearing portion is the same as cap. P.hippocraticus, the capeline bandage.

Pilewort $\left(p i l^{\prime}\right.$-wert $)$. See Ficary.

Pili (pi'-li) [pilus, a hair]. Hairs. P., Congenital, hair existing at birth. P., Post-genital, that appearing some time after birth.

Piliation (pil-e-a'-shun) [ pilus, hair]. The formation and production of hair.

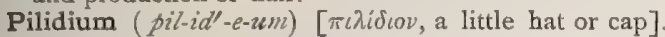
In biology : (r) A free-swimming, helmet-shaped larva, occurring among the Nemertina. It holds a position intermediate between the young Turbellarian larva of the Polyclada (cf. Miuller's Larva) and the typical Trochophoran Larva. (2) A hemispheric apothecium in certain lichens.

Piliferous (pi-lif'-er-us) [pilus, a hair; ferre, to bear]. In biology, bearing a slender bristle or hair, or beset with hairs. P. Cyst, a dermoid cyst.

Piliform (pi'-lif-orm) [ pilus, hair; forma, a form] Having the form or appearance of hair; filiform.

Piligerous ( $\left.p i-l i j^{\prime}-e r-u s\right)$ [ pilus, hair; gerere, to carry] Piliferous; covered with hair.

Pilimiction ( $\left.p i-l i m-i k^{\prime}-s h u n\right)$ [ pilus, hair; mingere, to urinate]. The passing of urine containing hair-like filaments.

Pill (pil) [ME., pille, pill]. See Pilula. P., Blair's, an empiric English preparation containing colchicum and used in the treatment of gout. P., Blaud's. See Blaud. P., Blue. See Hydrargyrum. P.box, a box for holding pills. P.-coater, a machine for coating pills with sugar, gelatin, or other material. P., Compound Cathartic. See Colocynth. P., Compressed, a pill made by compressing the powdered substance into proper shape by means of a powerful press, without the use of an excipient. P., Dupuytren's, a pill containing extract of opium, bichlorid of mercury, and extract of guaiac. P., Friable, a pill that crumbles into powder on slight pressure. P., Griffith's. See Ferrum. P.-mass, a cohesive mass into which the ingredients of the pills are worked. P.-tile, a metallic plate with semi-cylindric grooves on its upper surface. It is used in the manufacture of pills.

Pillar (pill-ar) [pila, a pillar]. In biology, a columnar structure, a columella, modiola, crus, peduncle. $\mathbf{P}$. of the Abdominal Ring, one of the columns on either side of the abdominal ring. P., Anterior, of the Fauces, the fold on each side of the uvula formed by the projection of the palatoglossus muscle covered by mucosa. P., Anterior, of the Fornix, the band of white matter on either side that passes from the anterior extremity of the fornix to the base of the brain, forming part of the corpus albicans, and that curves upward into the optic thalamus of the corresponding side. P. of Corti, one of the rods of Corti, two greatly modified epithelial cells in the organ of Corti ; they are slender, slightly S-shaped, longitudinally striated bodies, consisting of a denser substancethe pillar proper-and a thin, imperfect protoplasmic envelop. P. of the External Abdominal Ring, one of the two columns or pillars forming the free borders of the aponeurosis at the site of the external abdominal ring. The external pillar is formed by that portion of Poupart's ligament which is inserted into the spine of the pubis. The internal, or superior pillar is a broad, thin, flat band, which interlaces with its fellow on the opposite side in front of the symphysis pubis. P., External, of the Diaphragm. See Crus of the Diaphragm. P. of the Fauces, one of the folds of mucous membrane on either side of the fauces. P., Flexible, a jointed pillar for inclining the body of the microscope. P., Internal, of the Abdominal Ring. See $P$. of the External Abdominal Ring. P., Muscular, See Muscle-column. P. Posterior, of the Fauces, a fold at each side of the uvula formed by the palato-pharyngeus muscle, covered by mucosa. P., Posterior, of the Fornix, one of the two bands which pass from the posterior extremities of the fornix downward into the descending horn of the lateral ventricle. P., Superior, of the Abdominal Ring. Synonym of P., Internal, of the Abdominal Ring.

Pillicoshy (pil'-ik-o-she). A vulgar corruption of pilule cochice, cochia pills (see Cochia); hence, powder of aloes and canella, or hiera picra.

Pilliocausia (pil-e-o-karw'-se-ah). See Pillicoshy.

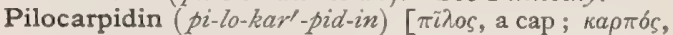
fruit], $\mathrm{C}_{10} \mathrm{H}_{10} \mathrm{~N}_{2} \mathrm{O}_{20^{\circ}}$ A syrupy, alkaline basic substance, obtained from jaborandi leaves; it is weaker in its action than pilocarpin.

Pilocarpin (pi-lo-kar'-pin). See Pilocarpus.

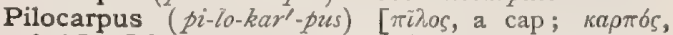
fruit]. Jaborandi. The young leaves of $P$. selloanus, $P$. pennatifolius, and Piper jaborandi, containing a volatile oil and 2 alkaloids, jaborin and pilocarpin. Jaborin is similar to atropin in action, and antagonistic to pilocarpin, but it is present in the leaves in only small amounts. Pilocarpin stimulates the peripheral ends of the secreting nerves going to glands, perhaps also the centers. It thus causes an increased flow of saliva, marked sweating, secretion of tears, of mucus from the nose and the bronchi, of the gastric and intestinal juices. It also stimulates involuntary muscle; on the vagus it acts as a stimulant, causing slowing of the pulse; in large doses it paralyzes the vagus. Vomiting is produced by jaborandi and sometimes by pilocarpin alone. Pilocarpin causes contraction of the pupil. Its action is antagonized very completely by atropin. Therapeutically, pilocarpin is used chiefly in renal dropsy to produce sweating, also in uremia, for the same purpose. It probably causes an elimination of urea, and other waste-products, both in the sweat and in the saliva. As a diaphoretic it is also employed in coryza and bronchitis. It has been used most successfully in erysipelas. Pilocarpus, Ext., Fld., dose $\eta_{\mathrm{v}} \mathrm{-}-3 \mathrm{j}$. J., Ext. (B. P.) Dose gr. iij-x. J., Infus. (B. P.)

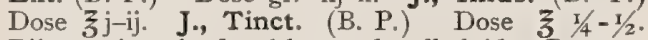
Pilocarpinæ hydrochloras, the alkaloid. Dose gr. $1 / 8-1 / 2$. P. nitras. Dose hypodermatically gr. $\frac{1}{16}=1 / 4$. Injectio $\mathbf{P}$. nitrat. hypodermica; I grain in 20 minims. Dose $m_{i j-v j .}$

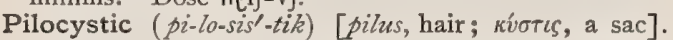
A term applied to encysted tumors containing hair and fatty matters, $e_{.} g_{\text {. }}$, some dermoid cysts.

Pilo-motor (pi-lo-mo'tor) [pilus, hair; movere, to move]. Causing movement of the hair. P. Nerves, nerves causing contraction of the erectores pilorum, as in horripilation of animals.

Pilonidal (pi-lo-ni'-dal) [pilus, hair; nidus, nest]. Containing an accumulation of hairs in a cyst. $\mathbf{P}$. Fistula, a fistula in the neighborhood of the rectum depending upon the presence of a tuft of hair in the tissues. It is also known as Coccygeal Fistula.

Pilose, Pilous ( $\left.p i^{\prime}-l \bar{o} z, p i^{\prime}-l u s\right)$ [pilosus, hairy]. In biology, covered with long, straight, soft hairs; hairy; hirsute.

Pilosis (pi-lo'-sis) [pilus, hair]. The development, and especially the abnormal or excessive development, of hairs.

Pilosity (pi-los'-it-e) [pilus, a hair]. The state of being pilose.

Pilous ( $p i^{\prime}$-lus). See Pilose.

Pilula (pil'-u-lah) [L.: pl., Pilula]. A pill. In 
pharmacy, a spheric mass containing a prescribed medicinal substance with the excipient necessary to make it cohesive. The excipient may be soap and water, a gum, or one of the various syrups. There are $\mathbf{I} 5$ official pilulce. See names, constituents, etc., under principal ingredient.

Pilular (pil'-u-lar) [ pilula, dim. of pila, ball]. Of the nature or form of a pill.

Pilule $\left(p i l^{\prime}-\bar{u} l\right)$ [pilula, a small pill]. A small pill, pellet, or parvule.

Pilulous (pit'-u-lus). Same as Pilular.

Pilum ( $p i^{\prime}-$ lum $)[\mathrm{L}$.$] . In pharmacy, a pestle.$

Pilus ( $p i^{\prime}$-lus) [pilus, a hair: pl., Pili]. In biology, a fine, slender, hair-like body. Pili gossypii, cotton staple. Pili tactiles, tactile hairs.

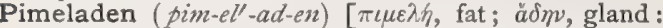
pl., Pimeladenes]. Any sebaceous gland.

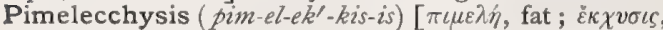
a pouring out]. An excessive discharge of fat or of sebaceous matter.

Pimelic Acid (pim-ell-ik). See Acid.

Pimelitis (pim-el-i'-tis) [ $\pi \iota \mu \varepsilon \lambda \dot{\eta}$, fat; $\iota \tau \iota \zeta$, inflammation]. Inflammation of any adipose tissue; also, of connective tissue in general.

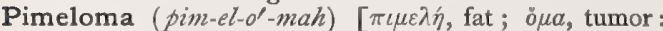
pl., Pimelomata]. A fatty tumor; lipoma.

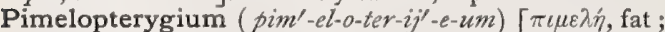
$\pi \tau \varepsilon \rho$ vy ${ }^{\prime} \nu$, a small wing]. A fatty outgrowth on the conjunctiva.

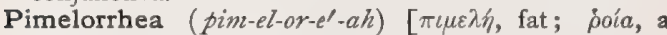
flow]. An excessive fatty discharge. Fecal discharge of undigested fat.

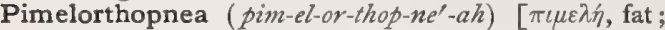

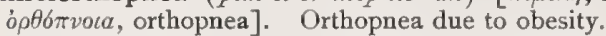

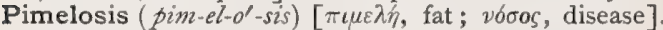
Conversion into fat. The fatty degeneration of any tissue; obesity, or corpulence.

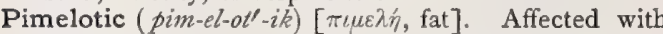
pimelosis.

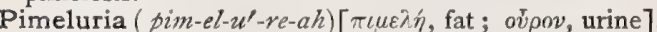
The excretion of fat in the urine; lipuria.

Pimenta (pi-men'-tah) [Sp., pimiento, the pepper-plant : gen., Pimente]. Allspice. The immature fruit of Pimenta officinalis. It contains an aromatic, pungent, volatile oil that is much used as a flavor and condiment. It is useful in flatulence and to prevent the griping of purgatives. Dose gr. $\mathrm{x}-\mathrm{xl}$. P., Aqua

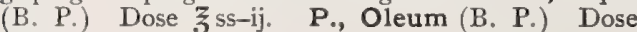
$m_{\mathrm{j}-\mathrm{iv}}$.

Pimento (pi-men'-to). Synonym of Pimenta.

Pimpernel (pim'-per-nel) [ME., pympyrnel, pimpernel]. See Anagallis arvensis.

Pimpinella (pim-pin-el'-ah) [Fr., pimpernel]. A genus of umbelliferous plants, the pimpernels.

Pimple $\left(\right.$ pim' $\left.^{\prime}-p l\right)$ [AS., pipel, a pimple]. A small pustule or papule. See Papule and Pustule. P., Maggot, a popular term for Comedo. P. Mite. See Demodex folliculorum, under Parasites (Animal), Table of.

Pimply (pim'-ple) [AS., pipel, a pimple]. Spotted; covered with pimples.

Pin [ME., pinne, a pin]. A metal instrument shaped like a needle, but with a globular head, used for fastening or holding parts together. P.-buttock, a sharp, angular buttock. P., Center, the pointed steel rod projecting from the center of the trephine-saw, used for fixing the trephine. P., Harelip, a strong, long pin passed through the lips of a wound in order to form a support for the sutures which are wound around it. P.-sensation. See Pins and Needles. P.worm. See Oxyuris vermicularis among Parasites (Animal), Table of.
Pinacocytal ( $\left.\not i n-a k-o-s i^{\prime}-t a l\right)$ [ $\pi i v a \xi$, a tablet; kítos, a cell]. Pertaining to pinacocytes.

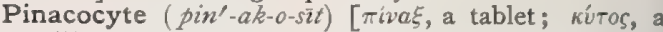
cell ]. In biology, one of the simple, pavement, epithelial cells composing the ectoderm of most sponges.

Pinacolin (pin-ak'-0-lin), $\mathrm{C}_{6} \mathrm{H}_{12} \mathrm{O}$. A ketone obtained from pinacone by the action of hydrochloric acid with heat. The pinacolins are ketones contain ing a tertiary, alkyl group, formed from the pinacones.

Pinacone (pin'-ak-on), $\mathrm{C}_{6} \mathrm{H}_{14} \mathrm{O}_{2}$. A diatomic alcohol which crystallizes from its aqueous solution in the form of the hydrate, $\mathrm{C}_{6} \mathrm{H}_{14} \mathrm{O}_{2}+\mathrm{CH}_{2} \mathrm{O}$, which consists of large, quadratic plates, melting at $42^{\circ} \mathrm{C}$. and gradu ally efflorescing on exposure. In the anhydrous state it is a crystalline mass that melts at $38^{\circ} \mathrm{C}$. and boils at $171^{\circ}$ or $172^{\circ} \mathrm{C}$. The pinacones are glycols that contain two hydroxyl groups attached to two adjoining carbon atoms, which in turn are linked to two alkyls.

Pinalic Acid (pin-al'-ik). See Acid, Valeric.

Pince-cystotome (pans'-sis'-to-tōm) [pince (Fr.), for-

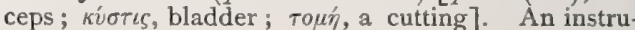
ment terminating in two triangular cutting-blades, and which is used as a cystotome in cataract-operations.

Pincement (pans'-ma(n)g) [Fr., "pinching"]. In massage, a pinching or nipping of the tissues; it is useful in neurasthenia.

Pince-nez (pans'-na) [Fr.]. Eyeglasses kept in place on the nose by a spring.

Pincers (pin'-sers) [Fr., pince]

Pincoffin (pin'-koff-in). Same as Azale.

Pindal, Pindar, Pinder ( $\operatorname{pin}^{\prime}-d a l$, pin'-dar, pin'-der). See Arachis hypogaa.

Pine $(\operatorname{pin})$ [pinus, pine]. See Pix. P.-apple Fiber, the leaves of the several varieties of Bromelia yield a fine, nearly colorless, fiber, which is worked, especially in Brazil, for the manufacture of the so-called "silkgrass." P.-apple Oil, an alcoholic solution of ethyl butyric ether. P.-bark, a bark that is much used in Austria, Bavaria, and Southern Germany in themanufacture of leather. It contains from seven to ten per cent. of tannin and considerable resinous extractive matter. It does not yield as good a leather as oak-bark. P.bath. See Bath. P.-gum, a variety of sandarach, from the Australian trees Callitris robusta and $C$. rhomboidea. P.-needle Bath, a bath in which pine or fir needles are mixed with the water; it is used in Germany as a stimulant tonic.

Pineal $\left(p i-n e^{\prime}-a l\right)$ [pinus, a pine-cone]. Belonging to or shaped like a pinecone. P. Body (so called from its resemblance in shape to a pine-cone), a small, reddish-gray, vascular body situated behind the third ventricle, which is embraced by its two peduncles; it is also called the conarium, from its conic shape. It rests upon the pregeminum, and is connected with the thalami by two peduncles. Its function is unknown. It is considered to be the remains

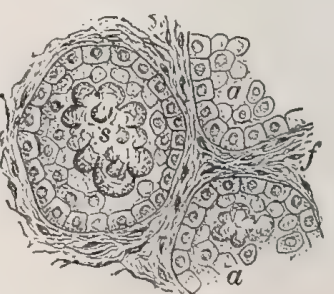

Section of Human Pineal BODY.

$a, a$. Acini lined and partially filled with epithelium and calcareous concretions $(s)$ $f$ Intertubular fibrous tis. sue. (After Piersol.) of the pineal eye of lower vertebrates. P. Eye, a rudimentary third, median or unpaired eye of certain lizards (Anouis, Hatteria, Veranus, Calotes, Seps, Leiodera), connected with the homologue of the pineal 
gland of higher animals by the pineal stalk. It is the vestige of what was a functionating sense-organ in extinct reptiles (Labyrinthodonta), and perhaps in mesozoic mammals (Tritylodon), or possibly an organ for the perception of warmth; the pineal body, epiphysis, or conarium, epiphysial eye, parietal eye,

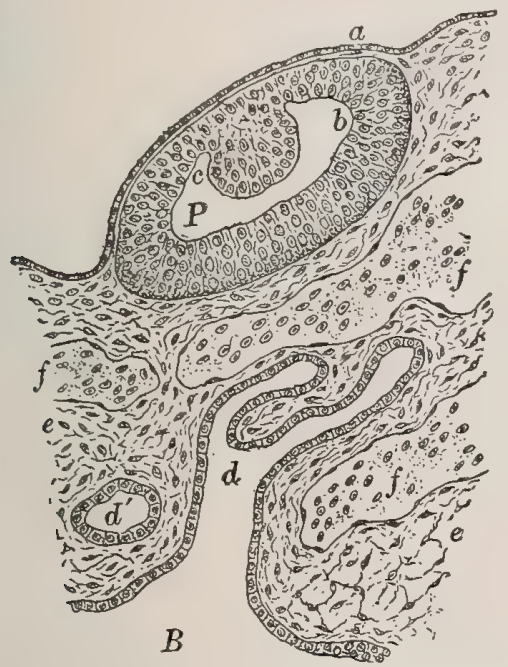

Sagittal Section Through part of Head of Embryo LIZARD, showing so-called pineal eye.

$P$. Specialized isolated extremity of pineal diverticulum from brain-vesicle $(B)$. b.c. So-called retinal and lenticular areas of its walls. a. Ectoderm. $d$. Remains of diverticulum undergoing division into tubules $\left(d^{\prime}\right)$. $f$. Blood-vessels. $e$ Mesodermic tissue. (After Piersol.)

third eye. P. Gland. See P. Body. P. Peduncles, the habence or habenule. P. Sand, the brainsand, often found in the pineal body. P. Ventricle, the cavity occasionally found within the pineal body; it represents the persistence of a fetal condition.

Pinenchyma (pin-en'-kim-ah) [ $\pi i v a \xi$, tablet; $\check{\varepsilon} \gamma \chi v \mu a$, infusion]. Tissues composed of flat cells.

Pinene $\left(p i^{\prime}-n e ̂ n\right)$ [pinus, pine], $\mathrm{C}_{10} \mathrm{H}_{16}$. A hydrocarbon, the chief ingredient of the turpentine-oil prepared from the different varieties of pine, of eucalyptus-oil, juniper-berry oil, sage-oil, etc.

Ping Ping. The root of a Chinese plant, used in vesical affections. Unof.

Pinguecula, Pinguicula (pin-grvek'-u-lah, pin-mwik'$u$-lah) [pinguis, fat]. A small, yellow-white tumor of the conjunctiva, situated between the cornea and the canthus of the eye.

Pinguefaction (pin-gwe-fak'-shun) [finguis, fat; facere, to make]. Conversion into fat.

Pinguicula (pin-grik'-u-lah) [pinguis, fat]. I. A genus of some thirty species of plants of wide geographic distribution; the butterworts. They have vulnerary and aperient properties, and are locally used in thickening milk. They are insectivorous plants, and contain one or more digestive ferments. 2. A small tumor of the conjunctiva.

Pinguid (ping'-gwid) [pinguis, fat]. Fat; unctuous.

Pinguidinous (ping-greid"-in-us) [ pinguis, fat]. Containing fat.

Pinguitude (ping'-grvit-ūd) [pinguis, fat]. Fatness.

Pinguoleum (ping-gwo'-le-um) [pinguis, fat; oleum, oil]. A fatty or fixed oil.

Pinhole ( $\left.\operatorname{pin}^{\prime}-h^{\prime} l\right)$ [ME, pinne, pin; AS., hol, a hole]. A minute perforation, like that made by a pin. P. Os, an extreme degree of atresia of the os uteri, seen in young and undeveloped women. P. Pupil, Pin-point Pupil, contraction of the iris to an extent that the pupil is scarcely larger than a pin's head. It is seen in opium-poisoning, after the use of myotics, in certain cerebral diseases, in locomotor ataxy, etc.

Pinic Acid (pin'-ik) [ pinus, pine], $\mathrm{C}_{20} \mathrm{H}_{30} \mathrm{O}_{2}$. A resinous body obtained from pine-resin, having the same formula as pinearic acid, with which it may be identical.

Pinicoline (pin-ik'-o-lin) [pinus, a pine-tree ; colere, to inhabit]. In biology, inhabiting pine forests, e.g., the Capercally, or Cock-of-the-wood (Tetrao urogallus).

Piniform ( $p i^{\prime}$-nif-orm) [pinus, pine; forma, form] Pine-shaped; resembling a pine-cone. P. Decussation, a decussation of fibers in the oblongata between the central gray matter and the pyramids.

Pining (pi'-ning) [ME., pinen, pain]. Vulgar synonym for tuberculosis of cattle. Also applied to a peculiar melancholic longing of pregnant women, commonly called "longings."

Pinion (pin'-yun) [penna, pinna, wing, feather]. In biology, the manus or distal segment of a bird's wing (carpus, metacarpus, phalanges) bearing the primary remiges.

Pinipicrin (pin-ip-ik'-rin) [pinus, pine ; $\pi \iota \kappa \rho b s$, bitter], $\mathrm{C}_{22} \mathrm{H}_{36} \mathrm{O}_{11}$. A bitter glucosid obtained from the needles and the bark of Pimus sylvestris and other plants.

Pinitannic Acid (pin-it-an'-ik) [pinus, pine; ME., tannen, $\tan ], \mathrm{C}_{14} \mathrm{H}_{16} \mathrm{O}_{8}$. A yellowish-red powder, a variety of tannic acid, found in Pinus sylvestris and other plants.

Pinite $\left(\right.$ pin' $\left.^{\prime} \bar{\imath} t\right)$ [pinus, pine $], \mathrm{C}_{2} \mathrm{H}_{12} \mathrm{O}_{5}$. A substance that occurs in the resin of Pinus lambertina. It melts at $150^{\circ} \mathrm{C}$. It is a pentahydric phenol of hexahydrobenzene.

Pinites (pin-i'-tēz) [ pinus, pine]. A genus of extinct coniferous trees, of which $P$. succinifer is thought to have been the source of amber.

Pink (ping $k$ ) [origin obscure]. A shade of pale-red. P. Crystals. Same as $P$. Salt. P.-eye, the popular term for a contagious muco-purulent conjunctivitis of horses, characterized by a red color of the eyeball. It may occur in man. P.-madder. See Pigments, Conspectus of. P.-root. See Spigelia. P. Salt. See Pigments, Conspecties of.

Pinna $\left(p^{\prime}{ }^{\prime}-a h\right)$ [pinna, penna, feather, wing: $p l$, Pinnce]. In biology, a name applied to various winglike or feather-like organs; as a wing, feather, fin, flipper, the ala auris or external cartilaginous flaps of the ear, the ala of the nose, one of the primary divisions of a pinnately-compound leaf. P. nasi. Synonym of Ala nasi.

Pinnadiform (pin- $a d^{\prime \prime}$-if-orm) [ pinna, feather, wing; $a d$, to ; forma, form]. In biology, applied to certain fishes in which the skin extends out on some or all of the fins.

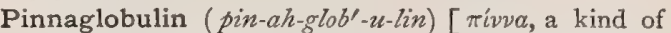
mussel; globulus, a round body]. A respiratory pigment containing manganese found in the blood of Pinna squamosa.

Pinnate $\left(\right.$ pin' $\left.^{\prime}-\bar{a} t\right)$ [pinna, a feather]. In biology, feathered or shaped like a feather.

Pinnatifid (pin-at'-if-id) [pinna, a feather; findere, to cleave]. In biology, cleft in a pinnate manner, with the marginal divisions reaching at least half way to the midrib; pinnatisected.

Pinnatilobate (pin-at-il-o'-bät). Same as Pinnatilobed.

Pinnatilobed (pin-at'-il-ōbd) [pinna, a feather; lobus, 
a lobe]. In biology, having several alternating rounded lobes and sinuses on each side of the midrib. Pinnation (pin-a'-shun) [ pinna, feather]. In biology, the state or condition of being constructed in a pinnate manner.

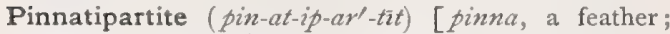
partiri, to divide]. In biology, pinnately parted; having the divisions reaching almost to the midrib.

Pinnatiped (pin-at'-ip-ed) [pinna, a feather; pes, foot]. In biology, pin-footed or flipper-footed; lobiped.

Pinnatisect (pin-at'-is-ekt) [pimna, a feather; secare, to cut ]. In biology, divided down to the midrib.

Pinnatulate (pin-at'-u-lata $[\mathrm{dim}$. of pennatus, feathered]. In biology, bearing secondary pinnations or subdivisions.

Pinniform (pin'-if-orm) [ pinna, feather; forma, form] In biology, resembling a feather, wing or flipper.

Pinnigrade (pin'-ignrād) [pinna, feather; gradi, to walk]. In biology, moving by means of fins.

Pinninerved (pin'-in-ervd) [ pinna, feather; nervum, nerve]. Same as Penninerved.

Pinniped (pin'-ip-ed) [pinna, feather, fin; pes (pedis), foot]. In biology, having feet like fins or flippers.

Pinnitarsal (pin-it-ar'-sul) [pinna, feather; tarsus, tarsus]. In biology, having pinnate feet.

Pinnitentaculate (pin-it-en-tak'-u-lāt) [ pinna, a feather; tentaculum, a tentacle]. In biology, having pinnate tentacles.

Pinnula ( pin' $^{\prime}-u$-la $)$ [L., a little plume : pl., Pinnula]. In biology, a small or secondary pinna.

Pinnule (pin'-iul) [pinnula, a little plume]. In biology, a small or secondary pinna; a pinnula, as a small pin or one of the ultimate divisions of a bipinnate or tripinnate leaf.

Pins and Needles. The popular name for those abnormal sensations of tingling experienced by patients in various diseased conditions of the nervous system, or after an injury of a nerve.

Pint (pint) [Fr. pinte, a spot]. The eighth part of a gallon. Octarius. Symbol 0 .

Pinta Disease [Sp. "painted"]. Spotted Sickness; a tropical, contagious disease, due to a fungus, that produces various discolorations of the skin. The spots are scaly, very variable in color, shape, number, and size, and the disease appears to be allied in its characters to tinea versicolor. It usually begins on uncovered parts such as the face and extremities, but may affect the scalp or other parts of the body. The color of the patches is black, grayish-blue, red, or dullwhite. The disease is very chronic.

Pinus ( $\left.p i^{\prime}-n u s\right)$. See $P i x$.

Pioscope ( $\left.p i^{\prime}-0-s k \bar{p} p\right)$ [ $\pi i \omega \nu$, fat; $\sigma \kappa o \pi \varepsilon \tilde{\imath} \nu$, to see]. A variety of galactoscope.

Piotrowski's Reaction. The "biuret-reaction" for proteids, developed by the addition of a few drops of dilute cupric sulphate and the subsequent addition of an excess of caustic potash or soda. It gives a reddishviolet color like that given by the substance biuret, a derivative of urea. The color deepens on boiling.

Pip [ME., pippe, pip]. A disease of fowls, characterized by a secretion of thick mucus in the throat and mouth.

Piper (pi'-per) [L.]. Pepper; Black Pepper. The unripe fruit of $P$. niorum, shriveled and dried. The plant is a native of the East Indies and contains an oleoresin, an alkaloid, and a volatile oil. It is stimulant to the stomach, and irritant to the skin and is used mainly to correct flatulence, and locally for hemorrhoids. Dose gr. $\mathrm{v}-\mathrm{xx}$. P. æthiopicum, the guinea corn (Habzelia athiopica). P. album. See Pepper, White. P. angustifolium. See Matico. P. anisatum, a species of Piper substituted for cubebs. P. betel. See Betel. P. clusii, the Ashanti-pepper of West Africa, P., Confectio. (B. P.) Dose 3 j-ij. P.cubeba. See Cubeb. P. jaborandi, Baillon's name for a species of Piper yjelding jaborandi. P. longum, an East Indian plant, no longer employed in medicine, but infused in milk as a poison for flies. P. methysticum. See Kava-kava. P. nigrum. See Pepper, Black, P., Oleo-resina, contains the volatile oil. Dose $m x / 4-j$. P. umbellatum, one of the sources of the Brazilian Caapeba, or Periparola, which is also obtained from Cissampelos caapeba.

Piperazin (pi-per-a'-zin), $\mathrm{C}_{3} \mathrm{H}_{10} \mathrm{~N}_{2}$. Diethylene diamin; a crystalline solid melting at $104^{\circ} \mathrm{C}$, and boiling at $145-146^{\circ} \mathrm{C}$. It is reported to be a powerful solvent of uric acid, and its dilute solution is prescribed in cases of urinary lithiasis. Dose gr. v-viij. Unof.

Piperic (pi-per'-ik) [piper, pepper]. Pertaining to, or containing pepper. P. Acid, $\mathrm{C}_{12} \mathrm{H}_{10} \mathrm{O}_{4}$, a monobasic acid obtained by boiling piperin with alcoholic potash in the presence of hydrochloric acid.

Piperidin (pi-perf-id-in) [piper, pepper], $\mathrm{C}_{5} \mathrm{H}_{11} \mathrm{~N}$. A substance that occurs attached to piperic acid as piperin in pepper. It is artificially prepared by reducing pyridin. It is an alkaline liquid that dissolves quite easily in water and alcohol. Its odor is like that of pepper. It boils at $106^{\circ} \mathrm{C}$

Piperin (pi'-per-in) [piperina; piper, pepper], $\mathrm{C}_{17} \mathrm{H}_{19}$ $\mathrm{NO}_{3}$. The alkaloid of pepper (Piper nigrum and other varieties). It is artificially produced by the action of piperic acid chlorid upon piperidin. It crys. tallizes in prisms and melts at $128^{\circ} \mathrm{C}$. Its medical virtues are those of black pepper; it has also febrifuge properties. Dose gr. j-x.

Piperinal (pip-er-in'-al). See Piperonal.

Piperitious (pip-er-ish'-us) [ piper, pepper]. Peppery; having a pungent taste.

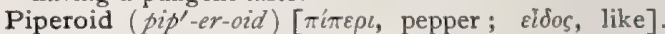
Any resin resembling the oleo-resin of pepper.

Piperonal (pip-er-o'-nal) [piper, pepper], $\mathrm{C}_{8} \mathrm{H}_{6} \mathrm{O}_{3}$. Heliotropin; the flavoring principle of heliotrope; a crystalline body, obtained by oxidizing piperic acid. It dissolves with difficulty in water, melts at $37^{\circ} \mathrm{C}$. and boils at $263^{\circ} \mathrm{C}$. It is largely used in perfumery, and is also antipyretic and antiseptic. Dose gr. xv. Unof.

Pipet, Pipette (pip-et') [Fr., dim. of pipe]. A glass tube open at both ends, but usually drawn out to a smaller size at one end. It may be graduated or not and it may or may not have a central expanded bulb. It is used for transferring small portions of a liquid from one vessel to another.

Pipmenthol (pip-men'-thol) [piper, pepper; mentha, mint]. A name for the menthol obtained from peppermint.

Pipsissewa (pip-sis'-e-zuah). See Chimaphila.

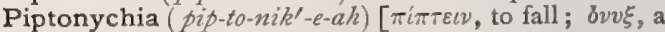
nail]. Shedding of the nails.

Pique (pék) [pique, a point]. See Sarcopsylla penetrans under Parasites (Animal), Table of.

Piqûre (pik-êr') [Fr.]. Puncture.

Piriform (pir'-if-orm). Synonym of Pyriform.

Pirogoff's Operation. A method of amputation at the ankle in which the greater part of the calcaneum is retained to give length and surface to the stump. See Operations, Table of.

Piscatology (pis-kat-al'-a-je) [piscis, fish; $\lambda 6 \gamma n s, \mathrm{sci}-$ ence]. The scientific study of fishes.

Piscicolous (pis-ik'-o-lus) [ piscis, fish; colere, to inhabit]. In biology, parasitic upon fishes.

Pisciculture (pis'-ik-ul-chür) [ piscis, a fish ; cultura, care]. The artificial breeding and culture of fish, es- 
pecially for the purpose of stocking streams and littoral waters with edible varieties of fish.

Pisciculus (pis-ik'-z-lus) [L.]. An old name for the biceps muscle of the arm.

Piscidia (pis-id'-e-ah) [piscis, fish; cadere, to kill]. Jamaica Dogwood; the bark of $P$. erythrina. Its active principle is thought to be a glucosid, piscidin. It resembles opium in its physiologic properties, which, however, are much less intense and without unpleasant after-results. It is useful in whooping-cough and neuralgia, but sometimes causes gastric distress. Dose of the (proprietary) fld. ext. $3 \mathrm{ss}-\mathrm{j}$, cautiously increased. Liquor sedans. See Vibumum. Unof.

Piscidin (pis-id'-in) [piscis, a fish; cadere, to kill] $\mathrm{C}_{29} \mathrm{H}_{24} \mathrm{O}_{8}$. A crystalline body, the active principle of Piscidia erythrina. Its action is chiefly on the spinal cord. It is said to paralyze the sensory ganglia, and to excite the motor ganglia; it also depresses the heart.

Pisciform (pis'-if-orm) [ piscis, fish; forma, form]. In biology, resembling a fish in form.

Piscivorous (pis-iv'-or-us) [ piscis, fish; vorare, to eat]. In biology, living upon fish.

Pisiform (pis'-if-urm) [pisum, a pea; forma, form]. Resembling a pea in shape. P. Bone, a small, nearly circular bone on the inner and anterior aspect of the carpus.

Piso $\left(p i^{\prime}-s o\right)$ [L.]. Mortar.

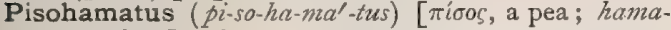
tus, hooked]. Same as Piso-uncinatus.

Piso-uncinatus (pi-so-un-sin- $\left.a^{\prime}-t u s\right)$ [ $[\pi i \sigma o s$, a pea ; uncinatus, hooked]. A rare muscle, passing from the pisiform to the unciform bone.

Piss (pis) [ME., pissen, to piss]. I. To urinate. 2. Urine.

Pisse, Chaude (shöd pés) [Fr.]. The scalding and painful urination of the acute stage of gonorrhea.

Pissocopy (pis-sok'-o-pe) [ME., picchen, pitch ; кó $\pi \tau \varepsilon \iota \nu$, to strike]. The process of covering with pitch; also epilation through the action of a pitch-plaster.

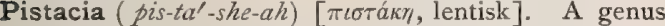
of anacardiaceous trees of warm regions. P. vera, yields the edible pistachio-nut, which is used in pharmacy in the preparation of emulsions. Mastic and Chian turpentine are also produced by trees of this genus.

Pistation (pis-ta'-shun) [ pistare, to pound]. The act of bruising in a mortar.

Pistic (pis'-tik) [ $\pi \iota \sigma \tau \iota k o ́ s$, a word of doubtful meaning; it may signify "drinkable," i.e., liquid, or "faithful,", i.e., genuine]. A qualification applied to the best and purest nard, or true spikenard.

Pistil (pis'-til) [pistillum, a pistle]. In biology, a modified leaf or leaves forming the central organ of a flower, bearing the ovules and seeds. It consists of the seed-containing portion, the ovary; the pollen-receiving portion, the stigma; and generally an intervening portion, the style.

Pistillary (pis'-til-a-re) [pistillum, a pistle]. In biology, of or pertaining to the pistil.

Pistillate (pis'-til-ät) [ pistillum, a pistle]. In biology, applied to flowers that possess pistils but not stamens.

Pistillidium (pis-til-id'-e-um). See Archegonizum.

Pistilliferous (pis-til-if'-er-us) [pistillum, a pistle ; ferre, to bear]. Same as Pistillate.

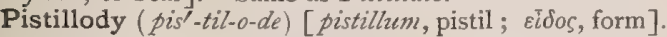
In biology, the metamorphosis of other organs into pistils or carpels.

Piston Pulse. See Corrigan's Pulse.

Pit [ME., pit, a pit]. I. A hole, depression, or cavity in the body; e.g., the pit of the stomach, the armpit. 2 . One of the pores in the more or less liquefied cellwalls of many glands. 3. Parts are said to pit on pressure where they preserve for a time the indentation made in them by pressing with the finger. I'itting on pressure is seen in edema. P. of the Stomach (I) a name popularly given to that part of the abdomen just below the sternum and between the car tilages of the false ribs. It is also termed Scrobic ulus cordis: (2) any one of the openings of gastric tubules visible on the mucous surface of the stomach. P., Tear, the lacrymal sinus.

Pitch (pich) [ME., picchen, pitch]. I. That quality of sound which depends upon the relative rapidity of the vibrations that produce the sound. In percussion, variations in the pitch of the sounds elicited may have a high diagnostic importance; $e_{.} g$., in the case of the lungs, a high-pitched note on percussing the chest usually indicates either consolidation of the lung-tissue or the presence of something abnormal between the lung and the chest-wall. 2. [Pix, pitch.] The residue remaining in the still after nearly all the volatile constituents have been driven off in the fractional distillation of coal-tar. It has a specific gravity of from 1.09 (soft pitch) to I.I2 (hard pitch). P., Burgundy, the prepared resin of Abies excelsa. When pure, it is a brittle, yellowish-brown, adhesive substance, readily soluble in water, in absolute alcohol, and in glacial acetic acid. It is used in the preparation of pitch-plaster. P., Canada, the prepared resin of Abies canadensis. It is a brittle, reddish, opaque substance, containing traces of a volatile oil. It is used for the manufacture of plasters. P., Jew's, P., Mineral, asphalt. P.plaster, emplastrum picis.

Pitcher (pich'-er) [ME., picher, a small jug]. See Ascidium. P.-plant. See Parracenia, and Nepenthes.

Pith [ME., pith, pith]. The soft cellular tissue found in the center of the stalks of plants. It has a very low specific gravity. Also the marrow of bones.

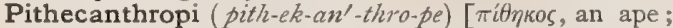

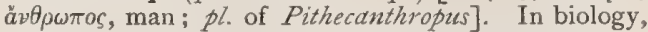
ape-men, the hypothetic prehistoric men, alali.

Pithing (pith'-ing) [ME., pith, pith]. I. The removal of the cerebral lobes of a frog or animal for the purpose of physiologic experimentation; decerebration. 2. The slaughter of animals by penetrating the cerebrospinal axis.

Pithode (pith'-ō'). See Karyokinesis.

Pitres' Method. The method of post-mortem examination of the brain by means of vertical transverse sections from before backward. The first or prefrontal section is carried down two and a quarter inches in front of the fissure of Rolando; the second. or pedunculo-frontal section is made three-quarters of an inch in front of that fissure and divides the second and third convolutions near their insertion into the ascending frontal convolution. The third or frontal section is made at the level of the ascending frontal convolution. The fourth or parietal section passes through the ascending parietal convolution. The fifth or pedunculo-parietal section is carried down an inch behind the fissure of Rolando. The sixth or occipital section is made a little less than half an inch in front of the parieto-occipital fissure. A vertical antero-posterior incision through the superior vermiform process of the cerebellum opens the fourth ventricle.

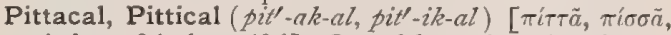
pitch ; $\kappa a \lambda o ́ s$, beautiful]. One of the aurin series of dyes, first obtained in oxidizing the fractions of beechwoodtar boiling at high temperatures. It consists of the dark blue salts of eupittonic acid. See Pigments, Conspectus of.

Pittacium ( $\left.p i t-\alpha^{\prime}-s h e-\imath m\right)[\pi i \tau \tau \bar{\alpha}, \pi i \sigma \sigma \tilde{a}$, pitch $]$. Pitchplaster. 
Pitted (pit'-ed) [ME., pit, a pit]. Marked by inden tations or pits, as from smallpox.

Pitting (pit'-ing) [ME, pit, a pit]. The formation of pits; also the quality of preserving, for a short time, indentations made by pressing with the finger.

Pituita (pit- $\left.u^{\prime}-i t-a h\right)$ [L.]. Phlegm; mucus.

Pituitary (pit-u'-it-a-re) [ piluita, phlegm]. Mucus; secreting or containing mucus. P. Body, a small, reddish-gray vascular body, weighing about ten grains, contained within the sella turcica. The pituitary body consists of two portions, the large anterior, oral and the small posterior, cerebral division. The anterior lobe is derived as a diverticulum from the primitive oral cavity, and, as such, is lined with oral ectoderm, while the posterior lobe descends as an outgrowth from the floor of the primary interbrain. The stalk of this outgrowth remains as the infundibulum. The pituitary body has attracted much attention on account of pathologic changes in its structure in certain obscure diseases, such as acromegalia, myxedema, and others. In some cases of the affection first named, it has been much enlarged. It is called also hypophysis cerebri and pituitary gland. P. Diverticulum, a flask-like outgrowth of the middle of the upper posterior portion of the buccal cavity of the embryo. It takes part in the formation of the pituitary body. P. Fossa. See Fossa. P. Gland. See P. Body and Gland. P. Membrane, the Schneiderian membrane. P. Space, in the embryo, the open space at the base of the skull that subsequently becomes the seat of the pituitary body. It corresponds to the sella turcica of the sphenoid bone.

Pituitous (pit-u'-it-us) [ pituita, phlegm]. Containing or resembling mucus.

Pituri (pit-u'-re). Same as Duboisia.

Piturin (pit'-u-rin). A liquid alkaloid obtained from $D u$ boisia hopwoodii. It is probably identical with nicotin.

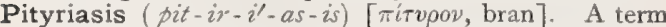
formerly applied to various pathologically dissociated skin-affections, the most striking clinical feature of which is the presence of fine, branny desquamation Also a synonym of Seborrhea. P. cachecticorum. Same as Seborrhea. P. capillitii, P. capitis. See Alopecia furfuracea. P. circinata et marginata, an eruption of rose-colored spots on the trunk, the limbs, and in the axillæ. It is of parasitic origin. P. gravidarum; Chloasma gravidarum; the discoloration of the skin sometimes observed during pregnancy. $\mathbf{P}$. infantilis, a desquamative eruption attacking infants; it is probably eczema. P. maculata et circinata. See $P$ rosea. P. nigra, pityriasis with pigmentation occurring in the aged. Also, a papular eruption terminating in slight desquamation, which attacks children brought to England from India. P. nigricans. Synonym of Chromidrosis. P. pilaris. See Keratosis pilaris. P. rosea ; $P$. naculata et circinata: Herpes tonsurans maculosus; an acute inflammatory skin-disease characterized by macular or circinate lesions, occurring mostly on the trunk. The eruption consists at first of rosy-red spots, which later become brownish. The lesions are round, but owing to their tendency to recover at the center and to extend peripherally, gyrate and irregular figures are formed. Furfuraceous desquamation is a marked feature. P. rubra; Dernatitis exfoliativa; a chronic inflammatory skin-disease, beginning in one or more localized patches, which coalesce and gradually invade the whole body. The skin may be of a dark or vivid red or bluish-red. There is no infiltration and no moisture, but there may be edema of the lower limbs. The desquamation is very free; the scales are thin and papery on the general surface, im- bricated, and from a line to an inch or more in diameter. The disease lasts months or years, and generally ends fatally from progressive emaciation and exhaustion, or from some intercurrent affection. P. rubra pilaris ; Lichen ruber acuminatus; a primarily non-inflammatory disease of the skin, characterized by follicular papules, with horny centers, tending to become general or even universal in distribution. The papules are hard, dry, brownish-red, and seated at the hair-follicles. An atrophied hair occupies the center, and is surrounded by a sort of horny sheath which penetrates into the follicle. The papules vary in size from a small pin's head to a millet-seed, and are most abundant on the limbs. Deep folds are formed at the joints. Pruritus is absent or only slight. The course is slow and irregular; the pathology is unknown. P. simplex. See Alopecia furfuracea. P. senilis, pityriasis of the aged. P. tabescentium. See Seborrhaca universatis. P. versicolor. See Tinea versicolor.

Pityrisma (pit-ir-iz'-mah). Synonym of Pityrisasis.

Pityroid (pit'-ir-oid) [ [írvoov, bran; Eidos, like]. Furfuraceous, branny.

Pivot (piv'-ot) [Fr., pivot, a pivot]. A pin on which a wheel turns. P.-joint. See Cyclarthrosis. P. Tooth, an artificial crown, designed to be applied to the root of a natural tooth, by means of what is usually termed a pivot, but more properly a dowel or tenon.

Pivoting (piv'-ot-ing) [Fr., pivot, a pivot]. 'The fixation of an artificial crown to a tooth by means of a pivot or pin.

Pix (piks) [L. : gen., Picis]. Pitch. The resinous exudation of certain coniferous trees. The varieties in common use are chiefly Burgundy Pitch, from the Norway spruce, Abies excelsa, and Canada Pitch, from $A$. canadensis. Pitch melts at about the temperature of boiling water and softens by the heat of the human body. It is soluble in glacial acetic acid and in absolute alcohol, and is used mainly as the base of plasters. Picis burgundicæ, Emplast., Burgundy pitch 80, oliveoil 5, yellow wax I5. P. canadensis, Emp., contains Canada pitch, 90, yellow wax Io parts. Picis cantharidatum, Emp., Burgundy pitch 92, cantharides cerate 8 parts. P. liquida, tar, an empyreumatic oleo-resin obtained by the destructive distillation of various species of pine; it is blackish-brown in color and possesses a well-known taste and odor. It yields oil of tar, pyroligneous acid, creasote, and carbolic acid. It is a complex mixture of resins and hydrocarbons. Externally, it is a stimulant to the skin; internally, a gastro-intestinal irritant. It is serviceable in scaly diseases of the skin and of benefit in bronchitis. Dose 3 j-ij. P. liq., Infus., unof, made by shaking I part of tar with 4 of water frequently for 24 hours. Dose Oj-ij daily. P. liq., Ol., a volatile oil distilled from tar; it consists of various hydrocarbons, phenols, etc, and is used locally. P. liq., Syr., contains 6 per cent. of tar in syrup. Dose $3^{i j}-z_{\text {ss. }}$ P. liq., Ung., equal parts of tar and suet. P. Liq., Vin., wine of pitch, unof., tar $3 \times v j$, glycer in, white wine, honey āā $\bar{\zeta}$ viij, acetic acid $\zeta$ j, boiling water Ovj. Carbonis detergens, Liq., unof, an alcoholic solution of coal-tar, a useful antiseptic in putrid sore-throat, etc. Vapor olei pini sylvestris, (B. P.) Inhalation of fir-wood oil, used in sorethroat and chronic laryngitis.

Pixol (piks'-ol) [pix, pitch; oleum, oil]. A disinfect. ant prepared by dissolving a pound of green soap in three pounds of tar and slowly adding a solution of a little over three ounces and a half of either potash or soda in three pounds of water. For use one part of the syrupy liquid thus formed is added to 19 parts of 
water, forming a five per cent. solution of pixol, and in this strength it is used for disinfecting linen and washing the hands. For the disinfection of dejecta a ten per cent. solution is required.

Pizzle $\left(p i z^{\prime}-l\right)$ [ME.]. The penis, especially of a domestic mammal.

Placebo (pla-se'-bo) ["I will please:" fut. of placere, to please]. Anything prescribed for the purpose of pleasing or humoring the whim of a patient rather than for its therapeutic effect.

Placenta ( $\left.p l a-s e n^{\prime}-t a h\right)$ [a particular use of placenta, $\pi \lambda a-$ roṽs, a cake: pl.,Placenta or Placentas]. In biology: (a) the organ of attachment of an embryo or fetus to the wall of the uterus, and by means of which it is nourished; $(b)$ the ovule-bearing portion of the ovary of a plant. The mammalian placenta is a spongy mass of tissue derived from the chorion and decidua, its evolution having begun with the differentiation of the ectoderm of the germinative area by the formation of a thickened region called the area placentalis. It is a flat, circular, spongy body, adherent during gestation to the inner wall of the uterus and connected by the umbilical cord to the fetus, and forming for it the organ of nutri-

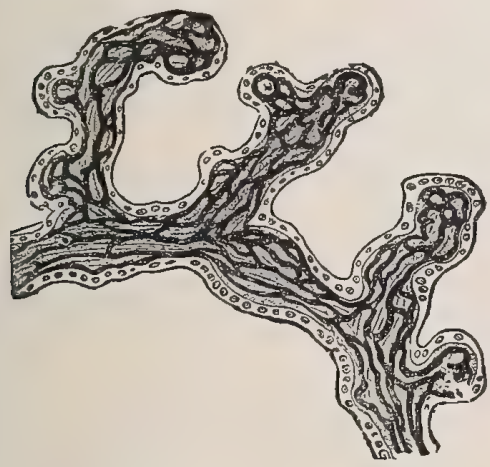

Human Placental Villi.

Blood-vessels black. (From Stirling.)

tion and respiration. The placenta is developed about the third month of embryonal life. The chorionic villi in contact with the decidua reflexa cease to grow, while at the decidua serotina the villi become exceedingly numerous. The uterine mucous membrane in which the villi are embedded contributes a share to the formation of the placenta. This is known as the maternal, in contradistinction to the chorionic or fetal portion. At term the placenta weighs one pound, is one inch thick at its center, and seven inches in diameter. The fetal side is covered by the amnion and penetrated by the umbilical cord. The maternal surface is dark-red, irregular, and covered by the upper layers of cells of the decidua serotina. The placenta is normally situated at the fundus, anteriorly or posteriorly. In the lower animals the placenta is somewhat different. Of the Choriata, those possessing a villous chorion, one class, including the horse, the pig, the camel, etc., presents the villi uniformly distributed; there is no special accumulation anywhere. In the other class the villi are aggregated and specialized in a particular region to form the placenta. Three varieties of placentæ are generally described: (a) That with numerous cotyledons (cow, deer, etc.); (b) zonal placenta (carnivora); (c) discoid placenta (monkey, man). The zonal and the discoid placentæ are deciduate. P., Adherent, abnormal adherence of the placenta to the uterine wall after childbirth. P. Allantoic, a placenta in which the chorion ac- quires vessels by growing together with the vascular walls of the allantoic vesicle (Ungulata), as distinguished from a chorionic placenta, q. $v$. P., Annular, a placenta extending around the interior of the uterus in the form of a belt. P., Battledore, one in which the insertion of the cord is at the margin of the placenta. P., Bell-shaped, one in which there is a partial persistence of the chorionic villi in the upper portion of the chorion. P.biloba, P. bipartita. See Placenta duplex. P., Chorionic, a placenta in which the chorion has its own vessels (Unguiculata). It is regarded as the most primitive type, as distinguished from an allantoic placenta. P. cirsoides, one in which the umbilical vessels have a cirsoid arrangement. P., Cordiform, a heart-shaped placenta. P., Cotyledonary, P., Cotyledonous, a placenta the villi of which are collected into groups; this variety is confined to the Pecora. In the giraffe, the placenta is partly diffused and partly cotyledonous. The Bovidae possess a large number of cotyledons (polycotyledonous), while the Cervide bave only a few. P., Deciduate, a placenta in which the fetal villi are so intimately connected with the uterine wall, that at birth a greater or less portion is brought away with the allantois (after-birth). It occurs in all those Eutheria not included among those mentioned as having non-deciduate placentas. P., Diffused, a placenta which extends over the whole of the chorion. It is characteristic of the Perissodactyla, the Suina, the Tragulina, the Tylopoda, the Sirenia, the Cetacea, and the Lemuroidea. P., Discoid, a placenta which is disc-shaped. It occurs in the Rodentia, Insectivora, Chiroptera, and the Loricata among the Edentata. The discoid chorionic placenta is regarded as the most primitive type, as distinguished from the zonary placenta of carnivora, the diffuse placenta of the lower primates, and the metadiscoid placenta of man, which have been evolved from it. P., Disseminated, one in which the cotyledons are not distinctly localized to one area, but are scattered. P., Dome-like. Synonym of $P .$, Bell-shaped. P., Double. Synonym of $P$. duplex. P. duplex, Placenta bipartita; an anomaly of the placenta, in which it is divided into two portions. P. evanida, the placenta of a blighted ovum in which all structure has been lost from pressure by the surviving ovum, as is seen in some cases of foetus papyraceus. P. fenestrata, one in which the true placental tissue is lacking in one or more places, and the chorion, being free from villi, forms a transparent membrane. P. fœtalis, the smooth amniotic surface of the placenta. P., Fundal, one attached at the fundus. P., Horse-shoe, in twin pregnancy, a condition in which the two placentæ are united by a strip of placental tissue. P., Hydatigenous, a placenta the seat of myxomatous degeneration, as in hydatidiform mole. P., Incarcerated, a placenta retained in the uterus on account of irregular contraction of that organ. P., Lateral, one attached to the lateral wall of the uterus. P. marginata, an anomaly of the placenta in which that organ is surrounded by a margin or collar of placental tissue. P., Maternal, the portion of the placenta contributed by the part of the mucous membrane of the uterus known as the decidua serotina. At birth the maternal portion is only a thin, grayish layer on the uterine surface of the placenta, and can only be stripped off in small pieces. P. membranacea ; occasionally there is a failure of the atrophy of a portion of the chorion which normally occurs, and, instead, placental villi are developed over the entire surface of the chorion. Such a placenta is called placenta membranacea, and is thinner than the normal placenta. P., Metadiscoid, P., Secondary Discoid, a form of placenta found in the Anthropoidea. 
in which the villi are at first diffuse, but ultimately become restricted to the ventral surface. P. multiloba, a placenta consisting of more than three lobes in an animal in which the organ normally is one-lobed. P., Non-deciduate, the simplest form of placenta, in which the papilla-like elevations of the chorion fit into corresponding depressions in the uterus, and in which the chorion can be withdrawn from the placenta at birth. The Artiorlactyla, Prissodactyla, Sirenia, Cetacea, Lemuroidea, and some Edentata (Squamata) have a non-deciduate placenta. In some of them the villi are more or less branched and complicated, at times interlocking so closely that the parts of the epithelium of the maternal cotyledons may be carried away at birth. P. obsoleta, in a twin pregnancy the condition in which the two placentæ are entirely dis-

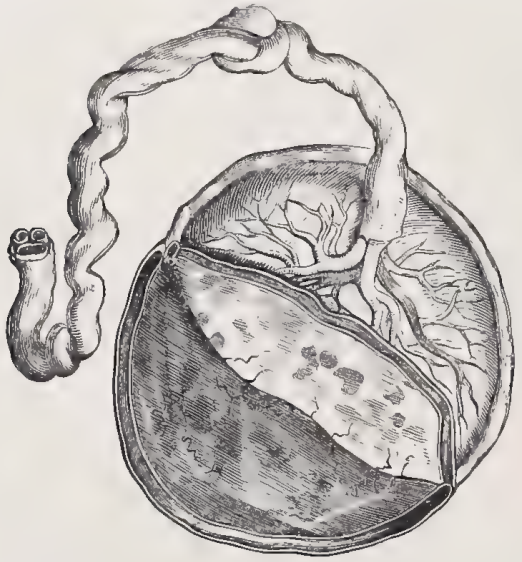

Placenta and Membranes (Stripped UPWARD).

tinct and separate. P. panduriformis, one shaped like a violin. P., Polycotyledonary, P., Polycotyledonous, a placenta such as is seen in ruminants, in which the chorionic villi are collected in a number of large separate tufts, the latter dipping into corresponding crypts in the uterine mucosa. P. prævia, a term applied to a placenta when it is fixed to that part of the uterine wall that becomes stretched as labor advances, so that it precedes the advance of the presenting part of the fetus. P., Retained, one not expelled by the uterus after labor. P.sanguinis. See Blood-clot. P., Secondary Discoid. See $P$., Metadiscoid. P. spuria. See Placenta succenturiata. P., Subsidiary, a distinct and separate lobe in addition to the usual placental mass; such lobes are called Placenta succenturiato. P. succenturiata, an accessory growth to the placenta. When this does not act as true placental tissue it is termed Placento spuria. P. tripartita, an anomaly of the placenta in which there are three portions of that organ. P., Triple, the united placentæ of a triple gestation. P., Twin. Synonym of $P$. duplex. P. uterina, the rough cotyledonous or uterine surface of the placenta derived from the decidua serotina. P., Velamentous, one in which the cord is inserted between the layers of the fetal membranes, presenting a broad surface of attachment in place of the normal round insertion. P., Villous. See $P$., Disseminated. P., Zonary, a placenta which occupies a broad band around the chorion; it is found in the Carnivorn, Hyrax, Elephas, and in the Tubulidentata among the Edentata. Same as P., Annular.

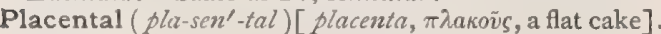

Pertaining to the placenta. P. Dystocia, difficult birth of the placenta. P. Murmur. Same as $P$. Souffe. P. Souffe, a sound erroneously attributed to the circulation of blood in the placenta.

Placentalia (pla-sen-ta'-le-ah) [placenta, $\pi$ iakñ̃s, a cake]. Mammals in which the fetus is nourished through the medium of a placenta.

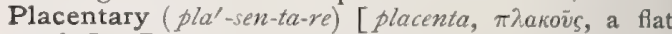
cake]. Pertaining to the placenta.

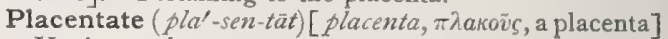
Having a placenta.

Placentation (pla-sen-ta'-shun) [placenta, $\pi \lambda a \kappa o \tilde{s}$, a placenta]. In biology: (a) the process of attachment of the embryo or fetus to the uterus ; $(b)$ the type of placenta or the manner in which it is constructed; the arrangement of the seeds in the pericarp or the arrangement of the placenta itself.

Placentiferous (pla-sen-tif'-er-us) [placenta, $\pi$ hakoüs, placenta; ferre, to bear]. In biology, bearing a placenta.

Placentiform (pla-sen'-tif-orm) [placenta, miakoũs, placenta; forma, form]. In biology, resembling a placenta; discoid with biconcave surfaces.

Placentigerous (pla-sen-tij'-er-us). Same as Placentiferous.

Placentitis (pla-sen-ti'-tis) [placenta, $\pi$ hakoūs, a flat cake; $\iota \tau \iota$, inflammation]. Inflammation of the placenta. P. decidualis, placentitis secondary to inflammation of the decidua.

Placentoid (pla-sen'-toid) [placenta, $\pi$ haкoūs, a flat cake; عidos, like]. Resembling a placenta.

Placentula (pla-sen'-tu-lah) [dim. of placenta, $\pi \lambda a-$ kov̄s, placenta]. A small placenta.

Placoderm, Placodermal (plak'-o-derm, plak-o-der'mal) $[\pi \lambda a ́ \xi$, a plate; $\delta \varepsilon ́ p \mu \alpha$, skin $]$. In biology, having the skin covered with broad flat plates, as a fish.

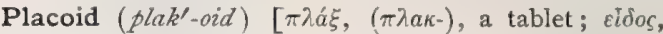
form ]. In biology, plate-like; applied to the ectoskeletal pieces of certain fishes.

Placula (plak'-u-lah) [ $\pi \lambda a ́ \xi$, a tablet, plate: pl., Placula ]. In biology, a little plate; applied to certain discoid embryos, which consist of a plate of cleavage cells.

Placular (plak'-u-lar) [ $\pi \lambda a ́ \xi$, a plate]. Plate-like; like a placula.

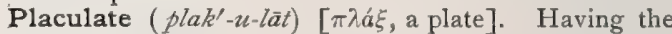
form of a placule.

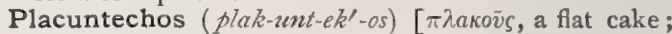

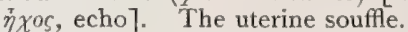

Placuntitis (plak-un-ti'tis). Synonym of Placentitis.

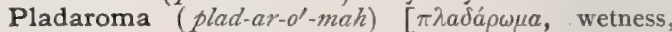
softness: pl., Pladaromata $]$. A soft wart, or tumor of the eyelid.

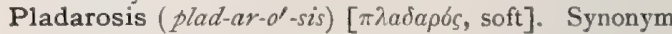
of Pladaroma.

Plaga ( $\left.p l a^{\prime}-g a h\right)[\pi \lambda \eta \gamma \dot{\eta}$, stroke : pl., Plagre $]$. Wound; plague. In biology, a stripe or streak. P. ignis. Anthrax. P. scapularis. Same as Parapsis.

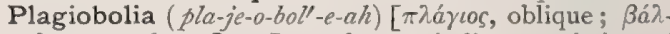
$\lambda \varepsilon i v$, to throw]. Imperfect or indirect emission of spermatic fluid into the vagina.

Plagiocephalia (pla-je-o-sef-a'-le-ah). See Plagiocephaly.

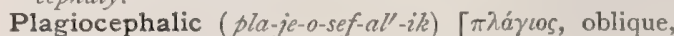
twisted; $\kappa \varepsilon \phi a \lambda \eta$, head]. Exhibiting or dependent on plagiocephaly.

Plagiocephalous ( $\left.p l a-j e-0-s e f^{\prime}-a l-u s\right)$. Synonym of Placiocephatic.

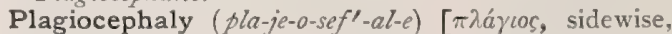
slanting, oblique; $\kappa \varepsilon \phi r \lambda \dot{n}$, head]. In biology, a malformation of the head, produced by the closing of 
half of the coronal suture, giving an oblique growth to the cranial roof.

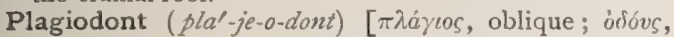
tooth]. In biology, having the teeth oblique, as in the converging series seen in serpents.

Plagiopatagium, of Kolenati (pla-je-o-pat-a'-je-um) [ $\pi \lambda \dot{a} \gamma \cos$, oblique; $\pi a \tau a \gamma \varepsilon i o \nu$, a border, as of a gown]. In biology, that portion of the wing-membrane of bats included in the endopatagium and mesopatagium.

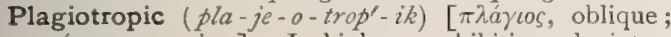

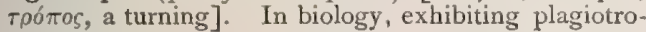
pism.

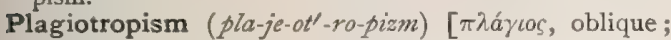
трб́́tos, a twining]. In biology, oblique geotropism; growth at an angle from the vertical axis, either upward or downward, Cf. Orthotropism.

Plague $(p l \bar{a} g)[\pi \lambda \eta \gamma \dot{\eta}$, a stroke]. A pest, or pestilence. A contagious and highly fatal epidemic which occurred in Europe in the 14 th century, and also at later periods. The disease had many of the characteristic symptoms of malignant typhus fever, accompanied by buboes, carbuncles, pustules, petechiæ, and similar skin-affections. The period of incubation is from two to seven days; the disease appears in a grave or ordinary form, a fulminant form, and a larval or abortive form. P., Black, the plague which decimated the European nations in the I4th century. P., Bubonic, a very fatal, contagious epidemic disease, formerly prevalent in various parts of the world. It is characterized by fever, pain, swelling of the axillary, cervical, or inguinal lymphatic glands, delirium, coma, and in the majority of cases ends in death. P., Cold, a fatal form of bilious pneumonia. P., Hunger, relapsing fever. P., Indian. Synonym of Pali. P., Levantine, the plague of the eastern part of Europe. P., Lung, pleuropneumonia of cattle. P.-sore, a sore resulting from the plague: P.-spot, a spot characteristic of the plague. P., Swine, hog-cholera. P., Syrian. Synonym of Aleppo boil.

Plagycephalus (pla-je-sef'-al-us). See Plagicephalus. Planæa (pla-ne'-ah) [planus, flat]. In biology, a hypothetic, astomatous metazoan, having the form of a ciliated planula; morphologically, a simple diaderm ; a blastaca.

Planar, Planary (pla'-nar, pla'-nar-e) [planus, flat]. Lying in a plane.

Planarthragra (plan-ar-thra'-grah) $[\pi \lambda a v \tilde{a} \nu$, to cause to wander; á $\mu \hat{\theta} \rho \circ \nu$, joint; $\grave{a} \gamma \rho r$, a seizure]. Gout which wanders from one joint to another.

Planat's Tincture. See Picrotoxin.

Planate (pla'-nāt) [planus, flat]. In biology, flat, flattened.

Plane $(p l \bar{a} n)$ [planus, flat]. Any flat and smooth surface, especially any assumed or conventional surface, whether tangent to the body, or dividing it. P. of Aeby, in craniometry, that passing through the nasion and the basion perpendicular to the median plane. P., Alveocondylean, in craniometry, a plane passing through the alveolar point and tangent to the condyles. $\mathbf{P}$., Anterior Focal. See under P., Focal. P., Auriculoinfraorbital, in craniometry, that passing through the upper edge of the auricular foramen and the lower edge of the orbit. P. of Baer, in craniometry, that passing through the upper border of the zygomatic arches. P., Barclay's. See P., Palatine. P. of Blumenbach, the surface parallel with the base of a cranium deprived of the lower jaw. P. of Broca. See P., Visual (of Broca). P. of Busk. See $P$., Horizontal (of Busk). P., Camper's, in craniometry, the plane passing through the auricular points and the base of the inferior nasal spine. P. of the Chasma, the plane drawn tangent to the punctum spinæ nasalis posterioris and the punctum foraminis magni anterius. P., Coccygeal. See under P., Parallel (of the pelvis). P. of Daubenton, in craniometry, that passing through the opisthion and the inferior borders of the orbits. P., Double-inclined, two rectangular boards united at an angle at their short sides. It is used in the treatment of fractures of the femur to support the limb and to relax certain muscles. P., Dumontier's. See P., Horizontal (of Dumontier). P. of Dürer, in craniometry, a plane tangent to the lobules of the ear and the base of the nose. P., Focal, one of the two planes drawn through the principal foci of a dioptric system, perpendicular to the axis, or line joining the two foci. P., Frankfort, in craniometry, the auriculo-infraorbital plane. P., Glabello-lambdoidean (of Hamy), in craniometry, the plane of the glabella and the lambda, perpendicular to the median plane. P., Glabellooccipital, in craniometry, the vertical plane passing through the line joining the glabella and the occiput. P. of Hamy. See P., Glabello-lambdoidean. P., Holder's. See P., Horizontal (of Holder). P., Horizontal (of $B u s k$ ), in craniometry, that which, passing through the auricular points, is vertical to a plane drawn through those points and the bregma. P., Horizontal (of Dumontier), in craniometry, a plane tangent to the superior borders of the zygomatic arches. P., Horizontal (of Holder), in craniometry, the auriculoinfraorbital plane. P., Horizontal (of Luce), in biology, that passing through the axis of the zygomatic arches. P., Horizontal (of Van Shering), a plane tangent to the lower rim of the orbit and passing through the auricular points. P., Inclined, a plane forming an angle with the plane of the horizon; one of the mechanical powers. P., Inclined (of the pelvis); the ischiatic spines divide the pelvic cavity into two unequal sections. In the larger anterior section the walls slope toward the symphysis and pubic arch, and are known as the anterior inclined planes. Behind the spines, the lateral slopes are known as the posterior inclined planes. They slope in the direction of the sacrum and coccyx. P. of the Ischium, the lateral wall of the true pelvis. P. of Lucæ. See P., Horizontal (of Luca). P. of Mastication, that tangent to the masticating surface of the teeth of the upper jaw. P., Meckel's, in craniometry, that passing through the auricular and alveolar points. P., Medial, P., Median, P., Mesial, a plane, generally antero-posterior, dividing a body into two symmetric halves. The median plane of the animal body is termed the meson. P., Merkel's, in craniometry, that passing through the auricular points and the lower borders of the orbits. P. of Morton, in craniometry, that passing through the most prominent points. of the occipital and parietal protuberances: P., Munich. See P., Auriculo-infraorbital. P., Naso-iniac, in craniometry, a plane passing through the nasion and the inion. P., Naso-opisthiac, a plane passing through the nasion and the opisthion P., Nuchal, the surface of the occiput between the foramen magnum and the superior curved line. P., Orbital, the orbital portion of the upper maxilla, or the maxillary portion of the orbit. The visual plane of Broca. P., Occipital, the surface of the occiput above the superior curved line. P., Palatine (of Barclay), in craniometry, the plane tangent to the arch of the palate along the middle line. P., Parallel (of the pelvis), any plane intersecting the pelvic axis at a right angle, hence really not parallel. There are four parallel planes : one corresponds to the superior strait; the second extends from the middle of the sacrum to the level of the sub-pubic ligament; the third passes through the spines of the ischia; the fourth is the inferior strait. 
Ps. of the Pelvis, four planes are generally described: the plane of the inlet, that of the outlet, the plane of pelvic expansion, and that of pelvic contraction. The plane of the inlet, or brim, is bordered by the linea terminalis, and has an elliptic contour, with a depression posteriorly, produced by the projection of the sacral promontory. Its diameters are-the antero-posterior, or conjugate, from the upperedge of the promontory of the sacrum to a point an eighth of an inch below the upper border of the symphysis, measuring II cm.; the transverse, the longest possible transverse distance, measuring $131 / 2 \mathrm{~cm}$; and the oblique, from the upper edge of one sacro-iliac junction to the opposite iliopectineal eminence, measuring $123 / 4 \mathrm{~cm}$. The plane of the outlet is bounded by the sub-pubic ligament, the pubic rami, the rami and tuberosities of the ischia, the sciatic ligaments, and the coccyx. Its diameters are-the antero-posterior, measuring $91 / 2 \mathrm{~cm}$ (during labor II cm.), and the transverse, measuring II $\mathrm{cm}$. The plane of pelvic expansion perforates the middle of the symphysis, the tops of the acetabula, and the sacrum between the second and third vertebræ. Its diameters are-the antero-posterior, measuring $123 / 4 \mathrm{~cm}$., and the transverse, measuring $121 / 2 \mathrm{~cm}$. The plane of pelvic contraction passes through the tip of the sacrum, the spines of the ischia, and the under surface of the symphysis. Its diameters are-the antero-posterior, measuring $\mathrm{I} \mathrm{I} 1 / 2 \mathrm{~cm}$, and the transverse, measuring IO $1 / 2 \mathrm{~cm}$. See Pelvis. P. of Refraction, a plane passing through a refracted ray of light and drawn perpendicular to the surface of the refracting medium. P. of Regard, a plane cutting the center of rotation of the eye and the point of fixation P. of Rolle, in craniometry, that passing, through the auricular and the alveolar points. P., Sagittal, any antero-posterior (cephalo-caudal) plane parallel with the meson or median plane. P., Single-inclined, a board arranged as an inclined plane, with the distal end elevated; it is used in the treatment of fractures of the lower limb. P.-symmetric, in chemistiy, a term introduced by Wislicenus to indicate that class of unsaturated stereo-isomers in which similar substituting radicles lie on the same side of a plane passing through the points of junction of the linked carbon atoms. The contrasting condition is central (or axial) symmetric in which similar radicles are symmetric to an axis passing through the linked atoms. Maleîc and fumaric acids are respectively plane-symmetric, and central-symmetric stereo-isomers. P., Van Shering's. See $P$., Horizontal (of Van Shering). P., Visual, the plane passing through the visual axis. P., Visual (of Broca), the orbital plane.

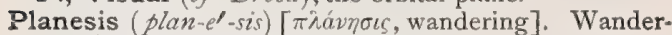
ing; mental aberration; metastasis.

Planicaudate (plan-ik-aw'-dät) [planus, flat; cauda, tail]. In biology, having a flattened tail.

Planicipital (plan-is-ip'-it-al) [planus, flat; caput, head]. In biology, having a flat head.

Planidorsate (plan-id-or'-sät) [planus, flat; dorsum, back]. In biology, having a flat back.

Planiform (plan'-if-orn) [planus, flat; forma, form]. In anatomy, presenting a flat surface.

Planipennate (plan-ip-en'-ät) [planus, flat; penna, wing]. In biology, having flat wings.

Planipetalous (plnn-ip-et'-al-us) [planus, flat; $\pi \varepsilon ́ \tau a-$ $\lambda o v$, petal]. In biology, having flat petals.

Planirostral (plan-e-ros'-tral) [planus, flat; rostrum, beak]. In biology, having a flattened beak.

Planispiral (plan-is-pi'-ral) [planus, flat; spira, a coil]. In biology, coiled in one plane

Planities (plan'-it-ēz) [planus, flat]. Plane; also, the sole of the foot.
Planktology (plank-tol'-o-je) [plankton, the drifting life of the sea, from $\pi \lambda a \gamma \chi \tau \delta ́ s$, wandering, roaming; $\lambda$ 'bos, science]. In biology, the department of science which treats of the constituents, character, distribution, evolution and relations of the plankton or drifting organisms of the ocean.

Plankton (plank'-ton) [ $\pi \lambda a \gamma \chi \tau o ́ s$, wandering, roaming]. In biology, the term proposed by Hensen and adopted by Hrekel to designate all plants and animals found at the surface of the ocean and which are carried about involuntarily in the water (ploteric). It corresponds to the German terms Auftrieb and "pelagischer Mulder" introduced by Johannes Müller; and is employed in contradistinction to benthos ( $\beta \varepsilon$ vovs, the bottom of the ocean; hence the organisms living there) and nekton (the actively suimming surface organisms). Plankton may be separated into Limnoplankton, the swimming and floating population of fresh water, and Haliplankton or that of salt water; or again into Oceanic Plankton or that of the open ocean, and Neritic Plankton, or that of the coast regions. Hæckel also distinguishes: (a) Pelagic Plankton, those actively swimming or passively floating animals or plants which are taken at the surface of the sea; no matter whether they are found alone or at a variable depth below the surface, they constitute the superficial and interzonary organisms of Chun. (b) Zonary Plankton, those organisms which occur only at definite depths of the ocean, and are only occasionally found above and below this, e. g., many Phaodaria and Crustacea and Siphonophora. (c) Bathybic Plankton, animals of the deep sea, which only hover upon the bottom but never touch it, whether they stand in definite relation to the abyssal benthos or not, e. g., Tomapteris euchata, Megalocereus abyssorum. (d) Autopelagic Plankton, the constant superficial fauna and flora of the sea, e.g., Eucopida, Forskalida, Eucharis, sp., Bolina, sp., Sagitta punctata, Pontellina, sp., etc. (e) Bathypelagic Plankton, all those organisms which occur not merely at the surface, but extend down into the depths; these are called by Chun interzonary pelagic animals. Here belongs properly the chief mass of the plankton. These last organisms may be distinguished as: (I) Nyctipelagic, those which rise to the surface only at night, living in the depths during the day; very many Medusa, Siphonophora, Pyrosoma, most Pteropoda and Heteropocia, very many Crustacea, etc. (2) Chimopelagic, those which appear at the surface only in winter, and in summer are hidden in the depths; Radiolaria, Meduse, Siphonophora, Ctenophora, a part of the Pteropoda, and Heteropoda, many Crustacea, etc. (3) Allopelagic, those which perform irregular vertical wanderings, sometimes appearing at the surface, sometimes in the depths, independently of changes of temperature. (f) Spanipelagic Plankton, those animals which always live in the oceandepths (zonary or bathybic) and come to the surface only exceptionally and rarely. Holoplanktonic organisms, those that pass their whole life and whole cycle of development hovering in the ocean, with no relation whatever to the benthos; here belong the greater part of the diatoms, and oscillaria, all Murraycites and Peridinea, all Ratiolaria, many Globigerina, the hypogenetic Meduse, all Siphonophora and Ctenophora, all Chatognatha, Pteropoda, the Copelata, Pyrosoma, and Thalidia, etc. Meroplanktonic organisms, on the contrary, are found in the sea only for a part of their life, passing the other part vagrant or sessile in the benthos, $e_{0} g .$, a part of the diatoms and oscillaria, the planktonic fucoids, the metagenetic medusæ, some turbellarians and annelids, 
the "pelagic larvæ" of hydroids and corals, many helminthes, echinoderms, acephala, gasteropods, etc. Plankton may be Monotonic (simple tow-stuff), showing a homogeneous composition, or it may be Polymixic (mixed tow-stuff), composed of organisms of different species and classes in such a way that no one form or group of forms composes more than onehalf of the whole volume

Planktonic (plank-ton'-ik) [plankton, the drifting life of the sea]. In biology, pertaining to plankton.

Planoblast (plan'-o-blast) $[\pi \lambda a ́ v o s$, wandering; $\beta \lambda \alpha \sigma$ ros, germ]. In biology, the free swimming medusoid bud, or gonophore of a gymnoblastic hydrozoan, as distinguished from the sedentary bud or hedrioblast, $q . v$.

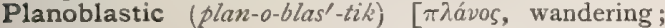

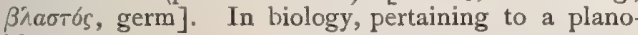
blast.

Plano-cellular (plan-o-sel'-2u-lar) [planus, flat ; cellula, cell]. Flat-celled.

Plano-concave, Plano-convex ( $p l a^{\prime}-n o-k o n$ - kä ${ }^{\prime}$, pla'-no-kon-veks'). See Lens.

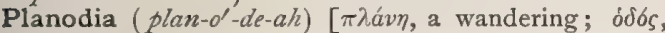
a way]. Any false or artificial passage made by an instrument.

Planogamete (plan'-o-ga-mêt) $[\pi \lambda a ́ v \eta$, a wandering;

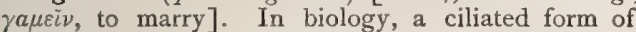
gamete, or protoplasmic conjugating body; a zoögamete. Cf. Gamele.

Planogastrula (plan-o-gas'-tru-lah) [ planula ( $\pi \lambda a ́ v o s$, wandering); gastrula, a two-layered, saccular germ

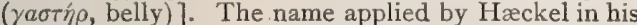
gastræa theory to that stage in the evolution of the gastrula from the planula, characterized by the hollowing out of the endoderm of the latter.

Planomania (plan-o-mál-ne-ah) [ $\pi \lambda a ́ v o s$, wandering ; pavia, madness]. A morbid and insane desire for wandering.

Plant [planta, a plant]. Any member of the vegetable kingdom. P., Aerial, P., Air, a plant which derives its nourishment from the air. P., Carnivorous. Synonym of $P$., Insectivorous. P., Flowering. See Phanerogam. P., Flowerless. See Phanerogam. P., Insectivorous, a plant which entraps and digests insects: $e . g .$, Drosera rotundifolia. P., Pitcher. See Pitcher-plant. P., Sensitive, Mimosa pudica, and other species, the leaves of which contract when they are touched.

Planta (plan'-tah) [L.]. 1. A plant. 2. The sole of the foot. P. pedis, the sole of the foot.

Plantago (plan-ta'-go) [L., gen. plantaginis]. The leaves of $P$. major and $P$. lanceolata, or common ribbed grass, or plantain. The bruised fresh leaves are a popular remedy for hemorrhage, painful abrasions of the skin, burns, erysipelas, etc. Dose $m v-x v$. Unof.

Plantain (plan'-tän) [ME., planteyne, plantain]. I. Same as Plantago. 2, The tropical plant Musa paradisiaca, and its fruit; they are of great economic importance in the tropic regions as a food for mankind.

Plantar (plan'-tar) [plantaris; planta, sole of the foot]. Pertaining to the sole of the foot. $\mathbf{P}$. Aponeurosis. Synonym of $P$. Fascia. P. Arch, a name given to one of the parts into which the external plantar artery is divided. P. Arteries. See Arteries, Table of P. Fascia, the dense, triangularshaped aponeurosis occupying the middle and sides of the sole of the foot beneath the integument. P. Muscle. See Muscles, Table of. P. Nerve. See Nerves, Table of. P. Reflex. See Reflexes, Table of. P. Tubercle, the tubercle of the first metatarsal bone, and to which the tendon of the peroneus longus muscle is attached.
Plantaria (plan-ta'-re-ah). Synonym of Denoue.

Plantaris (plan-ta'-ris) [planta, sole of the foot]. See Plantar. P. Muscle. See Muscles, Table of.

Plantigrade (plan'-tig-rád') [planta, sole; gradi, to walk]. Bringing the entire length of the sole of the foot to the ground in walking, as is seen in the bear and in certain birds which apply the back of the tarsus as well as the toes to the ground in walking.

Plantivorous (plan-tiv'-o-rus) [planta, plant; vorare, to devour]. In biology, living on plants, e.g., caterpillars.

Plantosseous (plan-tos'- $\iota^{\prime}-u s$ ) [ planta, sole; osseosus, bony]. Both plantar and interosseous.

Plantosseus (plan-tos'-e-us) [ planta, sole; osseosus, bony]. Any plantar interosseous muscle.

Plantula (plan'-tu-lah) [planta, the sole of the foot: pl., Plantule]. In biology, the appendage, generally cushion-like, between the claws of certain insects; it corresponds to the structure in other forms called onychium and pulvillus.

Plantular (plan'-tu-lar) [plantula, a little plant] Pertaining to a plantula.

Planula (plan'-u-lah) [ $\pi \lambda a ́ v o s$, wandering: $p l$., Planula ]. In biology, the globular or oval, free-swimming, two-layered, solid larva of certain of the Porifera and Colenterata. It is destitute of a mouth or blastopore, and succeeds the blastula in those metazoans in which gastrulation takes place by immigration and delamination, instead of by invagination. The planula is succeeded by the Planogastrula and this in turn by the gastrula stage proper, with its blastopore. Salensky describes a three-layered planula in the Rotatoria and other forms. The term planula was first applied by Dalzell to the motile larvæ of certain hydrozoans ("zoöphytes"), but it has come to have a broader application. Planula may be regarded as the ancestral form of the Cnidaria. It appears to correspond to the parenchymula of Metschnikoff.

Planulan (plan'-u-lan) [ $\pi \lambda a^{\prime} \nu o s$, wandering]. A planula.

Planular (plan'-u-lar) [ $\pi \lambda a ́ v o s$, wandering]. Pertaining to a planula.

Planuliform (plan'-u-lif-orm) [ $\pi$ iávos, wandering; forma, form]. In biology, resembling a planula.

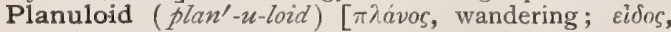
like]. Resembling a planula.

Planum (plan'-um) [L.]. A plane or surface

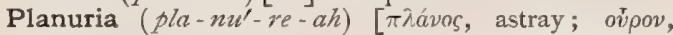
urine]. The discharge of urine through passages other than the normal duct.

Plaque $(p l a k)$ [Fr.]. A plate, patch or spot. P., Blood. See Blood-plaque. P., Mucous, P. muqueuse [Fr.]. Mucous patch; condyloma latum. Plaques, Pterygoidean. See Pterygoidean. Ps., Sclérose en. See Sclérose en plaques.

Plasm (plazm) [ $\pi \lambda \alpha \dot{\sigma} \sigma \mu \alpha$, a figure molded from clay or wax]. In biology, same as Plasma. P., Germ, a distinct form of protoplasm acting as the vehicle of inheritance.

Plasma-(plaz'-mah) [ $\pi \lambda \hat{c} \sigma \mu \alpha$, a thing molded]. I. The original undifferentiated substance of nascent living matter. The primordial protoplasm or "physical basis of life." 2. The fluid part of the blood and the lymph; the blood and lymph exclusive of the corpuscles. See Blood-plasma and Liquor sanouinis. P.-cells of Waldeyer, the highly vacuolated connec tive-tissue cells, irregular, extended or spindle-shaped. They probably bear a somewhat constant relation to young tissues in which the formation of new bloodvessels is still progressing. P.-fibrin, Landois' term for fibrin formed in the usual way, as distinguished from stroma-fibrin, or that formed directly from stroma. 
P.-globulin. Same as Paraglobulin, q.v. P., Histogenetic, P., Lymph, the fluid part of the lymph. $\mathbf{P}$. of Invertebrates, that perivascular or intercellular fluid of invertebrates which corresponds to the blood of vertebrates. It is both respiratory and nutritive in function, clots like vertebrate blood, contains fibrinogen and a substance corresponding to hemoglobin, and is called by Fredericq hemocyanin; it is also in some instances a reddish lipochrome pigment tetronerythrin. P., Muscle, the fluid obtained from muscle by pressure at a low temperature, $\mathbf{I}^{\circ} \mathrm{C}$. It is spontaneously coagulable, forming myosin. P., Nutritive, the portion of the cell devoted to nutritive functions. P. sanguinis, blood-plasma. P., Somatic. Synonym of $P$., Histogenetic.

Plasmasome (plaz'-mas-ōm) [ $\pi \lambda a ́ \sigma \mu \alpha$, a molded figure; $\sigma \tilde{\omega} \mu a$, body]. In biology, a protoplasmic corpuscle.

Plasmatic (plaz-mat'-ik) [ $\pi \hat{n} a ́ \sigma \mu a$, a molded figure]. Same as Plasmic. P. Stain. See Plasmic Stain.

Plasmatoparous (plas-mat-op'-ar-us) [plasma, a molded figure; parere, to bring forth]. In biology, a term applied to certain species of fungi (e.g., Peronospora densa, Rab., and $P$. pygmaa, Ung.), in which the whole protoplasm escapes from the spore in a mass through the opening of a papilla-like point in the wall, and at once becoming globular, secretes a cellulose membrane and subsequently germinates by the emission of a short, thick germ-tube. (Bennett and Murray.)

Plasment ( $\left.p l a z^{\prime}-m e n t\right)$ [ $\pi \lambda a ́ \sigma \mu a$, something molded]. A proprietary emollient and lubricant application made from Iceland moss.

Plasmic (plaz'-mik) [ $\pi \lambda a ́ \sigma \mu a$, a molded figure]. In biology, of or pertaining to protoplasm; formative, protoplasmic. P. Stain, a pigment which colors the tissue uniformly throughout, employed in microscopy as a ground or counter-stain, following and in contrast with a nuclear stain. Thus, after blue or green nuclear or specific stains, use benzo-purpurin (brownish red), eosin (yellowish-red), erythrosin (pink), orange, or acid fuchsin (orange); after red use picric acid (yellow). See Stains, Table of, also, Stain, Nuclear Stain, Specific Stain.

Plasmin (plaz'-min) [ $\pi \lambda a ́ \sigma \mu a$, a molded figure]. Denis mixed uncoagulated blood with a saturated solution of sodic sulphate, and allowed the corpuscles to subside. The salted plasma thus obtained he precipitated with sodic chlorid. The precipitate, when washed with a saturated solution of sodic chlorid, he called plasmin. Mixed with water, it coagulates spontaneously, resulting in the formation of fibrin, another proteid remaining in solution. According to Denis' view, fibrin is produced by the splitting up of plasmin into two bodies-fibrin and a soluble proteid. (Landois and Stirling.)

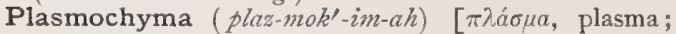
$\chi v \mu a$, juice $]$. The portions in the cytochylema rich in proteids; paraplasm; heteroplasm; the fluid substance of a cell.

Plasmode (plaz'-mōd). Same as Plasmodium.

Plasmodiblast (plaz-mo'-dib-last). See Trophoblast.

Plasmodieresis (plaz-no-di-er'-es-is) [ $\pi \lambda a ́ \sigma \mu \alpha$, plasma; Stalpeiv, to divide in two parts]. The division of the cell-body, in contradistinction to the division of the cell-nucleus.

Plasmodiocarp (plas-mo'-de-o-karp) [ $\pi \lambda \alpha \sigma \sigma u a$, a molded figure; $\varepsilon i \delta o \varsigma$, form; $\kappa \alpha \rho \pi \delta \varsigma$, a fruit]. In biology, applied to the fructification of fungi when of irregular shape.

Plasmodiocarpous (plaz-mo-de-o-kar'-pus) [ $\pi \lambda a ́ \sigma \mu a$, a molded figure; $\varepsilon i \delta o s$, form; $\kappa a \rho \pi \sigma \varsigma$, a fruit]. Resembling a plasmodiocarp.
Plasmodium (plaz-mo'-de-um) [ $\pi \lambda a ́ \sigma \mu \alpha$, a molded figure; cidos, form: pl., Plasmodia]. In biology : (a) the naked, motile mass of protoplasm formed by the organic fusion of two or more amebiform bodies, as in the mes. odermic cells of young Spongilla, Bipinnaria, many Annelida and by phagocytes in general; (b) the colossal ameboid organism or vegetative body (also called plasmode) formed by the coalescence of peculiar swarm-spores in the Myxomyceles (e.g., Fuligo varians, or, as it is more commonly called, Aithatium septicum or "flowers of tan"), or by the mere aggregation of such swarm-spores in the Acrasiea. $\mathbf{P}$. malaria. Synonyms, Hamutophyllum malaria, Hematozoön of Malaria, Laveran's Bodies, Laveran's Organisms; a parasite found in the blood of persons suffering from malaria. Many different forms have been observed, which by some are held to be stages in the life-history of the same organism, by others to be different species. As to the nature of the parasite it is generally admitted that it is a Protozoonn. See Polimitus malaria, Danilewsky, under Parasites (Animal), Table of. The development and multiplication of the organism take place within the red corpuscles. Typical intermittent fever is associated with large forms of the parasite, which differ somewhat according as the fever is a tertian or quartan intermittent. In the former case the developmental cycle of the organism occupies two days, in the latter three. In both forms the small intracorpuscular ameboid body enlarges and gradually fills the entire cell, becoming pigmented at the same time. The pigment-granules are formed from the hemoglobin of the blood corpuscle. When the plasmodia have acquired a certain size, the pigment-granules begin to aggregate at the center of the body. At this time, in the quartan form, the organism becomes radially striate, or rosetshaped. The further step consists in the breaking up of the organisms into a number of small spheric bodies, the young plasmodia. The blood-corpuscle is destroyed, and the small free elements enter other red cells. In the tertian form the cycle is similar, but more rapid and active; the blood-corpuscle becomes decolorized much sooner; the pigment-granules are smaller, and the parasite forms from 15 to 20 new cells, while in the quartan only from 6 to 12 are produced. In quotidian intermittent, the organisms are small, possess very active ameboid movements (that can be observed within the red corpuscles), and become pigmented just before each paroxysm. Then they divide into spores. Peculiar crescentic bodies, endoglobular and ectoglobular, have also been described. They occur in acute forms, but are most constant in malarial cachexia. The significance of certain flagellate bodies has not been fully determined. The Italian writers generally believe that the various forms are distinct species, while Laveran and others look upon them as developmental variations of the sporozoòn. As to the relation of the parasite to malaria, the evidence of its being an etiologic one is very strong. The constant presence of the organisms, the fact of their causing rapid destruction of the red corpuscles, their disappearance coincidently with the symptoms on the administration of quinin, and the successful inoculation of the disease from man to man, are points strongly in favor of their etiologic relation to the disease. The organism has not yet been cultivated artificially outside of the body. P., Small, a variety or species present in remittent and pernicious forms of malaria.

Plasmogen (plaz'-mo-jen) [ $[\pi \lambda a \dot{\sigma} \mu \alpha a$, a molded figure; $\gamma_{\varepsilon v \eta ́} \varsigma$, producing]. In biology, germ-plasm, true protoplasm, bioplasm, anabolic perfection in plasma.

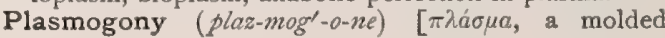


figure; yoveia, generation]. In biology, the generation of an organism from plasma.

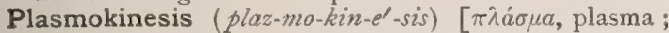

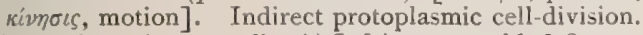

Plasmology ( plaz-mol'-o-je) [ $\pi \lambda a ́ \sigma \mu a$, a molded figure; tóyos, science]. In biology, the study of cells and cell-stuff, or plasma ; histology.

Plasmolysis (plaz-mol' $-i s-i s)[\pi \lambda a ́ \sigma \mu a$, plasm; $\lambda \dot{v} \varepsilon \iota \nu$, to loose]. In biology: $(a)$ the separation of cellprotoplasm from the inclosing cell-wall; (b) the contraction of living protoplasm under the influence of reagents.

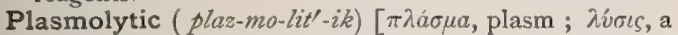
loosing]. In biology, exhibiting or characterized by plasmolysis. P. Agent, any substance that causes contraction of protoplasm.

Plasmoma (plaz-mó-mah) [ $[\pi \lambda a ́ \sigma \mu a$, plasm; ó $\mu a$, tumor; plo, Plasmomata]. A fibro-plastic tumor.

Plasmon (plaz'-mon) [ $\pi \lambda \hat{\alpha} \sigma \mu a$, a thing molded]. An albuminous food-product, introduced by Siebold, of high nutritive property and easily absorbed.

Plasmoschisis (plaz-mos'-kis - is) [ $[\pi \lambda a ́ \sigma \mu \alpha$, plasma ; $\sigma \chi i \sigma \iota$, cleavage]. A name given by Lowit to the separation of protoplasmic particles from the bodies of leukocytes, first observed by him in the blood of crabs kept at a low temperature.

Plasmosoma (plaz-mo-so'-mah) [ $\pi \lambda a ́ \sigma \mu \alpha$, plasm ; $\sigma \tilde{\omega} \mu \alpha$, body: pl., Plasmosomata]. A karyosoma, especially one which is safranophilous.

Plasodermatosis (plaz-o-der-mat-o'-sis) $[\pi \lambda a ́ \sigma \sigma \varepsilon \imath v$, to

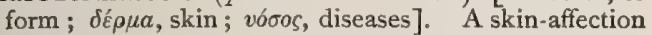
characterized by the formation of new tissue.

Plasodermitis (plaz-o-der-mi'-tis) [ [ $\lambda \lambda a ́ \sigma \mu a$, plasma;

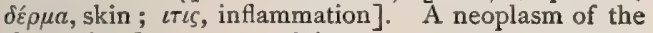
skin, of inflammatory origin.

Plasome $\left(p l a^{\prime}-s \bar{m}\right)$ [ $\pi \lambda \dot{\alpha} \sigma \mu \alpha$, a molded figure; $\sigma \tilde{\omega} \mu a$, body, matter]. In biology, one of the hypothetic, minute vital particles of Wiesner and Brücke, resembling, as regards their properties, the pangenes of De Vries and the biophors of Weismann.

Plasson (plas'-son) [ $\pi \lambda a ́ \sigma \sigma \varepsilon \iota v$, to form or mold]. In biology, primitive or undifferentiated protoplasm; the cell in the cytode stage.

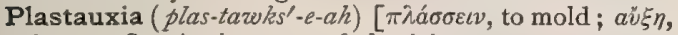
increase]. An increase of plasticity.

Plaster (plas'-ter) [ $\tilde{\varepsilon} \mu \pi \lambda \alpha \sigma \tau \rho o \nu$, emplastrum, plaster]. An adhesive, solid or semi-solid medicinal substance spread upon cloth or other flexible substance, for application to the external part of the body. According to the principal ingredient, it is called Emplastrum Aconiti, Ammoniaci, Arnicæ, Belladonnæ, Capsici, Hydrargyri, Picis cum cantharidæ, Resinæ, Saponis, etc. P., Adhesive, resin-plaster. The adhesive plaster used by surgeons must be warmed before being applied; it will also stick after having been dipped in ether. P., Antiseptic, a plaster consisting of the ordinary adhesive plaster dipped in a hot solution of carbolic acid (I to 60). P., Black, lead plaster. P.cast, a model of an object produced by pouring plaster-of-Paris mixed with water into a mold of that object. P., Court, a plaster prepared by dissolving 30 grams of isinglass in enough water to make 360 grams, and spreading the mixture thinly upon silk in two portions, one the watery solution, the other mixed with I 20 grams of alcohol and three of glycerin. The reverse side of the silk is painted with tincture of benzoin. It adheres firmly to the skin when moistened. P., Diachylon. Synonym of P., Lead. See Plumbum. P., English. Synonym of P., Court. P., Isinglass, a substitute for adhesive plaster, used in superficial wounds. P. Jacket, a bandage surrounding the trunk, and made of plaster-of-Paris. It is used in caries of the vertebræ. P., Lead. See Plumbum. P., Logan's, a plaster containing litharge, lead carbonate, Castile soap, butter, olive-oil, and mastic. P.-machine, an apparatus used by pharmacists for spreading plasters. P., Mahy's, one containing lead carbonate, olive-oil, yellow wax, lead-plaster, and Florentine orris. P., Mercurial. See Hydrar gyrum. P., Miraculous, one containing red oxid of lead, olive-oil, alum, and camphor. P.-mull, a plaster made by incorporating with mull or thin mushin a mixture of gutta-percha and some medicament dissolved in benzin. P., Mustard, one made by spreading upon muslin powdered mustard, or a mixture of mustard with flour or other powder, reduced to the consistency of paste by the addition of water. P.-of-Paris, gypsum, or calcium sulphate, used for making stiff or immovable bandages or dressings, or for the preparation of casts. P., Pitch, a plaster containing Burgundy pitch, frankincense, resin, yellow wax, oil of nutmeg, and olive-oil. See Pix. P., Rademacher's, a plaster composed of red lead, olive-oil, amber, camphor, and alum. P., Resin, a plaster composed of resin, lead-plaster, and yellow wax or hard soap. See $P$., Adhesive, and Resina. P., Rubber, a plaster in which the adhesive material is spread on thin muslin, and which sticks without being previously warmed. P., Soap, soap and lead-plaster, with or without resin. P., Spice, a plaster composed of yellow wax, suet, turpentine, oil of nutmeg, olibanum, benzoin, oil of peppermint, and oil of cloves. P., Sticking, emplastrum resinæ. See Resina. P., Stomach. See P., Spice. P., Strengthening, emplastrum ferri. P., Surgeons', adhesive plaster. P., Thapsia, one containing yellow wax, Burgundy pitch, resin, terebinthina cocta, Venice turpentine, glycerin, and thapsia resin. P., Vesicating. Same as Cantharides Plaster. P., Vigo, one containing lead-plaster, yellow wax, resin, olibanum, ammoniac, bdellium, myrrh, saffron, mercury, turpentine, liquid storax, and oil of lavender. P., Warm, P., Warming, emplastrum picis cum cantharide.

Plastering (plas'-ter-ing) [ย̌ $\mu \pi \lambda \alpha \sigma \tau \rho o \nu$, a plaster]. A method of improving wines largely practised in Southern Europe. It consists in adding plaster-ofParis (burnt gypsum) either to the unpressed grapes or to the must. The plaster takes up water, and so increases the alcoholic strength of the fermenting must. The wine is given better keeping-qualities, as well as deeper color. However, soluble acid sulphate of potassium is left dissolved in the wine, and has an injurious effect upon the consumers of the wine.

Plastic (plas'-tik) [ $\pi \lambda \alpha \dot{\sigma} \sigma \sigma \varepsilon \iota \nu$, to mold]. Capable of being formed or molded; plasmic ; formative ; easily modified; applied to morbid processes attended with fibrinous exudate. P. Bronchitis, pseudo-membranous bronchitis. P. Linitis, a name given to cirrhosis of the stomach. P. Lymph, the inflammatory exudate that covers wounds or inflamed serous surfaces, and which becomes organized by the development in it of blood-vessels. P. Operation, the restoration of lost parts by the transfer of tissue from an adjacent part or by transplantation. P. Surgery, the art of performing plastic operations; the surgical replacement of lost parts.

Plasticity (plas-tis'-it-e) [ $\pi \lambda a ́ \sigma \sigma \varepsilon v v$, to mold]. Plastic force. The quality of being plastic.

Plasticule (plas'-tik- $\bar{u} l$ ) [ $\pi \lambda a ́ \sigma \sigma \varepsilon l v$, to mold]. A molecule of plastic material not yet fully organized.

Plastid (plas'-tid) [ $\pi \lambda a \sigma \tau o ́ s$, verbal adj. of $\pi \lambda \dot{r} \sigma \sigma \varepsilon \iota \nu$, to mold or form]. In biology: $(a)$ any unicellular elementary organism, cell, or cytode; a cell; a mass of protoplasm or of plastic material; $(b)$ one of a class of protoplasmic granules in the protoplasm of certain plant-cells; they are referred to three 
types the synonymy of which is given by Goodale as follows :-

\begin{tabular}{|c|c|c|c|c|}
\hline & $\begin{array}{l}\text { OLDER NO- } \\
\text { MENCLATURE. }\end{array}$ & SCHIMPER, & MEYER. & $\begin{array}{l}\text { VAN } \\
\text { TIEGHEM }\end{array}$ \\
\hline $\begin{array}{l}\text { General } \\
\text { Term. }\end{array}$ & $\begin{array}{l}\text { Colorless pro- } \\
\text { top lasmic } \\
\text { granule. }\end{array}$ & $\begin{array}{l}\text { Plastid. } \\
\text { Leukoplas- } \\
\text { tid. }\end{array}$ & $\begin{array}{l}\text { Troph o- } \\
\text { plast. } \\
\text { Anaplast. }\end{array}$ & $\begin{array}{l}\text { Leucite. } \\
\text { Leucite } \\
\text { proper. }\end{array}$ \\
\hline $\begin{array}{l}\text { Special } \\
\text { Term. }\end{array}$ & $\begin{array}{l}\text { Chlorophyl - } \\
\text { granule. } \\
\text { Color-granule. }\end{array}$ & $\begin{array}{l}\text { Chloroplas- } \\
\text { tid. } \\
\text { Chrom o- } \\
\text { plastid. }\end{array}$ & $\begin{array}{l}\text { A utoplast. } \\
\text { Chromo- } \\
\text { plast. }\end{array}$ & $\begin{array}{l}\text { Chloro- } \\
\text { leucite. } \\
\text { Chromo- } \\
\text { leucite. }\end{array}$ \\
\hline
\end{tabular}

P., Connective-tissue, the connective-tissue corpuscles.

Plastidium (plas-tid"-e-um) [dim, of $\pi \lambda a \sigma \tau o ́ s$, formed: pl., Plastidia $]$. The cell, or plastid, considered with reference to its evolutionary or developmental possibilities. See Plastid.

Plastidular (plas-tid'-u-lar) [ $\pi \lambda a \sigma \tau o ́ s$, formed]. Pertaining to plastidules.

Plastidule (plas'-tid- $\vec{u} l)$ [ $[\pi \lambda \alpha \sigma \tau \delta ́ s$, verbal adj. of $\pi \lambda a ́ \sigma-$ $\sigma \varepsilon \iota \nu$, mold, form]. In biology : $(a)$ a protoplasm-molecule; (b) a term proposed by Elsberg as a substitute for gemmule as used by Darwin. See Heredity, Gemmule, Biophor, Pangene, Plasome. P. of Elsberg, the ultimate physical units of living matter. See Heredity.

Plastilytic (plas-til-it'-ik) [ $\pi \lambda a \sigma \tau o ́ s, ~ m o l d e d ; ~ \lambda v ́ \varepsilon v$, to dissolve]. Diminishing plasticity, or tending to soften plastic materials.

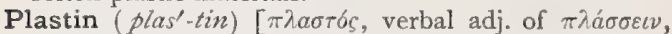
to form, mold]. In biology, one of the nucleins or special nitrogenous proteids more insoluble in alkalies and poorer in phosphorus than others; called cytoplasm by Schwartz. Cf. nuclein, histon, adenin.

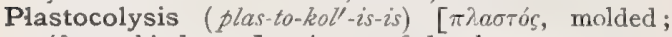
$\kappa \omega \lambda v \sigma \iota$, , hindrance]. Arrest of development.

Plastodynamia (plas-to-di-nam $-e-a h)[\pi \lambda a \sigma \tau b s$, molded; dóvauts, power]. Nutritive plastic power.

Plastodynamic (plas-to-di-nam'-ik) [ $\pi \lambda a \sigma \tau o ́ s$, molded; dovauls, force]. Pertaining to nutritive power.

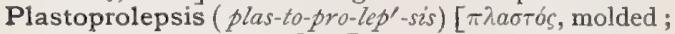
$\pi \rho 6 \lambda \eta \psi s$, anticipating]. Premature development of an organ or part.

Plastral (plas'-tral) [plastron, a breast-plate]. In biology, of or pertaining to the plastron, $q . v$.

Plastron (plas'-tron) [Fr., "breast plate"]. The sternum and costal cartilages, with the attached parts, such as are removed when a post-mortem examination is made of the condition of the thorax. In biology : (a) the ventral portion of the exo-skeleton of a tortoise or turtle; $(b)$ one of the similar ventral, exoskeletal plates of certain amphibia; (c) the ventral shield of the fossil armadillo; $(d)$ a colored area on the ventral surface of a bird.

Plastrum (plas'-timm) [an accom. form of plastron, a breastplate: pl., Plastra]. Same as Plastron.

Plate (plat) [ME., plate, a plate]. The horizontal plate of the ethmoid bone constituting the floor of the olfactory fossa and perforated for the passage of the olfactory nerves, P., Abdominal. See P., Lateral Mesoblastic. P., Ambulacral, one of the coronal plates of a sea-urchin, which are perforated to form part of an ambulacrum. P., Approximation, one of the plates of decalcified bone or other material, leaving a central hole and openings for sutures in the margin, which are used in enterectomy to bring the resected ends of intestine together. Also known as Senn's Plate. P., Auditory, the plate of bone forming the roof of the auditory meatus. P., Axial, the primitive streak of the embryo. P., Basilar, P., Basicranial. in embryology, the cartilaginous plate at the anterior end of the notochord, formed by the latter and the parachordal cartilages. P., Blood. See Blood-plaque. P.: Bone. Synonym of $P$., Approximation. P., Branchial, one of the branchial arches of the embryo. P., Cathammal, in biology, one of the vascular lamellx of certain Medusce, formed by the pressing together of the two layers of the persistent endoderm by the subumbrellar and exumbrellar jelly. P., Cribriform, the anterior fossa of the base of the skull. P.-culture, in biology, a method devised by Koch to separate bacteria by pouring the liquid, gelatin culture-medium upon a sterilized glass plate, after inoculation. The plates of Koch have been replaced somewhat by Petri's Dishes, q.v. P., Dorsal, each of the two longitudinal ridges on the dorsal surface of the embryo, which subsequently join to form the neural canal. P., Electric, the finely granular end-plates composed of nerve-endings and large cells, found in the electric organs of electric fishes. P., End, a term given to the termination of a motor nerve in a muscle-fiber. P., Equatorial, in biology, the compressed mass of chromatic segments, aggregated about the equator of the nuclear spindle at a certain stage of karyokinesis. It is also called nuclear plate, nuclear disc, mother-star. Ps., Facial, the fronto-nasal and external group of nasal and maxillary plates of the embryo. P., Flesh. See Lamella carnosa. P., Foot, the flat, plate-like portion of the stapes which fills the fenestra ovalis. P., Frontal, in the fetus, a cartilaginous plate interposed between the lateral parts of the ethmoid cartilage and the lesser wings and anterior portion of the sphenoid bone. P. Frontonasal, the middle of the facial plates, which subsequently forms the external nose. P., Gill, a bronchial lamina of molluscs. P., Gray. Synonym of Lamina cinerea. P., Ground, the ground-substance of connective tissue and endothelial cells, in which are embedded the nucleus and intracellular network. $\mathbf{P}$., Hair. Synonym of Scales, Hair. Ps., Hyoid, the second pair of the subcranial plates of the embryo, from which the hyoid bone is in part developed. P., Inferior Maxillary, in the embryo, the first pair of subcranial plates from which the mandible is developed. P., Internasal. Synonym of $P$., Frontonasal. P., Intervertebral, the disc of fibro-cartilage between adjacent vertebræ. P., Intrafissural (of the pia), the fold of pia passing into the ventral fissure of the spinal cord. P., Lateral Mesoblastic, the thick portion of the mesoblast situated one on each side of the notochord. Each plate splits into two portions, the ectal divisions coalescing to form the body-wall, or Somatopleure, the ental, to forma the Splanchnopleure, or visceral covering. P., Ligamentous, one of the intervertebral fibrous discs of the embryo. P., Mandibular. Synonym of $P$. Inferior Maxillary. P., Maxillary. Synonym of $P$., Inferior Maxillary. P., Medullary. Synonym of P., Dorsal. P., Mesenteric, P., Mesentery, P., Mesial. Synonyms of P., Lateral Mesoblistic. P., Motor. Synonym of $P$., End. P., Muscle, P., Muscular. See Myocomma. P., Negative, of a storage cell, that plate which by the action of the changing current is partly covered with a coating of spongy lead; of a voltaic cell, that element of a voltaic couple which is negative in the electrolyte of the cell. P., Nuclear. Synonym of P., Equatorial. P., Orbital: (I) the smooth plate of the ethmoid bone forming part of the inner wall of the orbit; (2) of the frontal bone, a horizontal plate forming the roof of the 
orbit. P., Palate, of the palate bone, the horizontal portion which, with its fellow of the opposite side, forms the greater part of the hard palate. P., Parachordal. Synonym of $P$., Lateral Mesoblastic. P., Positive, of a voltaic cell, the electro-positive element of a voltaic couple. P., Protovertebral. Synonym of P., Lateral Mesoblastic. P., Pterygoid, one of the processes of the sphenoid bone. P., Senn's. Synonym of $P$., Appraximation. P., Sieve. See under Sieve. P., Spindle, the part of a cell-plate located within the cell-nucleus. P., Subcranial. See Post-oral Arches. P., Tympanic. The plate of bone forming the sides and floor of the auditory meatus. P., Uteroplacental. Synonym of Decidua serotina. P., Valvular, a valve-like fold of tissue which fills the foramen ovale in the fourth month of fetal life, permitting the passage of blood from the right to the left auricle, but not in the contrary direction. P., Vascular. Synonym of Lamina, Vascular. Ps., Vertebral, undivided masses of mesoblast, running longitudinally between the lateral mesoblastic plates and the medullary ridges. Also, the laminæ on each side of the primitive groove by the union of which the vertebræ are formed. P., Visceral, the splanchnopleure layers of the lateral mesoblastic plates. P., Vitelline, the peculiar, doubly refractive crystals, probably albuminoid in character, found in the egg-yolk of turtles, frogs, and certain fishes.

Plated (pla'-ted) [ME., plate, a plate]. In biology, covered with dermal scales or scutes ; scutate, loricate.

Platelet (plat t'-let) [dim. of ME., plate]. In biology, a blood-plate. Haliburton and Lilienfield regard the platelets as probably disintegration-products of leukocytes. They are composed of a substance rich in phosphorus, which by gastric digestion is separated into nuclein and albumin.

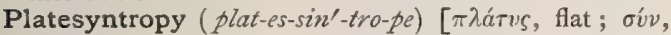
together; $\tau \rho \varepsilon ́ \pi \varepsilon \iota \nu$, to turn]. In biology, Wilder's term for the morphotropic relation between parts upon the same side of the meson; e. $g$., the brachium and the cubitum.

Platetrope (plat'-et-röp) [ $\pi \lambda \alpha \tau \hat{v} s$, flat; $\tau \rho \varepsilon ́ \pi \varepsilon \imath \nu$, to turn]. In biology, one of two symmetrically related parts on opposite sides of the meson; a lateral homologue.

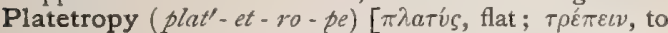
turn]. In biology, bilateral symmetry; Wilder's term for the antitropical relation between parts upon opposite sides of the meson; e.g., the relation between the right and the left ear.

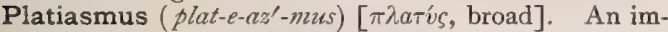
pediment to speech, due to a defect of the tongue, causing thickness of speech.

Platina (plat-e'-nah) [Sp., platina]. The older name of platinum.

Platinamin (plat-in'-am-in) [Sp., platina, platina; amin]. An amin-compound of platinum in which the metal is quadrivalent.

Platinammonium (plat - in - am - o' -ne-um) [Sp., platina, platina ; ammonium $], \mathrm{PtN}_{2} \mathrm{H}_{6^{*}}$ A quadrivalent radicle.

Platinate $\left(p l a t^{\prime}-i n-\vec{a} t\right)$ [Sp., platina, platina]. A salt of platinic oxid-a compound of platinum dioxid and basic oxid.

Platinic (plat-in'-ik) [Sp., platina, platina]. Containing platinum as a quadrivalent element. $P$. Chlorid is used to distinguish potassium from sodium and to precipitate salts of ammonium and of compound ammonias, such as alkaloids.

Platiniferous (plat-in-if'-er-us) [Sp., platina, platina; ferre, to bear]. Producing platinum.

Platinous (plat'-in-us) [Sp., platina, platina]. Containing platinum as a divalent element.
Platinum (plat'-in-um $)$ [Sp., platina, platina]. Pt. $=197$; quantivalence II, IV; Sp. gr. 21.5. A metal of silver-white luster, only soluble in nitro-hydrochloric acid. It is employed in making vessels for chemic and pharmaceutic use. In the form of wire, affixed to a glass rod, it is used as the platinum needle or Oese in bacteriologic work. Platinum salts are poisonous. See Elements, Table of. P., Black, a very finely divided metallic platinum, which has a great capacity for absorbing hydrogen and for condensing oxygen upon its surface. It is used for testing amylic alcohol by oxidizing it into valerianic acid.

Platode, Platoid (plat'-öt, plat'-oid) $[\pi \lambda a \tau \dot{v}$, broad; Eidos, form ]. In biology, broad or flat, as a worm.

Plattner's Bile-crystals. A whitish semi-crystalline mass obtained from an extract of bile-acids, by distilling off the alcohol, dissolving the residue in a little absolute alcohol, and adding ether until the solution becomes turbid

Platula (plat'-u-lah). Synonym of Pediculus pubis.

Platurous (pla-tu'-rus) [properly, platyurous; $\pi \lambda a \tau$ tús, broad; ov́pá, tail]. In biology, having a broad tail.

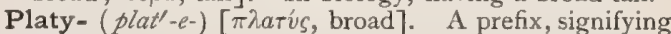
broad.

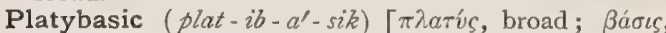
base]. Having a flat base, as certain skulls.

Platybrachycephalic (plat-ibrak-is-ef-al'-ik) [ $\pi \lambda a \tau i s$,

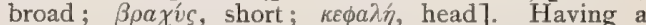
flat and broad skull.

Platybregmate (plat-ib-reg'-māt) $[\pi \lambda a \tau$ ís, broad; $\beta \rho \varepsilon ́ \gamma \mu \alpha$, bregma]. Having a wide bregma.

Platybregmatic (plat-ib-reg-mat'-ik). Synonym of Platybregmate.

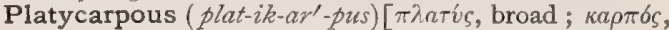
fruit]. In biology, having broad fruit.

Platycelian, Platycelous (plat-is-el'-e-an, plat-is-el'us). Synonym of Opisthocelous.

Platycephalia (plat-is-ef-a'-le-ah). Synonym of Platycephaly.

Platycephalic, Platycephalus (plat-is-ef-all-ik, plat$\left.i s-e f^{\prime}-a l-u s\right)$ [ $\pi \lambda a \tau \dot{s} s$, wide; $\kappa \varepsilon \varphi a \lambda \dot{r}$, head]. Having a broad skull; with a vertical index of less than $70^{\circ}$.

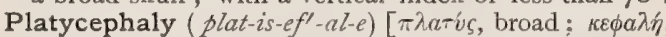
head]. The quality of being platycephalous.

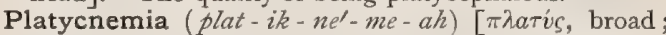
$\kappa \nu \eta \dot{u}$, leg]. The quality of being platycnemic; broadness of the tibia. Platycnemia is a characteristic of many tribes of the African race, and is generally associated with pilastered femur.

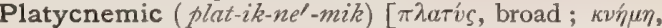
leg]. Having a tibia which is exaggerated in breadth.

Platycnemism (plat-ik-ne'-mizm). See Platycnemia. Platycoria, Platycoriasis (plat-ik-o'-re-ah, plat-ik-o$\left.r^{\prime}-a s-i s\right)[\pi \lambda a \tau u s$, broad; $\kappa o ́ p \eta$, pupil]. Expansion of the pupil; mydriasis.

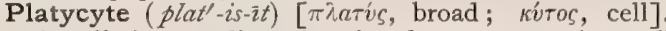
A cell intermediate in size between a giant-cell and a leukocyte, found in tubercle-nodules.

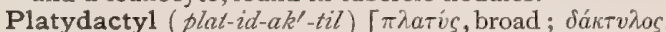
finger]. In biology, having broad or thick digits.

Platyelminthes, Platyhelminthes (plat $-e-e l-m^{\prime} n^{\prime}$

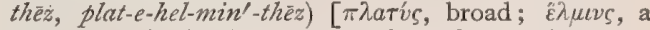
worm ]. Flat-bodied, more or less elongated worms, usually containing both sexual elements at the same time. They include flat-worms, flukes, and tapeworms.

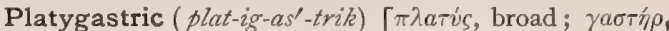
belly]. In biology, having a broad, gastric cavity.

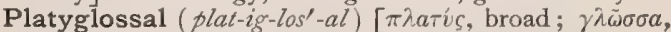
tongue]. In biology, having a broad tongue.

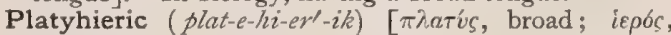
holy, sacrum]. Having a broad sacrum, in distinction 
from dolichohievic, having a narrow sacrum. As a rule, females are platyhieric.

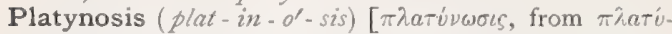
$\nu \varepsilon \iota \nu$, to make broad]. Amplification; enlargement.

Platynotal, Platynote (plat - in - $o^{\prime}-t a l$, plat' $-i n-\bar{o} t$ )

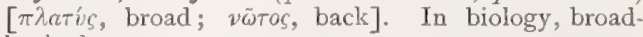
backed.

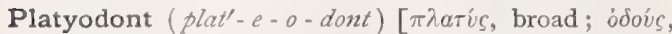
(ofovt-) tooth]. In biology, having broad teeth; an animal with broad teeth.

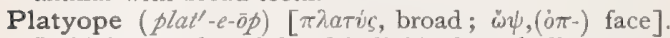
In biology, a broad-faced individual, or skull.

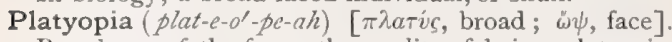
Broadness of the face; the quality of being platyopic.

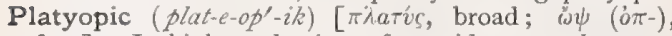
face ]. In biology, having a face wide across the eyes, as in the Mongolian races; having the naso-malar index below $107.5^{\circ}$.

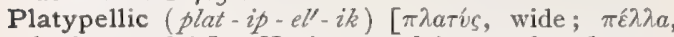
basin, a pelvis]. Having a pelvis very broad transversely, in distinction from dolichopellic, having a narrow pelvis.

Platypelvic (plat-ip-el'-vik). Same as Platypellic.

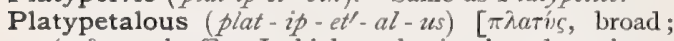

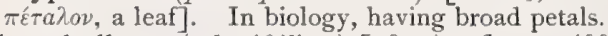

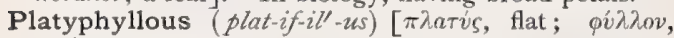
leaf]. In biology, having broad leaves.

Platypod (plat'-ip-od) [ $\pi \lambda a \tau$ v́s, broad; $\pi$ oús, foot]. In biology, a broad-footed animal, as a syndactylous bird.

Platypodia (plat-ip-o'-de-ah) $[\pi \lambda a \tau u ́ s$, broad; $\pi$ oús, foot]. Flat-footedness.

Platypygous (plat-ip-i'-gus) $[\pi \lambda a \tau i ́ s$, broad; $\pi v \gamma \dot{\eta}$, rump]. In biology, having broad buttocks.

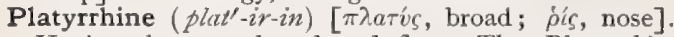
Having the nose broad and flat. The Platyrrhini are a tribe of apes with broad and flat noses. See Index.

Platyrrhinic (plat-ir-in'-ik) [ $\pi \lambda a \tau \hat{v} s$, broad; $\rho$ is, nose $]$. Applied to individuals characterized by $a$ width of nose the index of which exceeds $53^{\circ}$. See Index.

Platyrrhiny, Platyrhiny (plat'-ir-i-ne) $[\pi \lambda a \tau i v$, broad; pis, nose]. The condition of having a platyrrhine skull.

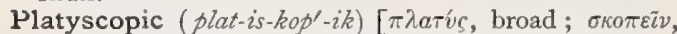
to view]. In optics, having a broad field of view.

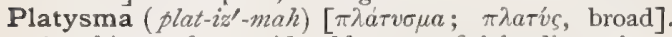
Anything of considerable superficial dimensions. Also, a plaster. P. myoides. See Muscles, Table of. The platysma of man is the homologue of part of the Panniculus carnosus of quadrupeds. P. Reflex. See Reflexes, Table of.

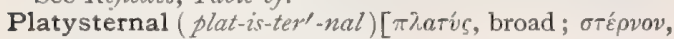
breast-bone]. In biology, having a broad flat breastbone.

Platystomous (plat-is'-to-mus) [ $\pi \lambda a \tau \dot{v} s$, wide; $\sigma \tau b \mu a$, mouth]. Having a broad mouth.

Plaut's Method. A method of staining actinomyces. Either (I) place sections in Gibbes' magenta-solution, or carbolized fuchsin-solution for ten minutes at $45^{\circ}$ C.; wash in distilled water, place in a mixture of equal volumes of saturated aqueous solution of picric acid and absolute alcohol for from five to ten minutes, wash again in water, pass gradually up to absolute alcohol ; clear in cedar-oil, mount in balsam; or (2) place sections in carbolized fuchsin for ten minutes and decolorize in fluorescin alcohol. Stain the nuclei with Ehrlich's hematoxylin, and counterstain faintly with benzo-purpurin. (After Squire.)

Plax (plaks) $\left[\pi \lambda a^{\xi} \xi\right]$. A genus of microscopic fungi. P. scindens, a name given by Eklund to a microörganism which he found in the blood and urine of scarlet-fever patients.
Playfair's Food. A food for infants composed of rennet-whey, plus milk, cream, and lactose. The casein is diminished in amount, but that remaining is unaltered in quality, hence the coagulum is objectionable. P.'s Treatment. See Rest-cure.

Plecolepidous (plek-o-lep'-id-us) [ $[\pi \lambda \hat{\varepsilon} \kappa \varepsilon \iota v$, to twine, twist; $\lambda \varepsilon \pi i s$, a scale]. In biology, applied to Composite in which the bracts of the involucre are coherent.

Plectana (plek'-tan-ah) [ $\pi \lambda \varepsilon \kappa \tau a ́ v \eta$, coil $]$. A cornu of the uterus.

Plectrum (plek'-trum) [ $\pi \lambda \bar{n} \kappa T \rho o v$, a spur : pl., Plectra $]$. The styloid process of the temporal bone; the tongue; the uvula.

Pledget (plej'-et) [origin obscure]. A small flattened compress of lint, wool, cotton, or other fiber, sometimes medicated, designed for application to the surface of a wound to prevent contact with the air, and to absorb discharges or to still hemorrhage.

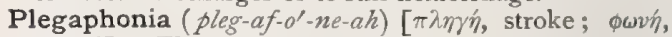
sound]. The sound produced in auscultatory percussion of the larynx, the glottis being open.

Plegometer (pler-om'-et-er). Synonym of Pleximeter.

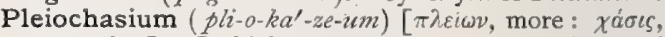
separation]. In biology, a cyme with several lateral axes; a multiparous cyme.

Pleiochromia (pli-o-kro'-me-ah) [ $\pi \lambda \varepsilon i \omega v$, more ; $\chi \rho \hat{\omega} \mu a$, color]. Increased secretion of biliary coloring-matter. Pleiomazia (pli-o-ma'-ze-ah). Same as Polymastia.

Pleiomorphism (pli-o-mor'-fizm) [ $\pi \lambda \varepsilon i \omega v$, more ; $\mu$ o $\phi \dot{\eta}$, form]. In biology: $(a)$ change of form due to excessive growth of an organism; (b) polymorphism; the occurrence of several distinct forms in the life-cycle of an individual; e.g., no less than three form-genera (Acidium, Uredo, and Puccinia) were established to denote the stages of the life-cycle of Puccinia graminis, the well-known corn mildew. Such transforma. tion or pleiomorphism does not exist in the animal kingdom. Cf., Polymorphism.

Pleiomorphy (pli'-o-mor-fe) [ $\left[\pi \lambda \varepsilon i \omega \nu\right.$, more; $\mu \circ \rho \phi \eta^{\prime}$, form ]. In biology: $(a)$ same as Pleiomorphism; $(b)$ the state of regularity in the flowers of plants normally irregular. Cf. Peloria.

Pleiophyllous (pli-off'-il-us) [ $\pi \lambda \varepsilon i \omega \nu$, more; $\phi u ́ \lambda \lambda o v$, leaf]. In biology, exhibiting pleiophylly.

Pleiophylly (pli-off'-il-e) [ $\pi \lambda \varepsilon i \omega v$, more ; $\phi \dot{v} \lambda \lambda o v$, leaf]. In biology, the state in which, starting from a given point the leaves of a plant are found abnormally increased in number.

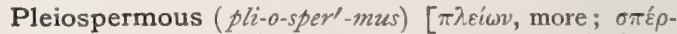
$\mu a$, seed]. In biology, containing an abnormally large number of seeds.

Pleiosporous (pli-o-spo'-rus) $[\pi \lambda \varepsilon i \omega v$, more; $\sigma \pi b \rho o s$, spore]. In biology, producing an abnormally large number of spores.

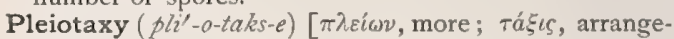
ment]. In biology, an abnormal multiplication in the number of whorls in a plant.

Pleiothalamous (pli-o-thal'-am-us) $[\pi \lambda \dot{c} \omega \omega v$, more; Aćiauos, a bed-chamber]. In biology, having more chambers or cells than usual.

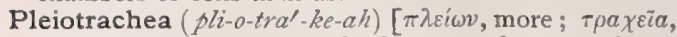
windpipe]. In biology, Cooke's term for a membranous trachea containing a compound spiral fiber.

Plemmyria (plem-ir'-e-ah). Synonym of Plethora.

Plenalvia (plen-al'-ve-ah) [plenus, full; alvus, belly]. Overfilling or impaction of the stomach in lower animals.

Plenck's Digestive. A preparation consisting of 16 parts of clarified turpentine, 8 parts of yolk of egg, 2 parts of honey, 32 parts of spring-water, and 48 parts of alcohol. It is used as an injection for fistulæ. 
P's. Solution, a solution for application to condylo mata and other hypertrophic syphilitic lesions. The formula is: Bichlorid of mercury and alum, each one ounce; acetate of lead and camphor, each one dram; alcohol and vinegar, each 12 ounces. This is applied with a camel's hair pencil. It is likely to produce pain and should be used only in hospitals.

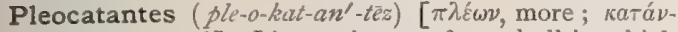
$\tau \eta \zeta$, downward]. Lissauer's term for a skull in which the angle formed between the radius fixus and the line joining the hormion and the staphylion is between $45^{\circ}$ and $67^{\circ}$.

Pleochroism (ple-ok'-ro-izm) $[\pi \lambda \varepsilon i \omega \nu$, more ; $\chi \rho o \iota \dot{a}$, color]. The property possessed by some bodies, especially crystals, of presenting different colors when viewed in the direction of different axes, due to the fact that the rays having vibrations in different planes, suffer absorption in different degrees.

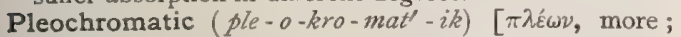
$\chi \rho \tilde{\omega} \mu a$, color]. Pertaining to pleochroism.

Pleocleis (ple'-o-klis) [ $[\pi \lambda \dot{\varepsilon} \omega \nu$, pp. of $\pi \lambda \varepsilon \varepsilon \iota \nu, \pi \lambda \varepsilon i \nu$, to

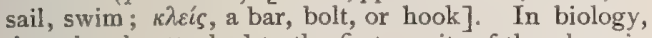
the tubercle attached to the first somite of the pleon in crustaceans and precluding the carapace from being raised posteriorly.

Pleokatantes (ple-o-kat-an'-tēz). See Pleocatantes.

Pleomastia, Pleomazia (ple-o-mas'-te-ah, ple-o-ma'-

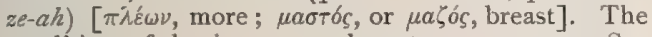
condition of having more than two mammæ. See Polymastia.

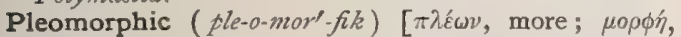
form]. Having more than one form.

Pleomorphism (ple-o-mor'-fizm). See Pleiomorphism.

Pleor (ple'-on) [ $\pi \lambda \varepsilon \varepsilon^{\prime} \omega v, \pi \lambda \varepsilon i \omega \nu$, more]. In biology, Nægeli's term for aggregates of organic matter which cannot be increased or diminished without changing their chemic nature.

Pleon (ple'-on) [ $\pi \lambda \varepsilon i v$, to sail, to swim]. In biology : (a) the abdomen of a crustacean, as distinguished from the cephalon or head and pereion or thorax; (b) the telson of certain crustaceans, as Limulus, so called by Owen from the idea that it represents the abdomen.

Pleonasm (ple'-o-nazm) [ $\pi \lambda \varepsilon o v \alpha \sigma \mu o ́ s$, an exaggeration $]$. Any deformity marked by superabundance of certain organs or parts.

Pleonectic (ple-o-nek'-tik) [ $\pi \lambda \varepsilon o v \varepsilon \xi i a$, greediness]. Characterized by pleonexia.

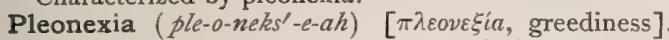
Greediness or arrogance due to mental disease.

Pleopod (ple'-o-pod) [ $\pi \lambda e^{\prime} \varepsilon t v$, to swim; $\pi$ óvs, foot]. In biology, one of the swimmerets or abdominal swimming-legs of a crustacean.

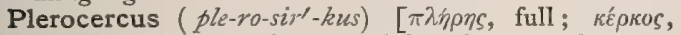
tail]. In biology, the second larval stage of certain platodes, e.g., Bothriocephalus latus. (Braun.)

Plerom, Pleroma (ple'-röm, ple-ro'-mah) [ $\pi \lambda h \rho \omega \mu \alpha$, that which fills]. Same as Plerome.

Plerome (ple'-rōm) [ $\pi \lambda \dot{\eta} \rho \omega \mu \alpha$, that which fills]. In biology, the axial portion of the growing point; the cylinder or shaft of nascent fascicles; plerom, pleroma. P.-sheath, in biology, the phloëm-sheath in its nascent state.

Plerosis (ple-ro'-sis) [ $\pi \lambda \eta \rho \omega \sigma \iota s$, a filling $]$. I. The restoration of lost tissue. 2. Plethora.

Plerotic (ple-rot'-ik) [ $\pi \lambda \eta p \omega \sigma \iota \zeta$, a filling]. Tending toward, or pertaining to, a plerosis. As a noun, a drug promoting the filling up of wounds by new tissue.

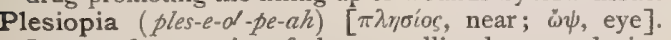
Increased convexity of the crystalline lens, producing myopia, and due to long-continued accommodationstrain.
Plessimeter (ples-im'-et-er). Synonym of Pleximeter. Plessor (ples'-or). Synonym of Plexor.

Plessy's Green. Same as Mittler's Green.

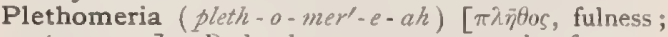
$\mu \varepsilon \hat{\varepsilon} \rho \varsigma$, part]. Redundancy or over-growth of an organ or part.

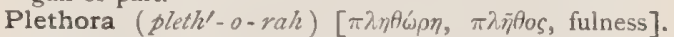
Abnormal fulness of the blood-vessels, or superabundance of blood. See Polyemia. P. apocoplica, the condition that follows major amputations attended with little loss of blood. P., Hydremic. Synonym of Hydremia. P. hyperalbuminosa, an increase of the albuminoid elements of the blood-plasma. P. polycythæmica. Synonym of Polycythemic. P., Serous, an excess of serum in the blood. P. universalis, plethora affecting all the body.

Plethoric (pleth'-o-rik) [ $[\pi \lambda \tilde{\eta} \theta 0 \varsigma$, fulness]. Pertaining to plethora.

Plethysmograph (pleth-iz'-mo-graf) $[\pi \lambda \eta \theta v \sigma \mu \delta \delta$, in-

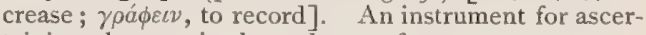
taining changes in the volume of any organ or part, dependent upon changes in the quantity of the blood.

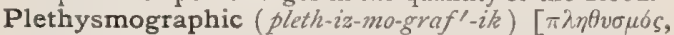

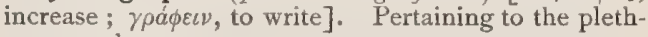
ysmograph.

Pleumonia ( $\left.p l u-m \sigma^{\prime}-\dot{n} e \cdot a h\right)$ [ $\pi \lambda \varepsilon \dot{v} \mu \omega \nu$, the lung]. Synonym of Pneumonia.

Pleura $\left(p l u^{\prime}-r a h\right)$ [ $\pi \lambda \varepsilon v \rho a ́$, a side $]$. The serous membrane which envelops the lung (P., Pulmonary), and, which being reflected back, lines the ental surface of the thorax $(P .$, Costal $)$. In biology: $(a)$ the lateral portion of the integumentary segments of an arthropod. It lies between the tergum and stermum, and consists of the epineron and episternum; $(b)$ one of the lateral tracts of the rachis of the lingual ribbon of gastropod molluscs. P. costalis. See P., Cosial. P., Diaphragmatic, the reflection of the pleura upon the upper surface of the diaphragm. P., Parietal. Synonym of $P$., Costal. P., Pericardial, the portion of the pleura contiguous to the pericardium. P. phrenica. Synonym of $P$., Diaphragmatic. P. pulmonalis. Synonym of $P$., Pulmonary. P., Visceral. Synonym of $P$., Pulmonary.

Pleural ( $\left.p l u^{\prime}-r a l\right)$ [ $[\pi \lambda \varepsilon v \rho a ́$, pleura $]$. I. Pertaining to the pleura. $2[\pi \lambda \varepsilon v \rho \sigma v$, rib]. Pertaining to a rib, or the ribs; costal. P. Eclampsia. See P. Epilepsy. P. Epilepsy, a convulsion sometimes following the procedure of washing out the pleural cavity. It may terminate fatally, or may end in monoplegia or hemiplegia. P. Reflexes, grave nervous phenomena which develop in the course of removal of a pleural effusion, either at the time of aspiration or, more often, during the process of washing out the pleural cavity. Sudden unconsciousness, with tonic and clonic convulsions, hemiplegia, with or without aphasia, paralysis of the arm on the affected side, sometimes with hemichorea, are some of the conditions that have been observed.

Pleuralgia (plu-ral'-je-ah) [ $\pi \lambda \varepsilon v \rho a ́$, side; $a \dot{\lambda} \gamma o s$, pain $]$. Intercostal neuralgia.

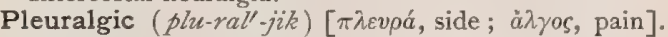
Pertaining to or affected with pleuralgia.

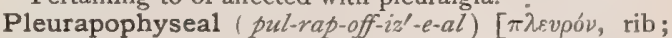
ámó $\phi v \sigma \iota s$, offshoot]. Pertaining to a pleurapophysis.

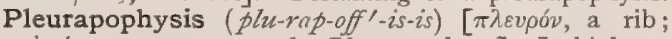

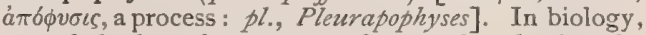
one of the lateral processes of a vertebra, having the morphologic valence of a rib; a true rib.

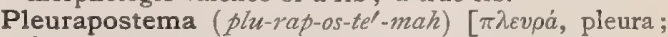
á $\pi \sigma \sigma \tau \eta \mu a$, abscess]. A collection of pus in the cavity of the pleura.

Pleurarthrocace (plu-rar-throk'-as-e) [ $[\pi \lambda \varepsilon v \rho b v$, rib; 


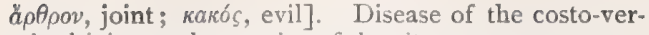
tebral joints; also, caries of the ribs.

Pleurarthron (plu-rar'-thron) [ $\pi \lambda \varepsilon v \rho o ́ v$, rib; à $\rho \rho \rho o \nu$, joint]. The articulation of a rib.

Pleurenchyma (plu-rengl-kim-ah) $[\pi \lambda \epsilon v \rho a ́$, side; $\tilde{\varepsilon} \gamma \chi v \mu a$, infusion]. In biology, woody tissue.

Pleurenchymatous (plu-reng-kim'-at-us) [ $\pi \lambda \varepsilon v \rho a ́$, side; $\dot{\varepsilon} \gamma \chi v \mu \alpha$, that which is poured in]. Pertaining to, or of the nature of pleurenchyma.

Pleurisy ( $\left.p u^{\prime}-r i s-\ell\right)[\pi \lambda \varepsilon v \rho \dot{a}$, side $]$. Pleuritis; inflammation of the pleura. It may be acute or chronic. Three chief varieties are usually described, depending upon the character of the exudate: (a) Fibrinous or Plastic; (b) Sero-fibrinous; (c) Purulent. In Fibrinous Pleurisy, the pleura is covered with a layer of lymph of variable thickness, which, in the acute form, can be readily stripped off. This form is usually secondary to another disease, as pneumonia. Carcinoma, abscess, and gangrene of the lungs usually give rise to a plastic pleurisy when the disease reaches the surface of the lung. Then there seems to be an apparent idiopathic form, following exposure to cold. P., Serofibrinous, is generally due to tuberculosis, either of the lung, or, more rarely, primarily of the pleura. Other infectious diseases such as measles, scarlet fever, influenza, rheumatic fever, and sepsis sometimes cause a sero-fibrinous pleurisy. In a few cases no microöryanismal cause can be discovered. P., Purulent, or Empyema, may be (I) a sequence of the acute sero-fibrinous form; (2) it may arise as a purulent pleurisy in the beginning, especially in acute infectious diseases - thus in scarlet fever, typhoid fever, pneumonia, influenza, measles, whoopingcough; tuberculous pleurisy is often purulent; (3) empyema may be due to local disease, as fracture or caries of the ribs, caries of the vertebræ, penetrating wounds, malignant disease of the lung or esophagus, or to perforation into the pleura of tuberculous cavities, of perityphlitic abscesses, of subdiaphragmatic abscesses, of hepatic abscesses, and of gastric uilcers. The onset of acute pleurisy is marked by agonizing pain in the side, sharp and stabbing, increased on coughing, and in its milder forms called a "stitch;" there may be an initial chill, followed by fever; or the disease may begin insidiously; friction-fremitus may be felt on palpation and a to-and-fro friction-sound is heard on auscultation. In the sero-fibrinous variety a liquid effusion takes place, varying in amount. The pain now stops and the signs of effusion become marked: bulging of the intercostal spaces and chest-wall, absence of vocal fremitus, displacement of the heart, movable dulness with a curved upper line, and a tympanitic percussion-note (skodaic resonance) beneath the clavicle and above the level of the effusion. Chronic pleurisy may be sero-fibrinous, coming on insidiously or following an acute sero-fibrinous pleurisy. A dry chronic pleurisy is a sequence of acute sero-fibrinous pleuritis, or is a primitive plastic inflammation. Tuberculosis and syphilis may cause chronic plastic pleurisy. Peripleuritis is a rare affection in which the connective tissue between the costal pleura and the thoracic wall becomes the seat of an inflammation that generally proceeds to suppuration. The etiology is obscure. P., Areolar. Synonym of $P$., Multilocular. P., Calcareous, a process characterized by the deposition of lime-salts in a thickened pleura, $\mathbf{P}$., Costo-pulmonary, pleurisy affecting both the costal and the pulmonary pleura. P., Diaphragmatic, a form of the disease which is restricted to the pleural surface of the diaphragm. Vomiting, hiccough, and icterus are occasionally present. P., Double, pleurisy on both sides of the chest. P., Dry, that form in which there is little or no effusion of fluid. It is common in rbeumatic and tuberculous patients. P., Dyscrasic, the presence of a fetid exudate in the pleural, as well as in the pericardial and peritoneal sacs, of still-born infants. It is a septic condition, and is most frequent in, if not confined to, hospitals in which puerperal sepsis rages. P., Encysted, pleurisy in which the effusion is circumscribed by adhesions or separated into pockets or loculi. It is most common in empyema. P., Gangrenous, pleurisy in which the exudate and the pleural membrane become gangrenous. P., Hemorrhagic, a variety in which the exudate contains a varying proportion of blood. It occurs: $(a)$ in the pleurisy of asthenic states, such as carcinoma, chronic nephritis, and in the malignant infectious fevers; sometimes also in hepatic cirrhosis; $(b)$ in tuberculous pleurisy; $(c)$ in carcinomatous pleurisy; $(d)$ blood may become accidentally mixed with the effusion from the wounding of the lung during aspiration. P., Ichorous; Putrid Pleurisy; a form characterized by the presence of a gray or dirty-brown fluid which gives off an offensive odor. It is usually dependent upon pyemia, septicemia, pulmonary gangrene, or putrid bronchitis. P., Interlobar, inflammation of the pleural layers between adjoining lobes of the lung. P., Latent, a form in which the subjective symptoms are absent. P., Mediastinal, inflammation of the pleural layers about the mediastinum. P., Metapneumonic, pleurisy dependent upon a pneumonia. P., Multilocular, an encysted pleurisy in which connective-tissue bands separate the effusion into several, usually intercommunicating, sacs. P., Postpneumonic. Synonym of $P$., Metapneumonic. P., Putrid. See P., Ichorous. P., Pulsating. Synonym of Empyema, Pulsating. P.-root. See Asclepias. P., Spurious. Synonym of Pleurodynia. P., Suppurative. Synonym of $P$., Purulent. See under Pleurisy. P., Tuberculous, pleurisy due to the tubercle-bacillus.

Pleuritic (plu-rit'-ik) [ $\pi \lambda \varepsilon v \rho a ́$, pleura ; $\iota \tau \varsigma$, inflammation]. Pertaining to, or affected with, or of the nature of, pleuritis.

Pleuritis (plu-ri'-tis) [ $\pi \lambda \varepsilon v \rho a ́$, pleura; $\iota \tau \iota \zeta$, inflammation]. Inflammation of a pleura. See Pleurisy. P. deformans, chronic inflammation with great thickening and induration of the pleura, usually accompanying fibroid pneumonia. P. duplicata, bilateral pleurisy. $\mathbf{P}$. humida, pleurisy with effusion. P. incapsulata. Synonym of Pleurisy, Encysted. P. pulsans, a form that usually, but not always, occurs in chronic cases, and in which the fluid is purulent. The pulsation is generally universal. It occurs more frequently among men, and between the ages of twenty and thirty years. It may be confounded with aneurysm. Its seat, however, is different; there is no bruit; it grows smaller under pressure and larger after coughing. P. sicca, dry pleurisy. P. spuria. Synonym of Pleurodynia. P. vera, simple pleurisy without complication.

Pleuro- $\left(p l u^{\prime}-r o-\right)\left[\pi \lambda \varepsilon v \rho a^{\prime}\right.$, side $]$. A prefix to denote connection with the pleura, or with a side.

Pleuroblastic ( $\left.p l u-r o-b l a s^{\prime}-t i k\right)[\pi \lambda \varepsilon v \rho a$, the side;

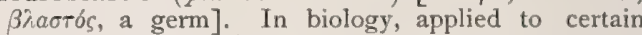
fungi (Peronosporea) that produce globular or branched lateral outgrowths which act as haustoria.

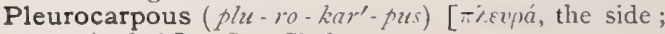

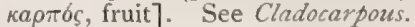

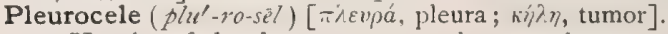
I. Hernia of the lung; pneumocele. 2. A serous effusion into the pleural cavity. 
Pleurocentral (plu-ro-sen'-tral) $[\pi \lambda \varepsilon v \rho a ́$, side; $\kappa \varepsilon ́ v \tau-$ pov, center]. Pertaining to a pleurocentrum.

Pleurocentrum (plu-ro-sen $-t r u m)[\pi \lambda \varepsilon v \rho \alpha ́$, side;

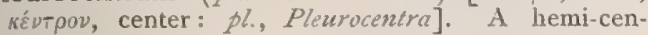
trum; the lateral element in a vertebral centrum.

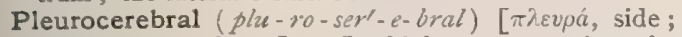
cerebrum, cerebrum]. In biology, connecting the side of the body with the head.

Pleuroclysis, Pleuroklysis ( $\left.p l u-r o k^{\prime}-l i s-i s\right)[\pi \lambda \varepsilon v \rho a ́$, rib, side; $\kappa \lambda \dot{v} \sigma \iota, a$ wash]. The injection of fluids into the pleural cavity.

Pleuroccenadelphus (plu-ro-sen-ad-ell-fus) [ $[\pi \lambda \varepsilon v \rho a ́$,

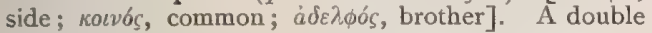
monster consisting of two nearly perfect bodies joined laterally by the trunk.

Pleurocolic $\left(p l u-r o-k o l^{\prime}-i k\right) \quad[\pi \lambda \varepsilon v \rho a ́$, side; $\kappa \tilde{\omega} \lambda \sigma \nu$, colon]. Costo-colic; joining the side and the colon.

Pleurocollesis ( $\left.p l u-r o-k o l-e^{\prime}-s i s\right)[\pi \lambda \varepsilon v \rho a$, pleura; $\kappa o ́ \lambda \lambda \eta \sigma \iota \varsigma$, a glueing]. Adhesion of the pleural layers.

Pleuro-cutaneous ( $\left.p l u^{\prime}-r o-k u-t \alpha^{\prime}-n e-u s\right)$ [ $\pi \lambda \varepsilon v \rho a ́$, pleura: cutis, skin]. In relation with the pleura and the skin, as a pleuro-cutaneous fistula.

Pleurodiscous (plu-ro-dis'-kus) $[\pi \lambda \varepsilon v \rho a ́$, the side ;

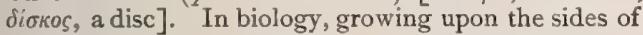
the disc, as the ray-flowers in the Composite.

Pleurodont (plu'-ro-dont) [ $[\pi \lambda \varepsilon v \rho a ́$, the side; ódoús, (ofovT-), tooth]. In biology, a tooth, or an animal bearing teeth, fastened into the jaw by a lateral ankylosis; as in certain lizards.

Pleurodyne ( $\left.p l u^{\prime}-r o-d i n\right)$. See Pleurodynia.

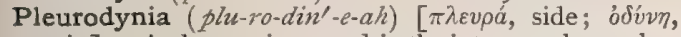
pain]. A sharp pain seated in the intercostal muscles. It is considered a myalgia of rheumatic origin.

Pleurogenic, Pleurogenous (plu-ro-jen'-ik, plu-roj'-

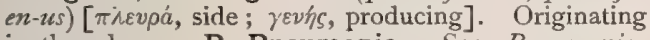
in the pleura. P. Pneumonia. See Pneumonia, Pleurogenous. P. Phthisis, pulmonary tuberculosis starting from a pleurisy.

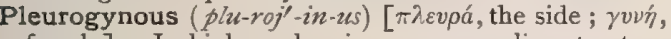
female]. In biology, bearing some peculiar structure alongside the ovary.

Pleurohepatitis (plu-ro-hep-at-i'-tis) [ $[\pi \lambda \varepsilon v \rho a ́$, pleura; $\eta \pi \alpha \rho$, liver; $\iota \tau \iota \zeta$, inflammation]. Inflammation of the pleura and the liver.

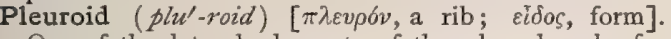
One of the lateral elements of the pleural arch of a vertebrate. Cf. Neuroid.

Pleuroklysis (plu-rok'-lis-is). See Pleuroclysis.

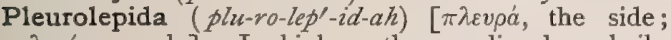
$\lambda \varepsilon \pi$ is, a scale]. In biology, the peculiar dermal ribs in extinct ganoids (Pycnodonts) that covered the whole body, or the anterior portion, with a sort of lattice-work.

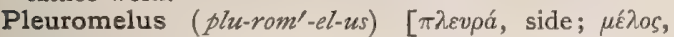
limb]. A monster possessing supernumerary thoracic limbs, the scapulæe of which are in contact with the properly developed arms.

Pleuron (plu'-ron) [ $\pi \lambda \varepsilon v \rho o ́ v$, a rib : pl., Pleura $]$. In biology: $(a)$ a rib; $(b)$ the lateral piece of a somite of an arthropod. Cf. Mesopleuron, Metapleuron, Propleuron.

Pleuro-cesophageus (plu-ro-e-sof-aj-el-us) [ $[\pi \lambda \varepsilon v \rho a ́$, side; oi $\sigma \delta \phi a \gamma \delta \delta$, , esophagus]. A band of smooth muscle-fibers joining the left pleura posteriorly with the esophagus.

Pleuropathia, Pleuropathy ( $p l u-r o-p a^{\prime}-t h e-a h$, plu-

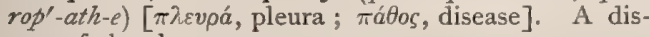
ease of the pleura.

Pleuropedal (plu-ro-példal) [ $\pi \lambda \varepsilon v \rho a ́$, side; pes, foot]. In biology, joining the side of the body with the foot.

Pleuropericarditis (plu-ro-per-ik-ar-di'-tis) [ $\pi \lambda \varepsilon v \rho a ́$, pleura; $\pi \varepsilon \rho i$, around; $\kappa a \rho \delta i \dot{\alpha}$, heart ; $\iota \tau \iota \varsigma$, inflammation]. Pleurisy associated with pericarditis.

Pleuro-peripneumonia ( $\left.p l u^{\prime}-r o-p e r-e-n u-n o^{\prime}-n e-a h\right)$. Synonym of Pleuro-pneumonia.

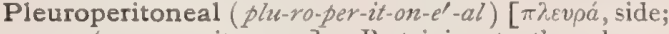
$\pi \varepsilon \rho \iota t o ́ v a \iota s v$, peritoneum]. Pertaining to the pleuroperitoneum.

Pleuroperitoneum, Pleuroperitonæum (plu-ro-per-it$\left.o-n e^{\prime}-u m\right)$ [ $\pi \hat{\lambda} \varepsilon v \rho a ́$, the side ; $\pi \varepsilon \rho \iota \tau o v a \iota v$, peritoneum]. In biology, the lining serous membrane of the pleuro. peritoneal cavity of those vertebrates in which the thoracic and abdominal cavities are not separated by a diaphragm.

Pleuroperitonitis ( $\left.p l u^{\prime}-r o-p e r-i t-o n-i^{\prime}-t i s\right)$ [ $\pi \lambda \varepsilon v p a ́$, pleura; $\pi \varepsilon \rho \iota t o ́ v a \iota o v$, peritoneum; $\iota \tau \iota \varsigma$, inflammation]. The simultaneous existence of pleurisy and peritonitis.

Pleuroplegia ( $\left.p l u-r o-p l e^{\prime}-j e-a h\right)$ [ $[\pi \lambda \varepsilon v \rho a ́$, side ; $\pi \lambda \eta \gamma \dot{\eta}$, stroke]. Absence of the power of conjugate movement of the eyes to the right or left, though convergence may be preserved.

Pleuropneuma (plu-ro-nu'-mah). Synonym of Pneumothorax.

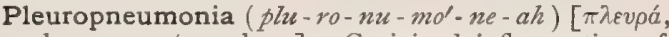
pleura; $\pi \nu \varepsilon \dot{v} \mu \omega \nu$, lung]. Conjoined inflammation of the pleura and the lung. The ordinary croupous pneumonia is generally a pleuropneumonia. Usually the term refers to an acute, febrile, contagious disease of cattle. P. contagiosa. Synonym of P., Epizootic. P., Epizoötic, P., Exudative, characterized by lobar pneumonia and by pleurisy, generally plastic in type. The period of incubation is from two to three weeks. The cause of the disease is thought to be the pneumococcus of Fränkel. The disease is very fatal, especially at the beginning of an epidemic, and governments have established rigid quarantine measures against it. P., Hypostatic, hypostatic pneumonia associated with pleurisy.

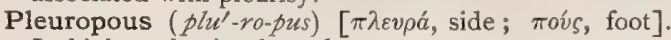
In biology, having lateral supports.

Pleuropyesis (plu-ro-pi-é-sis) [ $[\pi \lambda \varepsilon v \rho a ́$, pleura; $\pi v ́ \eta$ $\sigma \iota s$, suppuration]. Purulent pleurisy.

Pleurorhizal (plu-ro-ri'-zal) [ $\pi \lambda \varepsilon v \rho a ́$; the side; $\rho i \varsigma a$, root]. See Accumbent.

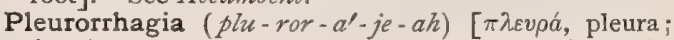
in fvivva, to burst forth]. Hemorrhage from the pleura.

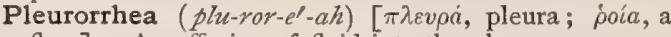
flow]. An effusion of fluid into the pleura.

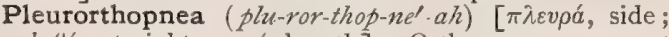
óflós, straight; $\pi \nu$ on, breath $]$. Orthopnea on account of pain in the side, either from pleurisy or pleurodynia.

Pleurosoma (plu-ro-so'-mah) [ $[\pi \lambda \varepsilon v \rho a ́$, side ; $\sigma \tilde{\omega} \mu \alpha$, a body]. A variety of single autositic monsters of the species celosoma in which there is a lateral eventration occupying principally the upper portion of the abdomen and extending to the ventral portion of the chest, with atrophy or imperfect development of the upper extremity on the side of the eventration.

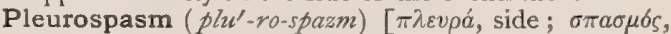
spasm]. Cramp, or spasm in the side.

Pleurosteal (plu-ros'-te-al) $[\pi \lambda \varepsilon v \rho a ́$, side; óotéov, a bone]. Pertaining to the pleurosteon.

Pleurosteon (plu-ros'-te-on) [ $\pi \lambda \varepsilon v \rho a ́$, the side; óctéov, a bone: pl., Pleurostea]. In biology, the anterior lateral portion of the breast-bone of a bird, giving attachment to the ribs; as distinguished from lophosteon, coracosteon, metosteon.

Pleurosthotonos (plu-ros-that'-o-nos). See Pleurothotonos.

Pleurostosis (plu-ros-to'-sis) [ $\pi \lambda \varepsilon v \rho a ́$, pleura; óotéon, bone]. Calcification of the pleura. 
Pleurothotonic (plu-ro-t/zo-ton' $-i k)[\pi \lambda \varepsilon v \rho b \theta \varepsilon v$, from

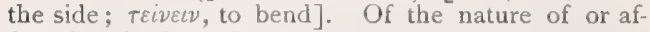
fected with pleurothotonos.

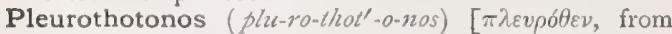
the side; $\tau \varepsilon i \nu \varepsilon \iota \nu$, to bend]. A bending of the body to one side during a tetanic or other convulsion.

Pleurotomy (plu-rot'-o-nue) [ $\pi \lambda \varepsilon v \rho a ́$, pleura; $\tau o \mu \dot{\eta}$, a cutting]. Incision into the pleura, as in empyema for the evacuation of the purulent collection. The incision is made between two ribs, usually in the eighth intercostal space dorsad of the posterior axillary line.

Pleurotonus ( $p$ hu-rot'-o-nus). Synonym of Pleurothotonos.

Pleurotribe ( $\left.p l u^{\prime}-r o-t r \bar{\imath} b\right)$ [ $\pi \lambda \varepsilon v \rho a$ á, the side ; $\tau \rho i \beta \varepsilon t \nu$, to rub]. In biology, applied to such flowers as have the stamens so arranged that an insect entering will receive the pollen upon its side, as in the pea. Cr., Nototribe, Sternotribe.

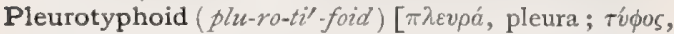
stupor]. Pleuritis due to the presence of the bacillus of typhoid fever.

Pleurovisceral (plu-ro-vis'-er-al) [ $\pi \lambda \varepsilon v \rho a ́$, pleura, side ; viscus, an organ or viscus]. Pertaining to the pleura or side, and to the viscera.

Plexal (pleks'-al) [plectere, to knit]. Pertaining to or of the nature of a plexus.

Plexed (plekst) [plexus, plaited]. Netted; plexiform. Plexiform (pleks'-if-orm) [plexus, plexus; forma, form]. Resembling a plexus. P. Angio-sarcoma, an angio-sarcoma in which the sarcomatous vessels anastomose, forming a winding network. P. Glands. See Gland. P. Neuroma, a convoluted serpentine enlargement of the peripheral nerves. Generally it is only the connective tissue of the nerves that is involved; these are then fibromatous masses. Rarely, however, the nerves themselves participate, becoming lengthened and increased in number.

Pleximeter (pleks-imi-et-er) $[\pi \lambda \tilde{\eta} \xi \iota s$, a stroke; $\mu \dot{\varepsilon} \tau \rho o \nu$, measure]. An ivory disc or other hard substance placed on the body to receive the stroke in mediate percussion. Sometimes a pleximeter is used that consists of two flat discs joined at their centers by a short cylinder or rectangular rod.

Pleximetric (pleks-im-et'-rik) [ $[\pi \lambda \tilde{\eta} \xi \iota s$, a stroke; $\pi \dot{\varepsilon} \tau$ $\rho \circ \nu$, measure]. Pertaining to or performed with a pleximeter.

Plexometer (pleks-om'-et-er). Same as Pleximeter.

Plexor (pleks'-or) [ $\pi \hat{\eta} \tilde{\xi} \iota \varsigma$, stroke]. The hammer used for striking upon the pleximeter.

Plexure $\left(p l e k s^{\prime}-\bar{i} r\right)$ [plectere, to interweave]. An interweaving; a plexus.

Plexus (pleks'-us) [plectere, to knit]. An aggregation of vessels or nerves forming an intricate network. A table of the nerve-plexuses is appended. P.articularis, a small venous plexus near the outer aspect of the temporo-maxillary articulation. P. cerebri, either of the choroid plexuses. P., Choroid, a fringelike membrane, occupying the margin of a fold of the pia mater in the interior of the brain. In structure, it consists of minute and highly vascular villous processes, composed of large round corpuscles, containing, besides a central nucleus, several yellowish granules and fat-molecules, and covered by a single layer of flattened epithelium. P. ciliaris. Synonym of Canal of Schlemm. P. cirsoides. Synonym of P., Pampiniform. P. digitalis, one of the venous plexuses on the anterior and posterior surfaces of the second and third phalanges. P., Fundamental. See P., Principal. P., Ganglionic, a nervous plexus in which ganglion-cells are found. P. gangliosus, one of the small plexuses formed at the junction of the spinal nerves and the inferior hypogastric plexus. They contain a number of ganglia. P. glandularis, $\mathbf{P}$. glanduliformis. Synonym of $P$, Choroid. P., Hemorrhoidal, a plexus of veins surrounding the lower part of the rectum, beneath the mucous membrane, and giving origin to the inferior, middle, and superior hemorrhoidal veins. P., Hovius', a plexus of veins in the ciliary region of the eye. P., Interlaminar, a lymphatic plexus formed by the lymphatic vessels in the muscular coat of the intestines. P., Lymphatic, a plexus of lymphatic vessels. P. Malleal, P., Manubrial, a plexus of veins surrounding the handle of the malleus. P., Medulli-spinal, a venous plexus surrounding the spinal cord. P., mirabilis. Synonym of $P$., Choroid. P. nervorum spinalium, a plexus formed by the spinal nerves, e.g., the cervical, brachial, lumbar, or sacral. P., Pampiniform, the spermatic plexus, collecting the blood from the testicle, and emptying by a single vein, the spermatic, into the right renal vein on the right side, and into the inferior cava on the left. In the female, the plexus collects the blood from the uterus, the oviduct, and the ovary. P., Parotid. Synonym of Pes anserinus. P., Perineal, a superficial and a deep venous plexus are found in the perineum. The superficial is formed by veins from the labia majora and some from the prepuce of the clitoris and the bulbs. Its blood is carried to the superficial epigastric, pudic and external obturator veins. The deep plexus is formed by the veins from the cavernous bodies, from the bulbs, and a branch from the dorsal vein of the clitoris. P., Pharyngeal, a venous plexus surrounding the pharynx. P. plantaris, a plexus of veins on the sole of the foot. P., Principal or Fundamental, a plexus formed by the larger nerves of the body. They frequently contain ganglionic cells which are collected into microscopic ganglia. P., Prostatic: (I) A plexus of veins surrounding the prostate gland; it receives the dorsal veins of the penis. (2) See also $P$., Prostatic, in Table. P., Pterygoid, a plexus of veins formed by branches of the internal maxillary vein, and situated between the temporal and external pterygoid muscles. $P$., Pudendal, a venous plexus into which veins from the clitoris, the labia minora, the urethra, and the vaginal vestibule empty. The corresponding plexus in the male surrounds the prostate and membranous urethra. P., Santorini's, the prostatic plexus of veins. P. seminalis. Synonym of Rete testis. P. spinalis, the plexus formed by the spinal veins. There are two, an anterior and a posterior spinal plexus. P., Sympathetic, a plexus formed by sympathetic nerve-fibers. P. thyroideus impar, a venous plexus situated beneath the isthmus of the thyroid gland. It is derived from the inferior thyroid veins. P. tonsillaris: (I) a venous plexus surrounding the tonsil; (2) See also P., Tonsillar, in Table. P., Urethro-vesical, a venous plexus situated about the urethra and the lower portion of the bladder. It receives the dorsal vein of the clitoris, the pudic veins (right and left), veins from the cavernous bodies of the clitoris, a branch from the obturator vein, and a few small branches from the urethra and the neck of the bladder. P., Utero-vaginal, a venous plexus surrounding the vagina, the neck and the body of the uterus. P. Vaginal: (I) a venous plexus surrounding the vagina; (2) See also P., Vaginal, in Table. P., Venous, a network or plexus of veins. P., Vesical : (I) a plexus of veins in the wall of the bladder, outside of the muscular coat; it communicates with the hemorrhoidal and prostatic plexuses in the male, and with the vaginal plexuses in the female; (2) See also $P$. Vesical, in Table. 


\section{TABLE OF NERVE-PLEXUSES.}

\begin{tabular}{|c|c|c|c|}
\hline NAME. & LOCATION. & DERIVATION. & Distribution. \\
\hline Aortic (abdominal). & $\begin{array}{l}\text { Sides and front of } \\
\text { aorta. }\end{array}$ & $\begin{array}{l}\text { Semilunar and lumbar ganglia, renal } \\
\text { and solar plexuses. }\end{array}$ & $\begin{array}{l}\text { Inferior mesenteric, spermatic and } \\
\text { hypogastric plexuses, filaments to } \\
\text { the inferior vena cava. }\end{array}$ \\
\hline Aortic (thoracic). & $\begin{array}{l}\text { Surrounding the tho- } \\
\text { racic aorta. }\end{array}$ & $\begin{array}{l}\text { Thoracic ganglia of the sympathetic } \\
\text { nerve; cardiac plexus. }\end{array}$ & Solar plexus, aorta. \\
\hline Auerbach's. & $\begin{array}{l}\text { Between the circular } \\
\text { and long it ud inal } \\
\text { muscular coats of } \\
\text { the small intestine. }\end{array}$ & Sympathetic. & Intestinal walls. \\
\hline Axillary. & See Brachial. & & \\
\hline Brachial. & $\begin{array}{l}\text { Lower part of neck to } \\
\text { axilla. }\end{array}$ & $\begin{array}{l}\text { Ventral branches of the four lower } \\
\text { cervical and the greater part of the } \\
\text { first thoracic nerve. }\end{array}$ & $\begin{array}{l}\text { Suprascapular, thomboid, median, ul- } \\
\text { nar, musculo-spiral, posterior thor- } \\
\text { acic, muscular thoracic, subscapular, } \\
\text { circumflex, Wrisberg's musculo- } \\
\text { cutaneous. }\end{array}$ \\
\hline Cardiac (great or deep). & $\begin{array}{l}\text { In front of the bifurca- } \\
\text { tion of the trachea. }\end{array}$ & $\begin{array}{l}\text { Cardiac nerves of the cervical ganglia } \\
\text { of the sympathetic, branches of the } \\
\text { recurrent laryngeal and vagusnerves. }\end{array}$ & $\begin{array}{l}\text { Pulmonary, coronary, and cardiac } \\
\text { plexuses. }\end{array}$ \\
\hline $\begin{array}{l}\text { Cardiac (superficial or } \\
\text { anterior). }\end{array}$ & $\begin{array}{l}\text { Beneath the arch of } \\
\text { the aorta. }\end{array}$ & $\begin{array}{l}\text { Left superior cardiac, branches of the } \\
\text { vagus and deep cardiac plexus. }\end{array}$ & Coronary and pulmonary plexuses. \\
\hline Carotid (external). & $\begin{array}{l}\text { Around the external } \\
\text { carotid artery. }\end{array}$ & $\begin{array}{l}\text { Pharyngeal plexus, superior cardiac } \\
\text { nerve, superior cervical ganglion. }\end{array}$ & $\begin{array}{l}\text { Exterual carotid artery and its } \\
\text { branches. }\end{array}$ \\
\hline Carotid (internal). & $\begin{array}{l}\text { Outer side of the in- } \\
\text { ternal carotid artery. }\end{array}$ & Sixth nerve and Gasserian ganglion. & $\begin{array}{l}\text { Carotid artery, petrosals, communicat- } \\
\text { ing branches. }\end{array}$ \\
\hline Caudal. & See Coccygeal. & & \\
\hline Cavernous. & Cavernous sinus. & $\begin{array}{l}\text { Third, fourth, fifth, and sixth nerves, } \\
\text { and ophthalmic ganglion. }\end{array}$ & Wall of the inferior carotid. \\
\hline Cavernous (of penis). & Cavernous bodies. & Vesical plexus. & Cavernous bodies. \\
\hline Celiac. & Celiac axis. & $\begin{array}{l}\text { Solar plexus, splanchnic ( lesser), } \\
\text { vagus. }\end{array}$ & $\begin{array}{l}\text { Coronary, hepatic, pyloric, gastro- } \\
\text { duodenal, gastro-epiploic, and splenic } \\
\text { plexuses. }\end{array}$ \\
\hline Cervical. & $\begin{array}{l}\text { Opposite the four } \\
\text { upper vertebræ. }\end{array}$ & $\begin{array}{l}\text { Ventral branches of the four upper } \\
\text { vertebra. }\end{array}$ & $\begin{array}{l}\text { Superficial: To skin of head and neck. } \\
\text { Deep: Phrenic, communicans noni, } \\
\text { two muscular, two communicating. }\end{array}$ \\
\hline Cervical (posterior). & See Cruveilhier's plex & us. & \\
\hline Coccygeal. & $\begin{array}{l}\text { Dorsal surface of } \\
\text { coccyx and caudal } \\
\text { end of sacrum. }\end{array}$ & $\begin{array}{l}\text { Fourth and fifth sacral and the coccy- } \\
\text { geal nerves. }\end{array}$ & Ano-coccygeal nerves. \\
\hline Coronary (anterior). & Below arch of aorta. & Superficial and deep cardiac plexuses. & Ventral surface of heart. \\
\hline Coronary (gastric). & $\begin{array}{l}\text { Lesser curvature of } \\
\text { stomach. }\end{array}$ & Celiac, vagus, solar plexus. & Stomach. \\
\hline Coronary (posterior). & $\begin{array}{l}\text { Coronary artery at } \\
\text { dorsum of heart. }\end{array}$ & Deep cardiac plexus. & Filaments to ventricles. \\
\hline Crural. & $\begin{array}{l}\text { Around the upper por- } \\
\text { tion of femoral artery. }\end{array}$ & Anterior crural nerve. & Adjacent structures. \\
\hline Crural (of Cruveilhier). & $\begin{array}{l}\text { Posterior cervical re- } \\
\text { gion. }\end{array}$ & $\begin{array}{l}\text { Great occipital nerve, first and second } \\
\text { cervical nerves. }\end{array}$ & Posterior cervical region. \\
\hline Cystic. & Gall-bladder. & Hepatic plexus. & Gall-bladder. \\
\hline Dental (inferior). & $\begin{array}{l}\text { Around the roots of } \\
\text { the teeth of the } \\
\text { mandible. }\end{array}$ & Inferior dental nerve. & Teeth. \\
\hline Diaphragmatic. & See Phrenic. & & \\
\hline $\begin{array}{l}\text { Of the ductus choledo- } \\
\text { chus. }\end{array}$ & $\begin{array}{l}\text { Around the common } \\
\text { bile-duct. }\end{array}$ & Hepatic plexus. & Bile-duct. \\
\hline Epigastric. & See Solar. & & \\
\hline Esophageal. & Around the esophagus. & $\begin{array}{l}\text { Vagus nerve, thoracic sympathetic } \\
\text { ganglia. }\end{array}$ & Esophagus. \\
\hline Gangliform. & & $\begin{array}{l}\text { The roots of origin of the inferior } \\
\text { maxillary nerve. }\end{array}$ & Inferior maxillary nerve. \\
\hline
\end{tabular}


TABLE OF NERVE-PLEXUSES.-Continued.

\begin{tabular}{|c|c|c|c|}
\hline NAME. & LOCATION. & DERIVATION, & DISTRIBUTION. \\
\hline Gastric. & Gastric artery. & Celiac plexus. & Stomach. \\
\hline Gastro-duodenal. & $\begin{array}{l}\text { Pancreatico-duodenal } \\
\text { artery, right gastro- } \\
\text { epiploic artery. }\end{array}$ & Celiac plexus. & $\begin{array}{l}\text { Pancreatico-duodenal, gastro-epiploic } \\
\text { plexuses. }\end{array}$ \\
\hline Gastro-epiploic. & Near the stomach. & Hepatic plexus. & Filaments to stomach and mesentery. \\
\hline Gulæ. & See Esophageal. & & \\
\hline Hemorrhoidal (inferior). & Rectum. & Pelvic plexus. & Rectum. \\
\hline Hemorrhoidal (middle). & Sides of rectum. & Pelvic plexus, inferior mesenteric. & Filaments to rectum. \\
\hline Hepatic. & Hepatic artery. & $\begin{array}{l}\text { Celiac plexus, left vagus, right } \\
\text { phrenic. }\end{array}$ & Liver. \\
\hline Hypogastric. & Promontory of sacrum. & Aortic plexus and lumbar ganglia. & Pelvic plexuses. \\
\hline Infra-orbital. & $\begin{array}{l}\text { Under the levator labii } \\
\text { superioris muscle. }\end{array}$ & Infra-orbital, facial. & Muscular. \\
\hline Intermesenteric. & See Aortic. & & \\
\hline Intestinal submucouş. & See Meissner's. & & \\
\hline Ischiadic. & See Sacral. & & \\
\hline Jacobson's. & See Tympanic. & & \\
\hline Lienalis. & See Splenic. & & \\
\hline Lingual. & $\begin{array}{l}\text { Around the lingual ar- } \\
\text { tery. }\end{array}$ & External carotid plexus. & Tongue and lingual artery. \\
\hline Lumbar. & Psoas muscle. & $\begin{array}{l}\text { Anterior divisions of the four upper } \\
\text { lumbar nerves. }\end{array}$ & $\begin{array}{l}\text { Ilio-hypogastric, ilio-inguinal, genito- } \\
\text { crural, external cutaneous, obturator } \\
\text { and accessory, anterior crural. }\end{array}$ \\
\hline Maxillary (inferior). & See Dental (inferior). & & \\
\hline Meissner's. & $\begin{array}{l}\text { Submucosa of small } \\
\text { intestines. }\end{array}$ & $\begin{array}{l}\text { Sympathetic, branches of Auerbach's } \\
\text { plexus. }\end{array}$ & Intestinal walls. \\
\hline Mesenteric (inferior). & $\begin{array}{l}\text { Inferior mesenteric ar- } \\
\text { tery. }\end{array}$ & Left side of the aortic plexus. & Parts supplied by the artery. \\
\hline Mesenteric (superior). & $\begin{array}{l}\text { Superior mesenteric } \\
\text { artery. }\end{array}$ & Solar plexus. & Parts supplied by the artery. \\
\hline Myenteric. & See Auerbach's. & & \\
\hline Naso-palatine. & At the incisor foramen. & Branches of the naso-palatine nerves. & The naso-palatine region. \\
\hline Of the obturator nerve. & $\begin{array}{l}\text { Around the obturator } \\
\text { nerve. }\end{array}$ & $\begin{array}{l}\text { Obturator nerve; internal saphenous } \\
\text { nerve. }\end{array}$ & Obturator muscle. \\
\hline Occipital. & $\begin{array}{l}\text { Around the occipital } \\
\text { artery. }\end{array}$ & External carotid plexus. & $\begin{array}{l}\text { Posterior portion of parotid gland; } \\
\text { occipital region of skull. }\end{array}$ \\
\hline Ophthalmic. & $\begin{array}{l}\text { Around the ophthal- } \\
\text { mic artery and optic } \\
\text { nerve. }\end{array}$ & Ciliary nerves; sympathetic fibers. & Optic region. \\
\hline Ovarian. & See Spermatic. & & \\
\hline Pancreatic. & Near pancreas. & Splenic plexus. & Filaments to pancreas. \\
\hline Pancreatico-duodenal. & Near head of pancreas. & Hepatic plexus. & Filaments to pancreas and duodenum. \\
\hline Patellar. & In front of the patella. & $\begin{array}{l}\text { Internal saphenous; internal, middle, } \\
\text { and external cutaneous nerves. }\end{array}$ & The region around the patella. \\
\hline Pelvic. & $\begin{array}{l}\text { Side of rectum and } \\
\text { bladder. }\end{array}$ & $\begin{array}{l}\text { Hypogastric plexus, second to fourth } \\
\text { sacral nerves, first two sacral gan- } \\
\text { glia. }\end{array}$ & Viscera of pelvis, plexuses of pelvis. \\
\hline Phrenic. & Phrenic artery. & Solar plexus. & Diaphragm and adrenal capsule. \\
\hline Prostatic. & Vesical arteries. & Pelvic plexus. & Bladder. \\
\hline Pudendal. & $\begin{array}{l}\text { Lower portion of the } \\
\text { pyriformis muscle. }\end{array}$ & Inferior hypogastric plexus. & $\begin{array}{l}\text { Middle and inferior hemorrboidal } \\
\text { nerves. }\end{array}$ \\
\hline Pulmonary (anterior). & $\begin{array}{l}\text { Root of lungs, ventral } \\
\text { side. }\end{array}$ & $\begin{array}{l}\text { Anterior pulmonary branches, vagus } \\
\text { and sympathetic. }\end{array}$ & Ventro-caudal part of lungs. \\
\hline
\end{tabular}


TABLE OF NERVE-PLEXUSES.-Continued.

\begin{tabular}{|c|c|c|c|}
\hline NAME. & LOCATION. & DERIVATION. & DISTRIBUTION. \\
\hline Pulmonary (posterior). & $\begin{array}{l}\text { Root of lungs, dorsal } \\
\text { side. }\end{array}$ & $\begin{array}{l}\text { Posterior pulmonary branches, vagus } \\
\text { and sympathetic. }\end{array}$ & Root of lungs, dorsal side. \\
\hline Pyloric. & Near pylorus. & Hepatic plexus. & Filaments to pylorus. \\
\hline Renal. & Renal artery. & $\begin{array}{l}\text { Solar and aortic plexuses and semi- } \\
\text { lunar ganglia. }\end{array}$ & Kiduey, post-cava, spermatic plexus. \\
\hline Sacral. & Ventrad of sacrum. & $\begin{array}{l}\text { Lumbo-sacral cord, ventral divisions } \\
\text { of the three upper sacral nerves, } \\
\text { and part of the fourth. }\end{array}$ & $\begin{array}{l}\text { Muscular, pudic, superior gluteal, } \\
\text { great sciatic, small sciatic. }\end{array}$ \\
\hline Of Santorini & See Gangliform. & & \\
\hline Semilunar. & See Solar. & & \\
\hline Solar (semilunar). & Dorsad of stomach. & Splanchnics and right vagus. & $\begin{array}{l}\text { Semilunar ganglia, phrenic, supra- } \\
\text { renal, renal, spermatic, celiac, supe- } \\
\text { rior mesenteric, and aortic plexuses. }\end{array}$ \\
\hline Spermatic. & Spermatic vessels. & Renal plexus. & Testes (ovaries in female). \\
\hline Sphenoid. & $\begin{array}{l}\text { The upper portion of } \\
\text { the Carotid (inter- } \\
\text { nal), } q . v \text {. }\end{array}$ & & \\
\hline Splenic. & Splenic artery. & $\begin{array}{l}\text { Celiac plexus, left semilunar ganglia, } \\
\text { right vagus nerve. }\end{array}$ & $\begin{array}{l}\text { Spleen, pancreatic plexuses, left gas- } \\
\text { tro-epiploic plexus. }\end{array}$ \\
\hline Subsartorial. & $\begin{array}{l}\text { At the posterior bor- } \\
\text { der of the sartorius } \\
\text { muscle, a little be- } \\
\text { low the middle of the } \\
\text { thigh. }\end{array}$ & $\begin{array}{l}\text { Obturator, long saphenous, and inter- } \\
\text { nal cutaneous nerves. }\end{array}$ & Filaments to adjacent skin. \\
\hline Subtrapezial. & $\begin{array}{l}\text { Beneath the trapezius } \\
\text { muscle. }\end{array}$ & $\begin{array}{l}\text { Cervical plexus and spinal accessory } \\
\text { nerve. }\end{array}$ & Trapezius muscle. \\
\hline Suprarenal. & $\begin{array}{l}\text { A round the supra- } \\
\text { renal bodies. }\end{array}$ & $\begin{array}{l}\text { Diaphragmatic, solar, and renal plex- } \\
\text { uses. }\end{array}$ & $\begin{array}{l}\text { Filaments to the medullary portions } \\
\text { of the adrenals. }\end{array}$ \\
\hline Thyroid (inferior). & $\begin{array}{l}\text { Around the external } \\
\text { carotid and inferior } \\
\text { thyroid arteries. }\end{array}$ & Middle cervical ganglion. & Larynx, pharynx, thyroid gland. \\
\hline Thyroid (superior). & $\begin{array}{l}\text { Around the thyroid } \\
\text { gland. }\end{array}$ & $\begin{array}{l}\text { Superior laryngeal and superior car- } \\
\text { diac nerves. }\end{array}$ & Thyroid region. \\
\hline Tonsillar. & Tonsil. & Glosso-pharyngeal. & Tonsil, soft palate, fauces. \\
\hline $\begin{array}{l}\text { Tracheal (a nterior in- } \\
\text { ferior). }\end{array}$ & $\begin{array}{l}\text { See Pulmonary (an- } \\
\text { terior). }\end{array}$ & & \\
\hline Tympanic. & Tympanum. & $\begin{array}{l}\text { Tympanic nerve, sympathetic gan- } \\
\text { glia, }\end{array}$ & Tympanum. \\
\hline Uterine. & Uterine arteries. & Pelvic plexus. & Cervix and lower part of uterus. \\
\hline Vaginal. & Vagina. & Pelvic plexus. & Vagina. \\
\hline Vertebral. & $\begin{array}{l}\text { Surrounding the ver- } \\
\text { tebral and basilar } \\
\text { arteries. }\end{array}$ & $\begin{array}{l}\text { First thoracic ganglion, upper cervi- } \\
\text { cal nerves. }\end{array}$ & Vertebral and cerebellar regions. \\
\hline Vesical. & Vesical arteries. & Pelvic plexus. & Vesicula seminales ${ }_{2}$ vas deferens. \\
\hline Vidian. & & Vidian nerve. & \\
\hline
\end{tabular}

Pli courbe (ple koorb) [Fr.]. The angular gyrus.

Plica ( $p l i i^{\prime} k a h$ ) [L. : pl., Plica]. A fold; a convolution of the brain; a valve of a vein. P. adiposæ : (I) folds of the costal pleura containing fat; (2) the synovial fringes. P. aliformes, the alar ligaments of the knee-joint. See Ligament. P. ary-epiglotticæ. See Folds, Aryteno-epiglottidean. P. centralis retinæ, a fold found post-mortem in the retina, extending transversely on each side of the optic disc. P. ciliares, the choroidal folds posterior to the ciliary processes. P. coli, a fold of mucosa forming the upper margin of the ileocecal valve. P. conniventes. Synonym of Valvula conniventes. P. Douglasii. See Douglas's Pouch. P. fimbriata, a fold of mucous membrane, with a fimbriated edge, extending in mammals from the frenum to the tip of the tongue. It is looked upon as the analogue of the sublingua of lower vertebrates. P. ilei, a fold of mucosa constituting the lower margin of the ileocecal valve. P. interarticularis coxæ. Synonym of Ligamentum teres. See Ligament. P. linguæ perpendicularis, one of the grooves or fissures on the dorsum of the tongue extending laterally on both sides of the median line. P. longicauda, a variety of $P$. polonica, in which the hair forms a long, matted or twisted coil. P. longitudinalis duodeni, a fold of mucosa extending from the duodenal papilla for a short distance along the posterior wall of the descending portion of 
the duodenum. P. longitudinalis meningis, the falx cerebri. P.lunata. Synonym of $P$. semilunaris. P. palato-epiglottica of Mojsisovics, a few thin, wrinkled folds of mucosa running across in front of the epiglottis between the two posterior pillars of the fauces in elephants. P. palmatæ, oblique projections of the mucosa of the cavity of the neck of the uterus. P. petro-clinoidea lateralis, a fold of dura mater extending from the petrous portion of the temporal bone to the anterior clinoid process. It forms the upper and lateral wall of the cavernous sinus. P petroclinoidea medialis, a similar fold extending between the upper border of the petrous portion of the temporal bone and the posterior clinoid process. $P$. pharyngo-epiglottica, a fold of mucosa extending from the neighborhood of the pharyngeal opening of the Eustachian tube to the vicinity of the epiglottis. It marks the insertion of the stylo-pharyngeus muscle. P. polonica, a matted, entangled condition of the hair, due to want of cleanliness in certain diseases of the scalp, with purulent discharge. P. pterygomandibularis, a mucous fold on the pterygo-maxillary ligament. P. recti, the folds of mucosa in the rectum. P. recto-uterina. See Douglas's Pouch. P. rectovesicalis. See Recto-vesical Folds. P. salpingopalatina, a fold of mucosa passing downward from the anterior margin of the Eustachian orifice. P. salpingopharyngea, a prominent fold passing downward from the posterior margin of the Eustachian orifice in the naso-pharynx. P. saxonica. Synonym of $P$. polonica. P. semilunaris, a conjunctival fold in the inner canthus of the eye, the rudiment of the membrana nictitans of birds. P. semilunaris Douglasii. See Douglas's Pouch. P. semilunaris fascialis transversalis, the fold of transversalis fascia forming the lower edge of the internal abdominal ring. $\mathbf{P}$. serosæ, any folds of serous membrane. P. sigmoidea coli, P. sigmoidea recti, one of the folds of mucosa in the colon and in the rectum. P. sublingualis, the frenum of the tongue. P. synovialis, fringes of the synovial membrane. P. thyroarytenoideæ. Synonym of Ligaments, Thyroarytenoid. See Ligament. $\mathbf{P}$. transversalis recti. See $P$. sigmoidea recti. $\mathbf{P}$. urachi, the peritoneal fold covering the urachus. $\mathbf{P}$. urogenitalis, a fold in the posterior wall of the peritoneal cavity of the embryo which surrounds the lower extremity of the Wolffian duct. P. utero-rectalis. See Douglas's Pouch. P. vaginalis, the rugæ of the vaginal mucosa. P. vasculosæ, the synovial fringes. P. vesico-uterinæ. Synonym of Vesico-uterine Folds. P. villosæ ventriculi, folds of the mucosa of the stomach forming a ventriculum, in the meshes of which are the openings of the gastric tubules.

Plicate (pli'-kāt) [plicatus, p.p. of plicare, to fold, to bend]. Folded like a fan.

Plicatile (pli'-kat-il) [plica, a fold]. Capable of being folded.

Plicatio (pli-ka'-she-o). Synonym of Plica polonica.

Plication (pli-ka'-shun) [plicare, to fold]. A plica, or fold.

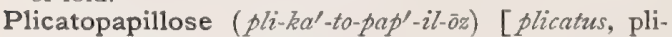
cate; papillosus, papillose]. In biology, both plicate and papillose

Plicatulate (pli-kat'-u-lät) [plicatulus, dim. of plicatus, folded]. In biology, minutely folded, or plicate; e. $\delta$., certain plant-portions.

Plicatura (pli-kat-ut-pah) [plicare, to fold]. A cerebral convolution; also a ligament; also synonym of Plica polonica.

Plicature (plik'-at-ür) [plicare, to fold]. Same as Plication.

Plicidentine (plis-id-en'-tin) [plica, fold; dens, tooth].
Applied to dentine which is folded so as to form a series of plates.

Pliciferous (pli-sif'-er-us) [plica, a fold; ferre, to bear]. In biology, possessing folds or plicæ.

Pliciform (plis'-if-orm) [plica, a fold; forma, form]. In biology, like a plait or fold.

Plicotomy (pli-kot'-o-me) [ plica, a fold; Touń, a cutting]. Division of the posterior fold of the membrana tympani.

Plombierin. See Glairin.

Plongeade (plon'-jahd) [Fr.]. The physiologic condition of a diver with suspended respiration. The blood accumulates in the veins and right side of the heart.

Ploteric (plo-ter $-i k$ ) [ $\pi \lambda \omega \tau \hbar \rho$, drifting]. In biology, applied by Hreckel to those organisms of the ocean (plankton) which are carried about involuntarily. Cf. Necteric.

Ploucquet's Test. See Birth, Live.

Plug [D., plug, a bung]. Something that occludes a circular opening or channel. P., Cervical. Synonym of $P$., Mucous. P., Kite-tail, a tampon resembling a kite-tail. P., Mucous, the mass of inspissated mucus which occludes the cervix uteri during pregnancy and is discharged at the beginning of labor. Ps., Dittrich's, small, dirty-green masses found in the lowest layer of the sputum in fetid bronchitis.

Plugging (phug'-ing) [D.,plug, a bung]. See Tampon. P. Instruments, dental instruments for introducing and consolidating fillings. P. Teeth. See Filling Teeth.

Pluma (plu'-mah) [ pluma, a small, soft feather: pl., Pluma ]. In biology, a quill-feather, or contourfeather, as distinguished from a down-feather.

Plumaceous (plu-ma'-se-us) [ pluma, a plume]. In biology, having the character of a pluma; pennaceous.

Plumacoleum (plu-mak-o'-le-um) [pluma, feather; oleum, oil]. A pledget of lint.

Plumage (plu'-māj) [pluma, plume]. The feathery covering of birds.

Plumate ( $\left.p l u^{\prime}-m \bar{a} t\right)$ [pluma, plume]. In biology, resembling a plume.

Plumbago (plum-ba'-go). See Graphite.

Plumbeus (plum'-be-us) [plumbum, lead]. Leadcolored.

Plumbi et Opii, Liquor. Lead-and-opium wash-a mixture of a solution of lead acetate and laudanum.

Plumbic (plum'-bik) [plumbum, lead]. Pertaining to lead. P. Acid, $\mathrm{PbH}_{2} \mathrm{O}_{3}$; a dibasic acid produced during the electrolysis of lead salts.

Plumbiferous (plum-bif'-er-us) [plumbum, lead; ferre, to bear]. Producing lead.

Plumbism (plum'-lizm) [plumbum, lead]. Leadpoisoning. See Saturnism.

Plumbous (plum'-bus) [plumbum, lead]. Containing the element lead in a lesser valency than the plumbic compounds.

Plumbum (plum'-bum) [L.]. Lead. Symbol Pb. Atomic weight, 207; quantivalence, II or IV. A bluish-white, soft, malleable metal, having a specific gravity of II.4, and melting at $332^{\circ}$. See Elements, Table of. Lead is obtained from a native sulphid called galena, by roasting. Soluble salts of lead combine with albumin, forming albuminates. In large doses by the stomach they are irritant to the mucous membrane. Upon the intestines they act as powerful astringents. If absorbed into the circulation in small quantities for a considerable period of time, lead causes a very interesting and varied group of symptoms, which are described under Saturnism, $q . v$. Lead is eliminated through the kidneys and the intestinal mucosa. It appears to check the elimi- 
nation of uric acid, and is, especially in England, a factor in the causation of gout in lead-workers. In medicine, lead is used locally as a sedative to inflamed parts; as an astringent to mucous surfaces, as in gonorrhea and leukorrhea. Internally, it is used in pyrosis, in diarrhea and dysentery; and for its astringent action on the vessels, in hematemesis, hemoptysis, and bleeding from the kidneys and the uterus. It has also been employed in edema and in gangrene of the lungs. $P$. acetas, $\mathrm{Pb}\left(\mathrm{C}_{2} \mathrm{H}_{3} \mathrm{O}_{2}\right)_{2} \cdot 3 \mathrm{H}_{2} \mathrm{O}$, astringent. Dose gr. ss-v. P. acetat., Ung. (B. P.), gr. xij to the ounce. $\mathbf{P}$. carbonas, $\left(\mathrm{PbCO}_{3}\right)_{2} \mathrm{~Pb}(\mathrm{HO})_{2}$, used locally as an ointment. P. carbonat., Ung., finelypowdered lead carbonate Io, benzoinated lard go parts. P., Emplastrum, lead-plaster, contains lead oxid 32, olive-oil 60 , water 10 parts, triturated and boiled until homogeneous. P. iodidum, $\mathrm{PbI}$, locally and internally. Dose gr. $\frac{1}{5}$. P. iodid., Emplast. (B.P.), contains iodid of lead, lead-plaster, and resin. P. iodidi, Ung., finely powdered lead iodid ro, benzoinated lard 90 parts. P. nitras, $\mathrm{Pb}\left(\mathrm{NO}_{3}\right)_{2}$, locally ; astringent, escharotic, and disinfectant. P., Oleatum, unof, lead oxid 20 , oleic acid 80 per cent. P. cum Opii, Pil. (B. P.). Dose gr. iij-v. P. oxidum, $\mathrm{PbO}$, litharge, a constituent of lead-plaster. P. subacetat., Ceratum, Goulard's cerate, has plumbi subacetatis 20, fresh cerate of camphor 80 parts. P. subacetat, Glycerin (B. P.) See Glycerin. P. subacetat., Linimentum, Goulard's extract 40, cotton-seed-oil 60 parts ; anodyne. P. subacetat., Liq., Goulard's extract, lead acetate I7o, lead oxid roo, distilled water q. s. ad 1000 parts; an astringent and cooling solution. P. subacetat., Liq., Dil., 3 parts of the preceding and 97 of water. P., Suppos., Comp. (B. P.) each containing I gr. of opium to three grains of lead acetate. P., Ung. diachylon, diachylon ointment, contains lead-plaster 60 , olive-oil 39 , oil of lavender $\mathbf{I}$.

Plume (plüm) [pluma, a feather]. A feather; a tuft of feathers; plumage; a plumate hair.

Plumelet (plüm'-let) [pluma, a feather]. A plumule, or plumula ; a small feather or plume.

Plumicorn (plu'-mik-orn) [ pluma, a feather; cornu, a horn]. In biology, one of the tufts of feathers on the heads of certain birds, as the so-called ears or horns of owls.

Plumigerous ( to bear]. In biology, feathered; having plumes.

Plumiped, Plumipede (plu'-mip-ed, plu'-mip-ēd) [pluma, feather; pes, foot]. In biology, having the feet feathered.

Plummer's Pills. See Antimonium.

Plumose, Plumous (plu'-möz, plu'-mus) [bluma, feather]. In biology, having feathers; feathery; feathered.

Plumosity (plu-mos'-it-e) [pluma, feather]. In biology, the state of being plumose.

Plumper (plum'-per) [ME., plomp, bulky]. One of a pair of pads worn in the hollow of the cheeks to give them a rounded appearance; sometimes attached to a set of artificial teeth.

Plumula ( $\left.p l u^{\prime}-m u-l a h\right)$ [ plumula, a little feather: $p l$, Plumula]. Same as Plumule.

Plumulaceous (plu-mu-la'-se-us) [plumula, a plumule]. In biology, of or pertaining to a plumule; downy; not pennaceous.

Plumular (plu'-mu-lar) [plumula, a little feather]. In biology, plumulaceous.

Plumulate (plu'-mu-lāt) [plumula, a little feather]. In biology, minutely plumose

Plumule (plu'-mül) [plumula, a little feather]. In biology: (a) the primary bud or rudimentary stem and leaves in the seed; $(b)$ a down-feather; $(c)$ any small, plume-like organ.

Plumuliform (plu'-mu-lif-orm) [plumula, a plumule ; forma, form]. Having the appearance of a small feather

Plumulose ( $\left.p l u^{\prime}-m u-l \bar{z} z\right)$ [ plumula, a little feather]. In biology, resembling a down-feather.

Plunge (plunj) [ME., plungen, to plunge]. To thrust suddenly into water or other fluid; to immerse. P.-bath, a bath in which the person is placed or places himself in a large tub containing sufficient water to cover him all but the head. P.-tracheotomy. See Tracheotomy.

Plunkett's Caustic, or Ointment. A caustic paste composed of the bruised plant of Rununculus acris and of $R$. flammula, each 24 parts; arsenious acid, 3 parts; sulphur, 5 parts. These are mixed into a paste, rolled into balls, and dried in the sun. When used the ball must be reduced to a pasty consistence by rubbing with yolk of egg.

Plural (plu'-ral) [plus; pluris, more]. More than one. P. Birth, the bringing forth of more than one offspring at a time.

Pluricapsular (plu-rik-ap'-su-lar) [ plus, more; capsula, capsule]. In biology, having several capsules.

Pluricellular (plu-ris-el'-u-lar) [plus, more ; cellula, cell]. In biology, made up of several cells.

Pluriceps (plu'-ris-eps) [plus, more; caput, head] Many-headed; having more than one stem springing from one root.

Pluricipital (plu-ris-ip'-it-al). Synonym of Pluriceps.

Pluricuspid (plu-rik-us'-pid) [plus, more; cuspis, a point]. In biology, having several cusps.

Pluridentate (plu-rid-en'-tät) [plus, more; dens, tooth]. In biology, having several tooth-like processes, as distinguished from parcidentate or paucidentate.

Pluriflagellate (plu-rif-laj'-el-āt) [ plus, more; flagellum, flagellum]. In biology, having several flagella.

Pluriflorous (plu-rif-lo'-rus) [plus, more; flos, a flower]. In biology, having many flowers.

Plurifoliate (plu-rif-ó-le-āt) [plus, more; folium, a leaf]. In biology, having several leaves.

Plurifoliolate (plu-rif-o'-le-o-tât) [plus, more; foliolum, dim. of folium, a leaf ]. In biology, applied to a compound leaf which has many leaflets.

Pluriguttulate (plu-rig-ut'-u-lät) [plus, more; gut tula, dim. of gutta, a drop]. In biology, characterized by having many drop-like particles or structures.

Plurilocular (plu-ril-ok'-u-lar) [plus, more; loculus, a cell]. In biology, having more than one cell or loculus; multilocular, as the ovaries of some plants.

Plurinominal (plu-rin-om'-in-al). Same as Polynominal.

Plurinucleate (plu-rin-u'-kle-āt) [plus, more; nucleus, a kernel]. In biology, having more than one nucleus; multinucleate.

Pluripara (plu-rip'-ar-ah). Synonym of Multipara.

Pluriparity (plu-rip-ar'-it-e) [plus, more; parere, to bring forth]. The condition of having borne several children.

Pluriparous (plu-rip'-ar-us) [plus, more; parere, to bring forth]. Bringing forth several young at once.

Pluripartite (plu-rip-arlitit) [plus, more; partire, to divide]. In biology, having more than one septum or partition; pluriseptate.

Pluriradial (plu-re-ra'-de-al) [plus, more; radius, a ray]. Developed from germs that assume a radial arrangement (a term used by Rauber to characterize a hypothetic method of accounting for double monstrosities).

Pluriseptate (plu-ris-ep'-tât) [plus, more; septum, a partition]. Same as Pleuripartite. 
Pluriseriate (plu-ris-e'-re-ät) [plus, more; series, a row]. In biology, arranged in more than one row.

Plurisetose (plu-ris-é-tōz) [plus, more; seta, a bristle]. In biology, having a number of bristles or setæ.

Plurispiral (plu-ris-pi'-ral) [plus, more; spira, a coil, fold]. In biology, having more than one spiral; multispiral.

Plurisporous (plu-ris-po'-rus) [plus, more; $\sigma \pi o \rho a ́$, seed]. In biology, having two or more spores.

Plurivalve (plu'-riv-alv) [plus, more; valva, a folding door]. In biology, having more than one valve; multivalve.

Pluteiform (plu'-te-if-orm) [pluteus, pluteus; forma, form]. In biology, resembling or having the morphologic valence of a pluteus.

Pluteus (plu'-te-us) [ pluteus, pluteum, a protective roof or shed used by Roman soldiers: $p l$., Plutei]. In biology, the full-grown larva of the Ophiuroids. Echinoidea, as distinguished from the Auricularia and Bipinnaria type of larva of Holothuroids and Asteroids.

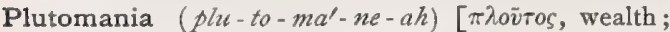
ravia, madness]. An insane belief that one is the owner of much property.

Pluvial (plu'-ve-al) [pluvia, rain]. Pertaining to rain or telluric moisture. Of flowers, having the property of expanding before a rain.

Plyntriopsora (plin-tre-op'-so-rah) [ $\pi \lambda v \nu \tau \rho \iota a$, washerwoman; $\psi \omega \rho \alpha$, scurvy]. A psoriatic affection of washerwomen due to the effects of alkalies.

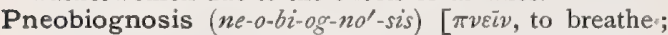
ßíos, life; $\gamma v \omega \sigma \iota \varsigma$, knowledge ]. Docimasia pulmonum.

Pneobiomantia (ne-o-bi-o-man'-she-ah). Synonym of Pneobiognosis.

Pneodynamics (ne-o-di-nam'-iks) [ $\pi v \varepsilon i v$, to breathe; divvaus, power]. The dynamics of respiration.

Pneogaster (ne'-o-gas-ter) [ $\pi \nu \varepsilon i \nu$, to breathe; $\gamma \alpha \sigma \tau \dot{\eta} \rho$, stomach]. In biology, the respiratory tract.

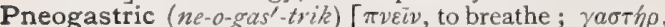
the stomach]. Pertaining to the pneogaster.

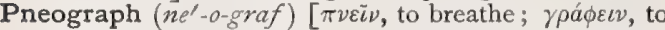
write]. I. An instrument consisting of a semi-disc, suspended in front of the mouth, for the purpose of recording the force, rhythm, and duration, of the expiration. 2. Synonym of Pneumograph.

Pneometer (ne-om'-et-er). Synonym of Spirometer. Pneometry (ne-om'-et-re). Synonym of Pulmometrv.

Pneophore (ne'-o-för) [ $\pi v \varepsilon i v$, to breathe ; dopós, carrying]. An instrument to aid artificial respiration in the asphyxiated.

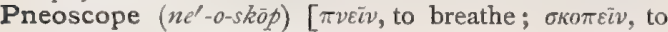
examine]. An instrument for measuring respiratory movements.

Pneuma $\left(n u^{\prime}-m a h\right)[\pi \nu \varepsilon \tilde{v} \mu a$, breath $]$. I. Air; a breath. 2. The vital principle.

Pneumapostema (nu-map-os-te'-mah). Synonym of Pneumonapostema.

Pneumapyothorax (nu-map-i-o-tho'-raks). Synonym of Pyopneumothorax.

Pneumarthrosis (nu-mar-thro'-sis) $\cdot[\pi v \varepsilon \bar{v} \mu a$, air ; ă $\rho$ Apov, a joint]. A collection of air or gas in an articular cavity.

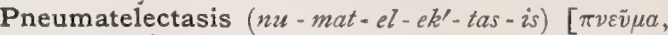
breath ; $a \tau \varepsilon \lambda \hat{n} s$, imperfect; $\varepsilon \kappa \tau a \sigma \iota$, expansive]. Atelectasis of the lungs

Pneumathemia (nu-math-e $\left.e^{\prime}-m e-a h\right)\left[\pi \nu \varepsilon \tilde{v} \mu \alpha\right.$, air; a ${ }^{\top} \mu a$, blood]. The presence of air or free gas in the bloodvessels.

Pneumatic $\left(n u-m a t^{\prime}-i k\right)$ [ $\pi v \varepsilon \bar{v} \mu a$, air $]$ Pertaining to gases or to the atmosphere; pertaining to respiration. P. Cabinet, a device for enclosing the whole or a part of the body so that it may be subjected to compressed or rarefied air. P. Differentiation, the treatment of disease by inhalation of air more rarefied than that which surrounds the body. P. Malting. See Malting. P. Medicine, the treatment of disease by inhalation of vapors or gases, or by fumigation. P. Occlusion, Maisonneuve's plan of dressing stumps. It consists in draining away the accumulation from the wound by aspiration. P. Physician, a pneumatist; one of a sect of physicians who regarded health and disease as consisting in the different proportions of an element, pneuma. P. System. See Serwage, Disposal of. P. Trough, a trough partly filled with water for facilitating the collection of gases.

Pneumatics (nu-mat'-iks) [ $\pi v \varepsilon \tilde{v} u \alpha$, air]. That branch of physics treating of the physical properties of air and gases.

Pneumatism (mu'-mat-izm) [ $\pi \nu \varepsilon \tilde{v} \mu \alpha$, air $]$. The doctrine of the pneumatists.

Pneumatist (nu'-mat-ist) $[\pi \nu \varepsilon \tilde{v} \mu a$, air $]$. A pneumatic physician.

Pneumato- $\left(n u^{\prime}-m a t-o^{-}\right)[\pi v \varepsilon v \mu a$, air, breath $]$. A prefix to denote connection with the air or breath.

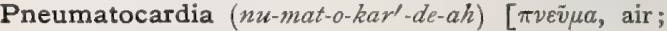
kapdia, heart]. The presence of air or gas in the chambers of the heart.

Pneumatocephalus (nu-mat-o-sef'-al-us). Synonym of Physocephalus.

Pneumatochemia (nu-mat-o-kem'-e-ah) [ $\pi \nu \varepsilon \tilde{v} \mu a$, air ; $\chi \eta \mu \varepsilon i a$, chemistry]. The chemistry of gases.

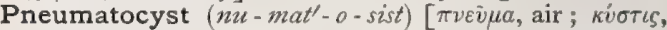
bladder]. In biology, an air-sac; a pneumatophcre.

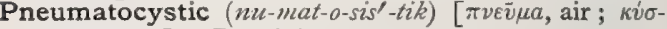
T८s, bladder]. Pertaining to a pneumatocyst.

Pneumatodic (nu-mat-o'-dik) [ $\pi v \varepsilon v \mu a \tau \omega \delta \eta \zeta]$. Filled with air.

Pneumatodyspnea (nu-mat-o-dìsp-ne'-ah) $[\pi \nu \varepsilon \bar{\nu} \mu a$,

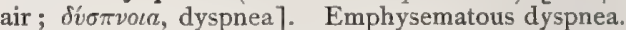

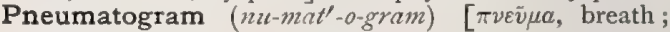
үoá $\mu \mu \alpha$, writing]. A tracing showing the frequency, duration, and depth of the respiratory movements.

Pneumatologic $\left(n u-m a t-o-l o j^{\prime}-i k\right)[\pi \nu \varepsilon \tilde{v} \mu \alpha$, breath; $\lambda \delta$ yos, science ]. Pertaining to pneumatology.

Pneumatologist (nu-mat-ol'-o-jist) $[\pi \nu \varepsilon v \vec{u} u$, breath ; $\lambda \delta$ yos, science]. One versed in pneumatology.

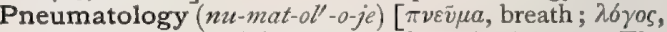
knowledge]. I. The science of respiration. 2. The physics and chemistry of gases.

Pneumatometer (nu-mat-ont -et-er). An instrument designed by Waldenburg to measure the pressure of inspiration or expiration by the force exerted upon a mercuric column contained in a u-tube.

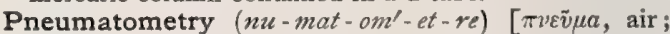
$\mu \hat{\varepsilon} \tau \rho o \nu$, measure]. I. The measurement of the force in respiration. It is used as a means of diagnosis. 2. The treatment of pulmonary and circulatory diseases by means of a pneumatic apparatus.

Pneumatomphalocele (nu-mat-om-fal'-o-sēl) [ $\pi \nu \varepsilon \tilde{u} \mu a$, air; ó $\mu \phi \alpha \hat{\lambda} o ́ s$, navel; $\kappa \dot{n} \lambda \eta$, tumor]. An umbilical hernia containing flatus.

Pneumatomphalus ( $m u$-mat-om'-fal-us). Synonym of Pneumatomphalocele.

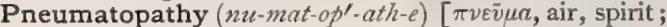
$\pi a ́ \theta o s$, disease]. Mind-cure; the curing of diseases by psychic influence.

Pneumatophore (nu-mat'-o-for) [ $\pi v \varepsilon \vec{v} \mu a$, air; фópos, bear]. In biology, an air-sac, or swim-bladder. The hydrostatic apparatus or specialized person of a Siphonophora colony. It represents a metamorphosed Medusa umbrella. The contained air can be expelled through a pore, and again secreted by the glandular epithelium at its base.

Pneumatophorous (nu-mat-off'-sr-sus) [ $\pi \nu \varepsilon \tilde{v} \mu a$, air; 
фbpos, bear]. In biology, bearing a pneumatocyst; pertaining to or like a pneumatophore.

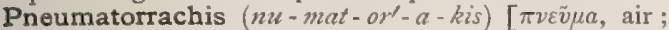
jáxıs, spine]. The presence of air in the spinal canal.

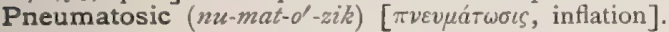
Affected with pneumatosis.

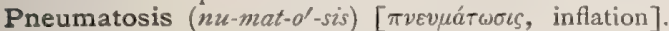
I. The presence of gas or air in abnormal places, or of an excessive quantity where a little exists normally. 2. The condition of flatulent distention of the stomach and bowels.

Pneumatotherapeutics (nu-mat-o-ther-ap-u'-tiks). See Aërotherapeutics.

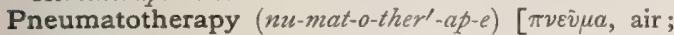
$\theta \varepsilon \rho a \pi \varepsilon i a$, treatment]. The treatment of diseases by means of compressed or rarefied air.

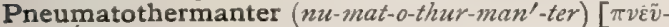
$\mu a$, air ; $\theta \varepsilon \rho \mu a i \nu \varepsilon \imath \nu$, to warm ]. A respirator.

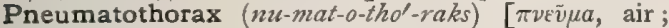

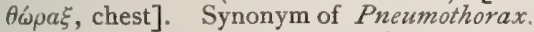

Pneumatotomy (nu-mat-ot'-o-me). Synonym of Pneumotomy.

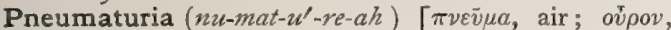
urine]. The evacuation of free gas with the urine.

Pneumatype ( $\left.n u^{\prime}-m a t-i \bar{p}\right)$ [ $\pi v \varepsilon \bar{v} \mu a$, air; $\tau \dot{v} \pi o s$, type]. Breath-picture. The deposit formed upon a piece of glass by the moist air exhaled through the nostrils when the mouth is closed. It is employed in the diagnosis of nasal obstruction. Slate-paper may be used, pulverized sulphur or boric acid being blown upon the moistened surface to make a permanent record.

Pneumectasis (nu-mek'-tas-is). Synonym of Pneumonectasis.

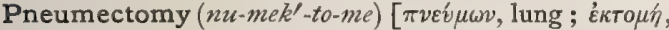
excision]. Excision of a portion of the lung.

Pneumic (nu'-mik) [ $\pi \nu \varepsilon \tilde{v} \mu \omega n$, the lung]. Pertaining to the lung. P. Acid, a crystalline acid extracted from the pulmonary tissue of mammals. It is thought by Verdeil to be a compound of lactic acid and taurin.

Pneumique (nu-mék $k^{\prime}$ [Fr.]. Pertaining to air. P., Osteoarthropathie hypertrophiante. See Osteoarthropathy.

Preumo- $\left(n u^{\prime}-m o-\right)$. Same as Pneumon-

Pneumoactinomycosis ( $\left.n u-m o-a k-t i n-o-m i-k o^{\prime}-s i s\right)$

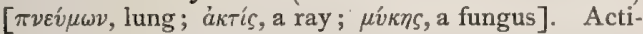
nomycosis of the lung.

Pneumobacillus (nu-mo-bas-il'-us). See Micrococcus pasteuri and Bacillus pneumonia, in Bacteria, Synonymatic Table of.

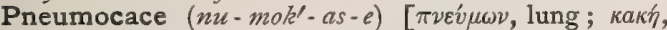
evil]. Gangrene of the lung.

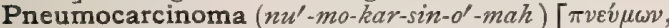

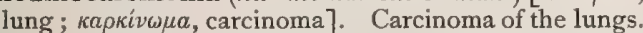

Pneumocele ( $\left.\mathrm{nu}^{\prime}-m o-s \bar{l} l\right)$. Synonym of Pneumatocele.

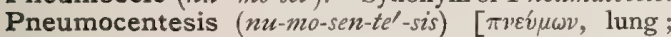

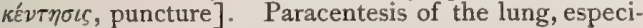
ally of a pulmonary cavity.

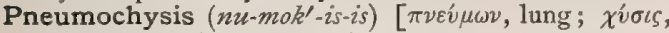
a pouring]. Pulmonary edema.

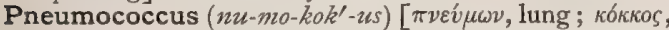
kernel]. A micrococcus of the lung. P. of Frænkel. See Micrococcus pasteuri. P. of Friedländer. See Micrococcus pneumonia, in Bacteria, Synonymatic Table of.

Pneumoconiosis (nu-mo-ko-ni'-o-sis) [ $\pi \nu \varepsilon \dot{v} \mu \omega \nu$, lung ;

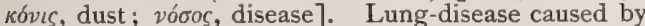
the inhalation of dust. Examples are: Anthracosis, chalicosis, siderosis.

Pneumocysto-ovarium (nu-mo-sis'-to-o-va'-re-um)

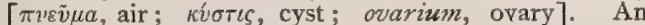
ovarian cyst containing air or gas.
Pneumoderma, Pneumodermis ( $n u-m o-d e r^{\prime}-m a h$,

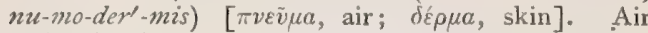
under the skin; subcutaneous emphysema.

Pneumodynamics (mu-mo-di-nam'-iks). Synonym of Pneodjunamics.

Pneumoënteritis (nu-mo-en-ter-i'-tis) [ $\pi v \varepsilon v \mu \omega v$, lung;

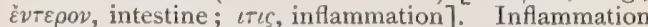
of the lungs and of the intestine. See Hog-cholera. P., Infectious. Synonym of Hog-cholera.

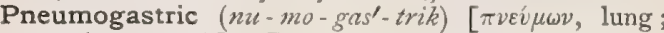

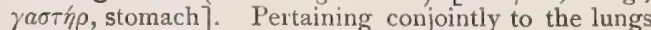
and the stomach, or to the pneumogastric or vagus nerve. P. Nerve. See Nerves, Table of.

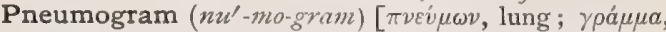
writing]. The tracing afforded by the pneumograph.

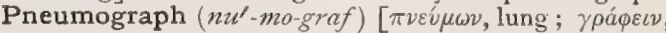
to write]. A registering instrument for measuring the movements of the chest in respiration.

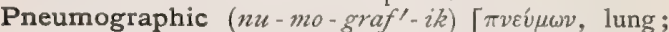
$\gamma \rho a ́ \phi \varepsilon \nu$, to write]. Pertaining to pneumography.

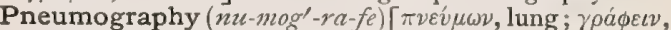
to write]. The description of the lungs.

Pneumohemia (nu-mo-hem'-e-ah). Synonym of Pneumonemia.

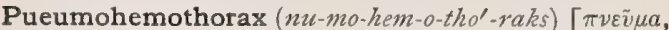
air; $\alpha^{\top} \mu \alpha$, blood; $\theta \omega \alpha a \xi$, thorax ]. A collection of air or gas, and blood, in the pleural cavity.

Pneumohydropericardium ( $n u-m o-h i-d r o-p e r-i k$ $\left.a \gamma^{\prime}-d e-u m\right)[\pi v \varepsilon \tilde{v} u \alpha$, air ; $i \delta \omega \rho$, water; $\pi \varepsilon \rho \dot{\imath}$, around ;

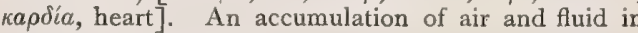
the pericardial cavity.

Pneumohydrothorax (nu-mo-hi-dro-tho'-raks) [ $\pi \nu \varepsilon \tilde{v} \mu \alpha$, air; $v \delta \omega \rho$, water; $\theta \omega \rho a \xi$, thorax ]. A collection of air or gas, and fluid, in the pleural cavity.

Pneumokoniosis. See Pneumoconiosis.

Pneumolith (nu'-mo-lith) [ $\pi v \varepsilon v ́ \mu \omega \nu$, lung; $\lambda \dot{i} \theta 0 s$, a stone]. A stony concretion in the lungs, as a calcified tubercle.

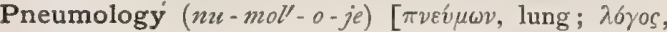
science]. The sum of scientific knowledge concerning the lungs and air-passages.

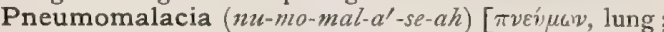
налакіa, softness]. Abnormal softness of the lung.

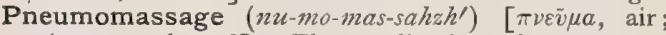
$\mu a ́ \sigma \sigma \varepsilon t \nu$, to knead]. The application of massage or passive motion to the tympanic membrane and auditory ossicles by pneumatic means.

Pneumometer (nu-mom'-et-er). Synonym of Spirometer.

Pneumometry (nu-mom'-et-re). Same as Spirometry. Pneumomycosis (nu-mo-mi-ko'-sis) [ $\pi \nu \varepsilon i ́ \mu \omega \nu$, lung; $\mu v \kappa \eta \varsigma$, fungus]. The presence of fungi in the lung. The etiologic relation of fungi to lung-diseases is not fully determined

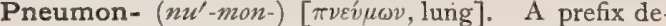
noting connection with or relation to the lungs.

Pneumonæmia (nu-mo-ne'-me-ah). See Pneumonemia.

Pneumonalgia (nu-mo-nal'-je-ah) [ $\pi v \varepsilon v \mu \omega v$, lung ;

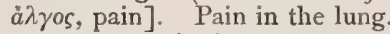

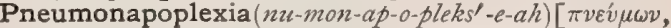

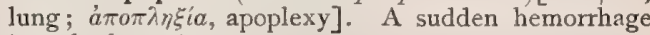
into the lung-tissue.

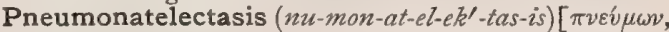

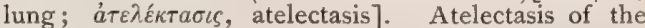
lung.

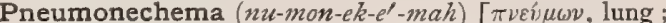
$\dot{\eta} \chi \eta \mu a$, sound]. The normal vesicular murmur heard over the lung in respiration.

Pneumonectasia, Pneumonectasis (nu-mon-ek-ta'.

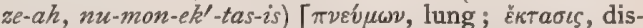
tention]. Emphysema of the lung. 
Pneumonectomy (nu-mon-ek'-to-me) [ $[\pi v \varepsilon \dot{v} \mu \omega v$, lung; $\varepsilon \kappa \tau o \mu \eta \dot{y}$, excision]. Excision of a portion of a lung; pneumectomy.

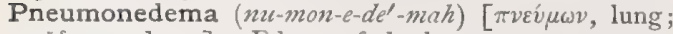
oi $i \eta \mu a$, edema]. Edema of the lungs.

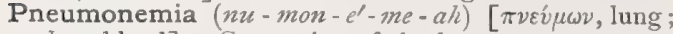
airua, blood]. Congestion of the lungs.

Pneumonemphraxis (mu-mon-em-fraks'-is) [ $\pi v \varepsilon v \mu \omega \nu$, lung; $\varepsilon \varepsilon_{\phi} \rho a \xi \iota s$, obstruction]. Obstruction of the lungs or the bronchi.

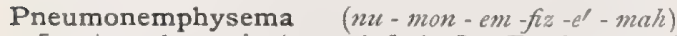

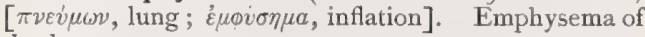
the lungs.

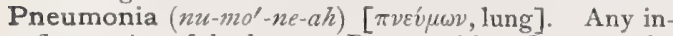
flammation of the lungs. Pneumonitis. By usage the word pneumonia, used without qualification, implies croupous pneumonia, $q . v$. P., Abortive, a condition of acute congestion, such as is seen in the first stage of pneumonia, but which is not succeeded by the other stages. P., Acute. Synonym of $P$., Croupous. P., Adynamic, pneumonia attended with debility, depression of the circulation and of the nervous system. P. alba. Synonym of $P$., White. P., Alcoholic, the croupous pneumonia of drunkards. It is often associated with delirium and is very fatal. P., Apex, P., Apical, croupous pneumonia of the apex of a lung, by some believed to be more grave than basal pneumonia; many cases, however, run a favorable course. Cerebral symptoms are said to be more common when the apex is affected. P., Apoplectic, pneumonia associated with hemorrhage into the lung. P., Aspiration, a broncho-pneumonia due to the inspiration of food-particles or other irritant substances into the lung. The condition is met with in cases in which the sensitiveness of the larynx and trachea is benumbed, as in apoplectic coma or uremia, and in low fevers; also in the insane from stuffing of the mouth with food and in defective deglutition. P., Ataxic. Synonym of P., Adynamic. P., Bilious, pneumonia accompanied by icterus. P., Broncho-. See Broncho-pneumonia. P., Caseous Lobular. Synonym of P., Desquamative. P., Catarrhal. Synonym of Broncho-pneumonia. P., Central, a croupous pneumonia beginning in the interior of the lobe of the lung. The physical signs are obscure until the inflammation reaches the surface. P., Cerebral, that form of pneumonia associated with marked cerebral symptoms. It is most common in children and in the beginning resembles meningitis. P., Cheesy. Synonym of P., Caseous. P., Chronic. Synonym of P., Interstitial. P., Cirrhotic. Synonym of P., Interstitial. P., Contusion, pneumonia following contusion of the chest. P., Creeping. See $P$, Migratory. P., Crossed, croupous pneumonia of the lower lobe on one side, associated with the same disease in the upper lobe of the other side. P., Croupous, Lobar Pneumonia, that commonly called simply pneumonia, an acute disease, running a definite course and tending to recovery. It is most often due to a specific microorganism, the pneumococcus of Frænkel, and may be epidemic in certain districts. But besides the pneumococcus, of Fræenkel, which is really a lanceolate bacillus occurring in pairs, other microörganisms can give rise to croupous pneumonia, $e_{.} g$. , the bacillus pneumonix of Friedländer, the streptococcus and the staphylococcus pyogenes, the bacillus of typhoid fever. The disease occurs more frequently during the winter months, and in males than in females. The lower lobes are the parts usually affected, and especially that of the right side. The apex, however, may be the part involved, especially in children. Occasion- ally a double or bilateral pneumonia is encountered, both lower lobes or both apices being involved. The disease is ushered in by a chill, followed by high fever, flushed cheeks, dry, coated tongue, rapid, shallow respiration, and pain in the affected side. More or less cough is present, and there is usually the characteristic bloody or rusty expectoration. The respirations are rapid, and quite a characteristic feature is the disturbance of the pulse-respiration ratioinstead of 4 to $I$, it may be 3 to $I$, or 2 to $I, i_{0} e$, we may have a pulse of 84 and respirations 42 , or even more. The pliysical signs are distinctive-immobility of the affecled portion of the chest, increased tactile fremitus, dulness on percussion (rarely a peculiar wooden tympany), a tine, crepitant râle in the first stage, bronchial breathing and bronchophony in the second, to which moist rales are added when resolution begins. In nearly every case there is an associated plastic pleurisy, which is responsible for the pain. It may give rise to a friction-sound. The urine is high-colored and deficient in chlorids, the bowels sluggish. A crisis usually occurs on the seventh day. The anatomic change consists in the appearance of a firm or solid exudation in the pulmonary alveoli. The disease proceeds through the following stages: I. Congestion, in which there is intense congestive hyperemia. 2. Red Hepatization, in which the lung is bulky, heavy, firm, and airless, and its surface granular, its red tint being due to extravasated corpuscles and distended capillaries. 3. Gray Hepatization, due to the degeneration of the exudate and anemia from compression of the capillaries. In the majority of cases resolution takes place and the lung returns to its previous condition. P., Deglutition. Synonym of P., Aspiration. P., Desquamative, a form characterized chiefly by an intense desquamation of the cells lining the air-vesicles, a proliferation of the connective-tissue cells of the septa between the vesicles, and the exudation of a scanty albuminous fluid. The exudate goes on to caseous degeneration. Three sub-varieties are described : the lobular form, the confluent, or lobar, and the bronchial, or caseous broncho-pneumonia. The cause of the disease is, in the majority of cases, the tubercle-bacillus. P., Dissecting, a suppurative inflammation extending along the interlobular and peribronchial tissues. P., Double, croupous pneumonia of both lungs. P., Drunkards'. Synonym of $P$., Alcoholic. P., Embolic, pneumonia due to embolism of the vessels of the lung. P., Epithelial. Synonym of $P$. , Desquamative. P. epizoötica, pneumonia of animals. P., Erysipelatous, a severe pneumonia, usually migratory, occurring in connection with, or after exposure to erysipelas, and apparently influenced by that disease. P., Fibrinous. See P., Croupous. P., Fibroid, P., Fibrous. Synonym of $P$., Interstitial. P., Food, a form of inspiration-pneumonia, $q . v$. P., Gangrenous, gangrene of the lung. $\mathbf{P}_{\text {. }}$ Gouty, pneumonia developing in a gouty subject.

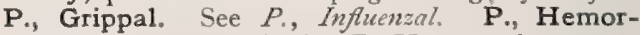
rhagic. See Hemorrhagic. P., Hypostatic, a pneu monia, generally lobular, occurring in the debilitatec and those suffering from other diseases. It usually affects the lower posterior portions of the lung, and is dependent upon the dorsal decubitus, the weak circulation, and the inspiration of food and other particles. Section of the vagus nerve in animals also gives rise to this form of pneumonia, because the paralysis of the air-passages favors the aspiration of foreign matters. P., Influenzal, a peculiar condition of the lung observed in association with influenza. There appears to be a failure of function due to pneumoparesis. There may also be inflammation of croup 
ous or catarrhal type. P., Insular. Synonym of $P$., Lobular. P., Intermittent. Synonym of $P$., Bilious. P., Interstitial, Acute, inflammation of the interstitial tissues of the lung, sometimes terminating in suppuration. P., Interstitial, Chronic, cirrhosis of the lung; a chronic inflammation of the lung, characterized by an increase of the interstitial connective tissue. It may be a termination of acute croupous pneumonia or of pulmonary tuberculosis; it may follow bronchopneumonia ; in some cases it is due to extension of a chronic inflammation from the pleura, the so-called pleurogenous interstitial pneumonia; finally, pneumonokoniosis is a form of interstitial pneumonia. Cirrhosis of the lung is often associated with bronchiectasis. P., Larval, a term given in epidemics of pneumonia to those cases that present only some of the initial symptoms of the disease, slight chill, moderate fever, and a few indefinite local signs. P., Latent, one in which the physical signs are obscure or wanting. $\mathbf{P}$., Lobar. Synonym of $P$., Croupous. P., Lobular. Synonym of Broncho.pneumonia and $P$. , Catarrhal. P., Malarial. Synonym of $P$, Bitions. P. maligna. Synonym of $P$., Septic. P. malleosa, pneumonia due to the glanders-bacillus. It is a broncho-pneumonia as a rule, but may assume a lobar form or manifest itself as multiple abscesses. P., Massive, one in which not only the air-cells, but the bronchi of an entire lobe, or even of a lung, are filled with the fibrinous exudate. The auscultatory physical signs are wanting; percussion yields an absolutely flat note. The condition simulates pleurisy with effusion. $P$. migrans, P., Migratory, a peculiar and well-recognized form, involving one lobe after the other. It seems occasionally to be in some way associated with erysipelas. Synonym of $P$., Creeping, $P$., Wandering. P., Necrotic, Goodhart's name for the non-tuberculous variety of pulmonary disorganization sometimes occurring in diabetic patients. The disease is characterized by rounded patches at the apex or base of the lung, the size of a hazel-nut or larger, in which a cavity rapidly forms containing a central slough. P. notha. Synonym of Capillary Bronchitis. P., Periodic. Synonym of P., Bitious. P., Phreno-, pneumonia associated with diaphragmitis. P., Plastic. Synonym of $P$., Croupous. P., Pleuritic. Synonym of Pleuropneumonia. P., Pleurogenic, P., Pleurogenous, a pneumonia secondary to disease of the pleura. $\mathbf{P}$. potatorum. Synonym of $P$., Drunkards', P., Purulent: this appears in three varieties: $(\boldsymbol{I})$ the suppuration may involve the surfaces of the minute bronchi and air-vesicles-purulent catarrh; (2) there may be a true abscess of the lung; (3) there may be a suppurative lymphangitis and perilymphangitis. The causes of purulent pneumonia are: the aspiration of matters containing pyogenic microörganisms-this producing the first or second form; an abscess may result from the lodgment in the lung of a septic embolus, derived often from a focus of purulent phlebitis; from traumatism; from chronic diseases of the lung, especially tuberculosis with cavity-formation; from extension of suppuration from neighboring organs, as from empyema or hepatic abscess. P., Pythogenic, a contagious form rising under miasmatic influences. P., Scrofulous, an old name for $P$, Caseous Lobular. P., Secondary, that occurring as a complication of some preëxistent disease. P., Senile, the broncho-pneumonia of the aged; it may be due, in part at least, to inability to expectorate the phlegm that collects in the smaller bronchi. P., Septic, a lobular pneumonia due to the inspiration of septic material. It may also be caused by septic emboli. In the new-born it is usually due to the aspiration of the maternal fluids during labor. P., Septinous, $\mathbf{P}$., Sewer-gas, a pneumonia following the inhalation of sewer-gas. P. serosa, edema of the lungs. P., Stripe [G. Streifenpneumonie], a pneumonia in which the affected area has the form of a band or stripe, usually running parallel with the spinal gutter. P., Syphilitic; disease of the lung due to syphilis is rare. Three forms are usually described-the pneumonia alba of the fetus $(q \cdot v$.$) ; the deposit of gum-$ mata in the lung; and an interstitial pneumonia, taking its origin at the root of the lung and passing along the bronchi and vessels. French writers also speak of an acute syphilitic phthisis, analogous to acute pneumonic phthisis. P., Traumatic, pneumonia following injury of the lung; also that consecutive to section of the vagus nerves. P., Tuberculous, a lobular or lobar inflammation of the lung due to the tubercle-bacillus. P., Tubular. Synonym of Broncho-pneumonia. P., Typhoid, a pneumonia with the symptoms of the typhoid state. It is to be distinguished from Pneumo-typhus. P., Vagus, that produced by section of the vagus nerves. P., Wandering, a form of pneumonia in which different portions of the lung present different stages of the pneumonic process. It seems, according to Guitéras, to be in some way associated with erysipelas. P., White, a catarrhal form of pneumonia occurring in a syphilitic fetus and resulting in death. By an overgrowth of epithelium in the air-vesicles the lung dies, and fatty degeneration follows, giving the lungs a dead white appearance, with the imprint of the ribs on their surface.

Pneumonic (nu-mon'-ik) [ $\pi v \varepsilon v ́ \mu \omega v$, lung]. Pertaining to the lungs or to pneumonia. P. Phthisis, tuberculous pneumonia of the lungs. P. Spot, the circumscribed flush of the cheek in croupous pneumonia.

Pneumonicula (nu-mon-ik'-u-lah) [ $\pi v \varepsilon v ́ \mu \omega v$, lung]. A slight inflammation of the lung.

Pneumonique (nu-mon'-ék) [Fr.]. Pertaining to the lung.

Pneumonitic (nu-mon-it'-ik) [ $\pi v \varepsilon v ́ \mu \omega v$, lung; $\iota \tau \iota s$, inflammation]. Pertaining to or affected with pneumonitis.

Pneumonitis (nu-mon-i'-tis) [ $\pi v \varepsilon v \mu \omega v$, lung; $\iota \tau \iota \varsigma$, inflammation]. Pneumonia.

Pneumono- $\left(n u-m o n^{\prime}-0\right)$ [ $\pi v \varepsilon v \mu \omega v$, lung]. A prefix denoting connection with or relation to the lungs.

Pneumonoblenozemia (nu-mon-o-blen-o-ze'-me-ah)

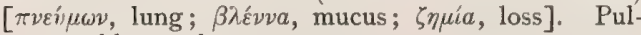
monary blennorrhea.

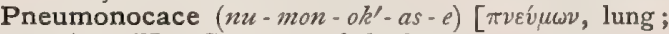
какós, evil]. Gangrene of the lung.

Pneumonocarcinoma (nu-mon-o-kar-sin- $o^{\prime}=$ mah) [ $\pi \nu \varepsilon v ́ \mu \omega \nu$, lung; $к \alpha \rho \kappa i \nu \omega \mu \alpha$, carcinoma]. Carcinoma of the lung.

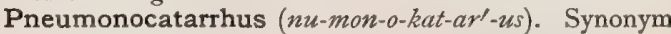
of Pneumonia, Catarrhal.

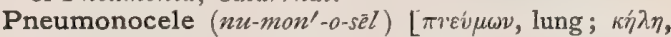
tumor, hernia]. Hernia of the lung.

Pneumonocholosis (nu-mon-o-kol-o'-sis). Synonym of P., Bilious.

Pneumonochysis (nu-mon-ok'-is-is) [ $\pi \nu \varepsilon v \mu \omega \nu$, lung;

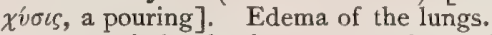

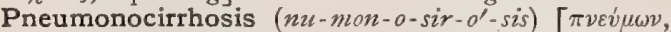
lung; «ıp’ós, yellowish]. Cirrhosis of the lung, interstitial pneumonia.

Pneumonodynia (mu-mon-o-din'-e-ah) [ $\pi \nu \varepsilon \dot{v} \mu \omega \nu$, lung;

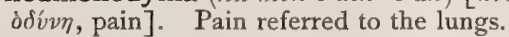

Pneumonœedema (nu-mon-e-de'-mah). See Pneumonedema.

Pneumonokoniosis (mu-mon-o-kon-e-o'-sis) [ $\pi \nu \varepsilon v \mu \omega \nu$,

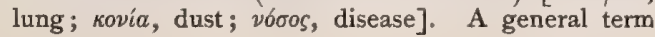


indicating chronic disease of the lungs due to the inhalation of dust. Various names have been devised denoting the kind of dust causing the inflammation: anthracosis, or coal-miner's disease; siderosis, due to inhalation of metallic dust; chalicosis, due to inhalation of mineral dust. The dust-particles, when they can no longer be disposed of by the natural protective agencies of the lungs, find their way into the peribronchial and peri-arterial lymph-spaces, where they set up an inflammation. This is characterized by a marked tendency to fibroid change, manifesting itself in the formation of hard, indurated nodules of various size. The lungs always present evidences of chronic bronchitis, usually also of emphysema, and, in many cases, of tuberculosis. The fibroid areas may soften and break down, forming the so-called ulcers of the lung. The softening may be due to tuberculosis, but sometimes it is not.

Pneumonolith (nu-mon'-o-lith). Synonym of Pneumolith.

Pneumonolithiasis (nu-mon-o-lith-i' $\left.i^{\prime}-a s-i s\right) \quad[\pi \nu \varepsilon v \mu \omega v$, lung; $\lambda i \theta 0 s$, stone $]$. The formation of pneumoliths.

Pneumonomalacia (mu-mon-o-mal-a'se-ah). Synonym of Pneumomalacia.

Pneumonomelanosis (nu-mon-o-mel-an-ó-sis) [ [रveu$\mu \omega \nu$, lung; $\mu \varepsilon^{\lambda} a \varsigma$, black; $\nu \sigma \sigma o \varsigma$, disease]. Anthracosis of the lung.

Pneumonometer (nu-mon-om'-et-er). Synonym of Spirometer.

Pneumonomycosis (nu-mon-o-mi-ko'-sis). Same as Pneumomycosis.

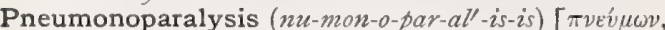

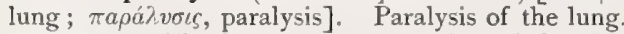

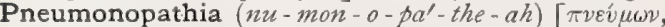
lung; $\pi \alpha ́ \theta 0 s$, disease ]. Any disease of the lung.

Pneumonophlebitis (nu-mon-o-Reb-i'-tis) [ $\pi v \varepsilon v u \omega v$, lung; $\phi \lambda \hat{\psi} \psi$, vein; $\iota \tau \iota \varsigma$, inflammation]. Inflammation of the pulmonary veins.

Pneumonophthisis (nu-mon-off'-this-is) [ $\pi v \varepsilon i \mu \omega v$, lung; $\phi \theta i \sigma \iota s, a$ wasting]. A destructive process in the lungs.

Pneumonophyseter (nu-mon-o- $\left.f-s e^{\prime}-t e r\right)[\pi v \varepsilon v \mu \omega \nu$, lung; $\phi v \sigma \eta \tau \eta \rho$, blowpipe]. An apparatus for inflating the lungs

Pneumonopleuritis ( $n u-m o n-o-p l u$-ri'-tis). Synonym of Pleuropneumonia.

Pneumonoptysis ( $\left.n u-m o n-o p^{\prime}-t i s-i s\right)$. Synonym of Hemoptysis.

Pneumonorrhagia (nu-mon-or $\left.-a^{\prime}-j e-a h\right)[\pi v \varepsilon v \mu \omega v$, lung; '́nvvivac, to burst forth]. Hemorrhage from the lungs.

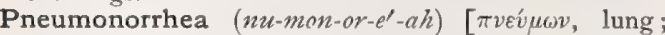
joía, a flow]. A chronic mucous discharge from the lung; also small, oft-repeated hemorrhages from the lungs.

Pneumonosaprosis (nu-mon-o-sap-rol-sis). Synonym of Pneumonocace.

Pneumonoscirrhus (nu-mon-o-skir'-us) [ $\pi v \varepsilon v ́ u \omega v$, lung;

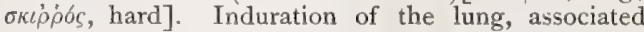
with bronchiectasis.

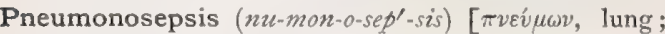
$\sigma \tilde{\eta} \psi \iota$, putrefaction]. Septic inflammation of the lung.

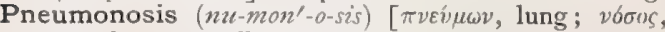
disease]. Any affection of the lungs.

Pneumonospasmos ( $\left.n u-m o n-o-s p a z^{\prime}-m o s\right)$. Synonym of Asthma.

Preumonostenosis (nu-mon-o-sten-ó-sis) [ $\pi \nu \varepsilon i n \omega v$, lung; $\sigma \tau^{\prime} v \omega \sigma \iota s$, contraction]. Contraction of a lung.

Pneumonosyrinx (nu-mon-o-si'-ringles) [ $\pi \nu \varepsilon v \mu \omega v$, lung; $\sigma \tilde{\nu} \iota \nu \xi$, pipe]. A fistula of the lung; also, a syringe for making injections into the lung. Synonym also of Pneumonophyseter.
Pneumonotelectasis (nu-mon-o-tel-ek'-tas-is) [ $\pi \nu \varepsilon^{\prime} \mu \omega \nu$,

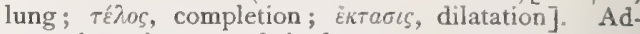
vanced emphysema of the lung.

Pneumonotomy ( $\left.n u-m o n-o t^{\prime}-o-m e\right)$. Synonym of Pneumotomy.

Pneumony (nu-mo'-ne). Synonym of Pneumonia.

Pneumonyperpathia (nu-mon-i-per-pa'-the-ah) [ $\pi \nu \varepsilon v-$

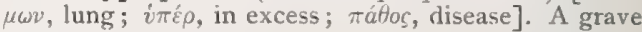
disease of the lung.

Pneumonypostasis (nu-mon-i-pos'-tas-is). Synonym of Pneumonia, Hypostatic.

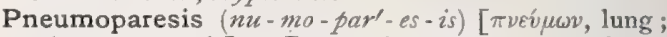

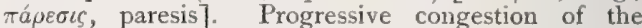
lungs apparently depending on vaso-motor deficiency or other fault of innervation; simple respiratory failure.

Pneumopathy (nu-mop'-ath-e). Synonym of Pneumonopathia.

Pneumopericarditis (nu-mo-per-ik-ar-di'-tis) [ $\pi v \varepsilon \tilde{v} \mu a$, air; $\pi \varepsilon \rho \hat{\imath}$, about; $\kappa a \rho \delta i ́ a$, heart; $\iota \tau \iota \zeta$, inflammation]. Pericarditis with the formation of gas in the pericardial sac.

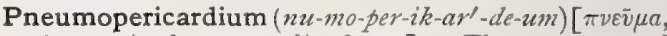

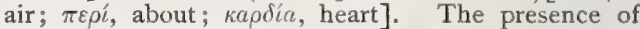
gas in the pericardial sac. It is due to traumatism, or to communication between the pericardium and the esophagus, stomach, or lungs. 'It is marked by tympanitic resonance over the precordial region, metallic rhythmic gurglings, and friction-sounds.

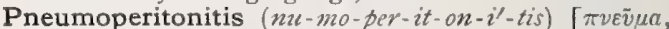
air; $\pi \varepsilon \rho \iota \tau \delta$ va $\iota v$, peritoneum; $\iota \tau \iota S$, inflammation]. Peritonitis with the presence of gas in the peritoneal cavity.

Pneumophthalmos (nu-moff-thal'-mos) [ $\pi v \varepsilon v \tilde{v} \mu$, air; oofanuós, eye]. The presence of air within the eve.

Pneumophthisis (nu-moff'-this-is) [ $\pi v \varepsilon v ́ \mu \omega v$, lung; $\phi \theta i \sigma r s$, wasting]. A destructive process in the lung.

Pneumophyma (nu-mo-fi'-mah) [ $[\pi v \varepsilon v \mu \omega v$, lung; $\phi v \mu a$, growth: pl., Pneumophymata]. A tubercle of the lung.

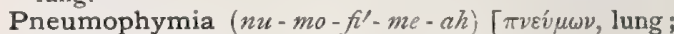
$\phi v \mu a$, growth]. Tuberculosis of the lung.

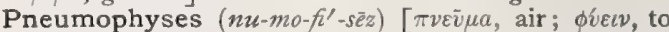
produce; фireotal, to grow]. In biology, two membranous sacs, always more or less filled with air, connected with the reproductive organs of the dronebee. In repose they are bent and flattened, but when swollen they become hard and resistant, and take the form of divergent horns, which, as they expand in undergoing eversion, pass into and fill the bursa copulatrix of the queen. (Cheshire.)

Pneumopleuritis (nu-mo-plu-ri' $i^{\prime}-t_{i s)}$ [ $\pi v \varepsilon v \mu \omega v$, lung; $\pi \lambda \varepsilon v \rho \alpha$, pleura; $\iota \tau \iota \zeta$, inflammation $]$. Conjoined inflammation of the lungs and pleura.

Pneumopyopericardium ( $n u^{\prime}-m o-p i^{\prime}-o-p e r-i k-a r^{\prime}-d e-$

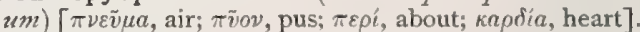
The presence of air or gas and pus in the pericardial sac.

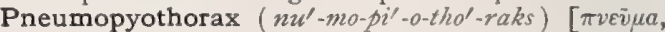
air; $\pi \tilde{v} o \nu$, pus; $A \omega \rho a \xi$, chest]. The presence of air and pus in the cavity of the thorax.

Pneumor (nu'-mor) [ $\pi \nu \varepsilon \tilde{v} \mu a$, air ; amor, love]. Desire for air, or to breathe.

Pneumorrhagia (nu-mor-a'-je-ah). See Hemoptysis.

Pneumoscope ( $\left.n u^{\prime}-m o-s k o ̄ p\right)$. Synonym of Pneumograph.

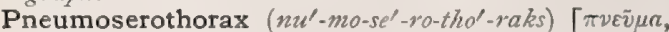
air: semum, serum; $\theta \omega \rho a \xi$, chest $]$. The presence of air or gas and serum in the pleural cavity.

Pneumosis (nu-mo'-sis). Same as Pneumonosis.

Pneumoskeletal (nu-mo-skel'-et-al) [ $\pi v \varepsilon v \mu \omega n$, lung ; $\sigma \kappa \varepsilon \lambda \varepsilon \tau 6 v$, a dry body]. Pertaining to a pneumoskeleton. 


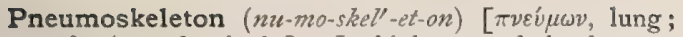

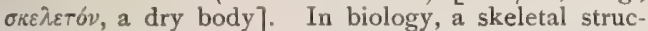
ture developed in connection with a respiratory organ.

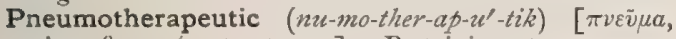
air; $\theta \varepsilon \rho a \pi \varepsilon i a$, treatment]. Pertaining to pneumotherapy.

Pneumotherapeutics (nu-no-ther-np-u'-tiks). Synonym of Pneumotherapy.

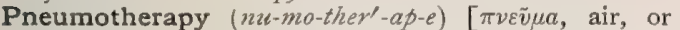
$\pi \nu \varepsilon \dot{u} \mu \omega \nu$, lung ; $\theta \varepsilon \rho a \pi \varepsilon i a$, treatment]. The treatment of diseases of the lung. Synonym of Pneumatotherapy.

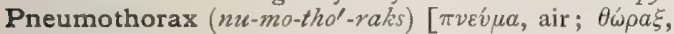
chest]. Distention of the pleural cavity with air or gas. This condition may be due to traumatism or to communication between the pleural cavity and some one of the air-containing organs. It is not rare as a complication of pulmonary tuberculosis, following rupture of a cavity. It is marked by dyspnea, shock, pain, a tympanitic (sometimes a dull) percussion-note over the affected side, displacement of the heart, belltympany, and diminished respiratory murmur. If there be also serum or liquid present, as is likely to be the case unless death ensue rapidly, the condition is called Hydro-pneumothorax, or pneumothorax with effusion. P. by Occlusion, a condition in which there is no apparent communication between the air in the pleural cavity and the external atmosphere. P., Patent, a term used when the opening through which the air has entered the pleura is free and unobstructed. P. subphrenicus, pneumothorax due to perforation of the diaphragm. P., Valvular, a term used when the opening possesses a valvular character.

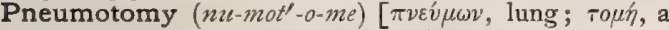
cutting]. I. Surgical incision of the lung. 2. The anatomy, or dissection, of the lung.

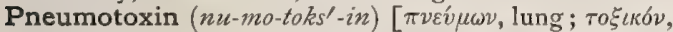
a poison ]. Klemperer's term for a poisonous albuminoid body produced by the pneumococcus, and which, when introduced into the circulation of an animal causes elevation of temperature. Subsequently there is produced in the body a substance, antipneumotoxin, which possesses the power of neutralizing the poison which is formed by the bacteria.

Pneumotuberculum (nu-mo-tu-ber'-ku-lum) [ $\pi \nu \varepsilon v \mu \omega \nu$, lung; tuberculum, tubercle]. A tubercle of the lung.

Pneumo-typhoid $\left(n u-m o-t i^{\prime}-\right.$ foid $)$. Synonym of Pneumo-typhus.

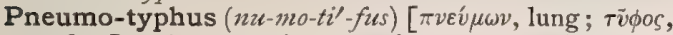
typhus]. A term given to those cases of typhoid fever that begin with a definite pneumonia dependent upon the typhoid-bacillus.

Pneuobiomantia (nu-o-bi-o-man'-she-ah). Same as Pneusiobiognosis.

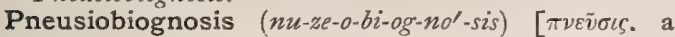
blowing; $\beta$ ios, life; $\gamma \nu \bar{\omega} \sigma \iota$, knowledge]. Docimasia pulmonum, $q \cdot v$.

Pneusis $\left(n \boldsymbol{u}^{\prime}\right.$-sis $)[\pi \nu \varepsilon i v$, to breathe]. Respiration. $\mathbf{P}$. pertussis. Synonym of Whooping-cough.

Pneusometer (nu-som'-et-er). Synonym of Spirometer.

Pnigalion (ni-ga'-le-on) [ $\pi \nu \iota \gamma a \lambda i \omega \nu ; \pi \nu i \gamma \varepsilon \iota \nu$, to choke]. Nightmare ; incubus.

Pnigma (nig'-mah) [ $\pi v^{\prime}(\gamma \varepsilon v v$, to choke]. Strangulation.

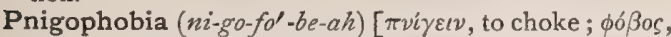
fear]. The fear of choking that sometimes accompanies angina pectoris.

Pnigos, Pnix, Pnixis (ni'-gos, niks, niks'-is). Synonyms of Pnigma.

Pock (pok) [D., pok, a little pouch]. A pustule of an eruptive fever, especially of smallpox. P., Black. Synonym of Black Smallpox. P.-broken, marked with smallpox. P., Diphtheric, in smallpox, a pock the seat of coagulation-necrosis with the production of a whitish membrane. P.-hole, P.-mark, the pit left by the smallpox pustule. P., Horn. Synonym of Variola verrucosa. P.-house, a smallpox hospital. P.-marked, marked with the cicatrices of the smallpox-pustule. P., Master, a large pock seen in some cases of smallpox, and which resembles the pustule of inoculation-smallpox. P.-pitted. Synonym of Pockmarked. P., Stone, an obselete term for an acne pustule.

Pocked (pokt) [D.,pok, a little pouch]. Pitted; marked with pustules.

Pocket (pok'-et) [ME., pocket, a pocket]. In anatomy, a blind sac, or sac-shaped cavity; the abdominal cavity of certain fish. A diverticulum communicating with a cavity.

Pocketing (pok'-et-ing) [ME., pocket, a pocket]. A name given by Storer to a mode of treating the pedicle in the operation of ovariotomy. It is accomplished by bringing the extremity of the pedicle between the inner lips of the incision, at its lower angle, thus securing its attachment to the raw surface of the abdominal wall.

Pocky $\left(p o k^{\prime}-e\right)$ [D., pok, a little pouch]. Having pocks or pustules; infected with variola or syphilis.

Poculiform (pok'-u-lif-orm) [poculum, cup; forma, form]. In biology, deeply cup-shaped, goblet-shaped.

Poculum ( $\left.p \circ k^{\prime}-\imath-l u m\right)$ [L.]. A teacup. P. Diogenis [Diogenes' cup]. 'The hollow of the hand.

Pod [origin obscure]. In biology, a more or less elongated cylindric seed-vessel.

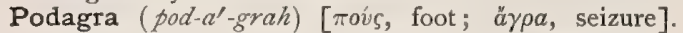
Gout, especially of the great toe or the joints of the foot. P. aberrans, retrocedent gout.

Podagral (pod-a'-gral). Same as Podagric.

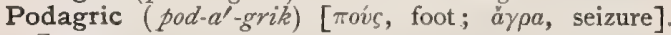
Gouty.

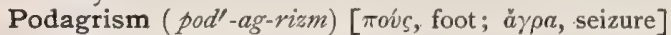
Goutiness.

Podagrous (pod-a'-grus). Synonym of Podagric.

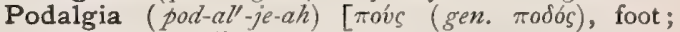
ád yos, pain]. Pain in the foot.

Podalic $\left(p o d^{-}-a l^{\prime}-i k\right)$ [ $[\pi o v s$, foot]. Pertaining to the feet. P. Version, in obstetrics, the operation of changing the position of the fetus in utero so as to bring the feet to the outlet.

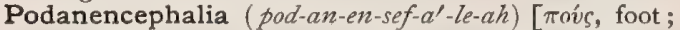

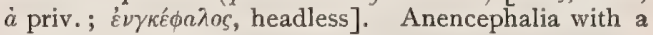
pedunculated head.

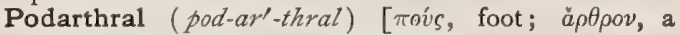
joint]. Pertaining to the podarthrum.

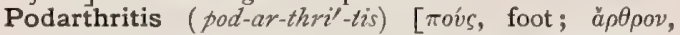
joint; $\tau / \zeta$, inflammation]. Gouty inflammation of the joints of the feet.

Podarthrocace (pod-ar-throk'-as-e) $[\pi o v s$, foot ; ă $\rho$ A $\rho o \nu$, joint; kakos, evil]. Caries of the articulations of the feet.

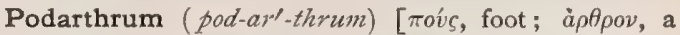
joint: pl., Podarthra ]. In biology, the foot-joint or metatarso-phalangeal articulation.

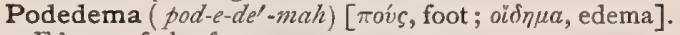
Edema of the foot.

Podelcoma, Podelkoma ( pod-el-ko'-mah). See Fungus. foot.

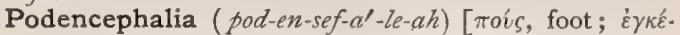
$\phi a \lambda o s$, brain]. The condition present in a podencephalus.

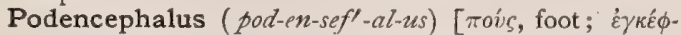
$a \lambda o \zeta$, brain ]. A variety of single autositic monsters of the species exencephalus, in which there is a pro. trusion of the cranial contents from the top of the 
head, the tumor assuming a pedunculated character. There is usually a considerabie degree of hydrocephalus present.

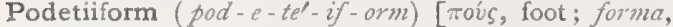
form]. Resembling a podetium.

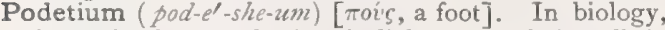
the stalk of an apothecium in lichens or a fruit-stalk in Marchantio.

Podex ( $p o^{\prime}$-deks) [podex, the anus : pl., Podices]. In biology, the rump, uropygium, or pygidium.

Podical (pod'-ik-al) [podex, the anus]. Pertaining to the podex

Podismus ( $\left.p \circ d-i z^{\prime}-m u s\right)$ [ $\pi \circ \delta i \zeta \varepsilon v v$, to measure by feet]. Spasm of the muscles of the foot.

Podite $\left(p o d^{\prime}-\bar{\imath} t\right)[\pi o v$, foot]. In biology, the limb of a crustacean, usually seven-jointed. Cf., Endopodite, Exopodite, Epipodite, Basipodite, Coxopodite, Dactylopodite, Ischiopodite, Meropodite.

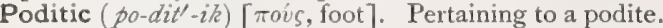

Podium ( $\left.p o^{\prime}-d \ell-z \iota m\right)[\pi \delta \delta\llcorner o v$, a little foot: pl., Podia $]$. In biology, the foot or supporting organ. Commonly used in compounds, as Monopodium, Sympodium, Propodium, Mesopodium, Metapodium, Epipodium.

Podobranchia (pod-o-brang-ke-ah) [ $\pi$ oús a foot;

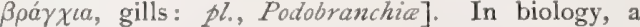
branchial plume or foot-gill; a respiratory organ of crustaceans attached to the coxa.

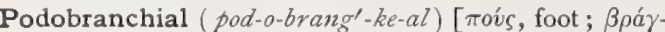
$\chi \iota a$, gills]. Pertaining to a podobranchia.

Podobranchiate $\left(p o d-0-b r a n g^{\prime}-k e-\bar{a} t\right)[\pi o v s$, foot; $\beta \rho a ́ \gamma \chi \iota a$, gills]. In biology, provided with podobranchiæ.

Podobromhidrosis ( pod-o-brōm-hid-ro'sis) [ $\pi$ oús, foot;

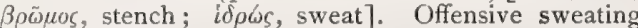
of the feet.

Podocace (po-dok'-as-e). Synonym of Podarthrocace.

Podocephalous (pod-o-sef'-al-us) [ $\kappa \varepsilon \phi r \lambda \eta n$, head]. In biology, applied to a head of flowers when borne upon a distinct stalk.

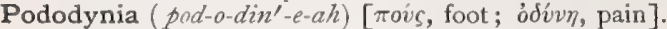
Pain in the foot, and especially in the sole of the foot; the word is now usually limited to painful heel, a neuralgic condition about the heel, attended with little or no swelling, no discoloration, and no affection of the joints. The pains are very severe, though often limited to a very small area. It may be associated with rheumatism or gout, and with certain occupations requiring much standing

Podøedema (pod-e-de'-mah). See Podedena.

Podogyn, Podogynium ( $\left.p o^{\prime}-d o-j i n, p o-d o-j i n^{\prime}-\ell-u m\right)$

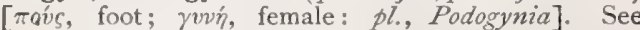
Gynophore and Basigynium.

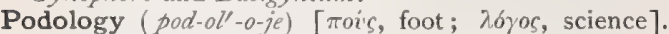
The anatomy and physiology, etc., of the foot.

Podophthalmic, Podophthalmous (pod-off-thal'-mik,

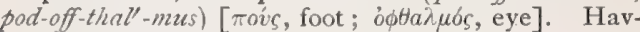
ing the eye fixed at the end of a projecting, movable stalk, as in crustaceans

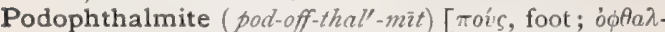
$\mu 6 s$, eye]. In biology, the distal of two joints of the eye-stalk or ophthalmite of a stalk-eyed crustacean, as distinguished from the basiophthalmite.

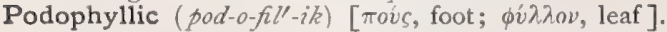
Derived from podophyllin. P. Acid, a resinous, amorphous substance, found in the podophyllin of commerce.

Podophyllin ( pod-o-fll'-in). See Podophyllum.

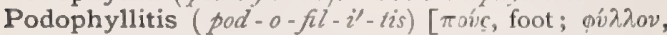
leaf; $\iota T \iota S$, inflammation]. Inflammation of the podophyllous tissues of the hoof.

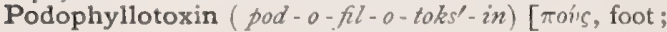

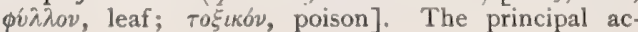

tive constituent of the resin of podophyllum. It is a white, amorphous resin, very poisonous, soluble in alcohol, ether, and chloroform, slightly so in water.

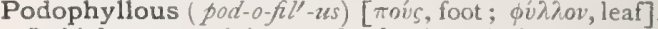
In biology, pertaining to the laminated tissues of the foot, as those inside the hoof; having compressed, leaf-like feet

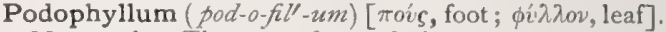
May-apple. The root of mandrake, $P$. peltatum. It contains podophyllin, and this a poisonous material, podophyllotoxin. It is a tonic astringent, cholagogue, and purgative, and is apt to produce nausea. It is recommended in remittent fever, bilious vomiting, and malarial jaundice. Dose of the root gr. $v-x x$; of the resin, podophyllin, gr. 1/8-j. P., Abstract. Dose gr. 1/4-j. Unof. P., Ext. Dose gr. j-v. P., Ext., Fld. Dose mij-xx. P., Tinct. (B.P.) Dose $m_{\mathrm{xxv}}-3 \mathrm{j}$.

Podorrheumatism (pod-or-ru'-mat-izm) [ [rov́s, foot; $\varepsilon \varepsilon \tilde{v} \mu a$, flux]. Rheumatism of the foot.

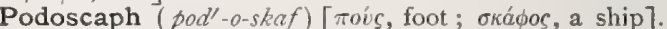
In biology, a hollow, skiff-like member attached to the foot of certain water birds.

Podosperm, Podospermium (pod'-o-sperm, pod-o-

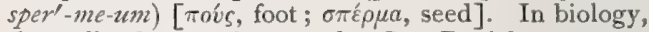
the stalk of an ovule or seed. See Funicle.

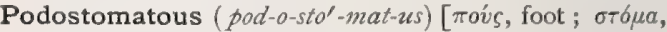
mouth]. In biology, having foot-like mouth-parts.

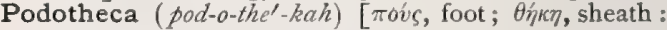
pl., Podotheca]. In biology: $(a)$ the envelop of the legs and feet of a bird; $(b)$ the covering of a leg in the pupa of an insect.

Podotrochilitis (pod-o-trok-il-i'tis) [ $\pi$ oís, foot; $\tau \rho \circ \chi^{\prime}$ $\lambda_{\iota} a$, pulley; $\iota \tau \iota s$, inflammation]. Navicular disease; an inflammatory disease of the fore-foot in the horse, involving the synovial sheath between the sesamoid or navicular bone of the third phalanx and the flexor perforans muscle over it.

Podwyssozki's Theory of Inflammation. See under Theory.

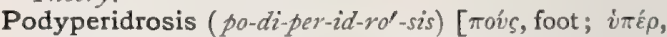
over; $i \delta \rho \omega \sigma \iota$, sweating]. Excessive sweating of the feet.

Pœcilia ( $p e-s i l$-e-ah). Same as Achroma.

Pœcilocyte ( $p e^{\prime}$-sil-o-sit). See Poikilocyte.

Pocilocytosis (pe-sil-o-si-to'-sis). See Poikilocytosis.

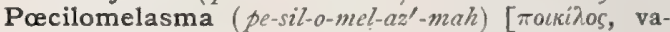

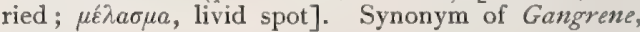
Senile.

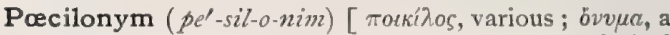
name]. In biology, one of many onyms or technical names for the same part.

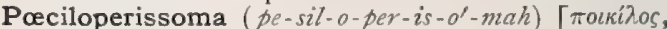
varied; $\pi \varepsilon \rho i \sigma \sigma \omega \mu \alpha$, superabundance ]. An excessive growth of heterogeneous tissues.

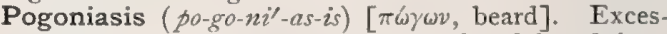
sive growth of the beard; growth of beard in a woman.

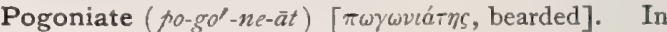
biology, webbed; bearded.

Pogonium (po-go'-ne-um) [ $\pi \hat{\omega} \gamma \omega v$, beard]. A small beard; also, the web of a feather.

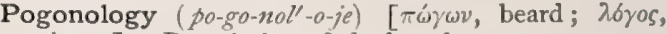
science]. Description of the beard.

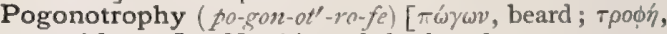
nourishment]. Nutrition of the beard.

Poikiloblast (poi'-kil-o-blast). See Corpuscle.

Poikilocyte (poi'-kil-o-sit) [ cell]. A large, irregularly shaped red blood-corpuscle. Poikilocytes are most abundant in the blood in pernicious anemia, but also occur in other forms of anemia. 


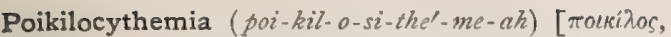
varied; кútos, cell; aija, blood]. The presence of poikilocytes in the blood.

Poikilocytosis (poi-kil-o-si-to'-sis) [ кútos, cell]. A condition of the blood marked by irregularity in the shape of the red corpuscles; it occurs preeminently in pernicious anemia, but also in other forms of anemia.

Poikilothermal (poi-kil-o-ther'-mal). Synonym of Poikilothermic.

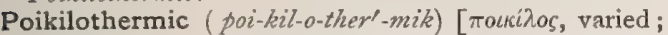
tép $\mu \eta$, heat]. Varying in temperature according to the surroundings. A term applied to cold-blooded animals, the temperature of which adapts itself easily to their environment.

Point [ME., point, a point]. The sharp end of an object; in the mathematic sense, that which has position but no dimensions. P., Alveolar, the central point in the lower margin of the upper alveolar arch. $\mathbf{P}$. apophysaire, P., Apophyseal, a name given by Trousseau to a tender spot over the spinous process of a vertebra, which, in neuralgic affections, corresponds to the origin of the nerve involved. P., Auricular, in craniometry, the center of the external auditory meatus. P., Boiling, the degree of temperature at which a liquid passes into the vaporous state with ebullition. P., Cardinal, in optics, one of the six points that determine the direction of the rays entering or emerging from a series of refracting media. P., Cardinal, of Capuron. See Pelvis. P., Craniometric. See Craniometric Points. P., Critical (of gases), a temperature at or above which a gas cannot be liquefied by pressure alone. Different gases have different, but fixed critical points. P., Critical (of liquids), that temperature at which a liquid, regardless of the pressure to which it is subjected, assumes a gaseous form. P., Deaf (of the ear), one of certain points near the ear where, as shown by Urbantschitsch, a vibrating tuning-fork cannot be heard. The fork is held perpendicularly and is moved from the zygoma backward toward the occiput. The first point is at the lower end of the tragus; the second, where the helix intersects the line along which the fork is moved. P., Dew, the temperature at which the atmospheric moisture is deposited as dew. P. of Dispersion, in optics, the virtual focus. Ps. douloureux, the tender spots at the exit of nerves the seat of neuralgic pain. See Ps., Valleix's. P. of Election, in surgery, that point at which a certain operation is done by preference. P., Erb's, the supraclavicular point, a point above the middle of the clavicle where a group of muscles consisting of the deltoid, biceps, brachialis anticus, and supinator longus can be stimulated to contraction. P., Eye: r. An ocellus, $q . v$. 2. The bright circle seen at the crossing-point of the rays above the microscopic ocular. P., Far-, the remotest point of distinct vision ; in the emmetropic eye, it is at infinity, but it is practically considered to be at 20 feet from the eye; in the myopic eye at a finite distance in front of the eye; in the hyperopic eye, beyond infinity,- practically beyond 20 feet. P., Fixation, that point on the visual axis at which an object is most distinctly seen. P., Focal, one of the two principal foci of a dioptric system. In the eye there is an anterior and a posterior focal point. The former is that point at which emerging rays that are parallel in the vitreous would converge in front of the eye; while the posterior is that point in the back of the eye at which entering rays, that are parallel when they strike the cornea, meet. P., Freezing, the degree of temperature at which a liquid substance, usually water or watery fluids, becomes solid. P., Fusing,
P., Fusion. Synonym of $P$, Melling. P., Hysteroepileptogenous, P., Hysterogenic. See Zone. P. of Incidence, in optics, that point on a surface upon which a ray of light falls. P., Intersuperciliary, the central point of a line joining the most prominent points of the two superciliary arches. P., Jugal, the point of intersection of a line tangent to the upper border of the zygoma and one marking the posterior border of the frontal process of the malar bone. $P$. of Least Resistance. See Locus minoris resistentice. P., Malar, the most prominent point on the external surface of the malar bone. P., McBurney's, a point two and a half inches distant from the anterior superior spine of the right ilium, on a line drawn from the spine to the umbilicus. It is often the seat of greatest tenderness in appendicitis. P., Melting, the degree of temperature at which fusible solids begin to melt. P., Metopic, the glabella, q. v. P., Motor, the point on the surface of the body corresponding to the place where the motor nerve enters a muscle, and where an electrode must be applied to produce the maximum contraction of the muscle by electric stimulation. See Motor Point. P., Nasal. Synonym of Nasion. P., Near-, the nearest point at which the eyes can accommodate to see distinctly. P., Near-, Absolute, the nearest point at which accommodation in a single eye is still possible without vision becoming indistinct. P., Near-, Binocular, the nearest point at which the means of accommodation and the convergence of the visual axes of an object can be seen distinctly. P., Nodal, in optics, the center of curvature of a spherical lens or refracting surface, through which rays of light pass, joining conjugate points. P., Occipital, the pointed posterior extremity of the occipital lobe of the brain. P., Occipital, Maximum, in craniometry, the point of the longest antero-posterior diameter which is most distant from the glabella. P., Ophryon. Synonym of Ophryon. P., Orbital, External, in craniometry, the most prominent point at the outer edge of the orbit. It is just above the fronto-malar bones. $\mathbf{P}$. of Ossification, the center of ossification in a bone. P., Painful, the point where a nerve, the seat of neuralgia, is tender on pressure. It is usually at the exit of the nerve from a bony canal, or where it passes through fascia. See $P_{s}$, Valleix's. P., Physiologic Middle (of the retina), the fovea centralis. Ps., Principal, in optics, the two points in the optic axis of a lens that are so related that lines drawn from these points to the corresponding points in the object and its image are parallel. P. of Reflection, in optics, the point from which a ray of light is reflected. $P$. of Refraction, in optics, the point at which a ray of light is refracted. P. of Regard, the point at which the eye is directly looking. Its image falls in the middle of the macula lutea. P., Retinal, Corresponding. See P., Retinal, Identical. P., Retinal, Disparate, one of those points on the retinæ whence images are projected, not to the same, but to different points in space. Ps., Retinal, Identical, corresponding points on the two retinæ, the images of which are projected to the same spot in space. P. of Sight. Same as $P$. of Vision. P., Subnasal, in craniometry, the middle of the inferior border of the anterior nares, or the root of the anterior nasal spine. P., Supraauricular, in craniometry, the point at the root of the zygomatic process directly over the auricular point. P., Supraclavicular. See P., Erb's. P., Supranasal. Same as Ophryon. P., Supra-orbital, a tender point in neuralgia just above the supra-orbital notch. P., Vaccine. See Vaccine Point. Ps., Valleix's (Pointes douloureux), the points at which neuralgic nerves are tender on pressure. This ten- 
derness is of diagnostic significance, and generally persists in the intervals between attacks. In trigeminal neuralgia these points are at the supra-orbital notch, at the infraorbital, and at the mental foramen. P. of Vision, the position from which anything is observed. P., Vital, a spot in the oblongata corresponding to the seat of the respiratory center, and puncture of which causes immediate death.

Pointed (point'-ed) [ME., point, a point]. Having a point. P. Condyloma. See Venereal Wart.

Pointillage (pwan'-til-yahzh) [Fr.]. Massage by means of the finger-tips.

Pointing (point'-ing) [ME., point, a point]. The coming to a point. $\mathbf{P}$. of an Abscess, the process by which pus from the deeper structures reaches the surface.

Poiseuille's Space. The peripheral zone in the capillary vessel between the wall of the capillary and the central current of the red blood-discs.

Poison $\left(p 0 i^{\prime \prime}-z n\right)$ [ME., poisoun, poison]. A substance that destroys the life of an organism or impairs the functions of one or more of its organs. "A substance capable of producing noxious and even fatal effects upon the system, no matter by what avenue it be introduced; and this, as an ordinary result, in a healthy state of the body, and not by a mechanical action." (Reese.) See Poisons, Table of, pp. II361149. P., Aërial. Same as Miasm. P., Arrow, a poison, generally a vegetable extract, applied by savages to the heads of their arrows. Curare, employed by the inhabitants of Guiana, is one of the best known of these poisons. P.-ash. See Chionanthus. P.-bag. See $P_{\text {.-sac. }} \quad$ P., Blood, a substance having a destructive action upon the blood. P., Frog, an animal poison applied by the Indians of Colombia to their arrow-heads. P., Gaboon. See $P$. of Pahonias. P.gland, a gland secreting poison. P., Hematic. Synonym of $P$, Blood. P., Irritant, one producing irritation or destruction, such as mineral acids, alkalies, caustics, and other corrosive substances. P.-ivy, a shrub vine of North America, Rhus toxicodendron. It produces a severe cutaneous inflammation. See Rhus. P., Morbid, the etiologic poisonous element of a specific disease. P., Muscle: I. A substance that impairs or destroys the proper functions of muscles. 2. A poisonous albumin developed during muscular activity. P., Narcotic, one affecting the cerebral or cerebral and spinal centers, producing stupor, delirium, etc., such as opium, hydrocyanic acid, and carbon monoxid. See, also, Antidote, and Drug. P., Nerve, one impairing or destroying the conductingpower of nerves. P.-oak, a low form of the poisonivy. P., Ordeal, any one of the vegetable poisons, such as Physostigma, used by savages in the trial of accused persons to determine their guilt or innocence. P.organ, an organic apparatus for producing a poisonous material. P. of Pahonias, or Phonias, a very virulent poison obtained from the seeds of Strophanthus hispidus, and used as an arrow-poison. It is also called Gaboon poison. P., Protoplasmic, one destroying the vital properties of living protoplasm. P.-sac, a sac containing or secreting poison; a poison-gland. P.-vine. See $P$-ivy.

Poisoning (poi'-zn-ing) [ME., poisoun, a poison]. The act of administering or ingesting any poisonous substance in doses sufficient to destroy life or health. P., Blood, a condition in which the quality of the blood is altered by reason of the presence in it of a poison; ordinarily, synonymous with Septicemia.

Poisonous (poi'-zn-us) [ME., poisoun, poison]. Having the properties of a poison; venomous.

Poke-root (pök'-nüt). See Phytolacca.
Polar $\left(p o^{\prime}\right.$-lar $)$ [polus, a pole]. Pertaining or belonging to the poles. P. Crown, the disc of chromatingrains at each pole of the nuclear spindle in karyokinesis. P. Field, the clear space enclosed by the chromatin-loops of the loose skein. in karyokinesis, and in which the nuclear spindle appears. Cf. Sphere of Atraction, Centrosome. P. Globules, two masses of nuclear substance detached from the nuclear spindles during karyokinesis. They appear to be necessary to the complete maturation of the ovum, although they ultimately disappear. Only one polar globule occurs in parthenogenetic ova. They have been described by Fleming in white blood-corpuscles. The significance of the polar bodies is not definitely known. According to certain embryologists the ovum is originally hermaphroditic, the polar bodies representing the male element, which the ovum expels in order to prepare for the entrance of the male pronucleus. An analogous condition, leading also to the loss of certain elements, is thought to exist in the spermatozoön, which likewise is originally hermaphroditic. Weismann looks upon the polar bodies as masses of ovogenetic nucleoplasm which are expelled from the ovum, in order that the more important germ-plasm may develop actively. The bodies are also known as the polar globules of Robin. P. Method, a method of applying electricity in electrotherapeutics, in which the pole whose distinctive effect is wanted is placed over the part to be treated, and the other pole over some indifferent part. P. Nucleus, in biology, the fourth nucleus in each group at the two extremities of the embryo-sac. P. Reaction, in electricity, the measure of muscular contraction that follows the application of the positive (anode) or negative (kathode) pole to a nerve or muscle. P. Vesicle. Same as $P$. Globule. P. Zone. See Zone.

Polarimeter (po-lar-im'-et-er) [ polus, pole ; $\mu \varepsilon \tau \rho o v$, a measure]. An instrument for determining the degree to which an optically active substance changes the plane of polarization to the right or to the left.

Polarimetry (po-lar-im'-et-re) [polus, pole ; $\mu \varepsilon ́ \tau \rho o v$, measure]. The use of the polarimeter.

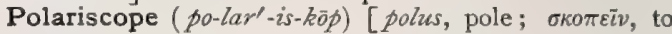
view ]. An optic instrument for exhibiting the polarization of light, or for examining substances in polarized light. The essential parts are the polarizing and analyzing prisms.

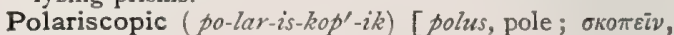
to view]. Pertaining to a polariscope.

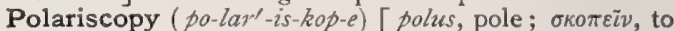
view]. The use of the polariscope.

Polaristrobometer (po-lar-is-tro-bom' - et-er) [polus,

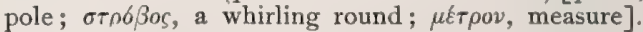
A form of polarimeter or saccharimeter that furnishes a delicate means of fixing the plane of polarization as rotated by the sugar-solution under examination.

Polarite $\left(p o^{\prime}-l a \gamma^{-}-\bar{t} t\right)$ [polus, a pole]. A filteringmaterial containing 50 per cent. of magnetic oxid and iron carbonate; it is used in the artificial filtration of sewage.

Polarity (po-lart-it-e) [polus, pole]. The state or quality of having poles or points of intensity with mutually opposite qualities. In electro-therapeutics, that condition of a nerve in which the part nearest the negative pole is in a state of increased, and that nearest the positive is in a state of decreased irritability.

Polarization (po-lar-iz-a'-shun) [polus, pole]. The act of forming poles or points of intensity having qualities mutually opposite. P., Chromatic, polarization accompanied by a play of colors. P., Circular, the turning of the plane of polarization to the 
right or left. P. of Light, the breaking up of a ray of light into two separate parts whose planes of vibration are at right angles to each other. It is usually accomplished by passing the ray through a doubly refracting medium.

Polarizer (pol-lar-i-zer) [palus, pole]. In microscopy, one of the Nicol prisms placed beneath the object and by means of which the light is polarized.

Pole $(p \bar{o} l)[\pi \delta \lambda o s$, polus, a pole]. The extremity of an axis; a point on a sphere equally distant from every part of the circumference of a great circle of the sphere. In electricity, one of the points of a body at which its attractive or repulsive energy is concentrated. In galvanic or dynamic electricity, the electrodes of a cell or of a generator. In magnetism, one of the points of maximum intensity of magnetic force. P., Antigerminal, the pole of an ovum opposite the germinal pole; it is the pole at which the food-yolk is situated. P., Cephalic, the end of the fetal ellipse where the head of the fetus is situated. P.-changer, a switch or key for changing or reversing the direction of a current produced by any electric source, such as a battery. P. Corpuscles. See Polar Globules. Ps. of the Eye, the anterior and posterior poles of the optic axis. P., Germinal, P., Germinative, the pole of the egg at which the development of the embryo begins. P., Lower, of an egg. See P., Antigerminal. P., Negative, the electrode or any other termination of the wire which is attached to the positive element in the galvanic cell. P., North, in a magnet, the extremity directed toward the north. P., Nutritive. Synonym of $P$., Antigerminal. P., Occipital, the posterior pointed extremity of the occipital lobe. P., Pelvic, the extremity of the fetal ellipse at which the breech is situated. P., Positive, the electrode or other terminal portion of the wire which is connected with the negative element of a galvanic battery. P., South, in a magnet, the extremity directed toward the south. P., Upper, in an egg, the $P$., Germinal, $q . v$. P., Vitelline. Synonym of $P$., Antigerminal.

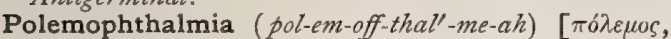

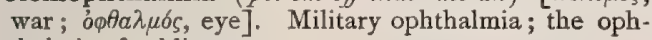
thalmia of soldiers.

Polenta (po-len'-tah) [L.]. In Italy, a maize-meal porridge.

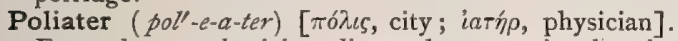
Formerly, a physician licensed to practise by the public authorities of a city.

Police $\left(p o-l e ̂ s^{\prime}\right)\left[\pi \hat{\lambda}_{\imath \iota}\right.$, a city]. I, Public order. 2. An organized civil force for maintaining order. P., Sanitary, the body of officials in the employ of a city, state or nation, whose duty it is to look after the hygienic condition as it affects the public health.

Policeman's Disease. Synonym of Tarsalgia.

Policlinic (pol-ik-lin'-ik) [ $\pi \hat{\lambda} \iota s$, city; $\kappa \lambda i v \eta$, couch]. A general city hospital. Cf. Polyclinic.

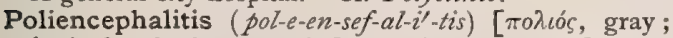

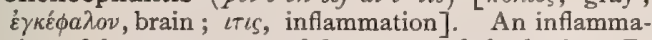
tion of the gray matter of the cortex of the brain. P. acuta, an acute inflammation of the cerebral cortex in children, giving rise to infantile cerebral palsy. $\mathbf{P}$., Anterior Superior, an inflammatory disease of the gray matter of the third ventricle, of the anterior portion of the fourth, and of that about the Sylvian aqueduct. The condition is usually acute and has, as a rule, a well marked clinical picture, including ophthalmoplegia, chiefly external, and a peculiar somnolent state; there is no other paralysis; sensation is not affected. The disease appears as if caused by infection, and is usually fatal, although recovery may take place. This disease may be related to the African sleeping- sickness, nélavan, and to a similar disease occasionally observed in Switzerland and Lombardy. P. corticalis, inflammation of the gray matter of the cerebral cortex. P., Posterior, inflammation of the gray matter of the posterior portion of the fourth ventricle.

Polimitus malarix (pol-im'-it-us). See under Parasites (Animal), Table of.

Polioencephalitis (pol-e-o-en-sef-al-i'-tis). See Poliencephalitis.

Polioencephalo-myelitis (pol-e-o-en-sef'-al-o-mi-el-i'. tis). Synonym of Poliomyelencephalitis.

Poliomyelencephalitis (pol-e-o-mi-el-en-sef-al-i'-tis)

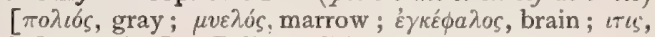
inflammation]. Poliomyelitis and poliencephalitis existing together.

Poliomyelepathy ( $\left.p o l-e-o-m i-e l-e p^{\prime}-a t h-e\right)[\pi 0 \lambda \iota \delta s$, gray; $\mu \nu \varepsilon \lambda o ́ s$, marrow ; $\pi a ́ t o s$, disease]. Disease of the gray matter of the spinal cord.

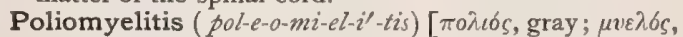
marrow; $t \tau \iota$, inflammation]. Inflammation of the gray matter of the spinal cord. P., Acute Anterior, acute inflammation of the anterior horns of the gray matter of the spinal cord, leading to a destruction of the large multipolar cells of these horns. It is most common in children, coming on during the period of the first dentition and producing a paralysis of certain musclegroups or of an entire limb. The onset is sudden, and the paralysis is usually most extensive in the beginning, a certain amount of improvement taking place subsequently. There are no sensory disturbances. The affected muscles atrophy rapidly, the reflexes in them are lost, and reactions of degeneration are present. From contraction of antagonistic muscles deformities develop later in life. The disease is also known as Infantile Palsy. P., Chronic Anterior. Synonym of Progressive Muscular Atrophy.

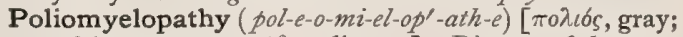

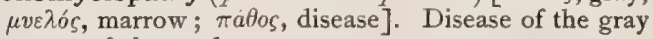
matter of the cord.

Polioplasm, Polioplasma ( $p o l^{\prime}-e-o-p l a z m$, pol-e-o-plaz'$m a h)$ [ $\pi 0 \lambda \iota b \varsigma$, gray; $\pi \lambda a ́ \sigma \mu a$, plasm]. Granular protoplasm.

Poliosis (pol-e-o'-sis) [ $\pi 0 \lambda \iota \sigma s$, hoary or gray]. A condition characterized by absence of pigment in the hair. See Canities.

Poliotes ( $\left.p o l-e-o^{\prime}-t e ̂ z\right)$ [ $\pi 0 \lambda \iota c_{s}$, hoary or gray. Synonym of Canities.

Poliothrix ( $\left.p o l^{\prime}-e-o-t h r i k s\right)$ [ $\pi 0 \lambda \iota s s$, gray; $\theta \rho i \xi$, hair]. Synonym of Canities.

Polish ( $\left.p o^{\prime}-l i s h\right)$ [Pol., Polski, Polish]. Pertaining to Poland. P. Plait. See Plica palonica. P. Ringworm. Same as Plica polonica.

Polishing Red. Same as Colcothar.

Polity ( $\left.p \circ l^{\prime}-i t-e\right)\left[\pi \delta \lambda_{\iota s}\right.$, a city]. A form of government. The functions of the government of a city or town. P., Medical, the sanitary regulations of a community.

Politzer's Ear-bag. An instrument for filling the tympanic cavity with air. It consists essentially of a large, gourd-like rubber bulb and a tube with a hardrubber tip to fit into the nose. P.'s Method, a method of inflating the middle ear and clearing the Eustachian tube by filling one nostril with air from a rubber-bag, the other ear being closed and the patient, at the moment of inflation, performing the act of swallowing, during which the pharyngeal end of the Eustachian tube is open.

Politzeration, Politzerization ( pol-its-er-a'-shun, polits-er-iz-a $a^{\prime}-$ hhun) [after Adam Politzer, an Austrian physician]. The inflation of the middle ear by means of Politzer's bag. 


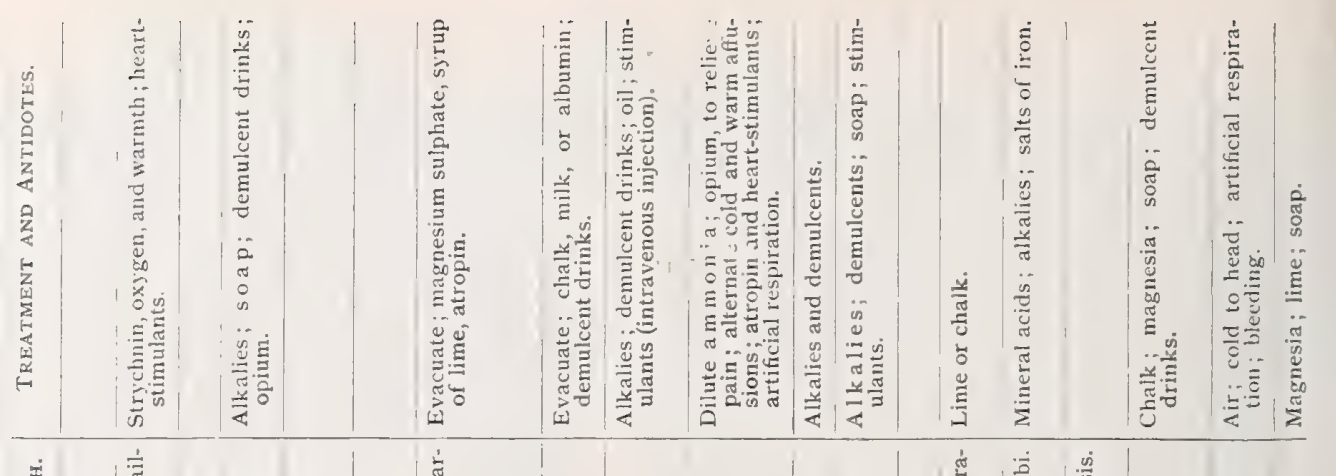

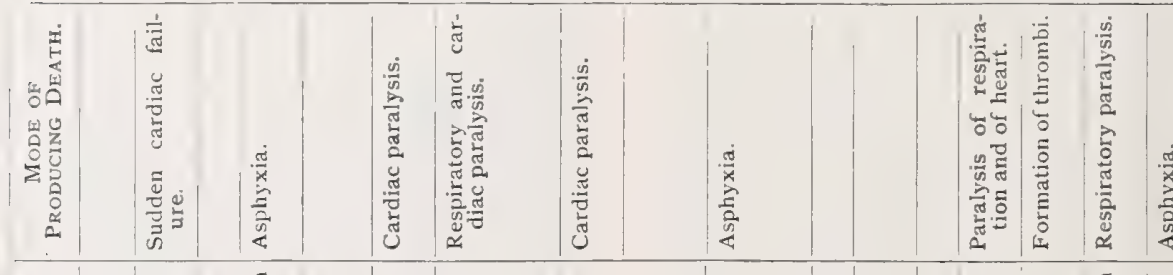
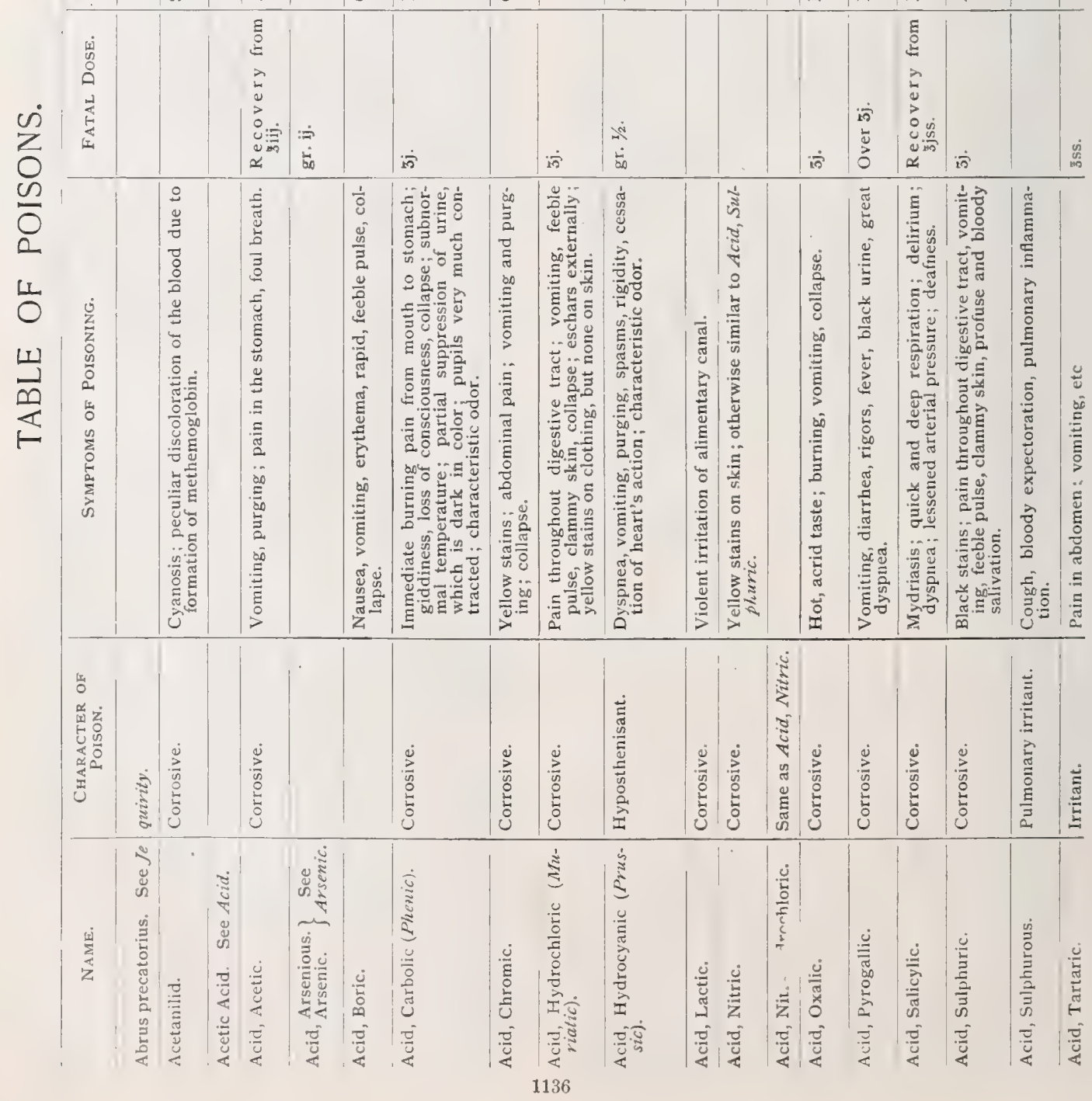


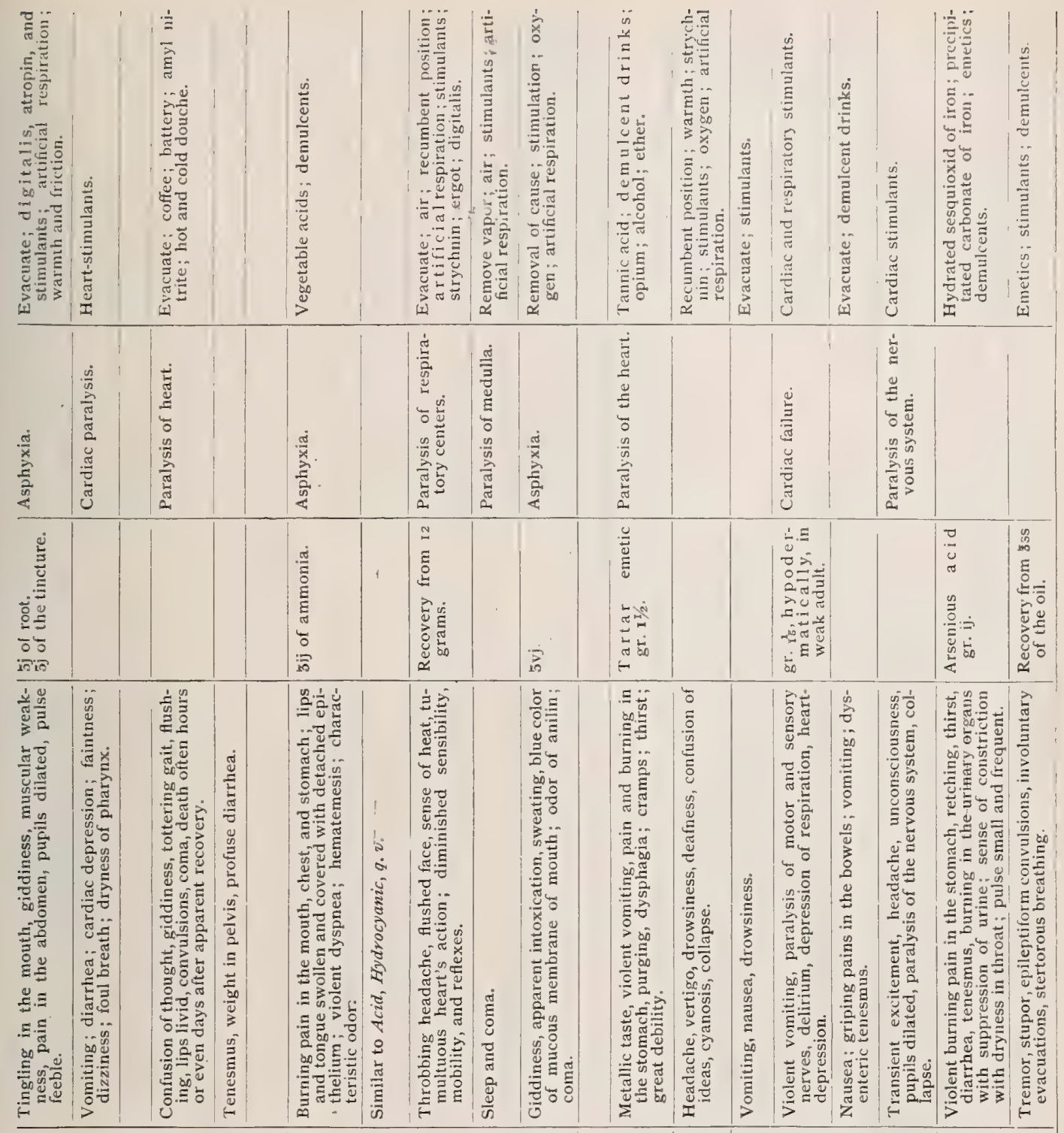

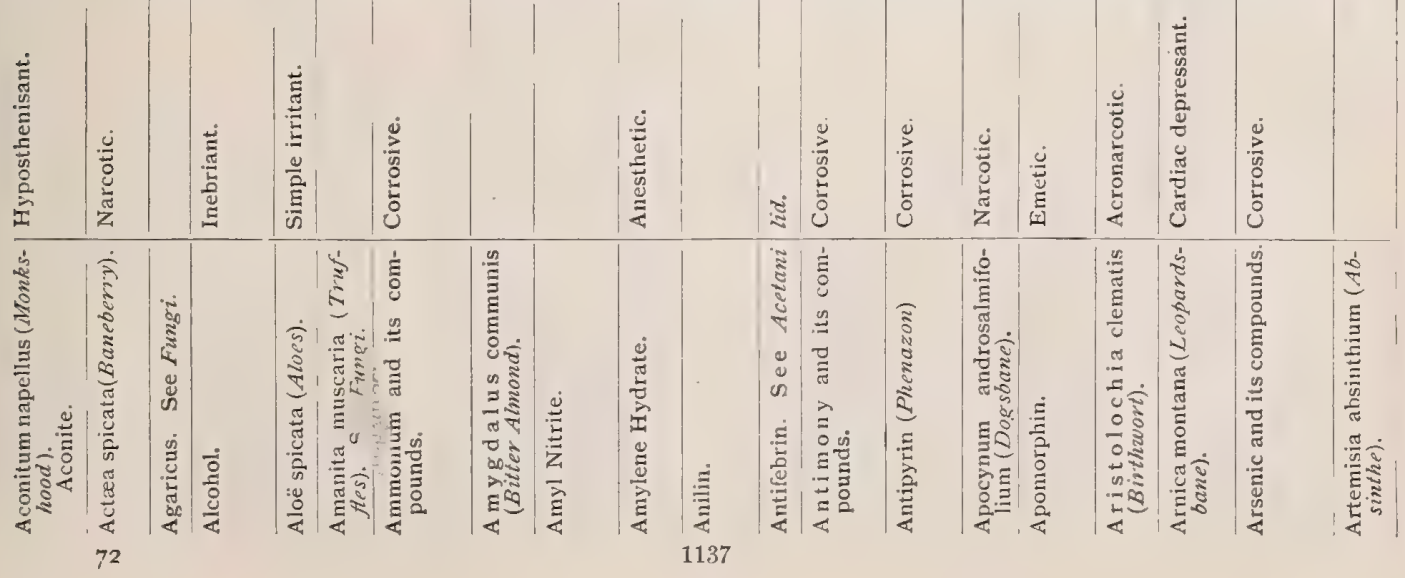




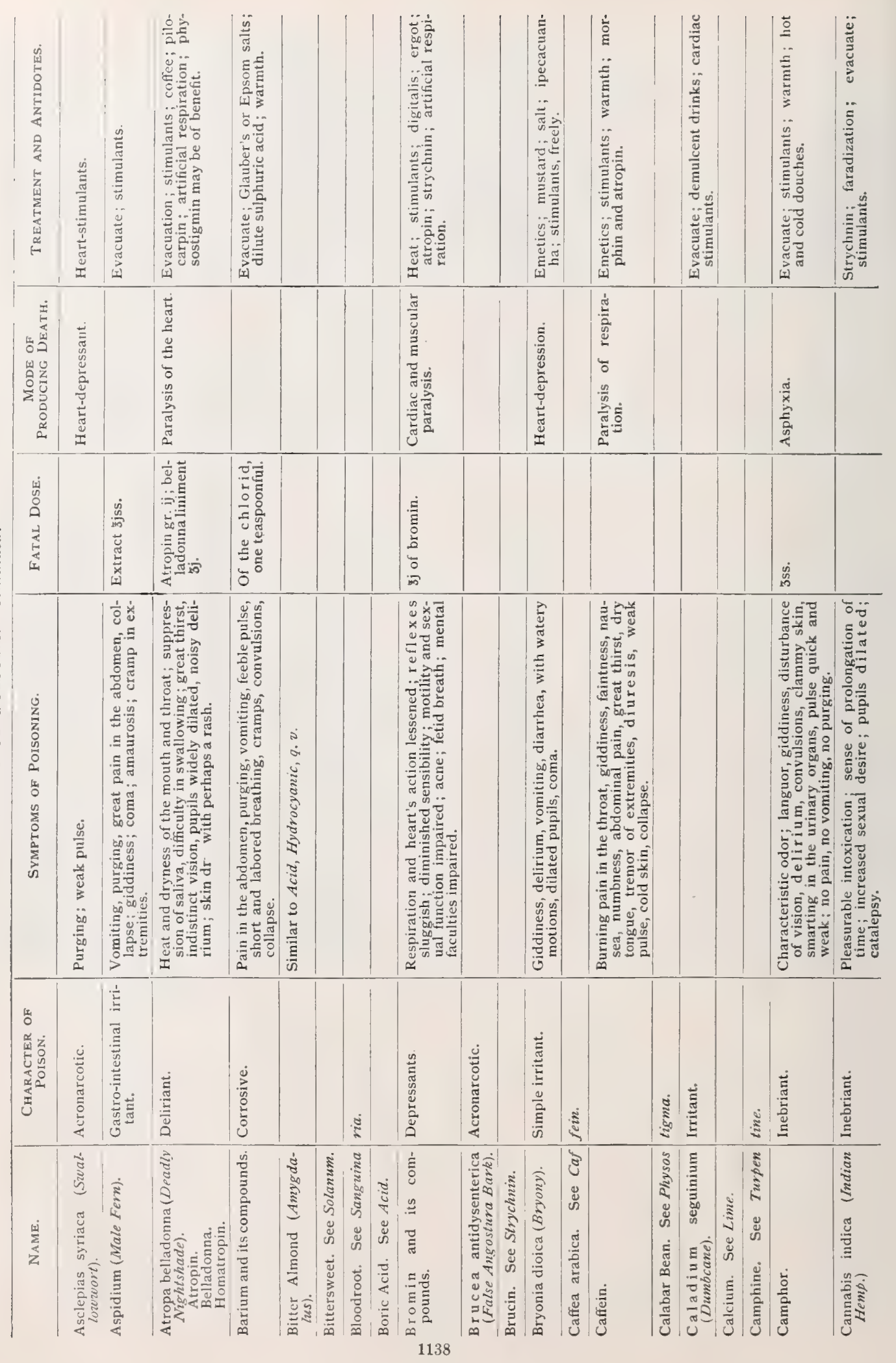



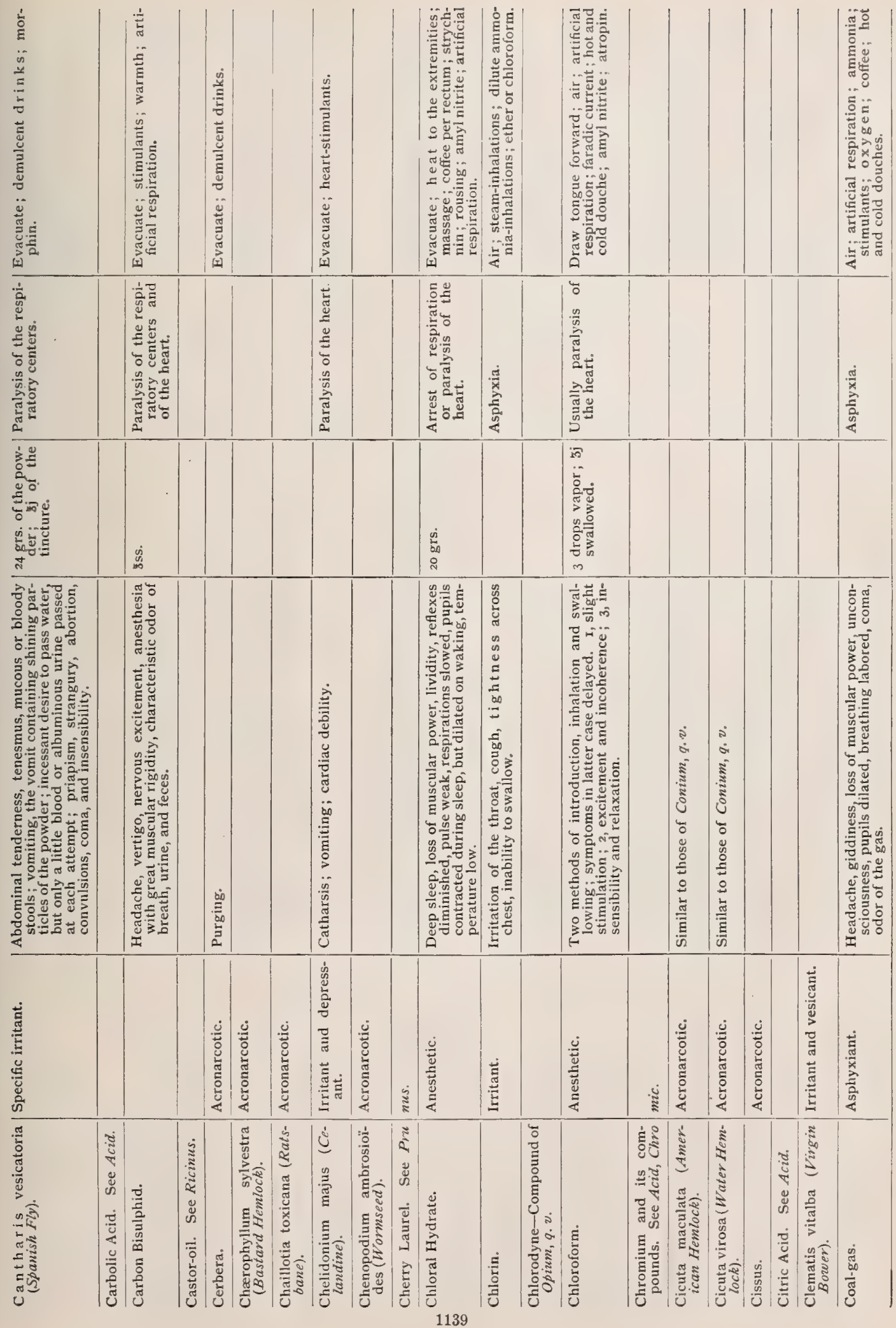


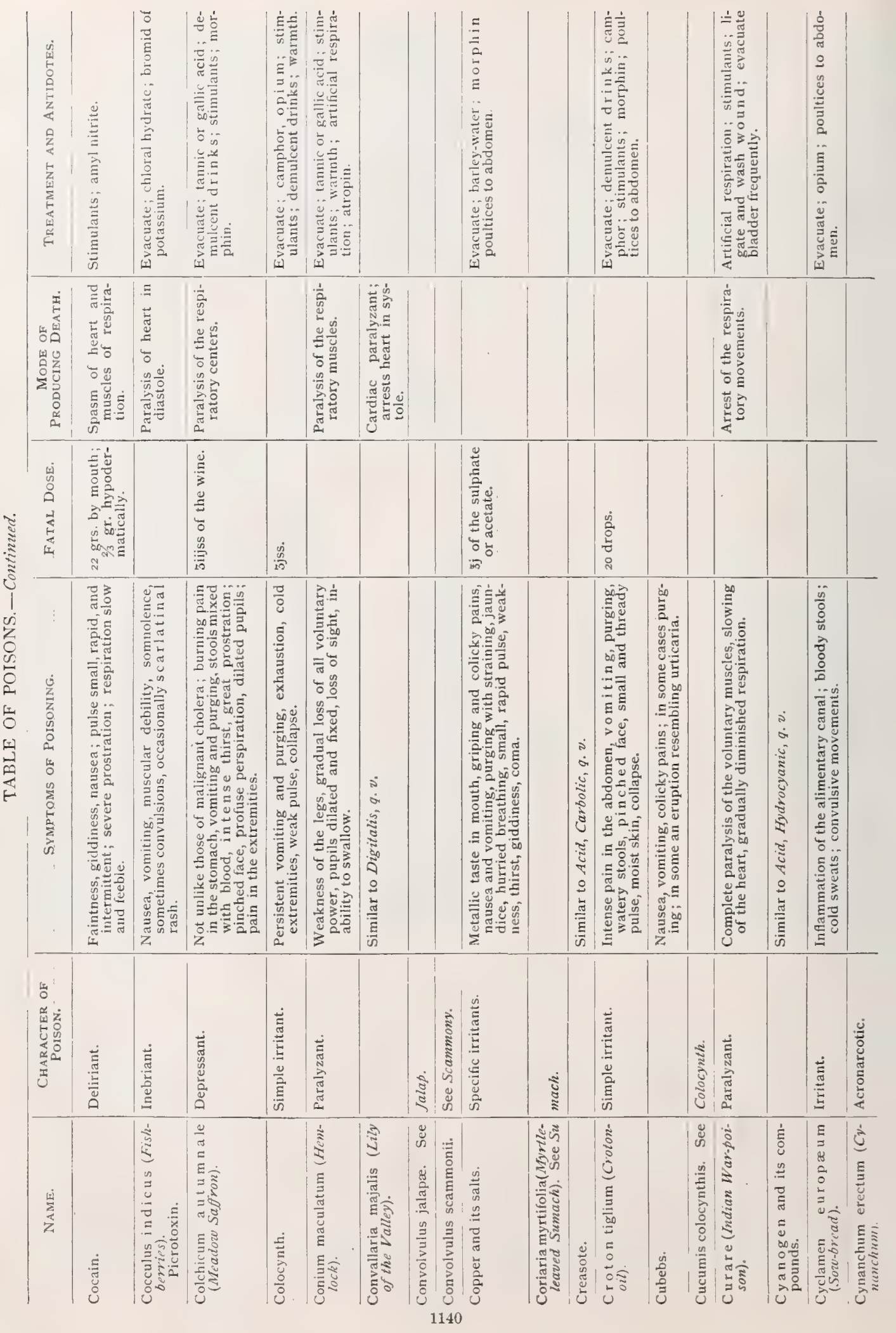



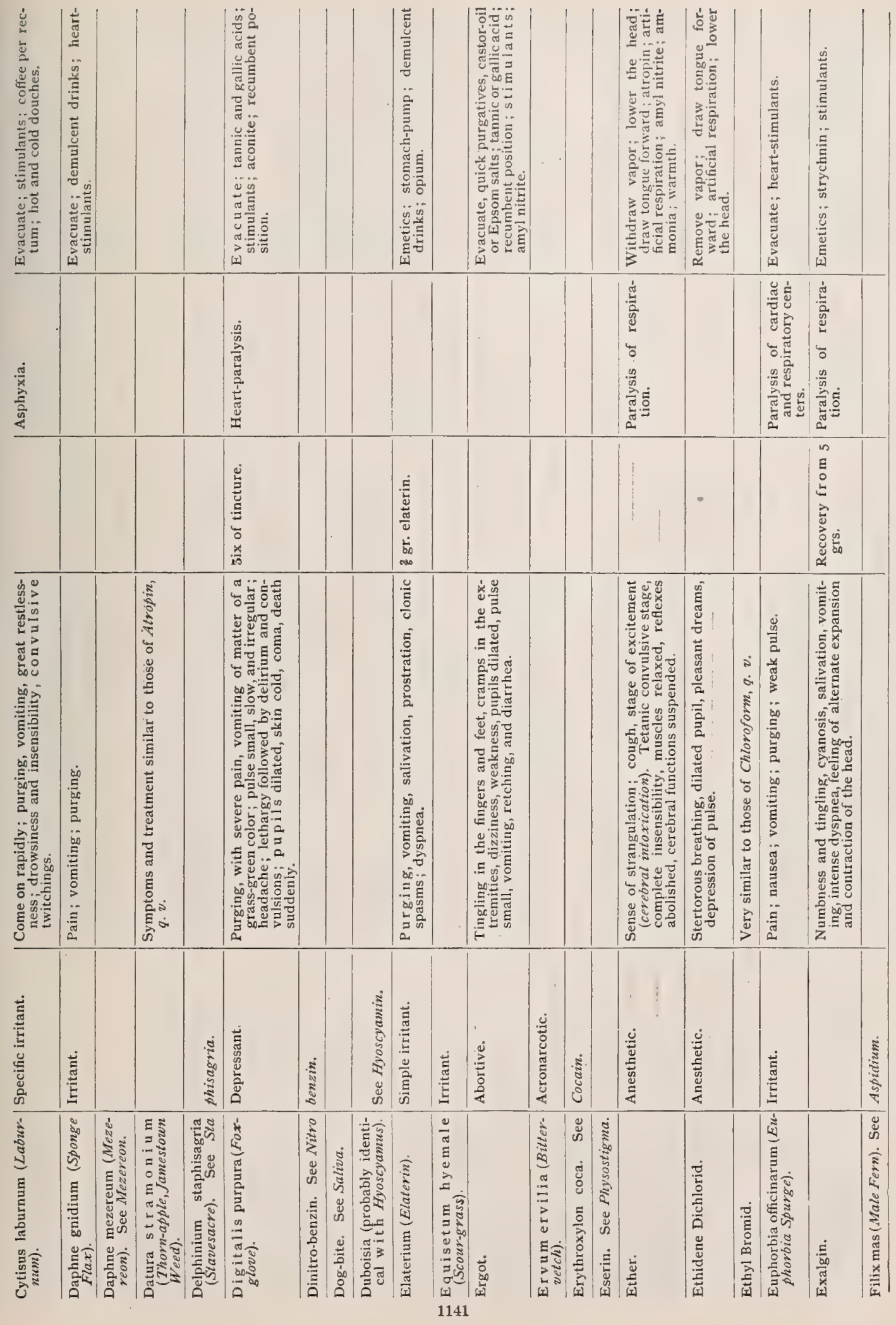

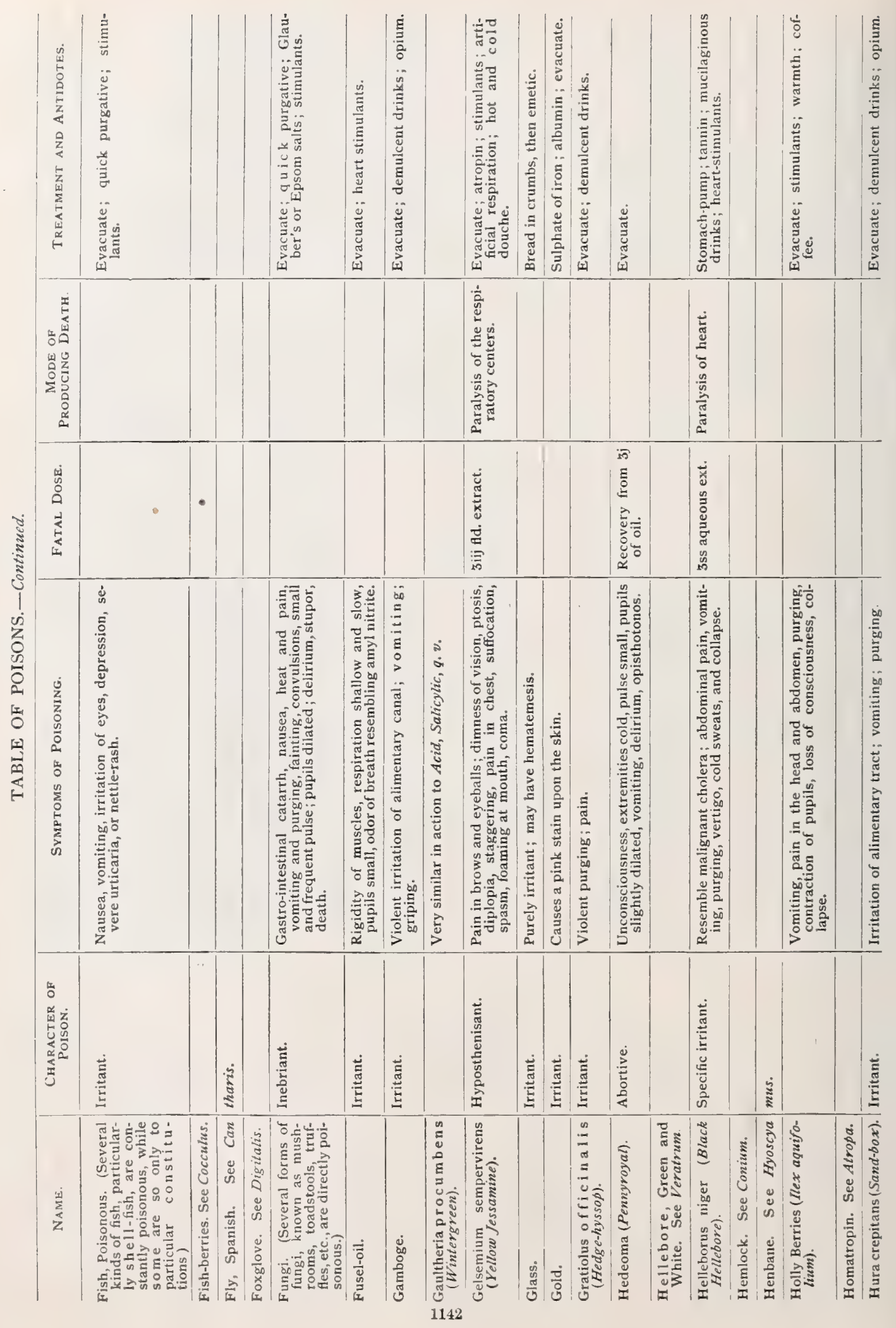


\begin{tabular}{|c|c|c|c|c|c|c|c|c|c|c|c|c|}
\hline 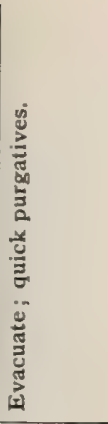 & 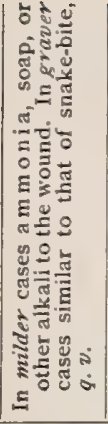 & 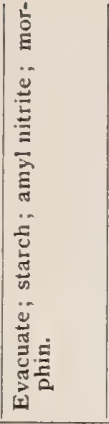 & 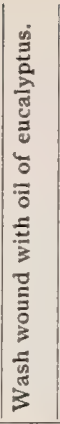 & 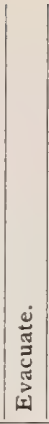 & 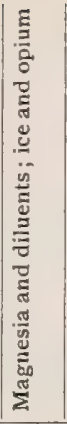 & 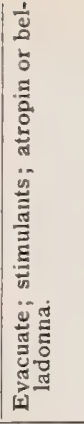 & 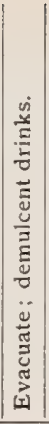 & 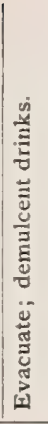 & & 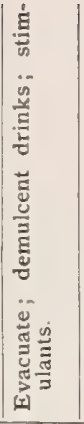 & & 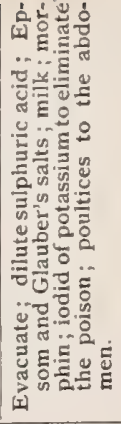 \\
\hline 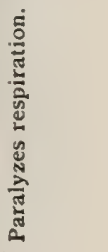 & & 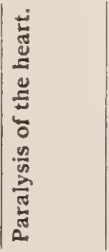 & & & & & & & & & & \\
\hline 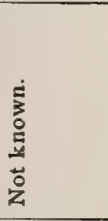 & & 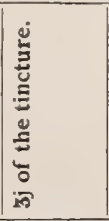 & & & 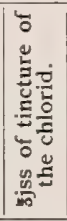 & & & & & & - & \\
\hline 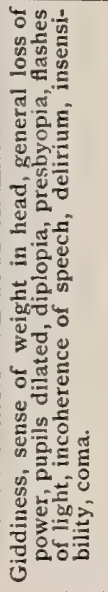 & 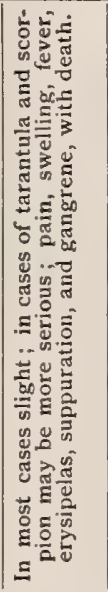 & 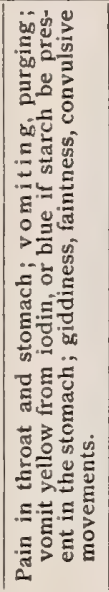 & 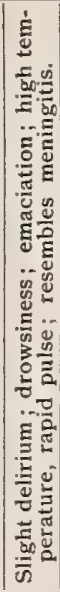 & 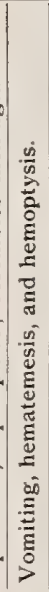 & 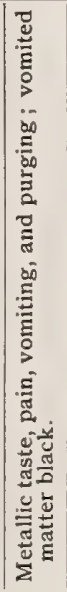 & 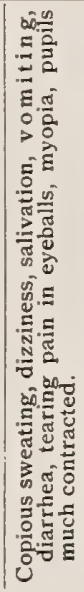 & 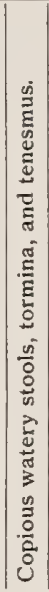 & 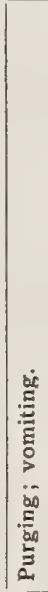 & 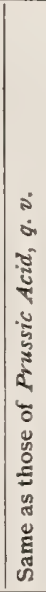 & 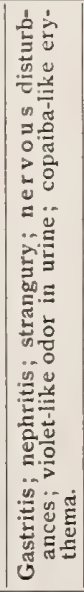 & 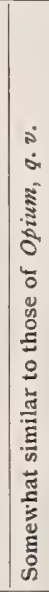 & 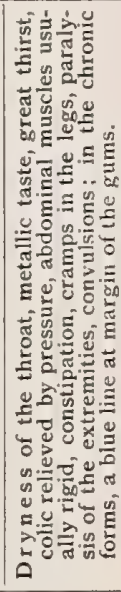 \\
\hline
\end{tabular}

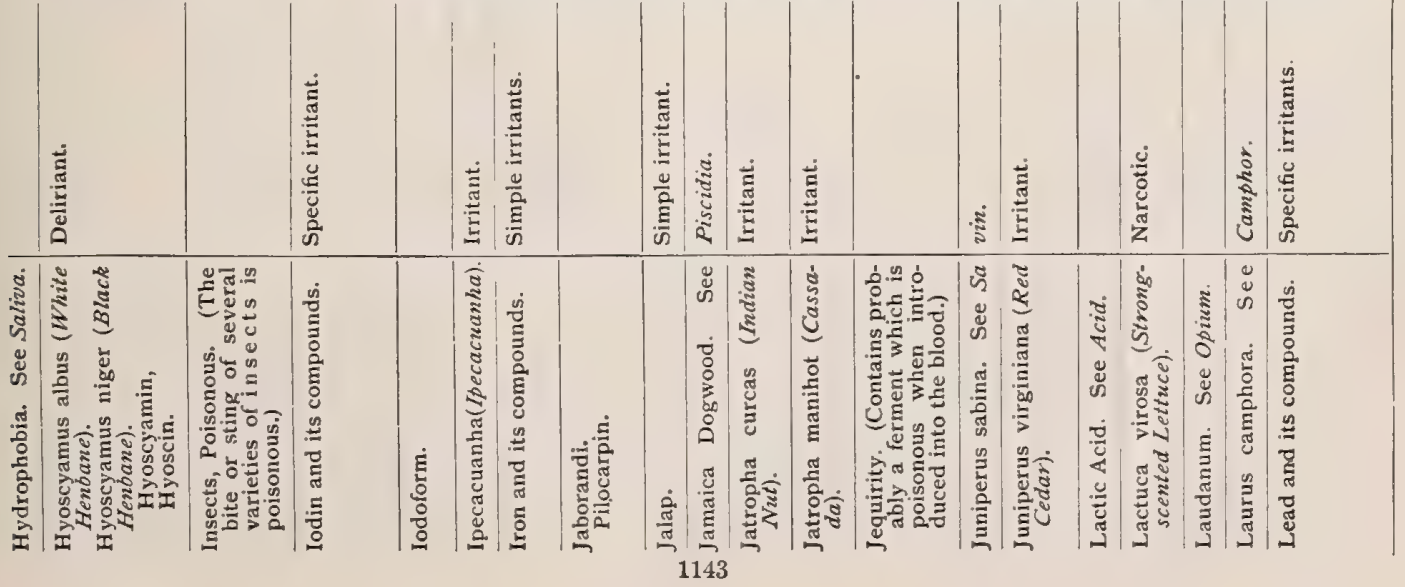




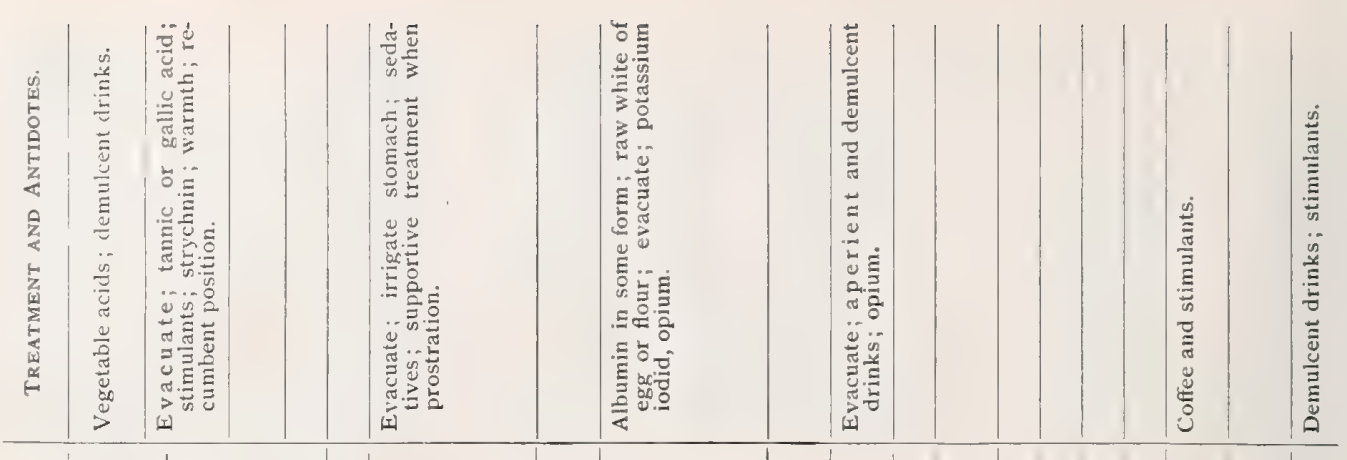

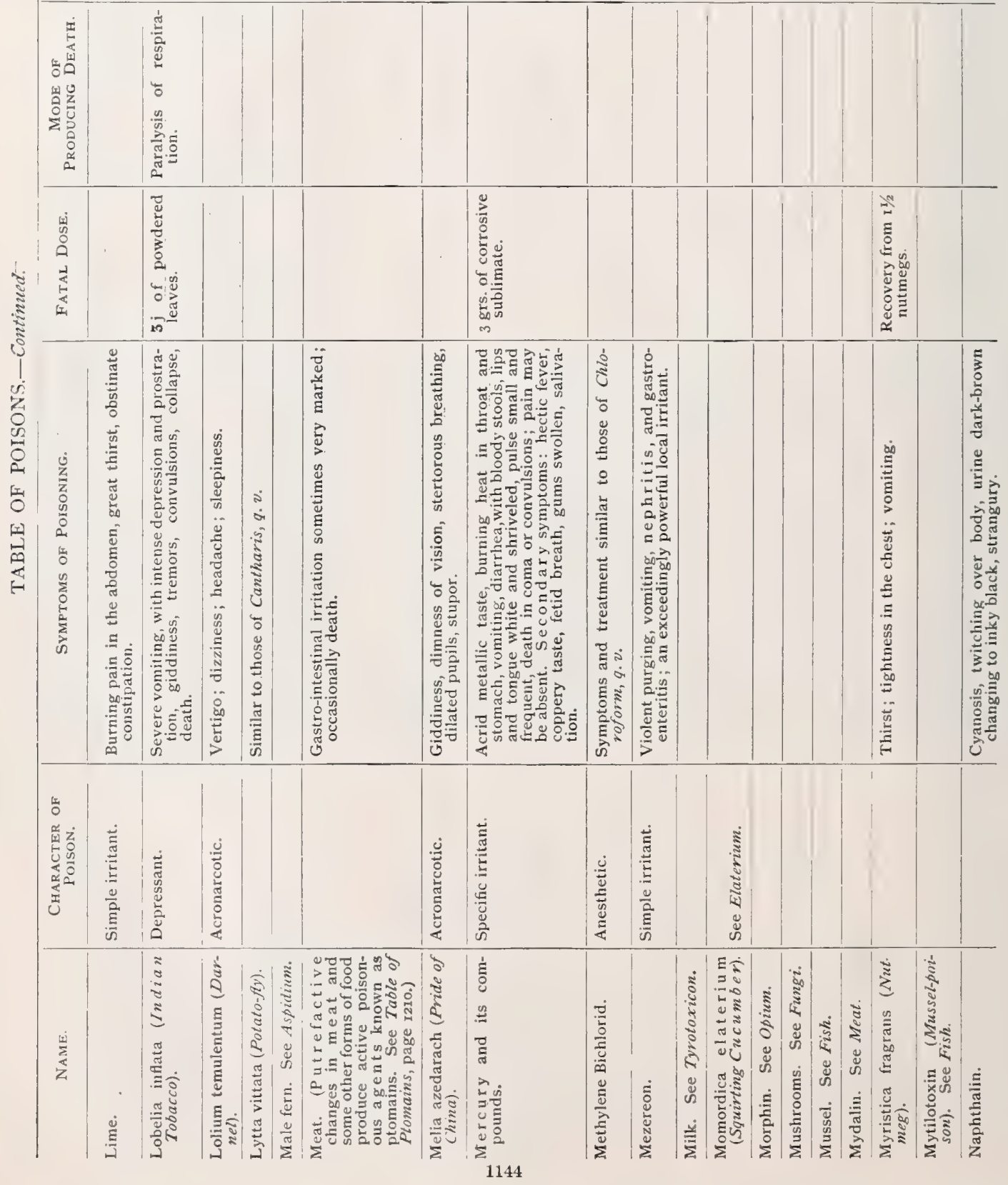




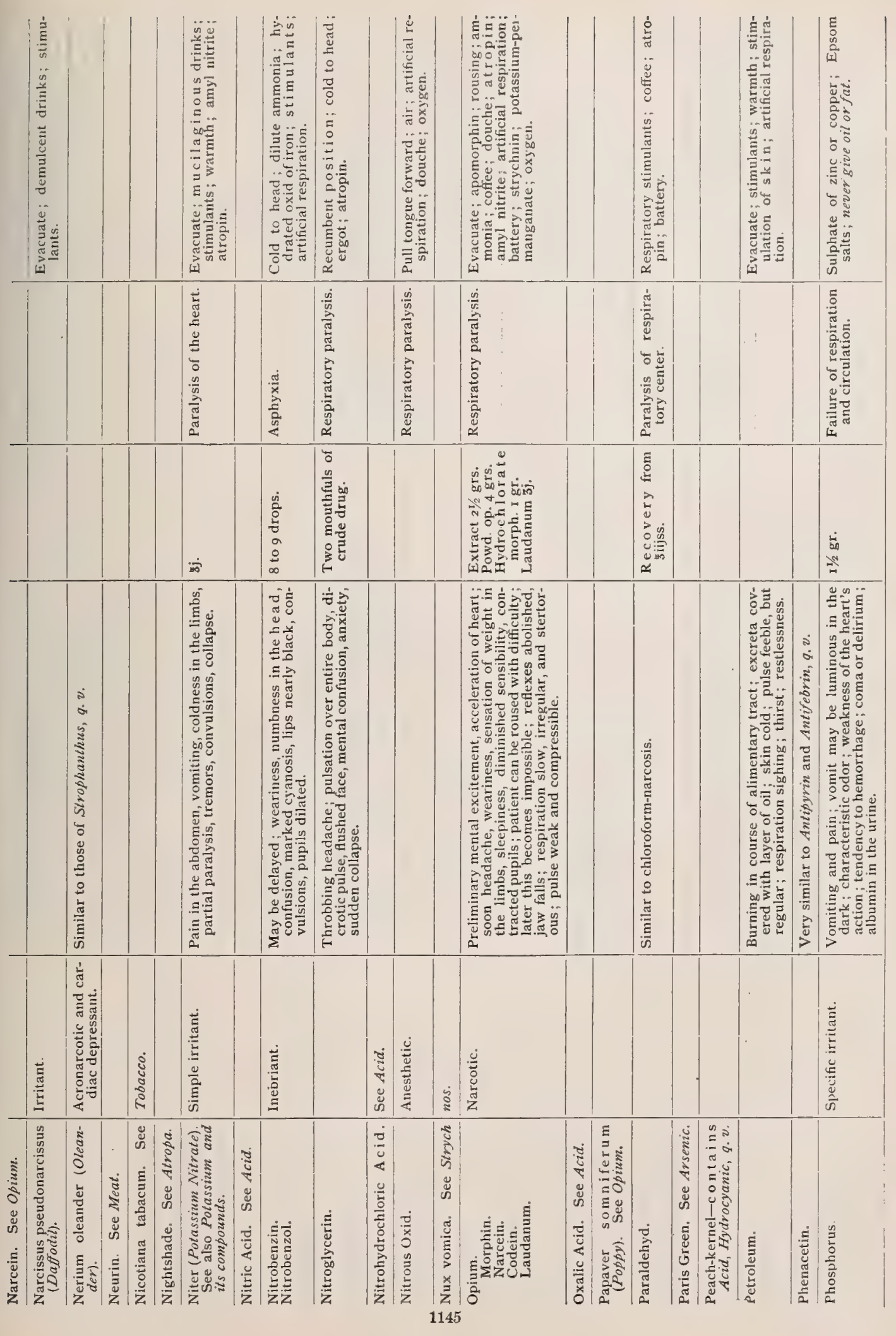




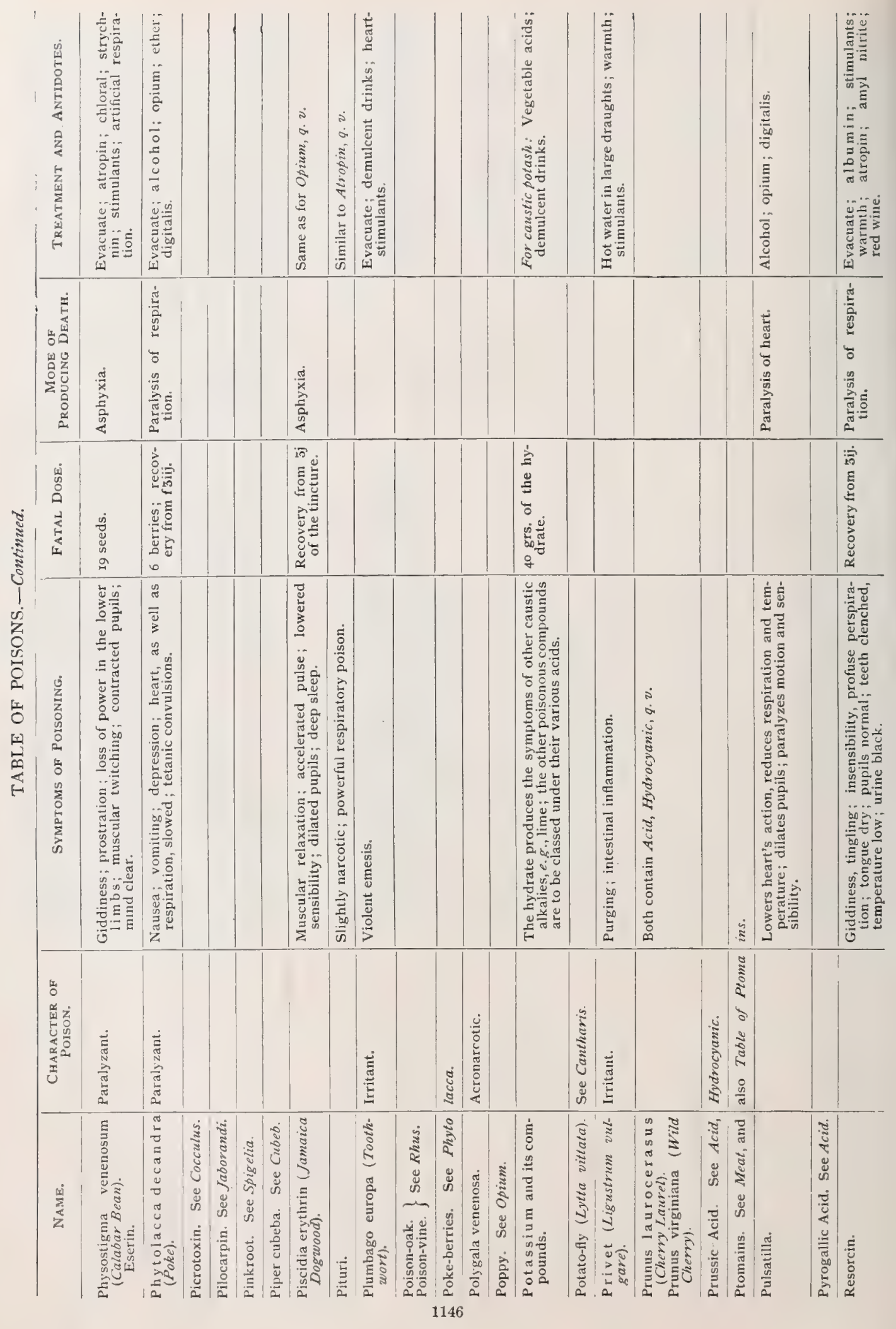




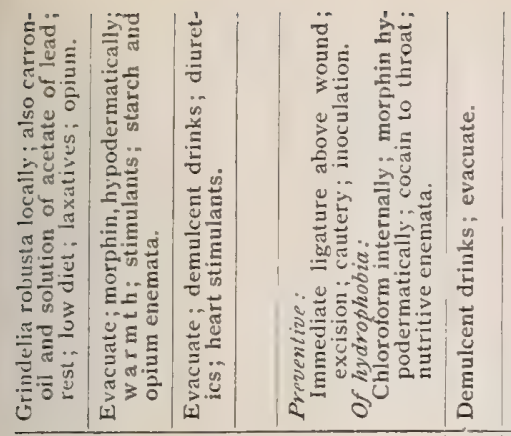
| $\mid$

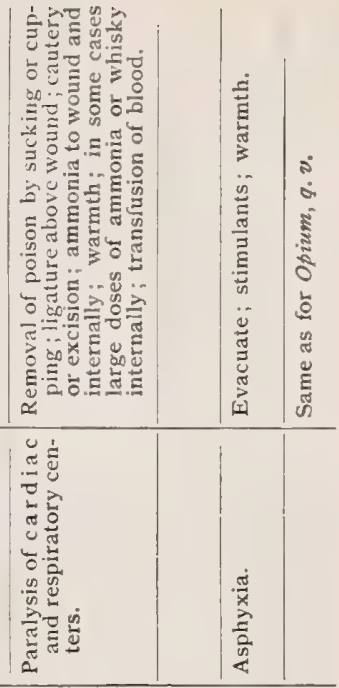

\begin{tabular}{|c|c|c|c|c|c|c|c|c|c|c|c|c|c|c|}
\hline & 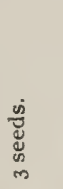 & & & & - & 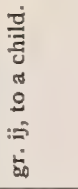 & & & & & & & & \\
\hline 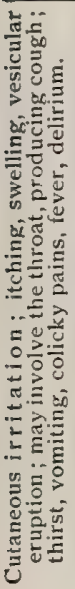 & 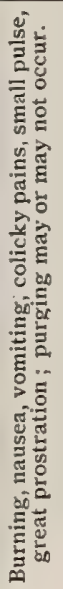 & 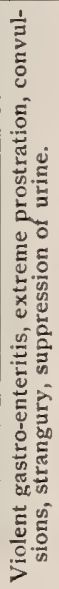 & 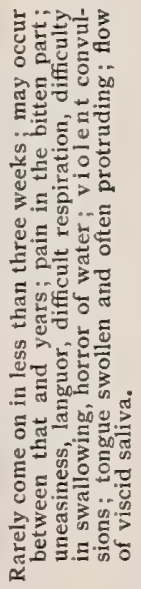 & 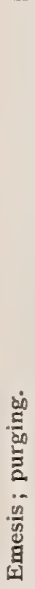 & 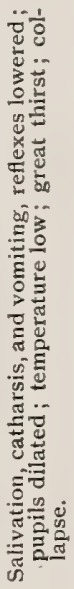 & 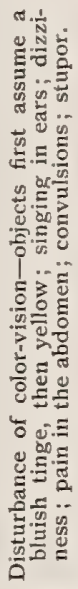 & 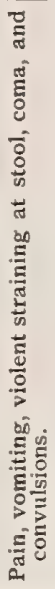 & 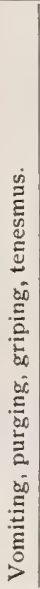 & 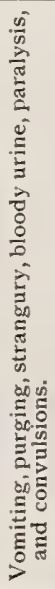 & 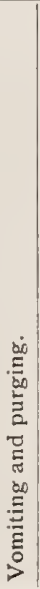 & 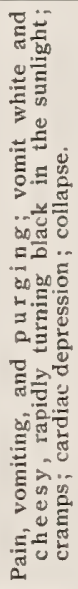 & 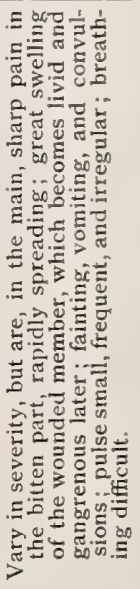 & 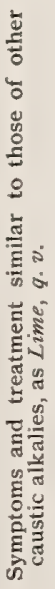 & 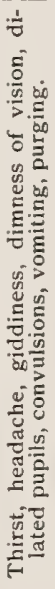 \\
\hline
\end{tabular}

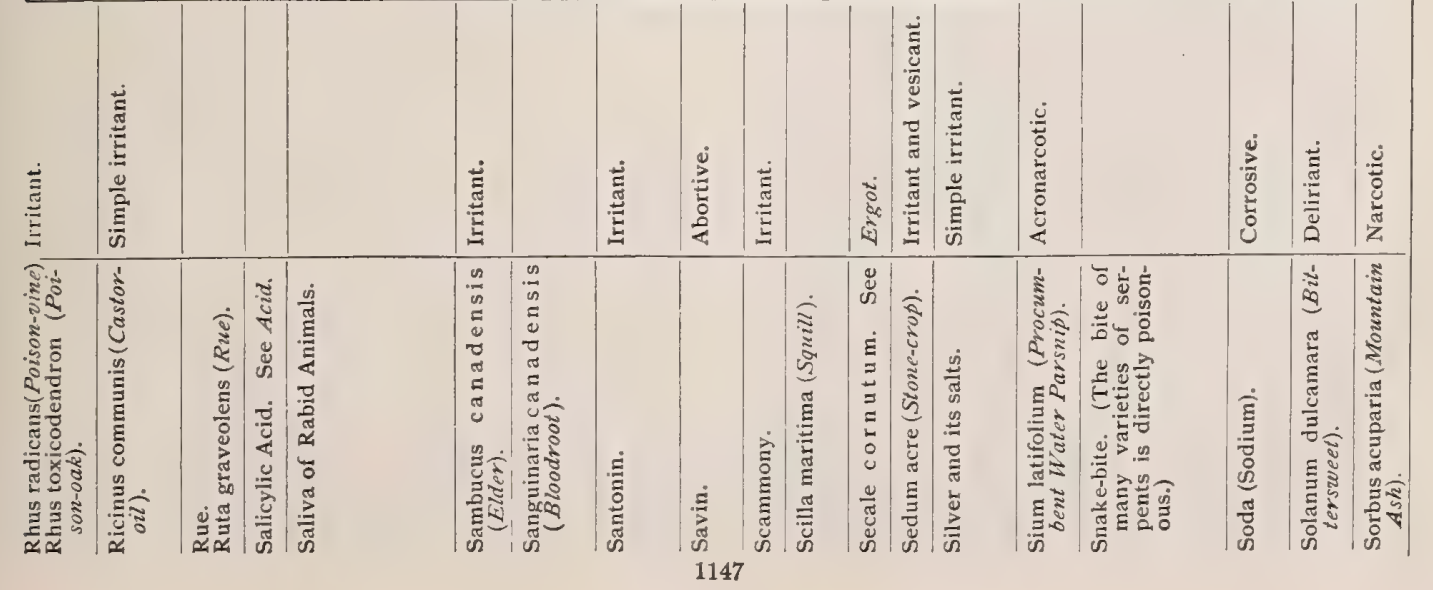



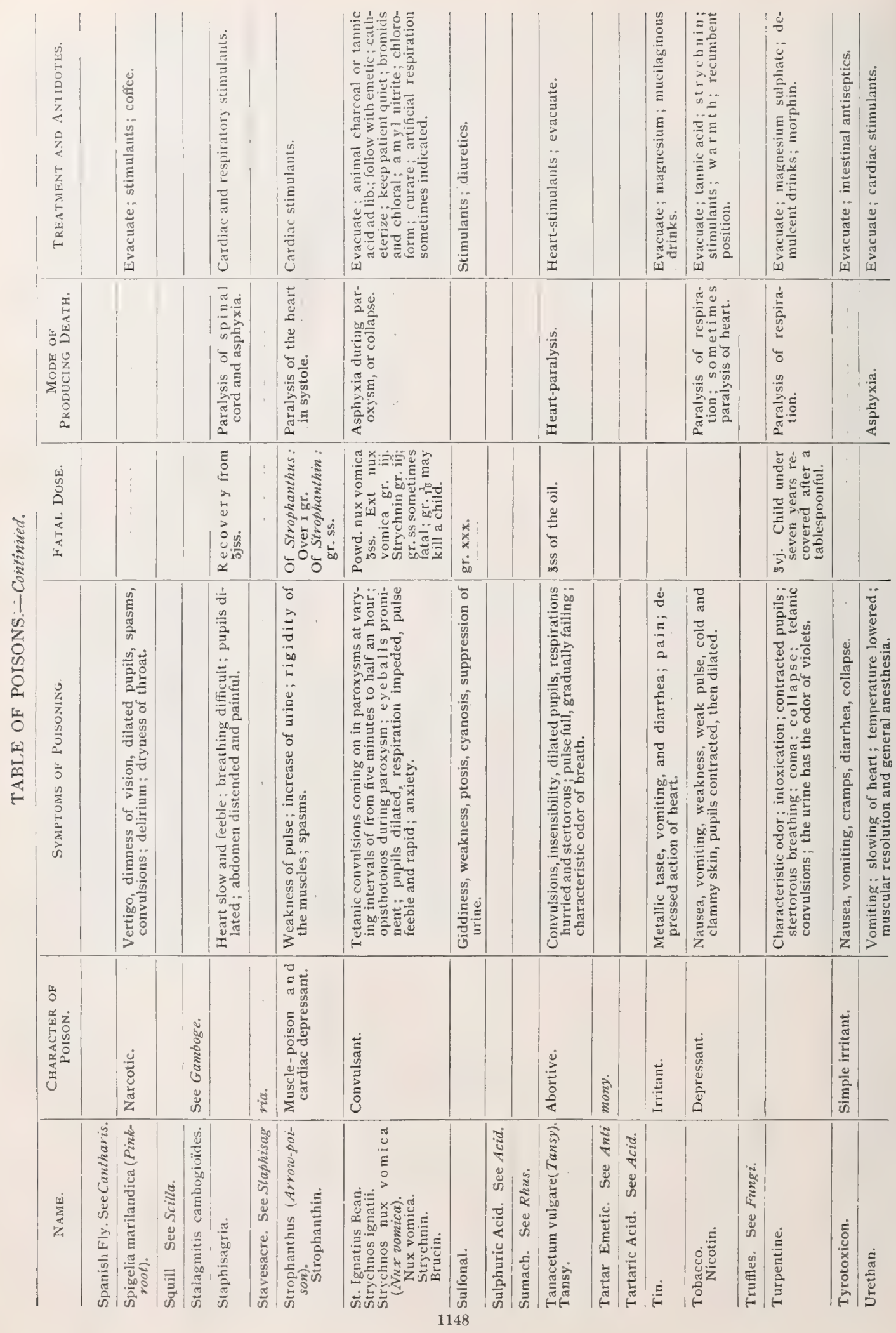


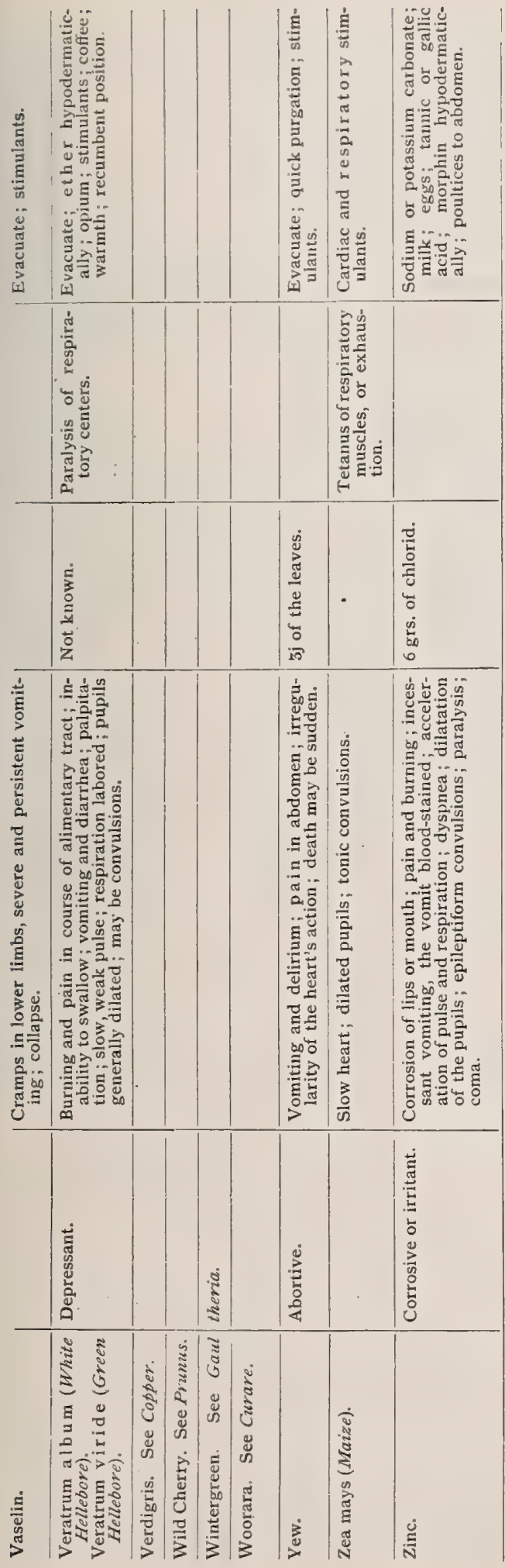

Politzerize (poll-its-er-iz) [after Politzer, an Austrian physician]. To treat by Politzer's method.

Poll (pöl) [ME., poll, head]. The head, especially the back portion, of an individual or of an animal. P.-evil, in farriery, an abscess behind the ears of a horse, producing a fistula.

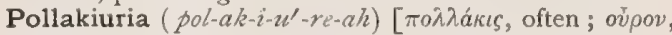
urine]. Abnormal increased frequency of micturition.

Polled (pöld) [ME., poll, the head]. A term applied to cattle without horns. P. Angus, a race of cattle without horns, indigenous to Great Britain.

Pollemphytensis (pol-em-fi-ten'-sis) [ $\pi 0 \lambda \lambda \sigma s$, many;

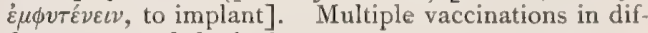
ferent parts of the body.

Pollen $\left(p o l^{\prime}-e n\right)$ [pollen, fine dust]. In biology, the fecundating element produced in the anthers of flowering plants. It occurs as separate one-celled, globular, or irregular grains varying as to species. The central protoplasm is inclosed in two coats, the inner of which is called the intine, the outer the extine. P.-basket. See Corbiculum. P. Catarrh. See Hay-fever. P.cell, in biology, the cell, sac, or chamber of an anther in which the pollen is produced. P.-chamber, the cavity at the apex of the ovule of gymnosperms, in which the pollen-grains lie after pollination. P.-fever. See Hay-fever. P.-grain, one of the unicellular bodies found in the anthers of flowering plants. They are generally yellow, and may be united into a mass by a viscid material. P.-mass. Same as Pollinium. P.-paste, pollen as it is stored up by bees. P.plate. See Corbiculum. P.-sac. See P.-chamber. P.-spore. Same as P.-grain. P. Theory, a theory first proposed by Gordon in 1829 and finally. confirmed by Blackley, in 1873 , that hay-fever is due to the irritation of the Schneiderian mucosa produced by the pollen of grasses and other plants. P.-tube, in biology, a slender tube formed by a protrusion of the intine of a pollen-grain, after its contact with the stigma, and by means of which the contents of the pollen-grain are conducted into the ovule.

Polleniferous (pol-en-if'-er-us). See Polliniferous.

Pollenization (pol-en-iz- $a^{\prime}-$ shun). See Pollination.

Pollex (pol'-eks) [pollex, the thumb, the great toe: $p l$, Pollices]. The digit at the radial side of the quinquedigital hand.

Pollical (pol'-ik-al) [pollex, thumb]. Pertaining to the thumb.

Pollicate (pol'-ik-ät) [pollex, thumb]. In biology, having thumbs.

Pollinar (pol'-in-ar) [pollen, pollen]. In biology, covered with a fine dust resembling pollen.

Pollinarium (pol-in- $\Omega^{\prime}-r e-u m$ ) [pollen, pollen]. In biology, one of the organs growing on the hymenium of certain fungi (Agaricini), thought by some to be male organs; also called cystidia, barren basidia. Cf. Antheridium.

Pollination (pol-in- $a^{\prime}$-shun) [pollen, pollen]. The act of conveying the pollen to the stigma.

Pollinic ( $\left.p o l-i n^{\prime}-i k\right)$ [pollen, pollen]. Pertaining to pollen. P. Chamber. See Pollen-chamber.

Polliniferous (pol-in-if'-er-us) [pollen, pollen; ferre, to bear]. I. Producing or containing pollen. 2. Bearing pollen, as certain insects.

Pollinigerous (pol-in-ij'-er-us). Same as Pollinifer. ouss.

Pollinium ( $\left.p o l-i n^{\prime}-\ell-\imath m\right)$ [pollen, fine flour: pl., Pollinia]. In biology, a mass of united pollen-grains, as in orchids, milk-weeds and other plants.

Pollinivorous (pol-in-iv'-or-us) [pollen, pollen; vorare, to devour]. Feeding upon pollen.

Pollinose (pol'-in-öz) [pollen, fine flour]. In biology, powdered over as if with pollen. 
Pollution (pol-u'-shun) [pollutio; pollueve, to defile]. In sanitary science, the introduction or dissemination of any deleterious or filthy substance about a locality where its presence would be conducive to disease. Especially the defilement of potable water by sewage or excreta. In physiology, the production of the orgasm in either male or female by means other than sexual intercourse. See Masturbation. P., Nocturnal, a nocturnal, involuntary, seminal discharge. $P$. Self, masturbation.

Polonica (po-lon'-ik-ah). See Plica.

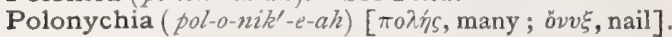
See Polyony'chia.

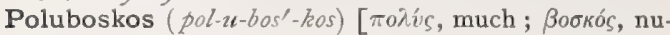
tritious]. A pure gluten food for infants and invalids. It has the following composition: Moisture, 7.50; fat, 0.50 ; mineral salts, almost wholly phosphates, 0.60 ; carbohydrates, 0.40 ; nitrogenous substances, 91.

Poluria (pol-u'-re-ah). Synonym of Polyuria.

Poly- $\left(p o l^{\prime}-e^{-}\right)[\pi o \lambda v s$, many $]$. A prefix that denotes much or many.

Polyacanthid (pol-e-ak-an'-thid) [nohis, many ; àkavAa, thorn, spine]. In biology, applied to certain echinoderms in which there are several series of adambulacral spines.

Polyacanthus ( $\left.p o l-e-a k-a n^{\prime}-t h u s\right)$ [ $\pi 0 \lambda v s$, many ;

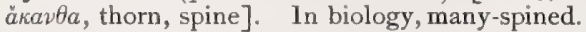

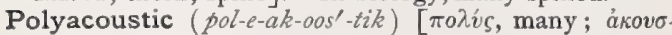
$\tau \iota \kappa b \varsigma$, acoustic]. I. Multiplying sound. 2. An instrument for intensifying sound.

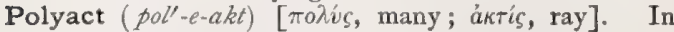
biology, having numerous rays.

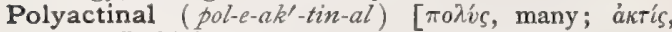
ray]. In biology, many-rayed; multiradiate.

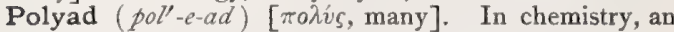
element whose valence is greater than two.

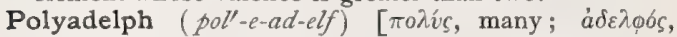
brother]. In biology, a plant having its stamens united into three or more bundles.

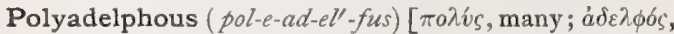
brother]. In biology, having the stamens united by their filaments into several sets.

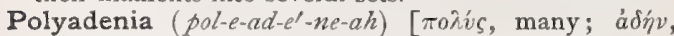
gland]. Pseudo-leukemia, or Hodgkin's disease.

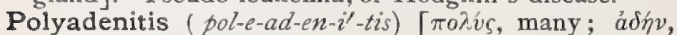
gland; $t \tau \ell$, inflammation]. Inflammation of many glands at once

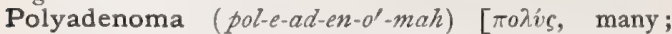
$a ́ \delta \dot{\eta} \nu$, gland; ò $\mu a$, tumor]. Adenoma of many glands.

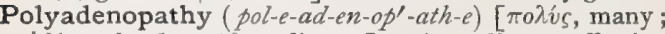

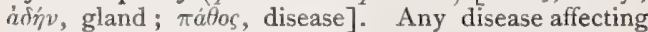
many glands at once.

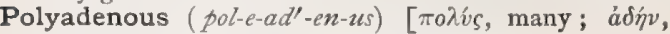
gland]. In biology, bearing many glands.

Polyæmia (pol-e-e'-me-ah). See Polyemia.

Polyrsthesia (pol-e-es-the'-ze-ah). See Polyesthesia.

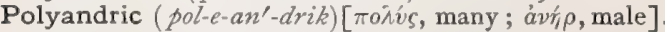
Characterized by polyandry.

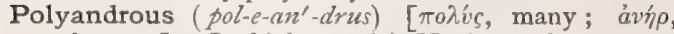
male, man]. In biology: (a) Having a large number of stamens. Cf. Icosandrous. (b) Having more than one male mate. Cf. Monothelious,

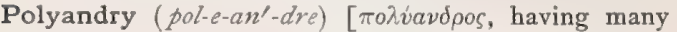
men]. In biology, plurality of husbands or male mates

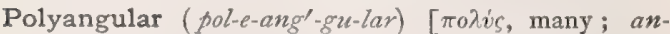
gulus, an angle]. Having many angles.

Polyanhemia (pol-e-an-hem'-e-ah). Synonym of Anemia.

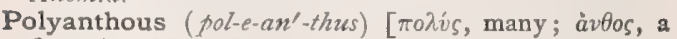
flower]. Many-flowered.

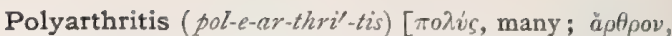
joint; $\iota \tau \iota \zeta$, inflammation]. Inflammation of many joints at once. P., Acute, a term given to acute articular rheumatism. P. rheumatica acuta. Synonym of Rheumatism, Acute Articular. P. synovialis. See Kheumatism, Articular.

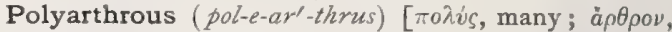
a joint]. In biology, many-jointed; multiarticulate.

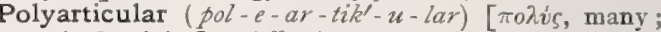
articulus, joint]. Affecting many joints together.

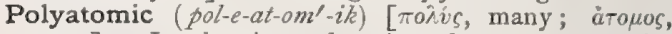
atom ]. In chemistry, denoting elements or radicles that have an equivalence greater than two; also, denoting compounds having three or more hydroxyl groups, in which hydrogen is easily replaceable by other elements or radicles without otherwise changing the structure of the original compound.

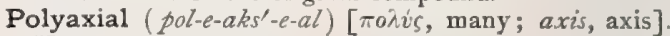
Having several axes.

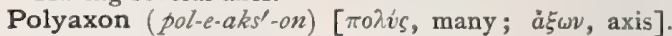
In biology, having several axes of growth.

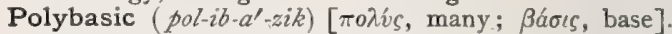
Of alcohols or acids, having more than one hydrogen atom replaceable by a base; of a salt, formed from a polybasic acid by the replacement of more than one hydrogen atom by a basic element or radicle.

Polyblennia ( $\left.p o l-i b-l e n^{\prime}-\ell-a h\right)$ [ $\pi 0 \lambda \hat{v}$, , many; $\beta \lambda \hat{\varepsilon} v v a$, mucus]. The secretion of an excess of mucus.

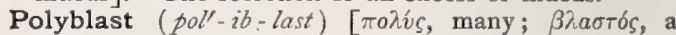
germ]. In biology, the mass of embryo-cells resulting from the cleavage of the ovum; the morula stage of development.

Polybrachia (pol-ib-ra'-ke ah). Same as Polymelus.

Polybrachus ( $\left.p o l-i b-r \cdot a^{\prime}-k u s\right)$ [ $\pi \alpha \lambda v s$, many ; $\beta \rho a \chi i o v$, arm]. A monster with supernumerary arms.

Polybrephia ( $\left.p o l-i b-r e f^{\prime}-\ell-a h\right)$ [ $\pi \circ \lambda u ́ s$, many; $\beta \rho \varepsilon \phi o s$, infant]. The condition of having many young.

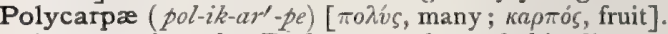
A name given by Fuchs to a class of skin-diseases characterized by the eruption of plastic lesions, such as papules, pustules, vesicles, etc., comprising eczema and herpes.

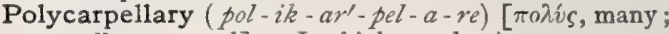
carpellum, carpel]. In biology, having many carpels.

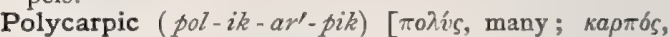
fruit]. In biology, fruiting many times.

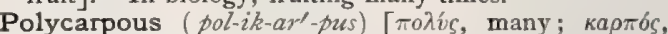
fruit]. In biology, having a pistil composed of several distinct ovaries or carpels. Cf. Monocarpous.

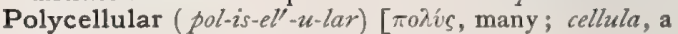
cell]. In biology, having many cells.

Polycentric (pol-is-en'-trik) [ center]. Having many centers or nuclear points.

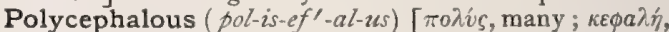
head]. In biology, bearing many heads.

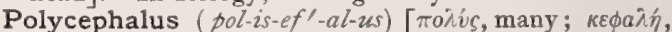
head]. A genus of Taniada. See Parasites (Animal), Table of.

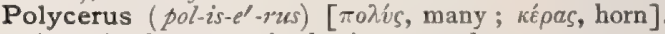
An animal monstrosity having many horns.

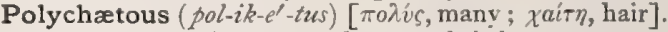
In biology, having many chætæ or bristles.

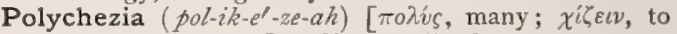
evacuate the bowels]. Chronic diarrhea.

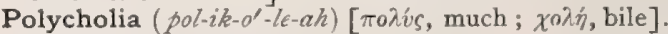
Excessive secretion of bile.

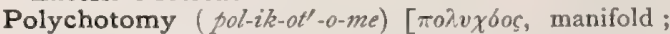

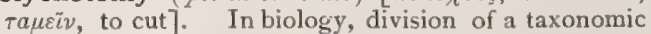
group of organisms into screral sub-groups.

Polychrest, Polychrestus (pol'-ik-rest', pol-ik-res'-tus)

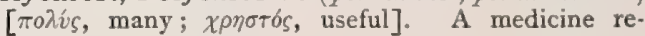


garded as efficacious in many diseases. A word employed in many combinations.

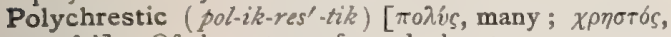
useful]. Of the nature of a polychrest.

Polychroism (pol-ik-ro'-izm) [ color]. A property possessed by certain crystals, of exhibiting two shades of color under polarized light, which vary as the polarizing instrument is rotated.

Polychroit (pol-ik-ro'-it). Siee Crocin.

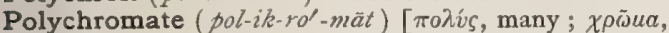
color]. A salt of chromic acid, containing several atoms of chromium in the molecule.

Polychromatic (pol-ik-ro-mat'-ik) [ $\pi 0 \lambda \dot{s} s$, many ; $\chi \rho \tilde{\omega}-$ $\mu a$, color]. Many-colored.

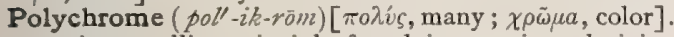
1. A crystalline principle found in quassia and giving rise in a watery solution to a variegated color. 2 . Esculin.

Polychromia ( $\left.p o l-i k-r o^{\prime}-m e-a h\right)$. See Pleiochromia.

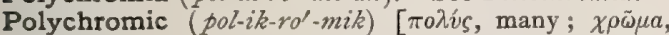
color]: Same as Polychromatic. P. Acid, an acid produced by the action of $\mathrm{HNO}_{3}$ upon aloes.

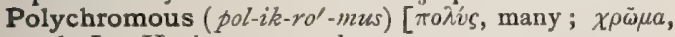
color]. Having many colors.

Polychylia $\left(p o l-i k-i^{\prime}-l e-a h\right) \quad[\pi o \lambda v s$, much; $\chi v \lambda o ́ s$, chyle]. An excessive formation of chyle.

Polychymia (pol-ik-i'-me-ah). Same as Polychylia.

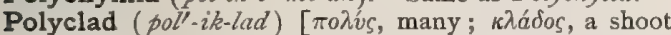
or branch]. In biology, applied to those platode worms in which the intestine is very much branched (marine Planaria).

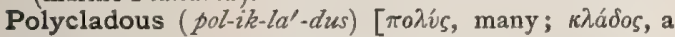
young slip]. In biology, many-branched.

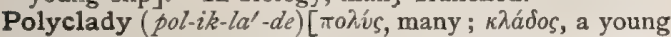
slip or shoot]. In biology, the production of an unusually large number of branches.

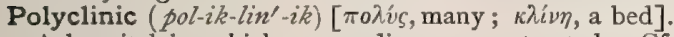
A hospital in which many diseases are treated. Cf. Policlinic.

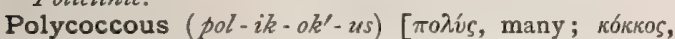
berry]. In biology, consisting of several cocci.

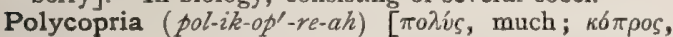
dung]. Excessive defecation.

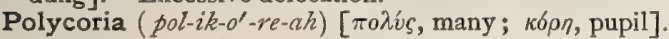
The existence of more than one pupil or opening in the iris.

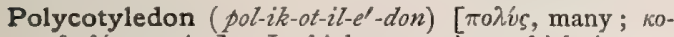
$\tau v \lambda \eta \delta \omega \nu$, cavity]. In biology, a plant which in embryo possesses more than two cotyledons.

Polycotyledonary ( $\left.p o l-i k-o t-i l-e^{\prime}-d o n-a-r e\right)[\pi o \lambda v s$, many; кот $\nu \lambda \eta \delta \omega \nu$, cavity]. In biology, applied to mammalian placentas having many tufts of fetal villi. See under Placenta.

Polycotyledonous ( $\left.p o l-i k-o t-i l-e^{\prime}-d o-n u s\right)$ [ $\pi 0 \lambda \dot{s} s$, many ; котvй $\delta \omega v$, a hollow]. Of, or pertaining to, a plant or a placenta having many cotyledons. See Placenta.

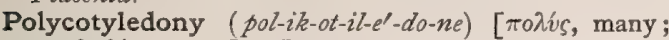
$\kappa \circ \tau \nu \lambda \eta \delta \omega \nu$, cavity]. In biology, an aberrant increase in the number of cotyledons.

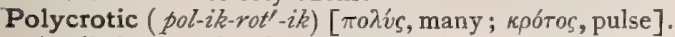
Applied to a pulse that appears to have more than two waves for each cardiac systole.

Polycruria ( $\left.p o l-i k-r u^{\prime}-r e-a h\right)$ [ $\pi \circ \lambda v_{s}$, many; crus, leg]. Having supernumerary legs, as certain monsters.

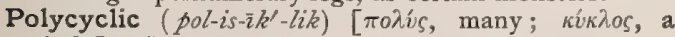
circle]. In biology, having many whorls.

Polycyesia, Polycyesis ( $\left.p \circ l-i s-i-e^{\prime}-z e-a h, p o l-i s-i-e^{\prime}-s i s\right)$

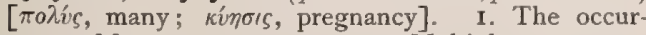
rence of frequent pregnancy. 2. Multiple pregnancy.

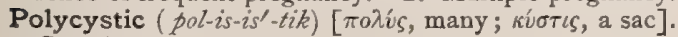
Containing many cysts.
Polycythemia (pol-is - i-the' - me - ah) [ $\pi 0 \lambda \hat{s} s$, many ; кútos, cell; aipa, blood]. Excess of red corpuscles in the blood.

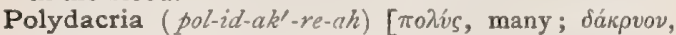
tear]. Excessive lacrymation.

Polydactyl, Polydactyle (pol-id-ak'-til) [ $\pi 0 \lambda \dot{s} s$, many ; $\delta a ́ \kappa \tau v \lambda o s$, a finger, a toe ]. In biology, an animal having supernumerary fingers and toes.

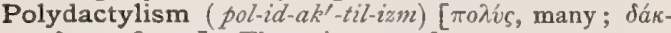
Tvhos, a finger]. The existence of one or more supernumerary fingers or toes. The condition is sometimes hereditary.

Polydactylous ( $p o l-i d-a k^{\prime}-t i l-u s$ ). Same as Polydactyl.

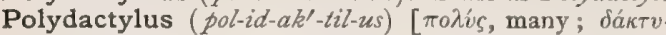
hos, finger]. A monster having supernumerary digits.

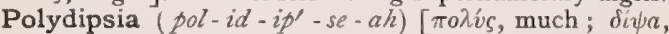
thirst]. Excessive thirst. It is usually present in fever and in diabetes. P. ebriora, dipsomania.

Polyembryonate, Polyembryonic (pol-e-em'-bre-on-

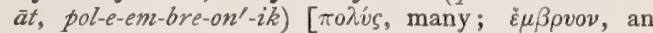
embryo]. In biology, pertaining to polyembryony; having several embryos.

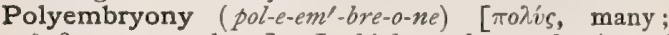
$\varepsilon \mu \beta \rho v o v$, an embryo]. In biology, the production of more than one embryo in a seed. Parthenogenesis occurs in most instances of polyembryony.

Polyemia, Polyæmia ( $\left.p o l-e-e^{\prime}-m e-a h\right)$ [ $[\pi 0 \lambda v ́ s$, much ; ai $\mu a$, blood]. Abnormal increase of the mass of the blood; plethora. After major amputations, with little loss of blood, there is a transient increase, relatively speaking, and this is called $\mathbf{P}$. apocoptica. $\mathbf{P}$. aquosa, a simple increase in the amount of water in the blood. P. hyperalbuminosa, an excess of albumin in the blood-plasma. P. polycythæmica, an increase of the red corpuscles. P. serosa, that condition in which the amount of blood-serum is increased.

Polyesthesia, Polyesthesis ( $p o l-e-e s-t h e^{\prime}-z e-a h$, pol-e-

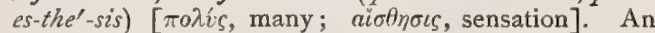
abnormality of sensation in which a single touch is felt as two or more.

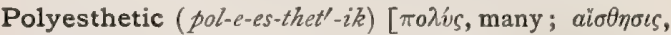
sensation]. Pertaining to polyesthesia.

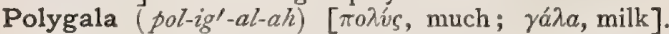
A genus of herbaceous or shrubby plants of some 260 species. P. senega, of N. America, is therapeutically the most important. See Senega.

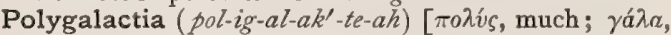
milk]. The excessive secretion of milk. See Galactorrhea.

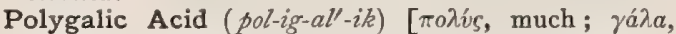
milk], $\mathrm{C}_{32} \mathrm{H}_{54} \mathrm{O}_{18}$. A glucosid extracted from Polygala senega. It is probably the same as saponin.

Polygalin (pol-ig'-al-in). See Senega.

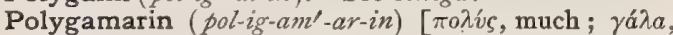
milk; amanum, bitter]. A crystalline bitter principle obtained from Polygala amara.

Polygamia ( $\left.p o l-i g-a^{\prime}-m e-a h\right)$ [ $\pi \circ \lambda \hat{v} \gamma a \mu o s$, polygamous]. A class of plants bearing both hermaphrodite flowers and those with the sexes separated.

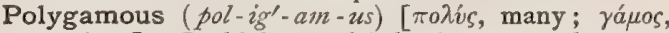
marriage]. In biology: $(a)$ having more than one mate of the opposite sex; cf. Polyandrous, Polygynous; (b) producing perfect flowers, together with staminate or pistillate flowers, on the same plant or species.

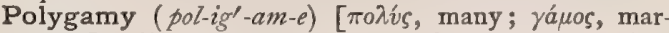
riage]. The state or practice of having more than one wife or husband.

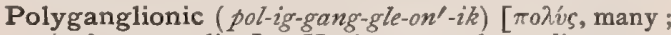

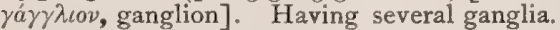

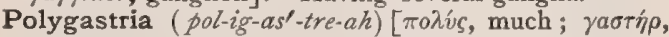
stomach]. Excessive production of gastric juice. 


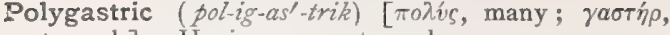
stomach]. Having many stomachs.

Polygastrulation ( $\left.p o l-i g-a s-t r u-l a^{\prime}-s h u n\right)$ [ $\pi o \lambda v s$,

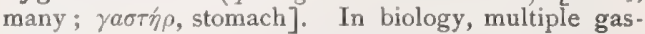
trulation.

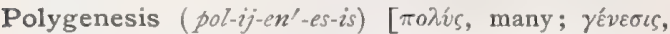
origin]. In biology, the doctrine that organisms may arise from cells of different kinds.

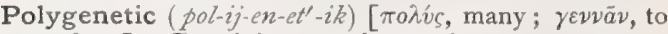
produce]. Pertaining to polygenesis.

Polygenism, Polygeny (pol'-ij-en-izm, pol'-ij-en-e)

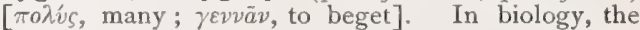
theory that the different races of man are descended from distinct species. The independent origin of the human races, Cf. Monogeny.

Polyglottides (pol-ig-lot'-id-ez). See Alternations of Generation.

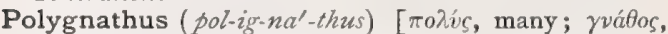
jaw]. A form of double monster in which the parasite is attached to the jaws of the host. It includes epignathus and hypognathus.

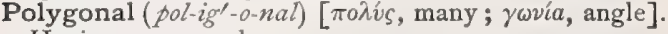
Having many angles.

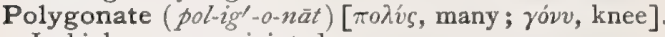
In biology, many-jointed.

Polygonatum (pol-ig-o-na'-tum). See Solomon's Seal.

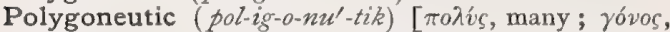
offspring]. In biology, having several broods during the year.

Polygoneutism (pol-ig-o-nu'-tizm) [ $\pi 0 \lambda i ́ s$, many; róvos, offspring]. In biology, the state of being polygoneutic.

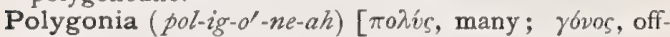
spring]. Great fecundity, especially of the male.

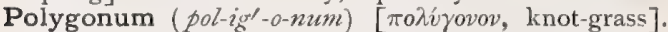
A genus of polygonaceous plants. P. hydropiperoides, Smart Weed, Water Pepper, is a plant common in the United States. Its active principle is thought to be polygonic acid. It stimulates the action of the heart and increases arterial tension. It is diuretic, emmenagogue, and aphrodisiac. Externally, it is a rubefacient and vesicant. It is valuable in amenorrhea and impotence. Dose of the ext. gr. $\mathrm{j}-\mathrm{v}$; of the fid. ext. $m x-3 j$. All unof.

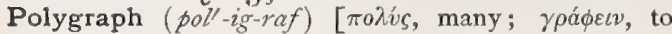
record]. A cylindric recording-instrument for multiplying sphygmographic tracings. It is made to rotate upon its axis by clockwork.

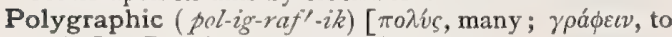
write]. Pertaining to the polygraph.

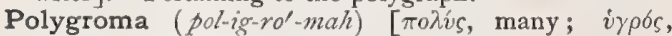
moist; $b ّ \alpha \alpha$, tumor]. A large hygroma.

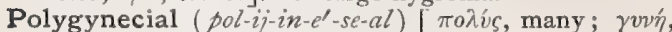
female; oikos, house]. In biology, containing the pistils or gynecia of several flowers, as a collective fruit.

Polygynous (pol-ij'-in-us) [ $\pi 0 \hat{n} v s$, many; $\gamma v v \dot{\eta}, \mathrm{fe}-$ male, wife]. In biology : (a) possessing many pistils; (b) having more than one wife or female mate.

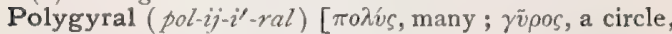
ring]. In biology, having several whorls.

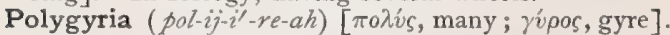
Having many gyres.

Polyhemia (pol-e-hem'-e-ah). See Polvemia.

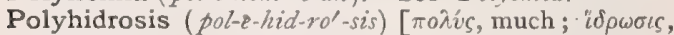
sweating]. Excessive perspiration.

Polyhydramnios (pol-e-hi-dram'-ne-os) [ $\pi 0 \lambda \dot{v} s$, many;

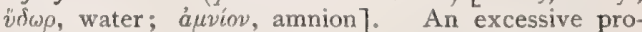
duction of the amniotic liquor.

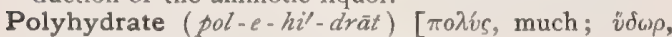
water]. A hydrate containing more than one hydroxyl group.

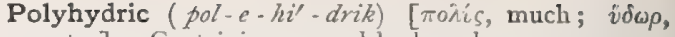
water]. Containing several hydroxyl groups.

Polyidrosis (pol-e-id-ro'sis). Same as Polyhidrosis.

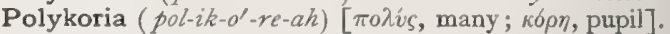
Multiplicity of pupils of the eye.

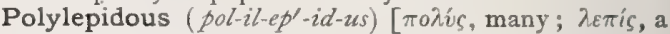
scale]. In biology, having many scales.

Polyleukocythemia (pol-il-u-ko-si-the'-me-ah). Same as Leukocythemia.

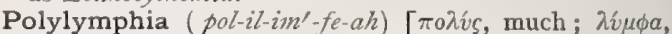
lymph]. Synonym of Anasarca.

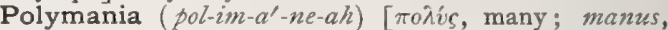
hand]. The condition of having more than two hands; polychiria.

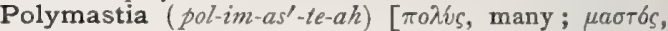
breast]. The presence in the same person of more than two breasts or nipples. The supernumerary organs may be below the breast proper, in the axilla, or elsewhere about the body. The condition is seen in both sexes.

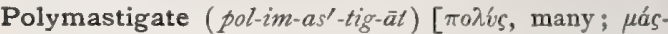
$\tau \iota \xi(\mu a \sigma \tau l \gamma-)$, a whip]. In biology, having several flagella.

Polymastigous (pol-im-as'-tig-us). Same as Polymastigate.

Polymastodont (pol-im-as'-to-dont) [ $\pi 0 \lambda v ́ s$, many ;

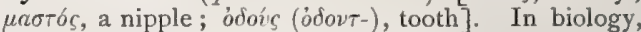
having numerous tubercles on the molar teeth.

Polymazia (pol-im-a'-ze-ah). Synonym of Polymastia.

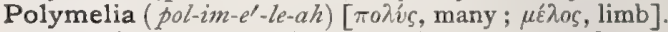
A malformation consisting in the presence of more than the normal number of limbs.

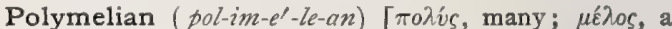
limb]. Having supernumerary limbs.

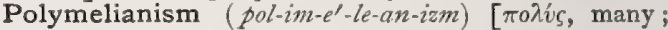
$\mu \varepsilon \hat{\lambda} \circ$ s, a limb]. In biology, having supernumerary limbs.

Polymelius, Polymelus (pol-im-e'-le-us, pol-im'-el-us)

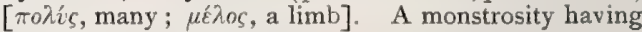
more than the normal number of limbs.

Polymely (pol-im'-el-e). Synonym of Polymelus.

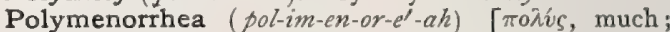
$\mu \tilde{\eta} \nu$, month; poia, a flow]. Excessive menstrua] flow.

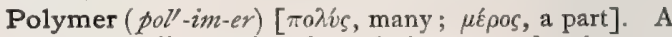
term usually employed to designate a chemic compound, the formula of which is a multiple of that of the lowest compound of a chemic series.

Polymeria (pol-im-e'-re-ah). See Polymerism.

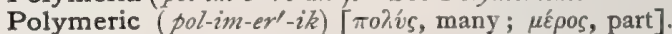
Exhibiting polymerism.

Polymerid (pol-im'-er-id). Synonym of Polymer.

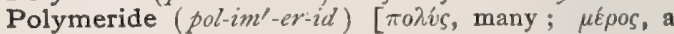
part]. In chemistry, a compound having the properties of polymerism.

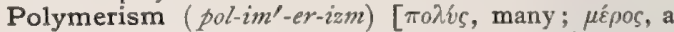
part]. I. The existence of more than a normal number of parts. 2. A variety of isomerism dependent upon a difference in molecular weight. The compounds presenting it have a formula that is a multiple of that of the lowest compound of the respective series.

Polymerization (pol-im-er-iz- $a^{\prime}-s h u n$ ) [ $\mu \varepsilon \hat{\varepsilon} \rho \circ$, a part]. The apparent fusion or union of two or more molecules of a compound, forming a more complex molecule, with a higher molecular weight and somewhat different physical and chemic properties.

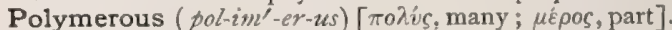
In biology, having many parts or organs in a given arrangement or structure.

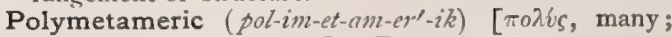
$\mu \varepsilon \tau a ́$, beside; $\mu \varepsilon \hat{\varepsilon} \rho \varsigma$, part]. Extending over.or comprising two or more metameres. 


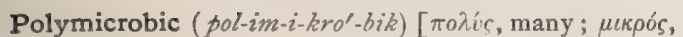
small; ßios, life]. Containing many kinds of microörganisms.

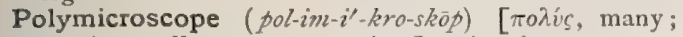

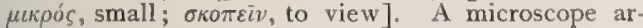
ranged on the principle of the revolving stereoscope.

Polymicrotome (pol-im-i $\left.i^{\prime}-k r o-t o m\right)$ [ $\pi 0 \lambda$ us, many; $\mu \iota \kappa \rho o ́ s$, small ; $\tau \hat{\varepsilon} \mu \nu \varepsilon \iota \nu$, to cut]. An instrument making many microscopic sections in a short time.

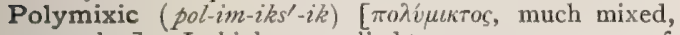
complex]. In biology, applied to groups or masses of materials or organisms, consisting of many species and classes; the opposite of monotonic, $q . v$.

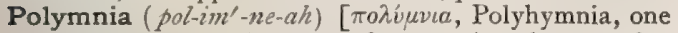
of the Muses]. A genus of composite plants. See Bear's Foot.

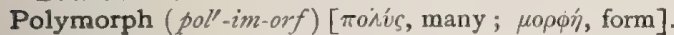
In biology, a variant form or type.

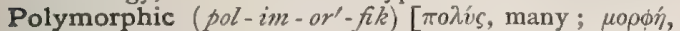
form]. Having, or existing in, many forms. In crystallography, applied to any substance that crystallizes in more than one form. P. Cells of Carcinoma, the peculiarly-shaped cells found in the center of cancernests. Their modified form is due to pressure. The cells were formerly considered diagnostic of carcinoma, but are no longer so.

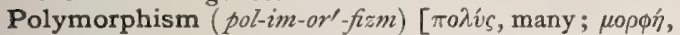
form]. In biology, the exhibition of physiologic or morphologic dissimilarity among members of a given group. Sexual dimorphism, trimorphism, or polymorphism is of frequent occurrence in the animal kingdom; it may be permanent, or temporary and seasonal. P., Colonial, arises in consequence of a division of labor among the individuals of a colony.

Polymorpho-cellular ( $p o l-i m-o r^{\prime}-f o-s e l^{\prime}-u$-lar) [ $\pi v \lambda u ́ s$, many; $\mu \rho \rho \phi \eta ́$, form; cellula, cell]. Having cells of many forms.

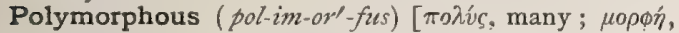
form]. In biology, exhibiting variations in form, either at different stages of individual development, or among the members of a group.

Polymorphy (pol'-im-or-fe). Same as Polymorphism. Polymyositis (pol-im-i-o-si'-tis) [ $\pi 0 \lambda \hat{v} s$, many; $\mu \tilde{v} s$, muscle; $\iota \tau \iota$, inflammation ]. A disease of the muscles characterized by pain, tension, deformity, prostration, edema, sweats, insomnia. The extensor muscles are preferably involved; the diaphragm, larynx, tongue, and pharynx are exempt in mild cases. The spleen is enlarged. The disease is generally fatal. The lesion consists in an actual inflammation-the muscle-fibers present all stages of degeneration, and the interstitial tissue is the seat of a marked roundcell infiltration. P., Acute Progressive, an acute form in which, in a short time nearly all the muscles are involved. It usually ends fatally. P., Parenchy matous, Puerperal. Synonym of P., Puerperal. P., Puerperal, polymyositis occurring during the puerperium.

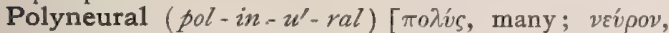
nerve]. Supplied or innervated by several nerves.

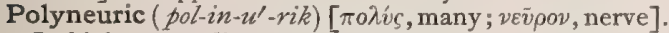
In biology, applied to a nerve-cell possessing several processes (or neurons) which go to form the axis-cylinder of a nerve-fiber, as distinguished from a mononeuric or dineuric cell.

Polyneuritis (pol-in-u-ri'-tis). See Neuritis, Multiple. P. potatorum; Psendo-tabes; alcoholic neuritis; ataxia of drunkards; a chronic form of neuritis following the immoderate use of alcoholic stimulants. It appears in two distinct varieties, the paralytic and the ataxic. It is characterized by pain in the lower extremities, ataxia, areas of anesthesia, loss of the deep and at times of the superficial reflexes; later paraly. sis and atrophy, chiefly of the extensors of the fingers and toes. See Neuritis, Multiple.

Polynomial (pol-in-o'-me-al) [ $\pi \circ \lambda v_{s}$, many; nomen, name ]. In biology, denoting a method of nomenclature in which the technical names of species are not confined to two terms, the generic and the specific.

Polynuclear (pol-in-u'-kle-ar) [ $\pi \circ \lambda u s$, many; nucleus, nucleus]. In biology, having several nuclei; applied to cells in which the nucleus is either lobed or com. posed of several portions united by such delicate nuclear filaments as to give the impression of a multi nucleated cell in distinction from a mononuclear cell.

Polynucleate (pol-in-u'-kle-ät). Synonym of Multinuclear.

Polyodont (pol'-e-o-dont) [ [oגús, many ; ódoús, tooth]. In biology, having many teeth; multidentate.

Polyodontia (pol-e-o-don'-she-ah) [ $\pi 0 \lambda u ́ s$, many; ódoús, tooth]. The presence of supernumerary teeth.

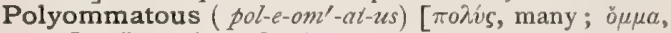
eye]. In biology, having many eyes.

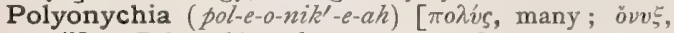
nail]. Polonychia; the presence of supernumerary nails.

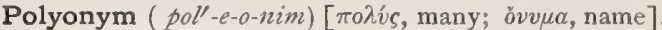
In biology, possessing a technical name composed of several terms, such as levator anguli oris; iter a tertio ad quartum ventriculum, etc.

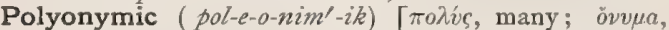
name]. In biology, consisting of more than two terms.

Polyophthalmia (pol-e-off-thal'-me-ah) [ $\pi 0 \lambda$ ís, many; o $\phi \theta a \lambda \mu o ́ s$, eye]. A monstrosity possessing supernumerary eyes.

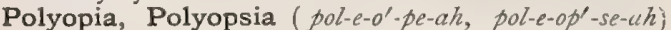

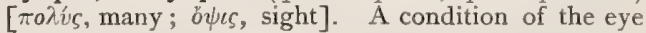
wherein more than one image of an object is formed upon the retina. P. monophthalmica, the phenomenon of multiple vision with a single eye.

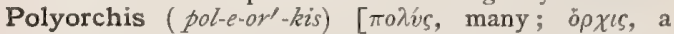
testicle]. One who has more than two testicles.

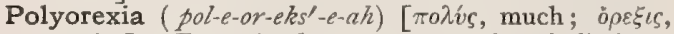
appetite]. Excessive hunger, or appetite; bulimia.

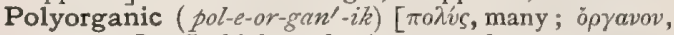
an organ]. In biology, having several organs.

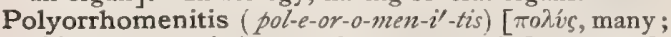
ó $\rho ́ o s$, serum; $\hat{v} \mu \dot{\eta} v$, membrane; $\iota \tau \iota s$, inflammation]. Concato's Disease; a symptom-group defined by Concato as "a phthisis of serous membranes." The patients are said to suffer from a progressive and malignant inflammation of various serous membranes, the disease finally assuming the aspect of a severe type of pneumonia. The post-mortem findings are mainly those of "dry pleurisy."

Polyorrhymenitis (pol-e-or-i-men-i'-tis). Synonym of Polyorrhomenitis.

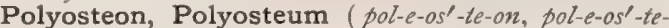

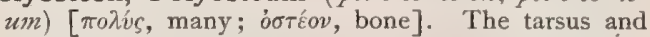
metatarsus. [Old.]

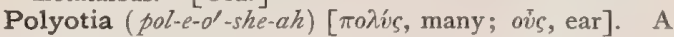
condition of malformation in which there is more than one auricle on a side.

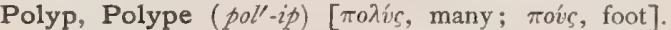
In biology, the name given by Reaumur to the freshwater hydra ( $H y d r a$ viridis) and allied animals, "The word is used ambiguously by writers, being often employed to designate the entire composite fabric, the aggregate result of gemmation [in the Hydrozoa], while at other times it is intended to indicate each of those organisms which, almost always furnished, with a mouth and tentacles, are developed upon varions points of a common living basis, and are eminently 
characteristic of the zoöphytic form." (Allman.) See Polypus. P.-colony, a colony of polyps. P.-stem, a polyp-stock. P.-stock, in biology, a polypary, or polypidom.

Polypanarthritis (pol-ip-an-ar-thri'-tis). Synonym of Arthritis deformans.

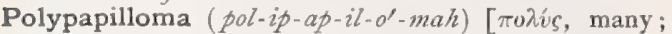
papilla, papilla; ó $\mu a$, tumor: pl., Polypapillomata]. A disease of the skin characterized by the formation of multiple papillomata. P. tropicum. Same as Yazes.

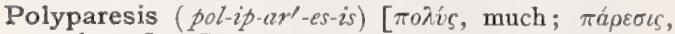
weakness]. General progressive paralysis of the in sane, or paralytic dementia.

Polyparium (pol-ip-a'-re-um). Same as Polypary.

Polyparous ( $p o l-i p^{\prime}-a r-u s$ ). Same as Multiparous.

Polypary (pol'-ip-a-re) [polypus, a polyp, or manyfooted animal]. In biology, "The term polypary has been used with just as little precision as polyp, being sometimes employed to express the common connecting basis-conosarc of a polyp-stock-and at other times being applied exclusively to the solid protective structures, whether forming for the zoöphyte an external covering or constituting an internal axis; the ambiguity which then results will be got rid of by using the word cœnosarc as here defined, and restricting the term polypary to the solid protective structures of the zoöphyte." (Allman).

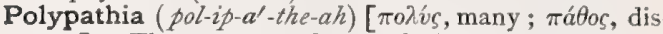
ease]. The presence of several diseases at one time, or the frequent recurrence of disease.

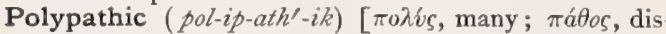
ease]. Pertaining to polypathia; affected with several diseases at once.

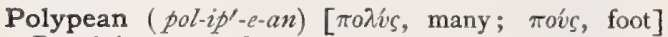
Pertaining to a polyp.

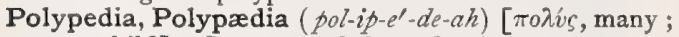

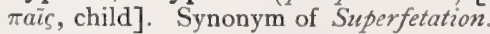

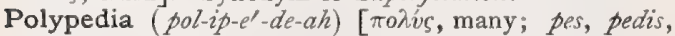
foot]. Synonym of Polypodia.

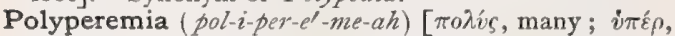
in excess; $\alpha^{i} \mu \alpha$, blood]. Plethora.

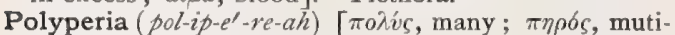
lated]. Congenital malformation of many organs or parts.

Polyperythrin (pol-ip-er'-ith-rin) [ $\pi 0 \lambda v \pi o v s$, a polyp ;

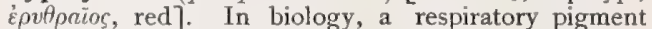
found by Moseley in various Calenterate; it is identical with the hematoporphyrin of MacMunn. See Pigments, Conspectus of.

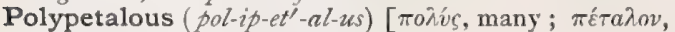
leaf]. In biology, having several distinct petals; apopetalous, as opposed to gamopetalous, $q . v$.

Polyphagia ( $\left.p o l-i f-a^{\prime}-j e-a h\right)$. Synonym of Bulimia.

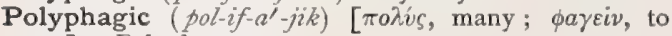
eat]. Polyphagous.

Polyphagous (pol-if'-a-gus). Synonym of Omnivorous.

Polyphagy ( $\left.p o l-i f^{\prime}-a j-e\right)$ [ $\pi \circ \lambda v \phi a ́ \gamma o s$. eating too much]. The habit of living on various kinds of food.

Polypharmacon, Polypharmacum (pol-if-ar'-mak-on,

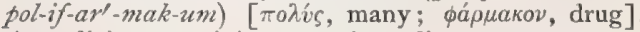
A medicine containing many ingredients; a panacea.

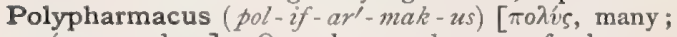
фа́рцакор, drug]. One who uses drugs too freely.

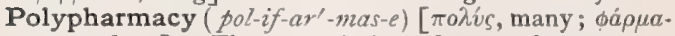
$\kappa o \nu$, a drug]. The prescription of many drugs at one time; the too free use of drugs.

Polyphemous ( $\left.p o l-i f-e^{\prime}-m u s\right)$ [ $\pi 0 \lambda i s$, many ; $\phi \eta \mu \eta$, voice]. One-eyed; cyclopean.

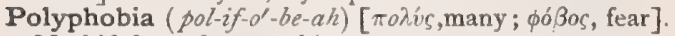
Morbid fear of many things.

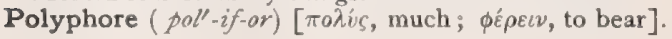

In biology, a common carrier or receptacle, as of many distinct carpels, e. $g_{-}$, the strawberry.

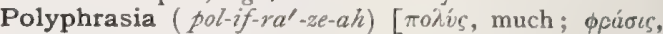
speech]. Morbid excess of speech; insane volubility; verbigeration.

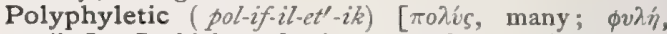
tribe]. In biology, having several lines of descent; of or pertaining to the doctrine of polygenesis, or special creation.

Polyphylline, Polyphyllous (pol-if-il'-in, pol-if-il'-us)

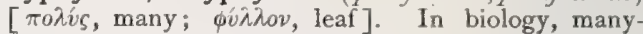
leaved. Applied to the calyx or corolla, and also to the leaflets of compound leaves.

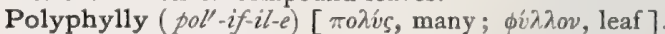
In biology, an abnormal increase of the number of organs in a whorl.

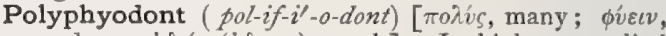
produce; ódovis (ojovt-), tooth]. In biology, applied to animals, as the shark, in which tooth-germs are produced throughout life, and replacement of lost teeth continues indefinitely; opposed to monophyodont and diphyodont.

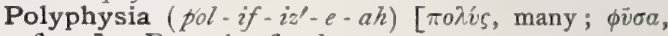
flatus]. Excessive flatulence.

Polypiarium (pol-ip-i-a'-re-um). Same as Polypary.

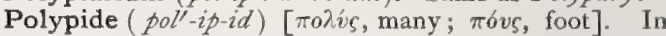
biology, the zoöid, consisting of alimentary canal, with tentacles, nervous ganglion, etc., which is developed within the zoècium of Polyzoa; the polype of older writers and bryozoid of Reichert.

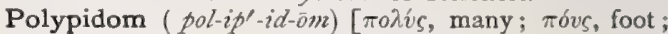
$\delta \delta \mu o s$, house]. In biology, the aggregate of persons in a coelenterate colony; a polyp-stock.

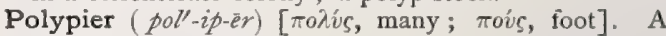
polypide; a polypidom.

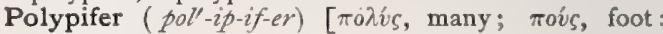
$\phi \varepsilon ́ p \varepsilon \imath v$, to bear]. In biology, a polyp-stock.

Polypiferous (pol-ip-if'-er-us) [polypus, polyp; ferre, to bear]. Bearing or giving origin to a polypus.

Polypiform (poll-ip-if-orm) [ polypus, polyp; forma, form ]. Having the form of a polyp.

Polypigerous (pol-ip-ij'-er-us). Same as Polypiferous.

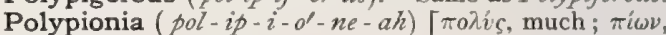
fat]. An excessive deposit of fat in the subcutaneous connective tissue.

Polypiosis (pol-ip-i-o'-sis) [ $\pi 0 \lambda i s$, much; $\pi i \omega v$, fat $]$. Obesity.

Polypiparous (pol-ip-ip'-ar-us). Same as Polypiferous.

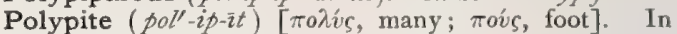
biology, an individual zoöid, or person, of the Hydrozoa or Actinozoa, whether separate or one of a colony.

Polypitrite (pol-ip'-it-rit). See Polypotrite.

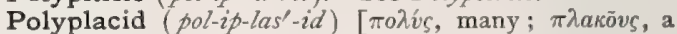
flat cake]. In biology, bearing more than one madreporic body, as distinguished from Monoplacid.

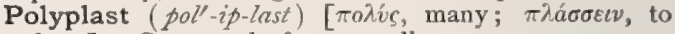
form ]. Composed of many cells.

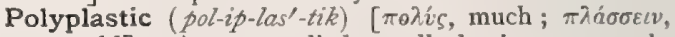
to mold]. A term applied to cells having many substances (more than two) in their composition; also to cells that undergo many modifications during their transformation into tissues.

Polyplastid (pol-ip-las'-tid). See Monoplastid.

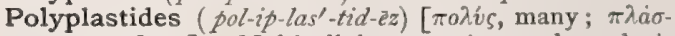
$\sigma \varepsilon \iota \nu$, to form ]. Multicellular organisms; the substi tute proposed by Götte for Metazoa.

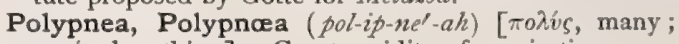
$\pi$ voia, breathing]. Great rapidity of respiration.

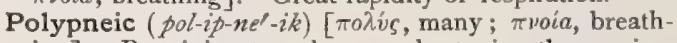
ing]. Pertaining to polypnea; hastening the respiration. P. Center, a center the stimulation of which 
tends to quicken the respiratory movements. Such a center is said to exist in the brain between the striatum and the thalamus.

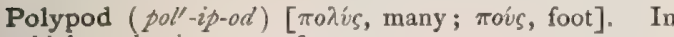
biology, having many feet.

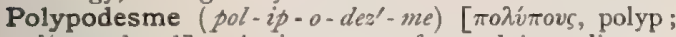
$\delta \varepsilon ́ \sigma \mu o \zeta$, bond]. An instrument for applying a ligature to the pedicle of a polypus.

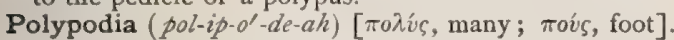
A monstrosity possessing supernumerary feet.

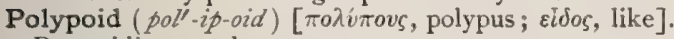
Resembling a polypus.

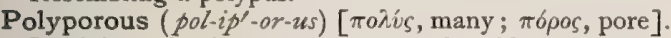
In biology, having many pores; ethmoid.

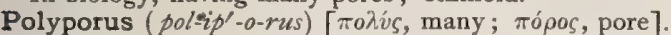
A genus of hymenomycetous Fungi represented by many species. P. fomentarius, Amadou; German Tinder: Moxa; a species parasitic on trees, especially the birch. It is a source of amadou.

Polyposia, Polyposis ( $p o l-i p-o^{\prime}-z e-a h$, pol-ip-o'-sis)

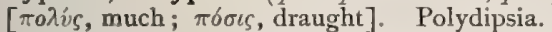

Polypostem (pol'-ip-o-stem). Same as Polypstem.

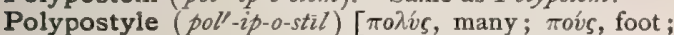

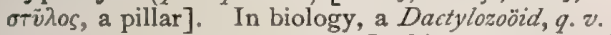

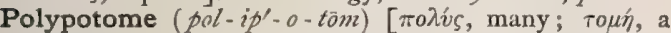
cutting]. An instrument for the excision of polypi.

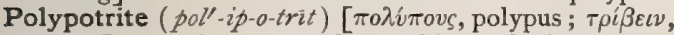
to rub]. An instrument for crushing polypi.

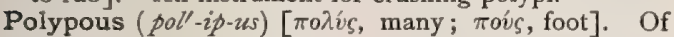
the nature of a polyp.

Polyprite (pol'-ip-rit) [polpyus, a polyp]. In biology, the manubrium of a medusa.

Polyptome ( $p o l^{\prime}$-ip-töm). Synonym of Polypotome.

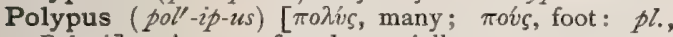
Polypi]. A tumor found especially on mucous membranes, as in the nose, bladder, rectum, uterus, etc. and growing from the surface. The majority of polypi are not true tumors, but inflammatory hyperplasias. $\mathbf{P}$., Blood. Synonym of P., Placental. P., Carcinomatous, a polyp which is carcinomatous in character. P. carnosus. Synonym of Sarcoma. P., Fibrinous, a polypoid mass on the uterine wall, resulting from the deposition of fibrin from retained blood. The mass may be attached to portions of an ovum or to thrombi at the placental site. P., Fibrous, P., Fleshy, a polypus composed of fibrous tissue chiefly, and common in the intestines and uterus. P., Follicular, one containing many small mucous glands. P., Gelatinous. Synonym of P., Mucous. P., Glandular: 1. A term given by Thomas to a polypus consisting of enlarged mucous glands of the cervix uteri. 2. Adenoma. P. of the Heart, a fibrinous heart-clot. [Old. ] P., Lardaceous, one that has undergone lardaceous, or amyloid, degeneration. P., Lipomatous, a pedunculated lipoma. P., Malignant, a malignant tumor, usually carcinoma, having a polypoid appearance. P. mamillæ, the nipple. P., Mucous, a soft polypus containing mucoid tissue. P., Myomatous, one consisting largely of unstriped muscle-tissue. P., Osseous, one containing bony tissue. P., Placental, a fibrinous polyp resulting from the deposit of fibrin upon a portion of placenta retained after parturition. P., Raspberry Cellular, the most common variety of aural polypus, consisting of many small, raspberry-like masses, attached to a central stem which forms the pedicle. P., Sarcomatous, a sarcoma of polypoid form. P., Scirrhous, a dense carcinomatous polypus. P., Soft. Synonym of $P$., Mucous. P., Spongy. Synonym of P., Mucous. P., Stony, one the seat of calcareous infiltration. P., Tooth, a polyp developed from the pulp of a carious tooth. P., Vascular, a polypoid angioma.
Polyrhizal (pol-ir-i'-zal). Same as Polyrhizous.

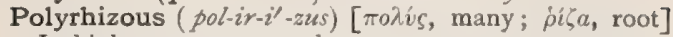
In biology, many-rooted.

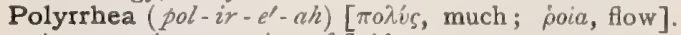
An excessive secretion of fluid.

Polysaccharides (pol-is-ak-arl-id-ez). See Carbohydrates.

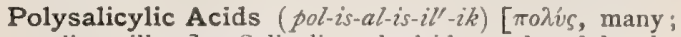
salix, willow]. Salicylic anhydrids produced by the action of phosphoric oxychlorid on sodium salicylate.

Polysarcia ( $\left.p o l-i s-a r^{\prime}-k e-a h\right)$ [ $\pi 0 \lambda v i s$, much; $\sigma a ́ \rho \xi$, flesh]. Excessive corpulency; obesity. P. cordis, Synonym of Cor adiposum.

Polysarcosis $\left(p o l-i s=a r-k o^{\prime}-s i s\right)$. Synonym of Polysarcia.

Polysarcous ( $\left.p o l-i s-a r^{\prime}-k u s\right)[\pi o \lambda v s$, much; $\sigma a ́ \rho \xi$, flesh]. Corpulent; exhibiting polysarcia.

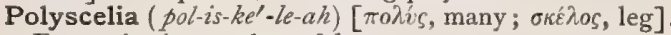
Excess in the number of legs.

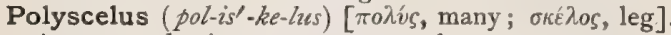
A monster having supernumerary legs.

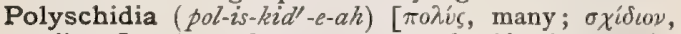
splinter]. A tendency to carry classification to excess.

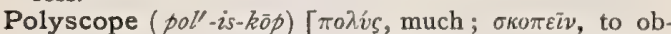
serve]. An instrument for examining the cavities of the body by illuminating them. P., Electric, an instrument provided with an electric light which is introduced into a hollow viscus in order to illuminate its internal surfaces. The walls of the organ are protected from the effects of the heat by the presence of water.

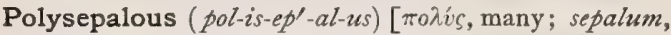
sepal]. Having several or many distinct sepals.

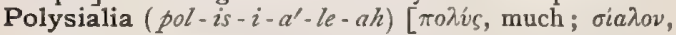
spittle]. Excessive flow of saliva.

Polysiphonous (pol-is-i'-fon-us) [ $\pi 0 \lambda \dot{v} s$, many ; $\sigma i \phi \omega \nu$, tube]. In biology, having many siphons.

Polysolve (pol'-is-olv). See Sulphoricineolic Acid.

Polysomatia ( $\left.p o l-i s-o-m a^{\prime}-s h e-a h\right)$. Synonym of Polysarcia.

Polysomatic ( $\left.p o l-i s-o-m a t^{\prime}-i k\right)[\pi o \lambda v s$, many; $\sigma \hat{\omega} \mu a$, body]. Consisting of an aggregation of grains.

Polysomia (pol-is-o'-me-ah) [ $\pi \alpha \lambda \hat{s} s$, many; $\sigma \bar{\omega} \mu a$, body]. A type of monstrosity having more than a single body or trunk.

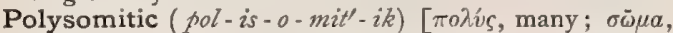
body]. In biology, made up of a number of distinct somites.

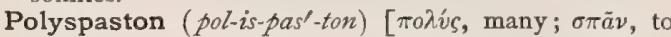
draw]. A pulley used for the reduction of dislocations.

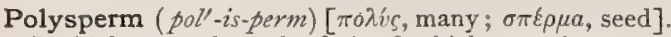
In biology, a plant the fruit of which contains many seeds.

Polyspermal (pol-is-per'-mal). Same as Polyspermous.

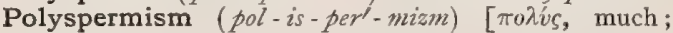
$\sigma \pi \varepsilon \rho \mu a$, seed]. The secretion and discharge of an excessive quantity of seminal fluid.

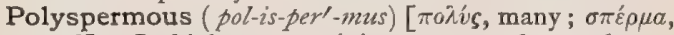
seed]. In biology, containing many seeds, as a berry. Cf. Pleiospermozs.

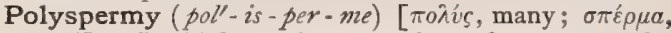
seed]. In biology, impregnation of an ovum by several spermatozoids.

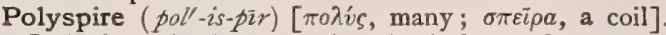
In biology, having a continued spiral growth.

Polysporangium (pol-is-po-ran'-je-um) [ $\pi 0 \lambda$ v́s, many ; $\sigma \pi \delta \rho_{0}$, spore]. In biology, a sporangium containing many spores.

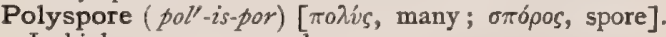
In biology, a compound spore. 
Polyspored ( $\left.p \circ l^{\prime}-i s-p o r d\right)$ [ $\pi 0 \lambda v ́ s$, many; $\sigma \pi o ́ p o s$, spore] In biology, containing or producing many spores.

Polysporic (pol-is-por'-ik). Same as Polysporous.

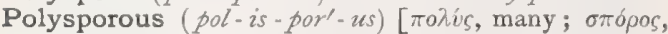
spore]. In biology, producing many spores.

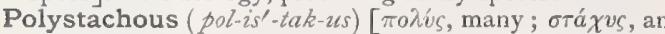
ear of corn, a spike]. In biology, having many spikes.

Polystemonous (pol-is-tem'-o-nus) [ $\pi 0 \lambda \dot{v} \zeta$, many; $\sigma \tau \dot{\eta}$ $\mu \omega \nu$, wasp (stamen) ]. In biology, having many more stamens than petals. Cf. Isostemonous, Polyandrous.

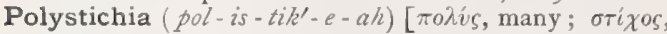
row]. A condition in which the eye-lashes are arranged in two or more rows

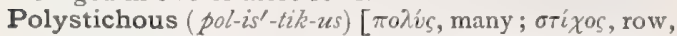
line]. In biology, arranged in many rows. Cf. Monostichous, Distichous.

Polystigmous (pol-is-tig'-mzes) [ $\pi 0 \lambda v ́ s$, many ; $\sigma \tau i \gamma \mu a$, mark]. In biology, applied to flowers that present many stigmas, from being polycarpellary.

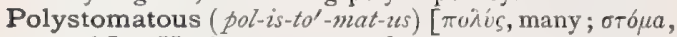
mouth]. Having many mouths or apertures.

Polystylous ( $\left.p o l-i s-t i^{\prime}-l u s\right)$ [ $\pi o \lambda v s$, many; $\sigma \tau \bar{v} \lambda o s$, column ]. In biology, having several styles.

Polysulphid, Polysulphuret ( $p \circ$-is-ul'-fid, pol-is-ul'

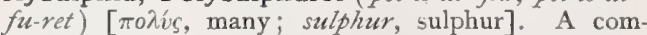
pound of an element or radicle with one or more molecules of sulphur.

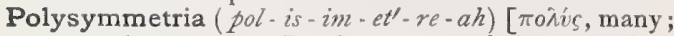

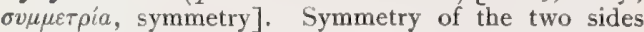
of the body at two or more points.

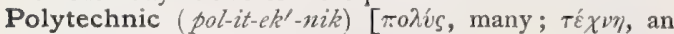
art]. Comprising many arts.

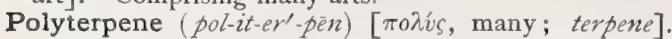
In chemistry, one of a class of substances polymeric with the terpenes. Caoutchouc, gutta-percha, and dammar-resin are polyterpenes.

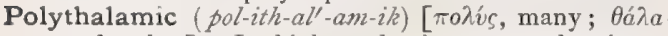
pos, chamber]. In biology, having many chambers; thalamophorous.

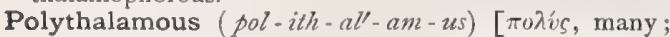
$\theta a ́ \lambda a \mu o s$, chamber]. In biology, having several chambers or compartments; multilocular.

Polythecial ( $\left.p o l-i t h-e^{\prime}-s e-a l\right)$ [ $\pi o \lambda v s$, many; $\theta \dot{k} \kappa \eta$, case]. In biology, forming or pertaining to a polythecium.

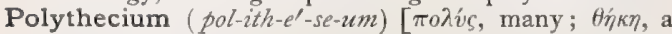
box: pl., Polythecia ]. In biology, a compound zoöthecium.

Polythelia, Polythelism (pol-ith-e'-le-ah, pol'-ith-el$i z m)[\pi 0 \lambda \hat{s}$, many; $\theta \eta \lambda \dot{\eta}$, nipple]. The presence of supernumerary nipples.

Polytocia (pol-it-o'-se-ah). Synonym of Fecundity.

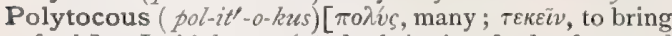
forth]. In biology : $(a)$ the bringing forth of several young at a birth; $(b)$ producing fruit year after year.

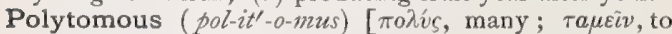
cut]. In biology, applied to leaves which are divided into numerous parts, not true leaflets, or to stems repeatedly forked.

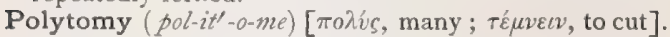
In biology, division into several parts.

Polytrichia, Polytrichosis (pol-it-rik'-e-ah, pol-it-rik$\left.o^{\prime}-s i s\right)[\pi o \lambda i s$, many; $\theta \rho i \xi$, hair $]$. Excessive development of hair.

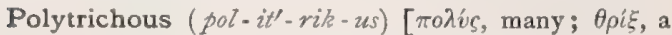
hair]. In biology, bearing numerous hairs or cilia.

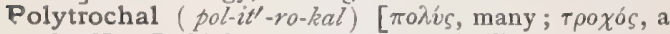
wheel]. In biology, having several ciliated zones, as certain embiyos. Cf. Mesotrochal, Telotrochal.

Polytrochous (pol-it-ro'-kus). Same as Polytrochal.

Polytrophia, Polytrophy (pol-it-ro' $\left.-f e-a h, p o l^{\prime}-i t-r o-f e\right)$

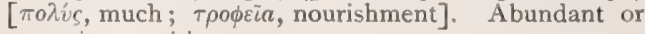
excessive nutrition.

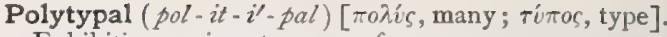
Exhibiting various types, or forms.

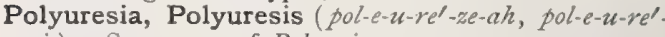
sis). Synonyms of Polyuria.

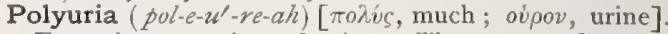
Excessive secretion of urine. The causes of temporary polyuria are, excessive ingestion of fluids, cold, suppression of perspiration, the use of diuretics; it occurs in the crisis of fevers, and in certain neurotic conditions, as hysteria, and in nervous excitement. A permanent polyuria is met with in diabetes mellitus, diabetes insipidus, chronic interstitial nephritis, and in amyloid disease of the kidneys.

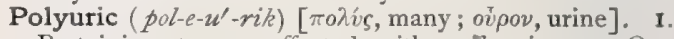
Pertaining to, or affected with, polyuria. 2. One affected with polyuria.

Polyvalent (pol-iv'-al-ent). Synonym of Multivalent.

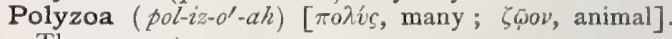
The sea-mats, or sea-mosses.

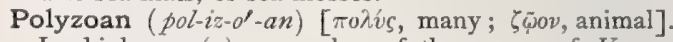
In biology: $(a)$ a member of the group of Vermes more properly termed Bryozoa, which are developed in variously-shaped attached stocks; $(b)$ one of the segmented tape-worms or cestode stocks arising by strobilation.

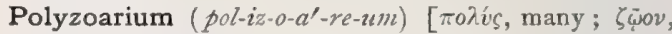
an animal : pl., Polyzoaria $]$. Same as Zoarium.

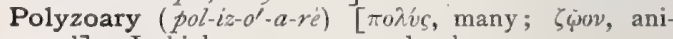
mal]. In biology, a compound polyzoan.

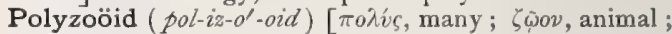

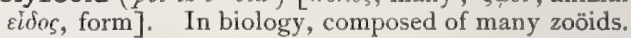

Poma $\left(p o^{\prime}-m a h\right)[\pi \tilde{\omega} \mu a$, lid, cover : pl., Pomata]. The name applied to the so-called occipital operculum of the brain of the monkey.

Pomaceous (po-ma'-se-us) [pomum, apple]. Pertaining to the apple, or to fruits like the apple.

Pomade ( $\left.p o^{\prime}-m a \tilde{d}\right)$ [pomum, apple]. Any perfumed ointment or preparation for inunction of the scalp or other parts. P., Putz, a proprietary preparation used to burnish metal.

Pomander (po-man'-der) [pomum, apple]. A ball composed of aromatics, formerly carried about the person to prevent infection; also, the globular case in which the same was kept.

Pomarine (pom'-ar-in). See Pomatorhine.

Pomatic $\left(p o-m a t^{\prime}-i k\right)[\pi \tilde{\omega} \mu a$, lid]. Pertaining to the poma.

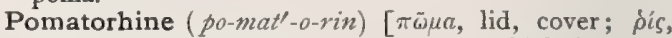
nose]. In biology, applied to birds which have an operculum over the nostrils.

Pomatum ( $\left.p o-m a^{\prime}-t u m\right)$. Same as Pomade.

Pome (pōm) [pomum, fruit]. In biology, a fleshy fruit like the apple, which is syncarpous, succulent, and whose bulk is made up chiefly of enlarged and adherent calyx.

Pomegranate (pom'-gran-et). See Granalum.

Pomiferous (po-mif'-er-us) [ pomum, fruit; ferre, to bear]. Pome-bearing.

Pomiform ( $\left.p o^{\prime}-m i f-o r m\right)$ [pomum, an apple; forma, form]. Having the form of a pome.

Pommade (pom-ahd') [Fr.]. See Pomade.

Pommelière $\left(p o m n^{\prime}-l e-\bar{a} r\right)\left[\mathrm{Fr}_{\mathrm{r}}\right]$. Tuberculosis of cattle.

Pompeian Red. Same as Ocher.

Pompholygmus (pom-fo-lig'-mus) [ $\pi 0 \mu \phi 6 \hat{\prime} \nu \xi$, bubble]. A bullous eruption.

Pompholygodermatitis (pom-fo-lig-o-der-mat-i'tis). Synonym of Pemphigus.

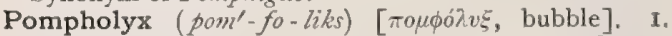
Cheiropompholyx; Dysidrosis. A disease of rare occurrence, characterized by, vesicular and bullous eruptions limited to the hands and feet. The disease occurs in depressed states of the nervous system, is 
more common in women, but is met with chiefly in adult and middle life. By some it is considered a disease of the sweat-glands, by others not. The disease is curable, but tends to recur. 2. Sometimes used as a synonym for Pemphigus. 3. Zinc oxid, called Filowers of Zinc, and Philosophers' Wool.

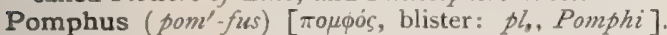
Wheal: Urtica; a circumscribed edema of the corium, producing a flat elevation of the epidermis at that point; it is usually the result of angio-neurotic irritation. Pomphi vary in size from a pin's head to a goose's egg, are of irregular outline, and of a whitish color with a pink areola. They are evolved rapidly, and usually last only a few hours or days.

Pomum (po'-mum) [L., pl., Pona $]$. Apple. P. adami [L., Adam's apple], the ridge or prominence in the front of the neck caused by the projection of the thyroid cartilage. It is most marked in males. P. quercina, nut-gall.

Ponceau (pon-so'). See Pigments, Conspectus of.

Pond's Extract. See Hamamelis. P.'s Recipe, a recipe for varnish to preserve sphygmographic and cardiographic tracings. Alcohol, one pint; gum sandarac, three ounces; castor-oil, half ounce. Mix.

Ponding (pond'-ing) [ME., pond, a pond]. The accumulation of liquid as in a pond. P. of the Liquor amnii, the collection of a considerable amount of liquor amnii above the presenting part of the fetus after the membranes have ruptured in the second stage of labor.

Pongamia (pon-ga'-me-ah) [E. Ind. pongam]. A genus of East Indian trees. Kurung oil is the oil expressed from the seeds of $P$. glabra, native to India, China, and Australia. It is recommended in parasitic diseases of the skin, and is efficacious in pityriasis versicolor, herpes, and rheumatism, and is useful in lepra. Unof.

Ponos $\left(p o^{\prime}-n o s\right)$ [ $\pi \delta$ vos, pain]. A chronic febrile disease endemic on the Greek islands of Spetzia and Hydra. The disease bears some resemblance to pseudoleukemia and to tuberculosis.

Pons [pons, bridge]. A process or bridge of tissue connecting two parts of an organ. P. cerebelli. Same as $P$.varolii. P. hepatis, the hepatic substance sometimes extending from the quadrate to the left lobe of the liver. P.tarini, the posterior perforated space, a mass of gray substance lying behind the corpora albicantia and joining the crura cerebri. It helps to form the floor of the third ventricle. P. varolii (or simply Pons), a convex white eminence situated at the base of the brain, behind its center. It is placed cephalad of the oblongata, ventrad of the cerebellum, and caudad of the cerebrum, and is connected with all three. It rests upon the sphenobasilar groove; it is quadrate in outline, about $25 \mathrm{~cm}$. wide antero-posteriorly, and is marked on its ventral surface by a longitudinal groove for the lodgment of the basilar artery. It is contracted laterally on account of the closer aggregation of its fibers, which converge to form the middle peduncles of the cerebellum. Its cephalic margin is convex and well defined, and arches over the crura. From the cephalad surface of the pons, a little ventral, arises the fifth or trigeminus nerve. In structure the pons consists chiefly of nerve-fibers, but it contains also areas of gray matter, the pontine nuclei. On section it consists of two portions, a dorsal and a ventral. The latter contains transverse commissural fibers and is traversed by the ventral pyramids of the oblongata. The pyramidal fibers in the caudal half of the pons are collected into two closely-packed groups of bundles invested in front and behind by a layer of transverse fibers; higher up, above the middle of the pons, the pyramidal tracts be- come separated by the penetrating transverse bundles into a number of fasciculi. The presence of the pyra mids thus gives rise to three sets of fibers-the ventral or superficial, the dorsal or deep, and the middle or penetrating. Interspersed in the gray matter occupying the interstices of the ventral portion of the pons small multipolar cells are found. The dorsal portion of the pons consists largely of gray matter which is continued up from below, especially the formatio reticularis and the dorsal tracts of gray substance. In places the gray matter is grouped to form the nuclei of the fifth, sixth, seventh, and eighth nerves. In the lower part of the pons there is a small, folded gray lamina, distinguished as the superior olivary nucleus. It is enclosed by some transverse fibers known as the trape zium. A group of darkly-pigmented cells is found in

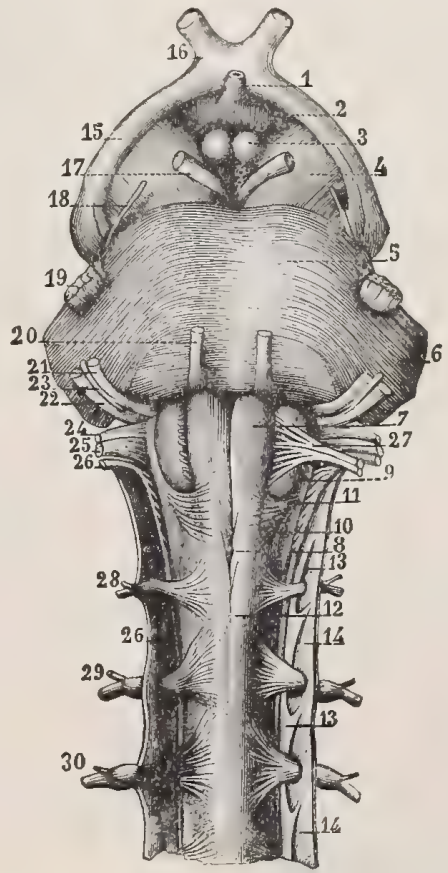

Pons and Medulla. Anterior Aspect.

1. Infundibulum. 2. Tuber cinereum. 3. Corpora albicantia or mammillaria. 4. Cerebral peduncle. 5. Pons varolii. 6 Middle cerebellar peduncle. 7. Anterior pyramid. 8. Decussation. 9. Olivary body. 10. Gray tubercle of Rolando. Ir. Arciform fibers. Superior extremity of spinal I1. Arciform frbers. 12. Superior extremity of spmal cord. 13. I3. Denticulate ligament. 14. Spinal dura mater. 15 Optic tract. I6. Optic chiasm. I7. Third nerve. 18. Fourth nerve. I9. Fifth nerve. 20. Sixth nerve. 21. Facial nerve. 22. Auditory nerve. 23. Nerve of Wrisberg. 24. Glossopharyngeal nerve. 25. Vagus nerve. 26, 26. Spinal accessory nerve. 27. Hypoglossal nerve. 28. Ist cervical pair. 29. 2 d cervical pair. 30. 3 d cervical pair.

the floor of the fourth ventricle; collectively, this is visible to the naked eye as a dark area, known as the substantia ferruginea; seen through the floor of the fourth ventricle, this area appears of a bluish-gray color, whence the name locus corruleus. Mesad of the substantia ferruginea lies an angular tract of white matter, the posterior longitudinal bundle, which is a continuation upward of the ventral groundbundle of the cord. The pons is developed from that part of the third brain-vesicle known as the hindbrain or epencephalon.

Pontal (pon'-tal) [pons, bridge]. Same as Pontile. 
Pontibrachium (pon-tib-ra'-ke-um) [ pons, bridge ; brackium, arm]. The middle peduncle of the cerebellum.

Pontic (pon'tik) [pons, bridge]. Same as Pontile.

Ponticulus (pon-tik'-u-lus) [dim. of pons, bridge]. A small, transverse ridge between the pyramids of the oblongata and the pons. P. auricula, a slight prominence on the eminentia conchre for the attachment of the retrahens aurem muscle. $P$. hepaticus, a bridge of tissue, containing a plexus of blood-vessels, and extending from the surface of the Spigelian to that of the right lobe of the liver.

Pontile (pon'-til) [pons, bridge]. Pertaining to the pons. P. Hemiplegia, this is very often an alternate hemiplegia, in which the arm and leg on one side, and the face on the other, are paralyzed. This condition occurs when the lesion is situated low down in the pons, below the decussation of the fibers of the facial nerve, and above that of the pyramidal tracts. Small lesions high in the pons, produce an ordinary hemiplegia, P. Nuclei, a collection of gray matter in the pons.

Pontinal (pon'-tin-al) [pons, a bridge]. In biology, bridging ; applied specifically to one of the bones in the skull of certain fishes, bridging the space between the sub-orbital region and preoperculum (Dactylopteroidea).

Pontine (pon'-tin) [pons, bridge]. Same as Pontile.

Ponto-bulbar (pon'-to-bul'-bar) [ pons, bridge ; bulbus, bulb]. Pertaining to the pons varolii and to the bulbus spinalis (or oblongata).

Ponto-crural (pon'-to-krw'-ral) [pons, bridge; crus, leg]. Pertaining to the pons varolii and the crura cerebri.

Poop, Pope ( $p o p p$, $p o p p)$ [origin obscure]. A colloquial term used by foot-ball players to designate an injury to the front and outer side of the thigh, which causes more or less disability.

Poor-man's Bandage. See Galen's Bandage.

Pop-eyed (pop'-ìd). Having pop-eyes. P.-eyes, full and bulging eyes. See Exophthalmos.

Poplar ( $p o p^{\prime}-$ lar). See Populus.

Poples $\left(p \circ p^{\prime}-l \bar{e} z\right)[\mathrm{L}$.$] . The back of the knee, or pop-$ liteal space.

Poplitead ( $\left.p \circ p-l i t-e^{\prime}-a d\right)$ [poples, ham; ad, to]. Toward the popliteal aspect.

Popliteal ( $\left.p \circ p-l i t-e^{\prime}-a l\right)$ [poples, ham, hock, or knee]. Pertaining to the hinder part of the knee-joint or ham.

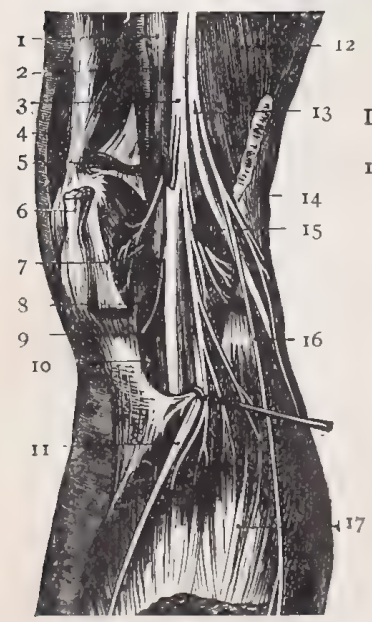

DEEP VIEW OF THE POPLITEAL SPACE

1. Popliteal vein. 2 Popliteal artery. 3. Internal popliteal nerve. 4. Vastus internus. 5. Superior internal articular artery. 6. Tendon of semi-membranosus. 7 . Inner head of gastrocnemius. 8. Inferior internal mius. 8. Inferior internal teal vein. ro. Popliteus. II. Tendon of plantaris. 12. Short head of biceps External popliteal nerve. 14. Long head of biceps, cut. 15 . Outer head of gastrocnemius. 16. Communicans peronei nerve. I7 Soleus.

P. Aneurysm, aneurysm of the popliteal artery, P. Artery. See Arteries, Table of. P. Aspect, the posterior aspect of the knee. P. Bursa, one of the bursæ in the popliteal space. P. Glands, the lymphatic glands of the popliteal space. P. Ligament, the posterior ligament of the knee-joint. P. Nerve. See Nerves, Table of. P. Region. Same as $P$. Space. P. Space, the lozenge-shaped space occupying the lower third of the thigh and the upper fifth of the leg. Its boundaries are : above, and to the outer side, the tendon of the biceps; on the outer side, and below, the plantaris and the outer head of the gastrocnemius; on the inner side, above, from within outward the semitendinosus, the semimembranosus, and the gracilis, on the inner side, below, the inner head of the gastrocnemius. The roof is formed by the popliteal fascia; the floor, by the lower part of the posterior surface of the sbaft of the femur, the posterior ligament of the knee-joint, the upper end of the tibia, and the fascia covering the popliteus muscle. The contents of the space are: the popliteal vessels and their branches, the termination of the external saphenous vein, the internal and external popliteal nerves and their branches, the small sciatic nerve, the articular branch from the obturator nerve, a few lymphatic glands, and some adipose tissue. P. Surface, the surface of the femur between the supracondylar lines. P. Tendons, the tendons of the muscles forming the boundaries of the popliteal space; the hamstrings. P. Vein, the companion vein of the popliteal artery.

Popliteen (pop-lit-e'-en) [poples, ham]. Belonging to the poples in itself.

Popliteus, Poplitæus (pop-lit-él-us) [poples, ham]. Pertaining to the poples. The ham or hinder part of the knee-joint. P. accessorius, a small anomalous muscle arising from the external femoral condyle or from a sesamoid bone in the external gastrocnemius, and inserted into the capsular ligament of the knee-joint. P. biceps, P. geminus. Synonyms of $P$. accessorius. P. Muscle. See Muscles, Table of.

Poplitic (pop-lit'-ik) [poples, the ham]. Popliteal.

Poppy $\left(p \circ p^{\prime}-e\right)$ [ME., popy, poppy]. See Papaver. P.-seed, the seeds of Papaver sominiferum, used in Germany, and sometimes among Germans in this country, to strew on the bread-dough in order to give it a certain flavor. P.-seed Oil, Oleum papaveris, is obtained from the seeds of the opium-poppy by pressure. It is of a pale-yellow color and a slightly sweetish taste; specific gravity, .925 at $15^{\circ} \mathrm{C}$. It is used for salads, paints, soaps, and to adulterate oliveoil and almond-oil.

Population (pop-u-la'-shun) [populus, people]. The mass of people dwelling within a given geographic or political area. P., Malthusian Law of Increase of, that the number of individuals of a society tends to increase faster than the fond-product, so that there is always a pressure on the means of subsistence.

Populin (pop'-u-lin) [populus, poplar], $\mathrm{C}_{20} \mathrm{H}_{22} \mathrm{O}_{8}$. I. Benzosalicin. A substance contained in several varieties of poplar; it is the benzoyl derivative of salicin; it crystallizes in small prisms containing two molecules of water, dissolves with difficulty in water, and possesses a sweet taste. It is said to possess febrifuge properties, and has also been used in dysuria. 2. A precipitate from a tincture of the bark of Populus tremuloides; tonic, stomachic, vermifuge, anti-periodic, and febrifuge. Dose 2 to 4 grains. Unof.

Populus ( $p \circ p^{\prime}-u$-lus) [L. ]. Poplar. The resin of the leaf-buds of several species is used for pectoral and nephritic troubles. Unof.

Porcate (por'-kāt) [ porca, a ridge between two furrows]. In biology, deeply furrowed.

Porcelain(pors'-len) [It., porcellane, porcelain]. An 
impure silicate of aluminum, non-transparent and exceedingly infusible. It is made from porcelain-clay, or kaolin $\left(\mathrm{H}_{2} \mathrm{Al}_{2} \mathrm{Si}_{2} \mathrm{O}_{8}+\mathrm{H}_{2} \mathrm{O}\right)$, derived from feldspar rock by the atmospheric process known as "weathering." Heated in a furnace, it loses water, and a porous mass is produced. In making porcelain the powdered kaolin is mixed with water to a thick paste, and then molded into the desired shape. A little feldspar, chalk, or gypsum is added to the clay in order to form a fusible silicate, in quantity just sufficient to bind the particles of clay firmly together. Upon firing, as the process is called, a porous " biscuit-ware " is obtained, which is afterward subjected to the process of glazing. For the finest porcelain the glazing material is feld. spar; for the cheaper varieties a mixture of clay, chalk, ground-flints, and borax is used. Earthenware is salt-glazed. There are also other methods of glazing. The colors used in decorating porcelain consist of various metallic oxids, and may be applied before or after glazing. P.-glass, a glass which resembles porcelain, made by fusing cryolite, a double fluorid of aluminum and sodium, with sand. P. Teeth, mineral teeth; incorruptible teeth; silicious terrometallic teeth; vitrescent teeth: dental substitutes, resembling, more or less closely, the shape and color of the natural teeth, so constructed that they may be securely fixed to the various attachments employed for their adjustment and retention in the mouth. They are composed of feldspar, silex, and other mineral substances.

Porcupine ( $\left.p o r^{\prime}-k u-p \bar{i} n\right)$ [ porcus, a hog ; spina, spine]. A rodent quadruped of the family Hystricida. It is covered with sharp spines. P. Disease. See Hystrix. P.-men, persons affected with Ichthyosis hystrix. P.-skin, an extreme degree of Ichthyosis hystrix.

Pore (pōr) [ $\pi \delta \rho_{\rho}$, , a pore]. In biology, a minute circular opening or perforation. P., Abdominal, in certain fishes, the opening by which the abdominal cavity communicates with the exterior, and through which the ova are discharged. Ps. of the Skin, the openings of the ducts of the sebaceous and sweatglands of the skin. Ps., Sweat, the orifices of the ducts of the sweat-glands. P., Vascular, in the round-worms, a transverse opening situated on the ventral surface and forming the common orifice of the two lateral vessels which are thought to be excretory organs.

Porencephalia (por-en-sef-a'-le-ah) [ $\pi 6 \rho \circ s$, cavity ; $\varepsilon \gamma \kappa \varepsilon \dot{\phi} \dot{\lambda} \sigma$, brain]. The presence of depressions on the surface of the hemispheres of the brain, owing to absence of portions of brain-substance. The defects are covered by pia and arachnoid, except in cases in which a communication with the ventricles exists. The term is generally restricted to limited congenital defects, although by some it is extended to include those that are acquired.

Porencephalic (por-en-sef-al'-ik). Same as Porencephalous.

Porencephalous (por-en-sef'-al-us) [ $[\pi b \rho s$, cavity;

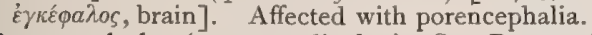

Porencephalus (por-en-sef'-al-us). See Porencephalia.

Porencephaly ( por-en-sef'-al-e). Synonym of Porencephatia.

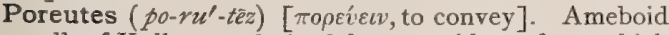
cells of Kollmann, derived from aëroblasts, from which the blood and its corpuscles, the endothelium of the vessels, and the wandering cells are developed.

Poriferous (por-if'-er-uss) [ $\pi 6 \rho \circ s$, pore; ferre, to bear]. In biology, provided with pores.

Poriform (por'-if-orm) [ $\pi$ ópos, pore; forma, form]. Having the form of a pore.

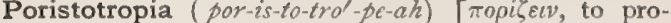
vide; $\tau \rho \circ \pi \dot{\eta}$, a turning]. A chemic process by which, according to Ritgen, the existing atoms are destroyed and new atoms produced whenever a new substance is formed.

Pork [ porcus, hog]. The flesh of swine, Sus scrofa. P., Diseases of, the parasitic diseases are of interest. Pork may be infested with the scolices of the Tania solium and with the Trichina spiralis. The former, known as cysticercus cellulose, or "measle," is contained within a fibrous capsule. If such measly pork is ingested in the raw state by man, the cyst-wall is dissolved in the stomach, and the scolex is set free, and develops into a tape-worm. Pork containing trichinæ, if eaten without proper cooking, gives rise to trichiniasis, a grave and sometimes fatal disease. See Trichiniasis and Measles; also Cysticercus and Trichina, under Parasites (Animal), Table of. An important infectious disease of swine is Rouget du porc, Schweinerothlauf, or Swine-plague. See Rouget du porc, and Bacillus erysipelatos suis, Pasteur, and Bacillus of Swine-plague, Marseilles, Rietsch and Jobert, under Bacteria, Synonymatic Table of

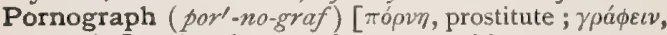
to write]. An obscene picture or writing.

Pornographer (por-nog $-r a-f e r)[\pi \sigma o v \eta$, prostitute ; $\gamma \rho \alpha \dot{\phi} \varepsilon i \nu$, to write]. One who writes of prostitutes or obscene subjects.

Pornographic (por-no-graf'-ik) [ $[\pi \delta \rho v \eta$, prostitute; $\gamma \rho a ́ \phi \varepsilon \imath v$, to write]. Of or pertaining to pornography.

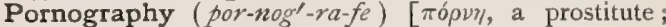
$\gamma \rho a ́ \phi \varepsilon \iota \nu$, to write]. I. A treatise on prostitution, with reference to public hygiene. 2. Obscene writing.

Porocele $\left(p o^{\prime}-r o-s e ̂ l\right)$ [ $\pi \tilde{\omega} \rho o \varsigma$, callus; $\kappa \eta \hat{\lambda} \eta$, tumor]. A scrotal hernia in which the coverings are calloused or hardened.

Porodinic (po-ro-din'-ik) [ $\pi$ óos, a pore; divos, rotation, a round area]. In biology, reproduction by means of genital pores; distinguished from Schizodinic. Cf. Nephrodinic, Idiodinic.

Porokeratosis ( $\left.p o-r o-k e r-a t-o^{\prime}-s i s\right)[\pi \tilde{\omega} \rho o s$, callus;

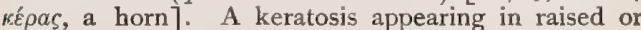
smooth areas, of varying size, irregular form, circumscribed outline, at the summit of which a thin layer of horny tissue of linear arrangement is present. The affection is usually seated on the dorsal aspect of the hands and feet (never on the palmar or plantar surface), the extensor aspect of the forearms and legs, neck, face and scalp.

Poroma (po-ro'-mah) [ $\pi \omega \rho \omega \mu a]$. A callosity.

Poromphalocele (po-rom-fal'-o-sel) [ $[\pi \tilde{\omega} \rho \circ$, callus ; $\dot{\alpha} \mu \phi a \grave{\lambda} \delta$, navel; $\kappa \dot{\eta} \lambda \eta$, tumor]. An umbilical hernia with hardened contents.

Poromphalon, Poromphalos (po-rom'-fal-on, po-rom'fal-os). Synonym of Poromphalocele.

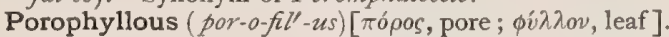
In biology, having leaves sprinkled with transparent points.

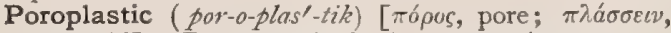
to mold]. Porous and plastic. P. Felt, a porous felt which is readily molded; it is used in the preparation of splints and jackets. P. Jacket, a form of jacket used in the treatment of spinal curvatures.

Porose (por'-oz) [porus, a pore]. In biology, perforate.

Porosis $\left(p o-r o^{\prime}-s i s\right)[\pi \tilde{\omega}) \rho o s$, callus]. The formation of callus. P., Osteo-. See Osteoporosis. P. palpebræ. Synonym of Chalazion.

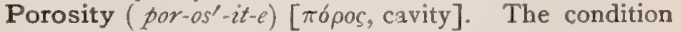
of being porous.

Porotic (po-rot'-ik) [ $\pi \tilde{\omega} \rho o s$, callus]. Favoring the formation of callus. Of the nature of callus. 


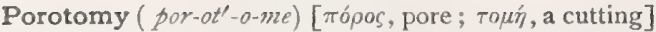
The operation of enlarging by incision the meatus of the urethra.

Porous ( $\left.p o^{\prime}-r u s\right)$ [ $\pi$ ópos, cavity, pore]. Having small openings, or pores.

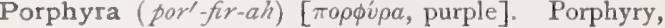
one of the eruptive rocks. The leaf or tablet of porphyra is used by pharmacists in the preparation of compounds. The name has been used to designate scurvy and purpura, $q . v$. P. nautica. Synonym of Scurvy. P. of the Greeks. Synonym of Purpura.

Porphyration (por-fir-a'-shun) ( $\pi 0 \rho \phi^{\prime} \rho a$, purple]. The term applied by Kuiss and Duval to the first stage in the gastric digestion of albuminoid substances.

Porphyrin (por'-fir-in) [ $\pi 0 \rho \phi v \rho a$, purple ]. An amorphous substance contained in a variety of Dita bark.

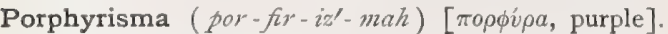
Synonym of Scarlet-fever.

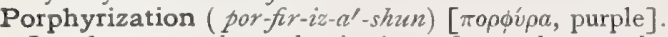
In pharmacy, the pulverization of a substance by crushing it with a muller on a hard surface, usually of porphyry.

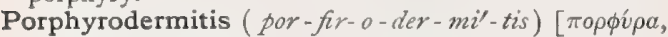

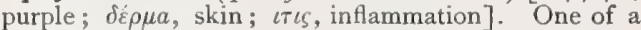
group of skin-diseases including hemorrhagic maculæ and petechiæe

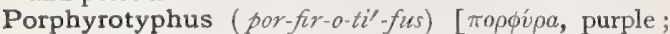
Tíos, typhus]. Synonym of Typhus Fever.

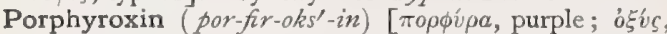
acid]. I. One of the alkaloids of opium, becoming purple when heated with dilute hydrochloric acid. 2. Porphyrin, $q . v$

Porphyruria (por-fir- $\left.u^{\prime}-r e-a h\right)$ [ $\pi 0 \rho \phi i j \rho a$, purple ; ov $\rho o v$, urine]. The discharge of urine colored with purpurin.

Porpoise Oil. See Oleum delphini.

Porraceous (por-a'-se-us) [porrum, leek]. Of stools, green-colored. like leek-leaves.

Porrect (po'-rekt) [ por, forth; reorer, to stretch]. In biology, outstretched.

Porret's Phenomenon. When a galvanic current is conducted through living, fresh, sarcous substance, the contents of the muscular fiber exhibit a streaming movement from the positive to the negative pole (as in all other fluids), so that the fiber swells at the negative pole. See also Phenomenon.

Porrigo (por-i'-go) [L., gen. Porriginis]. An obsolete term applied to several diseases of the scalp. P. amiantacea. Synonym of Seborrhrea capitis. P. contagiosa. See Impetigo contagiosa. P. decalvans. See Alopecia areata. P. favosa. See Favus. P. furfurans. Synonym of Tinea tonsurans. P. larvalis, impetigo of the scalp conjoined with eczema. P. lupinosa. Synonym of Tinea favosa. P. scutulata. Synonym of Favus. P. tonsoria. Synonym of Alopecia areata.

Porrigophyta, Porrigophyte ( por-ig-off'-it-ah, por'-igo-fit). Same as Favus.

Porrisic Acid (por-iz'-ik). See Euxanthinic Acid.

Porro's Operation. See Operation, Porro's.

Port [after Oporto, a city in Portugal]. A wine of Portugal. P.-wine. Same as Port. See also Vinum. P.-wine Mark or Stain. See Nevus vascularis and N. maternus.

Porta (por'-tah) [L.]. I. Gate; the hilus of an organ through which the vessels enter. 2. The foramen of Monro. P. hepatis, P. jecoris, the transverse fissure of the liver, through which the vessels enter. $P$. labyrinthi, the fenestra rotunda. P. omenti, the foramen of Winslow

Portagion (por-ta'-je-on) [portagium, portage ; portare, to carry. Cf. Contagion]. A portable materies morbi, a disease-germ that may be carried; the transmission, or carrying from place to place, of disease-germs.

Portal (por'tal) [porta, gate]. Pertaining to the porta or hilus of an organ, especially to the porta hepatis. P. Canals, tubular passages in the hepatic substance, containing each a branch of the portal vein, of the hepatic artery, and of the hepatic duct. P. Circulation, "the passage of venous blood from the capillaries of one organ to those of another before reaching the heart. There are two such circulations, through the liver and through the kidneys, distin guished as hepatoporial and reniportal. Only the former occurs in man." The portal circulation of the human body includes the venous blood from the chylopoietic viscera (stomach, spleen, and intestines), and this is carried to the liver by means of the portal vein. P. Fissure. See Fissure. P. Fossa, the transverse fissure of the liver. P. System, the system of veins collecting the venous blood from the digestive tract. P. Vein, the large vein entering the liver at the transverse fissure, and bringing to it the blood from the digestive tract and the spleen.

Portal's Syrup. A syrup used in scurvy, and containing horseradish-root, scurvy - grass, nasturtium, gentian, cinchona, and madder.

Porte-, or Port- [portare, to carry]. A carrier, or holder. P.-acid, an instrument for the local application of an acid. P.-aiguille. See Needle-holder. P.-caustique, a holder for the stick of caustic. P.cordon, an instrument for replacing a prolapsed funis. P.-crayon. See $P$-caustic, P.-fil. Synonym of $P$-ligature. P.-fillet, an instrument for applying a fillet to some part of the fetal body. P.ligature, an instrument for applying a ligature to a deep part. P.-moxa. See Moxa. P.-nceud, an instrument for applying a ligature to the pedicle of a tumor. P.-pierre. Synonym of $P$-caustique.

Porter (por'-ter). See Malt Liquors.

Porter's Sign. See Tracheal Tugging, and Signs and Symptoms, Table of.

Porticus subgenitalis. See Syndemnium.

Portio (por'-she-o) [L.]. Portion. Also, an abbreviated expression for portio vaginalis uteri-the vaginal portion of the uterus. P. alba cerebri, the white substance of the brain. P. aryvocalis, a short muscle attached anteriorly to the vocal band and posteriorly to the vocal process of the arytenoid cartilage. P axillaris, the second part of the axillary artery. P. brachialis, the third part of the axillary artery. P. cervicalis, the third part of the subclavian artery. $P$. cervicis uteri, the cervix of the uterus. P. corporis striati externa, the lenticular nucleus. $\mathbf{P}$. corporis striati interna, the caudate nucleus. P. dura, the facial nerve. That part of the seventh pair of nerves of Willis controlling the muscles of facial expression. $\mathbf{P}$. infravaginalis, the vaginal portion of the neck of the uterus. P. inter duram et mollem, a small funiculus between the portio dura and portio mollis of the seventh cranial nerve. $P$. intermedia wrisbergii. Synonym of $P$. inter duram et mollem. P. mollis, the auditory nerve. P. muscularis, the second division of the subclavian artery. P. pectoralis, the first division of the subclavian artery. P. pylorica ventriculi, the pyloric extremity of the stomach. P. splenica ventriculi, the cardiac extremity of the stomach. P. thoracica, the first part of the axillary artery. $P$. ventriculi lienalis. Synonym of $P$. splenica ventriculi.

Portion (por'-shun) [ portio, a part]. A part or section. P., Descending, of the Duodenum, the second portion of the duodenum. It is about three inches in length, covered anteriorly by the peritoneum, and attached 
laterally to the head of the pancreas. It lies behind the transverse colon and in front of the right kidney. The ductus communis choledochus empties into it. P., Iliac (of the fascia lata), the portion of the fascia lata to the outer side of the saphenous opening. P., Infra-vaginal, $\mathbf{P}$., Intravaginal, the portion of the uterine cervix projecting into the vagina. P., Membranous (of the urethra), the portion of the urethra enclosed between the two layers of the triangular ligament. P., Pes, the lower surface of a crus cerebri (Spitzka). P., Prostatic (of the urethra), the part of the urethra surrounded by the prostate gland; it is the most dilatable portion and is rarely, if ever, the seat of stricture. P., Spongy (of the urethra), the part of the urethra anterior to the anterior layer of the triangular ligament, and extending from the latter to the glans. P., Vaginal (of the uterus), the part of the neck of the uterus projecting into the vagina.

Portiplex, Portiplexus (por'-tip-leks, por-tip-leks'-us) [porta, gate; plexus, plexus]. The plexus or vas cular fringe that connects the two lateral choroid plexuses. It passes through the porta, or foramen of Monro, whence the name.

Porus ( $p o^{\prime}$-rus) [тópos, porus, a pore: pl., Pori]. A callosity. Also a canal, duct, or pore. P. acusticus externus, the external opening of the external auditory canal. P. acusticus internus, the opening of the internal auditory canal. P. auditorius externus. Synonym of $P$. acusticus externus. P. biliaris, one of the biliary ducts. P. centralis, the canal in the optic nerve through which the central artery of the retina passes. P. cranio-nasalis, the foramen cæcum of the frontal bone. P. deferens. Synonym of Vas deferens. P. opticus, the large opening in the center of the lamina cribrosa, transmitting the central artery of the retina. P. pulmoneus, an air-cell.

Posis $\left(p o^{\prime}-s i s\right)$ [ $\pi a ́ \sigma \iota$, a drinking]. A potion.

Position (po-zish'-un) [ponere, to place]. I. Location; situation; attitude; posture. See Posture. See, also, Table of Pusition and Direction, appended. 2. In chemistry, a term corresponding to that of "union" (linking), formerly used. P., Articulation. See
Consonants. P., Cadaveric, of the vocal bands, the position which they assume in paralysis of the recurrent laryngeal nerve. The affected band is in the median position, and is perfectly motionless. P. of the Fetus, the relation of the presenting part to the cardinal points of Capuron. For the vertex, the face and the breech, there are each four positions: a right anterior, a rignt posterior, a left anterior and a left posterior. For each of the shoulders there is an anterior and a posterior position. In order to shorten and memorize these positions, the initials of the chief words are made use of as follows: For vertex presentations the word occiput is indicated by the letter $O$., and preceded by the letter $R$. or $L$., for right or left, and followed by $A$. or $P$., according as the presenting part is anterior or posterior. We thus have the initials $L$. $O$. $A$., left-occipito anterior, to indicate that the presenting occiput is upon the anterior left side. In the same way are derived the terms, $L . O . P . R$. O.A., R. O.P. For facial presentations we have in the same way, $L . F . A$. (left fronto-anterior), $L, F, P, R, F, A, R, F, P$. For breech or sacral presentations, $L$. S. A., L. S. $P$., R. S. A., R. S. $P$., and for shoulder (dorsal) presentations, L. D. A., L. D. P., R. D. A., R. D. P. See Table of Fetal Positions, under Fetus. P., Primary (of the eyes), that position in which the eyes can move laterally and vertically without rotating the vertical axis. P., Roser (of the head), the head dependent over the end of a table. P., Secondary (of the eyes), that position in which the vertical meridian is rotated away from its vertical position. P., Shoe-and-Stocking, a position so named by Allis, in which the limb of one side is crossed upon the other, as in putting on the shoe and stocking, with the external malleolus of one side upon the patella of the opposite side. Inability to do this is diagnostic of disease in the hip-joint on that side. P.-test, a test for the function of coördination. If a normal individual be placed in a strictly erect position, with the heels and toes of the two feet closely approximated, a certain amount of swaying of the body occurs, especially if the eyes be shut. If, however, there be loss of coördinating power, this swaying is greatly augmented. See Romberg's Symptom in Signs and Symptoms, Table of.

\section{POSITION AND DIRECTION-TABLE OF INTRINSIC TERMS}

\section{EMPLOYED IN HUMAN AND COMPARATIVE ANATOMY AND ZOÖLOGY. THE TERMS ARE IN PAIRS, AND THE ADVERBIAL FORM FOLLOWS THE LATIN AND ENGLISH ADJECTIVE FORMS.}

\begin{tabular}{|c|c|c|c|c|}
\hline \multirow{3}{*}{$\begin{array}{l}\text { LATIN ADJECTIVE } \\
\text { FORM. } \\
\begin{array}{l}\text { Afferens. } \\
\text { Efferens. }\end{array}\end{array}$} & \multirow{3}{*}{$\begin{array}{l}\text { ENGLISH ADJECTIVE } \\
\text { AND ADVERBIAL FORM. } \\
\text { Afferent. } \\
\text { Efferent. }\end{array}$} & \multirow{3}{*}{$\begin{array}{l}\text { DEFINITIONS. } \\
\text { or conducting toward. } \\
\text { r conducting from. }\end{array}$} & \multicolumn{2}{|c|}{ Extrinsic Equivalents. } \\
\hline & & & $\begin{array}{l}\text { In Human Anat:- } \\
\text { omy. }\end{array}$ & $\begin{array}{l}\text { In Comparative } \\
\text { Anatomy. }\end{array}$ \\
\hline & & & $\begin{array}{l}\text { Same as the in- } \\
\text { trinsic. }\end{array}$ & $\begin{array}{l}\text { Same as the in- } \\
\text { trinsic. }\end{array}$ \\
\hline $\begin{array}{l}\text { Caudalis. } \\
\text { Cephalicus. }\end{array}$ & $\begin{array}{l}\text { Caudal, caudad. } \\
\text { Cephalic, cephalad. }\end{array}$ & $\begin{array}{l}\text { At or in the direction of the tail end or as- } \\
\text { pect of the body or part. } \\
\text { At or in the direction of the head end or } \\
\text { aspect of the body or part. }\end{array}$ & $\begin{array}{l}\text { Lower; inferior. } \\
\text { Upper; superior. }\end{array}$ & $\begin{array}{l}\text { Back ; backward; } \\
\text { posterior. } \\
\text { Front; forward; } \\
\text { anterior. }\end{array}$ \\
\hline $\begin{array}{l}\text { entralis. } \\
\text { eripheralis. }\end{array}$ & $\begin{array}{l}\text { Central, centrad. } \\
\text { Peripheral, peripherad. }\end{array}$ & $\begin{array}{l}\text { At or in the direction of a center. } \\
\text { At or in the direction of the periphery. }\end{array}$ & $\begin{array}{l}\text { Same as the in- } \\
\text { trinsic. }\end{array}$ & $\begin{array}{l}\text { Same as the in- } \\
\text { trinsic. }\end{array}$ \\
\hline $\begin{array}{l}\text { Dextralis, dexter. } \\
\text { Sinistralis, sinister. }\end{array}$ & $\begin{array}{l}\text { Dextral, dextrad. } \\
\text { Sinistral, sinistrad. }\end{array}$ & $\begin{array}{l}\text { At or in the direction of the right side or } \\
\text { aspect of the body. } \\
\text { At or in the direction of the left side or } \\
\text { aspect of the body. }\end{array}$ & $\begin{array}{l}\text { Same as the in- } \\
\text { trinsic. }\end{array}$ & $\begin{array}{l}\text { Same as the in- } \\
\text { trinsic. }\end{array}$ \\
\hline $\begin{array}{l}\text { Distalis. } \\
\text { Proximalis, proxi- } \\
\text { mus. }\end{array}$ & $\begin{array}{l}\text { Distal, distad. } \\
\text { Proximal, proximad. }\end{array}$ & $\begin{array}{l}\text { At or in the direction of the extremity of } \\
\text { an appendage; peripheral }(q . v .) \text {. } \\
\text { At or in the direction of the attached or } \\
\text { more important end of an appendage; } \\
\text { central }(q \cdot v .) \text {. }\end{array}$ & $\begin{array}{l}\text { Same as the in- } \\
\text { trinsic. }\end{array}$ & $\begin{array}{l}\text { Same as the in- } \\
\text { trinsic. }\end{array}$ \\
\hline
\end{tabular}


POSITION AND DIRECTION-TABLE OF INTRINSIC TERMS.Continued.

\begin{tabular}{|c|c|c|c|c|}
\hline \multirow{2}{*}{$\begin{array}{l}\text { LATIN ADJECTIVE } \\
\text { FORM. }\end{array}$} & \multirow{2}{*}{$\begin{array}{l}\text { ENGLISH ADJECTIVE } \\
\text { AND ADVERBIAL FORM. }\end{array}$} & \multirow{2}{*}{ DEFINITIONS. } & \multicolumn{2}{|c|}{ EXTRINSIC EQUIVALENTS. } \\
\hline & & & $\begin{array}{l}\text { In Human Anat- } \\
\text { omy. }\end{array}$ & $\begin{array}{l}\text { In Comparative } \\
\text { Anatomy. }\end{array}$ \\
\hline $\begin{array}{l}\text { Dorsalis. } \\
\text { Ventralis. }\end{array}$ & $\begin{array}{l}\text { Dorsal, dorsad. } \\
\text { Ventral, ventrad. }\end{array}$ & $\begin{array}{l}\text { At or in the direction of the dorsum, or } \\
\text { dorsal aspect of the body or of an organ. } \\
\text { At or in the direction of the ventral aspect } \\
\text { of the body or of an organ. }\end{array}$ & $\begin{array}{l}\text { Back; backward; } \\
\text { posterior. } \\
\text { Front; forward; } \\
\text { anterior. }\end{array}$ & $\begin{array}{l}\text { Upper; upward; } \\
\text { superior. } \\
\text { Lower; down- } \\
\text { ward; inferior. }\end{array}$ \\
\hline $\begin{array}{l}\text { Dorsimesalis. } \\
\text { Ventrimesalis. }\end{array}$ & $\begin{array}{l}\text { Dorsimesal, dorsime- } \\
\text { sad. } \\
\text { Ventrimesal, ventrime- } \\
\text { sad. }\end{array}$ & $\begin{array}{l}\text { At or in the direction of the dorsimeson. } \\
\text { At or in the direction of the ventrimeson. }\end{array}$ & $\begin{array}{l}\text { Same as the in- } \\
\text { trinsic. }\end{array}$ & $\begin{array}{l}\text { Same as the in- } \\
\text { trinsic. }\end{array}$ \\
\hline $\begin{array}{l}\text { Dorsimeson. } \\
\text { Ventrimeson. }\end{array}$ & $\begin{array}{l}\text { Dorsimeson. } \\
\text { Ventrimeson. }\end{array}$ & $\begin{array}{l}\text { The dorsal edge of the meson. } \\
\text { The ventral edge of the meson. }\end{array}$ & $\begin{array}{l}\text { Same as the in- } \\
\text { trinsic. }\end{array}$ & $\begin{array}{l}\text { Same as the in- } \\
\text { trinsic. }\end{array}$ \\
\hline $\begin{array}{l}\text { Ectalis. } \\
\text { Entalis. }\end{array}$ & $\begin{array}{l}\text { Ectal, ectad. } \\
\text { Ental, entad. }\end{array}$ & $\begin{array}{l}\text { At or in the direction of some surface } \\
\text { away from the center or axis. } \\
\text { At or in the direction of some surface } \\
\text { nearer a center or axis. }\end{array}$ & $\begin{array}{l}\text { Outer; superficial; } \\
\text { external. } \\
\text { Inner; inward : } \\
\text { internal; pro- } \\
\text { found. }\end{array}$ & $\begin{array}{l}\text { Same as the in- } \\
\text { trinsic. }\end{array}$ \\
\hline $\begin{array}{l}\text { Lateralis. } \\
\text { Mesalis. }\end{array}$ & $\begin{array}{l}\text { Lateral, laterad. } \\
\text { Mesal, mesad. }\end{array}$ & $\begin{array}{l}\text { At or in the direction of the side (right or } \\
\text { left of the body). } \\
\text { At or in the direction of the meson. }\end{array}$ & $\begin{array}{l}\text { Same as the in- } \\
\text { trinsic. }\end{array}$ & $\begin{array}{l}\text { Same as the in- } \\
\text { trinsic. }\end{array}$ \\
\hline $\begin{array}{l}\text { Longisectio. } \\
\text { Medisectio. } \\
\text { Transectio. }\end{array}$ & $\begin{array}{l}\text { Longisection. } \\
\text { Medisection. } \\
\text { Transection. }\end{array}$ & $\begin{array}{l}\text { A section lengthwise of the body or of an } \\
\text { organ. } \\
\text { A sagittal section at the meson. } \\
\text { A section across the long axis of the body } \\
\text { or of an organ. }\end{array}$ & $\begin{array}{l}\text { Same as the in- } \\
\text { trinsic. } \\
\text { Median section. } \\
\text { Same as the in- } \\
\text { trinsic. }\end{array}$ & $\begin{array}{l}\text { Same as the in- } \\
\text { trinsic. } \\
\text { Median section. } \\
\text { Same as the in- } \\
\text { trinsic. }\end{array}$ \\
\hline Sectio frontalis. & $\begin{array}{l}\text { Frontal section. } \\
\text { Sagittal section. }\end{array}$ & $\begin{array}{l}\text { A section dividing the body into equal or } \\
\text { unequal dorsal and ventral parts or sec- } \\
\text { tions. } \\
\text { A section dividing the body into equal } \\
\text { or unequal right and left sections or } \\
\text { parts. }\end{array}$ & $\begin{array}{l}\text { Same as the in- } \\
\text { trinsic. }\end{array}$ & $\begin{array}{l}\text { Same as the in- } \\
\text { trinsic. }\end{array}$ \\
\hline
\end{tabular}

Positive (poz'-it-iv) [positivus, positive]. In static electricity, a term denoting that quality of the force produced by rubbing glass with silk. In galvanic and dynamic electricity, the current flowing from the less oxidizable element through the wire or conductor. $\mathbf{P}$. Electrode. Synonym of $P$. Pole. P. Element, the more oxidizable element of a battery-usually a plate of zinc. P. Ocular. See Ocular. P. Pole, the pole connected with the negative plate or element. See Anode.

Posologic, Posological ( $p o z-o-l o j^{\prime}-i k$, poz-o-loj'-ik-al)

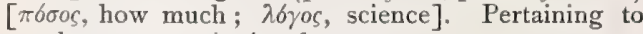
posology or quantitative dosage.

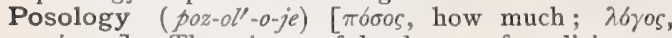
science]. The science of the dosage of medicines.

Possession (poz-esh'-un) [ possedere, to possess]. The condition of being possessed or possessing; madness, lunacy. P., Demoniac, the condition of being possessed or inhabited by demons.

Posset $\left(p \circ s^{\prime}-e t\right)$ [posca, sour wine and water]. A preparation of milk curdled with wine.

Possetting (pos'-et-ing) [posca, sour wine]. The regurgitation of infants.

Post- $(p \bar{s} s t)[\mathrm{L}$.$] . A preposition meaning after. Pre-$ fixed to words it places them in antithesis to those combined with pre or pre, and has the force of either an adverb or an adjective. Also as a noun, a mononym for postmortem; as a verb, a popular expression signifying to perform an autopsy.

Postabdomen (pōst-ab-do'-men) [post, behind; $a b d o$ men, abdomen]. In biology, the posterior abdominal part of the body in insects or crustaceans.

Postabdominal (pōst-ab-dom'-in-al) [ post, after; abdomen, abdomen]. Pertaining to the postabdomen.

Postacetabular (pōst-as-el-ab'-u-lar) [post, after; acet- abulum, acetabulum]. Situated behind the acetabulum.

Postanal (pōst-a'-nal) [post, after; anus, anus]. Situated behind the anus.

Postapoplectic (pōst-ap-o-plek'-tik) [post, after; $\dot{a} \pi 0 \pi \lambda \eta \xi_{i} a$, apoplexy]. Coming on, or occurring, after a stroke of apoplexy. P. Coma, the coma that often succeeds an apoplectic stroke.

Postarytenoid (pōst-ar-i'-te-noid) [ post, after ; ápítal$\nu a$, a pitcher; $\varepsilon i \delta o s$, like]. Situated behind the arytenoid.

Postauditory (pöst-aw'-dit-o-re) [ post, behind; audire, to hear]. Situated behind the auditory nerve, or chamber. P. Fossa, a crescentic notch on the temporal bone, separating the temporal ridge from the auditory plate. P. Processes, in biology, processes situated behind the auditory chamber in certain fishes.

Postaxial (pöst-aks'-e-al) [post, after; axis, axes]. Situated posterior to the long axis; in the arm, situated on the ulnar, in the leg, on the fibular side. In the embryo, directed dorsad from the long axis.

Post-boys' Malady. See Malady.

Postbrachial (pöst-bra'-ke-al) [post, after; brachium, arm]. Situated posterior to, or beyond, the arm.

Postbrachium (pōst-bra'-ke-um) [post, after; brachium, arm ]. The posterior brachium of the corpus quadrigeminum, seen on the lateral slope of the mesencephal. It is between the prebrachium and the lemniscus.

Postbranchial (pōst-brang'-ke-al) [post, after; $\beta \rho a ́ \gamma$ $\chi \iota a$, gill $]$. Situated behind the branchiæ.

Postcalcaneal (pöst-kal-ka'-ne-al) [post, behind; calcaneum, the heel]. In biology, back of the calcaneum; applied to part of the patagium of bats.

Postcarpium (post-kar'-pe-um) [ post, behind; $\kappa a \rho \pi \delta s$, carpus]. The metacarpus. 
Postcava (pöst-kav'-ah) [ post, after, behind ; cavus, hollow]. The vena cava posterior.

Postcaval (pōst-kav'-al) [post, behind; cavus, hollow]. Pertaining to the postcava.

Postcentral (pöst-sen'-tral) [ post, behind; centrum, center]. Situated behind the center.

Postcephalic (pōst-sef-al'-ik) [post, behind; $\kappa \varepsilon \phi a \lambda \eta^{\prime}$, head]. In biology, situated behind the head, or cephalic segment.

Postcerebellar (pōst-ser-e-bel'-ar) [post, behind; cerebellum, cerebellum]. Situated behind, or in the posterior portion of the cerebellum.

Postcerebral (pöst-ser'-e-bral) [ post, behind; cevebrum, cerebrum]. Situated behind, or in the posterior part of the cerebrum.

Postcerviciplex (pōst-ser-vis'-ip-leks) [post, behind; cervix, neck; plexus, plexus]. The posterior cervical plexus.

Postcibal (pōst-si'-bal) [ post, after; cibum, food]. Occurring after meals.

Postcisterna (pöst-sis-te"'nah) [post, behind ; cisterna, a vessel]. That portion of the spaces separating the ental layer of the arachnoid from the pia of the cerebellum, and communicating with the true encephalic cavities through the metapore, and also with the spinal subarachnoid space; the cisterna magna.

Postclavicle (pöst-klav'-ik-l) [ post, behind ; clavicula, clavicle]. In biology, the posterior element of the scapular arch of some fishes.

Postclavicular (pōst-kla-vik'-u-lar) [post, after; clavicula, clavicle]. Pertaining to the postclavicle.

Postclitellian (post-kli-tel'-e-an) [post, behind; clitellum, a pack-saddle]. In biology, applied to such earth-worms as have the ducts of the testes opening behind the clitellum.

Postcommissure (pöst-kom'-is-ūr) [ post, behind; commissura, commissure]. The posterior commissure of the brain, $q . v$.

Postconnubial (pōst-kon-nu'-be-al) [post, after; connubium, marriage]. Coming on, or occurring, after marriage.

Postconvulsive (pōst-kan-vul'-siv) [post, after; convellere, to tear away]. Coming on after a convulsion.

Postcornu (post-kor'-nu) [post, after ; cornu, horn : pl., Postcornua]. The occipital horn of the lateral ventricle of the brain.

Postcornual (pöst-kor'-mu-al) [post, after; cornu, horn]. Pertaining to the postcornua (of the ventricles or of the spinal cord).

Postcostal (pōst-kos'-tal) [post, behind; costa, a rib, the side]. In biology, located behind the costal nervure or vein of the wing.

Postcoxal (pōst-koks'-al) [post, behind; coxa, the thigh-bone]. In biology, situated behind the coxæ.

Postcribrum (post-krib'-rum) [post, behind ; cribrum, sieve]. The posterior perforated space of the brain.

Postcruciate (pöst-kru'-se-āt) [post, after; crux, a cross]. Situated posterior to the cruciate fissure of the cerebrum.

Postcubital (pöst-ku'-bit-al) [ post, behind; cubitus, the forearm]. Situated on the posterior aspect of the forearm.

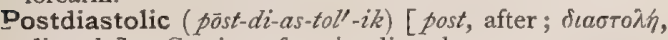
diastole]. Coming after the diastole.

Postdicrotic (pōst-di-krot'-ik) [post, after; ঠікротоs, double-beating]. Coming after the dicrotic wave of the pulse. $\mathbf{P}$. Wave, a second recoil-wave in the sphygmographic tracing. It is not always present.

Postdigastricus (pōst-di-gas'-trik-us) [post, after; dis, double; $\gamma a \sigma \tau \eta \dot{\rho} \rho$, belly]. The posterior belly of the digastric muscle.
Postdilatator ( $\left.p \bar{o} s t-d \bar{t}^{\prime}-l a-t a-t o r\right)$ [post, after; dilator, a dilator]. The posterior dilatator alæ nasi.

Postdorsulum (pöst-dor'-su-lum) [post, after; dorsulum, dim. of dorsum, the back]. See Metascutum.

Postembryonic (pōst-ent-bre-on'-ik) [post, after; $\dot{\varepsilon} \mu$ $\beta \rho v o v$, embryo]. In biology, subsequent to the embryonic stage

Postepileptic (posst-ep-il-eppl-tik) [post, after; $\dot{\varepsilon} \pi i \lambda \eta \psi \iota s$, epilepsy]. Occurring after an epileptic attack.

Posterior ( $\left.p \bar{o} s-t e^{\prime}-r c_{-o r}\right)$ [(neuter, posterius) comparative of posterus, after, behind]. Having a position to the back or rear; opposed to anterior (or anterius).

Posterolateral ( $p o s^{\prime}$-te-ro-lat'-er-al) [ posterus, behind; latus, side]. Posterior and lateral at the same time.

Posteroparietal (pōs-te-ro-par-i'-et-al) [posterus, behind; paries, wall]. Posterior and parietal.

Posterosuperior ( $\left.p \bar{o} s^{\prime}-t e-r o-s u-p e^{\prime}-r e-o r\right)$ [posterus, hinder; superior, superior]. Posterior and superior.

Posterotemporal (pös-te-ro-tem'-por-al) [posterus, behind; tempus, temple]. Posterior and temporal, or behind the temporal region. In biology, a bone in the scapular arch of many fishes; also called the scapula and the supraclavicle.

Posteroterminal $\left(p \bar{o} s^{\prime}-t e-r o-t e r^{\prime}-m i n-a l\right)$ [posterus, hinder; terminatis, terminal]. Situated at the hind end.

Posteroventral ( $p o s^{\prime}$-te-ro-ven'-tral) [ posterus, hinder; venter, stomach]. In biology, situated at the hind end of the ventral surface.

Posterula (pos-ter'-u-lah) [posterus, posterior]. In biology, Harrison Allen's term for that portion of the naso-pharynx between the posterior nares and the salpingo-palatal fold.

Postesophageal (pōst-e-sof-aj'-e-al) [post, behind; oiøoфáyos, the gullet]. In biology, situated behind (dorsad or caudad) the gullet or esophageal ring.

Postfebrile (pōst-feb'-ril) [post, after; febris, fever] Occurring after a fever.

Postfemoral (pöst-fem'-or-al) [post, behind; femur, thigh]. Situated on the posterior aspect of the thigh.

Postfontanel (pöst-fon-tan-el') [ post, behind; fontana, a spring]. The posterior fontanel.

Postforceps (post-for'-ceps) [post, behind; forceps, forceps]. The name given to the oblique fibers at the posterior extremity of the callosum entering the occipital lobes.

Postfovea (pōst-fo-ve'-ah) [ post, after; fovea, pit]. The posterior fovea, a depression in the floor of the fourth ventricle of the brain.

Postfrenum ( pöst-fre'-num) [post, behind; frenum, a bridle, curb, bit]. In biology, a part of the metathorax of an insect.

Postfrontal (pöst-frun'-tal) [post, behind; frons, the forehead]. I. Situated behind the forehead. 2. A bone of the skull in many animals situated at the back portion of the orbit. P. Process, a process of bone in many animals on the upper and posterior portion of the brim of the orbital cavity.

Postfurca (pöst-fir'-kah ) [ post, behind; furca, fork $p l .$, Postfurca]. In biology, the hinder sternal apodeme projecting into the cavity of a thoracic somite in certain insects.

Postfurcal (pōst-fir'-kal) [post, behind; furca, a fork]. Pertaining to the postfurca.

Postgeminum (pöst-jem'-in-um) [ post, after; geminus, twin]. The posterior pair of bodies of the corpora quadrigemina, considered as forming together a single organ.

Postgeneration (posst-jen-er-a'-shun) [post, after; generare, to generate]. In biology, the term applied by Roux to a very peculiar regenerative process observed in frogs' eggs, in which a segmentation-cell 
may be "re-animated" after it has been deprived of its capacity for development.

Postgeniculatum (post-jen-ik-u-la'-tum) [post, behind; geniculatum, the geniculate body]. The internal geniculate body

Postgeniculum (pöst-jen-ik'-u-lum). See Geniculum.

Postgenital (pöst-jen'-it-al) [ post, behind; genitalis, genital]. In biology, pertaining to those segments of the body behind the openings of the genital pores.

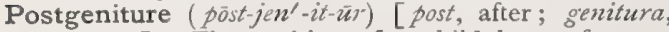
begetting]. The position of a child born after another, as in the second child of twins.

Postglenoid (post-gle'-noid) [ post, behind; $\gamma \lambda \dot{n} v \eta$, socket; Eidos, like]. I. Behind the glenoid cavity or fossa. 2. A process or tubercle of the temporal bone that descends behind the condyle of the jaw and prevents backward displacement during mastication.

Postgraduate (pōst-grad'-u-ät) [post, after; graduare, to confer a degree]. I. Belonging to or prosecuting a course of study after graduating. 2. A graduate.

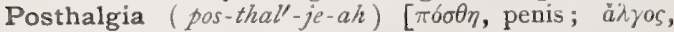
pain]. Pain in the penis.

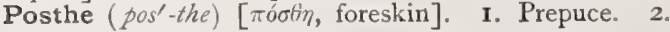
Penis.

Posthectomy (pos-thek'-to-me) [ $\pi \sigma \sigma \theta \eta \eta$, foreskin ; $\check{k} \kappa \tau o \mu \eta$, excision]. Circumcision of the prepuce.

Posthemiplegia (post-hem-ip-le'-je-ah) [post, after; $\dot{\eta} \mu$, half; $\pi \lambda \eta \gamma \dot{\eta}$, stroke]. Following an attack of hemiplegia.

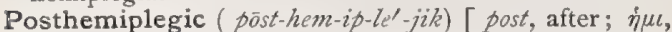
half; $\pi \lambda \eta \gamma \dot{\eta}$, stroke]. Appertaining to a condition following an attack of hemiplegia. P. Chorea, choreiform movements in paralyzed limbs. They are most marked in the hand and arm, next in the face, rarely in the leg. Almost every variety of motion may occur.

Posthetomist (pos-thet'-o-mist) [ $[\pi \sigma \sigma \theta \eta$, prepuce ; $\tau o \mu$, a cutting]. A circumciser.

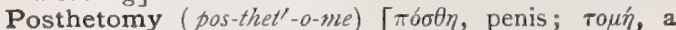
cutting]. Circumcision.

Posthia (pos'-the-ah). Synonym of Hordeolum.

Posthioplastic (pos-the-o-plas'-tik) [ $[$ ó $\sigma \theta \eta$, foreskin; $\pi \lambda a ́ \sigma \sigma \varepsilon i \nu$, to shape] Pertaining to, or involving, plastic surgery of the prepuce.

Posthioplasty (pos'-the-o-plas-te) [ $[\pi \sigma \sigma \theta \eta$, foreskin ; $\pi \lambda a ́ \sigma \sigma \varepsilon v v$, to mold]. Plastic surgery of the prepuce.

Posthippocampal (pöst-hip-o-kam'-pal) [post, be-

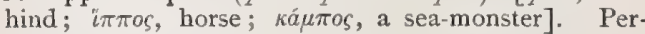
taining to the calcar or hippocampus minor.

Posthitis (pos-thi'-tis) [ $\pi \delta \sigma \theta \eta$, prepuce; $\iota T \iota \zeta$, inflammation]. Inflammation of the prepuce.

Posthocalymma (pos-tho-kal-im'-ah) [ $[\pi o ́ o \theta \eta$, penis ; $\kappa a ́ \lambda v \mu \mu a$, veil]. Synonym of Condom.

Posthocalyptron (pos-tho-kal-ip'-tron). Synonym of Condom.

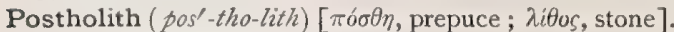
A preputial calculus.

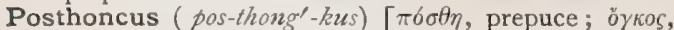
swelling]. A swelling or tumor of the prepuce.

Posthumeral (pōst-hu'-mer-al) [ post, behind; humerus, the humerus]. Situated behind the humerus.

Posthumous (pos'-tu-mus) [post, after; humus, the ground; more correctly, postumus, latest]. Occurring after death. P. Child, one born after the death of its father, or taken by the Cesarean operation from the body of its mother after death.

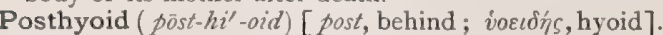
Posterior to the hyoid bone.

Posthypophysis (post-hi-poff'-is-is) [post, behind ;

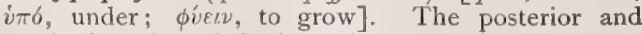
cerebral portion of the hypophysis.

Posticous (pōs'-tik-zes) [posticus, hinder, back]. See Extrorse.
Posticus (pöst'-ik-us) [L.]. Posterior.

Postinsula (pôst-in'-su-lnh) [post, behind; insula, island]. The caudal region of the insula.

Postmastoid (pōst-mas'-toid) [post, behind; $\mu a \sigma \tau o ́ s$, nipple; $\varepsilon i \delta o s$, like]. Situated behind the mastoid process of the temporal bone. P. Tenderness, a tender point located one inch behind and about onehalf inch above the external auditory meatus in cases of septic thrombosis of the lateral sinus dependent upon otitis media.

Postmedian (post-me'-de-an) [post, behind; medius, the middle]. Behind the middle transverse line of the body.

Postmediastinal ( $\left.p \bar{s} t-m e-d e-a s-t i^{\prime}-n a l\right)$ [post, behind; mediastinum ]. Pertaining to the postmediastinum.

Postmediastinum (pōst-me-de-as-ti't -num) [ post, behind; mediastinum ]. The posterior dorsal mediastinal space.

Postminimus (post-min'-im-us) [ post, after ; minimus (sc., digitus), the little finger: pl., Postminimi]. In biology, an additional little finger or little toe in cases of polydactylism. In anatomy, the ulnar sesamoid bone, commonly called pisiform. Cf. Prehallux, Prepollux.

Postmortem (pōst-mor'-tem) [post, after; mors, mortis, death ]. I. Occurring after death. 2. An examination of the body after death; an autopsy. The general technique of a postmortem is as follows: First, the appearance of the body is described, including sex, height, apparent age, discoloration of the skin, rigor mortis, state of the nutrition, injuries, deformities, and any peculiarities that may be observed. An incision is then made from the top of the sternum to the pubic symphysis, the abdomen being the cavity first opened. Then the position of the viscera, their condition, the presence of hernia, if it exist, the state of the peritoneum, and the quantity of fluid are noted, but all without disturbing the relation of the contents. The thorax is now opened. In order to do this, the ribs are divided at the costo-chondral junction, and the sternum and clavicles disarticulated. The relation of the structures exposed on lifting up the separated portion of sternum and ribs is noted-the presence of fluid in the pleural cavity, pleural adhesions, the extent to which the lung covers the pericardium. The pericardial sac is next opened, and its condition and the quantity of fluid recorded. The opening of the heart is the next step. This may be done in several ways ; one of the best is Virchow's method, $q . v$. After noting the character of the blood and clots in the chambers, the heart is excised, close to the origin of the great vessels. After completing the incisions, the state of the valves of the muscle, especially its firmness, and the size of the walls of the two ventricles, are carefully observed and measured. The lungs are next removed, usually the left first. Section of these organs is made by a long sweep of the knife-in the case of the left preferably from the apex to the base; in the case of the right, from the base to the apex. Attention is now directed to the abdomen, the spleen being the first organ removed. Next come the suprarenals and the kidneys. In order to gain access to these, it is wise to dissect off, by a few quick cuts, the entire colon from the sigmoid flexure to the ileo-cecal valve. A double ligature is placed around the sigmoid, and the gut divided between the ligatures. The removal of the kidneys is further facilitated by cutting the diaphragm loose from its costal attachments and throwing it upward, with the liver, into the thoracic cavity. The adrenals and kidneys are then exposed; the course and condition of the ureters are noted. The suprarenals may now be removed separately, or 
taken out with the kidneys; in either case it is best to remove the organs on the left side first. Section is made of the adrenals; also of the kidneys. In the latter the capsule is stripped off, and a note is made of the extent, if at all, to which it is adherent; also whether the renal substance is torn on removing the capsule. The next step consists in the removal of the intestines. These are cut closely to their mesenteric attachment, care being taken to leave as little of the mesentery attached to the gut as possible. The fecal contents are then washed out by a running stream of water through the bowel, which is opened at the attachment of the mesentery and examined. In removing the intestines, the rectum and the first and second portion of the duodenum are left in situ. The next step is usually the opening of the stomach and remaining portion of the duodenum. This is accomplished, like the opening of the intestines, by means of the enterotome. After the duodenum is opened, the gall-bladder is pressed until bile is made to flow from the mouth of the common duct in the duodenum. If this is impossible, obstruction exists. The gastric contents are described, and the condition of the walls noted. The pancreas is now examined, the condition of its duct, and the presence of cysts or stones being noted. It is then removed and incised longitudinally. The liver is next taken out, the condition of the vessels entering the portal fissure having been noted before they were divided. The liver is weighed and measured transversely, longitudinally, and vertically, the width of the two large lobes being taken separately. A long incision is now made into the substance of the organ and the conditions noted, especially the relation of the connective tissue to the hepatic substance proper. The pelvic organs are next removed. This is best accomplished by first making a cut into the bladder; into the opening a finger is inserted, while the other fingers grasp the rectum. By making the tissues tense, their separation from the bony wall of the pelvis is facilitated. After removal they are cut open; in the case of a female subject, the uterus is opened by a longitudinal cut through the anterior wall. A fine probe is passed into the oviducts to ascertain their patulousness; they may also be opened by a delicate pair of scissors. Nothing of importance remains now in the abdomen except the vessels and the semilunar ganglia. The latter should be examined in situ and also after removal. The aorta should be opened by a longitudinal incision extending from the beginning of the arch down to its bifurcation, thence prolonged out into the iliac arteries. The thoracic duct should be looked for at the side of the aorta. The trachea, larynx, thyroid gland, pharynx, and tongue can be removed either through a median incision in the front of the neck or from the base of the neck. For the removal of the brain it is necessary to saw out a portion of the cranial vault. It is customary to divide the scalp about on a line with the coronal suture. The vault is sawn through in front and behind, a large, wedge-shaped piece being removed. The dura is then divided on a line with the sawn edge of the bone, and also separated from its attachment to the crista galli in front. The brain is then carefully lifted from its bed, the nerves passing from it divided, and the attachment of the dura to the petrous portion of the temporal bone cut loose. If possible, the pituitary body should be kept attached to the brain. A long knife is now introduced into the spinal canal, and the cord cut as low down as possible. The brain is then lifted out and placed on a board or plate. After a careful survey of its external appearances, the organ is dissected. A number of methods are in vogue. One of the best is that known as Edinger's method; only its general features can be indicated here. The lateral ventricles are first opened; then the cerebral bemispheres are cut away from the basal ganglia. Longitudinal and transverse cuts are made into the cerebral mantle, observing always to make the incisions as near as possible at right angles to the course of the convolutions. The basal ganglia are examined by making multiple incisions into them; the cerebellum is similarly treated. The spinal cord is generally removed from the back; special saws have been devised to cut the pedicles of the vertebræ. The cord itself is removed in its membranes from below upward, the most important point being the avoidance of traction. The membranes are opened, and the cord-substance divided at short intervals by transverse cuts. The eyes, if it be necessary, can be removed without difficulty. The removal of the organ of hearing requires considerable labor. All organs should, if possible, be weighed.

Postmortuary (pöst-mor'-tu-a-re) [post, after; mors, mortis, death]. Postmortem.

Postnares [ post-na'-rēz) [post, behind; naris, nostril]. The posterior nares.

Postnarial (pōst-na'-re-al) [post, behind; naris, a nostril]. Situated behind the nostrils.

Postnasal (post-na'-sal) [post, behind; nasus, nose]. Situated behind the nose. P. Catarrh, catarrhal in. flammation of the naso-pharynx.

Postnasus (pōst.na'-sus) [post, after; nasus, nose]. In biology, a division of the clypeus in certain insects; the supraclypeus.

Postnatal (pōst-na'-tal) [post, after; natus, born]. Subsequent to birth, as a postnatal disease.

Postoblongata (pöst-ob-long-g* $\left.a^{\prime}-t a h\right)$ [ post, after; oblongrata, medulla oblongata]. The caudal or metencephalic portion of the oblongata, forming the floor of the metacele.

Postocular (posst-ok'-u-lar) [post, behind; oculus, the eye]. In biology, situated back of, behind, or beneath the eye.

Postolivary (pöst-ol'-iv-a-re) [post, behind ; olivarius, olivary]. Behind the oliva.

Postomosternal (pōst-o-mo-ster'-nal) [post, behind;

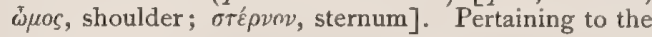
postomosternum.

Postomosternum (pōst-o-mo-ster'-num) [ post, behind ;

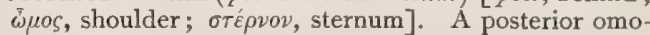
sternum.

Postoperative (pōst op'-er-a-tiv) [post, after; operatio, operation]. Occurring after an operation, as postoperative insanity.

Postoperculum (post-o-per'-ku-lum) [post, after; operculum, lid]. That one of the folds covering the insula which is formed of a part of the supertemporal gyrus; the temporal operculum.

Postopticus (post-op'tik-us) [post, after; $\omega \psi$, eye : $p l .$, Postoptici ]. Either one of the posterior pair of optic lobes, or corpora quadrigemina.

Postoral (pōst-o'-ral) [post, after; os, oris, mouth]. Situated either dorsad or caudad of the mouth. $\mathbf{P}$. Arches. See Arch. P. Segments, in biology, the primary segments behind the mouth of certain arthropods.

Postorbital (pōst-or'-bit-al) [post, behind; orbitr, orbit]. In biology: $(a)$ situated behind the orbit; (b) placed back of the compound eye of an insect; (c) a separate bone in the orbit of certain reptiles.

Postpalatal (post-pal'-at-al) [ post, behind; palatum, the palate]. Situated behind the palate bones.

Postpalatine ( pöst-pal'-at-in) [post, behind; palatum, palate]. In biology, a bone in the skull of certain reptiles, also called pterygoid. 
Postparalytic (pōst-par-al-it'-ik) [post, after; $\pi \alpha \rho a ́$ $\lambda v \sigma \iota \zeta$, paralysis]. Following an attack of paralysis, P. Chorea, Synonym of Posthemiplegic Chorea.

Postparietal (pōst-par-i'-et-al) [post, behind; paries, wall]. In biology, situated behind the parietal plate. Postpartum (pōst-par'-tum) [post, after; partus, birth]. Following childbirth. P. Chill, a chill, as a rule of no pathologic significance, closely following the expulsion of the child in some cases. It usually lasts several minutes. P. Hemorrhage, hemorrhage following delivery. Its causes are such as interfere with or prevent uterine contraction, as general debility, weakness of the uterine muscle, anomalies of innervation of the uterus, retained placenta or clots, old adhesions, tumors, distention of the bladder and rectum, as well as a hemorrhagic diathesis. The symptoms are a sudden gush of blood from the vulvar orifice, relaxation of the uterus, and the constitutional signs of severe hemorrhage : pallor, vertigo, air-hunger, dimness of vision, sometimes a peculiar vocal sound, a rapid, feeble pulse, rarely a convulsion. The mortality is given as $\mathbf{I}$ in 300 . P. Shock, the sense of fatigue and exhaustion immediately succeeding labor.

Postpectoral (pöst-pek'-to-ral) [post, behind; pectus, the breast]. Pertaining to the postpectus.

Postpectus (pöst-pek'-tus) [post, behind; pectus, the breast]. In biology, the hinder part of the breast.

Postpeduncle (pöst-pe'-dunk-l) [post, behind; pedunculus, peduncle]. The inferior cerebellar peduncle.

Postpeduncular (pöst-pe-dung'-ku-lar) [ post, behind; pedunculus, peduncle]. Of or pertaining to the postpedunculus.

Postpedunculus (pöst-pe-dung'-ku-lus). See Postpeiuncle.

Postperforatus ( $p \bar{o} s t$-per-for- $a^{\prime}$-tus) [ post, behind; perforare, to perforate]. The posterior perforated space.

Postpetiole (post-pet'-e-ôl) [ post, behind; petiolus, a petiole]. In biology, that portion of the abdomen of an insect just behind the petiole or narrow section.

Postpharyngeal (pōst-far-in'-je-al) [post, behind; $\phi \alpha \rho v \gamma \bar{\xi}$, pharynx]. Situated behind the pharynx,

Postphenomenon (pöst-fe-nom'-en-on) [post, after;

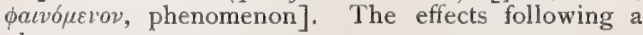
phenomenon.

Postpituitary (pōst - pit $-u^{\prime}-i t-a-r e$ ) [post, behind; pituita. phlegm]. Situated behind the pituitary body.

Postpleuritic (pöst-plutrit'-ik) [post, behind; $\pi \lambda \varepsilon v \rho a ́$, pleura; $\iota \tau \iota$, inflammation]. Following pleurisy.

Postplexus (post-pleks'-us) [post, behind; plexus, plexus]. In biology, the analogue in lower vertebrates of the lumbo-sacral plexus in man.

Postpone (pöst-pön') [post, after; ponere, to place]. In relation with the paroxysm of malarial fever, it means to occur after the regular time.

Postpontile (pōst-pon'-til) [post, behind; pons, bridge]. Situated behind the pons varolii. P. Recess, the foramen cæcum.

Postprostatic (pōst-pros-tat'-ik) [post, after; $\pi \rho o ́$, be-

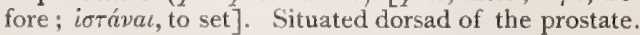
P. Pouch. See Trigonmm vesica.

Postpubic (pōst-pu'-bik) [post, behind; pubis, pubes]. Pertaining to the postpubis.

Postpubis (pōst-pu'-his) [post, behind; pubis, pubes: pl., Postpubes]. In biology, the postacetabular portion of the pubic bone; used especially in connection with the pubis of certain Sauropsida.

Postpuerperal (póst-pu-er'-pe-ral) [post, after; puer, child; pareve, to bear]. Occurring after childbirth.

Postpyramidal (post-pir-an'-id-al) [post, behind; byramis, pyramid]. Situated behind the pyramidal tract. P. Nucleus, the nucleus funiculi gracilis, $q . v$.
Postramus (pōst-ra'-mus) [post, behind; ramus, branch]. The caudal or horizontal branch of the stem of the arbor of the cerebellum.

Postremus (pos-tre'-mus) [superlative of posterus, behind]. Hindermost. P. pedis, the extensor brevis digitorum muscle of the foot. See Muscles, Table of.

Postrhinal (pöst-ri'-nal) [post, behind; ṕss, nose]. Posterior and rhinal. P. Fissure, Wilder's term for the basirhinal fissure.

Postrolandic (pōst-ro-lan'-dik) [post, after; Rolando, an anatomist]. Situated behind the Rolandic fissure.

Postrorse (pōs'-trorz) [post, back; versus, turned]. In biology, turned back; retrorse, the antonym of antrorse.

Postsacral (pōst-sa'-kral) [post, behind; sacrum, sacrum]. Situated behind the sacrum.

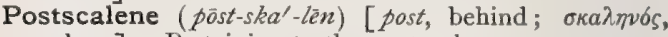
scalene]. Pertaining to the postscalenus.

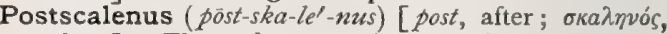
scalene]. The scalenus posticus muscle.

Postscapula (pōst-skapp-u-lah) [post, behind; scapula, shoulder-blade]. The part of the scapula below or posterior to the spine.

Postscapular (pōst-skap'-u-lar) [post, behind; scapula, shoulder-blade]. Pertaining to the postscapula.

Postscapularis (pöst -skap-u-la'-ris) [ post, behind; scrpula, shoulder-blade]. Synonym of the infraspinatus muscle.

Postscutellar (pōst-sku-tel'-ar) [post, behind; scutellum, dim. of scutum, shield]. Pertaining to the postscutellum.

Postscutellum (pōst-sku-tel'-um) [post, behind ; scutellum, dim. of scutum, shield: pl., Posiscutella]. In biology, the last of the four sclerites of which the pronotum, mesonotum, and metanotum of an insect consist.

Postsphenoid (pōst-sfe'-noid) [post, behind; $\sigma \phi \dot{v} v$, wedge; $\varepsilon i \delta o s$, like]. Situated behind the sphenoid bone; also, forming its posterior portion.

Postsylvian (pöst-sil"-ve-an) [post, behind; Sylvius, an anatomist]. Situated behind the Sylvian fissure of the brain.

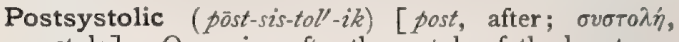
systole]. Occurring after the systole of the heart.

Posttemporal (pōst-tem'-po-ral) [post, after; tempus, temple]. In biology, situated back of the temporal region; specifically applied to a bone of the scapular arch in certain fishes, forming at times an integral portion of the skull. Also called supra-scapula and supra-clavicle.

Posttibial (pōst-tíb'-e-al) [post, behind; tibia, tibia]. Situated upon the posterior aspect of the tibia.

Posttympanic (pōst-tim-pan'-ik) [post, after; tympanum, drum]. In biology, situated back of the tympanic bone or auditory meatus.

Postumbonal (pōst-um'-bo-nal) [post, behind; umbo, a boss]. In biology, situated behind the umbo.

Postural (pos'-tu-ral) [ ponere, to place]. Pertaining to posture or position. P. Respiration, a treatment of apnea by the induction of respiration through changes of posture. P. Treatment, treatment by position, as the reposition of a prolapsed funis by placing the woman in a favorable position.

Posture (pos'-tūr) [ ponere, to place]. Position; atti tude. An illustrated table of the various postures of the body is appended.

Postuterine (pōst-u'-ter-in) [post, behind; uterus, uterus]. Situated behind the uterus.

Postvermis (pōst-ver'-mis) [post, behind; vermis, worm]. The inferior vermiform process of the cerebellum. 


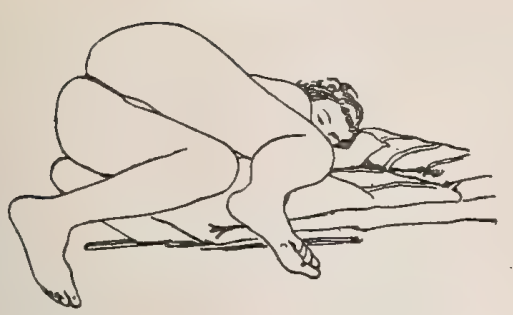

The Semi-Prone, or Sims' Posture. Anterior View.

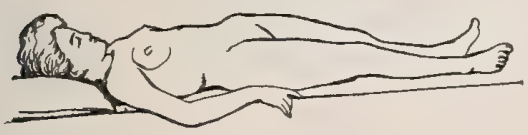

The Horizontal Posture.

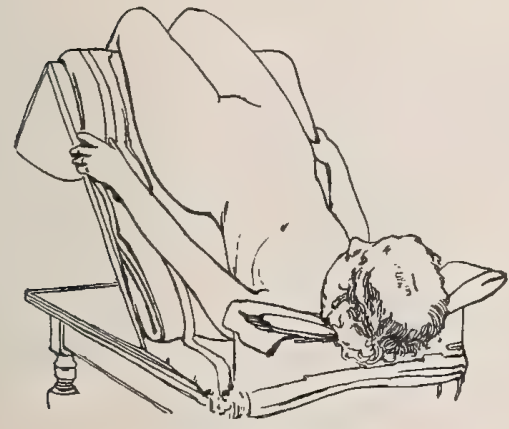

The Trendelenburg Postur $r$.

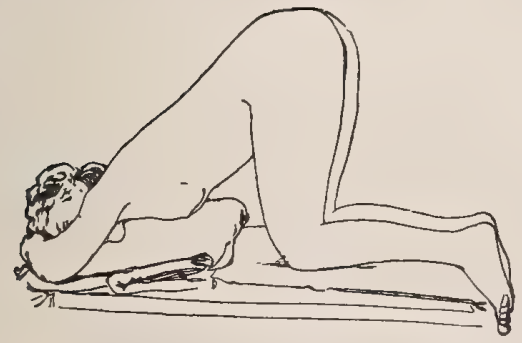

The Genu-pectoral Posture.

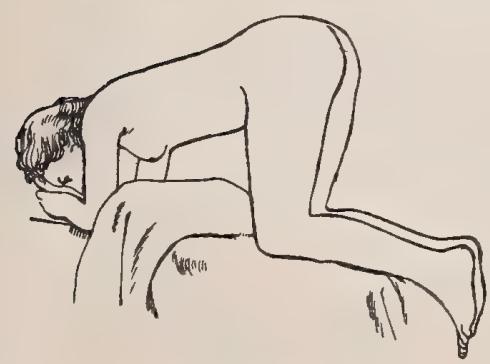

ThE KNEES-ELBOW Posture.

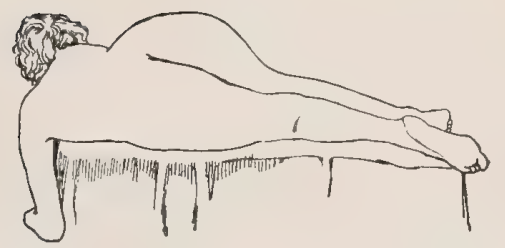

The Semi-prone, or Sims' Posture. Posterior View

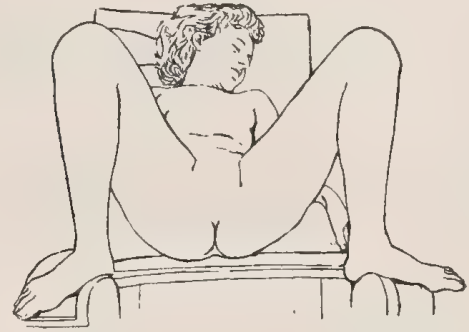

The Dorsal Elevated Posture.

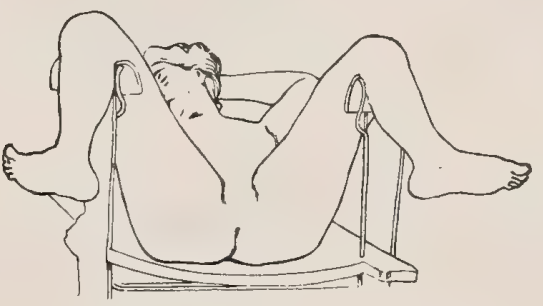

The Dorsal Recumbent Posture.

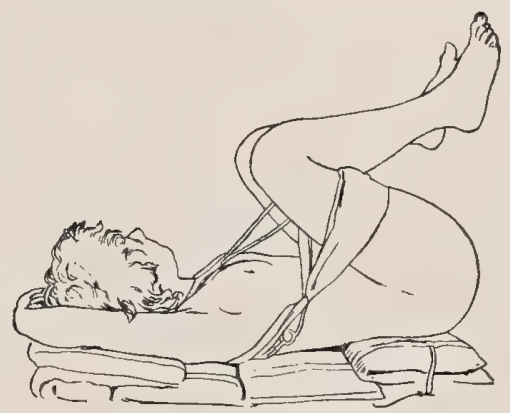

The Dorso-sacral, Posture. Lateral View

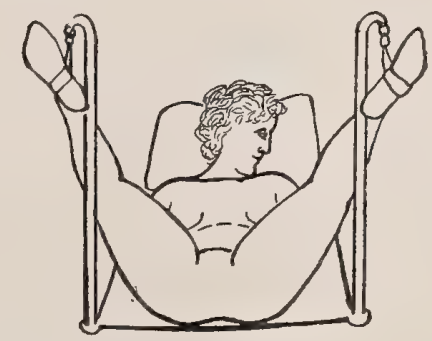

EDEBohl's POSTURE. 


\section{TABLE OF POSTURES AND POSITIONS.}

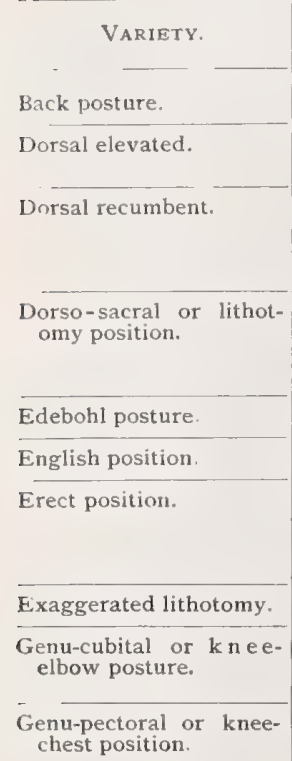

\section{High pelvic posture.}

Horizontal abdominal posture.

Horizontal position.

\section{"Jack-knife" posture.}

Knee-chest posture.

Knee-elbow posture.

Kneeling-squatting position.

Latero-prone.

Latero-semi-prone

Left lateral recumbent, English, or obstetric position.

Lithotomy

Obstetric.

Reclining posture.

Semi-prone or Sims position, or side posture.

Side posture.

Simon's position, or exaggerated lithotomy position.

Sims'.

Trendelenburg's position.
DESCRIPTION

See Dorsal recumbent

Patient on back, with head and shoulders elevated at an angle of $30^{\circ}$ or more.

I. Patient on hack, with the extremities moderately flexed and rotated outward.

Patient flat on back, with legs flexed on thighs and thighs on abdomen. The thighs are abducted.

\section{Same as Simon's position.}

See Left lateral recumbent.

The occiput and heels on a line; also the nose groins and great toes are in the same vertical plane.

\section{See Simon's position.}

Patient upon the knees, with the thighs upright, and the body resting upon the elbows, the head down upon the hands.

Patient upon the knees, with the thighs upright; the head and upper part of the chest resting upon the table; the arms crossed above the head.

\section{See Trendelenburg's position.}

Patient flat on the belly, with the feet extended.

Patient supine on the back, with the feet extended.

Patient reclining on the back with the shoulders elevated, legs flexed on thighs and thighs at right angles to abdomen.

\section{See Genu-pectoral.}

See Genu-cubital.

Patient stooping, with knees pressed upon the ab. domen, trunk erect.

\section{Same as Semi-prone.}

Same as Semi-prone.

Patient on left side, with the right knee and thigh drawn up.

Same as Dorso-sacral.

See Left lateral recumbent.

Same as "Jack-knife" posture.

Patient on left side, with right knee and thigh drawn well up above the left; left arm back of patient and hanging over the edge of the table; chest inclined forward so that the patient rests upou it.

\section{See Semi-prone.}

Patient flat on back, with legs flexed on thighs and thighs on abdomen, and hips somewhat elevated. The thighs are strongly abducted.
Thighs on abdomen, and hips somev

\section{See Semi-prone.}

Patient in dorsal position, with body elevated at an angle of about $45^{\circ}$, feet and legs hanging over the end of the table.
WhEN EMPLOYED.

I. Digital exploration of the genitalia.

2. Bimanual examination.

1. Application of obstetric forceps.

2. Repair of lesions following parturition.

3. Vaginal examination.

4. Bimanual palpation.

I. Plastic operations on the genital tract

2. Vaginal hysterectomy.

3. Diagnosis and treatment of diseases of the urethra and bladder.

I. In the practice of ballottement.

2. In differentiation of tumors, cystic, solid, and hernial.

3. In diagnosticating loosening of pelvic joints.

I. When not possible to employ the classic kneechest position.

I Replacement of prolapsed funis.

2. Dislodgment of an impacted head.

3. Management of transverse presentations.

4. Replacement of a retroverted uterus or prolapsed ovary.

5. Flushing of the intestinal canal.

I. Examination of the back and spinal column.

1. For employment of palpation.

2. Auscultation of the fetal heart.

3. The position for operative procedures.

I. For passing the urethral sound.

I. Childbirth in difficult cases, and in uncivilized nations.

I. Childbirth.

I. Curettement of uterus

2. Intra-uterine irrigation after labor.

3. Tamponuade of vagina.

4. Rectal exploration.

5. Operations upon the cervix.

I. Operations upon the vagina.

I. In abdominal surgery to favor gravitation upward of the abdominal viscera. 
Postzygapophysial (pöst-zi-gap-off-iz'-e-al) [post, be-

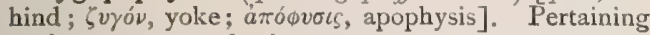
to the postzygapophysis.

Postzygapophysis (post-zi-gap-off'-is-is) [ [post, be-

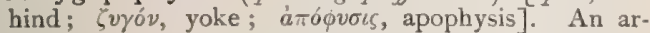
ticular process proceeding from the posterior face of the neural arch of a vertebra.

Pot [ME., pot, a pot]. A urinal. P.-bellied, having a prominent belly. P.-belly, a protuberant belly. P.-gutted, pot-bellied.

Potable $\left(p o^{\prime}-t a-b l\right)$ [potare, to drink]. Fit or wholesome to drink-applied to waters for drinking in distinction to those for medicinal use.

Potain's Solution. A solution for diluting the blood in counting the red corpuscles. It consists of three solutions-one of gum arabic, one of sodium sulphate, and one of sodium chlorid, each of a specific gravity of 1020. These liquids are mixed in equal proportions.

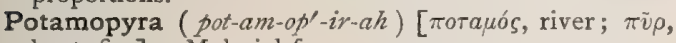
heat, fire]. Malarial fever.

Potash $\left(p o t^{\prime}-a s h\right)$ [potassa, potash]. I. Potassium carbonate prepared by boiling wood-ashes with water and evaporating the solution. It is also obtained from potassium chlorid and potassium sulphate found in the Stassfurt salt-beds. The residue left behind in the manufacture of beet-root sugar also yields potash. Finally, from the wash-water of sheep's wool, considerable quantities of potash are obtained. 2. Caustic potash, potassium hydroxid.

Potassa (po-tas'-ah) [L.]. I. See Potash. 2. Potassium hydroxid. P. cum calce, Vienna paste, made by rubbing together equal parts of caustic potash and quick-lime. It is used as a caustic. Potassæ, Liquor, "solution of potassa," consists of hydrate 56 , distilled water 944 parts; combined with bitter tonics it is useful in atonic dyspepsia. Locally, it is used as a wash in scaly skin-diseases. Dose $\eta^{v} \mathrm{v}-3 \mathrm{ss}$, diluted.

Potassamid (po-tas'-am-id) [ potassa, potassium; amid], $\mathrm{NH}_{2} \mathrm{~K}$. A substitution-compound of ammonia; a yellowish-brown, inflammable substance, produced by heating metallic potassium in ammoniacal gas.

Potassic $\left(p 0\right.$-tas $\left.s^{\prime}-i k\right)$ [potassa, potash]. Containing Potassium.

Potassiferous (po-tas-if'-er-us) [ potassa, potash; ferre, to bear]. Containing or yielding potassic salts.

Potassinum (po-tas'-in-um). Synonym of Potassium.

Potassio-ferric (po-tas'-e-o-fer'-ik) [potassa, potassium ; ferrum, iron]. Combined with iron and potassium.

Potassio-mercuric (po-tas'-e-o-mer-ku'-rik) [potassa, potassium; Mercury, a Grecian god]. Combined with potassium and mercury.

Potassium (po-tas'-e-um) [potassa, potash]. $\mathbf{K}=$ 39; quantivalence I ; sp. gr. 0.865. A metallic element, of silvery luster, and characterized by intense affinity for oxygen. See Elements, Table of. Its peculiar reactions are: its precipitation when converted into the acid tartrate; its precipitation by platinum perchlorid; the violet color it imparts to the flame. Physiologically, salts of potassium are protoplasmic poisons when applied locally in sufficient concentration. They dialyze more readily than sodium salts. In the body they occur especially in the solid structures, while sodium salts predominate in the fluids. In large doses, by the mouth, potassium salts act as irritants to the gastro-intestinal tract. The circulation is generally depressed by potassium salts-after small doses the primary depression of the pulse-rate and arterial pressure is followed by a rise of both; large doses cause a rapid fall of pressure and pulse-rate.
Injected into a vein, salts of potassium cause paralysis of the heart. Potassium salts are obtained from the ash of plants, from saltpeter, from the potassiumn bitartrate deposited from urine in the process of fermentation, and from the washings of sheeps' wool. The action of the various salts is given under their proper heading. P. acetas, $\mathrm{KC}_{2} \mathrm{H}_{3} \mathrm{O}_{2}$, an easily soluble salt having marked diuretic properties. Dose gr. v-3j. Purgative doses $3^{i j-i v, ~ P . ~ A m a l g a m, ~}$ a mixture, in various proportions, of potassium and mercury. The compound may be a liquid, or an amorphous or crystalline solid. P. arsenitis, Liquor, Fowler's solution. See under Arsenic. P. bicarbonas, $\mathrm{KHCO}_{3}$, a salt with properties like the carbonate, to which it is preferable. Dose gr. v-xxx. Liq. potas. efferves. (B. P.) Dose $\xi v-x$. P. bichromas, $\mathrm{K}_{2} \mathrm{Cr}_{2} \mathrm{O}_{7}$, a substance occurring in large, irregular, yellow crystals. It is used in the preparation of hardening fluids, and has been applied externally in syphilis. P. bitartras, $\mathrm{KHC}_{4} \mathrm{H}_{4} \mathrm{O}_{2}$. See $P$. tartras. Dose gr. $\mathrm{xx}-\zeta$ ss. Pulvis effervescens comp., compound effervescing powder, "Seidlitz powder," contains of the preceding gr. I2O, mixed with sodium bicarb. gr. 40, in the blue paper; and tartaric acid gr. 35 in the white paper. P.-blue, the blue color resulting when potassium cyanid and a ferric salt are mixed. It is used in dyeing. P. bromas, $\mathrm{KBr}$, a colorless, crystalline, bitter salt, readily soluble in water. It is extensively employed as a sedative in nervous excitement, and is one of the best drugs in epilepsy. Its prolonged use causes the condition known as Bromism, q. v. P. carbonas, $\left(\mathrm{K}_{2} \mathrm{CO}_{3}\right)_{2} \cdot 3 \mathrm{H}_{2} \mathrm{O}$, useful locally in acne and acute eczema, internally in rheumatism, in the uric-acid diathesis, and in jaundice. Dose gr. ij-xx. P., Caustic, potassium hydroxid, $q . v$. P. chloras, $\mathrm{KClO}_{3}$, a crystalline compound, with a saline, cooling taste. It is soluble in 15 or 16 parts of cold, and readily soluble in boiling water. It is used as a gargle in diseases of the mouth and throat, in mercurial stomatitis, etc. Dose gr. $\nabla-x x$. In toxic doses it causes disorganization of the blood (converting the hemoglobin into methemoglobin) and intense irritation of the kidneys, with hematuria and bloodcasts. Sir James Y. Simpson recommended it in doses of 20 grains thrice daily, in threatened abortion from fatty degeneration of the placenta. P. chloratis, Troch., each containing gr. v. of the salt. Dose j-iij. P. chlorid., $\mathrm{KCl}$, a colorless, crystalline substance, of bitter taste. $P$. citras, $\mathrm{K}_{3} \mathrm{C}_{6} \mathrm{H}_{5} \mathrm{O}_{7} \cdot \mathrm{H}_{2} \mathrm{O}$, is used in solution as a febrifuge, a diuretic, and to alkalinize the urine. Dose gr. $\mathrm{x}$-xxx. P. citratis, Liq., citric acid 6 , potas. bicarb. 8 ; filter and add distilled water ad 50 parts. Dose $3 \leqslant s-j$. P. citratis, Mist., "neutral mixture" -lemon-juice Ioo, potas. bicarb. q. s. ad saturationem. Dose $\xi s s-j$. P. cobalto-nitrite, unof., has been used successfully in angina pectoris and asthma. Dose gr. ss-j. P. cyanid., KCN, made from potassium ferrocyanid by the action of heat, sometimes with (also without) the addition of potassium carbonate and charcoal. It is very soluble in water, has active reducing powers, and is very poisonous. It has the sedative and antispasmodic action of hydrocyanic acid, and, like it, is used in gastric irritability and cough. Dose $\frac{1}{2 \pi}$ grain. $P$. dichromas. Synonym of $P$. bichromas. $P$. ethylas, $\mathrm{C}_{2} \mathrm{H}_{5} \mathrm{OK}$, a crystalline substance, decomposing in the presence of organic matter into metallic potassium and ethyl alcohol. The potassium abstracts oxygen from the tissues, and thus is caustic; the ethyl alcohol is antiseptic. P. et sodii tartras, $\mathrm{KNaC}_{4} \mathrm{H}_{4} \mathrm{O}_{6} .4 \mathrm{H}_{2} \mathrm{O}$, "Rochelle salt," laxative. Dose $\zeta_{\text {ss-j. }} \quad$ P. ferricyanid, $\mathrm{K}_{3} \mathrm{FeC}_{6} \mathrm{~N}_{6}$, red prussiate 
of potash, made from potassium ferrocyanid by the action of chlorin. The latter is passed through the salt until a blue color with ferric chlorid is no longer obtained. It is poisonous. P. ferrocyanid, $\mathrm{K}_{4} \mathrm{Fe}$ $\mathrm{C}_{6} \mathrm{~N}_{6}+{ }_{3} \mathrm{H}_{2} \mathrm{O}$, yellow prussiate of potash, prepared from blood, and by heating together animal charcoal, iron, and pearl-ash. It occurs in yellow crystals, soluble in water. It has many uses in chemic analysis. P. hydras, KHO, potassa, "caustic potash," deliquescent and very alkaline. A powerful escharotic. $\mathrm{P}$. iodid., KI, used in syphilis, metallic poisoning, and as an antirheumatic. Dose gr. ij-xx. P. Iodid. cum sapone, Lin. (B. P.), contains potassium iodid, curd soap, glycerin, oil of lemon, and distilled water. P. iod., Unguent., contains iodid and carbonate of potassium, distilled water and benzoated lard. P. nitras, $\mathrm{KNO}_{3}$, saltpeter, niter, crystallizing in long, white prisms. It occurs naturally in the soil of many tropical countries, especially in Egypt and the East Indies. It originates in the decomposition of organic matter rich in nitrogen, in the presence of potassium compounds. Commercially, it is also prepared by double decomposition of potassium chlorid and Chile saltpeter, sodium nitrate. Dose gr. $x-x x$. P. nitratis, Charta, unsized paper saturated with a 20 per cent. solution. It is used, when burnt, by inhalation in asthma. P. permanganas. See Manganese. P. picras, $\mathrm{C}_{6} \mathrm{H}_{2}\left(\mathrm{NO}_{2}\right)_{3} \mathrm{OK}$, a yellow, crystalline bitter substance, which explodes on heating. It is insoluble in water; it has been used for tape-worm. P. platinichlorid., $\mathrm{K}_{2} \mathrm{PtCl}_{6}$, a yellow, crystalline powder. P. platinochlorid., $\mathrm{K}_{2} \mathrm{PtCl}_{4}$, a compound occurring in rose-colored crystals. P., Prussiate of : $\mathbf{I}$. Potassium ferricyanid, or red prussiate of potash. 2. Potassium ferrocyanid; the yellow prussiate of potash. P., Red Chromate of. Synonym of $P$. bichromas. $P$. succinas, has been used internally in hemorrhage. P. sulphas, $\mathrm{K}_{2} \mathrm{SO}_{4}$, an hepatic stimulant and laxative; soluble in 10 parts of water at ordinary temperature. Dose gr. $x x-\bar{z}$ ss. P. sulphis, several compounds of potassium and sulphur are known. $\mathrm{K}_{2} \mathrm{~S}$, the monosulphid, is the one commonly called potassium sulphid. It is used in the treatment of skin-diseases. P., Sulphurated, $\mathrm{K}_{2} \mathrm{~S}$, potassium sulphid. P. tartras, $\left(\mathrm{K}_{2} \mathrm{C}_{4} \mathrm{H}_{4} \mathrm{O}_{6}\right)_{2} \cdot \mathrm{H}_{2} \mathrm{O}$, nomal potassium tartrate, a crystalline, or amorphous substance, soluble in water. The acid tartrate, potassium bitar. trate, or "cream-of-tartar," $\mathrm{C}_{4} \mathrm{H}_{5} \mathrm{O}_{6} \mathrm{~K}$, is nearly insoluble in water. Both salts are diuretic and laxative. Potassium tartrate is also a remote antacid, that is, it renders the urine alkaline by being converted into a carbonate, in which form it is excreted. Dose gr. $\mathrm{xx}$ zss. P.telluras, $\mathrm{K}_{2} \mathrm{TeO}_{4}$, an efficacious antihydrotic in pulmonary tuberculosis. Dose gr. $1 / 2-3 / 4$. Unof.

Potate $\left(p o^{\prime}-t \bar{a} t\right)$ [potare, to drink]. In chemistry, liquefied.

Potato $\left(p o-t a^{\prime}-t o\right)$ [Sp., patata, sweet potato]. The tuber of Solanum tuberosum. P.-brandy, a brandy distilled from a mixture of potatoes and barley-malt. P.-blight. Same as P.-rot. P.-culture, a culture of microörganisms on potato. Several methods have been employed, the one now in general use being that known as Bolton and Globig's. It is as follows: Cylinders are cut with a cork-borer out of the center of large potatoes, trimmed of skin and imperfections, and cut obliquely, so as to make two wedge-shaped pieces. These are placed in sterile test-tubes with the thin end upward. The tubes are then sterilized for twenty minutes on three successive days. In Esmarch's method, slices of potato are placed in small sterilized glass dishes, and the latter, with the contained discs of potato, are sterilized in the steam sterilizer for an hour. In the original method potatoes were cleaned, then soaked in $\mathbf{I}$ to Iooo mercuric chlorid solution, and finally steamed for an hour. They were then carefully cut with a sterilized knife and allowed to fall apart in a moist chamber. Whichever method is used, the inoculation with the bacteria is the same, namely, by means of the Oese or sterilized needle dipped in the material to be cultivated. $\mathbf{P}$. cure. See Cure. P.-disease: I. Same as P.-rot. 2. A French term for tuberculosis in cattle. P.fungus, the cause of P.-rot, $q . v$. P.-mold. Same as P.-rot. P.-murrain. Same as P.-rot. P.paste, a substitute for the solid potato as a culturemedium for bacteria, when a very extensive surface is desired. It is a stiff paste made with water from the dry, floury centers of well-boiled potatoes. P.-rot. See under Mildew. P., Spanish, P., Sweet, the tuber of Ipomea batatas. P.-spirit. See Alcohol, Amyl. P.-sugar, a sugar obtained from potatoes. P.-treatment. Same as $P$.-cure.

Potency ( $p o^{\prime}$-ten-se) [posse, to be able]. Power. Efficacy.

Potential (po-ten'shal) [potens, able]. Able or powerful. A term applied to remedies or agents that are energetic. In electricity, the tension or pressure of the current. It is estimated quantitatively in volts. P. Cautery. See Cautery. P., Difference of, a term employed to denote that portion of the electromotive force which exists between any two points in a circuit. P. Energy, the force that an organism is capable of exerting under full stimulation. P., Zero, in electricity, the potential of a point infinitely distant from all electrified bodies.

Potentilla (po-ten-till-ah). See Tormentilla, and Hardhack.

Potentiometer (po-ten-she-om'-et-er) [potentia, power;

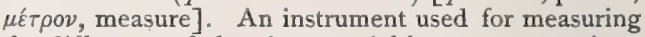
the difference of electric potential between two points.

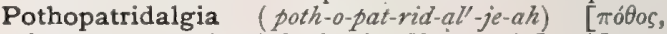

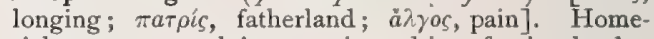
sickness, or nostalgia, experienced in a foreign land.

Potio, Potion ( $\left.p o^{\prime}-s h e-o, p o^{\prime}-s h u n\right)$ [potio, a drink]. A drink or draught of a medicinal preparation.

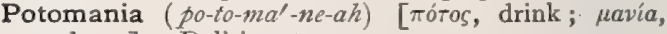
madness]. Delirium tremens.

Potometer (po-tom' ure]. In biology, an instrument for measuring the amount of water absorbed by a plant in a given time.

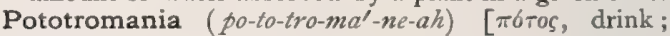
$\tau \rho b \mu o s$, tremor; $\mu a v i a$, madness]. Delirium tremens.

Pototromoparanoia ( $\left.p o-t o-t r o m-o-p a r-a n-o i^{\prime}-a h\right)[\pi 6 \tau o s$,

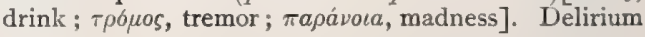
tremens.

Potpourri (po-poo-re') [Fr.]. A mixture of aromatic substances formerly used to perfume rooms.

Pott's Aneurysm. See Aneurysm, and Diseases, Table of. P.'s Boss, the projecting spinous process usually found in cases of Pott's disease. See Signs and Symptoms, Table of. P.'s Disease, or Curvature, caries of the vertebræ, generally of tuberculous origin. It originates usually in an osteitis of the bodies of the vertebræ. The symptoms are stiffness of the spinal column, pain on motion, tenderness on pressure, undue prominence of one or more of the spines; spasmodic pain in the abdomen; in late stages, sometimes paralysis. Abscess usually forms ; it may appear quite early. P.'s Fracture. See Fracture. P.'s Gangrene, senile gangrane. P.'s Paralysis, or Paraplegia, the paralysis resulting from pressure on the cord in Pott's disease.

Potters' Asthma. Synonym of a form of pneumonokoniosis prevalent among potters. P. Bronchitis. 
See Bronchitis. P. Clay. See Argilla. P. Consumption, a form of pneumonokoniosis prevalent among potters. P. Lung, a chronic inflammation of the lungs common among potters, and due to the inhalation of dust.

Pouch (pozech) [Fr., poche, a pouch, pocket]. In biology, a sac, cecum, diverticulum or bag-like structure. P.-bone, a marsupial bone. P.-corona, the coronal intestine of Medusa. Same as Canal, Corona. P. of Douglas, the cul-de-sac of Douglas, a pouch formed by the recto-uterine fold of the peritoneum. P. of Fabricius. See Bursa fabricii. P.-gestation, gestation in a pouch, as in marsupials. P.-gill, one of the gills of the lamprey, or marsipobranchs. P., Gut tural, in biology, one of the large mucous bags in solipeds situated between the atlas and the anterior portion of the pharynx and larynx. P., Hair, the depression in the skin in which the hair grows. Ps., lleo-cecal, narrow-necked folds of the peritoneum, at the termination of the ileum. P., Inguinal, a fold of the peritoneum behind the internal abdominal ring. P., Laryngeal, a blind pouch of mucosa opening into the ventral part of the ventricle of the larynx. P., Marsupial; in marsupials, the bag on the anterior abdominal wall in which the young are carried. P., Needham's, in biology, an enlargement or cecal diverticulum of the seminal duct of a cephalopod. P., Pararectal, the lateral portion of Douglas's pouch. P., Paravesical, the paravesical fossa. P. of Rathke, the diverticulum from the pharynx in the embryo, which goes to form the anterior portion of the hypophysis. P., Rectal, of sharks and rays, a vascular and glandular dorsal diverticulum of the rectum, which Wilder thinks may represent the allantois of higher vertebrates. P., Recto-uterine, a pouch-like fold of the peritoneum that is reflected over the uterus. P., Recto-vaginal. Same as P., Recto-uterine. P., Recto-vesical, the pouch of the peritoneum that is reflected on the bladder. P., of Seesel, a pouch in the embryo behind the summit of the hypophysis. P., Subcecal, a fold of the peritoneum behind and below the cecum. P. of the Tympanic Membrane, folds of mucosa around the horizontal portion of the chorda tympani nerve as it passes through the tympanic cavity. P., Utero-vesical, P., Vesico-uterine, a pouch of peritoneum situated between the uterus and the bladder.

Poudret, Poudrette (poo-dret') [Fr.]. A form of commercial fertilizer formerly made, the basis of which was night-soil, dried and mixed with charcoal, gypsum, and other ingredients.

Poultice ( $\left.p \bar{o} l^{\prime}-t i s\right)$ [ $\pi \hat{\partial} \lambda \tau o \zeta$, porridge]. A mixture of certain substances, as slippery elm, meal, flaxseed, mustard, etc., into a soft, mush-like mass, for application to the skin of a part. The poultice-material should be mixed with hot water into a mass of even consistence, and should be neatly spread upon muslin, linen, or lint, or even upon paper. Flaxseed or elm poultices should not be more than $1 / 4$ inch in thickness, and should receive a thin coating of olive-oil before being applied. This prevents their sticking to the surface of the body. P., Anodyne, one yielding an anodyne effect; it usually contains some preparation of opium. P., Antiseptic, one containing some germ-destroying substance. P., Fermenting, a poultice made by mixing wheat or corn flour with half its weight of yeast, and gently warming it until it begins to swell. It is used as an application to sloughing sores. P., Galvanic. See Galvanic. P., Porter, a flaxseed poultice made with a quantity of porter; its uses are those of the fermenting poultice, $q . v$. P., Vaginal, a poultice introduced into the vagina in the treatment of gonorrhea in the female.
Pound (pozend) [AS., pund, pound]. In Troy weight $12 \mathrm{oz}$. or 5760 grains ; in avoirdupois, $16 \mathrm{oz}$. or 7000 Troy grains, or 453.6 grams. Symbol tb. See Weights and Measures. P., Foot, the force necessary to raise one pound through the height of one foot. P.-nose, a nose that weighs a pound, a vulgarism for hypertrophy of the nose.

Poundal (pown'-dal) [AS., pund, pound]. A unit of force; that force which applied to a pound of matter for one second generates in it a velocity of one foot per second. P., Foot. See Poundal.

Poupart's Ligament. See Ligament.

Poverty (pov'-er-te) [ME., povertee, poverty]. The state or condition of being poor. P. of the Blood, a condition of the blood in which there is a deficiency of the red corpuscles or of the coloring-matter of the blood. P.-plants, a class of plants the names of which relate either to the fact that they greatly injure the farmer by impoverishing the soil, or to the extremely poor kind of soil in which they grow, e. g., Poverty (Polemonium caruleum), Poverty-weed (Sper. gula arvensis), Hunger-weed (Kanunculus arvensis), etc.

Powder (poru'-der) [ME., powder, powder]. Fine, minute, loose particles, as of dust. See Pulvis. P. of Algaroth, a powder prepared by adding an excess of water to an aqueous solution of the terchlorid of antimony. It is composed chiefly of the oxychlorid of antimony. P., Aromatic, a powder composed of cinnamon, ginger, and carda. mom, with or without nutmeg. P., Bleaching. Synonym of chlorinated lime. P.-blower, an apparatus for blowing powder into cavities, as the ear, the nose, the larynx, etc. P., Compound Chalk, a powder containing prepared chalk, acacia and sugar. P., Compound Effervescing. Same as $P$., Seidlitz. P., Compound Licorice, a powder containing senna, glycyrrhiza and sugar, with or without fennel and washed sulphur: P., Compound Morphin -- Same as P., Tully's. P., Dover's, a diaphoretic and sedative powder composed of powdered opium and ipecac, each one part, and eight parts of sugar of milk. P., Effervescing. See $P$., Soda. P., Fever, of James. See Pulvis antimonialis. P., Goa. See Chrysarobin. P., Gray. See Hydrar. gyrum. P., Insect. See Insect Powder. P., James's: Synonym of Pulvis antimonialis. P., Jesuits', powdered cinchona, so-called because the Jesuit priests distributed it gratuitously to the poor. P., Knox's : I. Calx chlorata; 2. A mixture of 3 parts calcium chlorite (?) and 8 parts sodium chlorid. P., Pearl. Bismuth subnitrate. P., Ringworm. Synonym of Chrysarobin. P., Seidlitz. See Potassium. (Pulv. effervesc. comp.) P., Soda, a powder containing sodium bicarbonate, 30 grains, and tartaric acid, 25 grains. P., Styptic, a powder containing alum, gum acacia, and colophony, sometimes with the addition of argil and tragacanth. P., Talcum, powdered soapstone, used often as a local application to inflamed surfaces. P., Tennant's, chlorinated lime. P., Tully's, a powder composed of camphor, prepared chalk, and licorice, 20 parts each, and morphin sulphate, I part. It is used as a substitute for Dover's powder. P., Vienna, potassa and lime. P., Vigo's, red oxid of mercury.

Power (pow'-er) [ME., poer, power]. Strength ; energy. P., Absolute, the weight which must be attached to a muscle to keep it from contracting when stimulated. $\mathbf{P}_{\text {i }}$, Combining, in chemistry, the number of hydrogen atoms with which an element is able to combine. P., Mechanical, either of the elementary powers, the lever and the inclined plane, from 
which all other mechanisms are derived. P., Sensorial, the power of receiving and emitting impulses. P., Sexual, the ability of having sexual intercourse. P., Specific Refractive, a quantity which is constant for every refractive substance, and is found by dividing the index of refraction of the substance, minus one, by the specific gravity of the substance. The quotient multiplied by the molecular weight of the substance gives the refraction equivalent. P., Specific Rotatory, the amount of rotation of a substance, in degrees of a circle of the plane of polarized light, produced by one gram of the substance dissolved in one c.c. of liquid examined in a column one decimeter long.

Pox (poks) [pocks: pl. of Pock]. I. A term applied to several infectious eruptive diseases. 2. Syphilis. P., Ape, an exanthematous disease of West Indian monkeys, observed during smallpox epidemics. P., Bastard. Synonym of Varicella. P., Chicken. See Varicella. P., Cow. See Coze-pox. P., False. Synonym of Varicella. P., French. See Syphilis. P., Gland, P., Glans. Synonyms of Varicella. P., Grease. Synonym of Horse-pox. P., Great. Synonym of Syphilis. P., Horn. See Horn-pox. P., Horse. See Horse-pox. P., Small. See Variola.

Practice (prak'-tis) [practicare, to practise]. The official duties of a physician or surgeon in his professional work; also, the exercise of these duties.

Practitioner (prak-tish'-un-er) [Fr., practicien; practicare, to practise]. One who practises a profession, especially that of medicine. (A badly-formed word.) P., General, one who treats all ailments, in distinction from the specialist, who treats only one or a few diseases, or the diseases of one or a few organs.

Pra- (pre-) [L.]. A Latin preposition meaning before, used as a prefix to denote position. It places the words with which it is combined in antithesis to those combined with post-. For anglicized words thus begining see Pre-

Præbium (pre'-be-um) [prabere, to furnish]. Dose.

Præcava ( pre-ka'-vah), See Precava.

Præcinctum (pre-sink'-tum). Synonym of Diaphragm.

Præcordia (pre-kor'-de-ah). See Precordia.

Præcornu (pre-kor'-nu). See Precornu.

Præcuneus (pre-ku-ne'-us). See Precuneus.

Præforceps (pre-for'-seps). See Preforceps.

Prægeniculatum (pre-jen-ik-u-la'-tum). See Pregeniculatum.

Præglobin (pre-glo'bin). See Preglobin.

Præhallux (pre-hal'-uks). See Prehallux.

Prælabrum (pre-la'-brum) [prce, before; labrum, lip: pl., Pralabra]. In biology, the clypeus or epistoma.

Præmaxilla (pre-maks-il'-ah). See Premaxilla.

Præmedulla (pre-me-dul'-ah). Synonym of Medulla oblongatr.

Præmose ( $\left.p r e^{\prime}-m o \bar{z}\right)$. See Premose.

Prænomen (pre-no'-men). See Prenomen.

Præoperculum (pre-o-per'-ku-lum). See Preoperculum.

Præpedunculus (pre-pe-dung'-ku-lus). See Prepedunculus.

Præpelvisternum (pre-pel-ris-ter'-num). See Prepelvisternum.

- Præperforatus (pre-per-for= $a^{\prime}$-tus). See Preperforatus. Præputium (pre-put'she-um). See Prepuce.

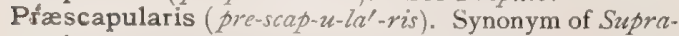
spinatus.

Præscutum (pre-sku'-tum) [pra, before; scutum, a shield: pl.,Prescuta $]$. In biology, the most anterior of the sclerites, composing the tergal portion of each thoracic segment of an arthropod.

Præseminal (pre-sem'-in-al). See Preseminal.

Præsternum (pre-ster'-num). See Presternum.
Prævia ( $\left.p r e^{\prime}-v e-a h\right)$ [pre, before; via, a way]. First: coming before. P., Placenta. See Placenta.

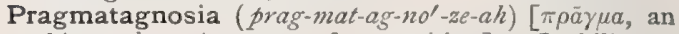
object; a jvwoia, want of recognition]. Inability to recognize an object. P., Visual, a term suggested by Dr. John Wyllie for object-blindness.

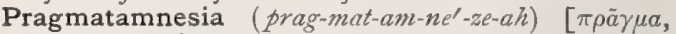

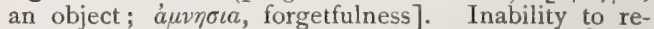
member the appearance of an object. P., Visual, a term suggested by Dr. John Wyllie for that mental condition in which there is inability to call up the visual image of an object.

Prague Method. A method of delivery of the aftercoming head. The child's ankles are grasped above the internal malleoli with the right hand. The index finger of the left hand is flexed over one clavicle, and the remaining fingers of the same hand over the other clavicle. Traction directly down is now made with both hands until the perineum is well distended. The right hand then loosens its hold upon the ankles and again grasps higher up the legs, the child's feet being in contact with the back of the right hand. By a circular movement the feet are now raised toward the mother's abdomen, the obstetrician using the left hand, as originally placed, as a fulcrum around which the head moves.

Prairie (pra'-re) [Fr.]. A meadow. P. Digs. See Army Itch. P. Itch, a name given to a combination of pruritus hiemalis and scabies. See Army Itch.

Pratal (pra'-tal) [pratum, a meadow]. In biology, inhabiting meadows. Cf. Pascual.

Pratesi's Reagent. A reagent for the detection of sugar in the urine. It consists of potassium bichromate and an alkaline silicate. See Tests, Table of.

Pravaz's Syringe. A hypodermatic syringe with a long trocar and cannula.

Praxis $\left(\right.$ praks $\left.^{\prime}-i s\right)$. See Practice.

Pray's Test-letters or Test. A test for astigmatism, consisting of capital letters composed of strokes that run in different directions for each letter.

Prazmowski, Bacillus of. See Bacteria, Synonymatic Table of.

Pre-acetabular ( pre-as-et-ab'-u-lar) [pra, before; acetabulum, acetabulum]. Situated in front of the acetabulum.

Pre-albuminuric (pre-al-bu-min-u'-rik) [pra, before; albumen, albumin; ovjov, urine]. A condition or symptom coming or occurring before the appearance of albuminuria.

Pre-anal (pre-a'-nal) [pra, before; anus, anus]. In biology, situated in front of the anus.

Pre-aortic (pre-a-or'-tik) [pra, before; áoprí, aorta]. Situated in front of the aorta.

Pre-aseptic (pre-as-ep'-tik) [pree, before; à, priv.; $\sigma \tilde{\eta} \psi \iota$, sepsis]. Pertaining to the period before the introduction of aseptic surgery.

Pre-ataxic (pre-at-aks'-ik) [pre, before; ả, priv.; $\tau a ́ \xi ı$, , order]. Occurring before ataxia.

Pre-auditory ( pre-aw'-dit-ar-e) [ pra, before ; audire, to hear]. In anatomy, situated in front of the auditory nerve or canal.

Pre-axal (pre-aks'-al) [pre, before; axis, axis]. Prechordal; placed in front of the axon.

Pre-axial (pre-aks'-e-al) [pra, before; axis, axis]. Situated in front of the axis; in a limb, situated on the internal or anterior aspect-in the arm, on the radial, in the leg, on the tibial side.

Prebacillary (pre-bas'-il-a-re) [pra, before; bacillus, bacillus]. Occurring before the invasion of the system. by bacilli.

Prebasal (pre-ba'-zal) [pre, before; basis, step, pedes. tal]. In biology, in front of a basal portion. 
Prebasilar ( $p r e-b a^{\prime}$-zil-ar) [ pra, before; basis, base] Situated, or occurring, in front of any basilar structure, especially, in front of the basilar process of the occipital bone.

Prebrachial (pre-bra'-ke-al) [prce, before; brachium, upper arm ]. (a) Located on the anterior aspect of the brachium or upper arm, e.g., the group of prebrachial muscles: biceps, coraco-brachialis, and brachialis anticus. (b) A vein in the wings of certain insects.

Prebrachium (pre-bra'-ke-um) [pra, before; brachium, arm]. The anterior brachium of the brain seen on the lateral slope of the mesencephal. The fibers run obliquely dorsoventrad. In biology, the antebrachial membrane or propatagium. The wingmembrane of bats, above the arm or forearm.

Prebranchial (pre-brang'-ke-al) [pre, before; branchice, gills]. In biology, located in front of the gills.

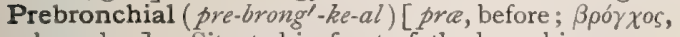
bronchus]. Situated in front of the bronchi.

Prebuccal (pre-buk'-al) [prce, before; bucca, cheek]. In biology, placed in front of the mouth; preoral; prostomial.

Precancerous (pre-kan'-ser-us) [ pra, before; cancer, carcinoma]. Occurring before the development of a carcinoma.

Precardiac (pre-kar'-de-ak) [pra, before; кapdia, heart]. Cephalad of the heart.

Precartilaginous (pre-kar-til-aj'-in-us) [pra, before ; cartilago, cartilage]. Prior to the formation of cartilage, as in a certain stage of an embryo.

Precaudal (pre-kaw'-dal) [pra, before; cauda, tail]. Situated in front of the tail or tail-vertebræ.

Precava (pre-ka'-vah) [pre, before; cavus, hollow]. The anterior, or superior vena cava; the vena cava descendens.

Precaval (pre-ka'-val) [pra, before; cavus, hollow]. Pertaining to the precava.

Precentral (pre-sen'-tral) [pra, before; centrum, center]. Situated in front of the central fissure. P. Convolution. See Convolutions, Table of. P. Fissure. See Fissures, Table of. P. Sulcus. Synonym of $P$. Fissure.

Precerebellar (pre-ser-e-bel'-ar) [pra, before; cerebellum, cerebellum]. Situated before (above) the cerebellum.

Precerebral (pre-ser'-e-bral) [ pra, before; cerebrum, cerebrum ]. Situated, or occurring before (above), the cerebrum.

Prechordal (pre-kor'-dal) [ pra, before; chorda, chord, string]. Situated in front of the notochord.

Precipitant (pre-sip'-it-ant) [pre, before; caput, head]. Any reagent causing precipitation.

Precipitate (pre-sip'-it-ät) [pre, before ; caput, head]. The solid substance thrown down from a solution of a substance on the addition of a reagent which deprives it of its solubility. [Abbreviation: Ppt.] P., Atmospheric, one formed on simple exposure to the air. P., Red. See Hydrargyrum oxidum rubum. P., White, $\mathrm{N}_{2}\left(\mathrm{Hg}_{2}\right)_{3} \mathrm{Cl}_{2}$, formed by adding ammonium hydrate to a solution of mercuric chlorid. Hydrargyrum ammoniatum.

Precipitate (pre-sip'-it-it) [pre, before; caput, head]. Headlong; hasty. P. Labor. See Labor.

Precipitation (pre-sip-it-a $-a^{\prime}$ shun) [precipitatio]. The process of throwing down solids from the liquids which hold them in solution. It is usually effected by chemic reaction. Precipitates are crystalline, amorphous, curdy, flocculent, granular, or gelatinous, according to the form assumed. The agent causing precipitation is the precipitant, the solid thrown down, the precipitate. P., Fractional, the process employed in separating a mixture of fatty acids by the addition of small portions of the acetate of a heavy metal. The precipitate consists of a combination of the metal with a large proportion of the less volatile acid and a small proportion of the more volatile acid. In the filtrate the proportions are reversed. The metal is separated from the less volatile acid by dissolving the precipitate in hydrochloric acid. The process is repeated until finally the filtrate contains practically only the more volatile acid, and the precipitate only the less volatile acid. P., Partial, a process of separating two soluble salts by precipitation of a portion of each, and subsequent decomposition of the precipitate. The latter is redissolved and again precipitated.

Preclitellian (pre-kli-tell-e-an) [pree, before; clitellum, a pack-saddle]. In biology, applied to such earthworms as have the ducts of the testes opening in front of the clitellum.

Precloacal (pre-klo'-a-kal) [pre, before; cloaca, a sewer]. In biology, of or pertaining to, the front part of the cloaca.

Precocity (pre-kos'-it-e) [pre, before; coquere, to ripen]. Early development or maturity. It is applied especially to great development of the mental faculties at an early age.

Precommissure (pre-kom'-is-ür) [pre, before; commissura, commissure]. The anterior commissure of the brain; it is a marked thickening of the parietes, a compact bundle of nerve-fibers extending laterad and dividing a short distance from the meson into two portions, a temporal and an olfactory.

Precoracoid, Præcoracoid (pre-kor'-ak-oid) [pre, before; $\kappa \tilde{\omega} \rho a \xi$, raven; $\varepsilon l \delta o s$, like]. In biology : $(a)$ placed in front of the coracoid process of the scapula; (b) a specific part of the pectoral arch of certain vertebrates.

Precordia ( pre-kor'-de-ah) [ pre, before; cor, the heart: either sing., nom., fem., or pl. of Precordium ]. A name applied to the diaphragm, the thoracic viscera, or the epigastric region, but often more especially to the area of the chest overlying the heart.

Precordial (pre-kor'-de-al) [pre, before; cor, heart]. Situated, or occurring, in the region of the precordia. Precordialgia ( $\left.p r e-k o r-d e-a l^{\prime}-j e-a h\right)$ [ $p r c$, before; cor, heart; a $\lambda$ yos, pain $]$. Pain in the precordial region.

Precordium (pre-kor'-de-um). Synonym of Precordia.

Precorneal (pre-kor'-ne-al) [prce, before; corneus, horny]. Situated on the front of the cornea of the eye.

Precornu (pre-kor'-nu) [pra, before; cornu, a horn]. The anterior cornu of the lateral ventricle of the brain.

Precribrum (pre-krib'-rum) [pra, before; cribrum, sieve]. The anterior perforated space of the brain.

Precuneal (pre-ku'-ne-al) [ pra, before; cuneus, wedge]. Situated in front of the cuneus; specifically, pertaining to the precuneus.

Precuneus (pre-ku'-ne-us) [pra, before; cuneus, wedge]. The quadrate lobule of the parietal lobe situated cephalad of the cuneus of the occipital lobe.

Precurrent (pre-kur'-ent) [pre, before; currere, to run]. In biology, extending cephalad; antrorse.

Precursor (pre-kur'sor) [pra, before; currere, to run]. A forerunner; a premonitory sign.

Precursory (pre-kur'-sor-e). Synonym of Premonitory.

Predacean ( $p r e-d a^{\prime}$-se-an) [pradax, given to preying]. In biology, a carnivorous or predaceous animal.

Predelineation (pre-de-lin-e-a/shun). Synonym of Preformation.

Predentary (pre-den'-ta-re) [pra, before; dens, tooth]. In biology, a portion of the jaw-bone of certain reptiles. 


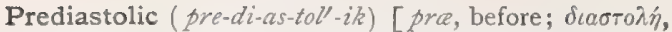
diastole]. Occuring before the diastole of the heart.

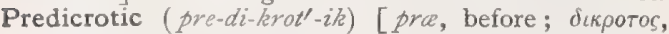
double beating]. Preceding the dicrotic. P. Wave, the primary wave in the dicrotic curve of a sphygmogram.

Predigastric (pre-di-gas'-trik) [pra, before; digastric] Pertaining to the predigastricus.

Predigastricus (pre-di-gas'-trik-us) [pra, before; digastric ]. The anterior belly of the digastric muscle,

Predigested (pre-di-jes'-ted) [ pree, before; diverere, to digest]. Partly digested by artificial means before being taken into the stomach. P. Foods, foods that have been prepared by a process of artificial digestion through the agency of various ferments.

Predigestion (pre-di-jes'-chun) [ pra, before, digerere, to digest]. Previous digestion.

Predilatator (pre-dil-at-a'-tor) [pra, before; dilator, a dilator]. The anterior dilator muscle of the nostril.

Predisponent ( $\left.p r e-d i s-p o^{\prime}-n e n t\right)$. Synonym of Predisposing.

Predisposing ( $\left.p r e-d i s-p o^{\prime}-z i n g\right)$ [ pro, before ; disponere, to dispose]. A peculiar condition of the system that renders it liable to attack, under a slight exciting cause ; making susceptible.

Predisposition ( $\left.p r \bar{e}-d i s-p o-z i s h^{\prime}-u n\right)$ [pra, before; disponere, to dispose]. That condition of the body in which causes that leave other persons unaffected call forth an attack of disease in individuals predisposed. Predisposition may be inherited or acquired. The term at the present time refers especially to susceptibility to infectious diseases, and implies a peculiar condition of the bodily juices or cells, in which these are unable to repel the invasion of pathogenic microorganisms.

Predormition (pre-dor-mish'-un) [ [pra, before; dormition]. Applied to the stage of unconsciousness immediately preceding actual sleep.

Predorsal (pre-dor'-sal) [pra, before; dorsum, back]. Situated in front of the dorsum or back.

Preëfficients (pre-ef-fish'-entz) [pro, before; efficiens effecting]. ' In biology, Galton's term for the sum total of predisposing causes, or factors, in the consideration of any given phenomenon.

Pre-esophageal, Præesophageal (pre-e-so-faj'-e-al)

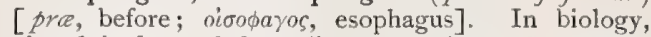
placed in front of the gullet or anterior to the esophageal ring of an invertebrate.

Prefloration (pre-flo-ra'-shun) [pra, before; florare, to blossom]. See Estivation.

Prefoliation (pre-fo-le-a'-shun) [ pra, before; foliare, to put forth leaves]. See Vernation.

Prefontanel (pre-fon-tan-el') [pra, before; fontana, a little fountain]. The anterior fontanel.

Preforceps (pre-for'-seps) [prce, before; forceps, forceps]. Those hooked or curved anterior fibers of the callosum that reach cephalad into the frontal lobe.

Preform (pre-form') [pra, before; formare, to shape, fashion]. In biology, the antecedent determination of a form or shape.

Preformation (pre-for-ma'-shun) [pra, before; formare, to form]. A previous formation. P., Theory of, a theory prevalent at one time, according to which the germs of all individuals of a species were contained in the first individual of that species created; that, e. $g^{*}$. Eve held in her ovary the germs of all human beings, one encased within the other. Those who espoused this theory of female encasement were known as Ovulists. An opposing school taught that the spermatozoön was the essential element in reproduction; that the ovum simply offered a favorable soil for its development, and that in the spermatozoon of Adam all mankind had been preformed. The adhe- rents of the theory of the encasement of the male were styled Animalculists. See Incasement.

Prefrontal (pre-frun'-tal) [pra, before; frons, forehead]. In biology: (a) the fore part of the frontal region; $(b)$ one of the anterior cranial bones of certain vertebrates.

Pregeminal (pre-jem'-in-al) [pre, before; geminus, twin]. Relating to the anterior pair of the corpora quadrigemina.

Pregeminum (pre-jem'-in-um) [pre, before; geminus, twin]. The anterior pair of the corpora quadrigemina, considered as forming together a single organ.

Pregeniculatum (pre-jen-ik-u-ln'-tum) [pra, before; geniculatum, geniculate]. Same as Pregeniculum.

Pregeniculum (pre-jen-ik'-u-lum). The external geniculate body, on the outer side of the corpora quadrigemina and under the back part of the optic thalamus. It is characterized by the regular alternation of deeply gray and white lamina. The nerve-cells in the gray substance are large, multipolar, and pigmented.

Pregenital (pre-jen'-it-al) [pra, before; genitalis, belonging to generation]. In biology, located in front of the external genital organs.

Preglenoid (pre-gle'-noid) [pra, before; $\gamma \lambda \dot{\eta} v \eta$, pit; cidos, like]. Situated in front of the glenoid fossa.

Preglobin (pre-glo'-bin) [pra, before; globus, a globe]. An albuminoid derivable from cytoglobin by the influence of dilute acids. It differs from other albuminoids in being insoluble in an excess of acetic acid.

Preglobulin (pre-glob'-u-lin) [ pree, before; globulus, a little ball]. An albuminous body present in small amount in cells, insoluble in water, soluble in a ten per cent. sodium chlorid solution and a dilute alkaline solution. It slightly inhibits coagulation.

Pregnancy (preg'-nan-se) [pregnans, with child]. The state of the female corresponding to the presence within her body of the product of conception; the period from conception to delivery. If delivery is protracted far beyond the normal time and the ovum is dead, the condition of pregnancy cannot be said to exist. The normal duration of pregnancy in woman is 280 days, or ten lunar months of twenty-eight days each, or nine calendar months. Various methods have been devised to estimate the probable termination of pregnancy, one of which, Ely's Table, is here introduced. The period of gestation varies in different animals, as shown in the following table:-

PERIOD OF GESTATION OR INCUBATION (Schenk). Days.

Coluber, ....... 12

$\left.\begin{array}{l}\text { Hen, } \\ \text { Duck }\end{array}\right\} \ldots . . .2$. .

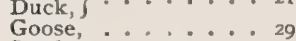

Stork, :...... 42

Cassowary, ..... 65

Mouse, ...... 24

$\left.\begin{array}{l}\text { Rabbit, } \\ \text { Hare, }\end{array}\right\} \ldots . . .32$

Weeks.

Rat, ...... 5

Guinea-pig, ..... 7

$\left.\begin{array}{l}\text { Cat, } \\ \text { Marten, }\end{array}\right\} . . . .88$

Dog,

Fox,

9

Weeks.

P., Abdominal, the lodgment of the developing ovum in the abdominal or peritoneal cavity; it is primary, if the fertilization take place in the cavity, and secondary, if the embryo or ovum break through the enclosing walls of a tube or uterine cornu into the peritoneal cavity. P., Cervical: 


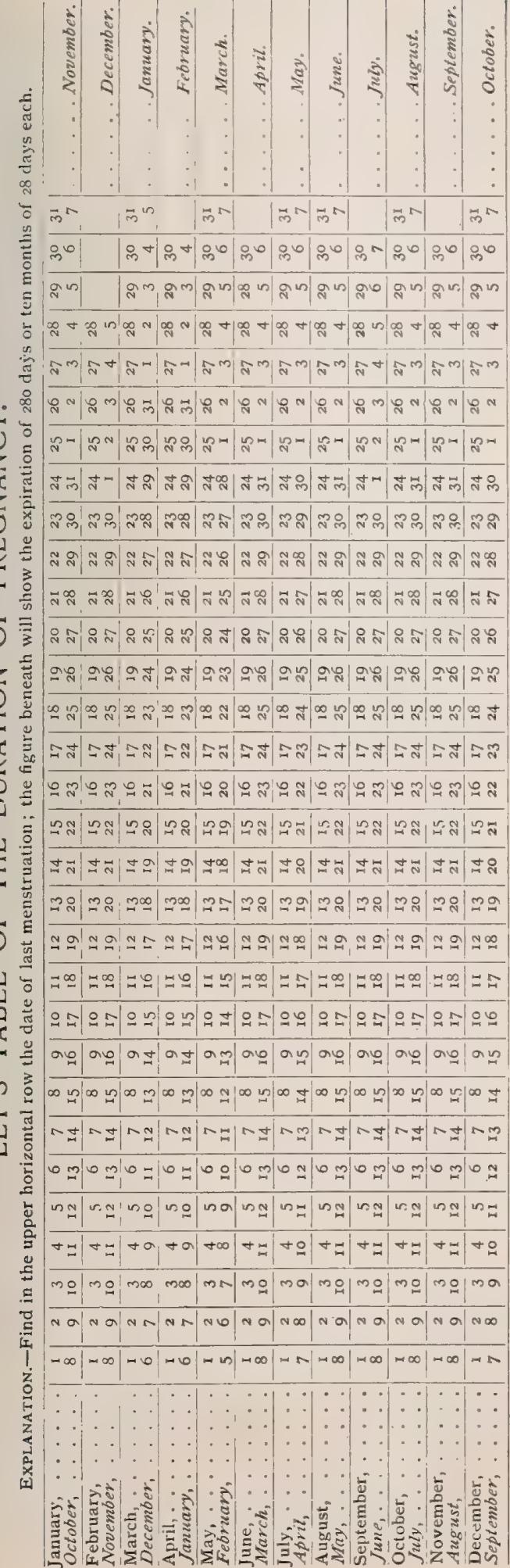

primitive, a variety of ectopic gestation wherein the ovum is arrested and developed in the cervical canal; secondury, in early abortion the ovum expelled from the uterine cavity, remains in the cervical cavity. P., Cornual, pregnancy in one of the horns of a twohorned uterus. P., Extra-uterine, ectopic restation; the development of the ovum outside of the cavity of the uterus. It is due to any condition that will prevent the entrance of the ovum into the uterus, as, for instance, inflammation of the Fallopian tubes. Pregnancy may take place within the tube, in the ovary, in the part of the tube that traverses the uterine wall, or in the abdominal cavity. P., False, any condition in the abdomen that simulates pregnancy. P., Fatty, false pregnancy due to the presence of a large quantity of fat in the abdominal walls. P., Feigned, pregnancy simulated by malingerers. P., Gemellary, twin pregnancy. P., Hysterical, a very deceptive condition of certain hysterical females which simulates pregnancy. There is abdominal enlargement, generally from tympanites, cessation of menstruation, and other symptoms of pregnancy; movements of the intestines may counterfeit fetal movements. The tympany of the abdomen and the modifications of the signs usually produced by anesthetization are important in the diagnosis. P., Interstitial, a variety of extra-uterine and tubal pregnancy, the ovum developing in that portion of the oviduct that passes through the wall of the uterus. P., Molar, pregnancy in which the ovum is converted into a mole. P., Multiple, that form of pregnancy in which the uterus contains two or more fetuses. P., Mural, pregnancy in the uterine wall; it is classed as one variety of extra-uterine pregnancy. P., Nervous. Synonym of $P$., Hysterical. P., Ovarian, the fecundation and growth of the ovum taking place within the ovisac. P., Phantom. Synonym of $P$., Hysterical. P., Plural, the development of more than one fetus at one time. P., Precocious, pregnancy at an early age, sometimes before the establishment of menstruation. P., Signs of. See Hegar's, Braxton Hicks and Jorisenne's in Signs and Symptoms, Table of. P., Signs or Tests of, those clinical manifestations by which the existence of pregnancy may be demonstrated. There are three so-called absolute signs of pregnancy : Ballottement, fetal movements, and the fetal heart-sounds. Hegar's sign and Braxton Hicks' sign are also valuable. Beccaria's sign of pregnancy is an intense pulsating pain in the occipital region. P., Single or Simple, the normal development of a single fetus. P., Spurious. Synonym of $P$., False. P., Tubal, development of the ovum in the oviduct. P., Tubo-abdominal, the ovum is de veloped in the ampulla and extends into the abdominal cavity. P., Tubo-ovarian, the ovum is attached to the oviduct and ovary. P., Tubo-uterine. Same as P., Interstitial. P., Twin, the presence of two fetuses in the uterus. P., Unconscious, pregnancy, of the existence of which the woman has not become aware.

Pregnant (preg'-nant) [pragnans]. With child; gravid.

Prehallux (pre-hal'-uks) [ pra, before; hallex or allex, the great toe: gen., Prehallucis; pl., Prehalluces]. In biology, the tibial sesamoid bone found in mammals having complete digits. A rudimentary structure corresponding to the prepollux is seen in the human embryo of the second month. Cf. Prepollex and Postminimus.

Prehalter (pre-hazul'-ter) [ pra, before; halter, leaping weights: pl., Prehalteres]. In biology, a membran- 
ous scale in front of the balancer or halter of dipterous insects.

Prehemiplegic (pre-hem-ip-le'-jik) [ pre, before ; $\eta \mu$, half; $\pi \lambda \eta \gamma \dot{\eta}$, stroke]. Occurring before an attack of hemiplegia, P. Chorea, choreiform movements of a limb, precedıng its paralysis. P. Pain, painful sensations in a limb which subsequently becomes paralyzed.

Prehensile (pre-hen'-sil) [prehendere, to lay hold of]. In biology, adapted for grasping or holding.

Prehension (pre-hen'-shun) [prehendere, to seize] The act of taking hold or seizing.

Prehensorium (pre-hen-so'-re-um) [prehendere, to lay hold of, seize]. In biology, a structure adapted for grasping; specifically applied to the hind legs of certain spiders.

Prehensory (pre-hen'-so-re). Same as Prehensile.

Prehnitic Acid (pren-it'-ik). See Acid.

Prehnitol (pren'-it-ol), $\mathrm{C}_{10} \mathrm{H}_{14}$, A hydrocarbon, produced by warming durene with concentrated $\mathrm{H}_{2} \mathrm{SO}_{4}$. It is a liquid boiling at $204^{\circ} \mathrm{C}$.

Prehypophysis (pre-hi-poff'-is-is) [pre, before ; $i \pi b \phi$ $v \sigma \iota$, hypophysis]. The anterior and larger portion of the hypophysis, derived from the enteron.

Pre-insula (pre-in'-su-lah) [pra, before; insula, insula]. The cephalic region of the insula.

Prelacrymal (pre-lak'-rim-al) [ pre, before; lacryma, tear]. Situated in front of the lacrymal bone.

Prelum (pre'-lum) [L.]. Press. P. abdominale, the squeezing of the abdominal viscera between the diaphragm and the rigid abdominal wall, as in the processes of defecation, micturition, and parturition. P. arteriole. Synonym of Tourniquet.

Prelumbar (pre-lum'-bar) [pre, before; lumbus, loin]. Anterior to the lumbar vertebræ or the loins.

Premandibular (pre-man-dib'-u-lar) [pra, before ; mandibula, mandible]. See Predentary.

Premaniacal (pre-ma-ni'-ak-al) [pra, before; $\mu a v i a$, mania]. Previous to insanity, or to an attack of mania.

Premature (pre-mat-ū $r^{\prime}$ ) [pre, before; maturare, to ripen]. Occurring before the proper time. P. Labor. See Labor. P. Respiration, respiration taking place before complete birth of the fetus.

Premaxilla (pre-maks-il'-ah) [pra, before; maxilla, jaw]. The intermaxillary bone.

Premaxillary (pre-maks'-il-a-ree). See Intermaxillary.

Premenstrual (pre-men'-stru-al) [pre, before; menstrua, menstrua]. Preceding menstruation.

Premolar (pre-mo'-lar) [pre, before; mola, millstone]. I. Situated in front of the molar teeth. 2 . One of the two anterior permanent molars. A term applied to the bicuspids (bicuspidati, two spear-points) of a horse, from the two eminences on their crowns.

Premonitory (pre-mon'-it-or-e) [ pra, before; monere, to warn]. Indicating the approach of an event or the oncoming of a disease.

Premorse (pre-mors') [ pre, before; mordere, to bite]. In biology, irregularly truncate, as if bitten off.

Prenarial (pre-na'-re-al) [pre, before; naris, nostril]. Pertaining to the prenares.

Prenaris (pre-na'-ris) [pre, before; naris, nostril]. The anterior naris.

Prenasal (pre-na'-zal) [ pra, before; nasus, nose]. In front of the nose or nasal passages.

Prenatal (pre-na'-tl) [pra, before; nasci, to be born]. Existing previous to birth.

Prenomen, Prænomen (pre-no'-men) [ pre, before; nomen, name: pl., Prenomina, Pranomina]. In biology, the first, or generic, portion of an onym in binominal or polynominal nomenclature.

Pre-occipital (pre-ok-sip'-it-al) [pra, before; occiput, occiput]. Situated anterior to the occipital region. P.
Fissure, a fissure on the ventral, lateral surface of the cerebrum separating the occipital and sphenotemporal lobes.

Preoccupation ( $p r e-o k-u-p a^{\prime}-s h u n$ ) [ $p r c e$, before; occupare, to occupy]. The condition of being so engrossed in one's own thoughts as not to answer or hear when accosted; a symptom of melancholia.

Preocular (pre-ok'-ular) [pre, before; oculus, eye]. In biology, placed in front of the eye; as the preocular antenna of certain insects.

Preomosternal (pre-o-mo-ster'-nal) [pra, before ; $\omega \mu \sigma$, shoulder; orépvov, sternum]. Pertaining to the preomosternum.

Preomosternum (pre-o-mo-ster'-num) [ proe, before;

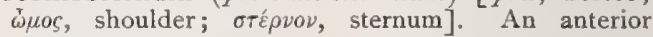
omosternum.

Preopercle (pre-o-per'-kl). Same as Preoperculum.

Preoperculum, Præoperculum (pre-o-per'-ku-lum) [pra, before; operculum, a lid: pl., Preopercula]. In biology : (a) the fore-lid, or operculum, of a mosscapsule; $(b)$ one of the opercular bones of a fish; $(c)$ the frontal operculum of the brain, between the presylvian and subsylvian fissures.

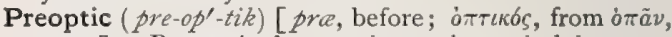
to see]. Pregeminal; anterior to the optic lobes.

Preopticus (pre-op $\left.p^{\prime}-t i k-u s\right)$ [pra, before; $\bar{\psi} \psi$, sight]. The anterior pair of the quadrigeminal bodies.

Preoral (pre-o'-ral) [pra, before; os, oris, mouth]. Situated in front of the mouth; prebuccal. P. Segments, in biology, certain bypothetic, primitive rings in articulated animals, supposed to be cephalad of those bearing the mouth-organs, and to be folded back, thus forming the top of the head.

Preosseous (pre-os'-e-us) [pra, before; os, a bone]. Preceding the formation of bone. Applied to a transparent substance having the chemic characters of ostein, with cavities containing osteoblasts, from which the bone is formed.

Prepalatal (pre-pal'-at-al) [pre, before; palatum, palate]. Situated in front, or in the anterior part, of the palate.

Prepalatine (pre-pal'-at-in) [prce, before; palatum, palate]. Synonym of Prepalatal. Also, as a plural noun, the maxillary processes of the palate bone.

Preparation (prep-ar-a'-shun) [praparare, to make ready]. Anything made ready. In anatomy, any part of the body prepared or preserved for illustrative or other uses. In pharmacy, any compound or mixture made after a formula.

Prepared (pre-pārd') [proparare, to make ready]. Made ready. P. Cover-glass, in bacteriology, a thin glass cover upon which a delicate film of the substance to be examined has been spread, and after having dried, has been fixed by passing the cover-glass thrice through the flame of a spirit-lamp or Bunsenburner. The cover-glass is now ready to be stained.

Preparoccipital (pre-par-ok-sip'-it-al) [pra, before;

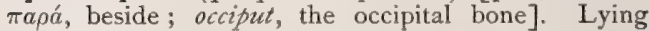
anteriorly in the paroccipital gyre of the brain, as a certain fissure.

Prepatellar (pre-pat-cl'-ar) [ pro, before; patella, patella]. Situated in front of the patella, as a bursa.

Prepeduncle (pre-pe'-dung-kl) [pra, before; pedunculus, peduncle]. The anterior of the cerebellar peduncles extending to the mesencephal.

Prepeduncular (pre-pe-dung - ku-lar) [pra, before; pedunculus, peduncle]. Pertaining to the prepedunculus.

Prepedunculate (pre-pe-dung $g^{\prime}-k u$-lät) [pra, before; pedunculus, peduncle]. Same as Prepeduncular.

Prepedunculus (pre-pe-dung $\left.g^{\prime}-k u-l u s\right)$ [pre, before: pedunculus, peduncle]. See Prepeduncle. 
Prepelvisternal (pre-pel-vis-ter'-nal) [pre, before;

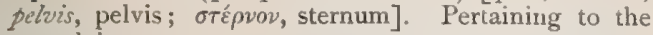
prepelvisternum.

Prepelvisternum (pre-pel-vis-ter'-num) [pre, before;

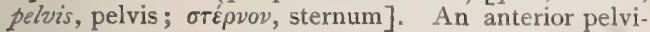
sternum.

Preperforatus (pre-per-for-a'-tus) [ pre, before; perforare, to perforate]. The anterior perforated space.

Prephthisis, Præphthisis (pre-ti'-sis, pre-te'-sis) [ pra, before; $\phi \theta i \sigma \iota s$, phthisis]. The pretuberculous state. The predisposition to tuberculosis.

Prepigmental (pre-pig-men'-tal) [pra, before; pigmentum, a pigment]. Situated within the pigmented layer of the eye.

Prepituitary (pre-pit-u'-it-a-re) [pree, before ; pituita, phlegm]. Situated in front of the pituitary body.

Preplacental (pre-plas-en'-tal) [prce, before; $\pi \lambda \alpha \kappa o u ̄ s$, placenta, placenta]. Previous to the formation of the placenta.

Prepollex (pre-pol'-eks) [pre, before; pollex, the thumb: gen., Prepollicis: pl., Prepollices]. In biology, the radial sesamoid bone of such mammals as have five complete digits. Occasionally, as in Pedetes caffer, the so-called prepollex consists of two bones, of which the distal one bears a distinct nail-like horny covering. Cf. Prehallux, Postminimus.

Prepontile (pre-pon'-til) [pre, before; pons, a bridge]. Situated in front of the pons varolii.

Prepotency (pre-po'-ten-se) [pre, before; posse, to be powerful]. In biology, dominant "force of heredity." The power that one parent may have of impressing his or her own character upon the offspring, the peculiar characters of the other parent being less obviously transmitted. P., Individual, a phenomenon, recognized by breeders of plants and animals, in which it seems that a marked tendency occasionally exists in certain individuals to transmit their special, individual characters to the majority of the offspring. Among plants, Vilmorin distinguishes as "bons etalons" individuals that possess the capacity of transmitting their own characters to their offspring in a great degree. One of the best known examples among animals is that of the "otter sheep." P., Racial, a particularly marked power of transmission in a given race in contrast to other races; this power is more marked in the pouter pigeon than in the fantail, so that when these two races are crossed, the characters of the pouter predominate in the offspring.

Prepubic (pre-pu'-bik) [pra, before; pubis, pubis]. In biology, placed in front or in the fore part of the pubis.

Prepubis ( $\left.p r e-p u^{\prime}-b i s\right)$ [pra, before; pubis, pubis : $p l$., Prepubes]. In biology, the pubis of a bird; the preacetabular part of the pubic bone.

Prepuce (pre'-pūs) [praputium, prepuce]. The foreskin of the penis. It is lined with mucosa. P. of the Clitoris, the superior folds of the nymphæ surrounding the glans clitoris.

Preputial ( $\left.p r e-p u^{\prime}-s h e-a l\right)$ [ proputium, prepuce]. Pertaining to the prepuce.

Preputium (pre-pu'-she-um). See Prepuce.

Prepyloric (pre-pi-lor'-ik) [pra, before; pylorus, the distal orifice of the stomach]. Placed in front of the pylorus.

Prepyramid (pre-pêr'-am-id) [pree, before; pyramis, pyramid]. One of the anterior (ventral) pyramids of the oblongata.

Preramus (pre-ra'-mus) [pra, before; ramus, branch]. The vertical (anterior or cephalic) branch of the stem of the arbor of the cerebellum.

Prerectal (pre-rek'tal) [prce, before; rectum, rectum]. Situated in front of the rectum.
Prerenal (pre-re'-nal) [pre, before; ren, kidney]. Situated in front of the kidney.

Preretina (pre-ret'-in-ah) [pro, before; retina, retina]. The thin lamina which represents the retina on that part of the inner surface of the chamber of the eye which lies anterior to the ora.

Preretinal (pre-ret'-in-al) [pro, before; retina, retina]. Pertaining to the preretina.

Prerima (pre-ri'-mah) [pre, before; rima, a fissure]. An extension of the rima cephalad from the porta, as in certain fishes.

Prerimal (pre-ri'-mal) [pra, before; rima, cleft]. Pertaining to the prerima.

Presacral (pre-sa'-kral) [pre, before; sacrum, sacrum]. Situated in front of the sacrum.

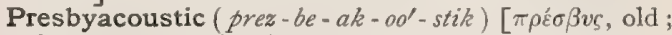
ákoviecv, to hear]. Pertaining to the loss of acoustic acuity in old age, half an octave in range being lost from the maximum to the beginning of old age, the loss continuing during the period of old age.

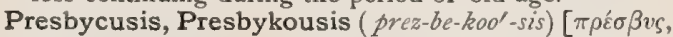
old; ákovicuv, to hear]. The lessening of the acuteness of hearing that occurs in old age.

Presbyonosus ( $\left.p r e z-b e-o n^{\prime}-o-s u s\right)[\pi \rho \varepsilon \sigma \beta v \varsigma$, old; vboos, disease]. Any disease peculiar to old age.

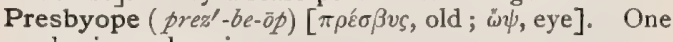
who is presbyopic.

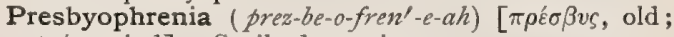
$\phi \rho \hat{\eta} \nu$, mind]. Senile dementia.

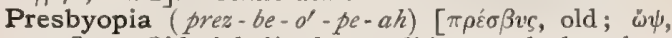
eye]. "Old sight"; the condition reached at about 45-50 years of age, in which from growing inelasticity of the crystalline lens of the eye (failure of accommodation) the near-point of distinct vision is removed to an inconvenient distance from the eye, with consequent diminution in size of the retinal image.

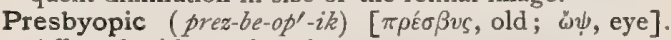
Affected with presbyopia.

Presbyopy (prez'-be-o-pe). Same as Presbyopia.

Presbyosphacelus $\left(p r e z-b e-o-s f a s^{\prime}-e l-u s\right)[\pi \rho \varepsilon ́ \sigma \beta v \varsigma$, old; $\sigma \phi a ́ k \varepsilon \lambda \varsigma^{\circ}$, gangrene]. Senile gangrene.

Presbytia (prez-bish'-e-ah). Synonym of Presbyopia.

Prescapula (pre-skap'-u-lah) [pre, before; scapula, scapula]. The part of the scapula anterior or cephalad to its spine or median axis.

Prescapular (pre-skapp-u-lar) [pre, before; scapula, shoulder-blade]. $\quad$. Situated in front of the scapula. 2. Pertaining to the prescapula.

Prescapularis (pre-skap-u-la'-ris) [pra, before; scap. $u l a$, scapula]. The supraspinatus muscle.

Prescription (pre-skrip'-shun) [pra, before; scribere, to write]. A formula written by the physician to the dispenser of medicines, designating the substances to be employed in a mixture or preparation. P.-blank, a square or rectangular slip of paper, usually bearing the physician's name, residence, and office hours, and the symbol $\mathbf{B}$, and upon which the prescription is written. P.-book, a book in which prescriptions are pasted for future reference. P.-file, a contrivance for holding prescriptions. P.-glass: (I), a graduated glass vessel for administering medicines; (2), a spectacle glass made according to an oculist's prescription.

Prescutal (pre-sku'-tal) [pre, before; scutum, a shield]. Pertaining to the prescutum.

Prescutum, Præscutum. See Prescutum.

Presemilunar (pre-sem-il-u'-nar) [pre, before; semilunar]. Anterior to the semilunar lobe of the cerebellum, as the presemilunar lobe.

Preseminal (pre-sem'-in-al) [ pra, before; semen, seed]. Prior to insemination.

Presentation (pre-zen-ta'-shun) [ prasentare, to place before]. In obstetrics, that part of the fetal body 
which presents itself to the examining finger in the center of the plane of the superior strait of the maternal pelvis. P., Abdominal, presentation of the abdomen. P., Arm, prolapse of the arm, usually associated with shoulder-presentation. P., Breast, presentation of the anterior aspect of the child's chest. P., Breech, presentatation of the pelvic extremity of the fetal ellipse. P., Brow, presentation of the brow. P., Cephalic, presentation of any part of the head. P., Cheek, presentation of the cheek. P., Chin, presentation of the chin. P., Coccygeal, breech-presentation. P., Complete Foot, presentation of both feet. P., Complicated. Synonym of P., Compound. P., Compound, the presentation of two or more parts at the same time, as the head and hand, etc. P., Ear, presentation of the ear. P., Face, presentation of the face. P., Foot, P., Footling, presentation of one or both feet. P., Frontal. Synonym of $P$., Face. $\mathbf{P}$., Funis, presentation of the umbilical cord. P., Head, presentation of any part of the head. The vertex-presentation is most common. P., Incomplete Foot, presentation of one foot. P., Knee, presentation of one or both knees. P., Longitudinal, the presentation of either the cephalic or the pelvic extremity of the fetal ellipse. P., Mouth, presentation of the mouth. P., Neck, presentation of the neck. P., Occipital, presentation of the occiput. P., Occipito-anterior, a vertex-presentation in which the occiput is anterior. P., Occipito-lateral, presentation of the vertex, with the occiput directed toward one or the other side of the pelvis. P., Occipito-posterior, a vertex-presentation in which the occiput is directed toward the back of the mother's pelvis. P., Occipito-sacral, one in which the occiput has rotated into the hollow of the sacrum. P., Pelvic, presentation of the pelvic extremity of the fetal ellipse, including breech, foot, and knee presentations. P., Placental, placenta prævia. P., Polar. Synonym of P., Longitudinal. P., Preternatural, a transverse position of the fetus. P., Primary, a presentation that has existed from before the beginning of labor. P., Secondary, a presentation that is developed while labor is in progress. P., Shoulder, presentation of the shoulder. $\mathbf{P}_{\text {., Side, presentation }}$ of the side of the trunk. P., Transverse, one in which the axis of the fetus lies transversely. P., Vertex. See Presentation.

Preservative (pre-ser'-va-tiv) [ proservare, to preserve]. Tending to keep from decay. P. Fluid (for section-cuttings of specimens). Many are used. Hamilton recommends equal parts of glycerin and water with about eight minims of carbolic acid to the ounce. One of the best is $80 \%$ alcohol. See Stains, Table of.

Presis (pre'-sis) [ $\pi \rho \dot{\prime} \theta \varepsilon \iota v$, to burn]. Inflammation; tumor.

Presphenoid ( $\left.p r e-s f e^{\prime}-n o i d\right)$ [ pre, before ; $\sigma \phi \dot{\prime}^{\prime} \nu$, wedge ; $\varepsilon i \delta o s$, like]. In human anatomy the anterior part of the body of the sphenoid bone, with its lesser wings. In some of the lower animals it is a separate bone.

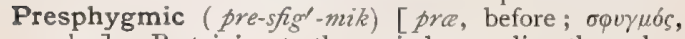
pulse]. Pertaining to the period preceding the pulsewave.

Prespinal (pre-spi'-nal) [pra, before; spina, spine]. In anatomy, ventrad of the spine.

Presse-artére (pres'-ar-tār) [Fr.]. An instrument for the compression or temporary occlusion of an artery.

Pressing (pres'-ing) [ME., pressen, to press]. A passive Swedish movement of great service in the treatment of nervous affections.

Pressions (presh'-unz) [ME., pressen, to press]. In massage, exercises in pressing and squeezing the tis- sues, either by the ends of the fingers, by the whole hand, or by means of the roulet.

Pressor (pres'-or) [premere, to press]. Stimulating. P. Fibers, nerve-hbers, stimulation of which excites the vaso-motor centers, and consequently increases the arterial tension. Others reflexly diminishing the excitability of these centers are called Depressor Fibers.

Pressure (presh'-ur) [prencere, to press]. Force, weight, or tension. In massage, a proceeding midway between kneading and percussion. It consists in making firm pressure with a small surface, as the tips of the fingers held stiffly, or the knuckles. It is used especially when it is desired to reach deep-seated nervetrunks. P., After, the sense of pressure that remains for a brief period after the removal of an object from the surface of the body. P., Arterial, the tension of the blood within the arteries. P., Atmospheric, the pressure of the atmosphere; it equals about fifteen pounds to the square inch at sea-level. P.bandage. See Bandage. P., Blood, the pressure of the blood against the walls of the vessels or of the heart. It is measured by means of the manometer. P., Endocardial, the pressure of the blood within the heart. P. of Inspiration, the pressure of the air in the respiratory organs during the act of inspiration. P., Intra-abdominal, the pressure exerted upon the parietes by the abdominal viscera. P., Intra-cranial, the pressure of the contents of the cranium upon its walls. P., Intra-ocular. See Tension, Intraocular, P., Intra-thoracic, the pressure of the intra-thoracic organs upon the walls of the chest. P., Negative, the force of suction; also absence of pressure. P.-phosphenes. See Phosphenes. P.-Points (or Spots), points of marked sensibility to pressure or weight, arranged like the temperature-spots, and showing a specific end-apparatus arranged in a punctated manner and connected with the pressure-sense. P.-sense, the sense by which pressure upon the surface is appreciated. P.-sore. See Bed-sore. P.-symptoms : 1. Nervous symptoms due to pressure upon the brain or spinal cord. In general, if the pressure is light, the symptoms are those of irritation of the area pressed upon, manifesting themselves as spasmodic movements, tonicity of the muscles, pain, byperesthesia, etc. ; if the pressure is great, there results paralysis, motor or sensory or both, of the parts innervated by the areas pressed upon. 2. The symptoms produced by an aneurysm or a tumor, as of the pelvis, adjacent organs being impinged upon. P.-tests, tests made to ascertain the quality or acuteness of the pressure-sense. They may be made by using objects of the same form and size but of different weights. P.-theory, a theory that ascribes the formation of hernia to an overcoming of the resistance of the abdominal parietes at a weakened spot by the intra-abdominal pressure. $\mathbf{P}$., Venous, the blood-pressure in the veins.

Presternal (pre-ster-nal) [pre, before; sternum, the breast-bone]. In biology, of or pertaining to the presternum.

Presternalis (pre-ster-na'-lis) [pra, before; sternum, sternum]. A muscle passing along one or both sides of the sternum, from above downward to the fourth or fifth rib, or lower.

Presternum (pre-ster'-num) [ pra, before; sternum, the breast-bone]. In biology, the manubrium or cephalic segment of the sternum.

Prestomial (pre-sto'-me-al) [ pra, before; $\sigma \tau \delta \mu \alpha a$, mouth]. Extending beyond or in front of the mouth.

Prestomium (pre-sto'-me-um) [pre, before; oró $\mu a$, mouth]. In biology, a distinct cephalic segment of the higher polychetous worms. 
Preston Smelling-salts. See English Smelling-salts. Presylvian (pre-sil'-ve-an) [pra, before; Sylvius, an anatomist]. Cephalad of the fissure of Sylvius.

Presymphysial (pre-sim-fiz'-e-al) [prce, before; $\sigma i j-$ фvoเs, symphysis]. Situated in front of the symphysis menti.

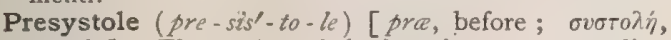
systole]. The period of the heart's pause preceding the systole.

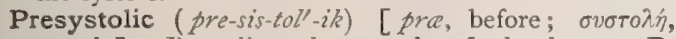
systole]. Preceding the systole of the heart. P. Murmur, the murmur of mitral or tricuspid stenosis, which occurs just before the systole. P. Thrill, a thrill felt over the precordia during the pause of the heart, just before the systole. It is very commonly present in mitral stenosis.

Pretibial (pre-tib'-e-al) [pra, before; tibia, tibia]. Situated in front of the tibia.

Pretuberculous' (pre-lu-ber'-ku-lus) [ pra, before ; tuberculum, tubercle]. Preceding the development of tuberculosis.

Pretympanic (pre-tim-pan'-ik) [pra, before; tympanum, tympanum]. Situated in front of the tym. panic region.

Preventive (pre-ven'-tiv) [prevenire, to anticipate, to prevent]. Warding off. P. Medicine, that branch of medical science that aims to prevent or ward off disease by properly directed hygiene, personal and public.

Prevermis (pre-ver'-mis) [prce, before; vermis, worm]. The superior vermiform process of the cerebellum.

Prevertebral (pre-verl-te-bral) [ pra, before; vertebra, vertebra]. Situated ventrad of a vertebra or the vertebral column.

Prevesical (pre-ves'-ik-al) [pra, before; vesica, bladder]. Situated in front of the bladder.

Prezygapophysial (pre-zi-gap-off-iz'-e-al) [pra, before; $\zeta v\rangle o v$, yoke; áró $\phi v \sigma \iota s$, process]. Pertaining to the prezygapophysis.

Prezygapophysis (pre-zi-gap-off'-is-is) [pra, before;

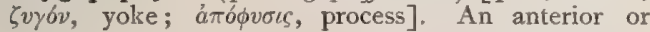
superior zygapophysis; a superior oblique, or articular process of a vertebra.

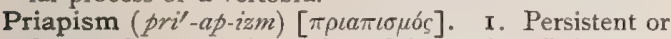
frequently repeated erection of the penis. It is sometimes caused by injuries to the spinal cord; also by injuries to the penis and by vesical calculus. 2. The erection of the clitoris in the female, under the influence of venereal desire.

Priapitis ( $\left.p r i-a p-i^{\prime \prime}-t i s\right)$. Synonym of Phallitis.

Priapus ( $\left.p r i^{\prime}-a p-u s\right)$ [II $\rho$ iatos, the god of procreation]. Penis.

Prickle (prik'-l) [prica, a point]. In biology, a hardened, ridged, hair-like, epidermal outgrowth; a senile
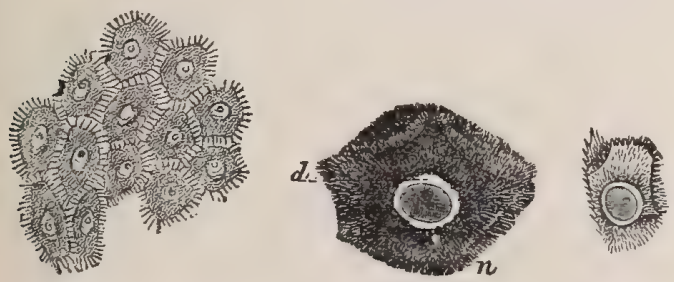

Prickle-CElls From PRICKLE-CELls ISOLATED From the THE DEEPER LAYERS HUMAN EPIDERMIS BY MEANS OF OF THE EPIDERMIS IODIZED SERUM. OF THE PALM, SHOWING INTERCELLULAR BRIDGES AND CHAN-
NELS. (From Stirling.)

. Prickles ; $d$. Space between nucleus and cell-body. $\times 800$. (From Stirling.)

spine. P.-cells, irregularly polyhedral cells, constituting the middle strata of the human epidermis, which are mutually connected by means of delicate processes that bridge the intervening intercellular clefts and establish direct continuity between neigh. boring cells; when such elements are isolated, the delicate threads are broken and the disassociated cells appear as if beset with minute spines. (Piersol.) P.-layer, the lowest stratum of the epidermis, the stratum spinosum.

Prickly (prik'-le) [prica, a point]. In biology, covered with prickles. P. Ash. See Xanthoxylum. P. Heat. See Miliaria.

Pride of China. See Azedarach

Priestley's Matter. A name formerly given to small algæ found in stagnant water and even in closed vessels, which led Mayer (I827) and Kützing (1833) to assume that they were produced by spontaneous generation.

Primæ viæ (pri'-me vi'-e) [L., "the primary passages" ]. The alimentary canal, the lacteals being "the secondary passages." Old.

Primalia (pri-ma'-le-ah) [primus, first]. A name given by Wilson and Cassin to a group of beings, including the simplest plants and animals, which propagate by cell-development. Comprised in these groups are the algæ, lichens, fungi, infusorians, and sponges.

Primary (pri'-ma-re) [primus, first]. First in time or in importance. P. Amputation, one that is done before the development of inflammation, usually within the first twenty-four hours. P. Body-cavity, the space included between the somatopleure and the splanchnopleure. It is also known as the coelom. $\mathbf{P}$. Bubo, a simple adenitis of an inguinal lymphatic gland, resulting from mechanical irritation. It is also known as Bubon d'emblée. P. Confusional Insanity, a form of insanity in which there is confusion of ideas and marked incoherence of speech, without decided emotional disturbance. See Insanity. P. Curable Dementia. Synonym of $P$. Dementia. P. Dementia, a form of insanity coming on suddenly or gradually, in young adults, and characterized by an extreme degree of apathy, the patient lying motionless, absolutely listless, without wants and seemingly without perception of his surroundings. The condition resembles melancholia attonita, but there is no distinct emotional disturbance. P. Growth, the original growth or tumor from which secondary growths are derived. P. Lesion, the original lesion which forms the starting-point for secondary lesions. P. Neural Tube, the canal formed by the meeting of the medullary plates, $q$. $v$. P. Sore, the initial sclerosis or chancre of syphilis.

Primates (pri-mu't-tez) [primus, first]. The highest order of mammals, including man, the apes, the morkeys, and the lemurs.

Primigenial (pri-mij-e'-ne-al) [ primus, first; gignere, to beget]. In biology, applied to organisms which are primitive or early types of their kind.

Primigenious ( $p$ ri-mij-e $\left.e^{\prime}-n e-u s\right)$ [ primus, first ; gignere, to beget]. In biology, original.

Primigenous (pri-mij'-en-us). Same as Primigenious.

Primigravida (pri-mig-rav'-id-ah) [primus, first; gravidus, pregnant]. A woman in her first pregnancy.

Primine (pri'-min) [primus, first]. In biology, the ectal coat of the ovule, becoming the testa of the seed. On account of the ental coat being first formed, Mirbel and others have called it the primine. Cf. secundine.

Primipara (pri-mip'-ar-ah) [primus, first; parere, to bear: pl., Primipara ]. A woman bearing or giving birth to her first child. See Primigravida. 
Primiparity (pri-mip-ar'-it-e) [primus, first; parere, to bear]. The condition of being a primipara.

Primiparous (pri-mip'-ar-us) [primus, first; parere, to bear]. Bearing a child, or being in labor for the first time.

Primisternate (pri-mis-ter'-nāt) [ primus, first; oré $\rho$ vov, sternum $]$. The manubrium of the sternum.

Primitize (pri-mish'-e-e) [primus, first]. The part of the liquor amnii discharged before the extrusion of the fetus at birth.

Primitive (prim'-it-iw) [ primus, first]. First-formed; original. P. Chorion. See Chorion. P. Groove, the enlargement and deepening of the primitive streak. See $P$. Streak. P. Streak, a streak appearing at the end of the germinal disc, and indicating the first trace of the embryo. It represents, according to many, the concrescence of the lips of the blastopore. P. Trace. See $P$. Streak.

Primordial (pri-mor'-de-al) [primordium, origin, beginnings : pl., Primordia]. In biology, existing in the beginning, first-formed, primitive, original, of the simplest character. P. Cell, a term applied to a cell of the simplest character, one which does not possess a cell-wall. P. Cranium, the membranous skull of the embryo. P. Kidney, the Wolffian body. P. Ova, cells lying among the germ-epithelium of the surface of the embryonic ovary, P. Utricle, a term applied to the outer layer of the protoplasm, which is somewhat denser than the rest, and is immediately applied to the cell-wall.

Primordium (pri-mor'-de-um) [primus, first ; ordiri, to begin: pl., Primardia $]$. In biology, any structure or organ in its earliest condition. Same as Proton.

Primula (prim'-u-lah) [primulus, dim. of primus, first]. Primrose, a genus of the Primulacee. P. odorata, P. officinalis, lady's-fingers, bedlom (or common) cowslip, is mildly diuretic. Unof.

Primum movens [L. ]. The starting point of change ; the site of the earliest lesion.

Prince's Method of Resuscitation. In suspended animation, especially from ether or chloroform narcosis, Prince recommends that the person be suspended by the flexed knees from the shoulders of the operator, and that in this hanging position he be carried about the room on a trot. Artificial respiration may be performed while the patient is thus suspended.

Princeps (prin'-seps) [L.]. First, original. P. cervicis, a branch of the occipital artery; it supplies the trapezius muscle. P. pollicis, a branch of the radial artery, going to the palmar surface of the thumb. See Arteries, Table of.

Princess Water. A famous cosmetic used in Vienna, said to prevent sunburn and remove freckles. There are two formulæ, one with and the other without any metal. These are :-

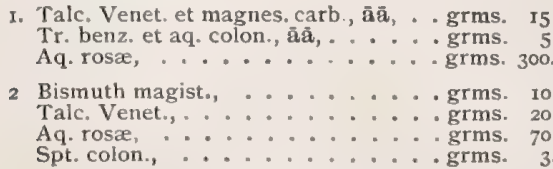

Principle (prin'-si-pl) [principium]. Element, essence, or primary quality of a body. P., Immediate, the components of an organized tissue as it exists functionally in the living tissue. P., Mediate, the chemical compounds and simple bodies into which the immediate principles are decomposed. P., Proximate. See Proximate. P., Ultimate, any one of the elements which a compound body contains.

Prinos (pri'-nos) [L.]. Black Alder; the bark of $P$ vercillatus, astringent and tonic. It is used in inter- mittent fever, diarrhea, and, locally, in cutaneous diseases. Dose $3 \mathrm{ss}-\mathrm{j}$; of a decoction $\xi_{j}$-ij. Unof.

Prionoid ( $\left.p r i^{\prime}-o-n o i d\right)$ [ $\pi \rho i \omega \nu$, saw ; $\varepsilon i \delta o s$, like]. Sawshaped.

Prior (pri'-or) [L.]. Former; previous. P. annularis, the dorsal interosseous muscle, inserted into the ring-finger. P. medii, the dorsal interosseous muscle inserted into the middle finger, on its ulnar side.

Prisis $\left(p r^{\prime} i^{\prime}-s i s\right)[\pi p i \xi \varepsilon \imath$, to saw $]$. Synonym of Trephining.

Prism (prizm) [prisma; $\pi \rho i \xi \varepsilon \iota \nu$, to saw]. "A solid whose bases or ends are any similar, equal, and parallel plane polygons and whose sides are parallelograms." (Cent. Dict.) Made of glass, it is used for refracting the sun's rays and forming a spectrum, and to make prismatic lenses. Prismatic lenses refract the light toward the base of the prism. Their chief use in ophthalmology is in cases of unbalance of the external ocular muscles. P., Amice, one consisting of a triangular prism of heavy flint-glass wedged in between two triangular prisms of crown-glass, the apical edges of the crown-glass prisms pointing toward the base of the flint-glass prism, $i, e_{\text {, }}$ the apical edges of the crown and flint-glass prisms point in opposite directions. The flint-glass gives the dispersion or separation into colors, while the crownglass makes the emergent rays approximately parallel with the incident rays, so that one looks directly into the prism along the axis of the microscope. P.diopter, P.-dioptre, or P.-dioptry, a standard of prismatic refractive power consisting in a prism that deflects a ray of light one centimeter on a tangent plane situated at a distance of one meter. Ps., Enamel, the irregular columns of from four to six sides composing the enamel of teeth, closely packed together and generally vertical to the surface of the underlying den tine. P., Nicol, one consisting of two somewhat elongated rhombs of Iceland spar cut obliquely and cemented together with Canada balsam. These are mounted in such a way that the light passes through them lengthwise, and in passing is divided into two rays of plane polarized light.

Prismatic (priz-mat'-ik) [ $\pi \rho i \sigma \mu a(\tau)$, a prism]. Prismshaped; having three or more angles bounding flat sides. P. Colors, colors developed by the refracting action of a prism. P. Spectrum. See Spectrum.

Prismenchyma (priz-men'-kim-ah) [ $\pi \rho i \sigma \mu a$, prism; $\varepsilon \gamma \chi v \mu \alpha$, infusion]. Tissue composed of prismatic cells.

Prismoid (priz'-moid) [ $\pi \rho i \sigma \mu \alpha$, prism; $\varepsilon i \delta o s, ~ l i k e]$. Resembling a prism. P., Liquid, of J. Thompson, the "refracting watery liquid in the entrant corner between the lip of the eyelid and the cornea." P., Watery. Synonym of P., Liquid.

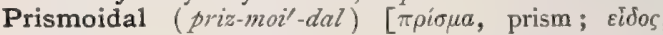
form]. In biology, applied to elongated bodies, as the joints of an insect's antennæ, when resembling a prism.

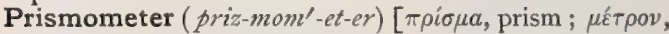
measure]. An instrument for measuring the refractive power of prisms.

Prisoptometer (priz-op-tom' ${ }^{\prime}$-et-er) $[\pi \rho i \sigma \mu a$, prism; $\omega \psi$,

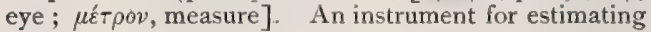
ametropia by means of two prisms placed base to base.

Pritchard's Method. See Stains, Table of.

Privates, or Privities (pri'-vets, priv'-it-èz) [ privatus, private]. A vulgar term for the genital organs.

Privy (priv'-e). Synonym of Water-closet. P.councillor's Muscle, Von Ziemssen's name for the levator menti muscle. See Muscles, Table of. P.midden. Same as Midden.

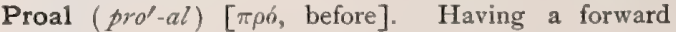
direction or movement. Cf. Palinal and Propalinal. 
Proamnion (pro-am'-ne-on) $[\pi \rho o ́$, before; áuviov, amnion]. In biology, a term introduced by Ed. van Beneden to designate that part of the area embryonalis at the sides and in front of the head of the developing embryo, which remains without mesoderm for a considerable period. [Minot.]

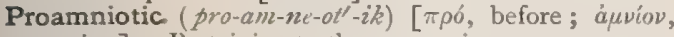
amnion]. Pertaining to the proamnion.

Proangiosperm (pro-an'-je-o-sperm) $[\pi p \delta$, before ;

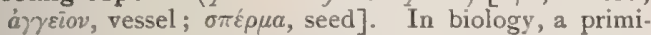
tive or ancestral angiosperm.

Proangiospermic (pro-an-je-o-sper'-mik) [ $\pi \rho o ́$, before ;

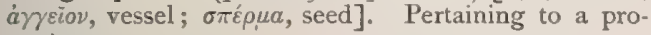
angiosperm.

Proatlas (pro-at'-las) [pro, before; atlas, the first cervical vertebra]. A primitive or rudimentary atlas.

Probable Duration of Life. The time, considering all circumstances, that a person of a given age may expect to live, as determined by statistics. The age at which any number of children born into the world will be reduced to one-half, so that there are equal chances of their dying before and after that age. The age at which a given population is reduced by onehalf its number.

Probang (pro'-bang) [probare, to try]. A rod of whalebone or other material for the making of local applications to the esophagus or pharynx, P., Ball, a probang having an ivory bulb attached to one end. P., Sponge, one provided with a small sponge at one end.

Probarbium (pro-bar'-be-um) [pro, before; barba, beard]. The soft, downy hair which precedes the growth of a beard

Probasis (pro-ba'-sis) [ $\pi \rho \circ \beta a ́ l v \varepsilon v$, to step forward]. Change of place; prolapse.

Probe (pröb) [probare, to prove]. A slender rod or wire, flexible, rigid, or jointed, for exploring a wound or sinus. As a verb, to explore with a probe. P., Anel's, a delicate silver or gold probe for exploring or dilating the lacrymal puncta and lacrymal canals. P., Blunt, one with a blunt extremity. Ps., Bowman's, flexible graduated probes used for dilating the nasal duct. P., Chemic, one carrying charpie with dilute acetic acid or other drug. P., Drainage, one so constructed and used as to assist drainage. P., Drum, one provided with a drum or reverberator to enable the ear to detect contact with foreign bodies. P., Ear, one used in exploring the ear. P., Electric, one having two insulated wires, so that contact with a bullet or metal completes the circuit, and thus indicates the presence of such a foreign body. P., Eyed, a probe having a slit at one end through which a tape or ligature can be passed. P., Flexible, one that can be bent into any desired shape. P., Jointed, a probe used in exploring for carious bone through sinuses. P., Lacrymal, one used for dilating the lacrymal passages. P., Magnetic, the employment of the telephone as an indicator. P., Meerschaum, a probe the end of which is tipped with meerschaum. It is used in searching for bullets, its advantage consisting in its being streaked by the lead when it comes in contact with the ball. P., Nelaton's, a probe that is capped with unglazed porcelain upon which a leaden ball makes a metallic streak. P.-nippers, an instrument used in searching for foreign bodies in wounds. By means of it a minute portion of the foreign body can be withdrawn for examination. P., Scissors, sur'geons' scissors that may be thrust into a sinus, like a probe. P., Sharp-pointed, one having a sharp end for introduction into a wound or sinus P., Stethoscopic, a probe having the tube of a stethoscope attached to the outer end. P., Uterine, a long, flexible probe used in exploring the uterine cavity. P., Vertebrated, a probe made of small links so jointed together that it is very flexible. P., Wire, a simple wire used as a probe.

Problematic (prob-lem-at'-ik) $\left[\pi \rho \circ \beta \lambda \eta \mu a\left(\tau_{-}\right)\right.$, a problem]. Uncertain, unsettled. P. Bodies, or Organs, Müller's name for the tubes of the water-vascular system of invertebrates.

Probole (prob'-o-le) [ $\pi \rho \circ \beta a ́ \lambda \lambda \varepsilon \iota \nu$, to throw forward]. A process, as of bone.

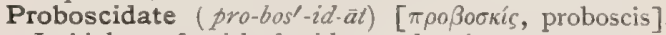
In biology, furnished with a proboscis.

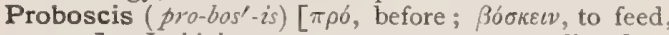
graze]. In biology, any part or organ extending from the anterior end of an animal after the manner of an elephant's trunk ; a long, flexible nose, snout, rostrum, beak, sucking-mouth, tongue, or other buccal or pharyngeal organ. P.-sheath, the receptacle of the proboscis in the Acanthocephala and Nemertina. Cf. Rhynchodceum.

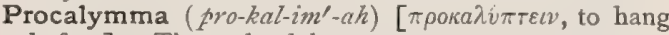
before]. The pudendal apron.

Procambial (pro-kam'-be-al) [pro, before; cambire, to exchange $]$. Pertaining to the procambium.

Procambium (pro-kan'-be-um) [pro, before; cambire, to exchange]. In biology, the primitive undifferentiated fibro-vascular tissue.

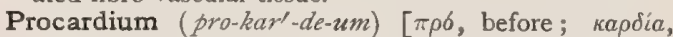
heart]. The pit of the stomach.

Procarp ( $\left.p r o^{\prime}-k a r p\right)$ [ $\pi \rho \delta$, before; $\kappa a \rho \pi b s$, fruit]. Same as Procarpium.

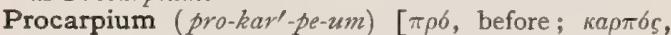
fruit: $p l .$, Procarpia $]$. In biology, the unfertilized female organ of certain algæ (Floridece). It is analogous to the pistil of flowering plants. In its simplest form (Porphyracea and Nemaliea) it consists of a single cell with a lateral hair-like prolongation, the trichogyne. In higher forms it is composed of one or more infertile cells which make up the trichophore, the function of which is to convey the fertilizing substance from the trichogyne to the carpogone. It is usually formed on the youngest parts of the plant and often originates from the terminal cell of a lateral branch.

Procatarctic (pro-kat-ark'-tik) [ $\pi \rho \circ \kappa a \tau \alpha \rho \chi \varepsilon \imath \nu$, to begin first]. Primary, predisposing.

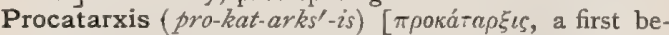
ginning]. The kindling of a disease into action by a procatarctic cause.

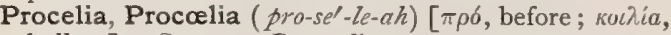
hollow]. Same as Paracelia.

Procelous, Proccelous (pro-se'-lus) $[\pi \rho \sigma$, before; кoínos, hollow]. Being concave in front and convex behind.

Procephalic (pro-sef-al'-ik, or pro-sef'-al-ik) [ $[\pi \rho o ́$, before; $\kappa \varepsilon \phi a \lambda \hat{\eta}$, head]. In biology, of or pertaining to the fore part of the head.

Procephalon (pro-sef'-al-on) [ $\pi \rho o ́$, before; $\kappa \varepsilon \phi a \lambda \dot{\eta}$, head]. The anterior part of the head of arthropods.

Procerebral (pro-ser'-e-bral) [pro, before; cerebrum, cerebrum]. Pertaining to the procerebrum.

Procerebrum (pro-ser'-e-brum). See Prosencephalon.

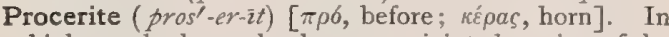
biology, the long, slender, many-jointed portion of the antenna or feeler of a crustacean. The larger basal joints are the coxocerite, basicerite, scaphocerite, ischiocerite, merocerite, carpocerite.

Procerous (pro-se'-rus) [procerus, high]. In biology, tall, or tall and slim.

Process (pros'-es) [processus; procedere, to issue]. I. A more or less well-defined outgrowth or projecting structure. 2. Method; phenomenon; occurrence. P., A, B, C. See Sewage, Disposal of. P., Acromion. See Acromion. P., Alar, one of the 
small wing-like processes of the crista galli which surround the foramen crecum. P., Alveolar, the thick border of the upper or lower jaw containing the sockets for the teeth. P., Ankyroid. Synonym of $P$. Coracoid. P., Anterior Clinoid. See $P$., Clinoid. P., A pex, P., A pical, the large process extending from the apex of the pyramidal cells of the cerebral cortex toward the free surface of the cortex. P., Articular, the small processes projecting from the upper and lower surfaces of the vertebræ, by means of which adjacent vertebræ articulate with each other. P., Auditory, the curved plate of bone surrounding the external auditory meatus for the greater part of its circumference, and serving for the attachment of the cartilage of the external ear. P., Axis. Synonym of P.,Axis-cylinder. P., Axis-cylinder, that process of a nerve-cell which becomes the axis-cylinder of a nerve. P., Basilar (of the Occipital Bone), the quadrilateral plate of bone in front of the foramen magnum articulating with the sphenoid bone. P., Calcarine. Synonym of Hippocampus minor. P., Central Base, the axis-cylinder process arising from the central part of the base of the pyramidal cells of the brain-cortex. Ps., Ciliary, plaitings and foldings of the layers of the choroid at its anterior margin. They are received between corresponding foldings of the suspensory ligament of the lens, and are from 60 to 80 in number. Ps., Ciliary (of the Retina), the anterior part of the retina, in close contact with the choroidal ciliary processes. Ps., Clinoid, projections on the body and lesser wings of the sphenoid bone. There are three : the anterior is formed by the inner extremity of the lesser wings; the middle, a small eminence, one on each side, bounding the pituitary fossa or sella turcica anteriorly; the posterior, a tubercle on each side of the dorsum sellæ, P., Cochleariform. See Processus cochleariformis. P., Condylar, P., Condyloid, the posterior process of the lower jaw, consisting of the articular condyle and the neck which supports it. P., Conoid, the tuberosity of the clavicle. P., Coracoid, the hook-like process projecting from the scapula above the glenoid cavity. See Coracoid. P. Coronoid: I. A thin, flattened process projecting from the anterior portion of the upper border of the ramus of the lower jaw, and serving for the attachment of the temporal muscle. 2. A triangular projection from the upper end of the ulna, forming the lower part of the great sigmoid cavity. 3. Synonym of $P$., Coracoid. P., Costiform, the transverse processes of the lumbar vertebræ supposed to be rudimentary ribs. P., Deiters', the single, large, unbranched process of a multipolar nerve-cell, which becomes the axiscylinder of a medullated nerve-fiber. P., Ensiform, the cartilaginous tip at the lower end of the sternum. Same as Metasternum. P., Ethmoid, one of the projections from the superior border of the inferior turbinated bone, which joins the unciform process of the ethmoid bone. P., External Angular, the projection on the outer extremity of the supraorbital arch of the frontal bone, which articulates with the malar bone. P., External Nasal, a small lamina forming the outer portion of the nostril in the embryo. P., External Orbital. Synonym of P., External Angular. P., Falciform: I. A process of the fascia lata of the thigh, forming the outer and upper margin of the saphenous opening. It is known also as the P., Falciform, of Burns. 2. A prolongation of the great sacro-sciatic ligament along the ramus of the ischium. Same as Falx cerebri. P. of Folius, the long process of the malleus. P., Frontal, a process of the malar bone articulating with the frontal bone. P., Hamate (of the Ethmoid bone). Synonym of P.,
Unciform. P., Hamular: I. A hook-like process of bone on the lower extremity of the internal pterygoid plate, around which the tendon of the tensor palati turns. 2. Of the lacrymal bone, the hook-like termination of the lacrymal crest. P. of the Helix, a small projection of cartilage at the front part of the pinna, where the helix bends upward. P., Inferior Maxillary, the first post-oral arch. P., Inferior Turbinated, the middle turbinated bone. P., Inferior Vermiform, the central projection on the lower surface of the cerebellum, between the two hemispheres. Ps. of Ingrassius, the lesser wings of the sphenoid bone. P., Intermaxillary. Synonym of P., Fronto-nasal. P., Internal Angular, the inner extremity of the supraorbital arch of the frontal bone. P., Jugular, a rough prominence external to the condyles of the occipital bone, channeled by a deep notch which forms part of the jugular foramen. P., Lacrymal, a short, pointed process of the inferior turbinated bone which articulates with the lacrymal bone. P., Lateral Base, one of the branching processes of a pyramidal nerve-cell, arising from the thickest part of the latter. P., Lateral Frontal. Synonym of P., External Nasal. P. of Lenhossek. Synonym of $P$., Reticular. P., Lenticular, the extremity of the long process of the incus, covered with cartilage and articulating with the stapes. P., Long (of the Incus), a slender process that descends vertically from the body of the incus and articulates, by the lenticular process, with the head of the stapes. P., Long (of the Malleus), a long, delicate process that passes from the neck of the malleus outward to the Glaserian fissure, to which it is connected by cartilaginous and ligamentous fibers. P., Malar, a triangular eminence of the superior maxilla by which it articulates with the malar bone. Ps., Mammillary, the tubercles on the posterior part of the superior articular processes of the lumbar vertebræ. P., Mastoid, a conical projection at the base of the mastoid portion of the temporal bone. It contains the mastoid cells and the antrum. P., Maxillary, a thin plate of bone descending from the ethmoid process of the inferior turbinated bone, and hooking over the lower edge of the orifice of the antrum. P., Maxillo-palatine. Synonym of $P$., Superior Maxillary. P., Mental. Synonym of Prominence, Mentrl. P., Middle Clinoid. See $P$., Clinoid. P., Midfrontal. Synonym of $P$., Frontonasal. P., Modeling: I. A method of healing wounds while the part is immersed in water. (Macartney.) 2. See $P$., Molding. P., Molding, the change in shape of the fetal skull during labor, to accommodate itself to the shape of the pelvic canal. P., Morbid, the structural changes induced by disease. Ps., Muscular, the processes of a vertebra to which muscles are attached. P., Nasal (of the Frontal Bone). Synonym of Spine, Nasal. P., Nasal (of the Superior Maxilla), a thick, triangular process of bone that projects upward, inward, and backward by the side of the nose, forming a part of its lateral wall. P., Nerve. Synonym of $P$., Axis-cylinder. P., Odontoid, the tooth-like process of the axis which ascends and articulates with the atlas. P., Olecranon. Synonym of Olecranon. P., Olivary, a small, olivelike eminence situated behind the optic groove of the sphenoid bone. P., Orbicular. Synonym of $P$., Lenticular. P., Orbital (of the Superior Maxilla), a process projecting from the orbital margin of the superior maxilla. P., Orbital (of the Palate bone), a process directed upward and outward from the upper portion of the palate bone by means of which the latter articulates with the superior maxillary, the sphenoid, turbinated, and the ethmoid bones. The superior 
surface forms the back part of the floor of the orbit. Ps., Palatal, the processes of the superior maxillary plates of the embryo which join to form the bony palate. P.; Palate, a thick process projecting horizontally inward from the inner surface of the superior maxillary bone, and forming part of the floor of the nostril and the roof of the mouth. P., Palatine. Synonym of P., Palate. P., Paracondyloid, an anomalous process on the lower surface of the occipital bone. When present it articulates with the transverse process of the atlas. P., Paramastoid, P., Paroccipital. Synonyms of $P$., Paracondyloid. P., Pituitary. Synonym of Pituitary Body. P., Pneumatic, a process sometimes present on the occipital bone, containing air-cells that communicate with the mastoid cells. P., Posterior Clinoid. See P., Clinoid. P., Post-glenoid, a small tubercle separating the glenoid fossa from the auditory process. P., Premaxillary. Synonym of P., Fronto-nasal. P., Protoplasmic: I. The branched processes of nerve-cells that are not continued as axis-cylinders. 2. The pseudopoda of ameboid cells. P., Pterygoid (of the Palate Bone), a pyramidal process projecting from the posterior border of the palate bone and articulating with the sphenoid bone. Ps., Pterygoid (of the Sphenvid Bone), processes, one on each side, descending perpendicularly from the point of junction of the body with the greater wings of the sphenoid bone. Each process consists of an external and an internal plate. Ps., Pterygo-palatal. Synonym of $P_{s}$, Palatal. P., Pulp, a process connecting an odontoblast with a cell in the dental pulp. Ps., Pyramidal. Synonym of Pyramids of Ferrein. P. of Rau. Synonym of $P$., Long (of the Malleus). P., Reticular, a network of interlacing processes of gray and white matter in the spinal cord, which is visible in a cross-section and is situated near the center of the gray crescents. It is seen best in the cervical region of the cord. P., Short (of the Incus), a conic process projecting almost horizontally backward from the body of the incus and attached by ligamentous fibers to the margin of the opening leading into the mastoid cells. P., Short (of the Malleus), a slight projection from the root of the manubrium of the malleus, lying in contact with the tympanic membrane. P., Sphenoidal, a thin plate of bone directed upward and inward from the vertical plate of the palate bone. Ps., Spinous (of the Ilium), prominent eminences on the anterior and posterior borders of the ilium. The upper process on the anterior border is the anterior superior spinous process of the ilium. It can be readily felt, and is an important landmark. Below it is the anterior inferior spinous process, which gives attachment to the straight tendon of the rectus femoris muscle and to the iliotibial band. On the posterior border there are also two processes-a posterior superior and a posterior inferior. P., Spinous (of the Sphenoid Bone), a rough prominence descending from the posterior part of the greater wing of the sphenoid bone. It receives the attachment of the internal lateral ligament of the jaw and the tensor palati muscle. P., Spinous (of the Tibia), an eminence of bone on the upper surface of the tibia, between the two articular surfaces, and nearer to the posterior than the anterior border. P., Spinous (of a Vertebra), the prominent backward projection from the middle of the posterior portion of the arch of a vertebra. P., Styloid (of the Fibula), a pointed eminence projecting upward from the posterior portion of the head of the fibula. P., Styloid (of the Radius), a projection from the external border of the lower extremity of the radius. P., Styloid (of the Temporal Bone), a sharp spine about an inch in length descending downward, forward, and inward from the inferior surface of the petrous portion of the temporal bone. P., Styloid (of the Uina), a projec tion from the inner and posterior portion of the lower extremity of the ulna. Ps., Subgerminal, out growths from the inner surface of the epiblast (His) P., Superior Maxillary, an eminence on the face of the embryo which gives rise to the superior maxilla and the malar bone. P., Superior Vermiform, the upper part of the median lobe of the cerebellum, which connects together the two lateral hemispheres. It consists of the lobulus centralis, the monticulus cerebelli, and the commissura simplex. P., Temporal, the posterior angle of the malar bone by which it articulates with the zygomatic process of the temporal bone, P., Transverse, a process projecting outward from the side of a vertebra, at the junction of the pedicle and the lamina. $P_{\text {., }}$ Tubercular, Transverse, the lower transverse process of a vertebra, or the one which articulates with the tuberculum of a rib. It is best marked in the lower vertebrates. P., Unbranched. Synonym of $P$., Axis-cylinder. P., Unciform (of the Ethmoid Bone), a hook-like projection from the inferior portion of each lateral mass of the ethmoid bone. It articulates with the ethmoidal process of the inferior turbinated bone. P., Unciform (of the Hippocampal Gyrus), a hook-like projection from the anterior end of the gyrus hippocampi. P., Unciform (of the Unciform Bone), a hook-like projection from the palmar surface of the unciform bone. P., Uncinate. Synonym of $P$., Unciform. P., Ungual, the distal extremity of a terminal phalanx, P., Vaginal (of Peritoneum), the process of peritoneum which the testicle in its descent carries in advance, and which in the scrotum forms the tunica vaginalis testis. P., Vaginal (of the Sphenoid Bone), a projection from the inferior surface of the body of the sphenoid bone, running horizontally inward from near the base of the pterygoid process. P., Vaginal (of the Temporal Bone), a sheath-like plate of bone which extends from the carotid canal to the mastoid process. It separates behind into two laminæ, which enclose the styloid process. P., Vermiform: 1. See $P$., Inferior Vermiform, and $P$., Superior Vermiform. 2. The vermiform appendix of the cecum. See Vermiform Appendix. P., Vocal (of the Arytenoid Cartilage), the anterior angle of the arytenoid cartilage receiving the attachment of the true vocal band. P., Xyphoid, the ensiform cartilage. P., Zygomatic (of the Malar Bone), a long, serrated process which articulates with the zygomatic process of the temporal bone. P., Zygomatic (of the Temporal Bone), a long projection from the lower part of the squamous portion of the temporal bone; it articulates with the malar bone.

Processus (pro-ses'-us) - [L.]. Synonym of Process. P. a cerebello ad medullam spinalem. Synonym of Peduncle, Superior Cerebellar. P. acromialis. Synonym of Acromion. P. ad cerebrum. Synonym of Peduncle, Superior Cerebellar. P. ad medullam, the inferior peduncles of the cerebellum. P. ad pontem, the middle peduncles of the cerebellum connecting together its two hemispheres. P. ad testes. Synonym of Peduncles, Superior Cerebellar. P. alati, the wings of the sphenoid bone. P. anconæus. Synonym of Olecranon. P. ancoralis. Synonym of Process, Coracoid. P. annularis. Synonym of Pons varolii. P. anterioris mallei. Synonym of Process, Long (of the Malleus). P. articulares sporii, small prominences on the posterior surface of the sacrum, internal to the posterior sacral foramina, being the rudiments of the articular processes of the sacral verte- 
bree. P. auditorius, the tympanic ring. P. beloides, a styloid process. P. brevis incudis. Synonym of Process, Short (of the Incus). P. brevis mallei. Synonym of Process, Short (of the Malleus). P. cerebelli inferiores. Synonym of Peduncles, Superior Cerebel. lar. P. cerebelli medii. Synonym of Peduncles, Middle Cerebellar. P. cerebelli superioris. Synonym of Peduncles, Superior Cerebellar. P. cerebelli transversi. Synonym of Peduncles, Middle (of the Cerebellum). P. ciliares. Synonym of Processes, Ciliary. P. clinoideus. Synonym of Process, Clinoid. P. clavatus, the enlargement of the posterior pyramids of the medulla oblongata opposite the fourth ventricle, where they diverge. $P$. cochleariformis, a thin plate of bone separating the canal for the Eustachian tube from that for the tensor tympani muscle. P. conicus. Synonym of Process, Odontoid. P. corporis quadrigemini ad cerebellum. Synonym of Peduncles, Superior Cerebellar. P. cuneiformis. Synonym of Process, Unciform. P. dentatus. Synonym of Process, Odontoid. P. e cerebello ad testes, the superior peduncles of the cerebellum. See Peduncle. P. e cerebello ad cerebrum. Synonym of Peduncle, Superior Cerebellar. P. e cerebello ad medullam. Synonym of Peduncles, Inferior Cerebellar tubercle. P. e cerebello ad pontem. Synonym of Peduncles, Middle Cerebellar. P. e cerebro ad testes, the superior peduncles of the cerebellum. P. ensiformes, the lesser wings of the sphenoid bone. P. ensiformis, the ensiform cartilage. P. falciformis, the falx cerebri. $P$. folianus, P. Folii. Synonym of Process, Long (of the Malleus). P. glandulæ pinealis. Synonym of Peduncles of the Pineal Gland. P. globularis of His, a protuberance in the human embryo between the nasal pit on each side and the mouth; it is the incipient rudiment or Anlage of the nasal process. P. glottidis. Synonym of Process, Vocal (of the Arytenoid Cartilage). P. gracilis, a long, delicate process passing from below the neck of the malleus to the Glaserian fissure. P. hamatus. Synonym of Process, Unciform. P. horizontalis incudis. Synonym of Process, Short (of the Incus). P. incudis longus. Synonym of Process, Long (of the Incus). P. infundibuli: $\mathbf{I}$. The posterior lobe of the hypophysis cerebri. 2. Infundibulum. P. internus calcanei. Synonym of Sustentaculum tali. P. jugularis. Synonym of Process, Jugular. P. lachrimalis. Synonym of Process, Lacrymal. P. laterales vertebrarum. Synonym of Processes, Transverse. P. lateralis calcanei Synonym of Sustentaculum tali. P. lenticularis. Synonym of Process, Lenticular (of the Incus). P. longus incudis. Synonym of Process, Long (of the Incus). P. malaris. Synonym of Process, Zyromatic (of the Temporal Bone). P. mamillaris: I. Synonym of Process, Mammillary (of the Lumbar Vertebra). 2. Synonym of Process, Mastoid (of the Temporal Bone). P. mastoideus. Synonym of Process, Mastoid. P. maxillaris ossis malaris. Synonym of Process, Maxillary (of the Malar Bone). P. medulla cerebri. Synonym of Cruscerebri. P. medullaris transversus. Synonym of Pons varolii. P. membraniformis. Synonym of Plexus, Choroid (of the Fourth Ventricle). P. nasalis. See Process, Nasal. P. nucleiformis. Synonym of Process, Odontoid. P. obliqui, P. obliqui vertebrarum. Synonym of Processes, Articular. P. obtusus. Synonym of Process, Short (of the Malleus). P. occipitalis. Synonym of Process, Basilar. P. odontoideus. Synonym of Process, Odontoid. P. orbicularis. Synonym of Process, Lenticular. P. petrosus anticus. See Lingula. P. orbitalis. Synonym of Process, Orbital. P. paracondyloideus. P.paramastoideus. Synonyms of Process,
Paracondyloid. P. pinealis. Synonym of Pineal Gland. P. pterygoidei. Synonym of Processes, Pterygoid. P. ravii. Synonym of Process of Rau. P. restiformis. Synonym of Resliform Body. $\mathbf{P}$. reticularis. Synonym of Process, Reticular. P. rostriformis. Synonym of Process, Coracoid. P. sphenoidalis. Synonym of Process, Sphenoid. P. spinosi spurii, the bony eminences of the posterior surface of the sacrum, representing the spinous processes of true vertebræ. P. spinosus. Synonym of Process, Spinous. P. spinosus mallei. Synonym of Process, Long (of the Malleus). P. styloideus cranii. Synonym of Process, Styloid (of the Temporal Bone). P. styloideus fibula. Synonym of Process, Styloid (of the Fibula). P. styloideus radii, P. styloideus ulnze. Synonyms of $P$., Styloid (of the Radius and of the Ulna respectively). P. superior incudis. Synonym of Process, Short (of the Incus). P. transversi spurii, a row of bony prominences on the posterior aspect of the sacrum, or each side of the median line, representing the transverse processes of true vertebræ. P. transversus. Synonym of Process, Transverse. P.transversus occipitalis. Synonym of Process, Jugular. P. tubarius, a prominence on the internal plate of the pterygoid process upon which the extremity of the cartilaginous portion of the Eustachian tube rests. P. unciformis. Synonym of Process, Coracoid, and of Process, Unciform. P. vaginalis, an evagination of the peritoneum at the inguinal ring in the higher mammals; lying laterally and ventrally of the end of the gubernaculum, it undergoes a gradual descent and finally enters the scrotum. Synonym of Process, Vaginal. P. vaginalis peritonei. Synonym of Process, Vaginal (of the Peritoneum). P. vermicularis, P. vermiformis. Synonym of Vermiform Appendix. P. vermis inferior. Synonym of Process, Inferior Vermiform. P.vermis superior. Synonym of Process, Superior Vermiform. P. vocalis. Synonym of Process, Vocal (of the Arytenoid Cartilage). P. xiphoideus. Synonym of Process, Ensiform. P. zygomaticus. Synonym of Process, Zygomatic.

Prochilon, Procheilon (pro-ki'-lon) [ $\pi \rho \sigma$, before; $\chi \varepsilon \tilde{i} \lambda$ os, lip]. The prominence in the center of the lip.

Prochilous (pro-ki'-lus) [ $\pi \rho o ́$, before; $\chi \varepsilon i \bar{\lambda}$ os, lip, snout]. In biology, applied to organisms having protuberant or protrusile lips.

Prochondral (pro-kon'-dral) [ $\pi \rho b$, before, $\chi 6 ́ v \delta \rho o s$, cartilage]. Prior to the formation of cartilage.

Prochondrium (pro-kon'-dre-um) [ $\pi \rho 6$, before ; $\chi \delta$ vo $\rho \circ$, cartilage ]. In biology, young cartilage with colorable matrix, i.e., a great affinity for carmin and hematoxylon. The pracartilage of Minot and the Vorknorpel of Hasse.

Prochordal (pro-kor'-dal) [ $\pi \rho b$, before; $\chi o \rho \delta h$, cord]. Situated in front of the chorda dorsalis.

Prochorion ( $\left.p 10-k o^{\prime}-r e-o n\right) \quad[\pi \rho b$, before; $\chi \delta \rho \iota 0 \nu$, membrane]. I. The primitive chorion. 2. The zona pellucida and vitelline membrane considered as one.

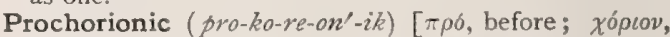
membrane]. Pertaining to the prochorion.

Procident (pross'-id-ent) [ procidens, falling forward]. Affected by prolapsus.

Procidentia (prōs-id-en'-she-ah) [procidere, to fall down]. Prolapse. P. ani, prolapse of the anus. P. bulba oculi. Synonym of Exophthalmos. P. intestini recti, prolapse of the rectum. P. oculi. Synonym of $P$. bulbi oculi. P. uteri, complete prolapse of the uterus.

Proclivity (pro-kliv'-it-e) [proclivitas]. Tendency or inclination.

Procnemium (prok-ne'-me-um). Synonym of Tibia. 
Procreant (pro'-kre-ant) [procreare, to beget]. Producing young.

Procreate (pro'-kre-ät) [procreare, to beget]. To beget.

Procreation (pro-kre-a'-shun) [procreare, to bring forth]. The act of generating or begetting offspring.

Procryptic (pro-krip'-tik) [ $\pi \rho o ́$, in favor of; for; $k \rho v \pi$ -

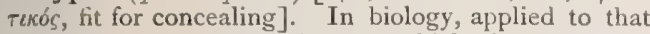
form of protective mimicry in which the coloration enables an animal to escape by hiding, $e . g$., the green pipe-fish (Siphonostoma typhle), which is conspicuous in open water, but is well concealed among the leaves of Zostera.

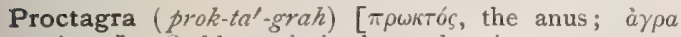
seizure]. Sudden pain in the anal region.

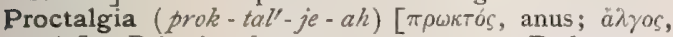
pain]. Pain in the anus or rectum. P. hæmorrhoidalis. See Hemorrhoid. P. inflammatoria. Synonym of Proctitis. P. intertriginosa, intertrigo of the anus.

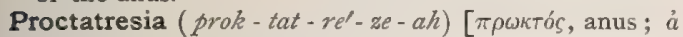
priv.; $\tau \rho \tilde{\eta} \sigma \iota \varsigma$, perforation $]$. An imperforate condition of the anus or rectum.

Proctectasia, Proctectasis (prok-tek-ta'-ze-ah, prok-

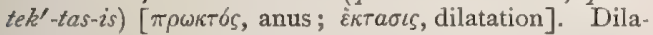
tation of the anus.

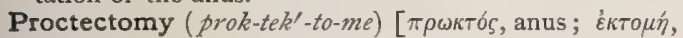
excision]. Excision of the rectum.

Proctenclisis (prok-ten'-klis-is) [ $\pi \rho \omega \kappa \tau \sigma ́ s$, anus; $\varepsilon \dot{v} v$, in ; $\kappa \lambda \varepsilon i \varepsilon \iota v$, to close]. Stricture of the rectum.

Procteurynter (prok-tu-rin'-ter) [ $[\pi \rho \omega \kappa \tau o s$, anus;

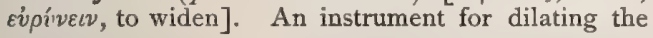
anus.

Procthemorrhagia (prokt-hem-or-a $\left.a^{\prime}-j e-a h\right)[\pi \rho \omega \kappa \tau b ́$, anus; aira, blood; pirvívas, to burst forth]. Hemorrhage from the anus.

Procthypodesmus (prokt-hi-po-dez'-mus) [ $\pi \rho \omega \kappa \tau b s$, anus; $i \pi \delta$, under; $\delta \varepsilon \sigma \mu \delta \zeta$, band]. An anal pessary.

Proctica (prok'-tik-ah) [ $\pi \rho \omega \kappa \tau o ́ s$, anus $]$. Any disease of the anus or rectum. P. marisca. Synonym of Hemorrhoid. P. simplex. Synonym of Proctalgia.

Proctisis (prok-tis'-is). Synonym of Proctitis.

Proctitis (prok-ti'tis) [ $\pi \rho \omega \kappa \tau \sigma \zeta$, anus; $\iota \tau \iota s$, inflammation]. Inflammation of the anus or rectum. P. fortida, inflammation of the rectum, with the discharge of very offensive material. P. gangrænosa, gangrenous inflammation of the rectum.

Procto- (prok $\left.k^{\prime}-t o-\right)[\pi \rho \omega \kappa \tau b s$, anus $]$. A prefix signifying connection with, or relation to, the anus.

Proctoblennozemia (prok-to-blen-o-ze'-me-ah) [ $\pi \rho \omega \kappa-$ $\tau \delta \varsigma$, anus; $\beta \lambda \varepsilon v \nu \nu$, mucus; $\zeta \eta \mu i a$, loss]. A mucous discharge from the anus.

Proctocase (prok-tok'-as-e). Synonym of Proctitis gangranosa.

Proctocele (prokl' $-t o-s \bar{e} l)$ [ $\pi \rho \omega \kappa \tau b \dot{s}$, anus; $\kappa \hat{\eta} \lambda \eta \eta$, hernia ]. The extroversion or prolapse of the mucous coat of the rectum. P., Vaginal, a hernia of the rectum appearing in the vagina.

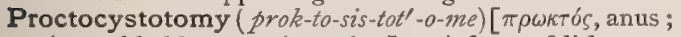

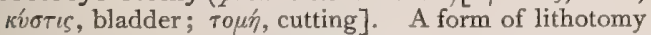
in which the incision is made through the walls of the rectum.

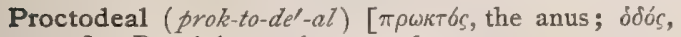
way]. Pertaining to the proctodeum.

Proctodeum, Proctodæum (prok-to-de'-um) $[\pi \rho \omega \kappa \tau o ́ s$, the anus; $\delta \delta b s$, way]. In biology, a very small anal invagination of the ectoderm in embryonic amniota, which grows inward toward the cloaca until the ectoderm and entoderm come into contact; the membrane formed by the two epithelia finally breaks through and the cloaca acquires an opening to the exterior; the primitive amus.
Proctodynia (prok-to-din'-e-ah) $[\pi \rho \omega \kappa \tau o ́ s$, anus ; idv́rm, pain]. Pain about the anus.

Proctoleukorrhea (prok-to-lu-kor-e'-ah). Synonym of Proctorrhea

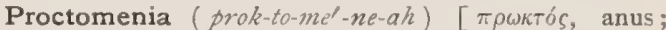
$\mu$ in, month ]. Vicarious menstruation from the rectum.

Proctoncus (prok-tong'-kus) [ $\pi \rho \omega \kappa \tau \delta ́ s$, anus; by/kos, tumor]. Any tumor or swelling at the anus.

Proctoparalysis ( prok-to-par-all-is-is) [ $\pi \rho \omega k \tau b s$, anus ; $\pi \alpha p a ́ \lambda v \sigma \iota s$, paralysis ]. Paralysis of the sphincter muscle of the anus.

Proctoplastic (prok-to-plas'-tik) [ $\pi \rho \omega \kappa \tau o ́ s$, anus; $\pi \lambda a ́ \sigma-$ $\sigma \varepsilon \iota \nu$, to form]. Pertaining to the plastic surgery of the anal region.

Proctoplasty (prok'-to-plas-te) [ $\pi \rho \omega \kappa \tau b \delta$, anus; $\pi \lambda a ́ \sigma-$ $\sigma \varepsilon \iota \nu$, to form]. Plastic surgery of the anus.

Proctoplegia (prok-to-ple'-je-rh). Synonym of Proctoparalysis.

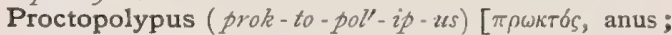
$\pi 0 \lambda \hat{v} \pi 0 v \varsigma$, polyp]. A polyp of the rectum.

Proctoptoma (prok - top-to - mah) [ $\pi \rho \omega \kappa \tau b s$, anus; $\pi \tau \tilde{\omega} \mu a$, fall]. Prolapse of the rectum.

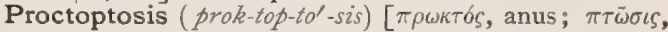
a falling]. Synonym of Proctoptoma.

Proctorrhagia (prok-tor-a'-je-ah). Synonym of Procthemorrhayia.

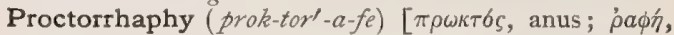
suture]. Suture of the rectum or anus.

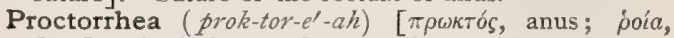
flow]. A discharge of mucus through the anus.

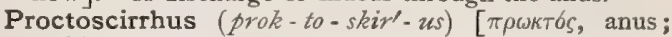

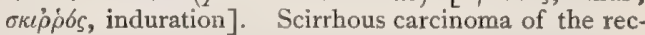
tum.

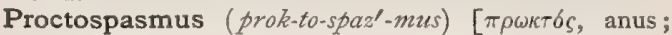
$\sigma \pi \alpha \sigma \mu \delta s$, spasm]. Spasm or tenesmus of the rectum.

Proctostenosis (prok-to-sten-o'-sis) [ $\pi \rho \omega k \tau b s$, anus, and $\sigma \tau \varepsilon v \omega \sigma \iota \zeta$, stenosis]. Stricture of the anus or rectum.

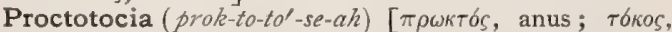
a bringing forth]. Delivery of the fetus through the anus.

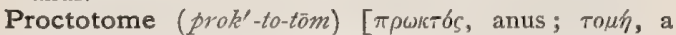
cutting]. A cutting-instrument used in proctotomy.

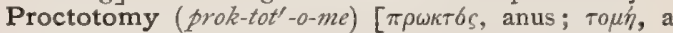
cutting]. Incision of the anus or rectum for imperforation or stricture.

Proctotoreusis (prok-to-tor- $u^{\prime}$-sis) [ $\pi \rho \omega \kappa \tau o ́ s$, anus ; $\tau o \rho-$ $\varepsilon \dot{\varepsilon} \varepsilon v$, to bore through]. The operation of making an opening into an imperforate anus.

Proctuchous (prok-tu'-kus) [ $\pi \rho \omega \kappa \tau \sigma \zeta$, anus ; $\varepsilon \chi \varepsilon \iota v$, to have]. In biology, having an anus.

Procumbent (pro-kum'-bent) [ pro, forward; cumbere, to lie]. In biology, prostrate, prone, trailing.

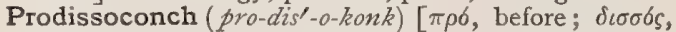
double; $\kappa \delta \gamma \chi \eta$, shell]. In biology, the first formed shell of many lamellibranchs, preceding the dissoconch or true shell. It is the complete shell of the veliger antemonomyarian and dimyarian stage, and the homologue of the protoconch of cephalous molluscs and the periconch of Dentalium.

Prodroma (pro-dro'-mah). See Prodrome.

Prodromal (pro-dro'-mal) [ $\pi \rho 6$, before; $\delta \rho b \mu o s$, a running]. Precursory; of the nature of a prodrome.

Prodrome ( $\left.p r o^{\prime}-d r o ̄ m\right)$ [ $\pi \rho 6$, before; $\delta \rho \sigma \mu o s$, a running]. A forerunner of a disease; a precursory symptom.

Prodromic (pro-dro'-mik). See Prodromal.

Prodromous (pro-dro'-mus). Synonym of Prodomal.

Prodromus (pro-dro'-mus) [ $\pi \rho \sigma$, before; $\delta \rho b \mu o s$, a running]. The prodrome; also the period in which the precursory signs of a disease occur.

Produce (pro-dūs') [producere, to bring forth]. To generate or bring forth. 
Productive (pro-duk'-tiv) [producere, to produce]. Generating; tissue-making. P. Arteritis, Acute, an acute inflammation of an artery characterized by round-cell infiltration, the formation of new bloodvessels and new connective tissue in their walls. It may proceed to obliteration of the lumen of the vessel.

Proëccrisis (pro-ek'-ris-is) $[\pi \rho o$, before ; $\varepsilon \kappa \kappa \rho \iota \sigma \iota$, separation]. A premature crisis in the course of a disease.

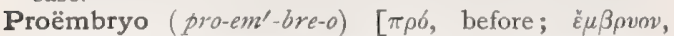
embryo]. In biology, the result of the germination of an oöspore, the Anlage or proton of the first stage of certain cryptogams (Characea, Archegoniate).

Proëmbryonic (pro-em-bre-on'-ik) [ $\pi \rho \hat{o}$, before ; $\varepsilon \mu$ $\beta \rho v o \nu$, embryo]. Pertaining to a proembryo.

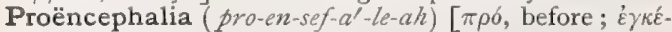
$\phi a \lambda o s$, brain]. An exencephalic condition involving the anterior part of the skull.

Proëncephalocele (pro-en-sef'-al-o-selt) $[\pi \rho \sigma$, before;

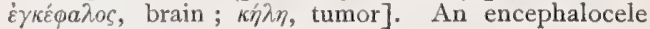
in the anterior part of the skull.

Proëncephalon (pro-en-sef'-al-on) [ $\pi \rho o ́$, forward; $\dot{\varepsilon} \gamma k \hat{\varepsilon}$ $\phi a \lambda{ }^{\prime}$, brain]. The fore-brain. Also, encephalocele in the frontal region of the brain.

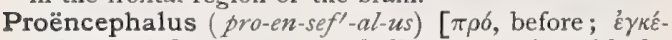
$\phi a \lambda o s$, brain]. An exencephalic monstrosity with the brain protruding through a fissure in the frontal region.

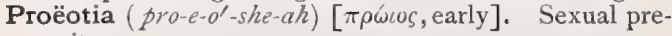
cocity.

Proëpimeral (pro-ep-im-e -ral) [pro, before; $\dot{\varepsilon} \pi \dot{\text {, }}$ upon; $\mu \eta \rho o ́ s$, thigh]. Pertaining to the proëpimeron.

Proëpimeron (pro-ep-im-e'-ron) [pro, before; $\dot{\varepsilon} \pi \dot{i}$, upon; $\mu \eta \rho o ́ s$, thigh $]$. The epimeron or prothorax.

Proëpisternal (pro-ep-is-ter'-nal) [pro, before; $\dot{\varepsilon} \pi i$, upon; $\sigma \tau \varepsilon \rho \nu o \nu$, breast-bone]. Pertaining to the proëpisternum.

Proëpisternum (pro-ep-is-ter'-num) [ pro, before ; $\dot{\varepsilon} \pi \dot{\prime}$,

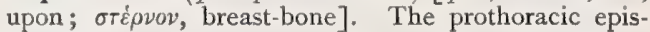
ternum.

Professional (pro-fesh'-un-al) [profiteri, to profess]. Pertaining to a profession or occupation; pertaining especially to the medical profession; in keeping with medical ethics. P. Cramp. See Writers' Cramp. P. Etiquette, those principles of honor which govern the conduct of medical men, both in dealings with one another and with the laity. P., or Occupation, Neurosis, a neurosis caused by continuous exercise in one's occupation of one set of muscles, or by some other peculiarity of one's employment. See Neurosis.

Professor (pro-fes'-or) [professor, a professor]. A teacher in a college or university.

Professorate (pro-fes'-or-ät) [professor, a professor]. The office of a professor.

Professorship (pro-fes'-or-ship). Same as Professorate.

Profile (pro'-fél) [pro, before; filum, thread]. The outline of the human face in a section at the meson. $\mathbf{P}$. Line, one employed in the determination of the general direction of the face. See Lines, Table of.

Profluvium (pro-flu'-ve-um) [profluere, to flow forth]. A flux or discharge P. alvi. Diarrhea. P. muliebre. Synonym of Leukorrhea. P. sanguinis. Hemorrhage. P. seminis. I. Synonym of Spermatorrhea. 2. Discharge of semen from the vagina after coitus.

Profunda Arteries (pro-fun'-dah). See Arteries, Table of.

Profundipalmar (pro-fun-dip-all-mar) [profundus, deep; palma, palm]. Pertaining to the deep-seated parts of the hand.

Profundiplantar (pro-fun-dip-lan'-tar) [profundus, deep; planta, sole]. Deep and plantar: pertaining to the deep-seated parts of the sole of the foot.
Profundus (pro-fun'-dus) [profundus, deep]. A term applied to any organ or part that is deep-seated.

Progametange, Progametangium ( pro-gam-et-an'-je,

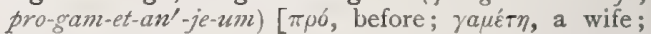
a) gametangium formed upon the mycelia of certain fungi (Protomycetacea), and from which, after a period of rest, is liberated the gametangium, within which the minute rod-shaped gametes are formed.

Progaster (pro-gas'-ter). Same as Archenteron.

Progeneration (pro-jen-er-a'-shun) [progenerare, to beget]. Propagation; the act of begetting.

Progenitor (pro-jen'-it-or) [pro, before; genitor, begetter]. Ancestor, sire, or father.

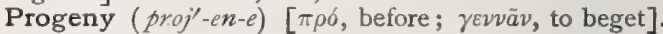
Offspring; descendants.

Proglossis (pro-glos'-is) [ $\pi \rho o ́$, before ; $\gamma \lambda \tilde{\omega} \sigma \sigma \alpha$, tongue]. The tip of the tongue.

Proglottid (pro-glot'-id) $[\pi \rho \delta$, before ; $\gamma \lambda \tilde{\omega} \sigma \sigma a$, tongue]. In biology, one of the mature segments or metameres of a tapeworm. Any person of the cestode chain or colony other than the pear-shaped or cone-shaped head or scolex; a proglottis.

Proglottis (pro-glot' $-i s)[\pi \rho \delta$, before; $\gamma \lambda \vec{\omega} \sigma \sigma \alpha$, tongue: pl., Proglottides]. Same as Proglottid.

Prognathic (prog-na'-thik). Synonym of Prognathous.

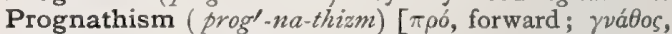
jaw]. The quality of having a projecting lower jaw, or of being prognathous. P., Alveolo-subnasal, in craniometry, the prognathism measured by the angle included between the line joining the alveolar and subnasal points and the alveolo-condylean plane.

Prognathous ( $\left.p r o g^{\prime}-n a-t h u s\right)$ [ $\pi p \delta$, before; rvátos, jaw]. Having a projecting lower jaw.

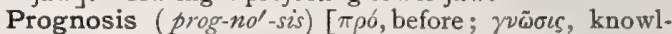
edge]. An opinion or judgment concerning the duration, course, and termination of a disease. P. anceps, a doubtful prognosis. P. fausta, a favorable prognosis. $\mathbf{P}$. infausta, an unfavorable prognosis.

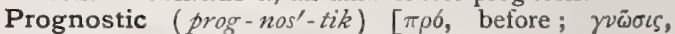
knowledge]. Pertaining to prognosis.

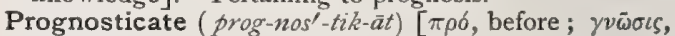
knowledge]. To make a prognosis.

Progression (pro-gresh'-un) [ progredi, to advance, to step forward]. The act of advancing or of moving forward. P., Arithmetic, a progression of numbers which increase or decrease by equal differences, as 2 , $4,6,8$, 10, or 10, $8,6,4,2$. P., Backward, a backward walking; a rare symptom of some nervous lesions in which the person can only walk backward. P., Cross-legged, walking with the legs almost crossing, a condition sometimes observed in double hip-disease and in certain disturbances of the nervous system. P., Geometric, a progression of numbers which increase or decrease by equal ratio, as $2,4,8$, $\mathbf{1} 6$, or $16,8,4,2$.

Progressive (pro-gres'-iv) [progredi, to go forward]. Marked by progress; of a disease extending over a wider area or increasing in severity. P. Muscular Atrophy, chronic anterior poliomyelitis in which the large ganglion-cells of the anterior horns, the motor and trophic cells of the muscles, are gradually destroyed. P. Ossifying Myositis, a chronic inflammation of muscles, associated with a tendency to excessive bony deposits in them. It is usually accompanied by the development of numerous exostoses.

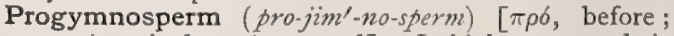
$\gamma v \mu \nu \delta s$, naked; $\sigma \pi \varepsilon \rho \mu \alpha$, seed]. In biology, an archaic or ancestral type of gymnosperm.

Progymnospermic (pro-jim-no-sper'-mik) [ $[\pi \rho \delta$, before; $\gamma v \mu \nu \sigma s$, naked; $\sigma \pi \varepsilon \hat{\varepsilon} \rho \mu a$, seed]. Pertaining to a progymnosperm. 
Projectile (pro-jek'-til) [projicere, to throw before]. Anything thrown forward violently. P., Vomiting, the vomiting sometimes observed in diseases of the brain; the material is projected out of the mouth to some distance, apparently without nausea.

Projection (pro-jek'-shun) [ projicere, to throw before]. $x$. The act of throwing forward, 2. A prominence or a part extending beyond the level of the surrounding surface. P., Monocular. Synonym of $P$., Uniocular. P., Ocular. See Ocular. P.-system of Meynert. See Meynert. P.-systems. See Meynert. P., Uniocular, the projection into space of the impression of an object made by rays emanating from it and entering one eye. A correct estimate of distance cannot be made by uniocular projection. P. of Visual Impressions, the projection into space of the impressions of objects made upon the retina by rays emanating from the objects. The ability to do this enables us to locate correctly the position or distance of objects in space.

Prolabial (pro-la'-be-al) [pro, before; labium, lip]. Pertaining to the prolabium.

Prolabium (pro-la'-be-zın) [ pro, before; labium, a lip]. The red exposed part of the lip; also, the central prominence of the lip.

Prolapse (pro-laps') [prolabi, to slip down]. The falling forward or downward of a part. $P$. of the Anus or Rectum, protrusion of the rectal walls beyond the anus. P., Artificial, the drawing down of a part or organ, as the uterus, for purposes of examination or treatment. P. of the Cord, premature expulsion of the umbilical cord during parturition. P. of the Iris, protrusion of the iris through a corneal wound. P. of the Uterus, protrusion of the womb beyond the vulva.

Prolapsed (pro-laps $\ell^{\prime}$ ) [prolabi, to fall forward]. In a condition of prolapse.

Prolapsion (pro-lap'-shun). Synonym of Prolapse. [Old.]

Prolapsus (pro-lap'-sus). Synonym of Prolapse. P. ani, prolapse of the rectum. P.cerebri. Synonym of Encephalocele. P. iridis, prolapse of the iris. P. linguæ. Synonym of Macroglossia. P. oculi. Synonym of Exophthalmos. P. palpebræ. Synonym of Ptosis. P. placentæ, prolapse of the placenta. P. recti, prolapse of the rectum. P. sclerotici, staphyloma of the sclerotic. P. uteri, prolapse of the uterus. P. uteri completus, complete prolapse of the uterus; procidentia uteri. P. uvulæ. Synonym of Staphyledema. P. vaginæ, prolapse of the vagina. $\mathbf{P}$. vesicæ, prolapse of the bladder.

Proleg (pro'-leg) [ pro, for; leg]. In biology, a false leg; a proped; an abdominal limb of the larvæ of insects.

Prolepsis (pro-lep'-sis) [ $[\pi \rho \delta$, before ; $\lambda a \mu \beta a ́ v \varepsilon \iota \nu$, to seize]. The return of a paroxysm before the expected time.

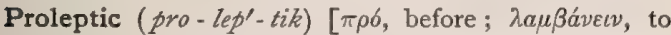
seize]. I. Prognostic. 2. Returning before the regular or expected time.

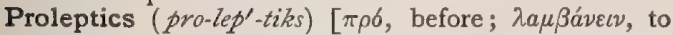
seize]. The art of prognosis.

Proles $\left(p r o o^{\prime}-l \bar{e} z\right)$ [L.]. Offspring.

Prolicide ( $p r o$-lis-id $)$ [proles, offspring ; cadere, to kill]. Feticide or infanticide.

Proliferate (pro-lif'-er-ät) [proles, offspring; ferre, to bear]. To begin ; to generate.

Proliferation (pro-lif-er-a'-shun) [proliferatio; proles, offspring ; ferre, to bear]. Cell-genesis. The continued formation and development of cells by multiplication. P., Atrophic, multiplication of the cellnuclei, with degeneration of the differentiated proto- plasm of the peculiar cells of the tissues. It occurs in inflammation and in regeneration.

Proliferative (pro-lif'-er-a-tiv) [ proles, offspring; ferre, to bear]. Multiplying; being the seat of cell-proliferation. P. Cyst, a cyst in which the lining epithelium proliferates and produces projections from the ental surface of the cysts.

Proliferous (pro-lif'-er-us) [proles, offspring ; ferr: to bear]. In biology, producing offspring; developing buds, branches, or generative zoöids. P. Cyst, with Vascular Intra-cystic Growths, a cyst, occurring in glands, especially the mammary and thyroid, from the ental wall of which spring irregular, usually cauliflower-like growths of a glandular character, which may eventually fill the cyst-cavity, or even break through the cyst-wall. The so-called sero-cystic sarcoma generally belongs to this class of cysts.

Prolific (pro-lif'-ik) [proles, offspring; facere, to make]. Fruitful; very fertile.

Prolification (pro-lif-ik-a'-shun) [prolificare, produce offspring]. In biology, the development of organs or structures from a part normally ultimate. P. Islands, numerous spots upon the chorionic villi; thickenings of the nucleated protoplasm of the ectoderm. The "Proliferationsinseln" of German authors.

Proligerous ( $p r o-l i j^{\prime}-e r^{\prime}-u s$ ) [ proles, offspring; gevere, to bear]. In biology, germinating; producing offspring; specifically applied to the film of infusions as the source of the microörganisms found in the infusion. P. Disc, see Discus proligerus.

Promala (pro-ma'-lah) [pro, before; mala, jaw]. In biology, the so-called mandibles of the myriopods, homologous with the lacinia of the hexopodous maxilla (Packard), less correctly called protomala.

Promanus (pro-ma'-nus) [pro, before; manus, hand]. The thumb.

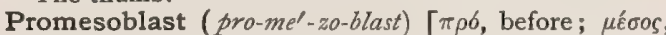
middle; $\beta \lambda a \sigma \tau o \zeta$, sprout]. The mass of primordial cells which subsequently develop into the mesoblast.

Prometopia (pro-met-o'-pe-ah) [ $\pi \rho \delta$, before ; $\mu \dot{\tau} \tau \tilde{\omega} \pi o \nu$, forehead]. The anterior portion of the forehead, or the skin covering it.

Prometopidia (pro-met-o-pid'-e-ah) [ $\left[\pi \rho \delta\right.$, before; $\mu \varepsilon^{\prime}$ $\tau \tilde{\omega} \pi o v$, forehead]. Bandages for the forehead.

Prominence (prom'-in-ens) [prominere, to jut out]. I. A projection on the surface of a part, especially on a bone. 2. The state of being prominent. 3. Importance ; distinction, P., Bony, a prominence on a bone, usually serving as a landmark, P., Doyère's. See Doyere's. P., Genital, an accumulation of cells on the ventral aspect of the embryonic cloaca and from which the generative organs are developed. P., Double, an abnormal prominence at the junction of the first and second sacral vertebræ. P. False. Synonym of $P$., Double. P., Mental, the triangular eminence projecting forward from the middle of the body of the lower jaw. P., Sacro-vertebral, the promontory of the sacrum.

Prominentia (prom-in-en'-she-ah) [L.: pl., Prominentia ]. Synonym of Prominence. P. albicans. Synonym of Corpus albicans. P. encephali. Synonym of Corpora quadrigemina. P. laryngea. Synonym of Pomum adami. P. lentiformis. Synonym of Nucleus, Lenticular. P. natiformis. Synonym of the Nates of the Corpora quadrigemina. P. oculi totius. Exophthalmos. P. orbiculares majores. Synonym of the Nates of the Corpora quadrigemina. P. orbiculares minores. Synonym of the Testes of the Corpora quadrigemina. P. semiovalis. Synonym of Olivary Body. P. sphærica, a cerebral convolution. P. spiralis, a slight prominence on the outer wall of the cochlear duct, containing a small capillary 
vessel. P. testiformes, the testes of the corpora quadrigemina.

Promontory (prom'-on-tor-e) [pro, before; mons, mountain]. An elevation or prominence. P. of the Sacrum, the prominence formed by the angle between the upper extremity of the sacrum and the last lumbar vertebra. $P$. of the Tympanum, the prominence formed by the first turn of the cochlea.

Promorph (pro'-morf) $\left[\pi \rho \sigma\right.$, before; $\mu$ o $\phi^{\prime}$, form $]$. In biology, a primitive or fundamental form-type.

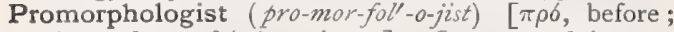

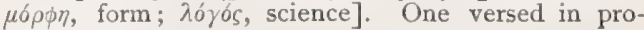
morphology.

Promorphology (pro-mor-fol'-o-je) $[\pi \rho \delta$, before; $\mu o ́ \rho \phi \eta$, form; $\lambda$ oyos, science ]. In biology, organic morphology as related to a few fundamental types of structure. The treatment of organic form from a mathematic or geometric basis.

Promuscidate (pro-mus'-id-āt) [promuscis, a corrupt form for proboscis]. Having the form of a promuscis.

Promuscis (pro-mus'-is) [promuscis, a corrupt form for proboscis : pl., Promuscides]. In biology, a proboscis, beak, or rostrum; usually applied to insects.

Promycele (pro-mi'-sel). Same as Promycelium.

Promycelial (pro-mi-sé-le-al) [ $[\pi \rho \delta$, before; $\mu$ íkns, a fungus; $\eta \lambda$ s , an excrescence ]. Pertaining to the promycelium.

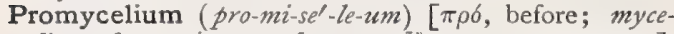
lium, from $\mu i \kappa \eta \varsigma$, a fungus; $\eta^{\prime}$ ios, an excrescence]. In biology, a short mycelium formed from the oösperm or resting spore in certain species of fungi (Oömycetes, Zygomycetes), and which dies after bearing a few conidiospores. These conidiospores in turn propagate new thalli, giving rise to a distinct alternation of generations.

Pronation (pro-na'shun) [pronatio; pronus, bent forward]. 1. The condition of being prone; the act of placing in the prone position. 2. Of the hand. The turning of the palm downward.

Pronator (pro-na'-tor) [pronare, to bend forward]. That which pronates. A term applied to several muscles. See Muscles, Table of.

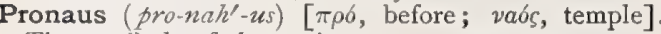
The vestibule of the vagina.

Prone $(p r o \bar{n})$ [pronus, prone]. With the palm directed downward. Also, lying with the face downward. The opposite is Supine. P. and Postural Respiration, "Marshall Hall's Ready Method of Artificial Respiration." See Respiration.

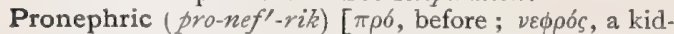
ney]. In biology, of or pertaining to the pronephron, or the primitive kidney. P. Duct, one of the four fundamental parts of the vertebrate urogenital system; the Wolffian duct. Cf. Archinephric Duct, Müllerian Duct.

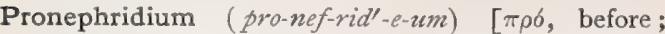
$\nu \varepsilon \phi \rho \circ s$, kidney]. One of the canaliculi which in lower orders of animals, especially the invertebrata, act as excretory organs.

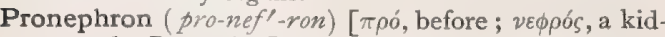
ney: pl., Pronephra]. In biology, "the first part of the urogenital system to be differentiated in the vertebrate embryo ; it is to be regarded as the phylogenetically oldest part. It is found in the embryos of (probably) all vertebrates, but disappears before adult life in selachians, some teleosts, and all amniota. It is always situated in the segments immediately behind the heart, and is a paired organ with a longitudinal duct, which finally opens into the cloaca." (Minot.) C. Head-kidney, Primitive Kidney, Okenian Body, Wolffan Body.

Pronephros (pro-nef'-ros). Same as Pronephron.
Proncea (pro-ne'-ah). Synonym of Proonosis.

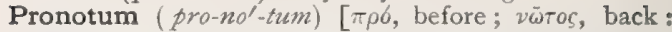
pl., Pronota $]$. The anterior of the three divisions of the dorsal section of the prothorax of an arthropod.

Pronuclear (pro-nu'-kle-ar) [pro, before; nuclews, nucleus]. Pertaining to a pronucleus.

Pronucleate (pro-nu'-kle-ät) [pro, before; nucleus, nucleus]. Having a pronucleus.

Pronucleolus (pro-nu-kle'-o-lus) [ pro, before; nucleolus, nucleolus]. A nucleolus of a pronucleus.

Pronucleus (pro-nu'-kle-us) [pro, before; nucleus, nucleus: pl., Pronuclei $]$. In biology, the name given by Ed. van Beneden to one of the two nuclear elements of a newly fecundated ovum, the male and the female pronucleus, the fusion (conjugation) of which results in the formation of the first embryonic nucleus. The nucleus which appears within the ovum after the formation of the polar bodies is the female pronucleus. According to Hertwig, the head of the spermatozoid is transformed directly into the male pronucleus, while Salensky holds that it is first dissolved and provokes secondarily the formation of the male pronucleus. P., Segmentation, the nucleus of the germ. P., Sperm. Synonym of $P$, Male.

Proödontus (pro-o-don'-tus) [ $\pi \rho \sigma$, before; ódoŕs, tooth]. Lissauer's term for a skull in which the angle formed between the radius fixus and the line joining the subnasal and alveolar points is between $23^{\circ}$ and $50^{\circ}$.

Proof-spirit. See Spirit.

Proösteon (pro-os'-te-on) [ $\pi \rho \sigma$, before ; óotéov, bone]. A bony process or prominence.

Proöstracal (pro-os'-trak-al) [ $\pi \rho \delta$, before; ò $\sigma \rho a k o v$, shell]. Pertaining to a proöstracum.

Proöstracum (pro-os'-trak-um) [ $\pi \rho \delta$, before; ö $\sigma \rho \alpha \kappa o v$, shell]. In biology, the projecting lamella of the thick covering of the phragmacone of a cephalopod.

Proötic (pro-o'-tik) [ $\pi \rho o ́$, before ; ov́s, ear ]. I. Before, or in front of, the ear. 2. One of the otic bones, very constant in the skulls of the lower vertebrata.

Propagate $\left(p_{r o p} p^{\prime}-a g-\bar{a} t\right)$ [ propagare, to generate]. To generate; to multiply.

Propagation (prop-ag-a'-shun) [propagare, to generate]. Reproduction; spreading, dissemination. $\mathbf{P}$., Arc of, a term given to that margin of the corneal creeping ulcer of Saemisch which assumes the form of an elevated curve, and is more decidedly opaque or yellow than the others.

Propagatorium (prop-ag-at-o'-re-um) [propagare, to generate, increase: pl., Propagatoria]. In biology, the entire mechanism of reproduction. Cf. Nutritorium, Locomotorium, Sensorium.

Propagule (pro-pag $\left.g^{\prime}-\overline{u l}\right)$ [propagare, to propagate]. Same as Propagulum.

Propagulum (pro-pag'-u-lum) [propagare, to propagate: $p l$, Propagula $]$. In biology, any structure, part, or organ utilized in the asexual propagation of plants; a stolon, offset, runner.

Propalanin (prō-pal'-an-in), $\mathrm{C}_{4} \mathrm{H}_{9} \mathrm{NO}_{2}$. Amidobutyric acid. It crystallizes in little leaflets or needles, and is very soluble in water.

Propalinal (pro-pal'-in-al) $[\pi \rho 6$, before ; $\pi a ́ \lambda \iota \nu$, back, backward]. In biology, applied to the forward and backward movement of the jaws of certain animals.

Propane (pro'-pann), $\mathrm{C}_{3} \mathrm{H}_{8}$. A hydrocarbon of the marsh-gas series. It is a constituent of petroleum.

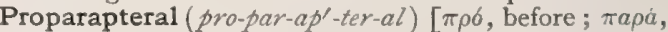
beside; $\pi \tau \varepsilon \rho 0 \nu$, wing $]$. Pertaining to the proparapteron.

Proparapteron (pro-par-aṕ-ter-on) [ $\pi \rho o ́$, before ; $\pi x \rho a ́$, beside; $\pi \tau \varepsilon a d v$, wing: pl., Proparaptera $]$. In biology, the third sclerite of the propleuron of an arthropod. 
Proparateresis (pro-par-at-er-e'-sis) [ $\pi \rho 6$, before ; $\pi a \rho a$,

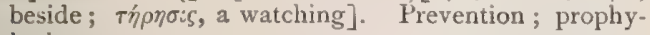
laxis.

Propargylic Acid (pro-par-gil'-ik). See Propiolic Acid.

Propatagial (pro-pat-a $\left.a^{\prime}-j e-a l\right)$ [ $[\pi \rho o ́$, before; $\pi \alpha \tau a \gamma \varepsilon i o v$, a border]. Pertaining to the propatagium.

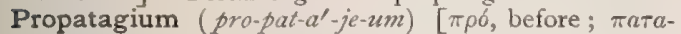
yeiov, a golden stripe, border: pl., Propatagia]. In biology, the fold of skin in front of and between the forearm and upper arm in the wing of a bird.

Propathy (pro'-path-e) [ $\pi \rho o ́$, before; $\pi a ́ \theta u s$, disease]. I. A premonitory symptom. 2. A past disease.

Prop-cells. Cells, generally columnar or fusiform, placed in the intervals of the rods and hair-cells of the organ of Corti. They are also known as Supporting Cells and Cells of Deiter.

Proped (pro'-ped). See Proleg.

Propedal (pro-pe'-dl) [pro, for; pes, a foot]. Pertaining to a proped.

Propendentia (pro-pen-den'she-ah). Synonym of Prolapse. P. uvulæe, relaxation of the uvula.

Propenyl ( $p r o$-pen-il). See Glyceryl. P. Trinitrate. Synonym of Nitroglycerin.

Propenyl Hydrate ( $\left.p r o^{\prime}-p e n-i l-h i^{\prime}-d r a \bar{t}\right)$. SeeGlycerin.

Propepsin $\left(p r o-p e p^{\prime}-\sin \right)[\pi \rho 6$, before; $\pi \varepsilon \dot{\varepsilon} \tau \varepsilon \iota \nu$, to cook ]. The zymogen, or mother-substance, of pepsin, found in the cells of the gastric glands.

Propeptone (pro-pep'-tōn). See under Peptone.

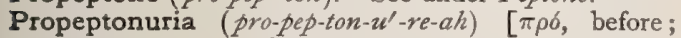

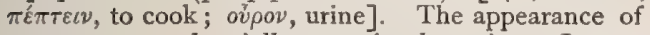
propeptone or hemialbumose in the urine. It may occur in fevers, diphtheria, or osteomalacia, or during medication with storax or phosphorus See Pepionuria.

Properistoma (pro-per-is-to'-mah) $\left[\pi \rho \dot{0}\right.$, before ; $\pi \varepsilon \rho \iota^{\prime}$,

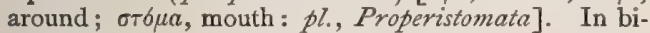
ology, the thickened edge of the gastrula.

Properistomal (pro-per-is-to'-mal) [ $\left[\pi \rho o^{\prime}\right.$, before ; $\pi \varepsilon \rho \dot{\prime}$, around; $\sigma \tau \delta \mu a$, mouth $]$. Pertaining to a properistoma.

Properistome (pro-per'-is-töm). Same as Properistoma.

Properitoneal (pro-per-it-o-ne'-al) [ $\pi \rho o ́$, before; $\pi \varepsilon \rho \iota \tau o ́-$ vaıov, peritoneum]. Situated in front of the peritoneum. P. Hernia, a hernia the sac of which extends in various directions within the abdominal walls. $\mathbf{P}$. Hernia, Cruro-, of Kroenlein, a femoral hernia in which an additional sac exists in the cellular tissue of the pelvis, between the peritoneum and the abdominal wall. P. Hernia, Inguino-, of Kroenlein; one which protrudes outward along the fold of the groin, within the abdominal walls; by the French termed hernie en bissac.

Prophasis (prof'-as-is) [ $\pi \rho b$, before ; $\phi a i v \varepsilon \imath \nu$, to show]. I. Prognosis. 2. In biology, a collective term proposed by Strasburger for the phenomena of karyokinesis up to the longitudinal splitting of the threads. Cf. anaphases, metaphases.

Prophetin (prof'-et-in), $\mathrm{C}_{20} \mathrm{H}_{36} \mathrm{O}_{7}$. A glucosid found in Ecballium officinale and Cucumis prophetarum.

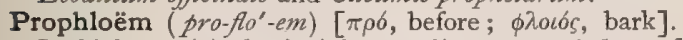
In biology, $(a)$ the incipient rudiment or Anlage of phloêm in a fibro-vascular bundle; $(b)$ a tissue in the sporophore of mosses resembling the phloêm of higher plants.

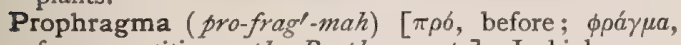
fence, partition : $p l$., Prophragmata]. In biology, an internal, anterior, transverse plate of the exoskeleton of an insect, serving for the attachment of internal organs.

Prophthalmos (prof-thal'-mos). Synonym of Exophthalmos.

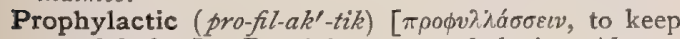
guard before]. Pertaining to prophylaxis. Also, a medicine or agent that prevents the taking of disease.
Prophylaxis (pro-fil-aks'-is) [ $\pi \rho \circ \phi v \lambda \lambda a ́ \sigma \sigma \varepsilon \iota \nu$, to 'keep guard before]. Prevention of disease; preventive measures; preventive medicine; hygiene.

Prophylaxy (pro'-fil-aks-e). Same as Prophylaxis.

Prophyllum (pro-fil'-um) [ $\pi \rho o ́$, before; $\phi \dot{v} \lambda \lambda \nu^{\prime} v$, leaf $]$. A primitive or primary leaf.

Prophysis (prof'-is-is). See Symblepharon.

Propiolic Acid (pro-pe-o'-lik). See Acid.

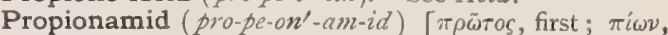
fat; amid], $\mathrm{C}_{3} \mathrm{H}_{7} \mathrm{NO}$. A substitution compound of ammonia.

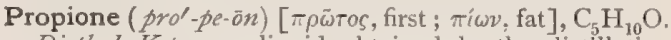
Diethyl Ketone, a liquid obtained by the distillation of calcium propionate. It boils at $\operatorname{IOI}^{\circ} \mathrm{C}$.

Propionic Acid (pro-pe-on'-ik). See p. 36.

Proplasm (pro'-plazm) [ $[\pi \rho \delta$, for ; $\pi \lambda \dot{a} \sigma \sigma \varepsilon \iota \nu$, to form $]$. A mold; a matrix.

Propleural (pro-plu'-ral) [ $\pi \rho \delta$, before ; $\pi \lambda \varepsilon v \rho a ́$, side $]$. Pertaining to the propleura.

Propleuron ( $\left.p r o-p l u^{\prime}-r o n\right)[\pi \rho \sigma$, before ; $\pi \lambda \varepsilon v \rho a ́$, side : $p l .$, Propleura $]$. In biology, one of the prothoracic parameres of an arthropod.

Proplexus (pro-pleks'-us) [pro, before; plexus, plexus]. The choroid plexus of the lateral ventricle of the brain. See Paraplexus.

Propodeum (pro-po'-de-um) [pro, before; pod (ex), fundament : pl., Propodea]. In biology, a part of the last thoracic ring of certain insects transferred during development from the first abdominal ring.

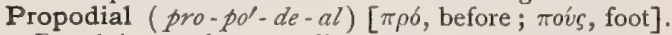
Pertaining to the propodium.

Propodite (prop'-o-dit ) [ $\pi \rho 6$, before; $\pi$ ov́s, foot]. Same as Propodos.

Propodium (pro-po'-de-um) [ $\pi \rho 6$, before; $\pi \delta v \varsigma$, foot : pl., Propodia ]. In biology, the anterior portion of the foot of a gasteropod or pteropod, as distinguished from the mesopodium and metapodium.

Propodos (prop'-o-dos) [ $\pi \rho \sigma$, before; $\pi$ ov́s, foot]. In biology, the sixth joint of any appendage of a crustacean; a prognathite, propodite (Bate). Cf. protopodite, endopodite or exopodite, ischiopodite, meropodite, carpopodite, and dactylopodite.

Propolis (prop'-o-lis) [ $\pi \rho \delta$, before; $\pi \delta \lambda \iota s$, city $]$. In biology, a resinous substance, exceedingly tenacious, varying much in color, but usually a rich brown, and which emits a balsamic odor, used by bees both as a cement and as a varnish. Bees varnish their combs with it, applying it quite thickly on the edges of the cells and thin on the cell-walls; they use it to fill up every crack the bottom of which they cannot reach. Propolis is collected in largest amounts toward the end of the season, from a variety of sources, e.g., the leaf-buds of shrubs and trees, the poplar, the alder, the beech, the willow, the fir, the horsechestnut, the hollyhock, etc.

Propoma ( $\left.p r o-p o^{\prime}-m a \hbar\right)$ [ $\pi p o \pi i \nu \varepsilon \varepsilon v$, to drink before]. A potion taken before meals.

Propons (pro'-ponz). Synonym of Ponticulus.

Propostscutellar (pro-pōst-sku-tel'-ar) $[\pi \rho 6$, before; postscutellum]. Pertaining to a propostscutellum.

Propostscutelium (pro-pōst-sku-tel'-um) [ $\pi \rho b$, before ; postscutellum]. In biology, the postscutellum of the pronotum.

Proprescutal (pro-pre-sku'-tal) [pro, before; prescutum]. Pertaining to the proprescutum.

Proprietary (pro-pri-et-ar-e) [proprietas, property]. Belonging to a proprietor. P. Medicine. One the manufacture or sale of which is controlled or limited by a monopoly of the sources of supply; by a propertyright in the trade-mark, the name, or the label; by a patent; by a secret of constitution or of method of manufacture; or by any other means. 


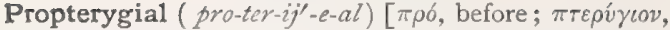
a little wing]. Pertaining to the propterygium.

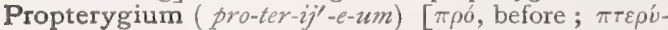
rov, a little wing, fin: pl., Propterygia]. In biology, one of the three segments of the skeleton of the anterior fin of a fish. Cf. Mesopterygium, Metaptery. gium.

Proptoma (prop-to'-mah) $[\pi \rho \delta$, before; $\pi \tau \tilde{\omega} \mu a$, a fall : pl., Proptomata]. A prolapse, or the protruding mass resulting from a prolapse. $\mathbf{P}$. auricularum, flap ears. P. mammarum, a pendulous condition of the breasts. P. palpebrarum. Synonym of Ptosis.

Proptosis (prop-to'-sis) [ $\pi \rho \sigma$, forward; $\pi \tau \tilde{\omega} \sigma \iota \zeta$, a falling]. A falling downward of an organ from its place. Prolapse. P., Entero-. See Enteroproptosis. P., Gastro-. See Gastroptosis. P. oculi. Synonym of Exophthalmos. P. palpebræ, ptosis. P. uvulæ. Synonym of Staphyledema.

Proptysis (prop'-tis-is). Synonym of Expectoration.

Propulsion (pro-pul'-shun) [pro, before; pellere, to push]. The act of pushing or being pushed forward. It is a symptom of paralysis agitans; as the patient walks there is a progressive increase in the rapidity of his gait, until he breaks into a run. This continues until he either falls or seizes a support. See Paralysis agitans and Festination.

Propupa (pro-pu'-pah) [pro, before; pupa, pupa]. In biology, that stage of insect development immediately preceding the pupa.

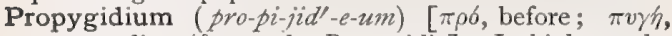
rump : dim, idiov : pl., Propyoidia ]. In biology, the penultimate dorsal segment of the abdomen of certain insects.

Propyl (pro'-pil) $[\pi \rho \tilde{\omega} \tau o s$, first ; $v \lambda \eta$, matter $], \mathrm{C}_{3} \mathrm{H}_{7}$ The radicle of propane.

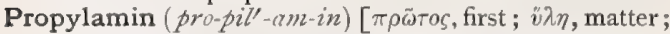
amin $], \mathrm{C}_{3} \mathrm{H}_{9} \mathrm{~N}$. A ptomain, isomeric with trimethylamin. There are two propylamins possible, represented by the formulæ $\mathrm{CH}_{3}, \mathrm{CH}_{2}, \mathrm{CH}_{2}, \mathrm{NH}_{2}$ and $\left(\mathrm{CH}_{3}\right)_{2}$ $\mathrm{CH}_{2}$. The former, or normal compound, boils at $47^{\circ}$ $48^{\circ} \mathrm{C}$. ; while the latter, or isopropylamin, boils at $31.5^{\circ} \mathrm{C}$. Iso-propylamin has been found among the distillation-products of beet-root molasses. Normal propylamin has been obtained from cultures of the bacteria of human feces, and a strongly similar basic substance from a cadaver. Both are non-poisonous liquids possessing an ammoniacal, fish-like smell. See Ptomains, Table of.

Propylene $\left(p r o^{\prime}-p i l \cdot \bar{e} n\right)[\pi \rho \tilde{\omega} \tau o \zeta$, first ; $\pi i \omega v$, fat ; $v \lambda \eta$, matter $], \mathrm{C}_{3} \mathrm{H}_{6}$. A gaseous hydrocarbon belonging to the series of the olefins.

Prora $\left(p r o^{\prime}-r a h\right)[\pi \rho \bar{\omega} \rho a$, the prow of a ship $]$. I. Occiput. 2. In biology, prow-shaped or C-shaped, as certain sponge-spicules. Proræ, Sutura, the lambdoid suture.

Proral (pro'-ral). See Cephalic.

Prorenal (pro-re'-nal) [ pro, for, before ; ren, the kidney]. In biology, preceding the true kidney. See Duct, Segmental.

Pro re nata (pro-re-na'-tah) [L.]. A phrase signifying according to the circumstances of the case.

Prorrhesis (pror-e'-sis). Synonym of Prognosis.

Prorsad (pror'-sad) [prorsum, forward]. Toward the anterior aspect.

Prorsal (pror'-sal) [prorsum, forward]. Anterior; forward.

Proruption (pror-up'-shun). Synonym of Eruption.

Pros's Apparatus. A contrivance for making continuous traction on the obstetric forceps, the counterpressure being exerted upon the bed, that forms part of the apparatus.

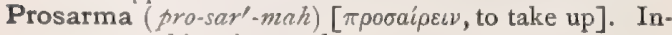
gesta; anything ingested.

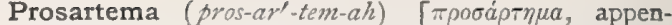
dage]. In biology, the appendage connected with the inner side of the first joint of the first pair of antennæ in macrurous crustaceans. (Bate.)

Prosarthrosis (pros-ar-thro'sis). Synonym of Diarthrosis.

Proscapula (pro-skap'-u-lah) [pro, before; scapula, shoulder-blade: pl., Proscapula $]$. In biology, one of the principal parameric elements of the shoulder-girdle of a fish. The humerus of Cuvier, the coracoid of Owen, and the clavicle of later writers.

Proscapular (pro-skap'-u-lar) [pro, before; scapula, shoulder-blade]. Pertaining to the proscapula.

Proschysis (pros'-kis-is) [ $\pi \rho \circ$, before; $\chi v \sigma \iota s$, a pouring]. Affusion.

Proscolecine (pro-skol'-es-in) [ $\pi \rho \sigma$, before; $\sigma \kappa \omega \lambda \eta \xi$, a worm]. Pertaining to a proscolex.

Proscolex (pro-sko'-leks) [ $\pi \rho o ́$, before; $\sigma \kappa \omega \lambda \eta \eta \xi$, a worm: pl., Proscolices]. In biology, the embryo of a cestode worm immediately after leaving the egg. It is a microscopic spheric or oval body provided at one pole with three pairs of divergent spicules by which it is enabled to penetrate the walls of the stomach or intes. tine of its host.

Proscolla (pros-kol'-ah) [ $\pi \rho o ́ s$, before; $\kappa o ́ \lambda \lambda a$, glue : pl., Proscolle]. See Retinaculum.

Proscutal (pro-sku'-tal) [pro, before; scutum, a shield]. Pertaining to the proscutum.

Proscutellar (pro-sku-tel'-ar) [pro, before; sculellum, a little shield]. Pertaining to the proscutellum.

Proscutellum (pro-sku-tel'-um) [pro, before; scutellum, a little shield : pl., Proscutella]. In biology, the penultimate piece of the pronotum of an arthropod.

Proscutum (pro-sku'tum) [pro, before; scutum, a shield: pl., Proscuta $]$. The scutum, or second piece of the pronotum of an arthropod.

Prosection (pro-sek'-shun) [prosecare, to cut off from before]. Dissection practised by a prosector.

Prosector (pro-sek'-tor) [pro, for ; sector, cutter]. An officer of a medical college who prepares subjects for anatomic dissection, or to illustrate didactic lectures.

Prosectorship (pro-sek'-tor-ship) [ prosecare, to cut off from before]. The office of a prosector.

Prosencephal $\left(p r o s-e n^{\prime}-s e f-a l\right)$. Same as Prosencephalon.

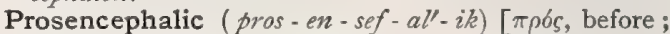

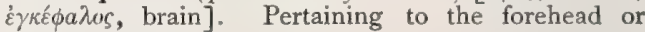
forebrain; frontal. P. Arch, the neural arch of a frontal vertebra.

Prosencephalon (pros - en - sef'-al - on ) [ $\pi \rho \delta$ s, before ;

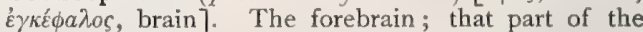
anterior cerebral vesicle from which are developed the hemispheres, the callosum, the anterior commissure, the fornix, the septum lucidum, the anterior perforated space, the olfactory lobes, and the corpus striatum. The cavity is the prosocele.

Prosenchyma (pros-eng'-kim-ah) [ $\pi \rho \sigma s$, near ; $\check{\gamma} \gamma \chi v \mu a$, an infusion]. In biology, a term used to designate the elongated, taper-pointed cells and vessels of plants.

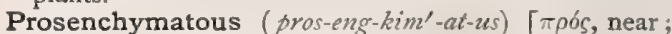
$\varepsilon \gamma \gamma \chi v \mu a$, an infusion]. Belonging or pertaining to the prosenchyma.

Prosenthesis (pros - en'-thes - is) $[\pi \rho \sigma s$, to ; $\varepsilon v \theta \varepsilon \sigma \iota s$, a putting in, insertion]. In biology, a supplementary relation which the measure of the phyllotaxis adopts in the transition from the last leaf of one cycle to the first of the next. (Sachs.)

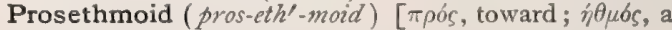
sieve]. In biology, the median ethmoid bone of the skull of a fish.

Proslysis (pros'-lis-is). Same as Catalysis. 


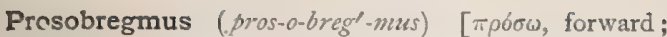

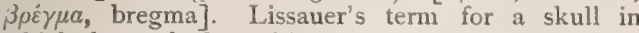
which the angle formed between the radius fixus and the line joining the hormion and the bregma is between $82^{\circ}$ and $95.5^{\circ}$

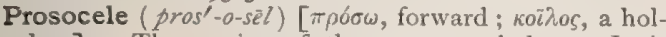
low]. The cavity of the prosencephalon. It is divided into three main divisions, a mesal cavity, the aula, and two lateral cavities, the paraceles, together with the rhinoceles (olfactory ventricles) or cavities of the olfactory bulbs.

Prosodal (pros'-o-dal) [ $\pi \rho \delta \delta s$, to ; óós, way, road]. In biology, incurrent.

Prosodiencephal (pros-o-di-en'-sef-al) [ $\pi \rho \sigma \sigma \omega$, forward ; $\delta \iota a$, through ; $\dot{\varepsilon} \gamma \kappa \varepsilon \dot{\phi} a \lambda$, brain]. The prim. ary fore-brain.

Prosodiencephalic (pros-o-di-en-sef-all-ik) [ $\pi \rho 6 \sigma \omega$, forward; diencephalon]. Pertaining to the prosodiencephal.

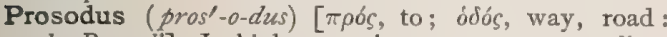
pl., Prosodi $]$. In biology, an incurrent pore; an aditus, as in a sponge.

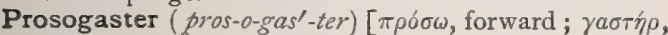
belly]. The foregut.

Prosognathous (pro-sog' -na-thus). Same as Prognathic.

Prosoma (pro-so'-mah) [ [ $\rho \delta$, before; $\sigma \tilde{\omega} \mu \alpha$, body]. In biology, the cephalic or anterior segment of the body of a mollusc or other animal.

Prosomal (pro-so'-mal) [ $\pi \rho \sigma$, before; $\sigma \tilde{\omega} \mu \alpha$, body]. Pertaining to the prosoma.

Prosomatic (pro-so-mat' $-i k)[\pi \rho \sigma$, before ; $\sigma \tilde{\omega} \mu a$, body $]$. Pertaining to the prosoma

Prosome (pro'-sōm). Same as Prosoma.

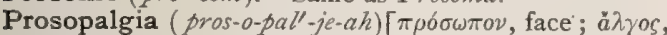
pain]. Face-ache; Tic douloureux.

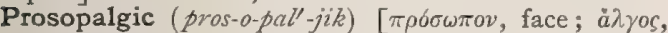
pain]. Affected with prosopalgia.

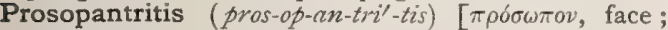

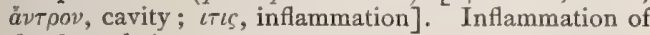
the frontal sinuses.

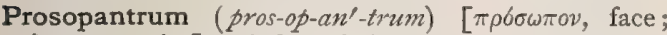
åvrpov, cavity]. A frontal sinus.

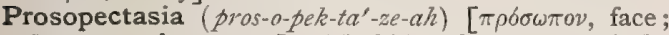
$\tilde{\varepsilon} \kappa \tau \alpha \sigma \iota \varsigma$, enlargement]. Morbid enlargement of the face.

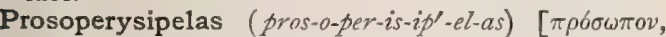

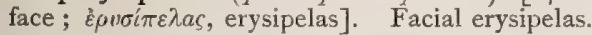

Prosoplexus (pros-o-pleks'-us) [ $\pi \rho \sigma \sigma \omega$, forward; plexus, plexus]. The choroid plexuses of the prosencephalic cavities, including the paraplexuses and intermediate portiplexuses and antiplexuses.

Prosopocarcinoma (pros-o-po-kar-sin-o'-mah) [ $\pi \rho o ́ \sigma \omega-$

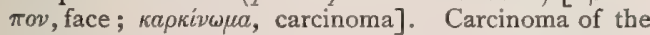
face.

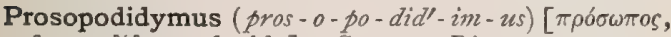
face ; dídvuos, double]. Same as Diprosopus.

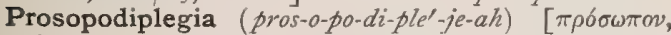
face; dis, double; $\pi \lambda \eta \gamma \dot{\eta}$, stroke]. Bilateral facial palsy.

Prosopodismorphia (pros-o-pod-is-mor'-fe-ah). Synonym of Atrophy, Progressive Unilateral Facial.

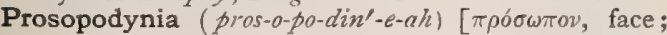
ódiv $\eta$, pain]. Facial pain, or neuralgia.

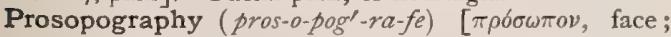

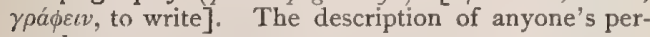
sonal appearance.

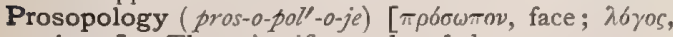
science]. The scientific study of the countenance; physiognomy.

Prosoponeuralgia ( $\left.p r o s-a-p o-n u-r a l^{\prime \prime}-j e-a h\right)$. Synonym of Prosopalgia.
Prosopoparalysis (pros-o-po-par-al'-is-is). Synonym of Prosopoplegia.

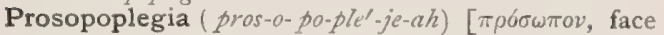
$\pi \lambda \eta \gamma^{\prime}$, stroke]. Facial palsy.

Prosoposalgia (pros-o-po-sal'-je-ah). Synonym of Prosopalgia.

Prosoposchisis (pros-o-pos'-kis-is) [ $\pi \rho o ́ \sigma \omega \pi o v$, face; $\sigma \chi i \sigma \iota s$, fissure]. An oblique fissure or cleft of the face of a fetal monstrosity. It passes from the mouth to one of the orbits, and is usually associated with mal. formation of the brain.

Prosoposis (pros-o-po'-sis) [ $\pi \rho 6 \sigma \omega \pi o \nu$, face $]$. Physiognomy.

Prosopospasmos (pros - o-po-spaz'- mos) [ $\pi \rho \delta \sigma \sigma \pi o v$, face; $\sigma \pi \alpha \sigma \mu \delta \delta$, spasm]. Risus sardonicus.

Prosoposternodynia (pros-o-po-ster-no-din'-e-ah)

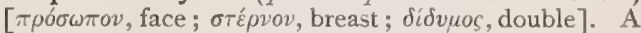
form of double monstrosity in which the twins are united by their faces and chests.

Prosopothoracopagus (pros-o-po-tho-rak-op'-ag-us) $[\pi \rho \delta \sigma \omega \pi o v$, face; $\theta \dot{\omega} \rho \alpha \xi$, chest; $\pi \alpha ́ \gamma o s$, that which is fixed]. A form of double fetal monstrosity in which the twins are united by the upper abdomen, chest, and faces, the spinal columns being quite separate and distinct.

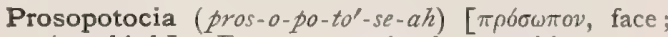
тóкоs, birth]. Face-presentation in parturition.

Prosoprosopus (pros-o-pros'-op-us) [ [ $\pi \rho \sigma \sigma \omega$, forward; $\pi \rho \sigma \sigma \omega \pi \nu \nu$, face]. Lissauer's term for a skull in which the angle formed between the radius fixus and the line joining the nasion and the alveolar point is between $66.5^{\circ}$ and $78^{\circ}$

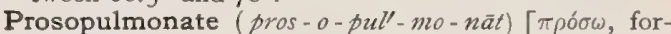
ward; pulmo, lung]. Having anterior pulmonary organs.

Prosopylar (pros-o-pi'-lar) [ $\pi \rho o ́ \sigma \omega$, forward; $\pi \dot{v} \lambda \eta$, a gate]. Pertaining to a prosopyle.

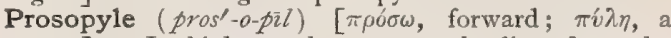
gate]. In biology, the aperture leading from the exterior into an endodermal chamber in a sponge, as distinguished from the apopyle, which furnishes communication between the endodermal chamber and the paragastric cavity.

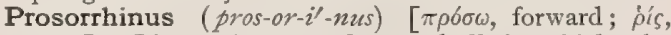
nose]. Lissauer's term for a skull in which the angle formed between the radius fixus and the line joining the nasion and the subnasal point is between $66.5^{\circ}$ and $77^{\circ}$.

Prosoterma (pros-o-ter'-mah) [ $\pi \rho b \sigma \omega$, forward; $\tau \varepsilon \dot{\varepsilon} \rho a$, limit]. A lamina uniting the two halves of the fornix.

Prosothoracopagus (pros-o-tho-rak-op'-ag-us) [ $\pi \rho 6 \sigma \omega$, forward; $\theta \omega \rho a \xi$, thorax; $\pi a ́$ yos, fixed]. A double monstrosity with fusion of the thoraces.

Prospegma (pros-peg'-mah) [ $[\pi \rho 0 \sigma \pi \eta \gamma v$ viva, to fix $]$ An inspissated mass, especially of mucus, in the anus.

Prosphysis (pros'-fis-is) [ $\pi \rho \circ \sigma \phi v e \sigma \theta a \iota$, to cling to ]. Adhesion. P. palpebrarum. Synonym of Ankyloblepharon.

Prosporangium (pro-spo-ran'-je-unt) [ $\pi \rho 6$, before ;

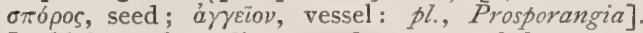
In biology, the rudiment or forerunner of the sporangium in the Chytridiea.

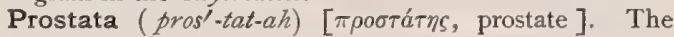
prostate gland.

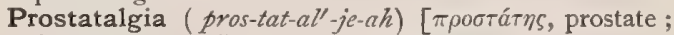

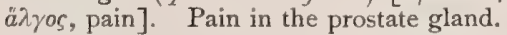

Prostatauxe (pros-tat-awks'-e) [ $\pi \rho 0 \sigma \tau a ́ \tau \eta s$, prostate; $a v \xi \eta$, increase]. Enlargement of the prostate gland. Prostate, or Prostate Gland (pros'-tat $)$ [ $\pi$ pootatís,

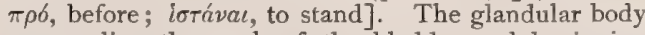
surrounding the neck of the bladder and beginning of the urethra. It is situated behind the symphysis 
pubis, and upon the rectum, through which it is palpable when enlarged. It measures an inch and a half in its transverse diameter, an inch in its antero-posterior, and three-quarters of an inch in thickness. Its weight is about 6 drams. It consists of two lateral and a midale lobe. In structure it consists of muscular and glandular tissue; a distinct capsule surrounds it. The prostate often becomes enlarged in advanced life, and may then interfere with the emptying of the bladder. P., Anterior, a small glandular body sometimes found in front of Méry's glands. P., Enlarged, the enlargement of the prostate gland, so frequent in advanced life. One of the most constant symptoms is frequent urination, especially at night.

Prostatectomy (pros-tat-ek'-to-me) [ $\pi \rho 0 \sigma \tau a ́ \tau \eta s$, prostate; $\dot{\varepsilon}$ Touń, excision]. Excision of a part of the prostate, also known as Mercier's Operation.

Prostatelcosis, Prostathelcosis (pros-tat-el-ko'-sis,

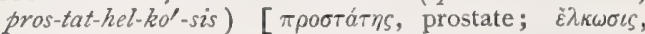
ulceration]. Ulceration of the prostate.

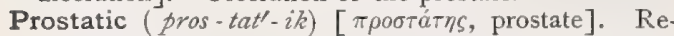
lating to the prostate. P. Acini, highly developed urethral glands, opening by several ducts on the free surface of the urethra. P. Calculus, a stone lodged in the prostate gland. P. Ducts, a number of short ducts opening upon the floor of the urethra, and communicating with the prostate gland. P. Plexus. I. A collection of veins surrounding the neck and base of the bladder and the prostate gland. 2. A plexus of nerves derived from the pelvic plexus, and distributed to the prostate gland, seminal vesicles and erectile tissue of the penis. P. Sinus, a depression in the prostatic urethra, one on each side of the verumontanum, which marks the entrance of the prostatic ducts. P. Urethra, that portion of the urethra surrounded by the prostate gland. P Vesicle, a small cul-de-sac situated at the middle of the highest portion of the crest of the urethra. It is the analogue of the uterus of the female, and is also called the uterus masculinus, the sinus pocularis and the utricle.

Prostaticus (pros-tat'-ik-us). Same as Prostatic.

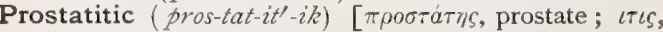
inflammation]. Affected with prostatitis.

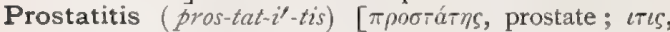
inflammation]. Inflammation of the prostate gland.

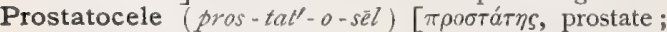
$\kappa \eta \dot{\lambda} \eta$, tumor]. An enlargement of the prostate gland, causing a tumor-like projection.

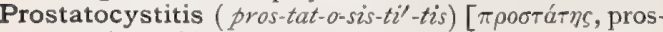

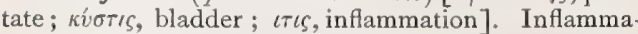
tion of the prostate and urinary bladder

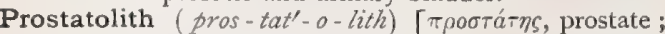
$\lambda i \theta o s$, a stone]. A prostatic calculus.

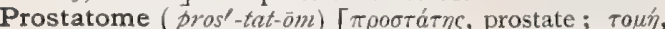
a cutting]. A cutting-instrument used in operations upon the prostate.

Prostatomele (pros-tat-om'-el-e) [ [ $\mu \dot{\eta} \lambda \eta$, probe]. A sound for exploration of the prostate gland.

Prostatometer (pros-tat-om'-et-er) [ $\pi \rho \circ \sigma \tau a ́ \tau \eta s$, prostate;

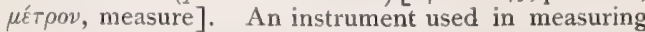
the prostate.

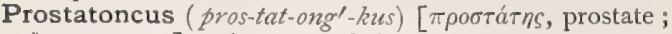
bүкоs, tumor]. A tumor of the prostate.

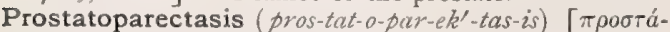

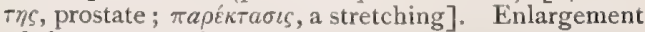
of the prostate gland.

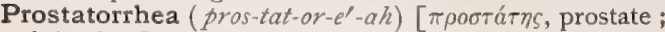
poia, flow]. A thin, urethral discharge coming from the prostate gland in prostatitis.

Prostatoscirrhus (pros-tat-o-skir'-us) [ $\pi \rho 0 \sigma \tau a \dot{\tau} \eta s$, pros-

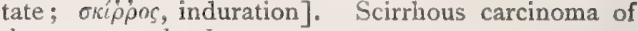
the prostate gland.

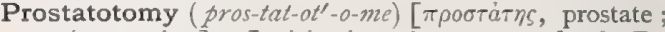
$\tau o \mu \eta^{\prime}$, a cutting]. Incision into the prostate gland. P., Thermo-electric, perforation of an enlarged prostate by means of the galvanic cautery, for the purpose of establishing a channel through it.

Prosternal (pro-ster'-nal) $[\pi \rho o ́$, before; atépvov, the breast-bone]. Pertaining to the prosternum.

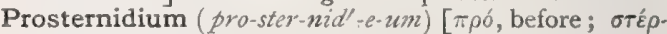
vov, breast-bone]. A plaster for the chest.

Prosternum (pro-ster'-numu) [ $\pi \rho o$, before; $\sigma \tau \varepsilon$ ćvov, the breast-bone: pl., Prosterna]. In biology, the sternal piece of the prothorax of an arthropod.

Prostethedium (pro-steth-ed'-e-um) [ $[\pi \rho 6$, before; $\sigma \tau \tilde{\eta}$ Oos, breast]. See Prosternidium.

Prostheca (pros-the'-kah) [ $\pi$ poot'k $\eta$, an addition, appendage: pl., Prostheca]. In biology, a process on the mandibles of certain insects (e. gr., Staphylinida, or rove-beetles).

Prosthecal (pros-the'-kal) [ $[\pi \rho o \sigma \theta \dot{\eta} \kappa \eta$, an addition, appendage]. Pertaining to the prostheca.

Prosthema ( $\left.\operatorname{pros}^{\prime}-t h e-m a h\right)$ [ $\pi \rho \circ \sigma \theta \varepsilon \mu \alpha$, an addition, appendage: pl., Prosthemata $]$. In biology, the leaflike appendage of the nose of a bat, as in Phyllorhina.

Prosthencephalon (pros-then-sef'-al-on) $[\pi \rho \sigma \sigma \theta \varepsilon v$, be-

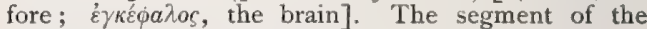
brain consisting of the cerebellum and oblongata.

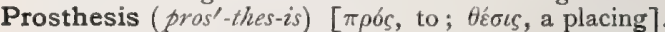
I. Substitution of an artificial for a natural part; replacement of a missing part by an artificial substitute. 2. The branch of surgery which is devoted to supplying by artificial means parts that are defective. P., Dental, the replacement of the loss of one or more teeth by an artificial substitute.

Prosthetic (pros-thet'-ik) [ $\pi \rho{ }^{\prime} s$, to ; $\theta \dot{\varepsilon} \sigma \iota \varsigma$, a placing]. Pertaining to prosthesis, or the use of artificial substitutes to replace lost or wanting parts of the body. P. Apparatus, an apparatus which serves as a substitute for a part that is missing. P. Dentistry, the replacement of natural teeth by artificial substitutes.

Prosthetics (pros-thet'-iks) [ $\pi \rho \sigma \varsigma$, to ; $\theta \varepsilon \sigma \iota \varsigma$, a placing]. The branch of surgery which deals with prosthesis.

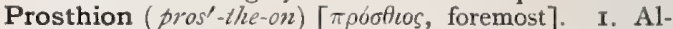
veolar point. See Cranionetric Points. 2. Penis.

Prostitution (pros-tit-u'-shun) [prostitutio]. The condition or act of a woman who indiscriminately lets her body for sexual intercourse. In many of the countries of Europe prostitution is recognized as a matter for hygienic inspection, the prostitutes being subject to police surveillance and medical inspection. In the United States the existence of the evil is, in general, legally ignored.

Prostoma (pro-sto'-mah) [ $\pi \rho \sigma$, before; $\sigma \tau \delta \mu a$, mouth]. The blastopore

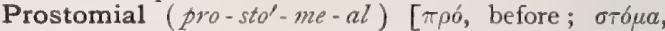
mouth]. Preoral; pertaining to the prostomium.

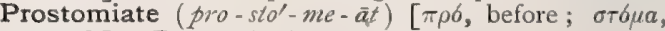
mouth]. Provided with a prostomium.

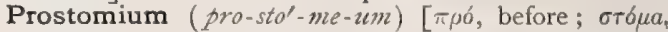
mouth: pl., Prostomia]. In biology, the region in front of the mouth ; said of embryos or invertebrates.

Prostrate ( pros $\left.^{\prime}-t r a \bar{a}\right)$ [ pro, before; sternere, to spread]. Lying flat or at full length.

Prostrated (pros'-tra-ted) [pro, before; sternere, to spread]. Exhausted; stricken down.

Prostration (pros-tra'-shun) [pro, before; sternere, to spread]. The condition of being prostrate. Extreme exhaustion of nervous or muscular force. P., Nervous, general exhaustion from excessive expenditure of nervous energy. Intense mental application may produce it. 
Protagon (pro'-tag-on) [ $\pi \rho \tilde{\omega} T o s$, first ; à $\gamma \varepsilon \iota v$, to lead], $\mathrm{C}_{760} \mathrm{H}_{308} \mathrm{~N}_{5} \mathrm{PO}_{35}$. A crystalline substance discovered in nervous tissue, by Liebreich. It separates out from warm alcohol on gradual cooling in the form of very small needles, often arranged in groups; it is slightly soluble in cold, more soluble in hot alcohol, and in ether. It is insoluble in water, but swells up and forms a gelatinous mass. It melts at $200^{\circ} \mathrm{C}$. and forms a brown sirupy fluid.

Protalbumose (prōt-all'-bu-möz). Same as Protoalbumose.

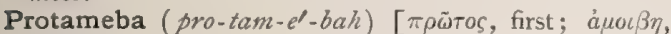
ameba]. A genus, or perhaps only a stage of development, of moners, or protists, of the very simplest type.

Protamin (pro-tam'-in) [ $[\pi \rho \tilde{\omega} T o s$, first; amin], $\mathrm{C}_{16} \mathrm{H}_{32} \mathrm{~N}_{9} \mathrm{O}_{2}$, An organic base found in the nuclein of the outer covering of spermatozoa.

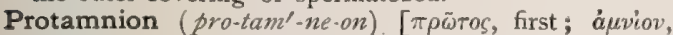
amnion]. The hypothetic ancestral type of existing amniotic animals.

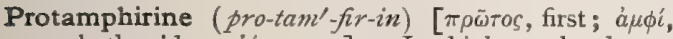
on both sides; pic, nose]. In biology, the hypothetic ancestral type of existing amphirhine animals.

Protandric (pro-tan'-drik). Same as Protandrous.

Protandrous (pro-tan'-drus). Same as Proterandrous. Protandry (pro-tan'-dre) [ $\pi \rho \tilde{\omega} \tau o \varsigma$, first; ávíp, mate]. See Proterandry.

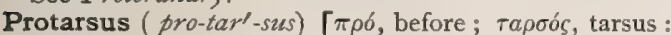
$p l .$, Protarsi $]$. In biology, the tarsus of the fore-leg of a six-footed insect.

Protean ( $p r o^{\prime}$-te-an) [like the ancient god Proteus]. Existing in many shapes; as a protean disease, protean eruption.

Protective (pro-tek'-tiv) [ pro, before; tegere, to cover]. I. That which covers or protects. 2. As a noun, a water-proof substance, which is laid directly upon a wound as a part of the antiseptic dressing. P. Bandage. See Bandage. P. Dressing, an antiseptic dressing, shielding the part involved from injury or septic contamination. P., Green. See Protective, second definition.

Proteids (pro'-te-ids) [ $\pi \rho \tilde{\omega} T \delta c$, first]. A general term for the albumins and albuminoid constituents of the organism. They are the anhydrids of peptones, are colloid, non-crystallizable, and levogyrous, and are composed of carbon, oxygen, hydrogen, and nitrogen in certain proportions. They are precipitated from solutions by alcohol and various metallic salts, and are coagulated by heat and mineral acids. They form the principal solids of the muscular, nervous, and glandular tissues, of the serum of the blood, of serous fluids, and of lymph. Proteids are divided by Landois into: r. The Native Albumins, comprising Serum-albumin, Egg-albumin, Metal-albumin, and Paralbumin (the last two are probably the same substance); 2. The Derived Albumins, or Albuminates, comprising Acid-albumin, Syntonin, Alkali albumin, and Casein, or Native Alkali-albumin; 3. The Globulins, subdivided into Crystallin, the globulin of the crystalline lens, Vitellin, Para-globulin or Serumglobulin, Fibrinogen, Myosin, Globin; 4. The Fitrins; 5. Coagulated Proteids; 6. Albumoses and Peptones; 7. Lardacein or Amyloid Substances. For the tests for proteids, see Xanthoproteic Reaction, Millon's Rengent, Piotrowski's Reaction, Brücke's Reagent, and Adamkiewicz's Reaction, in Tests, Table of. P., Defensive, certain bacteria-destroying substances, either existing normally in the animal economy, or produced therein by the process of vaccination or inoculation. Buchner proposes for them the name of alexins. Those defensive proteids that exist normally in the animal are termed by Hankin
Sozins, while those that are present in artificially immune animals are termed Phylaxins. My:o-sozins and Myco-plyylaxins are sub-divisions that act by destroying the microbes, while Toxo-sozins and Toxophylaxins act by destroying microbic products. P., Vegetal, or Vegetable, proteid substances found in plants, especially in seeds, closely resembling those in animals. They have been given the same names with the prefix vegetal, as, e.g., vegetal globulin, myosin, vitellin, casein, glutin, etc. A true peptone has not been found, but allied substances called albumoses, and divided into Alpha $(a)$-albumoses, Beta $(\beta)$-albumoses and Phytalbumoses, have been differentiated.

Proteiform (pro-te'-if-orm) [Proteus, a mythical character that assumed various shapes; forma, a form]. Having various forms. See Protean.

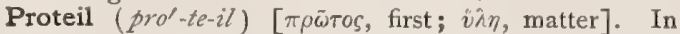
biology, the term applied by Lankester to that definite chemic substance of very high complexity which is probably present in all protoplasm. The hypothetic essential basis of every variety of living matter.

Protein (pro'-te-in) [ $\pi \rho \omega \tau \varepsilon v \varepsilon \varepsilon v$, to be first]. In biology: r. The term introduced by Mulder (1838) to designate the hypothetic compound common to all albuminoids. It is now loosely used to denote the whole class. Cf. Proteid. 2. A nitrogenous substance analogous to fibrin. It is formed artificially by the action of an alkaline hydrate on albumin, fibrin, or casein. The addition of acetic acid precipitates the protein as a gelatinous translucent deposit. P., Anthrax, a proteid obtained from cultures of bacillus anthracosis. It resembles mykoprotein in not containing sulphur. $\mathbf{P}$. Bodies. See Proteids. P. Granules. See Aleurone. P., Myco-, Nencki's term for any one of the albuminous bodies contained within bacterial organisms.

Proteinchrome, Proteinchromogen (pró-te-in-krōm,

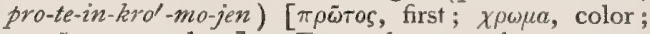
$\gamma \varepsilon \nu \nu a ̃ \nu$, to produce]. Trvptophan; a substance produced from hemi-peptone by the action of trypsin. It gives with chlorin or bromin a reddish-violet product, proteinchrome.

Proteinol (pro'-te-in-ōl) [ $\pi \rho \tilde{\omega} T o s$, first; oleum, oil]. A form of nutritious food for infants and invalids. It contains proteids, fats, carbohydrates and lime-salts.

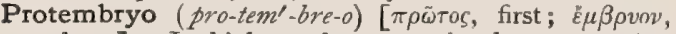
embryo]. In biology, that stage in the segmenting ovum of a metazoön in which it resembles the colonial stage of certain protozoans.

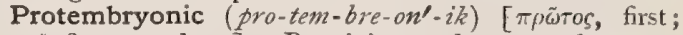
$\varepsilon \mu \beta \rho v o v$, embryo]. Pertaining to the protembryo.

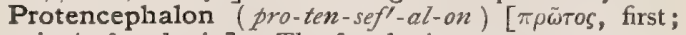
$\varepsilon \dot{\gamma} \varepsilon \dot{\phi} \phi \lambda \circ$ s, brain]. The fore-brain.

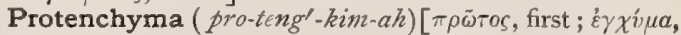
an infusion]. In biology, Nægeli's term for all planttissues not of the fibro-vascular system (epenchyma).

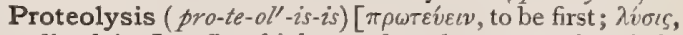
dissolving]. In biology, the change produced in proteids by organized or unorganized ferments. $\mathbf{P}_{\text {s, }}$ Digestive, the decomposition of proteids during the process of digestion.

Proteolytic (pro-te-o-lit'-ik) [ $\pi \rho \tilde{\omega} \tau \sigma$, first; $\lambda \hat{v} \sigma \iota$, solution]. Pertaining to, characterized by, or effecting, proteolysis. See Ferments.

Proteoses (pro-te-ó $-s \bar{e} z)[\pi \rho \tilde{u} \tau o s$, first]. The bodies formed in gastric digestion intermediate between the food proteids and the peptones, called anti-peptone, hemi-peptone, etc.

Proterandrous, Protandrous (pro-ter-an'-drus, pro$\tan ^{\prime}$-drus). In biology, terms descriptive of hermaphrodite flowers that mature their stamens before the stigmas are ready to receive the pollen. P. Hermaphroditism. See Hermaphroditism. 


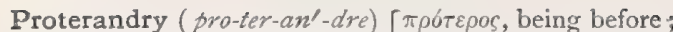
ávíp, male]. In biology, the maturation of the stamens in a perfect flower before the pistil is sufficiently mature to admit of fertilization.

Proteranthous (pro-ter-an'-thus) [ àvfos, flower]. In biology, flowering before leafing.

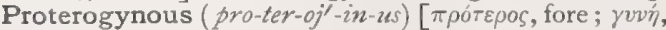
female]. In biology, possessing stigmas that are first to mature.

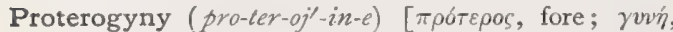
female]. In biology, the maturation of the pistil of a perfect flower before the stamens have matured their pollen.

Proteus (pro'-te-us) [I..]. A genus of microbes of the order of schizomycetes. See under Bacteria, Synonymatic Table of.

Prothallium (pro-thal'-e-um) [pro, before; thallus, a young shoot]. In biology, the thalloid oöphyte of sexual generation of a fern or other pteridophyte, produced by the germination of a spore and giving rise by means of antheridia and archegonia to the frondose generation. Cf. Protonema.

Prothallus (pro-thal'-us). Same as Prothallium.

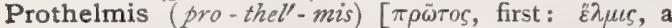
worm]. In biology, a hypothetic ancestral worm, having a structure homologous to the four-layered germ of metazoans.

Prothesis (proth'-es-is) [ $\pi \rho \delta$, for; $\theta \dot{\varepsilon} \sigma \iota s$, a placement $]$. Synonym of Prosthesis. P. ocularis, an artificial eye.

Prothetic (pro-thet'-ik). Synonym of Prosthetic

Prothoracic (pro-tho-ras'-ik) [ $\pi \rho b$, before; $\theta \omega \omega a \xi$, breast]. Pertaining to the prothorax.

Prothoracotheca (pro-tho-rak-o-the'-kah) [ $\pi \rho 0$, before ; $\theta \omega \rho a \xi$, breast; $\theta \dot{\eta} \kappa \eta$, a case: pl., Prothoracotheca $]$. In biology, that part of a pupa-case inclosing the prothorax.

Prothorax (pro-tho'-raks) [ [ $\rho^{\prime}$, before; $\theta \omega \rho a \xi$, breast]. In biology, the most anterior of the three thoracic somites of an insect.

Prothrorubin (pro-thro-ru'-bin). One of the bodies which influence the breaking up of cystin and favor coagulation of the blood. (Schmidt.)

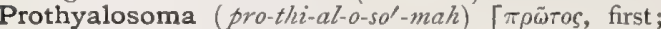
va $a s$, glass; $\sigma \tilde{\omega} \mu a$, body: pl., Prothyalosomata]. The name proposed by van Beneden $\left(188_{3}\right)$ for the envelop of the nucleolus of an ovum.

Prothyalosomal (pro-thi-al-o-so'-mal) $[\pi \rho \tilde{\omega} \tau o s$, first ; $v a \lambda o s$, glass; $\sigma \tilde{\omega} \mu \alpha$, body]. Pertaining to the prothyalosoma.

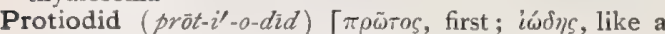
violet]. One of a series of salts in which the metal or radicle fixes, relatively, the smallest proportion of iodin, e.g., Protiodid of Mercury, $\mathrm{Hg}_{2} \mathrm{I}_{2}$, in contradistinction to the biniodid, $\mathrm{Hg} \mathrm{I}$.

Protist (pro'tist) [protiston; $\pi \rho \omega$ itotos, the very first]. Any unicellular organism. Any protophyte, or protozoön; a microörganism.

Protista (pro-tis'-tah) [ $p l$., superlative of $\pi \rho \omega \bar{T} \sigma \varsigma$, first]. In biology, the name proposed by Hæckel (I 868) for those lower organisms which are not readily referred to the plant or animal kingdom. See Oozoa.

Protmesis (prot-me'-sis). Synonym of Umbilicus.

Proto- (pro'-to-) [ $\pi \rho \tilde{\omega} T o s$, first]. A prefix signifying first.

Protoalbumose (pro-to-al'-bu-1nöz). See Albumose.

Protoblast $(p r o ́-t o-b l a s t)[\pi \rho \bar{\omega}-o s$, first; $\beta \lambda \alpha \sigma \tau \sigma \varsigma$, germ]. I. A cell without a distinct cell-wall. 2. The nucleus of the ovum. (Villot.)

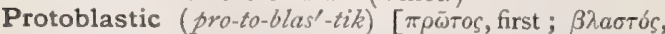
germ]. See Holoblastic.

Protocaseose (pro-to- $\left.k a^{\prime}-z e-\bar{o} z\right)$ [ [ $\pi \rho \tilde{\omega} \tau o \zeta$, first ; caseum, cheese]. The first product of the digestion of casein.
Protocatechuic Acid (pro-to-kat-e-chu'-ik) [ $\pi \rho$ örros, first; catechu]. Dioxy-benzoic acid. See Acid. It sometimes occurs in urine. P. aldehyd. See Aldehyd.

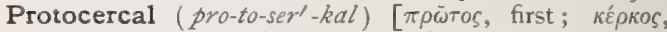
tail]. In biology, having a tail-fin of primitive type.

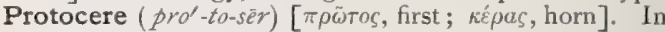
biology, the rudimentary antler of a deer.

Protocerebral (pro-to-ser'-e-bral) [ $\pi \rho \omega \ddot{T}$ os, first ; cerebrum, cerebrum]. Pertaining to the protocerebrum.

Protocerebrum (pro-to-ser'-e-brum) [ $\pi \rho \bar{\omega}$ Tos, first; cerebrum, cerebrum]. The embryonic rudiment or vesicle from which the cerebrum is evolved.

Protochlorid (pro-to-klo'-nid) $[\pi \rho \omega ̈ \tau o s$, first ; $\chi \lambda \omega p o s$, green]. One of a series of salts in which the metal or radicle fixes, relatively, the smallest amount of chlorin, $\varepsilon_{.} g$., the Protochlorid of Mercury, $\mathrm{Hg}_{2} \mathrm{Cl}_{2}$ "

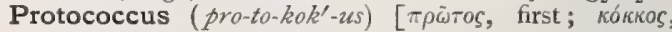
berry]. A genus of unicellular algæ.

Proto-compound (pro-to-kom'-pownd) [ $[\pi \rho \tilde{\omega}$ Tos, first ME., compounen, to mix or compound]. $\Lambda$ salt in which the metal or radicle fixes, relatively, the smallest proportion of the acid element. See Protiodid and Protochlorid.

Proto-conch (pro'-to-kongk) [ [ $\rho \tilde{\omega} \tau o \varsigma$, first; $\kappa \delta \gamma \gamma \chi \eta$, a mussel, shell]. In biology, the primitive type of shell in an ammonoid cephalopod.

Protoconchal (pro-to-kong $-k a l)$ [ $\pi \rho \bar{\omega} \pi \%$, first; $\kappa 6 \gamma \gamma \eta$, a mussel]. Pertaining to the protoconch.

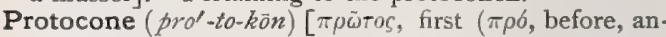
terior) ; kĩvos, cone]. In biology, the anterior, internal cusp of an upper molar.

Protoconid (pro-to-ko'-nid) [ $\pi \rho \omega \bar{\tau}-\alpha$, first $(\pi \rho \sigma$, before, anterior); $\kappa \tilde{\omega} v o s$, cone]. In biology, the anterior internal cusp of a lower molar.

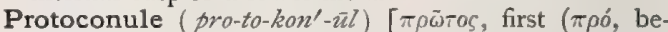
fore, anterior; $\kappa \tilde{\omega} \nu$ os, cone]. In biology, the anterior intermediate cusp of an upper molar.

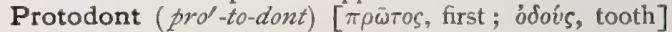
A simple molar tooth in which the cusps are not well defined.

Proto-elastin (pro-to-e-las'-tin) [ $\pi \rho \omega \tau o s$, first ; elastin]. A chemic substance obtained by Frenzel from the cuticula of gregarinæ.

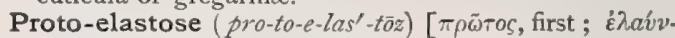
$\varepsilon \iota v$, to urge forward]. Hemi-elastin; one of the products of digestion of elastin. It is precipitable by saturation with sodium chlorid.

Protogala (pro-tog'-al-ah). Synonym of Colostrum.

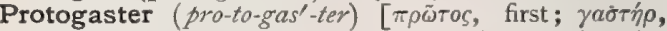
stomach]. In biology, the primitive intestinal cavity of a gastrula or two-layered germ.

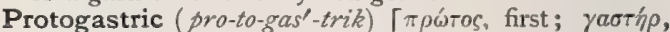
belly]. Pertaining to the protogaster.

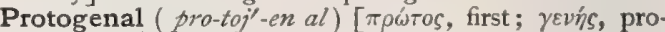
duced]. Primitive; original ; first-born.

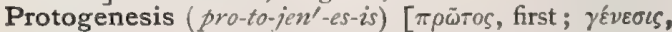
generation]. See Abiogenesis.

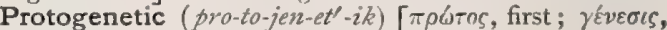
genesis $]$. Pertaining to protogenesis.

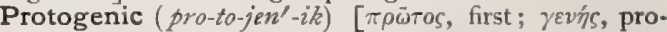
duced]. In biology, applied to intercellular spaces formed at the time the tissues are beginning to differentiate.

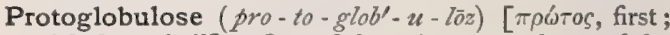
globulus, a ball]. One of the primary products of the digestion of globulin.

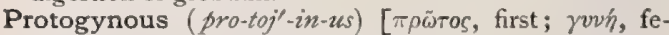
male]. Pertaining to protogyny.

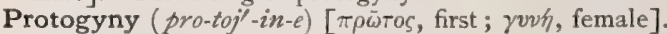
See Proterogyny.

Protohemoblast (pro-to-hem'-o-blast) [ $[\pi \rho \tilde{\omega} \tau o s$, first ;

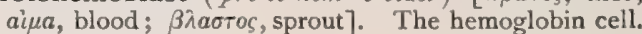


Protoiodid (pro-to-i'-o-did). Synonym of Protiodid.

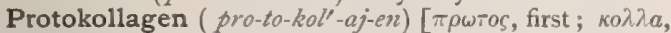
glue; jevvā $v$, to produce]. A substance isolated by Frenzel from gregarina. Cf. Proto-elastin.

Protoleucyte (pro-to $\left.-l u^{\prime}-s i t\right)[\pi \rho \tilde{\omega} T o s$, first; $\lambda \varepsilon v \kappa o ́ s$, white; кivos, a cell]. In biology, the name given by Salensky to the formative portion of the ovum, in which the finely granular protoplasm predominates, as distinguished from the dentolencyte, in which the vitelline granules are most abundant.

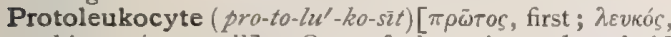
white; кv́ros, cell]. One of the minute lymphoid cells found in the red bone-marrow and also in the spleen.

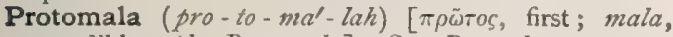
mandible: pl., Protomale]. See Promala.

Protomalal (pro-to-ma'-lal) [ $\pi \rho \tilde{\omega} \tau o s$, first; mala, mandible]. Pertaining to the protomala.

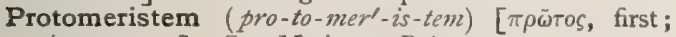
$\mu$ ́́pos, a part]. See Meristem, Primary.

Protomerite (pro-tom'-er-īt) [ $[\pi \rho \tilde{\omega} \tau o s$, first; $\mu \dot{\varepsilon} \rho \circ \varsigma$, a part]. In biology, the anterior of the two cells of a septate gregarine, as distinguished from the posterior cell, the deutomerite $(q . v$.$) . If it bear a proboscis, or$ epimerite, the organism is spoken of as Cephalont.

Protomeritic (pro-to-mer-it'-ik) [ $\pi \rho \tilde{\omega} \tau o s$, first; $\mu$ '́eos, a part]. Pertaining to a protomerite.

Protomorphic (pro-to-mor'- $f k$ ) $[\pi \rho \bar{\omega} \tau o s$, first ; $\mu \rho \rho \phi \eta n$, form]. In biology, of a primitive or original form or structure.

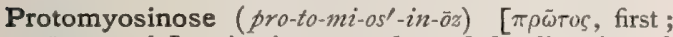
$\mu \tilde{v}$, , muscle]. A primary product of the digestion of myosin.

Proton (pro'-ton) $[\pi \rho \omega$ ros, first]. A term suggested by Wilder to designate the primitive, undifferentiated mass or rudiment of a part. It is the equivalent of the words Anlage and fundament as employed by Minot and Mark respectively.

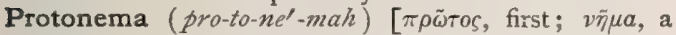
thread]. In biology, a colorless, confervoid or filamentous structure produced from the germinating spore and forming one stage in the life-history of a moss. Upon it the leafy plant containing chlorophyl arises as a lateral shoot. Cf. Prothallizm.

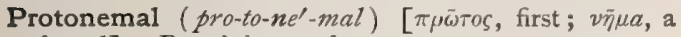
thread]. Pertaining to the protonema.

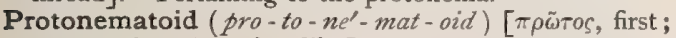
$\nu \tilde{\eta} u a$, a thread; $\varepsilon i \delta o s$, like]. In biology, resembling a protonema.

Protoneme (pro'-to-nèm). Same as Protonema.

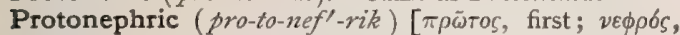
kidney]. Pertaining to the protonephron.

Protonephrium (pro-to-nef'-re-um). Synonym of Protonephron.

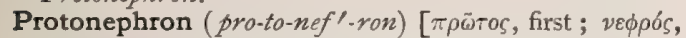
kidney]. The pronephron, metanephron, and mesonephron taken together; the Wolffian body in its largest extent; the primitive or embryonic kidney. Cf. Pronephron, Mesonephron, Metanephron, Okenian Body, Wolffian Body.

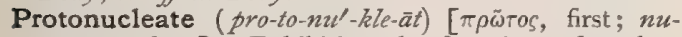
cleus, nucleus]. Exhibiting the first signs of nucleation.

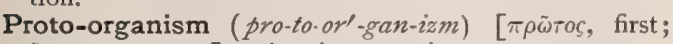

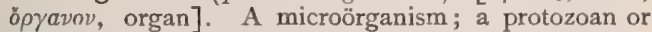
protophyte ; a protist.

Protopathia (pro-to-pāth'-e-ah). See Protopathy.

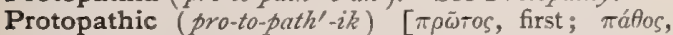
disease ]. Primary; relating to the first lesion. Opposed to deuteropathic.

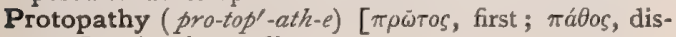
ease]. A primary disease.

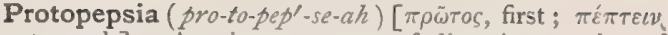
to cook]. A primary process of digestion, as that of starches by the saliva.

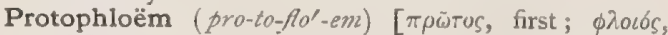
bark]. See Prophloëm.

Protophyte (pro'-to-fit) [ $\pi \rho \omega \tilde{T} o s$, first; $\phi v \tau o ́ v$, plant]. Any plant of the lowest and most primitive type. The Schizomycetes, or bacteria $(q . v$.$) , may be classed as$ protophytes, with other low vegetable forms. The protophytes have no visible reproductive organs.

Protophytic (pro-to-fit'-ik) [ $\pi \rho \tilde{\omega} \tau o \varsigma$, first ; $\phi v \tau \sigma v$, plant]. Pertaining to a protophyte.

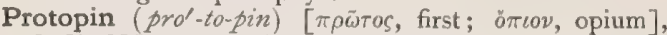
$\mathrm{C}_{20} \mathrm{H}_{19} \mathrm{NO}_{5}$. An alkaloid obtained from opium.

Protoplasis (pro-to-pla'-sis) [ $\pi \rho \tilde{\omega} \tau o \varsigma$, first ; $\pi \lambda a ́ \sigma \sigma \varepsilon \iota v$, to form]. The primary formation of tissue.

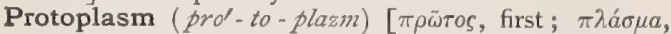
anything formed or molded]. In biology, the slimy material constituting the substance of living plant and animal cells, the chemic and physical properties of which underlie all the vital functions of nutrition, secretion, growth, reproduction, irritability, motility, etc. The word is not now applied to a definite compound, but rather to the physical appearance always found in living cells; the actual chemic composition varying from cell to cell, from organism to organism, from moment to moment. Underlying all this diversity there seems to be one definite chemic basal substanceproteil-a complex molecule derived from various aldehyds, glycols, and ketones, in combination with a number of chemic substances, some of them on the way up to the highest point, some on the downward path. Hugo von Mohl was the first to employ the word protoplasm $(1846)$ in his description of the substance which is essential to the formation and development of plant-cells. Max Schultze (I86I) demonstrated the identity of this with the essential substance of animal cells, called Sarcode by Dujardin (1835), an identity which had been suggested by Schwann as early as 1839 , and by Cohn in 1850 . When highly magnified the protoplasm of most cells appears as a network (spongioplasm, reticulum), containing a more fluid substance (hyaloplasm, or enchylema) in its meshes. P., Mother. Synonym of Germ-plasm.

Protoplasma (pro-to-plaz'-mah) [ $\pi \rho \tilde{\omega} \tau o s$, first ; $\pi \lambda a ́ \sigma \mu a$, anything molded]. See Protoplasm.

Protoplasmal (pro-to-plaz'-mal). Same as Protoplasmic.

Protoplasmatic (pro-to-plaz-mat'-ik). Synonym of Protoplasmic.

Protoplasmic (pro-to-plaz'-mik) [ $\pi \rho \tilde{\omega} \tau o s$, first; $\pi \lambda \dot{\sigma} \sigma-$ $\sigma \varepsilon \imath \nu$, to mold]. Pertaining to protoplasm.

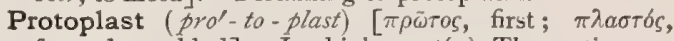
formed, molded]. In biology: (a) The entire unspecialized organic cell. See under Heredity. $(b)$ The primitive type, or original, of some organic being.

Protoplastic (pro-to-plas'-tik) [ $\pi \rho \tilde{\omega} \tau o s$, first ; $\pi \lambda \dot{\lambda} \sigma \sigma \varepsilon \iota \nu$, to form]. Synonym of Protoplasmic. Applied also to a solution for determining the influence of the bloodplaques upon the coagulation of blood. P. Liquid, Schmidt's; its preparation is as follows: One part of blood is allowed to flow into 3 parts of a 28 per cent. watery solution of magnesium sulphate at $0^{\circ} \mathrm{C}$. This is well stirred and allowed to stand until sedimentation of the corpuscular elements has taken place. The supernatant liquid is then drawn off and filtered at $0^{\circ} \mathrm{C}$.

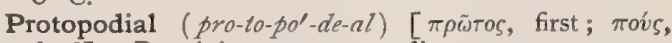
food]. Pertaining to a protopodium.

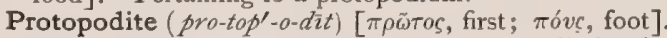
In biology, the shaft or stem of a biramose limb of a crustacean, as distinguished from the inner branch 
(endopodite) and the outer branch (exopodite); or a third division added in appendages concerned in respiration (epipodite)

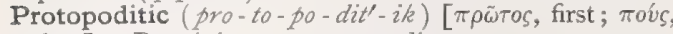
foot]. Pertaining to a protopodite.

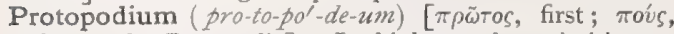
foot: $p l .$, Protopodia $]$. In biology, the primitive or typical podium or foot of a mollusc.

Protoproteose (pro-to-pro'-te-az) [ $\pi \rho \tilde{\omega} \tau o \varsigma$, first; proteose $]$. A white powder, readily soluble in water, yielding a slightly turbid fluid.

Protopsyche (pro-to-si'-ke) [ $\pi \rho \tilde{\omega}$ Tos, first; $\psi v \chi \dot{\eta}$, soul] In biology, Hæckel's term for the fore-brain. Cf. Psyche.

Protopterous (pro-top'-ter-us) [ $[\pi \rho \tilde{\omega} \tau o s$, first; $\pi \tau \varepsilon \rho o ́ v$, wing]. In biology, having a simple or primitive type of limb.

Protopterygium (pro-to-ter $\left.-i j^{\prime}-e-u m\right)[\pi \rho \tilde{\omega} \tau o s$, first ; $\pi \tau \varepsilon \rho v \xi$, fin]. In biology; the anterior osseous piece joining the pectoral fin of fishes to the pectoral arch.

Protoquinamicin (pro-to - krwin-an'-is - in) [ $\pi p \tilde{\omega} \tau o s$, first ; Sp., quina, bark; amin], $\mathrm{C}_{17} \mathrm{H}_{20} \mathrm{~N}_{2} \mathrm{O}_{2}$. A substance which is obtained when quinamin sulphate is heated to $120^{\circ} \mathrm{C}$

Protosalt ( pró-to-sawlt) [ $\pi \rho \tilde{\omega} \tau o s$, first; ME., salt, salt]. In chemistry, that one of two or more compounds of a metal with an acid which contains relatively the least quantity of metal.

Protosoma (pro-to-so'-mah) $\pi \rho \tilde{\omega} \tau o s$, fish; $\sigma \tilde{\omega} \mu a$, body]. In embryology, a large oval spot in the center of the transparent area of the blastoderm, and representing the primitive stage in the development of the embryo.

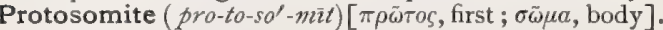
In biology, a rudimentary somite or segment in a worm or arthropod.

Protosomitic (pro-to-so-mit'-ik) $[\pi \rho \tilde{\omega} \tau o s$, first; $\sigma \tilde{\omega} \mu a$, body]. Primitively segmented; pertaining to a protosomite.

Protospasm (pro'-to-spazm) $\pi \rho \tilde{\omega} \tau o s$, first; $\sigma \pi a \rho \mu \delta \varsigma$, spasm]. A spasm beginning in one limb and extending to the other on the same side, to the head, or to the entire half of the body. It may become general

Protospermatoblast (pro-to-sper'-niat-o-blast) [ $\pi \rho \tilde{\omega}$ Tos, first; $\sigma \pi \varepsilon ́ \rho \mu \alpha$, seed; $\beta \lambda \Omega \sigma \tau o ́ c$, bud, sprout, shoot]. In biology, one of the "small cells," or "parent cells" (Samenstammzellen, Stammzellen, of German writers), forming part of the layer of cells next the tunica propria of the seminiferous tubules and from which arise the spermatoblast, and finally spermatozoa.

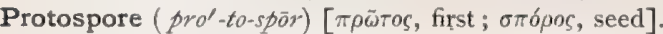
A primary spore or seed from which a prothallus or similar body is developed.

Protostoma (pro-tos'-to-mah) [ $\pi \rho \tilde{\omega} \tau o s$, first ; $\sigma \tau \delta \dot{\mu} a$, mouth : pl., Protostomata]. In biology, the primitive opening of the gastrula-sac, formed by the invagination of the blastula. It is also termed the Anus of Rusconi.

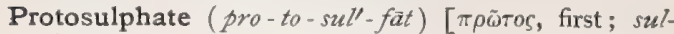
phur, sulphur]. The one of a series of sulphates which contains relatively the smallest amount of sulphuric acid.

Prototergite (pro-to-ter'-jit) [ $[\pi \rho \tilde{\omega} \tau o s$, first ; tergum, back]. In biology, the first dorsal segment of the abdomen of insects.

Protothallus (pro-to-thal'-us) [ $\pi \rho \tilde{\omega} \tau o s$, first; $\theta a \lambda \lambda \sigma s$, a young shoot: pl., Protothalli]. In biology: (a) Same as Prothallium. (b) Same as Hypothallus.

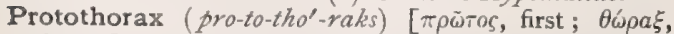
thorax]. Same as Prothorax.

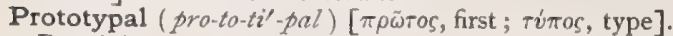
Pertaining to a prototype.

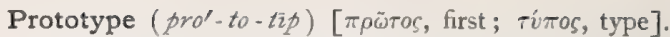
A model after which something is copied.

Prototypembryo (pro-to-tip-em'-bre-o) [ $\pi \rho \tilde{\omega} \tau o s$, first ;

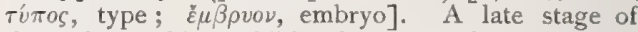
the embryo which exhibits the essential characters of the group to which it belongs.

Protoveratrin (pro-to-ver-at'-rin) [ $[\pi \rho \tilde{\omega} \tau o s$, first; veratrum, hellebore], $\mathrm{C}_{32} \mathrm{H}_{51} \mathrm{NO}_{11}$. A very poisonous alkaloid derived from veratrin.

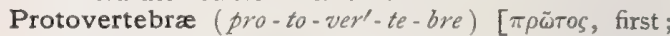
vertebra, vertebra]. A bastard word applied to any one of the few pairs of small, dark bodies, separated by lighter interspaces, on either side of the dorsal axis of the embryo. They were formerly thought to be the primitive vertebræ, but are now recognized as muscle-plates or myotomes. They are of mesoblastic origin. See Segment, Primitive.

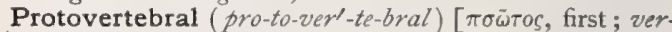
tebra, vertebra]. Pertaining to the protovertebræ. P. Somites, See Protovertebra.

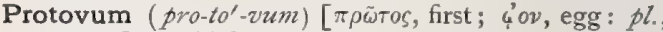
Protova $]$. In biology, an ovum or ovule at its most primitive stage.

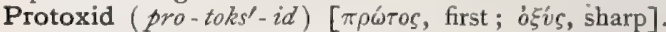
The one of a series of oxids of a metal or radicle which contains relatively the smallest proportion of oxygen.

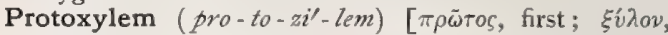
wood]. In biology, the first-formed elements of the xylem of a bundle.

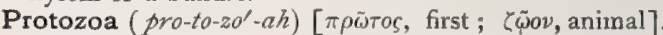
The lowest class of the animal kingdom, comprising organisms which consist of simple cells or colonies of cells, and which possess no nervous system, and no circulatory organs. Within recent years the study of the lower forms of animal life in relation to disease has been diligently pursued, and evidence is constantly accumulating in favor of the view that certain diseases of animals and of man are produced by protozoa. For the parasitic protozoa of man and domestic animals see the following genera under Parasites (Animal), Table of:-Amaba, Balantidium, Balbiania, Bodo, Bütschlia, Cercomonas, Coccidium, Cystomonas, Cytospermium, Dasytricha, Diplodinium, Eimeria, Entodinium, Globidium, Gregarina, Hamoplasmodium, Herpetomonas, Heteromita, Megastoma, Microsporidia, Miescheria, Monas, Monocercomonas, Ophryoscolex, Polimitus, Rhophalocephalus, Sarcocystis, Trichomonas, Trypanosoma.

Protozoal, Protozoan (pro-to-zo'-al, pro-to-zo'-an)

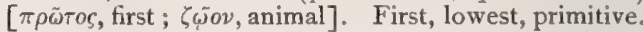

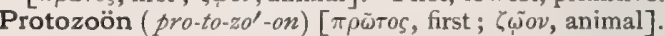
One of the Protozoc.

Protractile (pro-trak'-til) [pro, before; trahere, to draw]. Capable of being protruded or thrust out.

Protraction (pro-trak'-shun) [pro, before; trahere, to draw]. Extraction, as of foreign bodies from wounds.

Protractor (pro-trak'-tor) [ pro, before; trahere, to draw]. I. A surgical instrument used for drawing extraneous bodies from wounds. 2. A mathematic instrument employed in measuring angles and recording them on paper. 3. A muscle that draws forward.

Protrahens (pro-trah'-enz) [L.]. A drawing forward. P. auriculæ, a muscle drawing the pinna forward. It is known, also, as the Atrahens aurem. See Muscles, Table of. P. lentis, the ciliary muscle of the eye. Protrude (pro-trū $d^{\prime \prime}$ [ protrudere, to thrust forward]. To thrust forward or to be thrust forward.

Protrusile (pro-tru'-zil). Synonym of Protractile.

Protrusio (pro-tru'-ze-o) [L.]. Synonym of Protrusion. $P$. enorbitalis, protrusion of the orbit and the eye. P. exorbitalis, P. oculi. Synonym of Exophthalmos. 
Protrusion (pro-tru'-zhun) [protrudere, to thrust forward]. The act of thrusting forward; also the state of being thrust forward.

Protrusor (pro-tru'-zor) [protrudere, to thrust forward]. Anything protruded, or which protrudes. P. labii inferioris, the corrugator muscle of the lower lip. P. lingux. Synonym of Genio-glossus. See Muscles, Table of.

Protuberance (pro-tu'-ber-ans) [protuberantia; pro, forward; tuber, a swelling]. A knob-like projecting part. P., Annular. Synonym of Pons varolit. P., Cerebral: I. Synonym of Pons varolii. 2. The prominence formed by the upper or anterior of the cerebral flexures of the embryo. P., External Occipital, the central prominence on the outer surface of the flat portion of the occipital bone. P., Frontal : I. The prom inence of the frontal bone. 2. The prominence formed by the lower of the two flexures of the cephalic end of the embryo. P., Inferior Maxillary, in the embryo, a prominence formed on each side by a division of the first pharyngeal arch, and representing the rudiments of the lower jaw. P., Internal Occipital, a slight central prominence on the inner surface of the tabular portion of the occipital bone. P., Lateral Frontal, an elevation on either side of the frontal prominence of the embryo. P., Mental. A synonym of Prominence, Mental. P., Natiform, the nates of the corpora quadrigemina. P., Occipital. See P., External Occipital, and P., Internal Occipital. P., Parietal, the eminence of the parietal bone, situated near the sagittal suture. P., Superior Maxillary, a prominence formed on each side of the embryo by a division of the first pharyngeal arch.

Protuberantia (pro-tu-ber-an'-she-ah) [L.]. Synonym of Protuberance. P. basilaris, P. cerebralis. Synonyms of Pans. P. laryngea. Synonym of Pomum adami. P. scleralis, a small prominence of the sclera. posteriorly, below the entrance of the optic nerve.

Protuberate (pro-tu'-ber-ät) [protuberare, to swell out]. To swell, or become prominent, as the navel.

Protureter (pro-tu-re'-ter) [ $\pi \rho \tilde{\omega} T o s$, first; ovjom, urine]. A primitive ureter, or excretory duct of a protonephron.

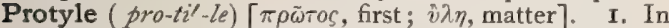
biology, the hpyothetic primal substance from which all living matter is supposed to be derived; also called biod, biogen, zoêther, psychoplasm. 2. Synonym of Methyl.

Protylic $\left(p r o-t i \psi^{\prime}-i k\right)[\pi \rho \tilde{\omega} \tau o \varsigma$, first ; $v \lambda \eta$, matter $]$. Pertaining to or derived from protyl.

Proud Flesh. A popular term for the sprouting of an inflamed area; granulations. Also, any fungous growth.

Provan's Paste. A. paste used in the treatment of eczema. Its formula is : Tragacanth and glycerin, each 4 drams; sodium borate, $1 / 2$ dram; distilled water, a sufficient quantity. Apply during the day and wash off at night.

Proventricular (pro-ven-trik'-u-lar) [pro, before; ventriculus, dim. of venter, stomach]. Pertaining to the proventriculus.

Proventriculus (pro-ven-trik'-u-lus) [pro, before; ventriculus, dim, of venter, stomach : pl., Proventric uli ]. In biology: (a) the glandular or true stomach of birds, between the crop and the gizzard; $(b)$ the first stomach of an insect.

Proximad (proks'-im-ad) [proximus, nearest]. Toward the proximal end or point of attachment.

Proximal (proks'-im-al) [ proximus, next to]. Situated at or nearest to the attached extremity of an appendage; thus, the proximal end of the arm is at the shoulder. Proximal is also made to include central, q.v., by some writers. See the opposite, Distal; also Position and Direction, Table of P. Clot. Sec Clot.

Proximate (proks'-iml-ät) [ proximus, nearest]. Next immediate. $P$. Cause, the immediate cause of any change. P. Principle, "any substance, whether simple or compound, chemically speaking, which exists under its own form, in the animal solid or fluid, and which can be extracted by means which do not alter or destroy its chemical properties." (Dalton.)

Proximen (proks'-im-en) [proximus, nearest]. Belonging to the proximal aspect in itself.

Pruinescence (pru-in-es'-ens) [pruina, hoar-frost]. In biology, the condition of being pruinose.

Pruinose, Pruinous ( $\left.p r u^{\prime}-i n-\bar{o} z, p r u^{\prime}-i n-u s\right)$ [pruina, hoar-frost]. In biology, applied to leaves or other organs that appear as if covered with hoar-frost.

Prune (prūn) [ prunum, a plum]. See Prunum and Pigments, Conspectus of. P.-juice Expectoration, a peculiar blood-containing sputum, of a dark purple color, resembling prune-juice. It is met with in low forms of croupous pneumonia, in gangrene and in carcinoma of the lung.

Prunella (pru-nel'-ah) [L., a disorder of the throat]. I. Sore-throat. 2. Thrush. 3. Angina pectoris.

Pruniform (pru'-nif-orm) [ prunum, a plum; forma, form ]. Plum-shaped; having the appearance of a plum.

Prunin (prün'-in) [prunus, plum-tree]. A solid substance, prepared by evaporating the tincture and powdering the extract of Prunus virginiana. It is palebrown in color, and has a characteristic odor. It is stimulant and expectorant. Dose $I$ to 5 grains.

Prunum ( $\left.p r u^{\prime}-n u m\right)$ [L.]. Prune. The fruit of $P$. domestica, native to W. Asia. It is laxative and nutritious. Dose indefinite.

Prunus (pru'-nus) [L.]. A genus of rosaceous trees. $P$. virginiana. Wild cherry. In pharmacy, the bark of Prunus serotina. It contains amygdalin, tannic acid, emulsin, and a bitter extractive. Amygdalin in watery solution with emulsin is decomposed into hydrocyanic acid and a volatile oil. Wild cherry is aromatic and feebly tonic; it is largely used in pulmonary tuberculosis to quiet the cough and to calm the nervous system; also in coughs of bronchitis. It is an ingredient of various proprietary cough-mixtures. Dose of the bark $3 \mathrm{ss}-\mathrm{j}$; of the fld. ext. $3 \mathrm{ss}-\mathrm{j}$; of a 4 per cent. infusion $\xi \mathrm{ss}-\mathrm{ij}$; of a 12 per cent. syrup $3 \mathrm{j}$-iv. P. virginiana (true). See Choke Cherry.

Prurient (pru'-re-ent) [prurire, to itch]. Itching; sensual.

Pruriginous (pru-rij'-in-us) [prurire, to itch]. Pertaining to or like prurigo.

Prurigo (pru-ri'-go) [prurire, to itch]. I. A chronic inflammatory skin-disease developing in childhood, and characterized by an eruption of pale, discrete papules, attended with severe itching. The papules are at first of the size of hempseed, more easily felt than seen, but soon become darker and covered by crusts of blood or serum, due to scratching. The usual sites are the extensor surfaces of the limbs. 2. Pruritus, $q . v$. P. adolescentium. Synonym of $P$. astivalis. P. astivalis, summer prurigo; a form of relapsing bullous eruption allied to the vesicular erythemata, and occurring in summer only. $\mathbf{P}$. agria, a very severe form of prurigo. P. ferox, a severe type of prurigo. P. mitis, a mild type of prurigo. P. partialis, prurigo limited to a part of the body. P. pediculosis, pruritus due to pediculosis.

Pruritic (pru-rit'-ik) [prurire, to itch]. Itching.

Pruritus (pru-ri'-tus) [prurire, to itch ]. An important neurosis of the skin, characterized by the 
single symptom of itching, occurring either over the entire cutaneous surface, or limited to certain regions. The itching may be more or less constant, but is likely to occur in paroxysms, and is usually worse at night. It is not dependent upon any primary structural lesion of the skin, but excoriations and thickening result from the scratching. P. analis, P. ani, itching around the anus. $P$. consensualis, eczema the result of disturbances of internal organs. $P$. flavescens. Synonym of Ecrema impetiginosum. P. hidroa. Synonym of Miliaria. P. hiemalis, a form following exposure to cold, or existing only in winter, especially in dry climates. P. localis, pruritus limited to a part of the body. P. opii, the itching that sometimes supervenes upon the administration of opium. P. porcellanea. Synonym of Urticaria. P. senilis, the pruritus of the aged, often due to degenerative changes in the skin. P. universalis, general itching of the surface of the body. P. vulvæ, itching around the vulva. This, it should not be forgotten, is sometimes due to diabetes.

Prussak's Chamber. Same as P.'s Space. P.'s Fibers, two short, tightly-stretched striæe extending from the tip of the short process of the malleus to the notch of Rivinus. P.'s Space, a small space lying above the short process of the malleus, and bounded externally by Shrapnell's membrane.

Prussian (prush'-an) [Prussia, Prussia]. Of, or pertaining to, Prussia. P. Blue, the ferrocyanid of iron, largely used in the arts as a dye and pigment; it was formerly used as a febrifuge, tonic, alterative, and antiepileptic. Dose gr. iij-v. Unof. See Pigments, Conspectus of. P. Brown, P. Green. See Pigments, Conspectus of. P. Red. Same as Venetian Red.

Prussiate (prus'-e-ät) [Prussia, Prussia]. A salt of prussic, or hydrocyanic acid.

Prussic (prus'-ik) [Prussia, Prussia]. Pertaining to Prussian blue. P. Acid. See Acid, Hydrocyanic.

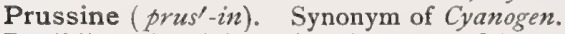

Psalidium (sal-id'-e-um). Synonym of Psalis.

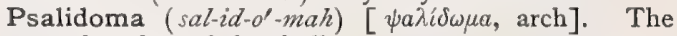
ental surface of the skull.

Psalis $\left(s a^{\prime}-l i s\right)[\psi a \lambda i s, a r c h]$. The fornix of the cerebrum.

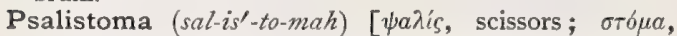
mouth]. In biology, the cutting margin of the mandible of an arthropod. (Bate.)

Psalloid (sal'-oid) [ $\psi \alpha \dot{\lambda} \lambda \varepsilon \iota v$, to play on a stringed instrument; $\varepsilon$ idos, form ]. Lyriform; resembling the lyra of the brain.

Psaloid (sa'-loid) [ $\psi a \lambda i s$, an arch; $\varepsilon i \delta o s$, like]. Resembling an arch.

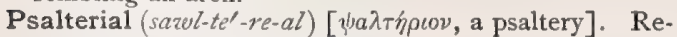
sembling a psalterium.

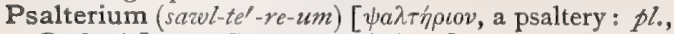
Psalteria]. 1. Synonym of the Lyra. 2. A group of longitudinal fibers on the floor of the Sylvian aqueduct. (Bergmann.) 3. In biology, the third compartment of the complicated stomach of the Pecora or true ruminants. It is globular in form and its lining membrane is raised into longitudinal folds or laminæ, arranged very much like the leaves of a book and very close together. It is also called Manyplies.

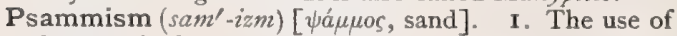
the sand-bath ; ammism. 2. The passage of gravel in the urine.

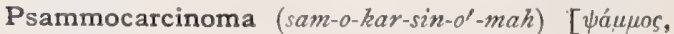
sand; каркірона, carcinoma]. A carcinoma containing a calcareous deposit.

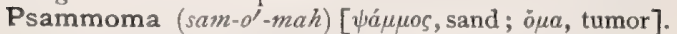
A meningeal tumor containing sand-like material. It is classed among the sarcomata.

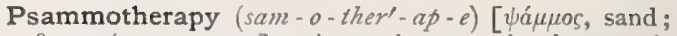
$\theta \varepsilon \rho a \pi \varepsilon i a$, treatment]. Ammotherapy; the therapeutic use of the sand-bath.

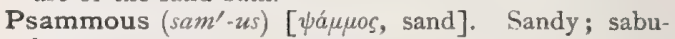
lous.

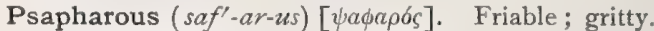

Psathyrous (sath'-ir-us). Synonym of Psapharous.

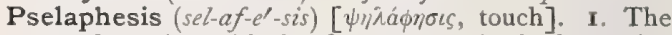
act of groping with the fingers, seen in the low delirium of fevers; carphology. 2. Tickling, or ticklishness.

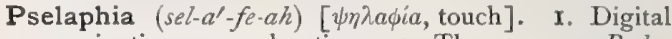
examination or exploration. 2. The same as Pselaphesis.

Pselaphotheca (sel-af-o-the'-kah) [ $\psi \eta \lambda a \phi a ̄ v$, to feel about; $\theta \dot{\eta} \kappa \eta$, a box, chest: pl., Pselaphothece]. In biology, the case or covering of the rudimentary palpi in many butterfly pupæ.

Psellism, Psellismus (sel'-izm, sel-iz'-mus) [ $\psi \varepsilon \lambda \lambda / \sigma-$ $\mu o ́ s]$. I. Stuttering or stammering. 2. Defect of speech due to hare-lip, or to cleft palate.

Pseud-(süd-). Same as Pseudo-.

Pseudacetic Acid (süd-as-e'-tik). Synonym of Propionic Acid.

Pseudaconin (su-dak'-o-nin) [ $\psi \varepsilon v \delta h \zeta$, false; ákóvıтov, aconite ], $\mathrm{C}_{27} \mathrm{H}_{41} \mathrm{NO}_{9}$. A decomposition-product of pseudaconitin.

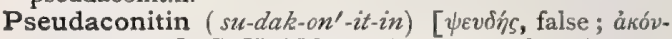
ıTov, aconite ], $\mathrm{C}_{36} \mathrm{H}_{49} \mathrm{NO}_{12}$. An extremely poisonous alkaloid from aconitum ferox. Unof.

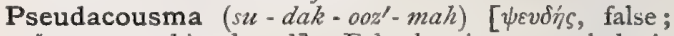
ákovø $\mu a$, a thing heard]. False hearing; a pathologic condition in which sounds are heard altered in pitch and quality.

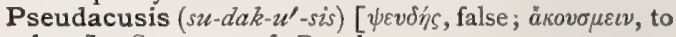
hear]. Synonym of Pseudacousma.

Pseudresthesia (su-des-the'ze-ah). See Psendesthesia.

Pseudallosematic (su-dal-o-se-mat'-ik) [ $\pi \sigma \varepsilon v \delta \not h s$, false; $a \ddot{\lambda} \lambda \alpha$, some other; $\sigma \tilde{\eta} \mu \alpha$, a sign, mark, token]. In biology, the displaying of a sign belonging to or characteristic of another. Applied by Poulton to the mimetic colors assumed by comparatively defenceless animals, by means of which they imitate foreign objects associated with some well-defined and aggressive species. Thus the leaf-carrying ants of South America ( Ecodo$m a)$, are mimicked by an immature homopterous insect possessing a shape and color closely resembling the ant, together with the leaf carried by it. Cf. Mimicry, Pseudaposematic, Pseudepisematic, Pseudosematic.

Pseudambulacral (su-dam-bu-la'-kral) [ $\psi \varepsilon v \delta \hbar s$, false ; ambulacrum, a walk]. In biology, simulating ambulacra.

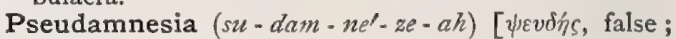
á $\mu \nu \eta \sigma i a$, forgetfulness]. I. Spurious amnesia; a condition resembling amnesia, but of a transient character. 2. An erroneous form of the word Pseudomnesia, q. $v$.

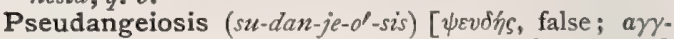

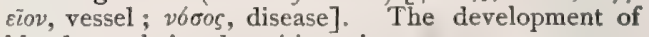
blood-vessels in adventitious tissue.

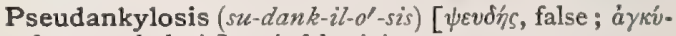
$\lambda \omega \sigma \iota$, ankylosis]. A false joint.

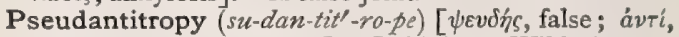
against ; $\tau \rho \varepsilon \varepsilon \varepsilon \iota \nu$, to turn]. In biology, Wilder's term for the apparently antitropic relation between parts which are opposed to each other, but lie upon the same side of an ideal plane. An example of longitudinal pseudantitropy is furnished by corresponding maxillary and mandibular teeth ; of lateral pseudantitropy, by the mesal and lateral canthi of the eye. 
Pseudaphe, Pseudaphia (su-da'-fe, su-d $a^{\prime}-f e-a h$ )

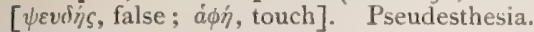

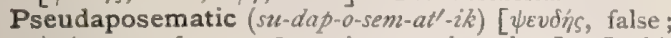
$a \dot{\pi} o ́$, away from; $\sigma \bar{\eta} \mu a$, sign, mark, token]. In bi ology, the displaying of a false warning signal. Ap plied by Poulton to those cases of mimicry in which enemies are repelled by the deceptive suggestion of some unpleasant or dangerous quality; e.g., both sexes of the India moth, Epicopeia philenora, mimic an unpalatable butterfy, P'apilio protenor. See, also, Mimicry, Pseudosematic, Pseudallosematic, Pseudepisematic.

Pseudargomorphosis (su-dar-go-mor-fo'-sis) [ $\psi \varepsilon v \delta$ í/s,

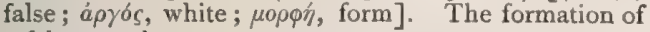
a false membrane.

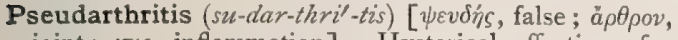
joint; $\iota \tau \iota \zeta$, inflammation]. Hysterical affection of a joint, simulating arthritis.

Pseudarthrosis (su-dar-thro'-sis) [ $\psi \varepsilon v \delta \not ́ s$, false ; ă $\rho \rho \rho v$, a joint]. A false joint or articulation. P., Diarthrodial, one closely resembling a natural joint; it is usually seen in fractured long bones. P., Ligamentous, one in which the fragments are united by fibrous bands, as in fracture of the patella or olecranon.

Pseudasthma (su-daz'-mah). Synonym of Dyspnea.

Pseudaxis (su-daks'-is). See Pseudoaxis.

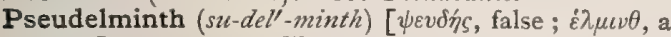
worm]. Any worm-like object mistaken for an entoparasitic worm.

Pseudelytrum, Pseudelytron ( su-del'-it-rum, su-del' it-tron) [ $\psi \varepsilon v \delta \not ́ s$, false ; $\varepsilon \lambda v \tau \rho o \nu$, a cover, sheath: $p l$. Pseudelytra]. In biology, a false elytrum, or wingcover.

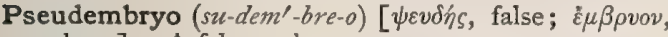
embryo]. A false embryo.

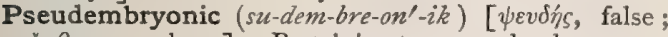
$\varepsilon \kappa \mu \beta \rho v o v$, embryo]. Pertaining to a pseudembryo.

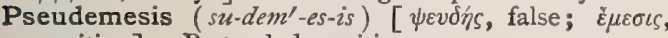
vomiting]. Pretended vomiting.

Pseudencephalia (su-den-sef-a'-le-ah). See Pseudencephalus.

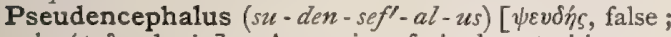

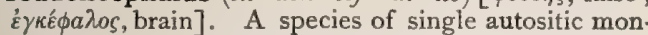
sters characterized by a partial development of the frontal, parietal, and occipital bones, while the brain is represented by a bunch of membranes, blood-vessels, connective and possibly nervous tissue, at the base of the skull.

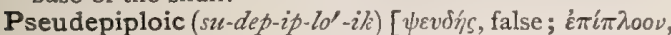
caul]. Pertaining to the pseudepiploön.

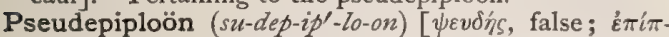
$\lambda o n v$, caul]. A false omentum found in birds.

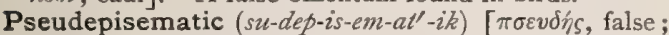
$\dot{\varepsilon} \pi i$, motion toward; $\sigma \tilde{\eta} \mu a$, a sign, mark, token]. In biology, the displaying of a lure or false safety-sign. Applied by Poulton to those cases of mimicry $(a)$ in which an animal resembles another animal, and is so enabled to approach and injure it in some way, or $(b)$ in which some lure is employed; thus, (I) the flies of the genus Volucella are enabled to lay their eggs in nests of bumble-bees by reason of their close resemblance to the latter; the larvæ of the fly feed on those of the bee; (2) the Asiatic lizard, Phrynocephalus mystaceus, possesses pink, flower-like structures at the corners of its mouth, by which flies are allured; or (3) the Terrapin, Malacoclemmys temminckii of the Southern States of America, when hungry, opens its mouth and moves about two filaments at the tip of its tongue; they look like worms moving in a crevice in the rock and therefore attract prey; the animal is otherwise perfectly motionless, and looks like a weedcovered rock.
Pseuderysipelas (su-der-is-iph-el-as). Synonym of Pseudo-erysipelas.

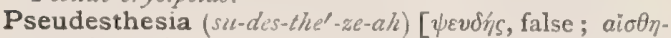
$\sigma \iota s$, feeling]. A sensation without a corresponding object. Also, an imaginary sensation in parts of the body that have been removed by accident or surgical operation.

Pseudhæmal (süd-hem'-al). Same as Pseudohemal.

Pseudhelminth (süd-hel'-minth). Same as Pseudelminth.

Pseudiatrus (su-de-at'-rus). Synonym of Quack.

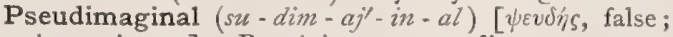
imago, imago]. Pertaining to a pseudimago.

Pseudimago $\left(s u\right.$ - dim - $\left.a^{\prime}-g o\right)$ [ $\psi \varepsilon v \delta h s$, false; imago, imago]. In biology, a false imago.

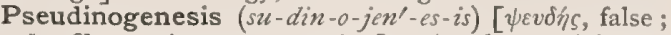
is, fiber; $\gamma^{\prime} \nu \varepsilon \sigma \iota \varsigma$, generation]. An abnormal formation of fibers or tissues.

Pseudinoma (su-din-o'-mah). Synonym of Scirrhus.

Pseudo- (su'-do-) [ $\psi \varepsilon v \delta \eta \eta s$, false]. A prefix denoting false, simulating, resembling, or seeming.

Pseudo-acephalia (su-do-as-ef-a'-le-ah). Synonym of Pseudencephatia.

Pseudo-acetic Acid (su-do-as-e'-tik). Synonym of Propionic Acid.

Pseudo-aconitin (su-do-ak-on'-it-in). Synonym of Pseudaconitin.

Pseudo-actinomycosis (su-do-ak-tin - o- $\left.m i-k o^{\prime}-s i s\right)$

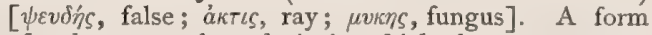
of pulmonary tuberculosis in which the sputum contains granular bodies resembling the grains of actinomycosis. They consist of a crystalline substance similar to leucin

Pseudo-albuminuria (su-do- $\left.a l-b u-m i n-u^{\prime}-r e-a h\right)$

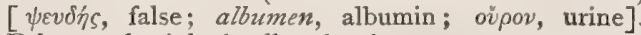
False or physiologic albuminuria.

Pseudo-anemia (su-do-an-e'-me-ah). Synonym of Anemia, Progressive Pernicious.

Pseudo-angina $\left(s u-d o-a n-j i^{\prime}-n a h\right)\left[\psi \varepsilon v \delta \eta^{\prime} s\right.$, false ; angere, to strangle]. Hysterical angina. See, also, angina pectoris.

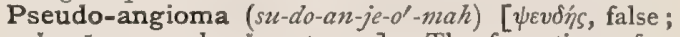
à $\gamma \varepsilon \bar{\imath}{ }^{\circ} \nu$, vessel; $\ddot{o} \mu a$, tumor]. The formation of a temporary angioma, as is sometimes seen in healing stumps. P., Urethral, urethral caruncle.

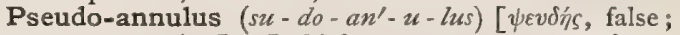
annulus, a ring]. In biology, an apparent annulus.

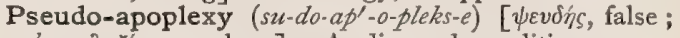
$a ́ \pi \sigma \pi \lambda \eta \xi i \alpha$, apoplexy]. A diseased condition resembling apoplexy, but in which cerebral hemorrhage is not found, post-mortem.

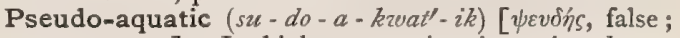
aqua, water]. In biology, growing in moist places, but not strictly aquatic.

Pseudo-arthrosis (su-do-ar-thro'-sis). Synonym of Pseudarthrosis.

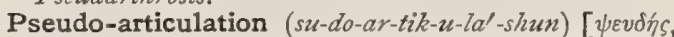
false; articulus, a joint]. A false joint. See Pseudarthrosis.

Pseudo-asthma (su-do-az'-mah). Synonym of Pseudasthma.

Pseudo-axis $\left(s u-d o-a k s^{\prime}-i s\right)$ [ $\psi \varepsilon v \delta h s$, false; axis, axis]. Same as Sympodium.

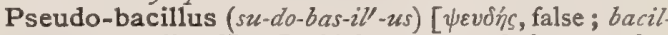
hum, a small rod]. In biology, one of the very fine fat crystals, which, according to Celli and Guarnieri, are sometimes found in sputum, and which react to the staining almost as tubercle-bacilli, but which may be distinguished by their varying size and their solubility in ether and chloroform.

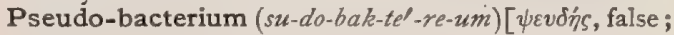
$\beta a \kappa \tau h \rho c o v$, a little rod or staff: pl., Pseudobacteria]. 
In biology, any object mistaken for a bacterium, as a pseudobacillus.

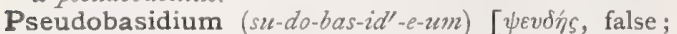
ßáoıs, a base]. A false basidium.

Pseudoblepsia, Pseudoblepsis (su-do-blep'-se-ah, su-

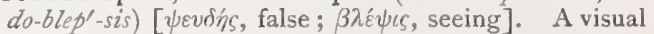
hallucination; a distorted visual image.

Pseudo-boina $\left(s u-d o-b o-i^{\prime}-n a h\right)[\pi \varepsilon v \delta \eta ́ n s$, false; bos, ox]. Spurious cow-pox.

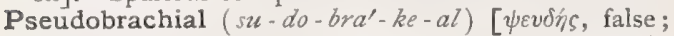

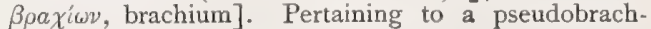
jum

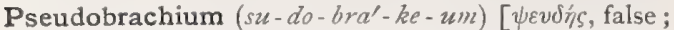

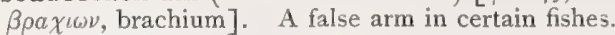

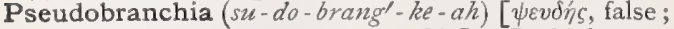

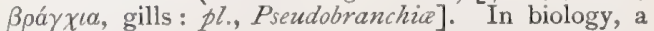
false gill

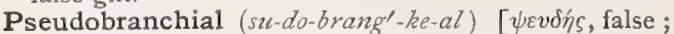

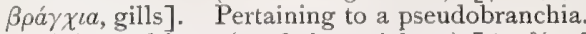

Pseudobranchiate (su-do-brang $\left.g^{\prime}-k e-\bar{a} t\right)[\psi \varepsilon v \delta \eta \dot{s}$, false ; $\beta \rho a ́ \gamma \chi \iota a$, gills]. In biology, provided with pseudobranchixe.

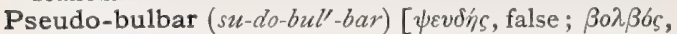
bulb]. Not truly bulbar. Denoting a kind of paralysis. P. Paralysis, symmetric disease of both cerebral hemispheres involving the centers or paths of the nerves of speech, and thus resembling disease of the oblongata.

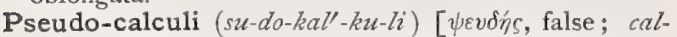
culus, calculus]. A name given by Poland to the fibrinous and sanguineous calculi or masses, sometimes seen in urine

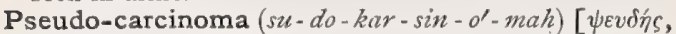
false; $\kappa \alpha \rho \kappa i v \omega \mu \alpha$, carcinoma]. A benign tumor resembling a carcinoma.

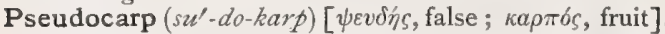
In biology, any fruit made up of parts other than those belonging exclusively to a single ovary. The apple, rose, mulberry, and juniper are examples of pseudocarps.

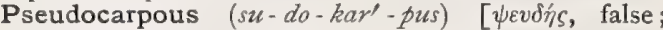
$\kappa ґ \rho \pi o ́ s$, fruit]. Same as Anthocarpous.

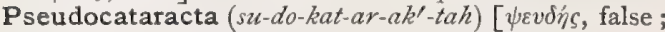

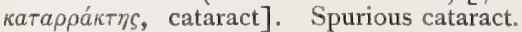

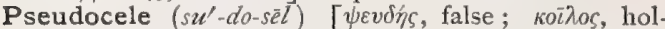
low]. The fifth ventricle of the brain. It is the space between the two opposed halves of the septum; in man and apes it is completely circumscribed by the continuity of the callosum with the fornix at the splenium and at the copula.

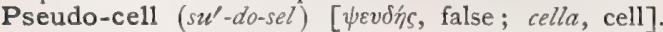
One of the peculiar vesicular bodies, albuminoid in character, found in the ova of many species of hydrozoa, and by Balfour considered to be analogous to the vitelline granules of birds' eggs.

Pseudo-cephalocele $\left(s u^{\prime}-d o-s e f^{\prime}-a l-o-s e ̄ l\right)[\psi \varepsilon v \delta \dot{\eta} \varsigma$, false; $\kappa \varepsilon \phi a \lambda \dot{\eta}$, head; $\kappa \dot{\lambda} \lambda \eta$, tumor]. A cephalocele acquired subsequently to birth through disease of the cranial bones or subcutaneous fractures.

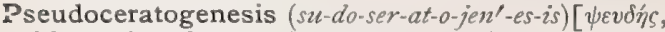

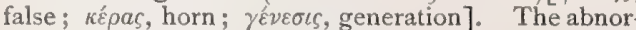
mal proliferation of horny tissue.

Pseudoceratosis $\left(s u-d o-s e r-a t-o^{\prime}-s i s\right)$. Synonym of Pseudoceratogenesis.

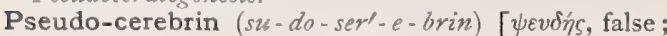
cerebrum, cerebrum], $\mathrm{C}_{44} \mathrm{H}_{92} \mathrm{NO}_{8}$. A substance extracted from brain-tissue by alcohol.

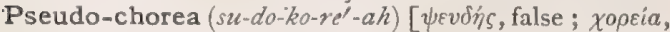
dance]. Spurious chorea, usually hysterical in origin.

Pseudo-chromesthesia (su-do-kro-mes-the'-ze-ah) [ $\psi \mathrm{Fv}$ -

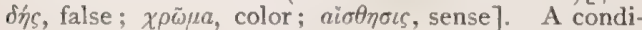
tion in which the vowels of a word (whether seen, heard, or remembered) each seem to have a distinct visual tint. See Photism, Phonism.

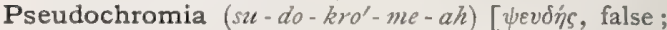
$\chi \rho \bar{\omega} \mu a$, color $]$. A false or incorrect perception of color.

Pseudo-chrysalis (su-do-kris'-al-is). Same as Pseudopupa.

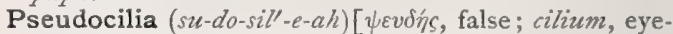
lash]. An abnormal growth of hairs on the conjunctiva.

Pseudocœle, Pseudocœlia (su-do-sèll', su-do-se'-le-ah). Synonym of Pseudocele and of Pseudocolom.

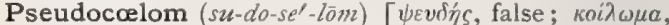
a hollow cavity]. In biology, one of those interstitial spaces or cavities sometimes found in invertebrates (Platyhelminthes, Arthropoda, Mollusca), which, not being lined by an epithelium derived from the archenteron, is to be distinguished from a true body-cavity or colom derived from archenteric diverticula. Cf. Archical.

Pseudo-coloboma (su-do-kol-o-bo'-mah) [ $\psi \varepsilon v \delta n ́ s$, false ; $\kappa \circ \lambda \sigma \beta \omega \mu \alpha$, mutilation]. A scarcely noticeable fissure of the iris, the remains of the embryonic ocular fissure, which has almost, but not perfectly, closed.

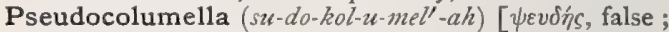
columella, a little column]. In biology, a parietal or septal columella.

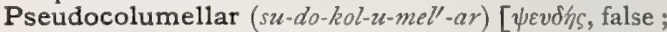
columella, a little column]. Pertaining to a pseudocolumella.

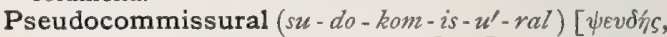
false; commissura, a commissure]. Pertaining to a pseudocommissure.

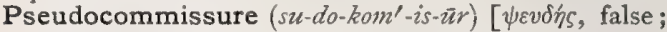
commissura, a commissure]. A sort of commissure between the olfactory lobes of the frog.

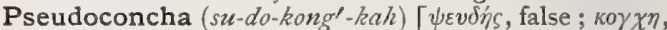
a shell : pl., Pseudoconcha]. In biology, a turbinated structure connected with the inter-nasal septum in front of and below the turbinate bones of birds. It separates the vestibule of the nose from the internal nasal cavity.

Pseudo-cortex (su-do-kor'-teks) [ $\psi \varepsilon v \delta h s$, false ; cortex, bark]. In biology, a false cortex.

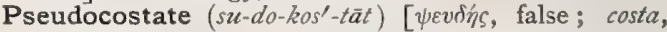
rib]. In biology, false-ribbed, as certain leaves.

Pseudocotyledon (su-do-kot-il-el-don) [ $\psi \varepsilon v \delta \eta \dot{\eta} s$, false ; $\kappa о \tau \nu \lambda \eta \eta \delta \omega v$, cotyledon]. In biology, one of the germinating threads of the spores of cryptogams.

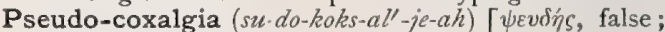
coxa, hip; à $\lambda$ os, pain]. False or spurious coxalgia, an hysterical affection of the hip-joint

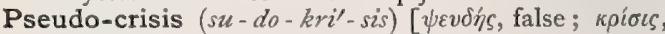
separating]. Variation in the course of the temperature in acute pneumonia due to variations in the local process. The fall of temperature varies from $2^{\circ}$ to $7^{\circ}$ $\mathrm{F}$., but rarely is the normal temperature reached, and a subsequent rise soon appears. Pseudo-crises are most frequent from the fifth to the seventh day, but may occur earlier or later.

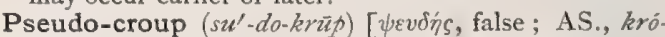
pan, to cry aloud]. False croup; laryngismus stridulus.

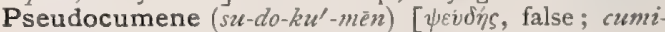
num. cumin $], \mathrm{C}_{9} \mathrm{H}_{12}$. A liquid occurring with mesitylene in coal-tar. It boils at $166^{\circ} \mathrm{C}$

Pseudocurarin (su-do-ku-rar'-in) [ $\psi \varepsilon v \delta \hbar j s$, false ; curara]. A non-poisonous alkaloid found in Nerium oleander.

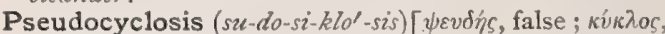
a circle]. The apparent circulation of food in an ameba.

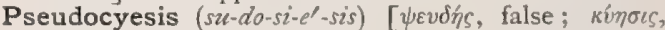
pregnancy]. False pregnancy. The belief in the 
existence of pregnancy on the part of a woman (usually the result of desire), accompanied, perhaps, by uncertain signs. P. abdominalis, abdominal pregnancy. P. ovaria, gestation in an ovary. P. tubaria, tubal pregnancy.

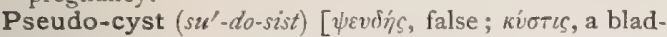
der]. In biology, a globular body produced by the breaking up of the protoplasm in a filament in certain of the lower plants; an asexual reproductive body. Cf. Gonidium, Spore, Carpospore.

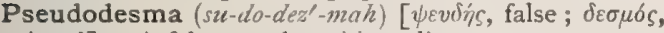
bond]. A false or adventitious ligament.

Pseudo-diarthrosis (su-do-di-ar-thro'-sis). Synonym of Pseudarthrosis, Diarthrodial.

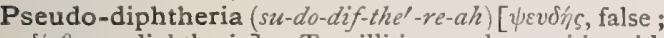

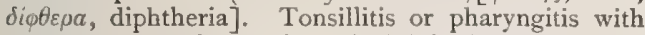
an exudate simulating that of diphtheria, but not due to the Klebs-Löffler bacillus.

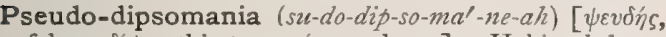

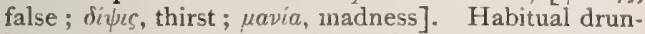
kenness, without maniacal impulse, or obsession, impelling the patient to drink.

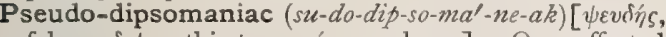
false; $\delta \downarrow \psi a$, thirst; $\mu a v i a$, madness]. One affected with pseudo-dipsomania.

Pseudodont (su'-do-dont) [ $\psi \varepsilon v \delta \eta^{\prime} \zeta$, false; ódov́s, tooth]. In biology, having false teeth, as a monotreme.

Pseudodontosis (su-do-don-to'-sis) [ $\psi \varepsilon v \delta \dot{n} s$, false ; ódoús, tooth]. The formation of anomalous teeth.

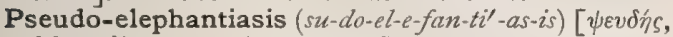
false; $\varepsilon$ ¿ $\varepsilon \phi \alpha \nu \tau i \alpha$, elephantiasis]. A tumor-like hypertrophy, resembling elephantiasis.

Pseudo-embryo (su-do-em'-bre-o). Synonym of Proembryo.

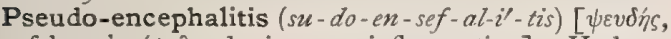

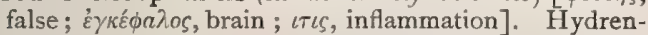
cephaloid disease.

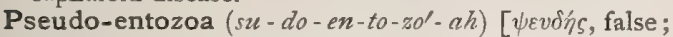

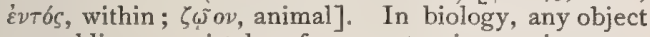
resembling or mistaken for an entozoic parasite, e.g., Ovuligira acephalocystis, q. v. under Parasites (Animal), Table of.

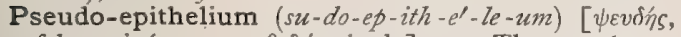
false; $\dot{\varepsilon} \pi i$, upon; $\theta \eta \lambda \eta$, nipple]. I. The membrane lining serous and vascular cavities of the body; true endothelium. 2. The layer of germinal cells found on the surface of the ovary after the ovarian tubes have formed.

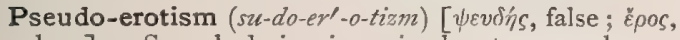
love]. Sexual desire in animals at unusual seasons.

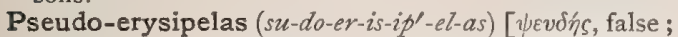
$\dot{\varepsilon} \rho v \sigma i \pi \varepsilon \lambda a \varsigma$, erysipelas]. A name vaguely applied to conditions having more or less resemblance to true erysipelas. P. subtendinosum colli. Synonym of Angina ludovici.

Pseudo-esophoria (su-do-ez'-o-fo'-re-ah). See Esophoria.

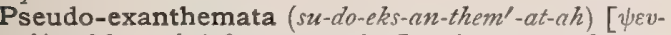
$\delta \not \zeta$, false ; $\hat{\xi} \xi \alpha \dot{\alpha} \eta \eta \mu a$, eruption]. A group of noncontagious eruptive diseases resembling the exanthemata in their onset and course.

Pseudo-exophoria (su-do-eks-o-fo'-re-ah). See Exophoria.

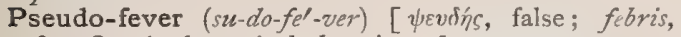
fever]. An hysterical elevation of temperature.

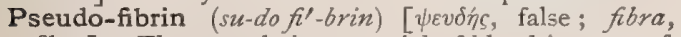
fiber]. The coagulative material of blood in cases of "buffy coat."

Pseudo-filament $\left(s u-d o-f i l^{\prime}-a m-e n t\right)[\psi \varepsilon v \delta \eta ́ s$, false ; flum, a thread]. In biology, an object that looks like, but is not, a real filament. The term is applied to 76 cocci or other bacteria arranged in rows in the direction of the successive divisions.

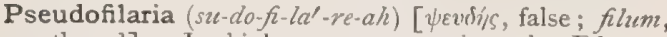
a thread]. In biology, a name given by Ed. van Beneden to a stage in the development of gregarines, in which they resemble minute nematode worms (Filaria).

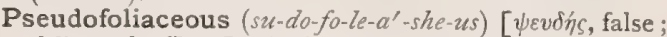
folium, leaf]. In biology, provided with lobes or expansions resembling leaves.

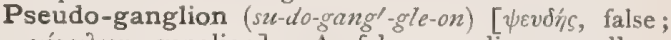

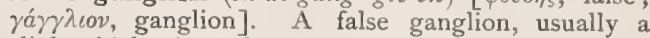
slight thickening of a nerve. P. of Bochdalek, an enlargement of a branch of the middle alveolar nerve from which fibers descend to supply the canine teeth. P. of the Circumflex Nerve, an expansion of a branch of the nerve which goes to the teres major. P. of Cloquet, a thickening of the palatine branches of the naso-palatine nerve. P., Valentin's, a slight thickening at the junction of certain divisions of the middle alveolar branch of the maxillary nerve.

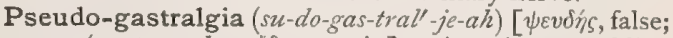
$\gamma \alpha \sigma \tau \eta \dot{ } \rho$, stomach; à $\lambda$ yos pain]. A pain resembling gastralgia, but not caused by disease of the stomach. It may be dependent upon disease of the aorta.

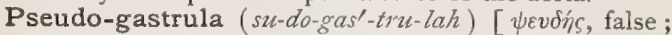
$\gamma \alpha \sigma \tau \hat{p} \rho$, stomach]. In biology, an embryonic stage which resembles, but is not, a true gastrula.

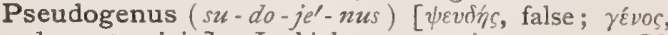
descent, origin]. In biology, a spurious genus. Cf. Form-genus.

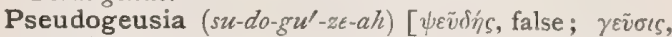
taste]. A false perception, or hallucination, of taste.

Pseudogeustia (su-do-güs'-te-ah). See Pseudogeusia.

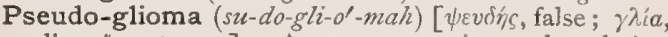
glia; $0 \mu \alpha$, tumor]. A name sometimes, though im. properly, given to inflammatory changes of the vitreous tumor, the result of irido-choroiditis, which cause a condition simulating glioma. P. of Retina. See Glioma.

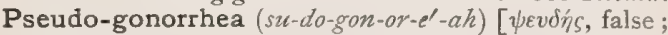
yovóp $\rho \circ \circ a$, gonorrhea]. A simple non-specific urethritis.

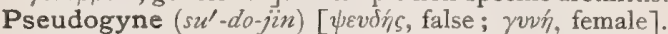
In biology, the agamic females of certain insects (e.g., Aphidida), successive generations of which are sometimes born viviparously without copulation with the males.

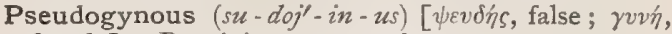
female]. Pertaining to a pseudogyne.

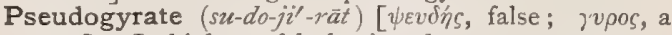
gyre]. In biology, falsely ringed.

Pseudohæmal (su-do-hem'-al). See Pseudohemal.

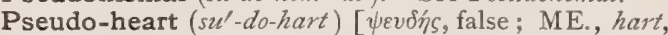
heart]. In biology, one of the glandular organs found in Brachiopoda, having the double function of renal organs and genital ducts; they are the homologues of the organs of Bojanus of the Mollusca and of the segmented organs of Vermes.

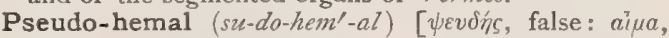
blood]. In biology, pertaining to that form of respiratory or nutritive fuid of many invertebrates which is analogous to blood but is not true blood. It is found in most annelids, is red or green, corpusculated or noncorpusculated, and flows through a system of vessels with contractile walls, either shut off from or communicating with the perivisceral cavity.

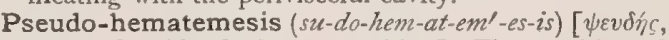
false ; ai $\mu \alpha$, blood; $\check{\varepsilon} \mu \varepsilon \sigma \iota$, vomiting]. The vomiting of bile, red-wine, fruit-juices, or any other substance simulating blood.

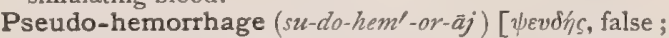
ai $\mu \alpha$, blood; 'ं $\gamma$ vivval, to burst forth]. A hemorrhage without rupture of the vessels; vicarious hemorrhage. 
Pseudo-hermaphrodism (su-do-her-maf'- ro-dizm )

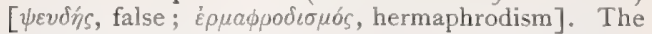
condition presented by a pseudo-hermaphrodite. P., Feminine, a condition in which the genitals of the female resemble those of the male. There are three varieties. See $P$., Male. P., Male, a condition in which the genitals of the male resemble those of the female. There are three varieties; the external, the internal, and the complete, according as the external or internal generative organs, or both, are affected.

Pseudo-hermaphrodite (su-do-her-maf'-ro-dit) [ $[\psi \varepsilon v-$

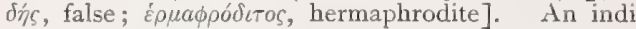
vidual in which there is a double sexual formation of the external genitals, but a unisexual development of the reproductive glands (ovaries and testicles). According to the development of one or the other of the latter will the sex of the individual be determined.

Pseudo-hermaphroditism (su-do-her-maf'-ro-dit-izm). See Psoudohermaphrodism.

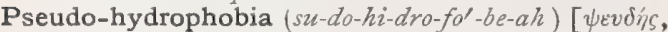
false; $v \delta \omega \rho$, water; $\phi o ́ ß o s$, fear ]. Hysterical convulsions in one believing himself to have been bitten by a rabid animal. There is, however, absence of the true respiratory spasm. It has also been called Lyssophobia and Hydrophobophobia.

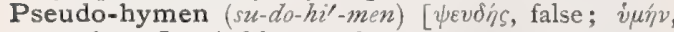
membrane]. A false membrane.

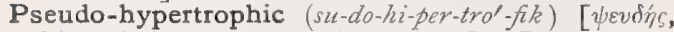
false; $\dot{v} \pi \hat{\varepsilon} \rho$, over; $\tau \rho \circ \phi \dot{\eta}$, nutrition]. Pertaining to pseudohypertrophy. P. Paralysis, loss or diminution of the power of motion, accompanied by enlarged, and apparently hypertrophied muscles. The types are the Leyden-Möbius, Zimmerlin, and Landouzy-Déjerine. See Paralysis, Pseudohypertrophic.

Pseudo-hypertrophy $\left(s u t-d o-h i-p e r^{\prime}-t r o-f e\right)$ [ $\psi \varepsilon v \delta \eta ́ s$,

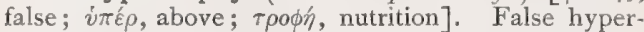
trophy; increase in the size of an organ or part on account of overgrowth of an unimportant tissue. It is accompanied by diminution in function.

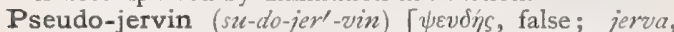
green hellebore-root], $\mathrm{C}_{29} \mathrm{H}_{43} \mathrm{NO}_{7}$. An alkaloid found in Veratrum viride.

Pseudo-joint (su'-do-joint). Same as Pseudo-articulation.

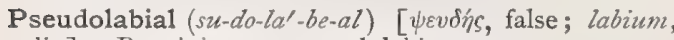
lip]. Pertaining to a pseudolabium.

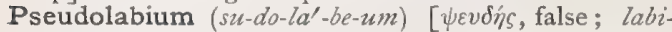
um, lip]. In biology, the sternite of the sub-basilar plate of certain Myriapoda.

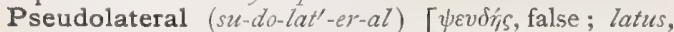
side]. In biology, having a tendency to become lateral when normally terminal.

Pseudo-leukemia (su-do-lu-ke'-me-ah). See Hodgkin's Disease and Lympliadenoma.

Pseudo-leukocythemia (su-do-lu-ko-si-the'-me-ah)

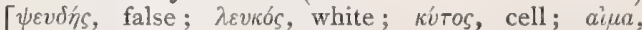
blood]. Same as Psendoleukemia.

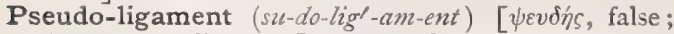
ligamentum, ligament]. An inflammatory band of adhesion.

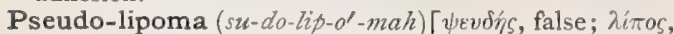
fat; $\delta \mu \alpha$, tumor]. A localized edema resembling an accumulation of fat, occurring above the clavicle and about the knee, especially in cases of rheumatism.

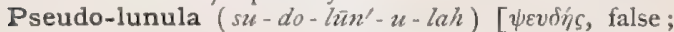
lunula, a little moon]. An aggregation of mucous cells in the salivary glands, forming lunula-like masses.

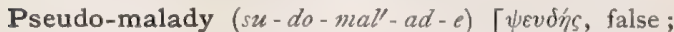
malum, evil]. An imaginary or simulated illness.

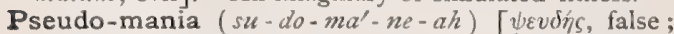
pavia, mania]. I. A form of insanity in which the person afiected accuses himself of a crime or crimes of which be is innocent. 2. A mania characterized by lying.

Pseudomedicus (su-do-med'-ik-us). Synonym of Quack.

Pseudo-melanemia (su-do-mel-an-el-me-ah). Synonym of Pseudomelanosis.

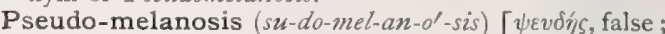
$\mu \varepsilon ́ \lambda a s$, black; vó oos, disease]. The dark staining of gangrenous parts or the tissues after death, due to the deposit of ferrous sulphid, which is formed by a reaction of hydrogen sulphid and the hemoglobin of the blood.

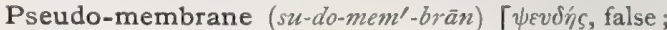
membrana, membrane]. A false membrane, such as is seen in diphtheria.

Pseudo-membranous (su-do-mem'-bra-nus) [ $\psi \varepsilon v \delta y^{\prime} /$, false; membrana, membrane]. Characterized by, or pertaining to false membranes. P. Inflammation, any inflammation characterized by the formation of a false membrane.

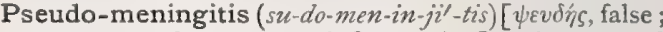
$\mu \tilde{\eta} \nu \iota \gamma \xi$, membrane; $\iota \tau \iota \zeta$, inflammation]. A group of symptoms resembling that produced by meningitis, but with absence of the lesions of meningeal inflammation. P., Dental, meningeal symptoms occurring in children during difficult dentition.

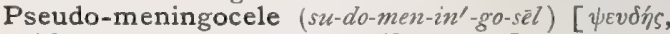
false; $\mu \tilde{n} \nu \imath \xi \xi$ membrane; $\kappa \dot{n} \lambda \eta$, tumor]. A tumor formed beneath the scalp as a result of a traumatic lesion of the skull and dura, by the pouring out of cerebro-spinal fluid.

Pseudo-menstrual (su-do-men'-stru-al) [ $\psi \varepsilon v \delta \not ́ s$, false; menstruus, monthly]. Pertaining to pseudo-menstruation.

Pseudo-menstruation (su-do-men-stru-a'-shun) [ $\psi \varepsilon v-$ $\delta$ ins, false; menstruus, monthly]. Hemorrhage from the uterus due to systemic disease. It is sometimes seen during the course of eruptive fevers.

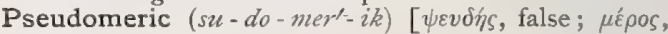
part]. A qualification applied to unstable forms of tautomeric bodies.

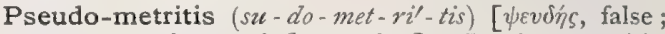
$\mu \eta \tau \rho a$, womb ; $\iota \tau \iota \varsigma$, inflammation]. Spurious metritis.

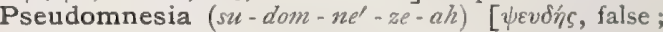
$\mu \nu \tilde{\eta} \sigma \iota s$, remembrance]. A perversion of the memory, in which the patient recalls as facts things which never have occurred.

Pseudomonocotyledonous (su-do-mo-no-kot-il-e'-do-

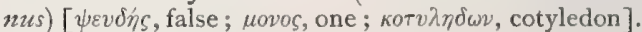
In biology, having two or more cotyledons consolidated into one mass.

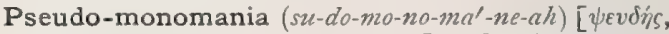
false; $\mu$ óvos, one; $\mu \alpha v i a$, mania]. Spurious monomania, a condition not monomania, yet presenting similar symptoms.

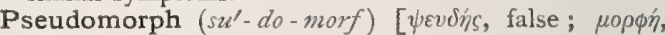
form ]. A false form.

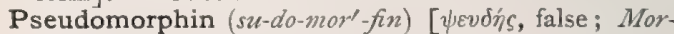
pheus, the god of sleep], $\mathrm{C}_{34} \mathrm{H}_{36} \mathrm{~N}_{2} \mathrm{O}_{6}$ (Foster). A finely crystalline alkaloid of opium, insoluble in water, alcohol, ether, and chloroform; it is soluble in alkalies and lime-water, neutral, tasteless. It is also called Phormia and Oxymorphin.

Pseudomorphic (su-do-mor'-fik). Same as Pseudomorphous.

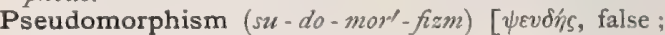
$\mu \circ \rho \varphi \eta$, form]. The state of having a form different from that normal to the substance.

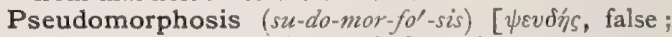
$\mu о \rho \phi \eta$, form]. An abnormal formation, as a tumor, deformity, or monstrosity. 


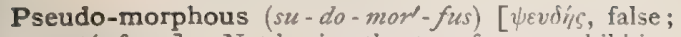
$\mu \circ \rho \phi$, form $]$. Not having the true form; exhibiting pseudomorphism.

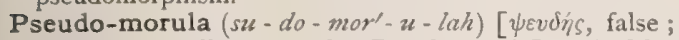
morus, a mulberry: pl., Pseudomorula]. A false morula.

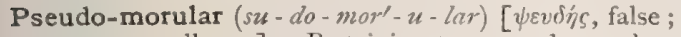
morus, a mulberry]. Pertaining to a pseudomorula.

Pseudo-mucin $\left(s u-d o-m u^{\prime}-\sin \right)$ [ $\psi \varepsilon v \delta \prime \eta s$, false; mucus, mucus]. A substance allied to mucin, from which it cliffers in not being altered by acetic acid. It is found in proliferative ovarian cysts, being the cause of the gelatinous nature of the contents of the cysts. It is produced by the epithelial cells lining the cyst-walls.

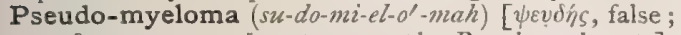
$\mu \nu \varepsilon \lambda o s$, marrow; $\delta \mu \alpha$, tumor: pl., Pseudonyelomata]. A sarcoma resembling the white substance of the brain.

Pseudonarcissin $\left(s u-d o-n a r-s i s^{\prime}-i n\right)$ [ $\psi \varepsilon v \delta \eta / s$, false váркıббоร, narcissus]. An alkaloid found in the bulb of Narcissus pseudonarcissus.

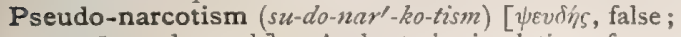

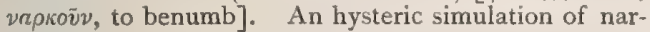
cotism.

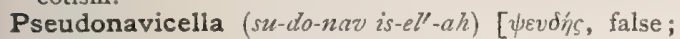
navicella, a small boat, dim. of navis, a ship: pl., Pseudonavicellce]. A name given by Lieberkühn to a developmental stage of gregarines, resembling the navicellæ or naviculæ of diatoms.

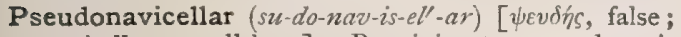
navicella, a small boat]. Pertaining to a pseudonavicella.

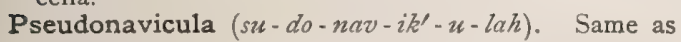
Pseudonavicella.

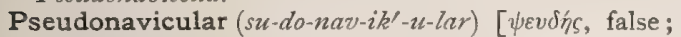
navicula, a small boat]. Pertaining to a pseudonavicula.

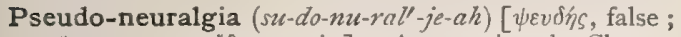

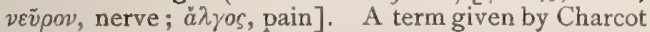
to the pains of rickets.

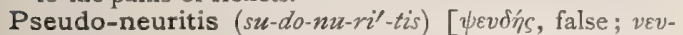
$\rho \circ \nu$, nerve; $\iota \tau \iota$, inflammation]. A disease simulating a neuritis.

Pseudo-nipple (su-do-niph-l) [ $\psi \varepsilon v \delta h s$, false; ME., neple, nipple]. A false nipple of the mamma.

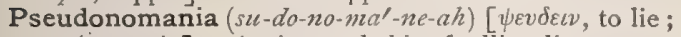
uavia, mania]. An insane habit of telling lies.

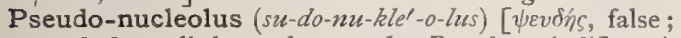

- nucleolus, a little nucleus: pl., Pseudonucleoli ]. A false nucleolus.

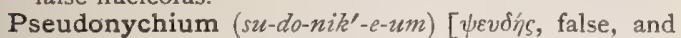
óvvx the spurious claw between the true tarsal claws of an insect.

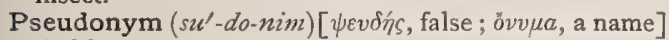
A false name.

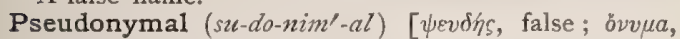
name]. In biology, vernacular; not having the character of an onym.

Pseudo-osteomalacia (su-do-os - te - o-mal- $\left.a^{\prime}-s e-a h\right)$

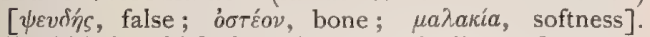
Rachitis in which the pelvic basin is distorted so as to resemble in form that of osteomalacia.

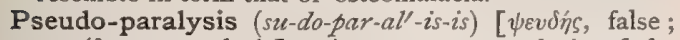
$\pi \alpha \rho a ́ \lambda v \sigma \iota s$, paralysis]. An apparent paralysis of the limbs. P. of Rickets, the inability to walk in severe cases of rickets, due to distortion of the bones. P., Syphilitic, an inflammatory condition of the epiphyses of the bones in acquired syphilis, which causes a marked impairment of motion.

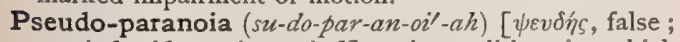
$\pi a \rho a ́$, beside; vóos, mind]. A condition in which there is a primarily more active mentality, as well as an increased responsivity to emotional impulses, associated with a heightened desire for activ. ity.

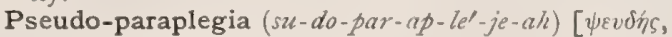
false ; $\pi \alpha \rho a ́$, beside; $\pi \lambda \eta \gamma \dot{\eta}$, stroke]. Spurious paraplegia. P., Tetanoid. Synonym of Paralysis, Spastic.

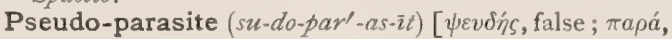
beside; бiтos, food]. In biology, a term properly restricted to various objects, such as hairs, vegetable tissues, etc., which have been mistaken for parasites and even described as such; also to frogs, snakes, spiders, etc., which have been stated by many authors to have existed for years in the human alimentary canal, although it is perfectly certain that animals of this kind cannot endure the moist heat of the body of a mammal for more than six hours (Leuckart); a commensal, inquiline messmate. One of certain bodies sometimes seen in the blood in anemia, resembling microörganisms. They are probably altered blood-corpuscles.

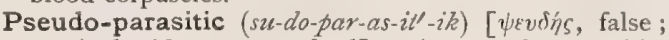

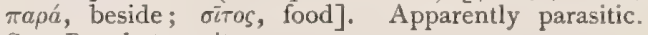
See Pseudo-parasite.

Pseudo-parenchyma (su-do-par-eng'-kim-ah) [ $\psi \varepsilon v \delta \eta ́ h$, false; $\pi \alpha \rho a ́$, beside; $\dot{\varepsilon} \gamma \chi \varepsilon \tilde{\imath} \nu$, pour in ]. In biology, DeBary's term for the tissue of fungi produced by the interlacing of the hyphr.

Pseudo-parenchymatous (su-do-par-en-kim'-at-us)

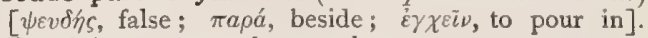
Pertaining to a pseudoparenchyma.

Pseudo-parenchyme (su-do-par-en'-kīm). Same as Pseudoparenchyma.

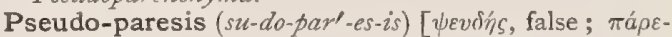
$\sigma \iota s$, paresis]. An affection resembling paresis, but regarded as distinct from the ordinary forms.

Pseudo-parthenogenesis (su-do-par-then-o-jen'-es-is)

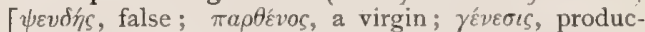
tion]. In biology, a mode of reproduction intermediate between metagenesis and parthenogenesis.

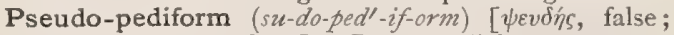
pes, foot; forma, form $]$. Pseudopodial.

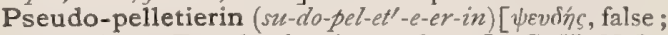
Pelletier, a French chemist, I $76 \mathbf{I}-97], \mathrm{C}_{18} \mathrm{H}_{30} \mathrm{~N}_{2} \mathrm{O}_{2}$. An alkaloid found in the root-bark of pomegranate.

Pseudo-peptone (su-do-pep'-tön). Same as Hemialbumose.

Pseudopercular (su-do-per'-ku-lar) [ $\psi \varepsilon v \delta \dot{s} s$, false ; operculum, a lid]. Pertaining to or of the nature of a pseudoperculum.

Pseudoperculate $\left(s u-d o-p e r^{\prime}-k u-l a \vec{a} t\right)$ [ $\psi \varepsilon v \delta \delta^{\prime}$, false ; operculum, lid]. In biology, provided with a pseudoperculum.

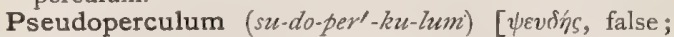
operculum, lid: pl., Pseudopercula ]. A false operculum.

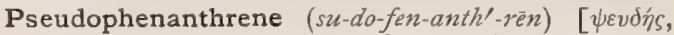
false; $\phi \circ \tilde{\imath} \nu \xi$, purple-red; à $\nu \rho \rho \alpha \xi$, coal], $\mathrm{C}_{16} \mathrm{H}_{12^{\circ}}$ A hydrocarbon found in crude anthracene, crystallizing in large glistening plates that melt at a temperature of $115^{\circ} \mathrm{C}$.

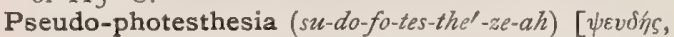
false; $\phi \tilde{\omega} \varsigma$, light; ai $\sigma \theta \eta \sigma \iota$, perception ]. The seeing of photisms.

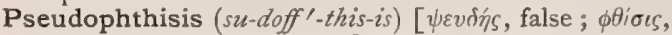
wasting]. Emaciation and general wasting arising from other causes than pulmonary tuberculosis.

Pseudopia (su-do'-pe-ah). Synonym of Pseudopsia.

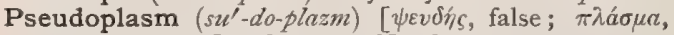
a thing molded]. Same as Neoplasm.

Pseudoplasma (su-do-plaz'-mah). Synonym of Pseudoplasm. 


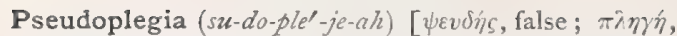
stroke]. Spurious, or hysteric paralysis.

Pseudo-pleuritis $\left(s u-d o-p l u-v i^{\prime}-t i s\right)$. Synonym of Pleurodynia.

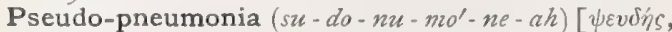
false, $\pi \nu \varepsilon v \mu \omega v$, lung]. Any disease of the lung simulating pneumonia.

Pseudopod, Pseudopodium (su'-do-pod, su-do-po'-de-

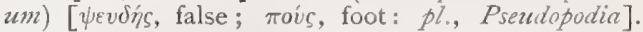
A protrusion of a portion of the substance of a cell, especially of one possessing ameboid movement. See Pseudopodium.

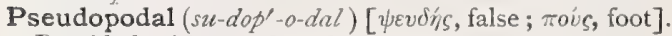
Provided with pseudopods.

Pseudopode $\left(s u^{\prime}-d o-p o ̈ d^{\prime}\right)$. Same as Pserdopodium.

Pseudopodial, Pseudopodian (su-do-po'-de-al, su-do-

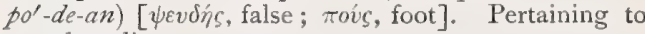
pseudopodia.

Psendopodic (su-do-po'-dik). Same as Pseudopodal.

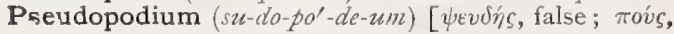
foot: pl., Pseudopodia]. In biology, a temporary or permanent, filose or lobose process of the exoplasm of Rhizopoda, Heliozoa, Radiolaria, and other ameboid cells; leukocytes, plasmodia, etc. "There are two principal sorts of pseudopodia, myxopadia and axopodia. The former are not stiff, but protrusible and retractile; they can fuse with neighboring pseudopodia into a network, and chiefly in the Rhizopoda, can collect into small masses by flowing together outside the body at points where they meet with food. Such myxopodia are characteristic of the Rhizopoda, and most Radiolaria. The axopodia, which are found in the Heliozor and in Acantharia among Radiolaria, are on the contrary, more or less stiff, and not inclined to reticulate and fuse. In their axes there generally runs a stiff axial filament, a sort of elastic organ of support formed of organic substance. These axial filaments run toward the central point of the body-to the boundary of the endoplasm (Actinospharizm), or to the nucleus near the center (Actinophrys), or they meet actually in the center (Acantharia). All pseudopodia show more or less swift granular streaming."' (Lang.)

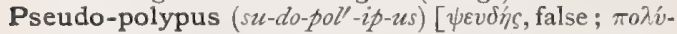
tovs, polypus]. A mass of mucus or blood assuming the shape of a polypoid tumor.

Pseudo-pregnancy (su-do-preg'-nan-se) [ $\psi \varepsilon v \delta / h s$, false ; pregnans, pregnant]. Synonym of Pregnancy, False.

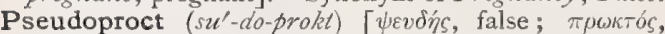
anus]. In biology: $(a)$ the anal opening of the echinopadium of an echinoderm. (b) The secondary opening replacing the original ascule in a sponge.

Pseudoproctous $\left(s u\right.$-do-prok'-tus) [ $\psi \varepsilon v \delta \delta^{\prime} s$, false ; $\pi \rho \omega \kappa-$ $\tau \sigma \zeta$, anus]. In biology, provided with a pseudoproct.

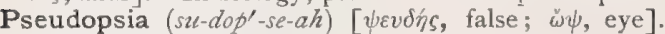
Visual hallucination, or error of visual perception.

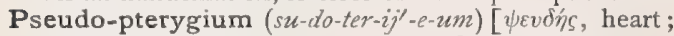
$\pi \tau \hat{\varepsilon} \rho v \xi$, wing]. False, or cicatricial, pterygium.

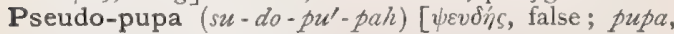
pupa). A false pupa.

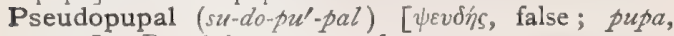
pupa]. Pertaining to a pseudopupa.

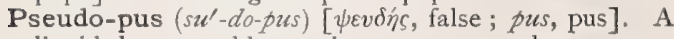
liquid that resembles pus in appearance only.

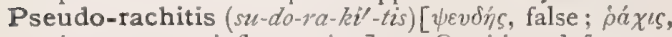
spine; $t \tau \iota$, inflammation]. Osteitis deformans (Pozzi).

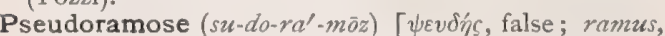
branch ]. In biology, forming false branches.

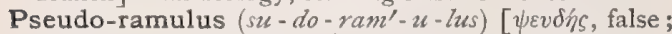
ramulus, a little branch]. In biology, a false branch. Pseudorasis (su-dor-á-sis): Synonym of Pseudopsia. Pseudorcin (su-dor'-sin). Synonym of Erythrite.
Pseudoresia, Pseudorexia $\left(s u-d o r^{n}-e^{\prime}-z e-a h\right.$, su-dor$\left.e k s^{\prime}-e-a h\right)$ [ $\psi \varepsilon v \delta \hat{\eta} \zeta$, false; $b \rho \varepsilon \xi \iota \zeta$, desire]. A perverted appetite.

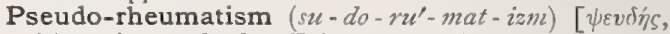
false; $\dot{\rho} \varepsilon v a, f l u x]$. False rheumatism. P., Infectious, a term given by Lapersonne to certain cases of multiple synovitis or arthritis, the prime cause of which it is impossible to discover.

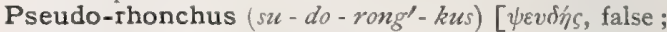
$\dot{\rho} 6 \gamma \chi 0 s$, rhonchus]. A false or spurious rhonchus; a deceptive auscultatory sound.

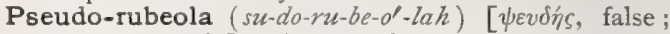
rubeola, rubeola]. An exanthematous disease simulating rubeola.

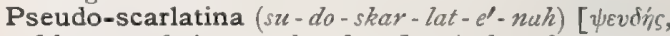
false; scarlatina, scarlet fever]. A low fever associated with a cutaneous rash like that of scarlet fever, occurring as a result of gonorrhea, or after puerperal infection.

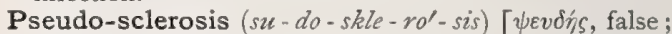
$\sigma \kappa \lambda \eta \rho \sigma \delta$, hard]. An affection similar in symptoms to multiple sclerosis of the nervous system, but without the anatomic lesions.

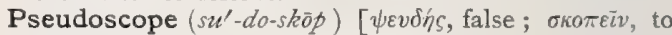
see]. An instrument consisting of a pair of rectangular prisms so arranged that the projecting portions of objects looked at appear depressed, and their deeper portions prominent.

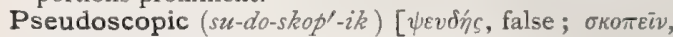
to view]. Pertaining to the pseudoscope.

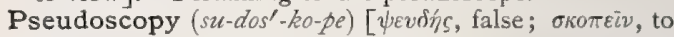
view]. The use of the pseudoscope.

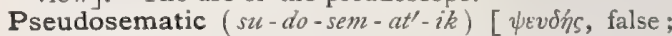
oñ $\mu \alpha$, a sign, mark, token]. In biology, false signaling, as the colors and disguises acquired by animals for purposes of deception, and generally referred to as mimicry, q.v. Cf. Pseudallosematic, Pseudaposematic, Psendepisematic.

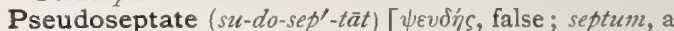
fence]. In biology, having pseudosepta. Presenting the appearance of being septate when not so.

Pseudoseptum (su-do-sep'-tum) [ $\psi \varepsilon v \delta \eta^{\prime}$, false; septum, fence: $p l .$, Pseudosepta $]$. In biology, a false septum.

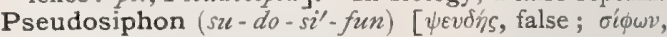
siphon]. In biology, a false siphon.

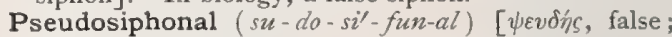

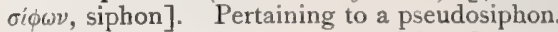

Pseudosiphuncle $\left(s u-d^{2} o-s i^{\prime}-f u n g-k l\right)$. Same as Pseudosiphon.

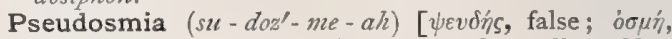
smell]. Perversion of the sense of smell; olfactory hallucinations.

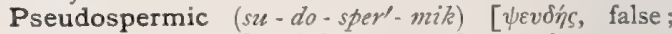
$\sigma \pi \varepsilon \rho \mu a$, seed]. Pertaining to pseudospermium.

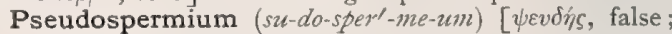
$\sigma \pi \varepsilon \rho \mu a$, seed : pl., Pseudospermia]. In biology, a term applied to such fruits as have the pericarp so closely applied to the seed that it is readily mistaken for a simple seed.

Pseudospermous (su-do-sper'-mus). Same as Pseudospermic.

Pseudosphresia (su-dos-fre'-ze-ah). Synonym of Pseudosmia.

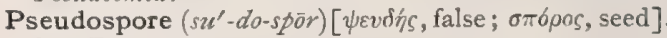
See Telentospore.

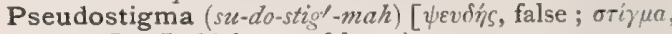
stigma]. In biology, a false stigma.

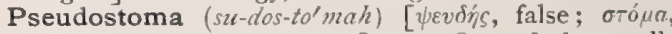
mouth: pl., Pseudostomata]. I. One of the small, deeply-stained areas in silver preparations of endothelium. They are regarded by some as minute openings filled by silver-stained albuminous substances; 
according to Klein, however, many of these stigmata are the protruding, stained processes of connectivetissue cells. 2. The oral orifice of the echinopredium of an echinoderm.

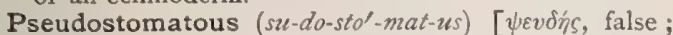
от́́ $\mu a$, mouth]. Provided with pseudostomata ; pertaining to a pseudostoma.

Pseudostome $\left(s u^{\prime}-d o-s t o m\right)$ [ $\psi \varepsilon v \delta \delta^{\prime} \zeta$, false; $\sigma \tau o ́ \mu a$, mouth]. See Pseudostoma.

Pseudostomosis $\left(s z-d o-s t o-m o^{\prime}-s i s\right)\left[\psi \varepsilon v \delta \eta^{\prime} s\right.$, false ; $\sigma \tau \delta \mu \alpha$, mouth]. The formation or existence of a pseudostome.

Pseudostomotic $\left(s u-d o-s t o-m o t^{\prime}-i k\right)[\psi \varepsilon v \delta \dot{\eta} s$, false ; oт $6 \mu a$, mouth]. Characterized by pseudostomosis.

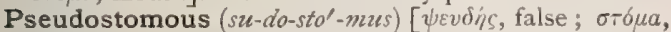
mouth]. In biology, having pseudostomes.

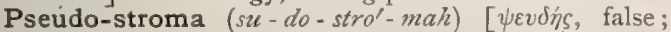

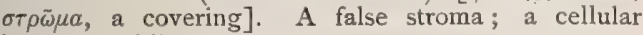
body resembling a stroma.

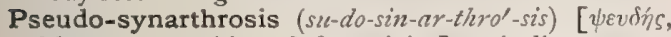
false; $\sigma v \nu$, with; $\dot{\alpha} \rho \theta \rho o \nu$, joint]. A ligamentous pseudarthrosis.

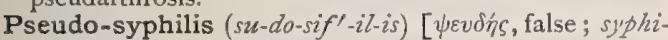
lis, syphilis]. Chancroid.

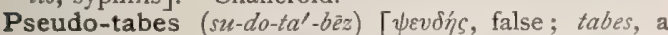
wasting]. Any disease simulating locomotor ataxia. See Polyneuritis potatorum. P.mesenterica, a functional disorder most common in young women and hysterical persons, and resembling tabes mesenterica.

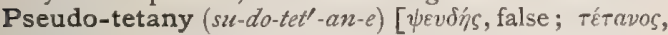
tetanus]. A disease simulating tetany.

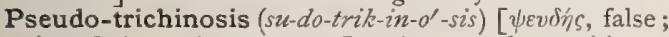
$\theta \rho \iota \xi$, hair; voбos, disease]. Acute polymyositis resembling trichinosis of the muscles.

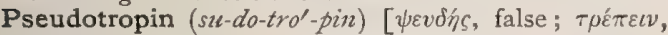
to turn], $\mathrm{C}_{8} \mathrm{H}_{15} \mathrm{NO}$. An isomeric form of tropin.

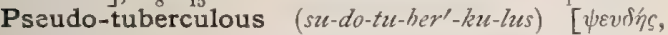
false ; tubercuhım, tubercle]. Simulating tuberculosis.

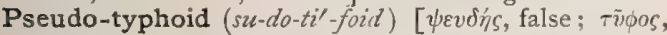
smoke]. False typhoid; simulating typhoid fever. P. Bacilli, bacteria that resemble the bacillus of enteric fever, but are not identical with it.

Pseudo-urticaria (su-do-ur-tik-a $\left.a^{\prime}-r e a h\right)$ [ $\psi \varepsilon v \delta \eta^{\prime}$, false ; urtica, nettle]. A skin-affection resembling urticaria in appearance, but not identical with it.

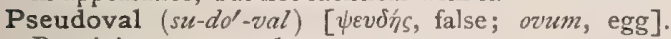
Pertaining to a pseudovum.

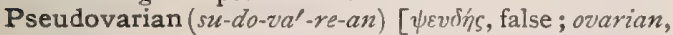
ovary]. Pertaining to a pseudovarium.

Pseudo-variola (su-do-va-ri'-o-lah). Synonym of Varicella.

Pseudovarium, Pseudovary (su-do-va'-re-um, su-do'$v a-r e)$ [ $\psi \varepsilon v \delta \eta \zeta$, , false; ovarium, ovary]. The ovary of a viviparous insect.

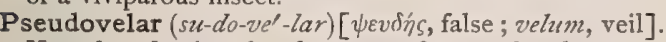
Vascular; having the character of a pseudovelum.

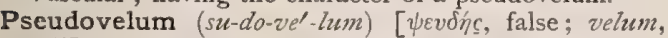
veil]. The vascular velum of some hydrozoans.

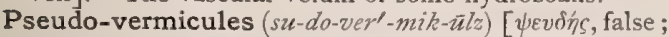
vermes, a worm]. The crescentic bodies found by Laveran in the blood of persons suffering from malarial fever. See Parasites (Animal), Table of.

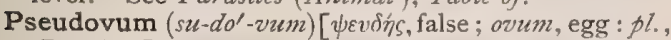
Pseudova]. An egg that develops parthenogenically.

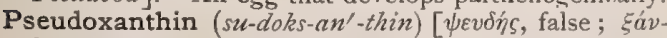
fos, yellow]. A name given, it is thought inappropriately, by Gautier to a leukomain-base, $\mathrm{C}_{4} \mathrm{H}_{5} \mathrm{~N}_{5} \mathrm{O}$, isolated from fresh muscle-tissue of beef. It so much resembles xanthin, however, that it may have been often mistaken for that compound-hence, the name given by Gautier; but it differs from xanthin in its empiric composition, solubility, and crystalline form.
The name Pseudoxanthin was also given by Schultzen and Filehne to a body isomeric with xanthin, obtained by action of sulphuric upon uric acid.

Pseudymen $\left(s u-d i^{\prime}-m e n\right)[\psi \varepsilon v \delta \dot{h} s$, false; $i \mu \dot{\eta} v$, membrane]. A false membrane.

Psiloma (si-lo'-mah) [ $\psi i \lambda o ́ s$, bare]. Baldness.

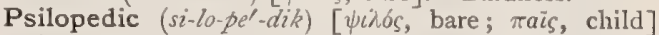
Of birds born featherless.

Psilosis $\left(s i-l 0^{\prime}-s i s\right)[\psi i \lambda \sigma s$, bare $]$. I. The removal of the hair from a part. Depilation. 2. A term for certain forms of tropical diarrhea.

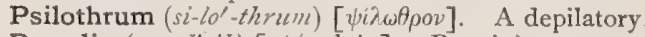

Psoadic $\left(s o-a d^{\prime \prime}-i k\right)[\psi o ́ a$, loin]. Pertaining to a psoas muscle, or to the loin.

Psoas (so'-as) [ yón, loin]. The loin. P. Abscess, an abscess, usually dependent upon tuberculous disease of the vertebra, making its way along the sheath of the psoas muscle and pointing at the front of the thigh, below Poupart's ligament, to the outer side of the spine of the pubis. See Abscess. P. magnus, P. major. See Muscles, Table of. P. minor, P. parvus. See Muscles, Table of. P. quartus. Synonym of Obturator internus.

Psoatic (so-at'-ik). Same as Psoadic.

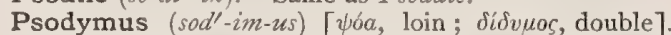
A sysomic monstrosity with two heads and thoraces, and conjoined abdominal and pelvic cavities. There are two legs, and occasionally the rudiments of a third.

Psoitis $\left(s o-i^{\prime}-t i s\right)$ [ $\psi o ́ \alpha$, loin; $\iota \tau \iota \zeta$, inflammation]. Inflammation of the psoas muscles, or of the region of the loins.

Psoloncus (so-long $-k u s)$ [ $\psi \omega \lambda \lambda$, the bared glans penis ; "̈ккоร, tumor]. Tumefaction of the prepuce and the glans penis, due to paraphimosis.

Psora (so'-rah) [ $\psi \omega \rho \alpha ; \psi \sigma \varepsilon \varepsilon \nu$, to scratch]. Scabies. See also Psoriasis.

Psoralin (so-ral'-in). Synonym of Caffein.

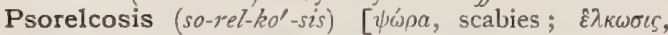
ulceration]. Ulceration occurring during the progress of scabies.

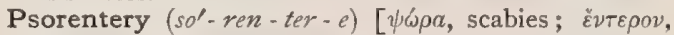
intestine]. Asiatic cholera.

Psoriasis (so-ri'-as-is) [ $\psi \omega \omega \rho$, the itch]. Lepra alphos; Lepra; Dry Tetter; Psora; a common chronic inflammatory disease of the skin, characterized by variously-sized lesions having red bases, covered with white scales resembling mother-of-pearl. It affects by preference the extensor surfaces of the body. The lesions are infiltrated, elevated, clearly defined, cove ered with white, shining, easily-detachable scales, which upon removal reveal a red, punctate, bleeding surface. The eruption is absolutely dry, and itching is usually absent. The etiology is obscure, though heredity plays a considerable rôle in its production. $P$. annularis. Synonym of $P$. circinata. P., Buccal, P. buccalis. Synonym of Leukoplakiabuccalis. See also $P$., Lingual. P. centrifuga, psoriasis in which the patches heal in the center while spreading at the periphery. $\mathbf{P}$. circinata, psoriasis in which the central part of the lesions has disappeared, leaving ringshaped patches. P. diffusa, a form in which there is coalescence of large contiguous lesions, P. discoidea. Same as $P$. nummularis. P., Eczematous, an acute form with bright-red patches, less defined at the margin than usual, with thin and papery scales, which are thrown off so rapidly that they have no time to aggregate into masses. The part is hot and tender, itches severely, and very little irritation will produce discharge. P. empyodes, a form in which a little pus forms underneath the crusts; a rare event. P. figurata, P. geographica, psoriasis in which the patches are arranged in irregular patterns. P. gut- 
tata. See $P$. punctata. P. gyrata, psoriasis with a serpentine arrangement of the patches. P. inveterata, a very obstinate form in which the skin is much thickened and fissured, with large adherent scales. P. nigra, a variety of psoriasis in which deep pigmentation has taken place. P. nummularis, P. nummulata, psoriasis in which the patches develop in the shape and size of coins. P. ophthalmica, squamous eczema of the eyelids. P. orbicularis. Synonym of $P$. circinata. P. palmæ, a dry eczema of the hands, or a squamous syphiloderm. P. palmaris et plantaris syphilitica, a squamous syphiloderm of the palms and soles. P. pilaris, a form affecting the region of the hair-follicles. P. punctata, a form in which the lesion consists of minute red papules which rapidly become surmounted by pearly scales. These spread peripherally and soon resemble drops of mortar ( $P$. guttata); when they attain the size of a coin the name $P$. nummularis is applied to them. By coalescence of these, larger patches are produced $(P$. diffusa), the outline of which is festooned and convex outward. Healing begins in the center of the patches, causing a ringed appearance ( $P$. circinata), composite patches thus assuming serpiginous outlines $(P$. gyrata $)$. $\mathrm{P}$. rubra, an acute form of psoriasis. P. rupioides, a form in which the scales are excessive in quantity and piled up like the shell of a limpet. P. simplex:(I) the usual form of psoriasis; (2) synonym of Eczema. P. striata, psoriasis in which the lesions are disposed in striæ or lines. P., Syphilitic. See Syphiloderma papulo-squamosum. $\mathrm{P}$. unguium, psoriasis of the nails, which become brittle, rough, ridged, and their ends broken off. P. universalis, a form in which the lesions are all over the body.

Psoriatic $\left(s o-r e-a t^{\prime}-i k\right)[\psi \omega \rho a$, itch]. I. Pertaining to psoriasis. 2. One affected with psoriasis.

Psoric $\left(s o^{\prime}-r i k\right)[\psi \omega \rho a$, itch]. Pertaining to or affected with psora.

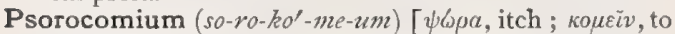
take care of]. A hospital for patients affected with the itch.

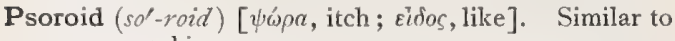
psora or scabies.

Psorophthalmia (so-roff-thal'-me-ah) $[\psi \omega \rho \alpha$, itch; $\dot{\phi} \phi \theta-$ $a \lambda \mu o ́ s$, eye]. Marginal blepharitis.

Psorophthalmic (so-roff-thal'-mik) [ $\psi \omega \omega \rho$, itch ; $b \phi \theta$ $a \lambda \mu \delta s$, eye]. Pertaining to psorophthalmia.

Psororheumatismus (so-ro-rut-mat-iz'-mus) [ $\psi \omega \dot{\omega} \rho a$, itch : $\rho \varepsilon v \mu a \tau \iota \sigma \mu o s$, rheumatism]. Rheumatism ascribed to scabies.

Psorosperm (so'-ro-sperm) [ $\psi \omega \rho a$, the itch; $\sigma \pi \varepsilon \rho \mu a$, seed]. In biology, one of the Psorospermic, the name originally created by Muiller to designate the sporozoa of Fishes, but later applied to such a variety of low forms of animal life as to have lost its specific value, and now having but the general, vague significance of any or all sporozoa. Coccidia, Myxosporidia, Sarcosporidia, Microsporidia, q. v. P. Nodules. See Coccidium aiforme in Parasites (Animal), Table of. P. Saccules. See Sarcocystis miescheri, under Parasites (Animal), Table of.

Psorospermial, Psorospermic (so-ro-sper-me-al, so-ro-sper'-mik) [ $\psi \omega \rho a$, itch; $\sigma \pi \varepsilon \rho \mu \alpha$, seed]. Pertaining to or of the nature of psorosperms.

Psorospermiasis (so-ro-sper-mi'-as-is) [ $\psi \omega \rho a$, itch ; $\sigma \pi \varepsilon ́ p \mu \alpha$, seed]. A term embracing several parasitic affections produced by psorosperms.

Psorospermosis (so-ro-sper-mo'-sis) [ $\psi \omega \rho a$, itch ; $\sigma \pi \varepsilon \rho \mu a$ seed: pl., Psorospermoses $]$. A diseased condition associated with the presence of psorosperms. P., Proliferative Follicular. Synonym of Keratosis follicularis and Darier's Disease.

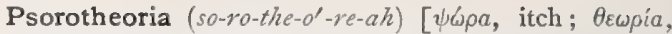
theory]. Hahnemann's theory that many diseases were due to the driving in ward of scabies.

Psorous $\left(s o^{\prime}-r u s\right)[\psi \omega \rho \alpha$, itch $]$. Pertaining to or affected with the itch.

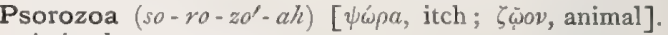
Animal psorosperms.

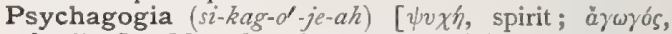
leading]. Mental excitement or activity.

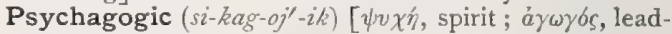
ing]. I. Restorative of the consciousness. 2. A remedy that restores to consciousness, as in fainting.

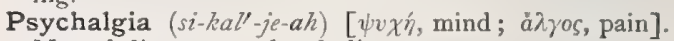
Mental distress; melancholia.

Psyche $\left(s i^{\prime}-k e\right)[\psi v \chi \eta$, soul]. The brain and myelon considered as one organ; the cerebro-spinal axis.

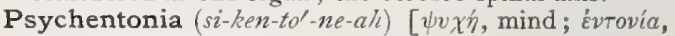
tension]. Mental strain or over-work.

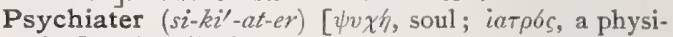
cian]. An alienist; one who cures mind-diseases.

Psychiatria (si-ki-a'-tre-ah). Same as Psychiatry.

Psychiatric $\left(s i-k e-a t^{\prime}-r i k\right)[\psi v \chi \dot{\eta}$, mind; ¿atpeía, healing art]. Pertaining to pschiatry.

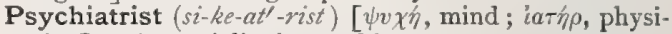
cian]. A specialist in psychiatry.

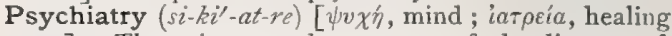
art]. The science and treatment of the diseases of the mind.

Psychic, or Psychical $\left(s^{\prime}-k i k, s i^{\prime}-k i k-a l\right)[\psi v \chi \dot{\eta}$, mind $]$. Pertaining to the mind. P. Blindness. See Wordblindness. P. Centers. Nerve-centers connected with sensation in the sense of conscious perception, feeling, volition, intellectual acts, and will.

Psychics $\left(s i^{\prime}-k i k s\right)\left[\psi v \chi^{\prime}\right.$, soul]. The science of psychology.

Psychism (si'-kizm) [ $\psi v \chi h$, soul]. The character of being psychic, or mental.

Psychist $\left(s i^{\prime}-k i s t\right)\left[\psi v \chi^{\prime}\right.$, soul]. One who engages in psychic research.

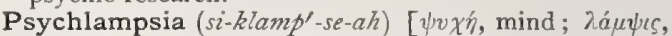
a flashing]. Mania, viewed as a discharging phenomenon of perverted cerebral activity.

Psycho-auditory $\left(s i-k o-a w^{\prime}-d i t-o r-e\right)[\psi v \chi \dot{\eta}$, mind ; audire, to hear]. Pertaining to the psychic perception of sound. P. Area, the cortical area concerned in the conscious perception of sound.

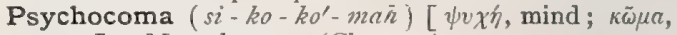
coma]. Mental stupor (Clouston).

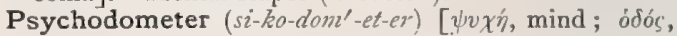
way ; $\mu \varepsilon$ t ing the rapidity of psychic processes.

Psychodynamic $\left(s i-k o-d i-n a n^{\prime}-i k\right)[\psi v \chi \eta$, soul; divvaus, power]. Pertaining to psychodynamics.

Psychodynamics (si-ko-di-nam'-iks) [ $\psi v \chi \dot{\eta}$, mind; Sivaus, power]. The science of the laws of mental activity.

Psychodynamy (si-ko-di'-nam-e). Synonym of Magnetism, Animal.

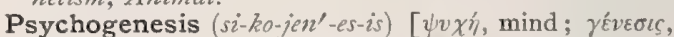
generation]. The development of mental characteristics.

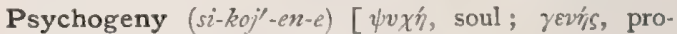
ducing]. The development of mind.

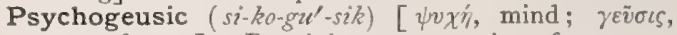
sense of taste]. Pertaining to perception of taste.

Psychogony (si-kog'-o-ne) [ $\psi v \chi h$, soul; rovia, generation]. The doctrine of the development of mind.

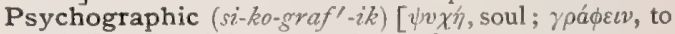
write]. Pertaining to psychography.

Psychography $\left(s i-k o g^{\prime}-r a-f e\right)\left[\psi x^{\prime} x^{\prime}\right.$, soul; $\gamma \rho a \phi \varepsilon v$, to write]. The natural history of mind. 


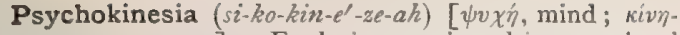

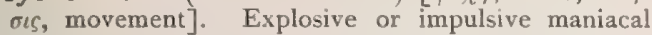
action, due to defective inhibition; psychlampsia.

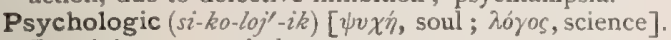
Pertaining to psychology.

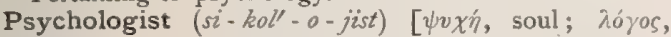
science]. One versed in psychology.

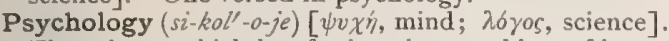
The science which has for its primary subject of investigation all the phenomena of human consciousness, or of the sentient life of man (Ladd).

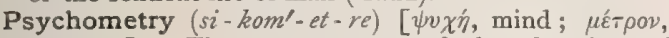
measure]. The measurement of the duration of psychic processes; measurement of sense-relations in mental action. P., Physiologic, psychology studied from a physiologic standpoint. There is a growing tendency on the part of scientists to study the phenomena of the mind from the physical and physiologic side. Important results have been achieved by the aid of psycho-physics, and a number of psychic phenomena can now be defined in mathematic terms. P., Transcendental, psychic processes which are believed not to be dependent on cerebral function.

Psycho-motor (si-ko-mo'-tor) [ $\psi v \chi \dot{\eta}$, mind; movere, to move]. Pertaining to the mind and to voluntary movement. P. Area, the motor area of the brain; disposed chiefly at the sides of the central (Rolandic) fissure.

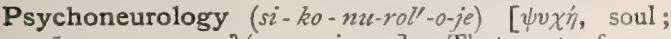
$\nu \varepsilon \bar{v} \rho o v$, nerve; $\lambda \dot{6}$ yos, science]. That part of neurology treating of mental action.

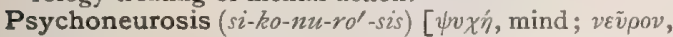
nerve; vó́os, disease]. Mental disease, especially such as is not accompanied by or dependent on any demonstrable bodily disorder.

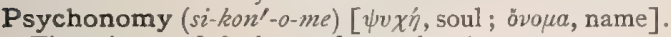
The science of the laws of mental action.

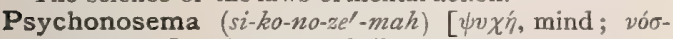
$\mu \eta \nu$, disease]. Any mental disease.

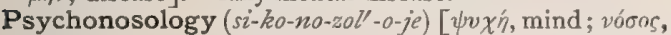

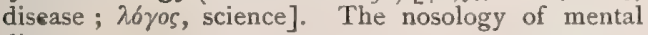
diseases.

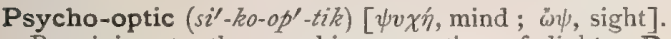
Pertaining to the psychic perception of light. $\mathbf{P}$. Area, the cortical area concerned in conscious perception of retinal impulses.

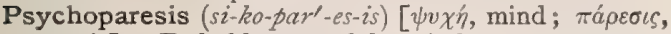
paresis]. Enfeeblement of the mind.

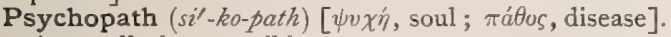
A morally irresponsible person.

Psychopathic $\left(s i-k o-p a t h^{\prime}-i k\right)$ [ $\left[\psi v \chi^{\prime} \eta\right.$, mind; $\pi a ́ \theta 0 \varsigma$, disease]. Pertaining to psychopathy.

Psychopathist (si-kop'-ath-ist). Synonym of Psychiatrist.

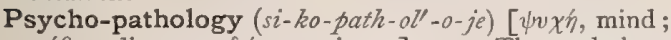

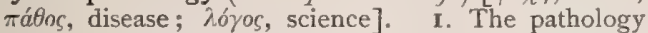
of mental disease. 2. In legal medicine, the legal aspect of insanity; the law as to the rights and responsibilities of insane persons; legal psychiatry, incorrectly called criminal anthropology.

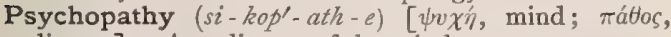
disease]. Any disease of the mind.

Psycho-physical (si-ko-fiz'-ik-al) [ $\psi v \chi^{\prime} \dot{n}$, mind; $\phi v \sigma l-$ $\kappa \delta \varsigma$, physical]. Pertaining to pyscho-physics. P. Law. See Lare, Fechner's.

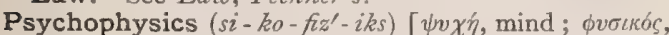
physical]. The study of mental processes by physical methods; the study of the relation of stimuli to the sensations which they produce, especially the determination of the differences of stimulus required to produce recognizable differences of sensation; experimental psychology.

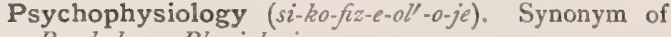
Psychology, Physiologic.

Psychoplasm (si'-ko-plazm) [ $\psi v \chi \eta \dot{n}$, soul, mind; $\pi \lambda a ́ \sigma$. $\mu a$, anything formed]. In biology: "The sentient material out of which all forms of consciousness are evolved, incessantly fluctuating, incessantly renewed." (Lewes.) See Protyl.

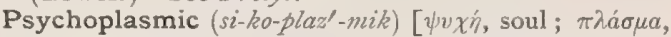
anything formed]. Pertaining to pyschoplasm.

Psychorrhythm (si'-ko-rithm) [ $\psi v \chi \dot{\eta}$, mind; $\rho v \theta \mu o ́ s$, rhythm]. Any cyclic or alternating mental condition.

Psycho-sensory, Psycho-sensorial (si-ko-sen'-sor-e,

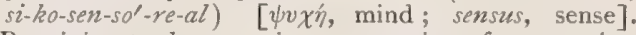
Pertaining to the conscious perception of sensory impulses. P. Area, an area in the brain-cortex connected with the perception of sensory impulses, particularly those of special sense.

Psychosin $\left(s i-k o^{\prime}-\sin \right)[\psi v \chi \eta \dot{\eta}$, mind $]$. A cerebrosid resembling sphingosin, occurring in brain-tissue.

Psychosis (si-ko'-sis) [ $\psi v \chi \dot{\eta}$, mind: pl., Psychoses]. I. Any disease of the mind. 2. The neural act corresponding to a mental phenomenon. "In all intellectual operations we have to distinguish two sets of successive changes-one in the physical basis of consciousness and the other in consciousness itself; one set which may, and doubtless will, in course of time, be followed through all its complexities by the anatomist and the physicist, and one of which only the man can have immediate knowledge. As it is very necessary to keep up a clear distinction between these two processes, let the one be called neurosis, q. $v$, and the other psychosis." (Huxley.)

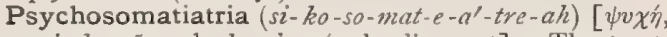
mind; $\sigma \tilde{\omega} \mu \alpha$, body; iatpia, healing art]. The treatment of diseases of the mind and body.

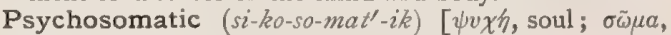
body]. Relating to both soul and body.

Psychotherapeutic (si-ko-ther-ap-u'-tik) [ $\psi v \chi^{\prime} \eta^{\prime}$, soul ; $\theta \varepsilon \rho a \pi \varepsilon v \tau \iota \kappa \delta s$, pertaining to medical treatment]. Pertaining to psychotherapeutics.

Psychotherapeutics (si-ko-ther-ap-u'-tiks) [ $\psi v \times \hat{n}$, mind; $\theta \varepsilon \rho a \pi \varepsilon i a$, treatment]. The treatment of disease by mental influence, or by suggestion.

Psychotherapy $\left(s i-k o-t h e r^{\prime}-a p-e\right)$. Same as Psychotherapeutics.

Psychovital (si-ko-vi'-tal) [ $\psi v \chi \eta$, soul; vita, life]. Psychic and vital.

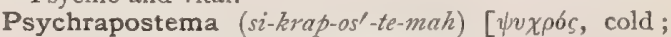
$\dot{a} \pi \hat{\sigma} \sigma \tau \eta \mu \alpha$, abscess]. Cold abscess.

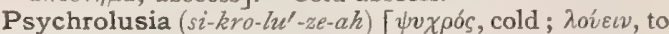
wash]. Cold bathing.

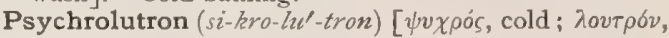
bath]. Cold bath.

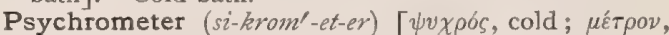
measure]. An instrument for determining the amount of atmospheric moisture by precipitation on a cold surface.

Psychrometric (si-kro-met'-rik) [ $\psi v \chi \rho o ́ s$, cold; $\mu \varepsilon ́ \tau \rho o \nu$, measure]. Pertaining to a psychrometer.

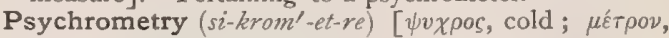
measure]. The use of the psychrometer.

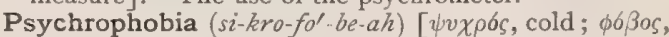
dread]. Morbid dread of or impressibility to cold.

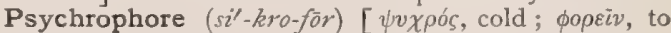
carry]. An instrument for applying cold to parts deeply placed, as by a double-current catheter to the prostate gland.

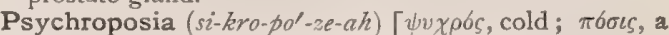
drinking]. The drinking of cold beverages.

Psydracia (si-dra'-se-ah) [ $\psi v \delta p a c$, blister, pimple : $p l$., Psydracice]. I. Eczema (Fuchs). 2. In Plenck's classification, a variety of skin-diseases characterized 
by red, elevated spots. P. spontaneæ, a form of large-whealed urticaria usually affecting covered parts. P. vulgaris. Synonym of Eczema simplex.

Psydracium (si-dra'-se-um) [ $\psi \dot{v} \delta \rho a \xi$, a blister or pimple:plo, Psydracia]. A small pustule.

Psygma (sig'-mah) [ $\left.\bar{v}^{\prime} \gamma \mu a\right]$. A refrigerant medicine.

Ptarmic (tar'-mik) [ $\pi \tau a \rho \mu o ́ s, a$ sneezing]. Pertaining to the act of sneezing. Sternutatory. Also, a substance that produces sneezing

Ptelea $\left(t e^{\prime}-l e-a h\right)[\pi \tau \varepsilon \lambda \dot{n} a, e I m]$. A genus of polypetalous shrubs and trees. P. trifoliata, Hop-tree; Wafer-ash; Wing-seed. The bark of a shrub yielding a bitter tonic extractive. It is a popular tonic in debility and dyspepsia, and is also used as an anthelmintic. Unof.

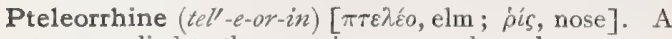
term applied to the anterior nares when the aperture is asymmetric.

Ptenopleural (ten-o-plu'-ral) [ $\pi \tau \eta v o ́ s$, feathered; $\pi \lambda \varepsilon v \rho a$, side]. In biology, having the sides of the body winged or alate.

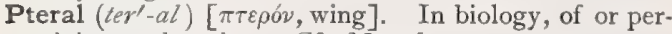
taining to the wing. Cf. Manal.

Ptere (têr) [ $\pi \tau \varepsilon \rho o ́ n$, feather, wing]. In biology, a wing-like structure.

Pteridium (ter-id'-e-um) [ $\pi \tau \varepsilon \rho b v$, wing]. See Samara.

Pterion (te'-re-on) [ $\pi \tau \varepsilon \rho \delta o v$, wing]. See Craniometric Points.

Pterna $\left(t e r^{\prime}-n a h\right)[\pi \tau \varepsilon \rho v a]$. I. Calcaneum. 2. The heel-pad of birds.

Ptero- $\left(t e \gamma^{\prime}-o\right)$ [ $\pi \tau \varepsilon \rho \delta v$, wing]. A prefix to denote resemblance to a wing, or wing-shaped.

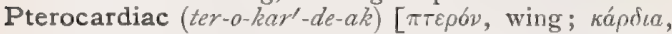
the heart]. In biology, applied by Huxley to a winglike ossicle that articulates with the cardiac ossicle in the stomach of the crawfish.

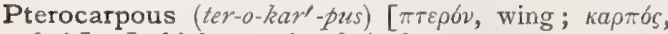
fruit]. In biology, wing-fruited.

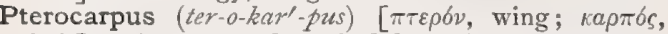
fruit]. A genus of tropical leguminous trees. P. draco, of tropical America, affords some of the dragon's blood of commerce. P. erinaceus, of Africa, and P. marsupium, of India, yield kino. P. santalinus, affords red saunders.

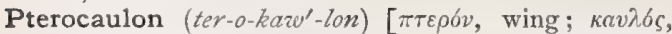
stem]. A genus of the Inuloidea. P. pycnostachyum, black-root, a species found in Georgia, where it is used as a tonic, emmenagogue, and alterative.

Pterodium (ter-o'-de-um). Same as Pteridium.

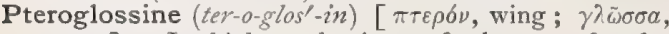
tongue]. In biology, having a feathery or brushy tongue.

Pterologic (ter-o-loj'-ik) [ $\pi \tau \varepsilon \rho o ́ v$, wing ; $\lambda 6 \gamma o s$, science $]$. Pertaining to pterology.

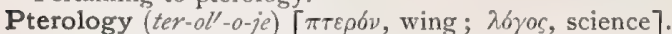
In biology, that department of entomology or ornithology which treats of the wings.

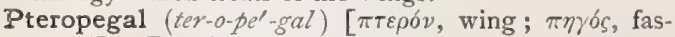
tened]. Pertaining to a pteropegum.

Pteropegum (ter-o-pe'-gum) [ $\pi \tau \varepsilon \rho b v$, feather, wing; $\pi \eta \gamma$ ós, fastened: pl., Pteropega ]. In biology, the articular socket or surface on the thorax of an insect for the reception of the base of the wing.

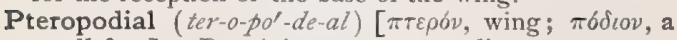
small foot]. Pertaining to a pteropodium.

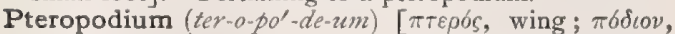
a small foot]. The podium of a pteropod.

Pterorhine (terl-o-rin) [ $\pi \tau \varepsilon \rho o ́ v$, wing; ṕis, nose $]$. In biology, having feathered nostrils.

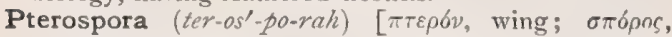
seed]. A genus of plants belonging to the order Monotropece. P. andromeda, scaly dragon-claw, dragon-root, fever-root, a plant found in New York, Vermont, and Canada, and having anthelmintic, diaphoretic, and emmenagogue properties

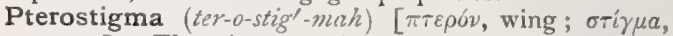
a spot]. The stigma on the wings of some insects.

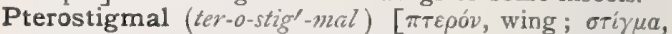
stigma]. Pertaining to a pterostigma.

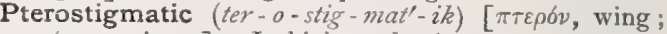

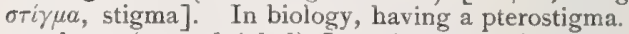

Pterotheca (ter-o-the'-kah) [ $\pi \tau \varepsilon \rho \delta v$, wing ; $\theta y_{i} \kappa \eta$, case : pl., Pterothece $]$. In biology, that part of the pupa-case which covers the developing wings.

Pterotic $\left(t e r-o t^{\prime}-i k\right)[\pi \tau \varepsilon \rho o ́ v$, wing $]$. Wing-like.

Pterygial (ter-ij'-e-al) [dim. of $\pi \tau \varepsilon \rho v \xi$, wing]. Pertaining to a pterygium.

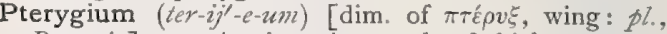
Pterygia]. I. A triangular patch of thickened conjunctiva, the apex pointing toward the pupil, the fan-shaped base extending toward the canthus. It is most common on the nasal side. 2. One of the alre

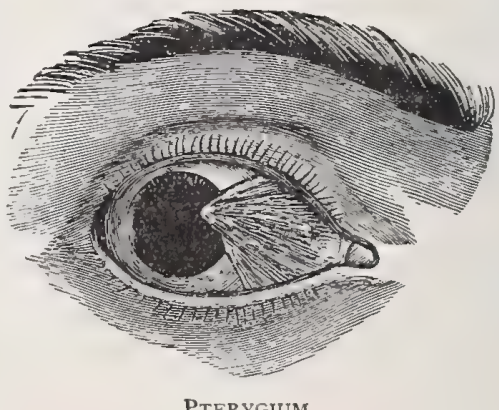

nasi. 3. In biology, the generalized vertebrate limb. Cf. Archipterysium, Icthyopterygium, Cheiropterygium, Mesopterygium, Metapterygium, Propierygium. P. carnosum, a flesh-like vascular pterygium. P. crassum. Synonym of $P$. carnosum. P. membranaceum, a thin, membrane-like pterygium. P. sarcomatosum. Synonym of $P$. carnosum. $\mathbf{P}$. tenue. Synonym of $P$. membranaceum. P. unguis, an abnormal growth of skin over the finger-nail. P. vasculosum. Synonym of $P$. carnosum.

Pterygo- $\left(t e \gamma^{\prime}-i g_{-0}\right)$ [ $[\pi \tau \hat{f} \rho v \xi$, wing $]$. A prefix denoting connection with or relation to the pterygoid process.

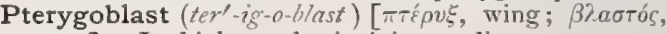
germ]. In biology, the incipient rudiment or proton of the fin-ray.

Pterygobranchiate (ter $\left.-i g-o-b r a n g^{\prime}-k e-a \bar{t}\right)$ [ $\pi \tau \dot{\varepsilon} \rho n \xi$, wing; $\beta \rho a ́ \gamma \chi \iota a$, gills]. In biology, having feathery gills.

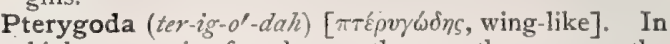
biology, a pair of scales on the mesothorax, near the insertion of the first legs, in Lepidoptera. Cf. Tegula.

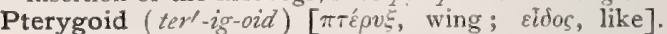
Wing-shaped. P. Artery. See Arteries, Table of. P. Canal, the Vidian canal. P. Fossa. See Fossa. P. Muscle. See Muscle. P. Notch. Same as $P$. Fossa. P. Plate, one of the two plates of a pterygoid process, $q . v$. P. Plexus. See Plexus. P. Process. See Process, Pterygoid.

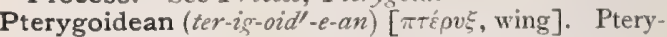
goid. P. Plaques, the characteristic sores seen on the hard palate in children affected with Bednar's aphthæ.

Pterygoma (ter-ig-o'-mah) [ $\pi \tau \hat{\varepsilon} \rho v \xi$, wing; ö $\mu a$, tumor]. A chronic swelling of the labia minora which interferes with coitus (Severin). 


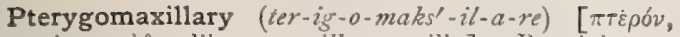
wing; Eidos, like; maxilla, maxilla]. Pertaining to a pterygoid process and the maxilla. P. Fissure, an elongated fissure formed by the divergence of the superior maxillary bone from the pterygoid process of the sphenoid. It gives passage to branches of the internal maxillary artery. P. Ligament, a ligamentous branch extending from the apex of the internal pterygoid plate to the posterior end of the internal oblique line of the lower jaw.

Pterygopalatal, Pterygopalatine (ter-ig-o-pal'-at-al, ter-io-o-pal'-at-in). See Palatopterygoid. P. Artery. See Arteries, Table of. P. Canal, a canal formed by the articulation of the pterygoid process of the sphenoid bone, with the sphenoid process of the palate bone and transmitting the pterygo-palatine vessels and nerves. P. Nerve, a small nerve arising from the back part of Meckel's ganglion and passing through the pterygo-palatine canal to the mucous membrane of the upper part of the pharynx, behind the Eustachian tube. Also known as the pharyngealnerve.

Pterygo-pharyngeus (ter-ig-o-far-in-je'-us) [ $\pi \tau \varepsilon \rho o ́ v$,

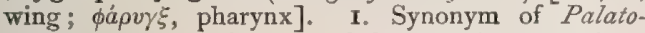
pharyngezes. 2. The part of the superior constrictor of the pharynx which arises from the internal pterygoid plate.

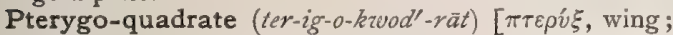
quadratus, quadrate]. Pertaining to the pterygoid bone and to the quadrate bone.

Pterygosphenoid (ter-ig-o-sfe'-noill). See Sphenopterygoid.

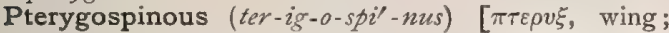
spinosus, spinous]. Pertaining to a pterygoid process and to the spine of the sphenoid.

Pterygo-staphylinus (ter-ig-o-staf-it-i'-nus) [ $\pi \tau \dot{t} \rho v \xi$,

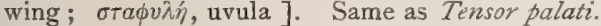

Pterygostium (ter-ig-os'-te-um) [ $\pi \tau \varepsilon \rho u ́ \xi$, wing ; ostium, mouth]. One of the veins of an insect's wing.

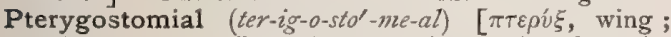
$\sigma \tau o ́ \mu a$, mouth ]. In biology, applied to the plate-like extensions of the carapace running forward parallel with the axis of the body in certain crustaceans.

Pterygo-syndesmo-staphylo-pharyngeus (ter'-ig-osin-dez'-mo-staf'-il-o-far-in-je'-us). Synonym of Constrictor, Superior, of the Pharynx.

Pterygote $\left(t e \gamma^{\prime}-i g-\bar{o} t\right)$ [ $\pi \tau \varepsilon \rho v \gamma \omega \tau$ ós, winged]. Winged, alate.

Pterygo-temporal (ter-ig-o-tem'-po-ral) [ $\pi \tau \varepsilon \rho v \xi$, wing ; tempus, temple]. Pertaining to the pterygoid process and to the temporal bone.

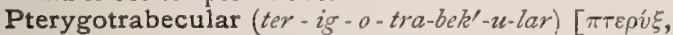
wing; trabecula]. Pertaining to the pterygoid bone and the trabecular region of the skull.

Pteryla (ter'-il-ah) [ $\pi \tau \varepsilon \rho o ́ v$, feather, wing; $v \lambda \eta$, wood: pl., Pteryla]. In biology, a "feather tract," an area of the skin on which feathers grow, as distinguished from apteria, or tracts on which no feathers grow.

Pterylographic (ter-il-o-graf'-ik) $[\pi \tau \varepsilon \rho b v$, feather; $\gamma \rho a ́ \phi \varepsilon \iota v$, to write]. Pertaining to pterylography.

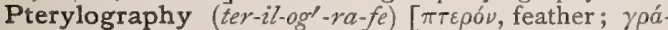
$\phi \varepsilon \imath v$, to write]. In biology, the written description of the arrangement of the feathers in the skin of birds.

Pterylosis (ter-il-o'-sis) [pteryla, from $\pi \tau \varepsilon \rho b \nu$, wing, feather; $i \lambda \eta$, wood]. In biology, the arrangement or distribution of the feathers of a bird, as distinguished from the character of the plumage, ptilosis.

Ptiloma $\left(t i-l o^{\prime}-m a h\right)$ [ $\pi \tau i \lambda o v$, down]. The part of the eyelid deprived of its cilia by ptilosis.

Ptilosis $\left(t i-l o^{\prime}-s i s\right)$ [ $\pi \tau i$ inov, feather $]$. In biology, the plumage or feathering of a bird regarded as to character rather than as to the distribution of the feathers, for which see pterylosis. See also Madarosis.
Ptisan (tiz'-an) [ $\pi r\llcorner\sigma a ́ \nu \eta$, peeled barley]. Barleywater. Any decoction of barley designed as a medicinal drink.

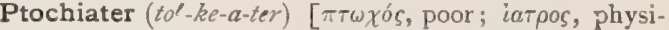
cian]. A physician who attends the poor.

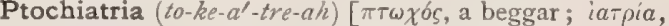
healing art]. Medical treatment of the poor.

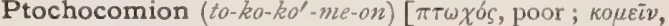
to take care of]. A hospital for the care of the poor. Ptoma $\left(t o^{\prime}-m a h\right)[\pi \tau \tilde{\omega} \mu a]$. Cadaver.

Ptomain $\left(t o^{\prime}-m a-i n\right)[\pi \tau \tilde{\omega} \mu a$, corpse $]$. Any one of the active, inanimate septic or toxic substances resulting from processes of decomposition and disintegration of albuminous materials. (Farquharson.) As ptomains are chiefly developed during putrefaction, they have been termed putrefactive alkaloids. The name cadaveric alkaloids has also been given to them, but applies properly only to those obtained from the dead animal body. Some of the ptomains are poisonous; the greater number are not. As a rule, each distinctive ptomain is produced by a different microörganism, but there are instances of several bacteria producing the same ptomain. The dependence of a ptomain upon microörganisms may be indirect and complicated by or dependent upon purely chemic changes. The kind of ptomain produced depends somewhat upon the stage of putrefaction, as ptomains are "transition products in the process of putrefaction." Their production is also influenced by the media in which the bac. teria grow. A ptomain that is formed by a certain bacterium in one medium may not be produced by the same bacterium in another medium. Ptomains have been found in foods, as in mussels, oysters, eels, sausage, ham. canned meats, cheese, milk, ice-cream, etc. The pathogenic action of certain bacteria may be due to their production of ptomains. In addition to the ptomains given in the following table, a number of unnamed substances have been studied that possess reactions and physiologic effects similar or identical with those of well-known vegetable alkaloids. These at present can only be called after analogues, e.g., Coniïnlike Substances; others are called Atropin-like, Delphinin-like, Digitalin-like, Morphin-like, Nicotin-like, Strychnin-like, Veratrin-like, etc. The table beginning on page 12 Io is modified from Vaughan and Novy.

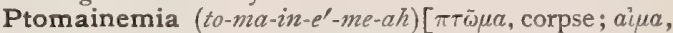
blood]. The presence of ptomains in the blood.

Ptomainic $\left(t^{\prime}-m \alpha-i n-i k\right)$ [ $\pi \tau \tilde{\omega} \mu \alpha$, corpse]. Due to or associated with a ptomain.

Ptomapeptone $\left(t^{\prime}-m a h-p e p^{\prime}-t o n\right)[\pi \tau \tilde{\omega} \mu \alpha$, a corpse; peptone, from $\pi \varepsilon \tau \tau \varepsilon \varepsilon \nu$, to cook, digest]. In biology, one of the putrefactive alkaloids produced in cereals by the action of ergot, molds, etc.

Ptomatin (to'-mat-in). Synonym of Ptomain.

Ptomatopsia (to-mat-op'-se-ah) $[\pi \tau \tilde{\omega} \mu c$, corpse ; ö $\psi(s$, view]. The examination of the cadaver; necropsy.

Ptomatropin (to-mat'-ro-pin). A ptomain resembling the vegetable alkaloid atropin in its physiologic properties. That isolated by Zuelzer and Sonnenschein did not give the odor of blossoms when heated with sulphuric acid and oxidizing agents (Reuss's test), but a ptomatropin found by Selmi gave the reaction.

Ptosis $\left(t o^{\prime}-s i s\right)[\pi \tau \tilde{\omega} \sigma \iota s, \pi i \pi \tau \varepsilon \iota \nu$, to fall]. Complete or partial drooping of the upper eyelid, due to paralysis of the levator palpebræ or to thickening of the lid. P. iridis, hernia of the iris. P. oculi. Synonym of Exophthalmos. P. palpebræ, P. palpebrarum. See Ptosis, P. sympathica, ptosis in connection with paresis of the cervical sympathetic and associated with myosis and vaso-motor paralysis of the side of the face affected. 


\section{TABLE OF PTOMAINS.}

\begin{tabular}{|c|c|c|c|c|}
\hline NAME. & FORMULA. & DISCOVERER. & SOURCE. & $\begin{array}{l}\text { Physiologic } \\
\text { Action. }\end{array}$ \\
\hline Amido-valerianic acid. & $\mathrm{C}_{5} \mathrm{H}_{31} \mathrm{NO}_{2}$ & $\begin{array}{l}\text { E. and H. Salkow- } \\
\text { ski. }\end{array}$ & Putrefying fibrin and meat. & Non-toxic. \\
\hline Amylamin. & $\mathrm{C}_{5} \mathrm{H}_{13} \mathrm{~N}$ & Hesse. & Cod-liver oil, horn, putrid yeast. & Toxic. \\
\hline Asellin. & $\mathrm{C}_{25} \mathrm{H}_{32} \mathrm{~N}_{4}$ & $\begin{array}{l}\text { Gautier and Mour- } \\
\text { gues. }\end{array}$ & Cod-liver oil. & Toxic. \\
\hline Betain. & $\mathrm{C}_{5} \mathrm{H}_{13} \mathrm{NO}_{3}$ & Brieger. & Mussel, human urine. & Non-toxic. \\
\hline Butylamin. & $\mathrm{C}_{4} \mathrm{H}_{11} \mathrm{~N}$ & $\begin{array}{l}\text { Gautier and Mour- } \\
\text { gues. }\end{array}$ & Cod-liver oil. & Toxic (?). \\
\hline Cadaverin. & $\mathrm{C}_{5} \mathrm{H}_{14} \mathrm{~N}_{2}$ & Brieger. & $\begin{array}{l}\text { Putrefying animal tissues, cultures } \\
\text { of comma-bacillus. }\end{array}$ & Slightly toxic. \\
\hline Caproylamin. & See Hexylamin. & & $\cdot$ & \\
\hline Cholin. & $\mathrm{C}_{5} \mathrm{H}_{15} \mathrm{NO}_{2}$ & Brieger. & $\begin{array}{l}\text { Decomposing animal tissues, proteus } \\
\text { and comma-bacillus cultures. }\end{array}$ & Toxic. \\
\hline Collidin (?). & $\mathrm{C}_{8} \mathrm{H}_{11} \mathrm{~N}$. & Nencki. & $\begin{array}{l}\text { Putrid mixture of pancreas and gela- } \\
\text { tin. }\end{array}$ & \\
\hline Diethylamin. & $\mathrm{C}_{4} \mathrm{H}_{11} \mathrm{~N}$ & Bocklisch. & Putrefying fish (pike). & Non-toxic. \\
\hline Dihydrolutidin. & $\mathrm{C}_{7} \mathrm{H}_{11} \mathrm{~N}$ & $\begin{array}{l}\text { Gautier and Mour- } \\
\text { gues. }\end{array}$ & Cod-liver oil. & Toxic. \\
\hline Dimethylamin. & $\mathrm{C}_{2} \mathrm{H}_{7} \mathrm{~N}$ & Brieger. & Putrid gelatin, yeast, fish. & Non-toxic. \\
\hline Eczemin. & & Griffith. & $\begin{array}{l}\text { Extracted from the urine in eczema. A } \\
\text { white, crystalline substance, soluble } \\
\text { in water, feebly alkaline in reaction. }\end{array}$ & Toxic. \\
\hline Ethylamin. & $\mathrm{C}_{2} \mathrm{H}_{7} \mathrm{~N}$ & Hesse. & Putrefying yeast, wheat flour. & Non-toxic. \\
\hline Ethylidenediamin (?). & $\mathrm{C}_{2} \mathrm{H}_{8} \mathrm{~N}_{2}$ & Brieger. & Putrefying haddock. & Toxic. \\
\hline Gadinin. & $\mathrm{C}_{7} \mathrm{H}_{17} \mathrm{NO}_{2}$ & Brieger. & Decomposing haddock. & Toxic. \\
\hline Hexylamin. & $\mathrm{C}_{6} \mathrm{H}_{15} \mathrm{~N}$ & Hesse. & Putrid yeast. & Toxic. \\
\hline Hydrocollidin (?). & $\mathrm{C}_{8} \mathrm{H}_{13} \mathrm{~N}$ & Gautier and Etard. & $\begin{array}{l}\text { Putrefying mackerel, horse, and ox- } \\
\text { flesh. }\end{array}$ & Toxic. \\
\hline Hydrocoridin. & $\mathrm{C}_{10} \mathrm{H}_{17} \mathrm{~N}$ & Griffiths. & Agar-culture of bacterium album. & \\
\hline Methylamin. & $\mathrm{CH}_{5} \mathrm{~N}$. & Bocklisch. & Putrefying fish. & Non-toxic. \\
\hline Methyl-guanidin. & $\mathrm{C}_{2} \mathrm{H}_{7} \mathrm{~N}_{3}$ & Brieger. & Putrefying horse-flesh. & Toxic. \\
\hline Morrhuic acid. & $\mathrm{C}_{9} \mathrm{H}_{13} \mathrm{NO}_{3}$ & $\begin{array}{l}\text { Gautier and Mour- } \\
\text { gues. }\end{array}$ & Cod-liver oil. & \\
\hline Morrhuin. & $\mathrm{C}_{19} \mathrm{~N}_{27} \mathrm{~N}_{3}$ & $\begin{array}{l}\text { Gautier and Mour- } \\
\text { gues. }\end{array}$ & Cod-liver oil. & $\begin{array}{l}\text { Diuretic and diapho- } \\
\text { retic. }\end{array}$ \\
\hline Muscarin. & $\mathrm{C}_{5} \mathrm{H}_{15} \mathrm{NO}_{3}$ & Brieger. & Decomposing haddock. & Toxic. \\
\hline Mydalein. & & Brieger. & Putrefying human organs. & Toxic. \\
\hline Mydatoxin. & $\mathrm{C}_{6} \mathrm{H}_{13} \mathrm{NO}_{2}$ & Brieger. & Putrefying human organs. & Toxic. \\
\hline Mydin. & $\mathrm{C}_{8} \mathrm{H}_{11} \mathrm{NO}$ & Brieger. & $\begin{array}{l}\text { Putrid human tissues, blood-serum } \\
\text { cultures of Eberth's bacillus of } \\
\text { typhoid fever. }\end{array}$ & Non-toxic. \\
\hline Mytilotoxin. & $\mathrm{C}_{6} \mathrm{H}_{15} \mathrm{NO}_{2}$ & Brieger. & Poisonous mussel (Mytilus edrulis). & Toxic. \\
\hline Neuridin. & $\mathrm{C}_{5} \mathrm{H}_{14} \mathrm{~N}_{2}$ & Brieger. & Putrefying flesh. & Non-toxic. \\
\hline Neutin. & $\mathrm{C}_{5} \mathrm{H}_{13} \mathrm{NO}$ & Brieger. & Putrefying flesh. & Toxic. \\
\hline Parvolin (?). & $\mathrm{C}_{9} \mathrm{H}_{13} \mathrm{~N}$ & Gautier and Etard. & Putrefying mackerel and horse-flesh. & \\
\hline Peptotoxin. & & Brieger. & Decomposing proteid substances. & Toxic. \\
\hline Phlogosin. & & Leber. & $\begin{array}{l}\text { Cultures of staphylococcus pyogenes } \\
\text { aureus. }\end{array}$ & Powerful local irritant. \\
\hline Propylamin. & $\mathrm{C}_{3} \mathrm{H}_{9} \mathrm{~N}$. & Brieger. & $\begin{array}{l}\text { Gelatin-cultures of bacteria of human } \\
\text { feces. }\end{array}$ & \\
\hline Putrescin. & $\mathrm{C}_{4} \mathrm{H}_{12} \mathrm{~N}_{2}$ & Brieger. & Putrefying flesh, gelatin, etc. & Slightly toxic. \\
\hline
\end{tabular}


TABLE OF PTOMAINS.-Continued.

\begin{tabular}{|c|c|c|c|c|}
\hline NAME. & Formula. & DISCOVERER. & SOURCE. & $\begin{array}{l}\text { PhySIOLOGIC } \\
\text { ACTION. }\end{array}$ \\
\hline Pyocyanin. & $\mathrm{C}_{14} \mathrm{H}_{14} \mathrm{NO}_{2}$ & Ledderbose. & Cultures of bacillus pyocyaneus. & Non-toxic. \\
\hline Pyridin-base (?). & $\mathrm{C}_{10} \mathrm{H}_{25} \mathrm{~N}$ & De Coninck. & Putrefying sea-polyps. & \\
\hline Pyridin-base. & $\mathrm{C}_{8} \mathrm{H}_{11} \mathrm{~N}$ & De Coninck. & Putrefying sea-polyps. & \\
\hline Saprin. & $\mathrm{C}_{5} \mathrm{H}_{14} \mathrm{~N}_{2}$ & Brieger. & Putrefying human liver and spleen. & Non-toxic. \\
\hline Spasmotoxin. & & Brieger. & Cultures of tetanus-bacillus. & Toxic. \\
\hline Susotoxin. & $\mathrm{C}_{10} \mathrm{H}_{26} \mathrm{~N}_{2}(?)$ & Novy. & Cultures of hog-cholera bacillus. & Toxic. \\
\hline Tetanin. & $\mathrm{C}_{13} \mathrm{H}_{30} \mathrm{~N}_{2} \mathrm{O}_{4}$ & Brieger. & Cultures of tetanus-bacillus. & Toxic. \\
\hline Tetanotoxin. & $\mathrm{C}_{5} \mathrm{H}_{11} \mathrm{~N}(?)$ & Brieger. & Cultures of tetanus-bacillus. & Toxic. \\
\hline Triethylamin. & $\mathrm{C}_{6} \mathrm{H}_{16} \mathrm{~N}$ & Brieger. & Putrefying fish (haddock). & Non-toxic. \\
\hline Trimethylamin. & $\mathrm{C}_{3} \mathrm{H}_{9} \mathrm{~N}$ & Dessaigues. & Herring-brine. & Non-toxic. \\
\hline Trimethylenediamis. & $\mathrm{C}_{3} \mathrm{H}_{10} \mathrm{~N}_{2}(?)$ & Brieger. & Beef-broth cultures of comma-bacillus. & Toxic. \\
\hline Typhotoxin. & $\mathrm{C}_{7} \mathrm{H}_{17} \mathrm{NO}_{2}$ & Brieger. & $\begin{array}{l}\text { Beef-broth cultures of Eberth's bacil- } \\
\text { lus. }\end{array}$ & Toxic. \\
\hline Tyrotoxicon. & & Vaughan. & Poisonous cheese, ice cream, milk, etc. & Toxic. \\
\hline Unnamed. & $\mathrm{C}_{5} \mathrm{H}_{12} \mathrm{~N}_{2} \mathrm{O}_{4}$ & Pouchet. & Flesh, bones, etc. & Toxic. \\
\hline Unnamed. & $\mathrm{C}_{6} \mathrm{H}_{18} \mathrm{NO}_{2}$ & Brieger. & Cultures of tetanus-bacillus. & Non-toxic. \\
\hline Unnamed. & $\mathrm{C}_{7} \mathrm{H}_{10} \mathrm{~N}_{2}$ & Morin. & $\begin{array}{l}\text { Sugar undergoing alcoholic fermenta- } \\
\text { tion. }\end{array}$ & Non-toxic. \\
\hline Unnamed. & $\mathrm{C}_{7} \mathrm{H}_{17} \mathrm{NO}_{2}$ & Brieger. & Putrefying horse-flesh. & Toxic. \\
\hline Unnàmed. & $\mathrm{C}_{7} \mathrm{H}_{18} \mathrm{~N}_{2} \mathrm{O}_{6}$ & Pouchet. & Flesh, bones, etc. & Toxic. \\
\hline Unnamed. & $\mathrm{C}_{10} \mathrm{H}_{15} \mathrm{~N}$ & $\begin{array}{l}\text { Guareschi and } \\
\text { Mosso. }\end{array}$ & Putrid fibrin. & Toxic. \\
\hline Unnamed. & $\mathrm{C}_{13} \mathrm{H}_{20} \mathrm{~N}_{4}$ & Oser. & Fermenting cane-sugar. & \\
\hline Unnamed. & $\mathrm{C}_{14} \mathrm{H}_{20} \mathrm{~N}_{2} \mathrm{O}$ & Guareschi. & Putrefying fibrin. & \\
\hline Unnamed. & $\mathrm{C}_{17} \mathrm{H}_{38} \mathrm{~N}_{4}$ & Gautier and Etard. & $\begin{array}{l}\text { Putrefying mackerel, horse-flesh and } \\
\text { ox-flesh. }\end{array}$ & \\
\hline Unnamed. & $\mathrm{C}_{32} \mathrm{H}_{31} \mathrm{~N}$ & Delezinier. & & \\
\hline
\end{tabular}

Ptotic (to'-tik) [ $\pi \tau \tilde{\omega} \sigma \iota \varsigma$, a falling]. Affected with or pertaining to ptosis.

Ptotostereoscope (lo-tos-te'-re-o-skōp) [ $[\pi \tau \omega \tau \sigma c$, fallen;

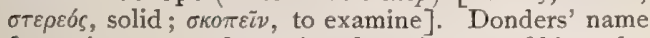
for an instrument for testing the existence of binocular vision.

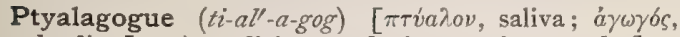
leading]. A medicine producing an increased flow of saliva. A sialagogue.

Ptyalin $\left(t i^{\prime}-a l-i n\right)[\pi \tau \dot{v} a \lambda o \nu$, saliva]. An amylolytic or diastatic ferment found in saliva, having the property of converting starch into dextrin and sugar. The starch first becomes converted into achroödextrin and erythrodextrin; these by hydration into maltose, and the latter, by further hydration, into dextrose. Ptyalin is most active in a slightly alkaline medium and at the temperature of the body.

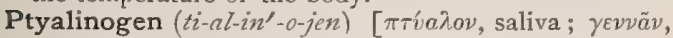
to produce]. The hypothetic zymogen of ptyalin.

Ptyalism $\left(t i^{\prime}-a l-i z m\right)$ [ $\pi \tau \dot{v} a \lambda \_\nu$, saliva]. An excessive secretion of saliva. Sometimes it is used to signify mercurial ptyalism. P., Mercurial, that produced by mercury. It is attended with profuse salivation, a coppery taste, swelling and sponginess of the gums, and sometimes by looseness of the teeth and fetid breath.

Ptyalismus (ti-al-iz'-mus). See Ptyalism. P. mercurialis. Synonym of Ptyalism, Mercurial.
Ptyalith (ti'-al-ith) [ $\pi \tau^{\prime} v a \lambda o v$, saliva; $\lambda i^{\prime}$ fos, stone]. A salivary calculus.

Ptyalize $\left(t i^{\prime}-a l-i z\right)$ [ $\pi \tau v a \lambda i \zeta \varepsilon t \nu$, to salivate]. To produce pytalism.

Ptyalocele $\left(t i-a l^{\prime}-o-s \bar{e} l\right)$ [ $\pi \tau \dot{v} a \lambda o \nu$, saliva; $\kappa \dot{\eta} \lambda \eta$, tumor]. A cyst due to obstruction of the duct of a salivary gland.

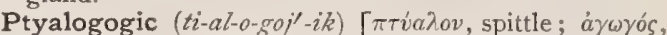
leading]. Promoting a flow of saliva.

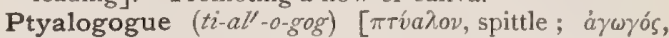
leading]. A medicine causing a flow of saliva.

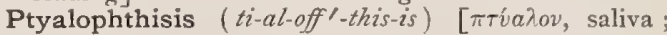
$\phi$ Hioıs, a wasting]. Wasting from excessive discharge of saliva.

Ptyalose $\left(t i^{\prime \prime}-a l-\bar{o} z\right)$ [ $\pi \tau^{\prime} v a \lambda o v$, saliva]. A sugar found in saliva; it is identical with maltose.

Ptyalum $\left(t i^{\prime \prime}-a t-u m\right)$. Synonym of Saliva.

Ptychodont $\left(t i^{\prime}-k o-d o n t\right)\left[\pi \tau \dot{\prime} \xi\left(\pi \tau v, \chi^{-}\right)\right.$, a fold; ódov́s,

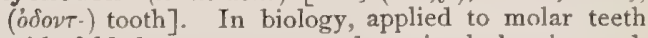
with folded crowns, or to the animals bearing such teeth.

Ptysis $\left(t i^{\prime}-s i s\right)\left[\pi \tau^{\prime} i^{\prime} \sigma \varsigma\right]$. The act of spitting.

Ptysma (tiz'-mah) $[\pi \tau v \sigma \mu \pi]$. Saliva.

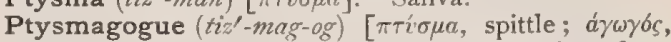
leading]. A drug that promotes the secretion of saliva; a ptyalagogue, or sialagogue.

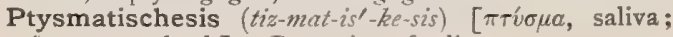
¿ $\sigma$ $\varepsilon \iota \nu$, to check]. Retention of saliva. 
Ptyxis (tiks'-is) [ $\pi \tau i \xi \xi \varsigma$, a folding]. In biology, the arrangement of a single part in the bud, as distinguished from the conjoint disposition of the parts in estivation and vernation.

Pubal ( $\left.p u^{\prime}-b a l\right)$. Synonym of Pubic.

Puben (pu'-ben) [pubes, adult]. Belonging to the pubes in itself.

Pubeotomy ( $\left.p u-b e-o t^{\prime}-o-m e\right)$. See Pubiotonny.

Puberal $\left(p u^{\prime}\right.$-ber-al) [puber, adult]. Relating to puberty.

Puberty (pu'-ber-te) [pubertas; puber, adult]. I. The period at which the generative organs of the male or of the female become capable of exercising the function of reproduction. 2. The changes in the generative organs and in the general system that accompany the inauguration of this period.

Puberulent (pu-ber'-u-lent) [pubes, puber, downy, pubescent]. In biology, covered with a fine, soft, almost imperceptible down. Cf. Holosericens.

Pubes $\left(p u^{\prime}-b \bar{e} z\right)$ [L.: gen., pubis]. I. The os pubis, or pubic bone; that portion of the os innominatum forming the front of the pelvis. 2. The hairy region covering the os pubis. 3. The pubic hair. P., Angle of. See Angle. P., Crest of. See Crest. P., Spine of. See Spine. P., Symphysis of. See Symphysis.

Pubescence (pu-bes'-ens) [pubescenticl]. I. Hairiness; the presence of down; fine, soft hairs. 2. Puberty, or the coming on of puberty.

Pubescent (pu-bes'-ent) [pubes, pubes]. I. Downy, or hairy, 2. Approaching or arriving at the age of puberty. P. Uterus, an abnormality of the uterus in which the characters of that organ peculiar to the epoch preceding puberty persist in the adult.

Pubetrotomy (pu-be-trot'-o-me) [pubes, pubes; $\eta^{\top} \tau o v$,

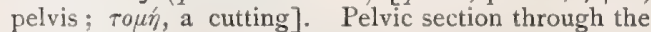
pubes.

Pubic (pu'-bik) [pubes, pubes]. Pertaining to the pubes. P. Symphysis. See Symphysis.

Pubigerous (pu-bij'-er-us) [pubes, hair; gerere, to carry]. Bearing or covered with down or soft hairs.

Pubio-femoralis (pu-be-o-fem-or-a'-lis). Synonym of Adductor longus.

Pubio-infra-abdominalis ( $p u$-be-o-in-frah-ab-dom-in$a^{\prime}$-lis). Synonym of Pyramidalis.

Pubio-ischiadic, Pubio-ischiatic ( $p u-b e-0-i s-k e-a d^{\prime \prime}-i k$,

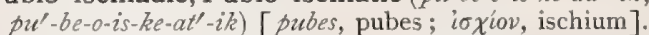
Pertaining to the pubes and the ischium.

Pubio-prostaticus ( $\left.p u-b e-o-p r o s-t a t^{\prime}-i k-u s\right)$. Synonym of Compressor prostate.

Pubio-sternalis (pu-be-o-ster-na'-lis). Synonym of Rectus abdominis.

Pubiotomy ( $\left.p u-b e-o t^{\prime}-o-m e\right)$ [pubes, pubes; тouń, a cutting]. An operation for enlarging the diameter of the pelvic outlet by cutting through the pubic bone to facilitate delivery in cases of pelvic malformation; it is now generally termed symphysiotomy.

Pubio-umbilicalis ( $\left.p u^{\prime}-b e-0-u m-b i l-i k-a^{\prime}-l i s\right)$. Synonym of Pyramidalis.

Pubis, or Os Pubis $\left(p u^{\prime}-b i s\right)$. Same as Pubes.

Pubo- (pu'-bo-) [pubes, pubes]. A prefix denoting relation to the pubes.

Pubo-cavernosus ( $p u$-bo-kav-ern-o'-sus). Synonym of Compressor vena dorsalis.

Pubo-coccygeal ( $\left.p u-b o-k o k-s i j-e^{\prime}-a l\right)$ [ $\kappa \delta \kappa \kappa v \xi$, coccyx]. Pertaining, or having relation to the os pubis and the coscyx.

Pubo-femoral ( pu-bo-fem'-o-ral)[ pubes, pubes; femur, femur]. Pertaining to the pubes and the femur.

Pubo-iliac $\left(\not u-b o-i l^{\prime}-e-a k\right)$ [pubes, pubes; ilium, ilium]. Common to the pubes and the ilium.

Pubo-ischiatic ( $\left.p u-b o-i s-k e-a t^{\prime}-i k\right)$. Synonym of Pubioischiatic.

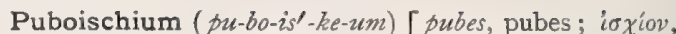
ischium]. The os pubis and the ischium considered as a unit.

Pubo-prostatic (pu-bo-pros-tat'-ik) [ pubes, pubes;

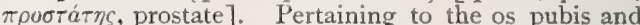
the prostate gland. As a noun, Wilson's Muscle. See Muscles, Table of

Pubo-tibial ( $\left.p u-b o-t i b^{\prime}-e-a l\right)$ [ pubes, pubes; tibia, tibia]. Pertaining to the pubes and the tibia.

Pubo-trochantericus ( $\left.p u-b o-t r o-k a n-t e r^{\prime}-i k-u s\right)$. Synonym of Pectineus.

Pubo-urethral ( $\left.p u-b o-u-r e^{\prime}-t h r a l\right)$ [pubis, pubis; urethra, urethra]. Passing from the pubis to the urethra.

Pubo-urethralis ( $\left.p u-b o-u-r e-t h r a^{\prime}-l i s\right)$. Synonym of Wilson's Muscle.

Pubo-vesical ( $\left.p u-b o-v e s^{\prime}-i k-a l\right)$. Synonym of Compressor prostatce. See Muscles, Table of.

Puccin $\left(p u k^{\prime}-\sin \right)$. A substance found in Sanguinaria canadensis. Its exact nature is not yet known.

Pucelage $\left(p u^{\prime}-s e l-\bar{a} j\right.$, or $\left.p u-s e l-a h z h^{\prime}\right)[\mathrm{Fr}$.$] . Virginity.$

Pudenda ( $\left.p u-d e n^{\prime}-d a h\right)$. See Pudendum.

Pudendagra (pu-den-da'-grah) [pudere, to be ashamed; á $\gamma \rho \alpha$, a seizure]. I. Pain in the genital organs. 2. Primary syphilis, especially of the female genital organs. P. pruriens, pruritus vulvæe.

Pudendal ( $p u$-den'-dal) [ pudere, to be ashamed]. Pertaining to the pudenda.

Pudendum (pu-den'-dum) [pudere, to be ashamed: pl., Pudenda]. The genital organs, especially those

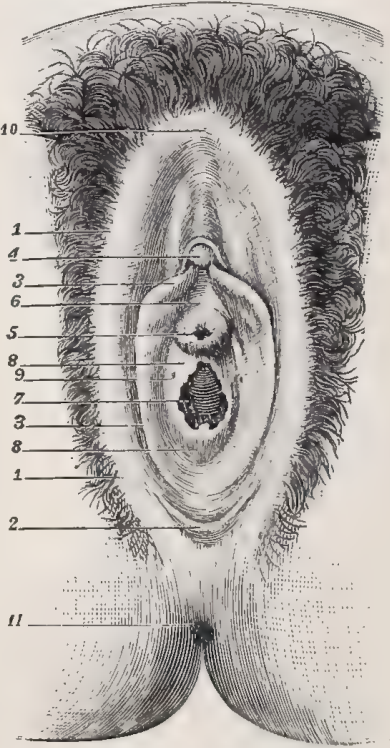

External Genitalia of Female.

I. Labium majus of right side. 2. Fourchet. 3. Labium minus Clitoris, 5. Urethral orifice, 6. Vestibule. 7. Orifice of the vagina. 8. Hymen. 9. Orifice of the vulvo-vaginal gland. Io. Anterior commissure of the labia majora. xI. Orifice of the anus.

parts of the female genital organs visible externally. These are the mons veneris, the labia, clitoris, nymphr, and hymen.

Pudibilia (pu-dib-ill-e-ah) [pudibilis, shameful]. The genital organs, especially of the male.

Pudic ( $p u^{\prime}$-dik) [pudicus; pudere, to be ashamed]. Pertaining to the genital organs or related parts. $\mathbf{P}$. Artery. See Arteries, Table of. P. Nerve. See Nerves, Table of. 
Puerile $($ pu'-er-il) [puerilis; puer, boy]. Pertaining to boyhood or childhood. P. Respiration, a form of respiration sometimes observed in adults and similar to that heard in vigorous, healthy children.

Puerpera ( $\left.p u-e \gamma^{\prime}-p e-r a h\right)$ [puer, boy, child; parere, to bear]. A woman in labor, or one recently delivered.

Puerperal (pu-er'-pe-ral) [ puerpera, puerpera]. Pertaining to the state of a woman in childbed. P. Convulsions. See Eclampsia. P. Fever, an acute, grave, febrile affection of women in childbed, usually due to septic infection. See Fever. P. Insanity, insanity occurring during the puerperium, usually within five or ten days after delivery. The insanity may take the form of mania, melancholia, or dementia. P. Mania, a delirious condition of women sometimes occurring in the puerperium. See Insanity, Confusional. P. Sepsis, P. Septicemia. See P. Fever. P. Tetanus, tetanus, occurring rarely in the puerperium. It is usually fatal.

Puerperality (pu-er-per-al'-it-e) [Fr., Puerpéralité]. The puerperal condition.

Puerperium ( pu-er-pe'-re-um) [L. ; puer, boy, child; parere, to bear]. The puerperal state or season; the period from birth to the time when the uterus has regained its normal size, which is about six weeks.

Puerperopyra (pu-er-per-o-pi'-rah) [puer, boy, child; parere, to bear; $\pi \tilde{v} \rho$, fire, fever]. Puerperal fever.

Puerpero-typhus ( parere, to bear; rũ $\varphi$ os, stupor]. A typhoid state developing in the course of any grave puerperal disease.

Puerperous ( $\left.p u-e r^{\prime}-p e r-u s\right)$. Same as Puerperal.

Puerpery (pu-er'-per-e) [puerperum, childbirth]. The puerperal state.

Puff-ball. See Lycoperdon giganteum, bovista.

Puffiness (puf'-in-es) [ME., puf, a puff]. Swelling or intumescence of the tissues; an edematous condition.

Puffy $\left(p u f^{\prime}-e\right)$ [ME., puf, a puff]. Tumid, swollen, or puffed up, as with air; swollen and soft. P. Tumor, Pott's. See Tumor.

Pug [origin obscure]. A term signifying dwarf. P.nose, Snub-nose, turned-up nose; a deformity of the nose characterized by a flattening of the organ and a tilting up of its tip. P.-tooth, a canine tooth.

Pugil, Pugillus ( $\left.p u^{\prime}-j i l, p u-j i l^{\prime}-u s\right)$ [L., a handful]. The amount of a substance that can be grasped between the thumb and two or three fingers. See also Maniple.

Pugioniform ( $p u-j e-o n^{\prime}-i f$-orm) [ pugio, a dagger; forma, form]. Shaped like a dagger.

Puke ( $p \vec{u} k)$ [origin obscure]. A colloquialism signifying vomit and generally used as a verb.

Puking ( $\left.p u^{\prime}-k i n g\right)$ [origin obscure]. Vomiting. P. Fever. Synonym of Milk-sickness.

Pulex ( $p u^{\prime}$-leks) [L.]. A flea. A genus of insects partly parasitic upon the skin. P. irritans, Flea; a transient parasite on man. The bite causes an itching, circular, red spot of hyperemia, in the center of which is a little speck where the boring apparatus has entered. It may produce an irritable urticaria. P. penetrans, the chigoe, or jigger flea, a species the female of which, much smaller than the ordinary flea, burrows under the skin of the feet to deposit its ova. A high degree of irritation, which may go on to serious inflammation, is produced. It is found mainly in tropical America and in Africa. See Parasites (Animal), Table of.

Pulicatio (pu-lik-a'she-o) [pulex, flea]. The state of being infested with fleas.

Pulicene $\left(p u^{\prime}-l i s-e n\right)$ [pulex, a flea]. Pertaining to fleas.

Pulicose $\left(p u u^{\prime}-l i k-\bar{o} z\right)$ [pulex, flea]. Abounding with fleas.
Pulley [origin uncertain]. x. One of the mechanical powers, 2. A trochlea, q. $\%$ 3. A ligamentous structure which serves to change the direction of the action of a muscle passing through or over it.

Pulling [ME., pullen, to pull]. One of the Swedish movements that may be either active or passive.

Pullulate (pul'-u-lât) [pullulare, to put forth]. To germinate, to bud.

Pullulation (pul-u-la'-shun) [pullulare, to put forth to bud, to sprout]. In biology, that form of cellmultiplication in which the mother-cell forms a minute protuberance on one side, which afterward increases to the size of the parent-cell. It is also called budding. This is the ordinary form of cell-multiplication in the yeast-plant and its allies.

Pullus (pul'-us) [pullus, a young animal]. In biology, the young of a bird or other animal.

Pulmo-aortic (pul-mo-a-or'-tik) [pulmo, lung; àoptí, aorta]. Pertaining to the lungs and the aorta.

Pulmobranchiæ (pul-mo-brang'-ke-e) [pulmo, lung; branchia, gills]. In biology, the modified gills of certain animals (snails, spiders) adapted to breathing in air.

Pulmobranchial ( $\left.p u l-m o-b r a n g^{\prime}-k e-a l\right)$ [pulmo, lung; branchice, gills]. Pulmonate, breathing by gills.

Pulmobranchiate (pul-mo-brenng' ke-ät) [pulmo, lung; branchice, gills]. Provided with pulmobranchiæ.

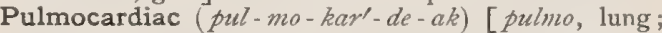
kapdia, heart]. Pertaining to the lungs and the heart. P. Region, that portion of the thorax in which the heart is covered by the lungs.

Pulmocutaneous ( $\left.p u l^{\prime}-m o-k u-t a^{\prime}-n e-u s\right)$ [pulmo, lung; cutis, skin]. Pertaining to the lungs and the skin.

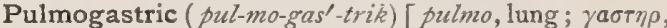
stomach]. Pertaining to the lungs and the stomach. P. Region, that portion of the thorax in which the lungs overlap the stomach.

Pulmohepatic ( $\left.p u l-m o-h e-p a t^{\prime}-i k\right)$ [pulmo, lung; $\bar{\eta} \pi a \rho$, liver]. Relating to the lungs and the liver, P. Region, that portion of the thorax in which the lungs overlap the liver.

Pulmometer (pul-mom'-et-er) [pulmo, a lung ; $\mu \varepsilon ́ \tau \rho \curvearrowright v$, measure]. Synonym of Spirometer.

Pulmometry (pul-mom'-et-re) [pulmo, lung; $\mu \dot{\varepsilon} \tau \rho o \nu$, measure]. The quantitative determination of the air concerned in respiration. Also, the determination of the volume of the lungs.

Pulmonar (pul'-mo-nar) [pulmo, lung]. Having lungs or lung-like organs.

Pulmonarious ( pul-mo-na'-re-us) [pulmo, lung]. Affected with pulmonary disease.

Pulmonary (pul'-mo-na-re) [pulmo, lung]. Pertaining to the lung. P. Alveoli, air-cells. P. Artery. See Arteries, Table of. P. Cartilage, the second costal cartilage of the left side. P. Circulation, the lesser circulation of the blood from the right cardiac ventricle through the pulmonary vessels and back to the left auricle. P. Consumption. See Phthisis. P. Emphysema. See Emphysema. P. Groove, the groove within the thorax on either side of the spinal column. P. Incompetence. See Endocar ditis. P. Murrain, a contagious form of pleuropneumonia. P. Nerves, branches of the vagus nerve going to the lungs. There are two sets, an anterior and a posterior. P. Sinuses, the sinuses of Val salva of the pulmonary artery. P. Stenosis. See Endocarditis. P. Valves, the semilunar valves at the opening of the right ventricle into the pulmonary artery. P. Veins, four veins returning the oxygenated blood from the lungs to the left auricle. P. Vesicies, air-cells of the pulmonary parenchyma. 
Pulmonata (pul-mo'-nat-ah) [pulmo, lung]. A class of land or fresh-water molluscs breathing by means of a pulmonary sac, gills being absent.

Pulmonate (pul'-mo-natt) [pulmo, lung]. In biology, possessed of lungs or organs adapted to aërial respiration.

Pulmonectomy ( $p u l-m o-n e k^{\prime}$-to-me). See Pneumonectomy.

Pulmonic (pul-mon'-ik) [pulmo, lung]. Synonym of Pulmonary. P. Circulation. See Pulmonary Circulation. P. Fever, a synonym of Croupous Pneumonia.

Pulmoniferous (pul-mon-if'-er-us) [ pulmo, lung; ferre, to bear]. Provided with lungs; pulmonate

Pulmonitis (pul-mon-i'tis). Synonym of Pneumonia.

Pulmotracheal (pul-mo-tra'-ke-al) [pulmo, lung; trachea, trachea]. Pertaining to the lungs and the trachea.

Pulp [pulpa, pulp]. A soft, moist tissue; chyme. P.cavity, the hollow space in a tooth containing the dental pulp. P.-cells, cells found in the pulp-tissue of any organ. P., Dental, a soft tissue filling the pulp-cavity of a tooth. It consists of loose connective tissue and cells, vessels, and nerves. Also the rudiment of a tooth. P., Digital, the sensitive, elastic, convex prominence on the palmar or plantar surface of the terminal phalanx of a finger or toe. $\mathbf{P}$. of the Finger. See P., Digital. P., Fruit, the fleshy part of fruits by which the seeds are surrounded. P., Hair. Synonym of Papilla, Hair. P. of the Intervertebral Discs, the soft substance in the center of the intervertebral dics, the remains of the chordæ dorsalis. P., Spleen, P., Splenic, the substance filling the spaces formed by the trabeculx of the spleen. See Spleen. P. of a Tooth. See P., Dental.

Pulpa $\left(p u l^{\prime}-p a h\right)$ [L.]. Pulp. P. cerebralis, the white matter of the brain. P. dentis, a dental pulp. P. digitorum. Synonym of Pulp, Digital. P. lienis. Synonym of Pulp, Splenic. P. pili. Synonym of Papilla, Hair. P. testiculi, P. testis, the tissue contained in the space formed by the connectivetissue septa of the testis.

Pulpalgia (pul-pal'-je-ah) [pulpa, pulp; ăhyos, pain]. Pain in tooth-pulp.

Pulpamen ( $\left.p u l^{\prime}-p a^{\prime}-m e n\right)$. Synonym of Pulp.

Pulpefaction (pul-pe-fak'-shun) [pulpa, pulp; facere, to make]. Conversion into a pulpy substance.

Pulpezia ( $\left.p u l-p e^{\prime}-z e-\alpha h\right)$. Synonym of Apoplexy, Cerebral.

Pulpitis (pul-pi'-tis) [pulpa, pulp: ıTıs, inflammation]. Inflammation of dental pulp. The causes of pulpitis are exposure of the pulp by decay, abrasions of the teeth, etc

Pulpose, Pulpous, Pulpy ( $p u l^{\prime}-p \bar{o} z$, pul'-pus, pul'-pe) [pulpa, pulp]. Resenbling or containing pulp. P. Disease. See Brodie's Disease.

Pulque ( $\left.p u l^{\prime}-k e\right)$ [Sp.]. A fermented beverage prepared in Mexico from the juice of various species of Agave. P. Brandy. See Mezcal. P. Plant. See Agave.

Pulsate $\left(p u l^{\prime}-s \vec{a} t\right)$ [pulsare, to beat]. To beat or throb.

Pulsatile (pul'-sat-il) [pulsare, to beat]. Pulsating; throbbing; exhibiting pulsation.

Pulsatilla (pul-sat-il'ah) [L.]. Pasque Flower. Meadow Anemone. The leaves and tops of Anemone $P$. Its properties are due to a camphoraceous principle, anemonin, $\mathrm{C}_{15} \mathrm{H}_{12} \mathrm{O}_{6}$, which depresses the circulation; in larger doses paralyzes motion. The extract in toxic doses causes convulsions, but anemonin does not. It has been used in amenorrhea, dysmenorrhea, bronchitis, and asthma. It is a valuable alterative. An unofficial tincture consists of equal parts of the juice and alcohol. Dose $\eta \frac{1}{10}-x$; of the active principle gr. $\frac{1}{10}-\mathrm{ij}$; of the liquid extract, $m j-\mathrm{v}$.

Pulsating (pul'-sa-ting) [pulsare, to beat]. Exhibiting pulsation. P. Aorta, the pulsation of the abdominal aorta seen in nervous and anemic persons. P. Bronchocele, a goiter exhibiting pulsation. P. Empyema, an accumulation of pus in the pleural cavity, and which displays pulsation. P. Tumor, one which pulsates, in consequence of an enlarged state of its blood-vessels.

Pulsation (pul-sa'-shun) [pulsatio; pellere, to drive]. Any beating or throbbing. The visible or sensible elevation of a vessel synchronously with or following the heart's beat; the pulse-beat. P., Abdominal, pulsation in the abdomen, usually in the median line. It is due to a pulsating aorta, $q . v$., or to aortic aneurysm, or to the impulse transmitted to a tumor resting on the aorta. P., Carotid, pulsation of the carotid arteries in the neck. It occurs in aortic regurgitation, exophthalmic goiter, anemia, and cardiac excitement. P., Epigastric, pulsation in the epigastrium. It is seen in excitement of the action of the heart, in aneurysm of the aorta, in enlargement of the right heart, in tumors resting on the aorta ; in hysteric and anemic subjects the pulsation of the abdominal aorta may be visible in the epigastrium. P., Hepatic, pulsation of the liver at each cardiac systole, due to insufficiency of the tricuspid valve, with a consequent transmission of a pulse along the vena cava. P., Retinal, pulsation of the retinal vessels, seen in the eye as a consequence of the disturbance of the relation between the intraocular and the extraocular pressure. P., Secondary, the contraction in the muscle of a muscle-nerve preparation if its nerve is laid on a second contracting muscle. P., Stair-case, the increase in the length of successive contractions of a frog's heart that has been filled with serum. P., Suprasternal, pulsation at the suprasternal notch. It may be due to aneurysm, dilated aortic arch, or to the presence of an anomalous artery.

Pulsatory (pul'-sat-or-e) [pulsare, to beat]. Exhibiting or characterized by pulsation.

Pulse (puls') [pulsus, the pulse]. The change in the shape and size of an artery due to a temporary increase in the tension of its walls following the contractile action of the heart. It can only be felt when the artery is somewhat compressed and flattened against a bone or other hard substance. P., Abrupt. Synonym of $P$., Quick. P., Allorrhythmic. See Allorrhythmia. P., Anacrotic. See Anacrotism. P., Aneurysmal, the pulse produced by an aneurysm of the thoracic aorta or one of its large branches. The impulse is not sudden, is long in duration, and subsides gradually; it may be much slower than the pulse on the opposite side. P., Angry. Synonym of $P$., Wiry. P., Apoplectic, a condition of the radial artery at the wrist, marked by fulness, without great hardness, the vessel generally being dilated and tortuous. The predicrotic notch is deep and close to the percussion-wave, the dicrotic notch is deep, and the dicrotic wave is short; the total extent of the wave is small. It is seen in impoverished conditions of the blood, in rheumatism, gout, lithemia, and contracted kidneys. P., Arachnoid, a small, feeble, tremulous pulse. (Old.) P., Bounding, a pulse in which a weak beat is succeeded by a strong, full beat. P., Capillary, seen when the capillaries are dilated and the blood-pressure is high, as in aortic regurgitation. P., Catacrotic, one with an elevation in the line of descent in the syphygmographic tracing. P.-clock. See Angiomeler. P., Collapsing. See Corrigan's 
Pulse. P., Compressible, a pulse that is easily obliterated by pressure with the finger; a soft pulse. P., Cordy, a tense pulse. P., Corrigan's. See Corrigan. P.-curve, the tracing, called a sphygmogram or arteriogram, of the pulse, made by the sphygmograph or sphygmoscope. P., Decurtate. see Pulsus myums. P., Dicrotal, P., Dicrotic, an exaggerated dicrotic wave, or recoil wave, the larger of the catacrotic elevations corresponding to the closure of the aortic valves. It is observed when the arterial tension is low and gives to the finger the impression of two beats. P., Dropped-beat. Synonym of P., Intermittent. P., Elastic, one that feels elastic to the finger. P., Endopleural, a pulsation of pulsating pleurisy which can only be rendered visible by means of a manometer. P., Entoptic, the subjective-illumination in a dark, visual field, after violent exercise, corresponding to each heart-beat. P., Epigastric. See Pulsation, Epigastric. P., Exopleural, the pulsation of a pulsating pleurisy that is visible without the use of a manometer. P., Filiform. Synonym of $P$. Thready. P., Full, a pulse in which the artery is filled with a large volume of blood and conveys a feeling of being distended. P., Gas eous, the pulse of an artery that has lost its tone; it is full, but exceedingly compressible. P., Goatleap. See Pulsus caprizans. P., Hard, one with character of high tension and rigidity. P., Hemorrhagic. Synonym of $P .$, Gaseous. P., Heterochronic. Synonym of $P$., Irregular. P., High Tension, one due to increase of the peripheral resistance, together with a corresponding increase in the force of the ventricular systole. It is gradual in its impulse, long in duration, slow in subsiding, with difficulty compressible, and the artery between the beats feels like a firm, round cord. P., Hyperdicrotic, P., Hyperdicrotous, a pulse of which the aortic notch falls below the base line, indicating very low tension, a symptom of great exhaustion. P., Infrequent, properly, a pulse due to diminished rate of heart-beat; often, however, used as synonymous with slow pulse. P., Intermittent, one in which one or more beats may be dropped. P., Irregular, one in which the beats occur at irregular intervals, or in which the force, or even both the rhythm and force, vary. P., Jerking, a pulse in which the artery is suddenly and markedly distended, as in aortic regurgitation. P., Jugular, pulsation of the jugular veins in the neck. It may be merely transmitted from the arteries or may be due to tricuspid regurgitation. P., Locomotive. Synonym of Corrigan's Pulse. P., Low Tension, one that is sudden in its onset and short, and quickly declining. It is easily obliterated by pressure. P.. Monocrotic, P., Monocrotous, one with absence of the dicrotic wave. P., Myurous. See Pulsus myurus. P. paradoxic, one due to failure of the heart during inspiration, seen sometimes in adherent pericardium. P., Polycrotic, a pulse in which there are a number of secondary waves, as in the smaller arteries. It can only be demonstrated with the sphygmograph. P., Quick, one that strikes the finger rapidly, but leaves it also rapidly. Corrigan's pulse is a quick pulse. P.-rate, the number of pulsations of an artery in a given time, usually in a minute. P., Recurrent, the appearance of the pulse o' the distal side of the point of compression of an artery. P., Renal, the tense, full pulse seen in association with chronic nephritis. P., Respiratory, the alternate dilatation and collapse of the cervical veins occurring synchronously with expiration (dilatation) and inspiration (collapse). P., Short, one in which the systolic wave is short. P., Slow, one indicating a lengthened systolic contraction of the heart and prolonged diastole; as generally used, it signifies a pulse of slow rate. P., Soft, a pulse that is readily compressed. P., Splashing. Synonym of $P$, Jerking. P., Steel-hammer, the abrupt, full pulse felt in the arteries near a joint the seat of acute rheumatism. P., Tense. Synonym of P., Hard. P., Thready, one which is scarcely perceptible. It is met with in syncope, under conditions of collapse; and in the terminal stage of fatal diseases. P.tracing. See $P$-curve and Sphygmogram. P., Tremulous, one in which the finger detects a quivering of the artery with each pulse. P., Tricrotic, a pulse in which the three waves usually present are unusually well marked. P., Undulating, one that conveys to the finger a sensation of successive waves. P., Unequal, one in which the beats vary in force. P., Unsustained. See Corrigan's Pulse. P., Vaginal, a throbbing or pulsation felt in the vagina during pregnancy, or in conditions of intense pelvic engorgement. P., Venous, I. Pulsatile phenomena occasionally observed in veins, especially in the eye. It is also sometimes seen in the jugular veins. See $P$., Jugular. 2. The normal pulse in the cervical veins due to the respiratory movements. See $P$., Respiratory. P., Vermicular, a pulse, usually small and rapid, conveying to the finger a sensation of wormlike motion. P., Virtual Tension, the pulse of high tension associated with a failing heart; the artery is still full between the beats, but is generally large, the impulse is sudden, lasts but a short time, and suddenly declines. See also Pulses. P., Water-hammer. See Corrigan's Pulse. P.-wave, the condition of expansion which begins with each cardiac systole, and is propagated along the aorta and the arteries, ending normally at the capillaries. P., Waxing and Waning. See Pulsus inciduus, P., Wiry, a small, rapid, tense pulse, feeling like a cord under the finger. It is typified by the pulse of acute peritonitis.

Pulsellum (pul-sel'-um) [pulsellum, dim. of pulsus, a beating: pl., Pulsella ]. In biology, a propulsive filament; a modified form of flagellum, characteristic of spermatozoa.

Pulsilegium (pul-sil-e'-je-um). See Pulsilogium.

Pulsilogium (pul-sil-o'-je-um) [pulsus, pulse; $\lambda 6$ бos, a reckoning]. An obsolete instrument, invented by Galileo and improved by Sanctorius, for registering the character of the pulse; a pulse-clock.

Pulsilogon (pul-sil'-o-gon). See Pulsilogium.

Pulsilogram (pul-sil'-o-gram). The record of a Pul. silogizem.

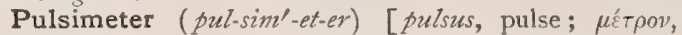
measure]. Any instrument for the quantitative determination of the rate or force of the pulse.

Pulsograph (pul'-sa-graf). Same as Sphygmograph. Pulsometer (pul-som'-et-er). Same as Pulsimeter.

Pulsus (pul'-sus) [L.]. The pulse. P. æqualis, one in which the beats are equal. P. alternans, one in which there is a regular alternation of strong and weak beats. The weak beat may be imperceptible, in which case two heart-beats correspond to only one beat of the pulse. P. araneosus. Synonym of Pulse, Arachnoid. P. bigeminus, one in which the beats occur in pairs, so that a longer pause follows every two beats. P. bisferiens, observed in aortic stenosis in which there is a reinforcement of a prolonged ventricular systole near its close by an accessory spasmodic contraction. P. bisiliens, P. bispulsorus. See $P$. Bisferiens, P. caprizans, in the hyperdicrotic pulse, a condition in which the second beat is felt as a grace-note to the succeeding primary beat; goatleap pulse. P. celer, the quick, short pulse. 
P. celer et altus, the quick, full pulse, seen especially in aortic regurgitation. P. cerebralis, the slow pulse sometimes present in apoplexy. P. cordis, the apexbeat. P. crassus, a strong, full pulse. P. debilis, a feeble pulse. P. deficiens, true intermittence of the pulse, due to actual absence of systole. P. dicrotus. See Pulse, Dicrotic. P. differens, a condition in which the pulse of one artery is found to differ from that of the corresponding vessel of the other side. $\mathbf{P}$. duplex. Synonym of Pulse, Dicrotic. P. durus, the hard pulse of high tension. It is characterized chiefly by early, distinct, and numerous elastic elevations, and a small dicrotic wave. P. endopleuricus. See Pulse, Endopleural. P. exopleuricus. See Pulse, Exopleural. P. filiformis. Synonym of Pulse, Thready. P. fortis. Synonym of Pulse, Hard. P. imminutus. Synonym of Pulse, Mywrous. P. inæqualis. See Pulse, Unequal. P. inanis. Synonym of Pulse, Thready. P. inciduus, the waxing and waning pulse; it consists of successive short periods of pulsations, beginning with a strong beat, and, after gradual diminution, ending with a weak beat. $\mathbf{P}$. inflammatorius, the tense pulse met with in inflammation. $\mathrm{P}$. intercidens. Same as $P$. intercurrens. P. intercisus. Synonym of Pulse, Dicrotic. P. intercurrens, one in which an extra beat is intercalated in a normal series. P. intermittens, one in which in an otherwise regular rhythm a beat is omitted. $\mathbf{P}$. lentus. Synonym of Pulse, Slow. P. magnus, the large, full pulse. P. mollis, the soft pulse of low tension. P. myurus, a pathologic curiosity, in which the pulse-strength gradually tapers away "like the tail of a mouse." It was formerly frequently present after the practice of bleeding. P. paradoxicus, P. paradoxus. See Pulse, Paradoxic. P. parvus, the small pulse of failing heart. P. plenus, a full pulse. $P$. quadrigeminus and $P$. trigeminus, pulses in which the irregularities occur after every fourth and third beat respectively. P. rarissimus. See Bradycardia. $P$. rarus, a pulse of slow rhythm; an infrequent pulse. P. tardus, the slow or long pulse, observed when the heart's action is labored. It is present in aortic and mitral stenosis, in aneurysm, and in senility. P. triferiens, observed in aortic stenosis, due to the reinforcement of a prolonged ventricular systole near its close by two accessory spasmodic contractions. P. undosus, P. undulosus. See Pulse, Undulating. P. vacuus. Synonym of Pulse, Thready. P, venosus. See Pulse, Venozis.

Pultaceous ( $\left.p u l-t a^{\prime}-s e-u s\right)$ [ $p u l s$, pottage]. Having the consistence of pulp or pottage.

Pulver (pul'-ver). See Pulvis.

Pulveraceous (pul-ver-a'-she-us). Synonym of Pulverulent.

Pulveres (pul'-ver-ēs). Plural of Pulvis.

Pulverflator (pul'-ver-fa-tor) [pulvis, powder; flare, to blow]. An instrument designed for blowing or spraying impalpable powders.

Pulveris (pul'-ver-is). Genitive case of Pulvis.

Pulverization (pul-ver-iz-a'-shun) [pulvis, powder]. The operation of reducing a substance to powder.

Pulverous (pul'-ver-uss) [pulvis, powder]. Consisting of dust or powder.

Pulverulent (pul-ver--u-lent) [pulverulentus, full of dust; pulvis, powder]. I. In biology, powdery, dusty. Covered with something resembling a fine powder. 2. Readily reduced to a powder; but slightly coherent (said of tissues).

Pulvillar (pul'-vil-ar) [pulvillus, a little cushion]. Cushion-like.

Pulvilliform (pul-vil'-if-orm) [ pulvillus, a little cushion; forma, form]. In biolosy, resembling a pulvillus.
Pulvillus (pul-vill-us) [pulvillus, a little cushion: $p l$. , Pulvilli]. In biology, the cushion, pad, or suckerlike structure of an insect's foot. Cf. plantula, onychium, empodium.

Pulvinar (pul"-vin-ar) [L., "couch"]. 1. The posterior tubercle of the thalamus opticus. 2. The fatty mass that occupies a part of the acetabulum. 3. A surgical pad. 4. A medicated cushion.

Pulvinate (pul'-vin-ät). Same as Pulvinar.

Pulviniform (pul-vin'-if-orm). Same as Pulvinate.

Pulvinulus (pul-vin'-u-lus). Same as Pulvillus.

Pulvinus (pul-vi'-nus) [ pulvinus, cushion, pillow : pl., Pulvini.]. In biology, an enlargement at the base of some leaves or of the leaflets of some compound leaves. Cf. cushion.

Pulvis [L.; gen., pulveris: pl., Pulveres]. A powder. In pharmacy, one or more medicinal substances reduced to a state of very fine division. There are nine official pulveres P. antimonialis. See Powder, James'. P. aromaticus, a mixture of cinnamon and ginger, each 35 parts, in No. 60 powder, and with nutmeg in No. 20 powder and cardamom seeds, each 15 parts. P. cretæe compositus, consists of prepared chalk 30 , powdered acacia 20 , and sugar 50 parts. Dose 10-60 grains. A mild astringent. P. Doveri. See Powder, Dover's. P. effervescens compositus, Seidlitz powder. A preparation consisting of two powders : the white paper contains 35 grains of tartaric acid, the blue paper, 40 grains of sodium bicarbonate and 2 drams of Rochelle salt. P. glycyrrhizæ compositus, consists of senna, I8; licorice, I6; fennel, 8 ; washed sulphur, 8 ; sugar, 50. P. ipecacuanhæe et opii. See Powder, Dover's. P. jalapæ compositus, consists of jalap, 35 parts; cream of tartar, 65 parts. It is a useful hydragogue cathartic. Dose 30 to 60 grains. P. opii. See Opium. P. parturiens, an old name for ergot. P. rhei compositus, consists of rhubarb, 25 ; magnesia, 65 ; ginger, Io parts. A mild laxative. Dose 30 to 60 grains.

Pumice ( $p u m^{\prime}-i s$, or $\left.p u^{\prime}-m i s\right)$ [pumex]. Pumice-stone, used as a detergent for the skin and an ingredient in some dentrifices.

Pumiced Sole. In farriery, that condition in which the horny sole in the neighborhood of the toe readily crumbles away and leaves the sensitive tissues more or less exposed.

Pumiceous (pum-is'-e-us) [pumiceus, of pumice]. Pertaining to or consisting of pumice.

Pump [ME., pumpe, a pump]. A mechanical apparatus which, by creating a vacuum between its valves, either sucks up a liquid into its hollow chamber, or, after sucking up the liquid, forcibly ejects it from one end. P., Air, a pump used to exhaust the air from a chamber or vessel, or to force more air into a vessel already filled with air. P., Breast, a pump for removing milk from the breast. P., Dental, a device for removing saliva from the mouth during dental operations. P. Force, one which forcibly ejects from one end the liquid which it has sucked into the barrel. P., Lift, the ordinary suction-pump. P., Milk. Synonym of P., Breast. P., Stomach, a pump for removing the contents of the stomach in cases of poisoning. It consists of a barrel, a delivery tube, and a flexible tube to be introduced into the stomach. P., Suction, one which sucks up the liquid into a barrel.

Pumpkin Seed. See Pepo.

Puna ( $p u^{\prime}$-nah). See Mountain Sickness.

Punch [punctuare, to pierce]. I. A mixed alcoholic or vinous beverage. There are many kinds; as milkpunch, tea-punch, claret-punch, rum-punch, arrack- 
punch. 2. An instrument used in extracting stumps of teeth.

Punch's Voice. A peculiar bell-like, or ringing tone of voice, like that assumed by "Punch" in the l'unch and Judy shows. It is sometimes heard among the insane, and has been thought to be sometimes a forerunner of violent and homicidal attacks.

Punching-bag ( $\left.p u n c h^{\prime}-i n g-b a g\right)$. A bag suspended from the ceiling, to be struck and punched, in physical exercise.

Puncta ( $\left.p u n k^{\prime}-t a h\right)$ [pl. of Punctum, a point]. Points. P. cruenta. Synonym of $P$. vasculosa. P. dolorosa, tender or painful points in the course of nerves in an inflamed condition, or at the exit of nerves the seat of neuralgia. See Valleix's Puints. P. lacrimalia, the orifices of the lacrymal canaliculi in the eyelids near the inner canthus. P. vasculosa, minute red spots studding the cut surface of the white central mass of the brain. They are produced by the blood escaping from divided blood-vessels.

Punctate, Punctated (punk'-tät, punk-ta'-ted') [punctum, point]. Having many points. Dotted. Full of minute punctures.

Punctation ( $\left.p u n k-t a^{\prime}-s h u n\right)$. See Tapotement.

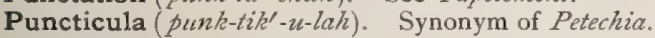

Puncticulate, Puncticulose (punk-tik'-le-lāt, punk$\left.t_{i} k^{\prime}-u-l o z\right)$ [puncticulum, dim. of punctum, point]. Marked by minute puncta.

Punctiform (punk'-tif-orm) [punctum, point; forma, form]. Having the nature or qualities of a point; seeming to be located at a point; as a punctiform sensation.

Punctulate (pungk'-tu-lät) [punctulum, a small point]. Minutely punctate.

Punctule (pung $\left.k^{\prime}-t \bar{u} l\right)$ [punctulum, a small point]. A small puncture or dot.

Punctum (pung $k^{\prime}-t u m$ ) [L., a point, dot: $p l$., Puncta]. A point or minute area. P. aureum. See Macala lutea. P. creum. See Blind Spot. P. fixum, the point of attachment of a muscle. $P$. foraminis incisivi, Lissauer's term for the posterior border of the incisor foramen. P. foraminis magni anterius. Synonym of Basion. P. insertionis, the point of insertion of a muscle. $\mathbf{P}$. nasale inferius. Synonym of Rhinion. P. ossificationis. See Center of Ossifiction. P. præmaxillare. Synonym of Point, Alveolar. P. proximum, the point nearest the eye at which an object can be seen with distinctness and without diplopia. P. remotum, the farthest point at which an object can be distinctly seen with suspended accommodation. In the emmetropic eye it is theoretically at an infinite distance; in the hyperopic eye it is theoretically beyond this, as such an eye is adapted only for convergent rays. $P$. saliens, the first trace of the embryonic heart. P. spinæ nasalis anterioris, the apex of the anterior nasal spine, or if it be absent, the upper extremity of the suture between the two maxillæ. P. spinæ nasalis posterioris, the center of the posterior nasal spine. $\mathrm{P}$. vegetationis, the vegetating point. Applied to the growing-point of an organ, as of a stem or root.

Puncturation (punk-tu-ra'-shun) [pungere, to prick]. The making of punctures; acupuncture.

Puncture (punk'-chür) [ pungere, to prick]. A wound or hole made by a pointed instrument. P., Capillary, a puncture made with a needle of capillary fineness. P.-diabetes, diabetes caused by puncture of the oblongata near the hepatic vaso-motor center (diabetic center). P., Diabetic, puncture of the fourth ventricle in animals, which produces glycosuria.

Pungence (pun'-jens) [pungens, penetrating]. Pungent quality; tartness.

Pungent (pun'-jent) [pungens; pungere, to prick]. 77
Acrid; penetrating; producing a pricking or painful sensation.

Punica $\left(p u^{\prime}-n i k-a h\right)$ [ punicum, the pomegranate]. A genus of polypelatous plants. P. granatum. See Pomegranate.

Punicin $\left(p u^{\prime}-n i s-i n\right)$ [puniceus, reddish]. I. A crystalline coloring-matter obtained from the colorless juices of certain kinds of shell-fish (Purpura lapellus, $P$. patula); on exposure to the sunlight it becomes of a purple color. See Pigments, Conspectus of. 2. Synonym of Pelletierin.

Punning (pun'-ing) [origin uncertain]. Play upon words. This practice is very common among some classes of lunatics, especially during periods of excitement and exaltation.

Pupa ( $\left.p u \ell^{\prime}-p a h\right)$ [ $p u p a$, a girl, doll, puppet: $p l$, $P u p c e]$. In biology, the second stage of development from the egg, of such insects as undergo complete metamorphosis.

Pupal (pu'-pal) [pupa, a doll]. Pertaining to a pupa. Puparium ( $\left.p u-p a^{\prime}-r e-u m\right)$ [pupa, a pupa: pl., Puparia]. In biology, a pupa inclosed in the larval skin.

Pupate $\left(p u t^{\prime}-p a \bar{t} t\right)$ [pupa, a doll]. In biology, to become a pupa.

Pupation ( $\left.p u-p a^{\prime}-\operatorname{sh} u n\right)$ [pupa, a doll]. The act of pupating; the pupal condition.

Pupiform ( $\left.p u^{\prime}-p i f-o r m\right)$ [pupa, pupa ; forma, form]. Having the form of a pupa.

Pupigenous ( $\left.p u-p i j^{\prime}-e n-u s\right)$. Same as Pupiparous.

Pupigerous $\left(p u-p i j^{\prime}-e r-u s\right)$ [pupa, pupa ; gerere, to carry]. Forming a puparium.

Pupil (pu'-pil) [pupilla]. The round aperture in the iris of the eye. P., Argyll Robertson, one of the early symptoms of tabes, in which a myotic pupil responds on accommodative effort, but not to light. $\mathrm{P}$., Artificial, an iridectomy made in an iris the pupil of which is occluded by inflammatory deposits. P., Cat's-eye, an elongated, slit-like pupil. P., Exclusion of, total posterior synechia, the entire pupiilary edge of the iris being adherent to the capsule. P., Hutchinson's, one-sided dilatation of the pupil in hemorrhage from the middle meningeal artery. P., Occlusion of, the pupillary area is filled with semiopaque inflammatory exudation-products. P., Pinhole, extreme myosis.

Pupillary (pu'-pil-a-re) [pupilla, pupil]. Pertaining to the pupil of the eye. P. Membrane, a fetal membrane covering the eye until the seventh month of gestation. P. Membrane, Persistent, fibrillar bands springing from the iris, passing to or across the pupil, and sometimes attached to the lens-capsule-the unabsorbed remains of the pupillary membrane, $\mathbf{P}$. Reflex. See Reflexes, Table of.

Pupillate (pu'-pit-āt) [pupilla, a pupil]. Having a central spot or pupil.

Pupillometer (pu-pil-om'-et-er) [ pupilla, pupil ; $\mu \varepsilon ́ \tau \rho o v$, a measure]. An instrument designed for the measurement of the pupil of the eye.

Pupilloscopy (pu-pil-os'-ko-pe) [pupilla, pupil; $\sigma \kappa o-$ $\pi \varepsilon i \nu$, to inspect]. Same as Koroscopy, or Retinoscopy. More exactly, the diagnostic inspection of the pupil.

Pupillostatometer (put'pit-a-stat-om'-e-ter) [pupilla,

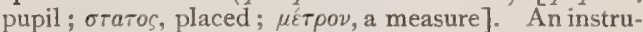
ment for measuring the exact distance between the centers of the two pupils.

Pupiparous ( $\left.p u-p i p^{\prime}-a r-u s\right)$ [pupa, pupa; parere, to bring forth]. Bringing forth pupæ.

Pure (pür) [ purus, pure]. Unstained; unalloyed. P. Scarlet. See Pigments, Conspectus of.

Purgament, Purgamentum (per'-gam-ent, per-gamen'-tum) [purgare, to purge: pl., Purgamenta]. I. A purge. 2. In the plural, the lochia; also, excrement. 
Purgantia (pur-gan'-she-ah) [purgare, to purge]. Laxatives.

Purgation ( $\left.p u y^{\prime}-g a^{\prime}-s h u n\right)$ [ purgare, to cleanse]. The evacuation of the bowels by means of purgatives.

Purgative (pur-gat-iv) [purgare, to purge]. I. Having a tendency to purge; cathartic. 2. A medicine producing copious evacuations of the bowels.

Purge (purj) [purgare, to purge]. A purgation; a dose of purgative medicine. As a verb, to cause free evacuations of the bowels.

Purging ( free evacuations of the bowel. P. Agaric. See Asaricus. P. Cassia. See Cassia. P. Nut. The seed of the tropical tree, Jatropha curcas. The nut affords a purgative oil much like castor-oil, though not so active.

Purified ( $p u^{\prime}-r i f-\bar{z} d$ ) [purus, pure; facere, to make]. Cleansed; freed from extraneous matter.

Puriform (pu'-ri-form) [pus, pus; forma, form]. Resembling pus.

Puritic (pu-rit'-ik) [pus, pus]. Pertaining to jus.

Purkinje, Axis-cylinder of (per-kin'-je) [a Bohemian physiologist, I $787-1869$ ]. The viscous fluid contents of a nerve-tube, solidified by coagulating agents, and

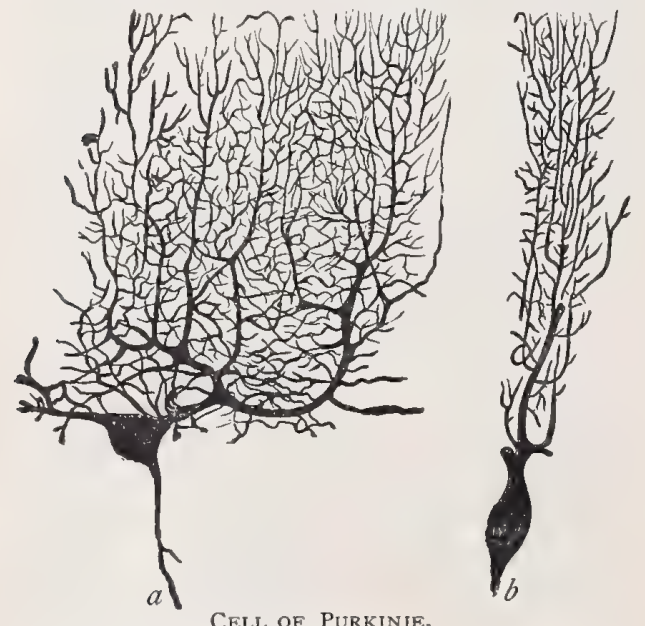

$a$, Seen on the flat, and $b$, from the side. $X$ I20. (From Stirling.)

after treatment with chromic acid appearing as a solid rod running down the center of the tube. P.'s Cells, the cells forming the thinnest but, at $\mathrm{the}$ same time, the most characteristic layer of the cerebell ar cortex. They are among the largest ganglion-cells in the body, are dis posed as a single row at the junction of the nuclear and the molecular layer, and present py- c. Cell, $f$. Striated substance. $n$. Nuriform or flask-

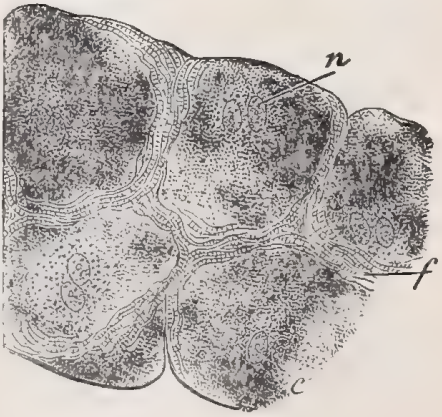

Purkinje's Fibers.

cleus. $\times 300$, (Landois.)

shaped bodies, 60-70 $\mu$ in their longest diameter, placed vertically to the plane of the zone, with the larger rounded end resting on the outer margin of the nuclear layer, while the smaller end is directed toward the periphery. (Piersol.) P., Corpuscles of. See Bone-lacuna. P.'s Fibers, an anastomosing system of grayish muscular fibers that exists in the sub-endocardial tissue of the ventricles, especially in the heart of the sheep and ox. The fibers are composed of nucleated polyhedral cells, containing some granular protoplasm. P.'s Figures, shadows of the retinal blood-vessels upon the retina. P. Vesicle, the nucleus of the human ovum first discovered by Purkinje ( 1830 ), and known as the vesicula germinativa, Purkinje'schen Bläschen, or Germinal Vesicle.

Purkinje-Sanson's Images. Three pairs of images of one object seen in an observed pupil : the first, erect, reflected from the anterior surface of the cornea; the second, erect, reflected from the anterior surface of the lens; the third, inverted, reflected from the posterior capsule of the lens.

Puro-hepatitis (pu-ro-hep-at-i'-tis) [pus, pus; $\eta^{\top} \pi a \rho$, liver; $\iota \tau \iota s$, inflammation ]. Purulent hepatitis.

Putomucous (pu-ro-mu'-kus) [pus, pus; mucus, mucus]. Purulent and mucous.

Purple $\left(p u r^{\prime}-p l\right)$ [purpureus]. Of a color possessing the elements of blue and red. As a noun, the color itself, or a body possessing it. P.-brown. See Pigments, Conspectus of. P.-carmin. Same as Murexid. P. of Cassius, the purplish-red precipitate resulting when a solution of gold trichlorid is brought in contact with a mixture of stannous and stannic chlorids. P., French. Synonym of Orchellin. P.-madder. See Pigments, Conspectus of. P., Mineral. Synonym of $P$. of Cassius. P. of Mollusca. Same as Tyrian Purple. P., Ocher. Same as Mineral Purple. P., Visual. See Rhodopsin.

Purples (pur'-plz) [purpureus, purple]. A popular name for purpura; also, for petechial spots.

Purposive (pur'-po-siv) [ME., purposen, to propose]. Functional; not vestigial, and not rudimentary; regarded as fulfilling an end or purpose in the economy. P. Acts, those acts performed with the consent of the will.

Purpura (pur'-pu-rah) [L. for "purple" ]. Hamorrhaea petechialis; a general term including all extravasations of blood into the skin and mucous membranes not resulting from traumatism. It is symptomatic of many conditions. P. apyretica. Synonym of $P$. simplex. P., Aqueous. Synonym of Hamophitia. P. bullosa. See Pemphigus hamorrhagicus, P. febrilis, purpura with elevation of temperature. $\mathbf{P}$. fulminans, a grave form of purpura, developing in young children as a sequel to acute infectious diseases. It is of short duration, is marked by extensive extravasations, grave constitutional symptoms, and usually ends fatally. P. hæmorrhagica, Morbus maculosus werthofi; Land-scurvy; a greatly aggravated form of purpura simplex. There are marked constitutional symptoms followed by an eruption of hemorrhagic points, larger than in purpura simplex, upon the lower limbs, extending in successive crops over the whole body-surface, coalescing to form irregularly-shaped extensive ecchymotic patches, or even raised, bloody tumors (ecchymomata). Hemorrhages may take place from the mucous surfaces or into the serous cavities. Recovery is the rule. See Werlhof's Disease. The disease may be infectious. P. hypertrophica. See P.tuberculosa. P., Iodic, a purpuric eruption caused by the use of iodin or the iodids. P., Malignant. Synonym of Fever, Cerebrospinal. P. medicamentosa, purpura due to the action of drugs. See $P$., Todic. P. menstrualis, 
purpura associated with the menstrual period. P. miliaris. Synonym of Miliaria. P. nautica. Synonym of Scurvy. P. neonatorum, that occurring in the newborn from sudden changes in the circulation. P. neurotica, purpura due to a nervous disease. P. papulosa, the variety in which the effusion is round a hair-follicle and papules are formed. $P$. Pestilential. Synonym of Fever, Cerebrospinal. P. puerperalis, P. puerperarum, a purpuric eruption occurring during the puerperium, and probably due to septicemia. P. pulicosa, petechial spots produced by flea-bites. P. rheumatica. See Peliosis rheumatica. P. scorbutica. Synonym of Scurvy. $P$. senilis, that occurring in old age from want of support to the vessels due to relaxation of the tissues. P. simplex, the mildest degree of purpura. It generally occurs suddenly in young persons who are apparently healthy. Small, flat, roundish, or irregularly-shaped petechix appear, of a deep-red color, which does not disappear on pressure and soon becomes purplish, the lesions usually remaining discrete. There are no concomitant constitutional, or subjective symptoms. In children the spots are commonest about the upper part of the trunk, neck, and arms; in adults, about the inner surface of the thighs. P. syphilitica, purpura due to syphilis; it may be localized, as in the area of distribution of a certain nerve, or it may be general. P. thrombotica, pur pura due to thrombosis of the veins. See Erythema purpuricum. P. traumatica, purpuric spots due to traumatism. P. tuberculosa, $P$. hypertrophica; a rare form associated with the formation of tubercles or nodules upon the skin, and edema of the affected part. Death follows from gradual exhaustion. P. urticans. See Unticaria hemorrhagica. P. variolosa. See Small-pox, Hemorrhagic. P., Vascular, purpura due to changes in the character of the blood or changes in the vessel walls.

Purpuraceous (pur-pu-ra'-se-us) [purpura, purple]. Of a purple color.

Purpurate (pur'-pu-rāt) [purpurn, purple]. Of a purple color.

Purpuremia (pur-pu-re'-me-ah) [ purpureus, purple; ai $\mu a$, blood]. Intermittent malarial fever with hematuria.

Purpurescent (pur-pu-res'-ent) [purpura, purple]. Purplish

Purpuric (pur-pu'-rik) [purpura, purple]. Purplish. Pertaining to, or of the nature of purpura. P. Acid. See Acid.

Purpurigenous (pur-pu-rij'-en-us) [ purpura, purple; genere, to bear]. Producing purple.

Purpurin (pur'-pu-rin) [ purpura, purple], $\mathrm{C}_{14} \mathrm{H}_{8} \mathrm{O}_{5}$. I. A dye present with alizarin in the madder-root. It is prepared artificially by heating alizarin and quinizarin with manganese dioxid and $\mathrm{H}_{2} \mathrm{SO}_{4}$ to $150^{\circ} \mathrm{C}$. It crystallizes with one molecule of water in reddishyellow needles or prisms, and dissolves with a purered color in hot water, alcohol, ether, and the alkalies. 2. Uroerythrin; a red coloring-matter sometimes present in urinary deposits. It may attend serious lesions, but is often of no special significance. See Pigments, Conspectus of.

Purpuriparous ( $p u r-p u$-rip'-ar-us). Same as Purpurigenous.

Purpuroxanthic Acid (pur-pu-ro-zan'-thik) [purpura, purple; $\xi \dot{\alpha} \nu 0$ os, yellow ], $\mathrm{C}_{15} \mathrm{H}_{8} \mathrm{H}_{6}$. A substance found in madder.

Purrée $\left(p u r^{\prime}-a\right)$ [E. Ind.]. See Euxanthinic Acid, and Pigments, Conspectus of.

Purreic Acid, Purrheic Acid (pur-e'-ik). See Euxanthic Acid.
Purring Thrill. A fine, trembling vibration in the precordium, either heard or perceived by palpation. It may be due to aneurysm, or to some valvular heartlesion, especially mitral stenosis.

Purse-string Operation. See Stoltz's Operation in Operations, Table of.

Pursy (pur'-se) [ME., pursy, short-winded]. Fat, or corpulent, and short of breath. [Popular.]

Purulence ( $p u v^{\prime}-u$-lens) [pus, pus]. The quality of being purulent; suppuration.

Purulent (pur'-u-lent) [pus, pus]. Having the character of or forming pus. P. Catarrh, an inflam. mation of a mucous membrane accompanied by the production of pus. P. Edema, a general infiltration of pus with much fluid.

Puruloid (pur'-u-loid) [pus, pus; eỉoós, like]. Resembling pus; puriform.

Pus $[\pi \tilde{v} \sigma \nu]$. A fluid of varying consistence produced in the process of suppuration. It is formed by a liquefactive necrosis of the intercellular substance of tissues, the cells themselves floating in the fluid and undergoing fatty degeneration. Clinically, pus is due to the action of microörganisms. P., Blue, pus colored blue by the bacillus pyocyaneus, P.-corpuscles, the corpuscles found in pus; they are small, usually multinuclear cells, chiefly outwandered leukocytes, but also degenerate connective-tissue cells. The nuclei may be hidden by granules, but can be made to appear by adding a little acetic acid to the pus. P., Curdy, containing cheesy-looking flakes. P.-disease. Synonym of Pyemia. P., Healthy. See P., Laudable. P., Ichorous, pus when thin and acrid. P., Laudable, a whitish, inodorous pus, formerly thought to be essential to the healing of wounds. P., Muco-, pus mixed with mucus. P.-poison, a chemic compound that gives rise in the tissues to purulent inflammation. The proteid extracts of many bacteria act thus, e. g., tuberculin. P., Sanious, pus mixed with blood. P. Sero-, pus largely admixed with serum. P.-tube, a term frequently applied to a Fallopian tube the seat of suppurative inflammation. See Pyosalpinx. P., Watery. Synonym of $P$., Ichorous. For microörganisms of pus see Bacteria, Synonymatic Table of.

Pustula (pus'-tu-lah) [L.]. A pustule. A vesicle or bleb containing pus. P. maligna, Anthrax; Char. bon; Malignant Pustule; Woolsorters' Disease; Splenic Fever; Carbuncle, Milzbrand; an acute specific disease, due to the introduction of the bacillus anthracis into the system. It is characterized by the appearance of a localized inflammation beginning as a vesicle, and is situated on the face, neck, hands or arms, closely resembling carbuncle. The tumefaction may be very great, and this is associated with a profound degree of depression and exhaustion, the patient often dying on the fourth or fifth day. In favorable cases recovery takes place. The fever is slight; in fact, there is often a subnormal temperature. In some cases general infection does not occur. Internal Anthrax, mycosis intestinalis, anthrax intestinalis, may be secondary to infection of the skin, but in some cases no primary focus can be discovered. The symptoms are diarrhea, vomiting, dyspnea, and a tendency to collapse. The temperature is usually not elevated, often subnormal. Death occurs in profound collapse in a very few days. The lesions consist of necrotic foci in the intestines; bacilli are abundant in the vessels of these areas. The spleen is not much enlarged, but the lymphatic glands are greatly tumefied. See Pustule.

Pustulant (pus'-tu-lant) [pustula, a pustule]. I. Causing the formation of pustules. 2. An irritant substance which does not affect the whole skin 
alike, but especially irritates isolated portions and gives rise to the formation of pustules. Croton-oil and tartar emetic are examples.

Pustular (pus'-tu-lar) [pustula, pustule]. Pertaintaining to or characterized by pustules. In biology, a term descriptive of a surface which has blister-like elevations. P. Grease. See Horsepox.

Pustulate (pus'-tu-lät) [pustulare, to blister]. To form pustules. 2. Same as Pustular.

Pustulation (pus-tu-la'-shun) [pustula, pustule]. condition marked by the formation of pustules.

Pustulatous (pus'-tu-lät-us). Same as Pustular.

Pustule $\left(p u s^{\prime}-t \bar{u} l\right)$ [pustula, pustule]. A vesicle or bleb containing pus. It is always of inflammatory origin, of a yellowish color, and has, as a rule, a red areola, sometimes with induration. P., Malignant. See Pustula maligna.

Pustuliform (pus'-tu-lif-orm) [pustula, pustule; forma, form]. Resembling a pustule.

Pustulocrustaceous (pus-tu-lo-krus-tá-se-us) [ pustula, pustule; crusta, crust]. Pustulous, and also covered with crusts, or scabs.

Pustulose (pus'-tu-lōz). Same as Pustulirr.

Pustulose, Pustulous (pus'-tu-lōz, pus'-tu-lus) [pustula, pustule]. Characterized by pustules.

Pusula $\left(p u s^{\prime}-u-l a h\right)[$ L. $]$. I. Pustule. 2. Erysipelas.

Putamen (pu-ta'-men) [ putamen, husk: pl., Putamina $]$. I. The lateral or darker part of the lenticular nucleus of the brain. 2. In biology: (a) the stone of a drupe, or shell of a nut; (b) the soft or inner shell of an egg.

Putaminous (pu-tam'-in-us) [putamen, husk]. Pertaining to the membrana putaminis.

Putchuk (put'-chuk) [India]. The costus root; the root of Saussurea lappa, a composite plant of India. In that country and China it is extensively used in medicine. It is a stimulant and aromatic tonic. Also the root of Aristolochia recurvilabra, an Asiatic plant; useful as an emmenagogue, diuretic, tonic, and stimulant. Unof.

Putrefacient (pu-tre-fa'-se-ent) [putridus, putrid; facere, to make]. r. Causing putrefaction. 2. An agent that causes putrefaction.

Putrefaction ( $\left.p u-t r e-f a k^{\prime}-s h u n\right)$ [putridus, rotten; facere, to make]. The decomposition of nitrogenous organic matter under the influence of microörganisms, and accompanied by the development of disagreeable odors, due to the evolution of ammonia and hydrogen sulphid.

Putrefactive (pu-tre-fik'-tiv) [putridus, putrid; facere, to make]. Pertaining to or causing putrefaction.

Putrefy $\left(p u^{\prime}-\operatorname{tre}-f i\right)$ [putrefacere, to putrefy]. To render putrid.

Putrescence (pu-tres'-ens) [putrescere, to become rotten]. The state or process of putrefaction.

Putrescent (pu-tres'-ent) [putrescere, to become rotten]. Undergoing putrefaction.

Putrescin (pu-tres'in) [putrescere, to become rotten], $\mathrm{C}_{4} \mathrm{H}_{12} \mathrm{~N}_{2}$. A poisonous ptomain. It is a clear, rather thin liquid of a disagreeable odor, boiling at $\mathbf{I} 56^{\circ}-157^{\circ} \mathrm{C}$. See Ptomains, Table of.

Putrid (pu'-trid) [putridus, rotten]. Rotten; having undergone putrefaction. P. Fever. Synonym of Typhus Fever, q.v. P. Infection, pyemia due to infection from a gangrenous focus. P. Pleurisy. See Pleurisy, Ychorous. P. Sore-mouth. See Stomatitis, Ulcerative. P. Sore-throat. See Pharyngitis, Gansrenous.

Putridity (pu-trid'-it-e) [putridus, rotten]. The quality or state of being putrid; putrid material.

Putrilage (pu-trit-ahzh') [putris, rotten]. Putrescent or gangrenous material.
Putty $($ put'-e) [OF., potee, brass]. A pasty, inelastic substance usually made from whiting and linseed-oil, and hardening on exposure to the air. P., Horsley's, a mixture of white and yellow wax, vaselin, and carbolic acid, used to check bleeding from the vessels of cut bone.

Pyæmia ( $\left.p i-e^{\prime}-m e-a h\right)$. See Pyemia.

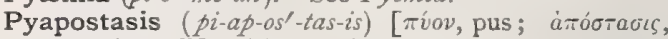
a standing off ]. Metastasis of pus.

Pyarthrosis ( $\left.p i-a r-t h r o^{\prime}-s i s\right)[\pi \tilde{v} o v$, pus; à $\rho \theta \rho o v$, joint $]$. Suppuration of a joint.

Pyaulacomele $\left(p i-a w-l a k-o m^{\prime}-\ell l-\ell\right)\left[\pi v o v\right.$, pus ; avin $a_{\xi}$, furrow ; $\mu \eta \dot{\lambda} \lambda \eta$, probe]. A grooved probe used in exploring for pus.

Pycnicmasia, Pycnicmasis (pik-nik-ma'-ze-ah, pik-

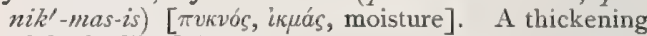
of the bodily fluids.

Pycnid, Pycnide ( $p i k^{\prime}$-nid). Same as Pycnidium.

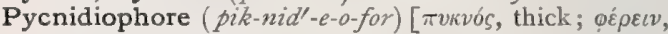
to bear]. In biology, a compound sporophore bearing pycnidia.

Pycnidiospore (pik-nid'-e-o-spōr). Same as Stylospore.

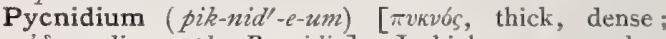
idıov, dim.: pl., Pycnidia]. In biology, are productive body resembling a perithecium, found in certain fungi (Ascomycetes). Pycnidia arise interstitially on mycelial hyphæ, and consist of a wall of several layers, from the inner surface of which there converge series of cells producing successively (terminally and laterally) pycnospores (Bennett and Murray).

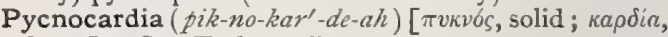
heart]. See Tachycardia.

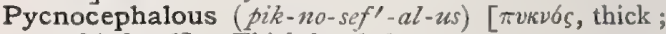
$\kappa \varepsilon \phi a \lambda \eta$, head]. Thick-headed.

Pycnoconidium (pik-no-ko-nid'-e-um) [ $\pi v \kappa v o ́ s$, thick ;

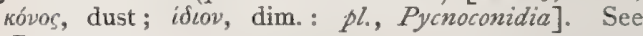
Pycnospore.

Pycnogonidium (pik-no-go-nid'-e-um) [ yov'n, generation; idıov, dim.: pl., Pycnogonidia ]. See Pycnospore.

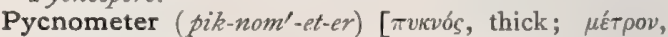
measure]. A specific-gravity bottle, or a small, light flask of known weight.

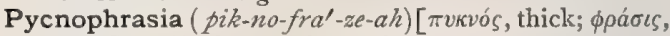
speech]. Thickness of speech.

Pycnosis (pik-no'-sís) [ $\pi v \kappa v o ́ s$, thick]. Thickening; inspissation.

Pycnospore (pik'-no-spōr) [ $\pi v \kappa v o ́ s$, close; $\sigma \pi \measuredangle p o s$, seed]. In biology, De Bary's term for the stylospores produced in the pycnidia of the Ascomycetes.

Pycnotic (pik-not'-ik) [ $\pi v \kappa v o ́ s$, thick]. Pertaining to pycnosis.

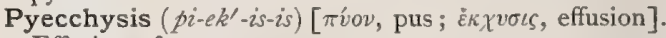
Effusion of pus.

Pyedema, Pyœdema ( $\left.p i-e-d e^{\prime}-m a h\right)[\pi \bar{v} o v$, pus ; ò $\delta \eta \eta \mu$, edema]. Edema due to purulent infiltration.

Pyelitic $\left(p i-e l-i t^{\prime}-i k\right)$ [ $\pi \dot{v} \varepsilon \lambda o s$, trough; $\iota \tau \iota s$, inflammation]. Relating to or affected with pyelitis.

Pyelitis ( $\left.p i-e l-i^{\prime}-t i s\right)$ [ $\pi \dot{v} \varepsilon \lambda o \zeta$, a trough; $\iota \tau \iota \zeta$, inflammation]. Inflammation of the pelvis of the kidney. It may be due to the mechanical irritation of calculi, or to tumors, animal parasites, tubercles, etc., or it appears in the course of acute specific fevers, or, perhaps most commonly, is secondary to diseases of the bladder. It is marked by pain and tenderness in the lumbar regions, and the presence in the urine of albumin, mucus, epithelial cells from the pelvis of the kidney, and pus-corpuscles in large amount. The urine is generally acid. Blood is also frequently seen in the urine. Gradually a swelling or tumor appears in the lumbar region, dull on percussion and slightly fluctu- 
ating. P., Calculous, that due to calculi. Hemorrhagic, that attended with hemorrhage.

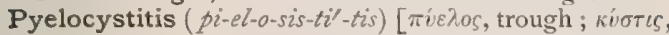
bladder; $\iota \tau \iota$, inflammation]. Pyelitis with cystitis.

Pyelo-lithotomy ( $\left.p i-e l-o-l i t h-o t^{\prime}-0-m e\right)$ [ $\pi i \varepsilon \dot{i} o s$, trough; $\lambda i t o s$, stone; $\tau$ oun, a cutting]. Removal of a renal calculus through an incision into the pelvis of the kidney.

Pyelometer (pi-el-om'-et-er). Synonym of Pelvimeter. Pyelonephritic (pi-el-o-nef-rit'-ik) [ $[\pi v \varepsilon \lambda o s$, trough;

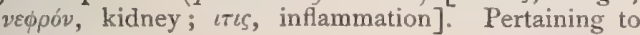
pyelonephritis.

Pyelo-nephritis ( $\left.p i-e l-o-n e f-r i^{\prime}-t i s\right)$ [ $\pi v \varepsilon \lambda o s$, trough ;

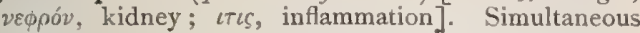
inflammation of the kidney and its pelvis.

Pyelonephrosis ( $\left.p i-e l-o-n e f-r o^{\prime}-s i s\right)$. Synonym of Pyelonephritis.

Pyelotomy ( $\left.p i-e l-o t^{\prime}-o-m e\right)$ [ $\pi v \varepsilon \lambda o s$, trough; $\tau o \mu^{\prime}$, a cutting]. Incision of the renal pelvis.

Pyemesis (pi-em'-is-is) [ $\pi v o ́ v$, pus ; $\dot{\varepsilon} \mu \varepsilon \sigma \iota$, vomiting]. Vomiting of pus.

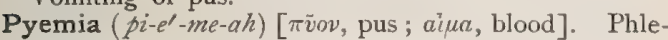
bitic septicemia, with the presence of pyogenic microörganisms in the blood and with the formation wherever they lodge of secondary embolic or metastatic abscesses. It is characterized by intermittent fever, with recurrent rigors, profuse sweats, a sweetish odor to the breath, a dry, brown tongue, and rapid emaciation. Slight jaundice frequently develops; sometimes, also, a purpuric eruption; the temperature may be very high, $105^{\circ}$, or even more. It usually terminates in death. P., Arterial, a name given to pyemia produced by disorganization of a cardiac thrombus and the dissemination of emboli through the arterial circulation. P., Cryptogenetic, a condition in which the primary suppuration occurs in the deeper tissues of the body.

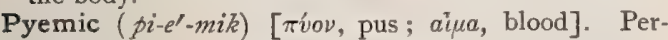
taining to or affected with pyemia.

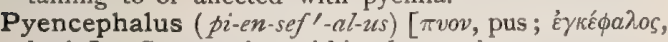
brain]. Suppuration within the cranium.

Pyesis ( $\left.p i-e^{\prime}-s i s\right)$. Synonym of Suppuration.

Pyetia ( $\left.p i-e^{\prime}-s h e-a h\right)$. Synonym of Colostrum.

Pygagria ( $\left.p i-g a^{\prime}-g r e-a h\right)$ [ $\pi v \gamma \dot{\eta}$, buttock; $\dot{a} \gamma \rho a$, seizure]. Pruritus ani ; eczema, or pain, of the anal region. $\mathbf{P}$. granulata, eczema of the anal region.

Pygal ( $\left.p i^{\prime}-g a l\right)[\pi v \gamma \eta$, rump]. In biology, of or pertaining to the rump.

Pygidial ( $\left.p i-j i d^{\prime}-e-a l\right)$ [ $\pi v \gamma \eta$, rump]. Pertaining to a pygidium.

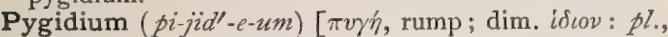
Pygidia]. In biology, a term applied to the hinder or rump region of the body in various animals, especially insects, crustaceans, and worms.

Pygme ( pig $\left.^{\prime}-m e\right)\left[\pi v y \mu \eta^{\prime}\right.$, fist]. The distance between the elbow and the knuckles. Fist. Forearm.

Pygmy, Pigmy ( pig' $\left.^{\prime}-m e\right)$ [ $\pi v \gamma \mu \dot{n}^{\prime}$, a fist]. A dwarf or dwarfish person.

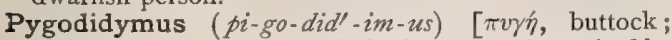
didvuos, twins]. A double fetal monstrosity united by the buttocks.

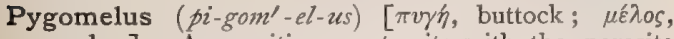
member]. A parasitic monstrosity with the parasite united to the hypogastric region or to the buttock.

Pygopagus ( $\left.p i-g \circ p^{\prime}-a g-u s\right)\left[\pi v \gamma \dot{\eta}\right.$, buttock; $\pi a ́ \gamma^{\prime} \circ \varsigma$, joined]. An ensomphalic monstrosity with conjoined buttocks or backs.

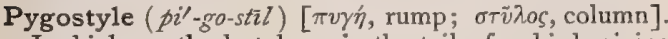
In biology, the last bone in the tail of a bird, giving support to the tail-feathers. It theoretically consists of ankylosed or coalesced caudal vertebræ, as there are pairs of feathers in the tail.
Pyic $\left(p i^{\prime}-i k\right)$. Synonym of Purulent.

Pyin $\left(p i^{\prime}-i n\right)[\pi \tilde{v}$ ov, pus]. An albuminous substance of complex constitution occurring in pus. It may be separated by adding sodium chlorid and filtering.

Pyknometer (pik-nom'-et-er). See Pycnometer.

Pyla ( $\left.p i^{\prime}-l a h\right)[\pi i \lambda \eta$, gate: pl. and gen., Pylce]. The orifice by which the mesal portion of the mesocele communicates with the lateral.

Pylemia ( $\left.p i-l e^{\prime}-m e-a h\right)\left[\pi v i \eta \eta\right.$, gate; $\alpha^{\top} \mu a$, blood $]$. The blood of the portal vein.

Pylemphraxis (pi-lem-fraks'-is) [ $\pi \hat{v} \lambda \eta$, gate; $\dot{\varepsilon} \mu \phi \rho a \xi \iota s$, obstruction]. Obstruction of the portal circulation.

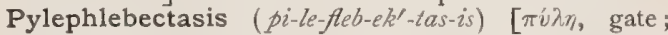

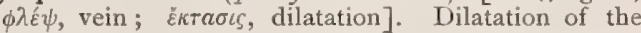
portal vein. This is usually caused by some obstruction in the liver, or it may be due to relaxation of the vesselwalls from some disturbance of innervation.

Pylephlebitis ( $\left.p i-l e-f l e b-i^{\prime}-t i s\right)[\pi \dot{v} \lambda \dot{\eta}$, gate ; $\phi \lambda \varepsilon \dot{\psi}$, vein ; $\iota \tau \iota$, inflammation]. Inflammation of the portal vein. The symptoms are those of pyemia; the liver is usually enlarged and tender. The condition is usually secondary to disease of the intestines. P., Adhesive, thrombo-phlebitis of the portal vein.

Pylethrombosis (pi-le-throm-bo'-sis) [ $[\pi \hat{\lambda} \lambda \eta$, gate; $\theta \rho 6 \mu \beta o s, c l o t]$. Thrombosis of the portal vein.

Pylic $\left(p i^{\prime}-l i k\right)[\pi \hat{\lambda} \eta$, gate]. Pertaining to the portal vein.

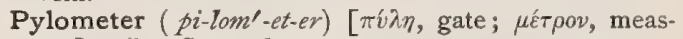
ure]. See Cystopylometer.

Pylophlebitis ( $p i-l o-f l e b-i$-tis). Synonym of Pylephlebitis.

Pylorectomy $\left(p i-l o r-e k^{\prime}-t o-m e\right)[\pi v \lambda \omega \rho o ́ s$, pylorus; $\dot{\varepsilon} \kappa \tau o \mu \dot{n}$, excision]. Excision or resection of the pylorus.

Pyloric ( $\left.p i-l o r^{\prime}-i k\right)$ $[\pi v \lambda \omega \rho$ os, pylorus]. Pertaining to the pylorus. $\mathbf{P}$. Artery, the pyloric branch of the hepatic artery. P. G I a n d s, glands of the pylorus, secreting the gastric juice. P. Plexus, branches of the hepatic plexus accompanying the pyloric artery.

Pyloristenosis ( pi-lor-is-ten-o' sis) $[\pi v \lambda \omega \rho 6 s, \mathrm{py}-$ lorus ; $\sigma \tau \varepsilon \nu \delta s$, narrow]. Contraction of the pylorus.

Pyloritis ( $p i-$ lor $-i^{\prime}$ -

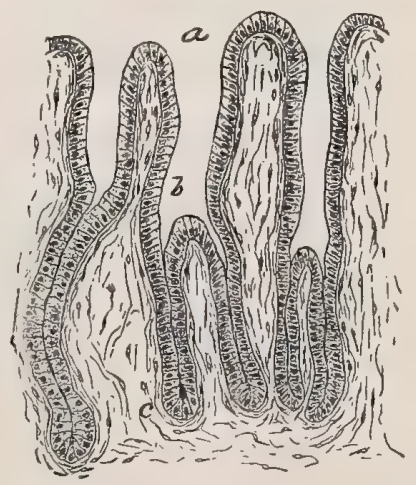

SECTION OF Pyloric GLANDS From HUMAN STOMACH.

a. Mouth of gland leading into long, wide duct $(b)$, into which open the terminal divisions. $c$. Connective tissue of the mucosa. (After Piersol.) tis) $[\pi v \lambda \omega \rho o ́ s$, pylorus ; $\iota \tau \iota s$, inflammation $]$. Inflammation of the pylorus.

Pylorochesis ( $\left.p i-l o r-0-k e^{\prime}-s i s\right)$ [ $\pi v \lambda \omega \rho o ́ s$, pylorus; ¿ $\chi y \sigma \iota s$, a holding]. Obstruction of the pylorus.

Pylorocleisis (pi-lor-ok'-lis-is). Synonym of Pylorochesis.

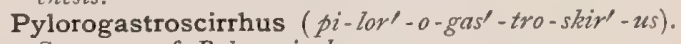
Synonym of Pyloroscirrhus.

Pyloroplasty ( $\left.p i-l o r^{\prime}-o-p l a s-t e\right)[\pi v \lambda \omega \rho \sigma s$, pylorus; $\pi \lambda a ́ \sigma \sigma \varepsilon \iota v$, to form]. Plastic operation upon the pylorus.

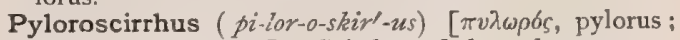

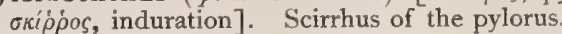

Pylorostenoma ( $p i$-lor-o-sten-o'-mah). Synonym of Pylorostenosis. 
Pylorostenosis (pi-lor-o-ste-ne'-sis) [ $\pi v \lambda \omega \rho \sigma<$, pylorus;

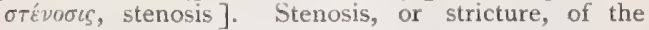
pylorus.

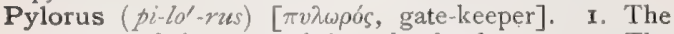
opening of the stomach into the duodenum. 2. The pyloric valve.

Pyo- $\left(p i^{\prime}-o\right)[\pi \bar{v} o v$, pus $]$. A prefix that indicates connection with or relation to pus.

Pyoblenna ( $\left.p i-o-b l e n^{\prime}-a h\right)$ [ [ivov, pus ; $\beta \lambda \varepsilon v v a$, mucus $]$. Muco-pus.

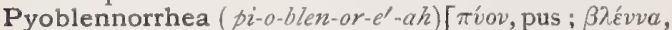
mucus; poia, a flow ]. A muco-purulent discharge.

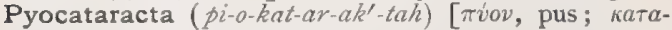

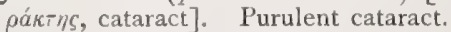

Pyocele $\left(p i^{\prime}-o-s \bar{l} l\right)[\pi \vec{v} o v$, pus; $\kappa \hat{n} \hat{\eta} \eta$, hernia]. Hernia with pus in its sac

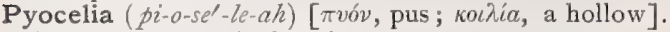
Pus in the abdominal cavity.

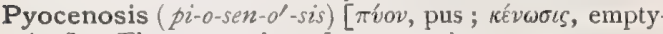
ing]. The evacuation of a pus-cavity.

Pyochezia ( $\left.p i-o-k e^{\prime}-z e-a h\right)$ [ $\pi v o ́ v$, pus ; $\chi \dot{\varepsilon} \xi \varepsilon \iota \nu$, to defe cate]. Discharge of pus from the intestines.

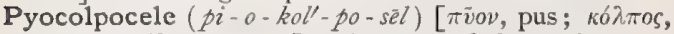
vagina; $\kappa \hat{\eta} \hat{\eta}$, a tumor]. A tumor of the vagina containing pus.

Pyocolpos (pi-a-kol'-pos) [ $\pi \dot{v} o \nu$, pus; $\kappa o ́ \lambda \pi o s, v a g i n a]$. An accumulation of pus within the vagina.

Pyoctanin (pi-ok'-tan-in). See Pyoktanin.

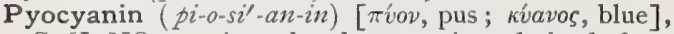
$\mathrm{C}_{14} \mathrm{H}_{14} \mathrm{NO}_{2}$. A colored extractive derived from blue pus, and from cultures of the Bacillus pyocyaneus. On exposure to the air it is oxidized to pyoxanthose. It has positive chemotactic properties. See Pigments, Conspectus of.

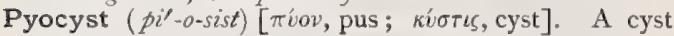
containing pus.

Pyocyte $\left(p i^{\prime}-o-s i ̄ t\right)$ [ $\pi \dot{v} o v$, pus ; kv́ros, cell]. The puscorpuscle.

Pyodermatitis ( $p i$-o-der-mat-i't-tis). A skin-affection produced by inoculation with pyogenic material.

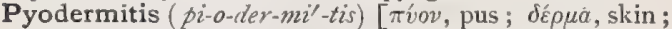
$\iota \tau \iota$, inflammation]. An inflammatory skin-affection attended by pus-formation.

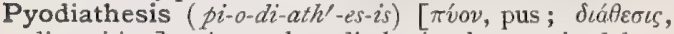
disposition ]. A purulent diathesis, characterized by a tendency of inflammation to proceed to suppuration.

Pyœdema (pi-e-de'-mah). See Pyedema.

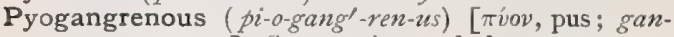
grana, gangrene]. Suppurating, and also gangrenous. P. Inflammation. See Inflammation.

Pyogenes ( $\left.p i-o j^{\prime}-e n-\bar{e} z\right)$. Synonym of Pyogenic.

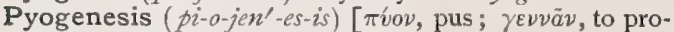
duce]. The formation of pus.

Pyogenetic $\left(p i-o-j e n-e t^{\prime}-i k\right)[\pi v o v$, pus; $\gamma \varepsilon \nu \nu a \tilde{v}$, to produce $]$. Pertaining to pyogenesis.

Pyogenia (pi-o-je'-ne-ah). Same as Pyogenesis.

Pyogenic ( $\left.p \bar{z}-o-j e n^{\prime}-i k\right)$ [ $\pi \hat{v} o v$, pus; $\gamma \varepsilon v \nu \tilde{a} \nu$, to beget]. Producing or relating to pus-formation. P. Fever. See Strangles. P. Membrane, the thin, yellow layer forming the wall of an abscess. The wall is pyogenic only as long as the abscess is spreading, for it is then that breaking down and suppuration are going on in it; when the abscess ceases to spread, the membrane becomes a healing one. P. Microörganisms, the ordinary pyogenic microörganisms are the staphylococcus albus, aureus, and citreus, and the streptococcus pyogenes. Under certain circumstances pus may be produced by the pneumococcus of Fränkel, the bacillus coli communis, the bacillus of typhoid fever, the gonococcus, and others. See Bacteria, Synonymatic Table of.

Pyohæmia (pi-o-hem'-e-ah). Synonym of Pyemia.
Pyohemothorax ( $\left.p i-o-h e m-o-t h \sigma^{\prime}-r a k s\right)[\pi i o v$, pus ; airua, blood; $\theta \dot{\omega} \rho a \xi$, thorax]. The presence of pus and blood in the pleural cavity.

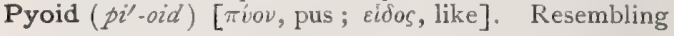
pus.

Pyoktanin $\left(p i-o k^{\prime}-t a n-i n\right)[\pi v ́ o v$, pus; kreivelv, to kill]. A name given to methyl-violet and auramin (both anilin dyes), from their power of arresting suppuration. Both are antiseptic, but are harmless, as well as odorless. One to two per cent. ointments, and one per cent, gauzes and cottons are recommended. Unof.

Pyolymph ( $\left.p i^{\prime}-o-l i m f\right)$ [ $\pi \dot{v} o v$, pus; $\lambda \dot{v} \mu \phi a$, lymph]. Lymph containing pus-corpuscles.

Pyomalgia (pi-o-mall-je-ah) [ $\pi \dot{v} o v$, pus; ijuos, shoulder; ähyos, pain]. Pain in the shoulder due to suppuration.

Pyomele (pi-om'-el-e). See Pyaulacomele.

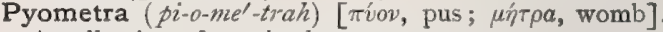
A collection of pus in the uterus.

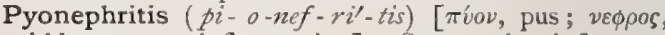
kidney; $\iota \tau \iota s$, inflammation]. Suppurative inflammation of the kidney.

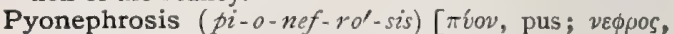
kidney]. Pus in the kidney and its pelvis.

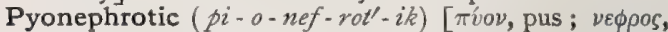
kidney]. Pertaining to pyonephrosis.

Pyonoma ( $\left.p i-o-n o^{\prime}-m \alpha h\right)\left[\pi v o v\right.$, pus ; vo $\mu^{\prime}$, an eating sore]. I, A suppurative focus. 2. A tumor infiltrated with pus.

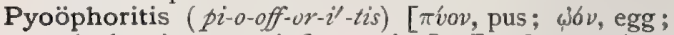

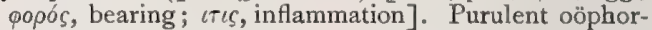
itis.

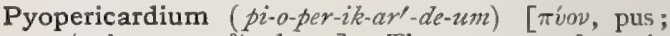
$\pi \varepsilon \rho i$, about; $\kappa a \rho \delta i \alpha$, heart]. The presence of pus in the pericardium

Pyoperitonitis ( $\left.p i-o-p e r-i t-o n-i^{\prime}-t i s\right)$. Synonym of Peritonitis, Purulent.

Pyophthalmia (pi-off-thal'-me-ah) [ $[$ íov, pus ; $\dot{\phi} \phi \theta a \lambda-$ uós, eye]. Purulent ophthalmia.

Pyophthisis (pi-off'-this-is) [ $\pi \dot{v} o v$, pus ; $\phi \theta \iota \sigma \iota s$, a wasting]. Wasting from long-continued suppuration.

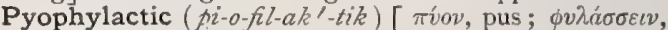
to guard]. Same as Pyogenic. P. Membrane. See Membrane.

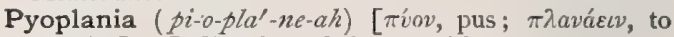
wander]. Infiltration of tissues with pus.

Pyopneumopericardium ( $p i-0-n u-m o-p e r-i k-a r^{\prime}-d e-$

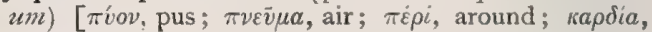
heart]. Pus and air or gas in the pericardium.

Pyopneumoperitonitis ( $\left.p i-0-n u-m o-p e r-i t-o n-i^{\prime}-t i s\right)$

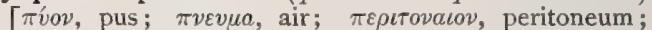
iTı, inflammation]. Peritonitis complicated by the presence of pus and air in the peritoneal cavity.

Pyopneumothorax (pi-o-nu-mo-tho'-raks) [ $\pi \dot{v} o v$, pus; $\pi \nu \varepsilon \bar{v} \mu a$, air; $\theta \omega \rho \alpha \xi$, thorax]. An accumulation of air or gas and pus in the pleural cavity.

Pyopoiesis ( $\left.p i-o-p o i-e^{\prime}-s i s\right)$. Synonym of Suppuration.

Pyoptysis ( $\left.p i-o p^{\prime}-t i s-i s\right)$ [ $\pi \dot{v} o v$, pus; $\pi r^{\prime} \varepsilon \imath v$, to spit]. The expectoration of pus.

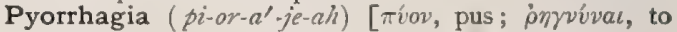
burst forth]. A profuse discharge of pus.

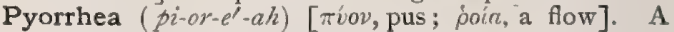
purulent discharge. P., Alveolar. Same as Fauchard's Disease. See Diseases, Table of.

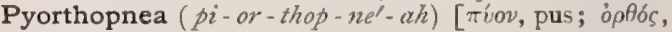
straight; $\pi \nu$ \% , breath]. Orthopnea due to the presence of pus in the pleural cavity.

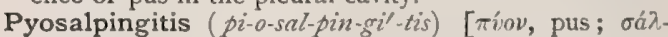
$\pi \iota \gamma \xi$, tube; $\iota \tau \iota \zeta$, inflammation]. Purulent inflammation of the Fallopian or Eustachian tube.

Pyosalpinx (pi-a-sal'-pinks) [ $\pi \dot{v} o v$, pus; $\sigma \dot{\lambda} \lambda \pi \iota \gamma \xi$, tube $]$. 
A formation of pus in the oviduct or the Eustachian tube.

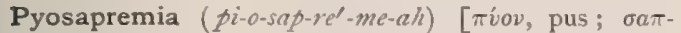
pós, rotten; ai $\mu a$, blood]. Infection of the blood by putrid pus.

Pyoscheocele $\left(p i-o s^{\prime}-k e-o-s e ̄ l\right)[\pi i v o v$, pus ; ò $\sigma \chi \varepsilon n v$, scrotum; $\kappa \eta \dot{\lambda} \lambda \eta$, tumor]. A suppurative swelling of the scrotum.

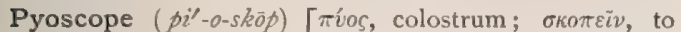
examine]. An instrument for determining the richness of milk by its color.

Pyosepthemia ( $\left.p i-o-s e p-t h e^{\prime}-m e-a h\right)$. Synonym of Pyo-seplicemia.

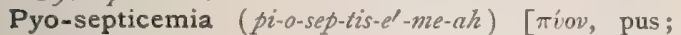

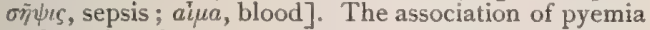
and septicemia.

Pyosis $\left(p i-o^{\prime}-s i s\right)[\pi \tilde{o} o v$, pus]. I. Suppuration. 2. Suppuration of the eye.

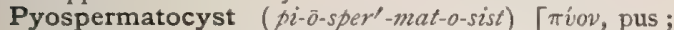

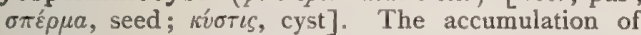
pus in a spermatic vesicle.

Pyostercorous (pi-o-ster'-kor-us) [ [ivov, pus ; stercus, feces]. Pertaining to purulent discharges from the bowels.

Pyothorax (pi-o-tho'-raks) [ $\pi \dot{v} o v$, pus; $\theta \dot{\omega} \rho a \xi$, thorax]. The accumulation of pus in the pleural cavity; empyema.

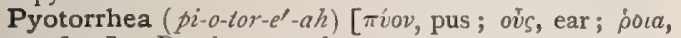
a flow]. Purulent otorrhea.

Pyoxanthin, Pyoxanthose (pi-o-zan'-thin, pi-o-zan'-

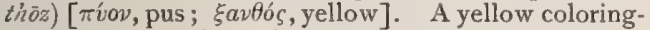
extractive sometimes found in pus, and resulting from the oxidation of pyocyanin, $q . v$.

Pyozemia ( $\left.p i-n-z e^{\prime}-m e-a h\right)$ [ $\pi \dot{v} o \nu$, pus; $\zeta v \mu \dot{n}$, a ferment]. The constitutional condition dependent upon the pres. ence of a pus. Probably an intoxication, in contradistinction to pyemia, which is an infection.

Pyra ( $\left.p i^{\prime} \cdot r a h\right)$. Synonym of Anthrax.

Pyracetic Acid (pi-ras-e $\left.e^{\prime}-t i k\right)$. Synonym of Pyrolig. neous Acid.

Pyramid (pir'-am-id) [ $\pi v \rho a \mu i s] . \quad$ Any conic eminence of an organ, as $P$. of the cerebellum, $P$. of the tympanum, etc. Ps., Anterior (of the Oblongata), the two pyramidal bundles of white matter, one on either side of the ventral median fissure of the medulla. They are continuous with the ventral columns of the spinal cord, except the decussating bundles, which are continuous with the deeper portions of the lateral columns of the cord. P. of the Cerebellum, a conic projection forming the central portion of the inferior vermiform process. Ps., Cortical. Synonym of $P_{S .}$. of Malpighi. Ps. of Ferrein, a prolongation of the striæ of the Malpighian Pyramids into the cortex. They are also known as medullary rays. Ps., Giant, Betz's name for the large pyramidal cells of the cortex of the paracentral convolution of the human brain. P., Lateral. Synonym of Restiform Body. P. of Light, the triangular reflection from the normal membrana tympani. Ps., Malpighian, the conic masses composing the medullary substance of the kidneys. There are from eight to eighteen. Ps., Posterior (of the Oblongata), two narrow bundles of white matter placed one on either side of the dorsal median fissure of the oblongata. They are continuous with the dorsal median columns of the spinal cord.

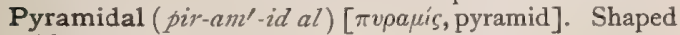
like a pyramid. P. Tracts. See Tracts.

Pyramidale (pir-am-id-a $-l e)$ [ $\pi v \rho \alpha \mu i s$, pyramid]. The cuneiform bone of the carpus; the os pyramidale.

Pyramidalis (pir-am-id-a'-lis). See Muscles, Table of.

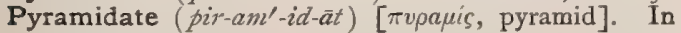
biology, pyramidal.
Pyramis (pir-am-is). Synonym of Pyramid. P. cerebelli. See Pyramid of the Cerebellum.

Pyrazol ( $\left.p i^{\prime}-r a z-\bar{l} l\right)$ [ $\pi \tilde{v} \rho$, fire; azotum, nitrogen $], \mathrm{C}_{3}$ $\mathrm{H}_{4} \mathrm{~N}_{2}$. A derivative of pyrrol, crystallizing in colorless needles, melting at $70^{\circ} \mathrm{C}$, and boiling at $185^{\circ} \mathrm{C}$.

Pyrazolin (pi-raz'-o-lin) [ $\pi \vec{v} p$, fire; azolum, nitrogen], $\mathrm{C}_{3} \mathrm{H}_{6} \mathrm{~N}_{0}$. A reduction-product of pyrazol.

Pyrazolon ( $\left.p i-r a z^{\prime}-o-l o n\right)$ [ $\pi \tilde{v} \rho$, frre ; azotum, nitrogen], $\mathrm{C}_{3} \mathrm{H}_{4} \mathrm{~N}_{2}(\mathrm{O}$. An oxidation-product of pyrazolin.

Pyremetin (pi-rem'-et-in) [ $\pi v \rho \dot{v} v$, mass ; $\varepsilon \mu \varepsilon \sigma \iota s$, vomit]. A substance obtained from impure creasote; it has emetic properties.

Pyrene $\left(p i^{\prime}-r e ̄ n\right)[\pi v \tilde{\rho}$, fire $], \mathrm{C}_{16} \mathrm{H}_{10}$. . . A hydrocarbon occurring in the "stubb-fat" obtained from the distillation of the "stubb." It is sparingly soluble in hot alcohol, readily in ether, benzene, and carbon disulphid; it crystallizes in colorless leaflets or plates, and melts at $148^{\circ} \mathrm{C}$. 2. A hydrocarbon occurring with fluoranthene in the highest fractions of coal-tar.

Pyrene $\left(p i^{\prime}-r \bar{e} n\right)$ [ $\pi v \rho \eta^{\prime} v$, the stone of a fruit]. In biology, a nutlet; the stone of a small drupe.

Pyrenematous (pi-ren-em'-at'-us) [ $\pi v \rho h v$, mass; ai $u a$, blood]. Pertaining to, or having nucleated red corpuscles.

Pyrenemia $\left(p i-r e n-e^{\prime}-m e-a h\right)[\pi v \rho \dot{n} \nu$, mass; ai $i \mu a$, blood]. The existence of nucleated red cells in the blood.

Pyrenin ( $\left.p i-r e^{\prime}-n i n\right)[\pi \tilde{v} \rho$, fire ]. In biology, the name given by Schwartz to the substance composing nucleoli, as distinguished from the nuclear membrane, ampliipyrenin.

Pyrenium ( $\left.p i-r e^{\prime}-n e-u m\right)$ [ $\pi v \rho \eta ́ v t o v, \operatorname{dim}$. of $\pi v \rho \eta \dot{v} v$, the stone of a fruit]. In biology, the hypothecium of a nucleiform apothecium.

Pyrenocarp ( $\left.p i-r e^{\prime}-n o-k a r p\right)[\pi v \rho j v$, the stone of a fruit ;

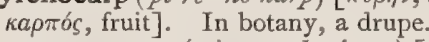

Pyrenocarpous ( $\left.p i-r e-n o-k a r^{\prime}-p u s\right)\left[\pi v p \eta^{\prime}\right.$, the stone of

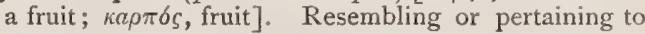
a pyrenocarp.

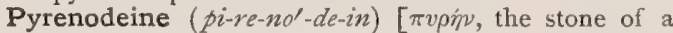
fruit; cidos, form]. Same as Pyrenoid.

Pyrenoid ( $\left.p i-r e^{\prime}-n o i d\right)[\pi v \rho \eta ́ v$, the stone of a fruit;

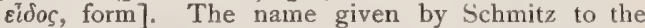
small, bright globules found imbedded in the chromatophores of green algæ and of certain invertebrates, and having the reactions of nuclein and the function of forming starch and similar carbohydrates.

Pyrenomycetes (pi-re-no-mi-se'-tez) [ $\left[\pi v \rho^{\prime} / n\right.$, the stone of a fruit ; $\mu \hat{v} k \eta s$, fungus]. An order of ascomycetous fungi.

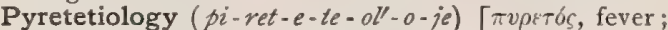
airia, cause; 26 yos, science]. The study of the etiology of fevers.

Pyrethrum ( $p i-r e^{\prime}$-thrum) [ $\pi \dot{v} \rho \varepsilon \theta \rho o \nu$, a certain plant]. Pellitory. The dried root of Anacyclus $P$. It contains a resin, a volatile oil, and sugar. When taken into the mouth, it increases the flow of saliva, and is used as a masticatory in dry conditions of the mouth, in relaxed states of the throat, and in aphonia; also in headache and facial neuralgia. It is valuable mainly as a masticatory and sialagogue. Dose $z$ ss-j. P., Tinct, 20 per cent. strong-used externally. Dose of the British tincture $m x v-3 j$. P. roseum, Persian Pellitory. The powdered flower-heads are used as an insecticide. See Buhach.

Pyretic $\left(p i-r e t^{\prime}-i k\right)$ [ $\pi v \rho \varepsilon T \delta s$, fever]. Pertaining to or affected with fever.

Pyreticosis (pi-ret-ik-o'-sis) [ $\pi v \rho \varepsilon \tau o ́ s$, fever]. Feverishness.

Pyretogenesia, Pyretogenesis (pi-ret-o-jen-e'-ze-ah,

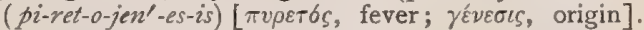
The origin and progress of fever. 


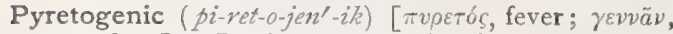
to produce]. Causing or producing fever.

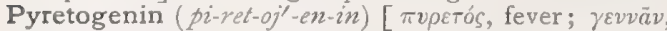
to produce]. A substance (probably a ptomain) formed by microörganisms. Its composition is unknown. It has the property of producing fever when inoculated into animals.

Pyretogenous (pi-ret-oj'-en-us). Synonym of Pyretorenic.

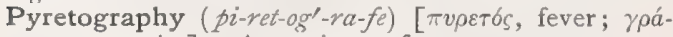
$\phi \varepsilon \imath \nu$, to write]. A treatise on fevers.

Pyretology (pi-ret-oll-o-je) [ $\pi v \rho \varepsilon \tau o ́ s, ~ f e v e r ; \lambda o ́ \gamma o s$, treatise]. The science of the nature and characteristics of fevers.

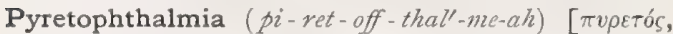
fever; $\dot{\phi} \theta a \lambda \mu o ́ s$, eye ]. I. Ophthalmia caused by a febrile disease. 2. A febrile affection complicated by ophthalmia.

Pyretorthopnea (pi-ret-or-thop-ne'-ah) [ $\pi v \rho \varepsilon \tau \sigma s$, fever ; opfós, straight; $\pi v o n$, breath]. Orthopnea attended with fever.

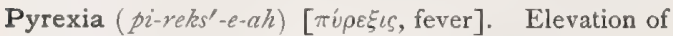
temperature above the normal. Fever.

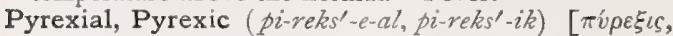
fever]. Pertaining to pyrexia. P. Tincture. See Warburg's Tincture.

Pyrexialis, Tinctura ( $\left.p i-r e k s-e-a^{\prime}-l i s\right)$. See Warburg's Tincture.

Pyrexy (pi-reks'-e). Same as Pyrexia.

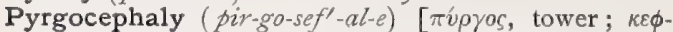
$a \lambda \eta$, head]. The condition in which the vertex rises as an eminence above the level of the skull.

Pyria $\left(p i^{\prime}-r e-a h\right)[\pi \tilde{v} \rho$, fire $]$. Hot bath, vapor-bath; hot fomentation.

Pyriastes (pir-e-as'-tēz). Synonym of Colostrum.

Pyridin ( $\left.p i^{\prime}-r i d-i n\right)$ [ $\pi v \rho$, fire $], \mathrm{C}_{5} \mathrm{H}_{5} \mathrm{~N}$. An alkaloid, prepared from bone-oil, and also obtained from all the pyridin-carboxylic acids on distillation with lime. It is a pungent-smelling liquid, miscible with water, of sp. gr. I.0033 at $0^{\circ} \mathrm{C}$. and boiling at $\mathbf{I} 4.8^{\circ} \mathrm{C}$. It is useful in allaying asthmatic paroxysms. Dose gtt. $\mathrm{vj}-\mathrm{xv}$; by inhalation, $\mathrm{f} z \mathrm{j}-\mathrm{f} 3$ iss. Unofficial.

Pyriform (pir-if-orm) [pyrus, pear; forma, a form]. Pear-shaped. Pyriformis Muscle. See Muscles, Table of.

Pyrimania (pi-rim-a'-ne-ah). Synonym of Pyromania.

Pyrites $\left(p i^{\prime}-r i t-\vec{e} z\right)$ [ $\pi v p i \tau \eta$, flint]. Either of the common sulphids of iron, pyrite and marcasite. P., Arsenical, pyrites occurring as a mixture of several sulphids of arsenic. P., Iron, the ordinary pyrites.

Pyro- ( $\left.p i^{\prime}-r o-\right)$ [ $\pi \tilde{v} \rho$, fire $]$. A prefix signifying connection with or relation to fire, or heat.

Pyro-acetic (pi-ro-as-é-tik) [ $\pi \tilde{v} \rho$, fire ; acetum, acid]. Pertaining to or obtained from acetic acid by the action of heat. P. Spirit. Synonym of Acetone.

Pyro-acid ( $\left.i^{2}-r o-a s^{\prime}-i d\right)$ [ $\pi \tilde{v} \rho$, fire; acidus, acid]. A product obtained by subjecting certain organic acids to heat.

Pyroantimonic Acid ( $\left.p i-r o-a n-t i m-o^{\prime}-n i k\right)$. See Pyrantimonic Acid.

Pyroarsenic Acid ( $\left.p i-r o-a r-s e n^{\prime}-i k\right)[\pi \tilde{v} \rho$, fire ; arsenicum, arsenic $], \mathrm{H}_{4} \mathrm{As}_{2} \mathrm{O}_{7}$. A tetrabasic acid produced when arsenic is heated to $180^{\circ} \mathrm{C}$.

Pyroboric Acid (pi-ro-bo'-rik) [ $\pi \tilde{v} \rho$, fire; boron], $\mathrm{H}_{4} \mathrm{~B}_{4} \mathrm{O}_{8}$. A dibasic acid produced by heating boric acid.

Pyrocatechic Acid (pi-ro-kat'-e-chik). Synonym of Pyrocatechin.

Pyrocatechin (pi-ro-kat-e'-chin) [ $\pi \tilde{v} \rho$, fire; catechu $]$, $\mathrm{C}_{6} \mathrm{H}_{4}(\mathrm{OH})_{2}=\mathrm{C}_{6} \mathrm{H}_{6} \mathrm{O}_{2}$. Catechol; a substance first obtained in the distillation of catechin (the juice of Mintosa catechu). It is formed by the dry distillation of proto-catechuic acid. It crystallizes in short rhombic prisms and sublimes in shining leaflets; is soluble in water, alcohol, and ether; melts at $104^{\circ}$ $\mathrm{C}$. and boils at $245^{\circ} \mathrm{C}$. Its alkaline solutions turn black on exposure to air. It is an antipyretic. Dose gr. j-iij.

Pyrocatechinic Acid, Pyrocatechuic Acid (pi-ro$\left.k a t-e-c h i n^{\prime}-i k, p i-r o-k a t-e-c h u^{\prime}-i k\right)$. Synonyms of Pyrocatechin.

Pyrocitric Acid (pi-ro-sit'-rik) [ $[\pi \tilde{v} \rho$, fire; citrus, lemon]. An acid formed from citric acid by distillation. The term includes several acids.

Pyrocoll ( $\left.p i^{\prime}-r o-k o l\right)$ [ $\pi \ddot{v} \rho$, fire; $\kappa$ o $\lambda \lambda a$, glue ]. I. The amid anhydrid of carbopyrrolic acid. It crystallizes in yellow leaflets, melting at about $268^{\circ} \mathrm{C}$. 2. $\mathrm{C}_{10} \mathrm{H}_{6} \mathrm{~N}_{2} \mathrm{O}_{2}$. A substance obtained in the dry distillation of gelatin.

Pyrocomane (pi-ro-ko'-mān). See Pyrone.

Pyrodextrin ( $\left.p i-r o-d e k s^{\prime}-t r i n\right)$ [ $\pi \bar{v} \rho$, fire ; dexter, right], $\mathrm{C}_{48} \mathrm{H}_{74} \mathrm{O}_{37}$. A brownish solid resulting from the action of heat upon dextrin.

Pyrodin ( $\left.p i^{\prime}-r o-d i n\right)$ [ $\pi \tilde{v} \rho$, fire $], \mathrm{C}_{6} \mathrm{H}_{5} \cdot \mathrm{C}_{2} \mathrm{H}_{3} \mathrm{O} . \mathrm{N}_{2} \mathrm{H}_{2}$. Acetyl-phenyl-hydrazin. A white, sparingly soluble powder, a powerful antipyretic. Dose $1 / 2$ to 4 grains.

Pyrogallate (pi-ro-gal'-ät) [ $\pi \tilde{v} \rho$, fire; galla, galls]. A salt of pyrogallic acid.

Pyrogallic Acid (pi-ro-gal'-ik). See Acid.

Pyrogallocarbonic Acid ( $\left.p i^{\prime}-r o-g a l^{\prime}-o-k a r-b o n^{\prime}-i k\right)$ $[\pi v \rho$, fire; galla, galls; carbon, carbon]. A substance prepared by heating pyrogallic acid with a five per cent. solution of sodium carbonate, and dissolving the product in cold strong sulphuric acid. It is used as a delicate test for nitric acid.

Pyrogallol (pi-ro-gal'-ol) [ $\pi \tilde{v} \rho$, fire; galla, galls], $\mathrm{C}_{6} \mathrm{H}_{3}(\mathrm{OH})_{3}$. Pyrogallic acid; a phenol derivative produced by the action of heat on gallic acid. It occurs in long, flattened prisms, colorless, bitter to taste, soluble in water, alcohol, and ether. It will affect the blood and produce hemoglobinuria. It is a powerful reducing agent. It is used as a local application in dermatology.

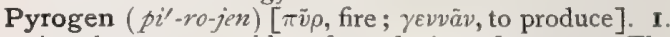
A substance capable of producing fever. 2. The electric fluid.

Pyrogenesia, Pyrogenesis (pi-ro-jen-e'-ze-ah, pi-ro-

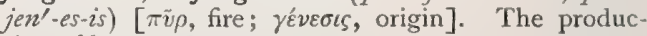
tion of heat or fever.

Pyrogenetic, Pyrogenic ( $p i-r o-j e n-e t^{\prime}-i k, p i-r o-j e n^{\prime}-i k$ ) $[\pi \tilde{\nu} \rho$, fire; $\gamma \varepsilon \nu \nu a \tilde{\nu}$, to produce]. Producing heat or fever.

Pyrogenic $\left(p i-r o-j e n^{\prime}-i k\right)[\pi \bar{v} \rho$, fire; $\gamma \varepsilon v v a ́ v$, to produce]. Producing fever.

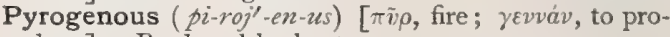
duce]. Produced by heat.

Pyroglucic Acid (pi-ro-glu'sik). Synonym of Pyrodextrin.

Pyroglycin (pi-ro-gli'sin). Synonym of Melaglycerin.

Pyroguaiacic Acid ( $\left.p i-r o-g z \bar{l}^{2}-a k^{\prime}-i k\right)$. Synonym of Guaiacol.

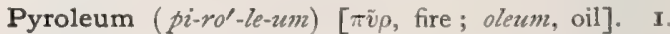
Petroleum. 2. An oil produced by dry distillation.

Pyroligneous ( $\left.p i-r o-l i g^{\prime}-n e-u s\right)$ [ $\pi \tilde{v} p$, fire; lignum, wood]. Pertaining to the destructive distillation of wood. P. Acid, wood-vinegar. See Acid, Pyroligneous. P. Alcohol, P. Spirit. Synonym of Methylalcohol. P. Vinegar. Synonym of Acid, Pyroligneous.

Pyrolithic Acid (pi-ro-lith'-ik), Synonym of Acid, Cyanuric.

Pyrology (pi-roll-o-je) [ $\pi \bar{v} p$, fire; $\lambda 6 \gamma o s$, science]. A study of the application of heat, especially with reference to surgical processes. 


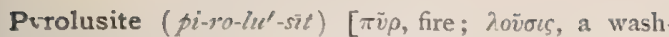
ing]. Native manganese dioxid.

Pyrolysis ( $\left.p_{i-1} l^{\prime}-i s-i s\right)$ [ $\pi i \rho$, fire; $\lambda i \sigma \iota s$, solution] Decomposition by means of heat.

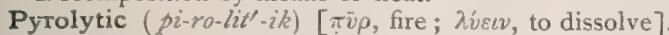
Pertaining to pyrolysis.

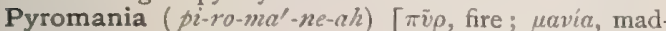
ness]. A form of moral insanity which actuates incendiarism.

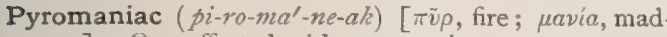
ness]. One affected with pyromania.

Pyromeconic Acid (pi-ro-me-kon'-ik) [ $\pi \vec{v} \rho$, fire; me conic], $\mathrm{C}_{5} \mathrm{H}_{4} \mathrm{O}_{3}$. A crystalline acid obtained by the dry distillation of meconic acid.

Pyromel ( $\left.p i^{\prime}-r o-m e l\right)$ [ $\pi \tilde{v} \rho$, fire; mel, honey]. Molasses.

Pyromellitic Acid ( $\left.p i-r o-m e l-i t^{\prime} i k\right)$. See Acid.

Pyrometamorphism ( $\left.p i-r o-m e t-a m-o r f^{\prime}-i z m\right)[\pi \tilde{v} \rho$, fire; metamorphism]. Metamorphism resulting from the action of heat.

Pyrometer (pi-rom'-et-er) [ $\pi \tilde{v} \rho$, fire; $\mu$ ś $\rho \circ \nu \nu$, measure $]$ An instrument for measuring the intensity of beat of too high a degree to be estimated by the ordinary thermometer. P., Optic. A photometer used as a pyrometer, on the principle that the luminosity of a body is proportionate to its temperature.

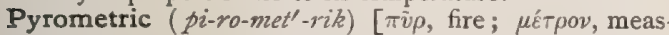
ure]. Pertaining to the pyrometer.

Pyronaphtha (pi-ro-naf'-thah). See Burning Oil.

Pyrone $\left(p i^{\prime}-r o ̄ n\right) ~[\pi \tilde{v} \rho$, fire $], \mathrm{C}_{5} \mathrm{H}_{4} \mathrm{O}_{2}$, Pyrocomane; a substance formed when comanic and chelidonic acids are heated to $250^{\circ} \mathrm{C}$. It is a neutral solid readily soluble in water; it melts at $32.5^{\circ} \mathrm{C}$, and boils at about $315^{\circ} \mathrm{C}$.

Pyropemphigus (pi-ro-pem'-fig-us) [ $[\pi \tilde{v} \rho$, fire ; $\pi \varepsilon \dot{\varepsilon} \mu \phi \iota \xi$, pemphigus]. Pemphigus attended with fever

Pyrophlyctis syriaca. Synonym of Aleppo Boil.

Pyrophobia (pi-ro-fo'-be-ah) [ $[\pi \nu \rho$, fire ; $\phi \delta \beta o s$, dread $]$. Morbid dread of fire.

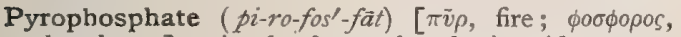
phosphorus]. A salt of pyrophosphoric acid.

Pyrophosphoric Acid ( $i^{2}$-ro-fos-for'-ik). See Acid.

Pyroptothymia (pi-rop-to-thi'-me-ah) $[\pi \tilde{v} \rho$, fire ; $\pi \tau o \varepsilon v$, to terrify; $\theta v \mu o ́ s$, mind]. A form of insanity in which the person imagines himself enveloped in flame.

Pyropuncture (pi-ro-pung-k'-tīr) [ $\pi \tilde{v} \rho$, fire; punctura, puncture]. Puncturing with hot needles.

Pyroscope ( $\left.p i^{\prime}-r o-s k o p\right)$ [ $[\pi \tilde{v} \rho$, fire; $\sigma \kappa o \pi \varepsilon \bar{\nu} \nu$, to examine]. An instrument employed in determining the intensity of thermal radiation.

Pyrosin ( $\left.p i^{\prime}-r o-s i n\right)$. Same as Erythrosin.

Pyrosis ( $\left.p i-r o^{\prime}-s i s\right)$ [ $\pi \tilde{v} \rho$, fire $]$. An affection of the stomach characterized by a burning sensation, accompanied by eructations of an acrid, irritating fluid. "Heartburn." P., Oatmeal. See Oatmeal Pyrosis.

Pyrosphyre ( $\left.p i^{\prime}-r o-s f i r\right)$ [ $\pi \tilde{v} \rho$, fire; $\sigma \phi \tilde{v} \rho n$, hammer]. Same as Moxosphyra.

Pyrosulphuric Acid ( $\left.p i-r o-s u l-f u^{\prime}-r i k\right)$ [ $\pi \vec{v} \rho$, fire; sulphur], $\mathrm{H}_{2} \mathrm{~S}_{2} \mathrm{O}_{7}$. A fuming crystalline body prepared by crystallization from cold Nordhausen sulphuric acid.

Pyrotartaric Acid (pi-ro-tar-tar'-ik). See Acid.

Pyrotechnia (pi-ro-tek'-ne-ah) [ $\pi \tilde{v} \rho$, fire; $\tau \hat{\varepsilon} \chi \nu \eta$, art]. The scientific application of heat. P. chirurgica, the employment of fire in surgical procedures.

Pyrothonid ( $\left.p i-r o t h^{\prime}-a-n i d\right)$ [ $\pi \tilde{v} \rho$, fire $]$. A tarry substance resulting from the imperfect combustion of hemp, cotton, and linen.

Pyrotic ( $p i-$ rot $\left.^{\prime}-i k\right)[\pi \tilde{v} \rho$, fire $]$. I. Having the property of inflammability. 2. Caustic.

Pyrotoxic (pi-ro-toks'-ik) [ $\pi \tilde{v} \rho$, fire; $\tau \dot{j} \xi$ lkos, poison]. A caustic poison.

Pyrotoxin (pi-ro-toks'-in) [ $\pi \bar{v} \rho$, fre; $\tau o \xi \iota \kappa o v$, poison].
A toxic agent generated in the course of the febrile process.

Pyrouric Acid (pi-ro-u'-rik). See Acid, Cyanuric.

Pyrovinic Acid (pi-ro-vin'-ik). See Acid, Pyrotartaric.

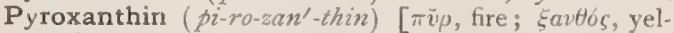
low]. A crystalline substance found in crude woodspirit.

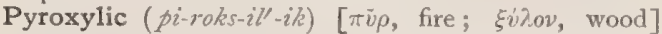
Obtained by distilling wood. P. Spirit, methylic alcohol, a product of the distillation of wood. It is also called wood-spirit and wood-alcohol.

Pyroxylin, Pyroxylinum (pi-roks'-il-in, pi-roks-il-i' -

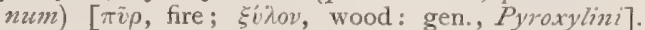
Gun-cotton. Ordinary cotton fiber treated with strong fuming nitric acid, the cellulose, $\mathrm{C}_{6} \mathrm{H}_{10} \mathrm{O}_{5}$, being changed to trinitro-cellulose, $\mathrm{C}_{6} \mathrm{H}_{7} \mathrm{O}_{5}\left(\mathrm{NO}_{2}\right)_{3}$. It is soluble in ether, and is highly explosive by percussion. Collodium, contains pyroxylin 4, ether 70 , alcohol 26. Solution should be complete. C. cum cantharide (C. desiccans, B. P.), flexible collodion 85 , cantharides 60 , chloroform, q. s. C. flexile, flexible collodion contains collodion 92, Canada turpentine 5, castor-oil 3 parts. C. stypticum, styptic collodion, tannic acid 2, alcohol 5 , ether 25 , collodion q. s. ad, Ioo.

Pyrozone ( $\left.p i^{\prime}-r o-z o ̄ n\right)$ [ $\pi \tilde{v} p$, fire; ozone]. A rapidly acting antiseptic, containing 3 per cent. of $\mathrm{H}_{2} \mathrm{O}_{2}$ in water. It may be employed either internally or externally without danger of toxic effects. It decomposes pus with rapidity, causing effervescence. Unof.

Pyrrhol, Pyrrol (pir'-ol) [ $\pi \tilde{v} \rho$, fire ; oleum, oil $], \mathrm{C}_{4} \mathrm{H}_{4}$ (NH). A liquid first found in coal-tar and bone-oil. It is produced by the distillation of ammonium saccharate or mucate, or upon heating glycerol to $200^{\circ}$ C. It is a colorless liquid, with an odor like that of chloroform. It becomes brown on exposure, and boils at $131^{\circ} \mathrm{C}$.; it has a sp. gr., 0.9752 at $12.5^{\circ} \mathrm{C}$.; it is but slightly soluble in water. P. Red, $\mathrm{C}_{12} \mathrm{H}_{14} \mathrm{~N}_{2} \mathrm{O}$, a reddish powder obtained by treating pyrrhol with a strong acid.

Pyrrolidin (pi-rol'-id-in) [ $\pi \tilde{v} \rho$, fre ; oleum, oil $], \mathrm{C}_{4}-$ $\mathrm{H}_{9} \mathrm{~N}$. A substance formed by the action of sodium upon succinimid dissolved in absolute alcohol.

Pyrrolin (pir'-ol-in) $[\pi \tilde{v} \rho$, fire ; oleum, oil $], \mathrm{C}_{4} \mathrm{H}_{6} \mathrm{NH}$. An oily liquid formed when pyrrhol is digested with zinc dust and acetic acid. It is readily soluble in water, and boils at $9 \mathrm{I}^{\circ} \mathrm{C}$.

Pyruric Acid ( $\left.p i-r u^{\prime}-r i k\right)$. Synonym of Acid, Cyanuric. Pyrus (pi'-rus) [L., a pear-tree]. A genus of the Pomea, including the apple (Malus), the pear ( $P$. communis, and other species) and others.

Pyruvic Acid ( $p i r-u^{\prime}-v i k$ ). See Acid.

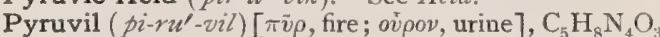
A substance formed from urea and pyroracemic acid.

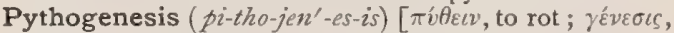
genesis]. Production by means of filth.

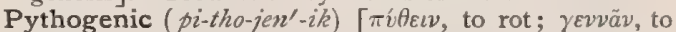
produce]. Arising from decomposing matter. P. Fever. Synonym of Typhoid Fever. P. Pneumonia. See Pneumonia.

Pytia $\left(p i^{\prime}-s h e-a h\right)$. Synonym of Colostrum.

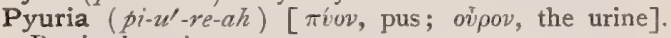
Pus in the urine.

Pyxidate $\left(p i k s^{\prime}-i d-\bar{a} t\right)$ [ $\pi v \xi i s$, a box $]$. Resembling a pyxidium, or bearing pyxidia; furnished with a lid.

Pyxidium (piks-id"-e-um) [dim. of $\pi v \xi i s$, a box: $p l$., Pyxidia]. In liology, a capsule which dehisces along a circular transverse line, so that the upper part comes off like a lid; also called a pyxis.

Pyxinin (piks'-in-in) [ $\pi v \xi i s$, a box $]$. A characteristic chemic substance found by Frenzel in the gregarina Pyxina. 
Q. S. Abbreviation of quantum sufficit-as much as suffices.

Qinbil (kin'-bil) [Arab.]. See Kamala.

Quack (kwak) [ME., quakken, to quack]. One who practises quackery; a pretender to medical skill. Q.salver, a quack, or mountebank; a peddler of his own medicines and salves. See Mountebank.

Quackery (kwak'-er-e) [ME., quakken, to quack]. The pretence of medical knowledge, skill, or success, by one without either. Medical charlatanism.

Quackism (krvak'-izm) [ME., quakken, to quack]. The practice of quackery.

Quadrangular (kwod-rang'-gu-lar). [quadrangulum, a four-cornered figure]. Having four angles. Applied especially to a lobe of the cerebellum.

Quadrant (kwod'-rant) [quadratus, squared]. The fourth part of a circle, subtending an angle of 90 degrees. Q. of Wilder, such an area of the ventral aspect of the crus cerebri in the cat.

Quadrate (kwod'-rāt) [quadratus, square]. I. Square ; four-sided. 2. In biology, the bone which in birds and reptiles articulates with the squamosal above, the mandible below, the pterygoid internally, and the quadratojugal externally. Q. Lobule. See Lobule.

Quadratiferous (kwod-rat-if'-er-us) [quadratus, quadrate; ferri, to bear]. Having a distinct quadrate bone.

Quadratiformis (kwod-rat-if-or'-mis). Same as Quadratus femoris. See Muscles, Tuble of.

Quadratipronator (kwod-rat-ip-ro-na'-tor). Same as Pronator quadratus. See Muscles, Table of.

Quadratojugal (kzeod-ra-to-ju'-gal) [quadratus, square; jujum, a yoke]. Common to the quadrate and malar bones.

Quadratomandibular (kvood-ra-to - man- dib' - u-lar) [quadratus, quadrate; mandible]. Pertaining to the quadrate bone and inferior maxilla.

Quadratopterygoid (kwod-ra-to-ter'-ig-oid) [quadratus, quadrate; $\pi \tau \varepsilon \rho v \zeta$, any ; $\varepsilon i \delta o s$, like]. Pertaining to the quadrate and pterygoid bones.

Quadratosquamosal (kwod-ra-to-skwa-mo'-zal) [quadratus, quadrate; squama, scale]. Pertaining to the quadrate and squamosal bones.

Quadratum (kivod-ra'-tum) [quadra, a square: $p l$., Quadrata]. The os quadratum, or quadrate bone

Quadratus (kwod-ra'-tus) [L.]. Squared. Having four sides. Q. Muscle, See Muscles, Table of.

Quadrauricular (kwod-raw-rik'-u-lar) [quadri-, four; auricula, auricle]. In biology, having four auricles, as the heart of certain cephalopods (Nautilus).

Quadri- (kwod"-re-) [L.]. A prefix used to denote four, or four times.

Quadriarticulate (kwod-re-ar-ti $k^{\prime}-u$-lät) [quadri, four; articulare, to divide into single joints]. Possessing four articulations or joints.

Quadribasic (krvod-rib-a'-zik) [quadri, four; basis, base]. In chemistry, applied to an acid having four replaceable hydrogen atoms.

Quadricapsular (kwod-re-kap'-su-lar) [quadri, four ; capsula, capsule]. In biology, having four capsules.

Quadricarinate (kwod-re-kar'-in-ät) [quadri, four; carina, keel]. In biology, applied to such insects or other animals as possess four ridges or keel-like structures.

Quadricellular (ktuod-ris-el'-u-lar) [quadri, four; cellula, little cell]. Having four cells.

Quadriceps (kwod"-ris-eps). See Muscles, Table of.

Quadriciliate (kwod-ris-il'-e-ät) [quadri, four; cilium, an eyelash]. In biology, having four cilia or fiagella.
Quadricipital (kwod-ris-ip'-it-al) [quadri, four; caput, head]. Having four heads, as a muscle.

Quadricorn (kwod"-rik-orn) [quadri, four; comm, horn]. In biology, having four horns or horn-like structures.

Quadricornous (kwod-rik-or'-mus). Same as Quadricorn.

Quadricostate (kwod-rik-os'-tât) [quadri, four; $\cos ^{\prime} \alpha$, rib]. In biology, having four costæe.

Quadricuspidate (kwod-rik-us'-pid-ät) [quadri, four ; cuspis, a point]. Having four cusps, as a tooth.

Quadridentate (kzwod-rid-en'-tât) [quadri, four; dens, a tooth]. Having four teeth or tooth-like parts.

Quadridigitate $\left(k w v o d-r i d^{\prime}-i j^{\prime}-i t-\bar{a} t\right)$ [quadri, four; digitus, a digit]. Having four digits.

Quadrifid (kwod'-rif-id) [quadri, four; findere, to cleave]. Four-cleft.

Quadrifocal (kzood-rif-o'-kal) [quadri, four; focus, a focus]. Having four foci.

Quadrifoliate (kzood-rif-o'-le-ät) [quadri, four; folium, leaf ]. With four leaves.

Quadrifoliolate (kzood-rif-ó-le-o-lät) [quadri, four; foliolus, leatlet]. In biology, having four leaflets or folioles.

Quadrifurcate (kwod-rif-ir'-kāt) [quadri, four ; furca, fork ]. In biology, having four branches or subdivisions, doubly bifurcate.

Quadrigeminal (krood-rij-enn'-in-al) [quadrigeminus, fourfold]. Fourfold. Pertaining to the corpora quadrigemina. Q. Bodies. See Corpora quadrigemina.

Quadrigeminate (kwod-rij-em'-in-ät) [quadri, four ; geninus, twin born]. In biology, growing in fours, as Sircina.

Quadrigeminous (kreod-rij-em'-in-us) [quadrigeninus, four-fold]. Pertaining to the corpora quadrigemina.

Quadriglandular (kwod-rig-lan'-du-lar) [quadri, four; glans, gland]. Having four glands:

Quadrijugate (kwod-rij-u'-gāt, kzerod-rij'-u-gāat). In biology, having four pairs of leaflets.

Quadrilaminar, Quadrilaminate (kwod-ril-am'-in-ar, kzeod-ril-an'-in-ät) [quadri, four; lamina, a thin plate]. Four-layered.

Quadrilateral (kwod-ril-at'-er-al) [quadri, four; latzes, a side]. Having four sides.

Quadrilobate (kwod-ril-o'-bät) [quadri, four; lobus, lobe]. In biology, having four lobes.

Quadrilobular (kzeod-ril-ob'-u-lar) [quadri, four; lobus, lobe]. Having four lobes. Q. Brain, a double brain, or a brain with four hemispheres; a rare form of cerebral deformity.

Quadrilocular (kwod-ril-ok'-u-lar) [quadri, four; loculus, a cell]. In biology, having four cells or compartments, as the ovary of a flower, or the heart of a bird or mammal.

Quadriloculate (kwod-ril-ok'-u-lät). Same as Quadrilocular.

Quadrimembral (kwod-rim-em'-bral) [quadri, four; membrum, a limb]. In biology, having four limbs.

Quadrinucleate (kzvod-rin- $\left.u^{\prime}-k l e-\bar{a} t\right)$ [quadri, four ; mucleus, a nucleus]. In biology, having four nuclei.

Quadripara (kzeod-rip'-ar-ah) [quadri, four; parere, to bear]. A woman who is bearing, or has borne, her fourth child, or has had her fourth confinement.

Quadriparous (kwod-rip'-ar-us) [quadri, four; parere, to bring forth]. Pertaining to a quadripara, or to a fourth confinement. 
Quadripartite (kwod-rip-ar'-tit) [quadri, four; partire, to divide]. In biology, divided into four parts.

Quadripennate (krood-rip-en'-ät) [quadri, four; penno, wing]. In biology, having four functional wings.

Quadriphyllous (krvod-rif-il'-us) [yuadri, four; фv́n$\lambda o v$, leaf]. In biology, having four leaves.

Quadripulmonary (kwod-rip-ul'-mo-na-re) [quadri, four; pulmon, lung]. In biology, applied to such spiders as have four pulmonary sacs.

Quadriradiate (kwod-re-ra'-de-ät) [quadri, four; radius, ray]. In biology, four-rayed.

Quadriseptate (kwod-ris-ep'-tāt) [quadri, four; septum, a partition]. In biology, having four septa.

Quadriserial (kwod-ris-e'-re-al) [quadri, four; series, a row]. In biology, arranged in four rows or series; tetrastichous.

Quadrisetose (krood-ris-e -tōz) [quadri, four; sata, seta, a bristle]. In biology, having four setæ, or bristles.

Quadrispiral (kwod-ris-pi'-ral) [quadri, four; spira, coil]. In biology, having four spirals.

Quadrisulcate (kwod-ris-ul'-kāt) [quadri, four; sulcus, a furrow]. In biology, having four grooves, or furrows.

Quadrituberculate (kzvod-rit-u-ber'-ku-lät) [quadri, four; tuberculum, tubercle]. Having four tubercles.

Quadriurate (kwod-re-u'-rât) [quadri, four; ov pov, urine]. A term applied to the mixed urates of the lateritious deposits of urine.

Quadrivalent (kzvod-riv'-al-ent) [quadri, four; valens, power]. Having a quadruple chemic valence; having a combining power equivalent to that of four hydrogen atoms.

Quadrivalvular (kwod-riv-al'-vu-lar) [quadri, four ; valva, a valve]. In biology, having four valves, as certain pericarps.

Quadrivoltine (kwod-riv-ol'-tin) [quadri, four; volta, turn, time]. Applied to such silkworms as yield four crops of cocoons a year

Quadroon. See Mulatto.

Quadrumana (kwod-ru'-man-ah) [quadri, four ; manus, a hand]. Formerly, an order of mammalia, including monkeys, apes, etc. The term is now mostly used merely as a descriptive word.

Quadrumanous (kwod-ru'-mān-us) [quadri, four: manus, hand]. Having four hands. Pertaining to the Quadrumana.

Quadruped (kwod'-ru-ped) [quadri, four ; pes, foot]. In biology, having four ambulatory limbs, as distinguished from aliped and biped. Cf. quadrumanous.

Quadruple (kwod'-ru-pl) [quadruplare, to make fourfold]. Four-fold.

Quadruplet (kwod-ru'-plet) [quadruplare, to make fourfold]. Any one of four children brought forth at one birth.

Quain's Fatty Heart. That form of fatty heart in which the muscular fiber is replaced by fatty tissue. See Diseases, Table of.

Quaker Button. A popular name for $N u x$ Vomica.

Qualitative (krvol"-it-a-tiv) [qualitas]. Pertaining to quality. Q. Analysis. See Analysis.

Qualitive (kwol'-it-iv). See Qualitative.

Quantation (kwon-ta'-shun) [quantus, how great]. The determination of quantity, or volume, as in observations regarding specific gravity.

Quantitative (kwon'-tit-a-tiv) [quantus, how much]. Pertaining to quantity. Q. Analysis. See Analysis. Quantitive (kzuon'-tit-iv). Same as Quantitative.

Quantivalence (kwon-tiv'-al-ens) [quantus, how much; valere, to be able]. The chemic strength of an element or radicle expressed in terms of the number of atoms of hydrogen with which it will unite. Univalent or monad atoms, as chlorin, $\mathrm{Cl}-$, are saturated with one atom. Bivalent or dyad atoms, as uxygen, -()-, require two. Trivalent or triad atoms, as Boron,

- $\mathrm{B}$-, take three. Tetravalent or tetrad atoms, as carbon, - C - take four, etc. Nitrogen is a pentad, and sulphur a hexad.

Quarantine (kwor'-an-lèn) [It., quaranta, forty]. The time (formerly forty days) during which a vessel from ports infected with contagious or epidemic diseases is required by law to remain outside the port of its destination, as a safeguard against the spreading of such disease. Also, the place of detention. Q., Land the isolation of a person or district on land for similar purposes. Q. Period, the length of time required to insure immunity after exposure, or the length of time necessary after an attack, to render the disease innocuous.

Quart (kwort) [quartus, fourth]. The fourth part of a gallon.

Quartan (kwor'-tan) [quartus, fourth]. Recurring on the fourth day (both days of occurrence being reckoned). A form of intermittent fever, the paroxysms of which occur every fourth day. Q., Double, milder and severer paroxysms occurring alternately, with a day between, - a severe one the first day, a milder one the second, then a free day, followed by a severe paroxysm on the fourth day.

Quarter-crack. In farriery, a fissure of the hoof on the inner side of the fore-foot of a horse.

Quarter-evil (kwor'-ter-e'-vil). An infectious disease of cattle, prevalent during the summer months, and characterized by the appearance of irregular emphysematous swellings of the subcutaneous tissue and muscles, especially over the quarters, hence the name: it is also called-Symptomatic Anthrax, Black-Leg. Fr., "Charbon symptomatique." Ger., Rauschbrand. See Bacillus chauvci, Bollinger and Feser, under Bacteria, Synonymatic Table of, and also Black-leg.

Quarteroon, Quarteronne (kwor-ter-oon'). See Mulatto.

Quartine (kwar'-tin) [quartus, fourth]. In biology, a fourth integument, counting from the outside.

Quartipara (kwor-tip'-ar-ah) [quartus, fourth; parere, to bring forth]. A woman in her fourth pregnancy.

Quartz (kworts). See Silica.

Quassation (kzwas-a'-shun) [quassatio, a shaking or shattering]. The reduction of barks, roots, and other drugs to morsels in preparation for further pharmaceutic treatment; cassation.

Quassia (kwosh'-e-ah) [after Quassi, a negro slave in Surinam]. I. The wood of Picrena excelsa, native to the W. Indies and other tropical regions. It is a bitter stomachic tonic. Dose gr. $\mathrm{xx}-\mathrm{xxx}$. Q.-cup, a cup made of quassia wood, called also bitter-cup, from which water may be drunk, the bitter principles becoming dissolved in the water. Q., Ext. Its properties are due to a bitter principle, quassin, $\mathrm{C}_{31^{-}}$ $\mathrm{H}_{42} \mathrm{O}_{9}$. Dose gr. j-iij. Q., Fld. Ext. Dose $3 \mathrm{ss}-\mathrm{j}$. Q., Infus., quassia chips $3 \mathrm{j}$, water $\xi^{x}$. Dose $\xi_{j} \mathrm{j}$ iij. Q., Tinct., ro per cent. in strength. Dose $m^{v-3 j}$. 2. Originally, as still in France and Germany, the wood of Quassia amara was the official quassia; the therapeutic properties of this tree and its wood are much the same as those of the ordinary quassia of commerce.

Quassin (kwos'-in) [after Quassi, a negro slave in Surinam]. The active principle of quassia.

Quaternary (kwn-ter'-na-re) [quaterni, four each]. Consisting of four. Q. Union or Structure, an old 
chemic term denoting union of four elements, as in fibrin or gelatin.

Quaternate (kwat-er'-nat) [quaterni, four each]. In biology, made up of four parts, as leaflets.

Quatrefages, Angle of. See Angle.

Quatuor (kzuat'-u-or) [L.]. Four. Q. Pills [Pilulæ Quatuor, N. F.]. The pilule ferri et quinine composite, made up of four ingredients, iron sulphate, quinin, aloes, and nux vomica.

Queasy (krve'-ze) [ME., quaysy, causing a feeling of nausea]. Nauseated; inclined to vomit. [Colloquial.]

Quebrachin (ke-brah'-kin) [contr. from Pg. quebrahacho, "ax-breaker."] An alkaloid of Quebracho. It occurs in colorless crystals, which become yellow in the light.

Quebracho (ke-brah'-ko) [contr. from Pg. quebrahacho," ax-breaker."] The bark of Aspidosperma quebracho, a bitter tonic and antispasmodic. In large doses, it lowers the heart's action. It is much used in Chile as an antiperiodic. The alkaloid, aspidosper. min, $\mathrm{C}_{22} \mathrm{H}_{30} \mathrm{~N}_{2} \mathrm{O}_{2}$, is used in cardiac neuroses, asthma, and as an antipyretic. Q., Ext. Dose gr. ij-viij.

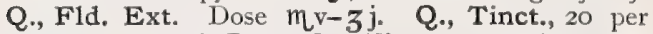
cent. Dose $3 \mathrm{j}-z_{\mathrm{ss}}$. Q., Vinum, contains quebracho I, alcohol 2, white wine 16 parts. Dose $3 \mathbf{j}-$ 亏j. All unof.

Quebrachomin (ke-brah'-ko-min) [contr. from Pg. quebra-hacho, "ax-breaker."] An alkaloid of Quebracho resembling quebrachin.

Queen (kwèn) [AS, cwèn, a woman]. I. The consort of a king. 2. A name applied to the pectens or mussels (Mytilus edulis) caught for food and bait off the southern coast of England. $Q$. of the Meadow. Also, Spirca ulmaria, of Europe; the flower, leaf, and root are diuretic and astringent. Also, rarely, Spiraa salicifolia. Q.'s-root. See Stillingia.

Quenuthoracoplasty (kwen - u-tho-rak-o-plas'-te) [Quenu, a physician; $\theta \omega \rho a \xi$, thorax; $\pi \lambda \dot{\alpha} \sigma \sigma \varepsilon \iota \nu$, to form]. Richelot's term for an operation devised by Quenu for empyema, consisting in simple section of the ribs, without resection, to favor retraction of the chest-wall.

Quercin (kzer'-sin) [quercus, oak], $\mathrm{C}_{6} \mathrm{H}_{6}(\mathrm{OH})_{6}$. A bitter, crystallizable carbohydrate extracted from acorns and oak-bark.

Quercitannic Acid (kwer-sit-an'-ik) [quercus, oak; tannin, tannin], $\mathrm{C}_{17} \mathrm{H}_{16} \mathrm{O}_{9}$. A substance found in oak-bark, forming an amorphous yellowish-brown mass, and differing from gallotannic acid in not being convertible into gallic acid or hydrogallol. See $O a k$ bark.

Quercite (kzerer'-sīt) [quercus, oak], $\mathrm{C}_{6} \mathrm{H}_{7},(\mathrm{OH})_{5}$. A crystallizable substance, the so-called oak-sugar, or acorn-sugar, which is a sweet and optically active sugar-like carbohydrate, derivable from acorns.

Quercitrin (kwer'-sit-rin) [quercus, oak ; citrus, lemon], $\mathrm{C}_{36} \mathrm{H}_{38} \mathrm{O}_{20}$. A glucosid found in the bark of Quercus tinctoria, and used as a yellow dye. It consists of yellow needles or leaflets.

Quercivorous (kwer-siv'-o-rus) [quercus, an oak; vorare, to devour]. In biology, applied to insects or other organisms that feed upon the oak.

Quercus (kwer'-kus) [L.]. A genus of dicotyledonous trees. Q. alba, the bark of the white oak. Its properties are due to quercitannic acid, a variety of tannic acid with which its medical properties are identical, It is much used as an astringent lotion, and is commonly exhibited in a decoction of $\xi_{j}$ to the Oj. Q. ballota. See Racahout, Q. bicolor, the swamp whiteoak of North America. Q., Decoct. (B. P.) is used as an astringent gargle. Q. infectoria, Dyer's oak ;
Aleppo gall-oak ; nut-gall oak, growing in Greece and Asia Minor, and from which the nut-gall of commerce is mainly derived. Q. robur, the common black-oak. The bark (cortex) is astringent and tonic, containing gallic acid, quercitannic acid, and a little quercite. The leaves and acorns are also used. Q. rubra, red oak or Champion oak of Canada and the Northern United States. Q. suber. See Cork. Q. tinctoria (Angulosa), black, or dyers' oak. Q. virens, American live-oak, bearing edible acorns.

Quevenne's Iron. See Ferrum.

Quick, or Quick with Child (kreik) [ME.,quik, alive]. A term used in legal medicine to denote pregnancy. Q. Anatomy. See Vivisection. Q. Consumption. See Galloping Consumption. Q.-lime, the popular name for calcic oxid. See Calcium. Q.-silver, the popular name for mercury or hydrargyrum.

Quicken (kwik'-en) [ME., quik, alive]. To experience the sensation of quickening, $q . v$.

Quickening (krvik'-en-ing) [ME., quik, alive]. The first feelings on the part of the pregnant woman of fetal movements, occurring about the fifth month.

Quiddany (kwid'-an-e) [cydoneum]. An old name for a confection of quinces.

Quiescence (kwi-es'-ens) [quiescence, repose]. A condition of animal life approaching torpidity, but in which the animal may receive food and move slightly.

Quiet (kwi'-et) [quies, quietis]. Repose; complete rest. See Rest-cure. Q.-disease, hip-joint disease in children (sometimes destructive and always of progressive tendency), which has no strongly marked symptoms, and is often overlooked for a long time, there being in many cases little or no pain.

Quigila (kzio'-il-ah). Synonym of Ainhum.

Quill (kwil) [ME., quille, a quill]. The tube, barrel, calamus, or hollow shaft of a feather, principally of the domestic goose; it has a limited use in surgery. Q.-suture. See Suture.

Quillaic Acid (krvil-a $a^{\prime}-i k$ ). See Acid.

Quillain (kzil-a'-in), See Saponin.

Quillaja (kwil'-a-yah) [Chilean, quillai, hair]. A genus of rosaceous trees, including Soap-bark, the inner bark of Q. saponaria, indigenous to the Andes. Its properties are due to a glucosid, saponin, $\mathrm{C}_{32} \mathrm{H}_{54} \mathrm{O}_{18^{*}}$. It is a sternutatory, irritant to the mucous membranes, and an expectorant. Dose of a 5:200 decoction $\xi \mathrm{j}-\mathrm{ij}$.

Quiltor (kwil'-tor). See Quittor.

Quinaldin (kwin-al'-din), $\mathrm{C}_{10} \mathrm{H}_{9} \mathrm{~N}$. Methyl-quinolin; formed by digesting anilin with paraldehyd and $\mathrm{HCl}$. It is a liquid with a faint odor resembling that of quinolin, and boils at $238^{\circ} \mathrm{C}$.

Quinaldinic Acid (kwin-al-din'-ik). See Acid.

Quinamicin (kwin-am'-is-in) [quinamin, an arbitrary form ]. An artificial alkaloid, $\mathrm{C}_{19} \mathrm{H}_{24} \mathrm{~N}_{2} \mathrm{O}_{2}$, obtained from quinamin.

Quinamidin (kzin-am'-id-in). An isomer of Quinamicin.

Quinamin (kwin'-am-in) [Sp., quina, bark; amin], $\mathrm{C}_{19} \mathrm{H}_{24} \mathrm{~N}_{2} \mathrm{O}_{2}$. An alkaloid of the Cinchonas.

Quinary (krvin'-a-re) [quinarizs, containing five]. Divided into five parts.

Quinate (kroin'-ät) [quini, five each]. Applied to a palmately compound leaf with five leaflets.

Quince (quins). See Scrofula. Q.-seed. See Cydonium.

Quincke's Capillary Pulse. Capillary pulsation with a marked blanching of the finger nails at each diastole of the heart; a symptom of aortic insufficiency. Q.'s Disease. See Urticaria adematosa, and Diseases, Table of. Q.'s Puncture, puncture of the spinal canal for withdrawal of cerebrospinal fluid in hydrocephalus.

Quincuncial (kwin-kun'-she-al) [quincunx, fivetwelfths]. In biology, applied to that form of 
estivation in which there are five leaves, two outside, two inside, and one with one edge outside and the other inside. Also five-ranked.

Quincunx (kwin'-kuinglss) [quinque, five; uncia, a twelfth part]. In biology, an arrangement of five parts, or objects, in a square with the odd one in the center, $i . e_{.},:$:

Quinetum (kvi-ne"i-tum) [Sp. quina, bark]. Cinchona febrifuga; the mixed alkaloids from red cinchona bark used as a cheap febrifuge in India. Dose gr. j-v.

Quinic $\left(k w i n^{\prime}-i k\right)$ [Sp., quina, bark]. Pertaining to quinin. Q. Fever, febrile symptoms, with an eruption; it occurs among workmen making quinin.

Quinicin (kwin'-is-in) [Sp., quina, bark]. One of the constituents of chinoidin.

Quinidin $\left(k w i n^{\prime}-i d-i n\right)$. See Quinidina.

Quinidina (kwin-id-i'-nah) [Sp., quina, bark], $\mathrm{C}_{20}$ $\mathrm{H}_{24} \mathrm{~N}_{2} \mathrm{O}_{2}$. A cinchona alkaloid, considered by most writers to be isomeric with quinin, with which it corresponds in therapeutic effects, but it is thought to produce less unpleasant symptoms in the head. Q., Sulph., $\left(\mathrm{C}_{20} \mathrm{H}_{24} \mathrm{~N}_{2} \mathrm{O}_{2}\right)_{2} \mathrm{H}_{2} \mathrm{SO}_{4} \cdot 2 \mathrm{H}_{2} \mathrm{O}$, readily soluble in acidulated water and alcohol; it is an excellent antipyretic and antiperiodic. Dose gr. j-xx or more.

Quinin, Quinia, Quinina (kwi'-nīn,kwin'-èn, or kin-èn'; kzvin'-e-ah, kwin-i'nah) [Sp., quina, bark], $\mathrm{C}_{20} \mathrm{H}_{24}$ $\mathrm{N}_{2} \mathrm{O}_{2}, 3 \mathrm{H}_{2} \mathrm{O}$. Quinin is a finely crystalline or amorphous white alkaloid obtained from various species of cinchona. It is odorless, very bitter, alkaline in reaction, and soluble in 1600 parts of cold water or 6 parts of alcohol. It is a valuable tonic, antiseptic, antipyretic, and antiperiodic. It is extremely valuable in malarial affections. Quinin and its salts are distinguished from all other alkaloids, excepting quinidin and quinicin, by the emerald-green color given to their solution by chlorin-water followed by ammonia. Q.-bush. See Garrya. Q.-flower, the root of Sabbatia elliottii, abundant in southeast U. S. It is tonic, febrifuge, and antiperiodic, and is of high repute in malarial fevers. Dose of the fld. ext. $3 \mathrm{ss}-\mathrm{j}$. Unof. Q., Amorphous, an alcoholic extract of powdered calisaya bark mixed with calcium hydrate. Beta-Q. See Quinidina. Q., Amorphous Boric, borate of quinin. Unof. It is highly recommended, soluble, and is said to cause little congestion of the membrana tympani. Q., Poor man's, the seeds of Casalpinia bonduc and $C$. bonducella. Q. and urea bimuriate, a soluble salt, especially useful for hypodermatic injection. Q. bibromas, $\mathrm{C}_{20} \mathrm{H}_{24} \mathrm{~N}_{2} \mathrm{O}_{2}, 2 \mathrm{HBr}, 3 \mathrm{H}_{2} \mathrm{O}$. Dose gr. j-ijj. $Q$. bisulphas, $\mathrm{C}_{20} \mathrm{H}_{24} \mathrm{~N}_{2} \mathrm{O}_{2}, \mathrm{H}_{2} \mathrm{SO}_{4}, 7 \mathrm{H}_{2} \mathrm{O}$, very soluble in water. Dose gr. j-xxx. Q. hydrobromas, $\mathrm{C}_{20} \mathrm{H}_{24}$. $\mathrm{N}_{2} \mathrm{O}_{2} \mathrm{HBr}, 2 \mathrm{H}_{2} \mathrm{O}$, best salt for hypodermatic use. Dose gr. j-xx, Q. hydrochloras, $\mathrm{C}_{20} \mathrm{H}_{24} \mathrm{~N}_{2} \mathrm{O}_{2} \mathrm{HCl} .2 \mathrm{H}_{2} \mathrm{O}$, muriate of quinin, antipyretic in gr. $\mathrm{v}-\mathrm{x}$ doses. $\mathrm{Q}$. hydrochlor. carbamidat, a compound salt of quinin and urea. Dose gr. j-iij. Suitable for hypodermatic use. Q. lactas, $\mathrm{C}_{20} \mathrm{H}_{24} \mathrm{~N}_{2} \mathrm{O}_{2} \cdot \mathrm{C}_{3} \mathrm{H}_{6} \mathrm{O}_{3}$, very soluble. Dose gr. j-xx. Q. salicylas, valuable in neuralgia and rheumatic gout. Dose gr. j-vj. Q. sulphas $\left(\mathrm{C}_{20} \mathrm{H}_{24} \mathrm{~N}_{2} \mathrm{O}_{2}\right)_{2^{*}}$ $\mathrm{H}_{2} \mathrm{SO}_{4} \cdot 7 \mathrm{H}_{2} \mathrm{O}$, soluble in hot and acidulated water. Dose gr. j-xx or xl. Q. sulphocarbolas. Dose gr. j-v. Q. tannas, tasteless, but insoluble in the stomach. Dose gr, $\mathrm{x}-\mathrm{xx}$. Q., Tinctura, Ammoniata (B. P.). Dose $3 \mathrm{ss}-\mathrm{ij}$. Q. valerianas, $\mathrm{C}_{20^{-}}$ $\mathrm{H}_{24} \mathrm{~N}_{2} \mathrm{O}_{2} \mathrm{C}_{5} \mathrm{H}_{10} \mathrm{O}_{2} \cdot \mathrm{H}_{2} \mathrm{O}$, the only salt affected by constituent acid. Dose gr. j-iij. Q., Vinum (B. P.). Dose $\frac{2}{3} \mathrm{ss}-\mathrm{j}$.

Quinina (kwin- $\left.\bar{\imath}^{\prime}-n a h\right)$. See Quinia.

Quininic Acid (kwin-in'-ik). See Acid.

Quininism (kzvin-ền'-izm) [Sp., quina, bark]. Cinchonism; the condition induced by the continued use or by large doses of quinin. It is marked by deafness, ringing in the ears, etc.

Quinizarin (kzin-iz-a -rin) [Sp., quina, bark], $\mathrm{C}_{14} \mathrm{H}_{8} \mathrm{O}_{4}$ An isomerid of alizarin.

Quinoa (ke-no'-ah) [Peruv.]. A plant, Chenopodium quinoa, of Peru and Chile, where it is cultivated for its seeds, which are used as a substitute for the true cereals. The seed-husks of red quinoa are said to be antiperiodic and emetic. Unof.

Quinodin (kwin'-o-din) [Sp., quina, bark]. An alkaloid-like body found in the organs, tissues, and fluids of human and other animal bodies, resembling by its bluish fluorescence the sulphate of quinin. Obtained by Du Prè and Bence Jones, 1866 .

Quinoidin (krvin-oi'-din). See Chinoidinum.

Quinol (kwi'-nol). See Hydroquinone.

Quinolin (kvin'-o-lin) [Sp.,quina, bark], $\mathrm{C}_{9} \mathrm{H}_{7} \mathrm{~N}, \mathrm{~A}$ substance occurring in bone-oil and coal-tar. It results when many alkaloids are distilled. It is a colorless, strongly refracting liquid, with a penetrating odor. It boils at $239^{\circ} \mathrm{C}$.; its specific gravity is 1.095 at $20^{\circ} \mathrm{C}$. It is also called Chinolin, q. $v$. Q.-colors. See Pigments, Conspectus of.

Quinology (kzein-ol'-a-je) [Sp., quina, bark; $\lambda 6$ yos, science]. The scientific study of the cinchona trees and of their alkaloids.

Quinone (kzin'-ōn) [Sp., quina, bark]. A general term for certain derivatives of the benzene series. Also a specific substance of yellowish color and volatile at ordinary temperatures, derived from members of the aromatic group by oxidation with sulphuric acid and manganese dioxid.

Quinotannic Acid (krvin-o-tan'-ik) [Sp.,quina, bark ; tannin, tannin]. A special form of tannic acid found in certain classes of cinchona-bark.

Quinova (kwin-o'-vah) [a contraction of quina nova, false cinchona bark]. The bark of Portlandia grandiflora.

Quinovin (kwin'-o-vin) [Sp., quina, bark], $\mathrm{C}_{30} \mathrm{H}_{48} \mathrm{O}_{8}$. Kinovin; an amorphous bitter glucosid derived from cinchona bark. It is said to be an antipyretic.

Quinoxalin (kwin-oks'-al-in) [Sp., quina, bark; ókis, sharp], $\mathrm{C}_{8} \mathrm{H}_{6} \mathrm{~N}_{2}$. A substance obtained from phenylene diamin and glyoxal or its compounds by digesting the aqueous solution at $60^{\circ} \mathrm{C}$. with sodium bisulphite. It is a crystalline mass, melting at $27^{\circ} \mathrm{C}$. and boiling at $229^{\circ} \mathrm{C}$. Its odor resembles that of quinolin and piperidin. The Quinoxalins are prepared by the condensation of the ortho-phenylene diamins with glyoxal. The quinoxalins that do not contain oxygen are feeble monacid bases, generally soluble in water, alcohol, and ether. Their odor resembles that of quinolin.

Quinoxim (kwin-oks'-im) [Sp., quina, bark; '́cvis, sharp], $\mathrm{C}_{6} \mathrm{H}_{4}(\mathrm{NO})$.OH. Nitrosophenol; prepared by the action of nitrous acid upon the phenols. It crystallizes from hot water in colorless, delicate needles, which readily brown on exposure. It is soluble in water, alcohol, and ether, and imparts to them a brightgreen color.

Quinquaud's Disease. See Folliculitis decalvans, and Diseases, Table of. Q.'s Plaster, a plaster used in treating syphilis. It consists of emplastrum diachylon, 3000 parts ; calomel, tooo parts ; castor-oil, 300 parts. The calomel is suspended in the oil and is then added to the melted plaster; it is then spread on linen so that I4 strips each 9 feet by $73 / 4$ inches are produced. Of this plaster a square of $21 / 2$ inches contains 18 grains of calomel.

Quinquecapsular (kwin - kwe-kap'-su-lar) [quinque, five; capsula, capsule]. In biology, having five capsules. 
Quinquecostate (kwin-kwe-kos'-tât) [quinque, five; costa, a rib]. In biology, having five costæ.

Quinquedentate (kwin-kwe-den'-tät) [quinque, five; dens, tooth]. In biology, five-toothed.

Quinquedigitate (kiwn-kwe-dij'-it-ät) [quinque, five; digitus, finger]. Having five fingers or toes.

Quinquefid (kwin'-kwe-fid) [quinque, five; findere, to cleave, split]. In biology, five-cleft.

Quinquefoliate (ktvin - kwe - fo'-le-ät) [quinque, five; folium, leaf ]. In biology, five-leaved.

Quinquefoliolate (kwin-kzue-fo'-le-a-lät) [quinque, five; foliolum, a leafiet]. In biology, applied to any compound leaf that has just five leaflets.

Quinquelobate (kwin-kwe-lo'-bät) [quinque, five ; lobus, lobe]. In biology, having five lobes.

Quinquelocular (kwin-kwe-lok'-ze-lar) [quinque, five; loculus, a cell]. In biology, having five cells or compartments, as a five-celled ovary.

Quinqueloculine (kwin-krve-lok'-u-lin) [quinque, five; loculus, a cell]. In biology, the same as quinquelocular. Applied to certain Foraminifera.

Quinquepartite (kwin-kwe-par'-tit) [quinque, five ; partire, to divide]. In biology, five-parted.

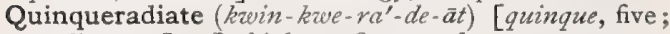
radius, ray]. In biology, five-rayed.

Quinqueseptate (kwin-kre-sepp'tāt) [quinque, five; septum, a partition]. In biology, having five septa or partitions.

Quinqueserial (kwoin-kwe-se'-re-al) [quinque, five; series, a row]. In biology, arranged in five rows.

Quinquetuberculate (kwin-kwe-tu-ber'-ku-lāt) [quinque, five; tuberculum, tubercle]. Having five tubercles.

Quinquevalve (kzin'-kzue-valv) [quinque, five; valva, door]. In biology, having five valves.

Quinquinina (kwin-kwe-ni'-nah) [Sp.,quina, bark]. A preparation containing alkaloids of cinchona-bark, extracted by macerating in acidulated water, and precipitated by a soluble alkali.

Quinquino (kwin-ke'-no) [S. Amer.]. The tree Myroxylon pereire, which produces balsam of Peru.

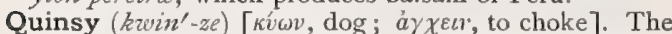
popular name for Cynanche tonsillaris, an acute, severe inflammation of the tonsils and mucous membrane of the fauces, accompanied by fever. It is specially applied to suppurative tonsillitis. Q., Malignant. See Diphtheria.

Quintan (kwin'-tan) [quintus, fifth]. An intermittent fever, the paroxysms of which occur every fifth day, counting the first and last day.

Quinteroon (kwin'-ter-oon). See Quintroon.

Quintessence (kwin-tes'-ens) [quintus, fifth; essentia, essence]. The active principle of any substance, concentrated to the utmost degree. A term anciently much employed in medicine and pharmacy for a tincture prepared by digestion at a moderate heat.

Quintine (kwin'-tin) [quintus, fifth]. In biology, a fifth integument counting from the outside.

Quintroon (kwin-troon') [Sp., quinteron]. A person, one of whose parents is of the white race, and the other has one-sixteenth part of African blood.

Quintuple (kzin'-tu-pl) [quintuplex, fivefold]. Fivefold.

Quintuplets (kzvin-tu'-plets) [quintuplex, five-fold]. A set of five children all born at one confinement.

Quitch-grass (krvitch'-gras). See Triticum repens, or Ouicken.

Quittor, Quitter (kwit'-or, kwit'-er) [ME., quite), rottenness]. In farriery, a fistulous wound upon the quarters or the heel of the coronet, caused by treads, pricks in shoeing, corns, or other injuries which produce suppuration at the coronet or within the font.

Quiz (kwiz) [quasare, to ask]. In medical pedagogics, an informal recitation or exercise in which the student familiarizes himself with his medical studies. Q.-master, one who conducts a quiz.

Quizzer (kwiz'-er) [quarare, to ask (?)]. 'The preceptor who conducts the quiz-exercise.

Quotidian (kwo-tid" $-e-a n)$ [quot, as many as; dies, day]. An intermittent fever, the paroxysms of which occur daily.

Quotient (kwo'shent) [quoties, how often]. The result of the process of division. Q., Respiratory, the mathematic relation of the free oxygen that is inspired to that which is expelled from the lungs as carbon dioxid.
R. The abbreviation of Recipe, take; also of Right, of Reaumur, and of Resistance (electric).

R, or R. An abbreviation of Recipe, used in physicians' prescriptions, signifying tike. The stroke across the tail of the $\mathrm{R}$ is probably a remnant of the symbol of Jupiter (2), used of old as the superscription to formu$l æ$, in accordance with the custom of propitiating the gods by pious invocations.

Rabic $\left(r a b^{\prime}-i k\right)$ [rabies, rage]. Pertaining to rabies; rabietic.

Rabid $\left(r a b^{\prime}-i d\right)$ [rabidus, mad]. Affected with rabies, or hydrophobia. Pertaining to hydrophobia, as rabid virus.

Rabidity (ra-bid'-it-e) [rabidus, rabid]. The state of being rabid.

Rabidness (rab'-id-nes) [rabidus, rabid]. Madness; the state of being rabid.

Rabidus (rab'-id-uss) [L.]. Madness. R. canis. Synonym of Hydrophobia.
Rabies $\left(r a^{\prime}-b e-\bar{e} z\right)$ [L.]. Lyssa, or Hydrophobia. The latter term is popularly applied to the human disease consequent upon the bite of a rabid dog or other animal. Rabies is an acute infectious disease of animals, dependent upon a specific virus, and communicable to man by inoculation. All animals are liable to the disease, but it occurs most frequently in the wolf, the cat, and the dog, and is chiefly propagated by the latter, which is specially susceptible. The nature of the poison is as yet unknown; it has a special affinity for the nervous system, and is found in the secretions, particularly in the saliva. The period of incubation in man varies from six weeks to three months. Three stages of the disease are recognized: a premonitory, characterized by depression and irritability, followed by a stage of great excitability, and excessive sensitiveness to afferent stimuli, giving rise to intensely painful spasms, particularly of the oral and laryngeal muscles. The fact that the attempt to 
take water will induce a spasm, and makes the sufferer dread the sight of it, gives the popular name to the affection. There may be rise of temperature. In the last, or paralytic stage, the spasms are succeeded by quiet and gradual unconsciousness, ending in death. The cerebro-spinal system shows congested vessels, perivascular exudation of leukocytes, and minute hemorrhages, particularly in the oblongata (Gowers), and the larynx, trachea, and bronchi show acute hyperemia (Osler). R., Dumb, rabies in rodents, in which the preliminary and second periods are absent, and the paralytic stage is pronounced from the onset (Osler). $\mathbf{R}$, canina, $\mathbf{R}$. felina, rabies in or acquired from the dog or cat respectively. R., False. See $R$., Pseudo. R., Paralytic: I. Of Gamaleia, rabies in which the third stage is the only manifestation of the infection. 2. An acute ascending spinal paralysis due to infection, probably rabietic. R., Pseudo: I. A neurotic or hysteric manifestation closely simulating rabies, but of longer duration and amenable to treatment (Osler). 2. A morbid condition resembling rabies induced experimentally in animals, and occurring in dogs infested with the Sirongylus gigas. R., Tanacetic, a morbid condition resembling rabies induced in rabbits by the intravenous injection of oil of tanacetum.

Rabietic (ra-be-et'-ik) [rabies, rage]. Pertaining to, affected with, or of the nature of, rabies.

Rabific $\left(r a-b i f^{\prime}-i k\right)$ [rabies, rage]. Causing rabies; communicating hydrophobia.

Rabiform (ra'-bif-orm) [rabies, rage ; forma, form]. Resembling rabies.

Rabigenic ( $\left.r a-b i g-e n^{\prime}-i k\right)$. Same as Rabific.

Rabious (ra'-be-us) [rabies, rage]. Wild; raging.

Rabl's Fluid. See Stains, Table of.

Rabuteau's Method. A method of estimating the amount of acids in the stomach. It consists in driving off the volatile acids by heat and shaking the residue with a large excess of ether, which takes up the lactic acid. This is separated and cinchonin or quinin is added to the remainder until the reaction is neutral. The cinchonin or quinin hydrochlorid is dissolved out by shaking with chloroform, the latter is distilled off from this extract, and the chlorin estimated in the residue.

Racahout (rah-kah-oot') [Fr.; Arab., ragaut]. A kind of starchy food prepared from the acorns of Quercus ballota, an oak-tree of the Mediterranean region. Most of the commercial racahout is, however, quite factitious. It is recommended as an analeptic, and as a food for invalids. Unof.

Raccoon-berry (rak-oon-ber'-e). Synonym of Podophyllum peltatum.

Race (räs) [Dan., race, a breed of horses]. In biology, a genealogic, ethnic, or tribal stock; a breed or variety of plants or animals made permanent by constant transmission of its characters through the offspring.

Race (räs) [radix, root]. A root, especially of ginger. R.-ginger, ginger in the race or root.

Raceme (ra-semm') [racemus, a cluster of grapes]. In biology, an indeterminate inflorescence having a common peduncle with one-flowered pedicels arranged along its sides. R., Compound, a raceme in which the pedicels branch and form secondary racemes. R., False, a circinate, or scorpioid, cyme.

Racemed (ra-sēmd') [racemus, a cluster of grapes]. In biology, disposed in racemes; said of flowers or fruits.

Racemic (ra-se'-mik) [racemus, a bunch of grapes]. Pertaining to clusters of grapes, or to racemes. $\mathbf{R}$. Acid. See Acid.

Racemiferous (ras-em-if'-er-us) [racemus, a cluster of grapes; ferre, to bear]. Bearing racemes.
Racemiform (ra-se'-mif-orm) [racemus, a bunch of grapes; forma, form]. In biology, having the form of a raceme.

Racemose (ras'-e-möz) [racemus, a bunch of grapes]. Having a shape resembling that of a bunch of grapes; applied especially to certain glands. R. Aneurysm, anastomotic aneurysm. $\mathbf{R}$. Cells, clusters of cells arranged around a central duct. R. Varix, anastomotic varix.

Racemule (ras'-e-mül) [racemulus, dim. of racemus, a cluster]. In biology, a small raceme.

Racemulose $\left(r a-\operatorname{sen}^{\prime}-u-l \bar{o} z\right)$ [racemulus, a small raceme]. In biology, resembling a racemule, or arranged in racemules.

Rach - See, also, Rhach-

Rachiæi $\left(r a-k i^{\prime}-e-i\right)$ [ $\rho \dot{\alpha} \chi \iota s$, the spine]. Spinal muscles.

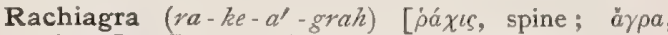
seizure]. Gouty or rheumatic pain in the muscles of the spine.

Rachial $\left(r a^{\prime}-k e-a l\right)$. Same as Rachidial.

Rachialgia ( $\left.r a-k e-a l^{\prime}-j e-a h\right)$ [ $\rho a ́ \chi \iota s$, spine; $a ̀ \lambda \gamma o s$, pain]. Vertebral disease; pain in or about the spine. Metallic colic. R. mesenterica, tabes mesenterica. R. pictorum, Rachialgia of painters. R. pictoniensium, metallic colic.

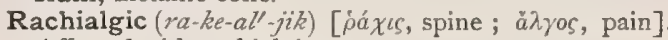
Affected with rachialgia.

Rachialgitis $\left(r a-k e-a l-j i^{\prime}-t i s\right)[\dot{\rho} a ́ \chi \iota \varsigma$, spine; àn yos, pain; $\iota \tau \iota$, inflammation]. Inflammatory rachialgia; myelitis.

Rachiasmus ( $\left.r a-k e-a z^{\prime}-m u s\right)$ [ $\rho a ́ x \iota s$, spine]. The spasmodic action of the muscles of the back of the neck, occurring early in epilepsy.

Rachidial ( $\left.r a-k i d^{\prime}-\ell-a l\right)$ [ $\dot{\alpha} \alpha \chi \iota s$, the spine]. Belonging to a rachis, or spine.

Rachidian (ra-kid'-e-an) [ $\dot{\alpha} \alpha \iota \iota$, spine]. Spinal; vertebral. R. Arteries, the spinal arteries. R. Bulb, the medulla oblongata. R. Canal, the vertebral canal.

Rachiglossate $\left(r a-k i g-l o s^{\prime}-\bar{a} t\right)$ [ ${ }^{\prime} a ́ \chi \iota \varsigma$, the spine;

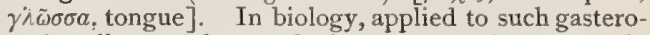
pod molluscs as have only from one to three teeth in each transverse series on the radula or lingual ribbon.

Rachilla (ra-kil'-ah) [ $\rho a ́ \chi \iota s$, the spine]. In biology, a secondary rachis; the pedicel of a spikelet in grasses.

Rachiocampsis (ra-ke-o-kamp'-sis) [ $\dot{a}^{\prime} \chi \iota s$, a spine;

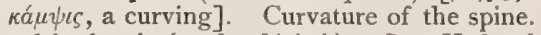

Rachiochysis (ra-ke-ok'-is-is). See Hydrorhachis.

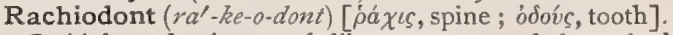
In biology, having tooth-like processes of the spinal column.

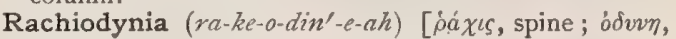
pain]. Spasmodic pain in the spine.

Rachiokyphosis (ra-ke-o-ki-fo'-sis). See Kyphosis.

Rachiometer (ra-ke-om'-et-er). Same as Skoliosometer.

Rachiomyelitis (ra-ke-o-mi-el-i'-tis). See Myelitis.

Rachiomyelophthisis (ra-ke-o-mi-el-off'-this-is), Synonym of Locomotor ataxia.

Rachiomyelos (ra-ke-o-mi'-el-os), Synonym of Spinal Cord.

Rachioparalysis (ra-ke-o-par-al'-is-is) [ $\rho a ́ \chi \iota s$, spine; $\pi a \rho a ́ \lambda v \sigma \iota \varsigma$, paralysis]. Spinal paralysis; paraplegia.

Rachioplegia (ra-ke-o-ple'-je-ah). See Rachiofaralysis.

Rachiorrheuma ( $\left.r a-k e-o r-u^{\prime}-m a h\right)$ [ $\rho a ́ \chi \iota s$, spine ; $\rho \varepsilon v \mu x$, flux]. Rheumatism affecting the back.

Rachioscoliosis $\left(r a-k e-o-s k o-l e-o^{\prime}-s i s\right)$. Synonym of Scoliosis.

Rachiostrophosis (ra-ke-o-stro-fo'-sis) [ [óá $\iota s$, spine; $\sigma \tau \rho \varepsilon \dot{\phi} \varepsilon \imath$, to curve]. Curvature of the spine.

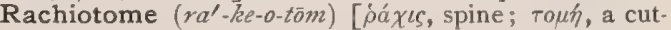
ting]. An instrument for performing rachiotomy. An 
instrument devised by Aral for opening the vertebral canal without injury to the cord.

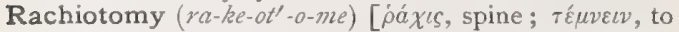
cut]. Incision into the vertebral column. The operation of cutting through the spine of the fetus to facilitate delivery

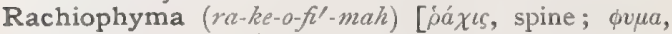
growth]. A spinal tumor.

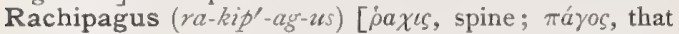
which is fixed]. A double monster with the individuals joined at the spine.

Rachis (ra'-kis) [ $\rho \dot{a} \chi \iota s$, spine: pl., Rachides]. The vertebral column. In biology, the main petiole of a compound leaf; the axis of inflorescence; the shaft of a feather. $\mathbf{R}$. nasi, the line extending from the root to the tip of the nose.

Rachisagra ( $\left.r a-k i s-a^{\prime}-g r a h\right)$. See Rachiagra.

Rachischisis (ra-kis'-kis-is). See Spinabifida.

Rachitæ $\left(r a-k i t^{\prime}-e\right)$ [ $\rho \dot{a} \chi \iota \varsigma$, spine]. The muscles attached to the spinal column.

Rachitic $\left(r a-k i t^{\prime}-i k\right)$ [ $\dot{\rho} a ́ \chi \iota \zeta$, spine ; $\iota \tau \iota s$, inflammation]. Affected with, relating to, or of the nature of rachitis; rickety. $\mathbf{R}$. Rosary, $\mathbf{R}$. Rose-garland, the row of nodules appearing on the ribs, at their junction with the cartilages, in rachitis. See Beads, Rachitic.

Rachitis (ra-kiv-tis) ['́á $\chi \iota s$, spine; $\iota \tau \iota s$, inflammation]. 1. Rickets, the "English disease," a constitutional disease of infancy, characterized by impaired nutrition and changes in the bones. Rachitis was first accurately described by Glisson, in the seventeeth century, The disease comes on insidiously at about the period of dentition, and three general symptoms are usually present-a diffuse soreness of the body, slight fever, and profuse sweating about the head and neck. Coincident with these the skeletal lesions appear, the chief of which are the bending of the ribs, the arching of the long bones, with thickening at the junction of the shaft and the epiphysis, and the development of hyperostoses on the frontal and parietal eminences, producing the caput quadratum. Dentition is delayed, nervous symptoms are marked, as peevishness and sleeplessness, and in some cases convulsions and laryngismus stridulus; and all the manifestations are accompanied by a state of general weakness. The cartilage between the shaft and the epiphysis of the long bones is greatly thickened, the line of ossification is irregular and more spongy and vascular than normal, and beneath the periosteum, which strips off easily, there is spongioid tissue resembling decalcified bone. Chemic analysis shows a marked diminution in the lime-salts. Kassowitz regards the hyperemia of the bone, the marrow, the cartilage, and the periosteum as the primary lesion, on which all the others depend. 2. In biology, a disease causing abortion of the fruit or seed. R. adultorum, osteomalacia; mollities ossium. R. annularis, congenital rachitis characterized by the production, after birth, of furrows of the bones and fractures (Winckler). R. micromelica, intrauterine rachitis, characterized by shortening of the limbs and thickening of the diaphyses (Winckler). R. senilis. See $R$. adultorum.

Rachitome (ra'-kit-ōm) [ $[\dot{\rho} \alpha \iota \varsigma$, spine; $\tau \varepsilon \dot{\varepsilon} \mu \nu \varepsilon \iota \nu$, to cut]. An instrument for opening the spinal canal. See Rachiotome.

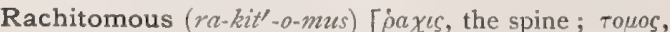
cut]. In biology, applied to the vertebræe consisting of separate pieces, or to animals possessing segmented vertebre. Cf. embolomerous.

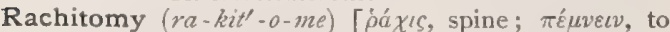
cut]. I. Section of the spine. 2. Decollation of the fetus.

Rachoma, Rachosis ( $\left.r a-k o^{\prime}-1 n a h, r a-k o^{\prime}-s i s\right)[\rho a ́ x \iota s$, spine]. I. Relaxation of the integument of the scrotum. 2. The production of a ragged, irregular abrasion.

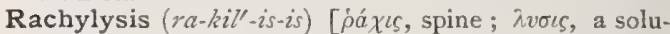
tion]. A method of forcible correction of lateral spinal curvature; the abnormal curve is opposed by traction or pressure applied by means of apparatus.

Racial $\left(r a^{\prime}-s e-a l\right)$ [origin obscure]. Pertaining or due to one's race.

Rack (rak). See Arrack.

Raclage (rak-lahzh') [Fr.]. The destruction of a soft growth by rubbing, as with a brush or harsh sponge; grattage.

Raclement. See Raclage.

Racleur (rah-klür'). See Curet.

Radcliffe's Elixir. See Tinctura aloës composita.

Rademacher's Plaster. See Plaster.

Radesyge ( $\left.r a d-e-s i^{\prime}-g e\right)$ [Norwegian]. A disease popularly known as Scandinavian syphilis, or Norwegian leprosy, bearing more or less similarity to the yaws, and characterized by malignant ulceration and other cutaneous lesions. It occurred in the last century in an endemic form in Norway, the east Adriatic coast, Scotland, and Canada, and is regarded by some authorities as a syphilitic, and by others as a leprous disorder. $\mathbf{R}$. istrica. See Scherlievo. R. scabieuse. See Spedalskhed. R. scotica. See Sibbens.

Radiad $\left(r \alpha^{\prime}-d e-a d\right)$ [radius, a spoke]. Toward the radial aspect.

Radial ( $\mathrm{r}^{\prime}$-de-al) [radius, a spoke]. Pertaining to the radius or bone of the forearm. In biology, diverg. ing from a common center. Relating to the radiating processes of animals, or to the ray of an umbel, or the ligulate corolla of an outer floret of Composita. Gobel uses it in opposition to bifacial or dorsoventral. R. Artery. See Artery. R. Aspect, the aspect or view from the side on which the radius is situated. $R$. Bundle, in biology, a fibro-vascular bundle in which the xylem is arranged in rays, with the phloêm in intervening rays or masses. R. Fibers (of the Retina), Müller's fibers. R. Fossa, a depression on the humerus for the reception of the head of the radius in flexion. R. Glands, lymphatic glands of the forearm following the radial vessels. $R$. Nerve. See Nerve. R. Tap, percussion of the lower end of the radius to elicit the reflex contraction of the biceps and supinator longus. R. Veins. See Veins.

Radiale (ra-de-a'-le) [radius, ray: $p l .$, Radialia]. In biology : (a) the radio-carpal or scaphoid bone of the wrist; cf. ulnare; (b) one of the cartilages at the base of the fin in certain fishes (Elasmobranchs); (c) one of the rays of a crinoid cup.

Radialis $\left(r a-d e-a^{\prime}-l i s\right)$ [L.]. Pertaining to the radius. Various muscles are so called. See Muscles, Table of. Radiate $\left(r a^{\prime}\right.$-de-āt) [radius, a spoke]. Diverging from a central point; extending around the circumference in rays; furnished with ray-flowers. R.-veined, palmately veined. R. Venation, or Veined, that form of venation in which the main veins radiate from the top of the petiole.

Radiatiform (ra-de-a'-tif-orm) [radiatus, radiate ; forma, form]. In biology, having a radiate appearance; applied to heads with the marginal disc-flowers enlarged, but not ligulate.

Radiatio ( $r a-d e-a^{\prime}-$ she-o) [L.]. See Radiation.

Radiation (ra-de- $a^{\prime}$-shun) [radiare, to radiate]. Diver gence from a center; having the appearance of rays. R., Optic, of Gratiolet, a large strand of fibers continuous with those of the corona radiata, derived mainly from the pulvinar, the external and internal geniculate bodies, and the optic tract, and radiating into the occipital lobes. R., Thalamic, certain tracts of fibers from the optic thalami, which radiate into the 
hemispheres (Spitzka). R.-theory of Rauber, a theory to explain the origin of double monsters. "It is based upon the fact that in the earliest stage the embryonic trace extends from the edge of the germinal wall or ridge toward the area pellucida as a radius. When a plural formation occurs, Rauber assumes that two, or even three, of these embryonic traces appear instead of one, the development being designated as 'pluri-radial.'

Radical $\left(\mathrm{rad}^{\prime}-i k-a l\right)$ [radix, a root]. Designed to destroy disease instead of modifying it. The opposite of palliative. The opposite of conservative. In biology, belonging to the root. Radical leaves are those which, like the leaves of the dandelion, appear to spring from the root, but which in reality arise from a very short stem at or near the surface of the ground.

Radicant ( $\mathrm{rad}^{\prime}-i k$-ant) [radicari, to take root]. In biology, rooting; applied to roots proceeding from some part of the ascending axis, as for climbing, like Rhus toxicodendron.

Radicate $\left(\mathrm{rad}^{\prime}-i \bar{k}-\bar{a} t\right)$ [radicari, to take root]. In biology, rooted or adherent, as by a byssus.

Radicel ( $\left.\mathrm{rad}^{\prime}-i s-e l\right)$ [radicella, a little root]. In biology, a tiny root; the rootlet produced in germination.

Radicicolous (rad-is-ikl-o-lus) [radix, root; colere, to inhabit]. In biology, living upon or devouring roots.

Radiciflorous (ra-dis-if-lo'-rus) [radix, root; flos, flower]. In biology, having the appearance of flowering from the root

Radiciform (ra-dis'-if-orm) [radix, root; forma, form]. In biology, having the form and function of a root.

Radicle $\left(\mathrm{rad}^{\prime}-i k-l\right)$ [dim, of radix]. I. A rootlet, the germ of a root. 2. The primary root or stem of the embryo. 3. The initial fibril of a nerve; the begin ning of a vein. 4. A group of atoms having unsatisfied valency; an unsaturated molecule which goes into and out of combinations without change, and which determines the character of the compound. R., Acid. See Acid. R., Alcohol, a radicle which, when it substitutes half the hydrogen in one or more molecules of water, forms an alcohol. R., Aldehyd, a radicle which, when it replaces two atoms of hydrogen in an alcohol, forms an aldehyd. R., Ascending, (of the Fornix), the anterior crura or fibers, extending upward from the corpora albicantia. R., Descending, (of the Fornix), the posterior crura or those fibers of the fornix extending from the optic thalami to the corpora albicantia. R., Electro-negative, the nonmetallic constituent of a compound which, in electrolysis, is evolved at the anode. R., Electro-positive, that constituent of a salt which, in electrolysis, appears at the kathode, and which is either a base or a group of atoms having basic properties.

Radicose (rad'-ik-ōz) [radix, root]. In biology, having large or numerous roots.

Radicula, Radicule ( $\mathrm{rad}-i k^{\prime}-u$-lah, $\left.\mathrm{rud}^{\prime}-i k-\bar{u} l\right)$ [radic$u l a$, little root]. Same as Kadicle.

Radicular (rad-ik'-u-lar) [radicularis, radix, a root]. Pertaining to the roots of nerves. R. Arteries, arteries accompanying nerve-roots into the spinal cord. $\mathbf{R}$. Fasciculus, Internal, of Charcot, runs a longitudinal course in the postero-external column and then enters the gray substance of the posterior cornu. R. Fibers, External, of Charcot, fibers of the posterior roots of spinal nerves passing through the substantia gelatinosa of Rolando to the posterior cornu.

Radicule $\left(\mathrm{rad}^{\prime}-i \bar{k}-\bar{u} l\right)$. See Radicle.

Radiculose (rad-i $i \bar{k}^{\prime}-u$-lō $z$ ) [raticula, a rootlet]. In biology, having rootlets.

Radien ( $r \alpha^{\prime}$-de-en) [radius, a spoke]. Belonging to the radius in itself.
Radiism ( $\left.r^{\prime}-d e-i z m\right)$ [radius, a ray]. Same as Radiation.

Radio-(ra'-de-o-) [radius, a spoke]. A prefix denoting connection with the radius.

Radio-bicipital ( $r a^{\prime}$-de-o-bi-sip'-it-al) [radius, a spoke; biceps, two-headed]. Relating to the radius and the biceps.

Radio-carpal (ra'-de-o-kar'-pal) [radius, a spoke; $\kappa \alpha \rho \pi o ́ s$, carpus]. Relating to the radius and the carpus. R.- Amputation, removal of the hand at the wrist-joint.

Radio-digital ( $r a-d e-o-d i j^{\prime}-i t$-al) [radius, a spoke; digitus, a digit]. Relating to the radius and the fingers

Radio-humeral $\left(r a^{\prime}-d e-a-h u^{\prime}-m e r-a l\right)$ [radius, a spoke; humerus, the humerus]. Relating to the radius and the humerus.

Radiolus (ra-di'-o-lus) [dim. of radius, a ray: pl., Radioli]. In biology, one of the secondary rays of the main rachis of a feather. In surgery, a probe or sound.

Radio-metacarpalis ( $r \alpha^{\prime}-$ de-o-met-ak-ar-pal$\left.-l i s\right)$ [radius, spoke; metacarpus]. The flexor carpi radialis brevis when the insertion is at a metacarpal bone.

Radiometer $\left(r a-d e-o m^{\prime}-e t-e r\right)$ [radius, ray; $\mu$ t́ $\rho o v$, measure]. An instrument for transforming radiant energy into mechanical work.

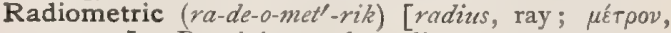
measure]. Pertaining to the radiometer.

Radio-muscular (ra-de-o-mus'-ku-lar) [radius, radius ; musculus, a muscle]. Relating to the radius and its muscles. The name of branches of the radial artery distributed to the muscles of the forearm, and of filaments of the radial nerve going to the same muscles.

Radio-palmar ( $r a^{\prime}-d e-0-p a l^{\prime}-$ mar $)$ [radius, radius; palma, palm]. Relating to the radius and the palm.

Radio-ulnar $\left(r a^{\prime}-d e-o-u l^{\prime}-n a r\right)$ [radius, spoke; ulna, ulna]. Pertaining to the radius and the ulna.

Radius $\left(r a^{\prime}-d e-u s\right)$ [radius, a staff, rod, spoke of a wheel, ray: pl., Radii]. In biology: (a) spokebone, the outer of the two bones of the antibrachium or anterior limb of a vertebrate; see Muscles, Table of: (b) one of the veins of an insect's wing; $(c)$ a ray of the first order, of the shaft of a feather (used in the plural) ; $(d)$ one of the radiating threads of a spider's web; $(e)$ a bifurcated piece, of which there are five, in the oral skeleton of an echinoderm. I. In geometry, the line drawn from the center of a circle to its circumference. 2. One of the cartilaginous rods supporting the fins in fishes. 3. See Ray. Radii auriculares, lines projected on the cranium at right angles to a line passing through the auricular points. $\mathbf{R}$. ciliares, the ciliary processes. $\mathbf{R}$. fixus, in craniometry, a line connecting the inion and the hormion. $R$. frontis, wrinkles of the forehead. R. lentis. lines radiating from the poles of the crystalline lens. $\mathbf{R}$. medullares, bundles of receiving tubules of the kidney, beginning in one tubule at the apices of the papillæ, dividing dichotomously, and extending nearly to the cortical surface.

Radix (ra'-dix) [gen., radicis: pl., radices]. The root or lower extremity of a plant, constituting its organ of prehension, and also, to a great extent, of nutrition. Applied also to root-like organs or parts of the body. The five greater aperient roots: smallache, parsley, fennel, asparagus, and butchers' broom. The five lesser aperient roots: dandelion, caper, restharrow, madder, and eryngo. Radices accessoriæ breves ganglii ciliaris, nerve-branches occasionally seen uniting the ciliary ganglion with the oculomotor and other nerves. Radices accessoriæ mediæ ganglii ciliaris, inconstant nerve-branches which connect the ciliary 
ganglion with the internal carotid plexus, or the sym pathetic plexus surrounding the ophthalmic artery R. accessoriæ sphenopalatina ganglii ciliaris, an accessory nerve-branch of the ciliary ganglion going to the sphenopalatine ganglion. R. antica processus transversi vertebræ (Sömmering). See Parapoph. ysis. R. aortæ, bulb of the aorta. R. brasiliensis. See Ipecacuanha. R. brevis ganglii ciliaris, a branch of the oculomotor nerve going to the ciliary ganglion. R. brevis ganglii submaxillaris, branches of the lingual nerve going to the submax illary ganglion. R. cerebelli. See Restiform Body. $\mathbf{R}$. cordis, the base of the heart. $\mathbf{R}$. dentis, the root of a tooth. R. dysenterica. See Ipecacuanha. R. epiglottidis, the constricted part of the epiglottis, by which the organ is attached to the thyroid cartilage. R. externa nervi sapheni externi. See Peroneal Nerve. Radices fornicis, the crura of the fornix. R. gangliosa, the sensory root of the fifth nerve. R. inferior ganglii ciliaris. See $R$. brevis ganolii ciliaris. $\mathbf{R}$. lingux, the root of the tongue. Radices longæ superiores ganglii ciliaris, inconstant branches running from the naso-ciliary nerve to the ciliary ganglion. R. longa ganglii sphenopalatini. See Great Superficial Petrosal Nerve. R. longa inferior ganglii ciliaris, an additional in constant branch going from the ciliary ganglion to one of the ciliary nerves. R. lopez, lopez-root; a root discovered by Pigneiro at the mouth of the Zambezi, and introduced into Europe by Gaubius in $177 \mathbf{I}$, where it was used in the treatment of chronic dysentery and of pulmonary tuberculosis. It is probably a derivative of Toddalia aculeata, which it resembles in appearance and properties. R. media nervi olfactorii, the median root of the olfactory nerve. R. medullæ spinalis, of Varolius, the medulla oblongata. R. mesenterii, the root of the mesentery. $R$. minor trigemini, the motor root of the fifth nerve. R. mollis ganglii otici, fibers connecting the otic ganglion with the sympathetic plexus upon the middle meningeal artery. R. mollis ganglii submaxillaris, fibers of the sympathetic plexus upon the external maxillary artery going to the submaxillary ganglion. R. motoria ganglii ciliaris. See $R$. brevis ganotii ciliaris. R. motoria ganglii otici, the fibers of the inframaxillary nerve going to the otic ganglion. $\mathbf{R}$. motoria ganglii sphenopalatini. See Great Superficial $P_{e}$ trosal Nerve. R. motoria ganglii submaxillaris, the fibers of the chorda tympani going to the submaxillary ganglion. $\mathbf{R}$. nasi, the root of the nose. $\mathbf{R}$. nervi optici, the optic tract. $\mathbf{R}$. olfactoria grisea. See $R$. media nervi olfactoria. $R$. olfactoria superioris, those fibers of the olfactory nerve derived from the caruncula mammillaris. Radices penis, the crura of the penis. $\mathbf{R}$. pili, hair-root. $\mathbf{R}$. postica processus transversi vertebræ (Sömmering). See Diapophysis. R. prior processus transversi vertebræ. See Parapophysis. R. processus spinosa, the anterior part of a spinous process of a vertebra. $\mathbf{R}$. pulmonis, the root of a lung. $\mathbf{R}$. recurrens ganglii ciliaris. See $R$. longa inferion ganglii citiaris. Radices sensitivæ ganglii ciliaris. See Radices longa superiores ganglii ciliaris. Radices sensitivæ ganglii otici, fibers of the glossopharyngeal nerve going to the otic ganglion. Radices sensitivæ ganglii sphenopalatini, the sphenopalatine nerves. R. sensitivæ ganglii submaxillaris. See $R$. brevis ganglii submaxillaris. Radices sympathicæ ganglii otici. See $R$. mollis ganglii ofici. R. sympathicæ ganglii ciliaris, the fibers of the ophthalmic ganglion coming from the carotid plexus. R. sympathica ganglii sphenopalatini. See Great
Deep Petrosal Nerve. Radices sympathicæ ganglii submaxillaris. See $R$. mollis ganglii submaxillaris. $R$. unguis, the root of a nail. $R$. vestibularis, the anterior root of the auditory nerve.

Radula (rad'-u-lih) [radula, a scraper: pl., Radulic]. In biology, the rasping surface of the odontophore or lingual ribbon of certain molluscs. See Raspatory.

Radulate ( $\mathrm{rad}^{\prime}-u$-laेt) [radula, a scraper]. In biology, having a radula.

Raduliferous (rad-u-lif'-er-us) [radula, a scraper; ferre, to bear]. In biology, bearing a radula.

Raduliform (rad'-u-lif-orm) [radula, a scraper; forma, form ]. In biology, applied to structures having a rasp-like surface.

Radzyge (rad-zi'-ge). See Radesyge.

Raffinose (raf'-in-ozz). See Melitose, under Carbohydrales, Table of.

Rafflesia (raf-le'-ze-ah) [after Sir Stamford Raffles, a British statesman]. A genus of parasitic plants, bearing large, fetid flowers. R. arnoldi, a styptic species found in Sumatra. R. patma, a Javanese species. A decoction of the styptic buds is used for metrorrhagia. Rafle $\left(r a^{\prime}-A\right)$ [Fr.]. A pustular disease of cattle.

Rag [ME., ragge, a rag]. A worn garment; a shred of cloth. R.-picker's disease (Hadernkrankheit), malignant pustule or anthrax. An infection transmitted by old rags and caused by the presence of the Bacillus (Proteus) hominis capsulatus, q.v., under Bacteria, Synonymatic Table of. R.-weed, a plant of the genus Ambrosia. R.-weed Fever. See Hay-fever and Rhinitis, Hyperesthetic. R.-wort. See Life-root.

Rage $(r \bar{a} j)$ [ME., rage, rage]. I. Violent passion or anger. 2. Any intensely painful affection. 3. [Fr. Hydrophobia; rabies.

Ragle $\left(\mathrm{rag}^{\prime}-\mathrm{l}\right)$ [Fr.]. An hallucination due to isolation and insomnia, observed in French troops while in the desert, in which they imagined they saw prairie and water.

Railway (rāl'-zva) [ME, rail, a bar or rail ; way]. A road way composed of iron rails. $\mathbf{R}$. Brain, traumatic hysteria; Erichsen's disease. A morbid condition following shock, in which the symptoms are those of neurasthenia or hysteria, or both. Erichsen ascribed the condition to inflammation of the meninges and cord, and gave it the name of Railruay Spine. $\mathbf{R}$. Kidney, a renal affection said to be due to the constant jar of railway journeys. R. Spine. See $R$. Brain.

Rain (rän) [ME., rein, rain]. The descent of water in drops through the atmosphere. R.-bath. See Bath. R.-bow Disease, R.-bow Worm, herpes iris. R.gauge, an instrument for measuring the quantity of rain that falls in a given area in a given time.

Rainey's Corpuscles, R. Tubes. Psorosperms occurring in the muscles of the pig and other animals. See Miescher's Tubes, and Sarcocystis miescheri, under Parasites (Animal), Table of.

Raised (räzd) [ME., raisen, to raise]. Elevated. $\mathbf{R}$. Base (for artificial teeth), a term applied in mechanical dentistry to a metallic base, surmounted by a box or chamber soldered to it, and designed to compensate for the loss of substance which the parts have sustained. A base thus constructed is usually termed by dentists a raised plate. See Melallic base for artificial teeth.

Raisin (ral-zin) [ME., raisin, raisin]. Dried grapes. See Uva and Passa.

Raising ( $\left.\mathrm{r}^{\prime}-z i n g\right)$ [ME., raisen, to raise]. I. See Pigments, Colors, and Dyestuffs. 2. One of the Swedish movements, either active or passive. It is used for deformities of the back, to relieve constipation, to act upon the abdomen, etc. 
Rak (rak). See Arrak.

Rake Teeth, a term applied to teeth separated by intervals, like those of a rake.

Raki (rak'-e) [Turk., spirits]. A Turkish liqueur, in the preparation of which mastic is used.

Rakli pili $\left(r a k^{\prime}-l e-p i^{\prime}-l e\right)$. An Indian term for lep. rosy.

Rale $(\mathrm{rahl})$ [Fr., râler, to rattle]. The sound caused by the breaking of air through impediments or passing over obstructions in the lungs and bronchi. They vary in character according to the consistency of the surrounding lung-tissue. Sometimes a distinction is made between râles and rhonchi. The first word is applied to sounds generated by vibrations set up in fluids, the second to sounds generated in the narrowed or obstructed lumen of tubes. See Tiable of Râles.

\section{TABLE OF RÂLES.}

\begin{tabular}{|c|c|c|c|c|}
\hline VARIETY. & WHEN HEARD. & How and Where Produced. & I SIZE AND CHARACTER. & $\begin{array}{l}\text { CONDITION IN WHICH } \\
\text { HEARD. }\end{array}$ \\
\hline Amplyoric. & $\begin{array}{l}\text { Inspiration and expira- } \\
\text { tion. }\end{array}$ & $\begin{array}{l}\text { By movement of air in a tense- } \\
\text { walled cavity containing air and } \\
\text { communicating with a bronchus. }\end{array}$ & $\left|\begin{array}{c}\text { Large, musical, and } \\
\text { tinkling }\end{array}\right|$ & $\begin{array}{l}\text { In tuberculous and abscess } \\
\text { cavities. }\end{array}$ \\
\hline Bubbling, large. & $\begin{array}{l}\text { Inspiration and expira- } \\
\text { tion. }\end{array}$ & $\begin{array}{l}\text { By passage of air through frothy } \\
\text { mucus in the trachea and larger } \\
\text { bronchi. }\end{array}$ & $\begin{array}{l}\text { Larger than the } \\
\text { medium bubbling ; } \\
\text { moist. }\end{array}$ & $\begin{array}{l}\text { Bronchitis and pulmonary } \\
\text { engorgement. }\end{array}$ \\
\hline $\begin{array}{l}\text { Bubbling, me- } \\
\text { dium. }\end{array}$ & $\begin{array}{l}\text { Inspiration and expira- } \\
\text { tion. }\end{array}$ & $\begin{array}{l}\text { By passage of air through mucus } \\
\text { in the larger tubes. }\end{array}$ & $\begin{array}{l}\text { Larger than the } \\
\text { small bubbling } \\
\text { moist. }\end{array}$ & $\begin{array}{l}\text { In capillary bronchitis, } \\
\text { especially in children. }\end{array}$ \\
\hline $\begin{array}{l}\text { Bubbling, } \\
\text { small. }\end{array}$ & $\begin{array}{l}\text { Inspiration and expira- } \\
\text { tion. }\end{array}$ & $\begin{array}{l}\text { By passage of air through mucus } \\
\text { in the bronchioles. }\end{array}$ & $\begin{array}{l}\text { Small; moist; like the } \\
\text { bursting of soft bub- } \\
\text { bles. }\end{array}$ & $\begin{array}{l}\text { In capillary bronchitis, } \\
\text { especially in children. }\end{array}$ \\
\hline Cavernous. & $\begin{array}{l}\text { Inspiration and expira- } \\
\text { tion. }\end{array}$ & $\begin{array}{l}\text { By passage of air through a small } \\
\text { cavity with flaccid walls, which } \\
\text { collapse with expiration. }\end{array}$ & Hollow and metallic. & $\begin{array}{l}\text { In the third stage of pul- } \\
\text { monary tuberculosis. }\end{array}$ \\
\hline Clicking. & Inspiration only. & $\begin{array}{l}\text { By passage of air through soften- } \\
\text { ing material in smaller bronchi. }\end{array}$ & Small; sticky. & $\begin{array}{l}\text { The apex in pulmonary } \\
\text { tuberculosis. }\end{array}$ \\
\hline Consonating. & $\begin{array}{l}\text { Inspiration and expira- } \\
\text { tion. }\end{array}$ & $\begin{array}{l}\text { When bronchial tubes surrounded } \\
\text { by consolidated tissue. }\end{array}$ & Bright, clear, ringing. & Tuberculous pneumonia. \\
\hline Crackling, dry. & In inspiration. & $\begin{array}{l}\text { By the breaking down of lung- } \\
\text { tissue. }\end{array}$ & $\begin{array}{l}\text { Sharp, short, and } \\
\text { clicking. }\end{array}$ & $\begin{array}{l}\text { In the second or softening } \\
\text { stage of pulmonary tuber- } \\
\text { culosis and in pulmonary } \\
\text { gangrene. }\end{array}$ \\
\hline $\begin{array}{l}\text { Crackling, } \\
\text { large. }\end{array}$ & $\begin{array}{l}\text { Inspiration and expira- } \\
\text { tiou. }\end{array}$ & By fluid in very small cavities. & $\begin{array}{l}\text { Larger than the } \\
\text { medium crackling: } \\
\text { dry. }\end{array}$ & $\begin{array}{l}\text { In pulmonary tuberculosis } \\
\text { and pneumonia, after for- } \\
\text { mation of small cavities. }\end{array}$ \\
\hline $\begin{array}{l}\text { Crackling. } \\
\text { medium }\end{array}$ & Chiefly in inspiration. & By fluid in the finer bronchi. & $\begin{array}{l}\text { Larger than the } \\
\text { small crackling; dry. }\end{array}$ & $\begin{array}{l}\text { Softening of tuberculous } \\
\text { deposit or pneumonic } \\
\text { exudation. }\end{array}$ \\
\hline $\begin{array}{l}\text { Crackling, } \\
\text { small. }\end{array}$ & Chiefly in inspiration. & By fluid in the finer bronchi. & $\begin{array}{l}\text { Small ; dry; like the } \\
\text { breaking of small } \\
\text { shells. }\end{array}$ & $\begin{array}{l}\text { Softening of tuberculous } \\
\text { deposit or pneumonic } \\
\text { exudation. }\end{array}$ \\
\hline Crepitant. & End of inspiration. & $\begin{array}{l}\text { By passage of air into vesicles coi- } \\
\text { lapsed, or containing fibrinous } \\
\text { exudation. Usualiy at the base } \\
\text { of the lungs. }\end{array}$ & $\begin{array}{l}\text { Small ; like rubbing } \\
\text { the hair between the } \\
\text { fingers. }\end{array}$ & $\begin{array}{l}\text { Pneumonia, early stage: } \\
\text { edema of lungs; hypo- } \\
\text { static pneumonia; local- } \\
\text { ized in pulmonary tuber- } \\
\text { culosis. }\end{array}$ \\
\hline Dry. & $\begin{array}{l}\text { Inspiration and expira- } \\
\text { tion. }\end{array}$ & $\begin{array}{l}\text { By narrowing of the bronchial } \\
\text { tubes from thickening of the } \\
\text { mucous lining, from spasmodic } \\
\text { contraction of the muscular coat, } \\
\text { viscid mucus within, or pressure } \\
\text { from without. }\end{array}$ & $\begin{array}{l}\text { Large and sonorous, } \\
\text { or small and hissing, } \\
\text { or whistling. }\end{array}$ & $\begin{array}{l}\text { In bronchitis, asthma, and } \\
\text { localized in beginning } \\
\text { pulmonary tuberculosis. }\end{array}$ \\
\hline Extra-thoracic. & & In the trachea or larynx. & & \\
\hline Friction. & $\begin{array}{l}\text { Inspiration and expira- } \\
\text { tion : most distinct at } \\
\text { the end of inspiration. }\end{array}$ & $\begin{array}{l}\text { By the rubbing together of serous } \\
\text { surfaces, roughened by inflam- } \\
\text { mation or deprived of their nat- } \\
\text { ural secretion. }\end{array}$ & $\mid \begin{array}{l}\text { Grazing, rubbing, } \\
\text { grating, creaking, or } \\
\text { crackling. }\end{array}$ & $\begin{array}{l}\text { In pleurisy and pericar- } \\
\text { ditis. }\end{array}$ \\
\hline Gurgling. & $\begin{array}{l}\text { Inspiration and expira- } \\
\text { tion. }\end{array}$ & $\begin{array}{l}\text { By the passage of air through fluid } \\
\text { in cavities, on coughing. }\end{array}$ & $\begin{array}{l}\text { Larger than the large } \\
\text { bubbling moist: } \\
\text { like the bursting of } \\
\text { large bubbles. }\end{array}$ & $\begin{array}{l}\text { Pulmonary tuberculosis } \\
\text { after formation of cavi- } \\
\text { ties. }\end{array}$ \\
\hline Guttural. & & In the throat. & & \\
\hline Moist. & & $\begin{array}{l}\text { By the passage of air through } \\
\text { bronchi containing fluid. }\end{array}$ & & \\
\hline $\begin{array}{l}\text { Mucous } \\
\text { Lænnec). }\end{array}$ & $\begin{array}{l}\text { Inspiration and expira- } \\
\text { tion. }\end{array}$ & $\begin{array}{l}\text { By viscid buhbles bursting in the } \\
\text { bronchial tubes. }\end{array}$ & $\begin{array}{l}\text { A modification of the } \\
\text { sub-crepitant. }\end{array}$ & Pulmonary emphysema. \\
\hline
\end{tabular}


TABLE OF RÂLES--Continued.

VARIETY.

WHEN HEARD.

HoW AND WhERE PRODUCED.

SIZE AND CHARACTER.

CONDITION IN WHICH

HEARD.
Râleredux, râle Inspiration and expira- By the passage of air through fluid de retour. tion.

Sibilant. Inspiration and expiration.

Sonorous.

Inspiration and expiration.

in a bronchial tube.

By narrowing of the smaller bronchi from viscid mucus adhering to the walls, from thickening of the lining membrane or spasmodic contraction.

By lessened caliber of the larger bronchi, from spasm, tumefaction of mucous lining or external pressure.

Sub-crepitant.

Inspiration and expiration.
By passage of air through mucus in the capiliary bronchial tubes

$\begin{aligned} & \text { Crackling and un- } \\ & \text { equal. }\end{aligned}$
$\begin{aligned} & \text { High-pitched and even } \\ & \text { hissing or piping. }\end{aligned}$
Low-pitched and snor-
ing.

In pneumonia in the stage of resolution.

In bronchitis, asthma, and localized in beginning pulmonary tuberculosis.

Small; moist.

Capillary bronchitis.

Ramal $\left(r a^{\prime}-m a l\right)$ [ramus, a branch]. Pertaining to a ramus; branching; growing on a branch. Ramalis vena, the portal vein and its branches.

Ramastrum (ra-mas'-trum) [ramus, branch]. In biology, one of the secondary petioles of compound leaves.

Ramdohr's Suture. See Suture.

Ramellose (ram'-el-ös) [ramellus, a small branch]. Bearing ramelli.

Ramellus $\left(r a-m e l^{\prime}-u s\right)$ [dim. of ramus, a branch: pl., Ramelli]. In biology, a branch less than a ramulus occurring at the growing point of an algal filament.

Ramenta (ra-men'-tah) [L., pl., Filings, Scrapings]. I. Shreds, filings, or shavings. 2. Fine chaffy scales on the surface of plants, consisting of elongated cells. $\mathbf{R}$. intestinorum. shreds of intestinal mucus discharged with the evacuations in severe dysentery.

Ramentaceous (ram-en-ta'-se-us) [ramenta, filings]. In biology, covered with ramenta.

Ramentum (ra-men'-tum) [L., ascraping, a chip, ascale: $p l$., Ramenta]. In biology, a scale-like or hairy outgrowth of the epidermis, of a membranous texture, found on the stems and petioles of many ferns.

Ramex (ra'-meks) [gen,, Ramicis: pl., Ramices]. A hernia, or hernial tumor]. $\mathbf{R}$. varicosus, varicocele.

Ramicorn ( $\left.r a^{\prime}-m i k-o r n\right)$ [ramus, a branch; cornu, horn]. In biology, the horny covering or sheath of the rami of the lower mandible of a bird.

Ramie (ram'-e) [Malay]. See China Grass. R. Fiber, China-grass. The bast fiber from two varieties of Boehmeria nivea, known in India as Rhea, and in the Malay Archipelago as Ramie. The properly prepared fiber is of fine, silky luster, soft, and extraordinarily strong. It is the most perfect of all the vegetable fibers, and is composed of pure cellulose.

Ramification (ram-if-ik-a'-shun) [ramus, a branch; facere, to make]. The branching and division of an organ or part, as observed in the nerves and bloodvessels.

Ramiflorous (ra-mif-lo'-rus) [ramus, branch; flos, flower]. Flowering on the branches.

Ramiform (ram'-if-orm) [ramus, a branch ; forma, form ]. Resembling a branch in form.

Ramify (ram'-if-i) [ramus, a branch ; facere, to make]. To form branches.

Ramiparous (ra-mip'-ar-us) [ramus, branch; parere, to bear]. Producing branches.

Ramolescence (ram-o-les'-ens) [Fr., ramollir, to soften]. A softening; mollification.

Ramollissement $\left(r a-m o-l e s^{\prime}-m o n(g)\right)$ [Fr. $]$. A morbid softening of any tissue or part. R. des os. See Osteomalacia. R. hémorrhagipare, softening giving rise to hemorrhage.

Ramose (ran'-oz) [ramus, branch]. Provided with many branches; branching.

Rampion (ram'-pe-on) [Sp., rampion, a species of lobelia]. An herbaceous plant, Campanula rapunculus, with an edible root, resembling a small turnip. R., Horned, the genus Phyteuma.

Ramsden's Eye-piece. An eye-piece having two plano-convex lenses, used with a micrometer.

Ramsted (ram'-sted). See Antirrhinum linaria.

Ramuliferous (ram-u-lif'-er-us) [ramulus, a little branch; ferre, to bear]. In biology, bearing ramuli.

Ramulose $\left(\mathrm{ram}^{\prime}-u-l o ̈ z\right)$ [ramus, a branch]. Full of branchlets.

Ramulous (ram'-ze-lus) [ramulus, a little branch]. In biology, having many small branches.

Ramulus (ram'-u-lus) [L.: pl., Ramuli]. A small branch, or ramus.

Ramus ( $\left.r a^{\prime}-m u s\right)$ [L.]. The branch of an organ, especially of a vein or an artery. $\mathbf{R}$. abdominalis, the hypogastric nerve. $\mathbf{R}$. acetabuli, a branch of the internal circumflex artery supplying the hip-joint. $\mathbf{R}$. anastomoticus, the branch of an artery by which an anastomosis is established. $\mathbf{R}$. anterior ascendens, R. anterior nervi acustici. See Cochlear Nerve. $\mathbf{R}$. ascendens, the anterior branch of the fissure of Sylvius. R. ascendens glabellaris, the branch of the angular artery going to the inner angle of the orbit. $R$. ascendens nervi vagi, a branch of the superior laryngeal nerve going to the epiglottis. $\mathbf{R}$. ascendens (seu inferior) ossis ischii, the ascending branch of the ischium. R., Ascending (of the 1schium), the portion between its tuberosity and the acetabulum. R., Ascending (of the Pubic Bone), the portion between its body and the acetabulum. $\mathbf{R}$. auricularis nervi vagi. See Nerve of Amold. R. bulbocavernosus. See Artery of the Bull of the Urethra. R. canalis spinalis, the branch of the intercostal artery supplying the walls of the spinal canal. $\mathbf{R}$. cardiacus nervi vagi inferior, inferior cardiac nerve. R. cardiacus nervi vagi superior, superior cardiac nerve. R. cervico-facialis (nervi facialis), cervicofacial nerve, $\mathbf{R}$. cochleæ, $\mathbf{R}$. cochlearis, the cochlear nerve. R. communicans anterior, anterior com municating artery of the brain. $R$. communicans medullæ spinalis, a branch of a spinal nerve uniting it with the sympathetic. R. communicans posterior, the posterior communicating artery of the brain. $\mathbf{R}$. cruralis, lumbo-inguinal nerve. $\mathbf{R}$. cutaneus nervi 
radialis. See Radial Nerve. R. cutaneus palmaris longus. See $R$. palmaris longus nervi mediani. $\mathbf{R}$. descendens. $I$. The descendens noni nerve. 2. The inferior division of the inferior maxillary nerve, $\mathbf{R}$. descendens nervi hypoglossi, the descendens noni nerve. R. descendens (seu superior) ossis ischii, the descending branch of the ischium. $\mathbf{R}$. descendens ossis pubis, the descending branch of the pubic bone. R., Descending (of the Ischium), the portion between its body and tuberosity. R., Descending (of the Pubic Bone), the portion included between its body and its junction with the ischium. $\mathbf{R}$. dexter arteriæ pulmonalis, the right pulmonary artery. R. dorsalis nasi, the dorsal artery of the nose. $\mathbf{R}$. dorsalis nervi radialis. See Radial Nerve. $\mathbf{R}$ dorsalis nervi ulnaris. See Ulnar Nerve. R dorsalis pollicis radialis, that part of the radial artery which winds round the outer side of the carpus and crosses the thumb beneath the extensor tendons. $R$. dorsalis pollicis ulnaris, $\mathbf{R}$. duræ matris vagi, a branch from the jugular ganglion going to the meninges. $\mathbf{R}$. externus, $\mathbf{R}$. femoralis, lumbo-inguinal nerve. R. hepaticus dexter, the right hepatic artery. $\mathbf{R}$ hepaticus sinister, the left hepatic artery. R., Horizontal (of the Pubic Bone). See R., Ascending (of the Pubic Bone). R. horizontalis fissuræ sylvii, the posterior limb of the fissure of Sylvius. R. horizontalis mandibulz, the body of the inferior maxilla. $R$. horizontalis (seu superior) ossis pubis (seu pectinis), the horizontal ramus of the pubic bone, $\mathbf{R}$. hyoideus. See Hyoid Artery, $\mathbf{R}$. of the Inferior Maxilla, the portion ascending from the angle, and terminating in the condyle and coronoid process. $\mathbf{R}$ intermedius. See $R$. anastomoticus. R. lingualis recurrens. See $R$. ascendens nervivagi. R. magnus nervi mediani, the musculo-cutaneous nerve, $\mathbf{R}$. major nervi maxillaris inferioris, the greater of the two primary branches of the inferior maxillary nerve R. malaris, the inferior branch of the orbital nerve. R. marginalis, the dorsal branch of the radial nerve supplying the thumb. R. mastoideus. I. 'The small occipital nerve. 2. The occipital branch of the posterior auricular artery. 3. The posterior division of the great auricular nerve. R. maxillaris inferior nervi trigemini. See Inferior Maxillary Nerve. R. maxillaris superior (seu medius) nervi trigemini. See Superior Maxillary Nerve. R. medullæ spinalis, the spinal branch of the intercostal artery supplying the spinal cord. R. meningeus posterior. See $R$. durce matris vagi. $\quad$ R. minor nervi vidiani, the great superficial petrosal nerve. $R$. muscularis nervi radialis, the radial nerve. $R$. nasalis nervi ophthalmici. See Naso-ciliary Nerve. R. nutriens, the nutrient artery of a bone. $R$. ophthalmicus (quinti), the ophthalmic nerve. $\mathbf{R}$. ossis maxilla inferioris. See $R$. of the Inferior Maxilla. R. ovarii See Ovarian Artery. R. palmaris longus nervi mediani, a branch of the median nerve distributed to the integument of palm of the hand. $R$. perpendiculares (mandibulæ). See $R$. of Inferior Maxilla. $R$. posterior. I. The ilio-lumbar artery. 2. The posterior limb of the fissure of Sylvius. R. primus nervi trigemini (seu primus quinti). See Ophthalmic Nerve. R. profundus nervi radialis. See Radial Nerve. R. recurrens vagi, a branch of the jugular ganglion which goes to the transverse sinus through the jugular foramen. $\mathbf{R}$. secundus (ganglii gasserii), $R$. secundus nervi trigemini (seu quinti paris), the superior maxillary nerve. $\mathbf{R}$. sinister arteriæ pulmonalis, the left pulmonary artery. $\mathbf{R}$. sinualis, the recurrent branch of the ophthalmic nerve going to the tentorium. $\mathbf{R}$. sublimis (seu volaris superficialis) arterize radialis, the superficial volat artery. R. superficialis nervi radialis, the radial nerve. $R$. superior ossis ischii, the descending ramus of the ischium. $\mathbf{R}$. superioris nervi trigemini, R. superioris quinti, the ophthalmic nerve. $\mathbf{R}$. supraspinatus, the suprapinous artery. $\mathbf{R}$ tertius nervi trigemini, the inferior maxillary nerve. $\mathbf{R}$. vestibularis, the vestibular nerve. $\mathbf{R}$. volaris nervi ulnaris, the volar distribution of the ulnar nerve. Rami accelerantes, accelerator nerves. R. alares, branches of the lateral nasal artery supplying the nasal pinnæ. $\mathbf{R}$. anteriores nervorum spinalium, the anterior divisions of the spinal nerves. $\mathbf{R}$. cardiaci (nervi vagi), the cardiac branches of the pneumogastric nerve. $\mathbf{R}$. communicantes noni, the branch of the descendens noni which joins the com municating branches of the second and third cervical nerves. $\mathbf{R}$. emissaria, branches of the anterior spinal plexuses which emerge through the intervertebral and anterior sacral foramina. R. intestinales, branches of the cerebro-spinal nerves supplying the abdominal vis cera. R., Ischio-pubic, the descending rami of the ischium and the pubes taken as one. $\mathbf{R}$. linguales (nervi glossopharyngei), the terminal branches of the ninth nerve. $\mathbf{R}$. marginales, the branches of the palpebral arteries which aid in forming the arcus arteriosus palpebræ. R. molles (nervi vagi). See Auditory Nerve. R. musculares, unnamed branches of nerves or blood-vessels distributed to the muscles. $\mathbf{R}$. olfactorii, the olfactory nerve. $\mathbf{R}$. pectorales laterales (seu perforantes laterales, seu posteriores, seu superficiales). See Lateral Thoracic Cutaneous Nerves. R. pharyngei (nervi vagi), the branches of the vagus going to the pharynx. Rami ventrales, the branches of the intercostal arteries distributed to the intercostal muscles and to the ribs.

Ramuscule (ra-mus'-kül) [ramusculus]. A little branch, especially of the pial arteries.

Rancid (ran'-sid) [rancidus, rancere, to become sour]. The condition, marked by a sharp taste and disagreeable odor, that fats and oils acquire by oxidation in the presence of light and fermentation of certain of their principles.

Rancidification (ran-sid-if-ik-a'-shun) [rancidus, rancid: facere, to make]. The act of making or the process of becoming rancid.

Rancidity (ran-sid'-it-e) [rancidus, rancid]. The state of being rancid.

Randia (ran'-de-ah) [after Isaac Rand, a London botanist of the eighteenth century]. A genus of cinchonaceous shrubs. R. aculeata, of West India ; ink-berry, indigo plant. The juice of the fruit is astringent. $\mathbf{R}$. dumetorum, of India; has a poisonous and strongly emetic fruit. Unof. R. longifora, of Bengal; the cortex is used in intermittent fever.

Range (rānj) [Fr., ranger, to dispose]. Scope, extent or compass. $\mathbf{R}$. of Accommodation. See Accommodation. R. of Sensibility. See Law, Fechner's.

Rangoon Tar. A variety of petroleum obtained in India.

Ranine $\left(r a^{\prime}-n e n\right)$ [rana, a frog]. I. The designation of a branch of the sublingual artery ; also of its accompanying vein. See Artery. 2. Relating to that part of the tongue subject to ranula.

Ranke, Angle of. See Angle.

Ranson's Apparatus. See Disinfection.

Ranstead (ran'-sted). See Antirrhinum linaria.

Ranula (ran'-u-lah) [rana, frog]. A cystic tumor beneath the tongue, connected with the duct of the sublingual salivary gland. R. lapidea, salivary calculi. $R$. pancreatica, a dilated saccular condition of the larger pancreatic ducts due to calculous obstruction. 
R., Suprahyoid, a cystic tumor situated above the hyoid bone.

Ranunculaceous (ra-nung-ku-la'-se-us) [ranunculus, a medicinal plant]. Noting, or relating to plants of the order Ramunculacece.

Ranunculus (ra-nung $\left.{ }^{\prime}-k z t-l u s\right)$ [L.]. A genus of acrid herbs of many species, growing in many temperate and cold regions, e.g., buttercups, or crowfoot. Many of the species are acrid poisons, and have been used (especially $R$. acris, bulbosus, fammula, and sceleratzes) as counter-irritants and vesicants. Unof. R. aconitifolius, a native of Europe. The root, juice, and green leaves are used. R. acris, blister-plant; very irritant, causing erythema æstivum. R. alpestris, white crowfoot of the Alps. The chamois-hunters chew the leaves, which are said to prevent giddiness and fatigue. R. aquatilis, water anemone, floating white crowfoot; a species of Europe and North America. It is said to be poisonous when fresh, but otherwise wholesome and nutritive. R. asiaticus, turkey crowfoot; the common garden species. R. bulbosus, crow-flower; buttercup; a European and North American species; very acrid. It was once official as radix ranunculi bulbosi, and is still used by the homeopathists. R. creticus, a species known to the ancients, and used by them for the cure of warts, chilblains, scabies, and ulcers, also for toothache. R. ficaria, the lesser celandine, an edible species found in Europe; the leaves are eaten as salad, the root prepared as a vegetable. $\mathbf{R}$. glacialis, a species found in the Alps. The root possesses sudorific properties, and is used in rheumatism and bronchial affections. R. lingua, R. longifolius, spearwort; great crowfoot; found in Europe, Asia, and North America. The root and herb were formerly official. R. muricatus, a European species, possessing stimulant and vesicant properties, and used for skin-diseases, R. paludensis, R. palustris, old pharmaceutic names for $R$. sceleratus. R. repens, creeping crowfoot; buttercup; occurring in Europe, Asia, and North America. The herbs and flowers were formerly official. R. sceleratus, water celery ; a very acrid species found in Europe, Asia, and North Ameria, and formerly used as a vesicant. It contains a resin and a volatile oil which yields anemonin and anemonic acid.

Ranvier's Constrictions. See $R$.'s Nodes, R.'s Crosses, brownish-black cruciform figures which appear at each node of Ranvier in preparations of nerve-tissue stained with silver nitrate. The silver diffuses into the nerve-fiber only at the nodes, stains the cement-substance joining one internode with another, thus forming the transverse bar of the cross, and as it diffuses along the axis-cylinder stains the cement-substance on the latter for a short distance, and so makes the vertical bar. R.'s Lemon-juice Method, a method of tracing nerve-fibers. Small pieces of tissue, $\mathrm{I} / 4$ inch square, are soaked in lemonjuice 5 or 10 minutes, washed quickly in distilled water, and placed in I per cent. solution of gold chlorid for from Io minutes to $I$ hour, according to the density of the tissue. Wash in water, place in $50 \mathrm{c} . \mathrm{c}$. water containing two drops of acetic acid, and expose to the light; or, if it is not desired to keep the superficial epithelium, after treating with lemon-juice and gold the tissue is placed for 24 hours in formic acid (sp. gr, I.2) diluted with three times its volume of water, and kept in the dark (after Squire). R.'s Nodes. See Node. R.'s Picrocarmin. See Stains, Table of. R.'s Tactile Discs, nerve-endings consisting of small, cup-shaped bodies, the concave side of which is always directed toward the free surface of the epidermis. They are those tactile corpuscles of Merkel, also of Grandy, which terminate, not in the cells, but in the intercellular substances.

Rape $(r \bar{a} p)$ [rapere, to seize]. Forcible sexual intercourse with a woman. According to the laws of some States, the intercourse with a young girl is also considered as rape when not effected through force, but by reason of her ignorance. R.-oil. See Colza-oil. R.-plant. See Brassica.

Raphania (ra-fa'-ne-ah) [raphanus, a radish]. A nervous affection attended with spasmodic disorder of the joints and the limbs. It has been attributed to a poisonous principle in the seeds of the wild radish, which are likely, at certain times, to become mixed with grain. The affection is allied to ergotism and pellagra. See Ergotism. R. maisitica, pellagra; so named because it was supposed to be caused by the use of maize as food.

Raphe $\left(r a f^{\prime}-a\right)[\rho a ́ \phi \eta$, suture]. r. Any line, suture, ridge, or crease having the appearance of a seam. It is applied especially to the median line of the body. 2. A ridge or cord; the continuation of the seedstalk, extending from the hilum to the chalaza along the side of an anatropous or an amplitropous ovule or seed. R., Exterior, the stria longitudinalis medialis. $\mathbf{R}$. inferior corporis callosi, the raphe on the inferior surface of the corpus callosum. R. palati duri. Same as $R$. palatine. $\mathbf{R}$., Palatine, the narrow ridge of mucosa in the mesial line of the palate. $\mathbf{R}$. of the Penis, a continuation of the raphe of the scrotum upon the penis. R., Perineal, the ridge of skin in the middle line of the perineum. $\mathbf{R}$. of the Pharynx, a fibrous band in the median line of the posterior wall of the pharynx. R. post-oblongata, the posterior median fissure of the medulla oblongata. $\mathrm{R}$. of the Scrotum, a median ridge dividing the scrotum into two lateral halves; it is continuous, posteriorly, with the raphe of the perineum, anteriorly with the raphe of the penis. The septum of the medulla oblongata, of Stilling. R. superior corporis callosi, the longitudinal raphe in the middle of the superior surface of the corpus callosum. $\mathbf{R}$. of the Tongue, a median furrow on the dorsal surface of the tongue corresponding to the fibrous septum which divides it into symmetric halves.

Raphis (ra'-fis) [ $\rho$ ro $\iota s$, a needle: $p l .$, Raphides]. In biology, one of the needle-shaped crystals found in bundles in the cells of many plants. See also $R h a$ phis.

Raptus (rap'-tus) [rapere, to seize]. Any sudden attack or seizure ; rape. R. hæmorrhagicus, a sudden hemorrhage. R. maniacus, transient frenzy. R. melancholicus, sudden and vehement melancholy. R. nervorum, cramp or spasm.

Rarefaction (rar-e-fak'-shun) [rames, rare; facere, to make]. The decreasing of the density or tension of a gaseous substance, especially the air; attenuation; dilution. $\mathbf{R}$. of Bony Tissue, the attenuation of bony tissue as a result of ostitis or senile atrophy. See Usteoporosis. R., Pulmonary. See Emphysema.

Raritas $\left(r a r^{\prime}-i t\right.$-as) [L.]. Rarity. R. dentium, fewness of teeth: less than the usual number of teeth, with or without interspaces between them.

Rarity of the Atmosphere. See Atmospheric.

Rasceta (ra-se'-tah) [L.]. The transverse lines or creases of the skin on the inner side of the wrist.

Rash [OF., rasche, a rash]. Any exanthematous eruption of the skin. R., Canker. Same as Scarlatina. R., Caterpillar, a localized eruption attributed to the irritant action of the hairs of certain caterpillars. R., Doctors', a transitory rash sometimes seen in nervous persons undergoing medical ex- 
amination. R., Drug, a rash due to the toxic action of arsenic, potassium iodid or bromid, quinin or other drug. R., Medicinal. See R., Drug. R., Milletseed. See Miliaria. R., Mulberry, an eruption resembling the exanthem of measles, sometimes occurring in the course of typhus (Jenner). R., Nettle. See Urticaria. R., Rose. See Roseola. R., Scarlet. See Scarlet Fever. R., Tooth, any rash attributed to dentition. Strophulus. R., Typhoid. See Typhoid Fever. R., Wildfire, any transitory erythematous rash.

Rasorian (ra-zo'-re-an) [after Rasori]. Following the teachings of Rasori; contrastimulant. R. Method, in phlebotomy, repeated bleeding.

Rasorianism, Rasorism ( $\left.r a-z o^{\prime}-r e-a n-i z m, r a-z o^{\prime}-r i z m\right)$ [after Rasori]. The doctrine of Rasori; contrastimulism.

Raspail's Eau Sedatif. See Ammonium and Camphor.

Raspatory (ras'-pat-o-re) [raspatorium; radere, to scrape]. In surgery, a rasp or file for trimming the rough surfaces of bones or for removing the periosteum.

Raspberry (raz'-ber-e). See Rubus idaus.

Rasura (ra-zu'-rah) [L.]. I. The process of rasping, shaving, or scraping. 2. That which is scraped or shaved off.

Rat [ME., ratte, rat]. A rodent of the family Muride. R.-tail Sutures, fibers from the rat's tail, used instead of silk or gut, for surgical sutures. R.-tooth Forceps. See Forceps.

Ratafia (rat-a-fe'-ah) [Malay, arag, arrack; tafia, a spirit distilled from molasses]. A name for various liqueurs, or aromatized and sweetened cordials.

Ratanhia (rat-an'-e-ah) [Peruv, ratana]. See Kraneria, R., Decoctum (radicis), a decoction made by boiling one part of ratanhia with 40 parts of water, and filtering when cold. R., Extractum, Alcoholicum, an extract prepared from an infusion of ratanhia in 22 per cent. alcohol, which is driven off by distillation, and the residue evaporated. R., Extractum, Americanum (seu falsum). See American Kino. R., Extractum, Equosum (seu depuratum). See Extractum kramerice. R., Extractum, Fluidum. See Extractum krameria fuidum. R., Extractum, Venale. See Extractim krameria. R., Infusum. See Infusum kramerie. R., Poudre de. Dried ratanhia, powdered and sifted. R., Red, a red pigment, $\mathrm{C}_{26} \mathrm{H}_{22} \mathrm{O}_{11}$, obtained from the bark of ratanhia. R.-tannic Acid, a tannic acid occurring in the roots of several kinds of krameria. R., Suppositoriæ, suppositories consisting of one grain of ratanhia and three of oil of theobroma (Fr. Cod.). R., Syrupus, cum extracto, R., Syrupus. See Syrupus kramerice. R., Tinctura. See Tinctura krameria.

Ratanhin (rat'-an-in) [Peruv, ratana], $\mathrm{C}_{10} \mathrm{H}_{13} \mathrm{NO}_{3}$. Methylated tyrosin.

Ratany (rat'-an-e). See Ratanhio.

Rathke, Glands of. See Gland. R., Investing Mass of, the membranous capsule covering the end of the chorda dorsalis in the developing embryo and forming the rudiment of the base of the skull. It molds itself on the cerebral vesicles, so as to constitute the membrane in which the vault of the skull is developed. The membranous capsule at the base of the skull presents two thickenings, the lateral trabecule of Rathke. directed forward and enclosing the pituitary opening. R., Lateral Trabeculæ of. See R., Investing Mass of. R., Pouch of. See Pouch.

Rathke's Organ, an extremely muscular division of the gut in certain crustaceans (parasitic, or female, Isopoda) which carries on energetic rhythmic contractions. It is the third division; following the cephalogaster and typhlosolis.

Ratio $\left(r a^{\prime}-s h e-o\right)$ [L.]. I. The mind or reasoning faculties. 2. In chemistry and pharmacy, the proportion of ingredients or of atomic composition. $R$. medendi, the theory or scheme of a course of medical treatment. R., Ocular Micrometer, the number obtained by finding the number of divisions on the ocular micrometer required to include the image of an entire millimeter of the stage micrometer.

Ration $\left(\mathrm{r}^{\prime} \mathrm{t}^{\prime}\right.$-s/un $)$ [ratio, proportion]. The daily allowance of food of a soldier or a sailor.

Rational ( $\mathrm{r}^{\prime}$-shon-al) [ratio, reason]. Relating to reason; reasonable. In therapeutics, opposed to empiric. R. Formula, in chemistry, a structural formula. See Formula.

Ratsbane (ratz-bän') [ME., rätte, rat; bane]. A popular name for rat-poisons containing arsenic; arsenious acid. See Rough on Rats. R., Yellow, orpiment.

Rattle $($ rat' $-l)$ [ME., ratelen, rattle]. See Râle. $\mathbf{R}$., Death-, a gurgling sound observed in dying persons, due to accumulation of mucus in the trachea obstructing the passage of air. R.-herb, the Actea spicata. $\mathrm{R}$.-weed, the Actaa racemosa.

Ratula (rat'-u-lah). See Raspatory.

Rau, Process of. The longer process at the junction of the handle with the neck of the malleus. It is also called the Process of Folizes.

Rauber's Convolution. See Convolutions, Table of. $\mathbf{R}$.'s Layer, a superficial stratum of flat cells occurring in the center of the embryonal spot at an early stage in the development of the blastodermic membranes.

Raucedo (raw-se'-do) [raucus, hoarse]. Hoarseness arising from inflammation of the mucosa of the larynx and throat. $\mathbf{R}$. catarrhalis, hoarseness resulting from laryngitis. $\mathbf{R}$. potatorum, hoarseness caused by drinking whiskey or other distilled liquors, $\mathbf{R}$. syphilitica, chronic hoarseness due to secondary syphilitic affections of the larynx.

Raucitas (raw'-sit-as). See Raucedo.

Raucous (raw'-kus) [raucus, hoarse]. Husky; hoarse. Raulin's Liquid. A nutritive liquid composed entirely of mineral constituents, upon which the common mold, Aspergillus niger, grows more perfectly and to a greater size than upon any of the natural (organic) substances upon which the parasite habitually develops. It is composed, in grams, of the following: water, I 500 ; crystallized sugar, 70 ; tartaric acid, 4; ammonium nitrate, 4 ; ammonium phosphate, 0.6 ; potassium carbonate, 0.6 ; magnesium carbonate, 04 ; ammonium sulphate, 0.25 ; zinc sulphate, 0.07 ; iron sulphate, 0.07 ; potassium silicate, 0.07 . The suppression or diminution of the quantity of a single one of these salts diminishes the harvest, often far more than the proportion of the weight of the changed salt.

Rauracienne (ro-ras-e-en'). Same as Orseillin and Fiast Red. See Pigments, Conspectus of.

Rauschbrand (rowsh'-brant) [Ger.]. The German name for black-leg, $q$. $v$.

Ravaton's Amputation. An amputation performed by making a circular incision through all the structures down to the bone and a lateral lengthwise incision, to secure flaps. See Operations, Table of.

Ray $(r a)$ [ME., raye, a ray]. I. A beam, pencil, or cone of light; a line of light or heat proceeding from a luminous point. One of the component elements of light or of the spectrum.. 2. One of a number of lines diverging from a common center. In biology, the branch of an umbel: the marginal flowers of an inflorescence when their structure varies from those of the disc, $e . g_{.}$, ligulate flowers, or circle of enlarged tubular flowers in heads of Composita, outer flowers 
in cyme of wild hydrangea. Rs., Actinic, solar rays that produce chemic change. Rs., Bipolar, rays leading from one point of divergence to another, as in the diaster of a cell undergoing indirect division. Rs., Chemic. See Rs., Actinic. R., Extraordinary, the polarized ray that departs farthest from the ordinary law of refraction. Its vibrations are parallel to the vertical axis. R., Fin-, one of the radiating, bony spines forming the framework of the fins in fishes. R.-floret. Same as R.-flower. R.-flower, one of the marginal flowers of an inflorescence when distinct from those of the disc. R.-fungus. See Actinomyces. R., Medullary, one of the vertical partitions of parenchyma radiating from the pith to the bark in woody plants, and separating the bundles of fibro-vascular tissue. R.-oil, the oil of the liver of the fish called ray or skate, Raja batis, said to be an effective substitute for cod-liver oil. R., Ordinary, the polarized ray which follows most nearly the ordinary law of refraction. Its vibrations are perpendicular to the vertical axis.

Ray's Mania. A form of general moral insanity. See Diseases, Table of.

Raygat's Test. See Birth.

Raymond's Blue. Same as Napoleon Blue.

Raynaud's Disease. A vascular disorder characterized by three grades of intensity: $(a)$ Local syncope, observed most frequently in the extremities, and producing the condition known as dead fingers or dead toes; it is analogous to that induced by intense cold. $(b)$ Local asphyxia, which usually follows local syncope, but may develop independently. Chilblains are the mildest manifestation of this condition. The fingers and toes and the ears are the parts usually affected. In the most extreme degree the parts are swollen, stiff, and livid, and the capillary circulation is almost stagnant. (c) Local or symmetric gangrene, the mildest form of which follows local asphyxia. Small areas of necrosis appear on the pads of the fingers and of the toes, also at the edges of the ears and tip of the nose. Occasionally symmetric patches appear on the limbs or trunk, and in severe cases terminate in extensive gangrene. Raynaud suggested that the local syncope was produced by contraction of the vessels; the asphyxia is probably caused by dilatation of the capillaries and venules with persistence of the spasm of the arterioles. Two forms of congestion occur, which may be seen in adjacent fingers, one of which may be swollen, intensely red, and extremely hot; the other swollen, cyanotic, and icy cold (Osler). See Sphaceloderma. R.'s Gangrene. Same as $R$.'s Disease. R.'s Phenomenon. See Acroasphyxia and Diseases, Eponymic, Table of.

Re-. A Latin prefix signifying back or again.

Reabsorption (re-ab-sorp'-shun). See Resorption.

Reaching (rêch'-ing) [ME., rechen, to reach]. To attempt to vomit; to retch.

Reacquired (re-ak-zwird') [re, again; acquirere, to acquire]. Acquired a second time. R. Movements. See Acquired Movements.

Reaction (re-ak'-shun) [re, again; agere, to act]. I. Mutual action; interaction. The response of an organ, tissue, or the system, to a stimulus, agent, or influence. Recuperation or return of power after depression or "shock." The supervention of fever after a surgical operation, or trauma. 2. In chemistry, the result of introducing a reagent or test. See Tests, Table of. 3. In electro-therapeutics, the muscular contraction following the making or breaking of the current. $\mathbf{R}$., Acid, the reddening of blue litmus paper by the action of an acid; a test for the presence of acids. R., Adamkiewicz's, a reaction employed as a test for albuminoids. See Tests, Table of. R., Alkaline, a reaction indicative of alkaline properties, and in which red litmus paper is changed to blue. R., Amphicroitic, R., Amphigenous, R., Amphoteric, a double reaction occurring occasionally in urine, owing to the presence of substances by which the liquid responds to both the acid and alkaline tests. R., Biuret. See Tests, Table of. R. of Degeneration ("De.R."), diminution and loss of faradic excitability in both nerves and muscles, the galvanic excitability of the muscles remaining unimpaired, sometimes notably increased, andal ways undergoing definite qualitative modifications. It is due to a degenerative atrophy in the nerves and muscles, eventually in the muscles only, whose origin is always nervous, paralytic, or atrophic, and whose seat is in the peripheral nerves, motor roots, or central gray substance. Strict cerebral disease is excluded. The lesion is either in the peripheral nerves or spinal cord. De. $R$. is of special value in prognosis. When there is only Partial De. R. (i.e., slight diminution of both galvanic and faradic excitability, "a less maximum contraction rather than a later minimum "), the disease will probably last one or two months; if complete, it will last much longer. The De. R. embraces the following modifications of irritability: $\mathbf{r}$. Disappearance or diminution of nervous irritability to both galvanic and faradic currents, 2. Disappearance of faradic and increase of galvanic irritability of muscles, generally associated with an increase of mechanical irritability. 3. Disappearance of faradic and increase of galvanic muscular irritability, associated generally with increased mechanical irritability. 4. Tardy, delayed contraction of muscles, instead of the quick reaction of normal muscles. 5. Marked modification of normal sequence of contraction. A special variety of the De. R. is the so-called Reaction of Exhaustion, which is a condition of nervous and muscular irritability to electric excitation in which a certain reaction produced by a given current-strength cannot be reproduced without an increase of current-strength. $\mathbf{R}$., Galvano-trophic, of L. Herrmann, a phenomenon observed in small aquatic animals subjected to the influence of a galvanic current. After a few spasmodic movements, they place themselves in the direction of the current, with the head toward the positive pole. R., Gmelin's. See Tests, Table of. R., Hemiopic Pupillary, of Wernicke, a reaction in which a pencil of light thrown on the blind side of the retina gives rise to no movement in the iris, but thrown upon the normal side produces contraction of both irides. R.impulse, the supposed recoil of the cardiac ventricles after the discharge of the blood into the aorta and pulmonary artery. R., Isofaradic, of Adamkiewicz, a condition of muscle in which it responds only to the faradic current. R., Myotonic, of Erb, a reaction seen in Thomsen's disease, in which there is quantitative and qualitative increase in the faradic excitability. R., Neutral, a reaction indicating the absence of both acid and alkaline properties; also, of positive opposite qualities. $\mathbf{R}$.-period, the period following a trauma or operation in which there is recovery from the incident shock. R.-time, in physiology and psycho-physics, the interval between the application of a stimulus and the beginning of the corresponding muscular contraction. R., Xanthoproteic. See Tests, Table of.

Readjustment (re-ad-just'-ment). See Advancement.

Reagent (re-a -jent) [re, again; agere, to act]. In chemistry, anything used to produce a reaction, or to test for the presence of an element. A test. See Tests, Table of. R., General, a reagent that indicates the group of substances to which a body belongs, with- 
out determining which one of the group it is. $\mathbf{R}$, Special, a reagent which indicates the presence of an individual substance, and not only the group of which it is a member.

Real $\left(r e^{\prime}-a l\right)$ [ME, real, real]. Actual; true; genuine. R. Image. See Image.

Realgar (re-al'-gahr) [Arab., ralij alghar, realgar]. An old name for arsenous disulphid, $\mathrm{As}_{2} \mathrm{~S}_{2}$. See Pigments, Conspectus of.

Reamer (re'-mer) [ME., remen, to widen]. An instrument for gouging out holes. R., Dentists'. See Nerve-canal Reamer.

Reanimate (re-an'-im-at) [re, again; animare, to animate]. To revive; to resuscitate; to restore to life, as a person apparently dead.

Reanimation (re-an-iml-a'-shun) [reanimare, to reanimate]. The act of restoring to life ; reviving.

Reason $\left(r e^{\prime}-z n\right)$ [ME., reson, reason]. The intellectual faculty.

Réaumur's Thermometer. See Thermometer.

Reboulleau's Blue. Same as Schreinfurth Blue.

Recaulescence (re-kaze-les'-ens) [re, again; caulis, a stem]. In biology, Schimper's term to indicate the union of a petiole to a peduncle or branch.

Receiver (re-se'-ver) [recipio, to receive]. I. In chemistry and pharmacy, the vessel receiving the products of distillation. 2. A popular term for the blanket in which an infant is placed after division of the umbilical cord.

Receptacle (re-seṕlta-kl) [receptaculum, a receptacle]. I. A vessel or place in which something is contained; a receiver or container. 2. In biology, $(a)$ the more or less expanded part of an axis upon which the floral. organs are inserted (torus), or the collected flowers of the head, as the disc-like apex of the peduncle in Composite. In cryptogams a structure of similar nature. An organ or part or intercellular space formed for the storing of secretions; $(b)$ a receptaculum. $\mathbf{R}$., Common, the short rachis bearing a flower-head. R. of the Flower, the axile part of a single flower. R. of Fungi, a receptacle of cellular tissue, developed from the mycelium, for the reception of the reproductive organs, R. of Inflorescence. See $R$., Common. R. of the Ovules, See Placenta. R., Polliniferous, of $\mathrm{R}$. Brown, a cellular plate in an anther-cell, dividing it into two compartments. R., Seminal. See Receptaculum seminis.

Receptacular (re-sep-tak'-u-lar) [receptaculum, a receptacle]. Pertaining to a receptaculum.

Receptaculum (re-sep-lak'-u-lum)[recipere, p.p. receptus, receive, hold, contain]. In biology, any part or organ for the reception of a secretion. See Receptacle. R. chyli, an expansion of the thoracic duct opposite the last dorsal vertebra. See Pecquet's Reservoir. R. cotunni, a triangular space near the middle of the posterior surface of the petrous portion of the temporal bone, at the termination of the aquæductus vestibuli. It is formed by the separation of the laminæ of the dura mater.

Receptive (re-sep'-tiv) [recipere, to receive]. Having the quality of or capacity for receiving. R. Centers, In physiology and psycho-physics, nerve-centers to which influences arrive that may excite sensations or some kind of activity not associated with consciousness.

Receptum (re-sep'-tum). See Prescription.

Recess (re-ses') [recessus, a recess]. A fossa, ventricle, or ampulla ; an anatomic depression. R., Chiasmal, a pit in front of the infundibulum bounded by the optic chiasm and the cinereous lamina. R., Cochlear, an elliptic pit below the oval window of the vestibule, forming part of the cochlea. R., Intercrural. See In- terpeduncular Space. R., Interscapular, the depression between the scapulæ. R., Lateral, the lateral extension of the fourth ventricle in the angle between the cerebellum and the oblongata. R., Postpontile, the foramen crecum of the brain.

Recessus (re-ses'-us) [L.]. I. See Recess. 2. Abscess. 3. A cornu of a lateral ventricle. $R$. acetabuli, the cotyloid cavity. R. chiasmatica. See Lamina cinerea. $\mathbf{R}$. cochlearis, a shallow depression between the diverging portions of the crista vestibuli. $\mathbf{R}$. conarii, the cavity at the base of the pineal body, situated between the supracommissure and postcommissure, R. ellipticus. See Fovea hemielliptica. R. hemiellipticus. See Fovea hemielliptica. R. hemisphæricus, a tiny perforated cavity in the inner wall of the vestibule, anterior to the crista vestibuli ; it transmits the branches of the auditory nerve. $R$. infundibuli, the cavity of the infundibulum in the floor of the third ventricle. $\mathbf{R}$. intercruralis, the interpeduncular space. R. labyrinthi, a cavity formed in the base of the fetal skull, developing into the primitive auditory vesicle, and finally into the internal ear. R. naso-palatinus, the nasal orifice of the naso-palatine canal, $\mathbf{R}$. occipitalis, the posterior horn of the lateral ventricle. $\mathbf{R}$. opticus. See Lamina cinerea. R. peritonæi, the pocket-like processes formed by the peritoneum. R. pharyngeus, a pouch-like process of the mucosa of the pharynx situated below the opening of the Eustachian tube. R. sphæricus. See Fovea hemispharica. R. spheno-ethmoidalis, a small depression or groove between the sphenoid bone and the superior turbinated bones. R. superior sacci omenti, the cavity of the lesser omentum.

Recidivation (re-sid-iv- $a^{\prime}$-shun) [recidivus, a falling back]. The relapsing of a disease. In criminology, a relapsing into crime.

Recidive (re-sid ễ $\left.{ }^{\prime}\right)$. See Relapse and Recurrence.

Recidivist (re-sid'-iv-ist) [recidivus, falling back]. I . A patient who returns to a hospital for treatment, especially an insane person who so returns. 2. In criminology, a confirmed or relapsed criminal; $(a)$ one who for the most part has no mental or bodily signs of degeneration, caused by bad bringing up, society, poverty, sexual disorders, and who makes crime a trade or a vengeance; $(b)$ one with inborn criminal inclinations and a positive tendency to insanity or epilepsy; and $(c)$ one whose antecedents and environment lead him to crime by blunting his sense of honor and morality. The latter classes are inclined to coarseness, boldness, resistance, and wilful spoiling of their clothes; but are not legally re garded as insane.

Recidivity (re-sid-iv'-it-e) [recidivatus, a restoration]. Tendency to return or to relapse.

Recipe (res'-ip-e) [recipere, to take]. A Latin word contracted to $\mathbf{B}$, used as the heading of a physician's prescription and signifying take. See also Prescription.

Recipiomotor (re-sip-e-o-mo'-tor) [recipere, to receive : motor, mover]. Receiving motor impulses.

Recklinghausen, Canals of. See Canal.

Reclinate (rek'-lin-ât) [reclinare, to bend back, recline]. In biology, reclined or bent downward. Applied to stems, branches, etc. Also applied to that form of vernation in which the apex of the leaf is bent downward toward the base, and to a cotyledon doubled over in the seed. It is used to qualify the hairs and processes of insects when they bend toward a surface as if to rest on it.

Reclinatio (rek-lin-a'-she-o). See Reclination. $\mathbf{R}$. palpebrarum, ectropion. 
Reclination (rek-lin-a'-s/un) [reclinare, to recline] The act of lying, or of laying down. R. of Cataract. See Couchino.

Recline (re-klin') [reclinare, to lean back]. To lean backward or downward ; to rest in a recumbent posture.

Reclining (re-kli'-ning) [reclinare, to recline]. Bending downward or backward; having a leaning posture. $\mathbf{R}$. Board, a board to which young persons are sometimes strapped to prevent stooping and to give erectness to the figure. R. Posture. See Postures.

Reclivate (rek'-liv-at) [re, back; clivus, sloping]. In biology, doubly curved, as the letter $s$.

Reclus' Disease. Cystic disease of the mammary gland. See Diseases, Taule of.

Reclusor (re-klu'-zor) [recludere, to shut up]. A mus cle that opens a part, as the levator palpebre superioris.

Reclusus (re-klu'-szes) [recludere, to shut up]. Shut in, enveloped, as a plant-embryo embedded in albumin.

Recognition Time. See Time.

Recoil Wave. See Pulse.

Recondite (re-kon'-ditt, or rek'-on-dit) [re, back; condere, put together]. Hidden; not readily perceived Said of organs of insects that are not exserted.

Reconstitution (re-kon-stit-u'-shun) [re, again; consti tuere, to constitute]. Continuous repair of decaying tissue, or restoration to compensate loss by tissue-waste.

Recovery (re-kuv'-er-e) [Fr., recovrer, recover]. The restoration of health; return to a state of health.

Recreate (rek'-re-ät) [recreare, to revive]. To revive or refresh; to reanimate

Recreation (rek-re-a'shun) [recreatio, restoration] The act of recreating or refreshing. Diversion.

Recrement (rek'-re-ment) [recrementum]. A secretion that is reabsorbed or reabsorbable.

Recremental (rek-re-men'-tal) [recrementum, dross]. Pertaining to recrement.

Recrementitious (rek-re-men-tish'-us) [recrementum, dross]. Of the nature of a recrement; pertaining to such natural secretions as saliva and gastric juice, that, after excretion are again absorbed.

Recrescence (re-kres'-ens) [re, again; crescere, to come forth, to grow]. The reproduction of a lost part.

Recrudescence (re-kru-des'-ens) [re, again; crudescere, to becorne raw ]. The beginning anew or increase in the symptoms of a disease after a short intermission.

Rectal (rek'tal). Pertaining to the rectum. $\mathbf{R}$. Etherization. See Anesthetic. R. Glands. From two to six projecting glandular bodies in the rectum of many insects (Orthoptera, Diptera). In certain larvæ (Libellula aschna) they take the form of respiratory organs. R. Pouch, of rays and sharks, a dorsal diverticle of the rectum characteristic of the group.

Rectalgia (rek-tal'-je-ah) [rectum, rectum; ànyos, pain]. Pain in the rectum; proctalgia.

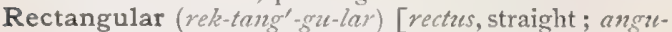
lus, an angle]. Having straight sides or right angles. R. Flap Amputation. See Teale's Operation in Operations, Table of.

Recticruræus (rek-tik-ru-re'-us) [rectus, straight ; crus, leg]. The rectus femoris muscle.

Rectification (rek-tif-ik-a'-shun) [rectus, straight; facere, to make]. A straightening, as of a crooked limb. In chemistry, the redistillation of weak spirit in order to strengthen it. R., Artificial, the operation of correcting a faulty position of the fetal head during labor by the hand or with the forceps.

Rectified (rek'-tif-i $\left.d^{\prime}\right)$ [rectus, straight; facere, to make]. Refined; made right or straight. R. Spirit, alcohol containing 85 per cent. of spirit.

Rectinerved (rek'-tin-ervd) [rectus, straight; nervus, nerve]. In biology, with straight nerves or veins.
Rectipetality (rek-tip-et-al'-it-e) [rectus, straight; petere, to seek]. In biology, the inherent tendency of growing organs to advance in a right line, modified, however, by Heterauxesis (q. v.), as demonstrated by Voechting.

Rectirostral (rek-te-ros'-tral) [rectus, straight; rostrum, beak]. Straight-beaked.

Rectischiac (rek-tis'-ke-ak). Same as Ischiorectal.

Rectiserial (rek-tis-e'-re-al) [rectus, straight; series, a row]. In biology, arranged in straight lines or ranks.

Rectitic (rek-tit'-ik) [rectum, rectum; $\iota \tau \iota \zeta$, inflammation]. Of the nature of or affected with rectitis.

Rectitis (rek-ti'-tis) [rectum, rectum; -itis, inflammation]. Inflammation of the rectum; proctitis. $\mathbf{R}$. proliferans, chronic inflammation of the rectum, with increase of the connective-tissue elements and the development of small granulomata.

Recto- (rek'-to-) [rectum, rectum]. A prefix used to denote connection with or relation to the rectum.

Rectocele $\left(r e k^{\prime}-t o-s e l l\right)$ [rectum, rectum; kinh $\eta$, tumor]. Prolapse of the rectum, causing a rectal tumor and even protrusion of the rectum.

Rectococcygeal (rec-to-kok-sij-el-al) [rectum, rectum; $\kappa \delta \kappa \kappa v$, the coccyx]. Pertaining to the rectum and the coccyx.

Rectococcypexy (rek-10-kok-si-peks'-e) [rectum, rectum; $\kappa \kappa \kappa v \xi$, coccyx; $\pi \eta \xi \iota \varsigma$, a fastening]. Suturing of the rectum to the coccyx.

Recto-colonic (rek-to-ko-lon'-ik) [rectum, rectum; $\kappa \omega \lambda$ ov, colon]. Pertaining to the rectum and the colon.

Rectogenital (rek-to-jen'-it-al) [rectum, straight; genitalis, pertaining to generation]. Pertaining to the rectum and the genital organs.

Rectopexia (rek-to-peks'-e-ah) [rectum, rectum; $\pi \dot{\eta} \xi \iota s$, a fastening]. Fixation of a prolapsed rectum in a desired position by artificial means.

Rectopexy (rek'-to-peks-e). Same as Rectopexia.

Rectophobia (rek-to-fo'-be-ah) [rectum, rectum; фóßos, fear]. A presentiment or sense of impending ill experienced by patients having rectal disease (Kelsey).

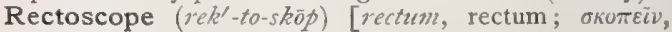
to inspect]. A rectal speculum.

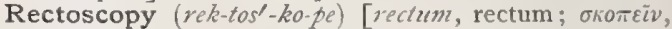
to inspect]. An examination of the rectum.

Rectostenosis (rek-to-sten-o'-sis) [rectum, rectum;

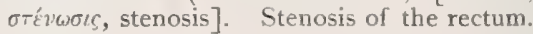

Rectotome $\left(\mathrm{rek}^{\prime}-t_{0}\right.$-tom $)$ [rectum, rectum; To $\mu \eta$, a cutting]. A cutting instrument used in rectotomy.

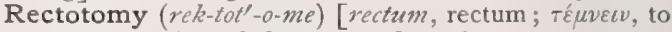
cut]. Incision of the rectum for stricture, etc.

Recto-urethral (rek-to-u-re'-thral) [rectum, rectum; oṽoov, urine]. Pertaining to the rectum and the urethra.

Recto-uterine (rek-to- $\left.u^{\prime}-t e r-i n\right)$ [rectum, rectum; uterus, the womb]. Pertaining conjointly to the rectum and the womb. R. Cul-de-sac, the pouch of Douglas. R. Folds, R. Ligaments. Semilunar folds of peritoneum passing on each side from the rectum to the posterior upper surface of the uterus. R. Fossa. The space between the uterus and the rectum above the borders of the recto-uterine folds. R. Pouch. Douglas's cul-de-sac.

Recto-uterinus (rek-lo-u-ter-i'-nurs) [rectum, rectum; zterus, uterus]. A band of non-striated muscles in the recto-uterine folds.

Recto-vaginal (rek-to-zaj'-in-al) [rectum, rectum; ragina, vagina]. Pertaining conjointly to the rectum and the vagina, R. Cul-de-sac, the pouch of Douglas. R. Fistula, an opening between the vagina and the rectum. R. Hernia. Same as Rectocele. $\mathbf{R}$. Septum, the tissues separating the rectum and the vagina. 
Recto-vesical (rek-to-ves'-ik-al) [rectum, rectum; vesica, the bladder]. Pertaining conjointly to the rectum and the bladder. $\mathbf{R}$. Folds, the posterior false ligaments of the bladder; lunate peritoneal folds between the bladder and the rectum in the male. Also called semilunar fold's of Douglas. R. Fossa, the pouch of peritoneum lying between the bladder and the rectum.

Rectrix (rek'-triks) [rectrix, governess, mistress: $p l$, Rectrices]. In biology, one of the rectrices, or tailfeathers, of a bird.

Rectum (rek'-tum) [rectus, straight]. The lower part of the large intestine, extending from the sigmoid flexure to the anus. Beginning opposite the left sacro-iliac synchondrosis, it passes obliquely downward to the middle of the sacrum, and thence descends in the median line to terminate in the anus. It presents two curves, one in the direction of the concavity of the sacrum and $\operatorname{coccyx}$, and a shorter one in the opposite direction as it turns backward to the anus. Narrower than the sigmoid flexure in its upper portion, it gradually increases in size, and just above the anus a considerable dilatation occurs. It has four coats, from within outward, as follows: mucosa, muscularis mucosæ, submucosa, muscularis. It has also a partial investment of peritoneum. The mucous coat has a lining of columnar epithelium, and is raised in longitudinal ridges or folds, the columne morgagni. The muscular coats consist of an outer longitudinal layer of fibers and an inner circular layer, especially thick at the lower end, where they constitute the internal sphincter. R., Encysted, Gross's disease of the anus; a pathologic sacculation of the rectum. See Diseases, Table of:

Rectus (rek'-thes) [L.]. Right. In a straight line. R. Muscles. See Muscles, Table of.

Recubant (rek'-u-bant) [recubans, lying back]. Lying down; reclining.

Recumbency (re-kum'-ben-se) [recumbere, to recline]. The posture of one who is lying down; decubitus.

Recumbent (re-kum' - bent) [recumbere, to recline]. Leaning back ; reclining.

Recuperate (re-ku'-per-ät) [recuperare, to regain]. To recover; to regain strength or health.

Recuperation (re-ku-per-a'-shun) [recuperatio; recuperare, to recover]. Convalescence. Restoration to health.

Recuperative (re-ku'-per-a-tiv) [recuperatious]. Pertaining to, or tending to, recovery of health or strength.

Recurrence (re-kur'-ens) [recurrere, to run back]. The return, as of a disease.

Recurrent (re-kur'-ent) [recurrere, to run back]. Recurring; reappearing. In anatomy, turning back in its course, as an artery or nerve. R. Erysipelas. See Erysipelas. R. Fever, the same as relapsing fever. R. Mania. Same as Periodic Mania. R. Pulse. See Pulse and Pulsus. R. Summer Eruption. See Hydroc vacciniforme.

Recurring (re-kur'-ing) [recurrere, to run back]. $\mathrm{Re}$ turning; occurring again. $\mathbf{R}$. Disease, one that returns or relapses. $\mathbf{R}$. Utterance, the involuntary utterance of certain words, usually a symptom of motor aphasia.

Recurvate (re-kur'-vät) [recurratus, curved back]. In biology, recurved.

Recurvation (re-kur-va'-shun) [recurvatus, curved back]. The act or process of recurving or of bending backward.

Recurved (re-kurvd') [re, back ; curvare, to curve]. In biology, bent back or downward. Curved upward when applied to the bill or beak of a bird.
Recurvirostral (re-kur-ve-ros'-tral) [recurvus, bent back; rostrum, beak]. Having a recurved bill

Recurvous (re-kur'-vus) [recurvus]. Bent bacliward. Recutitus (rek-u-te'-tus) [re, back; cutis, skin]. I. Circumcised. 2. In biology, apparent denudation of the epidermis.

Red [ME, red, red]. The least refrangible color of the spectrum. R. Antimony. See Kermes Mineral. R. Arsenic. Same as Realgar. R. Baneberry, the root of Acetata rubra, a very violent purgative. Dose of the ffd. ext. $\mathrm{q}^{\mathrm{v}-\mathrm{x}}$. Unof. R. Bark. See Cinchona. $\mathbf{R}$. or Black Water, a blood-disease affecting cattle and sheep, in which in cattle the urine is of a red or blood color, while in sheep there is an effusion of bloody serum into the abdominal cavity. R.-blindness. See Blindness. R.-blooded, having red blood. R. Bole. Same as Ocher. R. Braxy. See Braxy. R. Bud. See Judas Tree. R., Chinese. Mercuric sulphid. R. Cohosh. See Actea. R., Congo, a red dye which is turned blue by acids, and is a delicate test for them. R. Corpuscles. See Corpuscles. R.-crested, having red crests. R.-cross Society, an international society founded by Clara Barton, and intended to act upon the principles laid down in the Geneva Convention of 1864. It furnishes nurses and supplies for service in wars, and relieves the distress, needs, or wants of those who suffer in floods, pestilences, and public calamities. R.-green blindness, a form of color-blindness in which shades of red and green cannot be distinguished. R. Gum: I. A disease of grain. 2. A red papular eruption of infants Also called gum-rash and strophulus. See Miliaria, also Eucalyplus and Strophulus. R. Induration. See Induration. R. Infarct. See Infarct. R. Infiltration. See Infiltration. R. Jaundice. See Phenigmus. R. Lane, a vulgarism for the throat. R. Lead. Same as Minium. See Antimonial Cinnabar in Pigments, Conspectus of. R. Lip-salve. See Theobroma, Ol. R. Maple. See Acer. R.-milk Bacillus, Bacillus prodigiosus. Milk affected by it is called "bloody milk" by farmers. See Bacteria, Synonymatic Table of. R. Mixture, a combination of rock salt, potassium nitrate, sodium carbonate, and molasses, used for injecting bodies for the dissecting room. It imparts a beautiful red color to the muscles. It is also called Horner's Mixture. R. Neuralgia. See Erythromelalgia. R. Nucleus. See Nucleus tegmenti. R. Osier, the bark of the common Comus serica. Tonic and astringent. Dose of fld. ext. $3 \mathrm{ss}-\mathrm{j}$. Unof. R. Pestilence. See R. Plague. R. Plague, a form of the plague characterized by a red spot, boil, or bubo. R.-polled, having a red poll, or the top of the head red. R. Precipitate. See Hydrargyrum. R., Retinal, R., Visual. See Visual Purple. R. Root, Jersey tea. The root of Ceanothus americanus. Alterative and astringent. A popular remedy for the sore-throat of scarlatina. Dose of a decoction, ad lib. Unof. See Ceanothus, also Lachnanthes tinctoria. R. Rose. See Rosa gallica. R. Saunders. See Santalum rubrum. R.-shafted, having the shafts of the wing and tailfeathers red. R. Softening, a form of acute softening of the cerebral substance characterized by a red, punctiform appearance due to the presence of blood. R. Soldier. See Cholera, Hog. R. Sweat. See Chromidrosis and Micrococcus hamatodes, under Bacteria, Synonymatic Table of. R.-thighed, having red thighs, $\mathbf{R}_{\text {. }}$-throated, having a red patch on the throat. R., Violet. See Pigments, Conspectus of. R. Vision. See Erythropsia. R. Vitriol. Same as Colcothar. R.-water, a common name for hemoglobinuria in cattle. R.-winged, having red wings. 
Redia $\left(r e^{\prime}-d e-a h\right)$ [Redi, an Italian naturalist: $p l$., Redice]. In biology, the larval stage of a trematode, which results from the development of a parthenogenetic egg of the first larval stage (Sporocyst). The redice have at the anterior extremity of their body a sucker-like formation, a pharynx, a simple intestinal tube, and a birth-aperture. The first redice give rise to a second and these to a third parthenogenetic generation and these finally to larvæ called Cercaria, $q . v$.

Redintegration (red-in-te-gra'-shun) [redintegrare, to renew]. I. Regeneration. In chemistry, the restora tion of any mixed substance to its former nature. 2 The complete restitution or reforming of a part that has been injured or destroyed.

Redresser (re-dres'-er) [Fr., redresseur]. An instrument used to replace a displaced organ or part.

Redressment (re-dres'-ment) [Fr., redressement]. The correction of a deformity, or replacement of a dislocated part.

Reds (redz) [ME., red, red]. Popular term for the menses.

Reduce $\left(r e-d \bar{u} s^{\prime}\right)$ [reducere, to bring back]. To restore a part to its normal topographic relations, as to reduce a hernia or fracture.

Reduced (re-düs $\left.d^{\prime}\right)$ [reducere, to lead back]. I. Restored to its proper place, as a dislocated bone. 2. In chemistry, brought into the metallic form. 3. Diminished in size. $\mathbf{R}$. Eye. See Listing. $\mathbf{R}$. Hematin, the product of the reduction of hematin in alkaline solution. $\mathrm{R}$. Hemoglobin, the result of deoxidation of oxyhemoglobin. $\mathbf{R}$. Iron, iron by hydrogen; ferrum reductum. R. Oil. See Lubricating Oils.

Reducible (re-du'-sib-l) [OF., redusible]. Capable of being reduced. R. Circuit. See Circuit. R. Hernia, a hernia capable of being reduced by manipulation or posture.

Reducing (re-dūs'-ing) [reducere, to lead back]. Restor ing to the proper position. R. Division, a synonym of the term, Extrusion of the polar bodies or globules.

Réducteur ( $r a-d u k^{\prime}$-tur) [Fr.]. The India-rubber bag of A. Favrot for replacing a retroverted gravid uterus. It is introduced into the rectum and inflated.

Reduction (re-dul'-shun) [reductio; reducere, to lead back]. In surgery, the replacing a dislocated bone, hernia, or other part in its normal position. In chemistry, the operation of extracting a metal from its salt or other combination. R., False, a false forcing of a strangulated hernia through a rent in the neck of the sac and beneath a portion of detached parietal peritoneum. $R$. en masse, the reduction of a strangulated hernia in its sac, thus failing to relieve the strangulation. R., La Mothe's, a method of reducing shoulder-dislocations by manipulation. The patient is placed in the dorsal position, with the arm parallel to the side of the head and face and the hand of the operator fixing the scapula. R., Thomas's, a method of approximating and fixing the fragments of bone in case of fracture of the inferior maxilla, by passing a wire through them and twisting each end of it upon the other until the fragments are brought together. R.-works, a cremating establishment for disposing of the filth and refuse matter of a city.

Reductor $\left(r e-d u k t^{\prime}-o r\right)$ [L.]. I. An instrument for effecting reduction. 2, A retractor muscle.

Reduplicate (re-du't-plik-ät) [re, again; duplicare, to double]. In biology, double-back. Applied to that form of valvate estivation in which the margins of the organs are turned outward.

Reduplication (re-du-plik-a'shun) [L., reduplicatio, a doubling]. The doubling of the paroxysms in certain forms of intermittent fever. $R$. of the Heart- sounds, a simulated doubling of either the first or second sound of the heart. In the case of the first sound it is probably the effect of a shock caused at the pre-systolic period by a sudden tension of the auriculoventricular valves of the left side as a result of the contraction of the auricle. In the case of the second sound it is due to tension of the mitral leaflets occurring in mitral stenosis during the auricular systole. $\mathbf{R}$. of the Muscles, a doubling of a muscle due to some abnormal relation of its fasciculi.

Reduplicative (re-du'-plik-a-tiv). Same as Reduplicate.

Reduvia (red-u'-ve-ah). See Paronychia.

Redux ( $\left.r e^{\prime}-d u k s\right)$ [L.]. Noting the return of certain physical signs after their disappearance in consequence of disease. R., Crepitation. See Crepitation. R., Crepitus, the small mucous râles of the early stage of resolution after pneumonia.

Reed (rềd)[D., riet, a reed]. The abomasum, "fourth," or proper digestive stomach of ruminants. Cf. $a b o-$ masum, omasum, manyplies, psalterium, paunch.

Reedy Nail ( $\left.r e^{\prime}-d e-n a \bar{l}\right)$. A condition of the nail in which the natural longitudinal striæ become very marked, apparently from wasting of the intermediate portions. The condition is regarded by Fothergill as a sign of gout.

Reef-knot (rêf'-not). A sailor's knot used in the ligature of arteries. It is not likely to slip or loosen. See Knot.

Reel-foot (rêl' -foot). Synonym of Club-foot.

Reeling ( $\mathrm{re}^{\prime}$-ling $)$ [ME, relen, to turn round and round]. Swaying of the body, as in intoxication.

Reeves' Method. See Stains, Table of.

Refining (re-fil-ning) [Fr., raffiner, to refine]. In chemistry and pharmacy, the separation of a substance from the foreign matter with which it is mixed.

Reflected (re-fek'-ted) [reflectere, to bend backward]. Cast or thrown back. In anatomy, turned back upon itself. R. Light. See Light.

Reflection (re-flek'-shun) [reflexio, re, back ; fectere, to bend]. In optics, the bending or turning back of a ray of light from a surface that neither absorbs, transmits, nor scatters it. In pathology, the bending back of an organ or part from its normal direction.

Reflector (re-flek'-tor) [reflectere, to bend back]. I. A mirror or speculum by which light is reflected for use in diagnostic or operative processes. 2. A muscle the function of which is to turn a part back. R. epiglottidis. See Depressor epiglottidis in Muscles, Table of. R., Forehead. See Head-mirror.

Reflex (re'-feks) [reflexus, thrown back]. A bounding back or return of an impulse or body. R. Arc, R. Movement, the stimulus of an afferent nerve, and the transference or return, by a center, of the impulse through an efferent nerve, resulting in movement or function of a peripheral organ. Reflexes may be motor, sensory, secretory, tactile or inhibitory. A table of reflexes is appended. R., Crossed. See Crossed. R., Cutaneous, that arising from stimulation of the skin. $\mathbf{R}$., Deep, the so-called tendon-reflex, such as the kneejerk, ankle-clonus, etc. R. Epilepsy, epileptic seizures due to reflex influences, such as irritation from a cicatrix, etc. ; genuine cases are rare. R. Neurosis. See Neurosis. R., Reinforced. See Reinforcement. $R$., Tendon, muscle reflex action; myotatic reaction; deep reflex. See, also, Clonus, R., Vestigial, a reflex due to conditions, or to the environment, which affected one's ancestry, but which does not affect the subject of the reflex. R., Watered-silk, a vivid reflex often existing in the retina of children, especially pronounced along the vessels, changing its place with every movement of the mirror, and giving the retina a luster somewhat like that of watered silk. 


\section{TABLE OF REFLEXES.}

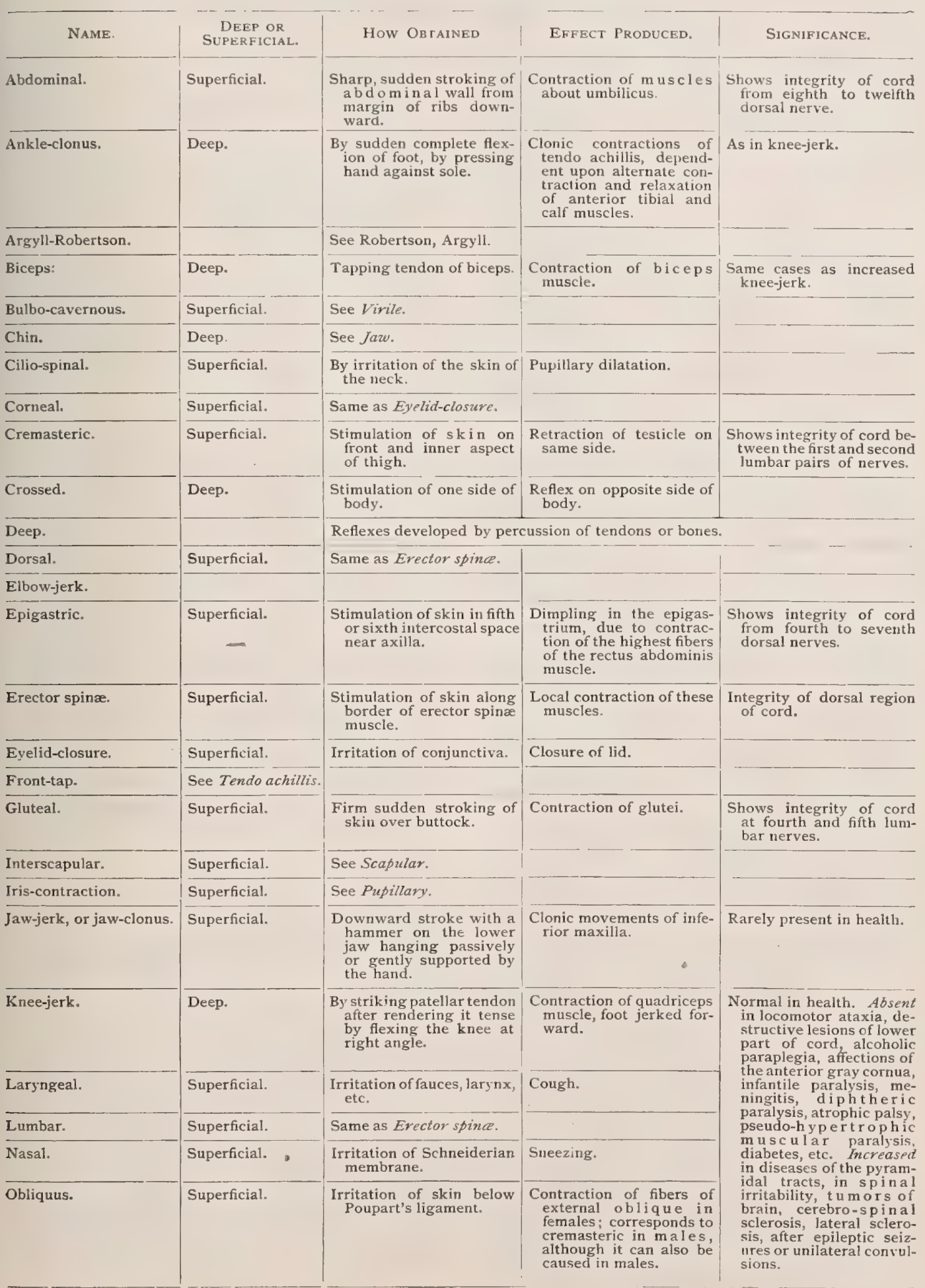


TABLE OF REFLEXES.-Continued.

\begin{tabular}{|c|c|c|c|c|}
\hline NAME. & $\begin{array}{l}\text { DEEP OR. } \\
\text { SUPERFICIAL. }\end{array}$ & How OBTAINED. & EFFECT PRODUCED. & SIGNIFICANCE. \\
\hline Palatal. & Superficial. & Irritation. & Swallowing. & \\
\hline Palmar. & Superficial. & Tickling of palm. & $\begin{array}{l}\text { Contraction of digital } \\
\text { Hexors. }\end{array}$ & $\begin{array}{l}\text { Shows that cervical region } \\
\text { of cord is normal. }\end{array}$ \\
\hline Patellar. & Deep. & Same as Knee-jerk. & & \\
\hline Patellar, Paradoxic. & Superficial. & $\begin{array}{l}\text { Percussing patellar tendon } \\
\text { with the patient in the } \\
\text { dorsal decubitus. }\end{array}$ & $\begin{array}{l}\text { Contraction of the adduc- } \\
\text { tor, but not of the quad- } \\
\text { riceps muscle. If the } \\
\text { patient be in the sitting } \\
\text { posture the normal re- } \\
\text { flex is elicited. }\end{array}$ & Spinal concussion. \\
\hline Penis-percussion. & Superficial. & See Virile. & & \\
\hline Periosteal. & Deep. & $\begin{array}{l}\text { Tapping the bones of the } \\
\text { forearm or leg. }\end{array}$ & $\begin{array}{l}\text { Sharp contractions of the } \\
\text { muscles. }\end{array}$ & $\begin{array}{l}\text { Indicates disease of the } \\
\text { spinal cord (a m y o- } \\
\text { trophic lateral sclerosis). }\end{array}$ \\
\hline Peroneal. & Superficial. & $\begin{array}{l}\text { Stroke on peroneal mus- } \\
\text { cles when tense or when } \\
\text { the foot is turned in- } \\
\text { ward. }\end{array}$ & Reflex movements. & \\
\hline Pharyngeal. & Superficial. & Irritation. & Swallowing. & \\
\hline Plantar. & Superficial. & Stroking sole of foot. & Contraction of toes. & Muscular exertion. \\
\hline Platysma. & Superficial. & $\begin{array}{l}\text { Pinching the platysma } \\
\text { myoides muscle. }\end{array}$ & Dilatation of pupil & \\
\hline Pupillary. & & $\begin{array}{l}\text { Exposure of retina to } \\
\text { light. }\end{array}$ & Contraction of iris. & $\begin{array}{l}\text { Absent in basal meningitis, } \\
\text { etc. }\end{array}$ \\
\hline Paradoxic. & & $\begin{array}{l}\text { Stimulation of retina by } \\
\text { light. }\end{array}$ & Dilatation of pupil. & In rare abnormal states. \\
\hline Paradoxic Patellar. & See Patellar, Par. & adoxic. & & \\
\hline Reinforced. & $\begin{array}{l}\text { Any reflex is height } \\
\text { mental distraction }\end{array}$ & $\begin{array}{l}\text { tened by coincident muscula } \\
\text { n. }\end{array}$ & ar exertion of other parts th & an those being tested or by \\
\hline Robertson, Argyll. & & Light and accommodation. & $\begin{array}{l}\text { Pupil reacts in accom- } \\
\text { modation, but not to } \\
\text { light. }\end{array}$ & Locomotor ataxia. \\
\hline Scapular. & Superficial. & $\begin{array}{l}\text { Irritation of interscapular } \\
\text { region. }\end{array}$ & $\begin{array}{l}\text { Contraction of scapular } \\
\text { muscles. }\end{array}$ & $\begin{array}{l}\text { Shows integrity of cord be- } \\
\text { tween upper two or three } \\
\text { dorsal and lower two or } \\
\text { three cervical nerves. }\end{array}$ \\
\hline Skin. & Superficial _ & See Platysma. & & - \\
\hline Sole. & & Same as Plantar. & & \\
\hline Spinal. & & Those reflex actions emanat & ting from centers in the spin & nal cord. \\
\hline Superficial. & . & Such as are developed from & $n$ irritation of the skin. & \\
\hline $\begin{array}{l}\text { Tendo achillis, or front- } \\
\text { tap contraction. }\end{array}$ & Superficial. & $\begin{array}{l}\text { By striking muscles on } \\
\text { anterior part of leg. } \\
\text { while in extension, the } \\
\text { foot being extended by } \\
\text { the hand upon the sole. }\end{array}$ & $\begin{array}{l}\text { Reflex contraction of } \\
\text { gastrocnemius. }\end{array}$ & $\begin{array}{l}\text { Considered hy Gowers as } \\
\text { a delicate test of height- } \\
\text { ened spinal irritability. }\end{array}$ \\
\hline Tendon. & & See Myotatic Irritability. & $-\ldots+\cdots$ & - \\
\hline Toe (great). & Superficial. & Strong flexion of great toe. & $\begin{array}{l}\text { Involuntary flexion of foot, } \\
\text { then flexion of leg, and, } \\
\text { last } 1 \text {, Hexion of the } \\
\text { thigh on the pelvis. }\end{array}$ & $\begin{array}{l}\text { Met with in cases in which } \\
\text { the knee-jerk and other } \\
\text { tend on-reflexes are } \\
\text { strongly developed. }\end{array}$ \\
\hline Virile. & Superficial. & $\begin{array}{c}\text { Sharp percussion of back } \\
\text { of pen is, the sheath } \\
\text { having been made tense. }\end{array}$ & $\begin{array}{l}\text { Retraction of bulbo- } \\
\text { cavernous portion. }\end{array}$ & Occurs in health. \\
\hline Wrist-clonus. & Deep. & $\begin{array}{l}\text { By pressing hand back- } \\
\text { ward, causing extreme } \\
\text { extension. }\end{array}$ & $\begin{array}{l}\text { A series of jerking move- } \\
\text { ments of the hand. }\end{array}$ & $\begin{array}{l}\text { In the late rigidity of } \\
\text { hemiplegia. }\end{array}$ \\
\hline
\end{tabular}


Reflexa (re-fleks'-ah) [L.]. See Decidua reflexa.

Reflexed (re-flekst') [reflectere, to bend back]. In biology, curved abruptly backward. Applied to sepals, petals, etc.

Refiexio (re-fleks'-e-o) [L.]. See Reflection. R. palpebrarum. See Eitropion.

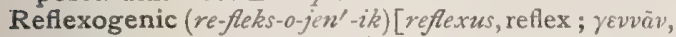
to produce]. Causing or increasing a tendency to reflex action; producing reflexes.

Reflexometer (re-fleks-oin'-et-er) [reflexus, reflex; $\mu \varepsilon \dot{\tau}$ pov, a measure]. An instrument used to measure the force required to produce myotatic movement.

Reflux (re'-fuks) [refuxus; re, back ; fluere, to flow] Any return of a current by reversal along its former course.

Refoulement ( $r a-f o o l^{\prime}$-mon $\left.(g)\right)$ [Fr. $]$. A forcing back R.dú sacrum en arrière, a backward inclination of the sacrum that marks one of the changes in the pelvis of girls at puberty.

Refracted (re-frak'-ted) [refractus, p. p. of refrangere, break back or up]. In biology, bent suddenly, so as to appear broken at the bend.

Refraction (re-frak'-shun) [refractio; re, up or back; frangere, to break]. The deviation of light from a straight line in passing obliquely from one transparent medium to another of different density. R., Angle of, the angle formed by a refracted ray of light with the perpendicular at the point of refraction. R., Atomic, the product of the refractive index of the constituent elements of a compound and their atomic weights. R., Coeffficient of, the quotient of the sine of the angle of refraction into the sine of the angle of incidence. R., Double, the power possessed, e. g., by Iceland spar, of dividing a ray of light and thus producing a double image of an object. R., Dynamic, the static refraction of the eye, plus that of the accommodative apparatus. R., Errors of, departures from the power of producing a normal or well-defined image upon the retina, because of ametropia. $\mathbf{R}$. of the Eye, the influence of the ocular media upon a cone or beam of light, whereby a normal or emmetropic eye produces a proper image of the object upon the retina. R.-image. See Image, R., Index of, the refractive power of any substance as compared with air. R., Molecular, the molecular weight of a compound. The molecular refraction of a liquid carbon compound is equal to the sum of the atomic refractions. R., Static, that of the eye with paralyzed accommodation.

Refractionist (re-frak'-shun-ist) [refrangere, to break up]. One who corrects errors of ocular refraction, or ametropia.

Refractive (re-frak'-tiv) [refrangere, to break up]. Tending to refract. Capable of being turned from a straight line. R. Equivalent. See Refractive Power, Specific. R. Index. Same as Refraction, Index of, $q . v$. R. Power, the measure of influence which a transparent body exercises on the light which passes through jt. R. Power, Specific, an alınost constant quantity representative of the relation between the coefficient of refraction, the temperature, and the specific gravity of a given fluid.

Refractometer (re-frak-tom'-et-er) [refrangere, to break

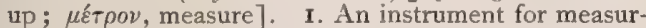
ing the refraction of the eye. 2. An instrument for the determination of the refractive indices of liquids.

Refractory (re-frak'-tor-e) [refrangere, to break up]. I. Resisting treatment. 2. Resisting the action of heat; slow to melt.

Refracture (re-frak'-tūr) [refrangere, to break up]. The re-breaking of fractured bones that have joined by fauity or improper union.
Refrangibility (re-fran-jib-il'-it-e) [L., refrangere, to refract]. In optics, capability of being bent away from a straight line; a property shown by a ray of light in passing obliquely from one transparent medium into another of different density.

Refresh (re-fresh') [L., re, again; friscus, new]. In surgery, to restore the character of a fresh wound; as to refresh the edges of a fissure before closing it.

Refreshing (re-fresh'-ing') [re, again; friscus, fresh]. Tending to refresh; invigorating; reviving. $\mathbf{R}$. Action (of the electric current). The restoration of excitability after fatigue by the effect of voltaic alternatives.

Refrigerant (re-frij'-er-ant) [refrigerans, making cool]. A medicine or agent having cooling properties, or lowering bodily temperature.

Refrigerated (re-frij'-er-a-ted) [refrigerare, to make cool again]. Cooled; made cool. R. Meat, meat which is kept at a temperature of from $36^{\circ}$ to $40^{\circ} \mathrm{F}$. from the time of slaughter until used.

Refrigeration (re-frij-er-a'-shun) [refrigeratio, a cooling again]. The act of lowering the temperature of a body, by conducting away its heat to a surrounding cooling substance.

Refrigeratory (re-frij'-er-a-tor-e) [L, , refrigeratorius]. A condenser. Also, a vessel filled with ice or with cold water for maintaining a low temperature.

Refuse (ref'-uz) [L., refusus, restored]. Waste from manufacturing establishments, and all inorganic waste.

Refusion (re-fu'-zhun) [refusio, an overflowing]. The act of withdrawing blood from the vessels, freeing it from poisonous substances, and passing it back again.

Regenerate $\left(r e-j e n^{\prime}-e r-a ̈ t\right)$ [regenerare, to generate again]. To generate anew; to reproduce.

Regeneration (re-jen-er-a'-shun) [regeneratio; regenerare, to beget]. I. The new growth or repair of structures or tissues lost by disease or by injury. 2 . In chemistry, the process of obtaining from the byproducts or end-products of an operation a substance which was employed in the earlier part of the operation. R., Cell-processes in, these consist in either simple hypertrophy (increase in the size of existing cells), or numerical hypertrophy, hyperplasia, increase in the number of cells in the tissue. $\mathbf{R}$. after Inflammation, repair by multiplication of the tissuecells. R. after Necrosis, repair by absorption of dead tissue and its replacement by newly formed normal tissue. R., Pathologic, the renewal of destroyed tissue by a pathologic rather than a physiologic process.

Regenerative (re-jent-er-a-tiv) [regenerare, to regenerate]. Tendency to regenerate. $\mathbf{R}$. Inflammation. See Inflammation.

Regenesis (re-jen'-es-is) [regenerare, to generate anew]. The state of being reproduced.

Régime $\left(r a-z h e \bar{e} n^{\prime}\right)$ [Fr.]. See Regimen.

Regimen (rej'-im-en) [regimen, guidance]. The methodic and systematized use of food, and the sanitary arrangement of surroundings essential to the preservation of life, both in health and in disease.

Regina Purple. Same as Rosanilin Violet.

Regio $\left(r e^{\prime}-j e^{\prime}-0\right)$ [L.]. See Region. R. aulica, the region about the aula and portas (foramina of Monro). $\mathbf{R}$. cardiaca, the region of the heart. $R$. coxarum, the lower portion of the lumbar region. R. germinativa, of Waldeyer, the germ-epithelium of the embryo. R. glutea, the region about the gluteal muscles. $\mathbf{R}$. subthalamica, the area between the ventral face of the thalamus, the body of Luys, and the red nucleus. It consists of a fine, felt-like mass of fibers, whose relations are so obscure that even their boundary is not well determined (zona incerta). 
Region (re'-jun) [regio, a region]. One of the artificial and conventional divisions of the body, as the Abdominal R. See Abdomen, and Pectoral R. R., Acromial, the parts near the acromion. R., Anal, pertaining to the anus. $\mathbf{R}$., Aulic, the area about the aula. R., Auricular, the parts near the ear. R. Axillary, a region upon the lateral aspect of the thorax, extending from the axilla to a line drawn from the lower border of the mammary region to that of the scapular region. R., Basilar, the region at the base of the skull. R., Brachial, the region of the arms. R. of Broca, the third left frontal convolution of the brain. R., Central Gray, the medullary substance of the cerebellar hemispheres. R., Cervical, the parts around the neck. R., Ciliary. I. The zone of the eyeball in which the ciliary body is situated. 2. The part of the eyeli d containing the cilia. R. Clavicular, the area about the clavicle. R., Costal, the lateral chestarea, R., Diaphragmatic, the region of the diaphragm. R., Epicranial, the region above the cranium. R., Epigastric, the region over the stomach bound. ed laterally by two vertical lines passing through the middle of Poupart's ligament; above by a horizontal line touching the lower margin of the sternum, and below by a horizontal line touching the lowest part of the thorax, and including the pyloric end and middle of stomach, the left lobe of the liver, the lobulus spigelii, the pancreas, the duodenum, parts of the kidneys, the aorta, vena cava, thoracic duct, semilunar ganglia. R., Femoral, the parts about the femur. R., Fibular, the parts about the fibula. R., Gastric, the region over the stomach. R., Gluteal, the region of the gluteus muscle. R., Groin, the region of the groin. R., Gustatory, the tips, margins, and root of the tongue in the neighborhood of the circumvallate papillæ; also the lateral parts of the soft palate and the anterior surface of the anterior pillars of the fauces, R., Humeral, the parts about the humerus. R., Hyo-mental. See R., Supra-hyoid. R., Hyo-sternal. See R., Infra-hyoid. R., Hypochondriac, the region that joins the epigastric region laterally. The right hypochondriac region in- cludes the surface of the abdomen covering the right lobe of the liver, the gall-bladder, the hepatic flexure of the colon, and part of the right kidney; the left that covering the spleen, the splenic end of the stomach, the extremity of the pancreas, the splenic flexure of the colon, and part of the left kidney, R., Hypogastric, that part of the abdominal surface between a horizontal line drawn through the anterior superior crests of the ilia above and on either side by vertical lines drawn through the center of Poupart's ligament. It overlies the small intestines, the bladder in children and in adults when distended, the uterus during pregnancy, sometimes the vermiform appendix, the cecum, and the sigmoid flexure of the colon. R., Iliac, the

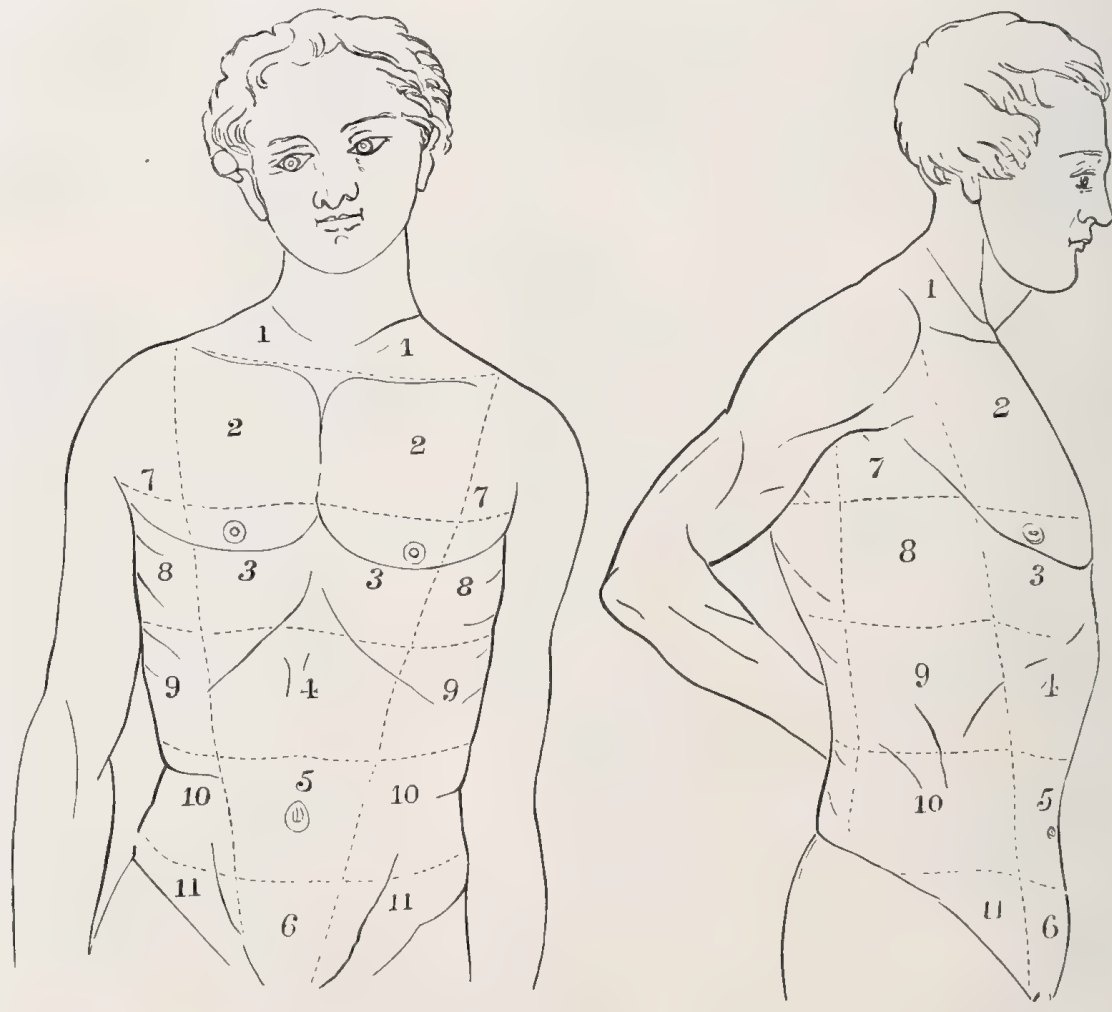

. Supraclavicular region. 2. Clavicular region. 3. Mammary region. 4. Epigastric region. 5. Unbilical region. 6. Hypogastric region. 7. Axillary region. 8. Infra-axillary region. 9. Hypochondriical region. 6. Hypogastric region. 7. Axillary region
ac region. 10. Lumbar region. II. Inguinal region.

region of the ilium. See also $R$., Inguinat $\mathbf{R}$, Ilioinguinal, the iliac region and the groin conjointly. R., Inferior Sternal, the space corresponding to the part of the sternum below the lower margin of the third costal cartilages. R., Infra-axillary, the space between the anterior and posterior axillary lines. $\mathbf{R}$., Infra-clavicular, the area circumscribed superiorly by the lower border of the clavicle, inferiorly by the lower border of the third rib, on one side by a line extending from the acromion to the pubic spine, and on the other side by the edge of the sternum. R., Infrahyoid, the space below the hyoid bone, between the sterno-cleido-mastoidei and the sternum. R., Inframammary, the space between a line drawn along the upper border of the xiphoid cartilage and the margin of the false ribs, and between the middle line of the 
xiphoid cartilage and a vertical line passing through the pubic spine. R., Infra-scapular, the region on either side of the vertebral column below a horizontal line drawn through the inferior angle of each scapula. It is called also the Subscapular Region. R., Infraspinous, that included between the spine of the scapula and a line passing through the angle of the scapula. R., Inguinal, R., Iliac, the right and left inguinal or iliac regions are two of the nine abdominal regions. The right includes the abdominal surface covering the cecum and the cecal appendix, the ureter, and the spermatic vessels; the left that covering the sigmoid flexure of the colon, the ureter, and the spermatic vessels. R., Interscapular, the space between the

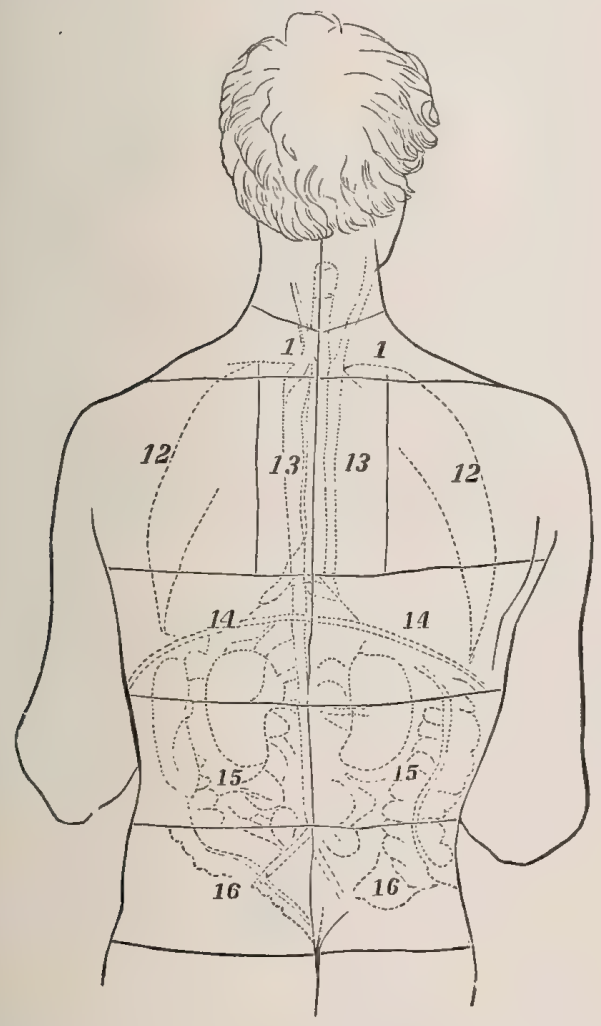

t. Supra-scapular region. I2. Infra-spinous region. I3. Interscapular region. I4. Infra-scapular region. I5. Lumbar region. I6. Sacro-iliac region.

scapulæ. R., Ischio-rectal, the region corresponding to the posterior part of the pelvic outlet, between the ischium and the rectum. R., Jugal, the space over the zygoma. R., Laryngo-tracheal, the parts about the larynx and the trachea. R., Lenticulo-striate, the anterior parts of the lenticular and caudate nuclei, and the intervening portion of the internal capsule. $\mathbf{R}$., Lenticulo-thalamic, the posterior part of the lenticular nucleus, the optic thalamus, and the part of the internal capsule which intervenes. R., Lingual, the region of the tongue. $\mathbf{R}$., Lumbar, the surface of the abdomen between a curved line drawn parallel with the cartilage of each ninth rib above and a curved line parallel with the iliac crests below, and a vertical line through the center of Poupart's ligament anteriorly, and the lumbar vertebræ posteriorly. $\quad$ R., Mammary, the space on the anterior surface of the chest between a line drawn through the lower border of the third rib, and one drawn through the upper border of the xiphoid cartilage. R., Maxillary, the parts about the jaws. R., Mesogastric, the umbilical and the right and left lumbar regions together. R., Middle Cervical, the area between the lower jaw, the sternum, and the anterior edges of the sternocleido-mastoidei. R., Mylo-hyoid. See Mylo-hyoid Triangle. R., Nasal, the parts around the nose. R., Olfactory, the region of the nasal mucous membrane including the ramifications of the olfactory nerve. R., Orbital, the region of the orbits. R., Palatal, the parts about the palate. R., Palpebral, the region of the eyebrows. R., Parasternal, the space between the mid-axillary line and the edge of the sternum. R., Perineal, the region of the perineum. R., Pharyngeal, the parts about the pharynx. R., Popliteal. See Popliteal Space. R., Precordial, the surface of the chest covering the heart. R., Psycho-motor, the cerebral cortex. R., Pterygo-maxillary, the parts connecting or lying between the pterygoid process of the sphenoid and the maxillary bone. R., Pulmo-cardiac, the region of the left thorax in which the left lung overlaps the heart. R., Pulmo-gastric, the portion of the left thorax in which the lung overlaps the stomach. R., Pulmo-hepatic, the portion of the right thorax in which the lung overlaps the liver. R., Respiratory (of the nose), the portion of the nasal passages having to do with the act of respiration. R., Sacral, the area above the sacrum. R., Scapular, the space over either scapula. R., Sternal, the space overlying the sternum. R., Sub-auricular, the space immedi. ately below the ear. R., Sub-maxillary. Same as R., Supra-hyoid. R., Sub-mental, the region just beneath the chin. $\mathbf{R}$., Sub-ocular, the anterior extremity of the temporo-sphenoidal lobe. R., Subthalamic, the extension of the tegmentum beneath the posterior portion of the optic thalamus. R., Superior (of the skull), the space between the superior curved line of the occipital bone behind, the supra-orbital ridge in front and, laterally, between the temporal lines. R., Superior Sternal, the surface corresponding to that portion of the sternal region above the lower border of the third rib. R., Supra-clavicular, the space above either clavicle. R., Supra-hyoid, the space between the upper margin of the hyoid bone, the lower border of the inferior maxilla and the sternocleido-mastoid muscles. R., Supra-mammary. Same as $R$., Infra-clavicular, q. $v$. R., Supra-scapular, the area above the spine of the scapula. R., Supraspinous, the region corresponding to the supraspinous fossa, $q . v$. R., Supra-sternal. See Suprasternal Notch. R., Temporo-maxillary, the area over the junction of the temporal and maxillary bones. R., Thoracic, relating to the entire surface of the thorax. R., Umbilical, the surface of the abdomen immediately about the umbilicus, bounded as follows : above by a horizontal line connecting the cartilages of the ninth ribs; below, by a line joining the crests of the ilia, and laterally, by lines passing vertically through the center of Poupart's ligament. R., Vertebral, relating to the region over the vertebral column.

Regional (re'-jun-al) [regionalis]. Pertaining to a region. R. Anatomy, the anatomic study of a definite and limited region of the body that has close anatomic, surgical, or pathologic inter-relations of parts or functions.

Register (rej'-ist-er) [registrum]. The compass of a voice; also a subdivision of its compass, consisting in 
a series of tones produced in the same way and of a like character.

Registrar (rej'-is-trar) [registrarius, one who keeps a record]. A keeper of records.

Registrarship (rej'-is-trar-ship) [registrarizes, one who keeps a record]. The office of a registrar.

Registration (rej-is-tra'-shun) [registratio, a registering]. The act of recording, as of deaths, births, etc.

Regius $\left(r e^{\prime}-j e-u s\right)$ [regius, royal]. A descriptive term applied to the golden or royal color observed in certain forms of jaundice. R. Professor, a royal professor, as in one of the English universities.

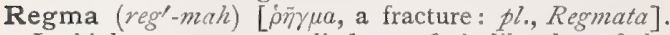
In biology, a term applied to a fruit like that of the geranium, in which the carpels separate elastically from the base of the carpophore.

Regmacarp $\left(r e g^{\prime}-m c k k-a r p\right)[\rho \tilde{\eta} \gamma \mu \alpha$, a fracture ; $\kappa a \rho \pi o ́ s$, fruit]. In biology, a dehiscent fruit.

Regnauld's Anesthetic or Liquid. A mixture of chloroform 4 parts, and methylic alcohol I part. It is sometimes used in place of chloroform. See Anesthetic.

Regnault and Reiset, Method of. A method of investigating the changes in the air brought about by respiration. The animal is placed in a closed chamber, and the carbonic acid formed is continually removed, the necessary oxygen being supplied in measured quantities.

Regnoli's Operation. See Operations, Table of.

Regorgement (ra-gorzh'-mon(g)) [Fr.]. An overflowing. $\mathbf{R}$. de la vessie, or R. urinaire, involuntary urination; incontinence of urine.

Regression (re-gresh'-un) [regressio, regression]. Retrogression.

Regressive (re-gres'-iv) [regredi, to go back]. Passing back ; returning.

Regressus (re-gres'-us) [p. p. of regredi, to go back]. In biology, the change of an organ from a higher to a lower type.

Regrowth (re-grōth') [re, again; ME., growen, to grow]. A growing again; a new or second growth.

Regular (reg'-u-lar) [regularis; regula, a rule]. According to rule, custom, or normal procedure; opposed to irregular or exceptional. In biology, applied to symmetrically disposed parts or organs; specifically to a flower that has all the parts of each floral circle uniform in shape and size. Having normal menstruation. R. Physician, one of the school of scientific medicine who adberes to no clique, sect, "-pathy," or "-ism."

Regulator $\left(\right.$ reg' $^{\prime}-u-l a-$ tor $)$ [regulare, to direct]. The person or the thing that regulates. $R$. radii. See Supinator longus in Muscles, Table of.

Regurgitation (re-ger-jit-a'-shun) [regurgitatio; re, again; gurgitare, to engulf ]. An eructation, flowing,

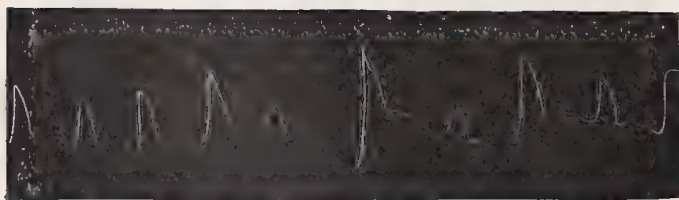

Irregular Pulse of Mitral Regurgitation.

or throwing back of the contents of a canal or vessel. R., Cardiac. See Heart-murmurs. R. of Food, a symptom of acid dyspepsia.

Rehmannia (ra-man'-e-ah). A genus of the Digitalea. R. chinensis, a plant the root of which is used in China as a tonic and alterative. R. Lutea, a plant used in the same manner as $R$. chinensis.

Reichert's Cartilage. That cartilaginous structure which appears in the embryo on the hyoid arch, event- ually becoming the styloid process, the stylo-hyoid ligaments, and the lesser cornu of the hyoid bone. R.'s Membrane, the anterior layer of the cornea, also called Bowman's Membrane. See Membrane.

Reichmann's Disease. A chronic disease of the stomach characterized by a condition of permanent gastric hypersecretion, associated with marked dilatation of the stomach, with thickening of its walls and hypertrophy of the glands. It is accompanied by violent attacks of pain that are typical of the disease, together with vomiting, and is usually followed by the formation of a round ulcer on the wall of the stomach. See Diseases, Table of. R.'s Test-breakfast, a breakfast composed of 30 grams of meat-powder, 2 grams of salt, 200 grams of water, 1 wheaten roll. It is used in testing the digestive power of the stomach.

Reid's Base Line. See Lines, Table of. R.'s Method, to determine the position of the fissure of Rolando; a method of cerebral localization; a base line is drawn from the infraorbital ridge through the middle of the external auditory meatus. To this two perpendicular lines are drawn, one through the depression in front of the external auditory meatus, and the other at the posterior border of the mastoid process ; a diagonal line from the upper extremity of the posterior line, drawn to the junction of the anterior line with the fissure of Sylvius, indicates the fissure of Rolando. See Treatment, Methods of.

Reil, Ansa of. The lemniscus. See Ansa. R.'s Band, a fibrous band extending across the right ventricle of the heart from the base of the anterior papillary muscle to the septum. It is quite common in man and corresponds to the moderator band of the heart of some lower animals. See Moderator. R., Fissure of. See Fissures, Table of. R., Island of. See Island of Reil.

Reimplantation (re-im - plan - ta' $a^{\prime}$ shun) [reimplantio, implant again]. In dental surgery, the replacing of a drawn tooth within its socket.

Reindeer Moss. See Cladonea.

$\mathrm{Re}$-infection (re-in-fek'-shun) [re, again; inficere, to infect]. Infection a second time with the same virus or contagium.

Re-inflame (re-in-fām') [re, again; inflammare, to inflame]. To inflame anew.

Reinforcement (re-in-fors'-ment) [OF., reinforcer, to strengthen]. The act of reinforcing. Any augmentation of force. $\mathbf{R}$. of Reflexes, increased myotatic irritability (or reflex response) when muscular or mental actions are synchronously carried out, or other stimuli are coincidently brought to bear upon other parts of the body than that concerned in the reflex arc. It has been asserted that the synchronous act of winking increases the knee-jerk, or patellar tendon-reflex. See Reflexes, Table of.

Reinfusion (re-in-fu'-zhun). Same as Refusion, $q . v$.

Reinoculation (re-in-ok-u-la'-shun) [re, again; inoculare, to inoculate]. Inoculation a second time.

Reins (ränz) [ren, kidney]. The kidneys; the loins.

Reinsch's Test. See Tests, Table of.

Reinversion (re-in-ver'-zhun) [re, again; invertere, to turn upside down]. The act of reducing an inverted uterus by the application of pressure to the fundus.

Reiset's Method. A method of estimating $\mathrm{CO}_{2}$ in the air. See Ventilation.

Reissner, Canal of. See Canal. R.'s Membrane, an extremely fragile membrane forming the vestibular wall of the cochlear duct and separating the duct from the scala vestibuli. It begins on the vestibular border of the lamina spiralis, about $0.2 \mathrm{~mm}$. inside the free edge of the crista, and extends at an angle of about 
forty-five degrees until it meets the outer bony wall. It consists of three layers, a central connective tissue stratum, the vestibular endothelium on one side, and the epithelium of the cochlear duct on the other.

Rejectamenta (re-jek-tam-en'-tah) [rejectare, to throw away]. Ejecta; excrement.

Rejuvenescence (re-ju-ven-es'-ens) [re, again; juvenescere, to grow young]. In biology: I. Literally, the growing young again; a renewal of strength and vigor. 2. A process first described by $\mathrm{A}$. Braun in which the whole protoplasm of a vegetative cell is transformed into a primordial cell, which in time becomes invested with a cell-wall and develops a new plant, as in CEdogonium. "We may regard the idea of rejuvenescence as presented by Braun as an extension of the idea of metamorphosis, in which extended form it is adapted to take in even the results of the celltheory, of the history of development, and of the modern knowledge of the cryptogams from the idealistic point of view." (Sachs.)

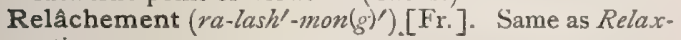
ation.

Relapse (re-laps') [re, again; labi, lapsus, to fall]. The return or recurrence of a disease during convalescence, or shortly afterward.

Relapsed (re-lapst') [re, back; labi, to slip]. Returned; slipped back. R. Club-foot, the occurrence of deformity after tenotomy, making the condition difficult of further treatment.

Relapsing ( $\left.r e-l a p^{\prime}-\sin g\right)$ [re, back; labi, to slip]. In pathology, returning to a morbid condition from which there had been partial or complete recovery. $\mathbf{R}$. Fever, or Famine Fever, a specific infectious disease caused by the spirocheta of Obermeier, characterized by definite febrile paroxysms which usually last six days, and are followed by a remission of about the same length of time, then by a second paroxysm, which may be repeated three or four times, whence the name relapsing fever. (Osler.)

Relation (re-la'-shun) [relatio]. I. Interdependence; mutual influence or connection between organs or parts. 2. Connection by consanguinity; kinship.

Relaxant (re-laks'-ant) [relaxare, to loosen]. Any remedy or agent that diminishes tension.

Relaxation (re-laks-a'-shun) [relaxatio]. A diminution of tension in an organ or a part. Also, a condition of languor. $R$. of the Pelvic Joints, increased mobility and softening of the pelvic joints occurring in pregnancy, giving rise to pain in the thighs, joints, and lumbar region, and difficulty in walking.

Relaxative (re-laks'-at-iv). Same as Laxative.

Reliquiæ (re-lik'-we-e) [L., leavings, remains, remnants]. In biology, persistent parts of a flower which cover the ripened ovary; dry and withered leaves which remain upon the stems of some plants. Same as Induvia.

Remak, Band of. See Axis-cylinder of Purkinje. $\mathbf{R}$.'s Contractions, so-called diplegic contractions occasionally seen in progressive muscular atrophy when an electric current is applied. The positive electrode is placed above and the negative below the fifth cervical vertebra, the contractions occurring on the side opposite to the anode. R.'s Fibers, non-medullated, longitudinally fibrillated, sometimes branching axis-cylinders, surrounded by a delicate, structureless, elastic neurilemma, or primitive sheath ; abundant in sympathetic and olfactory nerves, they constitute all the nerves of the embryo and of many invertebrates. See Nerve-fibers. R.'s Ganglion, a ganglion of nerve-cells in the sinus venosus of the frog's heart. See Ganglia, Table of.
Remasticate (re-mas'-tik-ät) [re, again; masticare, to chew]. To ruminate; to chew again.

Remastication (re-mas-tik- $\left.\dot{a}^{\prime}-s h u n\right)[r e$, again; masticare, to chew]. Rumination.

Remedial (re-me'-de-al) [r"emedium, a remedy]. Having the nature of a remedy.

Remedy (rem'-ed-e) [remedium]. Any agent or substance used in the treatment of disease. It may be curative, palliative, or preventive.

Remex $\left(r-e^{\prime}-m e k s\right)$ [remex, a rower: pl., Remiges]. In biology, one of the remiges or large quill-feathers (flight-feathers) of a bird's wing.

Remigial (re-mij'-e-al) [remex, a rower]. Of or pertaining to a remex.

Remijia (re-mij'-e-ah) [after Remijō, a Spanish surgeon]. A genus of rubiaceous shrubs and trees. R. pedunculata and $R$. purdiana afford cuprea-bark, and are important as sources of quinin and other cinchona salts. The genus is closely related to Cinchona. Unof.

Remiped (rem'-ip-ed) [remus, oar; pes, foot]. In biology, having oar-shaped feet.

Remission (re-mish'-un) [remissio]. Temporary abatement or subsidence. The period of diminution of a paroxysmal disease, especially that of remittent fever.

Remittent (re-mit'-ent). Characterized by alternate periods of increment and cessation. R. Fever, a malarial fever characterized by periods of remission and exacerbation, but without periods of complete apyrexia.

Ren [L. : pl., Renes]. The kidney. R. amyloideus, amyloid degeneration of the kidneys. $\mathbf{R}$. mobilis, Movable Kidney, $q . v$. R. unguiformis. See Horseshoe Kidney.

Renal (re'-nal) [renalis; ren, a kidney]. Pertaining to the kidneys. $\mathbf{R}$. Apoplexy, ischuria, or suppression of urine from hemorrhage into the substance of the kidney or other renal lesion. R. Calculus, any concretion in the kidney. $\mathbf{R}$. Glands, the suprarenal capsules. $\mathbf{R}$. Inadequacy, that peculiar condition in which the amount of urinary solids, and often the quantity of urine itself, is considerably diminished. It is probably due to an exhausted condition of the epithelial cells of the kidney. R. Storm, Murchison's term for a peculiar form of neurosal attack referred to the kidney, frequently seen in patients suffering from aortic regurgitation. There is sudden excruciating pain over the region of the kidney, like renal colic, but without nausea or retraction of the testicle, and with the passage of normal urine. In a few hours the pain passes off as suddenly as it appeared.

Renascence (re-nas'-ens) [renascen, new-born]. In biology, a new birth, a rejuvenescence. (Same as and preferable to renaissance.)

Renascent (re-nas'-ent) [renascen, p.p. of renasci, be born again $]$. In biology, reproduced, revivified, coming into being a second time.

Renculin $\left(r e n^{\prime}-k u-l i n\right)$ [ren, kidney]. An albuminoid reported to have been found in the supra-renal capsules.

Renculus (ren'-ku-lus). See Reniculus.

Rendle's Inhaler. See Anesthetic.

Renealmia (ren-e-al'-me-ah). A genus of zingiberaceous plants. R. exaltata, of South America, is emetic, diuretic, diaphoretic, and stimulant. The leaves and bruised root-stalk are applied externally for rheumatism. Unof.

Renicapsular (ren-ik-ap'-su-lar) [ren, kidney; capsula, capsule]. Pertaining to a renicapsule.

Renicapsule (ren-ik-ap'-sül) [ren, kidney; capsula, capsule]. A suprarenal capsule; an adrenal.

Renicardiac $\left(r e n-i k-a r^{\prime}-d e-a k\right)$ [ren, kidney; kapdia, heart]. Pertaining to the renal and cardiac organs of a mollusc. 
Reniculus (ren-ik'-u-lus) [L., dim. of ren, kidney]. A lobule of the kidney; renculus.

Renifleurs (ren'-if-lūrz). See Passivism.

Reniform (ren'-if-orm) [ren, kidney; forma, form]. In biology, kidney-shaped.

Reniglandular (ren-ig-lan'-du-lar). Same as Renicapsular.

Renin $\left(r e n^{\prime}-i n\right)$. See Orcanotherapy.

Reniportal (ren-ip-or'-tal) [ren, kidney; porta, gate]. Relating to the portal system of the kidney.

Renisexual (ren-is-eks'-u-al) [ren, kidney; sexualis, sexual]. Both renal and sexual.

Renitent (ren'-it-ent) [reniti, to resist]. Resisting pressure.

Rennet $($ ren'-et) [ME., renet, rennet]. The prepared inner membrane of the fourth stomach of a calf, or an infusion of this membrane. It contains a milk-curdling ferment that decomposes the casein. R.-bag, in biology, the abomasum, $q . v$.

Rennie's Formula. See Alimentation, Rectal.

Rennin $\left(r e n^{\prime}-i n\right)$ [ME, renet, rennet]. An enzyme to whose action is due the clotting of milk produced upon the addition of rennet. Nothing is known as to its chemic nature. It is most copiously present in the gastric mucous membrane of the calf, but may be obtained from the walls of the stomach of most animals.

Renninogen (ren-in'-o-gen) [ME.,renet, rennet]. The zymogen whence rennin is formed. It exists in the cells of the mucous membrane of the stomach.

Renovation (ren-o-va'-shun) [renovatio; renovare, to render new]. The repair or renewal of that which has been impaired.

Renuent (ren'-u-ent) [renuens, nodding back the head]. In anatomy, throwing back the head; applied to certain muscles.

Renule $\left(r e n^{\prime}-\bar{u} l\right)$ [ren, the kidney]. A small kidney.

Repand (re-pand') [re, back; pandus, bent, crooked]. In biology, applied to a leaf-margin which is toothed like the margin of an umbrella.

Repandodentate (re-pan-do-den'-tät) [repandus, bent back; dens, tooth]. In biology, repand and toothed.

Repandous (re-pan'-dus) [repandus, bent back]. Bent upward.

Reparative (re-par'-at-iv) [reparare, to repair]. Reinstating, or restoring to the normal

Repatency $\left(r e-p a^{\prime}-t e n-s e\right)$ [re, again; patens. open]. The reopening of a part or vessel. R. of a Vessel, after ligation, the reopening of the lumen of a ligated vessel from too rapid absorption of the ligature, or from slipping of the knot.

Repel (re-pel') [repellere, to repel]. To drive back; to cause resorption.

Repellent (re-pel'-ent) [repellere, to repel]. Pertaining to or having the power of acting upon morbid processes to determine or repel them.

Repent (re'-pent) [repere, to creep]. In biology, creeping, i.e., prostrate and rooting underneath.

Repercolation (re-per-ko-la'-shun) [re, again; percolare. to percolate]. Renewed or repeated percolation; the passage of a percolation over and over again through fresh instalments of the same drug.

Repercussion (re-per-kush'-un) [re, again; percutere, to percuss]. I. See Ballottement. 2. A driving in, or scattering of a tumor or eruption; repellent action.

Repercutient (re-per-ku'-she-ent) [re, again; percutere, to percuss]. Effecting a repercussion; pertaining to a process or function of rebound, or reaction.

Repetition (rep-e-tish'-un) [repetere, to seek again, repeat]. See Homotopy.

Replantation (re-plan-ta'-shun) [replantare, to plant again]. The act of planting again. R. of the Teeth, the replacement of teeth which have been extracted or otherwise removed from their cavities; when diseased, the thickened periosteum is scraped off before returning such teeth to their sockets.

Repletion (re-ple'-shun) [repletio; replere, to fill again]. The condition of being full.

Repletory (re-ple'-tor-c) [replere, to fill again]. Pertaining to repletion.

Replicate (rep'-lik-ät) [replicare, to fold or bend back]. In biology : (a) that mode of vernation in which the apex of the leaf is folded backward to the base ; (b) applied to wings of insects in which the outer part slides or folds back on the base, or is folded like a fan.

Replication (rep-lik-a'-shun) [replicatio; re, back; plica, a fold]. A refolding or turning back of a part so as to form a duplication.

Replum (rep'-lum) [replum, a doorcase]. In biology, the frame-like placenta in Crucifera, certain Papaveracee, etc., across which the septum is drawn and which persists after the valves have fallen away in dehiscence.

Repose (re-pōz $)$ [re, back; ponere, to place]. Rest, relaxation. To be at rest.

Reposition (re-po-zis $h^{\prime}-u n$ ) [repositio]. Return of an abnormally placed part to its proper position. Reduction of hernia, dislocation, etc.

Repositor (re-poz'-it-or) [reponere, to replace]. An instrument for putting back a presenting foot or prolapsed cord in labor; an instrument used in the replacement of a displaced uterus.

Repoussoir $\left(r a-p o o-s w a h r^{\prime}\right)$ [Fr.]. An instrument for extracting the roots of teeth. See Repulsorium.

Reprise (ra-prēz') [Fr. "recovery "]. That part of the cry of a child which is heard during the act of inspiration. The loud inspiration in pertussis. The "whoop."

Reproduce (re-pro-dus') [re, again; producere, to bring forth]. To procreate, or bring forth, offspring.

Reproduction (re-pro-duk'-shun) [reproductio; re, again ; producere, to produce]. The begetting of other individuals similar to the parent organism. In biology : (a) sexual or asexual generation. Cf. Abiogenesis, Archigenesis, Biogenesis, Fission, Gemmation, Heterogenesis, Homogenesis, Parthenogenesis, Schizogenesis, Xenogenesis, (b) a conscious repetition of perceived sensations. R., Asexual, that without sexual intercourse. R., Endogenous, internal cell-formation. R., Sexual, that by the union of sexually distinct cells. Reproductive (re-pro-duk'-tiv) [reproducere, to reproduce]. Having the functions of, or pertaining to, reproduction. R. Function, the power and capability of begetting. R. Organs, the organs employed in the procreation of offspring. $\mathbf{R}$. Organs, Development of; the Primitive Kidneys or Wolffian Ducts or ducts of the pronephros, are the first indication of the urinary and generative apparatus in the fertilized ovum. They appear at the side of the provertebræ from the fifth to the last vertebra. Müller's Duct, parallel to the Wolffian duct, unites with it to open into the uro-genital sinus, the other end opening into the abdominal cavity. The Müllerian ducts become the Fallopian tubes, hydatid, uterus, and vagina, in the female, and in the male the lower part becomes the male uterus or vesicula prostatica and the hydatid of Morgagni. The Wolffian body or mesonephros becomes in the female the parovarium (orgar: of Rosenmüller), or paroöphoron, and round ligament of the uterus; while in the male there are produced from it the vasa efferentia (coni vasculosi), the organ of Giraldès and the gubernaculum testis. In the female the Wolffian ducts become the chief tube of the parovarium and the ducts of Gärtner; in the male, 
they become the convoluted tubes of the epididymis, the vas deferens, and the vesiculae seminalis. See, also, Metanephros. R. System, in biology, all the organs directly or indirectly concerned in generation.

Reptation (rep-ta'-shun) [reptatio, a creeping]. In biology, the act of creeping.

Reptatorial, Reptatory (rep-ta-to'-re-al, rep'-ta-to-re) [reptare, to creep]. In biology, creeping.

Reptilian Heart. See Cor biloculare.

Repugnatorial (re-pug-nat-o'-re-al) [repugnatus, p.p. of repugnare, to fight against, oppose]. In biology, of use in repelling enemies. $R$. Pores, the external openings of cutaneous glands in certain myriapods, from which is discharged a strongly odorous secretion containing prussic acid. Cf. Stink-glands, under Gland.

Repullulate (re-pul'-u-lât) (re, again; pullulare, to sprout]. To grow again.

Repullulation (re-pul-u-la'-shun) [re, again; pullulare, to sprout]. The return of a morbid growth.

Repulsion (re-pul'-shun) [repellere, to repulse]. The influence which two bodies exert upon each other when they tend to increase the distance between them. R., Capillary, repulsion due to the forces causing movements of liquids in small tubes.

Repulsorium (re-pul-so'-re-um) [repellere, to drive back]. See Repoussoir.

Resectio (re-sek'-she-o) [L.]. See Resection. R. subperiostialis, a substitute operation for symphysiotomy suggested by Christoforis. Subperiosteal resection of the ends of the pubic bones on either side of the pubic joint, with the idea of replacement by deposition of bone.

Resection (re-sek'-shun) [resectio; resecare, to cut off]. Excision of a portion of bone, nerve, or other structure.

Reserve Air (re-zerv'). See Air.

Reservoir (rez'-er-vwor) [reservoir, a storehouse]. In biology, a cell, tissue or organ in which assimilated substances are stored up for future use. See Receptaculum. R. of Pecquet. See Receptaculum chyli and Cistern of Pecquet.

Resident (rez'-id-ent) [residere, to remain behind]. In biology, not migratory. R. Physician, Housephysician, a physician residing in a hospital.

Residual Air $\left(r e-z i d^{\prime \prime}-u-a l\right)$. See Air.

Residue $\left(r e z^{\prime}-i d-u\right)$ [residum, a remnant]. That which remains after a part has been removed. In pharmacy and chemistry, any part remaining after filtration. See also Radical.

Residuum (re-zid'-u-um). The balance or remainder.

Resilience (re-zill-e-ens) [re, back; salire, to leap]. The quality of being elastic or resilient. The act of springing or leaping back. Healthy reaction.

Resilient (re-zil'-e-ent) [re, back; salire, to leap]. Rebounding; elastic. R. Stricture, one that is not permanently dilatable.

Resin (rez'-in) [L.; resina: gen. and pl., Resina]. r. Any member of a class of compounds made by treating the substances from which they are obtained with alcohol and precipitation with water. The precipitate constitutes the resin of pharmacy. There are four official resinæ. 2. Any member of a class of oxidized terpenes. Resins either accompany terpenes in crude essential oils, or occur as exudations from their hardening on exposure to the air. They are amorphous, mostly vitreous bodies, insoluble in water. They melt at a low heat, are non-volatile, and burn quickly with a smoky flame. They are largely used in the preparation of varnishes, and several are employed in medicine. Resins are divided into (I) true resins, (2) gum-resins, and (3) oleo-resins or balsams. The true resins are hard, compact products of oxidation, made up chiefly of what are termed "resin acids," which, admixed with fatty acids, are capable of saponifying with alkalies, and yield "resin soaps; " the gum-resins differ from the true resins only in containing some gum capable of softening in water; and the oleo-resins include the nixtures of essential oils and resin of whatever consistency, and the mixtures of benzoic and cinnamic acid, and salts of these acids. This last class is much the largest of the three. To the first class belong the hard resins, which serve for the manufacture of varnishes, such as copal, dammar, mastic, sandarach, dragons' blood, gum-lac, and amber; to the second class, olibanum or frankincense, myrrh, ammoniacum, asafetida, galbanum, and tragacanth; and to the third class, crude turpentine, benzoin, storax, copaiba, Peru and Tolu balsams. The following table (Sadtler's Industrial Organic Chemistry) gives the bromin-absorption, the saponificationequivalent, and the proportions of potash neutralized by the various resins. A classified table of the resins is also appended. R.-cell, a cell that secretes resin. R., Ceratum, Basiticon Ointnent, resin 35, yellow wax 15, lard 50 parts. R., Common, Colophony, Rosin, the residue after the distillation of the volatile oil from turpentine. R.-duct. Same as $R$.-passage. R., Emplastrum, Resin Plaster, Adhesive Plaster, resin $\mathrm{I}_{4}$, lead plaster 8o, yellow wax 6 parts. R.-flux, a disease caused by the fungus Agaricus melleus, which attacks conifers, giving rise first to an excessive flow of resin, and ultimately to the death of the tree. R.gland, a large cell, or a group of smaller cells, secreting resin. R.-passage, an intercellular cavity formed by masses of tissue becoming separated from each other, and whose function it is to secrete resin. R.tube. Same as R.-passage. R., Ung. (B. P.), used for the same purpose as the plaster or cerate.

\section{TABLE OF RESINS.}

I. Copaline or VARNish RESINS.

African Copal. Black Dammar. Conarium strictum.

Brazilian Copal.

Dammar.

East Indian Dammar.

Hymenia, and Trachylobium martianum.

Hopea robusta, H. micrantha, Conarium strictum.

Dammara orientalis, D. australis, $D$. vitiensis ("Mabradra" ), $D$. obtus $a, D$. moorii, D. robusta.

Gum Animé.

Kaurie, or Coudie Resin. Lac.

Mastic.

Mexican Copal.

Piney Resin, or White Dammar.

Sal Dammar.

Sandarach.

Dammara australis.

Schleichera trijuga, Croton lacciferum, C. draco. lacciferum, C. drac
Pistacia lentiscus. Hymenea.

Vateria indica and $V$. acuminata.

Shorea robusta et al.

Callitris quadrivalvis.

\section{SOFT RESINS, OR OLEO-RESINS.}

Balsam of Canada.

Brazilian Elemi.

Chian Turpentine.

Frankincense.

Abies canadensis.

Icica icicariba.

Pistacia terebinthus.

Pinus halepensis, Boswellia carteri, $B$. freveana, $B$. thusifera.

Manila Elemi.

Mexican Elemi.

Riga Balsam.

Tacamahac (American)

Tacamahac (Curaca).

Tacamahac (East Indian).

Turpentine.

Turpentine (Venetian).

Wood Oil.

\section{Conarium commune.}

Pinus cembra.

Elephrium tomentosum.

Fagara octandra.

Calophyllum inophyllum.

Abies balsamifera, Pinus palustris, etc.

Larix europcea

Dipterocarpus turbinatus.
Amyris elemifera. 


\section{TABLE- OF RESINS-Continued.}

III. Fragrant OLEO-RESINS AND GUM-RESINS.

Balsam of Gilead, or Mecca|Balsamodendron perryi, $B$. Balsam.

Balsam of Peru.

Balsam of Tolu.

Bdellium, or Grogul.

Benzoin.

Labdanum, or Ladanum.

Liquid Storax

Myrrh.

Olibanum, or Frankincense.

Solid Styrax.

West Indian Balsam.

IV. Fetid Gum-REsins.

Ammoniacum

Asafetida.

Galbanum.

Opoponax.

Sagapenum

Sarcocol.

opobalsamum and Amyris gileadensis.

Myrospermum peruiferum.

Myrospermum toluiferum.

Balsamodendron roxburghii.

Styrax benzoin and balsamo-

dendron Mukul.

Cistus creticus var, labdanif-

Liquidambar orientalis.

Balsamodendron myrrha.

Boswellia carteri, $B$. serrata. Juniperus lycia.

Styrax officinalis.

Clusia multiflora, C. grandiflora, $C$. insignis.

Dorema ammoniacum.
Ferula narthex and $F$. scoro-
dosma.
Ferula galbanifera and $F$.
mubricaulis.
Opoponax chironium.
Ferula.
Penea sarcocolla, $P$. mucro-
nata.

V. MEdicinal Resins.

Balsam of Copaiba.

Copaifera officinalis, C. multijuga, etc. Euphorbia resinifera. Garcinia.

Guaiacum officinale.

Euphorbium

Gamboge.

\section{EXTRACT-RESINS.}

Churrus.

Cubeb Resin.

Jalap Resin.

Podophyllum Resin.

Scammony.

Cannabis sativa.

Cubeba officinalis.

Ipomea jalapa.

Podophyllum peltatum.

Convolvulus scammonia.

\begin{tabular}{|c|c|c|c|c|}
\hline KIND OF RESIN. & 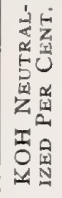 & 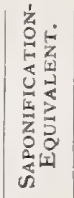 & 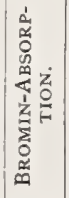 & $\begin{array}{l}\text { HYDROBROMIC } \\
\text { ACID FORMED. }\end{array}$ \\
\hline 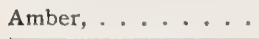 & I6. I & $347 \cdot 6$ & 53.5 & Some. \\
\hline 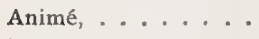 & 9.5 & $5^{8} 5 \cdot 5$ & 60.2 & Much. \\
\hline Benzoin, ...... & 22.3 & 256.0 & 38.9 & Some. \\
\hline Copal. ....... & 12.4 & 450.8 & 89.9 & Much. \\
\hline $\begin{array}{l}\text { Copal (reduced to } 3 / 4 \\
\text { by boiling), }\end{array}$ & 12.9 & 433.4 & 84.5 & Much. \\
\hline Dammar, ...... & 5.2 & I068.I & 117.9 & Much. \\
\hline Elemi, .......... & 3.3 & $x 697.9$ & 122.2 & Very much. \\
\hline Gamboge,...... & I5.5 & 361.1 & 71.6 & Much. \\
\hline Kauri, ........ & 12.9 & $433 \cdot 4$ & 108.2 & $\cdots \cdot$ \\
\hline Mastic, ....... & II.7 & $47^{8.6}$ & $124 \cdot 3$ & Much. \\
\hline Rosin (refined), . . . & I8.I & 308.6 & 112.7 & $\cdots \cdot$ \\
\hline Sandarach, ..... & 16.4 & 340.6 & 96.4 & Very much. \\
\hline Shellac, . . . . . & 23.0 & 242.7 & 5.2 & $\therefore$. \\
\hline Shellac (bleached), . . & 18.2 & 306.9 & 4.6 &.$\cdot$. \\
\hline 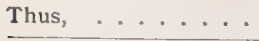 & 21.0 & 340.6 & 108.5 & . . . \\
\hline
\end{tabular}

Resina (rez-i'nah) [L.]. A resin. R. lutea. See Acaroides.

Resinaceous (rez-in-a'-she-us) [resina, resin]. Having the qualities of resin.
Resiniferous (rez-in-if'-er-us) [resina, resin; ferre, to bear]. Producing resin.

Resiniform ( $r e z$-in-if-orm). Same as Resinoid.

Resinoid (rez'-in-oid) [resina, a resin; cỉঠōs, like]. I. Resembling a resin. 2. A substance which has some of the properties of a resin. Most of the so-called resinoids are of indefinite chemic composition ; others are impure resins.

Resinous $\left(r e z^{\prime}-i n-u s\right)$ [resina, a resin]. Having the nature of a resin.

Resistance (re-zis'-tans) [resistare, to withstand]. In electricity, the opposition offered by a conductor to the passage of the current. It is estimated in ohms. See Ohm. R., Essential, the resistance to conduction within the battery itself. R., Extraordinary, the resistance to conduction outside of the battery.

Resolution (rez-o-lu'-shun) [resolvere, to resolve]. A quick improvement in the course of a febrile disease. See Crisis. R. of Anesthesia, the condition when muscular and nervous reactions are permanently absent. Complete anesthesia. R. of Inflammation, the return of tissues implicated in the inflammatory process to their normal condition.

Resolvent (re-zol'-vent) [resolvere, to dissolve]. That which causes solution or dissipation of tissue. A discutient.

Resolving (re-zol'-ving) [resolvere, to dissolve]. Causing solution or dissipation of tissue. R. Power, the power of a microscopic objective to show small parts.

Resonance (rez'-o-nans) [re, again; sonare, to sound]. The peculiar quality given to sounds by their reverberation and modification by the resonance-organs, or by the morbid conditions of the chest in auscultation. R., Amphoric, a variety of tympanitic resonance having a metallic quality. R., Bell-metal, a bell-like sound heard on auscultation in pneumothorax when the chest is percussed with two coins used as plexor and pleximeter. R., Cough, a sound heard on auscultation during the act of coughing. R., Cracked-pot, a variety of tympanitic resonance elicited by percussing over a pulmonary cavity communicating with a bronchus. R.organs, the supra-laryngeal cavities that modify the quality of vocal sounds. R., Skodaic. See Skoda's Tympany. R., Tympanic, resonance elicited on percussion over the intestines and over large lung-cavities with thin, yielding walls. R., Vesicular, the normal pulmonary note. R., Vesiculo-tympanitic, an admixture of vesicular and tympanitic resonance. $\mathbf{R}$., Vocal, the sound heard on auscultation of the chest during ordinary speech. R., Whispering, the sound heard on auscultation of the chest during the act of whispering.

Resonant (rez'-o-nant) [resonans, resounding]. I. Sounding or ringing in the nasal passages. 2. A resonant or nasal sound. See Consonant.

Resonator (rez'-o-na-tor) [re, again ; sonare, to sound]. An instrument used to intensify sounds. See Resonance-organs.

Resopyrin (rez-o-pi'-rin) [resina, resin; orcin; $\pi \tilde{v} \rho$, fire]. A compound of resorcin and antipyrin. The physiologic and therapeutic actions of this body are still undetermined. Unof.

Resorcin $\left(r e-z o r^{\prime}-\sin \right)$ [resina, resin; Orcus, Pluto], $\mathrm{C}_{6} \mathrm{H}_{4}(\mathrm{OH})_{2}$. Resorcinol; a substance produced from different resins, and from umbelliferous gum-resins on fusion with caustic potash. It is isomeric with hydroquinone. It crystallizes in colorless rhombic prisms or plates, melts at $118^{\circ} \mathrm{C}$., and boils at $276^{\circ} \mathrm{C}$. It rerembles carbolic acid in many of its properties; is odorless, antiseptic, and a powerful germicide. It is valuable chiefly as an antipyretic, in malarial fevers, and locally as a lotion in diphtheria. Dose gr. $\mathrm{v}-\mathrm{xv}$; 
as an antipyretic, $3 j$. It is readily soluble in water, alcohol, and ether. In dyeing it yields a fine purplered coloring-matter, and several other dyes of commercial importance, R. Colors. See Pigments, Conspectus of.

Resorcinal (re-zor'-sin-al). See Resorcin. R. Yellow. See Pigments, Conspectus of.

Resorcinism (re-zor'-sin-izm) [resina, resin; Orcus, Pluto]. A toxic condition caused by injudicious or excessive use of resorcin.

Resorcinum (re zor'-sin-um) [L.: gen., Resorcini]. The official name of resorcin, $q . v$.

Risorption (re-sorp'-shun) [resorptio; re, again; sorbere, to absorb]. The absorption of morbid deposits, as of the products of inflammation, exudations, etc. R., Lacunar (of bone), resorption of bone by osteoclasts forming and occupying Howship's lacunæ. Resorptions-diabetes (Ger.), a glycosuria due to absorption of sugar.

respiratio (res-pe-ra'-she-o) [L.]. Respiration. R. difficilis. Synonym of Dyspnea.

Respiration (res-pe-ra'-shun) [respiratio; respirare, to breathe again]. The inspiration and expiration of air through the lungs. In biology, the continuous interchange between the gases of living organisms and the gases of the medium in which they live, continuous throughout life. This consists in all active cells in plants of a constant absorption of the oxygen of the air into the tissues, where it causes oxidation of the assimilated substances and the release of carbon dioxid. The movements of protoplasm are dependent upon respiration. It is the opposite of assimilation. $\mathbf{R}$. A bdominal, respiration caused by the contraction of the diaphragm and the elasticity of the abdominal walls and viscera. It is more common in men than in women. R., Aërial, respiration in which the respiratory membrane receives oxygen and is relieved of carbon dioxid by means of atmospheric air. R., Amphoric, a blowing respiration engendered in large cavities with firm walls. Its peculiar character is due to an echo from the walls of the cavity. R., Aquatic, respiration in which the respiratory membrane, the branchial mucosa (gills), the skin, etc., receive oxygen and are relieved of carbon dioxid by means of water. R., Artificial, artificial production of the normal respiratory movements. See Artificial Respiration. R., Biot's, periodic respirations without any variation in the extent of the individual respirations. It occurs normally during sleep. R., Blood, the giving off of carbon dioxid and taking up of oxygen by the blood during its passage through the lungs. The blood while passing through the capillaries gives up its oxygen to the tissues and takes up carbon dioxid. R., Blowing. See R., Bronchial. R., Branchial, respiration by means of gills or branchiæ, as in aquatic animals. R., Bronchial, respiration as heard over the trachea or bronchial tubes in health; it is high in pitch, equal in inspiration and expiration, blowing in character, especially the expiratory element, and is marked by a brief pause between inspiration and expiration. It is well defined only in case of pulmonary consolidation. R., Broncho-cavernous, a form intermediate in character between bronchial and cavernous respiration. R., Broncho-vesicular, respiration having the characters of both bronchial and vesicular respiration. It is heard over areas of consolidation surrounded by patches of healthy lung-tissue. R., Buccal. See Mouth-breathing. R., Cavernous, a blowing respiration of low pitch, circumscribed, alternating with gurgling, and deriving its chief character from the nature of the cavity in which it is generated. R., Center of, the nervous center regulating the act of respiration is situated in the Hoor of the fourth ventricle near the point of the calamus. It is automatic in its action. R., Cerebral, respiration in which the lips are closed, the cheeks distended, the nostrils dilate with each expiration, which is attended with a puffing sound; the respirations are irregular. It is observed especially in typhus fever and in apoplexy. R., CheyneStokes, a peculiar type of breathing in which there is a rhythmic increase of the respirations up to a certain degree of rapidity, then gradually decreasing again to temporary cessation. This pause may be as long as half a minute. This form of respiration is most commonly seen in the late stages of tuberculous meningitis, but it may also be noted in apoplexy, fatty degeneration of the heart, and nephritis with uremia. R., Clavicular, a form resorted to by singers and in which the clavicle is brought into play in the respiratory movements, the shoulders being elevated. R., Cogged or Cogwheel. See R., Intermpted. R., Costal, respiration in which the chest-movement predominates over the diaphragmatic movement. It is seen especially in women, and is supposed to be related to gestation or perhaps partially to the mode of dress. R., Costo-inferior, respiration in which the elevation and depression (respiratory movements) are confined chiefly to the lower ribs. It is best seen in dogs. R., Costo-superior, respiration in which the respiratory movements involve chiefly the upper ribs. It is most common in women. R., Cutaneous, the giving off of carbon dioxid and taking up of oxygen through the skin. R., Diaphragmatic. See $R$., Abdominal. $\quad$ R., Direct, respiration in which the living substance of an organism, as an ameba, takes oxygen directly from the surrounding medium and returns carbon dioxid directly to it, no respiratory blood being present. R., Divided, respiration in which there exists a distinct interval between inspiration and expiration. It is seen in emphysema as a result of the distention of the air-vesicles and consequent reduction in expelling force. R., Exaggerated, an increase in intensity, without alteration in character or rhythm of the respiratory movements. R., External. See $R$., Blood. R., Extrinsic (of $F$. Hezvitt), the inspiration and immediate expiration of a gas, so that a portion that has once been inspired is not inspired again. $\mathbf{R}$., Facial, a term applied to all the movements of the face during inspiration and expiration. R., Feeble, diminution in the intensity, without alteration in the character or rhythm of the respiratory movements. R., Fetal, the interchange of gases between the fetal and the maternal blood through the medium of the placenta. R., Forced, respiration induced by blowing air into the lungs by means of a bellows, or in some other way, as in physiologic experiments. R., Harsh. See R., Broncho-vesicular. R., Hissing, an increased vesicular murmur causing a hissing sound. R., Hollow. See R., Amphoric. R., Indeterminate, the most pronounced vesicular grade of broncho-vesicular respiration. R., Indirect, respiration in which the living substance of the organism, as in all the higher animals, gets rid of carbon dioxid and obtains oxygen by means of a circulating respiratory blood. R., Inner or Internal, the taking up of oxygen and giving off of carbon dioxid by the body-elements for their own requirements. It occurs in man in the capillary system. R., Interrupted, respiration in which either inspiration or expiration is divided into two or more parts. It is most often heard at the apex of the righ: lung, anteriorly. R., Intestinal, the interchange of respiratory gases in the mucous membrane of the intestines. R., Intra-uterine, respiration by the fetus before delivery. R., Intrinsic (of $F$. Hewritt), the 
breathing over and over again of a limited volume of gas. R., Jerking. See R., Interrupted. R., Labored, respiration in which, owing to lack of ability on the part of the ordinary muscles of respiration to sufficiently aërate the blood, the auxiliary muscles of respiration are called into play. R., Laryngeal, the widening of the glottis during inspiration and its narrowing during expiration. R., Lung. See R., Pulmonary. R., Metamorphosing (of Seitz), respiration in which the first part of the inspiratory sound is tubular and the last part cavernous; a cavernous element is also heard during expiration. It is a certain sign of a cavity (Vierordt). R., Muscle, respiration by a muscle when in action. R., Nasal, nose-breathing. R., Nervous. See R., Cerebral. R., Normal, respiration as it occurs in a normal individual in a state of rest or moderate action. R., Oral. See Mouth-breathing. R., Ordinary. See R., Normal. R., Organs of, any parts of the body by means of which certain constituents of the blood are exchanged for those of the surrounding air or water. R., Pharyngeal (of Garland), rhythmic expansions and contractions of the pharnyx in connection with other movements of respiration. The expansion is pre-inspiratory and the contraction inspiratory. R., Placental. See R., Fetal. R., Puerile. See R., Exaggerated. R., Pulmonary, respiration in which the interchange of gas between the blood and air occurs in the lungs. R., Rough, a variety of broncho-vesicular respiration. R., Rude. See R., Rough. R., Senile, the feeble respiration of old age. $\mathbf{R}$., Sighing, deep respiration accompanied with sighing. It is seen in pulmonary congestion and dyspepsia. R., Stertorous, the sound produced by breathing through the nose and mouth at the same time, causing vibration of the velum pendulum palati between the two currents of air. R., Subsibilant (of Laennec), a duli, whistling sound heard over the bronchi, and due to an obstruction by mucus. R., Superficial. See $R$., Blood. R., Supplementary. See R., Exaggerated. R., Thoracic. See $R$., Costal. R., Tissue. See R., Internal. R., To-and-fro. See R., Intrinsic. R., Tracheal, the respiratory murmur heard in a normal individual by placing a stethoscope over the supra-sternal fossa. R., Tranquil. See R., Normal. R., Tubular. See R., Bronchial. R., Uremic. See R., CheyneStokes. R., Vaginal, the movements of the vagina caused by the movements of the diaphragm in respiration. R., Ventral. See $R$., Abdominal. R., Vesicular, a soft, gradual, low-pitched inspiration immediately followed by a shorter and less distinct expiration-sound heard over the normal lung during respiration. R., Vesiculo-bronchial. See R., Bronchovesicular. R., Wavy. See R., Interrupted.

Respirative (res-pi'-rat-iv) [respirare, to respire]. Performing respiration.

Respirator (res-pe-ra'-tor) [respirare, to respire]. An instrument through which one breathes to modify the coldness of the air or to exclude its impurities, or for the inhalation of volatile medicaments. R.-veil, a muffler for women, devised by Lennox Browne. It consists of a piece of plain veiling with a double thickness of silk gossamer on the lower four inches. The part that covers the mouth and nostrils is stiff. ened with a layer of thin wire gauze, so that the veil may stand a little away from the face and be more comfortable.

Respiratorium (res-pe-ra-to'-re-um) [respirare, to respire, to breathe out: pl., Respiratoria]. In biology, one of the delicate folds of the integument of the aquatic larve of certain insects, richly supplied with minute tracheæ.
Respiratory (res' $-p e-r a-t o-r e)$ [respiratorius]. Pertaining to respiration. Also, to the murmur heard upon auscultation over the lungs of a healthy person during ordinary breathing. R. Blood, Huxley's name for the fluid present in the pseudo-hemal system of vessels of certain invertebrates (Annelida). It contains a dissolved red substance allied to hemoglobin. R. Capacity, the capacity of the blood for taking up oxygen in the respiratory organs and depositing it in the tissues, and of taking up carbon dioxid from the tissues and giving it off in the respiratory organs. R. Cavity, the same as the thoracic cavity; also used as a general term to describe the air-passages. R. Chamber, a respiratory cavity. R. Filaments, thread-like organs arranged in tufts near the head of the larva of the gnat. R. Glottis, that part of the glottis between the arytenoid cartilages. $\mathbf{R}$. Leaffets, the laminated organs of respiration of the pulmonary arachnidans. $\mathbf{R}$. Murmur, the sound produced by the air entering and escaping from the lungs during the respiratory period. R. Nerve, one of two nerves involved in respiration. The external is the posterior thoracic nerve; the internal, the phrenic nerve. R. Nerve (of the Face), the facial nerve. R. Nerves (of $B e l l$ ), the Phrenic, Posterior Thoracic, and Facial Nerves. $\mathbf{R}$. Orifice, a breathing pore. R. Percussion, Da Costa's term for the method of physical examination by noting the sound elicited by percussion of the chest while the breath is held after a full inspiration, and also after a prolonged expiration. $\quad \mathbf{R}$. Periods, the time elapsing between the beginning of one inspiration and that of the next. R. Pigments, a series of pigments discovered by McMunn, Moseley, Krukenberg, and others in the fluids and tissues of many plants and animals. They are capable of existing in a state of oxidization and reduction, and play an important rôle in the function of respiration. See Pigments, Conspectus of. R. Plate. See Respiratorium. $\mathbf{R}$. Portion of the Nose, the lower portion of the nasal cavity. R. Pulse, the modifications in the pulse produced by respiration. $\mathbf{R}$. Quotient, the ratio between the amount of oxygen given off by the lungs and that taken up by them in the same period of time. $\mathbf{R}$. Sac, a sac-like respiratory organ of various animals. R. Sound. See R. Murmur. R. Surface, the entire surface of pulmonary tissue coming in contact with the respired air. $\mathbf{R}$. Tract, a term descriptive of the sum of the air-passages. R. Tubes, a term applied to all tubular organs of respiration. R. Vesicular Murmur, the normal respiratory murmur. See Respiration, Normal.

Respire (re-spir $r^{\prime}$ [re, back; spirare, to breathe]. To breathe.

Respirometer (res - pi-rom' - et -er) [respirare, to take breath; $\mu \varepsilon ́ \tau \rho o \nu$, measure]. An instrument for ascertaining the condition of the respiration. Also the apparatus used to supply air to a diver under water by supplying compressed oxygen, which is made to combine in proper proportion with nitrogen chemically filtered from the air expired from his lungs.

Responsibility (re-spon-sib-ill-it-e) [respondere, to answer]. In medical jurisprudence, the accountability of a person for an act committed. It usually turns upon the question as to whether or not the person was of sound mind and capable of controlling his actions and thoughts.

Resserrement (res-air-mon $\left.(g)^{\prime}\right)$ [ Fr.]. Constriction ; constipation.

Rest [ME., resten, to rest]. Cessation of all motion, labor, or action; to sleep, to lie dormant. R. of Royce, an epithelial formation arising either early, during the 
development of the embryo or accidentally during later life and apparently left over from the formation of a part or organ. Thus the remains of the craniopharyngeal, lingual, and neural canals are in adult life observed in the lines of old incisions. R.cure, the mode of treatment of patients suffering from hysteria and neurasthenia, as suggested by Weir Mitchell. It consists in (I) rest, (2) isolation, (3) systematic feeding, (4) massage, and (5) electricity. The electricity is the least important factor in the system of treatment. The duration of the treatment should never be under six weeks, and usually should continue for ten or twelve weeks.

Restant (res'-tant) [Fr., restant, remain]. In biology, remaining; of leaves, remaining on the plant over winter; of a corolla or calyx, remaining unwithered till the fruit ripens.

Restaurans (res'-taw-rans) [restaurare, to restore] Restorative, tonic.

Restibrachial (res-tib-ra'-ke-al) [restis, a rope; brachium, an arm]. Pertaining to the restibrachium.

Restibrachium (res-tib-ra'-ke-um) [restis, a rope; brachium, an arm]. The inferior peduncles of the cerebellum; the myelobrachium.

Restiform (res'-tif-orm) [restis, a cord ; forma, form] Corded or cord-like. R. Bodies, a descriptive term applied to certain cord-like bodies or processes of the medulla oblongata.

Resting (rest'-ing) [ME., resten, to rest]. Ceasing from motion; at rest. R.-cell. Same as $R$. spore. R.-sporangium, in biology, Pringsheim's term for peculiar resting-cells formed by the mycele of a few fungi $(e . g$. . Saprolegnia), in which zoöspores are produced. R.-spore, in biology, a spore invested with a firm cell-wall, which remains dormant for a period, often during the whole winter, before it germinates. R.-stage, in biology, the period of dormancy in the history of a plant or germ. R.-state, in biology, a state of suspended activity, the condition of perennial plants, bulbs, seeds, and spores during their period of dormancy.

Restis (res'-tis) [L., a cord]. A name given to the restiform body.

Restitution (res-tit- $u^{\prime}$-shun) [restituere, to set up again]. The act of restoring to a previous condition. See Rotation.

Restoration (res-tor- $a^{\prime}-s h u n$ ) [restaurare, to restore]. The renewal of or return to a state of health.

Restorative (re-stor -at-iv) [L., restaurare, to restore] I. Renewing health and vigor. 2. A medicine, cordial, or food that is efficacious in restoring one to health and vigor.

Restraint (re-strānt') [restringere, to draw back]. I. Hindrance of any action, physical, moral, or mental. 2. The state of being controlled; specifically, abridgement of liberty in the care of the insane. $R$.-bed and R.-chair. See R., Mechanical. R., Mechanical, restraining the insane by mechanical means. $\mathbf{R}$., Medicinal, the use of narcotics and sedatives in quieting the insane.

Restringent (re-strin'-gent) [restringere, to restrain]. An astringent or styptic.

Resublimation (re-sub-lim- $a^{\prime}-$ shun) [re, again; sublimare, to raise on high]. The process of subliming a drug for the second time.

Resudation (re-su-d $\left.a^{\prime}-s h u n\right)$ [re, again ; sudor, sweat; resudure, sweat again]. A renewed sweating; the return of sweating as a symptom.

Resupinate (re-su'-pin- $\bar{a} t)$ [re, again; supinare, to bend backward]. Turned in a direction directly opposite to the usual one; as in an ovary with its apex directed downward; inverted; reversed.
Resupination (re-su-pin-a -shun) [re, back ; supinare, to bend backward]. In biology, a term applied to the torsion which the long inferior ovary of most orchids undergoes at the time of the opening of the flower, which causes the posterior side of the flower to assume an anterior position.

Resupine $\left(r e-s u^{\prime}-p i n\right)$ [re, back; supinus, lying on the back]. Lying with the face upward.

Resurrectionist (rez-ur-ek'-shun-ist) [resurgere, to rise again]. Colloquially, one who steals dead bodies from the grave as subjects for dissection.

Resuscitant (re-sus'-it-ant) [resuscitans, p. p. resuscitare, to revive again]. The person by whom or the thing by which one is resuscitated.

Resuscitate (re-sus'-it-ät) [resuscitare, to revive]. To revive; to recover from apparent death.

Resuscitation (re-sus-it-a'-shun) [resuscitatio; resuscitare, to raise up again]. The bringing to life, or restoration of one apparently dead from asphyxiation or suffocation.

Resuscitative (re-sus'-it-a-tiv) [resuscitare, to revive]. Tending to resuscitate; reviving.

Resuscitator (re-sus'-it-a-tor). See Resuscitant.

Retainment (re-tän'-ment). See Retention.

Retanilla (ra-tan-il'-ah) [Fr., rétanille]. A genus of the rhamnex. R. ephedra, R. obcordata, two Chilian and Peruvian astringents and tonic styptics. Unof.

Retardation (re-tar-da'-shun) [retardatio; retardare, to delay]. Any hindering or delaying of a function. In obstetrics, delay in expelling the fetus. In biology, the change of structure during growth accomplished by the subtraction of parts. The opposite of acceleration, $q \cdot v$.

Retarding (re-tar'-ding) [retardare, to delay]. Hindering; delaying. R. Ague, a variety of ague in which the paroxysm is postponed to a later hour each day.

Retch [AS, hrocan, to cough, Ital., recere, to vomit]. To strain at vomiting. To suffer the spasmodic muscular contractions by which the stomach is emptied in vomiting, without discharging any matter.

Rete $\left(r e^{\prime}-t e\right)$ [L., a net: pl., Retia]. Any network or decussation and interlacing, especially of capillary blood-vessels. R., Acromial, a plexus of arteries on the surface of the acromial process, formed by anastomoses between the acromial branch of the acromio. thoracic, the suprascapular, and the anterior and posterior circumflex. R. articulare cubiti, an arterial anastomosis over the elbow. R., Bipolar, applied to blood-vessels that unite into larger stems and again divide and end in capillaries. $\mathbf{R}$. calcaneum, an arterial anastomosis over the os calcis. R., Carpal, Anterior, and Posterior, two plexuses of arteries formed by the carpal branches of the radius and ulna, one in front and the other at the back of the wrist. $\mathbf{R}$. carpi dorsale, the posterior carpal arch. $\mathbf{R}$. carpi volare, an arterial meshwork made up of branches from the radial and ulnar arteries and deep palmar arch upon the anterior surface of the carpus. R. choroideum, vascular prolongations of the pia. R., Epidermal. Same as R. mucosum. R. halleri, the upper part of the Wolffian body by which the communication between the seminiferous tubules and the Wolffian duct is established and maintained. R. malleolare internum and externum, the network surrounding the inner and the outer ankle. $\mathbf{R}$. malpighii, the layers of epithelial cells above the corium. R. mirabile ( $p l$., Retia mirabilia), is seen when an artery splits into branches and reunites in a trunk, without forming capillaries. R. mirabile duplex. See $R$. mirabile geminum or conjugatum. 
R. mirabile (of Galen), a network of vessels formed by the intracranial portion of the internal carotid artery in some animals. R. mirabile geminum or conjugatum, a plexus in which arteries and veins are combined. R. mirabile simplex, a network involving only veins or arteries. $\mathbf{R}$. mucosum, the three lower layers of living cells of the epidermis. R. olecrani, the network of vessels around the olecranon and at the back of the elbow, formed by the divisions of the profunda and other arteries. R. pateliare, the plexus of vessels surrounding the patella. R. tarseum dorsale, an arterial network upon the dorsal surface of the tarsus. R. testis, the network of seminal tubules in the corpus highmori of the testicle. R., Unipolar, the capillary divisions of bloodvessels which do not reunite. R., Vascular (of $B$. Ridge), a membranous sac, very vascular, which with the meconic membrane forms an envelop for the meconium of the fetus. $R$. vasculosum, a network of blood-vessels. $\mathbf{R}$. vasculosum testis. See $R$. halleri. $\quad R$. venosum dorsale manus, a venous network on the back of the hand. $\mathbf{R}$. venosum dorsale pedis, a venous network on the dorsum of the foot.

Retecious (re-te'-se-us). Same as Retiform.

Retene $\left(r e^{\prime}-t \bar{e} n\right), \mathrm{C}_{18} \mathrm{H}_{18}$. A hydrocarbon occurring in the highest fractions of coal-tar and also a derivative of phenanthrene. It occurs in the tar of highly resinous pines and in some mineral resins. It is very soluble in alcohol and benzene, and crystallizes in leaflets with a mother-of-pearl luster; it melts at $98^{\circ} \mathrm{C}$., and boils at about $390^{\circ} \mathrm{C}$.

Retention (re-ten'-shun) [retentio; re, back; tenere, to hold]. The holding back or stoppage of any of the natural discharges of the body, as the feces, lochia, urine, menstrual flow, etc. R.-cyst, a cyst formed by a secretion, the natural outlet being closed. R., Hystero-cystic, retention of urine caused by pressure from a gravid uterus. $\mathbf{R}$. of Milk. Same as Galactoschesis, q. v. R. of Menses : I. Retention of menstrual blood due to mechanical interference with its outward flow. 2. Postponement of menstruation after the proper age for its establishment. $\mathbf{R}$. of Placenta, failure of expulsion of a placenta as a result of improper or deficient uterine contractions. $\mathbf{R}$. of Urine, inability to empty the bladder voluntarily.

Retentive (re-ten'-tiv) [retinere, to retain]. That which holds anything in place

Retia $\left(r e^{\prime}-t e-a / 2\right)$ [L., plural of Rete]. See Rete.

Retial $\left(r e^{\prime}-t e-a l\right)$ [rete, a net]. Relating to, or of the nature of, a rete.

Retiary $\left(r^{\prime}-t e-a-r e\right)$ [rete, a net]. Net-like.

Reticular (ret-ik'-u-lar) [reticulum, a little net]. Formed by reticulation; areolar; abounding in interstices. R. Cartilage. Same as yellow elastic cartilage, $q \cdot v$. R. Formation, a formation occupying the anterior and lateral area of the oblongata dorsad of the pyramids and lower olives and extending up into the pons. R. Lamina of Kölliker. See Membrane, Reticular. R. Layer of the Skin, the deep layer of the derma, consisting of strong interlacing bands of white and yellow fibrous tissue.

Reticulare (ret-ik- $u$-la'-re) [reticularis, like a net]. The rete mucosum. See Rele.

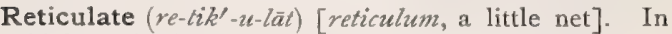
biology, in the form of network; said of the veins of leaves and the surface-markings of different organs.

Reticulated (ret-ik'-u-la-ted). Having net-like meshes,

Reticulation (ret-ik-u-la'-shun) [reticulatus, like a net]. The character of being reticulated.

Reticulose (ret-ik'-u-löz) [reticulum, a net]. Minutely or finely reticulate.
Reticulum (re-tik'-u-lum) [reticulum, a little net: $p l$, Reticula]. 1. A network. 2. In biology, applied to various reticulated structures, $e . g .,(a)$ the second division (hood or honey-comb-bag) of the complicated stomach of a ruminant ; $(b)$ the intracellular or intranuclear network; $(c)$ the neuroglia; $(d)$ the fibrous substance growing at the base of the petioles of certain palms, also called mattulla. R. cutaneum, R. mucosum. See Rete mucosum. R.-Germ (of Von Ebner), a network of fibers occasionally seen between layers of seminal cells

Retiferous (re-tif'-er-us) [rete, a net; ferre, to bear]. That which has a rete.

Retiform (re'-tif-orm) [retiformis]. Net-shaped ; reticulated. R. Tissue. See Animal Tissue.

Retina (ret'-in-ah) [rete, a net]. The chief and essential peripheral organ of vision, the third or internal coat or membrane of the eye, made up of the endorgans or expansion of the optic nerve within the globe. It is composed of ten layers from without inward, as follows: I. Pigment-cells. 2. Rods and

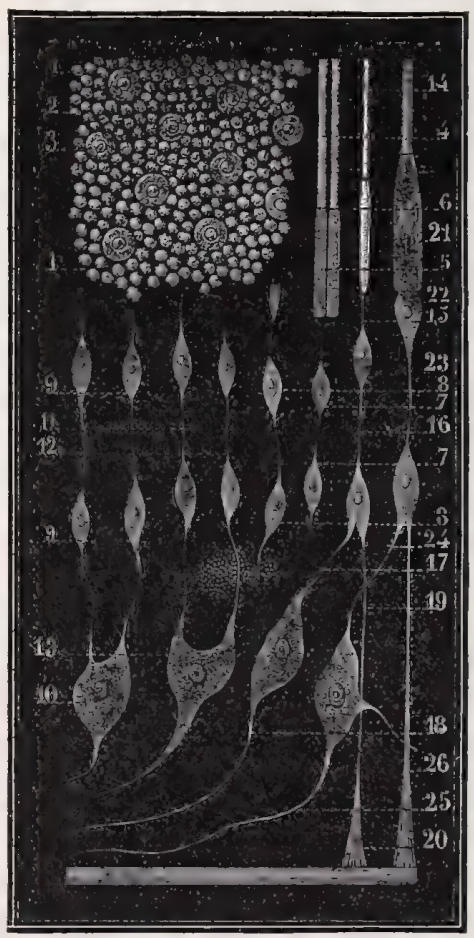

ELEMENTS OF THE RETINA.
I, I. Laver of rods and cones. 2. R od s. 3 . portion of rods. 5. Lower por tion. 6. Point of 5ion. 6. Point of twion of these wo parts. 7,7 Two cells of the granular layer. 8, 8. Two other cells of the same layer 9 a Still layer. 9, 9. Still two other cells of the same layer, 10. Cell of the layer of gray matter with which these communicate. II, I2. Other cells of the granular layer 13. Tripolar cell with which these are continuous. I4. A rod contin14. A rod continthe elements of the other layers. I5. Process by which it communicateswithacell of the external granular layer. 16. Process by which this cell com $\mathrm{mun}$ icates with a cell of the internal granulat layer. $\quad 17$. Process by which this cell communicates with the laver of gray matter. 18.

Process from the last entering into the fibrous layer. 19. A radiating fiber of Mïller.20. Conoid swelling by which this fiber is attached to the internal limiting layer. 2I. A cone continuous with the other elements of the retina. 22. Cell of external granular layer. 23. Intermediary process hetween two cells of the granular laver, 24. Process connecting a cell of the granular layer with a cell of the layer of gray matter. 25. Process of cell of layer of gray matter. 26. A radiating fiber.

cones. 3. External limiting. 4. External granular. 5. Outer molecular. 6. Internal granular. 7. Internal molecular. 8. Ganglionic. 9. Nerve-fiber. Io. Internal limiting. R., Central Artery of, a branch of the ophthalmic artery that pierces the optic nerve in the orbit, branching within the globe, and supplying the retina. $\mathbf{R}$., Coarctate, a term used to describe 
the morbid condition caused by an effusion of liquid between the retina and the choroid. R., Detachment of, disconnection from the choroid. R., Epilepsy of, a symptom of migraine or of epilepsy, characterized by transient loss of sight. R., Fovea centralis of. See Fovea. R., Leopard or Tiger,

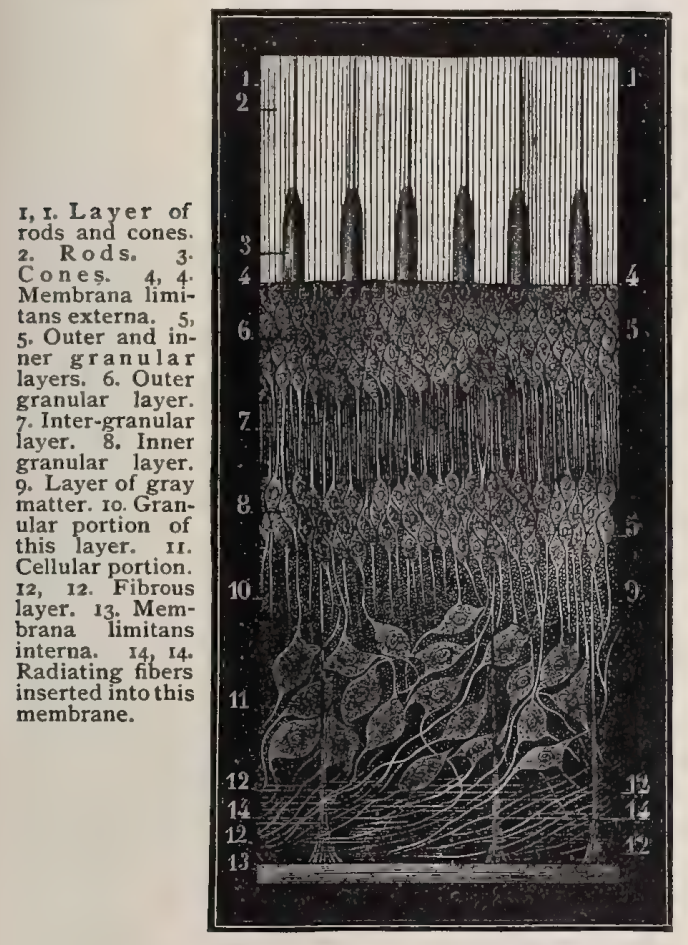

Vertical Section of the Retina.

the appearance of the retina in chronic retinitis pigmentosa. R., Limbus luteus of. See Macula lutea. R., Membrana limitans of. See Membrana limitans. R., Pulsation of. See Pulsation. R., Shot-silk Appearance of. See Reflex, Wateredsilk. R., Sustentacular Fibers of. See Fibexs of Müller.

Retinaculum (ret-in-ak'-u-lum) [retinere, to hold back: pl., Retinacula]. I. A term applied to such bands or membranes as hold back an organ or part, as the Retinaculum of the ileo-cecal valve. 2. An instrument at one time used in operations for hernia. 3. In biology : $(a)$ That viscid, discoid portion of the rostellum of an orchid which holds the pollen masses in place and is removed with them by a visiting insect; it is also called proscolla, and viscid disc; (b) the hardened, uncinate funiculus of the seeds of many of the Acanthacea; (c) the little plate or scale which in certain insects restrains the protrusion of the sting. Retinacula of Barry, tense filaments running from the thickened portion of the cellular membrane lining the Graafian follicle to other parts of the membrane. $\mathbf{R}$. costæ ultimatæ. Same as Lumbo-costal Ligament, $q . v$. Retinacula cutis, fibrous bands connecting the corium with the underlying fascia. R. ligamenti arcuati, the short external lateral ligaments of the knee-joint, $q . v$. Retinacula morgagni, or Retinacula of the Ileo-cecal Valve, the membranous ridge formed by the coming together of the valve-segments at each end of the opening between the cecum and the ileum. Retinacula ossis brachii, fibrous bands inserted into the neck of the humerus and having their origin in the capsule of the humero-scapular articulation. R. patellæ externum, the lateral patellar ligaments. R. patellæ internum, the ligamentum patellæ mediale. Retinacula patellæ, laterale et mediale. See Lateral Patellar Ligaments. R. peroneorum inferius, a fibrous band running over the peroneal tendons as they pass through the grooves on the outer side of the calcaneum. $\mathbf{R}$. peroneorum superius, R. tendinum peroneorum. See Ligament, Extreme Angular (of Ankle). Retinacula valvulæ. See Retinacula morgagni. R. of Weitbricht, bands of ligamentous tissue situated on the neck of the trochanter of the femur.

Retinal (ret'-in-al) [retinalis; rete, a network]. Pertaining to the retina. R. Apoplexy, hemorrhage into the retina. R. Horizon, a term used by Helmholtz to describe the horizontal plane passing through the transverse axis of the eyeball. $\mathbf{R}$. Image, the image of external objects as reflected on the retina. $\mathbf{R}$. Ischemia, anemia of the retina. R. Melanin. See Fuscin. R. Purple. Same as Rhodopsin.

Retinerved (re'tin-ervd) [rete, net; nervus, nerve]. In biology, reticulate; netted-veined.

Retinitis (ret-in-i'-tis) [retina, retina ; $\iota \tau \iota s$, inflammation]. Inflammation of the retina, classed, according to its etiology, into albuminuric, diabetic, leukemic, pigmentary ( $R$. pigmentosa), syphilitic, etc., most of which are characterized by distinctive ophthalmoscopic appearances. $\mathbf{R}$. albuminurica, the form due to nephritis, usually chronic. Numerous white spots may be seen scattered over the fundus, some having an irregular outline, while others are stellated. There are also spots of hemorrhagic extravasation. R., Central Punctate, a form seen most in the aged. A great number of striæ or white spots are visible in the fundus. R., Central Relapsing, a form of syphilitic retinitis in which there is a gray or yellow area in the macular region, or numerous small yellowish-white spots and pigment-dots. It is a rare form, and is inclined to relapse. $R$. cerebralis, retinitis due to intracranial inflammation. R., Choroido-, a form of syphilitic retinitis with cellular infiltration, exudation, atrophy, and proliferation of the pigment-epithelium in the choroid, between the choroid and retina, and in the retinal layers. R. circumpapillaris, a form in which there is proliferation of the outer layers of the retina around the disc. R., Diabetic, the form of retinitis occurring in diabetes. R., Diffuse. See $R$. serosa. R., Diffuse Parenchymatous, the parenchymatous form affecting the limitans, the externa, the interna, and the adventitia. $R$. exsudativa, retinitis with parenchymatous exudation. R., Glycosuric. Same as $R$., Diabetic, $q . v$. R. gravidarum, a form occurring in pregnant women and which is similar to retinitis albuminurica, and is of grave prognostic import. R. hæmorrhagica, a form in which there is swelling of the papilla and opaque infiltration of the surrounding retina; there are distended, dark, and tortuous veins, and the arteries are small; there are hemorrhages, linear or irregular and round in appearance. $\mathbf{R}$. hepatica, a rare form which sometimes occurs in cases of parenchymatous hepatitis. $\mathbf{R}$. leukæmica, a form characterized by pallor of the retinal vessels and optic disc, the boundary of the latter being indistinct. Hemorrhages appear at various points of the membrane, while numerous white patches and round bodies are visible about the disc in the retina. It is a result of systemic anemia. $R$. macularis. Same as $R$., Central Relapsing, $q . v$. 
$R$. nephritica. See $R$. albuminurica. R. nyctalopica, a diffuse, streaked opacity of the retina and swelling of the disc, with central scotoma or colorscotoma, and more or less marked amblyopia. It indicates retro-bulbar neuritis. $R$. paralytica (of Klein), retinitis caused by paralysis affecting the optic nerve. R., Parenchymatous, a simple chronic retinitis affecting the connective tissue of the retina. R. pigmentosa, an affection involving all the layers of the retina, and consisting in a slowly-progressing connective-tissue and pigment-cell proliferation of the entire membrane, with wasting of its nerve-elements. The disease is most common in males, is often hereditary, and begins at a very early period of life, and may be congenital. Both eyes are attacked simultaneously, though occasionally only one suffers, $R$. postica, inflammation of the ectal retinal layer. R., Proliferating, a development of connective tissue in the retina, with the formation of dense bluish-white masses within the retina, and extending into the vitreous humor. $R$. punctata albescens. Same as $R$, Central Punctate, $q . v$. R., Purulent, a form in which there are small circumscribed white spots near the papilla and in the macular region. R., Renal. See $R$. albuminurica. R., Septic. Same as R., Purulent. R. serosa, a form characterized by an infiltration, most marked in the nerve-fiber and ganglionic layer of the retina, creating opacity, edema, and hyperemia, most marked in the veins. R., Simple Syphilitic, a form of syphilitic retinitis in which the ophthalmoscope shows a gray opacity surrounding the papilla, which is discolored and cloudy, and the veins darker than normal. R. simplex. Same as R. serosa, q. v. R., Solar, retinal change from the effect of sunlight. $\mathbf{R}$. sympathetica, retinitis of sympathetic origin, and attended with retinal hyperemia, redness of the disc, engorgement of the veins, and great disturbance of vision. R., Syphilitic, the form occurring in syphilis; it is chronic, diffuse, and a late manifestation of the systemic disease.

Retinochoroiditis (ret - in -o-ko-roi-di'-tis) [retina,

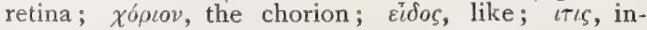
flammation]. Inflammation of the retina and choroid. See Choroido-retinitis.

Retinogen (ret'-in-o-jen) [ retina, retina; $\gamma \varepsilon v v a \tilde{v}$, to produce]. In biology, the ectal of the two layers composing the ectoderm of the embryonic eye of arthropods, the ental layer being called the ganoliogen.

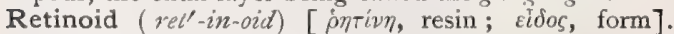
Resin-like, or in the form of a resin.

Retinol (ret'-in-ol) [ $\rho \eta$ iv, a resin], $\mathrm{C}_{32} \mathrm{H}_{16}$. Rosinol; a liquid hydrocarbon derived from the destructive distillation of resin. It is employed in capsules for blennorrhea. It is a good solvent for iodol, aristol, camphor, etc., and is antiseptic, tonic, and cicatrizant. Dose $m$ viij three or four times daily. Unof.

Retinophora (ret-in-off'-or-ah) [retina, retina; $\phi \varepsilon \varepsilon \rho \varepsilon v$, bear: pl., Retinophore ]. In biology, one of the crystalline cone-cells of the arthropodan eye. The retinophoræ are surrounded by pigment-cells.

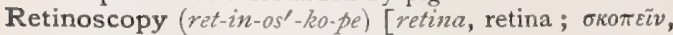
to observe]. A method of estimating the refraction of the eye by observation of the movements of the retinal images and shadows through the ophthalmoscopic mirror. The method has also been called, and very properly, the Fundus-reflex Test; other terms are: Keratoscopy, Pupilloscopy, Umbrascopy, Skiascopy, Koroscopy, etc. R., Phosphenic, a method of learning the condition of the retina when the crystalline lens is opaque. It consists in making slight pressure on different regions of the closed eye; if the retina is healthy under the region pressed, a luminous circle is seen by the patient on the side opposite to the point of pressure.

Retinoskiascopy (ret-in-o-ski-as'-ko-pe). See Retinoscopy.

Retinula (ret-in'-u-lah) [dim. of retina, retina: $p l$., Retinula]. In biology, an aggregation of retinal cells; that portion of the whole retina of the compound eye which belongs to each of the single eyes, as in the lateral eyes of scorpions and Limulus, and the eyes of Myriapoda.

Retinular (ret-in'-u-lor) [retinula, a little retina]. In biology, of or pertaining to a retinula, $q . v$.

Retinulate (ret-in'- $-\imath$-lât $)$ [retinula, a little retina]. In biology, aggregated into retimule.

Retiped (ref-tip-ed) [rete, a net; pes, foot]. Having netted tarsi ; said of certain birds.

Retort (re-tort') [retorquere, to bend back]. A vessel employed in distillation, containing the liquid to be distilled.

Retract (re-trakt') [re, back; trahere, to draw]. To draw back; to contract; to shorten.

Retractile (re-trak'-til) [retrahere, to draw back]. That which may be drawn back. R. Carcinoma, mammary carcinoma with retraction of the nipple.

Retractility (re-trak-til'-it-e) [retrahere, to draw back]. 1. Capable of retraction. 2. Of Pajot, a property of the uterine tissue by virtue of which the uterus, having been emptied of a part of its contents, becomes thickerwalled, while its capacity and volume diminish.

Retraction (re-trak'-shun) [retractio, a drawing back]. The shortening of a fractured limb from the broken ends slipping past one another. R., Cicatricial, that due to cicatrices. See Cicatricial Contraction. R., Muscular, post-paralytic atrophy of a muscle. R. of the Uterus, a chronic contraction of the uterus by which it applies itself closely to its contents without any change of contraction and relaxation. R.-ring. See Bandl, Ring of. R., Spasmodic, irregular contraction of the uterus.

Retractor (re-trak'-tor) [retrahere, to draw back]. I. An instrument for withdrawing the lips or edges of a wound, or for pulling the soft parts away from the place of incision in amputations. 2. A muscle that retracts the organ into which it is inserted. $\mathbf{R}$. anguli oris. See Buccinator Muscle, in Muscles, Table of $\mathbf{R}$. bulbi, the retractor muscle of the eyeball present in some animals. R., Emmet's Perineal, a self-retaining vaginal speculum. R., Eyelid, a metallic instrument used to hold the eyelids away from the eyeball during an examination or operation. R., Minor's Trachea, an instrument used as a substitute for tracheotomy tubes, consisting in a hollow rod, slightly curved, and holding a bent wire retractor by means of a screw at each end. R. oculi. See R. bulbi. R., Pilcher's, a small pair of blunt hooks on a single delicate stem. An instrument used in tracheotomy. R. urethræ or urethralis. See Bulbo-cavernous. R. uteri : (I) the recto-uterini of both sides considered as one; (2) of Luschka, a uterine fold. R., Rose's, an instrument used to hold open a tracheotomy-wound; it consists in a piece of steel wire bent to form a pair of spring hooks. R., Wells's, two wires bent into hooks and tied in place about the neck by bands. It is advised for the purpose of keeping the wound open after tracheotomy.

Retrad (re'-trad) [retro, backward]. In or toward the rear or posterior part.

Retrahens (re'-trah-henz) [retrahere, to draw back]. Drawing back. R. Muscle. See Mruscles, Table of. Retrahent (re'-trah-hent) [retrahens, drawing back]. Drawing backward; retracting. 
Retral (re'-tral) [retro, backward]. Situated toward the back; posterior, caudal.

Retrenchment (re-trench'-ment) [Fr., retrenchement]. A plastic operation the object of which is to obtain cicatricial contraction by the removal of superfluous tissue.

Retriment (ret'-ri-ment) [retrimentum, refuse]. Dregs ; refuse, or marc.

Retro-(re'-tro-) [retro, back]. A prefix meaning backward or behind; usually relating to place or position.

Retroaction (re-tro-ak'-shun) [retro, backward; agere, to do]. Reverse action.

Retroanterograde (re-tro-ant'-er-o-grād) [retro, backward; anterius, before; gredi, to go]. Reversing the order of succession. R. Amnesia, a perversion of the memory in which recent events are referred to a far-off and past time, while the occurrences of the remote past seem recent.

Retrobuccal (re-tro-buk'-al) [retro, back; bucca, the mouth]. Pertaining to the back part of the mouth, or of the cheek.

Retrobulbar (re-tro-bul'-bar) [retro, back; bulbus, bulb]. Situated or occurring behind the eyeball. R. Neuritis, inflammation in the orbital part of the optic nerve. $\mathbf{R}$. Perineuritis, inflammation of the sheath of the orbital part of the optic nerve.

Retrocedent (re-tro-se'-itent) [retro, back; cedere, to go]. Pertaining to a retrograde condition or action of disease; going back; disappearing from the surface, as an eruption. R. Gout. See Gout.

Retroceps ( $r e^{\prime}$-tro-seps) [Fr.]. A variety of obstetric forceps used to grasp the fetal head from behind.

Retrocervical (re-tro-ser'-vik-l) [retro, behind; cervix, the neck]. Situated behind the cervix uteri.

Retrocession (re-tro-sesh'-un) [retrocessio]. Disappearance from the surface, as of an exanthem. R. of Labor, of Charrier, a rare condition in which, after labor has begun, but before the membranes are ruptured, the uterine contractions cease, and the cervix, formerly a small ring, becomes a canal again.

Retroclavicularis (re-tro-kla-vik-u-la'-ris) [retro, behind; clavicula, the clavicle]. See Sterno-clavicularis posticus.

Retroclusion (re-tro-klu'-2hun) [retro, back ; claudere, to shut]. A form of acupressure, in which the pin is passed first above the artery, twisted a half circle and then driven below the artery into the tissues upon the side first entered.

Retrocollic (re-tro-kol'-ik) [retro, back; collis, the nape of the neck]. Pertaining to the muscles at the back of the neck. R. Spasm, that form of wry-neck involving the retrocollic muscles. Spasmodic torticollis.

Retrocopulant (re-tro-kop'-u-lant) [retro, back; copulans, copulating]. Copulating backward or from behind.

Retrocopulation (re-tro-kop-u-la'-shun) [retro, backward; copulare, to copulate]. The act of copulating from behind or aversely.

Retrodeviation (re-tro-de-ve- $a^{\prime}-$ shun) [retro, back; deviatio, a wandering]. Any backward displacement; a retroflexion or retroversion.

Retrodisplacement (re-tro-dis-plās'-ment) [retro, back; OF., desplacer, to put out of place]. Displacement backward of a part or organ.

Retro-esophageal (re-tro-e-so-faj'-e-al) [retro, behind; oíoфáyos, esophagus]. Located behind the esophagus.

Retroflected (re-tro-flek'-ted). Same as Retrofexed.

Retroflection (re-tro-flek'shun). See Retroflexion.

Retroflex (re'-tro-fleks) [retro, back; flectere, to turn]. Turning back abruptly.

Retroflexed (re-tro-flekst') [retro, back ; flectere, bend]. Peut backward.
Retroflexion (re-tro-flek'-shun) [retro, back; flectere, to bend]. Any abrupt displacement, bending or changing of normal direction. R. of Uterus. See Uterus.

Retrofract (re'-tro-frakt). Same as Refracted.

Retrogenerative (re-tro-jen'-er-a-tiv). Same as Retrocopulant.

Retrognathous (re-trog'-na-thus) [retro, backward; yvátos, jaw]. Retracted jaw.

Retrograde (re'-tro-grād, or ret'-ro-grāa) [retro, backward; gradus, a step]. Receding, or going backward. R. Carcinoma, a carcinoma which grows firmer and less in size and remains so. R. Metamorphosis, katabolic change.

Retrograde (re'-tro-gra ad, or rel'-ro-grād) [retrogradi, go backward]. In biology, (I) showing degeneration from a more complex structure or higher function to a lower one. 2. Descriptive of animals that walk or swim backward.

Retrography (re'-tro-graf-e) [retro, back; $\gamma \rho a ́ \phi \varepsilon \iota v$, to write]. Writing backward; a symptom of certain nervous diseases.

Retrogressive (re-tro-gres'-iv) [retrogressus]. Declining in strength; degenerating. In biology, degeneration, backward metamorphosis, as the transformation of bracts into foliage leaves, stamens into petals, sepals into bracts, etc.

Retro-insular (re-tro-in'-su-lar) [retro, behind; insu$l a$, island]. Situated or occurring behind the insula, or island of Reil. R. Convolutions, two or three convolutions behind the insula and wholly within the fissure of Sylvius.

Retrojection (re-tro-jek'-shun) [retro, back; jectio, a throwing]. The washing out of a cavity from within outward.

Retro-lingual (re-tro-lin'-grval) [retro, back; lingua, tongue]. Relating to that part of the throat back of the tongue. Serving to retract the tongue.

Retro-location (re-tro-lo-ka'-shun) [retro, back; locatio, location]. Same as Retro-position, $q . v$.

Retro-malleolar (re-tro-mal-e $\left.e^{\prime}-o-l a r\right)$ [retro, back ; malleolus, malleolus]. Located back of a malleolus.

Retromammary (re-tro-mam' - ar - e) [retro, behind ; mamma, breast]. Situated or occurring behind a mammary gland.

Retro-maxillary (re-tro-maks'-il-a-re) [retro, back; maxilla, maxilla]. Situated behind the maxilla.

Retromorphosis (re-tro-mor'-fo-sis) [retro, back; $\mu$ o $\phi \dot{\eta}$, form]. Katabolism; retrograde metamorphosis ; katabolic change.

Retro-nasal (re-tro-na'-zal) [retro, behind; nasus, nose]. Situated back of the nose or nasal cavities.

Retro-ocular (re-tro-ok'-u-lar) [retro, behind; oculus, the eye]. Situated behind the eyeball. Same as Retrobulbar.

Retroperitoneal (re-tro-per-it-on-é-al) [retro, behind; $\pi \varepsilon \rho \iota$ Tovaıov, peritoneum]. Occurring or situated behind the peritoneum. R. Hernia, hernia of the intestine into the iliac fossa back of the peritoneum.

Retroperitoneum (re-tro-per-it-on-e'-um) [retro, behind;

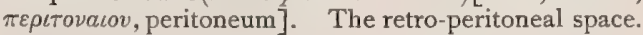

Retroperitonitis (re-tro-per-it-on-i'tis) [retro, behind; $\pi \varepsilon \rho \iota T a v a \iota \nu$, peritoneum; $\iota \tau \iota s$, inflammation]. Inflammation of the retroperitoneal structures.

Retropharyngeal (re-tro-far-in'-je-al) [retro, behind; $\phi a \rho v \gamma \xi$, the pharynx]. Situated or occurring behind the pharynx. Pertaining to parts situated behind the pharynx. R. Abscess, abscess occurring in the tissues back of the pharynx.

Retropharyngitis (re-tro-far-in-ji'tis) [retro, be-

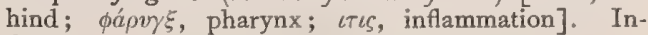
flammation of the retropharyngeal tissues. 
Retroposed (re'-tro-pōzd) [retro, back; ponere, to place]. Displaced backward.

Retro-position (re-tro-po-zish'-2un) [retro, back; positio, position]. Backward displacement of the uterus without flexion or version.

Retropulsion (re-tro-pul'-shun) [retro, back; pulsio, beating]. I. A driving or turning back, as of the fetal head. 2. A running backward; a disorder of locomotion sometimes witnessed in paralysis agitans.

Retrorse (re-trors') [retro, backward; vertere, turn]. In biology, turned backward.

Retroserrate (re-tro-ser'-ät) [retro, back; serratus, sawshaped]. In biology, furnished with serrations which are turned backward, as the sting of a bee.

Retroserrulate (re-tro-ser'-u-lāt) [retro, back; serrula, a little saw]. Furnished with diminutive retrorse teeth.

Retrosiphonate (re-tro-si'-fun-āt), [retro, back; oi $\phi \omega \nu$, siphon]. In biology, having the siphon and surrounding partitions directed back ward.

Retrostalsis (re-tro-stal'-sis) [retro, backward; orá $\lambda$ $\sigma \iota$, compression]. Reversed peristaltic action; peristaltic action that tends to drive the intestinal contents cephalad instead of caudad.

Retrosternal (re-tro-ster'-nal) [retro, back; $\sigma \tau \varepsilon \dot{\rho} \rho \nu o v$, sternum]. Situated or occurring behind the sternum.

Retrotarsal (re-tro-tar'-sal) [retro, back; rápoos, tarsus]. Situated or occurring behind the tarsus. $R$. Fold, the fornix of the conjunctiva.

Retrotracheal (re-tro-tra'-ke-al) [retro, behind; $\tau \rho a-$ $\chi \varepsilon i a$, trachea]. Situated or occurring behind the trachea.

Retro-uterine (re-tro- $u^{\prime}$-ter-in) [retro, behind; uterus, uterus]. Behind the uterus. R. Hematocele, a blood-tumor behind the uterus in the pouch of Douglas.

Retrovaccination (re-tro-vak-sin- $\left.a^{\prime}-\operatorname{shun}\right)$ [retro, back; vaccinus, of a cow]. Vaccination with virus from a cow that had been inoculated with the virus of smallpox from a human subject.

Retrovaccine (re-tro-vak'-sin) [retro, back; vaccinus, of a cow]. The virus obtained after inoculating a cow with human virus.

Retroversion (re-tro-ver-shun) [retro; versio, a turning]. A turning back; applied especially to such organs as the bladder, the womb, etc. R. of Uterus. See Uterus.

Retti (ret'-i) [Hind, ratti]. The seed of Abrusprecatorius. See Jequirity.

Retuse (re-tūs's [retusus, blunted, dull]. In biology, applied to a leaf or other flattened organ that has a broad, shallow sinus at the apex.

Retzius, Brown Lines of. Fine parallel lines in the enamel of a tooth. R., Cavity of. See Cavity, Preperitoneal. R., Ligament of. See Ligament. R., Space of. Same as R., Cavity of. R., Stripes of. See Stripe. R., Veins of, small veins uniting the radicles of the portal branches in the intestines and mesentery with the inferior vena cava and its branches. They include all the retroperitoneal veins and are often enormously enlarged in hepatic cirrhosis.

Reunion (re-ūn'-yun) [re, again; unio, to become one]. The joining of parts whose continuity has been destroyed. R. of Wound. See Healing.

Reuss's Test. See Tests, Table of.

Revaccination (re-vak-sin-a'-shun) [revaccinatio]. Renewed or repeated vaccination.

Revalenta (rev-al-en'-tah) [transposed from Ervum lens]. A commercial and proprietary food-preparation for invalids, said to be composed principally of lentil meal.

Revealed (re-veld') [re, back; velare, to veil]. In biology, not concealed under other parts.
Réveilleur (ra-vel-yur') [Fr.]. The instrument used in Baunscheidtism.

Revellent (re-vel'-ent). See Revulsive.

Reverdin's Operations. See Operations, Table of.

Reverie (rev'-er-e) [Fr, rêverie ]. A state of dreamy abstraction; visionary mental or ideational movement, the mind itself, at least so far as volition is concerned, being passive

Reverse (re-vers') [revertere, to turn back]. In bandaging, a half-turn employed to change the direction of a bandage.

Reversion (re-ver'-shun) [revertcre, to turn back]. In biology: I. The appearance of characteristics which existed in remote ancestors; thus many endoparasites (Cestoda, Acanthocephala, Rhizocephala) show reversion to a very low type of digestion, while the Ascidians are held by Dohrn, Lankester, and others to be degenerate Vertebrata. The loss of eyes by the Cirripedia, the Penellina, and the Lernoodea, when these animals become fixed, as well as by various cave-animals, may be included as examples of reversion. 2. The backward development of plant-organs, as stamens into petals, etc. 3. Becoming wild after having been domesticated or cultivated.

Revert (re-vert'). See Latent.

Revitalization (re-vi-tal-i-za'-shun) [re, again; vita, life]. The act or process of refreshing or revitalizing.

Revive $\left(r e-v \bar{\imath} v^{\prime}\right)$ [re, again; vivere, to live.] To return to life after seeming death.

Revivement (re-vin $v^{\prime}$-ment) [revivere, to live again]. The act of reviving.

Revivification (re-viv-if-ik-a'-shun) [revivificatio]. I Restoration to consciousness. 2. The refreshing of surfaces by paring before placing them in apposition.

Reviviscence (re-viv-is'-ens) [reviviscere, inceptive of revivere, to revive]. The awakening from a period of dormancy; said of insects after hibernation.

Revolute (rev'-o-lüt) [re, back; volvere, to roll]. That form of vernation or estivation in which the margins of the organ are rolled backward.

Revolver (re-vol'-ver). See Nose-piece.

Revomit (re-von'-it) [re, again; vomere, to vomit]. To reject from the stomach.

Revulsant (re-vul'-sant) [revellere, to push away]. I. Revulsive. 2. A medicine or agent that, by irritation, draws the blood from a distant part of the body.

Revulsion (re-vul'-shun) [revulsio]. The reduction of morbid action in any part by means of counterirritation.

Revulsive (re-vul'-siv) [revellere, to turn away]. Capable of causing revulsion; applied to therapeutic agencies designed to withdraw the blood from or counteract the tendencies toward a morbid focus or process.

Revulsor (re-vul'-sor) [revellere, to turn away]. I. An apparatus for effecting revulsion by means of the alternate application of heat and cold. 2. A plate or cylinder set with needles, and used in producing counterirritation.

Reybard's Suture. An interrupted loop-suture for wounds of the intestine. See Suture.

Rhabarbarin (ra-bar'-bar-in) [rhabar-barum, barbarian rhubarb]. Same as Chrysophanic Acid, q.v.

Rhabarbarum (ra-bar'-bar-um) [rhabarbarum, barbarian rhubarb]. Rhubarb.

Rhabdia $\left(r a b^{\prime}-d e-a h\right)$ [ $\dot{\alpha} \dot{\beta} \delta \delta o s$, a rod]. In biology, the great rods lying beneath the crystalline cones of the insect's eye.

Rhabdite (rab'-dit) [ $p a ́ \beta \delta o s$, a rod]. In biology, (a) one of the spindle-shaped glandular secretions occurring in the skin of certain invertebrates. They are specially characteristic of the Turbellaria; (b) one of 
the paired appendages of the abdominal sternites forming the ovipositor of certain insects.

Rhabditic $\left(r a b-d i^{\prime}-i k\right)[\rho a j \beta \delta o s$, a rod]. Pertaining to a rhabdite.

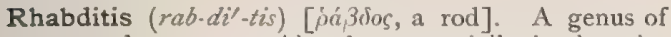
nematode worms. Abundant especially in decaying organic matter, garden earth, etc. Several species are parasitic in snails, a few in man. See $R$. niellyi, $R$. pellio and R. terricolit, under Parasites (Animal), Table of.

Rhabdium ( $\left.r a b^{\prime}-d e-u m\right)$ [dim. of páßjos, rod: $p l$., Rhabdia]. A fiber of striped or voluntary muscle.

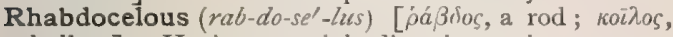
hollow]. Having a straight digestive cavity.

Rhabdoid ( $r a b^{\prime}$-doid) [ $\rho a \beta \delta o s$, a rod; cidos, form ]. In biology, an acicular or spindle-shaped body chemically related to the plastids, which is found lying diagonally across the stalk-cells of the tentacles of Drosera and in the mesophyl-cells of Dionea, and tends to grow spherical when the part is irritated. Its importance is not fully known.

Rhabdoidal (rab-doi'-dal) [ $\dot{\alpha} a \beta \delta o \varepsilon \iota \delta \dot{h} s$, like a rod]. Rod-like.

Rhabdomal ( $\left.r a b^{\prime}-d o-m a l\right)$ [ $\rho a ́ \beta \delta \omega \mu a$, a bundle of rods]. Having the character of a rhabdom.

Rhabdome $\left(r a b^{\prime}-d \bar{o} m\right)$ [ $\rho a ́ \beta \delta \omega \mu a, a$ bundle of rods]. In biology, a tubular rod forming the central axis of the retinula of the arthropod eye.

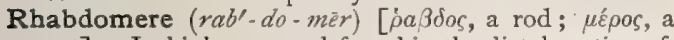
part]. In biology, a rod found in the distal portion of each of the retinular cells of the arthropod eye.

Rhabdomyoma (rab-do-mi-o'-mah) [ $\rho \dot{\alpha} \beta \delta o s$, a rod ; $\mu v_{s}$, a muscle; $\ddot{\mu} \mu a$, a tumor : $p l$, Rhabdomyomata]. A rare form of myoma characterized by the presence of striated muscular fiber.

Rhabdonema (rab-do-ne'-mah) [ $\rho a ́ \beta \delta o s, a \operatorname{rod} ; \nu \eta \mu a$, a thread]. A genus of parasitic Anguillulida. See under Parasites (Animal), Table of.

Rhabdonemiasis (rab-do-ne-mi'-as-is) [Rhabdonema, a genus of parasitic nematode worms; $\hat{\alpha} a ́ \beta \delta \rho$, a rod; $\nu \tilde{\eta} \mu \alpha$, a thread]. The disease arising from the presence of parasites of the genus Rhabdonema. See Parasites (Animal), Table of.

Rhabdosphere $\left(r a b^{\prime}-d o-s f e ̂ r\right) ~[\rho a ́ \beta \delta o s, a$ rod; $\sigma \phi a \check{\rho} \rho a$, a sphere]. A minute spheric body bristling with rhabdolithic rods.

Rhabdous $\left(r a b^{\prime}-d u s\right)$ [ $\rho \dot{\alpha} \beta \delta o \varsigma$, a rod]. Having the character of a rhabdus.

Rhabdus (rab'-dus) [ $\dot{\rho} a ́ \beta \delta o s$, a rod]. In biology, $(a)$ a simple, straight spicule; (b) the stipe of certain fungi.

Rhachi. See also Rachi.

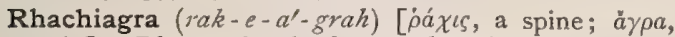
pain]. Rheumatism in the muscles of the spine.

Rhachial ( $\left.r a^{\prime}-k e-a l\right)$ [ $\rho a a^{\prime} \iota s$, spine]. Pertaining to the spine.

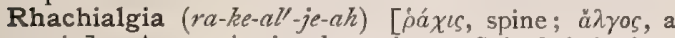
pain]. Any pain in the spine. Spinal irritation. R. mesenterica. Same as Tabes mesenterica, q. $v$. R. pictonum. See Metallic Colic.

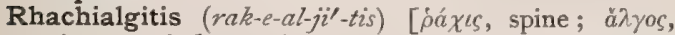
pain; $\iota \tau \iota$, inflammation]. Inflammatory rhachialgia.

Rhachiasmus ( $\left.r a-k e-a z^{\prime}-m u s\right)$ [ $\rho a ́ \chi \iota s$, spine]. Spasm of the muscles at the back of the neck, as seen in the early part of many epileptic attacks.

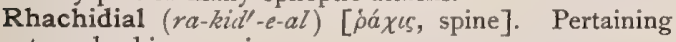
to a rhachis, or spine.

Rhachidian (ra-kid'-e-(in). Same as Rhachidial.

Rhachilysis (ra-kil'-is-is) [ $\rho a ́ \chi \iota s$, spine; $\lambda v \varepsilon \varepsilon v$, to loose]. A method of treating lateral curvature of the spine by mechanical counteraction of the abnormal curves.

Rhachio- or Rachio- $\left(r a^{\prime}-k e-o^{-}\right)$[ $\dot{\rho}^{\prime} \chi \iota \varsigma$, spine]. A prefix denoting connection with or relation to the spine.

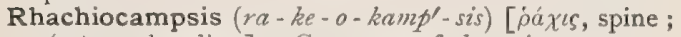
$\kappa a ́ \mu \psi r s$, a bending]. Curvature of the spine.

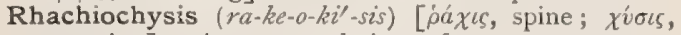
a pouring]. An accumulation of water or watery substance within the spinal canal.

Rhachiodynia (ra-ke-o-din'-e-ah) [ $\rho a ́ \chi \iota s$, spine; ódúvn, pain]. Pain in the spinal cord.

Rhachiokyphosis ( $\left.r a-k e-o-k i-f o^{\prime}-s i s\right)$ [ $\rho a ́ \chi \iota s$, spine;

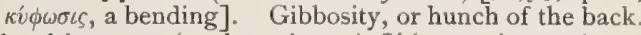

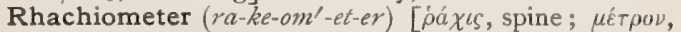
a measure]. An instrument used to measure the degree of spinal deformities.

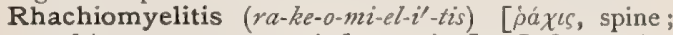
$\mu v \varepsilon \lambda \sigma \varsigma$, marrow ; $\iota \tau \iota$, inflammation]. Inflammation of the spinal cord. Myelitis.

Rhachiomyelophthisis ( $\left.r a-k e-0-m i-e l-o f^{\prime}-t h i s-i s\right)$

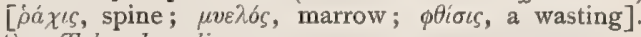
See Tabes dorsalis.

Rhachiomyelos (ra-ke-ö-mí-el-os) [ $[\dot{a} a ́ \chi \iota s$, spine; $\mu v \varepsilon-$ hos, marrow]. See Spinal Cord.

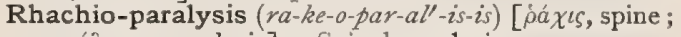
$\pi \alpha \rho a ́ \lambda v \sigma \iota s$, paralysis]. Spinal paralysis.

Rhachiophyma ( $\left.r a-k e-o-f^{\prime}-m a h\right)$ [’á $\chi \iota \varsigma$, spine; $\phi \tilde{v} \mu a$, a growth]. A spinal tumor.

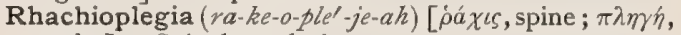
stroke]. Spinal paralysis.

Rhachiorrheuma ( $r a-k e$ - or- $\left.r u^{\prime}-m a h\right)$ [ $\rho a ́ \chi \iota s$, spine ; $\dot{\rho} \varepsilon \tilde{v} \mu a$, a flowing]. Spinal rheumatism.

Rhachioscolioma (ra-ke-o-sko-le-o'-mah) [ $\dot{\rho} a ́ \chi \ell s$, spine; $\sigma \kappa о \lambda i \omega \mu a$, a curve]. Lateral distortion and curvature of the spine.

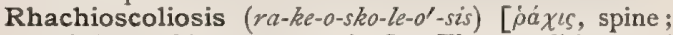

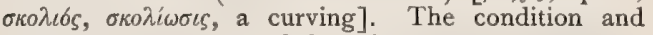
progress of curvature of the spine.

Rhachiostrophosis (ra-ke-o-stro-fó-sis) [ $\rho a ́ \chi \iota s$, spine; $\sigma \tau p o \phi \circ \varsigma$, twisted]. Curvature of the spine.

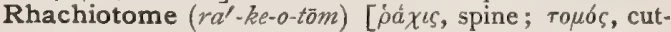
ting]. A cutting instrument used in rhachiotomy.

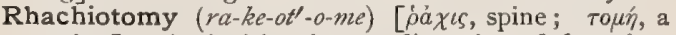
cutting]. An incision into or dissection of the spine.

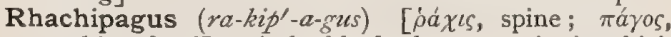
anything fixed]. A double fetal monstrosity in which the twins are joined back to back by any portion of the spinal column.

Rhachis (ra'-kis) [ $\rho a ́ \chi \iota c]$. The spinal column. In biology, $(a)$ the main petiole of a compound leaf; $(b)$ the axis of inflorescence; $(c)$ the shaft of a feather; (d) the arched middle area of the dorsal surface of a trilobite.

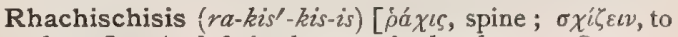
cleave]. A cleft in the vertebral column. Same as Spina bifida.

Rhachitæ $\left(r a-k i^{\prime}-t e\right)[\dot{\rho} a \chi i \bar{\tau} \alpha \iota]$. The muscles attached to the vertebral column.

Rhachitic (ra-kit'-ik). See Rachitic.

Rhachitis. See Rachitis.

Rhachitome (ra'-kit-ōm). Same as Rhachiotome, $q . v$.

Rhachus ( $\left.r a^{\prime}-k u s\right)$ [ $\left.\rho \dot{\alpha} \chi o s\right]$. A ragged wound.

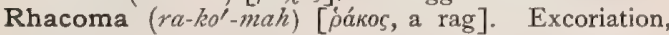
rent, or chapping. Also a pendulous, relaxed condition of the scrotum.

Rhacosis (ra-ko'-sis) [ $\dot{\rho} a ́ k o s$, a rag]. The condition of one affected with rhacoma.

Rhacous (rā'-kus) [’́ákos, a rag]. Wrinkled. Lacerated.

Rhæbocrania or Rhebocrania (re-bo-kra'-ne-ah)

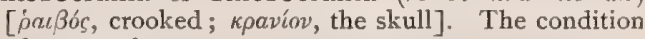
of wry-neck.

Rhæboscelia, Rhæbosis (re-bo-se'-le-ah, re-bo'-sis)

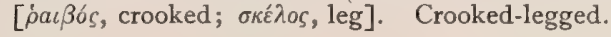


Rhæstocythemia (res-to-si-the'-me-ah). See Rhestocy themar.

Rhagades (rag'-ad-ēz) [jayás: pl. of Rhagas]. Rha. cadia; linear cracks or fissures in the skin, whether due to injury or disease. They are most frequently seen on the palmar and plantar surfaces of the hands and feet, at the angles of the mouth, the anus, and the flexures. They are painful on movement.

Rhagadia (rag-a'-de-ah). See Rhagades.

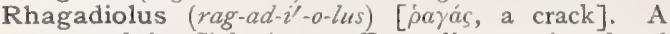
genus of the Cichoriacea. R. etulis, a variety found in southern Europe and which possesses aperient and diuretic properties. $\mathbf{R}$. hedypnois, a variety supposed to possess aperient properties

Rhagas ( $r a^{\prime}$-gas) [ $\rho a \gamma a ́ s$, a rent: pl., Rhagades]. Singular of Rhagades (seldom used in the singular).

Rhagite $\left(\mathrm{rag}^{\prime}-\bar{i} t\right)[\hat{\rho} a \gamma a \varsigma$, a crack $]$. A hydrous arseniate of bismuth occurring in yellow or yellowish-green crystals.

Rhagon (rag'-on) [ $\rho a ́ \xi$, a grape]. In biology, a type of sponge-structure characterized by the grape-like arrangement of the spheric chambers. Also called Dyssycus. Cf. Ascon, Leucon, Sycon.

Rhagonate (rag'-o-nât) [ $\hat{\rho}^{\prime} \hat{\xi}$, a grape]. Having the character of a rbagon; rhagose

Rhagose $\left(\mathrm{rag}^{\prime}-\bar{o} z\right)$ [ $\rho \dot{a} \xi$, a grape]. Racemose; arranged like a bunch of grapes.

Rhamma $\left(\mathrm{ram}^{\prime}-a h\right)[\rho a ́ \mu \mu \alpha]$. Suture, q. v.

Rhamnegin (ram'-ne-jin) [páuvos], $\mathrm{C}_{12} \mathrm{H}_{10} \mathrm{O}_{5}$. A glucosid derived from buckthorn-berries.

Rhamnetin (ram-ne'tin). See Rramnin.

Rhamnin ( $\left.\mathrm{ram}^{\prime}-n i n\right)$ [ $\rho a \mu \nu o s$, the buckthorn]. A yellow, neutral, crystalline substance found in buckthorn. It contains rhamnetin, a valuable yellow coloringmatter.

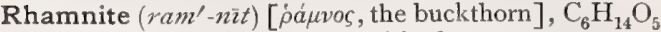
Pentaoxyhexane. Its aldehyd is rhamnose.

Rhamnocathartin $\left(\mathrm{ram}^{\prime}-\right.$ no-kath-art'-in) [ $\rho$ á $\mu \nu \mathrm{s}$, buck-

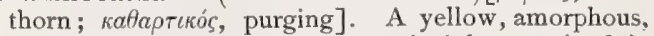
translucent substance; a bitter principle contained in the berries of Rhamnus cathartica.

Rhamnose (ram'-nōz) [ $\rho$ á $\mu v o s$, the buckthorn], $\mathrm{C}_{6} \mathrm{H}_{12}$ $\mathrm{O}_{5}$. Isodulcite or methyl arabinose, one of the glucoses. It results upon decomposing different glucosids (quercitrin, xanthorhamnin, lesperidin) with dilute $\mathrm{H}_{2} \mathrm{SO}_{4}$. It forms large, vitreous crystals containing one molecule of water, and melting at $93^{\circ} \mathrm{C}$. It reduces alkaline copper solutions, but is not fermented by yeast. See Carbohydrates, Table of.

Rhamnotannic Acid, Rhamnotannin (ram-no-tan'ik, ram-no-tan'-in] [ 'páuvos, buckthorn; tannin, tannin]. An astringent, amorphous, neutral greenishyellow mass, probably an impure coloring-matter derived from some variety of Rhammus.

Rhamnoxanthin (ram-no-zan'-thin) [ $\rho a ́ \mu v o s$, buckthorn; $\xi a v \theta b \varsigma$, yellow]. See Frangulin.

Rhamnus (ram'-nus) [ $\mathrm{rá}^{\prime} \mu v o s$, buckthorn]. One of a genus of polypetalous shrubs and trees. R. alaternus, a plant indigenous to northern Africa and the south of Europe, of which the leaves are astringent and the fruits bitter and purgative. R. alpinus, Alpine buckthorn. The fruits and bark are purgative. R. baccæ, the berries of $R$. calharticus. $\mathbf{R}$. californica, California buckthorn, the bark of which has strong purgative properties. $\mathrm{R}$. carolinianus, a shrub or small tree with purple berries, found in the soutbern United States. R. cathartica, or catharticus, common buckthorn; purging thorn; harts-thom; rain-berry; thornway; thorn ; a shrub indigenous to Europe, Asia, and northern Africa: it is cultivated in the United States. The berries are actively purgative. They are usually given in a syrupy vehicle to counteract their irri- tant effect. $\quad \mathbf{R}$. catharticæ iructus, the berries of $R$. catharica. R. crocea, California mountain holly; an extract of the bark is used in medicine as a mild laxative and tonic. R. ellipticus, a species used in medicine as an antisyphilitic. R. frangula, dogwood; alder (United states and $\mathrm{Br}$. Ph.). The bark only is official and occurs in thin quills, grayish-brown externally, and rough ; internally, smooth and yellowish in color. It is a laxative, but too irritant to prove of much value in medicine. The berries have been used as a cathartic. R. frangulæ, Extractum, an aqueous or alcoholic extract of the bark of $R$. frangula. $\mathbf{R}$. lineatus, a species indigenous to China. The root is used in medicine and has diuretic properties. R. lycioides, a Spanish variety. A decoction of the berries is used as an external application in rheumatic joint-enlargements. $\mathbf{R}$. pumilus, dwarf buckthorn; a variety having mild purgative properties, the fruit and bark being used. $\mathbf{R}$. purshiana, or purshianus, California buckthorn; a small tree which grows in California. The bitter bark constitutes cascara sagrada-official in the Br. Ph. as Rhamni purshiani cortex. It contains three resins; tannic, malic, and oxalic acids ; a neutral, crystallizable principle, and an essential oil. It is used as a laxative, and is especially valuable in that it exerts a protracted influence upon the gastro-intestinal tract. $\mathbf{R}$. sanguinea, or sanguineus, used in the treatment of itch; a Spanish variety. $\mathbf{R}$. saxatilis, rock buckthorn; the berries and a portion of the bark are said to be purgative. Rhamni, Succus, the expressed juice of the fruit of $R$. catharticus. $\mathbf{R}$. virgatus, a variety found in Hindostan. The fruit is used as a purgative. R. wightii, an Asiatic variety. The bark is akin in its action to cascara sagrada. See Buckthorn, Cascara sagrada.

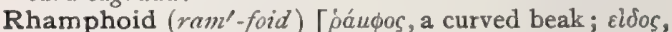
like]. Beak-shaped.

Rhamphos ( $\mathrm{ram}^{\prime}$-fos) [ $\dot{\rho} a \mu \phi o s$, a beak]. A rostrum.

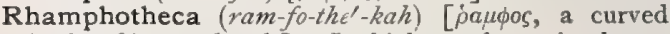
beak; $A \eta \kappa \eta$, a sheath]. In biology, the entire horny integument of the beak of a bird. Cf. dertrotheca, gnathotheca, rhinotheca.

Rhanter (rant'-er) [ $\operatorname{\rho }^{\prime} \alpha \nu T h \rho$, sprinkle]. The inner canthus, $q . v$.

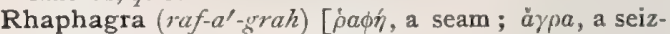
ure]. Pain in the cranial sutures.

Rhaphanedon $\left(r a f-a n^{\prime}-e d-o n\right)[\dot{\rho} a \phi a v \eta \delta o ́ v] . ~ A ~ t r a n s-$ verse fracture.

Rhaphania (raf-a'-ne-ah) ['́á $\phi a v o s$, the radish]. Poisoning by the black radish, strawberries, or ergot. $\mathbf{R}$. marsitica, pellagra, so named because it was thought to be due to using maize as a food.

Rhaphe $\left(r a^{\prime}-f e\right)$. See Raphe.

Rhaphides $\left(r a^{\prime}-f d-\hat{e} z\right)$. See Raphis.

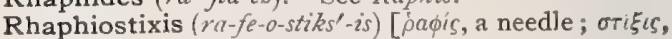
a piercing]. Same as Acupuncture, q.v.

Rhaphis $\left(r a^{\prime}-f s\right)$. See Raphis.

Rhaphosymphysis (ra-fo-sim'-fis-is) [ $\dot{\rho} a \phi \dot{n}$, a seam;

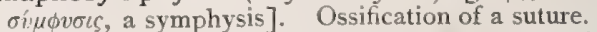

Rhapontic (ra-pon'-tik) [rhaponticum]. Rhubarb.

Rhatany (rat'-an-e). See Krameria.

Rhea $\left(r e^{\prime}-a h\right)$. Synonym of Ramie-fiber, $q . v$.

Rheadin $\left(r e^{\prime}-a d^{\prime}-i n\right)$. An insoluble crystalline alkaloid of opium.

Rhegma (res'-mah) [ $\dot{\rho} \bar{\eta} \gamma \mu a: p l .$, Rhegmata]. A rent, rupture, or puncture of the walls of a vessel or of the containing membrane of a tissue, as, for example, the coats of the eye, the walls of the peritoneum. Also, the bursting of an abscess.

Rhegmatous (reg'-mat-us) [ $\rho \eta \gamma \mu a$, a rent]. In a rent or ruptured condition. 
Rheic Acid (re'-ik) [ $\rho$ jov, rhubarb], $\mathrm{C}_{20} \mathrm{H}_{16} \mathrm{O}_{9}$. $\Lambda \mathrm{n}$ amorphous red powder. Synonym of Chrysophanic Acid.

Rhein ( $\left.r e^{\prime}-i n\right)$ [ $\dot{\eta} \overline{o v}$, rhubarb]. x. The precipitate from a tincture of Rhenm palmatum; it is cathartic, tonic, cholagogue, and antiseptic. Dose I to 4 grains. Unof, 2. Same as Chrysarobin.

Rheinic Acid (re-in'-ik). See Acid, Chrysophanic

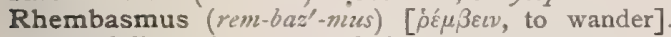
Mental distraction, or wandering.

Rhenchos (ren'-kos) [ $\rho \varepsilon^{\prime} \gamma \kappa \varepsilon t v$, to snore]. Synonym of Snoring.

Rheocord (ré-o-kord) [ $\rho \varepsilon i \nu$, flow; $\chi 0 \rho \delta \dot{n}$, a cord]. An instrument serving to graduate the strength of the galvanic current. See Rheostat.

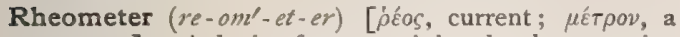
measure]. A device for ascertaining the electromotive force or voltage of a given current. A galvanometer. Also, an instrument for measuring the amount of fluid (e. g., blood) passing through a canal or vessel. See Stromuhr.

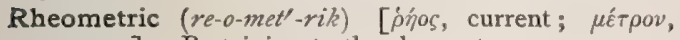
measure]. Pertaining to the rheometer,

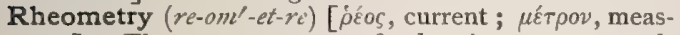
ure]. The measurement of electric currents; galvanometry.

Rheomotor (re-o-mo'-tor) [ $\rho \varepsilon i \nu$, to flow ; motor, a mover]. An apparatus used to generate an electric current.

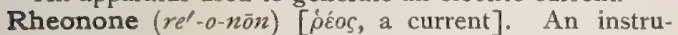
ment constructed by von Fleischl to measure the exact effect of nerve-irritation.

Rheophore ( $\left.r e^{\prime}-o-f o r\right)$ [ $\rho \dot{\varepsilon} o \varsigma$, current; $\phi \varepsilon \dot{\rho} \varepsilon \iota \nu$, to carry]. Any conducting substance leading from the poles of a galvanic battery, coil, or dynamo. Practically the terminals or electrodes which the patient receiving the current grasps in his hands, or which are applied to his body.

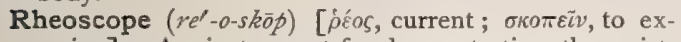
amine]. An instrument for demonstrating the existence of an electric current. R., Physiologic, or Rheoscopic Limb, a moist conductor placed upon a sensitive nerve-muscle preparation.

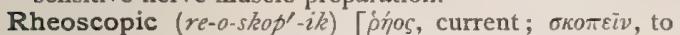
view]. Pertaining to the rheoscope.

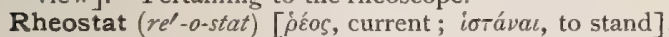
An instrument for the measurement or comparison of the resistance of an electric current. When a batterycurrent of absolute uniformity of electromotive force is required, a rbeostat is usually introduced within the circuit in order to effect such uniformity. R., Water, a rheostat the resistance of which is obtained by means of a mass of water of fixed dimensions.

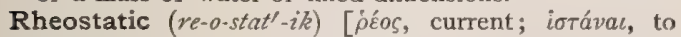
stand]. Pertaining to the rheostat.

Rheostatics (re-o-stal'-iks) ['éos, current ; iotávaı, to stand]. The statics of fluids.

Rheotannic Acid (re-o-tan'-ik) [ $\rho \dot{\rho} \tilde{o} o v$, rhubarb; tannin, tannin], $\mathrm{C}_{26} \mathrm{H}_{26} \mathrm{O}_{14^{*}}$ A reddish or yellowish-brown powder obtained from rhubarb.

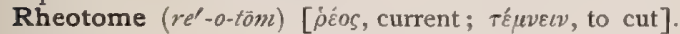
An instrument for breaking and making the Faradic current.

Rheotrope ( $\left.r e^{\prime}-o-t r o ̄ p\right)$ [ $\rho \varepsilon \bar{\imath} \nu$, to flow: $\tau \rho \varepsilon \dot{\pi} \pi \varepsilon(\nu$, to turn]. A device for periodically reversing the direction of an electric current.

Rheotropism (re-ot'-ro-pizm) [ $\rho \varepsilon \imath \nu$, to flow ; $\tau \rho \varepsilon ́ \pi \varepsilon \iota \nu$, to turn]. In biology, Jönsson's term applied to the effect produced by a current of water upon the direction of plant-growth. The phenomenon is called positive rheotropism when the plant grows with the current; negative rheotropism when the plant grows against it.

Rhestocythemia, or Rhæstocythrmia (res-to-si-thc'-

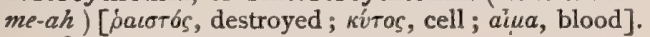

A condition related to the presence of the products of degeneration of red blood-corpuscles contained in cells within the liver and spleen and perhaps other organs,

Rhetoranche $\left(r e t-o r^{\prime}-a n g^{-k e}\right)$ [ $\rho \dot{n} T \omega \rho a$, a public speaker; áүкєı, to press tight]. Synonym of Pharyngitis, Follicular.

Rheum ( $\left.\mathrm{re}^{\prime}-u m\right)$ [ $\dot{\rho} \tilde{o} \mathrm{v}$, rhubarb]. Rhubarb. The root of $R$. officinale, the Chinese variety being commonly used. It contains several active extractives, and is a popular tonic astringent, and in large doses purgative. R., Ext. Dose gr. x-xv. R., Ext., Fld. Dose

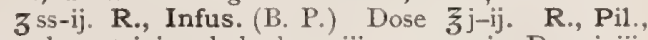
each containing rhubarb gr. iij, soap gr. j. Dose j-iij. R., Pil., Comp., each contains rhubarb gr. ij, aloes gr. jss, myrrh gr. j, oil of peppermint gr. $\frac{x}{10}$. Dose ij-iv. R., Pulv., Comp., rhubarb 25, magnesia 65, ginger IO. Dose $7 \mathrm{j}$. R. et sodæ., Mist., sod. bicarb. 3.5, fld. ext. rhubarb I.5, fld. ext. ipecac. 3, glycerin 35 , spt. peppermint 3-5, water q.5. ad. 1000 parts. Dose

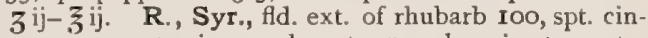
namon 4 , potassium carbonate 10 , glycerin 50 , water

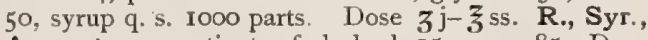
Aromat., arom. tinct. of rhubarb 15, syrup 85. Dose 3 j- z ss. R., Tinct., rhubarb I 2, cardamom 2, dil. alcohol ad roo parts. Dose $3 \mathrm{j}-\xi_{\text {ss. }}$ R., Tinct., Aromat., rhubarb 20 , cinnamon 4 , cloves 4 , nutmeg 2 , dil. alcohol ad 100 parts. Dose 3 j-iij. R., Tinct., Dulcis, rhubarb 8, licorice 4, anise 4, cardamom I, dil. alcohol ad Ioo parts. Dosé 3 ss-ij. R., Vinum, rhubarb Io, calamus I stronger white wine ad roo parts. Dose $3 j-\xi$ ss.

Rheum $(r \bar{u} m)[\dot{j} \varepsilon \tilde{v} \mu a$, flow $]$. Any catarrhal discharge, or watery flux; the fluid of such a discharge. [Old.] R.-salt, a vulgar term for chronic eczema.

Rheuma ( $\left.r u^{\prime}-m a h\right)$. Same as Rheum. R. epidemicum. Synonym of Infucenza. R, ventris. Synonym of Dysentery.

Rheumarthritis (rum-arth-ri'-tis) [ $\rho \varepsilon \tilde{v} \mu a$, a flowing; à $\rho$ tpov, a joint; $\iota \tau \iota$, inflammation]. A synonym of Acute Articular Rheumatism.

Rheumarthrosis (ru-mar-thro'-sis) [ $\rho \varepsilon \tilde{v} \mu a$, flow; ă $\rho$ t)$\rho o v$, a joint]. Rheumatism of the joints.

Rheumatalgia (ne-mat-al"-je-ah) [ $[\tilde{\rho} \varepsilon \bar{v} \mu a$, flux; $\ddot{a} \lambda \gamma o s$, pain]. Rheumatic pain.

Rheumatic (ru-mat'-ik) [ $\dot{\rho} \varepsilon v \mu \alpha \tau \iota \kappa \delta s]$. Relating to, of the nature of, or affected with, rheumatism. R. Anesthesia, anesthesia associated with rheumatism. $\mathbf{R}$. Apoplexy, the stupor or coma sometimes present in the course of acute rheumatism. R. Diathesis, the condition of body tending to the development of rheumatism. R. Fever. Synonym of Rheumatism. R. Gout. Synonym of Rheumatoid Arthritis.

Rheumatism (rüm'-at-izm) [ $\rho \varepsilon v \mu a \tau \ell \sigma \mu o ́ s]$. Rheumatic Fever; a disease characterized by severe, fitful, and shifting lancinating pains in the joints, and in the muscles, with fever, and inflammatory swelling of the affected parts. It may be acute or chronic. Acute rheumatism is a self-limited affection lasting, untreated, for about six weeks. It is characterized by elevation of temperature, acid perspiration, and pain, redness and swelling of various large joints, often with effusion. Inflammation of the serous membranes, particularly of the endocardium, is a common association. There is a great tendency to relapses. The blood contains an excess of fibrin, and is said to contain an excess of lactic acid. To this latter cause, also to cold and to microörganisms, has been ascribed the origin of the affection. Subcutaneous nodules form frequently in connection with the fibrous structures, such as tendons, fasciæ, etc. The disease is most frequent in young persons under twenty-five years of age and in those who show a strong hereditary 
tendency. Chronic rheumatism appears rather in mid dle and late life than in the young: Stiffness, pain and deformity are the most prominent symptoms. R., Apoplectic, rheumatism complicated with apoplexy due to cerebral congestion. R., Articular. See Rheumatism. R., Blennorrhagic. Sec R., Gonorrheal. R., Cerebral, rheumatism associated with well-marked cerebral symptoms. R., Diaphragmatic, rheumatism of the diaphragm. R., Encephalic. Synonym of $R$., Cerebral. R., Epidemic Muscular, muscular rheumatism occurring in an epidemic form. R., Gonorrheal, Gonorrheal Synovitis; Urethral Rheumatism: arthritis associated with urethritis. It is probably a metastatic infection and attacks the wrist, ankle, or knee by preference. It is most common in men, and is sometimes attended with endocardial involvement. R., Gouty. Synonym of Rhenmatoid Arthritis. R. of the Gullet, a functional condition of the esophagus causing painful deglutition. $\mathbf{R}$. of the Heart, an affection of the heart occurring in the course of rheumatism. Also a synonym of Angina pectoris. R., Heberden's, rheumatism of small joints, with the formation of nodosities. R., Hemorrhagic, rheumatism with a tendency to hemorrhage. R., Infectious, articular manifestations of a general infection. $\mathbf{R}$., Muscular, that form affecting single muscles or groups of muscles. R., Neuralgic, muscular rheumatism which is truly a neuralyia of the sensory nerves of a muscle. R., Nodular. See Arthritis deformans. $\mathbf{R}$., Periosteal, a variety of periostitis common in syphilitics. R., Puerperal, a variety of rheumatism supposed to originate from some disorder of the urogenital tract in pregnant, lying-in or menstruating women, as does gonorrheal rheumatism. R.-root. See Jeffersonia diphylla. R., Scarlatinal, a rheumatoid affection occurring occasionally in the course of scarlet fever and which may lead to suppurative arthritis. R., Scorbutic, an enlargement of the joints in a person suffering from scurvy. R., Spinal, a mild form of spinal meningitis: $\mathbf{R}$. of the Spine. A synonym of Spondylitis deformans. R. of the Superior Portion of the Spinal Cord. Synonym of Tetany. R., Synovial, a rheumatic affection of the synovial membranes usually leading to large serous effusions. R., Syphilitic. Synonym of R., Periosteal. R., Urethral. Synonym of $R$., Gonorrheal. R. of the Uterus, a true rheumatism of the uterine muscle, but, according to some authorities, a neuralgia of the uterus. R., Venereal. Synonym of $R$., Gonorrheal. $R .$, Vertebro-meningeal. Synonym of $R$., Spinal. R., Visceral, rheumatism affecting the viscera.

Rheumatismal (ru-mat-iz'-mal). Same as Rheumatic. Rheumatismus (ru-mat-iz'-mus) [L.]. See Rheumatism. R. calidus. Synonym of Acute Articular Rhenmatism. R. cervicis. Synonym of Torticollis. $\mathbf{R}$. colli. Synonym of Torticollis, R. cordis, rheumatism of the heart. R. coxæ. Synonym of Coxalgia. R. dorsi, rheumatism of the spinal muscles and ligaments. R. febricosus. Synonym of Rheumatic Fever. R. febrilis exanthematicus. Synonym of Dengue. R. flatuosus. Synonym of $E m$ physema. R. lumborum muscularis. Synonym of Lumbago. R. muscularis. Synonym of Muscular Rheumatism. R. nodosus. Synonym of Rheumatoid Arthritis. R. odontalgicus. Synonym of Odontalgia. R. pectoris. Synonym of Pleurodynia.

Rheumatocolica (rüm' $\left.{ }^{\prime}-a t-o-k o l^{\prime}-i k-a h\right)$ [ $\rho \varepsilon \bar{v} \mu \alpha, a$ flux; $\kappa \omega \lambda \kappa_{0} \delta$, pertaining to the colon]. Rheumatic colic.

Rheumatodynia (rūm-at-o-din'- $\rho-\alpha h)$ [ $[\dot{\varepsilon} \bar{v} \mu \alpha$, a flux ; ódivn, pain ]. A dull rheumatic pain.

Rheumatoid (rüm'-at-oid) [ $\delta \varepsilon v \tilde{v} u \alpha$, a flux; cìos, resemblance]. Resembling rheumatism. R. Arthritis, a disease of the joints characterized by chronic inflammatory and degenerative changes involving the structure of the various articulations and resulting in rigidity and deformity.

Rheumatoidal (ru-mat-oi'-dal). Same as Rheumaloid.

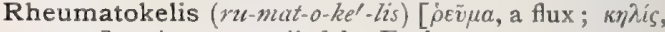
a spot]. A term applied by Fuchs to purpura occurring in conjunction with rheumatism.

Rheumatophthisis (ru-nuat-off'-this-is) [ $\rho \varepsilon \bar{v} \mu a$, a flux; ofioss, wasting]. Atrophy the result of rheuma. tism.

Rheumato-pneumonia ( $u$ - mat-o-nu-mol-ne-ah)

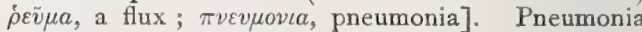
dependent upon rheumatism.

Rheumatopyra (ru-mat-o-pi'-rah) [ $\dot{\rho} \varepsilon \tilde{v} \mu a$, flux; $\pi \bar{v} \rho$, fire]. Rheumatic fever.

Rheumic $\left(r u^{\prime}-m i k\right)[\dot{\rho} \varepsilon \tilde{v} \mu \alpha$, flux $]$. Allied to rheumatism. A term applied to a diathesis which gives rise to cutaneous eruptions. R. Acid, $\mathrm{C}_{20} \mathrm{H}_{16} \mathrm{O}_{9}$, an acid formed by treating rheotannic acid with diulte acids.

Rheumin $\left(r e-u m^{\prime}-i n\right)$. Synonym of Acid, Chrysophanic.

Rheumoparotiditis (ru-mo-par-o-tid-i'-tis) [ $\dot{\rho} \varepsilon \tilde{y} \mu \alpha$, a

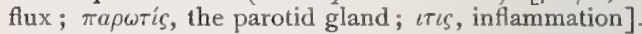
Rheumatic parotiditis.

Rheumophthalmia (ru-moff-thal'-me-ah) [ $\rho \in \bar{v} \mu a$, flux; ó $\phi a \lambda \mu i \alpha$, ophthalmia]. Rheumatic ophthalmia.

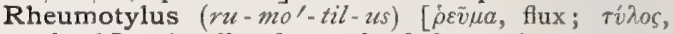
a knob]. A callus the result of rheumatism.

Rheumy (ru'-me) [óṽua, flux]. Affected by or causing rheum.

Rheusis $\left(r \iota^{\prime}-s i s\right)[\dot{\rho} \varepsilon \tilde{v} \sigma \iota \mathrm{s}]$. A flow. Especially applied to a discharge from the gevitals of the female.

Rhexis $\left(r e k s^{\prime}-i s\right)$ [ $\dot{\eta} \bar{\xi} \xi \varsigma$, rupture]. Rupture of any organ.

Rhicnosis (rik-no'-sis) [ $\rho \iota k v o ́ s$, shriveled]. A wrinkling of the skin, the result of muscular atrophy.

Rhigolene (rig'-o-lèn) [jīyos, cold]. A product of petroleum obtained by repeated distillation. It is used as a spray to produce local anesthesia in minor surgical operations, as in the use of the actual cautery. It acts by chilling the part to which it is applied. Unof.

Rhigos ( $r i^{\prime}$-gos) [ $\rho\llcorner\chi \varepsilon i v$, to shiver]. Synonym of Rigor.

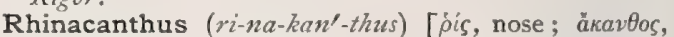
a canthus]. The leaves and root of the Asiatic plant, $R$. communis, with properties due to rhinocanthin, a substance resembling hydroquinone. It is a local remedy for parasitic skin-diseases. Unof.

Rhinæsthesia (ri-nes-the'-ze-ah). See Rlinesthesia.

Rhinæus (ri-ne'-us) ['is, the nose]. Synonym of Compressor naris. See Muscles, Table of.

Rhinal (ri'-nal) [ócs, nose]. Pertaining to the nose.

Rhinalgia (ri-nal'-je-ah) [ ${ }^{\prime} i s$ (gen, jovós), nose; $\dot{a} \lambda$ yos, pain]. Pain in the nose.

Rhinanchone (ri-nan'-ko-ne) [ $\rho i c$, the nose; $a y^{\prime} \chi 6 v \eta$, strangulation]. Painful constriction of the nasal passages.

Rhinantralgia (ri-nan-tral'-je-ah) [ $[\dot{i} s$, the nose;

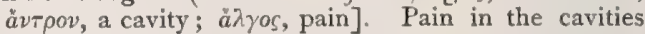
of the nose.

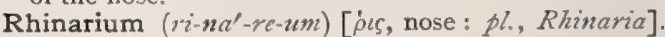
I. A small nose. 2. In biology, a portion of the front part of the cephalic exoskeleton of certain insects (Neuroptera, Coleoptera).

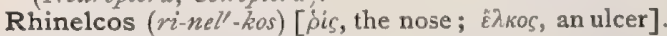
A nasal ulcer.

Rhinencephal ( $r i$-nen'-sef-al). Same as Rhinercephalon. 
Rhinencephalia (ri-nen-sef-a'-le-ah) [pis, the nose;

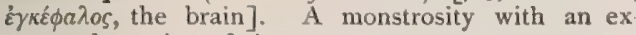
treme elongation of the nose.

Rhinencephalic (ri-nen-sef-al'-ik) [óı, nose; $\dot{\varepsilon} \gamma \kappa \varepsilon \dot{\phi} \phi a-$ nos, brain]. I. Pertaining to or of the nature of a rhinencephalus. 2. Pertaining to the rhinencephalon.

Rhinencephalon (ri-nen-sef'-al-on) [ós, nose ; $\dot{\varepsilon} \gamma \kappa \hat{\varepsilon} \phi \alpha$ $\lambda o s$, brain]. The olfactory lobe or segment of the brain.

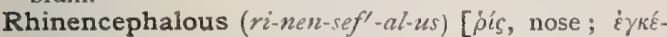
$\phi a \lambda o s$, brain]. Same as Rhinencephalic.

Rhinencephalus (ri-nen-sef'-al-us). See Rhinocephalus.

Rhinenchysia ( $\left.r i-n e n-k i^{\prime}-z e-a h\right)$ [ $\rho$ 's, the nose ; $\varepsilon^{\prime} \gamma \chi v \sigma \iota \zeta$, a pouring in]. Douching of the nasal passages.

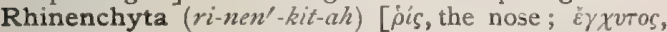
poured in]. A nasal syringe.

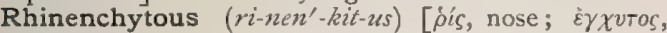
poured in]. Pertaining to nasal injections.

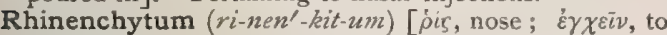
pour in]. A liquid used in nasal douching.

Rhinesthesia, Rhinesthesis (ri-nes-the'-ze-ah, ri-nes' the-sis) [öis, nose; aiotrols, sensation]. The sense of smell.

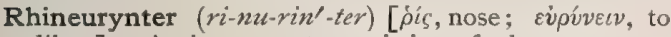
dilate]. An instrument consisting of a bag or sac, to be intlated after insertion into the nostril.

Rhiniatry ( $\left.r i-n i^{\prime}-a t-r e\right)$ [ $\rho \iota s$, the nose; 'ar $\rho \varepsilon$, a medical treatment]. Synonym of Rlinology.

Rhinic $\left(r^{\prime}{ }^{\prime}-i k\right)$ [ $\rho i s$, nose $]$. Pertaining to the nose

Rhinion (rin'-e-on) [ $\rho \iota v i o v$, a small nose]. In craniometry, the lower point of the suture between the nasal bones. See Craniometric Points.

Rhinismus (ri-niz'-mus) [óis, nose]. A nasal quality of voice.

Rhinitis (ri-ni'-tis) [p's, the nose; $\iota \tau \iota s$, inflammation]. Inflammation of the nasal mucous membrane, R., Acute, acute nasal catarrh; coryza; the so-called " cold in the head." It is marked by chilliness, sneezing, profuse mucous discharge, and a feeling of stuffiness in the nose. $\mathbf{R}$. caseosa, a rare affection of the nose characterized by occlusion of the nasal fossæ, extreme fetor, and the discharge of a gelatinous mass from time to time from the nares and choanæ. This mass is composed of an amorphous substance containing a great number of white corpuscles and fatty cells and crystals of stearin. R. catarrhalis. See Coryza. R., Chronic Atrophic, ozena; a chronic inflammation, with subsequent atrophy of the mucous membrane of the nose, accompanied by the formation of dry crusts and by a very offensive odor. This disease is most frequently seen in anemic young women. R., Chronic Catarrhal. Synonym of $R$., Chronic Hypertrophic。 R., Chronic Hypertrophic, chronic nasal catarrh, a chronic inflammatory condition of the mucous membrane of the nose, with profuse watery or muco-purulent discharge and an hypertrophied condition of the nasal mucous membrane. It follows repeated acute coryzas. R., Cirrhotic. Synonym of R., Atrophic. R., Fetid Atrophic. See R., Chronic Atrophic. R. Fibrinous, a rare form of rhinitis, with development of false membrane in the nose. R., Pruriginous. Synonym of Hay-fever. $\mathbf{R}$, Pseudo-membranous, a rhinitis in which an opaque exudate covers the inflamed area. R., Sclerotic. See Orena. R. sicca. See Atrophic Catarrh. R., Simple, the stage of rhinitis preceding hypertrophic or atrophic changes. R. sympathetica, a term descriptive of reflex neuroses of the nasal passages. R. ulcerosa. Synonym of Ozena. R., Vasomotor. Synonym of Hay-fever.
Rhino- $\left(r i^{\prime}-n o^{-}\right)[\dot{\rho} \iota s, \dot{\rho} \iota v o ́ s$, nose]. A prefix denoting relation to or connection with the nose.

Rhinoblennorrhea (ri-no-blen-or-e'-ah) [jis, the nose ; $\beta \lambda \varepsilon ́ v \nu \alpha$, mucus; poia, a flowing]. Synonym of $R h i$. norrhea.

Rhinobyon ( $\left.r i-n o^{\prime}-b e-o n\right)$ [ $\rho i s$, nose ; $\beta \dot{v} \varepsilon \iota \nu$, to stop] A nasal plug or tampon.

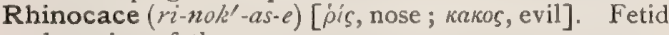
ulceration of the nose.

Rhinocarcinoma ( $\left.r i-n o-k a r-\sin -o^{\prime}-m a h\right)$ [ $\rho i s$, the nose;

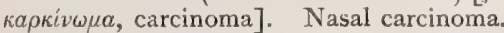

Rhino-catarrhus (ri-no-kat-ar'-rus) [ois, the nose; kaтáṕos, catarrh]. Synonym of Coryza.

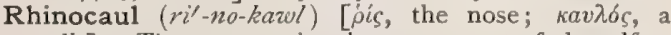
stalk]. The crus, peduncle, or support of the olfac tory bulb.

Rhinocele, Rhinocœle $\left(r i^{\prime}-n o-s \bar{e} l\right)$, or Rhinocœlia $\left(r i-n o-s \bar{e}^{\prime}-l e-a\right)$ [óis, nose ; koinia, hollow]. The hollow, or ventricle, of the rhinencephalon; in man it is very small, or quite obliterated.

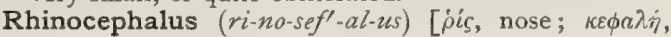
head]. A cyclocephalic monster, the nose resembling a tube or trunk, the eyes fused in the median line and below the nose.

Rhinocereal (ri-no-se'-re-al). Synonym of Puo-nose.

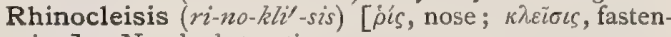
ing]. Nasal obstruction.

Rhinocnesmus (ri-nok-nez'-mus) [ $\rho$ is, the nose; $\kappa \nu \eta \sigma$ uós, an itching]. Itching of the nose.

Rhinodacryolithus (ri-no-dak-re-o-lith'-us) [ois, the nose; dákpvov, a tear; $\lambda i \theta o s$, a stone]. A lacrymal stone in the nasal duct.

Rhinoderma ( $r i$-no-der'-mah). Synonym of 'Keratosis pilaris.

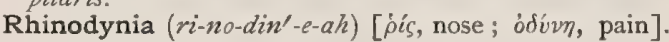
Any pain in the nose.

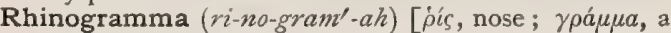
line]. The nasal line.

Rhinolalia $\left(r i-n o-l a^{\prime}-l e-a h\right)[\rho i ́ s$, the nose; $\lambda a \lambda i \dot{a}$, speech]. Synonym of Dyslatia nasalis. R. aperta, naso-palatine dyslalia, the nasal fossa and naso-pharyngeal cavity communicating with the pharynx. $\mathbf{R}$. clausa, naso-palatine dyslalia caused by a separation of the nasal fossa or naso-pharyngeal cavity from the pharynx.

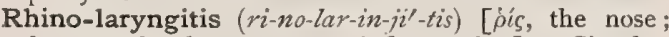
$\lambda a \rho v \gamma \xi$, the larynx; $\iota \tau \iota \zeta$, inflammation]. Simultaneous inflammation of the mucosa of the nose and the larynx.

Rhinolaryngology (ri-no-lar-in-gol'-o-je) [ $\dot{\rho}^{\prime} s$, nose ; $\lambda a ́ \rho v \gamma \xi$, larynx ; $\lambda 6 \gamma o s$, science $]$. The science of the anatomy, physiology and pathology of the nose and the larynx.

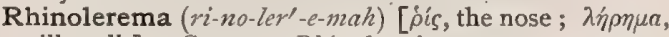
silly talk]. Same as Rhinoleresis.

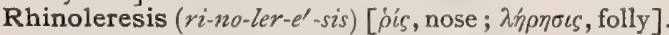
Perverted olfactory sense.

Rhinolethrum (ri-no-leth'-rum) [ $\rho$ is, the nose ; $\partial \lambda \varepsilon \theta \rho o \varsigma$, destruction]. Destruction of the nose.

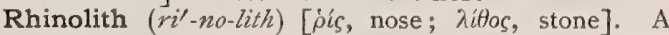
nasal calculus. Cozzolini makes a distinction between true rhinoliths, in which the calcareous deposit becomes formed around a nucleus of mucus or of blood, and folse rhinoliths, the more common, in which a foreign body, such as a cherry-stone, a bead, or the like, has formed the nucleus. The former are rarely found before the fortieth year of age; the latter may be found at any age, the foreign body often having been inserted in play during childhood.

Rhinolithiasis (ri-no-lith-i'-as-is) [óc, nose; $\lambda i \theta 0 \varsigma$, stone]. The condition and progress of calculus of the nasal fossa. 


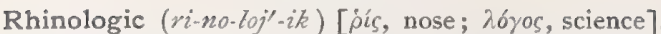
Pertaining to rhinology.

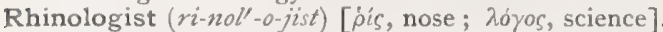
A specialist in the treatment of nasal diseases.

Rhinology (ri-nol'-o-je) [ós, nose; hóyos, science]. The science of the anatomy, functions, and diseases of the nose.

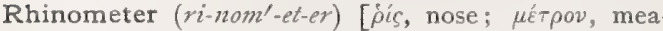
sure]. An instrument for aiding in the diagnosis of obstructive diseases of the naso-pharynx.

Rhinommectome (ri-nom-mek'-tome) [ $\rho$ is, the nose;

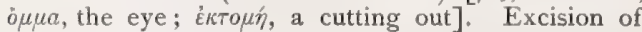
the inner canthus of the eye.

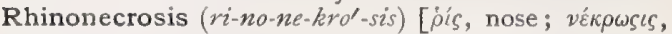
death]. Necrotic disease of the nasal bones.

Rhinopharyngitis ( $\left.i \hat{-}-n o-f a r-i n-j i^{\prime}-t i s\right)$ [ $\rho i s$, nose ; $\phi a \rho v \xi \xi$, pharynx ; $\iota \tau \iota s$, inflammation]. Inflammation of the nose and pharynx, or of the naso-pharynx.

Rhino-pharynx (ri-no-far'-ingks). See Naso-pharynx.

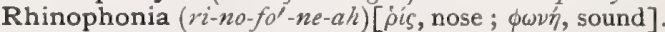
A nasal tone in speaking.

Rhinophore (ri'-no-for) [ $\dot{\rho} i s, \dot{\rho} \iota v$, nose; $\phi \varepsilon \rho \varepsilon \iota v$, to bear]. In biology, one of the posterior pair of tentacles of certain molluses, possibly olfactory in function. Any external olfactory organ

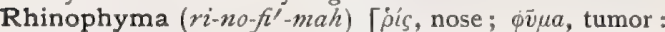
pl., Rhinophymata]. A hypertrophic form of rosacea confined to the nose, perinasal portions of the cheeks and forehead, and the lobes of the ears, and marked by a new growth of vessels and connective tissue and chronically enlarged glands, producing a bulbous and knotted organ. It is usually seen in advanced alcoholism.

Rhinoplastic (ri-no-plas'-tik) [ $\rho$ ís, nose ; $\pi \lambda a ́ \sigma \sigma \varepsilon \imath \nu$, to mold]. Pertaining to or having the character of rhinoplasty. R. Operation, a surgical operation for creating an artificial nose or reconstructing a nose partially destroyed.

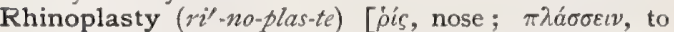
mold]. A plastic operation upon the nose, to replace lost tissue. R., English, Syme's operation, in which flaps are taken from the cheek. R., German, v. Graefe's modification of the Tagliacotian rhinoplasty. The entire operation is done at a single sitting. R. of v. Graefe, R., German, q. $v$. R., Heteroplastic, rhinoplasty in which the tissues are removed from some person other than the one operated upon. R., Indian, an operation originating in India, in which the flap is taken from the forehead. $\mathbf{R}$, Italian. Synonym of R., Tastiacotian. R., Langenbeck's, a modification of the Indian method, in which the periosteum is included in the frontal flap. See Operations, Trble of. R., Osteoplastic, rhinoplasty with transplantation of a cartilaginous flap to replace the septum nasi. R., Periosteal. See $R$., Lansenheck's. R. of Post, a modified Tagliacotian rhinoplasty, in which the flap is taken from the finger of the patient. R. of Syme, English rhinoplasty, q.v. R., Tagliacotian, rhinoplasty as performed by Tagliacozzi. The flap is taken from the skin of the arm. $\mathbf{R}$. of Wood, rhinoplasty in which an inverted flap from the upper lip is elongated by detaching the mucous from the cutaneous surface from the root of the flap to its free border. This defect is covered with lateral flaps from the cheeks.

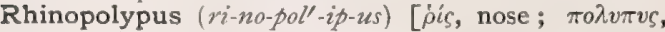
polypus]. Polypus of the nose.

Rhinoptia (ri-nop'-she-ah) [ós, the nose ; $\delta \pi \tau b \zeta$, seen]. Internal strabismus.

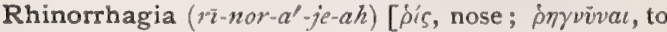
burst forth]. Copious hemorrhage from the nose.

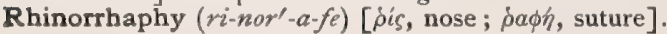

Reduction of the tissue of the nose by section, and by suturing the edges of the wound.

Rhinorrhea (ri-nor-e'-ah) [ $e^{\prime} \zeta$, nose; poia, a flow ]. A mucous discharge from the nostrils.

Rhinorrheal (ri-nor-é-al) [óis, nose; poía, a flow]. Relating to or of the nature of rhinorrhea.

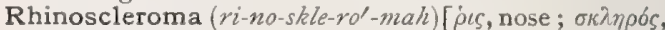
hard; ó $\mu a$, tumor]. A granulation new-growth of almost stony hardness, affecting the anterior nares and adjacent parts. The disease commences in the mucous membrane of the anterior nares and adjoining skin. The lesions consist of flattish, isolated, or coalescent nodules or raised plaques, imbedded in the cutis vera. Their growth is slow, and recurrence takes place if removal is attempted. The cause of the affection is not certainly known, but it is thought by some to be due to a bacillus which is nearly always present.

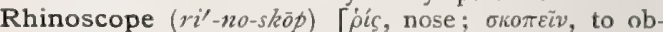
serve]. An instrument for examination of the cavities of the nose.

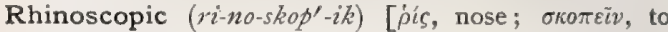
view ]. Pertaining to the rhinoscope, or to rhinoscopy.

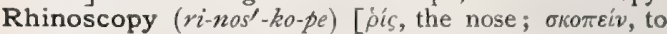
observe]. Examination of the nasal fossæ by means of the rhinoscope; that of the anterior nares is termed anterior rhinoscopy; that of the posterior nares, posterior rhinoscopy.

Rhinosis ( $\left.r i-n 0^{\prime}-s i s\right)$. Synonym of Rhicnosis.

Rhinostegnosis (ri-no-steg-no'-sis) [ $\rho i s$, nose; orḱ . $v \omega \sigma \iota s$, obstruction]. Nasal obstruction.

Rhinostenose (ri-nos-te'-nozz). A synonym of Rhinitis atrophica.

Rhinotheca (ri-no-the'-kah) [ó $\iota s$, nose ; $\theta \dot{n} k \eta$, a sheath : pl., Rhinotheca]. In biology, a portion of the integument of the upper mandible of a bird.

Rhinothecal ( $\left.r i-n o-t h e^{\prime}-k a l\right)$ [ $\dot{\rho} \iota \zeta$, nose; $\theta \dot{y} \kappa \eta$, a sheath]. Pertaining to the rhinotheca.

Rhinothrix (ri'-no-thriks) [ $\dot{\rho} i s$, nose; $\theta \rho i \xi$, hair; $p l$, Rhinotriches]. A hair growing in the nostril.

Rhipidium (ri-pid'-e-umi) [ $\dot{\rho} \iota \pi \imath \delta \iota \mathrm{v}$, dim. of $\dot{\rho} \iota \pi i s$, a fan : pl., Rhipidio]. In tiology, Eichler's term for a fan-shaped cymose inflorescence, occurring in monocotyledons, in which the successive branches are in the same plane, each from the back of the preceding. The Fächel of Buchenau.

Rhipidura (rip-i $\left.d^{\prime \prime}-\imath-r a h\right)$ [ $\rho \iota \pi i s$, a fan; ovpa, tail]. The posterior pair of pleopoda and the telson, when these parts are developed as in the Macmura.

Rhiptasmus (rip-taz'-mus) [ Ballismus.

Rhis (ris) [pis]. Synonym of Nose.

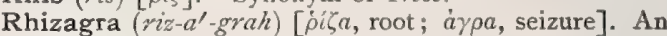
instrument for extracting the roots of teeth.

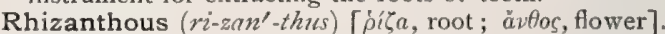
In biology, flowering from the root.

Rhizantoicous (ri-zan-toi'-kus) [ $\rho i \zeta a$, root; $\dot{a} v \tau \iota$, opposite; oikos, dwelling]. In biology, applied to mosses that bear both organs of reproduction on the same plant, the antheridium on a short branch connected with the archegonium by the rhizome.

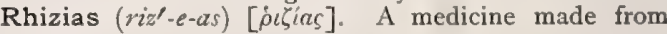
roots.

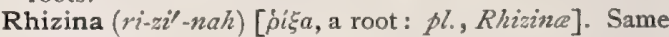
as Rhizoid.

Rhizine $\left(r i^{\prime}-z i n\right)[\dot{\rho} i \zeta a$, root]. Same as Rhizoid.

Rhizinous ( $\left.r i-z i^{\prime}-n u s\right)$ [ $\dot{\rho} i \zeta \alpha$, root]. In biology, having rhizoids.

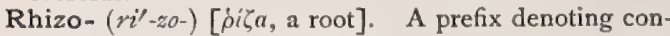
nection with or relation to a root.

Rhizocarpic ( $\left.r i-z o-k a r^{\prime}-p i k\right)$ [ $\rho \prime \xi a$, root ; $\kappa a \rho \pi \delta \zeta$, fruit]. In biology, having the stem annual, but the root perennial. 
Rhizocarpous $\left(r i-z o-k a r^{\prime}-p u s\right)[\rho i \zeta \alpha$, root; $\kappa a \rho \pi o ́ s$, fruit]. In biology, a term sometimes applied to herbaceous plants whose roots live on from year to year.

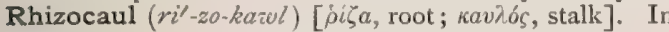
biology, the portion of a polyp by which it is fastened to its support.

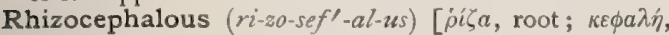
head]. In biology, rooted by the head.

Rhizodontropy (ri-zo-don'-tro-pe) [ $\dot{i} i \zeta \alpha$, root; odov́s, tooth; $\tau \rho o \pi \eta$, turn, pivot]. The pivoting of an artificial crown upon the root of a tooth.

Rhizodontrypy (ri-zo-don'-trip-e) [ $[\dot{\rho} \zeta \zeta a$, root; ódoús, tooth; $\tau \rho v i \pi \eta$, hole]. The surgical puncture of the root of a tooth.

Rhizogen $\left(r i^{\prime}-z o-j e n\right)$ [ $\dot{i} \zeta \alpha, \operatorname{root} ; \gamma \varepsilon v \eta \dot{s}$, producing] A plant parasitic upon the roots of another plant. A part or organ from which roots or root-hairs grow.

Rhizogenic $\left(r i-z o-j e n z^{\prime}-i k\right)[\rho i \zeta \alpha$, a root ; $\gamma \varepsilon v \eta \dot{s}$, produc ing]. In biology, root-producing. A term applied to the cells in the pericambium, just in front of a xylem ray of a fibro-vascular bundle, and which give origin to root-branches.

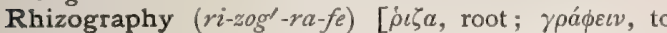
write]. A descriptive treatise on the roots of plants.

Rhizoid ( $i^{\prime}$-zoid) [ $\rho \iota \zeta \alpha$, root; $\varepsilon i \delta o \varsigma$, form]. In biol ogy, slender, root-like filaments, the organs of attachment in many cryptogams; like a root.

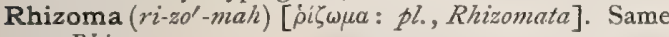
as Rhizone.

Rhizomania (ri-zo-ma'-ne-ah) [ $\rho \hat{i} \zeta a$, a root; $\mu a v i \alpha$, madness]. In biology, an unusual or abnormal development of adventitious roots.

Rhizomatoid (ri-zo'-mat-oid) [ $\rho \dot{i} \zeta \omega \mu a$, a mass of roots; cidos, resemblance]. Resembling a rhizome.

Rhizome $\left(r i^{\prime}-z o m\right)[\rho i \zeta a$, root $]$. In biology, a prostrate or subterranean stem, having roots at its nodes and a bud or shoot at its apex.

Rhizomorph (ri'-zo-morf) [ $\rho i \zeta \alpha$, root ; $\mu \alpha \rho \phi \dot{\eta}$, form]. In biology, the long, flocculent mycelium of several species of Agaricus.

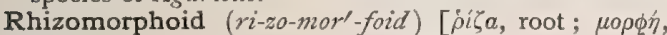
form ; $\varepsilon i \delta o \zeta$, form $]$. Having the form of a root.

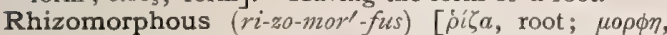
form]. In biology, in shape and appearance like a root.

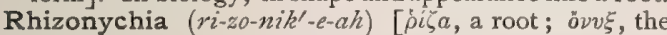
nail]. The root of the nail.

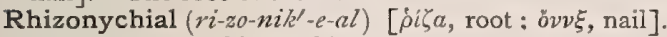
Pertaining to a rhizonychium.

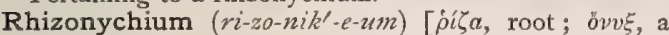
claw : pl., Rhizonichia ]. In biology, the claw-bearing phalanx of a digit.

Rhizophagous ( $\left.r i-z \circ f^{\prime}-a g r-u s\right)$ [ Root-eating.

Rhizophora (ri-zoff'-or-ah) [ $\rho i \zeta a$, a root; фopós, a bearing]. Mangrove. In its several varieties it is used medicinally.

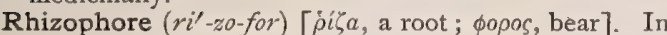
Selaginella a leafless shoot, which grows downward and from the end of which the true roots originate as soon as it penetrates the ground.

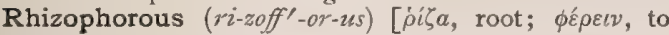
bear]. In biology, root-bearing.

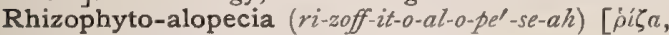
a root; $\phi v \tau o ́ v$, a plant; $a \lambda \omega \pi \varepsilon \kappa i a$, alopecia]. Synonym of Trichomycosis circinata.

Rhizopod (ri'-zo-pod) [ $\dot{\rho} i \zeta a$, root; $\pi$ oús, foot]. A member of the Rhizopoda, a sub-class of Protozoa or animalcules. Locomotion and ingestion of food take place by means of pseudopodia, which at times fuse and form a reticulum.

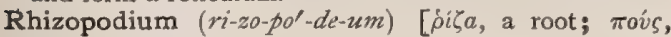
foot]. In biology, the mycelium of fungi.

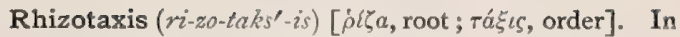
biology, the arrangement of roots. Cf. also Phyllotaxis.

Rhizotaxy (ri'-zo-taks-e). Same as Rhizotaxis.

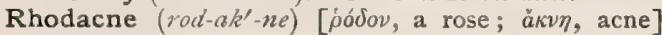
Synonym of Acne rosacea.

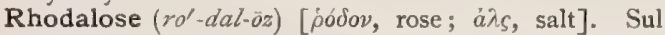
phate of cobalt.

Rhodamin $\left(r o^{\prime}-d a m-i n\right)[\hat{\rho} b \delta o v$, rose; amin $]$. A violet. red, magnificently fluorescent dyestuff, analogous in constitution to the fluoresceins.

Rhodanic $\left(r o-d a n^{\prime}-i k\right)$ [ $\rho o ́ \delta o v$, rose]. Denoting an acid which produces a red salt with persalts of iron. $\mathbf{R}$. Acid. See Acid.

Rhodelæon, Rhodelæum (ro-del-e'-on, ro-del-e'-um) [ $\dot{\phi} \sigma \delta o \nu$, a rose ; $\dot{\lambda} \lambda \alpha \omega \nu$, oil $]$. The oil of rose.

Rhodeorrhetin (ro-de-or-re'tin). Synonym of Convolvulin.

Rhodic Acid ( $r o^{\prime}$-dic) $[\dot{\rho} b \delta \iota \iota s, r o s y], \mathrm{RhO}_{2}$. A flaky powder; the precipitate of a solution of rhodium sesquioxid by nitric acid.

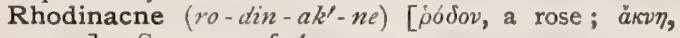
acne]. Synonym of Acne rosacea.

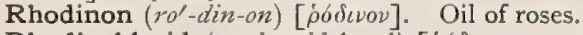

Rhodiochlorid (ro-de-o-klo'-rìd) [ $[\dot{\omega} \delta \iota s$, rosy ; $\chi \lambda \omega \rho o s$, green]. A double chlorid of rhodium and one of the alkali metals.

Rhodionitrite (ro-de-o-ni'-tritt) [ $\dot{\rho} \delta \delta$ cos, rosy; nitrum, niter]. A combination of rhodium nitrite with the nitrite of some other element or radicle

Rhodis $\left(r o^{\prime}-d i s\right)$ [jódios, rosy]. An ointment or powder made from roses.

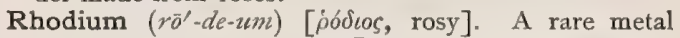
(symbol, Rh. ; at. wt., $\mathbf{I} \overline{3}$ ) of the platinum group. Its medicinal qualities are little known. See Elements, Table of. R., Oil of: (I) a fragrant oil derived from the root-wood of Convolvulus scoparius and C. floridus of the Canaries; (2) a factitious compound which commercially replaces the preceding for the most part; (3) an oil from Amyris balsamifera, a West Indian tree. The foregoing oils are mainly used by veterinarians.

Rhodizite $\left(r o^{\prime}-d i z-i t\right)[\rho o \delta i \zeta \varepsilon \iota \nu$, be like a rose]. A rare borate of aluminum and potassium; it occurs in minute isomeric crystals.

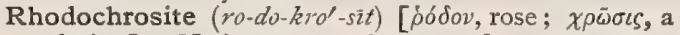
coloring]. Native protocarbonate of manganese, a delicate, rose-red color, occurring in rhombohedral crystals.

Rhododendron (ro-do-den'-dron) [ $\rho \circ \delta b \delta \varepsilon v \delta \rho o v$, the oleander]. A large genus of shrubs of the order ericaceæ and species rhodoreæ. R. campanulatum, the bell-flowered rhododendron. The leaves are used as an errhine. $\mathbf{R}$. chrysanthum, a variety of Eastern Siberia. The leaves and flowering branches are used in rheumatism and gout. They are stimulant, diaphoretic, and diuretic, and in large doses narcotic. R. cinnabarinum, an East Indian variety-poisonous. R. dahuricum, Dahurian rhododendron. The leaves are used in gout and rheumatism. R. maximum, American great laurel. The leaves are sometimes used in rheumatism and gout. $\mathbf{R}$. officinale. Synonym of $R$. chrysanthum. $\mathbf{R}$. ponticum, pontic rhododendron of Asia Minor, Armenia, and Spain. It is used in gout and rheumatism. R., Tinctura, made by treating I part of the leaves of $R$. chrysanthum with 3 parts each of brandy and white wine for two weeks, and filtering.

Rhodomel (ro'-do-mel) [ $\rho \dot{\delta} \delta o \nu$, rose; $\mu \varepsilon \hat{\imath} \iota$, honey]. Synonym of Mel rosa. R. cydoniatum, a mixture consisting of 7 parts of honey, 30 parts of honey of roses, and $\mathbf{I} 80$ parts of quince-seed mucilage. 


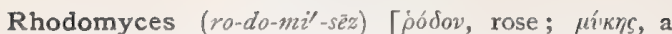
fungus]. A fungus resembling the Oidium albicans. R. kochii, a fungus appearing as a delicate pink mold and producing enormous numbers of conidia. It is sometimes found in the gastric juice in pyrosis.

Rhodon $\left(r o^{\prime}-d o n\right)[\rho o ́ \delta o v]$. I. The rose. 2. The vulva. Rhodonite $\left(r o^{\prime}-d o-n \bar{t} t\right)[\rho 6 \delta o v$, rose $]$. Native silicate of manganese. It occurs in masses, and is occasionally found in distinct crystals of a fine rose-red or pinkish hue

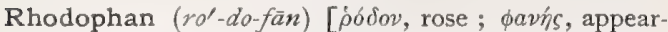
ing]. In biology, a red lipochrome pigment found by Kiubne and others in the retinal cones of fishes, reptiles, and birds. Cf. Pigments, Conspectus of.

Rhodophyl, Rhodophyll $\left(r o^{\prime}-d o-f l\right)$ [ $\rho o \delta \varepsilon \sigma \varsigma$, red; $\phi \hat{v} \lambda-$ $\lambda o v$, a leaf]. A name given by Schuitt to the compound pigment of the Red Alga. Cf. Pigments, Conspectus of.

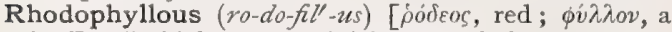
leaf]. In biology, containing rhodophyl.

Rhodopsin $\left(r o-d o p^{\prime}-\sin \right)$ [ $\hat{\rho}^{\prime} \delta o v$, rose ; $\omega \psi$, eye]. Visual purple, a retinal substance the color of which is preserved by darkness, but bleached by daylight; it is found in the outer segment of the rods.

Rhodorrhiza (ro-dor-i'-zah) [ $\dot{\rho} b \delta \delta o v$, a rose; $\dot{\rho} \iota \zeta a$, a root]. Synonym of Convolvulus.

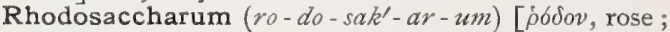

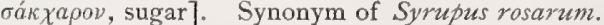

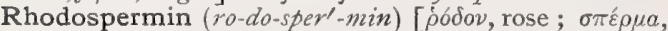
seed]. Crystalloids of an albuminous substance found in the Floridea, forming the rhodophyl, or red coloringmatter. Cf. Pigments, Conspectus of.

Rhodotannic Acid (ro-do-tan'-ik) [ $\rho 6$ bov, rose; tannin, tannin], $\mathrm{C}_{14} \mathrm{H}_{6} \mathrm{O}_{7}$. A tannin derived from the leaves of Rhododendron fumigineum.

Rhodymenia palmata (ro-di-me'-ne-ah) [ $\rho \dot{\delta} \delta o \nu$, rose ; vuñv, a membrane]. A marine Alga (Scotch, Dulse; Irish, Dillesk), parasitic on littoral Fuci, Laminarice, etc. It contains a mucilage which is used in scrofula. Its value is probably dependent upon contained iodin. It is largely used as food in the west of Ireland, also in the Mediterranean regions, where it forms a common ingredient of soups.

Rhcea $\left(r e^{\prime}-a / h\right)[\rho o l a ́]$. Synonym of Leukorrhea.

Rhœadic Acid (renad'-ik) [’́otás, a kind of poppy]. See Papaveric Acid.

Rhceadin $\left(r e^{\prime}-a d-i n\right)$ [ $\rho \circ c^{\prime} s$, a kind of poppy], $\mathrm{C}_{21} \mathrm{H}_{21} \mathrm{NO}_{6}$. A crystallizable alkaloid obtained from Papaver rhacas.

Rhceagenin (re-aj'-en-in) [ $\dot{\rho} o t a ́ s$, a kind of poppy], $\mathrm{C}_{21} \mathrm{H}_{21} \mathrm{NO}_{6}$. A base isomeric with rhœeadin found in acidified solutions of rhœadin

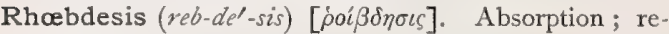
sorption.

Rhœzus (re'-zus) [ $\dot{\rho} b \tilde{\imath} \zeta o s]$. A purring auscultatory sound.

Rhogmos (rog'-nzos) [ $\dot{\rho} \omega x \mu \delta s]$. See Snoring.

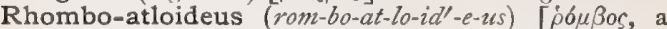
rhomb; ărhas, the atlas ]. An anomalous muscle arising from the spinal processes of the lower cervical and upper dorsal vertebræ and having its insertion in the transverse process of the atlas.

Rhombocele, Rhomboccle $\left(\mathrm{rom}^{\prime}-b o-s \bar{e} l\right)[\dot{\rho} b \mu \beta o s$, rhomb; koili $\eta$, cavity]. Same as Rhomboccetia.

Rhomboccelia (rom-bo-se'-le-ah) [j́bußos, rhomb; koi $\lambda i a$, hollow]. The simus rhomboidalis; a dilatation of the cavity of the spinal cord in the sacral region of birds.

Rhombogen (rom'-bo-jen) [ $\delta \delta \mu \beta o s$, rhomb; yevís, producing]. In biology, one of the early embryonic stages of a nematode worm; to be distinguished from the nematogen.
Rhombohedral (rom-bo-he'-dral) [ $[\dot{b} \mu \beta o s$, rhomb; $\varepsilon \delta \rho a$, base]. Of the shape of a rhombohedron. $\mathbf{R}$. Carbonates, the isomorphous group of the native carbonates of calcium, magnesium, iron, manganese, zinc, and the intermediate compounds, as the double carbonate of calcium and magnesium, etc.

Rhomboid, Rhomboidal (rom'-boid, rom-boi'-dal)

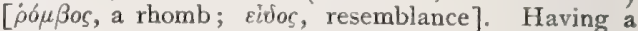
shape similar to that of a rhomb. A quadrilateral with opposite sides equal and parallel, and oblique angles. R. Fossa, the fourth ventricle of the brain. R. Impression. See Impression. R. Ligament. See Ligament. R. Sinus. See Rhombocalia.

Rhomboideus (rom-bo-id'-e-us). See Muscles, Table of. Rhoncal (rong'-kal) [ $\dot{\rho} 6 \gamma \gamma \chi s$, a snoring]. Relating to a rhonchus. R. Fremitus. See Fremitus.

Rhonchial (rong'-ke-al). Same as Rhoncal.

Rhoncus (rong'-kus) [ [ $\circ \circ \gamma \chi \circ \varsigma$, snore]. A rattling or musical sound produced in the throat or bronchial tubes during respiration. Rhonchi may be sonorous or sibilant, the former being loud, low-pitched, and snoring, and the latter high-pitched and whistling. Rhonchi are especially marked during the early stages of acute bronchitis, when the mucous membrane is swollen and thickened, but has not begun to secrete mucus; also in the spasm of the bronchial tubes in asthma and in the chronic bronchitis of emphysema.

Rhoodes $\left(r o o^{\prime}-d \bar{e} z\right)$ [ $j o \omega \delta o c$, like a stream]. Of fevers, associated with fluid discharges.

Rhopal Nich (ro'-pal-nitch). See Antra rhopalaria. Rhopalismus (ro-pal-iz'-mus) [óó $a \hat{n} o v$, club]. Priapism; also plica polonica.

Rhopalium (ro-päl't-e-um) [ $\rho \dot{o} \pi a \lambda o v, a$ club; pl., Rhopalia $]$. In biology, the so-called sense-club of an acraspede Medusa; a compound sense-organ of which the auditory organ is the principal factor; it is at the same time a metamorphosed tentacle into which a hollow process of the gastric system penetrates.

Rhopalocephalus carcinomatosus (ro-pal-o-sef'-alus kar-sin-o-mat'o-sus ). A name given to a parasitic organism found by Korotneff in the cells of carcinomata. The formation of pearls is attributed to it. See Parasites (Animal), Table of.

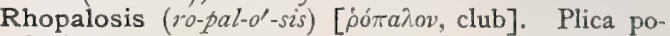
lonica.

Rhophesis (ro-fe'-sis) [ $\rho \circ \phi \varepsilon i v$, to gulp down]. Sipping ; absorption.

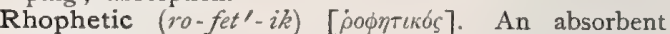
medicine.

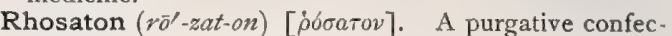
tion of roses. Cf. Actius.

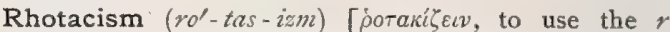
sound]. I. The substitution of some other speechsound for that of the letter $r$; more correctly, the too frequent or too strong utterance of the $r$ sound; the use of the $r$ sound in place of some other speechsound.

Rhothones (ro-tho'-néz) [ $\dot{\rho} \omega \theta \omega v \varepsilon \zeta]$. The nasal cavities.

Rhubarb (ru'-barb) [ $\left.\tilde{p}^{\prime} \circ \nu\right]$. See Rheum.

Rhubarbaric Acid, Rhubarbarin (ru-bar'-bar-ik, mubar'-bar-in). Synonym of Acid, Chrysophanic.

Rhus (rus) [ [ order Anacardiacee, of which the sumachs are the best known. R. aromatica, Sweet Sumach; the bark of the root is an astringent, acting upon the urethral canal. It is useful in cystitis, incontinence of urine, and diabetes. Dose of the fld. ext. $m x x-x x$. Unof. R. coriaria, Elm-leaved Sumach, the dried leaves and fruit are used in dyeing and tanning and contain gallo-tannic acid. The berries are used as a condiment and contain binoxalate of calcium. They 
have been used in the East in cholera. R. cotinus, Purple-fringed Sumach, indigenous to Southern Europe. The bark (cortex cotini) is used as an antiperiodic. The leaves (folia cotini) are used in the form of a gargle in sore-throat. R.-dermatitis, a form of inflammation of the skin, the result of poisoning produced by the poison-oak and other species of sumach. R. diversiloba, the hiedra of California ; the poison-oak; a high grade of cutaneous irritation results from contact with it. $\mathbf{R}$. glabra, Smooth Sumach, the fruit of $R$. glabra. Its properties are due to tannic acid and potassium and calcium malates. The diluted juice is a pleasant, astringent drink in catarrhal affections of the stomach and bowels. Dose of the fld. ext. $3 \mathrm{j}-\mathrm{ij}$. R. glab., Ext., Fld., a gargle for sore-throat. $\mathbf{R}$. perniciosa, a variety which has been used in the treatment of scorpion-bites. R.-poisoning. See Dirmatitis venenata. $\mathbf{R}$. pumila, Dwarf Sumach, found in North Carolina. It is probably the most poisonous variety. R. radicans, Poison-vine, found in Canada and the United States. The juice of the berries is very poisonous. $\mathbf{R}$. toxicodendron, Poison-oak, the fresh leaves of the poison-oak, $R$. toxicodendron, and the poison-ivy, $R$. radicans. Locally applied, it causes swelling and a vesicular eruption upon the skin and mucous membranes. It is recommended in certain affections of the skin, in rheumatism, and locally in erysipelas and eczema. It is a favorite remedy with homeopathic practitioners. An unof. tinct. contains fresh leaves I, alcohol 2 parts. Dose $\eta_{\frac{1}{1} 0^{-i j}}$. R. venenata, Poison-ash, a highly poisonous shrub found in North America and Japan. R. venicifera, Japan lacquer-tree; it is used chiefly in the preparation of varnish, and is highly poisonous.

Rhusin $\left(r \iota^{\prime}-\sin \right)$ [óṽs, sumac]. A precipitate from a tincture of the root-bark of Sumach, Rhus glabra; it is tonic, astringent, and antiseptic. Dose I to 2 grains. Unof.

Rhusma (rus'-muh) [Turlsish]. A depilatory of orpiment, lime, and water, used to remove superhluous human hair.

Rhyas $\left(r i^{\prime}-a s\right)[\dot{\rho} \varepsilon i \nu$, to flow]. Synonym of Discharge.

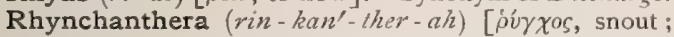
à Anpós, blooming]. A genus of melastomaceous herbs: R. grandiflora, a West Indian species; the flowers are used as a sedative expectorant in chronic cough.

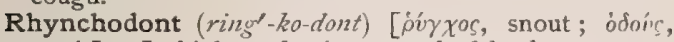
tooth]. In biology, having a toothed beak.

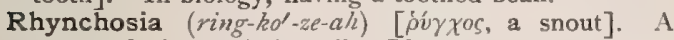
genus of plants of the tribe Phaseolea. R. diversifolia, a variety used as an expectorant in spasmodic cough.

Rhyostomaturia (ri-o-sto-mat-u'-re-ah) [ $\rho$ vás, fluid; $\sigma \tau o ́ \mu x$, the mouth; oupov, urine]. Excretion of the urinary constituents by the salivary glands.

Rhypia (rip'-e-ah). Synonym of Rupia.

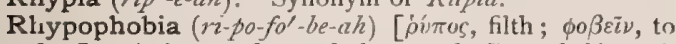
fear]. A better form of the word Rupophobia. A morbid dread of dirt.

Rhyptic (rip'-tik) [ $\rho v \pi \tau \iota \kappa b s ; \rho \dot{\rho} \pi \tau \varepsilon \iota v$, to cleanse]. Detergent ; cleansing ; cathartic.

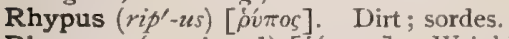

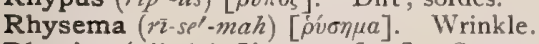

Rhysis- $\left(r i^{\prime}-s i s-\right)[\dot{\rho} \varepsilon i v$, to flow]. Synonym of Discharge.

Rhythm (rithm) [ $\dot{\rho} \theta \mu o ́ s]$. Action or function recurring at regular intervals or according to some systematic plan or type, as the rhythm of the heart, of respiration, etc.

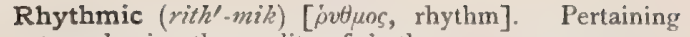
to or having the quality of rhythm.

Rhytidosis cornez [ $\rho v \tau_{i}$, , a wrinkle]. Wrinkling of the cornea.

Rib (rib) [ME., rib, rib]. I. In anatomy, a rib is a long, flat, curved bone, with an ectal and an ental broad smooth surface, cephalic rounded border, and a caudal sharp one. Within the greater part of the length of the lower border there exists a groove for the intercostal blood-vessels. The dorsal end is the head, and this presents two articular facets (separated by the intervertebral ridge) which articulate with corresponding facets of a contiguous pair of vertebræ. Slightly ventral, just beyond a slight constriction, the neck, is the tubercle, upon which is a facet for articulation with the transverse process of the lower of the two

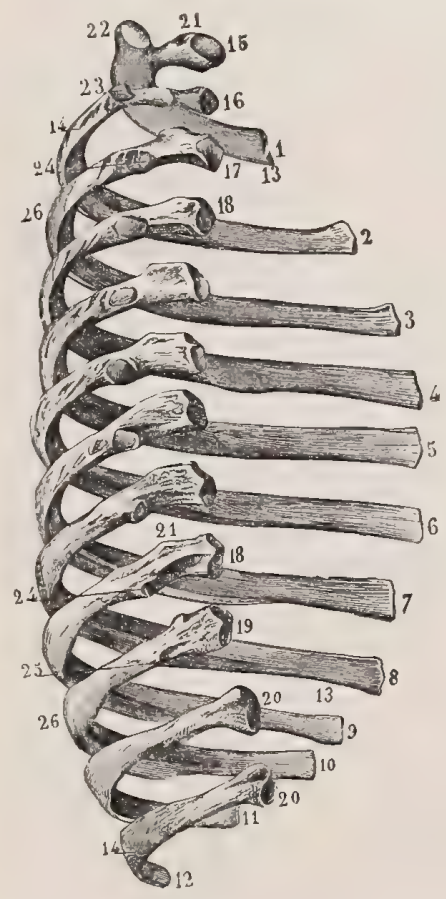

RIBS OF LEFT SIDE, POSTERIOR ASPECT.

1-12. Anterior extremities of 12 ribs of left side. 13, I3. I n ternal surface. 14, I4. External surface. r. Head of Ist rib. I6. Head of $2 d$ rib. 17. Head of $3 \mathrm{~d}$ rib, 18,18 Heads of ribs from $4^{\text {th }}$ to 9 th. 19. Head of 1oth rib. 20, 20. Heads of Irth and I2th ribs. 2I,21. Necks of ribs. 22. Tubercle of ist rib. 23 Articular facet of tubercle of $2 \mathrm{~d} \mathrm{rib}$. 24, 24. Articular facets of tubercles of ribs from $3 \mathrm{~d}$ to 9th. 25. Articular facet for tubercle of Ioth rib. 26, 26. Angles of rit)s.

vertebræ united by the head of the rib. Externally to the tubercle is a rough mark called the angle, at which point the rib is directed abruptly ventrad. The ventral portion is more compressed and is continuous with the costal cartilage. The ribs successively increase in length from the first to the eighth and then decrease to the last. They number twelve pairs, forming a series of narrow arches on each side of the trunk extending from the thoracic vertebræ to the sternum. The seven superior or sternal ribs are attached to both the spine and the sternum. The remaining five are called asternal ribs. Three of these are attached dorsally to the spine, and ventrally by costal cartilages to the cartilages of adjacent ribs. The two last are free at their anterior extremities, and are called free ribs. 2. A primary or principal vein of a leaf.

Ribbail's Bandage. See Bandage.

Ribes, Ganglion of. See Ganglia, Table of.

Ribesin (ri-be'-zin) [ribesium, currant]. The juice of the black currant (Ribes nisrum), used for staining microscopic sections.

Ribgrass (rib' gras). See Plantago, Plantain. 
Riblet (rib'-let) [ME, rib, rib]. Any pleurapophysis not developed into a rib and not destined to be so developed; a costal process of a vertebra.

Rice $(r \bar{s} s)$. See Oryza. R.-seed Bodies, peculiar small, white bodies resembling grains of rice, found in the so-called ganglia occurring on tendons. R.water Evacuations. See Oryza.

Richard's Styptic Collodion. A solution of tannin in collodion.

Richardson's Bellows. An instrument for injecting vapors into the middle ear. R.'s Mixture. See Anesthetic. R.'s Neutral Blue Fluid, a fluid for injecting tissues. Dissolve $0.648 \mathrm{gm}$. of ferrous sulphate in $15 \mathrm{c}$.c. of glycerin; and $2.07 \mathrm{gms}$. of potassium ferrocyanid in a liter of water, to which $\mathbf{I}_{5}$ c.c. of glycerin have been added. Mix the two solutions gradually; then add 30 c.c. of alcohol and 120 c.c. of water. R.'s Test. See Death, Signs of.

Richet's Bandage. See Bandage.

Richter's Collyrium. A mixture of rose-water and the white of egg beaten to a froth. R.'s Hernia, Parietal Enterocele, Partial Enterocele, Littré's Hernia. Strangulated enterocele in which only part of the circumference of the gut is constricted. See Diseases, Table of.

Ricin (ri'-sin) [ricinus, a genus of the euphorbiacea]. The toxalbumin of the castor-oit bean; a vegetable albuminoid employed in the study of immunity. A dose of $\frac{1}{10} \mathrm{gr}$. by the skin, or $\frac{9}{10} \mathrm{gr}$. by the stomach is toxic. It induces multiple hemorrhages of the intestines and stomach, and appears to break down the blood-corpuscles. Unof.

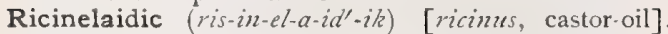
Derived from castor-oil. R. Acid, an acid derived from and isomeric with ricinoleic acid.

Ricinic (ris-in'-ik) [ricinus, castor-oil]. Pertaining to or having the properties of castor-beans or castor-oil. Also applied to an acid derived from castor-oil. See Ricinus.

Ricinine $\left(r^{\prime}\right.$-sin-in) [ricinus, castor-oil]. A crystalline substance obtained from castor-oil.

Ricinoleic Acid (ri-sin-o-le'-ik). See Acid.

Ricinus (ris'-in-us) [L.]. A genus of apetalous euphorbiaceous plants. R. communis, the only species is the well-known castor-oil plant, indigenous in America and Asia. The height is from 4 to I 4 feet; the leaves are alternate, peltate, palmately seven-lobed or nine-lobed; the flowers are monecious and apetalous. The fruit is a grooved, rather triangular tricoccous capsule, generally spinescent; with a single oval or elliptic seed enclosed in each cell. The embryo has foliaceous, heart-shaped cotyledons, is straight, white, and imbedded in an oily albumin, having a bland and slightly acrid taste. The seeds are chiefly used in the manufacture of oleum ricini, castor-oil. They are first crushed and freed from their coverings, then kiln-dried and subjected to powerful pressure. The oil is heated with water to remove albuminous matters. The yield is 38 to 45 per cent., by cold pressure 25 to 30 per cent. The oil prepared by the latter method requires no further purification. It is viscid, nearly transparent, pale greenish-yellow or almost colorless. The specific gravity varies between .950 and .960 . The oil is partly soluble in petroleum benzine, but is more soluble in absolute alcohol, ether, and glacial acetic acid in all proportions. When fresh, it has a neutral reaction to testpaper, and is composed of several fats. The solid fatty acid is related to palmitic acid, the liquid one is ricinoleic acid. The acrid principle to which its purgative properties are due has not been isolated. Tuson claimed, in $\mathbf{1} 864$, to have discovered an alka- loid, ricinin. The oil is used medicinally to overcome constipation or to cure diarrhea due to the presence of irritating substances. The dose for an adult is from half an ounce to an ounce. R., Olei, Mist. (B.P.), castor-oil, oil of lemon, oil of cloves, potash, syrup, orange-flower water, Dose $\overline{3}$ ss-ij.

Rickets (rik'-ets) [já $\chi \iota$, spine]. The common name for Rachitis; it is a constitutional disease of childhood, characterized by increased cell-growth of the bones, with deficiency of earthy matter, resulting in deformities, and with abnormal changes in the spleen and liver. See Rachitis.

Rickety $\left(r i k^{\prime}-\ell t-\ell\right)[\rho \dot{a} \chi \iota \varsigma$, spine]. Affected with, or distorted by, rickets. R. Rosary, the beaded condition of the ribs in rickets. See Rachitis.

Rictal (rik'-tal) [ringi, to gape]. Pertaining or relating to rictus.

Rictus (rik'-tus) [L., from ringi, to gape]. A fissure or cleft; a gaping, as of the mouch; the gape of a bird. See Risus sardonicus. R. lupinus, cleft palate.

Rider $\left(r i^{\prime}\right.$-der) [ME., ridere, a rider]. One who rides, especially one who rides on horseback. R.s' Bone, an osseous formation in the adductor muscles of the leg, from long-continued pressure of the leg against the saddle. See Exercise-bones. R.s' Bursa, an enlarged bursa, produced in the same way as the riders' bone. R. Garbage - furnace, a form of furnace with two chambers, the foremost of which is the combustion-chamber in which the garbage to be destroyed is placed, and the rear one the receiving-tank.

Ridge ( $r i j)$ [ME., rigge, the back of a man or beast]. An extended elevation or crest. Rs., Bicipital, the borders of the bicipital groove of the humerus. Rs., Condylar, the ridges ascending from the condyles of the humerus. Rs., Dorsal. See Rs., Medullary. R., Genital, the germ-ridge in front of and internal to the Wolffian body, from which the internal reproductive organs are developed. R., Gluteal, the anterior intertrochanteric line. R., Interosseous (of the fibula), the ridge on the fibula which gives attachment to the interosseous membrane. R., Intervertebral, a crest on the vertebral end of a rib dividing the articular surface into two portions. R., Lambdoidal, the lambdoid crest. Rs., Lateral (of the blastoderm), two ridges on the posterior end of the embryonic shield that coalesce and close the primitive groove. R., Maxillary, dental crest; a ridge of vascular fibrous tissue along the alveolar processes of the maxillary bones of the fetus. Rs., Medullary, the laminæ dorsales, or longitudinal elevations of the epiblast, which coalesce and close in the medullary or neural tube. R., Mylo-hyoid, the ridge on the inner surface of the inferior maxilla for the attachment of the mylo-hyoid muscle. R., Neural, neural crest; the ridge of epiblastic cells on the superior margin of the medullary groove, from which the dorsal nerves of the embryo are developed. Rs., Occipital, the superior and inferior curved lines of the occipital bone. Rs., Palatine, one longitudinal and several transverse corrugations of the mucosa of the hard palate. R., Parietal, the ridge on the parietal bone; a continuation of the temporal ridge. Rs., Pectoral, the bicipital ridges of the humerus. R., Pterotic, a ridge on the upper and external portion of the auditory capsule. R., Pterygoid, the infra-temporal crest or ridge on the external surface of the greater wing of the sphenoid bone. Rs. of the Skin, the delicate ridges of the skin which intersect at various angles, and correspond to the rows of papillæ of the corium. R., Superciliary, the arched ridge of the frontal bone 
corresponding to the eyebrow. Rs., Supracondyloid. See Rs., Condylar. R., Temporal, the ridge extending from the external angular process of the frontal bone upward and backward across the frontal and parietal bones, curving downward, and terminating in the posterior root of the zygomatic process. R., Wolffian, germ-epithelium. See R., Genital.

Ridge's Food. A farinaceous food for infants. Its composition is: Water, 9.23 ; fat, 0.63 ; grape-sugar, 2.40 ; cane-sugar, 2.20 ; starch, 77.96 ; soluble carbohydrates, 5.19 ; albuminoids, 9.24 ; ash, 0.60 .

Ridgel (rij'-el) [origin uncertain]. A male animal having one testicle removed or wanting.

Ridgeling ( $r i j^{\prime}$-ling). See Ridgel.

Ridgil ( $\left.r i j^{\prime}-i l\right)$. See Ridgel.

Riding of Bones. In surgery, the displacement of the fractured ends of bones which are forced past each other by muscular contraction, instead of remaining end to end.

Riding-hag. Incubus; nightmare.

Riegel's Syndrome. Respiratory disturbance simulating asthma, combined with tachycardia. R.'s Testmeal, a test-meal consisting of 400 grams broth, 50 grams scraped beef, 60 grams white bread.

Riga's Disease. See Aphtha, Cachectic, and Diseases, Table of.

Riggs' Disease. See Diseases, Table of.

Right (rit) [ME., right, right]. Belonging to or located upon that side which, with mammals contains less of the heart and is on the east when the face is toward the north; dextral. R.-brained, having the speech-center in the right instead of the left hemisphere. R. Hand. See Dexter. R.-handed, using the right hand with more freedom and effect than the left. R.handedness, the condition of being right-handed.

Rigiditas (rij-id'-it-as) [L.] Stiffness; rigidity. $\mathbf{R}$. articulorum, spurious ankylosis.

Rigidity (rij-id'-it-e) [rigidus, stiff]. Stiffness; inflexibility; immobility; tonic contraction of muscles. R., Anatomic (of the cervix uteri), rigidity in which the cervix, though neither edematous nor tender, is not wholly effaced in labor, but retains its length and dilates only to a certain extent, beyond which the contractions of the uterus are without effect. R., Cadaveric, rigor mortis. R., Cerebellar, rigidity of the spinal muscles, due to tumor of the middle lobe of the cerebellum. The head is drawn backward, the spine curved, and the arms and legs made rigid $(H$. Jackson). R., Hemiplegic, spastic rigidity of the paralyzed limbs in hemiplegia. R., Muscular. See Thomsen's Disease. R., Pathologic (of the cervix uteri), rigidity due to organic disease or cicatricial contraction. R., Post-mortem, rigor mortis. R., Spasmodic (of the cervix uteri), rigidity due to spasmodic contraction of the cervix.

Rigor (ri'-gor) [rigor, cold]. Coldness, stiffness, or rigidity. In the plural, chills, shivering. R. cadaverosus. See $R$. mortis. R. maxillæ inferioris, trismus. R. mortis : I. The muscular rigidity that occurs a short time after death, due to chemic changes resulting in the production of myosin. 2. The rigor due to changes occurring in a muscle that has lost its irritability, in which its acidity is increased and its electric currents are absent. $\mathbf{R}$. nervorum, $\mathbf{R}$. nervosus. See Tetanus.

Rima $\left(r^{\prime}-m a h\right)[$ rima, crack, cleft : pl., Rima $]$. In biology: r. A chink, cleft, or fissure. 2. The chief part of the great transverse fissure of the brain. It is a line of interruption of the nervous parietes of the paracele, beginning at the dorsal end of the porta, and extending to near the tip of the medicorun. R. ad infundibulum, the anterior aperture of the third ventricle of the brain.
R., Anterior, the calamus scriptorius (Monro). Rimæ cæcæ hepatis, the hepatic fissures lodging the branches of the portal vein. $\mathbf{R}$. cerebri transversa, the transverse fissure of the cerebrum. R. clunium, the cleft of the nates. Rimæ cutis, the normal furrows of the skin. $\mathbf{R}$. glottidis, the cleft between the true vocal bands; the glottis. R. glutæa. See $R$. clunium. R. helicis, an anomalous cleft in the inferior anterior portion of the helix. R. labiorum. See $R$. oris. $\mathbf{R}$. laryngis. See $R$. glottidis. $\mathbf{R}$. oris, the line formed by the junction of the lips. $R$. palpebrarum, the palpebral fissure. $R$. pudendi, the fissure between the labia majora. R. pudendi connivens, the fissure between the labia majora when they completely conceal the nymphr. R. transversa cerebelli, the sulcus between the peduncles of the cerebellum. $\mathbf{R}$. ventriculi laryngis, the aperture of the ventricle of the larynx. R. vocalis. See $R$. glottidis. R. vulvæ. See $R$. pudendi.

Rimiform (ri'-mif-orm) [rima, a chink ; forma, form] In biology, possessing a longitudinal chink or furrow.

Rimose $\left(r i^{\prime}-m \bar{o} z\right)$ [rimosus, full of chinks]. In biology, full of crevices or furrows.

Rimous ( $\mathrm{ri}^{\prime}$-mus) [rima, a cleft]. Having cracks, clefts, or fissures.

Rimula (rim'-u-lah) [L., dim. of rima, a crack: pl., Rimula]. A fissure; applied especially to the ventral mesal fissure of the spinal cord; an interfoliar cleft of the cerebellum.

Rimule (rim'-ül) [rimula, dim. of rima, a cleft]. Any minute cleft, crack, or fissure.

Rinar ( $r i^{\prime}$-nar). Limatura; filings.

Rind (rind) [ME., rind, crust]. In biology, an outer coat, skin, or integument. Cortex.

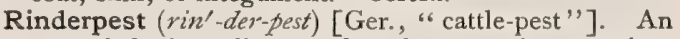
acute infectious disease of cattle, appearing occasionally among sheep, and communicable to other ruminants. It is called also cattle-plague. Cf. Bacillus septicamice hamorthagica, under Bacteria, Synonymatic Table of.

Rindfleisch's Granule-cells. Eosinophile leukocytes with granulations.

Ring [ME., ring, ring]. A circular opening or aperture; the structure surrounding a circular opening. See Annulus. Rs., Abbe's, rings of catgut, used in the establishment of an artificial communication between one part of the bowel and another, or between the bowel and the stomach. R., Abdominal, the internal or external abdominal ring. R., Annual, one of the successive circles of wood produced yearly in exogenous trunks. R., Antimonial, a ring produced when volatilized antimony impinges on a glass surface. Rs., Apposition. See Rs., Abbe's. R., Arsenical, a ring produced when fumes of arsenic impinge on a glass surface. R., Bandl's, an annular muscular thickening of the uterus during labor between the contractile portion of the organ and the relaxed attenuated portion below; the true os uteri internum of Bandl. R.-bone, a bony callus or exostosis, the result of inflammation on one or both pastern-bones of a horse. It may extend to the interphalangeal joints and cause immobility and lameness. R.-canal: (a) the circumesophageal canal of the water-vascular system of Echinoderms; (b) the annular enterocele of Calenterates. R., Contraction. See R., Bandl's. R., Crural. See R., Femoral. R., Femoral, the abdominal opening of the femoral canal. Rs., Fibrous (of the Heart), the fibrous bands surrounding the arterial and auriculo-ventricular orifices of the heart, and to which the muscular fibers are attached. R.-finger, the fourth digit or third finger. $\mathbf{R}$.-infiltration (of the Cornea), an infiltration of cells, circular in shape, in the 
laminæe of the cornea, sometimes following perforating septic wounds of the cornea. R., Inguinal. See $R$., Abdominal. R., Löwe's, a bright violet ring seen on looking through a solution of chromic chlorid. R., Marsh's. See R., Arsenical. R., Maxwell's, a faintly defined halo around the fovea when the eye rests on a homogeneous blue surface. R., Müller's, a muscular ring observed in an advanced stage of gestation, situated where the canal of the cervix joins the cavity of the body of the uterus. R.-muscle of Müller. See Muscles, Table of. R., Omphalic. See R., Umbilical. R.-scotoma. See Scotoma. R., Spermatorrhea, a metallic ring furnished with sharp points, to be worn during sleep to prevent seminal emissions. R., Tracheal, a tracheal cartilage. R., Tympanic, an osseous ring forming part of the tem. poral bone at the time of birth, and which develops into the tympanic plate. R., Umbilical, the ray-like aperture of the abdominal wall by which the umbilical cord communicates with the fetal system, and through which, in extra-uterine life, the urachus and the remains of the umbilical vessels pass to the umbilicus. R.-worm, a general term for vegetable parasitic diseases of the skin characterized by circinate lesions. R.-worm of the Beard, sycosis parasitica. R.-worm of the Body, tinea circinata. R.-worm, Burmese, a cutaneous affection occurring in Burmah, resembling, and probably identical with, the form of tinea circinata called eczema marginatum. R.worm, Chinese, ringworm due to Tinea imbricata. R.-worm, Honeycomb, favus. R.-worm of the scalp, tinea tonsurans. R.-worm of the Thighs and Genitalia, eczema marginatum. R.-worm, Tokelan, ring-worm due to Tinea imbricata.

Ringed (ringd) [ME., ring, ring]. In biology, marked with rings. R. Hair, a very rare form of canities, in which the hairs are white or colored in rings or bands.

Ringent (rin'-jent) [ringi, gape, open-mouthed]. In biology, irregularly gaping; applied to a bilabiate corolla when the throat is wide open or gaping; opposite of personate.

Rinmann's Green. See Pigments, Conspectus of.

Rinne's Test. This consists in applying a vibrating tuning-fork with moderate pressure first over the mastoid process, leaving it there until the patient seems no longer to hear the sound, and then as quickly as possible bringing it immediately in front of the external meatus, avoiding all contact with the head or ear. If the patient then is able to hear the sound of the tuning-fork once more, it indicates that the conduction through the air is better than through the bone, and vice versa.

Rinolite (ri'-no-lit). See Rhinolith.

Riolan, Bouquet of. See Bouquet. R., Mesocolic Arch of, the arch of mesentery attached to the transverse meso-colon. R.'s Muscle. See Muscles, Table of. R.'s Nosegay. See Nosegay and Bouquet

Ripa $\left(r^{\prime}-p a h\right)$ [ripa, a bank]. The line formed by the reflection of the endyma upon any plexus or tela of the brain.

Riparial, Riparious (ri-pa'-re-al, ri-pa'-re-us) [ripa, the bank of a stream or body of water]. Living on or associated with, or pertaining to the shore.

Ripault Sign. See Death.

Ripe (rip) [ME., ripe, ripe]. Mature

Ripening (rip'-en-ing) [ME, ripe, ripe]. Becoming mature. $\mathbf{R}$. of Cataract. See Cataract. $\mathbf{R}$. of Cream, the allowing of cream to sour before churning, whereby a larger amount of butter is obtained. The process is attended with a multiplication of bacteria, the proper temperature for ripening being that at which the bacteria best multiply. It is attended with the production of lactic acid and various decompositionprocesses.

Risidontrophy (riz-id-on'-tro-fe) [ $\rho \zeta \zeta a$, a root]. The operation of drilling the root of a tooth.

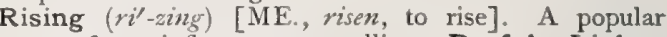
term for an inflammatory swelling. $\mathbf{R}$. of the Lights, a popular term for pleurisy and for croup.

Risipola lombarda (riz-ip-o'-lah lom-bar'-dah). Synonym of Pellagra.

Risorius $\left(r i-z o^{\prime}-r e-w s\right)$ [ridere, to laugh]. The upper portion of the Platysma myoiles. It controls certain motions of the lips and adjacent parts in laughing. See Muscles, Table of.

Ristorum (ris-to'-rum) [L.]. A nutritive preparation of egg-yolk.

Risus $\left(r i^{\prime}-z u s\right)[\mathrm{L}$.$] . A grin or laugh. R. sardoni-$ cus, an involuntary sardonic or convulsive grin or drawing down of the angles of the mouth in certain spasmodic or tetanic conditions.

Ritgen's Method. A method of manual delivery of the fetal head. It consists in lifting the head upward and forward through the vulva, between the pains, by pressure made with the tips of the fingers upon the perineum behind the anus close to the extremity of the coccyx.

Ritter's Disease. See Dermatitis exfoliativa neonatorum and Diseases, Tuble of. R.'s Law of Contraction, "a nerve is stimulated both at the moment of the occurrence and that of the disappearance of electrotonus: (I) When the current is closed, the stimulation occurs only at the kathode, i.e., at the moment when the kathelectrotonus takes place; (2) when the current is opened, stimulation occurs only at the anode, $i . e_{\text {. }}$, at the moment when the anelectrotonus disappears." (Landois and Stirling.) R.'s Opening Tetanus. See Tetanus. R.'s Tetanus, a temporary tetanic state caused by sending a constant current of electricity to a nerve and then suddenly interrupting it. R.-Valli Law, "If a nerve be separated from its center, or if the center die, the excitability of the nerve is at first increased; the excitability then falls until it disappears entirely. This process takes place more rapidly in the central than in the peripheral part of the nerve, so that the peripheral end of a nerve separated from its center remains excitable for a longer time than the central end." (Landois and Stirling.) See Law.

Rivallie's Paste. A caustic made by adding concentrated nitric acid to lint.

Riverius, Salt of. An old name for normal potassic citrate.

Rivini, or Rivinus, Canal of. See R., Ducts of. R. Ducts of, the excretory ducts of the sublingual gland. R., Foramen of, an opening in the tympanum, of doubtful existence. R., Glands of, the sublingual glands. R., Notch of, a notch in the osseous tympanic ring, filled by Shrapnell's Membrane. R., Segment of, an opening in the upper and anterior part of the annulus tympanicus.

Rivolta's Disease. Synonym of Actinomycosis.

Rivose $\left(r i^{\prime}-v \bar{o} z\right)$ [rivus, a stream. channel, groove]. In biology, marked with furrows that are sinuate rather than parallel.

Rivulose (riv'-u-lōz) [rivulus, a small stream]. In biology, marked with small sinuate lines.

Rivus (ri-z'us) [L., "a stream: $p l$., Rivi]. Any one of the smaller conduits of the subarachnoidean space. R. lacrymalis. See Palpebra.

Riziform (riz'-if-orm). Having an appearance resembling grains of rice. 
Rizzoli-Esmarch Operation. An operation for the relief of ankylosis of the lower jaw, consisting in making a section of the ramus. See Operations, Table of.

Roads, Animal. See Zoöcurrent.

Roaring (rör'-ingo) [ME, roren, to roar]. A disease of horses that causes them to make a singular noise in breathing under exertion. The disease is due to paralysis and wasting of certain laryngeal muscles, usually of the left side, resulting in a narrowing of the glottis.

Roasting ( $\left({ }^{\circ} \bar{s} t^{\prime}-i n g\right)$ [ME., rosten, to roast]. The application of heat to a degree less than that of carbonization, as the roasting of coffee ; torrefaction.

Rob, Robb [Arab.]. A confection made of fruit-juice, especially of that of the mulberry.

Roberts' Macula. See Mircula. R. Pelvis, the ankylosed transversely contracted pelvis. See Pelvis. R. Reagent, to five volumes of filtered saturated solution of magnesium sulphate add one volume of strong nitric acid ; it is used to obviate the objections to nitric acid in Heller's test. Proceed as in Heller's test. R. Test. See Tests, Table of.

Robertson's Pupil. See Pupil.

Robin's Fluid. A fluid used in the microscopic study of the blood. It consists of distilled water containing one per cent. of chlorid of sodium, and one-half of one per cent. of bichlorid of mercury.

Robin's Gelatin Vehicle. A warm, flowing mass for injecting tissues. One part of gelatin is soaked in seven, eight, nine, or ten parts of water, according to the consistency of the mass desired, and when soft is melted on a water-bath. This vehicle is then combined with any of the coloring-matters employed in injecting tissues in the proportion of one part color to three parts vehicle. Filter through flannel before injecting. R.'s Rye. See Hair-cap Moss.

Robinia (ro-bin'-e-ah) [after Jean Robin, the royal gardener at Paris (1550-1629)]. A genus of leguminous shrubs indigenous in North America. $R$. amara, of China, is used as a stomachic tonic. $\mathbf{R}$. pseudacacia, the locust tree of North America. Various parts of it are used by eclectic physicians. The bark is said to be emetic and cathartic, the flowers antispasmodic. Cases of poisoning from chewing the root are recorded in which the symptoms resembled those of belladonna-intoxication.

Robinin (ro'-bin-in) [after Robin, a French gardener], $\mathrm{C}_{25} \mathrm{H}_{20} \mathrm{O}_{16}$. A glucosid obtained from the fresh flowers of the locust-tree.

Robinson's Ointment. An ointment used in treating eczema of the beard. It consists of diachylon and zinc-oxid ointments, each $\bar{z}$ ss; ammoniated-mercury ointment, 3 iij; bismuth subnitrate, 3 iss. R.'s Patent Barley, a farinaceous food for infants. Its composition is: water, 10.10; fat, 0.97; grape-sugar, 3.08 ; cane-sugar, 0.90 ; starch, 77.76 ; soluble carbohydrates, 4.II ; albuminoids, 5.13; gum, cellulose, etc., I.93; ash, I.93.

Robiquet's Paste. A caustic paste consisting of equal parts of zinc chlorid and flour with gutta-percha. It is firm and tenacious.

Robor $\left(r o^{\prime}\right.$-bor) [L.]. Strength.

Roborant (ro'-bo-rant) [robur, an oak; also strength]. Tonic. Strengthening.

Robur (ro'-bur). See Robor.

Roburite (ro'-bu-rit) [robur, strength]. An explosive composed of dinitrobenzene, chloronitrobenzene, and ammonitin 'nitrate. Its fumes, when inhaled by miners, cause headache, vertigo, vomiting, etc.

Robust (ro-bust') [robustus; robus, robur, an oaktree]. Strong; vigorous.
Roccella, Rocella (rok-sel'-ah, ro-sel'-ah). A genus of lichens. R. tinctoria, litmus-plant, archil ; a species growing in the Canary Islands, Africa, and Europe. It yields litmus.

Roccellic (rok-sel'-ik). Related to or derived from Roccella. R. Acid, $\mathrm{C}_{17} \mathrm{H}_{32} \mathrm{O}_{4}$, a dibasic acid obtained from Roccella tinctoria and Lecanora tartarea.

Roccellin (rok-sel'-in). A dye consisting of the sodium salt of $\beta$-naphthalazonaphthalinsulphonic acid. See Orseillin.

Roche's Embrocation. An embrocation containing amber-oil.

Rochelle Salt (ro-shel'-sawlt). See Potassium.

Rock $(r o k)$ [ME., rocke, rock]. A mass of stone R.-candy. See Saccharum. R.-fever. See Medi terranean Fever. R.-oil. See Petroleum. R.rose. See Helianthemum. R.-tripe. See Gyrophora. R.-weed. See Fucus.

Rockdale System. See Servage, Disposal of.

Rocky Mountain Fever. A form of typhoid fever occurring at high altitudes; mountain fever.

Rod [ME., rod, rod]. I. One of numerous slender rod-like or bacillary structures, as in the retina. 2. A shoot or slender stem of any woody plant. Rs., Acoustic. See Rs. of Corti. Rs., Auditory. See Rs. of Corti. R.-bacterium, any member of the genus bacillus. Rs. of Corti. See Corti. R.-epithelium, the striated cells lining certain structures, as the ducts of the salivary glands and the convoluted portions of the uriniferous tubules of the kidney. Rs. of Heidenhain, the rod-like cells of the renal tubules. See Rs., Intracellular. Rs., Intracellular, the fibrilla of rod-like cells. Rs. of Kœnig. See Konig. Rs., Muscle: I. 1. ROD - E PITHELIUM tile disc of a muscle-fiber. 2. ROUS TUBULES. The rod-shaped elements form- $x$. On the flat with ing the non-contractile part of a interlocking procesmuscle-fiber (Schäfer) Rs. of ses. 2. On edge, the Retina, cylind ric bodies character of outer found in the layer of rods and portion. (From Stircones of the retina.

Rodent (ro'-dent) [rodere, to gnaw]. Eating; gnawing. R. Cancer. See $R$. Ulcer. R. Ulcer, Jacob's ulcer; cancroid ulcer; ulcus excedens; noli me tangere; a carcinomatous ulceration of the skin, generally held to be a form of epithelioma, occurring usually in the eyelid or the side of the nose, and frequently persisting for years before developing malignancy.

Rodostrophone (ro-dos'-tro-fon). An instrument for transmitting articular sounds from the skull of one person directly to that of another.

Rodrigues' Aneurysm. See Aneurysm and Diseases, Table of.

Rœderer's Obliquity. See Obliquity.

Rokitansky's Disease. Acute yellow atrophy of the liver. See Diseases, Table of. R.'s Theory, a theory of inflammation in which it is supposed that the first step in the inflammatory process is a sweating out of a fluid from the blood-vessels, and that in this fluid cells are formed.

Rolando, Arciform Fibers of. White fibers curving around the lower border of the olivary body and around the sides of the medulla. R., Column of. See Column. R., Fissure of. See Fissures, Table of. R., Funicle of. See Funiculus. R., Nucleus of. See Nucleus. R., Tubercle of. See Tubercle. Rolle, Plane of. See Plane. 
Roller (ro'-ler) [ME., rolle, a roll]. A long strip of cloth varying from one to six inches or more in width, made, for convenience, into a cylindric roll.

Rollet, Delomorphous Cells of. See Delomorphous. Roman Ocher. Same as Ocher. R. Theory, of Marchiafava and Celli, as to the nature of the crescentic forms of the parasites found in the blood of malarial patients. According to this theory, the crescents are sterile forms and do not reproduce new bodies. Mannaberg's theory considers them as conjugation-forms, or syzygies. See Syzygies. R. White. Same as White Lead.

Romberg's Sign or Symptom. The increased incoordination of movement in tabes caused by placing the feet in juxtaposition and closing the eyes. It is also called the Brach-Romberg Symptom. See Signs and Symptoms, Table of.

Romershausen's Eye-water. A wash frequently employed in chronic ophthalmic catarrh. It is a mixture of fennel water and tincture of fennel.

Röntgen Rays. See $X$-Rays.

Root [ME., roote, root]. The place of origin of a nerve; the proximal and cutaneous end of a hair; the intra-alveolar portion of a tooth. The base of an organ. See Radix. In biology, the descending axis of a plant, originating in the radicle of the embryo. It fixes the plant in the soil and absorbs nutrition. It differs from a stem in producing no buds or branches. Rs., Aërial or Adventitious, those springing from the stem above ground for climbing or bracing purposes, e.o., ivy, corn. R., Anterior (of the auditory nerve), the root of the auditory nerve arising from the large-celled auditory nucleus. R., Anterior (of the zygoma), a ridge passing from the temporal portion of the zygoma to the squamous portion of the temporal bone. R., Antero-lateral (of the optic tract), that strand of fibers arising from the optic thalamus and passing through the geniculate body. R., Ascending (of the auditory nerve), those fibers of the auditory nerve which arise from the median line of the oblongata (Roller). R., Ascending (of the fifth nerve), those fibers of the sensory root of the fifth nerve which have their origin in a group of cells in the gelatinous substance of the medulla. R., Brazil, an old name for Ipecac. R.-cap, a mass of tissue that covers like a helmet the growing-point of every root. R., Deep (of the auditory nerve). See R., Anterior (of the auditory nerve). R., Descending (of the fifth nerve), those fibers of the motor root of the fifth nerve having their origin in the gray substance of the aqueduct of Sylvius. R., External (of the olfactory nerve), those fibers of the olfactory nerve which have their origin in the insula, R.-fillings, fillings of different materials inserted into the pulp-canals of the teeth. R.form, applied to that form of an insect, if it has two forms, which it assumes when infesting roots, as in Phylloxera vastatrix, the grape-vine pest. R., Gray (of the olfactory nerve). See $R$., Middle (of the olfactory nerve). R.-hairs, slender filaments growing from the epidermis of the younger roots which increase the power of absorption. R., Inferior Auditory, the posterior of the two roots which unite to form the auditory nerve. $\mathbf{R}$.-leaf. Same as radicle leaf; apparently springing from the root, but really from a short stem. $\mathbf{R}$.-louse. See Phylloxera and Schizoneura. R.-neck (Collet), the point of union between the root and the stem of a plant, or where the radicle and the plumule of the embryo unite. R.-parasite, a plant parasitic upon the root of another. $\mathbf{R}$.-pressure, in biology, a force exerted in plants by which the water absorbed from the soil by the roots in greater quantity than required drives the sap up the stem. R.-sheath, the thick layer of tissue covering the radicle of grasses, etc., and which is ruptured on germination; it is called also Coleorhiza. R.-sheath (of hair), the epithelium of the hair-follicle. R.stock, in biology, (I) a rhizome; (2) a cormus or rhizocaulus. R.-symptoms (of Gowers), in compression of the spinal cord. The functions of the nerve-roots are interfered with at the level of the morbid process. A second class of coexistent symptoms are denominated by Gowers as Cord-symptoms, and consist in interference with the function of the cord itself. R.-trimmer, an instrument for shaping and reducing the roots of natural teeth in crown and bridge work. R.-zone, a name given to the columns of Burdach in the spinal cord.

Rootlet [Dan., rod, a root]. A little root.

Roquefort Cheese. See Cheese.

Rorulent (ro'-ru-lent) [rorulentus, full of dew]. In biology, covered with a powdery bloom.

Rosa $\left(r o^{\prime}-z a h\right)$ [L., gen., rosa]. A genus of the family rosacea, the rose. R. Acidum, Infus. (B. P.) Dose 亏j-ij. R., Aqua, pale rose 40, water 200 parts, mixed and distilled. R., Aq., Ung., cold cream; oil of almond 50 , spermaceti, white wax ãā Io, rosewater 30 parts. A useful emollient. R. Caninæ Confectio (B. P.) Dose $3 \mathrm{j}-\mathrm{ij}$. R. canina, the dogrose, a European plant four to eight feet high. Rosæ caninæ, Fructus. Hips. These are the enlarged calyxtubes, not the fruit. They have a sweet, acidulous, rather astringent taste, and are inodorous. For medicinal use, the fleshy calyx-tube is employed, the akenes being removed. The pulp contains malic and citric acids. Confectio rosæ caninæ, prepared from hips. R. centifolia, pale rose; hundred-leaved rose, probably a native of Western Asia, but cultivated in all countries. The petals alone are used, and are roundish obovate, pink in color, having a delicious odor, due to a volatile oil, and a sweetish, rather bitter and astringent taste. The chief constituents are tannin, fat, resin, sugar, mucilage, a bitter principle, malates, tannates, phosphates, and a coloring-matter. The petals are used in the distillation of Aqua rosa, and dried in preparing Syrupus sarsaparilla comp. R., Confectio, red rose 8 , sugar 64 , honey $\mathbf{1 2}$, rose-water $\mathbf{I} 6$ parts. A basis for pills. R., Damascena. See Attar of Rose. R., Ext., Fld. Dose $\eta^{v-3 i j . ~ R . ~ g a l l i c a, ~ r e d ~}$ rose; rose rouge. A native of Southern Europe and the Levant, but extensively cultivated. The buds are collected, the petals cut off near the base and rapidly dried. The chemic constituents are nearly identical with those of pale rose. Confectio rosæ, red rose 8 parts, sugar 64, honey I2, rose-water I6 parts. Used as a basis for pills. Infus, rosæ acidum, dried red rose petals broken up $1 / 2$ troy-ounce, diluted sulphuric acid I fluidram, boiling distilled water ro fluidounces. Infuse in a covered vessel for half an hour and strain. Extr. rosæ fluid., red rose in No. 30 powder $100 \mathrm{gm}$., glycerin $\mathbf{I}$ gm., dilute alcohol to make $100 \mathrm{c} . \mathrm{c}$. Pack the mixture in a percolator, and add enough of the menstruum to saturate the powder and leave a stratum above. Used in gargles and mouth-washes. Syrupus ros $\mathfrak{x}$, made from the fluid extract. Mel rosæ, honey of rose. Red rose in No. 140 powder 8 parts, clarified honey 92 parts, dilute alcohol, a sufficient quantity to make 200 parts. R. solis ("Rose of the sun"), a cordial or liqueus, flavored with cassia bark and orange-flower. Cf, Rosoglio.

Rosacea (ro-za'-se-ah). See Acne rosacea.

Rosaceous (ro-zal-she-us) [rosa, a rose]. Rose-like; rose-red. In biology, a term descriptive of flowers that have five spreading, clawless, or short-clawed petals, as the flowers of the apple, rose, etc. 
Rosanilin (ro-zan'-il-in) [rosa, rose; anilin], $\mathrm{C}_{20} \mathrm{H}_{21}$ $\mathrm{N}_{3} \mathrm{O}$. A derivative of anilin. It crystallizes from alcohol and hot water in colorless needles or plates. It reddens on exposure, and when heated suffers decomposition. Its salts are employed as dyes. R. blue; Triphenyl rosanilin, Spirit-blue. An anilinblue derived from coal-tar, used for dyeing, and soluble in spirit (alcohol). It is prepared by heating rosanilin with an excess of anilin and some benzoic acid. It gives a very pure blue to silks. See $P_{i y}$ ments, Conspectus of. R.-violet. See Pigments, Conspectus of.

Rosary $\left(r o^{\prime}-z a r-\ell\right)$ [rosa, a rose]. A rope suspended from the ceiling of a room; and strung with blocks a foot or eighteen inches apart. It is used in gymnastic training. In biology, applied to the string of eggs of certain batrachians (Alytes obstetricans). R., Rachitic. See Rachitis.

Rose $(r \overline{o z})$ [rosa, a rose]. I. A flower of a plant of the genus Rosa. 2. A synonym in Scotland for Ery. sipelas. 3. A tetronerythrin pigment around the eyes of certain birds. R. des Alpes. Same as Daphnin. R.-anilin. See Azalein. R., Bengale. See Pigments, Conspectus of. R.-catarrh. See Hay-fever. R.-cold. See Hay-fever. R.-fever, a condition resembling hay-fever, in which the emanations from the rose are the exciting cause. R.-lake. See Pigments, Conspectus of. R.-madder. See Pigments, Conspectus of. R.-pink, a chromatic crimson-pink color. R.-pearl. See Celluloid. R.-rash. See Erythema and Roseola. R.-ringed, having a collar of rose-red feathers. R.-sickness. See Pelade, Pellagra. R.vinegar, an infusion of rose-leaves in vinegar. It is used as a local application in headache. $\mathbf{R}$.-water, water tinctured with oil of roses by distillation. R.wood, the wood of several varieties of tropical plants, notably the Dalberyia.

Rosein (ro'-ze-in). See Fuchsin and Magenta.

Rosellin (ro-zel'-in). See Pigments, Conspectus of.

Rosemary ( $\left.r o ̈ z^{\prime}-m a-r e\right)$. See Rosmarinus.

Rosen's Liniment. A liniment composed of oil of nutmeg, spirit of juniper, and oil of cloves.

Rosenbach's Bacilli. See Bacteria, Synonymatic Table of. R.'s Sign. Absence of movement of the abdominal muscles in inflammatory intestinal disease. See Signs and Symptoms, Table of.

Rosenmüller, Accessory Gland of. See Gland of Rosenmuller. R., Body of. See Parovarium. R.'s Fossa. See Fossa. R.'s Glands. See Gland. $\mathbf{R}$.'s Organ, the parovarium, $q$. $v$.

Rosenstrehl's Green. Same as Manganese Green.

Rosenthal, Canal of. See Canal. R.'s Hyperacid Vomiting. See Rossbach's Disease. R.'s Paste, a paste used in treating sycosis. It consists of tannic acid, 75 grains; precipitated sulphur, $21 / 2$ drams; powdered starch and zinc oxid, each $\mathrm{I} 1 / 2$ drams; vaselin, I $1 / 2$ ounces. M. S. To be used at night. R.'s Test, a test for commencing vertebral disease, made by pressing one pole of a faradic battery in contact with the front of the body, and passing the other pole along the spine. If disease exists, pain will be felt.

Roseola (ro-ze'-o-lah) [roseus, rosy]. Rose-rash, or erythema. The name is also given to other diseases, such as Rubella, or German measles. See Erythena. R. xstivalis. See Erythema roseola. R. annulata. See Erythema roseola. R. autumnalis. See Erythema roseola. R., Balsamic. See Erythema. $\mathbf{R}$. cholerica, an eruption which often appears upon the ninth day of an attack of cholera. R., Circinal, a form with ring-shaped eruptions. $\mathbf{R}$. circinata. Synonym of Pityriasis rosea. R., Epidemic. See Rötheln, also Rubeola. R. febrilis, a name given to the Erytheme roseola occurring in malaria. $\mathbf{R}$., Herpetic, R., Miliary, a form attended with the formation of vesicles. $\mathbf{R}$, infantilis. See Erythema roseola. R., Rheumatic, the reddish eruption that appears in rheumatism. R., Secondary, R., Symptomatic, roseola occurring as a secondary symptom of other disorder. R., Syphilitic, Syphilitic Exanthem; Erythematous Syphilid; Macular Syphilid, the earliest of the skin-manifestations of syphilis. It arises usually six or seven weeks from the first appearance of the initial lesion. It is a diffuse mot tling or marbling of the skin in spots the size of the finger-tip, or smaller, with ill-defined and irregular borders. The color at first is a bright rose-pink, disappearing on pressure, but it soon becomes purplish or yellow. Favorite seats are the front of the trunk, flank, back, and flexor surfaces of limbs. It lasts from one to four weeks. R. typhosa, the typhoid rash $\mathbf{R}$. vaccina, an erythematous eruption appearing from the third to the eighteenth day after vaccination, analogous to that seen sometimes at the onset of variola. The eruption consists of red maculæe, at times reaching the size of the palm, commencing usually upon the arms, and thence spreading at times all over the body.

Roseolar (ro-ze'-o-lar) [roseus, rosy]. Pertaining to or exhibiting roseola.

Roseoloid (ro-ze'-o-loid). Same as Roseolous.

Roseolous (ro-ze'-o-lus) [roseus, rosy]. Having the character of roseola.

Roseous (ro'-ze-us) [roseus, rosy]. Rose-colored.

Roser's Method. The dependent position of the head in operations on the respiratory passages, to prevent blood flowing into the trachea. R.'s Line. See Line. R.'s Position. See Position. R.'s Theory of Inflammation. See under Theory.

Roser-Nélaton Line. A synonym of Nélaton's Line. See Lines, Table of.

Roset, Rosette (ro-zet'). See Karyokinesis.

Rosewood-oil. "A pale-yellow, viscid, volatile oil, having an odor resembling that of sandal-wood or rosewood, and obtained by distillation with water from a kind of rosewood" (Cent. Dict.).

Rosin $\left(r o z^{\prime}-i n\right)$ [a variation of resin]. See Resina, and Colophony Resin. R.-grease. See R.-oil. R.oil, a violet-blue fluorescent liquid, varying in specific gravity from .98 to $\mathbf{1 . 1}$, obtained by dry distillation from colophony resin. It is largely used as a lubricant, especially for machinery and wagon-wheels. It is used in the condition of "rosin-grease" (made by stirring rosin-oil with milk of lime), and largely as a substitute for linseed-oil in the manufacture of printers' ink. R.-plant. Same as R.-weed. R.-soap, a soap made of rosin and soda or potash. R.-weed, Compass Plant. The plant Silphium laciniatum secretes an oleo-resin commonly used as a chewing-gum. Tonic, alterative, and emetic. Dose of fld. ext. 3 ss-j. Unof. Rosinol (roz'-in-ol). See Retinol.

Rosmal (roz'-mal). A commercial name for liquid storax.

Rosmarinus (roz-ma-ri'-nus) [ros, dew ; marinus, marine: gen., Rosmarini]. Rosemary. The leaves of $R$. officinalis. Its properties are due to a volatile oil and a resinous principle. It is somewhat useful as an external stimulant in liniments and lotions. R., Oleum, the volatile oil. Dose $\eta_{\text {j }}-\mathbf{v}$. R., Spiritus. (B. P.) Dose $m_{\text {j-v. }}$.

Rosoglio or Rosolio (ro-söl'-yo) [Ital.]. I. A kind of red wine. 2. A cordial highly popular in the Mediter ranean region. The plant called sundew (Drosera) is believed to be used in making some brands of this liqueur. 
Rosolene (roz'-o-lèn) [rosin, a variation of resin; oleum, oil]. The oily distillate of colophony.

Rosolic (ro-zol'-ik) [ME., rose, rose]. Relating to rosanilin. R. Acid. See Acid and Aurin. R. Blue. Same as Azulin.

Rossalia, Rossania (ros- $a^{\prime}-l e-a h$, ros- $\left.a^{\prime}-n e-a h\right)$. Synonym of Scarlatina.

Rossbach's Disease. See Diseases, Table of.

Rostel (ros'-tel) [rostellum, a little beak]. Same as Rostellum.

Rostellar (ros-tel'-ar) [rostellum, a little beak]. Pertaining to a rostellum.

Rostellate (ros-tel'-ät) [rostellum, a little beak]. Having a small rostrum.

Rostelliform (ros-tel'-if-orm) [rostellum, a rostellum; forma, form]. Having the form of a rostel.

Rostellum (ros-tel'-um) [dim. of rostrum, a beak: pl., Rostella]. In biology: (a) A little beak; the hookbearing or spine-bearing portion of the head of certain worms; (b) A peculiar viscid modification of the upper stigma of the three confluent styles in many orchids, which holds the retinaculum or disc to which the pollen-masses are attached.

Rostral (ros'-tral) [rostrum, beak]. I. Pertaining to or resembling a rostrum. 2. See Cephalic.

Rostrate (ros'-trāt) [rostrum, a beak]. In biology, furnished with a beak, or a beak-like process or extension.

Rostriferous (ros-trif'-er-us) [rostrum, beak; ferre, to bear]. Having a beak or rostrum.

Rostriform (ros'-trif-orm) [rostrum, beak; forma, form]. Shaped like a rostrum.

Rostroid (ros'-troid). Same as Rostriform.

Rostrular (ros'-tru-lar) [rostrulum, a small beak] Pertaining to a rostrulum.

Rostrulate (ros'-tru-lāt) [rostrulum, a small beak] In biology, provided with a rostrulum.

Rostrulum (ros'-tru-lum) [dim. of rostrum, a beak, snout: pl., Rostmula]. In biology, a term for the peculiar mouth-parts of fleas.

Rostrum (ros'-trum) [L., the beak (of a bird): pl., Rastrums or Rostra]. A projection or ridge, as the rostrum of the sphenoid or of the corpus callosum. The ventral continuation of the genu of the callosum. In biology, a beak or snout or proboscis; a beak-like structure.

Rosula $\left(r o z^{\prime}-u\right.$-lah $)$ [dim. of rosa, a rose]. A roset.

Rosular (roz'-u-lar). Same as Rosulate.

Rosulate $\left(r o z^{\prime}-u-l \bar{t} t\right)$ [rosa, a rose]. In biology, having the leaves arranged in the form of a roset.

Rosy $\left(r o^{\prime}-z e\right)$ [ME., rose, rose]. Blushing; like a rose. R.-colored, having a rosy color. R.-drop, acne rosacea; grog-blossoms; brandy-face. See Rosacea.

Rot [ME., rot, rot]. To suffer putrefactive fermentation. In biology: (a) Loosely applied to various processes of organic disintegration, dissolution, decomposition, or decay ; (b) A disease of sheep. due to the fluke, Fasciola hepatica; also called waterrot, fuke-rot, bane, pourriture, cachexie aqueuse, Exelseuche, Leberkrankheit, Fäule. R., Dry, a form of decomposition of wood-tissue due to chemic or fungoid change. R., Potato. See Mildere.

Rotate $\left(r o^{\prime}\right.$-tât $)$ [rotore, to revolve]. Wheel-shape. In dentistry, the term implies the turning of a tooth on its axis. R.-plane, in biology, wheel-shaped and flat.

Rotating (ro-ta'-ting) [rotare, to revolve]. Revolving. R. Devices, appliances, either single or double, for correcting torsion of single-rooted teeth.

Rotation (ro-ta'-shun) [rotare, to rotate]. I. Turning with a circular motion. That movement in a joint by which the bone rotates on its own axis, as in the atlas and axis, also the hip-ioint and the shoulderjoint. 2. A Swedish rotatory movement, by which the different joints are brought into motion within their natural limits. The aim is to lengthen and shorten the veins, so as to produce a sucking of their contents, thus stimulating the circulation and assisting the heart in its action. $\mathbf{R}$. of Protoplasm, applied to the movement of the whole mass of protoplasm in a cell revolving on its own axis and carrying with it the grains and granules contained in it. Cf. Cyclosis. R.-stage of Labor, one of the stages of labor, consisting in a rotatory movement of the fetal head or other presenting part, whereby it is accommodated to the birth-canal. It may be internal, occurring before the birth of the presenting part, or external, occurring afterward.

Rotator (ro-ta'-tor) [rotare, to turn]. Any mechanical device that produces rotation. Also, the name of several muscles that turn the parts to which they are attached.

Roth, Bacillus of. See Bacteria, Synonymatic Trble of.

Rothein (ro'te-in). Same as Phenyl-brozun.

Rötheln (rāt'-eln). See Rubeola.

Rotiferous (ro-tif'-er-us) [rota, a wheel; ferre, to bear]. In biology, having a wheel.

Rotiform (ro'tif-orm) [rota, a wheel; forma, form]. Shaped like a wheel; rotate.

Rotten $\left(\right.$ rot $\left.^{\prime}-n\right)$ [ME., roten, rotten]. The state re sulting from natural decomposition.

Rotterin (rot'-er-in) [after Rotter, of Munich]. A soluble, non-toxic antiseptic introduced by Rotter, of Munich.

Rottlera (rot-le'-rah). See Kamala.

Rotula $\left(r^{\prime} t^{\prime}-u-l a h\right)$ [L., dim. of rota, wheel : pl., Rotulce]. Any small, circular body. The patella or knee-cap. In biology, a radial piece in the oral skeleton of certain echinoderms.

Rotulad (rot'-u-lad) [rotula, a little wheel]. Toward the rotular aspect.

Rotular $\left(r o t^{\prime}-u-l a r\right)$ [rotula, a little wheel]. Of or pertaining to the rotula, or to the patella, e. $g$., the patel lar aspect of a limb; opposed to popliteal.

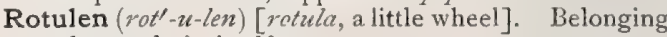
to the rotula in itself.

Rotuliform (rot'-u-lif-orm) [rotula, a litcle wheel; forma, a form ]. Shaped like a rotula.

Rotund (ro-tund') [rota, a wheel]. In biology, having a rounded outline.

Rotundate (ro-tun'-dàt) [rotundus, round]. Rounded off.

Rotundifolious (ro-tun-dif-o'-le-us) [rotundus, round; folium, leaf ]. In biology, having round leaves.

Roubain Blue. Same as Coupier's Blue.

Roucou (roo'-koo). Same as Annotto. See Pigments, Conspectus of.

Rouge (roozh) [Fr.]. A dye made from the safflower, Carthamus tinctorius, used as a cosmetic. Also, any cosmetic for producing a flush of the skin. Also, the form of ferric oxid known as crocus martis and colcothar, used for polishing glass. R., Végétal. Same as Carthrmin.

Rouge's Operation. See Operations, Table of.

Rouget, Bacillus of. See Bacteria, Synonymatic Table. Roulet, Roulette (roo-let") [Fr., a "roller"]. A roller, or light wheel, used in some forms of massage, and in the application of labile currents of electricity.

Round [ME., round, round]. In anatomy, applied to various parts having a nearly circular section. R. Foramen, a foramen of the sphenoid bone transmitting the second or superior maxillary branch of the fifth pair of nerves. R.-headed, having a round hẹd. 
R. Ligaments of the Uterus, a name given to two cords originating in the superior lateral parts of the uterus and terminating in the areolar tissue of the groins and labia. $\mathbf{R}$.-shouldered, having the shoulders drooped. R. Ulcer, a name given to simple ulcer of the stomach. R. Window of the Ear. See Fenestra rotundu. R.-worm, ascaris lumbricoides. See Thread-worms.

Roundel (rown'-del) [ME., roundel, anything round and flat]. The bone button removed by the trephine.

Rounder (rown'-der). See Rounding.

Rounding (rown'-ding) [ME., round, round]. A term given to that propensity manifested by certain hypochondriac individuals to run the round of all the free dispensaries in a vicinity. Such patients are termed "rounders."

Roup (roop). A contagious disease of poultry, characterized by offensive breath, discharge from the nostrils, and swollen face and eyes. It is probably tuberculous in nature, and is very commonly fatal.

Rousseau's Laudanum. See Laudanum.

Roussel's Treatment. See Treatment, Methods of.

Roussillon (roo-se-yon $\left.(g)^{\prime}\right)$ [Fr.]. A sweet red wine, used as a substitute for port. It contains from II to 16 per cent. of alcohol.

Roussin's Fluid. A fluid used in the microscopy of the blood. It consists of glycerin three parts, sulphuric acid one part, with water sufficient to reduce the specific gravity to $\mathbf{1 . 0 2 8}$.

Royal (roi'-al) [ME, roial, royal]. Pertaining to a king; kingly. R. Blue. See Pigments, Conspectus of. R. Fern. See Buckhorn Fern. R. Green. Same as Schweinfurth Green. R. Suture, a form of suture used in the treatment of hernia. See Suture.

Rubber ( $\left.m b^{\prime}-e r\right)$ [origin uncertain]. Caoutchouc; india-rubber. R.-dam, or Coffer-dam, Barnum's, consists of a small piece of sheet-rubber, or rubber cloth, about six inches wide and from six to ten inches long, used for preventing the saliva and breath from interfering with the operation of filling teeth. It is secured by ligatures and clamps. R.-dam Clamps, flexible steel clamps to prevent the rubber-dam from being forced off the tooth by movements of the lips and tongue, and also useful in forcing the rubber higher up on the tooth, and pressing it aside to facilitate access to the cavity. See Clamp. R.-dam Holder, consists of an elastic ribbon, attached to two oval plates, upon which spring catches are adjusted to hold the rubber. R-dam Punch, an instrument used for perforating the rubber-dam for the reception of the teeth. R.-dam Weights, small weights of metal intended to be suspended from the free ends or borders of the dam, to keep it out of the way of the operator. R., Hard. See Vulcanite. R., India, or R., Indian, Caoutchouc, q.v. Also, see Vulcanite Base.

Rubbers (rub'-ers). See Scab.

Rubbing ( $\left.m b^{\prime}-i n g\right)$. One of the methods of carrying out massage. See Massage.

Rubedo $\left(r u-b e^{\prime}-d o\right)$ [ ruber, red ]. Any diffused redness of the skin; blushing.

Rubefacient (ru-be-fa'-se-ent) [ruber, red; facere, to make]. I. Causing redness of the skin. 2. A medicine or agent that by irritation of the ends of the nerve-filaments of the skin causes distention of the capillaries and reddening of the skin.

Rubefaction (ru-be-fak'-shun) [rubefacere, to make red]. Redness of the skin produced by a rubefacient.

Rubella ( $\left.r u-b e l^{\prime} \cdot a h\right)$ [dim. of ruber, red]. A synonym of Rubeola, q. v., Rötheln, or German Measles, This term is also vaguely applied to other somewhat similar affections attended with slight eruptions.
Ruben's Madder. See Pigments, Conspectus of.

Rubeola (ru-be'-o-lah) [rubeus, red]. Rötheln; Rubella, or Germon Measles; French Mersles; an acute, specific, exanthematous, contagious disease of childhood, characterized by enlargement of the superficial lymphatic glands, especially those of the neck, by catarrhal symptoms, and by an eruption appearing first upon the face and scalp, and consisting of small rose-colored spots. It is followed by a slight, branny desquamation. The period of incubation is usually eleven or twelve days. The term rubeola was formerly used synonymously with measles. See Exunthemata, Table of. R. confluens. See Scarlet Fever. R. maligna. Synonym of Black Measles. R. nigra, R. scorbutica, black measles. $\mathbf{R}$. notha, an anomalous form of measles, with a papular eruption, the papulæ not being arranged in crescentic clusters, being less obvious, and not appearing at all, or showing themselves but imperfectly, on the limbs. The patches are of dusky hue, and there is no distinct sore-throat, but considerable constitutional disturbance. $\mathbf{R}$. scarlatinosa. See Scarlatina. R. vulgaris. See Measles.

Rubeolar (ru-be'-o-lar) [rubeus, red]. Of the nature of or pertaining to rubeola.

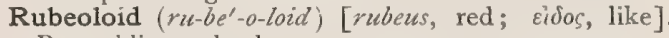
Resembling rubeola.

Rubescence (ru-bes'-ens) [rubescere, to become red]. Blushing ; redness of countenance or complexion.

Rubescent (ru-bes'-ent) [rubere, to be red]. Blushing; becoming red.

Rubiacin $\left(r u-b i^{\prime}-a s-i n\right)$. See Pigments, Conspectus of.

Rubicund ( $r u^{\prime}$-bik-und) [nbicundus, very red]. Ruddy ; inclined to redness.

Rubidin (ru'-lidi-in). See Orseillin.

Rubidium (ru-bid'-e-zm) [rubidus, red]. $\mathrm{Rb}=85.3$; quantivalence I. One of the rare alkaline metals, resembling potassium in physical and chemic properties. See Elements, Table of. R.-alum, an alum much resembling potash-alum, but less soluble in water. In Europe alum prepared from the mineral, bepidolite, sometimes contains a considerable proportion of rubidium-alum. Unof. R.-ammonium Bromid, $\mathrm{RbBr}\left(\mathrm{NH}_{4} \mathrm{Br}\right)_{4}$, a double salt of rubidium, introduced as a substitute for potassium bromid. It is a white, crystalline powder, having a cooling, saline taste, and is readily soluble in water. It is used as a hypnotic and sedative, with special recommendation in the treatment of epilepsy. Dose I to 2 drams, in divided doses, best given in mixture with syrups flavored with lemon or orange. It has not been adopted generally, although endorsed by good authorities, and it is comparatively little known. R. Bromid, a serviceable but expensive substitute for potassium bromid. Unof. R. Chlorid, unof., lowers the pulse-rate and raises the arterial tension. Dose gr. ij-v.

Rubiginose $\left(r u-b i j^{\prime}-i n-\bar{o} z\right)$ [rubiginosus, rusty]. Brownred.

Rubiginous ( $\left(r \bar{u}-b i j^{\prime}-i n-u s\right)$ [rubiginosus]. Rust-colored.

Rubigo (ru-bi'-go). See Rust.

Rubijervin (ru-bij-er'-vin) [rubeus, red; jerva, green hellebore root], $\mathrm{C}_{26} \mathrm{H}_{43} \mathrm{NO}_{2}$. An alkaloid of Veratrum album.

Rubin. Same as Fuchsin.

Rubini's Tincture of Camphor. See Camphor.

Rubor (ru'-bor). [L.] The redness or discoloration due to inflammation.

Rubores $\left(r u-b o r^{\prime}-\bar{e} z\right)$. Synonym of Scarlatina.

Rubreserin (ru-bres'-er-in). A product of the decom position of physostigmin. 
Rubricose (mu'brik-öz) [mbricosus, full of red earth] In biology, marked with red.

Rubula $\left(r u^{\prime}-b u-l u h\right)$. See Frambasia.

Rubus (ru'-bus) [L., gen., Rubi]. Blackberry. The bark of several species of Rubus. It contains about Io per cent. of tannic acid, to which its properties are mainly due. It is useful in the summer complaints of children. Dose gr. $x v-x \times x, \quad R$, chamæmorus, the cloud-berry. It is used in Russia as a diuretic and sudorific, the berries, leaves, and flowers being employed in infusion or extract. Unof, R., Ext., Fld. Dose $m x-3 j$. R. idæus, Raspberry, the fruit of several species of rubus. It contains various fruit-acids, flavors, etc. It is used as a flavor for syrups. R. id., Syr., contains the clarified juice of the fruit with sugar q. S. R., Syr., fld. ext. rubus 25 , syrup 75 parts. Dose 3j-zj. R., Syr, Aromat., unof, contains the rootbark with cloves, cinnamon, nutmeg, etc. Each fluidounce contains gr. $\mathrm{xxx}$ of the drug.

Ructamen (ruk-ta'-men) [L., pl., Ructamina]. A ructation

Ructation (ruk-ta'-shun) [ructatio]. An eructation or belching of wind.

Ructus (ruk'-tus) [L.]. $\Lambda$ belching of wind from the stomach. R. hystericus, hysteric belching, the gas escaping with a loud, sobbing, gurgling noise

Rudbeckia (rud-bek'-e-ah) [after Olaus Rudbeck, a Swedish botanist]. A genus of composite-flowered plants, chiefly North American; cone-flowers. R. laciniata, and $\mathbf{R}$. purpurea, are diuretic and alterative. See Thimblezved. Unof.

Ruddy (rud'-e) [ME., ruddy, ruddy]. Of a red color, reddish.

Ruderal ( $\left.r u^{\prime}-d e r-a l\right)$ [rudus, rubbish, stones broken small and mixed with lime]. In biology, growing among rubbish.

Rudiment ( $\mathrm{ru}^{\prime}$-dim-ent) [rudimentum, a beginning]. In biology, a part or organ in a primary stage, or aborted or remaining as a functionless trace of something once important to the organism. Cf. Anlage, and Proton.

Rudimentary (ru-dim-en'-ta-re) [ruiimentum, a rudiment]. In an undeveloped or unfinished state. $\mathbf{R}$. Organ, one whose development was arrested before reaching a state of normal growth.

Rue $(r u)$. See Ruta.

Rufescent $\left(r u-f e s^{\prime}-e n t\right)$. Developing a reddish-brown color. Rufous.

Ruficarmin (ru-fik-ar'-min) [rufus, red; carmin]. A bright-red substance obtained by heating carmin and water. See Pigments, Conspectus of.

Ruficoccin ( $\left.r u-f i k-o k^{\prime}-s i n\right)$. A brick-red animal coloring-matter obtained from carmic acid by heating with concentrated $\mathrm{H}_{2} \mathrm{SO}_{4}$ to $120^{\circ} \mathrm{C}$. $\left(248^{\circ} \mathrm{F}\right.$.). It is soluble in alcohol with a yellow fluorescence. See Pigments, Conspectus of.

Rufigallic Acid ( $\left.r u-f g-n l^{\prime}-i k\right)$. See Arid.

Rufous (ru'-fus) [rufus, red]. Reddish-brown.

Ruga $\left(r u^{\prime}-\zeta a h\right)$ [L., a wrinkle: pl, Rugn]. x. A wrinkle, furrow, crease, or ridge, as, $e_{.} g$. , in the mucosa of the stomach, vagina, etc. 2, A fold of pia on the ental surface of the piarachnoid.

Rugine (ru'-gin, or $\left.r u^{\prime}-z h \bar{e} n\right)$ [Fr.]. A surgeon's rasp, or scraper.

Rugitus (ru-gi'-tus). See Bomlus.

Rugose (ru'-gōz) [ruga, a wrinkle]. Applied to a surface that is rough or wrinkled.

Rugosity (ru-gos'-it-e) [rugositas, the state of being wrinkled]. A condition of being in folds, or wrinkles. Roughness.

Rugous ( $\left.r u^{\prime}-g u s\right)$. Same as Rugose.

Ruhmkorff Coil. See Coil.
Rule (rül) [ME., rule, rule]. A formula or general proposition. R., Goodell's. See Law, Goodell's, R. of Ready Practice. See Law, Goodell's.

Rum [abbreviation of rumbultion]. A spirit obtained in the West Indies and the U. S. from the molasses - of the sugar-cane by fermentation and distillation. When new, it is white and transparent, and has, when freshly distilled, an unpleasant odor, due to oils contained. These are removed by treatment with charcoal and lime. Cf. Bay.rum. R.-blossom, a pimple on the nose caused by excessive drinking; rum-bud; acne rosacea. R.-bud. See $R$-blosson.

Rumbling (rum'-bling). See Borborygmus.

Rumen (ru'-men) [rumen, the throat, or gullet]. In biology, $(a)$ the first compartment of the complicated stomach of a ruminant, also called the paunch, plain tripe, and farding-bag (see Farding $b a g$ ); (b) the cud of a ruminant.

Rumex (ru'-meks) [L., gen., Rumicis]. Yellow Dock. The root of $R$. crispus and other species of $R$. Its properties are due to tannin, calcium oxalate, and chrysophanic acid. It is astringent and tonic and is useful in combination with the iodids. Dose $g r . x \nabla-3 j$. R., Decoct., contains $z_{j}$ of the dried root to $\mathrm{O}_{j}$ of water. Dose $\mathbf{z j}$-ij. R., Fld. Ext. Dose $\{\times \mathbf{x v}-\mathbf{z}$.

Rumicin $\left(r u^{\prime}-m i s-i n\right)$. Synonym of Acid, Chrysophanic.

Rumin $\left(\mathrm{ru}^{\prime}\right.$-min) [rumex, sorrel]. A precipitate from a tincture of the root of Yellow Dock, Rumex crispus; resolvent, anti-scorbutic, mildly astringent, and laxative. Dose 3 grains. Unof.

Ruminant (ru'-min-ant) [ruminare, to chew the cud]. In biology, chewing the cud; specifically applied to one of the best defined and most closely united of any of the groups of Mammalia (the Pecora or Cotylophora), the complicated stomach of which is characteristic, consisting of four well-defined compartments known as (I) the rumen, or paunch; (2) the reticulum, or honey-comb bag; (3) the psalterium, or manyplies; (4) the abomasum, or reed.

Ruminate ( $r u^{\prime}$-min-ät) [muminare, to chew the cud]. In biology, $(a)$ to chew the cud; $(b)$ applied to the albumin of certain seeds, when channeled or perforated with holes through which the inner coat penetrates, as in the nutmeg.

Ruminatio (ru-min-a'-she-o). See Rumination.

Rumination (ru-min-a'-shun) [ruminare, to chew the cud]. I. Merycismus; a remarkable and rare condition in which patients regurgitate and chew the cud, like ruminants. It occurs in neurasthenic or hysteric persons, epileptics, and idiots. It may be hereditary. Certain persons have the power of returning food from the stomach to the mouth at will. 2. In biology, the return of ingesta-the cud-to the mouth from the paunch, and its remastication. Among certain of the lower animals this function is normal.

Rump [ME. rumpe, rump]. The end of the backbone; the buttocks, or nates. R.-bone, the sacrum.

Run [ME., rinnen, to run]. In pathology, to discharge pus or purulent matter from a diseased part. R.-around. See Paronychia.

Runcinate $\left(\right.$ run' $\left.^{\prime}-\sin -\bar{a} t\right)$ [runcina, a plane]. In biology, a modification of a pinnatifid leaf, in which the points of the large central lobes are reflected, e.g., in the dandelion.

Runge's Method. A method of dressing the umbilical cord. The stump is powdered with a mixture of boric acid and starch, one part to three.

Runner (run'-er) [AS., ryne, course, path]. In biology, (a) a stem or branch, like that of the strawberry, that creeps along the ground, rooting at intervals; $(b)$ a cursorial animal. 
Running (run'-ing) [ME., rimen, to run]. Moving quickly. R. Amuck. See Amuck. R. Scall. Synonym of Eczema.

Runt [E. dialect.]. A dwarf.

Rupestrine (ru-pes'-trin) [rupes, a rock]. In biology, living or growing upon or among rocks.

Rupia $\left(m i^{\prime}-p e-a h\right)[p v \pi o s, f i l t h]$. A term used to denote a variety of pustular syphiloderm characterized by the formation of large, dirty-brown, stratified, conic crusts, like limpet shells. R. escharotica. See Dermatitis gangranosa infantum.

Rupial ( $\left.r u^{\prime}-p e-a l\right)[\hat{\rho} \dot{\pi} \sigma \varsigma$, filth]. Resembling rupia.

Rupophobia (ru-po-fo'-be-ah) ['íros, filth; $\phi 6 \beta o s$, fear]. Insane dread of filth. See Mysophobia.

Ruptorium (rup-to'-re-um) [ruptio, a breaking]. An apparatus for the breaking of continuity.

Rupturo (rup'-tur) [ruptura; rhexis; rumpere, to break]. Breakage or laceration of the walls or continuity of an organ, especially of a viscus. Also, the popular name for hernia.

Ruptured (rup'-tūrd) [ruptura; rumpere, to break]. Burst; affected with hernia.

Rusconi, Anus of. See Protostoma.

Ruscus (rus'-kus) [ruscum, butchers' broom]. A genus of monocotyledonous plants. $\mathbf{R}$. aculeatus, the butchers' broom or knee-holly of Europe. The rhizome is diuretic. $\mathbf{R}$. hypophyllum and $\mathbf{R}$. hypoglossum have similar qualities. Unof.

Rusma (nus'-mah). See Rhusma.

Russel and West's Method. See Urea.

Russian (rush'-an) [Russ., Rossuja, Russia]. Pertaining to Russia. R. Bath. See Bath. R. Disease. Synonym of Influenza. R. Glue. See Glue. R. Pest. Synonym of Infuenza. Russo-Polish Fever. Synonym of Typhus Fever.

Russow's Potash-alcohol. An alcoholic solution of potassium hydrate employed in vegetable histology as a solvent of suberin and other substances incrusting the cell-wall.

Rust [ME., rust, rust]. I. The oxids, hydrates, and carbonates collecting on the surfaces of metals exposed to moist air. 2. In biology, a disease common on cereals, causing masses of rust-like dust to break out from the tissues of the plant. It is caused by fungi of the class Uredinea. R., Apple, R., Quince, Rastelia aurantiaca, Pk. ; $R$. transformans, EIl.; Acidium piratum, S. R., Bean, R., Pea, Uredo appendiculata. R., Beet, Uromyces bete, Kühn. R., Blackberry, and R., Raspberry, Acidium (Cooma) niteus, S. R. of Carnation-pinks, Uromyces caryophyllinus. R., Celery, Puccinia bullata. R., Clover, Uromyces trifolii, Abb. R., Corn, Puccinium sorghi, S. P. maydis, Berenger. R., Elder, Acidium sambuci, Schw. R. Flax., Melampsora lini, Desm. R., Hollyhock, Puccinia malva cearum,
Mont. R., Oat, R., Wheat, Puccinia graminis, P.; P. coronata; Pucinia rubigo vera, D. C. R., Peach, R., Plum, R., Cherry, Puccinia pruni spinose, P. R., Pear, Gymnosporangium nidus avis, Thaxter; Ecidium cancellatum, Gmel. R., Rose, Phragmidium subcorticum. R., Strawberry, Ramularia fragaria, Pk. R., Sugar-cane, Uromyces Kühnii. 3 . The "brusone," "white blast," or "water weevil," (Lissorhoptrus simplex, Say), a coleopterous enemy of the rice-plant.

Rust's Disease. See Malum. R.'s Disinfectant, a mixture of camphor and myrrh, each seven parts, powdered charcoal and styrax, each 30 parts, and oil of turpentine sufficient to make an ointment.

Rusty (rus'-te) [ME., rust, rust]. Of the nature or appearance of rust. R. Expectoration, the common name for the usual form of expectoration in croupous pneumonia, due to the presence of a small amount of blood in the sputa.

Ruta $\left(n^{\prime}-t a h\right)[\mathrm{L} .$, gen. ruta $]$. Rue. The leaves of $R$. graveolens, which furnish oil of rue by distillation. R., Oleum is irritant, rubefacient, and vesicatory. Internally, it is an efficient emmenagogue. Dose $m_{\mathbf{j}}-\mathbf{v}$, in mucilage.

Ruthenic, Ruthenious (ru-then'-ik, ru-thén'-e-us) [Ruthenia, a province of Russia]. Containing ruthenium as a radicle.

Ruthenium (ru-the'-ne-um) [Ruthenia, a province of Russia]. A rare metal of the platinum group. Symbol. Ru ; atomic weight, I03.5. Little is known of its medicinal properties. See Elements, Table of.

Rutherford's Solution. A decalcifying and hardening solution for tissue-specimens: chromic acid I grm., water 200 c.c.; then add 2 c.c. nitric acid.

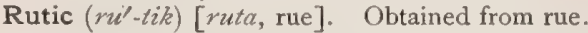

Rutidosis (ru-tid-o'-sis) [ $\rho v \tau^{\prime} i \delta \omega \iota \zeta ; \rho v \tau i \varsigma$, a wrinkle]. A contraction or puckering of the cornea that precedes death.

Rutin ( $\left(u^{\prime}\right.$-tin) [mita, rue]. A crystalline neutral substance obtained from the leaves of rue.

Rutting (rut'-ing) [ME., rut, rut]. The stage of sexual excitement in female animals coincident with the rupture of ovisacs.

Rutulin (rut'-u-lin). A substance obtained from salicin and sulphuric acid.

Rutyl ( $\left.r u^{\prime}-t i l\right)$. Synonym of Cupryl.

Ruysch, Membrane of. See Membrane.

Ruyschiana (ru-she-an'-ah). See Membrane.

Rye $(r \bar{i})$ [ME., rye, rye]. The popular name of the grain Secale cereale, one of the Graminacea. R.asthma, a form of hay-fever occurring at the time of the flowering of rye. R., Ergot of. See Ergot. R., Spurred. Same as Ergot.

Rypia (ri'-pe-ah). See Rupia. 
S. The chemic symbol of sulphur. Letter of "S" Curve, of Pleurisy; the upper line of dulness of a pleural effusion is said to be curved like the letter " $\mathrm{S}$." S. romanum, the sigmoid flexure of the colon. $\sigma$, the symbol of one-thousandth of a second. A microsecond.

Sabadilla (sab-ad-ill-ah). See Cebadilla.

Sabadillin (sab-ad-il'-ins) [cevadilla], $\mathrm{C}_{20} \mathrm{H}_{26} \mathrm{~N}_{2} \mathrm{O}_{5} . \quad \mathrm{A}$ colorless, crystalline alkaloid obtained from cevadillaseed.

Sabal (sa'.bal). See Saw Palmetto.

Sabalol $\left(s a^{\prime}-b a l-o l\right)$. A substance prepared from the active principles of the Saw Palmetto (Serenoa sermlata).

Sabatier's Suture. See Suture.

Sabatrin (sab'-at-rin) [cevadilla], $\mathrm{C}_{31} \mathrm{H}_{86} \mathrm{~N}_{2} \mathrm{O}_{17}$. An alkaloid found in cevadilla-seed.

Sabbatia (sab-a'-she-ah) [after Liberatus Sabbati, an Italian botanist]. The herb $S$. campestris, of value in the sick headache of indigestion. Dose of the fid. ext. $m x v-3 j$. Unof. S. angularis is a good bitter tonic and appetizer. Other plants of this genus have similar properties, especially S. chloroides. They have the medicinal virtues of the gentians, to which they are nearly related. $\mathbf{S}$. eliotti is known as quininflower. S. paniculata is used for the same purposes as $S$. angularis.

Sabina (sa-bi'-nah) [L., gen., sabina]. Savine. The tops of Juniperus $S$; its properties are mainly due to a volatile oil which resembles turpentine, but is more irritant. In large doses it produces violent purging and vomiting. It is used as an emmenagogue. Externally, it is useful to prolong the discharge from blisters and to stimulate ulcers to cicatrization. S., Ceratum, fld. ext. savine 25 , resin cerate 90 parts. S., Fld. Ext. Dose $m^{v-x v}$. S., O1., the volatile oil. Dose $m_{\mathrm{j}-\mathrm{v}}$. S., Tinct. (B. P.) Dose $\eta_{\mathrm{x} x}-z_{\mathrm{j}}$.

Sabulose (sab'-u-lōz) [sabulum, sand]. In biology, growing in sand.

Sabulosity (sab-u-los'-it-e) [sabulum, sand]. Sandiness ; grittiness.

Sabulous (sab'-u-lus) [sabulum, sand]. Gritty; sandy. Growing in sandy or gravelly places. Pertaining to the sandy deposit sometimes found in urine. Also, to the gritty matter called brain-sand, found in the pineal gland and in psammoma. See Acervulus.

Saburra $\left(s a b-u r^{\prime}-a h\right)$ [coarse sand]. Foulness of the stomach, or of the tongue or teeth; sordes.

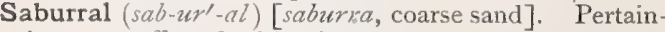
ing to or affected with saburra.

Saburration (sab-ur-a'-shun) [saburra, coarse sand]. The use of the sand-bath; ammotherapy, or arenation. In biology, the act of rolling in the sand, as practised by poultry

Sac (sak) [saccus, a bag]. The bag-like bulging or covering of a natural cavity, hernia, cyst, or tumor. S., Air, the air-cells of the lung. S., Allantoid. Synonym of Allantois. S., Amniotic, the amnion. Ss., Auditory, the rudimentary organs of hearing of the embryo of certain vertebrates. S., Dental. See Dental Sac. S., Embryonic, the sac-like stage of the embryo, which it presents early in its development, just after the abdominal plates have closed. S., Fetal. See S., Gestation. S., Gestation, the sac enclosing the embryo in ectopic pregnancy. $\mathbf{S}$., Hernial, the peritoneal covering of a hernia. S., Lacrymal, the dilated upper portion of the lacrymal duct. Ss., Latex, milk-sacs, spaces con- taining the latex of plants. S., Omental, the sac formed between the ascending and descending portions of the great omentum. S., Peritoneal, the cavity formed by the peritoneal serous membrane. S, Pleural, the cavity formed by the pleura. S., Vitelline, the sac enclosing the vitellus or yolk in the embryo. S., Yolk. See Umbilical Vesicle.

Sacatra (sak'-a-trah). A person of seven-eighths black and one-eighth white blood.

Saccade (sak-ahd') [F., saccade, pull, draw]. The involuntary jerk of deglutition.

Saccaneurysma (sak-an-u-riz'-mah) [бákкos, bag ; Ev̉oíveıv, to dilate]. A sacculated aneurysm.

Saccate, or Saccated $\left(s a k^{\prime}-\bar{a} t, s a k^{\prime}+a-t e d\right)$ [saccus, sac or pouch]. Sac-shaped or contained in a membranous envelop. Encysted; pouched; furnished with a sac.

Saccharate $\left(s a k^{\prime}-\alpha r-\bar{a} t\right)$ [saccharum, sugar]. I. Having or containing sugar. 2. A compound of saccharic acid and a base. 3. A compound of cane-sugar with a base. S. of Iron (Ferrum oxydatum saccharatum solubile, Ger. Ph.). A compound of cane-sugar and iron, important as an antidote for arsenic. S. of Lead, a salt of saccharic acid and lead, used in forming the nitro saccharate of lead, which has been vaunted as a safe and effective solvent of urinary calculus. S. of Lime, a compound of cane-sugar with lime. A syrup charged with it has been recommended as a cure for chronic rheumatism. A solution of this compound is a good antidote in carbolicacid poisoning.

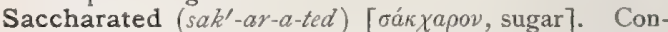
taining sugar. S. Carbonate of Iron, a greenishgray powder containing sulphate of iron. S. Iodid of Iron, iodid of iron with milk-sugar. S. Pepsin, milk-sugar with pepsin from the stomach of the hog. $\mathrm{S}$. Tar, a mixture of $\operatorname{tar}$ (4 parts) and sugar ( 96 parts), a soluble medium for medicinal administration.

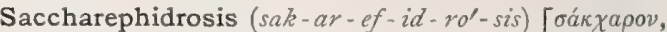
sugar; $\dot{\varepsilon} \phi \delta \rho \omega \sigma \iota s$, ephidrosis]. A form of hyperidrosis characterized by the excretion of sugar in sweat.

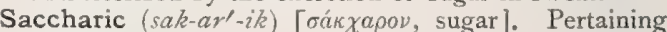
to or obtained from sugar. S. Acid. See Acid.

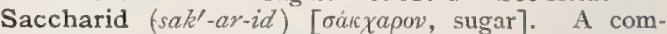
pound of a base with sugar. A sucrate. See Casein Saccharid.

Sacchariferous (sak-ar-if'-er-us) [ $\sigma a ́ k \chi \propto \rho o v$, sugar; ferre, to carry]. Containing sugar.

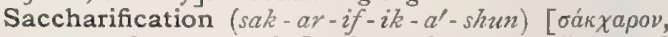
sugar; facere, to make]. Sugar-forming. The act of converting into sugar.

Saccharimeter (sak-ar-iml-et-er). See Saccharometer.

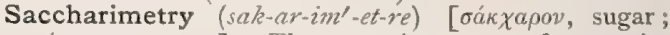
$\mu \varepsilon$ r $\rho \circ \nu$, measure]. The operation or art of ascertaining the amount or proportion of sugar in solution in any liquid.

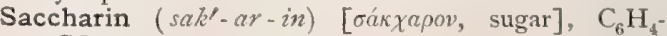
$<\mathrm{SO}_{\text {. }}>\mathrm{NH}$. I. A benzol-sulphonicimid derived from coal-tar, occurring as six-sided, colorless tablets, melting at $224^{\circ} \mathrm{C}$. It is 280 times sweeter than canesugar. It is used as a substitute for sugar in diabetes. and is recommended for use in the treatment of corpulency and gout. It is also antiseptic, and has been found useful in erysipelas, septic fever, and gonorrhea. Dose, gr. 3/4. See Glusidum. 2. $\mathrm{C}_{6} \mathrm{H}_{10} \mathrm{O}_{5}$. The anhydrid of monobasic saccharic acid. $\mathrm{It}$ is soluble in I8 parts of water, forms large crystals, having a bit- 
ter and salty taste, melts at $160^{\circ} \mathrm{C}$., is dextrorotatory and non-fermentable.

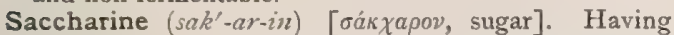
the nature of or containing sugar. An old term for oxalic acid.

Saccharinin $\left(s a k-a \gamma^{\prime}-i n-i n\right)$. Synonym of Saccharin (Ist def.).

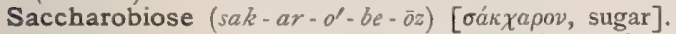
Synonym of Saccharose. The name has been given on account of the property possessed by saccharose of giving rise, when hydrated, to two carbohydrated molecules. $\mathrm{C}_{12} \mathrm{H}_{22} \mathrm{O}_{11}+\mathrm{H}_{20}={ }_{2} \mathrm{C}_{6} \mathrm{H}_{12} \mathrm{O}_{6}$.

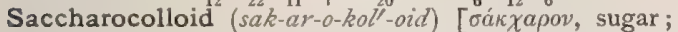
$\kappa \delta \dot{\lambda} \lambda a$, glue; $\varepsilon i \delta o \varsigma$, like]. Any member of that group of carbobydrates to which starch, pectin, and gum belong, which are amorphous, crystallize with difficulty, and diffuse through animal membranes very slowly.

Saccharogalactorrhea (sak-ar-o-gal-ak-tor-e'-ah) [0ak-

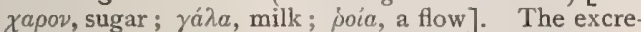
tion of an excess of sugar with the milk.

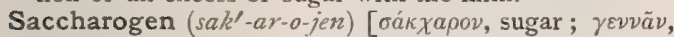
to produce]. A material found in milk, and convertible into lactose. A glucosid.

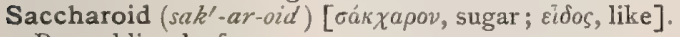
Resembling loaf-sugar.

Saccharometer (sak-ar-om'-et-er) [бákxapov, sugar;

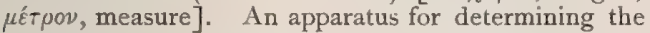
amount of sugar in solutions, either in the form of a hydrometer which indicates the strength in sugar by the specific gravity of the solution; or of a polarimeter, which indicates the strength in sugar by the number of degrees of rotation of the plane of polarization. S., Fermentation, an instrument for collecting and estimating the percentage of carbon dioxid evolved in the fermentation of saccharine urine.

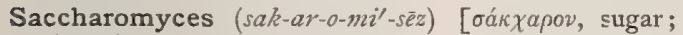
$\mu \hat{v} \kappa \eta$, fungus: $p l$., Saccharomycetes]. A genus of unicellular vegetable organisms, of which the yeast-plant is a common example. S. albicans, the same (Rees) as the Oidium albicans of Robin; the fungus of thrush. S. apiculatus, a fungus-ferment found upon gooseberries, etc, S. capillitii, a form found on the human scalp and supposed to cause Pityriasis capitis. S. cerevisiz, the ferment of beer-yeast. S. conglomeratus, found in grape-must when fermentation is nearly over. S. coprogenus, a form observed in human feces. S. ellipsoideus, the common ferment of wine. S. exiguus, found in the last stages of the fermentation of beer. S. glutinis, a species forming a rose-colored coating on gelatin or potatoes. S. guttulatus, occurs in the digestive tract of various animals. S. mesentericus, destroys fruit acids. S. minor, according to Engel, the fungus of bakers' yeast. S. mycoderma (Grawitz), same as S. albicans. S. pasteurianus, a form closely allied to $S$. ellipsoideus. $\mathbf{S}$. psoriasis, occurs in the human scalp, around the hairs. S. reessi, probably a variety of $S$. ellipsoideus. S. sphæricus, found on fermenting tomatoes. S. tyricola, found in fermenting cheese. It resembles S. minor. See Bacteria, Synonymatic Table of.

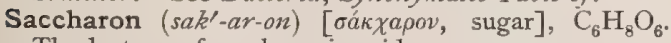
The lactone of saccharonic acid.

Saccharonic Acid (sak-ar-on'-ik). See Acid.

Saccharorrhea $\left(s a k-a r-o r^{\prime}-\ell^{\prime}-a h\right)$ [ $\sigma \alpha ́ k \chi a \rho o v$, sugar; $\rho o i \alpha$, flow]. The secretion of saccharine fluid. S. cutanea. See Saccharephidrosis. S. lactea. See Saccharogalactorrhea. S. pulmonalis, the exudation of sweetish sputa. S. urinosa. See Diabetes mellitus.

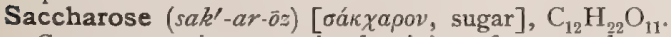
Cane-sugar; it occurs in the juice of many plants, chiefly in sugar-cane, in some varieties of maple, and in beet roots (10-20 per cent.). The syrupy mother liquid from the sugar is called molasses. Saccharose crystallizes in large monoclinic prisms, of a sp. gr. 1.606. Its aqueous solution is levorotatory. Cane-sugar melts at $160^{\circ}$; at $190-200^{\circ}$ it changes into a brown noncrystallizable mass called caramel, used in coloring liquids. It is not directly fermentable and does not reduce alkaline copper-solutions. The ordinary pure sugar of commerce. See Carbohydrates, Table of.

Saccharous $\left(s a k^{\prime}-a \gamma^{\prime}-u s\right)$. Same as Saccharine.

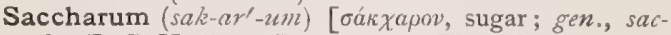
chari], $\mathrm{C}_{12} \mathrm{H}_{22} \mathrm{O}_{11}$. Cane-sugar. The soluble crystalline substance occurring naturally in the juice of the sugar-cane, S. officinarum; maize, Zea mays; the sugarbeet, Beta vulgaris, and the sugar-maple, Acer saccharinum. In pharmacy, in the form of syrups, it is used mainly as a vehicle, and in a solid state as a protective coating for pills and troches. See, also, Glucose, Lactose, and Levulose. S. album, white or pure crystallized sugar. S. canadense, Maple-sugar, obtained from Acer saccharinum. S. candidum, Rockcandy. S. lactis, Sugar of Milk. S. purificatum, pure white sugar.

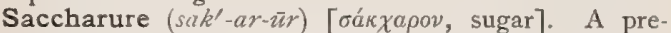
paration obtained by saturating sugar with a tincture, then drying, and pulverizing.

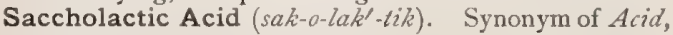
Mucic.

Sacciferous (sak-sif'-er-us) [saccus, sack; ferre, to bear]. In biology, having a sac; saccate.

Sacciform (sak'-sif-orm) [saccus, a pouch; forma, form ]. Resembling a sac; saccate. S. Disease of the Anus, distention and inflammation of the pouches of the rectum.

Saccular (sak'-u-lar) [saccus, sac]. Sac-shaped. S. Aneurysm, a saccular dilatation of an artery, communicating with the latter by a narrow neck.

Sacculate $\left(s a k^{\prime}-u\right.$-lāt $)$ [saccus, a bag]. Having small, sac-like projections.

Sacculated (sak'-u-la-ted) [saccus, sac]. Encysted. Divided into little sacs.

Sacculation (sak-u-la'-shun) [saccus, sac]. A sac-like formation; a sac, or set of sacs; as the sacculation of the colon, or of the uterus in rare cases.

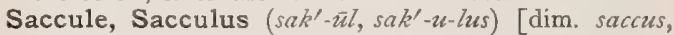
sac]. A small sac. S. communis, oblongus, or semiovalis, the utricle. S. laryngis, the laryngeal pouch between the superior vocal bands and the inner surface of the thyroid cartilage. S. mucosus, the bursa of the rectus femoris muscle. $\mathbf{S}$. of the Vestibule, the smaller of two vestibular sacs of the membranous labyrinth of the ear.

Saccus $\left(s a k^{\prime}-u s\right)$. Synonym of Sac. S. vitellinus. See Sac, Vitelline.

Sacer $\left(s a^{\prime}-s e r\right)$ [L.]. Sacred. S. ignis, erysipelas. S. morbus, epilepsy.

Sachet $($ sash-a') [saccus, a sac]. A small bag of perfumed or medicated substances. S. resolutif [Fr.], a sachet of equal parts of sal ammoniac, iron sulphate, and calcium sulphate.

Sachse's Solution and Test. A solution for testing for sugar in the urine. It consists of 18 grams of red iodid of mercury, 25 grams of potassium iodid, and 80 grams of potassium hydrate in water, diluted to one liter.

Sachs's Theory of Inflammation. See Theory.

Sack (snk) [siccus, dry]. An old name for dry Spanish and Canary wine; sherry. Synonym of Sac.

Sacrad $\left(s a^{\prime}-k r a d^{\prime}\right)$ [sacrum, the sacrum]. Toward the sacral aspect.

Sacral (sa'-kral) [sacrum, sacrum]. Pertaining to the sacrum. S. Bone. See Sacrum. S. Canal. See Canal. S. Cornua. See Cornu. S. Flexure, the 
curve of the rectum in front of the sacrum. S. Foramen. See Foramen. S. Groove. See Groove. S. Index, the sacral breadth multiplied by 100 , and divided by the sacral length. S. Nerves. See Nerves. S. Plexus. See Plexus.

Sacralgia (sa-kral'-je-ah) [sacrum, sacrum; à $\lambda \gamma o s$, pain]. Pain in the sacrum; hieralgia.

Sacrarthrocace (sak-rar-throk'-as-e). See Sacro-iliac Disease.

Sacred (sa'-kred) [ME., sacten, to render holy]. Hallowed; holy. S. Bark. See Cascara Sagrada. S. Malady. Synonym of Epilepsy.

Sacren $($ sa'-kren $)$ [sacrum, sacrum]. Belonging to the sacrum in itself.

Sacrifical (sa-krif'-ik-al) [sacrificare, to sacrifice]. Employed in sacrifice. S. Operation, an operation in which some organ (as an ovary), is sacrificed or destroyed for the general good of the patient.

Sacriplex (sa'-krip-leks) [sacmun, sacrum; plexus, plexus]. The sacral plexus of nerves.

Sacriplexal (sa-krip-leks'-al) [sacnem, sacrum; plexus, plexus]. Pertaining to the sacriplex.

Sacro- $\left.\left(s \alpha^{\prime}-k\right)^{\prime}\right)$ [sacrum, sacrum]. A prefix denoting connection with or relation to the sacrum

Sacro-caudal (sa-kro-kaw'-dal) [sacrum, sacrum; cauda, tail]. In biology, pertaining to the sacrum and the tail.

Sacrococcygeal (sa'-kro-kok-sij'-e-al) [sacrum, sacrum; $\kappa o ́ \kappa \kappa v \xi, \operatorname{coccyx}]$. Pertaining jointly to the sacrum and the coccyx.

Sacrocostal (sa-kro-kos'-tal) [sacrum, sacrum; costa, rib]. Connected with the sacrum and having the character of a rib.

Sacro-cotyloid (sa-kro-kot'-il-oid) [sacmun, sacrum;

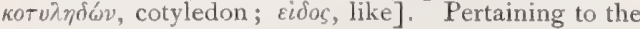
sacrum and the acetabulum.

Sacro-coxalgia (sa-kro-koks-al'-je-ah). See Sacro-iliac Disease.

Sacro-coxitis (sa-kro-koks-i'-tis). See Sacro-iliac Disease.

Sacro-iliac (sa-kro-ill-e-ak) [sacrum, sacrum; ilium, ilium ]. Pertaining to the sacrum and the ilium. S. Disease, sacro-coxitis; sacrarthrocace; sacro-coxalgia; an inflammation of the sacro-iliac joint, characterized by pain and tenderness, with swelling over the line of the sacro-iliac junction. The limb on the diseased side is usually extended, elongated from downward displacement of the os innominatum, wasted, and sometimes edematous. The hip is deformed. Suppuration may occur at a late period of the disease. The affection occurs in early life, and is probably tuberculous in nature.

Sacro-ischiatic (sa-kro-is-ke-at'-ik) [sacrum, sacrum; ioxiov, ischium]. Pertaining both to the sacrum and the ischium.

Sacrolumbal (sa-kro-lum'-bal) [sacrum, sacrum; lumbus, loin 1 . Sacrolumbar; pertaining to both the sacrum and the loins.

Sacrolumbalis (sa-kro-lum-ba'-lis). See Muscles, Table of

Sacrolumbar (sa-kro-lum'-bar) [sacrum, sacrum; lumbus, loin]. Pertaining conjointly to the sacrum and the loins. S. Angle, the angle formed by the articulation of the sacrum and the last lumbar vertebra.

Sacro-median (sa-kro-me'-de-an) [sacrum, sacrum ; medius, middle]. Running along the median line of the sacrum.

Sacro-pubic (sa-kro-pu'-bik) [sacrum, sacrum; pubes, pubis]. Pertaining to the sacrum and the os pubis.

Sacro-rectal (sa-kro-rek'-tal) [sacrum, sacrum; rectum, rectum]. Pertaining to both sacrum and rectum.

Sacro-sciatic $\left(s a-k r o-s i-a t^{\prime}-i k\right)$. Synonym of Sacro-

ischiatic. S. Foramen. See Foramen. S. Notches. See Ischiatic.

Sacro-spinal (sa-kro-spi'-nal) [sacrum, sacrum; spina, spine]. Pertaining to the sacrum and the spine.

Sacrospinalis (sa-kro-spi-na'-lis) [sacrum, sacrum; spina, spine]. The erector spina muscle.

Sacro-vertebral (sa-kro-ver'-te-bral) [sacrum, sacrum ; vertebra, vertebra]. Pertaining conjointly to the sacrum and the vertebræ.

Sacrum (sa'-krum) [sacer, sacred]. A curved, triangular bone composed of five united bones, which are

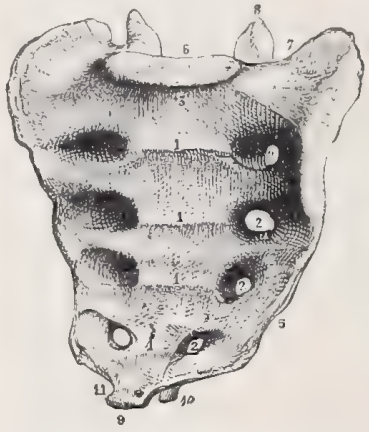

$I, I, I, I$. Bodies of sacral vertebra, with transverse lines of union. $2,2,2,2$. Anterior sacral foramina. 3. Base. 4. Auricular surface of lateral aspect. 5. Its inferior portion. 6. Articular surface of base. 7. Notch for formation of last lumbar intervertebral foramen. 8. Superior articular process of first sacral vertebra. Apex of sacrum ro Apex of sacrum. 10 transmission of fifth sacral nerve.

SACRUM, ANTERIOR ASPECT

really vertebræ, situated between the last lumbar vertebra above, the coccyx below, and the two ilia on

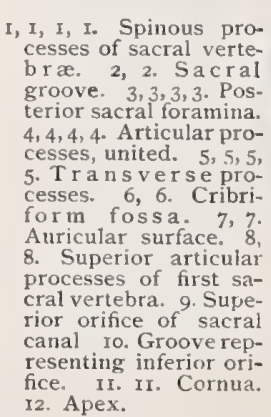

I2. Apex.

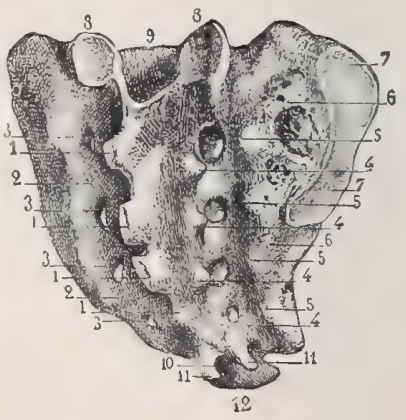

SACRUM, POSTERIOR ASPECT.

either side, and forming the posterior boundary of the pelvis. S., Ala of. See Ala.

Saddle $\left(\operatorname{sad}^{\prime}-l\right)$ [ME, sadel, saddle]. A contrivance secured on the back of a horse or other animal to serve as a seat for a rider. S.-bags, a pair of leathern cases, formerly, and still locally, carried by physicians upon the saddle, and containing their medicines and instruments. S.-joint, an articulation concave in one direction and convex in the opposite. S.-nose, one of which the bridge is deep or wanting. A nose in which there has been a collapse of the bridge from necrosis of the nasal bones.

Sadism, Sadismus (sa'-dim, $\left.s a-d i z^{\prime}-m u s\right)$ [from the Marquis de Sade, author of obscene books]. Sexual perversion which leads to rape, with circumstances of great violence and inhuman cruelty.

Sadist (sa'-dist) [from the Marquis de Sade]. One af fected with sadism, $q . v$.

Saemisch's Ulcer. An acute serpiginous, or creeping ulcer of purulent keratitis. It is due to local infection. Infectious ulcer of the cornea. See Diseases, Table of. Sæpimentum (se-pe-men'-tum) [sapire, to fence]. I. The tissue enclosing the three umbilical vessels. 2 . Pons varolii. 
Sxeptometer (sep-tom'-et-er). See Septometer. Sxptum $($ sep $-t u m)$. See Septum.

Safflower (saf'-low-er). See Carthamus. S. Carmin. Same as Carthamin.

Saffranin (saf'-ran-in). See Pigments, Conspectus of. Saffrol (saf'-rol). See Safrol.

Saffron (saf'-ron) [ME., saffron, saffron]. See Crocus. S., American. See Carthumus. S., Meadow. See Colchicum. S. Substitute. Same as Victoria Yellow. S.-tea. See Carthamus. S.-yellow. Same as Martius's Yellow. See Pigments, Conspectus of

Safranin (saf'-ran-in) [Fr., safran, saffron], $\mathrm{C}_{18} \mathrm{H}_{18} \mathrm{~N}_{4}$. A coal-tar color used in dyeing and staining, obtained by oxidizing a mixture of amido-azotoluene and toluidin. It gives yellowish-red shades on wool, silk, and cotton, and is fairly fast to light. It is used in histology to stain karyokinetic figures. Physiologically, it is very poisonous, producing death, if in sufficient dose, by respiratory paralysis. The safranins are diamido-derivatives of hypothetic phenylphenazonium. They are produced upon oxidizing a mixture of an indoamin and a primary amin. They are strong bases. See Pigments, Conspectus of.

Safraninophile or Saphranophile (saf-ran-in'-o-fll, safran'-o-fil) [Fr., safran, saffron; $\phi i \lambda \varepsilon i \bar{v}$, to love]. In bacteriology, or histology, applied to microbes or histologic elements that show a peculiar affinity for safranin. Cf. Eosinophile.

Safrene $\left(\right.$ saf'-rèn) [Fr., safran, saffron], $\mathrm{C}_{10} \mathrm{H}_{16^{*}} \mathrm{~A}$ hydrocarbon obtained from sassafras.

Safrol (saf'-rol) [Fr., safran, saffron; oleum, oil], $\mathrm{C}_{10} \mathrm{H}_{10} \mathrm{O}_{2}$. The stearoptene of the oil of sassafras. When the oil is chilled, it separates as a white crystalline mass, melting at $+8^{\circ} \mathrm{C}$. It is used in headache, neuralgia, and subacute rheumatism. Its dose is $m x-x x$. It is also employed for perfuming soaps.

Safrosin (saf'-ro-sin) [Fr., safran, saffron], $\mathrm{C}_{20} \mathrm{H}_{8} \mathrm{Br}$ $\left(\mathrm{NO}_{2}\right)_{2} \mathrm{O}_{5}$. A coloring-matter used in the arts for dyeing silk or wool scarlet. It occurs chiefly as a sodium salt. See Pigments, Conspectus of.

Safrosin (saf'-ro-sin). Same as Daphnin.

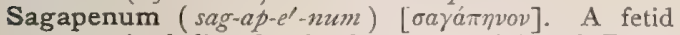
gum-resin, believed to be the concrete juice of Ferula persica. It has the general properties of asafetida, but is now little used. Unof.

Sage $(s a \bar{j})$ [ME., sage, sage]. See Salvia. S., Mountain. See Sierra salvia. S.-brush. See Serra salvia; also Eurotia.

Sage-femme (sahzh-fam') [Fr., literally a wise woman] A midwife.

Sagitta (saj-it'-ah) [sagitta, an arrow, a bolt]. In biology, (a) the sagittal suture; (b) an otolith in the ear of a fish.

Sagittal (saj'-it-al) [sagitta, an arrow]. Pertaining to the antero-posterior median plane of the body, the meson, or to planes parallel with it. S. Furrow, a channel extending along the median line of the inner surface of the vault of the cranium. S. Nucleus, that of the oculo-motor nerve. S. Plane, the median plane of the body. S. Section. See Section. S. Sinus, the longitudinal sinus. S. Suture, the suture uniting the parietal bones.

Sagittate $\left(s a j^{\prime}-i t-\bar{a} t\right)$ [sagitta, an arrow]. In biology, shaped like the head of an arrow, with the basal lobes pointing downward when applied to leaves.

Sagittocyst (saj'-it-o-sist) [sagitta, an arrow; cystus, a bag, a pouch]. In biology, applied to certain glandular cutaneous celis in turbellarian worms; they contain the so-called rods or rhatdites; also called rodcells or rhabdite-cells.

Sago $\left(s \alpha^{\prime}-g o\right)$ [Malay, sāgu, sago]. The starchy fecula obtained from the pith of Sagus levis and several species of palms and cycads. It is an excellent food for invalids when completely softened by long boiling. S. Spleen, a spleen presenting on section the appearance of sago-grains, as a result of amyloid degeneration. The apparent grains represent the degenerated Malpighian bodies. S.-grain, a vesicular granulation of the eyelid, seen in granular ophthalmia.

Sailors' Colic. See Colic

Saint Agatha's Disease. Mammitis. S. Aignon's Disease, tinea or favus. S. Andrew's Cross, the herb or shrub Ascyrum crux andrea of N. America, a discutient remedy. Unof. S. Anthony's Dance. Synonym of Charea. S. Anthony's Fire. See Errysipelas. S. Apollonia's Disease, toothache. S. Avertin's Disease, epilepsy. S. Avidius' Disease, deafness. S. Blasius' Disease, quinsy. S. Clair's Disease, ophthalmia, or sore eyes. S. Dymphna's Disease, insanity. S. Erasmus' Disease, colic. S. Fiacre's Disease, hemorrhoids, or condylomata. S. Francis' Fire, erysipelas. S. Germain Tea, the species laxantes (N. F.) ; a mixture of elder flowers, senna, fennel, anise, and potassium bitartrate ; a useful aperient. S. Gervasius' Disease, rheumatism. S. Giles' Disease, carcinoma or leprosy. S. Guy's Dance. Synonym of Chorea. S. Helena Tea, a plant of the island of St. Helena, Beatsonia portulacifolic, a local substitute for tea. Unof. S. Hilaire (Geoffroy), Angle of. See Angle. S. Hubert's Disease, hydrophobia. S. Ignatius' Bean. See Ignatia. S. Jacob's Oil. See Aconitum. S. Job's Disease, syphilis. S. John Long's Liniment. See Linimentum. S. John's Dance. Synonym of Chorea. S. John's Evil. See Epilepsy. S. John's Wort. See Hypericum and Johnsteort. S. Kilda Cold ; Strangers' Cold; a form of influenza in the Hebrides, supposed to be due to the presence of strangers on the arrival of a ship. S. Lazarus' Disease, leprosy. S. Main's Disease, the itch. S. Martin's Evil, drunkenness. S. Mary's Thistle. See Carduus. S. Mathurin's Disease, insanity, idiocy or epilepsy. S. Modestus' Dance. Synonym of Chorea. S. Robert's Herb, the Geranium robertianum. S. Valentine's Disease, epilepsy. S. Vitus' Dance. Synonym of Chorea. S. With's Dance. Synonym of Chorea. S. Zachary's Disease, dumbness.

Saké $\left(s a h^{\prime}-k e\right)$ [Jap.]. Japanese rice-beer or other alcoholic beverage.

Sakitlakar (sak-it-lak'-ar). Synonym of Palmus.

Sal [sal, salt]. Salt; a term applied to various crystalline substances. S. aëratus, potassic bicarbonate. S. alembroth. See Alembroth, and Listerian Method. S. ammoniac. See Ammonium. S. carolinum, Carlsbad salts. S. communis, common salt. See Sodium. S. cornus cervi, hartshorn; same as Ammonia. See Ammonium. S. de duobus, potassic sulphate. S. epsom, magnesium sulphate. See $\mathrm{Mag}$ nesium. S. glauberi, sodium sulphate. See Sodium. S. kissingense, Kissengen salts. S. mirabile, sodium sulphate. S. polychrest, S. polychrestum, potassic sulphas cum sulphure. S. seignetti, potassium and sodium tartrate. S.-soda. Crystallized sodium carbonate. S. vichyanum, Vichy salt. S. volatilis, a name applied to various preparations of ammonium carbonate used as smelling-salts.

Salaam Convulsion. See Eclampsia nutans, and Spasmus nutans.

Salabreda (sal-ab-rel-dah). Brittle gum, $q . v$.

Salacetol (sal-as'-et-öl) [salix, willow; acetum, vinegar]. The salicylic acid ester of acetone-alcohol. It is proposed as a substitute for sodium salicylate and salol. It has been recommended as an intestinal and 
genito-urinary antiseptic, and for the treatment of acute or chronic rheumatism. Dose, 30-45 grains.

Salacious (sa-la'-se-zes) [salax, lustful]. Lustful.

Salacity $\left(s a-l a s^{\prime}-i t-e\right)$ [salax, lustful]. Lustful or venereal desire.

Salad Oil (sal'-ad oil). See Oleum Olive.

Salamandrin (sal-am-an'-drin). See Leukomains, Table of.

Salap $\left(s a l^{\prime}-\alpha p\right)$. Synonym of Salep.

Salbromalid (sal-bro'-mal-id). See Antinervin.

Salempien (sal-em'-pe-en). See Serempion.

Salep $(s a l$-ep $)$ [Ar., sahleb, salep]. A drug chiefly used in India and the Levant, consisting of the dried bulbs of various species of Orchis, $q . v$. A mucilaginous and nutritious drink is made of it, which is considered to be an analeptic, aphrodisiac, and nervine. Unof.

Saleratus (sal-er-a'-tzs) [sal, aëratus, aërated salt]. Properly, sal-aëratus. Potassium bicarbonate; also, sodium bicarbonate.

Salicin $\left(\right.$ sal'-is-in) [salix, willow], $\mathrm{C}_{13} \mathrm{H}_{18} \mathrm{O}_{7}$. The glucosid of saligenin; it occurs in the bark and leaves of willows and some poplars. It forms shining crystals, that dissolve easily in hot water and alcohol, and melt at $\mathbf{I} 98^{\circ} \mathrm{C}$. Its taste is bitter. It possesses tonic properties, and is used as a substitute for salicylic acid in the treatment of rheumatism.

Salicinum (sal-is-i'-num). Official name of Salicin.

Salicol (sal'-ik-ol). Synonym of Carbolic Acid.

Salicyl (sal'-is-il) [salix, willow], $\mathrm{C}_{7} \mathrm{H}_{5} \mathrm{O}_{2}$. The hypothetic radicle of salicylic acid. S. Orange, S. Yellow. See Pigments, Conspectus of.

Salicylage $\left(s a l^{\prime}-i s-i l-a j\right)$ [salix, willow]. Preservation of articles of diet by the use of salicylic acid.

Salicylamid (sal-is-il'-am-id) [salix, willow; amid], $\mathrm{C}_{5} \mathrm{H}_{4}(\mathrm{OH}) \mathrm{CONH}_{2}$. A tasteless compound produced by treating methyl salicylate with an alcoholic solution of ammonia. It is used like salicylic acid.

Salicylate $\left(s a l-i s^{\prime}-i l-\bar{a} t\right)$ [salix, willow]. Any salt of salicylic acid. The salicylates of ammonium, atropin, bisrouth, caffein, cinchonidin, lithium, methyl, physostigmin, quinin, and sodium, etc., have been employed in medicine, especially in rheumatic affections.

Salicylic $\left(s a l-i s-i l^{\prime}-i k\right)$ [salix, willow]. Containing salicyl or pertaining to it. Derived from the willow S. Acid. See Acid, Salicylic, and Salix. S. Acid Colors. See Pigments, Conspectus of. S. Aldehyd. See Aldehyd.

Salicylism $\left(s a l^{\prime}-i s-i l-i z m\right)$ [salix, willow]. A toxic condition, produced by the injudicious or excessive use of salicylic acid or its salts.

Salicyluric Acid (sal-is-il-u'-rik) [salix, willow; ovjpov, urine]. An acid found in the urine after the administration of salicylic acid. It is a compound of the latter with glycol.

Salifiable $\left(s a l-i f-i^{\prime}-\alpha-b l\right)$ [sal, salt; fieri, to become]. Forming a salt by union with an acid.

Saligenin (sal-ij'-en-in) [salix, willow; yevvãv, to produce], $\mathrm{C}_{7} \mathrm{H}_{8} \mathrm{O}_{2}$. A substance formed by the action of sodium amalgam upon salicylic aldehyd or in the decomposition of salicin with dilute acids or ferments. It consists of pearly tables, soluble in hot water, alcohol and ether, and melting at $82^{\circ} \mathrm{C}$.

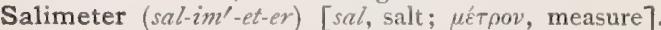
An hydrometer for ascertaining the strength of saline solutions.

Salinaphtol (sal-in-af'-tol). See Betol.

Saline $\left(s a^{\prime}-\overline{l e} n\right.$ or $\left.s a^{\prime}-\bar{\imath} n\right)[s a l$, salt]. Salty. In biology, growing in a salt-marsh or by the sea-shore. S. Solution, a 0.6 per cent. solution of sodium chlorid.

Salines (sq'-lens) [sal, salt]. Salts of the alkalies or of magnesium, used as hydragogue cathartics. Mag- resium sulphate and citrate, sodium sulphate and Rochelle salts are examples.

Salinometer (sal-in-om'-et-er). Synonym of Salimeter. Salipyrin (sal-ip-i'-rin) [salix, willow; $\pi \bar{v} \rho$, fire], $\mathrm{C}_{11} \mathrm{H}_{12} \mathrm{~N}_{2} \mathrm{O} \cdot \mathrm{C}_{7} \mathrm{H}_{6} \mathrm{O}_{3}$. A white powder, the salicylate of antipyrin, consisting of 57.7 parts of salicylic acid, and 42.3 parts of antipyrin. It is readily soluble in water and has been recommended as an analgesic and antipyretic in doses of $\mathrm{gr} . \mathrm{XV}-\mathrm{xxx}$.

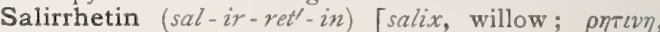
resin], $\mathrm{C}_{14} \mathrm{H}_{14} \mathrm{O}_{3}$. An amorphous, resinous powder, produced by treating saligenin with acids.

Salisbury Method. A method of treating obesity. It consists in restricting the diet absolutely for a time to large quantities of rump-steak, cod-fish and hot water. It is thought by the advocates of this method that an excess of albuminates favors the reduction of obesity by promoting the oxidation and combustion of the excess of deposited fat.

Saliva $\left(s a-l i^{\prime}-v a\right)[\mathrm{L}$.$] . The mixed secretion of the$ parotid, submaxillary, and sublingual glands, and the small mucous glands of the mouth. Physiologically, three kinds of secretion may be distinguished: a serous from the parotid, a mucous from the mucous glands, and a mixed secretion from the submaxillary and the sublingual. Mixed saliva is opalescent, tasteless, alkaline and has a specific gravity of 1004-IOOg. The daily quantity secreted is approximately I500 c. c. (Bidder and Schmidt.) Saliva contains serum-albumin, globulin, mucin, urea, an amylolytic ferment called ptyalin, and a proteolytic and a lipolytic ferment; also, salts, among which is potassium sulphocyanid, derived especially from the parotid gland. Among formed elements are epithelial cells, salivary corpuscles and bacteria. The functions of saliva are physical and chemic. Its physical functions are to moisten the food and lubricate the bolus, to dissolve certain substances, and to facilitate tasting and aid in deglutition and articulation. Its chemic action depends upon its ferments, the most important of which is pytalin. This converts starch into dextrin and sugar. The proteolytic and lipolytic ferments are not important. It is possible that any other fermentation save the amylolytic is due to bacteria. S., Chorda, that produced by stimulation of the chorda tympani nerve. S., Ganglionic, that produced by irritating the submaxillary glands.

Salival (sa-li'-val) [saliva, spittle]. Same as Salivary. Salivant $\left(s a l^{\prime}-i v\right.$-ant $)$ [saliva, saliva]. Stimulating the secretion of saliva.

Salivary $\left(s a l^{\prime}-i v-a-r e\right)$ [saliva, saliva]. Pertaining to

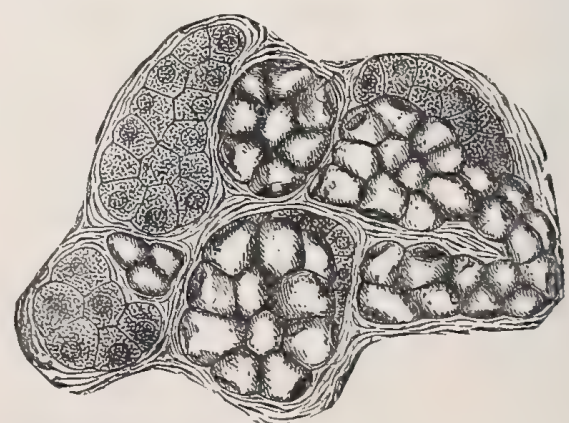

Human Submaxillary Gland.

On the right are groups of mucous, and on the left, groups of serous alveoli. $\times 300$. (From Stivling.)

saliva or to its secretion.

S. Calculus, Odontolith; odontia incrustans; tartar of the teeth, an 
earthy concretion found upon the teeth and in the mouths of the salivary ducts. S. Corpuscles, pale,

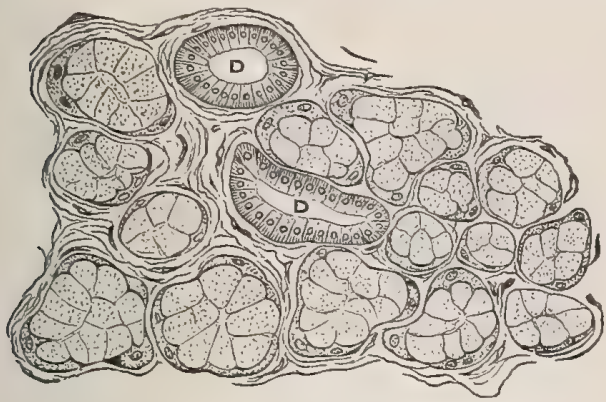

Small Lobuie of Submaxillary Gland.

D. Duct of the Lobule. (From Stirling.)

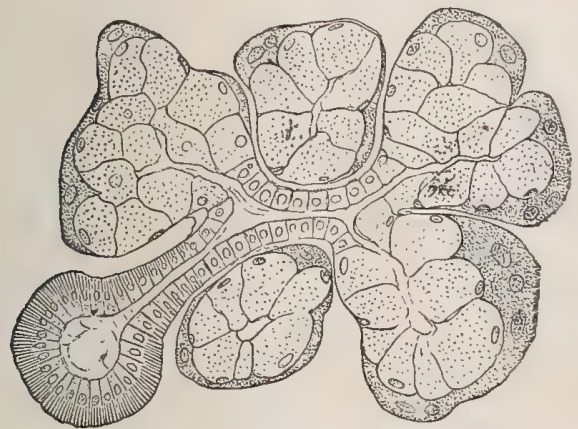

Submaxillary Gland, Doc.

Showing duct communicating with an alveolus by a narrow ductule. The alveoli containing mucous cells and dense demilunes. $\times 300$. (From Stirling.)

spheric, nucleated bodies found in the saliva. S. Diastase. Same as Ptyalin. S. Digestion, the conversion of starches into dextrin and sugar by the action of saliva. $\mathbf{S}$. Fistula, an abnormal opening communicating with a salivary
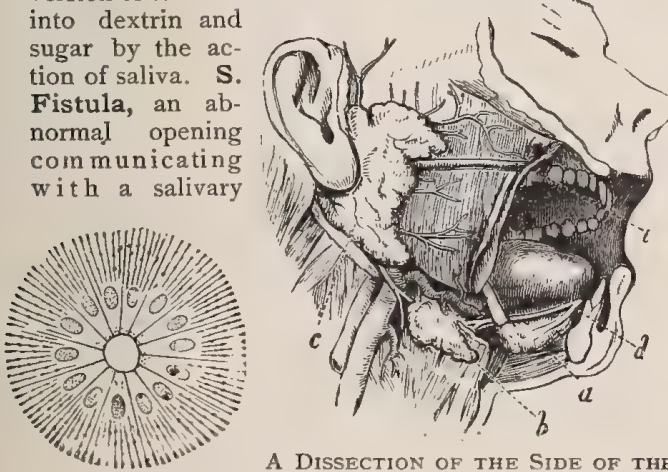

A Dissection OF THE SIDE OF THE FACE, SHOWING THE SALIVARY GLANDS.

TRANSVERSE SECTION OF A SALIVARY DUCT.

Showing only the "rodded" epithelium lining it. $\times 300$. (From Stirling.)

$a$. Sublingual gland. $b$. Submaxillary gland with its ducts opening on the floor of the mouth beneath the tongue at $d$. $c$. Parotid gland and its duct, which opens on the inner side of the cheek.

duct. S. Glands, the glands, six in number, situated on each side of the mouth, which secrete the saliva. See Parotid, Submaxillary, and Sublingual.

Salivate (sal'-iv-att) [salivare, to spit out]. To purge by the salivary glands. To bring about an undue discharge of saliva.
Salivatio (sal-iv-a'-she-o) [L.]. Salivation. S. mercurialis. Synonym of Slomatitis, Mercurial.

Salivation (sal-iv-a'-shun) [saliva, saliva]. An excessive secretion of saliva. It may be produced by cer tain poisons, by such drugs as mercury and pilocarpin, or by nervous disturbances.

Salivin $\left(s a l^{\prime}-i v-i n\right)$. Same as Ptyalin

Salivous $\left(s a-l h^{\prime \prime}\right.$-vus $)$ [saliva, spittle]. Of or pertaining to saliva.

Salix (sa'-liks) [L.]. The bark of the common white willow, $S$. alba. Its properties are due to a constituent, salicin, $\mathrm{C}_{13} \mathrm{H}_{18} \mathrm{O}_{7}$, which is tonic and antiseptic. It is useful as an antipyretic in rheumatic fever. Dose of the glucosid gr, $x-3$ ij. Lithium Salicylate, $2 \mathrm{Li}$ $\mathrm{C}_{7} \mathrm{H}_{5} \mathrm{O}_{3} \cdot \mathrm{H}_{2} \mathrm{O}$. Dose gr. $\mathrm{v}-3 \mathrm{j}$. Sodium Salicylate, $2 \mathrm{NaC}_{7} \mathrm{H}_{5} \mathrm{O}_{3} \cdot \mathrm{H}_{2} \mathrm{O}$, properties like those of the acid, though less irritant. Dose gr. $\mathrm{v}-3 \mathrm{j}$. Salicylic Acid, $\mathrm{HC}_{7} \mathrm{H}_{5} \mathrm{O}_{3}$, a derivative of Salix, a powerful antipyretic in rheumatic fever, and locally in eczema and indolent ulcers; and also an antiseptic. Dose gr. $v-x x x$. Ung. acid. salicyl. (B. P.) Used in chronic deep-seated skin diseases.

Salkowski-Ludwig Method. A method for the estimation of uric acid in solution. When an ammoniacal solution of nitrate of silver is added to a solution of uric acid, to which a mixture of magnesium chlorid and ammonium chlorid has been previously added, the uric acid is precipitated as a magnesio-silver salt. This is collected, washed, and decomposed by sodium or potassium sulphid, whereupon the uric acid passes again into solution as a urate of the alkali. On the addition of an excess of $\mathrm{HCl}$ to this solution the urate is decomposed, uric acid separates out and is collected and weighed.

Salkowski's Mixture. See Camerer's Method.

Sallow $\left(\mathrm{sal}^{\prime}-\mathrm{o}\right)$ [ME., salow, sallow]. Having a yellowish color, as the complexion or skin.

Salmon-disease. A disease of salmon and other fishes, due to the fungus, Saprolegnia ferox. S.-louse. Caligus piscinus, a crustacean parasitic upon the salmon and other fishes. S.-patch. See Keratitis, Inter. stitial.

Salocoll (sal'-o-kol) [salix, willow]. A chemic combination of phenocoll and salicylic acid; in other words, the salicylate of phenocoll. It is a white powder; odorless and tasteless; only slightly soluble in cold water. Salocoll is said to be a reliable antipyretic, anti-neuralgic, and anti-rheumatic, combining the favorable actions of its constituents, and as a rule, free from the by-effects common to the new antipyretics. The dose is from 15 to 30 grains, in powder or in capsules, to be repeated three or four times per day.

Salol $\left(\right.$ sal'-ol) $[$ salix, willow $], \mathrm{C}_{13} \mathrm{H}_{10} \mathrm{O}_{3}$. Salicylic Phenol Ester; or Phenyl Salicylate. A white, odorless, crystalline substance, melting at $43^{\circ} \mathrm{C}$. It is used as an intestinal antiseptic, and as a substitute for salicylic acid, being less irritating to the stomach. Dose gr. ij-xv. It is decomposed in the intestines into salicylic acid and phenol. On this account it has been employed to test the motor power of the stomach. A few grains are given in capsule and the urine tested at intervals for the decomposition-products of salicylic acid.

Saloop (sa-loop $p^{\prime}$ [see Salep]. A drink prepared from salep; also from sassafras bark and herbs. It is regarded as a cure for drunkenness. Unof.

Salophen (sal'-o-fen) [salix, willow],

$$
\mathrm{C}_{6} \mathrm{H}_{4}<\mathrm{COO} . \mathrm{C}_{6} \mathrm{H}_{4} . \mathrm{N}<\mathrm{CO} . \mathrm{CH}_{3} \mathrm{C}_{15} \mathrm{H}_{13} \mathrm{NO}_{4} \text {. }
$$

A derivative of salicylic acid, of value in acute artic. ular rheumatism. Dose gr. $1 \mathrm{x}-\mathrm{xc}$ daily. Unof. 
Salphonic Test for Proteids. See Tests, Table of.

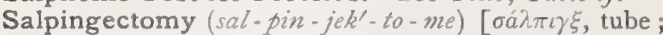

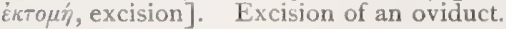

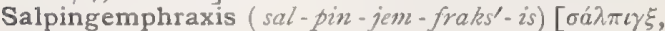
tube; $\dot{\varepsilon} \mu \phi \rho \alpha \xi \iota \zeta$, obstruction]. Closure of the Eustachian tube.

Salpinges (sal-pin'-jezz). Plural of Salpinx

Salpingian, or Salpingic (sal-pin'-je-an, sal-pin'-jik)

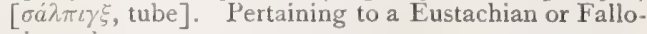
pian tube.

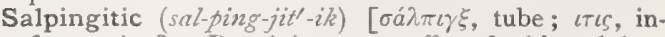
flammation]. Pertaining to, or affected with, salpingitis

Salpingitis (sal-ping- $\left.\ddot{i}^{\prime}-t i s\right)[\sigma a \dot{\lambda} \pi \iota \gamma \xi$, tube ; $\iota \tau \iota s$, inflammation]. Inflammation of the Eustachian tube, or of the Fallopian tube.

Salpingocyesis (sal-ping-go-si-e'-sis) $[\sigma a ́ \lambda \pi \iota \gamma \xi$, tube;

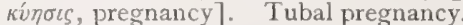

Salpingo-mallearis, Salpingo-malleus (sal-ping-gomal-e-a'-ris, sal-ping-go-mal'-e-us). The tensor tympani muscle. See Muscles, Table of

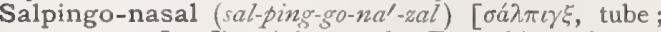
nasus, nose]. Pertaining to the Eustachian tube and the nose.

Salpingo-oöphorectomy (sal-ping-go-o-o-for-e $k^{\prime}-t o-m e$ )

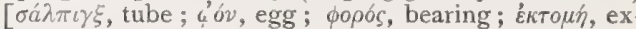
cision]. Excision of an oviduct and an ovary.

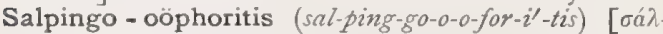

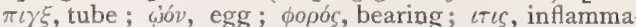
tion]. Inflammation of an oviduct and an ovary.

Salpingo-palatal (sal-ping-go-pal'-at-al) [ $\sigma a ́ \lambda \pi l \gamma \xi$, tube; palatum, palate ]. Pertaining to the Eustachian tube and the palate. S. Fold, a fold of mucosa covering the levator palati muscle.

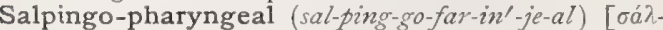
$\pi \iota \gamma \xi$, tube; $\phi a ́ \rho v \gamma \xi$, pharynx]. Pertaining to both the Eustachian tube and the pharynx.

Salpingo-pharyngeus ( sal-ping-go-far-in-je' - us)

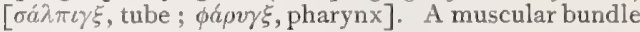
passing from the Eustachian tube downward to the constrictors of the pharynx.

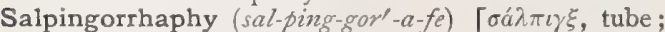
$\dot{\rho} a \phi \dot{\eta}$, suture]. Suture of the Fallopian tube.

Salpingo-staphylinus (sal-ping-so-staf-il-i' $\left.i^{\prime}-n u s\right)$

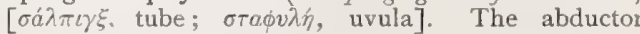
muscle of the Eustachian tube. S. internus. Synonym of Levator palati. See Muscles, Table of.

Salpingostenochoria (sal-ping - go-ste-no-ko'-re-ah)

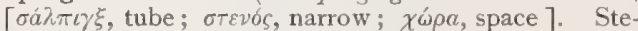
nosis or stricture of the Eustachian tube.

Salpingostomy (sal-ping-gos'-to-me) [ $[\sigma a ́ \lambda \pi \imath \gamma \xi$, tube ; бTópa, mouth]. Establishment of a fistula of a Fal lopian tube.

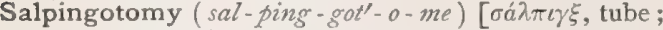
Toun, a cutting]. The surgical division or excision of a Fallopian tube.

Salpingysterocyesis (sal-ping-gis-ter $\left.-0-s i-e^{\prime}-s i s\right)$

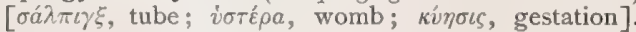
Interstitial pregnancy.

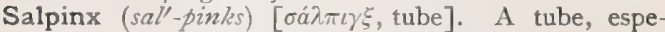
cially the Eustachian or the Fallopian tube.

Salsilago (sal-sit-a'-go) [sal, salt]. Salty liquid.

Salsuginose (sal-su'-jin-öz) [salsugo, saltness]. In biology, growing in brackish soil, or in situations liable to an overflow of salt water.

Salt [sal, salt]. A common name for sodium chlorid. See Sodium. In chemistry, a substance produced by the union of a base or radicle acting as such with an acid. See also Sal. S., Acid, a salt formed from a dibasic or polybasic acid in which only a portion of the replaceable hydrogen atoms has been replaced by the base. This salt, therefore, has acid properties. S., Bakers', sodium bicarbonate. S., Basic, a compound formed by the union of a normal salt with a basic oxid or hydroxid. S., Bay, sodium chlorid; also the sea-salt obtained by the evaporation of sea-water by solar heat. S., Bitter, magnesium sulphate. S.-cake, crude sodium sulphate obtained in the manufacture of sodium carbonate by what is known as Leblanc's process. S., Cheltenham, a mixture, in equal proportions, of magnesium sulphate, sodium sulphate, and sodium chlorid, or of sinilar salts. S., Common, sodium chlorid. S., Diuretic, potassium acetate. S., Double, one in which the hydrogen atoms of an acid are replaced by two metals. S., Epsom, magnesium sulphate. S.-flour, finely crystalline potassium nitrate. S. Frog, a frog from whose vascular system all blood has been artificially removed and replaced by normal salt-solution. Also known as Cohnheim's Frog. S., Glaser's Polychrest, potassium sulphate. S., Glauber'8, sodium sulphate. S., Halogen, S., Haloid, any salt of the halogen elements, bromin, chlorin, fluorin, iodin. $\mathbf{S}$. Hornberg's Sedative, boric acid. S., Lémery's, potassium sulphate. S., Marine Epsom, magnesium chlorid. S., Martial Sea, iron chlorid. S., Microcosmic, $\mathrm{NaHNH} \mathrm{PO}_{4} .4 \mathrm{H}_{2} \mathrm{O}$, a reagent in blow-pipe analysis. S., Monsel's, subsulphate of iron, used chiefly in solution as a styptic. S., Neutral, one formed by the replacement of all of the hydrogen atoms of an acid by a base or a radicle. S., Normal. Synonym of S., Neutral. S., Oxy-, S., Oxygen, a salt of an oxy-acid, i. e., one containing oxygen. S., Purgative. Synonym of S., Epsom. S. Rheum, a form of chronic eczema. S. of Riverius, neutral potassium citrate. S., Rochelle, sodium and potas. sium tartrate: S., Rock, native sodium chlorid, occurring in crystalline masses; also the large crystals of sodium chlorid obtained in its manufacture from sea-water. S., Schlippe's, sodium sulphantimoniate. S., Sea, the sodium chlorid obtained by the evaporation of sea-water. It is not perfectly pure. S., Sedative, boric acid. S., Seidlitz, magnesium sulphate. S. of Seignette, sodium and potassium tartrate. S. Smelling, any pungent, irritant salt which when inhaled usually acts reflexly as a respiratory or circulatory stimulant. Ammonium carbonate is generally used. S.-solution, a solution of sodium chlorid in distilled water. One containing from 0.6 to 0.75 per cent. of sodium chlorid is known as a normal or physioloyic salt-solution, and on account of its unirritating character is much used in physiologic experiments on living tissues. In medicine, it has been employed to restore to the system the fluids lost by severe hemorrhage or profuse diarrheal discharges. Infusions of salt-solution are made either into the subcutaneous tissues or into a vein; sometimes also into the rectum. S., Table, sodium chlorid. S., Wall, calcium nitrate. The name has been given to it because it is found on the walls of stables and similar places over which urine flows. S.-wort. See Glaux.

Saltation $\left(s a l-t a^{\prime}-s h u n\right)$ [saltare, to dance]. The dancing or leaping sometimes noticed in chorea.

Saltatorial (sal-tat-o'-re-al) [saltare, to dance, to leap]. Applied to such animals as progress by leaping.

Saltatoric (sal-tat-or'-ik) [saltare, to dance]. Pertaining to dancing or leaping. S. Cramp or Spasm, a clonic spasm which sometimes attacks a patient when he attempts to stand, causing him to leap or jump. It is rare and transient, and is quite distinct from the condition known as palmus. See Palmus.

Saltatory $($ sal-tat-or'-e). Synonym of Saltatoric. $\mathbf{S}$. Theory of Evolution, in biology, that form of the doctrine of evolution which holds that the evolution of 
species is frequently marked by abrupt variations. Cf Niatism.

Salter, Incremental Lines of. Lines due to want of uniformity in the calcification of the outer zone of dentine. See Lines, Table of. S.'s Swing, a movable suspension-cradle for a fractured leg.

Saltpeter (sazull-pe'-ter) [sal, salt; $\pi \varepsilon \tau \rho a$, rock]. Native potassium nitrate. See Potassium. S., Chile, sodium nitrate. S., Lead, lead nitrate. S., Lime, calcium nitrate. S., Lye, the liquor obtained by treating saltpeter with water.

Salts (sazults) [sal, salt]. A popular name for Epsom salt, or magnesium sulphate. See also Glauber's Salt, Rochelle Salt, etc, under Salt.

Saltus (sal'-tus) [L.]. I. A leap. 2. Vulva.

Salubrious (sa-lu'-bre-us) [salus, health]. Healthful; applied especially to telluric and atmospheric conditions.

Salubrity ( $\left.s a-l u^{\prime}-b r i t-e\right)$ [salubritas, healthfulness]. The state or character of being wholesome.

Salufer (sal'-u-fer) [salus, health; ferre, to bring]. Sodium silico-fluorid, recommended as an antiseptic and deodorant. Unof.

Salumin (sal'-u-min) [satix, willow; aluminum]. Aluminum salicylate. It is employed in the treatment of diseases of the nose and throat.

Salutary (sal'-u-ta-re) [salus, health]. Promotive of health.

Salutiferous (sal-u-tif'-er-us) [salutifer, health-bringing; ferre, to bear]. Medicinal; health-bearing.

Salvatella (sal-vat-el'-ah) or Vena salvatella [salvatus, from salvare, to save]. The vein on the back of the little finger. See Vein.

Salve (sahv) [ME., salve, salve]. Ointment. S.-bug, a sailor's name for various parasitic crustaceans or "fish-lice," one of which, Caligus curtus, lives upon the common cod-fish. These crustaceans are made into salves by mariners. Unof. S., Deshler's, compound resin cerate.

Salver-shaped (sal'-ver-shāpt) [salva, a plate]. In biology, applied to corollas having a slender tube, spreading suddenly into a flat limb, as a phlox.

Salvia $\left(s a l^{\prime}-v e-a h\right)[\mathrm{L}$.$] . Sage. The leaves of S. affici-$ nalis, common garden sage. Its properties are due to tannin, a resin and a volatile oil. It is tonic, stimulant, and astringent.

Salviol (sal'-ve-ol) [salvia, sage; oleum, oil], $\mathrm{C}_{10} \mathrm{H}_{16} \mathrm{O}$. A liquid substance obtained from oil of sage.

Salvioli, Micrococcus of. See Bacteria, Synonymatic Table of.

Samadera or Samandura (sam-ad-e'-rah or sa-man'. $d u$-rah). [E. Ind.] A genus of old-world trees of the simarubaceous type. S. indica produces a bitter, febrifugal bark. Unof.

Samara (sa-mar'-ah or sam'-ar-ah) [samara, also samera, the fruit of the elm]. In biology, an indehiscent dry fruit provided with a wing-like appendage, as the fruits of the ash and elm.

Samariform (sam-ar'-if-orm) [samara, the seed of an elm; forma, form]. In biology, having the form of a samara.

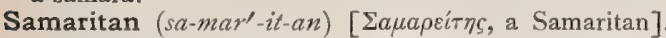
I. A benevolent person, or benefactor of the helpless. 2. Devoted to charitable work or to the service of the helpless, as a S. Hospital. S.'s Balsam, a mixture of wine and oil, formerly used in treating wounds. S. Schools, schools established for the instruction of the general public in the means of giving prompt succor to the wounded and injured before the arrival of the physician. In England these schools are known as ambulance-classes.

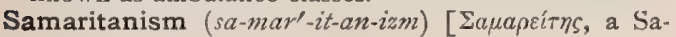

maritan]. Active philanthropy; devotion to the relief of suffering.

Samarium $\left(s a m-a^{\prime}-r e-u m\right)$ [L.]. A metallic element belonging to the didymium group. Symbol Sm; atomic weight 150 .

Samaroid (sam'-ar-oid). Same as Samariform.

Sambucus (sam-bu'-kus) [L., gen., Sambuci]. Elder. The flowers of $S$. canadensis and $S$. nigra (B.P.); stimulant and diaphoretic. The inner bark of Sambucus is cathartic. Dose gr. $\mathrm{xxx}-3 \mathrm{j}$ in hot infusion. S. Aqua (B. P.) Dose $引 \mathrm{j}-\mathrm{ij}$.

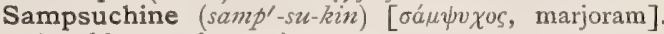
An old name for marjoram.

Samshu $\left(\operatorname{sam}^{\prime}-s h w\right)$ [Chinese]. An alcoholic drink distilled in China from rice or millet, or both.

Samuel's Theory of Inflammation. See Theory.

Sanable $\left(\operatorname{san}^{\prime}-a-b l\right)$ [sanare, to heal]. Curable.

Sanation $\left(\operatorname{san}-a^{\prime}-\operatorname{shun}\right)$ [sanare, to heal]. The process of healing; cure.

Sanative $\left(\operatorname{san}^{\prime}-a t-i v\right)$ [sanare, to heal]. Promoting health.

Sanatol ( $\left.\operatorname{san}^{\prime}-a t-o l\right)$. The trade name of a disinfectant said to consist of sulphuric acid, esters of phenol, and its homologues.

Sanatorium (san-at-o'-re-um) [sanare, to heal]. An establishment for the treatment of the sick; especially a private hospital. See Sanitarium.

Sanatory $\left(\operatorname{san}^{\prime}-a t-o r-\ell\right)$ [sanare, to heal]. Curative.

Sand [ME., sand, sand]. Fine, rounded, polished grains of silicic oxid. S.-bath, a vessel containing dry seasand in which a substance requiring a slowly-rising and uniform temperature may be heated. See Bath; also, Ammotherapy, Saburration, Psammism. S., Brain. See Acervulus. S.-crack, a crack or fissure in the hoof of a horse, extending from the coronet toward the sole, and due to a diseased condition of the horn-secreting membrane. S.-flea. See Chigoe. S.-lobster. See Buckle-shell.

Sandalwood (san'-dal-zurd). See Santalum album.

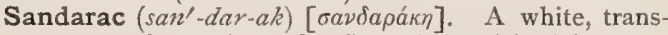
parent resin. produced by Callitris quadrivalvis, a tree of North Africa, and by other species. It is now seldom used in medicine. S., German, the resin of the common juniper.

Sane $(\operatorname{san} n)$ [sanus, whole]. I. Mentally sound; of a sound mind. 2. Healthy, free from disease.

Saneness (sän'-nes). Same as Sanity.

Sanford's Mixture. See Anesthetic.

Sangaree (sang-ga-re') [Sp., sangria]. A sweetened and flavored drink, consisting essentially of diluted wine or porter.

Sänger's Operation. See Operations, Table of.

Sang-mêlé (sang-ma-la'). See Mulatto.

Sangrado $($ sang-gra'-do) [sanguis, bloody]. A term sometimes applied to a physician who employs bloodletting extensively. From Le Sage's novel of "Gil Blas," in which a Doctor Sangrado treats all diseases by blood-letting.

Sanguicolous (sang-grvik'-o-lus) [sanguis, blood; colere, to inhabit]. Living in the blood, as a parasite.

Sanguiferous (san-gwif'-er-us) [sanguis, blood ; ferre, to carry]. Carrying, or conveying, blood.

Sanguification (sang-gwif-ik-a'-shun) [sanguis, blood; facere, to make]. The formation of blood; hematogenesis. Conversion into blood, as of the elements absorbed from the intestines.

Sanguifluous (sang-owif'-lu-us) [sanguis, blood ; fuere, to flow]. Running with blood.

Sanguigenous (sang-gwij'-en-us) [sanguis, blood; ymuns, producing]. Producing blood.

Sanguinaria (sang-gzin- $a^{\prime}-r e-a h$ ) [sanguis, blood]. Blood-root. The rhizome of $S$. canadensis. Its 
properties are due to an alkaloid, sanguinarin, $\mathrm{C}_{17} \mathrm{H}_{15}$. $\mathrm{NO}_{4}$. In large doses it causes vomiting and purging. Toxic doses cause convulsions, and then paralysis; death results from failure of respiration. It is used as an expectorant in chronic bronchitis. S., Acetum, vinegar of sanguinaria; sanguinaria I0, dil. acetic acid 90. Dose $\eta x-x x x$; as an emetic $3^{i j-\zeta}$ ss. S., Ext., Fld. Dose $m j-v$ as an expectorant, $m x-l x$ as an emetic. S., Tinct., I5 per cent. strong. Dose $\eta_{v} v-$ $3 \mathrm{j}$ as an expectorant, $3 \mathrm{j}$-iij as an emetic. Sanguinarin, the alkaloid, unof. Dose gr. $\frac{1}{12}-\frac{1}{8}$; as an emetic gr. $1 / 2-j$. Sanguinarin Nitrate. Unof. Expectorant. Dose gr. $\frac{1}{10}-\frac{1}{4}$

Sanguinarin (sang-gwin'-ar-in) [sanguis, blood]. I. The alkaloid of sanguinaria. 2. The precipitate from a tincture of the root of Sanguinaria canadensis; emetic, stimulant, diuretic, emmenagogue, antiseptic, errhine, antiperiodic, etc. Dose I to 3 grains. Unof. Sanguine (sang $g^{\prime}$-grin) [sanguis, bloody]. I. Bloody, 2. Hopeful. S. Temperament, a hopeful, active, energetic disposition.

Sanguineous (sang-grvin'-e-us) [sanguis, blood]. Pertaining to the blood. Bloody; blood-red. S. Cyst, a cyst containing blood-stained fluid.

Sanguinicolous (sang-grin-ik-o-lus). Same as Sanguicolous.

Sanguinification (sang-gwin-if-ik-a'-shun). See Sanguifucation.

Sanguinity (sang-grin'-it-e) [sanguis, blood]. The quality of likeness or dissimilarity between parents, a certain degree of the latter being most favorable for the production of well-organized offspring. "Parents who are more similar (Consanguine), or more dissimilar (Exsanguine), will probably have inferior offspring" (Mercier).

Sanguinivorous (sang-gwin-iv'-or-us) [sanguis, blood; vorare, to devour]. Same as Sanguivorous.

Sanguinol (sang'-gwin-ol) [sanguis, blood; oleum, oil]. A hematinic constituted of the iron combinations found in plants and animals. It consists of evaporated blood and hemoglobin in liquid form, and is free from the intermediate products of the degeneration of albuminous bodies. It consists of natural blood-salts 46 parts, oxyhemoglobin Io parts, and peptonized muscle-albumin 44 parts.

Sanguinolent (sang-grvin'-o-lent) [sanguis, blood]. Having the appearance of blood; tinged with blood.

Sanguinous (sang'-grvin-us). Same as Sanguinary.

Sanguis (sang'-gmers) [L.]. Blood.

Sanguisuction (sang-gwis-uk'-shun) [sanguis, blood ; suctus, p.p. of sugere, suck]. The abstraction of blood by suction, as by a leech or other parasite.

Sanguisuga (sang-gwi-su'-gah) [sanguis, blood; sugere, to suck]. A blood-sucker. A leech. S. medicinalis or officinalis, a leech.

Sanguisugent (sang-grwis-u'-jent) [sanguis, blood ; sugere, to suck]. Bloodsucking.

Sanguivorous (sang-gwiv'-or-us) [sanguis, blood; vorare, to devour]. Feeding on blood, as a leech.

Sanicle $\left(\operatorname{san}^{\prime}-i k-l\right)$ [saniculum, sanicle]. Any plant of the genus Sanicula. S. europoea, of the old world, and S. marilandica, of America, are considered to be antispasmodic, diaphoretic, and stimulant. Unof.

Sanies $\left(s a^{\prime}-n e-\bar{e} z\right)\left[\mathrm{L}_{0}\right]$. The thin, fetid, greenish, sero-purulent fluid discharged from ulcers, wounds, and fistulas.

Sanious (sa'-ne-us) [sanies]. Pertaining to or resembling sanies. S. Pus. See Pus.

Sanitarian (san-it- $\left.a^{\prime}-r e-a n\right)$ [sanitas, health]. One skilled in sanitary science.

Sanitarium $\left(s a n-i t-a^{\prime}-r e-u m\right)$ [sanitas, health]. A health-station. A place or institution where the conditions are such as especially to promote health and vigor. The word is often incorrectly employed for sanatorium, which is a hospital or place for curing those who are sick. A sanitarium may he used as a sanatc. rium but it is not necessarily the same thing.

Sanitary (san'-it-a-re) [sanitas, health]. Pertaining to health, or preventing disease; not. as often used, pertaining to the cure of disease. S. Science, the science which includes a consideration of all that can be done for the prevention of disease and the promotion of the public bealth

Sanitas $\left(s a n^{\prime}-i t-a s\right)$ [L.]. Health. Also a proprietary antiseptic solution, containing hydrogen dioxid, camphor, and camphoric acid.

Sanitation (san-it-a'-shun) [sanitas, health]. The application or enforcement of sanitary rules or laws.

Sanity $\left(\operatorname{san}^{\prime}-i t-e\right)$ [sanitas; sanus, sound]. Soundness of mind.

Sansom's Inhaler. See Anesthetic.

Sanson-Purkinje's Images. See Purkinje-Sanson.

Santalin (san'-tal-in) [santalum, sandalwood], $\mathrm{C}_{15} \mathrm{H}_{14}$ $\mathrm{O}_{5}$. I. The coloring-matter of red sandalwood, obtained by evaporating the alcoholic infusion to dryness. It is a red resin, fusible at $212^{\circ} \mathrm{F}$, and is very soluble in acetic acid as well as in alcohol, essential oils, and alkaline lyes. See Pigments, Conspectus of. 2. $\mathrm{C}_{14}$ $\mathrm{H}_{12} \mathrm{O}_{4}$. The active principle of Red Saunders. It crystallizes in minute red prisms soluble in alcohol and ether.

Santalum (san'-tal-um) [L, ]. Pterocarpi lignum (B. P.) White Sandalwood. The wood of a species of $S$. aibum and $S$. citrinum, or yellow sandalwood. It yields oil of santal, an astringent oil, useful in chronic bronchitis and gonorrhea. It is often adulterated with oil of cedar. Dose of the volatile oil $m x-$ $\mathrm{xxx}$, in emulsion or capsule; of the fld. ext., unof., alcoholic, $3 \mathrm{j}$-iij. S. rubrum, Red Saunders, the wood of Pterocarpus santolinus, imparts a brilliant-red color to ether and alcohol.

Santonic Acid (san-ton'-ik) [бavтovıkóv, wormwood], $\mathrm{C}_{15} \mathrm{H}_{20} \mathrm{O}_{4}$. An acid obtained by treating santonin with alkalies.

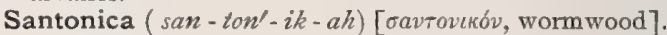
Levant Wormseed. The flower-heads of Artemisia maritima, the properties of which are due to a crystalline principle, santonin, $\mathrm{C}_{15} \mathrm{H}_{18} \mathrm{O}_{3}$. The flower-heads yield about 2 per cent. of santonin, which is a very efficient anthelmintic against the round-worm, Ascaris lumbricoides. In large doses it produces yellow vision, and gives a yellow color to the urine. In toxic doses it causes headache, vertigo, sometimes convulsions, and death by respiratory paralysis. Santonini, Troch. (B. P.) Each contains gr. ss of the active principle. Dose ij-x. Sodii santoninas, $2 \mathrm{NaC}_{15} \mathrm{H}_{19} \mathrm{O}_{4} 7 \mathrm{H}_{2} \mathrm{O}$, colorless rhombic crystals. Dose gr. $\mathrm{ij}-\mathrm{x}$. This preparation is much less effective as a vermifuge than santonin, and is also much more poisonous. Sodii sant. Troch., each contains gr. $\mathrm{j}$ of the preceding. Dose ij-x.

Santonin, Santoninum (san'-to-nin, san-to-ni'-num ) [santoninum, gen., Santonini; (U. S. P.)], $\mathrm{C}_{15} \mathrm{H}_{18} \mathrm{O}_{3}$. The active principle of wormseed; it crystallizes in shining prisms, and melts at $170^{\circ} \mathrm{C}$. It is odorless, insoluble in cold water, and an active poison. It is one of the most efficacous vermifuges for roundworms. Dose gr. 1/4 to gr. ij. See Santonica.

Santoninate $\left(\operatorname{san}-t_{0} n^{\prime}-i n-\bar{a} t\right)$ [бavтovekov, wormwood]. Any salt of santoninic acid. See Santonica.

Santoninic Acid (san-to-nin'-ik). See Acid.

Santorini, Canal of. See Canal. S., Cartilages of. See Cartilage. S., Duct of. See Duct. S., Fis- 
sure of. See Fissures, Table of. S.'s Muscles. See Muscles, Table of. S.'s Tubercles, the cornicula laryngis.

Sap [sapa, must, new wine boiled]. The nutritive fluid which circulates by endosmosis in plants. S.cavity, in biology, one of the sacs in the leaves of plants, filled with sap. S.-green. Same as Bladder-green. S.-wood. See Alburnum.

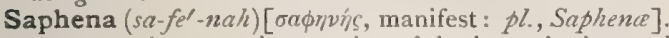
A name given two large veins of the leg-the internal or long, and the external, or short saphena.

Saphenal (sa-fe'-nal). Same as Saphenous.

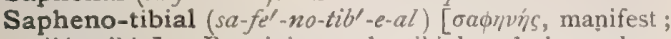
tibia, tibia]. Pertaining to the tibial and the saphenous veins. S. Vein, a vein that runs from the long saphenous to one of the tibial veins.

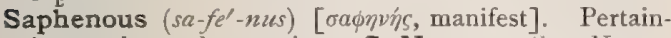
ing to the saphena veins. S. Nerves. See Nerves, Table of. S. Opening, an opening in the fascia lata at the upper part of the thigh anteriorly, the external terminus of the femoral canal, where a complete femoral hernia emerges and becomes subcutaneous. S. Veins. See Saphena.

Sapid $\left(s a p^{\prime}-i d\right)$ [sapere, to taste]. Capable of being tasted.

Sapientia (sa-pe-en'-she-ah) [L.]. Wisdom. Sapientix dentes, the posterior or third molar teeth.

Sapo $\left(s a^{\prime}\right.$-po) [L., gen., Saponis]. (Sapo duris, B. P.) r. Soap. 2. Of the U. S. Ph., castile soap, one made from olive-oil by treating it with sodium hydroxid. S. alba, olive-oil soap, castile soap. S. animalis, curd soap. Unof. Prepared from animal fat and soda. S. calcis, lime soap. See Linimentum calcis. S. durus, hard soap, made with olive-oil and soda. S. emplastrum, soap-plaster, has soap Io, lead-plaster 90 parts. S. fuscus, brown soap. S. fuscum, emplast. (B. P.), curd soap, yellow wax, olive-oil, oxid of lead, vinegar. S., Liniment., soap 7, camphor 45, oil of rosemary I, alcohol 75, water q.s. S. medicatus, made from almond-oil and soda. S. mollis. Unof. Made from olive-oil and potash. S. mollis, Lin., tincture of green soap. S. plumbi oxidi, lead-soap. See Lead-plaster. S. viridis (S. mollis, B.P.), green soap, soft, and usually brown in color. S. viridis, Tinct., green soap 65 , oil of lavender 2, alcohol q. s. ad IoO parts. Similar to opodeldoc.

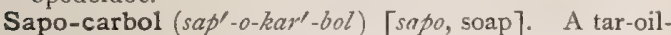
soap solution. A disinfectant of unknown composition and uncertain activity.

Saponaceous $\left(s a p-o-n a^{\prime}-s e-u s\right)$ [sapo, soap]. Having the nature of soap.

Saponaria (sap-o-na'-re-ah). See Soapreort.

Saponic Acid (sap-on'-ik). Synonym of Sapogenin.

Saponification (sap-on-if-ik-a'-shun) [sapo, soap; facere, to make]. I. Conversion into soap. 2. The process of decomposing a neutral fat into glycerin and a fatty acid by the action of an alkali, which combines with the fatty acid, forming a soap. S. Equivalent, a term used to indicate the number of grams of an oil saponified by one equivalent in grams of an alkali. S., Fermentation, saponification brought about by the action of a ferment.

Saponiment (sap-on'-im-ent) [sapo, soap]. A term denoting a medicinal compound of soap.

Saponin (saṕ-o-nin) [sapo, soap], $\mathrm{C}_{32} \mathrm{H}_{51} \mathrm{O}_{18}$. A glucosid contained in the roots of Saponaria officinalis and other plants; a white, amorphous powder, provoking sneezing, and in aqueous solution forming a strong lather. Dose gr. $\frac{1}{10}-\frac{1}{5}$.

Saporific (sap-o-rif'-ik) [sapor, savor; facere, to make]. Producing taste, flavor, or relish.
Saporous (sapp-a-rus) [sapor, savor]. Having flavor or taste.

Sapotoxin $\left(s a p-o-t o k s^{\prime}-i n\right)$ [sapo, soap; тoł̌ıóv, poison], $\mathrm{C}_{17} \mathrm{H}_{30} \mathrm{O}_{10}$. An active protoplasmic poison obtained from saponin. It is a glucosid.

Sappey's Accessory Portal System. Numerous small vessels formed around the liver and gall-bladder, in the suspensory ligament, and in the gastroepiploic omentum, in cases of hepatic cirrhosis. It is for the purpose of compensatory circulation.

Sapphism, or Sapphismus (saf'-izm, saf-iz'-mus) [from $\Sigma a \pi \phi \omega$, Sappho, a Greek poetess]. Tribadism. The unnatural passion of one woman for another.

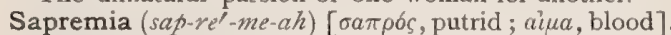
A febrile condition due to introduction into the blood of the products of putrefaction.

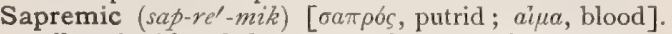
Affected with, of the nature of, or pertaining to, sapremia.

Saprin $\left(s a p^{\prime}-r i n\right)[\sigma a \pi \rho o ́ s$, rotten]. A non-poisonous ptomain, the product of bacterial decomposition of flesh.

Saprodontia (sap-ro-don'-she-ah) [ $\sigma a \pi \rho o ́ s$, rotten, carious; óduns, tooth]. Caries or rottenness of the teeth.

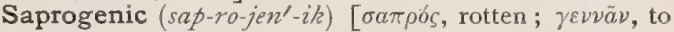
beget]. Causing putrefaction; caused by putrefaction.

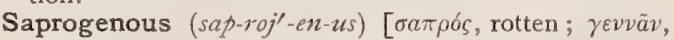
to beget]. Arising in decaying matter.

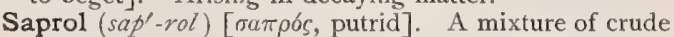
cresols, to which considerable quantities of pyridin are attached, with carbohydrates. It is probably derived in the process of refining petroleum, and is used for coarse disinfection.

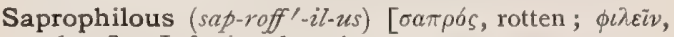
to love]. Infesting decaying matter.

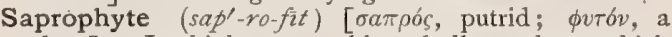
plant]. In biology, a chlorophylless plant which derives its sustenance from decaying organic matters.

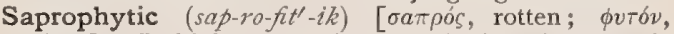
plant]. In biology, growing on or in decaying organic matter.

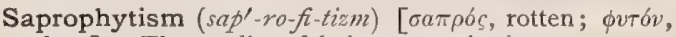
plant]. The quality of being saprophytic.

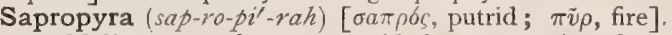
I. Malignant typhus, or putrid fever. 2. Any fever due to putrid infection.

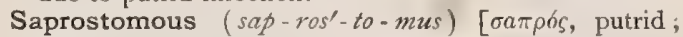
oró $\mu a$, mouth]. Having a fetid breath.

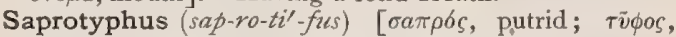
stupor]. Malignant or putrid typhoid fever.

Saraca indica (sar'-ak-a in'-dik-ah) [L.]. Asak; Jasundi. The bark is reputed as an astringent uterine sedative, useful in menorrhagia. Dose of the fld. ext. $m \times v-3 j$. Unof.

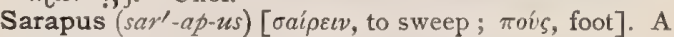
flat-footed person.

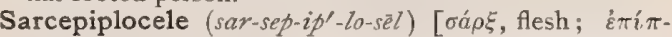

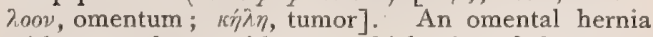
with sarcocele, or with great thickening of the omentum.

Sarchydrocele (sar-ki'-dro-sèl). Synonym of Hydrosarcocele.

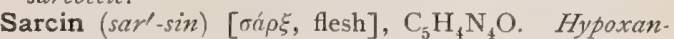
thin, a constant attendant of xanthin in the animal organism. It crystallizes in needles, not very soluble in water, but dissolved by alkalies and acids.

Sarcina (sar-si'-nah) [L., a bundle]. A genus of Schizomycetes, or bacteria, having spheric or ovoil cells dividing in three directions, thus producing cubic masses of greater or less size. See Bacteria, Synonym. atic Table of. 


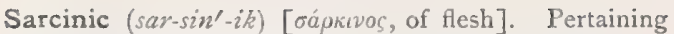
to or caused by sarcinæ.

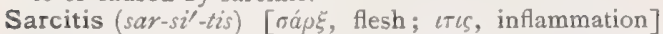
Inflammation of theshy tissue; especially inflammation of muscle.

Sarco- $\left(s u r^{\prime}-k o-\right)[\sigma a ́ \rho \xi$, flesh $]$. A prefix to denote con nection with or relation to flesh.

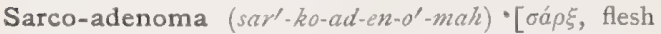
$a \delta \dot{\eta} \nu$, gland; $\dot{o} \mu a$, tumor]. A fleshy glandular tumor.

Sarcobasis $\left(s a r-k o b^{\prime}-a s-i s\right)$ [ $\sigma a ́ p \xi$, flesh; $\beta a ́ \sigma \iota s$, a step, foot]. See Carcerule.

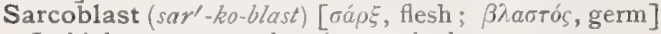
In biology, a protoplasmic germinal mass.

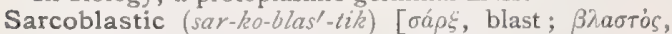
sprout]. Of the nature of a sarcoblast.

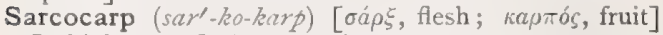
In biology, a fleshy, succulent mesocarp.

Sarcocele $\left(s a r^{\prime}-k o-s e ́ l\right)$ [ $\sigma a ́ \rho \xi$, flesh; $k \grave{\eta} \lambda \eta$, a tumor]. A solid or fleshy tumor of the testicle. S. of the Egyptians, elephantiasis of the scrotum. S., Malignant, any malignant tumor of the testicle.

Sarcocol, Sarcocolla (sar'-ko-kol, sar-ko-kol'-ah)

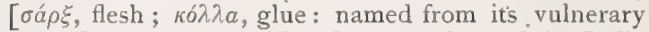
power]. I. A gum-like drug, much used in India and Arabia, supposed to be the product of some species of Astragalus. 2. An African resin with purgative qualities, the product of various plants of the genera Pencea and Sarcocolla. It is acrid and nauseous. Unof.

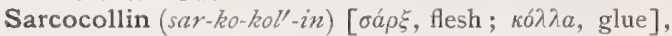
$\mathrm{C}_{22} \mathrm{H}_{19} \mathrm{O}_{10^{\circ}}$ A brownish, sweetish substance obtained from sarcocolla.

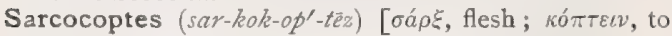
cut]. A preferable term for sarcoptes.

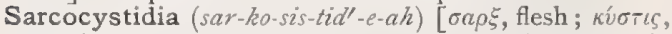
cyst]. A sub-class of the sporozoa. Sarcocystis miescheri is a parasite found in pork and beef; it is very common, but it is not known to be injurious to butchers' meat. See also Parasites (Animal), Table of.

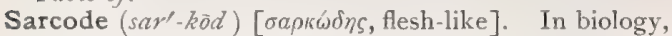
a term applied by Dujardin to the protoplasm of cells. C. Protoplasm.

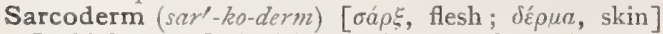
In biology, a fleshy layer in the coat of certain seeds.

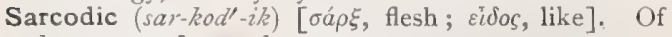
the nature of sarcode.

Sarcodous (sar'-ko-dres). Synonym of Sarcodic.

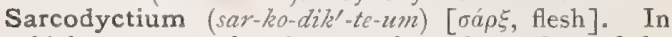
biology, a protoplasmic network on the surface of the calymma of certain Radiolaria. Cf Sarcomatrix.

Sarcoëpiplocele (sar-ko-e-piph-lo-sèl). Synonym of Sarcepiplocele.

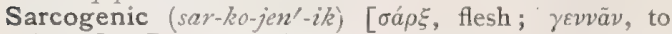
beget]. Producing flesh or muscle.

Sarcoglia $\left(s a r-k \circ g^{\prime}-l e-a h\right) \quad[\sigma a ́ p \xi$, flesh; $\gamma \lambda i a$, glue]. Sarcoplasm; a protoplasmic substance containing the granules and nuclei composing the eminence of Doyère, or the point of entrance of a motor nerve into muscular fiber.

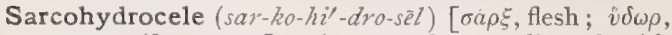
water; $\kappa \dot{\lambda} \lambda \eta$, tumor]. A sarcocele complicated with hydrocele of the tunica vaginalis.

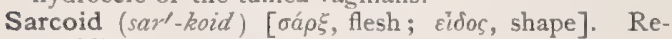
sembling or having the nature of flesh.

Sarcolactic Acid (sar-ko-lak'-tik). See Acid.

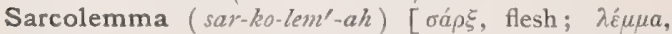
husk: pl., Sarcolemmata]. The membrane that envelops a muscle-fiber.

Sarcolemmic, Sarcolemmous (sar-ko-lem'-ik, sar-ko-

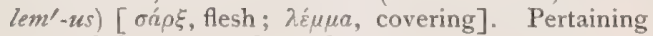
to or of the nature of sarcolemma.

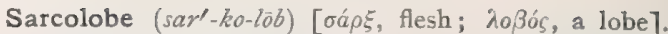
In biology, a fleshy cotyledon.

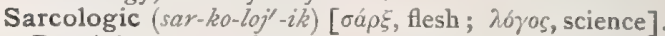
Pertaining to sarcology

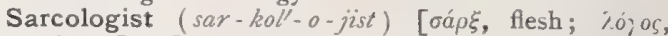
science]. One versed in sarcology

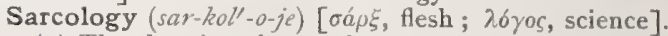
(a) The doctrine that each part nourishes a part, as held by the ancients, and revived in modern organotherapy. (b) That part of anatomy treating of the soft tissues.

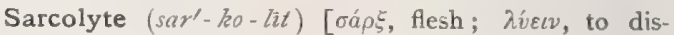
solve]. A cell which is actively concerned in effecting the retrograde metamorphosis of soft tissues.

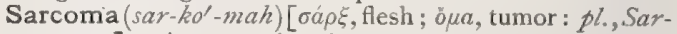
comata]. A connective-tissue tumor in which the cells so predominate in number, and often also in size, that the intercellular substance becomes a secondary element. It may also be defined as a tumor made up of embryonal connective tissue. Sarcomata are malignant tumors, the small-celled forms and those of soft consistency excelling in this respect. They appear, as a rule, at an earlier age than carcinoma. The problem of their causation is not solved : in many instances it is possible to trace a history of injury. It is probable, however, that the trauma merely acts as a predisposing cause. To the naked eye sarcomata appear, as the etymology of the word indicates, flesh-like. Microscopically, the picture varies with the variety of tumor, and whether it is a round-cell, a spindle-cell, or a giantcell sarcoma, or one of the other derivative forms. Sarcomata are well supplied with blood, which, however, is not contained in true vessels, but in spaces lined by endothelium. They are often combined with other new-growths, especially with the so-called mixed tumors and with certain congenital neoplasms, as the rhabdomyoma. The most frequent seats of sarcoma are the connective-tissue of the skin, periosteum, intermuscular septa, tendons, subserous connective-tissue, and the eye. The following are the chief varieties: S., Alveolar, one in which alveolar spaces are filled with sarcoma-cells. The walls of those spaces are formed by embryonal tissue. The growth resembles carcinoma. S., Angio-, one in which the vessel-walls have been conerted into sarcomatous tissue. S., Angio-lithic. Synonym of Psammoma. $\mathbf{S}$, Chloromatous, a round-celled sarcoma found in the periosteum of the skull. It has a greenish color. S., Cylindromatous, a sarcoma traversed by cylinders of myxomatous tissue. If the myxomatous degeneration affects the walls of the blood-vessels, the tumor is termed Angio-sarcoma myxomatodes. S., Encephaloid, a soft, rapidly growing sarcoma, usually of the round-cell variety. S., Endotheliomatous, a sarcoma formed by the multiplication of the endothelial cells of lymphatic spaces. S., Fascicular, S., Fasciculated. Synonyms of S., Spindle-celled. S., Gelatinous. Synonym of $S ., M_{y} x_{0-}$. S., Giant-celled, one containing giant-cells as a prominent feature. It is comparatively benign. S., Lympho-, a roundcelled sarcoma in which the cells are held in a reticulum. S., Medullary. Synonym of S, Encephaloid. S., Melano-, S., Melanotic, a sarcoma, usually spindle-celled, in which the cells contain a pigment, mela nin. It is a very malignant tumor, occurring most often in the eye, with a tendency to metastasis to the liver, intestinal tract, skin, etc. S., Mixed-celled. Synonym of S., Polymorphous. S., Myeloid. Synonym of S., Giant-celled. S., Myxo-, one which in part has undergone myxomatous degeneration. $\mathbf{S}$., Nest-celled. Synonym of Psammoma. S., Netcelled. Synonym of S., Myxo. S., Ossifying, S., 
Osteo-, S., Osteoid, one which has a tendency to the formation of bony tissue. S., Pigmented. Synonym of S., Melanotic. S., Plexiform, an angio-sarcoma presenting an intricate interlacing of vessels covered by sarcomatous tissue. S., Polymorphous, one containing several varieties of cells, as in the $S$, Giantcelled. S., Pulpy. Synonym of S., Encephaloid. S., Round-celled, one made up of round cells. There are two varieties, the small round-celled and the large round-celled sarcoma. The latter contains spindlecells and sometimes giant cells, but the dominant feature is large round-cells. S., Spindle-celled, one made up of spindle-cells. Also known as a Recurrent Fibroid.

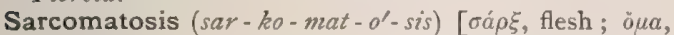
tumor]. The formation of multiple sarcomatous growths. S. generalis. Synonym of Granuloma fungoides.

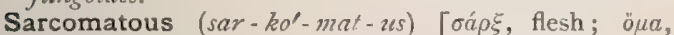
tumor]. Like or having the nature of sarcoma.

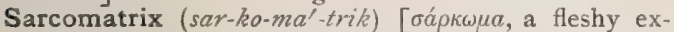
crescence; $\mu$ í $\uparrow \eta \rho$, mother]. A protoplasmic layer on the exterior of the capsular membrane in certain Radiolaria. Cf. Sarcodyctium.

Sarcome $\left(s a r^{\prime}-k o ̄ m\right)$. Same as Sarcoma.

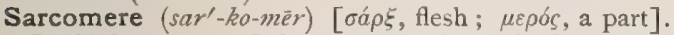
In biology, one of the segments into which a sarcostyle or muscle-fibril appears to be divided by transverse septa. A sarcous element.

Sarcomoscheocele (sar-ko-1nos'-ke-o-sēl) [oópł, flesh;

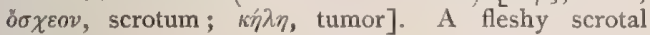
tumor.

Sarcomphalocele, Sarcomphalon (sar-kom-fal'-o-sell,

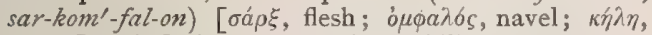
tumor]. A fleshy tumor at the umbilicus.

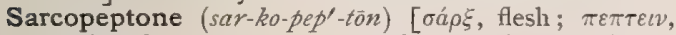
to digest]. A trade name for certain proprietary predigested meat-extracts.

Sarcophaga (sar-koff'-a-gah). Synonym of Sarcophila.

Sarcophagal (sar-koff'-ag-al). Same as Sarcophagous.

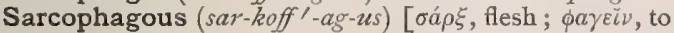
eat]. Flesh-eating.

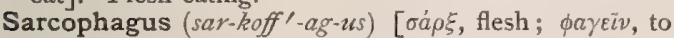
eat]. Coffin; tomb.

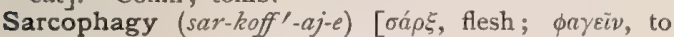
eat]. The habit of eating flesh.

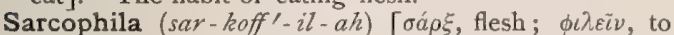
love]. See Parasites, Table of.

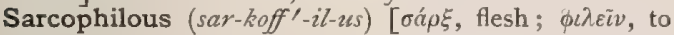
love]. Fond of flesh as food; sarcophagous.

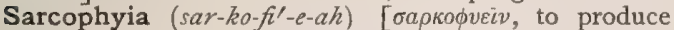
flesh]. Sarcoma; also fungous granulations.

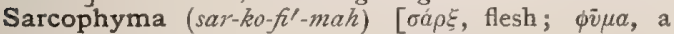
tumor]. A fleshy tumor.

Sarcophyte $\left(s a r^{\prime}-k o-f i t\right)$. Synonym of Bioplast.

Sarcoplasm, Sarcoplasma (sar'-ko-plazm, sar-ko-

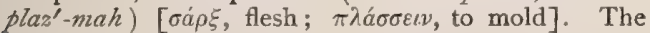
hyaline or finely granular interfibrillar material of muscle-tissue.

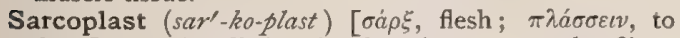
form]. I. A cell that develops into a muscular fiber. 2. Same as Sarcolyte.

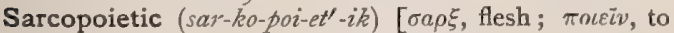
make]. Producing flesh or muscle.

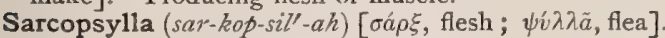
A genus of siphonapterous or aphanipterous insects. See Parasites (Animal), Table of.

Sarcopterygium $\left(s a r-k o-t e r-i j^{\prime}-e-u m\right)$. Synonym of Pterygium carnosum.

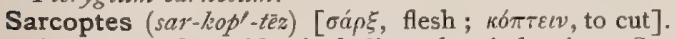
A genus of acarids, including the itch-mite. See Parasites, Table of. S. scabiei. See Scabies.

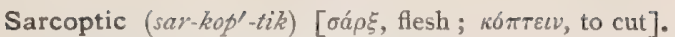
Due to or caused by sarcoptes.

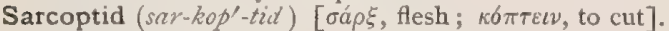
Any acaridan, or mite, of the family Sarcoptide, to which the genus Sarcoptes belongs.

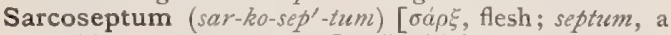
partition: pl., Sarcosepta]. In biology, an ordinary septum of a Cnidarian, lying between two sklerosepta.

Sarcosin (sar'-ko-sin) [ $\sigma a \rho \xi$, flesh $], \mathrm{C}_{3} \mathrm{H}_{7} \mathrm{NO}_{2}$. Methylglycocoll; a substance produced when creatin and caffein are heated with baryta ; it crystallizes in rhombic prisms that dissolve readily in water, but with difficulty in alcohol. It melts at from $210^{\circ}$ to $220^{\circ} \mathrm{C}$.

Sarcosis $\left(s a r-k o^{\prime}-s i s\right)$ [ $\sigma a ́ p \xi$, flesh]. I. The condition of one affected with sarcoma; sarcomatosis. 2. The formation of flesh or muscle-tissue.

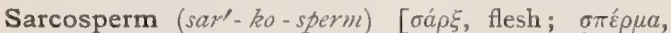
seed]. Same as Sarcoderm.

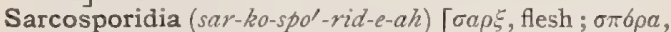
seed]. Utriculiform psorosperms frequently found in the muscles of cattle, sheep, swine, and other mammals. Cf. Miescher's Tubes, Rainey's Tubes, Sarcocystis miescheri, under Parasites (Animal), Table of.

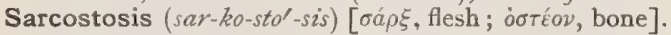
Bone-formation in muscular tissues.

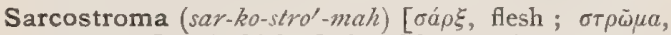
a covering]. A thick, fleshy, false membrane.

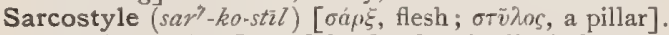
In biology : $(a)$ One of the fine longitudinal elements running from end to end in a striated muscle-fiber; a muscle-fibril; a muscle-column. (b) The name given by Hincks to the sarcode mass contained in the chitinous (sarcotheca) lasso-cell of a Cnidarian.

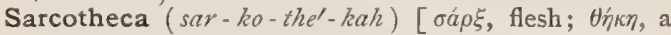
sheath: $p l$., Sarcotheca $]$. In biology, the name applied by Hincks to the chitinous cups of a thread-cell or lasso-cell of the Cnidaria.

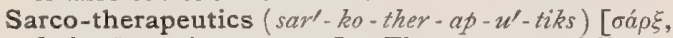

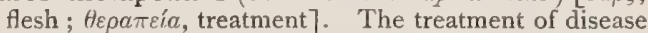
by means of animal extracts or substances. See Orsanotherapy.

Sarcothlasia, Sarcothlasis (sar-koth-la'-ze-ah, sar-

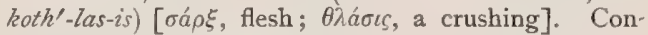
tusion of the soft tissues.

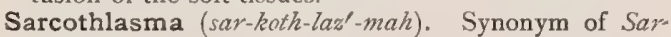
cothlasis.

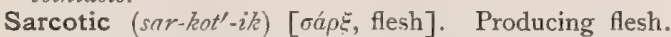
Also, pertaining to sarcosis.

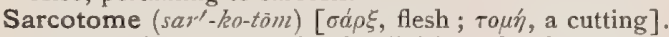
A surgical instrument for the division of soft tissues.

Sarcous (sar'-kus) [oá $\rho \xi$, flesh]. Fleshy. Pertaining to muscles. S. Elements, the dark prisms of the ultimate fibrillæ of striped muscle-fibers, formerly regarded by Bowman as the units of muscular tissue. A sarcoma.

Sardiasis, Sardoniasis (sar-di'-as-is, sar-do-ni'-as-is). Synonym of Risus sardonicus.

Sardonic (sar-don'-ik) [ $\Sigma \alpha \rho \delta \omega ́$, Sardinia]. Resembling the grimace produced by eating a certain Sardinian plant. See Risus sardonicus.

Sarkin (sar'-kin). See Sarcin and Hypoxanthin.

Sarment (sar'-ment) [sarmentum, twigs, light branches]. In biology, a long, slender stolon or branch.

Sarothrum (sa-ro'-thrum) [ $\sigma a ́ \rho o v$, a broom: pl. Sarothra]. In biology, the comb-like or brush-like hairs of the corbiculum or pollen-basket of a bee.

Sarracenia (sar-a-se'-ne-ah) [after Dr. Sarrazin, of Quebec]. A genus of American insectivorous plants, e.g., side-saddle flower, or pitcher-plant, remarkable for their trumpet-shaped leaves. S. purpurea, $\mathbf{S}$. flava, and $\mathbf{S}$. variolaris are said to afford roots serviceable in dyspepsia and gout. S. purpurea, and S. 
violaris have been vaunted as a cure for smallpox They are diuretic, diaphoretic, and stimulant. Dose of the fld. ext. gtt. Xxv. See also, Trumpet-plant.

Sarracenin $\left(s a r-a-s e^{\prime}-n i n\right)$ [after Dr. Sarrasin, of Quebec]. A substance, perhaps an alkaloid, found in Sarracenia purpurea

Sarrazin $\left(s a r^{\prime}-n z-i n\right)$. Same as Buckwheat.

Sarsa (sar'-sa/h). Same as Sarsaparilla.

Sarsaparilla (sar-sap-ar-il'-ah) [origin obscure]. Sarsæ Radix (B. P.) The root of Smilax officinalis, and several other species of the Smilax family, native to tropical America. It contains an essential oil and several extractive principles, and is diuretic, tonic and alterative. It has mild alterative properties and is a good vehicle for potassium iodid. It is used somewhat in tertiary syphilis, scrofula and similar diseases. S., Comp., Fld. Ext., sarsaparilla 75, licorice root 12, sassafras bark I0, mezereum 3, glycerin 10, water and alcohol q. s. ad 100 parts. Dose $3^{\text {ss }-j . ~ S ., ~ C o m p ., ~}$ Syr., fld. ext. sarsaparilla 20, fld. ext. glycyrrhiza I.5. fld. ext. senna 1.5, sugar 65, oil of sassafras, oil of anise, and oil of gaultheria, each I c.c., water q. s.

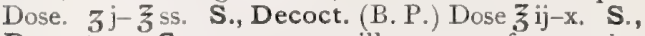
Decoctum, Comp., sarsaparilla Io, sassafras, guaiac wood, licorice root āā 2, mezereum I, water ad Ioo parts. Dose Zj-iv. S., Ext., Liq. (B. P.) Dose

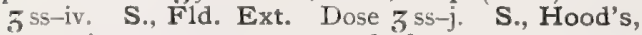
a proprietary nostrum composed of comp. ext. sarsap., taraxacum, podophyllum and juniper in about the proportion of their dosage. S., Indian. See Hemidesmus. S., Syr., unof., consists of a mixture of the oils of gaultheria and sassafras with syrup ad lib. Used as a flavoring for soda water.

Sartian Disease. An endemic rheumatic affection of the tropics, characterized by red indurated spots that finally ulcerate.

Sarticrureus (sar-tik-ru-re'-us) [sartor, a tailor; cmeraus, crureus]. The sartorius muscle.

Sartorius (sar-to'-re-us) [sartor, tailor]. See Muscle.

Sassa Gum. A gum resembling tragacanth; the product of Albizzia fastigiata, an African tree.

Sassafras (sas'-a-fras) [Sp., sasafras, sassafras]. The root-bark of $S$. officinalis. Its properties are due to a volatile oil. S., Australian. See Atherosperma moschata. It is aromatic and stimulant diaphoretic. S., Infus., unof., "sassafras tea." Dose ad libitum. See Salvop. S., Medulla, the pith of the sassafras stem, useful with 98 per cent. water as a demulcent drink; used also as a collyrium. S. Oil, the volatile oil. Dose $m_{\mathrm{j}} \mathrm{-v}$. A constituent of sarsaparilla syrup.

Sassaparilla (sas-ap-ar-il'-ah). Synonym of Sarsaparilla.

Sassolin (sas'-o-lin) [It., Sasso, a town near Florence]. A native boric acid. See Boron.

Sassy Bark (sas'-e bark). See Casca.

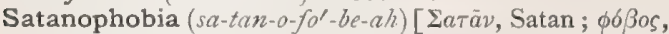
fear]. Morbid fear of the devil.

Satellite $($ sat'-el-it $)$ [satelles, an attendant]. In anatomy, the vein accompanying an artery.

Satiety $\left(s a-t i^{\prime}-e-t e\right)$ [satis, enough]. Fulness beyond desire.

Satin White. See Pigments, Conspectus of:

Satterthwaite's Method. See Artificial Respiration.

Saturable $\left(s a t^{\prime}-u-r a-b l\right)$ [saturabilis, saturable]. Capable of saturation.

Saturant (sat'-u-rant) [saturare, to saturate]. Saturating.

Saturate $($ sat'-u-vät) [saturare, to saturate]. Filling to excess.

Saturated (sat'-u-ra-ted) [saturare, to fill full]. I. A qualification applied to compounds constituted according to the general formula $\mathrm{C} \mathrm{X}_{2 n+2}$ (in which
$\mathrm{X}$ represents the valences directly joined to $\mathrm{C}$ ). Such compounds are known as paraffins. 2. Of a liquid, containing in solution all of a substance that it can dissolve. 3. Of solids, completely permeated with fluid. S. Solution. See Saturated, 2d definition.

Saturation (sat-u-ra'-shun) [saturare, to satisfy]. I. A term used to denote that a fluid holds as much of a soluble substance as it can dissolve. 2. Also a term denoting that an atom, molecule, or radicle has combined with all the atoms, molecules, or radicles it can hold. The complete satisfaction or neutralization of valency in any molecule, so that further combination can occur only by increasing the valency of some atoms, or releasing some atom or molecule from the compound. Thus, carbon, is saturated with 4 monad or 2 dyad atoms, H

as $\frac{\mathrm{H}-\mathrm{C}}{\mathrm{C}}-\mathrm{H}$, or $\mathrm{O}=\mathrm{C}=\mathrm{O}$. $\mathrm{S}$. of the Atmosphere, that condition in which any reduction of temperature will be followed by a precipitation of the aqueous vapor mingled with the atmosphere. S.-point, the temperature at which the atmosphere contains as much moisture as it can possibly hold, in the form of vapor.

Satureia (sat-u-re'-e-ah). See Summer Savory.

Saturn Cinnabar. Same as Minium.

Saturnine $\left(s a t^{\prime}-e r^{2}-n \bar{\imath} n\right)$ [Saturnus, a Roman deity; the alchemic symbol of lead]. I. Pertaining to lead or produced by lead. 2. Of gloomy nature. S. Amaurosis. See Saturnism. S. Arthralgia. See Saturnism. S. Cerebritis. See Encephalitis and S. Encephalopathy. S. Colic. See Colic. S. Encephalitis, inflammation of the brain, arising from lead-poisoning. S. Encephalopathy, a sudden outburst of grave cerebral symptoms: convulsions, coma, delirium, headache, sometimes amaurosis. It is often fatal, but at the autopsy, the brain usually shows no lesions. $\mathbf{S}$. Paralysis, paralysis from lead-poisoning. S. Poisoning, lead-poisoning. S. Red. Same as Minium.

Saturnism or Saturnismus (sat'-er-nizm, sat-er-niz'mus) [Saturnus, a Roman deity; the alchemic term for lead]. Lead-poisoning; plumbism. A chronic form of poisoning due to the more or less prolonged ingestion of small quantities of lead. It is most common in those whose occupation exposes them to contact with salts of the metal, such as painters. glaziers, workers in white-lead works, etc. Drinking-water and foods may also convey the poison to the system; so may cosmetics impregnated with lead; indeed, the sources of poisoning are manifold and often very curious. The forms of chronic lead-poisoning may be grouped as follows: I. Lead-colic, the most frequent. The pain is centered about the umbilicus, the abdomen retracted, constipation obstinate, the pulse corded. 2 . Lead-palsy, wrist-drop or drop-wrist. This is a paralysis of the extensor muscles of both forearms; it may be associated with sensory disturbances. Paralysis of the ocular and the laryngeal muscles has also been observed. 3. Saturnine encephalopathy, q.v. 4. Saturnine arthralgia. A painful affection of the joints, especially the knee, rarely the others. Objective signs are usually absent. The disease may resemble chronic gout. 5. Chronic contracted kidney. 6. Amblyopia due to atrophy of the optic nerve. The general symptoms of lead-poisoning are a marked anemia and cachexia, and a blue line at the edge of the gums.

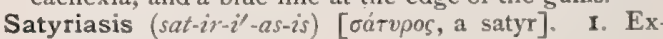
cessive venereal desire. 2. Leprosy.

Satyromania (sat-ir-o-ma'-ne-ah). Same as Satyrinsis. Satyromaniac (sat-ir-o-ma'-ne-ak) [бátvoos, satyr; $\mu a v i a, \operatorname{madness}]$. One who is affected with satyriasis. 
Saunders $\left(s a / m n^{\prime}\right.$-derz). See Santalum rubrum.

Sauriasis (saze-ri'-a-sis). Same as Ichthyosis.

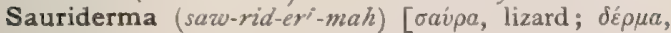
skin]. Ichthyosis.

Sauriosis (saw-ri-o'-sis). See Tchthyosis sauroderma.

Sauroderma (saw-ro-der'mah). See Sauriderma.

Saurognathism (saw-rog'-na-thizm) [ $\sigma a v ́ \rho a$, lizard

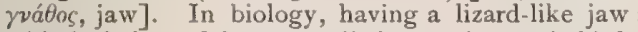
with the halves of the vomer distinct, as in certain birds.

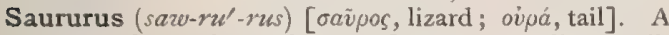
genus of apetalous plants. S. cernuus, lizard-tail, or breast-weed. A N. American water-plant; the root, bruised or boiled, is discutient and emollient, and is said to relieve pleurodynia. Unof.

Sausage $\left(s a w^{\prime}-s \bar{a} j\right)$ [ME., saucige, sausage]. An article of food consisting mainly of minced meat with seasoning. S.-poison. See Allantotoxicon. S.poisoning. See Botulismus and Allantiasis.

Sauterne (so-tern') [Sauterne, a place in France]. A certain white wine.

Savanna $\left.(s a-v) a n^{\prime}-a h\right)$ [Sp., sávana, a sheet]. A treeless plain. S.-flower, yellow nightshade. The leaves of Urechites suberecta, a highly poisonous West Indian plant. It resembles aconite in action. Its properties are not fully known. Unof.

Savelieff's Method. See Sputum, Methods of Examination.

Savigny's Tubules. The very fine branched and ampullated tubules ramifying over the wall of the intestine in nearly all the Tunicata, functioning as a pancreas.

Savine (sav'-in). See Sabina.

Saviotti's Canals. Fine passages between the secreting cells of the pancreas. They are now believed to be formed artificially.

Savor $\left(s a^{\prime}\right.$-vor) [savor, taste]. The taste or odor of a substance.

Savory (sa'-vo-re) [savor, odor, or flavor]. Having a pleasant odor or flavor. See Summer Savory.

Savory and Moore's Food. A Liebig's food for infants. Its composition is: Water, 8.34 ; fat, 0.40 ; grape-sugar, 20.41 ; cane-sugar, 9.08 ; starch, 36.36 ; soluble carbohydrates, 44.83 ; albuminoids, 9.63 ; cellulose, gum, etc., 0.44; ash, 0.89 .

Saw [ME., sarve, saw]. An instrument for cutting bone. It consists of a thin blade with sharp teeth on one edge. S., Amputating, one especially devised for amputations. S.-box. See Macrotome. S., Butcher's, one which allows the blade to be fixed at any angle. S., Chain, one in which the teeth are set in links movable upon each other. The saw is moved by pulling alternately upon one and the other handle. S., Crown. See Trephine. S.-dust, small particles of wood, produced by sawing. Saw-dust was formerly used in surgery, in preparing pads for fractured bones, and as a dressing for wounds. S., Hemp, a cord slipped over the part to be excised, and drawn back and forth till it cuts through the tissue; it is of service in embryotomy and in amputations of deepseated parts. S., Hey's, a rigid disc with saw-teeth and handle, for enlarging an opening. S. Palmetto, the fruit of Serenoa sermlata, sedative, nutritive and

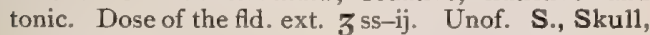
the trephine. S.-wort. See Pigments, Conspectus of.

Sawing (saw'-ing). See Sciage.

Sawyer's Cramp. See Cramp.

Saxatile (saks'-at-il) [saxum, a rock]. In biology, growing upon or among rocks.

Saxifrage (saks'-if-rāj]) [saxum, a rock; frangere, to break]. Any plant of the genus Saxifragr, including many species of herbs, to some of which doubtful medicinal properties are ascribed.

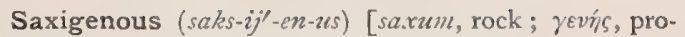
duced]. In biology, growing on rocks.

Saxolinum (saks-o-li'-num) [saxum, rock; oleum, oil]. Synonym of Pelrolatum.

Saxony Blue. Same as Indigo Blue. S. Green. Same as Rinmann's Green.

Sayre's Apparatus, S.'s Jacket. A jacket of plasterof-Paris molded to support the spine in certain diseases of the vertebral column. S.'s Method. See Treatment, Methods of. S.'s Shoe, the high shoe used in hip-joint disease. S.'s Sign or Test. See Signs and Symptoms, Table of.

Scab $(s k a b)$ [scabere, to scratch]. I. The crust formed by the desiccation of the secretions of an ulcer or wound. 2. In biology: (a) Psoroptic scabies of domestic animals, also called, Shab, Ray, Rubbers, Räude, Krätze, Schabe, Grind (Ger.) ; Rogne, Tac, Gall épizoötique (Fr.); Rogna, Scabbia (Ital.); Sarna (Sp.); Tschesotka (Rus.); Rüh (Hung.); Skab (Dan.); Scabb, (Swed.); Maracane (Guayana) ; Car. racha (Peru); a dermatosis due to the presence of Psoroptes communis, var. equi, bovis, ovis, capre, cuniculi. See under Parasites (Animal), Table of. (b) A diseased condition of plants produced by a parasitic fungus, and characterized by a scabby appearance; e.g., Apple-scab, Fusicladium dendriticum, Fuckel. Pear-scab, Fusicladium pyrinum, Fuckel. Potato-scab, Oöspora scabies, Spongospora solani, Fusarium diplosporum, C. E. Wheatscab, Fusarium culmorum. Orange-scab, Cladosporium herbarum, Pk., Fusarium sarcochroum, Sacc. S.-weavers. Synonym of Scabies.

Scabbed (skabd) [scabere, to scratch]. Mangy, affected with scabies.

Scabby $\left(s k a b^{\prime}-e\right)$. Same as Scabbed.

Scaberulous $\left(s k a-b e r^{\prime}-u\right.$-lus $)$ [scaber, rough]. In biology, slightly roughened.

Scabies $\left(s k a^{\prime}-b e-\bar{e} z\right)$ [scabere, to scratch]. Itch; a parasitic skin-disease, caused by an animal parasite, the Sarcoptes scabiei, var. hominis, or itch-mite. See Parasites (Animal), Table of. The acarus, burrowing in the epidermis, irritates the skin, causing various inflammatory lesions, such as papules, vesicles, and pustules, accompanied by intense itching. The scratching resorted to to relieve this itching produces the long scratch-marks so commonly seen in itch. The insect shows a marked predilection for certain localities, as between the fingers, the flexor surface of the wrists, the axillæ, and the buttocks. S. norwegica. See Itch, Norway, and Sarcoptes scabiei, var. lupi, under Parasites (Animal), Table of.

Scabiola $\left(s k a-b i^{\prime}-0-l a h\right)$. Synonym of Scabies.

Scabiophobia (ska-be-o-fo'-be-ah) [scabies, itch; $\phi 6 \beta 0 s$, fear]. Morbid or insane fear of scabies.

Scabious $\left(s k a^{\prime}-b e-u s\right)$ [scabiosus, rough, scabby]. I. Scabby or scaly. 2. As a noun, any plant of the genus Scabiosa; popularly regarded as useful in skin. diseases and gout, and as vulneraries. Unof.

Scabrate (ska'-brät). Same as Scabrous.

Scabrid (ska'brid) [scaber, rough]. In biology, slightly rough.

Scabrities (ska-brit'-e-ēz) [scaber, rough]. Roughness; scabbiness. S. unguium, abnormal thickening of the finger nails.

Scabrous (ska'-brus) [scaber, rough]. In biology, rough or harsh to the touch, with points or hairs. Applied to leaves, etc.

Scala $\left(s k a^{\prime}-l a h\right)$ [L.]. A stair-case or ladder. S., Collateral. Synonym of Canal, Cochlear. S. of Löwenberg. Synonym of Canal, Cochlear. S. media, the space between the membrane of Reissner and the basilar membrane; containing the essential peripheral 
organs of hearing. S., Posterior Cochleal. Synonym of S. tympani. S., Superior Cochlear. S. vestibuli. S. tympani, the canal lying below the osseous lamina and the basilar membrane of the internal ear. S. vestibuli, the canal bounded by the osseous lamina and the membrane of Reissner. See Ear.

Scalariform (ska-lar-if-omn) [scalaria, a ladder; forma, form]. In biology, shaped like a ladder. Applied to ducts or vessels on which the markings are so placed as to resemble the rounds and spaces of a ladder.

Scald (skazuld) [ME., scalden, to scald]. I. The burn caused by hot liquids or vapors. 2. A scabby skindisease, especially of the scalp. S.-head. See Favus.

Scale $(s k \bar{a} l)$ [ME., scale, a scale]. Of fishes, any one of the small semi-opaque laminæ of modified epidermis covering the surface of the body. 2. An exfoliated shell of bone. 3. The semi-opaque laminæ of horny epidermis occurring upon the skin in various skin-diseases. See Squama. Ss., Hair, the imbricated platelike cells forming the cortical portion of a hair.

Scale [scala, ladder]. A series of marks placed at regular distances from each other and used as standards in measuring. S., Centigrade, S., Fahrenheit, S., Reaumur. See Thermometer.

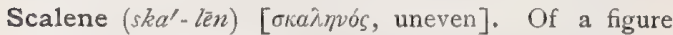
having unequal sides.

Scalenus (ska-le'-nus). See Muscles, Table of.

Scaler (ska'-ler) [ME., scale, scale]. In dentistry, an instrument for removing the tartar from the teeth.

Scalesiasis (ska-le-si'-as-is). Synonym of Measles.

Scaling (ska'-ling) [ME., scale, scale]. Desquamating ; producing scales. $\mathrm{S}$. the Teeth, an old name for the operation, in dentistry, which consists in the removal of salivary calculus, commonly called tartar, from the teeth. See Salivary Calculus.

Scall (skrzol) [ME., skalle, a scab]. Favus, impetigo, psoriasis, eczema, or other skin-disease. [Old.] S., Dry, psoriasis, scabies. S., Moist, eczema.

Scalled (skawld) [ME., skalle, a scab]. Affected with scall.

Scalma (skal'-mah) [OHG., scalmo, pestilence]. A contagious and infectious febrile disease of the horse, with local lesions of the bronchi, trachea, and larynx, which produce cough. It is further characterized by great irritability of temper. It is rarely fatal, except from complications.

Scalp (skalp) [ME., scalp, the top of the head]. The integumentary covering of the cranium. S., Hairy, that portion of the scalp usually covered by hair.

Scalpel (skal-pel') [scalpellum, a little knife]. A small knife, having a blade somewhat wider than a bistoury, the cutting edge being convex.

Scalpellum (skal-pel'-um) [L., a surgical knife]. In biology, one of the lancet-like organs of the promuscis of certain insects (Heniptera).

Scalper (skal'-per) [L.]. See Scalprum.

Scalping (skall-ping). See Gerdy's Operation in Table of Operations.

Scalpriform (skal'-prif-orm) [scalprum, a knife, chisel ; forma, form ]. In biology, chisel-shaped; applied to the incisor teeth of rodents and some other mammals.

Scalprum (skal"-prum) [scalpere, to scrape]. A toothed raspatory used in trephining and in removing carious bone

Scaly $\left(s k a^{\prime}-l e\right)$ [ME., scale, scale]. Covered with or having scales. S. Tetter. See Psoriasis.

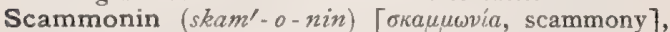
$\mathrm{C}_{34} \mathrm{H}_{56} \mathrm{O}_{16}$. A glucosid found in scammony. It may be identical with jalapin.

Scammonium, Scammoneum, Scammony (skam-o'-

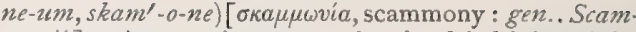
monii]. A purgative gum-resin, the dried juice of the root of Convolvulus scammonia, a South-western Asiatic plant. It is generally given in combination with other drugs. Its properties are due to an active principle, jalapin. A drastic cathartic. Dose gr. $\nabla-x$. S., Confectio (B. P.) Dose gr. x-xx. S., Mist. (B. P.)

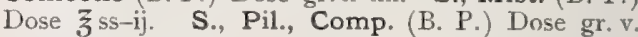
S., Pulv., Comp. (B. P.), contains scammony, ginger, and jalap. Dose gr. x-xx. S., Resina. Dose gr. iij-viij.

Scandent (skan'-dent) [scandere, climb]. In biology, climbing. Applied to stems that climb by means of organs modified for the purpose.

Scandium (skan'-de-um) [Scandia, Scandinavia]. A metal belonging to the aluminum group. Symbol $\mathrm{Sc}$; atomic weight 44 . See Elements, Table of.

Scanning (skan'-ing) [scandere, to climb]. A peculiar, slow, and measured form of speech, met with in various nervous affections, chiefly in multiple sclerosis.

Scansorius (skan-so'-re-us). See Muscles, Table of.

Scape $(s k a \bar{a} p)$ [ $\sigma \kappa a ̈ \pi o s$, a shaft, a staff]. In biology, a leafless, radical peduncle

Scapel $\left(s k a p^{\prime}-e l\right)$ [scapellus, dim. of scapus, scape]. In biology, the neck or caulicle of the germinating embryo.

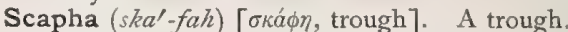

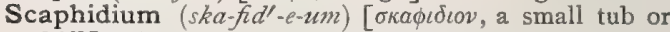
skiff ]. In biology, the receptacle of the spores in certain algæ.

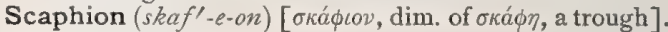
Synonym of Cranium.

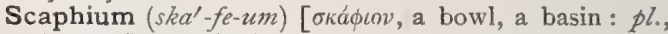
Scaphia]. In biology: (a) the carina or keel of a papilionaceous flower; (b) an unpaired appendage of lepidopterous insects.

Scaphocephalic (skaf-o-sef-al'-ik). See Scaphocephalous.

Scaphocephalism (skaf-o-sef'-al-izm). See Scaphocephaly.

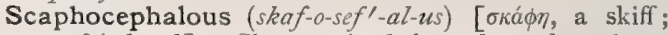
$\kappa \varepsilon \phi a \lambda \dot{\eta}$, head]. Characterized by a boat-shaped appearance of the cranium, arising from ossification of the sagittal suture in infancy.

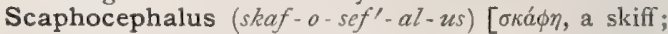
$\kappa \varepsilon \phi a \lambda \dot{\eta}$, head]. A boat-shaped appearance of the cranium, due to a premature union of the sagittal suture, or abnormal development.

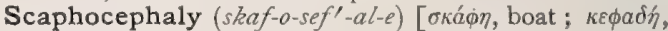
head]. The condition of having a boat-shaped skull.

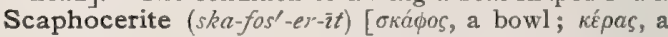
horn]. In biology, the scale-like appendage of the second pair of antennæe of a crustacean.

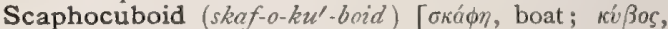
cube; eisós, like]. Pertaining to the scaphoid and cuboid bones.

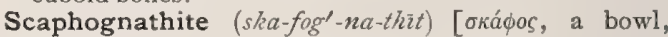
boat; rvátos, jaw]. In biology, the scale-like appendage of the second maxilla of a crustacean.

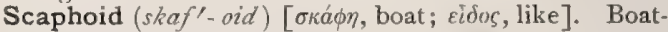
shaped. S. Abdomen, the sunken appearance of the belly, seen in meningitis and in great emaciation from wasting diseases. S. Bone, a name given to a boatshaped bone of the tarsus and also to one of the carpus. S. Fossa. See Fossa.

Scaphoideum $\left(s k a-f o i^{\prime}-d e-u m\right)$ [L.]. The scaphoid bone of the wrist or ankle.

Scaphoido-cuneiform Amputation. See Chopart's Amputation and Forbes's Amputation, in Operations, Table of.

Scapholunar (skaf-o-lu'-nar) [ $\sigma \kappa a ́ \phi \eta$, boat; luna, moon]. Pertaining to the scaphoid and semilunar bones. 


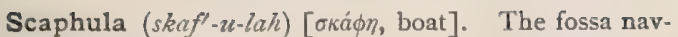
icularis.

Scapiform (ska'-pif-orm) [scapus, a stalk; forma, form]. In biology, scape-like.

Scapula $\left(s k n p^{\prime}-u\right.$-lah) [L.]. The large, flat, triangular bone forming the back of the shoulder and belonging

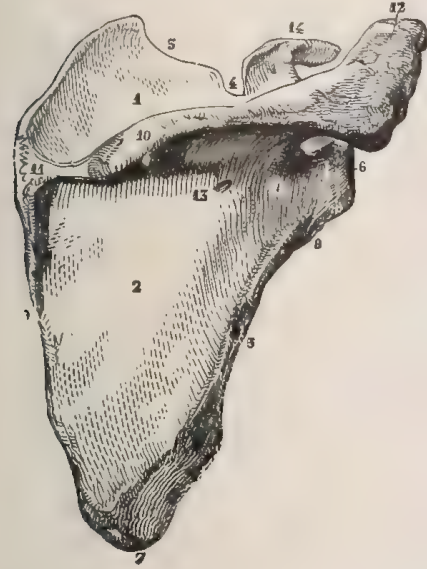

Scapula. PosteroEXTERNAL ASPECT. Supraspinous fossa. 2. Infra-s p in o us fossa. 3. Superior or coracoid border. 4. Coracoid or suprascapular notch. 5. Axillary or exter. Al border 6. terior angle and glenoid cavity. 7 . Inferior angle. 8 Rough impression for long head of triceps. 9. Internal or spinal or verteor spinal or verteSpine. II. Smoth Spine. r1. Smooth surface over which trapezius muscle glides. 12. Acromion. 13. Base of spine, 14. Coracoid process.

to the shoulder-girdle. The shoulder-blade. See Bones, Table of.

Scapulacromial (skap-u-lak-ro'-me-al) [scapula, shoul-

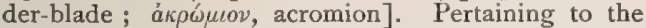
acromion process of the scapula.

Scapulalgia (skap-u-lal'-je-ah) [scapula, the shoulderblade; $\dot{a} \lambda$ yos, pain]. Pain in the neighborhood of the shoulder-blade.

Scapular (skap'-u-lar) [scapula, the shoulder-blade]. Pertaining to the shoulder-blade. S. Arch, the pectoral arch or shoulder-girth. S. Line, a vertical line drawn on the back through the inferior angle of the scapula. S. Point, a tender point developed in neuralgia of the brachial plexus and situated at the inferior angle of the scapula. S. Reflex. See Reflexes, Table of. S. Region, the region in and about the scapula. In biology, a well-defined longitudinal area of feathers lying along the back and over the shoulderblade of a bird (regio scapularis).

Scapulary $\left(s k a p^{\prime}-u-l a-r e\right)$ [scapula, scapula]. A shoulder-bandage.

Scapulated $\left(s k a p^{\prime}-u-l a-t e d\right)$ [scapula, the shoulderblades]. In biology, having the feathers of the scapular region well marked, as in Corvus scapulatus, the scapulated crow.

Scapulen $\left(s k a p^{\prime}-u\right.$-len) [scapula, the shoulder-blade]. Belonging to the scapula in itself.

Scapulet, Scapulette (skap'-u-let) [scapula, the shoulder]. In biology, one of the leaf-like appendages of the manubrium of certain Cnidaria.

Scapulo- $\left(s k a p^{\prime}-u-l o-\right)$ [scapula, scapula]. A prefix denoting relation to the shoulder or scapula

Scapulo-clavicular (ska $p^{\prime}-u$-lo-kla-vik'-u-lar) [scapula, scapula ; clavis, key]. Pertaining to the scapula and the clavicle.

Scapulo-coracoid (skap'-u-lo-ko'-rak-oid) [scapula,

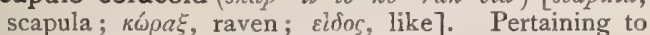
the scapula and the coracoid process.

Scapulodynia $\left(\operatorname{skap}-u-l o-d i n^{\prime}-e-a h\right)$. Synonym of Scapulalgia.

Scapulo-humeral (skap'-u-lo- hu'- mer - al) [scapula, scapula; humerus, humerus]. Pertaining to the scapula and the humerus. S. amputation, removal of the arm at the shoulder-joint.
Scapulo-radial (skap $\left.p^{\prime}-\imath t-l o-r \alpha^{\prime}-d^{\prime} e-a l\right)$ [scapula, scapula; radius, ray]. Pertaining to both scapula and radius.

Scapulo-ulnar (skap'-u-lo-ul'-nar) [scapula, scapula; ulna, ulna]. Pertaining to both scapula and ulna.

Scapulo-vertebral (skap'-u-lo-ver'-te-bral) [scapula, scapula; vertebra, vertebra]. Pertaining to the scapula and the spine.

Scapus $\left(s k a^{\prime}-p u s\right)$ [scapus, a shaft, stem: pl., Scapi]. In biology, the scape of a flower, a feather, or an antenna. $\mathbf{S}$. penis, the body of the penis. S. pili, the hair-shaft.

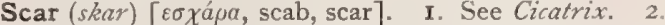
In biology, the mark left on the stem when the leaf falls away, or on the seed when it separates from the funiculus.

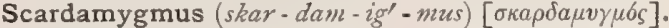
Winking

Scarenzio's Treatment. The treatment of syphilis by the hypodermatic injection of calomel. S.'s Method. See Treatment, Methods of.

Scarfskin (skarf'-skin) [Sw.,skarf, a scarf; ME., skin, skin]. The epidermis or cuticle

Scarification (skar-if-ik-a'-shun) [scarificare, to scarify]. The operation of making numerous small, superficial incisions or punctures, for giving vent to serum or blood or gases.

Scarificator (skarl-if-ik-a-tor) [scarificare, to scarify]. An instrument used in scarification. It consists of a number of small lancets, operated by a spring, so that a number of slight incisions are made synchronously.

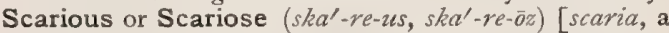
thorny shrub]. Dry, thin, and membranous. Applied to parts of flowers, etc.

Scarlatina (skar-lat-e'-nah) [scarlatinus, scarlet]. See Scarlet Fever. S. anginosa, S. cynanchica, scarlet fever with angina. S. gastrica, scarlet fever complicated with gastro-enteritis. S. gravior, malignant scarlet fever. S. hamorrhagica, scarlet fever, or more usually septic fever with hemorrhagic spots. S. lævis, mild scarlet fever. S. latens, scarlet fever without eruption. S. maligna, malignant scarlet fever. S. papulosa, scarlet fever in which there are prominent papules, due to involvement of the hairfollicles. S. pruriginosa. Synonym of Urticaria. S. puerperalis. See Scarlet Fever, Puerperal. S. pustulosa, scarlet fever with a pustular eruption. $\mathbf{S}$. rheumatica. Synonym of Dengue. S. septica, a grave form of scarlet fever characterized by symptoms of septic intoxication. S. simplex, mild scarlet fever. S. sine angina, scarlet fever without throat-symptoms. S. sine eruptione, S. sine exanthemate, scarlet fever without the rash. S. traumatica, the eruption similar to that of scarlet fever, accompanied by febrile symptoms, which sometimes follows wounds or surgical operations. S. typhosa, malignant scarlet fever, with grave nervous symptoms. S. urticata, urticaria

Scarlatinal (skar-lat' - in - al, skar-lat-e'-nal) [scarlatinus, scarlet]. Pertaining to scarlatina. S. Angina, the throat-affection produced by scarlet fever. $\mathbf{S}$. Nephritis, the acute catarrhal nephritis that arises in the course of or during the convalescence from scarlet fever. S. Tongue, the "strawberry" tongue of scarlet fever.

Scarlatiniform (skar-lat-in'-if-orm). Synonym of Scarlatinoid.

Scarlatinoid (skar-lat'-in-oid) [scarlatinus, scarlet ; Eidos, like]. Resembling scarlatina.

Scarlatinous (skar-lat' - in-zes) [scarlatinus, scarlet]. Having the nature of or pertaining to scarlatina.

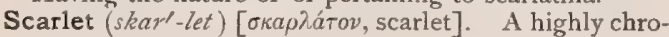
matic and brilliant-red color. S--faced, having a 
very red face. S. Fever, an acute, specific, epidemic, contagious disease, characterized by a scarlet flush spreading progressively from the face over the body, ending on about the seventh day in desquamation of the cuticle. The fever is not high in the simple cases, but may rise to a very high point in the graver cases. "The tongue is the characteristic "strawberry tongue," with prominent papillx, and there is a red, swollen, and inflamed condition of the tonsils, uvula, and soft palate, upon which a soft, white film may be deposited. Acute nephritis and suppurative otitis are frequent complications or sequelæ. In a small proportion of the cases the patient will undergo a relapse, and pass through a second attack of the disease of varying severity. One attack of the disease protects against a second attack, but not quite to the same extent as in measles. The disease is most frequent in children near the age of five years, and after this period the liability to contract the disease diminishes rapidly. See Exanthemata, Table of. S. Ocher. Same as Ocher.

Scarpa's Aplatissement. A form of ligature used by Scarpa for the purpose of arresting the circulation temporarily by mechanical pressure without lacerating the tissues of the vessel. S.'s Fascia, the deep layer of the superficial abdominal fascia. S., Foramen of. See Foramina, Table of. S.'s Ganglion. See Ganglia, Table of. S.'s Hiatus, the helicotrema, or opening between the scala vestibuli and the scala tympani. S.'s Ligature. See Ligature. S.'s Liquor, the endolymph. S.'s Nerve. See Nerves, Table of. S.'s Shoe, a shoe for club-foot. S.'s Triangle. See Triangle.

Scatacratia (skat-ak-ra'-she-ah). See Scoracratia.

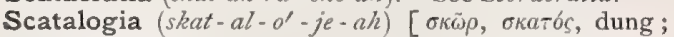
à oyia, senselessness ]. Insanity characterized by great filthiness.

Scatol (ska'-tol). See Skatol.

Scatologia, Scatology (skat-o-lo'-je-ah, skat-ol'-o-je)

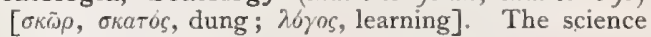
or study of excreta.

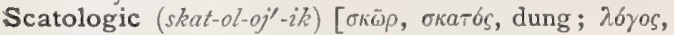
science]. Pertaining to scatologia.

Scatomancy (skat'-o-man-se). Same as Scatoscop 1.

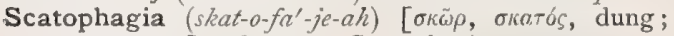
ouyeiv, to eat]. Same as Coprophagia.

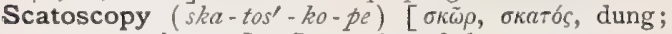
бколєіv, to inspect]. Inspection of the excreta.

Scattered (skat'-erd) [ME., scateren, to scatter]. In biology, few, or without regularity of arrangement.

Scatula (skat'-u-lah) [L., a parallepiped: pl., Scatule]. An oblong flat box for powders or pills.

Scavenger (skav'-en-jer) [ME., scavager, scavenger]. One who cleans; specifically one who cleans the streets, etc., of a city. S.-cells, a name applied to certain lymph-cells of the brain. In general paralysis and chronic alcoholism they are said to become highly developed, but have individually only a brief existence, their growth and decay leading to a degradation of the tissue. S.-service, collectively, those employed to clean the streets of a city by scraping or sweeping together and carrying off the filth or other waste products.

Scavenging (skav'-en-jing) [ME., scavager, a scavenger]. Removal of the waste products, as the cleansing of out-houses, sewers, etc.

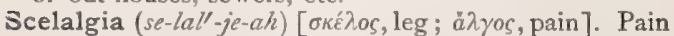
in a leg. S. puerperarum. Synonym of Phlegmasia alba dolens.

Sceleteuma (sel-et-u'-mah) [ $\sigma \kappa \varepsilon \hat{\lambda} \lambda \varepsilon \iota v$, to dry up]. Synonym of Mummification.

Sceleton (sel'-et-on). Synonym of Skeleton.

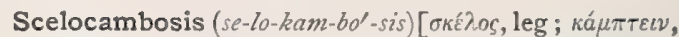
to bend]. Curvature of a leg or of the legs; genu varum.

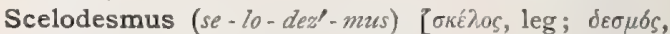
band]. I. A bandage for the knee. 2. Gout in the knee.

Scelodidymus (se-lo-did'-im-us). Synonym of Ischioprgus.

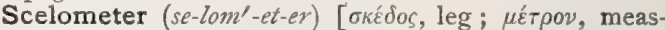
ure]. An instrument for measuring the lower limbs in fractures or dislocations.

Sceloncia, Sceloncus (se-lon'-se-ah, se-lon'-kus)

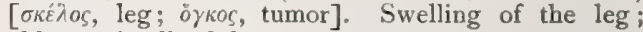
phlegmasia alba dolens.

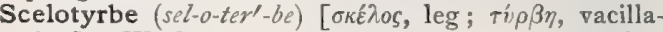
tion]. Weakness, or indecision in stepping, often due to a palsied condition. S. pituitosa. Synonym of Enteritis, Pseudo-membranous.

Scempsis (semp'-sis). Synonym of Decubitus.

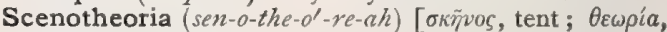
theory]. The cell-doctrine.

Scent (sent) [ME., senten, to smell]. An effluvium from any body capable of affecting the olfactory sense; odor, fragrance. S.-bag. Same as S.-organ. S.gland, an odoriferous gland, or one secreting an odoriferous substance. S.-organ. See Osmeterium. S.pore, the orifice of a scent-gland. S.-vesicle, a vesicle containing odoriferous matter.

Schacher's Ganglion. The ophthalmic ganglion. See Ganglia, Table of.

Schachowa, Spiral Tubule of. The spiral portion of a uriniferous tubule.

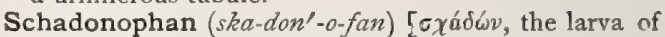
some insects; $\phi a i v \varepsilon v$, to appear]. In biology, the name applied by Henking to a larval stage of certain acaridans.

Schæfer's Dumb-bells. Dark, dumb-bell shaped structures, imbedded in a light intermediate substance, and which, according to Schæfer, constitute the basis of striated muscular tissue.

Schaller's Method. A method of preparing carminic acid. The aqueous extract of cochineal is precipitated with plumbic acetate acidulated with acetic acid; the precipitate is decomposed with hydrogen sulphid, and filtered. The filtrate is evaporated to dryness on a water-bath, and the residue dissolved in absolute alcohol; this solution is allowed to evaporate, when the crystals of carminic acid separate. They are washed with cold water to remove impurities, the water dissolving only the carminic acid.

Schallphotismen (shahl-fo-tiz'-men). See Audition colorée.

Scharling and Pettenkofer, Method of. A method of investigating the changes in the air brought about by respiration. The animal is placed in a chamber through which atmospheric air is passed, and the change in the composition in the air after passing through the chamber is determined.

Schatz's Method. A method of performing external version in face-presentation. See Treatment, Methods of.

Schede's Method, See Treatment, Methods of.

Scheelate $\left(s h \bar{e} l^{\prime}-\bar{a} t\right)$. Synonym of Tungstate.

Scheele's Green. The arsenite of copper. See Copper and Rinmann's Green.

Scheelization (she-liz-a'-shun) [after Scheele, a chemist]. A method of improving wines, that consists in the addition of glycerin to the finished wine, so as to improve the sweet taste without injuring its keeping qualities. The limits of the addition of glycerin lie between one and three liters to the hectoliter of wine. 
Scheiner's Experiment or Test. A method of illustrating refraction and accommodation of the eye by two pin-holes in a card placed at a less distance apart than the diameter of the pupil. If the eye is emmetropic, or if in accurate accommodation

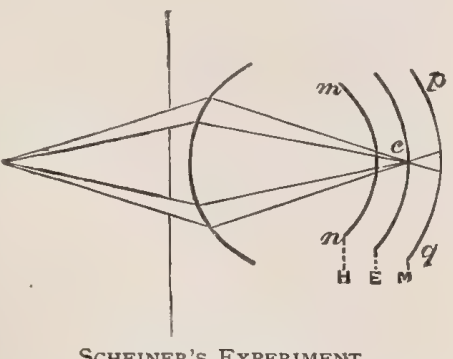

SCHEINER'S EXPERIMENT. the two sets of rays passing through the pin-holes unite at $c$ and form a single image. In a myopic eye the focus of the rays is at $p, q$, and in an hyperopic eye at $m, n$, and the object appears double: The same doubling of the image occurs when accommodating for a point beyond or nearer than the object.

Schema $\left(s k e^{\prime}-m a h\right)[\sigma \chi \tilde{\eta} \mu \alpha$, form $]$. I. A simple design to illustrate a complex mechanism. 2. An outline of a subject.

Schematic (ske-mat'-ik) [ $\sigma \chi \tilde{\eta} \mu \alpha$, form]. Pertaining to or of the nature of a schema. S. Eye, one showing the proportions of a normal or typical eye.

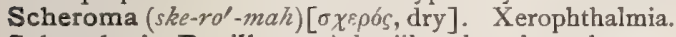

Scheurlen's Bacillus. A bacillus thought to be specially connected with carcinoma, but not peculiar to it. See Bacteria, Synonymatic Table of.

Schias $\left(s k i^{\prime}-a s\right)$. Synonym of Ischias.

Schidacedon, Schidacedum (skid-as-e -don, skid-as-e' -

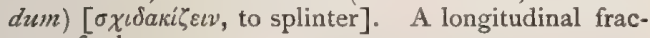
ture of a bone.

Schiefferdecker's Fluid. A fluid for dissociating nervetissues. It consists of methyl alcohol 5 c. c., glycerin 50 c.c., distilled water roo c.c. Allow the tissues to remain in this for several days. It is specially useful for staining the retina and the central nervous system. It is best prepared fresh.

Schiff's Test. See Tests, Table of.

Schimper's Theory. See Theory.

Schindalamus, Schindalmus (skin-dal'-am-us, skindal'-mus]. Synonym of Schidacedon.

Schindylesis (skin-dil-e -sis) [ $\sigma \chi \iota v \delta \dot{u} \lambda \eta \sigma \iota \varsigma$, a cleavage]. Articulation by the reception of a plate of one bone into a fissure of another ; a variety of synarthrosis.

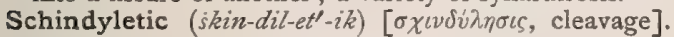
Pertaining to, or of the nature of, schindylesis.

Schinus (ski'-nus). See Pepper Tree.

Schirrus (skir'-us). Synonym of Scirrhus.

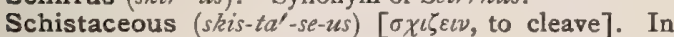
biology, slate-gray; bluish-gray.

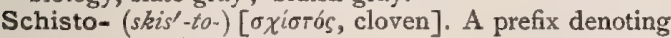
a fissure or cleaving.

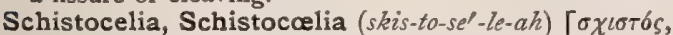
cloven; koinia, cavity]. Abdominal fissure.

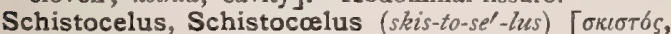

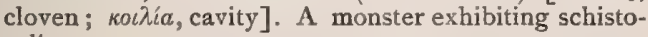
celia.

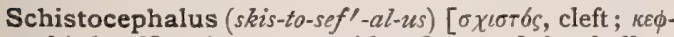
$a \lambda \dot{n}$, head]. A monster with a fissure of the skull.

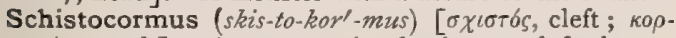
$\mu \sigma \varsigma$, trunk]. A monstrosity having a cleft thorax, neck, or abdominal wall.

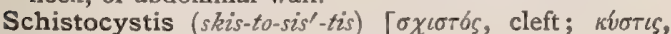
bladder]. Fissure of the bladder.

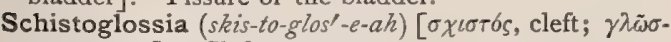
$\sigma a$, tongue]. Cleft tongue.

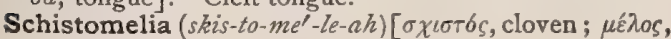
limb]. The condition of schistomelus.

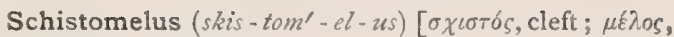
limb]. A monstrosity with a cleft lower extremity.

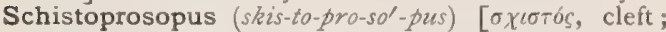
$\pi \rho \sigma^{\sigma} \omega \pi \sigma o \nu$, face]. A monster with "Cleft-face." A cavity in the middle of the face due to a failure of development of the first branchial arch and the frontonasal plate.

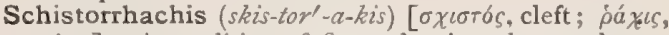
spine]. A condition of fissured spine, the canal containing two channels. Also, spina bifida.

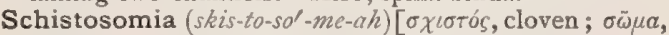
body]. The condition of a schistosomus.

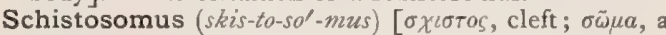
body. A variety of single autositic monsters of the species celosoma in which there is a lateral or median eventration extending the whole length of the abdomen, with the lower extremities absent or very imperfect.

Schistosternia (skis - to - ster'-ne-ah) [ $\sigma \chi$ cotós, cloven; бrépvov, sternum ]. Sternal fissure. Synonym of Schistothorax.

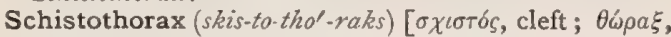
chest]. Fissure of the sternum or chest.

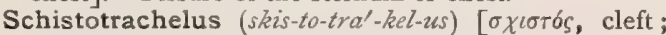
$\tau \rho a ́ \chi \eta \ddot{o s}$, neck]. Fissured neck or cervix.

Schizoblepharia (skiz-o-blef- $\left.a^{\prime}-r e-a h\right)[\sigma \chi i \zeta \varepsilon \omega v$, to split; $\beta \lambda \dot{\varepsilon} \phi a \rho o \nu$, eyelid]. Fissure of the eyelid.

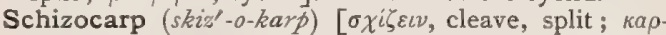
$\pi o ́ s, a$ fruit]. In biology, a pericarp that dehisces into two or more one-seeded indehiscent mericarps.

Schizocarpic (skiz-o-kar'-pik) [ $\sigma \chi i \zeta \varepsilon \iota \nu$, to cleave; $\kappa a \rho-$ $\pi$ ós, fruit]. Resembling a schizocarp.

Schizocarpous (skiz-o-kar'-pus]. Same as Schizocarpic.

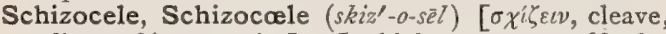

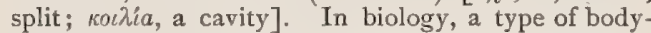
cavity distinguished by its being formed by a simple splitting of the mesoderm. Cf. Enterocele, Epicele.

Schizodinic $\left(s k i z-0-d i n^{\prime}-i k\right)[\sigma \chi \imath \zeta \varepsilon \iota \nu$, cleave, split ; $\omega \delta i s$, travail]. In biology, the bringing forth of genital products by rupture, as in certain molluscs. Cf, Idiodinic, Porodinic.

Schizogenesis (skiz-o-jen'-es-is) [ $\sigma \chi i \zeta \varepsilon \iota \nu$, cleave, split;

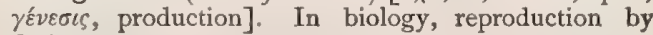
fission.

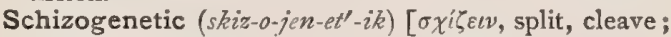

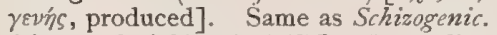

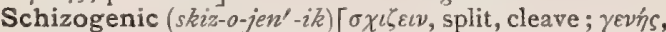
produced]. In biology, formed by the separation of parts, as certain cavities or intercellular spaces. Cf. Lysigenous, Protogenic, Hysterogenic.

Schizogenous (skiz-oj'-en-us). Same as Schizogenic.

Schizognathism (skiz-og'-na-thizm) [ $\sigma \chi^{\prime} i \zeta \varepsilon c \nu$, to cleave; rvátos, jaw]. Cleavage of the jaw.

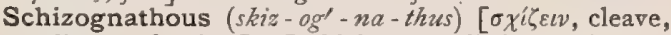
split; $\gamma \nu a \theta 0 \varsigma$, jaw ]. In biology, applied to such birds as bave the maxillo-palatine bones separated.

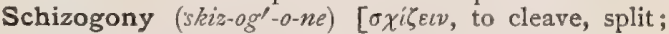
yovia, generation]. Same as Schizogenesis.

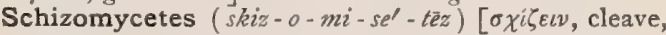

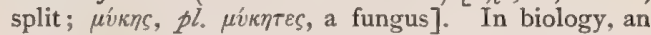
order of Fungi; the so-called Fission-fungi or Bacteria, q. $v$.

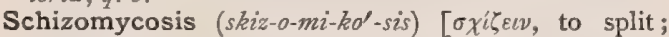
$\mu$ $\kappa^{\prime} \eta$, fungus]. A disease due to schizomycetes.

Schizoneura (sḱiz-o-nu' - rah) [ $\sigma \chi i \zeta \varepsilon \iota \nu$, to cleave;

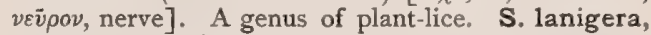
the root-louse of the apple.

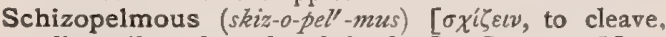
split; $\pi \dot{\varepsilon} \lambda \mu a$, the sole of the foot]. Same as Monopelmous.

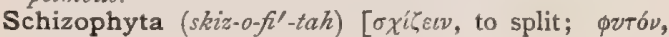
plant]. Dried but viable schizomycetes. 


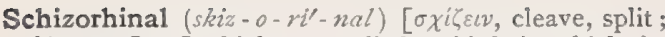
$\rho i c$, nose]. In biology, applied to birds in which the posterior margin of the osseous nares has a distinctly slit-like, triangular form, instead of being simply concave. In most of these forms the line joining the posterior extremities of the nostrils passes behind instead of in front of the ends of the nasal processes of the premaxillæ. Cf. Holorhinal.

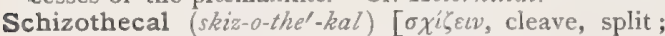
$\theta \dot{\eta} \kappa \eta$, case]. In biology, applied to such birds as have the tarsal envelop (podotheca) scaled or reticulated, as distinguished from holothecal.

Schizothorax (skiz-o-tho'-raks). Synonym of Schistothorax.

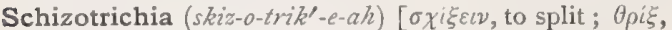
hair]. Splitting of the hair.

Schlemm, Canal of. A flattened annular channel within the sclera and close to the corneal juncture. It is also called the circular venous sinus, and is the outlet whereby the aqueous humor finds its way into the general circulation. S., Ligament of. See Ligament.

Schleich Anesthesia, or Infiltration - Anesthesia. Local insensibility induced by the injection into the subcutaneous tissues of dilute solutions of sodium chlorid, morphin, and cocain. Tropacocain in I per cent. solution has also been employed. S. Method (general anesthesia), the administration of small doses of a mixture of chloroform 45 parts, petroleum ether 15 parts, sulphuric ether 180 parts.

Schmiedel's Ganglion. The inferior carotid ganglion.

Schmerzfreude (schmärtz'-froy'-de) [Ger., Painjoy']. A rare symptom of hysteria, in which pain or normally painful operations seem to the patient pleasant.

Schmidt, Arrow-markings of. Certain lines occasionally seen upon the axis-cylinders of nerves and supposed to be masses of protoplasm by some and connective tissue by others. S., Incisures of, minute fissures in the medullary sheaths of nerves, separating the segments of Lautermann. S.'s Nodes. See Node. S.'s Test. See Birth.

Schneiderian Membrane. The pituitary membrane. The nasal mucosa.

Schnitzer Green. Same as Mittler's Green

Scholeciasis (sko-le-si'-as-is). A term proposed by Hope (1840) for the diseased condition caused by the presence of the larvæ of lepidopterous insects.

Scholl's Method. A method of percussion by which the diffusion of sound along the ribs is prevented. Three fingers are pressed toward the chest, and the second phalanx of the third finger is used for percussion.

Schöller's Method. A method of inducing premature labor. It consists in inserting a tampon of charpie into the vagina, and allowing it to remain until the pains commence.

Schönlein's Disease. Peliosis rhenmatica; a peculiar affection characterized by multiple arthritis, and an eruption which varies greatly in character, and is sometimes purpuric, but more commonly associated with urticaria or with erythema exsudativum.

Schott Method. A system of gymnastic exercises and mineral baths employed in heart disease and chronic rheumatism.

Schräger's Lines. A coarse striation, concentric with the outline of the pulp-cavity, produced by the dentinal tubules in cross-section. See Lines, Table of.

Schreiner's Base. See Spermin

Schröder's Method. See Artificial Respiration.

Schroth's Cure. A painful form of treatment of pleural effusion, consisting in an entire abstinence from drinking for some days, though fluid is allowed at intervals during the existence of the effusion.
Schrötter's Catheters. See Catheter.

Schultze, Cells of. See Cell, Olfactory. S.'s Fold, a falciform fold of the amnion extending from the insertion of the cord in the placenta to the remains of the umbilical vesicle. S.'s Granules or Granulemasses, minute particles in the blood, produced by the breaking up of the blood-platelets; also called granules of Max Schultze. S.'s Macerating Fluid, a fluid employed to dissolve cutin and to dissociate plant-cells. It consists of potassium chlorate 3 grains, nitric acid 2 drams. Keep the sections in this, cold, for a fortnight. After careful washing in alcohol the preparations may be placed on the slide in glycerin, and the cells easily separated with needles, in consequence of the solution of the middle lamellæ. S.'s Method. See Artificial Respiration. S.'s Reagent, a solution for use in laboratories. It is prepared as follows: Iodin is dissolved to saturation in a solution of zinc chlorid, sp. gr. I.8, to which 6 parts of potassium iodid have been added. Cross and Bevan recommend the following: Zinc is dissolved to saturation in $\mathrm{HCl}$, and the solution evaporated to sp. gr. 2.0; to 90 parts of this solution are added 6 parts of potassium iodid dissolved in ro parts of water, and in this solution iodin is finally dissolved to saturation.

Schuster's Treatment. See Treatment, Methods of.

Schwalbe's Convolution. See Convolutions, Table of. S., Fissures of. See Fissures, Table of. S.'s Method. See Treatment, Methods of.

Schwann, Sheath of. The neurilemma of a nervefiber, a delicate, connective-tissue membrane, investing the white substance. See Neurilentma. S.'s Theory of Inflammation. Same as Rokitansky's Theory. See Theory. S., White Matter or Substance of, a coat of myelin deposited within the neurilemma, and surrounding the axis-cylinder of a medullated nervefiber. It contains cerebrin and lecithin and some fatty matter, is semi-fluid, homogeneous, bright, and refractive. The medullary sheath. Cf. Myelin.

Schweigger-Seidel's Acid Carmin. See Stains, Table of.

Schweinerothlauf (shwi-neh-rōt'-lowf) [Ger.]; Rouget du porc [Fr.]. Hog-erysipelas. An infectious disease of hogs, characterized by fever and the appearance, on neck, chest, and belly, of reddish or brownish spots. Intestinal hemorrhages are sometimes present. Onehalf of the animals affected die. The lesions consist in a hemorrhagic infiltration of the intestinal mucosa, swelling and ulceration of the follicles, tumefaction of the mesenteric glands, and petechire of the serous membranes. The blood and organs contain a bacillus which is considered the cause of the disease. See Bacillus erysipelatos suis, Koch, under Bacteria, Synonymatic Table of.

Schweinfurth Blue, S. Green. See Pigments, Conspectus of.

Schweininger Cure. See Treatment, Methods of.

Schweizer's Reagent. A solution o, hydrated cupric oxid in ammonia, for use in chemic and physiologic laboratories. This reagent is prepared as follows: Oxyhydrate of copper is carefully precipitated from the sulphate by a dilute solution of ammonia; the clear green precipitate, separated and washed, is added while still moist to strong ammonia, in which, on slightly warming, it is dissolved. Upon cooling, crystals of sub-sulphate of copper and ammonia fall to the bottom. The filtered liquid contains only the ammoniacal cupric oxid in solution. It must be kept in bottles of dark glass, or in the dark. It can also be prepared by digesting copper turnings in an open bottle with liquor ammonil of the Pharmacopeia. As it is very easily decomposed by light, it is perhaps best 
prepared fresh when required. This reagent has the power of dissolving pure cellulose. It is fit for use only so long as it rapidly dissolves cotton-wool. (Strasburger.) This reagent possesses its chief interest from the fact that it is the only liquid known in which cellulose appears to dissolve without essential change in composition. It has a limited application in the discrimination of the fibers used in the arts.

Schwelle (shwel'-eh) [Ger, " threshold"']. The threshold, or limen, of any sensation; nerve-excitation which just fails of producing a sensation.

Schwendener's Theory. See Schwendenerism.

Schwendenerism (shwen'-den-er-izm) [Schwendener, a German botanist, born $\mathbf{1} 829$ ]. A theory suggested by De Bary, but avowed by Schwendener, that lichens consist of fungi parasitic upon algæ.

Schwimmer's Ointment. An ointment for application to smallpox pustules to prevent pitting. It consists of carbolic acid 15 grains, olive-oil one dram, prepared chalk sufficient to make half an ounce. This is applied on pieces of clean soft linen.

Sciage (se-ahzh') [Fr., "sawing"]. A to-and-fro sawing movement in massage, practised with the ulnar border, or with the dorsum of the hand.

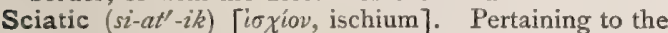
ischium. S. Nerve. See Nerve. S. Notch. See Notch. S. Spine, a triangular eminence on the dorsal border of the body of the ischium. Sciatic Scoliosis. See Scoliosis.

Sciatica (si-at'-ik-ah) [Sciaticus, pertaining to the ischium]. Pain in the course of the sciatic nerve. This may be confined to the proximal half of the thigh, or follow out the entire course of the nerve and its branches. The pain is constant and gnawing, subject to exacerbations, and occurs most commonly in adults of middle age.

Science (si'-ens) [scire, to know]. Systematized knowledge of the order of nature. "Science is that knowledge which enables us to demonstrate, so far as our limited faculties permit, that the appearances which we recognize in the world around us are dependent in definite ways on certain properties of matter; science is that knowledge which enables or tends to enable us to assign to its true place in the series of events constituting the universe, any and every thing which we can perceive." (E. Ray Lankester.) S., Christian, a method of treating disease upon principles similar to those upon which faith-cure rests.

Scientific (si-en-tif'-ik) [scientia, knowledge; facere, to make]. Relating to science. That which is based upon science.

Scientist (si'-en-tist) [scientia, science]. A savant; one versed in science.

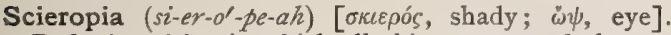
Defective vision in which all objects appear dark.

Scilla $($ sil'-ah) [L., gen., Scilla]. Squill. The bulb of $S$. maritima or Urginea maritima, found near the Mediterranean Sea. Its properties are due to a glucosid, scillitoxin, and several other principles. It acts like digitalis upon the circulation. In large doses it causes vomiting and purging. It is diuretic and expectorant. In cases of nephritis it should be used with caution, as it may prove irritant to the kidneys. Dose gr. j-iv. S., Acetum, "vinegar of squill," Io per cent. in strength. Dose $m x-3 j$. S., Fld. Ext. Dose $m_{\mathrm{j}-\mathrm{v} .}$ S., Oxymel (B. P.). Dose $\mathbf{3} \mathrm{ss}-\mathrm{j}$. S., Pil., Comp. (B. P.) Dose gr. v-x. S., Syr, has of vinegar of squill, 45 , sugar 80 , water q. 5.. Dose 3 ss-ij. S., Syr., Comp., fld. ext. squill and fld. ext. senega, each 80, tartar emetic 2, precipitated calcium phosphate IO, sugar 750 , water q. s. Dose $m v-3 j$, for children as an emetic; $\eta_{x-x x x}$, for adults as an ex- pectorant. Commonly known as Coxe's Hive Mixture, S., Tinct., 15 per cent. Dose $m_{v-\mathrm{xxx}}$.

Scillin $\left(s^{\prime} l^{\prime}-\right.$ in $)[\sigma \kappa i \lambda \lambda a$, squill]. An inactive substance obtained from squills.

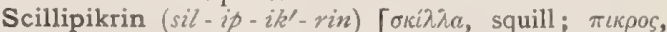
bitter]. A yellowish-white, amorphous, hygroscopic powder obtained from squills.

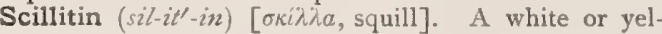
lowish resinous substance, the bitter principle of squill.

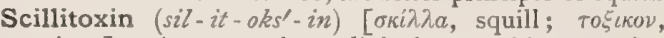
poison]. An amorphous light-brown, bitter, active principle of scilla. It is soluble in alcohol, insoluble in ether and water, and a cardiac poison somewhat resembling digitalis

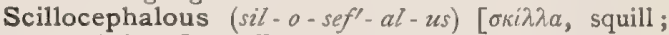
$\kappa \varepsilon \phi a \lambda \dot{n}$, head]. Affected with scillocephalus.

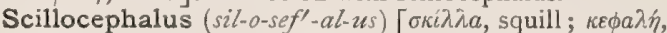
head]. I. Congenital deformity of the head, in which it is small and conically pointed, or squillshaped. 2. A person with a squill-shaped head, usually an idiot.

Scillopicrin (sil-o-pik'-rin). See Scillipicrin.

Scillotoxin (sil-o-toks'-in). See Scillitoxin.

Scinde Boil. See Delhi Boil.

Scintillation (sin-til-a'-shun) [scintillare, to sparkle]. An emission of sparks. Also a subjective visual sensation as of sparks.

Scion (si'-on) [ME., OF, sion, a shoot, twig]. A twig or young shoot.

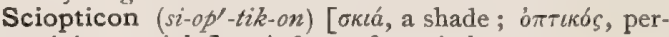
taining to sight]. A form of magic lantern.

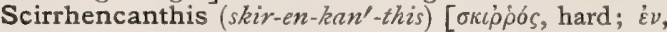
in; $\kappa a ́ v \theta 0 \varsigma$, canthus]. Scirrhus of the lacrymal gland.

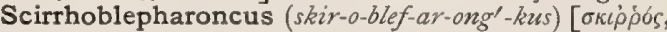

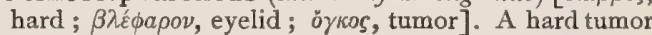
of the eyelid.

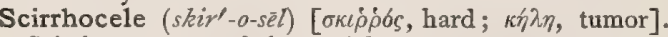
Scirrhous tumor of the testicle.

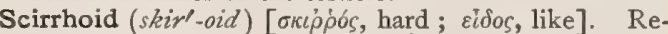
sembling a scirrhus.

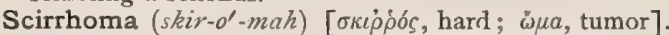
Scirrhous tumor. S. caminariorum, chimney-sweeps' carcinoma.

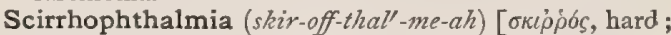
$\dot{\phi} \phi \theta \lambda \lambda \mu \delta s$, eye]. Scirrhus of the eyeball.

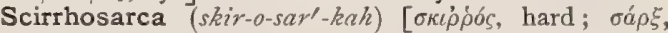
flesh]. The hardening of the flesh of new-born infants; sclerema of infants.

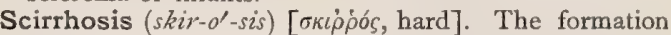
of a scirrhous carcinoma.

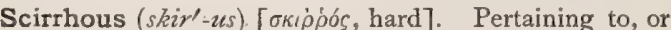
of the nature of, scirrhus or hard carcinoma. S. Carcinoma. See Scirrhus.

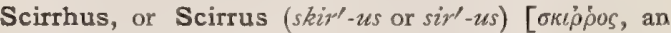
induration ]. A scirrhous or hard carcinoma.

Scission (sizh'-un) [scindere, to cut]. A cutting or splitting of anything; fission.

Scissiparity (sis-ip-ar'-it-e) [scissus, p.p. of scindere, cut, divide; parere, to bring forth]. In biology, generation by fission; schizogenesis.

Scissor-leg (siz'-or-leg). Same as Cross-leg.

Scissors (siz'-ors) [scindere, to cut]. An instrument with crossed, closing blades for cutting. The blades may be straight, angular, or curved. S., Artery, a scissors, one blade of which is probe-pointed, for introduction into a duct or canal. S., Canalicular, delicate scissors, one blade of which is probe-pointed, used in slitting the lacrymal canal. S., Cannula, scissors for slitting any canal or tube longitudinally. S., Craniotomy, a strong S-shaped instrument used in craniotomy for perforating the skull and cutting away portions of bone. S., Iris, one having flat blades which 
are bent in such a manner that they may be applied to the eyeball. Also, scissors used in iridectomy. S. Perforator. See S., Craniotomy. S., Skin-grafting, an instrument consisting of a forceps and a scissors, the former for seizing a small piece of skin, and the latter for cutting it off. S., Uvula, one designed for re. moval of the uvula. S., de Wecker's, a peculiar modification of iris-scissors.

Scissura (siz-u'-rah) [scindere, to cut]. A fissure, rent, or cleavage. S. longitudinalis, the longitudinal fissure of the brain.

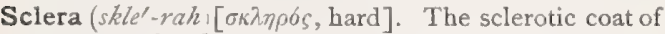
the eye; the firm, tough, white, outer membrane of the eyeball, continuous with the sheath of the optic nerve behind and with the cornea in front. S. testis, the tunica albuginea of the testis.

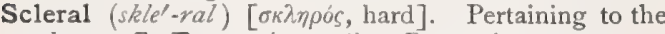
sclera. S. Extraction. See Extraction.

Scleratitis (skle-rat-i'-tis). Same as Sclerotitis.

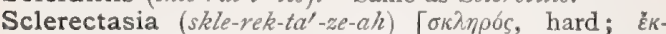
raбıs, extension]. Staphyloma of the sclera. posterioris, posterior staphyloma.

Sclerectasis (skle-rek'-tas-is). See Sclerectasia.

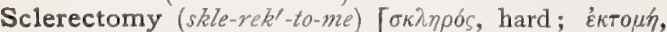
excision]. 1. Excision of a portion of the sclera. 2. The excision of the sclerosed and ankylosed conductors of sound in chronic catarrhal otitis media.

Sclerema (skle-re'-mah) [ $\sigma \kappa \lambda \eta \rho \sigma ́ s$, hard]. Sclerosis, or hardening, especially of the skin. S. adultorum, a synonym of Scleroderma. S. neonatorum, Scleroderma neonatorum; Induratio tela cellulose; a disease found only in premature infants; it is characterized by a hardening of the skin, beginning in the legs, and spreading, usually sparing breasts and belly. Jaundice or a hemorrhagic condition may be present; the temperature is very low, $95^{\circ}$, and the condition is apt to end fatally. The pathology of the disease is not positively known. By some the disease is believed to consist in a solidification of the subcutaneous fat, which in infants contains more palmitic and stearic acids than in the adult, and relatively less oleic acid.

Sclerencephalia (skle-ren-sef- $\left.a^{\prime}-l e-a h\right)$ [ $\sigma \kappa \lambda \eta \rho \sigma s$, hard;

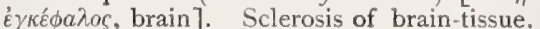

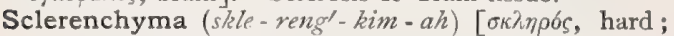
$\varepsilon \gamma \chi v \mu a$, an infusion]. In biology, hard bast, or bastfibers. Used by some in a more extended sense, to include all lignified fibrous cells or cell-derivatives.

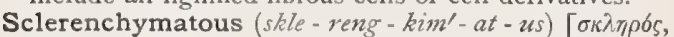
hard; $\tilde{\varepsilon} \gamma \chi v \mu \alpha$, an infusion]. Having the character of sclerenchyma.

Sclerenchyme (skle-reng'-kīm). Same as Sclerenchyma.

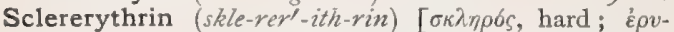
$\theta \rho \circ s$, red]. A red substance obtained from ergot.

Scleriasis (skle-ri'-as-is) [ $\sigma \kappa \lambda \eta \rho o ́ s$, hard]. Induration; sclerema; scleroderma.

Scleriritomy (skle-rir-it'-o-me) [ $\sigma \kappa \lambda \eta \rho b s$, hard, sclera; roun, a cutting]. Incision of the conjunctiva, sclera, and iris, followed by excision of a piece of the iris and anterior capsule, in staphyloma of the cornea and secondary glaucoma.

Sclerite $\left(s k l e^{\prime}-r i t\right)$ [ $\sigma \kappa \lambda \eta \rho \delta \zeta$, rough]. In biology, a separate or definite element in the exoskeleton of an arthropod.

Scleritic (skle-rit'-ik) [ $\sigma \kappa \lambda \eta \rho \sigma s$, hard]. Sclerous.

Scleritis (skle-ri'tis). See Sclerotitis.

Sclero-(skle'-ro-) [ $\sigma \kappa \lambda \eta \rho o ́ s$, hard]. A prefix denoting hardness or induration, or connection with the sclera.

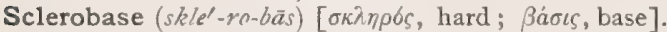
In biology, the cornified or calcified axial connective tissue of an actinozoan zoanthodeme. The hard endoskeletal portion of a colony of coral polyps, as the precious red coral.

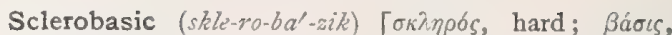
base]. Pertaining to a sclerobase.

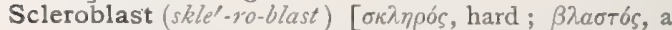
germ]. In biology, a spicule-cell in sponges.

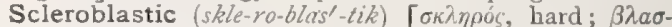
tós, germ]. Forming sclerous tissue.

Sclerobronchiorthoncus (skle-ro-brono-ke-or-ong'-kus)

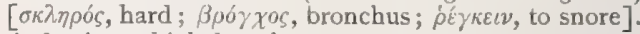
A dry bronchial rhonchus.

Sclero-cataracta $\left(s k l e-r o-k a t-a r-a k^{\prime}-t a h\right)[\sigma \kappa \lambda \eta \rho b s$,

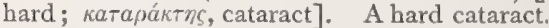

Sclero-choroiditis (skle-ro-ko-roid-i't-tis) [ $\sigma \kappa \lambda \eta \rho o ́ s$, hard;

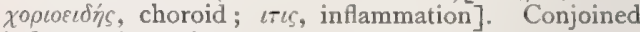
inflammation of the choroid and the sclerotic coat of the eye.

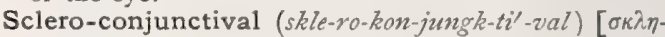
pos, hard; conjunctiva, conjunctiva ]. Pertaining conjointly to the sclerotic coat of the eye and the conjunctiva.

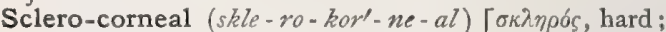
corneus, horny]. Pertaining conjointly to the sclerotic coat and the cornea of the eye.

Sclerocrissorrhonchus (skle - ro - kris - or - rong' - kus)

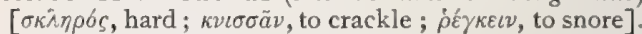
A dry crackling râle.

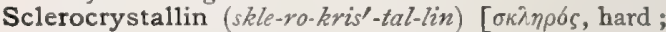

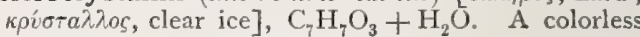
substance derived from ergot.

Sclerodactylia, Sclerodactyly (skle-ro-dak-til'-e-ah,

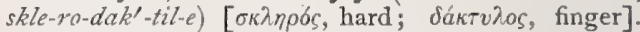
A dystrophy, thus far met with in women only, and characterized by a symmetric involvement of the fingers, which become deformed, shortened, and atrophied. The skin thickens and becomes of a waxy color, and occasionally is pigmented.

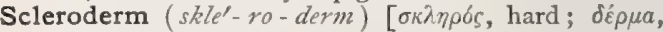
skin ]. In biology, the calcareous skeleton of a madrepore coral.

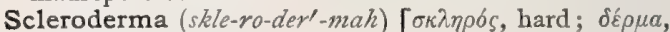
skin ]. Sclerodermia; sclerema; scleriasis; hidebound skin; dermato-sclerosis; hide-bound disease. A rare affection of the skin, characterized in general by infiltration of its substance, followed by shrinking or contraction and impairment of the secreting apparatus, resulting in a characteristic stiffness and hardening of the integument, occurring in diffuse and symmetric forms, and spreading more or less rapidly over the surface of the body, involving especially the scalp, face, neck, chest, and upper limbs. Itching may or may not be present. The etiology is obscure, but the disease is evidently of nervous origin. S., Circumscribed. See Morphea.' S. diffusa, a form confined to a particular area. $\mathbf{S}$. localis, morphea; circumscribed scleroderma. S. neonatorum. See Sclerema neonatorum.

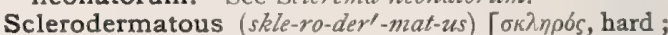
$\delta_{\varepsilon} \rho \mu a$, skin ]. Having a hard outer covering.

Sclerodermia (skle-ro-der'-me-ah). See Scleroderma.

Sclerodermic (skle-ro-der'-mik). Same as Sclerodermatous.

Sclerodermite (skle-ro-der'-mīt) [ $\sigma \kappa^{\lambda} \eta \eta \rho \sigma s$, hard ; $\delta \dot{\varepsilon} \rho \mu \Omega$, skin]. In biology, a calcareous or chitinous exoskeletal element or sclerite of an arthropod.

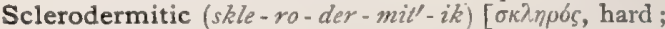
$\delta \dot{\varepsilon} \rho \mu a$, skin; $\iota \tau \iota s$, inflammation]. Of the nature of or affected with sclerodermitis.

Sclerodermitis $(s k l e-r o-d e r-m i$ - tis $)[\sigma \kappa \lambda \eta p o b s$, hard;

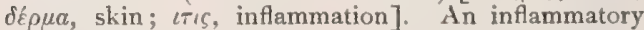
skin-affection, with induration of the structures of the skin.

Sclerodermous (skle-ro-der'-mus). Same as Sclerodermatous. 


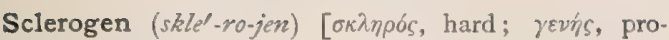
ducing]. In biology, a name for the hard matter deposited in sclerotic or stone-cells.

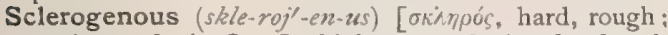
yev'n, producing]. In biology, producing hard, calcareous, silicious, or chitinous tissue. S. Method, a method of treating tuberculous joint-disease, by interstitial injections of zinc chlorid.

Sclerohymenitis (skle-ro-hi-men-i'-tis). Synonym of Sclerotitis.

Sclerohystera (skle-ro-his'-ter-ah). Synonym of Sclerystera.

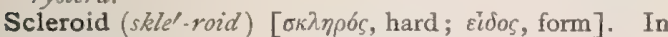
biology, hard or bony in texture.

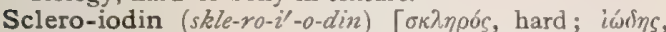
violet]. A brownish coloring-matter found in ergot.

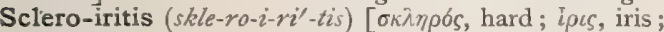
ıтєS, inflammation]. Inflammation of the sclera and the iris.

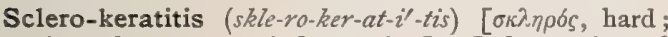

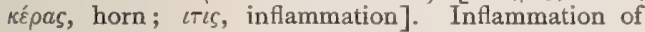
the sclera and the cornea.

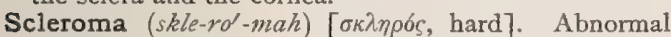
hardness or induration of a part. A neoplasm that forms in the nose and larynx particularly, and which is characterized by its density. A bacillus has been found which is believed to be the cause of the condition. $\mathbf{S}$. adultorum. Synonym of Scleroderma.

Scleromeninx (skle-ro-me'-ninks) $\left[\sigma \kappa \lambda \eta \rho b s\right.$, hard; $\mu \eta^{\prime} v-$ $\iota \gamma \xi$, membrane]. The dura mater.

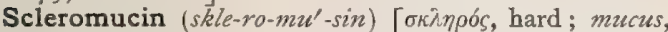
mucus]. A gummy substance obtained from ergot, and said to be one of its active principles.

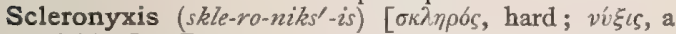
pricking]. Puncture of the sclerotic.

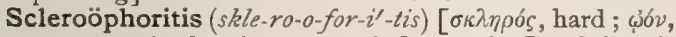
egg; фopós, bearing; $\iota \tau \iota s$, inflammation]. Sclerosis of the ovary.

Scleropathia (skle-ro-pa'-the-ah). See Sclerosis.

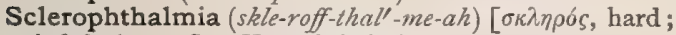

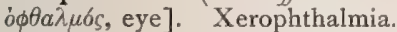

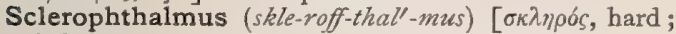

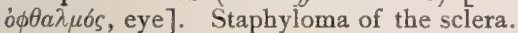

Sclerorrhonchus (skle-ror-rong'-kus). See Sclerobronchorrhonchus.

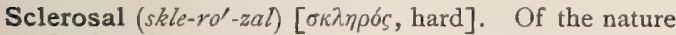
of sclerosis.

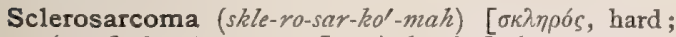
$\sigma a ́ \rho \xi$, flesh; ö $\mu a$, tumor]. A hard, fleshy tumor, especially of the gums.

Sclerose $\left(s k l e^{\prime}-r \bar{o} z\right)$ [ $\sigma \kappa \lambda \eta \rho \sigma \zeta$, hard]. To affect with sclerosis; to become affected with sclerosis.

Sclérose en plaques (skla-röz' on plak). Synonym of Sclerosis, Multiple.

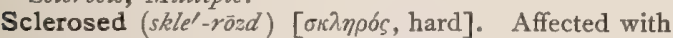
sclerosis; rendered abnormally hard. S. Arteries, arteries whose coats are thickened.

Sclerosis (skle-ro'-sis) [ $\sigma \kappa \lambda \eta \rho o ́ s$, hard]. I. A process which consists essentially in an overgrowth of the connective tissue of an organ. The term is applied chiefly to the nervous system and the arteries. 2. In biology, the hardening of a plant cell-wall by the formation of lignin; the induration of a normally soft tissue. S., Amyotrophic Lateral, a combination of chronic anterior poliomyelitis with lateral sclerosis. The symptoms are in the main wasting of the muscles and a spastic condition of the limbs, with exaggeration of the reflexes. The disease is prone to end fatally by involvement of the medulla oblongata. S., Annular, a chronic myelitis, in which the sclerosis extends about the cord like a ring. S., Arterio-. See Endarteritis. S., Atrophic, sclerosis with atrophy. S.,
Cerebro-spinal. See Charcot's Disease. S. Combined, simultaneous sclerosis of the posterior and the lateral columns of the spinal cord. S., corii. Synonym of Sileroderma. S. dermatis. Synonym of Sileroderma. S., Diffuse, when the sclerosts extends through a large part of the brain and cord. S., Disseminated. See Charcot's Disease. S., Focal, one confined to a particular region of the brain or cord. S., General, a connective-tissue hyperplasia affecting an entire organ. S., Initial, the syphilitic chancre. S., Insular. See Charcot's Disease. S., Lateral. See Charcot's Disease. S., Lobar, sclerosis of a lobe of the brain. S. of the Lung. Synonym of Pneumonia, Interstitial. S., Miliary, small sclerotic patches such as have been observed in the spinal cord in some cases of pernicious anemia. S., Multilocular. See Sclerosis, Disseminated. S., Multiple. See Charcot's Disease. S. ossium. Synonym of Osteitis, Condensing. S., Posterior Spinal, locomotor ataxia ; tabes dorsalis, q.v. S., Postero-lateral. See Friedreich's Ataxia. S., Progressive Muscular. Synonym of Pseudohypertrophic Muscular Paralysis. S., Renal. Synonym of Nephritis, Interstitial. S., Syphilitic Arterio-, the arterial sclerosis due to syphilis. It affects chiefly the intima, but also the adventitia. It occurs as a diffuse form, as in the brain; also in distinctly localized lesions, as in the chancre.

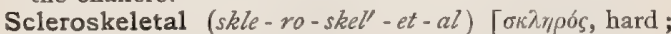
$\sigma \kappa \varepsilon \lambda \varepsilon \tau \sigma v$, a dry body]. Pertaining to a scleroskeleton.

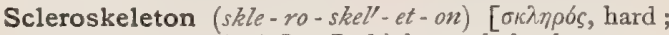
$\sigma \kappa \varepsilon \lambda \varepsilon \tau o ́ v$, a dry body]. In biology, skeletal parts or ossifications other than the bones of the main endoskeleton, as sesamoid bones, ossified tendons, marsupial bones, etc.

Sclerostenosis (skle-ro-ste-no'-sis) [ $\sigma \kappa \lambda \eta \rho b s$, hard ; $\sigma \tau \varepsilon ́ \nu \omega \sigma \iota s$, constriction]. I. Sclerosis with constriction. 2. Also, synonym of Scleroderna.

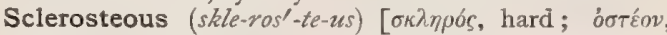
bone]. A bony formation resulting from osseous deposit in a tendon.

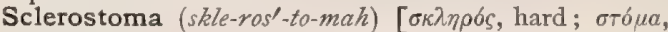
mouth]. A genus of nematoid worms. See Parasites (Animal), Table of.

Sclerotal (skle-ro'-tal) [ $\sigma \kappa \lambda \eta \rho \delta s$, hard]. In biology, one of a circlet of bones about the eyeball of certain birds ; an eye-bone.

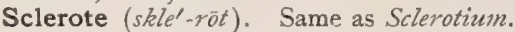

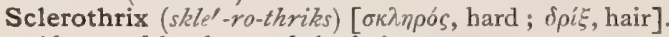
Abnormal hardness of the hair.

Scleroth's Cure. The treatment of pleuritic effusions by diet, $i . e$, the withdrawal of fluids for the purpose of causing absorption of the effusion.

Sclerotic $\left(s k l e-r o t^{\prime}-i k\right)$ [ $\sigma \kappa \lambda \eta \rho o ́ s$, hard]. I. Hard, indurated; pertaining to the outer coat of the eye. 2. Related to or derived from ergot. S. Arteritis. See Arterio-sclerosis and Endarteritis. S. Coat. See Sclerotica. S. Endocarditis, a hyperplasia of the fibrillar layer of the endocardium. It may be a regenerative process following infarcts, abscesses, or wounds of the heart which implicate the endocardium; it may be a termination of acute endocarditis; it may (and this is the commonest form) be a chronic inflammation from the beginning, occurring as a part of a general vascular sclerosis. The last form affects especially the valves, and leads either to insufficiency or to obstruction of the valvular orifice. In the early stages it presents itself as a slight thickening; this increases in extent; the new tissue undergoes fatty degeneration (atheroma); eventually calcareous matter and, occasionally, cholesterin are deposited. S. Myocarditis, a 
hyperplasia of the connective tissue of the myocardium. It may be a reparative process following wounds, in farcts, or abscess of the heart-wall, or it may be a diffuse chronic process, the heart participating in a general vašcular sclerosis. S. Parenchyma, in biology, hardened parenchyma, as the grit-cells of pears.

Sclerotica (skle-rot'-ik-ah) [ $\sigma \kappa \lambda \eta \rho o ́ s$, hard]. The sclera or sclerotic coat of the eye; the firm, tough, white, outer membrane of the eyeball, continuous with the sheath of the optic nerve behind and with the cornea in front.

Scleroticectomy (skle-rot-ik-ek'-to-me) [ $\sigma \kappa \lambda \eta n \rho \delta s$, hard; $\varepsilon \kappa \tau o \mu \eta$, excision]. The removal of a part of the sclera.

Scleroticitis (skle-rot-ik-i'tis). Synonym of Sclerotitis.

Sclerotico-choroiditis (skle-rot'-ik-o-ko-roi-di'-tis). Synonym of. Sclero-choroiditis.

Scleroticonyxis (skle-rot'-ik-o-niks'-is). See Scleronyxis

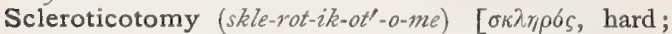
Touŕ, a cutting]. Incision of the sclerotic.

Sclerotinic (skle-ro-tin'-ik). Same as Sclerotic, second definition. S. Acid. See Acid, Sclerotinic

Sclerotis (skle-ro'-tis) [ $\sigma \kappa \lambda \eta \rho \sigma s$, hard]. The ergot of rye, $q . v$.

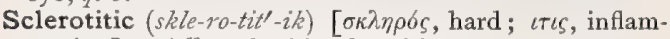
mation]. Affected with sclerotitis.

Sclerotitis (skle-ro-ti'-tis) [ $\sigma \kappa \lambda \eta \rho o ́ s$, hard, sclera; $\iota \tau \iota s$, inflammation]. Inflammation of the sclerotica.

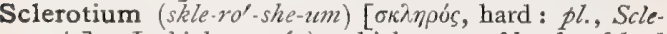
rotia]. In biology: $(a)$ a thick mass of hyphæ felted together, constituting a resting-stage in the development of some fungi, and acting as a store of reserve material; (b) the hypnocyst of mycetozoa.

Sclerotized (skle'-ro-tized). Same as Sclerosed.

Sclerotome (skle'-ro-tomn) [ $\sigma \kappa \lambda \eta \rho o ́ s, ~ h a r d ; \tau \xi \mu v \varepsilon \iota v$, to cut]. I. A knife used in sclerotomy. 2. In biology, a hard tissue separating successive myotomes in certain of the lower vertebrates.

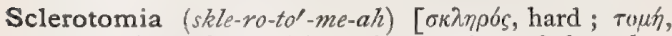
a cutting]. The excision of a portion of the sclera for the purpose of forming an artificial pupil.

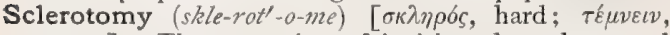
to cut]. The operation of incising the sclera, and also the choroid and retina. S., Anterior, the making of an incision through the sclera anterior to the ciliary body and most of the iris, and entering the anterior chamber; it is done in glaucoma. S., Posterior, sclerotomy done by an incision through the sclera behind the ciliary body, and entering the vitreous chamber.

Sclerotonyxis (skle-ro-to-niks'-is) [ $\sigma \kappa \lambda \eta \rho o ́ s$, hard; $\nu v \dot{\xi} \iota s$, a pricking]. An operation for cataract formerly practised, in which a broad needle was introduced into the sclera, behind the ciliary region, passed between the iris and the lens, and the latter depressed into the vitreous.

Sclerotrichia (skle-ro-trik'-e-ah) $[\sigma \kappa \lambda \eta \rho \sigma s$, dry; $\theta \rho i \xi$, hair]. A harsh and dry state of the hair.

Sclerous (skle'-rus) [ $\sigma \kappa \lambda \eta \rho o ́ s$, hard]. Hard; indurated.

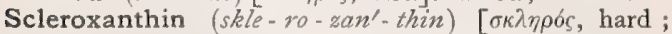
$\xi \alpha \dot{\nu} \theta 0 s$, yellow]. A crystalline substance derived from Ergot.

Sclerymen (skle-ri'-men). See Sclera.

Sclerymenitis (skle-ri-men-i'-tis). See Sclerotitis.

Sclerysma, Sclerysmus (skle-riz'-mah, skle-riz'-mus). See Silerosis.

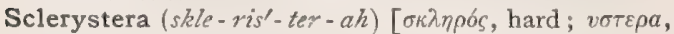
womb]. Induration in malignant disease of the uterus.

Scobiform (skot-bif-orm) [scobis, saw-dust, filings; forma, form]. In biology, resembling saw-dust.
Scoleciasis, Scolecicis (sko-les-i'-as-is, sko-les-is'-is). See Helminthiasis, also Scholeciasis.

Scoleciform (sko-les'-if-orm) [ $\sigma \kappa \omega \lambda \eta \bar{s}$, a worm; forma, form]. Having the form or character of a scolex.

Scolecite $\left(s k \sigma^{\prime}-l e s-i t\right)$ [ $\sigma \kappa \omega \lambda \eta \xi$, a worm]. In biology, a name given by Tulasne to the vermiform carpogonium of the fungus Ascobolus. It is a branch of the mycelium, consisting of a row of short cells. Woronin's "vermiform body."

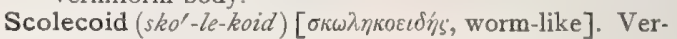
miform.

Scolecology (sko-le-kol'-o-je). See Helminihology.

Scolecophagous (sko-le-kof'-ag-us) [ $\sigma \kappa \omega \lambda \eta \xi$, worm; $\phi a \gamma \varepsilon i v$, to eat]. In biology, worm-eating.

Scolesis (sko-le'-sis). See Scoliosis.

Scolex (sko'-leks) [ $\sigma \kappa \omega \lambda \eta \xi$, a worm]. In biology, the knot-like head of a cestode worm, which by budding gives rise to the proglottides of the chain. See Tania.

Scolices (sko-le'-sèz). Plural of Scolex, q. v.

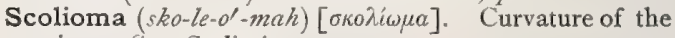
spine. See Scoliosis.

Scoliometer, Scoliosometer (sko-le-ont'-et-er, sko-le-o-

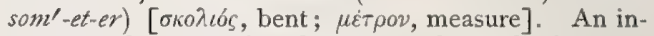
strument for measuring the extent of a scoliosis.

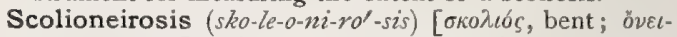
pos, a dream]. Oppressive, disagreeable dreaming.

Scolio-rachitic $\left(s k o-l e-o-r a k-i t^{\prime}-i k\right)$ [ $\sigma \kappa o \lambda \iota o ́ s$, bent ;

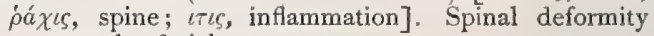
as a result of rickets.

Scoliosis (sko-le-o'-sis) [ $\sigma \kappa o \lambda \iota o ́ s$, curved]. Any morbid distortion or curvature of the spine, especially a lateral curvature. S., Cicatricial, scoliosis due to cicatricial contraction, such as occurs after costal necrosis. S., Empyematic, that due to empyema. S., Habit, scoliosis as a result of faulty posture. S., Inflammatory, scoliosis due to caries of the vertebre. S., Myopathic, a form due to paresis of the muscles of the spine. S., Osteopathic, spinal curvature caused by disease of the vertebræ. S., Paralytic, the same as S., Myopathic. S., Rachitic, spinal curvature due to rachitis. S., Rheumatic, temporary scoliosis caused by rheumatism of the muscles of the spine. S., Sciatic, scoliosis in sciatica with the convexity toward the affected side. Frequently there is compensatory curvature higher up, and the leg is slightly flexed and supported on the toe. S., Static, scoliosis as a result of inequality in the length of the lower limbs.

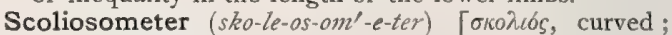
$\mu \varepsilon \tau \rho \infty$, measure]. An instrument for measuring the amount of deformity in scoliosis.

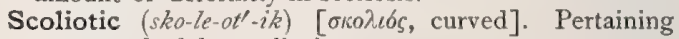
to or marked by scoliosis.

Scolopophore $\left(s k o-l o^{\prime}-p o-f o r\right)$ [ $\sigma \kappa b^{\prime} \lambda o \psi$, anything pointed, a rod, stake; $\phi \varepsilon \rho \varepsilon \iota \nu$, bear]. In biology, the long, slender, stretched tube which conceals the terminal rod of the peripheral auditory nerve-fiber in certain arthropods. When grouped they form the peculiar chordotonal organs, q. $v$.

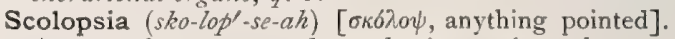
A suture between two bones having reciprocal movement.

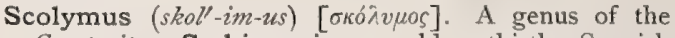
Composite. S. hispanicus, golden thistle, Spanish oyster-plant; the root was formerly used as a diuretic. S. maculatus, spotted golden thistle of the Mediterranean regions.

Scoop (sküp) [ME., scope, a scoop]. In surgery, an instrument resembling a spoon, for the extraction of foreign bodies from the softer tissues or from passages or cavities. S., Ear, an instrument having a slender handle and a small, shallow bowl, used in removing epidermal scales or cerumen from the external audi- 
tory canal. S.-extraction, an operation for cataract in which the lens is removed by means of a lensscoop, or spoon, passed, behind and lifted out with the lens. S., Leroy d'Etiolle's, a scoop resembling a lithotrite in shape, and used in removing urethral calculi. S., Lithotomy, an instrument used to remove calculi in the operation of lithotomy. S., Placental, a scoop or curet furnished with a long handle, and used to detach adherent portions of the placenta. S., Schaffer's Throat, an instrument for the throat, made so that it can be introduced closed, and then opened by means of a rod sliding within a hollow stem.

Scoopers' Pneumonia. The chronic form of pneumonia occurring in grain-scoopers from exposure to cold and dust.

Scopa (sko'-pah) [scopa, twigs, shoots, a broom]. See Sarothrum.

Scoparin (sko'-par-in) [scopa, a broom]. A diuretic principle obtained from scoparius. See Scoparius.

Scoparius (sko-pa'-re-us) [scopa, a broom: gen., Scoparii]. Broom. The tops of the common broomplant, Cytisus scoparius. Its properties are due to a neutral principle, scoparin, $\mathrm{C}_{21} \mathrm{H}_{22} \mathrm{O}_{10}$, and an alkaloid, spartein. It is diuretic and laxative; in large doses cathartic and emetic. It is a favorite remedy in cardiac dropsy and kidney-complaints. Dose of an $\bar{\jmath}$ to Oj decoction, $\overline{3} \mathrm{j}$; of scoparin, gr. $\mathrm{v}-\mathrm{x}$; of the fluid extract gtt. xxx. S., Decoct. (B. P.) Dose Zj-iij. S., Succus (B. P.) Dose 3 j-ij.

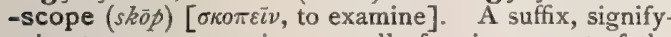
ing to see or examine; usually forming a part of the name of some instrument.

Scopoleïn, or Scopolin (sko-po'-le-in, sko'-po-lin) [after Scopoli, an Austrian naturalist]. An alkaloid extractive of Scopolia japonica. It is a powerful mydriatic, whose effects are more rapid and more lasting than those of atropin, and are neutralized by those of eserin. It is recommended in keratitis and corneal ulcers. Unof. It is said by some to be a natural mixture of hyoscin, hyoscyamin, and atropin.

Scopoletin (sko-pol'-et-in) [after Scopoli, an Austrian naturalist $], \mathrm{C}_{10} \mathrm{H}_{8} \mathrm{O}_{4}$. A fluorescent, crystalline substance obtained from the root of Scopolia japonica and Scopolia atropoides.

Scopolia (sko-po'-le-ah) [after Scopoli, an Austrian naturalist]. A genus of the Hyoscyamece. S. Atropoides. See S. carniolica. S. carniolica, the rhizome of a European solanaceous plant, of use as an efficient anhydrotic, checking sweating without producing dryness of the mouth or dilatation of the pupil. Also a local anesthetic. Dose of the fluid extract, $m j$-iij. Unof. S. japonica, of Asia, has in general the properties of belladonna, for which it is substituted in Japanese practice. See Scopolein.

Scoptula (skop'-tu-lah) See Scopula.

Scopula (skop'-u-lah) [dim. of scopa, a broom]. See Sirothrum.

Scopulate $\left(s k o p p^{\prime}-u\right.$-lät $)$ [scopula, a little broom]. In biology, broom-shaped.

Scopuliform (skop'-u-lif-orm). Same as Scopulate.

Scoracratia $\left(s k o-r a k-r a^{\prime}-s h \epsilon-a h\right)[\sigma \kappa \omega \tilde{\rho}$, feces; ákparia, want of control]. Involuntary evacuation of the bowels.

Scorax (sko'-raks). A gum obtained from the olivetree.

Scorbutic (skor-hu'-tik) [scorbutus, scurvy]. Pertaining to, affected with, or of the nature of scorbutus. S. Cancer. Synonym for Cancrum oris.

Scorbutus (skor-bu'-tus) [L.]. See Scurvy. S. alpinus. See Pellagra. S. nauticus. See Scurvy.

Scordein (skor'-de-in) [ $\sigma \kappa \delta \rho \delta \iota \sigma$, a garlicky plant]. An aromatic substance of a yellow color found in Teu. crium scordium.

Scordinema (skordin-e'-mah). See Pandiculation.

Scordium (skor'-de-zm) [ $\sigma \kappa o ́ \rho \delta \iota \nu$, a garlicky plant]. The Teucrium scordium. Aqua scordii, a mixture of one part of scordium and three parts of water, reduced one-fourth by distillation. Aqua scordii composita, a preparation containing II parts each of scordium, Cretan dittany, spikenard, and the roots of Virginia snakeroot, sweet flag, and angelica, 4 parts each of opium and saffron, 6 each of cinnamon, cardamom, and cloves, and 360 of brandy. Extractum scordii, a preparation made by infusing I part of scordium in 4 parts of boiling water, pouring off the infusion, repeating the process with a like volume of water, mixing the two infusions, and evaporating. Syrupus scordii, a preparation made by digesting 32 parts of scordium in 1000 of aqua scordii, and adding to the filtered liquid twice its weight of sugar. Tinctura scordii, a filtered infusion of I part of scordium in 4 parts of alcohol.

Scorodolasarum (skor-o-do-las'-ar-um). See Asafetida.

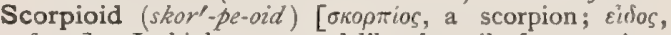
form]. In biology, curved like the tail of a scorpion. Applied to certain cymes, like those of the forget-menot and heliotrope.

Scorteum (skor'-te-um). Synonym of Scrotum.

Scorzonera (skor-zo-ne'-rah) [It., "black bark" "]. A genus of composite plants of many (Old World) species. S. hispanica, S. deliciosa, S. tuberosa, and other species are cultivated for their esculent roots, which also are called scorzonera. S. humilis is diaphoretic and stimulant. Unof.

Scotasma (sko-taz'-mah). See Scotoma.

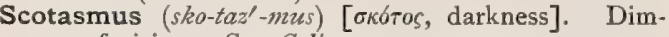
ness of vision. See Coligo.

Scotch (skoch) [a contraction of Scottish]. Pertaining to Scotland. S. Fiddle, the itch. S. Method. See Anesthetic. S. Pine, Pinus sylvestris.

Scotodia (sko-to'-de-ah). See Amblyopia.

Scotodinia (sko-to-din'-e-ah) [бкótos, darkness; divos, a whirl]. Giddiness, with the appearance of black spots before the eyes.

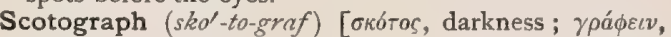
to write]. An instrument for aiding the blind to write.

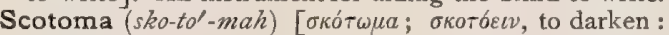
pl., Scotomata]. A fixed spot or space in the field of vision corresponding to some abnormality in the retina or optic centers of the brain. S., Absolute, a scotoma in which perception of light is entirely absent. S., Central, a scotoma limited to the region of the macula lutea, or its immediate vicinity. S., Color, color - blindness limited to a part of the visual field, and which may exist without interruption of the field for white light. S., Flittering, a scotoma with serrated margins extending peripherally and producing a large defect in the visual field. S., Negative, a defect due to the destruction of the retinal center, and which is not noticeable to the patient. S., Positive, a scotoma perceptible to the patient as a dark spot before his eyes. S., Relative, a scotoma within which perception of light is only partially impaired. S., Ring, zones of scotoma surrounding the center of the visual field. S., Scintillating. See S., Flittering.

Scotome (sko'-tōm $)$ [ $\sigma \kappa o t o ́ s$, darkness]. A scotoma.

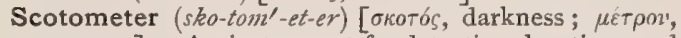
measure]. An instrument for detecting, locating, and measuring scotomata.

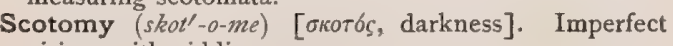
vision, with giddiness.

Scotopsia (sko-top'-se-ah). See Myiodesopsia. 
Scotos (sko'-tos). See Scotodinia.

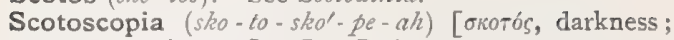
$\sigma \kappa \cap \pi \varepsilon i \nu$, to inspect]. See Retinoscopy.

Scott-Battam's Method. See Treatment, Methods of.

Scott's Dressing. "A method of treating fungous arthritis consisting in rubbing on compound mercury ointment and then applying pitch-plaster spread on leather."

Scour (skowr) [ME., scouren, to scour]. Diarrhea, as in cattle.

Scourge (skerj) [ME., scourge, scourge]. I. Any severe epidemic disease of a fatal character. 2. To strike the skin with light withes or with knotted cords in order to produce counter-irritation.

Scourging (skerj'-ing) [ME., scourge, scourge]. A beating or flagellation. S. Mania, a religious mania of the I $3^{\text {th }}$ and I 4 th centuries characterized by the self-flagellation of the persons affected.

Scouring (skowe -ing) [ME., scouren, to scour]. Purging; also, diarrhea. S. Rush, the stalks of Equisetum hyemale. Diuretic and astringent. Dose of fld. ext. $m x x-3 j$. Unof. See Equisetum.

Scrape (skrāp) [ME., scrapien, to scrape]. Galipot; a white viscid resin obtained from fir-trees; an inferior sort of turpentine.

Scraper (skra'-per) [ME., scrapien, to scrape]. An instrument used to produce an abrasion. S., Tongue, an instrument used to remove accumulations of exfoliated epithelium and other foreign material from the tongue.

Scrat (skrat) [ME., scrat, a monster]. An hermaphrodite.

Scratched (skracht) [ME., scrat ]. Excoriated. S. Skin, a group of lesions directly and indirectly due to the constant irritation of the nails, and, as a whole, a symptom of prurigo, urticaria, scabies, and other pruritic diseases.

Scratches (skrach'-es) [from ME, scrat]. I. Excoriations produced by the nails in scratching. 2. Grease ; an eczematous inflammation of the feet of the horse. S., Ohio, prairie itch.

Screable $($ skre'-a-bl) [screare, to hawk]. That which may be spit out.

Screaming Fits. See Convulsions, Infantile.

Screation (skre-a'-shun) [screare, to hawk]. The act of spitting.

Screatus (skre-a'-tus) [L., a "hawking."']. I. Excretion. 2. Agnew's term for a singular neurosis of the nasal passages, characterized by paroxysms of short, noisy inspirations or snortings, "as though an effort were being made to draw into the pharynx some worrying secretion from the back of the nose." The paroxysms last for two or three minutes, are frequent in occurrence, and are utterly independent of the patient's volition. The patient is exhausted and becomes emaciated from the excessive wear. The condition is often due to some local irritation, and is, as a rule, amenable to treatment.

Screw (skru) [Dan., skrue, a screw]. A cylindric rod on the surface of which is a projecting fillet or thread, passing spirally around at a constant angle to its axis. This fits into a hollow cylinder with its surface spirally grooved to correspond with the thread on the screw, which moves within it backward and forward in the direction of its length. S.-driver Teeth, peculiar teeth occurring in the subjects of hereditary syphilis. S.-hook, an instrument devised by Elsberg for the removal of foreign bodies from the ear. S., Micrometer, a screw with a very slight pitch for the measurement of very minute spaces and motions, as in the fine adjustment of microscopes. S., Oral, a screw of hard rubber or bone for insertion between the teeth to separate the jaws. S., Pancoast's, a screw for drilling the fragments in ununited fracture.

Scriptulus (skrip'-tu-lus). See Scruple.

Scriveners' Cramp, or Palsy. See Paralysis, Writers'.

Scrobe (skrōb) [scrobis, a ditch, a trench]. In biology, a groove for the reception of the basal joint of the antenna, occurring at the side of the rostrum in certain beetles. S., Mandibular, a groove in the side of the mandible in certain insects.

Scrobicula (skro-bik'-u-lah) [L.]. In biology, a smooth space surrounding a tubercle on the test of a sea-urchin.

Scrobicular (skro-bik'-u-lar) [scrobiculus, a little ditch]. Pertaining to scrobiculæ.

Scrobiculate (skro-bik'-u-lät) [scrobiculus, a little ditch or trench]: In biology, pitted or grooved. Possessing minute or shallow depressions.

Scrobiculus (skro-bik'-u-hus) [L.]. A small pit or furrow. S. cordis. See Anticardium. S. variolz, a scar made by a small-pox pustule.

Scrofula (skrof'-u-lah) [dim. of scrofa, a sow]. Tuberculous adenitis. A morbid condition, usually constitutional, and frequently hereditary, characterized by glandular tumors, having a tendency to suppuration, and leaving indolent ulcers very stubborn to treatment. It is now generally accepted as a manifestation of tuberculosis. The term is gradually falling into disuse. S., Benign, a condition characterized by inflammation, not endangering life, as lupus erythematosus. S., Fixed Primitive, a condition in which the symptoms presented at the onset of the disease are maintained to its close. S. fugax. See $S$, Fitgitive. S., Fugitive, suppurative cervical adenitis with eczema capitis (Cullen). S., Ganglionic, scrofulous adenitis. S., Malignant, lymphadenoma. S. mesenterica, tabes mesenterica. S. moluccana. See Yaws. S., Mucous, an old term for a supposed scrofula of the mucous membranes. S., Phagedenic, of Bazin, a scrofula with a marked tendency to phagedenic ulceration. S., Primitive, a term formerly applied to scrofula in its early stage. S., Pulmonary, pulmonary tuberculosis. S., Quaternary, visceral tuberculosis. S., Senile, a condition occurring in advanced age, and characterized by strumous ulcers, which are apt to develop into rodent ulcer or epithelioma. S., Visceral, the same as quaternary scrofula.

Scrofulelcosis (skrof-u-lel-ko'-sis) [scrofula, scrofula; $\hat{\varepsilon} \lambda \kappa \omega \sigma \iota$, ulceration]. Scrofulous ulceration.

Scrofulide (skrof'-u-lid) [scrofula, scrofula]. See Scrofuloderma. S. boutonneuse bénigne, of Bazin, prurigo. S.s malignes, of Bazin, lupus erythematosus and lupus vulgaris. S. tuberculeuse, lupus vulgaris.

Scrofulism (skrof'-u-lizm) [scrofule, scrofula]. The scrofulous diathesis or condition.

Scrofuloderm (skrof'-u-lo-derm) [scrofula, scrofula; dép $\mu a$, skin]. See Scrofuloderma. S., Large Pustular, ecthyma scrofulosum. S., Small Pustular. See Lichen scrofulosus.

Scrofuloderma (skrof-u-lo-der'-mah) [scrofula, scrofula; $\delta$ é $\mu a$, the skin]. A term applied to the various forms of suppurating dermatitis. The lesions most commonly occur in the skin of the face and neck, over caseating and softening lymphatic glands. S. gummatosum. See S. tuberiulosum. S. papulosum. See Lichen scrofulosus. S. squamosum, a furfuraceous exfoliation of the epidermis occurring in scrofulous subjects. S. tuberculosum, a condition characterized by cellular infiltrations, forming nodes and having a tendency to ulcerate. The lesions begin as hard, rounded, subcutaneous nodules, freely movable 
beneath the skin. Later the skin is implicated, becomes adherent and violaceous, and the tumors soften, with obvious fluctuation ( $S$. gummatosum). They may then be absorbed or evacuated spontaneously, in which case they cicatrize slowly or form spreading ulcers with thin, red, undermined edges, uneven bases, and pale, pus-covered, unhealthy granulations, sometimes associated with numerous deep sinuses ( $S$. ulcerosum). S. ulcerosum, granuloma fungoides. See $S$. tuberculosum. S. verrucosum, tuberculosis verrucosa cutis (Riehl and Paltauf); lupus verrucosus and verruca necrogenica (Unna).

Scrofulome (skrof'-u-lōm) [scrofula, scrofula; ö $\mu a$, tumor]. A tumor of a supposed scrofulous nature or origin.

Scrofulonychia (skrof-u-lo-nik'-e-ah) [scrofula, scrofula; òv

Scrofulophyma (skrof-u-lo-fil-mah) [scrofula, scrofula; $\phi v \mu \alpha$, growth]. Scrofuloderma tuberculosum. S. diffusum, elephantiasis scrofulosa.

Scrofulosis (skrof-u-lo'-sis) [scrofula, scrofula; vó os, disease]. A scrofulous condition, disease, or diathesis. S. erethica. Scrofulosis with a tendency to suppurative adenitis. S. torpidus, scrofulosis, as it is manifested by the puffy face with thick nose and lips, slender limbs, and prominent abdomen, and also other characteristic features of the facies scrofulosus.

Scrofulous (skrof'-u-lus) [scrofula, scrofula]. Having the nature of scrofula. Affected with scrofula. S. pneumonia, secondary inflammatory processes in the lungs occurring in pulmonary scrofula. S. teeth, teeth similar in some respects to those of syphilis, but distinguished by a muddy-white color; they are large, rough, and irregular; their lingual surfaces are indented; the arch is broad, and the teeth regular in arrangement.

Scrofulousness (skrof'-u-lus-nes) [scrofula, scrofula]. The scrofulous character or condition.

Scroll $(s k r o \bar{l})$ [ME., scrolle, scroll]. A roll of paper, or anything folded so as to resemble a roll. Ss., Olfactory, the turbinate bones.

Scrophula (skrof'-u-lah). See Scrofula.

Scrophularia (skrof-u-la'-re-ah) [scrofule, scrofula]. A genus of flowering plants called figworts; the type of the important order of Scrophulariacea. There are some I2O species. S. nodosa, of Europe and North America, has been much used in the treatment of scrofula, piles, and ulcers. Unof. S. officinalis, S. vulgaris. See $S$. nodosa.

Scrophulelcosis. See Scrofulelcosis.

Scrophulophyma. See Scrofulophyma.

Scrotal (skro'-tal) [scrotum, scrotum]. Pertaining to the scrotum. S. Hernia, protrusion of the gut through the external ring and into the scrotum; oscheocele.

Scrotiform (skro'tif-orm) [scrotum, scrotum; forma, form]. In biology, shaped like a purse or pouch with two compartments, as the pod of shepherd's purse (Capsella).

Scrotitis (skro-ti'tis) [scrotzım, scrotum; $\iota \tau \iota S$, inflammation]. Inflammation of the scrotum.

Scrotocele (skro'-to-sēl) [scrotum, scrotum; $\kappa \dot{\eta} \lambda \eta$, tumor]. Same as Scrotal Hernia.

Scrotum (skro'-tum) [L.]. The pouch containing the testicles, consisting of a thin, brownish skin marked by numerous rugæ, and beneath which are the dartos, the spermatic fascia, the cremasteric fascia, the infundibuliform fascia, and the parietal tunica vaginalis. $\mathbf{S}$. cordis, the pericardium. S. lapillosum, multiple calcareous atheroma of the scrotum.

Scrubgrass (skrub'-gras). See Scouring Rush.
Scruff (skruf) [origin obscure]. A popular name for the nape, or back of the neck.

Scruple $\left(s k r u^{\prime}-p l\right)$ [scrupulum, a scruple]. In Apothecaries' weight, 20 grains. Represented by the sign $\exists$.

Scrupulosity (skru-pu-los'-it-e) [scrupulosus, exact]. An over-precision, or morbid conscientiousness as to one's thoughts, words, and deeds. It is somewhat common among insane persons of a certain type.

Scull (skul). See Skull. S.-cap. See Skull and Scutellaria.

Scultetus, Bandage of. See Bandage.

Scurf (skerf) [ME., scurf, scurf]. The bran-like exfoliation of the epidermis, especially from the scalp. It is popularly known as "dandruff" or "dandriff." S.-skin, the epidermis.

Scurvy (sker'-ve) [ME., scurvy]. A disease observed both on land and at sea among persons who have been deprived of wholesome diet for any length of time; it is characterized by spongy gums, extravasations of blood, livid, indurated patches of skin, hemorrhages from the mucosa, fetor of the breath, and painful contractions of the muscles. It is aggravated by want of cleanliness and by a diet of fat, salt meat. It soon disappears under a vegetable diet, vegetable acids, etc. S. of the Alps. See Pellagra. . S., Button, a disease which prevailed among the peasantry of Ireland, in I8I4. It was described as an eruption of "convex tubercles, varying from the size of a split pea to that of a shilling," having " an appearance somewhat like the surface of a raspberry," and exuding "a white, tenacious matter which formed thin, yellow crusts" (Carmichael). S.-grass, plants of the genus Cochlearia; spoonwort. Common scurvy-grass, Cochlearia officinalis, is stimulant, diuretic, and antiscorbutic. It is administered in an infusion made of one part of the herb in $\mathbf{I} 2$ parts of water, evaporated one-half by heating. Dose §ij. S., Land, scurvy affecting landsmen. See Purpura hamorrhagica. S., Norwegian. See Radesyge. S. Rickets, a form of scurvy associated with rickets occurring in young infants improperly fed. It appears especially in those cases in which there is a lack of fresh milk in the diet.

Scutate $\left(s k u^{\prime}-t \bar{a} t\right)$ [scutum, a shield]. In biology, shaped like a buckler.

Scute (skūt $)$ [scutum, a shield]. In biology, a scale or plate, a siutum, q. $v$.

Scutellar (sku-tel'-ar) [scutellum, a little shield]. Of or pertaining to a scutellum.

Scutellaria (sku-tel-a'-re-ah) [scutellum, a little shield]. A genus of labiate plants. Skull-cap, the leaves and twigs of $S$. lateriflora, have reputed properties as a tonic nervine, in tremors, chorea, hysteria, etc. Dose of the fld. ext. $3 \mathrm{ss}-\mathrm{ij}$. S. galericulata is considered astringent and febrifuge, as is also $\mathbf{S}$. integrifolia. All unof.

Scutellarin (sku-tel-a'-rin) [scutellum, a little shield]. A precipitate from a tincture of Scutellaria lateriftora; nervine, tonic, diuretic, and antispasmodic. Dose gr. j-ij. Unof.

Scutellate (sku'-tel-ät) [scutellum, a little shield]. In biology : (a) provided with scutella or transverse scales, as the feet of certain birds; (b) plate-shaped.

Scutelliform (sku-tel'-if-orm) [scutellum, a little shield; forma, form]. Scutellate.

Scutelligerous $\left(s k u-t e l-i j^{\prime}-e r-u s\right)$ [scutellum, a little shield; gevere, to carry]. In biology, provided with a scutellum.

Scutelliplantar (sku-tel-ip-lan'-tar) [scutellum, a little shield; planta, the sole of the foot]. In biology, applied to certain birds in which the planta or back of the tarsus is provided with transverse scales. 
Scutellum (sku-tel'-rmn) [dim. of scutum, a shield: pl., Scutella]. 1. Scutulum; the characteristic "plate" of Tinea favosa. It shows a typical central depression with raised edges (cupped), is usually marked with concentric lines, and may be as large as a split pea. It is whitish or pale-yellow in the center, vividyellow at the periphery. 2. In biology: (a) (I) In lichens a sessile shield-shaped apothecium; (2) in Graminea, the cotyledon that envelops the embryo and is modified to absorb the reserve materials and convey the nutriment to the embryo; $(b)(I)$ one of the sclerites composing the tergum of an insect; (2) one of the plates of the tarsus of certain birds.

Scutia $\left(s c c^{\prime}-t e-a h\right)$ [scutum, a shield]. A genus of the Rhamnea. A shrub growing in Asia; the leaves, made into an ointment, are used as an oxytocic in India.

Scutiform (sku'tif-orm) [scutum, a shield]. Shieldshaped. S. Leaf, the first-formed leaf or cotyledon in Salvinia, so naned from its peculiar shape.

Scutigerous (sku-tij'-er-uts) [scutum, shield; gevere, to carry]. In biology, provided with a scute.

Scutiped (sku'tip-ed) [scutum, a shield; pes, foot]. In biology, a bird with scaled tarsi.

Scuto-auricularis (sku-to-aw-rik-u-la'-ris) [scutum, shield; auricula, ear]. A muscle attached to the scutiform cartilage of the ear.

Scutulatio (sku-tu-la'-she-o) [scutum, a shield]. A cutaneous disease of new-born infants. See Ichthyosis congenita and Ichthyosis sebacea.

Scutulum (sku'-tu-lum). See Scutellum.

Scutum $\left(s k u^{\prime}-t u m\right)$ [scutum, a long shield: pl., Scuta]. I. An exoskeletal scale or plate. 2. The thyroid cartilage. S. cordis, the sternum. S. genu, the patella S. pectoris, the thorax. S. thoracis, the sternum. S. tympanicum, the semilunar plate of bone separating the attic of the tympanum from the outer mastoid cells.

Scybala (sib'-al-ah). Plural of Scybalum,q. v.

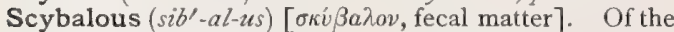
nature of a scybalum.

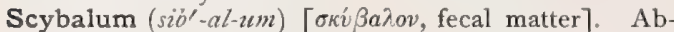
normally hard fecal matter that has aggregated into lumps.

Scyllite $\left(s i l^{\prime}-\bar{\imath} t\right)$ [ $\sigma \kappa \dot{\gamma} \beta a \hat{\lambda} o \nu$, fecal matter $], \mathrm{C}_{6} \mathrm{H}_{12} \mathrm{O}_{6}{ }^{*} \mathrm{~A}$ glucose obtained from the intestines, kidney, liver, etc., of the hag-fish, skate, and shark.

Scyphistoma (si-fis'-to-mah) or Scyphostoma, (si-fos' -

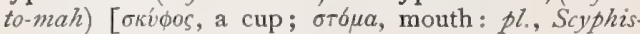
tomata, Scyphostomata]. In biology, the hydra-tube stage in the development of Medusce. It arises from the scyphula, and gives rise to the free-swimming medusa by the tearing away of the larger portion of the body. The remaining stem can, however, become regenerated into a complete attached medusa (monodisc strobila); or the stem of the scyphistoma may become regenerated into a new scyphistoma before the first medusa has detached itself; and when this regenerative process continues without the medusæ at once fully detaching themselves we have a polydisc strobila, a temporary animal stock. The whole process is called strobilation, $q . v$.

Scyphula (sif'-u-lah) [scyphulus, dim. of scyphus, a cup]. In biology, a stage in the development of the acraspede Medusa, in which the primitive larva resembles an attached coral-like animal. It later develops into an attached young Medusa, the Scyphistoma, q. v.

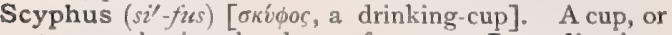
structure having the shape of a cup. S. auditorius, S. cochleæ, S. vieussenii, the infundibulum of the cochlea. S. lapideus in oculo, a cup-shaped con- cretion in the eye, probably identical with what is known as ossification of the choroid.

Scyros (si'-ros.) Synonym of Callosity.

Scytalis $\left(s i t^{\prime}-a l-i s\right)[\sigma \kappa v \tau a \lambda \eta$, a staff $]$. A phalanx of the fingers

Scythian Disease (sith'-e-an dis-êz $\left.z^{\prime}\right)$. Atrophy of the male generative organs, with consequent loss of physical power, masculinity, etc. It is an attendant or result of sexual perversion, its victims adopting the dress and manners of women. It prevails locally in the Caucasus (as in the time of Herodotus), and is common as far eastward as Alaska.

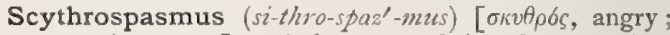
$\sigma \pi \alpha \sigma \mu \delta \varsigma$, spasm]. A heavy or fatigued expression, regarded as an evil symptom in grave disease.

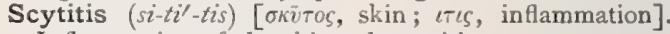
Inflammation of the skin; dermatitis.

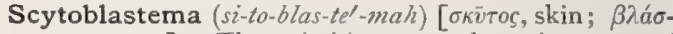
$\tau \eta \mu \alpha$, germ]. The primitive or embryonic stage of the development of the skin.

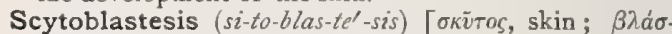
$\tau \eta \mu a$, germ]. The condition and progress of scytoblastema.

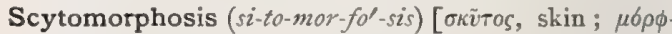
$\omega \sigma / s$, shaping]. An abnormal development of the skin

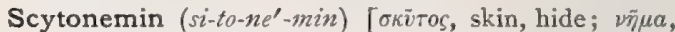
a thread]. A deep yellow or brown pigment coloring the filament-sheath in many of the Scytonemacea. See Pigments, Conspectus of.

Sea (se) [ME., see, sea]. The ocean. S.-moss. See Carragheen. S.-sickness, the nausea and vomiting affecting persons at sea, or those who are subjected to any undulatory motion like that of a vessel. S.tangle, the stem of Laminaria digitata, a marine plant. The dried stem, introduced into a moist canal or hollow organ, swells and dilates the cavity. See Tent. S.-water bath. See Bath. S.-weed, any marine plant of the order Alga. S.-weed bath, a bath in seawater charged with an infusion of some medicinal seaweed. S.-wrack. See Fucus vesiculosus.

Seal (sel) [ME., seel, seal]. A body of water, or other material, placed in the trap of a house-drain for the purpose of preventing the ingress of sewerair.

Sealing (se'-ling) [ME., seelen, to seal]. The exclusion of air from a wound during the process of healing. S.-wax, a product manufactured from shellac, to which have been added Venice turpentine to make it more fusible and less brittle, and some mineral coloring. matter, usually vermilion. For black sealing-wax the best ivory-black is used ; for golden-color wax, " mosaic gold" (stannic sulphid); for green wax, powdered verdigris, and for the commoner varieties earthy materials.

Seam (sèm). See Suture and Raphe.

Searcher $\left(\operatorname{serch}^{\prime}-e r\right)$ [ME., serchen, to search]. An instrument used for the detection of stone in the bladder.

Searching (serch'-ing) [ME., serchen, to search]. Probing; sounding. The operation of exploring the bladder by means of a metallic sound, for the purpose of detecting the presence or absence of calculi. $\mathbf{S}$. Ocular. See Ocular.

Seamstress's Cramp. See Cramp.

Seaside Grape. West Indian kino, from Coccoloba uvifera.

Seasoning $\left(s e^{\prime}-z n-i n g\right)$ [Fr., saismner, to have a good flavor]. Adding a higher relish to food; acclimatizing. S. Fever, the febrile symptoms occurring during the process of acclimatization

Seat (sêt) [ME., sete, seat]. Breech; nates. S.-bone, 
the ischium. S.-worm, thread-worm. See Oxynris, under Purasites (Animal), Tuble of.

Seb $(s e b)$. Gold of the alchemists; also alum.

Sebaceous $\left(s e-b a^{\prime}-s h u s\right)$ [sebum, suet, fat]. Pertaining to fat or suet, and especially to the sebaceous glands of the corium of the skin. S. Cyst, we $n$, atheroma, st e atoma; a cystic tumor varying in size from a milletseed to an orange, situated in the skin or subcutaneous tissue. It occurs most frequently on the scalp, face, back, and scrotum, and may be single or mul-

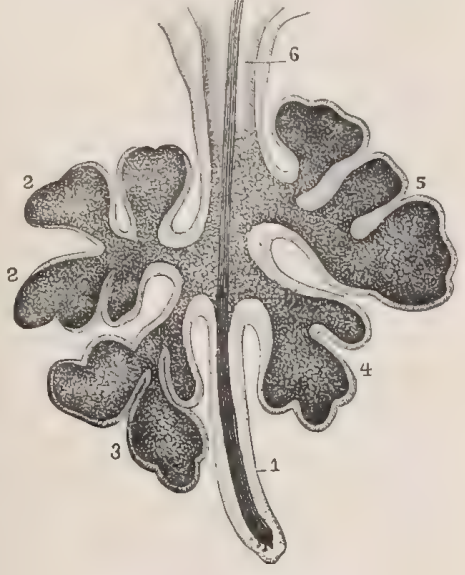

Large Sebaceous Gland.

. Hair in its follicle. 2, 3, 4, 5. Lobules of the gland. 6. Excretory duct traversed by the hair. tiple. S. Flux. See Seborrhea.

Sebacic (se-ba'-sik) [sebum, fat]. Pertaining to or derived from sebum. S. Acid,

$$
\mathrm{C}_{10} \mathrm{H}_{18} \mathrm{O}_{4}=\mathrm{C}_{8} \mathrm{H}_{16}<\mathrm{COOH}
$$

a dibasic acid obtained by dry distillation of oleic acid and by the action of sodium hydroxid on castoroil.

Sebacin $\left(s e-b a^{\prime}-\sin \right)$ [sebum, fat]. I. A hydrocarbon obtained by distilling calcium sebate with an excess of calcium carbonate. 2. An unctuous substance found in the fruit of Myristica sebifera.

Sebadilla (seb-ad-il'-ah). See Cevadilla.

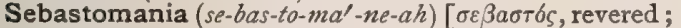
$\mu a v i a$, madness]. Religious insanity.

Sebate $\left(s e^{\prime}-b \bar{a} t\right)$ [sebum, fat]. A salt of sebacic acid.

Sebel. See Pannus oculi.

Sebesten (se-bes'-tcn) [Ar. sebestān, the fruit sebesten]. A tree of Asia, Cordia myxa L. ; also, C. obliqua; also their edible fruits, called sebesten plums. The latter, dried, have been much used for their demulcent qualities, Unof.

Sebic $\left(s e^{\prime}-b i k\right)$. See Sebacic

Sebiferous (se-bif'-er-us) [sebum, fat ; ferre, to bear]. Same as Sebiparous.

Sebiparous (se-bip'-ar-us) [sebum, fat ; parere, to produce]. Forming or producing sweat.

Sebolith (seb'-o-lith) [sebum, fat; $\lambda$ itos, stone]. A calculus, or hard concretion, in a sebaceous gland.

Seborrhagia (seb-or-a'-je-ah). See Seborrhea.

Seborrhea, Seborrhcea (seb-or-e'-ah) [sebum, suet; $\rho$ bia, a flow]. Sebaceous fux ; stearrhea; seborrhagia; steatorrhea; a disorder of the secretory organs of the skin, in which there is an alteration and increase of sebaceous secretion, and, according to some, an involvement of the sweat-coils, as well as of the sebaceous glands. It is characterized by the formation of an oily, waxy, or scaly accumulation on the surface. S. adiposa. See S. oleosa. S. amianthacea, S. capillitii, S. capitis, seborrhea of the scalp. See S. sicca and Alopecia furfuracea. S. cerea, the waxy form of $S$. sicca. It is the vernix caseosa of the new-born. It occurs at almost any age after birth, and includes the accumulation of smegma beneath the prepuce. At puberty and onward it is seen most commonly on the scalp, where it forms dirty-looking, yellowish or greenish. brown, or even black, plates or crusts of fat and epithelium. It leads to atrophy of the hair. S. congestiva, lupus erythematosus of Hebra; it is the early stage of lupus erythematosus. S. corporis, S. papulosa seu lichenoides, a papular, ringed, serpiginous eruption, confined to the trunk, and characterized by slight scaliness and marked greasiness, and frequently associated with $S$. capitis. It is popularly known as "flannel rash." Its synonyms are: Lichen circinatus, L. circumscriptus, L. annulatus serpiginosus, L. gyratus. S. crustosa. See S. sicca. S. dermatitis. See S. corporis, S. eczema, S. eczemiformis, $S$. psoriasiformis, the various forms resembling ordinary dermatitis, and comprised under the general term, $S$. dermatitis. $\mathbf{S}$. eczema of Unna. See $S$. dermatitis. S. eczematoid, seborrhea associated with active inflammation of the scalp. The margin of the affected area is well defined, and there is abundant formation of flaky, fatty scales. This acute condition is due to some depressing influence, mental or physical. S. faciei, a common sequel of variola and other exanthemata, and often associated with rosacea. It affects chiefly the forehead, superciliary regions, and sides of the nose and cheeks. The scales are often greenish or blackish. S. fluida. See $S$. oleosa. S. furfuracea seu pityriasiformis, the scaly form of $S$. sicca. It constitutes the condition known as scurf or dandruff, and is the alopecia pityrodes of Pincus. S. genitalium, the accumulation of smegma beneath the prepuce, about the clitoris, and between the labia and the nymphæ. S. lichenoides. See S. corporis. S. localis, circumscribed seborrhea, as when it occurs on the face only. S. nasi, seborrhea attended with the formation of yellow crusts on the tip of the nose ( $S$. Alavescens). S. nigra, S. nigricans, seborrhea with the formation of dark-colored crusts, the coloration being usually from dirt. See Chromidrosis. S. oleosa, a variety in which there is an excess of oily secretion on the surface. The face has a greasy appearance and feel; the complexion is generally thick and muddy-looking. It occurs usually in young adults. S. papulosa. See $S$. corporis. S. psoriasiformis, one of the least common forms of seborrhea, consisting of well-defined bright-red patches, with scanty, scaly, and fatty crusts. The individual patches may coalesce and cover a considerable area. The eruption is chieffy met with in the axilla and on the trunk. S. sicca, the commonest form of the disease, characterized by fine greasy or branny scales; the underlying skin is pale and leaden. There are no subjective symptoms. It is one of the chief causes of premature baldness. S. squamosa (seu sicca) neonatorum, ichthyosis congenita; regarded by Hebra as a general seborrhea. The entire surface of the body is covered with fatty, thick, epidermic plates, firmly adherent to the skin, and broken by deep rhagades extending down into the corium. Owing to the stiffiness and contraction of the skin, the eyes cannot be completely opened or closed, the lips are retracted, the nose and ears are atrophied, and the toes contracted and cramped. If not born dead, the subject soon succumbs from starvation and depression of temperature. S. syphilitica, $S$, capitis when associated with syphilitic lesions of the scalp. S. tabescentium, a form of $S$. furfuracea, occurring in diabetes and chronic wasting diseases. S. universalis, Pityriasis tabescentium; a variety occurring only at the end of wasting dis. 
eases, as diabetes mellitus. It consists in a universal, branny desquamation, especially over the trunk and extremities.

Sebum $\left(s e^{\prime}-6 u m\right)$ [L.]. The secretion of the sebaceous glands. See also Sevum. S. palpebrale, Lema: the dried glandular secretion of the eyelids. S. præputiale, S. præputii, smegma præputii.

$\mathrm{Sec}(\mathrm{sek})[\mathrm{Fr}$.$] . Dry ; said of bloodless surgical opera-$ tions.

Secale $\left(s e k-a^{\prime}-l e\right)$ [L.]. Rye. S. cereale, common rye; rye-flour furnishes a nutritious bread. Alone or mixed with bran it is used as an absorbent and emollient application, and as a mush it is said to be laxative. Carbonized Rye is used in tooth-powders. S. cornutum. See Ergot. S. farina, rye-meal.

Secalin (sek'-al-in). See Trimethylamin.

Secamone $\left(\operatorname{sek}-a m-o^{\prime}-n e\right)$ [L.]. A genus of the Secamonea. S. emetica, a shrub of India; the root contains an acrid, emetic principle.

Secernment, Secerning (se-sern'-ment, se-sern'-ing) [secernere, to separate]. Secreting; applied to the function of a gland or a follicle.

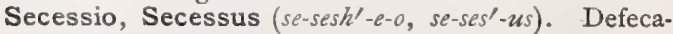
tion.

Secohm $\left(s e k^{\prime}-\bar{o} m\right)$ [secundus, following; ohm]. A unit of electric self-induction.

Second (sek'-und) [secundus, next]. Next after the first. S. Intention. See Healing. S.-sight. See Clairvoyance.

Secondaries $\left(s e k^{\prime}-u n-d a-r e \bar{z}\right)$ [secundus, second]. A name sometimes applied to the secondary symptoms of syphilis, in contradistinction from the primaries.

Secondary (sek'-un-da-re) [secundarius]. I. Following, succeeding to a first. Subordinate in order of time or development; an induced or faradic electric current. 2. In chemistry, a hydrocarbon having a substituted radicle attached to a carbon atom which is attached to two other carbon atoms. S. Amputation, consecutive amputation, or amputation done after the subsidence of inflammatory symptoms. S. Cataract. See Cataract. S. Dentine, dentine formed at a later period than the rest of the dentine; when the pulp, for example, is converted into solid material and no pulp-cavity remains the material so formed is called "secondary dentine." S. Hemorrhage. See Hemorrhage, Consecutive. S. Syphilis. See Syphilis. S. Tertiary, those diatomic alcohols in which one molecule of hydroxyl is attached to a carbon atom which is attached to two other carbon atoms, and the other molecule of hydroxyl is attached to a carbon atom itself connected with three other carbon atoms.

Secreta (se-kre'-tah) [secernere, to separate]. The substances secreted by a gland, follicle, or other organ; products of secretion.

Secreting (se-kre'-ting) [secernere, to separate]. Effecting secretion]. S. Fringes, synovial fringes.

Secretion (se-kre'-shun) [secretio: pl., Secretiones]. The natural function of certain organs of the body, mainly the glands and follicles. It consists in the separation and elaboration of fluid or semi-fluid substances differing according to the organ in which they are secreted. Also, the substance secreted. S., Antilytic, the saliva secreted by a submaxillary gland with intact nerves, as distinguished from that which flows from a gland which has had its nerves divided (Langley). S., Menstrual, menstrual blood. S., Paralytic, the abnormal discharge from a gland after section of its motor nerve. S., Sebaceous, sebum. S., Internal, the secretion of an organ that is not excreted or discharged, as, e.g., glycogen.

Secretitious (se-kre-tish'-us) [secretio, a secretion]. Of the nature of a secretion.
Secretodermatosis (se-kre-to-der-mat-o'-sis) [secretio, a secretion; $\delta \dot{\varepsilon} \rho \mu \alpha$, skin; vóoos, disease]. An affection of the secretory apparatus of the skin.

Secreto-motor (se-kre'-to-mo'-tor) [secretio, a secretion; motor, a mover]. Applied to nerves intermediating the function of secretion.

Secretory (se'-kre-tor-e) [secernere, to separate]. Performing secretion; applied to those glands or organs that form or produce secretions. S. Fibers, centrifugal nerve-fibers exciting secretion.

Secretum (se-kre'-tum). See Secretion.

Sectio (sek'-she-o) [L.]. Section. S. abdominis. See Laparotomy and Celiotomy. S. agrippina, Cesarean section. S. alta, high or supra-pubic section in lithotomy. S. alta subpubica, transverse section beneath the pubic arch in lithotomy. S. anatomica, a dissection. S. bilateralis, bilateral cystotomy. S. cadaveris, an autopsy. S. cæsarea, Cesarean section. $\mathbf{S}$. corneæ, keratotomy. S. fistularum, section of the tissues between the two openings of a complete anal fistula. S. frænuli præputii, division of the preputial frenum for the relief of penile curvature and premature seminal emissions. S. franconiana, suprapubic cystotomy. S. hypogastrica, suprapubic cystotomy. S. lateralis, lateral cystotomy. S. lecatiana, lithotomy done partly by incision and partly by dilatation (Le Cat). S. legalis, a post-mortem examination made by order or consent of the law. S. mediana, median lithotomy. S. musculorum, myotomy. S. nervorum, neurotomy. S. postrolandica, a transection of the brain at the posterior margin of the postcentral gyrus. S. prærolandica, a transverse section of the brain at the anterior margin of the precentral gyrus. S. rectovesicalis, rectal cystotomy. S. renalis, nephrotomy. S. rolandica, a transverse section of the cerebrum passing through the fissure of Rolando. S. tendinum, tenotomy. S. urethralis, urethrotomy. S. vaginalis, elytrotomy. S. vaginovesicalis, colpocystotomy. S. ventralis, suprapubic cystotomy. S. vesicæ felleæ, cholecystotomy. S. vesicalis, cystotomy.

Section (sek'-shun) [secare, to cut]. Division by cutting; also, the condition made thereby ; dissection; post-mortem examination; a cut or thin slice made for histologic or anatomic study. S., Abdominal. See Celiotomy. S., Cesarean. See Cesarean Operation. S., Frontal, a longisection serving to divide the body into equal or unequal dorsal and ventral parts. It is, therefore, approximately parallel with the dorsal and ventral aspect of the body. See also Sayittal and Transection; also Position and $D i$ rection, Table of Intrinsic Terms. S., Longitudinal. See Longisection and S., Frontal. S., Optic; the appearance resulting from microscopic examination of transparent or nearly transparent objects, when some plane below the upper surface of the object is in focus. S., Sagittal, a longisection parallel with the sagittal suture, and hence with the meson or median plane of the body, and serving to divide the body into equal or unequal right and left parts. See also Medisection, Frontal, and Transection; also Position and Direction, Table of Intrinsic Terms. Ss., Segmentation. See Segmentation. Ss., Serial, the arrangement, consecutively, of microscopic sections in the order in which they are cut. S., Sigaultian. See Symphysiotomy. S., Transverse. See Transection.

Sector (sek'-tor) [secare, to cut]. An area of a circle included between two radii and an arc. Ss., Craniometric, sectors in circles having the punctum alæ vomeris as a center. The frontal sector is that bounded by a radius to the punctum naso-frontale, and one which, if prolonged, would pass through the punctum 
bregmatis; the maxillury sector is that bounded by a radius to the punctum naso-frontale and one passing through the punctum spinæ nasalis pusterioris; the medullary sector is that included between a radius to the punctum foraminis magni anterius and one passing through the punctum foraminis magni posterius; the nasal sector is that bounded by a radius to the punctum spinæ nasalis anterioris and one which, if prolonged, would pass through the punctum naso-frontale ; the occipital sector is included between a radius to the punctum occipitale and one to the punctum protuberantiæ occipitalis; the palatine sector is contained between a radius to the punctum spinæ nasalis posterioris and one passing through the punctum præmaxillare; the parielal sector is included between a radius to the punctum bregmatis and one passing through the punctum occipitalis; the premaxillary sector is that bounded by a radius to the punctum præmaxillare and one to the punctum spinæ nasalis anterioris: the sector for the cavum naso-pharyngeum is contained between a radius terminated by the punctum foraminis magni anterius and one to the punctum spinæ nasalis posterioris (Lissauer).

Sectorial (sek-to'-re-al) [sextor, a sector]. Carnassial.

Secund (sek'-und) [secundus, following]. In biology, arranged on one side of a stem or axis.

Secundina (se-kun'-de-nah) [L.]. Something following. S. cerebri, the pia mater.

Secundine or Secundines (se-kun'-din) [secundine]. In biology: (a) the "after-birth," or that which remains in the uterus after the expulsion of the fetus. It includes the placenta, part of the umbilicus, and the membranes of the ovum; $(b)$ the inner coat of an ovule; also called the mesosperm.

Secundum artem (se-kun'-dum ar'-tem) [L., "according to art" ]. In the approved, professional, or official manner (used in writing prescriptions, as a direction to the apothecary).

Securiform (se-ku'-rif-orm) [securis, an ax; forma, form ]. In biology, ax-shaped.

Secus (se'-kus) [L.]. Sex.

Sedan Black. See Pigments, Conspectus of.

Sedans (se'-danz) [L.: pl., Sedantia]. Sedative; a sedative medicine. See Liquor sedans.

Sedation (se-da'-shun) [sedatio]. A condition of quiet and tranquillity, especially when following excessive functional activity.

Sedative (sed'-at-iv) [sedare, to soothe]. I. Soothing or tranquilizing. 2. An agent that exerts a soothing effect by lowering functional activity. S. Salt, boric acid.

Sedentaria (sed-en-ta'-re-ah) [L.]. Plural of Sedentarius, sedentary. S. ossa, the ischia and os coccygis, the bones on which the body rests while in a sitting posture.

Sedentary (sed'-en-ta-re) [sedentarius; sedere, to sit]. Occupied in sitting; sitting at one's work. Pertaining to the habit of sitting.

Sedes $\left(s e^{\prime}-d \bar{e} z\right)$ [L.]. Anus; stools. S. cruentæ, bloody stools. S. lactescentes, celiac flux. S. procidua, prolapse of the anus.

Sedigitate, Sedigitated (se-dij'-it-āt, se-dij'-it-a-ted) [sedigitus; sex, six; digitus, digit]. Having six fingers on a hand, or six toes on a foot.

Sedilia (se-dil'-e-ah) [sedile, a seat]. The nates.

Sediment (sed'-im-ent) [sedimentum:pl., Sedimenta]. That which settles to the bottom of a liquid. S., Urinary, the solid constituents of urine, organic and inorganic, which are deposited on standing. See Urinary.

Sedimentation (sed-im-en-ta'-shun) [sedimentum, sediment]. The process of producing rapid deposition of the sediment of urine or sewage by means of centrifugal or other apparatus.
Sedlitz $\left(\operatorname{sed}^{\prime}-l i t z\right)$. See Seidlitz

Sedum $\left(s e^{\prime}\right.$-dum) [L., houseleek]. A,genus of crassulaceous plants. Stonecrop, wall-pepper, creeping Jack, gold-dust. S. acre, a moss-like creeping plant indigenous to Europe, and naturalized in some places in North America. The expressed juice is emetic, pur. gative, and also capable of vesication. It was formerly used as a remedy for scrofula, and administered internally in decoction, while externally the bruised fresh plant was applied. Unof. S. telephium, Live-for-ever, a species of salad indigenous to Europe, and introduced in the United States. The root and herb were formerly official as radix et herba telephii.

Sée's Treatment. See Treatment, Methods of.

See-saw Eczema, a form of eczema alternating with some other disease.

Seed (sêd) [AS., sced, seed, sowing]. (a) A fertilized ovule or ovum, as the egg of the silkworm-moth. [" Naked seeds meant to all botanists up to the time of A. L. de Jussieu and J. Gärtner (I788) dry indehiscent fruits," Sachs] ; (b) seminal fluid ; sperm or milt; (c) offspring, as young oysters. S.-coat, in biology, the testa or exterior coat of the seed. Cf. Primine, Secundine. S.-lac. See Lac.

Seedy-toe (se'-de-to) [Fr, fourmilière]. The English common name for an affection of the hoof of Equide. More frequent in the ass and mule than in the horse. It is held to be due to the fungus, Achorion keratophagus, $q . v$. (Ercolani.)

Seegen's Dietetic Regimen. A regimen for diabetics, consisting of meats of all kinds, eggs, corn, vegetables, cheese, and gluten bread.

Seemann and Hehner's Method. A method of estimating the amount of acids in the stomach. It consists in neutralizing the gastric contents by titrating with $\mathrm{NaOH}$, evaporating to dryness, and carefully incinerating. The ash is extracted with water, and the alkali present in the extract is estimated by titrating with an acid; the difference between the amount of alkali added and the amount of alkali found gives the amount which must have combined with $\mathrm{HCl}$, the lactic and volatile acids being decomposed during incineration.

Seessel's Pocket or Pouch. See Pouch.

Segestor (se-jes'-tor) [se, self; gerere, to carry]. A proprietary embalming fluid, introduced into the vessels of the cadaver by a syringe; so called because it has the alleged property of finding its way to all parts of the dead organism.

Segment (seg'-ment) [segmentum; secare, to cut]. I. A small piece cut from the periphery of anything. 2 . A natural division, resulting from segmentation; one of a series of homologous parts, as a myotome; the part of a limb between two consecutive joints. A subdivision, ring, lobe, somite, or metamere of any cleft or articulated body. S. of Bandl. See Bandl's Ring. S., Interannular, the portion of a nerve included between two consecutive nodes of Ranvier. S., Intermediate (of a cilium), the isotropous, delicately striated portion of a cilium. between the cilium proper and its pedicle. S., Lower (of the uterus), all that portion of the uterus situated below the ring of Bandl. Ss., Medullary, the incisures of Schmidt and Lautermann, or oblique markings in the medullary sheath of a nerve-fiber. S., Primitive, Minot's word for a primitive division of the vertebrate celom. The protovertebra, mesoblastic somite, mesomere, metamere, Ursegment, Ur. wirbel, of authors. S., Pubic (of the pelvic floor); this " consists of what extends from the symphysis pubis to the anterior vaginal wall, inclusive of the latter, and is chiefly made up of bladder." (D. B. Hart.) 
S., Rivinian (of the tympanic ring), that portion of the temporal bone between the two points of attach ment of its tympanic portion to its squamous portion. S., Sacral (of the pelvic floor), that portion which "extends from the sacrum to the posterior vaginal wail." (D. B. Hart.) S., Schmidt-Lautermann's, the elongated pieces making up the medullary sub st ince of nerve-fibers, several pieces being included within each internode

Segmental (seg-men'-tal) [segmentum, a segment]. Pertaining to, or of the nature of, a segment; made up of segments. S. Duct, the duct of the pronephros, $q . v$ S. Organs. See Nephridia. S. Senseorgans, a series of organs formed by the temporary or permanent union of the sensory ganglia; the ear, eye, and nose possibly belong to this class; the branchial sense-organs of Beard, and the ganolionic sense-organs of Minot.

Segmentation (seg-men-ta'-shun) [segmentum, a piece cut off 7 . In biology, the process of cleavage or division. In embryology, the term is restricted by usage " to the production of cells up to the period of development when the two primitive germ-layers are clearly differentiated and the first trace of organs is beginning to appear." (Minot.) Merogenesis. S.-cavity, the central space in the blastula stage of the segmentation of an ovum. S.-cells, homogeneous indifferent cells formed by the repeated division of the fecundated egg-cell, and which compose first of all the solid mulberry germ. (Hæckel.) S., Centro-lecithal, a form of segmentation in which the spheres enclose a central nutritive yolk. S., Complete, holoblastic segmentation. S., Direct, amitosis, or direct celldivision. S., Discoidal, a form of segmentation in which the germinal disc alone is involved. S., Duplicative, segmentation peculiar to the gonococcus, marked by an interval between the two segments. S., Free, cleavage of zymoplasts. S., Germ, segmentation of the impregnated ovum, or of the first embryonic segmentation-sphere, or blastosphere. S., Holoblastic, segmentation in which all the contents of the ovum undergo cleavage. S., Incomplete, S., Meroblastic, segmentation in which only a portion of the contents of the ovum, the formative yolk, undergoes cleavage, the other portion, or food-yolk, being a reserve store of food for the developing embryo. S., Metameric, division of the embryo into metameres. S.-nucleus. See under Nucleus. S., Partial. See S., Incomplete. S., Protovertebral, division of the mesoblast on each side of the notochord into somites, or protovertebræ. S., Regular, segmentation in which the spheres are equal in size and symmetrically arranged. S.-sphere, one of the cells of an ovum during the early stages of segmentation. See Blastosphere and Morula. S., Total. See S., Holoblastic. S., Unequal, a variety of segmentation, in which, after cleavage of the ovum into four equal segments, the spheres of one pole are smaller and more numerous than those of the other.

Segmentellum (seg-men-tel'-um) [segmentum, a segment]. A blastula.

Segnitia, Segnities (seg-nish'-e-ah, seg-nish'-e-êz) [L.]. Torpor; sluggishness, as of the bowels ; languor.

Segond, Angles of. See Angle.

Segregate (seg'-re-gät) [segregare; se, by one's self ; grex, a flock]. To separate or set apart; separated from each other. S. Fecundity. See Homogamy.

Seguin's Signal-symptom. The warning of the beginning of the epileptic attack, consisting in affection of the muscle or muscles habitually first involved in the epileptic convulsion.
Seiage $\left(s a^{\prime}-a h z h\right)$ [Fr.]. In massage, a pressing with a to-and-fro movement, similar to the action of a saw. It is practised with the ulnar border of the hand, or the palmar side of the hand.

Seidlitz Powder (sed'-litz). Pulvis effervescens compositus. See Potassium.

Seignette Salt. Potassium and sodium tartrate, $\mathrm{KNaC}_{4}$. $\mathrm{H}_{4} \mathrm{O}_{6}+{ }_{4} \mathrm{H}_{2} \mathrm{O}$. It crystallizes in large prisms with hemihedral faces. See Rochelle Salt.

Seiler's Treatment. See Treatment, Methods of.

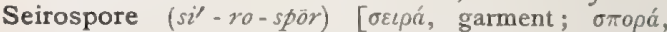
seed]. In biology, a special organ of non-sexual propagation occurring in some genera of Alga (Ceramiacee).

Seizure $\left(s \bar{e} z^{\prime}-\vec{u} r\right)$ [ME., seisen, to seize]. The sudden onset of a disease or an attack. In surgery, the grasping of a part to be operated upon.

Sejugous (se-ju'-gus) [sex, six; jugum, a yoke]. In biology, having six pairs of leaflets.

Sel [L.]. Salt. S. alembroth, a solution of mercuric chlorid and ammonium chlorid, each gr. $\mathrm{x}$, in distilled water, $\mathrm{Oj}$ (Imperial). S. amarum, S. amer, magnesium sulphate. S. ammonia, $\mathbf{S}$. ammoniac, $\mathbf{S}$. ammoniacum, ammonium chlorid. S. ammoniac martial, ammonio-chlorid of iron. S. ammoniacal nitreux, ammonium nitrate. S. de Chrestien, gold and sodium chlorid. S. commune, S. culinare, sodium chlorid. S. digestif, potassium chlorid. S. digestif de Vichy, sodium bicarbonate. S. d'Epsom, magnesium sulphate. $\mathrm{S}$. de Figuier. See $S$. de Chrestien. S. de Glauber, sodium sulphate. S. de Perse, sodium borate. S. de saturne, lead acetate. S. secret de Glauber, ammonium sulphate. S. de Seidlitz, magnesium sulphate. S. de Seignette, potassium and sodium tartrate. S. de soude, sodium carbonate. S. végétale, potassium tartrate.

Selection (se-lek'-shun) [selectus, p.p. of seligere, to choose]. In biology, the process of choosing from a number. S., Artificial, the artificial choice, definitely planned, of such forms of animals or plants as will by differentiation develop and reproduce given or desired characteristics. S., Natural, " the preservation of favorable individual differences and variations and the destruction of those which are injurious" (Darwin "Survival of the fittest"). S., Physiologic, "the selection of those varieties, the individuals of which are fertile among themselves, but sterile or less fertile with other varieties and with the parent stock. This has been called segregate fecundity by Gulick, and homogamy by Romanes" (De Varigny). S., Sexual, the selection by females, among varying and competing males, of the strongest or most attractive.

Selene $\left(s e-l e^{\prime}-n e\right)[\sigma \varepsilon \lambda \dot{\eta} \nu \eta$, moon]. 'The white spot sometimes occurring on the finger-nails. Cf. Lunula.

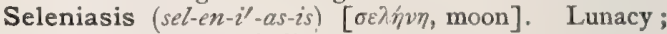
epilepsy ; somnambulism.

Seleniasmus (sel-en-i-az'-mus). See Seleniasis.

Selenic $\left(s e-l e n^{\prime}-i k\right)[\sigma \varepsilon \lambda \eta \dot{\nu} \eta$, the moon]. A compound containing selenium combined directly with three atoms of oxygen. S. Acid, $\mathrm{H}_{2} \mathrm{SeO}_{4}$, a dibasic acid, resembling sulphuric acid in its properties.

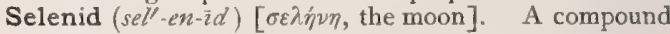
containing selenium.

Selenion $\left(s e-l e n^{\prime}-e-o n\right)$. See Selenium.

Selenite $\left(s e l^{\prime}-e n-\bar{\imath} t\right)$ [ $\sigma \varepsilon \lambda \dot{\eta} v \eta$, moon]. I. A salt of selenous acid. 2. A translucent form of calcium sulphate.

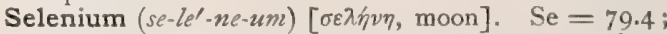
usually bivalent, sometimes quadrivalent or hexavalent. A rare element, resembling sulphur in its properties. See Elements, Table of. 
Selenodont (sel-en'-o-dont) [ $\sigma \varepsilon \lambda \dot{\eta} 1 \eta \eta$, the moon; odous, tooth]. In biology, applied to such animals as have molar teeth with crescentic ridges on the crowns.

Selenoplegia (sel-en-o-ple'-je-ah) [ $\sigma \varepsilon \lambda \dot{\eta} \eta \eta$, moon; $\pi \lambda \eta$ $\gamma^{\prime}$, stroke]. A kind of apoplexy said to be caused by exposure to the moon's rays.

Selenoplexia (sel-en-o-pleks'-e-ah). See Selenoplegia.

Selenotropic (sel-en-o-trop'-ik) [ $\sigma \varepsilon \lambda \dot{\eta} \nu \eta$, the moon; $\tau \rho \varepsilon ́ \pi \varepsilon \iota v$, to turn]. In biology, turning toward the moon; applied to growing parts of plants which are influenced in their direction of growth by the influence of the moon,

Self [ME., self, self]. Same; identical; own; personal. S.-abuse. See Masturbation. S.-differentiation, the theory that cells control themselves; that is to say, the fate of the cells is determined by forces situated within them, and not by external influences; a conception first propounded by His, and later demonstrated by Roux, Pflüger, Born, Weismann, and others. S.-digestion. See Autodigestion. S.-fertilization, in biology, fertilization of a flower by its own pollen. S.-heal, Prunella vulgaris; healall; a perennial herb growing in North America, Europe, and Asia. S.-incasement, a condition in which the small intestine is inclosed, as in a pouch, between the layers of the mesentery (J. S. Thatcher). S.-infection, the spread of infectious material from a circumscribed area to others or to the entire organism. S.-inflation, a process suggested by $\mathrm{H}$. R. Silvester, by which a person in danger of drowning is to render himself buoyant. After having made a puncture in the mucous membrane of the mouth, at the reflection of the cheek from the lower jaw, air is to be forced into the subcutaneous tissue of the neck by vigorous blowing efforts, with the mouth and nose closed. S.limited, a term applied to certain diseases, which even without treatment run a definite course within a given time. S.-pollution. See Self-abuse. S.-repositor, Pneumatic, a curved and bulbous glass tube used at bed-time for the reposition of the displaced uterus, the instrument being used by the patient, and operated by air-pressure. S.-suggestion. See Autosteggestion. S.-suspension, suspension of the body for the purpose of stretching or making extension on the vertebral column. See Suspension. S.-S., Axillo-cephalic, suspension by the axillæ and the head. S.-s., Cephalic, suspension by the head.

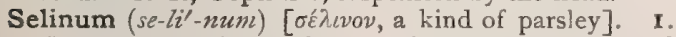
Carum petroselinum of the ancients. 2. A genus of perennial herbs belonging to the Umbelliferce.

Sella ( $\left(\mathrm{sel}^{\prime}-a h\right)$ [L.]. A seat; a part having a shape like a seat or saddle. S. turcica (Turkish saddle), the pituitary fossa of the sphenoid bone, lodging the pituitary body.

Sellanders, Sellenders (sel'-an-derz, sel'-en-derz) [origin obscure]. A kind of eczema occurring on the tarsus of the horse. See Mallenders.

Selliform (sell-if-orm) [sella, a saddle; forma, form]. In biology, saddle-shaped.

Selters, Seltzer (sel'-ters, selts'-er) [German]. I. A place in Hesse-Nassau, Prussia, where there are gaseous springs containing chiefly carbonates and sulphates. 2. An abbreviated name for seltzer water, an acid-soda mineral water; the term is also applied to artificial seltzer water.

Selza Water. See Seltzer.

Sematic (se-mat'-ik) [ $\tilde{\eta} \mu \alpha$, a sign, mark, token]. In biology, applied to colors in mimicry, used as signals or warnings for repelling enemies by the indication of some unpleasant or dangerous quality. Cf. Aposematic, Episematic, Allosematic.

Semeiography (se-me-og $\left.g^{\prime}-r \bar{a}-f e\right)[\sigma \eta \mu \varepsilon i o v, \operatorname{sign} ; \gamma \rho a ́ \phi \varepsilon \imath$, 83 to write]. A descriptive treatise on the symptoms of disease.

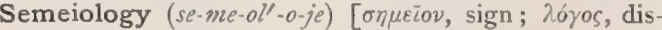
course]. Same as Symptomatology.

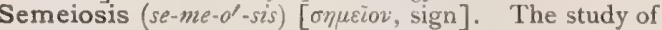
symptoms as indications of disease.

Semeiotic $\left(s e-m e-o t^{\prime}-i k\right)$ [on $\mu \varepsilon i o \nu$, sign]. Pertaining to semeiotics, or to symptoms.

Semeiotics $\left(s e-m e-o \ell^{\prime}-i k s\right)[\sigma \eta \mu \varepsilon i o v, s i g n]$. The science of symptomatology.

Semelincident (sem-el-in'-sid-ent) [scmel, once; incidere, to happen]. Happening only once; a qualification applied to certain diseases which, as a rule, occur but once in the same individual, as, e. $g$., smallpox.

Semen (se'-men) [serere, to sow: gen., seminis]. The fecundating fluid of the male, chiefly secreted by the testicles, composed of the liquor seminis, the seminal granules, and spermatozoa. For testing for semen in medico-legal examinations, see Lassaione's Test, in Tests, Table of. S. contra, worm-seed. See Santonica. S. multiplex. Same as Sporiderm.

Semester (se-mes'-ter) [semestris, half yearly ; sex, six; mensis, month]. A period of six months.

Semi- $\left(\operatorname{sen}^{\prime}-e-\right)$ [semi, one-half]. A prefix to denote the half of anything.

Semiacid (sem-e-as'-id) [semi, half; acidum, acid]. Half acid.

Semiadherent (sem-e-ad-he'-rent) [semi, half; $a d$ harere, to adhere]. In biology, having the lower half adherent, as a seed.

Semiaquatic (sem-e-a-kwat'-ik) [semi, half; aqua, water]. In biology, growing, or living close to the water, and having the capacity for existence either within it or out of it.

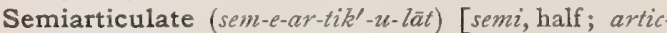
ulus, a joint]. Loose-jointed.

Semibulb (sem'-e-bulb) [semibulbus, half bulb]. Either half of the bulbus vestibuli of the corpus spongiosum of the clitoris.

Semicartilaginous (sem-ik-ar-til-aj'-in-us) [semi, half; cartilago, gristle]. Gristly; partially cartilaginous.

Semi-castration (sem-e-kas-tra'-shun) [semi, half; castrare, to cut]. The removal of one testicle.

Semicaudate (sem-ik-aw'-dät) [semi, half; cauda, tail]. In biology, having a rudimentary tail.

Semicell (sem'-is-el) [semi, half; cella, a small room]. In biology, one of the halves into which a cell is nearly divided by constriction in the middle, as in Desmidiacee. Called also half-cell.

Semicephalus (sem-is-ef'-al-us). See Anencephalus.

Semicircular (sem-e-sir'-ku-lar) [semi, half; circulus, a circle]. Having the form of a half-circle. $\mathbf{S}$. Canals. See Canal.

Semicircumference (sem-e-sir-kum'-fer-ens) [semi, half; circumfere, to carry around]. Half the circumference of a circle.

Semiconscious (sem-ik-on'-shus) [semi, half ; conscius, knowing]. Half-conscious; partially conscious.

Semicordate (sem-e-kor'-dàt) [semi, half; cor, a heart]. Having the form of a lateral half of a heart.

Semicorneous (sem-ik-or'-ne-us) [semi, half; corneus, horny]. Partly horny.

Semicostiferous (sem-ik-os-tif'-er-us) [semi, half ; costa, rib; ferre, to bear]. Having a costal demifacet.

Semicretin (sem-e-kre'-tin) [semi, half; cretin]. A person having a form of cretinism in which the rudiments of language have been developed. Intellection reaches only to the most ordinary bodily wants.

Semicupium (sem-e-ku'-pe-um) [semi, half; cupa, tub]. A half-bath, hip-bath, or sitz-bath. 
Semiflexion (sem-e-Rek'-shun) [semi, half; flexion, a Hexion]. A posture half-way between flexion and extension.

Semi-floret (sem-if-lo'-ret) [semi, half; flos, flower]. In biology, a ligulate floret in Compositee.

Semi-flosculous, Semi-flosculose (sem-if-los'-ku-lus, sen-if-los'-ku-loz ) [semi, half; flosculus, a little flower]. In biology, having all the florets ligulate in a head of Composita.

Semi-globose (sem-e-glo'-bōz) [semi, half; globus, a ball]. Hemispheric.

Semilunar (sent- $\left.\ell^{\prime}-l u^{\prime}-n a r\right)$ [semi, half; luna, moon] Resembling a half-moon in shape. S. Bone, one of the carpal bones. S. Cartilages, two interarticulating cartilages of the knee. S. Fold, the conjunctival folding at the inner canthus. S. Ganglia. See Ganglia. S. Notch, a notch in the scapula through which the supra-scapular nerve passes. S. Space of Traube, that portion of the left inferior anterior thoracic region corresponding to the tympanitic resonance of the stomach. S. Valves. See Valves.

Semiluxation (sem-e-luks-a'-shun) [semi, half; luxus, a luxation]. Subluxation.

Semimembranosus (sem-e-mem-bra-no'-sus). See Muscles, Table of.

Semimembranous (sem-e-men'-bra-nus) [semi, half; membranosus, like a membrane]. Formed partly of membrane.

Semi-metal (sem-e-met'-al). See Metalloid.

Semi-molecule (sem-e-mol'-e-kül) [semi, half; molecule]. A radicle having in composition one-half the molecules it had in the free state.

Semi-mute (sem $\left.{ }^{\prime}-e-m u ̈ t\right)$ [semi, half; mute]. A person whose speech is imperfect by reason of impairment of the hearing. One who has lost his hearing by accident or disease after having acquired the use of articulate speech. Semi-mutes differ from deaf-mutes in having the ability to express themselves orally, and in their natural mode of thought, which is in words and not in gestures.

Semina $\left(\operatorname{sem}^{\prime}-\right.$ in- $\left.a h\right)$. Plural of Semen, $q . v$

Seminal (sem'-in-al) [semen, seed]. Pertaining to the semen. S. Cells. See Cell. S. Granules. See Gramules. S. Tubes. See Tube. S. Vesicles. See Vesicula seminales.

Semination (sem-in-a'shun) [seminatio, a sowing]. The intromission of semen into the uterus. In biology, the production of seeds; also their dissemination.

Seminervosus (sem-in-er-vo'-sus). See Semitendinosus. Seminiferous (sem-in-if'-er-us) [semen, seed; ferre, to carry]. Carrying semen. S. Scale, in botany, the scale bearing the ovules in Conifera. S. Tubules, the small, convoluted canaliculi of the testicles. (See illustration in adjacent column).

Seminific (sem-in-if'-ik) [semen, semen; facere, to make]. Producing semen.

Seminulum (sem-in'-u-lum) [dim. of semen, seed]. A little seed; a spore.

Seminuria (sem-in-u'-re-ah) [semen, seed; ovoov, urine]. The presence of semen in the urine.

Semiology (se-me-ol'-o-je). See Semeiology.

Semiotic $\left(s e-m e-o t^{\prime} \cdot i k\right)$. See Semeiotic.

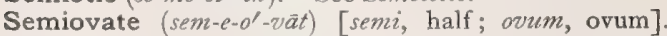
Having the form of a lateral half of the longitudinal section of an egg. The qualification may be applied to either flat or solid bodies.

Semioxidized (sem-e-oks'-id-izd) [semi, half ; ókús, sharp]. Containing half the amount of oxygen for complete oxidization.

Semipalmate (sem-e-pal'-mät) [semi, half; palma, palm]. Having the toes or fingers half-webbed.

Semiplegia $($ sem-ip-le'-je-ah). See Hemiplegia.
Semiplume $\left(\operatorname{sem}^{\prime}-i p-\ln m\right)$ [semi, half; pluma, a small, soft feather]. In biology, a feather having a pennaceous rhachis and a plumulaceous web.

Semipronation (sem-ip-ro-na'-shun) [semi, half; pronatus, prone]. The assumption of a semiprone, or partly prone position; an attitude of semisupination.

Semiprone (sem'-ip-rōn) [semi, half; pronus, bent]. Half prone. S. Posture. See Postures, Table of.

Semiptosis (sem-ip-to'-sis) [semi, half; $\pi \tau \omega \sigma \iota s$, a fall ing]. Partial ptosis.

Semipupa (sem-ip-u'-pah) [semi, half; pupa, pupa: pl., Semipupe]. Same as Pseudopupa or Propupa.

Semisideratio (sem-is-id-er-a'she-o). Synonym of Hemiplegia.

Semispeculum (sem-is-pek'-u-lum) [semi, half; speculum, a mirror7. An instrument for inspecting the bladder in lithotomy.

Semispinalis (sem-is-pi-na'-lis). See Muscles, Table of.

Semissis $\left(\operatorname{sem}-i s^{\prime}-i s\right)$ [L.]. One-half.

Semisulcus (sem-is- $\left.u^{\prime}-k u s\right)$ [semi, half; sulcus, a sulcus]. A name of various grooves, forming sinuses in the cranial bones.

Semisupination (sem-is-u-pin- $\left.a^{\prime}-\operatorname{shun}\right)$ [semi, half; supinare, to bend backward]. The assumption of a position half-way between supination and pronation.

Semita (sem'-it-ah) [semita, a narrow way, a path: $p l$. Semita]. In biology, an ambulacra-like area bearing clubbed spines, in spatangoid sea-urchins.

Semitendinosus (sem-it-en-din-o'-sus). See Muscles, Table of.

Semitendinous (sem-it-en'-din-us) [semi, half; tendo, a tendon]. Partially tendinous.

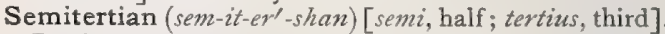
Partly tertian and partly quotidian (applied to intermit. tent fevers).

Semolina (sem-o- le'-nah). See Semolino.

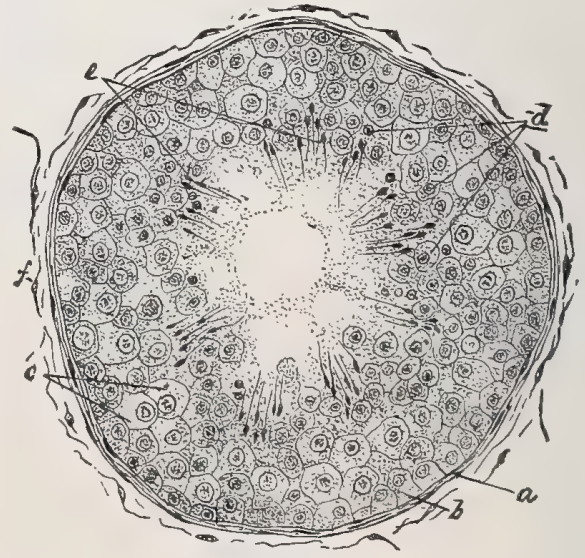

Transverse Section of SEMINiferous Tubule From HUMAN TESTICLE.

a. Membrana propria. b. Zone of parietal cells, $c$. Mothercells undergoing division. $d$. Daughter-cells, or spermatoblasts. e. Partially-developed spermatozoa. $f$. Surrounding inter-tubular connective tissue. (After Piersol.)

Semolino (sem-o-le'-no) [It.]. A kind of coarse flour or grits prepared from hard wheat.

Semper's Method. A method of making dry preparations for exhibition or class-room purposes. It is especially adapted for the preservation and exhibition of dissections. The animal, e.g., a mouse, is dissected so as to show the desired organs. It is then hardened by chromic acid; after hardening, it is removed and thoroughly washed in water. It is then 
transferred from one to another of a series of alcohols, until it reaches 96 per cent. to 98 per cent., the object being to remove all the water. From the strong alcohol it is transferred to spirit of turpentine, where it remains until thoroughly impregnated, after which it is simply dried in the air, when it will be found to have a soft kid-like texture, not easily broken. The various organs can now be painted suitable colors and the preparation labeled for use.

Sempervirent (sem-per-vi'-rent) [semper, always; virere, to be green]. Evergreen.

Senary $\left(\operatorname{sen}^{\prime}-a r-e\right)$ [senarius, consisting of six each]. In sixes.

Seneca Snake-root. See Senega. S. Oil, Petroleum (so-called because found near Lake Seneca).

Senecin (sen'-es-in) [senecio, groundsel]. A precipitate from a tincture of Senecio gracilis; diaphoretic, emmenagogue, febrifuge, pectoral, tonic. Dose I to 3 grains.

Senecio $\left(s e-n e^{\prime}-s e-o\right)$ [senex, an old man]. Groundsel, a genus of composite-flowered plants, said to contain 960 species, many of them medicinal. S. aureus. See Life-root. S. gracilis, a slender species, generally regarded as a variety of $S$. aureus. S. jacobæa, ragwort, or ragweed, tonic and astringent.

Senectus (se-nek'-tus) [senex, old]. Old age.

Senega $\left(\operatorname{sen}^{\prime}-e-g a\right)$ [L.; gen., Senega $]$. The root of Polygala senega (called also Seneca snake-root), with properties due to a glucosid, senegin (or polygalin), $\mathrm{C}_{32} \mathrm{H}_{54} \mathrm{O}_{18^{\circ}}$. It is expectorant and diuretic; in large doses a gastro-intestinal irritant, and is useful in bronchitis, asthenic pneumonia, asthma, etc. S., Abstractum. Dose gr. $v-x$. Unof. S., Ext., Fld.

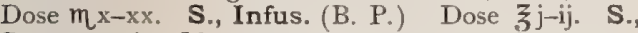
Syr., contains fld, ext. senega 200 , ammonia-water 5 , sugar 700, water q. s. Dose $3 \mathrm{j}-\mathrm{ij}$. S., Tinct.

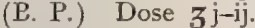

Sinegal-root (sen'-e-gal-rüt). The root of Cocculus bakis.

Senegin (sen'-e-gin) [senega, senega]. An amorphous glucosid obtained from Senega. It is soluble in water, making a frothy solution, and is sternutatory. It contains sapogenin and sugar.

Senescence (se-nes'-ens) [senex, old]. The condition or time of growing old. Senility.

Senile $\left(s e^{\prime}-n \bar{l} l\right)$ [senilis, old]. Pertaining to or having the nature of old age. Arcus senilis. See Arcus. S. Chorea. See Paralysis agitans. S. Gangrene. See Gangrene.

Senility (se-nil'-it-e) [senex, old]. The weakness and decrepitude characteristic of old age.

S znn's Bone-plates. [After Nicholas Senn, surgeon.] Plates of decalcified bone used in intestinal anastomosis. S.'s Test, the introduction of hydrogen-gas into the bowel through the rectum, for the detection and localization of an abnormal opening.

Senna (sen'-ah) [Ar., sena, senna]. The leaflets of Cassia acutifolia and C. angustifolia. Senna contains a complex glucosid, cathartic acid $\left(\mathrm{C}_{180} \mathrm{H}_{192} \mathrm{~N}_{2} \mathrm{SO}_{80}\right)$, and other extractives. It is an excellent cathartic for children and infants. S., American. See Cassia marilandica. S., Confectio, senna 10, oil of coriander 5 , cassia fistula 16, tamarind 10 , prune 7 , fig 12 , sugar 55 , water q. s. Dose $3 \mathrm{j}$-ij. Known as "Tamar Indien" and "Tropical Fruit Laxative." S., Ext., Fld. Dose 3 j. S., Infus., (B. P.) Dose $\xi_{\text {j-ij. }}$ S., Infus., Comp., "black draught," senna 6, manna, magnesium sulphate āã 12, fennel 2, water 100 parts. Dose zj-iij. S., Mist., Comp. (B. P.) Dose 3j-ij. S., Syr., senna 250, oil of coriander 5, alcohol i5o, sugar 700, water q. S. Dose 3 ss-ij. S., Tinct. (B. P.) Dose $3 \mathrm{j}$-iv.
Sennacrol (sen'-ak-rol) [Ar., sen $\alpha$, senna ; acris, sharp]. A bitter principle obtained from senna.

Sennapicrin (sen-ap-ik'-rin) [Ar., sena, senna; $\pi \iota k \rho o s$, bitter]. An insoluble bitter principle obtained from senna.

Sennine $\left(\operatorname{sen}^{\prime}-i n\right)$ [after Nicholas Senn, surgeon]. A proprietary preparation described as a chemically pure product of boric acid and phenol. It is a fine, white powder, odorless, slightly astringent, and of sweetish taste. It is antiseptic, antizymotic, bactericidal, deodorant, and disinfectant.

Senocular (sen-ok'-u-lar) [sex, six; oculus, an eye] In biology, having six eyes.

Sensation (sen-sa'-shun) [sensatio; sentire, to feel] The cognizance or perception of an impression coming from an external source by means of the peripheral organs of sensation

Sense (sens) [sensus; sentire, to feel]. The faculty of the nervous system whereby impressions of the external world are received by the mind. Organs of the Senses are those of touch, taste, smell, hearing, and sight. S.-body, a peripheral sense-organ. S.capsule, the hollow cup-like receptacle of a peripheral sense-organ. S.-club. See Rhopalium. S.-epithelium, a tract of epithelium having some specialized function of sensation. S.-filament, the thread-like peripheral termination of a sensory nerve-fiber. S.organ, the peripheral termination of a sensory nerve. S.-scale. See Sizama rhopalaris. S.-seta, the bristle-like termination of a peripheral sensory nervefiber. S.-shock, a condition observed in hysteric women and overworked men, and occurring at the moment of waking from sleep. A sensation like an aura rises from the feet or hands, and, passing upward to the head, disappears in the sense of a blow or shock, or of a bursting in the head. It is of no serious significance. S.-sinus, one of the antrarhopalaria; a hollow containing a compound senseorgan, or rhopalia, q. $v$.

Sensibility (sen-sib-il'-it-e) [sensibilitas]. The capability of receiving and transmitting impressions, arid of being conscious of them. S., Organic, the capability of transmitting and receiving impressions without being conscious of them (Bichat). S., Range of. See Fechner's Law. S., Transference or Externalization of. See Sensitivization.

Sensible (sen'-sib-l) [sensibilis]. Perceptible by the senses; capable of receiving an impression through the senses. Endowed with the sense of feeling.

Sensiferous (sen-sif'-er-us) [sensus, sense; ferre, to bear]. Conveying a sensation, or sense-impression.

Sensigenous (sen-sij'-en-us) [sensus, sense; gignere, to produce ]. In biology, giving rise to a sensory impulse.

Sensitive (sen'-sit-iv) [sensitivus]. Capable of feeling; reacting to stimulus. $\mathrm{S}$. Dentine, a hypersensitive condition of the dental structure of the teeth, due to distal irritation of the tubular fibrils.

Sensitiveness (sen'-sit-iv-nes) [sentire, to perceive]. In biology, responsive to external stimulus or irrita. tion.

Sensitivity (sen-sit-iv'-it-e) [sensitivus, sensitive]. Acuteness of the perception, or discrimination of sensations; capacity of receiving sense-impressions.

Sensitivization (sen-sit-iv-iz-a $a^{\prime}$ shun) [sensitivus, sensitive]. A phenomenon, real or supposed, occurring during hypnotic sleep, in which by action upon objects or strata of the atmosphere these are seemingly endowed with power to affect the patient as if he himself were acted upon. This condition is called also Externalization of Sensation, Transference of Sensibility, etc. 
Sensorial (sen-so'-re-al) [sensorium, the organ of sen sation]. Pertaining to the sensorium or to sensory im pressions

Sensori-digestive (sen'-so-re-di-jes'-tiv) [sensorius, sensory; digestivus, digestive]. Pertaining to or con cerned in sensation and digestion.

Sensori-motor (sen'-so-re-mo'-tor) [sensus, feeling; notor, mover]. Concerned in the phenomena of feeling and muscular contraction; both sensory and motor. S. Centers, sensory centers which are also motor, or are intimately associated with the motor centers.

Sensorium (sen-so'-re-um) [L.]. The common center of sensations. More especially that part of the brain that is the seat of sensation, in distinction from the centers of thought and motion. The mechanism of sensation considered in toto.

Sensori-volitional (sen'-so-riv-o-lish'-un-al) [sensus; sense; volitio, willing]. Pertaining to or concerned in sensation and volition.

Sensory (sen'-so-re) [sentive, to feel]. Pertaining to or conveying sense or sensation; having the quality of sensation. S. Aphasia. See Aphasia. S. Nerves, those that convey sensations or impressions from the periphery to their proper centers, being afferent in func tion, in distinction from motor nerves, which are efferent. Also, the nerves of the special senses. S. Nervefiber, a centripetal nerve-fiber conveying sensory impulses. The fibers of this kind may be: (I) General, conveying to the nerve-centers in the brain impulses of an indeterminate or general character; or (2) Special, conveying to the nerve-centers in the brain impulses that cause visual, auditory, gustatory, olfactory, tactile, or thermal sensations.

Sensualism (sen'-su-al-izm) [sensus, sense]. The condition or character of one who is controlled by the animal passions.

Sensus (sen'-sus) [L.]. Sense; feeling. S. communis, the state of the consciousness or sense of normal sensations at any one time. See Cenesthesia.

Sentient (sen'-she-ent) [sentire, sentiens, to feel]. Having sensation; conscious of feeling.

Sentisection (sen-tis-ek'-shun) [sentire, to feel; sectio, section]. Painful vivisection; vivisection of an animal not under the influence of anesthetics.

Sepal $\left(\right.$ sep $\left.^{\prime}-a l\right)$ [sepalum, sepal]. I. One of the leaflets or divisions of the calyx of a flower. 2. In the anatomy of the lower animals, certain thin, leaf-like organs are also called sepals.

Sepalody (sep'-al-o-de) [sepal, fr. separ, different, separate]. Reversion of petals into sepals.

Separating and Closing. Certain concentric Swedish movements intended to develop the chest and other parts of the body.

Separator $\left(s e p^{\prime}-a r-a\right.$-tor $) . \quad$ An instrument for separating the teeth.

Separatorium (sep-ar-a-to'-re-um) [separare, to separate]. In pharmacy, a strainer. In surgery, an instrument for separating the pericranium from the skull.

Sepia $\left(s e^{\prime}-p e-a h\right)[\sigma \eta \pi i \alpha$, the cuttle-fish]. I. The ink or black secretion of the common cuttle-fish; used as a pigment. 2. See Sepiost.

Sepicolous $\left(s e p-i k^{\prime}-0\right.$-lus $)$ [sepes, a hedge; colere, to inhabit]. In biology, growing in hedge-rows.

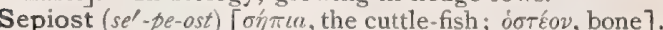
In biology, the endoskeleton of the cuttle-fish (Sepia); cuttle-fish bone, sepium, is sometimes prescribed as an antacid and used in dentifrices.

Sepium $\left(s e^{\prime}-p e-u m\right)$ [ $\sigma \dot{\eta} \pi \iota v$, the bone of the cuttle-fish]. Same as Sepiost.

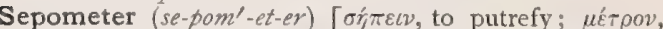
measure]. An apparatus for detecting organic impurities in the air.
Sepsin $\left(\operatorname{sep} p^{\prime}-\sin \right)$ [ $\sigma \dot{y} \pi \varepsilon \iota v$, to make rotten]. A poisonous, nitrogenous, crystallizable substance obtained by Berg mann and Schmiedeberg (I868) from the yeast of putrefying beer. See Ptomains, Table of.

Sepsis $\left(s e p^{\prime}-s i s\right)[\sigma \vec{\eta} \psi \iota s]$. A toxic or putrefactive condition. Infection by pathogenic germs. Decay.

Septa $\left(s e p^{\prime}-t a h\right)$. Plural of Septum.

Septal (sep'-tal) [septum, septum]. Pertaining to a septum. S. Gland. See under Gland.

Septan (sep'-tan) [septem, seven]. Recurring on the seventh day. A malarial fever in which the paroxysms occur every seventh day

Septate (seṕ-tāt) [septum, a fence]. Possessing septa or partitions.

Septemia, Septæmia (sep-te'-me-ah). See Septicemia.

Septenate (sept-ten-ät) [septeni, seven apiece]. In biology, having seven parts or the parts in sevens.

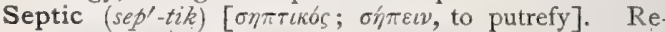
lating to putrefaction. S. Infection, infection with pathogenic microörganisms. S. Intoxication, absorption of septic matter. S. Pestilence. Synonym of the Plague, q. .

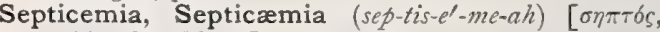
putrid; aina. blood]. A condition induced by the absorption of septic products. Pyemia is septicemia plus the formation of secondary or embolic abscesses. S., Phlebitic. See Pyemia.

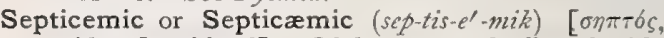
putrid; ai $\mu a$, blood]. Of the nature of, affected with, or pertaining to, septicemia.

Septicidal (sep-tis-i'-dal) [septum, a fence; cedere, cut]. In biology, applied to that form of capsular dehiscence in which the opening takes place along the line of junction of the carpels. Cf. Loculicidal.

Septicin (sep'-tis-in) [ $\sigma \eta \pi \tau b s$, putrid]. A ptomain resembling quinin and obtained from decaying flesh. See Ptomains, Table of.

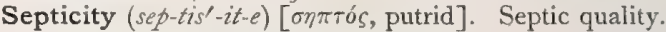

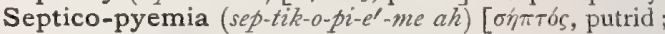
$\pi v o \nu$, pus; a a $\mu a$, blood]. The condition of combined septicemia and pyemia; septic and purulent infection. S., Spontaneous, Leube's term for a form of pyemia which comes on without obvious cause, or is perhaps preceded by a fall or a slight skin-wound, and is attended with pain and tenderness in joints and muscles, ecchymosis of the conjunctiva, vesicles in the skin containing blood, high temperature, swelling of the spleen, albuminous urine, delirium, cramps, involuntary discharges and coma. It is called cryptogenetic septicemia by Jürgensen.

Septiferous (sep-tif'-er-us) [septum, a fence; ferre, to bear]. In biology, having a septum. Same as Septate.

Septifolious (sep-tif-o'-le-us) [septem, seven; folium, a leaf]. In biology, having seven leaves.

Septiform (sep'-tif-orm) [septum, an inclosure ; forma, form ]. Having the form or function of a septum.

Septifragal (sep-tif'-ra-gal) [septum, an inclosure; frangere, to break]. In biology, applied to that form of capsular dehiscence in which the opening takes place length wise along the middle of each carpel.

Septile (seṕ-til) [septum, an inclosure]. In biology, pertaining to septa.

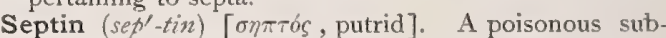
stance developed as the ultimate product of putrid fermentation of organic matter. According to Richardson, a contagious principle derived from any animal secretion.

Septivalent $\left.(s e p-t i)^{\prime}-a l-e n t\right)$ [septem, seven; valens, valere, to be worth]. Having an atomicity of seven.

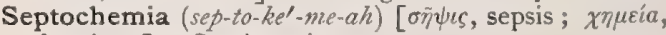
chemistry]. Septic action. 
Septodiarrhea $\left(s e p-t o-d i-a r-e^{\prime}-a h\right)[\sigma \dot{\eta} \psi \iota s$, sepsis; $d i-$ arrhea]. Septic diarrhea.

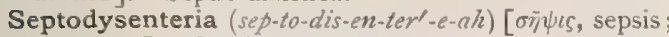
dysentery]. Septic dysentery.

Septometer (sep-ton'-el-er) [septum, septum, or onırós putrid; $\mu \varepsilon \tau \mu o \nu$, measure]. I. An instrument for determining the thickness of the nasal septum. 2. An apparatus for determining organic impurities in the air.

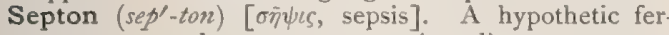
ment supposed to cause a contagious disease.

Septonasal (sep-to-na'-zal) [septum, septum; nasus, nose]. Pertaining to the nasal septum.

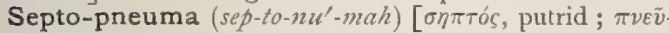
$\mu a$, air]. A microörganism said to have been found in cemetery-air, and to cause typhoid symptoms in the living.

Septopyra (sep-to-pi'-rah). Synonym of Septicemia.

Septulate (sep'-tu-lāt) [septulum, a little partition]. In biology: 1. Having a small septum or septa; 2. Having imperfect or false septa.

Septulum (sep'-tu-lum) [L.: pl., Septula]. A small septum.

Septum (sep'-tum) [sepire, to hem in: pl., Septa]. A lamina or division-wall of bone, cartilage, or membrane; a partition, as the membrane or wall which separates adjacent loculi in an ovary. S. auricularum, the septum between the two auricles of the heart. $\mathbf{S}$. cerebelli, the falcula. $\mathbf{S}$. cerebri, the falx. S. cordis, the wall between the two sides of the heart. S. crurale, the layer of areolar tissue closing the femoral ring. S. linguæ, the vertical mesal partition of the tongue, which divides the muscular tissue into two halves. S. lucidum, that between the lateral ventricles of the brain. S. of the Nose, that between the two nasal fossæ. S., Pectiniform, that between the lateral portions of the corpora cavernosa of the penis. S., Recto-vaginal, the tissue forming the partition between the rectum and the vagina. $\mathbf{S}$. scroti, the septum dividing the scrotum into two cavities for the two testes. S., Subarachnoid. See Space, Subarachnoid. S. of the Tongue, a vertical layer of fibrous tissue extending the entire length and depth of the middle line of the tongue. $\mathbf{S}$. transversum, the diaphragm, and also the tentorium cerebelli. S. ventriculorum, the septum between the two ventricles of the heart.

Septuplet (sep'-tu-plet) [septem, seven]. One of seven offspring born from a single gestation.

Sepulture (sep'-ul-tūr) [sepultura; sepelire, to entomb]. The disposal of the dead by burial.

Sequel (se'-kzvel). See Sequela.

Sequela $\left(s e-k w e l^{\prime}-a h\right)$ [L.: $t$., Sequela, that which fol lows]. The consequence or abnormal condition following an injury or the abatement of a disease ; any diseased or abnormal condition that follows an attack of disease or an injury.

Sequence (se'-kwens) [sequentia]. I. The order of occurrence, as of symptoms. 2. A sequela.

Sequential (se-kzven'-shal) [sequentia]. Occurring as a sequence, as sequential insanity.

Sequestral (se-kwes'-tral) [sequestrum, sequestrum]. Pertaining to, or of the nature of, a sequestrum.

Sequestration (se-krees-tra'-shun) [sequestratio, a sequestration]. I. The formation of a sequestrum. 2. The isolation or seclusion of lunatics or persons suffering from contagious disease.

Sequestrectomy (se-kives-trek'-to-me) [sequestrum, se-

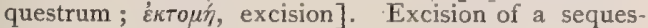
trum

Sequestrotomy (se-kives-trot'-o-me) [sequestrum, sequestrum; $\tau o \mu$, section]. A cutting operation for the removal of a sequestrum.
Sequestrum (se-kzves'-trum) [sequestrare, to separate pl., Sequestra]. A detached or dead piece of bone within a cavity, abscess, or wound. S., Primary, that entirely detached and demanding removal. S., Secondary, one that is partially detached, and that unless very loose may be pushed into place. S., Tertiary, cracked or partially detached and remaining firmly in place.

Seralbumin (sèr-all-bu-min) [serum, serum; albumen, albumin]. Serum-albumin; the albumin found in the blood, in distinction from that of the egg, ovalbumin.

Serempion (se-rem'-pe-on) [W. Ind.]. A form of epidemic measles encountered in the West Indies, and causing great mortality, especially among children.

Serene-drop (se-rēn'-drop). See Gutta serena.

Serial (se'-re-al) [series, a succession]. Following in regular order; occurring in rows. $\mathbf{S}$. Sections, anatomic or microscopic sections made in consecutive order. S. Symmetry, in biology, the resemblance of metameres, as distinguished from bilateral symmetry, the resemblance of parameres, or radial symmetry, the resemblance of actinomeres.

Seriate $\left(s e^{\prime}-r e-\bar{a} t\right)$ [seriare, to arrange in a series]. In biology, to arrange in a series or connected sequence.

Sericeous $\left(s e-r i s^{\prime}-\ell-u s\right)$ [опрєкós, silken]. With a pubescence of very fine, silky hair.

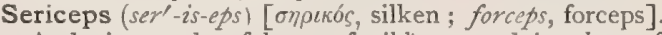
A device made of loops of ribbon, used in place of the forceps in making traction upon the fetal head.

Sericin $\left(s e \gamma^{\prime}-i s-i n\right)$ [onpıkós, silken]. Silk gelatin.

Sericission $\left(s e r-i s-i s h^{\prime}-2 \iota n\right)$ [onplkós, silken; scindere, to cut]. The cutting of tissues by means of a thread.

Sericterium $\left(s e r-i k-t e^{\prime}-r i-u m\right)$ [onpırós, silken : $p l$, Sericteria]. In biology, the spinning-gland, or silkgland, of an insect.

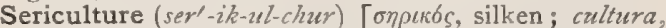
culture]. The rearing of silk-worms for their silk.

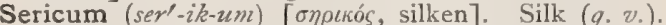
Sericum was formerly much prescribed as a cordial, tonic, nervine, and as a restorative of the memory, reason, and reproductive power. It was an ingredietit of various electuaries.

Series $\left(s e^{\prime}-r e-\bar{e} z\right)$ [L.]. A succession or chain of similar parts, or activities. S. dentium, a row of teeth. S., Numbering Parts in, the rule almost universally followed is to commence with the part at the proximal, or at the cephalic aspect, e. $g$., the most cephalic vertebra (atlas) is number one. The shouldergirdle is the proximal segment of the pectoral limb.

Serifluxus (se-rif-luks'-us) [serum, serum; fluxus, flow: pl., serifuxus]. Any serous or watery discharge, or a disease characterized by such a discharge.

Serin (ser'-in $), \mathrm{CH}_{2}(\mathrm{OH}) \cdot \mathrm{CH}\left(\mathrm{NH}_{2}\right) \cdot \mathrm{CO}_{2} \mathrm{H}$. Amidoglycerol, obtained by boiling serecin with dilute sulphuric acid, $\mathrm{H}_{2} \mathrm{SO}_{4}$. It forms hard crystals, soluble in water, but insoluble in alcohol and ether.

Seringos $\left(s e r-i n^{\prime}-g \bar{o} s\right)$. A form of suppurative dysentery, peculiar to South Africa.

Serious (se'-re-uss) [serizs, grave]. Applied to such morbid conditions or symptoms as indicate a grave prognosis.

Sero- (se'-ro-) [serum, serum]. A prefix denoting connection with or relation to serum. S.-cystic, containing cysts filled with serum. S.-fibrinous, constituted of both serum and fibrin. S.-gelatinous, having the nature of both serum and gelatin. S.purulent, pertaining to or being of the nature of a combination of serum and pus. S.-pus, a fluid which consists of serum and pus. S.-sanguineous, having 
the nature of both serum and blood. S--synovial, having the characters of both serum and synovia.

Serodermatosis (se-ro-der-mat-o'-sis) [ semm, serum; dép $\mu a$, skin; vó oos, disease]. A skin-disease charac terized by serous effusion into the tissues of the skin.

Serodermitis (se-ro-der-mi'-tis) [serum, serum; $\delta \dot{\varepsilon} \rho \mu a$, skin; $\imath \tau \iota s$, inflammation]. An inflammatory skinaffection attended with serous effusion.

Sero-lactescent (se-ro-lak-tes'-ent) [serum, serum; lactis, milk]. Having the characters of both serum and milk. The secretion of Montgomery's glands is said to be serolactescent.

Serolin (ser/-o-lin) [serum, serum; oleum, oil]. A fatty constituent of blood occurring in small amount, and the nature of which is undetermined.

Sero-mucous (se-ro-mu'-kus) [serum, serum; mucus, mucus]. Having the nature of or containing both serum and mucus.

Serophthisis (se-roff'-this-is) [serum, serum; $\phi \theta i \sigma \iota$, a wasting]. An insufficient proportion of serum in the blood. S., Endemic Pernicious. Synonym of Beriberi.

Sero-pneumothorax (se-ro-nu-mo-tho'-raks) [serum, serum; $\pi \nu \varepsilon v \mu \alpha$, air; $\theta \omega \rho a \xi$, thorax]. Pleurisy with serous effusion, associated with pneumothorax.

Serosa $($ se-ro'-sah) [serum, serum]. The delicate membrane of connective tissue, lining closed cavities of the body. A serous membrane.

Sero-serous (se-ro-se'-rus) [serum, serum]. Pertaining jointly to two or more serous membranes.

Serosity (se-ros'-it-e) [serum, serum]. The quality of being serous; a serous fluid not the true secretion of serous membranes.

Sero-sublimate Gauze (se-ro-sub'-lim-ät gazuz). See Listerian Method.

Sero-synovitis (se-ro-si-no-vi'tis) [serum, serum; synovitis]. A synovitis accompanied or marked by an increase of the synovial fluid of the joint.

Sero-therapy (se-ro-ther'-ap-e) [serum, serum; $\theta \varepsilon \rho a \pi \varepsilon i \pi$, therapy]. The whey-cure. See, also, Serum-therapy.

Serotina (ser-o-ti'-nah). The portion of the decidua that eventually becomes the site of the placenta. See Decidua serotina.

Serotinous (ser-ot'-in-us) [serotinus, late]. In biology, coming late, or comparatively late in the season.

Serous (se'-rus) [serum, serum]. Pertaining to, characterized by, or of the nature of serum. S. Gland, a

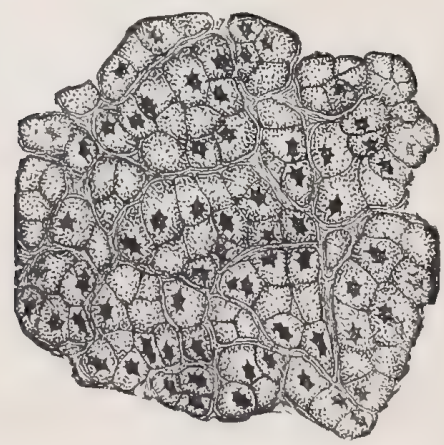

Resting Serous Gland, RabBit. (From Stirling.)

gland secreting serum. See Salivary Gland. Membrane. See Membrane.

Serpens (ser'-pens) [L.]. Serpentine, sinuous ; creeping. S., Ulcus, a fistulous ulcer; a sinuous ulcer of the cornea.

Serpentaria $($ ser-pen-ta'-ra-ah) [L.]. Virginia Snake- root. The roots of Aristolochia serpentaria, and $A$. reticulata. Its properties are due to a volatile oil, a camphor-resin, and a bitter extractive. It is a stimulant, tonic, and diaphoretic, promoting appetite and digestion. It is used mainly as a vehicle for other medicines. S., Ext., Fld. Dose $\eta_{x-x x x}$. S., Infus. (B. P.) Dose $\xi_{j}-\mathrm{ij}$. S., Tinct., ro per cent. in strength. Dose $3_{\text {ss-ij. }}$.

Serpentine (ser'-pen-tén) [serpens, serpent]. Sinuous. Having a snake-like form or movement.

Serpent-poison (ser'-pent-poi'-zn). See Echidnin.

Serpiginous (ser-pij'-in-us) [serpigo, ringworm]. Resembling serpigo. Also, applied to such skin diseases as move or creep progressively from one part to another. S. Ulcer, one that changes its seat, or seems to creep from one part to another.

Serpigo (ser-pi'-go) [L.]. Ringworm. See Tinea.

Serra $\left(s e r^{\prime}-a h\right)$ [L., a saw]. In biology, a saw or sawlike structure. S. salvia, mountain sage, an herb of the U. S., introduced as a substitute for quinin in the treatment of periodic fevers. Also of service in rheumatism, scarlet fever, and diphtheria. Dose of the fluid extract $3 \mathrm{j}-\mathrm{ij}$. Unof.

Serrate $($ ser'-ät) [serra, a saw]. Provided with sharp teeth or projections directed forward like the teeth of a hand-saw.

Serratiform (ser-at'-if-orn) [serra, a saw; forma, a form]. Same as serrated.

Serration (ser-a'-shun) [serra, a saw]. In biology, the state or condition of being serrate. A tooth of a serrate border; a set of serrate processes.

Serratus (ser-a'-tus). See Muscles, Table of.

Serre-fine (săr-fen' ${ }^{\prime}$ [Fr.]. A small suture used in accurate apposition of the lips of a wound.

Serre-nceud [Fr.]. An instrument used in ligation.

Serres, Angle of. See Angle. S., Glands of. See Gland.

Serriped (ser'-ip-ed) [serra, a saw; pes, foot]. In biology, having serrated feet, as certain insects.

Serrula $\left(\operatorname{ser}^{\prime}-u\right.$-lah) [dim, of serra, a saw: pl., Serrula]. In biology, one of the paired appendages placed on either side of the copula of the Mud fish (Amia) and covered by the operculum.

Serrulate $\left(\operatorname{ser}^{\prime}-u\right.$-lāt $)$ [serrula, dim. of serra, a saw]. Minutely notched or serrated.

Sertoli's Cells. The cells in the testicles which give origin to the spermatoblasts. S.'s column, the long column or supporting cell holding the spermatozoa together and formed by the breakdown of a mass of daughter-cells in the seminiferous tubules; identical with Merkel's Stiutzzellen, La Vallette's Spermatogonien, and Swaen and Masquelin's Cellules folliculaires.

Serum $\left(s e^{\prime}-\mathrm{rum}\right)$. The yellowish fluid separating from the blood after the coagulation of the fibrin. See Blood. S.-albumin, a native albumin or proteid constituent of the human body, especially of the blood, differing from egg-albumin in several respects. It is changeable into syntonin or acid-albumin by dilute hydrochloric acid, and by dilute alkalies into alkali-albuminate. S.-globulin. See Paraglobulin. S. lactis, whey: S.-lutein, the pigment contained in the serum from the blood of most animals. Serum-lutein is bleached by the action of light. S.-therapy: 1. The treatment of disease (as tetanus) by injections of sterilized blood-serum from immune animals. 2. See Whey-cure.

S. Serumuria (se-rum-u'-re-ah). See Albuminuria.

Sesame (ses'-am-e). See Sesamum. S., Oleum, Benné Oil, a fixed oil expressed from the seeds of Sesamum indicum, or Benné plant. It resembles olive-oil in composition and properties and is employed mainly as a hair-oil. 


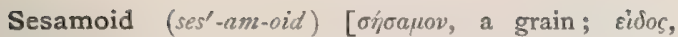
form]. Resembling a grain. S. Bones, small bones (cartilaginous in early life) developed in tendons submitted to much pressure.

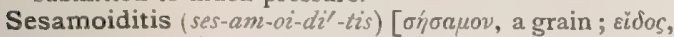
like; $\iota \tau \iota$, inflammation]. Inflammatory disease of the sesamoid bones of the fetlock of the horse.

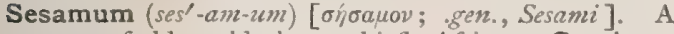
genus of old-world plants, chielly African. S. orientale (or S. indicum) is widely cultivated for the oil of its seeds; called also benné, til, etc. See Sesami, Oleum.

Sesqui- (ses'-kwe-) [L., one and one-half]. A prefix denoting one and one-half.

Sesquialter (ses-kwe-al'-ter) [sesqui, one-half more ; alter, another]. In biology, a large spot with a smaller one in the center; a sesquiocellus.

Sesquibasic (ses-kzve-ba'-zik) [sesqui-, one-half more; $\beta a \sigma u$, base]. Applied to salts formed from a tribasic acid by the replacement of three atoms of hydrogen by two of a basic element or radicle.

Sesquiocellus (ses-kwe-o-sel'-zs) [sesqui, one-half more ; ocellus, a little eye: pl., Sesquiocelli]. In biology, a large spot with a smaller one in the center of it; a sesquialter.

Sesquioxid (ses-krve-oks'-id) [sesqui-, one-half more; $\dot{v} v s$, acid]. A compound of oxygen and another element, containing three parts of oxygen to two of the other element. S. of Iron, ferric oxid, a salt of iron having the composition $\mathrm{Fe}_{2} \mathrm{O}_{3}$.

Sesquisalt (ses'-kwe-sarult) [sesqui; ME., salt, salt]. A salt which contains one and one-half times as much of a given radicle as a protosalt.

Sessile (ses'-il) [sessilis, sedere, to sit]. Attached by a broad base; not pedunculated; e. g., a sessile tumor. In biology, not stalked; inserted directly on the axis, as when a leaf-blade is attached directly to a stem. S.-eyed, in biology, having eyes without stalks.

Seta $\left(s e^{\prime}-t a h\right)$ [seta, a bristle: pl., Sete]. In biology, a stiff, stout, bristle-like appendage; a chrta, vibrissa.

Setaceous (se-ta'-se-us) [seta, a hair, a bristle]. In biology, bristly, bristling, bristle-shaped.

Setaceum (se-ta'-se-um). See Seton.

Setiform (se'tif-orm) [seta, a bristle ; forma, form]. Bristle-like in shape.

Setigerous, or Setiferous (se-tij'-er-us, se-tif'-er-us) [seta, bristle; gevere or ferre, to bear]. In biology, bearing bristles or stiff hairs.

Setiparous (se-tip'-ar-us) [seta, a bristle; parere, to bear]. In biology, producing bristles or setæ, e. g., certain glands.

Setireme (se'-tir-ēm) [seta, a bristle; remus, an oar]. In biology, applied to the leg of an aquatic insect or other animal when beset with setæ.

Seton (se'-ton) [seta, a bristle]. I. A thread, or skein drawn through a fold of the skin, so as to maintain an issue. 2. A sinus kept from healing by the introduction and drawing through it of a thread. S.-needle, a needle used in passing a seton through the skin.

Setschenow's Inhibitory Center. A hypothetic cerebral mechanism for the inhibition of refiex movements. It is supposed to be located in the corpora quadrigemina and the oblongata.

Setula $($ set' $-u$-lah) [dim. of seta, a bristle: $p l$., Setule]. A diminutive bristle.

Seven $(\operatorname{sev}-n)$ [ME., seven, seven]. A numeral. S.bark, the plant Hydrangea arborescens. See Hydrangea. See also Nine-bark. S.-day Fever. Synonym of Relapsing Fever. S.-days' Disease. Synonym of Trismus.

Sevum $\left(s e^{\prime}-v u m\right)$ [L.: gen., Sevi]. Suet. The adipose tissue or fat from the abdomen of the sheep, strained and clarified. It is soluble in benzine and ether, and consists mainly of stearin, with a small percentage of palmitin and olein. It is used in the preparation of ointments and liniments.

Sewage $\left(s u^{\prime}-\bar{a} j\right)$ [ME., sewer, a canal]. The heterogeneous substances constituting the excreta and waste matter of domestic economy and the contents of drains. It consists mainly of putrescent animal and vegetable tissues, fecal matter, and urine-the latter in a state of ammoniacal fermentation-mixed with water or dissolved in it. In the process of fermentation, marshgas, ammonia, hydrogen sulphid, and other gases are freely given off, and as these are more or less soluble in water, an ordinary water-trap only partially prevents their passage. In addition, the constituents of the solution are such as to form an excellent culture-fluid for numerous pathogenic microbes, especially those constituting the contagium of cholera, typhoid fever, and similar diseases. S.-farming, use of sewage as a manure. S.-fungus. See Beggiatoa alba under Bacteria, Synonymatic Table of.

Sewer $\left(s u^{\prime}-e r\right)$ [ME., sewer, a canal]. A canal for the removal of sewage. S.-air Throat, acute tonsillitis. S.-gas, the mixture of air, vapors, and gases, which emanates from sewers. It varies greatly in respect to its pathogenic qualities. S.-g. Pneumonia. See Pneumonia.

Sewerage $\left(s u^{\prime}-e r-\bar{a} j\right)$ [ME., sewer, a canal]. The collection and removal of sewage.

Sewing Spasm. See Spasm.

Sex-(seks) [L.]. A numeral used as a prefix, meaning six.

Sex (seks) [sexus, also secus, sex]. In biology, the state or condition of being either male or female. See Law, Kofacker-Sadler's.

Sexdigital, Sexdigitate (seks-dij'-it-al, seks-dij'-it-āt) [sex, six; digitus, a finger]. Having six fingers or six toes.

Sexdigitism (seks-dij'-it-izm) [sex, six ; digitus, finger]. The condition of having six digits on a hand or foot.

Sexiferous (seks-if'-er-us) [sex, six; ferre, to bear]. Having sexual organs.

Sextan $\left(\operatorname{sek} s^{\prime}-t a n\right)$ [sex, six]. A malarial fever in which the paroxysms occur every sixth day.

Sextuplet $\left(\right.$ seks-tūp $\left.p^{\prime}-l e t\right)$ [sex, six]. One of six offspring from a single gestation.

Sexual (seks'-u-al) [sexus, sex]. Pertaining to sex. $\mathrm{S}$. Bondage, the dependence of one person upon another of the opposite sex that is abnormal but not perverse. S. Diseases, diseases of the sexual organs. S. Intercourse, copulation. S. Inversion, a variety of sexual perversion in which there is an abnormal liking for a person of the same, instead of for one of the opposite sex. S. Metamorphosis, a variety of sexual perversion in which the individual has the tastes and feelings and assumes the dress and habits of the opposite sex. S. Selection. See Evolution.

Sexualia (seks-u-a-le-ah). See Gonades.

Sexuality (seks-u-all-it-e) [sexus, sex]. The collective differences which in an individual make one male or female.

Sexually (seks'-u-al-e) [sexus, sex]. In a sexual manner. Sexvalent (seks-va'-lent) [sex, six; valere, to be worth]. Having an atomicity of six.

Shab (shab). See Scab.

Shackle $\left(s h a k^{\prime}-l\right)$ [ME., schakkyl, shackle]. Something that hinders or confines. S.-joint, a variety of articulation formed by passing a bony ring of one part through a perforation of another part. It is seen in the exoskeleton of some fishes. S.-vein, a vein of the horse, probably the median antebrachial, from which blood was formerly abstracted. 
Shadow (shad'-o) [ME., schadowe, shadow]. A phantom-cell, or skeletonized blood-cell, formed by the removal of the hemoglobin from a red corpuscle. S.-test. See Retinoscopy.

Shaft [ME., shaft, shaft]. The trunk of any columnar mass, especially the diaphysis of a long bone.

Shakes (shäks) [ME, shaken, to shake]. A popular designation for Ague.

Shaking (sha'-king) [ME., shaken, to shake]. A passive Swedish movement used in the treatment of nervous affections. S. Cure, the treatment of disease by a shaking or vibratory movement, advocated by Charcot in paralysis agitans, by means of a vibrating arm-chair. S. Palsy. See Paralysis agitans.

Shale (shäl) [G., schale, a scale]. Clay with a fissile structure. S. Naphtha. See Photogene. S. Oil. See Benzine.

Shampoo (sham-poo') [Hind., tshampna, shampoo]. I. Synonym of Massage. 2. To lather, rub, or wash the head.

Shampooing (sham-poo'-ing) [shampoo]. The performance of massage with the application of a liniment or other medicinal substance, and also in connection with the Turkish bath.

Shank [ME., shanke, the bone of the leg]. The leg from the knee to the ankle; the tibia or shin-bone.

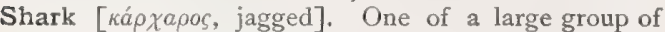
sea-fishes constituting the order, Squalida. S.-oil, an oil prepared from the livers of various species of shark, It is the lightest of the fixed oils, the specific gravity ranging from .865 to .876 . It is used in the adulteration of cod-liver oil and for tanning.

Sharpey's Perforating Fibers. Transverse or perpendicular periosteal fibers, most numerous in the superficial lamellæ of spongy bones; they are also present

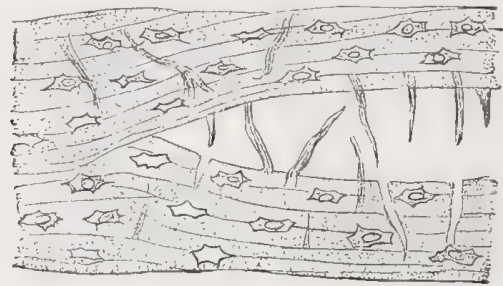

Sharpey's Perforating Fibers. (From Stirling.)

in the interstitial lamellæ of other bones, transfixing the lamellæ. Kölliker recognized a smaller, soft, uncalcified, and a larger, partly calcified, variety.

Shavegrass (shā⿲'-gras). See Scouring Rush.

Shaven-beard Appearance. A peculiar appearance of the enlarged intestinal glands in typhoid fever. They are dark-red or reddish-gray in color, and marked with fine white striations.

Shearing (sher'-ing) [ME., sheren, to clip]. I. The overlapping of the cranial bones of the fetus during its passage through the pelvis. 2. In biology, the result of attrition of the incisorial region of the lower jaw against the front of the upper jaw in aged persons who have lost their teeth. Shearing takes place in proportion as the upper jaw at its anterior arc is beaked, and when present the articular surface of the condyloid process is invariably at the anterior part. (Harrison Allen.)

Shears (shērz) [ME., sheres, shears]. A large pair of scissors. S., Bandage. Strong shears for cutting bandages, usually bent at an angle.

Sheath (sheth) [ME., shethe, sheath]. An envelop; a covering. In anatomy, applied to the coverings of arteries, muscles, nerves, fascia, etc. S., Arach- noidean, a delicate partition lying between the pial sheath and the dural sheath of the optic nerve. S., Axis-cylinder. See Huxley's Layer. S., Capillary, or S., Circumvascular, a wide lymphatic tube surrounding some of the smallest blood-vessels. S., Cellular. See Epineurium. S., Cortical, the bast-bundles. S., Dentinal, the structure lining the dentinal canals. S., Dural, a strong fibrous membrane forming the external investment of the optic nerve. See Dura. S., Femoral. See Femoral. S., Fibril, a sheath formed of connective-tissue fibrils and surrounding individual nerve-fibers. $\mathbf{S}$. of Henle, an attenuated extension of the perineurium investing the fibers composing funiculi of a nerve-trunk; it consists of a delicate fibrous envelop lined with endothelial plates, which in some cases alone represent the entire sheath. S., Huxley's. See Huxley's Layer. S., Lamellar. See Perineurium. S., Leaf. See Vagina. S. of Mauthner, a protoplasmic investing membrane beneath the neurilemma and the nodes of Ranvier, passing inward to separate the myelin from the axiscylinder. S., Medullary, the myelin-sheath surrounding the axis-cylinder. S., Myelin. Medullary Sheath and Neurilemma. S., Nerve. See Perineurium. S., Neumann's. See S., Dentinal. S., Perivascular. See S., Capillary. S., Pial, the extension of the pia which closely invests the surface of the optic nerve. See Pia. S., Primitive, See Neurilemma. S., Root. See Rootsheath. S. of Schwann. See Neurilemma. S., Synovial, a synovial membrane which lines the cavity attached to a bone and through which a tendon glides. S., Tangential, the fibro-cellular sheath surrounding the carotids.

Shed [ME, sheden, to shed]. To throw off.

Shedding (shed'-ing) [ME., sheden, to shed]. Throwing off. $\mathrm{S}$. Teeth, the teeth of the first dentition; the term is also applied to the loss of the first or temporary set of teeth.

Sheep (shepp) [ME, sheep, sheep]. A ruminant mammal of the family Bovidce and genus Ovis. S.-bug. See Argas tholozani in Parasites (Animal), Table of. S.-cough. See Hoose. Also Strongylus filaria, Rudolphi, under Parasites (Animal), Table of. S. Gadfly. See Oestrus ovis, L., under Parasites (Animal), Table of. S--laurel. See Kalmia. S.-louse. See Trichodectis spharocephalus, Nitzsch, in Parasites (Animal), Table of. S.-pest, the sheep-tick. S.-pox, a contagious pustular disease of sheep similar to cowpox. See Ovination. S.-sorrel, the leaves of common soriel, Rumex acetosella. Their acidity is due to potassium oxalate and tartrate. They are refrigerant and diuretic, and are useful as an antiscorbutic. Dose of the infusion $a d$ lib., of the fld. ext. $3 \mathrm{j}-\mathrm{ij}$. Unof. S.-tick. See Melophagus ovinus, under Parusites (Animal), Table of. S.s' Wool, a fine grade of Bahama and Florida sponge. S.s'-wool Fat. See Suint and Lanolin.

Sheet $(s h e t)$ [ME., shete, sheet]. A large piece of linen or cotton used as bed-clothing. S.-bath. See Bath. S., Draw, a sheet so folded as to be placed, or removed, from beneath the patient with the least inconvenience.

Sheffield Grinders' Rot. Synonym of Pneumonokoniosis.

Shell (shel) [AS., scil; D., schel, shell]. In biology: I. A hard, bony, calcareous, chitinous or silicious outer covering; a scale, husk, test, lorica, carapace, elytron. 2. A thin or hollow structure, as the outer ear. S-follicle, the integumentary sac containing the primitive shell of a mollusc. S.-gland, $(a)$ the 
shell-secreting gland of a mollusc; ( $b$ ) a coiled tubular gland lying in the shell-fold or in the cephalothoracic carapace, opening near the posterior maxillæ of a crustacean; it is widely distributed among Entomostraca. It acts as a renal organ. S., Hearing, a small concave plate used to concentrate the soundwaves in the ear.

Shellac $\left(s h e l^{\prime}-a k\right)$. See Lac. S. Cement. See Cement.

Shells (shels) [ME., schelle, shell]. Tinted spectacles, for protection of the eyes. Coquilles.

Shepherd's Purse. The Capsella bursa pastoris. A common herb possessing tonic and stimulant and active diuretic properties. Dose of the fluid extract $m x v-3 j$. Unof.

Sheringham Valve. See Ventilation.

Sherry Wine $($ sher'-e). See Vinum xericum.

Sherwood Oil. See Petroleum Ether.

Shield (shêld) [ME., shęld, shield]. I. A protective structure or apparatus. 2. In biology, a protective plate, scute, lorica, or carapace. S., Nipple, a protective covering for sore nipples. S.-shaped, same as Sculate or Peltate. S., Sims', an instrument used in the application of wire sutures.

Shifting-type, Foerster's. See Foerster's.

Shima-mushi (shi-mah-mush'-e) [Jap.]. A Japanese febrile disease supposed to be due to the bite of an insect.

Shin [ME., shinne, shin]. The anterior margin of the tibia or fore-part of the leg. S.-bone, the tibia.

Shingles (shing-gles). A name for herpes zoster.

Ship Fever. Synonym of Typhus Fever, q. v.

Shiver (shiv'-er) [ME., chiveren, to shiver]. A tremor or shaking of the body. It may arise from a sense of coldness, but it is often concomitant with or symptomatic of fevers, especially those of an infectious nature.

Shock (shok) [ME., schok, a shock]. The depression or grave effect produced by severe injuries, operations, or strong emotion. A relaxation or abolition of the sustaining and controlling influence which the nervous system exercises over the vital organic functions of the body. It is the result of a profound impression made on the cerebro-spinal axis, either directly through the agency of an afferent nerve, or through the circulatory medium. S., Deferred, that curious condition in which the manifestations of shock, due not to severe bodily injury but to purely mental causes, develop after the lapse of some time from the occurrence. This variety of shock may be even more profound than that produced by bodily injury. S., Discharging, a shock produced by a discharge of electricity. S., Electric, the physiologic effect produced upon an organism by the opening or closing of an electric circuit in which it is included. S., Epigastric, the result of a blow upon the epigastrium. S., Erethismic, a form of shock attended with symptoms of excitement. S., Fetal, the sensation produced by movements of the fetus in utero. S., Railway, the mental impression produced by a railway accident. S., Secondary, or Insidious, a second attack occurring after the first. S., Sexual, shock caused by rape or coitus. S., Torpid, shock in which marked depression is a prominent symptom. S., Traumatic, shock due to traumatism.

Shoddy $\left(s^{\circ} \circ d^{\prime \prime}-e\right)$ [E. dial]. A material made from fragments of cast-off woolen clothing torn into fibers and re-spun into yarn. It is looser in texture than mungo, which is made from remains of finer fragments, such as old dress-coats, tailors' clippings, etc. S. Fever or Disease, a febrile condition caused by the inhalation of the dust arising in making "shoddy" yarns and fabrics. It is characterized by feverishness, headache, nausea, dryness of the mouth, dyspnea, cough, and expectoration. See Fever.

Shoe $(s h u)$ [ME., shoo, shoe]. A covering for the foot, S., Club-foot, a shoe provided with braces for the correction of talipes. S.-salesmen's Disease, one of the occupation-neuroses, characterized by a paradoxic paralysis of muscles (anterior tibial) that are placed in extreme relaxation by the movements which caused and intensified the paralysis. It is produced by sitting on the heels while engaged in fitting shoes, the feet being sharply flexed on the legs and the legs on the thigh. Degenerative changes take place in the muscles or nerve-endings. S., Sayre's. See Sayre. S.-and-stocking Position. See Position. S.-boil, in farriery, an enlargement at the point of the elbow, the result of pressure of the heels upon the spot. It is also called capped elboze.

Shone's System. See Serwage, Disposal of.

Short [ME., short, short]. Neither long nor tall. $\mathbf{S}$. Breath. Synonym of Dyspnea. S. Circuit, a cir. cuit in which an electric current encounters an abnormally small resistance. S.-sight. See Myopia.

Shortening (short'-en-ing) [ME., short, short]. The process of making short.

Shot [ME., shot, a shot]. A projectile, especially a ball or bullet; anything thrown forth. S.-gun Prescription, one with many ingredients, written with the expectation that some one may prove curative. S.-gun Quarantine, the extemporized and unauthorized establishment of a cordon against a place suspected of being the seat of an epidemic of a com. municable disease. S.-silk. See Retina.

Shoulder (shöl'-der) [ME., scholdre, shoulder]. The popular designation for the scapulo-clavicular articulation and adjacent parts. S.-blade, the scapula. S.-girdle. See Girdle.

Show (sho) [ME., scherve, a show]. A sanguino-serous discharge from the birth-canal prior to labor; the first appearance of a menstrual flow.

Shower (shau'-er) [ME, shour, shower]. A light fall of rain. S.-bath. See Bath. S.-bath, Electric. See Electric Shower-bath.

Shrapnell's Membrane, the membrana flaccida; the skin-layer of the membrana tympani, with the mucosa of the attic. See Membrane.

Shreds [ME., shrede, a shred]. Patches of filmy material passed with the fecal discharges in some cases of enteritis and diarrhea. They may be composed of false membrane, of actual sloughs from the intestinal mucosa, or of flakes of hardened mucus.

Shrivel (shriv'-l) [origin obscure]. To shrink in bulk and become wrinkled.

Shriveled (shriv'-ld) [origin obscure]. Contracted into wrinkles; corrugated.

Shrub (shrub) [AS., scrob, a shrub]. 1. A low, branching, woody plant; a bush. 2. [Arab., sharab]. A drink, or cordial made of fruit-juice, often with the addition of rum; as currant, or raspberry shrub.

Shudder (shud'-er) [ME., schuderen, to shudder]. A convulsive but momentary tremor, caused usually by fright, disgust, or nervous shock.

Shunt [ME., schunt]. In electricity, a conductor of low resistance, joining two points in an electric current, and completing a path through which the current will pass.

Shurly-Gibbes Treatment. See Treatment, Methods of.

Shuttle Pulse (shut'-l). See Corrigan's Pulse.

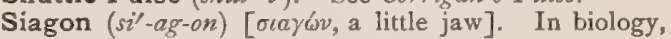
the mandible of a crustacean.

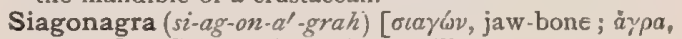
seizure]. Gouty pain in the maxilla. 


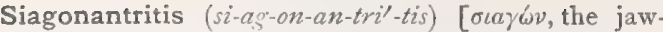
bone; a sipov, antrum]. Inflammation within the antrum of Highmore

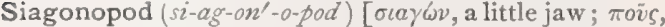
foot]. In biology, the maxilla of a crustacean.

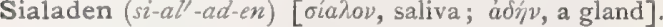
A salivary gland.

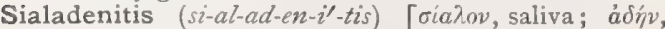
gland; $\iota \tau \iota \varsigma$, inflammation]. Inflammation of a salivary gland.

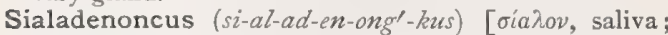

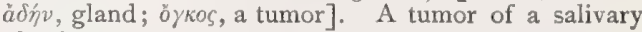
gland.

Sialagogue (si-al'-ag.og). See Ptyalagogue.

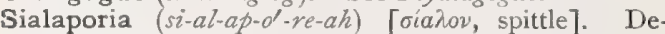
ficiency in the amount of saliva.

Sialin $\left(s i^{\prime}-a l-i n\right)$. Same as Ptyalin.

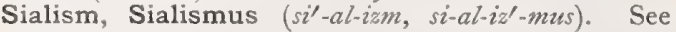
Ptyalism.

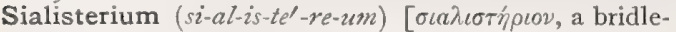
bit: $p l$., Sialisteria $]$. In biology, one of the salivary glands of an insect.

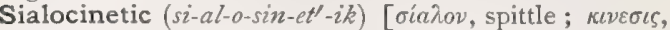
motion]. Stimulating the flow of saliva.

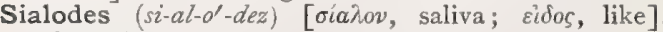
Like saliva.

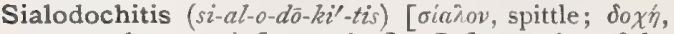
receptacle; $\iota \tau \iota$, inflammation]. Inflammation of the salivary ducts. S. fibrinosa, inflammation of a salivary duct obstructed by a fibrinous exudate.

Sialodochium $\left(s i-a l-o-d o^{\prime}-k e-u m\right)[\sigma i a \lambda o v$, saliva ;

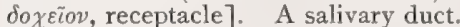

Sialogogic (si-al-o-goj'-ik) [oía leading]. I. A sialogogue. 2, Promoting a flow of saliva.

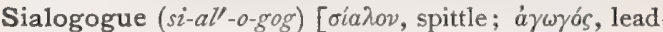
ing]. A ptyalogogue; a drug producing a flow of saliva.

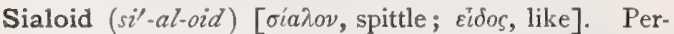
taining to, or like saliva.

Sialolith, Sialolithus (si'-al-o-lith, si-al-o-lith'-us)

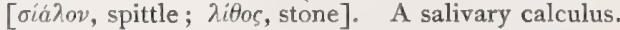

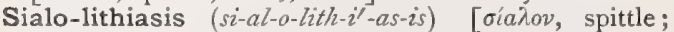
$\lambda i \theta 0 s$, stone]. The presence of salivary calculi.

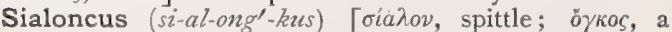
tumor ]. A tumor under the tongue, arising from the obstruction of the duct of a salivary gland by calculus or other cause.

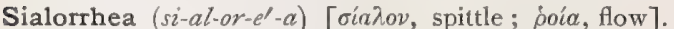
Salivation. S., Pancreatic, a flow of pancreatic juice.

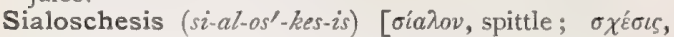
holding]. Suppression of the secretion of saliva.

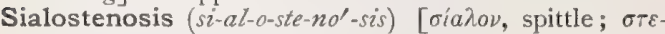
vos, narrow ]. Occlusion of a salivary duct.

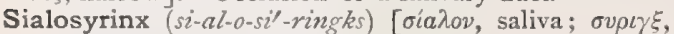
tube]. I, A salivary fistula. 2. A syringe for washing out the salivary ducts. 3. A drainage-tube for the salivary ducts.

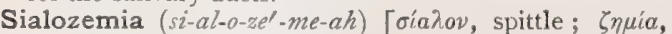
loss]. Loss of saliva.

Siam Disease. See Fever, Yellow.

Sibbens (sib'-enz) [Gael., subhan, raspherries]. A disease formerly endemic in the Scotch highlands, by some identified with syphilis, by others with yaws.

Siberian Plague (si-bél-re-an plāo). See Plague.

Sibi $\left(\sin ^{\prime}-b e\right)$ [Fiji]. A Fiji term for elephantiasis or a tumor of the leg or arm.

Sibilant (sib'-il-ant) [sibilare, to hiss]. Articulating with a hissing sound. Also, the nature of certain wheezy sounds observed in auscultation. S. Râle. See Râle.

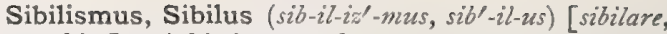
to hiss]. A hissing sound.

Siccant, Siccative (sik'-ant, sik'-at-iv) [siccare, to dry]. 1. Drying; tending to make dry. 2. A drying agent or medicine.

Siccate $\left(\operatorname{sik}^{\prime}-\bar{a} t\right)$ [siccare, to dry]. In biology, to dry, as plants for a herbarium.

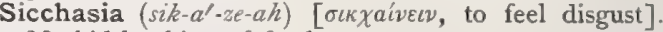
Morbid loathing of food.

Siccus $\left(s_{i k}^{\prime}-u s\right)$ [L.]. Dry.

Sick (sik) [ME, sik, sick]. Ill. Not well. In England the term commonly means nauseated, or " sick at the stomach." "S. Time," popularly used for the period of menstruation. S.-headache, headache with anorexia, nausea, vomiting, etc. Migraine. S. list, a list of persons, especially in military or naval service, who are disabled by sickness. S.-report, a sick-list. S.-room, a room occupied by one who is sick. S.-stomach. Synonym of Nausea, and of Milk-sickness.

Sickle-germs (sik'-l-jermz). A falciform stage in the development of Cocridia.

Sickliness (sik'-le-nes) [ME., sik, sick]. Predisposition to easily contract disease; insalubrity of climate.

Sickly $\left(s i k^{\prime}-l e\right)$ [ME., sik, sick]. Predisposed to disease. Unhealthy.

Sickness (sik'-nes) [ME., siknesse, sickness]. Nausea. Also, a general term including all morbid conditions, also menstruation. S., African Sleeping. See Afri can Lethargy. S., Bleeding, hemophilia. S., Falling, epilepsy. S., Gall, remittent fever. S., Green, chlorosis. S., Hungarian, remittent fever. S., Milk, a form of poisoning due to the ingestion of diseased milk or meat. S., Miners'. See Ankylostomiasis. S., Monthly. See Menstruation. S., Morning. See Morning Sickness. S., Mountain, a sensation of nausea, with impeded respiration and irregular heart's action, due to the rarefied air of high altitudes. S., Sea, nausea, with vomiting and often extreme weakness, caused by unaccustomed motion. Naupathia.

Side (sid) [ME, side, side]. A lateral half of the body or of any bilateral organ. S.-bone: I. The hip-bone. 2. The disease or disordered condition in horses which causes the lateral cartilages above the heels to ossify. 3. An abnormal ossification of the lateral elastic cartilage in a horse's foot. S.-saddle Flower. See Sarracenia.

Sideration (sid-er-a'-shun) [sideratio, blight produced by the stars]. I. Apoplexy, 2, Gangrene. 3. Lightning-stroke. [Obs.]

Siderine Yellow. See Pigments, Conspectus of.

Siderodromophobia (sid-er-o-dro-mo-fo'-be-ah) [oínpos, iron; $\delta \rho \delta$ uss, way; $\phi 6 \beta o s$, fear $]$. Morbid dread of traveling by railway.

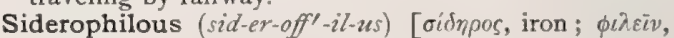
to love]. Applied to cells that show a tendency to take up iron, e.g., the red blood-corpuscles

Siderosis (sid-er'-o-sis) [ $\sigma i \delta n \rho o s$, iron]. The pigmentation of the lymphatic glands, liver, and kidneys, so called from the presence of iron in the pigment.

Siegle's Speculum. An apparatus for pneumatically testing the mobility of the membrana tympani.

Sielon $\left(s i^{\prime}-e l-o n\right)$. See Saliva.

Sienna $\left(s e-e n^{\prime}-a h\right)$. See Pigments, Conspectus of.

Sierra salvia. See Serra salvia.

Sieve (siv) [ME., sive, sieve]. A vessel with a reticulated bottom, used for the separation of pulverized from coarse substances. The gauge of the sieve is usually expressed in the number of meshes per square inch. S.-cells, long cells of tubular or prismatic form constituting an essential element in fibro-vascular 
bundles of the inner bark of exogenous stems. They are peculiar in the possession of circumscribed panels, with time perforations, which allow of communication between contiguous cells. S.-disc. See S.-plate. S.hypha; a hypha in which sieve-plates occur. S.plates, the perforated panels of sieve-cells occurring at the points of contact of sieve-cells. S.-pores, the perforations in the panels of sieve-cells. S.-tissue, a cellular tissue made up of thin-walled cells which possess areas with sieve-like markings. The tissue is characteristic of the phlöem. S.-tubes. See S.-cells. S.-vessel. See S.-cells.

Siewer's Test. See Tests, Table of.

Sig (sig). 1. Abbreviation for signa, "label it," or for "signetur, "let it be labeled." 2. A colloquial name for urine.

Sigault's Operation. See Operations, Table of:

Sigh (si) [ME., sighen, to sigh]. A peculiar prolonged and deep respiration; suspirium.

Sighing (si'-ing) [ME., sighen, to sigh]. I. The act of giving forth a sigh. 2. A deep respiration accompanied by sighs. 3. Characterized by sighs.

Sight (sit) [ME., sight, sight]. That sense by which the image of an object projected upon the retina is conveyed to the mind. S., Day. See Hemeralopia. S., Depraved. See Paropsis. S., Long. See Hy. peropia. S., Mouse. See Myopia. S., Night. See Nyctalopia. S., Old. See Presbyopia. S., Short. See Myopia. S., Skew. See Dysopia. S., Weak. See Asthenopia.

Sigillate $\left(s i j^{\prime}-i l-\bar{a} t\right)$ [sigilluth, a seal]. In biology, marked as if with a seal.

Sigmatism, Sigmatismus (sig'-mat-izm, sig-mat-iz' mus) [sigma, the Greek letter $s(\sigma)]$. 1. Defectuve utterance of the sound of s. 2. Too frequent use of the $s$ sound in speech. See Lisping.

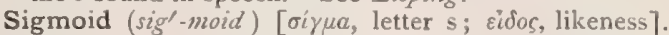
Bearing a resemblance to the shape of the letter sigma; curved in two directions. S. Catheter, one shaped like an S, for passing into the female bladder. S. Cavities, a name applied to the depressions on the head of the ulna; the greater is a depression formed by the olecranon and coronoid process for articulation with the humerus; the lesser, on the outer side of the coronoid process, is for articulation with the radius. S. Flexure, the bend in the colon between the descending portion and the rectum. S. Gyrus, the S-shaped cerebral fold about and behind the cruciate fissure in Carnivora. S. Mesocolon, the fold of the peritoneum attaching the sigmoid flexure of the colon to the left iliac fossa. S. Notch. See Notch. S. Valves, the cardiac semilunar valves.

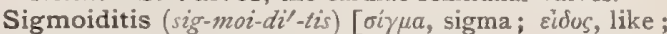
ITLS, inflammation]. Inflammation of the sigmoid flexure of the colon.

Sigmoidostomy (sig-moi-dos'-to-me) [ $\sigma^{\prime} \gamma \mu a$, sigma; oró $\mu a$, mouth]. The creation of an artificial anus in the sigmoid flexure of the colon.

Sign $(\sin )$ [signum, a mark or device]. In pathology, any diagnostic symptom. In pharmacy, a conventional character implying a direction or order. A table of Eponymic Signs and Symptoms is appended. See Ataxia, Signs of; Death, Signs of, etc. S.-language, the method of intercommunication employed by deaf-mutes, in which ideas are communicated by means of signs.

\section{TABLE OF EPONYMIC SIGNS AND SYMPTOMS OF DISEASES.}

\begin{tabular}{|c|c|c|c|c|}
\hline NAME. & DESCRIPTION, & How Elicited. & Disease PREsent IN. | & SIGNIFICANCE. \\
\hline Abadie's sign. & $\begin{array}{l}\text { Spasm of the levator palpebræ } \\
\text { superioris muscle. }\end{array}$ & Inspection. & Exophthalmic goiter. & $\begin{array}{l}\text { Said to be pathogno- } \\
\text { monic (?). }\end{array}$ \\
\hline Allis's sign. & $\begin{array}{l}\text { Relaxation of the fascia be- } \\
\text { tween the crest of the ilium } \\
\text { and the trochanter major. }\end{array}$ & Inspection. & $\begin{array}{l}\text { Fracture of the neck of } \\
\text { the fernur. }\end{array}$ & \\
\hline $\begin{array}{l}\text { Argyll-Robertson } \\
\text { pupil. }\end{array}$ & $\begin{array}{l}\text { A pupil that acts in accom- } \\
\text { modation but not to light. }\end{array}$ & $\begin{array}{l}\text { Usual tests for accommo- } \\
\text { dation and light. }\end{array}$ & Locomotor ataxia. & \\
\hline $\begin{array}{l}\text { Baccelli's sign } \\
\text { (aphonic pectori- } \\
\text { loquy). }\end{array}$ & $\begin{array}{l}\text { Reverberation of the whis- } \\
\text { pered voice, heard through } \\
\text { the chest-wall. }\end{array}$ & $\begin{array}{l}\text { Whispered voice of patient } \\
\text { auscultated through the } \\
\text { chest. }\end{array}$ & Pleural effusion. & \\
\hline Baruch's sign. & $\begin{array}{l}\text { The resistance of the rectal } \\
\text { temperature to a bath of } 75^{\circ} \\
\text { for fifteen minutes with fric- } \\
\text { tion. }\end{array}$ & Immersion in bath of $75^{\circ} \mathrm{F}$. & Typhoid fever. & \\
\hline $\begin{array}{l}\text { Biermer's change } \\
\text { of sound. }\end{array}$ & $\begin{array}{l}\text { See Gerhardt's change of } \\
\text { sound (in this table). }\end{array}$ & & & \\
\hline $\begin{array}{l}\text { Bouillaud, T inte- } \\
\text { ment metallique } \\
\text { of. }\end{array}$ & $\begin{array}{l}\text { A peculiar clink sometimes } \\
\text { heard to the right of the } \\
\text { apex-beat of the heart. }\end{array}$ & Auscultation. & Cardiac hypertrophy. & \\
\hline $\begin{array}{l}\text { Brach - R om berg } \\
\text { symptom. }\end{array}$ & See Romberg's symptom. & & & \\
\hline $\begin{array}{l}\text { B rown-Sequard's } \\
\text { paralysis. }\end{array}$ & $\begin{array}{l}\text { Hemiparaplegia with hemi- } \\
\text { anesthesia of opposite side. }\end{array}$ & & $\begin{array}{l}\text { Lesion of lateral half } \\
\text { of spinal cord. }\end{array}$ & \\
\hline Burton's sign. & $\begin{array}{l}\text { Biue line at junction of teeth } \\
\text { with gums. }\end{array}$ & Visual examination. & Chroniclead-poisoning. & \\
\hline $\begin{array}{l}\text { 'beyne-S tokes' } \\
\text { respiration. }\end{array}$ & $\begin{array}{l}\text { A succession of respirations } \\
\text { becom in progressively } \\
\text { shorter and more shallow, } \\
\text { then an intermission of vary- } \\
\text { ing duration, followed by pro- } \\
\text { gressive increase in depth } \\
\text { and length of respirations. }\end{array}$ & & $\begin{array}{l}\text { In various affections in } \\
\text { which the brain is im- } \\
\text { plicated. Cerebral } \\
\text { edema. Uremia. }\end{array}$ & Approaching deaih. \\
\hline
\end{tabular}


TABLE OF EPONYMIC SIGNS AND SYMPTOMS OF DISEASES.-Continued.

\begin{tabular}{|c|c|c|c|c|}
\hline NAME, & DESCRIPTION. & How Elicited. & Disease Present in. & SigNIFICANCE. \\
\hline Chvostek's sign. & $\begin{array}{l}\text { Sudden spasm of one side of } \\
\text { the face. }\end{array}$ & $\begin{array}{l}\text { A slight tap upon the side } \\
\text { of the face. }\end{array}$ & Post-operative tetany. & \\
\hline $\begin{array}{l}\text { Clark's (Alonzo) } \\
\text { sign. }\end{array}$ & $\begin{array}{l}\text { Obliteration of the hepatic dul- } \\
\text { ness due to tympanitic dis- } \\
\text { tention of the abdomen. }\end{array}$ & Percussion. & $\begin{array}{l}\text { Appendicitis and other } \\
\text { peritoneal inflamma- } \\
\text { tions. }\end{array}$ & $\begin{array}{l}\text { The presence of the in- } \\
\text { flated bowel, ot of gas } \\
\text { between the liver and } \\
\text { the abdominal or the } \\
\text { thoracic wall. }\end{array}$ \\
\hline Corrigan's line. & $\begin{array}{l}\text { A purple line at the junction } \\
\text { of the teeth with the gums. }\end{array}$ & Visual examination. & $\begin{array}{l}\text { Chronic copper-poison- } \\
\text { ing. }\end{array}$ & \\
\hline Corrigan's pulse. & $\begin{array}{l}\text { A forcible pulse-wave, which } \\
\text { quickly recedes. }\end{array}$ & $\begin{array}{l}\text { By the finger or sphygmo- } \\
\text { graph over a superfical } \\
\text { artery. }\end{array}$ & Aortic insufficiency. & $\begin{array}{l}\text { Regurgitation of blood } \\
\text { at the aortic orifice. }\end{array}$ \\
\hline Dalrymple's sign. & $\begin{array}{l}\text { Abnormal widening of the pal- } \\
\text { pebral aperture. }\end{array}$ & Visual examination. & Exophthalmic goiter. & \\
\hline Davidsohn's sign. & $\begin{array}{l}\text { Reflection of light through the } \\
\text { pupil in translumination. }\end{array}$ & $\begin{array}{l}\text { Electric light in the } \\
\text { mouth. }\end{array}$ & & Health. \\
\hline Drummond's whiff. & $\begin{array}{l}\text { A whiff heard at the open } \\
\text { mouth, during expiration, } \\
\text { proceeding from the glottis. }\end{array}$ & Auscultation. & Aortic aneurysm. & \\
\hline $\begin{array}{l}\text { Duroziez's mur- } \\
\text { mur. }\end{array}$ & $\begin{array}{l}\text { A double murmur occasionally } \\
\text { heard in the femoral artery. }\end{array}$ & Auscultation. & Aortic incompetency. & $\begin{array}{l}\text { Escape of blood past } \\
\text { imperfectly closed } \\
\text { aortic valve. }\end{array}$ \\
\hline Farre's tubercles. & $\begin{array}{l}\text { Superficial masses felt pro- } \\
\text { jecting beneath the capsule } \\
\text { of the liver. }\end{array}$ & Palpation. & Carcinoma of the liver. & \\
\hline Filipovitch's sign. & $\begin{array}{l}\text { A saffron-like coloration of all } \\
\text { the prominent parts of palms } \\
\text { of hands and soles of feet. }\end{array}$ & Inspection. & Typhoid fever. & $\begin{array}{l}\text { Doubtful. Blood and } \\
\text { circulatory changes. }\end{array}$ \\
\hline $\begin{array}{l}\text { Fisher's brain-mur- } \\
\text { mur. }\end{array}$ & $\begin{array}{l}\text { A systolic murmur over the } \\
\text { anterior fontanel or in the } \\
\text { temporal region of infants. }\end{array}$ & Auscultation. & $\begin{array}{l}\text { Rickets and other con- } \\
\text { ditions. }\end{array}$ & \\
\hline Flint's murmur. & $\begin{array}{l}\text { A second murmur frequently } \\
\text { heard at the apex; it has a } \\
\text { rumbling quality and may be } \\
\text { presystolic, and is probably } \\
\text { produced at the mitral orifice. }\end{array}$ & Auscultation. & Aortic incompetency. & $\begin{array}{l}\text { Improper passage of } \\
\text { the blood. }\end{array}$ \\
\hline $\begin{array}{l}\text { Fqerster's shifting } \\
\text { type. }\end{array}$ & $\begin{array}{l}\text { Variations in the field of } \\
\text { vision. }\end{array}$ & $\begin{array}{l}\text { Perimetric limits differ ac- } \\
\text { cording as they are deter- } \\
\text { mined by moving the } \\
\text { disc from the center out- } \\
\text { ward or from without to } \\
\text { the center. }\end{array}$ & $\begin{array}{l}\text { Anesthesia of the ret- } \\
\text { ina, traumatic neuro- } \\
\text { ses, etc. }\end{array}$ & \\
\hline $\begin{array}{l}\text { Friedreich's respi- } \\
\text { ratory change of } \\
\text { sound. }\end{array}$ & $\begin{array}{l}\text { The pitch of the percussion- } \\
\text { note becomes increased at } \\
\text { the height of a deep inspira- } \\
\text { tion. }\end{array}$ & On percussion. & $\begin{array}{l}\text { Pulmonary tuberculosis } \\
\text { and other conditions. }\end{array}$ & $\begin{array}{l}\text { Excavation; increased } \\
\text { tension. }\end{array}$ \\
\hline Friedreich's sign. & $\begin{array}{l}\text { Diastolic collapse of the cervi- } \\
\text { cal veins. }\end{array}$ & Palpation. Inspection. & Adherent pericardium. & \\
\hline Garel's sign. & $\begin{array}{l}\text { Absence of luminous percep- } \\
\text { tion on the affected side of } \\
\text { the walls and sinuses about } \\
\text { the mouth-antrum of High- } \\
\text { more. }\end{array}$ & Electric transillumination. & Disease of the antrum. & \\
\hline $\begin{array}{l}\text { Gerhardt's change } \\
\text { of sound. }\end{array}$ & $\begin{array}{l}\text { A change of percussion-note } \\
\text { according to the patient's } \\
\text { position, whether upright, } \\
\text { lying on the back, or on the } \\
\text { side. Due to changes in the } \\
\text { form of the air-space and } \\
\text { fluid-contents of the thoracic } \\
\text { cavity. }\end{array}$ & $\begin{array}{l}\text { Percussion in the differ- } \\
\text { ent positions. }\end{array}$ & $\begin{array}{l}\text { Pneumothorax, pulmo- } \\
\text { nary tuberculosis. }\end{array}$ & \\
\hline Graefe's sign. & $\begin{array}{l}\text { Failure of the upper lid to } \\
\text { follow the eyeball in glancing } \\
\text { downward. }\end{array}$ & $\begin{array}{l}\text { By having the patient al- } \\
\text { ternately rotate the eyes } \\
\text { up and down. }\end{array}$ & Exophthalmic goiter. & Intraorbital pressure. \\
\hline Grancher's sign. & $\begin{array}{l}\text { The expiratory murmur equals } \\
\text { in pitch that of the inspira- } \\
\text { tory. }\end{array}$ & Auscultation. & $\begin{array}{l}\text { Pulmonary condensa- } \\
\text { tion. }\end{array}$ & $\begin{array}{l}\text { Obstruction to expired } \\
\text { air. }\end{array}$ \\
\hline $\mathrm{ru}$ & $\begin{array}{l}\text { A prominence seen on the } \\
\text { dorsum of the carpus. }\end{array}$ & By flexing carpus. & $\begin{array}{l}\text { Wrist-drop of chronic } \\
\text { lead-poisoning. }\end{array}$ & $\begin{array}{l}\text { Probably some effusion } \\
\text { into the synovial sacs. }\end{array}$ \\
\hline
\end{tabular}


TABLE OF EPONYMIC SIGNS AND SYMPTOMS OF DISEASES,-Continued.

\begin{tabular}{|c|c|c|c|c|}
\hline NAME. & DESCRIPTION. & How Elicited. & Disease PResent IN. & SignIFICANCE. \\
\hline Guyon's sign. & Renal ballottement. & Palpation. & Floating kidney. & \\
\hline $\begin{array}{l}\text { Heberden's nodos- } \\
\text { ities. }\end{array}$ & $\begin{array}{l}\text { Hard nodules, usuaily on the } \\
\text { distal joints of the fingers. }\end{array}$ & Palpation. & $\begin{array}{l}\text { Rheumatoid arthritis, } \\
\text { usually in advanced } \\
\text { life. }\end{array}$ & \\
\hline Hegar's. & $\begin{array}{l}\text { A softening of the lower uter- } \\
\text { ine segment. }\end{array}$ & $\begin{array}{l}\text { By forefinger in the rec- } \\
\text { tum and the thumb in the } \\
\text { vagina, with pressure } \\
\text { from above. }\end{array}$ & Pregnancy. & Pregnancy. \\
\hline Hicks' (Braxton). & $\begin{array}{l}\text { Intermittent uterine contrac- } \\
\text { tions, Begins to be appar- } \\
\text { ent at end of third month. } \\
\text { May also be produced by } \\
\text { any tumor that distends } \\
\text { uterus. }\end{array}$ & Palpation. & Pregnancy. & $\begin{array}{l}\text { Almost a positive sign } \\
\text { of pregnancy. }\end{array}$ \\
\hline Hippocratic facies. & $\begin{array}{l}\text { That of agony, as in impend- } \\
\text { ing dissolution. }\end{array}$ & $\begin{array}{c}\text { By involuntary contrac- } \\
\text { tion of the facial muscles. }\end{array}$ & $\begin{array}{l}\text { In peritonitis and fatal | } \\
\text { diseases. }\end{array}$ & Approaching death. \\
\hline $\begin{array}{l}\text { Hippocratic fin- } \\
\text { gers. }\end{array}$ & $\begin{array}{l}\text { Clubbing of the finger-tips, } \\
\text { with incurvation of the nails. }\end{array}$ & Inspection. & $\begin{array}{l}\text { Pulmonary tuberculosis } \\
\text { and other wasting } \\
\text { diseases. }\end{array}$ & Emaciation. \\
\hline $\begin{array}{l}\text { Hippocratic suc- } \\
\text { cussion. }\end{array}$ & Splashing sound. & $\begin{array}{l}\text { By shaking body of pa- } \\
\text { tient. }\end{array}$ & Pyopneumothorax. & $\begin{array}{l}\text { Air and fluid in the } \\
\text { pleural cavity. }\end{array}$ \\
\hline $\begin{array}{l}\text { Hutchinson's } \\
\text { patch. }\end{array}$ & $\begin{array}{l}\text { Dull-red coloration of the cor- } \\
\text { nea. }\end{array}$ & Ciliary injection. & Interstitial keratitis. & Syphilis. \\
\hline Hutchinson's teeth. & $\begin{array}{l}\text { Upper central permanent in- } \\
\text { cisor teeth are peg-shaped, } \\
\text { and notched on the cutting } \\
\text { edge. }\end{array}$ & Inspection. & Inherited syphilis. & Inherited syphilis. \\
\hline $\begin{array}{l}\text { Hutchinson's trio } \\
\text { of symptoms. }\end{array}$ & $\begin{array}{l}\text { Notched teeth, interstitial ker- } \\
\text { atitis and otitis. }\end{array}$ & Inspection. & Inherited syphilis. & Inherited syphilis. \\
\hline Jaccoud's sign. & $\begin{array}{l}\text { Prominence of the aorta in the } \\
\text { suprasternal notch. }\end{array}$ & Inspection. & $\begin{array}{l}\text { Leukemia (and pseudo- } \\
\text { leukemia). }\end{array}$ & \\
\hline Jacquemin's sign. & $\begin{array}{l}\text { Violet color of the mucous } \\
\text { membrane of vagina; appears } \\
\text { about the fourth week of ges- } \\
\text { tation. }\end{array}$ & Inspection. & Pregnancy. & Venous congestion. \\
\hline Jadelot's lines. & $\begin{array}{l}\text { Various lines on the face of } \\
\text { infants. }\end{array}$ & Inspection. & $\begin{array}{l}\text { Various diseased con- } \\
\text { ditions. }\end{array}$ & \\
\hline Jorisenne's. & $\begin{array}{l}\text { Pulse does not become accel- } \\
\text { erated on changing from } \\
\text { the horizontal to the erect } \\
\text { position. }\end{array}$ & $\begin{array}{l}\text { Change of position as de- } \\
\text { scribed. }\end{array}$ & Pregnancy. & Pregnancy. \\
\hline Keen's. & $\begin{array}{l}\text { Increased diameter through } \\
\text { the leg at the malleoli. }\end{array}$ & Measurement. & $\begin{array}{c}\text { Fracture of fibula } \\
\text { (Pott's). }\end{array}$ & $\begin{array}{l}\text { Solution of the tibio- } \\
\text { fibular articulation. }\end{array}$ \\
\hline Küster's. & $\begin{array}{l}\text { Presence of a cystic tumor in } \\
\text { the median line anterior to } \\
\text { the uterus. }\end{array}$ & Palpation and inspection. & Ovarian dermoids. & $\begin{array}{l}\text { Needs further confir- } \\
\text { mation. }\end{array}$ \\
\hline Laennec's perles, & Rounded gelatinous masses. & Expectorated. & Bronchial asthma. & $\begin{array}{l}\text { Mucous molds of the } \\
\text { smaller bronchial } \\
\text { tubes. }\end{array}$ \\
\hline Laennec's râle. & A modified subcrepitant rale. & Auscultation. & $\begin{array}{l}\text { Pulmonary emphy- } \\
\text { sema. }\end{array}$ & $\begin{array}{l}\text { Mucous in the bron- } \\
\text { chioles. }\end{array}$ \\
\hline $\begin{array}{l}\text { Mannkopf's symp- } \\
\text { tom. }\end{array}$ & $\begin{array}{l}\text { Increase in the frequency of } \\
\text { the pulse. }\end{array}$ & $\begin{array}{l}\text { By pressure on peripheral } \\
\text { points. }\end{array}$ & $\begin{array}{l}\text { Pain (not present in } \\
\text { simulated pain). }\end{array}$ & True pain. \\
\hline Oliver's sign. & Tracheal tugging. & $\begin{array}{l}\text { By grasping the larynx be- } \\
\text { tween the thumb and fin- } \\
\text { ger and pressing up- } \\
\text { ward. }\end{array}$ & Aneurysm of the aorta. & Transmitted impulse. \\
\hline Palmo-plantar. & See Filipovitch's. & & & \\
\hline Parkinson's facies. & $\begin{array}{l}\text { Face expressionless, "wood- } \\
\text { en:" movements of the lips } \\
\text { slow; eyebrows elevated. } \\
\text { The whole expression is im- } \\
\text { mobile and mask-like. }\end{array}$ & Inspection. & Paralysis agitans. & \\
\hline
\end{tabular}




\section{TABLE OF EPONYMIC SIGNS AND SYMPTOMS OF DISEASES.-Continued.}

\begin{tabular}{|c|c|c|c|c|}
\hline NAME. & DESCRIPTION. & How Elicited. & Disease PREsent IN. ! & SIGNiFICANCE. \\
\hline Parkinson's mask. & See Parkinson's facies. & & & \\
\hline Parrot's nodes. & Osteophytes of the skull. & Palpation. & Of syphilitic origin. & Inherited syphilis. \\
\hline Parrot's sign. & Dilatation of the pupil. & $\begin{array}{l}\text { By pinching the skin of the } \\
\text { neck. }\end{array}$ & Meningitis. & \\
\hline Paul's sign. & $\begin{array}{l}\text { A feeble apex-beat, with a for- } \\
\text { cible impulse over the body } \\
\text { of the heart. }\end{array}$ & Palpation. & Pericarditis. & $\overline{\text { Pericardial adhesions. }}$ \\
\hline Porter's sign. & See Oliver's sign and tra & cheal tugging. & & \\
\hline Pott's boss. & Projecting spinous process. & Palpation. & Pott's disease. & Vertebral caries. \\
\hline $\begin{array}{l}\text { Quincke's pulse } \\
\text { (symptom). }\end{array}$ & $\begin{array}{l}\text { Blanching of the finger-nails } \\
\text { at each diastole of the heart. }\end{array}$ & Inspection. & Aortic insufficiency. & $\begin{array}{l}\text { Very marked regurgi- } \\
\text { tation. }\end{array}$ \\
\hline $\begin{array}{l}\text { Ray na ud's phe- } \\
\text { nomena. }\end{array}$ & $\begin{array}{l}\text { A white and cold condition of } \\
\text { the fingers, alternating with } \\
\text { burning heat and redness. }\end{array}$ & & Raynaud's disease, $q . v$. & $\begin{array}{l}\text { Vaso-motor disturb. } \\
\text { ance. }\end{array}$ \\
\hline Ritter's tetanus. & Tetanus of a muscle. & $\begin{array}{l}\text { By suddenly breaking the } \\
\text { circuit while a strong } \\
\text { constant current is pass- } \\
\text { ing through a nerve. }\end{array}$ & & Health. \\
\hline $\begin{array}{l}\text { Ritter-Rollet phe- } \\
\text { nomenon. }\end{array}$ & $\begin{array}{l}\text { Flexion of the foot by gentle } \\
\text { electric stimulation. Exten- } \\
\text { sion of the foot by energetic } \\
\text { stimulation. }\end{array}$ & $\begin{array}{l}\text { Voltaic or faradic stimu- } \\
\text { lation. }\end{array}$ & & \\
\hline $\begin{array}{l}\text { Romberg's symp- } \\
\text { tom. }\end{array}$ & Swaying of the body. & $\begin{array}{l}\text { By standing patient with } \\
\text { feet close together and } \\
\text { with eyes closed. }\end{array}$ & Locomotor ataxia. & $\begin{array}{l}\text { Disturbance of equilib- } \\
\text { rium. Static incoör- } \\
\text { dination. }\end{array}$ \\
\hline Rosenbach's sign. & Abolition of abdominal reflex. & & $\begin{array}{l}\text { In inflammatory intesti- } \\
\text { nal diseases. }\end{array}$ & \\
\hline $\begin{array}{l}\text { Rosenthal's hyper- } \\
\text { acid vomiting. }\end{array}$ & $\begin{array}{l}\text { The vomiting of very acid ma- } \\
\text { terial. }\end{array}$ & & $\begin{array}{l}\text { Exaggerated secretion } \\
\text { of HCI in the gastric } \\
\text { juice. }\end{array}$ & Rossbach's disease. \\
\hline $\begin{array}{l}\text { Seguin's signal } \\
\text { symptom. }\end{array}$ & $\begin{array}{l}\text { The contraction of one mus- } \\
\text { cle or group of muscles, pre- } \\
\text { ceding the epileptic attack. }\end{array}$ & Involuntary. & Epilepsy. & \\
\hline Skeer's symptom. & $\begin{array}{l}\text { A small circle that forms in } \\
\text { the iris near the pupil in both } \\
\text { eyes simultaneously. }\end{array}$ & Inspection. & $\begin{array}{l}\text { Tuberculous menin- } \\
\text { gitis. }\end{array}$ & $\begin{array}{l}\text { Considered pathogno- } \\
\text { monic. }\end{array}$ \\
\hline $\begin{array}{l}\text { Skoda's consonat- } \\
\text { ing râles. }\end{array}$ & $\begin{array}{l}\text { Bronchial rales heard through } \\
\text { consolidated pulmonary tis- } \\
\text { sue. }\end{array}$ & Auscultation. & Pneumonia. & $\begin{array}{l}\text { Mucus in the bronchial } \\
\text { tubes, surrounded by } \\
\text { consolidated struct- } \\
\text { ure. }\end{array}$ \\
\hline $\begin{array}{l}\text { Skoda's resonance, } \\
\text { sign or tympany. }\end{array}$ & $\begin{array}{l}\text { A tympanitic note on percus- } \\
\text { sion. }\end{array}$ & $\begin{array}{l}\text { By percussing the chest } \\
\text { above a large pleural ef- } \\
\text { fusion or above the line } \\
\text { of consolidation in pneu- } \\
\text { monia. }\end{array}$ & $\begin{array}{l}\text { Heard when a pleural } \\
\text { effusion extends up to } \\
\text { the 4th rib or above. }\end{array}$ & $\begin{array}{l}\text { Vicarious action of the } \\
\text { portion of lung not in- } \\
\text { volved (apex or upper } \\
\text { lobe). }\end{array}$ \\
\hline Stairs-sign. & Difficulty in descending stairs. & Attempt to descend stairs. & $\begin{array}{l}\text { Early symptom of loco- } \\
\text { motor ataxia. }\end{array}$ & Incoördiuation. \\
\hline $\begin{array}{l}\text { Stellwag's symp- } \\
\text { tom. }\end{array}$ & $\begin{array}{l}\text { Apparent widening of the paI- } \\
\text { pebral aperture. }\end{array}$ & $\begin{array}{l}\text { Retraction of upper eye- } \\
\text { lid. }\end{array}$ & Exophthalmic goiter. & \\
\hline Stokes' sign. & $\begin{array}{l}\text { Violent throbbing in the abdo- } \\
\text { men to the right of the um- } \\
\text { bilicus. }\end{array}$ & Palpation. & Acute enteritis. & \\
\hline $\begin{array}{l}\text { Tache cérébraie or } \\
\text { Ta che méning- } \\
\text { eale. }\end{array}$ & The appearance of a red line. & $\begin{array}{l}\text { By drawing the finger-nail } \\
\text { over the skin. }\end{array}$ & $\begin{array}{l}\text { Tuberculous me n in - } \\
\text { gitis, acute fevers, and } \\
\text { other conditions. }\end{array}$ & $\begin{array}{l}\text { Supposed at one time } \\
\text { to be pathognomonic } \\
\text { of tuberculous men- } \\
\text { ingitis. }\end{array}$ \\
\hline Tarnier's sign. & $\begin{array}{l}\text { The effacement of the angle } \\
\text { between the upper and lower } \\
\text { uterine segments. }\end{array}$ & Digital examination. & Pregnancy. & Inevitable abortion. \\
\hline $\begin{array}{l}\text { Trousseau's phe- } \\
\text { nomenon or sign. }\end{array}$ & $\begin{array}{l}\text { Muscular spasm, which con- } \\
\text { tinues as long as pressure is } \\
\text { applied. }\end{array}$ & $\begin{array}{l}\text { Pressure on the larger ar- } \\
\text { teries or on the nerve- } \\
\text { trunk. }\end{array}$ & Tetany. & $\begin{array}{l}\text { Heightened neuro- } \\
\text { muscular irritability. }\end{array}$ \\
\hline Trousseau's spots. & See Tache cérébrale. & & & \\
\hline
\end{tabular}


TABLE OF EPONYMIC SIGNS AND SYMPTOMS OF DISEASES-Continued.

\begin{tabular}{|c|c|c|c|c|}
\hline NAME. & DESCRIPTION. & How Elicited. & DISEASE PRESENT IN. & SIGNIFICANCE. \\
\hline Valleix's points. & $\begin{array}{l}\text { Tender spots along the course } \\
\text { of a nerve. }\end{array}$ & Pressure. & Neuralgia. & \\
\hline $\begin{array}{l}\text { Wallerian degen- } \\
\text { eration. }\end{array}$ & $\begin{array}{l}\text { Degeneration of nerves after } \\
\text { separation from their trophic } \\
\text { centers. }\end{array}$ & & Injuries to nerves. & $\begin{array}{l}\text { Loss of trophic in- } \\
\text { fluence. }\end{array}$ \\
\hline Weber's symptom. & $\begin{array}{l}\text { Paralysis of the oculo-motor } \\
\text { nerve of one side and hemi- } \\
\text { plegia of the opposite side. }\end{array}$ & & & \\
\hline $\begin{array}{l}\text { Wernicke's symp- } \\
\text { tom. }\end{array}$ & $\begin{array}{l}\text { The condition of the pupillary } \\
\text { reaction. }\end{array}$ & $\begin{array}{l}\text { By throwing a ray of light } \\
\text { on the blind half of the } \\
\text { retina. }\end{array}$ & Hemianopsia. & $\begin{array}{l}\text { If reaction is present, it } \\
\text { would indicate a cen- } \\
\text { traltruuble; if absent, } \\
\text { a lesion of the path } \\
\text { between the retina } \\
\text { and the geniculate } \\
\text { bodies may be in- } \\
\text { ferred. }\end{array}$ \\
\hline $\begin{array}{l}\text { Westphal's foot- } \\
\text { phenomenon. }\end{array}$ & Ankle-clonus. & $\begin{array}{l}\text { By suddenly flexing foot } \\
\text { on leg. }\end{array}$ & Lateral sclerosis. & $\begin{array}{l}\text { Indicates disease of the } \\
\text { pyramidal tracts. }\end{array}$ \\
\hline $\begin{array}{l}\text { Westphai's para- } \\
\text { doxic contrac- } \\
\text { tion. }\end{array}$ & $\begin{array}{l}\text { The tonic contraction of a } \\
\text { muscle caused by the passive } \\
\text { approximation of its extrem- } \\
\text { ities. Best known in the } \\
\text { tibialis anticus. }\end{array}$ & $\begin{array}{l}\text { In anterior tibial, by rapid } \\
\text { dorsal flexion of the foot. }\end{array}$ & $\begin{array}{l}\text { Paralysis agitans(West- } \\
\text { phal), and sclerosis of } \\
\text { the postero-lateral col- } \\
\text { umns of the cord. }\end{array}$ & $\begin{array}{l}\text { Always indicates dis- } \\
\text { ease. }\end{array}$ \\
\hline Westphal's sign. & Abolition of the knee-jerk. & $\begin{array}{l}\text { Percussion over the quadri- } \\
\text { ceps tendon. }\end{array}$ & $\begin{array}{l}\text { Locomotor ataxia, de- } \\
\text { structive lesions of } \\
\text { lower part of cord, pe- } \\
\text { ripheral neuritis, etc. }\end{array}$ & \\
\hline $\begin{array}{l}\text { Westphal-Erb } \\
\text { symptom. }\end{array}$ & Same as Westphals. & & & \\
\hline $\begin{array}{l}\text { Williams' tracheal } \\
\text { tone. }\end{array}$ & $\begin{array}{l}\text { A dull tympanitic resonance, } \\
\text { becoming higher pitched on } \\
\text { opening the mouth. }\end{array}$ & Percussion. & Pleural effusion. & $\begin{array}{l}\text { Arises from the vibra- } \\
\text { tion of air in a large } \\
\text { bronchus surrounded } \\
\text { by compressed lung. }\end{array}$ \\
\hline Wintrich's sign. & $\begin{array}{l}\text { Change in the pitch when the } \\
\text { mouth is opened and closed. }\end{array}$ & Percussion. & $\begin{array}{l}\text { Tuberculosis pulmon- } \\
\text { alis. }\end{array}$ & Pulmonary cavity. \\
\hline $\begin{array}{l}\text { Zenker's degenera- } \\
\text { tion. }\end{array}$ & $\begin{array}{l}\text { A degeneration of the muscu- } \\
\text { larfibers, causing them to be- } \\
\text { come brittle and easily } \\
\text { broken on forcible contrac- } \\
\text { tion. }\end{array}$ & & $\begin{array}{l}\text { High or continued } \\
\text { fevers. }\end{array}$ & \\
\hline
\end{tabular}

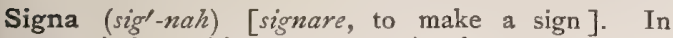
prescription-writing, a conventional term meaning "mark." It designates the physician's directions to the patient concerning the medicine prescribed.

Signal (sig'-nal) [signum, a sign]. A sign. S., Marcel Duprez', the interruption of an electric current produced by a tuning-fork of Ioo vibrations per second.

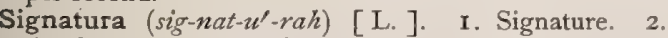
A characteristic mark. 3. The directions showing how medicines are to be taken.

Signature (sig'-na-tūr) [signare, to sign, mark]. In biology, a characteristic, distinguishing, or significant mark or appearance. Ss., Doctrine of, a system of discovering the medicinal uses of a plant or mineral from something in its external appearance (color, shape, or markings) that resembled the disease it would cure. Accordingly, the stony seeds of grom. well (Lithospermum officinale) were held good for gravel, the knotty tubes of Scrophularia for scrofulous glands, while the scaly pappus of Scabiosa showed it to be a specific in leprous diseases; the spotted leaves of Pulmonaria, that it was a sovereign remedy for tuberculous lungs, and the growth of Suxifrage in the fissures of rocks that it would disintegrate stone in the bladder; Turmeric and Celandine were recommended for jaundice on account of their color ; Liverzort for torpidity of the liver; Euphrasy, being marked with an eye, was good for sore eyes; Orchis, resembling a testis, was good as an aphrodisiac; Dock-root was yellow, and therefore good for jaundice. Many plants still possess common names based on this doctrine, e.g., Backwort (Symphytum officinale); Bladder-herb (Physalis alkekengi); Blood-root (Potentilla tormentilla); Breakstone (Saxifraga sp., Pimpinella saxifraga); Bruisewort (Bellis perennis); Burstwort (Herniaria glabra); Cancerwort (Linaria spuria, $L$. elatine); Chafeweed (Gnaphalium sylvaticum); Colickwort (Alchemilla arvensis); Dropwort (Spirca filipendula); Eyebright (Euphrasia officinalis); Felonwort (Solanum dulcamara); Gallwort (Linaria vulgaris); Goutweed (Aggopodium podagraria); Jaundice Tree (Berberis vulgaris); Milkwort (Polygala vulgaris); Nailwort (Draba verna); Navelwort (Cotyledon umbilicus); Neckweed (Cannabis sativa); Open-arse (Mespilus germanica); Palsywort (Primula veris); Pestilence-wort (Petasites vul- 
garis); Quinseywort (Asperula cynanchica) ; Sharewort (Pallenis spinosa); Spleenwort (Asplenium ceterach); Stitchwort (Stellaria holostea); Tetterberry (Bryonia dioica); Throatwort (Campanula trachelium); Toothwort (Lathrea squamuria); Uvulawort. See Throatroort.

Signum (sig'-num) [L.]. A mark, sign, or indication. Siguatera (sig-zwah-te'-rah) [Sp.]. The name given by Spanish colonists to a complex of symptoms that resulted from eating poisonous fishes indigenous to certain hot countries.

Sikimin $\left(s^{\prime} k^{\prime}-i m-i n\right)$ [sikkim, a region of the Himalaya]. A poisonous principle derived from Illicium religiosum. Unof.

Silent Region of the Brain and Cord. The gray matter of the cord.

Silex (si'-leks) [L.]. See Silica.

Silica Quartz (sil'-ik-ah kworts) [silex, flint]. The oxid of silicon, $\mathrm{SiO}_{2}$, It occurs in nature in the mineral form, of which sea-sand is a familiar example.

Silicate $\left(s i l^{\prime}-i k-\bar{a} t\right)$ [silex, flint]. A salt of silicic acid.

Silicic $\left(s i l-i s^{\prime}-i k\right)$ [silex, flint]. Containing silicon.

Silicide (sil'-is-id) [silex, flint]. A combination of silicon with another element.

Silicious, Siliceous (sil-ish'-us) [silex, flint]. Having the nature of or containing silicon.

Silicium $($ sil-ish'-e-um). See Silicon.

Silicle $($ sill-ik-l) [silicula, a little husk or pod]. In biology, a short pod not over three times longer than broad, e.g., that of the Shepherd's Purse (Capsella bursa-pastoris)

Silicol (sil"-ik-ol) [silex, flint]. An alcohol from a silicon or silicon-carbon radicle.

Silicon (sit -ik-on) [silex, flint], $\mathrm{Si}=28$; quantivalence IV. One of the elements, and, next to oxygen, the most abundant, forming about one-fourth of the crust of the globe. See Elements, Table of. In medicine, it is used in the form of an alkaline silicate chiefly. See Potassium, Sodium, and Magnesium; also Tabasheer. Some forms are used in dentifrices, and others in pharmacy. S. hydrid, a colorless inflammable gas

Silicosis $($ sil-ik-o'-sis). See Chalicosis.

Silicula (sil-ik'-u-lah) [L.]. Same as Siticle.

Silicular (sit-ik'-u-lar) [silicula, a silicle]. In biology, having the shape or appearance of a silicle.

Silicule $\left(s i l^{\prime}-i k-\bar{u} l\right)$. Same as Silicle.

Siliculose (sil-ik'-u-lōz) [silicula, a little husk]. In biology, the same as Siticular.

Silicyl (sil'-is-il) [silex, flint]. A radicle containing silicon directly combined with a trivalent radicle.

Siliqua (sil-ik'-wah) [siliqua, a busk, pod : pl., Siliqua]. Same as Silique

Silique (sit-êk') [siliqua, a husk, pod]. In biology, the slender, two-valved capsule of some Cruciferce. It is divided into cells by a false partition stretched between two opposite parietal placentæ, and which often persists after the valves have fallen away.

Silk [ME, silk, silk]. The simplest and most perfect of the textile fibers. It differs from all other fibers in that it is found in nature as a continuous fine thread. Silk is the product of the silk-worm (Bombyx mori), and is simply the fiber that the worm spins around itself for protection when entering the pupa or chrysalis state. The silk-fiber consists, to the extent of rather more than half its weight, of fibroin, $\mathrm{C}_{15} \mathrm{H}_{23} \mathrm{~N}_{5} \mathrm{O}_{6}$, a nitrogenous principle. Covering this is the silk-glue, or sericin, $\mathrm{C}_{15} \mathrm{H}_{25} \mathrm{~N}_{5} \mathrm{O}_{8}$. The most important physical properties of the silk-fiber are its luster, strength, and avidity for moisture. Besides the true silk, we have several so-called "wild silks," the most important of which is the Tussur silk, the product of the larva of the moth, Antherca mylitta, found in India. The cocoons are much larger than those of the true silk. worm, are egg-shaped, and of a silvery drab color. The cocoon is very firm and hard, and the silk is of a drab color. It is used for the buff-colored Indian silks, and latterly largely in the manufacture of silk plush. Other wild silks are the Eria silk of India, the Muga silk of Assam, the Atlas or Fagara silk of China, and the Yamamai silk of Japan. Silk has been used as a hemostatic. See Sericum. S., Epispastic, silk containing some vesicant. S. Floss, Dentists', untwisted filaments of fine silk, prepared expressly for the purpose of cleaning the surfaces of the teeth, and used by some dentists for finishing the surfaces of fillings in the sides of teeth. S.-grass. See Pineapple Fiber. S., Saddler's, a heavy silk used by saddlers, and to some extent in surgery. S.-weed. See Milk-weed. S.-worm, the larva of the silk-moth. S.-worm Gut, the thread drawn from a silk-worm killed when ready to spin the cocoon.

Sillonneur (sil on-u/') [Fr.]. A three-bladed scalpel used by ophthalmologists.

Sillyhow (sil'-e-howe) [E. dia.]. The caul which sometimes covers the head of the new-born child.

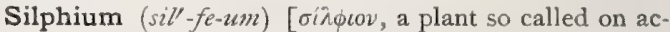
count of its resinous juice]. An umbelliferous plant, Thapsia silphium, Viviani, so highly esteemed among the ancients for its juice, which according to Pliny was a remedy for sixty diseases, internal and external, that it was sold for its weight in silver, and figured largely on the coins of Cyrene, its native home. The Greeks called it silphium, from silphi, its African name; the Romans laserpitium.

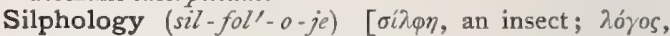
science]. The morphology and development of larvæ.

Silver (sil'-ver). See Argentum and Elements, Table of. S., Coin, an alloy consisting of nine parts silver to one of copper. S. Fir. See Abies. S.-fork Deformity, a peculiar displacement of the wrist and hand in fracture of the lower extremity of the radius. S., Sterling, an alloy consisting of 925 parts silver to 75 parts copper. S. White. Same as White Lead.

Simaba (sim- $\left.a^{\prime}-b a h\right)$ [native name in Guiana]. A genus of simarubaceous tropical trees. S. cedron, S. ferruginea, S. floribunda, etc., have exceedingly bitter barks, and are tonic and febrifuge. Unof.

Simaruba (sim-ar-u敞-bah) [native name in Guiana]. I. A genus of tropical American trees, the type of the order Simarubacea. S. amara, S. glauca, S. officinalis, S. medicinalis, and others have barks with tonic properties. Unof.

Similar (sim'-il-ar) [L.]. Having the same characteristics.

Simon's Position. See Postures, Table of. S.'s Triangles. See Triangles, Table of.

Simple $\left(\operatorname{sim}^{\prime}-p l\right)$ [simplex, simple]. I. Not complex; consisting of a single ingredient; not compound. 2. Wanting in intellect. 3. A medicinal plant.

Simpler, Simplist (sim'-pler, sim'-plist). An herbdoctor.

Simpler's Joy. The common vervain, $q . v$.

Simples (sim'-plz) [simplex, simple]. A common term for herbs having a medicinal value.

Simplist $\left(\operatorname{sim}^{\prime}\right.$-plist). See Simpler.

Simpson's Method. See Trealment, Methads of.

Sims' Depressor. An instrument for holding back the wall of the vagina in examination of that cavity. S. Feeder, an instrument for aiding in the suture of tissues. S. Posture or Position. See Postures, Table of: S. Speculum. See Speculum. 
Simulation (sim-u-ll'-shun) [simulatio : simulare, to feign]. In medicine, the feigning or counterfeiting of disease. The pretence of a malingerer.

Simulo $\left(\sin ^{\prime}-u-l o\right)$. The fruit of certain species of Capparis, especially $C$. coriacea, of Peru; it is recommended as a cure for epilepsy, and possesses antiscorbutic and stimulant properties. Dose of the tincture $3 \mathrm{ss}-\mathrm{iij}$; of the fluid extract $3 \mathrm{j}$-iij. Unof.

Sinalbin (sin-al/-bin). A neutral crystalline glucosid found in white mustard, soluble in cold water.

Sinamin (sin'-am-in), $\mathrm{C}_{3} \mathrm{H}_{5} \mathrm{CN}$. Allyl cyanamid, a substance obtained from crude oil of mustard.

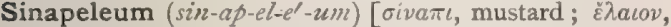
oil]. Mustard-oil.

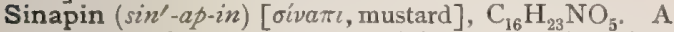
substance that occurs as a sulpho-cyanate in white mustard. Free sinapin is soluble and decomposable.

Sinapis (sin'-a-pis) [oivart, mustard]. Mustard. The seeds of $S$. alba, white mustard, and $S$. nigra, black mustard. They contain a ferment, myrosin, and a crystalline substance, which, when moistened, unite to form a volatile oil of allyl sulpho-cyanid. Locally the seeds act as a powerful rubefacient ; internally, as a stomachic stimulant; in large doses as an emetic. Sinapis is much used locally in the form of the well-known " mustard-plaster." S., Cataplasma (B. P.), mustardpoultice, contains mustard, linseed meal, and water. S., Charta, mustard-paper, consists of black mustard mixed with a solution of India-rubber and spread on paper. S., Liniment., Comp., contains oil of mustard 3, fld. ext. mezereum 20, camphor 6, castor-oil I5, alcohol q. s. S., O1., the volatile oil. Dose $m 1 / 8-1 / 4$.

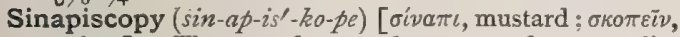
to view]. The use of mustard as a test of sensory disturbances, analogous to a similar use of metalloscopy.

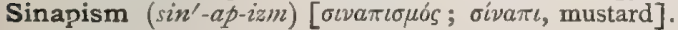
A mustard-plaster.

Sincaline (sin'-kal-èn). Same as Cholin.

Sincipital (sin-sip'-it-al) [sinciput, the head]. Pertaining to the sinciput.

Sinciput $\left(\sin ^{\prime}-\operatorname{sip}_{-} u t\right)$ [semi, half; caput, head]. The superior and anterior part of the head. Also, the top of the head; the bregma.

Sindon $\left(\sin ^{\prime}-d o n\right)[\sigma \iota \nu \delta \sigma \nu$, linen $]$. A pledget or dossil.

Sinew $\left(\sin ^{\prime}-u\right)$ [ME., sinewe, sinew]. Tendinous or ligamentous tissue. S.-shrunk, having some of the sinews wasted; said of horses or mules. The condition is mainly caused by overwork.

Singultus (sing-gul'-tus). See Hiccongh.

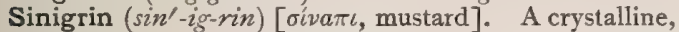
bitter-tasting, inodorous glucosid of black mustard, soluble in water, but not in alcohol or ether.

Sinistrad ( $\sin ^{\prime}$-is-trad) [sinister, the left hand]. Toward the left.

Sinistral (sin'-is-tral) [sinister, left]. At or in the direction of the left side of the body. See the opposite, dextral; also Position and Direction, Table of.

Sinistren (sin'-is-tren) [sinister, left]. Belonging to the sinistral side in itself.

Sinistrin (sin'-is-trin) [sinister, left]. A dextrin-like substance found in squills.

Sinistrocerebral (sin'-is-tro-ser'-e-bral) [sinister, left; cerebrum, cerebrum]. Occurring or situated in the left hemisphere of the brain.

Sinistrorse (sin'-is-trors) [sinister, left ; vertere, turn]. In biology, turning from right to left; said of a plant climbing in an opposite direction from the sun.

Sinual ( $\sin ^{\prime}-u$-al) [sinus, a curve]. Possessing the characteristics of a sinus.

Sinuate $\left(\sin ^{\prime}-u-\vec{a} t\right)$ [sinuare, to curve, swell out in 84 curves]. In biology, wavy, or winding in and out Applied to the margins of leaves and other flattened organs.

Sinuation ( $\left.\sin -u-\alpha^{\prime}-\operatorname{shu} n\right)$ [sinuatus, from sinuare, to bend]. I. The state of being sinuate. 2. A cerebral gyre.

Sinu-auricular (sin-u-arv-rik'-u-lar) [sinus, a curve; auricula, auxicle]. In biology, pertaining to the sinus venosus and the auricle.

Sinuose $\left(\sin ^{\prime}-u-\vec{o} z\right)$. Same as Sinuous.

Sinuosity (sin- $\left.\imath-0 s^{\prime}-i t-e\right)$ [simuare, to bend]. Anfractuosity; the state of being sinuous or bent.

Sinuous $\left(\sin ^{\prime}-u-u s\right)$ [sinuosus; sinus, a curve]. Wavy; applied especially to tortuous fistulæ and sinuses.

Sinus (si'-nus) [sinus, a curve, fold, hollow: pl., Sinus or Sinteses]. A hollow or excavation, a cavity, recess, pocket, dilatation, or channel in a bone or other structure. The term is applied also to an abnormal pathway or canal, usually the result of ulceration. S. acusticus internus. See Canal, Internal Auditory. S., Air, any one of the cavities within bones, containing air, especially those communicating with the nasal passages. $\mathbf{S}$. alæ parvæ. See S., Spreno-parietal. S. amplus ureteris, the pelvis of the kidney. S. ampullaceus. See Ampulla os sea. S., Anterior. See Lateral Ventricle. S. of Aorta. See $S$, of Valsalva. S., Aortic. See $S$. of Valsalva. S. aritii. See Lacrymal Fossa. S. arteriosus. See $S$. pulmonalis, S. atlantis, a depression for the passage of vessels and nerves on the upper surface of the posterior part of the arch of the atlas. S. auditorius, the cavity of the tympanum. S., Basilar. See S., Transverse. S. basilaris anterior. See S., Transverse. S. of Breschet, the sphenoparietal sinus. S. bulbi. See S. bulbi urethra. S bulbi rhachidici. See Fourth Ventricle. S. bulbi urethræ, a dilatation of the bulb of the urethra. S. canalis vertebralis, any of the spinal veins. S. caroticus, S. carotidien. See S., Cavernous. S. cavernosus. See $S$, Cavernous. S., Cavernous, a large sinus extending from the sphenoid fissure to the apex of the petrous portion of the temporal bone, communicating behind with the inferior and superior petrosal sinuses and receiving the ophthalmic vein in front. S. cavi cranii. See S., Cranial. S. choroidien, See $S$., Straight. S. circulaire de Ridley. See $S$.. Circular. S. circulaire du trou occipital. See $S$. circularis foraminis magni. S., Circular, a venous sinus surrounding the hypophysis, communicating on each side with the cavernous sinus. S., Circular (of the placenta), a plexus of veins in the maternal portion of the placenta in communication with the utero-placental sinus. S. circularis. See S., Circular. S. circularis foraminis magni (seu occipitalis). A venous plexus surrounding the posterior margin of the foramen magnum. S. circularis iridis. See Canal of Schlemm. S., Clinoid. See S., Circular. S. cochlex, a vein in the aqueduct of the cochlea opening into the internal jugular vein. $\mathbf{S}$. du ccur. See Atrium. S. columnæ vertebralis, the anterior longitudinal spinal veins. S. communis. See Utricle (2d def.). S. communis venarum cardiacarum (seu cordis). See S., Coronary (of the heart). S. condylorum anterior. See Fossa intercondyloidea anterior. S., Confluence. See Torcular herophili. S. cordis. See Atrium. S. coronaire du placenta. See S., Circular (of the placenta). S. coronarius. See S., Coronary (of the heart). S., Coronary (of the heart), a vein in the transverse groove between the left auricle and the left ventricle of the heart on its posterior aspect; it is by some regarded as a dilatation of the great cardiac vein into which it opens. 
S. of Coronary Vein. See S., Coronary (of the heart). S. coronoideus. See S., Circular. S. du corps calleux. See Callosal Fissure. S. costales. See Incisura costales. S. costarii. See Fovece articulares laterales. S. coxæ. See Acetabulum. S., Cranial, one of certain venous channels between the folds of the dura lined with a continuation of the tunica intima of the veins. S. craniens. See S., Cranial. S. of Cuvier. See Ducts of Cuvier. S., Diploic, channels containing veins which traverse the diploe of cranial bones. S. ductus lactiferi. See Ampulla ductus lactiferi. S. duræ matris. See S., Cranial. S. ellipticus. See S., Circular. S. epididymidis, the furrow between the posterior surface of the epididymis and the testicle. S., Ethmoid. See Ethmoid Cells. S. ethmoidales. See Ethmoid Celis. S. of the External Meatus, a space at the bottom of the external auditory canal between the concave inferior wall of the osseous meatus and the membrana tympani. S. falciformis inferior. See S., Inferior Longitudinal. S. falciformis superior (seu triangularis). See S., Superior Longitudinal. S. fossæ basilaris. See S., Transverse. S. frænuli, the depression at the side of the frenum of the penis. S., Frontal, an irregular cavity in the frontal bone, underlying the prominence at the root of the nose, and over the superior orbital margin, extending upward and outward between the two tables of the bone, separated from its fellow of the opposite side by a thin septum, and communicating with the nose by the infundibulum. S., Galactophorous. See Ampulla ductus lactiferi. S. genæ pituitarius (highmori). Se e Maxillary Antrum. S., Genital, the cleft of the vulva. S., Genitourinary. See S., Urogenital. S. Great (of the aorta), a dilatation generally found on the right side of the ascending portion of the aorta. S. of Highmore. See Maxillary Antrum. S. hippocampi inferior. See Hippocampus Major. S., Inferior Intercavernous, the lower of the two veins sometimes replacing the single sinus intercavernosus anterior. S., Inferior Longitudinal, a venous sinus which extends along the posterior half of the lower border of the falx cerebri and terminates in the straight sinus near the anterior margin of the tentorium. S., Inferior Petrosal, a large venous sinus arising from the cavernous, running along the lower margin of the petrous portion of the temporal bone, and joining the lateral sinus, to form the internal jugular vein. S. intercavernosus anterior, the anterior half of the circular sinus. S. intercavernosus posterior, the posterior half of the circular sinus. S. Intercavernous, the anterior and posterior halves of the circular sinus. S., Internal. See $S$, Straight. S. jugularis spurius. See S., Petro-squamous. S. of the Jugular Vein, the bulbi venæ jugularis (distinguished as inferior, internus, and superior). S. of Kidney, the prolongation inward of the bilum of the kidney. S. lacrimales. See Cells, Anterior Ethmoid. S. lacrimalis. See S., Lacrymal. S., Lacrymal, a small pouch formed by a fold of skin at the inner angle of the eye in the deer and some other quadrupeds. It can be opened or shut at will, has no connection with the lacrymal passages, and contains a gland which secretes a viscid substance resembling the cerumen of the ear. S., Lacteal. See Ampulla ductus lactiferi. S. lacteus lactiferus. See Ampulla ductus lactiferi. S. lactiferi secundarii, dilatations of the milk-ducts in addition to the ampulla. S. laiteux. See Ampulla ductus lactiferi. S. laryngis (of Morgagni). See Ventricle of the Larynx. S. of the Larynx. SeeVentricle of the Larynx. S., Lateral, a venous sinus which begins at the torcular and runs horizontally on the inner surface of the

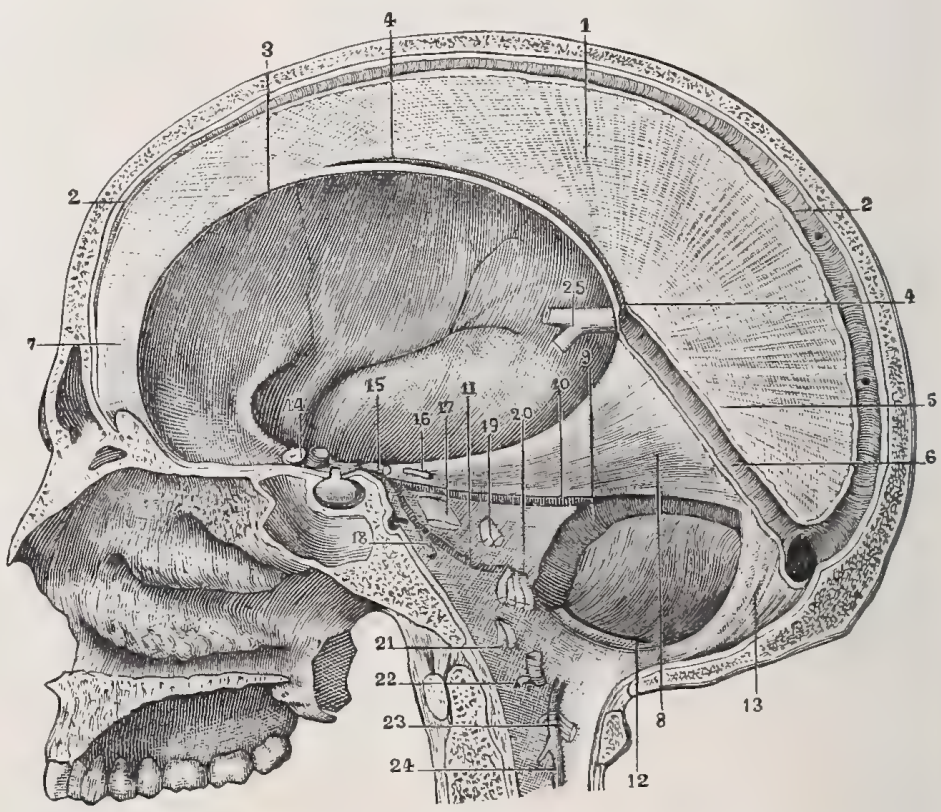

Falx cerebri. 2, 2, Its convex border, with the great longitudinal sinus. 3 . Its concave border. 4, 4. Inferior longitudinal sinus. 5. Base of falx cerebri. 6. Straight sinus. 7. Apex of falx cerebri. 8. Right half of the tentorium, seen from below. 9. Right lateral sinus. I0. Superior petrosal sinus. Ir. Inferior petrosal sinus. I2. Posterior occipital sinus. 13. Falx cerebelli. I4. Optic nerve. 15. Motor oculi. 16. Pathetic. I7. pneumogastric and spinal accessory nerves. 21. Hypoglossal nerve. 22. First cervical nerve. 23. Second cervical nerve. 24, 24. Upper extremity of ligamentum denticulatum. 
Mammary Gland. See Ampullu ductus lactiferi. S., Marginal, a variety of the occipital sinus opening into the transverse. S., Marginal (of the placenta). See S., Circular (of the placenta). S. marginalis. See S., Marginal. S., Mastoid. See Mastoid Cells. S. mastoideus. See Mirstoid Cells. S. maxillaris. See Maxillary Antrum. S., Maxillary. See Maxillary Antrum. S. maximus. See Olecranon Fossa and S., Great (of the aorta). S. maximus aortx. See S., Great (of the aorta). S. maximus cubitalis (seu humeri). See Olecranon Fossa. S., median sxptum. See S., Superior Longitudinal. S., Median, Superior. See S., Superior Longitudinal. S. medianus. See Vestibular Saccule. S. mediastinocostalis (pleurce), the part of the pleura where the costal and mediastinal portions unite'behind the sternum. S. mediastinophrenicus, the part of the pleura where the mediastinal and diaphragmatic portions unite. S. of Morgagni, the interval between the upper border of the superior constrictor muscle and the basilar process of the occipital bone. See Lacuna morgagni, S. of. Valsalva, and Ventricle of the Larynx. S. mucosi urethræ. See Lacunce morgagni. S. muliebris. See Vagina. S. nasi accessorii, the various air-sinuses connected with the nose. S. obliquus. See S., Straight. S., Occipital, a small venous sinus in the attached margin of the falx cerebelli, opening into the torcular herophili. See S., Lateral. S. occipitalis, $\mathbf{S}$. occipitalis posterior. See $S_{\text {. }}$ Occipital. S. occipitalis anterior. See S., Transverse. S. occipitalis transversus. See S., Transverse. S. opertus minor. See Occipital Fissure. S. ophthalmicus. See S, Cavernous. S. ophthalmopetrosus, an anomalous opening into the transverse sinus. $\mathbf{S}$. palatinus. See Ethmoid Cells, Posterior. S. parieto-occipitalis. See Occipital Fissure. S. pedis, the internal sinus between the astragalus and the os calcis. S. pericardiacocostalis, the left mediastinocostal sinus. S. pericardii. See $S$. transversus pericardii. S. perpendicularis. See S., Straight. S., Petit's. See.S. of Valsalva. S. petrobasilaris. See S., Superior. Petrosal. S. petro-occipitalis inferior, a vein uniting the cavernous sinus and the circellus venosus hypoglossi. S., Petro-occipitalis superior. See S., Superior Petrosal. S., Petrosal, venous sinuses along the borders of the petrous portion of the temporal bone. S., Petroso-squamous. See S., Petro-squamous. $S$. petro-squamous, a venous sinus running along the petro-squamous suture, and opening into the transverse sinus; it is believed to be a relic of a fetal communication with the internal jugular vein. $\mathbf{S}$. petrosus inferior. See S., Inferior Petrosal. S. petrosus medius, an anomalous communication between the inferior and superior petrosal sinuses. S. petrosus profundus. See $S$, Inferior Petrosal. S. petrosus superficialis (seu superior). See S., Superior Petrosal. S., Pharyngo-laryngeal. See Fossa laryngopharyngea. S. pharyngolaryngei. See Fossa laryngopharyngea. S. phrenicocostalis, the part of the pleura where the costal and diaphragmatic portions join. S. phrenicomediastinalis. See $S$. mediastinophrenicalis. S., Pilo-nidal. See Foveola coccygea. S. pituitarius frontis. See S., Frontal. S., Placental. See $S$, Utero-placental. S. pleuræ, the spaces in the pleural sac, along the lower and inferior portions of the lung, which the lung does not occupy. S. pocularis. See Uterus masculinus. S. of the Portal Vein, an enlargement of the portal vein near the right end of the transverse fissure of the liver. S., Posterior Basilar. See S., Occipital. S., Posterior
Ethmoid. See Ethmoid Cells, Posterior. S., Pos. terior Occipital. See S., Occipital. S. primus et secundus (of Galen), the transverse sinus. S., Prostatic. See Uterus masculinus. S. prostaticus. See Uterus masculinus. S. protuberantiæ annularis, the basilar groove of the pons. S. pulmonalis, the atrium of the left auricle. S., Pulmonary. See S. pulmonalis. S., Pyramidal (of the lar$y n x$ ). See Fossa laryngopharynoea. S. pyriformis. See Fossa laryngopharyngea and Fossa, Hyoid. S. quartus. I. The fourth ventricle of the brain. 2 . (Of Galen). See S., Straight. S. quartus aortæ. See S., Great (of the aorta). S. quintus, the fifth ventricle of the brain. $\mathbf{S}$. ad radicem linguæ (Morgagni). See Foramen cacum (of the tongue). S. rectus. See S., Straight. S, renalis. See $S$. of the Kidney and Hilum of the Kidney. S. reuniens. See Meatus venosus. S. Rhomboidal, S. Rhomboid: I. A dilatation in the sacral region of the central canal of the spinal cord of birds. 2. The fourth ventricle of the brain. S. rhomboidalis, the fourth ventricle of the brain. S. rhomboidalis lumbalis, the expansion of the central canal of the spinal cord near the lumbar enlargement. S., rhomboideus, the fourth ventricle of the brain. S., Ridley's. See S., Circular. S. sæpti (lucidi), the fifth ventricle of the brain. S. sagittalis superior. See S., Superior Longitudinal. S. secundus. See S., Superior Petrosal. S. of the Seminiferous Tubules. See Corpus highmori. S. semiovalis. See Fovea hemielliptica. S. septimus (of Guidi), the superior longitudinal sinus. S. sigmoideus. See S., Lateral. S. speculi, the fifth ventricle of te brain. S., Sphenoid, air-sinuses which occupy the ody of the sphenoid bone and communicate with tile nasal cavity. S., Sphenoparietal, a vein uniting the cavernous sinus and a meningeal vein. S. sphenoparietalis. See S., Sphenoparietal. S. squamopetrosus. See S., Petrosquamous. S., Straight (of the tentorium), a sinus which is continuous with the inferior longitudinal sinus and, running along the junction of the falx cerebri and tentorium, is continuous with the lateral sinus. S. subarachnoidalis. See Subarachnoid Space. S. sulciformis. See Fossula sulciformis. S. sulciformis (Mororagni), the Aditus ad aquaductum sylvii. S., Superior Longitudinal, a triangular canal which runs along the upper edge of the falx cerebri, beginning in front at the crista galli and terminating at the torcular. It is received into a median groove in the frontal, parietal, and occipital bones. S., Superior Petrosal, a venous canal running in a groove in the petrous portion of the temporal bone extending from the posterior part of the cavernous sinus to the lateral sinus on the mastoid portion of the temporal bone. S., Tarsal, the passage between the tarsal bones occupied by the intertarsal ligament. S. tentorii. See S., Straight. S. tentorii lateralis. See S., Superior Petrosal. S. tentorii lateralis (seu posterior). See S., Lateral. S. tentorii medius. See S., Straight. S. tentorii medius (seu posterior). See S., Straight. S., Terminal. I. See S. terminalis. 2. Of Toldt, sinus-like spaces near the hilum of a lymph-gland. S. terminalis, a vein that encircles the vascular area of the blastoderm, and empties either by one trunk, the anterior vitelline vein, into the left vitelline vein, or by two trunks into both vitelline veins. S. tertius, the third ventricle of the brain. S., Transverse : I. A sinus uniting the inferior petrosal sinuses. 2. A venous network in the dura over the basilar process of the occipital bone. It opens into the inferior petrosal and the anterior spinal veins. S. transversus. See S., 
Transverse. S. transversus pericardii, an opening connecting the prolongation of the pericardium which covers the pulmonary artery and the aorta with that covering the auricles. S. triangularis. See $S$, Superior Longitudinal. S. tuberculi (ossis metacarpi), a depression upon the external surface of a metacarpal bone just above its distal articular surface. S. tympani. See Sulcus tympani. S. of the Urethra. See Bulbi urelhra. S., Urino-genital, S., Urogenital: I. The canal or duct into which, in the embryo, the Wolffian ducts and the bladder empty, and which opens into the cloaca. 2. In comparative anatomy, the common receptacle of the genital and urinary ducts. S. urino-genitalis, S. urogenitalis. See S, Urino-genital. S., Uterine, the veins of the uterus when in a state of dilatation due to the enlargement of the organ, as in pregnancy. S. Utero-placental, slanting venous channels which is. sue from the placenta at its uterine surface by piercing the decidua serotina, and serve to convey the maternal blood from the intervillous lacunæ back into the uterine veins. S. of the Uterus. See S., Uterine. S. of Valsalva, dilatations of the aorta and pul monary artery opposite the segments of the aortic and pulmonary valves. S. valsalvæ. See $S$. of Valsalva. S., Valvular. See S. of Valsalva. S. of a Vein, a pouch-like enlargement of a vein on the cardiac side of its valves. S. venæ coronariæ (magna proprius). See S., Coronary (of the heart). S. venæ jugularis. See $S$. of the Jugular Vein. S. venæ portæ, the sinus of the portal vein. $S$. venarum cavarum, the right auricle of the heart. S. venosi duræ matris. See $S_{1}$, Cranial. $\mathbf{S}$. venosus, the canal of Schlemm. See S., Venous. S. venosus anterior. See Vena mediana medulla spinalis anterior. S. venosus cordis. See Atrium. S. venosus cornez. See Canal of Schlemm. S. venosus hovii, a ring-like anastomosis of the venæ vorticosæ. S. venosus iridis. See Canal of Schlemm. S., Venous, one conveying venous blood. See also Meatus venosus. S., Vertebral, veins within the bodies of the vertebræ. S. vesicæ urinariæ. See Recessus vesice urinaria.

Siphilis (sif'-il-is). See Syphilis.

Sipho $\left(s^{\prime}-f o\right)[\sigma i \phi \omega \nu$, tube]. A syringe.

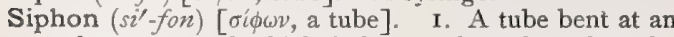
angle one arm of which is longer than the other, for the purpose of transferring a liquid from one vessel to another. Trocars and aspirating instruments constructed on this principle are called S.-trocars and S.-aspirators. 2. In biology, a tubular organ for the passage of some fluid, as the inhalent and exhalent siphons of certain molluscs, or the sucking-tube of various parasitic arthropods.

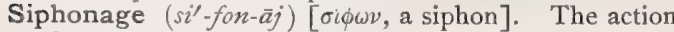
of a siphon, whether in drainage of wounds or in house-plumbing.

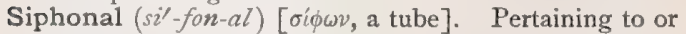
resembling a siphon.

Siphonate $\left(s i^{\prime}-f o n-\bar{a} t\right)$ [ $\sigma \iota \phi \omega v$, tube]. In biology, provided with a siphon.

Siphonet (si'-fon-et) [oi $\phi \omega v$, a tube]. In biology, one of the pair of excretory tubes on the upper surface of the abdomen of a plant-louse (Aphis). It exudes honey-dew

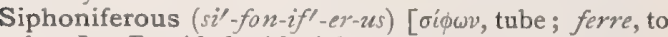
bear]. Provided with siphons.

Siphoniform (si'-fon-if-orm) [ $\sigma i \phi \omega \nu$, tube ; forma, form ] Shaped like a siphon.

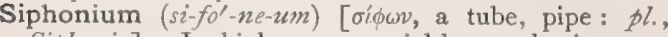
Siphonia]. In biology, a special bony tube in some birds, which conducts the air from the tympanum to the articular piece of the mandible.

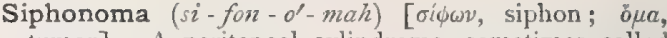
tumor]. A peritoneal cylindroma, sometimes called Henle's tubular tumor.

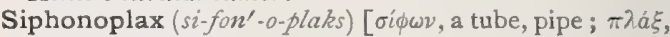
a plate]. In biology, one of the calcareous plates which form a tube about the siphons of boring molluscs (Pholadida)

Siphosome $\left(s i^{\prime}-f o-s o ̄ m\right)$ [ $\sigma i \phi \omega \nu$, a tube ; $\sigma \tilde{\omega} \mu \alpha$, the body]. In biology, that portion of a siphonophoran stock devoted to obtaining food; the feeding-polyps. See Nectosome.

Siphuncle (si'-fung-kl) [ $\sigma i \phi \omega v$, a tube]. In biology, a small siphon, as the siphonet or honey-tube of a plantlouse, or the funnel of a cephalopod.

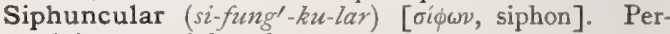
taining to a siphuncle.

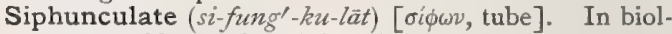
ogy, provided with a siphuncle.

Siphunculus (si-fungt-ku-lus). Same as Siphuncle. See Syringe.

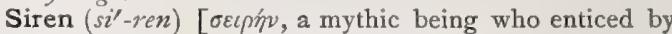
her singing]. 1. An instrument for studying the qualities and properties of musical sounds. 2. Same as Sirenomelus.

Sirenomelia $\left(s i-r e n-o-m e^{\prime}-l e-a h\right)$. Same as Sirenomelus.

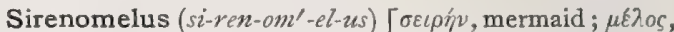
limb]. A form of single autositic monster of the species symelus, in which the lower extremities are intimately fused, without the trace of a foot, or, at most, with but a single toe.

Siret's Disinfectant. A disinfecting mixture containing copperas 100 parts, zinc sulphate 50 parts, sawdust 40 parts, coal-tar 5 parts, and rapeseed-oil 5 parts.

Siriasis $\left(s i r-i^{\prime \prime}-a s-i s\right)$ [ $\sigma \varepsilon i \rho t o s$, the dog-star $]$. An old name for a supposed attack of sideration, resembling sunstroke, and caused by the influence of the dogstar.

Sirloin (sir'-loin) [Fr., surionge, a sirloin]. The muscular mass from the loin of animals, particularly cattle.

Siro $\left(s i^{\prime}-r o\right)$ [L.]. See Comedo. An old name for certain parasites. See Parasites (Animal), Table of.

Sirup $\left(\operatorname{sir}^{\prime}-u p\right)$. See Syrup.

Sisal Hemp $\left(s e^{\prime}-s a l\right)$. See Hemp.

Sister (sis'-ter) [ME., sister, sister]. A female relative in the first degree of descent. S.-cells, cells produced by the fission or gemmation of any given mother-cell; daughter-cells.

Sit [ME., sitten, to sit]. To occupy a seat.

Site (sìt) [situs, place]. Situation. S., Placental, the area to which the placenta is attached.

Sitfast. In farriery, a piece of dead tissue in the skin which would be thrown off but that it has formed firm connections with the fibrous skin beneath, or with the deeper tissues, and is thus bound in its place as a persistent source of irritation.

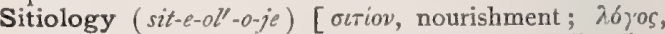
a treatise]. The science of nourishment or dietetics.

Sitiomania (sit-e-o-ma'-ne-ah). See Sitomania.

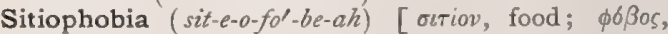
dread]. A form of insanity marked by abhorrence of food.

Sitis morbosa (si'-tis-mor-bo'-sah) [morbid thirst]. Synonym of Polydipsia.

Sitology (si-tol"-o-je). See Sitiology.

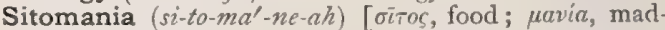
ness]. A mania occurring periodically, characterized by loss of volition and an overwhelming desire to partake of food to an unlimited extent.

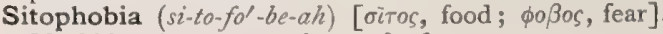
Morbid or insane aversion to food. 
Situs (si'-tus) [situs, site]. A position. S. viscerum inversus, an anomaly in which the organs or viscera of the body are changed from the normal to the opposite side of the body.

Sitzbath (sits'-bath) [Ger., sitz, a seat; bath]. A hipbath or half-bath; a bath taken in a sitting posture; semicupium.

Sivvens (siv'-enz). Same as Sibbens.

Size (s⿱亠䒑厶) [ME., sise, size]. Extent or volume. S.glue. See Glue.

Sizy $\left(s i^{\prime}-z e\right)$ [siza, glue]. Viscous, like glue or size.

Sizygium $\left(s i-z i g^{\prime}-e-u m\right)$. See Syzygy.

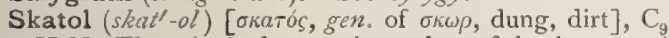
$\mathrm{H}_{9} \mathrm{~N}$. The principal aromatic product of the decomposition of albumin in the intestinal canal. It resembles indol, crystallizes in brilliant, white plates, and possesses an intense fecal odor. It fuses at $93.5^{\circ} \mathrm{C}$, and is soluble with difficulty in water. Warmed with dilute hydrochloric acid or nitric acid it gives a violet color. Its vapor-density is 65.2. Serum-albumin digested with pancreas and water at $36^{\circ} \mathrm{C}$. for from six to ten days yields skatol on distillation; two and a half kilograms of albumin give one gram of skatol.

Skatophagia (skat-o-fa'-je-ah). See Scatophagia.

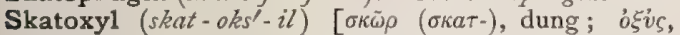
acid]. A product of the oxidation of skatol. It is obtained from the urine in cases of disease of the large intestine.

Skeer's Symptom. See Signs and Symptoms, Table of.

Skein (skän) [ME., skeyne, skein]. I. A fixed length of any thread or yarn of silk or other material, doubled again and again and knotted. 2. A synonym of Spirem. S., Close. See Spirem. S., Loose, the thickened chromatin fibrils resulting from a loosening of the spirem or close skein in mitotic cell-division.

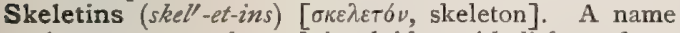
given to a number of insoluble epithelial products found chiefly in invertebrates. The group includes chitin, conchiolin, cornein, spongin, fibroin, and silk.

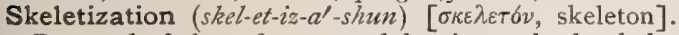
Removal of the soft parts and leaving only the skeleton.

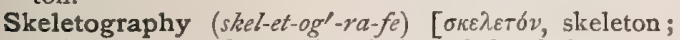
$\gamma \rho a ́ \phi \varepsilon \imath \nu$, to write]. A description of the skeleton.

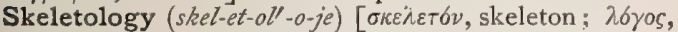
science]. The sum of knowledge concerning the skeleton. See Osteology.

Skeleton (skel'-et-on) [ $\sigma \kappa \varepsilon \lambda \varepsilon \tau \delta \nu$, a dried body, a skeleton ]. In biology, the supporting or inclosing structure for sustaining or protecting the soft parts of an organism. Cf. Endoskeleton, Exoskeieton, Dermoskeleton, Scleroskeleton, Splanchnoskeleton. S., Cartilaginous, the cartilaginous development from which the bony skeleton is formed through ossification.

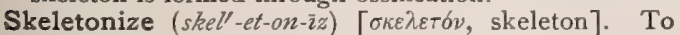
remove all the soft parts, leaving only the skeleton.

Skelos $\left(s k e^{\prime}-l o s\right)[\sigma \kappa \tilde{\varepsilon} \lambda o s$, the leg: pl., Skelea]. In biology, the vertebrate hind limb taken as a whole; it includes the meros or thigh, the crus or leg, and the pes or foot. Cf. Armus.

Skene's Glands. See Gland. S.'s Instillationtube, a tube or pipet used for making applications of drugs to the interior of the uterus. S.'s Tubes, minute tubular outgrowths from the rudiments of the Wolffian ducts, corresponding to the vesiculæ seminales in the male.

Skew Muscles. Triangular-shaped or quadrilateralshaped muscles, the plane of whose line of origin intersects that of the insertion.

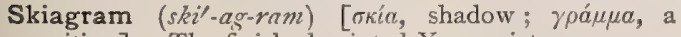
writing]. The finished printed X-ray picture.

Skiagraph (ski'-ag-raf). See Skiagran.

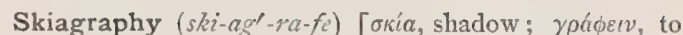
write]. Photography by the X-Rays. Skotography, Skiography, Kadiography, Electrography, Electro-skiagraphy, Röntography, and the New Photography, are names that have been used to designate the method.

Skiascopy (ski-as'-ko-pe). See Retinoscopy.

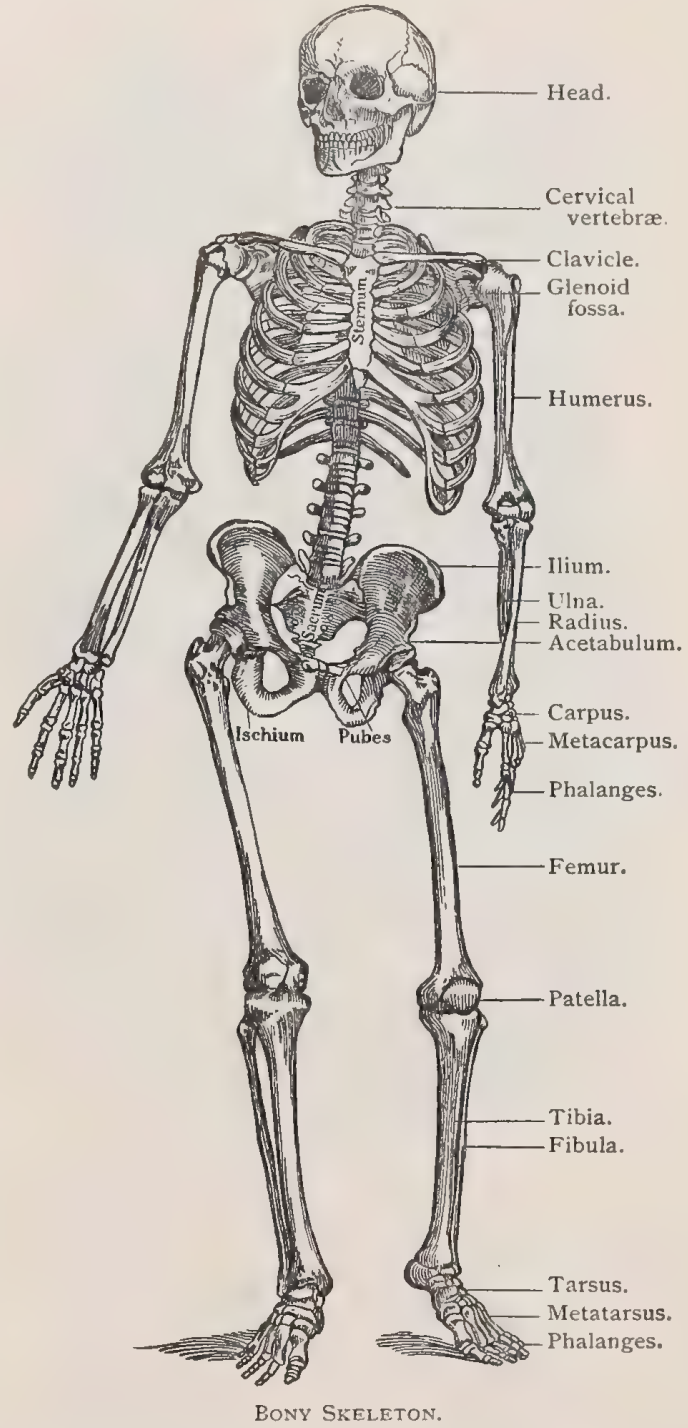

Skin [ME., skin, skin]. The external protective membranous covering of the body. Also the chief organ of touch. It is composed of three layers, the epidermis, or scarf-skin, the cutis (derma), or true skin, and the rete mucosum, which gives the color to the skin. S.bone, an ossification of the skin. S.-bound, affected with sclerema, q. $v$. See also Scleroderma. S., Bronzed. See Addison's Disease. S.-disease, a disease of the cutaneous surface. A classification of skin-diseases is appended. S., Fish. See Tchthyosis. S., Glossy, a neurotic dermatosis in which the skin becomes smooth and glossy. S., Goldbeaters', a thin, tenacious sheet from the cecum of cattle, occa- 
sionally used as a surgical dressing. S., Goose. See Cutis anserina. S.-graft, a graft, $q$. $v$. S.-grafting, the application of minute pieces of the outer layers of healthy skin to a granulating surface for the purpose of hastening its cicatrization. See Dermatoplasty. S.,

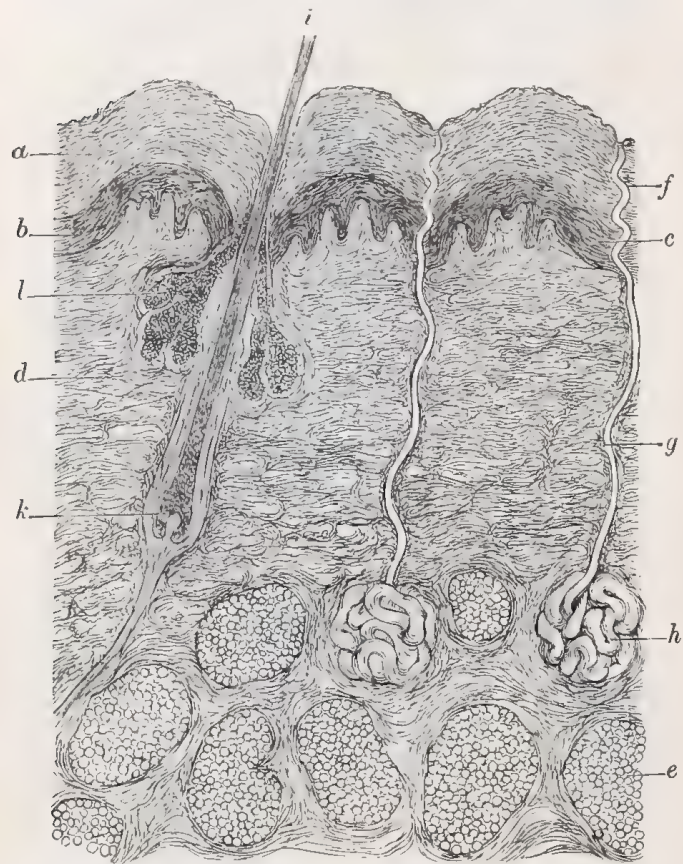

Section Perpendicularly Through the Healthy Skin. a. Epidermis, or scarfskin. $b$. Rete mucosum, or rete malpighii. c. Papillary layer. $d$. Derma, corium, or true skin. e. Panniculus adiposus, or fatty tissue $f, g, h$. Sweat-gland and duct, $i, k$. Hair, with its follicle and papilla. $l$. Sebaceous gland.

Piebald. See Vitiligo. S.-planting. Same as S.grafting. S., Scale. See Icthyosis. S.-transplantation, or S.-transportation. Same as Dermatoplasty.

SKIN-DISEASES, CROCKER'S CLASSIFICATION OF.

Class I.-HyPEREMIE-CONGESTIONS.

Most Prominent Primary Lesion.

Erythema simplex, ......... Erythema. ab igne, ... and pigmenta-

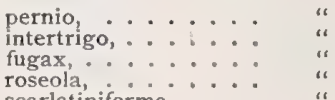

scarlatiniforme, : " "

Class II.-Exudationes-Inflammations.

Most Prominent Primary Lesion.

Erythema exsudativum multiforme, Erythema.

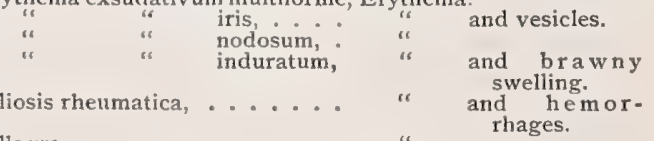

Pellagra,

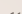

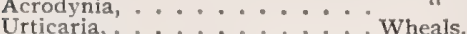

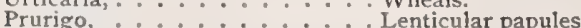

Eczema, Multiform lesions.

Dermatitis repens, . . . . Epidermic denudation and fuid exudation.

Impetigo contagiosa, ...... Vesicles and pustules.

Furunculus, .......... Phlegmons.

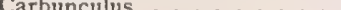

Pompholyx, .............. Herpes zoster, ......... Grouped vesicles.

facialis progenitalis,

Pemphigus,

...... Grouped bullæ.

Psoriasis, .... Scaly crusts on red base

Ptyriasis rubra, : . Diffuse redness with large

" rosea, ...... Patches, with fine scales.

" rubra pilaris, ..... Papules, ". " "

" planus, : . "

" scrofulosus, . "

pilaris, . . " follicular.

Conglomerative pustular folliculi- Pustules en plaques, aggre-

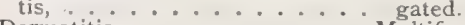

Dermatitis, ............ Multiform lesions.

Class III.-HEMORRHAGIA-HEMORRHAGES.

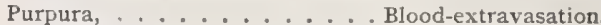

\section{ClASS IV.-HYPERTROPHIA-HYPERTROPHIES.}

Parts Affected.

Ichthyosis, ......... Epidermis and papillæ.

Keratosis pilaris, ........ Hair-follicles.

Verruca, .............. Epidermis and papillæ.

Clavus, .

Cornu cutaneum

Callositas, . . . . . . Epidermis.

Tylosis

Tylosis, ............

Scleroderma, ......... Corium

Sclerema neonatorum, ..... ". "

Fidema

Elephantiasis, ........ The whole skin.

Lentigo, ........... Pigment.

Acanthosis nigricans, : ... " with papillary

Nævus pigmentosus,....... in neoplasm.

\section{Class V.-Atrophise-Atrophies.}

\section{Parts Affected.}

Albinism t-deficiency.

Albinism, . . . . . Pigment-defuency.

Atrophoderma (or xeroderma) pig

Atrophoderma (or xeroderma) pig-
mentosum,

Atrophoderma albidum, ..... "

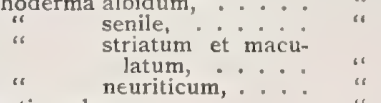

Perforating ulcer,

Morvan's disease, : . . . . Sensory nerves.

Ainhum, .............. Analges

Analgesic whitlows.

Class VI.-Neoplasmata-New-GRowths, General Character.

Darier's disease,
Molluscum contagiosum, . . . :

Molluscum contagiosum, .....

Colloid, : . . . . . . .

Crusted papules.

Lupus vulgaris, . . . . . . .

Scrofuloderma, ........

Tuberculosis, . . . . . ....

Syphilis, ..........

Rhinoscleroma,

Keloid, .............

Fibroma,

Myoma,

Neuroma, .......

Telangiectasis, . . . :

Angioma serpiginosum, .....

Angiokeratoma, . . . . . . .

Lymphangiectodes, .......

Lymphangioma tuberosum multi

plex, ...........

Carcinoma, .

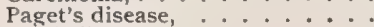

Epithelioma,

Rodent ulcer

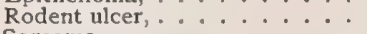

Sarcoma, . . . . . .

Mycosis fungoides, ........

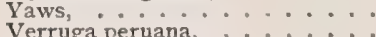

Verruga peruana,

Phagedana tropica, ........
Infiltrating.

Benign.

Malignant. 
Hyperesthesia.
Dermatalgia.

Class VII. - Neuroses-Sensory Diseases.

Pruritus.

Anesthesia.

Class VIII,-MORBI APPENDICIUM-Diseases OF THE APPENDAGES.

Most Prominent Primary Lesion.

A. SWEAT-GLANDS

Hyperidrosis, ........ Excessive secretion.

Bromidrosis,

hosphorescent......"

Uridrosis,

Anidrosis, Altered quality. "s vesiculosa, ...... Inflammation. papulosa,

B. Sebaceous Glands.

Seborrhea, Seborrheic dermatitis, . . . . Mucessive secretion.
Multiform.

Sebaceous cysts, ....... Retention

Milium,

Comedones,

Acne vulgaris, ....... Inflammation,

"i rosacea.

"varioliformis,

Adenoma sebaceum, ..... Papular neoplasms.

C. HAIR-FOLLICLES.

Hirsuties, ........ Excessive growth.

Atrophy, .......... Defective

Alopecia, ......... Baldness.

" areata, ....... " ". in patches.

Concretiones, . . . . . . Growths on the hairSycosis, . ....... Inflammation.

Dermatitis papillaris capillitit, . "

D. NaILS.

Pterygium, .......... Overlapping of nail-

Onychia, .......... Inflammation in matrix.

Paronychia, ......... is around ma-20

Atrophy, ......... Defective growth.

Onychogryphosis, ...... Overgrowth.

Onycho-mycosis, ....... Fungus-growth in the nail.

A. Vegetable.

Class IX.-Parasiti-Parasites.

Favus, ........ Hair and skin, onsurans, . Hair

Tinea trichophy- $\left\{\begin{array}{l}\text { decalvans, : } \\ \text { circinata, Skin. }\end{array}\right.$ tina, barbae, Hair. imbricata, "Skin.

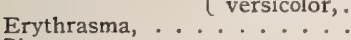

Fungus-foot of India, $\ldots \ldots$ ss and deeper tissues.

\section{B. ANIMAL.}

Scabies, folliculorum, . . . . Acarus.

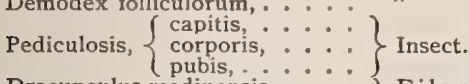

Dracunculus medinensis, .... Filaria or threadFiliaria sanguinis hominis, : $\}$ worms

Cysticercus cellulosæ cutis, : Tania, or tape-worm embryo.

Skinniness (skin'-e-nes) [ME., skin, skin]. Leanness.

Skinny $\left(\operatorname{skin}^{\prime}-e\right)$ [ME., skin, skin]. 1. Cutaneous. 2. Emaciated.

Skleriasis (skle-ri'-as-is). See Scleroderma.

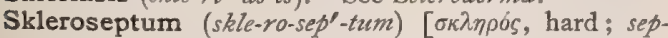
tum, fence, partition : pl., Sklerosepta]. In biology, one of the radially arranged, perpendicular calcareous ridges arising from the foot-plate of a stone coral (Hexacorallia, Madreporaria), also called starridges. Cf. Sarcosepta.
Skoda, Consonating Râles of. Bronchial râles heard through the consolidated pulmonary tissue of pneumonia. S.'s Resonance Sign or Tympany, a tympanitic note heard above the line of fluid in a pericardial effusion, or above the line of consolidation in pneumonia. It is almost as tympanitic as the abdomen. See Bruit skodique.

Skodaic Resonance. See Skoda's Resonance.

Skodaic Tympany (sko'-da-ik tim'-pan-e). See Skoda's Resonance.

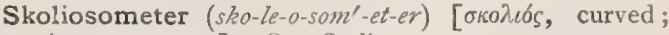

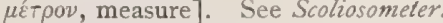

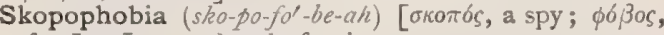
fear]. Insane dread of spies.

Skull (skul) [ME., skulle, skull]. The superior expansion of the vertebral column, the protective bony

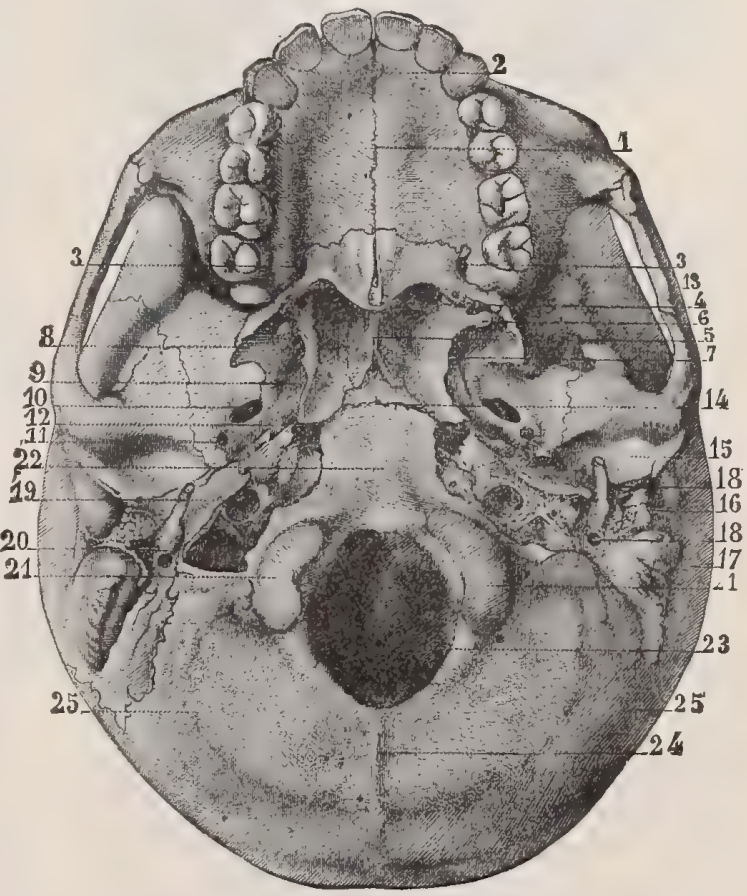

BASE OF SKULl.

I. Median suture of palatine vault. 2. Inferior orifice of anterior palatine canal. 3, 3. Inferior openings of posterior palatine canals. 4. Posterior border of palatine vault ; posterior nasal spine. 5. Posterior border of nasal septum. 6. Hamular process of internal pterygoid plate of sphenoid bone. 7. Internal pterygoid plate. 8. External pterygoid plate. 9. Scaphoid fossa. 10. Oval or inferior maxillary foramen. II. Foramen spinosum. I2. Foramen lacerum medium. 13. Zvgomatic arch. I4. Spheno-occipital suture. 15. Glenoid cavity. 16. External auditory canal. I7. Mastoid process. 38,18 . Styloid process and stylo-mastoid foramen. I9. Inferior orifice of carotid canal. 20. Foramen men. 19. Inferior orife of carotid canal. 20. Foramen process. 23. Foramen magnum. 24. External occipital crest. 25, 25. Inferior curved lines of occipital bone..

covering or container of the brain and organs of the special senses, consisting of the cranium and face. The cranium is made up of 8 bones-the occipital, 2 parietal, the frontal, 2 temporal, the sphenoid, and the ethmoid. The face is composed of $\mathbf{1} 4$ bones-nasal, superior maxillary, lacrymal, malar, palate, inferior turbinated, two each, and vomer and inferior maxillary, one each. S.-cap, the dome of the skull. See Scutellaria. S., Landmarks of, the eminences, chiefly the frontal 
and parietal, the 2 temporal ridges, the sutures, and the craniometric points, q.v. S., Natiform, a skull

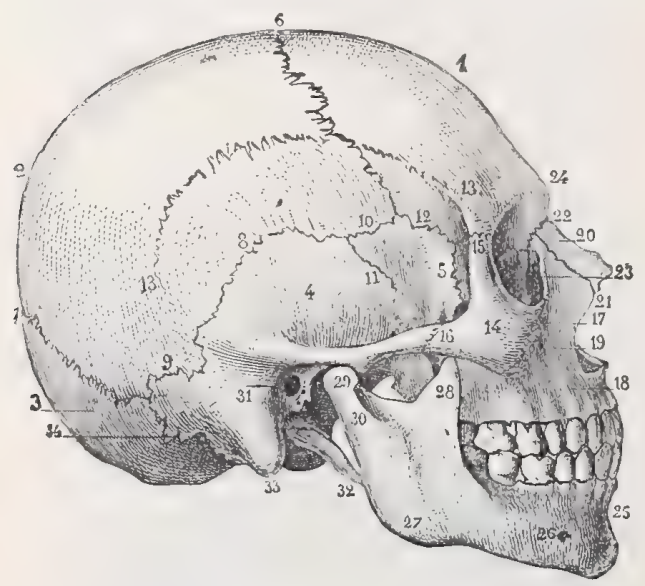

LATERAL ASPECT OF SKULL.

1. Frontal bone. 2. Parietal bone. 3. Occipital bone, 4. Temporal bone. 5. Greater wing of sphenoid bone. 6. Lambdoid suture. 7. Occipito-parietal suture. 8. Squamo-parietal suture. 9. Masto-parietal suture, 1o. Spheno-parietal suture, II. Spheno-temporal suture. 12. Spheno-frontal suture I3, I3. Temporal ridge. I4. Malar bone. I5. Fronto-malar suture. 16. Malo-temporal suture. I7. Malo-maxillary suture. 18. Superior maxillary bone. I9. Infraorbital foramen. suture. 23. Lacrymal groove, at the bottom of which may be seen the suture between the lacrymal and the superior maxillary bones. 24. Nasal eminence. 25. Inferior maxillary bone. 26. Mental foramen. 27. Angle of lower jaw. 28. Coronoid process. 29. Condyle. 30. Neck of condyle. 3I. External auditory canal. 32. Styloid process. 33. Mastoid process. 34. Masto-occipital suture.

covered with osteophytes. S.-roof, the roof of the skull; skull-cap.

Skunk. See Mephitis. S.-bush. See Garrya. S. Cabbage, the root of Symplocarpus foetidus, a stimulant, antispasmodic, and narcotic. Dose of the fld. ext. $m x-x l$. Unof.

Slag [Sw., slagg, dross]. The earthy matter separated, in a more or less completely fused and vitrified condition, during the reduction of a metal from its ore.

Slaver (slav'-er) [ME., slaver, slaver]. Drivel; saliva, especially such as is involuntarily discharged.

Sleek (slèk) [ME., slicke, smooth]. Smooth; glossy, as the skin.

Sleep (slep) [ME., slepen, to sleep]. The state of rest and recuperation of the bodily and mental voluntary powers. The consciousness may also be inactive or dreaming, $i_{.} e_{\text {. }}$, without the guidance and data of the will and lower centers, and hence illogically functional, S.-drunkenness. See Somnolentia. S.-epilepsy. See Narcolepsy. S., Hypnotic, S., Magnetic, S., Mesmeric, sleep produced by hypnotism. S.-paralysis, paralysis produced by pressure during sleep. S., Paroxysmal. See Narcolepsy: S.-walking. See Somnambulism.

Sleeping (slep'-ing) [ME., slepen, to sleep]. Resting in slumber. S.-dropsy, a singular disorder seen only on the Atlantic coast of Africa, and characterized by daily paroxysms of somnolence, tending to become more and more continuous and profound until merged in fatal coma. Its onset is gradual, commencing with a slight frontal headache. It may persist for from three months to a year or more, and always ends fatally. It is also called African Lethargy, and is said by some to be only one of the manifestations of filariasis. See
Narcolepsy. S.-sickness. See African Lethargy, Narcolepsy, Nelavan, and Filariasis.

Sleeplessness (slep'-les-nes). See Insomnia.

Sleepy $($ sle'-pe) [ME, slepen, to sleep]. Inclined to sleep. S.-disease. See Hypropathy. S. Staggers, a symptom in the horse, resulting from a variety of brain-affections, characterized by more or less drowsiness or coma associated with a staggering gait. See Staggers.

Slender Lobe of the Cerebellum. See Lobe.

Slick (slik). Same as Sleck.

Slide (slid) [ME., sliden, to slide]. A small, rectangular slab of clear glass for the mounting, preservation, and ready examination of microscopic objects. The slides may vary in size; for ordinary work the most common dimensions are $26 \times 7^{6}$ millimeters, or $1 \times 3$ inches.

Slime $(\sin m)$ [AS., shin, slime]. In biology, a viscid secretion of the cutaneous glands of various animals. Mucus. S.-fungus. Same as S.-mold. S.-gland, (a) one of the modified leg-glands, with ducts emerging at the ends of the oral papillx in the Protracheata: (b) one of the glands furnishing the viscid mucuslike substance of snails, fishes, etc. S.-mold. See Myxomycetes.

Sling [ME., slinge, a sling]. A swinging bandage and carriage for supporting a fractured $\operatorname{limb}$. S. of the Lenticular Nucleus, a tract of nerve-fibers which enter the lenticular nucleus by passing beneath the optic thalamus.

Slink (slingk) [origin obscure]. To bear young or cast prematurely; said of a female beast; to miscarry. $\mathrm{S}$. Meat, the meat of calves or lambs that have been cast prematurely.

Slinking (sling $\left.k^{\prime}-i n g\right)$ [origin obscure]. Abortion in cows or other beasts.

Slip (slip) [MD. D., slippen, slip, escape]. I. A male fowl which has been unsuccessfully caponized. 2. A scion or cutting of a plant made for grafting or rooting. 3. Same as Slide.

Slippery Elm. See Ulmus, and Fremontia.

Slit [ME., slit, a slit]. A narrow opening; a visceral cleft; the separation between the labia; the vulvar cleft. S., Genito-urinary, S., Urino-genital, S., Uro-genital, the uro-genital opening. $\mathbf{S}$. of the Micro-spectroscope, the spectral ocular, in place of an ordinary diaphragm, has two movable knife edges so arranged that a slit-like opening of greater or less width and length may be obtained by the use of screws for that purpose.

Sloid, Sloyd (sloid) [Sw., slojd, slight, skill]. A system of manual training taught in elementary schools; it is of Swedish origin.

Slop [ME., sloppe, a pool]. A general term for liquid foods used in the course of acute diseases and during convalescence.

Slough (sluf) [ME., slouh, the skin of a snake]. A term applied to the separating and dying particles of tissue in suppurative and ulcerative processes. As a verb, to separate or die in consequence of gangrene; said of tissues.

Sloughing (sluf'-ing) [ME., slouh, the skin of a snake]. Gangrenous.

Slows (slōz). Synonym of Milk-sickness.

Sludge (shij) [AS., slog, mud]. Sewage-deposit.

Slumber (shm'-ber) [ME., slumberen, to slumber]. I. To sleep lightly. 2, Light sleep.

Small (smawl) [ME., small, not large]. Iittle in size; diminutive. S.-pox. See Variola. S.-pox, A bortive, variola in which but few pustules are present; these rapidly disappear. S.-pox., Bastard. See Varicella. S.-pox, Confluent. See Variola confuens. S.-pox, Crystalline. See Varicella. S.- 
pox, False. See Varicella. S.-pox, Hemorrhagic. See Variola. S.-pox, Ichorous. See Varicella. S.pox, Malignant. See Variola. S.-pox, Modified. See Varioloid. S.-pox, Ovine. See Sheep-pox. S.pox, Spurious. See Varicella. S. Red Granular Kidney. See Bright's Disease. S. White Kidney. See Bright's Disease.

Smalts (smazoltz). See Pigments, Conspectus of.

Smart [ME., smerten, to smart]. I. To feel a pungent pain. 2, A sharp, quick, active pain. S.weed. See Polygonum hydropiperoides.

Smead-Dowd System. See Ventilation.

Smear-cultures (smèr). See Culture.

Smectic (smek'-tik). Same as Detergent.

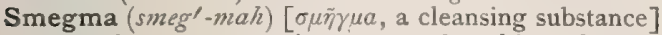
The sebaceous accretions upon the skin. S. embryonum. See Vernix. S. of Prepuce, the case ous substance secreted by the follicles of the prepuce.

Smegmatic (smeg-mat'-ik) $[\sigma \mu \tilde{\eta} \gamma \mu a$, a cleansing substance]. Pertaining to, or of the nature of, smegma.

Smegmatorrhea (smeg-mat-or-e'-ah). Synonym of Seborrhea.

Smell (smel) [ME., smellen, to smell]. The perception of an odor by means of the olfactory organ. S.-hollows, elliptic pits on the antennæ of bees having olfactory functions.

Smelling (smel'-ing) [ME., smellen, to smell]. The sense of smell; olfaction. S.-bottle, a small bottle containing smelling-salts. S.-salts, a popular name applied to various preparations of ammonium carbonate flavored with aromatic substances. S.-salts, English, carbonate of ammonium impregnated with ethereal oils, such as oil of lavender or bergamot.

Smelting (smelt'-ing) [ME., smelten, to smelt]. The treatment of ore by which it is subjected to intense heat for the purpose of separating the contained metal.

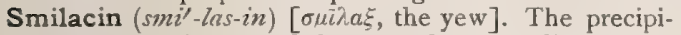
tate from a tincture of the root of sarsaparilla, Smilax officinalis, alterant, detergent, diaphoretic, and stimulant. Dose 2 to 5 grains. Unof.

Smilax (smi'-laks). See Sarsaparilla, China-root, Bamboo-brier.

Smith, Bacillus of, S., Spirillum of. See Bacteria, Synonymatic Table of.

Smith's Method. See Treatment, Methods of.

Smiths' Cramp or Spasm. See Spasm.

Smoke $(s m o ̈ k)$ [ME., smoken, to smoke]. To emit a vapor or exhalation while burning. S--rockets, an inflammable substance used in making the smoke-test for sewer-gas. S.-test, a method for finding defects in drains by means of smoke.

Smoker (smo'-ker) [ME., smoken, to smoke]. One who uses tobacco. S.s' Cancer. See Cancer. S.s' Dyspepsia. See Dyspepsia. S.s' Patch, a chronic inflammation of a small spot of the mucous membrane of the mouth arising from an irritation produced by the pipe. It varies in size from a quarter to a half of an inch in diameter, and is smooth and red in appearance. S.s' Sore-throat, the condition of catarn of the pharynx and larynx, with hoarseness, common in habitual smokers. S.s' Vertigo. See Vertigo.

Smooth Sumach. See Rhus glabra.

Smother (smuth'-er) [ME., smothren, to suffocate]. To suffocate; to stifle.

Smothering (smuth'-er-ing) [ME., smothren, to suffocate]. Exclusion of air from the respiratory organs, as by covering the mouth and nostrils.

Smut [AS., smitta, a spot]. I. A foul spot; the fouling matter itself. 2. A parasitic disease of plants, caused by fungi of the order Ustilaginea, the first exact researches concerning which were published about 1850 by the brothers Tulasne. S. of Broom
Corn, Ustilago sorghi (L. K.), Passerini. S., Covered, of Barley, Ustilaso hordei (P.), Kell and Swingle. S. of Indian Corn, Ustilago maydis (D. C.). S., Naked, of Barley, Ustilago nuda (Jensen), Kell and Swingle. S. of Oats, Ustilago avenue (P.), Jensen, var. lavis, Kell and Swingle. S. of Rye, Ustilago occulta (Walls), Rabh. S. of Wheat, Bunt, or Stinking Smut, Tilletic fotens, Trelease; Tilletiatritici (Bjerk), Wint. The disease is spread by spores of these fungi adhering to the sound grains before they are planted, or by spores in the soil.

Smyrna (smir'-nah). Synonym of Mymh.

Snake $(s n a \bar{k})$ [ME., snake, a snake]. A serpent. S.head. See Balmony. S.-root, Black. See Cimicifuga. S.-root, Canada. See Asarum. S.-root Seneca. See Senega. S.-root Virginia. See Serpentaria. S.-stone. See Madstone. S.-weed. See Bistort.

Snap-finger. See Spring-finger.

Snare (snär) [ME., snare, snare]. A light or small écraseur, or wire loop, used in removing polypi and small excrescences.

Snarling Muscle. See Muscles, Table of.

Sneering Muscle. See Muscles, Table of.

Sneeze (snèz) [ME., snesen, to sneeze]. To expel the breath audibly and spasmodically through the nose for the removal of mucus or foreign bodies. S.-cough, a peculiar explosive sound produced by an attempt on the part of the patient to sneeze and cough at the same time. It is due to an irritation of the lower and posterior portions of the nasal cavities. S.-wort. See Achillea.

Sneezing (snèz'-ing) [ME., snescn, to sneeze]. Sternutation.

Snellen's Types. See Test-types.

Sniffles (snif'-lz). See Snuffles.

Snore (snōr) [ME., snoren, to snore]. I. To breathe through the nose in such a manner as to cause a vibration of the uvula and soft palate, thereby producing a rough, audible tone. 2. The sound so produced.

Snoring (snōr'-ing). See Stertor.

Snort [ME., snorten, to snore]. To snore loudly.

Snout (snowt) [ME., snoute, snout]. The nose of an animal. See Muzzle.

Snow (sno) [ME., snow, snow]. The aqueous vapor of the atmosphere precipitated in a frozen form. S.blindness. See Blindness. S.-shoe Disease, pain in the feet following a long march on snow-shoes. S.white. Same as Zinc White.

Snow's Inhaler. See Anesthetic.

Snub-nose (snub'-nöz). See Pug-nose.

Snuff (snuf) [ME., snuffen, to snuff]. I. Powdered tobacco, variously perfumed and mixed, used for inhalation into the nostrils. 2. A medicated powder to be insufflated into the nostrils. 3. To inhale; to smell. S.-box, Anatomist's, the Foreola radialis.

Snuffie (snuf'- $f$ ) [LG., snuffeln, to snuffle]. To breathe hard through the nose. As a plural noun, a popular name for a catarrhal discharge from the nose in infancy. It is not infrequently symptomatic of syphilis.

Soap (söp) [ME., sope, soap]. A chemic compound made by the union of certain fatty acids with a salifiable base. It is used for washing and cleansing purposes. See Sapo. A table is appended showing the composition of the chief soaps of pharmacy, as analyzed by M. Dechan. S.-balls, balls made of starch and soap. S.-bark. See Quillaia. S., Black. See Sapo viridis. S., Castile, soap made from olive-oil. S., Cocoanut-oil, soap made from cocoanut-oil. It is soluble in hard water. S., Glassmakers', native dioxid of manganese. S., Green. See Sapo viridis. S., Hard, soap prepared by means of soda alkali; 
soda soap. S.-liniment. See Linimentum saponis. S., Petroleum, a soap made by heating together 5 parts of petroleum, 4 of white wax, 5 of alcohol, and $I 0$ of hard soap. S., Soft, soap made by means of potash alkali; potash soap. S., Taxidermists', a soap made by mixing 32 parts each of grated olive-oil soap, arsenious acid and boiling water, 12 of potassium carbonate, 4 of unslaked lime, and I of camphor. S., Tincture of Green. See Sapo viridis. S.-wort, Bouncing Bet, the root of Saponaria officinalis. Its properties are due to an extractive, saponin. It is a paralyzant to the peripheral nerve-endings and the respiratory centers, and is a useful alterative in syphilitic and scrofulous complaints. Dose of the fld, ext. $m_{x v}-3 j$. Unof.

\begin{tabular}{|c|c|c|c|c|c|c|c|c|}
\hline VARIETY. & 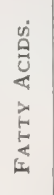 & 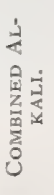 & 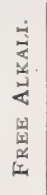 & $\frac{d}{d}$ & 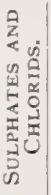 & 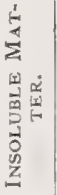 & 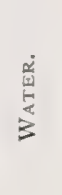 & 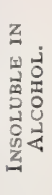 \\
\hline $\begin{array}{l}\text { Hard Soap ( } S a p o \\
\text { durus). }\end{array}$ & $8 \mathrm{x} .5$ & 9.92 & .08 & .00 & .28 & 0.20 & 10.65 & 0.50 \\
\hline $\begin{array}{l}\text { White Castile Soap } \\
\text { (S. Cast. alb.). }\end{array}$ & 76.7 & 9.14 & .09 & .00 & .36 & 0.90 & 13.25 & 0.60 \\
\hline $\begin{array}{l}\text { Mottled Castile } \\
\text { Soap. }\end{array}$ & 68.1 & 8.9 & .19 & . I5 & .63 & 0.80 & 21.70 & 1.30 \\
\hline $\begin{array}{l}\text { Tallow Soap (Sapo } \\
\text { animalis). }\end{array}$ & 78.3 & 9.57 & $.28^{\circ}$ & .00 & .47 & 0.40 & 12.50 & I.IO \\
\hline $\begin{array}{l}\text { Soft Soap ( } S a p o \\
\text { mollis). }\end{array}$ & 48.5 & I2. 6 & $\cdot 3^{8}$ &.$I^{\prime} 7$ & .93 & I.00 & 39.50 & 1.60 \\
\hline
\end{tabular}

Sobbing $\left(s^{\prime} b^{\prime}-i n g\right)$ [ME., soblien, to sob]. Convulsive inspirations due to contraction of the diaphragm and spasmodic closure of the glottis. The sound produced is characteristic.

Soboliferous (sob-o-lif'-er-us) [soboles, a shoot; ferre, to bear]. Bearing vigorous shoots.

Socaloin (so-kal'-o-in) [Socotra, an island in the Indian Ocean; $\dot{\alpha} \lambda_{\imath o} \eta$, aloes], $\mathrm{C}_{15} \mathrm{H}_{16} \mathrm{O}_{7}$. The aloin derived from socotrine aloes.

Socia $\left(s o^{\prime}-s e-a h\right)$ [L.]. One accompanying. S. parotidis, an occasional small, separate lobe, or exclave, of the parotid gland.

Social (so'-shal) [socius, a companion]. In biology, gregarious, growing near, or together. S. Evil, prostitution.

Society Screw. The screw at the lower end of the drawtube or body-tube of a microscope for receiving the objective.

Socin's Antiseptic Paste. See Paste.

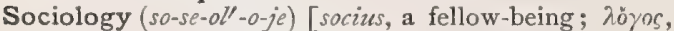
a treatise]. A treatise on the mutual relations of people and of social organization.

Sock (sok) [ME., socke, a sock]. A short-legged stocking. Ss., Neapolitan, socks containing mercurial ointment, which are to be worn continuously for the purposes of inunction.

Socket $\left(s o k^{\prime}-e t\right)$ [ME., soket, a socket]. The concavity or excavation of an articulation.

Socle $\left(s o^{\prime}-k l\right)$ [soccus, a light shoe]. In biology, the supporting structure of the sense-organs of certain worms. See Pedalia.

Soda (so'-dah) [L.], $\mathrm{Na}_{2} \mathrm{O}$. The oxid of the metal sodium, Also, popularly, almost any salt of sodium. See Soctium. S.-ash, a substance produced in the manufacture of sodium carbonate. S., Baking, sodium bicarbonate, S., Caustic, sodium hydroxid, a strongly alkaline base with a great affinity for water. S.-powder, a baking-powder. S., Washing, sodium carbonate. S.-waste, a by-product in the manufacture of sodium carbonate. S.-water, the so-called soda-water sold by druggists and confectioners consists of filtered water impregnated or aërated with carbon dioxid. It contains no soda.

Sodium (so'-rle-zm) [soda, soda; gen., Sodii]. $\mathrm{Na}=$ 23; quantivalence I ; sp. gr. 0.972. A metal of the alkaline group, characterized by its strong affinity for oxygen. It has a silver-white luster, and is softer than lead. It decomposes water, forming sodium hydrate. The action of the sodium-salts is similar to that of potassium-compounds. See Elements, Table of. S. acetas, $\mathrm{NaC}_{2} \mathrm{H}_{3} \mathrm{O}_{2} \cdot 3 \mathrm{H}_{2} \mathrm{O}$, diuretic, a good saline draught. Dose gr. $x x-3 j$. S.-amalgam, a compound of sodium and mercury. S. arsenias, $\mathrm{Na}_{2} \mathrm{HAsO}_{4}$, used in preparing liquor sodii arseniatis. $\mathbf{S}$. benzoas, $\mathrm{NaC}_{7} \mathrm{H}_{5} \mathrm{O}_{2}$. Dose gr. $\mathrm{x}-\mathrm{xxx}$. S. bicarbonas, $\mathrm{HNa}$ $\mathrm{CO}_{3}$, "saleratus," "baking-soda ;" antacid ; $20 \mathrm{gr}$. neutralize $16.7 \mathrm{gr}$. of citric acid or $17.8 \mathrm{gr}$. tartaric acid. Effervescent. It is much used for the aeration of bread. Dose gr. $x-z j$. S. bicarb., Troch., each contains gr. iij of the salt. $\mathbf{S}$. bicarb. venalis, commercial bicarbonate. S. bisulphis, $\mathrm{NaHSO}_{3}$, sodium bisulphite. S. boras, $\mathrm{Na}_{2} \mathrm{~B}_{2} \mathrm{O}_{7}$, borax, $\mathrm{S}$. bromidum (B. P.), NaBr. Dose gr. $x-x x x$. S. carbonas, $\mathrm{Na}_{2} \mathrm{CO}_{3}$, antacid; $20 \mathrm{gr}$. neutralize $9.7 \mathrm{gr}$. citric, or IO. 5 gr. tartaric acid. Effervescent. Dose gr. $\mathbf{v}-\mathrm{xxx}$. S. carb., exsiccatus, the carbonate dried until it loses 50 per cent. of its weight. S. chloras, $\mathrm{NaClO}_{3}$, the basis of an agreeable gargle. Dose gr. $\mathrm{v}-\mathrm{xx}, \mathbf{S}$. chloridum, $\mathrm{NaCl}$, common salt, Dose gr. $\mathrm{x}-\mathbf{z} \mathrm{j}$. S. ethylas, $\mathrm{C}_{2} \mathrm{H}_{5} \mathrm{NaO}$, caustic alcohol, unof, in contact with water breaks into caustic soda and alcohol ; S. formas, $\mathrm{NaCHO}_{2} \cdot \mathrm{H}_{2} \mathrm{O}$, used in the form of parenchymatous injections in surgical tuberculosis. Dose gr. ss-iij. S. hydras, $\mathrm{Na}(\mathrm{HO})$, "caustic soda," very alkaline and powerfully escharotic. S. hypophosphis, $\mathrm{NaPH}_{2} \mathrm{O}_{2}$, used in preparing syrupus hypophosphitum. S. hyposulphis, $\mathrm{Na}_{2} \mathrm{~S}_{2} \mathrm{O}_{3}+5 \mathrm{H}_{2} \mathrm{O}$, an antiseptic salt. S. iodidum, NaI. Dose gr, iij-x. Sodæ, Liq., solution of soda. Dose $\eta^{v}-3$ ss; contains 56 parts of the hydrate in 944 of distilled water. S. nitras, $\mathrm{NaNO}_{3}$, "cubic niter," "Chili saltpeter." S. nitris, $\mathrm{NaNO}_{2}$, used in preparing sweet spirit of niter. S. phosphas, $\mathrm{Na}_{2} \mathrm{HPO}_{4}$, sodium orthophosphate. S. pyrophosphas, $\mathrm{Na}_{2} \mathrm{P}_{2} \mathrm{O}_{7}$, sodium pyrophosphate. S. salicylas, $\mathrm{NaC}_{7} \mathrm{H}_{5} \mathrm{O}_{3}$, sodium salicylate. Dose gr. $x$-xy. S. santonas, $\mathrm{Na}_{2} \mathrm{C}_{15} \mathrm{H}_{18} \mathrm{O}_{4}$, a vermifuge for threadworms. Dose gr. v. S. sulphas, $\mathrm{Na}_{2} \mathrm{SO}_{4}$, "Glauber's Salt," a mild purgative. Dose gr. $\mathrm{v}-\mathrm{xx}$; as a purgative $\xi_{s s-j}$. S. sulphis, $\mathrm{Na}_{2} \mathrm{SO}_{3}$, sodium sulphite. S. sulphocarbolas, $\mathrm{NaC}_{6} \mathrm{H}_{5} \mathrm{SO}_{4} 2 \mathrm{H}_{2} \mathrm{O}$. Dose gr. $\mathrm{x}-\mathrm{xv}$. S. valerianas, $\mathrm{NaC}_{5} \mathrm{H}_{9} \mathrm{O}_{2}$, Dose gr. $\mathrm{j}-\mathrm{v}$.

Sodomist, Sodomite (sod'-om-ist, sod'-om-it) [ $\Sigma \delta \delta o \mu a$, Sodom ]. One guilty of sodomy.

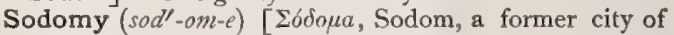
Asia]. Sexual connection by the anus. S., Masturbating, a name proposed for intromission of objects into the rectum to produce sexual excitement.

Scemmering's Bone. The marginal process of the malar bone. S.'s Crystalline Swelling, an annular swelling behind the iris, due to proliferation of the cells of the capsule after cataract-operation. S., Foramen of. See Foramina, Table of. S., Ganglion of, the substantia nigra of the thalamus. S., Nerve of. See Nerves, Table of. S., Yellow Spot of. See Macula lutea. 
Soft [ME, soft, soft]. Yielding readily to pressure; not hard. S. Palate. See Pulate.

Softening (sof'-en-ins) [ME., soft, soft]. The act of becoming less cohesive, firm, or resistant. S., Acute Gastric, a disease of childhood in which the stomach and intestines are said to undergo softening. It is probably a post-mortem phenomenon. S., Anemic, disintegration and liquefaction of the brain-substance from lack of blood-supply. S. of the Bones, osteomalacia. S. of the Brain, a disease of the cerebral tissue dependent upon inflammation or bloodfailure, the symptoms varying according to the part affected, but consisting in loss of function, partial or complete. According to the appearances presenting the softening has been distinguished as red, yellow, or white. See General Paralysis of the Insane. S. Colliquative, the name applied to that condition in which the affected tissues liquefy. S., Esophageal, softening of the lower portion of the esophagus due to the solvent action of the gastric juice. $\mathbf{S}$. of the Heart, myomalacia cordis, a softening of the cardiac muscle consequent on arterial anemia, S., Hemorrhagic, the softening of parts involved in a hemorrhage. S., Mucoid, myxomatous degeneration. S., Red, or Yellow (of the brain), when hemorrhage accompanies the ischemic softening, and the products of disintegration of the blood mingle with the nervesubstance, giving it a red or yellow hue. S. of the Spinal Cord, various stages in myelitis known by the terms gray, green, red, while, and yellow softening. S. of the Stomach, gastromalacia, consequent upon highly acid contents with a feeble circulation in the walls, but usually a post-mortem phenomenon. See Auto-digestion. S. of a Thrombus, may be simple or red, puriform or yellow, the latter resulting in the extremely unfavorable condition of Thrombophlebitis. S., White (of the brain), when the ischemia is unaccompanied with hemorrhage.

Soil [ME., soile, soil]. The ground; earth. S.-diseases, those diseases produced by emanations from a decomposing organic soil, or arising from imperfect drainage of decaying animal matter. S.-pipe, the main discharge-pipe of a system of house-plumbing; usually an upright, hollow cylinder of iron.

Sola $\left(s o^{\prime} l a\right)$ [Beng., sola, the sola]. A plant of tropical regions, Eschynomene aspera. Its pith-like wood is largely manufactured into pith helmets, or sun-hats, especially in India.

Solanidin (so-lan'-id-in). See Solanin.

Solanin (sol'-an-in) [solanum, the nightshade]. A glucosid found in Bittersweet. It is composed of sugar and another substance, solanidin. It is a poisonous narcotic. Dose gr. 3/4-iv. Unof. See Bittersweet.

Solanoid (sol'-an-oid) [solanum, nightshade; Eidos, like]. Of a potato-like texture, as a solanoid carcinoma.

Solanum (so-la'-num) [L.]. A genus of the family of Solanacee. The tomato, potato, jurubeba, and black nightshade belong to this genus. See also Bittersweet.

Solar (sol-lar) [solaris, of the sun]. Pertaining to or resembling the sun. S. Ganglion. See Ganglia, Table of. S. Oil, an oily liquid produced from tar-oil by rectification and employed as an illuminant. $\mathbf{S}$.

Plexus. See Plexus.

Solarium (so-la'-re-um) [solaris, solar; sol, sun]. A room enclosed with glass, and arranged for the administration of sun-baths.

Solayre's Obliquity. See Obliquity.

Soldaini's Reagent and Test. A reagent for testing for sugar in the urine. It consists of a solution of cupric carbonate in potassium dicarbonate. It is made by dropping into a saturated solution of potassium dicarbonate iron water, very gradually and with constant shaking, a saturated solution of cupric sulphate until it ceases to be redissolved; filter, and preserve in bottles. In testing add 2 c.c. to 4 c.c. of urine and heat. A yellow precipitate indicates glucose.

Sole $(s \bar{l} l)$ [ME., sole, sole]. The plantar surface of the foot. S.-leather. See Leather. S.-plate, $(a)$ the name given by Boas to the palmar side of claws and hoofs, as distinguished from the volar side (Sohlenhorn); (b) the flattened nucleated mass of soft, faintly granular protoplasm closely applied to the surface of a voluntary muscle to receive the ultimate fibrillæ of the medullated nerve-fibers composing its motor supply. It forms part of the motor disc or endplate. S.-reflex. See Reflexes, Table of.

Solea $\left(s o^{\prime}-l e-a h\right)$. See Sole.

Solearis $\left(s o-l e-a^{\prime}-r i s\right)$. Synonym of Soleus

Solen $\left(s \sigma^{\prime}-l e n\right) \quad[\sigma \omega \lambda \eta \dot{\eta}$, a channel]. I. A channel. 2. The central canal of the spinal cord.

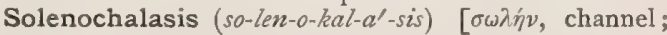
$\chi \alpha \lambda a \sigma \tau \iota \kappa 6 ́$, making supple]. Dilatation of a tubular organ.

Solenostegnosis (so-len-o-steg-no'-sis) [ $\sigma \omega \lambda \eta \dot{v}$, a channel; $\sigma \tau \varepsilon \gamma \nu \omega \sigma \iota$, stenosis]. Constriction of a tubular organ.

Soleus (so-le'-us). See Muscles, Table of.

Solid (sol'-id) [solidus, solid]. A substance the molecules of which are in a condition of strong mutual attraction. S. Green. See Pigments, Conspectus of. S. Ocular. See Ocular. S. Violet. Same as Gallocyanin.

Solidago (sol-id-a'-go) [solidus, solid: gen., Solidaginis]. Golden-rod, a genus of some IOo species of compositeflowered plants, mostly American. S. odora is carminative, diaphoretic, stimulant, diuretic, and antemetic. $\mathbf{S}$. rigida is tonic and astringent. S. virgaurea, of both continents, is astringent, tonic, and vulnerary.

Solidarity (sol-id-ar'-it-e) [solidus, solid]. The unitary nature of the relations of the various parts of an organism, whereby all individual parts are subordinated to the welfare of the whole.

Solidification $\left(s o l-i d-i f-i k-a^{\prime}-s h u n\right)$ [solidus, solid; facere, to make]. The act of becoming solid, or of possessing molecular attraction.

Solidism (sol'-id-izm) [solidus, solid]. The theory that diseases depend upon alterations in the solids of the body.

Solidist (soll-id-ist) [solidus, solid]. The name given to one opposed to the doctrines of the humoralists.

Solitarius (sol-it-a'-re-us) [L.]. Single, solitary.

Solitary (sol'-it-a-re) [solitarius, solitary]. Marked by solitude; single. S. Bundle, a strand of nerve-fibers in the medulla. S. Follicles, certain minute glands found in the mucous membrane of the intestines. $\mathbf{S}$. Glands. See Gland. S. Kidney, Rokitansky's term for the single mass produced by the congenital fusion of the two kidneys.

Solium $\left(s o^{\prime}-l e-u m\right)$. See Tania solium.

Solomon's Seal (sol'-o-monz-sèl). The root of Convallaria polygonatum, a tonic, mucilaginous and slightly astringent. It was formerly a popular domestic remedy for rheumatism and gout, and is externally employed in contusions. Dose of fld. ext. $3 \mathrm{j}-\mathrm{ij}$. Unof.

Soluble $($ sol' $-u-b l)$ [solubilis, soluble]. That which may enter into solution. Capable of being dissolved. S. Albumin. See Native Albumin. S. Blue. See Pigments, Conspectus of. S. Eosin. See Pigments, Conspectus of. S. Glass, the silicate of sodium, potassium, or magnesium. A viscid liquid that hard- 
ens into a firm varnish when applied to bandages and dressings. S. Primrose. Same as Erythrosin. S. Starch $\left(\mathrm{C}_{6} \mathrm{H}_{10} \mathrm{O}_{5}\right)$. Anylodextrin; a substance obtained by heating starch paste to $40^{\circ} \mathrm{C}$. on a water-bath and digesting with a small amount of saliva. The solution loses its opalescent appearance and becomes limpid and clear, like water. It is dextrorotatory and does not reduce Fehling's fluid. S. Stool, feces of semi-solid consistency.

Solute (so-lut') [solvere, to set free]. In biology: (a) free; not adhering or adnate; $(b)$ soluble.

Solutio (so-lúl-she-o) [L. ]. A solution.

Solution $\left(s o-h u^{\prime}-\operatorname{sh} u n\right)$ [solutio, a solution]. The overcoming of cohesion in the molecules of a solid by means of a liquid menstruum and their diffusion among those of the liquid. The infusion of the molecules of a gaseous or of a liquid substance among those of a liquid; a liquid in which a solid has been dissolved; " a homogeneous mixture exerting an osmotic pressure." S., Arsenical, Liquor potassii arsenitis. S., Burnett's, an aqueous solution of zinc chlorid. S., Centinormal, a solution $\frac{1}{10}$ of the strength of a normal solution. S. of Contiguity, the separation of two parts normally in contact. S. of Continuity, division of a tissue by traumatism, inflammation, or disease. S., Decinormal, a solution $\frac{1}{10}$ of the strength of a normal solution. S., Dobell's, a solution containing 2 drams of borax, I of sodium bicarbonate, 45 grains of carbolic acid, I oz. of glycerin, and water to make I pint. S., Donovan's, a solution of the iodids of arsenic and mercury. S., Fehling's, a solution of cupric sulphate, potassium tartrate, and sodium hydrate in water. It is used in testing for sugar. See Tests, Table of. S., Fowler's. Liquor potassii arsenitis. S., Koppeschaar's, a decinormal bromin volumetric solution. It is employed to test the strength of carbolic acid. S., Labarraque's, a solution of chlorinated soda. S., Lugol's, a solution of iodin and potassium iodid in water. S., Magendie's, a solution of $\mathbf{I} 6$ grains of sulphate of morphin in I oz. of water. S., Mayer's, decinormal mercuric potassium iodid volumetric solution. S., Monsel's, Liquor ferri subsulphatis. S., Normal, a standard solution containing in each liter an amount of the reagent sufficient to exactly replace or combine with one gram of hydrogen. S., Normal Saline, a solution of 75 parts of sodium chlorid in Io, 000 of water. S., Saturated, a solution in which no more of the molecules of the solid can be diffused through the menstruum. See also Liquor. S., Seminormal, a solution having $1 / 2$ the strength of a normal solution. S., Standard, a solution containing definite quantities of chemicals whose exact reactions are known. S., Standardized, one made of standard strength. S., Vlemingkx's, a solution of quicklime and flowers of sulphur in water. It is useful in seborrhea. S., Volhard's, decinormal potassium sulphocyanate volumetric solution. S., Volumetric. See S., Standard.

Solutol $($ sol'-u-tól) [solvere, to dissolve]. An alkaline solution of cresol in sodium cresol. It is prepared by adding cresol to an excess of caustic soda and then adding more cresol. It is used as a disinfectant.

Solvent (sol'-vent) [solvere, to dissolve]. A liquid menstruum for effecting solution or overcoming molecular cohesion. Water is the chief solvent for crystalline substances and salts, alcohol for gums and resins, and ether, chloroform, and benzine for fats.

Solveol (sol't-ve-ol). A neutral solution of cresol in sodium cresol; it is disinfectant and makes a clear mixture with water: 0.3 per cent. solutions may be used for asepsis ; 0.5 per cent. solutions for antisepsis.

Solvine (sol'-vin) [solvere, to dissolve]. One of a number of liquids obtained from certain oils, by the action of concentrated sulphuric acid. They are blood-poisons, dissolving the red corpuscles. See Sulphoricineolic Acid.

Soma $\left(s o^{\prime}-m a h\right)$ [ $\sigma \tilde{\omega} \mu a$, the body: pl., Somata $]$. In biology, the body alone, considered without the limbs. Somacule $\left(s o^{\prime}-m a k-\bar{u} l\right)$ [dim. of $\sigma \tilde{\omega} \mu a$, the body]. Foster's term for a physiologic unit corresponding to, but greatly more complex than, the chemic molecule, any division of which will interfere with its physiologic specificity.

Somascesis (so-mas-se'-sis). See Gymnastics.

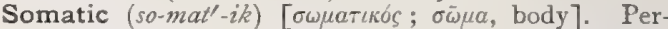
taining to the body or organism as a whole. S. Cavity, the body-cavity or perivisceral cavity. S. Cells, undifferentiated body-cells or parenchyma-cells. S. Death, the final cessation of all vital activities in the body at large. See Death. S. Mesoderm, the upper or outer leaf of the mesoderm (Hautfaserblatt) separated by the colomic fissure from the lower or inner leaf. (Darmfaserblatt). S. Musculature, the muscles of the outer wall of the body-cavity or somatopleure, as distinguished from those of the splanchnopleure, the splanchnic musculature.

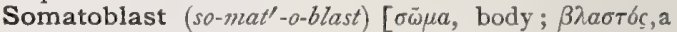
germ]. Any plastidule from which cell-material (in contradistinction to nuclear material) is built up or developed.

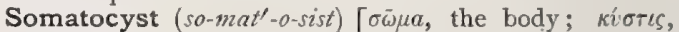
bladder]. In biology, a pneumatophore formed by inflation of the stem or body, as in some Siphonophora (Physalia).

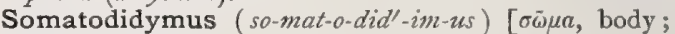
didvuos, twin]. A double monster having the trunks united.

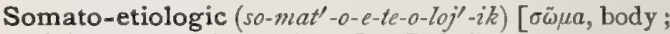
airía, cause; $\lambda \sigma^{\prime} \gamma o \varsigma$, science]. Relating to some mental disturbance caused by physical disease.

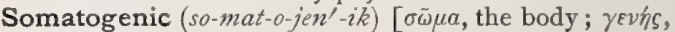
produced]. Pertaining to somatogeny.

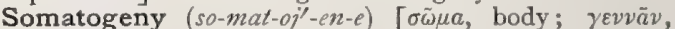
to produce]. The acquirement of bodily characters, especially the acquirement of characters due to the environment.

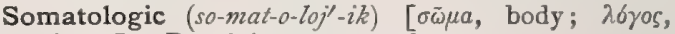
science]. Pertaining to somatology.

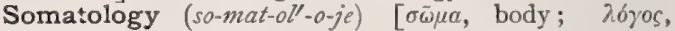
science]. The study of anatomy and physiology, or of organized bodies; biology, apart from psychology.

Somatome $\left(s o^{\prime}-m a t-\bar{o} m\right)$ [ $\sigma \bar{\omega} u \alpha$, body; touń, section] In biology, a transverse segment of an organized body; a somite or metamere, actual or ideal. Goodsir's term for one of the primitive segments of a vertebrate; "primitive vertebra" (Urwirbel). Cf. Metasomatomes.

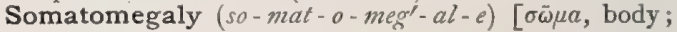
$\mu \varepsilon \gamma a ́ \lambda \eta$, large]. Gigantism.

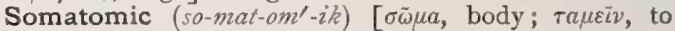
cut]. Pertaining to a somatome.

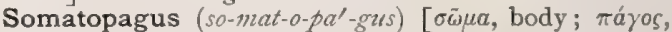
fixed]. A double monstrosity having two trunks.

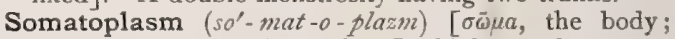
$\pi \lambda a ́ \sigma \mu a$, anything formed]. In biology, the protoplasm of the body-cells; Weismann's term for that form of living matter which composes the mass of the body, and which is the subject of death, as distinguished from germ-plasm, which composes the reproductive cells and is possessed of potential immortality. See Heredity.

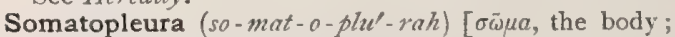
$\pi \lambda \varepsilon v \rho a ́$, the side: pl., Somatopleura]. In biology, the body-wall, composed of the somatic mesoderm and the ectoderm. 


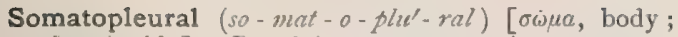
$\pi \lambda \varepsilon v \rho \dot{a}$, side]. Pertaining to a somatopleura.

Somatopleure $\left(s o^{\prime}-m a t-o-p l \bar{u} r\right)$. Same as Somatopleura.

Somatopleuric (so-mat-o-plu'-rik). Same as Somatopleural.

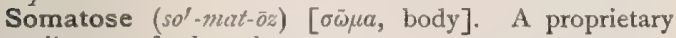
albumose food-product.

Somatotomy (so-mat -ot' $-0-m e)[\sigma \tilde{\omega} \mu a$, body; $\tau o \mu \eta \dot{n}$, section]. Anatomy; dissection.

Somatotridymus (so-mat-o-trid'-im-us) [ $\sigma \tilde{\omega} \mu \alpha$, body ; toidvuos, triple]. A monster with three trunks or bodies.

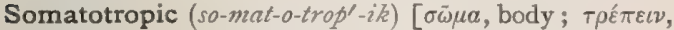
to turn]. In biology, exhibiting somatotropism.

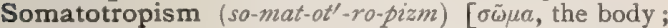
$\tau \rho \varepsilon ́ \pi \varepsilon(\nu$, to turn]. In biology, the influence of the attraction of gravitation on growing organs in plants.

Sombrerite (som-bra'-rit) [Sp., sombrero, a soundingboard]. An impure calcium phosphate, a source of phosphorus, found in West Indian guano.

Somital (so'-mit-al). Same as Somitic.

Somite $\left(s o^{\prime}-m \bar{\imath} t\right)[\sigma \tilde{\omega} \mu a$, the body]. In biology, one of the segments, arthromeres, diarthromeres, or metameres of an articulated organism.

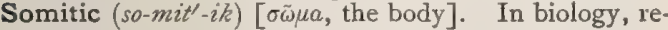
sembling or pertaining to a somite.

Somnal (som'-nal) [somnus, sleep],

$$
\mathrm{CCl}_{2}-\mathrm{CH} / \mathrm{OC}_{2} \mathrm{H}_{2} .
$$

A hypnotic formed by the union of chloral, alcohol and urethan. It acts like chloral, but is more pleasant. Dose $m \times x x$

Somnambulism (som-nam'-bu - lizm) [somnus, sleep; ambulare, to walk]. The condition of half-sleep, in which the senses are but partially suspended; also termed sleep-walking. Also, the type of hypnotic sleep, in which the subject is possessed of all his senses, often having the appearance of one awake, but whose will and consciousness are under the control of the operator. Charcot calls this simply somnambulism, which constitutes the third type of the hypnotic state. The second he calls catalepsy, produced by the gong suddenly sounded or the electric light suddenly brought before the subject's eyes; the eyes are wide open and the muscles acquire the curious waxy condition designated as flexibilitas cerea. The subject seems to have no mental communication with the outside world. This latter characteristic also distinguishes lethargy, or the first type of the hypnotic state, in which there is unconsciousness, irresponsiveness of the senses to stimulation, and a fixed position of certain muscles. See, also, Hypnotism.

Somniation (som-ne-a'-shun) [somniatio]. Dreaming. Somnifacient (som-nif-a'-se-ent) [somnus, sleep; facere, to make]. I. Narcotic or soporific. 2. A medicine producing sleep; a hypnotic.

Somniferin (som-nif'-er-in) [somnus, sleep; ferre, to bear]. I. A morphin-ether discovered by Bombelon, said to be stronger than morphin, and without bad effects or influence upon the heart. 2. An alkaloid derived from Withania somnifera, a solanaceous plant of Asia and the Mediterranean region. It is said to be narcotic. Unof.

Somniferous, Somnific (som-nif'-er-us, som-nif'-ik) [somnus, sleep; ferre]. Producing sleep.

Somnific (som-nif'-ik) [somnus, sleep]. Causing sleep.

Somnifugous (som-nif'-u-gus) [somnus, sleep; fugere, to flee]. Driving away sleep.

Somniloquence, Somniloquism, Somniloquy (somnil'-o-kwens, som-nil'-o-kwizm, som-nil'-o-kwe) [som- mus, sleep; loqui, to talk]. The act of talking in one's sleep.

Somnium (som'-ne-zum), See Dream

Somnolence (som'-no-lens) [somnolentia; sommus, sleep]. A condition of drowsiness or sleep.

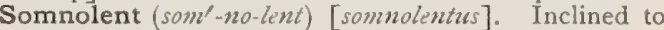
sleep.

Somnolentia (som-no-len'-she-ah) [L.]. Sleep-drunkenness; a condition of incomplete sleep in which a part of the faculties are abnormally excited, while the others are in repose.

Somnovigil (som-no-vij'-il). See Coma-vigil.

Somnus (som'-nus). See Hypnosis.

Sonde (sond) [Fr.]. See Sound.

Sonitus $\left(\right.$ son' $\left.^{\prime}-i t-u s\right)$. See Timnitus.

Sonometer (so-nom'-et-er) [sonus, a sound; $\mu \dot{\varepsilon} \tau \rho o v$, a measure]. An instrument for determining the pitch of a sound, and also for determining its relation to a chord.

Sonora $($ so-no'-rah). Gum. The gum of the creasote plant, Larrea mexicana.

Sonorous (so-no'-rus) [sonus, sound]. Ringing; capable of producing a musical sound.

Sonstadt's Solution. A solution used to test the specific gravity of gems. It consists of 3720 grains of red iodid of mercury and 2830 grains of iodid of potassium in $151 / 2$ drams of distilled water.

Sonus $\left(s 0^{\prime}-n u s\right)$. See Sound.

Soor (Sōr) [G.]. See Thrush.

Soot [ME., soot, soot]. A complex carbon deposit of wood-smoke; an old-time remedy in certain diseases. S.-cancer. See Chimney-sweeps' Cancer.

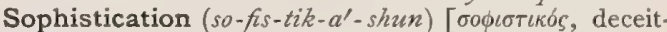
ful]. The adulteration or imitation of a substance.

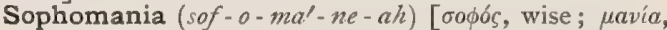
madness]. Insanity in which the patient believes himself to excel in wisdom.

Sophora (so-fo'-rah) [Arab.]. A genus of leguminous trees, shrubs, and herbs, mostly growing in warm regions. S. sericea (see Loco) is a poisonous plant of the U. S. ; its seeds contain sophorin. S. speciosa, a tree of Texas, also yields sophorin.

Sophorin (so-fo'-rin) [Arab.]. A paralyzant, poisonous alkaloid which exists in the seeds of some species of Sophora.

Sophronistæ dentes (sof-ro-nis'-te den'-tēz). Wisdomteeth, or dentes sapientiæ.

Sopient $\left(s o^{\prime}\right.$-pe-ent $)$ [sopor, sleep]. Sedative, soporific. Sopor (so'-por) [L.]. Sleep, especially the profisund sleep symptomatic of a morbid condition.

Soporifacient (so-por-if- $a^{\prime}$-se-ent) [sopor, sleep; facere, to make]. A drug producing sleep; a hypnotic.

Soporiferous (so-por-if'-er-us) [sopor, sleep; ferre, to bear]. Producing or causing sleep.

Soporific $\left(\right.$ so-por-if $\left.{ }^{\prime}-i k\right)$ [sopor, sleep; facere, to make]. I. Narcotic; inducing sleep. 2. A medicine or agent which induces sleep; a hypnotic.

Soporose, Soporous (so'-por-ōz, so'-por-us) [sopor, sleep]. Sleepy; partaking of the nature of sound sleep.

Sora $\left(s o^{\prime}-r a h\right)$. Synonym of Urticaria.

Sorbefacient (sor-be-fa'-se-ent) [sorbere, to suck; facere, to make]. I. Promoting absorption. 2. A medicine or agent that induces absorption.

Sorbic (sor'-bik) [sorbus, the sorb-tree]. Pertaining to or derived from the mountain ash. S. Acid. See Acid.

Sorbin (sor'-bin). See Sorbinose.

Sorbinose (sor'-bin-ōz) [sorbus, the sorb-tree], $\mathrm{C}_{6} \mathrm{H}_{12} \mathrm{O}_{6}$. Sorbin, a ketone alcohol, found in mountain-ash berries, and consisting of large crystals, which possess a very sweet taste. It reduces alkaline copper-solutions, 
but is incapable of fermentation under the influence of yeast. See Carbohydrates, Table of.

Sorbite $($ sor'-bit $)$ [sorbus, the sorb-tree], $\mathrm{C}_{6} \mathrm{H}_{14} \mathrm{O}_{6}+$ $\mathrm{H}_{2} \mathrm{O}$. A hexahydric alcohol occurring in mountainash berries, forming small crystals which dissolve readily in water. They melt at $110^{\circ} \mathrm{C}$. Sorbite corresponds, in all probability, to grape-sugar.

Sorbose $\left(\right.$ sor $\left.{ }^{\prime}-b 0 z\right)$. Same as Sorbinose.

Sordes $\left(s o r^{\prime}-d e z\right)$ [sordere, to be foul]. Filth. Pus or suppuration. Also, any filthy or morbid secretion or deposition, especially the crusts that accumulate on the teeth and lips in low fevers. S. aurium, cerumen. S. capitis. See Scabies capitis. S., Dental, the collection of matter found upon the teeth in some diseases. Sordid (sor'-did) [sordere, to be dirty]. In biology, dull or dirty in hue.

Sore (sör) [ME., sore, sore]. I. Any ulcer, chafe, or wound; a sensitive, inflamed spot. 2. Painful. S., Bed-. See Bed-sore. S.-eyed, affected with ophthalmia or blepharitis. S., Fungating, a soft chancre with abundant granulations. S., Hard. Synonym of Chancre. S.-heels. See Horse-pox. S., Hunterian, a true or hard chancre. S., Indurated, S., Infecting. Synonyms of Chancre. S.-mouth, stomatitis. S.-mouth, Nursing, that produced by nursing. S., Oriental, a general term for any one of a number of suppurative sores of the Orient. S., Soft, a chancroid. S.-throat, a popular name embracing almost every inflammation or morbid affection of the throat. S.-throat, Clergymen's, chronic follicular pharyngitis. S.-throat, Gouty, a pharyngitis due to gout. S.-throat, Hospital, chronic pharyngitis. S.throat, Malignant, S.-throat, Putrid, pharyngitis attended with ulceration. S.-throat, Rheumatic, pharyngitis due to rheumatism. S.-throat, Ulcerated, pharyngitis attended with ulceration. S., Veneral, a chancroid.

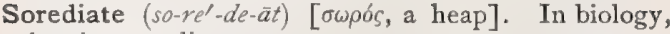
bearing soredia.

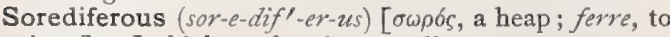
bear]. In biology, bearing soredia.

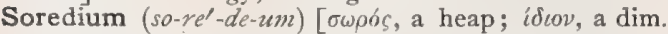
suffix: pl., Soredia]. In biology, one or more algal cells wrapped in hyphæ and discharged from the fronds of lichens, serving the purposes of vegetative propagation.

Sorghum $($ sor'-gum) [sorgum, sorghum]. A variety of sugar-cane, S, saccharatum, of the family Graminacea. Also a syrup made from the expressed inspissated juice of the same

Soroche $\left(s o-r o^{\prime}-k e\right)[\mathrm{Sp}$.$] . Mountain sickness.$

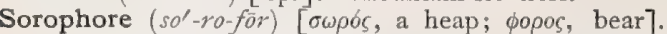
In biology, the cushion lying along the ventral edge of the sporocarp of Marsilea, which at germination becomes detached at one end, and exposed in the form of a cord, bearing the sori in two rows.

Sororiation (sor-or-e-a'-shun) [soror, a sister]. The development which takes place in the female breasts at puberty.

Sorose $\left(s o^{\prime}-r o \bar{z}\right)$ [ $\sigma \omega \rho o ́ s$, a heap]. In biology, bearing a sorus or a sorosis.

Sorosis (so-ro'sis) [owob́s, a heap]. In biology, a fruit like that of the mulberry, which consists of a collection of small, fleshy fruits, the product of a compact flower-cluster.

Sorrel (sor'-el) [ME., sorel, sorrel]. See Sheep-sorrel. S.-tree. See Sourwood.

Sorts (sortz) [ME., sort, sort]. In the drug-trade, refuse or culls; the poorest grade of any drug.

Sorus $\left(s o^{\prime}\right.$-rus) [owpós, a heap: pl., Sori ]. The name applied to the fruit-dot or collection of sporangia of the ferns.

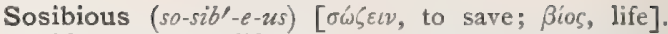
Able to preserve life.

Soteriology (so-te-re-ol'-o-je). Synonym of Hygiene.

Soudan Brown. See Pigments, Conspecius of. S. Red. Same as Naphthalin-red.

Souffle $\left(s o o^{\prime}-f l\right)$ [Fr.]. A blowing sound. See Murmur. S., Cardiac. See Heart-murmur. S., Fetal, an inconstant murmur heard during pregnancy, and supposed to be due to the compression of the umbilical cord. S., Funic or Funicular, a hissing sound, synchronous with the fetal heart-sounds, heard over the abdomen of a pregnant woman. S., Splenic, a sound said to be audible over the spleen in cases of malaria, leukemia and biliary calculus. S., Umbilical. See S., Funic. S., Uterine, the proper term for what was formerly called the Placental Souffe, a sound heard in the latter montbs of pregnancy, and caused by the entrance of blood into the dilated arteries of the uterus.

Soul (sōl) [ME, soule, soul]. The moral and emotional part of man's nature. S.-blindness. See Blindness, Psychic, and Apraxia. S., Spinal, a supposititious consciousness present in the spinal cord.

Sound (sozund) [ME., sozonde, sound]. The sensation produced upon the auditory nerve by aërial vibrations. See Hearing. Also, an instrument for insertion into the bladder to test for calculus. S., Anasarcous, a moist bubbling sometimes heard on auscultation when the skin is edematous. S., Bandbox, the resonant percussion-note sometimes heard in emphysema. S., Bellocq's. See Bellocq's cannula. S., Bellows, an endocardial murmur which sounds like a bellows. See Bellores. S., Blowing, a blowing murmur. S., Bottle. See Amphoric Murmur. S., Bronchial, the large, harsh sound of bronchial respiration. Ss., Cardiac. See S., Heart. S., Cracked-pot, a form of tympanitic resonance indicative of a cavity. S., Esophageal, a long flexible sound for examination of the esophagus. Ss., Fetal Heart-, the sounds produced by the beating of the fetal heart, best heard near the umbilicus of the mother. S., Flapping, the clap made by the closure of the cardiac valves. Ss., Friction-, the sounds produced by the rubbing of one rough surface upon another. S., Funicular Bellows. See Sonffle. Ss., Heart-, the two sounds heard over the cardiac area. The first, dull and prolonged, is said to sound like $l u b b$, and is isochronous with the systole of the ventricles. The second, sharp and short, is said to sound like dup, and is isochronous with the closure of the semilunar valves. S., Hollow. See Amphoric Percussion. S., Kettle-singing, a chest-sound sometimes heard in incipient pulmonary tuberculosis. It resembles water boiling in a kettle. S., Lacrymal, a fine sound for exploring or dilating the lacrymal canal. S., Metallic Heart-. See Metallic Murmur. S., Metamorphosing Breath-, a sound due to the passage of air through a narrow opening into and out of a pulmonary cavity. S., Muscle-, the sound heard through the stethoscope when placed over a muscle in the state of contraction; sussurus. S., Osseous, a high-pitched intense auscultatory sound having a slightly metallic timbre. S., Pulmonary, the respiratory murmur. S., Respiratory, respiratory murmur. S., Sawing, a cardiac murmur resembling the sound produced by sawing. S.-shadow, the interference with a sound-wave caused by an object being placed between the ear and the source of sound. S., Subjective. See Phonism. S., To-and-fro, the friction-sound of pericarditis and pleuritis. S., Tubular, the sound of tracheal respiration. S., Urethral, an elongated steel instrument, usually slightly conical, for examination and 
dilatation of the urethra. S., Uterine, a graduated probe for measurement of the uterine cavity.

Sour (sozur) [ME., sour, sour]. Having an acid taste; fermented. S. Dough. See Leaven. S.-wood, sorreltree; the leaves of Oxydendron arboreum; they are tonic, refrigerant and diuretic, and of reputed value in dropsy. Dose of the fld. ext. $m x x x-3 \mathrm{ij}$. Unof.

Souring (sozer'-ing) [ME., sour, sour]. A disease of wine due to the conversion of the alcohol into acetic acid. It is caused by the formation in the wine of the vinegar plant.

Southern (suth'-ern) [ME., southerne, southern]. Pertaining to the south. S. Vanilla. See Liatris odoratissima. S.-wood. See Artemisia.

Southey's Drainage-tubes. Simall tubes employed for draining away the fluid from limbs that are the seat of extensive anasarca. It is said that large amounts of fluid can thus be drained away in a comparatively short time, and that there is but slight risk of erysipelas or other inflammatory process being set up around the puncture.

Soy Bean, or Soya Bean (soi' or soi'-yah) [Jap.]. A kind of bean, the seed of Glycine soja (also referred to as Soja hispida and Dolichos sinensis), a plant of Japan and China and India. Diabetic bread, biscuits, and cakes are prepared from its flour, which contains no starch. The sauce called soy is also made from this bean.

Soyka's Plates. Dishes employed in the cultivation of bacteria. They are similar to Petri's capsules, but differ from them in having from eight to ten depressions ground in the lower plate, which resemble the "wells" in hollow slides.

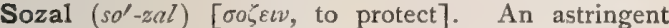
organic salt of aluminum, used as an antiseptic.

Sozin $\left(s o^{\prime}-\sin \right)$ [ $\sigma \omega \zeta \varepsilon \iota \nu$, save, keep]. In biology, a defensive proteid which occurs naturally in a normal animal; one of the two provisional classes into which Hankin divides Alexins or defensive proteids. See Proteids, Defensize, and Toxosozin.

Sozodont $\left(s o^{\prime}-z o-\right.$ dont $)[\sigma o \zeta \varepsilon \iota \nu$, to protect; ódov, tooth]. A dentrifice supposed to be prepared mainly of Castile soap and alcohol.

Sozoiodol (so-zo-i'-o-dol) [ $\sigma \omega \zeta \varepsilon c \nu$, to save ; $i \omega \delta \eta \varsigma$, like a violet], $\mathrm{C}_{6} \mathrm{H}_{2}\left(\mathrm{HSO}_{3}\right) \mathrm{I}_{2}$. OH. A combination of sul phur, iodin, and carbolic acid. It is useful as an antiseptic.

Sozolic Acid (so-zo'-lik). See Aseptol.

Space (spās) [ME., space, space; spatium, space]. A name given for purposes of description to sundry enclosed or semi-enclosed places within or about the body. S., Anterior Perforated, a triangular space at the mesal side of the Sylvian fissure. S., Arachnoid. See S., Subarachnoid, and S., Subdural. S., Axillary, the axilla. S., Bregmatic, the anterior fontanel. S., Circumlental, the interspace between the ciliary body and the equator of the lens. Ss., Circumvascular Lymph-, channels surrounding the blood-vessels and communicating with lymphatic vessels. S., Corneal, that between the corneal layers. S., Douglas's. See Douglas's Pouch. S., Epidural (of the spinal canal), a lymph-space between the spinal dura and the periosteum lining the canal. S.-feelings, Hering's term for the perceptions or inferences of space-relations resulting from the retinal image. $\mathbf{S}$. of Fontana, one of the intercommunicating cavities in the spongy tissue occupying the angle between the cornea and the iris. S., Haversian or Medullary, in the cancellous tissue of bone. S. of His. See S., Cir cumvascular Lymph-. Ss., Intercellular, cavities formed by the splitting or separation of the walls of adjoining cells. S., Intercostal, the space between two contiguous ribs. S., Intercrural. See $S$., Interpedun cular. Ss., Interfascicular, spaces between the bundles in fibrous tissue. S., Interglobular, an apparent, irregular space in the interglobular substance of the dentine. S., Intermesoblastic, the cavity between the visceral and parietal laminæ of the mesoblastic plates of the embryo. Ss., Intermetatarsal, spaces between the metatarsal bones. S., Interosseous, the space between two parallel bones. S., Interparietal. See S.,Virchow-Robin. S., Interpeduncular, a diamond-shaped depression at the base of the brain, lying between the optic tracts and the crura cerebri. S., Intertunical. See S.,Virchowo-Robin. S., Intervaginal (of the optic nerve). See $S$., Subvaginal. S., Investing. See Lymph-sinus. S., Ischiorectal. See Ischio-rectal Fossa. S., Lacunar. See Lacuna. S., Lymph, a sinus or space through which lymph passes. S., Marrow. See Medullary Cavity. S., Mediastinal, the cavum mediastinum. S., Pelvirectal, the same as the Ischiorectal Fossa, q.v. Ss., Pericellular, lymph-spaces in the brain. S., Perichoroidal, a lymph-space between the sclera and the choroid. S., Perigastric, the cavity surrounding the stomach and other viscera. Ss., Perineurial, lymph-spaces between the lamellæ of the perineurium. S., Perivascular. See S., Circumvascular Lymph-. S., Perivitelline. See S., Yolk. Ss., Placental Blood-, the intervillous lacunæ of the placenta. Ss., Pleuro-peritoneal. See S., Intermesoblastic. S., Poiseuille's. See S., Lymph-. S., Popliteal, a lozenge-shaped space at the back of the knee and thigh. S., Posterior Perforated, the depression just behind the albicantia at the base of the brain. S., Posterior Triangular, the space lying above the clavicle and between the sternocleido-mastoid and the trapezius muscle and the occiput. S., Prevesical, a space lying immediately above the pubis and between the transversalis fascia and the posterior surface of the rectus abdominis. S., Retroperitoneal, the space lying behind the peritoneum, but in front of the spinal column and the lumbar muscles. S., Semilunar, of Traube. See Semilunar. S.-sense, the faculty by which the form of objects is recognized. S., Subarachnoid, the space between the arachnoid and the pia proper. It contains the cerebrospinal fluid. S., Subdural, the space between the dura and the arachnoid. Normally it contains only a capillary layer of fluid. S., Subvaginal, a lymph-space within the sheath of the optic nerve. $\mathbf{S}$. of Tenon, a lymph-space between the sclera and the fascia of Tenon. S., Traube's, a semilunar tympanitic space overlying the stomach. See Semilunar. S., Utero-rectal. See Douglas's Pouch. S., Utero-vesical, the utero-vesical fossa. S., Virchow - Robin, an adventitious lymph-space found between the coats of the cerebral capillaries. $\mathbf{S}$. Visual, the visual field. S., Yolk, the space formed by the retraction of the vitellus from the zona pellucida.

Spadiceous (spa-dish'-us) [ $\sigma \pi a ́ \delta \iota \xi$, a palm branch]. In biology, bearing a spadix.

Spadicose $\left(s p a^{\prime}-d i k-o z z\right)$ [ $\sigma \kappa a ́ \delta \iota \xi$, a palm branch]. In biology, spadiceous.

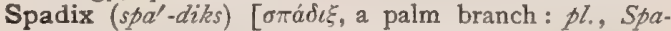
dices]. In biology, a fleshy spike, commonly en veloped in a spathe.

Spaeth and Braun, Iodoform-bacillus of. A medi cated bacillus for use in puerperal fever. It consists of iodoform 20 grams, gum arabic, glycerin, and pure starch each 2 grams, made into three suppositories. One is introduced into the uterine cavity.

Spagiric $\left(s p a j-i \gamma^{\prime}-i k\right)$ [ $\sigma \pi \alpha \dot{\varepsilon} \varepsilon v$, to stretch or rend: 
áyeipeiv, to collect]. Pertaining to the obsolete chemic, or Paracelsian, school of medicine.

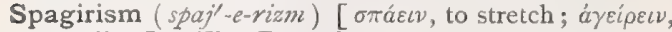
to collect]. The Paracelsian, or spagiric school, or doctrine, of medicine.

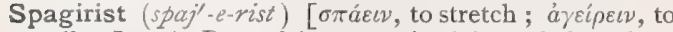
collect]. A Paracelsian; a physician of the obsolete alchemistic school.

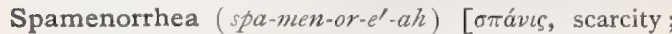
$\mu$ in, month; poia, flow ]. Scantiness of menstruation.

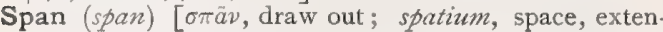
sion]. The distance between the tip of the thumb and the little finger outstretched.

Spanemia, Spanæmia (span-e'-me-ah). See Anemia. Spanemic, Spanæmic (span-e'-mik). See Anemic

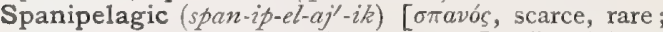
$\pi \varepsilon \lambda a \gamma \iota \kappa o ́ s$, pertaining to the open sea ]. In biology, applied to such marine organisms as only rarely come to the surface, living mostly in the ocean-depths. Cf. Plankton.

Spanish (span'-ish) [ME., Spainisc, Spanish]. Pertaining to Spain. S. Black. See Pigments, Conspectus of. S. Brown. See Pigments, Conspectus of. S. Catarrh. Synonym of Influenza. S. Fly. See Cantharis. S. Needle. See Bidens. S. Red. Same as Venetian Red. S. White. Same as Bismuth White. S. Windlass. See Garrot.

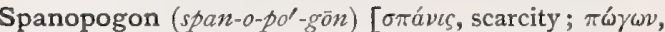
the beard]. A man having little or no beard.

Sparadrap (spar'-a-drap) [sparadrapum: pl., Sparadrapa]. A waxed cloth; also a plaster, spread upon cotton, linen, silk, leather, paper, or the like.

Sparagmatodes (spar-ag-mat-o $-d \bar{e} z)[\sigma \pi \alpha ́ \rho \alpha \gamma \mu \alpha$, a piece torn off; $\varepsilon i \delta o s$, like]. Afflicted with convulsions or cramps.

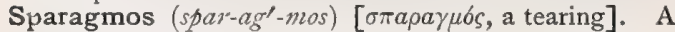
cramp; a choking sensation.

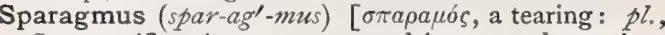
Sparagmi]. A severe convulsion; a laceration, or tearing.

Sparallium (spar-al'-e-um) [L.]. An old name for a vaginal clyster.

Spare (spār) [AS., speer, sparing]. Lean; thin.

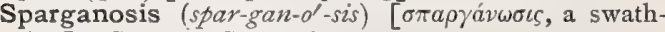
ing]. Same as Spargosis.

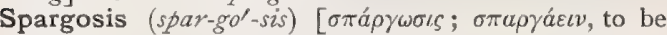
distended]. A term loosely applied to enlargement of the breasts; distention of a secretory organ; the swathing of a child's head in cloth; elephantiasis, $q . v$.

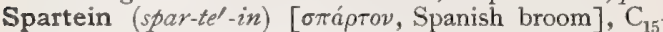
$\mathrm{H}_{26} \mathrm{~N}_{2}$. A volatile liquid alkaloid not containing oxygen. It occurs in Sarothamnus scoparius (see Scoparius), and is a colorless, thick oil, boiling at $3 \mathrm{II}^{\circ}$ C. It is narcotic. It stimulates the action of the vagus, and acts more quickly than digitalis, but not as powerfully. It is an uncertain diuretic and cardiac tonic, but is often efficacious when digitalis fails. Dose gr. $\frac{1}{25}-\frac{1}{5}$

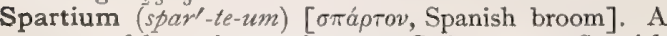
genus of leguminous plants. S. junceum, Spanish broom, a leguminous Old-world shrub. In small doses its seeds are diuretic and tonic; in larger doses, cathartic and emetic.

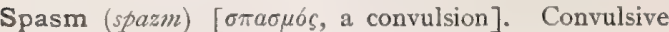
muscular contraction, local or general, voluntary or involuntary, S., Bell's, convulsive facial tic. S. Bronchial, asthma. S., Clonic, alternate muscular contraction and relaxation. S., Cynic. See Spasmus cynicus. S., Drivers', one of the so-called professional neuroses. It consists of cramp-like pains in the arms of drivers upon taking the reins in the hands. S., Facial, a peculiar clonic contraction of the muscles supplied by the facial nerve, at times confined to the muscles surrounding the eye, or else involving one entire side of the face. It is usually reflex in origin, and due to carious teeth or other local irritation. S., Fixed, permanent or continuous tetanic rigidity of one or more muscles. S. of the Glottis. See Laryngismus stridulus. S., Habit-, half-voluntary spasmodic movements, the result of habit, sometimes called Habit-chorea. S., Histrionic, a condition in which local involuntary twitchings of the face, acquired in childhood, persist during adult life, and are increased by emotional causes. S., Inspiratory, a spasmodic contraction of nearly all the inspiratory muscles. S., Lingual. See Aphthongia. S., Mobile, slow, irregular movements depending upon hemiplegia. S., Perineal. See Vaginodynia. S. Phonetic (of the glottis), spastic aphonia consisting of a spasm of the glottis, with elevation, resulting in interference with respiration. S., Salaam, clonic spasm of the muscles of the leg, causing jumping movements. S., Sewing, an affection of tailors, seamstresses, and shoemakers, in which clonic and tonic spasms attack the muscles of the hands on attempting to use them in the regular work. S., Smiths', a spasm that occurs in those engaged in pen-blade manufacturing, sawstraightening, razor-blade striking, scissors-making, file-forging, etc. It consists in spasmodic movements of the arm used, and finally paralysis. See Hemiplegia, Hephestic. S., Spinal Accessory. See Tic rotatoire. S., Synclonic, tremulous agitation. S., Tonic, persisting rigidity of contraction. See, also, Carpopedal, Histrionic, Nictitating, Nodding, Saltatorial, Tetanic, etc. S., Winking. See Spasmus nictitans. S., Writers', writers' cramp, $q . v$.

Spasmatic (spaz-mat'-ik) [ $\sigma \pi a ́ \sigma \mu o s$, spasm]. Pertaining to spasm ; also, one in convulsions.

Spasmi (spaz'-mī) [pl., Spasmues]. Spasms.

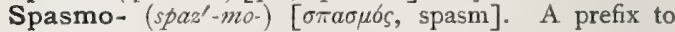
denote connection with, or relation to, spasm.

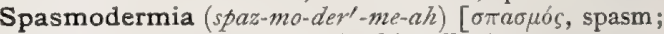
$\delta \varepsilon ́ \rho \mu \alpha$, skin]. A spasmodic skin-affection.

Spasmodic $\left(s p a z-m o d^{\prime}-i k\right)$ [ $\left.\sigma \pi a \sigma \mu \omega \delta \eta \zeta\right]$. Pertaining to, or characterized by, convulsion or a spasm. S. Cholera. Synonym of Cholera morbus. S. Colic. See Cramp Colic. S. Croup. See Larynoismus stridulus. S. Dorsal Tabes. See Charcot's Disease. S. Dysmenorrhea. Same as Dysmenorrhea, Idiopathic. S. Neurosis. See Neurosis. S. Spinal Paralysis. See Lateral Sclerosis, Primary. S. Tabes dorsalis. See Paraplegia, Infantile Spasmodic and Lateral Sclerosis, Primary. S. Theory of Inflammation. See Theory. S. Torticollis. See Tic rolatoire.

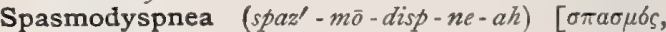
spasm; dyspnea]. Spasmodic difficulty of breathing.

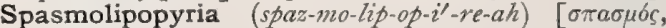
spasm; $\lambda \varepsilon i \pi \varepsilon \iota \nu$, to leave; $\pi \tilde{v} \rho$, fever]. A disease in which death takes place from convulsions, there being no fever present. It is supposed to be a form of yellow fever.

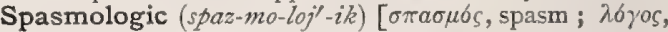
science]. Pertaining to spasmology.

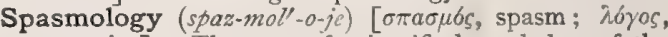
a treatise]. The sum of scientific knowledge of the nature and causes of convulsions.

Spasmolygmus (spaz-mo-lig'-mus). See Hiccough.

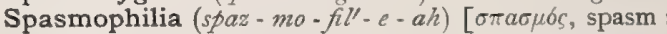
$\phi \iota \lambda \varepsilon \varepsilon \varepsilon v$, to love]. A morbid ease or tendency of being thrown into spasms.

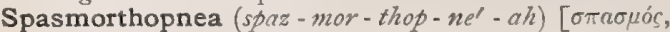
spasm; öptos, straight ; $\pi \nu \varepsilon i v$, to breathe]. Spasmodic orthopnea.

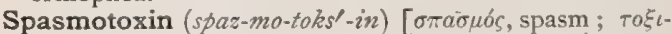
кóv, poison]. A ptomain-base of composition yet 
undetermined, obtained by Brieger from cultures of the tetanus-germ, together with other unnamed toxins, one of which induced complete tetanus, with salivation and lacrymation. Spasmotoxin induces in animals violent clonic and tonic convulsions. See Ptomains, Table of.

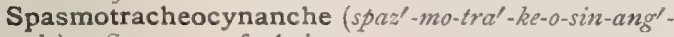
ke). Synonym of Asthma.

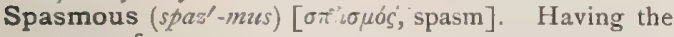
nature of a spasm.

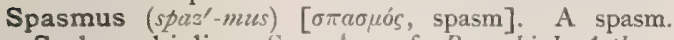
S. bronchialis. Synonym of Bronchial Asthma. S. cynicus, spasmodic contraction of muscles on both sides of the mouth, giving a grinning expression. S. intestinorum. Synonym of Enteralgia. S. muscularis. Synonym of Cramp. S. nictitans, spasmodic action of the orbicularis palpebrarum muscle, causing a winking-like movement of the lid. S. nutans, salaam convulsions, nodding spasm. S. oculi. Synonym of Nystrgmus. S. ventriculi. Synonym of Enteralgia and of Gastrodynia.

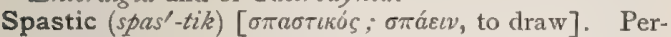
taining to or characterized by spasms. Drawn out of shape or contracted by disease; applied especially to a miscle. S. Anemia, anemia with abnormal smallness of the arteries. S. Diplegia. See Paraplegia, Infantile Spasmodic. S. Paralysis. See Paralyitis.

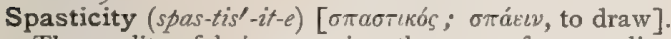
The quality of being spastic; the state of, or tending toward, spasm.

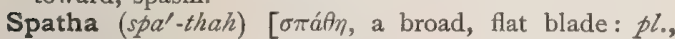
Spathce]. Same as Spathe.

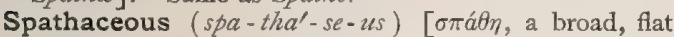
blade]. Furnished with a spathe, or resembling a spathe.

Spathal (spa'-thal) [ $\sigma \pi a ́ \theta \eta$, a broad, flat blade]. In biology, inclosed in or furnished with a spathe.

Spathe (späth) [ $\sigma \pi a ́ t \eta$, a broad, flat blade]. In biology, a peculiar bract, often large and colored, which subtends or encloses a spadix.

Spathed (späthd). Same as Spathaceous.

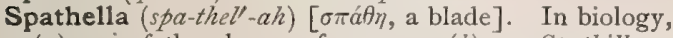
(a) one of the glumes of a grass; (b) see Spathilla.

Spathilla (spa-thil'-ah) [dim. of spatha, a spathe]. In biology, a diminutive spathe. In the palms spathillæ surround separate parts of the inflorescence.

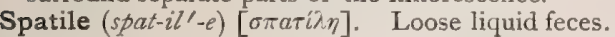

Spatium (spa'-she-um). See Space.

Spatula (spat'-u-lah). A flexible steel blade used for spreading ointments, dispensing medicines, and other purposes in the manipulation of medicines. S., Tongue, a tongue-depressor.

Spatular (spat'-u-lar) [spatula, a spatula]. Like a spatula.

Spatulate (spat'-u-lāt) [spatula, a blade]. In biology, resembling an old-fashioned spatula in outline. Applied to leaves and other flattened organs.

spatule . $($ spat'-ül) [spatula, a blade]. In biology, a structure having a spatulate shape.

Spatuliform (spat'-u-lif-orm). Same as Spatulate.

Spatuligerous (spat-u-lij'-er-us) [spatula, spatula; gerere, to bear]. In biology, provided with a spatula.

Spavin (spav'-in) [ME., spaveyne, spavin]. A disease of horses affecting the hock-joint, or joint of the hind leg between the knee and the fetlock. S., Blood, a dilatation of the vein that runs along the inside of the hock of a horse, forming a soft swelling. S., Bog, an encysted tumor on the inside of the hock of a horse, containing gelatinous matter. S., Bone, a disease of the bones at the hock-joint. S., High, an enlargement on the upper and inner part of the hock.
Spawn [ME., spawnen, to spawn]. In biology: I. Applied to aggregates of young animals during their early stages. 2. To produce or lay eggs, e.g. a fish.

Spay $(s p \bar{\imath}) \quad[\sigma \pi \dot{\alpha} \delta \omega v$, a eunuch $]$. To castrate. To remove the ovaries of a female.

Speak (spék) [ME., speken, to speak]. To use articulate utterance.

Speakers' Cramp. See Dysphonia spastica

Spearmint (spēr'-mint). See Mentha viridis. S., Oil of, a colorless oil obtained from Mentha viridis by distillation.

Specialist (spesh'-al-ist) [specialis, particular, special]. One, especially a physician or surgeon, who limits his practice to certain specified diseases, or to the diseases of a single organ or class.

Speciality, Specialty (spesh-e-al'-it-e, spesh'-al-te) [species, species]. The particular branch pursued by a specialist.

Specialization (spesh-al-iz-al-shun) [specialis, particular, special]. In biology, the modification of simple homogeneous tissues into special organs or parts adapted to the localization of function. See Differen. tiation.

Species $\left(s p e^{\prime}-s h \bar{e} z\right)$ [species, species]. I. That which may be distinguished by its characteristics. Also, in biology, a group of things having a number of common characteristics ; one of the constituent groups of a genus. "The smallest group to which distinctive and invariable characters can be assigned." (Huxley.) "An assemblage of individuals which differ from each other by very small or trifing and inconstant characters, of much less value than those in which they differ from any other assemblage of individuals." (J. L. Le Conte.) 2. A name in German and French pharmacy, and in the National Formulary, for certain mixtures of herbs, used in making decoctions and infusions. S.-cycle, in biology, the entire series of forms exhibiting or illustrating all the phases in the life-history of a species. S. emollientes, a mixture of the leaves of althea and mallow, of the leaves and branches of the melilot, of matricaria and flaxseed, in equal parts; used as an emollient cataplasm; it is official in Germany and is given in the National Formulary. S. laxantes. See Saint Germain Tea. S., Morphologic, one of "such living beings as constantly resemble one another so closely that it is inpossible to draw any line of demarcation between them, while they differ only in such characters as are associated with sex." (Huxley.) S., Nascent, an incipient species; a form undergoing modification. S., Origin of, a term employed by naturalists to denote the evolution of differentiated groups or species from groups of individuals characterized by general similarity or by homogeneity of structure. S. pectoralis. See Breast-tea, German.

Specific (spe-sif'-ik) [species, species; facere, to make]. Of or pertaining to a species; that which distinguishes a thing or makes it of the species of which it is. Also, a medicine which has a selective curative influence on an individual disease. S. Conduction-resistance, the special conduction-resistance dependent upon the molecular properties of the conducting material. $\mathbf{S}$. Diseases, those supposed to be directly the result of the action of a distinct contagium, virus, or microbe; especially applied to syphilis. S. Gravity. See Gravity. S. Heat, the amount of heat given off or absorbed by a definite weight (I th or I kilo) in undergoing a measured change of temperature $\left(\mathrm{I}^{\circ} \mathrm{C}\right.$. or $\mathrm{r}^{\circ} \mathrm{F}$.). S. Intensity, a term used in vital statistics to represent the number living at any age divided by the number dying at that age. It is highest at about I4 years of age. S. Names, the last term of an onym 
in binomial nomenclature. S. Rotatory Power, the angle of rotation which a layer of unit-thick ness would give to a certain light-ray. S. Stain, a pigment used in microscopy, having a peculiar affinity for certain histologic elements. The chief are Anilin Chlorid, Acid Fuchsin, Congo Red, Gold Chlo rid, Iodin, Methyl-violet, Nigrosin, Osmic Acid, Phloroglucin, Rose Bengale, Safranin, Silver Nitrate, Victoria Blue. See Stain, Plasmatic Stain, Nuclear Stain, and Table of Stains. S. Warmth, that amount of warmth which is necessary to warm one gram of a given substance one degree. According to Adamkiewicz, the specific warmth of muscle is even greater than that of water, although it has been assumed that the specific warmth of water is greater than that of any other known substance, with the exception of hydrogen.

Specificity (spes-if-is'-it-e) [species, species; facere, to make]. The quality of being specific, or of accomplishing a determinate function and not another. The qualities giving an organ or tissue a distinct character. Specillum $\left(s p e-s i l^{\prime}-u m\right)$ [L.: pl., Specilla]. A probe, especially one of silver, armed with a button-shaped head, for exploring wounds, fistulæ, etc.

Specimen (spes'-im-en) [L.]. An example; an exhibit. S., Living, sometimes applied to a patient exhibited before an audience.

Spectacles $\left(s p e k^{\prime}-t a k-l s\right)$ [spectaculum, a show]. Framed or mounted lenses for the correction of optical or muscular defects of the eye. See Lens. The difference between the old and new systems of numbering lenses is shown in the annexed Table, from Landolt.

COMPARATIVE TABLE OF THE INCH AND THE METRIC SYSTEMS OF NUMBERING SPECTACLELENSES. (From Landolt.)

\begin{tabular}{|c|c|c|c|c|c|c|c|}
\hline \multicolumn{4}{|c|}{ INCH SYSTEM. } & \multicolumn{4}{|c|}{ MEtRIC System. } \\
\hline 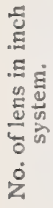 & 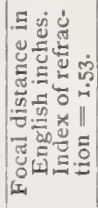 & 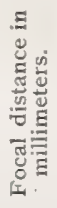 & 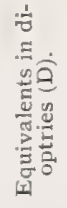 & 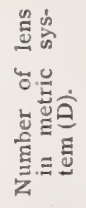 & 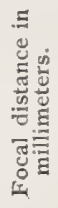 & 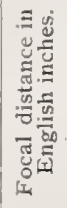 & 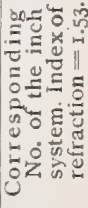 \\
\hline 72 & 67.9 & 1724 & 0.58 & 0.25 & 49000 & 157.48 & I 66.94 \\
\hline 60 & $5^{6.6}$ & 1437 & 0.695 & 0.5 & 2000 & 78.74 & 83.46 \\
\hline 48 & $45 \cdot 3$ & II5o & 0.87 & 0.75 & 1.333 & 52.5 & 55.63 \\
\hline 42 & 39.6 & I005 & 0.99 & I. & 1000 & 39.37 & 41.73 \\
\hline 36 & 34. & 863 & 1.16 & 1.25 & 800 & 31.5 & 33.39 \\
\hline 30 & 28.3 & 718 & I. 39 & 1.5 & 666 & 26.22 & 27.79 \\
\hline 24 & 22.6 & 574 & I. 74 & I. 75 & $57 \mathrm{I}$ & 22.48 & 23.83 \\
\hline 20 & 18.8 & 477 & 2.09 & 2. & 500 & 19.69 & 20.87 \\
\hline 18 & I7. & 431 & $2.3 \mathrm{I}$ & 2.25 & 444 & 17.48 & 18.53 \\
\hline 16 & I5. & 381 & 2.6 & 2.5 & 400 & 15.75 & 16.69 \\
\hline$I_{5}$ & I4. $\mathrm{I}$ & $35^{8}$ & 2.79 & 3. & 333 & 13.17 & 13.9 \\
\hline$x_{4}$ & 13.2 & 335 & 2.98 & 3.5 & 286 & II. 26 & II.94 \\
\hline$x_{3}$ & 12.2 & 312 & 3.20 & 4. & 250 & 9.84 & I0. 43 \\
\hline I2 & II. 3 & 287 & 3.48 & 4.5 & 222 & 8.74 & 9.26 \\
\hline II & 10.3 & $26 \mathrm{i}$ & 3.82 & 5. & 200 & 7.87 & 8.35 \\
\hline Io & 9.4 & 239 & 4.38 & 5.5 & 182 & 7.16 & 7.6 \\
\hline 9 & 8.5 & 216 & 4.63 & 6. & 166 & 6.54 & 6.93 \\
\hline 8 & 7.5 & 190 & 5.25 & 7. & 143 & 5.63 & 5.97 \\
\hline 7 & 6.6 & 167 & 5.96 & 8. & 125 & 4.92 & 5.22 \\
\hline $6 \pi / 2$ & 6.13 & 155 & 6.42 & 9. & III & 4.37 & 4.63 \\
\hline 6 & 5.6 & 142 & 7 & 10. & 100 & 3.94 & 4.17 \\
\hline $5^{1 / 2}$ & 5.2 & 132 & 7.57 & II. & $9 I$ & $3.5^{8}$ & \\
\hline & 4.7 & 119 & 8.4 & 12. & 83 & 3.27 & 3.46 \\
\hline $4^{1 / 2}$ & 4.2 & 106 & $9 \cdot 4$ & 13. & 77 & 3.03 & 3.21 \\
\hline 4 & 3.8 & 96 & 10.4 & 14. & 71 & 2.8 & 2.96 \\
\hline $3^{T / 2}$ & 3.3 & 84 & II.9 & 15. & 67 & 2.64 & 2.8 \\
\hline $3^{1 / 4}$ & 3.1 & 79 & 12.7 & 16. & 62 & 2.44 & 2.59 \\
\hline & 2.8 & 7 I & 14.0 & 17. & 59 & 2.32 & 2.46 \\
\hline $23 / 4$ & 2.6 & 66 & IS.I & Is. & 55 & 2.17 & 2.29 \\
\hline $21 / 2$ & 2.36 & 60 & 16.7 & 20. & 50 & x.97 & 1.09 \\
\hline $2 \pi / 4$ & 2.1 & 53 & 18.7 & & & & \\
\hline 2 & 1.88 & $4^{8}$ & 20.94 & & & & \\
\hline
\end{tabular}

S., Bifocal. See Bifocal. S., Orthoscopic. See Orthoscopic. S., Pantoscopic, a synonym of $S$. Bifocal, q.v. S., Periscopic. See Periscopic. S., Prismatic, spectacles with prismatic lenses, either alone or combined with spheric or cylindric lenses. S., Protective, lenses, usually tinted, to shield the eyes from light, dust, heat, etc.

Spectra $\left(s p e k^{\prime}-t r a\right)$ plural of Spectrum, q.v

Spectral (spek'-trul) [spectrum, specter]. Pertaining to a spectrum." S. Ocular. See Ocular.

Spectro-colorimeter (spek'-tro-kul-or-in'-et-er) [spec-

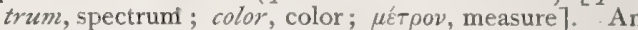
apparatus for the isolation of a single spectral color. It is used for the detection of culor-blindness.

Spectrology (spek-trol'-o-je) [spectrum, spectrum;

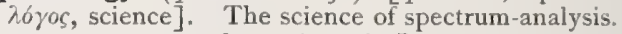

Spectrometer (spek-trom'-et-er) [spectrum, spectrum;

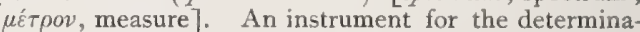
tion of the refractive indices of liquids.

Spectrometry (spek-trom'-et-re) [spectrum, spectrum; $\mu \varepsilon ́ \tau \rho o \nu$, measure ]. The measurement of the spectrum, or the observational use of the spectrometer.

Spectro-microscope (spek'-tro-ni'-kro-skopp). See $M i$ cro-spectroscope.

Spectrophotometer (spek'-tro-fo-tom'-et-er) [spectrum, spectrum ; $\phi \omega \tau$ os, light; $\mu \varepsilon ́ t \rho o v$, measure]. An apparatus for determining the amount of color in spectrum-analysis.

Spectro-polarimeter (spek'-tro-po-lar-im'-et-er) [spec-

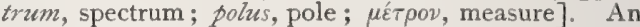
instrument in which a spectroscope and polarizing apparatus are combined for the purpose of determining the concentration of solutions of substances that rotate the plane of polarized light.

Spectroscope (spek'-tro-sköp) [spectrum, an image; $\sigma \kappa о \pi \varepsilon i \nu$, to see]. An instrument for the production and examination of the spectrum. Hénoque's analyseur shromatique is a modified spectroscope by means of which the spectrum of the blood in living tissues, as the nail or palm, may be analyzed. Hyperemia, it is said, may be definitely measured, and the change which the blood undergoes in the tissues observed and timed.

Spectroscopic (spek-tro-skop'-ik) [spectrum, spectrum ; $\sigma \kappa o \pi \varepsilon i v$, to view]. Pertaining to the spectroscope. S. Ocular. See Ocular.

Spectroscopy (spek-tros'-ko-pe) [spectrum, spectrum; $\sigma \kappa o \pi \varepsilon \tilde{i}$, to see]. The use of the spectroscope, as in chemic analysis.

Spectrum (spek'-trum) [L.: pl., Spectra]. The band of ether-waves from a radiant body, having passed through a prism, or having been reflected from a diffraction-grating, and thereby arranged regularly, according to their wave-lengths. S., Absorption, a spectrum which contains dark lines or bands. These are produced in a continuous spectrum by the absorption of incandescent vapors, through which the light has passed, as in the solar atmosphere. S--analysis, determination of the nature of bodies by the character of their spectra. S., Auditory. See Phonism, Photism. S., Comparison, the arrangement side by side of the spectra of two different substances. A prism is placed just below the slit of the spectroscope, so that light entering from a mirror at the side of the drum shall be totally reflected in a vertical direction, and thus parallel with the rays from the microscope. S., Complementary, a spectrum de rived from bodies which change in chemic or molecular constitution before reaching a sufficiently high temperature to become luminous. S., Continuous, a spectrum without sudden variations of hue, in which the various rainbow or spectral colors merge gradually 
into one another. S., Double. See S., Compari son. S., Line, the spectrum resulting from incandescent gas. It consists not of the various rainbow colors, but of sharp, narrow, bright lines, the color depending on the substance; all the rest of the spec trum is dark. S., Normal, a spectrum in which the red color occupies about the same space as the blue and the violet. S., Solar, the spectrum of sunlight. It contains many dark lines, the greater part of which can be identified in the spectra of known terrestrial substances. The presence in the sun's atmosphere of thirty-six elements has been established. (Rowland, I891.)

Speculum (spek'-u-lum) [L. : pl., Specula or Speculums]. An instrument for examining the ear, nose, and other cavities; also, an instrument for dilating parts. In biology, see Ocellus. S., Sims', a peculiar form of vaginal speculum, sometimes called duckbill speculum.

Spedalskhed (sped-als'-ked). A Skandinavian term for leprosy.

Speech (spēch) [ME., speche, speech]. Vocal sounds conveying ideas. S.-center. See Center. S., Disorders of; three principal classes of speech-disorders niay be made:-I. Those in which speech is entirely absent. a. MUTISMs an inability to utter articulate sound, secondary to a lesion of the auditory apparatus. b. ANARTHRIA, inability to utter articulate sound, due to a cerebral lesion. c. AlALIA, inability to utter articulate sound, due to paralysis of the vocal mechanism. d. APTHONGIA, temporary inability to speak, due to spasm of the hypoglossus. II. Those in which speech is impaired or made difficult through an extracerebral lesion, Dyslatia, q. v. a. APHONIA, loss of the power of intonation, the faculty of articulation being preserved. $b$. STAMmering, STUtTering, a hesitancy in pronunciation due to a want of promptitude in the rocal mechanism. c. LALLING, the imperfect pronunciation of letters or words, as by children or inebriated persons. It is due to a want of precision in the vocal mechanism. It includes: $\mathbf{I}$. SLURRING, thickness of speech. 2. Mogilalia, the inability to articulate some single letter. Rhotacism, Sigmatacism, Lambdacism, Iotacism, and Gammacism, are subclasses due to the omission or defective pronunciation of $R, S, L, J$, and $K$ and $G$, respectively. 3. Paralalia, the production of a distinctly different sound from that desired or the substitution of one letter for another. Pararhotacism, Parasigmatacism, Paralambdacism, Paraiotacism, and Paragammacism, are the substitution of other distinct sounds for $R, S, L$, $J$, and $K$ and $G$, respectively. When $T h$ is substituted for $S$ it is called Lisping. 4. RHINOLALIA, defects of articulation caused by increase or decrease of the nasal resonance. III. Those in which speech is impaired or made difficult by a central lesion. $a$. BRADYLALIA, or BRADYPHASIA, an abnormal slowness of speech due to pathologic cause. $b$. LOGORRHEA, excessive volubility of speech. The unmeaning volubility in certain forms of insanity is called Verbigeration. c. Echolalia, the echo-like repetition of words just heard, without attempt to attach meanings to them. d. Embololalia, or EmboloPHRASIA, the frequent interpolation into speech of a useless or meaningless word or syllable. 1. Angophrasia, hemming and liawing. 2. Logospasmus choreiformis, the spasmodic interpolation of a word; a subvariety when the word is of a disreputable or dirty character is called Coprolatia. e. APHASIA, $q . v$.

Spelter (spell-ter) [origin obscure]. Crude zinc.

Spend [Med. Lat., spendere, Lat., dispendere, to lay out, to expend]. Vulgarly, to ejaculate the semen.
Spent [spendere, to spend]. Exhausted; impotent. $\mathbf{S}$. Acid, a battery-acid that has become too weak for efficient action.

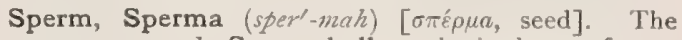
semen, or seed. Sperm-ball, a spheric cluster of spermatozoa. S.-blastoderm, a blastodermic layer of formative spermatozoa. S.-blastula, a spheric blastula whose surface is a sperm-blastoderm. S.-cell, a spermatozoön. S.-morula, a spermatic morula. S.nucleus, the nucleus of a spermatozoön. S.-oil, an oil procured from the deposits in the head of the sperm-whale. In the living animal, the solid spermaceti is held in solution in the liquid sperm-oil; when the liquid becomes cold the spermaceti separates out. The oil is very limpid, relatively free from odor, and burns well in lamps; specific gravity 0.875 . It is used as a lubricant on account of its low cold-test and its viscosity, and also as an illuminant. S.-rope, a string of spermatozoa.

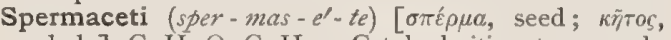
whale], $\mathrm{C}_{16} \mathrm{H}_{31} \mathrm{O}_{2} . \mathrm{C}_{16} \mathrm{H}_{33}$. Cetylpalmitic ester; a substance that occurs in the oil from peculiar cavities in the heads of sperm-whales; upon standing and cooling, it separates as a white, crystalline mass, which can be purified by pressure and by recrystallization from alcohol. It occurs then in waxy, shining needles or leaflets, melting at $49^{\circ} \mathrm{C}$. Its specific gravity is 0.943 at $15^{\circ} \mathrm{C}$. ; its melting-point is from $43^{\circ}$ to $49^{\circ} \mathrm{C}$. It is only slightly soluble in ether, chloroform, and carbon disulphid. It is used in the manufacture of candles and in pharmaceutic preparations. See Cetaceum.

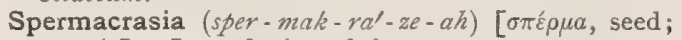
acrasia]. Imperfection of the semen.

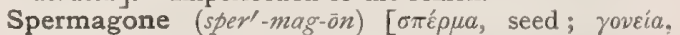
generation]. Same as Spermogone.

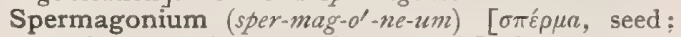
yoveia, generation: pl., Spermagonia ]. Same as Sper. mogonium.

Spermalist (sper'-mal-ist). Same as Spermist.

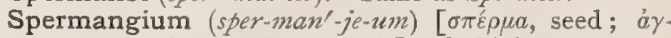

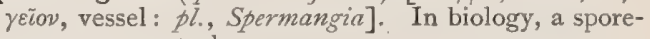
case or conceptacle.

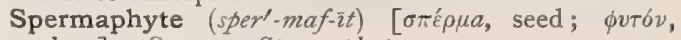
plant]. Same as Spermophyte.

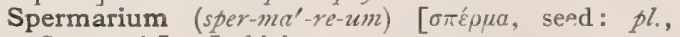
Spermaria]. In biology, a spermary, q. v.

Spermary $\left(\right.$ sper' $\left.^{\prime}-m \alpha-r e\right)$ [ $\sigma \pi \varepsilon \rho \mu \alpha$, seed]. The analogue in the male of the ovary; $i . e$. , the organ generating the sperm-cells; in the higher animals, called the testis, or testicle.

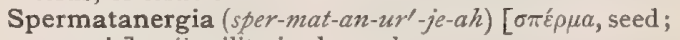
anergia]. Sterility in the male.

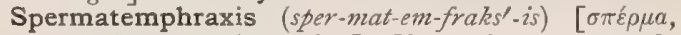
seed; $\check{\varepsilon} \mu \phi \rho a \xi \iota$, obstruction]. Obstructive spermatocele of the tubules.

Spermatheca (sper - math- $\left.e^{\prime}-k a\right)[\sigma \pi \varepsilon \dot{\varepsilon} \mu \alpha$, seed ; $\theta \dot{\eta} \kappa \eta$, a case: pl., Spermatheca]. In biology, a receptacle for spermatozoa; specifically, a globular pouch connected with the oviduct of the queen-bee, and which receives and becomes the depository of the millions of spermatozoa ejaculated during the marital flight.

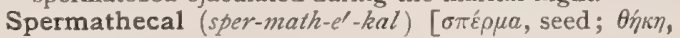
a case]. Pertaining to a spermatheca.

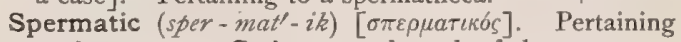
to the semen. S. Artery, a branch of the aorta supplying the testicle. S. Canal. See Inguinal Canal. S. Cones. See Cone. S. Cord, the cord of arteries, veins, lymphatics, nerves and the excretory duct of the testicle passing from the testicle to the internal abciom. inal ring. S. Crystals, a variety of crystals formed in seminal fluid after prolonged standing. See under 
Spermin. S. Gelatin, a gelatinous substance found in the spermogonia of certain cryptogams. S. Rete. See Rete testis.

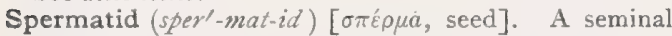
cell.

Spermatin (sper'-mat-in) [ $\sigma \pi \varepsilon \dot{\varepsilon} \rho \alpha$, seed]. The odorous, mucilaginous matter found in semen. Its nature is unknown.

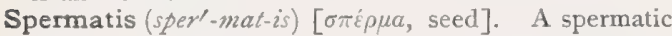
vein.

Spermatischesis (sper-mat-is'-ke-sis). Synonym of Aspermatism.

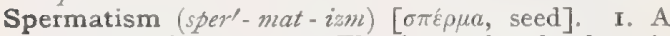
discharge of semen. 2. The theory that the fetus is the direct development of the male element or spermatozoön.

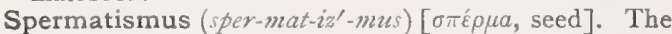
emission of semen.

Spermatist (sper'-mat-ist). Same as Spermist.

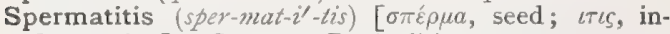
flammation]. Same as Funiculitis.

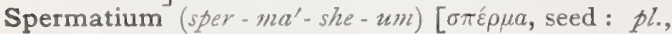
Spermatia]. In biology, one of the rod-shaped bodies, supposed to be male gametes, found in the spermogonia of certain fungi.

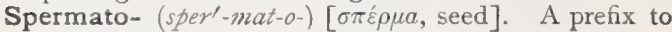
denote connection with the semen.

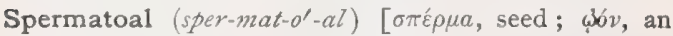
egg]. Pertaining to a spermatoön.

Spermatoblast (sper'-mat-o-blast) [ $\sigma \pi \varepsilon \dot{\varepsilon} \rho \mu a$, seed; $\beta \lambda \alpha \sigma$ Tos, bud, sprout]. In biology, one of the nuclei of daughter-cells, produced by mother-cells, and derived by cell-division from spermatogenic cells. The spermatoblasts are originally round, but soon elongate, become pyriform, and give rise directly to spermatozoids. Cf. Spermatogenetic cells.

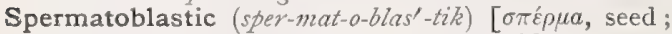
$\beta \lambda n \sigma \tau o ́ s$, germ]. Pertaining to spermatoblasts.

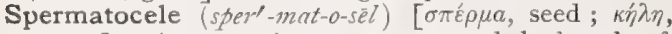
tumor]. A spermatic cyst or encysted hydrocele of the testicle or epididymis.

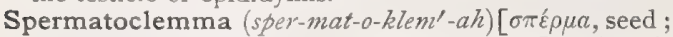
к`éuua, a stealing: pl., Spermatoclemmata]. Involuntary emission of semen during waking. A synonym of Pollution.

Spermatocratia (sper-mat-o-kra'-she-ah). Synonym of Spermatorrhea.

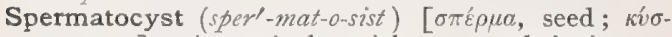
$\tau \iota \varsigma$, cyst]. A seminal vesicle; a pathologic cyst containing spermatozoa.

Spermatocystic (sper-mat-o-sis'-tik) [ $\sigma \pi \varepsilon \rho \mu \alpha$, seed ;

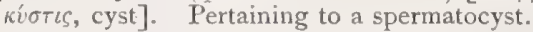

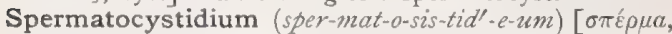
seed; kírıs, bladder: pl., Spermatocystidia]. Same as Antheridium.

Spermatocystidorrhagia (sper-mat-o-sis-tid-or-a'-je-ah)

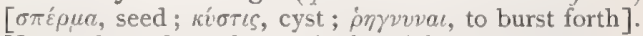
Hemorrhage from the seminal vesicles.

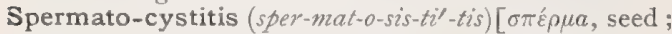

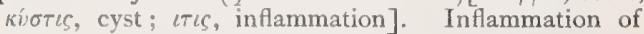
the vesicula seminales.

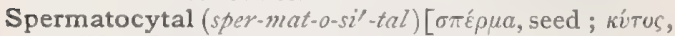
a cell]. Pertaining to a spermatocyte.

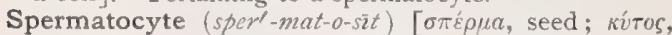
cell]. The germinal cell from which the spermatozoön develops. Cf. also, Cell, seminal, Cell, spermatogenetic, and Seminiferous Tubule.

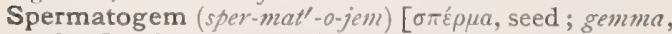
a bud]. See Spermosphere.

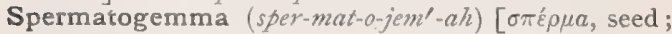
gemma, bud]. In biology, a tissue formed of spermatocytes; a spermatoblast.

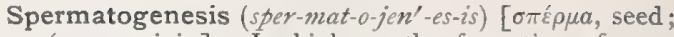
$\gamma \varepsilon$ $v \varepsilon \sigma \iota$, origin]. In biology, the formation of spermatozoa.
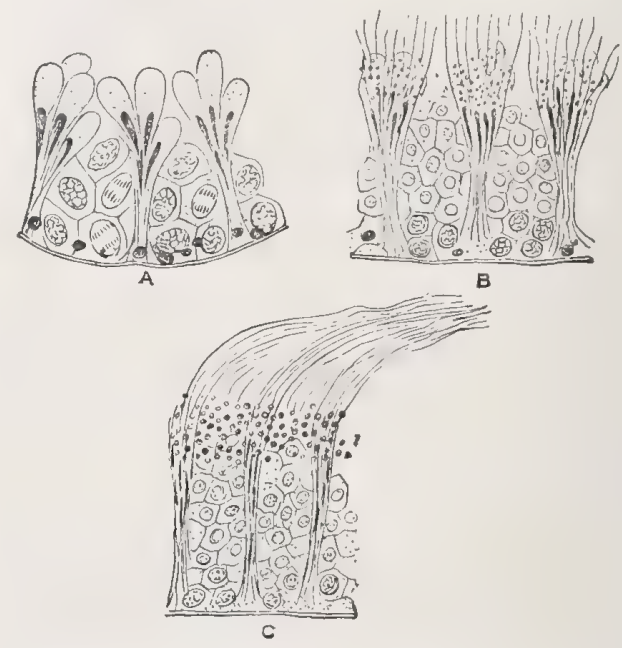

TUBULES OF TESTIS OF RAT, showing spermatogenesis.

A. Less advanced stage. B. and C. More advanced stages. $A$. and B. Transverse section. C. Longitudinal section. $\times$ 300. (From Stivling.)

Spermatogenetic (sper-mat-o-jen-et'-ik) [ $\sigma \pi \hat{\varepsilon} \rho \mu \alpha$, seed ; $\gamma_{\varepsilon}^{\prime} v \varepsilon \sigma \iota s$, genesis]. Pertaining to spermatogenesis. S. Cell, one of two kinds of cells forming a layer next the basement-membrane of the seminiferous tubules; they produce mother-cells, which in turn produce daughter-cells, the nuclei of which constitute the spermatoblasts and give rise to spermatozoa. Cf. Spermatoblast.

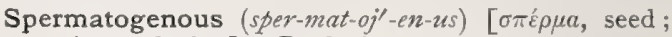

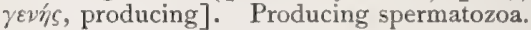

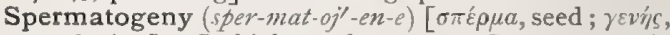
producing]. In biology, the same as Spermatogenesis.

Spermatogonia (sper-mat-o-go'-ne-ah). See Gonepoiesis.

Spermatogonium (sper-mat-o-go'-ne-um) [ $\sigma \pi \varepsilon \rho \mu a$, seed ; yov', generation: pl., Spermatogonia]. In biology, a formative seminal cell or mass of spermatoblasts; a pycnidium.

Spermatoid (sper'-mat-oid). See Spermatozoön.

Spermatolepsis (sper-mat-o-lep'-sis). Synonym of Pollution.

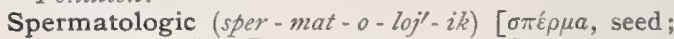
$\lambda o ́ \gamma o s$, science]. Pertaining to spermatology.

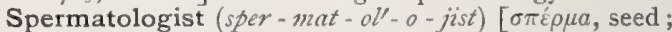
$\lambda 6$ yos, science]. One versed in spermatology.

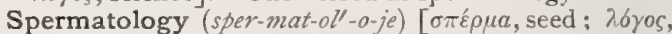
a treatise]. The sum of what is known regarding the origin, nature, qualities and characteristics of the seminal fluid.

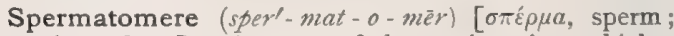
$\mu \varepsilon ́ \rho o s$, share]. Any one of the portions into which a pronucleus of the fertilized ovum may divide.

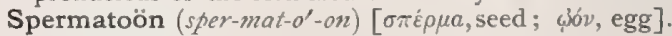
The nucleus of a sperm cell or spermatozoön.

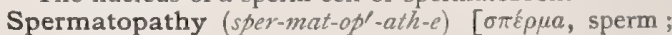
$\pi a ́$ os, disease]. Disease of the sperm-cells or of their secreting mechanism.

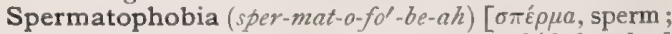
$\phi 6 \beta o s$, fear ]. False spermatorrhea; morbid dread of spermatorrhea.

Spermatophoral (sper-mat-off'-o-ral) [ $\sigma \pi \hat{\varepsilon} \rho \mu \alpha$, seed; $\phi \dot{\rho} \rho \varepsilon \nu$, to bear]. Pertaining to a spermatophore.

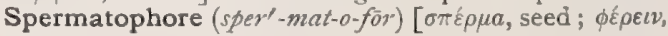


to bear]. In biology, a receptacle of seminal pro ducts, common among invertebrates.

Spermatophorous (sper-mat-off'-or- $2 \epsilon$ ) $[\sigma \pi \varepsilon \rho \mu a$, seed ; фé $\rho \varepsilon \varepsilon v$, to bear]. Bearing seed or spermatozoa.

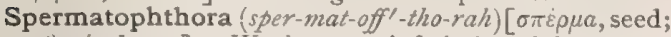
$\phi H_{0} \alpha$, decay]. Weakness or inferiority of the semen.

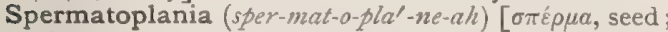
$\pi \lambda \bar{a} \nu \eta$, a wandering]. A supposed metastasis of the semen.

Spermatopoietic (sper-mat-o-poi-et'-ik) [ $\sigma \pi \hat{\varepsilon} \rho \mu \alpha$, semen $\pi \circ \varepsilon \varepsilon \varepsilon v$, to make]. The production or secretion of semen.

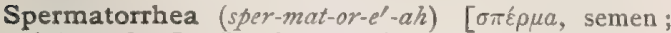
joia, a flow]. Involuntary discharge of semen without sexual excitement. S. dormientum, a nocturnal emission of semen. S., False, when spermatozoids are not in the fluid; called, also, prostatorrhea. S., True, when spermatozoids are present.

Spermatoschesis (sper-mat-os'-kes-is) [ $\sigma \pi \varepsilon \rho \mu \alpha$, semen; $\sigma \chi \varepsilon$ $\iota$, suppression]. Suppression of the seminal fluid.

Spermatosis (sper-mat-o'-sis). See Gonepoiesis.

Spermatosome (sper'-mat-o-sōm). See Spermatozoön. Spermatosphere (sper'-mat-o-sfer). See Spermatoblast.

Spermatospore (sper'-mat-o-spor) [ $\sigma \pi \varepsilon \hat{\varepsilon} \rho \mu a$, seed; $\sigma \pi \hat{-}$ pos, a sowing]. In biology, a primitive cell giving rise by division to spermatoblasts.

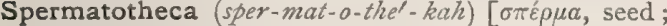
$\theta \dot{\eta} \kappa \eta$, a case]. Same as Spermatheca.

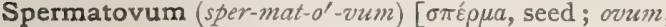
egg: pl., Spermatova]. In biology, an impregnated ovium.

Spermatozemia (sper-mat-o-ze'-me-ah). See Sperma torrhea.

Spermatozoal, Spermatozoan (sper-mat-o-zo'-al, sper

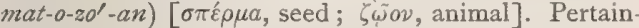
ing to a spermatozoön.

Spermatozoid or Spermatozoöid (sper-mat-o-zo'-id, sper-mat-o-zo'-oid). Same as Spermatozoön.

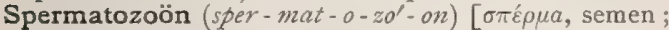
$\zeta \bar{\omega}$ ov, animal: pl., Spermatozoa $]$. The detached, in-

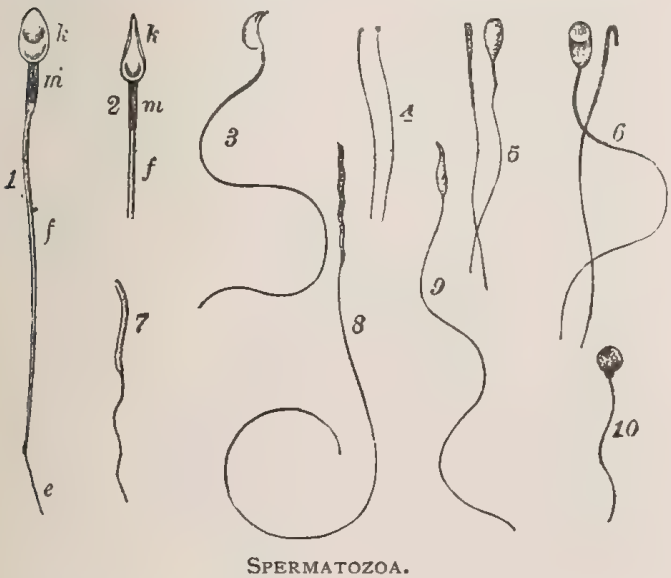

I. Human $(\times 400)$, the head seen from the side, 2. On edge. $k$. Head. $m$. Middle piece. $f$. Tail. $e$. Terminal filament. 3. From the mouse. 4. From bothriocephalus latus. From the deer. 6. From the mole. 7. From the green woodpecker. 8. From the black swan. 9. From a cross woodpecker. 8. From the black swan. 9. From a cross
between a goldfinch and a canary. Io. From cobitis. (Landois.)

dependently mobile cilium of an enlarged epithelial cell of the seminal tubules. The essential element of fecundation of the semen.

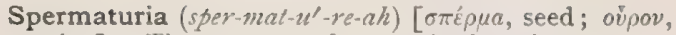
urine ]. The presence of semen in the urine.

Spermic (sper'-mik). Same as Spermatic

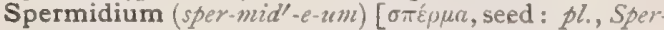
midia]. See Achinium.

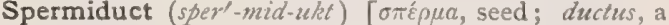
duct]. A duct for the passage of semen; the vas deferens.

Spermin (sper'-min) [ $\sigma \pi \varepsilon p \mu a$, seed $], \mathrm{C}_{2} \mathrm{H}_{5} \mathrm{~N}$. A non poisonous alkaloid obtained from sputum, human se men, the organs of leukemic patients, and alcoholic anatomic preparations. "Charcot's Crystals," "CharcotLeyden Crystals," or "Charcot-Neumann crystals," are said to be simply phosphate of spermin. Such crystals have been found in the sputa of emphysema associated with catarrh, in the bronchial discharges of acute bronchitis, in the blood and spleen of leukemic and anemic patients, in the normal marrow of bones, and in human semen. These crystals are said to be identical with "spermatic crystals" a variety of crystals formed in seminal fluid after prolonged standing. According to Fürbringer they are probably formed by the action of semen on the prostatic secretion. As these crystals are found almost constantly, after death, in the fluid of the prostate, and not within the contents of the seminal vesicles, they are more appropriately termed prostatic crystals. (Piersol.) Spermin seems to have a very wide distribution in certain diseases, especially leukemia. See also Piperazin.

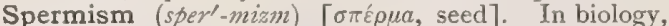
the theory that the animal is the result of the development of a spermatozoön, the ovum acting only as an accessory matrix.

Spermist (sper'-mist) [ $\sigma \pi \varepsilon \hat{\varepsilon} \rho \mu a$, seed]. A believer in spermism.

Spermoblast (sper'-mo-blast). See Spermatoblast.

Spermoblastic (sper-mo-blas'-tik). Same as Spermatoblastic.

Spermobole (sper-mob'-o-le). See Spermatismus.

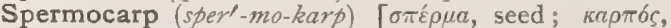
fruit]. In biology, an antheridium.

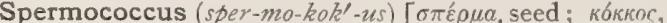
berry]. The head of the spermatozoon without its protoplasmic sheath; the nucleus of a spermule.

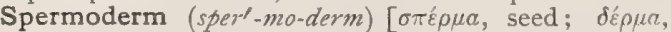
skin]. In biology, the same as Episperm; the outer covering of the seed.

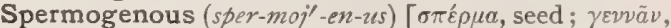
to produce]. Active in the formation of spermatozoa.

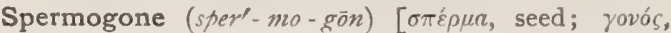
producing]. Same as Spermogonium.

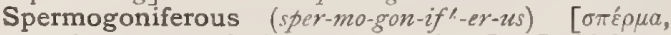
seed; rovos, producing; ferre, to bear]. In biology, producing spermogonia.

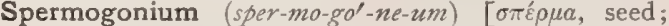
yovos, producing; pl., Spermogonia $]$. In biology, a receptacle in which spermatia are developed. See Peridium.

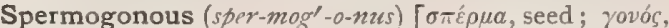
bearing]. In biology, resembling spermogonia.

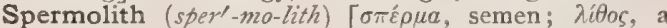
stone]. A calculus in the spermatic duct or vesiculæ seminales.

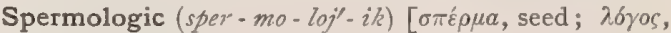
science]. Pertaining to spermology.

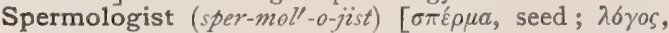
science]. One versed in spermology.

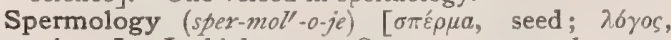
science]. In biology: $\mathbf{I}$. Same as spermatology. 2. That branch of science which treats of the seeds of plants. 


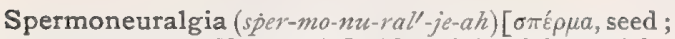

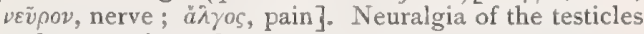
and spermatic cord.

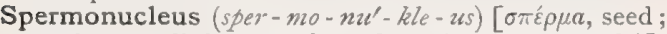
nucleus, a little nut, kernel: pl., Spermonuclei]. In biology, the male pronucleus.

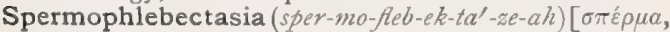
seed; $\phi \lambda \varepsilon \dot{\psi} \psi$, vein; $\varepsilon \hat{k} \tau \alpha \sigma \iota \zeta$, distention]. Varicosity of the spermatic vein.

Spermophore (sper'-mo-for). Same as Spermophorum.

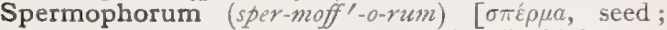
фépeiv, to bear: pl.s Spermophora]. In biology, a seminal vesicle; a spermatophore.

Spermophyte $\left(s p e r^{\prime}-m o-f i t\right)$ [ $\sigma \pi \varepsilon p \mu a$, seed; $\phi v \tau o ́ v$, plant]. In biology, a phanerogam, a plant bearing seeds, in distinction from one that produces spores.

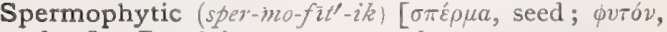
plant]. Pertaining to a spermophyte.

Spermoplasm, Spermoplasma (sper'-mo.plazm, sper-

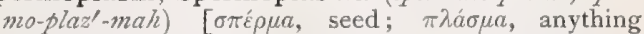
molded]. In biology, the substance of a spermule.

Spermorrhagia (sper-mor-a'-je-a/l). See Spermatorrhea.

Spermorrhea (sper-mor-e'-ah). See Spermatorrhea.

Spermosphere (sper'-mo-sfér) [ $\sigma \pi \dot{\varepsilon} \rho \mu a$, seed; $\sigma \phi \bar{a} \iota \rho a$, sphere]. In biology, a mass of spermatoblasts, or incipient spermatozoa.

Spermospore (sper'-mo-spōr). See Spermatophore.

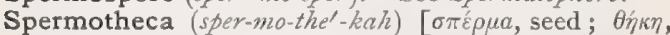
a case]. In biology, a pericarp.

Spermous (sper'-mues). Same as Spermatic.

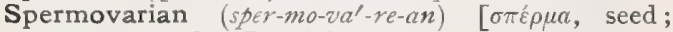
ovum, an egg]. Pertaining to a spermovarium.

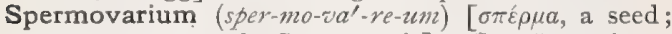
ovum, an egg: pl., Spermovaria]. See Orotestis.

Spermovary (sper-mo'va-re). Same as Spermovarium.

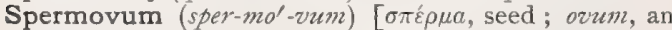
egg: pl., Spermova]. In biology, same as Spermatcontum.

Spermozoön (sper-mo-zo'-on). See Spermatozoön.

Spermule $($ sper'-mül) $[\sigma \pi \varepsilon \rho \mu a$, seed]. In biology, a spermatozoön, or male generative element.

Spermulum (sper'-mu-lum). Same as Spermule.

Sphacel $\left(s f a s^{\prime}-e l\right)$. Same as Sphacelus.

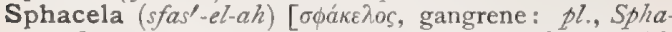
cele]. In biology, a hollow chamber, filled with a mucilaginous or watery substance and oöspheres, developed from the apical cells in certain marine Algre (Sphacelariacea)

Sphacelate, Sphacelated (sfas'-el-ät, sfas'-el-a-ted)

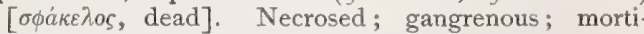
fied.

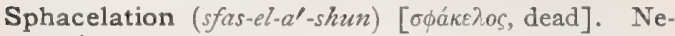
crosis.

Sphacele $\left(s f a s^{\prime}-\bar{e} l\right)$. Same as Sphacela.

Sphacelinic Acid (sfas-el-in'-ik). See Ergot.

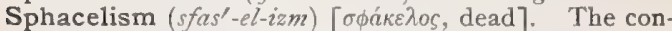
dition of being affected with sphacelus

Sphacelium $\left(s f a-s e^{\prime}-\not e-u m\right)[\sigma \phi a \kappa \varepsilon \lambda i \zeta \varepsilon t v$, to destroy, mortify]. The Claviceps purpurea, or the first stage of the formation of ergot.

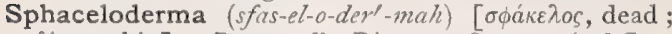
dépua, skin]. Raynaud's Disease; Symmetrical Gangrene; Gangrene of the Skin. A rare disease characterized by a local stagnation occurring at the periphery of the circulation, producing symmetrically distributed gangrenous spots on the body. The essential factor in the disease is a vaso-motor spasm of the capillaries of the extremities. The disease occurs in three welldefined grades, which are, in the order of severity, local syncope, local asphyxia, and local ganorene. The so-called "dead finger," frequently seen in females, is an example of the first grade. The affected part is cold, dead-white, and bloodless; this is but temporary, and is followed by a period of reaction. In the second form of the disease the affected parts become cold and cyanotic, while in the third form a true gangrene of the affected parts takes place. Pain is the most prominent symptom of the disease, which usually attacks children or adults under thirty years of age. Women of the neurotic temperament are more liable to be affected, and especially does it occur after some sudden mental shock. See Dermatitis gangranosa. Dermatitis gangrænosa infantum, a gangrenous eruption following certain pustular eruptions in children. Diabetic Gangrene, a serpiginous form of gangrene occurring in advanced cases of diabetes, and consisting of patches forming on the skin of the limbs.

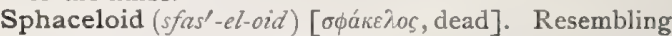
a sphacelus or gangrenous part.

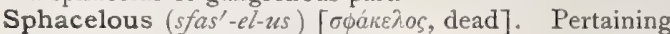
to sphacelus; gangrenous; necrosed.

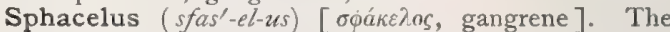
disorganized or dead part of a limb or organ affected with gangrene. Formerly any excessive pain or agitation. See Gangrene.

Sphæræsthesia (sfe-res-the'-ze-ah). See Spheresthesia.

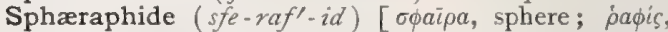
needle ]. In biology, one of a cluster of needleshaped crystals arranged in spheric masses and found in ferns and other plants. The term is extended to include other crystalline masses having a somewhat rounded shape; a spherocrystal.

Sphærenchyma $\left(s f e-r e n g^{\prime}-k i m-a h\right)$. See Spherenchyma.

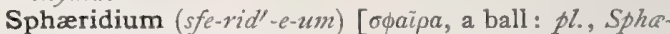
ridia]. In biology, one of the minute spheroid bodies described by Löven as resting upon the ambulacral plates, especially upon those nearest the mouth, in all the Echinidea, except Cidaris. It is possibly auditory in function.

Sphærobacterium (sfe-ro-bak-te'-re-um). See Spherobacterizm

Sphæroid (sfe'-roid). See Spheroid.

Spharoma (sfe-ro'-mah). See Spheroma.

Sphæromere $\left(s f e^{\prime}-r o-m \bar{e} r\right)$. See Spheromere.

Sphærometer (sfe-rom'-et-er). See Spherometer.

Sphærospore (sfe'-ro-spōr). Same as Spherospore.

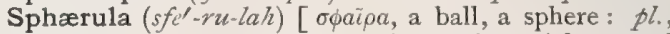
Spharulc]. In biology, a form of special asexual reproductive bud, developed in fresh-water sponges at certain seasons at the expense of the parent animal and usually associated with the decay of the latter.

Sphage ( $s f a j)[\sigma \phi \alpha \gamma \dot{\eta}$, the throat]. The throat; the anterior portion of the neck.

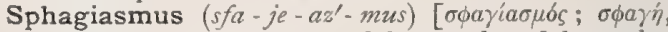
throat ]. Epileptic spasm of the muscles of the neck.

Sphagitis ( $\left.s f a-j i^{\prime}-t i s\right)[\sigma \phi a \gamma \eta \dot{\eta}$, the throat; $\iota \tau \iota s$, inflammation]. Inflammation of the jugular vein.

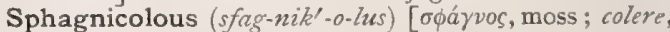
to inhabit]. In biology, growing among mosses.

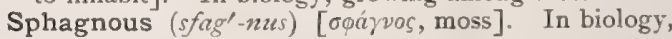
pertaining to mosses.

Sphagnum (sfag'-numu). See Muskeg Moss.

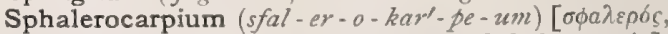
slippery, uncertain; $\kappa a \rho \pi b s$, fruit: pl., Sphalerocarpia]. In biology, a naked seed, surrounded, except at the apex, by a fleshy cup or aril. It is produced by the yew (Taxus baccata) and other members of the Taxacer.

Sphenencephalus (sfe-nen-sef'-al-us): See Sphenocephalus.

Sphenic $\left(s f e^{\prime}-n i k\right)\left[\sigma \phi \eta^{\prime}\right.$, wedge]. Wedge-like. 
Sphenion $\left(s / e^{\prime}-n e-o n\right)$ [ $\sigma \phi^{\prime} j$, wedge $]$. The apex of the sphenoid angle of the parietal bone on the surface of the skull. See Craniometric Points.

Spheno- $\left(s f e^{\prime}-n o^{-}\right)[\sigma \phi \eta v$, wedge]. A prefix used to denote connection with the sphenoid bone, or to indicate a wedge-like shape.

Spheno-basilar $\left(s f e^{\prime}-n o-b a^{\prime}-z i l-a r\right)[\sigma \phi \dot{\eta} v$, wedge; $\beta a ́ \sigma \iota s$, base]. Pertaining conjointly to the sphenoid bone and the basilar portion of the occipital bone. S. Groove, the depression on the body of the sphenoid bone and the basilar portion of the occipital bone, upon which the pons rests.

Sphenoccipital (sfe-nok-siṕ-it-al) [ $\sigma \phi \dot{\eta} v$, wedge; occiput, occiput]. Pertaining to the sphenoid and the occiptal bone; spheno-basilar.

Sphenocephalia (sfe-no-sef-a $\left.-a^{\prime} l e-a h\right)[\sigma \phi \eta \dot{\nu}$, wedge ; $\kappa \varepsilon \phi a \lambda \eta$, head]. The condition of a sphenocephalus.

Sphenocephalus $\left(s f e-n o-s e f^{\prime}-a l-u s\right)\left[\sigma \phi^{\prime} \nu\right.$, wedge; $\kappa \varepsilon \phi a \lambda \eta$, head]. A variety of single autositic monsters of the species otocephalus, in which the two eyes are well separated; the ears are united under the head; the jaws and mouth are distinct; and the sphenoid is altered in shape, so that it is analogous in form to what is found normally in birds.

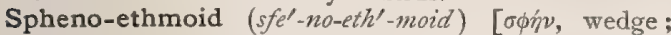
$\dot{\eta} \theta \mu o \delta$, sieve; $\varepsilon i \delta o s$, like]. Belonging or relating to both the sphenoid and ethmoid bones.

Spheno-frontal (sfe'-no-frun'-tal) [ $\sigma \phi \eta n v$, wedge; frons, forehead]. Belonging or relating to both the sphenoid and frontal bones.

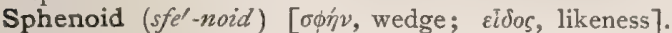
Cuneiform. Relating or pertaining to the sphenoid bone. $\mathbf{S}$. Bone, one of the cranial bones at the anterior base of the skull, articulating with all the other bones of the head. S. Fontanel, the membranous interspace at the junction of the squamous and coronal sutures of the fetal skull. S. Sinus. See Sinus.

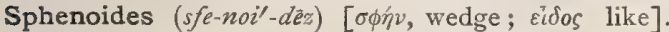
The sphenoid bone.

Sphenoido-auricular (sfe-noi'-do-aze-rik'-u-lar) $\left[\sigma \phi \eta^{\prime} \nu\right.$, wedge; auriculus, auricle]. Pertaining to the sphenoid and binauricular diameters of the skull. S.-a. Index, the ratio of the minimum sphenoid diameter of the skull with the binauricular diameter, the latter being taken as 100

Sphenoido-frontal $\left(s f e-n o i^{\prime}-d o-f r u n^{\prime}-t a l\right)\left[\sigma \phi \phi^{\prime} \nu\right.$, wedge; frons, forehead]. Pertaining to the sphenoid and frontal diameters of the skull. S.-f. Index, the relation between the minimum sphenoid diameter of the skull and the minimum frontal diameter taken as Ioo.

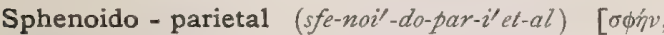
wedge; paries, wall $]$. Belonging or relating to the sphenoid and parietal diameters of the skull. S.-p. Index, the relation between the minimum sphenoid diameter of the skull and the maximum frontal diameter taken as 100

Spheno-malar $\left(s f e^{\prime}-n o-m a^{\prime}-l a r\right)\left[\sigma \phi r^{\prime} v\right.$, wedge; mala, the cheek]. Pertaining to the sphenoid and malar bones.

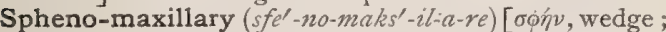
maxilla, maxilla]. Pertaining conjointly to the sphenoid and maxillary bones. S.-m. Fossa. See Fossa.

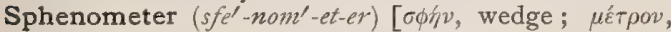
measure]. An instrument for measuring the wedge to be removed in osteotomy for curvature.

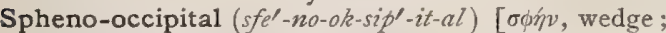
occiput, occiput]. Belonging or relating to both the sphenoid and occipital bones.

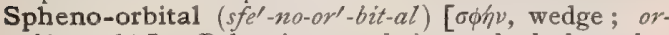
bitc, orbit]. Belonging or relating to both the sphenoid bone and the orbit.

Spheno-palatine $\left(s f e^{\prime}-n o-p a l^{\prime \prime}-a t-i n\right)\left[\sigma \phi \eta^{\prime}\right.$, wedge; palatum, palate]. Pertaining conjointly to the sphenoid bone and the palate. S.-p. Foramen, the sphenopalatine notch converted into a foramen by articulation with the sphenoidal turbinated bone. S.-p. Ganglion. See Ganglion. S.-p. Notch, a deep notch separating the orbital and sphenoid processes of the palate bone. See Notch.

Spheno-parietal $\left(s f e^{\prime}-n o-p a r-i^{\prime}-e t-\alpha l\right)$ [ $\sigma \phi i ́ p$, wedge ; paries, wall]. Belonging or relating to both the sphenoid and parietal bones.

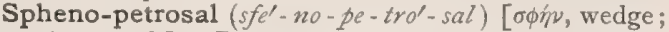
$\pi \varepsilon ́ \tau \mu a$, rock ]. Pertaining conjointly to the sphenoid bone and the petrous portion of the temporal bone.

Sphenopharyngeus (sfe-no-far-in-je'-zis). See Mus* cles, Table of.

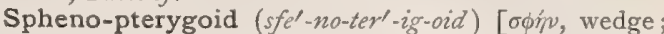

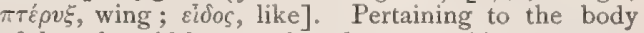
of the sphenoid bone and to the pterygoid process.

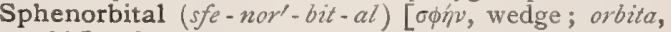
orbit]. See Spheno-orbital.

Sphenosis $\left(s f e-n \sigma^{\prime}-s i s\right)$ [ $\sigma \phi \dot{\eta} \nu$, wedge]. The wedging of the fetus in the pelvis.

Spheno-squamosal, Spheno-squamous (sfe'-no-skwa-

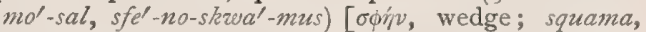
scale]. Belonging or relating to both the sphenoid bone and the squamous portion of the temporal bone.

Spheno-temporal $\left(s f e^{\prime}-n o-t e m l^{\prime}-p o-r a l\right)$ [ $\sigma \phi \eta v$, wedge ; tempora, the temple; temporal]. Pertaining con. jointly to the sphenoid and temporal bones.

Sphenotic $\left(s f e-n o^{\prime}-t i k\right)$ [ $\sigma \varphi^{\prime} \nu$, wedge; ov̀s, ear]. Pertaining to the sphenoid bone and the otic capsule.

Sphenotresia (sfe-no-tre'-ze-ah) [ $\sigma \phi \dot{\eta} v$, wedge; $\tau \rho \tilde{\eta} \sigma \iota s$, perforation]. A variety of craniotomy in which the basal portion of the fetal skull is perforated.

Sphenotribe $\left(s f e^{\prime}-n o-t \bar{i}^{\prime} b\right)\left[\sigma \phi \eta \dot{v}\right.$, wedge; $\tau \rho^{\prime} \beta \varepsilon \varepsilon \nu$, to rub]. The instrument used in performing sphenotresia.

Spheno-turbinal, Spheno-turbinate (sfe-no-ter'-bin$a l$, sfe-no-ter'-bin- $\bar{a} t)$ [ $\sigma \phi^{\prime}{ }^{\prime}$, , wedge; turbo, a scroll]. I. Pertaining to the sphenoid and turbinate bones. 2. One of the sphenoidal spongy bones situated cephalad of the body of the sphenoid.

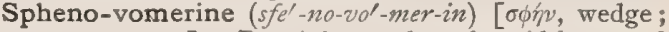
vomer, vomer]. Pertaining to the sphenoid bone and the vomer.

Spheral (sfe'-ral) [ $\sigma \phi a \tilde{\imath} \rho a$, sphere]. Like a sphere.

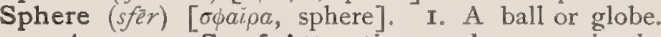
2. A space. S. of Attraction, a clear spot in the cell-plasma, outside of and close to the nucleus of an ovum undergoing mitosis. It contains the centrosoma of Boveri, and is the center of the formation of the amphiasters in karyokinesis, $q . v$. S.-crystal. Same as Spharaphide. S., Embryonic. See S., Segmentation-. S.-Granule, a large granular corpuscle found in serous exudations. S., Hearing, the area in the brain which is supposed to be the seat of hearing. It is in the temporal lobe. S., Motor, a region in the central nervous system which, when stimulated, gives rise to motion. S., Protoplasmic Primordial. See S., Segmentation-. S., Segmentation-, a nucleated cell derived from division of the vitellus in the process of segmentation. S., Sensory, a sensory area of the central nervous system. S., Vitelline, S., Yolk-, the mulberry-like mass of cells that results from the fission of the substance of the ovum after fertilization. S., Yeast-, in biology, an aggregation of certain sprouting forms of the genus Mucor.

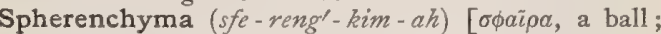
$\varepsilon$ $\gamma \chi v \mu \alpha$, an infusion]. In biology, applied to a form of parenchyma in which the cells are globular.

Spheresthesia (sfe-res-the'-ze-ah) [ $\sigma \phi a i \rho a$, globe; aìs $\theta \eta-$

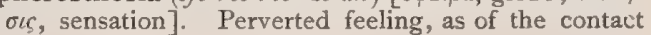
of a ball or globe-shaped body. 
Spheric, Sphericai (sfe'-rik, sfe'-rik-al). Having the shape of or pertaining to a sphere, S. Aberration. See Aberration. S. Homology, in biology, Wilder's term for the topical relation between the morphically identical, converging spheromeres of a radiate animal.

Sp̣heriform (sfe'-rif-orm) [ $\sigma \phi a i p a$, sphere; forma, form]. Spheric.

Spheriocarcinoma $\left(s f e-r e-o-k a r-s i n-o^{\prime}-m a h\right)[\sigma \phi a i ̄ \rho a$,

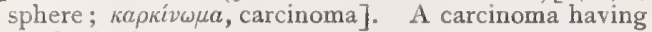
a spheric shape.

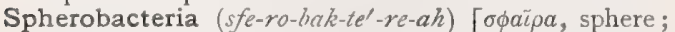
ßakтńpıov, a rod]. In Cohn's classification a genus of unicellular microbes, round or oval, stationary, and devoid of cilia or flagella. The micrococci.

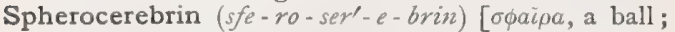
cerebrum, cerebrum]. A nitrogenized substance occurring in brain-tissue among a group of cerebrinacides.

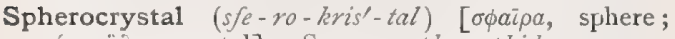

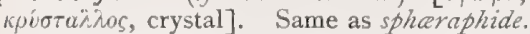

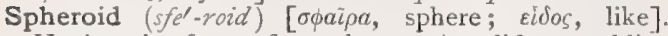
Having the form of a sphere. A solid resembling a sphere. S., Oblate, one in which the polar axis is less than the equatorial diameter. S., Prolate, one in which the polar axis exceeds the equatorial diameter.

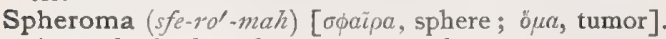
Any spheric-shaped tumor or protuberance.

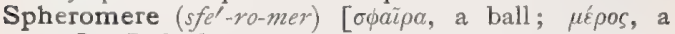
part]. In biology, an actinomere, $q . v$.

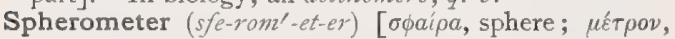
a measure]. An instrument for determining the degree of curvature of optic lenses and of the tools for their grinding.

Spherosiderite (sfe-ro-sid'-er-it ). Carbonate of iron in spheroidal masses, occurring in trap.

Spherosome $\left(s f \ell^{\prime}-r o-s \bar{o} m\right)$ [ $\sigma \phi a i ̄ \rho$, sphere; $\sigma \tilde{\omega} \mu \alpha$, body]. In biology, the body-wall of a radiated animal; suggested by L. Agassiz in place of perisome.

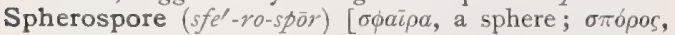
a seed]. In biology, Agassiz' name for a tetraspore.

Spherular (sfe'-ru-lar) [dim. of $\sigma \phi a i ̈ \rho a$, a sphere]. Resembling a spherule.

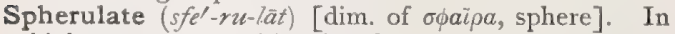
biology, studded with spherules.

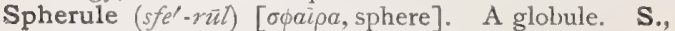
Segment. See Sphere, Segmentation.

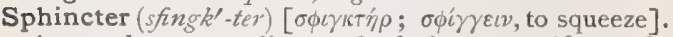
A muscle surrounding and closing an orifice. $\mathbf{S}$. ani. S. vaginæ. See Muscles, Table of. S. of the Pupil. See Iris. S., Third, of the rectum, a duplicature of mucosa projecting well into the lumen of the gut from the right side, forming rather more than a semicircle, and involving more of the ventral than of the dorsal wall. It is also called Kohlrausch's fiold.

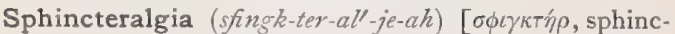
ter; $a \lambda \lambda \gamma o s$, pain $]$. Pain in the sphincter ani muscle, or about the anus.

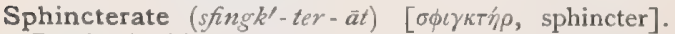
Provided with a sphincter.

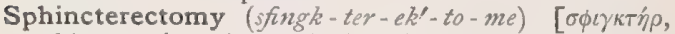
sphincter; $\dot{\varepsilon} \kappa \tau o \mu$, excision]. Oblique blepharotomy ; Stellwag's operation for the dilatation of the palpebral fissure, or for blepharospasm.

Sphincterial, Sphincteric (sfingk-te'-re-al, sfing-k-ter'$i k)[\sigma \phi i \gamma k \tau \eta ́ p$, sphincter]. Pertaining to a sphincter or to its function.

Sphincterismus (sfingk-ter-i $\left.Z^{\prime}-m u s\right)[\sigma \phi \ell \gamma \kappa r h \rho$, sphincter]. A spasmodic contraction of the sphincter ani muscle, usually attendant upon fissure or ulcer of the anus, but occasionally occurring independently of such lesion.

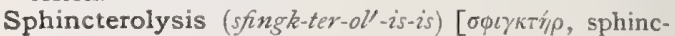
ter; $\lambda \dot{v} \sigma \iota s$, solution]. The operation of freeing the iris in anterior synechia.

Sphincteroplasty (sfing $k^{\prime}-t e r-o$ - plas $\left.-t e\right)[\sigma \phi \imath \kappa \kappa \eta ́ p$, sphincter; $\pi \lambda a \sigma \sigma \varepsilon \iota$, to form]. The formation of an artificial sphincter by plastic operation.

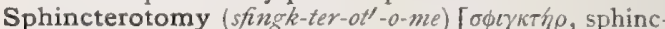

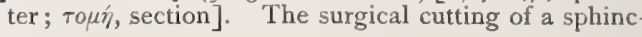
ter.

Sphingoin (sphing $-g o-i n)$ [ $\sigma \phi^{\prime} \gamma \gamma \varepsilon t v$, to bind]. An alkaloid derived from cerebral tissue.

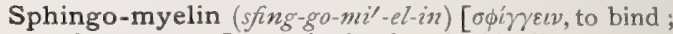
$\mu v \varepsilon$ ios, marrow]. A brain-phosphatid allied to myelin. It is capable of being decomposed into neurin and a substance which is convertible into sphingosin.

Sphingosin $\left(s f i n^{\prime}-g o-\sin \right)$ [ $\sigma \phi i \gamma \gamma \varepsilon \iota \nu$, to bind]. An alkaloidal cerebroside occurring in brain-tissue.

Sphingostearic Acid (sfing-go-ste-ar'-ik). See Acid.

Sphinxis (sfingks'-is). See Constriction.

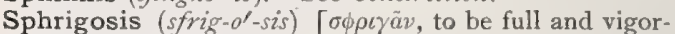
ous]. In biology, excessive growth of wood, stem, and leaves in plants.

Sphygmic, Sphygmical (sfig'-mik, sfig'-mik-al) [ $\sigma \phi v \gamma-$ $\mu \varkappa \kappa o ́ s ; \sigma \phi v \gamma \mu \sigma \delta$, pulse]. Pertaining to the pulse; pulsatile.

Sphygmochronograph $(s f g r-m o-k r o d-n o-g r a f)$. See Sphygmograph.

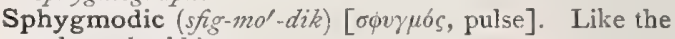
pulse; throbbing.

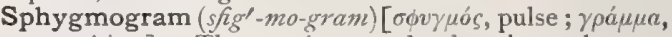
a writing]. The tracing made by the sphygmograph. Called, also, Pulse-tracing, Pulse-curve, and Arteriogram.

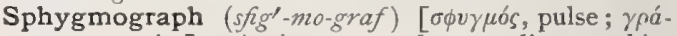
$\phi \varepsilon \imath$, to write]. An instrument for recording graphic-

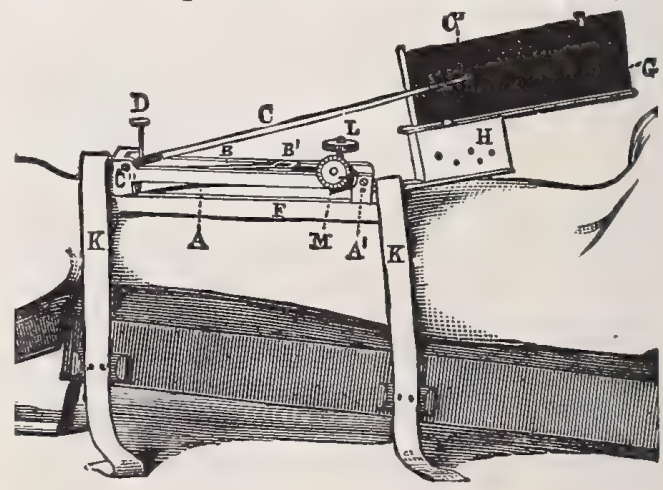

MAREY'S SPHYGMOGRAPH.

A. Steel spring. B. First lever. C. Writing lever. $C^{\prime}$. Its free writing end. D. Screw for bringing $B$ in contact with $C$. G. Slide with smoked paper. H. Clockwork. L. Screw for increasing the pressure. M. Dial, indicating the pressure. $K, K$. Straps for fixing the instrument to the arm and the arm to the double inclined plane or support.

ally the differential features of the pulse in health and disease.

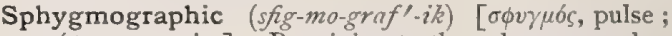

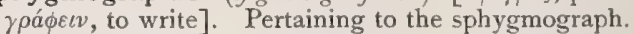

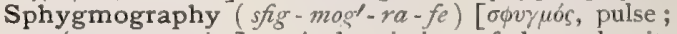

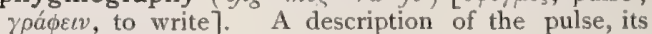
pathologic variations and their significance.

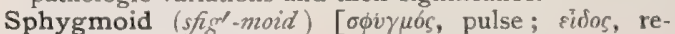
semblance]. Resembling or having the nature of continuous pulsation. 


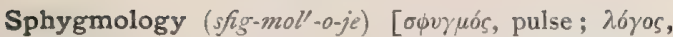
treatise]. The sum of what is known regarding the pulse.

Sphygmomanometer $\left(s f g-m o-m a n-o m z^{\prime}-e t-e r\right)$

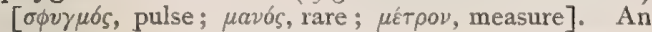
instrument for measuring the tension of the bloodcurrent. See Blood-pressure.

Sphygmometer (sfig-mom'-et-er). See Sphygmograph.

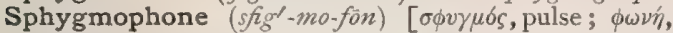
sound]. I. A sphygmograph that marks each pulsewave by sounding. 2. An apparatus in which a microphone is employed for the medical examination of the pulse.

Sphygmoscope $\left(s f g^{\prime}-m o-s k o ̄ p\right)\left[\sigma \phi v \gamma \mu \sigma_{s}\right.$, pulse ; $\sigma \kappa o \pi \varepsilon i v$, to examine]. An instrument for showing mechanically the movements of the heart or the pulsations of a blood-vessel. S., Gas-, makes registration by a gasjet.

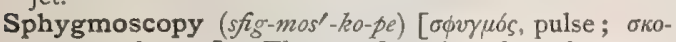
$\pi \varepsilon i \nu$, to observe]. The art of tracing the pulse-curve by the sphygmoscope.

Sphygmo-systole (sfig-mo-sis'-to-le) [ $\sigma \phi v \gamma \mu o ́ s$, pulse;

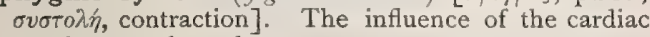
systole upon the pulse.

Sphygmotechny $\left(s f i g^{\prime}-m o-t e k-n e\right) \cdot[\sigma \phi v \gamma u o ́ s$, pulse ; $\tau \hat{\varepsilon} \chi \nu \eta$, art]. 'The art of diagnosis and prognosis by means of the pulse.

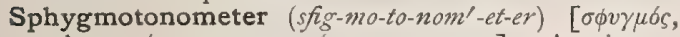
pulse; $\tau 6 \nu o s$, tone; $\mu \varepsilon \tau \rho o \nu$, measure ]. An instrument for use in estimating the elasticity of the arterial walls.

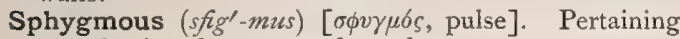
to or having the nature of a pulse.

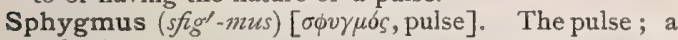
pulsation.

Sphyrotomy $\left(s f-r o t^{\prime}-o-m e\right)[\sigma \phi \tilde{v} \rho a$, malleus; $\tau o \mu \eta \dot{\eta}$, a cutting]. An operation consisting in the removal of the malleus or its handle, together with a portion of the membrana tympani.

Sphyxis (sfks'-is). See Pulsation.

Spica $\left(s p i^{\prime}-k a h\right)[$ L. ]. I. A spike or spur. 2. A spiral bandage with reversed turns. S.-bandage. See Bandage.

Spicate (spi'-kät) [spica, a spike]. In biology, arranged in the form of a spike; spurred.

Spice (spis) [ME., spice, spice]. An aromatic vegetable substance used for flavoring; a condiment. S.-berry, a popular name for Gaultheria procumbens. S.-plaster. See Emplastrum aromaticum. S.-poultice, a poultice made from the mixture of a variety of spices. S.wood. See Fever Bush.

Spiced (spīst) [ME., spice, spice]. Flavored by means of spice.

Spiciferous (spi-sif'-er-us) [spica, a spike; ferre, to bear]. In biology, bearing spikes.

Spiciform (spi'-sif-orm) [spica, spike; forma, form]. Having the form of a spica.

Spicose, Spicous $\left(s p i^{\prime}-k \bar{o} z, s p i^{\prime}-k u s\right)$ [spica, spike]. In biology, having spikes.

Spicula (spik'-u-Iah) [dim. of spica, a spike: $p l$., Spicula]. A small spike-shaped bone or fragment of bone.

Spicular (spik'-u-lar) [spicula, a spicule]. Having the form of a spicule.

Spiculate (spik'-u-lāt) [dim. of spica, a spike]. Having the shape of, or covered with spicules.

Spicule $\left(s p i k^{\prime}-\bar{u} l\right)$ [dim. of spica, a spike]. A needleshaped body; a spike. S., Bony, a needle-shaped bone or fragment of bone. S.-sheath, in biology, the investment of a sponge-spicule.

Spiculiferous (spik-u-lif'-er-us) [spicula, spicule; ferre, to bear]. Having spicula.
Spiculiform (spik'-u-lif-orm) [spicula, spicule ; forma, form ]. Having the form of a spicule.

Spiculigenous (spik-u-lij'-en-us) [spicula, spicule; yevins, producing]. Producing spicules.

Spiculigerous $($ spik-u-lij'-er-us) [spicula, spicule; gerere, to bear]. Same as Spiculiferous.

Spiculose, Spiculous (spik'-u-löz, spik'-u-lus) [spicula, spicule]. Having spicules.

Spiculum (spik'-u-lum) [spiculum, a little sharp point: pl., Spicula]. In biology, a spicule, or spicular organ, as the spiculum amoris or copulatory organ of certain worms and molluscs.

Spider (spi'-der) [ME., spither, a spider]. An arthropod of the class Arachnida. S. Cancer. See Acne rosacea. S.-cells; in biology: $(a)$ Bacilli the flagella of which are present in such numbers as to give the microbes the appearance of minute spiders. See Bacillus typhi abdominalis, under Bacteria, Synonymatic Table of; $(b)$ the characteristic cells of the neuroglia. They have numerous long and delicate prolongations. See also Deiters' Cells. S. Nevus. See Acne rosacea. Ss'. Web (tela aranea), formerly much used as a hemostatic, and also in some systemic diseases; used also as a moxa, with the blow-pipe.

Spigel's Line. See Lines, Table of.

Spigelia (spi-je'-le-ah) [after Adrian van der Spiegel, a Belgian physician]. Pink-root. The roots of $S$. marilandica. A popular vermifuge, generally admin istered with senna. In large doses an uncertäin cathartic. Dose gr. $x x-z$ ij. S., Ext., Fld. Dose for a child $m x-x x$; for an adult $3 \mathrm{j}-\mathrm{ij}$. S., Infus., Comp., " worm-tea," " pink and senna," unof, ; spigelia I 5, senna, fennel āā Io, manna 30, water 500 . Dose Zjss-v. S. anthelmia, of tropical America, has similar properties.

Spigelian Lobe (spi-je'-le-an) [after Adrian van der Spiegel, a Belgian physician]. The lobe of the liver projecting from the back part of the under surface of the right lobe.

Spigelin (spi-je'-lin) [after Adrian van der Spiegel, a Belgian physician]. An alkaloid said to exist in the anthelmintic species of Spigelia, of which it appears to be an active principle.

Spigelius, Line of. See Lines, Table of. S., Lobulus of. See Spigelian Lobe.

Spike (spik) [spica, a spike, ear of corn]. I. In biology, that form of indeterminate anthotaxy in which the flowers are sessile, or nearly so, and arranged on a lengthened axis. 2. A sharp point. 3. S.-lavender, a plant, Lavandula spica; it yields oil of spike.

Spiked (spikt). See Spicate.

Spikelet (spi'-klet) [spica, a spike, ear of corn]. In biology, a small or secondary spike; applied to the inflorescence of grasses.

Spikenard (spi $k^{\prime}$-nard) [ME., spikenard, spikenard]. Nard. A name given to the rhizome of various species of valerian, and especially to Nardostachys jatamansi, formerly much used in medicine, now used in washes and unguents, chiefly in the Orient. Unof. It is not to be confounded with American spikenard, Aralia racemosa.

Spillman's Soap. A soap used in treating syphilis. It is made of pure olive-oil and caustic potash, with which is incorporated 50 per cent. of mercury. It is neutral in reaction and causes no irritation. A portion of the body is lathered with the soap, and after drying it is covered with thin paper or some suitable garment. After 24 hours the part is washed off and dusted with rice-powder.

Spiloma (spi-lo'-mah). See Nerus vascularis.

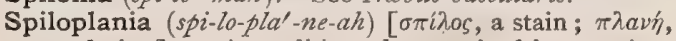
wandering]. A condition characterized by transient 
or wandering maculæ of the skin. Also, a synonym of Elephantiasis gracorum.

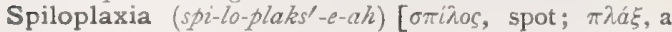
broad surface]. A condition marked by the large red spots symptomatic of elephantiasis; seen also in some cases of pellagra.

Spilosis poliosis. Synonym of Canities.

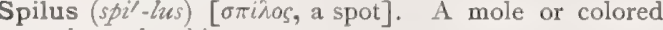
mark on the skin; nevus.

Spina $\left(s p i^{\prime}-n a h\right)$ [L., the backbone]. I. A thorn. 2 . The spine. S. bifida, a hernia of the spinal mem. branes through a cleft or abnormality of the lower part of the vertebral column; called, also, Hydrorrhachitis. S. cervina. Same as Buckthorn. S. helicis. See Crista helicis. S. suprameatum, an elevation just above the superior angle of the mastoid process of the temporal bone. It appears to be the posterior part of the zygomatic line. It is an important guide in the operation of opening the mastoid. $\mathrm{S}$. ventosa, a rarefying form of osteitis in which the bone is eroded or destroyed, and the subperiosteal tissue and osseous marrow contain numerous small cells with transuded red blood-corpuscles. It is frequently a result of syphilis.

Spinal (spi'-nal) [spina, spine]. Pertaining to the spine. S. Accessory Nerve. See Nerve. S. Accessory Spasm. See Tic rotatoire. S. Bulb,

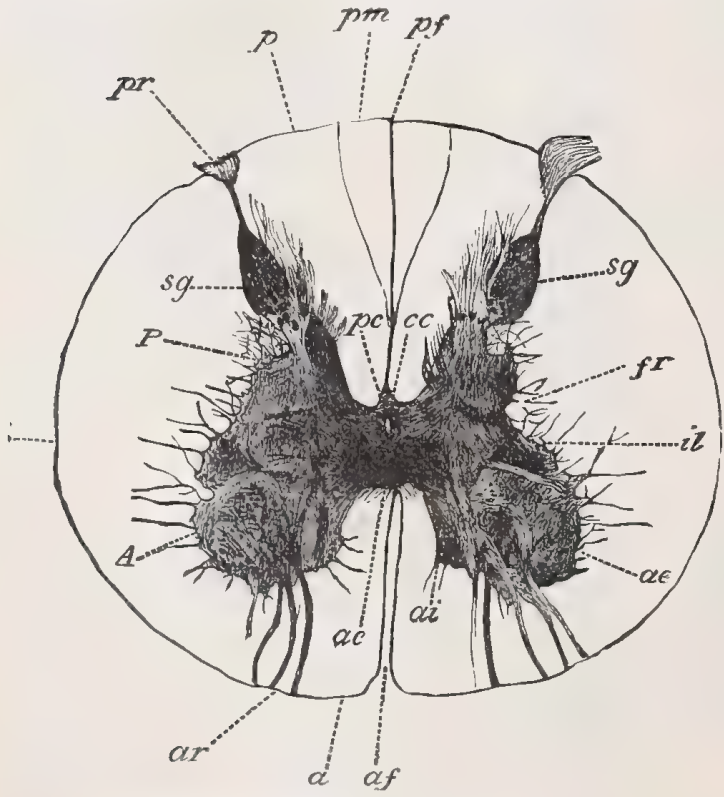

Transection of the Spinal Cord in the Cervical REGION.

A. Ventral gray column. a. Ventral white column. l, Lateral white column. $a c$. Ventral commissure. ar. Ventra roots. af. Ventral median fissure. it. Intermediolatera gray column. vc. Vesicular column of Clarke. $P$. Dorsa gray column. p. Dorsal-external white column. pm. Dorsal-mediau column, pc. Dorsal commissure cc. Central canal. pr. Dorsal roots. pf. Dorsal-median fissure ae and $a i$. External and internal ventral vesicular columns. sg. Substantia gelatinosa. (Bevan Lewis.)

the oblongata. S. Canal. See Canal, Vertebral. S. Centers, motor centers situated in the spine. The principal are the cilio-spinal, connected with the dilatation of the pupil; the auro-spinal; the vesico-spinal; the erection-center; the ejaculatory center; the parturition, and numerous vasomotor centers. S. Col- umn, the vertebral column, composed of 33 vertebræ. $\mathbf{S}$. Cord, the myelon, or medulla spinalis; the neural structure occupying the vertebral canal and extending from the atlas to the first lumbar vertebra, and terminating in the flum terminale. It is the great conduct-

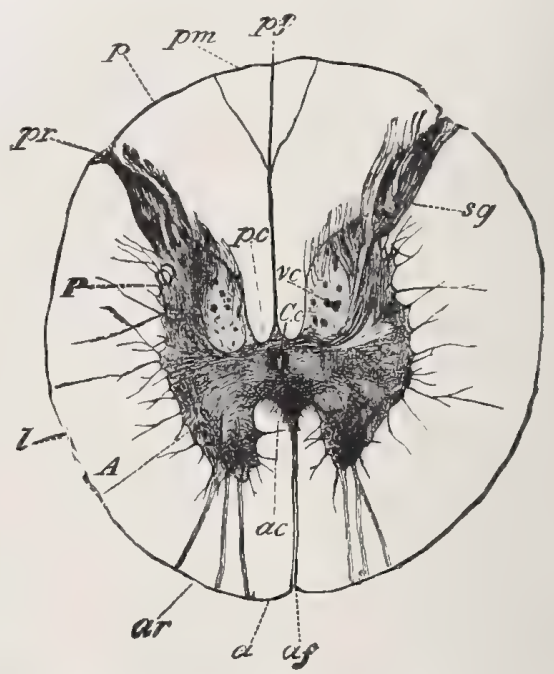

TRANSECTION OF THE SPINAL CORD IN THE THORACIC REgION. (Bevan Lewis.)

ing medium of nervous impulses both afferent and efferent and within itself from side to side. and is the great organ of reflexes. It consists of white matter externally and gray matter internally. Fissures, the

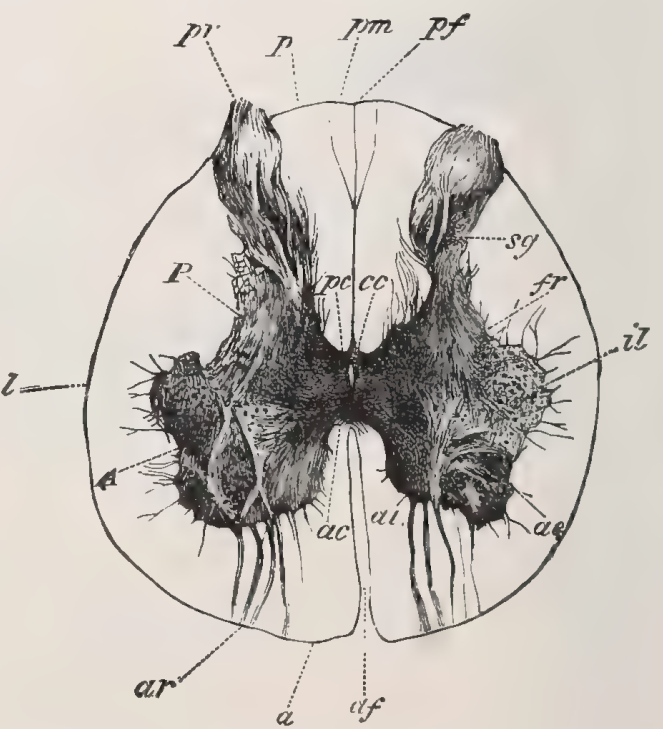

TRANSECTION OF THE SPINAL CORD IN THE LUMBaR REgION. (Bevan Lewis.)

ventral median, dorsal median, and two lateral, divide each half of the cord into four Columns, $a$ ventral, lateral, dorsal, and dorsal median. In the Ventral Column lie the uncrossed, ventral, or direct 


\section{TABLE SHOWING THE LOCALIZATION OF FUNCTION IN THE DIFFERENT SEGMENTS OF THE SPINAL CORD.}

(After Starr.)

\begin{tabular}{|c|c|c|c|}
\hline $\begin{array}{l}\text { SEG- } \\
\text { MENT. }\end{array}$ & MUSCles. & REFLEX. & SENSATION. \\
\hline $\begin{array}{l}\text { II and } \\
\text { III C. }\end{array}$ & $\begin{array}{l}\text { Sterno- mastoid; trapezius; } \\
\text { scaleni and neck; diaphragm. }\end{array}$ & $\begin{array}{l}\text { Hypochondrium (?). Sudden inspiration induced by } \\
\text { sudden pressure beneath the lower border of ribs. }\end{array}$ & $\begin{array}{l}\text { Back of the head to the vertex. } \\
\text { The neck. }\end{array}$ \\
\hline IV C. & $\begin{array}{l}\text { Diaphragm ; deltoid ; biceps } \\
\text { coraco-brachialis; supinator } \\
\text { longus; rhomboid; supra- } \\
\text { spinatus and infra-spinatus. }\end{array}$ & $\begin{array}{l}\text { Pupil. Fourth to } 7 \text { th cervical. Dilatation of the pupil } \\
\text { induced by irritation of neck. }\end{array}$ & $\begin{array}{l}\text { The neck, upper part of the } \\
\text { shoulder, and outer part of } \\
\text { the arm. }\end{array}$ \\
\hline V C. & $\begin{array}{l}\text { Deltoid ; biceps; coraco-bra- } \\
\text { chialis ; supinator longus; } \\
\text { supinator brevis; rhom- } \\
\text { boid; teres minor; pector- } \\
\text { alis (clavicular part); ser- } \\
\text { ratus magnus. }\end{array}$ & $\begin{array}{l}\text { Scapular. Fifth cervical to ist dorsal. Irritation of } \\
\text { skin over the scapula induces contraction of the } \\
\text { scapular muscles. Supinator longus. Tapping its } \\
\text { tendon at wrist induces flexion of forearm. }\end{array}$ & $\begin{array}{l}\text { Back of the shoulder and arm. } \\
\text { Outer side of the arm and } \\
\text { forearm, front and back. }\end{array}$ \\
\hline VI C. & $\begin{array}{l}\text { Biceps; brachialis anticus; } \\
\text { pectoralis (clavicular part) } \\
\text { serratus magnus; triceps; } \\
\text { extensors of wrist and } \\
\text { fingers; pronators. }\end{array}$ & $\begin{array}{l}\text { Triceps. Sixth to } 7 \text { th cervical. Tapping elbow-tendon } \\
\text { induces extension of forearm. Posterior wrist. } \\
\text { Sixth to 8th cervical. Tapping tendons causes ex- } \\
\text { tension of hand. }\end{array}$ & $\begin{array}{l}\text { Outer side of the forearm, } \\
\text { front, and back. Outer half } \\
\text { of the hand. }\end{array}$ \\
\hline VII C. & $\begin{array}{l}\text { Triceps (long head); exten- } \\
\text { sors of wrist and fingers; } \\
\text { pronators of wrist ; flexors } \\
\text { of wrist; subscapular; pec- } \\
\text { toralis (costal part); latissi- } \\
\text { mus dorsi ; teres major. }\end{array}$ & $\begin{array}{l}\text { Anterior wrist. Tapping anterior tendons causes } \\
\text { flexion of wrist. Palmar. } 7 \text { th cervical to 1st dorsal. } \\
\text { Stroking palm causes closure of fingers. }\end{array}$ & $\begin{array}{l}\text { Inner side and back of arm } \\
\text { and forearm. Radial half of } \\
\text { the hand. }\end{array}$ \\
\hline VIII C. & $\begin{array}{l}\text { Flexors of wrist and fingers; } \\
\text { intrinsic muscles of hand. }\end{array}$ & & Forearm and hand, inner half. \\
\hline I $\mathrm{T}$. & $\begin{array}{l}\text { Extensors of thumb; intrinsic } \\
\text { hand-muscles; thenar and } \\
\text { hypothenar eminences. }\end{array}$ & & $\begin{array}{l}\text { Forearm, inner half. Ulnar } \\
\text { distribution to the hand. }\end{array}$ \\
\hline $\begin{array}{l}\text { II to } \mathrm{XII} \\
\mathrm{T} \text {. }\end{array}$ & $\begin{array}{l}\text { Muscles of back and abdo- } \\
\text { men; erectores spinæ. }\end{array}$ & $\begin{array}{l}\text { Epigastric. Fourth to } 7 \text { th thoracic. Tickling mam- } \\
\text { mary region causes retraction of the epigastrium. } \\
\text { Abdominal. Seventh to I Ith thoracic. Stroking } \\
\text { side of abdomen causes retraction of belly. }\end{array}$ & $\begin{array}{l}\text { Skin of chest and abdomen, in } \\
\text { bands running around and } \\
\text { downward, corresponding to } \\
\text { spinal nerve. Upper gluteal } \\
\text { region. }\end{array}$ \\
\hline I L. & $\begin{array}{l}\text { Ilio-psoas ; sartorius ; muscles } \\
\text { of abdomen. }\end{array}$ & $\begin{array}{l}\text { Cremasteric. First to } 3 \mathrm{~d} \text { lumbar. Stroking inner thign } \\
\text { causes retraction of scrotum. }\end{array}$ & $\begin{array}{l}\text { Sikin over the groin and front } \\
\text { of the scrotum. }\end{array}$ \\
\hline II L. & $\begin{array}{l}\text { Ilio-psoas; sartorius; flexors } \\
\text { of knee (Remak); quadri- } \\
\text { ceps femoris. }\end{array}$ & $\begin{array}{l}\text { Patella tendon. Striking tendon causes extension of } \\
\text { leg. }\end{array}$ & Outer side of the thigh. \\
\hline III L. & $\begin{array}{l}\text { Quadriceps femoris; inner ro- } \\
\text { tators of thigh; abductors } \\
\text { of thigh. }\end{array}$ & & $\begin{array}{l}\text { Front and inner side of the } \\
\text { thigh. }\end{array}$ \\
\hline IV L. & $\begin{array}{l}\text { Abductors of thigh; adductors } \\
\text { of thigh; flexors of knee } \\
\text { (Ferrier); tibialis anticus. }\end{array}$ & $\begin{array}{l}\text { Gluteal. Fourth to } 5 \text { th lumbar. Stroking buttock } \\
\text { causes dimpling in fold of buttock. }\end{array}$ & $\begin{array}{l}\text { Inner side of thigh and leg, to } \\
\text { the ankle. Inner side of the } \\
\text { foot. }\end{array}$ \\
\hline V L. & $\begin{array}{l}\text { Outward rotators of thigh; } \\
\text { flexors of knee (Ferrier); } \\
\text { flexors of ankle; extensors } \\
\text { of toes. }\end{array}$ & - & $\begin{array}{l}\text { Back of the thigh and leg, and } \\
\text { outer part of the foot. }\end{array}$ \\
\hline I to II $\mathrm{S}$. & $\begin{array}{l}\text { Flexors of ankle; long flexors } \\
\text { of toes; peronei ; intrinsic } \\
\text { muscles of foot; perineal } \\
\text { muscles. }\end{array}$ & $\begin{array}{l}\text { Plantar. Tickling sole of foot causes flexion of toes } \\
\text { and retraction of leg. Foot-reflex. Achilles' ten- } \\
\text { don. Over-extension of foot causes rapid flexion; } \\
\text { ankle-clonus. Bladder and rectal centers. }\end{array}$ & $\begin{array}{l}\text { Back of thigh. Leg and foot, } \\
\text { outer side. Skin over sa- } \\
\text { crum. An us. Perineum. } \\
\text { Genitals. }\end{array}$ \\
\hline
\end{tabular}

pyramidal tract and the ventral ground bundle of fibers. In the Dorsal Column are Goll's Column (postero-median, postero-internal) and the funiculus cuneatus (Burdach's Column, posterior radicular zone, or postero-external column). In the Lateral Column are the antero-lateral tract, the lateral mixed paths (lateral limiting tract), the lateral or crossed pyramidal tract, and the direct cerebellar tract. S. Cord, Degeneration of; injury of certain parts of the brain causes descending secondary degeneration of certain parts of the cord bearing centrifugal impulses, and whose trophic centers lie in the motor areas of the brain. Ascending secondary degeneration follows injury of the cord in those fibers conducting impulses in a centripetal direction, the trophic centers being probably in the spinal ganglia of the dorsal roots. See Wallerian Law. S. Epilepsy, Brown-Séquard's name for ankle-clonus. See also Epilepsy. S. Foramina. See Foramina, Table of. S. Ganglia. See Ganglia, Table of. S. Gutter, the depression on either 
side of the spinous processes of the vertebral column. S. Incurvation. See Lordosis. S. Irritation. See Neurasthenia, Spinal. S. Localization, the determination of the functions of the various portions of the spinal cord. S. Marrow, the spinal cord itself within the vertebral canal. S. Nerves, the $3 \mathbf{I}$ pairs of nerves arising from the cord are grouped into pairs each, Cervical 8, Dorsal 12, Lumbar 5, Sacral. 5, Coccygeal I. Each arises by two roots, a dorsal (gan-

S., Achromatic, S., Cleavage, S., Karyokinetic, S., Nuclear, S., Segmentation, the double, conelike appearance of the nucleus during certain stages of karyokinesis. S.-cataract, a form of cataract characterized by a spindle-shaped opacity extending from the posterior surface of the anterior portion of the capsule to the anterior surface of the posterior portion of the capsule, with a central dilatation. S.cell, a fusiform cell. S.-celled, having fusiform cells, a form of cell typical of certain morbid growths, especially sarcoma; fusocellular. S.-legged, having long, thin legs. S.-oils. See Lubricating Oils. S.shanked. Same as S.-legged. S.-shaped, shaped like a spindle. Fusiform.

Spine (spin) [spina, a thorn, a prickle]. In biology, $(a)$ a sharp-pointed dermal outgrowth; (b) a point or process of a bone; a sharp, hard, stiff bone or ossicle; (c) a back-bone or spinal column, so called from its spinous processes. S.-ache, pain in or about the spine. S., Cauda equina of. See Cauda equina. S., Cleft, or Cloven. See Spina bifida. S., Cruciate. See $S$. of Tibia. S., Ethmoid, the spine on top of the sphenoid bone. S., Filum terminale of. See Filum terminale. S., Frontal. See Frontal Crest. S., Hemal, the part that closes in the hemal arch of a typical vertebra. Ss., Iliac, there are four of these: the anterior inferior is the eminence immediately above the acetabulum; the anterior superior is the anterior termination of the crest; the posterior inferior is a slight eminence upon the margin immediately above the great sciatic notch; the posterior superior is the posterior extremity of the crest. S., Irritable. See Spinal Irritation. S., Ischiatic. See S. of Ischium. S. of Ischium, a pointed eminence on the posterior border of the body of the ischium. It is the lower border of the great sciatic notch. S., Mental. See Genial Tubercles. Ss., Nasal, there are three of these: the anterior, or nasal spine of the superior maxillary, is the inferior sharp edge of the nasal crest of this bone; the posterior, or nasal spine of the palute bone, is the prominence upon the posterior margin of the palatal plate of the palate bone; the third, or common nasal spine, is the sharp process projecting from the middle of the inferior surface of the frontal bone. S., Neural, the part that closes in

NFERIOR PORTION OF CORD A.
EQUINA.
SERERIOR OR CERVICAL CORD.

. Floot of fourth ventricle. 2. Superior cerebellar peduncle. 3. Middle cerebellar peduncle. 4. Inferior cerebellar peduncle. 5. Enlargement at upper extremity of postero-median column. 6. Glosso-pharyngeal nerve. 7. Vagus. 8. Spinal accessory. 9, 9, 9, 9. Ligamentum denticulatum. IO, IO, 10, IO. Posterior roots of spinal nerves. II, II, II, II. Postero-lateral fissure. I2, 12, I2, 12. Ganglia of posterior roots. 13, 13. Anterior roots. I4. Division of united roots into anterior and posterior nerves. 15. Terminal extremity of cord. I6, I6. Filum terminale. I7, I7. Cauda equina. I, VIII. Cervical nerves. I, XII. Dorsal nerves. I, V. Lumbar nerves. I, V. Sacral nerves.

gliated) root, and a ventral (anterior, non-gangliated) root. On the dorsal root is the spinal ganglion. Beyond the ganglion the two roots unite to form, in the spinal canal, the mixed trunk of a spinal nerve. The ventral roots supply efferent fibers to all the voluntary muscles of the trunk and extremities, to the smooth muscular fibers of the bladder, ureter, uterus, etc., vasomotor, inhibitory, secretory, and trophic fibers. The dorsal roots intermediate sensory and tactile impulses. S. Point. See Point apophysaire and Craniometric Points. S. Reflexes: See Reflexes, Table of. S. System, the spinal cord and nerves considered as a whole.

Spinalis $\left(s p i-n a^{\prime}-l i s\right)$. See Muscles, Table of.

Spinate $\left(s p i^{\prime}-n \bar{a} t\right)$ [spinatus, having spines]. Armed with spines or thorn-shaped processes.

Spindle $\left(\right.$ spin' $\left.^{\prime}-d l\right)$ [ME., spindle, spindle]. A tapering rod or pin. A body having a fusiform shape. the neural arch of the typical vertebra. S., Occipital, External, the external occipital crest. S., Palatine. See S., Nasal. S., Pharyngeal, the ridge on the under surface of the basilar process of the occipital bone. $\mathbf{S}$. of the Pubes, the prominent tubercle on the upper border of the body of the pubes. S., Pubic. See $S$, of the Pubes. S., Railway, the designation given to a series of nervous symptoms developed from shock produced by a railway accident or from the concussion produced by constant travel. S. of the Scapula, the plate of bone crossing the dorsum of the scapula and dividing it into two unequal parts. S., Sciatic. See S. of Ischium. S., Sphenoid, the spinous process of the greater wing of the sphenoid bone. S. of the Sphenoid. See S., Sphenoid, and S., Ethmoid. S. of the Tibia, the elevation upon the upper surface of the tibia between its two articulating surfaces. S., Typhosd, 
acute inflammation of one or more vertebræ following typhoid fever.

Spinescent (spi-nes'-ent) [ spinescere, to grow thorny]. In biology, coarse, harsh, or spiny.

Spinicerebral (spin-is-er'-e-bral). See Cerebro-spinal.

Spiniferous (spi-nif'-er-us) [spina, spine; ferre, to bear]. Bearing spines.

Spiniform (spi'-nif-orm) [spina, a thorn; forma, form]. In biology, spine-like.

Spinigerous (spi-nij'-er-us). Same as Spiniferous.

Spinirector (spi-ne-rek'-tor) [spina, spine; erector, erector]. The erector spinæ muscle.

Spinitis (spi-ni'-lis). See Myelitis.

Spinobulbar (spi-no-bul'-bar) [spina, spine; bulbus, the oblongata]. Pertaining jointly to the spinal cord and the oblongata.

Spinola (spi-no'-lah). See Spina bifida

Spinometer (spi-nom'-et-er). Same as Scoliosometer.

Spinose $\left(s p i^{\prime}-n \bar{z} z\right)$ [spinosus, full of thorns]. In biology, possessing thorns; or shaped like a thorn.

Spinous (spi'-nus) [spina, spine]. Pertaining to the spine ; spiny or spiniform. S. Process, the apophysis or prominence at the posterior part of each vertebra.

Spintherism, Spintherismus (spin'-ther-izm, spin-

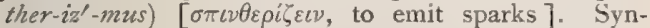
chisis scintillans; the illusory sensation of sparks dancing before the eyes.

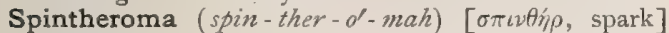
Photopsia due to the presence of cholesterin-crystals.

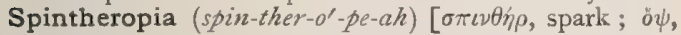
sight]. Same as Spintherism.

Spinula $\left(\operatorname{spin}^{\prime}-u-l a h\right)$ [spinula, dim. of spina, a spine: pl., Spinula]. In biology, a little hook or spine.

Spinulate (spin'-u-lāt) [spinula, a little spine]. Provided with a spinula.

Spinule $\left(\operatorname{spin}^{\prime}-\bar{u} l\right)$. Same as Spinula.

Spinulose, Spinulous (spin'-u-lör, spin'-u-lus) [spina, spine]. Spiny; having spines.

Spiny $\left(s p i^{\prime}-n e\right)$ [spina, spine]. Full of spines. $\mathbf{S}$. Clotbur, the herb Xanthium spinosum, reported to be a specific in hydrophobia. Its properties have not been investigated. Unof.

Spira $\left(s p i^{\prime}-r a h\right)$ [L., a spire]. A convolution of the brain ; a spiral.

Spiracle (spi'-rak-l) [spiraculum, a breathing-hole]. In biology, a respiratory aperture.

Spiraculum (spi-rak'-u-lum) [L., a breathing-hole: pl., Spiracula]. In biology, a spiracle.

Spiræa $\left(s p i-r e^{\prime}-a h\right)$. See Hardhack and Queen of the Meadow.

Spiral (spi'-ral) [spiralis; spira, a spire]. A curve with constantly increasing diameters; wound like the threads of a screw. S. Bandage. See Bandage. S. Canal. See Cochlea. S., Cheese, the Spirillum tyrogenum. Ss., Curschmann's, a form of curled and tufted fibrous exudate, seen in the sputum of asthma, pneumonia, etc. They are held to be pathognomonic of exudative bronchiolitis. See Ss., Leyden's. S. Duct, a duct whose wall has a spiral thickening on its inner surface. S., Finkler and Prior's. See Spirillum. S. Ganglion. See Gangtion, S. Groove. See Sulcus spiralis. S., Herxheimer's, peculiar fibers in the epidermis and the epithelium of certain mucous membranes. Eddowes thinks them to be of a fibrinous nature. S. Lamina. See Lamina. S. Layer, the middle of the three layers of the tracheal tube of an insect. Ss., Leyden's, a mesh of delicate fibers usually arranged in spiral form, which are found in the sputum and are the result of desquamative catarrhal inflammation. $\mathbf{S}$. Tendency. See under Theory. S. Tubes of Kidney. See Tubuli uriniferi.
S. Vessel, a tubular structure formed by the endwise coalescence of elongated cells with spiral layers of thickening in their walls

Spiration (spi-ra'shun). See Respiration.

Spire (spir) [spira, a coil, twist]. In biology, a conic, tapering structure, a sprout, a stalk, or the exserted whorls of the shell of a spiral gasteropod mollusc.

Spirem (spi'-rem) [spira, a coil, a twist]. In biology, the "close skein," or "mother-skein" of chromatinfibrils in a cell undergoing mitotic division. The first stage in karyokinesis.

Spiricle $\left(s p i^{\prime}-r i k-l\right)$ [spira, a coil]. In biology, a coiled thread found in the hairs on some seeds; they uncoil when dampened and give rise to a motion which tends to bury the seed in the soil.

Spiriferous (spi-rif'-er-us) [spira, a coil ; ferre, to bear]. Spired; having a spire.

Spirillum (spi-ril'-um) [spirillum, a curled hair]. A genus of bacteria whose elements are curved, often forming a spiral of several turns. See Bacteria, Synonymatic Table of. S. Fever. See Relapsing Fever. Spirit (spir'-it) [spiritus, spirit]. In pharmacy, an alcoholic or hydro-alcoholic solution of a volatile substance. It is prepared either by solution or by distillation. See Spiritus. S.-blue, S.-brown, S.-colors. See Pigments, Colors, and Dyestuffs. S. Diphenylamin-blue. Same as Bavarian Blue. S.-eosin. Same as Primrose. S. of Mindererus. See Ammonium. S.-proof, any liquor containing at least 49 per cent. of absolute alcohol. S., Rectified, spirit free from fusel-oil, and containing at least 85 per cent. absolute alcohol. S., Rum, a spirit distilled from fermented alcohol. S.-vinegar. See Vinegar. S.-violet. Same as Rosanilin-violet. S. of Wine. See Spiritus. S.-yellow. Same as Anilin-yellore. See Pigments, Conspectus of.

Spiritism (spir'-itizm). See Spiritualism.

Spiritous (spir'-it-us) [spiritus, spirit]. Alcoholic.

Spiritualism (spir'-it-u-al-izm) [spiritus, spirit]. The theory of an immaterial entity underlying or causing organic phenomena, as opposed to materialism, which last explains such phenomena by the operation of mechanical forces. The term has been incorrectly used for Spiritism, or " necromancy by the supposed evocation of the spirits of the dead."

Spirituous (spir'-it-u-us) [spiritus, spirit]. Pertaining to alcoholic liquors.

Spiritus (spir'-it-zs) [L.]. Spirit. In pharmacy, an alcoholic mixture obtained by the distillation of wine, or fermented saccharine mixtures. Good spirit should contain not less than 40 per cent. of absolute alcohol. There are 25 official spiriti. S. frumenti, whiske1', spirit obtained by the distillation of fermented grain (mainly corn or rye). It should contain 44-50 per cent. of alcohol. S. juniperi, gin or whiskey (rye or barley) with which juniper-berries and hops have been distilled. S. odoratus, cologne-water, consists of alcohol 800 , water 158 , acetic ether 2 , oil of bergamont 16 , oils of lemon and rosemary āa 8 , oils of lavender-flowers and orange-flowers āà 4 parts. $\mathrm{S}$. rector, in biology, a force exerted by the aggregate of an organism over its parts, constraining newly integrated atoms to take a definite form. See Nisus formativus. S. vini gallici, or Spirit of Wine, brandy : a liquor obtained by the distillation of wine. It should contain 39-47 per cent. of alcỏhol.

Spirobacterium (spi-ro-bak-te're-um) [spira, a spiral ;

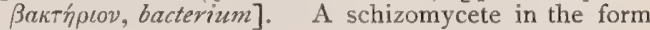
of spiral filaments.

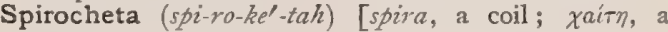
bristle]. In biology, a genus of Schizomycetes, characterized by flexible, spiral filaments. But one species 
is known, $S$ obermeieri. See under Bacteria, Synonymatic Table of. S. evansi, Steel. Not a bacterium at all, but an infusorian, Trypanosoma evansi (Evans), Balbiani, the cause of the epizoötic pernicious anemia in horses, mules, and camels, called Surra, $q . v$. See Parasites, Animal, Table of.

Spirocolon (spi-ro-ko'-lon). A form of syphilis at one time prevalent in Greece.

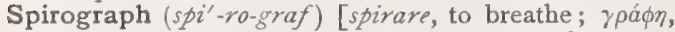
a record]. An instrument for registering the movements of respiration.

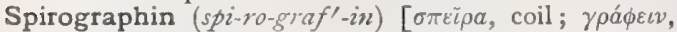
to write]. A substance obtained from the cartilage and skeletal tissues of the worm, Spirographis.

Spiroid (spi'-roid) [spira, spire]. Resembling a screw; having spiral convolutions.

Spiroloculine (spi-ro-lok'-u-lin) [spira, a coil ; loculus, a little box or cell]. In biology, characterized by spirally arranged loculi.

Spirometer (spirom'-et-er) [spirare, to breathe;

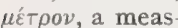
ure]. An instrument used to measure the quantity of air exhaled.

Spirometric (spiro - met' - rik) [spirare, to breathe; $\mu \varepsilon^{\prime}$

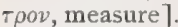
Pertaining to th e spirometer.

Spirometry (spi rom'-et-re) [spi rare, to breathe;

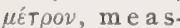
ure]. The estimation of the amount of air used in respiration, or of the quantity of air which the lungs can contain.

Spirophore (spi'-ro-for) [spirare, to breathe; $\phi \varepsilon \dot{\varepsilon} \varepsilon v$, to carry]. An instrument for use in artificial respiration.

Spiroscope (spi'-ro-skopp). See Spirometer.

Spirozoöid (spi-ro-zo'-oid) [spira, a coil, spire; $\zeta \bar{\omega} \omega$, an animal ; $\varepsilon i \delta o \zeta$, form ]. In biology, a defensive zoöid of certain hydrozoans, consisting of a long, slender, spirally coiling filament provided with lasso-cells.

Spirulate (spit'-ru-lät) [spira, a coil, spire]. Spiral in form or arrangement.

Spissate $($ spis'-ät). See Inspissate.

Spissitude (spis'-it-îd) [spissitudo, spissare, to thicken]. The state of being thick.

Spit [ME., spitten, to spit]. I. To eject sputum from the mouth. 2. Saliva. 3. In biology, a frothy secretion produced by certain insects as a means of protection.

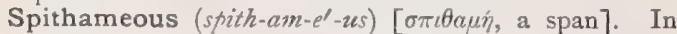
biology, span-high.

Spitting (spit'-ing) [ME., spitten, to spit]. The act of expectorating. S. of Blood. See Hemoptysis.

Spittle $($ spit'll). Same as Sputum or Saliva.

Spittoon. See Cuspidor.

Spitzka-Lissauer, Column of. See Column.

Spix, Angles of. In craniometry, those angles formed: (I) between the alveolo-nasal line and the coronal line: (2) between the alveolo-nasal line and the nasobasilar line. S., Horizontal Plane of, in craniometry, the alveolo-condylean plane.

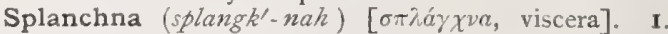
The intestines. 2. The viscera.

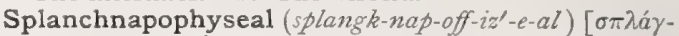
$\chi v a$, viscera; áróфvơs, apophysis]. Pertaining to a splanchnapophysis.

Splanchnapophysis (splangk-nap-off'-is-is) [ $\sigma \pi \lambda a ́ \gamma \chi v \alpha$,

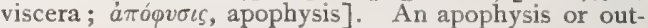
growth of a vertebra on the opposite side of a vertebral axis from a neurapophysis, and inclosing some viscus.

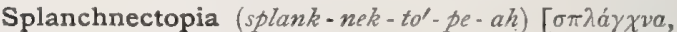
viscera ; г̇ктоло , displaced]. The abnormal position or dislocation of a viscus.

Splanchnemphraxis (splangk-nem-fraks'-is) [ $\sigma \pi \lambda \dot{\alpha} \gamma \chi-$ $v \alpha$, viscera; $\tilde{\varepsilon} \mu \phi \rho \alpha \xi \varsigma$, obstruction]. Obstruction of the intestine.

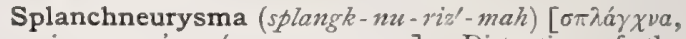
viscera; ávevór $\mu a$, aneurysm]. Distention of the intestines.

Splanchnic (splang $\left.k^{\prime}-n i k\right)\left[\sigma \pi \lambda a \gamma \chi^{\nu} e_{k o ́ s} ; \sigma \pi \lambda a ́ \gamma \chi \nu a\right.$, viscera]. Pertaining to the viscera.

Splanchnoblast (splang $\left.k^{\prime}-n o-b l a s t\right) \quad[\sigma \pi \lambda a ́ \gamma \chi v a$, the viscera; $\beta \lambda a \sigma \tau \sigma s$, a germ]. In biology, an Anlage, proton, or incipient rudiment destined to take part in the formation of the viscera ; one of the " histoblasts" of Künckel and Herculais. Cf. Neuroblast and Imaginal Disc.

Splanchnocele (splang $\left.\bar{k}^{\prime}-n o-s e ̂ l\right) ~[\sigma \pi \lambda a ́ \gamma \chi \nu \alpha$, the viscera ; кой ${ }^{\circ}$, , hollow]. I. A protrusion of any abdominal viscus. 2. In biology, Hajek's name for that part of the celom which persists in the adult, and gives rise to the pericardial, pleural, and abdominal cavities; the ventral celom, or pleuro-peritoneal space. It appears as a narrow fissure in the parietal zone of the mesoblast.

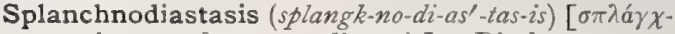

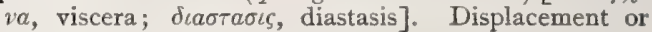
separation of the viscera.

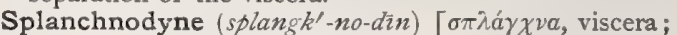
o $\delta v v \eta$, pain ]. Intestinal pain.

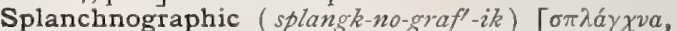
viscera ; $\gamma \rho a ́ \phi \varepsilon t \nu$, to write]. Pertaining to splanchnography.

Splanchnography (splangk-nog'-ra-fe). See Splanchnology.

Splanchnolith (splangk'-no-lith) [ $\sigma \pi \lambda a ́ \gamma \chi v a$, viscera; $\lambda i \theta o s$, a stone]. Calculus of a viscus.

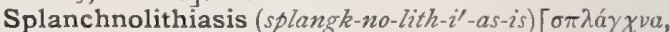
viscera; $\lambda i \theta 0 s$, stone]. The condition of calculus of the intestine.

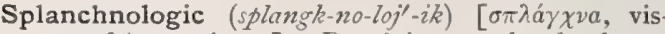
cera; $\lambda o ́ \gamma o s$, science]. Pertaining to splanchnology.

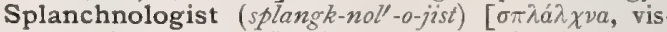
cera; $\lambda 6 \gamma$ os, science]. One versed in splanchnology.

Splanchnology (splangk-nol'-o-je) [ $\sigma \pi \lambda a ́ \gamma \gamma \chi v a$, viscera; $\lambda$ oyos, treatise]. The sum of what is known of the nature and functions of the viscera.

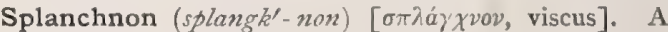
viscus. See Splanchna.

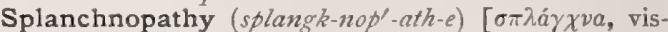
cera; $\pi a ́ \theta 0 s$, disease]. Disease of viscera.

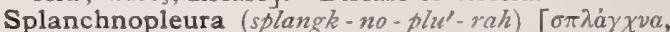
viscera; $\pi \lambda \varepsilon v \rho \dot{a}$, the side]. In biology, the wall of the alimentary tract of a vertebrate, formed by the splanchnic mesoderm and the entoderm.

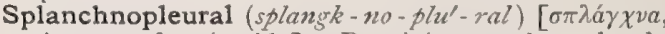
viscera; $\pi \lambda \varepsilon v \rho a$, side]. Pertaining to the splanchnopleura.

Splanchnopleure (splangk'-no-plür) [ $\sigma \pi \lambda a \gamma \chi \nu a$, the 
viscera; $\pi \lambda \varepsilon v \rho a ́$, the side]. Same as Splanchnopleura.

Splanchnopleuric (splangk-no-plu'-rik). Same as Splanchnopleural.

Splanchnoptosis (splans $\left.k-n o p-\ell 0^{\prime}-s i s\right)$ [ $\sigma \pi \lambda a ́ \gamma \kappa v a$, viscera; $\pi \tau \tilde{\omega} \sigma \iota \varsigma$, a falling]. A condition of relaxation of the abdominal viscera; it includes gastroptosis, enteroptosis, nephroptosis, less commonly hepatoptosis and splenoptosis.

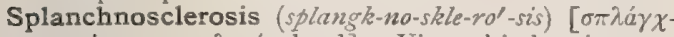
$v a$, viscera; $\sigma \kappa \lambda \eta \rho o ́ s$, hard]. Visceral induration.

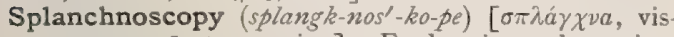
cera; $\sigma \kappa o \pi \varepsilon i \nu$, to examine]. Exploration and examination of the viscera.

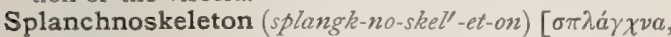

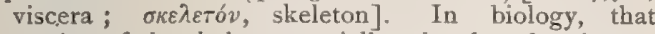
portion of the skeleton specially related to the viscera.

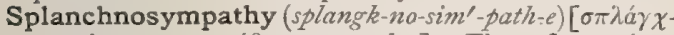
$\nu a$, viscera; $\sigma \nu \mu \pi \dot{\theta} \theta \varepsilon<a$, sympathy]. The reflex actions among the viscera themselves and between the viscera and other organs.

Splanchnotomic (splangk-no-tom $\left.{ }^{\prime}-i k\right)$ [ $\sigma \pi \lambda a ́ \gamma \chi v a, v i s-$

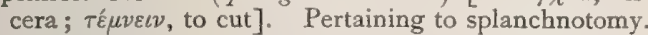

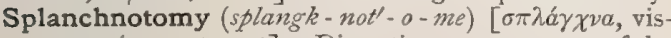
cera; $\tau \varepsilon \mu \nu \varepsilon \iota \nu$, to cut]. Dissection, or anatomy, of the viscera.

Splashing (splash'-ing) [origin obscure]. Making a plashing sound. S. Fremitus, a noise heard in succussion in some cases of pleural effusion; it may be simulated by the presence of fluid in a distended stomach.

Splay (spla) [ME., splayen, to splay]. To dislocate, as a horse's shoulder. S.-foot. See Talipes, S.-mouth, a wide mouth.

Spledget $\left(s p l e j^{\prime}-e t\right)$. A pledget, or cloth, used in dressing a sore or wound. [Old.]

Spleen (splēn) $[\sigma \pi \lambda \dot{\eta} \nu$, spleen]. I. One of the abdominal viscera, situated just below the diaphragm upon the left side; its function is not certainly determined, though probably hematopoietic. 2. Melancholy; low spirits ; hypochondriasis ; ill-temper ; surliness. S., Accessory, a loose portion of splenic tissue in the neighborhood of the spleen. S., Bacon, a uniformly lardaceous spleen. S., Floating. See S., Wandering. S., Indian, an indurated spleen sometimes found in Anglo-Indians. S., Lardaceous, an enlargement of the spleen due to waxy degeneration. S.-pulp, the proper tissue of the spleen. S. Sago-, a spleen of which the Malpighian follicles are the seat of amyloid change. S. -sick, splenetic. S., Wandering. See Wandering Spleen. S., Waxy. See S., Lardaceous. S.-wort. See Filix and Asplenium.

Spleeny (sple'-ne) [ $\sigma \pi \lambda \eta \dot{\eta}$, spleen]. Hypochondriacal; melancholy; ill-tempered; perverse.

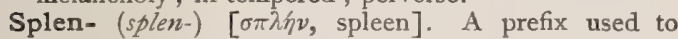
denote connection with or relation to the spleen.

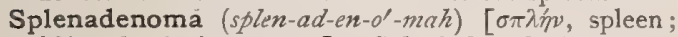
$a ́ \delta \dot{v} \nu$, gland; bua, tumor]. Splenic lymphadenoma.

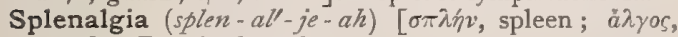
pain]. Pain in the spleen.

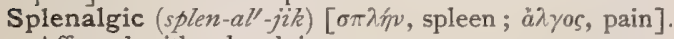
Affected with splenalgia.

Splenalgy (splen-al'-je). Same as Splenalgia.

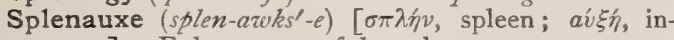
crease]. Enlargement of the spleen.

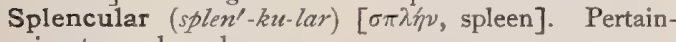
ing to a splenculus.

Splenculus (splen'-ku-lus) [ $\sigma \pi \lambda h v$, spleen: pl., Splenculi]. A supplementary spleen; an exclave of the spleen.

Splendid Line of Haller. See Lines, Table of.
Splenechos, Splenechus (splen-e'-kos, splen- $\ell^{\prime}-k u s$ ) $\left[\sigma \pi \lambda \dot{\eta} \nu\right.$, spleen; $\eta \chi \alpha^{\circ}$, sound]. The percussion-sound obtained over the spleen.

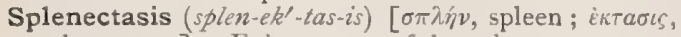
enlargement]. Enlargement of the spleen.

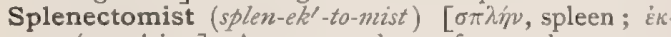
Touŕ, excision]. A surgeon who performs splenectomy.

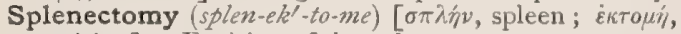
excision]. Excision of the spleen.

Splenectopia, Splenectopy (splen-ek-to'-pe-ah, splen$\left.e k^{\prime}-t o-p e\right)[\sigma \pi \lambda \dot{m}$, spleen; в̌ктотоs, dislocated]. Displacement of the spleen.

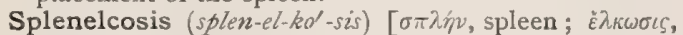
ulceration]. Ulceration of the spleen.

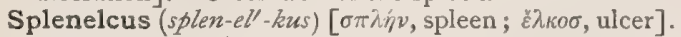
An ulcer upon the spleen.

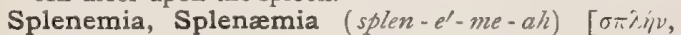
spleen; ai $\mu a$, blood]. Splenic leukemia.

Splenemphraxis (splen-em-fraks'-is) [ $[\sigma \pi \lambda \dot{\eta} v$, spleen; $\varepsilon \mu \phi \rho a \xi \iota \varsigma$, obstruction]. Congestion of the spleen from any cause.

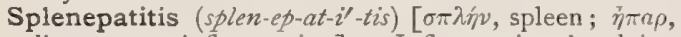
liver; $\iota \tau \iota s$, inflammation]. Inflammation involving both liver and spleen.

Splenetic $($ splen-et'-ik) $[\sigma \pi \lambda \dot{\eta} v$, spleen $]$. Splenic. Per= taining to the spleen; ill-humored ; fretful; hypochondriacal.

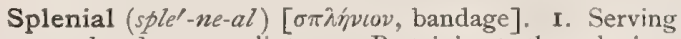
as a bandage or splint. 2. Pertaining to the splenium or to the splenius.

Splenic $\left(s p l e n^{\prime}-i k\right)[\sigma \pi \lambda \eta \nu \epsilon o ́ c]$. Pertaining to or affecting the spleen. S. Fever. See Anthrax. S. Pulp. See Pulp.

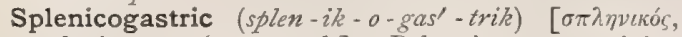
splenic; $\gamma a \sigma \tau \dot{\eta} \rho$, stomach]. Belonging or pertaining to both the spleen and the stomach.

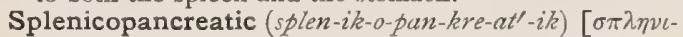
$\kappa o ́ s$, splenic; $\pi a ́ \gamma \kappa \rho \varepsilon a \zeta$, pancreas]. Belonging or pertaining to both the spleen and the pancreas.

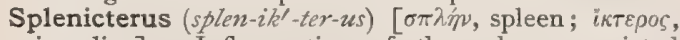
jaundice]. Inflammation of the spleen associated with jaundice.

Spleniculus (splen-i $k^{\prime}-u$-lus). See Splenculus.

Splenicus (splen'-ik-us) [ $\sigma \pi \lambda \dot{\eta} v$, spleen]. 1. Splenic. 2. A drug acting upon the spleen.

Splenification (splen - if - ik- $a^{\prime}-\operatorname{shun)}[\sigma \pi \lambda \dot{\eta} v$, spleen; facere, to make]. In pathology, the conversion, during certain diseases, of the substance of the lungs or of the liver into tissue resembling that of the spleen.

Spleniserrate (splen-is-er'-ät) [ $\sigma \pi \hat{\lambda} \eta \dot{v} \nu$ เov, bandage; serra, saw]. Pertaining to the splenius and serrate muscles.

Splenisis (splen-is'-is) [ $\sigma \pi \lambda \hat{n} \nu$, spleen $]$. A degeneration of the lung sometimes found in yellow fever. The lung contains dark-brown spots having a color and consistency resembling those of the spleen.

Splenitis (splen-i'tis) [ $\sigma \pi \lambda \dot{\nu} \nu$, spleen; $\iota \tau \iota \zeta$, inflammation]. Inflammation of the spleen.

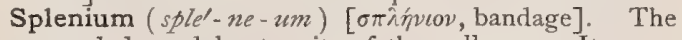
rounded caudal extremity of the callosum. It represents a flexion of the callosal sheet upon itself, so that there is a dorsal lamina, a ventral lamina, and a caudal connecting portion. The thick fold or pad at the posterior end of the corpus callosum.

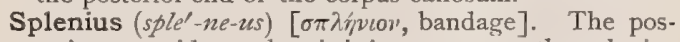
terior mastoid muscle ; it is in two parts-the splenius capitis and the splenius colli. See Muscles, Table of.

Splenization (splen-iz-a'-shun) [ $\sigma \pi \lambda \dot{m}$, spleen $]$. A condition of the lungs during the first or second stage of pneumonia, in which period the tissue of the lungs resembles that of the spleen. $\mathbf{S}$. Hypostatic, hypostatic pneumonia. 
Spleno- (splen'-o-). Same as Splen-.

Splenocele (splen'-o-sell) [ $\sigma \pi \lambda \dot{\eta} \nu$, spleen ; $\kappa \dot{\lambda} \lambda \eta$, hernia] Hernia of the spleen.

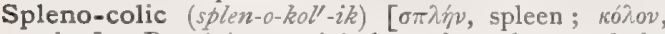
colon]. Pertaining conjointly to the spleen and the colon. S.-c. Ligaments, a peritoneal fold between the spleen and the mesocolon.

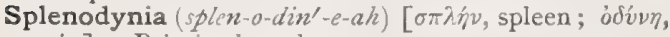
pain]. Pain in the spleen.

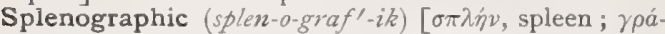
$\phi \varepsilon \imath$, to write]. Pertaining to splenography.

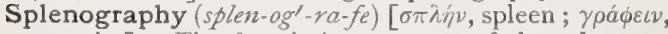
to write]. The descriptive anatomy of the spleen.

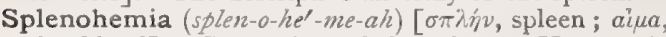
the blood]. Congestion of the spleen. Hyperemia of the spleen.

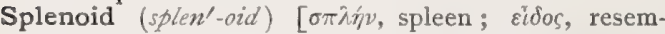
blance]. Resembling the spleen.

Splenokeratosis (splen-o-ker-at-o'-sis) [ $\sigma \pi \lambda \dot{\eta} v$, spleen ; $\kappa \tilde{\varepsilon} \rho \alpha$ s, wax ]. Splenic induration.

Splenologic (splen-o-loj'-ik) [ $\sigma \pi \lambda \dot{n} v$, spleen; $\lambda 6 \gamma o s$, science]. Pertaining to splenology.

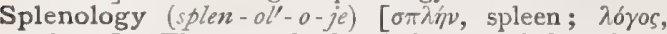
science]. The sum of what is known of the splenic structure, function, and diseases.

Splenolymphoma (splen-o-lim-fo'-mah). See Splenadenoma.

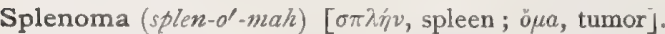
Tumor of the spleen.

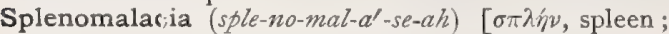
малакía, softness]. Softening of the tissue of the spleen.

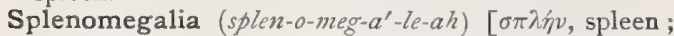
$\mu \varepsilon ́ \gamma a s$, large]. Idiopathic hypertrophy of the spleen; an essential hypersplenia. Simple enlargement of the spleen apart from leukemia, or cachexia; by some it is considered merely as Hodgkin's disease of exclusively splenic type, while others (Debove and Grancher) hold it to be a special disease.

Splenomegaly (splen-o-meg'-al-e). See Splenomegalia. Splenoncus (splen-ong'-kus). See Splenoma.

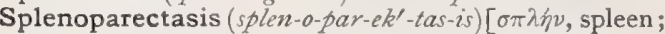

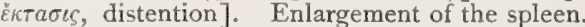

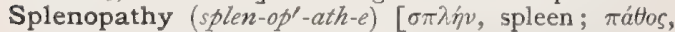
disease]. Disease of the spleen.

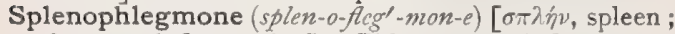
$\phi \lambda \varepsilon \gamma \mu o v \eta$, inflammation]. Phlegmonous inflammation of the spleen.

Splenophraxia, Splenophraxis (splen-o-fraks'- $e$-ah, sple-no-fraks'-is). See Splenemphraxis

Spleno-phrenic (splen-o-fren'-ik) [ $\sigma \pi \lambda \dot{\eta} v$, spleen ; $\phi \rho \dot{\eta} \nu$, diaphragm ]. Pertaining to the spleen and the diaphragm. S. - p. Ligament, a peritoneal fold between the spleen and the diaphragm.

Splenophthisis (splen-off'-this - is) $\left[\sigma \pi \lambda \dot{n}{ }^{\prime}\right.$, spleen ; $\phi \theta i \sigma \iota s$, wasting]. Atrophy of the spleen.

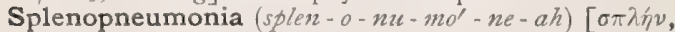
spleen; $\pi v \varepsilon v$ usv, lung]. Pneumonia with splenization of the lung.

Splenorrhagia (splen-or- $\left.a^{\prime}-j e-a / 2\right)[\sigma \pi \lambda i \dot{\nu}$, spleen; onyvivar, to burst forth]. Hemorrhage from the spleen.

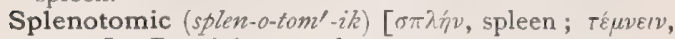
to cut]. Pertaining to splenotomy.

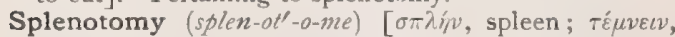
to cut]. Incision or dissection of the spleen.

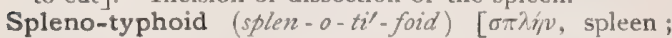
ríbos, stupor]. Typhoid fever with splenic complication.

Splent (splent) [ME, splente, splint]. An exostosis occurring on the inner surface of the metacarpal bone of the horse.
Splenypertrophia (splen-i-per-trol $-f e-a h)[\sigma \pi \lambda \dot{\eta} v$, spleen; $v \pi \varepsilon \rho$, over; $\tau \rho \circ \phi \dot{\eta}$, nourishment]. Hypertrophy of the spleen.

Splint [ME., splinte, splint]. I. A piece of wood, metal, or other material for keeping the ends of a fractured bone in permanent apposition during the process of contact while healing. 2. See Splent. S., Agnew's (for hip-joint disease), a long splint with a perineal band (fitted closely against the tuber ischii) and a foot-piece; used after the disappearance of acute symptoms, and designed to support the weight of the trunk. S., Anchor, a splint used for fracture of the jaw. Metal loops fit over the teeth, and are held in contact by a rod and nut. S.-bandage, an immovable bandage. S., Bavarian, coarse flannel is cut to fit the part, and stitched over the limb. A thick paste of plaster-of-Paris is rubbed upon the cloth to secure immobility. S., Bond's (for fracture of the lower end of the radius), a thin, wooden splint, with sole-leather edges an inch high, and a curved block to rest in the palm of the hand. A pasteboard splint is used on the back of the forearm, both reaching from below the elbow to almost the distal ends of the metacarpal bones. S.-bone, the fibula. S., Bracketed, a splint consisting of two pieces of wood or metal joined by brackets. S., Levis's, a perforated metal splint extending from below the elbow almost to the distal ends of the metacarpal bones. It is hollowed to fit the arm and palm, and the metacarpal joints are flexed over it.

Splinter (splin'-ter) [ME., splinteren, to split]. See Sequestrum. Applied, also, popularly to a bit of wood or other material that pierces the skin. S.-bone, the fibula; a term applied to one of the two small bones extending from the knee to the fetlock of the horse, behind the shank-bone.

Split [origin obscure]. A longitudinal fissure. S. Pelvis, congenital non-union of the bones of the pubes at the symphysis.

Spodiomyelitis $\left(s p o-d e-0-m i-e l-i^{\prime}-t i s[\sigma \pi v \delta \iota o ́ s\right.$, gray ; $\mu v \varepsilon \lambda o ́ s$, marrow ; $\iota \tau \iota \varsigma$, inflammation]. An acute inflammation in the anterior cornua of the spinal cord, in which the larger multipolar ganglion-cells are destroyed; it occurs usually in children during their period of first dentition. See Polioniyelitis, Acute Anterior.

Spodium $\left(s p o^{\prime}-d e-u m\right)$ [ $\sigma \pi o \delta \sigma s$, ashes]. An old term for animal charcoal.

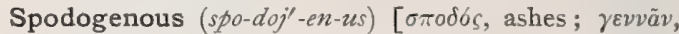
to produce]. Arising from débris, or from the waste matters of the economy.

Spokebone (spökl-bön). See Radius.

Spoliative (spo'-le-a-tiv) [spoliare, to plunder]. Diminishing ; applied to venesection practised for the purpose of diminishing the mass of blood.

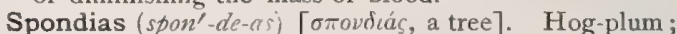
a genus of trees of the order Anacardiacea, growing in China, the West Indies, tropical South America, and the islands of the Pacific. The trees bear an edible fruit, which is aperient and refrigerant; the leaves are mildly anodyne and diaphoretic, and the root and bark possess astringent properties. The seeds are poisonous.

Spöndle, Foramen of. See Foramina, Table of

Spondles $\left(s p o n^{\prime}-d l s\right)[\sigma \pi \delta v \delta v \lambda \omega s$, a vertebra]. The ver tebræ.

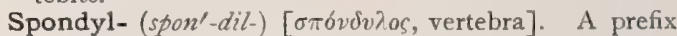
used to denote connection with one or more vertebra.

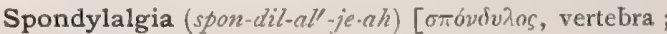
à yos, pain]. Pain referred to a vertebra.

Spondylarthritis (spon-dil-ar-thri'-tis) [ $\sigma \pi \delta v \delta v \lambda o s, v e r-$ tebra; ă $\rho \rho \rho \nu$, joint; $t \tau \iota$, inflammation]. Inflamma- 
tion at a vertebral articulation. S. synovialis, inflammation of the synovial membranes of the articular processes of the vertebre (Huter).

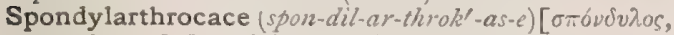
vertebra ; å $\theta$ pon, joint; kaký, evil]. Caries of a vertebra.

Spondylexarthrosis (spon-dil-eks-ar-thro'-sis) [ $\sigma \pi b v$ -

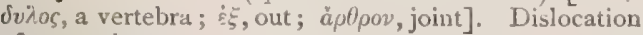
of a vertebra.

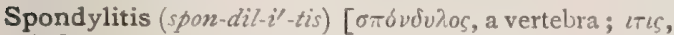
inflammation]. Inflammation of one or more vertebra; Pott's disease. S. cervicalis, arthritis of one or more cervical vertebre. $\mathbf{S}$. deformans, chronic inflammation of the vertebræ, of a gouty or rheumatic nature, terminating in ankylosis and deformity. S. tuberculosa, tuberculous spondylitis. See Pott's Disease in Diseases, Table of.

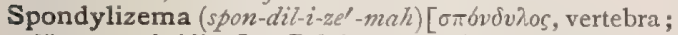

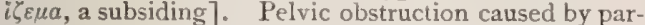
tial or total loss of a vertebra, in consequence of which the vertebræ above overhang the brim of the pelvis. See Spondylolisthesis.

Spondylocace (spon-dil-ok'-as-e). See Spondylarthrocace.

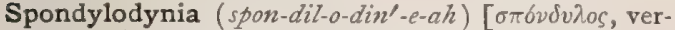
tebra; óvovvn, pain]. Pain in a vertebra.

Spondylolisthesis (spon-dil-ol-is-the'-sis) [ $\sigma \pi \delta v \delta v \lambda o s$,

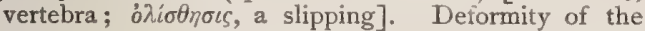
spinal column produced by the gliding forward of the lumbar vertebre in such a manner that they overhang the brim and obstruct the inlet of the pelvis; especially the separation of the last lumbar vertebra from, and its slipping forward on, the sacrum.

Spondylolisthetic (spon-dil-o-lis-thet'-ik) [ $\sigma \pi 6 v \delta v i o s$,

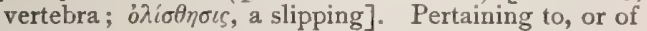
the nature of spondylolisthesis.

Spondylomyelitis (span-dil-o-mi-el-i'-tis) See Spondylitis.

Spondylopathia (spon-dil-o-pa'-the-a/h). See Spondylopathy.

Spondylopathy (spon-dil-op'-ath-e) [ $\sigma \pi \delta \nu \delta v \lambda o s$, vertebra; $\pi \alpha \theta_{0 s}$, a suffering ]. Any disease of the vertebræ.

Spondyloptosis (spon-dil-op-tol-sis). See Spondylo. listhesis.

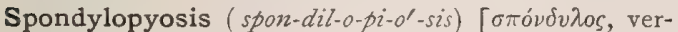
tebra; $\pi \tilde{v} o \nu$, pus]. Suppurative inflammation of one or more vertebræ.

Spondyloschisis (spon-dil-os'-kis-is) [ $\sigma \pi \delta v \delta v \lambda o s$, vertebra]. Deficient ossification in the arch of the fifth lumbar vertebra; this is said to be one of the causes of spondylolisthesis. The condition may affect one or both sides of the vertebræ.

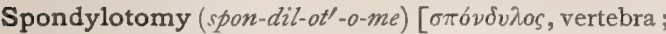
Touŕ, section]. Section of a vertebra in embryotomy; section of a vertebra in correcting a deformity. Cf. Rachiotomy.

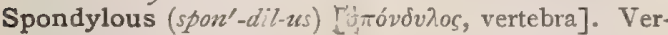
tebral ; like a vertebra.

Spondylus $\left(s p o n^{\prime}-d i t-u s\right)[\sigma \pi b v \delta v\rangle$ os, vertebra $]$. A vertebra.

Sponge (spunj) [ $\sigma \pi 6 \gamma \gamma o \varsigma$, any spongy substance]. In biology, a coelenterate animal of the class Porifera. The sponge of commerce belongs to the order Ceraspongia, having a skeleton of horn-fibers (spongin), without proper spicules. S.-animalcule, a spongecell. S., Antiseptic, a sponge that has been rendered destructive of germs. S., Burnt, sponge-charcoal made from fine sponges cleansed and burned, then powdered, and sifted through a No. roo silk sieve. S., Compressed, a fine sponge, cleansed, exposed to pressure, and dried. It is used particularly as "sponge80 tents" in gynecology, and in the treatment of mastitis. S., Fine Levant (Euspongia officinalis mollis$\operatorname{sim} a$ ), this is the finest sponge of conmerce; it is obtained from the Adriatic Sea, the Eastern Mediterranean Sea, and the Red Sea. S.-graft. See Graft. S.-grafting, a method of promoting the repair of chronic ulcers and other solutions of continuity rebellious to ordinary treatment by the application of pieces of sponge covered with oil-silk. Speedy cicatrization follows as a rule. S., Grass, the Honey-comb Sponge (Spongia cerebriformis), a poor quality of sponge from Florida and the Bahamas. S.-holder, an instrument, consisting of a rod, which serves as the handle, furnished at the distal end with a device for clasping a sponge. S.holder, Finger, a sponge-holder having a thimble at one end; it is used within the throat. S., Horse, Venetian Bath-sponge, Gerbis Sort (Hippospongia equina), the coarsest of all the Mediterranean sponges. It is obtained along the Mediterranean coast. $\mathbf{S}$., Levant. See S., Fine Levant. S.-method of Voltolini, the removal of soft tumors from the vocal bands, by means of a small sponge firmly attached to a suitable handle, introduced into the glottis, and roughly moved up and down. S., Prepared, a sponge rendered soft and elastic, and suitable for surgical uses by soaking in cold water and separation of the calcareous matter. S., Sheepswool (Spongia gossypina), the finest and toughest of the sponges from the Bahamas and the Florida Keys. S.-tent. See Tent. S., Turkey. See Fine Levant. S., Vegetable, the fibrous network of the fruit of Luffa asyptiaca; it is used as a sponge-brush and flesh-brush. $\mathbf{S}$., Waxed, a fine sponge, which, after being cleansed, is soaked in melted yellow wax, and then exposed to pressure in a warm press; it is used to make spongetents. S., Worsted, a substitute for sponge in surgery. Cut up coarse, white "four-ply fingering" worsted into lengths of about two meters; tie up a large handful of these in a double thickness of ordinary " unprepared gauze," boil them for an hour or more, and put away for use in a I-20 carbolic lotion. S., Zimocca (Euspongia zimocca), the flat, tough sponge of commerce, obtained from the Adriatic, about the Greek Islands, and the coast of Barbary.

Spongia (spon'-je-a/). See Sponge. Carbo spongix. See Sponge, Burnt. Pulvis spongiæ ustæ. See Sponge, Burnt. S. cerata. See S., Waxed. S. Compressa. See Sponge Compressed. S. cynorrhodontis, $\mathrm{S}$. cynosbati, bedegar; an excrescence occurring on various species of the wild-rose, due to the puncture of cynips rosæ. S. fluviatilis, small sponges found on stones and on water-plants in. streams, ponds, and marshy places. S. lacustris, a Russian variety used by homeopaths in the preparation of a tincture. $\mathbf{S}$. officinalis. See $S$. praparata. S. præparata. See Sponge, Compressed, and S., Prepared. S. Usitatissima, sponges with fine pores cleansed and pressed. S. usta. See Carbo spongia.

Spongiform (stun'-jif-orm) [ $\sigma \pi b \gamma \gamma o s$, sponge ; forma, a form]. Resembling or having the physical characters of a sponge.

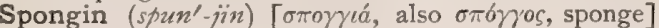
In biology, the horny substance forming the skeletal fibers of the ceratose sponges. It resembles silk in chemic composition, but differs from it in being insoluble in an ammoniacal solution of copper sulphate (cuproso-ammonium sulphate). It is also called spongiatin.

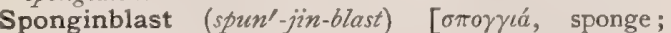
$\beta \lambda a \sigma \tau \delta s, a$ germ]. In biology, a spongin-secreting cell. 


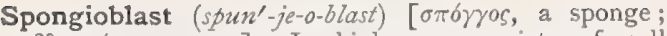
$\beta \lambda a \sigma \tau b s$, a germ]. In biology, a variety of cell derived from the invaginated ectoderm forming the

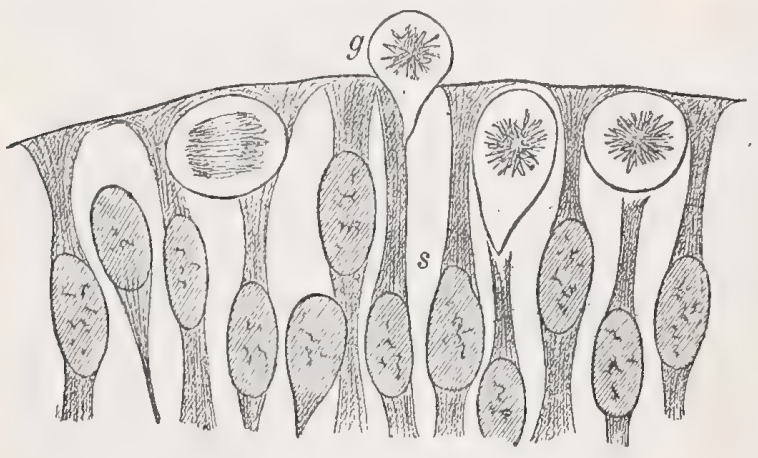

Portion of Wall of Neural TUbe,

Exhibiting germ-cells $(g)$ among the differentiating spongioblasts. (From Piersol, after His.)

neural tube. The spongioblasts are especially concerned in the production of the neuroglia-cells. Cf. Neuroblasts.

Spongiole $\left(\operatorname{spun}^{\prime}-j e-\bar{o} l\right)$ [spongiola, a little sponge]. In biology, a name formerly applied to the spongy tissue of the root-tip, on account of its supposed property of sucking up moisture like a sponge.

Spongiolin (spun'-je-o-lin). See Spongin.

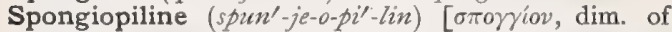
$\sigma \pi 6 \gamma \gamma o s$, sponge; $\pi i \lambda$ s, felt]. Felted or woven cloth, into which tufts of sponge are incorporated; one side is coated with rubber; it is a good substitute for a cataplasm.

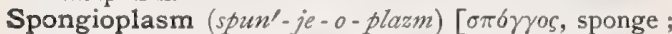
$\pi \lambda a ́ \sigma \mu \alpha$, anything formed or molded]. In biology, the extremely fine, elastic, protoplasmic threads forming the intracellular reticulum, and containing between them the clear, homogeneous, active hyaloplasm, q.v. " In muscle-fibers the spongioplasm is regularly arranged, consisting of parallel filaments which run longitudinally and are bound by transverse filaments at regular intervals in a plane at right angles to the longitudinal axis." (Lang.)

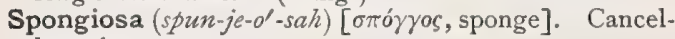
lous tissue.

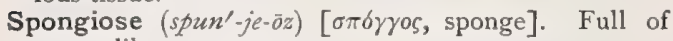
pores, like a sponge.

Spongoblast (spung'-go-blast). Same as Spongioblast.

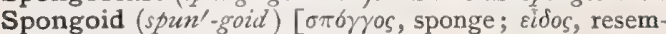
bling]. Resembling sponge.

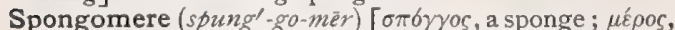
a part]. In biology, the upper portion of a sponge, characterized by the presence of chambers lined with collar-cells. Cf. Hypomere.

Spongos, Spongus (spun'-gos, spun'-gus). See Sponge.

Spongy (spun'-je) [ $\sigma \pi b \gamma \gamma o s$, sponge]. Having the texture of sponge; very porous. $\mathrm{S}$. Bones, bones having a porous, reticulated structure, especially the turbinated bones of the nose, and the sphenoid and ethmoid bones. S. Portion of the Urethra. See Urethra.

Spontaneity (spon-tan-e'-it-e) [spons, will, abl. sponte, of one's own accord]. In biology, variation in structure or function attributable to some innate or hereditary condition of the organism and not to its environment; purposeless, or uncalled-for activity.

Spontaneous (spon-ta'-ne-us) [spons, will]. Voluntary, or without extraneous impulse ; instinctive ; automatic.
S. Ankle-clonus, a rhythmic movement of the leg and foot, corresponding to ankle-clonus, but occurring spontaneously. S. Combustion. See Combustion. S. Cretinism. See Cretinism. S. Evolution. See Evolution. S. Generation. See Abiogenesis. S. Version. See Version.

Spool-worm. Synonym of Oxyuris vermicularis. See under Parasites (Animal), Table of.

Spoon [ME., spoon, spoon]. A utensil consisting of an oval or circular bowl and a handle; a spoon-shaped instrument; a curet. S.-saw, a spoon-shaped instrument or curet with serrated edges, used for scraping away fungous growths. S.-nail, a condition of the nail in which it is thinned and concave from side to side, with the edges everted, and with hollowing to a less degree antero-posteriorly. It has been observed in some wasting diseases.

Spora (spo'-rah) [L.]. See Spore.

Sporaceous (spor-a'-shus) [spora, spore]. Consisting of or convertible into spores.

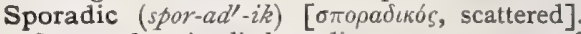
Scattered. Applied to diseases, or cases of disease, that may spread, but which are not epidemic. S. Cholera, a synonym of Cholera morbus.

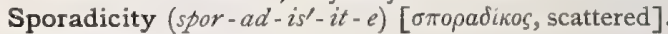
The quality of being sporadic.

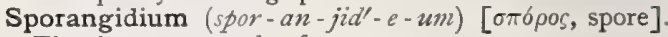
The theca or capsule of mosses.

Sporangiferous (spor - an - jiff'-er-us) [ $\sigma \pi 6 \rho 0 s$, spore ; ferre, to bear]. Bearing sporangia.

Sporangiform (spor-an'-jif-orm) [ $\sigma \pi$ ópos, spore ; forma, form ]. Having the form of a sporangium.

Sporangioid (spor-an'-je-oid) [ $\sigma \pi \delta \rho o s$, spore; $\varepsilon i \delta o s$, like]. Sporangiform.

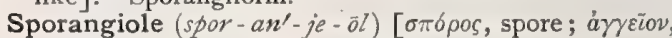
vessel]. A capsule containing spores. Same as Sporangium.

Sporangiophore (spor- $a n^{\prime}$-je-o-för). See Sporangiophorum.

Sporangiophorum (spor-an-je-off'-or-um) [ $\sigma \pi \delta$ óos, seed;

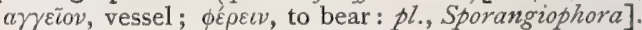
In biology, the stalk or receptacle of a sporangium, including the leaf-like organ which bears the spores in Equisetacec, and the axis of the sporangia of certain ferns.

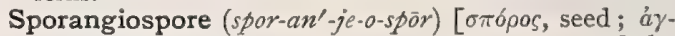
$\gamma \varepsilon i o \nu$, vessel; $\sigma \pi \delta \rho o s$, seed]. In biology, one of the spores of a slime-mold (Myxomycetes).

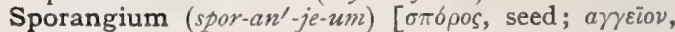
vessel: pl., Sporangia]. In biology, a capsule producing or enclosing spores. Cf. Macrosporangium, Microsporangium, Oösporangium, Zoösporangium.

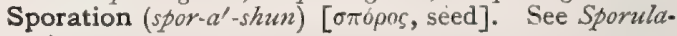
tion.

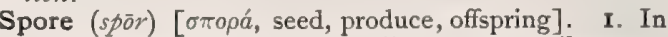
biology, one of the free, motile or non-motile repro. ductive bodies of a cryptogam, which arise by ordinary processes of vegetation and not directly by a union of sexual elements. In some cases its first stage is that of a naked primordial mass of protoplasm (zoöspore); rarely it is multicellular, composed of merispores or breaking up into sporids (polyspore). 2. In animals, any germ or reproductive element less organized than a true cell; also, any spermatic or ovulary cell ; also, the germ of a disease. Cf., Accidiospone, Androspore, Ascospore, Auxospore, Basidiospore, Bispore, Carpospore, Chlamydospore, Clinospore, Macrospore, Megaspore, Merispore, Microspore, Oöspore, Polj'spore, Protospore, Pseudospore, Pycnidiospore, Resting-spore, Sporid, Stylospore, Swarmspore, Teleutospore, Tetraspore, Uredospore, Zoöspore, Zygospore. S.-capsule, 
a spore-case. S.-case, the sporangium or covering of a spore. S.-cell, a spore. S., Compound, a spore that produces secondary spores. S., Daughter, a spore produced in a mother-cell. S.-formation, the origination of spores. S.-group. Same as Sporidesm. S., Inactive, a non-motile fertile cell. S., Mother-, a mother-cell. S., Naked, a gymnospore. S.-plasm, the protoplasm of a sporangium. S., Primary, a spore the germination of which produces a prothallium; a protospore. S.-sac, the sac lining the cavity of the sporangium of mosses. See Sporangium. S., Secondary, a merispore. Cf. S. Compound. S., Swarm, a spore endowed with the power of locomotion.

Sporid (spor'-id) [otópos, seed]. See Sporidium.

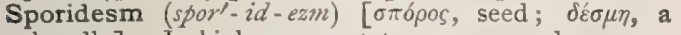
bundle]. In biology, a septate or compound spore.

Sporidiferous (spor-id-if'-er-us) [otópos, spore; ferre, tó bear]. Bearing sporidia.

Sporidiola (spor-id-e-o'-lah). See Spomule.

Sporidiolum (spor-id-i'-o-lum) [dim. of sporidium, from orópos, seed: pl., Sporidiola]. In biology, a spermatium.

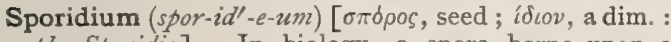
pl., Sporidia]. In biology, a spore borne upon a promycelium.

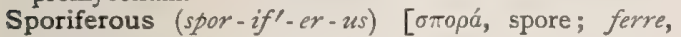
bear]. In biology, spore-bearing.

Sporiparity (spor-ip-ar'-it-e) [ $\sigma \pi \delta \rho o s$, spore; parere, to bear]. Reproduction by means of spores.

Sporiparous (spor-iṕ-ar-us) [ [ 0 ropá, spore; parere, to produce ]. In biology, reproducing by means of spores.

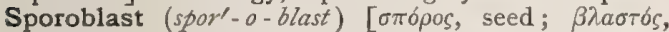
germ]. In biology, one of the four round bodies produced by the process of endogenous cell-formation in a Coccidium. Pfeiffer and Wolters refer to these as sporogonia, while Neumann broadens the application of the word "sporoblast" to make it include the "spore" as well as the "sporoblast" of other authorities. Cf. Sporophore.

Sporocarp (spor'-o-karp) [ $\sigma \pi 6 \rho o \varsigma$, seed; $\kappa a \rho \pi b \varsigma$, fruit]. See Sporocarpium.

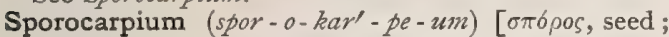
$\kappa a \rho \pi \delta s$, fruit: pl., Sporocarpia]. In biology, the fructification resulting from the conjugation of two sexual elements of identical structure, as found in the ascomycetous fungi; also, the structure inclosing the sporangia in heterosporous ferns.

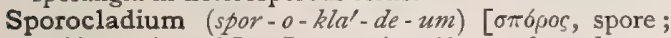
$\kappa \lambda a ́ \delta o s, a$ branch]. In certain Alge a branch producing spores.

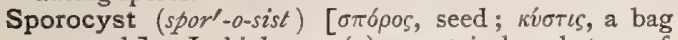
or pouch]. In biology: $(a)$ a certain larval stage of fluke-worms (trematoda), which gives rise to new germs called redia, $q . v$. ; $(b)$ used by Wolters as equivalent to macrospore and microspore of gregarines; $(c)$ the mother-cell of a spore; a sporocyte.

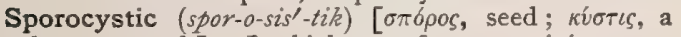
bag or pouch]. In biology, of or pertaining to a sporocyst.

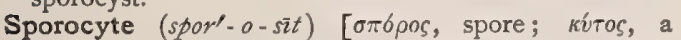
hollow]. In biology, the mother-cell of a spore; a sporocyst.

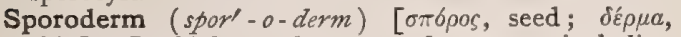
skin]. In biology, the coat of a spore, including exospore and endospore. Cf. Spermoderm.

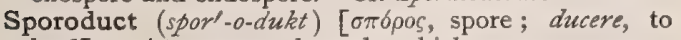
lead]. A passage through which spores are conducted.

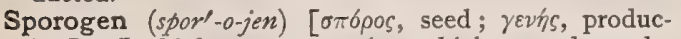
ing]. In biology, an organism which reproduces by means of spores.

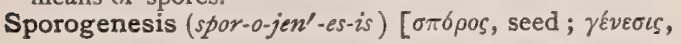

generation]. In biology, spore-formation or reproduction by spores.

Sporogenous (spor-oj'-en-us) [ $\sigma \pi 6 \rho \circ s$, seed ; revís, producing]. In biology, spore-producing.

Sporogone (spor'-o-gön). Same as Sporogonizum.

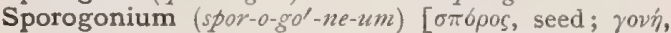
generation: pl., Sporogonia]. In biology, the nonsexual generation of a moss, proceeding from the fertilized oösphore; cf. Sporophyte, Sporocarp; also called Sporogone.

Sporogony (spor-ogf-o-ne). Same as Sporogenesis.

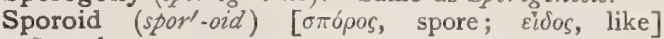
Sporular.

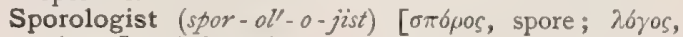
science]. A botanist.

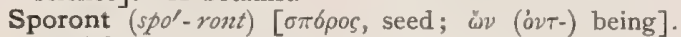
In biology, a gregarine without an epimerite, as distinguished from a cephalont.

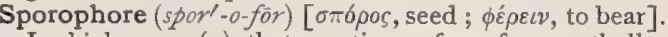
In biology: (a) that portion of a fungus thallus specialized for the bearing of propagative bodies; a special hypha; (b) Pfeiffer's name for the protoplasmic material of a Coccidium which remains after the formation of the sporoblasts. It is the Theilungskörper of German authors and the reliquat de segmentation of Railliet et Lucet. Wolters, however, employs the term sporophore in speaking of the noyau de reliquat, a small portion of protoplasm which is left unused in the macrospores and microspores of the Gregarina after the formation of the falciform boclies.

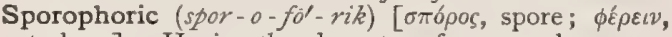
to bear]. Having the character of a sporophore.

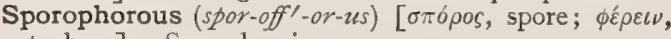
to bear]. Spore-bearing.

Sporophyl, Sporophyll, Sporophyllum (sporl-o-fil,

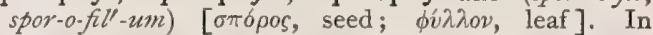
biology, the modified leaf which bears the spores, or receptacles holding the spores, in many of the vascular cryptogams; the fertile leaf.

Sporophyte (spor'-o-fit $)$ [ $\sigma \pi b \rho o s$, seed; $\phi v \tau b v$, plant]. In biology, the non-sexual generation of one of the vascular cryptogams and higher cellular cryptogams. It is often of great size and extended length of life, and is that which is commonly known as the fern, clubmoss, etc. On it are produced, without any process of fertilization, the spores.

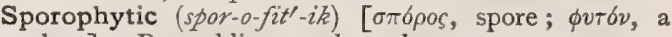
plant]. Resembling a sphorophyte.

Sporos $\left(s p o r^{\prime}-o s\right)$ [ $\sigma \pi 6 \rho o s$, spore]. Semen.

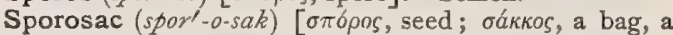
sack]. In biology: $(a)$ one of the medusiform reproductive buds of certain Hydrozoa (Tubularia, Campanularia). They are Medusa which have undergone retrograde formation, without oral-opening tentacles or sense-organs; $(b)$ a sporocyst.

Sporostegium (spor-o-ste'-je-um) [ $\sigma \pi \delta \rho o s$, seed; $\sigma \tau \varepsilon ́ \gamma \varepsilon \iota v$, cover, roof]. In biology, the oösporangium or fructification of the Characee; the Chara-fruit.

Sporotrichium (spor-o-trik'-e-um) [ $\sigma \pi \sigma \rho o s$, spore; $\theta \rho i \xi$, hair]. A genus of hyphomycetous Fungi. S. dermatodes, a whitish mold that infests Anundo donax in Provence and contact with which causes the maladie des cannes, a dermatitis of the face, genitalia, etc. It is common among basket-makers and others handling the reeds.

Sporous (spot-rus) [ $\sigma \pi 6 \rho o s$, spore ]. Pertaining to a spore.

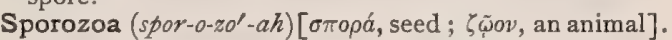
A class of parasitic Protozon including five orders: the Gregarinidia, parasitic in various worms and arthropods ; the Coccidiidia, or oviform psorosperms, parasitic in the hepatic and intestinal epithelium of 
various mammals, including man; the Sarcosporidia, or tubuliform psorosperms, parasitic in the muscles of various animals. See Sarcocystis miescheri under Parasites (Animal), Table of; the Myxosporidia, the psorosperms of fishes; the Microsporidia, or the psorosperms of articulates. See Pébrine and Microsporidia.

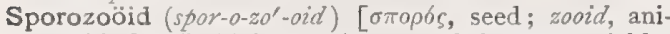
mal-like]. In biology: (a) one of the two "sicklecells" or "falciform bodies" produced by every spore of the true Coccidia. The small portion of the spore-plasma remaining unused is called the noyau de reliquat or reliquat de differentiation, or Restkörper; (b) any oöspore.

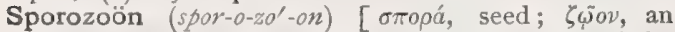
animal: pl., Sporozoa]. In biology, a member of the Sporozon.

Sport (spōrt) [ME, sport, sport]. A branch bearing foliage, blossoms, and fruit unlike those of the parent plant.

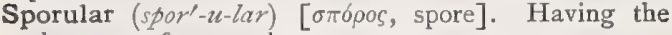
character of a sporule.

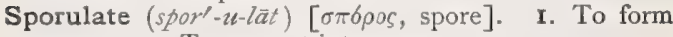
spores. 2. To convert into spoles.

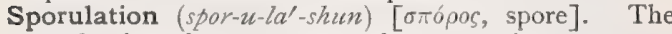
production of spores or sporules; sporation.

Sporule (spor'-ül) [ $\sigma \pi o ́ \rho o s$, seed]. A term applied to a minute spore; also sometimes to minute granules within a spore.

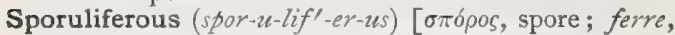
to bear]. Bearing sporules.

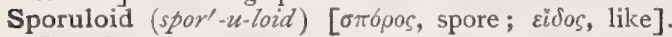
Sporular.

Spot [ME., spot, spot]. See Macula and Spilus. Ss., Acoustic. See Macula. S., Blind (of Mariotte). The entrance of the optic nerve, where the rods and cones are absent. S., Corneal, an opacity of the cornea; leukoma. Ss., Cribriform. See Macula cribrosa. S.-disease. See Pébrine. S., Embryonic, the nucleolus of the ovum. S., Germinal, S., Germ. See S., Embryonic. S., Hectic, the bright flush on the cheek of a person suffering from hectic fever. Ss., Lenticular, ephelides; the exanthem of typhoid fever. S., Light (on the membrana tympani), a cone of light on the anterior and inferior part of the tympanic membrane, with its apex directed inward. S. Mariotte's, the optic disc. S., Milk, a spot found post-mortem on the external surface of the visceral layer of the pericardium, usually over the right ventricle ; it varies from a half to one inch in diameter, and is of common occurrence in persons who have passed middle life. S., Mothers', mothers' mark; nevus. Ss., Rose, the typhoid rash. S., Sömmerring's. See Macula luter. Ss., Sun. See Lentigo. S. of Wagner, the macula germinativa. S., Wine, portwine mark; strawberry mark. S., Yellow. See Micula lutea.

Spotted (spot'-ed) [ME., spot, spot]. Marked with maculæ. S. Fever. See Fever, Cerebro-spinal. S. Sickness. See Pinta Disease.

Spotting (spot'-ing) [ME., spot, spot]. A disease of plants in which small black spots appear, and beneath which the tissues decay.

Sprain (sprän) [OF., espreindre, to press]. Injury and consequent soreness from strain of a muscle, tendon, or ligament by too great traction upon it. S.-fracture, separation of a tendon, with detachment of a small shell of bone. S., Riders', a sprain of the adductor longus muscle of the thigh, resulting from a sudden effort on the part of the horseman to maintain his seat or equilibrium, owing to "shying" or other unexpected movement of his horse.
Spray (sprā) [Ger, spreiden, to spread]. A liquid blown into minute particles by a strong current of air or steam. S., Listerian Steam, a carbolized spray from a steam atomizer, formerly used at surgical operations. S.-producer, an atomizer.

Spread (spred) [ME., spreden, to spread]. To scatter; to disperse; to distribute over a surface. S. of Dividers, the space including the image between the points of the dividers. This is measured in determining the magnification of a simple microscope.

Spreio $(s p r i$ '-o). Written also Sprue. A popular term for thrush.

Spring [ME., spring, spring]. The first of the four seasons of the year; also, a device having resiliency. S. Conjunctivitis. See Vernal. S. Fever. See Eonosus. S.-finger, a condition in which there is an obstruction to flexion and extension of one or more fingers at a certain stage of these movements. It is due to injuries or may result from inflammation of the tendinous sheaths: S.-halt, an involuntary convulsive movement of the muscles of either hind leg in the horse, by which the leg is suddenly and unduly raised from the ground and lowered again with unnatural force. S.-ligament, the inferior calcaneoscaphoid ligament of the sole of the foot. S.-nail, a hangnail. S. Ophthalmia. See Vernal. S.-worm. See Oxyuris vermicularis under Parasites (Animal), Table of.

Sprout (sprowt) [D., spruite, a sprout]. A young root or stem from a seed; a quickly-grown branch. S.chain, a chaplet of cells formed by that mode of multiplication in which the parent-cell sends out a small process, which increases in size and is gradually separated by the formation of a septum at the point of junction.

Spruce (spruss). The name of certain species of Abies, or fir. S.-beer, a beverage made by boiling four ounces each of pimenta, ginger, and hops, and a half-pint of essence of spruce in three gallons of water for about ten minutes, straining, adding one pint of yeast, six gallons of molasses, and eleven gallons of water, and leaving it to ferment for twenty-four hours. S.-gum, a resinous exudate obtained from Abies alba and Abies nigra.

Sprue (sprü). Synonym of Thrush.

Sprung Knee. In the horse an alteration in the direction and articulation of the bones which form the various carpal joints, so that instead of forming a vertical line from the distal end of the forearm to the cannon-bone, the knee (wrist) is more or less bent forward.

Spumescent, Spumose (spu-mes'-ent, spu'-mōz) [spuma, froth, foam]. Appearing like froth.

Spunk (spungk). See Agaricus.

Spur (sper) [ME., spure, spur]. A sharp point, or projection. The angle made by any branch with the main blood-vessel. In biology, a pointed spine-like outgrowth, either of the integument or a projecting appendage. S.-gall, a callous and hairless place on the side of a horse, caused by the use of a spur.

Spurge (sperj) [ME., sporgen, spurge]. A general name for plants of the genus Euphorbia.

Spurious (spu'-re-us) [spurius, false]. Not legitimate; bastard. S. Hydrocephalus. See Diarrhea, Acute Infammatory. S. Labor. See False Pains. S. Melanosis. See Miners' Phthisis. S. Pregnancy. See Psendocyesis.

Spurred (sperd) [ME., spure, spur]. In biology, having spurs. S. Rye. See Ercot.

Sputa $\left(s p u^{\prime}-t a h\right)$. Plural of Sputum, $q . v$.

Sputum (spu'-tum) [spuere, to spit]. The secretion ejected from the mouth in spitting. It consists nor- 
mally of saliva and mucus from the nasal fossæ and the fauces. In disease it may be purulent, muco-purulent, fibrinous, nummular, bloody, and may contain the débris of suppuration of any part finding an outlet through the mouth. Certain diseases, especially pneumonia and pulmonary tuberculosis, are marked by the specific character of their sputa. Microscopically, in diseased conditions, there are found various materials, as follows: blood, oil-globules, pus-corpuscles, granular débris, fragments of lung-tissue, bacteria, Curschmann's spirals, and Charcot-Leyden crystals. S., Black-pigmented, sputum having a black color from inhaled particles of carbon. S., Cavernous, nummular sputum, from a pulmonary cavity. S. coctum, opaque, yellowish or greenish, viscid, generally partially confluent, though occasionally nummulated, sputum of the later stages of acute bronchitis. S. crudum, scanty, viscid expectoration in the early stages of acute bronchitis. S., Egg-yolk, sputum having a yellow color. S., Globular, spheric masses of sputum of the later stages of bronchitis; yellow in color, and consisting of epithelium, pus-corpuscles, mucus, etc. S., Green, bloody sputum in which oxidation of the hemoglobin has taken place; it is seen in pneumonia. S., Icteric, sputum tinged green or yellow, due to the presence of bilepigment; it is observed in icterus. S., Nummular, heavy, round, coin-like masses of sputum, such as occurs in pulmonary tuberculosis. S., Prune-juice, S., Rusty, the typical, dark-colored sputum of the third stage of pneumonia; the color is due to the admixture of blood. S. puriforme, sputum having the appearance of pus, S. rotunda. See $S$., Nummular. S. tuberculosum, a purulent or mucopurulent sputum containing tubercle-bacilli, occurring in pulmonary tuberculosis and in caseous pneumonia. S., Yellow, sputum having a yellow color, due to the presence of fungi; the term is also applied to sputum rendered yellow by oxidation of the contained hemoglobin.

Spyrokolon (spi-ro-ko'-lon) [literally, pustules on the nates]. A form of syphilis which has been more or less prevalent throughout Greece. It begins usually on the nates or scrotum and genitals as an eruption of pustules, which spreads to various parts of the body. No ordinary primary lesion can be discovered.

Squalor (skwol'-or, or skme'-lor) [L.]. Filth. Disorder and uncleanliness.

Squama (skwa'-mah) [L.: pl., Squama]. Scale; a dry, laminated exfoliation of the epidermis; it is usually the result of an inflammation, but may be due to preternatural dryness of the skin, or follow an acute hyperemia. Scales may be small and branny or very large and thin, and of a silvery-white or yellowish color. S. rhopalaris, the sense-scale, or covering of the rhopal niche in acraspede Medusce.

Squamate (skwa'-mät) [squama, a scale]. Scaly, or scale-like.

Squamation (skwa-ma'-shun) [squama, a scale]. The state of being squamate.

Squame (skwām) [squama, a scale]. In biology, a scale.

Squamella (skwa-mel'-ah) [L., dim. of squama]. A very small scale.

Squamellate (skwa-mel'-ät) [squama, scale]. Same as Squamulate.

Squamelliferous (skwa-mel-if'-er-us) [squama, scale; ferre, to bear]. Furnished with squamellæ.

Squamiferous (skwa-mif'-er-us) [squama, scale; ferre, to bear]. Provided with squamæ.

Squamiflorous (skwa-mif-lōr'-us) [squama, scale; flos, flower]. Having flowers like scales.
Squamiform (skwa'-mif-orm) [squama, scale; forma, form]. Squamate.

Squamigerous (skwa-mij'-er-us). Same as Squamiferous.

Squamo-cellular (skwa-mo-sel'-u-lar) [squama, scale ; cellula, a small cell]. Flat-celled.

Squamoid (skwa'-moid) [squama, scale; cidos, like]. Resembling a squama.

Squamomastoid (skwa-mo-mas'-toid) [squama, scale ; mastoid]. Pertaining to the squamous and mastoid portions of the temporal bone.

Squamoparietal (skwa-mo-par-i'-et-al) [squama, scale ; paries, wall]. Pertaining to the squamosal and parietal bones.

Squamopetrosal (skwa-mo-pe-tro'zal) [squama, scale; $\pi \varepsilon \tau \rho a ́$, rock]. Pertaining to the squamous and petrous portions of the temporal bone.

Squamosal (skwa-mio'-zal). See Squamous.

Squamose (skwa'-mōz) [squama, scale]. Scaly.

Squamosphenoid (skwa-mo-sfe'-noid) [squama, scale ; sphenoid]. Pertaining to the squamous portion of the temporal bone and to the sphenoid bone.

Squamotemporal (skwa-mo-tem'-po-ral) [squama, scale; temporal]. Squamosal.

Squamotympanic (skwa-mo-tim-pan'-ik) [squama, scale; tympanic]. Pertaining to the squamosal and tympanic bones.

Squamous (skwa'-mus) [squamosus, scaly]. Scaly. Characterized by thickened laminæ of morbid cuticle. A term applied to an order of cutaneous diseases distinguished by desquamation. It is applied also to certain parts of bones having a scale-like appearance. S. Suture, the suture between the squamous portion of the temporal bone and the frontal and parietal bones.

Squamozygomatic (skwa-1no-zi-go-1nat'-ik) [squama, scale; zygomatic]. Pertaining to the squamous and zygomatic portions of the temporal bone.

Squamula (skwa'-mu-lah) [L.]. A minute scale.

Squamulate (skwa'-mu-lāt) [squamula, a little scale]. Having little scales.

Squamule (skwa'-mūl) [squamula, a little scale]. A squamula.

Squamuliform (skwa'-mu-lif-orm) [squamula, a little scale; forma, form ]. Having the form of a squamula.

Squamulose (skwa'-mu-loz) [squamula, a small scale]. Covered with minute scales.

Square Cap. A variety of provisional head-dressing. A handkerchief is folded so that the edge of one side is three inches in advance of that of the other. The long side is placed next to the head, allowing it to hang down some distance in front of the face. The ends of the short side are drawn down and tied under the chin; then the ends of the long side are drawn downward and forward, folded back, and tied behind over the back of the neck.

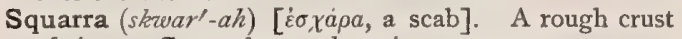
of tinea. S. tondens, alopecia areata.

Squarrose (skwar'-oz) [squarrosus, scurfy, scaly]. In biology, applied to stems or other organs that are roughened with closely arranged bracts or other spreading processes.

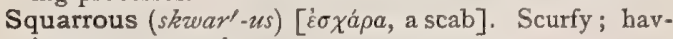
ing crusts or scabs.

Squaw-root. See Caulophyllum.

Squibb's Diarrhea-mixture. See Opii, Tinct., Comp.

Squill (skzvil). See Scilla.

Squinancy (skwin'-an-se). See Quinsy.

Squint (skwint) [origin obscure]. See Strabismus. S.-hook, a hook for picking up the tendon in an operation for strabismus.

Squirrhus (skwir'-us). See Scirrhus.

Squirting Cucumber. See Elaterium. 
Srint [Hungarian]. A disease characterized by inflammatory swellings in the mouth, throat, or anus. It is endemic in Hungary.

Stab-culture, a culture in which the inoculating point is thrust into a tube of agar, or other suitable solid culturematerial; it is used for the propagation of anaêrobic schizomycetes; it is also called Stichcultur. Stickculture or Thrust-culture.

Stabile (sta'-bil) [stabilis]. Not moving; permanent; in electrotherapeutics, opposed to Iabile, the electrode being held continually upon one point.

Stable-fly $\left(s t a^{\prime} \cdot b l-f i\right)$. See Stomoxys calcitrans in Parasites (Animal), Table of.

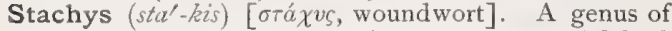
labiate plants, including motherwort, a perennial herb growing in Europe, Asia, and North America. It is said to possess tonic and diuretic properties, and to be a vascular stimulant. S. palustris. Hedge-nettle; it grows in marshy places in Europe and North America.

Stachytarpha, Stachytarpheta (stak-it-ar'-fah, stak-

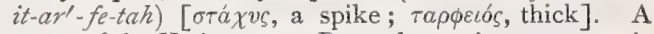
genus of the Verbenacece. Bastard vervain; an aromatic shrub growing in the West Indies and South America. The leaves and root are said to be tonic, stimulant, diuretic, and anthelmintic. The leaves are known as Brazilian tea, and in Europe are used to adulterate tea.

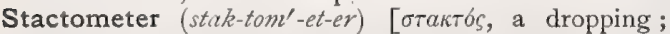
$\mu \varepsilon ́ \tau \rho o \nu, a$ measure]. An instrument for measuring drops.

Stadium $\left(s t a^{\prime}-d e-u m\right)$ [L.]. Stage or period. S. acmes, the height of a disease; crisis. S. augmenti, the period in which there is increase in the intensity of the disease. S. caloris, the period during which there is fever; the hot stage. S. contagii, the prodromal stage of an infectious disease. S. convalescentix, the period of recovery from disease. $\mathbf{S}$. decrementi, defervescence of a febrile disease ; the period in which there is a decrease in the severity of the disease. S. decrustationis, the stage of an exanthematous disease in which the lesions form crusts. $\mathbf{S}$. desquamationis, the period of desquamation in an exanthematous fever. S. eruptionis, that period of an exanthematous fever in which the exanthem appears. S. exsiccationis. See $S$, decrustationis. S. florescentia, the stage in an eruptive fever in which the exanthem develops. S. incubationis. See Stage, Latent. S. maniacale, the last stage of excitement in mania, after which the nervous manifestations gradually subside. S. nervosum, the paroxysmal stage of a disease. S. prodromorum, in eruptive fevers, the stage prior to the appearance of the eruption. $\mathbf{S}$. staseos. See $S$ acmes. S. suppurationis, the period in the course of variola in which suppuration occurs. S. ultimum, the final stage of a febrile affection.

Staff (staf) [ME., staff, staff]. An instrument used in lithotomy for passing into the bladder through the urethra. S.-tree. See Celastrus.

Staffordshire Knot. See Knot.

Stage $(s t \bar{a} j)$ [ME., stage, stage]. I. A definite period of a disease characterized by certain symptoms; a condition in the course of a disease. 2. The horizontal plate projecting from the pillar of a microscope, for supporting the slide or object. S., Algid, a condition characterized by subnormal temperature, feeble, flickering pulse, secondary nervous manifestations, etc. It occurs in cholera and other diseases marked by exhausting intestinal discharges. S., Amphibolic, the stage of a disease intervening between its height and its decline. S., Asphyxial, the preliminary stage of Asiatic cholera, marked by extreme thirst, muscular cramps, etc. , due to loss of water from the blood. S., Cold, the initial stage, rigor or chill of an attack of a malarial paroxysm. S., Expulsive (of labor), the stage which begins when dilatation of the cervix uteri is complete. See Labor. S., First (of labor), that stage in which the molding of the fetal head and the dilatation of the cervix are effected. See Labor. S., Flexion (of labor), the expulsive stage up to the period in which extrusion of the head occurs. S., Hot, the second or pyrexial stage of a malarial paroxysm. S., Infective, that period of an eruptive fever during which it is infectious. S., Initial, the prodromal stage of an eruptive fever. $\mathbf{S}$. of Invasion, the period in the course of a disease in which the system comes under the influence of the morbific agent. $\mathrm{S}$. of Latency, the incubation-period of an infectious disease, or that period intervening between the entrance of the virus and the manifestation of the symptoms to which it gives rise. S., Latent. See $S$. of Latency. S., Placental (of labor), the period occupied by the expulsion of the placenta and fetal membranes. S., Pre-eruptive, the period of an eruptive fever following infection and prior to the appearance of the eruption. S., Pyrogenetic, the stage of invasion in febrile diseases. S., Second (of labor). See S., Expulsive. S., Sweating, the third or terminal stage of a malarial paroxysm. S., Third (of labor). See S., Placental.

Staggers (stag'-erz) [MD., staggeren, to stagger]. One of the various forms of functional and organic disease of the brain and spinal cord in domestic animals, especially horses and cattle. Enzoötic cerebritis of horses, sheep, etc., blind-staggers, louping-ill, gid, sturdy, turnside, stavers. See Conurus cerebralis, under Parasites (Animal), Table of. See, also, Loco and Grass-staggers. S., Blind, staggers due to cerebral disease. S.-bush, Andromeda mariana; a plant allied to the mountain laurel, growing in the seaboard States of North America. S.-Grass, Loco, or Loco Disease, q. $v$., produced by eating various so-called loco-weeds, e. g., Amaryllis atamasco, Astragalus mollio-sinus, A. hornii, Oxytropis lamberti, etc. S., Mad, S., Sleepy, staggers due to inflammation of the cerebral envelops. S., Stomach, staggers due to cerebral disturbance dependent on gastric disorder.

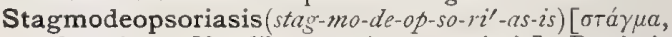

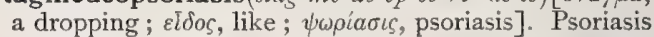
in which the lesions "look like drops of mortar on the skin ;" psoriasis guttata.

Stagnation (stag-na'-shun) [stagnare, to settle]. A cessation of motion. In pathology, a cessation of motion in any fluid; stasis.

Stahl's Ear. See Ear, Deformities of. S.'s Theory. See Animism.

Stain $(s t a \bar{n} n)$ [by apheresis from distain, dis, priv.; tingere, to color]. I. A discoloration. 2. A pigment employed in microscopy to render visible minute and transparent elements or to produce certain microchemic reactions. See Nuclear Stain, Plasmatic Stain, Specific Stain, also Stains, Table of, page $\mathbf{1} 367$.

Stainable $\left(s t a^{\prime}-n a-b l\right)$ [ME., steinen, to stain]. Capable of being stained.

"Stairs" Sign. A sign in locomotor ataxy, consisting in a difficulty in descending stairs. It is an early symptom of the disease.

Staircase $\left(s t \bar{a} r^{\prime}-k \bar{a} s\right)$ [ME., staire, stair; case]. A continuous series of responses to nerve-stimuli, varying from a minimal intensity to a maximum intensity. (Romanes.) See Summation.

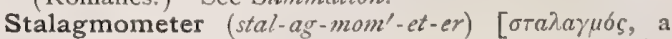

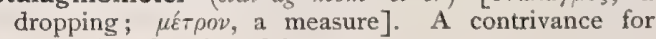
measuring the size of drops. 


\section{TABLE OF STAINS,}

\section{FLUIDS FOR FIXING AND HARDENING, MEDIA FOR EXAMINATION AND PRESERVA- TION, ETC., AND METHODS EMPLOYED IN BIOLOGIC INVESTIGATION.}

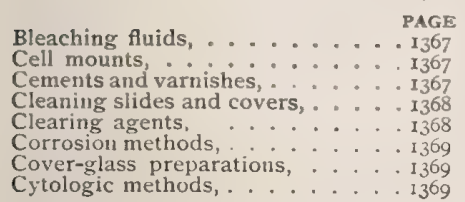

\section{INDEX.}

Decalcifying fluids,

Decolorizing, etc., solutions,

Dissociating fluids,

Embedding,

Embryologic methods,

Examination of blood,

Examination and preservation media,.

\section{PAGE
1371
1372
1372
1373
1375
1376}

\begin{tabular}{|c|c|}
\hline $\begin{array}{l}\text { Fixatives, } \\
\text { Fixing and hardening fluids, } \\
\text { Injection masses, } \\
\text { Staining of con and other tissues, } \\
\text { Staining of microörganisms, } \\
\text { Staining of nerve-tissues, . . } \\
\text { Staining reagents, . . . . } \\
\text { Zoölogic methods, . . . . }\end{array}$ & 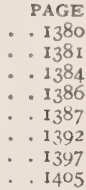 \\
\hline
\end{tabular}

\section{BLEACHING FLUIDS.}

These are used to dissolve and decolorize organic pigments in tissues containing them, and to overcome the staining of objects treated with osmic acid. Chloroform, combined with nitric acid, will clear strongly pigmented chitin. Grenacher's Mixture. For the eyes of Arthropods and other animals. Mix I part of glycerin with 2 parts of 80 per cent. alcohol, and add 2 or 3 drops of hydrochloric acid. This fluid dissolves pigment, while at the same time a stain is formed which, in the course of from 12 to 24 hours, colors the nuclei. The object may be previously stained with borax-carmin. The carmin does not wash out as rapidly as the pigment, but the decolorization must be watched. Hydrogen Dioxid (Hydrogen Peroxid, Oxygenated Water $)$. The sections, fastened on slides, are placed in a Io-volume, or 2 per cent. solution. The melanin is reduced to a paleyellow color in from 6 to 48 hours, according to the amount of pigment present and the light to which the specimen is exposed (strong sunlight materially hastens the process). If the treatment is continued longer the coloring-matter can be entirely removed, and by watching the process a little carefully the decolorization can be stopped at any point before absolute removal. Practically it has been found to be of advantage to leave sufficient color to mark the position of the pigment-cells. The liquid does no appreciable injury to the structural elements. See also Pouchet's Mixture. Javelle Water. See Corrosion-fluids, Eau de Javelle. Labarraque's Solution. See Corrosion-fuids, Eau de Labarraque. Mayer's Chlorin-solution. To remove the staining that occurs as a result of treatment with osmic acid. The specimen is put in from 70 to 90 per cent. alcohol; the bottom of the vessel is then covered with crystals of potassium chlorate, and a few drops of strong hydrochloric acid are added by means of a pipet. The appearance of a green color indicates the evolution of chlorin, which should be diffused through the alcohol by shaking the vessel. Objects are bleached in half a day. Nitric acid may be used instead of hydrochloric, in which case the bleaching agent is the freed oxygen. Marsh generates chlorin in a small bottle, and conveys it by means of glass tubing to the bottom of a bottle containing the sections in water. Pouchet's Mixture. Treat the tissue with glycerin to which hydrogen dioxid has been added -5 or 6 drops to from 5 to Io c. c. of glycerin. Osmium preparations may be bleached in this mixture. The same author recommends creasote as a solvent and decolorizer for granular animal pigments. Sargent's Chlorin-solution. For bleaching insects, and suitable only for the preparation of the hard parts. The solution consists of 2 grams of potassium chlorate, ro drops of hydrochloric acid, and water, 30 c.c. Soak the objects for two days and then wash thoroughly.

\section{CELL-MOUNTS.}

Balsam-paraffin for Cells (Julien). This substance consists of paraffin saturated with balsam-cement, and is prepared as follows: Reduce commercial Canada balsam to a wax-like consistence by slow evaporation in a shallow tin pan over a low flame. Test by cooling a few drops from time to time. Melt slowly a quarter of a pound of paraffin, with a melting-point above $45^{\circ}$ C. (II $3^{\circ} \mathrm{F}$.), add a lump of the balsamcement about the size of a marble, and then digest at gentle heat, stirring frequently, for about an hour. The appearance of a slight, yellow tinge indicates the saturation of the paraffin by the balsam. When it is desired to prepare a cell, the balsam-paraffin is cautiously heated to the melting-point in a shallow porcelain capsule. These paraffin cells are suitable for dry or liquid mounts, excepting for the latter when Canada balsam, dammar, or oils are used as preservatives. The great advantage of the balsam-paraffin is its chemic indifference to the reagents employed in the preservation-media. Paper-cell Method (Lee). By means of a punch cut out a ring of paper, one $\mathrm{mm}$. in breadth and about one $\mathrm{mm}$. smaller in diameter than the cover-glass. Moisten this paper circlet with the mounting-fluid and center it on the slide. Fill the cell thus formed with the mountingfluid; place the object in it; put on the cover; fill the annular space between the paper and the margin of the cover with glycerin-jelly, and as soon as this has set turn a ring of Bell's cement on it. For Mountingmedia. See under Mounting.

\section{CEMENTS AND VARNISHES.}

These substances are chiefly used for sealing fluid mounts, to prevent the admission of air and evaporation of the liquid. Before applying a cement, all fluid mounts should be ringed with glycerin-jelly, to avert "running in." Amber Varnish. Fuse 6 lbs. of clear, pale amber, add 2 gallons of hot clarified linseed-oil, boil until the mixture "strings," and when partially cooled add about 4 gallons of turpentine. Behrens recommends this cement for its extreme tenacity. Apáthy's Cement. Heat together, in a porcelain capsule, equal parts of hard paraffin $\left(60^{\circ} \mathrm{C}\right.$. meltingpoint) and Canada balsam, until the mixture assumes a golden tint and no longer emits vapors of turpentine. On cooling, this forms a firm mass, which for use is warmed, and applied with a glass rod. This cement is suitable for closing glycerin mounts. Asphalt Varnish. This is one of the best media, used either as a cement or as a varnish. Kitton advises asphalt 
dissolved in benzol and a small quantity of gold size. Bell's Cement. Useful as a cement and varnish. It is soluble in ether and chloroform, and resists the action of cedar-oil. Its composition is unknown. Brunswick or Japan Black. See Pigments, Conspectus of. Equal parts of this substance and gold size, with a little Canada balsam, may be used. It works easily and dries quickly. Colophonium and $\mathbf{W a x}$. To 2 parts of melted wax add, piecemeal, from 7 to 9 parts of colophonium; filter and cool. For use, melt by placing the vessel containing the mass in hot water. This cement is impervious to water, glycerin, and caustic potash. Gold Size. An excellent cement when of good quality. Kitton's White-lead Cement. Rub together thoroughly, with a little turpentine, equal parts of powdered white lead, red lead, and litharge; then mix with gold size. The cement should be thin enough to work with a brush, and must be made as required. Marine Glue. That known in commerce as $\mathrm{G} \mathrm{K}_{4}$ is the best. It is soluble in ether, naphtha, and potassium hydroxid, and is used for securing glass cells to slides. Sealing-wax Varnish. Cover coarsely powdered sealing-wax with alcohol, and digest at a gentle heat. Useful only as a varnish. Shellac Varnish (Beale). Break shellac in small pieces, and shake in a bottle with alcohol until a thick solution is obtained. The addition of 20 drops of castor-oil to the ounce is said to improve this varnish, which is useful chiefly for protecting balsam mounts from the action of cedar-oil. The addition of Venice turpentine renders it less brittle. Stieda's White-zinc Cement. Rub up zinc oxid with turpentine, and for every gram add eight grams of a thick, syrupy solution of dammar in turpentine. This makes a white cement like Ziegler's, the composition of which is unknown. Cinnabar, in place and in double the quantity of the zinc, will give a red cement. Tolu-balsam Cement (Carnoy). A superior cement, consisting of tolu balsam 2 parts, Canada balsam I part, and a saturated solution of shellac in chloroform 2 parts, with the addition of enough chloroform to give the mixture a syrupy consistence. Turpentine (Parker). Dissolve true Venice turpentine in enough alcohol to make a solution that will pass through a filter. After filtering, evaporate about one-fourth of the whole on a sand-bath. Test it by dropping a little in cold water, and if on removing it from the water it is hard and gives a vitreous fracture, evaporation has proceeded far enough. Csoker uses common resinous turpentine, which he melts in small pieces over a waterbath. When cool, the resulting mass should be darkbrown and brittle. This cement is used for closing glycerin mounts, and is applied by means of a wire bent at right angles, the short arm being just the length of the side of the cover-glass, which should be square; the wire is heated in a spirit-lamp, plunged into the cement, and brought down flat on the slide at the margin of the cover. The turpentine distributes itself evenly and hardens immediately. This is a safe and valuable inedium and fixes rapidly.

\section{CLEANING OF SLIDES AND COVERS.}

Strong nitric acid, water, alcohol, and ether are recommended by Behrens, to be used in the order named. James treats slides that have been used with a mixture of equal parts of benzine, turpentine, and alcohol. For slides on which are balsam-mounted objects the balsam should first be removed by xylol, turpentine, or other solvent. Gibbes' (Heneage) Method. Place the covers in concentrated sulphuric acid for an hour or two hours; wash until the drainings give no acid reaction, first with methylated spirit, then with absolute alcohol, and wipe dry with an old silk handkerchief. Potassium Bichromate and Sulphuric Acid. Potassium bichromate 200 grams ; water IOOO c.c.; sulphuric acid I000 c.c. Dissolve the bichromate in the water with the aid of heat. Pour the solution into a bottle that has been warmed and surrounded by a wet towel. Add slowly and at intervals the sulphuric acid. This mixture is corrosive and must be kept in glass vessels. It may be used more than once, but when the color changes markedly from that seen in the first mixture, it should be thrown away. Seiler's Solution. Potassium bichromate $25 \mathrm{gm}$.; sulphuric acid 75 c.c.; water 325 c.c. Place the slides and covers in the solution for a few hours, then rinse well with water, and dry with a soft, linen cloth. Slides and covers that have been used are treated as follows: The covers are put into a mixture of equal parts of alcohol and hydrochloric acid, and in a few days are transferred to the bichromate solution, and treated like new ones. The slides are scraped with a knife, to free them from the mounting-medium, and are then put into the bichromate mixture. Sulphuric and Nitric Acid Mixture. Nitric acid 200 c.c.; sulphuric acid 300 c.c.

\section{CLEARING AGENTS.}

Liquids used to render microscopic preparations transparent, to rid them of alcohol, and to facilitate penetration of the mounting-media. Those chiefly employed are essential oils. Anilin-oil. An important medium, because of its ability to clear watery objects; it will even clear aqueous media without the intervention of alcohol, which sometimes renders it valuable as a penetrating medium prior to paraffin embedding. It is also used for clearing celloidin sections. Bergamot-oil. Clears 95 per cent. alcohol preparations, also celloidin or collodion sections, and does not extract anilin dyes. It is one of the least refractive of the clearing agents. Carbolic Acid. A concentrated solution in alcohol clears instantaneously even very watery preparations. It is a good medium for celloidin sections, but should not be used for soft objects to be mounted in balsam, as they are apt to shrink by osmosis in the latter medium. Gage employs a mixture of melted carbolic acid, $40 \mathrm{c}$. c., and turpentine, 60 c. c. Carbolic Acid and Xylol. A mixture of one part of carbolic acid and three parts of xylol is used to clarify celloidin sections, which may be taken from 70 per cent. alcohol, and do not require further dehydration. A layer of previously heated copper sulphate in the bottom of the bottle will keep the mixture free from water. Cedar-oil. This agent clears readily tissues in 95 per cent. alcohol, and does not extract anilin colors. Five or six hours are required to clear celloidin sections. When of good quality the oil has a light-yellow color. Chloroform is deficient in penetrating power, and requires a long time to clear an object of any size. It may be used for celloidin and paraffin sections. Clove-oil. New oil is pale; the tint deepens with age. Long immersion in this medium renders tissues brittle, sometimes an advantage in making minute dissections, as is also its tendency to form very convex drops. If desired, these properties may be counteracted by mixing it with bergamot-oil. As this oil is a solvent of celloidin, it cannot be used for clearing celloidin sections. New oil extracts anilin colors more rapidly than old. This agent has the highest index of refraction of all the usual clearing agents, and is one of the most important. Creasote. The properties of this agent are similar to those of carbolic acid. Beechwood creasote is a good clearing medium for celloidin sections. Lavender-oil has 
the same properties and is used in the same way as clove-oil. Naphtha clears paraffin or celioidin sections, but is too volatile for a general clearing agent. Oil of Origanum. Ninety-five per cent. alcohol preparations are quickly cleared, also celloidin sections. For the latter, Oleum origani cretici should be used. Anilin colors are somewhat extracted by this agent. Sandal-wood Oil. Ninety-five per cent. alcohol preparations are cleared rapidly, celloidin sections more slowly, by this agent. Anilin colors are not affected by it. Toluol clears paraffin and celloidin sections, and is sometimes used as a penetrationfluid before the paraffin bath. Turpentine. This agent has a low index of refraction, and, used for al cohol objects, causes contraction and alters the struc ture of cells. It is much used for paraffin sections, as it possesses the property of dissolving the paraffin and clearing the section at the same time. Xylol is used for paraffin and celloidin sections. It causes shrinkage if the sections are not thoroughly dehydrated.

\section{CORROSION-METHODS.}

Boiling or prolonged soaking in strong solution of Caustic Soda will remove the soft parts from skeletal structures. Caustic potash may be used in the same way. Eau de Javelle (Potassizem Hypochlorite). Rub up $20 \mathrm{gm}$. of chlorinated lime in $100 \mathrm{c.c}$. of distilled water; dissolve $20 \mathrm{gm}$. of potassium carbonate in $\mathbf{1 0 0}$ c.c. of distilled water; mix, and after one hour filter. This solution is particularly recommended for preparing the skeleton of siliceous sponges and that of similar structures. In the study of the iris, choroid, and other pigmented organs, Altmann recommends Javelle water. Fat, especially when previously treated with osmic acid, resists the action of this fluid. The tissue impregnated with fat is hardened in osmic acid, and treated with Javelle water, which destroys everything but the fat, which remains as an osmium-stained mold of the tissue-spaces. Eau de Labarraque. (Sodium Hypochlorite). Twenty grams of chlorinated lime are rubbed up in 100 c.c. of distilled water and mixed with $40 \mathrm{gm}$. of crystallized sodium carbonate dissolved in the same quantity of water. Let the mixture stand for an hour, and filter. This is used in the same way as Javelle water. With the aid of heat, chitin is dissolved in either of the solutions in a short time (Loos). Chitinous structures, macerated for 24 hours or more in these solutions diluted with 4 to 6 volumes of water, become soft and transparent, and permeable to staining fluids, aqueous or alcoholic. This method is especially applicable to Nematoda and their ova. Hyrtl's Corrosion-method. Commercial mastic varnish is gradually evaporated over a spirit-lamp, or by other means, until it is of such a hardness that it cannot be indented with the finger, and with difficulty with the finger nail. The varnish should never be heated to boiling. By means of a glass rod, allow a drop of hot varnish to fall in cold water; if this cannot be flattened out between the fingers when cold, and only with difficulty after warming in the palm of the hand or on the tongue, it is sufficiently evaporated. To six parts of hardened varnish add one part of white beeswax. To color the injection-mass, five colors are recommended: For red mass, cinnabar; for blue, cobalt or ultramarine; for yellow, light or dark chrome-yellow; for green, emerald green; for white, carbonate of lead. The latter holds more poorly than the others, becoming somewhat brownish after heating. To 24 ounces of the mass, add from 16 to 20 drams of the color: a little more than this for the blue and green. The colors should be rubbed up evenly in a mortar, with enough of the fluid varnish to give a syrupy consistency, and this mixture poured slowly into the heated mass, while constantly stirring with a small wooden spatula. The mass is warmed, preparatory to injection, over an ordinary spirit-lamp, to a temperature just short of boiling, and should be constantly stirred. The method of injecting the varnish mass differs in no way from that of ordinary jnjections. For corroding away the fleshy parenchyma, concentrated hydrochloric acid is used. The organ is placed in a glass jar, of a depth at least two inches greater than the diameter of the organ. It is first rinsed with cold water, and then the cold acid poured over it in sufficient quantity to float it. The greater the amount of acid, the quicker the corrosion. From two to ten days will be required for corrosion, according to the size and density of the organ. A fine spray or jet of water is then played upon the organ, and the corroded flesh carefully washed away. The preparation is then laid for two or three hours in clean water and then dried and mounted. Noll's Method: Place a piece of sponge on a slide, and treat it with a few drops of eau de Javelle; the soft parts will dissolve in 20 to 30 minutes ; remove any precipitates by cautious treatment with acetic acid, wash several times in alcohol, treat with oil of cloves, and mount in balsam. In Wood's Metal Corrosion Method, the organ to be injected is placed in water of a temperature to keep the metal used in a fluid condition, and the liquid metal is injected by ordinary methods. The injected organ is then placed in cold, running water until the flesh has macerated away, when the cast is cleaned with a brush.

\section{COVER-GLASS PREPARATIONS.}

Such preparations are usually made in examining blood, sputum, or other fluid or semi-fluid substance. In the case of sputum a tiny mass is placed on a cover-glass, another is pressed gently down upon this, and the two glasses are separated by sliding one over the other, the object being to secure a thin, even film on each glass. The film may also be spread with the edge of a coverglass or with a platinum spatula. The preparations are then left to dry in air, or they may be dried by exposing them to a temperature of $120^{\circ}$ for twenty minutes, or by passing them quickly thrice through the flame of a spirit-lamp or Bunsen burner. When dry, they are ready to stain. To obtain a cover-glass preparation of blood, cleanse the finger, prick the pad, wipe off the first drop of blood that exudes, touch the apex of the second drop with a cover-glass, spread in the manner described, and dry in air.

\section{CYTOLOGIC METHODS.}

Cell-structure may be studied in living cells, in fresh, unhardened cells, and in hardened tissue in sections. Accessory Nuclei. Fix the tissue in Flemming's solution for I hour, then place it for 24 hours in Flemming's fluid diluted 3 or 4 times; wash thoroughly, harden in alcohols of increasing strength. Stain for 24 hours with hematoxylin according to Apáthy's modification of Heidenhain's method; keep in the dark. Decolorize in a I per cent. alcoholic solution of potassium bichromate prepared just before using (by mixing 70 c. c. of strong alcohol with 30 c.c. of a stock solution of potassium bichromate 10 parts, distilled water 300 parts). The decolorizing mixture should be put in a dark-colored glass bottle, and the tissue left in for from I 2 to 24 hours, according as a light or dark stain is desired. Pass into yo per cent. alcohol-also in a dark bottle, and after one or more days dehydrate in abso- 
lute alcohol. Infiltrate with thick cedar-oil, embed in paraffin which is overheated, and section. (Gustav Platner, Arch. f. mikr. Anat., 1889, Bd. 33, Heft I.) Achromatin and Plasma Stains. Foremost among these is the Ehrlich-Biondi fluid, which is used by Heidenhain as follows: Dilute 6 parts of the staining fluid with 400 parts of water. Fill two beakers with distilled water, and add to each a few drops of the diluted staining solution. To one beaker add, with continual agitation, drop by drop, a I : 500 solution of acetic acid, until a crimson color appears. The contents of the two beakers are to serve as controls. The dilute solution first prepared is now acidified with dilute acetic acid, added drop by drop, with continual agitation, and from time to time a few drops are added to a beaker of distilled water, until a crimson tint is obtained corresponding to that of the test-beaker, when the staining bath is ready. Treat sections for two hours with 0 . I per cent. acetic acid, then for Io to $\mathbf{I} 5$ minutes with official tincture of iodin, rinse in alcohol, and place in the stain for from 12 to 18 hours. Altmann's Granules, Almann's (R.) Method. The tissue is fixed in osmic acid and stained with cyanin. The granules then appear in chains of a violet color The substance between the granules stains readily with hematoxylin or carmin, but not with cyanin, and vice versâ. ("Die Structur des Zellkernes;" Arch. v. Du B. Reymond, Anat. Abth., I889.) Chromatin Stains. Of these the foremost in importance, for fresh tissues, is methyl-green, which may be used alone or in the Ehrlich-Biondi mixture (see Staining Reagents) ; also Bismarck-brown in dilute glycerin, or in aqueous solution with acetic acid. For osmium objects, Mayer's hemalum. For sections of hardened tissues, Böhmer's hematoxylin, the finer hematein stains, safranin, gentian-violet, Victoria-blue, and other anilins, used according to the indirect method. Babes stains in safranin, as follows: A supersaturated solution of safranin in water is warmed to $60^{\circ} \mathrm{C}$, and filtered warm. On cooling it becomes turbid through the formation of small crystals. Place the sections in a watch-glassful of this turbid solution, and warm for a few seconds (until the liquid clears); after one minute wash in water and treat with alcohol and turpentine in the usual way. Do not clear in clove-oil. Ehrlich's Granules and Granular Cells (Mastzellen). See Staining of the Blood. Fresh Cells. Tease out a piece of living tissue in a drop of a solution of methyl-green containing 0.75 per cent. of acetic acid; then expose for 15 minutes to vapor of osmic acid, by inverting the slide over the mouth of a bottle containing a small quantity of a one per cent. solution; remove when the cells are brown; add a drop of solution of Ripart and Petit, and cover. Scrapings from the freshly-cut surface of a recently excised liver or lymphatic gland, having been treated with I to 2 per cent. acetic acid, may be stained with fuchsin added in sufficient quantity to a 2 per cent. acetic acid to saturate it. This renders the nuclei visible ( $\mathrm{v}$. Kahlden). Segmenting ova of Echinodermata may be stained on the slide by placing a drop of safranin at the edge of the cover-glass. When the ova are dark, the excess of stain is removed by means of bibulous paper, and one per cent. acetic acid is allowed to flow under the cover. Karyokinesis. I. Place small pieces of tissue hardened in strong Flemming's solution in an alcoholic solution of safranin ( $2 \mathrm{gm}$. to $60 \mathrm{c} . \mathrm{c}$.) for from 24 to 48 hours. Wash for a few minutes in water, and carry to acidulated absolute alcohol (Io drops of acetic acid to $I 00$ c.c.) for from $x / 2$ to I minute. When thick clouds of color are no longer given off, carry to absolute alcohol. After $\mathrm{I}$ or 2 minutes, clear and mount. 2. Baumgarten's Method. This method may be em- ployed conjointly with a stain for bacteria. Harden the tissue for several weeks in a dilute solution of chromic acid; stain for from 5 to Io minutes in a concentrated alcoholic solution of fuchsin; rinse quickly in absolute alcohol; stain for from 5 to 10 minutes in an aqueous solution of methylene-blue. In examining for bacteria also, stain first for 24 hours in anilinwater methyl-violet (decolorize with dilute acid if staining for tubercle-bacilli); then follow with fuchsin and methylene-blue, as indicated. 3. Benda's Method. Fix in Flemming's fluid, imbed in paraffin, and stain the sections as follows: Place for 24 hours in a concentrated solution of neutral copper acetate, kept at a temperature of $40^{\circ} \mathrm{C}$. Wash well with water, and stain to a dark-gray tint in aqueous hematoxylin solution. Decolorize in 0.2 per cent. hydrochloric acid, until of a light-yellow, and then neutralize the acid by returning the sections to the copper solution, in which they should remain until they acquire a grayish-blue tint. Wash, dehydrate, and mount in balsam. 4. Bizzozero-Vassale Method. Fix in absolute alcohol. Stain Io minutes in Ehrlich's gentian-violet solution; wash quickly in absolute alcohol; transfer to Gram's solution for two minutes, then pass into absolute alcohol for 30 seconds ; O. I per cent. chromic acid, 30 to 40 seconds; absolute alcohol, 20 to 30 seconds; 0.1 per cent. chromic acid, 30 seconds; absolute alcohol, 30 seconds; oil of cloves; renew the last until no more color is given off. Treat with xylol, and mount in xylol-balsam. 5. Gram's Method. This is the same as for bacteria. The resting nuclei are either wholly or partially decolorized, while the dividing nuclei retain the dye. 6. Mitosis in the Ammion. Kill the pregnant animal, and place the uterus in a saturated watery solution of picric acid, opening the organ and the membranes under the fluid. Harden for 24 hours, wash in alcohol, and harden in alcohols, beginning with 70 per cent. Tinge a small part of the membrane in Ehrlich's acid hematoxylin diluted one-half. 7. Mitosis in Licberkühn's Glands. Harden a section of small intestine in mercuric chlorid, and stain with acid fuchsin and methyl-green. The resting nuclei will be blue and those in active mitosis green. 8. Mitosis in the Vermiform Appendix. Fix in Flemming's solution, Fol's solution, or absolute alcohol ; stain 5 to $10 \mathrm{~min}$ utes in the following mixture: gentian-violet, I gm.; absolute alcohol, I 5 c.c. ; anilin-oil, 3 c.c. ; water, 80 c.c. Wash in absolute alcohol; immerse 30 to 40 seconds in I per cent. chromic acid, then for the same length of time in absolute alcohol; repeat the chromic acid and absolute alcohol to remove all excess of dye; clear, and mount in balsam. Living Cells. Young larvæ of Amphibia are the best objects for the study of cells intra vitam. Place the larvæ of Salamandra in a watch-glassful of water containing 5 to 10 drops of a solution of $I$ part curare in roo parts each of water and glycerin. Half to one hour's immersion is required for curarization. It is not necessary to wait until the larvæ are motionless; they may be removed as soon as their movements have become slow. The gills and the caudal "fin " may then be studied. The tail may be excised from the living animal and studied for some time in one per cent. salt-solution or other indifferent medium. The adult animal offers for study the thin, transparent bladder. Larvæ may be bred from adults, if well fed with aquatic worms, and supplied with a vessel of water. The larvæ will be deposited in the water. The cytoplasm of living cells may be stained with methylene-blue, dahlia, or gentian-violet, dissolved in water or in an indifferent liquid. Microchemic Reactions. I. Chromatin is distinguished from lecithins and albuminoids by treating fresh cells 
with 0.1 per cent. hydrochloric acid, in which it is insoluble; the lecithins and albuminoids are dissolved out. Methyl-green is a test for chromatin, as it stains nothing else in the nucleus. 2. Glycogen in Leukocytes. Treat with I per cent. solution of iodin, containing $2 \mathrm{gm}$. of potassium iodid, a preparation of frogs' blood. The white corpuscles are killed, and many stained yellow. In some of them mahogany-colored granules of stained glycogen are seen. 3. Glycogen in Livercells. Harden the liver of a well-fed frog in osmic acid, make a thin section and wash it with iodin, and the granules of glycogen in the hepatic protoplasm will be colored brown. 4. Tizzoni's Reaction for Iron. Harden the spleen, kidney, or liver of a young animal in alcohol. Place the sections in a freshly prepared solution of 3 c.c. of $\mathbf{I}: \mathbf{I} 2$ potassium ferricyanid, 90 c.c of water, and 1. 5 c. c. of 25 per cent. hydrochloric acid. Particles of free iron are colored blue. Spermatologic Methods. Tease fresh material on a slide, fix with a strong solution of potassium permanganate, and stain with gentian-violet or dahlia. For aqueous mounts, use Ripart and Petit's solution or one of Pacini's mercurial fluids. Sections of the hemaphrodite gland of Lamellibranchiata may be stained for from 2 to 3 hours in a mixture of equal parts of a concentrated alcoholic solution of methyl-green and safranin diluted with 8 volumes of water; wash out in alcohol 5 to 10 minutes, and mount in balsam. Nuclei of ova are red; heads of spermatozoa, bluish-green. Watase's Method for Differentiating Sexual Cells. The sexual cells are fixed in Auerbach's fluid or simply in a saturated aqueous solution of sublimate, and the pieces embedded in paraffin. The sections are fixed to the slide with dilute alcohol or distilled water. Saturated solution of anilin-oil in water is added to alcohol until the latter is 20 per cent. in strength; with this menstruum one per cent. solution of cyanin $\beta \beta$ is made for a blue stain; and the same strength solution of chromotrop RR for a red stain; or for a more powerful red stain, use erythrosin in one per cent. solution. For contrast-staining it is immaterial which solution, cyanin or chromotrop, is used first; erythrosin must be used before the blue stain. Stain quickly, and wash in 50 per cent. alcohol. The nucleus of the ovum becomes red, while that of the spermatozoön becomes blue, showing the former to be erythrophilous, the latter cyanophilous.

\section{DECALCIFYING FLUIDS}

These fluids usually consist of an acid, combined with a hardening agent, to prevent swelling of the tissue. The specimen should be previously fixed by any of the usual methods, tested from time to time with a needle or razor, and when the process of decalcification is complete should be washed in water and placed in 67 per cent. alcohol, gradually increasing the strength to 82 per cent. Bayerls' Fluid. Chromic acid, I part; hydrochloric acid, I part; water, Ioo parts. Von Ebner's Fluid prevents swelling of the tissue. It has the following composition: Hydrochloric acid, 2.5 c.c., alcohol, 500 c.c., distilled water, 100 c.c., sodium chlorid, 2.5 grams. Use a large volume of the fluid and renew it frequently. If it be desired to examine the fibrillar structure of bone, mount the sections in Io per cent. sodium chlorid solution; otherwise the ordinary mounting-media may be employed. Fol's Fluid. Nitric acid, 3 c.c., one per cent. chromic acid, 70 c.c., water, IOO c.c. Let the tissues remain in this fluid for two weeks, renewing it every other day. Wash thoroughly and preserve in go per cent. alcohol. Gage's Fluid. This agent answers well for the preparation of small salamanders, etc., for sectioning. It consists of 67 per cent, alcohol, 100 c.c., and pure nitric acid, 3 c.c. More rapid in action, and recommended for the decalcification of teeth, is a fluid composed of nitric acid, 5 c.c., saturated aqueous solution of alum, IOO c.c., and water, Ioo c.c. It should be renewed every two days. Haug's Phloroglucin Fluid. One of the most rapid decalcifying agents, and without injurious action on the tissue-elements, with the exception of blood It is prepared as follows: Warm slowly and care fully one gram of phloroglucin in ro c.c. of pure nitric acid, and to the resulting ruby-colored solution add $50 \mathrm{c.c}$. of distilled water. If a larger quantity is desired, add nitric acid and water to the fore going proportion until the volume measures $300 \mathrm{c} . \mathrm{c}$, the limit of the protective influence of the phloroglucin. Previously to being brought into this fluid, the tissues should be well fixed. Fetal bones and those of lower vertebrates are decalcified in half an hour. Older and harder bones require several hours. When decalcification is completed, wash in running water for two days. The sections stain well. Another fornula, useful for teeth when rapid action is not necessary, consists of phloroglucin, I gram, nitric acid, 5 c.c., 95 per cent. alcohol, 70 c.c., distilled water, 30 c.c. The function of the phloroglucin is to protect the organic tissue-elements against the action of the acid. Hydrochloric Acid. A rapid decalcifying agent, usually employed in combination with chromic acid or alcohol. A Io per cent. solution of sodium chlorid in 3 per cent. hydrochloric acid is recommended. Hydrochloric acid and glycerin, 5 c.c. of the acid to 95 c.c. of the glycerin, constitute a good mixture for softening teeth. Mayer's Desilicification Method. A process for removing siliceous parts from sponges, etc. Place the object in alcohol in a vessel of guttapercha or glass coated internally with paraffin. $\mathrm{Hy}$ drofluoric acid is then added, drop by drop, care being taken to avoid the fumes, which attack mucous membranes with great energy. Contact with the acid causes wounds that heal with difficulty. Small pieces of sponge are freed from silica in a few hours or a day, and the tissues do not suffer. (A dangerous method.) Nitric Acid. An efficacious agent, which causes no swelling, and does not attack the tissue-elements. One per cent. and ro per cent. solutions are used, the latter for large, hard bones, the former for young bones. The specimens should previously have been fixed in absolute alcohol, and the decalcifying fluid changed daily. They must be removed as soon as decalcification is complete, or they will become discolored. They are then washed in running water for two hours, and preserved in alcohol, which should be renewed in a few days. Pereny's Fluid, is recommended for rapid action and preservation of the tissue-elements. It is composed of Io per cent. nitric acid, 4 parts, absolute alcohol and one-half per cent. chromic acid, each, 3 parts. Phosphoric Acid. A IO to I5 per cent. solution is recommended for young bones. Picric Acid. A saturated watery solution is employed, to which a few crystals of the acid are added to keep it saturated. The tissue is suspended in the fluid, and when soft is washed and preserved in alcohol. Young bone is usually decalcified in a fortnight. Thoma's Fluid. This consists of 95 per cent. alcohol and pure nitric acid, in the proportion of one c.c. of the latter to 25 c.c. of the former. Fix the tissue in 95 per cent. alcohol; then place it for several days in the decalcifying fluid, shaking and renewing it frequently. When this bas been done, wash in alcohol, and place it in a jar containing an excess of precipitated calcium carbonate; renew and shake until every trace 
of acid is removed from the tissue. Waldeyer's Chlorpalladium Fluid. Palladium chlorid, one ctg., and hydrochloric acid, I000 c.c. After decalcification, wash the tissue thoroughly in water, and place successively in 30,60 , and 90 per cent, alcohol.

\section{DECOLORIZING, DIFFERENTIATING, AND MORDANTING SOLUTIONS.}

Acid Alcohol. Hydrochloric acid I c.c., absolute alcohol 70 c.c., water 30 c.c. Acidulated Glycerin. See Examination and Preservation Media. Acidulated Water. Distilled water rooo c. c., hydrochloric acid I c.c. Anilin-water (Ehrlich). Shake up 3 c.c. of anilin-oil with 97 c.c. of distilled watex, and filter. The filtrate should be clear. Used as a mordant for anilin dyes. It does not keep well, and should be freshly prepared. Gram's Solution. Iodin I part, potassium iodid 2 parts, distilled water 300 parts. This solution gives a reaction with tissues which have undergone amyloid degeneration. It is much used in the staining of microörganisms by Gram's method. Lithia Water. Saturated aqueous solution of lithium carbonate I c. c., and distilled water 30 c.c., used as an intermediate agent in staining microörganisms. Lœffler's Mordant Solutions. I. Ten c.c. of a 20 per cent. solution of tannin, 5 c. c. of a cold saturated solution of ferrous sulphate, I c.c. of an aqueous or alcoholic solution of fuchsin (or I c.c. of an alcoholic solution of methyl-violet). 2. One per cent. solution of caustic soda. 3. Sulphuric-acid solution of such strength that I c.c. will be completely neutralized by I c.c. of I per cent. caustic-soda solution. Nitric Acid. Pure nitric acid Io c.c., distilled water 30 c.c. Used in the process of staining microörganisms. Pal's Solution. Oxalic acid I gm., potassium sulphate I gm., distilled water 200 c.c. Used in staining nerve-tissues after treatment with potassium permanganate. Potassium Permanganate. In one per cent. solution, used as a mordant for anilin dyes. In onequarter per cent. solution it is used to differentiate tissues after staining with hematoxylin. Sulphanilic and Nitric Acid Solution. Saturated solution of sulphanilic acid 30 c.c., nitric acid (sp. gr. r.42) ro c.c. Used in the process of staining microorganisms. Sulphuric Acid Solutions. (a) Sulphuric acid (sp. gr. I.84) Io c.c., distilled water $3^{\circ}$ c.c. (b) Sulphuric acid (sp. gr. 1.84) Io c.c., alcohol (9o per cent.) 90 c.c. Used in the process of staining microörganisms. Toluidin Water. Toluidin Io c.c., distilled water 90 c.c. Mix, agitate, and filter. Used for the same purpose as anilin-water, and may be substituted for it. Weigert's Differentiating Fluid. Borax 2 gm., potassium ferricyanid $2.5 \mathrm{gm}$., distilled water 200 c.c. Used after Weigert's hematoxylin.

\section{DISSOCIATING FLUIDS.}

These fluids soften and dissolve the interstitial material of tissues, and facilitate the separation of their histologic elements. I. Macerating FLuids. One-third Alcohol. See Fixing Fluids. This is particularly recommended by Ranvier for epithelia. Thin advises one-fourth alcohol for dissociating the retina. Ammonium and Potassium Sulphocyanid. A Io per cent. solution of either of these salts is recommended by Stirling as a dissociating medium for epithelium. Small pieces are macerated for 24 to 48 hours, and may then be stained with eosin, fuchsin, or picrocarmin. The fibers of a crystalline lens dissociated in either of these fluids become beaded or moniliform. Ammonium Chromate. A 5 percent. solution is used for dissociating the "rodded" cells of the renal tubules, cells of the salivary glands, Purkinje's fibers of the heart, etc. It acts in 24 to 36 hours, and the tissues must be well washed for preservation. Artificial Iodized Serum. See Examination and Preser. vation Media. Artificial Saliva. Calberla's formula: potassium chlorid $0.4 \mathrm{gm}$., sodium chlorid 0.3 gm., sodium phosphate and calcium chlorid, each 0.2 gm, in 100 parts of water saturated with carbon dioxid; of this solution one volume is combined with one volume of water and half a volume of Müller's fluid. This mixture is recommended particularly for dissociation of the developing muscle and nerve of Ophidia and Amphibia. The tissue-elements are isolated by teasing and shaking, and the preparation is mounted in concentrated potassium-acetate solution. Baryta Water. A 50 per cent. solution is useful for dissociating white fibrous tissue, $e . g$., tendon. Beale's Fluid. The mucus expressed from the gastric glands $c^{f}$ ihe pig is rapidly dried on glass plates, powdered, and preserved in a stoppered bottle. Dissolve the powder in distilled water or glycerin, and filter the solution. Tissues are digested several hours in this fluid at a temperature of $37^{\circ} \mathrm{C}$. Eight-tenths of a grain of the powder will dissolve Ioo grains of coagulated white of egg. The powder retains its properties for years. Brock's Medium. For the nervous system of Mollusca: equal parts of ro per cent. potassium-bichromate solution and the visceral fluid of the animal. Caustic Potash, Caustic Soda. Strong solutions, 35 to 50 per cent., should be employed; they do not greatly mar the forms of cells, while weak solutions destroy them. The tissue may be treated on the slide. Weak solutions may be employed for dissociating the cells of hair, nails, and epidermis. Professor and Mrs. Gage (Proceedings Am. Soc. Microscopists, 1889) have found that preparations treated with these alkalies can be permanently preserved by displacing the alkali with from 50 per cent. to 60 per cent. of potassium acetate and then mounting in glycerin or glycerin-jelly. Chloral. A mild, macerating medium in 2 to 5 per cent. solution. It preserves delicate elements admirably, and is recommended by Landowsky (Archiv. f. mik. Anat., I876, p. 359) for salivary glands ; by Hickson for the retinæ of Arthropods. Béla Haller's Mixture. One part glacial acetic acid, I part glycerin, 2 parts water. Recommended for the central nervous system of Mollusca. Maceration is complete in 30 to 40 minutes. Hertwig's Liquid, for the nervous system of Meduse. A mixture of equal parts of 0.05 per cent. osmic acid and 0.2 per cent. acetic acid. For Actine 0.04 per cent. osmic acid is used; both the solutions are made in seawater, and the washing out is done in 0.2 per cent. acetic acid. Iodized Serum. See Examination and Preservation Media. It is used in the study of fresh tissue, especially medullated nerve-fiber. A tiny fragment is placed in 4 or 5 c. c. of weak serum in a closed vessel, and allowed to soak for a day or more, fresh iodin being added as often as the serum becomes palc. When sufficiently macerated, the tissue is teased or pressed out and mounted. Landois' Fluid. Dissolve in IOo c.c. of distilled water $5 \mathrm{gm}$. each of neutral ammonium chromate, potassium phosphate, and sodium sulphate. This fluid is especially useful for the central nervous system, and small pieces must lie in it from one to five days. Möbius' Media. I. One part of sea-water and 4 to 6 parts of 0.5 per cent. solution of potassium bichromate. 2. For Lamellibranchiata: one per cent. each of osmic and acetic acids, and 0.25 per cent. of chromic acid dissolved in sea-water. Muiller's Solution. See Fixing Fluids. 
Nitric Acid. Twenty per cent. solution is a useful medium for the maceration of muscle. After 24 hours' treatment, the isolated fibers may generally be obtained by shaking the tissue with water in a test-tube. $\mathrm{Ni}$ tric Acid and Glycerin. A mixture of glycerin 50 c. c., nitric acid I c.c., and water I50 c.c., is recommended for isolating the elements of nerve tissue. Nitric Acid and Potassium Chlorate, Kiihne's Method. Mix in a watch-glass one part of potassium chlorate with four of nitric acid, and in this immerse a fragment of muscle for half an hour, and then shake it with water in a test-tube to separate the fibers. Oxalic Acid. Maceration for several days in a concentrated solution has been found useful in the examination of nerve-endings. Potassium Permanganate. See Fixing Fluids. Salt-solution. A Io per.cent. solution of sodium chlorid is a valuable macerating agent for white fibrous and other tissue. Schiefferdecker's Methyl Mixture. Methyl alcohol 5 c.c., glycerin 50 c.c., distilled water Ioo c.c. Used for dissociating the retina and other nerve-tissues. Macerate the perfectly fresh tissues for several days. Sulphuric Acid. Recommended by Max Schultze for isolating the fibers of the crystalline lens. Macerate for 24 hours in 30 c. c. of water containing 4 to 5 drops of pure sulphuric acid, and then agitate. Very dilute sulphuric acid is stated by Odenius to be the best medium for the examination of nerve-endings in tactile hairs. Hot sulphuric acid is used to dissociate horny epidermic structures-hair, nails, horn. II. DIGESTION Fluids. Bickfalvi's Fluid. One gram of dried gastric mucosa is mixed with 20 c.c. of 0.5 per cent. hydrochloric acid, put into an incubator 3 to 4 hours, and then filtered. The tissue should not remain in the solution for more than a half to one hour. Brücke's Fluid. This consists of glycerinated extract of pigs' stomach I volume, 0.2 per cent. hydrochloric acid 3 volumes, and a few crystals of thymol. Kühne's Fluid. Trypsin is obtained by extracting the pancreas of an ox with ether and alcohol, and evaporating to dryness; one part is then heated for 3 to 4 hours, at a temperature of $40^{\circ} \mathrm{C}$., with 5 to 10 parts of a 0 . I per cent. solution of salicylic acid, the solution pressed through linen, and filtered when cold. Kuskow's Fluid. Pepsin one part, dissolved in 3 per cent. oxalic acid, 200 parts. The solution should be freshly made, and objects macerated in it 10 to 40 minutes at the ordinary temperature. Schiefferdecker's Pancreatin Fluid. A saturated solution of pancreatin in cold distilled water is made and filtered. Pieces of epidermis are macerated in it for 3 to 4 hours, at about the body-temperature. The forms of the prickle-cells are clearly shown, and the nuclei are preserved.

\section{EMBEDDING.}

Embedding methods are divided into two classes, according to the end which it is intended to accomplish : I, simple embedding; 2, interstitial embedding, or infiltration. Simple Embedding consists in surrounding objects which are too small or too delicate to be firmly held by the fingers or by instruments with some plastic substance which gives them firm support without injurious pressure, and thus allows of the cutting of thin sections without distortion. Among the materials used are: (I) Moist Paper. Strips of printing paper softened in water are rolled around the object, which, thus wrapped, is firmly pressed into the microtome-cylinder. (2) Paraffin Infillration and Embedding. The initial step in this process consists in the infiltration of the object with a clearing agent; that is, by some substance which is a solvent of paraffin. It is then immersed in melted par- affin until it is thoroughly saturated. The paraffin should be kept just at the melting-point and should be renewed if the object is large. The duration of the bath depends on the size of the object. When this second step in the process is completed, embed in paraffin, as in simple embedding. To prevent crystallization of the paraffin, the embedded object should be quickly cooled, which may be done by floating it in the containing receptacle on cold water. When chloroform is the clarifying agent, the subsequent treatment differs from the foregoing, and is as follows: The object is saturated with absolute alcohol, then brought into chloroform (containing a tittle ether to prevent the object from floating), and then penetrated; the chloroform and the object are gradually warmed to the melting-point of the paraffin used, small pieces of paraffin being added during the warming. When bubbles are no longer given off from the object, the chloroform has been entirely displaced by the paraffin, and the object is ready to embed (Giesbrecht). A little tray or box is made of paper, and some melted paraffin is poured into it; as soon as the mass has cooled sufficiently to support the object this is placed on its surface. More melted paraffin is poured on until the object is enclosed. Boxes may be constructed by placing pieces of type-metal upon a plate of glass which has been wetted with glycerin and gently warmed. In such a box the paraffin may be kept in a liquid state by warming over a spirit lamp, thus allowing small objects to be placed in any desired position by means of a heated needle under a dissecting microscope. Small objects may be embedded in the following manner: A hole is melted in the end of a cylinder of paraffin by means of a piece of wire which has been heated in the flame of a spirit-lamp. The object is then pushed into the melted paraffin and placed in the desired position. The Watch-glass Method, which is unequaled for small objects, is as follows: Melt paraffin in a watch-glass, place the object in it, and allow it to cool; then cut out a block containing the object, or the whole mass of paraffin may be turned out by rapidly warming the bottom of the watch-glass. Pith. A cylinder of pith is halved longitudinally, a cavity corresponding to the object to be embedded is made by scooping out the inner face of either half-cylinder and the object is placed between them. The cylinder is then pushed into a microtorne well and moistened with alcohol, so that the pith may swell and firmly enclose the object. Heidenhain's Modified Method. Fix the object in a supersaturated solution of corrosive sublimate made in a one-half per cent. solution of common salt. After one-half hour's immersion, transfer to 95 per cent. alcohol, where it should remain 24 hours. Clear in bergamot-oil and embed in paraffin. Section, remove paraffin by xylol or benzine, and place in 95 per cent. alcohol. Then treat $\mathbf{1 5}$ minutes with pure tincture of iodin, to remove the excess of corrosive sublimate, and place again in 95 per cent. alcohol. The sections are now ready for staining. Interstitial Embedding. Practically, this is a process of hardening. The natural cavities of the object are filled with the embedding mass, and each separate anatomic element surrounded with the supporting substance, thus securing firmness and at the same time ensuring natural relations of all structural details. The materials mainly used are Parafin, for small sections, and Celloidin, or collodion, for large sections. Embedding Masses. The most generally useful is pure paraffin, melting at $45^{\circ} \mathrm{C}$. Soap Masses are very penetrating, and have the advantage of being transparent and of cutting better than 
paraffin. A transparent soap is prepared as follows: $25 \mathrm{gm}$. of shavings of sodium stearate soap, and $\mathbf{1 0 0}$ c. c. of 96 per cent. alcohol are heated in a retort over a water-bath until the soap is dissolved, and then filtered. The filtrate should be transparent. If a drop poured into a watch-glass solidifies into a white mass, add water in small quantities until the tested drop remains pellucid. Gelatin Masses are used for tissues that have not been dehydrated. The objects are prepared by penetration with water, instead of alcohol or a clearing agent. After the mass is cooled, it may sometimes be cut at once, but it is usually necessary to harden it, which may be done by freezing or by treating for a few days with 90 per cent. alcohol or with chromic acid, or for a few minutes with absolute alcohol. Brunotti's Cold Gelatin. Dissolve with heat $20 \mathrm{gm}$. of gelatin in $200 \mathrm{c} . \mathrm{c}$. of distilled water, filter, and add 30 c.c. of glacial acetic acid and I gm. of corrosive sublimate. Soak the object in a small quantity diluted with two or three volumes of water, embed in the undiluted mass, and harden in alcohol. This process does not require heat. Gerlach's Gelatin. Gelatin $40 \mathrm{gm}$., saturated solution of arsenious acid 200 c.c., glycerin 120 c. c. Clarify with white of egg. Objects are prepared for embedding by a bath of one-third glycerin. Klebs' Gelatin (Glycerin-jelly). A concentrated solution of isinglass mixed with half its volume of glycerin. Celloidin is stated to be a preparation of pure pyroxylin. It is non-explosive, and is soluble in ether and alcohol. Collodion, prepared by dissolving guncotton or soluble cotton in equal parts of 95 per cent. alcohol and sulphuric ether, is in every way as good as celloidin and considerably cheaper. Celloidin should be used in thin ( 2 per cent.) and in thick ( 6 per cent.) solutions. The object is thoroughly dehydrated in absolute alcohol, placed in a mixture of equal parts of ether and alcohol for 12 to 24 hours, or longer if the object be large. It is then placed for 24 hours in a thin solution of celloidin, $8 \mathrm{gm}$. in IOO c.c. each of alcohol and ether, and transferred from this to a thick solution of celloidin, $8 \mathrm{gm}$. in $50 \mathrm{c}$. c. each of alcohol and ether. Select a cork or piece of soft, dry wood, and dip it in the thick celloidin solution; when dry, place the prepared tissue upon it and drop the thick celloidin solution upon this with a pipet until it is embedded in a jelly-like mass. Blocks or cylinders of glass or vulcanized fiber serve better than cork as they sink in the liquids used. Harden in 90 per cent. alcohol, and preserve in 70 per cent. alcohol. When making sections, keep the knife and section wet with alcohol. Apáthy ađvises previous smearing of the knife with vaselin, as it cuts better and is protected from the alcohol. Use bergamot-oil to clear. Sections may be kept in from 60 per cent. to 80 per cent. alcohol. Fisk's Castor-oil and Oil of Thyme Method. The mixture consists of red oil of thyme 3 parts, castor-oil I part, and is used only with collodion-embedded objects. The castor-oil makes the collodion slightly flexile, so that the sections do not move so readily on the slide, when the balsam is applied. There is no true action as a fixative, for the collodion is not dissolved in any way, only softened and toughened. The edge of the knife is preserved for a longer time. The castor-oil gives more "body" to the mixture, making a good lubricator, and floats the sections readily. Very thin sections can be obtained by absorbing the oil and coating the object with a thin layer of I per cent. collodion before cutting each section. This coating is also useful if there is any tendency for the section to crumble or tear. The mixture is highly antiseptic, and specimens may be left in it indefinitely, to advantage and without shrinking. If the objects have been stained in toto, the process is very short. If section-staining is desired, the sections after their transfer to the slide, should have as much of the superfluous oil removed as possible and a few drops of ether-alcohol (equal parts of each) are poured over them to fasten them to the slide. The sections are then put into 95 per cent. alcohol to dissolve out any oil that may be left, and passed through from 70 per cent. to 35 per cent. alcohol, to water, stained, carried back through the same grades and mounted as usual. This is one of the best and most useful of methods. Von Koch's Copal Method. The object is dehydrated in alcohol, placed in a thin solution of copal in chloroform, made by triturating small fragments of copal in a mortar with fine sand, pouring on chloroform, and filtering. The solution is slowly evaporated by heating. When concentrated enough to draw out into threads that are brittle, the object is removed and allowed to dry. Sections are cut by means of a fine saw, rubbed smooth on one side and with the smooth side down, are cemented on a slide. When the cement has hardened, the sections are rubbed until they are of the requisite thinness, washed in water, and mounted in balsam. This method is used for the study of hard and soft structures in their natural relations. Kultschizky's Celloidin-paraffin Method. After the object is taken from the ether-andalcohol bath it is put into celloidin-solution for 24 hours, then into origanum-oil, then into a mixture of origanumoil and paraffin which has been heated to $40^{\circ} \mathrm{C}$, and finally into melted paraffin. The method is especially adapted for delicate specimens. Ryder uses chloroform instead of oil of origanum. Joliet's Gumand-glycerin Method. Pure gum arabic is dissolved in water to the consistency of a thick syrup. To a little of this solution in a watch-glass add 6 to Io drops of glycerin, and mix. Embed the object, previously soaked in glycerin, in the mass in the watch-glass and leave to dry for several days. Cut dry, dissolve the gum from the sections in water, and mount in glycerin. This mass has the advantage of being transparent. Photoxylin. A substance having the appearance of cotton-wool and chemically closely allied to celloidin. It dissolves in a mixture of ether and alcohol, equal parts, and is used in the same way as celloidin. It has the advantage of forming a mass that remains transparent. Syrup-andgum Congelation-mass. Hardened brain-tissue, previously soaked in water, is well soaked in a syrup made of double refined sugar 2 ounces, water I fluid-ounce. Wash the superfluous syrup from the surface and put into ordinary mucilage an hour before cutting. Embed in the freezing microtome and float the sections into water (Hamilton). Cole advises 4 parts of syrup and 5 parts of gum for the brain, spinal cord, retina, and all tissues liable to tear easily. The gum is made by dissolving 4 ounces of gum acacia in 6 ounces of water; the syrup, by boiling $\mathbf{I}$ pound of loaf-sugar in $\mathbf{I}$ pint of water. Add $5 \mathrm{gr}$. of carbolic acid to each ounce of the medium.

Collodionization of Sections. It sometimes happens that objects, such, for example, as ova, are too delicate and too easily broken to be cut in the ordinary way; it is necessary to cover the exposed surface before cutting each section with a thin layer of collodion or celloidin. The collodion should be of such consistency, from $1 / 2$ per cent. to I per cent. solution, that, when applied in a thin layer to a surface of paraffin, it will dry in two or three seconds without leaving a shiny surface. 
EMBRYOLOGIC METHODS.

Artificial Fecundation. This practice can be easily carried out with the Amphibia anura, Teleostea, Cyclostonata, Eihinodermata and many Vermes and Colenterata. In the Amphibia, the ova should be extracted from the uterus, placed in a watchglass, and treated with water in which the testes or vasa deferentia of the male have been teased. The spermatozoa of fish rapidly lose their vitality in water, hence, the milt must be added immediately to the spawned ova, then a little water added, and the whole placed in a suitable hatching apparatus with running water. Artificial fecundation of Invertebrates is performed in a like manner, and can sometimes be accomplished under the microscope. The penetration of the spermatozoon and some of the subsequent changes can thus be observed. Amphibia. Ova of amphibia are covered with thick coats of albumin, which must be removed in their preparation for sectioncutting. Whitman places the fixed eggs in a Io per cent. solution of sodium hypochlorite, diluted with 5 or 6 volumes of water, until they can be shaken free. Blochmann recommends eau de Javelle (see Bleaching Fluids), diluted three or four times with water, and agitates the eggs, previously fixed in Flemming's solution (see Fixing Fluids), for from I 5 to 30 minutes. Preserve the ova in alcohol. Axolotl. These ova have an albuminous layer separated from the yolk by a liquid which is not coagulated by reagents. Place them for a few hours in picrosulphuric acid, then pierce the inner chorion, and gently press out the ova. Harden in alcohol. Stain in the mass with boraxcarmin or Henneguy's acetic acid alum-carmin, and embed in paraffin or celloidin. Collodionize the sections. Rana. Place the ova in water heated to $90^{\circ}$ $96^{\circ} \mathrm{C}$. for 5 to 10 minutes. Incise the albuminous coverings, and remove the ova under water. Place them in 0.5 per cent. osmic-acid solution or in alcohols of 70,80 , and 90 per cent. Salamandra. Fix in warm, platinum-chlorid solution ( 0.25 to 0.3 per cent.) for 3 to 24 hours, according to the size of the embryo. Wash in water, and pass through successive alcohols. Stain sections on the slide. Triton. Incise the several concentric coats of albumin which surround the ovum; remove, and place it in Kleinenberg's fixing solution (see Fixing Fluids). Or, put the eggs in a solution of acetic acid 2 per cent, chromic acid 0.5 per cent., and after ten hours incise the membranes and turn the embryos out. Finally, pass through successive alcohols. Aves. Superficial Examination. During the first 48 hours of incubation of the egg (hen's) the blastoderm is always uppermost. To open the egg, place it in a dish and cover it with a 0.75 per cent. sodium-chlorid solution at a temperature of $38^{\circ}$ C. Break the shell at the broad end over the airchamber, to keep this end from tilting up. The shell is then filed through at one point, and the opening enlarged with forceps. Remove the upper half of the shell, bit by bit. Then remove the shell-membrane in the long axis of the egg, and the yolk and embryo will come into view. A quicker but less satisfactory method is to break the egg across and pour the yolk and white into the sodium-chlorid solution. Maintain the salt-solution during the period of examination at $38^{\circ}$ C. over a sand-bath. Duval's Orientation Method. To obtain sections of any desired direction of the ova of Aves, before the development of the primitive streak, Duval proceeds as follows. During incubation the embryo is generally lying on the yolk, so that the large end of the egg is to its left, and the small end to its right; hence, the position of the blastoderm can be marked out. Construct a triangular, bottomless box from a strip of paper $5 \mathrm{~mm}$. wide and $50 \mathrm{~mm}$. long; lay this on the yolk enclosing the cicatricula in such a position that the base corresponds to the anterior region of the embryo. By means of a pipet fill the paper triangle with 0.3 per cent. osmic-acid solution. When the preparation becomes dark, place the whole egg in a weak chromic-acid solution, remove the white, and place the rest in a fresh chromic-acid solution for several days; a black triangle will mark the position of the cicatricula, and may be cut out with scissors and scalpel. Examination of an Opaque Object. Place the blastoderm on a slide, and dry just sufficiently to make its edges adhere to the glass; immerse in a solution of picric acid for two or three hours, and examine with a simple lens. Examination and Pre servation in toto. Open the egg in salt-solution, pierce the blastoderm at the outer margin of the vas cular area with a fine scissors, and carry the incision completely around. Then place the excised blastoderm in a watch-glass, and remove the vitelline mem brane by gentle shaking with a needle. The blastoderm can then be placed on a slide, surrounded by a ring of putty, covered with salt-solution and a coverglass, and examined under the microscope. Keep the slide at about $38^{\circ} \mathrm{C}$. Permanent preparations of embryos in toto, up to about 50 hours, may be made by treatment with osmic acid, I per cent. After separation of the vitelline membrane, hold a drop of the acid, by means of a pipet in contact with the embryo for $\mathbf{1} 5$ or 20 minutes. Then mount in a cell in balsam. Development of the Blood-vesseis. Obtain blastoderms of 30 or 40 hours, immerse in gold chlorid, 0.5 per cent., for $\mathbf{I}$ minute, wash in distilled water, mount in glycerin, and examine. This method renders the nuclei and protoplasmic processes distinct. Or, immerse the blastoderm in I per cent. solution of potassium bichromate for I day, and mount in glycerin. Or, use a 0.5 per cent. solution of osmic acid for from $1 / 2$ to $I$ hour, then place in absolute alcohol for I day, and mount in glycerin. Gerlach's Windore Method. Remove the shell at the small end of the egg, withdraw a little white with a pipet; the blastoderm will change its position and appear under the window thus made. Paint the margins of the window with gum-mucilage, and build a small, circular wall of cotton-wool on it, cover with a cover-glass, and ring with gum. The progress of development can be followed thus to the fifth day. Preparation. During the first 24 hours of incubation the blastoderm can be separated from the yolk only with extreme difficulty, so that they must be fixed together. Open the egg in salt-solution, then lift so that the blastoderm is above the surface of the fluid, and treat it with a fixing solution dropped from a pipet; then remove it by a circular incision about its margins, free the vitelline membrane, and place the blastoderm in a hardening fluid. Dehydrate in absolute alcohol, clear in chloroform, and embed in paraffin. Segmentation. To observe this process, it is necessary to obtain the eggs from the oviduct of the hen. The yolk must be hardened as a whole, preferably in chromic acid. Fol's Method for Reconstruction of Embryos from Sections. Before cutting sections of the object, make an outline drawing of it, under the magnification to be employed for the reconstructed drawing, and in a plane perpendicular to that of the intended sections. Then cut the sections, and make drawings of all under the same magnification used for the sagittal drawing. Trace over the sagittal drawing a series of equidistant parallel lines corresponding to the sections cut. (If the sections are $\frac{1}{10} \mathrm{~mm}$. thick and the drawing is magnified Ioo times, the lines should be $1 \mathrm{~mm}$. 
apart.) The outline drawing is now to be filled in with the details of the drawings of the sections. This is accomplished as follows: A piece of glass, of the size of the intended drawing, is coated with gelatin and ruled with a series of close, parallel lines with differently colored inks, the colors recurring in regular order. Cut the plate in two equal parts on a line perpendicular to the ruled lines. Lay one plate on the outline drawing so that its cut edge covers the line corresponding to the first section to be filled in, then lay the other plate on the drawing of the sections in such a position that the limit of the drawing corresponds to the same colored lines that cover the limits of the outline drawing. Trace on the plate that covers the drawing of the section the outline of the internal organs. Lay it against its fellow on the outline drawing, making the lines correspond. Mark off the outlines of the internal organs. Repeat this operation for each section and connect the series of dots so made and the drawing is completed. Another method of reconstructing objects from microscopic sections is that suggested by Born. By the aid of the camera, the outlines of the sections are transferred to wax plates, which are then cut out so as to correspond, in outlines as well as dimensions, to the sections equally magnified in all three directions. With plates thus prepared, it is only necessary to put them together in the proper order to obtain a complete model. Mammalia. For the study of the early stages, the ova must be obtained from the tubæ (of a rabbit or other small animal) several hours after copulation. Dissect out the tubæ and cornua of the female, allow them to cool, and wait for the muscular contraction to cease. Dissect off all the peritoneal investment, and slit the tubæ open longitudinally. The folds of the tubal mucosa are spread out by means of needles and forceps, and the ova searched for by means of a magnifying glass. The ova are best examined in the peritoneal fluid of the mother or in the aqueous humor, blood-serum, or artificial serum. Kölliker injects Müller's fluid or a weak osmic-acid solution into the oviduct, and collects the fluid that runs out in a series of watch-glasses, which are examined for the ova under the microscope. During the fourth, fifth, and sixth days after copulation the ova are free in the uterine cornua, and are easily visible to the eye, and may be obtained in a like manner as from the tubæ. When the ova become fixed in the uterus they are easily distinguished by the peculiar aspect of the cornua in which there are small elevations at the site of each ovum. To obtain the ova it is necessary to incise the cornua transversely into as many segments as there are eminences, care being taken to have the ova in the center of the segments. The segments are then fixed to the bottom of a dissecting dish by pins, with the mesometrial surface downward. Fill the dissecting dish with serum, Müller's fluid, or Kleinenberg's picro-sulphuric-acid, or nitric-acid solution. The ovular eminence is then incised longitudinally and the ova carefully freed. Preparations. To make permanent preparations of the various stages of fecundation and segmentation, the living ovum is placed in a I per cent. solution of osmic acid, on a slide, then into Müller's or Kleinenberg's solution. In an hour the solution is changed and the whole is placed in a moist chamber for two or three days. It is then treated with increasing strengths of glycerin, and mounted in pure glycerin, acidulated with formic acid; or ova may be stained with picrocarmin after treatment with osmic acid and careful washing. To demonstrate the blastoderm cells, treat the living ova in a $1 / 3$ per cent. solution of argentic nitrate for $1 / 2$ to 3 minutes, then place in distilled water and expose to the light. These specimens cannot be rendered permanent; they ultimately become black. The blastodermic vesicle can be opened with a fine needle after 3 days, and the blastoderm washed, stained, and mounted in glycerin or balsam, or prepared with gold chlorid. For embryonic areas and the more advanced embryos, place ova in a 0.5 per cent. osmic-acid solution until quite dark (about I hour), then treat with successive alcohols for several hours. For sections, Kölliker fixes the ova in osmic acid, and v. Beneden treats them for 24 hours with I per cent. chromic-acid solution, washes thoroughly, and carries them through successive alcohols. Piersol recommends Kleinenberg's solution or, for young stages, Altmann's 3 per cent. nitric acid. Stain small embryos with borax-carmin or Delafield's hematoxylin (see Staining Reagents), and for larger ones Henneguy's acetic acid alum-carmin gives the best results. For sections, embed in paraffin and mount in balsam.

\section{EXAMINATION OF THE BLOOD.}

Alkalinized Urine. Used in the enumeration of bloodcorpuscles. Saturate a quantity of urine with borax, filter, and dilute until its sp. gr. is I020. The contour of the cells remains unchanged in this medium. Auerbach's Method for Amphibian Red Blood-cor puscles. By fixing the blood-film on the cover-glass by means of a saturated solution of picric acid or a mixture of 0.1 to 0.25 per cent. solution of corrosive sublimate, I per cent. solution of boric acid, I per cent. sodium chlorid, or 2 per cent. to ro per cent. ammonium chromate, certain differentiations of the corpuscle are possible. With picric-acid fixation and subsequent staining with eosin and anilin-blue, the cell-wall stains blue, while the adjacent protoplasm within stains red. The protoplasm may further be separated into a cortical and a medullary layer, the former containing the hemoglobin. In picric-acid preparations the cortical layer shows a beautiful network, while the medullary part is clear, like a large hole. In sublimate preparations the medullary part has dark granules. Blood-platelets. Ligate the finger and prick the pad. Wipe off the first blood that exudes, and touch the apex of the second drop with the cover-glass; drop it gently on the slide, do not press it on, and platelets will have their faces, not their edges, presented to view. Stirling recommends that the finger be pricked through a drop of normal saline solution containing methyl-violet $(0.75 \mathrm{~cm}$. in 1000 c.c.). The colorless corpuscles are stained light-blue, the platelets dark-violet or darkblue. Ehrlich's Methods. Ehrlich's Granules. Dry a cover-glass preparation of blood for several hours at $120^{\circ} \mathrm{C}$, or rapidly over the flame of a Bunsen-burner. Stain I hour or longer in eosin-glycerin; wash in water, dry, and mount in balsam. Or, stain in glycerin, 30 c.c., and $2 \mathrm{gm}$. each of aurantia, indulin, and eosin. If the eosin-indulin-glycerin solution be used the $\delta$-granulations are purplish-red and the nuclei bluish-black. I. Oxyphilous, or Eosinophi' ous Granules. Cover-glass preparations of blood are fixed by dry heat, as indicated, or by chemic reagents, corrosive sublimate, or osmic acid. The preparation is then floated on a I per cent. aqueous solution of eosin, a quarter to one minute. A trace of acetic acid added to the fluid causes the specimen to overstain rapidly, and the excess of dye is removed from all parts of the cells, except the oxyphilous granules, by dipping the cover-glass into a very dilute solution of sodium carbonate. 2. Neutrophile Granules. These are the $\varepsilon$-granulations of Ehrlich. They are stained only by neutral dyes, $e$. o. , acid fuchsin, fuchsin-S, methylene-blue. 3. Basophilous Granules. These are 
best stained with Loeffler's methylene-blue. If the specimen has been stained with eosin, and the excess washed out, a second or two suffices for the methyleneblue stain. Both oxyphilous and basophilous granules may be stained in the same specimen by preceding the blue stain with eosin. Ehrlich's "Mastzellen." I. In blood these cells are stained by a mixture composed of water, roo c.c., absolute alcohol, saturated with dahlia, 50. c.c., glacial acetic acid ro to $\mathbf{1 2 . 5}$ c. c. The leukocytes are stained blue, the granules have a "metachromic red-violet tint," and correspond to the $\gamma$-granulations. 2. In tissues : a small piece of fresh tissue, or a section previously hardened in alcohol, is placed in a watch-glass containing anilin-water and 20 to 30 drops of a concentrated alcoholic solution of dahlia or gentıan. Heat until vapor begins to arise, stain 24 hours, wash in acid-alcohol until nearly decolorized, dehydrate in absolute alcohol, clear, and mount. Nuclei of the cells are red, the granules in the protoplasm of the granular cells blue. The tissue may also be stained with lithium-carmin. Fixing of Blood. Garlinski's Modification of Gaule's Sublimate Method. A small pipet is filled with the indifferent fluid used in counting blood-corpuscles. A drop of blood is drawn into the pipet, where it mixes with the indifferent fluid. A little of this mixture is placed on a slide, and a concentrated watery solution of corrosive sublimate poured upon it. After a few minutes the morphologic elements of the blood become attached to the glass without alteration of form. The specimen is then washed with water, treated for some minutes with absolute alcohol, and again washed with water, when it is ready for staining. (Grundzüge der allg. Pathologied. Zelle. S. M. Lukjanow, Leipzig, I80I.) Garlinski's Method. Stain for 2 minutes in Böhmer's hematoxylin; wash in 1 per cent. aqueous solution of alum and distilled water; then stain in $\mathbf{I}$ per cent. aqueous solution of nigrosin for a few seconds ; wash and stain in I per cent. aqueous solution of rose bengal 5 minutes; wash and stain in anilin-yellow, I per cent. alcoholic watery solution, 5 minutes. Wash, dehydrate, mount in balsam. Cell-protoplasm is yellow; nuclei are blue or green; any parasites in the corpuscles are stained by the rose bengal. Hayem's Solution. Used for fixing blood-corpuscles of both animals and man. Dissolve in 200 c.c. of dis. tilled water, $0.5 \mathrm{gm}$. of corrosive sublimate, $5 \mathrm{gm}$. of sodium sulphate, and I gm. of sodium chlorid. Run directly from a blood-vessel $\mathrm{I}$ part of blood to $\mathrm{roo}$ of the fluid. The corpuscles will be fixed in about 24 hours. Decant the supernatant fluid, and wash the corpuscles in water to remove the salts. Hemin Crystals. Place a particle of dried blood on a slide, add a crystal of common salt and two drops of acetic acid, heat over the flame of a spirit-lamp until it steams, and allow it to cool. The crystals may be preserved by removing the acid and mounting them in glycerinjelly or balsam. Leukocytes. A cover-glass preparation of blood is floated on a solution of eosin, washed and floated on a solution of hematoxylin, washed, dehydrated, and mounted. Methylene-blue or methyl-violet may be used in place of the hematoxylin. Martinotti and Resigotti's Method. Harden small pieces of tissue in absolute alcohol, and color the sections in a watery solution of safranin-O; decolorize in 2 parts of a $I$ per cent. solution of chromic acid tó 8 or 9 parts of alcohol. Wash in absolute alcohol, clear in oil of bergamot, and mount in balsam. Only the fibrils of the nuclei are stained. Rollett's Method of Preparing Hemoglobin Crystals. Defibrinated blood is placed in a platinum capsule on a freezing mixture, frozen, and then 87 thawed. The lake-colored blood is then poured into a plate until it forms a stratum not more than $1 \mathrm{I} / 2 \mathrm{~mm}$. in thickness and allowed to evaporated slowly in a cool place. Sectioning Blood. I. Biondi's Meihod. Fix two drops of blood in 5 c.c. of 2 per cent. osmic-acid solution from one to 24 hours, and then mix the blood and osmium solution with agar-agar jelly melted at $35^{\circ}$ to $37^{\circ} \mathrm{C}$. When cool, harden in 85 per cent. alcohol. After a few days, or when the mass has acquired sufficient consistence, embed in paraffin. The sections are treated according to the usual methods, and may be stained with methyl-green, methylene-blue, fuchsin, or safranin; also, double-stained with methyl-green and eosin. 2. Fod's Method. Coagulated blood or small pieces of hematopoietic organs are fixed in a solution of $2 \mathrm{gm}$. of corrosive sublimate in Ioo gm, of Müller's fluid. The Latter fixes the hemoglobin, the sublimate fixes structures of protoplasm and nuclei. Embed in paraffin, section, and stain I to 3 minutes in a mixture of Böhmer's hematoxylin $25 \mathrm{gm}$., I per cent. aqueous alcoholic solution of safranin $20 \mathrm{gm}$., and distilled water $100 \mathrm{gm}$. Wash in water, then in a weak alcoholic solution of picric acid, dehydrate, and mount in balsam. Weigert's Method for Fibrin. Make celloidin sections, and stain one minute in Weigert's fibrin stain : 5 per cent. solution of gentian-violet 4.4 c.c., 96 per cent. alcohol 6 c.c., anilin-oil I c.c. Dry with unsized printing paper, and add a drop of Gram's solution saturated with iodin. Most of the stained parts are decolorized. Remove the iodin with printing paper; clear in equal parts of anilin-oil and xylol, renewing it until all the water is removed. The water gives the section a white appearance. Dry with filter-paper, wash well with xylol, and mount in xylolbalsam. Zenker's Method. For red blood-corpuscles in tissues. The tissue is taken as fresh as possible, placed in Müller's fluid for 24 hours, in which it turns yellow. Longer immersion is detrimental. Wash about two hours in running water; harden in 50, 70, and 96 per cent., and, lastly, in absolute alcohol. Embed in paraffin. Celloidin sections do not stain as well. Stain on the slide in the Ehrlich-Biondi triple mixture (see Staining Reagents) for 24 hours; rinse half a minute in running water, and decolorize in 96 per cent. alcohol, until clouds of color no longer appear; dehydrate in absolute alcohol. The red blood-corpuscles appear a brilliant golden-yellow; the nuclei of all cells have a violet or green tinge; the chromatin network and nucleoli are invisible. Weigert's fibrin stain may be used in the same way, but not after prolonged immersion in Müller's fluid. (Virch. Arch., I894, Bd. 135. Folge xiiz, $B d$. v.)

\section{EXAMINATION AND PRESERVATION MEDIA.}

Indifferent liquids, giycerin, and resinous preparations used in examining, preserving, and mounting tissues and organisms. I. INDIFFERENT LIQUiDs, Media having a composition and density similar to that of the plasma which constitutes the natural habitat during life of the object they are intended to preserve, and therefore, supposed to have no action on the tissues. To be "indifferent," these liquids must possess such a density and such a proportion of crystalloids and colloids as will reduce osmotic processes to a minimum. Alum Sea-water. A saturated solution of alum in seawater is useful for the study and preservation of the tissues of marine organisms. Aqueous Humor. This may be obtained from a freshly excised ox's eyeball. Puncture the cornea with a slender, triangular knife, and collect the aqueous humor as it exudes. If only a small quantity is desired, puncture the excised eye of a 
frog with a fine capillary pipet. Blood-serum. The blood is allowed to clot, and in a day or two the serum is poured ofi, and any red corpuscles removed from it by means of a centrifugal apparatus. This fluid does not keep, and must be fresh for use. Iodin is sometimes added, forming iodized serum. Chloral. One, 2.5 , and 5 per cent. aqueous solutions are recommended by Munson, Brady, and Landowsky respectively. Frey's Artificial lodized Serum. To a filtered mixture of white of egg $15 \mathrm{gm}$., sodium chlorid 0.2 gm., distilled water $\mathbf{I} 35$ c.c., add 3 c.c. of tincture of iodin. Filter through flannel, and add a little iodin to the filtrate. Fruit-juice requires no preparation beyond filtering. It may be iodized. Iodized Serum. To the fresh amniotic liquid of a sheep or cow add iodin crystals. Keep the solution in a stoppered bottle and shake frequently. It should acquire a darkbrown color. Kronecker's Artificial Serum. Sodium chlorid $6 \mathrm{gm}$., sodium hydroxid $0.06 \mathrm{gm}$, , distilled water 1000 c.c. Normal Salt-solution. Sodium chlorid from 6 to $7.5 \mathrm{gm}$., distilled water $1000 \mathrm{c.c}$. Used in the study of living structures. Physiologic Salt-solution. See Normal Salt-solution. Syrup. A good medium for examining fresh structures, and prepared by dissolving equal parts of loaf-sugar in water by boiling. The addition of I per cent. of carbolic acid or chloral will preserve it from mold. Water. Structures fixed in osmic or chromic acid, or a solution of a metallic salt, may be examined in water, which has the advantage of having a low index of refraction. A little thymol will preserve it from mold. White of Egg needs only to be filtered to prepare it for use. It may be iodized. II. GLYCERIN AND OTHER Fluid Media. Acidulated Glycerin. Glycerin 50 c.c., glacial acetic acid or formic acid I c.c., distilled water 50 c.c. Used after staining in borax or lithium-carmin, previous to mounting in glycerin. Beale's Glycerin-jelly. Equal parts of pure glycerin and gelatin, soaked, melted, and clarified. Brandt's Glycerin-jelly. Melted gelatin I part, and glycerin I. 5 parts. Filter through spun glass, and add a few drops of carbolic acid to the filtrate. For mounting, melt a little on the slide, having previously soaked the object for a short time in the medium warmed by gentle heat. Calberla's Liquid. One part each of glycerin, alcohol, and water. A valuable examination fluid. For very delicate objects, Lee recommends the same formula, with two parts of water instead of one. Calcium Chlorid. A 50 per cent. or saturated solution is used. The addition of a little camphor will preserve it. As this salt is very hygroscopic, the mount need not be closed at once. Carbolic Acid. A I per cent. solution is used as a mounting-medium. Carnoy's Solutions. I. A concentrated aqueous solution of methyl-green containing $\mathbf{I}$ per cent. of acetic acid and $0 . \mathbf{I}$ per cent. of osmic acid, used in the study and preservation of fresh tissues. It has a selective action on nuclei. 2. Powdered tannin $0.5 \mathrm{gm}$., water 100 c. c. Castor-oil. Recommended by Grenacher, on account of its low refractive index, for certain delicate tissues (sections of eyes of Cephalopods), on the supposition that it would augment visibility for the more refractive elements of these tissues. Copper Acetate. A solution of $\mathbf{I} \mathrm{gm}$. of copper acetate and $4 \mathrm{gm}$. of mercuric chlorid in 250 c.c. of glycerin and I C.c. of glacial acetic acid is used in preserving and mounting green algæ. Creasote. As a mounting-medium, a 5 per cent. aqueous solution is used. Deane's Glycerinjelly. Dissolve $30 \mathrm{gm}$. of gelatin in $60 \mathrm{gm}$. of water, and add $\mathbf{1} 20 \mathrm{gm}$. of glycerin. This must be used warm. Fabre-Domergue Glucose Medium. Dissolve glucose in warm water and dilute to $25^{\circ}$ of the areometer (sp. gr. I.I968). To I000 parts of this solution add 200 parts of methyl-alcohol, IOO parts of glycerin, and camphor to saturation. Neutralize by the addition of a little potash or soda. This medium is said to preserve, unchanged, nearly all animal pigments. Farrant's Solution (Hamilton). Make a saturated solution of arsenious acid in water by boiling, let it stand twenty-four hours, and filter. Then to equal quantities of water, glycerin, and arsenious acid solution add picked gum arabic until a thick, syrupy fluid is obtained. In about a week, filter slowly through frequently changed filter-paper. Fol's Glycerin-jellies. 1. Melt together one volume of Beale's jelly and one volume of water, and add 2 to 5 per cent. of car. bolic acid. 2. Gelatin 30 parts, water 70 parts, gly cerin, I00 parts, alcoholic solution of camphor 5 parts. 3. Gelatin 20 parts, water 150 parts, glycerin 100 parts, alcoholic solution of camphor 15 parts. Gage's Fluid. Mercuric chlorid $0.5 \mathrm{gm}$., salt $4 \mathrm{gm}$., white of egg 15 c. c., water 200 c. c. Mix thoroughly and filter. Used in the study of ciliated cells and red blood-corpuscles. Gannal's Solution. A preserving medium consisting of aluminum acetate I part, and water Io parts. Gilson's Fluid. Mercuric chlorid o. I5 gm., 15 per cent. acetic acid 2 c. c. , 60 per cent. alcohol 60 c.c., and water and glycerin each 30 c.c. An admirable medium for the study of fine cellular detail in well-fixed tissues. Glycerin. As a medium for examination and mounting, glycerin is usually diluted with water, which lowers its index of refraction, often an advantage from an optic point of view, on account of the increased visibility it gives to many structures. On the other hand, undiluted glycerin has the advantage of being a more efficacious preservative. Objects mounted in glycerin should be subjected to a prolonged preliminary soaking in glycerin of gradually increasing strength; if done on the slide, and treated with fresh glycerin daily, the edges of the cover-glass should be luted to make the preparation air-tight, glycerin being so hygroscopic as to rapidly diminish in strength when exposed to air. To facilitate the removal of the coverglass, warm the slide gently; this treatment will also counteract the shrinking action of glycerin on delicate tissue-elements and restore them to their normal contour and dimensions. Glycerin, being a solvent of calcium carbonate, is not a suitable medium for the preparation of calcareous structures. By dissolving in glycerin cadmium chlorid, chloral, and certain other substances, its index of refraction may be raised to about that of crown-glass, which greatly augments its clearing action, and allows the full aperture of homogeneous objectives to be brought to hear on the object. A saturated solution of zinc sulphocarbolate in glycerin will raise its index of refraction from I.46 to I.50I, and is prepared by taking equal parts by weight of Price's glycerin and zinc sulphocarbolate, and boiling for an hour or more. Filter while hot. Glycerin and Alcohol. Useful for bringing delicate objects gradually from weak into pure glycerin. Glycerin I part, alcohol I part, water 2 parts. Glycerin-jelly. Soak in 150 c. c. of distilled water, 25 gms. of gelatin for two hours, and add 3 c.c. of carbolic acid and $\mathbf{1 7 5}$ c.c. of glycerin; heat for fifteen minutes and filter through spun glass. Wrap the cork of the bottle in which the jelly is preserved in linen dipped in dilute carbolic acid. For use, melt it in hot water, place a drop on the section, upon which gently press a coverglass. Glycerin and Gum. Useful when the arsenious acid of Farrant's medium is objectionable. Take chloroform-water (I: 200) 200 c.c., gum acacia 130 gm., and glycerin 100 c.c. Dissolve the gum in the chloroform-water, with frequent stirring and without 
heat ; add the glycerin. Mix and filter through the best Swedish filter-paper, on which has been deposited a thin layer of talc. Glycerin and Formic Acid. This is especially used for picrocarmin preparations, and is made by adding formic acid to dilute glycerinI per cent. Goadby's Fluids. First formula: Bay. salt (coarse sea-salt) $\overline{\mathrm{iv}}$, alum $\mathrm{\zeta}_{\mathrm{ij}}$, mercuric chlorid 2 grs., boiling water I qt. This fluid, diluted with an equal volume of water, is recommended by Schultze for preserving Meduse, Echinodermata, Entomostraca, Polythalmia, Polycystina, and Annelid Larve. He advises the subsequent use of glycerin to secure transparency, Second formula: Bay-salt, 3 viij, mercuric chlorid gr. 2, water I qt. The absence of the alum renders this fluid suitable for the preservation of objects containing calcium carbonate. Häntsch's Liquid. Glycerin I part, alcohol 3 parts, water 2 parts. Harting's Fluid. One part of mercuric chlorid to 200 to 400 of water. It is recommended for preserving bloodcorpuscles, nerve-tissue and muscle-tissue, etc. Hayem's Mounting-media. These are solutions of gum with chloral, for objects stained with carmin or hematoxylin, and of gum with potassium acetate, for objects stained with anilin colors, and are prepared as follows : Fill a tall $60 \mathrm{c}$.c. glass two-thirds full with gum arabic, and add either a solution of chloral containing 5 to Io per cent. of glycerin or of potassium or ammonium acetate. The gum with frequent shaking dissolves in a few days, and the resulting syrupy fluid is then filtered. Iodin. Liquor iodi (Br. Ph.) roo c.c., distilled water 300 c.c., glycerin 200 c.c., gum arabic 260 gms. Mix and dissolve without heat; filter through Swedish paper coated with a thin layer of talc. Used in mounting tissues stained with iodin. Jæger's Liquid. Glycerin and alcohol each I part, sea-water Io parts. Kaiser's Glycerin-jelly. Soak one part of gelatin for 2 hours in 6 parts of distilled water, then add $7 \mathrm{gm}$. of glycerin and I $\mathrm{gm}$, of carbolic acid for every $\mathbf{I O O} \mathrm{gm}$. of the mixture. Warm for Io to I5 minutes, stirring constantly until the flakes produced by the acid have disappeared. Filter while warm through spun glass laid wet in the filter. For use it must be warmed. Klein's Dammar Lac. Dissolve in $2 \mathrm{oz}$. of turpentine, $\mathrm{I} 1 / 2 \mathrm{oz}$. of gum dammar, and filter. Dissolve $1 / 2 \mathrm{oz}$. of gum mastic in $2 \mathrm{oz}$. of chloroform, and filter. Mix the two solutions and filter again. Langerhans' Gum and Glycerin. A modification of Farrant's medium. Gum arabic 5 parts, in water 5 parts; after 12 hours add glycerin 5 parts, and 5 per cent. aqueous solution of carbolic acid Io parts. Used in preserving marine animals. Lawrence's Glycerin-jelly. Soak a quantity of Nelson's gelatin for 2 or 3 hours in cold water. Decant the superfluous water, and melt the gelatin by the aid of heat. To 8 parts of the gelatin, when it has cooled, but is still fluid, add I part of white of egg; boil until the albumin coagulates and the gelatin is clear; filter through flannel, and to 8 parts of the filtrate add 6 parts of a mixture of 1 part of glycerin and 2 parts of camphor-water. Levulose. This substance is non-crystallizable, and is recommended as a preservative of carmin and anilin stains (hematoxylin partially fades in it). Objects may be brought into it from water. The index of refraction is somewhat higher than that of glycerin. May's Fluid. Glycerin 60 c.c., I per cent. arsenic acid Io c.c., methyl-alcohol Io c. c., water 20 c.c. Methyl-green. See Carnoy's Solution. Meyer's Salicylic Vinegar. A solution of one part of salicylic acid in 100 parts of pyroligneous acid. For Lavve, Nematodes, etc., add I part of the salicylic vinegar to Io parts of glycerin diluted with twice its volume of water; for Infusoria, add I part of the vinegar to Io parts of glycerin diluted with four times its volume of water. Noll's Salicylic Vinegar and Gum. A mixture of equal parts of Meyer's dilute fluid and Farrant's medium. This mixture does not become turbid and does not dry up. It is an admirable medium for delicate Crustacea and their larvæ. Owen's Fluid. Mercuric chlorid 0.014 gm., alum $79 \mathrm{gm}$., salt $137 \mathrm{gm}$., water $\mathbf{1 6 8 0}$ gms. Used for preserving soft-bodied animals. Pacini's Fluids. (a) Mercuric chlorid I part, sodium chlorid 2 parts, water 200 parts. Especially useful for the blood-corpuscles of cold-blooded animals. (b) Solution a plus two parts of mercuric chlorid. For the examination of the blood-corpuscles of warmblooded animals. (c) Mercuric chlorid I part, acetic acid 2 parts, water 300 parts. For the examination of the nuclei of animal tissues. (d) Mercuric chlorid I part, sodium chlorid 2 parts, glycerin $\left(25^{\circ}\right.$ Beaumé) I 3 parts, water II 3 parts. Let the mixture remain undisturbed 2 months; then take for use $\mathbf{I}$ part, dilute it with 3 parts of water, and filter. This fluid is recommended as a preservative of all delicate tissues. (e) Mercuric chlorid I part, acetic acid 2 parts, glycerin $\left(25^{\circ}\right.$ Beaumé) 43 parts, water II 5 parts. This mixture is used for the same purposes as the preceding. It is said to preserve the white but to destroy the red corpuscles of the blood. ( $f$ ) One part of mercuric chlorid in 200 of water. This fluid has been used to remove the salt or acid, when necessary, from objects preserved in the preceding fluids. Modifications of the foregoing solutions: $a$. Sublimate I part, sodium chlorid 2 parts, water Ioo parts. Used for the more vascular tissues of warm-blooded animals. $b$. Solution $a$ diluted with an equal volume of water ; for similar tissues of coldblooded animals. $c$. One part each of sublimate and salt in 300 parts of water; for pus-corpuscles. $d$. One part of sublimate in 300 parts of water; for bloodcorpuscles. e. One part each of corrosive sublimate and acetic acid in 300 parts of water; for demonstrating the nuclei in epithelia, connective tissue, and pus-corpuscles. $f$. Solution $e$ plus 2 parts of acetic acid; for ligaments, muscles, and nerves. $g$. Solution $e$ plus 4 parts of acetic acid; for glandular tissues. $h$. Corrosive sublimate I part, phosphoric acid I part, water 30 parts; for cartilaginous tissues. Picrocarmin. Recommended by Ranvier as a medium for the examination of fresh tissues. Carnoy finds that cells live in it for a time, but finally become gorged with water and deteriorate. Potassium Acetate. A mounting-fluid for sections stained with anilin dyes. Dissolve by gentle heat $250 \mathrm{gm}$. of potassium acetate in IOO c.c. of distilled water. A nearly saturated solution is also employed. Let a drop flow under the cover-glass, and in 24 hours close the mount. Ripart and Petit's Fluid. A preserving medium for delicate, fresh tissues. Its fixing action is enhanced by the addition of a drop of osmic-acid or corrosive-sublimate solution, and it may be used in combination with methyl-green. It is prepared by dissolving $0.2 \mathrm{gm}$. each of copper acetate and crystallized copper chlorid in glacial acetic acid $0.5 \mathrm{gm}$., camphor-water and distilled water each 50 c.c. Seaman's Glycerin-jelly. Dissolve to parts of gelatin in water to the consistency of stiff jelly at the temperature of the room; add I part of glycerin and a little camphor-water. Filter through muslin, and add a little alcohol. Stephenson's Mercuric Iodid and Potassium Iodid. A saturated solution of these substances has an index of 1.680 , the highest of any known aqueous fluid. Tissues are well preserved in this medium, but a precipitate forms in it which ruins the preparations. III. REsinous MEdIA. Canada Balsam. Evaporate the balsam in a water-bath to dryness, and dissolve in an equal volume of xylol, 
benzol, toluol, chloroform, or turpentine. Filter through paper and keep in a "capped " bottle. If it gets too thick, dilute by adding more of the solvent employed. Colophonium. A solution in turpentine is recommended by Kleinenberg. This medium sets very slowly, and so affords ample time for arranging objects in it. Alcohol must not be used as a solvent, as in time it throws down a precipitate. Dammar. The menstrua are the same as for Canada balsam, and the solutions are prepared in the same way. A solution in a mixture of benzol and turpentine is recommended lyy Flemming and Pfitzner. Oil of Cedar. This medium soon sets hard enough to hold the cover in place, and so obviates the necessity of sealing the mount, except for immersion-work. See Clearing Agents. Seiler's Alcohol Balsam. Evaporate Canadabalsam todryness in a water-bath; dissolve while warm in warm absolute alcohol, and filter through absorbent cotton. Venice Turpentine. Vosseler recommends this medium as possessing certain advantages over Canada balsam and dammar. The turpentine is mixed with an equal volume of 96 per cent. alcohol, allowed to stand in a warm place for three weeks, and then decanted. Sections may be mounted in this medium without previous clearing in an essential oil, and it is said that stains are permanent in it. Its index of refraction being lower than that of the media already named, it gives better definition to the delicate details. Xylol-balsam. See Canada Balsam.

\section{FIXATIVES}

To facilitate the staining and mounting of sections, various preparations are used to cause them to adhere to the slide. The following include the more important fixatives and methods of procedure. I. AQUEOUS Sections. Fol's Gelatin Method. Dissolve 4 $\mathrm{gm}$. of gelatin in 20 c.c. of glacial acetic acid by means of the water-bath and agitation. Add to 5 c.c. of this solution 70 c.c. of 70 per cent. alcohol and $I$ to 2 c.c. of 5 per cent. aqueous solution of chrome-alum. Pour this preparation on the slide and allow it to dry. Immerse the slide in water containing the sections, arrange them on it, and remove it. This method is applicable to sections made under water. II. Celloidin Sections. Apáthy's Oil of Bergamot Method. Cut the sections with a knife anointed with vaselin and wetted with 95 per cent. alcohol and float them on bergamot-oil. Before they sink, push each one, by means of a needle, into place on a piece of tracing paper dipped in the oil. When the desired number are in position, the paper is drained, dried on the under side with blotting-paper, turned over, and gently pressed down on the slide. Remove the paper by rolling it up from one end; the sections remain adherent to the slide. The remaining bergamot-oil may be removed by cigaret-paper. Apathy's Series-on-the-Knife Method. The knife is evenly rubbed with yellow vaselin and moistened with 70 to 90 per cent. alcohol. The sections as they are cut, are drawn with a needle to a dry part of the blade, and arranged in rows, so that the celloidin of one section overlaps that of the next. When a series has been completed, the sections are dried by laying blotting-paper upon them and then painted over with the thickest celloidin solution used for embedding. This is allowed to evaporate for five minutes in air, and then wetted with 7 o per cent, alcohol, which hardens the celloidin into a continuous lamella which can be readily detached by means of a scalpel. Pregl's Acetone-celloidin Method (Sternberg). When not embedded in paraffin, the sections, completely dehydrated, are taken out of absolute alcohol on a thin cover-glass, upon which they are extended; a piece of filter-paper is applied to the side of the cover-glass to absorb the alcohol, and before the section is completely dry a drop of acetone-celloidin is placed upon it by means of a glass rod. The coverglass is now moved about in the air to promote rapid evaporation of the alcohol, and then placed in water. The sections remain attached to it. The acetone-celloidin solution is prepared by adding celloidin in small, dry pieces to acetone until a concentrated solution is obtained. A large drop of this added to 5 c.c. of absolute alcohol makes a suitable solution for use. This must be kept in a glass-stoppered bottle, and be frequently renewed, as it absorbs moisture from the air. The acetone obtained from dealers must be dehydrated by adding red-hot copper sulphate. Summers' Ether Method. After placing the sections in 95 per cent. alcohol for a minute or two, arrange them on the slide and pour over them ether vapor from a bottle partly full of liquid ether. This softens the celloidin and makes it perfectly transparent. The slide may now be placed in 95 per cent. alcohol, and the sections will be firmly fixed to it. Weigert's Method. This method consists in bolding the series between two adherent films of celloidin. A glass plate of sufficient size to accommodate the sections, cleansed with ether and alcohol, is coated with a thin film of celloidin and left to dry. The sections, as they are cut, are taken off on a strip of tissue-paper which has been laid upon a piece of blotting paper wet with 80 per cent. alcohol. When the series is complete the tissue-paper is lifted and turned, section-side down, on the celloidin film on the glass plate; the tissue-paper is then removed, and any remaining alcohol absorbed with bibulous paper. Another film of celloidin is then poured over the sections, and after a short exposure to the air, the plate is immersed in water, section-side up. In a short time the film enclosing the sections will become detached and float to the surface. Remove it on tissue paper, and stain, either whole or in parts, in the usual way. The plate, with the adherent films, may, if desired, be preserved in 80 per cent. alcohol. III. PARAFFIN SECTions. Flögel's Gum Method. To a filtered solution of I part of gum arabic in 20 parts of water, add a little alcohol to prevent mold. Pour this preparation over perfectly clean slides, and drain. Sections $\frac{1}{100}$ $\mathrm{mm}$. in thickness may be placed on the wet gum surface and floated to the proper position-a good method, when the slide is not subsequently treated with aqueous solutions. Frenzel's Gum Method. To a thin mucilage of gum arabic dissolved in water add an aqueous solution of chrome-alum, and then a little glycerin and a trace of alcohol. Put a little of the preparation on the slide, place the sections in position, and heat for I 5 minutes at a temperature of 30 to $45^{\circ} \mathrm{C}$., which renders the gum insoluble. This gum has the advantage of not reacting to the majority of staining fluids. Safranin and fuchsin should be avoided. Gaule's Methods. Moisten the slides with water or dilute alcohol, place the sections in position, remove the surplus fluid by means of bibulous paper, and dry in a thermostat at $50^{\circ} \mathrm{C}$. for 24 hours. Sections so treated are then heated for a moment above the melting-point of paraffin, which fixes them securely to the slide. Gaule's xylol method is as follows: Place the sections on a slide moistened with alcohol; warm slightly, cover, and run under a mixture of equal parts of Canada balsam and xylol. Or, refill the cell daily as the xylol evaporates, and complete with xylol-balsam. Mayer's Albumen Method. Mix equal volumes of fresh filtered white of egg and 
glycerin, and add a little thymol as a preservative. Paint a thin, even film on the slide; on this arrange the sections, and warm just enough to coagulate the albumen $\left(70^{\circ} \mathrm{C}\right.$.). A very useful fixative for sections that are to be stained on the slide. Acids, alkalies, and picrocarmin must be avoided, as they dissolve the albumen. Ohlmacher's Modification. Apply a thin, smooth layer of Mayer's albumen to the slide, and on this drop a little distilled water, which will diffuse evenly over the albumen. Arrange the sections in position, and heat gently over a spirit-flame until they flatten out, being careful not to melt the paraffin. Drain off the water, dry the slide with bibulous paper, and evaporate the remaining moisture in an oven at a temperature below the melting-point of paraffin. Obregia's Method. Coat slides with a solution prepared as follows: Mix $30 \mathrm{c}$. c. of a syrupy solution of confectioners' sugar, made with distilled water, 20 c. c. of absolute alcohol, and Io c. c. of a clear, syrupy solution of pure dextrin in distilled water; put them aside to dry. After 2 or 3 days, when the surface is just sticky to the moistened finger, arrange the sections in position, and heat for a few minutes; remove the paraffin with xylol, wash with alcohol, and then cover with a 3 per cent. solution of photoxylin in a mixture of equal parts of absolute alcohol and ether. Leave the slides to evaporate in the horizontal position, cut the sheet of collodion into ribbons, float them off in water, and proceed as in Weigert's method. Schällibaum's Collodion Method. Shake up one part of collodion with 3 to 4 parts of clove-oil. Apply this mixture thinly on the slide; place the sections in position, warm over a spirit-lamp until the oil collects in drops between the sections and the paraffin is melted; then hold the slide to the lips, blow upon it vigorously, and the paraffin and oil will be scattered, leaving the sections dry and securely fixed. This method is recommended for stained sections. The Shellac Method. A filtered solution of bleached, white shellac in absolute alcohol is spread over the slide with a glass rod. When dry, apply a very thin layer of creasote, which gives a sticky surface for the sections, then heat on a water-bath for 15 minutes at the melting-point of paraffin, allow the slide to cool, and the sections will be fixed.

\section{FIXING AND HARDENING FLUIDS.}

Reagents used to preserve the structural elements of tissues. Their action consists in the rapid coagulation of certain constituents of tissue-albuminoids, gelatin, mucin-by which their histologic and cytologic details are fixed in the form and attitude they normally had in life, and are also hardened so as to resist any change of form from the action of other reagents with which they may subsequently be treated. Acetic Acid. A valuable fixative of wide application, and especially useful for fixing very contractile objects, such as are found in the Vermes and Coienterata. Pour a liberal quantity of glacial acetic acid over the organism, and in five or six minutes wash in 50 per cent. alcohol, changing it frequently and gradually increasing the strength. Acidulated Alcohol. Used for the preparation of marine animals which are to be preserved in alcohol. It is a mixture of 97 volumes of 90 per cent. alcohol (in which is dissolved a little picric acid) and 3 volumes of pure hydrochloric acid. The acid facilitates penetration by preventing the precipitation of the salts of sea-water. After penetration, the organism is washed in 90 per cent. alcohol until the yellow stain of the picric acid no longer appears. Alcohol. An excellent fixing medium, suitable for all tissues, except those of the central nervous system and those undergoing fatty infiltration or degeneration. It is also used to harden and preserve objects that have been fixed in other fluids. As a preservative it is not without defects, as it alters the structure of tissues by continuously dehydrating their albuminoids. Toluol, ether, and xylol are recommended as substitutes (Kultschitzky). As a fixing agent alcohol is usually employed in gradually increasing strengths, beginning with 50 or 70 per cent. Absolute Alcohol. One of the most penetrating fixing agents, which has the advantage of preserving the structure of glands and of nuclei. It should be employed in large quantities. Hydration may be prevented by suspending in the alcohol strips of gelatin (Lowrie). After fixation, preserve the object in go per cent. alcohol. Mayer recommends boiling absoIute alcohol for fixing certain Arthropoda. Absolute alcohol is prepared in Ranvier's laboratory by adding anhydrous copper sulphate to 95 per cent. alcohol. Pulverized copper sulphate is heated to red heat, in order to drive off the water of crystallization; when cool, the white powder is placed in a wide-mouthed bottle, holding about a liter, and three-fourths full of alcohol. The bottle is quickly closed and the whole shaken. After standing a day or more-with occasional shakings-it is decanted, treated with fresh copper sulphate, and the operation repeated until the copper sulphate no longer shows a blue color on contact with the alcohol. As a test, a drop of the alcohol thus dehydrated may be mixed with a drop of turpentine on a glass slide and examined under the microscope; if no particles of water are to be seen, the alcohol is absolute enough for all practical purposes. Methylated Spirit contains a little methyl-alcohol, and is nearly as strong as absolute (ethyl) alcohol, and its strength may be increased by placing in it some well-dried potassium carbonate, which absorbs any water present in it. "One-third Alcohol" (Ranvier's Alcohol). This classic reagent consists of two parts of water and one part of alcohol of $36^{\circ}$ Beaumé, which contains nearly 89.6 per cent. absolute alcohol. It is a very mild fixative, and is chiefly used for extemporaneous and dissociation preparations. Rectified Spirit contains 84 per cent. of alcohol and 16 per cent. of water. Altmann's Nitric Acid. Particularly useful for preserving mitotic figures, nuclei, embryonic tissues, and the retina. A 3 per cent. pure acid is used, the solution having a sp. gr. of I.O2. Immersion for a quarter to half an hour is sufficient for blastoderms and small embryos; two to four hours are required for fixing larger objects. Wash out thoroughly and harden in strong alcohol. Any staining process may be used. Broca's Fluid. Used for the preservation of braintissue. It consists of zinc chlorid, ro grams, and alcohol, go per cent, , Ioo c.c. After two or three days, transfer the tissue to 95 per cent. alcohol. Carnoy's Fluid. One of the most penetrating and rapid of fixatives, applicable to tissues in general, and useful for the study of karyokinesis in the ova of Ascaris. First formula : glacial acetic acid I part, absolute alcohol 3 parts. Second formula : glacial acetic acid I part, absolute alcohol 6 parts, chloroform 3 parts. The chloroform is said to render the action of the mixture more rapid. Chromic Acid. Used in aqueous or alcoholic solution in strengths varying from 0.1 to 2 per cent. Weaker solutions are used for nerve-tissue. Wash out several hours in running water. If the object be preserved in alcohol, it must be protected from the light, or a precipitate will be thrown down on its surface. The brownish-green color of objects fixed in chromic acid may be removed by treating them with hydrogen dioxid. A 0.02 per cent. solu- 
fion is recommended for macerating nerve-tissue and non-striated muscle-tissue, a cube of $5 . \mathrm{mm}$. requiring about 24 hours' immersion in Io c.c. of the medium (Ranvier). Copper Sulphate. Recommended by Bedot for the preparation of delicate pelagic animals. A large volume of a 15 or 20 per cent. solution is added to the sea-water containing the animals. Fixation occurs in a few minutes. A few drops of nitric acid are added, and the whole is left for 4 or 5 hours. The animals are then hardened in a large volume of Flemming's fluid, in which they should remain for 24 hours, and are preserved in alcohol. Corrosive Sublimate. A most excellent reagent, generally applicable, useful particularly for fixing glands and glandular structures. Saturated aqueous and alcoholic solutions are usually employed. The tissues turn white when fixed. All the corrosive sublimate must be washed out in alcohol, or the sections will be sprinkled with crystals of the salt. The hardening is completed in alcohol. Glass, wood, or platinum should be used in manipulating objects immersed in this reagent. Sections may be stained with any of the usual reagents. Cox's Sublimate Solution. A combined hardening and impregnating fluid, consisting of 5 per cent. solutions of potassium bichromate and mercuric chlorid each 20 parts, potassium chromate 16 parts, water 30 or 40 parts. The reaction should be only slightly acid. The pieces are left in this solution two or three months, then cut with a freezing-microtome. The sections are put in 5 per cent. solution of sodium carbonate for an hour or two, washed in water, then in oil, and covered by a rapidly drying resin, like sandarac. This coating may be covered by castor-oil, and the cover-glass pressed down. The preparations are not permanent in balsam or dammar. Davidoff's Fixing Fluid. This is a mixture of a saturated solution of corrosive sublimate 75 c.c. and glacial acetic acid 25 c.c. It is useful for ova, which should remain in it for a half to one hour; then wash in water and transfer to alcohol, gradually increasing its strength. Delafield's Fluid. A fixing agent suitable for tissues having delicate structural elements. It has the following composition: I per cent. osmic acid solution Io c.c., 0.2 per cent. chromic acid solution IOO c.c., 95 per cent. alcohol roo c.c., acetic acid I c.c. Erlicki's Fluid. One of the best hardening agents for large objects, and more rapid in its action than Müller's fluid. It is composed of potassium bichromate 2.5 parts, copper sulphate I part, water Ioo parts. The formation of mold is prevented by adding a little camphor or naphthalene. Ferric Chlorid. Objects are fixed for a short time in a dilute alcoholic solution, washed in alcohol, and stained in pyrogallol. This process is recommended as a general zoölogic method, but chiefly for Infusoria and other ciliated organisms, and for its selective action on nerve end-organs. Fish's $(P . A$.) Liquid. This is found to preserve the shape, to harden, and to differentiate brain-substance. It contains alcohol (95 per cent.) 200 c.c., water 800 c.c., glycerin 75 c.c., zinc chlorid $50 \mathrm{gm}$. The alcohol and water should be mixed first, so as to get a strength of 22 - per cent., as determined by the alcoometer. More alcohol may be required, but the entire quantity of dilute alcohol should not exceed I000 c. C. Then add the glycerin and zinc until the specific gravity of the mixture is $\mathbf{1 . 0 4}$. When the brain is introduced, it should rest just at the surface, and the vessel should be deep enough to prevent it touching the bottom. Cotton may be laid over the top if any part projects. It is well also to inject the fluid into the cavities and blood-vessels daily for a week. After a few days the brain will sink, when, without removing it from the liquid, the pia is stripped off. Half of the liquid is now replaced by alcohol and the brain is steadied with cotton. After 2 days half of the lighter liquid is replaced by alcohol, and in 2 or 3 days more pure alcohol is used. Flemming's Fluid, rst Formula: Chromic acid $0.2 \mathrm{gm}$., glacial acetic acid o.I c.c., water I00 c.c. This is especially recommended for fixing the achromatic spindle-fibers in nuclei. 2d Formula: One per cent. chromic acid 45 c.c., 2 per cent. osmic acid 12 c.c., glacial acetic acid 3 c.c. This fixes small pieces $(2-3 \mathrm{~mm}$. thick) in from a few to twenty-four hours, and is useful for fixing the figures in cell-division and for many other purposes. A weaker solution is also used: One per cent. osmic and glacial acetic acids each Io c.c., one per cent. chromic acid 25 c. c., water 100 c.c. The second formula is the one generally known as Flemming's Fluid. Fol's Fluid. A modification of Flemming's fluid. It contains less osmic acid. To 2 c.c. of I per cent. osmic acid add 25 c.c. of I per cent. chromic acid, 5 c.c. of 2 per cent. glacial acetic acid, and 68 c.c. of water. Giacomini's Method of Preservation of the Brain consists of two stages. In the first stage the fresh organ, still enveloped in its membranes, is immersed in a saturated solution of zinc chlorid. In this it floats with a little of its surface above the fluid; and so, while its form is not interfered with by pressure, it must be turned two or three times a day, in order that all parts may be uniformly acted on. If the subject has been dead for some time, 600 grams of the solution may be injected through the carotids under slight pressure, so as to give a firmness to the somewhat softish brain before its removal. After 48 hours, the surface is hard enough to have the membranes removed. Let this be done without taking the organ out of the solution, or, if it be taken out, let it be put into water immediately, so that it may the less lose its form by pressure. After having been cleaned, let it remain in the solution till, as the hardening proceeds, it begins to sink no longer, and then remove it. At this stage it will be firm, slightly diminished in volume, the fissures a little opened, and the color whitish, unless the membranes have been left on too long, in which case the course of the large vessels will be stained of a rusty color from the blood pigment. It is now immersed in alcohol of commerce for not less than Io or 12 days, but it may be for an indefinite period; here it sinks, and so must be often turned, to avoid deformity by pressure on the bottom of the vessel, and it is well to renew the spirit 2 or 3 times-the oftener, the sooner the process is finished. After this immersion the consistence is greater, the size a little less, and the convolutions somewhat closer together. In the second stage the organ is immersed in glycerin of commerce, or with I per cent. of carbolic acid added. When first put in it floats, with some of its upper surface above the surface of the glycerin, but gradually becoming heavier as the alcohol evaporates, and glycerin is imbibed, it sinks more and more deeply till it is just level with the liquid-then it is to be taken out. In this part of the process, neither surface, color, consistence, nor volume is altered, but it becomes heavier. A brain should gain from I 50 to 200 grams in from twenty to thirty days, according to its volume. Now set aside for several days, till the surface is dry, and then cover it with several layers of gum mastic varnish, or, better still, marine glue, diluted with a little alcohol. This varnish is not to prevent evaporation-the glycerin does thatbut is simply as a protective against dust and injury. Hermann's Fluid. A modification of Flemming's fluid. Platinum chlorid is used instead of chromic 
acid; in other respects the formulæ are alike. Iodin. A good and rapid fixing agent for delicate tissues. Lugol's solution may be used, of which the formula is as follows: Iodin 4 parts, potassium iodid 6 parts, water 100 parts. Ranvier recommends a saturated solution of iodin in a saturated aqueous solution of potassium iodid, filtered, and diluted to a brown-sherry color. Johnson's (Lindsay) Fluid. Potassium bichromate, 2.5 per cent., 65 parts; 2 per cent. osmic acid 15 parts, 2 per cent. platinum chlorid 15 parts, acetic or formic acid 5 parts. Ten parts of a 5 per cent. solution of uranium nitrate may be added; this will prevent the tendency of the osmic acid to blacken and will give a delicate chestnut-brown tint. Klein's Fluid. This should be freshly prepared and kept in the dark. It is made by mixing 2 parts of 6 per cent. chromic acid with I part of methylated spirit. For hardening the intestine Klein recommends a 5 per cent. solution of neutral ammonium chromate. Kleinenberg's Fluid, Picro-sulphuric Acid. This reagent is especially adapted for fixing embryonic tissue and soft pathologic structures, as sarcoma and myxoma. it is prepared as follows: to roo c.c. of a saturated aqueous solution of picric acid add 2 c.c of strong sulphuric acid; after an hour filter, and to the filtrate add 300 c.c. of distilled water. A few hours to several days are required for fixation. Wash in warm alcohol to remove the acid. Kolossow's Fluid. Recommended for its great penetrating power. It consists of a 0.5 per cent. solution of osmium in a 2 or 3 per cent. solution of uranium nitrate or acetate. Kultschitzky's Fluid fixes tissues without causing the precipitation of the albuminoids, so likely to occur in solutions containing chromic acid. It is prepared by adding in excess finely powdered potassium bichromate and copper sulphate to 50 per cent. alcohol, and placing in the dark for 24 hours. At the moment of using, add a few drops of acetic acid, 5 or 6 to Ioo c.c. Fix objects for 12 to 24 hours in the dark, then treat with strong alcohol, and they are ready' for sectioning. Lang's Sublimate Solution. Used for fixing Planaria. Its composition is as follows: mercuric chlorid 5 grams, sodium chlorid 6 grams, acetic acid 5 c.c., water, roo c.c. The Planaria are placed on their backs and the fluid poured over them. After half an hour they are placed in 70 per cent., then in 90 per cent., and then in absolute alcohol. They are sufficiently hardened in two days. Lemon-juice. Recommended by Van Gehucten as a fixative for nuclei. . It should be fresh and filtered. Fix for five minutes, and wash out in water. Mercuric Chlorid. See Corrosive Sublimate. Merkel's Fluid. A delicate reagent, used for hardening fish ova, and consisting of equal volumes of 1.4 per cent. chromic-acid and $\mathbf{1 . 4}$ per cent. platinum-chlorid solutions. Several hours or days may be required for penetration. Prick the ova and wash in alcohol of 50 to 70 per cent. A few hours' immersion in this fluid will, it is claimed, effectually prevent blackening of objects fixed in osmic acid. Mưller's Fluid. This agent is very extensively used, as it penetrates well and hardens evenly. It has the following composition: potassium bichromate 2.5 parts, sodium sulphate $I$ part, water Ioo parts. The addition of a littie camphor, chloral, thymol, or naphthalene will prevent the formation of mold. The time required for hardening depends on the size of the object. This fluid diluted to 0.2 per cent. is used as a macerating agent. Osmic Acid. An aqueous solution is used in strengths varying from 0.05 to 2 per cent. The time required for fixing depends on the object and the strength of the solution, and varies from a few seconds for Infusoria in a 0.5 per cent. solution to 24 hours for tactile corpuscles in a per cent. solution. The osmium must be thoroughly removed by washing in water, as any remaining in the tissue in time over-colors it. Solutions of osmic acid must be protected from the light at all times. Fatty tissue should have the fat dissolved out by alcohol be fore immersion in osmic-acid solutions, or it may afterward be decolorized by turpentine. For delicate membranes osmic acid may also be employed in the form of vapor. As a macerating agent for the cortex cerebri (Rindfleisch), a o. I per cent. solution is used, and may be followed by dissociation in glycerin. A I or 2 per cent. solution is the best fixing agent for blood. Palladium Chlorid. Recommended by Cattaneo as the best fixative for Infusoria. It is prepared by dissolving Io grams in one liter of water containing 5 or 6 drops of hydrochloric acid. One or 2 minutes' immersion will suffice for the fixation of small objects. It is an impregnation reagent, and colors certain tissue-elements in various tones of brown. According to Schultze, it has a special faculty for penetrating tissues rich in connective tissue, and gives a better consistence than chromic acid or Müller's fluid. Paladino's Palladium Chlorid. Used to demonstrate the axis-cylinders in peripheral nerves. After hardening in potassium-bichromate solution place the tissue in a $0 . I$ per cent. solution of palladium chlorid, to which a little hydrochloric acid has been added; in 2 or 3 days transfer to a 4 per cent. solution of potassium iodid for $\mathbf{I}$ to 2 hours. Dehydrate and embed in paraffin. Perenyi's Fluid. An important embryologic reagent. It produces perfect fixation of segmentation-spheres and nuclei, and has the advantage that fuchsin, eosin, picrocarmin, and other stains may be dissolved in it. It is composed of Io per cent, nitric acid 4 parts, absolute alcohol and 0.5 per cent. chromic acid each 3 parts. Picro-nitric Acid. Mayer's formula. Water 100 c.c., nitric acid (25 per cent. $\mathrm{N}_{2} \mathrm{O}_{5}$ ) 5 c.c., and as much picric acid as will dissolve in the mixture. The properties of this fluid are similar to those of picro-sulphuric acid, and it has the advantage of not crystallizing lime-salts in tissues containing them. Eight c.c. of 25 per cent. hydrochloric acid may be substituted for the nitric acid, the mixture possessing the same properties and being known as picro-hydrochloric acid. Picric Acid. A fixing agent of great penetration, and, therefore, especially suitable for the preparation of chitinous structures. A saturated solution is employed. The time required for fixation varies from a minute to a day, and depends on the size of the object. Wash out in alcohol and stain in alcoholic solutions. Platinum Chlorid (Rabl). Objects are placed in an aqueous solution, I : 300 , for 24 hours, then washed with water and hardened in alcohol. Safranin or Delafield's hematoxylin may be used to stain. This reagent is valuable in the study of karyokinesis. It renders Pfitzner's granules and the longitudinal division of the elements plainly visible. Potassium Permanganate (Du Plessis). Useful for the study of isolated and very contractile cells, as spermatozoa. It is said to kill more rapidly than any other agent, 2 per cent. osmic acid not excepted. A saturated aqueous solution is used. It is also used for washing out over-staining with carmin, and in I per cent. solution as a mordant for anilin dyes (Henneguy), and for reducing silver impregnations. Rabl's Fluid, Especially useful for the study of mitosis and nuclei generally. It must be freshly prepared at the moment of using, and consists of 200 c.c. of 0.33 per cent. chromic acid and 4 or 5 drops of formic acid. Fix for 12 to 24 
hours, wash thoroughly in water, and harden in alcohol of gradually increasing strength. Sections may be stained in hematoxylin or safranin. Silver Nitrate. Used in the study of epithelia. Solutions of 0.5 to 2 per cent. are employed, and fix rapidly. Wash out in distilled water. Weak solutions do not interfere with subsequent staining

\section{INJECTION-MASSES.}

These are composed of a dye combined with some suitable substance, technically termed, respectively, the coloring-mass and the vehicle, and are used for injecting gland-tubes and blood-vessels. I. AQueous MAsses. Emery's Carmin. Add, with continual stirring, acetic acid to a Io per cent. ammoniacal solution of carmin until the color of the fluid is blood-red from incipient precipitation of the dye. The clear solution is poured off and injected cold, and the specimens are thrown at once in strong alcohol to fix the carmin. This fluid is for the injection of fishes. Letellier's Ammonium Vanadate and Tannin. Make a solution of ammonium vanadate in warm water and of tannin in hot water. For use, mix the two solutions according to the tint desired. The walls of vessels are stained black. Müller's Berlin Blue. Precipitate a strong solution of Berlin blue with 90 per cent. alcohol. The fluid is neutral and the precipitate finely divided. Taguchi's Indian Ink. Rub up on a hone Japanese or Chinese ink, until a fluid is obtained that does not run when dropped on thin blotting-paper or form a gray circle round the drop. Inject until the preparation appears black, and then put it into some hardening fluid, not pure water. This is useful for Invertebrata, lymphatics, and juice-canals. II. Cellordin MAsses. Schiefferdecker's Masses. For corrosion-preparations. I. Place pulverized asphalt in a closed vessel with ether for twenty-four hours, and shake occasionally. Pour off the ether into another vessel, and dissolve in it small pieces of celloidin until the solution is like the thicker fatty oils. The undissolved asphalt may be used to color fresh ether. 2. Vesuvianinbrozon. Dissolve celloidin in concentrated solution of vesuvianin in absolute alcohol. This color is not fast. 3. Opaque Blue. Add pulverized Berlin blue to celloidin dissolved in equal parts of absolute alcohol and ether. 4. Opaque Red. Rub up in a mortar pulverized cinnabar with a little absolute alcohol, and add the paste to celloidin dissolved in equal parts of absolute alcohol and ether. Too much pigment will make the injection brittle. Strain the mass through flannel wet with ether. Clear the syringes and nozzles with ether to free them from grease. Corrosion of the Preparations. Throw the injected organs into unrectified hydrochloric acid, and let them remain in it until all the soft parts are destroyed, changing the acid occasionally, if necessary. Wash under a slow stream of water, leave for some weeks in water, rinse, and put in glycerin or in equal volumes of glycerin, alcohol, and water. Artificial gastric juice is also excellent for corrosion. III. GELATIN MAsses. Brücke's Blue Mass. Take a Io per cent. solution of potassium ferrocyanid, and precipitate it with so much of a dilute solution of iron sesquichlorid that the weight of the dry chlorid employed shall be $\frac{1}{10}$ or $\frac{1}{8}$ that of the ferrocyanid. Wash the precipitale on a filter with the filtrate until only a clear-yellow liquid runs off, then wash with water until the water begins to be blue. Dry the precipitate, press it between blotting-paper in a press, break the mass in pieces and dry in the air. Carter's Carmin Mass. Rub up $4 \mathrm{gm}$. of carmin in a little water in a mortar, and add enough water to bring the measure up to 45 c.c. Add 8 c.c. of strong ammonia, and stir until the carmin is dissolved. Glacial acetic acid, 6 c.c., is then added, drop by drop, with continuous stirring, and finally the gelatin, 60 c.c. of a $I: 6$ solution in water. Fearnley's Modification: Cut up 7 $\mathrm{gm}$. of Coignet's gelatin, and soak it in 50 c.c. of water 4 to 5 hours. Rub up in a mortar with a little water $3 \mathrm{gm}$. of carmin, and add 6 c.c. of strong ammonia ; after standing for 2 hours, pour it in a bottle, rinsing the mortar with $30 \mathrm{c}$.c. of water. Place the gelatin and unabsorbed water on a water-bath to melt. Add about 6 c.c. of glacial acetic acid to the carmin solution (stop the acid when the color changes to crimson), and stir it into the gelatin. Cover the mass with methylated spirit, and keep it in a cool place. For use, dissolve it on a water-bath, and filter through fine flannel wrung out of hot water. Fol's Blue Mass. A Modification of Thiersch's Formula. a. To 120 c.c. of a cold saturated solution of iron sulphate add 300 c.c. of warm gelatin solution. $b$. To 600 c.c. of the gelatin solution add 240 c.c. of a saturated solution of oxalic acid, and then $240 \mathrm{c}$. c. of a cold saturated solution of potassium ferricyanid. Pour the first mixture gradually into the second, shaking vigorously, and warm for fifteen minutes over a boiling water-bath. When the mass has set, press it through netting into strings, wash in running water, and dry on prepared paper, without remelting. For use, swell the strings in cold water, and warm with enough oxalic acid for complete solution. Fol's Brown Mass. Soak $500 \mathrm{gm}$. of gelatin in 2 liters of water in which $140 \mathrm{gm}$. of salt have been dissolved. Melt the mass over a water-bath and add, gradually, with vigorous shaking, $300 \mathrm{gm}$. of silver nitrate in a liter of water. Press the mass out through netting, stir it up, in clear daylight, with a mixture of $1 \mathrm{I} / 2$ liters of a cold saturated solution of potassium oxalate and 500 c.c. of a cold saturated solution of iron sulphate. When the whole mass is black, wash for several hours, remelt, and pour on paper. Fol's Carmin Mass. Soak in water for a couple of hours one kilog. of Simeon's photographic gelatin, pour off the water, melt the gelatin over a water-bath, and add one liter of a solution of carmin made as follows: Dilute a strong solution of ammonia with 3 or 4 parts of water and add carmin to saturation, removing the excess by filtration just before adding the liquid to the gelatin. Add to the mass enough acetic acid to turn the dark-purple color to a blood-red hue, and when firm, cut it in pieces. Tie up the pieces in fine netting, and compress them with the hand under water acidulated with O. I per cent. of acetic acid. The mass is driven out in fine strings, which are washed for several hours in a sieve in running water, then remelted, and poured on large sheets of parchment-paper soaked with paraffin, and dried in an airy place. Separate the mass from the paper and cut into long strips. For use, soak them a few minutes in water and melt them over a water-bath. Frey's White Mass. Place I25 to I $85 \mathrm{gm}$. of a cold saturated solution of barium chlorate in a tall, glass cylinder, and add sulphuric acid very carefully, drop by drop. Allow the precipitate to settle for twelve hours; then decant almost all of the supernatant liquid. The remaining mucilaginous mass, containing the precipitate, is to be mixed with an equal part of concentrated gelatin solution. Injected organs may be preserved in chromic acid. Hoyer's Blue Mass. The filtered and washed precipitate of soluble Berlin blue is placed in a little water on a Graham's dialyzer, and the external water changed until the solution begins to pass through the parchment. After 
diluting, pass the solution through filter-paper. For injection the fluid may be used pure. It may also be combined with gelatin as follows: Warm the solution almost to boiling, and gradually add a warm, thin solution of gelatin until coagulation begins; then strain through wet flannel. Hoyer's Lead-chromate Mass. Filter through flannel I volume of a solution of gelatin, I : 4, and add I volume of a cold, saturated solution of potassium bichromate; warm the mixture almost to boiling, and add, gradually, I volume of a cold, saturated solution of neutral lead acetate, also warmed. Cool the mass to the body-temperature and inject at once. It flows so freely that even the lymphatics may be injected, and its intense color gives the vessels unusual distinctness. If the solution of lead acetate is added to a hot bichromate solution, an orange-red precipitate is obtained; if both the solutions are cold when mixed, the precipitate is bright-yellow. Hoyer's Silver-nitrate Yellow Mass. Mix with an equal volume of a 4 per cent. solution of silver nitrate a concentrated solution of gelatin, heat, and add a small quantity of an aqueous solution of pyrogallic acid, which reduces the silver in a few seconds. Add chloral and glycerin as in Hoyer's formula for carmin gelatin. The mass is brown in the larger vessels and yellow in the capillaries. It does not change in alcohol, chromic or acetic acid, or potassium bichromate. Neutralization of a Carmin Mass. Ville's Method. The traces of acid mechanically retained in commercial gelatin are eliminated by placing it in a stop-cock funnel and washing for an hour or more with running water. To test the reaction of the coloring-mass, moisten a strip of dichroic litmus-paper in distilled water, and hold as closely as possible to the injection-mass (which is kept melted on a water-bath) ; it becomes blue at first, but as the acid is added the reaction is less evident, and when the change of color appears very slowly, the addition of the acid should cease. Dichroic Litmuspaper is prepared as follows: A tincture obtained by decoction of cake-litmus is slightly acidified with an excess of sulphuric acid, then heated and agitated with an excess of precipitated barium carbonate and filtered. The solution is exposed to the air in wide vessels until the blue color has given place to a reddish tint, when strips of white, unsized paper are dipped into it and dried in the shade on stretched threads, in a place free from ammonia vapor. Ranvier's Blue Mass. Soak $5 \mathrm{gm}$. of Coignet's gelatin for one hour in distilled water, wash it, and place it in a beaker on a water-bath; when it is dissolved add $\mathbf{1 2 5}$ c.c. of a saturated aqueous solution of Brücke's blue, previously heated on a water-bath, and stir vigorously with a glass rod, which should show no granules when withdrawn. Filter through flannel. The precipitate thrown down by the gelatin disappears if the heating be continued. Ranvier's Carmin Mass. Mix in a stoppered bottle 2 to $5 \mathrm{gm}$. of pure carmin with a little distilled water; add ammonia, drop by drop, until the liquid is transparent, and shake. Place 5 gm. of Coignet's gelatin in distilled water for one hour, wash it in water, and heat it in a beaker over a water-bath. When the gelatin is dissolved, add, stirring briskly, the solution of carmin. Make a solution of 2 parts of distilled water to I part of glacial acetic acid, and pour it, drop by drop, into the mass, stirring with a glass rod. Stop adding the acid when the ammoniacal odor disappears and there is a faint acid scent. Filter the mass through new flannel. IV. Glycerin Masses. These are used cold. The addition of amyl nitrite to the mass just before using is advised, to counteract its tendency to stimulate con- traction of the arteries. The animal may also be anesthetized with a mixture of ether and amyl nitrite. Beale's Acid Blue Mass. Dissolve $0.5 \mathrm{gm}$. of potassium ferrocyanid in 30 c.c. of glycerin, and Io drops of tincture of iron sesquichlorid in $30 \mathrm{c.c}$. of glycerin, and add the latter solution, drop by drop, to the former. Then add $30 \mathrm{c} . \mathrm{c}$. of water and 3 drops of strong hydrochloric acid. If desired, $8 \mathrm{c}$. c. of alcohol may be added. This is said to be an admirable formula. Beale's Blue Mass. Dissolve $1.8 \mathrm{gm}$. of potassium ferrocyanid in $30 \mathrm{c.c}$. each of water and glycerin. Add to 30 c.c. of water. 4 c.c. of tincture of ferric chlorid. Gradually, and with agitation, add the iron solution to the potassium solution. Then add slowly $30 \mathrm{c} . \mathrm{c}$. of alcohol and $60 \mathrm{c}$. c. of water, the mixture being constantly shaken. Injected specimens should be preserved in acidulated glycerin, or the color may fade. Beale's Carmin Mass. Dissolve in a little water, with about 5 drops of ammonia, $0.4 \mathrm{gm}$. of carmin, and add 15 c.c. of glycerin; then add gradually, with agitation, another I5 c.c. of glycerin with 8 or 10 drops of acetic acid or hydrochloric acid. Test with blue litmus paper and add acid until the reaction is decidedly acid. Add another 15 c.c. of glycerin, 5 c.c. of alcohol, and 25 c.c. of water. Robin's Cold-flowing Masses. r. Carmin. Rub up $3 \mathrm{gm}$. of carmin in a mortar with a little water and enough ammonia to dissolve the carmin, add 50 c.c. of glycerin, and filter. Add a Io per cent. solution of acetic acid in glycerin, drop by drop, until a slightly acid reaction is obtained. 2. Prussian Blue. (a) Potassium ferrocyanid (sat. sol.) $90 \mathrm{c} . \mathrm{c}$., glycerin 50 c.c. ; (b) liquor ferri perchloridi, $80^{\circ}, 3$ c.c., glycerin 50 c.c. Mix $a$ with $b$ slowly. 3. Green. A saturated solution of potassium arsenite 80 c.c., and glycerin 50 c.c., is mixed with a saturated solution of copper sulphate $40 \mathrm{c.c}$, and glycerin $50 \mathrm{c} \mathrm{c}$. 4 . Mahogany-red. (a) Potassium ferrocyanid (concent. sol.) 20 c.c., glycerin 50 c.c.; (b) copper sulphate (concent. sol.) 35 c.c., glycerin 5o c.c. Mix $a$ and $b$ slowly, with agitation, and add to the vehicle at the moment of injecting. 5. Yellow. (a) Cadmium sulphate (sat. sol.) 40 c.c., glycerin 50 c.c.; (b) sodium sulphid (sat. sol.) 30 c.c., glycerin 50 c.c. Mix a with $b$, with constant shaking. V. VEHICLES AND Other MAsses. Bjeloussow's Gum Arabic Mass. Make a saturated solution of borax in water, and a syrupy solution of gum arabic. Mix the two, using 2 parts of the latter to I part of the former. Rub up the mass with distilled water, added gradually, and press through a fine cloth, repeating this until the mass is free from clots. It should coagulate in alcohol, and swell to twice its original volume. It must not be combined with cadmium or cobalt. Cold-blooded animals may be injected while alive. Cadmium Mass. a. Forty c.c. of a saturated solution of cadmium sulphate and 50 c.c. of glycerin. b. Thirty c.c. of a saturated solution of sodium sulphid and 50 c. c. of glycerin. Mix the two solutions with agitation and combine with 3 volumes of vehicle. Copper Ferrocyanid Mass. $a$. Twenty c.c. of a strong solution of potassium ferrocyanid and 50 c.c. of gly. cerin. b. Thirty-five c.c. of a strong solution of copper sulphate and 50 c.c. of glycerin. Mix the solutions, with agitation. Combine with 3 volumes of vehicle at the moment of using. Fol's Metagelatin Vehicle. To a solution of gelatin add a slight proportion of ammonia, and after heating several hours the mixture no longer coagulates on cooling. This vehicle may be thinned by the addition of weak alcohol, and coloring masses added. Its advantage is that it obviates the necessity of warm injections. The 
injected preparations are thrown into strong alcohol or chromic acid, which sets the mass. Hoyer's Oilcolor Masses. Mix with 30 parts of lavender, fennel, thyme, or rosemary oil, 5 parts of artists' Berlin blue oil-color, rubbed up with 5 parts of thickened linseed-oil. Let the mixture stand 24 hours in a closed vessel; then decant. Shake before using. This is useful for injecting the vessels of the spleen and other structures difficult of injection. Hoyer's Shellac Mass. Place in a wide-necked flask a quantity of good shellac, with enough 80 per cent. alcohol to cover it. After 24 hours, warm it on a water-bath, to complete the solution; cool, dilute with alcohol to a thin syrupy consistence, and strain through thick muslin. Color the solution with anilins in filtered concentrated alcoholic solution. Cinnabar may be used for corrosionpreparations. Berlin blue and yellow arsenic sulphid are useful; both yield a green color. The pigments should be rubbed to fine powder with water, and alcohol added. When the mixture has settled, pour off the dilute and add strong alcohol. By shaking the flask the coarser particles settle; pour off the fluid containing the finer ones, add it to the shellac solution; and strain through muslin. Hydrochloric acid does not attack this solution; hence it is useful for corrosionpreparations. Joseph's White-of-egg Mass. Take filtered white-of-egg and dilute it with I to 5 per cent. of carmin solution. This mass remains liquid when cold. It coagulates when immersed in dilute nitric, chromic, or osmic acid, is transparent, and indifferent to reagents. It is useful for Invertebrates. Robin's Gelatin Vehicles. I. Soak I part of "colle de Paris" gelatin in ro parts of cold water; heat in a water-bath, and add 2 per cent. of chloral as a preservative. 2. Dissolve in a water-bath $50 \mathrm{gm}$. of "colle de Paris" gelatin in $300 \mathrm{gm}$. of water containing a little arsenious acid; add a few drops of carbolic acid and $150 \mathrm{gm}$. of glycerin. This does not keep as well as the pure gelatin vehicle. Scheele's Green Mass. $a$. Eighty c.c. of a saturated solution of potassium arseniate and 50 c.c. of glycerin. $b$. Forty c.c. of a saturated solution of copper sulphate and 50 c.c. of glycerin. Combine the two solutions with three volumes of the vehicle.

\section{STAINING OF CONNECTIVE AND OTHER} TISSUES.

Areolar Tissue. Inject hypodermatically into the subcutaneous tissue of a dog or rabbit a $\mathbf{I}$ : 1000 solution of silver nitrate. With a pair of curved scissors snip off a little of the edematous tissue, and stain with picrocarmin for from Io to 12 hours in a moist chamber. The fibrous and cellular elements are then brought into view by treating with glycerin slightly acidulated with formic acid. Bile-capillaries. Golgi"s Method. Fix small cubes of liver 3 to 4 days in a mixture of 4 parts of a 3 per cent. solution of potassium bichromate and I part of a I per cent. osmic acid; then place in a 0.75 per cent. solution of silver nitrate for two days, wash in distilled water, and harden in alcohol. Section and mount in balsam. The capillaries appear as a black network on a yellow ground. Bone. I. Flemming's Method. Soak sections of decalcified bone in water, and place in a drop of water on a glass plate; remove the excess of water with bibulous paper and cover with another glass plate to prevent rolling; place the whole in a dish and cover with alcohol. In half an hour the sections will be fixed and flat. Place in absolute alcohol. To mount, wash in fresh alcohol, then in ether; place the sections on glass, cover with two thicknesses of blotting-paper and a glass plate, and dry for a day in the air or in an oven. Put a drop of melted balsam on a slide and another drop on a cover-glass ; place the section on the slide, cover, put on a clip, and warm. 2. White's Method. Suitable for osseous or dental tissue. Sections ground moderately thin are soaked in ether for 24 hours, then placed for 2 or 3 days in a thin solution of collodion stained with fuchsin, then hardened in alcohol, ground to the requisite thinness between two plates of ground glass, with water and pumice powder, and mounted, dry, in thick balsam. The stained collodion is prepared by dissolving fuchsin in methylated spirit and adding the ether and pyroxylin. 3. Vivante's. Method. Place very small pieces of young bone for 8 days in Müller's fluid, then in the osmium-bichromate mixture, then in silver solution. After impregnation decalcify for 20 days in von Ebner's fluid; then wash in water, place in a solution of sodium carbonate, and embed in paraffin. Cartilage. I. Ranvier's Method. Place sections of fresh cartilage for 24 to 48 hours in a few c.c. of Ranvier's purpurin solution (see Staining Reagents), wash in water, and mount in glycerin. The nuclei are stained, the matrix remaining almost colorless, 2. Rub the cartilaginous end of the freshly excised femur of a frog with a stick of silver nitrate, and expose to sunlight. Section, and mount in Farrant's solution. The matrix is stained brown, and the apparently' empty spaces contain the cells, which are too transparent to be readily seen. Columnar Cells. Wash a piece of the mucosa of the small intestine of a cat in distilled water, place for Io minutes in 0.5 per cent. silver-nitrate solution, and silver in the usual way. Harden in alcohol, detach the epithelium, mount in glycerin. A view is obtained of the free ends of the cells with the cement-substance between them as "silver lines," and also of the open mouths of the gobletcells. Cornea. Klein's Method. Remove from a living cornea, by brushing, the conjunctival epithelium, and rub the corneal surface with a stick of silver nitrate; in half an hour detach the cornea, and examine it in distilled water. Negative images of the corneal cells are thus obtained. To obtain positive images, treat according to Ranvier's gold chlorid lemon-juice method (see Staining Reagents, Metallic Stains). Rollett's Method. Immerse a fresh cornea in aqueous humor, place it in a moist chamber, and expose to the action of iodin vapor; when brown, peel off the epithelium and examine. A good method, the result being almost equal to that of the gold method. Corpuscles of Grandy. Remove the skin and papillæ from the margins of the fresh beak of a duck, and put pieces into 50 per cent. formic acid for 20 minutes, or until transparent; remove the corneous layer of epithelium, rinse in water, and treat with gold chlorid, according to Pritchard's method (see Staining Reagents, Metallic Stains). The same method may be used for the corpuscles of Herbst. Elastic Tissue. I. Martinotti's Method. Fix for 3 weeks in 2 per cent. chromic acid, wash, and stain 48 hours in 5 per cent. Pfitzner's safranin solution (see Staining Reagents). The elastic fibers appear of an intense black, the other tissues showing the usual tints of safranin staining. 2. Unna's Orcein Method. Dissolve O. I gm. of orcein (Grübler) in 20 gm. of 95 per cent. alcohol and $5 \mathrm{gm}$. of water; dissolve $0.1 \mathrm{gm}$. of strong hydrochloric acid in a like mixture of alcohol and water. Take a number of watchglasses, and pour ro drops of the stain in each; add 5 drops of the acid mixture to the first glass, 6 to the next, and so on, increasing the proportion by one drop, until all are acidulated. In each glass place $I$ or 2 sections, and stain 12 hours. Examine in a drop of glycerin; the elastic fibers appear a shiny brown on a lighter ground. Epithelium. Kromayer's Method. 
Stain sections of skin hardened in Müller's fluid for 5 minutes in a mixture of equal parts of anilin-water and concentrated aqueous solution of methyl-violet; wash in water, immerse for a few seconds in Gram's solution, wash again in water, dry with filter-paper, and differentiate in a mixture of $I$ part of anilin to 2 parts of xylol, and then place in pure xylol. This process demonstrates the "intra-cellular and intercellular fibrils" of epithelia. Mitrophanow's Method. For the study of prickle-cells and intercellular canals. Wash the tail of an axolotl larva in distilled water: immerse it for an hour in 0.25 per cent. gold-chlorid solution containing one drop of hydrochloric acid to about 5 c. c. ; wash, and reduce in a mixture of $I$ part formic acid and 6 parts water. Goblet-cells. Scrape the mucous surface of the stomach of a frog after hardening for 24 hours in dilute alcohol, and press the scrapings between two cover-glasses. Allow the film adhering to each glass to dry, and then stain with the Ehrlich-Biondi fluid. Inner Ear. Open the cochlea in Flemming's solution, and fix 4 or 5 hours: decalcify, if necessaiv, in $\mathbf{I}$ per cent. palladium-chlorid solution. Make paraffin sections and stain with Renaut's eosin-hematoxylin, or with safranin. Isolated Mucous and Demilune Cells. Place small fragments of the fresh submaxillary gland of a dog in 5 per cent. ammonium chromate for 4 to 6 days; then tease a small piece in the same fluid. Each isolated mucous cell has its fibrillar network, a spheric nucleus embedded in protoplasm, and what was the attached end of the cell prolonged into a process. "Mastzellen." Schiefferdecker's Method. Place a piece of the mesentery of a rat in a solution of gentian-violet in anilin-water for 24 hours; rinse in water, decolorize in acid alcohol, rinse again in water, counterstain with carmin, and mount in balsam. The nuclei appear red, the granules blue. See Staining of Blood, Ehrlich's "Mastzellen." Pacinian Corpuscles. Harden a piece of skin in alcohol or osmic acid. Stain sections in picrocarmin, safranin, or hematoxy lin, or stain in the mass with borax-carmin. Plasmacells. I. Nordmann's Method. Stain sections in a solution of vesuvin containing 4 or 5 per cent. of hydrochloric acid; after a few minutes' immersion, remove and dehydrate in absolute alcohol. 2. Unna's Method. Add 10 to 15 drops of a solution of methylene-blue $I$ part, caustic potash 0.05 parts, in distilled water 100 parts, to a watch-glassful of anilin-water; stain sections of tissue hardened in alcohol for several hours; dehydrate in absolute alcohol, differentiate in cresol, rinse in xylol, and mount in balsam. Red Marrow. $\mathbf{I}$. Expose a cover-glass preparation of red marrow to osmium vapor for one or two minutes, stain in picrocar$\mathrm{min}$, and mount in glycerin. 2. Stain a cover-glass preparation for 24 hours in the Ehrlich-Biondi mixture, and mount in xylol-balsam. Retina. I. Remove the lens and the vitreous body, and inject into the cavity of the eye a mixture of equal parts of acetic acid and osmic acid, 2 per cent.; 3 minutes are required to fix. Wash in alcohol for I5 minutes, and place for 2 hours in Johnson's bichromate and platinic mixture (see Fixing Fluids); wash in running water, suspend for 2 days in a large volume of 2.5 per cent. potassium-bichromate solution, and pass through successive alcohols, beginning with 20 per cent. and ending with absolute. Stain in the Ehrlich-Biondi mixture, adding to it one-third of 20 per cent. solution of nigrosin. The nuclear cells appear pale-brown, the nucleoli a deeper-brown. The Müller fiber layers, the molecular layers, and the rods are stained a beautiful green. 2. (a) Kill in the dark a frog that has been kept in darkness 36 hours, and harden the eye in alcohol. (b) Kill another frog kept in direct sunlight for a few hours, and harden the retina in alcohol, Make sections, and stain with picrocarmin. The pigment-cells covering the rods of the retina in $a$ are retracted, while those in $b$ are pushed out between the segments of the rods. Pin the excised eyeball of a triton (without opening the bulb) to a cork, and expose to osmium vapor for Io minutes. Then divide it by an equatorial incision, and place the posterior pole in one-third alcohol for from 6 to Io hours, and then for the same length of time in picrocarmin; harden in osmic acid, embed and cut in soft paraffin. Salivary Glands. I. Heidenhain's Method. Harden small pieces for I hour in 75 per cent. alcohol, 5 hours in absolute alcohol, 24 hours in a fresh supply of absolute alcohol. Stain 6 to 8 hours in Io c.c. of a I per cent. aqueous solution of hematoxylin, and differentiate 6 to 8 hours in I per cent. solution of potassium bichromate. Embed in paraffin. The nuclei appear bluishblack, the cell-substance steel-gray, and the demilunes very distinct. 2. Schiefferdecker's Method. Stain sections, hardened as described, for half an hour in a watchglassful of alcohol, to which a few drops of a 5 per cent. alkaline alcoholic solution of eosin have been added; then place them for a few minutes in a I per cent. aque ous solution of anilin-green; dehydrate and mount. Tactile Corpuscles. Impregnate pieces of skin with gold chlorid, according to Löwit's method (see Staining Reagents, Metallic Stains), harden in alcohol, section, and stain in picrocarmin, hematoxylin, or purpurin. Tendon. I. Take the tendon of the anterior and superior insertion of the gemini muscles of a rabbit, remove as far as possible the adherent muscle-fibers, treat according to Ranvier's formic-acid-gold method (see Staining Reagents, Metallic Stains); after reduction of the metal scrape with a fine scalpel, to remove the muscle-tissue that masks the corpuscles of Golgi, which this method is intended to demonstrate. 2 . Harden a rat's tail, denuded of integument, for 3 hours in 5 per cent. corrosive-sublimate solution, and wash well in alcohol. Stain in bulk in borax-carmin, decalcify in dilute hydrochloric acid, embed in paraffin, and make transverse sections. Terminal Discs in Tongue of Frog. Curarize or etherize the frog, and inject through the abdominal vein a solution of methylene-blue I part in 800 parts of 0.6 per cent. saltsolution, and secure access of air to the mouth. Good results are also obtained by simply pouring the stain into the mouth. Test for Non-striped Muscle. Fix the tissue in a mixture of Io volumes of 90 per cent. alcohol and I volume of formic acid; wash, and stain for 24 hours in alum-carmin. The connective-tissue cells are swollen and unstained. The cytoplasm of the muscle-cells appears red.

\section{STAINING OF MICROÖRGANISMS.}

I. General Methods. Ahrens' Method for Bacteria in Milk or Fatty Substances. Dilute the milk with an equal quantity of water or, in case of denser substances, with a larger volume. Spread on a coverglass, and fix by heating after it has become dry. Stain for 5 minutes in 12 or I 5 drops of methyl-blue to which 3 or 4 drops of chloroform have been added. Then remove, and allow the chloroform to evaporate ; wash in water ; mount. Bizzozero's Method, for microörganisms in the vermiform appendix. Stain the preparation in a gentian-violet solution, wash in absolute alcohol for half a minute, transfer to Gram's solution for two minutes; then wash alternately in $\mathbf{I}$ per cent. chromic acid and absolute alcohol, allowing the preparation to remain half an hour or more in each fluid; repeat the chromic acid and alcohol, clear, and mount. The surplus stain must be well removed by the alcohol. EhrlichWeigert Method. Float the cover-glass (film-surface 
downward) upon a watch-glassful of Ehrlich-Weigert's anilin-methyl-violet stain; heat the watch-glass gently until the fluid begins to steam; let it cool for 3 to 5 minutes; decolorize in I part nitric acid and 3 parts water, and then in 60 per cent. alcohol for 1 or 2 seconds; wash in water; counterstain with a saturated aqueous solution of Bismarck-brown; wash, dry, and mount. Anilin-gentian-violet or anilin-fuchsin may be used instead of anilin-methyl-violet. Sections of tissue should not be heated. Gram's Method. Heat 2 to 5 minutes, or stain cold 20 to 30 minutes (tuberclebacilli, 12 to 24 hours), in saturated solution of gentianviolet anilin-water; rinse quickly in absolute alcohol; transfer to Gram's solution ( $I$ to I I $/ 2$ minutes), in which the specimen turns black; wash in alcohol until the black color vanishes and a pale-gray color appears; dry and mount in Canada balsam. The decolorization may be hastened by adding 3 per cent. nitric acid to the alcohol and then washing in pure alcohol. All the tissue-cells are decolorized by this method, while the bacteria are stained a deep-blue. The cells may be subsequently stained with a watery or alcoholic solution of Bismarck-brown 2 to 5 minutes, then washed in absolute alcohol until the section is yellowish-brown. This method is of diagnostic value, as certain bacteria are stained, others decolorized by it. Bacteria stained by Gram's method : tubercle-bacillus; Fræenkel-Weichselbaum pneumococcus; streptococcus pyogenes; streptococcus of erysipelas; staphylococcus pyogenes aureus, albus, citreus, and flavus; anthrax-bacillus; bacillus of hog-erysipelas. Bacteria decolorized by Gram's method: 'Typhoid-bacillus, gonococcus, Friedländer's capsule-bacillus, Koch's comma-bacillus, glanders-bacillus, and the spirillum of relapsing fever. Botkin advises washing the preparation in plain anilinwater before decolorizing in the iodin-solution. Modifications of Gram's Method. I. Weigert's. The sections, stained with gentian-violet, or methyl-violet, are not transferred to alcohol from the iodin-solution, but are laid upon slides and covered with anilin-oil. This is removed with blotting-paper, and followed by xylol and xylol-balsam. The anilin-oil dehydrates and differentiates, 2. Kïhne's. (a) A solution is prepared of I gram of Victoria blue in 50 c.c. of 50 per cent. alcohol, and diluted to half its strength with 0.5 per cent. aqueous solution of ammonium carbonate. Stain from $\mathbf{I}$ to 5 minutes; decolorize in Gram's solution, and treat as in Gram's method, using fluoresceîn ( $1 \mathrm{gm}$. to $50 \mathrm{c.c}$. absolute alcohol) instead of alcohol, to extract the stain. (b) Add hydrochloric acid (I drop to $50 \mathrm{gm}$. water) to a concentrated aqueous solution of violet, and use for staining; continue as in Gram's method. 3. Günther's (Schenk). The cover-glass preparation or the section is left for about 2 minutes in gentian-violet anilin-water. Excess of stain is removed with blotting-paper, and the specimen brought for 2 minutes into Gram's solution, then into pure alcohol for half a minute, exactly ro seconds into 3 per cent. hydrochloric acid in alcohol, then directly into fresh, plain alcohol, which is changed until no more color is extracted from the preparation. Coverglass preparations are dried and mounted; sections cleared in xylol and mounted in xylol-balsam. Tuberclebacilli and lepra-bacilli must remain in the staining fluid I2 hours. Koch's Method, for bacteria in tissues. Stain in aqueous solution of methyl-violet, fuchsin, or methylene-blue. Wash in a saturated solution of potassium carbonate diluted with an equal volume of water. The color will be removed from the nuclei of the cells, but remains in the bacteria; dehydrate, clear in cedaroil, and mount in balsam. Kühne's Carbol-methylene-blue Method. The section is placed in the fol- lowing solution for about $1 / 2$ hour: methylene-blue $\mathbf{1} .5$ parts, absolute alcohol 10 parts; triturate in a watchglass and add, gradually, Ioo parts of a 5 per cent. solution of carbolic acid. After staining, wash the section in water; decolorize carefully in hydrochloric acid, to drops to 500 c.c. of water; immerse at once in a solution of lithium ( 8 drops of saturated solution of lithium carbonate in Io c.c. of water); place in a bath of distilled water for a few minutes; dip into absolute alcohol colored by methylene-blue; dehydrate in anilin-oil that contains a little methylene-blue in solution: wash in pure anilin-oil (not colored), then in a light fluid ethereal oil, as oil of thyme or terebene; clear in xylol; mount in balsam. Recommended for staining the bacillus of glanders. Kühne's Dry Method. Sections are stained for Io to $\mathbf{I} 5$ minutes in I per cent. solution of ammonium carbonate mixed with a concentrated aqueous solution of methylene-blue; then wash in water, decolorize in an aqueous solution of hydrochloric acid; wash in water, dry upon the slides, clear in xylol, and mount in balsam. Pregl's Substitute for Kühne's Method. The sections, fixed to a slide or cover-glass by Pregl's method (see Fixatives), are stained by dropping Kühne's carbol-methylene-blue solution upon them. Wash in water, and place immediately in 50 per cent. alcohol. When the sections acquire a pale-blue color with a greenish tinge, dehydrate in absolute alcohol, clear in xylol, and mount. Unna's Methods. For the recognition of fungi in epidermic scales. I. Place the crust or comedo on a slide, add a drop of acetic acid, and rub to a pulp by means of another slide laid crosswise upon the first; separate the slides, and dry quickly over a spirit-flame. Wash out the fat with a few drops of ether and alcohol, and stain in two drops of solutions of borax and methylene-blue, cover with the other slide, and warm over the flame for 10 to 20 seconds; rinse in water, decolorize in glycol 2 to 5 minutes, rinse again in water, then in alcohol, dry over the flame, and mount in balsam. 2. Treat sections for 5 minutes with an aqueous solution of borax-methylene blue, then for 5 minutes with a 5 per cent. solution of potassium iodid to which a crystal of iodin has been added. Rinse in alcohol until a blue cloud forms; differentiate in creasote for from a few seconds to half an hour, according to the intensity of the stain. Carry to rectified oil of turpentine. In this the bluish color changes to red or brown. Preserve in a solution of colophonium in oil of turpentine. Weigert's Iodin Method (Schenk). Sections are stained in gentian-violet anilinwater, rinsed in a solution of common salt, laid upon the slides, and dried; then solution of iodin is dropped upon them. After again drying, anilin-oil is poured over the sections, renewed several times, and finally displaced by xylol. Mount in balsam. II. SpEciat Methods. Actinomyces. Select whitish granules from the suspected pus ly spreading it on a glass plate upon a dark background. Prepare cover-glasses as for other methods. The preparation may be stained in lithium-carmin and then by Weigert's method for bacteria. I. Weigert advises a dark-red solution of orseille in absolute alcohol 20 parts, acetic acid 5 parts, and water 40 parts. The specimen is left in the stain I hour, then washed in alcohol and counterstained in I per cent. aqueous solution of gentian-violet. It is again washed in alcohol, and mounted. 2. Gram's Method, with eosin as a contrast-stain, shows the clubs very well. 3. Ehrlich's Method (Crookshank). Sections are placed in alcohol or distilled water, then in Ehrlich's logwood for about $1 / 2$ minute, and transferred to distilled water; then placed in a large dish of tap-water, $1 / 2$ hour or more, till a blue color appears. They are next stained in a solution of rubin $\mathrm{S}$. and orange, $\mathbf{I}$ to 2 minutes; washed in distilled water, 
dehydrated, cleared, and mounted. 4. Plaul's Method. Float sections for 10 minutes in a solution of magenta, 2 parts, anilin-oil 3 parts, alcohol (sp. gr, o.830) 20 parts, distilled water 20 parts (Gibbes). Warm the solution to $45^{\circ} \mathrm{C}$. Rinse in water, and counterstain 5 to 10 minutes in concentrated alcoholic solution of picric acid. Wash in water for 5 minutes and then in alcohol for $\mathbf{1} 5$ minutes. Pass through absolute alcohol and clove-oil, and mount. The clubs appear red, the tissue yellow. Better than the magenta is the ZiehlNeelsen solution. When this is used, remove the picric acid by long immersion in alcohol, and counterstain with gentian-violet or methylene-blue (Crookshank). Amoba coli. Councilman and Lafleur's Method. Sections of tissue hardened in alcohol are stained in Loffler's methylene-blue. The amebæ are colored darkblue. The nuclei are best demonstrated by fixing in Flemming's solution and staining with safranin, by which method the nucleoli may often be seen (Schenk). Cover-glass preparations may also be made. Bacillus anthracis. Kühne's Mcthod. Place the section for 5 minutes in carbolic black-brown solution, rinse in lithia-water and then in 90 per cent. alcohol, stain 5 minutes in carbol-fuchsin, and decolorize in fluoresceinalcohol. The carbolic black-brown acts as a mordant and fixes the red color. Bacillus of Eve and Lingard. Stains easily by Gram's method and in ordinary anilin dyes, but not by Lustgarten's method. Bacillus lepræ. Stains with the anilin dyes and by Gram's method. Double-stained preparations are easily made. I. Babes' Method. Stain in a solution of rosanilin hydrochlorate in anilin-water; decolorize in 33 per cent. nitric acid. Use methylene-blue as a contraststain for the nuclei. 2. Baumgurten's Method (C. v. Kahlden). Stain 6 to 7 minutes in a dilute alcoholic solution of fuchsin ( 5 drops of a concentrated solution to a watch-glassful of water); decolorize $1 / 4$ minute in nitric acid I part, alcohol Io parts: wash in water, counterstain in methylene-blue; wash again in water, dry, and mount in balsam. Lepra-bacilli appear red upon a blue ground. A longer time is necessary for staining tubercle-bacilli. 3. Lustrarten's Method. Cover-glass preparations are stained with anilin-water fuchsin, or gentian-violet; decolorized by I per cent. sodium hypochlorite; rinsed in water ; dried; mounted. Bacillus of Lustgarten. I. Lustgarten's Method. Place thin sections in Ehrlich-Weigert's gentian-violet solution for 12 to 24 hours, or 2 hours at $40^{\circ} \mathrm{C}$. Wash thoroughly in alcohol; transfer for $\mathbf{1 0}$ seconds to a $\mathbf{I} .5$ per cent. solution of potassium permanganate. A precipitate is formed that adheres to the section; wash in a dilute aqueous solution of pure sulphuric acid, then in water, and if not decolorized return to the potassiumpermanganate solution and repeat the process. When decolorized, dehydrate and mount in balsam. Coverglass preparations are washed off in water instead of in alcohol. Tubercle-bacilli and lepra-bacilli may be stained in the same way. 2. De Giacomini's Method. Leave sections 24 hours in anilin-water-fuchsin; wash in water; decolorize in ferric chlorid, first in a dilute, then in a saturated solution. Counterstain with Bismarck brown. Stain cover-glass preparations for a few minutes in the heated solution. Bacillus mallei. This bacillus stains in aqueous solutions of anilin colors, and best when the solution is feebly alkaline. I. Add to 3 c.c. of a I : ro,000 solution of caustic potash I c.c. of a saturated alcoholic solution of an anilin color; or the anilin-water-fuchsin or methyl-violet solution of Ehrlich may be used, diluting it at the moment of using with an equal quantity of a $1: 10,000$ solution of caustic potash (Sternberg). 2. Loffler advises for cover-glass preparations, heating for 5 minutes in Ehrlich's solu- tion, then decolorizing in $x$ per cent, solution of acetic acid to which tropeolin has been added to give it the yellow color of Rhine wine, and washing quickly in distilled water. 3. For sections, Loeffler advises his alkaline methylene-blue; decolorizes in a mixture of distilled water Io c.c., strong sulphuric acid 2 drops, 5 per cent. oxalic acid I drop. Sections are left in this about 5 seconds. 4. Noniewicz's Method (Schenk). Sections are transferred from alcohol to alkaline methylene-blue for 2 to 5 minutes, rinsed in water, and decolorized in a mixture of 0.5 per cent. acetic acid 75 parts and 0.5 per cent, aqueous solution of tropeolin OO 25 parts. Thin sections are only dipped quickly into the solution; thick sections remain 2 to 5 seconds. Wash with water; spread upon the slide, dry in air or over a flame, clear in xylol, and mount in balsam. The bacilli appear black on a blue ground. 5. Schütz's Method. Sections or cover-glass preparations are placed for several hours in an aqueous solution of methyleneblue, then washed in weak acetic acid (0.5 c.c. to roo c.c.), dehydrated in alcohol, cleared in cedar-oil, and mounted in balsam (after Squire). Bacillus tetani may be stained by Gram's method. For double staining of bacilli and spores, the method of Ziehl may be employed. Bacillus tuberculosis. I. Arens' Chloroform Method (Schenk). Three drops of absolute alcohol are dropped in a watch-glass upon a crystal of fuchsin the size of a millet-seed, and 2 to 3 c.c. of chloroform are added. This solution becomes turbid and then clears When clear, the cover glass preparation is laid in it for from 4 to 6 minutes, until the chloroform is evaporated, then decolorized in concentrated alcohol to which hydrochloric acid ( 3 drops to a watch-glassful) has been added, rinsed in water, and counterstained with dilute methylene-blue. 2. Craplezeski's Methods. (a) After staining in warm Ziehl's solution, drain, and immerse 6 or 10 times in as aturated alcoholic solution of fuoresceīn containing an excess of methylene-blue. Counterstain in a saturated solution of methylene-blue, and wash quickly in water. (b) Stain the cover-glass preparation in carbol-fuchsin, heating it until clouds of vapor arise. The following solution is then dropped upon the slide, held obliquely, until the surface is cleared: hydrochloric acid and sodium chlorid each 2.5 parts, dissolved in distilled water Ioo parts; then add 500 parts of alcohol. The slide is then washed with water, dried in air, and treated with a drop of some immersion-oil that can be removed by xylol. (Arbeiten aus dem Path. Anat. Institut zu Tübingen, 1892, Bd. 1, Heft 3. Also Monatschr. f. prakt. Derm. XviI, No. 4.) 3. Ehrlich's Method (Schenk) for tubercle-bacilli in pus. Spread the pus very thinly; place the cover-glass for I to 2 hours in cold anilin-fuchsin; decolorize with nitric acid I part, and sulphanil-nitric acid, saturated solution, 3 to 6 parts. The after-stain is methylene-blue. 4. Frankel's Method (Schenk). The cover-glass is stained with anilin-water-fuchsin, transferred to a fluid consisting of a saturated solution of methylene-blue in 50 parts of water, 30 of alcohol, and 20 of nitric acid. When the preparation appears blue, it is washed in alcohol and acetic acid or in pure water. 5. Friedländer's Method. Place upon the dried film-surface of the cover-glass 3 or 4 drops of carbol-fuchsin, heat until vapor arises, wash in dis. tilled water, drain, and add a few drops of a decolorizing solution (pure nitric acid 5 c.c. to 80 per cent. alcohol 100 c.c.); decolorization takes place quickly. Wash in water, counter-stain about 5 minutes with methylene-blue, without heat; wash; dry and mount. 6. Gabbet's Modification of Frankel's Method. Stain in Ziehl's carbol-fuchsin for ahout 2 minutes, without heating; wash in water; stain in 25 per cent. sul- 
phuric acid roo c. c. and methylene-blue 2 c. c., for 1 or 2 minutes; wash in water; dry and mount. In the case of sections, dehydrate with alcohol ; clear and mount. A good and quick method. 7. Gibbes' Method (Schenk). 'Two grams of fuchsin and one of methylene blue are slowly introduced into a solution of $3 \mathrm{c}$. c. of anilin-oil in $I 5$ c.c. of absolute alcohol. When they are completely dissolved, $\mathbf{1 5}$ c.c. of water are added. A few drops are heated in a test-tube and poured into a watch-glass. In this the cover-glass is laid for 5 minutes, then washed in alcohol until no more color is given off. The bacilli appear red on a blue ground. If desired, stain further with a concentrated aqueous solution of eosin. 8. Gïnther's Method (Schenk). Stain with warm anilin-water-fuchsin; carry the cover-glass, with the prepared side up, into alcohol acidulated with hydrochloric acid, 3: I00; move about for a moment and rinse in water. With a pipet, let a few drops of a dilute alcoholic solution of methylene-biue fall upon the cover-glass; wash in water, dry, pass three times over the flame, and mount in xylol-balsam. 9. Kaatzere's Method. Float the cover-glass preparation for 24 hours in a supersaturated alcoholic solution of gentianviolet, or, if warmed to $80^{\circ} \mathrm{C}$, for 3 minutes. Decolorize in a solution of 90 per cent. alcohol $\mathbf{I 0 0}$ c.c., water 20 c.c., strong hydrochloric acid 20 drops. Rinse in 90 per cent. alcohol, after-stain for 2 minutes in concentrated aqueous solution of vesuvin, wash in distilled water, dry, and mount in balsam. Io. Koch's Original Method (Sternberg). Stain sections or cover-glass preparations in Koch's methyleneblue solution, containing caustic potash, for 20 to 24 hours, or, if heated to $40^{\circ} \mathrm{C}$., for $I / 2$ to $I$ hour ; then in an aqueous solution of vesuvin for 2 minutes. Wash out excess of stain in water. Dry the coverglass preparation in air and mount. Dehydrate the sections in absolute alcohol, clear in cedar-oil, mount in balsam. The bacilli are stained blue and the tissues brown. This method has been superseded by the Koch-Ehrlich Method, II. Koch-Ehrlich Method (Schenk). Stain the cover-glass preparation for 24 hours at the temperature of the room, or for 15 minutes with heat, in anilin-water alcoholic solution of fuchsin, gentian-violet, or methyl-violet (prepared by adding to anilin-water enough of a concentrated alcoholic solution of the dye to produce opalescence). Then immerse the preparation in 33 per cent. nitric acid, and when it assumes a yellow-green tint transfer to 70 per cent. alcohol. Counterstain $I$ to 5 minutes in methylene-blue, malachite-green, or picric acid for fuch$\mathrm{sin}$, in Bismarck brown for gentian-violet or methylviolet. Wash in water, dry, and mount in balsam. Prolonged action of the nitric acid will decolorize the bacilli. 12. Pfuhl-Petri's Method (Schenk). Preparations are stained in Io c.c. of an alcoholic solution of fuchsin in 100 c.c. of water, decolorized in glacial acetic acid, washed in water, dried, and mounted in balsam. I3. Pittion's Method (Schenk). The prepared cover-glass is dipped for a minute into a mixture of an alcoholic fuchsin-solution 1 part, and 3 per cent. ammonia 10 parts, rinsed in water, carried to a concentrated solution of anilin-green in alcohol 50 c.c., water 30 c.c., nitric acid 20 c.c. for $3 / 4$ of a minute, rinsed, dried, and mounted. I4. Reeves' (J. E.) Method. A carbolized, double stain, used for either tissue or cover-glass preparations, is made as follows: Dissolve $2.5 \mathrm{gm}$. of rosanilin hydrochlorate and I. $5 \mathrm{gm}$. of methylene-blue in $20 \mathrm{c}$. c. of absolute alcohol and 3 c.c. of anilin-oil; agitate thoroughly, and gradually add 30 c.c. of 5 per cent. carbolized water. Filter a little of the stain into a watch-glass, heat it gently until it steams; drop enough of the hot stain on the cover-glass preparation to flood it, and cover it with a bell-glass for 5 to 10 minutes. Wash and decolorize in alcohol, dry, and mount in xylol-balsam. Fifteen to twenty minutes are required to stain sections; otherwise the procedure is the same as for cover-glass preparations. 15. Tubercle-bacilli in Milk (Schenk). Place a drop of the milk upon a cover-glass, add 2 or 3 drops of a 1 per cent. solution of sodium carbonate, and mix well with a platinum needle; then warm carefully until complete evaporation has taken place. A thin film of soap remains, and is stained like an ordinary cover-glass preparation. Unna's Method. Stain for from Io minutes to several hours in polychromic methylene-blue (Grubler), wash in water, and treat with a 33 per cent. aqueous solution of tannic acid 2 to 5 minutes. Wash thoroughly and transfer to absolute alcohol, goldorange alcohol, or to 25 per cent. nitric acid; follow with dilute alcohol, water, and absolute alcuhol. Clear in bergamot-oil. This process double-stains tuberclebacilli and leprosy-bacilli. 16. Weichselbaum's modification of the Ziehl-Neelsen Method (Schen/s). The redstained cover-glass preparations are transferred directly to an alcoholic methylene-blue solution, in which they remain until they show a homogeneous blue color. They are then rinsed in water, dried, and mounted in balsam. 17. Zieht-Neelsen Method. Float the cover-glass preparation upon Ziehl's carbol-fucbsin, heat till vapor arises (about 3 to 5 minutes), wash in water, and decolorize in 15 per cent. nitric or 5 per cent. sulphuric acid, then in 60 to 80 per cent. alcohol to remove the remnant of color. Wash well, dry, and mount in balsam. In the case of tissue-sections, stain cold for I5 minutes and decolorize as detailed; upon removal from the alcohol, counterstain with methylene-blue; wash, dehydrate, clear, and mount. Bacillus typhi abdominalis. Stains with anilin dyes, but is easily decolorized. Does not stain by Gram's method. Coverglass preparations stain well with aqueous solutions, especially fuchsin. They are to be rinsed in water, not in alcohol. Gaffky's Method for sections of tissues: Harden the tissue in alcohol, place sections for 20 to 24 hours in a deep-blue solution made by adding a saturated alcoholic solution of methyleneblue to distilled water, wash in distilled water, dehydrate in absolute alcohol, and clear in turpentine and balsam. The best stains for the typhoid-bacillus are Loffler's methylene-blue and Ziehl's carbol-fuchsin. The sections must remain in the dye at least 12 hours. Baumgarten recommends Ehrlich's stain for tuberclebacilli. In this case a very dilute solution of acetic acid is used for rinsing. The flagella may be shown by Loeffler's method. By leaving the specimens for several days in Ehrlich's anilin-water fuchsin the spores may be stained. Spores also appear if the stain is heated and then extracted by nitric acid. Counterstain with methylene-blue. Coccidium oviforme. Gibbes' Method. Sections of rabbit's liver, hardened in alcohol, are stained in a filtered solution of rosanilin sulphate, $2 \mathrm{gm}$, in IOO c.c. of a solution of anilin-oil 2 c.c., cologne Io c.c., distilled water 88 c.c. Ten minutes are required to stain. After washing in water and then in alcohol, the sections are differentiated in a solution of iodin-green, $\mathbf{I} \mathrm{gm}$. in roo c.c of the foregoing anilin-oil solution. When the red color has changed to a dull-purple, the substitution has proceeded far enough. It is well to make an examination in distilled water from time to time. Flagella. The first successful method was that of Koch, who used a concentrated aqueous solution of hematoxylin, and then transferred the cover-glass to a 5 per cent. solution of chromic acid or to Müller's fluid. The flagella were stained brown-black. I. Crookshank stains with 
a drop of a saturated solution of gentian-violet in absolute alcohol. Before evaporation takes place rinse with water, dry, and mount in balsam. 2. La'fler's Method (Sternberg). A small quantity of a pure culture is suspended in a few drops of distilled water. Small drops of water are distributed upon clean glass covers by means of a platinum-wire loop, and are sowed with bacilli from the first drop. The little drops are spread out by the platinum wire, allowed to dry in the air, then passed through the flame in the usual way. Care must be taken not to overheat. Lœffler's mordant $(\mathrm{No} . \mathbf{I})$ is placed upon the cover-glass so as to fully cover it as an arched drop. The cover-glass is then heated until steam begins to arise; too much heat produces a precipitate. The mordant is left for $1 / 2$ to I minute upon the cover-glass and gently moved about. Wash in distilled water, then in absolute alcohol to remove all remnants of the mordant. Drop the staining solution (preferably neutral saturated anilin-water fuch$\operatorname{sin)}$ so as to fully cover the glass, and heat till vapor begins to be given off; wash, dry, mount. 3. Trenkmann's Method (Schenk). A few drops of boiled water are placed upon a slide, and a small drop of the culture added and intermixed. Of this mixture a droplet is spread upon a cover-glass, dried in air, laid, without heating, in a 2 per cent. solution of tannin and 0.5 per cent. hydrochloric acid, in which it is allowed to remain for from 6 to 12 hours. It is then washed in water and placed in iodin-water for half an bour, washed, and carried to a weak solution of anilinoil gentian-violet for half an hour, again washed, then dried, and mounted. Gonococcus. The gonococci are seen in the pus-cells grouped around the nucleus. Watery solutions of auilin dyes, preferably methyleneblue, stain the cocci intensely. Gram's method decolorizes them. I. Schütz stains for 5 or ro minutes in a saturated solution of methylene-blue in 5 per cent. carbolic-acid water and differentiates for 3 seconds in acetic acid 5 parts, water 20 parts, washes in water, and counterstains in a dilute solution of safranin. 2. Czenzynski's solution of methylene-blue and eosin stains the cocci blue and the pus-cells pink. 3. Neisser stains for 2 or 3 minutes in a concentrated alcoholic solution of eosin, slightly warmed; removes the excess with filter-paper, and counterstains in a concentrated alcoholic methylene-blue solution for from a quarter to half a minute. The cocci appear blue, the cells red. Influenza-bacillus (of Pfeiffer and Canon). Canon's Method of staining it in blood: Spread the blood upon cover-glasses in the usual way. When dry, place the covers in absolute alcohol for 5 minutes and then transfer them to Czenzynski's staining solution. In this they remain for from 3 to 6 hours in an incubating oven at $37^{\circ} \mathrm{C}$, when they are washed, dried, and mounted. The bacillus also stains well in Loffler's methylene-blue, with heat, and in dilute Ziehl's solution. It does not stain by Gram's method. Koch's Comma-bacillus. Stains easily in diluted alcoholic or concentrated solutions of anilin dyes; if cold, in about ro minutes; if heated, more quickly and more deeply. Gram's method is not applicable. For sections use fuchsin or methylene-blue. I. Koch's Method. Stain sections well hardened in absolute alcohol for 24 hours in strong aqueous solution of metbylene-hlue. If the staining fluid be warmed, less time is necessary (Crookshank). 2. Nicati and Rietsch's Method (Crookshank). A small quantity of the stools or of the scrapings of the intestinal mucosa is spread and dried upon a slide, steeped for a few seconds in corrosive sublimate solution or in I per cent. osmic acid, and stained in fuchsin-anilin solution. 3. Babes' Method. Place sections for 24 hours in aqueous solution of fuchsin; wash in distilled water faintly acidulated with acetic acid or in $\mathbf{I}$ per cent. corrosive-sullimate solution; carry them quickly through alcohol and oil of cloves. Phagocytes. Sections of a Peyer's patch, hardened in absolute alcohol and embedded in paraffin, are stained first with alum-carmin, and then with gentian violet by Gram's method. The bacilli are stained a deep bluish-violet. Plasmodium malariæ. A minute drop of blood from the finger-end is spread upon cover-glasses and the film fixed by heat in the usual way, or by placing the covers in a mixture of equal parts of absolute alcohol and ether. Czenzynski's solution may be used to stain, the red corpuscles taking up the eosin, the malarial organisms the methylene-blue. Plehn recommends methylene-blue, concentrated aqueous solution 60 parts, eosin 0.5 per cent. solution in 75 per cent. alcohol 20 parts, 20 per cent. potassium-hydroxid solution I2 parts. Stain for 5 or 6 minutes and wash in water. Pneumo-bacillus of Friedländer. Friedländer's Method. Stain for 24 hours in warm, concentrated alcoholic solution of gentian-violet 50 parts, distilled water 100 parts, glacial acetic acid Io parts; then wash in I per cent. acetic acid, dehydrate in alcohol, dry or clear, and mount. The capsule is pale-blue, the center deep-blue. For cover-glass preparations Friedländer advises the following: place in acetic acid for a few minutes; displace the acid by blowing upon the preparation through a pipet; stain a few seconds in a saturated solution of anilin-water gentian-violet; rinse in water; dry with filter-paper; mount in balsam. Pneumococcus of Fraenkel, Klebs, Eberth, and Weichselbaum. This may be stained by Gram's method. Methods to demonstrate the capsules. I. Ribbert places the preparation for a few minutes in a hot, saturated solution of dahlia-violet in water 100 parts, alcohol 50 parts, glacial acetic acid I2.5 parts. Staining takes place rapidly; wash quickly in water. The capsules appear light-blue, the cocci dark-blue. An overstain makes the capsules also dark-blue. 2. Roux stains for a few seconds in an aqueous solution of methyl-violet, and, without washing, counterstains for the same length of time in Lœffler's alkaline methylene-blue. 3. C.v. Kahlden stains for some hours in a 1 per cent. solution of fuchsin in 5 per cent. carbolic acid. The capsule appears pale-red, the coccus deep-red. Protozoa in Carcinoma. Russell's Method. Stain sections for Io minutes in a saturated solution of fuchsin in 20 per cent. carbolic acid, wash in water. then in absolute alcohol, and stain for 5 minutes in a $\mathbf{I}$ per cent. solution of iodin-green in 2 per cent. carbolic acid; dehydrate in absolute alcohol, clear in clove-oil, and mount in balsam. The "parasites" are red or purple, the tissue-cells blue. Spirochætæ obermeieri. 'Stain with Lœffler's solution or any of the common basic anilin dyes. Günther's Method. Air-dried cover-glasses are placed in 5 per cent. acetic acid for Io seconds, removed, and the acid displaced by blowing upon the preparation through a glass tube and then holding it for a moment, film-surface downward, over strong ammonia just previously shaken. Then stain in gentian-violet anilinwater or in an aqueous solution of other anilin dyes, and proceed as usual. The acetic acid bleaches the red blood-corpuscles. Spores. Spores are more resistant to the action of stains than other parts of bacteria. I. Günther's Method. Float the prepared cover-glass on a solution of anilin-water fuchsin or gentian-violet heated to boiling, and remove from the flame for a minute. Repeat this process 5 times and then wash in a 3 per cent. solution of acetic acid in alcohol, and afterward in water. 2. Möller's Method (Sternberg). Dry the cover-glass preparation in air, pass it thrice 
through a spirit-flame, or place it for 2 minutes in absolute alcohol. Treat with chloroform for 2 minutes, rinse in water, and carry to 5 per cent. chromic acid for $I$ or 2 minutes, and wash in water. Pour a few drops of carbol-fuchsin upon the preparation and heat to boiling (which occurs in about a minute); drain and decolorize in 5 per cent. sulphuric acid, wash thoroughly in water, and counterstain for half a minute with methylene-blue or malachite-green in aqueous solution. The spores are stained dark-red, the protoplasm of the bacilli blue or green, according to the after-stain used. 3. Neisser's Method (Sternberg). Pass the coverglass preparation three times through the flame of a Bunsen burner, float upon a solution of anilin-fuchsin, and heat to near the boiling-point for $\mathbf{I}$ hour; wash in water, and decolorize in hydrochloric acid 25 parts, and alcohol 75 parts. Counterstain in a saturated aqueous solution of methylene-blue. The spores are stained red, the protoplasm of the bacilli blue. Prolonged action of the hydrochloric-acid solution will decolorize the spores as well as the bacilli. 4. Place the slide or cover-glass, with the culture dried upon it, in a hotair oven for 1 hour at $120^{\circ} \mathrm{C}$, or for 15 minutes at $180^{\circ} \mathrm{C}$, or the cover-glass may be passed 8 or Io times through the flame of a Bunsen-burner. Stain in an aqueous solution of a basic anilin dye. The spores alone are stained (Sternberg). Streptococcus erysipelatosus (Fehleisen) may be stained with the usual anilin dyes and by Gram's method. III. Preliminary Methods. Biedert's Method. Used in examining sputa which contain few tubercle-bacilli. Mix 15 c.c. of the sputa with from 75 to 100 c.c. of water and a few drops of potassium or sodium hydroxid solution. Boil until the sputa are thin. Place in a conical glass vessel and after two days pour off the supernatant liquid. Stain the precipitated sediment. Kaatzer's Method. Mix the sputa with from a I to a 3 per cent. solution of caustic soda or potash. This disolves the cells and mucus, but preserves the elastic fibers and bacteria. Stain the sediment. Clear the preparation with a dilute solution of acetic acid. Kühne's Method. This method is used to overcome the viscidity of sputum and to facilitate the spreading of a thin and even film on the cover-glass. It consists in adding to the sputa an equal volume of a saturated solution of borax. A concentrated aqueous solution of ammonium carbonate will reduce the consistency of less viscid sputa. Mühlhäusen's Method. This method is used to render sputa less viscid. It consists in adding to the sputum from 6 to 8 times its volume of a 2 per cent. solution of caustic potash. Preserving Sputum. Savelieff's Method. This is a process for preserving sputum for purposes of subsequent examination. Let the patient expectorate in a receptacle containing 95 per cent. alcohol, in which the sputum may remain for several months, and in which it is hardened by dehydration and coagulation. A few drops of caustic-potash solution added to a small lump of the hardened sputum on a slide will liquefy it in a few minutes, and from this the cover-glass preparations are made. When dry, fix the film by passing the cover-glass thrice through the flame of a spirit-lamp, wash in water to remove the potash, and then stain according to any of the given methods. Sectioning Sputum. Gabritscheres. ky's Method. Place the denser portions of freshly expectorated sputum in Müller's fluid, or some other hardening reagent, and then embed in celloidin. Stain the sections in safranin, alum-carmin or hematoxylineosin. Aronson and Philip treat the sputum first with corrosive sublimate, and, according to Schmidt, it may be embedded in paraffin as well as celloidin.
STAINING OF NERVE-TISSUE

Adamkiewicz's Method. Wash sections of spinal cord in water, then in water acidulated with nitric acid, and stain in a concentrated solution of safranin. Treat with alcohol and clove-oil until no more color is given off wash in water, then in water acidulated with acetic acid, stain in methylene-blue, and clear as before. 'This process is said to demonstrate the "chromoleptic zones" which surround the gray matter. The myelin ("erythrophilous substance" of Adamkiewicz) appears red, the nuclei of nerves, neuroglia, and vessels appear violet. This method is of value in the study of degenerative changes, as the erythrophilous substance of pathologic nerves does not take the stain. Alt's Method. Adapted to the study of peripheral axis-cylinders. Stain for two hours in a solution of Congo red in absolute alcohol; wash out in alcohol. Axis-cylinders of, Centric Fibers (Bevan W. Lewis). Remove the myelin from sections by prolonged immersion in water, and then stain with anilin blue-black. The axis-cylinders appear as slightly wavy, swollen bands. Ciaccio's Method. This method is especially suitable for the terminations of nerves in muscles and in the cornea. Place small pieces of tissue, about $2 \mathrm{~mm}$. cubes, for $5 \mathrm{~min}$ utes in the fresh, filtered juice of a lemon; wash, and place for from $1 / 2$ to $\mathbf{I}$ hour in a I per cent. solution of gold and cadmium chlorids in the dark; wash, and carry to a I per cent. solution of formic acid for 24 hours in the dark, then for $\mathbf{I} 2$ hours in sunlight; lastly, for 24 hours in pure formic acid; wash, tease, and mount in glycerin. Dausac's (A. Michel) Method. Very minute pieces of tissue are fixed in a watery solution of picric acid, chromic acid, and nitric acid (the proportions are not given) for from $\mathbf{I}$ to 2 hours; washed in water for from $1 / 2$ to I hour; embedded in celloidin, cut, and placed in 90 per cent. alcohol. The sections are now transferred to Ehrlich's fluid for from 2 to 5 minutes, rinsed in water, and placed for from 2 to 5 minutes in a I per cent. solution of potassio-gold chlorid ; rinsed in formic acid for I minute, carried to a caustic-soda solution, $1: 6$, rinsed in water, and placed in a Io per cent. solution of lithium carbonate for $1 / 2$ hour. From this they are brought into a 10 per cent. solution of potassium iodid for from 2 to 3 minutes, and are then reduced for 10 minutes in a strong solution of sodium thiosulphate. The axis-cylinders are stained a black-violet; the remaining tissue is faintly colored. Platinum chlorid or palladium chlorid gives the same result. Dausac recommends this method also for fibrin and elastic fibers. Exner's Method. A small piece of the cortex cerebri, not exceeding I cubic centimeter in size, is placed in a relatively large volume of I per cent. osmic acid, which should be renewed every 2 days. After from 5 to Io days, wash with water, treat with alcohol, and embed. Treat sections on the slide with strong ammonia, which clears the tissue, and reveals the medul. lated fibers stained black. Pieces of tissue, as fresh as possible, not over $1 / 2 \mathrm{~cm}$. in thickness, are placed in a I per cent. solution of osmic acid, the quantity of which must be at least Io times the volume of the tissue, and which should be renewed in 2 days. In 5 or 6 days wash in water and embed. The sections are placed on the slide in glycerin to which a drop of ammonia has been added (strong ammonia and water $1: 50$ ). The medullated fibers appear gray or black. The preparation is not permanent. Free Nerve-endings in the Skin. Place small cubes of the skin of the palmar surface of the fingers or toes, all adipose tissue being removed, in boiled yold chlorid and formic acid after this mixture has cooled. In an hour, transfer the tissues to slightly acidulated water and expose to sunlight until the gold is reduced. Harden in alcohol, section, and mount in 
formic glycerin. Freud's Method. Wash sections of tissue hardened in Erlicki's tluid with water, and place them for from 3 to 5 hours in a $\mathbf{I}$ per cent. gold-chlorid solution. Wash with water and treat for 3 minutes with a solution of caustic soda, $\mathbf{I}$ part, in water, 5 or 6 parts. Drain, but do not wash, and place in a Io per cent. solution of potassium iodid. Remove in from 5 to 15 minutes, wash in water, dehydrate, and mount. Impregnation of axis-cylinders is obtained by this process. Gerlach's Method. Harden pieces of spinal cord for from 15 to 20 days in I or 2 per cent. ammonium bichromate. Make thin sections, and immerse them in a solution of potassio-gold chlorid 1 part, water 10,000 parts, slightly acidulated with hydrochloric acid. In from Io to 12 hours, wash in hydrochloric acid, I : 3000 , and bring into a mixture of hydrochloric acid I part, and 60 per cent. alcohol Iooo parts, then for a few minutes into absolute alcohol. Clear and mount. Golgi's Gold Method. To demonstrate motor nerve-endings. Treat the tissue for $\mathbf{I}$ or 2 minutes in a 0.5 per cent. solution of arsenic acid, and then for from 15 to 20 minutes with a 0.5 per cent. solution of potassio-gold chlorid, and reduce in the sunlight in a I per cent. solution of arsenic acid. I. Flechsig's Modification. Harden in a 2 per cent. aqueous solution of potassium chromate, and impregnate with a I per cent. solution of corrosive sublimate, weeks or months, according to the size of the specimen. Place the sections in 96 per cent. alcohol. Stain for from 3 to 8 days at $35^{\circ} \mathrm{C}$. in the following: pure extract of Japanese redwood I gm., absolute alcohol ro c.c., distilled water 900 c.c., and 5 c.c. each of saturated solutions of tartaric acid and sodium sulphate. Each section is then placed in 3 c.c. of a 0.2 per cent. solution of potassium permanganate until the purple color of the fluid has faded out; then decolorize in Pal's solution. When the yellow color has vanished, carry into a mixture of a I per cent. potassio-gold chlorid solution 5 ärops, and absolute alcohol 20 c.c. After the precipitate of sublimate has turned black and the red tissue has become blue, wash quickly in distilled water 20 c.c. and a 5 per cent. solution of potassium cyanid I drop. Dehydrate in absolute alcohol, and clear in lavender-oil. The nerve-fibers are stained red, the ganglion-cells, with their processes, black. 2. Kühne's Modification. Used for nerve-endings. Instead of using Golgi's gold solution, place the tissue in the following: I per cent. potassio-gold chlorid I 2 c.c., 2 per cent. osmic acid 3 c.c., 5 per cent. arsenic acid 60 c.c. From this bring it into I per cent. arsenic acid, and reduce in sunlight. The tissue may be preserved in May's fluid. (See Examination and Preservation Media). Golgi's Silver Methods. 1. Soak pieces of perfectly fresh spinal cord in a 2 per cent. potassium bichromate solution, for from 8 to 15 days in summer and for about one month in winter. Wash them, and put them into a 0.75 per cent, solution of silver nitrate; in warm weather the reaction will be complete in 2 or 3 days, in from 8 to IO days in winter. Dehydrate in alcohol, section if necessary, clear in oil of turpentine, tease in turpentine, and mount in dammar. The preparations are then exposed to diffused daylight or to direct sunlight, to effect secondary impregnation. By this method may be demonstrated the chain of conical funnels, set one within the other, and embracing the axis-cylinder with their narrow apertures. Somewhat greater precision of reaction is obtained by interstitial injection of the fresh tissue with osmic acid before placing in the bichromate solution. 2. For the study of peripheral nerves, the process is modified as follows: Immerse pieces of nerve in the bichromate solution for from 4 hours to 2 days; transfer them to the silver bath, in which they should remain for from $\mathbf{I} 2$ to 24 hours. Wash with successive 88 alcohols, tease in alcohol, dehydrate, clear with turpentine, and mount in dammar. Reduce in direct sunlight. The preparations are permanent, but the results are not so fine as in the following method. 3. I'lace a piece of fresh nerve in a mixture of 10 parts of a 2 per cent. solution of potassium bichromate and 2 parts of a I per cent. solution of osmic acid; after an hour's immersion, cut into lengths of from $1 / 2$ to $1 \mathrm{~cm}$., and return to the solution. Four hours after the first immersion, begin to add pieces of silver nitrate to the bath, and, from time to time, transfer pieces of nerve, so as to ensure the proper duration of immersion for some of the pieces. The duration of the silver bath should not be less than 8 hours, and may be indefinitely prolonged. The strength of the silver solution should be 0.5 per cent. I. Obregin's Modification. The sections are transferred from absolute alcohol (after they have been in sublimate or silver solution) directly into Io c.c. of absolute alcohol containing 8 or Io drops of a I per cent. solution of gold chlorid. The latter should be made half an hour before and exposed to diffuse light. The specimens in the solution are kept in the dark for from 15 to 30 minutes, then washed rapidly in 25 per cent. alcohol, then in water, and for 5 or 10 minutes (not longer) in Io per cent. solution of sodium sulphid. They are again washed in water, and stained with carmin, hematoxylin, or Weigert's stain, and mounted in balsam. 2. Ramón y Cajal's Modification. Small pieces of brain are fixed for from $\mathrm{I} 2$ to 24 hours, in the dark, in potassium bichromate 3 parts, osmic acid, I per cent., 25 parts, water 100 parts. An abundant quantity of the fluid should be used, and changed several times during the first day. Embryonic tissue requires from I 2 to 24 hours' immersion, adult tissue from 2 to 3 days. After hardening, which must not be excessive, wash in a 0.25 per cent. solution of silver nitrate, for I5 minutes, and then place in a 0.75 per cent. solution of silver nitrate containing I drop of formic acid to each Ioo c.c. (Van Gehuchten). The tissue may be left in the silver bath for from 36 to 48 hours. The silver will be thrown down as a very fine precipitate of silver bichromate. 3. Sala's Modification. Place the tissue for 4 or 5 days in a 2 per cent. solution of potassium bichromate, for from 24 to 30 hours in 8 parts of the bichromate solution and 2 of the osmium solution, then in a silver bath of 0.75 per cent. strength. Wash with water, fix to a cork with gum, harden in alcohol for a few hours, and cut without embedding. 4. Sehrwald's Modification. Prior to bringing the tissues into the silver bath, put them into a 10 per cent. solution of gelatin in water; they may be embedded in the gelatin in a paper tray, with the aid of a little heat, and thus brought into the silver solution. The gelatin is removed by warm water saturated with silver chromate. This process prevents the formation of the precipitate that frequently occurs at the margins of the preparation in Golgi's method. Samassa holds that the precipitation may be prevented by preserving the preparation without" a cover. Fick and Huber recommend that the use of an aqueous fluid be avoided and that the section be mounted without a cover, or that the cover be raised from contact with the slide by means of wax feet, or that the balsam be rendered anhydrous (by heating it on the slide with the specimen) and the cover put on in the usual way. 5. Van Gehuchten's Modification, This process is like that of Ramon y Cajal, with this difference : I c.c. of formic acid is added to each roo c.c. of the silver bath, to assist its action. Twentyfour hours' immersion is sufficient. The tissue is then washed, treated for 15 minutes with alcohol, then for the same time with absolute alcohol, and for the same time with celloidin solution, after which it is 
hardened for 15 minutes in 70 per cent. alcohol, cut, and mounted in the usual way. Golgi's Sublimate Method. Harden the tissue for from 15 to 20 days in Müller's fluid, and pass it directly into a 0.25 or 0.5 per cent. solution of mercuric chlorid, which should be renewed until it no longer turns yellow. After at least Io days' immersion in this solution, sections are cut on a freezing microtome, washed thoroughly in water, dehydrated, cleared, and mounted. The nerve-cells, with their processes and nuclei, are brought out prominently. Pal's modification of this method consists in after-treatment of the sections with a weak solution of sodium sulphid. Hoyer's Method. For corneal nerves. Immerse cornex for from $\pi / 2$ to 5 hours, according to size, in an acidulated 0.5 per cent. solution of potassio-gold chlorid. To demonstrate the intra-epithelial ramifications of nerves, reduce for from 16 to 24 hours by exposure in distilled water containing 2 drops of pyrogallic-acid developing solution, such as is used in photography; or, instead, the corner may be placed in a warm, concentrated solution of tartaric acid at the temperature of an incubating oven until the gold is reduced. Isolated Neuroglia Cells. Make an interstitial injection of I per cent. osmic acid into the white matter of the spinal cord. Tease a piece, and stain it with picrocarmin. Jakimovitch's Method. Used to demonstrate Frohmann's lines and Ranvier's crosses. Place small pieces of nerve, in the dark, in a $\mathbf{I}$ per cent. silvernitrate solution; continue the immersion for 48 hours, and renew the solution frequently. Wash in water, and expose to light for from 5 to 7 days in $\mathbf{I}$ part each of formic acid and amyl-alcohol in roo parts of water. Tease, and mount in glycerin. Joseph's (M.) Method. Used to demonstrate Frohmann's lines and Ranvier's crosses. Place the fresh nerve in I per cent. silver nitrate and ro per cent. nitric acid mixture diluted with water. After several hours, transfer to a weak solution of potassium bichromate, and thence pass through solutions of increasing concentration until it is hardened. It may then be teased and mounted. Kaiser's Method. Stain celloidin sections of spinal cord in a solution of $\mathrm{I}$ part naphthylamin-brown (Grübler), alcohol Ioo parts, water 200 parts. Wash with alcohol and clear with origanum-oil. Chromophilous ganglion-cells appear dark-brown; chromophobous cells, light on a dark ground. KorybuttDaszkiewicz's Method. For the study of the central nervous system. Secure sections to the slide by means of distilled water. Stain for 1 minute in Böhmer's hematoxylin, and wash in a $\mathbf{I}$ per cent. solution of alum and distilled water; stain for $\mathbf{I}$ minute in a I per cent. aqueous solution of nigrosin, and wash in water; stain for from $I_{5}$ to 20 seconds in a 0.5 per cent. alcoholic, watery solution of eosin, and wash for a few minutes in distilled water; transfer to absolute alcohol ; stain for 20 minutes in a 0.5 per cent. alcoholic, watery solution of safranin; wash well in alcohol; clear, but not in cloveroil, and mount in balsam. Kupffer's Method. A nerve is stretched on a cork, and treated for 24 hours with 0.5 per cent, osmic acid; then washed in water for 2 hours, and stained for from 24 to 28 hours in a saturated, aqueous solution of acid fuchsin. After this it is washed out for from 6 to 12 hours (not more in any case) in absolute alcobol, and cleared in clove-oil, embedded in paraffin, and cut. The axis-cylinder appears as a bundle of red fibrils floating in an albuminous liquid. Magini's Method. Used to demonstrate the finer structure of ganglion-cells and their processes. Harden cubes of from 2 to $3 \mathrm{~cm}$. for from 2 to 3 months in Müller's fluid, wash well with distilled water, and bring for Io days into from a 0.5 to a I per cent. solution of zinc chlorid, which should be changed daily, until it does not become yellower than bichromate solution. Section, wash quickly with alcohol, clear partially with creasote, and mount in dammar. Marchi's Method. Used to demonstrate early degeneration of nerves, prior to sclerosis. After hardening in Müller's fluid, place the tissue in a large quantity of a mixture of Müller's fluid 2 parts, I per cent. osmic acid I part. The degenerated fibers are stained black, the normal are yellow or uncolored. Martinotti's Method. Stain for 2 or 3 hours or days in a saturated solution of nigrosin in a saturated solution of picric acid in alcohol; wash out in a mixture of $\mathbf{I}$ part formic acid and 2 parts alcohol, until the gray substance appears to the unaided eye differentiated from the white. This method is of value in the study of pathologic tissue. May's Methods. I. For peripheral nerves and ganglia, macerate pieces of muscle in 0.5 per cent. arsenic acid, and when swollen place for 20 minutes in solution of I per cent. potassio-gold chlorid 4 c.c., 2 per cent. osmic acid I c.c., 0.5 per cent. arsenic acid 20 c.c. Then wash in water, and expose to sunlight for 3 hours in a I per cent. solution of arsenic acid, kept at $45^{\circ} \mathrm{C}$. in a water-bath. Clear in a mixture of glycerin 40 c.c., water 20 c.c., 25 per cent. hydrochloric acid $\mathbf{l}$ c.c. 2. Treat a small piece of muscle for $\mathbf{I} 2$ hours with water containing 2 per cent. of glacial acetic acid, and transfer to a freshly made solution of 0.5 per cent. potassio-gold chlorid I c.c., 2 per cent. osmic acid, I c.c., 2 per cent. glacial acetic acid 50 c.c. After from 2 to 3 hours bring into acidulated glycerin, and when the tissue is transparent examine in glycerin or Farrant's solution. Modifications of Weigert's Method. I. Benda's Modification. Small pieces of nervous tissue are placed for 3 days or more in a saturated solution of picric acid, washed in water, and the hardening continued in alcohol. Embedding in paraffin is best. Thin sections are placed in a concentrated solution of iron sulphate, washed repeatedly, and put into a $I$ per cent. solution of hematoxylin until deep-black in color (about Io minutes). They are bleached in a solution of chromic acid, $\mathbf{I}: 2000$, washed, dehydrated, and mounted. The fibers and the intimate structure of the cells are well brought out. 2. Berkley's Modification. Small pieces are fixed in Flemming's solution for from 24 to 30 hours, at a temperature of $25^{\circ} \mathrm{C}$., then transferred directly into absolute alcohol, which is changed twice during the following 24 hours, and then placed from 12 to 24 hours in celloidin. Thin sections should be cut, washed in water, and put into a saturated solution of copper acetate over night, in a covered vessel. If necessary to be rapidly done, the sections may be heated over a water-bath to between $35^{\circ}$ and $40^{\circ} \mathrm{C}$. for 25 minutes, and then allowed to cool. After washing in water the sections are stained in a hematoxylin solution, prepared as follows: $50 \mathrm{c.c}$. of water are boiled in a flask and 2 c.c. of a saturated solution of lithium carbonate added; boil a little longer, and add I. 5 or 2 c.c. of a Io per cent. solution of hematoxylin in absolute alcohol. The flask is then shaken, corked, and allowed to cool. The solution improves in a day or two, but may be used at once. After staining, the sections are washed and put into Weigert's borax and potassium ferrocyanid solution, which may be diluted one-third. The decolorizing ought to be complete in from 1 to 3 minutes. Then wash several times in water, then in alcohol, and mount in xylol-balsam. The medullated nerves appear blue-black, the glia substance yellowish, the nerve-cells unstained. 3. Breglia's Modification. Mordant sections for from Io to 15 minutes in a mixture of $15 \mathrm{C} . \mathrm{c}$. of 90 per cent. alcohol and from 3 to 7 c.c. of a saturated aqueous solution of neutral copper 
acetate; then bring them for from 5 to Io minutes into $I$ part of a saturated aqueous solution of lithium-carbonate and 3 parts of water. Stain for from I 8 to 24 hours in Japanese red-wood solution (see formula in Flechsig's method), and differentiate in WVeigert's decolorizing mix ture. 4. Flesch's Modification. Celloidin or other sections are put for a few minutes or more in a 0.5 per cent. chromic-acid solution, then rinsed in water, and brought into the stain. Decolorize in the usual way. This method has the advantage of staining more rapidly and producing better differentiation of the nerve-cells, especially in the peripheral ganglia, and also of giving differentiation of the medulla of central and peripheral nerves. 5 . Haug's Modification. Small segments of fresh cord are put for 2 days into a saturated, aqueous solution of neutral copper acetate, then for from a day to a day and a half into a 5 per cent. or a saturated solution of potassium bichromate; rinsed in water, and placed in 70 per cent. alcohol, for from 36 to 48 hours, in the dark; then treated for the same period with absolute alcohol, in the dark, and embedded. Treat paraffin sections with alcohol, then water, and stain for from I5 to 30 minutes in a wellripened mixture of $\mathbf{I}$ part hematoxylin, I part ammoniumalum, $3^{\circ}$ parts alcohol, 300 parts water. Rinse in water, differentiate in acid alcohol until a red color appears, wash with water until they turn blue or bluish-gray, counterstain, if desired, by momentary immersion in a neutral carmin solution, and mount. 6. Hill's Modification. Pieces of nervous tissue are put in from a 2 to a 2.5 per cent. solution of potassium bichromate for 6 weeks ; then washed daily in 30 per cent. alcohol until the fluid re mains clear ; then fully hardened in strong alcohol. Wash in water small pieces and put them in solution of carmin and alum prepared thus: Boil for 3 hours, in water in which carmin and potash-alum have been placed, and restore the water lost by evaporation. Both carmin and alum should be in excess. Filter when cold. After 2 days put the pieces for 24 hours in a half-saturated solution of copper acetate, then into hematoxylin for 8 hours at $40^{\circ} \mathrm{C}$. Decolorize in Weigert's decolorizing fluid. The nerve-cells and non-medullated fibers are rendered susceptible of staining by the alumcarmin. 7. Kultschitzky's Modification. Harden for one or two months in Erlicki's solution, embed in celloidin and photoxylin, and cut. Stain sections for from I to 24 hours in hematoxylin $1 \mathrm{gm}$., dissolved in a little alcohol and added to IOO c.c. of 2 per cent. acetic acid. Wash out in a saturated solution of sodium or lithium carbonate. A finer differentiation is obtained by decolorizing in a lithium-carbonate solution containing Io per cent. of potassium ferricyanid. 8. Lissauer's Modification. A rapid method which gives good results with cerebral tissue even when it is imperfectly hardened. Place sections that have been hardened in Muiller's fluid in a I per cent. solution of chromic acid, and heat until bubbles begin to form; rinse in water, place in Weigert's hematoxylin, and heat again till bubbles begin to form. Differentiate by Pal's method. 9. Pal's Modification. After staining in the hematoxylin solution, the sections are washed in water, to which, if they are not stained a deep-blue, a trace of lithium carbonate is added. They are next placed in a 0.25 per cent. solution of potassium permanganate for half a minute, rinsed in water, and then brought into a decolorizing solution composed of I part each of chemically pure oxalic acid and potassium sulphite, and 200 parts of distilled water. In a few seconds the gray substance is decolorized, the white remaining blue. Wash well in water, and double-stain with eosin or picrocarmin. Io. Rossi's Modification. Harden in a solution of $\mathrm{I} \mathrm{gm}$. of chromic acid and $5 \mathrm{gm}$. of copper acetate in IOO c.c. of water. Dehydrate, and embed in celloidin. Stain for 2 hours in hematoxylin ( 7 or 8 drops of a 5 per cent., alcoholic solution to $30 \mathrm{c} . \mathrm{c}$. of alcohol). Differentiate in acid alcohol, wash out for 20 minutes in water, dehydrate, and mount. Double-stain if desired in borax-carmin. II. Schäfer's Modification. Harden the tissue for from 4 to 6 weeks, and put the sections in Marchi's fluid (I part of a I percent. osmic-acid and 2 parts of a 3 per cent. potassium-bichromate solution). Wash quickly in water, and stain in hematoxylin $\mathbf{I}$ gm., acetic acid 2 c.c., water Ioo c.c. Differentiate by Pal's method. This method is applicable when sections have been too long in alcohol. 12. Vasale's Modification. From alcohol the sections are transferred to a solution of hematoxylin $\mathbf{I ~} \mathrm{gm}$. to IOO c.c. of water, and decolorized by the aid of heat. After from 3 to 5 minutes they are put into a saturated, filtered solution of copper acetate and left for the same length of time, when they become black. They are washed in water and placed in a solution of borax 2 parts, potassium ferricyanid 2.5 parts, and water 300 parts, in which the degenerated areas, the cells, and the neuroglia become decolorized, the medullated fibers remaining dark. After decolorization, wash in water, dehydrate, clear, and mount. Counterstaining by picro-carmin or alumcarmin may be practised. 13. Wolter's Modification. 1. Stain sections in a solution of $2 \mathrm{gm}$. of hematoxylin in a little alcohol and Ioo c.c. of 2 per cent. acetic acid at $45^{\circ} \mathrm{C}$. for 24 hours. Dip them in Müller's fluid, and differentiate by Pal's method. This is an intense myelin stain ; medullated fibers appear blue-black, ganglion-cells yellow, the ground light. Or, sections of tissue hardened in Müller's fluid and cut in celloidin are mordanted for 24 hours in a mixture of 2 parts of ro per cent. vanadium chlorid and 8 parts of 8 per cent. aluminum acetate; then washed for 5 or 10 minutes in water, and stained in the foregoing solution of hematoxylin and differentiated with Weigert's decolorizing fluid. This is a myelin stain, with a splendid differentiation of the processes of Purkinje's cells. Monti's Copper Method. Small pieces of nervous tissue are hardened in a 2 or 3 per cent. solution of potassium bichromate or Müller's fluid until they are quite firm. They are then immersed in a mixture of equal parts of copper sulphate and Müller's fluid. A reaction takes place which stains the nerve-cells a reddish color in direct, or a blackish-yellow color in transmitted light. Nerves and Nerve-cells in a Frog's Heart. Find the sinus venosus, and ligate the inferior and two superior venæ cavæ opening into it; make an incision into one of the aortx, and into it tie a fine, glass cannula. Inject normal saline solution to wash out the cavities of the heart. Distend the cavities with 2 per cent. gold chlorid 4 parts and formic acid I part, previously boiled together and cooled. Ligate the other aorta, adjust a ligature below the cannula, cut out the heart, and place it for from a $1 / 2$ to I hour in 5 c.c. of the gold mixture. Open the auricles, wash the heart in water, and expose it to light in distilled water 50 c.c., containing 3 drops of acetic acid. Reduction of the gold takes place in from 3 to 4 days. Examine the auricular septum in glycerin, for pyriform nerve-cells with straight and spiral nerve-processes. A 2 per cent. solution of osmic acid, used in place of the gold solution, brings the nerve-fibers into prominence. Nigrosin Method. For axis-cylinders. Stain sections for from 5 to ro minutes in concentrated aqueous solution of nigrosin, decolorize in dilute, then in absolute alcohol, and clear in origanum. oil. Nikiforoff's Modification of Adamkiewicz's Method. Harden in a chrome-salt and transfer directly to alcohol. Section, and place in alcohol. From the alcohol sections are brought for 24 hours into a concentrated aqueous solution of safranin, or anilin-water safranin, or in 5 per cent. carbolic acid and safranin. Differentiate in alcobol until the gray is distinguishable from the white 
substance. Transfer to a o. I per cent gold-chlorid solution until the gray matter shows a violet tinge, wash carefully in water, place in absolute alcohol. When the rosy-violet of the gray substance forms a distinct contrast to the red medullary substance carry to clove-oil, then to xylol or toluol, and mount in balsam. Nissl's Method. Treat bichromate objects with 95 per cent. alcohol; then stain for 72 hours in an aqueous solution of Congo red, $5: 400$; wash out for from 5 to Io minutes in 95 per cent. alcohol; treat for 6 hours with a 3 per cent. solution of nitric acid in alcohol; dehydrate for 5 minutes in alcohol, clear in clove-oil and mount in balsam. A specific stain for axis-cylinders. Paladino's Method. For axis-cylinders. Pieces not more than from 5 to $8 \mathrm{~mm}$. in thickness, hardened in potassium bichromate, chromic acid, or corrosive sublimate, are put for two days into a large quantity ( $200 \mathrm{c}$.c. for each piece) of a $\mathrm{O}$. I per cent. aqueous solution of palladium chlorid. Then place them for 24 hours in a I per cent. solution of potassium iodid, using a relatively small volume, or the palladium iodid formed in the tissues may be extracted. After from I to 2 hours, dehydrate and embed in paraffin by the chloroform method. Medulla, axis-cylinders, and cell-processes are stained brown. Platner's Method. Small, fresh nerves are fixed and hardened for several days in I part of ferric-chlorid solution and 3 or 4 of water or alcohol, washed out in water or alcohol until the washings no longer give the reaction for iron with potassium rhodanid, and stained for several days or weeks in a concentrated solution of dinitroso-resorcin in 75 per cent. alcohol; then dehydrated, embedded, and sectioned. A specific reaction for the neurokeratin network of medullated nerves is obtained by this method. Rehm's Method. For axis-cylinders. Stain sections for a few minutes in a concentrated aqueous solution of Congo red, wash in alcohol, treat for Io minutes, until they become blue, with acid alcohol, clear with origanum-oil, and mount. This gives a clear axis-cylinder stain with considerable other detail. Or, alcohol-hardened sections may be stained for $\mathbf{I}$ or 2 days in a 0.5 per cent. aqueous solution of hematoxylin, washed out in an aqueous solution of lithium carbonate until no more color is given off, then dehydrated, and mounted. Counterstain for a few minutes in a $0 . \mathbf{I}$ per cent. aqueous solution of Bismarck brown. Axis-cylinders, cells, and processes appear grayblack. Sahli's Methods. I. Sections of nerve-tissue hardened in Müller's fluid are stained for a few minutes or hours in a liquid prepared as follows: Mix 24 parts of a saturated aqueous solution of methylene-blue, 16 parts of a 5 per cent. solution of borax, and 40 parts of water; Iet the mixture stand a day, and filter. Wash sections in water or alcohol until the gray matter can be distinguished from the white, clear in cedar-oil, mount in balsam. Nerve-tubes and nuclei of neuroglia appear blue, ganglion-cells greenish. Micrococci, if present, are stained, 2. Sections hardened as detailed, and washed for from 5 to Io minutes in water, may be stained for several hours in a concentrated aqueous solution of methylene-blue. When they have acquired a deep-blue color, rinse in water, and stain for 5 minutes in a saturated, aqueous solution of acid fuchsin. Rinse in alcohol, and differentiate in a liberal quantity of water. The axis-cylinders appear red, the myelinsheaths blue. A still finer differentiation is obtained by rinsing in alcohol containing from o.I to I per cent. of a potassium-hydroxid solution, and then differentiating in water. Clear with cedar-oil, mount in balsam dissolved in cedar-oil. Schmaus' Method. For axis-cylinders in the spinal cord. After hardening in Müller's fluid, stain sections for from 15 to 20 minutes in the following solution: sodium carminate $\mathbf{I}$ gm., uranium nitrate $0.5 \mathrm{gm}$., water $100 \mathrm{c.c}$, , heat for half an hour, and, when cold, filter. Wash out in water. Another stain that may be used is a 0.25 per cent. solution of Englișh blue-black in 50 per cent. alcohol, to which a little picric acid has been added. V. Thanhoffer's Methods. For multipolar nerve-cells. Press fresh tissue between two cover-glasses, separate these, and let them dry in air. Float them on a concentrated aqueous solution of methylene-blue for several hours. Wash in water, pass through alcohol and clearing fuid, or dry in air. Mount in balsam (that is not dissolved in chloroform). Or, place fresh tissue for 3 or 4 days in Landois' fluid; then stain in bulk for from 24 to 48 hours in equal parts of strong ammoniacal carmin and methylene-blue solutions. Üpson's Gold Methods. 1. Harden the tissue in Miller's fluid for from 2 to 5 months; then wash in water, and place for 2 days in $5^{\circ}$ per cent, and then for 2 months in 95 per cent. alcohol. Embed in celloidin, and treat the sections with 80 per cent. alcohol for a few days before staining. The section to be stained is first rinsed in water, then transferred to a I per cent. aqueous solution of gold chlorid for from Io to 30 minutes, washed in water, immersed for $1 / 2$ a minute in a 10 per cent. solution of sodium hydroxid, again washed in water, and then placed in a reducing fluid consisting of $5 \mathrm{c} . \mathrm{c}$. of sulphurous acid, from 5 to 10 drops of a 5 per cent. tincture of iodin, and $I$ drop of a 37 per cent. solution of ferric chlorid. When the sections assume a red color, they should be removed from this fluid, and washed, dehydrated, and mounted in the usual way. 2. Place the sections, soon after cutting, in a $\mathbf{I}$ per cent. goldchlorid solution for $1 / 2$ an hour; wash in water, and immerse for $1 / 2$ a minute in a 15 per cent. solution of sodium hydroxid, to which add, at the time of using, a trace of chromic acid. Wash again, and place in a reducing fluid consisting of 15 drops of solution of stannic chlorid, I or $2 \mathrm{gm}$., in $30 \mathrm{c.c}$. of a $\mathbf{I}$ per cent. tincture of iodin, distilled water 3 c.c., 3 drops of a 5 per cent. solution of iron phosphate, and 3 c.c. of sulphurous acid. 3. For axis-cylinders and nerve-cells, Harden in the dark in a solution of potassium bichromate for 4 months, increasing the strength from I to 2.5 per cent. Wash and transfer to alcohol, increasing in strength from 50 to 95 per cent. Section, free or embedded, dehydrate, and put sections in a I per cent. gold-chlorid solution with 2 per cent. of hydrochloric acid added. Wash, transfer on filter-paper to Io per cent. solution of potash 5 c.c., containing a trace of potassium ferricyanid. After $1 / 2$ a minute, wash, and transfer to the following: sulphurous acid 5 c.c.; 3 per cent. tincture of iodin from Io to 15 drops; mix, and add solution of ferric chlorid $\mathbf{I}$ drop. When the section has become rosecolored, wash, dehydrate, clear, and mount. 4. Sections made as detailed are placed in a $\mathbf{I}$ per cent. goldchlorid solution 5 c. c., saturated solution of ammonium vanadate Io drops, hydrochloric acid 3 drops. Remove after 2 hours' immersion, wash in distilled water, and place for from $1 / 2$ to $I$ minute in a mixture of a Io per cent. caustic-potash solution 5 drops, ro per cent. potassium-permanganate solution Io drops, and a trace of ammonium vanadate; rinse in distilled water, and treat until they become red with the following freshly prepared reducing mixture: 3 per cent. tincture of iodin to which has been added 15 drops of tin chlorid, 3 c.c. of distilled water, from 3 to 5 drops of a saturated solution of iron phosphate, and sulphurous acid 3 c.c. A precipitate will be thrown down when these solutions are mixed, and at the instant that this occurs the sections should be put into it. The remaining treatment is as in the other methods. Van Gieson's Picro-acid-fuchsin Method. Harden small pieces of nerve-tissue in Müller's fluid or alcohol, or both, and embed in celloidin. 
The sections are stained rather deeply in Delafield's hematoxylin, washed in water, and then placed for a few minutes in a solution of picric acid and acid fuchsin, made by adding to a saturated aqueous solution of picric acid a saturated aqueous solution of Grübler's acid fuchsin, drop by drop, until a garnet color appears; they are again washed in water, then dehydrated in alcohol, cleared in oil of origanum, and mounted in balsam. The ganglion-cells, neuroglia, blood-vessels, and sclerosed areas are stained garnet, the axis-cylinders red, and the myelin yellow. This stain is well adapted to all tissues in which picrocarmin is used. Weigert's Method. This method depends on the production in the tissues of a chromium or copper lake, in consequence of which hematoxylin acquires the property of staining the myelin of nerves in a specific way. The steps of the process are as follows: The tissue is hardened in Müller's or Erlicki's fluid, and, when it has acquired a brown coloration, is embedded by infiltration with celloidin, and placed for $\mathbf{I}$ or 2 days in a saturated solution of neutral copper acetate diluted with $\mathrm{I}$ volume of water and kept at the temperature of an incubating oven. In this the tissue becomes green and the celloidin bluish-green, and the change of color indicates that the mordantage is complete. Preserve in 80 per cent. alcohol. Stain sections in Weigert's hematoxylin (see Stain ing Reagents). The time required varies according to the tissue: for the spinal cord and the medullary layers of the brain 2 hours, for the cortical layers of the brain 24 hours; rinse in water, and differentiate in a solution of borax 2 parts, potassium ferricyanid 2.5 parts, water 200 parts, $1 / 2$ to several hours being necessary. Wash in water, dehydrate, and mount in balsam. The nuclei may be demonstrated by previous staining in alum-carmin. Weigert's New Method. See Weigert's Method without Decolorizing. Weigert's Method without Decolorizing. Tissues hardened in Müller's fluid and alcohol are embedded in celloidin, and then put into a mixture of equal parts of a ro per cent. solution of sodium-potassium tartrate and a cold saturated solution of copper acetate, which is kept at from $38^{\circ}$ to $40^{\circ} \mathrm{C}$. They are next placed in a half-saturated solution of copper acetate at the same temperature for 48 hours. The blocks, rinsed in water, may be kept in 80 per cent. alcohol and cut at any time. The staining fluid is com posed of $\mathbf{I}$ part of an alcoholic hematoxylin solution ( $\mathrm{I}$ to IO), and 9 parts of a saturated solution of lithium carbonate; this fluid is to be freshly made. Stain for from 4 to 12 hours; wash, dehydrate in 90 per cent. alcohol, and clear in anilin-xylol ( 2 to 1 ), then in pure xylol, and mount in xylol-balsam. The advantage of the method is the clearness with which the fine medullated fibers are distinguished from the cells and other parts, and it is less tedious than the old method. Wolters' Method. Harden either peripheral or central nervous tissue in Kultschitzky's fluid, and follow by alcohol. Embed in celloidin or paraffin. Mordant sections 24 hours in the vanadium-chlorid and aluminum-acetate mixture used in Wolters' modification of Weigert's method: wash for 1o minutes in water and stain for 24 hours in the hematoxylin solution used in Wolters' modification of Weigert's method. Wash out in acid alcohol until the sections acquire a light blue-red color. Remove the acid in pure alcohol, dehydrate, clear in oil of origanum, and mount. Besides the axis-cylinders, which are sharply stained, all the tissue-elements are colored, Ziehen's Method. Pieces of nerve-tissue are put for 5 weeks in a mixture of equal parts of $\mathbf{I}$ per cent. solutions of gold chlorid and corrosive sublimate. The sections are put in 0.25 per cent. solution of iodin. The nerve-fibers, medullated and non-medullated, the nerve-cells, and the neurolgia-cells are colored blue.
STAINING REAGENTS.

The stains employed in microscopic anatomy (histology) are divided into two groups, according to their selective action on the tissues: the histologic, or plasmatic stains, and the cytologic, or nuclear stains. The substances chiefly used are the coal-tar or anilin dyes, carmin, hematoxylin, gold and silver. I. ANiLin STAins. These are classified by Ehrlich as acid, basic, and neutral. The basic dyes are excellent nuclear stains, and are most used. Some of them have special affinities for certain tissues, and are of the utmost value in bacterio logic research. They are further classified as plasmatic stains, and, according to the method of staining, as direct and indirect nuclear stains. The indirect, or "Flemming" Method, which is suitable only for sections, consists in overstaining all the tissue-elements in a strong solution of the dye, and then decolorizing. As the nuclei have the strongest affinity for these stains, they resist the washing-out process longest, and still retain the color when it has been yielded up by the ground-substance. The washing-out is usually done in alcohol, but in some instances may be effected by staining with another anilin, which displaces the first in the ground-substance; this process is known as substitution. The initials attached to the names of anilin dyes indicate a certain tint of a color and its depth or intensity ; as, cyanin $B$, which means cyanin of a peculiar shade of blue, cyanin BB meaning a deeper shade of the same blue, and so on. The initials may also signify chemic change; as, fuchsin $\mathrm{S}$, which denotes sulphonation of the dye. Acid Fuchsin. A diffuse stain, having a special affinity for axis-cylinders. A solution of $2 \mathrm{gm}$. in $40 \mathrm{c}$. c. of 90 per cent alcohol and I6o c.c. of distilled water is employed. Wash out in 90 per cent. alcohol. Weigert stains sections of tissue hardened in Miiller's fluid in a saturated aqueous solution of acid fuchsin for from $\mathrm{I}$ to $\mathbf{2 4}$ hours, then rinses them quickly in water, immerses for a few minutes in a saturated solution of potassium hydroxid I part, alcohol Io parts. Wash thoroughly to remove the alkali, dehydrate, clear, and mount. This process differentiates the finer nerve-fibrils in the spinal cord. Acid Rubin. See Acid Fuchsin. Anilin Blue-black. See Nigrosin. Anilin Brown. Sections are stained in a saturated solution of anilin brown in equal parts of water and glycerin, and washed and preserved in glycerin. This stain is used especially in microphotography. Anilin Red. See Fuchsin. Artificial Indigo. See Nigro. sin. Bengalin. See Nigrosin. Benzopurpurin. A dark-red, plasmatic stain, affording a good contrast to hematoxylin and other blue nuclear stains. Sections are stained for from 2 to 5 minutes in a solution containing $0.25 \mathrm{gm}$. of purpurin to $20 . \mathrm{c}$.c. of 90 per cent. alcohol and $80 \mathrm{c}$. c. of distilled water. Bismarck Brown. A direct and indirect nuclear stain. A solution of $0.5 \mathrm{gm}$. in $20 \mathrm{c}$. c. of 90 per cent. alcohol and 80 c.c. of distilled water gives a good nuclear stain. The addition of carbolic acid is advised. This dye has also the property of staining certain cellular elements during life. Blackley Blue. See Nigrosin. Chromotrop. See, under Cytologic Methods, Watase's Method for Differentiating Sexual Cells. Congo Red. An acid stain used in the study of the central nervous system. Stain for 2 or 3 minutes in a 2 per cent. aqueous solution. Corallin. See Fuchsin. Cyanin (Quinolein Blue). A plasmatic dye. It stains fatty matters a deep-blue, other tissues a pale-blue. Dissolve I gm. in go per cent. alcohol, and then dilute with water. A weak solution should be used; a very weak solution, I : 500,000, in the medium that constitutes the native habitat of the organism, stains Infusoria intra vitam. Dahlia-violet. A nuclear stain, recom- 
mended for demonstrating the granules in Ehrlich's Mastzellen. Tissues hardened in alcohol are stained for several hours in a solution of dahlia-violet $2 \mathrm{gm}$., in 90 per cent. alcohol 25 c.c., distilled water 70 c.c., glacial acetic acid 5 c.c. Wash in alcohol until nearly colorless. Deltapurpurin. See Benzopurpurin. Dinitroso-resorcin. See Staining of Nerve-tissue, Platner's Method. Eosin. Stains rapidly and gives a beautiful, diffuse, rosy hue. It is one of the best con trast-stains with hematoxylin. Make a 5 per cent. aqueous solution, and dilute as required. It is also a specific stain for red blood-corpuscles (to which it gives a copper color), for certain leukocytes, and for the giantcells of leprosy and tubercle. Erythrosin. See Eosin. Fuchsin. Dissolve $I \mathrm{gm}$. of fuchsin in 15 c.c. of distilled water, and $50 \mathrm{c.c}$. of 90 per cent. alcohol, and add Ioo c.c. of glycerin. This solution is used for staining blood-corpuscles. Carbol-fuchsin: fuchsin I gm., carbolic acid 5 gm., alcohol $10 \mathrm{gm}$., distilled water Ioo gm. Gentian-violet. A nuclear stain, prepared by dissolving $0.5 \mathrm{gm}$. of the dye in $80 \mathrm{c}$. c. of distilled water, $20 \mathrm{c} . \mathrm{c}$. of 90 per cent. alcohol, and glacial acetic acid I c.c. Stains in 5 minutes. Dissolved in indifferent media it may be used for staining intra vitam, and in acid solutions colors the nuclei of fresh tissues. It may be used according to Gram's method. Hoffmann's Blue. A nuclear stain for sieve areas. Dissolve I gm. of Hoffmann's blue in 20 c.c. of 90 per cent. alcohol and 80 c.c. of distilled water, and add 0.5 c.c. of glacial acetic acid. Let sections remain in the solution for about ro minutes. Indulin. See Nigrosin. Iodin-green. See Methyl-green. Magenta. See Fuchsin. Manchester Brown. See Bismarck Brown. Metanil-yellow. A plasmatic stain with a special affinity for connective tissues. It is also used to differentiate certain preparations (Griesbach). Methylene-blue. An important reagent, which gives a specific stain for lymph-spaces and intercellular cement, closely resembling gold and silver impregnation, for medullated nerves, and for plasma-cells. It also stains intra vitam, and is a specific reagent for the axiscylinders of sensory nerves in living animals (Ehrlich). Small and permeable aquatic organisms may be stained during life by adding to the water containing them enough of the dye to give it a very pale tint. Nervetissue may be stained by injecting the dye into the vascular system of a living, narcotized animal, or by removing the organ and immersing it in the solution. From one-half to I per cent. solutions in physiologic saltsolution are employed for this purpose. The color is not permanent, but may be fixed by ammonium picrate. Parker fixes the color by dehydrating in a solution of mercuric chlorid, I gm., in methylal 5 c. c. ; washing in a mixture of 2 parts of the methylal and sublimate solution, I part pure methylal, 3 parts xylol. The object is then placed in xylol for 4 or 5 days, when it is ready to mount or embed. Mayer's albumen should not be used to fix sections to the slide, as it discharges the color. A solution of $0.25 \mathrm{gm}$. in 90 per cent. alcohol, 20 c.c., and distilled water, 80 c.c., is used for tissuestaining. One per cent. and saturated alcoholic (I5 gms. to 100 c.c.) solutions are used for staining microorganisms. Dogiel's Methylene-blue and Ammonium Picrate. Stain for Io minutes in a 4 per cent. solution of methylene-blue in normal salt-solution; soak for $1 / 2$ an hour or more in a saturated solution of ammonium picrate, wash in fresh ammonium picrate, and examine in dilute glycerin. This process is used to demonstrate epithelia and lymph-spaces, and has the effect of negative impregnation with silver nitrate. A positive image is obtained by a short bath in the stain, a negative image by from 15 to 30 minutes' immersion. Striking images of the cruciform figures in the nodes of Ranvier in medullated nerves are obtained by this reagent (S. Mayer). Methyl-green. This is chiefly used as a nuclear stain for fresh or recently fixed tissues; it is also a reagent for amyloid degeneration (Heschl), giving a violet color. Use $0.5 \mathrm{gm}$. of methyl-green in $20 \mathrm{c.c}$. of 90 per cent. alcohol, 80 c.c. of distilled water, and I c. c. of acetic acid. Stain the tissue for 5 minutes, wash in acidulated water, differentiate in 90 per cent. alcohol, and dehydrate. The nucleîn reaction depends on the presence of the acetic acid. Arnold recommends a dilute solution of methyl-green containing 0.6 per cent. sodium chlorid for staining cells and nuclei. Bizzozero has observed that the elements of blood and pus, also ciliated epithelium and spermatozoa, do not stain with methyl-green if the cells are highly alkaline: if the alkalinity is diminished they are dyed violet; if the cells are acid, they are colored green. Carnoy regards methyl-green as the best stain for nucleoli. Methylviolet. A good chromatin stain. Dissolve $0.5 \mathrm{gm}$. in 200 c.c. of distilled water and 5 c.c. of glacial acetic acid. Stain sections for 20 minutes, wash in distilled water, and then in equal parts of glycerin and water. Mount in Farrant's medium. This is also a reagent for tissues undergoing amyloid degeneration. The amyloid substance stains pink. Naphthylaminbrown. See Staining of Nerve-tissue, Kaiser's Method. Nigrosin (Anilin Blue-black). A plasmatic stain having a special affinity for ganglion-cells, and much used in the study of the central nervous system. Dissolve $2 \mathrm{gm}$. in IOO c.c. of distilled water, and stain sections for from to to 15 minutes. Orange. A plasmatic dye used for counter-staining. Dissolve 2 gm. in 20 c.c. of 90 per cent. alcohol and 80 c.c. of water. Stain for 10 minutes and wash out in alcohol. Phenylene-brown. See Bismarck Brown. Quinoleïn. See Cyanin. Rubin, Roseïn. See Fuchsin. Rosanilin Acetate, Sulphate, and Hydrochlorate. See Fuchsin. Rose-bengal. Take of rose-bengal I gm., 90 per cent. alcohol $20 \mathrm{c} . \mathrm{c}$., and distilled water 80 c.c. This solution is especially useful for demonstrating the beginning of amyloid degeneration; it stains the tissues bright-red. It is also recommended for staining the spinal cord and as a contrast-stain. Safranin. Pfitzner's formula: safranin (Grübler's) I part, absolute alcohol 100 parts, water 200 parts. Flemming uses a concentrated alcoholic solution diluted $1 / 2$ with water. Babes' formulce: (a) equal parts of a concentrated alcoholic and a concentrated aqueous solution; (b) water 100 parts, anilin-oil 2 parts, safranin in excess. The latter may be used according to the method of Gram, and is recommended for the demonstration of mitotic figures. Solferino. See Fuchsin. Spiller's Purple. Rub up in a mortar $2 \mathrm{gm}$. of Spiller's purple, No. I, with ro c.c. of alcohol, and add roo c.c. of distilled water. It is used as a double stain, and for the fibrin in coagulated blood. If the section is to be mounted in balsam, use cedar-oil to clarify it. Vesuvin. See Bismarck Brown. Victoria Blue. A beautiful nuclear stain. Use a saturated aqueous solution, or $0.25 \mathrm{gm}$., in $20 \mathrm{c}$ c. of 90 per cent. alcohol and 80 c.c. of distilled water. Chromatin and nucleoli are stained blue, cytoplasm greenish-blue, or not at all. As clove-oil washes out the color, clear in cedaroil. This stain has a special affinity for elastic fibers; fixation in Flemming's fluid or other chrom-osmium mixture is necessary to secure this reaction. II. CARMIN AND COCHINEAL. These dyes give nuclear reactions, and are chiefly used for staining in the mass. Acetic-acid Carmin. To boiling 45 per cent. acetic acid add carmin until no more will dissolve, and filter. For use, dilute to I per cent. The concentrated 
solution fixes and stains at the same time, and is a valuable reagent for the study of fresh objects. It is a pure nuclear stain. Acetic-acid Alum-carmin. Boil an excess of carmin in a saturated potash-alum solution; when cool, add Io per cent. of glacial acetic acid, and filter after several days For use, add enough of the filtrate to distilled water to give it a deep-rose tint, stain for from 24 to 48 hours, and wash for 2 hours in distilled water. Dehydrate in alcohol. This solution has great penetration, and stains the deeper tissue-layers as admirably as the more superficial ones. Beale's Carmin. Dissolve $0.6 \mathrm{gm}$. of carmin in $2 \mathrm{c}$.c. of strong ammonia; boil for a few seconds, and stand aside uncovered for an hour, or until the excess of ammonia has evaporated. Then add 60 c.c. each of glycerin and water and 15 c.c. of alcohol ; filter, stand aside to settle, and decant. Csokor's Alum-cochineal. A nuclear and diffuse stain. Nuclei are stained violet, and other tissues different tones of red. It is composed of powdered cochineal I gm., and calcined alum I gm., water IoO c.c., carbolic acid 0.5 c.c. Delage's Osmium-carmin has the staining properties of carmin and the fixing properties of osmium, and so stains and fixes tissues at the same time. It is prepared by evaporating on a water-bath a strong ammonium-carmin, until red clouds on its surface indicate that the excess of ammonia has disappeared; and when cool, adding an equal volume of a I per cent. solution of osmic acid. Filter under a bell-jar. As the reagent soon loses its fixing properties, the acid and carmin should be mixed at the time of using. It is said to rival gold chlorid in bringing out the more minute tissue-elements. De la Rue's Cochineal. Exhaust cochineal in boiling water, precipitate the extract with lead acetate slightly acidulated with acetic acid, being careful not to use an excess of the lead. Wash the precipitate with distilled water until the washwater ceases to give a precipitate with mercuric chlorid ; then decompose it with hydrogen sulphid, filter, and evaporate the filtrate to a syrupy consistence on a waterbath. Dry, and exhaust the dark-purple product with alcohol, which dissolves out the carminic acid. Frey's Carmin. Dissolve in 30 c.c. of distilled water 0.3 gm. of carmin, adding ammonia, drop by drop, until the solution is complete. Then add 30 c.c. of glycerin and 4 c.c. of alcohol; shake, and keep in a stoppered bottle. Grenacher's Alcoholic Borax-carmin. Dissolve $4 \mathrm{gm}$ of borax in Iooc.c. of distilled water; add $3 \mathrm{gm}$. of carmin, warm, and dilute with $\mathbf{I O O}$ c.c. of 7o per cent. alcohol. Filter before using, and transfer the tissue from the stain directly into alcohol acidulated with from 4 to 6 drops of hydrochloric acid, in which it should remain until it acquires a bright, transparent appearance. This solution is used for staining in bulk, and gives a splendid color. Grenacher's Alum-carmin. Dissolve $5 \mathrm{gms}$, of ammonium-alum in IOO c.c. of distilled water, adding I gm. of carmin, cooling, filtering, and bringing up to roo c.c. by adding water. This solution is not suitable for calcareous structures, but is otherwise an admirable reagent. Grenacher's Borax-carmin. Heat to boiling carmin 0.5 gm., borax $2 \mathrm{gm}$. in 100 c.c. of distilled water, and while hot add, drop by drop, about 17 c.c. of acetic acid, or until the color turns from purple to red. After 24 hours decant, filter, and add 0.5 c c. of carbolic acid. Hamann's Acid Carmin. Dissolve $30 \mathrm{gm}$. of carmin in $200 \mathrm{c.c}$. of strong ammonia; add acetic acid until the fluid besomes neutral, or is only slightly acid. Allow it to stand for from 2 to 5 weeks, and filter. Haug's Alum Borax-carmin. Take I gm. each of carmin and borax, $2 \mathrm{gm}$. of ammonium-alum, pulverize, and add 100 c.c. of liquor aluminis acetatis and boil for $1 / 2$ an hour; decant, and filter after 24 hours. The solution is ready for use in I week. Haug's Ammonium Lithiumcarmin. A permanent solution, recommended for preparations which stain with difficulty. Pulverize and boil in 100 c.c. of water, carmin $\mathbf{I} \mathrm{gm}$. and ammonium chlorid $2 \mathrm{gm}$.; after cooling add from 0.3 to $0.5 \mathrm{gm}$. of lithium carbonate and, drop by drop, from 15 to 20 c.c. of a strong solution of ammonia. This solution stains in from I to 3 minutes, and gives a gorgenus strawberryred color. Differentiate in acid alcohol, and follow with absolute alcohol. Heidenhain's Neutral Carmin. Dissolve $\mathrm{I} \mathrm{gm}$. of carmin in $3 \mathrm{c.c}$. of ammonia, and add 96 c.c. each of glycerin and water. Heat on a water-bath until the excess of ammonia is driven off, or neutralize with acetic acid. Henneguy's Aceticacid Alum-carmin. Boil an excess of carmin in a saturated solution of potassium-alum, and when cool add Io per cent. of glacial acetic acid, and leave the mixture to settle for several days; then remove the sediment by filtration, and for use add enough of the solution to distilled water to produce a deep-rose tint. Stain for from 24 to 48 hours, and wash for 2 hours in distilled water. Hoyer's Alcoholic Carmin. Heat the carmin in a retort with alcohol, acidulated with sulphuric acid, until dissolved; filter, and dilute freely with water. As long as a rose-red precipitate forms, add lead acetate to the filtrate. As soon as the precipitate is violet, filter, and add to the filtrate lead acetate as long as the violet precipitate forms; collect it on a filter, wash, and dry it. Suspend it in a small quantity of strong alcohol, add alcohol strongly acidulated with sulphuric acid until the violet precipitate loses its color and becomes intensely red. Filter. Two drops of the filtrate added to a watchglass of alcohol make a strong stain. Hoyer's Ammonium-carmin. Dissolve $\mathbf{I} \mathrm{gm}$. of carmin in from $\mathbf{I}$ to 2 c.c. of strong ammonia and from 6 to $8 \mathrm{c} \mathrm{c}$. of water. Heat in a glass vessel on a sand-bath until the large bubbles become small, and the purplish color turns to bright-red showing that the free ammonia has evaporated. Allow the solution to cool and settle, saving the bright-red deposit for use again, and add chloral to the neutral, dark fluid, which will keep well. Hoyer's Neutral Carmin. Dilute ammonium-carmin with from 4 to 6 times its volume of strong alcohol; collect the scarlet-red precipitate which forms on a filter, wash and dry it. Dissolve this powder in a solution of neutral ammonium picrate. Mayer's Aluminum Carminate. Carminic acid I gm, aluminum chlorid $3 \mathrm{gm}$, water 200 c.c., and a few crystals of thymol. Gives a blue-violet color, and is a good substitute for alum-carmin when the use of alum is contra-indicated. Mayer's Cochineal. A nuclear stain, which is red or blue according to the reaction of the tissues, which should previously have been hardened in 70 per cent. alcohol. Take I gm. of coarsely powdered cochineal and Io c.c. of 70 per cent. alcohol; digest for several days and filter. Let the tissues stain, according to size, for from 15 minutes to several days, wash in 70 per cent. alcohol, follow by acid alcohol for a light yellowish-red stain, or by alkaline water for a deep purple-red. New formula: Pulverize in a mortar, 5 $\mathrm{gm}$. of cochineal, mix with $5 \mathrm{gm}$. of calcium chlorid and $0.5 \mathrm{gm}$. of aluminum chlorid, add 8 drops of nitric acid (sp. gr. I. 20) and IOO c.c. of 50 per cent. alcohol ; heat to the boiling-point. Let the mixture stand a number of days, shake it frequently, and finally filter. The objects must be treated with 50 per cent. alcohol before and after staining. Mayer's Carmalum. Take I gm. of carminic acid, ro gm. of alum, and 200 c.c. of distilled water, heat the mixture, and filter, adding an antiseptic to keep it clear. The fluid is light-red in color, shading toward violet, and is said to have good penetrating powers, even in osmium preparations, and 
to be better than alum-carmin for staining in toto Mayer's Paracarmin. Dissolve carminic acid $\mathbf{I}$ gm., aluminum chlorid $0.5 \mathrm{gm}$., calcium chlorid $4 \mathrm{gm}$. in I 00 c.c. of 70 per cent. alcohol, with or without heat. Filter, after precipitation, and the solution will have a clear-red color. Suitable for staining bulky objects with large cavities, such as Salpa. Orth's Carmin Stains. Lithizm-carmin. Digest $2.5 \mathrm{gm}$. of carmin in 97.5 c.c. of a saturated solution of lithium carbonate and filter. The stain is diffuse, but on treatment with acid alcohol becomes restricted to the nuclei. Tissues refusing to stain in any other medium do so in this fluid. Picrolithium-carmin consists of $\mathbf{r}$ part of lithium carmin and 2 or 3 parts of a saturated solution of picric acid. After staining, wash out in acid alcohol. Partsch's Cochineal Alum-carmin. Boil powdered cochineal in 5 per cent. alum solution, filter, and add a little salicylic acid as a preservative. This is said to give more delicate differentiation than other alumcarmins. Partsch-Grenacher's Alum-carmin. A nuclear stain, prepared as follows: Boil for 15 minutes $2 \mathrm{gm}$. of pure carmin, No. 40, and $5 \mathrm{gm}$. of ammoniumalum in $200 \mathrm{c.c}$. of distilled water. Cool, filter, and add 2 c.c. of carbolic acid. Ranvier's Carmin. This is composed of carmin I gm., ammonia I c.c., water IOO c.c. Rub up the carmin in a mortar with a little water and add the ammonia. When the carmin is all dissolved add the rest of the water. If there is an excess of ammonia, heat the solution until the carmin begins to precipitate. Reeves' (J.E.) Borax-carmin. A nuclear stain, consisting of the best No. 40 carmin $4 \mathrm{gm}$., pulverized borax $8 \mathrm{gm}$., and carbolized water, 2 per cent., 120 c.c. Heat in a porcelain vessel to boiling, and, when cool, filter. Stains in from I minute to $1 / 2$ an hour, according to the character of the tissue. A decolorizing and differentiating fluid composed of pure hydrochloric acid Io c.c., 7o per cent. alcohol IO5 c.c. may be used with this stain. After immersion in this fluid the section must be well washed with water, to remove the acid, and if desired it may now be double-stained in a weak, aqueous solution of sodium sulph-indigotate. Rollet's Acid Carmin. Boil pulverized carmin in dilute sulphuric acid, filter off the red precipitate, and dissolve in water for use. Schneider's Acid Carmin. Boil pulverized carmin in 45 per cent. acetic acid until no more will dissolve, filter, and dilute to I per cent. for use. SchweiggerSeidel's Acid Carmin. Add an excess of acetic acid to ammonium-carmin, and filter. Sodium Carminate. See Staining of Nerve-tissue, Schmaus' Method. III. Hematoxylin and Hematein. Solutions of these substances are used for staining sections, and also tis. sues, in toto, especially such as have been fixed in chromium and osmium fluids. Böhmer's Hematoxylin. A valuable nuclear stain. Dissolve $\mathbf{I} \mathrm{gm}$. of hematoxylin in 100 c.c. of absolute alcohol. Make a second solution of $5 \mathrm{gm}$. of alum in $\mathrm{IOO} \mathrm{c} . \mathrm{c}$. of distilled water. Add the first solution, drop by drop, to the second, until a deep-violet color is obtained. Let the mixture stand in an open vessel, exposed to the light, for several days. Filter, and add a little thymol to the filtrate. Cook's (Alleyer) Hematoxylin. An alumhematoxylin containing copper sulphate. Reduce in a mortar 6 grams each of extract of logwood and alum and I gram of copper sulphate, and dissolve in 40 c.c. of water. Filter after 2 days, and add a crystal of thymol to the filtrate. Cuccati's Iodinhematoxylin. Dissolve $25 \mathrm{gm}$. of chemically pure potassium iodid in $25 \mathrm{c.c}$. of distilled water. Pour this solution, slowly and with constant agitation, into 75 c.c. of ahsolute alcohol, and keep in a well-stoppered bottle. Rub up in a mortar $75 \mathrm{cg}$. of crystallized hem- atoxylin with $6 \mathrm{gm}$. of chemically pure, neutral potashalum, and add 3 c.c. of the iodin-solution; keep the mixture agitated, and gradually add the remainder of the solution. Shake for some time, to dissolve the alum, stand aside for from Io to $\mathbf{1} 5$ hours, shake again, filter, and preserve in a tightly stoppered bottle. Objects should be left in the liquid for ro hours, then washed, dehydrated, and mounted. The solution is said to be a pure chromatin stain. Delafield's Hematoxylin. An excellent nuclear stain. Dissolve $4 \mathrm{gm}$. of hematoxylin in 25 c.c. of absolute alcohol, and add 400 c.c. of a saturated, aqueous solution of ammonium-alum. Expose to light and air for 3 or 4 days; filter; add to the filtrate 100 c.c. each of glycerin and methyl-alcohol. Ehrlich's Acid Hematoxylin. Used for staining sections and in the mass. Dissolve $\mathbf{I} \mathrm{gm}$. of hematoxylin in $30 \mathrm{c.c}$. of alcohol, and add $50 \mathrm{c.c}$. each of glycerin and water, alum in excess, and 4 c.c of glacial acetic acid. Let the mixture ripen in the light until it acquires a deep-red color. Objects stained in it should be washed in undistilled water. Ehrlich's Ammoniated Hematoxylin. Dissolve $2 \mathrm{gm}$. of hematoxylin and $0.4 \mathrm{gm}$. of ammonium carbonate in $80 \mathrm{c.c}$. of 90 per cent, alcohol. Expose in an evaporating dish for 24 hours, warm, and bring up to $40 \mathrm{c}$. c. by adding 50 per cent. alcohol, and then add $2 \mathrm{gm}$. of ammoniumalum, 80 c.c. of distilled water, IOO c.c. of glycerin, and Io c.c. of acetic acid. Dilute I: ro for use. Gage's Hematoxylin. Boil 7.5 gm. of alum in 200 c.c. of distilled water for about 5 minutes; when cool, add enough freshly boiled distilled water to make up the loss by evaporation; add $4 \mathrm{gm}$. of chloral, and then o. I gm. of hematoxylin dissolved in 10 c. c. of 95 per cent. alcohol. Let the mixture ripen for a week. It stains sections in from I to 5 minutes, and if too concentrated may be diluted with freshly distilled water. This solution does not readily deteriorate. Hamilton's Hematoxylin. A rapid and strong nuclear stain of the following composition: hematoxylin $12 \mathrm{gm}$., ammonium-alum $50 \mathrm{gm}$., glycerin 65 c.c., distilled water I30 c. c., carbolic acid 5 c. c. Heat the mixture to boiling before adding the carbolic acid, and expose to sunlight for I month. Haug's Hematoxylin. A nuclear stain, giving good results with nervous tissue. Dissolve $\mathbf{I} \mathrm{gm}$. of hematoxylin in Io c. c. of absolute alcohol, and add to 200 C. c. of an aqueous solution of aluminum acetate. Let the solution ripen until the violet-black hue becomes brown-black. After staining, treat the sections with acid alcohol, and wash in water until they appear blue. Heidenhain's Hematoxylin. Place the object to be stained in a 33 per cent. solution of hematoxylin in distilled water for from I 2 to 24 hours, and then for the same length of time in a 0.5 per cent. solution of neutral potassium chromate, and wash out the excess of this with water, treating further as desired. The stain is clear, from black to gray in color, rich in detail, and adapted to staining in mass, and has the advantage that objects can be decolorized to any extent by prolonging the washing in the chromate. If instead of this a I per cent. alum solution be used, the stain will be blue. Apathy's Modification. Make a I per cent. solution of hematoxylin in 70 or 80 per cent. alcohol. After staining, wash out in a I per cent. solution of potassium bichromate in from 70 to 80 per cent. alcohol. The mixture should be made freshly and kept in the dark while using, as should also the objects while being washed, and they should be finished by washing in several changes of 70 per cent. alcohol. Iron Hematoxylin. Sections are treated with a weak aqueous solution of ferric acetate, washed in water, and stained in 0.5 per cent. aqueous solution of hematoxylin. A blue-black or black-brown stain is obtained. This pro- 
cess is recommended by Bitschli for staining sections of protozoa I $\mu$ thick. Another method is as follows: Treat sections for from $1 / 2$ an bour to 2 or 3 hours with from a $\mathbf{1} .5$ to a 4 per cent. solution of ferric-ammonium sulphate; wash in water, and stain for from $\mathbf{I}$ to $\mathbf{I} 2$ hours in an aqueous solution of hematoxylin, about 0.5 per cent. Rinse with water and treat again with the iron solution. As soon as differentiation is complete, wash for 15 minutes in running water, and mount. The results vary accord. ing to the duration of the treatment with the iron and hematoxylin solutions; short baths give a blue preparation, in which the nuclear structures are highly differentiated ; prolonged baths give black preparations, showing connective-tissue fibers and red blood-corpuscles black, central and polar bodies intensely black, cytoplasm sometimes colorless, sometimes gray, in which case cellplates and achromatic spindle-fibers are stained. Microorganisms are sharply stained. Kleinenberg's Hematoxylin. Adapted to staining in the mass. Make a saturated solution of calcium chlorid in 70 per cent. alcohol. Shake it, and let it stand; decant, and add alum in excess; shake again, and, after a day or two, filter. To I volume of the filtrate add 8 volumes of a saturated solution of alum in 70 per cent. alcohol; to this mixture add, drop by drop, a saturated solution of hematoxylin in absolute alcohol, until a purple color appears. It becomes darker in time and on exposure to light. It should be prepared some months before it is wanted. Mallory's Phosphomolybdic-acid Hematoxylin. Ten per cent. solution of phospho-molybdic acid I part, hematoxylin I part, water Ioo parts, chloral from 6 to Io parts. Expose to sunlight for a week. Filter before using, and save the used portions. Stain sections for from Io minutes to an hour, wash in 40 to 50 per cent. alcohol, changing it 2 or 3 times. Dehydrate and mount. If the solution does not stain readily, add a little hematoxylin. The stain is blue, and in its general effect similar to nigrosin. It is recommended for preparations of the central nervous system. Mayer's Ammoniumnitrate Hemateîn. Hemalum Io c.c., 7o per cent. alcohol Io c.c., ammonium nitrate $5 \mathrm{gm}$. Dissolve, let the solution stand until the excess of alum crystallizes out, I2 to 24 hours, and filter. Useful for staining small objects in toto. Mayer's Hemalum. An excellent stain for large objects. It consists of two solutions; one of hemateîn, or ammonium-hemateĩn, I gm., dissolved by the aid of heat in 50 c.c. of 90 per cent. alcohol; the other of alum 50 grams and distilled water I liter. The solutions are mixed, left to cool, and then filtered. A crystal of thymol may be added to prevent the formation of mold. For most purposes it is advisable to dilute this stain with water or alum-solution. Hemalum plus 2 per cent. glacial acetic acid gives a more precise nuclear stain. Mayer's Hemacalcium. Rub together in a mortar, very thoroughly, $\mathbf{I} \mathrm{gm}$. each of hematein or ammonium-hemateïn and aluminum chlorid, and dissolve in 600 c.c. of 70 per cent. alcohol, to which Io c. c. of glacial acetic acid have been added; then add 50 grams of calcium chlorid. The color of the fluid is reddish-violet. Objects overstained in it are treated with a 2 per cent. alcoholic solution of aluminum chlorid or from a $1 / 2$ to a I per cent. solution of sodium or potassium acetate in absolute alcohol. Clearing with bergamot-oil or cloveoil causes early fading. Reeves' (J.E.) Hematoxylin. To one part of 5 or Io c.c. of 5 per cent. carbolized water add enough sodium sulphindigotate to produce a deep bluish-green color, and 7 parts of Delafield's hematoxylin. The mixing should be done at the time of using. After staining, which requires from $\mathbf{I} / 2$ to $\mathbf{I}$ hour or more, immerse the section in water acidulated with a few drops of nitric acid, and allow it to remain until it shows a clear, deep, sky-blue color; wash in water and delydrate for 20 minutes in alcohol. This stain differentiates the inclusions in carcinoma-cellschromatin, parasites, etc. Renaut's Glycerin-hematoxylin. To a saturated solution of alum in glycerin add, drop by drop, a saturated alcoholic solution of hematoxylin until the mixture has a deep color. Expose to light and air for several weeks, and then filter. Sections may be mounted in the stain. Sanfelice's Iodin-hematoxylin. Useful for staining in the mass. Make a solution of hematoxylin, $0.7 \mathrm{gm}$. in absolute alcohol $20 \mathrm{c} . \mathrm{c}$., and pour it, drop by drop, into a solution of alum $0.2 \mathrm{gm}$. and distilled water 60 c.c. Let the mixture stand exposed to the light for 3 or 4 days; then add Io to I5 drops of tincture of iodin, shake, and let it stand again for 3 or 4 days. Tissues are immersed in this fluid for from 12 to 24 hours, and then transferred for 24 hours to 90 per cent. alcohol acidulated with acetic acid. Weigert's Hematoxylin. See Staining of Nerve-tissue, Weigert's Method. After using, this stain may be regenerated as follows: Add about 5 per cent. of barytawater, shake it well, and let it stand for 24 hours : then pass carbon dioxid through it, let it stand another 24 hours, and filter (Fanny Berlinerblau). IV. METALLIC STAINS. These are chiefly used in the study of epithelial, connective, and nervous tissues, for which they exhibit a remarkable selectivity. The results obtained vary according to the method of impregnation, a negative or primary impregnation coloring the intercellular substance, leaving the cells colorless; a positive or secondary impregnation staining the cells and not the intercellular spaces. Ferric Chlorid. After impregnation in a solution of ferric chlorid, reduction is effected in tannic, gallic, or pyrogallic acid (Polaillon). Another method is to fix the preparation in the iron-solution and then treat for 24 hours with alcohol containing a trace of gallic acid $\left(F_{0} l\right)$. Gold Chlorid. Recommended for tracing nerve-endings in fresh tissues, and for staining connective-tissue and cartilage-cells. Place small pieces of tissue, $1 / 4$ inch square, in from a 0.5 to a $I$ per cent. solution of commercial gold chlorid in distilled water. Keep in the dark, and when the tissue has become yellow, wash in distilled water. Then expose to the light in 50 c.c. of water containing 2 drops of acetic acid for 48 hours, or until the tissue acquires a purple tint. Mount in glycerin. Boiled Gold Chlorid. Used in studying the terminations of nerves on sensory surfaces. To 4 parts of a I per cent. solution of gold chlorid add I part of formic acid, boil, and cool. In this place small pieces of fresh tissue for from Io minutes tc I hour; wash in water, and transfer to formic acid, I : 4, keeping in the dark, where reduction occurs. Cohn. heim's Method. Place fresh tissue in a 0.5 per cent. solution of gold chlorid until it is yellow; then expose it to the light in water acidulated with acetic acid until reduction occurs, and mount in acidulated glycerin. Chrchtschonovitsch's Method. Place the fresh tissue in a 0.5 per cent. solution of auric chlorid for from 30 to 45 minutes; then in distilled water for 24 hours; then in a saturated solution of tartaric acid at a temperature of $50^{\circ} \mathrm{C}$., until the gold is reduced. Wash in water and harden in alcohol. Freud's Method. Harden the tissue in Müller's fluid; stain in equal parts of a I per cent. gold chlorid solution and 95 per cent. alcohol for from 3 to 5 hours; wash in water, and place in a solution of caustic soda I c.c., and distilled water 6 c. c., for from 2 to 3 minutes. Wash in water and carry to a Io per cent. solution of potassium iodid for from 5 to 15 minutes, wash, dehydrate in alcohol, and mount. Glass instruments should be used. This method, when successful, gives islolated staining of axis-cylinders. Gold Chlorid and Chromic Acid (Kolosson). To $I 00$ parts of a $I$ per cent, solution of gold chlorid add 
I part of hydrochloric acid; place the tissues in this mixture for 2 or 3 hours; wash with water, and keep in the dark in chromic acid, $\frac{1}{50}$ or $\frac{1}{100}$ per cent. for 2 or 3 days; then wash thoroughly. Löwit's Method. Mix 2 parts of distilled water and I part of formic acid (sp. gr. 1. I6); in this mixture place small pieces of fresh tissue, from $I$ to $2 \mathrm{~mm}$. in thickness, for from a $\mathrm{x} / 2$ to $I$ minute, or until they become somewhat transparent. 'Then transfer to a I per cent, solution of gold chlorid, protecting the tissue from the light as much as possible; in from 15 to 20 minutes, or when it is yellow, place it in a solution of formic acid, 1 : 3 , for 24 hours, keeping it in the dark. Then immerse in pure formic acid for 24 hours, in the dark, and, finally, wash thoroughly in water. Pritchard's Method. After the tissues have been treated with a gold-solution, the gold is reduced with the following mixture: amyl-alcohol I c.c., formic acid I c.c., water 98 c.c. Remove the tissue from the gold-solution, wash it in water, place in the preceding mixture for 24 hours in the dark, when it will probably have become of a violet color; if not, place it in a fresh quantity of the fluid for 24 hours longer. Wash in water and harden in alcohol. Ranvier's Formic-acid Method. Place the tissue in a mixture of 4 parts of a $\mathbf{I}$ per cent. solution of gold chlorid to I part of formic acid, the mixture having been previously boiled and cooled. Allow muscle to remain in this solution for 20 minutes, epidermis for from 2 to 4 hours. The reduction of the gold is accomplished in acidulated water by the action of daylight, or in the dark in I part of formic acid to 4 parts of water. Ranvier's Lemon-juice Method. Express and filter the juice of a lemon, and place the fresh tissue in it for 5 or $10 \mathrm{~min}$. utes, when it becomes transparent. Quickly rinse in distilled water, and transfer to a $\mathbf{I}$ per cent. gold-chlorid solution for from Io minutes to I hour, the time depending on the tissue. Wash with water, and place in 50 c.c. of water acidulated with 2 drops of acetic acid; reduction occurs on exposure to light. Viallanes' Osmic-acid Method. Treat the tissues with a I per cent. solution of osmic acid until they begin to turn brown; then with $1 / 4$ formic acid for Io minutes; then place them in a solution of gold chlorid, I : 5000 , in the dark, for 24 hours. Reduce in the light in $1 / 4$ formic acid. Osmic Acid. Tissues fixed in osmic acid and subsequently treated with weak pyrogallic acid are stained greenish-black (Lee). A developing mixture of water, alcohol, tannin, and pyrogallic acid or a 5 per cent. solution of tannin is used by Kolosson. Treatment with oxalic acid I part, in water I5 parts, gives a Burgundy-red stain to osmiumobjects, which should be washed in water before they are put into the acid (Brösicke). Silver Nitrate. Particularly adapted to the study of epithelial and connective tissues. Make a I per cent. solution in distilled water, and dilute from 2 to 4 times for use. Very thin sections of fresh tissue are washed in distilled water, to remove the chlorids, immersed for $1 / 2$ hour in the solution, in the dark, washed in distilled water, and then placed in water and exposed to sunlight until brown. Fix in a solution of sodium hyposulphite, in the dark, and mount in glycerin-jelly. The Hertroig's employ a I per cent. solution for marine animals. Toumeux and Hermann, in their studies of the epithelia of Invertebrates used a solution of $3: 1000$, in which the tissues were left for I hour and then washed in alcohol $\left(36^{\circ}\right)$. Dekhuysen treats the tissue with a I. 3 per cent. solution of potassium nitrate, then immerses it in 0.25 per cent, solution of silver nitrate containing 3 per cent. of nitric acid. After fram 3 to 6 minutes in the silver-bath, the tissue is placed for a few minutes in pure 3 per cent. nitric acid, then in 96 per cent. alcohol, then in clove-oil, in which reduction occurs, in diffused light, in a few minutes. This method is said to give good fixation of tissues, and to permit the use of a nuclear after-stain with hematoxylin, safranin, or methyl-green. The process is the same as that employed by Harmer for marine animals. Von Recklinghausen effects reduction by washing the preparation in normal salt-solution before exposing to light in distilled water. Thanhoffer exposes to light for a few minutes in water acidulated with acetic acid. Krause uses, after washing, a light-red solution of potassium permanagate, in which reduction occurs very quickly even in the dark. Jakimovitch exposes the tissues to light in a mixture of formic acid $\mathbf{I}$ part, amyl-alcohol $\mathbf{I}$ part, water 100 parts; from 5 to 7 days are required, and the mixture must be renewed from time to time. The after-blackening is prevented by washing in sodiumhyposulphite solution (Legros). V. OTHER ORGANIC Stains. Grenacher's Purpurin. Dissolve from I to 3 per cent. of powdered alum in 50 c.c. of glycerin, add a knife-pointful of purpurin, and boil. No alcohol should be used. The orange-colored solution should stand for 2 or 3 days, and then be filtered. This is a nuclear stain which is stable, from 10 to 30 minutes producing a good result. Nuclear Black (Kernschwarz). A black liquid of unknown composition, recommended by Platner as a cytologic stain. Dilute the liquid somewhat and wash out in dilute ammonia or a saturated solution of lithium carbonate diluted with 3 or 4 volumes of water. Mitotic figures stain deeply, resting chromatin less deeply, cytoplasm faintly gray. Phloroglucin. For staining lignified cellulose. Take of phloroglucin I gm., 90 per cent. alcohol 20 c.c., distilled water 80 c.c. ; treat the sections for 15 minutes, and follow by strong hydrochloric acid. This gives a stain of cherry-red, varying in proportion to the extent of the lignification. Ranvier's Purpurin. Boil in a porcelain capsule 200 c.c. of water and I c.c. of alum; then add purpurin rubbed up in water, and continue the boiling. A saturated solution of purpurin is secured by having an undissolved excess in the capsule. Filter the hot mixture into a flask containing 60 c.c. of 90 per cent. alcohol. This solution does not keep well. Wedl's Orseille. French orchilla extract, a sufficient quantity, from which the excess of ammonia has been removed by warming in a sand-bath, is poured into a mixture of 20 c.c. of absolute alcohol, 5 c.c of glacial acetic acid, and 40 c.c. of distilled water, the dye being added gradually until a dark-reddish fluid is produced. This is a protoplasmic stain, the nuclei remaining colorless. VI. Combination-stains. These are of two kinds. In the one class a pure nuclear stain is combined with a dye taking effect on the extra-nuclear elements; in the other, a stain giving a reaction with all the elements of one tissue is combined with one or more stains taking effect on all the elements of the other tissues. Alum-carmin and Osmic Acid (Zoltán von Roboz). To 50 or $60 \mathrm{gm}$. of water add alum-carmin until the mixture is nearly rose-red; then add 10 drops of a $\mathbf{I}$ : 500 solution of osmic acid. Stain objects, in the dark, from 24 to 48 hours. A nuclear double stain ; resting chromatin and nucleoli appear pur. ple, kinetic chromatin red, protoplasm brown. Recommended for staining Pluteus and similar objects. Alumcarmin and Picric Acid. Mix ro volumes of alumcarmin and $\mathbf{I}$ of saturated picric-acid solution (Legal). Anilin Blue and Safranin (Garbini). Stain sections for from 2 to 4 minutes in 0.5 per cent. anilinblue solution, wash in water, then place in a 0.5 per cent. lithium-carbonate solution, then in 0.5 per cent. hydrochloric acid until a clear, blue color appears. Wash again in water, and stain for 10 minutes in I per cent. safranin-solution, dehydrate in methyl-alcohol and 
clarify in clove-oil 2 parts and cedar-oil I part. This stain is especially recommended for salivary glands; one set of cells is colored red, the other blue; and for the gastric glands, in which the parietal cells stain red, the central cells blue, the villous epithelium blue, the goblet-cells reddish. In hair-follicles, the sheath of Henle colors red, the sheath of Huxley blue. Anilin Green and Bismarck Brown (List). Used in the same way as methyl-green and Bismarck brown, and yields similar results. Anilin Green and Eosin (Schiefferdecker, Arch. f. Mik. Anat., xv, 1878, p. 30). To a watch-glassful of alcohol add a few drops of an aqueous solution of eosin, and stain for from $1 / 2$ to several hours; wash in water, and stain for a few minutes in a $\mathbf{I}$ per cent. aqueous solution of anilin green, rinse in water, extract in alcohol, and clear in clove-oil. This combination has a special affinity for glandular and connective tissue. Baumgarten's Fuchsin and Methylene-blue. Sections of tissue fixed in a chromic fluid are stained for 24 hours in a solution of from 8 to Io drops of a concentrated alcoholic solution of fuchsin in a watch-glassful of water. Rinse with alcohol, and stain for from 5 to Io minutes in a concentrated aqueous solution of methylene-blue; wash out in alcohol and clear in clove-oil. The nuclei are red, the other elements blue. Borax-carmin and Picrocarmin. A few drops of picrocarmin added to a watch-glassful of Grenacher's alcoholic borax-carmin gives a beautiful and precise double stain. Baumgarten's borax-picrocarmin is prepared by adding crystals of picric acid to Grenacher's solution, until it assumes a bright-red color. Carmin and Anilin Blue. Stain with carmin, dehydrate, and stain for a few minutes in an alcoholic solution of anilin blue. Clear with turpentine, then treat with alcohol, and mount. Carmin and Methylgreen (Flesch). Stain with picrocarmin and follow with an aqueous solution of methyl-green. This stain gives good differentiation. Chenzynsky's Stain. See Czenzynke's Stain. Czenzynke's Double Stain. Concentrated aqueous solution of methylene-blue 40 c.c. 0.5 per cent. solution of eosin in 70 per cent. alcohol 20 c.c., distilled water 40 c.c. This is used to stain the blood, and colors the red corpuscles red, the leukocytes blue; also for the plasmodium malarix, the gonococcus, and the influenza-bacillus of Pfeiffer and Canon. Dahlia and Eosin (Schiefferdecker). Use in the same way as anilin green and eosin, taking a I per cent. solution of dahlia. Ehrlich-BiondiHeidenhain Triple Stain. To Ioo c.c. of a saturated aqueous solution of orange add, with continual agitation, 20 c.c. of a saturated, aqueous solution of acid fuchsin and 50 c.c. of a like solution of methyl-green ; dilute with from 60 to roo volumes of water. A drop on blotting-paper should form a spot bluish-green in the center, orange at the periphery; a red zone outside the orange indicates that the mixture contains too much fuchsin. From 6 to 24 hours are required to stain. Wash out in alcohol and clear in xylol. Chromatic elements are colored blue; cytoplasm, violet or orange-red; caryoplasm the same, but in lighter tones, and all the denser protoplasmic elements the same, but darker (Gilson). The stain par excellence for photo-micrography, except for connective tissue (Lindsay Johnson). A slightly acid reaction of the alcohol used for washing out will produce a relatively strong coloration by the methyl-green, while that by the fuchsin will be relatively pale; the opposite result will be obtained if the alcohol contains a trace of alkali. The addition of very dilute acetic acid, until the red tint is markedly intensified, will restore the energy of the fuchsin, which is likely to decline after a time (Heidenhain). EhrlichBiondi Mixture. See Ehrlich-Biondi-Heidenhain
Triple Stain. Ehrlich - Westphal Dahiia and Carmin. Partsch-Grenacher's carmin solution IoO c.c., glycerin Ioo c.c., concentrated alcoholic solution of dahlia-violet Ioo c.c., glacial acetic acid 20 c.c. Nuclei are stained red, "Mastzellen" blue-violet. Flemming's Safranin, Gentian, and Orange. Stain in a strong alcoholic solution of safranin diluted with anilin-water; rinse in distilled water, and wash out in absolute alcohol containing 0 .I per cent. of hydrochloric acid; then stain in a strong, aqueous solution of gentian, wash in distilled water, treat with a concentrated aqueous solution of orange, and wash in absolute alcohol. The orange, by virtue of its acid properties, displaces the gentian and the result is a double, not a triple, stain. Chromatin and nuclei are stained purple-red; achromatin fibrils gray or violet; " attractive spheres," centrosomes, polar corpuscles, and Zwischenkörper, from reddish-violet or brownishviolet to black-brown, according to the intensity of the reagent. Gaule's Quadruple Stain. The object, fixed in a concentrated solution of corrosive sublimate, is stained successively in hematoxylin, nigrosin, eosin, and safranin. According to their affinity for the different stains, Gaule distinguishes hematoxylophile nucleoli, or caryosoma; safranophile nucleoli, or plasmosoma, and mixed nucleoli; and those that react to both hematoxylin and safranin. Genevan Double Stain. Useful for staining vegetable tissue. Decolorize the sections in Javelle water, and then immerse for a few seconds in a slightly alcoholic and ammoniacal solution of Congo red 2 per cent. and chrysoidin 0.2 per cent. A beautiful triple stain is obtained. Hanstein's Rosanilin-violet. Used for staining planttissues, and composed of fuchsin and methyl-violet, each I gm., in Ioo c.c. of 90 per cent. alcohol. It stains cellulose cell-walls a faint violet, lignified cellwalls red. It is also useful in differentiating the histologic details of bast; the fibers stain red, the sieve-tubes and parenchyma scarcely at all, the protoplasm bluish-violet, the amyloid substance, gums, and nuclei different shades of red, resins blue, tannin, foxyred, or brick-red (Borerer). Hematoxylin and Safranin. Stain feebly with dilute Delafield's hematoxylin for about 24 hours, wash in water, then in acid alcohol ; then stain in Pfitzner's safranin and wash out in absolute alcohol ( $R a b l)$. The stains may be combined in one mixture, as follows: Böhmer's hematoxylin 25 c.c., safranin (I per cent, aqueous and alcoholic solution) 20 c.c., distilled water Ioo c.c. From I to 3 minutes are required for staining, and before dehydrating treat the section with a weak alcoholic solution of picric acid or orange. This combination is recommended for staining marrow, for the investigation of the development of blood (Foá). Hematoxylin and Rubin and Orange. Stain in Ehrlich's hematoxylin, wash in distilled or acidulated water, then in water containing a trace of an alkali, and then stain in the rubin and orange (Pringle). Kossinski's Safranin and Indigo-carmin. Stain sections in a saturated aqueous solution of indigo-carmin, wash in water, then in alcohol, and stain in a 0.5 per cent. dilute alcoholic solution of safranin. Löwenthal's Sodium Picrocarmin. Dissolve I gm. of caustic soda in 1000 c.c. of distilled water, add Io gm. of carmin, boil, filter, and then add distilled water to make 2000 c.c. Add gradually, as long as agitation causes the ensuing turbidity to disappear, a I per cent. aqueous solution of picric acid. Merkel's Carmin and Indigo-carmin. Solution $a$. Dissolve $2 \mathrm{gm}$. of carmin and $8 \mathrm{gm}$. of borax in I $30 \mathrm{c.c}$. of water. b. Dissolve $8 \mathrm{gm}$. each of indigo-carmin and borax in 130 c.c. of water. When required, mix 
equal volumes of $a$ and $b$. Sections must remain in the mixture for 24 hours, and then be placed for $1 / 2$ an hour in a saturated solution of oxalic acid. Methylgreen and Bismarck Brown. Stain in Weigert's Bismarck brown for a few minutes, wash, and stain in a 0.5 per cent, aqueous solution of methyl-green. Clear with bergamot-oil or xylol (List). Methyl-green and Rosanilin Nitrate. Stain for a few minutes in a 0.5 per cent. aqueous solution of methyl-green, wash, and stain for from Io to 15 minutes in a $0.000 I$ per cent. aqueous solution of rosanilin nitrate, and wash out rapidly in absolute alcohol. Methyl-green and Eosin. Mix 60 parts of methyl-green and I of eosin, and dissolve in warm 30 per cent. alcohol. Sections stain in from 5 to 10 minutes, and should be quickly washed in successive alcohols (Calberla). Stain for a few minutes in a mixture of 3 parts of absolute alcohol and I part of a 0.5 per cent. aqueous solution of eosin, wash, and stain for 5 minutes in a 0.5 per cent. aqueous solution of methyl-green (List). Methyl-violet and Eosin. (Schiefferdecker). Proceed as for anilin green and eosin, using a I per cent. aqueous solution of methylviolet. Orcein. A vegetable dye obtained from tinctorial lichens, which unites in itself the properties of basic and acid stains, and also 2 contrast-colors. A saturated acetic-acid solution is used. After staining, the section is washed in distilled water, immersed in alcohol, and quickly transferred to cedar-oil, in which it is mounted. Nuclei are colored blue and protoplasm red. Pianese Double Stain. Prepare a saturated solution of nigrosin in a saturated alcoholic solution of picric acid; mix 2 volumes of this with I volume of anilin-water, and evaporate in open air. The crystals deposited are dissolved in absolute alcohol, and from this solution green crystals are obtained soluble in alcohol, ether, and water. For tissues, make a 2 per cent. solution in alcohol, for microörganisms, in water. Stain sections first in lithium-carmin, treat with acid alcohol, wash, and immerse in an alcoholic solution of picro-nigrosin until they assume a brown hue. Decolorize in oxalic acid. Nuclei are stained red, plasma dark. yellow; cartilage yellow ; connective tissue pale-green; elastic fibers violet. Picro-lithium-carmin. See Orth's carmin stains. Ranvier's Ammonium-picrocarmin. Dissolve I gm. of carmin in 3 c.c. of stronger ammonia and 5 c.c. of distilled water by gentle heat, then add 200 c.c. of a saturated, aqueous solution of picric acid, boil, and filter. This stain is valuable for complex tissues, like skin. Ranvier's Picrocarmin. This gives a double stain without the use of an acid or an alkali. Add a saturated, ammoniacal solution of carmin to a saturated, aqueous solution of picric acid until precipitation just appears, mix well, and leave protected from dust, in shallow vessels, to crystallize. When the bulk is reduced to $1 / 3$, decant the liquid, filter, and evaporate it to dryness on a water-bath. Dissolve the residue and the crystalline deposit in water, filter, and evaporate to dryness. A I per cent. solution of the resulting brown powder yields a good stain. Renaut's Eosin-hematoxylin. Concentrated aqueous solution of potassium eosin 30 c. c., saturated alcoholic solution of hematoxylin $40 \mathrm{c.c}$, saturated solution of potassium-alum in glycerin (sp. gr. I. 26) I 30 c.c. Mix, and stand aside for 5 or 6 weeks in a vessel covered with a sheet of perforated paper, until the alcohol is evaporated, and then filter. This reagent stains slowly. Objects may be mounted in the solution diluted with from $\mathbf{I}$ to 2 volumes of glycerin; the tissues gradually absorb the colors, leaving the medium colorless. This solution has a selective action on the cells of salivary and gastric glands; mucous cells become pale-blue, salivary ferment-cells rose-colored. Safranin and Indigo-carmin (Kossins- ki). Sections are stained for from 10 to 20 minutes in a saturated solution of indigo-carmin, and, after washing in water and then alcohol, are stained in a 0.5 per cent. solution of safranin in dilute alcohol. The same author also recommends safranin and nigrosin, and stains first in a 0.1 per cent. aqueous solution of nigrosin for 3 to 5 minutes. Stöhr's Picro-carmin. Dissolve $\mathbf{I g m}$. of carmin in $50 \mathrm{c.c}$. of water and $5 \mathrm{c}$. c. of liquor ammonix, then add $50 \mathrm{c} . \mathrm{c}$. of a saturated solution of picric acid. Leave the mixture for 2 or 3 days in a large, flat evaporating dish, then filter, and add a drop of chloroform to the filtrate to preserve it. Weigert's Picrocarmin. In a vessel protected from evaporation soak for 24 hours $2 \mathrm{gm}$. of carmin in $4 \mathrm{gm}$. of ammonia. Add $200 \mathrm{gm}$. of a concentrated solution of picric acid, and put the whole away for 24 hours more. Acetic acid is then added until the first precipitate appears. After another 24 hours, a precipitate will be formed that can only be partially removed by filtration. Now add ammonia, drop by drop, at intervals of 24 hours, until the solution becomes clear. If it stains too yellow, add acetic acid; if too red, a little ammonia. VII. STAINS FOR Microörganisms. Balmer-Fränzel's Anilin Gentian-violet. Gentian-violet $2 \mathrm{gm}$., anilin-water IOO c.c. Filter before using. Borofuchsin. This consists of equal parts of boric acid and fuchsin dissolved in dilute alcohol. Carbolic Black-brown. Black-brown I gm., absolute alcohol Io c. c., aqueous solution of carbolic acid Ioo c.c. Dissolve the dye in the alcohol, and add the carbolic acid. Cose and Simon's Gentianviolet. Gentian-violet 2 gm., 9 o per cent. alcohol 5 c.c., anilin-water roo c.c. Ehrlich's Anilin Gentianviolet. Five c.c. of a saturated alcoholic solution of gentian-violet and Ioo c.c. of anilin-water. EhrlichWeigert's Solutions. I. Anilin-water roo c.c., concentraied alcoholic solution of fuchsin I I c. c., absolute alcohol Io c.c. Methyl-violet may be substituted for the fuchsin. Keeps abont 2 weeks. 2. Saturated alcoholic solution of methyl-violet II c.c., anilin-water 100 c.c., absolute alcohol ro c.c. Frænkel's Polychromatic Stain, a. Fuchsin-solution. b. Ninety per cent. alcohol 50 c.c., distilled water 30 c. c., nitric acid 20 c. c., methylene-blue as much as will dissolve; filter. c. Alcohol 70 c.c., nitric acid 30 c.c., Bismarck brown as much as will dissolve. Stain tubercle-bacilli preparations in solution $a$, then in $b$. The bacilli will appear red and the nuclei and other bacteria blue. If a blue stain is used first the specimen may be counterstained in solution $c$, the nuclei then being brown. Friedländer's Fuchsin. Fuchsin I gm., glacial acetic acid 2 c. c., 90 per cent. alcohol 5 c.c., distilled water Ioo c.c. Friedländer's Gentian-violet. See Staining of Microörganisms, Pneumo-bacillus of Friedländer. Fuchsin. (Concentrated Alcoholic.) Fuchsin $25 \mathrm{gm}$. , absolute alcohol IOO c.c. (Aqueous.) Fuchsin I gm., 90 per cent. alcohol 20 c.c., distilled water 80 c.c. Gentian-violet. I. (Concentrated Alcoholic.) Gentian-violet 25 gm., absolute alcohol 100 c.c. 2. (Aqueous.) Gentian-violet I gm., 90 per cent. alcohol 20 c.c., distilled water 80 c.c. Gibbes' Double Stain. (See Staining of Microörganisms, Gibbes' Method.) Gibbes' Magenta. Fuchsin (magenta) 2 gm., anilin-oil 3 gm., 90 per cent. alcohol 20 c.c., distilled water 20 c.c. Gold Orange. See Staining of Microörganisms, Unna's Method. Koch's Differentiating or Polychromatic Stain. a. Koch's methylene-blue solution. $b$. Aqueous solution of Bismarck brown. Preparations of tubercle-bacilli are stained first in $a$, then in $b$. The blue of the nuclei and other bacteria is changed to brown, while the tubercle-bacilli retain the blue color. Koch's Methylene-blue. Saturated alcoholic methylene-blue solution I c.c., Io per cent. solution of caustic 
potash 0.2 c.c., distilled water 200 c.c. Kühne's Carbolic Methylene-blue. Methylene-blue I. 5 gm., absolute alcohol Io c. c., 5 per cent. aqueous solution of carbolic acid IOO c.c. Rub up the dye in the alcohol, and add, slowly, the carbolic acid. Deteriorates with age. Kühne's Methyl-violet. Methyl-violet I gm., distilled water 90 c.c., alcohol too c.c. When using add I drop of nitric acid to each 50 c.c. of the stain. Lœffler's Methylene-blue. Thirty c.c. of a concentrated alcoholic methylene-blue solution are added to IOO c.c of a solution of caustic potash (0.0I : IOO). Filter before using. Methyl-violet. I. (Alcoholic.) Methyl-violet 25 gms., absolute alcohol IOO c.c. 2. (Aqueous.) Methyl-violet I gm., alcohol 20 c.c., distilled water 80 c.c. Neelsen or Ziehl-Neelsen Carbol-fuchsin. See Fuchsin. Ribbert's Dahliaviolet. See Staining of Microöroanisms, Pneumococcus. Rindfleisch's Fuchsin. Distilled water, go per cent. alcohol, nitric acid, each 50 c.c., and enough fuchsin to saturate. Add the fuchsin gradually and stir frequently. Used for staining tubercle-bacilli. Sahli's Methylene-blue. Distilled water 40 c.c., saturated, aqueous solution of methylene-blue 24 c.c., borax-solution (5 per cent.) I6 c.c. Used when anilin-oil is not available. Trenkmann's Gentian-violet Anilin-water. A drop of a concentrated, alcoholic solution of gentian-violet is let fall into a test-glass and Io c.c. of water are added. Half of this is then poured away and the glass filled with anilin-water; a solution is thus obtained that remains clear and stains the bacteria deeply, but the ground very slightly. Coverglasses should remain about $1 / 2$ an hour in the staining fluid. Watson Cheyne's Contrast-stain. Saturated alcoholic solution of methylene-blue $20 \mathrm{c}$.c., distilled water 100 c.c., formic acid (sp. gr. I.2) I c.c. Used after staining in fuchsin anilin-water. Place sections in the solution for from I to 2 hours. Weigert's Differentiating Stain. $A$. Aqueous solution of gentian-violet; $B$. acidulated (acetic acid) picro-carmin. Stain sections in $A$, then in $B$. The blue of the nuclei will be altered to red and the bacteria will remain blue. Weigert's Gentian-violet. Gentian-violet 2 gm., ammonium hydroxid 0.5 c.c., distilled water 90 c.c., absolute alcohol Io c.c. ; mix and filter. Ziehl's Fuchsin. Filtered, saturated, aqueous solution of carbolic acid 90 parts, saturated alcoholic solution of fuchsin Io parts. Used for staining the typhoidbacillus. Ziehl's or Ziehl-Neelsen's Solution. See Staining of Microörganisms, Kühne's Fuchsin.

\section{ZOÖLOGIC METHODS.}

Annelids. The blood-vessels of annelids may be demonstrated by treating them for 2 or 3 hours with aqua regia (2 parts of hydrochloric acid to 4 parts of nitric acid). The animals should be laid open before being put into the mixture. The vessel-walls appear black on a yellow ground. The nerves may be brought to view by staining with methylene-blue (see Staining Reagents). Ehler's fluid (see Fixing Fluids) is recommended for fixing and hardening. The intestine of Lumbricus may be cleansed by putting the animal into a tall glass jar filled with scraps of moistened blotting-paper; they gradually evacuate the earthy contents of the gut and fill it with paper (Kükenthal). Coffeegrounds may be used instead of paper, and are said to cut better when embedded. The animals may be narcotized by exposing them for $1 / 2$ an hour to the vapor of chloroform; if exposed for a longer period they will die in a state of extension. Eyes of Arthropods. Hickson's Method. Remove the posterior wall of the head of a fly, and expose the rest to osmiumvapor for 20 minutes; wash in 60 per cent. alcohol, harden in absolute alcohol, and make sections. Fix sections to the slide with Mayer's albumin (see Fixatives), remove the paraffin with turpentine, wash with absolute alcohol, and decolorize by inverting the slide over a capsule containing 90 per cent. alcohol to which a few drops of nitric acid have been added; wash with pure alcohol. Parker?s Method. For the eye of Homarus. Make paraffin sections and fix them to the slide with Schällibaum's collodion, treat with alcohol, then with water, and then for $1 / 2$ a minute with a o. I per cent, caustic-potanh solution; wash thoroughly, and stain for 3 hours in Weigert's hematoxylin (see Staining Reagents) at a temperature of $50^{\circ} \mathrm{C}$.; wash, dehydrate, and mount in balsam. Eyes of Gastropods. Carrière's Method. Excise the eye and a part of the tentacle; expose them to osmium vapor for a few minutes, and prepare sections in the usual way. Fix the sections to the slide with Schällibaum's collodion (see Fixatives), decolorize with very dilute Javelle water, stain with picro-carmin, and mount in dammar. Gelatin Casts. A method for making anatomic models, etc., from a combination of gelatin $2 \mathrm{oz}$, glycerin $4 \mathrm{oz}$, the best Irish glue $4 \mathrm{oz}$, and boiled linseed-oil $1 / 4 \mathrm{oz}$. Soften the glue in 60 per cent. alcohol, melt it, stir in the glycerin and oil, and add a few drops of carbolic acid. This mixture has the merit of resisting ordinary temperature-changes, and models made of it are not softened by heat or rendered brittle by cold. In making a cast, melt the mixture and pour it into the mold, which should be previously warmed. If it is desired to color the casts, dry or tube colors may be used, and should be well mixed with the glycerin before being added to the glue (J. W. Scollick). Infusoria. As a mechanical means of slowing the movements of minute organisms, Eismond directs that a drop of a thick, aqueous solution of cherry-tree gum be added to the water containing them, and an intra vitam stain may be obtained by adding methylene-blue to the gum-solution. Jensen prepares a solution of $3 \mathrm{gm}$. of gelatin in 100 c.c. of water, which is a jelly at the ordinary temperature; for use it is warmed, and a drop of it is mixed in a watch-glass with a drop of water containing the organisms. This method inhibits movement while preserving life, and is recommended for vivisection. Living Infusoria may be stained in very dilute solutions of cyanin, methylene-blue, and other anilins, in the medium that constitutes their natural habitat. They may also be examined in a colored medium which does not stain them, but which simply serves as a dark background. For this purpose a solution of anilin black is recommended; the organisms will live in this for several weeks. Cattaneo fixes the organisms for a few minutes in a 0.33 per cent. aqueous solution of palladium chlorid, or with the double chlorid of gold and cadmium, which demonstrates the nuclei better than the palladium. Brass treats protozoa that are opaque through accumulation of nutritive material for a few minutes with Kleinenberg's fluid and then with boiling water; from this they are brought into water containing a little ammonia. To stain, neutralize the ammonia by adding acetic acid, and bring into borax-carmin; wash, and

- mount in dilute glycerin. The method of Certes is as follows: Expose the organisms to osmium-vapor for from Io to 30 minutes, cover, and remove the excess of liquid with bibulous paper. Prepare a solution of picrocarmin, I part, in I part each of water and glycerin, and place a little of this stain at the edge of the cover-glass; place the slide in a moist chamber, and when the water has evaporated and the glycerin taken its place, strong glycerin is added and gradually substituted for the dilute. The organisms thus prepared 
are fixed in their natural forms, and the nuclear struc tures clearly brought out by the picrocarmin. Larvæ of Echinodermata. Pluteus larvæ are placed for 2 or 3 minutes in a cold, saturated solution of corrosive sublimate, then washed in water and stained with Mayer's cochineal (see Staining Reagents). The stain should be diluted so as to possess a barely perceptible tinge of color, and the objects left in it from $\mathbf{1} 2$ to 24 hours. They are then mounted in balsam or oil of cloves (Barrios). This method is equally applicable to other forms. Medusæ. Van Beneden's Method. This consists in pouring glacial acetic acid over the organisms, and after 5 or 6 minutes washing them in alcohol, changing it frequently, and gradually increasing its strength. It is said that the tentacles may be kept from rolling up by imparting a swirling motion to the fixing fluid, putting in but one medusa at a time, and keeping up the vortex motion until the animal is fixed. The Hertwigs' Method. For the study of the nervous system. The organisms are treated with a mixture of equal parts of 0.05 per cent. osmic acid and 0.2 per cent. acetic acid, and after 2 or 3 minutes washed in $0 . x$ per cent. acetic acid until every trace of osmic acid is removed. They are then placed in $0 . I$ per cent. acetic acid for 24 hours, washed in water, stained with Beale's carmin, and mounted in glycerin. Nerve and Muscle of Arthropods. Place a number of Milnesium tardi gradum in a test-tube containing water from which the air has been expelled by boiling. Cover the surface of the water with a drop of oil, so as to exclude the air. After 24 hours or more the animals will be found fixed and extended in a cataleptic state, and they can then be examined in boiled water. They are quite transparent in this condition, and the nervous and muscular systems stand out distinctly. Porifera. Small sponges may be fixed by the usual reagents, preferably by osmic acid, and should be immediately transferred to absolute alcohol and stained with an alcoholic solution-Mayer's cochineal solution is recommended (see Staining Reagents). Sections may be made by decalcifying in alcohol acidified with hydrochloric acid, and then embedding in paraffin in the usual way. Rotifers. The living animal may be examined after quieting with warm water or a 2 per cent. solution of cocain hydrochlorate. For permanent preservation Rousselet recommends the following process. Place the animals in a trough containing water, and narcotize them by adding cocain of I or 2 per cent. strength; watch them under the microscope until the cilia cease to vibrate, and then fix them in Flemming's strong solution, which should be introduced into the trough by means of a pipet. After 15 minutes wash them in several changes of distilled water, and mount in distilled water containing a little Flemming's solution, about 8 drops to $30 \mathrm{c}$.c. of water. Sarcolemma of Insects. To demonstrate the two lamellæ of the sarcolemma, digest muscle of an insect in artificial gastric juice for from $1 / 2$ to I hour, at the temperature of the room in summer, and examine in gastric juice. Siphonophora. Bedot's Method. Add to the sea-water containing the animals a considerable quantity of from 15 to 20 per cent. solution of copper sulphate; this fixes them in a few minutes. Add a few drops of nitric acid, and after from 4 to 5 hours add Flemming's solution in the proportion of 2 parts to $I$ of the sulphate solution. After 24 hours, a few drops of a 25 per cent. alcohol are introduced by means of a pipet in such a manner as to disturb the colony as little as possible; alcohol of gradually increasing strength, up to 70 per cent., is cautiously added during the next $\mathrm{I}_{4}$ days, and 90 per cent. alcohol is used for preservation. This method has the advantage of preserving the specimens with all their swimming-bells and polyps in situ. Trematodes. Fisher's Method. These forms may be preserved entire as follows: Treat Opisthotrema cochleare with absolute alcohol, then stain with hematoxylin or picrocarmin, clear in clove-oil, and mount in balsam. Trichinæ. Examination of the living parasite. Place a piece of trichinized muscle about the size of a cherry-stone in a bottle containing 3 gr. of pepsin, 2 $\mathrm{dr}$. of water, and 2 drops of hydrochloric acid; keep at $98^{\circ} \mathrm{F}$, for about 3 hours, shaking occasionally. When the flesh and cysts are dissolved, pour the fluid into a conical glass and let it settle. The trichinze are then drawn off with a pipet, placed on a slide with water, and examined on a warm stage (Barnes).

Stalaxis $($ stal-aks'-is). Synonym of Staxis.

Stalk (stawk) [ME., stalken]. Any lengthened support to an organ.

Stallion (stal'-yon) [ME., stalyone, stallion]. The male of the horse.

Stamen $\left(s t a^{\prime}-m e n\right)$ [ $\sigma \tau \eta \dot{\eta} \mu \omega \nu$, a thread as spun, the warp in the loom: pl., Stamens]. In biology, the pollenbearing organ of the flower, when complete consisting of a stalk or filament and a pollen-sac or anther.

Stamina (stam'-in-ah) $\left[\sigma \tau^{\prime} \mu \omega \nu\right]$. Natural strength of constitution. Vigor. Inherent force.

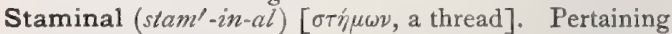
to a stamen.

Staminate $\left(\operatorname{stam}^{\prime}-i n-a ̈ t\right)$ [ $\sigma \tau^{\prime} \dot{\eta} \mu \nu$, a thread]. Possessing stamens. Applied to flowers which have stamens but not pistils.

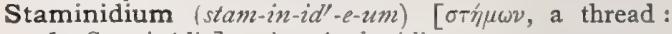
pl., Staminidia]. An Antheridium.

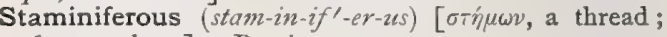
ferre, to bear]. Bearing stamens.

Staminigerous (stam-in-ij'-er-us). Same as Staniniferous.

Staminode $\left(\right.$ stam $\left.^{\prime}-i n-b d\right)$. Same as Staminodium.

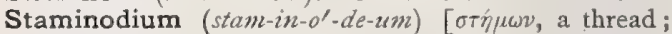
Eiঠos, form]. In biology, a stamen-like organ; a rudimentary or aborted stamen; a parastemon. See Lepal.

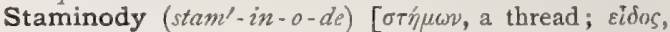
form]. In biology, the conversion of various organs of a flower into stamens.

Stammer (stam'-er) [ME, stameren, to stammer]. To utter with hesitation. To articulate only after repeated attempts; to stutter. In a wider sense, any speechdisturbance is called a stammer.

Stammers' Cell. See Cell.

Stanch (stanch, or stazunch) [ME, staunche, stanch]. To check or stop (a flow); as to stanch a hemorrhage or a wound.

Stand [ME., standen, to stand]. To have an upright posture. Also, a frame or a table to place things upon. S., Microscope, the tripod or base of the microscope with the tube, but without eye-pieces and objectives.

Standard (stan'-dard) [ME., standard; extendere, to spread out]. An established rule or model. A criterion for comparison. See Vexillum.

Standardization (stan-dar-diz- $a^{\prime}-$ shun) [ME., standard, standard]. Regulation by a standard; conformity to or use as a standard of comparison; the bringing of a preparation up to a definite standard.

Standstill (stand'-stil) [ME., standen, to stand; ME., stille, still]. A state of quiescence dependent upon suspended action. S., Expiratory, suspension of action at the end of expiration. S., Inspiratory, a halt in the respiratory cycle at the end of inspiration when the lungs are filled with air. The condition can be produced by stimulating the central end of the cut vagus. S., Respiratory, suspended respiration. 
Stannic (stan'-ik) [stannum, tin]. Pertaining to stannum, or tin. S. Acid, $\mathrm{H}_{2} \mathrm{SnO}_{3}$, a gelatinous, white precipitate, which, on drying, forms a semi-transparent, vitreous mass. It is dibasic. S. Anhydrid, tin oxid. S. Hydroxid. See $S$. Acid.

Stanniol (stan'-ne-ol) [stanmun, tin]. Tin-foil.

Stannius's Experiments. Experiments showing the action of the various cavities of the frog's heart under stimulation.

Stannum $\left(\operatorname{stan}^{\prime}-u m\right)$ [L.: gen., Stanni]. See Tin.

Stapedectomy $\left(\right.$ sta-pe-dek'-to-me) [stapes, stirrup; $\varepsilon \kappa \tau o \mu \eta^{\prime}$, excision]. Surgical removal of the stapes.

Stapedio-vestibular $\left(s t a-p e^{\prime}-d e-0-v e s-t i b^{\prime}-u\right.$-lar $)$ [L., stapes, stapes; vestibulum, vestibule]. Relating to the stapes and the margin of the fenestra ovalis.

Stapedius (sta-pe'-de-us). See Muscles, Table of.

Stapes (sta'-pezz) [L., a stirrup]. The stirrup-shaped bone of the middle ear articulating with the incus and the fenestra ovalis.

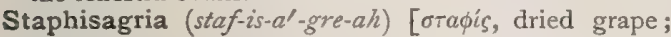
àypros, wild: gen., Staphysagria]. Stavesacre. The seed of Delphinium staphisagria. Its properties are due to an alkaloid, delphinin, $\mathrm{C}_{22} \mathrm{H}_{35} \mathrm{NO}_{6}$, and other extractives. It is a violent emetic, cathartic, and parasiticide. It lowers the activity of the heart, producing adynamia. It is used internally in asthma and rheumatism, and externally for itch and lice. S., Ung., unof, I part of powdered seeds with 2 each of olive-oil and lard. Delphinin. Unof. Dose gr. $\frac{1}{12}-\frac{1}{4}$.

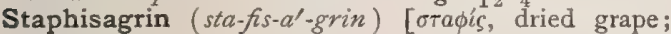
äyptos, wild]. An amorphous alkaloid obtained from Stavesacre.

Staphylæa (staf-il-e'-ah). Synonym of Staphylea.

Staphylagrum (staf-il- $\left.\alpha^{\prime}-g r u m\right)$ [ $\sigma \tau a \phi v \lambda \dot{\eta}$, uvula ; a $\gamma p \varepsilon i \nu$, to take hold of ]. An old instrument formerly used to hold the uvula during amputation of that body.

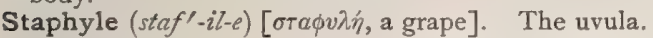

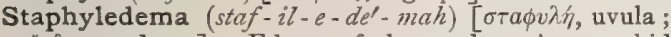
ö $\delta \eta \mu a$, edema]. Edema of the uvula. Any morbid enlargement of the uvula.

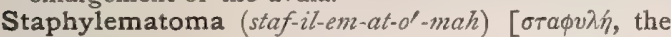
palate; aipa, blood]. Hematoma of the palate.

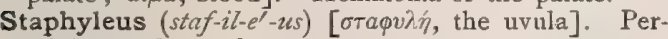
taining to the uvula.

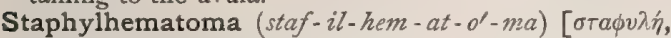
uvula; ai $\mu \alpha$, blood; $\check{\mu} \mu \alpha$, tumor]. An extravasation of blood into the uvula.

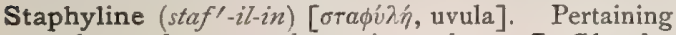
to the uvula or to the entire palate. S. Glands. Synonym of Palatine Glands.

Staphylinopharyngeus (staf - il - in - o-far-in-je'-us)

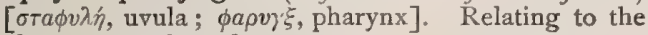
pharynx and the palate.

Staphylinotherapeutics (staf-il-in-o-ther-ap-u'-tiks)

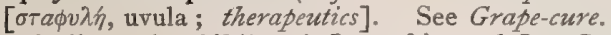

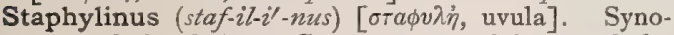
nym of Staphyleus. S. externus, abductor of the Eustachian tube. S. internus, elevator of the palate. S. medius, azygos uvulæ. See Muscles, Table of.

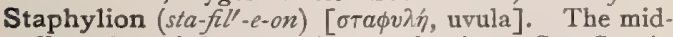
dle point of the posterior nasal spine. See Craniometric Points.

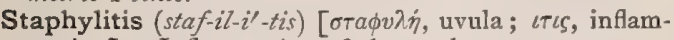
mation]. Inflammation of the uvula.

Staphylium (sta- $\left.f l^{\prime}-\ell-u m\right)$ [ $\sigma \tau \sigma \phi v \lambda \dot{n}$, a bunch of grapes]. The mammary nipple.

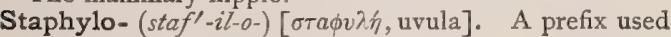
to denote connection with the uvula.

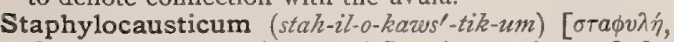
the uvula; кavorıkós, caustic]. A caustic used for application to the uvula.

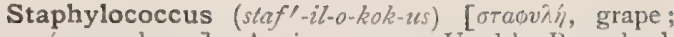
кóккоs, a berry]. A micrococcus. Used by Rosenbach as a generic name for the pus-cocci described by him. "Staphylococci are characterized by the fact that, for the most part, the individual cocci in a culture are solitary." (Sternberg.) See Bacteria, Synonymatic Table of.

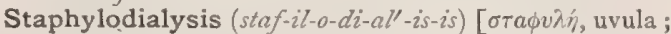

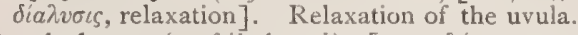

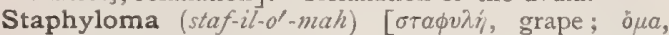
tumor: pl., Staphylomata]. A giving way or bulging of the cornea or sclera of the eye and the formation of a tumor. S., Annular, one surrounded on all sides by atrophic choroid. S., annulare, S. scleroticæ in the ciliary region extending around the entire corneal margin. S., Anterior. See Keratoglobus. S. anticum scleræ. Synonym of S., Ciliary. S., Ciliary, one in the region of the ciliary body. S. conicum. Synonym of S. pellucidum. S. corneæ, a bulging of the cornea, the result of traumatism or chronic inflammation, due to a thinning of the membrane, with or without previous ulceration. The cornea is opaque, and, at times, thickened instead of thinned. By some the term is restricted in its application to a protrusion beginning in prolapse of the iris, iridic tissue replacing the cornea. $\mathbf{S}$. corneæ racemosum, S. corner with perforation at several points, through which small portions of the iris protrude. S., Intercalary, one developing in that region of the sclera which is united with the periphery of the iris. S. iridis, hernia of the iris. S. laterale, staphyloma situated on one side of the equator of the eyeball. S. pellucidum, a term for the transparent ectasia of the cornea. S., Posterior, bulging backward of the sclerotic at the posterior pole of the eye. S., Projecting. Synonym of S. pellucidum. S. scleræ, a protrusion of the sclerotic at any point in its circumference. It is due to long-standing intraocular inflammation. S. uveæ, a protrusion of a portion of the uveal tract through a perforated sclera.

Staphylomatic, Staphylomatous (staf-il-o-mat'-ik,

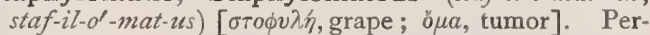
taining to, of the nature of, or affected with, staphyloma.

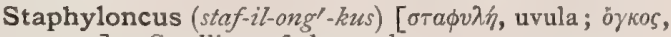
tumor]. Swelling of the uvula.

Staphylo-pharyngorrhaphy (staf-il-o-far-in-gor'-a-fe). See Passavant's Operation in Operations, Table of.

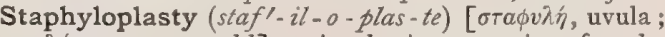
$\pi \lambda a ́ \sigma \sigma \varepsilon \imath \nu$, to mold]. A plastic operation for the closure of cleft palate. See Mosetig-Moorhof's, Schönbein's, and Trendelenberg's Operations, in Operations, Table of.

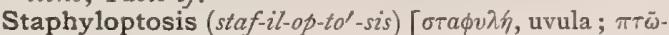
$\sigma \iota \zeta$, falling]. Abnormal elongation of the uvula.

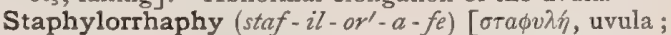
$\dot{\rho} a \phi \dot{\eta}$, suture]. Suture of the lips of a cleft palate or uvula. See Fergusson's and Pollock's Operations, in Operations, Table of.

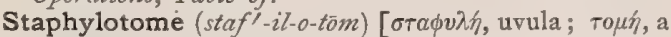
cutting]. A cutting instrument used in staphylotomy.

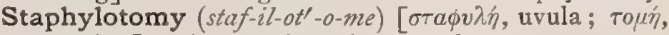
a cutting]. Amputation of the uvula.

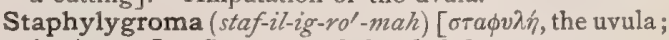
iүpós, wet]. Synonym of Staphyledema.

Star [ME., starre, star]. I. A celestial body appearing as a luminous point. 2. In biology, applied to various radiate structures, granules, cells, groups of cells, or organisms. S. Anise. See Illicium. S.cells, endothelial cells of vessels, first described by Kupfer and regarded as nervous elements on account of their shape and thin, elongated processes, but after- 
ward shown to belong to the endothelial tissues; they have the power of enclosing various granules; Kupffer's cells. S., Daughter. See Diaster. - S. Grass. See Aletris. S.-ridges. See Sclerosepta. Ss. of Verheyen. See Verheyen.

Starch (slarch) [ME., starche], $\mathrm{C}_{6} \mathrm{H}_{10} \mathrm{O}_{5}$. Amylum, $q . v_{.}$, one of the most widely-spread plant-substances, being found in nearly all plants above the fungi, except, perhaps, Nonotropa, and in nearly all the organs of plants, though not at all seasons. It occurs most abundantly in the seeds, tubers, bulbs, roots, and rhizomes, also in the pith, bark, and leaves. Starch is, perhaps, the most important of the heat-givers or forceproducers in the food of plant-eating animals. The following table, after Church and Krocker, gives the quantities of starch in roo lbs. of several kinds of vegetable products and preparations :-

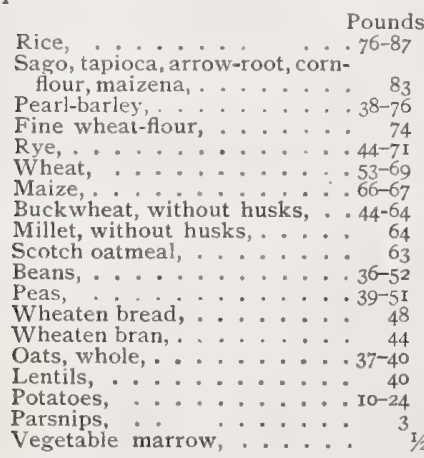

Starch occurs in peculiar forms called granules or grains, which in shape, size, and markings are often quite characteristic of the different plants in which they occur. These form a white, glistening powder, insoluble in cold water, but nearly completely dissolved by hot water. When heated with water the granules swell up at $50^{\circ} \mathrm{C}$, burst, partially dissolve, and form starch-paste. The soluble portion is called granulose, the insoluble, starch-cellulose. Iodin produces a characteristic blue coloration with starch. The most complete enumeration and classification of starches is that of Muter as amplified by Allen and Blyth, by which they are divided into five groups, on the basis of their physical and microscopic differences, as follows: I. The potato-group includes such oval or ovate starches

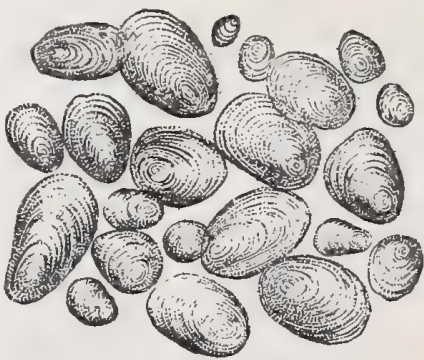

Potato-STARCH

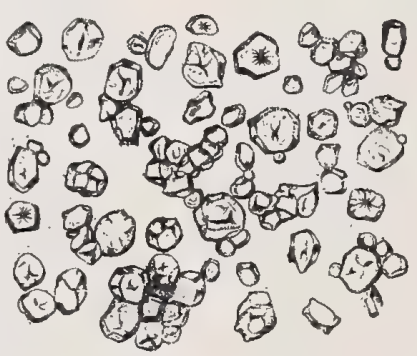

MAIZE.

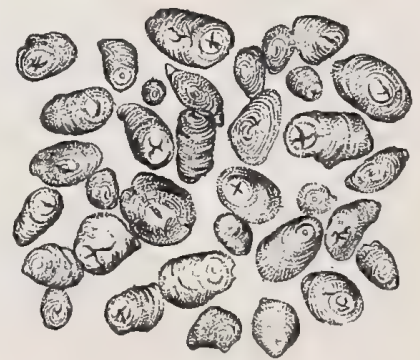

BERMUDA ARROW-ROOT.

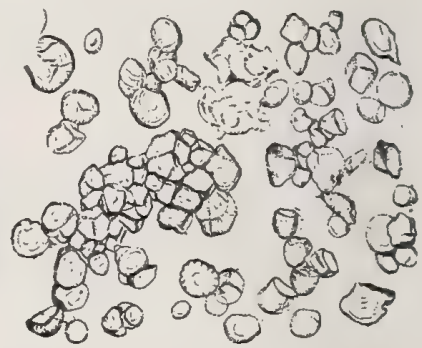

TAPIOCA.

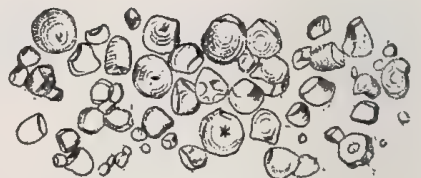

RIO ARROW-ROOT.

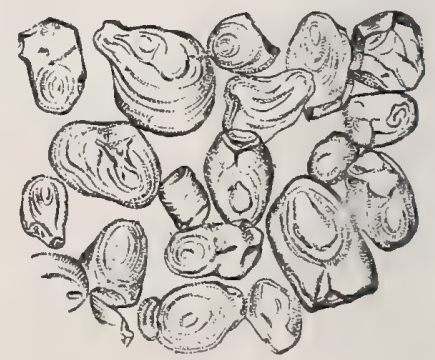

SAGO OF COMMERCE. as give a play of colors when examined by polarized light and a selenite plate, and having the hilum and concentric rings clearly visible. It includes tout les mois, or canna arrow-root, potato-starch, maranta, or St. Vincent arrow-root, Natal arrow-root, and curcuma arrow-root. II. The leguminous starches comprise such round or oval starches as give little or no color with polarized light, have concentric rings all but invisible, though becoming apparent in many cases on treating the starch with chromic acid, while the hilum is well-marked and cracked or stellate. It includes the starches of the bean, pea, and lentil. III. The wheat-group comprises those round or oval starches marking mentioned, the starch-granules differ in size according to their different sources, so that under the microscope they can be distinguished by the measurement of the average diameter of the granule. This ranges, according to Karmarsch, from . OI to . I 85 millimeter, or from .0004 to .0079 inch. See Tests, Table of. S., Animal. See Glycogen. S.-bath. See Bath. S., Corn, a substance that has very small granules, is highly nutritive, and is obtained from Indian corn. S.-enema, an enema consisting of starch-water. S., Gelatinized, a preparation used as a test in the U. S. Ph. S., Hepatic. See Glycogen. S., Hydrated, a paste produced by adding hot water 
to starch. S., Iceland. Synonym of Lichenin. S. Iodid, a compound of starch with iodin. S., Iodized, starch that has been acted upon by iodin. S. of the Liver. See Glycogen. S. and Opium Clyster, the opium-enema. S.-sugar. See Dextrose and Glucose.

Startin's Lotion. A lotion much used in acute vesicular eczema. It consists of oxid of zinc $z / 2$ ounce, prepared powdered calamin 4 scruples, glycerin I ounce, lime-water 7 ounces. Cheese-cloth cut in strips may be dipped into this and bound on the parts with a roller. S.'s Mixture. A mixture frequently used in the treatment of Acne vulgaris. It consists of sulphate of iron 2 grains, sulphate of magnesium I $1 / 2$ drams, dilute sulphuric acid 15 minims, infusion of quassia $\mathbf{I}$ ounce. This is taken three times a day immediately after meals. It acts as an aperient, and also corrects the anemia.

Starvation (star-va'-shun) [Ger., sterben, to die]. I. Death from hunger. 2. Severe hunger; extreme suffering from hunger or from cold. Deprivation of anything essential to nutrition or the proper discharge of the functions of the body. S.-cure. See Hungercure; Fasting.

Starve (stary) [ME, sterven, to die]. To perish from lack of food.

Starwort (star'-zurt). See Aletris.

Stas's Process. A process for the separation of alkaloids from organic matter in cases of suspected poisoning. It is based on the principle that the salts of the alkaloids are soluble in water and in ethylalcohol, but not in ether, amyl-alcohol, benzene, chloroform, or acetic ether; while the uncombined alkaloids (or most of them) are nearly insoluble in water, but are more or less soluble in ether and the other solvents named.

Stas-Otto Method. A method of extracting the putrefactive alkaloids from tissues. It depends upon the fact that the salts of the alkaloids are soluble in water and in alcohol, and generally insoluble in ether, while the free alkaloids are soluble in ether, and may be removed from alkaline fluids by agitation with ether. The method is applied as follows: "Treat the mass with twice its weight of pure 90 per cent. alcohol, and from to to 30 grains of tartaric or oxalic acid; digest the whole for some time at about $70^{\circ} \mathrm{C}$. and filter. Evaporate the filtrate at a temperature not exceeding $35^{\circ} \mathrm{C}$, either in a strong current of air or in vacuo over sulphuric acid. Take up the residue with absolute alcohol, filter, and evaporate again at a low temperature. Dissolve the residue in water, alkalinize with sodium bicarbonate, and agitate with ether. After separation, remove the ether and allow it to evaporate spontaneously. The residue may be further purified by redissolving in water and again extracting with ether. The method has been modified in some of its details, especially by Selmi and Marino-Zuco, S.-Otto Process. See Stas's Process.

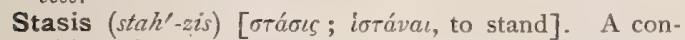
dition of standstill of the current of any of the fluids of the body, but especially of the blood, which condition forms an early stage of the inflammatory process, with resultant migration of the white corpuscles and serous exudation. S., Diffusion, stasis in which there occurs diffusion of serum or lymph. S., Venous, stasis due to venous congestion.

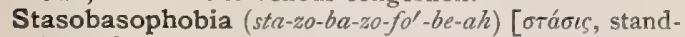

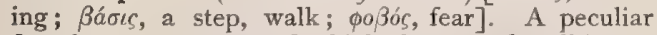
fear in consequence of which the act of walking or of standing becomes impossible. Cf. Basophobia.

State (stät) [status; stare, to stand]. A condition. S. Medicine, that department of medical study that 89 concerns public health, and is in part occupied with the statistics of disease.

Statement (stät'-ment) [stare, to stand]. A declaration. S., Ante-mortem, a declaration made immediately before death, and which if made with the consciousness of impending death is legally held as binding as a statement sworn to.

Static (stat'-ik) [бтatikós, causing to stand]. At rest. In equilibrium. S. Ataxia. See Ataxia. S. Breeze, a method of administration of static electricity, consisting in the withdrawal of a static charge from a patient by means of a pointed electrode. S. Electricity. See Electricity. S. Pelvis, the bony pelvis. S. Shock, a mode of applying Franklinic electricity, placing the patient on an insulated stool, and applying one pole of a static machine to this platform, while the other pole is applied to the body of the patient by the operator. S. Test. See Birth. S. Theory. See Goltz.

Statice (stat'-is-e). See Marsh Rosemary.

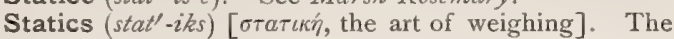
science relating to forces in a condition of equilibrium. See Mechanics.

Station (sta'-shun) [L., statio; stare, to stand]. Standing position, or attitude.

Stationary $($ sta'-shun-a-re) [stationarius, pertaining to a post]. Not moving. A descriptive term applied to diseases that remain in the same locality for a period without changing their geographic environment, or that persist without growing better or worse. S. Air, the amount of air which is constantly in the lungs during normal respiration.

Statistics (sta-tis'-tiks) [status, a state]. A numerical collection of facts relating to any subject. S., Medical, that part of medicine pertaining to details of mortality, climate, and the geographic distribution of diseases. S., Vital. Same as $S_{\text {., Medical. }}$.

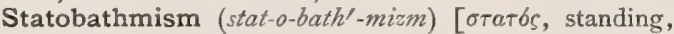
fixed; $\beta a \theta \mu o ́ s$, a step, threshold]. In biology, Cope's term for inherited growth-energy which has not been interfered with by physical energy; as distinguished from physiobathmism and kinetobathmism. Cf. Bathmism.

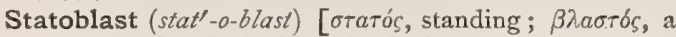
bud, germ]. In biology, in fresh-water Sponges and Bryozoa, a modified gemmule or parthenogenetic egg, provided with a protective horny envelop, and often with one or more layers of surrounding silicious spicules. These are produced on the approach of winter or in tropical climates just before the dry season. The so-called winter egg. See CEleoblast.

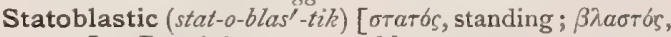
germ]. Pertaining to a statoblast.

Statogenesis (stat-o-gen'-es-is) [oratos, standing;

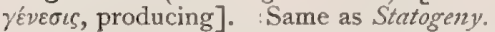

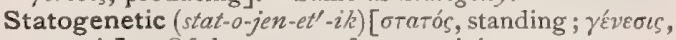
genesis]. Of the nature of or pertaining to statogeny.

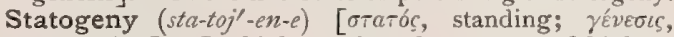
producing]. In biology, that department of biology which treats of the potential or static forms of energy involved in the adaptive processes or structure-modifications of living organisms; a form of ergogeny, as distinguished from kinetogeny.

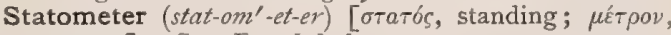
measure]. See Exophthalmometer.

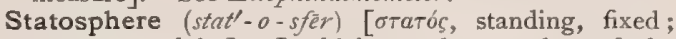
$\sigma \phi a i p a$, a globe]. In biology, the envelop of the statoblast of fresh-water sponges and bryozoans.

Statospore (stat'-o-spör) [бтaTós, standing, fixed; $\sigma \pi \circ \rho a$, seed]. In biology, a resting spore, or hypnospore.

Stature $($ stat'-ür $)$ [statura, stature]. The height of 
any animal when standing. In quadrupeds, it is measured at a point over the shoulders. In man, it is the measured distance from the heel to the top of the head.

Status $\left(s t a^{\prime}-t u s\right)$ [L.]. A condition, with the idea of permanence or continuance. A stage in disease in which, having reached its height, it remains there for a time before convalescence begins. S. arthriticus, nervous manifestation of masked gout. S. eclampticus, the state of a person in eclampsia. S. epilepticus, a condition, with rise of temperature, symptoms of gravity, and, frequently, death, associated with epileptic paroxysms succeeding one another rapidly, at intervals of a few minutes or an hour or two. S. hystericus, the hysteric state. S. nervosus. Synonym of Neurasthenia. S. præsens, the state of a case at the time the condition is noted. $\mathbf{S}$. typhosus, a condition of low, muttering delirium, attended with marked prostration, dull and heavy expression, congestion of the facial capillaries, stupor, mental sluggishness, heavy, dull eyes, contracted pupils, marked subsultus tendinum, slipping down into the bed, tongue slowly protruded, tremulous, dry and brown, the teeth and mouth covered with sordes; all sensibilities seem blunted; involuntary discharge of feces, incontinence of urine from retention; the pulse is small, feeble, dicrotic; the heart-sounds are very weak, the first sound may be inaudible, the second is short and relatively accentuated; venous congestion of the lungs naturally follows unless improvement occurs, pulmonary edema supervenes, the urine often becomes scanty and bloody, and the patient dies. S. vertiginosus, a condition of prolonged vertigo, in the course of which the patient for days or weeks together cannot turn or move in any fashion without being seized with the extremest vertigo.

Statuvolence (sta-tu'-vo-lens) [status, state; volens, willing]. Autohypnotism; voluntary somnambulism or clairvoyance; a trance into which one voluntarily enters without aid from another.

Staub's Fluid. A chloro-albuminous solution of mercury, used in the treatment of syphilis. It consists of the following: Bichlorid of mercury and chlorid of ammonium each 20 grains, chlorid of sodium I dram, liquor ovi albi and distilled water each 4 ounces. Of this 20 minims are injected as a dose.

Stauroplegia (staw-ro-ple'-je-ah) [ otavpós, cross; $\pi \lambda \eta \gamma \hat{\eta}$, a stroke]. Crossed hemiplegia, or paralysis of the arm on one side and the leg on the opposite side.

Stavers (sta'-vers). See Staggers.

Stavesacre (stāvz'-a-ker). See Staphisagria.

Stay Knot. See Knot.

Steam (stem) [ME., steem, steam]. The vapor of water; water in a gaseous state. S.-atomizer. See Atomizer. S.-doctor, an old name for a Thompsonian physician, from the extensive use of steaming and sweating made by that school. S.-tug Murmur, the double murmur of aortic obstruction and insufficiency. It may be expressed by the word hoo-chee, hoo representing the obstructive murmur, and chee the regurgitant murmur.

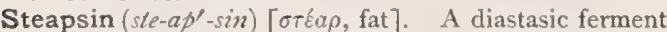
which causes fats to combine with an additional molecule of water and then split into glycerin and their corresponding acids. See Ferments.

Stear $\left(\right.$ sté $\left.^{\prime}-a r\right)[\sigma \tau \varepsilon \rho \rho$, fat]. See Adeps.

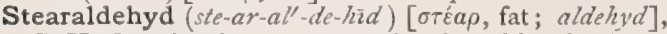
$\mathrm{C}_{18} \mathrm{H}_{36} \mathrm{O}$. A substance appearing in tablets having a bluish luster; it fuses at $63.5^{\circ} \mathrm{C}$. and boils at $192^{\circ} \mathrm{C}$.

Stearate $\left(s t t^{\prime}-a r-\bar{a} t^{\prime}\right)[\sigma \tau \dot{\varepsilon} \alpha \rho, f a t]$. A salt of stearic acid.

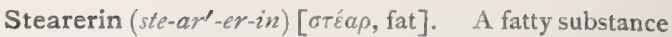
found in the oil of sheeps' wool and which is analogous to stearin.

Stearic $\left(s t e-a \gamma^{\prime}-i k\right)$ [ $\sigma \tau \varepsilon a \rho$, fat $]$. A name applied to an acid derived from fats and oils. S. Aldehyd, $\mathrm{C}_{17} \mathrm{H}_{35}$ $\mathrm{CHO}$, a substance bearing the same relation to stearic acid that an ordinary aldehyd bears to acetic acid. $\mathbf{S}$. Acid. See Acid.

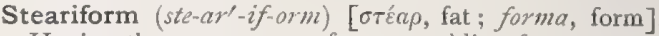
Having the appearance of or resembling fat.

Stearin $($ ste'-ar-in) [ $\sigma \tau \varepsilon \hat{\varepsilon} \rho$, fat $], \mathrm{C}_{3} \mathrm{H}_{5} \mathrm{O}_{3}\left(\mathrm{C}_{18} \mathrm{H}_{35} \mathrm{O}_{2}\right)_{3}$ An ether or glycerid formed by the combination of stearic acid and glycerin. When crystallized it forms white, pearly scales, soft to the touch, but not greasy, and odorless and tasteless when pure. It is insoluble in water, but soluble in hot alcohol and ether.

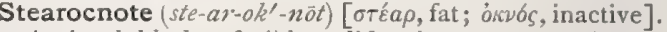
An insoluble but fusible solid substance occurring in brain-tissue.

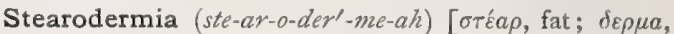
the skin]. An affection of the sebaceous glands of the skin.

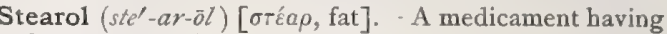
fat as an excipient.

Stearolic Acid (ste-ar-oll-ik). See Acid.

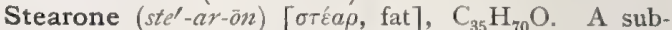
stance obtained by the partial decomposition of stearic acid. It is a volatile liquid, and seems to be the same as stearic acid deprived of two equivalents of carbonic acid.

Stearophanic Acid (ste-ar-o-fan'-ik). Synonym of Stearic Acid.

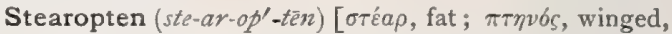
volatile]. Any camphor-like, crystalline substance held naturally in solution in a volatile oil.

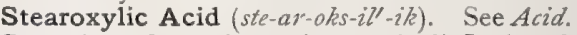

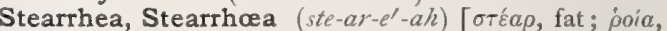
a flow]. See Seborrea. S. congestiva. Synonym of Seborrhac congestiva. S. flavescens, a seborrhea in which the sebaceous matter turns yellow after being deposited upon the skin. S. nigricans. See Chromidrosis. S. simplex, ordinary seborrhea.

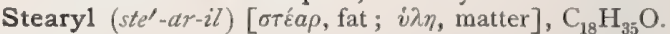
The radicle of stearic acid.

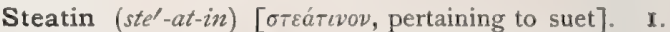
Same as Stearin. 2. Any cerate containing a considerable proportion of tallow.

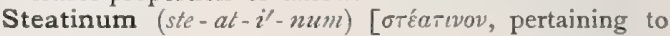
suet]. A name given to certain pharmaceutic preparations similar to cerates.

Steatite $\left(s t e^{\prime}-a t-i t\right)$. See Talcum.

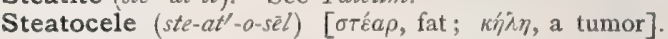
A tumor formed by a collection of fatty matter in the scrotum.

Steato-cryptosis $\left(s t e-a t-0-k r i f-t o^{\prime}-s i s\right)[\sigma \tau \varepsilon a \rho$, fat ; $\kappa \rho \hat{v} \pi \tau \eta$, a crypt, or sac]. Abnormality of function of the sebaceous glands.

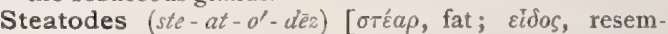
blance]. Fatty.

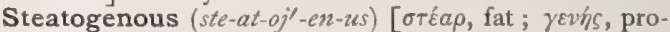
duced]. Producing steatosis.

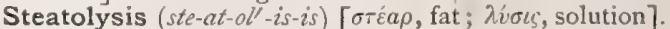
The emulsifying process by which fats are prepared for absorption and assimilation.

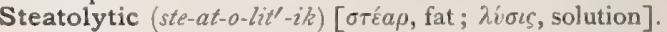
Accomplishing a steatolysis.

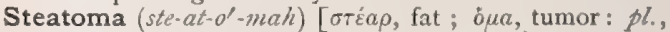
Steutomata]. A sebaceous encysted tumor; a lipoma. S. melliceris, a sebaceous cyst. S. testiculi. Synonym of Steatocele.

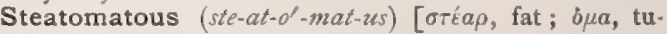
mor]. Pertaining to a steatoma. 


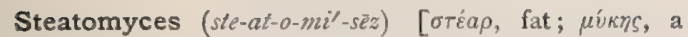
mushroom]. A fatty fungous growth.

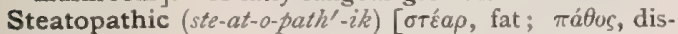
ease]. Pertaining to diseases of the sebaceous glands.

Steatopyga, or Steatopygia (ste-at-op'-igrah, ste-at-o$\left.p i^{\prime}-g \ell-a h\right)$ [orḱ $\rho$, fat; $\pi v y \eta ́$, buttock]. Hottentot deformity; enormous fatness of the buttock, common among the women of some African tribes.

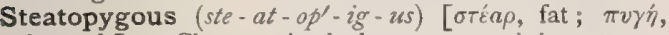
buttock]. Characterized by or pertaining to an abnormal largeness of the glutei muscles and adjacent parts.

Steatopygy (ste-at-op'-ij-e). See Steatopycia.

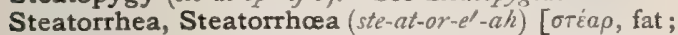
poía, flow]. An increased flow of the secretion of the sebaceous follicles. See Seborrhea. S. amianthaca, a form of seborrhea in which the excess of solid constituents gives the appearance of scaliness of the skin. See, also, Seborrhea. S. nigricans. Same as Seborrhcea nigricans. S. simplex, excess of sebaceous excretion of the face.

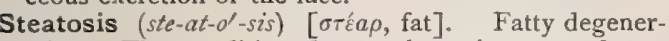
ation. The condition due to the existence and progress of steatoma, or fatty degeneration of a part. Also, any abnormal accumulation of fat.

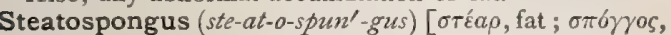
a sponge]. Synonym of Sieatomyces, q. $v$.

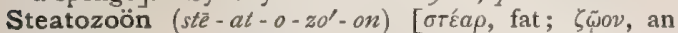
animal]. The parasite, Demodex folliculorum, contained in comedones. See Parasites (Animal), Table of.

Stechiologic, Stcechiologic, Stoicheiologic (stek-e-o-

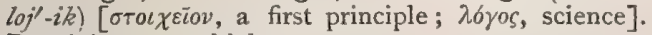
Pertaining to stechiology.

Stechiology, Stæchiology, Stoicheiology (stek-e-all.

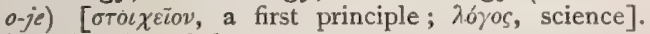
The doctrine of elements.

Steel (stèl) [ME., steel, steel]. Iron chemically combined with a certain proportion of carbon. It holds an intermediate position between white cast iron and wrought iron, partaking of the most valuable qualities of both. Steel of good quality is fine-grained, elastic, and tough. See, also, Ferrum. S. Balsam. Synonym of Lin. ferri nitrici. S.-blue. Same as Berlin Blue. S.-grinders' Phthisis. See Pneumonokoniosis. S.-pen Palsy. See Writers' Cramp. S. Wine. Synonym of Vinum ferri.

Stege $\left(s t e^{\prime}-j e\right)$ [ $\sigma \tau \dot{\varepsilon} \gamma o \sigma$, roof ]. The inner layer of the rods of Corti.

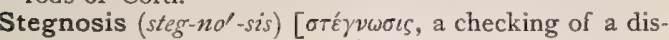
charge; a soldering]. Constipation, or costiveness; the checking of a discharge; the closing of a pasșage ; stenosis.

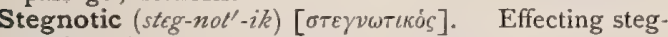
nosis. Astringent.

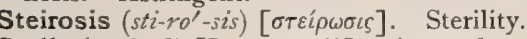

Stella $($ stel'-ah) [L., "star"']. A star-shaped bandage ; stellate bandage.

Stellate (stel'-ät) [stella, a star]. In biology, starshaped, or with parts radiating from a center, as stellate stigmas, stellate hairs, etc. S. Bandage, one that is wound crosswise on the back. S. Fracture, a fracture in which there are numerous fissures radiating from the central point of injury. It usually occurs in flat bones. S. Hair, a hair which divides at the end in a star-shaped fashion. S. Laceration, one involving the tissues in several directions, as a stellate laceration of the cervix uteri. S. Ligament. See Ligament. S. Veins, minute venous radicles arranged in stellate fashion and located just beneath the capsule of the kidney.
Stelliform (stel'-if-orm) [stella, star; forma, form]. Having the form of a star.

Stellula (stel'-u-lah) [dim. of stella, a star]. In anatomy, a plexus of veins in the cortex of the kidney. Stellula Verheynii, a stellate network of veins in the outer part of the cortex of the kidney.

Stellwag's Symptom. Slight retraction of the upper lid in exophthalmic goiter, whether complicated or not with Graefe's symptom, and giving rise to a widening of the palpebral fissure. See Signs and Symptoms, Table of.

Stem [ME., stem, stem]. The pedicle of a tumor; the shaft of a hair; the supporting stalk of a leaf or plant. S., Brain, the brain, less the fissured portion of the cerebrum. S.-eelworm. See S.-sickness. S., Gland, a gland-duct. S. of Hair. Synonym of Hair-shaft. S., Herbaceous, in biology, a stem that dies in winter. S.-pessary, a pessary having a stem or rod which enters the os uteri. S.-sickness, a parasitic disease of clover, due to the presence of the stem-eelworm (Tylenchus devastatrix).

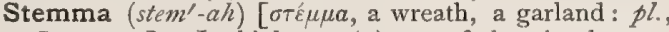
Stemmata]. In biology: $(a)$ one of the simple eyes of an invertebrate; an ocellus; $(b)$ one of the facets of a compound eye; $(c)$ the tubercle giving attachment to the basal joint of an antenna.

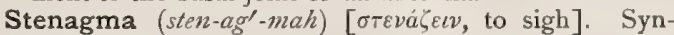
onym of Sigh.

Stenagmus (sten- $\left.a g^{\prime}-m u s\right)$ [ $\sigma \tau \varepsilon v a ́ \zeta \varepsilon c \nu$, to sigh]. Sighing.

Stench [ME., stench, a smell]. An ill smell; an offensive odor. S.-pipe, an upright pipe that reaches above the roof of a house; it is intended to give vent to foul vapors that accumulate in waste-pipes, and water-closets. S.-trap, in sewerage and plumbing, a device for preventing a reflux of foul vapors and gases.

Steno, Duct of. See Duct.

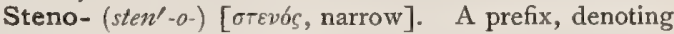
narrowing or constriction.

Stenobregmate (sten-o-breg'-mät) [orevos, narrow ; $\beta \rho \varepsilon$ f $\mu a$, the bregma]. The condition in which the upper and fore part of the head is narrow.

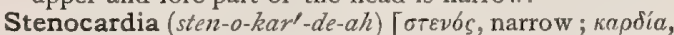
heart]. Contraction of the heart, or of its orifices; angina pectoris.

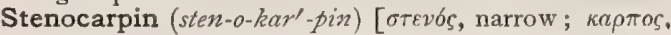
fruit]. A fraudulent anesthetic and mydriatic, asserted to have been obtained from the leaves of Gleditschia triacanthos, the tear-blanket tree. It has been proved to be a mixture of cocain and atropin.

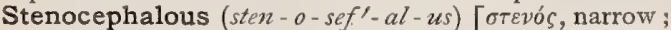
$\kappa \varepsilon \phi a \lambda \eta$, head]. Having a head narrow in one or more of its diameters.

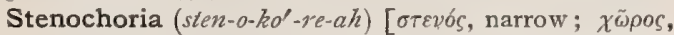
space]. Narrowness, stricture, or partial obstruction. Also, contraction of the vagina. S. saccilacrimalis, stenosis of the lacrymo-nasal duct.

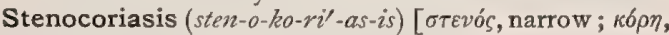
pupil]. Narrowing of the pupil.

Stenocrotaphia, or Stenocrotaphy (sten-ok-ro-ta'-fe-

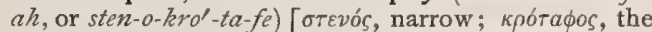
temple]. A narrowing of the temporal region of the skull.

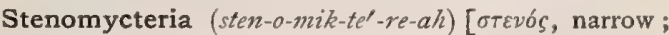
$\mu v \kappa \tau^{\prime} \rho$, the nose]. Nasal stenosis.

Stenon, Duct of. See Duct.

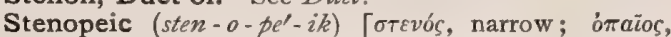
pierced]. Applied to lenses that allow the passage of rays only through a straight, narrow slit.

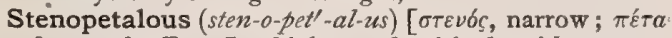
$\lambda o \nu$, a leaf]. In biology, furnished with narrow petals. 


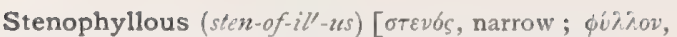
a leaf]. In biology, possessing narrow leaves.

Stenoraic (sten-o-ra'-ik). See Stenopeic.

Stenosis (sten-o'-sis) [ $\sigma^{\prime} \varepsilon v o ́ s$, narrow]. Constriction or narrowing of any pore, duct, vessel, or passage. S., Aortic, a narrowing of the aortic orifice at the base of the heart or a narrowing of the aorta itself. S., Cardiac, as a consequence of inflammation of the connective tissue in the myocardium, the conus arteriosus upon either side of the heart may become diminished in diameter, with consequent hindrance to the free passage of blood from the ventricle into its corresponding artery. This constitutes what is called stenosis of the heart. The second sound is fully formed and sharply defined, thus distinguishing the condition from valvular stenosis. S., Cicatricial, stenosis due to a contracted cicatrix. S., Granulation, narrowing caused by encroachment or contraction of granulations. S., Mitral, stenosis of left auriculo-ventricular orifice. S., Post-tracheotomy, stenosis after tracheotomy. S., Sub-aortic. See S., Aortic.

Stenostegnosis, Stenostenosis (sten - o-steg - no'-sis,

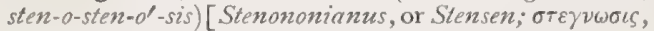
constriction]. Stenosis of Stensen's duct.

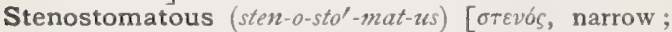

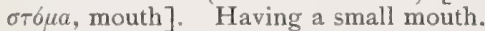

Stenostomia (sten-o-sto'-me-ah) [orevós, constriction; $\sigma \tau \delta \mu \alpha$, mouth]. A narrowing or closure of the mouth.

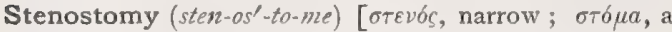
mouth ]: The contraction of any mouth or aperture.

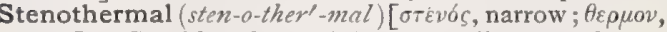
heat]. Capable of sustaining a small range of temperature.

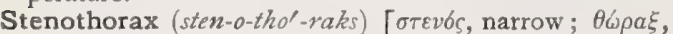
thorax]. Having a straight, short thorax.

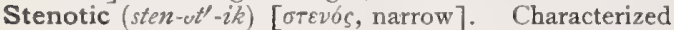
by stenosis; reduced in size or caliber; contracted.

Stensen, Canal of. See Duct. S., Duct of. See Duct: S., Foramen of. See Foramina, Table of. S.'s Experiment, compression of the abdominal aorts of an animal, so as to cut off the blood-supply to the lumbar region of the spinal cord. It leads to rapid paralysis of the posterior portion of the body.

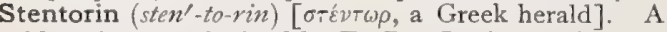
blue pigment obtained by E. Ray Lankester from infusorians of the genus Stentor.

Stephanial, Stephanic (stef-an'-e-al, stef-an'-ik)

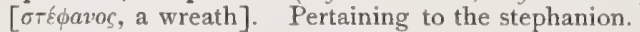

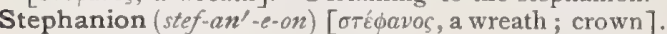
See Craniometric Points.

Stepmother's Blessing. A popular term for hangnail

Steppage $\left(\right.$ step $\left.^{\prime}-\bar{a} j\right) \quad[\mathrm{ME}$., steppe, a step]. The peculiar gait seen in dorsal tabes, arsenical, alcoholic, and other forms of neuritic paralysis.

Steppe Disease. Synonym of Rinderpest. S. Murrain. See Rinderpest.

Stercobilin (ster-ko-bill-in) [stercus, fecal matter; bilis, bile]. A coloring-matter found in intestinal excrement. It is identical with hydrobilirubin.

Stercoraceous (ster-ko-ra'-shus) [sterius, dung]. Fecal; having the nature of feces. Applied especially to vomiting when fecal matter is mixed with the ejected substances.

Stercoral (ster'-ko-ral). See Stercoraceous.

Stercoremia (stcr-ko-re'-me-ah) [stercus, dung; wima, blood]. A condition resulting from arrest of intestinal excretion, and absorption of toxic matters formed in the intestines.

Stercorin (ster'-ko-rin) [stercus, dung]. A fecal extractive resembling biliary cholesterin.
Sterculia (ster- $\left.k u^{\prime}-l e-a h\right)$ [stercus, dung]. A genus of some 85 species of tropical trees. S. urens of India, and $\mathbf{S}$. tragacantha of Africa afford some part of the gums known as tragacanth. S. acuminata produces the kola-nut. See Kola.

Sterculiaceous (ster-ku-le-a'-shus) [stercus, excrement]. Of, or pertaining to, the genus Sterculia:

Stercus (ster'-kus) [stercus, dung]. Feces.

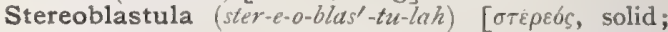

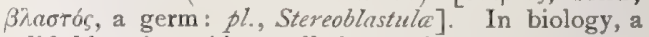
solid blastula. Also spelled sterroblastula.

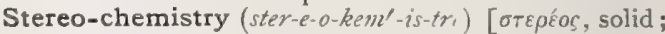
$\chi \eta \mu \varepsilon \iota a$, chemistry]. Stereo-isomerism; theoretic explanations of close isomerisms, by which it is assumed that the differences between the various isomers are due to the different positions of the same atoms or radicles in tri-dimensional representations of the molecules. Ordinary structural formulæ involve only two dimensions, length and breadth, but these are not sufficient to explain numerous cases of isomerism now known, and a "spatial " or "solid" conception of the molecule is necessary. The term allo-isomerism has been proposed for these cases.

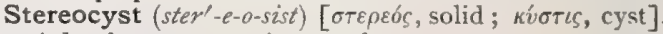
A hard cyst, or cystic growth.

Stereogastrula (ster-e-o-gas'-tru-lah) [ $\sigma \tau \varepsilon \rho \varepsilon b s$, solid;

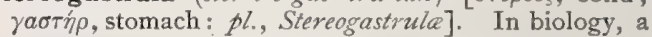
solid gastrula. Also spelled Sterrogastrula.

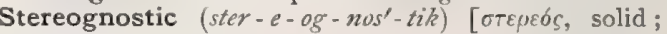
$\gamma \nu \omega \sigma \iota s$, knowledge]. Pertaining to the cognition of solidity, or tri-dimensional forms.

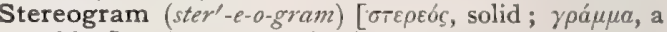
writing]. A stereoscopic picture.

Stereograph (ster'-e-o-graf). Same as Stereogram.

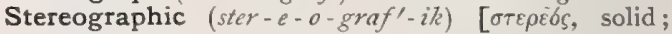
$\gamma \rho a ́ \phi \varepsilon i v$, to write]. Pertaining to stereography. S. Dermatoneurosis. See Urticaria, Factitious.

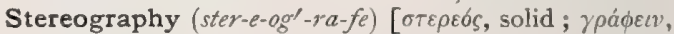
to write]. Graphic representation of the skull; a branch of craniometry.

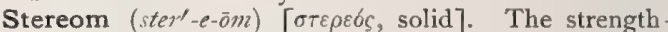
giving fibers of fibro-vascular tissue. See Mestome.

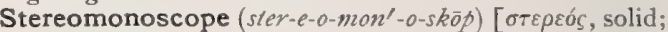

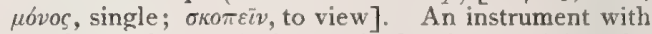
two lenses for producing a single picture giving the effect of solidity.

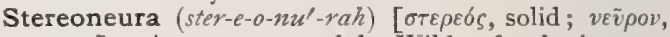
nerve]. A term proposed by Wilder for the invertebrates whose nervous axis, when it exists, presents no cavity as in the vertebrates or celoneura.

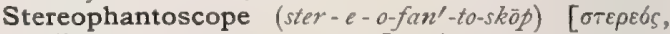

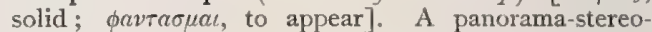
scope using rotating discs in place of pictures.

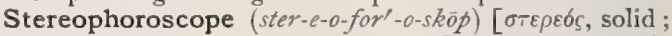
$\phi \varepsilon \rho \varepsilon \imath \nu$, to carry; $\sigma \kappa o \pi \varepsilon i \nu$, to see]. A stereoscopic zoetrope; an instrument for the production of a series of images apparently in motion and in stereoscopic relief.

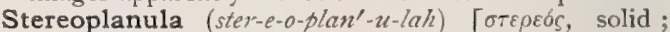
planula, from plames, flat]. In biology, a solid planula. Also spelled Sterroplanila.

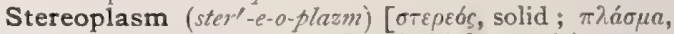
anything formed or molded]. In biology : $(a)$ a secretion of the basal membrane of certain Actinia, superseding and supplementing the dissepiments. (b) Nrgeli's term for the solid part of protoplasm. See Protoplasm.

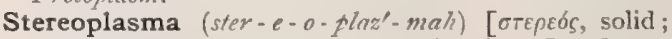
$\pi \lambda a ́ \sigma \mu a$, something formed or molded]. See Stereoplasm.

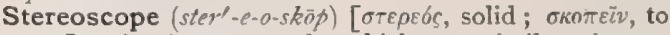
see]. An instrument by which two similar pictures of the same object are made to overlap so that the re- 
flected images are seen as one, thereby giving the appearance of solidity and relief. The stereoscope is used in the treatment of strabismus, in which condition it serves as an excellent means of ocular gymnastics. It is also of service in optometry to nullify convergence and diminish accommodation.

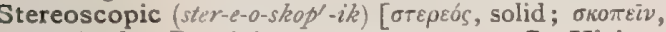
to view]. Pertaining to stereoscopy. S. Vision, binocular vision. See Stereoscope.

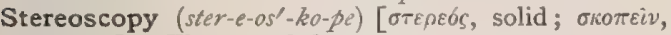
to view]. The use of the stereoscope.

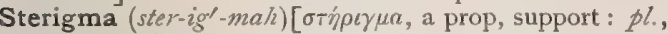
Sterigmata]. In biology, a stalk or support.

Sterile $\left(\right.$ ster $\left.^{\prime}-i l\right)$ [sterilis, barren]. Not fertile or capable of reproducing; applied mainly to females. Free from microörganisms or spores.

Sterility (ste-ril'-it-e) [sterilitas]. The condition of being sterile, infertile, or incapable of reproducing. S., Facultative, sterility caused by the prevention of conception. S., Idiopathic. See Azoöspermatism. S., Relative, sterility due to other causes than abnormality of the sexual organs.

Sterilization (ster-il-iz-a -shun) [sterilis, barren]. The condition of rendering sterile, infertile, or incapable of reproducing. In bacteriology, the destruction by heat of the spores or mature forms of bacilli, micrococci, or other forms of microscopic life. In most instances a temperature of $100^{\circ}$ C. $\left(212^{\circ} \mathrm{F}\right.$. $)$ devitalizes not only the mature forms, but the spores as well. In a few instances this temperature is not fatal to either. This, e. $g$., is the case with $B$. tenuis, the rods resisting $100^{\circ}$ and the spores $115^{\circ}$. S., Hueppe's Method of, the repeated exposure to a temperature of from $52^{\circ}$ to $65^{\circ} \mathrm{C}$. S., Intermittent, a method of sterilization of organic infusions introduced by Prof. Tyndall, in which an interval of time is allowed to elapse between the several heatings, giving an opportunity for any spores present to develop into adult microbes, in which form they readily succumb to the action of heat. S.-test, Hochenegg's, the surgical dressings are impregnated with a mixture composed of 150 parts of a solution of aluminum acetate of the Austrian Pharmacopeia, I50 parts water, and 5 parts of a $2 I$ per cent. paste of alizarin. This is a yellowish-brown mixture, but on exposure to the temperature of boiling water becomes bright-red.

Sterilizator (ster $-i l-i z-a^{\prime}$-tor) [sterilis, sterile]. An instrument for sterilizing or killing germs by heat, including the exact determination of the degree of heat required to effect this in the case of different species.

Sterilized (ster' $-i l-\bar{\imath} z d)$ [sterilis, sterile]. Rendered sterile.

Sterilizer (ster'-il-i-zer). See Sterilizator.

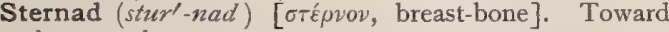
the sternal aspect.

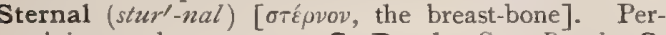
taining to the sternum. S. Band. See Bund. S. Canal. See Canal.

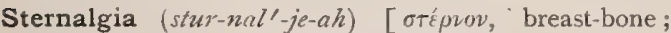
äryos, pain]. Pain in the sternum.

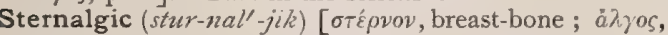
pain]. Affected with sternalgia.

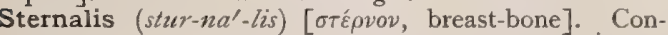
nected with the sternum; sternal.

Sterneber (stu' ${ }^{\prime}$-ne-ber). See Sternebra.

Sternebra (stur'-ne-bra/h) [sternum, sternum; vertebra, vertebra]. Any one of the serial segments of the sternum.

Sternebral (stur'-ne-bral) [sternum, sternum; vertebra, vertebra]. Pertaining to or of the nature of a sternebra.
Sternen (stur'nen) [sternum, sternum]. Belunging to the sternum in itself.

Sterniform (stur'-nif-orm) [sternum, sternum; forma, form]. Shaped like a sternum.

Sternite $\left(s t u \gamma^{\prime}-n \bar{i} t\right)$ [ $\sigma \tau \dot{\varepsilon} \rho \nu o v$, breast-bone]. The under or ventral sclerite of an abdominal segment.

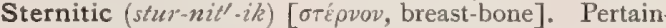
ing to a sternite.

Sterno- (ster'-no-) [sternum, sternum]. A prefix used to denote connection with the sternum. S.-clavicular, pertaining jointly to the sternum and the collar-bone. S.-cleido-mastoid; S.-hyoid; S.-thyroid. See Musiles, Table of.

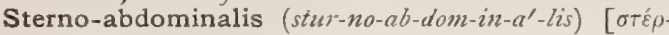
vov, breast-bone; abdomen, abdomen ]. The triangularis sterni and the transversus abdominis considered as a single muscle.

Sternocostal (stur-no-kos' - tal) [stermum, sternum; costa, a rib]. Pertaining conjointly to the sternum and the ribs.

Sternocoxal (stur-no-koks'-al) [sternum, sternum; coxa, hip]. Pertaining to the sternites and coxæ of an arthropod.

Sternofacial (stur-no-fa'-shal) [sternum, sternum; facies, face]. Pertaining to the sternum and the face.

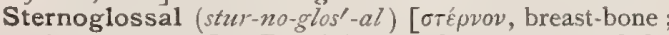
$\gamma \lambda \tilde{\omega} \sigma \sigma a$, tongue]. Pertaining to the sternum and the tongue.

Sternohyoid (stur-no-hi'-oid) [sternum, sternum; hyoid ]. Pertaining to the sternum and the hyoid bone.

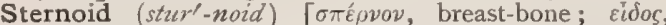
resemblance]. Resembling the sternum.

Sternomaxillary (stur - no-maks' $i l-a-r e)$ [sternum, sternum; maxilla, jaw]. Pertaining to the sternum and the mandible.

Sternon (stus -non). Same as Sternum.

Sternopagia (stur-no-pa $\left.a^{\prime}-j e-a h\right)$ [ $\sigma \pi \varepsilon$ pvov, breast-bone;

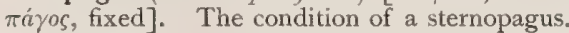

Sternopagus (stur-nop' - ag-zs) [sternum, sternum ;

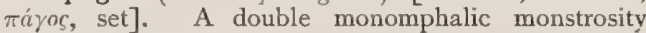
united by the sterna.

Sternoscapular (stur-no-skap'-u-lar) [sternum, sternum; scapula, scapula]. Pertaining to the sternum and the scapula.

Sternothyroid (stur-no-thi'-roid) [sternun, sternum; thyroid ]. Pertaining to the sternum and the thyroid cartilage.

Sternotracheal (stur-no-tra'-ke-al) [sternum, sternum; trachea $]$. Pertaining to the sternum and the trachea.

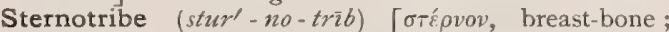
$\tau \rho i \beta \varepsilon \imath$, to rub]. In biology, touching the heart.

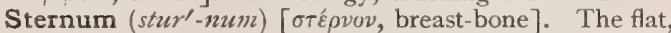
narrow bone in the median line in the front of the chest, composed of three portions, the manubrium, or presternum, the gladiolus, and the xiphisternum, or ensiform, or xiphoid, appendix. See illustration of Thorax, anterior view, page 224.

Sternutament (ster-nu'-tam-ent) [sternutamentum; sternutare, to sneeze]. A substance causing sneezing.

Sternutation (ster-mu-ta'-shun) [sternutatio, a sneezing]. The act of sneezing.

Sternutatory (ster-mu'-tat-or-e) [sternutare, to sneeze]. I. Provocative of sneezing. 2. An errhine; a drug or compound that causes sneezing.

Sterroblastula (ster-o-blas'-tu-lah) $[\sigma \tau \varepsilon \rho \varepsilon b s$, solid; $\beta \lambda a \sigma$. $\tau o ́ s$, a bud, a germ ]. See Stereoblastula.

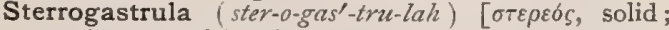

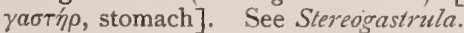

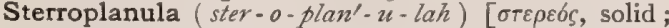
planula, from planus, flat]. See Stereoplanula.

Stertor (stur'-tor) [stertere, to snore]. Sonorous breathing, or snoring. The rasping, rattling sound produced 
when the larynx and the air-passages are obstructed with mucus.

Stertorous (stur'-to-rus) [stertere, to snore]. Breathing with a snoring sound.

Stetharteritis $\left(s t e t h-a r-t e r-i^{\prime}-t i s\right)[\sigma \tau \tilde{\eta} \theta 0 s$, heart; ápтnpia, artery; $\iota \tau \iota \varsigma$, inflammation]. Inflammation of the ar teries of the thorax.

Stetho- $\left(\right.$ stel $\left.^{\prime}-0\right)[\sigma \tau \tilde{\eta}$ Hos, chest $]$. A prefix to denote connection with or relation to the chest.

Stethocatharsis (steth-o-kath-ar'-sis). Synonym of $E x$ pectoration.

Stethocele (steth'-o-sêl). See Pneumonocele.

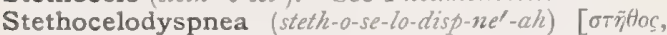

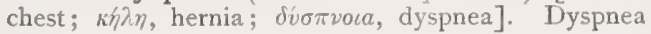
due to hernia of the lung.

Stethochysis (stelh-o $\left.k^{\prime}-i s-i s\right)$. See Hyitrothorax.

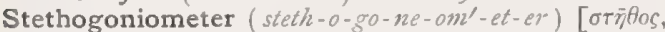

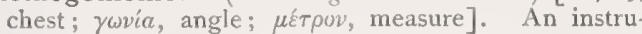
ment for measuring the curvature of the chest.

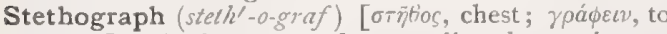
record]. An instrument for recording the respiratory movements of the chest-wall

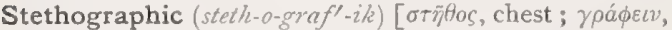
to write]. Pertaining to the stethograph or to steth ography.

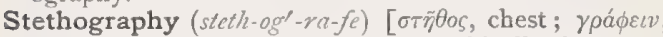
to write]. The art of recording graphically the movements of the chest-wall.

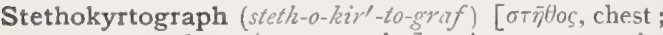

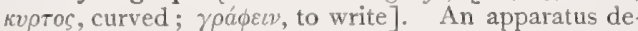
signed for measuring and recording the dimensions of the chest.

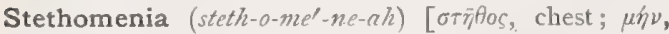
month]. Vicarious menstruation by way of the bronchial tubes.

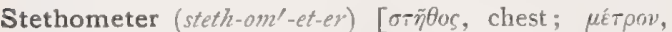
measure]. An instrument for measuring the amount of expansion of the chest and the relative expansibility of the two sides.

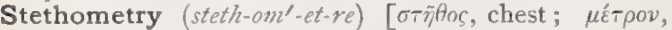
measure]. The measuring of respiratory movements by means of a stethometer.

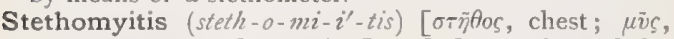
muscle; $1 \tau \ell S$, inflammation]. Inflammation of the muscles of the chest.

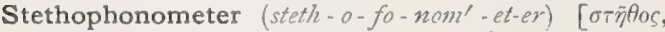

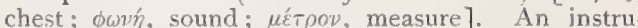
ment to measure the phenomena elicited by auscultation.

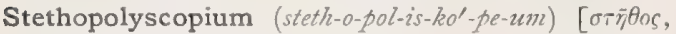

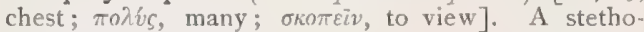
scope having several tubes for the simultaneous use of several observers.

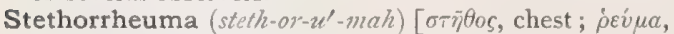
rheum ]. Rheumatism of the thorax.

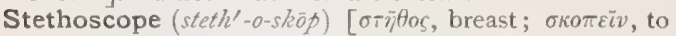
examine]. An instrument for ascertaining the condition of the organs of circulation and respiration by their sounds. It consists of a hollow tube, one end being placed over the locality to be examined, the other at the ear of the examiner. A binaural form of the instrument consists of a Y-shaped tube, the flexible branches being applied each to an ear of the listener. By this means not only are all extraneous sounds shut out, but an intensified sound is conveyed to the ear.

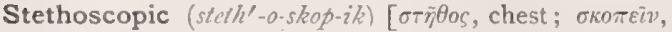
to view]. Pertaining to or detected by means of the stethoscope.

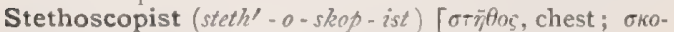
$\pi \varepsilon i v$, to view]. One versed in the use of the stethoscope.

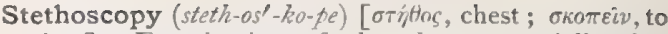
view]. Examination of the chest, especially that which is performed with the aid of the stethoscope.

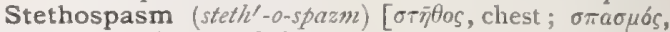
spasm]. Spasm of the pectoral muscles.

Stevens Saline Mixture. A mixture composed of sodium chlorid 20 grains, potassium chlorate 7 grains, sodium carbonate 30 grains, water 12 fuidrams; recommended to be taken every half hour in malignant cholera:

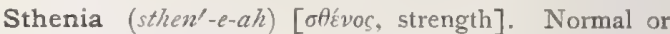
excessive force or vigor (opposed to asthenia).

Sthenic (sthen'-ik) [ofrvos, strength]. Strong, active. S. Fever, synochus; a form of continued fever marked by high bodily temperature, quick and tense pulse, and highly colored urine.

Sthenopyra (sthen-o-pi'-rah) [af'vos, strength; $\pi \bar{v} \rho$, fever]. Sthenic fever.

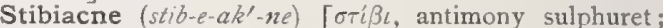

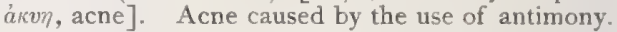

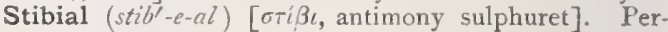
taining to stibium, or antimony.

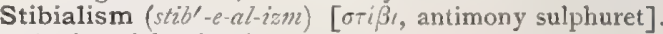
Antimonial poisoning.

Stibium (stib'-e-um). See Antimonizm.

Stichcultur (stich't-kül'-tūr') [Ger.]. See Stab-culture.

Stick (stik) [ME., stiken, to stick]. I. To pierce with a pointed weapon. 2. A slender piece of wood. S.caustic. See Argentum. S.-lac. See Lac.

Sticking Plaster. See Adhesive Plaster.

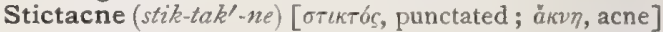
Acne punctata; acne in which the pustules have a red, raised base, with a central black point.

Stiebel, Canal of. See Canal.

Stiega, Canal of. See Canal.

Stiff (stif) [ME., stif, stiff]. Inflexible, unyielding, immovable in continuity; applied especially to normally movable parts. S. Joint. See Ankylosis. S. Neck. See Torticollis.

Stifle $\left(s t i^{\prime}-f\right)$ [ME, stifil, to choke]. 1. To choke up; to kill by impeding respiration. 2. The stifle-joint, $q$. $v$ 3. Disease or other affection of the stifle-bone, q.v. S.-bone, the patella of the horse. S.-joint, the knee-joint of the horse

Stifling (sti'-fing) [ME., stifil, to choke up]. Close ; oppressive. S.-bone. Same as Stifle-bone.

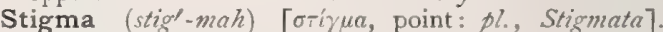
A minute cicatrix. In biology, a spot or mark, as $(a)$ one of the so-called eye-spots, usually red, in many colored Flagellata: (b) the outer aperture of a tubulartrachea, in the Antennata (Myrinpoda and Hexa. poda); (c) the external opening of a segmental organ in the Annelida; see Pscudo-stomata; $(d)$ that part of a pistil which receives the pollen; (e) the spot at which the ovisac ruptures in the escape of an ovum into the oviduct. See also, Stigmata.

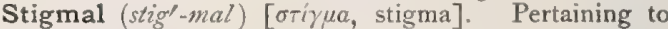
a stigma.

Stigmata, Bakers'. Nodules on the backs of the fingers caused by kneading dough. S., Hereditary, psychic stigmata resembling those of an ancestor and supposed to be inherited. S., Hysteric, the specific, peculiar phenomena or symptoms of hysteria -as the anesthesia, hyperesthesia, hysterogenic zones, reversal of the color-field, contraction of the visual field, the phenomena of transport, amblyopia, inlpairment of the sense of hearing, of taste, and of the muscular sense, etc, S. maydis. See Zen mays. S., Neurasthenic. See S., Hysteric. $\mathbf{S}$. nigra, the black spots caused by the presence of grains of gun-powder in the skin. S., Psychic, certain mental states characterized by susceptibility to 
particular suggestions. S. rubra, petechiee due to various causes. S., Somatic, the objective signs of certain nervous affections. S., Venous, varicose veins.

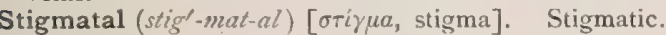

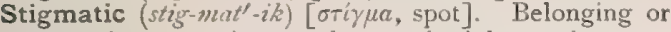
pertaining to a stigma ; characterized by a stigma, or by stigmata.

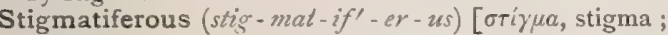
ferre, to bear]. Bearing stigmata.

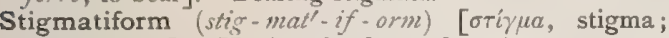
forma, form]. Having the form of a stigma.

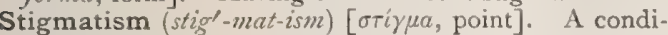
tion of the refractive media of the eye in which rays of light from a point are accurately brought to a focus on the retina. Synonymous with emmetropia. See, also, Astigmatism.

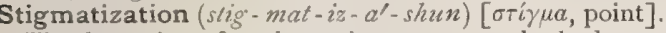
The formation of ecchymotic spots upon the body

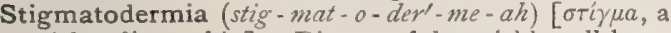
prick; $\delta_{\varepsilon}^{\prime} \rho \mu a$, skin].. Disease of the prickle-cell layer of the skin.

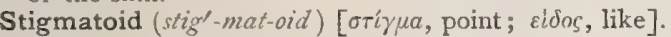
Resembling a stigma.

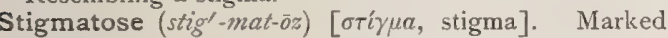
with stigmata.

Stil de grain. Same as Brown-pink, in Pigments, Conspectus of.

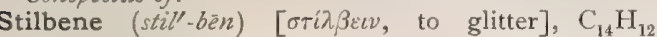
Toluylene, a substance produced by the action of sodium upon bitter-almond oil or benzol chlorid. It crystallizes in large monoclinic leaflets or prisms, and dissolves easily in hot alcohol, melts at $120^{\circ} \mathrm{C}$, and distils at $306^{\circ} \mathrm{C}$.

Stilet, Stilette (sti-let') [Fr., dim. of Lat. stilus, a point]. The small, sharp-pointed instrument enclosed in the cannula. Also, the wire of a flexible catheter.

Still (stil) [ME., stille, stili]. Quiet; at rest. S.born, born lifeless.

Stillicidium (stil-is-id'-e-um) [stilla, a drop; cadere, to fall down]. The flow of a liquid drop by drop. Also, the flow of the urine in strangury. S. lacrimarum, overflow of tears from obstruction of the canaliculus or nasal duct. S. narium, coryza. S. sanguinis. See Staxis. S. urinæ, dribbling of urine. S. uteri. See Menses. S., Virulent, gon orrhea.

Stilligoute (still-ig-oot) [Fr., stillare, to let fall ; gutta, a drop]. A dropper; a pipet that lets a liquid fall in drops.

Stilling, Canal of. See Canal. S.'s Sacral Nucleus, an island of nerve-cells in the sacral region of the spinal cord. See Nucleus.

Stillingia (stil-in'-je-ah) [after Benjamin Stillingfleet, an English botanist]. Queen's Root. The root of S. sylvatica, or "queen's delight." Its active principle is not known. It is expectorant, diuretic, and sialogogue, with reputed alterative properties; in larger doses, emetic and cathartic. It is used with sarsaparilla as an antisyphilitic in the tertiary stage. It is valuable with quinin in intermittent fever. Dose of the powd. root gr. $x-3 j$; of the fld. ext. $m x-3 j$; of the tinct., unof., $3 \mathrm{ss-ij}$; of the decoction (strength $\xi \mathrm{j}$ to $\mathrm{Oj})$, unof, ,

Stillingin (stil-in'-jin) [after Benjamin Stillingfleet, an English botanist]. A precipitate from a tincture of the root of Stillingia sylvatica; resolvent, stimulant, diuretic, antisyphilitic. Dose to 3 grains. Unof.

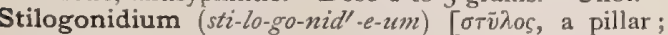
yovń, generation, seed: pl., Stilogonidia]. In biology, a stalked gonidium, or asexual reproductive body ; a stylospore.
Stilus (sti'-lus) [stilus, a point]. I. A more correct form of the word Stylus, used as an anatomic term. 2. A small tube or a bit of wire sometimes retained in the obstructed lacrymal duct, with a view to the restoration of its function.

Stimulant (stim'-zt-lant) [stimulus, a goad]. I. Quickening or increasing some trophic or functional process. 2. An agent exciting the functions of an organ or some process of the economy. S., Cardiac, one that increases the heart's action. S., Cerebral, one that exalts the action of the cerebrum. S., Cutaneous, one that increases the activity of the skin, producing diaphoresis. S., Diffusive, one that has a prompt but transient effect. S., Hepatic, one that excites the liver. S., Intestinal, one that acts upon the intestinal tract. S., Local, one acting directly on the endorgans of the sensory nerves of the skin. S., Renal, one producing diuresis. S., Spinal, one exciting the spinal cord. S., Stomachic, one giving tone to the stomach, aiding digestion, etc. S., Vasomotor, one exciting the vaso-motor apparatus.

Stimulate (stim'-u-lat) [stimulare, to stimulate]. To treat with stimulants. To induce increased activity.

Stimulating (stim'-u-la-ting) [stimulare, to stimulate]. Having the power to stimulate.

Stimulation (stim- $\left.-l \alpha^{\prime}-\operatorname{shun}\right)$ [stimulatio]. The action of a stimulant; the process of stimulating; the effect of the administration of a stimulant.

Stimulose (stim'-u-löz) [stimulus, a goad]. Provided with stinging needles or hairs.

Stimulus (stim'-u-lus). [L.: pl., Stimuli]. Anything exciting the animal economy, or any part thereof, to increased functional activity. Stimuli, Adequate or Homologous, those for whose action the senseorgans are specially adapted. S., Chemic, irritation caused by a chemic agent. S., Heterologous, one acting upon the nervous elements of the sensory apparatus along their entire course. S., Homologous, a stimulus only acting upon the end-organ. $\mathbf{S}$. Mechanical, irritation caused by mechanical means, as by pinching or striking. S., Summation of. See Summation.

Sting [ME., stingen, to sting]. I. A minute, punctured, and often a poisoned wound, made by the pointed defensive or offensive organ of some insect, or other animal or plant. 2. A sharp-pointed defensive organ of reptiles and insects.

Stinging (sting-ing) [ME., stingen, to sting]. 1. Producing a burning pain. 2. Wounding by means of a sting. S.-cell, one of the urticating cells or lassocells of a Cnidarian. See Cnida, Nematophore, Nematocyst.

Stink (stingk) [ME., stinken, to stink]. I. To emit a strong, offensive smell. 2. A disgusting odor. S.glands. See Gland. S.-trap. See Stench-trap.

Stinking Smut. See Smut.

Stipe (stip $)$ [stipes, a stock, post]. In biology, a stem, stalk or support. Cf., Thecaphore, Gynophore, Anthophore, Gynobase, Gonophore, Carpophore.

Stipel (sti'-pel) [stipes, a post]. The stipule of a leaflet.

Stipellate (sti'-pel-ät) [stipella, a stipel]. In biology, bearing stipels.

Stipes (sti'-pēz) [stipes, a stock, trunk]. In biology: I. A stalk, stem, or stipe. 2. A mesal branch of the paroccipital fissure of the brain.

Stipiform (sti'-pif-orm) [stipes, stock; forma, form]. Having the form of a stipe.

Stipitate (stip'-it-ät) [stipes, a stock, trunk]. In biology, placed upon a stalk or stipe.

Stipitiform (stip'-it-if-orm) [stipes, stock ; forma, form]. In biology, stipiform. 
Stipula (stip’-u-lah) [stipula, a stalk: plo, Stipula]. In biology: I. A pin-feather of a bird. 2. See Stipule. Stipulaceous (stip-u-la'-shus). Same as Stipular

Stipular, Stipulary (stip'-u-lar, stiph-u-la-re) [stipula, a stalk]. Pertaining to a stipule.

Stipulate (stiṕp-u-lât) [stipula, a stalk]. Having stipules.

Stipulation (stip-u-la'-shun) [stipula, a stalk]. In biology, the situation and structure of the stipules.

Stipule (stip'-ül) [stipula, a stalk, stem, blade]. In biology, $(a)$ one of the blade-like bodies at the base of the petioles of leaves; (b) Braun's term for the unicellular foliar structures arising from the basal nodes of Chara, on both the inner and outer sides of the leaf; $(c)$ one of the small leaves or hair-like appendages (paraphyllum) found among the true leaves of certain mosses; (d) a pin-feather of a bird.

Stipuliferous (stip-u-lif'-er-zes) [stipula, a stipule; ferre, to bear]. Having stipules.

Stipuliform (stip'-u-lif-orm) [stipula, stipula; forma, form ]. In biology, having the form of a stipula.

Stipulosus (stip-u-lo'-sus) [stipula, a stipule]. Having stipules which are comparatively large.

Stirling and Brito's Method. A method of preparing hemoglobin crystals. Mix a drop of blood with a few drops of water on a glass slide and seal the preparation. After a few days beautiful crystals are developed.

Stirosis (ste-ro'-sis). Synonym of Sterility.

Stirp (sturp) [stirps, a stock, root, race]. In biology, a term introduced to express the sum-total of hereditary organic units contained in the fertilized ovum.

Stirpicultural (stur-pik-ul'-tu-ral) [stirps, a race; cullura, culture]. Pertaining to stirpiculture.

Stirpiculture (stur'-pik-ul-tür) [s/irps, stock, race; cultura, culture]. The proposed improvement of the human species by attention to the laws of breeding.

Stirps (sturps) [stirps, stock, race, root: pl., Stirpes]. In biology, a race or permanent variety; a lineage, family

Stirrup, Stirrup-bone (stir'-up) [ME., stirop, stirrup]. The stapes.

Stitch [ME., stiche, twinge]. I. A sudden, sharp, lancinating pain. 2. See also Suture.

Stocking, Elastic. A stocking of elastic fibers for the compression of a limb affected with varicose veins and other diseases.

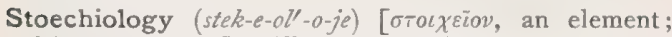
$\lambda$ cos , a treatise]. The study of the chemic elements of the gases, fluids, and solids of the body ; physiologic chemistry. See Stechiology.

Stoerck's Blennorrhea. A form of laryngitis sicca ending frequently in adhesion between the anterior portions of the vocal bands.

Stoicheiology (stoi-ke-ol'-o-je). See Stechiology.

Stokes' Disease. Exophthalmic goiter. See Disenses, Table of. S. Expectorant, a preparation used in the treatment of bronchitis. It consists of pulverized carbonate of ammonium 16 grains, fluid extract of senega and squills each $1 / 2$ dram, paregoric 3 drams, syrup of tolu sufficient to make two ounces. A dram of this is given p. r. n. S. Law. See Law, Angstrom's. S. Liniment. See Linimentum. S. Reagent. A reducing agent employed in the physiologic laboratory. It is a solution of ferrous sulphate to which a little tartaric or citric acid has been added and then ammonia till the reaction is alkaline. It should be freshly made when used. S. Sign, violent throbbing in the abdomen in cases of acute enteritis. The throbbing is to be felt to the right of the umbilicus, and may occasion much distress. See Signs and Symploms, Table of.
Stolidity (stol-id'-it-e) [stoliditas]. A term designating stupidity of various degrees, even to amentia, or complete imbecility - oftener, however, signifying merely a phlegmatic or immobile temperament.

Stolon (sto'-lon) [stolo, a shoot, branch]. In biology: (a) a slender, prostrate branch, taking root, or bearing a bulb at the tip, where it forms one or more new plants; (b) an analogous budding stock in certain compound animals; e.g., Social Infusoria, Actinozoa, $H y$ drozoa, Ascidice.

Stolonate (sto'-lon-ät) [stolo, a shoot]. Stoloniferous. Stoloniferous (sto-lon-if'-er-us) [stolo, a shoot; jerre, to bear]. Producing stolons.

Stoma $\left(s t o^{\prime}-m a h\right)[\sigma \tau o ́ \mu \alpha$, mouth $]$. I. The mouth. 2. In biology: $(a)$ an opening on the surface of a plant, especially the leaves, for the passage of gases and moisture. "A stoma is formed of an epidermal cell which divides into two equal sister-cells by a wall vertical to the leaf" (Sachs); (b) a mouth, ostium, or pore, as the openings in endothelial membranes, establishing direct communication between adjacent lymph-channels.

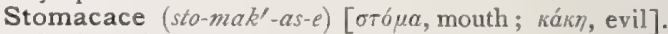
Canker of the mouth. Fetor of the mouth with ulcerated gums; also, scorbutic sore-mouth.

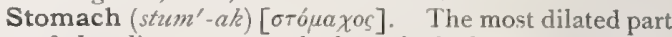
of the alimentary canal, the principal organ of digestion, situated in the abdomen in the left hypogastric, the epigastric, and part of the right hypochond ri a c regions, above the transverse colon and below the diaphragm. S.ache, pain in the stomach or abdomen. S.brush, a brush designed to be introduced into the stomach to stimulate secretion. S.-bucket, a small silver vessel attached to a thread. used in obtaining a specimen of the contents of the stomach. S--cough, a reflex cough excited by irritation of the stomach or of the small intestine. S.-drops. See Bitter Tincture. S., Honey-comb. See Reticulum. S., Hourglass, a stomach having an hour-glass shape, due to a band of exudation. S.-pump, an instrument for withdrawing the contents of the stomach. See $P u m p$. S.-staggers, a disease in horses depending on a paralytic affection of the stomach. S.-tooth, a lower canine tooth, especially one of the first dentition. S.tube, a flexible tube for irrigation, etc., of the stomach. S.-worm, a common intestinal roundworm. See Ascaris lumbricoides, under Parasites (Animal), Table of.

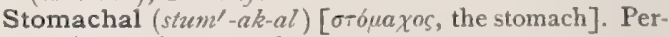
taining to the stomach.

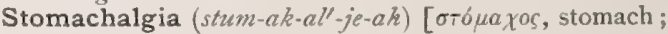

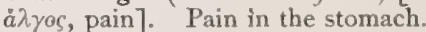

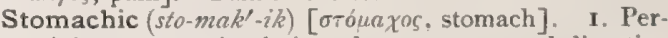
taining to or stimulating the secretory and digestive functions of the stomach. 2. A stimulant exciting the functional activity of the stomach. 


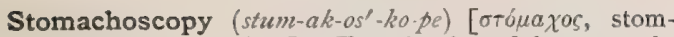

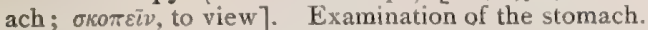
Stomata $($ sto'-mat-ah) [pl. of Stoma]. Mouths.

Stomatal (sto'-mal-al) [oтópa, mouth]. Relating to stomata.

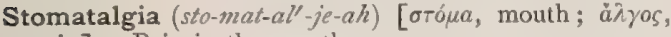
pain]. Pain in the mouth.

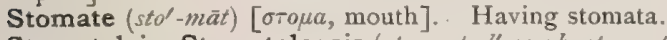

Stomatelcia, Stomatelcosis (sto-mat-ell-se-ah, sto-mat-

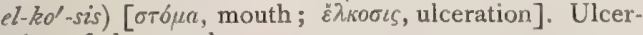
ation of the mouth.

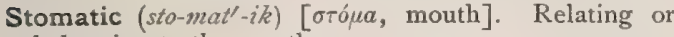
belonging to the mouth.

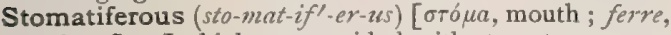
to bear]. In biology, provided with stomata.

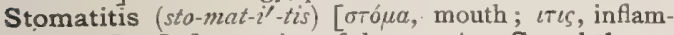
mation]. Inflammation of the mouth. S. aphthosa. See Aphtha. S., Aphthous. See Aphtha. S., Catarrhal, the most frequent form and especially encountered in infants, when it is often termed "erythema neonatorum." The mucous membrane is swollen, and the tongue furred; there is pain on sucking or in older children on chewing, and salivation is present to a more or less marked degree. This form of stomatitis is usually associated with the exanthemata and other acute dis eases. S., Corrosive. See S., Gangrenous. S. cremosa. Synonym of Thrush. S. epidemica, an acute infectious stomatitis which occurs in epidemics. S., Epizoötic, aphthæ epizoöticæ. S., Follicular. Synonym of Aphtha. S., Gangrenous. See Cancrum oris. S. materna, stomatitis occurring during pregnancy or lactation. S. Mercurial, that arising from poisoning by mercury. S. mycosa. See Thrush. S. parasitica. Synonym of Thrush. S., Phlegmonous. Synonym of S., Ulcerative. S., Pseudomembranosa. Synonym of Thrush. S., Pultaceous. See Aphthe. S., Saturnine, stomatitis due to leadpoisoning. S., Scorbutic, stomatitis due to scurvy. S., Simple, a simple erythema of the mouth. S., Ulcerative, a grave form of catarrhal stomatitis. It is characterized by the formation of small ulcers on the cheeks, lips, and tongue, with copious salivation, pain, fetid breath, slight fever, and at times great prostration. S. ulcerosa. Synonym of S., Ulcerative. S., Vesicular. Synonym of Aphthe.

Stomatium (sto-ma'-she-um). See Stoma.

Stomatocace (sto-mat-ok'-as-e) [бтópa, mouth; какós, evil]. Fetid ulceration of the mouth.

Stomatocatharsis (sto-mat-o-kath-ar'-sis). Synonym of Salivation.

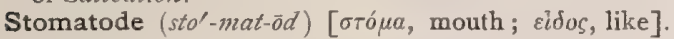
Having a stoma.

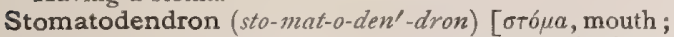
$\delta \varepsilon ́ v \delta \rho o v$, a tree : pl., Stomatodendra]. In biology, one of the branches of a complex tree-like mass suspended from the middle of the umbrella in the Rhizostomide. These branches end in and are covered with minute polypites interspersed with clavate tentacula.

Stomatodynia (sto-mat-o-din'-e-ah) [oró $\mu a$, mouth ; odivn, pain]. Pain in the mouth.

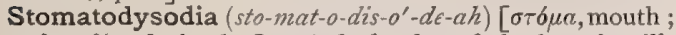

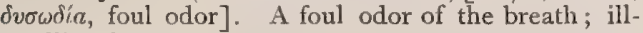
smelling breath.

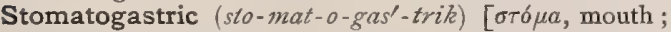
$\gamma a \sigma \tau \eta \rho$, stomach]. In biology, applied to the nerves; pertaining to the mouth and the stomach.

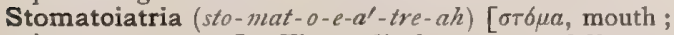

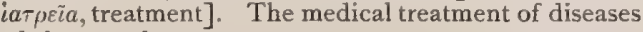
of the mouth.

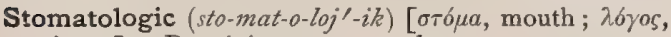
science]. Pertaining to stomatology.
Stomatologist (sto-mat-oll-o-jist ) [бrópn, mouth ; $\lambda o ́$ yos, science]. One versed in stomatology.

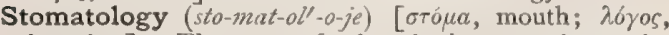
learning]. The sum of what is known about the mouth.

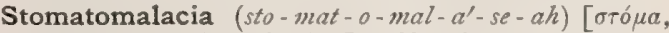
mouth; малакi $\alpha$, softening]. Sloughing or softening of parts of the mouth.

Stomatomenia (sto-mat-o-me'-ne-ah) [oтópa, mouth; $\mu \eta \dot{v}$, month]. Vicarious menstruation by way of the mouth.

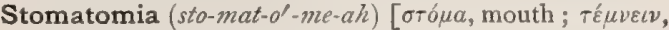
to cut]. A general term for the incision of a mouth, as of the uterus.

Stomatomorphous (sto-mat-o-mōr'-fus) [otóua, mouth ; $\mu о \rho \phi \eta$, form]. In biology, shaped like a mouth.

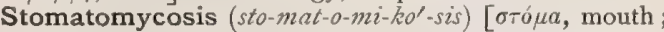
$\mu v i \kappa \eta s$, fungus]. A disease of the oropharynx due to the development therein of the Oidium albicans. S. oïdica. See Thrush.

Stomato-necrosis (sto-mat-o-ne-kro'-sis). Synonym of Cancrum oris.

Stomatonoma (sto-mat-o-no'-mah). Same as Stomacace.

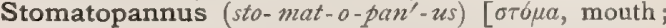
navvvs, thread]. Enlargement of the glands of the mouth.

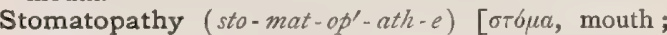
$\pi a ́ f o s$, disease]. Any disease of the mouth.

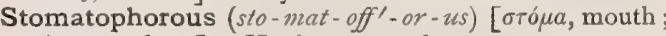

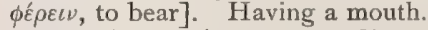

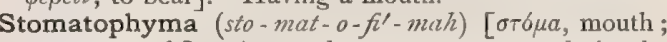
$\phi v \mu a$, growth]. Any enlargement or growth in the mouth.

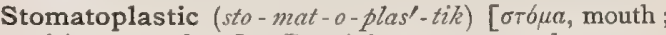

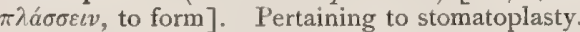

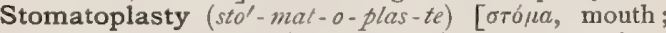
$\pi \lambda a ́ \sigma \sigma \varepsilon \iota \nu$, to form ]. Plastic operations upon or about the mouth.

Stomatopoiesis $\left(\right.$ sto-mat $\left.-0-p o i-e^{\prime}-s i s\right)$. See Stomatoplasty.

Stomatopyra (sto-mat-o-pi'-rah). See Aphthe.

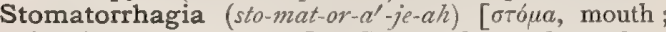
im $v v$ vveu, to burst forth]. Copious hemorrhage from the mouth.

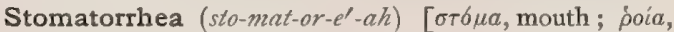
a flow]. A discharge of liquid from the mouth.

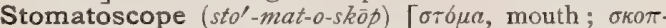
$\varepsilon \bar{\imath}$, to inspect]. An instrument to aid in the inspection of the mouth.

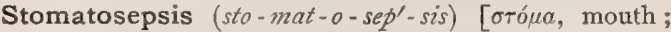
$\sigma \tilde{\eta} \pi \sigma \iota \zeta$, sepsis]. Stomatosis due to septic infection.

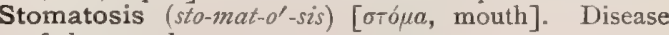
of the mouth.

Stomatospasmus (sto-nat-o-spaz'-mus). See Trismus.

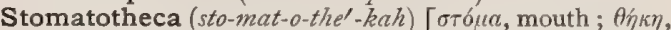
box, chest: pl., Stomatothece]. In biology, that part of a pupa-case which covers the mouth.

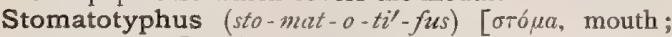
$\tau v \phi o s$, stupor]. A form of typhus in which the beginning lesions are found in the mouth.

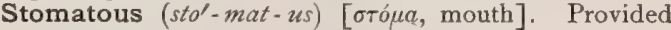
with stomata.

Stomencephalus (sto-men-sef'-al-us). See Stomocephalus.

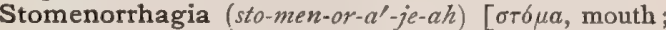
inyvival, to burst forth]. Bleeding from the mouth.

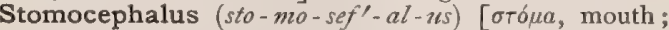
$\kappa \varepsilon \phi a \lambda \eta \dot{n}$, head]. A variety of single autositic monsters of the species cyclocephalus, in which there is the same deformity as in rhinocephalus or in cyclocephalus, as sociated with a defect of the maxillary bones, so that the excess of skin hangs in folds around the 
mouth, resembling somewhat the proboscis of rhinocephalus.

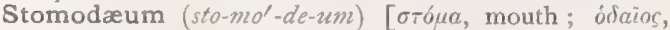
pertaining to a way: pl., Stomodaa]. In biology, the primitive mouth-cavity of embryos, larve, and young transition-stages. That part of the enteric tube formed at the oral pole by a depression of the ectoderm connecting the permanent mouth with the archenteric cavity.

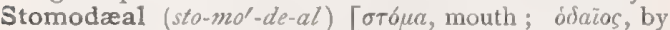
the way]. Having the character of a stomodreum.

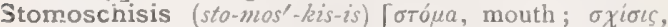
fissure]. Fissure of the mouth, particularly of the soft palate.

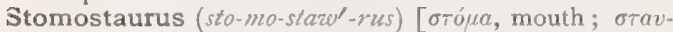
pós, cross]. In biology, the cross-shaped mouth of Mediuse.

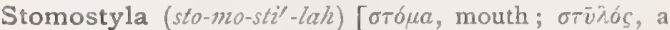
pillar: pl., Stomostyle]. In biology, one of the oral styles of the Anthomeduse.

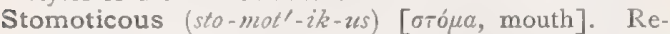
lating or pertaining to the mouth.

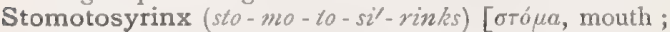
oùs, the ear; $\sigma v \rho v \gamma \xi$, tube]. The Eustachian tube. Stomuria (sto-mu'-re-ah). See Stomaturia.

Stone (stōn) [ME., stoon, stone]. 1. A hardened mass of mineral matter. 2. An English weight of $14 \mathrm{lbs}$. See also Calculus. S., Blue, copper-sulphate crystals. S., Break, a member of the genus Saxifraga, so called because of the belief that the hard bulbs were of virtue against calculus. See Signatures, Doctrine of. S.-crusher. See Lithotrite. S.-fruit, the same as Drupe, q.v. S., Gall. See Biliary Calculus. S., Liver, a mixture of bitumen and barium sulphate. S.-masons' Neurosis, loss of control of the hand in the use of the chisel, sometimes observed in stone-masons, as a result of over-use. Both spasm and weakness are likely to be present, and painful points often exist. S.-m. Phthisis. See Grinders' Asthma. S.-oil. See Petroleum. S., Philosopher's, a hypothetic substance believed to transmute the baser metals into gold and silver, and to be a panacea against all evils as well. S.-pock, S.-pox. See Acne vulgaris. S.-root. See Collinsonia canadensis.

Stool [ME., stool, stool]. The feces. The evacuation of the bowels. A chair or seat. Ss., Bilious, the discharges in bilious diarrhea, as after large doses of calomel. Ss., Caddy, yellow-fever stools which resemble fine, dark, sandy mud. Ss., Fatty, stools in which fat is present; due to pancreatic disease. S., Insulated, in electricity, a stool provided with insulated legs. Ss., Mucous, stools consisting of or containing mucus. They indicate the existence of intestinal inflammation. Ss., Pea-soup, the peculiar liquid evacuation of typhoid fever. Ss., Rice-water, the stools of cholera, in which there is a copious serous exudation containing detached epithelium.

Stop [ME., stoppen, to stop]. To plug up; to hold back; to hinder. S.-cock, a turning cock, connected with a pipe, for regulating the flow of gases or liquids. S.-needle, a lance-pointed needle used in the operation of discission, having an enlargement or shoulder upon the shank to prevent too deep penetration.

Stoppage (stop'- $\bar{a} j)$ [ME., stoppen, to stop]. Cessation of flow or action; closure or stegnosis.

Stopper, Stopple (stop $p^{\prime}-e r$, stop $\left.p^{\prime}-l\right)$ [ME., stoppen, to stop]. A plug or other closure for a bottle, commonly made of cork, rubber, or glass. S.-Dropper, a combination of stopper and medicine pipet in one piece.

Stopping $\left(\right.$ stop $\left.\phi^{\prime}-i n g\right)$. See Filling.

Storax (sto'-raks). See Styrax.

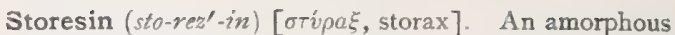
resin forming the largest ingredient of storax.

Stoughton, Stoughton's Elixir (sto'-ton). Tinctura absinthii composita; a tincture of wormwood, germander, gentian, rhubarb, orange-peel, cascarilla, and aloes; used as a flavor in alcoholic drinks and as a general tonic. Unof.

Stout (stowt) [ME., stout, stout]. I. Hardy, sturdy, corpulent. 2. A heavy beer or porter.

Strabilismus (stra-bil-iz'-mus). See Strabismus.

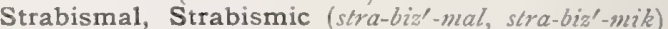

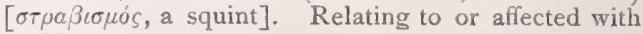
strabismus.

Strabismometer (stra-biz-mom'-et-er). See Strabometer.

Strabismometry $\left(\operatorname{str} a-b i z-m o m^{\prime}-c t-r e\right)[\sigma \tau p a \beta \iota \sigma \mu b s, a$ squint; $\mu \dot{\varepsilon} \tau \rho \circ \nu$, measure]. The measurement of the degree of strabismus.

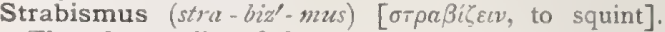
That abnormality of the eyes in which the visual axes do not meet at the desired objective point, in consequence of incoördinate action of the external ocular muscles. Stevens has devised the following terms to express the deviations of the visual lines in strabismus : Heterotropia, a generai term for deviation of any kind; Hypertropia, for one visual line above another; Esotropia, deviation inward; Exotropia, deviation outward. S., Alternating, when either eye fixes alternately. S., Apparent, due to a large angle alpha. S., Concomitant, the squinting eye has full range of movement. S., Constant, when the condition is a permanent one. S., Convergent, when the squinting eye is turned to the nasal side. S. deorsumvergens, the axis of vision is directed downward. S., Divergent, when the squinting eye is turned to the temporal side. S., Downward, strabismus in which the squinting eye turns downward below the point of fixation of the other eye. S., Dynamic. See Insufficiency. S., External. See S., Divergent. S., Intermittent, that disappearing without apparent cause and returning at regular intervals. It is usually seen in children, and is probably of nervous origin. S., Internal. See S., Convergent. S., Latent. See Insufficiency. S., Monocular, or Unilateral, when the same eye always deviates. S., Paralytic, due to paralysis of one or more muscles. S., Periodic, strabismus occurring sometimes on fixation for near but not for far points. S. Spastic, strabismus due to a spastic contraction of an ocular muscle. It occurs in connection with central nervous disease. S. sursumvergens, the visual axis is directed upward. S., Upward, strabismus in which the squinting eye turns upward beyond the point of fixation of the other eye.

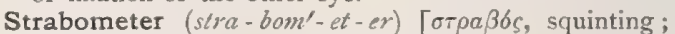

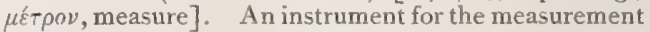
of the deviation of the eyes in strabismus.

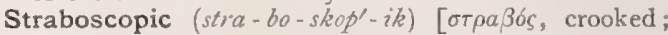
$\sigma \kappa o \pi \varepsilon i \nu$, to see]. Pertaining to the appearance of objects as seen by one with strabismus. S. Disc, an instrument producing distortion of objects.

Strabositas (stra-bos'-it-as). See Strabismus.

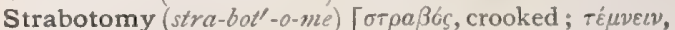
to cut]. An operation for the correction of strabismus. See Tenotomy.

Straddling Disease. See Quebrabunda.

Stragular (strag'-u-lar) [stragulum, a cover]. Pertaining to the mantle; pallial.

Stragulum (strag'-u-lum) [L.]. The mantle; the pallium.

Strain (strän) [ME., straynen, to strain]. In pharmacy, to separate insoluble substances from the liquid in which they occur. To filter. In pathology, any 
abncrmal tension put on an organ or part. See, also, Eye-strain.

Strainer (stro'-ner) [ME, streynour, strainer]. In phannacy, a sieve for filtration.

Strait (strât) [ME., strait, narrow]. I. Narrow. 2. A narrow or constricted place. S.-jacket, a strong coat especially designed to prevent injury of self or others by the delirious or violent patient; camisole. Ss. of Pelvis. See Pelvis. S.-waistcoat. See S.jucket.

Stramineous (stra-min'-e-us) [stramen, straw]. Strawcolored or straw-like.

Stramonium (stra-mo'-ne-tum) [L., gen., Stramonii]. Thorn-apple. The seeds and leaves of Datura $S$., the well-known Jamestown or "jimson" weed. Its properties are due to an alkaloid, daturin, $\mathrm{C}_{17} \mathrm{H}_{23} \mathrm{NO}_{3}$, identical with atropin (see Belladonna). It has the general properties of belladonna, but is more powerful. S., Ext. Dose gr. $1 / 6-1 / 2$. S., Fld. Ext. Dose $m$ j-v. S., Tinct., 15 per cent. strong. Dose $m v-$ xxx. S., Ung., contains of the extract Io, water 5 , benzoinated lard 85 parts. Daturin, the alkaloid. Dose gr. $\frac{1}{120}-\frac{1}{20}$.

Strangalesthesia (stran-gal-es-the'-ze-ah). See Zonesthesia.

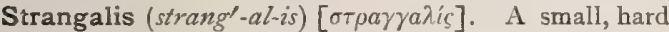
induration of the breast.

Strangers' Cold. See Saint Kilda Cold.

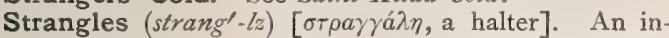
fectious catarrh of the upper air-passages, especially of the nasal cavity, of the horse, ass, and mule, associated with suppuration of the submaxillary and other lymphatic glands.

Strangling (strang-ling). See Strangulation.

Strangulate (strang-tu-lät) [strangulare, to strangle]. Irregularly expanded and contracted.

Strangulated (strang $\left.g^{\prime}-g^{\prime}-l a-t e d\right)$ [strangulare, to strangle]. So compressed that the normal function ceases, or is seriously interfered with. S. Hernia. See Hernia.

Strangulatio (strang-gu-la'-she-o) [L.]. Strangulation. S. uterina. Synonym of Hysteria.

Strangulation (strang-gu-la'-shun) [strangulatio; strangulare, to choke]. Choking. Constriction produced by a ligature, stricture, etc. Pressure round the neck, whereby the entrance of air into the lungs is prevented, the constricting force being either a ligature, the hands, or some power other than the weight of the body itself.

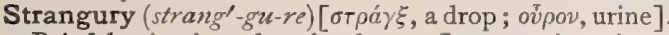
Painful urination, drop by drop. It occurs in poisoning by turpentine and by cantharides, and in inflammatory affections of the bladder and prostate.

Strap, Strapper (strap'-er) [ME., stropp, strap]. A flat thong, or flexible band, often of adhesive plaster. Straps of various kinds are much used in surgery.

Strapping (strap'-ing) [ME., stroppe, strap]. The compression of a pait (as the mamma, or testis) by means of adhesive straps.

Strassburg's Test. A test for biliary acids in the urine: Dip filter-paper into the urine, to which a little canesugar has been added; dry the paper and apply a drop of sulphuric acid; a violet color is obtained after a short time if biliary acids are present. See Tests, Table of.

Strassburger's Cell-plate. The equatorial plate produced in karyokinesis.

Stratification (strat-if-ik-a'-shun) [stratum, a layer; facere, to make]. Arrangement in layers; the thickening of a cell-wall by successive layers of formed material.

Stratiform (strat'-if-orm) [stritum, stratum; forma, form]. Formed into a layer. S. Fibro-cartilage.
Fibro-cartilage that lines those bony grooves through which the tendons of muscles pass. See Fibro-cartilase.

Stratum (stra'-tum) [stratum, a spread for a bed, a pavement: pl., Strata]. In biology, a layer, lamisia, or lamella; a membrane. S. bowmani, the anterior elastic layer of the cornea. $\mathbf{S}$. cinereum, the second layer of the anterior lobes of the corpora quadrigemina, consisting of gray matter and small cells in a network of nerves. S. corneum, the epidermis. S., Flesh, the Parietal Mesoblast. S. lucidum, one of the layers of the skin. S. malpighii. See Rete mucosum. S. of Oehl, a translucent layer of the epidermis consisting of irregular transparent cells with traces of a nucleus. S. opticum, a mass of gray matter forming the third layer of the anterior lobes of the corpora quadrigemina. S. of Remak, a layer of medullated nerve-fibers beneath the first layer of the cerebral cortex. S. of Visual Cells, a layer of cells in the retina.

Straw [ME., straze, straw]. The stalk, or stem, of certain species of grain. S., In the, in childbed; lying in; parturient. S.-berry Mark. Same as Navus maternus. S.-berry Tongue, the characteristic tongue of scarlet fever. The vessels of the fungiform papillæ become turgid, causing the papillæ to stand out as red points, in marked contrast with the thick coating of fur on the filiform papillæ.

Streak (streek) [Dan., streg, AS., strica, a streak, a line]. In biology, a furrow, line, band, stripe, or color-mark. S-culture. See Culture. S., Germinal. See S., Primitive. S., Medullary. See Medullary Groove. S., Primitive, an opaque band ex. tending some distance forward from the posterior mar gin of the area pellucida and forming the first noticeable sign of incubation in the blastoderm of the amniota. The accumulation of cells lying immediately behind the blastopore and representing the fusion of the lips of the blastoderm. In amphibia this accumulation is known as the Anus of Rusconi, q. $v$. In mammals the front end of the primitive streak is marked by the Knot of Hensen, $q . v$. S., Reflex, a shining, white streak running along the center of the vessels in the retina. It is due to the reflection of the light from the anterior surface of the column of blood.

Streamless (strēm'-les) [ME., streem, stream]. Lacking in electric activity.

Streblosis (streb-lo'-sis). See Dislocation.

Street (strêt) [ME., streete, street]. Any highway (not a turnpike road), and any public bridge (not being a county bridge), and any road, lane, footway, square, court, alley, or passage, whether a thoroughfare or not. (British Public Health Act, I876.)

Stremma (strem'-ah). Synonym of Sprain.

Strength [ME., strengthe, strength]. Physical power. Strengthen (streng'-then) [ME., strengthen, to strengthen]. To make strong.

Strengthening. (streng'then-ing) [ME, strengthen, to strengthen]. Making stronger. S. Plaster, emplastrum roborans. See Ferrum.

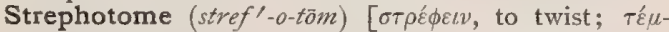
$\nu \varepsilon u$, to cut]. A cork-screw-like instrument used by Spanton to secure union in the operation for hernia.

Strepitus (strep'-it-zes) [L., noise]. A sound; a noise. S. aurium. See Tinnitus aurium. S. coriaceus, an auscultatory sound resembling the creaking of leather. S. uteri. See Uterine Souffle. S. uterinus, the Uterine Bruit, q. v.

Strepsis (strep'-sis). See Torsion.

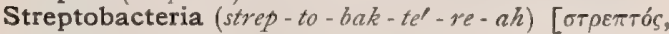

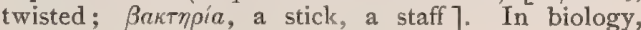
short, rod-shaped bacteria associated in chains. 


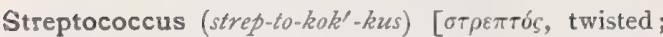
кóiккоs, a kernel: pl., Streptococci]. A genus of coccaceous schizomycetes, of which the cocci are arranged in strings or chaplets. Many of the species are believed to be pathogenic. See Bacteria, Synonymatic Table of.

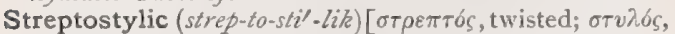
a pillar]. Having the quadrate bone freely articu. lated with the skull, as in ophidian and saurian reptiles.

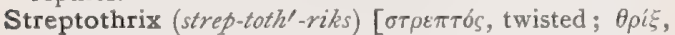
the hair]. In biology, a genus of Sinizomycetes, the cells uniting into simple or branching threads. See Cladothrix, under Bacteria, Synonymatic Table of.

Stretch [ME., strecchen, to stretch]. 'lo draw out to full length. S.-walk, a position in walking for physical development, with the arms stretched upward.

Stretcher $($ strech'-er) [ME., strecchen, to stretch]. A portable cot or litter for carrying the sick

Stria (stri'-ah) [L. a streak: pl., Stria]. A streak or line. S., Acoustic, S., Auditory, transverse white lines, on the lower part of the floor of the fourth ventricle, which unite with the auditory nerve-roots. S. atrophicæ, whitish, cicatricial lines of the skin caused by the contractions of skin that have been stretched by fat, pregnancy, etc. S., Callosal. See S. longitudinales et laterales. S. Cornea, a narrow, white streak interpolated between the thalamus and the caudatum, on the ventricular floor. In color it resembles translu. cent, bluish horn, owing to a vein which passes along and under it. S. gravidarum, the atrophic striæ observed upon the abdomen in pregnant women. S. of Heidenhain. See Rods of Heidenhain. S. longitudinales et laterales, appearances of part of the corpus callosum. S., Pineal, the habena or habenula. S. of Retzius, brown stripes on a tooth, parallel to its edge. They are the indications of enamel-formation. S. vascularis, the vascular layer of the cochlea. Corpora striata. See Corpus.

Striate (stri'-ät) [stria, a furrow]. Marked with minute ridges or furrows. S. Body. See Corpora striata. S.-plicate, in biology, having minute folds that form strize. S.-punctate, having parallel rows of spots or dots that form striz. S.-sulcate, in biology, striate with little furrows.

Striated (stri'-a-ted) [stria, a furrow]. Marked with furrows. S. Hair. See Ringed Hair.

Striation (stri-a'-shun) [stria, furrow]. An arrangement of lines. A striated structure. S. of Heidenhain. See Rods of Heidenhain.

Striatum (stri-a'-tum) [L.]. Same as Corpus striatum. Striature $\left(s t r i^{\prime}-a t-\bar{u} r\right)$ [striare, to furrow]. I. Mode of striation. 2. A stria.

Strichcultur (strich'-kül-tür) [Ger.]. See Cullure.

Strictura (strik-tu'-rah). See Stricture.

Stricture (strik'-tūr) [strictura: stringere, to compress]. The abnormal narrowing or contraction of the lumen of a canal or duct from external pressure, or as a result of inflammatory or other changes. The most constricted part of the opening through which a hemia protrudes. S., Annular, a ring-like obstruction produced by a fold of mucous membrane or constriction all around the urethra, gut, etc. S., Bridle, a fold of mucous membrane forming a crescentic obstruction, or perforated in its center; called, also, S., Linear, S., Pack-thread, S., Valvular and S., Hour-glass, according to the peculiar appearances. S., Cicatricial, a stricture due to cicatricial tissue. S., Congestive, a temporary obstruction of the urethra from subacute prostatitis or other passing inflammation. S.cutter, an instrument for dividing a stricture. S.fever, the constitutional disturbances sometimes the result of acute stricture. S., Functional. See $S$, Spasmodic. S., Impermeable, or S., Impassable, one not permitting the passage of a bougie or catheter. S., Irregular, or S., Tortuous, so named from the complications or peculiarities. S., Irritable, one in which the passage of the instrument causes great pain. S., Organic, narrowing of a canal due to tissuechange, to deposits, or to pressure from without. S., Permeable or Passable, one permitting the passage of an instrument. S., Recurrent or Contractile, one in which the constriction returns after dilatation. S., Simple, one that produces no interruption of function, pain, etc. S., Spasmodic, a stricture due to muscular spasm and not to organic change.

Strictureotome (strik'-tür-o-tōm). See Stricturotome.

Strictureotomy (strik-tür-ot'-o-me) [strictura, stricture ; Té $\mu \nu \varepsilon \iota \nu$, to cut]. See Stricturotomy.

Stricturotome (strik'-tū-ro-tom) [stricturn, stricture; $\tau \dot{\varepsilon} \mu \nu \varepsilon \iota v$, to cut]. A cutting instrument for use in di. viding a stricture.

Stricturotomy (strik-für-ot'-o-me) [strictura, stricture ; $\tau \varepsilon$ eveเv, to cut]. A cutting operation for the relief of stricture.

Stridor (stri'-dor) [stridere, to make a creaking sound]. A peculiar, harsh vibrating sound arising from some obstruction in the throat or larger respiratory tubes. It is most commonly due to compression of the trachea by some extraneous growth, or to spasm or paralysis of the vocal bands. S. dentium. See Odontoprisis. S., Inspiratory, the sound heard in inspiration through a spasmodically closed glottis. S., Laryngeal, stridor due to laryngeal stenosis. S. serraticus, a sound like that of sharpening a saw, sometimes produced by expiration through a tracheotomytube.

Stridulate (strid'-u-lät) [stridulus, creaking]. To make a stridulous noise, as an insect.

Stridulation (strid-u-la'-shun) [stridulare, to stridulate]. The act or function of making a stridulous sound.

Stridulous (strid'-u-lus) [stridere, to make a creaking sound]. Making a creaking or grating sound. S., Laryngismus. See Laryngismus.

Striga (stri'-gah) [striga, a swath, furrow : pl., Striga]. In biology: $(a)$ a bristle-like scale ; $(b)$ a streak.

Strigate (stri'-gatt). Same as Strigose.

Strigil (strij'-il) [strigilis, a scraper]. A flesh-brush.

Strigilate (strij'-il-ät) [strigilis, a scraper]. Provided with a strigilis.

Strigilation (strij-il-a'-shun) [s/rigilatus]. Friction by means of a brush.

Strigilis (strij'-il-is) [strigilis, a scraper: pl., Strigiles]. In biology, a comb-like organ on the first tarsal joint of the fore leg of the bee, employed to clean the antennx and to clear from the eye-hairs all pollengrains or foreign bodies; the eye-brush, eye-comb.

Strigilose (strij'-il-ōz) [striga, a furrow]. In biology, minutely strigose.

Strigmentum (strig-men'-tum) [L., a scraping]. The rolls of dirt and epithelium rubbed off the moist skin. S. capitis. See Pityriasis.

Strigose, Strigous (stri'-gōz, stri'-gus) [striga, a furrow]. Covered with bristles; armed with sharp and stout hairs.

Striking (stri'-king). See Black Leg.

String Method. See Treatment, Methods of.

Stringhalt (string'-hawlt) [a corruption of Springhalt]. A popular name for a nervous affection manifested in involuntary, convulsive movements of one or both hind legs of a horse. See Springhalt.

Striola (stri'-o-lah) [L., a little furrow]. A delicate stria. 
Striolate, Striolated $\left(s t r i^{\prime}-a-l a \bar{t}\right.$, stri'-o-la-ted) [striola, a little furrow]. Having striolae.

Stripe (strip) [ME., stripe, stripe]. A streak; a discolored mark. Ss. of Retzius, dark lines extending more or less parallel to the free surface of the tooth, due to inequalities in growth and density of the enamel.

Striped Maple (stript). See Acer.

Stripping (strip'-ing) [ME., stripen, to rob]. Uncovering; unsheathing. In the plural, the last and richest milk given at any one milking; so called because it is slowly removed by the milker, who strips the teat between the fingers. $\mathbf{S}$. of the Pleura, removal of the lining membrane of the thorax of an animal used for food, to remove the traces of pleurisy and of tuberculosis.

Strobic $\left(s_{r} b^{\prime}-i k\right)$ [ $\sigma \tau \rho b \beta o \varsigma$, a top]. Resembling or pertaining to a top. S. Discs, discs drawn with concentric circles, so as to produce an illusory impression as if they were revolving.

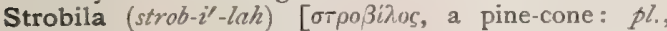
Sirobila]. In biology, a form of development occurring in the Cniduria and Cestoda, in which the products of asexual generation by a sort of fission remain attached to the proliferating organism or to each other. A name given to a tape-worm as a whole. S. Monodisc, the simplest form of strobilation, in which the disc (Scyphistona) separates from its peduncle. S., Polydisc, that form in which successively formed discs remain attached.

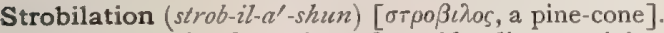
In biology, the formation of zoöids, discs or joints by metameric division, gemmation, or fission.

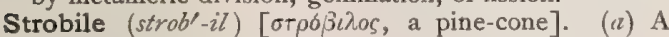
multiple fruit in which the seeds are enclosed by prominent scales, as a pine-cone; $(b)$ a strobila.

Strobiliferous $\left(s t r o b-i l-i f^{\prime}-e r-u s\right)$ [strobilus, a pinecone; ferre, to bear]. In biology, producing Strobila.

Strobiliform (stro-bil'-if-orm) [strobilus, a pine-cone; forma, form]. Having the form of a strobile.

Strobilization (strob-il-iz-a $\left.a^{\prime}-\operatorname{shun}\right)$. Same as Strobilation.

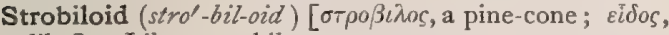
like]. Like a strobile

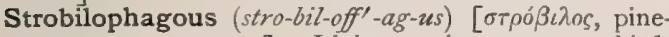
cone ; $\phi a \gamma \varepsilon i v$, to eat]. Living on pine-cones, as a bird.

Stroboscope (stro'-bo-skōp). See Zoescope.

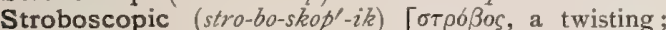

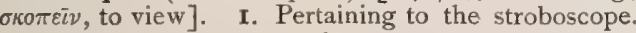
2. A term applied to a plate used in the study of the contractions of striated muscular fiber.

Stroke (strök) [ME., strook, a stroke; stroken, to stroke]. I. In pathology, a sudden and severe seizure or fit of disease. 2. A popular term for apoplexy. 3. To pass the hands gently over the body. S., Apoplectic. See Apoplexy. S., Back, of the Heart, the supposed "reaction-impulse," or recoil of the ventricles at the moment the blood is discharged into the aorta. $\mathrm{S}$. Heat. See Hyperpyrexia. S., Paralytic, sudden loss of muscular power from lesion of the brain or spinal cord.

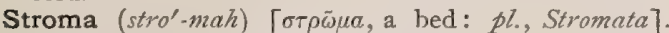
I. The tissue forming the substratum or framework upon which the essential structures of an organ rest. 2. In biology, a body composed of compactly arranged hyphæ, on which sporocarps are borne. S.fibrin, Landois' term for fibrin formed directly from stroma, as distinguished from plasma-fibrin or that formed in the usual way. S.-plexus, a plexus of axis-cylinders formed by the corneal nerves.

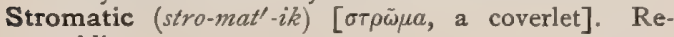
sembling a stroma.

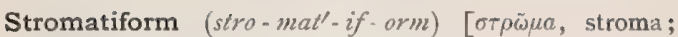
forma, form ]. Having the form of a stroma.

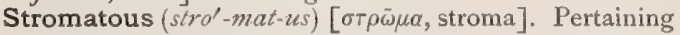
to a stroma.

Strombuliform (strom'-bu-lif-orm) [strombulus, a little top; forma, form]. In biology, twisted into a spiral form.

Stromuhr (strōm'-ürr) [Ger.]. See Rheometer.

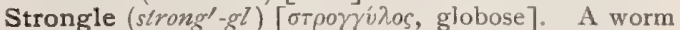
of the genus Strongylus.

Strongyl (stron'-jil). See Strongle.

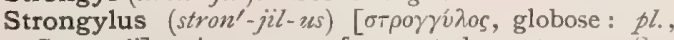
Strongyli]. A genus of nematode entozoa. See Parasites (Animal), Table of.

Strontian Yellow. See Pigments, Conspectus of.

Strontium (stron'-she-um) [after Strontian, in Scotland]. A metal somewhat resembling barium in its chemic relations. Symbol, Sr.; at. wt., 87.37 ; sp. gr., 2.54. See Elements, Table of. S. Bromid, a sedative remedy reported to be free from many of the objectionable qualities of potassium bromid. $\mathbf{S}$. Iodid, S. Lactate, used as a diuretic and as a teniacide.

Strophanthein (strof-an'-the-in) [orpóoos, a cord;

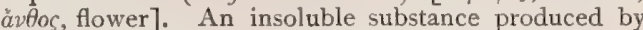
the decomposition of strophanthin by acids.

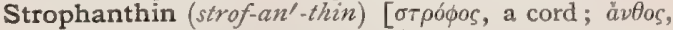
flower], $\mathrm{C}_{20} \mathrm{H}_{34} \mathrm{O}_{10}$. A toxic alkaloid, soluble in water and alcohol, derived from strophanthus.

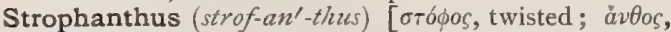
flower]. I. A genus of apocynaceous trees and shrubs, or climbers, of Africa and Asia, often with poisonous seeds. Some 20 species are described. 2. The seeds of a tropical plant, S. hispidus, or Kombé, yielding an arrow-poison. Its properties are due to strophanthin, $\mathrm{C}_{20} \mathrm{H}_{34} \mathrm{O}_{10}$, a glucosid, and inein, an alkaloid. In medical properties it closely resembles digitalis, producing loss of reflex sensibility and voluntary motion, but not to the same degree causing contraction of the arteries. Dose of the tincture gtt. $\mathrm{v}-\mathrm{x}$, of strophanthin, dose gr. $\frac{1}{120}-\frac{1}{60}$, hypodermatically. Unof

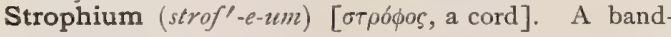
age.

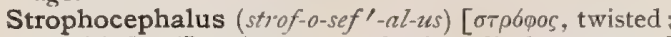
$\kappa \varepsilon \phi a \lambda \eta$, head]. A monster having displacement of the parts forming the head and face.

Strophocephaly (strof-o-sef'-al-e) [or ó́申os, twisted; $\kappa \varepsilon \phi u \lambda \dot{\eta}$, head]. Distortion of the head; the condition of having a distorted head.

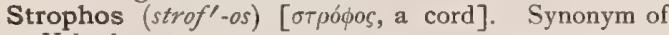
Volvulus.

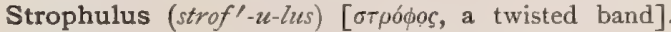
Red Gum; a form of miliaria occurring in infants. It generally results from too much wrapping up. $\mathbf{S}$. albidus. See Milium. S. confertus. See S. intertinctus. S. intertinctus, S. confertus, a papular dermatitis of more or less acute form, a variety of eczema common in infants. S. pruriginosus, an eruption, occurring in the young, of erythematous disseminated papules, accompanied by great itching. $\mathbf{S}$. volaticus, an acute skin-disease, a typical erythema papulatum, characterized by slight maculæ.

Structural (struk'-tu-ral) [structurn, structure]. Pertaining to or involving tissue or structure. In biology, relating to the form, arrangement, and development of parts of organisms.

Structure (struk'-tür) [structura; struere, to build]. In biology, the manner or method of the building up, arrangement, and formation of the different tissues and organs of the body or of a complete organism. Also, an organ, a part, or a complete organic body. 
Structureless (struk'-lūr-les) [structure, structure] Having no histologic differentiation; amorphous or homogeneous; having no distinctions of internal organization and no distinct parts.

Struma (stru'-mah) [struma, a scrofulous tumor] Scrofula. Also, a scrofulous swelling or tumor; a goiter. Also, Bronchocele. S. lipomatodes aberratæ renis, small, fatty tumors found beneath the renal capsule. S. maligna, carcinoma of the thyroid gland. S. pulsans, S. vasculosa, pulsating goiter.

Strumatic, Strumatous (stru-mat'-ik, stru'-mat-us) [struma, struma]. Strumous; scrofulous.

Strumectomy (stru-mekl-to-me) [struma, struma; $\dot{\varepsilon} \kappa \tau o \mu \eta \dot{n}$, excision]. Excision of an enlarged or strumous gland, or of a goiter.

Strumiferous (stmu-mif'-er-us) [struma, struma; ferre, to bear]. Strumose.

Strumiform (stru'-mif-orm) [struma, struma; forma, form]. Having the appearance of struma.

Strumipriva, Cachexia (stru-mip-re'-vah). See Ca chexia.

Strumitis (stru-mi'-tis) [struma, struma; $\iota \tau \iota s$, inflammation ]. Inflammation of the thyroid gland.

Strumoderma (stru-mo-der'-mah). See Scrofuloderma.

Strumose (stru'-mōz) [struma, struma]. Swollen on one side; possessing a wen-like protuberance.

Strumosis (stru-mo'-sis). See Strumositas.

Strumositas (stru-mos'-it-as) [struma, struma]. The tendency toward, or diathesis of, goiter or of scrofula.

Strumous (stru'-mus) [strumosus]. Scrofulous. Having the nature of scrofula. S. Inguinal Lymphadenitis, S. Bubo, hyperplastic lymphadenitis of the inguinal glands.

Strümpell's Disease. Acute primary hemorrhagic encephalitis. See Diseases, Table of.

Strumulose (stru'-mu-loz) [struma, struma]. Furnished with a small struma.

Struthin (stru'-thin). See Saponin.

Struve's Lotion. A lotion recommended as a counterirritant in whooping-cough, and composed of tartar emetic $3 \mathrm{j}$, tr. cantharides $3 \mathrm{j}$, water $\xi_{\mathrm{ij}}$. S.'s Method, a method of preparing hemin crystals. Add to a dilute solution of hemoglobin, ammonia, tannic acid, and afterward glacial acetic acid until it is acid; a black precipitate of tannate of hematin is thrown down. This is isolated, washed, dried on a glass slide, two or three drops of glacial acetic acid and a granule of ammoniun chlorid added; gentle heat is applied, and, on cooling, the crystals appear.

Strychnin, Strychnina (strik'-nin, strik-ni'-nah)

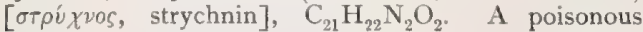
alkaloid in the fruit of Strychnos mux vomica and found in St. Ignatius' bean. It crystallizes in foursided prisms, melting at $284^{\circ} \mathrm{C}$., and possessing an extremely bitter taste. See $N u x$ vomica.

Strychninism (strik'-nin-izm) [orpúxvos, strychnin]. The condition of one under the influence of strychnin or nux vomica, or affected by either.

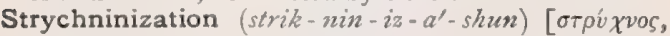
strychnin]. The condition produced by large doses of strychnin or nux vomica.

Strychninomania (strik-nin-o-ma'-ne-ah) [oтpíxvos, night-shade; $\mu$ avia, madness]. Delirium from the use of strychnin or nux vomica.

Strychnos (strik'-nos). See $N u x$ vomica.

Stubb (stub). See Phenanthrene.

Stuffed Meat. Any veal or lamb upon which or to which masses of fat from other animals have been affixed for the purpose of giving lean flesh the appearance of being in good condition.
Stultitia (stul-tish'-e-ah) [stullus, a fool]. Foolishness: dulness of intellect.

Stump [ME., stumpe, stump]. The extremity, pedicle, or basis of the part left after surgical amputation, excision, or ablation. S. of Eyeball, the remainder of the globe after excision of an anterior staphyloma or after other capital operation on the globe that deprives it of vision. S.-foot. Synonym of Club-foot. S., Sugar-loaf, a conic stump due to undue retraction of the muscles; called, also, S., Conical. S. of Tooth, that part remaining after removal or destruction of the corona.

Stun [AS., stunian, to make a din]. To confuse and render one temporarily insensible or unconscious, as by a blow.

Stunt [ME., stunt, dull]. A stunted or undeveloped state. See Cram-stunt.

Stunted (stun'-ted) [ME., stunt, dull]. Undeveloped, by reason of underfeeding, overwork, or other untoward condition.

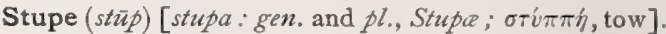
A fomentation. Also, the cloth used.

Stupefacient, Stupefactive (stu-pe-fa'-shent, stu-pefak'-tiv) [stupere, to be stunned; facere, to make]. I. Narcotic, or deadening the senses. 2. A narcotic agent.

Stupefaction (stu-pe-fak'-shun) [stupere, to be stunned]. Stupor, and the process of reaching it.

Stupemania (stu-pe-ma'-ne-ah) [stupor, stupor; $\mu a v i a$, mania]. Mental stupor with insanity.

Stupeous (stu'-pe-us) [stupa, tow]. In biology, applied to the palpi of some insects which are covered with loose scales like tow.

Stupiditas (stu-pid'-it-as). Synonym of Itiocy.

Stupor (stu'-por) [L.]. The condition of being but partly conscious or sensible. Also, a condition of insensibility. S., Anergic, acute dementia. S., Delusional, melancholic dulness of mind, with delusions; it is sometimes a kind of auto-hypnotism. S., Epileptic, S., Post-convulsive, the stupor following an epileptic convulsion. S. formicans, formication. S., Lethargic. See Trance. S. melancholicus, the stupor found in association with melancholia. S. miliaris, paresthesia of the fingers and toes in connection with miliary fever. S. vigilans, catalepsy.

Stuporous (stu'-por-us) [stupor, stupor]. In a condition of or attended with stupor. S. Insanity. See Insanity, Confusional.

Stupose (stu'-pöz) [stupa, tow]. Like tow; covered with mats of long hairs, resembling tow.

Stupration, Stuprum (stu-pra'-shun, stu'-prum) [stuprum, defilement]. Rape.

Stupulose (stu'-pu-loz) [stupa, tow]. In biology, covered with short, fine hairs.

Sturdy $($ stur'-de) [ME., sturdy, sturdy]. I. Vigorous; hardy. 2. See Gid and Staggers.

Stutter $($ stut'-er) [Ger., stottern, to stutter]. To hesitate or make repeated efforts to articulate a syllable. Stuttering is a variety of stammering. See Stammering. S.-spasm. See Lalophobia.

Stycerin (stis'-er-in), $\mathrm{C}_{9} \mathrm{H}_{12} \mathrm{O}_{4^{*}} \quad$ Phenylglycerol; a substance obtained from the bromid of cinnamic alcohol by long boiling with water. It is a gummy mass, easily soluble in water and alcohol.

Stye (sti). See Hordeolum.

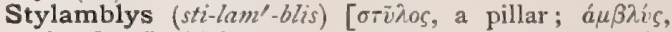
blunt]. In biology, a small process attached to the -inner branch of the pleopod of a crustacean. (Bate.)

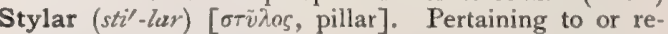
sembling a style.

Stylate $\left(s t^{\prime}\right.$-lât $)$ [stilus, a stake]. Having a persistent style. 


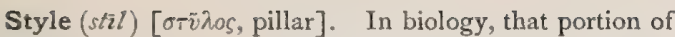
the pistil which connects the ovary with the stigma. S.-branch, in biology, a division of the style. S., Lacrymal. See Lacrymal.

Stylet (sti-let') [stilus, stake]. A probe; a probe or wire inserted into a catheter or trocar, in order to stiffen the instrument or to perforate the tissues. See Stilet.

Styletiform (sti-let'-if-orm) [stilus, stake ; forma, form]. Shaped like a stylet.

Styliferous (sti-lif'-er-us) [stilus, stake ; ferre, to bear] In biology, bearing a style.

Styliform (sti'-lif-arm) [stilus, stake; forma, form]. Shaped like a style.

Styline (sti'-lin) [stilus, stake]. Pertaining or relating to a style.

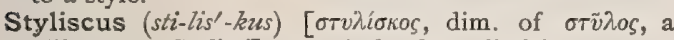
pillar: pl., Stylisci]. I.. A slender cylindric tent. 2. In biology, the passage leading from the stigma to the ovary through the style.

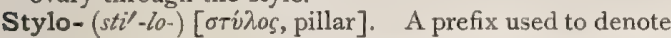
connection with or relation to the styloid process of the temporal bone.

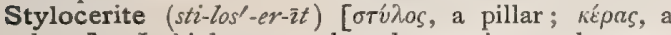
horn]. In biology, a style or large spine on the outer margin of the first joint of the first pair of antennæe of crustaceans (Bate).

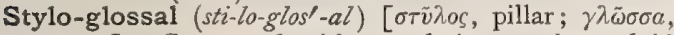
tongue . Connected with or relating to the styloid process of the temporal bone and the tongue.

Styloglossus (sti-lo-glos'-zus). See Muscles, Table of.

Stylogonidium (sti-lo-go-nid'-e-um) [otṽnos, a pillar ; yov'n, generation]. In biology, a gonidium formed by abstriction on the ends of special branches of the thallus in certain fungi.

Stylohyal (sti-lo-hi'-al) [stilus, stile; hyoid]. One of the bones of the hyoid arch of vertebrates.

Stylohyoid (sti-lo-hi'-oid). See Muscles, Table of, and Nerves, Table of.

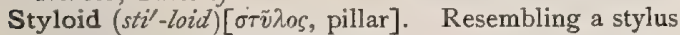
or slender, cylindric column.

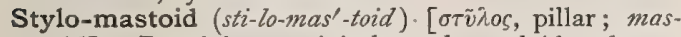
toid]. Pertaining conjointly to the styloid and mastoid processes. S.-m. Foramen, a foramen on the inferior surface of the petrous portion of the temporal bone. It transmits the facial nerve. See Foranina, Table of.

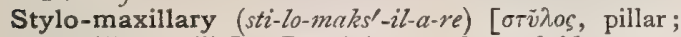
maxilla, maxilla]. Pertaining to the styloid process and the maxilla.

Stylo-pharyngeus (sti-lo-far-in-je'-us). See Muscles, Table of.

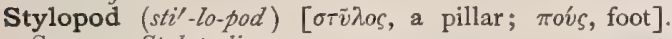
Same as Stylopodium.

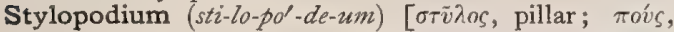
foot: pl., Stylopodia ]. In biology, a disc-like enlargement occurring at the base of the style in some flowers, e. g., Umbelliferce.

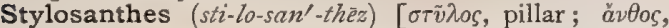
flower]. A genus of leguminous plants including the Pencil Flower; the herb $S$. elatior, which is of repute in relieving the irritability of the uterus during gestation. Dose of the fld. ext. $m x-x x$.

Stylospore (sti'-lo-spōr) [ $\sigma \tau \bar{v} \lambda o s$, a pillar; $\sigma \pi o \rho a ́$, seed]. Same as Pycnospore.

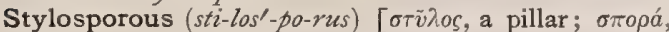
seed]. Of the nature of a stylospore.

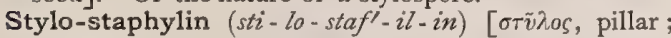
$\sigma \tau \alpha \phi v \lambda \dot{n}$, a bunch of grapes]. Connected with or relating to the styloid process of the temporal bone and the velum palati.

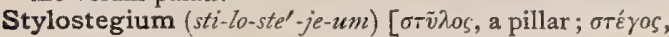

cover: pl., Stylostegia $]$. In biology, the corona covering the style peculiar to asclepiads.

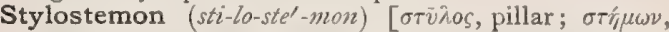
stamen]. An epigynous stamen.

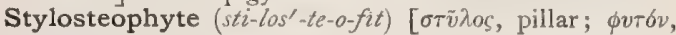
plant]. A style-shaped exostosis.

Stylostixis (sti-lo-stiks'-is). See Acupuncture.

Stylus $\left(s t i^{\prime}-l u s\right)$ [stilus, a pen]. A pointed instrument formerly used for writing on wax tablets. An instrument for writing on manifolding paper. In surgery, a sound.

Styma (sti'-mah). See Priapism.

Stymatosis (sti-mat-o'-sis) [oтṽ $\mu a$, stiffness]. A violent erection of the penis attended with hemorrhage.

Stypage (ste-pahzh') [Fr.]. The production of local anesthesia by an application made with a stype.

Stype (stēp, or $\left.s t i^{\prime}-p e\right)$ [Fr.; $\sigma \tau i \pi \eta$, tow]. A tampon or pledget, especially such as is used in producing local anesthesia.

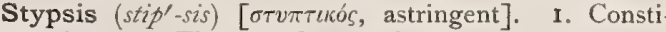
pation. 2. The use of a styptic.

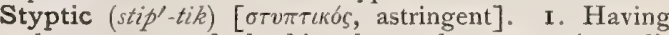
the property of checking hemorrhage. 2. A medicine or agent that causes vascular contraction of the blood-vessels. A hemostatic.

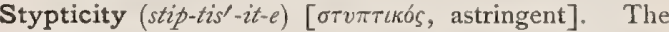
quality of being styptic.

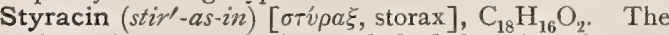
cinnamic ester of cinnamyl-alcohol. A substance present in storax. It crystallizes from hot alcohol in fine needles, melting at $44^{\circ} \mathrm{C}$, and is odorless and tasteless.

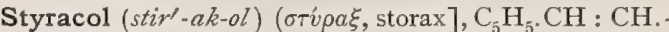
$\mathrm{COOC}_{6} \mathrm{H}_{4} \mathrm{OCH}_{3}$. The cinnamate of guaiacol, introduced as a tasteless substitute for guaiacol in gastrointestinal and genito-urinary catarrh. Dose gr. v. Unof.

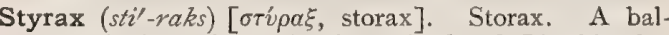
sam obtained from the inner bark of Liquidambar orientalis, or oriental sweet gum. It contains a volatile oil, styrol, several resins and cinnamic acid. It is stimulant, expectorant and antiseptic, acting like benzoin and tolu, and is used in bronchial affections and catarrh of the urinary passages. Externally it is an antiseptic and parasiticide. It is a constituent of Friar's balsam. Dose gr. $\mathrm{v}-\mathrm{xx}$.

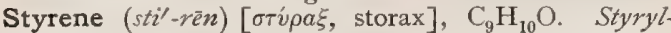
alcohol, Cinnamyl-alcohol; a substance obtained by saponifying styracin, its cinnamic ester, with potassium hydroxid. It crystallizes in shining needles, is sparingly soluble in water, possesses a hyacinth-like odor, melts at $33^{\circ} \mathrm{C}$., and distils at $250^{\circ} \mathrm{C}$.

Styrogallol (sti-ro-gall-ol). See Pigments, Conspectus of.

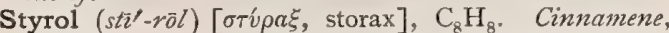
Phenylethylene. A colorless, strongly refractive liquid hydrocarbon, with an odor like that of benzine, and obtained by heating styracin with calcium hydrate. It boils at $\mathrm{r}_{44-1} 45^{\circ} \mathrm{C}$.; sp. gr. at $0^{\circ} \mathrm{C}$. is 0.925 .

Styrolene (sti'-ro-Ten). Same as Styrol, $q . v$.

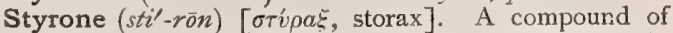
balsam of Peru and styrax. It occurs usually in the form of a brown, syrupy liquid, of a pleasantly aromatic odor, and a pungent, biting, persistent taste; it also crystallizes. It is antiseptic, deodorant, analgesic, and makes a pleasant deodorizer, in solution, used as a spray, likewise an agreeable mouth-wash, to neutralize tobacco and other odors, and is used as an antiseptic in dental practice. In from $I$ to 5 per cent. solutions it furnishes a strong antiseptic for surgical use, dissolved in olive-oil, or mixed with ointmentbases; it has also been recommended in the treatment 
of otorrhea. S. Method, a method of bleaching microscopic preparations of parasitic fungi by the use of styrone.

Styryl-alcohol (sti'-ril-al'-ko-hol). See Styrene.

Sub- [sub, under]. A Latin preposition. Used as a prefix it denotes under, beneath, ventrad, lower, or moderate in degree.

Subabdominal (sub-ab-dom'-in-al) [sub, under; $a b d o$ men, abdomen ]. Beneath the abdomen.

Subacetas $\left(s u b-a s^{\prime}-\epsilon t-a s\right)$. See Subacelate.

Subacetate $\left(s u b-a s^{\prime}-e t-\bar{a} t\right) \quad[s u b$, under; $a c c t u m$, vinegar]. A basic acetate.

Subacid $\left(s u b-a s^{\prime}-i d\right)$ [sub, under; acidum, acid] Moderately acid or sour.

Subacrid (sub-ak'-rid) [sub, under; acer, sharp]. Moderately acrid.

Subacromial $\left(s u b-a k-r o^{\prime}-m e-a l\right)$ [sub, under; acromial]. Lying below the acromion.

Subacuminate $\left(s u b-a k-u^{\prime}-m i n-\bar{a} t\right)[s u b$, under; acuminate]. Moderately acuminate.

Subacute $\left(s u b^{\prime}-a k-\bar{u} t\right)$ [sub, under; acutus, sharp]. Moderately acute or severe. Also, the stage of a disease when it is intermediate between an acute and a chronic form.

Subanal $\left(s u b-a^{\prime}-n a l\right)$ [sub, under; anus, anus]. Situated below the anus.

Subanconeal $\left(s u b-a n-k o-n e^{\prime}-a l\right)$ [sub, under; anconeus]. Beneath the anconeus muscle.

Subanconeus (sub-rn-ko-ne'-us). See Muscles, Table of

Subapical $\left(s u b-a^{\prime}-p i k-a l\right)$ [sub, under; apex, apex]. Beneath the apex.

Subaponeurotic (sub-ap-on-u-rot'-ik) [sub, under; aponeurosis]. Situated, or occurring beneath an aponeurosis.

Subaqueous $\left(s u b-a^{\prime}\right.$-kwe-us) [sub, under; aqua, water]. Living beneath the water.

Subarachnoid (sub-ar-ak'-noid) [sub, under; arachnoid]. That lying directly beneath the arachnoid membrane, as the subarachnoid space, subarachnoid fluid, etc. See Space.

Subarcuate $\left(s u b-a r^{\prime}-k u-\bar{a} t\right)$ [sub, under; arcus, an arc]. Slightly arcuate.

Subareolar $\left(s u b-a r^{\prime}-e^{\prime}-o-l a r\right)$ [sub, under; areola, areola]. Situated, or occurring beneath the mammary areola.

Subastragalar (szeb-as-trag'-al-ar) [sub, under; astragalus]. Under the astragalus. S. Amputation, a partial removal of the foot, in which only the astragalus is left.

Subastragaloid (sub-as-trag'-al-oid) [sub, under; astragalus, astragalus]. Occupying a position beneath the astragalus.

Subastringent (sub-as-trin'-jent) [sub, under; astringens, astringent]. Only slightly astringent.

Subaural (sub-aw'-ral) [sub, under; aiıra, ear]. Beneath the ear.

Subaxial (sub-aks'-e-al) [sub, under; axis, axis]. Lying below the axis.

Subaxillary $\left(s u b-a k s^{\prime}-i l-a-r e\right)$ [sub, under; axilla, axilla]. Situated below the axilla.

Subbasal $\left(s u b-b a^{\prime}-z a l\right)$ [sżb, under; $\left.\beta a ́ \sigma \iota s, b a s e\right]$. Situated near the base.

Subbrachial, Subbrachiate (sub-bra'-ke-al, sub-bra'. $\left.k_{\ell}-\bar{a} t\right)[s u b$, under; $\beta \rho a ́ \chi \imath o v, a r m]$. Under the pectoral muscles.

Subcalcareous (sub-kal-kal-re-us) [sub, under; $c a l x$, lime]. Somewhat calcareous.

Subcalcarine (sub-kal'-kar-in) [sub, under; calcar, the calcaneum]. Situated ventrad of the calcarine fissure of the brain.

Subcapsular (sub-kaph-su-lar) [sub, under; capsula, capsule]. Beneath the capsule.
Subcarbonas $\left(s u b-k a r^{\prime}-b o n-a s\right)$ [sub, under; carbo, charcoal]. See Subcarbonate.

Subcarbonate (sub-kar'-bon-ät) [sub, under; carbo, charcoal]. A neutral or basic carbonate.

Subcartilaginous (sub-kar-til-aj'-in-us) [sub, under; cartilago, cartilage]. I. Situated beneath cartilage. 2. Partly cartilaginous.

Subcaudal (sub-kaw'-dal) [sub, under; cauda, tail]. Situated under the tail.

Subcaudate (sub-kaw'-datt). Same as Subcaudal.

Subcecal (sub-se'-kal) [sub, under; cccum, cecum]. Lying below the cecum.

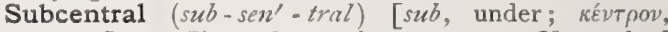
center]. I. Situated near the center. 2. Ventrad of the central fissure of the brain.

Subcerebellar (sub-ser-e-bel'-ar) [sub, under; cerebellum, cerebellum]. Situated beneath the cerebellum.

Subcerebral (sub-ser-e-bral) [sub, under: cerebrum, cerebrum]. Situated beneath the cerebrum.

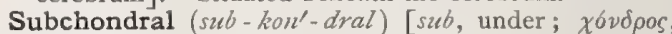
cartilage]. Lying beneath cartilage.

Subchordal (sub-kor'-dal) [sub, under; chorda, cord]. Beneath the notochord.

Subchorionic (sub-ko-re-on'-ik) [suh, under; xópıov, chorion]. Lying beneath the chorion.

Subchoroidal (sub-ko-roid'-al) [sub, under; $\chi 6$ puov, chorion; $\varepsilon i \delta o s$, like]. Situated or occurring under the choroid.

Subchronic (sub-kron'-ik) [sub, under; $\chi \rho \delta$ vos, time]. More nearly chronic than is indicated by the term subacute.

Subclavian (sub-kla'-ze-an) [sub, under; clavis, collarbone]. Situated under the collar-bone. S. Artery. See Arteries, Table of. S. Groove. See Groove. S. Triangle. See Triangles, Trble of.

Subclavicular (sub-kla-vik'-u-lar) [sub, under; clavis, collar-bone]. Pertaining to the subclavicular bone or the first rib.

Subclavius (sub-kla'-ve-us). See Muscles, Table of.

Subcollateral $\left(s u b-k o l-a t^{\prime}-e r-a l\right)$ [sub, under; con, together; lateralis, lateral]. Ventrad of the collateral fissure of the brain.

Subconchoidal (sub-kong-koi'-dal) [sul, under; $\kappa b \gamma \chi q$,

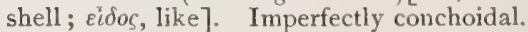

Subconical (sub-kon'-ik-al) [sub, under; көvєќ́s, conical]. Conoidal.

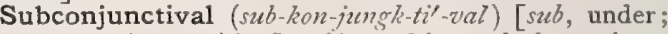
conjunctious, uniting]. Situated beneath the conjunctiva.

Subconsciousness (sub-kon'-shus-nes) [sub, under ; conscius, knowing]. Imperfect consciousness; that state in which mental processes take place without the mind being distinctly conscious of its own activity.

Subcoracoid (sub-kor'-ak-oid) [sub, under; кó $a \xi$, a crow; $\varepsilon^{i} \delta o s$, like]. Situated below the coracoid process.

Subcordate $\left(s u b-k o r^{\prime}-d \bar{a} t\right)$ [sub, under; cor, heart]. Having nearly the shape of a heart.

Subcordiform (sub-kor'-dif-orm) [sub, under; cor, heart]. See Subcordate.

Subcorneous (sub-kor-ne-us) [sub, under; corneus. horny]. Somewhat horny.

Subcortical (sub-kor'-tik-al) [sub, under; cortex, cortex]. Beneath the cortex.

Subcosta $\left(s u b-k o s^{\prime}-t a h\right)$ [sul, under; costa, rib]. The subcostal vein of the wing of some insects.

Subcostal (sub-kos'-tal) [sub, under; costa, rib]. Lying beneath a rib or the ribs.

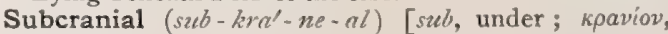
cranium]. Situated below the skull.

Subcrepitant (sub-krep'-it-ant) [sub, under ; crepitare, to make a crackling noise]. Applied to a sibilant rat- 
the, or to râles produced by the bubbling of air through a slightly viscous liquid, as the mucus of the bronchi

Subcrureus (sub-kmu-re'-us). See Muscles, Table of.

Subculture (sub-kul'-lür) [sub, under; cultura, culture]. In bacteriology, a part of a culture set aside for special treatment or observation.

Subcuneus (sub-ku-ne'-us) [sub, under; cuneus, a wedge]. An area of the occipital lobe ventrad of the cuneus, and caudad of the collateral fissure.

subcutaneous (sub-ku-ta'-ne-us) [sub, under; cutis, the skin]. Under the skin. Hypodermatic

Subcuticular (sub-ku-tik'-u-lar). See Subepidermal.

Subcutis $\left(s u b-k u^{\prime}-t i s\right)$ [sub, under; cutis, skin]. The deeper portion or layer of the true skin.

Subdelirium (sub-de-lir'-e-um) [sub, under; delirium, delirium ]. A muttering delirium, with lethargic features.

Subdental (sub-den'-tal) [sub, under; dens, a tooth] Situated beneath the teeth.

Subdermal (sub-der'-mal). See Subcutaneous.

Subdiaphragmatic $\left(s u b-d i-a f-r a y-m a t^{\prime}-i k\right)[s u b$, under; dıá $\rho а \gamma \mu a$, diaphragm]. Under the diaphragm.

Subdivided (sub'-div-i-ded) [sub, under; dividere, to divide]. Re-divided; making secondary or smaller divisions.

Subdolichocephalic (sub-dol-ik-o-sef-al'-ik) [sub,

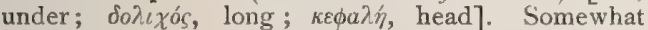
dolichocephalic; having the cephalic index above $75^{\circ}$ and below $77^{\circ}$

Subdorsal (sub-dorl-sal) [sub, under; dorsum, back]. In biology, situated on the side of the dorsal surface of the body.

Subdural (sub-du'-ral) [sub, under; dura, dura]. Beneath the dura. S. Space, the space between the dura and the arachnoid.

Subectodermal (sub-ek-to-der'-mal) [sub, under; غ́ктos, outside; dé $\rho \mu a$, skin $]$. Beneath the ectoderm.

Subectopic (sub-ek-top'-ik) [sub, under; غ̇ктолos, displaced]. Almost ectopic; applied to gestation in which the ovum is implanted in the lower zone of the inner surface of the uterus.

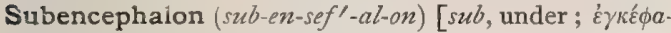
$20 v$, brain]. The oblongata, pons and corpora quadrigemina taken together.

Subendocardial (sub-en-do-kar'-de-al) [sub, under;

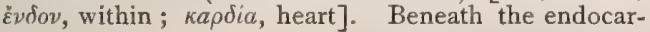
dium.

Subendothelial $\left(s u b-e n-d o-t h e^{\prime}-l e-a l\right)$ [sub, under; $\varepsilon ้ \nu \delta o \nu$, within; $\theta \eta \lambda \eta$, nipple]. Situated or occurring under an endothelial structure.

Subepidermal, Subepidermatic, Subepidermic (sub$e p$-id-er'-mal, sub-ep-id-er-mat'-ik, sub-ep-id'-er-mik) [sub, under; $\varepsilon \pi i$, upon; dép $\mu a$, skin]. Situated beneath the epidermis.

Subepithelial $\left(s u b-e p-i t h-e^{\prime}-l e-a l\right)$ [sub, under; $\dot{\varepsilon} \pi \dot{ }$, upon; $\theta \eta \lambda \dot{\eta}$, nipple]. Situated, or occurring, under an epithelial surface.

Suber (su'-ber) [L., gen. Suberis]. Cork.

Subereous $\left(s u-b e^{\prime}-r e-u s\right)$ [suber, cork]. In biology, corky.

Suberic Acid (su-ber'-ik). See Acid.

Suberiferous (su-ber-if'-er-us) [suber, cork; ferre, to bear]. Bearing suberin.

Suberification (su-ber-if-ik-a'-shun) [suber, cork; facere, to make]. Same as Suberization.

Suberin (su'-ber-in) [suber, cork]. I. Pulverized cork ; used as a dressing for wounds. 2. In biology, the impure cellulose forming the cellular tissue of cork. Its reactions are essentially those of cutin. It forms yellowish drops with potassa.

Suberization (su-ber-iz-a'shun) [suber, cork]. In biology, the change of a plant-tissue into suberin or cork. 90
Suberone (su'-ber-ön) [suber, cork], $\mathrm{C}_{7} \mathrm{H}_{12} \mathrm{O}$. A liquid obtained from cork by boiling it at $180^{\circ} \mathrm{C}$. Its odor resembles that of peppermint.

Suberose (sub'-er-oz) [sub, under; erodere, to gnaw, to consume]. In biology, slightly gnawed on the margin.

Subesophageal (sub-e-so-faj'-e-al) [sub, under;

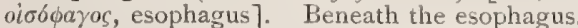

Subfalcial (sub-fal'-se-al) [sub, under; falx, falx]. At the free edge of the falx cerebri.

Subfascial (sub-fash'-e-al) [sub, under; fascia, fascia]. Beneath the fascia.

Subfebrile (sub-febl-ril) [sub, under; febris, fever]. Slightly febrile.

Subfemoralis (sub-fem-o-ra'-lis). Same as Subcrureus

Subfissure (sub-fish'-iur) [sub, under; fissura, fissure] A fissure of the brain which is concealed by a supergyre, and invisible until the lips of the superfissure are divaricated.

Subflavous (sub-fia'-vus) [sub, under; favus, yellow]. Somewhat yellow. S. Ligament, the ligament of yellowish, elastic material, found between the laminæ of adjacent vertebræ.

Subfoliar $\left(s u b-f o^{\prime}-l e-a r\right)$ [sub, under; folium, leaf]. Having the character of a subfolium.

Subfolium (sub-fol-le-um) [sub, under; folizm, leaf ]. A leaflet going to make up a part of any folium of the cerebellum.

Subfornical (sub-forl-nik-al) [sub, under; fornix, fornix ]. Beneath the fornix of the brain.

Subfrontal (sub-frun'-tal) [sub, under; frons, forehead]. Applied to a fissure and gyre (Broca's) in the ventral region of the frontal lobe of the brain.

Subgelatinous (sub-jel-at'-in-us) [sub, under; gelatina, gelatin]. Partly gelatinous.

Subgenital $\left.\left(s u b-j e n^{\prime}-i t-a l\right)\right][s u b$, under; genitalis, genita1]. Situated under the genital organs. S. Vestibule (porticus subgenitalis). See Syndemnium.

Subgerminal (sub-jer'-min-al) [sub, under; germen, a germ]. Situated beneath a germinal structure.

Subglabrous $\left.\left(s u b-g l a^{\prime}-b r u s\right)\right][s u b$, under; glaber, smooth]. In biology, almost devoid of hairs or other like covering.

Subglenoid (sub-gle'-noid). See Infraglenoid.

Subglossitis (sub-glos-i'-tis) [sub, under; $\gamma \lambda \hat{\omega} \sigma \sigma a$, tongue; $\iota \tau \iota s$, inflammation]. Inflammation of the tissues under the tongue. See Ranula.

Subglottic (sub-glot'-ik). See Infraglottic.

Subgrundation (sub-grum-da'-shun) [Fr., subgrondation]. The intrusion of one part of a cranial bone beneath another.

Subgular (sub-gu'-lar) [sub, under; gula, throat]. Same as Subjugular.

Subgyre (sub-jī $\left.\gamma^{\prime}\right)$ [sub, under;. $\gamma \tilde{v} \rho o s$, gyrus]. A gyre that is encroached upon or covered by another or supergyre (covering-gyre).

Subhepatic (sub-he-pat'-ik) [sub, under; $\eta \pi \alpha \rho$, liver]. Situated beneath or on the under surface of the liver.

Subhumeral (sub-hu'-mer-al) [sub, under; humerus, humerus]. Below the humerus.

Subhymenial (sub-hi-me'-ne-al) [sub, under; hymenium, hymenium]. Below the hymenium.

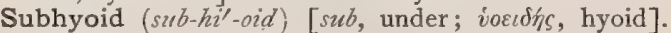
Beneath the hyoid bone.

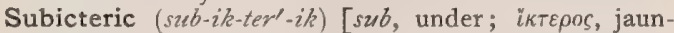
dice]. Moderately or slightly icteric.

Subiculum $\left(s u b-i k^{\prime}-u-l u m\right)$ [subex, a layer]. I. In biology, the thickened part of the leaf or stem of a host bearing the mycelium of a parasitic fungus. 2 . The uncinate gyrus.

Subiliac $\left(s u b-i l^{\prime}-e-a k\right)$ [sub, under; ilium, ilium]. Pertaining to the subilium. 
Subilium (sub-il'-e-um) [sub, under; ilium, ilium]. The lowest portion of the ilium.

Subimaginal (szb-im-aj'-in-al) [sub, under; imago, imago]. Having the character of a subimago.

Subimago (sub-im-á-go) [sub, under; imago, image: pl., Subimagos or Subimagine's]. See Psendimago.

Subinflammation (sub-in-fam-a'-shun) [sub, under; inflammatio, inflammation]. A slight degree of inflammation.

Subinflammatory $\left(s u b-i n-f a m^{\prime}-a t-o r-e\right)$ [sub; under; inflammatio, a burning]. Of the nature of a slight inflammation.

Subintegumentary ( $\left.s u b-i n-t e g-u-m e n^{\prime}-t a r-e\right)[s u b$, under; integumentum, integument]. Situated beneath the integument.

Subintestinal (sub-in-tes'-tin-al) [sub, under; intestinum, intestine]. Situated beneath the intestines.

Subintrant $(s u b$-in'-trant) [subinirare, to enter secretly]. A qualification applied to malarial fevers in which a new paroxysm begins before the termination of the preceding one.

Subinvolution (sub-in-vo-hu'-shun) [sub, under; involutio, a rolling up]. Imperfect involution. S., Menstrual, subinvolution of the mucous membrane of the uterus after menstruation. S. of the Uterus, the incomplete contraction of the womb after delivery.

Subjacent $\left(s u b-j a^{\prime}-s e n t\right)$ [sub, under; jacere, to lie]. Underlying; lying beneath.

Subject (sub $\left.b^{\prime}-j e k t\right)$ [subjicere, to throw or bring under]. I. An individual that serves for purposes of experiment or study, or that is under observation or treatment. 2 In anatomy, a body for dissection.

Subjective (sub-jek'-tiv) [sub, under; jacere, to throw]. I. Pertaining to the individual himself. 2. Of symptoms, experienced by the patient himself, and not amenable to physical exploration. S. Sensations, those not caused by external stimuli.

Subjectivism (sub-jek'-tiv-izm). See Passivism.

Subjugal (sub-ju'-gal) [sub, under; jugum, yoke]. Below the malar bone.

Sublanceolate (sub-lan'-se-o-lät) [sub, under; lanceo$l a$, a little lance]. Somewhat tapering and pointed.

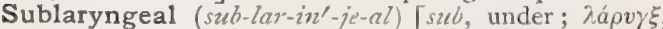
the larynx]. Situated below the larynx.

Sublatio, Sublation (sub-la'-she-o, sub-la'-shun) [sublatio, removal]. I. Removal; ablation. 2. Depression, or couching, of the lens in cataract. S., Retinal, detachment of the retina.

Subligamen (sub-li-ga'-men) [sub, under; ligare, to bind ]. A form of truss used in hernia.

Sublimate (sub'-lim-āt) [sublimare, to lift up high]. I. A substance which, under the action of heat, passes at once from a solid to a gaseous state, and again condenses in a solid form without intermediate liquefaction. 2. The product of sublimation. S., Corrosive, mercuric chlorid. See Hydrargyrum.

Sublimation (sub-lim- $a^{\prime}$-shun) [sublimare, to lift up high]. The vaporization and condensation of a volatile solid. The distilled product is called a sublimate.

Sublime (sub-lim $)$ [sublimare, to lift up high]. I. To subject to sublimation. 2. To undergo sublimation.

Sublimed (sub-limd") [sublimare, to lift up high]. Distilled, prepared, or purified by sublimation.

Subliminal (sub-lim'-in-al) [sub, under; limen, threshold 1. Below the threshold of consciousness, or of sensation. See Threshold.

Sublimis $\left(s u b^{\prime}-l i m-i s\right)$ [L.]. Elevated; superficial, a qualification applied to certain muscles.

Sublingua (sub-ling'-gwah) [sub, under; lingua, the tongue : pl., Sublingue ]. In biology, a process of the mucous membrane, below the tongue of many Prosimi and Chiroptera.
Sublingual (sub-ling'-gwal) [sub̆, beneath; lingua, tongue]. Lying beneath the tongue. S. Artery. See Arteries, Table of. S. Fossa. See Fossa. S. Gland. See Glands and Saliva. S. Triangle. See Triangles, Table of.

Sublinguitis (sub-ling-gwi'-tis) [sub, under; lingua, tongue; $\iota T L \zeta$, inflammation]. Inflammation of the sublingual gland.

Sublobular (sub-lob'-u-lar) [sub, under; lobulus, a lobule]. Situated or occurring beneath a lobule. $\mathrm{S}$. Veins, the radicles of the hepatic veins, situated at the base of a cluster of lobules.

Sublumbar (sub-lum'-bar) [sub, under; lumbus, loin]. Situated under the loins.

Subluxation (sub-luks-a'-shun) [sub, under; luxatio, luxation]. Incomplete luxation.

Submalleolar (sub-mal-e'-o-lar) [sub, under; malleolus, malleolus]. Under the malleoli. S. Amputation, removal of the foot at the ankle-joint.

Submammary (sub-mam'-ar-e) [sub, under; mamma, breast]. Situated beneath the breast.

Submarginal (sub-mar'-jin-al) [sub, under; margo, margin]. Situated near the border or margin.

Submarginate (sub-mar'-jin-ät) [sub, under; margo, margin]. Bordered with a mark which is slightly separated from the edge.

Submaxillary (sub-maks'-il-a-re) [sub, under; maxilla, maxilla]. Lying beneath the lower maxilla. S. Fossa. See Fossa. S. Gland. See Glands and Saliva. S. Triangle. See Triangle.

Submedial (sub-me'-de-al) [sub, under; medius, middle]. Situated beneath or near the middle.

Submembranous (sub-mem'-bra-nus) [sub, under; membrana, a membrane]. Somewhat membranous.

Submental (sub-men'-tal) [sub, under; mentum, chin]. Situated under the chin.

Submentum (sub-men'-tum) [sub, under; mentum, the chin: pl., Submenta]. In biology, the basal part of the labium of an insect, immediately in front of and joining the gula. Also applied to the basal part of the second maxilla.

Submerge (sub-merj') [sub, under; mergere, to dip]. To immerse. To place under the surface of a liquid.

Submersion (sub-mer'-shun) [sub, under; mergere, to dip]. The condition of being under the surface of a liquid.

Submetallic $\left(s u b-m e t-a l^{\prime}-i k\right)$ [sub, under; metallum, metal]. To a certain extent metallic.

Submissio $\left(s u b-m i s^{\prime}-\dot{e}-0\right)$ [L.]. A lowering. S. cordis, the systole of the heart.

Submucosa (sub-mu-ko'-sah) [sub, under; mucosus, mucous]. The layer of fibrous connective tissue that attaches the mucous membrane to the subjacent parts.

Submucous (sub-mu'-kus) [sub, under; mucosus, mucous]. Situated beneath the mucous membrane.

Submuscular (sub-mus'-ku-lar) [sub, under; muscular]. Beneath a muscle.

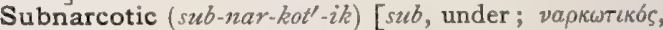
narcotic]. Moderately narcotic.

Subnasal (sub-na'-zal) [sub, under; nasus, nose]. Situated beneath the nose. S. Point. See Craniometric Points.

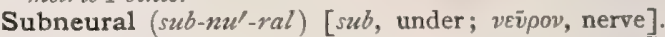
Situated under the neuron or under a nerve. S. Gland, the homologue in the amphioxus of the hypophysis of higher vertebrates.

Subnitrate $\left(s u b-n i^{\prime}-t r a \bar{t} t\right)$ [sub, under; nitrum, niter]. A basic nitrate.

Subnodal $\left(s u b-n o^{\prime}-d a l\right)$ [sub, under; nodus, node]. Behind or under a node.

Subnormal (sub-nor'-mal) [sub, under; norma, rule]. Below the normal. 
Subnucleus (sub-nu'-kle-us) [sub, under; nucleus, nucleus]. Any one of the subdivisions into which a group of nerve-cells is divided by the passage through it of intersecting nerve-bundles. [Spitzka.]

Subnude $\left(s u b-n u d^{\prime}\right)$ [sub, under; nudus, naked]. In biology, almost naked or bare of leaves.

Suboccipital (sub-ok-sip'-it-al) [sub, under; occiput, occiput]. Situated beneath the occiput. S. Triangle. See Triangles, Table of.

Suboccipito-bregmatic (sub-ok-sip'-it-o-breg-mat'-ik) [sub, under; occiput, occiput; $\beta \rho \varepsilon \gamma \mu a$, bregma]. Situated in the region extending from the bregma to beneath the occiput.

Subocellate (sub-os'-el-āt) [sub, under; ocellus, eye]. In biology, applied to the spots on the wings of butterflies which resemble ocelli.

Subocular (sub-ok'-u-lar) [sub, under; oculus, eye]. Beneath the eye.

Subopercular (sub-o-per'-ku-lar) [sub, under; operculum, lid]. Pertaining to a suboperculum.

Suboperculum (sub-o-per'-ku-lum) [sub, under; operculum, lid]. A gyrus of the brain between the presylvian and subsylvian fissures; the orbital operculum.

Suboptic $\left(s u b-o p^{\prime}-t i k\right)$ [sub, under; ó $\pi \tau \iota \kappa o ́ s$, from ó $\pi \tilde{a} \nu$, to see]. Same as Suborbital.

Suboral $\left(s u b-o^{\prime}-r a l\right)$ [sub, under; os, oris, mouth]. Beneath the mouth.

Suborbicular, Suborbiculate (sub-or-bik'-u-lar, sub-or$b i k^{\prime}-u$-latt) [sub, under; orbicularis, orbicular]. A]most orbicular.

Suborbital (sub-or'-bit-al) [sub, under; orbita, orbit] Beneath the orbit. Synonym of Infraorbital.

Subordination (sub-or-din- $\left.a^{\prime}-\operatorname{shun}\right)$ [sub, under; ordo, order]. The condition of being under subjection or control; the condition of organs that depend upon or are controlled by other organs.

Suboxid $\left(s u b-o k s^{\prime}-i d\right)$ [sub, under; $b \xi \xi \xi$, acid]. An oxid containing less oxygen than a protoxid.

Subpallial (sub-pal'-e-al) [sub, under; pallium, a mantle]. Beneath the pallium.

Subparalytic (sub-par-al-it'-ik) [sub, under; $\pi a \rho a ́ \lambda$. $v \sigma \iota$, paralysis]. Slightly paralytic

Subparietal (sub-par-i'-et-al) [sub, under; paries, wall]. Situated beneath the parietal bone, convolution, or fissure.

Subpatellar (sub-pat-el'-ar) [sub, under; patella, knee-cap]. Situated beneath or below the patella.

Subpectinate $\left(s u b-p e k^{\prime}-t i n-\bar{a} t\right)[s u b$, under; pecten, a comb]. Imperfectly pectinate.

Subpectoral $\left(s u b-p e k^{\prime}-t o r-a I\right)$ [sub, under; pectus, chest]. Situated beneath the chest.

Subpeduncular (sub-pe-dung -ku-lar) [sub, under; pedunculus, peduncle]. Situated beneath a peduncle.

Subpedunculate $\left(s u b-p e-d u n g^{\prime}-k u-l \vec{a} t\right)[s u b$, under; pedunculus, peduncle]. Slightly pedunculated.

Subpericardial (sub-per-ik-ar'-de-al) [sub, under; $\pi \varepsilon \rho i$, around; $\kappa a \rho \delta i a$, heart]. Situated beneath the pericardium.

Subperiosteal (sub-per-e-os'-te-al) [sub, under; $\pi \varepsilon \rho i$, around; $\delta \sigma \tau \varepsilon o \nu$, bone]. Situated beneath the periosteum. S. Amputation, the removal of a limb in which the immediate covering of the cut end of the bone consists of periosteum dissected up in the form of flaps before the section is made.

Subperitoneal (sub-per-it-o-ne'-al) [sub, under; $\pi \varepsilon \rho \iota \tau b v a c o v$, peritoneum]. Situated beneath the peritoneum.

Subpetiolar (sub-pet'-e-o-lar) [sub, under; petiolus, a petiole]. Beneath the petiole.

Subpetiolate (sub-pet'-e-o-lāt) [sub, under; petiolus, a petiole]. Having a very short petiole.
Subpharyngeal (sub-fur-in'-je-al) [sub, under; $\phi a ́ \rho v \gamma \xi$, pharynx]. Beneath the pharynx.

Subphrenic (sub-fren'-ik). Synonym of Subdiaphragmatic.

Subpial (sub-pi'-al) [sub, under; pia, pia]. Situated or occurring beneath the pia.

Subpilose (sub-pi'-lōz) [sub, under; pilus, hair]. Thinly pilose.

Subpleural (sub-plu'-ral) [sub, under; $\pi \lambda \varepsilon v \rho a ́$, side]. Situated beneath the pleura.

Subplexal (sub-pleles'-al) [sub, under; plexus, plexus]. Lying under a plexus of the brain.

Subpontile (sub-pon'-til) [sub, under; pons, pons]. Situated or occurring beneath the pons.

Subpreputial (sub-pre-pu'-shal) [sub, under; praputium, prepuce]. Beneath the prepuce.

Subprostatic (sub-pros-tat'-ik) [sub, under; $\pi \rho \circ \sigma \tau^{\prime} \operatorname{s}^{\prime} \eta \zeta$, prostate]. Beneath the prostate gland.

Subpubescent $\left(s u b-p u-b e s^{\prime}-e n t\right)[s u b$, under; pubes, downy]. Slightly pubescent.

Subpubic $\left(s u b-p u^{\prime}-b i k\right)$ [sub, under; pubes, pubis]. Situated beneath the pubic arch or symphysis. $\mathbf{S}$. Ligament. See Ligament.

Subpulmonary (sub-pul'-mo-na-re) [sub, under; pulmo, the lung]. Ventrad of the lungs.

Subpyramidal (sub-pir-ant'-id-al) [sub, under; pyramis, pyramid]. Approximately pyramidal.

Subradular (sub-rad'-u-lar) [sub, under; radula, a scraper]. Situated beneath the radula.

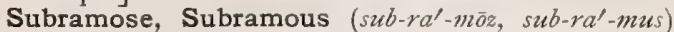
[sub, under; ramus, branch]. Slightly ramose.

Subreniform (sub-ren'-if-orm) [sub, under; ren, kidney; forma, form]. Shaped somewhat like a kidney.

Subresin $\left(s u b-r e z^{\prime}-i n\right)$ [sub, under; resina, resin]. That ingredient of a resin which is soluble in boiling alcohol, but is precipitated on cooling.

Subretinal (sub-ret'-in-al) [sub, under; retina, retina]. Situated beneath the retina.

Subsacral (sub-sa'-kral) [sub, under; sacrum, sacrum]. Situated or occurring ventrad of the sacrum.

Subsalt (sub'-sazult). Synonym of Salt, Basic.

Subscapular (sub-skap'-u-lar) [sub, under; scapula, the shoulder-blade]. Under the shoulder-blade. S. Artery. See Arteries, Table of. S. Nerve. See Nerves, Table of.

Subscapularis (sub-skap-u-la'-ris). See Muscles, Table of.

Subsclerotic (sub-skle-rot'-ik) [sub, under; ' $\sigma \kappa \lambda \eta \rho o ́ s$, hard]. Beneath the sclerotic.

Subscriptio (sub-skrip'-she-o) [subscribere, to write beneath]. That part of a prescription which contains the directions to the pharmacist, indicating how the ingredients are to be mixed and prepared.

Subserous (sub-se'-rus) [sub, under; serosus, serous]. Lying beneath a serous membrane.

Subsessile (sub-ses'-il) [sub, under; sessilis, sessile]. Not quite sessile.

Subsidence (sub'-sid-ens, or sub-si'-dens) [sub, under; sedere, to sit]. The gradual cessation and disappearance of an attack of disease.

Subsigmoid (sub-sig'-moid) [sub, under; $\sigma^{\prime} \gamma \mu \alpha$, sigma; Eiঠos, like]. Under the sigmoid cavity or flexure. S. Fossa, a fossa bounded in the median line by the attached mesentery of the sigmoid flexure, and above by the limit of the attachment of the mesentery of the descending colon. It may be seen by lifting the sigmoid flexure of the large intestine, and varies much in size in different individuals.

Subsistence (sub-sis'-tens) [sub, under; sistere, to stand]. That which nourishes or gives support. Food. 
Subsoil (sub'-soil) [sub, under; ME., soile, soil]. The under-soil. S. Water, water which has penetrated the soil, and is found immediately above the first impervious stratum.

Subspinous (sub-spi'-nus) [sub, under; spina, spine]. I. Situated beneath or ventrad of the spinal column. 2. Beneath a spine

Subspiral (sub-spi'-ral) [sub, under; spira, a coil]. Somewhat spiral.

Subsplenial (sub-sple'-ne-al) [sub, under; $\sigma \pi \lambda \eta v i o v$, a bandage]. Beneath the splenium.

Substage $\left(s u b^{\prime}-s t a \bar{j} j\right)$ [sub, under; ME., stage, a stage]. The arrangement beneath the stage of a microscope for the diaphragms, condenser, illuminator, and other accessories.

Substance (sub'-stans) [substantia, substance]. I. The material of which anything is composed. 2. A tissue. See Substantia. S., Adamantine. Synonym of Enomcl. S., Alible, the portion of the chyme which is utilized for nourishing the body. S., Alimentary, an article of food. S., Basis, the intercellular or ground substance. S., Cell, cell-protoplasm. S., Central Gelatinous. Synonym of Substantia gelatinosa. S., Contractile: 1 . Living protoplasm which has the property of contracting. 2. The contractile portion of a muscle-fiber. S., Cortical, the peripheral portion of an organ, situated just beneath the capsule. S., Fibrinoplastic. Synonym of Paraglobulin. S., Gelatinous. See Substantiu gelatinosa. S., Germinal. See Germ-plasma. S., Ground, the homogeneous matrix or intercellular substance of a tissue in which the cellular elements and fibers are embedded. S., Hyaline. Synonym of Cytoblastema. S., Hyaloid. Synonym of Vitreous Humor. S., Intercellular. See S., Ground. S., Interstitial: I. The connective tissue of an organ. 2. Achromatin. S., Intertubular. the matrix of dentine in which the dentinal canals are placed. S., Intervertebral, the intervertebral cartilages. S., Living, protoplasm. S., Medullary: I. The part of an organ constituting its central in contradistinction to its peripheral or cortical portion. 2. The tissue forming the medulla, as in bone. S., Nuclear: I. See Heredity, 2. Chromatin ; mitome. S., Parietal, the matrix of cartilage. S., Proteic. Synonym of Proteid. S., Reticular. Synonym of Formation, Reticular. S. of Schwann, White, the medullary sheath of a nerve-fiber. S., Supporting, a supporting tissue, as the neuroglia and connective tissue.

Substantia (sub-stan'-she-ah) [L.]. Substance. S. adamantina dentium, the enamel of the teeth. $\mathbf{S}$. cinerea, the gray matter of the nervous system. S. ferruginea. Synonym of Locus caruleus. S. filamentosa dentium, a name given by Malpighi to the enamel of the teeth. S. fusca. See Locus niger. S. gelatinosa rolandi, a jelly-like substance found in the spinal cord near the tip of the posterior horn. S. grisea, the gray matter of the spinal cord. $\mathbf{S}$. hyalina, Leydig's term for the inter-reticular portion of protoplasm. $\mathbf{S}$. intermedia, the portion of the cerebellar substance situated between the cortical and the central gray matter. S. medullaris, the medullary substance of the kidney; also, of a hair. S. nigra. See Intercalatum. S. opaca, Leydig's term for the reticulum of protoplasm. S. ossea dentium, a name given by Malpighi to dentine. S. parenchymatosa, parenchyma. S. perforata. See Space, Perforated. S. primaria, the medullary portion of the central nervous system. S. propria, the true or most important tissue of an organ. S. reticularis. Synonym of Formation, Reticular. S. rolandi. Synonym of $S$. gelatinosa rolandi. S. rubra (lienis), the splenic pulp. S. sœmmerringi. Synonym of Locus niger. S. striata. Synonym of Enamel. S. vasculosa, the pulp of the spleen.

Substantive Coloring-matter. See Pigments, Colors, and Dye-stuffs.

Substernal (sub-ster'-nal) [sub, under; orépvov, breastbone]. Situated or occurring beneath the sternum. S. Tenderness, a tenderness to pressure in the lower portion of the sternum, sometimes thought to be an evidence of constitutional syphilis.

Substitution (sub-stit-u'-shun) [sub, under; statuere, to place]. The replacement of one thing by another. $a$. In chemistry, the replacing of one or more elements or radicles in a compound by other elements or radicles. Substitution is the principal method employed in examining the chemic structure of organic bodies. It is also called metalepsy. $b$. In medicine, the action of the unaffected hemisphere of the brain in taking up the function of the diseased opposite hemisphere. In general, the vicarious action of organs. In pharmacy, the supplying of another drug or compound instead of the one ordered or called for.

Substratum (sub-stra'-tum ) [sub, under; stratum, a layer]. An under layer or stratum.

Substriate $\left(s u b-s t r i^{\prime}-\bar{a} t\right)$ [sub, under; stria, stria]. Having imperfect striæ.

Subsulphate (sub-sul'-fät) [sub, under; sulphur, sulphur]. A basic sulphate. S. of Iron. See Salt, Monsel's.

Subsultus (sub-sul'-tus) [sub, under; saltire, to leap]. Any jerking or twitching. $\mathbf{S}$. tendinum, involuntary twitching of the muscles, especially of the hands and feet, seen in low fevers.

Subsynovial (sub-si-no'-ve-al) [sub, under; synovia, synovia]. Situated within a synovial sac.

Subtegmen (sub-teg'-men) [subtexere, to weave under]. Weft. S. fornicis, in the fornix, the layer of nervefibers situated beneath the superficial longitudinal bundles.

Subtegumental (sub-teg-u-men'-tal) [sub, under; tegumentum, a cover]. Subcutaneous.

Subtemporal (sub-tem'-por-al) [sub, under; tempus, temple]. Situated beneath the temporal bone or muscle or below the temple.

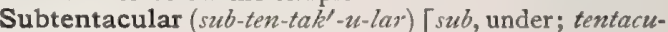
lum, a tentacle]. Beneath the tentacles of a crinoid.

Subterranean, Subterraneous (sub-ter-a'-ne-an, sub. ter-a'-ne-us) [sub, under; terra, earth]. Situated or growing beneath the surface of the earth.

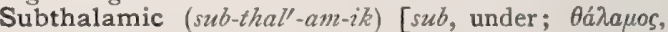
thalamus]. Situated beneath the optic thalamus.

Subthoracic $\left(s u b-t h o-r a s^{\prime}-i k\right)$ [sub, under; $\theta \omega \rho \alpha \xi$, thorax ]. Situated below the thorax.

Subtrochanteric (sub-tro-kan-ter'-ik) [sub, under;

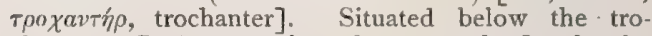
chanter. S. Amputation, the removal of a leg by amputation just below the trochanters.

Subtrochlear (sub-trok'-le-ar) [sub, under; $\tau \rho o \chi i \lambda i a$, pulley]. Beneath the trochlea.

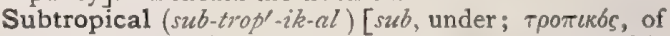
the solstice]. Pertaining to regions almost tropical in climate.

Sububeres $\left(s u b-u^{\prime}-b e r-a z\right)$ [sub, under; ubera, the breasts]. Children at the breast. Suckling children.

Subulate $\left(s u b^{\prime}-u\right.$-lät $)$ [subula, an awl]. In biology, awl-shaped.

Subuliform (sub'-u-lif-orm). Synonym of Subulate.

Subumbrella (sub-um-brel'-ah) [sub, under; umbra, shade]. In biology, the concave inner surface of the umbrella in Meduse.

Subungual, Subungial (sub-ung'-grwal, sub-ung'-ge-al) [sub, under; unguis, nail]. Situated beneath the nail. 
Subvaginal $\left(s u b-v a j^{\prime}-i n-a l\right)$. Synonym of Infravaginal.

Subvertebral (sub-ver'-te-bral) [sub, under; vertebra, vertebra]. Placed beneath a vertebra.

Subvirile $\left(s u b-v \bar{\imath} r^{\prime}-i l\right)$ [sub, under; viritis, virile]. Deficient in virility.

Subvola (sub-vo'-lah) [sub, under; vola, the palm of the hand]. I. The space between the second and fifth fingers. 2. See Hypothenar.

Subvolution $\left(s u b-v o-l u^{\prime}-s h u n\right)$ [sub, under; volvere, to roll]. A method of treatment recommended by Boerne Bettmann for pterygium. The pterygium is gathered up by the two branches of a fine forceps serrated at the extremities. A knife is passed beneath it close to the cornea and the triangular membrane is dissected off toward the apex. A suture, with a needle at either extremity, is passed through the apex. Both needles are introduced from above downward, thus leaving a loop of thread on the outer surface. The needles are now passed through the base from below outward, the points of puncture being the ends of parallel lines drawn from the punctures in the apex and just far enough back so that when the flap is turned upon itself beneath the base the roll will correspond with the corneo-scleral margin. The two extremities of the suture are now firmly tied.

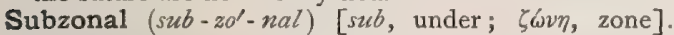
Situated within the zona pellucida.

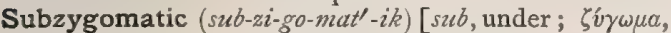
zygoma]. Situated below the zygoma.

Succedaneum (suk-se-da'-ne-um) [succedere, to take the place of]. A medicine that may be substituted for another. S., Caput. See Caput.

Succenturiate $\left(s u k-s e n-t u^{\prime}-r e-\bar{a} t\right)$ [succenturiare, to receive as a substitute]. Accessory. S. Placenta. See Placenta.

Succi $\left(s u k^{\prime}-i\right)[$ L.]. Genitive and plural of Succus, $q . v$.

Succiferous (suk-sif'-er-us) [succus, juice; ferre, to bear]. Producing sap.

Succinamic Acid (suk-sin-am'-ik) [succinum, amber], $\mathrm{C}_{4} \mathrm{H}_{7} \mathrm{NO}_{3}$. A crystalline monobasic acid, of pleasant acid taste.

Succinamid (suk-sin'-am-id) [succinum, amber; amid], $\mathrm{C}_{4} \mathrm{H}_{8} \mathrm{~N}_{2} \mathrm{O}_{2^{\circ}}$ A substance produced by shaking succinic ester with aqueous ammonia. It is a white powder, insoluble in water and in alcohol ; it crystallizes from hot water in needles.

Succinate (suk'-sin-āt) [succinum, amber]. A salt of succinic acid. S. of Ammonium, a salt sometimes prescribed in delirium tremens.

Succinctum $\left(\operatorname{suk}-\sin g k^{\prime}-t u m\right)$. Synonym of Diaphragm.

Succinic Acid (suk-sin'-ik). See Acid.

Succinimid (suk-sin'-im-id) [succinum, amber], $\mathrm{C}_{4} \mathrm{H}_{5} \mathrm{NO}_{2}$. A crystalline substance produced by gentle ignition of the anhydrid in a current of dry ammonia. It crystallizes from acetone in rhombic octahedra without any water; when anhydrous, it melts at $126^{\circ} \mathrm{C}$. and boils at $288^{\circ} \mathrm{C}$.

Succinin (suk'-sin-in) [succinum, amber], $\mathrm{C}_{7} \mathrm{H}_{10} \mathrm{O}_{2}$. 1. A dark-brown substance produced when equal parts of succinic acid and glycerin are heated together to about $230^{\circ} \mathrm{C}$. 2. The insoluble portion of amber.

Succinone $\left(s u k^{\prime}-\sin -\bar{o} h\right)$ [succinum, amber]. An oily liquid obtained in the dry distillation of calcium succinate. It has a decided empyreumatic odor.

Succinum (suk-si'-num) [L,: gen, Succini]. Amber. A fossil resin found in the alluvial deposits of Central Europe. It is thought to be derived from an extinct species of pine. Its properties are due to a volatile oil which may be obtained by destructive distillation. Succini, Ol., is an antispasmodic. It has been used in hysteria, etc. Externally, it is employed as a rubefacient in rheumatic affections and in bronchitis. Dose gtt. $\mathrm{v}-\mathrm{x}$

Succise $\left(s u k-s i z^{\prime}\right)$ [succidere, to cut off ]. In biology, appearing as if cut off at the lower end.

Succivorous (suk-siv'-o-rus) [succus, juice; vorare, to devour]. In biology, feeding upon plant-juices.

Succuba (suk'-u-bah) [sub, under; cumbers to lie: pl., Succubce]. A female demon formerly believed to consort with men in their sleep. Cf. Incubus.

Succubate $\left(s u k^{\prime}-u-b \bar{a} t\right)$ [succubare, to lie under]. To have carnal knowledge of a man.

Succubous (suk'-u-bus) [succumbere, to lie under]. In biology, having the basal margin of each leaf overlapping the apex of the preceding leaf, as distinguished from incubous.

Succubus $\left(s u k^{\prime}-u-b u s\right)$ [L.: pl., Succubi]. A male demon, once considered to be the counterpart of the succuba.

Succulent (suk'-u-lent) [succus, a juice]. In biology, thickened and juicy.

Succursal (suk-ur'-sal) [succursalis, subsidiary]. Subsidiary. S. Hospital, or Asylum, a branch provincial hospital, usually for mild cases.

Succus $\left(s u k^{\prime}-u s\right)$ [L.: gen. and pl. Succi]. Juice, as S. belladonnæ, S. conii, S. hyoscyami, S. limonis, S. mori, S. scoparii, S. taraxaci, all official in the B. P. S. alterans, a proprietary remedy composed of roots and herbs and much exploited in the treatment of syphilis. It consists as follows : fluid extracts of smilax, sarsaparilla, stillingia sylvatica, and kappa minor, each 2 ounces; extract. phytolaccæ decandræ 2 ounces, and tinct. xanthoxyli carolin. I ounce. Of this a dram is taken in water three times daily, gradually increasing the dose to a half-ounce. $\mathbf{S}$. entericus, the intestinal juice, secreted by the glands that are found embedded in the intestinal mucosa. It is thin, opalescent, alkaline, and has a specific gravity of IOII Its chief function is probably to act as a diluent. It contains an amylolytic and a proteolytic ferment. $\mathbf{S}$. gastricus, the gastric juice. S. spissatus, any extract prepared by evaporation of the natural juice of a plant.

Succussion (suk-ush'-un) [succutere, to shake]. The shaking of the individual from side to side for the purpose of determining the presence of fluid in a cavity or hollow organ of the body. S.-sound, or Splash, the peculiar splashing sound heard in hydropneumo-thorax or pyo-pneumo-thorax when the patient's chest is slightly shaken. It is due to the combined presence of air and fluid in a closed cavity. It was first described by Hippocrates, and hence is also known as the Hippocratic Sound. The sound may also be obtained in the presence of a dilated stomach partly filled with fluid.

Suck (suk) [sugere, to draw in]. To take nourishment, as a babe, at the breast; to draw in with the aid of the mouth.

Sucker $\left(s^{\prime} k^{\prime}-e r\right)$ [AS., sucan, also sugere, to suck]. In biology, an organ adapted for suction; a sprout, shoot, or haustorium. Cf. Propagulum.

Sucking (suk'-ing) [sugere, to suck]. Giving suck; nursing; drawing with the mouth. S.-bottle, a nursing-bottle. S.-stomach, an old and misleading term for the honey-sac of the hive-bee.

Suckle $($ suk'-l) [sugere, to suck]. To give suck. To nurse at the breast.

Sucrose (su'-kröz). See Saccharum.

Suction (suk'-shun) [suctio, a sucking]. The act of sucking. S. of Cataract, removal, by means of a syringe, of the fragments of lens-substance after discission. 
Suctorial (suk-to'-re-al) [sugere, to suck]. Suitable for sucking.

Sudamen, Sudamina (su-da'-men, su-dam'-in-ah). See Miliaria. S. crystallina. See Miliaria crystallina.

Sudaminal (su-dam'-in-al) [sudare, to sweat]. Of the nature of sudamina.

Sudation $\left(s u-d a^{\prime}-\right.$ shun $)$ [sudare, to sweat]. The act of sweating.

Sudatoria (su-dat-o'-re-ah). See Hyperidrosis and Miliaria.

Sudatorium (su-dat-o'-re-um) [sudor, sweat]. A room or apartment for the administration of a sweat-bath.

Sudolorrhea (su-do-lor-e'-ah) [sudare, to sweat; oleum, oil; poia, a tlow]. Synonym of Eczema seborrhaicum.

Sudor $\left(s u^{\prime}-d \bar{o} r\right)$ [L.]. Sweat. S. anglicus. See Miliaria. S. cruentus. Synonym of Hematidrosis. S. nocturnus, night-sweat. S. sabulosus. Synonym of Uridrosis crystallina. S. sanguinosus. See Hematidrosis. S. urinosus. See Uridrosis.

Sudoral $\left(s u^{\prime}\right.$-dor-al) [sudor, sweat]. Pertaining to sweat, or to active diaphoresis. S. Typhoid Fever, a form of typhoid fever characterized by chills, fever, and sweats, and which may be mistaken for intermittent fever.

Sudoriferous (su-dor-if'-er-us) [sudor, sweat ; ferre, to bear ]. Sweat-bearing; sweat-producing. S. Glands. See Sreat-glands.

Sudorific $\left(s u-d o r-i f^{\prime}-i k\right)$ [sudor, sweat; facere, to make]. I. Production of copious sweating. 2. A medicine or agent inducing profuse sweating.

Sudoriparous (su-dor-iṕ-ar-us) [sudor, sweat; parere, to beget]. Producing or secreting sweat. S. Glands. See Sweat-glands.

Sudorous (su'-dor-us) [sudorus, sweaty]. Sweaty; of the nature of sweat. [Rare.]

Suet (su'-et). See Tallore and Tallorv-oit; also Serum.

Suffocation (suf-o-ka'-shun) [suffocare, to choke]. Interference with the entrance of air into the lungs by means other than by external pressure on the trachea; asphyxia.

Suffocative (suf'-o-ka-tiv) [suffocare, to suffocate]. Tending to choke or suffocate. S. Catarrh, Laënnec's term for capillary bronchitis.

Suffraginis (suf-raj'-in-is) [suffrago, hock]. The large pastern-bone, a very compact bone in the foot of a horse, set in an oblique direction downward and forward, and extending from the cannon-bone to the coronet.

Suffraginous (suf-raj'-in-us) [suffrago, hock]. Pertaining to the suffrago of the horse.

Suffrago (suf-ra'-gō) [L. : gen., Suffraginis: pl., Suffragines ]. The hock of a horse's hind leg, whose convexity is backward. It corresponds to the human heel.

Suffrutescent (suf-ru-tes'-ent) [sub, under ; frutex, a shrub ]. In biology, applied to a stem which is slightly shrubby at the base only.

Suffrutex (suf'-ru-tcks) [sub, under; frutex, a shrub]. In biology, an under-shrub.

Suffruticose (suf-firu'-tik-ozz) [sub, under; frutex, a shrub]. Applied to an under-shrub, or low shrub. Same as Suffirutescent.

Suffumigation (suf-u-mig-a'-shun) [suffumigatio]. A fumigation; also, a disinfectant used in fumigation.

Suffumigium (suf-u-mij'-e-um) [L. : pl., Suffumigia]. A medicinal smoke, vapor, or fumigation.

Suffusio $\left(s u f-u^{\prime}-z e-0\right)$ [L. ]. Suffusion. S. dimidians [L., "a halving suffusion" ]. Hemicrania with hemianopsia.

Suffusion (suf- $u^{\prime}-z h u n$ ) [sub, under; fundere, to pour]. I. A spreading or flow of any fluid of the body into surrounding tissue; an extensive superficial extravasation of blood. 2. The pouring of water upon a patient as a remedial measure.

Sugar (shoog'-ar) [ME., suger, sugar]. The general name of a class of compounds belonging to the group of carbohydrates. See Saccharum. Chemically, sugars are divided as follows: Cane-sugar, $\mathrm{C}_{12} \mathrm{H}_{22} \mathrm{O}_{11}$, the ordinary sugar of commerce and pharmacy; glucose (grape-sugar or starch-sugar), $\mathrm{C}_{6} \mathrm{H}_{12} \mathrm{O}_{6}$; laclose, sugar of milk; and inosite, a variety found in certain muscular tissues and in the juice of asparagus. Closely allied to sugar are starch, cellulose, glycogen, and dextrin, q.v. See Carbohydrate. The following table from Sadtler's "Industrial Organic Chemistry" contains the composition of a variety of raw cane-sugars and beet-sugars :-

\begin{tabular}{|c|c|c|c|c|c|c|}
\hline $\begin{array}{l}\text { DESCRIPTION } \\
\text { OF SUGAR. }\end{array}$ & 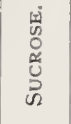 & $\begin{array}{l}\text { 语 } \\
8 \\
0 \\
0 \\
0\end{array}$ & 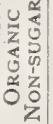 & 恋 & $\frac{2}{a}$ & AUTHORITY. \\
\hline $\left.\begin{array}{c}\text { Cane, Cuba } \\
\text { (centrif.), . }\end{array}\right\}$ & 91.90 & 2.98 & 2.70 & 0.72 & I.70 & $\left\{\begin{array}{c}\text { Wigner and } \\
\text { Harland. }\end{array}\right.$ \\
\hline $\left.\begin{array}{r}\text { Cane, Cuba } \\
\text { (muscovado), }\end{array}\right\}$ & 92.35 & 3.38 & 0.66 & 0.77 & 2.84 & Wallace. \\
\hline Cane, Jamaica, . & 90.40 & 3.47 & X.55 & 0.36 & 4.22 & $\left\{\begin{array}{c}\text { Wigner and } \\
\text { Harland. }\end{array}\right.$ \\
\hline Cane, Trinidad, & 88.00 & 5. I4 & 1. 67 & 0.96 & 4.23 & $\left\{\begin{array}{l}\text { Wigner and } \\
\text { Harland. }\end{array}\right.$ \\
\hline Cane, Porto Rico, & 87.50 & 4.84 & 2.60 & $0.8 \mathrm{I}$ & 4.25 & $\left\{\begin{array}{c}\text { Wigner and } \\
\text { Harland. }\end{array}\right.$ \\
\hline Cane, St.Vincent, & 92.50 & 3.61 & 2.45 & 0.63 & $0.8 \mathrm{I}$ & $\left\{\begin{array}{c}\text { Wigner and } \\
\text { Harland. }\end{array}\right.$ \\
\hline Cane, Demarara, & 90.80 & $4 . \mathrm{Ir}$ & 0.77 & I.12 & 3.20 & Wallace. \\
\hline Cane, Benares, . & 94.50 & 2.63 & 0.39 & I. 50 & 0.98 & $\left\{\begin{array}{c}\text { Wigner and } \\
\text { Harland. }\end{array}\right.$ \\
\hline $\begin{array}{c}\text { Cane, Unclayed } \\
\text { Manila, .... }\end{array}$ & 82.00 & 6.79 & 3.24 & 200 & 5.97 & $\left\{\begin{array}{c}\text { Wigner and } \\
\text { Harland. }\end{array}\right.$ \\
\hline Cane, Concrete, . & 84.20 & 8.45 & $\mathbf{x . 7 0}$ & I.10 & 4.55 & Wallace. \\
\hline Cane, Melada, . & 67.00 & II. 36 & I.93 & $0.9 \mathrm{I}$ & 18.80 & Wallace. \\
\hline Cane, Bastards, . & 68.30 & 15.00 & 1.20 & I. -50 & 14.00 & Wallace. \\
\hline $\left.\begin{array}{c}\text { Palm, East In- } \\
\text { dian, ..... }\end{array}\right\}$ & 86.00 & 2.19 & 2.89 & 2.88 & 6.04 & $\left\{\begin{array}{c}\text { Wigner and } \\
\text { Harland. }\end{array}\right.$ \\
\hline $\left.\begin{array}{c}\text { Beet, first pro- } \\
\text { duct, .... }\end{array}\right\}$ & 94.17 & $\cdots$ & 2.14 & I. 48 & $2.2 \mathrm{I}$ & Bodenbender. \\
\hline $\left.\begin{array}{c}\text { Beet, second } \\
\text { product, } . .\end{array}\right\}$ & 91.68 & & 2.49 & 2.92 & $2.9 \mathrm{I}$ & Bodenbender. \\
\hline
\end{tabular}

S., Beet, saccharose obtained from the species of Beta, especially the common beet, Beta vulgaris. It is now employed extensively as a substitute for cane-sugar. S., Brown, an impure cane-sugar. S.-cane, Saccharum officinarum and other species, a source of saccharose. See Sugar. S., Cellulose, sugar derived from cellulose; it has the same formula and properties as glucose. S., Chestnut, glucose. S. -coated, coated with sugar, as some pills. S., Diabetic, glucose. S., Fruit, levulose. S., Grape, glucose in the solid state. S., Gum, arabinose. S., Honey, glucose. S.-house Eczema, an eczema sometimes observed in laborers employed in sugar-refineries. S., Invert. See Invert. S., Liver, another name for glucose which is derived from the liver; glycogen. S., Manna. Synonym of Mannite. S., Maple, saccharose obtained from the sugar-maple. See Acer. S. of Milk. See Lactose. S.-mite, an acarid of the genus Glyciphagus that 
infests certain unrefined commercial sugar, and is said to be a cause of grocers' itch. S., Muscle, inosite. S., Refined, purified cane-sugar. S., Starch, glucose. S.-teat, a nipple-shaped linen rag containing a lump of sugar. It is given to an infant to quiet it. S., Uncrystallizable, levulose. S.-vinegar. See Vineoar. S., White. Synonym of S., Refined.

Suggestible (sug-jes'-tib-l) [suggerere, to convey, to excite]. Amenable to suggestion; said of hypnotized persons.

Suggestion (sug-jes'-chun) [suggerere, to lay under]. I. The artificial production of a certain psychic state in which the individual experiences such sensations as are suggested to him or ceases to experience those which he is instructed not to feel. 2. The thing suggested. S., Hypnotic. See Hypnotism. S., Post-hypnotic, the command to do certain acts given the subject while in the somnambulic stage, and which are executed by him after his return to his normal condition. S.-therapy, treatment of disordered states by means of suggestion.

Suggillation, Sugillation (suj-il-a'-shun) [sugillare, to beat black and blue]. An ecchymosis or bruise. A diffuse accumulation of blood in the interstices of the tissues.

Suicidal (su'-is-i-dal) [sui, of himself; cadere, to kill]. Self-destroying; having a tendency to suicide.

Suicide $\left(s u^{\prime}-i s-\bar{l} d\right)$ [sui, of himself; cadere, to kill]. 1. The intentional taking of one's own life; selfmurder. 2. One who takes his own life.

Suilla (swil'-ah). Synonym of Scrofula.

Suint (swint) [Fr.]. A soapy substance rich in potash and cholesterin, derivable from sheeps' wool. Lanolin, agnin, and potash-salts are obtained from it.

Sukha Pakla (su'-kah pak'-lah). Synonym of Ainhum.

Sulcate (sul'-kät) [sulcus, a furrow]. In biology, having straight, longitudinal furrows, grooves, or channels; fluted.

Sulcated (sul'-ka-ted) [sulcus, a furrow]. Grooved or furrowed.

Sulcation $\left(s u l-k a^{\prime}-s h \bar{u} n\right)$ [sulcus, furrow]. A furrow or set of furrows or sulci ; the state or quality of being furrowed.

Sulcature (sul'-kat-ür). See Sulcation.

Sulciform (sul'-sif-orm) [sulcus, a furrow; forma, form]. Like a groove or sulcus.

Sulciorales (sul-se-o-ra'-lèz) [sulcus, a furrow; os, the mouth]. The oral grooves of the Medusa. S. palatini, the palatine grooves of Hydropolypes.

Sulcus (sul'-kus) [L.: pl., Sulci] . A furrow or groove; applied especially to the fissures of the brain. For sub-headings see Fissures. S., Choroid. See Schwalbe, Fissure of. S., Harrison's. See Harrison. S., Intraparietal, the sulcus dividing the superior from the inferior parietal lobule. S., Precentral, a fissure situated in front of the fissure of Rolando and running nearly parallel with it. $S$. spiralis, the grooved extremity of the lamina spiralis of the cochlea. S., Vertical. Same as S., Precentral.

Sulfate (sul-fät). See Sulphate.

Sulfonal (sul'-fo-nal). See Sulphonal.

Sulfur (sul'-fer) [L.]. See Sulphur.

Sulph-(sulf-). See Sulpho-.

Sulph-aldehyd (sulf-al'-de-hĩd) [sulphur, sulphur; uldehya]. A substance produced by the action of hydrogen sulphid on ethylic aldehyd. It occurs in the form of an oleaginous liquid of a repulsive odor, solidifying at a temperature slightly below the freezing point. It is a hypnotic, and is said to produce tranquil sleep without any phenomena of excitation.

Sulphamid (sull-fant-id) [sulphur, sulphur; amid].
One of several compounds formed by the action of sulphuryl chlorid upon the free secondary amins.

Sulphaminol (sul-fam'-in-öl) [sulphur, sulphur; anin], $\mathrm{C}_{12} \mathrm{H}_{9} \mathrm{~S}_{2} \mathrm{NO}$. Thioxydiphenylamin. An antiseptic substance obtained by the action of sulphur on the salts of methoxydiphenylamin. It is used by insuffla tion in diseases of the antrum and frontal sinuses. It has been used with success by insufflation in the treat ment of laryngeal tuberculosis. Dose in cystitis gr. ij-v

Sulphanilic Acid (sul-fan-il'-ik) [sulphur, sulphur]. See Acid. This is used in Ehrlich's diazo-reaction. See Tests, Table of.

Sulpharsin (sul-far'-sin) [sulphur, sulphur; arsenicum, arsenic]. Cacodyl sulphid, a colorless, inflammable liquid, with an intensely disagreeable odor.

Sulphate (sul'-fät) [sulphur, sulphur]. A salt of sulphuric acid. Sulphuric acid being dibasic, there are acid and basic salts. Ss., Test for, in Urine ; acidify with hydrochloric acid; then add a solution of barium chlorid, and if soluble sulphates be present, a white, crystalline precipitate falls. Compare with that from healthy urine as to abnormality of amount. See Tests, Table of.

Sulphatid (sul'-fat-id) [sulphur, sulphur]. Any organic compound, of the type of a phosphatid, in which all, or a part, of the phosphorus is replaced by sulphur.

Sulphichthyolic Acid (sulf-ik-the-ol'-ik), See Acid.

Sulphid $\left(s u l^{\prime}-f \bar{d} d\right)$ [sulphidum]. A direct compound of sulphur with an element or radicle. It may be considered a salt of hydrogen sulphid. The alkaline sulphids are soluble in water, the others are generally insoluble. S., Hydrogen, $\mathrm{H}_{2} \mathrm{~S}$, unof., a gas having the odor of rotten eggs; highly poisonous. It is used as a precipitant for certain metals in solution; it has also been used in the treatment of tuberculosis. Sulphidum, Calcii, CaS, unof., the "hepar sulpluris" of homeopathy, used mainly in the preparation of other compounds. Locally, a specific for itch. Sulphurata, Calx, CaS $+\mathrm{CaSO}_{4}$, sulphurated lime, a variable mix ture containing about 36 per cent. of calcium sulphid and sulphate. It is used in furunculosis. Dose gr. $\frac{1}{10}-\frac{1}{2}$. S., Potassa, prepared by heating 2 parts of potassium carbonate with I of sulphur. Narcotic and irritant. Dose gr, ij-x. Sulphuris iodidum, $I_{2} S_{2}$, used in ointment, gr. $\mathrm{xxx}$ to $\mathrm{z}_{\mathrm{j}}$.

Sulphins (suil-finz) [sulphur, sulphur]. One of several crystalline compounds resulting from the combination of the thio-ethers with the iodids, bromids, and chlorids of the alcohol radicles at ordinary temperatures, but more rapidly on the application of heat.

Sulphite (sul'-fit) [sulphis]. Any salt of sulphurous acid. Being a dibasic acid, there are acid and basic sulphites.

Sulpho- $\left(s u l^{\prime}-f o\right)$ [sulphur, sulphur]. A prefix denoting chemic combination with sulphur, or a sulphur radicle.

Sulphocarbamid (sul-fo-kar'-bam-id). SeeThio-urea. Sulphocarbolate (sul-fo-kar'-bo-lät) [sulphur, sulphur; carbolic]. A salt of sulphocarbolic acid. Sulphocarbolate of Zinc is antiseptic and disinfectant. It is used as an intestinal antiseptic; sometimes also in small doses for fetor of the breath.

Sulphocarbolic Acid (sul-forkar-bol'-ik). See Aseptol. Sulpholeic Acid, Sulpholinic Acid (sul-fo-le'-ik, sulfo-lin'-ik) [sulphur, sulphur; oleic]. A yellowish, neutral liquid prepared by treating vegetable oils with sulphuric acid. It is recommended as a good solvent and has been used externally instead of vaselin and glycerin. 
Sulpholein (sul-fi-le-in). See Sulphwicinedic Acid. Sulphonal (sul'-fo-nal) [sulphur, sulphur], $\mathrm{C}_{7} \mathrm{H}_{16} \mathrm{~S}_{2} \mathrm{O}_{4}$. Acetone-diethylsulphone. It is soluble in 100 parts of water at $16^{\circ} \mathrm{C}$., in 20 parts at $100^{\circ} \mathrm{C}$., and readily soluble in alcohol ; it crystallizes in colorless leaflets or plates that melt at $126^{\circ} \mathrm{C}$., and is odorless and tasteless; in doses of from 8 to 45 grains it is used as an hypnotic. Unof.

Sulphone (sul'-fon) [sulphur, sulphur]. One of the products of the union of two oxygen atoms with an alkyl sulphid.

Sulphoricinoleic Acid (sul-fo-ri-sin-a-le'-ik). See Acidt. Sulpho-salt (sul"-fo-sawlt) [sulphur, sulphur; ME., salt, salt]. A salt in which sulphur talies the place of oxygen in the acid radicle.

Sulphoxid (sul-foks'-id) [sulphur, sulphur; ókus, acid]. One of the products of the union of one oxygen atom with an alkyl sulphid.

Sulphur (sul'-fer) [L.: gen., Sulphuris]. Brimstone. $\mathrm{S}=32$; quantivalence $\mathrm{II}, \mathrm{IV}$, VI. A non-metallic element distinguished by its yellow color and crystalline properties. It is one of the acid elements, and unites with oxygen to form the most powerful acid radicles. It is laxative and diaphoretic, and, long administered, causes emaciation and anemia. See Elements, Table of. S., Confectio (B.P.). Dose gr, $x-3$ ij. S. Dioxid, $\mathrm{SO}_{2}$, a colorless gas, of irritating odor, formed by the combustion of sulphur, and in the presence of moisture acting as a powerful bleaching and disinfecting agent. S., Flowers of, sublimed sulphur obtained in the form of light-yellow, powdery flakes. $\mathrm{S}$. iodidum, $\mathrm{I}_{2} \mathrm{~S}_{2}$, used as an ointment, gr. $\mathrm{xxx}-\mathrm{z}_{3} \mathrm{j}$. S. iodid, Ung. (B. P.), contains melted and hard paraffin and iodid of sulphur. S., Liver of, potassa sulphurata, a mixture of potassium trisulphid and potassium trisulphate. S. lotum, washed sulphur, prepared by digesting sublimed sulphur with water of ammonia, and afterward washing. S. præcipitatum, lac sulphur, "milk of sulphur;" a white, amorphous powder, devoid of taste and odor, prepared by decomposing calcium sulphid with hydrochloric acid. Dose gr. $x-3 j$. S. rotundum, roll sulphur, sublimed sulphur cast into rolls. S. sublimatum, sublimed sulphur, Dose gr. $\mathrm{x}-\mathrm{Ix}$. S., Trochisci (B. P.), each contains grs. v of sulphur. Dose $\mathbf{I}$ to 6 . S., Ung., sublimed sulphur 30 , benzoinated lard 70 parts. S., Ung., Alkalinum, washed sulphur 20, potassium carbonate 10 , water 5 , benzoinated lard 65 parts.

Sulphurain (sul'-fu-rän). See Glairin.

Sulphurate (sul'-fu-rât) [sulphur, sulphur]. To impregnate with sulphur.

Sulphurated (sul'-fu-ra-ted) [sulphur, sulphur]. A term applied to substances which contain or are combined with sulphur.

Sulphuration (sul-fu-ra'-shun) [sulphur, sulphur]. The act of dressing, anointing, or impregnating with sulphur.

Sulphur-bath. See Bath.

Sulphuret (sul'-fu-ret) [sulphur, sulphur]. A sulphid.

Sulphureted (sul'-fu-ret-ed) [sulphur, sulphur]. Having sulphur in combination. S. Hydrogen. See Acid, Hydrosulphuric

Sulphuretum (sul-fu-re'-tum) [sulphur, sulphur: gen., Sulphureti]. A sulphid.

Sulphuric (sul-fu'-rik) [sulphur, sulphur]. In chemistry, a technical name given to the anhydrid and derived acid of sulphur trioxid, $\mathrm{SO}_{3}$. See Acid, Sulphuric. S. Acid (Nordhausen), sulphuric acid containing more or less sulphur trioxid $\left(\mathrm{SO}_{3}\right)$. It has a specific gravity of I.860 to I.9, and is obtained by the distillation of dried ferrous sulphate.
Sulphuring (sul'-fer-ing) [sulfhur, sulphur]. Bleaching (e.g., dried fruit) with sulphurous acid.

Sulphurous (sul-fu'-rus, or sul'-fu-rus) [sulphur, sulphur]. Of the nature of sulphur. In chemistry, a technical name applied to the acids and anhydrid derived from sulphur dioxid, $\mathrm{SO}_{2}$. See Acid, Sulphurous. S.-acid Bath. See Baih.

Sulphydrate (sulf-hi'-drat) [sulphur, sulphur; $i \delta \omega p$, water]. One of the so-called salts of sulphydric acid. A compound of a metal with the univalent radicle, $\mathrm{SH}$

Sulphydric (sulf-hi'-drik). See Acid, Hydrosulphuric. S. Acid. Same as Sulphureted.

Sumac, Sumach $\left(s u^{\prime}-m a k\right)$ [Ar., summoq, sumac]. The powdered leaves, peduncles, and young branches of Rhus coriaria, R. cotinus, and other species of Rhus, used in the manufacture of leather. Sumac contains from 16 to 24 per cent. of a tannin that seems to be identical with gallotannic acid. See Rhus.

Sumbul (sum'-bul) [Hind, sumbul, spikenard]. Muskroot; the root of Ferula sumbul, which is distinguished by a musk-like odor and a bitter, balsamic taste. It contains angelic and valerianic acids, and is an excellent nerve-tonic, much used in Russia. It is useful as a substitute for musk in nervous affections, typhoid fever, etc. Dose gr. $\mathrm{xxx}-3 \mathrm{j}$. S., Tinctura, Io per cent. Dose $3 \mathrm{j}$-iv, S., Tinctura (B.P.). Dose $m x-x x x$.

Summation (sum- $a^{\prime}$-shun) [summatio]. The accumulation of effects, especially of those of muscular, sensory, or mental stimuli. S. of Stimuli, if a stimulus in itself insufficient to cause contraction of a muscle be repeatedly applied in proper tempo and strength, contraction will finally be produced. Similar summation occurs in nervous tissue, and the cardiac contractions exhibit a rhythm of increased force, called Staircase or Treppe Rhythm.

Summational (sum- $a^{\prime}-\operatorname{shun-al)}$ [summatio, a summing up]. Produced by summation. S. Tones, supposed production of new tones by the summation or addition of the number of vibrations of existing tones.

Summer (sum'-er) [ME., somer, summer]. The season of greatest heat. Also, applied to things connected with that season. S. Catarrh. See Hay-fever. S. Complaint. See Cholera infantum. S. Granulations. See Trachoma. S. Prurigo. See Prurigo estivalis. S. Rash, same as Lichen tropicus. S. Savory, the leaves of Satureia hortensis, stimulant, carminative, and emmenagogue. Dose of the fld. ext. $3 \mathrm{j}-\mathrm{iv}$. Unof.

Sun [ME., sunne, sun]. The central body of the solar system. S.-bath. See Bath. S.-burn, superficial inflammation of the skin caused by exposure to the sun. Also, the bronzing of the skin from long exposure to the sun or heat. $\mathbf{S}$.-dew. See Drosera. S.-fever. I. A name loosely applied to severe forms of various fevers of the tropical regions, as dengue. 2. A synonym for Simple Continued Fever. 3. See Insolation. S.-flower, the seeds of the common sunflower, Helianthus annuus. They contain a fixed oil and other extractive matters. The oil is not inferior in taste to olive-oil. The plant is expectorant and diuretic. Dose of the decoction ad lib. ; of the fld. ext. 3j-ij. Unof. S.-flower Retina (or Marula), S.-flower Appearance, a rare condition of the macular region in which there is some likeness to the appearance of the petals of the sunflower. S.-flower, Wild. See Grindelia. S.-gold. See Pigments, Conspectus of. S.-pain, a form of brow-ague appearing in the morning and disappearing at night, and aggravated by sunlight. S.-star. See Solister. S.-stricken. Same as S.-struck. S.-stroke, a popular term for inso- 
lation or heat-stroke. See Heat-stroke. S.-stroke, Electric, an illogical term for the symptoms, somewhat similar to those of heat-stroke, produced by too close and unprotected proximity to the intense light emitted in welding metals by electricity. S.-struck, overcome by the heat of the sun. S.-yellow. See Maize.

Sunn Hemp. See Hemp.

Super-(su'-per-) [L., above or upon]. A prefix denoting above, upon, dorsad, upper, or excessive in degre.

Superabduction (su-per-ab-duk'-shun) [super, over; abduction]. Excessive abduction.

Superacidity (su-per-as-id'-it-e). See Hyperacidity.

Superacromial (su-per-ak-ro'-me-al) [super, above; acromium]. Situated or occurring above or upon the acromion.

Superacute (su'-per-ak-üt) [super, over; acutus, pointed]. Extremely acute.

Superalbuminosis (su-per-al-bu-min-ol-sis) [super, over; albumen, albumin]. The over-production of albumin.

Superalimentation (su-per-al-im-en-ta'-shun) [super, over; alimentation]. Excessive nourishment.

Superambulacral (su-per-am-bu-la'-kral) [super, above; ambulacrum]. Above the ambulacra.

Superanal (su-per-a'-nal). Same as Supra-anal.

Superbus (su-per/-bus) [L., superb]. A term applied to the rectus oculi superioris muscle, and sometimes to the levator menti, because their action gives to the face a proud and haughty expression.

Supercallosal (su-per-kal-o'-sal) [super, over; callosum]. Situated above or occurring above the callosum.

Supercalorinesis (su-per-kal-o-rin-e'-sis) [super, over ; calor, heat: pl., Supercalorineses]. Any disease caused by increase of the animal heat.

Superciliary (su-per-sill-e-a-re) [super, above ; cilium, eyelash]. Pertaining to the eyebrow. S. Ridges, the projecting apophyses at the anterior surface of the frontal bone.

Supercilium (su-per-sil'-e-um) [L.]. The eyebrow.

Superconception (su-per-kon-sep'-shun). Same as Superfetation.

Superdentate (su-per-den'-tāt) [super, over; dens, tooth]. Having teeth only in the upper jaw.

Superdistention (su-per-dis-ten'-shun) [super, above; distendere, to distend]. Excessive distention.

Superextension (su-per-eks-ten'-shun) [super, above; extendere, to extend]. Excessive extension.

Superfecundation (su-per-fe-kun-da'shun) [super, over; fecundus, fertile ]. The fertilization of more than one ovum of the same ovulation resulting from separate acts of coitus

Superfecundity (su-per-fe-kun'-dit-e) [super, over; fecundus, fertile]. Superabundant fecundity.

Superfetate (su-per-fe't-tât) [superfetare, to conceive anew when already pregnant]. To conceive after a prior conception

Superfetation (su-per-fe-ta'-shun) [superfatatio; super, fretus]. A supposed fertilization of an ovum when there is another from a previous ovulation in uterogestation. This is now considered impossible

Superfibrination (su-per-fib-rin- $a^{\prime}$-shun) [super, over; fibrin, fibrin]. Excessive formation of fibrin in the blood.

Superficial (su-per-fish'-al) [superficialis; super, over; facies, face]. Confined to the surface. Not extending below the surface; shallow. S. Reflexes. See Reflexes, Table of.

Superficies $\left(s u^{\prime}-p e r-f i s h-\bar{e} z\right)$ [L.]. The surface or outside.

Superfissure (su'-per-fish-er) [super, over; fissura, fissure]. The lines of overlapping of a supergyre. Also, the lines of junction of two supergyres meeting from opposite directions.

Superflexion (su-per-flek'-shun) [super, over; flexio, a flexion]. Excessive flexion.

Superfoliation (su-per-fo-le- $\left.a^{\prime}-s h u n\right)$ [super, over; folium, leaf]. In biology, excess of leaves.

Superfrontal (su-per-frun'-tal) [super, over; frons, forehead]. Superior or upper, as a fissure of the frontal lobe of the brain.

Superfunctive (su-per-funk'-tiv) [super, over; functio, function]. Excessive functional activity.

Supergenual (su-per-jen'-u-al) [super, above; genu, knee]. Situated above the knee.

Supergyre (su'-per-jir $)$. See Subgyre.

Superimposed (su-per-im-pozzd') [super, over; imposed] Placed one upon another.

Superimpregnation (su-per-im-preg-na'-shun) [super, over; impregnation]. The development of more than one ovule at one time, as in plural pregnancy.

Superinduce (su-per-in-düs') [superinducere, to bring upon]. To bring on as a complication of a condition already existing.

Superinduced (su-per-in-dūst') [super, upon; inducere, to bring in]. Superimposed. S. Segmentation. See Homoplasis.

Superinvolution (su-per-in-vo-lu'-shun) [super, over; involutere, to involute]. Hyperinvolution; excessive rolling up.

Superior (su-pe'-re-or) [comparative of superus, high]. Higher; noting the upper of two organs or parts occupying a relatively high position. In biology, applied to an ovary that is not at all adherent to the calyx. Also applied to a calyx whose tube closely adheres to the ovary, so that its limb, or spreading portion, appears to spring from the top of the latter. S. Bulbar Palsy, ophthalmoplegia externa. S. Vermiform Process, the upper part of the median lobe of the cerebellum. It is divided into three lobes, the lobulus centralis, monticulus cerebelli, and commissura simplex.

Superlactation (su-per-lak-ta'-shun) [super, over; lac, milk]. Excess of the secretion of milk.

Superligula (su-per-lig'-u-lah). See Epiglottis.

Supermedial (su-per-me'-de-al) [super, over; medius, middle]. Lying above the middle.

Supernasolabialis (su-per-na-zo-la-be-a'-lis) [super, over; nasus, nose; labium, lip]. A muscle found in many of the lower animals, the analogue of the levator labii superioris alæque nasi of man.

Supernatant (su-per-na'-tant) [super, over; natans, swimming]. Floating upon the surface of a liquid.

Supernidation (su-per-nid-a'-shun) [super, over; nidus, nest]. Excessive proliferation of the menstrual decidua, resulting sometimes in membranous dysmenorrhea.

Supernumerary (su-per-nu'-mer-a-re) [super, over ; numerus, a number]. More than the usual or normal number.

Supernutrition (su-per-nu-trish'-un) [super, over; nutrive, to nourish]. Excessive nourishment. See Hypertrophy.

Superoccipital (su-per-ok-siṕ-it-al) [super, over; occiput, occiput]. Situated at or near the upper part of the occiput.

Superoxidized (su-per-oks'-id-izd ) [super, over; 'óv́s, acid]. Having an excess of oxygen above the usual amount which satisfies the combining capacities of the other elements of a body.

Superparasite (su-per-par'-as-itt) [super, over; parasite]. In biology, a parasite of parasites.

Superparasitic (su-per-par-as-it'-ik) [super, over; parasite]. Pertaining to superparasitism. 
Superparasitism (su-per-par-as-i-tizm) [super, over; parasile]. The infestation of parasites by other parasites.

Superposed (su-per-pōzd') [super, over; ponere, to place]. Stationed above anything.

Superpurgation (su-per-pur-ga'-shun) [super, over; purgation]. Over-purgation. A term applied in farriery to a diarrhea or flux from the bowels that, at times, is induced by and follows the action of a physic. It is accompanied by much irritation or even inflammation of the bowels, and is always serious.

Supersacral (su-per-sa'-kral) [super, over; sacrum, sacrum]. Situated over the sacrum.

Supersalt (su'-per-sazult) [super, over; ME., salt, salt] In chemistry, any salt containing an excess of acid. An acid, as distinguished from a basic salt.

Supersaturate (su-per-sat'-u-rāt ) [super, over; saturare, to saturate]. To saturate to excess.

Supersaturated (su-per-sat'-u-ra-ted) [super, over; saturare, to saturate]. A condition in which there is more of a substance dissolved in a liquid than would suffice to saturate it under ordinary conditions.

Supersaturation (su-per-sat-u-ra'-shun) [super, over; saturare, to saturate]. The operation of saturating to excess.

Superscapular (su-per-skap'-u-lar). Same as Suprascapular.

Supersecretion (su-per-se-kre'-shun) [super, over ; secernere, to secrete]. Excessive secretion.

Supersphenoid (su-per-sfen'-oid) [super, over; sphenoid]. Situated cephalad or dorsad of the sphenoid bone.

Supersquamosal (su-per-skwa-no'-zal) [super, over; squama, scale]. A bone of the skull of ichthyosaurus, behind the postfrontal and postorbital.

Supertemporal (su-per-tem'-po-ral) [super, over; temporal ]. Situated high up in the temporal region.

Supervenosity (su-per-ve-nos'-it-e) [super, over; venosus, venous]. The condition in which the blood has become venous to a high degree.

Supervention (su-per-ven'shun) [super, over; venire, to come]. That which is added; an extraneous, or unexpected condition added to another, as the supervention of septicemia, or other complication in disease.

Supervolute $\left(s u^{\prime}\right.$-per-vo-lüt $)$ [super, above; volvere, to roll]. In biology, that form of estivation in which the gamophyllous calyx or corolla is both plicate and twisted, as in the corollas of stramonium and morningglory.

Supination (su-pin-a'-shun) [supinatio; supinus, on the back]. The attitude of one lying upon the back; the act of turning or lying upon the back; the turning of the palm of the hand upward. In medicine, the condition of being supine.

Supinator (su'-pin-a-tor). See Muscles, Table of.

Supine $\left(s u^{\prime}-p_{i n}\right)$ [supinus, back]. Lying on the back face upward, or palm upward.

Suppage $\left(s u p^{\prime}-\bar{a} j\right)$ [sup, age]. A food that may be supplied.

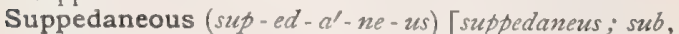
under; pes, foot]. Pertaining to the sole of the foot.

Supple (sup'-l) [ME., souple, pliant]. Pliant, flexible. S.-back, a term applied in the neighborhood of Aberdeen to caries of the rertebræe in lambs.

Supplemental (sup-le-nuen'-tal) [supplementum]. Additional. S. Air. See Air. S. Bags. See Anes thetic.

Support (sup-ort') [supporlare, to carry]. I. The act of holding anything in its position. 2. Any appliance acting as a supporter.

Supporter (sup-or'-ter) [supportare, to carry]. An ap- paratus intended to aid in supporting a prolapsed organ (as the uterus), or a pendulous abdomen.

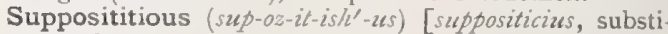
tuted]. Spurious; not genuine. S. Children, pretension by a woman, for purposes of extortion, of having given birth to a child.

Suppositorium (su-poz-it-o'-re-um) [supponere, to place under: gen., Suppositorii; pl., Suppositoria]. See Suppository.

Suppository (sup-oz'-it-o-re) [suppositorium]. A solid medicated compound designed to be introduced into the rectum, urethra, or vagina. Its consistency is such that while retaining its shape at ordinary temperatures it readily melts at the temperature of the body. The basis of most suppositories is oil of theobroma. For urethral suppositories a mixture of gelatin and glycerin is used. It is generally molded into a conic shape, but is sometimes cylindric or spheric. There is one official suppository.

Suppressed (sup-prest') [suppressus, concealed]. Overpowered; subdued. S. Breathing. See Breathsounds.

Suppression (sup-resh'-un) [suppressio; sub, under ; prinere, to press]. A condition of being concealed or retained; applied to the natural excreta of the body. S. of Menses, the abnormal abstention of the menses beyond their usual time of appearance. See Amenorrhea. S. of Urine, a condition due to a renal disorder, with interference with the secretion of urine.

Suppurant (sup'-u-rant) [suppuratio, suppuration]. I. Suppurating, or promoting suppuration. 2. An agent which promotes suppuration.

Suppuration (sup-u-ra'-shun) [suppuratio; sub, beneath; $\pi \tilde{v} o v$, pus]. The formation of pus. The process following inflammation, whereby the white bloodcorpuscles or leucocytes, together with other cells, become the distinctive corpuscles of pus, and thus form an abscess. In this process microörganisms play an important rôle. See, also, Theories of Inflammation, under Theory.

Suppurative $\left(s u p^{\prime}-u-r a-t i v\right)$ [suppuratio, a suppuration]. I. Promoting suppuration; producing pus, 2. An agent, medicine, or application that favors suppuration.

Supra-(su'-prah) [supra, above]. A prefix signifying upon or above. S.-acromial, situated above the acromion. S.-anal, above the anus, or above the top of the abdomen. S-axillary, above the axilla; above the axil.

Supra-auricular (su-prah-aw-rik'-u-lar). Situated or occurring above the external ear. S. Point. See Craniometric Points.

Suprabranchial (su-prah-brang'-ke-al) [supra, above; branchice, gills]. Above the gills.

Suprabuccal (su-prah-buk'-al) [supra, above; bucca, mouth]. Above the buccal region.

Supracephalic (su-prah-sef-al'-ik) [supra, above; кєф$a \lambda \eta$, head]. Placed on the head.

Suprachoroid (su-prah-ko'-roid) [supra, above; choroid ]. Situated above the choroid or the choroid plexus.

Supraciliary (su-prah-sill-e-a-re). Same as Superciliary.

Supraclavicle (su-prah-klav'-ik-l) [supra, above; clavis, key]. In biology, a distinct portion of the scapular arch of certain fishes (Dory, Sturgeon).

Supraclavicular (su-prak-kla-vik'-u-lar) [supra, above; clavis, collar-bone]. Above or upon the clavicle.

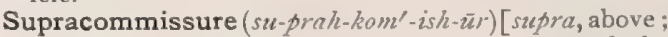
commissura, commissure]. The commissure of the brain just in front of the stalk of the epiphysis. 
Supracondylar (su-prah-kon'-dil-ar) [supra, above; condyle]. Situated above the condyles. S. Foramen, (1) the posterior condyloid foramen of the occipital bone; (2) a constant foramen in the inner condyloid ridge of the humerus. S. Ridges, ridges on the shaft of the humerus extending upward from the condyles.

Supracondyloid $\left(s u-p r a h-k o n^{\prime}-d i l-o i d\right)$. Same as Supracondylar.

Supracostal (su-prah-kos'-tal) [supra, above; costa, rib]. Situated above a rib or above the ribs.

Supradiaphragmatic (su-prah-di-af-rag-mat' $i k$ ) [supra, above; diaphragm]. Situated above the diaphragm.

Supradorsal (su-prah-dor'-sal) [supra, above; dorsum, back]. Dorsal ; placed dorsally.

Supraesophageal (su-prah-e-so-faj'-e-al) [supra, above; oiroфáyos, esophagus]. Situated above the gullet.

Suprafoliaceous (su-prah-fo-le-a'-shus) [supra, above; folizm, leaf ]. In biology, inserted upon the stem above the axil of a leaf.

Suprafoliar (su-prah-fo'-le-ar) [supra, above; folium, leaf ]. In biology, growing upon a leaf.

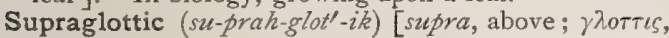
glottis]. Situated within the larynx and above the vocal bands.

Suprahyoid (su-prah-hi'-oid) [supra, above; hyoid]. Situated above the hyoid bone.

Supra-iliac $\left(s u^{\prime}-p r a h-i l^{\prime}-e-a k\right)$ [supra, above; itium, ilium]. Above or at the upper end of the ilium.

Supra-ilium (su-prah-il'-e-um) [supra, above; ilium, ilium ]. A proximal epiphysis of the sacral end of the ilium of some animals.

Supra-intestinal (su-prah-in-test'-tin-al) [supra, above; intestine]. Above the intestine.

Supralabial (su-prah-la'-be-al) [supra, above; labium, lip]. Pertaining to or situated above the upper lip.

Supramalleolar (su-pra-mal-e'-o-lar) [supra, above ; malleolus, malleolus]. Above the malleoli. S. Amputation, removal of the leg at the lower portion above the malleoli.

Supramammary (su-prah-mam'-ar-e) [supra, above ; mamma, breast]. Above the mammæ.

Supramarginal (su-prah-inar'-jin-al) [supra, above; marginal]. Bounding the Sylvian fissure on the upper side, as the supramarginal convolution.

Supramaxilla $\left(s u-p r a h-m a k s-i l^{\prime}-a h\right)$ [supra, above; maxilla, maxilla]. The supramaxillary bone.

Supramaxillary (su-prah-maks'-il-a-re) [supra, above; maxilla, maxilla]. Relating to the superior maxilla.

Supranasal (su-prah-na'-zal) [supra, above; nasus, nose]. Above the nose. $\mathbf{S}$. Point. See Craniometric Points.

Supraneural (su-prah-nu'-ral) [supra, above; veṽpov, nerve]. Over or above the neural axis.

Supra-occipital (su-prah-ok-sip'-it-al) [supra, above; occiput, occipital bone]. Situated above the occipital bone; also, the upper part of the occipital bone.

Supra-orbital (su-prah-or'-bit-al) [supra, above; orbita, orbit]. Situated above the orbit of the eye. S. Arch or Ridge, the curved prominent margin forming the upper boundary of the orbit. S. Foramen, a foramen at the inner third of the orbit. It transmits the supraorbital artery, vein, and nerve. Sometimes it is incomplete, being but a notch or groove, and then is called the S. Notch. S. Point. See Craniometric Points.

Suprapatellar (su-prah-pat-el'-ar) [supra, above; patella, patella]. Over or above the patella.

Suprapedal (su-prah-ped'-al) [supra, over; pes, foot]. Above the foot.
Suprapharyngeal (su-prah-far-in'-je-al) [supra, above; $\phi a ́ \rho v \gamma \xi$, pharynx ]. Above the pharynx.

Supraplex (su'-prah-pleks) [supra, above; plexus, plexus]. One of the plexuses of the brain of some animals.

Supraplexal (su-prah-pleks'-al) [supra, above; plexus, plexus]. Pertaining to the supraplex.

Suprapontile (su-prah-pon'-til) [supra, above; pons, bridge]. Situated or occurring above the pons.

Suprapromontorence (su-prah-prom-on'-to-rens) [supra, above; promontorence]. The convex eminence caused by the course of the facial canal over the oval window and inferior semicircular canal above. Called, also, Petro-mastoidean Canal.

Suprapubic (su-prah-pu'-bik) [supra, above; pubis, pubis]. Situated or occurring above the pubes, as a suprapubic operation.

Suprapygal (su-prah-pi'-gal) [supra, above; pyga, rump]. Above or over the rump.

Suprarectus (su-prah-rek'-tus) [supra, above; rectus, straight]. The rectus superior muscle of the eye.

Suprarenal (su-prah-re'-nal) [supra, above; ren, the kidney]. Above the kidney; applied especially to the suprarenal capsules or bodies. S. Bodies

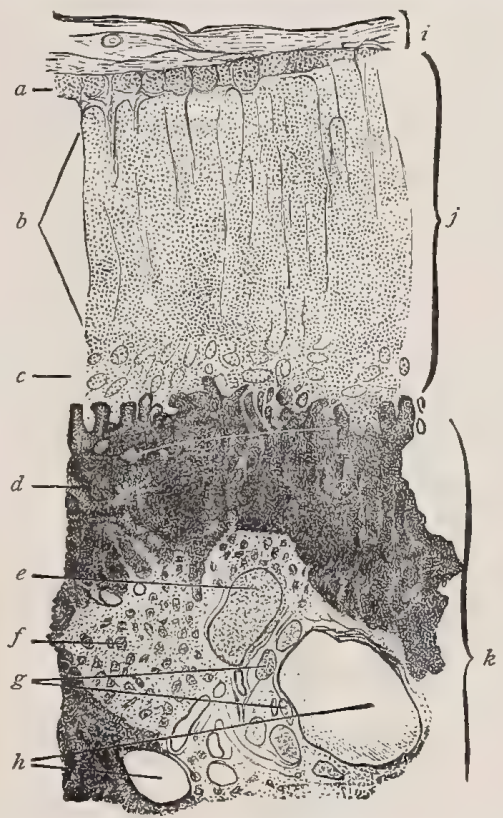

Transyerse Section of the Human Suprarenal Capsule, $\times$ 50. (From Stirling.)

a. Zona glomerulosa. b. Z. fasciculata. c. Z. reticularis. $d$. Strands of cells of the medulla. $e$. Transverse section of a nerve. $f$. Ganglionic cells. $g$. Transverse section of bundles of smooth muscle. $h$. Transverse section of a vein. i. Capsule. $j$. Cortex. $k$. Medulla.

or Capsules, small, flattened, ductless bodies, the adrenals, somewhat glandular in appearance, situated just above the kidneys. Their function is not known.

Suprascapula (su-prah-skap'-u-lah) [supra, over; scapula, scapula]. A bone of the shoulder-girdle in certain fishes.

Suprascapular (su-prah-skap'-u-lar) [supra, above; scapula, the shoulder-blade]. Situated above the shoulder-blade. S. Notch. See Notch.

Supraseptal (su-prah-sep'-tal) [supra, above; septum, septum]. Situated above a septum.

Supraserratus (su-prah-ser- $\left.a^{\prime}-t u s\right)$ [supra, above; serra, saw]. The serratus posticus superior muscle. 
Supraspinal (su-prah-spi'-nal) [supra, above; spina, the spine]. Situated on the spine or above its origin.

Supraspinales (su-prah-spi-na'-lēz). See Muscles, Table of.

Supraspinate (su-prah-spi'-nāt). See Supraspinous.

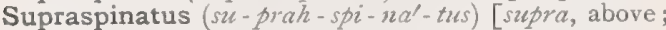
spina, spine]. A name given to various organs situated upon the spine or above its origin.

Supraspinous (su-prah-spi'-nus) [supra, above; spina, spine]. Situated over the spinous process of a vertebra. S. Fossa, the triangular depression above the spine of the shoulder-blade. S. Muscle. See Mus cles, Table of.

Suprastapedial (su-prah-sta-pe'-de-al) [supra, above; stapes, stapes]. Above the stapes.

Suprasternal (su-prah-ster'-nal) [supra, above; orépvov, sternum]. Cephalad of the sternum.

Supratemporal $\left(s u-p r a h-t e m^{\prime}-p o-v a l\right)$ [supra, over; tempus, time]. Over the temporal region.

Suprathoracic (su-prah-tho-ras'-ik) [supra, over; Ois $\rho a \xi$, thorax ]. Above the thorax

Supratrochlear (su-prah-trok'-le-ar) [supra, above; trochlea, pulley]. Situated or occurring above any trochlear part, but particularly above the trochlea of the humerus. See Trochlea.

Supratympanic (su-prah-tim-pan'-ik) [supra, over; tympanum, tympanum]. Above the tympanum.

Supravaginal (su-prah-vaj'-in-al) [supra, over; vagina, vagina]. Above the vagina.

Sura $\left(s u^{\prime}-r a h\right)[s u r a]$. The calf of the leg. The prominence formed by the gastrocnemius muscle.

Sural $\left(s u^{\prime}-\mathrm{ral}\right)$ [suralis; sura, calf]. Pertaining to the calf of the leg. S. Nerve, Superficial, that formed by the junction of the external cutaneous of the peroneal and the communicantes fibulares. S. Vein, one situated just beneath the skin of the calf; it opens into the popliteal vein.

Suralimentation (sur-al-im-en-ta'-shun) [super, over; alimentation]. The method of forced feeding or over-alimentation sometimes employed in pulmonary tuberculosis and other diseases.

Suranal (sur-a'-nal). Same as Supra-anal.

Surcingle (sur'-sin-gl) [super, over; cingulum, a belt]. The tail, or narrow end, of the corpus striatum.

Surculigerous (sur-ku-lij'-er-us) [surculus, a sucker; gerere, to bear]. Producing a sucker.

Surculose, Surculous (sur'-ku-loz, sur'-ku-lus) [surculus, a sucker]. Producing suckers.

Surculus (sur'-ku-lus) [L., a twig, shoot: pl., Surculi]. In biology, a sucker.

Surcurrent (sur-kur'-ent) [sub, under; currere, to run]. In biology, denoting a leafy expansion running up the stem.

Surditas (sur'-dit-as). Synonym of Deafness. $\mathbf{S}$. verbalis. See Aphasia.

Surdity (sur'-dit-e). See Deafness.

Surdomute (sur'-do-müt) [surdus, deaf; mutus, mute]. A deaf and dumb person.

Surdomutitas (sur-do-mu'-tit-as) [surdus, deaf; mutus, mute]. Deaf-muteness; deaf-mutism.

Surdus $\left(s u r^{\prime}-d u s\right)$. See Deaf.

Suren (su'-ren) [Ger.]. The old German name for the pustules of scabies; later Sarcoptes were named Suren, which was finally Latinized by Hildegard and others into surones, suriones.

Surface (sur'-fäs) [Fr., surface]. 1. The exterior of a body. 2. The face or faces of a body; a term frequently used in anatomy in the description of bones. S.-wells, those which obtain their supply from the subsoil water

Surfeit $\left(\right.$ sur $\left.^{\prime}-f t\right)$ [Fr., surfait, excessive]. A sense of fulness approaching nausea, arising from excess in eating or drinking. More than enough.

Surgeon (sur'-jun) [ME., sourgeon, surgeon]. One who practises surgery. See Chinurgeon. S.s' Agario. See Agaricus. S.-apothecary, in England, one who is licensed to practise by the Royal College of Surgeons and by the Apothecaries' Society. S.aurist, an otologist. S.-dentist, a dentist who practises the surgical as well as the mechanical parts of his profession. S.-general, the title of certain surgeons of high rank, chiefly in the military and naval services. S.-generalship, the office of a surgeon-general. S.-ship, the office of a surgeon. S., Veterinary, one who treats diseases of the domestic animals.

Surgeoncy (sur'-jun-se) [ME., sourgeon, surgeon]. The office of surgeon, military or naval.

Surgery (sur'-jer-e) [ME., surgerie, surgery]. See Chirurgery. Formerly that branch of medicine concerned with manual operations under the direction of the physician. The scope of the word is now widened, and is so bound up with general medicine that a strict and succinct definition is impossible. Instrumental and manual operative work is still the chief idea, and, so far as it is related to diseases commonly or possibly requiring operative procedure, surgery usually includes the treatment of systemic abnormalities. The term, as limited to a special branch of medical science, as obstetric, gynecologic, aural, ophthalmic, etc., is growing into disuse, while, at the same time, the division of these specialties has narrowed the field of work of surgery as now commonly understood. The surgeon has recouped himself by the inclusion in his department of many subjects not strictly requiring operative treatment, such as inflammation, fever, microbiology, syphilis, etc., etc. S., Antiseptic, the application of antiseptic methods in the treatment of wounds. S., Conservative, measures directed to the preservation rather than to the removal of a part. S., Military, that pertaining to gunshot wounds and other injuries peculiar to military life. S., Minor, includes the lesser surgical operations, bandaging, the making and application of splints, dressings and sutures, counter-irritation, cauterization, blood-letting, vaccination, etc. S., Operative, refers to the performance of operations. S., Orthopedic, the remedy of deformities by manual and instrumental measures. S., Plastic, repair of absent or defective tissue by transference of tissue from another part or person. See Transplantation, Autoplasty, Rhinoplasty, etc. S., Railway, deals with injuries received on railways. S., Veterinary, the surgery of domestic animals.

Surgical (sur'-jik-al) [ME., surgerie, surgery]. Pertaining to surgery. S. Fever. See Traumatic Fever. S. Insanity. See Insanitv, Confusional. S. Kidney, suppurative disease of the kidney. S. Knot. See Knot. S. Sore-throat, sore-throat due to the absorption of septic matters in hospitals; it sometimes attacks interne surgeons and nurses. S. Tuberculosis, tuberculous disease that may be reached by operative treatment, $e_{.} g_{*}$, that involving glands, joints, bone, and the like.

Surprise (sur-priz') [ME., surprisen, to surprise]. To strike with sudden astonishment; to come upon suddenly. S. Bath. See Bath. S., Cerebral, instantaneous and temporary stupor caused by mental shock or by a sudden lesion of the brain.

Surra, or Surrah Disease $($ soor'-rah) [native name in India]. The name given by English army veterinary surgeons to an epizoötic pernicious anemia in horses, mules, and camels, associated with the presence of an infusorian (Trypanosoma evansi, Balbiani). It has at 
times incapacitated the English cavalry service in India, killing 50 per cent. of the horses. See Parasites (Animal), Table of.

Surrogate (sur'-o-gät) [surrogatus, substituted]. Any medicine or ingredient used as a substitute for another and more expensive ingredient, or one to which there is a special objection in any particular case.

Sursumduction (sur'-sum-duk'-shun) [sursum, upon; ducere, to lead]. The power of the two eyes of fusing two images when one eye has a prism vertically before it.

Survival (sur-vi'-val) [super, over; vivere, to live]. In biology, the persistence of an individual or race, after the general extinction of related forms. S. of the Fittest. See Selection, Natural, and Evolution.

Susceptible (sus-sep'-tib-l) [suscipere, to undertake]. Sensitive to an influence. In pathology, liable to become affected with a disease.

Suspended (sus-pen'-ded) [suspendere, to hang up]. I. Hanging; applied to an ovule hanging from the ovarian wall, or a seed from the summit of a cell. 2. Interrupted. S. Animation, a term sometimes applied to the temporary cessation of the vital functions. It may be due to asphyxia, to syncope, or to the trance-like condition that closely simulates death, in which the patient may remain for some hours or even days. $\mathbf{S}$. Matter, undissolved particles diffused throughout a liquid.

Suspension (sus-pen'-shun) [suspensio; sub, under; pendere, to hang]. The act or condition of hanging, as applied to an organ or part. Also, a mode of treatment of certain diseases, especially tabes dorsalis, in which the patient is so placed that the whole weight of the body hangs upon the neck, the head being supported at the chin and the occiput. The stretching of the spinal cord sometimes removes the morbid process in a manner at present not well understood; also, that condition of a finely divided solid in which it is held undissolved in a liquid. S.-treatment. See under Suspension.

Suspensor (sus-pen'-sor) [suspendere, to suspend]. In biology, a term applied to the chain of cells formed by division of the germ cell in the embryo-sac previous to the formation of the embryo. A Suspensorium. See Pro-embryo.

Suspensorium (sus-pen-so'-re-um) [sub, under; pendere, to hang]. That upon which anything hangs for support. S. hepatis, the suspensory ligament of the liver. S. testis, the cremaster muscle. S. vesicæ, the superior false ligament of the urinary bladder.

Suspensory (sus-pen'-so-re) [sub, under; pendere, to hang]. Designed or useful for suspension. Suspending. S. Bandage, a supporting bandage for the scrotum. S. Ligament. See Ligament and Zona ciliaris. S. Ligament of the Lens. See Zonula of Zinn. S. Triangle. See Triangle.

Suspiral (sus'-pir-al) [suspirare, to breathe out]. A breathing-hole.

Suspiration (sus-pi-ra'-shun) [suspiratio]. A sigh, q. $v_{0}$; the act of sighing.

Suspirious (sus-pi'-re-us) [suspiriosus]. Characterized by sighing.

Suspirium (sus-pi'-re-um) [L.: pl., Suspiria]. A sigh.

Sustentacular (sus-ten-tak'-u-lar) [sustentaculum, sustentare, to support]. Pertaining to or serving as a sustentaculum. S. Cells, a name given to certain supporting cells in the testicle. S. Tissue, supporting tissue.

Sustentaculum (sus-ten-takl-u-lum) [sustentare, to support]. A support. S. lienis, the suspensory ligament of the spleen. S. tali, a process of the os calcis supporting the astragalus.
Susurration (sus-u-ru'-shun) [susurratio]. A murmur, or susurrus.

Susurrus $\left(s u\right.$-sut $\left.\boldsymbol{t}^{\prime}-m e\right)$ [L.]. A soft murmur in aneurysm, cardiac diseases, contracting muscle, etc. S. aurium. See Tinnitus aurium.

Sutela $\left(s u-t e^{\prime}-l a h\right)$ [L.]. To sew. See Suture.

Sütüghin's Method. A method of dressing the umbilical cord. The navel, funis, and stump are powdered with pure gypsum, and the cord is wrapped in hygroscopic cotton-wool sprinkled with the same powder. The dressing is changed twice daily. The cord in a short time becomes mummified.

Sutura $\left(s u-t u^{\prime}-r a h\right)$ [L.]. See Suture.

Sutural (su'-tu-ral) [sutura, suture]. Pertaining to or having the nature of a suture.

Suture $\left(s u^{\prime}-t \bar{u} r\right)$ [sutura, suture]. I. A line of joining or closure; a seam, raphe. 2. A stitch used in closing the lips of a wound. S., Antiseptic, the material used has been made aseptic by boiling, or by some other germicidal measure. S., Appolito's, a continued Gély's suture. S. of Apposition, a superficial suture, including only the skin, and employed to secure accurate apposition of the margins of the latter. S. of Approximation, one which is passed deeply through the lips of a wound to secure apposition of the deeper tissues. S., Base-ball, a continuous suture all around the wound. It has been employed in complete division of the intestine. S., Pesiard's, a modification of S., Bertrandi's. The needle is threaded with a white and a colored thread; in withdrawing the suture the white thread is withdrawn from one end and the colored thread from the other. S., Bell's (B.), a modification of the glovers' suture, in which the needle is passed from within out alternately on the two sides of the wound. S., Bertrandi's, à points passés; a continuous suture passed through and through, back and forth. S., Bishop's, an interrupted intestinal suture introduced on the mucous surface of the bowel, and the knots tied alternately on each siae of the wound. S., Bouisson's (intestinal), five pins are passed in and out on each side of the wound, which is closed by drawing the pins together by sutures introduced in the intervals. S., Bozeman's, or Bozeman's Button. See S., Button. S., Breidenbach's, Lembert sutures tied in the lumen of the bowel. S., Buried, a suture employed to approximate structures in the depths of wounds, the superficial tissues being brought together over them. Buried sutures are completely covered by skin, and do not involve this structure at all. S., Button, the use of button-like discs to prevent the thread from cutting through the tissues and to bring large masses in better apposition. S., Catgut, a suture in which the material employed is catgut. S., Circular, one that is applied to the entire circumference of a divided organ, as the intestine. S., Circumvoluted. See S., Treisted. S., Clamp, the shotted suture of Sims. S., Clavate. See S., Quilled. S. of Coaptation. See S. of Apposition. S., Cobblers', a suture made by arming a needle with two threads. S., Compound. See S., Quilled. S., Connell's, one for uniting intestine after circular resection. About half the lumen of the bowel is united by stitching through all the coats of both ends, from the mucous surface, back and forth. The remaining. portion is closed by continuous sutures, which are passed parallel with the margins of the wound and carried across the latter. S., Continued, or Glovers', one composed of a number of interrupted sutures, which are not cut apart. S., Cranial, the line of union of two or more cranial bones. There are three sets of cranial sutures: those at the base of the skull, those at the 
SUTURE
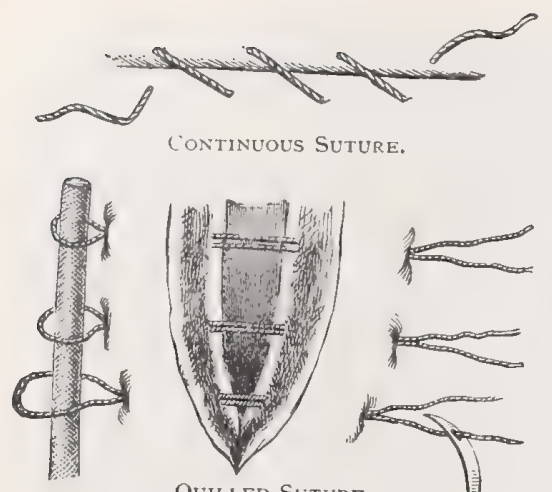

Quilled Suture.

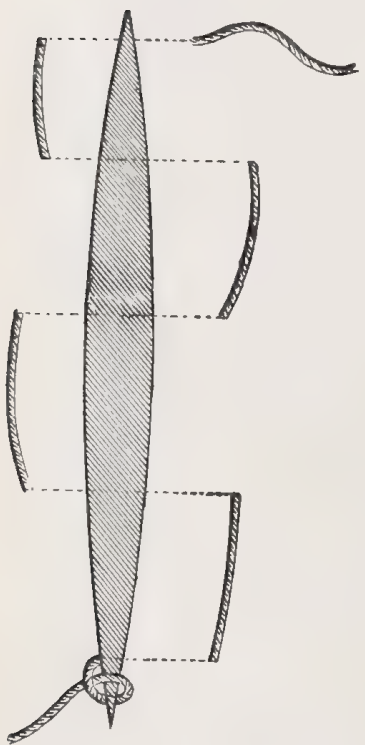

A

QUiLted Sutures.
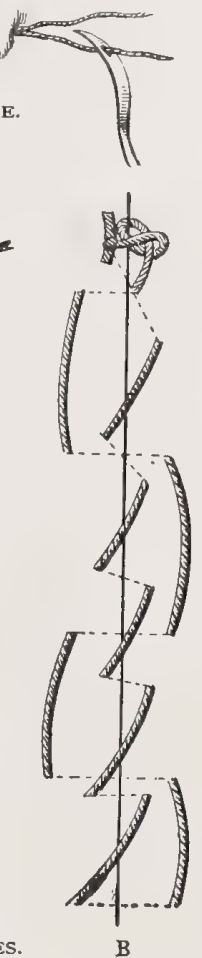

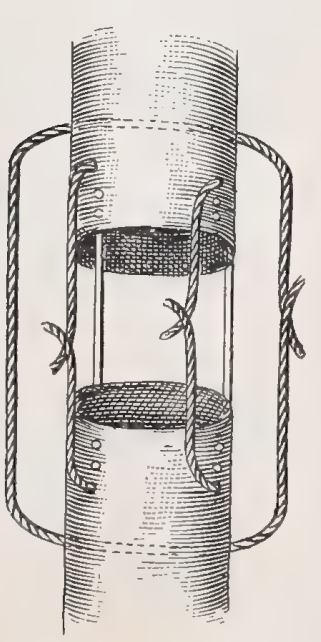

Suture of Le Dentu.
1438

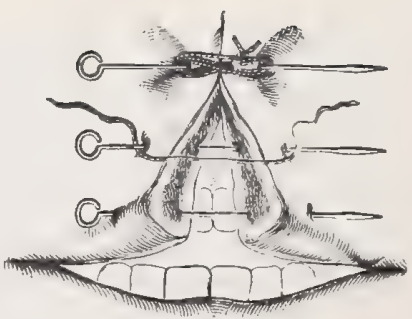

HARE-Lip SUTURE.

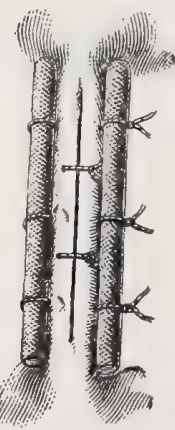

Quilled Suture.

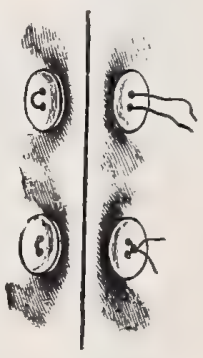

BUTTON-SUTURE.

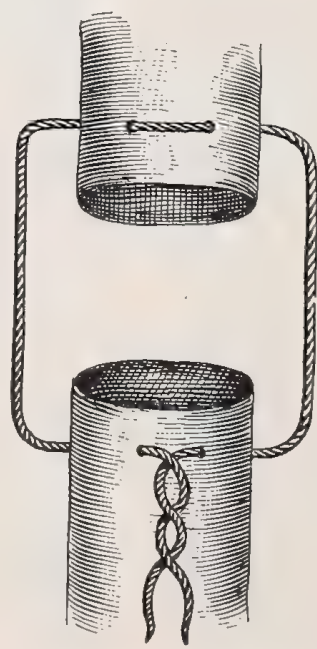

TENDON-SUTURE OF LE For'T.
SUTURE

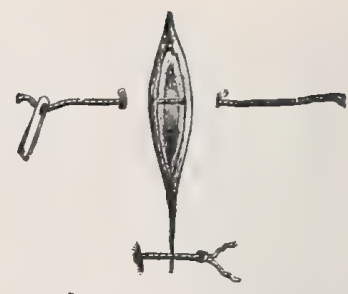

INTERRUPTED SUTURE.

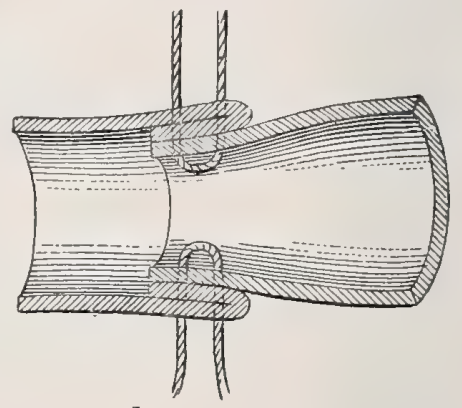

JOBERT'S SUTURE.

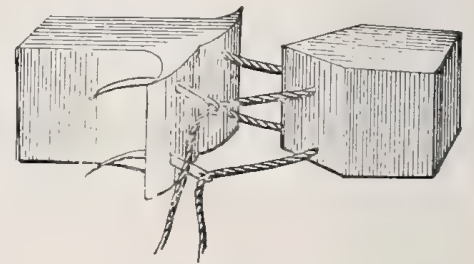

Tongue AND Groove Suture.

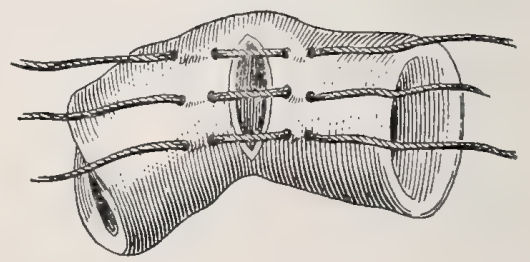

LEMBERT'S SUTURE.

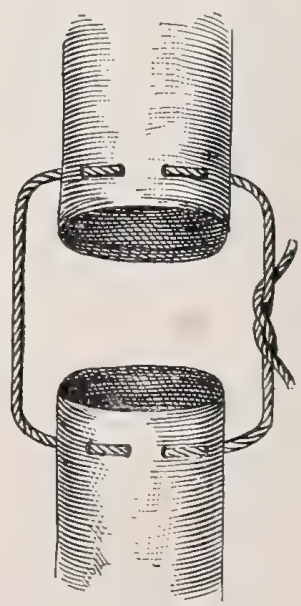

TENDON-SUtURE. (Wöfler, after Lejars.) 

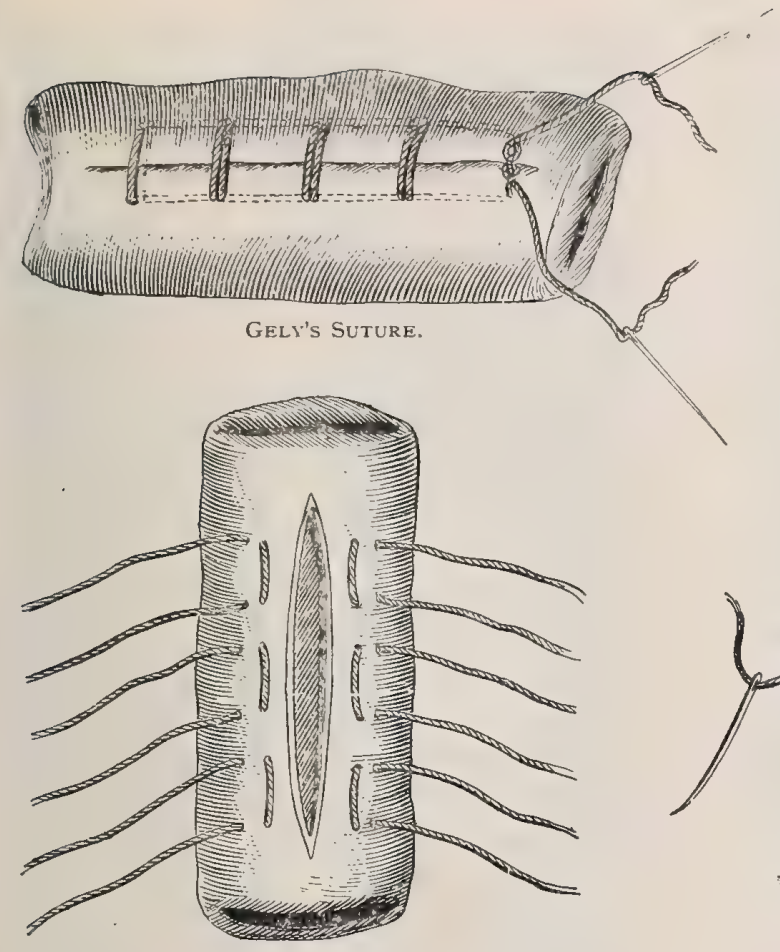

EMMERT'S METHOD.

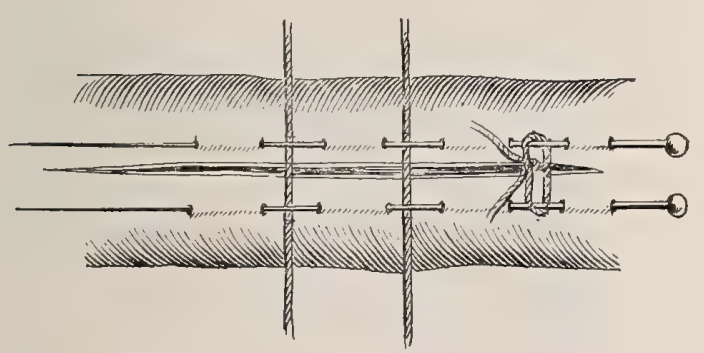

BOUISSON'S SUTURE.

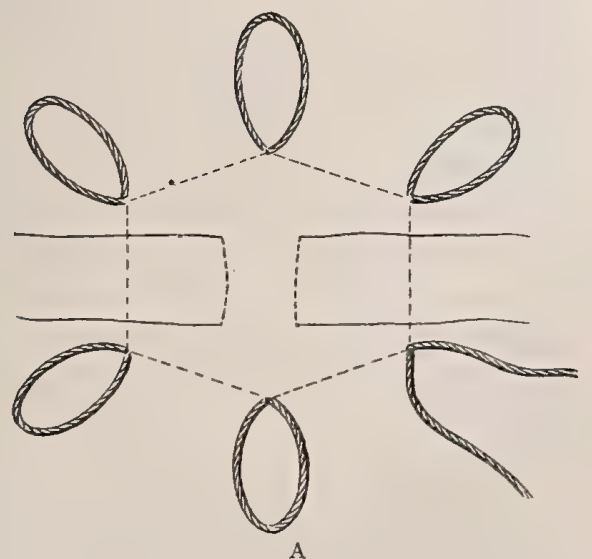

SUtURes for IMmediate Gastrostomy.

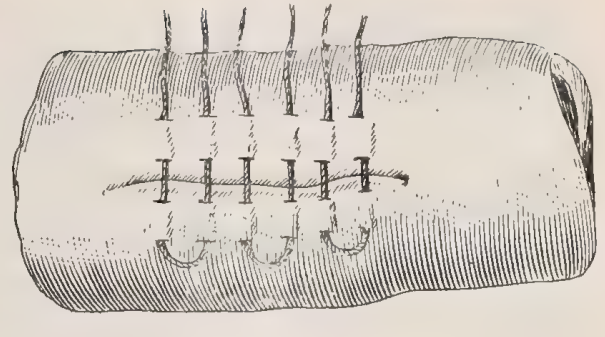

Halstead's Plain Quilt-suture.
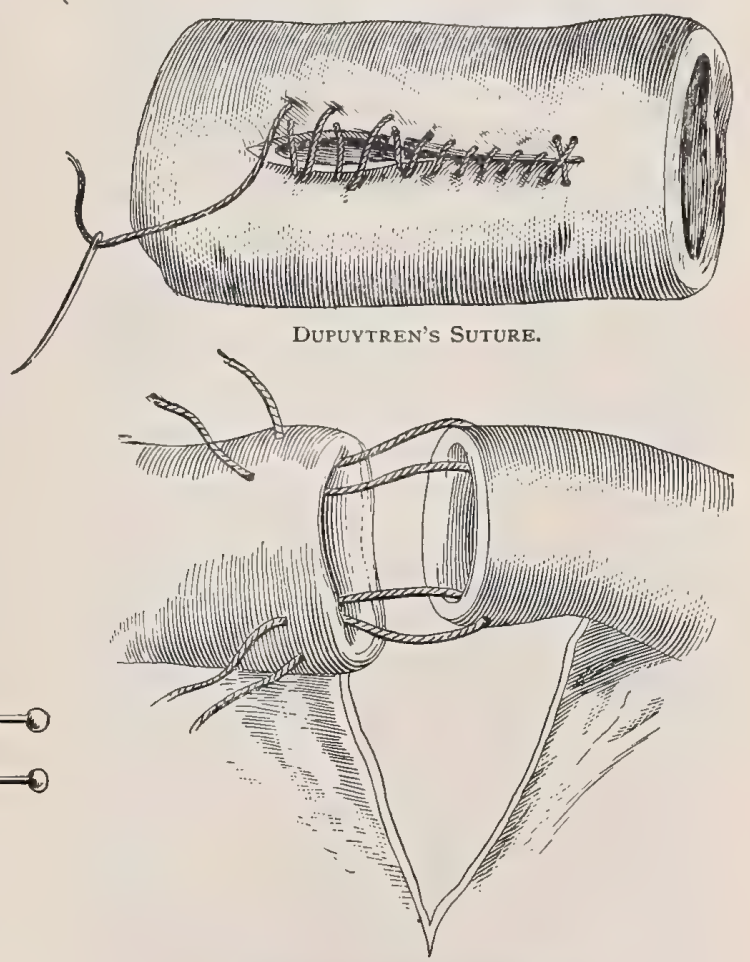

JOBERT'S INVAGINATION-SUTURE.

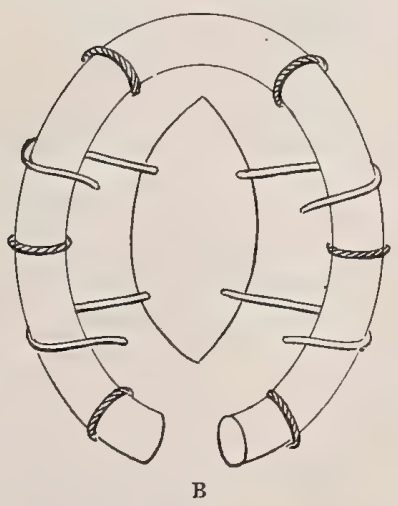

SUTURES FOR IMMEDIATE GASTROSTOMY. 
side, and those at the vertex. "These are as follows: Basilar, the junction between the basilar surface of the occipital bone and the posterior surface of the body of the sphenoid. S., Coronal (fronto-parietal), the union of the frontal with the parietal bones trans. versely across the vertex of the skull. S., Dentate, an irregular tooth-suture, as between the parietal bones. S., Ethmoido-frontal, the union between the frontal and ethmoid bones. S., Ethmo-lacrymal, the union between the lacrymal and ethmoid bones. S., Ethmosphenoid, the union between the sphenoid and ethmoid bones. S., False, any suture in which there is interlocking of the bones without serration. S., Frontal, a suture which at birth joins the two frontal bones from the vertex to the root of the nose. The bones afterward become one by its obliteration. S., Frontomalar, the union between the malar and frontal bones. S., Fronto-maxillary, the union between the superior maxillary and frontal bones. S., Fronto-nasal, the union between the nasal and frontal bones. S., Frontoparietal. See Coronal Suture. S., Fronto-sphenoid, the union between the alre of the sphenoid bone and the frontal bone. S., Fronto-temporal, the union between the frontal and temporal bones. S., Infraorbital, a suture sometimes found in the line of the infra-orbital canal. S., Intermaxillary, the union between the superior maxillary bones. S., Internasal, the union between the nasal bones. S., Interparietal. See S., Sagittal. S., Jugal. See S., Sagittal. S., Lambdoid, the union between the two superior borders of the occipital bone and the parietal bones. $S$., Lepidoid. See S., Squamo-parietal. S., Longitudinal. See S., Sagittal. S., Masto-occipital. See S., Occipito-mastoid. S., Mrasto-parietal. See S., Parieto-mastoid. S., Maxillo-lacrymal, the union between the lacrymal and superior maxillary bones. $S$, Maxillo-premaxillary, the union of the premaxillary portion of the superior maxillary with the rest of the bone. S., Medio-frontal. See S., Frontal. S., Metopic. See S., Frontal. S., Nuso-maxillary, the union between the superior maxillary and nasal bones. S., Neurocentral, the cartilages between the bodies of the dorsal vertebræ, posterior to the points of articulation of the ribs with the main portion. $S$, Occipilal. See S., Lambdoid. S, Occipito-mastoid, the union between the mastoid portion of the temporal bone and the occipital bone. S., Occipito-parietal. See S., Lambdoid. S., Palatine, the union between the palate bones. S., Palatine, Transverse, the union between the superior maxilla and the palatine processes of the palate bone. S., Parieto-mastoid, the union between the mastoid portion of the temporal bone and the parietal bone. S., Petro-occipital, the union between the occipital bone and the petrous portion of the temporal. S., Petro-sphenoid, the union between the ala magna of the sphenoid bone and the petrous portion of the temporal. S., Sagittal, the union between the medial margins of the parietal bones. $S$, Scaly. See S., Squamo-parietal. S., Serrated, a suture in which the interlocking indentations and projections are finer than those of a dentate suture. $S$, Spheno-malar, the union between the malar bone and the ala magna of the sphenoid. S., Spheno-parietal, the union between the ala magna of the sphenoid bone and the parietal bone. S., Spheno-petrosal. See S., Petro-sphenord. S., Spheno-squamous. See S. Squamo-sphenoid. S., Spheno-temporal, the union between the temporal bones and the sphenoid. $S$. Squamo-parietal, S., Squamosal, the union between the squamous portion of the temporal bone and the

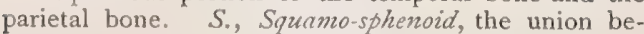
tween the great wing of the sphenoid and the squamous portion of the temporal bone. S., Squamous. See S., Squamo-parietal. S., Temporo-occipital. See S., Occipito-mastoid. S., Temporo-parietal, the union between the parietal and temporal bones, made up of the parieto-mastoid and squamosal sutures. S., Transverse (frontal). See $S$, Coronal. S., True, a union between bones by the interlocking of projections and indentations. S., Zygomatic, a union between the temporal bone and the zygomatic process of the superior maxilla. S., Cushing's Right-angled Continuous Intestinal, the needle is introduced parallel with the wound on the serous surface and carried back and forth across the wound in this way. S., Czerny's (intestinal), the needle is passed from the serous surface through the wound, down to, but not including, the mucous membrane, and through the wound on the opposite side and out on the serous sur. face. S., Czerny-Lembert, the application of Lembert sutures after the Czerny sutures are in place. S., Deep. See S., Buried. S., Distance, a suture used in uniting tendons, nerves, etc. S., Dry, adhesiveplaster strips are applied to the lips of the wound, and these are drawn together by suturing the selvaged edge of the strips. S., Duplay's Tendon. See S., Tillaux and Duplay's. S., Dupuytren's, a continued Lembert suture. See Illustration. S., Duverger's, a suture of the intestine in which the trachea of a calf is used as the basis of support. S., Emmert's, a suture for intestinal wounds. It consists of a series of double Lembert sutures. See Illustration. S., Furriers'. See S., Glovers'. S., Gaillard's, a suture for entropion. A threaded needle is passed in the lid near its free margin and at the junction of its middle and outer thirds and brought out about a thumb's breadth from the margin; the other end of the thread is passed parallel to and near the first, and the ends are tied over a roll of lint. A similar suture is passed at the junction of the middle and inner thirds. S., Garengeot's, the glovers' suture of the intestine, in which the stitches are placed farther apart than usual. S. for Gastrostomy, a suture is made to surround the proposed opening in the stomach, with loops left at convenient intervals. By means of a needle supplied with a hook these loops are drawn through the abdominal wall around the incision, and quills introduced through the loops, after which the suture is drawn tight. This approximates the stomach firmly to the abdominal wall. See Illustration. S., Gély's, an intestinal suture applied by a thread with a needle at each end. The wound is closed by a series of cross-stitches. See Mlustration. S., Glovers', a continued suture in which the needle is passed through the loop of the preceding stitch each time. S., Gussenbauer's, a figure-of- 8 suture for the intestine, intended to accomplish the same result as the CzernyLembert suture. S., Halstead's, a plain quilt-suture, a modification of Lembert's suture. See Illustration. S., Hare-lip, or Twisted, the edges of the wound are transfixed with pins and approximation secured by twisting or wrapping the ends of the pins with thread. See Illustration. S., Harris's, a suture for intestinal wounds. The mucous membrane of the distal end is denuded with a curet for one or two lines and the upper end invaginated, and sutures passed. S., Horse-hair, the strong hairs of the mane or tail of the horse, prepared as sutures. S., Implanted, hare-lip pins are passed through the skin on each side of the wound and parallel with it, which is then approximated by twisting thread around the exposed extremities of the pins. S., India-rubber, the same as S., Truisted, except that small rubber rings are used instead of string. S., Interrupted, a series of sutures passed through the margins of 
the wound, and each of which is knotted. See Illustration. S., Jobert's, a suture for intestinal wounds. This author has described three different forms of suture, which have been called after his name. See lilustration. S., Knotted. See $S$. Interrupied. S., Lace, a suture in which a small curved needle is repeatedly introduced around the wound, forming a continuous suture encircling the deficiency (fistula). S., Lapeyronie's, a modification of S., Palfyn's, the thread being passed through the mesentery. S., Lead-plate, a suture the ends of which are attached on either side of the wound to lead-plates. S., Le Dentu's (tendon). See Illustration. S., Ledran's, intestinal sutures passed through the wound one-fourth inch apart; the threads are tied separately on each side, forming two bundles. S., Le Fort's (tendon). See Illustration. S., Lembert's, an intestinal suture in which the needle is passed transversely to the wound through the peritoneal and muscular coats and out again on one side of the wound, and then carried across the wound and made to penetrate the two outer coats as before. See Illustration. S., Littré's, in cases of gangrene of the intestine, the inferior end is obliterated by ligation and the upper end is attached to the inguinal ring to form an artificial anus. S., Löffler's, a suture for intestinal wounds. Interrupted metallic sutures are crossed once and attached to the abdominal wound. S., Loop. See S., Internipted. S., Mansell's, a suture for complete transverse section of the intestine. The two ends are drawn through a longitudinal slit made for the purpose in one end, and the two sections accurately united by interrupted sutures; the invaginated portion is withdrawn, and the longitudinal slit closed. S., Mattress, a continuous suture which is made back and forth through both lips of the wound. S., Metallic-plate. See S., Button. S., Nerve, a suture of fine thread or catgut uniting the divided ends of a nerve. S., Noose. See S., Interrupted. S., Palfyn's, a loop of thread is passed through the intestinal wound, and the ends of which are then secured to the integument. S., Pancoast's. See $S$., Tongue and Groove. S., Petit's, a suture for intestinal wounds. As many stitches as are required are passed three lines apart, the ends on each side are tied together and then twisted into two bundles. S., Pin. See S., Hare-lip. S., Plastic, a suture devised by J. Pancoast, and used by him for superficial wounds, the extent of the approximated surfaces being enlarged to increase the chance of union. The cut surface of one lip of the wound is beveled to fit into a groove in the other lip. The thread is carried from without inward, first through the outer lip of the groove; then, the beveled lip, and then the deep lip of the groove; then forming a loop on the deep surface of this lip, it is carried again through the same structures in inverse order and at a different place. The free ends are tied over a little roll of adhesive plaster placed on the skin-surface of the grooved lip. S., Primary, one that is used to effect immediate closure of the wound. S., Primo-secondary, the insertion of sutures at the time of operation, then tamponing the wound. The tampon is removed in from $I 2$ to 48 hours and the sutures tied. S., Quilled, a doubled thread is passed and tied over quills or a soft catheter; usually employed as sutures of relaxation. See Illustration. S., Quilt, one similar to S., Mattress. S., Ramdohr, invagination of the upper portion of the intestine into the lower, followed by suture. S., Rat-tail, a material obtained from the rat's tail. S. of Relaxation, one that is introduced some distance from the wound-margin, carried through its depths, and made to emerge at some distance on the opposite side. The intention is to relieve the tension of the wound-sutures. S.. Relief. See S. of Relaxation. S., Reybard, the employment of thin, oval plates of deal carrying threaded sutures, to unite the divided intestine. S., Richter's, a suture for intestinal wounds. Interrupted metallic sutures that are twisted and brought out of the external wound. S., Rigal's. See S., India Rubber. S., Ritisch's, a suture for intestinal anastomosis. The suture is passed through the bowel and lumen from side to side, the ends twisted, and brought out of the external wound. S., Robinson's, a suture for uniting the ends of a divided intestine. A rubber tube is inserted in the proximal end and the mucous membrane is denuded for one-half inch to receive the proximal end. A row of sutures is introduced around the circumference. S., Royal. See Royal. S., Sabatier's, the employment of a piece of playing-card saturated with turpentine for the approximation of intestinal wounds. S., Sailors'. See S., Reef. S., Sänger's, in the Cesarean operation the insertion of 8 or Io deep sutures of silver wire through the uterine incision, followed by 20 or more superficial sutures through the peritoneum. S., Secondary, one that is introduced at a period subsequent to the operation, as in cases in which the wound has been tamponed. S., Seroserous, one that brings two serous surfaces together. S., Shotted, both ends of the suture are passed through a perforated shot, which is then tightly compressed. S., Silk-worm Gut, a suture-material prepared from the "silk-guts" of the silk-worm. S., Simon's, a suture for lacerated perineum involving the sphincter ani, in which the rectal mucous membrane, the vaginal mucous membrane, and the skin are sutured separately. S., Sims'. See $S_{\text {., Clamp. }}$ S., Spiral. See S., Glovers'. S., Spiroidal, a continuous spiral intestinal suture. S., Staple, a sharpened wire, bent like a staple, is passed through both lips of the wound and secured. S., Subcuticular, a buried, continuous suture in which the needle is passed horizontally into the true skin back and forth until the whole wound is closed. S., Sunk. See $S$, Buried. S., Superficial, one which includes the skin only. S. of Support. See S. of Relaxation. S., Symperitoneal, a sero-serous suture of the peritoneum. S., Taylors', the cobbler-stitch used to bring together the flaps after amputation of the cervix uteri. S. Tendon. See S., Le Dentu's, Le Fort's, and Wölfer's. S., Tobacco-bag. See Stoltz's Operation in Operations, Table of. S., Tongue and Groove, one margin of the wound is beveled on each side and a V-shaped section is taken from the thickness of the other flap along its free margin, longitudinally, to receive the first. This gives a greater extent of raw surface in apposition. See Illustration. S., Triangular (of Simon), a suture for laceration of the perineum through the sphincter ani; the skin, vaginal mucous membrane, and rectal mucous membrane are separately stitched. S., Twisted. See S., Hare-lip. S., Uninterrupted. See S., Continuous. S., Utero-parietal, suturing of the uterus to the inner surface of the abdominal incision after Cesarean section. S., Viscero-parietal, a suture used in the operation of stitching a wounded organ to the abdominal incision. S., Wölfler's, an interrupted intestinal suture in which the knots of the stitches in the mucous membrane are tied in the lumen of the bowel in three-fourths of the circumference, and on the outside in the remaining portion. The serous surfaces are then united by Lembert sutures. S., Wölfler's (tendon). See Illustration.

Suzanne's Gland. A pea-sized glandular body found 
near the alveolo-lingual sulcus of the mouth close to the median line. It is distinct from the sublingual gland.

Svapnia (svap'-ne-ah). Denarcotized opium.

Swab (swob) [MD., swabber, splash]. A piece of cloth or sponge upon the end of a stick, used in feeding the sick, making applications to the throat, cleansing the mouth and teeth, etc. S.-stick, a rod or shaft, one extremity of which is to be wound with cotton.

Swaddle (swod'-l) [ME., swathilen, to swaddle]. To swathe; to wrap in cloths, as a new-born child.

Swaddling (swod'-ling) [ME., swadling]. The act of wrapping in a swaddle. S.-cloth, S.-clout, a cloth wrapped about a new-born child.

Swallow (swol'-o) [ME, swolowen, to swallow]. I. To take into the stomach through the throat. The cavity of the throat and gullet; the esophagus. 2. A fissirostral oscine passerine bird, of the genus Hirundo. S.'s-nest, the nidus hirundinis; a deep fossa of the cerebellum between the commissure of the flocculus and uvula. S.-tails, notches on the teeth of a horse.

Swallowing (swol'-o-ing) [ME., swolowen, to swallow]. Taking into the stomach through the throat and esophagus.

Swamp (swomp) [origin obscure]. A piece of low, wet, marshy land. S.-apple, a parasitic growth found on swamp-azalea. S.-dogwood: I. Buttonbush. 2. A plant allied to Cornus florida; Cornus sericea. S.-fever, a malarial fever. S.-itch. Same as Army Itch. S--laurel, Kalmia glauca. S.-milkweed, Asclepias incarnata. S.-pine, Pinus australis; broom-pine. S.-sassafras, magnolia. S. Yellowfever. See Henaturia, Malarial.

Swan Alley Sore. Synonym of Chancre, Phagedenic. Swarm [ME., rwarm, a swarm]. A cluster of insects, as bees. S.-cell. See Zoöspore. S.-spore. See Zoüspore.

Swarming [ME, swarmen, to swarm]. I. Moving in a swarm. 2. Breeding multitudes. A form of endogenous cell-formation noted in certain algæ (Confervacea, Desmidiacea)

Swarthiness (swater'the-nes) [ME., swarty]. The state of being swarthy.

Swarthy (swazer'-the) [ME., swarthy]. Dark; tawny.

Swartzia (swawrt'-se-ah). See Panococco.

Sweat (swet) [ME., swette, sweat]. The secretion of the sudoriferous glands. It consists of a transparent and normally colorless, aqueous fluid, holding in solution neutral fats, volatile fatty acids, cholesterin, traces of albumin and urea, free lactic acid, sodium lactate, sodium and potassium chlorids, and traces of

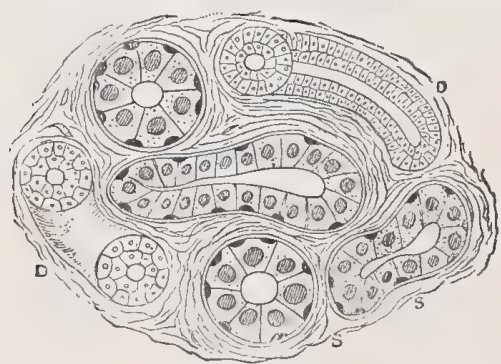

SEction OF PART OF COIL OF A SWEAT-GLAND.

D. Duct. S. Secrelory part. $\times$ 300. (From Stirling.)

alkaline phosphates. S., Bloody, purpura affecting the sweat-glands. See Hematidrosis. S., Blue, perspiration which has a blue color; it is thought by some to be due to oxidation of the colorless indican secreted in the sweat. S., Cold. perspiration accompanied by coldness of the surface of the body. S., Colored. See
Chromidrosis. S., Critical, the profuse perspiration which occurs at the crisis of a febrile disease. S., Diaphoretic. See S., Cold. S.-eczema, eczema seborrhoicum. S.-glands, the small, Jobular, reddish bodies situated in the true skin and subcutaneous areolar tissue. Each consists of a convoluted tube from which the excretory duct passes outward through the skin. In its passage through the epidermis the duct is more or less spiral. S., Green, sweat having a bluish or green-

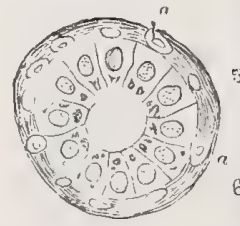

TRANSVERSE SECTION OF TH SECR ETORY PART OF A SWEAT - GIAND FROM THE AXFROM THE AX-
ILlA. Magnific.

a. Nuclei of unstri ated muscle. (From Stirling.)

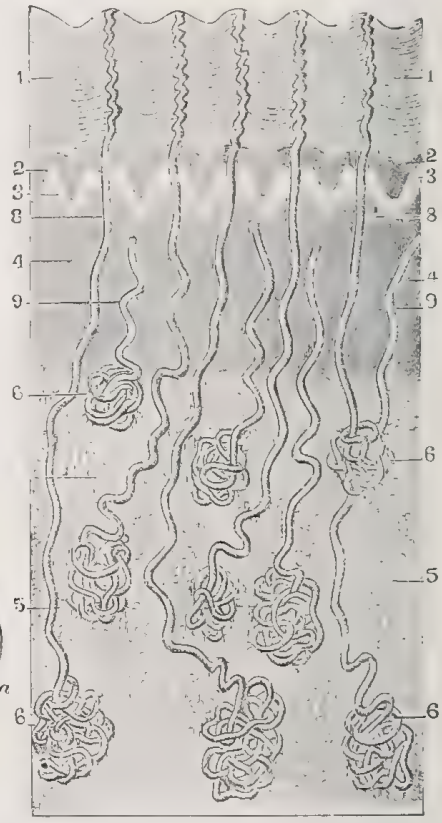

SWEAT-GLANDS FROM THE PALM OF THE HAND $\times 20$.

1. Horny layer of epidermis 2. Rete ma, or true skin. 5. Subcutaneous cellular tissue. $6,8,9$. Sudoriparous, or sweat-glands. mucosum. 3. Papillary layer. 4. Der-

ish color, seen mainly in copper-workers, and due to copper taken into the system by the inhalation of particles or fumes, or with food and drink (Crocker). S.-house, a room or inclosure furnished with apparatus for subjecting the occupant to the sudorific effects of steam; achicolum. S., Night, drenching perspiration occurring at night or whenever the patient sleeps, as in the course of pulmonary tuberculosis. S., Phosphorescent, a very rare peculiarity of the sweat, in which it becomes phosphorescent; it has been observed in some cases of miliaria and after eating phosphorescent fish. The phosphorescence is thought to be due to bacilli (Crocker). S., Red, a peculiar, red perspiration noted in the axillas and genital region, and due to microorganisms which have developed in the hairs of these warm, moist parts.

Sweating (swet'-ing) [ME., swette, sweat]. The excretion of the contents of the sudoriferous glands in sensible quantities. S. Fever, or $\mathbf{S}$. Sickness. See Miliaria and Fever, Miliary. S., Morbid, hyperidrosis. S., Unilateral, sweating on one side of the body, due usually to disease of the nervous system and often to the pressure of thoracic growths upon the sympathetic

Swedish (swe'-dish) [D., Zweedsch, Swedish]. Pertaining to Sweden. S. Green. Same as Rimmann's Green. S. Movements, certain scientific movements intended to exercise and develop the human body. They were originated by Ling, a Swede, in the early part of the -nineteenth century. Passive movements are such as are applied to the patient without his assistance; active movements are performed by the patient; 
concentric movements are performed by the patient, while the operator or some other power resists; excentric movements are performed by some power outside of the patient while he resists. S. System. See Ling's System.

Sweeny (swe'-ne) [origin obscure]. A wasting, or shrinkage, of the shoulder-muscles of the horse, generally due to some lameness of the foot or foreleg; it is also called szeinney.

Sweet (swet) [ME., swete, sweet]. A quality of taste of which sugar and honey furnish examples. S.bread, the true sweet-bread, regarded by gourmets as a great delicacy, is the thymus gland of the calf, found occasionally persistent, but as a rule only present in the fetus and young calf, at the ventral side of the trachea, partly without and partly within the chest, between the layers of the anterior mediastinum. It is elongated, of a grayish-white color, and lobulated on its surface. It is commonly known amongst butchers as the "throatbread." The pancreas is vulgarly termed the "gut-bread " or " belly sweet-bread," and is the article which would be supplied in the great majority of cases by butchers asked for the sweetbread. See Pancreas. S. Centaury. See Cacalia. S.-b., Chest, the thymus gland. S. Cicely, the root of Osmorrhiza longistylis. An aromatic stomachic, carminative, and expectorant. Dose of the fld. ext. 3 j-ij. Unof. S. Fern, the leaves and tops of Complonia asplenifolia. It is astringent, carminative, and alterative.

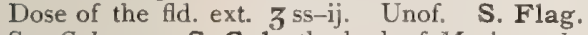
See Calamus. S. Gale, the bark of Myrica sale. Astringent and stimulant. Dose of the fld. ext. $m^{v-3}$ ss. Unof. S. Gum, the bark of Liquidambas styraciflua. Tonic and astringent. A popular domestic remedy in diarrhea. Dose of the fld. ext. $3 \mathrm{ss-j}$. The balsam exuding from the tree is much used as a corrigent of fetid breath. Unof. S. Niter, sweet spirit of niter, spiritus ætheris nitrosi. S.-oil. See Olivice, Oleum. S.-scented Water-lily. See $N_{y} m$ phaa odorata. S. Shrub. See Calycanthus. S. Sumach. See Rhus aromatica. S. Wine. See Wines.

Swell (swel) [ME., swellen, to swell]. To grow in bulk; to puff out. S.-bodies (Schwellkörper), Zuckerkandl's term for the venous plexuses found over the turbinated bodies.

Swelled (sweld) [ME., swellen, to swell]. Swollen. S. Head. Synonym of Actinomycosis.

Swelling ( swell-ing) [ME., swellen, to swell]. Any morbid enlargement, inflation, tumor, or protuberance. S., Albuminous, cloudy swelling. S., Blennorrhagic (of the knee), the enlargement of the knee which occlirs in gonorrheal synovitis. S., Cloudy, a swelling of cells due to disturbed nutrition (Virchow ). S., Glassy, amyloid degeneration. S., Lacteal, a swelling of the breast due to obstruction of the lacteal ducts. S., White, a disease of the bones which causes them to dilate as if distended by pressure from within. A tumor, usually of the wrist or ankle, due to caries; hydrarthrosis.

Swertia (swer'-te-ah). See Chirata.

Swim-bladder, or Swimming-bladder. See Pneumatophore.

Swimmeret (swim-er-et') [AS., swimman, to swim]. In biology, one of the abdominal or swimming limbs of a crustacean.

Swimmers' Cramp. See Cramp.

Swimming-bell (swim'-ing-bel). See Nectophore.

Swine (swin) [ME., swine, a pig]. A pig. S.-bread, the Tuber cibarium, an edible plant allied to lycoperdon or puff-ball. S.-cress, nasturtium, or water- cress. S.-fever. See Hog-cholera. S.-plague, an infectious disease of swine, appearing in more or less extensive epizoötics, in which usually most of the animals exposed to the infection succumb. It is due to specific bacteria, and is localized in the lungs, giving rise to pneumonia and pleurisy, with secondary involvement of the digestive tract; hence, it is not readily distinguished from hog-cholera. See Bacillus of Swine-plague, under Bacteria, Synonymatic Table of. S.-pox, a disease of swine characterized by inflammatory tubercles on the legs and thighs.

Swing, Salter's, an apparatus consisting of a cradle that moves on wheels along a horizontal bar on an

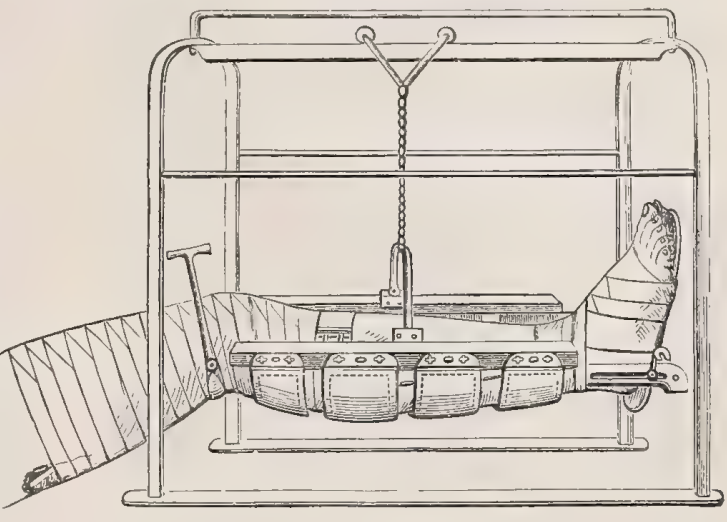

SALTER'S SWING.

iron framework; it is used in the treatment of frac tures of the lower extremity.

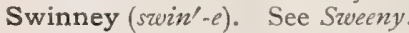

Swiss Tapeworm. The Bothriocephalus latus. See Parasites (Animal), Table of.

Swoon. See Syncope.

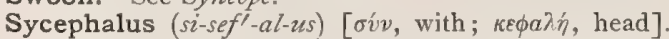
A double monster having two incomplete heads joined together.

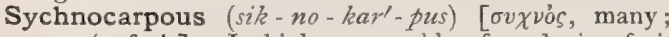
$\kappa a \rho \pi \delta ́ s$, fruit]. In biology, capable of producing fruit many times without perishing.

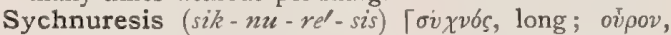
urine]. Preternaturally slow discharge of urine.

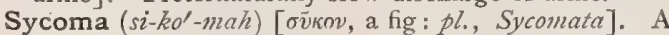
condyloma, or wart; a condition characterized by warty or fig-like excrescences on the soft tissues of the body, as the eyelids, tongue, anus, or genitals.

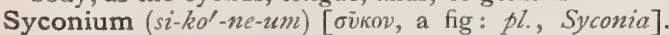
In biology, the peculiar multiple fruit of the fig, which consists of a fleshy, hollow receptacle containing numerous achenium-like fruits.

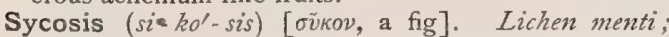
Sycosis non-parasitica; Mentagra; Folliculitis barba; Ficosis; Acne mentagra; an inflammatory, generally chronic, disease, which affects the hair-follicles, particularly of the beard, and due to microbic infection. It is characterized by papules, pustules, and tubercles, perforated by hairs, together with infiltration of the skin and with crusting. More or less scarring and permanent baldness result in long-continued cases. S., Bacillogenic, a variety of so-called "non-para sitic" sycosis, ascribed by Tommasoli to the Bacillus sycosiferus foctidus. See Bacteria, Synonymatic Table of. S. barbæ. Sycosis of the beard. S. capillitii : I. Dermatitis papillaris capillitii, of Kaposi; S. frambœesiformis, of Hebra; acne kœloid, of Bazin. 2. Kerion. 3. Pustular eczema of the scalp. S., 
Coccogenic, the so-called "non-parasitic" sycosis which is caused by an organism belonging to the schizomycetes (Unna). S. contagiosa. See $S$. parasitaria. S. frambosiformis. See Dermatitis papillaris capilliti. S., Hypertrophic. See S., Keloid. S., Hyphogenic, S., Hyphomycetous, S. parasitaria, of Unna; tinea sycosis, the inflammation excited by the Trichophyton tonsurans. S., Keloid, sycosis in which keloid degeneration occurs in the cicatrices resulting from the follicular inflammation (Milton). Also called Ulerythema sycosiforme (Unna). S., Lupoid. See S., Keloid. S. mentagra. See S. barba. S., Non-parasitic, sycosis due to the presence of coccogenic organisms. See S., Cocrogenic. S. non-parasitica. See S., Coccogenic. S. palpebræ marginalis, sycosis affecting the edge of the eyelids. S. parasitaria, S. parasitica, barbers' itch; a disease of the hair-follicles, usually affecting the region covered by the beard, and due to the presence of the Trichophyton tonsurans. See S., Hyphogenic. S., Parasitic. See S. parasitaria. S., Schizomycetic. See S., Coccogenic.

Sycum (si'-kum). See Ficus.

Sydenham's Chorea. See Chorea and Diseases, Table of. S.'s Disease, chorea. S.'s Laudanum. See Opii (Vinum).

Syderatio (sid-er-a'-she-o). See Sideratio.

Syfilis (sif'-il is). A mode of spelling Syphilis, q.v.

Syggignoscism (sig-jig'-no-sizm) [ $\sigma \bar{v} \nu$, together; $\gamma \iota \gamma$ $\nu \omega \sigma k \varepsilon l \nu$, to know]. The agreeing of one mind with another mind. A synonym of Hypnotism.

Syggignosticism (sig-jig-nos'tis-izm). See Syggignoscism.

Syllabic Utterance. Scanning speech, observed in insular sclerosis; the words are enunciated slowly and separately, and there may be a staccato accentuation of individual syllables.

Syllable-stumbling (sil'-ab-l-stum'-bling). A form of dysphasia wherein each sound and syllable can be distinctly uttered, but the word as a whole is spoken with difficulty. It occurs in paretic dementia.

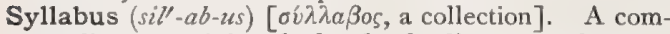
pendium containing the heads of a discourse ; the main propositions of a course of lectures; an abstract.

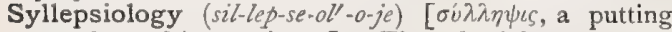
together; $\lambda 6 \gamma o s$, science]. The physiology of conception.

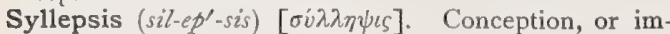
pregnation.

Sylvester's Method. See Artificial Respiration.

Sylvestrene (sil-ves'-trēn) [silvestris, belonging to a wood], $\mathrm{C}_{10} \mathrm{H}_{16}$. A substance that occurs in Swedish and Russian turpentine-oil, and may be obtained pure by digesting its hydrochlorid with anilin. It boils at $175-178^{\circ} \mathrm{C}$

Sylvestris (sil-ves'-tris). See Silvestris.

Sylvian ( sil've-an) [after Sylvius]. Relating to the anatomist Jacques Dubois, Latinized Sylvizes (I4781555). S. Artery, the middle cerebral artery, lying in the fissure of Sylvius. S. Convolution. See Convolutions, Table of. S. Fossa, the depression at the side of the fetal cerebrum where the insula is subsequently formed.

Sylvius, Aqueduct of. See Aqueduct. S., Fissure of. See Fissures, Table of.

Sym- (sim-). An euphonic form of Syn.

Symbion, Symbiont (sim'-be-on, sim'-be-ont) [oiv, along with; ßios, a life]. In biology, either of two organisms living in intimate association; a commensal.

Symbiosis ( $\left.\operatorname{sim}-b i-o^{\prime}-s i s\right)$ [ $\sigma \dot{v} v$, along with; ßios, a life]. In biology, the intimate association of two living organisms, not parent and offspring, male and female, or parasite and host. Commensalism.

Symblepharon (sim-blef'-ar-on) ['oív, together; $\beta \lambda \varepsilon \dot{\phi} \phi \alpha$ $\rho o \nu$, the eyelid]. The abnormal adhesion of the eyelids to the eyeball in consequence of burns, wounds, etc. S., Anterior, symblepharon of the anterior part of the conjunctival sac, in which the adhesion extends from the lid to the eyeball in such a manner as to admit of the passage of a sound between the two parts. S., Posterior, symblepharon of the peripheral part of the conjunctival sac. S., Total, symblepharon affecting the entire extent of the eyelid.

Symblepharosis (sim-blef-ar-o'-sis) [ovv, with; $\beta \lambda \varepsilon \dot{\phi} a-$ pov, eyelid]. Adhesion of the eyelids to the globe of the eye or to each other.

Symbol (sim'-bol) [ $\sigma \dot{\prime} \mu \beta o \lambda o v$, a pledge]. A sign or character denoting an idea. The following are commonly employed in medicine: $\mathrm{B}$, Recipe, take of; $\mathbf{A}$, Scruple; 3 , Dram; $\mathrm{f} 3$, Fluidram; $\overline{\tilde{j}}$ Ounce; $\mathrm{f} \bar{\jmath}$, Fluidounce; $m$, Minim. See, also, List of Abbreviations, p. $\mathrm{x}$.

Symboleusis (sim-bo-lu'-sis). Synonym of Consultation.

Symbolism $\left(\operatorname{sim}^{\prime}-b o l-i z m\right)[\sigma \tilde{v} \mu \beta o \lambda o v$, a symbol]. The delusional or hallucinational interpretation of all events or objects as having a mystic significance; a habit not uncommon in certain forms of insanity.

Syme's Operation. Amputation at the ankle-joint, the malleoli being sawn through, and a flap made with the skin of the heel. See Operations, Table of.

Symele $\left(\operatorname{sim}^{\prime}-\bar{e} l\right)$. See Symelus.

Symelus or Symmelus (sim'-el-us) [ $\sigma v \tilde{v}$, together;

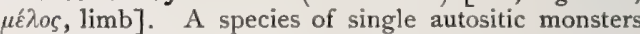
" characterized by imperfect development of the pelvis and lower extremities; by atresia ani et urethra; by more or less intimate fusion of the lower extremities, and by a twisting of the lower limbs so that the femurs are united by the external condyles, the legs by the fibulæ, and the feet, if they exist, by the fibular edge and little toes, so that the heels look forward."

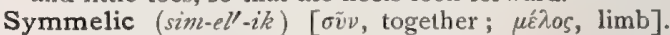
Characterized by a coalition of the limbs.

Symmelus (sim'-el-us). See Symelus.

Symmetric, Symmetrical (sim-et'-rik, sim-et'-rik-al)

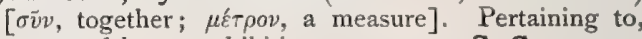
governed by, or exhibiting symmetry. S. Gangrene. See Sphaceloderma.

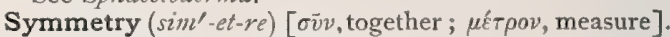
In anatomy, a harmonious correspondence of parts; also the relation of homologous parts at opposite sides or ends of the body. In pathology, the theory that constitutional diseases affect both lateral halves of the body impartially.

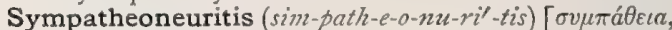
sympathy; veṽpov, nerve; $\iota \iota s$, inflammation]. Inflammation of the sympathetic nerve.

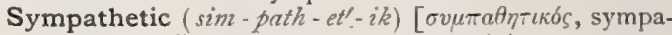
thetic]. Effecting consentaneous activity or sympathy. S. Bubo. See Bubo. S. Inflammation, or Irritation, affection of an organ arising by reflex action, infection, or other unknown way, synchronous or following similar affections of other organs. S. Nerve, or Nervous System, a series of ganglia connected by commissural fibers, upon each side of the vertebral column from the base of the skull to the coccyx. It may be also traced into the head. It gives origin also to numerous plexuses, ganglia, etc. See Plexus and Ganglia; also p.848. S. Ophthalmitis, inflammation of the uveal tract of an eye arising subsequent to some injury or affection of the other eye. The eye first affected is called the exciting eye, or excitor, the other the sympathizer. The inflammatory period may be 
preceded by sympathetic irritation, in which there is lacrymation, photophobia, etc. Removal of the excitor is the treatment usually prescribed.

Sympatheticus (sim-path-et'-ik-us). See Sympathetic Nerve.

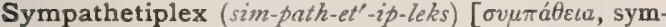
pathy; plexus, plexus]. A sympathetic plexus.

Sympathic (sim-path'-ik). Synonym of Sympathetic.

Sympathizer (sim'-path-i-zer). See Sympathetic Ophthalmitis.

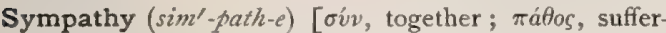
ing]. In pathology, the mutual relation between parts or organs more or less distant, shown in the translation of a morbid condition from an affected to an unaffected organ. A meaningless term for the facts of reflex neuroses, metastasis, secondary infection, etc.

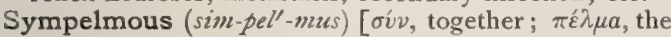
sole of the foot]. In biology, having the deep plantar tendons united.

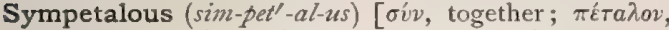
leaf ]. In biology, the same as gamopetalous.

Sympexion (sim-peks'-e-on) [augmented form of Sympexis: pl., Sympexia]. A sympexis.

Sympexis (sim-peks'-is) [ $\sigma \dot{v} \mu \pi \eta \xi$ is]. A concretion found in the vessels or crypts of certain glands, especially the thyroid and lymphatic, the prostate, and in the vesiculæ seminales.

Symphora (sim'-for-ah). Synonym of Congestion.

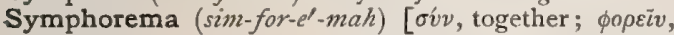
to bear]. The state of being congested.

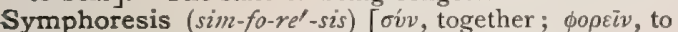
bear]. Congestion, or a congestive process.

Symphoricarpous (sim-for-ik-ar'-pus) [oív, together $\phi \circ \rho \varepsilon i v$, to bear; $\kappa a \rho \pi b \varsigma$, fruit]. In biology, bearing clustered fruits.

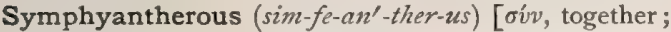

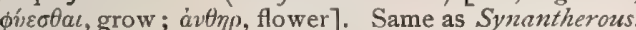

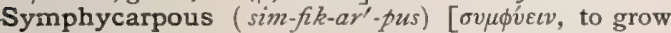

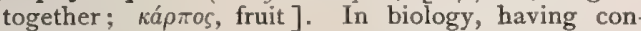
fluent fruits.

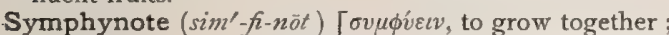
vĩTo, the back]. In biology, applied to such bivalve molluscs (Unio) as have the valves soldered together at the hinge.

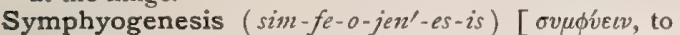

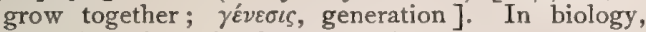
the union of previously separated parts.

Symphyogenetic ( $\left.\operatorname{sim}-f e-o-j e n-e t^{\prime}-i k\right)[\sigma v \mu \phi v \varepsilon \varepsilon v$, to

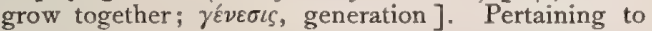
symphyogenesis.

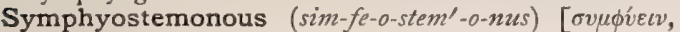
to grow together; $\sigma \tau^{\prime} \mu \omega \nu$, a thread]. See Monadelphous.

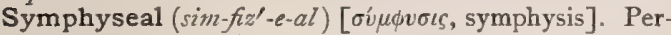
taining to a symphysis.

Symphyseotomy (sim-fiz-e-ot'-o-me). See Symphysiotomy.

Symphysial ( $\left.\operatorname{sim}-f z^{\prime}-e-a l\right)$. Same as Symphyseal.

Symphysic (sim-fiz'-ik). Same as Symphyseal. See also Teratism.

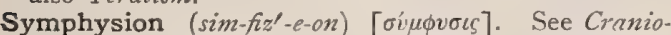
metric Points.

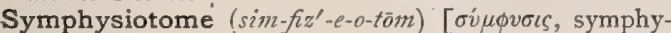
sis; Touń, cutting]. A cutting instrument used in pubic symphysiotomy.

Symphysiotomy ( $\left.\operatorname{sim}-f i z-e-o t^{\prime}-o-m e\right)$ [ $\sigma \dot{v} \mu \phi v \sigma \iota \varsigma_{\text {, sym- }}$

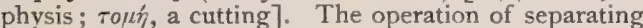
the bones forming a symphysis by division of the connecting tissues. Synonymous with S., Pubic. 'S., Pubic, the operation of cutting through the pubic symphysis for the purpose of increasing the conjugate diameters of the pelvic canal.
Symphysis $\left(\operatorname{sim}^{\prime}-f z-i s\right)$ [oviv, together; $\phi i \varepsilon \iota v$, to grow] The coalescence or junction of bones, usually of sym metric bones in the median line, as $S$. pubis and $S$. of the Jaw. S., Pubic, the line of union of the two pubic bones. S. Sacro-coccygeal, the sacrococcygeal articulation. S., Sacro-iliac, the union between the sacrum and the ilium.

Symphysodactylia (sim-fiz-o-dak-til'-e-ah). Synonym of Syndactylism.

Symphysopsia $\left(\operatorname{sim}-f z z-o p s^{\prime}-e-a h\right)$. Synonym of $C y$ clopia.

Symphysoskelia (sim-fiz-o-ske'-le-ah) [ $\sigma i v$, together; $\phi v \varepsilon r v$, to grow; $\sigma \kappa \varepsilon \lambda \sigma s$, leg]. The condition in which the lower extremities are united.

Symphysotomy (sim-fiz-ot'-o-me). Synonym of Sym physiotomy.

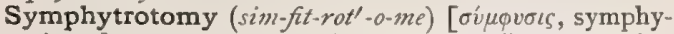
sis; $\eta \tau \rho \circ \nu$, pelvis; $\tau o \mu \eta$, section ]. Pelvic section through the symphysis pubis; pubic symphysiotomy.

Sympiesis ( $\left.\sin -p i-e^{\prime}-s i s\right)$ [ $\sigma u v$, together; $\pi i \varepsilon \sigma \iota \zeta$, a squeezing]. A pressing together of parts.

Symplast (sim'-plast). Synonym of Plasmodium.

Symplectic (sim-plek'-tik) [av'v, together; $\pi \lambda \varepsilon^{\prime} \kappa \varepsilon v$, to twine, weave]. A bone connecting the hyo-mandibular bone above with the quadrate bone below in certain vertebrates (fishes); also called mesotympanic.

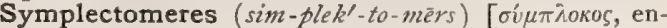
twined together; $\mu \varepsilon$ pos, a part]. In biology, the collective name applied by Dujardin to sarcode organisms.

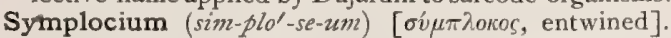
In biology, the band of thick-walled cells in the sporangium of most ferns; the annulus.

Sympode $\left(\operatorname{sim}^{\prime}-p \bar{o} d\right)$. Same as Sympodium.

Sympodia (sim-po'-de-ah) [ $\sigma \dot{v} v$, together; $\pi$ ov́s, foot]. The condition in which the lower extremities are united.

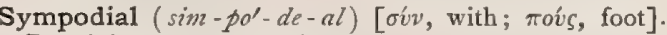
Pertaining to a sympodium.

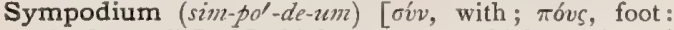
pl., Sympodia]. In biology, a stem which consists of a series of secondary stems or axes which have arisen as branches one from another, as in the grape-vine, the tomato, the linden, etc. See Psezdaxis.

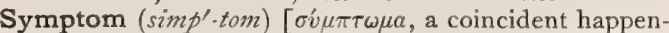
ing]. That change or phase which occurs synchronously with a disease and serves to point out its nature and location. See Signs and Symptoms, Table of. S.complex, the ensemble of symptoms of a disease. S., Direct, one depending directly upon disease. S., Dissociation. See Dissociation-symptom. S.grouping. Same as S.-complex. S., Indirect, one only indirectly due to disease. Ss., Labyrinthine, a group of symptoms due to lesion or disease of the internal ear. S., Negatively Pathognomonic, one which never occurs in a certain disease and therefore by its presence shows the absence of that disease. S., Objective, one observed by the physician. S., Pas-

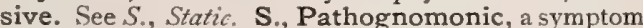
which exhibits itself only in a certain disease and therefore undeniably proves its presence. Ss., Physical, the physical signs of morbid conditions. S., Rosenbach's, loss of the abdominal reflex. S., Static, a symptom which indicates the condition in a single organ without reference to the rest of the body. S., Subjective, that observed only by the patient. Ss., Sympathetic, symptoms for which no adequate cause can be given other than so-called sympathy.

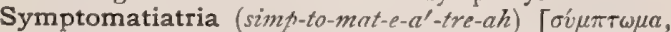

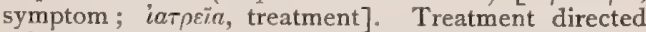
solely to the symptoms.

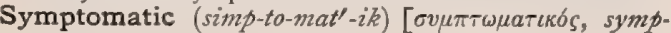


Iomatic ]. Having the nature of a symptom; that which may be interpreted as a symptom. That which may be a symptom of another affection; opposed to idiopathic. S. Anthrax, an epidemic, infectious disease of cattle, also called "Black-leg" and "Quarter-evil." See Bacillus chaurci in Table of Bacteria, and Black-leg. S. Fever, the febrile symptoms of a disease.

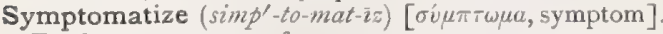
To show symptoms of.

Symptomatography (simp-to-mat-og $\left.g^{\prime}-r a-f e\right)[\sigma \dot{v} \mu \pi \tau \omega \mu a$, symptom; yoáde $v$, to write]. A written or printed description of symptoms.

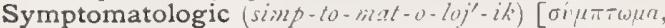
symptom; $\lambda 6 \gamma o \varsigma$, science $]$. Pertaining to symptomatology.

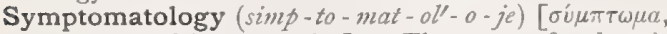
symptom; $\lambda$ ó ${ }^{\circ}$, treatise $]$. The sum of what is known of the nature, purport, and interpretation of symptoms

Symptomology (simp-to-mol'-o-je). Same as Symptomatology.

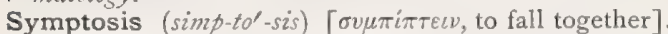
Wasting; emaciation; collapse.

Sympus (sim'-pus) [oúv, together; toús, foot]. A vice of development consisting in coalescence of the lower limbs; a siren monster. There may be but one foot $(S$. monopus), or two (S. dipus), or the feet may be represented only by toes ( $S$. apus)

Syn-(sin-) [oiv, together]. A prefix, signifying with or together.

Synacmic $\left(\sin -a k^{\prime}-m i k\right)$ [бóv, with; akuŕ, prithe]. Pertaining to synacmy.

Synacmy (sin-ak'-me) [ovv, with; $\alpha \kappa \mu \eta$, prime]. In biology, having the stamens and pistils ripen at the same time, as distinguished from heteracmy. Cf. proterandry, and proterogyny. Also called synanthesis.

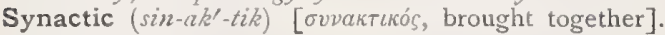
Accumulative.

Synadelphus $\left(\sin -a d-e l^{\prime}-f u s\right)$ [oiv, with; $\dot{a} \delta \varepsilon \lambda \phi o ́ s$, brother]. A monster having eight limbs with but one head and trunk.

Synæsthesia (sin-es-the'ze-ah). See Synesthesio.

Synagogue $\left(\sin ^{\prime}-a g^{\circ}-0 g^{\circ}\right)$. Synonym of Contraction.

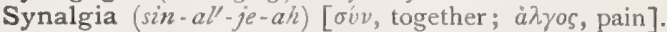
Pain felt in a distant part from an injury or stimulus to another part of the body.

Synanastomosis (sin-an-as-to-mo'-sis) [oiv, with ; anastomosis]. The joining of several blood-vessels.

Synanche (si-nang'-ke). Synonym of Diphtheria.

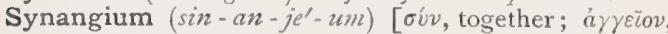
vessel : pl., Synangia]. An arterial axis, or trunk.

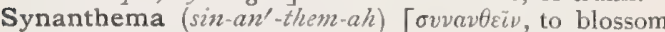
together]. In dermatology, a group of efflorescences on the skin.

Synantherous $\left(\sin -a n^{\prime}-t h e r-u s\right)$ [oiv, together; anthera, anther; from $a \nu \theta \varepsilon \iota v$, to bloom]. In biology, the same as syngenesious. Stamens coalescent by their anthers.

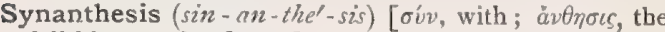
full bloom of a flower]. See Synacmy.

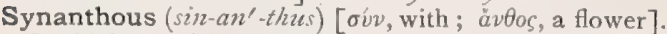
In biology, (a) exhibiting synanthy; (b) having flowers and leaves at the same time, as distinguished from proteranthous and hysteranthous.

Synanthrose ( $\left.\sin -a n^{\prime}-t h r o ̈ z\right)$ [ $\sigma \dot{v} \nu$, together; àv $\theta m \rho$, anther $], \mathrm{C}_{12} \mathrm{H}_{20} \mathrm{O}_{11}$. A sucrose found in rye and the roots of certain plants. It has no action on polarized light.

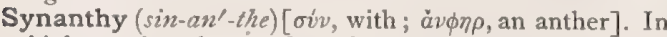
biology, the abnormal coalescence of two or more flowers.

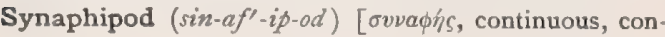

nected; Toús, foot]. In biology, Bates' term for the palp of a crustacean.

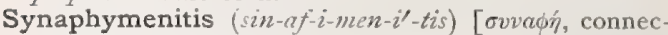
tion; $v \mu \eta \dot{v}$, a membrane; iT $\iota \zeta$, inflammation]. A former synonym for conjunctivitis.

Synaptase (sin-ap'-täz). See Emulsin and Amygdalin.

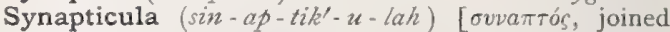
together: pl., Symapticula]. In biology, one of the cross-bars connecting the septa in certain corals.

Synarthrodia (sin-ar-thro'-de-ah). See Synarthrosis.

Synarthrodial (sin-ar-thro'-de-al) [ouv, together; a $\rho \theta \rho o v$, a joint]. Of the nature of a synarthrosis; belonging to a synarthrosis.

Synarthrœsis (sin-ar-thre'-sis). Synonym of Concestion.

Synarthrosis (sin-ar-thro'-sis) [ [oviv, together; à $\rho \rho o v$, joint]. A form of articulation in which the bones are immovably bound together (without any intervening synovial cavity). The various forms are: Sutura, in which the processes are interlocked; Schindylesis, in which a thin plate of one bone is inserted into a cleft of another, and Gomphosis, in which a conic process is held by a socket.

Syncampe $\left(\sin -k a m^{\prime}-p e\right)$ [ $\left.\sigma v \gamma \kappa a \mu \pi \eta j\right]$. A freely movable joint.

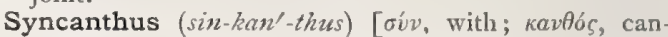
thus]. An obsolete term for abnormal union of the orbital margin and the ocular conjunctiva.

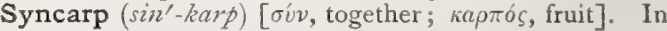
biology, a multiple fruit.

Syncarpium (sin-kar'-pe-um). Same as Syncarp.

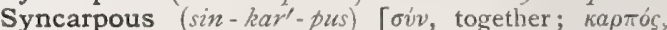
fruit]. Having the character of a syncarp.

Syncausis (sin-kaze'sis). Synonym of Combustion.

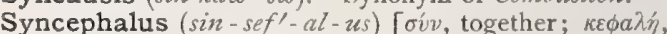
head]. A double monstrosity with the two heads fused into one.

Syncerebral (sin-ser'-e-bral) [ $\sigma \dot{v} v$, together; cerebrum, cerebrum ]. Pertaining to a syncerebrum.

Syncerebrum $\left(\sin -\operatorname{ser}^{\prime}-e-b r u m\right)$ [oiv, together; cerebrum, cerebrum]. A compound brain.

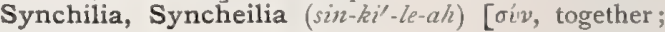
$x \varepsilon \tilde{\imath} \lambda$ os, lip]. Atresia of the lips.

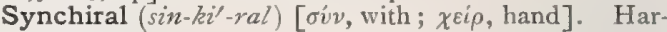
rison Allen's term for the movement in which the right and left foot of a single pair move together, as in the gallop of a horse.

Synchisis (sin'-kis-is). See Synchysis.

Synchiton ( $\left.\sin ^{\prime}-k i t-o n\right)$. Synonym of Conjunctiva.

Synchitonitis $\left(\sin -\right.$ kit - on $\left.-i^{\prime}-t i s\right)$. Synonym of Conjunctivitis.

Synchondrosial ( $\left.\sin -k \circ n-d r o^{\prime}-z e-a l\right)$ [ $\sigma i v$, with ; $\chi\langle\delta \delta \rho o s$, cartilage ]. Pertaining to a synchondrosis.

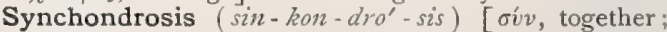
$\chi \not ́ v \delta \rho o s$, a cartilage]. A union by an intervening growth of cartilage. S., Pubic. See Symphysis, Pubic. S., Sacro-coccygeal. See Symphysis, Sacro-coccygeal. S., Sacro-iliac. See Symphysis, Sacroiliac.

Synchondrotomy (sin-kon-drot'-o-me) [oiv, together;

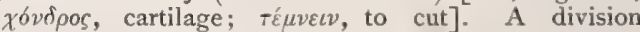
of the cartilage uniting bones, especially of the symphysis pubis.

Synchopexia (sin-ko-peks'-e-ah). Same as Tachycardia.

Synchronism ( $\sin ^{\prime}-k r o-n i z m$ ) [ $\sigma$ viv, with; $x \rho 6 v o s$, time]. Concurrence in time of two or more events.

Synchronous ( $\left.\sin ^{\prime}-k r o-n u s\right)$ [ $\sigma \dot{v} v$, together; $\chi \rho b v o s$, time]. Occurring contemporaneously, or at the same interval.

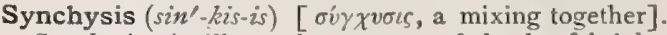
Synchysis scintillans; the presence of clouds of bright, shining particles in the vitreous bumor of the eye. 
As the eye moves from side to side these particles (crystals of tyrosin or cholesterin) look like showers of bright, shining gold or silver scales, which move with the eye. They occur more frequently in persons beyond middle life.

Syncleisis (sin-kli'-sis). Synonym of Occlusion.

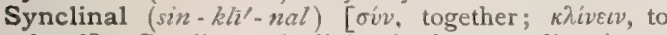
bend]. Bending or inclining in the same direction.

Synclisis (sin'-klis-is). Same as Synclitism.

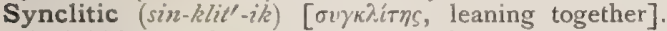
Exhibiting or characterized by synclitism.

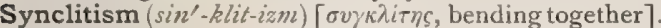
A condition marked by parallelism or similarity of inclination; parallelism between the pelvic planes and those of the fetal head.

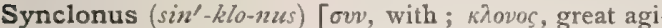
tation]. A genus of diseases, including those characterized by tremulous motion. Also, any abnormal, tremulous, muscular motion, as that of chorea. S ballismus, paralysis agitans. S. tremens, general tremor.

Syncopal ( $\left.\sin ^{\prime}-k o-p a l\right)$ [ $\sigma v \gamma k o \pi \dot{\eta}$, a cutting short]. Pertaining to, characterized by, or of the nature of syncope.

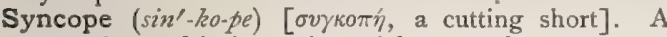
swooning or fainting. A partial or complete temporary suspension of the functions of respiration and circulation. S. anginosa. Synonym of Angina pectoris. S., Laryngeal, laryngeal vertigo. S., Local, sudden pallor and insensibility of a part.

Syncopic $\left(\sin -k o p^{\prime}-i k\right)$ [ $\sigma v \gamma \kappa o \pi \eta$, a cutting short]. Of the nature of syncope; syncopal.

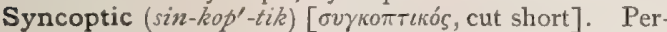
taining to, having the nature of, or causing syncope.

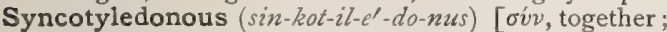
$\kappa о \tau \nu \lambda \eta \delta \dot{\omega} \nu$, any cup-shaped hollow]. In biology, charterized by coalescent cotyledons.

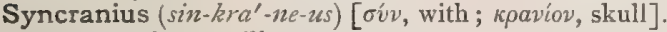
The superior maxilla.

Syncranterian (sing - kran -te'-re-an) [ $\sigma \dot{v} v$,-together ; $\kappa \rho ๘ \nu \tau \tilde{\eta} \rho \varepsilon s$, the wisdom-teeth]. In biology, applied to such serpents as have the posterior teeth forming a continuous row with the anterior.

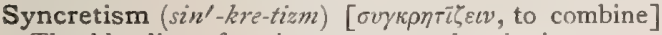
The blending of various tenets or theories into one.

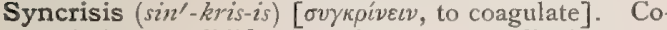
agulation or solidification of one or more liquids.

Syncritic (sin-krit'-ik). Synonym of Astringent.

Syncytial (sin-sit'-e-al) [ $\sigma \dot{v} v$, together; kv́ros, a hollow] Pertaining to a syncytium.

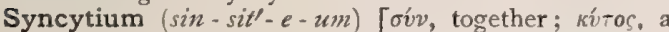
cell: pl., Syncytia]. In biology, a tissue in which no cell-boundaries can be recognized; a mass of protoplasm with nuclei scattered throughout.

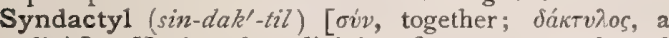
digit]. Having the adjoining fingers or toes bound together.

Syndactylia (sin-dak-till-e-ah). Same as Syndactylism. Syndactylism (sin-dak'-til-izm) [óvv, together;

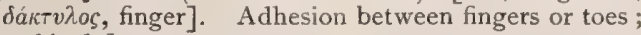
webbed fingers.

Syndactylous (sin-dak'-til-us). Same as Syndactyl.

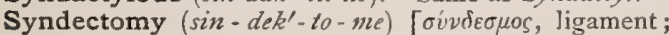

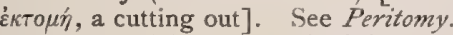

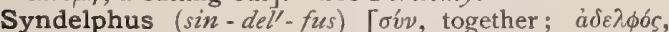
brother]. A monocephalic double monstrosity with a single pelvis, united thoraces, four upper and four lower extremities.

Syndemnium $\left(\sin -d e m^{\prime}-n e-u m\right)$ [ov́v, together ; dé $\mu \nu \imath o v$, couch, bed]. A peculiar, remarkable, hollow space in the middle of the subumbrella, the "porticus subgenitalis," the "subgenital vestibule," found only in two families of the Rhizostome (i. e., Versuride and Crambessida).

Syndendrium $\left(\sin -d e n^{\prime}-d r e-u m\right) \quad[\sigma v v$, together; $\delta \varepsilon \dot{v} \delta \rho \iota 0 v$, a little tree]. In biology, the thick, flat, quadrate disc, suspended from four stout pillars (dendrostyles) and formed of the united trunks of the polypiferous tree of the Rhizostoma.

Syndesis (sin-de'-sis) [ $\sigma v \nu \delta \varepsilon i v$, to bind together]. The state of being bound together.

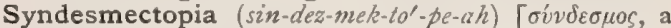
bond; $\dot{\varepsilon} \kappa \sigma \pi \tau \iota \varsigma$, out of place]. Ligamentous displacement.

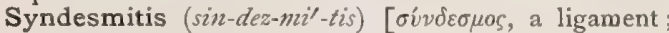
$\iota \tau \iota \zeta$, inflammation]. Inflammation of one or more ligaments. S. catarrhalis. Synonym of Conjunctivitis, Catarrhal.

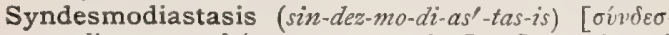

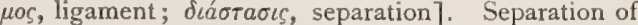
the ligaments.

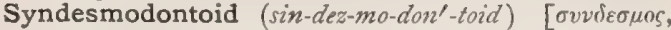
ligament; odontoid]. Formed by the transverse ligament of the atlas and the odontoid process of the axis:

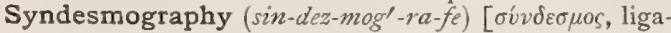
ment; $\gamma \rho a ́ \phi \varepsilon \imath \nu$, to write]. The structure and descriptive anatomy of the ligaments.

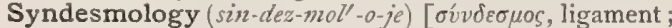
$\lambda$ bros, treatise]. The sum of what is known regard ing the nature, functions, and diseases of ligaments.

Syndesmoma $\left(\sin -d e z-m \bar{o} m^{\prime}-a h\right)$ [ $\sigma \dot{v} v \delta \sigma \mu o s$, ligament ; ö $\mu$, tumor]. A new growth containing a large amount of connective tissue.

Syndesmopathia ( $\left.\sin -d e z-m o-p a^{\prime}-t h e-a h\right)$. Synonym of Desmopathy.

Syndesmosis (sin-dez-mo'-sis) [ $\sigma \delta \nu \delta \varepsilon \sigma \mu o s$, ligament]. The articulation of two or more bones by ligaments.

Syndesmotic (sin-dez-not' $-i k)$ [ $\sigma v v \delta \varepsilon \sigma \mu o s$, ligament]. Bound together.

Syndesmotomy (sin-dez-mot'-o-me) [ $\sigma^{\prime} i v \delta \varepsilon \sigma \mu o s$, liga-

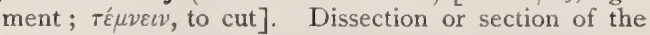
ligaments.

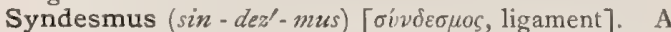
ligament.

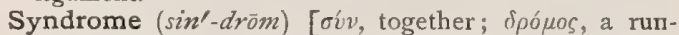
ning]. A word denoting the aggregate symptoms of a disease. See, also, Symptom-complex. S. of Weber, paralysis of the oculo-motor nerves of one side (that of the cerebral lesion) and of the members, the face, and the hypoglossal nerve of the other side. It is usually due to a lesion limited to the inferior and inner part of the one cerebral peduncle.

Syndyasmus (sin-di-az'-mus). Synonym of Copulation.

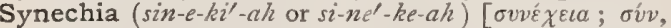
together; $\chi^{\varepsilon} \iota \nu$, to hold: pl., S Jnechio ]. A morbid union of parts. See Iris. Synechiæ pericardii, adhesions of the pericardium

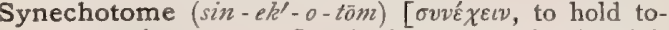
gether ; $\tau \dot{\varepsilon} \mu \nu \varepsilon \iota \nu$, to cut]. An instrument for the division of adhesions, particularly of the membrana tympani.

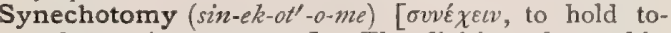

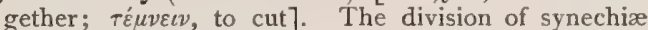
between the membrana tympani and the inner wall of the tympanum.

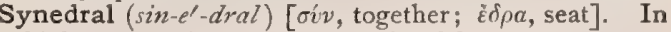
biology, growing upon the angle of the stem.

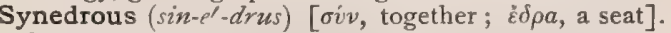
Same as Synedral.

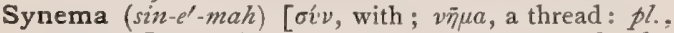
Synemata]. In biology, the column formed by the united filaments of monodelphous stamens.

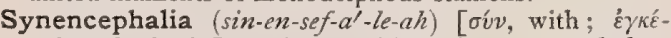
$\phi a \lambda o s$, the brain]. The condition of a synencephalus. 
Symencephalocele (sin-en-sef'-al-o-sēl) [oviv, with ; $\dot{\varepsilon} \gamma \kappa \varepsilon \dot{\varepsilon} \phi \dot{\lambda} \circ$ s, brain; $\kappa \dot{\eta} \lambda$, a tumor]. An encephalocele arising from abnormal adhesions, probably the result of some intra-uterine inflammation.

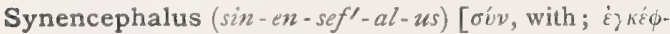
$a \lambda o 5$, brain]. A monster having two bodies with but a single head.

Synenergia (sin-en-ur'-je-ah). See Synergy.

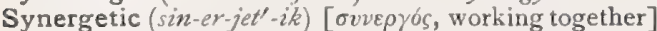
Exhibiting synergy; working together.

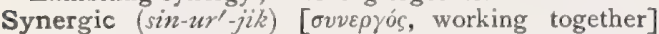
Exhibiting or pertaining to synergy.

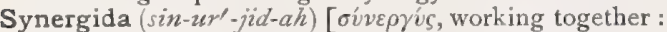
pl., Synergida]. In biology, a term applied to the two cells of the egg-apparatus that are associated with the germ-cell in the embryo-sac.

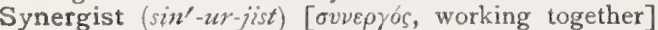
A thing or drug which co-operates with another.

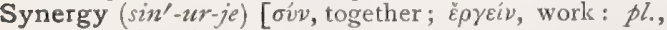
Synergies]. In biology, the simultaneous or sympathetic action of different organs.

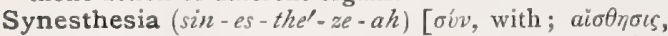
sensation]. A phenomenon consisting in a sensation being felt or located in one part of the body, as the result of an irritation at some remote or distant point.

Syneurosis $\left(\sin -u-r o^{\prime}-s i s\right)$. See Synneurosis.

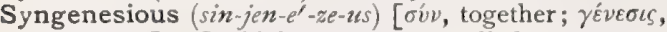
generation]. In biology, a term applied to stamens which are united by their anthers.

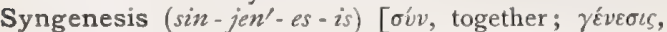
generation]. In biology, generation by means of the combined qualities of both the male and female reproductive bodies, as a doctrine distinguished from spermism or the theory of incasement, as well as from epiyenesis.

Syngenic $\left(\sin -j e n^{\prime}-i k\right)$. Synonym of Congenital.

Syngignoscism $\left(\sin -g i \sigma^{\prime}-n o-s i 2 m\right)$ [ $[\sigma i v$, together; $\gamma \iota \gamma \nu \omega \sigma \varepsilon \varepsilon \nu$, to know]. A term proposed as a synonym of hypnotism, from a prominent symptom, "the agreeing of one mind with another mind."

Syngonidium $\left(\sin g-g o-n i d^{\prime \prime}-e-u m\right)$ [ $\sigma i v$, together; yóvos, generation, seed]. In biology, an aggregation of gonidia.

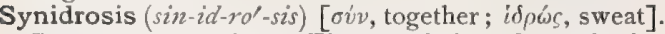
Concurrent sweating. The association of perspiration with another condition.

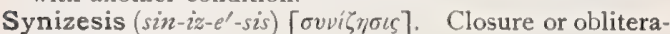
tion of the pupil.

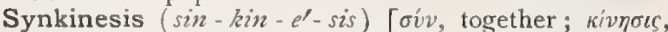
movement]. Involuntary movement taking place in one part of the body synchronously with or in consequence of a voluntary or reflex movement in another part.

Synneurosis $\left(\sin -n u-r o^{\prime}-s i s\right)$. See Syndesmosis.

Synocha ( $\left.\sin ^{\prime}-0-k a h\right)$. See Synochus.

Synochal (sin'-o-kal) [óvoxos, continued]. Pertaining to synocha.

Synochoid (sin'-o-koid) [óvvoxos, continued]. $\operatorname{Re}-$ sembling synochus.

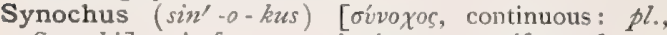
Synochi]. A fever continuing at a uniform degree for a considerable period. $\mathbf{S}$. anniversaria, a fever that returns annually at the same time for several years. S. ardens, $\mathbf{S}$. putris, typhoid fever. $\mathbf{S}$ scorbutica, a fever caused by scurvy.

Synocil ( $\left.\sin ^{\prime}-o-s i l\right)$ [ovv, with; cillum, lash]. In biology, a cylindric or conic bundle of sensory filaments in certain sponges, possibly having a visual function.

Synœcious, Synecious ( $\sin -e^{\prime}-\operatorname{shus)}[\sigma i v$, together; nike $i v$, to live]. In biology, having male and female flowers or organs in one cluster.

Synonym $\left(\sin ^{\prime}-o-n i m\right)$ [oiv, together; övoua, a name].
A word which can replace another word without alteration of meaning. In medicine, any variant name by which a disease, an organ, or a part of the body may be known.

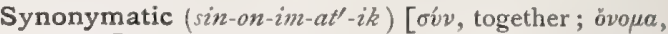
a name]. A purer form of Synonymic, or synonymical, and applied by naturalists to lists of technical names or onyms, including the synonyms.

Synophthalmia (sin-off - thal'-me-ah) [oiv, together; á $\theta a \lambda \mu o ́ s$, eye]. A malformation in which the orbits form a single, continuous cavity. This condition is called, also, Cyclopia.

Synophthalmos (sin-off-thal'-mos). Synonym of Cyclops.

Synophyty (sin-off'-it-e) [oív, together; $\phi v \tau b v$, plant]. In biology, the cohesion of two or more embryos in a seed.

Synopsia $\left(\sin -o p s^{\prime}-e-a h\right)$ [oiv, together; $\delta \psi$, eye]. Congenital union of the eyes.

Synopsis $\left(\sin -o p^{\prime}-s i s\right)$ [ $\sigma v v$, together; ö $\psi \varsigma$, a seeing] A classified collation. A general view.

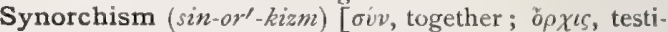
cle]. Adhesion or fusion of the two testicles.

Synoscheos $\left(\sin -o s^{\prime}-k e-o s\right)$ [ $\sigma \dot{v} v$, with; $\dot{0} \sigma \chi \varepsilon o s$, scrotum]. A condition of adherence between the skin of the penis and that of the scrotum.

Synosteography ( $\left.\sin -o s-t e-o g^{\prime}-r a-f e\right)$ [oiv, together ;

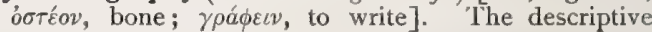
anatomy of the joints.

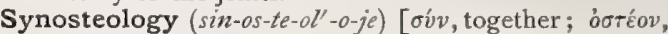

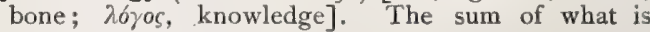
known regarding the joints.

Synosteosis (sin-os-te-o'-sis). See Synostosis.

Synosteotomy $\left(\sin -o s-t e-o t^{\prime}-o-m e\right) \quad[\sigma o ́ v$, together;

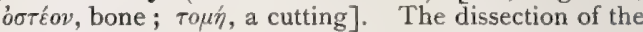
articulations of bones; anatomy of the joints.

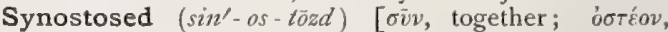
bone]. Joined in bony union.

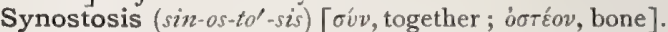
Union of fractures or bones by osseous material.

Synostotic $\left(\sin -o s-t o t^{\prime}-i k\right)$ [ $\sigma \dot{v} v$, together; $\dot{\sigma} \sigma \tau^{\prime} o v$, bone]. Pertaining to or of the nature of synostosis.

Synotia $\left(\sin -o^{\prime}-s h e-a h\right)$ [ $\sigma \dot{v} v$, together; ov́s, ear]. Union of the ears, as in certain monsters.

Synotus (sin-o'-tus) [ $\sigma \dot{v} v$, together; ov́s, ear]. A syncephalic monstrosity having the ears fused.

Synovectomy (sin-o-vek'-to-me). See Arthrectomy.

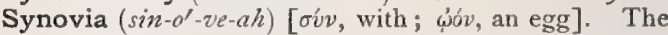
lubricating fluid secreted within synovial membranes.

Synovial (sin-o'-ve-al) [synovialis; $\sigma v v$, together; $\omega 6 v$, egg $]$. Pertaining to the synovia. S. Membrane. See Membrane.

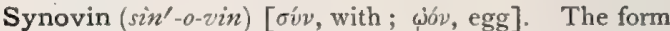
of mucin found in synovia.

Synoviparous ( $\sin$-o-viṕ-ar-us) [synovia, synovia ; parere, to produce]. Producing or secreting synovia.

Synovitis (sin-o-vi'-tis) [synovia, synovia; $\iota \tau \iota$, inflammation]. Inflammation of a synovial membrane. $\mathbf{S}$., Chronic Purulent. Synonym of Fungous Arthritis. S., Chronic Serous. Synonym of Hydrar. throsis. S., Dry, synovitis with little if any exudate. S., Exanthematous, synovitis produced by the exanthemata. S., Fibrinous. See $S$, Dry. S., Fungous. Synonym of Firnoous Arthritis. S., Gonorrheal. Synonym of Rheumatism, Gonorrheal. S., Lipomatous, synovitis in which the new-formation undergoes fatty degeneration. S., Metritic, a synovitis secondary to uterine infection. S., Puerperal synovitis occurring after childbirth, and due to septic infection. S., Purulent, synovitis with suppuration. S., Scarlatinal, synovitis occurring in an attack of scarlet fever: S., Syphilitic, synovitis due to syph- 
ilitic inflammation. S., Tendinous, inflammation of the synovial sheath surrounding a tendon. S., Tuberculous, synovitis with deposits of tubercle. S., Urethral. Synonym of Gonorrheal Synovitis.

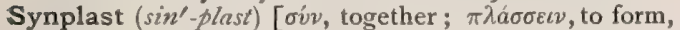
mold]. In biology, a unit or group of protoplasts.

Synsepalous (sin-sep'-al-us) [oív, together; sepalum, a sepal]. Same as Gamosepalous.

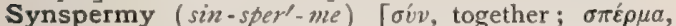
seed]. In biology, the union of two or more seeds.

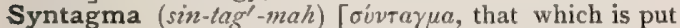
together]. In biology, Pfeiffer's term for a body or aggregation of tagmata. See Tagma.

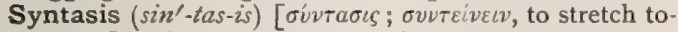
gether]. A stretching, or tension.

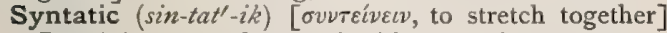
Pertaining to or characterized by syntasis.

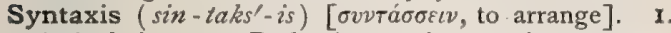
Articulation. 2. Reduction, taxis. 3. A suture.

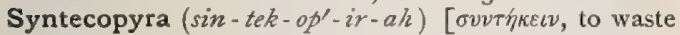
away; $\pi \bar{v} \rho$, fire ]. Colliquative fever.

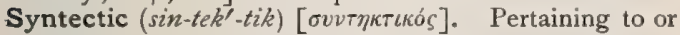
characterized by syntexis; wasting.

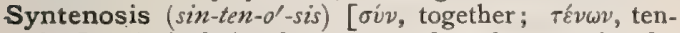
don]. Articulation by means of tendons, as in the human digits.

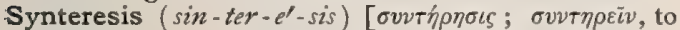
guard with]. Preventive treatment, or hygiene; prophylaxis.

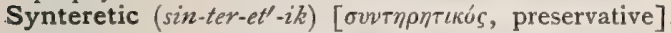
Pertaining to prophylaxis, or synteresis; hygienic; preventive.

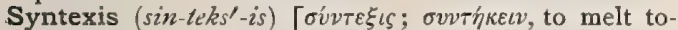
gether]. A wasting; tabes; phthisis.

Synthermal (sin-ther'-mal). Same as Isothermal.

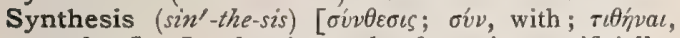
to place]. In chemistry, the formation, artificially, of a compound by combining its proximate parts.

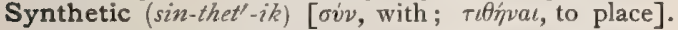
Pertaining to synthesis. Compounded.

Synthorax (sin-tho'-raks). Synonym of Thoracopagus.

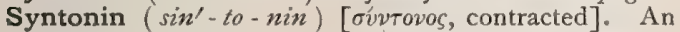
acid-albumin obtained by the prolonged action of dilute hydrochloric acid upon minced muscle. It is also formed in the stomach during digestion.

Syntrimma, Syntripsis ( sin-trim' $^{\prime}-a h$, sin-trip'-sis). Synonym of Comminution.

Syntrope ( $\sin ^{\prime}$-tröp $)$ [ $\sigma i v$, together; $\tau \rho \varepsilon \dot{\pi} \varepsilon \varepsilon v$, to turn]. One of a set of syntropic parts (opposed to antitrope).

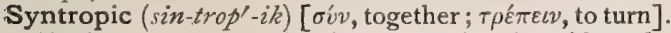
Similar, and turned in the same direction (thus the ribs of either side are syntropic; those of opposite sides are antitropic).

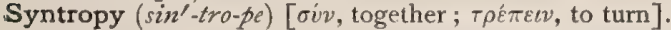
In biology, Wilder's term for the morphotropic relation between parts upon the same side of a structural plane.

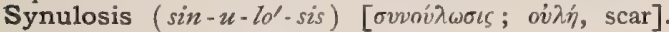
Cicatrization ; cicatrix

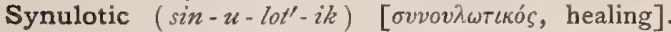
Promoting cicatrization.

Synymensis (sin-im-en'-sis). Synonym of Syndesmosis.

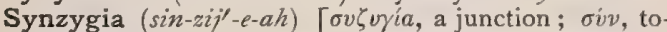
gether; $\zeta v \gamma o ́ v$, a yoke, any means of joining together]. See Syzygy.

Syphilelcos, Syphilelcus (sif-il-el'-kos, sif-il-el'-kus) [syphilis, syphilis; $\dot{\varepsilon} \lambda \kappa \delta s$, ulcer]. Syphilitic ulcer. Chancre.

Syphilelcosis (sif-il-el-ko'-sis) [syphilis, syphilis ; $\ddot{\varepsilon} \lambda \kappa_{\kappa}$, ulcer]. The condition or progress of syphilitic ulceration; the condition of having a chancre.
Syphilid, Syphilide (sif'-il-id) [ME., syphilis, syph. ilis]. Any disease of the skin due to syphilis. S., Acneiform, one of the early and rare forms of the cutaneous manifestations of syphilis. Its favorite positions are the face and shoulders. It is marked by the formation of flat pustules, about the eighth of an inch in diameter, on a dark-red, raised base, with a narrow areola. S., Annular. See Syphiloderma circinutum. S., Bullous, a syphilitic skin-ulceration that occurs in two forms, the rupial and "pempligoid." They differ from the other vesicular and pustular syphilids in not being placed on a raised, red base, and the areola is often pink, and not the usual raw-ham color. S., Circinate. See Syphiloderma circinatum. S., Ecthymatous, a form occurring only in the cachectic, and characterized by the presence of large pustules, which may be superficial or deep, the former occurring mainly in the early stage, the deep in the third period. The lesion commences around a hair-follicle, is about a third or a quarter of an inch in diameter, dries into a greenish scab on a raised, red base, develops slowly, and lasts for a few weeks. It is most common on the lower limbs. S., Erythematous. See Roseola, Syphilitic. S., Follicular, Miliary Syphilid; Syphilitic Lichen; a variety of papular syphilid in which the hair-follicles are the seat of the lesion. The lesion may be large or small. The larger occurs in the first six months of the disease, in irregular groups of from three or four to twenty, on the extensor aspect of the limbs and the back. The papules are about the size of a large pin's head or millet-seed, bright-red at first, soon changing to brownish-red, and crowned with a small scale. They appear in crops. The small form is very rare, is most common in women, and occurs in the first or second year of the disease. The papules are the size of a large or small pin's head, pink at first, then fawncolored, thickly crowded together in groups. S., Herpetiform. See S., Vesicular. S., Impetiginous, Syphilitic Impetigo; small pustules, single or aggregated, appearing on the scalp, and covered by yellowishgray or brown crusts, forming patches around a single hair-group. S., Lenticular, one of the common, early eruptions, often following closely upon or mixed up with the erythematous lesion. The papules are few or many, but not closely packed, and only grouped around the mouth and genitals. The usual sites are the forehead, lower part of the face, the nape and back, the flexor aspect of the limbs, and about the genito-anal passages. The lesions are from an eighth to half an inch in diameter, distinctly raised, sharply defined, flatly convex, of a deep-red tint (though they may be pale), firm and smooth. S., Macular. See Roseola, Syphilitic. S., Miliary. See S., Follic ular. S., Nodular, Tubercular Syphilid; convex projections of the skin, too large to be called papules. They are most common in the tertiary period, but may also be an early manifestation. They vary from a quarter to a half an inch in diameter, are sharply defined, considerably raised, of the characteristic coppery color, occasionally breaking down and ulcerating, with thick scabs, and much infiammation around, accompanied with much pain, and followed by white, depressed scars. They are solitary or few on the face, limbs, and trunk, but are not grouped, save in the tertiary stage. S., Nummular. See Syphiloderma papulo-squamosum. S., Orbicular. See Syphiloderma circinatum. S., Papular, a papular, syphilitic eruption on the skin or mucous membrane. S., Pemphigoid, Syphititic Pemphigus; a rare eruption in acquired syphilis and occurring almost exclusively in the congenital form. It is usually 
limited to the palms and soles, but may be widely spread. The contents seldom remain clear long. S., Pigmentary, Syphilitic Leukoderma; most common from the sixth to the twelfth month of the disease. It is rather a rare condition, but is seen much more frequently in women than in men, and in brunets than in fair women. Its seat is chiefly on the neck, especially at the sides and back; it may occasionally be seen on the face, chest, or flank. The lesions are irregularly margined, round or oval spots, from an eighth to one inch in diameter, well-defined or illdefined, with a yellowish-brown color. They may be discrete or confluent. They last from two months to several years, or may be permanent. S., Pustular, the termination occasionally of the vesicular syphilid. The contents become purulent, a crust forms, ulceration may go on under it, and a pigmented depression or scar is left. S., Rupial, one of the most characteristic syphilids occurring in the second and third years of the disease, and associated with profound cachexia. The lesion is the characteristic stratified, conic, limpetshell crust, which on removal leaves a sharply punched-out ulcer, shelving toward the center. These lesions are usually few in number, and on the limbs. S., Squamous. See Syphiloderma papulo-squamosum. S., Tubercular. See S., Nodular. S., Varicelliform, a form of vesicular syphilid in which the vesicles may be either convex or umbilicated, and their contents cloudy. They are situated on a slightly raised plateau, of the usual dull-red color. After a few days the vesicles dry into thick, adherent crusts of a greenish-black color. The course is slow. S., Varioliform, a slight modification of the varicelliform, causing the lesion to resemble the variolous eruption. S., Vesicular, an early skin-eruption of syphilis, appearing in the first six months. It may be small (very rare) or large. The lesions of the latter are grouped (herpetiform syphilid) in irregular, circinate, or serpiginous forms. The vesicles have a deep-red base, rupture at the end of a week, and dry up. They are common on the face, limbs, and trunk.

Syphilidiatria (sif-il-id-e-a'-tre-ah) [syphilis, syphilis ; iatpeia, treatment]. The medicinal treatment of syphilis.

Syphilidocolpitis (sif-il-id-o-kol-pi'-tis) [syphilis, syphilis; $\kappa \delta \lambda \pi \circ \varsigma$, vagina; $\iota \tau \iota \varsigma$, inflammation]. Syphilitic inflammation of the vagina.

Syphilidography (sif-il-id-og'-ra-fe). See Syphilography.

Syphilidology (sif-il-idt-ol'-o-je). See Syphilology.

Syphilidomania (sif-il-id-o-ma'ne-ah). See Syphilomania.

Syphilidophobia (sif-il-id-o-fo'-be-ah). See Syphilophobia.

Syphilidophthalmia (sif-il-id-off-thal'-me-ah) [syphilis, syphilis: $\dot{\alpha} \phi a \lambda \mu o ́ s$, eye]. Syphilitic ophthalmia.

Syphilifer (sif'-il-if-er) [syphilis, syphilis]. One who conveys syphilis.

Syphiliphobia (sif-il-if-o'-be-ah). See Syphilophobia. Syphilis (sif'-il-is) [syphilis, syphilis]. A chronic, infectious disease believed to be due to a specific organism and characterized by a variety of structural lesions of which the chancre, the mucous patch, and the gumma are the most distinctive. A bacillus has been found in the lesions by Lustgarten and others, but whether it is the real cause or not has not been definitely determined. The disease is generally acquired in sexual congress, hence its earliest manifestations appear upon the genital organs, but any abraded surface of the body, if brought in contact with the syphilitic poison, may give entrance to the infection. The earliest lesion of acquired syphilis is the chancre, initial sclero- sis, or primary sore, which appears after a period of incubation varying from two to three weeks. It is usually a reddish-brown papule with an ulcerated central spot, and has a slight serous or purulent discharge. Taken between the fingers, it is found to have a peculiar cartilaginous hardness. Microscopically it consists of an accumulation of round cells, epithelioid cells, with, perhaps, a giantcell here and there. The blood-vessels present a hyperplasia of the intima, to which in part the induration of the chancre is due. Very soon after the appearance of the chancre the nearest lymphatic glands become enlarged and indurated-the indolent buboes of syphilis. The chancre is generally solitary and is not auto-inoculable. The mucous patch, condyloma latum, moist papule, or mucous tubercle is located upon mucous membranes, at muco-cutaneous junctions, or where two skin-surfaces are in habitual contact. It is a flat, scarcely elevated patch, on mucous membranes generally covered by a whitish pellicle. Under the microscope we find a round-cell infiltration of the upper layers of the corium, some of the round cells penetrating between the cells of the epidermis. There is also a considerable quantity of fluid exudate, which in. filtrates and loosens the epithelial elements. The gumma or gummy tumor is a rounded nodule, varying in size from the dimensions of a pea to those of a small apple. Its favorite seats are the periosteum of flat bones, the membranes of the brain, the liver, spleen, and testicle. It is usually soft and contains in its interior a gelatinous "gummy" material. Radiating from and into it are bands of connective tissue; sometimes the latter forms a distinct capsule about the gumma. Histologically, it presents a cellular accumulation and some new blood-vessels, which, however, are inadequate for the nutrition of the newly formed tissue, hence its degeneration. In the viscera gummata are, as a rule, absorbed, their former sites being marked by stellate cicatrices. Another important though not distinctive lesion produced by syphilis is a diffuse sclerosis of the blood-vessels, especially of the parenchymatous organs. The cutaneous eruptions have histologically nothing peculiar-they are inflammatory lesions. The clinical course of syphilis is generally divided into three stages : the primary, characterized by the presence of the chancre and the indolent bubo; the secondary, by the mucous patch, cutaneous eruptions, sore throat, and general enlargement of the lymphatic glands; the tertiary, by the gumma and by severe skin-lesions. Between the appearance of the chancre and the secondary manifestations a period of six weeks usually elapses. The tertiary phenomena follow the secondary after a stage of quiescence of variable length. The tertiary lesions are the most destructive, but are, fortunately, rarer now than in former times. Syphilis also bears an important, but as yet obscure, relation to certain diseases of the nervous system, such as locomotor ataxy and paretic dementia. Although very wide-spread, syphilis is not contagious in the ordinary sense of the word. Infection generally proceeds from a chancre or from a mucous patch ; it may be conveyed by the blood. One attack as a rule confers immunity. S., Benign, syphilis in which the symptoms are mild. S. brephotrophica, syphilis spread among infants and those engaged in their care (Bulkley). S., Congenital, syphilis present at birth. S., Constitutional, syphilis characterized by general manifestations. See S., Secondary. S., Cutaneous. See Syphiloderma. S. e coitu illicito. See $S$. pravorum. S. e coitu legitimo. See S., Marital. S., Encephalic, syphilis of the brain. S. endemica. See $S$. pandemica. S. epidermica. See $S$. pandemica. S., Equine, 
an infectious disease of horses characterized by inflammatory lesions of the genital organs, enlarge ment of the lymphatic glands, and motor weakness, sometimes going on to complete paralysis of the hind limbs. The disease may be fatal. S., Extra-genital, syphilis in which the first lesion is situated elsewhere than on the genital organs. S., Gonorrheal, a chancre of the urethra producing a discharge resembling that of gonorrhea. S. hereditaria, S., Hereditary, S., Inherited, the syphilitic poison can traverse the placenta in either direction-as a rule, it is the mother who infects the child. Abortion is frequent, but if a living child is born it will develop symptoms of the inherited disease in from two weeks to three or four months after birth. These symptoms belong in part to the secondary stage, in part are peculiar. A hyperplasia of the connective tissue of the lung, liver, spleen, and pancreas is a common lesion. In the case of the first-named organ the condition is known as white pneumonia. The spleen and liver may be greatly enlarged. S. ingenita. See $S$., Hereditary. S. innocentium. Synonym of $S$ insontium. S. insontium, syphilis of the innocent, $i . e$, syphilis acquired in an innocent manner, or nonvenereal syphilis. S. insontium sine coitu, nonvenereal syphilis acquired otherwise than by sexual intercourse. S., Intra-uterine, syphilis acquired during intra-uterine existence. It is generally considered as a form of hereditary syphilis. S. inveterata. Synonym of S., Tertiary. S., Latent, syphilis in which the symptoms are in abeyance. S., Malignant, syphilis characterized by very destructive lesions, especially by gummata that appear early and degenerate rapidly. S., Marital, syphilis acquired in lawful wedlock. S. modificata. Synonym of Syphiloid. S., Non-venereal. Synonym of $S$. insontium. S. occulta, syphilis appearing in persons who give no history of primary or secondary lesions. S., œconomica, a form of syphilis insontium, in which the disease is acquired through eating and drinking or other household utensils, or by incidental contact with syphilitic persons (Bulkley). S. pandemica, syphilis which has extended widely after the manner of other contagious diseases. It may appear in an epidemic or an endemic form. In the former, the disease spreads with great rapidity and affects many persons; in the latter, it spreads more slowly and limits itself to a tribe or nation for a long time (Bulkley). S. pravorum, syphilis acquired in illegitimate sexual intercourse. S., Primary, syphilis during the period intervening between the appearance of the chancre and that of the secondary phenomena. S., Secondary, syphilis during the period in which the secondary phenomena are present. See Syphilis. S. sine coitu, syphilis not acquired by sexual contact. S. sporadica, syphilis insontium occurring in an isolated or sporadic manner (Bulkley). S. technica, syphilis acquired in following one's occupation, as by physicians, midwives, nurses. S., Tertiary. See Syphilis. S. universalis, syphilis affecting the entire body. S., Vaccination, syphilis acquired at the time of vaccination by the use of vaccine-lymph from a syphilitic subject, or subsequently by the inoculation of the wound. S., Venereal, syphilis acquired in illegitimate sexual intercourse. S., Visceral, syphilis of the viscera-the lesions are either inflammatory or in the form of gummata.

Syphilismus (sif-il-iz'-mus). Synonym of Syphilis.

Syphilitic (sif-il-it'-ic) [syphilis, syphilis]. Pertaining to or affected with syphilis.

Syphilization (sif-il-iz-a'-shun) [syphitis, syphilis]. In- oculation with the pus of a chancre. The term is also used to express a sort of immunity against fresh inocu. lation of syphilis, from the fact of previous inoculation.

Syphilized $\left(s i f^{\prime}-i l-i z d\right)$ [syphilis, syphilis]. Affected with hereditary syphilis.

Syphiloderma (sif-il-o-der'-mah) [syphilis, syphilis;

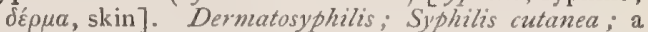
term including the various manifestations upon the skin due to syphilis. The early lesions are manifold, of a reddish-brown, coppery color and leave pigment-stains; they are symmetric, polymorphous, show a tendency to circular grouping, seldom itch or cause subjective symptoms, and develop slowly. The tertiary rashes are always ulcerative and result from the breaking down of gummata; they occur on any part of the body, are unsymmetrically distributed, extend centrifugally while healing in the center and leave flat, white scars. They are usually seen on the palms and soles. S. circinatum, circinate, orbicular, or annular syphilid; lepra syphilitica; a form of squamous syphilitic skin-eruption of the secondary period. It occurs during the first year of the disease and may be quite early. The favorite positions are the nape and other parts of the neck, forehead, and around the chin and mouth. It occurs in circles from half an inch to an inch in diameter, which may form gyrate figures with clear centers and sharply de fined, distinctly raised borders, with some scales. S. Papulo-squamosum, nummular syphitid; squamous syphilid; syphilitic psoriasis; a papular skin-eruption seen at any period of the first, and occasionally in the second year of syphilis, followed by desquamation, the scales ranging in size from a quarter to three-quarters of an inch in diameter. They are usually scanty and dirty-looking, but may be abundant and silvery. The lesions are seen all over the body, and may persist for months.

Syphilodermia (sif-il-o-der'-me-ah). Same as Syphiloderma.

Syphilographer (sif-il-og'-ra-fer) [syphilis, syphilis;

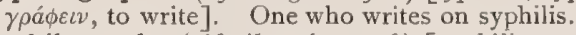

Syphilography (sif - il -og'-ra-fe) [syphitis, syphilis;

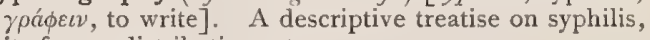
its forms, distribution, etc.

Syphiloid (sif'-il-oid) [syphilis, syphilis ; عidos, resemblance]. An endemic disease of Lithuania, Poland, and other regions, and which is probably identical with syphilis. Also known as Syphitis modificata. S., Canadian, a disease which in some respects resembled syphilis, and prevailed in Canada during part of the eighteenth century. S. of Courland, a disease observed at Courland, Russia, having many of the symptoms of syphilis. S., Hessian, a form of disease resembling syphilis, at one time prevalent in Hesse. S., Jutland, a disease resembling syphilis observed in Jutland, Denmark.

Syphilolepis (sif-il-ol'-ep-is) [syphilis, syphilis ; $\lambda \varepsilon \pi i s$, scale]. A scaly or furfuraceous eruption of syphilitic origin.

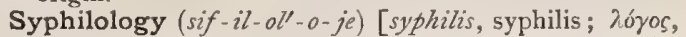
science]. The sum of knowledge regarding the origin, nature, and treatment of syphilis.

Syphiloma (sif-il-o'-mah) [syphilis, syphilis; ö $\mu a$, tumor: pl., Syphilomata]. A gummatous tumor of syphilitic origin.

Syphilomania (sif-il-o-ma'-ne-ah) [syphilis, syphilis; pavia, mania]. The inclination to attribute diseases to syphilis. The morbid belief in the presence of syphilis.

Syphilomatous (sif-il-o'-mat-us) [syphilis, syphilis; ö $\mu$, tumor]. Pertaining to syphiloma.

Syphilonychia (sif-il-o-nik'-e-ah) [syphilis, syphilis ; ovv $\xi$, nail]. An onychia of syphilitic origin. $\mathbf{S}$. 
exulcerans, syphilitic onychia with ulceration. sicca, syphilitic onychia without ulceration.

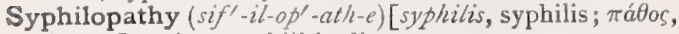
disease]. Any syphilitic disease.

Syphilopemphis $($ sif-il-o-pen' $-f i s)$ [syphilis, syphilis; $\pi \varepsilon \mu \phi i s$, a blister]. Pemphigus of syphilitic origin.

Syphilophobe (sij'-il-o-fól) [syphilis, syphilis; фóßos, fear]. One affected with syphilophobia.

Syphilophobia (sif-il-o-fo'-be-ah) [syphilis, syphilis; $\phi 6 \beta \ldots s$, dread]. A morbid condition in which the patient imagines himself to be diseased with syphilis. Also an intense dread of syphilitic infection.

Syphilophyma (sif-il-o- $\left.f^{\prime}-m a h\right)$ [syphilis, syphilis; $\phi \tilde{v} \mu \alpha$, growth]. Syphiloma of the skin.

Syphiloscleroma (sif-il-o-skle-ro'-mah). Synonym of Chancre.

Syphilosis (sif-il-o'-sis) [syphilis, syphilis]. Syphilitic disease.

Syphilous (sif'-il-zes). Same as Syphititic.

Syphionthus (sif-e-on'-thus) [syphilis, syphilis; iov 0 os, an eruption on the face]. The copper-colored eruptions or fawn-colored, furfuraceous patches of syphilitic origin.

Syphon (si'-fon). Synonym of Siphon.

Syphonage $\left(s i^{\prime}-f o n-\bar{a} j\right)$. See Siphonage.

Syphonoma (si-fon-o'-mah). Synonym of Siphonoma.

Syriac Ulcer. Synonym of Diphtheria.

Syrigmophonia (sir-ig-mo-fo'-ne-ah) [ $\sigma v p i \sigma \sigma \varepsilon \iota v$, to hiss; $\phi \omega \nu \eta$, voice]. A piping or whistling state of the voice.

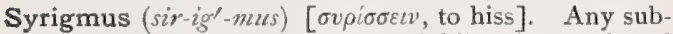
jective hissing, murmuring or tinkling sound heard in the ear.

Syringe $\left(s i r^{\prime}-i n j\right)$ [ $\sigma \tilde{u} \rho \imath \gamma \xi$, a pipe]. An apparatus for the injection of a liquid into a cavity of the body.

Syringeal $\left(s i r-i n^{\prime}-j e-a l\right)$ [ $\sigma \tilde{p} \rho \iota \xi \xi$, a pipe]. Relating or belonging to the syrinx.

Syringin $\left(\operatorname{sir}-i n^{\prime}-\not i n\right)$ [ $\sigma \ddot{\nu} \rho \iota \gamma \xi$, tube]. A crystalline glucosid obtained from Syringa vulgaris.

Syringitis $\left(s i r-i n-j i^{\prime}-t i s\right)$ [ $\sigma \vec{v} \rho \iota \gamma \xi$, tube; $\iota \tau \iota s$, inflammation]. Inflammation of the Eustachian tube.

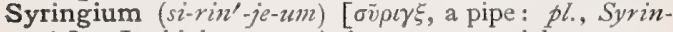
gia]. In biology, a tubular repugnatorial organ on certain caterpillars.

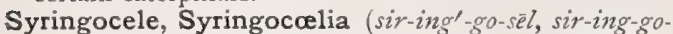

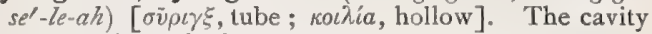
or central canal of the inyelon or spinal cord.

Syringo-cystadenoma (sir-ing'-go-sis-tad-en-o'-mah)

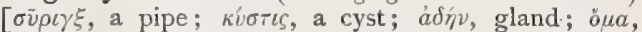
tumor]. A peculiar disease of the skin that probably begins in embryonic sweat-glands. The eruption consists in a number of small, round, hard, raised papules of the color of the skin, which tend to grow larger and become of a bluish-red color. There are no subjective symptoms.

Syringoid (sir-ing'-goid). Synonym of Fistulous.

Syringomeningocele (sir-ing $g^{\prime}-g o-m e n-i n^{\prime}$ - go-sél)

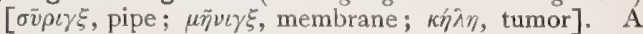
meningocele resembling a syringo-myelocele.

Syringomyelia (sir-ing $\left.\rho^{\prime}-g o-m i-e^{\prime}-l e-a h\right)[\sigma v \rho \iota \gamma \xi$, tube ; $\mu v \varepsilon \bar{\delta} \delta$, marrow]. The morbid condition caused by the presence of an adventitious cavity in the spinal cord or by the dilatation of the central canal.

Syringomyelitis $\left(\operatorname{sir}-i n g^{\prime}-g o-m i-e l-i^{\prime}-t i s\right)[\sigma \vec{v} \rho l \gamma \xi$, tube ; $\mu v \varepsilon \lambda \sigma_{S}$, marrow; $\iota T \iota s$, inflammation]. The inflammation coincident with or preceding syringomyelus.

Syringo-myelocele (sir-ing $\left.g^{\prime}-g o-m i^{\prime}-e l-o-s \bar{e} l\right)[\sigma \tilde{v} \rho \iota \gamma \xi$,

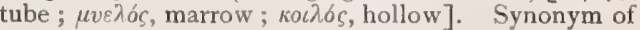
spina bifida.

Syringomyelus (sir-ing $\left.\sigma^{\prime}-g o-m i^{\prime}-e l-u s\right)$ [ $\sigma \bar{v} \rho \iota \gamma \xi$, tube ; $\mu v \varepsilon \not i o s$, marrow]. An abnormal dilatation of the central canal of the spinal cord in which the central gray column is converted into connective tissue, the interior softening and forming a cavity. A disease similar to this in children is called hydromyelia.

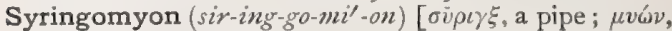
a muscle]. In biology, one of the intrinsic muscles of the syrinx in birds.

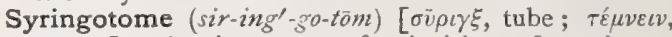
to cut]. An instrument for incision of a tube or fistula; a canaliculus-knife; it is also used by anatomists.

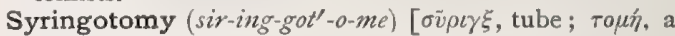
cutting]. The operation of laying open a fistula in ano by incision.

Syrinx (sir'-inks) [ov $\rho l \gamma \xi$, tube : pl., Syringes]. A tube, a fistula. In biology, the lower larynx or voice-organ of a bird. It is especially developed in the Uscines, or singing birds. See Syringe.

Syrup, Sirup $\left(\right.$ si $\left.^{\prime}-u p\right)$ [siropus, syrup]. A syrup. In pharmacy, a concentrated solution of sugar in an aqueous fluid. Syrups may be simple (consisting of sugar and water only), flavored, or medicated. There are thirty-one syrups official in the U. S. Pharmacopeia besides 37 in the N. F. S., Eaton's, syrup of the phosphates of iron, quinin, and strychnin. S., Hive, compound syrup of squills. S., Simple, the aqueous solution of sugar without other ingredients.

Syrupy $\left(\right.$ sir $\left.^{\prime}-u p-e\right)$ [siropus, syrup]. Of the nature or consistence of a syrup.

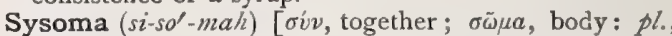
Sysomata]. A double monstrosity with two separate heads, but with the bodies fused in more or less intimate union.

Sysomic (si-so'-mik) [ $\sigma \dot{v} \nu$, together; $\sigma \bar{\omega} u a$, body]. Of the nature of a sysoma.

Syspasia (sis-pa'-ze-ah). Synonym of Convulsion.

Syssarcosic (sis-ar-ko'-sik) [ $\sigma \dot{v} v$, together; $\sigma a ́ \rho \xi$, flesh]. Of the nature of or relating to a syssarcosis.

Syssarcosis $\left(s i s-a r-k \sigma^{\prime}-s i s\right)$ [óv, together; $\sigma a ́ \rho \xi$, flesh]. The union of bone by the interposition of muscular tissue.

Systalsis (sis-tal'-sis). Synonym of Systole.

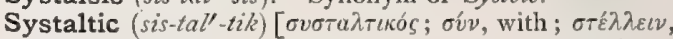
to set]. Pulsatory; contracting; having a systole.

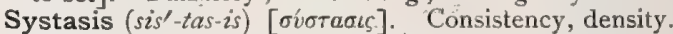

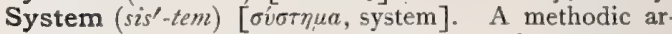
rangement of parts. A combination of parts into a whole. In biology, an assemblage of parts or organs of the same or similar tissues. In microscopy, there may be found from one to five systems in a single objective. Each system may consist of one, two, or three lenses. When more than one they are cemented together. The systems are called in their order: anterior or front, middle, and posterior. S., Anterior, or Front, in the microscope, the system of lenses nearest the object. S., Brunonian. See Brunonian. 'S., Cerebro-spinal, the brain, spinal cord, and their various branches. S., Circulatory, the blood-vessel system. S., Dermoid, Bichat's term for the skin and its derivatives. S.-disease, a disease of the cerebrospinal axis affecting a tract of nerve-fibers or nerve-cells having common anatomic relations and physiologic properties. S., Glandular, the glandular organs of the body considered as a whole. S., Human, the human body and its organs. S., Ling's. See Ling. S., Middle, the lenses of the microscope between the anterior and posterior systems. S., Muscular, the muscles, their mechanism, etc. S., Nervous, the nerves of the body, cerebral, spinal, and ganglionic. S., Osseous, the skeleton. S., Posterior, in the microscope the system of lenses farthest from the object. S., Vascular, the heart and blood-vessels. 
Systema (sis-te'-mah). See System.

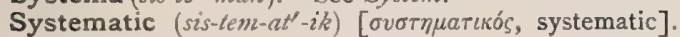
Methodic; taxonomic; classificatory.

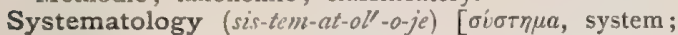
$\lambda$ yos, science]. The science of arrangement and classification.

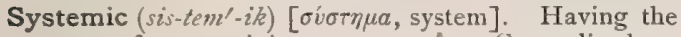
nature of or pertaining to a system. Generalized, or pertaining to the whole organism. Applied to the circulation in the body generally, as distinguished from that in the lungs.

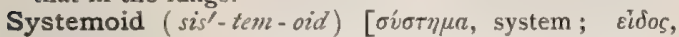
form]. A term applied to tumors composed of a number of tissues resembling a system of organs; teratoid.

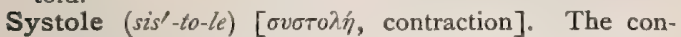
traction of the heart and arteries. S., Aborted, a cardiac systole which, on account of insufficient energy or mitral regurgitation, does not increase the arterial pressure. S., Anticipated, an aborted systole due to an imperfectly filled ventricle. S., Arterial, the arterial retraction following cardiac systole. S., Auricular, auricular contraction. S., Ventricular, the contraction of the ventricles.

Systolic $\left(s i s-t_{0} l^{\prime}-i k\right)$ [ $\sigma v_{\sigma \tau o} \eta \eta$, systole]. Pertaining to systole.

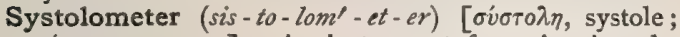
$\mu \varepsilon ́$ тpov, measure]. An instrument for estimating the intensity and quality of cardiac sounds and murmurs, and the length of the pauses.

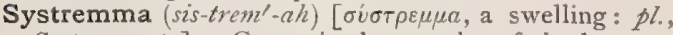
Systremmata]. Cramp in the muscles of the leg.

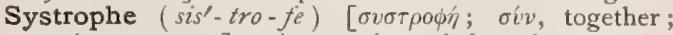
$\sigma \tau \rho \varepsilon \phi \varepsilon \varepsilon \nu$, to turn ]. A wrench, and the subsequent inflammation. In biology, the massing of the chlorophylbodies of a cell under intense light. Cf. Apostrophe, Epistrophe.

Systylous (sis'-til-us) [ $\sigma \dot{v} \sigma \tau v \lambda$ os, with columns standing close]. In biology, applied $(a)$ to flowers in which the styles cohere to form a single column; $(b)$ to mosses in which the lid is fixed to the columella.

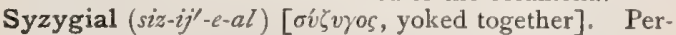
taining to syzygy.

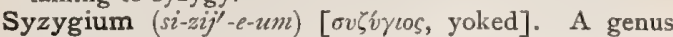
of E. Indian myrtaceous trees. S. jambolanum affords an astringent bark, which is asserted to be useful in diabetes. Same as Syzygy. Unof.

Syzygy $\left(s i z^{\prime}-i j-e\right)$ [ $\sigma i \zeta v \gamma o s$, yoked together; $\sigma i v$,

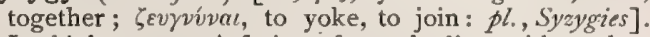
In biology: I. A fusion of two bodies, without loss of identity. 2. A zygote or conjugate body, formed by the union or conjugation of two similar gametes, and usually followed by encapsulation and later by sporulation; a syzygium.

Szydlowski's Method. A method of estimating $\mathrm{CO}_{2}$ in the air. See Ventilation.
T. The abbreviation of Tension, referring to the intraocular pressure. See Tension.

T.-bandage. See Bandage.

T.-bone. See Tau-bone.

Tabacosis $($ tab-ak-o'-sis) [tabacum, tobacco]. Zenker's term for disease of the lungs arising from inhalation of vegetable fibers, especially of cotton. Properly, that form of pneumonokoniosis due to the inhalation of tobacco-dust.

Tabacum (tab-ak'-um) [L. : gen., Tabaci]. Tobacco. The dried leaves of Nicotiana tabacum, native to America. Its properties are mainly due to an alkaloid, nicotin, $\mathrm{C}_{10} \mathrm{H}_{14} \mathrm{~N}_{2}$, which, next to prussic acid, is the most rapidly fatal poison known. Tobacco is a powerful depressant, nauseant, emetic, diaphoretic, and antispasmodic; it is also narcotic and sedative, lowering arterial tension. In toxic doses death occurs by paralysis of the respiratory centers. It is used chiefly as an antispasmodic, and is said to be effectual in tetanus. T., Enema, gr. $x x$ in $\xi$ viij hot water for each enema. T., O1., obtained by distillation; violently poisonous. T., Vinum, $\zeta_{j}$ to $O j$. Dose $\eta^{v-3 j}$. Nicotin, the alkaloid, efficient in strychnin-poisoning. Dose $m_{\frac{1}{20}-1}$ and up to $\eta_{i j}$ in two hours. Preparations unof.

Tabanid $\left(t a b^{\prime}-a n-i d\right)$ [tabanus, a gad-fly]. Any horsefly or gad-fly of the family Tabanide, of which the genus Tabanus is the type. More than 1300 species are known, the females of many of them being capable of inflicting a severe and painful bite. See under Parasites (Animal), Table of.

Tabasheer (tab'-a-shēr) [Hind, tabāshēr]. A corruption of Tabixir. An opal-like substance formed. abnormally in the joints of certain species of bamboos. This is probably the substance called Oculus mundi, and Lapis mutabilis by $\mathbf{1} 7$ th century writers. It played a great part in medieval therapeutics as a supposed remedy for all sorts of physical and mental ills. It is used locally as a tonic, aphrodisiac, pectoral, astringent, and anti-spasmodic, Unof.

Tabatière anatomique $\left(t a b-a t^{\prime}-e-\bar{a} r a n-a t-o m^{\prime}-\bar{e} k\right)$ [Fr.]. The depression at the base of the thumb on its radial aspect between the second and third extensor tendons.

Tabaxir $\left(t a b^{\prime}-a k s-\bar{e} r\right)$. See Tabasheer.

Tabby-cat Striation. Peculiar markings occurring on muscles that have undergone extreme fatty degeneration. The condition is especially seen in the musculi papillares of the heart in pernicious anemia.

Tabebuia (tnb-e-bu'-e-ah) [a native Braz. name]. A genus of bignoniaceous trees and shrubs of tropical America, of some 60 species. T. impetiginosa is mucilaginous and highly astringent, and is locally valued as a medicine. Unof.

Tabefaction ( $\left.a b-e-f a k^{\prime}-\operatorname{shun}\right)$ [tabefacere, to melt]. Wasting; emaciation.

Tabella $(t a-h e l l-a h)$ [L.: $p l .$, Tahelle $]$. A table. A troche. A tablet.

Tabellary (tab'-el-ar-e). Same as Tabular.

Tabes $\left(t a^{\prime}-b \bar{e} z\right)$ [L., a wasting]. Formerly used as a synonym of wasting, shrinking, or consumption. Now used as a synonym of Tabes dorsalis or Locomotor Ataxy, a disease dependent upon degeneration and sclerosis of the posterior columns of the spinal cord. Its most pronounced symptom, incoördination of the 
muscles of locomotion, has served to establish the term Locomotor Asaxy as the common designation of the affection. The anatomic changes consist of atrophy and degeneration of the nerve-fibers, with hypertrophy of the connective tissue, and extend from the lumbar region to the calamus scriptorius. The symptoms are numerous, but the chief are "lightning-pains ;" unsteadiness and incoördination of locomotor and other voluntary movements, extending even to the upper extremities; disorders of vision, among others the valuable Argyll-Robertson Pupil, q. v. ; cutaneous anesthesia; girdle-sense; abolition of the patellar reflex; diminution of sexual desire; peculiar "crises," etc. The disease is a very chronic one, but is not always progressive. It occurs most frequently in males, and usually between the ages of thirty and fifty. The most common cause, by some authorities said to be the only cause, is syphilis. Other predisposing, exciting or adjuvant causes are prolonged exposure to cold and wet, alcoholism, mentai strain and traumatism of the spine. $T$. coxaria, wasting from hip-joint disease. $T$. ergotica, a toxemia resulting from the use of ergot; its symptomatology closely simulates that of locomotor ataxia. T.glandularis. Synonym of $T$. mesenterica. T., Hereditary. See Friedreich's Ataxia. T., Lacteal. See Hyperlactation. T. mesentericus and T. scrofulosa, old terms descriptive of diseases of the digestive and assimilative organs, sometimes tuberculous, sometimes syphilitic, and attended with wasting. $T$. neurasthenica, neurasthenia with the symptoms of locomotor ataxia. T. pulmonalis, pulmonary tuberculosis. T. saturnina, the general disability due to lead-poisoning. T. scrofulosa. Synonym of $T$. mesenterica. T., Suspension Treatment of, see Sitspension. T. urinalis. Synonym of Diabetes mellitus.

Tabescence $\left(t a b-e s^{\prime}-e n s\right)$ [tabes, wasting]. Wasting ; marasmus; emaciation.

Tabescent (tab-es'-ent) [tabescere, tabescens, to waste]. Wasting, or becoming wasted, or emaciated.

Tabetic (tab-et'-ik) [labes, wasting]. Pertaining to or affected with tabes.

Tabic $\left(t a b^{\prime}-i k\right)$ [labes, wasting]. Affected with tabes; of the nature of or pertaining to tabes.

Tabid $\left(t a b^{\prime}\right.$-id $)$ [tabes, wasting]. Wasted, by disease ; emaciated; affected with tabes

Tabidness $\left(t a b^{\prime}-i d\right.$-nes) [tabes, wasting]. The state of being reduced by disease.

Tabific (tab-if'-ik) [tabes, wasting; facere, to make]. Tending to produce tabes or emaciation.

Tabitude (tab'-it-itd) [tabes, a wasting]. Emaciation; wasting of the body.

Tablature $\left(t a b^{\prime}-l a t-\bar{u} r\right)$ [tabula, a table]. Separation into tables, as exemplified in the frontal, parietal, and occipital bones.

Table $\left(t a^{\prime}-b l\right)$ [tabula, a table]. A flat-topped piece of furniture. Either one of the two layers, the outer and inner, of the cranial bones; the inner, from its brittleness, is also called the vitreous table. $\mathrm{T}$., Bed, a small, portable table arranged to go across the bed. T., Operating, a table used in surgical operations. T.-spoon, T.-spoonful. See Cochleare magnum. T., Vitreous (of the skull), the inner cranial table.

Tablet $\left(t a b^{\prime}-l e t\right)$ [tabula, a table]. I. A lozenge, a troche. 2. A table, as of a cranial bone. See Table. T.-triturates, in pharmacy, small, disc-shaped bodies, prepared by moistening medicated powders with a highly volatile liquid, then molding the moistened powder, ejecting the tablet, and allowing the liquid to evaporate, when the tablets retain their shape. The basis of tablet-triturates is mostly finely-powdered sugar. They disintegrate in the alimentary canal.
Tabloid (tab'-loid) [tubula, table; cidos, like]. A tablet-like pharmaceutic preparation; a flat troche, or lozenge.

Tabula (tab'-u-lah). See Table. T. cathamnales, the septal plates of Medusa.

Tabular (tabl-u-lar) [tabula, table]. Having the form of a table.

Tabulet $\left(t a b^{\prime}-u-l e t\right)$ [tabula, a table]. A lozenge; a tablet.

Tabum $\left(t a^{\prime}-b u m\right)$. Synonym of Ichor".

Tac $(t a k)$ [Fr., rot]. Synonym of Infuensa.

Tacahout $\left(t a k^{\prime}-a-h o w t\right)$ [nat. Indian]. A kind of gall produced upon the Tamarisk, $q . v$.; astringent. Unof.

Tacamahac, Tacamahaca ( $t a k^{\prime}-a m-a-h a k$, $t a k-a m-a-$ $\left.h a k^{\prime} \cdot a h\right)$ [Mexican]. A resin produced by various trees of the genera Bursera, Protium, and Calophyllum; also, the resin of the buds of Populus balsamifera, the Balm of Gilead poplar of N. America. These resins are now little used in medicine. Unof.

Tacca $\left(t a k^{\prime}-a h\right)$ [Malay]. A genus of large-leaved tropical plants. T. pinnatifida, Forst, yields a kind of arrow-root. Unof.

Tache (ta/hsh) [Fr.]. A spot, a coloration. T. blanches, certain white spots described by Hanot as occurring on the liver, especially on its convex surface, in infectious diseases. Microscopically they present a leukocytic infiltration with bacteria. $T$., bleuâtre, a spot of a delicate-blue tint, sometimes observed on the skin of typhoid-fever patients. The spots are of an irregularly rounded form, and from three to eight lines in diameter; not elevated above the skin, nor affected by pressure. They are most common on abdomen, back, and thighs. They usually precede the characteristic eruption of typhoid fever. Ts. cérébrales, irregular, red, angio-paralytic patches upon the skin, noticed in some cases of epilepsy; also, the spot on the blastoderm about the end of the first week, which becomes the center of embryonic development. $\mathbf{T}$. méningéale, the red line made when the finger-nail is drawn over the skin. It was thought to be distinctive of meningeal irritation, but may be observed in other conditions of vaso-motor paresis.

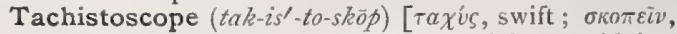
to view]. A form of stereoscope giving rapid impressions by means of a movable diaphragm.

Tachometer $\left(t a k-o m^{\prime}-e t-e r^{\prime}\right)$. See Hemotachometer.

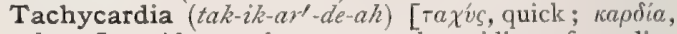
heart]. Abnormal paroxysmal rapidity of cardiac action. The pulse may rise as high as 200 per minute. It is a comparatively rare affection, due to paralysis of the inhibitory nerve of the heart or to stimulation of the cardiac accelerator nerves. T., Essential Paroxysmal, tachycardia occurring in paroxysms and due to functional disturbance of the cardiac nerves. T., Paroxysmal, tachycardia occurring periodically in paroxysms. T. strumosa exophthalmica. See Exophthalnic Goiter.

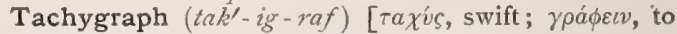
write ]. Synonym of Hemotachometer.

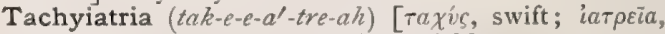
treatment]. The art of curing quickly.

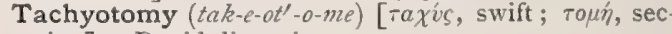
tion ]. Rapid dissection.

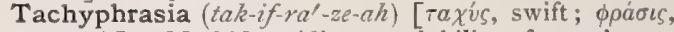
speech ]. Morbid rapidity or volubility of speech.

Tachypnea $\left(t a k-i p-n e^{\prime}-a k\right)[\tau a \chi v \zeta$, swift; $\pi$ vot $\eta$, breath]. Abnormal frequency of respiration.

Tachythanatous $\left(t a k-i t h-a n^{\prime}-a t-z e s\right)$ [Taxís, swift; Өávatos, death]. Rapidly fatal.

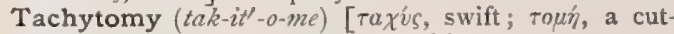
ting]. The art of operating quickly. 
Taciturn (tas'-it-umn) [tacitumus, silent]. Habitually silent or reserved.

Tact (takt) [tactus; tangere, to touch]. Delicacy of discrimination, judgment, and act. T., Medical, skill in the diagnosis and treatment of disease. See Tactus.

Tactile (tak'-til) [tactilis]. Pertaining to the sense of touch. T. Cells, cells representing special sensory nerve-endings, "found in the deeper layers of the epidermis, or the adjacent stratum of corium. They are, (I) simple, oval, nucleated elements $5-12 \mu$ in size, resembling ganglion-cells; (2) compound, in which two or more cells are associated to receive the nerve-

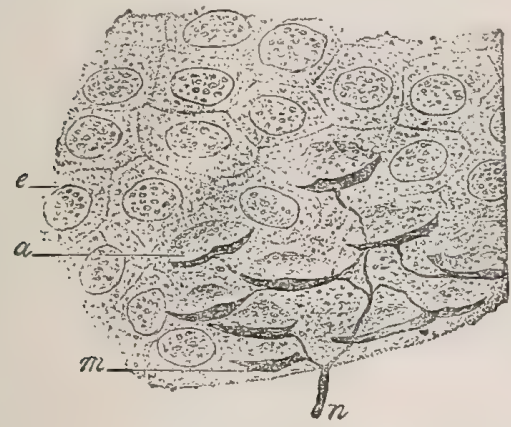

Tactile Cells, Snout of Pig.

a. Tactile cells. $m$. Tactile disc, n. Nerve-fiber. (From Stirling.)

fiber; the corpuscles of Grandry and of Merkel found respectively in the epidermis of birds and of mammals are examples of such structures" (Piersol). T. Corpuscles, special sensory nerve-endings exhibiting more complexity of structure than compound tactile cells. Cf. End-bulbs. T. C. of Grandry, see under T. Cells. T. C. of Meissner, oval or elliptic bodies, $45-140 \mu$ long and $35-55 \mu$ wide, situated usually at the apices of the papillae of the corium, in the skin of the palmar surfaces of the fingers and toes. Each corpuscle is supplied with one or two, sometimes three or four, medullated nerve-fibers. T.C. of Merkel, see under $T$. Cells. T. Disc, the flattened terminal expansion of the axis cylinder in a special sensory nerveending, or tactile corpuscle.

T. Meniscus, a peculiar crescentic expansion of a nerve-fiber over the ental surface of a tactile cell. T. Papillæ. See Papilla. T. Reflexes, reflex movements from stimulation of the tactile corpuscles.

Tactus $\left(t a k^{\prime}\right.$-tus $)$ [tangere, to touch]. Touch. Delicacy of tactile sensation. $T$. eruditus, or $T$. expertus, especial sensitiveness of touch acquired by long experience.

Tædium vitæ $\left(t e^{\prime}-d e-u m v i^{\prime}-t e\right)$ [L.]. Disgust, or weariness of life, a symptom witnessed in many cases of insanity; it is sometimes a precursor of suicide.

Tænia $\left(t^{\prime}-\right.$-ne-ah). See Tenia.

Tæniacide $\left(t e^{\prime}\right.$-ne-as-îd $)$. See Teniacide.
Tæniafuge (te'-ne-af-ijj). See Teniafuge

Tænidium (te-nid'-e-um) [Trtvia, a band, fillet: $p l$., Tanidia]. In biology, the spiral thread of the respiratory tracheæ of an insect.

Tafia (taf'-e-ah or ta-fe'-a/h)[Malay, täfi $a$, rum]. Rum.

Tag Alder (tag' aw $\left.\left.l^{\prime \prime}-d e\right)^{\prime}\right)$. See Alnus.

Tagliacotian (tal-e-ak-o'-she-an) [after Tagliacozzi, an Italian surgeon]. Pertaining to Tagliacozzi. T. Operation, a rhinoplastic operation by which, in case of destruction of the natural tissue, a part or the whole of a new nose is formed by a flap from the forehead or other part.

Tagma $\left(\operatorname{tag}^{\prime}-m a h\right)[$ tá $\gamma \mu a$, that which has been ordered or arranged]. In biology, a general term applied by Pfeiffer to all aggregates of molecules. Cf. Inotagmato micella, pleon, syntagmu.

Tail $(t \bar{a} l)$ [ME., tail, tail]. The caudal extremity of an animal. Applied to tail-like parts of an organ of the human body; e.g., the tail of the epididymis or of the pancreas. T.-coverts, the most posterior feathers of the body of a bird, or those which immediately cover the basal portion of the tail. T.-fold, an embryonic infolding or hollow, enclosing the hind-gut. See Head-fold.

Tailors' Cramp or Spasm. See Cramp. T.s'Muscle. See Scrrtorius (in Muscles, Tuble of).

Taint (tānt) [ME., teint, taint]. An infection, or pathogenic influence; as a syphilitic taint. A spot or blemish.

Tait's Knot. A peculiar method of ligating the pedicle in the operation of ovariotomy. See Knot, Staffordshire. T.'s Law. See Law. T.'s Method. See Perineorrhaphy.

Talalgia (tal-al'-je-ah) [talus, heel; ă $\lambda$ yos, pain]. Pain in the heel.

Talc, Talcum (talk) [gen., Talci]. A silicate of magnesium, a white; unctuous, neutral powder; sometimes used in insufflating-powders, and as a remedy in diarrhea.

Taliacotian (tal-e-ak-o'-she-an). See Tagliacotian.

Taliped (tal'-ip-ed) [talus, ankle; pes, foot]. person affected with talipes; club-footed.

Talipedic (tal-ip-e'-dik) [talus, ankle; pes, foot]. Belonging or relating to talipes.

Talipes $\left(t a l^{\prime}-i p-\vec{e} z\right)$ [talus, ankle; pes, foot]. The deformity commonly called club-foot, depending upon
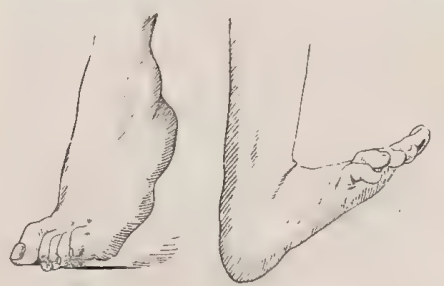

Talipes Eouinus. TAlipes CalcaNEOUS.

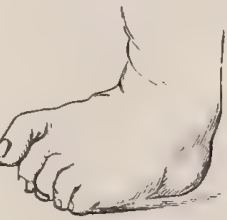

TALIPES VARUS.

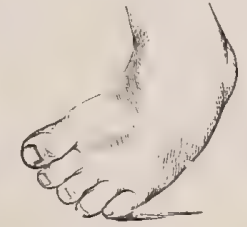

TALIPES EQuinoVARUS.

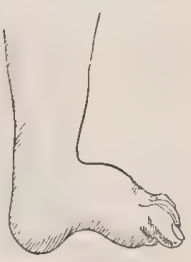

TALIPES CAVUS OR Arcuatus. contraction of muscles or tendons, either congenital or 
acquired. T. arcuatus, See $T$. carns. T. calcaneus, the patient walks upon the heel alone. $T$. cavus, an increased curvature of the arch of the foot. T. equinus, the heel is elevated and the weight thrown upon the anterior portion of the foot. T.planus, flat-
TAlipes Valgus.

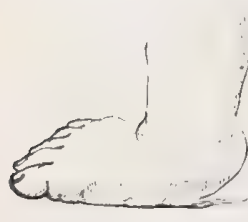

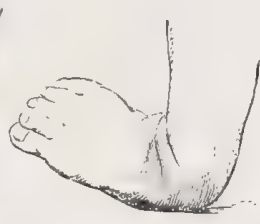

Talipes CalcaneoVALGUS.

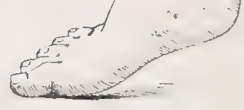

Talipes EquiNoVALGUS. foot. T., Spasmodic, non-congenital talipes due to muscular spasm. T. valgus ("flat" .or "splay" foot), the foot is everted or distorted outward. $T$. varus, the reverse of the last, the foot being bent inward. Combinations of these occur, called equinovarus, equino-valgus, calcaneo-varus, calcaneo-valgus, etc.

Talipomanus (tal-ip-o-ma'-nus) [talus, ankle; pes, foot ; manus, hand]. Deformity of the hand, analogous to club-foot, club-hand.

Tallow (tal'-o) [ME., talowe, tallow]. The solid fat of neat cattle, consisting mainly of stearic, palmitic, and oleic acids. Tallow is the name given to the fat extracted from "suet," the solid fat of oxen, sheep, and other ruminants. The quality of the tallow varies according to the food of the cattle and other circumstances, dry fodder inducing the formation of a hard tallow. Its melting-point varies from $115^{\circ}$ to $12 \mathrm{I}^{\circ} \mathrm{F}$. The best qualities are whitish, but tallow has in general a yellowish tint. Beef-tallow contains about 66 per cent. of solid fat and 34 per cent. of olein or tallow-oil ; mutton-tallow contains about 7o per cent. of solid fat and 30 per cent. of tallow-oil. The oil is used chiefly in the manufacture of soaps and the harder tallow for candle-making.

Talo- $\left(t \tau^{\prime}-l o\right)$ [talus, ankle]. A prefix denoting connection with or relation to the heel, as talo-calcaneal, talo-fibular, talo-tibial, etc.

Talon (tal'-on) [talus, ankle, heel]. In biology: (I) a claw, as of a bird of prey; (2) a posterior prolongation on the sectorial teeth of mammals. T.-toe. See Hammer-toe.

Talpa $\left(t a l^{\prime}-p a h\right)[\mathrm{L}$.$] . A mole or wen.$

Talus $\left(t a^{\prime}-l u s\right)$ [L.]. The astragalus. AIso, the ankle.

Tamarac (tam'-ar-ak) [Am. Ind.]. The bark of Larix americana, a tonic and mild astringent acting on mucous membranes. Dose of the fld. ext. 3 ss-j. Unof

Tamarind (tam'-ar-ind) [Ar., tamr ul Hind, the Indian date]. The pulp of the fruit of Tamarindus indica. It contains various fruit-acids, sugar, etc. It is laxative and refrigerant. It is usually prescribed with other laxatives. Dose indefinite. Also the fruit itself and the tree that produces it. T.-water, an infusion of tamarind in cold water. It is used as a cooling drink in fevers.

Tamar indien. See Senna.

Tamarindus (tam-ar-in'-dus) [L.]. A genus of oldworld leguminous trees. $T$. indica. See Tamarind.

Tamarisk (tam'-ar-isk) [L.]. A shrub or tree of the genus Tamarix. T. gallica and T. articulata yield tamarisk galls. See Tacahout. T. mammifera affords a kind of manna. Unof.

Tambor-oil $\left(\mathrm{tam}^{\prime}\right.$-bor-oil). A purgative oil from the seeds of Omphalea oleifera, a plant of tropical America. Unof.

Tambour (tan'-bor, or tam'-boor) [Fr., tambour, a drum]. A drum-like instrument used in physiologic experiments. It consists of a shallow cup of metal over which is stretched an elastic membrane and from which or to which passes a tube for transmitting a current of air. It is set into movement by the phenomena under observation.

Tampon (tan'-pon) [Fr.]. A portion of cotton, sponge, or other material, medicated or not, and used to plug the vagina, nose, etc., in cases of hemorrhage or for other therapeutic purpose. T., Kite-tail, a tampon consisting of a number of pledgets tied at intervals to a string. $\mathbf{T}$., Trendelenburg's, an inflatable rubber bag surrounding a tracheotomy-tube. It prevents the oozing of blood along the sides of the tube.

Tamponade, Tamponage, Tamponnement (tampon-ād', tam'-pon-ahj, tam'-pon-ment) [Fr., tampon]. The act or operation of plugging with a tampon.

Tamponing (tam-pon'-ing $)[\mathrm{Fr}$, tampon]. The operation of using or introducing a tampon.

Tamus $\left(t a^{\prime}-m u s\right)$ [tamnus, wild-grape vine]. A genus of dioscoreaceous old-world plants. The pulp of the bulb of T. communis (black bryony) is discutient, vulnerary, diuretic, and laxative. Unof.

Tanacetin (tan-as'-e-tin) [OF., tanasie, tansy]. $\Lambda \mathrm{n}$ amorphous, hygroscopic, bitter substance derived from Tansy, soluble in alcohol and water, but not in ether.

Tanacetum (tan-as- $\left.e^{\prime}-t u m\right)$ [OF., tanasie, tansy]. Tansy. The leaves and tops of $T$. vulgare. It contains a volatile oil and a bitter principle and is useful in amenorrhea and as an anthelmintic. $T$., Ext., Fld. Unof. Dose of the fld. ext. $m x-3 j$; of an ${ }_{j} \mathrm{j}$ to $\mathrm{Oj}$ infus. $3 \mathrm{j}-\mathrm{ij}$; of the volatile oil gtt. j-iij. Äll unof.

Tanalum (tan-al'-um) [tannin, tannin; alum]. Aluminum tanno-tartrate, employed in the treatment of diseases of the nose and throat.

Tangent (tan'-jent) [tangere, to touch]. Touching.

Tanghin (tang'-gin) [Malagasy]. A poisonous extractive obtained from Madagascar. See Tanohinia.

Tanghinia (tan-gin'-e-ah)[Malagasy]. The seeds of theplant $T$. venenifera, or ordeal bean, native to Madagascar. Its properties are due to tanghin, an extractive closely resembling curare in its medicinal properties.

Tangle (tang'-gl) [ME., tangel, seaweed]. See Laminaria. T.-tent. See Sea-tangle.

Tannal (tan'-al) [tannin, tannin; alum ]. Aluminum tannate, employed in the treatment of diseases of the nose and throat.

Tannas $\left(t a n^{\prime}-a s\right)$. Synonym of Tannate.

Tannate (tan'-at) [tannin, tan]. Any salt of tannic acid. Tannates of bismuth, iron, lead, quinin, etc. are used to some extent as remedies.

Tannic $\left(\tan ^{\prime}-i k\right)$ [tannin, tannin]. Obtained from or containing tannic acid. T. Acid. See Acid (Tannic).

Tannin $\left(\tan ^{\prime}-i n\right)$. See Acid (Tannic).

Tanret's Test (for albumin). The reagent is composed of mercuric chlorid I. 35 gms., potassium iodid 3.32 gms., acetic acid 20 c.c., distilled water to make Io 0 c.c. By contact it gives an opacity with all proteids. See Tests, Table of.

Tansy $\left(\tan ^{\prime}-z e\right)$. See Tanacetum.

Tantalum (tan'-tal-um) [Tantalus, father of Niobe]. A rare metal, allied in properties to antimony and bismuth; symbol Ta, at. wt. I92. Its medicinal qualities are unknown. See Elements, Table of.

Tape $(t \bar{a} p)$ [ME., tape, tape]. 1. A band of linen. 
2. A tape-worm. T.-worm. See Tenia, Bothriocephalus, and Parasites (Animal), Table of.

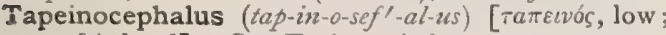

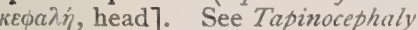

Tapeinocephaly $\left(t a p-i n-o-s e f^{\prime}-a l-e\right)$. See Tapinocephaly.

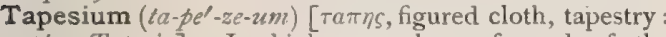
pl., Tapesia]. In biology, a layer formed of the mycelium of a fungus.

Tapetal $\left(t a p^{\prime}-e-t a l\right)[\tau a \pi \eta s$, carpet]. Pertaining to the tapetum.

Tapetum $\left(t a-p e^{\prime}-t u m\right)[\tau \dot{a} \pi \eta s$, a mat, or rug]. I. The layer forming the roof of the posterior and middle cornua of the lateral ventricles of the brain; it is composed of fibers from the corpus callosum. 2. In biology, a term applied to the lining membrane of the pollen-sac. $T$. cellulosum. See $T$. fibrosum. T. fibrosum, a shining structure in the choroid of the eye. It takes the place of the $T$. cellulosum of the carnivora, the iridescent portion of the choroid in these animals. T. lucidum, the brilliant, greenish, reflecting layer or membrana versicolor of the eyes of many of the lower animals. T. nigrum, the pigmentary layer of the retina. See Pigmeniary Layer. T. ventriculi, a bundle of white fibers of the brain uniting the cortex of the frontal with that of the occipital lobe.

Taphephobia, Taphiphobia (taf-e-fo'-be-ah) [Táфos, burial; $\phi 6 \beta 0 s, f e a r]$. Morbid fear of burial alive.

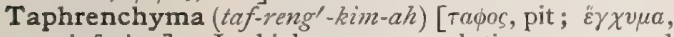
an infusion]. In biology, a vegetal tissue composed of pitted ducts. Also called Bothrenchyma and Pitted Tissue.

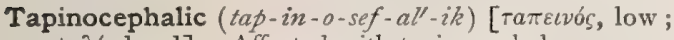
$\kappa \varepsilon \phi \alpha \lambda \eta$, head]. Affected with tapinocephaly.

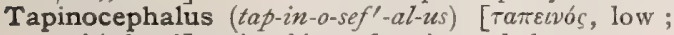
$\kappa \varepsilon \phi \bar{a} \lambda \dot{\eta}$, head]. A subject of tapinocephaly.

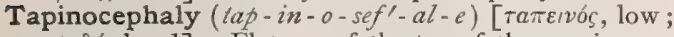
$\kappa \varepsilon \phi a \lambda \dot{\eta}$, head]. Flatness of the top of the cranium.

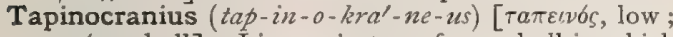
кpaviov, skull]. Lissauer's term for a skull in which the greatest height of the cranial cavity is from 74.5 to 82.5 per cent. of its greatest length.

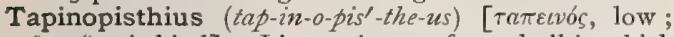
ö $\iota$ เftev, behind]. Lissauer's term for a skull in which the angle formed between the radius fixus and the line joining the occipital point and the punctum alæ vomeris is between $24.5^{\circ}$ and $33^{\circ}$.

Tapioca $\left(t a p-e-o^{\prime}-k a h\right)$ [Sp.]. A variety of starch obtained from the cassava or manioc plant, Jatropha manihot. It is an excellent food for invalids.

Tapir Mouth (ta'-për mouth). A separation and thickening of the lips, with disease of the orbicularis oris muscle, causing the lips to resemble those of the tapir. It is sometimes seen in facial muscular atrophy of the Landouzy-Déjérine type.

Tapotement (tap-öt-mong) [Fr.]. In massage, the percussing manipulation always performed by the operator's wrists, the hands striking quickly. There are four kinds of percussion: I. Clapping, performed with the palms of the hands. It is used to act upon the skin and the superficial nerves and vessels. 2. Hacking, performed with the ulnar border of the hand. It is used around nerve-centers and upon the muscles. 3. Punctation, performed with the tips of the fingers. It is used upon the head and in circles around the heart. 4. Beating, performed by the clenched hand. It is used upon the glutei, and upon the lower extremities over the sciatic nerve.

Tapping $\left(t a p^{\prime}-i n g\right)$. See Paracentesis.

Tap-root $\left(t a p^{\prime}-r u t\right)$. The main root, or downward continuation of the plant-axis.

Tar $(\operatorname{tah} r)$ [ME., tar, tar]. A material obtained by the destructive distillation of various substances, particu larly wood and coal. The name is commonly applied to wood-tar. See Pix liquida. T.-acne. See Acne picealis. T., Coal, a dark, highly complex, semiliquid substance obtained by the destructive distillation of coal. T.-colors. See Pigments, Conspectus of. T., Gas. See T., Coal. T., Juniper. Synonym of Cil of Cade. T., Oil of, a highly complex, volatile, oily liquid obtained in the distillation of woodtar. T.-ointment, a mixtuxe of equal parts of tar and suet. Unguentum picis liquida. T.-water, an infusion containing one part of tar to four of water. T., Wood, a thick, shining, black liquid obtained by the distillation of the wood of various species of conifers.

Tarantism (tar'-an-tizm) [tarantismus]. A choreic affection, largely a play of the imagination and often feigned, ascribed to the bite of a tarantula. It is perpetuated by force of tradition along certain parts of the Mediterranean coast. According to popular fancy, the affection was cured by music and dancing.

Tarantula (tar-an'-tu-lah) [Tápas, Tarentum]. A species of spider, Lvcosa tarantula, closely resembling the trap-door spider, Mygale henzii, with which it is often confounded. Its bite is poisonous. See $T a$ rantism.

Tarantulism (tar-an'-tu-lizm). Same as Tarantism.

Tarassis $\left(t a r-a s^{\prime}-i s\right)$ [ in the male.

Taraxacerin (tar-aks-as-e'-rin) [Ar., larasacon, a kind of succory; cera, wax]. A waxy substance found in dandelion.

Taraxacin (tar-aks'-as-in) [Ar., tarasacon, a kind of succory]. A crystallizable material derivable from the common dandelion; said to be tonic and diuretic.

Taraxacum (tar-aks'-ak-um) [Ar., tarasacon, a kind of succory: gen., Taraxaci]. Dandelion. The root of $T$. dens leonis. Its properties are due to a bitter extractive principle; it is tonic, diuretic, and aperient. It is of reputed use in dyspepsia. T., Decoct. (B.P.)

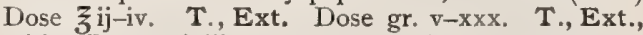
Fld. Dose 3 j-iij. T., Succus (B.P.) Dose 3 jij.

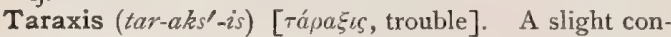
junctivitis, or eye-trouble.

Tardieu's Spots. Ecchymotic stains of the lungtissue indicative of death from asphyxia.

Tared (târd) [Ar., tarha, that which is thrown away] Allowed for as a tare or deduction; having the weight previously ascertained, as a Tared Filter. The term is used in pharmacy and chemistry.

Tarichentæ (tar-ik-en'-te). See Paraschistes.

Tarinus, Horny Band of. See Band. T., Foramen of. See Foramina, Table of. T., Pons of. See Pons. T., Space of, the posterior perforated space at the base of the brain.

Tarnier, Sign of. A sign of inevitable abortion. It consists in the effacement of the angle between the upper and lower uterine segments. This angle always exists in the pregnant uterus from an acute anteflexion, but as the escaping ovum descends the pressure thus produced causes the uterus to straighten out, and the angle disappears.

Tarropetrolin (tar-o-pet'-ro-lin) [ME., tar, tar ; $\pi \varepsilon \tau \rho o s$, sick; oleum, oil]. A compound of wood-tar and petroleum, recommended as a salve in various skindiseases. Unof.

Tarry $\left(\operatorname{tar}^{\prime}-e\right)$ [ME., tar, tar]. Of the nature of tar. T. Stools. See Melena.

Tarsal (tar'-sal) [Tajoós, instep]. Pertaining to the bones of the instep. T. Amputation, partial removal of the foot through the tarsus. T. Cartilage, 
the cartilaginous layers in the free edge of each eye lid. T. Cyst. See Chalazion. T. Ophthalmia. See Blepharitis.

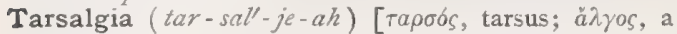
pain]. Any pain, especially one of gouty character, in the tarsus.

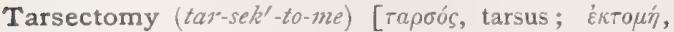
excision]. Excision of tarsal bones.

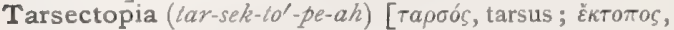
displaced]. Tarsal displacement.

Tarsen $\left(\operatorname{tar}^{\prime}-\operatorname{sen}\right)$ [ $\tau a \rho \sigma o ́ s$, tarsus]. Belonging to the tarsus in itself.

Tarsitis (tars-i'-tis). See Blepharitis.

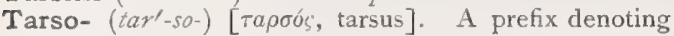
connection with or relation to the tarsus, as tarso metatarsal (articulation), etc.

Tarsocace (tar-sok'-as-e). Synonym of Podarthrocace.

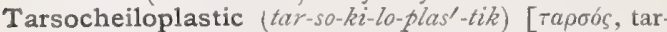
sus; $\chi \varepsilon i \lambda o \varsigma$, edge; $\pi \lambda a ́ \sigma \sigma \varepsilon \nu \nu$, to shape]. Pertaining to a plastic operation on the edge of the eyelid.

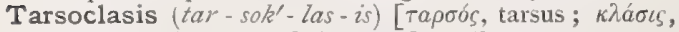
rupture]. Rupture of the tarsal cartilages.

Tarsomalacia (tar-so-mal-a'-se-ah) [ [apoós, tarsus;

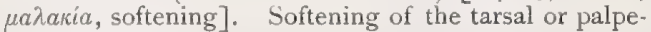
bral cartilages.

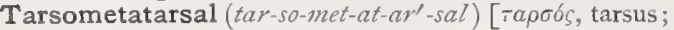
metatarsus]. I. Both tarsal and metatarsal; relating to the tarsus and the metatarsus. 2. In biology, a bone that unites the metatarsal and the tarsal bones in itself. T. Amputation, partial removal of the foot, as in Lisfranc's Amputation.

Tarsophalangeal (tar-so-fa-lan'-je-al) [ $\phi a ́ \lambda a \gamma \xi$, phalanx]. Pertaining to the tarsus and the phalanges.

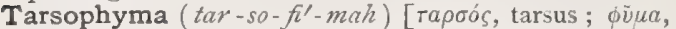
growth]. Any morbid growth or tumor of the tarsus.

Tarsoplasia (tar-so-pla'-ze-ah) [Tapó́s, tarsus; $\pi \lambda a ́ \sigma \sigma \varepsilon l \nu$, to form ]. Same as Tarsoplasty.

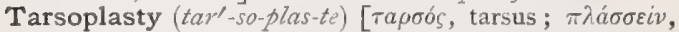
to form ]. Plastic surgery of the eyelid.

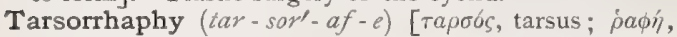
suture]. An operation upon the eyelids to diminish the palpebral opening, for ectropion, lagophthalmos, etc.

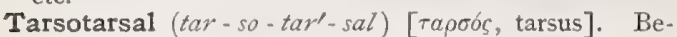
tween the tarsal bones; as an amputation through the foot-Chopart's amputation.

Tarsotibial (tar-so- $\left.\mid i b^{\prime}-e-a l\right)$. Same as Tibiotarsal.

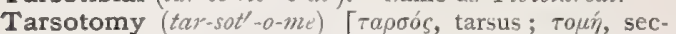
tion]. I. Operation upon the tarsal cartilage in cases of entropion, 2. Operation on the tarsus of the foot. T., Cuneiform, removal of a wedge-shaped piece of any of the tarsal bones.

Tarsus (tar'-sus) [tapoós, tarsus]. The instep, consisting of the calcaneum, or os calcis, the astragalus, cuboid, scaphoid, internal, middle, and external cuneiform bones. Also, the cartilage of the eyelid called the tarsal cartilage. which properly is dense connective tissue forming the support of the lid and giving it firmness and shape. In biology, the shank of a bird; the foot of an insect.

Tartar (tar'-tar) [táptapov, tartar]. I. Argol. A popular name given to the acid potassium tartrate, which is a natural product of certain fruits, especially the grape, being deposited on the inside of winecasks as a whitish or reddish crystalline crust, the impure super-tartrate of potassium. 2. The deposit of earthy or calcareous matter sometimes seen upon the teeth. T., Cream of, purified argol or acid potassium tartrate. T. Emetic, the tartrate of antimony and potassium. See Antimony.

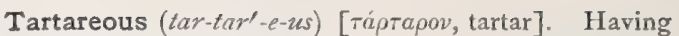
a rough, crumbling surface.

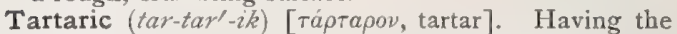
nature of tartar. Also, applied to the acid derived from tartar. T. Acid. See Acid, Tartaric.

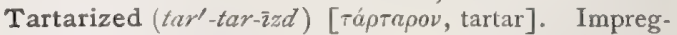
nated with tartar, or with tartaric acid. T. Antimony, tartrate of antimony and potassa. T. Iron, iron tartrate.

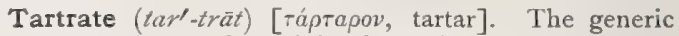
name of salts formed by the action of tartaric acid upon a base. T. of Antimony and Potassium. See Antimony. T. of Potash and Soda. See Potassizm.

Tartrazin (tar-tra'-zin). See Pigments, Conspectus of. Tartronic Acid (tar-tron'-ik). See Acid.

Tasajos $\left(t a z^{\prime}-a z h-o\right)$ [Sp.]. A preserved meat prepared in South America by cutting the meat in thin slices, then dipping it in brine and partially drying.

Taste (tāst) [ME., tasten, to taste]. The sense by which savors are perceived and discriminated. The glosso-pharyngeal nerve and the lingual branch of the fifth pair are the nerves mainly connected with this sense, of which the tongue is the chief organ. The lips, the inside of the cheeks, the palate, and the pharyn $\mathrm{x}$ also receive impressions from sapid substances. T., After, a secondary taste perceived after the immediate taste has ceased. T.-bud, an oval, flask-shaped body, embedded in the epithelium of the tongue. It consists of an enveloping layer of greatly elongated epithelial cells, the cortical or tegmental cells, within which is a group of highly specialized neuro-epithelial elements, the gustatory cells. It is also called T.-bulb. T.-bulb. See $T$.-bud. T.cell, one of a number of peculiarly shaped, flask-like bodies found between the epithelial cells covering the slopes of the circumvallate papillæ. They are the terminal end-organs of the gustatory nerve. T.-center, the gustatory nervous center. Its position is not determined. Ferrier places it close to that of smell, but even the course of the impulse is disputed. Gowers believes that taste-impressions reach the brain solely by the roots of the fifth nerve. $\mathbf{T}_{\text {. }}-$ end. See $T$.-cell. T.-goblets, flask-like bodies on the sides and base of the tongue enclosing the gustatory cells. See T.-cell. T.pore, the minute canal connecting the interior of a taste-bud with the surface of the mucous membrane.

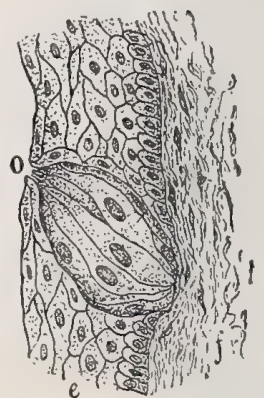

TASTE-BUD FROM CiRCUMVALlate Papilla OF A CHILD.

The oval structure is limited to the epithelium (e) lining the furrow, encroaching slightly upon the adjacent connective tissue $(f) ; 0$, taste-pore through which the tastecells communicate with the mucous surface. (After Piersol.)

Tasteless (täst'-les) [ME, tasten, to taste]. Without taste. T. Ague-drop, a solution of a soluble salt of arsenic, formerly used as a remedy for intermittent malarial fevers.

Tattooing (tat-too'-ing $)$ [Tahitian, tatu, tattooing]. The operation of producing permanent colors in the skin by the introduction of foreign substances, such as carbon, India ink, and vermilion. It is a common practice among sailors, the color being introduced into the true skin by pricking it with needles. Tattooing as a Therapeutic Measure, to restore the natural color in parts which are pigmented, is occasion 
ally resorted to. For white, use baryta white, and for other colors, the earth-colors (ochers; yellow, brown, red). To assist these cinnabar and ultramarine may be used. Mix the colors on a glass plate and impregnate the reedles. Electrolysis followed by tattooing is useful in cases of vascular nevi. T. of Cornea, an operation to diminish the unpleasant appearance of leukoma of the cornea by tattooing the same so as to simulate the appearance of the normal pupil and iris.

Taubenzecke (tou-ben-zek'-eh) [Ger.]. The German name for an insect, Aroas reflexa, whose sting produces local, and in some cases general edema. See under Parasites (Animal), Table of.

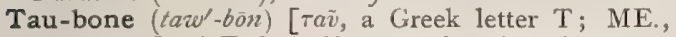
bone, bone]. A T-shaped bone, such as the episternum. It is also called $T$.-bone.

Taurin (taw'-rin) [taurus, bull], $\mathrm{C}_{2} \mathrm{H}_{7} \mathrm{NSO}_{3}$. Amidoethyl-sulphonic acid. A decomposition-product of bile; a stable compound that crystallizes in large colorless monoclinic prisms, insoluble in alcohol, but readily dissolved by hot water. It melts and decomposes at about $240^{\circ} \mathrm{C}$. It occurs in combination with cholalic acic and as taurocholic acid in bile. Traces are present in the juices of muscles and of the lungs.

Taurocholic Acid (tazl-ro-kol'-ik). See Acid.

Tautomeric (tazo-to-mer'-ik) [ [avтó, same ; $\mu$ épos, part]. Exhibiting tautomerism; a qualification applied to compounds to which two different structural formulæ may be rightly attributed.

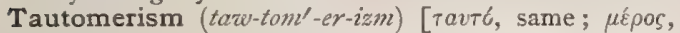
share]. I. The attribution of two different formulæ to one compound. 2. The quality exhibited by those cases in which two structural formulæ are possible, while but one compound appears to be obtainable. It is assumed that in such bodies the formulæ are susceptible of change from one arrangement to the other. The phenomenon has also been called desmotropy.

Tawed Leather (tawd). See Leather.

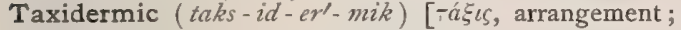

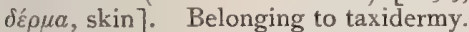

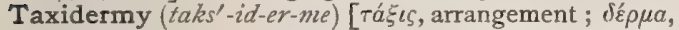
skin]. The art of preserving and stuffing the skins of animals, so as to represent the appearance, habits and attitudes during life.

Taxinomy (taks-in'-o-me) [Táłıs, arrangement; vóuos, law]. The science of systematic classification.

Taxin $\left(t a k s^{\prime}-i n\right)$ [ ${ }^{\prime} a \xi o \sigma$, yew-tree]. The resin of the leaves of the yew-tree, Taxus baccata; also, a poisonous alkaloid reported to have been found in the leaves and seeds of the same tree.

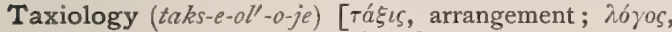
treatise ]. The science of classification.

Taxis (taks'-is) [ Arranging. A reduction of a prolapsed structure, as a hernia or a uterus, by methodic manipulation without instruments.

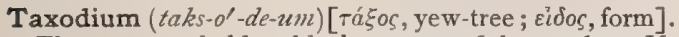
The common bald or black cypress of the southern $U$. S. and Mexico, said to destroy malarial germs. The leaves and seeds are used internally in hepatic diseases. Unof.

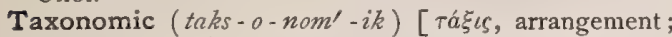
vónos, law]. Pertaining to systematic classification.

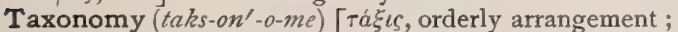
$v 6 ́ \mu o s$, a law]. That portion of a science which treats of classification and nomenclature.

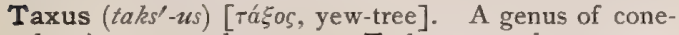
bearing trees, the yews. $T$. baccata, the common European yew-tree. Its leaves and seeds are poisonous and have sedative qualities. Unof.

Tay's Choroiditis, a form of central choroiditis seen in persons in advanced years. Its course is chronic and there occur changes which resemble those observed in albuminuric retinitis.

Taya $\left(t a^{\prime}-y a h\right)$ [S. America]. A S. American species of plants said to be exceedingly poisonous, and to be an ingredient of some kinds of curare.

Tayuya $\left(t a-u^{\prime}-y a h\right)$ [S. America]. The root of certain South American plants (Dermophylla pendulina, Trianospermia ficifolia, etc.) used in the treatment of syphilis and of certain cutaneous diseases. Dose of tinct., gtt. $\mathrm{v}-\mathrm{xv}$. Unof.

Tea (te) [Chinese $t s^{\prime} a$, tea]. Thea. The leaves of Camellia thea, a Chinese evergreen shrub. Tea contains an alkaloid, thein, and tannic acid, boheic acid, gallic acid, gluten, coloring-matter, etc. A decoction. of the leaves is a popular astringent, restorative beverage, which produces an exhilarating effect upon the nervous system. Its excessive use causes dyspepsia and various nervous derangements. The properties of tea are due to thein $\left(\mathrm{C}_{8} \mathrm{H}_{10} \mathrm{~N}_{4} \mathrm{O}_{2}\right)$, a substance identical with caffein and a mild cerebral stimulant. Dose of the fld. ext. $m x-3 j$. Unof. Thein is also given hypodermatically in doses of $\mathrm{gr}$. $\mathrm{s} / 6-\mathrm{j}$ several times a day, for the relief of pain. T.berry. See Gaultheria. T.-leaf Eye, a muco-purulent conjunctivitis caused by the prolonged application of tea-leaves to the eye for their supposed therapeutic effect in ocular disease-chiefly among the negroes of the southern United States. Tea, Substitute for, a decoction of pearl-barley. 'T., Teamsters'. See Tepopote.

Teale's Amputation. A form of amputation in which two rectangular flaps are made; the long flap, folding over the end of the bone, is formed of parts free from large blood-vessels and nerves, those structures being left in the short flap. The length and breadth of the long flap are equal, being one-half the circumference of the limb at the point of amputation. The short flap is one-fourth as long. See Operations, Table of.

Tears (terz) [ME., teer, tear]. I. The secretion of the lacrymal gland. 2. Hardened lumps, or drops, of any resinous or gummy drug.

Teasing $\left(t \bar{t} z^{\prime}-i n g\right)$ [ME., tesen, to tease]. The shredding or arranging of a minute object, with a needle or other suitable instrument, with a view of preparing it for microscopic study.

Teat (têt) [ME., tete, a teat]. The nipple: a part of the excretory duct of the mammary gland; the mammilla, or papilla.

Technic, Technique $\left(t e k^{\prime}-n \bar{e} k\right)$ [ $\tau \dot{\varepsilon} \chi v \eta$, art]. A systematic series of manipulative procedures. A formula of operation.

Technical $\left(t e k^{\prime}-n i k-\alpha l\right)$ [ $\tau_{\varepsilon}^{\prime} \chi \eta$, art]. Pertaining to any art.

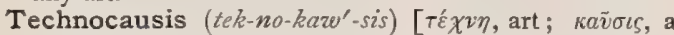
burning]. Mechanical cauterization, such as electrocauterization, moxa, etc., in distinction from the cauterization produced by chemicals.

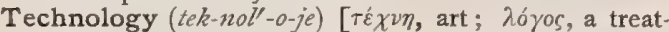
ise]. The science or explanation of the terms used in science or art.

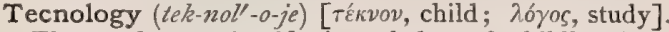
The study or scientific knowledge of childhood, its hygiene, diseases, etc.

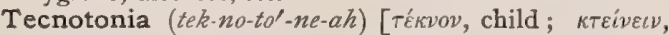
to kill]. Child-murder. Infanticide.

Tecoma (tek-o'-mah) [Aztec, teromaxochitl, the name of Solandra guttata]. A genus of bignoniaceous plants, mostly climbers, with showy, trumpet-like flowers. $T$. impetiginosa, the bark is used in lotions for inflamed joints. T. ipé, a Brazilian species; the leaves are used in ophthalmia. T. radicans, common in the United States; is said to be vulnerary and sudorific. Leaves 
and branches used as dyes. T. subvernicosa, of S. America, is diuretic; others are actively astringent.

Tectiform (tek'tif-orm) [tec tum, a roof; forma, form]. In biology, like a roof or lid.

Tectocephalic (tek-to-sef-al)

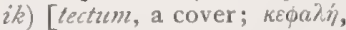
head]. Pertaining to a roofshaped skull.

Tectochrysin (tek-to-kris'-in)

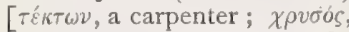
gold]. A coloring-matter obtained from Poplar Buds

Tectology $\left(t e k-t o l^{\prime}-o-j e\right)$ [Ték$\tau \omega \nu$, a builder; $\lambda o ́ \gamma o s$, science]. In biology, structural morphology.

Tectona $\left(t e k-t o^{\prime}-n a h\right)[\tau \varepsilon \kappa T \omega \nu i a$, carpentery]. Teak, a tree of the natural order Verbenacea, the East Indian oak. Its wood is valuable for shipbuilding. Its leaves are astringent and the flowers and seeds diuretic.

Tectorium (tek-to'-re-um) [tegere, to cover: pl., Tectoria]. In biology, a covering, as the coverts of a bird; also applie to the membrane of Corti.

Tectorial (tek-to'-re-al) [tectorium, a cover]. Serving as a tectorium, or covering. T. Membrane. See Membrane of Corti.

Tectrices (tek'tris-ēs) [tegere, cover, conceal] Plural of Tectrix. In biology, the feathers of the wing coverts or tail coverts of a bird, as distinguished from remiges, and rectrices.

T e c t r i x $\left(t e k^{\prime}-\right.$ triks ) [L., a cover: pl., Tectrices]. Cover. ing or hiding. Tectrices, the plural, applies to the smaller feathers $\mathrm{that}$ cover the quillfeathers, wings, or $t a i l$ of $a$ bird.

Tedium vitæ (te'-de-um vi'te). See Tadium.

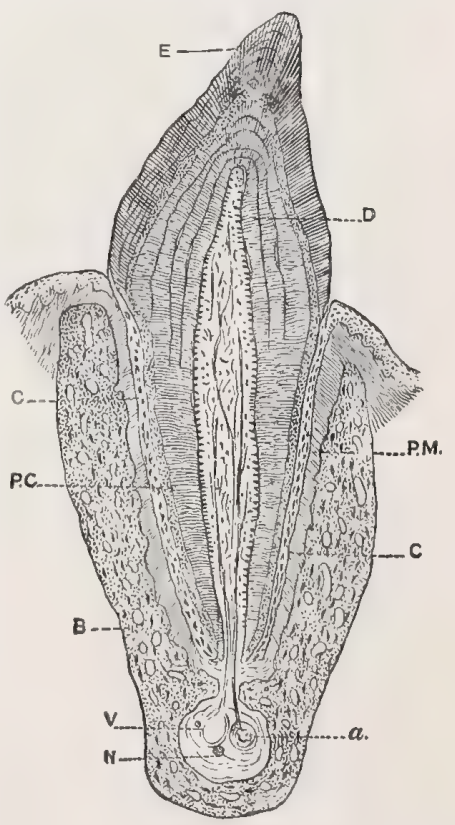

Teeth $(t e t h)[\mathrm{Plu}-$ ral of tooth, q. E. Enamel. D. Dentine, P. M. Periov.]. In man, dontal membrane. P. C. Pulp-cavity the hard bodies C. Cement. B. Bone of the Lower which occupy Jaw. V. Vein. a. Artery. N. Nerve. the alveolar

cavities of the upper and lower jaws. They are the hardest portions of the body and the principal organs of mastication. The first set of teeth in childhood,
20 in number, are called milk, temporary, or decuduous teeth. In the adult the permanent teeth consist of 2
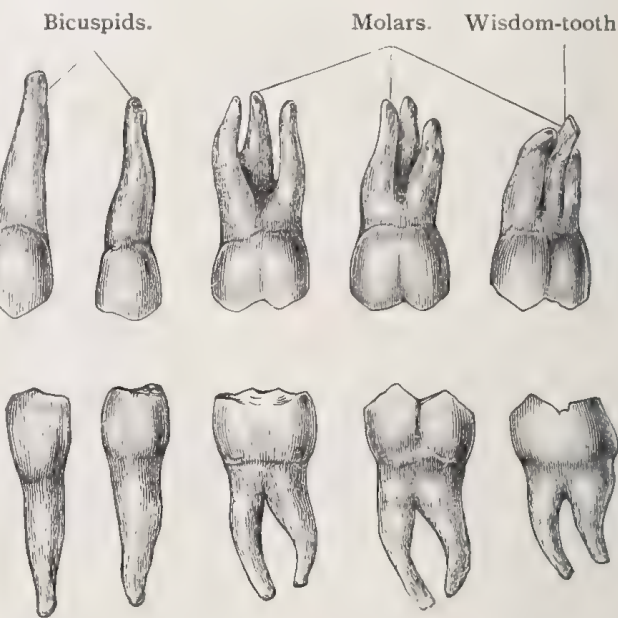

The TEETH OF AN AdUlt.

incisors, 1 cuspid or canine, 2 premolars or bicuspids, and 3 molars in each lateral half of each jaw. The last molar of each half-jaw is cut at an age of from $20-$ 25 years, and is therefore called a wisdom-tooth. In popular parlance the upper canine teeth are called eye-teeth; the lower canines, stomach-teeth. The upper central incisors are sometimes called butter-teeth In structure the tooth consists of a hard enamel, encasing the crown; the dentine, within the enamel, constituting the whole of the root and interior of the crown; and the pulp, a bulbous prolongation of the mucosa of the gums, which is traversed by bloodvessels and nerve-filaments. The dentine of the root is surrounded by the cement or crusta petrosa. The exposed part of the tooth is the crown, the middle part the neck, and the part within the alveoli the fang or root. T., Auditory, the tooth-like projections on the edge of the limbus laminæe spiralis of the ear. They extend between the epithelial cells and give the limbus an uneven, highly refracting surface. They are composed of the osteogenous tissue of the crista. T., Numbering of the, in numbering the teeth, the incisor next the symphysis menti or meson is first, the wisdom-tooth last, or eighth. The first incisor is also said to be central, mesal, or proximal, and the last or wisdom-tooth, distal. In numbering the groups of teeth, as incisors, bicuspids or premolars, molars, the one nearest the symphysis is number one of the particular group. T., Temporary, the teeth of the first dentition; milk-teeth; deciduous teeth; also, a provisional set of artificial teeth.

Teething (te'-thing) [ME., teethe, to cut the teeth]. The development and appearance of the first teeth in an infant. Dentition.

Teetotalism (te-to'-tal-izm) [redup, of total]. The practice of entire abstinence from alcoholic beverages. Tegmen (teg'-men) [legmen, a cover: pl., Tegmina]. In biology, a covering, as the coat of a seed, the coverts of a bird, or the elytrum of a beetle. T. tym . pani, the roof of the tympanic cavity.

Tegmentum (tco-men't tum ) [terere, to cover]. A covering. The dorsal portion of the crus cerebri, formed 
by the deep longitudinal fibers, interlaced with transverse and arched fibers. In biology, an outer covering, as of a bud or a mollusc.

Tegminal (teg'-min-al) [tegmen, a covering]. In biology, integumentary.

Tegminalia (teg-min- $\left.a^{\prime}-l e-a h\right)$ [tegmen, a covering]. Plural of Tegminalizum. In biology, the plates of a tessellated crinoid or other similarly protected animal.

Tegula $\left(\operatorname{teg}^{\prime}-u-l a h\right)$ [tgoula, a tile: pl., Tegula]. In biology, a sclerite covering the base of the fore-wing or the metathoracic spiracle of certain insects.

Tegumen (teg'-u-men). Same as tegmen.

Tegument (teg-u-ment) [tegere, cover, conceal]. In biology, an enveloping or protective coat; a tegmen, or tegmentum.

Teichmann's Crystals. See Hemin.

Teichmann-Neumann Test. See Tests, Table of.

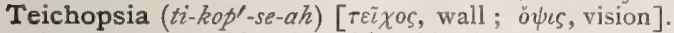
A temporary amblyopia, with subjective visual images like fortification-angles; probably due to vasomotor disturbances of the visual center.

Teigne [Fr.]. See Tinea. T. pelade. Synonyun of Alopecic areata.

Teinodynia (ti-no-din'-e-ah). See Tenodynia.

Teissier's Method. See Phosphates.

Tela $\left(t e^{\prime}-l a h\right)[\mathrm{L}$.$] . A web or web-like tissue ; a plexus.$ T. adiposa, adipose tissue. T. araneæ. See Spiders' $W_{e}$. T. cellulosa, areolar tissue. T. choroidea, the membranous roof of the parts of the third and fourth ventricles of the brain. See Diatela and Metatela. T. epithelialis, epithelial tissue. T. flava, elastic tissue. T. hæmelis, lymph-cells and blood-corpuscles, and, also, splenic tissue. T. vasculosa, the choroid plexus.

Telresthesia $\left(t e l-e s-t h e^{\prime}-z e-a h\right)$. See Telepathy.

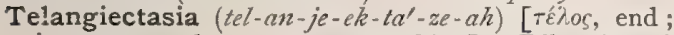

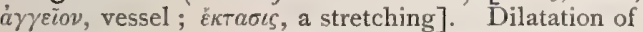
capillaries, or of the smaller blood-vessels.

Telangiectasis (tel-an-je-ek'-tas-is). See Telangiectasia and Novus vascularis. T. faciei. See Acne rosacea.

Telangiectasy (tel-an-je-ek'-tas-e). Same as Telangiectasia.

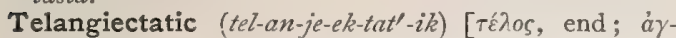
$\gamma \varepsilon \tilde{i} 0$, vessel ; $\check{\kappa} \tau \tau \sigma \iota \zeta$, a stretching]. Relating to or characterized by telangiectasia. T. Warts. See Angiokeratomia.

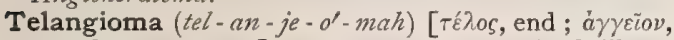
vessel; $\ddot{o} \mu a$, tumor]. A tumor composed of dilated capillaries.

Telangiosis $\left(t e l-a n-j e-o^{\prime}-s i s\right)[\tau \varepsilon ́ \lambda o s$, end; $\dot{a} \gamma \gamma \varepsilon \tilde{i} o v$, ves sel]. Disease of the capillaries or minute bloodvessels.

Telar (te'-lar) [tela, a web]. Pertaining to a tela; of the nature of a tela.

Telarian $\left(t e-l a^{\prime}-r e-a n\right)$ [tela, a web]. In biology, webmaking or tissue-making, as a spinning spider.

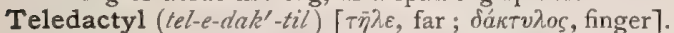
A device to avoid stooping when wishing to pick up things from the floor (in disease of the spine, injuries, etc.). It consists of six spring-forceps at the end of a cane, operated by a cord passing to the handle and provided with a ring for the index finger.

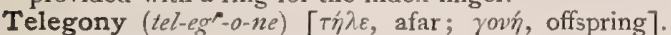
The influence of a previous husband on the children of a subsequent one through the same woman.

Telegraph (tel'-e-graf) [ $\tau \bar{\eta} \lambda \varepsilon$, far; $\gamma \rho a ́ \phi \varepsilon \iota \nu$, to write]. An electric apparatus for conveying information to a distance with great rapidity. T., Muscle, an apparatus for recording the contraction of muscles.

Telegraphers' Cramp. See Cramp.

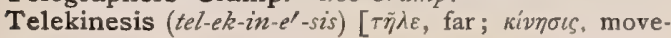

ment]. The power claimed for some wonder-workers of causing objects to move without touching them.

Telekinetic $\left(t e l-e k-i n-e t^{\prime}-i k\right)[\tau \tilde{\eta} \lambda \varepsilon$, far; $\kappa i v \eta \sigma \iota$, movement]. Pertaining to or characterized by telekinesis.

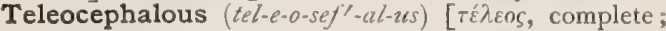
$\kappa \varepsilon \phi a \lambda \eta$, head]. Having the full number of bones in the skull.

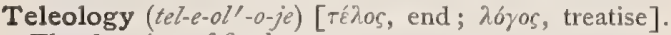
The doctrine of final causes.

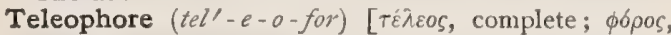
bear]. See Gonotheca.

Teleophyte (tel'-e-o-fit) [tela, a web or tissue; $\phi v \tau o ́ v$, plant]. In biology, a plant exhibiting well differentiated tissues

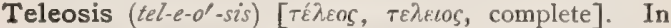
biology, progressive development.

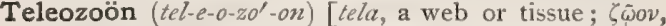
an animal: pl., Teleozoa]. In biology, an animal exhibiting well differentiated tissues; a metazoan.

Telepathic $\left(t e l-e p-a t h^{\prime}-i k\right)$ [ $\tau \tilde{\eta} \lambda \varepsilon$, far; $\pi \dot{a} A o s$, disease]. Pertaining to telepathy.

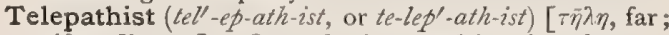
$\pi a ́ \theta 0 s$, disease]. One who is versed in telepathy.

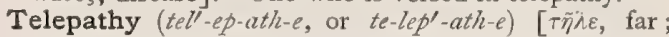
$\pi a ́ \theta 0 s$, disease]. Formerly an empiric form of treatment whereby cures were guaranteed by the exhibition of the remedy at a distance from the seat of disease. The term is now applied to a certain form of clairvoyance in which one is supposed to become conscious by dream or vision of distant events; the action of one mind upon another when the two persons are sundered by a considerable distance, and there is no communication by means of the senses; thoughtreading; thought-transfer.

Telephone (tel'-ef-ön) [ $\tau \tilde{\eta} \lambda \varepsilon$, far; $\phi \omega v \eta ́$, voice $]$. An apparatus which transmits the human voice or other sounds to a great distance. T.-tinnitus, a professional neurosis of the auditory mechanism said to be caused by constant use of the telephone.

Telescope (tel'-es-kop) [ $\tau \tilde{\eta} \lambda \varepsilon$, far ; $\sigma \kappa o \pi \varepsilon i \nu$, to examine]. An instrument for observing objects situated at a great distance, especially the heavenly bodies. T.eye, an abnormalism of the orbit said to be caused by the constant use of optic instruments, like the telescope, microscope, etc.

Telescopic (tel-es-kop'-ik) [ $\tau \tilde{\eta} \lambda \varepsilon$, far; $\sigma \kappa o \pi \varepsilon \tilde{\imath} v$, to view]. Pertaining to the telescope. $\mathbf{T}$. Catheterism, the passage of several catheters, each smaller than the one before it, one within another, until one is passed through a urethral stricture.

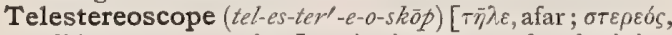
solid ; $\sigma \kappa \cap \pi \varepsilon \varepsilon \nu$, to view]. An instrument for obtaining a stereoscopic view of distant objects, by which such objects obtain a relief like that of near objects.

Teleutogonidium $\left(t e l-u^{\prime}-t o-g o-n i d^{\prime}-e-u m\right)[\tau \varepsilon \lambda \varepsilon v \tau \dot{\eta}$, completion; yovós, generation: pl., Teleutogonidia ]. See Teleutospore.

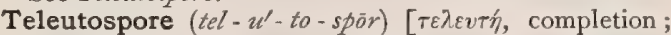
$\sigma \pi \rho \rho a ́$, seed]. In biology, a peculiar, thick-walled, often compound spore, produced by the Uredinea or Rusts late in the season; a brand-spore; pseudospore.

Telluric $\left(t e l-u^{\prime}-r i k\right)$ [tellus, earth]. Derived from the earth or soil ; as a telluric miasm.

Tellurism (tel'-u-rizm) [tellus, earth]. Telluric miasm; influence of the soil as a cause of disease.

Tellurist $\left(t_{e l} l^{\prime}-u\right.$-rist $)$ [tellus, earth]. One who believes in the telluric origin of any disease ( $e_{.} g$. , of tetanus).

Tellurium $\left(t e l-u^{\prime}-r e-u m\right)$ [tellus, the earth]. Te $=128$ : sp. gr. 6.24, quantivalence II, IV, and VI. A nonmetallic element of bluish-white color, brittle, brilliant, easily fusible, and resembling sulphur in chemic pro- 
perties. None of the preparations are used in medicine. The element itself, like selenium, imparts an extremely fetid odor to the exhalations and excreta of the body. See Elenents, Table of.

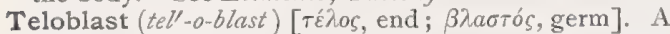
segmentation-sphere at the extremity of the germ-band, which becomes elongated by cells arising from the mesoblast

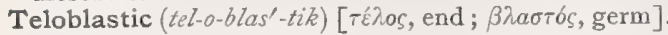
Pertaining to the teloblast.

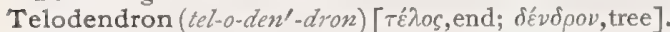
The terminal arborization of an axis-cylinder process.

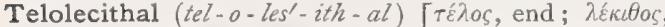
yolk]. Having a relatively large mass of food-yolk, eccentrically placed; said of certain meroblastic eggs.

Telolemma (tel-o-lem'-ah) [ $\tilde{\varepsilon} \lambda o s$, end; $\lambda \dot{\varepsilon} \mu \mu \alpha$, husk]. The membrane covering the eminence of Doyère, or the point of entrance of a motor nerve into muscular fiber.

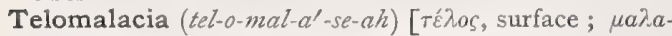
кia, softness]. Phlegmonous erysipelas.

Telopore, $\left(t e l^{\prime}-o-p \bar{o} r\right)\left[\tau \hat{k} \lambda_{o s}\right.$, end; $\pi \dot{o} \rho \circ$, pore]. A terminal pore in the embryos of certain insects.

Telotroch, Telotrocha (tel'-o-trok, tel-ot'-ro-kah)

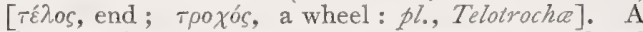
chretopod larva in which there is present a preoral and a postoral ( $i, e_{0}$, a perianal) ring of cilia; the latter sometimes has the form of a perianal patch. Cf. Atrocha, Monotrocha, Polytrocha, Nototrocha, Gasterotrocha, Amphitrocha, Actinotrocha, Trochophora.

Telson (tel'-son) [ terminal somite of the pleon of a crustacean.

Temper (tem'-per) [temperare, to regulate]. That mixture of mental and emotional qualities that produces a predominant quality of disposition or character. The temper is one of the points to be carefully noted in cases of insanity or other central nervous disorder. Moderation; equipoise of mind; also, as a verb, to mingle, modify.

Temperament (tem'-per-am-ent) [temperamentum]. A term vaguely applied to the predominance of one group or order of constitutional functions over others in an individual. The various divisions of temperament were based on the former doctrine of the four humors of the body-blood, lymph, bile, and atrabilis or black bile; the predominance of any one resulting respectively in a sanguine, lymphatic, bilious, or melancholic temperament. Although the doctrine of the temperaments has long since lost its significance, it is generally admitted that an individual may have a predisposition to types of mental action not improperly classed as nervous, phlegmatic, lymphatic etc. T., Bilious, that marked by a predominance of bile; persons of this type having sallow complexions, dark hair, sluggish circulations. They have great firmness and endurance. T., Lymphatic, that characterized by fair complexion, light hair, flabby muscles, slight force of character, and slightly developed passions. T., Nervous, that characterized by great activity and sensitiveness of the nervous system. $T$. Sanguineous, that characterized by fair or ruddy complexion, rapid pulse, a hopeful disposition, and strong passions.

Temperance $\left(t^{\prime} m^{\prime}\right.$-per-ans) [temperantia]. Moderation in satisfying desire; especially as regards the use of alcoholic beverages.

Temperate (tem'-per-ät) [temperatus, moderated]. Moderate, without excess. T. Zone, the zone of climate situated between the isotherms of $30^{\circ}$ and $70^{\circ}$.

Temperature $\left(t e m^{\prime}-p e r-a-t \bar{u} r^{\prime}\right)$ [temperatura]. The degree of intensity of heat or molecular vibration. T., Absolute, that reckoned from the absolute zero of temperature, estimated at $273^{\circ}$ below the zero of the Centigrade thermometer. T., Conversion, that at which the decomposition of artificially inactive, asymmetric compounds takes place. T., Morbid, any considerable variation from the normal temperature of the body. T., Normal, the temperature of the body in a state of health- $98.6^{\circ} \mathrm{F}$, as estimated by the clinical thermometer. See Themmometer. T.-spots, variations of the heat of the skin, showing a specific end-apparatus arranged in a punctated manner connected with the temperature-sense. Temperature-spots are arranged in a linear manner or in chains, usually slightly curved. Cold-spots, spots where only the sensation of cold will be felt. Hot-spots, where only heat will be felt. Both are anesthetic toward pain and pressure. The cold-spots are the more abundant.

Temple $\left(\right.$ tem $\left.^{\prime}-p l\right)$ [tempus, time; from the throbbing of the temporal artery, or from belief that the hair first turns gray at this place]. The flat or depressed portion of the head between the eye and ear and neighboring parts.

Templin-oil (tem'-plin-oil) [Templin, a town of Prussia]. Oil of pine-cones, from Pinus pumilio; it resembles ordinary oil of turpentine.

Temporal (tem'-po-ral) [temporalis; tempora, temples]. Pertaining to the temples. T. Artery. See Artery. T. Bone, the bone situated at the side and base of the skull. It is divided into a squamous, a mastoid, and a petrous portion. T. Diplopia. Same as Homonymous Diplopia. T. Fossa. See Fossa. T. Muscle. See Muscles, Table of. T. Operculum. See Post-operculum. T. Ridge. See Ridge.

Temporarii, Dentes (tem-po-ra'-re-i den'-téz) [L.]. The temporary, or milk, teeth.

Temporary (tem'-po-ra-re) [temporarius, lasting but for a time]. Not permanent. T. Stopping, a preparation consisting principally of bleached gutta-percha, carbonate of lime, and quartz, for filling teeth. $\mathbf{T}$. Teeth. See Teeth.

Temporen (tem'-po-ren) [tempora, the temples]. Belonging to the temporal bone in itself.

Temporization (tem-po-riz-a'-shun) [tempus, time]. The expectant treatment of disease. See Expectant.

Temporo- (tem'-po-ro-) [tempus, time]. A prefix denoting connection with the temple, as, e.g., temporofacial, temporo-malar, temporo-occipital, etc.

Temporo-auricular (tem-po-ro-azu-rik'-u-lar) [tempus, time; auricularis, of the ear]. Pertaining to the temporal and auricular regions of the head.

Temporo-occipital (tem-por-o-ok-sip'-it-al) [tempus, time; occiput, occiput]. Pertaining to the temple and back of the head.

Temporo-facial (tem-po-ro-fa'shal) [tempus, time ; facies, face]. The larger of the main branches of the facial nerve.

Temporo-hyoid (tem-po-ro-hi'-oid) [tempus, time ; hyoid]. Pertaining to the temporal and hyoid bones.

Temporo-malar (tem-po-ro-mál-lar) [tempus, time; mala, cheek]. Pertaining to the temporal and malar bones, or to the temple and the cheek.

Temporo-mandibular (tem-po-ro-man-dib'-u-lar) [tempus, time; mandible]. Pertaining to the temporal bone and the mandible.

Temporo-mastoid (tem-po-ro-mas'-toid) [tempus, time; mastoid]. Pertaining to the temporal and mastoid regions of the skull.

Temporo-maxillary (tem-po-ro-maks'-il-a-re) [tempus, time; maxilla, maxilla]. Pertaining to the temporal region and the upper jaw.

Temporo-parietal (tem-po-ro-par-i'-et-al) [tempus, time; paries, wall]. Pertaining to the temporal and parietal bones. 
Temporo-sphenoid (tem-po-ro-sfe'-noid) [lempus, time; sphenoid]. Same as Sphenotemporal.

Temulence (tem'-u-lens) [temulentia]. Inebriety; drunkenness.

Temulentia (tem-u-len'-she-ah). Synonym of Alcoholism.

Tenacious (te-na'-shus) [tenax, tough]. Having the quality of toughness or ability to resist mechanical strain or dissolution.

Tenacity (te-nas'-it-e) [tenacitas]. Toughness; resistance to fracture or dissolution.

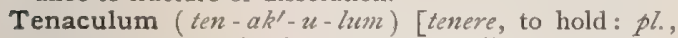
Tenacula]. I. An instrument, usually hook-shaped, for seizing and holding divided vessels, etc. 2. Onè of a pair of processes on the abdomen of certain insects (Podurida, spring-tails) serving to hold the elater in place. T.-forceps. See Forceps.

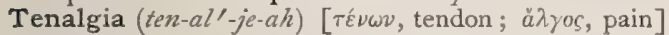
Same as Tenodynia.

Tenax (te'-naks) [L.]. Oakum especially prepared for surgeons' use.

Tench's Mouth. The os uteri (os tinca). T.'s Nose. Same as T. Mouth.

Tendency $\left(\operatorname{ten}^{\prime}-\right.$ den-se $)$ [tendere, to stretch]. The inclination or aim toward a given state or condition.

Tender $\left(\right.$ ten $^{\prime}$-der $)$ [tener, soft; Fr., tendre]. I. Sensitive to impressions, especially to touch; soft, and readily yielding to the knife. 2. Delicate, easily destroyed.

Tenderness (ten'-der-nes) [tener, soft]. The condition of abnormal sensitiveness to touch; soreness.

Tendinosus (ten-din-o'-sus) [1.]. Same as Semitendinosus. See Muscles, Table of.

Tendinous (ten'-din-us) [tendinosus]. Pertaining to or having the nature of tendon.

Tendo, Tendon (ten'-do, ten'-don) [tendo, tendinis, a tendon: pl., Tendines, Tendons ]. A tendon; the white, glistening, fibrous cord connecting the body of a muscle with its point of insertion. T. Achillis, the Achilles tendon or common tendon of the gastrocnemius and soleus muscles, the thickest and strongest of the body. T. Achillis Reflex. See Reflexes, Table of. T. calcaneus. Same as $T$. Achillis. T., Central, the trifoliate aponeurosis in the center of the diaphragmatic vault. T., Cordiform. See T., Central. T., Hamstring. See Han string. T.-reflex. See $R_{e}$ flexes, Table of. T.-spindle, a

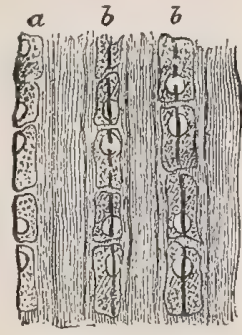

TENDON, TAIL OF RAT.

a. Tendon-cells seen on edge and embracing a fiber; $b \bar{b}$. On the flat, the cells with a ridge. peculiar nerve-ending in tendons described by Golgi as being found in the immediate vicinity of the union with the muscle, also called Golgi's corpuscle. T. of Zinn, the ligament of Zinn.

Tendophony (ten-doff'-o-ne) [tendo, tendon; $\phi \omega \nu \eta ்$, voice ]. Auscultatory sounds supposed to be caused by the chordæ tendineæ.

Tendoplasty $\left(\right.$ ten $^{\prime}$-do-plas-te $)$ [tendo, tendon; $\pi \lambda a ́ \sigma \sigma \varepsilon \iota v$, to form ]. A plastic operation on tendons.

Tendo-synovitis $\left(\operatorname{ten}^{\prime}-d o-s i-n o-v i^{\prime}-t i s\right)$ [tendo, tendon; synovia, synovia]. The "compound ganglion" of older text-books, now recognized as a local tuberculosis.

Tendotome (ten'-do-tön). See Tenotome.

Tendo-vaginitis granulosa (ten-do-vaj-in-i'tis gran$u$-lo'-sah) [L.]. Hueter's term for tuberculosis of tendon-sheaths, the sheaths being filled with granulation or fungous tissue.
Tendril (ten'-dril) [tener, soft, delicate]. In biology, a leaf, a portion of a leaf, or a branch so modified as to serve the purpose of a climbing organ.

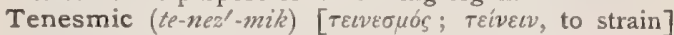
Of the nature of or affected with tenesmus.

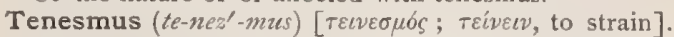
Rectal or vesical pain, with spasmodic contraction of the sphincter ani or sphincter vesicæ. The painful desire to empty the bowels or bladder without the evacuation of feces or urine.

Tenia, Tænia (te'-ne-ah) [Tacvía, a band, fillet, ribbon]. In biology, a genus of parasitic platode worms of the Class Cestoda (tapeworms) and Order Polyzoa. They form ribbon-like stocks, composed chiefly of a row of consecutive segments progressively increasing in size posteriorly (proglottides) and arising by strobilation from the knob-like head (scolex), which is provided with organs of adhesion. Over 300 species are recognized, having for their hosts very widely separated animals, with correspondingly wide geographic distribution. Cf. Parasites (Animal), Table of, also Cysticercus, Echinococcus, Measles. T.-chain, the chain formed by the proglottides or joints of a tapeworm. T.head. See Scolex. T. hippocampi, the corpus fimbriatum of the hippocampus major. See Fïmbria. T. semicircularis, a whitish band along the caudatum forming one of the margins of the rima; also called tenia. T. thalami, the habena or habenula. $T$. tubæ, the name given by F. B. Robinson to a band forming a thickening of the upper border of the perisalpinx or peritoneum covering the upper border of the Fallopian tube; being shorter than the tube, it aids in sacculating it, which is detrimental to the facility of trans mitting ova, leads to ectopic gestation by allowing the ovum to slip into portions of the tube which are not in the main stream of the menstrual fluid. The women possessing this band have usually premenstrual pain or tubal colic, and are either sterile or have few children. This band is considered a relic of embryonic life. T. violacea, a part of the fourth ventricle.

Teniacide, Tæniacide (te'-ne-as-î $d)$ [tenia, tapeworm ; cadere, to kill]. Destructive of tapeworms ; a remedy that destroys tapeworms.

Teniafuge, Tæniafuge $\left(t e^{\prime}-n e-a f-\ddot{i} j\right)$ [tenia, tape worm; fugare, to drive]. An agent that expels, without necessarily killing, tenia.

Teniasis (te-ni'-as-is) [tania, tenia]. The ensemble of symptoms resulting from the presence of tenia in the body.

Teniate $\left(t e^{\prime}-n e-a \bar{t}\right)$ [tenia, tapeworm]. Ribbon-like in shape.

Tenicide $\left(t^{\prime} n^{\prime}-i s-i d\right)$. See Teniacide.

Tenifuge $\left(\operatorname{ten}^{\prime}-i f-\bar{u} j\right)$. See Teniafuge.

Tenioid (te' -ne-oid) [Truvia, a band, ribbon; eidos, form ]. In biology, ribbon-like, or resembling a tapeworm.

Teniola $\left(t e n-i^{\prime}-o-l a h\right)[\mathrm{L}$.$] . A small ribbon. T. cin-$ erea. I. A thin, grayish ridge separating the striæ of the floor of the fourth ventricle from the cochlear division of the acoustic nerve. 2. In biology, one of the four ridges developed on the exumbrellar gastric wall of certain Medusce (Scyphopolyps), also called gastral teniola, gastric ridges, tenioles. Cf. Phacelli.

Teniophobia (te-ne-o-fo'-be-ah) [tania, tapeworm; $\phi \delta ́ \beta o s$, dread]. Morbid dread of becoming the host of a tapeworm.

Tennant's Powder. See Powder.

Tennis-arm. Same as T.-elbow. T.-elbow, a strain of the elbow, said to be frequent in tennis-players.

Tennysin $\left(t e n^{\prime}-i s-i n\right)$. A certain alkaloid occurring in brain-tissue. 


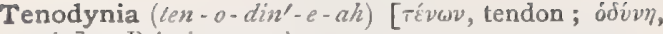
pain]. Pain in a tendon.

Tenography (ten-og'-ra-fe). See Tenontograpliy. Tenology (ten-oll-o-je). See Tenontology.

Tenon, Capsule of. A fibro-elastic membrane or fascia separating the eyeball from the surrounding tissues within the orbit. It is covered by a continuous layer of endothelial plates, and corresponds to a synovial sac, whose lubricated surfaces of contact facilitate the movements of the eyeball. (Piersol.) T.'s Membrane. See T.'s Capsule. T.'s Space, a lymph space separating the sclera from Tenon's capsule.

Tenonitis (ten - on - $\left.i^{\prime}-t i s\right)$ [ Tenon, an anatomist; $\iota T \iota S$, inflammation]. Inflammation of Tenon's capsule.

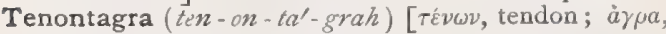
seizure ]. Gout in tendons.

Tenontodynia (ten-on-to-din'-e-ah). See Tenodynia.

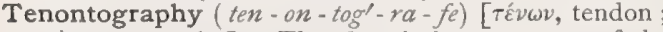

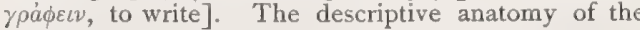
tendons.

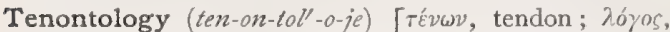
treatise]. The sum of what is known regarding the nature, etc., of tendons.

Tenontomia (ten-on-to'-me-ah). Synonym of Tenotomy.

Tenontophyma (ten - on - to - $\left.f^{\prime}-m a h\right)[\tau \varepsilon \dot{\nu} \omega \nu$, tendon ; $\phi \tilde{u} u a$, growth]. A tumor growing on a tendon.

Tenontophyte $\left(t e n-o n^{\prime}-t o-f i t\right)[T \varepsilon ́ v \omega v$, tendon; $\phi v т o \nu$, plant]. A new formation upon a tendon.

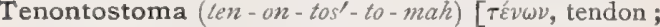
ó $\tau$ ćov, bone]. Bony change in a tendon.

Tenophyte $\left(t n^{\prime}-o-f i t\right)$ [ $\tau \hat{\varepsilon} v \omega v$, tendon; $\phi v \tau \delta v$, growth]. An osseous or cartilaginous growth on a tendon.

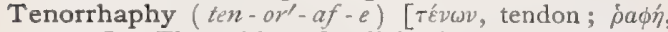
suture]. The uniting of a divided tendon by sutures.

Tenositis (ten-o-si'-tis) [ $\tau^{\prime} v \omega \nu$, tendon; $\iota \tau \iota s$, inflammation]. Inflammation of a tendon.

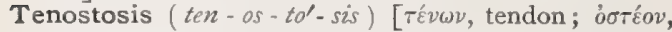
bone]. Ossification of a tendon.

Tenosuture (ten-o-su'-tür). Same as Tenorhaphy.

Tenosynitis (ten-o-sin-i't-tis). See Tenosynovitis.

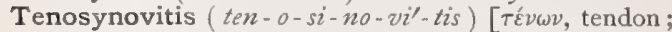
synovia, synovia; $\iota \tau \iota \varsigma$, inflammation $]$. Combined inflammation of a tendon and of its sheath. See Thecitis.

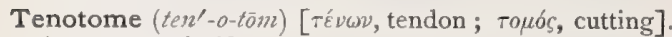
A tenotomy-knife.

Tenotomize (ten $\left.-o t^{\prime}-o-m \hat{\imath} z\right)[T \varepsilon ́ v \omega \nu$, tendon; Touń, a cutting]. To perform tenotomy.

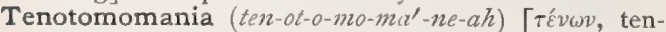

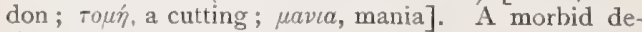
sire to perform tenotomy.

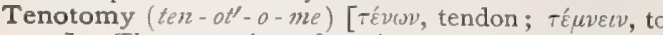
cut]. The operation of cutting a tendon to correct deficiencies, inequalities, derangements, or disorders due to muscular contractions or imbalance, and for the correction of heterophoria or strabismus. See Strabotomy. T., Graduated, cutting a part of the fibers of the tendon of an ocular muscle for heterophoria or slight degrees of strabismus. T., Tarsal, division of the peroneal tendon for the relief of spavin.

Tension (ten'-shun ) [tensio; tendere, to stretch]. In physics, that force apparent in mutual repulsion of the molecules of gases. It disappears when the repulsion is balanced by gravitation. The tendency of electricity to overcome resistance. In physiology, the condition of an organ when under a strain. T., Elastic, stretching by means of an elastic material. T., Intraocular, the pressure of the intraocular contents upon the sclerotic. Abnormal increase of tension is characteristic of glaucoma. Accurate measurement of tension is made by means of instruments called tonometers; for practical purposes it is estimated by palpa- tion with the fingers. The registration of tension is indicated by the following terms: $T n$. $=$ Tension normal; the varying degrees of subnormality by the sign -, prefixed to the figures, I, 2, 3, the last denoting extreme flaccidity; hypertension is indicated by the sign + , prefixed to $\mathbf{I}, 2,3$, the last indicating the extreme hardness of the highest glaucomatous pressure. T., Muscular, the state of moderate contraction which occurs when muscles are passively stretched.

Tensor (ten'-sor) [tendere, to stretch]. An organ or part whose function is to make tense. T. Muscles. See Muscles, Table of.

Tent [tenta, a tent: pl., Tentce]. An instrument made of compressed sponge, laminaria, tupelo, or other material that increases in volume by the absorption of water; it is used chiefly for dilating the cervix of the uterus. T., Cornstalk, a tent made of dried cornstalk pith. T., Laminaria, a tent made of dried Laminaria stems. 'T., Sponge, a tent made of compressed dry sponge. T.-wine [vinum tinctum, colored wine], a Spanish wine of dark-red color.

Tentacle (ten'-tak-l) [tentore, bandle, touch, feel]. In biology, loosely applied to any slender, tactile or prehensile organ, as a feeler, horn, proboscis, antenna, vibrissa, ray, or arm.

Tentacula (ten-tak'-u-lah). Same as Tentacle.

Tentaculate (ten-tak'-u-lät) [tentaculum, a tentacle]. Having tentacles.

Tentaculicyst (ten-tal' $-u$-lis-ist) [tentaculum, a ten-

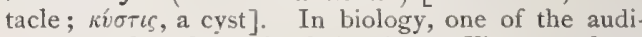
tory tentacles of certain Cnidaria. "They are short, transformed tentacles in which the solid endodermal axis, or the peripheral distal end-cells of the hollow tentacle-canal form one or more otoliths." Also spelled tentaculocyst.

Tentaculiferous (ten-tak-u-lifl-er-us) [tentaculum, tentacle; ferre, to bear]. Bearing tentacles.

Tentaculiform (ten-tak'-u-lif-orm) [tentaculum, tentacle; forma, form]. Tentacular.

Tentaculigerous (ten-tak-u-lij'-er-us). Same as Tentaculiferous.

Tentaculocyst. See Tentaculicyst.

Tentaculum (ten - tak'- $u$-lum) [tentare, feel, touch, handle: pl., Tentacula $]$. In biology, a tentacle.

Tentigo $\left(t e n-t i^{\prime}-g o\right)[\mathrm{L}$.$] . Lust; satyriasis, T. prava.$ Synonym of Lupus. T. venerea. Synonym of Nymphomania.

Tentorial (ten-to'-re-al) [tentorium]. Pertaining to the tentorium.

Tentorium (ten-to'-re-um) [tentorium, a tent: $p l .$, Tentoria. In biology: $(a)$ the endocranium; $(b)$ the partition between the cerebrum and the cerebellum formed by an extension of the dura; it is sometimes ossified.

Tenuifolious (ten-u-if-o'-le-us) [tenuis, thin ; folium, leaf ]. In biology, having slender leaves.

Tephromyelitis (tef-ro-mi-el-i'tis). Synonym of Paralysis, Infantile. See also Poliomyelitis.

Tephrosia (tef-ro'-ze-ah) [ $\tau \varepsilon \phi \rho o ́ s$, ashen]. A genus of some 125 species of leguminous plants, a few of which are $\mathrm{N}$. American. $\mathrm{T}$. apollinea, $\mathrm{T}$. senna, $\mathrm{T}$. leptostachya, and other tropical or subtropical species have purgative leaves. Unof. T. virginiana (catgut, hoary pea, goat's rue, turkey-pea, devil's shoestrings) is tonic and anthelmintic.

Tephrosis (tef-ro'-sis). See Incineration.

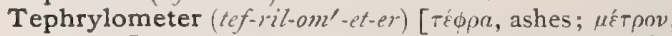
measure]. A graduated glass tube for measuring the thickness of the gray matter of the brain by means of the segment or core removed.

Tepid (tep'-id) [tepidus, warm]. About blood heat. T. Bath. See Bath. 
Tepidarium (tep-id-a'-re-um) [lepidus, warm]. A warm bath. See Bath.

Tepopote $\left(t e-p o^{\prime}-p o-t e\right)$. Teamsters' Tea. The twigs of Ephedra antisyphilitica, commonly known in the Southwestern U. S. as canutillo, or whorehouse tea. It is said to be serviceable in venereal diseases. Dose of the fld, ext. $3 \mathrm{j}-\mathrm{ij}$. Unof.

Ter- [L., three times]. A common prefix meaning three, or threefold. In chemistry, a prefix joined to the names of certain compounds containing three acid atoms or radicles.

Terabdelle $\left(t e r-a b^{\prime}-d e l\right)[T \varepsilon \rho \varepsilon \varepsilon \iota v$, to bore; $\beta \delta a ́ \lambda \lambda \varepsilon \iota \nu$, suck]. An instrument employed by Damoiseau to supersede the leech.

Teracrylic Acid (ter-ak-ril'-ik). See Acid.

Teras (te'-ras) [tépas, a monster: pl., Terata]. A monster. Terata anadidyma, an order of double autositic monsters in which there is an upward cleavage of the cerebro-spinal axes. Fusion has occurred at the cephalic extremity, with divergence of the caudal, and, as the result, a double monster is produced, single above and double below. T. anakatadidyma, an order of double autositic monsters in which there is both upward and downward cleavage of the cerebro-spinal axes. The two primitive traces approach at points in their continuity only, while the two extremities diverge. As a result, a double being is formed, double above and below, with union between. T. katadidyma, an order of double autositic monsters in which there is a cleft of the cerebrospinal axes from above downward; that is, the primi tive traces have fused at their caudal extremity, and diverge in varying degrees as they ascend. The result is a double being, separated above and joined below.

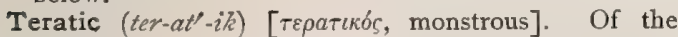
nature of a teratism; monstrous.

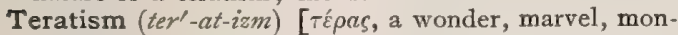
ster]. Any anomaly of conformation, whether congenital or acquired through disease or injury. Gouley classifies monstrosities as follows: A. Congenital monstrosities, or vices of primary conformation, grouped as follows: 1. The ectrogenic. Those monstrosities in which are absent or defective certain parts belonging to the normal body; for example, the absence of one kidney, of one or both testicles, of the external urogenital organs, etc. 2. The symphysic. Those monstrosities produced by fusion or coalition of organs, such as the kidneys. 3. The ceasmic. Those monstrosities in which the parts that should be united remain in their primitive, fissured state, as in hypospadias and epispadias. 4. The atresic. Those monstrosities in which natural openings are occluded, as in imperforate urethra. 5. The hypergenetic. Those monstrosities in which certain parts are disproportionately large, such as the penis, the testicles, etc. 6. The ectopic. Those monstrosities in which one or more than one part may be abnormally placed, such as a kidney or both kidneys, etc. 7. The hermaphroditic. Those monstrosities in which organs of both sexes exist. B. Acquired monstrosities, or those that are the outcome of disease, of violence, or of operations necessitated by diseased conditions or injuries. They may be grouped as follows: $\mathbf{I}$. The ectrogenic. Those monstrosities caused by the loss of some part from disease, injury, or operation. 2. The symphysic. Those monstrosities produced by the fusion of parts from disease, injury, or operation. 3. The ceasmic. Those monstrosities in which a cleft results through disease, injury, or operation. 4. The atresic. Those monstrosities in which natural openings are occluded through disease, injury, or operation. 5. The hypergenetic. Those monstrosities in which certain parts are inordinately enlarged through disease. 6. The ectopic. Those monstrosities in which a part is displaced through disease or injury. Other classifications of monstrosities have been given by Ahlfeld, Bischoff, Blumenbach, Breschet, Buffon, Fisher, Licetus, Meckel, and Otto. See Monstrosities, Table of Classification of, according to Geoffroy Saint-Hilaire, altered by Hirst and Piersol, under Monster.

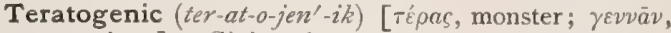
to produce]. Giving rise to teratism, or monstrosity.

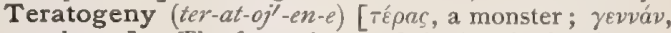
to beget]. The formation or bringing forth of monstrosities.

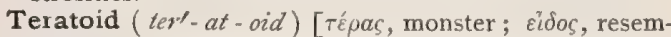
blance]. Resembling a monster, or anomalous organization.

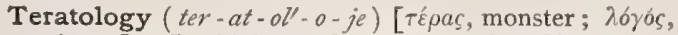
science]. In biology, the science of malformations and monstrosities in the vegetable or animal kingdom.

Teratoma (ter-at-o'-mah) [Tغ́pas, monster; ö $\mu \alpha$, tumor: pl., Teratomata]. A congenital tumor, which may contain various concretions of organic tissue, as teeth, hair, and other erratic material. Dermoid cyst.

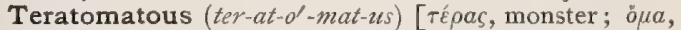
tumor]. Of the nature of or resembling a teratoma.

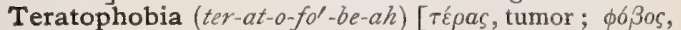
dread]. Morbid fear of monsters, or of deformed or peculiar individuals.

Teratosis $\left(t e r-a t-o^{\prime}-s i s\right)$ [Tépas, monster]. A congenital deformity

Terbasic $\left(t e r-b a^{\prime}-z i k\right)$. Synonym of Tribasic.

Terbium (tur'-be-um) [Ytterby, in Sweden]. A supposed metallic element, as yet not isolated. See Elements, Table of.

Terchlorid (ter-klo'-rid) [ter, three; $\chi^{\lambda \omega \rho o s, ~ g r e e n] . ~}$ Synonym for Trichlorid.

Terebella (ter-e-bel'-ah) [L., dim. of terebra: gen., Terebelle ]. A trephine or trepan.

Terebellum (ter-e-bel'-um) [L.]. An instrument used in craniotomy to perforate the skull.

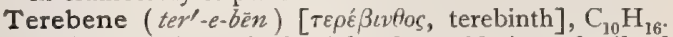
A hydrocarbon obtained by the oxidation of oil of turpentine by means of sulphuric acid. It is soluble in alcohol and is recommended for winter cough as an expectorant, and for inhalation in bronchitis. Dose m $\mathbf{v}-\mathbf{x x}$ on sugar or suspended in water.

Terebic Acid $\left(t e r-e b^{\prime}-i k\right)$. See Acid.

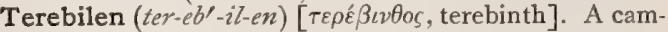
phoraceous liquid produced by the action of hydrochloric acid upon a terpene or oil of turpentine.

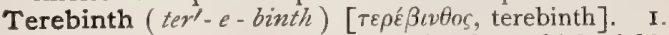
The turpentine tree, Pistacia terebinthus, which yields Chian turpentine. 2. Turpentine; terebinthina.

Terebinthina (ter-e-bin'-thin-ah) [ $\varepsilon \rho \hat{\varepsilon} \beta \iota \nu \theta o s$, terebinth: gen., Terebinthina]. Turpentine. The oleoresin obtained from yellow pine, Pinus australis, and other species. Its properties are due to an essential, volatile oil, which is the form mainly used. It is stimulant, antispasmodic, diuretic, and anthelmintic, and externally a rubefacient. It is useful in intestinal hemorrhage, as a cardiac stimulant, and in various zymotic fevers, and externally in neuralgia, gangrene, and rheumatism. Dose of the oil $m v-x v$ (of the oleoresin gr. $v-3$ j). T. canadensis, "balsam of fir," a liquid oleoresin. Dose gr. v-xxx. Turpentine, Chian, clear, yellowish-white turpentine produced from the Pistacia terebinthus, of reputed benefit in carcinoma. Dose gr. iij-v. T., Con-

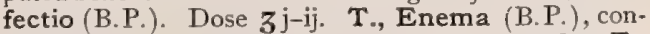
tains oil of turpentine and mucilage of starch. $T$., Liniment., resin cerate 65 , oil of turpentine 35 
parts. T., Lin., Aceticum (B.P.), oil of turpentine, glacial acetic acid, camphor-liniment. T., Oleum, Rectificatum, rectified oil of turpentine. Dose $\mathrm{mv}-$ 亏 ss. T., Ung. (B.P.), oil of turpentine, resin, yellow wax, prepared oil. Turpentine, Venice, a solution of resin in oil of turpentine. Terebene, prepared by the action of sulphuric acid on turpentine. Dose gtt. v.

Terebinthinate $\left(t e r-e-b i n^{\prime}-t h i n-\bar{a} t\right)[\tau \varepsilon \rho \dot{\varepsilon} \beta \iota \nu$ tos, terebinth]. A member or derivative of the turpentine group.

Terebinthine $\left(t e r-e-b i n^{\prime}-t h i n\right)$ [ $\tau \varepsilon \rho \varepsilon^{\beta} \beta \nu \theta 0 s$, terebinth] Of the nature or having the qualities of turpentine.

Terebration (ter-e-bra'-shun) [terebrare, to bore]. The operation of boring or trephining; also, a boring pain.

Teres $\left(t \ell^{\prime}-r e \bar{z}\right)$ [terere, to rub]. A name given to vari ous organs and parts characterized by a round, smooth appearance. T. Muscle (major and minor). See Muscles, Table of. See also Liramentum teres.

Terete (ter-êt') [teres, round, smooth]. In biology, nearly cylindric. A term descriptive of certain stems, leaves, pistils, etc.

Teretipronator (te-re-tip-ro-na'-tor) [L. ]. The pronator radii teres. See Muscles, Table of.

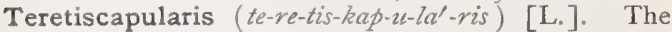
teres major muscle. See Muscles, Table of.

Tergal (ter'-gal) [tergum, back]. In biology, of or pertaining to the dorsal surface or aspect.

Tergeminate (ter-jen'-in-ät) [ter, thrice; geminatus, doubled]. In biology, having three pairs of parts, appendages, or organs.

Tergite $($ ter'-jit $)$ [tergum, the back]. In biology, the dorsal piece of an arthropodan somite.

Tergolateral (ter-go-lat'-er-al) [tergum, back; latus, side]. Pertaining to the back and the side.

Tergum (ter'-gum) [tergum, back: pl., Terga]. In biology, the back or dorsum, or the dorsal piece of an arthropodan somite.

Terhydrid (ter-hi'-drid) [ter, three; $v \delta \omega \rho$, water]. A combination of three atoms of hydrogen with an element or radicle.

Teriodid (ter-i'-o-did) [ter, three; 'i $\omega \delta 27 s$, like a violet]. A triiodid.

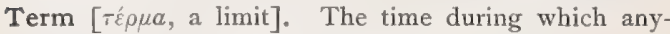
thing lasts; the time of expected delivery; monthly course.

Terma $\left(t e \gamma^{\prime}-m a h\right)[\tau \varepsilon ́ \rho \mu \alpha$ limit]. The lamina terminalis or lamina cinerea of the brain ; the cephalic boundary of the mesal, encephalic cavities.

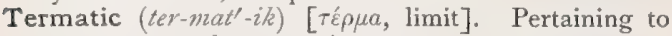
the terma; as the termatic artery.

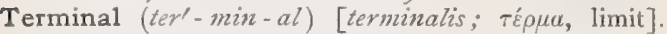
Pertaining to the end; placed at the end. In the plural, a name sometimes applied to the poles of a battery or other electric source, or to the ends of the conductors or wires connected thereto. T. Artery. See Artery. T. Carbon Atoms, those combined with three hydrogen atoms. T. Genital Corpuscles, Krause's name for the round dilatations terminating the nerves in the dermis covering the extremity of the penis in horses. T. Neuritis. See Erythromelalgia.

Terminalia (ler-min-a -le-ah) [L.]. A genus of combretaceous tropical trees. See Myrobalan.

Termination $\left(t e r-m i n-a^{\prime}-\operatorname{sh} u n\right)$. I. An ending. 2 . An issue. T., Nerve, a nerve-ending.

Terminology (ter-min-ol'-o-je) [terminus, a name; $\lambda o ́$ yos, science]. Nomenclature; a system of technical names or terms.

Terminthus (ter-min'-thus) [ $\tau \dot{c} \rho \mu \iota \nu \theta o s$, terebinth-tree]. An old name for a carbuncle or sore, said to resemble the fruit of the terebinth in its figure and its black-green color.
Ternary (ter'-na-re) [ter, three times]. Pertaining to the number three.

Ternate $\left(t e r^{\prime}-n \bar{a} t\right)$ [ternatus, arranged in threes]. In biology, applied to radiately compound leaves that have three leaflets.

Teroxid (ter-oks'-id) [ter, three; ó $\xi$ ś, acid]. A trioxid. Terpene (ter'-pén) [a modified form of terebene]. One of a number of hydrocarbons analogous to turpentineoil. They have the formula $\mathrm{C}_{10} \mathrm{H}_{16}$ or $\left(\mathrm{C}_{5} \mathrm{H}_{8}\right)_{n}$, and are contained in the volatile or ethereal oils obtained in the distillation of various plants (chiefly Coniferce and Citrus species). The terpenes that have been thus isolated are very numerous.

Terpin (ter'-pin) [see Terebene], $\mathrm{C}_{10} \mathrm{H}_{16}\left(\mathrm{H}_{2} \mathrm{O}\right)_{2} \mathrm{H}_{2} \mathrm{O}$. A terpin hydrate derived from turpentine. Useful in bronchial and pulmonary diseases to loosen and facilitate the expectoration of mucus. Dose gr. $\mathrm{v}-\mathrm{x}$.

Terpinene (ter'-pin-èn) [modified from terebene], $\mathrm{C}_{10} \mathrm{H}_{16}$ A substance that results from shaking pinene with concentrated $\mathrm{H}_{2} \mathrm{SO}_{4}$. It occurs already formed in cardamom-oil, and is very similar to dipentene; it boils at about $\mathbf{I} 80^{\circ} \mathrm{C}$.

Terpineol, Terpinol (ter-pin'-e-ol, ter'-pin-ol) [terpin; oleum, oil], $\mathrm{C}_{10} \mathrm{H}_{18} \mathrm{O}$. A substance formed by boiling terpin and terpin hydrate with aqueous mineral acids. It is a thick liquid, with a peculiar odor, boiling at $215-218^{\circ} \mathrm{C}$. Its uses are similar to those of terpin. Dose gr. viij-xv daily.

Terpinolene (ter-pin'-o-lèn) [terpin; oleum, oil], $\mathrm{C}_{10} \mathrm{H}_{15}$. A substance produced when terpin hydrate, terpineol, and cineol are boiled with dilute $\mathrm{H}_{2} \mathrm{SO}_{4}$. It boils at $185-190^{\circ} \mathrm{C}$.

Terra $\left(t e r^{\prime}-a h\right)[g e n .$, Terra $]$. Earth. T. alba, white clay. T. cariosa, rotten-stone. T. japonica. Same as Gambier. 'T., Oleum, petroleum. 'T. ponderosa, baryta or barium sulphate. See Bole, Fullers' Earth, Lemnian Earth, Cimolian Earth, etc. T. di sienna. Same as Ocher.

Terracing a Suture. A term indicating the closure of a wound by means of the insertion of successive tiers of sutures.

Terrain-cure $\left(t e r^{\prime}-\bar{a} n-k \bar{u} r\right)$ [Fr.]. A therapeutic method consisting in mountain-climbing, dietetics, etc., for plethora, corpulence, neurasthenia, chlorosis, incipient pulmonary tuberculosis.

Terraline (ter'-al-in) [terra, earth]. A (proprietary) tasteless preparation of petroleum, recommended as a substitute for cod-liver oil.

Terraqueous (ter- $\left.\alpha^{\prime}-k z v e-u s\right) \quad[$ terra, land; aqua, water]. Pertaining to or consisting of both land and water.

Terrene $\left(\right.$ tero $\left.^{\prime}-\bar{e} n\right)$ [terrenzss]. Terrestrial.

Territory (ter'-it-o-re) [territorium, territory]. An extent of land: $\mathbf{T}$. of a Cell, the extent of tissue supposed to be under the influence or control of any individual cell.

Terror (ter'-or) [L.]. Intense fear. See Night-terrors, Day-lerrors.

Tersion (ter'-z/unn) [tergere, tersus, to wipe]. The act of cleaning by friction, or dry rubbing.

Tersulphate (ter-sul'-fät) [ter, three; sulphur, sulphur]. A salt containing three molecules of the sulphuric-acid radicle.

Tersulphid (ter-sul'-fid) [ter, three; sulphur, sulphur]. Synonym of Trisulphid.

Tertian (ter'-shan) [tertius, third]. Tertianus; febris tertiana. Applied to a variety of intermittent fever the paroxysms of which recur every third day.

Tertiarism (ter'-she-ar-izm) [Fr., tertiarisme $]$. Tertiary syphilis.

Tertiary $($ ter'-she-a-re) [tertiarius: tertius, third]. Third in order. T. Syphilis. See Syphilis. T. Union, or 
Structure, the union of carbon atoms with three other carbon atoms.

Tervalence (ter-va'-lens). Synonym of Trivalence.

Tessellated (tes'-el-a-ted $)$ [tessellatus; tessera, a square]. Formed into little squares. Chequered Having quadrangular arrang ement. T. Cells, the flat tened cells of pavementepithelium.

Tessera (tes'-er-ah) [L.] The cuboid bone.

Test [testum, c r u cible, trial]. In chemistry, a characteristic $r$ eaction which distinguishes any one body from all others. Also, the reagent for producing a test. A Table of Tests is appended, see pages 1468-1506. In biology, a shell or hard, outer covering. See Testa. T.-breakfast, Ewald's, consists of one roll and one glass of water or a cup of weak tea, without milk or sugar. T.-glass, a small, glass vessel used in the chemic laboratory for purposes of experimentation and investigation. T.-meal, a meal given in order to test the action of the gastric juices. T.-m, Jaworski's, the whites of two, hard-boiled eggs and Ioo c.c. of water. T.-paper, paper impregnated with a chemic re agent, as litmus, and used for detecting the presence of certain substances 6 or conditions which cause a change in the color of the paper. See Litmus. T.-spoon, a small spoon with a spatula-shaped handle, used in chemic experiments. T.-tube, a cylinder of thin glass closed at one end, used in various chemic procedures. T.types, letters or figures of different sizes to test acuteness of vision.

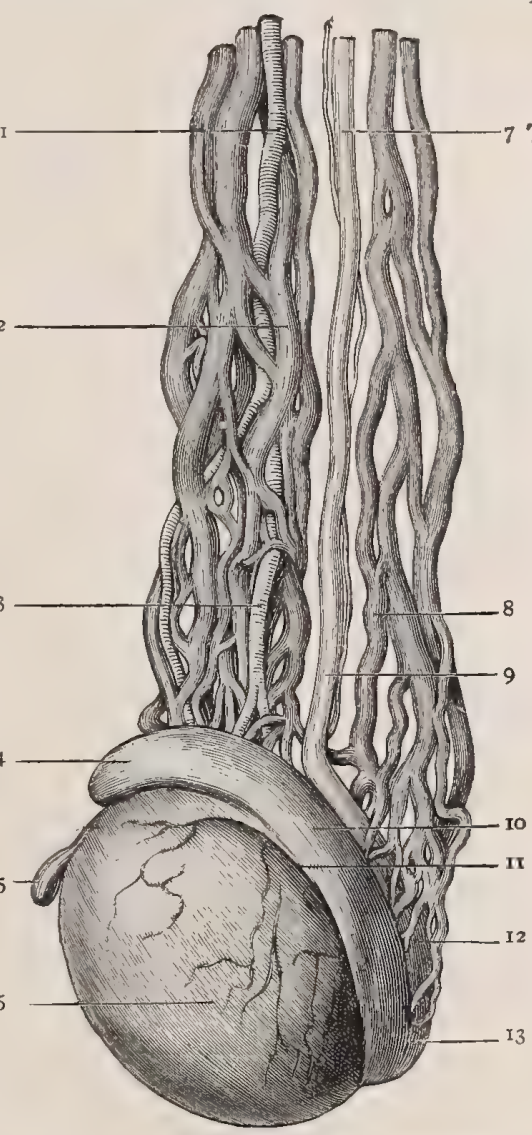

Left Testicle with Vessels and Duct. (After Sappey.)

I. Spermatic artery. 2 Spermatic veins. 3 Branch of spermatic artery. 4. Globus major of epididymis. 5. Hydatid of Morgagni. 6. Outer wall of body of testis. ? Vas deferens, with deferential artery. 8. Vein. 9. Vas deferens. 10. Body of epididymis. II. Digital fossa. I2. Vessels of epididymis. 13. Globus minor. of, passage of the testes through the inguinal canal into the scrotum. T., Female, the ovaries. T. muliebris. See Ovaries.

estibrachial (tes-tib-ra'-ke-al) [testis, testicle; brahium, arm]. Pertaining to the testibrachium.

Testibrachium (tes-tib-ra'-ke-zlm) [testis, testicle; brachium, arm]. The process connecting the cerebellum with the testis of the brain; the prepeduncle or superior crus of the cerebellum.

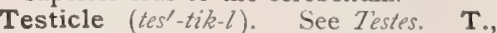
Displaced, a testicle in an abnormal situation, as in the pelvic cavity. T., Inverted, a testicle which is so placed in the scrotum that the epididymis is attached to the anterior part of the gland. T., Irritable, neuralgia of the testicle, due to some demonstrable pathologic condition in or about the testicle, or to a spasmodic contraction of the cremaster muscle. T., Pulpy, medullary sarcoma of the testicle. T.,

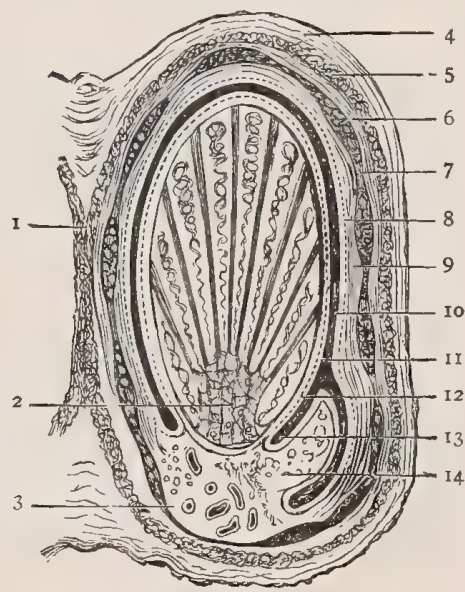

SECTION OF THE SCROTUM AND TESTICLE. Diagrammatic. (After Sappey.)

1. Septum scroti. 2. Mediastinum testis. 3. Vas deferens. 4. Skin. 5- Dartos. 6. External spermatic fascia. 7. Cremasteric fascia. 8. Parietal layer of tunica vaginalis. 9. Internal spermatic fascia and subperitoneal fascia ro. Cavity of tumica vaginalis. Is. Visceral layer giner of tunica vaginalis. 12. Tunica albuginea. 13. Digital fossa. 14. Epididymis.
Those most in use are Snellen's test-types, which, at proper distances, subtend an angle of five minutes.

Testa (tes'-tah) [L.: gen., Testce]. A shell. In biology, the outer coat or covering of the seed; a test. T. ovi, egg-shell; T. præparata, prepared oyster-shell ; both antacid. See Calcium.

Testaceous (tes-ta'-shus) [testa, a tile, a shell]. In biology: (a) of or pertaining to a shell; shelly; (b) the color of unglazed pottery, brick-red to orangeyellow.

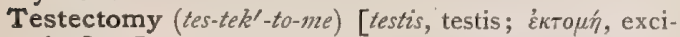
sion]. See Orchidectomy.

Testes (test'-ezz) [L.]. The two glandular bodies, situated in the scrotum, that secrete the semen. They lie in the abdominal cavity in early fetal life, and descend into the scrotum about the time of birth. $\mathbf{T}$. of Brain. See Corpora quadrigemina. T., Descent
Scrofulous. Synonym of Tuberculous Orchitis. T., Swelled. Synonym of Epididymitis. T., Syphilitic. Synonym of Syplititic Orchitis. T., Undescended, the condition in which one or both testicles remain in either the pelvis or the inguinal canal. Cf. Monorchid, and Cryptorchid.

Testicond (tes'-tik-ond) [testis, testicle; condere, to hide]. Having the testes undescended.

Testicular (tes-tik'-u-lar) [testiculus, a testicle]. Pertaining to a testicle. T., Therapy, the therapeutic employment of an extract from the testicles. See Organotherapy.

Testiculate (tes-tik'-u-lät) [testiculus, a testicle]. Having testicles, or having the shape of a testicle.

Testiculus (tes-tik'-u-lus) [L.: gen. and pl., Testiculi]. A testicle.

Testill (tes'-til) [testa, shell, tile]. See Frustule. 


\section{TABLE OF TESTS.}

AbBreviations: $R=$ Reagent. Vol.=Volume. Sol.=Solution; soluble. Sat. sol.=Saturated solution. Concent.=Concentrated. Dil.=Diluted. Aq. $=$ Aqueous. P. $=$ Phosphorus Ppt.=Precipitate. Eq. =Equal. c.c.=Cubic centimeter. gm. $=$ Gram. $\bar{a} \bar{a}=$ Of each. $\mathrm{HNO}_{3}=$ Nitric acid. $\mathrm{HgCl}_{2}=$ Mercuric chlorid. The small italicized letters $a, b, c, d, e$, refer to the reagents in column III which have corresponding letters prefixed in parenthesis.

\begin{tabular}{|c|c|c|c|c|c|}
\hline NAME. & USE & REAGENTS. & REACTION. & APPLICATION. & REMARKS. \\
\hline Acetic-acid test. & Albumin in urine. & Acetic acid. & White ppt. & $\begin{array}{l}\text { To boiled urine add } \\
\text { few drops } \mathrm{R} \text {., or add } \\
\mathrm{R} \text {., and then boil } \\
\text { upper portion of } \\
\text { liquid in test-tube. }\end{array}$ & Avoid excess of $\mathbf{R}$. \\
\hline Adamkiewicz' test. & $\begin{array}{l}\text { Albumins and pro- } \\
\text { teids. }\end{array}$ & $\begin{array}{l}\text { (a) Strong sulphuric } \\
\text { acid. }(b) \text { Glacial } \\
\text { acetic acid. }\end{array}$ & $\begin{array}{l}\text { Vinlet color and } \\
\text { fluorescence. }\end{array}$ & $\begin{array}{l}\text { Add mixture of I vol. } \\
\text { of } a \text { and } 2 \text { vol. of } b \text {, } \\
\text { and boil. }\end{array}$ & \\
\hline Alfraise's test. & Iodin. & $\begin{array}{l}\text { Add I drop hydro- } \\
\text { chloric acid to water } \\
\text { loo, starch I, potass. } \\
\text { nitrate I. Boil. }\end{array}$ & Blue color: & $\begin{array}{l}\text { Add one drop of } \mathrm{R} \text {. to } \\
\text { small quantity of } \\
\text { suspected fluid. }\end{array}$ & \\
\hline $\begin{array}{l}\text { Alkaline copper } \\
\text { test. }\end{array}$ & Glucose. & See Trommer's test. & & & \\
\hline Allen's test. & Carbolic acid. & $\begin{array}{l}\text { (a) Hydrochloric acid. } \\
\text { (b) Nitric acid. }\end{array}$ & $\begin{array}{l}\text { Purple-crims on } \\
\text { color. }\end{array}$ & $\begin{array}{l}\text { Few drops of } a \text { to I or } \\
2 \text { drops of liquid; } \\
\text { then I drop } b \text {. }\end{array}$ & \\
\hline Allen's test. & $\begin{array}{l}\text { Glucose in urine } \\
\text { in doubtful } \\
\text { cases. }\end{array}$ & Fehling's solution. & Turbidity. & $\begin{array}{l}\text { Boil io c.c. of } R_{\text {., add }} \\
\text { equal quantity of } \\
\text { urine; heat; then } \\
\text { allow to cool. }\end{array}$ & $\begin{array}{l}\text { No reaction means } \\
\text { absence of sugar } \\
\text { or less than to } \\
\text { per cent. }\end{array}$ \\
\hline Allen's test. & Strychnin. & $\begin{array}{l}\text { (a) Ether. (b) Sulphuric } \\
\text { acid. (c) Manganese } \\
\text { dioxid. }\end{array}$ & Violet color. & $\begin{array}{l}\text { Extract with } a \text {; let fall } \\
\text { (drop by drop) into } \\
\text { warmed porcelain } \\
\text { capsule; let cool; } \\
\text { add } b \text { and } c \text {. }\end{array}$ & \\
\hline Allen's test. & Zinc in solution. & Potassium ferrocyanid. & White ppt. & $\begin{array}{l}\text { Few drops of R. to } \\
\text { boiling solution, } \\
\text { slightly alkaline. }\end{array}$ & \\
\hline Almén's test. & Albumin in urine. & $\begin{array}{l}2 \text { per cent sol. of tannin } \\
\text { in dilute alcohol. }\end{array}$ & Cloudiness. & $\begin{array}{l}\text { One part R. to } 6 \text { of } \\
\text { urine. }\end{array}$ & \\
\hline Almén's test. & Blood. & $\begin{array}{l}\text { Tr. guaiaci and oil of } \\
\text { turpentine s h a } \mathrm{k} \text { e } \mathrm{n} \\
\text { into an emulsion. }\end{array}$ & Blue color. & Add liquid to $R$. & \\
\hline Almén's test. & Blood. & $\begin{array}{l}\text { (a) Tr. guaiaci. (b) I5 } \\
\text { per cent. sol. hydro- } \\
\text { gen dioxid in ether. }\end{array}$ & Blue color. & $\begin{array}{l}\text { Add } 2 \text { or } 3 \text { drops } a \text { to } \\
\text { liquid; shake; add } \\
20 \text { drops } b \text {. }\end{array}$ & $\begin{array}{l}\text { Other substances } \\
\text { respond ab- } \\
\text { sence of reaction } \\
\text { proves absence } \\
\text { of blood. }\end{array}$ \\
\hline Almén's test. & Carbolic acid. & $\begin{array}{l}\text { (a) A m mon i a. }(b) \\
\text { Chlorinated soda. }\end{array}$ & Blue color. & $\begin{array}{l}\text { Add } a \text { and } b \text { to solu- } \\
\text { tion. }\end{array}$ & \\
\hline Almén's test. & Carbolic acid. & $\begin{array}{l}\text { Mercury I, nitric acid } \\
\text { I ; dilute with twice } \\
\text { bulk of water. }\end{array}$ & $\begin{array}{l}\text { Yellow ppt., dis- } \\
\text { solving with a } \\
\text { red color. }\end{array}$ & $\begin{array}{l}5 \text { to Io drops R. to } 20 \\
\text { c.c. of liquid. }\end{array}$ & \\
\hline Almén's test. & Glucose in urine. & $\begin{array}{c}\text { Caustic soda } 8 \text {, water } \\
\text { roo. Add so d i c } \\
\text { potassium tartrate } 4, \\
\text { bismuth }\end{array}$ & $\begin{array}{l}\text { Ppt. of metallic bis- } \\
\text { muth. }\end{array}$ & $\begin{array}{l}\text { Remove albumin, add } \\
R \text {. I to urine } 10 \text {. }\end{array}$ & Very delicate. \\
\hline $\begin{array}{l}\text { Almén and Nyland- } \\
\text { er's test. }\end{array}$ & Glucose in urine. & See Almén's test. & & & \\
\hline $\begin{array}{c}\text { Alpha-naphthol or } \\
\text { a-Naphthol test. }\end{array}$ & Glucose. & See Molisch's test. & & & \\
\hline $\begin{array}{l}\text { Ammoniated-cop - } \\
\text { per test. }\end{array}$ & Glucose. & See Pavy's test. & & & \\
\hline $\begin{array}{l}\text { Ammonium - mo- } \\
\text { lybdenate test. }\end{array}$ & Albumin in urine. & See Jaworowski's test. & & & \\
\hline Andre's test. & Quinin. & $\begin{array}{l}\text { (a) Chlorin. (b) Am- } \\
\text { monia. }\end{array}$ & $\begin{array}{l}\text { Green color, turn- } \\
\text { ing blue on satu- } \\
\text { ration with an } \\
\text { acid; with excess } \\
\text { of acid, violet or } \\
\text { bright-red; turns } \\
\text { green on addi- } \\
\text { tion of ammonia. }\end{array}$ & $\begin{array}{l}\text { Add } a \text { and } b \text { to solu- } \\
\text { tion. }\end{array}$ & \\
\hline
\end{tabular}


TABLE OF TESTS.-Continued.

\begin{tabular}{|c|c|c|c|c|c|}
\hline NAME. & UsE. & REAGENTS. & REACTION. & APPLICATION. & REMARKS. \\
\hline Andreasch's test. & Iron. & $\begin{array}{l}\text { (a) Ammonia. (b) Sul- } \\
\text { phoglycolic acid. }\end{array}$ & $\begin{array}{l}\text { Dark purplish-red, } \\
\text { soon fading, but } \\
\text { restored on } \\
\text { shaking with } \\
\text { air. }\end{array}$ & Add $a$ and $b$ to liquid. & \\
\hline Anstie's test. & Alcohol in urine. & $\begin{array}{l}\text { Potassium bichromate } \\
\text { I, strong sulphuric } \\
\text { acid } 300 \text {. }\end{array}$ & $\begin{array}{l}\text { Emerald-green } \\
\text { color. }\end{array}$ & $\begin{array}{l}\text { To } R \text {, add urine, drop } \\
\text { by drop. }\end{array}$ & $\begin{array}{l}\text { Reaction signifies } \\
\text { presence of toxic } \\
\text { amount of alcohol. }\end{array}$ \\
\hline Antipyrin-test. & $\begin{array}{l}\text { Antipyrin in urine, } \\
\text { etc. }\end{array}$ & See Ferric-chlorid & test. & & \\
\hline $\begin{array}{l}\text { Austen and Cham- } \\
\text { berlain's test. } \\
\end{array}$ & Nitric acid. & $\begin{array}{l}\text { Ammonio-sulphate of } \\
\text { iron 200, water roo0, } \\
\text { sulphuric acid } 20 .\end{array}$ & Rose-red color. & Add R. to solution. & \\
\hline $\begin{array}{l}\text { Autenrieth and } \\
\text { Hinsberg's test. }\end{array}$ & Phenacetin. & Nitric acid. & $\begin{array}{l}\text { Yellow substance, } \\
\text { crystallizing out } \\
\text { in needles }\end{array}$ & $\begin{array}{l}\text { To finely powdered } \\
\text { phenacetin add ro to } \\
\text { i2 per cent. R.; heat } \\
\text { to boiling. }\end{array}$ & $\begin{array}{l}\text { Antipyrin and ace- } \\
\text { tanilid do not } \\
\text { respond. }\end{array}$ \\
\hline Axenfeld's test. & Albumin in urine. & $\begin{array}{l}\text { (a) Formic acid. (b) } \\
\text { Sol. } \mathrm{HgCl}_{2} \text { (1:1000). }\end{array}$ & $\begin{array}{l}\text { Rose or purple } \\
\text { color. }\end{array}$ & $\begin{array}{l}\text { Acidulate with } a \text {; add } \\
\text { a few drops } b \text {. }\end{array}$ & Not reliable. \\
\hline Bachmeier's test. & Alkalies. & Sol. of tannin. & $\begin{array}{l}\text { Red to reddish- } \\
\text { brown, turning } \\
\text { into dirty-green. }\end{array}$ & Add R. to the liquid. & \\
\hline Baeyer's test. & Eosin. & $\begin{array}{l}\text { (a) Sodium-amalgam. } \\
\text { (b) Sol of potass. } \\
\text { permanganate. }\end{array}$ & $\begin{array}{l}\text { Opaque-green } \\
\text { color in reflected } \\
\text { light. }\end{array}$ & $\begin{array}{l}\text { Shake substance with } \\
\text { water and } a \text {, heating } \\
\text { gently; dilute with } \\
\text { water; add drop of } b\end{array}$ & \\
\hline Bailey's test. & Nitric acid. & $\begin{array}{l}\text { Cyanhydrargyrate of } \\
\text { potass. iodid (one } \\
\text { equivalent each mer- } \\
\text { curic cyanid and } \\
\text { potass. iodid). } \\
\end{array}$ & $\begin{array}{l}\text { Crystal of } R \text {. turns } \\
\text { b lack; red in } \\
\text { other acids. }\end{array}$ & $\begin{array}{l}\text { Introduce crystal of } R \text {. } \\
\text { into liquid. }\end{array}$ & \\
\hline Bailey's test. & Sulphur. & $\begin{array}{l}\text { (a) Sodium carbonate. } \\
\text { (b) Sol. sodium nitro- } \\
\text { prussid. }\end{array}$ & Blood-red color. & $\begin{array}{l}\text { Heat substance with } a \text {, } \\
\text { dissolve in water, } \\
\text { and add } b \text {. }\end{array}$ & \\
\hline Barbsche's test. & Glycerin. & $\begin{array}{l}\text { (a) Water } 20 \text { vol., car- } \\
\text { bolic acid one drop. } \\
\text { (b) Sol. ferric chlorid. }\end{array}$ & $\begin{array}{l}\text { Blue color not } \\
\text { developed. }\end{array}$ & $\begin{array}{l}\text { Add to liquid } a \text {, thell } \\
\text { one drop } b \text {. }\end{array}$ & \\
\hline Bareswils' test. & Glucose. & $\begin{array}{l}\text { Potass. hy drate } 60, \\
\text { potass. tartrate } 40 \text {, } \\
\text { water } 200 \text {. Mix with } \\
\text { copper sulphate } 65, \\
\text { water } 500 . \\
\end{array}$ & Red precipitate. & Boil liquid with $\mathrm{R}$. & \\
\hline Barford's test. & Glucose. & $\begin{array}{l}\text { Sol. neutral copper } \\
\text { acetate } 200,38 \text { per } \\
\text { cent. acetic acid } 5 \text {. }\end{array}$ & Red precipitate. & $\begin{array}{l}\text { Add a few drops R. } 10 \\
\text { liquid and boil. }\end{array}$ & \\
\hline $\begin{array}{l}\text { Barium - chlorid } \\
\text { test. }\end{array}$ & $\begin{array}{l}\text { Ether-sulphuric } \\
\text { acids in urine. }\end{array}$ & $\begin{array}{l}\text { (a) Sol barium chlor- } \\
\text { id. }(b) \text { Hydrochlor- } \\
\text { ic acid. }\end{array}$ & $\begin{array}{l}\text { Ppt, of barium sul- } \\
\text { phate. }\end{array}$ & $\begin{array}{l}\text { Add } a \text { in excess; fil- } \\
\text { ter; boil filtrate with } \\
b \text {. }\end{array}$ & \\
\hline $\begin{array}{l}\text { Barium - chlorid } \\
\text { test. }\end{array}$ & Sulphates in urine. & $\begin{array}{l}\text { Barium chlorid (or } \\
\text { nitrate). }\end{array}$ & White precipitate. & $\begin{array}{l}\text { Acidulate urine; add } \\
\text { R. }\end{array}$ & $\begin{array}{l}\text { Creamy ppt. : sul- } \\
\text { phates increased ; } \\
\text { milky: normal; } \\
\text { translucent: di - } \\
\text { minished. }\end{array}$ \\
\hline Barry's test. & Hydrocyanic acid. & $\begin{array}{l}\text { (a) Acetic acid. } \\
\text { Silver nitrate. }\end{array}$ & Cloudiness. & $\begin{array}{l}\text { Two or three drops of } \\
\text { sol. acidified with } a \text {, } \\
\text { in w a } \mathrm{ch}-\mathrm{g} \text { las s. } \\
\text { Cover with another } \\
\text { watch-glass contain- } \\
\text { ing } 2 \text { or } 3 \text { drops } b \text {. }\end{array}$ & \\
\hline Basham's test. & Bile-pigment. & $\begin{array}{l}\text { (a) Chloroform. (b) } \\
\text { Nitric acid. }\end{array}$ & $\begin{array}{l}\text { Play of colors, } \\
\text { finally ruby-red. }\end{array}$ & $\begin{array}{l}\text { Shake liquid with } a \text {; } \\
\text { decant; a } 110 \text { w to } \\
\text { evaporate; add drop } \\
\text { of } b \text {. }\end{array}$ & Very delicate. \\
\hline Bastelaer's test. & $\begin{array}{l}\text { Phosphorus in tis- } \\
\text { sues and ejecta. }\end{array}$ & $\begin{array}{l}\text { (a) Ether. (b) Strong } \\
\text { ammonia, (c) Dil. } \\
\text { sulphuric acid. }\end{array}$ & $\begin{array}{l}\text { Pure phosphorus } \\
\text { recognized by its } \\
\text { properties. }\end{array}$ & $\begin{array}{l}\text { Dissolve out } \mathrm{P} \text {. with } \\
a \text {, by repeated shak- } \\
\text { ing; allow to evapo- } \\
\text { rate, adding water } \\
\text { toward end of evap- } \\
\text { oration; w a m to } \\
50^{\circ} \text { or } 60^{\circ} \mathrm{C} \text {. Shake } \\
\text { with } b \text {; wash with } \\
c \text {, then with water. }\end{array}$ & \\
\hline
\end{tabular}


TABLE OF TESTS.-Continued.

\begin{tabular}{|c|c|c|c|c|c|}
\hline NAME. & USE. & REAGENTS. & REACTION. & APPLICATION. & REMARKS. \\
\hline Baumann's test. & Carbohydrates. & $\begin{array}{l}\text { (a) Potass. hydrate. } \\
\text { (b) Benzoyl chlorid. }\end{array}$ & $\begin{array}{c}\text { Precipitation of all } \\
\text { carbohydrates. }\end{array}$ & $\begin{array}{l}\text { Alkalinize with } a \text {, and } \\
\text { treat with } b \text {. }\end{array}$ & \\
\hline $\begin{array}{l}\text { Baumann and } \\
\text { Preusse's test. }\end{array}$ & Hydrochinon. & & $\begin{array}{l}\text { Violet fumes, } \\
\text { which condense } \\
\text { as an indigo- } \\
\text { blue sublimate. }\end{array}$ & $\begin{array}{l}\text { Heat rapidly in an } \\
\text { open test-tube. }\end{array}$ & \\
\hline $\begin{array}{l}\text { Bayer's test. (Syn. } \\
\text { Drewsen's, Pen- } \\
\text { zoldt's, In digo } \\
\text { test.) }\end{array}$ & Acetone in urine. & $\begin{array}{l}\text { Nitrobenzaldehyd in } \\
\text { water. }\end{array}$ & Indigo-blue. & $\begin{array}{l}\text { R. and urine (or dis- } \\
\text { tillate) eq. vol.; } \\
\text { make alkaline. }\end{array}$ & $\begin{array}{l}\text { One part in } 2500 . \\
\text { May dissolve out } \\
\text { indigo-blue with } \\
\text { chloroform-ren- } \\
\text { ders test more } \\
\text { delicate. }\end{array}$ \\
\hline Bechamps' test. & $\begin{array}{l}\text { Nitrobenzol in oil } \\
\text { of bitter almonds. }\end{array}$ & $\begin{array}{l}\text { (a) Iron acetate. }(b) \\
\text { Chlorinated lime. }\end{array}$ & Blue color. & $\begin{array}{l}\text { Distil with } a \text {; test dis- } \\
\text { tillate with } b \text {. }\end{array}$ & \\
\hline Becquerel's test. & Glucose. & See Trommer's test. & & & \\
\hline Bedson's test. & $\begin{array}{l}\text { Apomorphin in sol. } \\
\text { of morphin. }\end{array}$ & Sol. potass. hydrate. & Brown color. & Boil with R. & \\
\hline Beilstein's test. & $\begin{array}{l}\text { Chlorin ; bromin; } \\
\text { iodin in organic } \\
\text { substances. }\end{array}$ & Cupric oxid. & $\begin{array}{l}\text { Green or blue } \\
\text { color. }\end{array}$ & $\begin{array}{l}\text { Make a bead with R., } \\
\text { dip into substance; } \\
\text { heat in lower part } \\
\text { of Bunsen flame. }\end{array}$ & \\
\hline Bellamy's test. & Copper ; iron. & Tincture of logwood. & Blue color. & Add R. & \\
\hline $\begin{array}{l}\text { Benzo-purpurin } \\
\text { test. }\end{array}$ & $\begin{array}{l}\text { Free hydrochloric } \\
\text { acid in gastric } \\
\text { juice. }\end{array}$ & See von Jaksch's test. & & & \\
\hline Bernouilly's test. & $\begin{array}{l}\text { Alcohol in essential } \\
\text { oils. }\end{array}$ & Dry potass. acetate. & Dense solution. & Add R. & \\
\hline Berthelot's test. & Alcohol. & Benzoyl chlorid. & $\begin{array}{l}\text { Formation of ben- } \\
\text { zoic ether: char- } \\
\text { acteristic odor. }\end{array}$ & Add R. & \\
\hline $\begin{array}{l}\text { Bertoni and Ray- } \\
\text { mondi's test. }\end{array}$ & $\begin{array}{l}\text { Nitrous acid in } \\
\text { blood. }\end{array}$ & $\begin{array}{l}\text { (a) Hot alcohol. }(b) \\
\text { Starch-paste a nd } \\
\text { potass. iodid. }\end{array}$ & Blue color. & $\begin{array}{l}\text { Dialyze, and evapo- } \\
\text { rate dialysate to dry- } \\
\text { ness. Take up with } \\
a \text {; test with } b \text {. }\end{array}$ & \\
\hline Berzelius's test. & Arsenic. & Charcoal. & $\begin{array}{l}\text { Mirror and alliace- } \\
\text { ous odor. }\end{array}$ & $\begin{array}{l}\text { Heat in test-tube with } \\
\mathrm{R} \text {. }\end{array}$ & \\
\hline Bettendorff's test. & Arsenic. & $\begin{array}{l}\text { (a) Fresh stannous } \\
\text { chlorid in concent. } \\
\text { hydrochloric acid. } \\
\text { (b) Tin-foil. }\end{array}$ & $\begin{array}{l}\text { Brown color or } \\
\text { brown ppt. }\end{array}$ & $\begin{array}{l}\text { To liquid containing } \\
\text { a good deal hydro- } \\
\text { chloric acid add } \\
\text { equal vol. } a \text {, and } \\
\text { piece of } b \text {. }\end{array}$ & $\begin{array}{l}\text { Gentle heat accele- } \\
\text { rates reaction. }\end{array}$ \\
\hline Bill's test. & Bromids. & $\begin{array}{r}\text { (a) Hydrochloric acid. } \\
\text { (b) Sol. gold chlorid. }\end{array}$ & $\begin{array}{l}\text { Yellow to dark } \\
\text { orange-red color. }\end{array}$ & $\begin{array}{l}\text { Add to liquid I drop } \\
a \text {, then I drop } b \text {. }\end{array}$ & \\
\hline Bismuth-test. & Glucose. & See Battger's test. & & & \\
\hline Biuret-test. & Proteids. & See Ritthausen's test. & & & \\
\hline Blachez' test. & $\begin{array}{l}\text { Alcohol in chloro- } \\
\text { form. }\end{array}$ & $\begin{array}{l}\text { (a) Potass. hydrate. }(b) \\
\text { Sol. copper sulphate. }\end{array}$ & Precipitate. & $\begin{array}{l}\text { Add small piece } a_{\text {, }} \\
\text { agitate; pour off } \\
\text { chloroform after } 5 \\
\text { minutes, and shake } \\
\text { with equal vol } \\
\text { water; pour off } \\
\text { water, and add } b \text {. } \\
\end{array}$ & \\
\hline Bloxam's test. & Alkaloids. & $\begin{array}{l}\text { (a) Dil. hydrochloric } \\
\text { acid. (b) Bromin- } \\
\text { water. }\end{array}$ & Color-reactions. & $\begin{array}{l}\text { Dissolve in } a \text {; add } b \\
\text { drop by drop. }\end{array}$ & \\
\hline Blythe's test. & $\begin{array}{c}\text { Lead in potable } \\
\text { water. }\end{array}$ & $\begin{array}{l}\text { Alcoholic tincture of } \\
\text { cochineal. }\end{array}$ & Precipitate. & Add I per cent. $R$. & \\
\hline Boas's test. & $\begin{array}{l}\text { Hydrochloric acid } \\
\text { iu gastric juice. }\end{array}$ & $\begin{array}{l}\text { Resorcin 5, sugar } 3, \\
\text { dil. alcohol I00. }\end{array}$ & Red color. & $\begin{array}{l}\text { Add R. to a few drops } \\
\text { liquid in evapora- } \\
\text { ting-dish. }\end{array}$ & $\begin{array}{l}\text { As delicate as } \\
\text { Günzburg's test; } \\
\text { not affected by } \\
\text { free organic } \\
\text { acids, and only } \\
\text { slightly by acid- } \\
\text { albumins. }\end{array}$ \\
\hline Boedeker's test. & Albumin. & See Hilger's test. & & & \\
\hline Boedeker's test. & Sulphurous acid. & $\begin{array}{l}\text { Sol. potass. ferrocy- } \\
\text { anid. }\end{array}$ & Purple ppt. & $\begin{array}{l}\text { Add } R \text {. to neutral } \\
\text { liquid. }\end{array}$ & \\
\hline Boedeker's test. & Sulphurous acid. & $\begin{array}{l}\text { (a) Sol. zinc sulphate. } \\
(b) \text { Sodium nitro- } \\
\text { prussid. }\end{array}$ & $\begin{array}{l}\text { Rose to dark-red } \\
\text { color. }\end{array}$ & $\begin{array}{l}\text { To neutral liquid add } \\
a \text { and } b \text {. }\end{array}$ & \\
\hline
\end{tabular}


TABLE OF TESTS.-Continued.

\begin{tabular}{|c|c|c|c|c|c|}
\hline NAME: & USE. & REAGENTS. & REACTION. & A PPLICATION. & REMARKS. \\
\hline Boettcher's test. & Glucose. & See Battger's test. & & & \\
\hline Bottger's test. & Alcohol. & $\begin{array}{l}\text { Sol, molybdic acid in } \\
\text { sulphuric acid. }\end{array}$ & Blué color. & Add R. & \\
\hline Baettger's test. & Alkalimetry. & $\begin{array}{l}\text { Alcoholic tincture of } \\
\text { petals of Coleus Ver- } \\
\text { schaeffeltii. . }\end{array}$ & $\begin{array}{l}\text { Red color is turned } \\
\text { green. }\end{array}$ & & \\
\hline Boettger's test. & Gaseousammonia. & Alkannin paper. & $\begin{array}{l}\text { Red color turns } \\
\text { biue. }\end{array}$ & $\begin{array}{l}\text { Expose strip of R. to } \\
\text { the gas. }\end{array}$ & \\
\hline Bœettger's test. & Ergot in rye-flour. & $\begin{array}{l}\text { (a) Ether. (b) Oxalic } \\
\text { acid. }\end{array}$ & Reddish color. & $\begin{array}{l}\text { Heat for several min- } \\
\text { utes with an equal } \\
\text { bulk of } a \text { and a few } \\
\text { crystals of } b \text {. }\end{array}$ & \\
\hline Bcettger's test. & Glucose. & $\begin{array}{l}\text { (a) Bismuth. (b) Strong } \\
\text { sol. sodium hydrate. }\end{array}$ & Black ppt. & $\begin{array}{l}\text { To urine add pinch of } \\
a \text { and a little } b \text {; boil. }\end{array}$ & $\begin{array}{l}\text { Very delicate; al- } \\
\text { bumin must be } \\
\text { removed. }\end{array}$ \\
\hline Boettger's test. & $\begin{array}{l}\text { Hydrogen diox- } \\
\text { id. }\end{array}$ & $\begin{array}{l}\text { (a) Cadmium iodid } \\
\text { starch-paste. }(b) \\
\text { Ferrous sulphate. }\end{array}$ & $\begin{array}{l}\text { Deep ultramarine- } \\
\text { blue colot }\end{array}$ & Add $a$ and a little $b$ & \\
\hline Boettger"s test. & $\begin{array}{l}\text { Hydrogen diox - } \\
\text { id }\end{array}$ & $\begin{array}{l}\text { Ammoniacal sol. sil- } \\
\text { ver nitrate (not con- } \\
\text { taining free ammo- } \\
\text { nia). }\end{array}$ & \begin{tabular}{r|} 
Cloudiness and re- \\
duction of silver.
\end{tabular} & $\begin{array}{l}\text { Heat liquid with a few } \\
\text { drops } R \text {. }\end{array}$ & \\
\hline Bœttger's test. & $\begin{array}{l}\text { Nitric acid in pot- } \\
\text { able water. }\end{array}$ & $\begin{array}{l}\text { (a) Sol of brucin. } \\
\text { (b) Sulphuric acid. }\end{array}$ & $\begin{array}{l}\text { Red to brownish- } \\
\text { red color. }\end{array}$ & $\begin{array}{l}\text { Mix } 3 \text { drops of water, } \\
2 \text { of } a \text {, and } 3 \text { or } 4 \text { of } b .1 \\
\end{array}$ & \\
\hline Boettger's test. & Nitrous acid. & $\begin{array}{l}\text { (a) Diluted sulphuric } \\
\text { acid. (b) Cadmium } \\
\text { iodid starch-paste. }\end{array}$ & Blue color. & Add $a$ and $b$. & \\
\hline Bcettger's test. . & Ozone. & $\begin{array}{l}\text { Strip filter-paper } \\
\text { moistened with } \\
\text { acid-free sol. of gold } \\
\text { chlorid. }\end{array}$ & Violet color. & Expose R. to gas. & \\
\hline Bottger's test. & Ozone. & $\begin{array}{c}\text { Strip filtering paper } \\
\text { dipped into a sol. of } \\
\text { thallium protoxid. }\end{array}$ & Brown color. & Expose R. to gas. & \\
\hline Bœettger's test. & Safranin. & Sulphuric acid. & Blue color. & $\begin{array}{l}\text { Add } R \text {. If water is } \\
\text { added color becomes } \\
\text { green. }\end{array}$ & \\
\hline Boettger's test. & $\begin{array}{l}\text { Sulphocy a n a tes } \\
\text { (Rhodanates). }\end{array}$ & $\begin{array}{l}\text { (a) Tr. guaiaci. (b) Dil. } \\
\text { sol. copper sulphate. }\end{array}$ & Blue color. & $\begin{array}{l}\text { Dip strip filter-pa- } \\
\text { per in } a \text {; let dry } \\
\text { mo isten with } b \\
\text { place on it a drop of } \\
\text { liquid. }\end{array}$ & \\
\hline Bcettger's test. & Water in ether. & Carbon disulphid & Milkiness. & $\begin{array}{l}\text { Agitate gently with } \\
\text { equal bulk R. }\end{array}$ & \\
\hline Bolas's test. & Nitric acid. & $\begin{array}{l}\text { Sulphuric acid Io, sol. } \\
\text { ferrous sulphate } \mathrm{I} .\end{array}$ & Brown zone. & $\begin{array}{l}\text { Heat R., and pour } \\
\text { liquid cautiously on } \\
\text { top. }\end{array}$ & \\
\hline Borntraeger's test. & $\begin{array}{l}\text { Acidimetry ; alka- } \\
\text { limetry. }\end{array}$ & $\begin{array}{l}\text { Concentrated tincture } \\
\text { orange-peel. }\end{array}$ & $\begin{array}{l}\text { Colorless with } \\
\text { acids, lemon-yel } \\
\text { low with alka- } \\
\text { lies. }\end{array}$ & $\mid \begin{array}{l}\text { Add } R ., \text { and shake up } \\
\text { with ether. }\end{array}$ & \\
\hline Bouchardat's test. & Alkaloids. & $\begin{array}{l}\text { Potass. iodo-iodid-io- } \\
\text { din Io, potass. iodid } \\
20, \text { water } 500 .\end{array}$ & Brown ppt. & Add R. to liquid. & \\
\hline Bourgoin's test. & $\begin{array}{l}\text { Nitrobenzol in oil } \\
\text { of bitter almonds. }\end{array}$ & Sol. potass. hydrate. & Green color. & $\begin{array}{l}\text { Shake I5 drops oil } \\
\text { with } 8 \text { of } \mathrm{R} \text {. }\end{array}$ & $\begin{array}{l}\text { If } 20 \text { drors water } \\
\text { are added, two } \\
\text { layers are } \\
\text { formed, upper } \\
\text { green, lower } \\
\text { vellow. }\end{array}$ \\
\hline $\begin{array}{l}\text { Bouss ing a ult's } \\
\text { test. }\end{array}$ & Nitric acid. & $\begin{array}{l}\text { (a) Hydrochloric acid. } \\
\text { (b) Indigo-solution. }\end{array}$ & Decolorization. & $\begin{array}{l}\text { Acidify with } a \text {, and } \\
\text { add drop of } b \text {. }\end{array}$ & \\
\hline Brandberg's test. & Benzol; benzine. & Pitch. & $\begin{array}{l}\mathrm{R} \text {, dissolves in } \\
\text { benzol, not in } \\
\text { benzin. }\end{array}$ & & \\
\hline Brandes' test. & Quinin. & $\begin{array}{l}\text { (a) Chlorin-water. (b) } \\
\text { Ammonia. }\end{array}$ & Green color. & $\begin{array}{l}\text { Treat liquid with } a \\
\text { and } b \text {. }\end{array}$ & \\
\hline
\end{tabular}


TABLE OF TESTS._Continued.

\begin{tabular}{|c|c|c|c|c|c|}
\hline NAME. & USE. & REAGENTS. & REACTION. & APPLICATION. & REMARKS. \\
\hline Braun's test. & Glucose. & $\begin{array}{l}\text { (a) Sol. picric acid. }(b) \\
\text { Sol. sodium hydrate. }\end{array}$ & Blood-red color. & $\begin{array}{l}\text { Alk a linize with } b, \\
\text { warm to } 90^{\circ} \text {, add } a \text {, } \\
\text { and boil. }\end{array}$ & \\
\hline Brautlecht's test. & $\mid \begin{array}{cc}\text { Organic impuri- } \\
\text { ties in potable } \\
\text { water. }\end{array}$ & $\begin{array}{l}\text { (a) Alumiuum sul- } \\
\text { phate I, hydrochlo- } \\
\text { ric acid I, water } 8 . \\
\text { (b) Ammonia. }\end{array}$ & $\begin{array}{l}\text { Examine under } \\
\text { microscope be- } \\
\text { fore and after } \\
\text { addition of saf- } \\
\text { ranin. }\end{array}$ & $\begin{array}{l}\text { Treat roo c c. water } \\
\text { with } 5 \text { c.c. } a \text { and add } \\
\text { I or } 2 \text { drops } b \text {. Filter } \\
\text { off ppt., redissolve } \\
\text { in Io-15 drops di- } \\
\text { lute acetic acid. }\end{array}$ & \\
\hline Brazil-wood test. & $\begin{array}{l}\text { Acidimetry; alka- } \\
\text { limetry. }\end{array}$ & $\begin{array}{l}\text { Sol, of coloring-matter } \\
\text { of Brazil-wood (Pel- } \\
\text { tophorum dubium). }\end{array}$ & $\begin{array}{l}\text { Turns purplish- } \\
\text { red with alka- } \\
\text { lies; yellow with } \\
\text { acids. }\end{array}$ & & \\
\hline Brieger's test. & Strychnin. & Pure chromic acid. & Violet color. & Add R. to liquid. & \\
\hline Brine-test. & Albumin in urine. & $\begin{array}{l}\text { (a) Saturated sol. so- } \\
\text { dium chlorid, acidu- } \\
\text { lated with } 5 \text { per } \\
\text { cent. sol. dilute hy- } \\
\text { drochloric acid. }\end{array}$ & White ring. & Overlay $R$. with urine, ! & | Very delicate. \\
\hline $\begin{array}{l}\text { Brou ardel and, } \\
\text { Boutmy's test. }\end{array}$ & $\begin{array}{c}\text { Ptomains from } \\
\text { plant-alkaloids. }\end{array}$ & $\begin{array}{l}\text { (a) Potass. ferricyanid. } \\
\text { (b) Ferric chlorid. }\end{array}$ & Blue color. & Apply $a$, then $\delta$ & \\
\hline Bruecke's test. & Bile-pigments. & $\begin{array}{l}\text { (a) Nitric acid. } \\
\text { Sulphuric acid. }\end{array}$ & Color-reactions. & $\begin{array}{c}\text { Add } a \text { to urine, shake; } \\
\text { let } b \text { flow to bottom. }\end{array}$ & \\
\hline Bruecke's test. & Glucose. & $\begin{array}{l}\text { Boil fresh bis muth } \\
\text { subnitrate with po- } \\
\text { tass. iodid } 30 \text {, water } \\
\text { I5o, and after ro min- } \\
\text { utes add } 5 \text { c.c. } 25 \text { per } \\
\text { cent. sol. hydrochlo- } \\
\text { ric acid. }\end{array}$ & Reduction. & & . \\
\hline Bruecke's test. & Proteids. & $\begin{array}{l}\text { (a) Hydrochloric acid. } \\
\text { (b) Potassio-mercu- } \\
\text { ric iodid. }\end{array}$ & Precipitate. & $\begin{array}{l}\text { Acidulate with } a \text {, and } \\
\text { add } b \text {. }\end{array}$ & \\
\hline Bruecke's test. & Urea & $\begin{array}{l}\text { (a) Fusel-oil. (b) Sol } \\
\text { oxalic acid in fusel- } \\
\text { oil. }\end{array}$ & $\begin{array}{l}\text { Crystalline de- } \\
\text { posit. }\end{array}$ & $\begin{array}{l}\text { Heat alcoholic extract } \\
\text { with } a \text {, filter, and } \\
\text { add } b \text {. }\end{array}$ & \\
\hline Brunner's test. & Glucosids. & $\begin{array}{l}\text { Pettenkofer's test for } \\
\text { bile-acids. }\end{array}$ & Red color. & & \\
\hline Buckingham's test. & Alkaloids. & $\begin{array}{l}\text { Fresh sol. of ammo- } \\
\text { nium molybdate } 8 \\
\text { grains, in sulphuric } \\
\text { acid } 2 \text { drams ; heat } \\
\text { till clear. }\end{array}$ & Color-reactions. & Add R. & ; \\
\hline $\begin{array}{l}\text { Bujwid and Dun- } \\
\text { ham's reaction. }\end{array}$ & $\begin{array}{l}\text { Products of bacil- } \\
\text { lus choleræ asi- } \\
\text { atica. }\end{array}$ & See Poehl's reaction. & & & \\
\hline Burchard's test. & $\begin{array}{l}\text { Cholesterin and } \\
\text { cholesterin-fats. }\end{array}$ & $\begin{array}{l}\text { (a) Chloroform. (b) } \\
\text { Acetic acid anhydrid. } \\
\text { (c) Sulphuric acid. }\end{array}$ & $\begin{array}{l}\text { Violet to green } \\
\text { color. }\end{array}$ & $\begin{array}{l}\text { Dissolve su bstance } \\
\text { in } a \text {, add } b \text {, and a } \\
\text { few drops } c \text {. }\end{array}$ & $\begin{array}{l}\text { Modification of } \\
\text { Liebermann's } \\
\text { test. }\end{array}$ \\
\hline Cadet's test. & Arsenic. & Sodium acetate. & $\begin{array}{l}\text { Kakodyl (charac- } \\
\text { teristic odor). }\end{array}$ & Heat with $\mathrm{R}$. & '. \\
\hline Caillan's test. & Glucose in urine. & Chloroform. & $\begin{array}{l}\text { Apply tests for glu- } \\
\text { cose. }\end{array}$ & $\begin{array}{l}\text { Shake } 2 \text { vol. urine } \\
\text { with one } \mathrm{R} \text {; ; allow } \\
\text { to settle; upper layer } \\
\text { contains all the glu- } \\
\text { cose. }\end{array}$ & \\
\hline $\begin{array}{l}\text { Calcium-carbonate } \\
\text { test. }\end{array}$ & $\begin{array}{l}\text { Free acids and } \\
\text { acid salts in gas- } \\
\text { tric juice. }\end{array}$ & See Leo's test. & & & \\
\hline Campani's test. & Glucose. & $\begin{array}{l}\text { Mix concent. sol. lead } \\
\text { subacetate with dil. } \\
\text { sol. copper acetate. }\end{array}$ & $\begin{array}{l}\text { Yellow to orange- } \\
\text { red ppt. }\end{array}$ & Add R. to sol. & $\begin{array}{l}0.5 \text { per cent. gives } \\
\text { red, o.I per cent. } \\
\text { yellow color. } \\
\end{array}$ \\
\hline Cappazuoli's test. & Glucose. & $\begin{array}{c}\text { Sol. copper hydroxid } \\
\text { in potass. hydrate. }\end{array}$ & Blue color. & Add R. to liquid. & \\
\hline
\end{tabular}


TABLE OF TESTS.-Continued.

\begin{tabular}{|c|c|c|c|c|c|}
\hline NAME. & UsE, & REAGENTS. & REACTION. & APPLICATION. & REMARKS. \\
\hline Capranica's test. & Guanin. & $\begin{array}{l}\text { (a) Aq. sol. picric acid. } \\
(b) \text { Concent. sol. po- } \\
\text { tass. bichromate. (c) } \\
\text { Concent. sol. potass. } \\
\text { ferricyanid. }\end{array}$ & $\begin{array}{l}\text { With a yellow, } \\
\text { crystalline ppt.; } \\
\text { with } b \text { orange- } \\
\text { colored, crystal- } \\
\text { line ppt.; with } c \\
\text { prismatic, yel- } \\
\text { low is h-br own } \\
\text { crystals. }\end{array}$ & Add R. to solution. & \\
\hline Carbolic-acid test. & Albumin in urine. & See $M e ́ h n ' s$ test. & & & \\
\hline Caro-Fischer's test. & Hydrogen sulphid. & See Fischer's test. & & & \\
\hline Carter's test. & Indican in urine. & Nitric acid. & $\begin{array}{l}\text { Play of colors as } \\
\text { in bile-test. }\end{array}$ & $\begin{array}{l}\text { Overlay acid with } \\
\text { urine, or allow the } \\
\text { two to come in con- } \\
\text { tact on porcelain } \\
\text { plate. }\end{array}$ & $\begin{array}{l}\text { Bile gives same } \\
\text { reaction : if a } \\
\text { deep-blue or } \\
\text { purp } 1 \mathrm{e} \text { ppt. } \\
\text { forms on addi- } \\
\text { tion of sulphuric } \\
\text { acid-play of } \\
\text { colors due to ex- } \\
\text { cess of indican. }\end{array}$ \\
\hline Casali's test. & Biliary matter. & $\begin{array}{l}\text { (a) Lead acetate, }(b) \\
\text { Ammonia. }(c) \text { Ether } \\
\text { and hy drochloric } \\
\text { acid. }\end{array}$ & $\begin{array}{l}\text { Yellow, red, violet, } \\
\text { blue color. }\end{array}$ & $\begin{array}{l}\text { Precipitate urine with } \\
a \text { and } b \text { and extract } \\
\text { with } c \text {. Let ethereal } \\
\text { layer evaporate, and } \\
\text { test with oxidizing } \\
\text { agents. }\end{array}$ & \\
\hline Casamajor's test. & Glucose. & Methylic alcohol. & Cloudiness. & Shake liquid with $\mathbf{R}$. & \\
\hline Casoria's test. & $\begin{array}{l}\text { Water in absolute } \\
\text { alcohol. }\end{array}$ & $\begin{array}{l}\text { Dehydrated copper } \\
\text { sulphate. }\end{array}$ & R. turns blue. & Pour liquid over $\mathbf{R}$. & \\
\hline $\begin{array}{l}\text { Chatin and Gaul- } \\
\text { tier de Claubry's } \\
\text { test. }\end{array}$ & lodin. & $\begin{array}{l}\text { Nitric acid I, sulphu- } \\
\text { ric acid } 6 \text {, starch. }\end{array}$ & Blue to violet color. & Add R. & \\
\hline Chautard's test A. & Acetone in urine. & $\begin{array}{l}\text { (a) Aq. sol. magenta. } \\
\text { (b) Sulphurous acid. }\end{array}$ & Violet color. & $\begin{array}{l}\text { To a drop of } a \text {, decolor- } \\
\text { ized by } b \text { add urine. }\end{array}$ & $\begin{array}{c}\text { Delicacy; o.or ace- } \\
\text { tone ; reaction } \\
\text { may appear after } \\
4 \text { or } 5 \text { minutes. } \\
\end{array}$ \\
\hline Chautard's test B. & Acetone. & $\begin{array}{l}\text { (a) Fuchsin } 0.25 \text {, water } \\
500 .(b) \text { Sulphurous } \\
\text { acid. }\end{array}$ & Red-violet color. & $\begin{array}{l}\text { Add } b \text { to } a \text { until } a \text { is } \\
\text { decolorized. Ad d } \\
\text { mixture to the liquid. }\end{array}$ & \\
\hline Chevreul's test. & Ammonia. & Hematoxylin-paper. & $\begin{array}{l}\text { Red color t urns } \\
\text { violet. }\end{array}$ & $\begin{array}{l}\text { Expose paper to } \\
\text { fumes. }\end{array}$ & \\
\hline Chloroform-test. & $\begin{array}{l}\text { Potass. jo did in } \\
\text { urine, etc. }\end{array}$ & $\begin{array}{l}\text { (a) Fumingnitric acid. } \\
(b) \text { Chloroform. }\end{array}$ & Violet-red color. & $\begin{array}{l}\text { Add a littie } a \text { and } 1 / 4 b ; \\
\text { shake. }\end{array}$ & $\begin{array}{l}\text { Delicate and reli- } \\
\text { able. }\end{array}$ \\
\hline $\begin{array}{l}\text { Cholera-red reac- } \\
\text { tion. }\end{array}$ & $\begin{array}{l}\text { Products of bacil- } \\
\text { lus choleræ asi- } \\
\text { atica. }\end{array}$ & See Poehl's test. & & & \\
\hline Cholestol reaction. & $\begin{array}{c}\text { Cholesterin a n d } \\
\text { cholesterin-fats. }\end{array}$ & See Liebermann'stest. & & & \\
\hline Chromic-acid test. & Albumin in urine. & See Rosenbach's test. & & & \\
\hline Citric-acid test. & Mucin. & See Mucin-test. & & . & \\
\hline Clark's test. & $\begin{array}{l}\text { Creasote; carbolic } \\
\text { acid. }\end{array}$ & $\begin{array}{l}\text { (a) Nitric acid. } \\
\text { Potass. hydrate. }\end{array}$ & $\begin{array}{l}\text { Creasote, no crys- } \\
\text { talline ppt.; car- } \\
\text { bolic acid, yel- } \\
\text { low crystals. }\end{array}$ & $\begin{array}{l}\text { Boil with excess of } a \\
\text { until red fumes are } \\
\text { no longer evolved } \\
\text { neutralize with } b \text {. }\end{array}$ & \\
\hline Claus's test. & $\begin{array}{l}\text { Water in absolute } \\
\text { alcohol. }\end{array}$ & $\begin{array}{l}\text { Anthrachinon and so- } \\
\text { dium amalgam. }\end{array}$ & $\begin{array}{l}\text { Red color; abso- } \\
\text { lute a lc oh ol } \\
\text { causes a green } \\
\text { color. }\end{array}$ & $\begin{array}{l}R \text {. is moistened with } \\
\text { the alcohol. }\end{array}$ & \\
\hline Cochineal-test. & $\begin{array}{l}\text { Acidimetry; alka- } \\
\text { limetry. }\end{array}$ & $\begin{array}{l}\text { Cochineal I gm., macer- } \\
\text { ated for four days in } \\
\text { alcohol 20, water } 60 ; \\
\text { filtered. }\end{array}$ & $\begin{array}{l}\text { Turns violet with } \\
\text { alkalies, yellow- } \\
\text { is h-red wit h } \\
\text { acids. }\end{array}$ & & \\
\hline Colasanti's test. & $\begin{array}{l}\text { Sulpho-cyanic } \\
\text { acid. }\end{array}$ & $\begin{array}{l}\text { Sol. of gold chlorid (I : } \\
\text { rooo-ro,ooo) in potass. } \\
\text { hydrate, or in sat. } \\
\text { sol. sodium bicarb. }\end{array}$ & $\begin{array}{l}\text { Violet color on } \\
\text { heating, metallic } \\
\text { gold deposited } \\
\text { on cooling. }\end{array}$ & $\begin{array}{l}\text { Warm R. with dilute } \\
\text { solution of the sub- } \\
\text { stance. }\end{array}$ & \\
\hline Congo-red test. & $\begin{array}{l}\text { Free hydrochloric } \\
\text { acid. }\end{array}$ & See Riegel's test. & & & \\
\hline
\end{tabular}


TABLE OF TESTS.-Continued.

\begin{tabular}{|c|c|c|c|c|c|}
\hline NAME, & USE. & REAGENTS. & REACTION. & APPLICATION. & REMARKS. \\
\hline Contejean's test. & $\begin{array}{l}\text { Hydrochloric acid } \\
\text { in gastric juice. }\end{array}$ & $\begin{array}{l}\text { Cobait oxid (freshly } \\
\text { precipitated). }\end{array}$ & $\begin{array}{l}\text { Blue cobalt chlo- } \\
\text { rid. }\end{array}$ & $\begin{array}{l}\text { Evaporate drop of } \\
\text { liquid on watch- } \\
\text { glass with } \mathrm{R} \text {. }\end{array}$ & \\
\hline Cotton's test. & Brucin. & $\begin{array}{l}\text { Sol. sodium sulph-hy- } \\
\text { drate. }\end{array}$ & $\begin{array}{l}\text { Violet to green } \\
\text { color. }\end{array}$ & $\begin{array}{l}\text { Add excess of } R \text {. to } \\
\text { brucin in nitric acid. }\end{array}$ & \\
\hline Cunisset's test. & $\begin{array}{l}\text { Biliary matter in } \\
\text { urine. }\end{array}$ & Chloroform. & Yellow color. & Shake urine with $\mathrm{R}$. & \\
\hline $\begin{array}{l}\text { Curdling - ferment } \\
\text { test. }\end{array}$ & $\begin{array}{l}\text { Curdling ferment } \\
\text { in gastric juice. }\end{array}$ & $\begin{array}{l}\text { (a) Io normal sodium } \\
\text { hydratesol. }(b) \text { Neu- } \\
\text { tral or amphoteric } \\
\text { milk. }\end{array}$ & Curdling. & $\begin{array}{l}\text { Neutralize } 5 \text { to ro c.c. } \\
\text { filtered gastric juice } \\
\text { with } \alpha \text { mix with } \\
\text { equal quantity of } b \text {, } \\
\text { warm to } 37^{\circ} \text { or } 40^{\circ} \mathrm{C} \text {. } \\
\end{array}$ & $\begin{array}{l}\text { Reaction takes. } \\
\text { place in Io-15 } \\
\text { min. }\end{array}$ \\
\hline Davy's test. & Alcohol. & $\begin{array}{l}\text { Molybdic acid } x \text {, sul- } \\
\text { phuric acid } 2 .\end{array}$ & Blue color. & $\begin{array}{l}\text { Essential oils first } \\
\text { shaken with water, } \\
\text { which is separated } \\
\text { urine is distilled. } \\
\text { Test with } \mathrm{R} \text {. }\end{array}$ & \\
\hline Davy's test. & Carbolic acid. & $\begin{array}{l}\text { Molybdic acid r; sul- } \\
\text { phuric acid Io. }\end{array}$ & $\begin{array}{l}\text { Dark olive-green } \\
\text { to blue and vio- } \\
\text { let color. }\end{array}$ & $\begin{array}{l}\text { Add } 3 \text { to } 4 \text { drops R. to } \\
\text { I to } 2 \text { drops of liquid. }\end{array}$ & \\
\hline Davy's test. & Strychnin. & $\begin{array}{l}\text { (a) Sulphuric acid. }(b) \\
\text { Potass. ferricyanid. }\end{array}$ & Deep-violet color. & Add $a$, then $b$. & \\
\hline Day's test. & Pus. & $\begin{array}{l}\text { Alcoholic sol. of guaiac } \\
\text { exposed to light until } \\
\text { it turns green in con- } \\
\text { tact with potass. } \\
\text { iodid. }\end{array}$ & Blue color. & $\begin{array}{l}\text { To watery sol. of pus } \\
\text { add a few drops of } \\
\text { R. }\end{array}$ & $\begin{array}{l}\text { Inert when applied } \\
\text { to dried pus. }\end{array}$ \\
\hline Debrunner's test. & $\begin{array}{l}\text { Water in absolute } \\
\text { alcohol. }\end{array}$ & Potass. permanganate. & $\begin{array}{l}\text { Purple discolora- } \\
\text { tion indicates } \\
\text { water. }\end{array}$ & $\begin{array}{l}\text { R. insoluble in absolute } \\
\text { alcohol, sol. in water. }\end{array}$ & \\
\hline Degener's test. & Alkalimetry. & $\begin{array}{l}\text { Phenacetolin, a brown } \\
\text { substance obtained } \\
\text { by heating for seve- } \\
\text { ral hours carbolic, } \\
\text { sulphuric, and } \\
\text { glacial acetic acids } \\
\text { ăa } r \text {. }\end{array}$ & $\begin{array}{l}\text { Alkalies turn it } \\
\text { red. }\end{array}$ & & \\
\hline Delff's test. & Caffein. & $\begin{array}{l}\text { Sol. red mercuric oxid } \\
\text { in potass. lodid. }\end{array}$ & Crystalline ppt. & Add R, to liquid. & $\begin{array}{l}\text { Other a l k a loids } \\
\text { yield amorphous } \\
\text { ppt. }\end{array}$ \\
\hline $\begin{array}{c}\text { Diazobenzol -s u } 1 \text { - } \\
\text { phuric-acid test. }\end{array}$ & Glucose in urine. & $\begin{array}{l}\text { (a) Sol. potass. hydrate. } \\
(b) \text { Sol. diazobenzol- } \\
\text { sulphuric acid ( } 1 \text { : } 50) \\
\text { made faintly alkaline } \\
\text { with } a \text {. }\end{array}$ & $\begin{array}{l}\text { Yell ow is h -red, } \\
\text { changing to dark- } \\
\text { red froth car- } \\
\text { min-red. }\end{array}$ & $\begin{array}{l}\text { Alkalinize } 20 \text { c. c. of } \\
\text { urine with } a ; \text { add } \\
\text { equal volume } b \text {. }\end{array}$ & Not very reliable. \\
\hline Diazo-reaction. & $\begin{array}{l}\text { A rom a tic com- } \\
\text { pounds in urine } \\
\text { in typhoid fever, } \\
\text { etc. }\end{array}$ & See Ehrlich's test. & & & \\
\hline Diphenylamin test. & Nitric acid. & $\begin{array}{l}\text { (a) Sol. of diphenyl- } \\
\text { amin. (b) Concent. } \\
\text { sulphuric acid. }\end{array}$ & $\begin{array}{l}\text { Deep-blue color at } \\
\text { zone of contact. }\end{array}$ & $\begin{array}{l}\text { Add I or } 2 \text { drops } a \text {; } \\
\text { pour in } b \text { to form } \\
\text { a layer beneath the } \\
\text { liquid. }\end{array}$ & \\
\hline $\begin{array}{l}\text { Donath and Mayr- } \\
\text { hofer's test. }\end{array}$ & Glycerin. & $\begin{array}{l}\text { (a) Carbolic acid. (b) } \\
\text { Sulphuric acid. (c) } \\
\text { Ammonia. }\end{array}$ & Carmin-red color. & $\begin{array}{l}\text { Evaporate to dryness; } \\
\text { heat to } 120^{\circ} \mathrm{C} \text {. with } \\
\text { two drops of } a \text { and } b \text {. } \\
\text { Extract with water, } \\
\text { and add to residue } c \text {. }\end{array}$ & \\
\hline Donné's test. & Pus. & Liquor potassa. & $\begin{array}{c}\text { Tenacious, gelat- } \\
\text { in if or m sub- } \\
\text { stance, resemb- } \\
\text { ling white of egg. }\end{array}$ & $\begin{array}{l}\text { To deposit of pus add } \\
\text { R. }\end{array}$ & \\
\hline Dragendorff's test. & Brucin. & $\begin{array}{l}\text { (a) Sulphuric acid I, } \\
\text { water 9. (b) Very } \\
\text { dilute sol. potass, bi- } \\
\text { chromate. } \\
\end{array}$ & $\begin{array}{l}\text { Raspberry-red to } \\
\text { brownish-orange } \\
\text { color. }\end{array}$ & $\begin{array}{l}\text { Dissolve in } a \text {, and add } \\
\text { with a glass rod } \\
\text { small quantity of } b .\end{array}$ & \\
\hline Dragendorff's test. & $\begin{array}{l}\text { Carbolic acid in } \\
\text { urine. }\end{array}$ & Petroleum-naphtha. & & $\begin{array}{l}\text { Take up with } R \text {. and } \\
\text { test as usual. }\end{array}$ & \\
\hline Dragendorff's test. & Strychnin. & Iodic acid. & $\begin{array}{l}\text { Red to reddish- } \\
\text { brown color. }\end{array}$ & Add R. & \\
\hline
\end{tabular}


TABLE OF TESTS.-Continzed.

\begin{tabular}{|c|c|c|c|c|c|}
\hline NAME. & USE, & REAGENTS. & REACTION. & APPLICATION. & REMARKS. \\
\hline Drechsel's test. & Biliary matter. & $\begin{array}{l}\text { (a) Syrupy phosphoric } \\
\text { acid. (b) Cane-sugar. }\end{array}$ & $\begin{array}{l}\text { Red to reddish- } \\
\text { brown color. }\end{array}$ & $\begin{array}{l}\text { Add to concent. liquid } \\
a \text { and } b \text {, and heat on } \\
\text { a water-bath. }\end{array}$ & \\
\hline Drechsel's test. & Xanthin-bodies. & Copper chlorid. & $\begin{array}{l}\text { Mud-colored ppt., } \\
\text { becoming white. }\end{array}$ & $\begin{array}{l}\text { Add R. to ammoniacal } \\
\text { solution of sub- } \\
\text { stance. }\end{array}$ & \\
\hline Drewsen's test. & Acetone in urine. & See Bayer's test. & & & \\
\hline Dudley's test. & Gallic acid. & Sol. of ammon. picrate. & $\begin{array}{l}\text { Reddish color, } \\
\text { changing to } \\
\text { green. }\end{array}$ & Add R. & \\
\hline Dudley's test. & Glucose. & $\begin{array}{l}\text { Bismuth nitrate, dis- } \\
\text { solved in a little } \\
\text { nitric acid; add } \\
\text { equal bulk acetic } \\
\text { acid, and dilute to ro } \\
\text { vol. with water. }\end{array}$ & Gray or black ppt. & $\begin{array}{l}\text { Add to urine (rendered } \\
\text { strongly alkaline by } \\
\text { sol. of sodiu m } \\
\text { hydrate) I or } 2 \text { drops } \\
\text { of R., and boil. }\end{array}$ & \\
\hline Duflos' test. & Picrotoxin. & Potass. bichromate. & Green color. & Add sol. R. & \\
\hline $\begin{array}{l}\text { Dus a r t-Blondlot's } \\
\text { test. }\end{array}$ & $\begin{array}{l}\text { Phosphorus in } \\
\text { tissues. }\end{array}$ & $\begin{array}{l}\text { Alcohol, ether, and } \\
\text { c a rbon bisulphid, } \\
\text { containing } 1 / 2 \text { per } \\
\text { cent. sulphur in sol. }\end{array}$ & $\begin{array}{l}\text { Place copper phos- } \\
\text { phid in tias k, } \\
\text { and proceed as } \\
\text { in Marsh's test } \\
\text { for arsenic. }\end{array}$ & $\begin{array}{l}\text { Treat substance with } \\
\text { R., allow to stand } 24 \\
\text { hours, decant, and } \\
\text { treat res id u e a } \\
\text { second and a third } \\
\text { time in same manner. } \\
\text { Mix the liquids, filter } \\
\text { into retort, and warm } \\
\text { mixture with por- } \\
\text { tions of metallic cop- } \\
\text { per, until la t t e r } \\
\text { remains bright. Al- } \\
\text { low to stand } 24 \text { hours, } \\
\text { distil off carbon di- } \\
\text { sulphid mixture, col- } \\
\text { lect copper on filter, } \\
\text { wash with alcohol, } \\
\text { then with ether. }\end{array}$ & \\
\hline $\begin{array}{l}\text { Earthy-phosphates } \\
\text { test. }\end{array}$ & $\begin{array}{l}\text { Earthy phosphates } \\
\text { in urine. }\end{array}$ & Any alkali. & White ppt. & & \\
\hline Edlefsen's test. & Naphthalin. & $\begin{array}{l}\text { (a) Sol. calcium chlorid. } \\
\text { (b) Concent. hydro- } \\
\text { chloric a ci d. (c) } \\
\text { Ether. (d) I per } \\
\text { cent. aq. sol. resor- } \\
\text { cin. }\end{array}$ & $\begin{array}{l}\text { On addition of } a \\
\text { and } b \text { lemon-yel- } \\
\text { low color; } d \text { over- } \\
\text { laid with ethereal } \\
\text { extract bluish- } \\
\text { green; cherry- } \\
\text { red on addition } \\
\text { of } \mathrm{HNO}_{3} \text {. }\end{array}$ & $\begin{array}{l}\text { Add } 3 \text { to } 4 \text { drops } a \text { and } \\
\text { a few drops } b \text {. Ex- } \\
\text { tract with } c \text {, and } \\
\text { overlay } d \text { with the } \\
\text { extract, adding a } \\
\text { little ammonia. }\end{array}$ & $\begin{array}{l}\text { Reliable but com- } \\
\text { plicated. }\end{array}$ \\
\hline Edlefsen's test. & Naphthalin. & $\begin{array}{l}\text { Ammonium or sodium } \\
\text { hydrate. }\end{array}$ & Fluorescence. & $\begin{array}{l}\text { Add a few drops } R \text {. } \\
\text { to liquid. }\end{array}$ & Delicate. \\
\hline Ehrlich's test. & $\begin{array}{l}\text { A romatic com- } \\
\text { pounds in urine } \\
\text { of typhoid-fever } \\
\text { patients. }\end{array}$ & $\begin{array}{l}\text { (a) Sulphanilic acid 5.0, } \\
\text { hydrochloric acid } 50 \\
\text { c. c., distilled water } \\
\text { Iooo.o. } \\
\text { (b) Sodium nitrite } 0.5 \\
\text { distilled water I00. }\end{array}$ & $\begin{array}{c}\text { Orange-red ring; } \\
\text { rose-red foam. }\end{array}$ & $\begin{array}{l}\text { Mix } 40 \text { c.c. of } a \text { and } \\
\text { I c.c. of } b \text {; mix with } \\
\text { equal quantity of } \\
\text { urine; allow am- } \\
\text { monia to flow down } \\
\text { the tube. Shake to } \\
\text { produce the foam. }\end{array}$ & $\begin{array}{l}\text { Of considerable } \\
\text { diagnostic value; } \\
\text { obtained also in } \\
\text { carcinoma, septi- } \\
\text { cemia, and per- } \\
\text { haps other condi- } \\
\text { tions. }\end{array}$ \\
\hline Ehrlich's test. & Bilirubin. & $\begin{array}{l}\text { (a) Dil. acetic acid. } \\
\text { (b) Sulphanilic acid } \\
\text { I gm., hydrochloric } \\
\text { acid } 15 \text { c.c., sodium } \\
\text { nitrite o.I gm. }\end{array}$ & $\begin{array}{l}\text { Dark color, becom- } \\
\text { ing violet on } \\
\text { add ition of } \\
\text { glacial acetic or } \\
\text { other acid. }\end{array}$ & $\begin{array}{l}\text { Add equal vol, } a \text {, and } \\
\text { drop by drop } b \text {. }\end{array}$ & \\
\hline Einbrodt's test. & Ammonia. & $\begin{array}{l}\text { Sol, a m mon. } \\
\text { chlorid. }(b) \text { Sol. } \\
\text { potass. hydrate. }(c) \\
\text { Sol. mercuric } \\
\text { chlorid. }\end{array}$ & White opalescence. & $\begin{array}{l}\text { To roo c,c. of liquid add } \\
\text { I drop each of } a, \text { of } \\
b \text {, and of } c \text {. }\end{array}$ & \\
\hline $\begin{array}{l}\text { Endemann and } \\
\text { Prochazka's test. }\end{array}$ & Copper. & Hydrobromic acid. & $\begin{array}{c}\text { Rose-red to red- } \\
\text { dish-brown or } \\
\text { blackish color. }\end{array}$ & $\begin{array}{l}\text { To I drop liquid add } \\
\text { I drop R. ; let evapo- } \\
\text { rate slowly. }\end{array}$ & \\
\hline Eosin-test. & $\begin{array}{l}\text { Acidimetry; alka- } \\
\text { limetry. }\end{array}$ & $\begin{array}{l}\text { Eosin I gm. in } 30 \text { c.c. of } \\
\text { water. }\end{array}$ & $\begin{array}{l}\text { Acids destroy fluo- } \\
\text { rescence; alkalies } \\
\text { restore it. }\end{array}$ & & \\
\hline Esbach's test. & Proteids in urine. & $\mid \begin{array}{cc}\text { Picric acid } & \text { Io, citric } \\
\text { acid } 20 . & \text { Distilled } \\
\text { water I000. }\end{array}$ & $\begin{array}{c}\text { Precipitate: quan- } \\
\text { tity indicated on } \\
\text { graduated tube. }\end{array} \mid$ & & \\
\hline
\end{tabular}


TABLE OF TESTS.-Continued.

\begin{tabular}{|c|c|c|c|c|c|}
\hline NAME, & USE. & REAGENTS. & REACTION. & APPLICATION. & REMARKS. \\
\hline Eschka's test. & Mercury. & & White stain. & $\begin{array}{l}\text { Heat substance in cru- } \\
\text { cible, and condense } \\
\text { vapor on cold gold } \\
\text { plate (as lid). }\end{array}$ & \\
\hline Everitt's test. & Opium. & $\begin{array}{l}\text { (a) Sol. ferric chlorid. } \\
\text { (b) Sol. mercuric } \\
\text { chlorid. }\end{array}$ & $\begin{array}{l}\text { Red color with } a \text {, } \\
\text { not altered by } b \text {. }\end{array}$ & Add $a$. & \\
\hline Ewald's test. & $\begin{array}{l}\text { Free hydrochloric } \\
\text { acid in gastric } \\
\text { juice. }\end{array}$ & $\begin{array}{l}\text { Similar to Mohr's test } \\
\text { B. }\end{array}$ & & & \\
\hline Ewald's test. & $\begin{array}{l}\text { Motor activity of } \\
\text { stomach. }\end{array}$ & See Siewer's test. & & & \\
\hline Eyckmann's test. & Carbolic acid. & $\begin{array}{l}\text { (a) Spirit of nitrous } \\
\text { ether. (b) Sulphuric } \\
\text { acid. }\end{array}$ & Red color. & $\begin{array}{l}\text { Add to I c.c. of liquid } \\
\text { I to } 3 \text { drops } a \text { and an } \\
\text { equal vol. } b \text {. }\end{array}$ & $\begin{array}{l}\text { Salicylic acid and } \\
\text { albumin s how } \\
\text { same color, but } \\
\text { not so intensely. }\end{array}$ \\
\hline Fairthorne's test. & Chloral. & $\begin{array}{l}\text { (a) Concent, sol. of } \\
\text { potass. bichromate. } \\
(b) \text { Nitric acid. }\end{array}$ & Blue color. & $\begin{array}{l}\text { Heat with } a \text {, then add } \\
b \text {. }\end{array}$ & \\
\hline Fairthorne's test. & Morphin. & $\begin{array}{l}\text { (a) Sodium hypochlo. } \\
\text { rite (c hlorinated } \\
\text { soda). (b) Ammonia. }\end{array}$ & Dark-red color. & Add $a$, then $b$. & \\
\hline Fat-test. & Fat. & See Osmic-acid test. & & & \\
\hline Fehling's test. & Albumin in urine. & $\begin{array}{l}\text { Fehling's, sol. (See } \\
\text { Fehling's test for } \\
\text { glucose.) }\end{array}$ & $\begin{array}{l}\text { Brownish-red or } \\
\text { mauve color. }\end{array}$ & $\begin{array}{l}\text { Heat R., and slowly } \\
\text { add urine. }\end{array}$ & \\
\hline Fehling's test. & Glucose in urine. & $\begin{array}{l}\text { (a) } 34.652 \text { gm. crystal- } \\
\text { lized copper s ul- } \\
\text { phate, water } 200 \\
(b) \times 73 \text { gm. Sodic po- } \\
\text { tassium tartrate, } 480 \\
\text { c.c. sol. sodium hy- } \\
\text { drate. Mix } a \text { and } b \\
\text { while stirring, and } \\
\text { dilute to rooo c.c. }\end{array}$ & $\begin{array}{l}\text { Ppt. of red cu- } \\
\text { prous oxid or yel- } \\
\text { low cuprous hy- } \\
\text { droxid. }\end{array}$ & $\begin{array}{l}\text { Dilute I c.c. of R. with } \\
4 \text { c.c. of water, and } \\
\text { boil. Add urine, drop } \\
\text { or two at a time, and } \\
\text { boil. }\end{array}$ & $\begin{array}{l}\text { Delicacy } 0.001 \text { per } \\
\text { cent. }\end{array}$ \\
\hline Fehling's test. & $\begin{array}{l}\text { Peptone and pro- } \\
\text { peptone in urine. }\end{array}$ & $\begin{array}{l}\text { Fehling's sol. (See } \\
\text { Fehling's test for } \\
\text { glucose.) }\end{array}$ & $\begin{array}{l}\text { Rose-colored halo } \\
\text { above ppt. of } \\
\text { phosphates. }\end{array}$ & $\begin{array}{l}\text { Heat I5 c.c. of R.; add } \\
\text { filtered urine slowly. }\end{array}$ & \\
\hline Fenton's test. & Tartaric acid. & $\begin{array}{l}\text { (a) Sol, of ferrous chlo- } \\
\text { rid or ferrous sul- } \\
\text { phate. (b) Hydrogen } \\
\text { dioxid. }(c) \text { An al- } \\
\text { kali. }\end{array}$ & Violet color. & $\begin{array}{l}\text { Add } a, 1 \text { or } 2 \text { drops } b \\
\text { and excess } c \text {. }\end{array}$ & \\
\hline Fermentation-test. & Glucose in urine. & See Roberts' test. & & & \\
\hline Ferric-chlorid test. & Antipyrin. & Sol. ferric chlorid. & Dark-red color. & Add dilute R. to liquid. & $\begin{array}{l}\text { Unreliable. The } \\
\text { red color in dia- } \\
\text { cetic-acid reac- } \\
\text { tion disappears } \\
\text { on heating : that } \\
\text { of antipyrin does } \\
\text { not. }\end{array}$ \\
\hline Ferric-chlorid test. & $\begin{array}{l}\text { Salicylic-acid com- } \\
\text { pounds. }\end{array}$ & Sol. ferric chlorid. & Violet-blue color. & $\begin{array}{l}\text { Add } \mathrm{R} \text {. to liquid; or } \\
\text { acidulate with } \mathrm{H}_{2-} \\
\mathrm{SO}_{4} \text {, sh a k with } \\
\text { ether, and test ether- } \\
\text { eal extract with } \mathrm{R} \text {. }\end{array}$ & $\begin{array}{l}\text { Delicate, especi- } \\
\text { ally by shaking } \\
\text { with ether. } \\
\text { Other substances, } \\
\text { less common, also } \\
\text { respond. }\end{array}$ \\
\hline Ferric-chlorid test. & Tamnic acid. & Ferric chlorid. & $\begin{array}{c}\text { Grayish-green or } \\
\text { blackish color. }\end{array}$ & Add R. & \\
\hline Filhol's test. & Alkalies. & $\begin{array}{l}\text { (a) Söl, sodium nitro- } \\
\text { prussid. }(b) \text { Hydro- } \\
\text { gen sulphid. }\end{array}$ & Blue color. & $\begin{array}{l}\text { Treat liquid with } a \text { in } \\
\text { the presence of } b \text {. }\end{array}$ & \\
\hline Filhol's test. & Iodin. & $\begin{array}{l}\text { (a) Potass, hy drate. } \\
\text { (b) Alcohol. (c) Hy- } \\
\text { drochloric acid. (d) } \\
\text { Chromic acid. (e) } \\
\text { Carbon disulphid. }\end{array}$ & Violet color of $e$. & $\begin{array}{l}\text { Extract iodin; evapo- } \\
\text { rate to dryness with } \\
a \text {, take up with } b, \\
\text { evaporate; dissolve } \\
\text { in water, add a few } \\
\text { drops } c \text {, then } d \text {, } \\
\text { then } e \text {. }\end{array}$ & \\
\hline
\end{tabular}


TABLE OF TESTS,-Continued.

\begin{tabular}{|c|c|c|c|c|c|}
\hline NAME. & USE. & REAGENTS. & REACTION. & APPLICATION. & REMARKS. \\
\hline Fischer's test. & Glucose in urine. & $\begin{array}{l}\text { (a) Phenylhydrazin } \\
\text { hydrochiorid. }(b) \\
\text { Sodium acetate. }\end{array}$ & $\begin{array}{l}\text { Yellow, crystalline } \\
\text { precipitate. }\end{array}$ & $\begin{array}{c}\text { Place in test-tube } 2 \mathrm{gm} \\
a \text { and } 1.5 \mathrm{gm} . b ; \text { fill } \\
\text { tube } 1 / 3 \mathrm{with} \text { water, } \\
\text { and a d d equ a I } \\
\text { quan tity urine. } \\
\text { Stand tube in boiling } \\
\text { water } 15-20 \text { minutes; } \\
\text { then in cold water. }\end{array}$ & Detects traces \\
\hline Fischer's test. & Hydrogen sulphid. & $\begin{array}{l}\text { (a) Hydrochloric acid. } \\
\text { (b) P a ramido-di- } \\
\text { methylamin sul- } \\
\text { phate. (c) Dil. sol. } \\
\text { ferric chlorid. }\end{array}$ & Blue color. & $\begin{array}{l}\text { To } 50 \text { c.c. liquid add } \mathbf{1} \\
\text { c. c. } a \text {; then a few } \\
\text { grains } b \text {, and } 1 \text { or } 2 \\
\text { drops } c \text {. }\end{array}$ & \\
\hline Fittig's test. & Alkalimetry. & $\begin{array}{l}\text { Ethereal sol. mesityl- } \\
\text { chinon. }\end{array}$ & $\begin{array}{l}\text { R. is yellow ; alka- } \\
\text { lies turn it violet. }\end{array}$ & Add liquid to $R$. & \\
\hline Fleitmann's test. & Arsenic. & $\begin{array}{l}\text { (a) Strong potassium } \\
\text { hydrate. }(b) \text { Pure } \\
\text { zinc. }(c) \text { Paper wet } \\
\text { with silver nitrate. }\end{array}$ & $\begin{array}{l}\text { Staining of paper } \\
(c) .\end{array}$ & $\begin{array}{l}\text { Put a little } a \text { and } b \text { in } \\
\text { a test-tube with the } \\
\text { substance clasp } c \\
\text { over it and boil. }\end{array}$ & $\begin{array}{l}\text { Marsh's method, } \\
\text { except that } a \text { is } \\
\text { substituted for } \\
\text { the acid. }\end{array}$ \\
\hline Flückiger's test. & Acetanilid. & $\begin{array}{l}\text { (a) Sol. potass hy- } \\
\text { drate. }(b) \text { Chloro- } \\
\text { form. }\end{array}$ & $\begin{array}{l}\text { Disagreeable odor } \\
\text { of isocyanphenyl. }\end{array}$ & $\begin{array}{l}\text { Add } a \text { and } b \text {; shake; } \\
\text { heat. }\end{array}$ & \\
\hline Flückiger's test. & Brucin. & $\begin{array}{l}\text { Mercurous nitrate } \\
\text { (free from excess of } \\
\text { acid). }\end{array}$ & Crimson color. & $\begin{array}{l}\text { An aqueous sol. mixed } \\
\text { with } R \text {. is heated. }\end{array}$ & \\
\hline Flückiger's test. & $\begin{array}{l}\text { Creasote; car- } \\
\text { bolic acid. }\end{array}$ & $\begin{array}{l}\text { (a) Sol. ferric chlorid. } \\
\text { (b) } 85 \text { per cent. alco- } \\
\text { hol. }\end{array}$ & Green color. & $\begin{array}{l}\text { Mix } a \text { I part, creasote } \\
9, b 5 \text {. Green color. } \\
\text { Add } 60 \text { wat er: } \\
\text { cloudy-brown is h } \\
\text { color. }\end{array}$ & $\begin{array}{l}\text { Carbolic acid gives } \\
\text { brown color with } \\
\text { alcohol, blue with } \\
\text { water. }\end{array}$ \\
\hline Flückiger's test. & $\begin{array}{l}\text { Creasote: car- } \\
\text { bolic acid. }\end{array}$ & $\begin{array}{l}\text { (a) Ammonia. (b) Bro- } \\
\text { min-vapor. }\end{array}$ & $\begin{array}{l}\text { Blue color: car- } \\
\text { bolic a c i d; } \\
\text { brown or dirty- } \\
\text { green; creasote. }\end{array}$ & $\begin{array}{l}\text { Add } 1 / 4 \text { vol. } a \text {, and ex- } \\
\text { pose to } b \text {. }\end{array}$ & \\
\hline Flückiger's test. & Digitalin. & Chloral alcoholate. & $\begin{array}{l}\text { Yellowish-green } \\
\text { color, turning } \\
\text { violet, then } \\
\text { blackish-green } \\
\text { on heating. }\end{array}$ & $\begin{array}{l}\text { Dissolve in } R_{\text {. }} \text {; then } \\
\text { heat. }\end{array}$ & \\
\hline Flückiger's test. & $\begin{array}{l}\text { Free mineral } \\
\text { acids. }\end{array}$ & $\begin{array}{l}\text { Mixture in sol., of fer- } \\
\text { rous sulphate, gallic } \\
\text { acid, sodium ace- } \\
\text { tate. }\end{array}$ & Decolorization. & $\begin{array}{l}\text { Add a drop of } R \text {, to } \\
\text { liquid. }\end{array}$ & \\
\hline Flückiger's test. & Gallic acid. & $\begin{array}{l}\text { (a) Fresh sol. ferrous } \\
\text { sulphate I, wa t e r } \\
\text { Ioo. (b) Sol. sodium } \\
\text { acetate. }\end{array}$ & Violet color. & $\begin{array}{l}\text { Add } a: \text { sol colorless; } \\
\text { then add } b \text {. }\end{array}$ & \\
\hline Fluorescein test. & Alkalimetry. & $\begin{array}{l}\text { Fluorescein I gm., agi- } \\
\text { tated with } 100 \text { c.c. } \\
\text { dilute alcohol ; filter. }\end{array}$ & $\begin{array}{l}\text { Green fluorescence } \\
\text { by r e flected } \\
\text { light, in pres- } \\
\text { ence of least ex- } \\
\text { cess of an alkali. }\end{array}$ & & \\
\hline Fourcroy's test. & Phosphoric acid. & $\begin{array}{l}\text { (a) Ammon. chlorid. } \\
\text { (b) Ammon. hydrate, } \\
\text { (c) Sol. magnes. sul- } \\
\text { phate. }\end{array}$ & $\begin{array}{l}\text { White, crystalline } \\
\text { ppt. }\end{array}$ & $\begin{array}{l}\text { Add } a \text { and } b \text {, and then } \\
c .\end{array}$ & \\
\hline Francis' test. & $\begin{array}{l}\text { Biliary acids in } \\
\text { urine. }\end{array}$ & $\begin{array}{l}\text { Glucose (dried over } \\
\text { water-bath) } 2 \mathrm{gm} \text {., in } \\
\text { sulphuric acid } 15 \mathrm{gm} \text {. }\end{array}$ & Purple color. & $\begin{array}{l}\text { Place } 4 \text { c.c. of } R \text {. in } \\
\text { test-tube and float } \\
\text { equal quantity urine } \\
\text { on top. }\end{array}$ & \\
\hline $\begin{array}{l}\text { Franqui and Van } \\
\text { de Vyvere's test. }\end{array}$ & Glucose in urine. & $\begin{array}{c}\text { Bismuth hydrate in } \\
\text { potass. hydrate. }\end{array}$ & Gray or black ppt. & Boil urine with $R$. & \\
\hline Frerich's test. & $\begin{array}{l}\text { Leucin and tyro- } \\
\text { sin in urine. }\end{array}$ & $\begin{array}{l}\text { (a) Basic lead acetate. } \\
\text { (b) Hydrogen sul- } \\
\text { phid. }\end{array}$ & $\begin{array}{l}\text { Crystals of tyrosin } \\
\text { in } 24 \text { hours; leu- } \\
\text { cin a p ears } \\
\text { later. }\end{array}$ & $\begin{array}{l}\text { Ppt. urine with } a \text {; re- } \\
\text { move excess of } a \\
\text { with } b \text { : evaporate } \\
\text { fluid on water-bath } \\
\text { to small vol. }\end{array}$ & \\
\hline Fresenius' test. & Nitrites. & $\begin{array}{l}\text { (a) Starch-paste. }(b) \\
\text { Sol, potass. iodid. } \\
\text { (c) Sulphuric acid. }\end{array}$ & Blue color. & Add $a, b, c$. & \\
\hline
\end{tabular}


TABLE OF TESTS.-Continued.

\begin{tabular}{|c|c|c|c|c|c|}
\hline NAME. & USE. & REAGENTS. & REACTION. & APPLICATION. & REMARKS. \\
\hline Freund's test. & Sulphates in urine. & $\begin{array}{l}\text { (a) I per cent. sol. ali- } \\
\text { zarin. (b) } 5 \text { per cent. } \\
\text { acetic acid. (c) Sol. } \\
\text { bar i u m a cet ate } \\
\text { (II.22 to rooo). }\end{array}$ & $\begin{array}{l}\text { I c. c. } c=3 \mathrm{mg} \text {. } \\
\text { sulphur trioxid. }\end{array}$ & $\begin{array}{l}\text { To } 50 \text { c.c. urine add } \\
\text { ro drops each } a \text { and } \\
b \text { till mixture shows } \\
\text { orange color. Trit- } \\
\text { urate with } c \text { till ppt. } \\
\text { becomes distinctly } \\
\text { red. }\end{array}$ & $\begin{array}{l}\text { If urine dark- } \\
\text { colored, decolor- } \\
\text { ize with acetic } \\
\text { acid and zinc } \\
\text { powder. }\end{array}$ \\
\hline Frchde's test. & Alkaloids. & $\begin{array}{l}\text { Sol, of sodium molyb- } \\
\text { date } 0.01 \mathrm{gm} \text {. in sul- } \\
\text { phuric acid Io c.c. }\end{array}$ & Color-reactions. & & \\
\hline Fürbringer's test. & Albumin in urine. & $\begin{array}{l}\text { Capsules (Stütz's) } \\
\text { containing sodio- } \\
\text { mercuric chlorid, } \\
\text { sodium chlorid, and } \\
\text { citric acid. }\end{array}$ & $\begin{array}{l}\text { Cloudiness or floc- } \\
\text { culent ppt. }\end{array}$ & $\begin{array}{l}\text { Open capsule at both } \\
\text { ends and introduce } \\
\text { into urine. }\end{array}$ & $\begin{array}{l}\text { Delicate and con- } \\
\text { venient. }\end{array}$ \\
\hline Fürbringer's test. & Albumin in urine. & $\begin{array}{l}\text { (a) Mercuric chlorid. } \\
\text { (b) Sodium chlorid. }\end{array}$ & Precipitate. & Add sol. of $a$ and of $b$. & \\
\hline Furfurol-test. & Carbohydrates. & See Schiff's and Mo & lisch's tests. & & \\
\hline Furfurol-test. & Glucose. & See Molisch's test. & & & \\
\hline Galipe's test. & Albumin in urine. & Sat. sol. picric acid. & White turbidity. & $\begin{array}{c}\text { Place a little } \mathrm{R} \text {. in } \\
\text { test-tube, add a few } \\
\text { drops of urine, or } \\
\text { overlay with urine. }\end{array}$ & $\begin{array}{l}\text { Prevents mistak- } \\
\text { ing of phosphates } \\
\text { or urates. }\end{array}$ \\
\hline Gallois' test. & Inosite. & $\begin{array}{l}2 \text { per cent. sol. mer- } \\
\text { curic nitrate or Lie- } \\
\text { big's sol. for estima- } \\
\text { tion of urea. }\end{array}$ & $\begin{array}{l}\text { Yellow residue, } \\
\text { turning red on } \\
\text { heating. }\end{array}$ & $\begin{array}{l}\text { Heat sol. with a few } \\
\text { drops of } R \text {. }\end{array}$ & $\begin{array}{l}\text { Proteids, tyrosin, } \\
\text { and sugar must } \\
\text { be absent. }\end{array}$ \\
\hline Garrod's test. & Uric acid in blood. & Acetic acid. & $\begin{array}{l}\text { The thread be- } \\
\text { comes incrusted } \\
\text { with uric-acid } \\
\text { crystals. }\end{array}$ & $\begin{array}{l}\text { To } 30 \text { c.c. of serum } \\
\text { add } 0.5 \text { c.c. of } R \text {. and } \\
\text { im merse a fine } \\
\text { thread. }\end{array}$ & $\begin{array}{l}\text { Obta in ed espe- } \\
\text { cially in gout, but } \\
\text { also in leukemia } \\
\text { and chlorosis. }\end{array}$ \\
\hline Gauthier's reagent. & Egg-albumin. & $\begin{array}{l}\text { Sol. sodium hydrate } \\
250 \text {, copper sulphate, } \\
\text { I } \% \text { sol. 50, glacial } \\
\text { acetic acid } 700 \text {. }\end{array}$ & Precipitate. & $\begin{array}{l}\text { To } 2 \text { c.c. liquid add } \\
\text { Io c.c. R. }\end{array}$ & $\begin{array}{l}\text { Serum-albuminwill } \\
\text { not be precipi- } \\
\text { tated. }\end{array}$ \\
\hline Geissler's test. & Albumin in urine. & $\begin{array}{l}\text { (a) Citric acid. }(b) \\
\mathrm{HgCl}_{2}, 3 \% \text { sol., con- } \\
\mathrm{taining} 12-\mathrm{I} \text { \% } \\
\text { potass. iodid. }\end{array}$ & Precipitate. & $\begin{array}{l}\text { Add to urine test-paper } \\
\text { dipped in } a \text { and } \\
\text { dried, then one } \\
\text { dipped in } b \text { and } \\
\text { dried. }\end{array}$ & Very delicate. \\
\hline Gentele's test. & Glucose. & $\begin{array}{l}\text { Sol. potass. ferricyanid } \\
\text { in potass. or sodium } \\
\text { hydrate. }\end{array}$ & Decolorization. & $\begin{array}{l}\text { Add liquid to } R \text {. and } \\
\text { warm. }\end{array}$ & $\begin{array}{l}\text { Uric acid gives } \\
\text { same reaction, } \\
\text { even in the cold. }\end{array}$ \\
\hline Gentian-violet test. & $\begin{array}{l}\text { Amyloid degener- } \\
\text { ation. }\end{array}$ & $\begin{array}{l}\text { (a) } 5 \text { per cent, aq. sol, } \\
\text { gentian-violet. }(b) \\
\text { ro-r.5 per cent. sol. } \\
\text { acetic acid. }\end{array}$ & Pink color. & $\begin{array}{l}\text { Treat section } 1 / 2 \text { to } I \\
\text { minute with } a \text {; wash } \\
\text { in } b \text {; examine under } \\
\text { microscope. }\end{array}$ & \\
\hline Gerhardt's test. & Acetone in urine. & Sol. ferric chlorid. & Red color. & Add R. to urine. & $\begin{array}{l}\text { Not very reliable; } \\
\text { other substances } \\
\text { respond. }\end{array}$ \\
\hline Gerhardt's test. & $\begin{array}{l}\text { Biliary pigments } \\
\text { in urine. }\end{array}$ & $\begin{array}{l}\text { (a) Chloroform }(b) \\
\text { Tr. iodi. (c) Sol. } \\
\text { potass. hydrate. }\end{array}$ & $\begin{array}{l}\text { Yellow to brown- } \\
\text { ish color, with } \\
\text { green fluores- } \\
\text { cence. }\end{array}$ & $\begin{array}{l}\text { Shake equa } 1 \text { parts } \\
\text { urine and } a \text { allow } \\
\text { to settle; add } b \text { and } \\
c \text { to extract. }\end{array}$ & \\
\hline Gerhardt's test. & $\begin{array}{l}\text { Diacetic acid in } \\
\text { urine. }\end{array}$ & Sol. ferric chlorid. & $\begin{array}{l}\text { Bordea ux-red } \\
\text { color; foam vio- } \\
\text { let-red. }\end{array}$ & $\begin{array}{l}\text { To urine add a few } \\
\text { drops of } R \text {. to pre- } \\
\text { cipitate phosphates; } \\
\text { then add a few more } \\
\text { drops of } R \text {.; or fil- } \\
\text { ter, and then add. }\end{array}$ & $\begin{array}{l}\text { Color disappears } \\
\text { on addition of } \\
\text { sulphuric acid. }\end{array}$ \\
\hline Gerhardt's test. & $\begin{array}{l}\text { Urobilin in urine } \\
\text { (in excess). }\end{array}$ & $\begin{array}{l}\text { (a) Potass. hydrate. }(b) \\
\text { Chloroform. (c) } \mathrm{Tr} \text {. } \\
\text { iodi. }\end{array}$ & $\begin{array}{l}\text { Green fluores- } \\
\text { cence. }\end{array}$ & $\begin{array}{l}\text { To chloroform extract } \\
\text { of urine add } a \text { and } b \text {. }\end{array}$ & \\
\hline $\begin{array}{l}\text { Glacial-phosphoric- } \\
\text { acid test. }\end{array}$ & Albumin in urine. & See Hindenlang's test. & & & \\
\hline $\begin{array}{l}\text { Gmelin-Heintz's } \\
\text { test. }\end{array}$ & $\begin{array}{l}\text { Biliary pigments } \\
\text { in urine. }\end{array}$ & Fuming nitric acid. & $\begin{array}{l}\text { Play of colors be- } \\
\text { ginn ing with } \\
\text { green and pass- } \\
\text { ing through blue, } \\
\text { violet, and red } \\
\text { to yellow. }\end{array}$ & $\begin{array}{l}\text { Bring urine and } R \text {, in } \\
\text { contact on porcelain } \\
\text { plate or overlay } R \text {. } \\
\text { with urine in test- } \\
\text { tube. }\end{array}$ & $\begin{array}{l}\text { Very delicate; I in } \\
70,000 \text { to } 80,000 .\end{array}$ \\
\hline
\end{tabular}


TABLE OF TESTS.-Continued.

\begin{tabular}{|c|c|c|c|c|c|}
\hline NAME. & USE. & REAGENTS. & REACTION. & APPLICATION. & REMARKS. \\
\hline Griess' test. & Nitrites in saliva. & $\begin{array}{l}\text { (a) Sulphuric acid. }(b) \\
\text { Metadiamido-ben- } \\
\text { zol. }\end{array}$ & $\begin{array}{l}\text { Intense, y ellow } \\
\text { color. }\end{array}$ & $\begin{array}{c}\text { Dilute saliva with } 5 \\
\text { vols, water; add a } \\
\text { few drops } a \text { and } b \text {. }\end{array}$ & \\
\hline Grismer's test. & Glucose in urine. & $\begin{array}{l}\text { (a) I : Iooo sol. safranin. } \\
\text { (b) Potass. hydrate. }\end{array}$ & $\begin{array}{l}\text { Decolorization de- } \\
\text { notes glucose. }\end{array}$ & $\begin{array}{l}\text { Boil I c.c. urine with } \\
5 \text { c.c. } a \text { and } 2 \text { c.c. } b \text {. }\end{array}$ & Not reliable. \\
\hline Guaiac-test. & Blood. & $\begin{array}{l}\text { See Van Deen's test, } \\
\text { Almén's test, and } \\
\text { Huehnerfeld's test. }\end{array}$ & & & \\
\hline Guaiac-test. & Hydrocyanic acid. & See Schönbein's test. & & & \\
\hline Guareschi's test. & Phenol. & Chloroform. & $\begin{array}{l}\text { Red ppt. sol. in } \\
\text { alcohol. }\end{array}$ & $\begin{array}{l}\text { Treat warm alkaline } \\
\text { sol. of phenyl with } R \text {. }\end{array}$ & \\
\hline Günzburg's test. & $\begin{array}{c}\text { Hydrochloric acid } \\
\text { in gastric juice. }\end{array}$ & $\begin{array}{l}\text { Phloroglucin - vanillin } \\
\text { sol. : Phloroglucin 2, } \\
\text { vanillin I, absolute } \\
\text { alcohol 30. }\end{array}$ & $\begin{array}{l}\text { Red color; cherry- } \\
\text { red crystals. }\end{array}$ & $\begin{array}{l}\text { To a few drops of juice } \\
\text { in evaporating dish } \\
\text { add a drop of } \mathrm{R} \text {. and } \\
\text { warm gently. }\end{array}$ & $\begin{array}{l}\text { I in } 15,000 \text {; very } \\
\text { delicate. }\end{array}$ \\
\hline Gutzeit's test. & Arsenic. & $\begin{array}{l}\text { (a) Zinc. (b) Sulphuric } \\
\text { acid ro, water Igo. } \\
\text { (c) Sol. lead acetate. } \\
\text { (d) Sat. sol. silver ni- } \\
\text { trate a c i d u la te d } \\
\text { with nitric acid. }\end{array}$ & $\begin{array}{l}\text { Bright-y e } 11 \text { ow } \\
\text { stain, becoming } \\
\text { black or brown } \\
\text { on addition of } \\
\text { water. }\end{array}$ & $\begin{array}{l}\text { Place a piece of } a \text { in } \\
\text { test-tube with } 5 \text { c.c. } \\
\text { of } b \text {; add liquid, not } \\
\text { exceed ing I c.c. } \\
\text { About I cm. below } \\
\text { open end of test-tube } \\
\text { insert a glass-wool } \\
\text { or cotton plug moist- } \\
\text { ened with o.5 c. } \\
\text { Cover tube with } 3 \\
\text { thicknesses filter-pa- } \\
\text { per, applying to up- } \\
\text { per one a drop of } d \text {. } \\
\text { Stand a side in a } \\
\text { dark place. } \\
\end{array}$ & \\
\hline Guyot's test. & Ammonia. & $\begin{array}{l}\text { To acid sol. of mer- } \\
\text { curic nitrate add sol. } \\
\text { potass. bromid until } \\
\text { first ppt. is redis- } \\
\text { solved; then add } \\
\text { potass. hydrate till } \\
\text { orange-yellow ppt. } \\
\text { appears. Filter. }\end{array}$ & White precipitate. & Mix R. and liquid. & \\
\hline Guyot's test. & Iodoform. & Starch. & Blue color. & $\begin{array}{l}\text { Heat in flask, and pass } \\
\text { vapor } t h r o u g h{ }^{2} \\
\text { heated tube over } R \text {. }\end{array}$ & \\
\hline Hagen's test. & Strychnin. & $\begin{array}{l}\text { (a) Sulphuric acid. (b) } \\
\text { Lead dioxid. }\end{array}$ & Bluish-violet color. & $\begin{array}{l}\text { Mix } a \text { and } b \text { with } \\
\text { liquid. }\end{array}$ & \\
\hline Hager's test. & Alkaloids. & Sol, picric acid (r:I000). & Yellow ppt. & Add R. to liquid. & \\
\hline Hager's test. & Ammonia. & Mercurous nitrate. & $\begin{array}{l}\text { Black ppt. or } \\
\text { brown color- } \\
\text { ation. }\end{array}$ & Add R. to liquid. & \\
\hline Hager's test. & Arsenic. & $\begin{array}{l}\text { (a) Potass. hydrate. } \\
\text { (b) Zinc. (c) Ribbon } \\
\text { of magnesium. }\end{array}$ & $\begin{array}{l}\text { Evolution of arsin, } \\
\text { which is tested } \\
\text { in any conveni- } \\
\text { ent way. }\end{array}$ & $\begin{array}{l}\text { Heat liquid with } a \text { in } \\
\text { excess, } b \text {, and small } \\
\text { piece of } c \text {. }\end{array}$ & \\
\hline Hager's test. & Arsenic. & $\begin{array}{l}\text { (a) Hydrochloric acid. } \\
\text { (b) Tinfoil. }\end{array}$ & $\begin{array}{l}\text { Steel-colored to } \\
\text { brown stain. }\end{array}$ & $\begin{array}{l}\text { Acidify with } a \text {, drop } \\
\text { in } b \text {, heat to } 90^{\circ} \mathrm{C} \text {. }\end{array}$ & \\
\hline Hager's test. & Dextrin. & $\begin{array}{l}\text { (b) Ammonium molyb- } \\
\text { date. }(b) \text { Citric acid. }\end{array}$ & Blue color. & $\begin{array}{l}\text { Boil liquid with } a \text { and } \\
b \text {. }\end{array}$ & \\
\hline Hager's test. & Glucose. & $\begin{array}{l}\text { Mercuric oxid (red) } 30, \\
\text { sodium acetate } 30, \\
\text { glac. acetic acid } 25, \\
\text { sodium chlorid } 50, \\
\text { water } 400 \text {. After } \\
\text { solution dilute up to } \\
\text { 1000. }\end{array}$ & $\begin{array}{l}\text { Ppt. of mercurous } \\
\text { chlorid. }\end{array}$ & $\begin{array}{l}\text { Add excess of } R \text {. to } \\
\text { liquid. }\end{array}$ & \\
\hline Hager's test. & Nitric acid. & $\begin{array}{l}\text { (a) Molybdic acid. (b) } \\
\text { Sugar. }\end{array}$ & Blue color. & Add $a$ and $b$. & \\
\hline Hager's test. & $\begin{array}{l}\text { Nitrobenzol in oil } \\
\text { of bitter almonds. }\end{array}$ & 45 per cent. alcohol. & Cloudiness. & $\begin{array}{l}\text { Dissolve Io drops oil } \\
\text { in to c.c. } R \text {. }\end{array}$ & \\
\hline Hager's test. & Nitrous acid. & Carbolic acid. & $\begin{array}{l}\text { Red, then brown } \\
\text { and green color- } \\
\text { ation. }\end{array}$ & Add R. to liquid. & \\
\hline Hager's test. & Phosphorus & $\begin{array}{l}\text { (a) Ether or benzine. } \\
\text { (b) Strip of silver- } \\
\text { nitrate paper. }\end{array}$ & Black stain. & $\begin{array}{l}\text { Dissolve in } a \text {, heat to } \\
30-40^{\circ} \mathrm{C} \text {., and expose } \\
b \text { to vapors. }\end{array}$ & \\
\hline
\end{tabular}


TABLE OF TESTS.-Continued.

\begin{tabular}{|c|c|c|c|c|c|}
\hline NAME. & USE. & REAGENTS. & REACTION. & APPLICATION. & REMARKS. \\
\hline Hager's test. & Purity of quinin. & $\begin{array}{l}\text { Sol. of sodium salicyl- } \\
\text { ate }(x: 5) \text {. }\end{array}$ & $\begin{array}{l}\text { Cloudiness indi- } \\
\text { cates other cin- } \\
\text { chona alkaloids. }\end{array}$ & $\begin{array}{l}\text { Shake } 2 \text { gm. quinin } \\
\text { sulph. with } 20 \text { c.c. } \\
\text { cold water; filter. } \\
\text { Dilute filtrate with } \\
\text { equal b ulk water, } \\
\text { add ro to I2 drops } \\
\text { R., and shake. }\end{array}$ & \\
\hline Hager's test. & $\begin{array}{l}\text { Strychnin in san- } \\
\text { tonin. }\end{array}$ & Sat. sol. picric acid. & Cloudiness or ppt. & $\begin{array}{l}\text { Shake } 2 \mathrm{gm} \text {. santonin } \\
\text { with } 6 \mathrm{c} \text {.c. water, } \\
\text { filter; to filtrate add } \\
\text { I to } 2 \mathrm{c.c} \text {. R. }\end{array}$ & $\begin{array}{l}\text { In case of reaction, } \\
\text { strychnin may } \\
\text { be present, and } \\
\text { should be further } \\
\text { tested for. }\end{array}$ \\
\hline Hager's test. & Sugar in glycerin. & $\begin{array}{l}\text { (a) Ammon. molybdate. } \\
\text { (b) } 25 \text { per cent. sol. } \\
\text { nitric acid. }\end{array}$ & Blue color. & $\begin{array}{l}\text { Boil } 5 \text { drops glycerin, } \\
\text { Ioo drops water, } 3 \text { to } \\
4 \mathrm{cg} . a \text {, and I drop } b .\end{array}$ & \\
\hline Hager's test. & Tannic acid. & Ammonium molybdate. & $\begin{array}{l}\text { Reddish - y e } 11 \text { ow } \\
\text { color. }\end{array}$ & & \\
\hline Haines' solution. & Glucose in urine. & $\begin{array}{l}\text { Copper sulphate } 3, \\
\text { potass hydrate 9, } \\
\text { glycerin 100, water } \\
600 .\end{array}$ & Red ppt. & $\begin{array}{l}\text { Use as in Fehling's } \\
\text { test. }\end{array}$ & \\
\hline Hammersten's test. & Indican in urine. & $\begin{array}{l}\text { (a) Chloroform. }(b) \\
\text { Fuming hydrochloric } \\
\text { acid. }(c) \text { Sat. sol } \\
\text { calcium } \\
\text { chlorite. }\end{array}$ & $\begin{array}{c}\text { Blue color of } \\
\text { chloroform. }\end{array}$ & $\begin{array}{l}\text { Mix ro of urine with } \\
3 \text { to } 5 a, 10 b \text {, and I } \\
\text { drop } c \text {. A gitat } \mathrm{e} \\
\text { gently. }\end{array}$ & $\begin{array}{l}\text { Too much or too } \\
\text { strong } c \text { changes } \\
\text { color to green. }\end{array}$ \\
\hline Hammersten's test. & Metalbumin. & $\begin{array}{l}\text { (a) Concent, sulphuric } \\
\text { acid. (b) Acetic } \\
\text { acid. }\end{array}$ & Violet color. & Add $a$ and $b$. & \\
\hline Hammersten's test. & $\begin{array}{l}\text { Milk-curdling fer- } \\
\text { ment. }\end{array}$ & $\begin{array}{l}\text { See Curdling-ferment } \\
\text { test. }\end{array}$ & & & \\
\hline Harley's test A. & Urohematin. & Nitric acid. & $\begin{array}{l}\text { Pink, crimson, or } \\
\text { purple color in- } \\
\text { dicates excess. }\end{array}$ & $\begin{array}{l}\text { Dilute } 24 \text { hours' urine } \\
\text { to fo oz., or concent. } \\
\text { if amount greater. } \\
\text { To } 2 \text { drams add } \pi / 2 \\
\text { dram R.; allow to } \\
\text { stand. }\end{array}$ & - \\
\hline Fiarley's test B. & Urohematin. & $\begin{array}{l}\text { (a) Nitric acid. (b) } \\
\text { Ether. }\end{array}$ & $\begin{array}{l}\text { Red color of } b \text { in- } \\
\text { dicates excess. }\end{array}$ & $\begin{array}{l}\text { Boil } 4 \text { oz. urine; add } a \text {; } \\
\text { when cool heat in } \\
6 \mathrm{oz} \text {. bottle with I } \\
\text { oz. } b \text {; shake; stand } \\
\text { aside } 24 \text { hours. }\end{array}$ & \\
\hline Harnack's test. & Iodin in urine. & $\begin{array}{l}\text { (a) Starch-paste. } \\
\text { Carbon disulphid. }\end{array}$ & Purple color of $b$. & Shake with $a$ and $b$. & \\
\hline Iinaslam's test. & Albumin. & $\begin{array}{l}\text { (a) Sol. sodium chlorid. } \\
\text { (b) Sol. ferric chlorid. }\end{array}$ & Whitish zone. & $\begin{array}{l}\text { Mix urine with few } \\
\text { drops } a \text {, and pour } b \\
\text { cautiously on top. }\end{array}$ & \\
\hline Hassalt's test. & Aconitin. & $\begin{array}{l}\text { Syrupy phosphoric } \\
\text { acid. }\end{array}$ & Violet color. & $\begin{array}{l}\text { Dissolve in R.. and } \\
\text { evaporate gently. }\end{array}$ & \\
\hline Hauck's test. & Hyposulphites. & $\begin{array}{l}\text { Sol. potass. per- } \\
\text { manganate. }\end{array}$ & $\begin{array}{l}\text { Color changed to } \\
\text { bluish-green. }\end{array}$ & Mix. & \\
\hline Hay's test. & Biliary acids. & Sulphur. & $\begin{array}{l}\text { R. sinks in fluid } \\
\text { containing bili- } \\
\text { ary acids. }\end{array}$ & $\begin{array}{l}\text { Throw a little } R \text {. on } \\
\text { surface of liquid. }\end{array}$ & \\
\hline Heat-test. & Albumin in urine. & Nitric acid. & $\begin{array}{l}\text { Cloudiness or } \\
\text { white ppt. }\end{array}$ & $\begin{array}{l}\text { Heat upper third of } \\
\text { urine contained in a } \\
\text { test-tube. To ppt. } \\
\text { add drop of R.; al- } \\
\text { bumin is not dis- } \\
\text { solved. }\end{array}$ & $\begin{array}{l}\text { Delicate. Alkaline } \\
\text { urine may not } \\
\text { throw down ppt. } \\
\text { until acid is } \\
\text { added. }\end{array}$ \\
\hline Heinrich's test. & Albumin. & $\begin{array}{l}\text { (a) Dilute acetic acid. } \\
\text { (b) Sol. sodi um } \\
\text { chlorid. }\end{array}$ & Precipitate. & $\begin{array}{l}\text { To } 5 \text {-roc.c. liquid add } \\
2 \text { drops } a \text {, and boil. } \\
\text { Add enough } b \text { to } \\
\text { make } 4 \text { per cent. sol. }\end{array}$ & \\
\hline Heinrich's test. & Glucose. & $\begin{array}{l}\text { Mercuric iodid } 18, \text { po- } \\
\text { tass. iodid } 25 . \text { Dis- } \\
\text { solve; add potass. } \\
\text { hydrate } 10 \text {, water to } \\
\text { I000. } \\
\end{array}$ & Reduction. & $\begin{array}{l}\text { Heat R. and add } \\
\text { liquid. }\end{array}$ & $\begin{array}{l}40 \text { c.c. }=0.1342 \text { glu. } \\
\text { cose. }\end{array}$ \\
\hline Heintz's test. & $\begin{array}{l}\text { Potassium in } \\
\text { urine. }\end{array}$ & $\begin{array}{l}\text { (a) Hydrochloric acid. } \\
\text { (b) A little platinum } \\
\text { chlorid dissolved in } \\
\text { eq. vol. alcohol and } \\
\text { ether. }\end{array}$ & $\begin{array}{l}\text { Octahedral crys- } \\
\text { tals. }\end{array}$ & $\begin{array}{l}\text { To roo c.c. urine add a } \\
\text { little } a \text {; then } 2 \text { vols. } \\
b .\end{array}$ & \\
\hline
\end{tabular}


TABLE OF TESTS.-Continued.

\begin{tabular}{|c|c|c|c|c|c|}
\hline NAME. & UsE. & REAGENTS. & REACTION. & APPLICATION. & REMARKS. \\
\hline $\begin{array}{l}\text { Heller's test or } \\
\text { method. }\end{array}$ & Albumin in urine. & Nitric acid. & $\begin{array}{l}\text { White ring or } \\
\text { disc. }\end{array}$ & $\begin{array}{l}\text { Place about } 30 \text { drops } \\
\text { R. in test-tube, and } \\
\text { overlay with equal } \\
\text { quantity of urine. }\end{array}$ & $\begin{array}{l}\text { Delicacy } 0.0025 \text { per } \\
\text { cent. }\end{array}$ \\
\hline Heller's test. & Biliary pigments. & $\begin{array}{l}\text { (a) Hydrochloric acid. } \\
\text { (b) Nitric acid. }\end{array}$ & Play of colors. & $\begin{array}{l}\text { In a beaker-glass mix } \\
6 \text { c. c. of a with } \\
\text { enough urine to col- } \\
\text { or. Allow b to trickle } \\
\text { down the side and } \\
\text { form a layer under- } \\
\text { neath. }\end{array}$ & \\
\hline Heller's test. & Blood in urine. & Liquor potassæ. & $\begin{array}{c}\text { Reddish - brown } \\
\text { ppt. of phos - } \\
\text { phates and blood } \\
\text { coloring-matter. }\end{array}$ & $\begin{array}{l}\text { Render urine alkaline } \\
\text { with } R \text {. and boil. }\end{array}$ & \\
\hline Heller's test. & Glucose. & See Moore's test. & & & \\
\hline Heller's test. & Urophain in urine. & Sulphuric acid. & $\begin{array}{l}\text { Black or opaque } \\
\text { color indicates } \\
\text { excess; pale } \\
\text { garnet-red, di- } \\
\text { minution. }\end{array}$ & $\begin{array}{l}\text { From height of about } \\
4 \text { inches pour } 4 \text { c.c. } \\
\text { urine upon } 2 \text { c.c. R. } \\
\text { in beaker-glass, so } \\
\text { that they mix inti- } \\
\text { mately. }\end{array}$ & \\
\hline Heller's test A. & Indican in urine. & $\begin{array}{l}\text { Strong hydrochloric } \\
\text { acid. }\end{array}$ & $\begin{array}{l}\text { Violet or blue } \\
\text { color. }\end{array}$ & $\begin{array}{l}\text { To } 4 \text { c.c. } R \text {. in small } \\
\text { beaker-glass add } 20 \\
\text { drops of urine while } \\
\text { stirring. Allow to } \\
\text { stand. }\end{array}$ & $\begin{array}{l}\text { If bile is present, re- } \\
\text { move by precipi- } \\
\text { tation with lead } \\
\text { acetate and filtra- } \\
\text { tion. }\end{array}$ \\
\hline Heller's test B. & Indican in urine. & $\begin{array}{l}\text { Strong hydrochloric or } \\
\text { nitric acid. }\end{array}$ & $\begin{array}{l}\text { Violet or blue } \\
\text { ring. }\end{array}$ & $\begin{array}{l}\text { Gently heat } 4 \text { c.c. R. } \\
\text { in test-tube; over- } \\
\text { lay with equal quan- } \\
\text { tity of urine freed } \\
\text { from albumin. }\end{array}$ & \\
\hline Hempel's test. & Iodids. & $\begin{array}{l}\text { (a) Sol, ferric chlorid. } \\
\text { (b) Sulphuric acid. } \\
\text { (c) Starch-paste. }\end{array}$ & Rose-red color. & Add $a$ and $b$, then $c$. & \\
\hline Henry's test. & Iodin. & $\begin{array}{l}\text { Sol. potass. perman- } \\
\text { ganate. }\end{array}$ & & $\begin{array}{l}\text { Liberate iodin with } \\
\text { R. }\end{array}$ & \\
\hline Heppe's test. & Chlorates. & $\begin{array}{l}\text { Sol, anilin sulphate } \mathrm{I} \\
\text { sulphuric acid } 2 \text {. }\end{array}$ & $\begin{array}{l}\text { Intensely blue col- } \\
\text { or. }\end{array}$ & Add R. & \\
\hline Herbst's test. & Aconitin. & Phosphoric acid. & Violet color. & Evaporate with $\mathbf{R}$. & \\
\hline Herbst's test. & Atropin. & $\begin{array}{l}\text { (a) Sulphuric acid. }(b) \\
\text { Potass. bichromate. }\end{array}$ & $\begin{array}{l}\text { Odor of oil of bit- } \\
\text { ter almonds. }\end{array}$ & $\begin{array}{l}\text { Add } a, b \text {, and a little } \\
\text { water. }\end{array}$ & \\
\hline Herse's test. & Codein. & $\begin{array}{l}\text { (a) Sulphuric acid. (b) } \\
\text { Sol. ferric chlorid. }\end{array}$ & Blue color. & Dissolve in $a$, add $b$. & \\
\hline Herzberg's test. & $\begin{array}{l}\text { Free hydrochloric } \\
\text { acid. }\end{array}$ & See Congo-red test. & & & . \\
\hline Heynsius' test. & Albumin. & $\begin{array}{l}\text { (a) Acetic acid. }(b) \\
\text { Sat. sol. so d i u m } \\
\text { chlorid. }\end{array}$ & Flocculent ppt. & $\begin{array}{l}\text { Add } a \text { and a few c.c. } \\
\text { of } b ; \text { boil. }\end{array}$ & \\
\hline Hilger's test. & Albumin in urine. & $\begin{array}{l}\text { (a) Acetic acid. (b) } \\
\text { Sol. potass. ferro- } \\
\text { cyanid. }\end{array}$ & Turbidity or ppt. & $\begin{array}{l}\text { To I vol. urine add } 1 / 4 \\
\text { vol. } a \text {; then add } 3 \\
\text { or } 4 \text { drops } b \text {. }\end{array}$ & $\begin{array}{l}\text { Extremely deli- } \\
\text { cate; } 0.0025 \text { per } \\
\text { cent. albumin. } \\
\text { Serum-albumin, } \\
\text { globulin, and al- } \\
\text { bumose respond; } \\
\text { peptone does not. }\end{array}$ \\
\hline Hindenlang's test. & Albumin in urine. & Metaphosphoric acid. & $\begin{array}{l}\text { White cloud } \\
\text { around } \mathrm{R} \text {. }\end{array}$ & $\begin{array}{l}\text { Drop pellet of } R \text {. into } \\
\text { filtered urine and } \\
\text { allow tube to stand. } \\
\text { Do not boil. }\end{array}$ & $\begin{array}{l}\text { Delicate; R. does } \\
\text { not keep well. }\end{array}$ \\
\hline Hinterberger's test. & Atropin. & Cyanogen. & Blood-red color. & $\begin{array}{l}\text { Pass current of R. into } \\
\text { alcoholic sol. }\end{array}$ & \\
\hline Hirsch's test. & Carbolic acid. & Tr. ferri chlorid. & Purple color. & Add R. to aqueous sol. & \\
\hline Hlasiwetz's test. & Hydrocyanic acid. & Picric acid. & Blood-red color. & $\begin{array}{l}\text { Heat alkaline sol. } \\
\text { with } \mathrm{R} \text {. }\end{array}$ & \\
\hline Hoffmann's test. & Alkalimetry. & Eupittonic acid. & $\begin{array}{l}\text { Ora nge color, } \\
\text { turned blue by } \\
\text { alkalies. }\end{array}$ & & Delicacy, $I: 60,000$. \\
\hline
\end{tabular}


TABLE OF TESTS.-Continued.

\begin{tabular}{|c|c|c|c|c|c|}
\hline NAME. & USE. & REAGENTS. & REACTION. & Application, & REMARKS. \\
\hline Hoffmann's test. & Carbolic acid. & $\begin{array}{l}\text { (a) Sulphuric acid. }(b) \\
\text { Potass. nitrate. }\end{array}$ & $\begin{array}{l}\text { Violet color or } \\
\text { streaks. }\end{array}$ & $\begin{array}{l}\text { To } 2 \text { c.c. } a \text { add } 2 \text { c.c. } \\
\text { liquid, and a little } b \text {. }\end{array}$ & $0.001 \mathrm{gm}$ \\
\hline Hoffmann's test. & Chloroform. & $\begin{array}{l}\text { (a) Anilin. (b) Alco- } \\
\text { hol. (c) Sodium hy- } \\
\text { drate. }\end{array}$ & Odor of isonitril. & Add $a, b, c$. & \\
\hline Hoffmann's test. & Tyrosin. & $\begin{array}{l}\text { Neutral sol. of mercu- } \\
\text { ric nitrate. }\end{array}$ & $\begin{array}{l}\text { Crimson or pink } \\
\text { coloration or ppt. }\end{array}$ & Heat solution with $\mathrm{R}$. & $\begin{array}{l}\text { Ppt.occurs if much } \\
\text { tyrosin is present. }\end{array}$ \\
\hline $\begin{array}{l}\text { Hoff } \mathrm{m} \text { an } \mathrm{n} \text { and } \\
\text { Ultzmann's test. }\end{array}$ & $\begin{array}{l}\text { Altered b il i a ry } \\
\text { coloring-matters } \\
\text { (bilifuscin). }\end{array}$ & & Brown color. & $\begin{array}{l}\text { Dip piece of clean, } \\
\text { white linen in urine, } \\
\text { and allow to dry. }\end{array}$ & \\
\hline Hofmeister's test. & Peptone in urine. & $\begin{array}{l}\text { (a) Concent. sol. so- } \\
\text { dium acetate. }(b) \\
\text { Concent. sol. ferric } \\
\text { chlorid. }(c) \text { Sol. po- } \\
\text { tass. hydrate. }(d) \\
\text { I per cent. sol. cop- } \\
\text { per sulphate. }\end{array}$ & $\begin{array}{l}\text { Bea ut iful, red } \\
\text { color ( } \mathrm{B} \text { iuret- } \\
\text { reaction). }\end{array}$ & $\begin{array}{l}\text { To } 500 \mathrm{c.cm} \text {. urine add } \\
50 \mathrm{c.cm} \text {; then } b \\
\text { guttatim until liquid } \\
\text { is red; neutralize } \\
\text { with } c ; \text { boil ; filter. } \\
\text { If filtrate free from } \\
\text { a } 1 \mathrm{~b} u \mathrm{~m} \text { in add few } \\
\text { drops } c \text { and } d \text {. }\end{array}$ & \\
\hline $\begin{array}{l}\text { Hoppe-S eyler's } \\
\text { test. }\end{array}$ & Santonin in urine. & $\begin{array}{l}\text { (a) Sodium hydrate. } \\
\text { (b) Amylic alcohol. }\end{array}$ & $\begin{array}{l}\text { Red color with } a \text {, } \\
\text { which is decol- } \\
\text { orized by } b \text {. }\end{array}$ & $\begin{array}{l}\text { Treat urine with } a ; \\
\text { extract with } b \text {. }\end{array}$ & $\begin{array}{l}\text { Distinction from } \\
\text { chrysophanic } \\
\text { acid urine not } \\
\text { decolorized by } b \text {. }\end{array}$ \\
\hline $\begin{array}{l}\text { Hoppe-Se y l er's } \\
\text { test. }\end{array}$ & Glucose in urine. & $\begin{array}{l}\text { o-Nitrop h e n y } 1 \text { p ro- } \\
\text { pionic acid } 5.76 \mathrm{gm} \text {. } \\
\text { with Ioo c.c. } 10 \text { per } \\
\text { cent. sol. sodium hy- } \\
\text { drate, dissolved in } \\
\text { water and diluted to } \\
\text { II50 c.c. }\end{array}$ & $\begin{array}{l}\text { Dark-blue color } \\
\text { (indicates o.5 } \\
\text { percent.glucose } \\
\text { or reducing sub- } \\
\text { stance). }\end{array}$ & $\begin{array}{l}\text { Boil } 5 \text { c.c. R. with Io } \\
\text { drops urine } 1 / 4 \mathrm{~min} \text { - } \\
\text { ute. }\end{array}$ & \\
\hline $\begin{array}{l}\text { Hoppe-S e y ler's } \\
\text { test. }\end{array}$ & Xanthin. & $\begin{array}{l}\text { Sol. sodium hydrate } \\
\text { mixed with chlor- } \\
\text { inated lime. }\end{array}$ & $\begin{array}{l}\text { Dark-green ring, } \\
\text { turning brown, } \\
\text { then disappear- } \\
\text { ing, around each } \\
\text { particle of xan- } \\
\text { thin. }\end{array}$ & Drop xanthin into $R$. & · \\
\hline Horsford's test. & Glycocoll. & Sol. potass. hydrate. & Bright-red color. & Boil with $\mathrm{R}$. & \\
\hline Horsley's test. & Glucose. & $\begin{array}{l}\text { Copper su } 1 \text { ph. } 30, \\
\text { water I } 440, \text { tartaric } \\
\text { acid } 30 \text {; let cool ; add } \\
\text { potass. hydrate } 90, \\
\text { potass. carbonate } 90 .\end{array}$ & $\begin{array}{l}\text { Reduction of cop- } \\
\text { per sulphate. }\end{array}$ & As in Fehling's test. & \\
\hline Horsley's test. & Morphin. & $\begin{array}{l}\text { Sol. potass. ferricy- } \\
\text { anid. }\end{array}$ & $\begin{array}{c}\text { Red color after } \\
\text { several hours. }\end{array}$ & Add R. & \\
\hline Horsley's test. & Morphin. & $\begin{array}{l}\text { (a) Sol. silver nitrate. } \\
\text { (b) Nitric acid. }\end{array}$ & $\begin{array}{l}\text { Reduction of sil- } \\
\text { ver; blood-red } \\
\text { color with } b \text {. }\end{array}$ & $\begin{array}{l}\text { Add } a \text {; filter; to fil- } \\
\text { trate add } b .\end{array}$ & \\
\hline Horsley's test. & Strychnin. & $\begin{array}{l}\text { (a) Sol. potass. bichro- } \\
\text { mate. (b) Sulphuric } \\
\text { acid. }\end{array}$ & $\begin{array}{l}\text { Purple-vi o let to } \\
\text { red color. }\end{array}$ & $\begin{array}{l}\text { Add } a \text {; to crystals } \\
\text { which form add } b \text {. }\end{array}$ & \\
\hline Huber's test. & $\begin{array}{l}\text { Free mineral } \\
\text { acids. }\end{array}$ & $\begin{array}{l}\text { Mixture of sol. ammon. } \\
\text { molybdate and sol. } \\
\text { potass. ferrocyanid. }\end{array}$ & $\begin{array}{l}\text { Red cloudiness, } \\
\text { wh ic h dis a p- } \\
\text { pears on adding } \\
\text { the smallest ex- } \\
\text { cess of alkali. } \\
\end{array}$ & Add R. & \\
\hline Huchard's test. & $\begin{array}{l}\text { Hepatic insuffici- } \\
\text { ency. }\end{array}$ & Sugar $150-200 \mathrm{gms}$. & $\begin{array}{l}\text { A p pearance of } \\
\text { sugar in urine. }\end{array}$ & $\begin{array}{l}\text { R. is introduced into } \\
\text { stomach; normally } \\
\text { destroyed in a few } \\
\text { hours; if liver in- } \\
\text { sufficient, appears in } \\
\text { urine. }\end{array}$ & \\
\hline Huehnerfeld's test. & Blood. & $\begin{array}{l}\text { Tr. guaiaci. }(b) \\
\text { Mixture of glacial } \\
\text { acetic acid 2, dis- } \\
\text { tilled water 2, oil of } \\
\text { turpentine Ioo, absol. } \\
\text { alcohol roo, chloro- } \\
\text { form 100. }\end{array}$ & Blue color. & $\begin{array}{l}\text { Treat liquid with } a \\
\text { and a little of } b \text {. }\end{array}$ & $\begin{array}{l}\text { A modification of } \\
\text { Van Deen's test. }\end{array}$ \\
\hline Huizinga's test. & Glucose. & $\begin{array}{l}\text { (a) Potass. hydrate. } \\
\text { (b) Ammonium mo- } \\
\text { lybdate or tungstate. } \\
\text { (c) Hy d rochloric } \\
\text { acid. }\end{array}$ & Blue color. & $\begin{array}{l}\text { Alkalinize with } a \text {, add } \\
b ; \text { boil, and acidu- } \\
\text { late with } c \text {. }\end{array}$ & \\
\hline
\end{tabular}


TABLE OF TESTS.-Continued.

\begin{tabular}{|c|c|c|c|c|c|}
\hline Name. & USE. & REAGENTS. & REACTION. & APPLICATION. & REMARKS. \\
\hline Hume's test. & Arsenic. & $\begin{array}{l}\text { Ammoniacal sol. silver } \\
\text { nitrate. }\end{array}$ & Black color. & $\begin{array}{l}\text { Pass arseniuretted hy- } \\
\text { drogen into } R \text {. }\end{array}$ & \\
\hline Huppert's test. & Bile-pigments. & $\begin{array}{l}\text { (a) Milk of lime (I per } \\
\text { cent. sol.), (b) Acid } \\
\text { alcohol (containing } \\
\text { hydrochloric acid). }\end{array}$ & Green color. & $\begin{array}{l}\text { Precipitate with } a \text {; ex- } \\
\text { tract with } b \text {. Warm } \\
\text { extract. }\end{array}$ & \\
\hline Husemann's test. & Morphin. & $\begin{array}{l}\text { (a) Sulphuric acid. (b) } \\
\text { Nitric acid. }\end{array}$ & $\begin{array}{l}\text { Blue-violet to red } \\
\text { color. }\end{array}$ & $\begin{array}{l}\text { Heat for half hour } \\
\text { with } a \text {; after cooling } \\
\text { add one drop } b \text {. } \\
\end{array}$ & $\frac{1}{13} \mathrm{mgm}$. \\
\hline $\begin{array}{l}\text { Hydrochloric-acid } \\
\text { test. }\end{array}$ & Balsam of copaiba. & Hydrochloric acid. & Red color. & $\begin{array}{l}\text { Add } R \text {. to urine. Cal- } \\
\text { cium chlorid or } \\
\text { tr. jodi facilitates re- } \\
\text { action. }\end{array}$ & Reliable. \\
\hline $\begin{array}{l}\text { Ihl and Pechmann's } \\
\text { test A. }\end{array}$ & Levulose. & $\begin{array}{l}\text { Concent. alcoholic sol. } \\
\text { resorcin with a little } \\
\text { hydrochloric acid. }\end{array}$ & Red color. & $\begin{array}{l}\text { Warm R., and add } \\
\text { substance to it. }\end{array}$ & \\
\hline $\begin{array}{l}\text { Ihl and Pechmann's } \\
\text { test B. }\end{array}$ & Levulose. & $\begin{array}{l}\text { (a) Concent. sol. di- } \\
\text { phenylamin. }(b) \mathrm{Hy}- \\
\text { drochloric acid. }\end{array}$ & $\begin{array}{l}\text { Yellowish-green, } \\
\text { then dark-blue } \\
\text { color. }\end{array}$ & $\begin{array}{l}\text { Boil with } a \text { and a little } \\
\quad b \text {. }\end{array}$ & \\
\hline Ilimow's test. & Albumin. & $\begin{array}{l}\text { (a) Acid sodium phos- } \\
\text { phate. (b) Carbolic } \\
\text { acid }(\mathrm{I}: 20) \text {. }\end{array}$ & $\begin{array}{l}\text { Cloudiness and } \\
\text { precipitate. }\end{array}$ & $\begin{array}{l}\text { Acidulate with } \alpha \text {; filter; } \\
\text { add } b \text {. }\end{array}$ & \\
\hline Indigo-test. & Acetone. & See Bayer's test. & & & \\
\hline $\begin{array}{l}\text { Indigo, or indigo- } \\
\text { carmin, test. }\end{array}$ & Glucose. & See Mulder's test. & & & \\
\hline Indol-reaction. & $\begin{array}{l}\text { Products of bacil- } \\
\text { lus choleræ asi- } \\
\text { aticæ. }\end{array}$ & See Poehl's test. & & & \\
\hline Iodin-test. & $\begin{array}{l}\text { Amyloid degenera- } \\
\text { tion. }\end{array}$ & Lugol's solution. & $\begin{array}{l}\text { M a hagony-red } \\
\text { color. }\end{array}$ & $\begin{array}{l}\text { Treat freshly cut sur- } \\
\text { face of organ with } \\
\text { diluted R. }\end{array}$ & $\begin{array}{l}\text { Glycogen and cho- } \\
\text { lesterin give } \\
\text { same reaction. } \\
\end{array}$ \\
\hline Iodin-test. & Starch. & $\begin{array}{l}\text { Iodin I gm., potass. } \\
\text { iodid } 3 \mathrm{gm} . \text {, water } 50 \\
\text { c.c. }\end{array}$ & Deep-blue color. & Add R. & \\
\hline Iodoform-test. & Acetone in urine. & See Lieben's test. & & & \\
\hline Isocyanphenyl-test. & $\begin{array}{l}\text { Nitrobenzol (a n i- } \\
\text { lin). }\end{array}$ & $\begin{array}{l}\text { See Flückiger's test } \\
\text { for Acetanilid. }\end{array}$ & & & \\
\hline Ittner's test. & $\begin{array}{l}\text { Hydrocyanic acid } \\
\text { in tissues. }\end{array}$ & $\begin{array}{l}\text { (a) Dil. sol. potass. hy- } \\
\text { drate. (b) Sol. fer- } \\
\text { rous sulphate (which } \\
\text { has become yellow } \\
\text { by exposure to air). } \\
\text { (c) Hydrochloric acid. }\end{array}$ & $\begin{array}{l}\text { B I ue or green } \\
\text { color; flocculent, } \\
\text { dark-blue ppt. }\end{array}$ & $\begin{array}{l}\text { Render liquid alkaline } \\
\text { with } a \text {; add a few } \\
\text { drops } b \text {, agitate, and } \\
\text { let stand Io minutes. } \\
\text { Now add } c \text { in slight } \\
\text { excess; w a r m } \\
\text { slightly. Allow to } \\
\text { stand several hours } \\
\text { if necessary. }\end{array}$ & $\begin{array}{l}\text { Large quantities, } \\
\text { immediate, blue } \\
\text { color and precip- } \\
\text { itate. Delicacy } \\
\text { I: } 50,000 \text {. }\end{array}$ \\
\hline Jacquemart's test. & Alcohol. & $\begin{array}{l}\text { (a) Sol. mercuric ni- } \\
\text { trate. (b) Ammonia. }\end{array}$ & $\begin{array}{l}\text { Reduction of } a ; \\
\text { black precipitate } \\
\text { on adding } b \text {. } \\
\end{array}$ & Add $a$, then $b$. & \\
\hline Jacquemin's test. & Alkalies. & $\begin{array}{l}\text { Sol. pyrogallic acid, } \\
\text { with trace of ferric } \\
\text { chlorid. }\end{array}$ & $\begin{array}{l}\text { Change of color to } \\
\text { blue. }\end{array}$ & Add $\mathrm{R}$ to liquid. & \\
\hline Jacquemin's test. & Carbolic acid. & $\begin{array}{l}\text { (a) Anilin. (b) Sodium } \\
\text { hypochlorite. }\end{array}$ & Blue color. & $\begin{array}{l}\text { Add eq. vol. } a_{;} \text {, then } \\
\text { add } b \text {. }\end{array}$ & $\begin{array}{l}\text { Acids color sol. } \\
\text { red, alkalies blue. }\end{array}$ \\
\hline Jaffe's test. & Indigo in urine. & $\begin{array}{l}\text { (a) Hydrochloric acid. } \\
\text { (b) Sat. sol. calcium } \\
\text { hypochlorite (bleach- } \\
\text { ing pow der). (c) } \\
\text { Chloroform. }\end{array}$ & Blue color. & $\begin{array}{l}\text { Mix equal parts urine } \\
\text { and } a \text {; add a few } \\
\text { drops } b \text { until maxi- } \\
\text { mum color appears. } \\
\text { Agitate with } c \text { : eva- } \\
\text { porate } c \text { extract, and } \\
\text { weigh to get ap- } \\
\text { proximate quantity. }\end{array}$ & $\begin{array}{l}\text { Albumin must first } \\
\text { be removed. }\end{array}$ \\
\hline Jaffe's test. & Kreatinin. & $\begin{array}{l}\text { (a) Sol. of picric acid. } \\
\text { (b) Sodium hydrate. }\end{array}$ & Intense red color. & $\begin{array}{l}\text { Add } a \text { and a few } \\
\text { drops of } b \text {. }\end{array}$ & I : 5000 \\
\hline Von Jaksch's test. & Bilirubin in blood. & & Yellow froth. & $\begin{array}{l}\text { Abstract some blood } \\
\text { with cupping-glass; } \\
\text { place in a test-tube } \\
\text { in refrigerator; after } \\
\text { coagulation, wi th- } \\
\text { draw serum into } \\
\text { another test-tube; } \\
\text { shake. }\end{array}$ & $\begin{array}{l}\text { Serum becomes } \\
\text { green if placed } \\
\text { in a warm cham- } \\
\text { ber three or four } \\
\text { hours. }\end{array}$ \\
\hline
\end{tabular}


TABLE OF TESTS,-Continued.

\begin{tabular}{|c|c|c|c|c|c|}
\hline NAME. & USE. & REAGENTS. & REACTION. & APPLICATION. & REMARKS. \\
\hline Von Jaksch's test. & Diacetic acid. & $\begin{array}{l}\text { (a) Sol. ferric chlorid. } \\
\text { (b) Sulphuric acid. } \\
\text { (c) Ether. }\end{array}$ & $\begin{array}{l}\text { Burgundy red } \\
\text { color. }\end{array}$ & $\begin{array}{l}\text { Ad d a, filter; add } \\
\text { more } a \text {; boil portion } \\
\text { of mixture; red } \\
\text { color should persist. }\end{array}$ & $\begin{array}{l}\text { To other portion } \\
\text { of urine add } z \\
\text { and } c \text { and per- } \\
\text { form test with } a \\
\text { on the ethereal } \\
\text { extract. }\end{array}$ \\
\hline Von Jaksch's test. & $\begin{array}{l}\text { Free hydrochloric } \\
\text { acid in gastric } \\
\text { juice. }\end{array}$ & $\begin{array}{l}\text { Sol. benzo-purpurin } 6 \\
\text { B. }\end{array}$ & Dark-blue color. & $\begin{array}{l}\text { Add } R \text {. or saturate fil- } \\
\text { ter-paper with } R \text {. } \\
\text { dry, and dip in gas- } \\
\text { tric juice. }\end{array}$ & \\
\hline Von Jaksch's test. & Glucose in urine. & $\begin{array}{l}\text { (a) Phenyl - hydrazin } \\
\text { hydrochlorate. }(b) \\
\text { Sodium acetate. }\end{array}$ & $\begin{array}{l}\text { Same as Fischer's } \\
\text { test. }\end{array}$ & $\begin{array}{l}\text { To } 6-8 \text { c.c. urine add } \\
2 \text { parts } a \text { and } 3 \text { parts } \\
b \text {; warm; place } \\
\text { tube in boiling water } \\
20-30 \text { minutes, then } \\
\text { into cold water. }\end{array}$ & $\begin{array}{l}\text { Modified Fischer's } \\
\text { test. }\end{array}$ \\
\hline Von Jaksch's test. & Kresol (Para-). & $\begin{array}{l}\text { (a) Sodium nitro-prus- } \\
\text { sid. }(b) \text { Potass,-hy- } \\
\text { drate. (c) Acetic } \\
\text { acid. }\end{array}$ & $\begin{array}{l}\text { Reddish - y e } 11 \text { ow } \\
\text { color; light pink } \\
\text { when } c \text { is add- } \\
\text { ed. }\end{array}$ & $\begin{array}{l}\text { Add } a \text { and } b \text {; add ex- } \\
\text { cess } c \text {. }\end{array}$ & \\
\hline Von Jaksch's test. & Melanin. & Sol. ferric chlorid. & $\begin{array}{l}\text { Black color ; also } \\
\text { black by trans- } \\
\text { mitted light. }\end{array}$ & Add $\mathbf{R}$. & \\
\hline Von Jaksch's test. & Thallin. & $\begin{array}{l}\text { (a) Ferric chlorid. (b) } \\
\text { Ether. }\end{array}$ & Dark-green color. & $\begin{array}{l}\text { Shake urine with } b ; \\
\text { to } b \text { extract add one } \\
\text { drop } a \text {. }\end{array}$ & $\begin{array}{l}\text { Urine on addition } \\
\text { of } a \text { alone, red. } \\
\text { Many substances } \\
\text { give red color, } \\
\text { therefore extract } \\
\text { with } b \text {. }\end{array}$ \\
\hline Jaworowski's test. & Albumin in urine. & $\begin{array}{l}\text { Ammon. molybdenate } \\
\text { 1, heated with water } \\
40 \text {; mix with tartaric } \\
\text { acid 5. Filter if not } \\
\text { clear. }\end{array}$ & Precipitate. & $\begin{array}{l}\text { Urine must be trans- } \\
\text { parent and acid (aci- } \\
\text { dify with tartaric } \\
\text { acid if necessary). } \\
\text { Add R. a few drops } \\
\text { at a time; filter. }\end{array}$ & $\begin{array}{l}\text { Said to detect } \mathrm{I} \text { in } \\
300,000 \text {. }\end{array}$ \\
\hline Johnson's test. & Glucose. & $\begin{array}{l}\text { (a) Sat. sol. picric acid. } \\
\text { (b) Sol. sodium hy- } \\
\text { drate. }\end{array}$ & Claret-red color. & $\begin{array}{l}\text { Add a few drops } a \text {, al- } \\
\text { kalinize with } b \text {; } \\
\text { warm. }\end{array}$ & $\begin{array}{l}\text { Delicacy } 0.01 \text { per } \\
\text { cent. }\end{array}$ \\
\hline $\begin{array}{c}\text { Johnson's test } \\
\text { (quantitative). }\end{array}$ & Sugar in urine. & $\begin{array}{l}\text { Standard claret color } \\
\text { prepared by boiling } \\
40 \text { minims cold, sat. } \\
\text { sol. picric acid with } \\
\text { f } 3 \mathrm{j} \text { sol. containing } \\
\text { gr. j glucose to f } 3 \text { j, } \\
\text { mixed with f } 5 \text { ss } \\
\text { potass. hy drate; } \\
\text { water is added to } \\
\text { make f } 3 \text { iv. }(a) \text { Sat. } \\
\text { sol. picric acid. }(b) \\
\text { Sol. potass. hydrate. }\end{array}$ & $\begin{array}{l}\text { If color same as } \\
\text { standard, urine } \\
\text { contains gr. j } \\
\text { glucose to f } 3 \mathrm{j} \text {. } \\
\text { If darker, dilute } \\
\text { to standard tint. } \\
\text { Number of dilu- } \\
\text { t i ons e q u a ls } \\
\text { number of grains } \\
\text { per ounce. }\end{array}$ & $\begin{array}{l}\text { Boil f } 3 \text { jof dilute urine } \\
\text { I minute, with } 40 \\
\text { minims } a \text { and } f 3 s s \\
b \text {; dilute to f } 3 i v . \\
\text { Cool by immersing } \\
\text { in cold water. }\end{array}$ & \\
\hline Jolles' test. & Albumin in urine. & $\begin{array}{l}\text { (a) Hydrochloric acid. } \\
\text { (b) Sat. sol. calcium } \\
\text { chlorid. }\end{array}$ & White turbidity. & $\begin{array}{l}\text { Treat urine with equal } \\
\text { volume } a \text {; overlay } \\
\text { with } 2 \text { or } 3 \text { drops } b \text {. }\end{array}$ & 0.0I per cent. \\
\hline Kammerer's test. & $\begin{array}{l}\text { Nitric and nitrous } \\
\text { acids in potable } \\
\text { water. }\end{array}$ & $\begin{array}{l}\text { (a) Potass. - iodid- } \\
\text { st a rch-paste. (b) } \\
\text { Acetic acid. (c) Sul- } \\
\text { phuric acid. (d) } \\
\text { Zinc-dust. }\end{array}$ & Blue color. & $\begin{array}{l}\text { To one portion add } a \\
\text { and } b \text {; blue color in- } \\
\text { dicates nitrous acid. } \\
\text { To another portion } \\
\text { add } a, c, d ; \text { blue } \\
\text { color indicates nitric } \\
\text { acid. }\end{array}$ & \\
\hline Kauder's test. & Globulin. & See Pohl's test. & & & \\
\hline Klemperer's test. & $\begin{array}{l}\text { Zymogen of ren- } \\
\text { net. }\end{array}$ & $\begin{array}{l}\text { (a) Milk Io c.c., } 3 \text { per } \\
\text { cent. sol. calcium } \\
\text { chlorid } 2 \text { c.c. (b) I } \\
\text { per cent. sol. sodium } \\
\text { carbonate. }\end{array}$ & Curdling of milk. & $\begin{array}{l}\text { To } 2 \text { c.c. filtered gas- } \\
\text { tric juice add } a \text { and } \\
\text { excess of } b ; \text { place in } \\
\text { incubator. }\end{array}$ & \\
\hline Knapp's test. & Glucose in urine. & $\begin{array}{l}\text { Alkaline sol, mercuric } \\
\text { cyanid. }\end{array}$ & $\begin{array}{l}\text { Reduction to me- } \\
\text { tallic mercury. }\end{array}$ & $\begin{array}{l}\text { Boil a few c.c. R., and } \\
\text { add urine. }\end{array}$ & \\
\hline
\end{tabular}


TABLE OF TESTS.-Continued.

\begin{tabular}{|c|c|c|c|c|c|}
\hline NAME. & USE. & REAGENTS. & REACTION。 & APPLICATION. & REMARKS. \\
\hline Knapp's method. & $\begin{array}{l}\text { Volumetric test for } \\
\text { sugar in urine. }\end{array}$ & $\begin{array}{c}\text { Standard alkaline sol. } \\
\text { mercuric cy anid } \\
\text { (mercuric cyanid ro, } \\
\text { sodium hydrate [r.I4] } \\
\text { roo, water up to 7000). } \\
40 \mathrm{C}, \mathrm{c}=0.1 \text { sugar. }\end{array}$ & $\begin{array}{l}\text { Absence of mer- } \\
\text { cury in sol. is in- } \\
\text { dicated by filter- } \\
\text { paper moistened } \\
\text { with I drop sol., } \\
\text { no longer being } \\
\text { blackened by } \\
\text { vapor of ammo- } \\
\text { nium sulphid. }\end{array}$ & $\begin{array}{l}\text { Run sugar sol. from } \\
\text { buret into hot, } \\
\text { standard sol. }\end{array}$ & \\
\hline Kossel's test. & Hypoxanthin. & $\begin{array}{l}\text { (a) Hydrochloric acid. } \\
\text { (b) Zinc. (c) So- } \\
\text { dium hydrate. }\end{array}$ & Ruby-red color. & $\begin{array}{l}\text { Treat with } a \text { and } b \text {, } \\
\text { and add excess of } c \text {. }\end{array}$ & \\
\hline Kost's test. & $\begin{array}{l}\text { Free hydrochloric } \\
\text { acid in gastric } \\
\text { juice. }\end{array}$ & $\begin{array}{l}\text { (a) Io per cent. sol. tan- } \\
\text { nin. }(b) \text { Sol. metbyl- } \\
\text { violet. }\end{array}$ & $\begin{array}{l}\text { Change from vio- } \\
\text { let to blue or } \\
\text { green. }\end{array}$ & Add $a$, then $b$ & $\begin{array}{l}\text { Modification of } \\
\text { Maly's test; a } \\
\text { precipitates the } \\
\text { interfering pep- } \\
\text { tones. }\end{array}$ \\
\hline Kuehne's test. & Syntonin. & Lime-water. & $\begin{array}{l}\text { Soluble in R.; sol. } \\
\text { coagulated, } \\
\text { though imper- } \\
\text { fectly, by boil- } \\
\text { ing. }\end{array}$ & Dissolve in $\mathrm{R}$, and boil. & $\begin{array}{l}\text { Reaction distin- } \\
\text { guishes it from } \\
\text { other acid-albu- } \\
\text { mins and from } \\
\text { alkali-albumins. }\end{array}$ \\
\hline Kuelz's test. & Biliary acids. & $\begin{array}{l}\text { (a) Dil. sol. cane-sugar. } \\
\text { (b) Concent. sulphur- } \\
\text { ic acid. }\end{array}$ & $\begin{array}{l}\text { Red, then violet } \\
\text { color. }\end{array}$ & $\begin{array}{l}\text { Evaporate substance : } \\
\text { add one drop } a \text {, and } \\
\text { a few drops } b \text {. }\end{array}$ & \\
\hline Kuelz's test. & $\begin{array}{l}\text { Hydrogen sulpho- } \\
\text { cyanid in urine. }\end{array}$ & $\begin{array}{l}\text { Dil. sol. ferric chlorid, } \\
\text { with a little hydro- } \\
\text { chloric acid. }\end{array}$ & Red color. & $\begin{array}{l}\text { Dilute R. until same } \\
\text { color as urine, then } \\
\text { add. }\end{array}$ & Not reliable. \\
\hline Landoldt's test. & Carbolic acid. & Bromin-water. & $\begin{array}{l}\text { White or yellow- } \\
\text { ish-white cloudi- } \\
\text { ness or ppt. }\end{array}$ & Add excess of $R$. & I : 40,000 \\
\hline Langley's test. & $\begin{array}{l}\text { Pepsinogen and } \\
\text { pepsin. }\end{array}$ & Sodium carbonate. & $\begin{array}{c}\text { R. destroys pepsin, } \\
\text { but has no action } \\
\text { on pepsinogen. }\end{array}$ & & \\
\hline Lassaigne's test. & Semen. & $\begin{array}{l}\text { Sol. of lead oxid in } \\
\text { liquor potassæ. }\end{array}$ & $\begin{array}{l}\text { No yellow color, } \\
\text { as would occur } \\
\text { in albuminous } \\
\text { fluids. }\end{array}$ & $\begin{array}{l}\text { Moisten stain with } \mathrm{R} . \\
\text { and dry at } 68^{\circ} \mathrm{F} \text {. }\end{array}$ & $\begin{array}{l}\text { If semen diluted } \\
\text { with an albumin- } \\
\text { ous s e r etion, } \\
\text { yellow color de- } \\
\text { velops. }\end{array}$ \\
\hline $\begin{array}{l}\text { Latschenberger's } \\
\text { test. }\end{array}$ & Ammonia in urine. & $\begin{array}{l}\text { Sat. sol, copper } \\
\text { sulphate. (b) Barium } \\
\text { hydrate. }\end{array}$ & $\begin{array}{l}\text { Apply to filtrate } \\
\text { Nessler's test, } \\
q . v .\end{array}$ & $\begin{array}{l}\text { Treat urine with equal } \\
\text { vol. } a \text {; neutralize } \\
\text { with } b \text {; filter. }\end{array}$ & \\
\hline Lea's (Carey) test. & Gelatin. & $\begin{array}{l}\text { Acid sol. mercuric ni- } \\
\text { trate. }\end{array}$ & Red color. & Add R. to liquid. & \\
\hline Lea's (Carey) test. & Hydrocyanic acid. & $\begin{array}{l}\text { Ammonio-sulphate of } \\
\text { iron I, uranium ni- } \\
\text { trate I, water } 240 .\end{array}$ & $\begin{array}{l}\text { Purplish-red color } \\
\text { or ppt. }\end{array}$ & $\begin{array}{l}\text { Add } 2 \text { drops of liquid } \\
\text { on a porcelain slab } \\
\text { to } 2 \text { drops } R \text {. }\end{array}$ & \\
\hline Leffmann's test. & $\begin{array}{l}\text { Urine in potable } \\
\text { water. }\end{array}$ & Sol. silver nitrate. & Brown color. & Add R. & \\
\hline Legal's test. & Acetone in urine. & 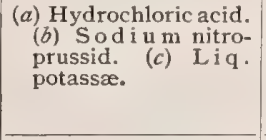 & $\left\{\begin{array}{l}\text { Red color, which } \\
\text { rapidly disap- } \\
\text { pears, and gives } \\
\text { place to purple } \\
\text { on the addition } \\
\text { of acetic acid. }\end{array}\right.$ & $\begin{array}{l}\text { Acidulate with } a \text {, dis- } \\
\text { til. To distillate add } \\
\text { a few drops each } b \\
\text { and } c \text {. }\end{array}$ & $\begin{array}{l}\text { Kreatinin strikes } \\
\text { similar color, } \\
\text { which disappears } \\
\text { when acetic acid } \\
\text { is added. }\end{array}$ \\
\hline Leo's test. & $\begin{array}{l}\text { Free acids and } \\
\text { acid salts in gas- } \\
\text { tric juice. }\end{array}$ & $\begin{array}{l}\text { Pure calcium carbon- } \\
\text { ate. }\end{array}$ & $\begin{array}{l}\text { Change of litmus- } \\
\text { test paper. }\end{array}$ & $\begin{array}{l}\text { Mix filtrate in watch- } \\
\text { glass with } R \text {, ; test } \\
\text { with blue litmus; if } \\
\text { latter not reddened, } \\
\text { acid salts absent; if } \\
\text { red less intense than } \\
\text { before, both pres- } \\
\text { ent; if red color not } \\
\text { altered, free acids } \\
\text { absent or inuch } \\
\text { diminished. }\end{array}$ & $\begin{array}{l}\text { Very delicate; } .002 \\
\text { free hy d ro- } \\
\text { chloric, o.0I lac- } \\
\text { tic acid. }\end{array}$ \\
\hline Lieben's test. & Acetone in urine. & $\begin{array}{l}\text { Liq. potassæ } 3.7 \text { c.c., } \\
\text { potass, iodid } 1.2 \\
\text { place in test-tube } \\
\text { and boil. }\end{array}$ & $\begin{array}{l}\text { Crystals of iodo- } \\
\text { form. }\end{array}$ & $\begin{array}{l}\text { ToR.add } 3.7 \text { c.c. urine, } \\
\text { distil, and acidulate } \\
\text { with hydrochlor, acid. } \\
\text { Ring of phosphates } \\
\text { is formed first; upon } \\
\text { this the iodoform is } \\
\text { depos it ed, later } \\
\text { sinking to bottom. }\end{array}$ & $\begin{array}{l}\text { Alcohol, lactic acid, } \\
\text { aldehyd, and cer- } \\
\text { tain fatty acids } \\
\text { also respond. }\end{array}$ \\
\hline
\end{tabular}


TABLE OF TESTS.-Continued.

\begin{tabular}{|c|c|c|c|c|c|}
\hline NAME. & USE. & REAGENTS. & REACTION. & APPLICATION. & REMARKS. \\
\hline Liebermann's test. & $\begin{array}{l}\text { Cholesterin and } \\
\text { cholesterin-fats. }\end{array}$ & $\begin{array}{l}\text { (a) Acetic acid anhy- } \\
\text { drid. (b) Sulphuric } \\
\text { acid. }\end{array}$ & $\begin{array}{l}\text { Violet to green } \\
\text { color. }\end{array}$ & $\underset{b}{\text { Add }} a$ and a few drops & \\
\hline Liebermann's test. & Lanolin. & $\begin{array}{l}\text { (a) Acetic acid anhy- } \\
\text { drid. (b) Sulphuric } \\
\text { acid. }\end{array}$ & $\begin{array}{l}\text { Rose-red color, } \\
\text { changing to } \\
\text { green or blue. }\end{array}$ & $\begin{array}{l}\text { Dissolve } 0.1-0.2 \mathrm{gm} \text {. } \\
\text { lanolin in } 4 \text { c.c. } a, \\
\text { and add } b .\end{array}$ & $\begin{array}{l}\text { Glycerin-fats do } \\
\text { not give this } \\
\text { color. }\end{array}$ \\
\hline Liebermann's test. & Proteids. & $\begin{array}{l}\text { Concent. hydrochloric } \\
\text { acid. }\end{array}$ & Violet-red color. & Boil substance with $\mathbf{R}$. & \\
\hline Liebig's test. & $\begin{array}{l}\text { Hydrocyanic acid } \\
\text { in tissues. }\end{array}$ & $\begin{array}{l}\text { (a) Dil. sol. sodium } \\
\text { hydrate. }(b) \text { Am- } \\
\text { monium sulphid. } \\
\text { (c) Sol, ferric chlorid. } \\
\text { (d) Hydrochloric } \\
\text { acid. }\end{array}$ & Red color. & $\begin{array}{l}\text { Place liquid in porce- } \\
\text { lain capsule ; add } a \\
\text { and } b \text {; evaporate to } \\
\text { dryness over water- } \\
\text { bath; add water } \\
\text { acidulate with } d \text {, and } \\
\text { add } 2 \text { or } 3 \text { drops } c \text {. }\end{array}$ & $\begin{array}{l}\text { Most delicate test- } \\
\text { I : } 4,000,000 .\end{array}$ \\
\hline Liebreich's test. & $\begin{array}{l}\text { Cholesterin and } \\
\text { cholesterin-fats. }\end{array}$ & See Burchard's test. & & & \\
\hline Lindo's test. & Glucose. & $\begin{array}{l}\text { Sol. in sodium or po- } \\
\text { tass. hydrate of yel- } \\
\text { low substance ob- } \\
\text { tained by action of } \\
\text { nitric acid on brucin. }\end{array}$ & $\begin{array}{l}\text { Yellow, then in- } \\
\text { tensely blue. }\end{array}$ & $\begin{array}{l}\text { Treat R. with sub- } \\
\text { stance. }\end{array}$ & \\
\hline Lipowitz' test. & $\begin{array}{l}\text { Phosphorus in or- } \\
\text { ganic matter. }\end{array}$ & $\begin{array}{l}\text { (a) Sulphuric acid, }(b) \\
\text { Sulphur. (c) Nitric } \\
\text { acid. }\end{array}$ & $\begin{array}{l}\text { Luminosity ; odor; } \\
\text { tests for phos- } \\
\text { phoric acid. }\end{array}$ & $\begin{array}{l}\text { Acidulate with } a \text {, boil } \\
1 / 2 \text { hour in retort with } \\
b \text {; collect distillate. } \\
\text { Wash pieces of sul- } \\
\text { phur and examine } \\
\text { for luminosity and } \\
\text { odor. Add } c \text {, and } \\
\text { test for phosphoric } \\
\text { acid. }\end{array}$ & \\
\hline Luck's test. & $\begin{array}{l}\text { Acidimetry, alka- } \\
\text { limetry. }\end{array}$ & Phenolphthalein. & $\begin{array}{r}\text { With acids color- } \\
\text { less; with alka- } \\
\text { lies purplish-red. }\end{array}$ & $\begin{array}{l}\text { Add I drop R. to roo } \\
\text { c.c. of liquid. }\end{array}$ & I : 100,000 \\
\hline Ludwig's test. & Alcohol (ethylic). & See Otto's test. & & & \\
\hline Ludwig's test. & Anilin. & $\begin{array}{l}\text { (a) Sol, carbolic acid. } \\
\text { (b) Sol. sodium hypo- } \\
\text { chlorite. (c) Hydro- } \\
\text { chloric acid. }\end{array}$ & $\begin{array}{l}\text { Dark-blue ; red on } \\
\text { addition of } c \text {. }\end{array}$ & $\begin{array}{l}\text { To watery sol. of sub- } \\
\text { stance add } a \text { and } b \text {. }\end{array}$ & \\
\hline Ludwig's test. & $\begin{array}{l}\text { Potassium chlor- } \\
\text { ate in vomit. }\end{array}$ & $\begin{array}{l}\text { (a) Acetic acid, }(b) \\
\text { D il. hydrochloric } \\
\text { acid. }\end{array}$ & $\begin{array}{l}\text { Crystals liberating } \\
\text { chlorin-gas with } \\
b \text {. }\end{array}$ & $\begin{array}{l}\text { Acidulate with } a \text {; boil } \\
\text { for one minute; } \\
\text { filter; evapor a te } \\
\text { filtrate to small bulk; } \\
\text { stand aside. Dry } \\
\text { crystals betw een } \\
\text { blotting-paper; add } \\
b \text {; warm. }\end{array}$ & \\
\hline Luecke's test. & Hippuric acid. & Nitric acid. & $\begin{array}{l}\text { Odor of nitroben- } \\
\text { zol. }\end{array}$ & $\begin{array}{l}\text { Add } R . \text { at boiling } \\
\text { temperature; evap- } \\
\text { orate; introd uce } \\
\text { residue into small } \\
\text { glass tube; heat. }\end{array}$ & \\
\hline Lunge's test. & Alkalimetry. & $\begin{array}{l}\text { Tropeolin (methyl- } \\
\text { orange). }\end{array}$ & $\begin{array}{l}\text { Mineral acids } \\
\text { change yellow to } \\
\text { crimson. }\end{array}$ & Add $\mathbf{R}$. & $\begin{array}{l}\text { Carbon dioxid has } \\
\text { no action. }\end{array}$ \\
\hline Lunge's test. & Alkalimetry. & $\begin{array}{l}\text { Phenacetolin (brown } \\
\text { substance obtained } \\
\text { by heating for seve- } \\
\text { ral hours carbolic, } \\
\text { sulphuric, and gla- } \\
\text { cial a cet ic acids, } \\
\text { each I part). }\end{array}$ & $\begin{array}{l}\text { Alkalies turn it } \\
\text { red. }\end{array}$ & & \\
\hline Lustgarten's test. & Chloroform. & $\begin{array}{l}\text { (a) Alpha-naphthol. }(b) \\
\text { Sol. potass. hydrate. }\end{array}$ & Blue color. & $\begin{array}{l}\text { Dissolve } a \text { in } b \text {, and } \\
\text { add to fluid. }\end{array}$ & \\
\hline Lustgarten's test. & Chloroform. & $\begin{array}{l}\text { Alpha-n a phth of or } \\
\text { beta-naphthol in pot- } \\
\text { ass. hydrate. }\end{array}$ & $\begin{array}{l}\text { Transient blue } \\
\text { color. }\end{array}$ & $\begin{array}{l}\text { Warm R. and mix } \\
\text { with substance. }\end{array}$ & $\begin{array}{l}\text { Chloral gives same } \\
\text { reaction. }\end{array}$ \\
\hline Lutke's test. & $\begin{array}{l}\text { Free hydrochloric } \\
\text { acid in gastric } \\
\text { juice. }\end{array}$ & Tropeolin O O. & $\begin{array}{l}\text { Yellow color of } \mathbf{R} . \\
\text { changes to red. }\end{array}$ & $\begin{array}{l}\text { Same as Riegel's test, } \\
g . v .\end{array}$ & \\
\hline
\end{tabular}


TABLE OF TESTS,-Continued.

\begin{tabular}{|c|c|c|c|c|c|}
\hline NAME. & USE. & REAGENTS. & REACTION. & APpLICATION. & REMARKS. \\
\hline MacMunn's test. & Indigo in urine. & $\begin{array}{l}\text { (a) Hydrochloric acid. } \\
(b) \text { Nitric acid. (c) } \\
\text { Chloroform. }\end{array}$ & $\begin{array}{l}c \text { becomes violet, } \\
\text { and shows ab- } \\
\text { sorption-bands } \\
\text { before and after } \\
\text { D., due to indigo- } \\
\text { blue. }\end{array}$ & $\begin{array}{l}\text { Boil equal parts urine } \\
\text { and } a \text {, and a few } \\
\text { drops } b \text {; cool, and } \\
\text { agitate with } c \text {. }\end{array}$ & \\
\hline MacWilliams' test. & Albumin. & $\begin{array}{l}\text { Sat. sol. salicyl-sul- } \\
\text { phonic acid. }\end{array}$ & Cloudiness or ppt. & $\begin{array}{l}\text { Mix drop or two of } \mathbf{R} \text {. } \\
\text { with } 20 \text { c.c. of liquid. }\end{array}$ & \\
\hline $\begin{array}{l}\text { Magnesia-mixture- } \\
\text { test. }\end{array}$ & $\begin{array}{l}\text { Phosphates in } \\
\text { urine. }\end{array}$ & $\begin{array}{l}\text { Magnes. sulphate, am- } \\
\text { mon. chlorid, am- } \\
\text { monia, each I, wa- } \\
\text { ter } 8 \text {. }\end{array}$ & Precipitate. & Add R. to urine. & $\begin{array}{l}\text { If ppt. thick, phos } \\
\text { phates increased; } \\
\text { if milky, normal; } \\
\text { if translucent, di- } \\
\text { minished. }\end{array}$ \\
\hline $\begin{array}{l}\text { M ag n es i u m - } \\
\text { nitric-test. }\end{array}$ & Albumin in urine. & See Roberts' test. & & & \\
\hline $\begin{array}{l}\text { Magnesium - su I- } \\
\text { phate-test. }\end{array}$ & $\begin{array}{l}\text { Paraglobulin in } \\
\text { urine. }\end{array}$ & Magnes. sulphate. & Precipitate. & $\begin{array}{l}\text { Saturate urine with } \\
\mathrm{R} \text {. remove para - } \\
\text { globulin by filtration. }\end{array}$ & \\
\hline $\begin{array}{l}\text { Magnier de la } \\
\text { Source's test. }\end{array}$ & Uric acid. & $\begin{array}{l}\text { (a) Bromin water. (b) } \\
\text { Sol. potass. hydrate. } \\
\text { (c) Ammon. hydrate. }\end{array}$ & $\begin{array}{l}\text { Brick-red color; } \\
\text { blue with } b ; \\
\text { purple with } c \text {. }\end{array}$ & $\begin{array}{l}\text { Rub up sediment with } \\
\text { water, add } a \text {, evapo- } \\
\text { rate. Add } b \text { or } c \text {. }\end{array}$ & \\
\hline Mahomed's test. & $\begin{array}{l}\text { Small quantities of } \\
\text { hemoglobin in } \\
\text { urine, unac- } \\
\text { companied by } \\
\text { albumin. }\end{array}$ & $\begin{array}{l}\text { (a) Tr. guaiaci. (b) } \\
\text { Ozonic ether. }\end{array}$ & Blue color. & $\begin{array}{l}\text { Dip slip blotting-paper } \\
\text { in urine; dry over } \\
\text { spirit-lamp; drop on } \\
2 \text { drops } a \text {, and after } \\
\text { alcohol has evapo- } \\
\text { rated, a drop of } b \text {. }\end{array}$ & \\
\hline Maly's test. & $\begin{array}{l}\text { Free hydrochloric } \\
\text { acid in gastric } \\
\text { juice. }\end{array}$ & Sol. methylene-blue. & $\begin{array}{l}\text { Change from violet } \\
\text { to blue or green. }\end{array}$ & Add R. & \\
\hline Maréchal's test. & $\begin{array}{l}\text { Bile-pigments in } \\
\text { urine. }\end{array}$ & Tr. iodi. & $\begin{array}{l}\text { Delicate green } \\
\text { color at line of } \\
\text { contact. }\end{array}$ & $\begin{array}{l}\text { Float a few drops of } \\
\text { urine on surface of } \\
\mathrm{R} \text {. in test-tube. }\end{array}$ & $\begin{array}{l}\text { Dilute urine if very } \\
\text { dark. }\end{array}$ \\
\hline Marsh's test. & Arsenic. & $\begin{array}{l}\text { (a) Dil. sulphuric acid. } \\
\text { (b) Zinc. }\end{array}$ & $\begin{array}{l}\text { Steel-white mirror } \\
\text { of metallic } \\
\text { arsenic. }\end{array}$ & $\begin{array}{l}\text { Introduce substance } \\
\text { into flask with } a \text { and } \\
b \text {. Light jet and } \\
\text { permit to impinge on } \\
\text { cold porcelain, or } \\
\text { heat delivery-tube, } \\
\text { when mirror is de- } \\
\text { posited in it. }\end{array}$ & $\begin{array}{l}\text { Distinguished from } \\
\text { similar deposit } \\
\text { of antimony by } \\
\text { solu bilit y of } \\
\text { arsenical mirror } \\
\text { in potassium hy- } \\
\text { pochlorite. }\end{array}$ \\
\hline Martin's test. & Peptones in urine. & $\begin{array}{l}\text { (a) Ammonium sul- } \\
\text { phate. }(b) \text { Sol. cop- } \\
\text { per sulphate. }(c) \\
\text { Sodium hydrate. }\end{array}$ & Rose-red color. & $\begin{array}{l}\text { Precipitate proteids } \\
\text { with } a \text {; filter; to } \\
\text { filtrate add } b \text { and } \\
\text { considerable } c \text {. }\end{array}$ & \\
\hline Maschke's test. & $\begin{array}{l}\text { Nitrous acid in } \\
\text { potable water. }\end{array}$ & $\begin{array}{l}\text { (a) Dil. acetic acid. } \\
\text { (b) Blue moly-bdic- } \\
\text { acid-solution. }\end{array}$ & $\begin{array}{l}\text { Bluish color dis- } \\
\text { appears within } \\
\text { one hour. }\end{array}$ & $\begin{array}{l}\text { Add } 6 \text { to Io drops } a \text {, } \\
\text { then } 1 \text { or } 2 \text { drops } b \text {. }\end{array}$ & \\
\hline Masset's test. & $\begin{array}{l}\text { Biliary coloring } \\
\text { matter. }\end{array}$ & $\begin{array}{l}\text { (a) Sulphuric acid. } \\
\text { (b) Potass. nitrite. }\end{array}$ & Grass-green color. & $\begin{array}{l}\text { To } 2 \text { c.c. urine add } 2 \\
\text { or } 3 \text { drops } a \text { and } \\
\text { crystal of } b \text {. }\end{array}$ & Not very delicate. \\
\hline Maumené's test A. & Glucose. & Stannous chlorid. & $\begin{array}{l}\text { Black-brown "icar- } \\
\text { amel"-like ppt. }\end{array}$ & $\begin{array}{l}\text { Heat glucose-sol. with } \\
\text { R. }\end{array}$ & \\
\hline Maumene's test B. & Glucose. & $\begin{array}{l}\text { Strips of woolen } \\
\text { soaked in } 33 \frac{1}{3} \text { per } \\
\text { cent.sol. of stannous } \\
\text { chlorid, and dried. }\end{array}$ & $\begin{array}{l}\text { Strip turns brown } \\
\text { to blackish- } \\
\text { brown. }\end{array}$ & $\begin{array}{l}\text { Boil strip in glucose- } \\
\text { solution. }\end{array}$ & \\
\hline $\begin{array}{l}\text { Mayer's reagent or } \\
\text { test. }\end{array}$ & Alkaloids. & $\begin{array}{l}\mathrm{HgCl}_{2} \mathrm{r}^{13.546,} \text {, potass. } \\
\text { 1o d i d } 49.8 \text {, water. } \\
\text { 1000. }\end{array}$ & White ppt. & Add $R$. & \\
\hline Mazzara's test. & Glucose in urine. & $\begin{array}{l}\text { (a) Nickel chlorid. }(b) \\
\text { Sol. potass. hydrate }\end{array}$ & Green ppt. & $\begin{array}{l}\text { Heat urine with } a \text { and } \\
\text { a little } b \text {. }\end{array}$ & \\
\hline Méhu's test. & Albumin in urine. & $\begin{array}{l}\text { (a) Nitric acid. }(b) \\
\text { Carbol. and acetic } \\
\text { acids each I, 90 per } \\
\text { cent. alcohol 2. }\end{array}$ & Precipitate. & $\begin{array}{l}\text { Treat urine with } 2-3 \\
\text { per cent. of its vol. } \\
\text { of } a \text {, add ro per cent. } \\
b \text {; shake and allow } \\
\text { to stand. }\end{array}$ & $\begin{array}{l}\text { Not very reliable; } \\
\text { normal urine } \\
\text { may give ppt. }\end{array}$ \\
\hline Menthol-test. & Glucose in urine. & Used like Thymol in & Molisch's test, $q . v$. & & \\
\hline
\end{tabular}


TABLE OF TESTS.-Continued.

\begin{tabular}{|c|c|c|c|c|c|}
\hline NAME. & UsE. & REAGENTS. & REACTION. & APPLICATION. & REMARKS. \\
\hline Mercuric-oxid-test. & Acetone in urine. & See Reynold-Gunning's & test. & & \\
\hline $\begin{array}{l}\text { Metaphosphoric- } \\
\text { acid-test. }\end{array}$ & Albumin in urine. & See Hindenlang's test. & & & \\
\hline Michailow's test. & Proteids. & $\begin{array}{l}\text { (a) Sol. ferrous sul- } \\
\text { phate. (b) Sulphuric } \\
\text { acid. (c) Nitric acid. }\end{array}$ & Red ring. & $\begin{array}{c}\text { Add } a \text {; underlay with } \\
b ; \text { add a little } c .\end{array}$ & \\
\hline Millard's test. & Albumin in urine. & $\begin{array}{l}\text { Mix glacial phenjc } \\
\text { acid (95 per cent } 2 \\
\text { dra ms, acefic } \\
\text { acid } 7 \text { drams; add } \\
\text { liq. potassæ } 2 \text { oz. } \\
6 \text { drams. }\end{array}$ & Precipitate. & Overlay $R$. with urine. & \\
\hline Miller's test. & Alkalimetry. & Same as Lunge's test, & $q \cdot v$. & & \\
\hline Von Miller's test. & $\begin{array}{l}\text { Free hydrochloric } \\
\text { acid in gastric } \\
\text { juice. }\end{array}$ & See Luttke's test. & & & \\
\hline Millon's test. & Albumin; urea. & $\begin{array}{l}\text { Metallic mercury } I_{1} \\
\mathrm{HNO}_{3}(1.42) 1 \text {; water } \\
\text { twice bulk; fiter in } \\
24 \text { hours. }\end{array}$ & $\begin{array}{l}\text { Yellow, then red } \\
\text { color on heating. }\end{array}$ & Add R. & \\
\hline Mitscherlich's test. & $\begin{array}{l}\text { Phosphorus in tis- } \\
\text { sues. }\end{array}$ & Dil. sulphuric acid. & Luminosity. & $\begin{array}{l}\text { Acidulate watery sol. } \\
\text { with R. and distil, } \\
\text { conducting vapors } \\
\text { through glass tube } \\
\text { surrounded by a con- } \\
\text { denser. Dark room. }\end{array}$ & $\begin{array}{l}\text { If alcohol, ether, or } \\
\text { oil of turpentine } \\
\text { is present lumin- } \\
\text { osity does not ap- } \\
\text { pear until it is re- } \\
\text { moved. Salts of } \\
\text { mercury, iodin, } \\
\text { metallicsulphids, } \\
\text { etc., in terfere } \\
\text { with luminosity } \\
\text { also. }\end{array}$ \\
\hline Mohr's test A. & $\begin{array}{l}\text { Free hydrochloric } \\
\text { acid in gastric } \\
\text { juice. (Free } \\
\text { mineral acids.) }\end{array}$ & $\begin{array}{l}\text { (a) Potass iodid starch- } \\
\text { paste. (b) Dil. sol. } \\
\text { ferric acetate. }\end{array}$ & Blue color. & $\begin{array}{l}\text { To gastric juice add } a \\
\text { and a few drops } b .\end{array}$ & $\begin{array}{l}\text { Not very reliable; } \\
\text { phosphoric acid } \\
\text { and phosphates } \\
\text { prevent reaction. }\end{array}$ \\
\hline Mohr's test B. & $\begin{array}{l}\text { Free hydrochloric } \\
\text { acid in gastric } \\
\text { juice. (Free } \\
\text { mineral acids.) }\end{array}$ & $\begin{array}{l}\text { (a) Dil. sol. ferric } \\
\text { acetate. (b) Sol. po- } \\
\text { tass. sulphocyanate. }\end{array}$ & Deep-blue color. & $\begin{array}{l}\text { Mixture of } a \text { and } b \\
\text { yellow; in presence } \\
\text { of mineral acid turns } \\
\text { blue. }\end{array}$ & \\
\hline Moleschott's test. & Cholesterin. & $\begin{array}{l}\text { Concent. sulphuric } \\
\text { acid, diluted with } \frac{1}{5} \\
\text { vol. water. }\end{array}$ & $\begin{array}{l}\text { Solution of } \mathrm{sub} \text { - } \\
\text { stance with red } \\
\text { color. }\end{array}$ & $\begin{array}{l}\text { On glass slide, under } \\
\text { microscope, add } R \text {. } \\
\text { to substance. }\end{array}$ & $\begin{array}{l}\text { On addition of } \\
\text { iodin, violet } \\
\text { color. }\end{array}$ \\
\hline Molisch's test. & Glucose in urine. & $\begin{array}{l}\text { (a) a-N a pht hol. }(b) \\
\text { Thymol. }(c) \text { Strong } \\
\text { sulphuric acid. }\end{array}$ & $\begin{array}{l}\text { Deep-violet color } \\
\text { with } a \text {, deep-red } \\
\text { with } b \text {. }\end{array}$ & $\begin{array}{l}\text { To } 2 \text { c.c. urine add } 2 \\
\text { drops rs to } 20 \text { per } \\
\text { cent. sol. } a \text { or } b ; \\
\text { mix, and add equal } \\
\text { vol. } c \text {. }\end{array}$ & $\begin{array}{l}\text { Very delicate, but } \\
\text { not very reliable; } \\
\text { unknown s ub- } \\
\text { stances give } \\
\text { same reaction. }\end{array}$ \\
\hline Moore's test. & Glucose in urine. & $\begin{array}{l}\text { Sodium or potass. hy- } \\
\text { drate. }\end{array}$ & $\begin{array}{l}\text { Yellow, brown, or } \\
\text { brownish-black } \\
\text { color. If nitric } \\
\text { acid is added- } \\
\text { odor of burnt su- } \\
\text { gar and formic } \\
\text { acid. }\end{array}$ & $\begin{array}{l}\text { Add R. and boil upper } \\
\text { stratum of mixture. }\end{array}$ & $\begin{array}{l}\text { Delicacy } 0.3 \text { per } \\
\text { cent.; normal } \\
\text { urine may re- } \\
\text { spond. }\end{array}$ \\
\hline Mucin-test. & Mucin. & $\begin{array}{l}\text { (a) Acetic acid. (b) } \\
\text { Nitric acid. }\end{array}$ & $\begin{array}{l}\text { Cloudiness on ad- } \\
\text { dition of } a \text {, dis- } \\
\text { appearing, when } \\
b \text { is added. }\end{array}$ & Add $a$, then $b$. & $\begin{array}{l}\text { If cloudiness in- } \\
\text { creases instead } \\
\text { of disappearing, } \\
\text { it is due to al- } \\
\text { bumin or urates; } \\
\text { the latter dissolve } \\
\text { on heating. }\end{array}$ \\
\hline Mucin-test. & Mucin. & Citric or acetic acid. & $\begin{array}{l}\text { Cloud-like coagu- } \\
\text { lum above line } \\
\text { of contact. }\end{array}$ & $\begin{array}{l}\text { Overlay } R \text {. with the } \\
\text { liquid. }\end{array}$ & \\
\hline Mulder's test. & Glucose in urine. & $\begin{array}{l}\text { (a) Sodium carbonate. } \\
\text { (b) Indigo, (Sodium } \\
\text { sulpho-indigotate.) }\end{array}$ & $\begin{array}{l}\text { Bilue color changes } \\
\text { to v i l le t-red, } \\
\text { finally to yellow } \\
\text { or w i t e. On } \\
\text { sha } \mathrm{k} \text { ing, blue } \\
\text { color is restored. }\end{array}$ & $\begin{array}{l}\text { Alkalinize with } a \text {, add } \\
\text { a few drops } b \text {, and } \\
\text { heat without boiling } \\
\text { or shaking. }\end{array}$ & $\begin{array}{l}\text { May use test } \\
\text { papers instead of } \\
\text { solutions. Test } \\
\text { not very reliable. }\end{array}$ \\
\hline
\end{tabular}


TABLE OF TESTS.-Continued.

\begin{tabular}{|c|c|c|c|c|c|}
\hline NAME. & USE. & REAGENTS. & REACTION. & APPLICATION. & REMARKS. \\
\hline Müller's test. & $\begin{array}{l}\text { Acetanilid (anti - } \\
\text { febrin). }\end{array}$ & $\begin{array}{l}\text { (a) Hydrochloric acid. } \\
(b) 3 \text { per cent. sol. } \\
\text { carbolic a c id. (c) } \\
\text { Sol. chromic acid, or } \\
\text { calcium chlorid, or } \\
\text { ferric chlorid. }\end{array}$ & $\begin{array}{l}\text { Red color, turning } \\
\text { blue with am- } \\
\text { monia. }\end{array}$ & $\begin{array}{l}\text { Buil urine with } \frac{1}{a} \text {; } \\
\text { allow to cool; add a } \\
\text { few c.c. } b \text {, and a drop } \\
c .\end{array}$ & $\begin{array}{l}\text { Paramidophenol re- } \\
\text { action. Reliable } \\
\text { but not very deli- } \\
\text { cate. }\end{array}$ \\
\hline Müller's test A. & $\begin{array}{l}\text { Hydrogen sulphid } \\
\text { in urine. }\end{array}$ & $\begin{array}{l}\text { Alkaline sol. lead ace- } \\
\text { tate. }\end{array}$ & Blackening. & $\begin{array}{l}\text { Pass current of air } \\
\text { through urine, and } \\
\text { against filter-paper } \\
\text { dipped in } R \text {. }\end{array}$ & \\
\hline Müller's test B. & $\begin{array}{l}\text { Hydrogen sulphid } \\
\text { in urine. }\end{array}$ & $\begin{array}{l}\text { Mix hydrochloric acid, } \\
\text { paramido-dimethyla- } \\
\text { min, and I or } 2 \text { drops } \\
\text { dil-sol. ferric chlorid. }\end{array}$ & Blue ring. & Overlay R. with urine. & $\begin{array}{l}\text { Modification of } \\
\text { Fischer's test. }\end{array}$ \\
\hline Munk's test. & $\begin{array}{l}\text { Hydrogen sulpho- } \\
\text { cyanid in urine. }\end{array}$ & $\begin{array}{l}\text { (a) Nitric acid. }(b) \\
\text { Sol.silvernitrate. }(c) \\
\text { Hydrogen sulphid. } \\
\text { (d) Ferrous sulphid } \\
\text { (containing iron } \\
\text { oxid). (e) Sodium } \\
\text { hydrate (f) Hydro- } \\
\text { chloric acid. }\end{array}$ & Prussian blue. & $\begin{array}{l}\text { Acidify } 200 \text { c.c. urine } \\
\text { with } a \text {; add } b \text {; fil- } \\
\text { ter; decompose fil- } \\
\text { trate with } c \text {. Distil. } \\
\text { Add } d \text { and } e \text {; warm; } \\
\text { add } f \text {. }\end{array}$ & \\
\hline Murexid-test. & Uric acid. & $\begin{array}{l}\text { (a) Nitric acid. (b) } \\
\text { Ammonia. }\end{array}$ & Beautiful red color. & $\begin{array}{l}\text { Cover substance or } \\
\text { residue on evapora- } \\
\text { tion with } a \text {; evapo- } \\
\text { rate to dryness on } \\
\text { water-bath; add } b \text {. }\end{array}$ & \\
\hline Musculus' test. & Urea. & $\begin{array}{l}\text { Filter putrescent } \\
\text { urine, wash filter- } \\
\text { paper, stain with } \\
\text { turmeric and dry. }\end{array}$ & Brown stain. & $\begin{array}{l}\text { Turns brown on being } \\
\text { dipped into a sol. of } \\
\text { urea, and allowed to } \\
\text { dry. }\end{array}$ & \\
\hline a-Naphthol-test. & Sugar in urine. & See Molisch's test. & & & \\
\hline Nessler's reagent. & Ammonium salts. & $\begin{array}{l}\text { Potass. iodid } 5 \text { gm. } \\
\text { hot water } 5 \text { c.c. Add } \\
\text { mercuric chlorid } 2.5 \\
\text { gm. in water Io c.c. } \\
\text { To mixture add po- } \\
\text { tass. hydrate } 16 \mathrm{gm} \text {. } \\
\text { in water } 40 \text { c.c. ; di- } \\
\text { lute up to 100 c.c. }\end{array}$ & $\begin{array}{l}\text { Yellow or reddish- } \\
\text { brown coloration. }\end{array}$ & & \\
\hline Neukomm's test. & $\begin{array}{l}\text { Biliary coloring- } \\
\text { matter. }\end{array}$ & $\begin{array}{l}\text { (a) Dilute sulphuric } \\
\text { acid. (b) So1. of } \\
\text { sugar. }\end{array}$ & Violet color. & $\begin{array}{l}\text { Extract with alcohol, } \\
\text { evaporate to small } \\
\text { bulk. To one drop } \\
\text { in porcelain dish add } \\
\text { one drop } a \text { and trace } \\
b ; \text { warm. }\end{array}$ & \\
\hline Niggl's test. & Lignin. & $\begin{array}{l}\text { (a) Aq. sol. of indol. } \\
\text { (b) Sulphuric acid. } \\
\text { (Spec. grav. I.2.) }\end{array}$ & Red color. & $\begin{array}{l}\text { Subject specimen to } a \\
\text { for a few minutes; } \\
\text { transfer to } b \text {. }\end{array}$ & \\
\hline Nigrosin-test. & Water. & Nigrosin. & Black color. & Add piece of $\mathrm{R}$. & \\
\hline Nitric-acid-test. & Albumin in urine. & See Heller's test. & & & \\
\hline Nitric-acid-test. & Urea. & $\begin{array}{l}\text { (a) Alcohol (b) Con- } \\
\text { cent. nitric acid. }\end{array}$ & $\begin{array}{l}\text { Six-sided crystals } \\
\text { of urea nitrate. }\end{array}$ & $\begin{array}{l}\text { Evaporate liquid to } \\
\text { syrupy consistence; } \\
\text { extract with } a \text {; dis } \\
\text { til } a \text { off; dissolve } \\
\text { residue in water; } \\
\text { add } b \text {, preferably un- } \\
\text { der microscope. }\end{array}$ & \\
\hline Nitroprussid-test. & Hydrocyanic acid. & See Vortmann's test. & & & \\
\hline Le Nobel's test. & Acetone in urine. & $\begin{array}{l}\text { (a) Sol. sodium nitro- } \\
\text { prussid. (b) Strong } \\
\text { ammonia. }\end{array}$ & Rose-violet color. & $\begin{array}{l}\text { To } 30 \text { c.c. urine add } 4 \\
\text { to } 7 \text { c.c. } a \text { and a few } \\
\text { drops } b \text {. }\end{array}$ & $\begin{array}{c}\text { Dilution may be } \\
\text { necessary to } \\
\text { bring out color. }\end{array}$ \\
\hline Noel's test. & $\begin{array}{l}\text { Biliary coloring- } \\
\text { matter. }\end{array}$ & Nitric acid. & Play of colors. & $\begin{array}{l}\text { Dip filter - p a per in } \\
\text { liquid; dry, and add } \\
\text { R. }\end{array}$ & \\
\hline Nylander's test. & Glucose in urine. & \begin{tabular}{|} 
Bismuth subnitrate 2, \\
sodicpotass.tartrate \\
4 , dissolved in sol. \\
sodium hydrate (10 \\
gm. in 9o c.c. water).
\end{tabular} & $\begin{array}{l}\text { B lack color of } \\
\text { liquid or of the } \\
\text { ppt. of phos- } \\
\text { phates. }\end{array}$ & $\begin{array}{l}\text { To ro parts urine add } \\
\text { I part R., and boil. }\end{array}$ & $\begin{array}{l}\text { Delica cy o.I per } \\
\text { cent.; very reli- } \\
\text { able. Albumin } \\
\text { must beremoved. }\end{array}$ \\
\hline
\end{tabular}


TABLE OF TESTS._Continued.

\begin{tabular}{|c|c|c|c|c|c|}
\hline NAME. & USE. & REAGENTS. & REACTION. & APPLICATION. & REMARKS. \\
\hline Oliver's test. & Albumin in urine. & $\begin{array}{l}\text { (a) Sodium tungstate. } \\
\text { (b) Citric acid. }\end{array}$ & Precipitate. & $\begin{array}{c}\text { Mix equal parts } a \text { and } \\
b, \text { and add to urine. }\end{array}$ & \\
\hline Oliver's test. & Biliary acids. & $\begin{array}{l}\text { Meat-peptone } 30 \\
\text { grains, salicylic acid } \\
4 \text { grains, acetic acid } \\
30 \text { minims, water } 8 \\
\text { ounces. }\end{array}$ & Precipitate. & $\begin{array}{l}\text { Dilute urine to sp. gr. } \\
\text { roos. Mix } 20 \text { minims } \\
\text { with a dram of } \mathrm{R} \text {. }\end{array}$ & \\
\hline $\begin{array}{l}\text { O'Shaughnessy's } \\
\text { test. }\end{array}$ & Opium. & Persalts of iron. & Red color. & Add R. & $\begin{array}{l}\text { Color not acted } \\
\text { upon by alkalies }\end{array}$ \\
\hline Osmic-acid-test. & Fat in tissues. & $\begin{array}{l}\text { Weak sol. of osmic } \\
\text { acid. }\end{array}$ & Black color. & Stain tissue with $\mathrm{R}$. & 1 \\
\hline Otto's test. & Alcohol (ethylic). & $\begin{array}{l}\text { (a) Concent sulphuric } \\
\text { acid. ( } b) \text { Sodium } \\
\text { acetate. }\end{array}$ & $\begin{array}{l}\text { Odor of acetic } \\
\text { ether. }\end{array}$ & $\begin{array}{l}\text { Add equal vol. } a \text { and } \\
\text { a little of } b \text {. }\end{array}$ & \\
\hline Otto's test. & Strychnin. & $\begin{array}{l}\text { (a) Sulphuric acid. }(b) \\
\text { Potass. bichromate. }\end{array}$ & Violet color. & Add $a$ and $b$. & \\
\hline Pagenstecher's test. & Hydrocyanic acid. & $\begin{array}{l}\text { (a) Tr. guaiaci. (b) } 1 / 4 \\
\text { per cent sol. of cop- } \\
\text { per sulphate. }\end{array}$ & Blue color. & $\begin{array}{l}\text { Soak filter-paper in } a \text {, } \\
\text { moisten with } b \text {, then } \\
\text { with liquid. }\end{array}$ & I : 300,000 \\
\hline Paraglobulin-test. & Paraglobulin. & $\begin{array}{l}\text { See Magnesium-sul- } \\
\text { phate.test. }\end{array}$ & & & \\
\hline Paton's test. & Globulin in urine. & $\begin{array}{l}\text { Sat. sol. magnesium } \\
\text { sulphate. }\end{array}$ & White ring. & $\begin{array}{l}\text { Alkalinize urine, and } \\
\text { underlay with } \mathbf{R} \text {. }\end{array}$ & \\
\hline Paul's test. & $\begin{array}{l}\text { Biliary coloring- } \\
\text { matter. }\end{array}$ & $\begin{array}{l}\text { Sol. of methylanilin- } \\
\text { violet. }\end{array}$ & Red color. & Add $R$, to urine. & \\
\hline Pavy's test. & Albumin in urine. & $\begin{array}{l}\text { Potass. or sodium fer- } \\
\text { rocyanid and citric } \\
\text { acid in tablets. }\end{array}$ & Precipitate. & $\begin{array}{l}\text { Pulverize tablets and } \\
\text { add urine. }\end{array}$ & Not very reliable. \\
\hline Pavy's test. & Glucose in urine. & $\begin{array}{l}\text { Copper sulph, } 4.158, \\
\text { dissolve in water } \\
\text { with slight heat. In } \\
\text { another bottle dis- } \\
\text { solve Rochelle salts } \\
20.4 \text { and a little po- } \\
\text { tass, hydrate. Mix ; } \\
\text { cool, and add } 300 \text { c.c. } \\
\text { strong a mm on i a } \\
(0.880) \text {; dilute to I } \\
\text { liter. }\end{array}$ & Yellow or red ppt. & $\begin{array}{l}\text { Use as in Fehling's } \\
\text { test. }\end{array}$ & \\
\hline Penzoldt's test. & Acetone in urine. & See Baeyer's test. & & & \\
\hline Penzoldt's test. & Bile-pigment. & Acetic acid. & Green color. & $\begin{array}{l}\text { Filter large quantity } \\
\text { through double fil- } \\
\text { ter; allow paper to } \\
\text { dry, and pour on a } \\
\text { fewc.c. R. Warming } \\
\text { accelerates forma- } \\
\text { tion of green color. }\end{array}$ & Very delicate. \\
\hline Penzoldt's test. & Bile-pigment. & $\begin{array}{l}\text { (a) Chloroform. (b) } \\
\text { Sol. ferric chiorid. }\end{array}$ & Green color. & $\begin{array}{l}\text { Acidify urine with } \\
\text { acetic acid; shake } \\
\text { with } a \text {; pour off } \\
\text { urine; add } b \text {. }\end{array}$ & Not very delicate. \\
\hline Penzoldt's test. & Glucose in urine. & $\begin{array}{l}\text { (a) Weakly alkaline } \\
\text { sol, diazobenzol-sul- } \\
\text { phonic a c id. }(b) \\
\text { Potassium hydrate. }\end{array}$ & $\begin{array}{l}\text { Yellowish-red or } \\
\text { light Bordeaux- } \\
\text { red color; red } \\
\text { foam. }\end{array}$ & $\begin{array}{l}\text { To a few c.c. urine } \\
\text { add } b \text {, and as much } \\
a \text { as urine. Shake } \\
\text { in } 1 / 4-1 / 2 \text { hour to pro- } \\
\text { duce foam. }\end{array}$ & $\begin{array}{l}\text { Very reliable. Con- } \\
\text { trol-test with } \\
\text { normal urine } \\
\text { should always } \\
\text { be employed. }\end{array}$ \\
\hline Penzoldt's test. & Naphthalin. & $\begin{array}{l}\text { Concentrated sulphur- } \\
\text { ic acid. }\end{array}$ & Dark-green color. & $\begin{array}{l}\text { Pour a little urine into } \\
\text { test-tube; empty so } \\
\text { that only a drop re- } \\
\text { mains; then add I } \\
\text { c.c. R. }\end{array}$ & $\begin{array}{l}\text { Delicate and re- } \\
\text { liable. }\end{array}$ \\
\hline Penzoldt's test. & Thallin. & $\begin{array}{l}\text { (a) Ferric chlorid. (b) } \\
\text { Chloroform. }\end{array}$ & Dark-green color. & $\begin{array}{l}\text { Shake liquid with } b \\
\text { to } b \text { extract add one } \\
\text { drop } a \text {. }\end{array}$ & \\
\hline Peptone-test. & For peptone. & $\mid$ See Hofmeister's test & and Biuret-test. & & \\
\hline Petri's test. & Kairin in urine. & $\begin{array}{l}\text { (a) Acetic acid. }(b) \\
\text { Sol. calcium chlorid. }\end{array}$ & Fuchsin-red color. & Add $a$ and $b$. & \\
\hline
\end{tabular}


TABLE OF TESTS.-Continued.

\begin{tabular}{|c|c|c|c|c|c|}
\hline NAME. & UsE. & REAGENTS. & REACTION. & ApPLICATION. & REMARKS. \\
\hline Petri's test. & Proteids. & $\begin{array}{l}\text { (a) Diazobenzol-sul- } \\
\text { phonic acid. (b) } \\
\text { Sodium hydrate. }\end{array}$ & $\begin{array}{l}\text { Orange-yellow to } \\
\text { brownish - red; } \\
\text { foam red. }\end{array}$ & Add $a$ and $b$ & \\
\hline Pettenkofer's test. & Biliary acids. & $\begin{array}{l}\text { Fresh sol. of sugar } \\
\text { and dilute sulphuric } \\
\text { acid. }\end{array}$ & $\begin{array}{l}\text { Yellowish-red } \\
\text { color, passing } \\
\text { into crimson. }\end{array}$ & $\begin{array}{l}\text { Add a few drops of } \\
\text { liquid to } R \text {. }\end{array}$ & $\begin{array}{l}\text { Albumin must be } \\
\text { removed; excess } \\
\text { of indican, and } \\
\text { albumin g ive } \\
\text { similar reaction. }\end{array}$ \\
\hline Phenic-acid-test. & Albumin. & See Millard's test. & & & \\
\hline $\begin{array}{l}\text { Phe ny l-hydrazin- } \\
\text { lest. }\end{array}$ & Glucose in urine. & See Fischer's test. & & & \\
\hline $\begin{array}{l}\text { Phloroglucin-vanil- } \\
\text { lin-test. }\end{array}$ & $\begin{array}{c}\text { Hydrochloric acid } \\
\text { in gastric juice. }\end{array}$ & See Günzburg's test. & & & \\
\hline Picric-acid-test. & Albumin. & See Galipe's test. & & & \\
\hline Picric-acid-test. & Glucose. & See Braun's test and & Johnson's test. & & \\
\hline $\begin{array}{l}\text { Piotrowski's reac- } \\
\text { tion. }\end{array}$ & Proteids. & See Ritthausen's test. & & & \\
\hline Piria's test. & Tyrosin. & $\begin{array}{l}\text { (a) Concentrated sul- } \\
\text { phuric acid. }(b) \\
\text { Barium carbonate. } \\
\text { (c) Dil. sol. ferric } \\
\text { chlorid. }\end{array}$ & Violet color. & $\begin{array}{l}\text { Moisten on watch- } \\
\text { glass with } a \text {, warm } \\
\text { 5-ro min utes on } \\
\text { water-bath. Dilute } \\
\text { with water, warm, } \\
\text { neutralize with } b \text {, } \\
\text { filter while warm. } \\
\text { Add } c \text { to filtrate. }\end{array}$ & $\begin{array}{l}\text { Excess of } c \mathrm{de}= \\
\text { stroys color. }\end{array}$ \\
\hline Pohl's test. & $\begin{array}{l}\text { Products of bacil- } \\
\text { lus choleræ asi- } \\
\text { aticæ. }\end{array}$ & $\begin{array}{l}\text { Concentrated sulphur- } \\
\text { ic acid. }\end{array}$ & $\begin{array}{l}\text { Rose color deepen- } \\
\text { ing into purple. }\end{array}$ & $\begin{array}{l}\text { Add } 10 \text { drops R. to } 7 \\
\text { c. c. pure cuiture of } \\
\text { the comma-bacillus. }\end{array}$ & $\begin{array}{l}\text { This is the indol- } \\
\text { reaction; other } \\
\text { bacteria elabor- } \\
\text { ate indol, but the } \\
\text { com m a-bacillus } \\
\text { and one or two } \\
\text { others elaborate } \\
\text { nitrous acid also, } \\
\text { which is neces- } \\
\text { sary for the reac- } \\
\text { tion. }\end{array}$ \\
\hline Pohl's test. & Globulin. & $\begin{array}{l}\text { (a) A m mon ium hy- } \\
\text { drate. (b) Sat. sol. } \\
\text { ammonium sulphate. }\end{array}$ & Precipitate. & $\begin{array}{l}\text { Alkalinize with } a \text {; fil- } \\
\text { ter after several } \\
\text { hours; add equal } \\
\text { part } b \text { to filtrate. }\end{array}$ & \\
\hline Pohl's test. & Picric acid. & & Yellow color. & $\begin{array}{l}\text { Soak woolen thread in } \\
\text { the liquid and rinse } \\
\text { in water. }\end{array}$ & \\
\hline Pollacci's test. & Glucose. & $\begin{array}{l}\text { (a) Sol. ferric chlorid. } \\
\text { (b) Sol. sodium hy- } \\
\text { drate. (c) Sulphuric } \\
\text { acid. (d) Fresh sol. } \\
\text { potass. ferricyanid. }\end{array}$ & Blue color. & $\begin{array}{l}\text { Shake liquid with } 4 \\
\text { c.c. water, x drop } a \text {, } \\
\text { and } 6 \text { drops } b \text {; boil } \\
\text { add } 2 \text { drops } c \text {. Let } \\
\text { cool; add } d \text {. }\end{array}$ & \\
\hline Pollak's test. & Melanin. & See Von Jaksch's test. & & & \\
\hline $\begin{array}{l}\text { Potassium-bromid- } \\
\text { test. }\end{array}$ & $\begin{array}{l}\text { Potass, bromid in } \\
\text { urine, etc. }\end{array}$ & $\begin{array}{l}\text { (a) Chlorin-water. }(b) \\
\text { Chloroform or car- } \\
\text { bon disulphid. }\end{array}$ & Yellow color. & Add $a$ and $b$. & $\begin{array}{l}\text { Reliable but not } \\
\text { delicate. }\end{array}$ \\
\hline $\begin{array}{l}\text { Potassium-ferrocy- } \\
\text { anid-test. }\end{array}$ & Albumin in urine. & See Hilger's test. & & & \\
\hline $\begin{array}{l}\text { Potassium-hydrate- } \\
\text { test. }\end{array}$ & $\begin{array}{c}\text { Chrysophanic acid } \\
\text { (rhubarb, senna) } \\
\text { in urine. }\end{array}$ & Potassium hydrate. & Red color. & $\begin{array}{l}\text { Add } \mathrm{R} \text {. to urine, or } \\
\text { better, to ethereal } \\
\text { extract (Penzoldt). }\end{array}$ & \\
\hline $\begin{array}{l}\text { Potassium-hydrate- } \\
\text { test. }\end{array}$ & $\begin{array}{l}\text { Santonin (its deri- } \\
\text { vatives). }\end{array}$ & Potassium hydrate. & Red color. & Add R. to urine. & $\begin{array}{l}\text { Distinguished from } \\
\text { chrysophanic } \\
\text { acid by reaction } \\
\text { not being ob- } \\
\text { tained with } \\
\text { ethereal extract. }\end{array}$ \\
\hline Pratesi's test. & Glucose in urine. & $\begin{array}{l}\text { Potass. hydrate } 2.5 \text {, } \\
\text { liquid potass. sili- } \\
\text { cate (concent.) } 60, \\
\text { potass. bichrom. } 2 . \\
\text { Allow } 5 \text { drops of this } \\
\text { mixture to dry on } \\
\text { strip of tin. }\end{array}$ & Green color. & $\begin{array}{l}\text { Heat tin, R, turns yel- } \\
\text { low; add uri ne: } \\
\text { green color if glu- } \\
\text { cose present. }\end{array}$ & \\
\hline
\end{tabular}


TABLE OF TESTS.-Continued.

\begin{tabular}{|c|c|c|c|c|c|}
\hline NAME. & USE. & REAGENTS. & REACTION. & APPLICATION. & REMAKKS. \\
\hline Price's test. & Iodin. & $\begin{array}{l}\text { (a) Starch. (b) Hydro- } \\
\text { chloric acid. (c) Sol. } \\
\text { potassium nitrite. }\end{array}$ & Biue color. & Mix liquid with $a, b, c$. & \\
\hline Propeptone-test. & Propeptone. & See Sodium-chlorid! & test. & & \\
\hline Propeptone-test. & $\begin{array}{l}\text { Propeptone in } \\
\text { urine. }\end{array}$ & Acetic or nitric acid. & $\begin{array}{l}\text { Cloudy precipitate, } \\
\text { disappearing on } \\
\text { heating. }\end{array}$ & $\begin{array}{l}\text { Boil urine, allow to } \\
\text { cool, add R. If ppt. } \\
\text { occurs, re-heat. }\end{array}$ & \\
\hline Prussian-blue test. & $\begin{array}{l}\text { Hydrocyanic acid } \\
\text { in tissues. }\end{array}$ & See Itiner's test. & & & \\
\hline Purdy's reagent. & Glucose in urine. & $\begin{array}{l}\text { Copper suIphate 4.I5 } \\
\text { gm., mannite ro gm., } \\
\text { glycerin 5o c.c.; dis- } \\
\text { solve in water. Add } \\
\text { potass, hydrate } 20.4 \\
\text { gm. dissolved in } \\
\text { water. Mix the solu- } \\
\text { tion s, a nd when } \\
\text { cold, add ammonia } \\
300 \text { c.c., and water } \\
\text { to make r liter. }\end{array}$ & Reduction. & & $\begin{array}{l}25 \text { c. c. of } \mathrm{R} .=1 / 4 \\
\text { grain glucose. }\end{array}$ \\
\hline Raabe's test. & Albumin in urine. & Trichloracetic acid. & White precipitate. & $\begin{array}{l}\text { Place crystal of } R \text {. } \\
\text { in filtered urine. }\end{array}$ & $\begin{array}{l}\text { See under Urine, } \\
\text { Tests for Serum- } \\
\text { albumin in. }\end{array}$ \\
\hline Rabourdin's test. & Iodin. & $\begin{array}{l}\text { (a) Nitric acid. }(b) \\
\text { Sulphuric acid. }(c) \\
\text { Chloroform. }\end{array}$ & Violet color of $c$. & $\begin{array}{l}\text { Add } 2 \text { drops } a \text {, I5 } b \text {, } \\
\text { and a little } c \text {. }\end{array}$ & \\
\hline Rabuteau's test. & $\begin{array}{l}\text { Hydrochloric acid } \\
\text { in urine. }\end{array}$ & $\begin{array}{l}\text { (a) Indigo-sulphuric } \\
\text { acid. }(b) \text { Sulphurous } \\
\text { acid. }\end{array}$ & Decolorization. & $\begin{array}{l}\text { Add a little } a \text { and suf- } \\
\text { ficient } b \text { to decom- } \\
\text { pose the hydro- } \\
\text { chloric acid. }\end{array}$ & \\
\hline Ralfe's test. & Acetone in urine. & $\begin{array}{l}\text { (a) Liq. potassæ. (b) } \\
\text { Potassium iodid. }\end{array}$ & $\begin{array}{l}\text { Yellow ring stud- } \\
\text { ded with specks } \\
\text { of iodoform at } \\
\text { line of contact. }\end{array}$ & $\begin{array}{l}\text { Boil } 4 \text { c.c. of } a \text { contain- } \\
\text { ing } 1.5 \mathrm{gm} . b \text {; over- } \\
\text { lay with } 4 \text { c.c. urine. }\end{array}$ & $\begin{array}{l}\text { Lactic acid and } \\
\text { some other sub- } \\
\text { stances respond. }\end{array}$ \\
\hline Ralfe's test. & Peptones in urine. & $\begin{array}{l}\text { Fehling's solut ion. } \\
\text { (See Fehling's test). }\end{array}$ & $\begin{array}{l}\text { Rose-colored halo } \\
\text { above zone of } \\
\text { phosphates. }\end{array}$ & $\begin{array}{l}\text { Place } 4 \text { c.c. } R \text {. in test- } \\
\text { tube overlay with } \\
\text { equal bulk of urine. }\end{array}$ & \\
\hline Randolph's test. & Peptones in urine. & $\begin{array}{l}\text { (a) Millon's reage n t } \\
\text { (see Millon's test). } \\
\text { (b) Sat. sol. potass. } \\
\text { iodid. }\end{array}$ & Yellow precipitate. & $\begin{array}{l}\text { To } 5 \text { c.c. of cold, } \\
\text { faintly acid urine } \\
\text { add } 2 \text { drops } b \text { and } \\
3 \text { or } 4 a \text {. }\end{array}$ & $\begin{array}{l}\text { Bile-acids respond. } \\
\text { Delicacy } I: 17,000 .\end{array}$ \\
\hline Read's test. & $\begin{array}{l}\text { Carbolic acid; cre- } \\
\text { asote. }\end{array}$ & Stronger ammonia. & $\begin{array}{l}\text { Carbolic acid solu- } \\
\text { ble ; creasote in- } \\
\text { soluble in } \mathrm{R} \text {. }\end{array}$ & & \\
\hline Rees' test. & Albumin. & See Almén's test. & & & \\
\hline Reichardt's test. & $\begin{array}{l}\text { Nitric acid in pot- } \\
\text { able water. }\end{array}$ & $\begin{array}{l}\text { (a) Sol. brucin. (b) Sul- } \\
\text { phuric acid. }\end{array}$ & Red color. & $\begin{array}{l}\text { To one drop of water } \\
\text { add } 3 \text { drops } a \text {, a few } \\
\text { of } b \text {. }\end{array}$ & \\
\hline Reiche's test. & Gum-arabic. & $\begin{array}{l}\text { Sol. of orcin in hydro- } \\
\text { chloric acid. }\end{array}$ & $\begin{array}{l}\text { Red to violet color } \\
\text { and blue precipi- } \\
\text { tate, dissolving } \\
\text { in alcohol with } \\
\text { greenis } \mathrm{h}-\mathrm{bl} \mathrm{u} \text { e } \\
\text { color. }\end{array}$ & Boil with $\mathrm{R}$. & $\begin{array}{l}\text { Alkalies turn last } \\
\text { color into violet, } \\
\text { with greenish } \\
\text { fluorescence. }\end{array}$ \\
\hline Reichl's test. A. & Glycerin. & $\begin{array}{l}\text { (a) Carbolic acid. (b) } \\
\text { Sulphuric acid. }\end{array}$ & $\begin{array}{c}\text { Brownish-y ellow } \\
\text { ppt., t } \mathrm{u} \text { r n ing } \\
\text { crimson on addi- } \\
\text { tion of water. }\end{array}$ & $\begin{array}{l}\text { Heat cautiously equal } \\
\text { parts of liquid, } a, \\
\text { and } b \text {. }\end{array}$ & \\
\hline Reichl's test. B. & | Glycerin. & $\begin{array}{l}\text { (a) Pyrogallic acid. }(b) \\
\text { Sulphuric acid. }(c) \\
\text { Stannic chlorid. }\end{array}$ & Violet-red color. & $\begin{array}{l}\text { Boil with } a \text { and } b \text {, di- } \\
\text { lute with equal vol- } \\
\text { ume of water, and } \\
\text { add } c \text {. }\end{array}$ & \\
\hline Reinsch's test. & Arsenic. & $\begin{array}{l}\text { (a) Hydrochloric acid. } \\
(b) \text { Clean slip of cop- } \\
\text { per. }\end{array}$ & Bluish spots. & $\begin{array}{l}\text { Boil liquid with few } \\
\text { drops } a \text { and with } b \text {. }\end{array}$ & \\
\hline Reinsch's test. & Sulphurous acid. & $\begin{array}{l}\text { (a) Bright strip of cop- } \\
\text { per. (b) Hy d ro- } \\
\text { chloric acid. }\end{array}$ & $\begin{array}{l}\text { Brown to black } \\
\text { stain. }\end{array}$ & $\begin{array}{l}\text { Moisten } a \text { with liquid } \\
\text { in presence of } b \text {. }\end{array}$ & \\
\hline
\end{tabular}


TABLE OF TESTS.-Continued.

\begin{tabular}{|c|c|c|c|c|c|}
\hline NAME. & USE. & REAGENTS. & REACTION. & APPLICATION. & REMARKS. \\
\hline Reissner's test. & $\begin{array}{l}\text { Nucleo-albumin in } \\
\text { urine. }\end{array}$ & Acetic acid. & | Turbidity. & $\begin{array}{l}\text { Filter urine; dilute, } \\
\text { and add excess of } R \text {. }\end{array}$ & \\
\hline Renzone's test. & Kairin in urine. & $\begin{array}{l}\text { (a) Sol. ferric chlorid. } \\
\text { (b) Sulphuric acid. }\end{array}$ & $\begin{array}{l}\text { Dark-violet or } \\
\text { reddish-brow } \\
\text { color. }\end{array}$ & $\begin{array}{l}\text { Add } a \text {. Subsequent } \\
\text { addition of } b \text {, light- } \\
\text { red color. }\end{array}$ & \\
\hline $\begin{array}{l}\text { Resorcin-sugar } \\
\text { test. }\end{array}$ & $\begin{array}{c}\text { Hydrochloric acid } \\
\text { in gastric juice. }\end{array}$ & See Boas' test. & & & \\
\hline Reuss' test. & Atropin. & $\begin{array}{l}\text { (a) Sulphuric acid. (b) } \\
\text { An oxidizing ageut. }\end{array}$ & Odor of blossoms. & Heat with $a$ and $b$. & \\
\hline Reynold's test. & Acetone. & See Reynold-Gun & : ning's test. & & \\
\hline $\begin{array}{l}\text { Reynold-Gunning's } \\
\text { test. }\end{array}$ & Acetone in urine. & $\begin{array}{l}\text { (a) Mercuric oxid } \\
\text { (freshyellow precipi- } \\
\text { tate) (b) Ammon- } \\
\text { ium sulphid. }\end{array}$ & $\begin{array}{l}\text { Black ring of mer- } \\
\text { curic sulphid. }\end{array}$ & $\begin{array}{l}\text { To urine add small } \\
\text { quantity of } a \text {. If } \\
\text { acetone present } \\
\text { some } a \text { is dissolved. } \\
\text { Filter and overlay } \\
\text { filtrate with } b \text {. }\end{array}$ & $\begin{array}{l}\text { Black ring shows } \\
\text { that a has been } \\
\text { dissolved, thus } \\
\text { indicating ace- } \\
\text { tone. Very deli- } \\
\text { cate; less so than } \\
\text { Lieben's test. }\end{array}$ \\
\hline Reynoso's test. & Iodin. & $\begin{array}{l}\text { (a) Barium oxid. (b) } \\
\text { Starch-paste. (c) } \\
\text { Hydrochloric acid. }\end{array}$ & Blue color. & $\begin{array}{l}\text { Mix } a, b \text {, and } c \text { in } \\
\text { water; when evolu- } \\
\text { tion of gas begins, } \\
\text { add liquid. }\end{array}$ & \\
\hline Rhien's test. & $\begin{array}{l}\text { Fixed oils in es- } \\
\text { sential oils. }\end{array}$ & (a) Steam. (b) Ether. & $\begin{array}{l}\text { Fatty matter con- } \\
\text { tained in } b .\end{array}$ & $\begin{array}{r}\text { Pass a through oil } \\
\text { until it distils over } \\
\text { shake residue with } b \text {. }\end{array}$ & \\
\hline Rice's test. & Carbolic acid. & $\begin{array}{l}\text { (a) Potass. chlorate. } \\
\text { (b) Hy droch loric } \\
\text { acid. (c) Ammonia. }\end{array}$ & $\begin{array}{l}\text { Brown to rose-red } \\
\text { color. }\end{array}$ & $\begin{array}{l}\text { Put Io gm. } a \text { into test- } \\
\text { tube, add I inch } b, \\
\text { and I I v vol. of water. } \\
\text { Remove gas by blow- } \\
\text { ing through a glass } \\
\text { tube; pour } c \text { on top, } \\
\text { and a few drops of } \\
\text { the liquid. }\end{array}$ & I : 1200. \\
\hline Richmont's test. & I Nitric acid. & $\begin{array}{l}\text { (a) Sulphuric acid. }(b) \\
\text { Sol. ferrous sulphate. }\end{array}$ & $\begin{array}{l}\text { Red color chang- } \\
\text { ing to violet and } \\
\text { brown. }\end{array}$ & Add $a$, then $b$. & \\
\hline Riegel's test. & $\begin{array}{l}\text { Free hydrochloric } \\
\text { acid in gastric } \\
\text { juice. }\end{array}$ & $\begin{array}{l}\text { Either Congo-red } \\
\text { paper or solution. }\end{array}$ & Blue. & $\begin{array}{l}\text { Moisten paper with } \\
\text { drop of filtered gas- } \\
\text { tric juice, or add } \\
\text { drop of } R \text {. to latter. }\end{array}$ & Very delicate. \\
\hline Righini's test. & Purity of myrrh. & Ammonium chlorid. & $\begin{array}{l}\text { Should dissolve } \\
\text { completely. }\end{array}$ & $\begin{array}{l}\text { Add equal weight of } \\
\text { R. in in times as } \\
\text { much water. }\end{array}$ & \\
\hline Rily's test. & Chlorin. & $\begin{array}{l}\text { (a) Potass. bichromate. } \\
\text { (b) Sulphuric acid. } \\
\text { (c) Ammonia, (d) } \\
\text { Acetic acid. (e) Sol. } \\
\text { lead subacetate. }\end{array}$ & $\begin{array}{l}\text { Yellow to orange } \\
\text { color. }\end{array}$ & $\begin{array}{l}\text { Mix } a \text { and substance } \\
\text { āa } I \text {, and } b 3 \text {, in } \\
\text { beaker-g la ss, and } \\
\text { suspend in it small } \\
\text { bea } \mathrm{k} \text { er containing } \\
\text { ice. To condensed } \\
\text { crystals add } c, d \text {, and } \\
e \text {. }\end{array}$ & \\
\hline Ritthausen's test. & Proteids. & $\begin{array}{l}\text { (a) Dilute sol. of cop- } \\
\text { per sulphate. (b) } \\
\text { Sol. potass. hydrate. }\end{array}$ & Violet-red color. & $\begin{array}{l}\text { Alkalinize with } b, \text { add } \\
a, \text { and shake. }\end{array}$ & $\begin{array}{l}\text { Delicacy or per } \\
\text { cent. }\end{array}$ \\
\hline Roberts' test. & Albumin in urine. & $\begin{array}{l}\text { Strong nitric acid I, } \\
\text { sat. sol. magnes. sul- } \\
\text { phate } 5 \text {. }\end{array}$ & White ring or disc. & Overlay $R$. with urine. & \\
\hline Roberts' test. & Albumin in urine. & $\begin{array}{l}\text { Sat. sol. sodium chlo- } \\
\text { rid in dilute hydro- } \\
\text { chloric acid ( } 5 \text { to } 100 \\
\text { of water). }\end{array}$ & White ring or disc. & Overlay R. with urine. & \\
\hline Roberts' test. & Glucose in urine. & German yeast. & \begin{tabular}{|} 
Difference in \\
specific gravity \\
between fer- \\
mented and un- \\
fermented urine.
\end{tabular} & $\begin{array}{l}\text { Add a little yeast to } \\
60-70 \text { c.c. of urine; } \\
\text { allow to ferment for } \\
24 \text { hours, and com- } \\
\text { pare specific gravity } \\
\text { with that of same } \\
\text { urine unfermented. }\end{array}$ & $\begin{array}{l}\text { Every degree lost } \\
\text { represents I grain } \\
\text { of glucose per } \\
\text { ounce, or } 0.23 \text { per } \\
\text { cent. }\end{array}$ \\
\hline Robin's test. & Alkaloids. & $\begin{array}{l}\text { (a) Sugar. (b) Sul- } \\
\text { phuric acid. }\end{array}$ & Color-reactions. & $\begin{array}{l}\text { Mix with twice its } \\
\text { weight of } a, \text { add } 2 \\
\text { drops } b \text {; stir. }\end{array}$ & \\
\hline
\end{tabular}


TABLE OF TESTS.-Continued.

\begin{tabular}{|c|c|c|c|c|c|}
\hline NAME. & USE. & REAGENTS. & REACTION. & APPLICATION. & REMARKS. \\
\hline Robiquet's test. & Morphin. & Sol. of a persalt of iron. & Blue color. & & \\
\hline Roch's test. & Albumin in urine. & Salicylsulphonic acid. & $\begin{array}{l}\text { Turbidity or pre- } \\
\text { cipitate. }\end{array}$ & $\begin{array}{l}\text { Add } 20 \text { per cent. sol. } \\
\text { or a few crystals of } \\
\text { R. to urine. }\end{array}$ & \\
\hline Rochleder's test. & Caffein. & $\begin{array}{l}\text { (a) Hydrochloric acid. } \\
\text { (b) Potass. chlorate. } \\
\text { (c) Ammonia. }\end{array}$ & \begin{tabular}{|} 
Yellowish-red \\
color, turning \\
violet on addi- \\
tion of $c$. \\
\end{tabular} & $\begin{array}{l}\text { Heat with } a \text { and } b \text {, } \\
\text { and evaporate gently; } \\
\text { add } c \text {. }\end{array}$ & \\
\hline Romei's test. & $\begin{array}{l}\text { Fuchsin in fruit- } \\
\text { syrups. }\end{array}$ & Fusel-oil. & $\begin{array}{l}\text { R. takes up only } \\
\text { the fuchsin. }\end{array}$ & Shake with $\mathrm{R}$. & \\
\hline Romel's test. & Water in ether. & Potass. carbolate. & $\begin{array}{l}\text { Dense solution in } \\
\text { presence of } \\
\text { water. }\end{array}$ & $\begin{array}{l}\text { R. insoluble in pure } \\
\text { ether. }\end{array}$ & \\
\hline Rosenbach's test. & Albumin in urine. & $\begin{array}{l}5 \text { per cent. sol. of chro- } \\
\text { mic acid. }\end{array}$ & $\begin{array}{l}\text { Yellow precipi- } \\
\text { tate. }\end{array}$ & $\begin{array}{l}\text { A few drops of R. } \\
\text { ad d ed to acidu- } \\
\text { lated urine. }\end{array}$ & \\
\hline Rosenbach's test. & $\begin{array}{l}\text { Bile-pigment in } \\
\text { urine. }\end{array}$ & Fuming nitric acid. & Play of colors. & $\begin{array}{l}\text { Filter urine, and pour } \\
\mathrm{R} \text {. over the inner } \\
\text { surface of the filter- } \\
\text { paper. }\end{array}$ & $\begin{array}{l}\text { Modification of } \\
\text { Gmelin's test, } \\
\text { but more deli- } \\
\text { cate. }\end{array}$ \\
\hline Rosenbach's test. & $\left\{\begin{array}{l}\text { Indigo-red in } \\
\text { urine. }\end{array}\right.$ & Nitric acid. & $\begin{array}{l}\text { Deep-red color: } \\
\text { foam violet } \\
\text { color soluble in } \\
\text { chloroform or } \\
\text { ether. }\end{array}$ & $\begin{array}{l}\text { Boil urine ; add R. drop } \\
\text { by drop. }\end{array}$ & \\
\hline Rosenstiehl's test. & Paratoluidin. & $\left\{\begin{array}{l}\text { (a) Sulphuric acid. }(b) \\
\text { Nitric acid. }\end{array}\right.$ & $\begin{array}{l}\text { Blue to violet, then } \\
\text { red, finally } \\
\text { brown. }\end{array}$ & To solution in $a$ add $b$. & \\
\hline Rosin's test. & $\begin{array}{l}\text { Bile-pigment in } \\
\text { urine. }\end{array}$ & Tr. iodi I, alcohol Io. & Grass-green ring. & Overlay urine with $\mathrm{R}$. & $\begin{array}{l}\text { In the absence of } \\
\text { bile urine is de- } \\
\text { colorized at line } \\
\text { of contact. }\end{array}$ \\
\hline Rosolic-acid test. & $\begin{array}{l}\text { Acidimetry, alka- } \\
\text { limetry. }\end{array}$ & $\begin{array}{l}\text { Rosolic acid I gm., di- } \\
\text { lute alcohol Io c.c., } \\
\text { water to make Ioo } \\
\text { c.c. }\end{array}$ & $\begin{array}{l}\text { Turns violet-red } \\
\text { with alkalies, } \\
\text { y el low with } \\
\text { acids. }\end{array}$ & & \\
\hline Ross' test. & Phosphoric acid. & $\begin{array}{l}\text { (a) Borax. (b) Sodium } \\
\text { tungstate. }\end{array}$ & $\begin{array}{c}\text { Blue color in re- } \\
\text { duction-flame. }\end{array}$ & $\begin{array}{l}\text { Dissolve in bead of } a \text {, } \\
\text { add } b \text {; heat in re- } \\
\text { duction-flame. }\end{array}$ & \\
\hline Roth's test. & Purity of olive-oil. & $\begin{array}{l}\text { Sulphuric acid sat. } \\
\text { with nitrous-acid } \\
\text { vapors. }\end{array}$ & Color-reactions. & Mix. & \\
\hline Ruber's test. & Glucose in urine. & See Rubner's test. & & & \\
\hline Rubner's test. & Glucose in urine. & $\begin{array}{l}\text { (a) Sol. lead acetate. } \\
\text { (b) Ammonium hy- } \\
\text { drate. }\end{array}$ & Rosy to flesh color. & $\begin{array}{l}\text { Add to urine excess of } \\
a \text {, filter, add to fil- } \\
\text { trate } b \text {, and warm. }\end{array}$ & $\begin{array}{l}\text { Delicacy } 0.25 \text { per } \\
\text { cent. }\end{array}$ \\
\hline Rubner's test. & Milk-sugar. & $\begin{array}{l}\text { (a) Sol. lead acetate, } \\
\text { (b) Ammonium hy- } \\
\text { drate. }\end{array}$ & $\begin{array}{l}\text { With a yellowish- } \\
\text { brown; when } b \\
\text { is added, brick- } \\
\text { red color and } \\
\text { cherry-red ppt. }\end{array}$ & $\begin{array}{l}\text { Boil with excess of } a \\
\text { add } b \text { as long as ppt. } \\
\text { is dissolved. }\end{array}$ & \\
\hline Ruempler's test. & $\begin{array}{l}\text { Free acids in fixed } \\
\text { oils. } \\
\end{array}$ & $\begin{array}{l}\text { Sodium } \text { carbonate } \\
\text { (C. P.). }\end{array}$ & Emulsion. & Shake liquid with $\mathrm{R}$. & \\
\hline Runge's test. & Anilin. & Sol, chlorinated lime. & $\begin{array}{l}\text { Purple-violet } \\
\text { color. }\end{array}$ & Add R. & \\
\hline Runge's test. & Anilin. & & $\begin{array}{l}\text { Pine-wood stained } \\
\text { yellow even by } \\
\text { dilute sol. of } \\
\text { anilin hydro- } \\
\text { chlorate. }\end{array}$ & & \\
\hline Runge's test. & Cane-sugar. & Dilute sulphuric acid. & $\begin{array}{l}\text { Blackening on } \\
\text { evaporating } \\
\text { with } R \text {. }\end{array}$ & $\begin{array}{l}\text { Evaporate substance } \\
\text { with } R \text {. }\end{array}$ & \\
\hline Runge's test. & Carbolic acid. & Hydrochloric acid. & $\begin{array}{l}\text { Blue color of a } \\
\text { pine shaving } \\
\text { moistened with } \\
\text { R. }\end{array}$ & $\begin{array}{l}\text { Dip shaving moist- } \\
\text { ened with } R \text { in to } \\
\text { carbolic acid. }\end{array}$ & \\
\hline
\end{tabular}


TABLE OF TESTS.-Continued.

\begin{tabular}{|c|c|c|c|c|c|}
\hline NAME. & USE. & REAGENTS. & REACTION, & APPLICATION. & REMARKS. \\
\hline Rust's test. & $\begin{array}{l}\text { Carbolic acid; } \\
\text { creasote. }\end{array}$ & Collodion. & $\begin{array}{l}\text { Carbolic acid } \\
\text { forms a jelly } \\
\text { with R. ; crea- } \\
\text { sote does not. }\end{array}$ & & \\
\hline $\begin{array}{l}\text { Sabanin and Las- } \\
\text { kowski's test. }\end{array}$ & Citric acid. & Ammonia. & Yellow color. & $\begin{array}{l}\text { Heat with } \mathrm{R} \text {. in sealed } \\
\text { tube at } 120^{\circ} \mathrm{C} \text {. } 6 \\
\text { hours; yellow color. }\end{array}$ & $\begin{array}{l}\text { Blue color when } \\
\text { poured out and } \\
\text { allowed to stand. }\end{array}$ \\
\hline $\begin{array}{l}\text { Sachse'stest (Quan. } \\
\text { titative). }\end{array}$ & Glucose in urine. & $\begin{array}{l}\text { Mercuric iodid } 18 \mathrm{gm} . \\
\text { potass. iodid } 25 \mathrm{gm} ., \\
\text { potas . hydrate } 80 \\
\text { gm., water up to } 1000 \\
\text { c.c. }\end{array}$ & Reduction. & $\begin{array}{l}\text { End of reaction ascer- } \\
\text { tained by means of } \\
\text { sol. of stann ous } \\
\text { chlorid, supersatur- } \\
\text { ated with sodium } \\
\text { hydrate. }\end{array}$ & $\begin{array}{l}40 \text { c.c. }=0.1342 \text { glu- } \\
\text { cose. }\end{array}$ \\
\hline Salicylic-acid test. & $\begin{array}{l}\text { For salicylic-acid } \\
\text { derivatives in } \\
\text { urine. }\end{array}$ & $\begin{array}{l}\text { See Ferric-chlorid } \\
\text { test. }\end{array}$ & & & \\
\hline Saliphonic-test. & Albumin. & $\begin{array}{l}\text { See MacWilliams } \\
\text { test. }\end{array}$ & & & \\
\hline Salkowski's test. & Carbolic acid. & $\begin{array}{l}\text { (a) Ammonia. (b) Sol. } \\
\text { ch lorinated lime } \\
(1: 20) \text {. }\end{array}$ & $\begin{array}{l}\text { Blue or greenish } \\
\text { color. }\end{array}$ & $\begin{array}{l}\text { Add } 1 / 4 \text { volume } a \text { and } \\
\text { a few drops } b \text {; warm. }\end{array}$ & I : 4000 \\
\hline Salkowski's test. & Cholesterin. & $\begin{array}{l}\text { (a) Chlor of orm. (b) } \\
\text { Sulphuric acid. }\end{array}$ & $\begin{array}{l}\text { Blood-red color of } \\
a ; \text { green fluores- } \\
\text { cence with } b \text {. }\end{array}$ & $\begin{array}{l}\text { Dissolve in } a \text {; add } \\
\text { equal volume } b \text {. }\end{array}$ & \\
\hline Salkowski's test. & Hematoporphyrin. & $\begin{array}{l}\text { (a) Sol. ba riu m hy- } \\
\text { drate a in d barium } \\
\text { chlorid. (b) Acid al- } \\
\text { cohol (alcohol con- } \\
\text { taining I per cent. } \\
\text { hydrochloric acid). }\end{array}$ & $\begin{array}{l}\text { In spectroscope } 2 \\
\text { characteristic } \\
\text { bands. }\end{array}$ & $\begin{array}{l}\text { Precipitate urine with } \\
a \text {, wash precipitate, } \\
\text { and extract with } b \text {. }\end{array}$ & \\
\hline Salkowski's test. & Oxalic acid. & $\begin{array}{l}\text { (a) Calcium hydrate. } \\
(b) \text { Calcium chlorid. } \\
\text { (c) Alcohol. (d) Dil. } \\
\text { hydrochloric a cid. } \\
\text { (e) Ammonium hy- } \\
\text { drate. }(f) \text { Acetic } \\
\text { acid. }\end{array}$ & $\begin{array}{l}\text { Octahedral crys- } \\
\text { tals of calcium } \\
\text { oxalate. }\end{array}$ & $\begin{array}{l}\text { A I k a linize Ioo c.c. } \\
\text { urine with } a \text {; add } \\
b \text {, evaporate parti- } \\
\text { ally; add } c \text {; wash } \\
\text { with } c \text { and hot wa- } \\
\text { ter; dissolve in } d \text {; } \\
\text { add } e \text { and } f \text {. }\end{array}$ & \\
\hline Salkowski's test. & $\begin{array}{l}\text { Potassium in } \\
\text { urine. }\end{array}$ & $\begin{array}{l}\text { Concent. sol, tartaric } \\
\text { acid. }\end{array}$ & $\begin{array}{l}\text { Crystals of acid } \\
\text { potass. tartrate. }\end{array}$ & $\begin{array}{l}\text { Evaporate } 100-150 \text { c.c. } \\
\text { urine to } 1 / 8 \text { vol.; fil- } \\
\text { ter in the cold; add } \\
\text { R. }\end{array}$ & \\
\hline Salkowski's test. & $\begin{array}{l}\text { Sulphurous acid } \\
\text { in urine. }\end{array}$ & $\begin{array}{l}\text { Hydrochloric acid } \\
\text { (spec. grav. 1, I2). }\end{array}$ & $\begin{array}{l}\text { Bluish or yellow- } \\
\text { ish-white ppt. on } \\
\text { upper portion of } \\
\text { cooling tube. }\end{array}$ & $\begin{array}{l}\text { Distil roo c.c. urine } \\
\text { and Io c.c. R. to } 1 / 3 \\
\text { or } 1 / 4 \text { vol. }\end{array}$ & \\
\hline Salomon's test. & $\begin{array}{l}\text { Xanthin, paraxan- } \\
\text { thin, heteroxan- } \\
\text { thin. }\end{array}$ & $\begin{array}{l}\text { Sodium or potass. hy- } \\
\text { drate. }\end{array}$ & $\begin{array}{l}\text { R. precipitates } \\
\text { paraxanthin and } \\
\text { heteroxanthin. }\end{array}$ & - & $\begin{array}{l}\text { Paraxanthin- } \\
\text { right-angled } \\
\text { p lan es and } \\
\text { prisms. Hetero- } \\
\text { xanthin - acute- } \\
\text { angled or obtuse- } \\
\text { angled, often } \\
\text { double, crystals. }\end{array}$ \\
\hline Salzer's test. & $\begin{array}{l}\text { Alcohol in essen- } \\
\text { tial oils. }\end{array}$ & Fuchsin. & $\begin{array}{l}\text { A l cohol evapo- } \\
\text { rates first a n d } \\
\text { dissolves } \mathrm{R} \text {. }\end{array}$ & $\begin{array}{l}\text { Dust } \mathrm{R} \text {. on upper part } \\
\text { of inside of a test- } \\
\text { tube; drop oil on } \\
\text { bottom without } \\
\text { touch ing sides of } \\
\text { tube; heat. }\end{array}$ & \\
\hline Schaal's test. & $\begin{array}{l}\text { Acidimetry, alka- } \\
\text { limetry. }\end{array}$ & Alizarin. & $\begin{array}{l}\text { Acids color it yel- } \\
\text { low; a Ik alies } \\
\text { rose-red. }\end{array}$ & & I : 300,000 alkali. \\
\hline Schack's test. & Oil of peppermint. & Fused salicylic acid. & $\begin{array}{l}\text { Blue-green color. } \\
\text { Dissolved in al- } \\
\text { cohol, blue by } \\
\text { transmitted, red } \\
\text { by reflected } \\
\text { light. }\end{array}$ & Mix liquid and $\mathrm{R}$. & \\
\hline Scherer's test. & Inosite. & $\begin{array}{l}\text { (a) Nitric acid. (b) } \\
\text { Ammonia. }(c) \text { Sol. } \\
\text { calcium chlorid. }\end{array}$ & Rose-red residue. & $\begin{array}{l}\text { Evaporate to dryness } \\
\text { with } a \text {; add } b \text {, one } \\
\text { drop } c \text {, and evapo- } \\
\text { rate. }\end{array}$ & $\begin{array}{l}\text { Of value only with } \\
\text { pure solutions. }\end{array}$ \\
\hline
\end{tabular}


TABLE OF TESTS.-Continued.

\begin{tabular}{|c|c|c|c|c|c|}
\hline NAME. & USE. & REAGENTS. & REACTION. & APPLICATION. & REMARKS. \\
\hline Scherer's test. & Leucin. & $\begin{array}{l}\text { (a) Nitric acid. (b) } \\
\text { Sodium hydrate. }\end{array}$ & $\begin{array}{l}\text { Transparent resi- } \\
\text { due, turn ing } \\
\text { brown on addi- } \\
\text { tion of } b \text {. }\end{array}$ & $\begin{array}{l}\text { Evaporate to dryness } \\
\text { with } a \text { on platinum; } \\
\text { add } b \text {. Re-evapora- } \\
\text { tion p roduces an } \\
\text { oily drop. }\end{array}$ & $\begin{array}{l}\text { Only applicable to } \\
\text { very pure leucin. }\end{array}$ \\
\hline Scherer's test. & $\begin{array}{l}\text { Phosphorus in tis- } \\
\text { sues. }\end{array}$ & $\begin{array}{l}\text { (a) Basic lead acetate. } \\
\text { (b) Ether. (c) Paper } \\
\text { moistened with sil- } \\
\text { ver-nitrate sol. }\end{array}$ & $\begin{array}{l}\text { Blackening of pa- } \\
\text { per; test for } \\
\text { pliosphoric acid. }\end{array}$ & $\begin{array}{l}\text { Mix with } a \text {, shake in } \\
\text { flask with } b ; \text { close } \\
\text { with cork, to under } \\
\text { surface of which } c \text { is } \\
\text { attached. }\end{array}$ & $\begin{array}{l}\text { Digest blackened } c \\
\text { with hot water; } \\
\text { separate silver } \\
\text { by hydrochloric } \\
\text { acid and filtra- } \\
\text { tion; test filtrate } \\
\text { for phosphoric } \\
\text { acid. }\end{array}$ \\
\hline Scherer's test. & Phosphorus. & $\begin{array}{l}\text { Slip of silver-nitrate } \\
\text { paper. }\end{array}$ & Black stain. & $\begin{array}{l}\text { Heat substance to } 30- \\
40^{\circ} \mathrm{C} \text {., and expose } \mathrm{R} \text {. } \\
\text { to vapor. }\end{array}$ & \\
\hline Schering's test. & Iodates in iodids. & $\begin{array}{l}\text { Crystal of tartaric } \\
\text { acid. }\end{array}$ & Yellow zone. & Add R. to solution. & \\
\hline Schiff's test. & $\begin{array}{l}\text { Carbohydrates in } \\
\text { urine. }\end{array}$ & $\begin{array}{l}\text { (a) Sulphuric acid. }(b) \\
\text { Xylidin and glacial } \\
\text { acetic acid, eq. vol., } \\
\text { with a little alcohol. }\end{array}$ & Red color. & $\begin{array}{l}\text { Warm urine with } a \\
\text { expose paper dipped } \\
\text { in } b \text { and dried to the } \\
\text { fumes of the urine. }\end{array}$ & \\
\hline Schiff's test. & Cholesterin. & $\begin{array}{l}\text { Sulphuric acid 2, dil- } \\
\text { ute sol. ferric chlo- } \\
\text { rid I. }\end{array}$ & Violet color. & Add R. & \\
\hline Schiff's test. & Cholesterin. & $\begin{array}{l}\text { (a) Nitric acid. (b) } \\
\text { Ammonia. }\end{array}$ & $\begin{array}{l}\text { Red color (not al- } \\
\text { tered by fixed } \\
\text { alkalies). }\end{array}$ & $\begin{array}{l}\text { Evaporate with } a \text {; add } \\
\quad b .\end{array}$ & \\
\hline Schiff's test. & Sulphurous acid. & $\begin{array}{l}\text { Mercurous-nitrate pa- } \\
\text { per. }\end{array}$ & Gray stain. & $\begin{array}{l}\text { Expose } R \text {, to the va- } \\
\text { pors of the sub- } \\
\text { stance. }\end{array}$ & \\
\hline Schiff's test. & Urea. & $\begin{array}{l}\text { (a) Sol. of furfurol. (b) } \\
\text { Hydrochloric acid. }\end{array}$ & $\begin{array}{l}\text { Purple color, turn- } \\
\text { ing brownish- } \\
\text { black. }\end{array}$ & Add $a$ and $b$. & \\
\hline Schiff's test. & Uric acid. & Silver-nitrate paper. & Brown stain. & $\begin{array}{l}\text { Treat } \mathrm{R} \text {. with alkaline } \\
\text { solution of sub- } \\
\text { stance. }\end{array}$ & \\
\hline $\begin{array}{l}\text { Schlagden hauf- } \\
\text { fen's test. }\end{array}$ & Magnesium salts. & $\begin{array}{l}\text { Sol. of iodin in } 2 \text { per } \\
\text { cent. sol. of potass. } \\
\text { or sodium hydrate, } \\
\text { till solution golden- } \\
\text { yellow. }\end{array}$ & $\begin{array}{l}\text { Brownish-red col- } \\
\text { or or precipitate. }\end{array}$ & Add R. & \\
\hline Schlienkamp's test. & Nux vomica. & Sulphuric acid. & $\begin{array}{l}\text { Crimson color: } \\
\text { disappears on } \\
\text { cooling. }\end{array}$ & Add R. and evaporate. & \\
\hline Schmid's test. & Metallic salts. & $\begin{array}{l}\text { Sol. of phosphorus in } \\
\text { carbon disulphid. }\end{array}$ & $\begin{array}{l}\text { Colored precipi- } \\
\text { tate. }\end{array}$ & $\begin{array}{l}\text { Shake } R \text {. with aqueous } \\
\text { solution of the salt. }\end{array}$ & \\
\hline Schmidt's test. & Glucose. & $\begin{array}{l}\text { Ammoniacal so 1. of } \\
\text { lead acetate. }\end{array}$ & Red color. & Boil with R. & \\
\hline $\begin{array}{l}\text { Schmie d eberg's } \\
\text { solution. }\end{array}$ & Glucose. & $\begin{array}{l}\text { Copper sulph. } 34.634, \\
\text { water } 200 \text {; mannite } \\
\text { I5, water roo; sod- } \\
\text { ium hydrate (1.145) } \\
400 \text {; water to rooo. }\end{array}$ & Reduction. & $\begin{array}{l}\text { Use as in Fehling's } \\
\text { test. }\end{array}$ & \\
\hline Schneider's test. & Alkaloids. & $\begin{array}{l}\text { (a) Sugar. (b) Sul- } \\
\text { phuric acid. }\end{array}$ & Color-reactions. & $\begin{array}{l}\text { Mix with } 6 a \text {, and add } \\
\text { I drop } b \text { on top. }\end{array}$ & \\
\hline Schneider's test. & Bismuth. & $\begin{array}{l}\text { Tartaric acid } 3 \text {, stan- } \\
\text { nous chlorid } x \text {, in suf- } \\
\text { ficient sol. potass. } \\
\text { hydrate. }\end{array}$ & $\begin{array}{l}\text { Blackish-brow n } \\
\text { precipitate. }\end{array}$ & Heat with $\mathrm{R}$. & \\
\hline Schœenbein's test. & Blood. & $\begin{array}{l}\text { (a) Tr. guaiaci. (b) Ol. } \\
\text { terebinth. (French). }\end{array}$ & Blue color. & Add $a$, then $b$. & \\
\hline Schoenbein's test. & Copper. & $\begin{array}{l}\text { (a) Potass. cyanid. }(b) \\
\text { Tr. guaiaci. }\end{array}$ & Blue color. & Add $a$, then $b$. & \\
\hline Schoenbein's test. & Hydrocyanic acid. & $\begin{array}{l}\text { (a) Fresh, defibrinated } \\
\text { blood 5, water } 45,(b) \\
\text { Hydrogen dioxid. }\end{array}$ & $\begin{array}{l}\text { Red color changed } \\
\text { to brown. }\end{array}$ & $\begin{array}{l}\text { Mix } a, b \text {, and liquid, } \\
\text { and add a little } c \text {. }\end{array}$ & \\
\hline
\end{tabular}


TABLE OF TESTS.-Continued.

\begin{tabular}{|c|c|c|c|c|c|}
\hline NAME. & USE. & REAGENTS. & REACTION. & APPLICATION. & REMARKS. \\
\hline Schœenbein's test. & Hydrocyanic acid. & $\begin{array}{l}\text { Strip of filter-paper } \\
\text { moistened with } 3 \% \\
\text { alcohol. sol. guaiac; } \\
\text { dry moisten with } \\
\text { drop of } 0.05 \% \text { sol. } \\
\text { copper sulphate. }\end{array}$ & Blue color. & $\begin{array}{l}\text { Moisten R. with drop } \\
\text { or two of the liquid. }\end{array}$ & $\begin{array}{l}\text { Very delicate, but } \\
\text { many substances } \\
\text { respond: am- } \\
\text { monia, tobacco- } \\
\text { smoke, ozone, } \\
\text { etc. }\end{array}$ \\
\hline Schœenbein's test. & Hydrogen dioxid. & $\begin{array}{l}\text { (a) Cadmium iodid } \\
\text { and starch-solution. } \\
\text { (b) Sol. ferrous sul- } \\
\text { phate. }\end{array}$ & Blue color. & Add $a$ and $b$. & \\
\hline Schoenbein's test. & Hydrogen dioxid. & $\begin{array}{l}\text { (a) } \mathrm{Tr} \text {. of gua ia c } \\
\text { (fresh). (b) Cold in- } \\
\text { fusion of malt. }\end{array}$ & Blue color. & $\begin{array}{l}\text { Add } a \text { and a few drops } \\
b \text {. }\end{array}$ & $I: 2,000,000$ \\
\hline Schcenbein's test. & Hydrogen dioxid. & $\begin{array}{l}\text { Sol. ferric chlorid and } \\
\text { potassium ferricy- } \\
\text { anid (red). }\end{array}$ & Blue color. & Add R. & I to $10,000,000$ \\
\hline Schoenbein's test. & $\begin{array}{l}\text { Nitrous acid in } \\
\text { potable water. }\end{array}$ & $\begin{array}{l}\text { (a) Sol. pyrogallic acid. } \\
\text { (b) Dilute sulphuric } \\
\text { acid. }\end{array}$ & Brown color. & Add $a$ and $b$. & \\
\hline Schcenbein's test. & $\begin{array}{l}\text { Nitrous a cid in } \\
\text { potable water. }\end{array}$ & $\begin{array}{l}\text { Indigo-sol. to water to } \\
\text { render it blue; add } \\
\text { hydrochloric acid; } \\
\text { stir, and add potas- } \\
\text { sium pentasulphid } \\
\text { till blue color disap- } \\
\text { pears ; filter. }\end{array}$ & Blue color. & $\begin{array}{l}\text { Add suspected water } \\
\text { to } R \text {. }\end{array}$ & \\
\hline Schcenn's test. & Cobalt. & $\begin{array}{l}\text { Neutral sol. sodium } \\
\text { sulphocyanid. }\end{array}$ & Blue color. & Add R. & \\
\hline Schœenn's test. & Hydrogen dioxid. & Sol. titanic acid. & $\begin{array}{l}\text { Yellow to deep- } \\
\text { red color. }\end{array}$ & Add $R$. & \\
\hline Schœenn's test. & Molybdic acid. & Sulphuric acid. & Blue color. & Heat with $\mathrm{R}$. & \\
\hline Schoenn's test. & Phosphorus. & Magnesium ribbon. & $\begin{array}{l}\text { Evolution of phos- } \\
\text { phin. }\end{array}$ & $\begin{array}{l}\text { Heat with } \mathrm{R} . ; \text { then add } \\
\text { a little water. }\end{array}$ & \\
\hline Schœenn's test. & Sulphur. & $\begin{array}{l}(a) \text { Sodium. (b) Sol. } \\
\text { sodium nitroprussid. }\end{array}$ & Red color. & $\begin{array}{l}\text { Heat with } a \text {; dissolve } \\
\text { in water ; add } b \text {. }\end{array}$ & \\
\hline Schreiter's test. & Glucose. & $\begin{array}{r}\text { Mixture of sodium } \\
\text { salicylate 2, copper } \\
\text { sulphate 2, sodium } \\
\text { hydrate Io, water } 40 . \\
\end{array}$ & Red precipitate. & Heat with $\mathrm{R}$. & \\
\hline $\begin{array}{l}\text { Schuetzenberger's } \\
\text { test. }\end{array}$ & Anthrachinon. & $\begin{array}{l}\text { Alkaline sol, sodium } \\
\text { hyposulphite. }\end{array}$ & Red color. & Heat with $\mathrm{R}$. & \\
\hline Schultz's test. & Cellulose. & $\begin{array}{l}\text { Dissolve } 25 \text { parts zinc } \\
\text { chlorid, } 8 \text { potass. } \\
\text { iodid, in } 81 / 2 \text { water; } \\
\text { filter through asbes- } \\
\text { tos, and add iodin } \\
\text { to saturation. }\end{array}$ & $\begin{array}{l}\text { Turns cellulose } \\
\text { cell-walls blue to } \\
\text { purple. }\end{array}$ & Add R. & $\cdot$ \\
\hline Schultz's test. & Cellulose. & $\begin{array}{l}\text { Dissolve zinc in pure } \\
\text { hydrochloric acid } \\
\text { evaporate in pres- } \\
\text { ence of metallic zinc } \\
\text { to syrupy consist- } \\
\text { ence ; saturate with } \\
\text { potass. iodid and io- } \\
\text { din. }\end{array}$ & $\begin{array}{l}\text { Turns cellulose } \\
\text { cell-walls blue to } \\
\text { purple. }\end{array}$ & Add $\mathbf{R}$. & \\
\hline Schultze's test. & Alkaloids. & $\begin{array}{l}\text { Mixture of sat. sol. so- } \\
\text { dium phosphate } 4 \\
\text { antimony chlorid } 1 \text {. }\end{array}$ & White precipitate. & Add R. & \\
\hline Schultze's test. & Alkaloids. & $\begin{array}{l}\text { Mixture of antimony } \\
\text { chlorid and phos- } \\
\text { phoric acid. }\end{array}$ & White precipitate. & Add R. & \\
\hline Schulz's test. & Salicylic acid. & Sol. copper sulphate. & Green color. & $\begin{array}{l}\text { Add R. to neutral solu- } \\
\text { tion of a salicylate. }\end{array}$ & \\
\hline Schulze's test. & Ammonia. & $\begin{array}{l}\text { Sol. chlorinated lime } \\
\text { and carbolic acid. }\end{array}$ & Green color. & Add $\mathbf{R}$. & \\
\hline Schulze's test. & Guanidin salts. & $\begin{array}{l}\text { Nessler's reagent. See } \\
\text { Nessler's test. }\end{array}$ & $\begin{array}{l}\text { White or pale-yel- } \\
\text { low precipitate, } \\
\text { flocculent, bu t } \\
\text { later becoming } \\
\text { dense. }\end{array}$ & Add R. & \\
\hline
\end{tabular}


TABLE OF TESTS.-Continued.

\begin{tabular}{|c|c|c|c|c|c|}
\hline NAME. & UsE. & REAGENTS. & REACTION. & APPLICATION. & REMARKS. \\
\hline Schulze's test. & $\begin{array}{l}\text { Nitric acid in } \\
\text { urine. }\end{array}$ & $\begin{array}{l}\text { (a) Sol. ferric chlorid. } \\
\text { (b) H yd } \mathrm{r} \text { och loric } \\
\text { acid. }\end{array}$ & $\begin{array}{l}\text { Formation of ni- } \\
\text { trous oxid. }\end{array}$ & Add $a$ and $b$. & \\
\hline Schwabe's test. & Quinin. & Sol. potass. cyanid. & Crimson color. & Add R. & \\
\hline $\begin{array}{l}\text { Schwarzenberg's } \\
\text { test. }\end{array}$ & Alkaloids. & $\begin{array}{l}\text { (a) Nitric acid. (b) } \\
\text { Ammonia. }\end{array}$ & Color-reactions. & Treat with $a$ and $b$. & \\
\hline Schweitzer's test. & Textile fibers. & $\begin{array}{l}\text { Copper sulphate Io, } \\
\text { water roo. Add po- } \\
\text { tass. hydrate } 5 \text {, in } \\
\text { water } 50 \text {. Wash ppt. } \\
\text { and dissolve in } 20 \\
\text { per cent. sol. am- } \\
\text { monia } 20 \text {. }\end{array}$ & $\begin{array}{l}\text { Dissolves silk, cot- } \\
\text { ton, linen. }\end{array}$ & & \\
\hline Scivoletto's test. & $\begin{array}{l}\text { Hydriodic acid in } \\
\text { urine. }\end{array}$ & $\begin{array}{l}\text { (a) Starch-paste. } \\
\text { Fuming nitric acid. }\end{array}$ & Blue color. & $\begin{array}{l}\text { Dip filter-paper in a } \\
\text { and dry; sprinkle } \\
\text { with urine; bang in } \\
\text { upper portion of a } \\
\text { flask containing } b \text {. }\end{array}$ & \\
\hline Seidel's test. & Inosite. & $\begin{array}{l}\text { (a) Nitric acid. }(b) \\
\text { Ammonia. }(c) \text { Sol. } \\
\text { strontium acetate. }\end{array}$ & $\begin{array}{l}\text { Gree } \mathrm{n} \text { is h color } \\
\text { and violet ppt. }\end{array}$ & $\begin{array}{l}\text { Evaporate } 0.03 \text { of sub- } \\
\text { stance in platinum } \\
\text { crucible to dryness } \\
\text { with } a \text {, treat resi- } \\
\text { due with } b \text { and } c \text {. }\end{array}$ & \\
\hline Seliwanoff's test. & Levulose. & $\begin{array}{l}\text { (a) Resorcin. (b) Hy- } \\
\text { drochloric acid. }\end{array}$ & $\begin{array}{l}\text { Ppt. soluble with } \\
\text { red color in al- } \\
\text { cohol. }\end{array}$ & $\begin{array}{l}\text { Warm substance with } \\
a \text { and } b \text {. }\end{array}$ & \\
\hline Selle's test. & Ammonia. & $\begin{array}{l}\text { Tincture of the petals } \\
\text { of blue hyacinth. }\end{array}$ & Green color. & $\begin{array}{l}\text { Dip filter-paper in R., } \\
\text { dry, and expose to } \\
\text { vapors. }\end{array}$ & \\
\hline Selmi's test. & Alkaloids. & $\begin{array}{l}\text { Sat. sol. iodic acid in } \\
\text { sulphuric acid, di- } \\
\text { luted with } 6 \text { volumes } \\
\text { of same acid. }\end{array}$ & Color-reactions. & & \\
\hline Selmi's test. & $\begin{array}{l}\text { Free phosphoric } \\
\text { acid. }\end{array}$ & & Green color. & $\begin{array}{l}\text { Hold substance on } \\
\text { platinum loop close } \\
\text { to lower part of hy- } \\
\text { drogen flame. }\end{array}$ & \\
\hline Selmi's test. & Morphin. & $\begin{array}{l}\text { Stir red lead oxid in } \\
\text { glacial acetic acid } 15 \\
\text { minutes; filter. }\end{array}$ & $\begin{array}{l}\text { Slightly yellow to } \\
\text { brig h t-yellow, } \\
\text { dark-y ellow, } \\
\text { violet color. }\end{array}$ & $\begin{array}{l}\text { To I drop R. add } 2 \\
\text { drops morphin-sol. }\end{array}$ & \\
\hline Selmi's test. & Morphin. & $\begin{array}{l}\text { (a) Sulphuric acid. (b) } \\
\text { Sodium bicarbonate. } \\
\text { (c) Tincture of iodin. }\end{array}$ & $\begin{array}{l}\text { Violet dissolved in } \\
a \text {; with } b \text { and } c \text {, } \\
\text { green color. }\end{array}$ & $\begin{array}{l}\text { Dissolve in } \alpha, \text { then } \\
\text { saturate with } b \text {, and } \\
\text { add } c \text {. }\end{array}$ & \\
\hline Selmi's test. & Strychnin. & $\begin{array}{l}\text { Sol. iodic acid in sul- } \\
\text { phuric acid. }\end{array}$ & $\begin{array}{l}\text { Yellow, brick-red, } \\
\text { a nd violet-red } \\
\text { color. }\end{array}$ & Moisten with $\mathbf{R}$. & \\
\hline Senier's test. & | Glycerin. & Borax bead. & Green color. & $\begin{array}{l}\text { Dip R. in alkaline } \\
\text { liquid and test in } \\
\text { Bunsen flame. }\end{array}$ & \\
\hline Serullas' test. & Morphin. & Iodic acid. & Red color. & Add R. & \\
\hline Siebold's test. & Albumin. & $\begin{array}{l}\text { (a) Ammonia, }(b) \text { Di- } \\
\text { lute acetic acid. }\end{array}$ & Cloudiness. & $\begin{array}{c}\text { Add small excess } a \text { and } \\
b ; \text {, heat to boiling. }\end{array}$ & \\
\hline Siebold's test. & $\begin{array}{l}\text { Alcohol in chloro- } \\
\text { form. }\end{array}$ & Iodin. & Reddish brown. & $\begin{array}{l}\text { R. in pure chloroform, } \\
\text { purple color; in pres- } \\
\text { ence of alcohol, red- } \\
\text { dish-brown. }\end{array}$ & \\
\hline Siebold's test. & Morphin. & $\begin{array}{l}(a) \text { Sulphuric acid. }(b) \\
\text { Potass, perchlorate. }\end{array}$ & Brown color. & Heat with $a$, add $b$. & \\
\hline $\begin{array}{l}\text { Siebold and Brad- } \\
\text { bury's test. }\end{array}$ & $\begin{array}{l}\text { Salicylic acid in } \\
\text { urine. }\end{array}$ & $\begin{array}{l}\text { (a) Potassium carbon- } \\
\text { ate. (b) Sol, lead ni- } \\
\text { trate. (c) Dilute sol. } \\
\text { ferric chlorid. }\end{array}$ & Violet color. & $\begin{array}{l}\text { Alkalinize with } a \text {, add } \\
\text { excess } b \text {, shake, fil- } \\
\text { ter; add } c \text {. }\end{array}$ & \\
\hline $\begin{array}{l}\text { Siewer's test (also } \\
\text { known as E. } \\
\text { wald's test). }\end{array}$ & $\begin{array}{l}\text { Motor activity of } \\
\text { stomach. }\end{array}$ & $\begin{array}{l}\text { Salol } 2 \text { grams in cap- } \\
\text { sule or wafer. }\end{array}$ & $\begin{array}{l}\text { Salicyluric-acid } \\
\text { reaction in urine. } \\
\text { (See Ferric- } \\
\text { chlorid test for } \\
\text { salicylic acid.) }\end{array}$ & $\begin{array}{l}\text { Administer } \mathrm{R} \text {.with the } \\
\text { meal: reaction in } 3 / 4 \\
\text { to } x \text { hour normally. }\end{array}$ & $\begin{array}{l}\text { Salol is decom- } \\
\text { posed in the in- } \\
\text { testines. }\end{array}$ \\
\hline
\end{tabular}


TABLE OF TESTS.-Continued.

\begin{tabular}{|c|c|c|c|c|c|}
\hline NAME. & USE. & REAGENTS. & REACTION. & APPLICATION. & REMARKS. \\
\hline Siewert's test. & Molybdic acid. & $\begin{array}{l}\text { Aqueous sol, potass- } \\
\text { jum xanthogenate } \\
\text { (ethylsulpho-carbon- } \\
\text { ate). }\end{array}$ & $\begin{array}{l}\text { Yellow to flesh-col- } \\
\text { ored ppt., turn- } \\
\text { ing to violet. }\end{array}$ & $\begin{array}{l}\text { Add } R \text {. to solution of } \\
\text { acid in nitric acid. }\end{array}$ & \\
\hline Silver-test. & Glucose in urine. & $\begin{array}{l}\text { (a) Ammonia. (b) Sol. } \\
\text { silver nitrate. }\end{array}$ & Metallic silver. & $\begin{array}{l}\text { Add } a \text { in excess to } b ; \\
\text { add urine and boil. }\end{array}$ & $\begin{array}{l}\text { Aldehyd and tar- } \\
\text { taric acid give } \\
\text { same reaction. }\end{array}$ \\
\hline Silver-nitrate test. & Chlorids. & $\begin{array}{l}(a) \text { ro per cent. sol. sil- } \\
\text { ver nitrate. }(b) \mathrm{Ni}- \\
\text { tric acid. }\end{array}$ & White ppt. & $\begin{array}{l}\text { Add a few drops } b \text { to } \\
\text { prevent precipita- } \\
\text { tion of phosphates; } \\
\text { then add } a \text {. }\end{array}$ & $\begin{array}{l}\text { In case of urine, if } \\
\text { curdy masses, } \\
\text { chlorids not dim- } \\
\text { inished; if milki- } \\
\text { ness only, dim- } \\
\text { inished ; if no } \\
\text { cloudiness, chlo- } \\
\text { rids are absent. }\end{array}$ \\
\hline Simon's test. & Cinnamic acid. & $\begin{array}{l}\text { (a) Potass, bichromate. } \\
\text { (b) Sulphuric acid. }\end{array}$ & $\begin{array}{l}\text { Formation of oil } \\
\text { of bitter al- } \\
\text { monds. }\end{array}$ & Add $a$ and $b$. & \\
\hline Simon's test. & Xanthin. & $\begin{array}{l}\text { Sodium chlorid or cal- } \\
\text { cium chlorid. }\end{array}$ & $\begin{array}{l}\text { Evolution of nitro- } \\
\text { gen, and a blue, } \\
\text { then a b rown, } \\
\text { finally a yellow } \\
\text { color. }\end{array}$ & $\begin{array}{l}\text { To substance dis- } \\
\text { solved in a fixed al- } \\
\text { kali add R. }\end{array}$ & \\
\hline Sjöqvist's method. & $\begin{array}{l}\text { Quantitative esti- } \\
\text { mation of hydro- } \\
\text { chloric acid in } \\
\text { gastric juice. }\end{array}$ & Barium carbonate. & $\begin{array}{l}\text { Ascertain quantity } \\
\text { of harium chlo- } \\
\text { rid. }\end{array}$ & $\begin{array}{l}\text { Evaporate gastric } \\
\text { contents to dryness } \\
\text { with R, and inciner- } \\
\text { ate. Extract bar- } \\
\text { ium chlorid formed } \\
\text { with water. }\end{array}$ & $\begin{array}{l}\text { Quantity of barium } \\
\text { chlorid is a meas- } \\
\text { ure of the hydro- } \\
\text { chloric acid. }\end{array}$ \\
\hline Skey's test. & Cobalt. & $\begin{array}{l}\text { (a) Citric (or tartaric) } \\
\text { acid. (b) Ammonia, } \\
(c) \text { Potass. ferricy- } \\
\text { anid. }\end{array}$ & Dark-red color. & $\begin{array}{l}\text { Add } a, b \text { in excess, } \\
\text { and } c .\end{array}$ & I : 60,000 \\
\hline Slater's test. & Strychnin. & $\begin{array}{l}\text { (a) Sulphuric acid. }(b) \\
\text { Potass. chlorate. }\end{array}$ & Maroon-red color. & Add $a$ and $b$. & \\
\hline Smith's test. & $\begin{array}{l}\text { Biliary coloring- } \\
\text { matter. }\end{array}$ & Tincture of iodin. & Green color. & Add R. & \\
\hline Smith's test. & Free acids. & $\begin{array}{l}\text { Fresh silver chlorid } \\
\text { dissolved in ammon- } \\
\text { ia. }\end{array}$ & $\begin{array}{l}\text { Ppt. of silver chlo- } \\
\text { rid. }\end{array}$ & Add R. & \\
\hline Smith's test. & Santonin. & $\begin{array}{l}\text { (a) Nitric acid. } \\
\text { An alkali. }\end{array}$ & Greenish-yellow. & Heat with $a$. & $\begin{array}{l}\text { With } b \text { turns deep- } \\
\text { red. }\end{array}$ \\
\hline Snelling's test. & Emetin. & $\begin{array}{l}\text { (a) Hydrochloric acid. } \\
\text { (b) Potass. chlorate. }\end{array}$ & $\begin{array}{c}\text { Orange-red color, } \\
\text { turning violet. }\end{array}$ & $\begin{array}{l}\text { Drop } a \text { on } b ; \text { then } \\
\text { drop on liquid. }\end{array}$ & \\
\hline $\begin{array}{l}\text { Sodium - ch lorid } \\
\text { test. }\end{array}$ & Propeptone. & $\begin{array}{l}\text { (a) Acetic acid. }(b) \\
\text { Concentrated s o 1. } \\
\text { sodium chlorid. }\end{array}$ & $\begin{array}{l}\text { Precipitate on } \\
\text { cooling of fil- } \\
\text { trate. }\end{array}$ & $\begin{array}{c}\text { Acidulate urine with } a \\
\text { add equal volume } b ; \\
\text { boil ; filter quickly. }\end{array}$ & \\
\hline $\begin{array}{l}\text { Sod i u m-sulphate } \\
\text { and acetic-acid } \\
\text { test. }\end{array}$ & Albumin in urine. & $\begin{array}{l}\text { (a) Sat. sol. sodiumsul- } \\
\text { phate. (b) Acetic } \\
\text { acid. }\end{array}$ & White precipitate. & $\begin{array}{l}\text { Acidulate urine with } \\
b \text {, add equal part } a, \\
\text { and boil. }\end{array}$ & $\begin{array}{l}\text { Reliable, but not } \\
\text { very delicate. }\end{array}$ \\
\hline Soldaini's test. & Glucose. & $\begin{array}{l}\text { Copper carbonate I5 } \\
\text { gm., in water; add } \\
\text { so i. potass. bicar- } \\
\text { bonate } 416 \mathrm{gm} \text {; add } \\
\text { water up to } \mathrm{r} 400 \text {. }\end{array}$ & Reduction. & & \\
\hline $\begin{array}{l}\text { Sonnenschein's } \\
\text { test. }\end{array}$ & Alkaloids. & $\begin{array}{l}\text { (a) Ceroso-ceric oxid. } \\
\text { (b) Sulphuric acid. }\end{array}$ & Color-reactions. & $\begin{array}{c}\text { Dissolve alkaloid in } \\
b \text {, and add trace } a .\end{array}$ & \\
\hline $\begin{array}{l}\text { Sonnens ch ein's } \\
\text { test. }\end{array}$ & Alkaloids. & $\begin{array}{l}\text { Phospho-moly bd ic } \\
\text { acid. }\end{array}$ & $\begin{array}{l}\text { Yellowish precipi- } \\
\text { tate. }\end{array}$ & & \\
\hline $\begin{array}{l}\text { Sonnenschein's } \\
\text { test. }\end{array}$ & Blood. & $\begin{array}{l}\text { (a) Sol. sodium tung- } \\
\text { state, acidified with } \\
\text { acetic acid. (b) Am- } \\
\text { monia. }\end{array}$ & $\begin{array}{l}\text { R ed dish-green } \\
\text { (fluorescence). }\end{array}$ & $\begin{array}{l}\text { Extract stains with } \\
\text { distilled water, pre- } \\
\text { cipitate with } a \text {; add } \\
b \text {. }\end{array}$ & \\
\hline $\begin{array}{l}\text { Sonnenschein's } \\
\text { test. }\end{array}$ & Proteids. & $\begin{array}{l}\text { Sat. sol. sodium tung- } \\
\text { state, strongly acidi- } \\
\text { fied with acetic or } \\
\text { phosphoric acid. }\end{array}$ & Precipitate. & Add R. & \\
\hline Sonstadt's test. & Calcium salts. & Sodium tungstate. & Precipitate. & Add R. & \\
\hline Source's test. & Uric acid. & See Magnier de la & Source's test. & & \\
\hline
\end{tabular}


TABLE OF 'TESTS.-Continued.

\begin{tabular}{|c|c|c|c|c|c|}
\hline NAME. & USE. & REAGENTS. & REACTION. & APPLICATION. & REMARKS. \\
\hline Southey's test. & Opium. & | Sulpho-molybdic acid. | & Blue color. & Add R. & \\
\hline $\begin{array}{l}\text { Spence and Esil- } \\
\text { man's test. }\end{array}$ & Free mineral acids. & Dil. sol. ferric chlorid. & $\begin{array}{l}\text { Yellow color of } \mathrm{R} \text {. } \\
\text { is discharged. }\end{array}$ & Add substance to $R$. & \\
\hline Spiegler's test, A. & Albumin in urine. & $\left\{\begin{array}{l}\text { Mercuric chlorid } 8, \\
\text { tartaric a cid } 4 \\
\text { sugar } 20 \text {, distilled } \\
\text { water } 200 .\end{array}\right.$ & White ring. & $\begin{array}{l}\text { Place } R \text {. in test-tube } \\
\text { and overlay with } \\
\text { urine acid ula ted } \\
\text { with acetic acid. }\end{array}$ & Very delicate. \\
\hline Spiegler's test, B. & Albumin in urine. & $\begin{array}{l}\text { Tartaric acid I, mer- } \\
\text { curic chlorid 2, gly- } \\
\text { cerin } 20 \text {, water } 50 .\end{array}$ & White ring. & $\begin{array}{l}\text { Acidulate urine with } \\
\text { acetic acid, filter if } \\
\text { necessary, and over- } \\
\text { lay } R \text {. with it. }\end{array}$ & \\
\hline Sprengel's test. & Nitric acid. & $\begin{array}{l}\text { Sol. of carbolic acid I, } \\
\text { sul ph u r ic acid } 4 \\
\text { water } 2 \text {. }\end{array}$ & $\begin{array}{l}\text { Red dis h-brown } \\
\text { color. }\end{array}$ & Add $R$, to dry nitrate. & \\
\hline Stadthagen's test. & Uric acid. & $\begin{array}{l}\text { (a) Arsenious acid in } \\
\text { alkaline sol. (b) Sol. } \\
\text { copper sulphate. }\end{array}$ & $\begin{array}{l}\text { Red cuprous oxid } \\
\text { or white copper } \\
\text { urate. }\end{array}$ & $\begin{array}{l}\text { Warm substance with } \\
a ; \text { add } b \text {. }\end{array}$ & \\
\hline Stædeler's test. & $\begin{array}{l}\text { Purity of chloro- } \\
\text { form. }\end{array}$ & Bilirubin. & $\begin{array}{l}\text { Green color if de- } \\
\text { composed. }\end{array}$ & & $\begin{array}{l}\text { R. dissolves with a } \\
\text { yellow color in } \\
\text { pure chloroform. }\end{array}$ \\
\hline Stanford's test. & Iodin. & $\begin{array}{l}\text { (a) Carbon disulphid. } \\
\text { (b) N itros ulphuric } \\
\text { acid (sulphuric acid } \\
\text { saturated with gas- } \\
\text { eous nitrous anhy- } \\
\text { drid). }\end{array}$ & Violet color. & Add $a$ and one drop $b$. & \\
\hline Starch-test. & Starch. & See Iodin-lest. & & & \\
\hline Steffanelli's test. & Alcohol in ether. & Anilin-violet. & $\begin{array}{l}\text { R. insoluble in pure } \\
\text { ether. }\end{array}$ & Add $R$. & \\
\hline Stein's test. & Narcein. & $\begin{array}{l}\text { (a) Sol. zinc iodid and } \\
\text { potass. iodid. (b) } \\
\text { Aq. sol. iodin. }\end{array}$ & Blue color. & Add $a$ and one drop $b$ & \\
\hline Stein's test. & Nitric acid. & $\begin{array}{l}\text { (a) Litharge. (b) Filter- } \\
\text { paper mo is tened } \\
\text { with sol. ferrous sul- } \\
\text { phate. }\end{array}$ & $\begin{array}{l}\text { Yellow to brown } \\
\text { color. }\end{array}$ & $\begin{array}{l}\text { Heat salt with } a \text {; ex- } \\
\text { pose } b \text { to the gas } \\
\text { evolved. }\end{array}$ & \\
\hline Stevenin's test. & $\begin{array}{l}\text { Acidimetry, alka- } \\
\text { limetry. }\end{array}$ & $\begin{array}{l}\text { Giycerin-extract of } \\
\text { petals of violet or } \\
\text { mallow flowers. }\end{array}$ & $\begin{array}{l}\text { Acids turn color } \\
\text { red; alkalies } \\
\text { green. }\end{array}$ & & \\
\hline Stevenson's test. & $\begin{array}{l}\text { Small quantities } \\
\text { of hemoglobin in } \\
\text { the urine, unac- } \\
\text { companied by } \\
\text { albumin. }\end{array}$ & $\begin{array}{l}\text { (a) Tr. guaiaci. (b) } \\
\text { Ozonic ether. }\end{array}$ & Blue color of $b$. & $\begin{array}{l}\text { To a drop or two of } \\
\text { urine add one drop } \\
a \text { and a few drops } b \\
\text { agitate, then let } b \\
\text { settle. }\end{array}$ & $\begin{array}{l}\text { Modification of } \\
\text { Mahomed's test. }\end{array}$ \\
\hline Stolba's test. & Potassium salts. & $\begin{array}{l}\text { Sodium or ammonium } \\
\text { fluoborid. }\end{array}$ & $\begin{array}{l}\text { Crystalline pre - } \\
\text { cipitate coloring } \\
\text { flame green to } \\
\text { violet. }\end{array}$ & & \\
\hline Storer's test. & Chromic acid. & $\begin{array}{l}\text { Ethereal sol. hydrogen } \\
\text { dioxid. }\end{array}$ & $\begin{array}{l}\text { Intensely blue } \\
\text { color. }\end{array}$ & Add R. & \\
\hline Strassburg's test. & Bile-acids. & $\begin{array}{l}\text { Cane-sugar. } \\
\text { Sulphuric acid. }\end{array}$ & Violet color. & $\begin{array}{l}\text { Dip filter-paper into } \\
\text { urine to which } a \text { has } \\
\text { been added; dry and } \\
\text { apply drop of } b \text {. }\end{array}$ & \\
\hline Strecker's test. & $\mathrm{X}$ anthin. & $\begin{array}{l}\text { (a) Nitric acid. (b) } \\
\text { Sodium or potassium } \\
\text { hydrate. }\end{array}$ & $\begin{array}{l}\text { Yellow residue, } \\
\text { turning reddish- } \\
\text { yellow on addi- } \\
\text { tion of } b \text {; red- } \\
\text { dish-violet on } \\
\text { subs equent } \\
\text { warming. }\end{array}$ & $\begin{array}{l}\text { Evaporate to dryness } \\
\text { with } a ; \text { add } b \text {. }\end{array}$ & $\begin{array}{l}\text { Reaction not ob- } \\
\text { tained with am- } \\
\text { monia-distinc- } \\
\text { tion from uric } \\
\text { acid. }\end{array}$ \\
\hline Streng's test. & Sodium salts. & Sol. uranium acetate. & $\begin{array}{l}\text { Minute, yellow } \\
\text { cryst als; ex- } \\
\text { amine by polar- } \\
\text { ized light under } \\
\text { microscope. }\end{array}$ & Add R. & \\
\hline Strohl's test. & $\begin{array}{l}\text { Free mineral acids } \\
\text { in vinegar. }\end{array}$ & $\begin{array}{l}\text { (a) Sol. ammonium } \\
\text { oxalate. (b) Calcium } \\
\text { chlorid. }\end{array}$ & $\begin{array}{l}\text { No ppt. in presence } \\
\text { of mineral acid. }\end{array}$ & Add $a$ and $b$. & \\
\hline
\end{tabular}


TABLE OF TESTS.-Continued.

\begin{tabular}{|c|c|c|c|c|c|}
\hline NAME. & USE. & REAGENTS. & REACTION. & APPLICATION. & REMARKS. \\
\hline Struve's test. & Hydrogen dioxid. & $\begin{array}{l}\text { (a) Alkaline sol. lith- } \\
\text { arge, }(b) \text { Dilute sol. } \\
\text { lead subacetate. }\end{array}$ & Blue color: & $\begin{array}{l}\text { Add } a \text { and } b \text {, and test } \\
\text { with potass.-iodid } \\
\text { starch-paste and } \\
\text { acetic acid. }\end{array}$ & \\
\hline Stuart's test. & $\begin{array}{l}\text { Alcohol in essen- } \\
\text { tial oils. }\end{array}$ & $\begin{array}{l}\text { (a) Compound tinc- } \\
\text { ture of iodin. }(b) \\
\text { Sol. potassium hy- } \\
\text { drate. }\end{array}$ & $\begin{array}{l}\text { Formation of jodo- } \\
\text { form. }\end{array}$ & $\begin{array}{l}\text { Distil off the alcohol; } \\
\text { add } a \text { and } b \text {. }\end{array}$ & . \\
\hline Stütz's test. & Albumin in urine. & See Fürbringer's test. & & & \\
\hline Sulphocyanid-test. & $\begin{array}{l}\text { Hydrocyanic acid } \\
\text { in tissues. }\end{array}$ & See Liebig's test. & & & \\
\hline Sulzer's test. & $\begin{array}{l}\text { Alcohol in essen- } \\
\text { tial oils. }\end{array}$ & See Salzer's test. & & & \\
\hline Svanberg's test. & Phosphoric acid. & $\begin{array}{l}\text { Sol. a m mon i u m } \\
\text { molybdate. }\end{array}$ & Yellow precipitate. & Add R. in excess. & \\
\hline Syntonin-test. & Syntonin. & Any alkali. & Precipitate. & $\begin{array}{l}\text { Neutralize the acid } \\
\text { sol. with } \mathrm{R} \text {. }\end{array}$ & \\
\hline Tanret's test. & Albumin in urine. & $\begin{array}{l}\text { Mercuric chlorid } \mathrm{x} .35 \text { : } \\
\text { potass. iodid } 3.32 \text {; } \\
\text { glacial acetic a cid } \\
20 \text {; water to } 1000 .\end{array}$ & White precipitate. & $\begin{array}{l}\text { Add } R \text {, to urine. If } \\
\text { precipitate occurs, } \\
\text { boil to dissolve pep- } \\
\text { tones, alkaloids, and } \\
\text { urates, which } R \text {, also } \\
\text { precipitates. }\end{array}$ & $\begin{array}{l}\text { Very delicate. Mu- } \\
\text { cus in excess is } \\
\text { precipitated and } \\
\text { not dissolved by } \\
\text { heat. }\end{array}$ \\
\hline $\begin{array}{l}\text { T ass inari and } \\
\text { Piazza's test. }\end{array}$ & Nitric acid. & $\begin{array}{l}\text { (a) Potassium hydrate. } \\
\text { (b) Zinc dust. }\end{array}$ & $\begin{array}{l}\text { Formation of am- } \\
\text { monia. }\end{array}$ & Add $a$ and $b$. & \\
\hline Tattersall's test. & Cobalt. & $\begin{array}{l}\text { (a) Sol. potassium cy- } \\
\text { anid. (b) Ammo- } \\
\text { nium sulphid. }\end{array}$ & Blood-red color. & $\begin{array}{l}\text { Add } a \text { till ppt. is redis- } \\
\text { solved; then } b \text {. }\end{array}$ & \\
\hline Tattersall's test. & Codein. & $\begin{array}{l}\text { (a) Sulphuric acid. }(b) \\
\text { Sodium arseniate. } \\
\text { (c) Sodium hydrate. }\end{array}$ & $\begin{array}{l}\text { Dark-blue. On } \\
\text { addition of water } \\
\text { and excess } c \\
\text { turns orange. }\end{array}$ & $\begin{array}{l}\text { Dissolve in } a ; \text { add } b ; \\
\text { heat. }\end{array}$ & \\
\hline Tattersall's test. & Delphinin. & $\begin{array}{l}\text { (a) Malic acid. (b) Sul- } \\
\text { phuric acid. }\end{array}$ & $\begin{array}{l}\text { Orange color, } \\
\text { turning pin } \mathrm{k}, \\
\text { then violet. }\end{array}$ & $\begin{array}{l}\text { Rub with } a \text {, then with } \\
\text { a few drops } b \text {. }\end{array}$ & \\
\hline Tattersall's test. & Morphin. & $\begin{array}{l}\text { (a) Sulphuric acid. }(b) \\
\text { Sodium arseniate. }\end{array}$ & $\begin{array}{r}\text { Dirty-violet, be - } \\
\text { coming sea-green. }\end{array}$ & Dissolve in $a ;$ add $b$. & \\
\hline Tattersall's test. & Papaverin. & $\begin{array}{l}\text { (a) Sulphuric acid. }(b) \\
\text { Sodium arseniate. } \\
\text { (c) Sodium hydrate. }\end{array}$ & $\begin{array}{l}\text { Red to violet: } \\
\text { black on addi- } \\
\text { tion of water } \\
\text { and excess } c \text {. }\end{array}$ & Dissolve in $a ;$ add $b$. & \\
\hline Teichmann's test. & Blood. & $\begin{array}{l}\text { (a) Glacial acetic acid. } \\
\text { (b) Sodium chlorid. }\end{array}$ & Hemin-crystals. & $\begin{array}{l}\text { Dissolve blood in } 2 \text { to } \\
3 \text { c.c. water; add } a \text {, } \\
\text { and o.or } b \text {. Spread } \\
\text { on slide, let evapo- } \\
\text { rate; examine under } \\
\text { microscope. }\end{array}$ & \\
\hline $\begin{array}{l}\text { Teichmann - N e u- } \\
\text { mann's test. }\end{array}$ & Blood. & See Teichmann's test. & & & \\
\hline Terreill's test. & Cellulose. & $\begin{array}{l}\text { (a) Potass, iodid, I per } \\
\text { cent. sol. (b) Sul- } \\
\text { phuric acid. }\end{array}$ & Blue color. & $\begin{array}{c}\text { Dip into } a, \text { then into } \\
b \text {; rinse in water. }\end{array}$ & \\
\hline Tessier's test. & $\begin{array}{l}\text { Iodin in presence } \\
\text { of tannin. }\end{array}$ & $\begin{array}{l}\text { Tincture of ferric } \\
\text { chlorid. }\end{array}$ & Blue color. & $\begin{array}{l}\text { Liberate by a d ding } \\
\text { R.; test with starch- } \\
\text { paper. }\end{array}$ & \\
\hline Thomas' test. & $\begin{array}{l}\text { Strychnin in the } \\
\text { presence of mor- } \\
\text { phin. }\end{array}$ & & $\begin{array}{l}\text { Potassium hydrate } \\
\text { dissolves mor- } \\
\text { phin: chloro- } \\
\text { form, strychnin. }\end{array}$ & $\begin{array}{l}\text { After separation, ap- } \\
\text { ply customary tests. }\end{array}$ & \\
\hline Thompson's test. & Thein. & $\begin{array}{l}\text { Hypochlorous acid } \\
\text { (euchlorin). }\end{array}$ & Blood-red residue. & $\begin{array}{l}\text { Pass R. through sol. } \\
\text { and evaporate. }\end{array}$ & \\
\hline Thomson's test. & Iodin. & $\begin{array}{l}\text { (a) Chlorin. (b) Starch- } \\
\text { paste. }\end{array}$ & Blue color. & $\begin{array}{l}\text { Pass a through sol u- } \\
\text { tion; test with } b \text {. }\end{array}$ & \\
\hline Thormählen's test. & Melanin. & $\begin{array}{l}\text { (a) Sol. sodium nitro- } \\
\text { prussid. }(b) \text { Sol. } \\
\text { potass. hydrate. }(c) \\
\text { Acetic acid. }\end{array}$ & Deep-blue color. & Add $a, b, c$ & \\
\hline
\end{tabular}


TABLE OF TESTS.-Continued.

\begin{tabular}{|c|c|c|c|c|c|}
\hline NAME: & USE. & REAGENTS. & REAction. & APPLICATION. & REMARKS. \\
\hline Thresh's test. & Alcohol. & $\begin{array}{l}\text { (a) Sat. sol: potassium } \\
\text { bichromate. (b) Dil. } \\
\text { sulphuric acid (I: }: \text { ). } \\
\text { (c) Sol. sod. hydrate. }\end{array}$ & Yellow color. & $\begin{array}{l}\text { Add } 2 a, 8 b \text {, to } 100 \mathrm{c.c} \text {. } \\
\text { of liquid; distil off } \\
20 ; \text { add } 3 c \text {; boil; let } \\
\text { cool. }\end{array}$ & \\
\hline Thresh's test. & Alkaloids. & $\begin{array}{l}\text { (a) Bismuth oxid } 4.68, \\
\text { dissolved in } 80 \text { hy } \\
\text { drochloric a c id, } \\
\text { water to } 300 .(b) \\
\text { Potass, iodid } 20 \text {, in } \\
\text { water } 700 .\end{array}$ & $\begin{array}{l}\text { Reddis } h-b \text { rown } \\
\text { precipitate. }\end{array}$ & $\begin{array}{l}\text { Mix } a \text { and } b ; \text { add } \\
\text { drop by drop to solu- } \\
\text { tion of alkaloid. }\end{array}$ & \\
\hline Thresh's test. & Bismuth. & $\begin{array}{l}\text { (a) Hydrochloric acid. } \\
\text { (b) Potass. iodid. }\end{array}$ & $\begin{array}{l}\text { Orange-red to yel- } \\
\text { low color. }\end{array}$ & Add $a$ and $b$. & I : 100,000 \\
\hline Thudichum's test. & Kreatinin. & $\begin{array}{l}\text { Dilute sol, ferric chlor- } \\
\text { id. }\end{array}$ & $\begin{array}{l}\text { Dark-red color, } \\
\text { increased by } \\
\text { warming. }\end{array}$ & Add substance to $\mathbf{R}$. & \\
\hline Thymol-test. & Glucose in urine. & See Molisch's test. & & & \\
\hline Tidy's test. & Albumin. & $\begin{array}{l}\text { Equal volumes car- } \\
\text { bolic acid and gla- } \\
\text { cial acetic acid. (If } \\
\text { drop mixes turbidly } \\
\text { with wat er, add } \\
\text { more acetic acid.) }\end{array}$ & White precipitate. & Add $\mathbf{R}$. & $1: 15,000$ \\
\hline Tidy's test. & Albumin. & $\begin{array}{l}\text { (a) Alcohol. (b) Car- } \\
\text { bolic acid. }\end{array}$ & White precipitate. & $\begin{array}{l}\text { Add to urine } 15 \text { drops } a, \\
\text { and then } 15 \text { drops } b .\end{array}$ & \\
\hline $\begin{array}{l}\text { Tiedemann and } \\
\text { Gmelin's test. }\end{array}$ & Bille-pigments. & $\begin{array}{l}\text { See Gmelin-Heintz's } \\
\text { test. }\end{array}$ & & & \\
\hline Tilden's test. & Iodin. & Potass. permanganate. & $\begin{array}{l}\text { Test as most con- } \\
\text { venient. }\end{array}$ & $\begin{array}{l}\text { Liberate by means of } \\
\mathrm{R} \text {. }\end{array}$ & \\
\hline Tizzoni's test. & Iron in tissues. & $\begin{array}{l}\text { (a) } 2 \text { per cent. sol. } \\
\text { potass. ferrocyanid. } \\
\text { (b) } 1 / 2 \text { per cent. sol. } \\
\text { hydrochloric acid. }\end{array}$ & Blue color. & $\begin{array}{l}\text { Treat section of tissue } \\
\text { with } a \text {, then with } b \text {. }\end{array}$ & \\
\hline Tollen's test. & Glucose. & Hydrochloric acid. & $\begin{array}{l}\text { Levulinic acid } \\
\text { and formic acid. }\end{array}$ & Heat liquid with $\mathrm{R}$. & \\
\hline Tommasi's test. & Carbolic acid. & $\begin{array}{l}\text { Hydrochloric acid } 50, \\
\text { water 50, potass. } \\
\text { chlorate } 0.2 \text {. }\end{array}$ & Blue color. & $\begin{array}{l}\text { Dip pine-shaving into } \\
\text { liquid, then into } \mathrm{R} \text {; } \\
\text { then expose to sun's } \\
\text { rays. }\end{array}$ & \\
\hline Trapp's test. & Veratrin. & Hydrochloric acid. & $\begin{array}{l}\text { Dark-red to dark- } \\
\text { violet color. }\end{array}$ & Heat with $\mathrm{R}$. & \\
\hline Traube's test. & Hydrogen dioxid. & $\begin{array}{l}\text { (a) Sulphuric acid and } \\
\text { zinc-iodid starch - } \\
\text { paste. }(b) 2 \text { percent. } \\
\text { sol. copper sulphate. } \\
\text { (c) } 1 / 2 \text { per cent. sol. } \\
\text { ferrous sulphate. }\end{array}$ & Blue color. & $\begin{array}{l}\text { To } 6 \text { c.c. } a \text { add } 2 \\
\text { drops } b \text { a little } c \text {. } \\
\text { Mix with liquid. }\end{array}$ & \\
\hline Treumann's test. & Theobromin. & $\begin{array}{l}\text { (a) Chlorin-water. (b) } \\
\text { Ammonia. }\end{array}$ & Purple color. & $\begin{array}{l}\text { Evaporate to dryness } \\
\text { with } a \text {; add } b \text {. }\end{array}$ & \\
\hline $\begin{array}{l}\text { Trich lor acetic- } \\
\text { acid test. }\end{array}$ & Albumin in urine. & See Raabe's test, and & under Urine, Tests & for Serum.Albumin in. & \\
\hline Trommer's test. & Glucose in urine. & $\begin{array}{l}\text { (a) Sodium or potass. } \\
\text { hydrate. }(b) \text { 10 per } \\
\text { cent. sol. copper sul- } \\
\text { phate. }\end{array}$ & $\begin{array}{l}\text { Orange-red pre- } \\
\text { cipitate. }\end{array}$ & $\begin{array}{l}\text { Add to urine } 1 / 3 a \text {, and } \\
\text { drop in } b \text { until it } \\
\text { ceases to be dis- } \\
\text { solved; boil. }\end{array}$ & $\begin{array}{l}\text { Delicacy o,or per } \\
\text { cent. Salicylic } \\
\text { acid, chloral, uric } \\
\text { acid, give similat } \\
\text { reaction. }\end{array}$ \\
\hline $\begin{array}{l}\text { Trom msdorffs } \\
\text { test. }\end{array}$ & Nitrous acid. & $\begin{array}{l}\text { (a) Sulphuric acid. (b) } \\
\text { Potass i m - iodid } \\
\text { starch-paste. }\end{array}$ & Blue color. & $\begin{array}{l}\text { Mix } a, b, \text { and sub- } \\
\text { stance. }\end{array}$ & \\
\hline Trotarelli's test. & Ptomains. & $\begin{array}{l}\text { (a) Sol. sodium nitro- } \\
\text { prussid. }(b) \text { Palla- } \\
\text { dium nitrate. }\end{array}$ & Color-reactions. & $\begin{array}{l}\text { Add } a \text { and then } b \text { to } \\
\text { the sulphate of the } \\
\text { ptomain. }\end{array}$ & \\
\hline $\begin{array}{l}\text { Troussea u and } \\
\text { Dumontpallier's } \\
\text { test. }\end{array}$ & Bile-pigment. & See Maréchal's test. & & & \\
\hline $\begin{array}{l}\text { Von Udránsky's } \\
\text { test. }\end{array}$ & Bile-acids. & $\begin{array}{l}\text { (a) o.I per cent. sol. } \\
\text { furfurol. }(b) \text { Con- } \\
\text { cent. sulphuric acid. }\end{array}$ & $\begin{array}{l}\text { Red, then violet } \\
\text { color. }\end{array}$ & $\begin{array}{l}\text { To I c.c. of sol. of sub- } \\
\text { stance add I drop } a, \\
\text { and underlay with I } \\
\text { c.c. } b \text {; cool. }\end{array}$ & \\
\hline
\end{tabular}


TABLE OF TESTS.-Continued.

\begin{tabular}{|c|c|c|c|c|c|}
\hline NAME. & USE:- & REAGENTS. & REACTXON. & APPLICATION. & REMARKS. \\
\hline $\begin{array}{l}\text { Von Udránsky's } \\
\text { test. }\end{array}$ & Carbohydrates. & See Molisch's lests for & glucose. & & \\
\hline $\begin{array}{l}\text { Von Udránsky's } \\
\text { test. }\end{array}$ & Tyrosin. & $\begin{array}{l}\text { (a) } 0.5 \text { per cent. sol. } \\
\text { furfurol. (b) Concent. } \\
\text { sulphuric acid. }\end{array}$ & Pink color. & $\begin{array}{l}\text { To I c.c. sol. of sub- } \\
\text { stance add I drop } a \text {, } \\
\text { and underlay with I } \\
\text { c.c. } b \text {. }\end{array}$ & \\
\hline $\begin{array}{l}\text { Von Udránsky and } \\
\text { Baumann's test. }\end{array}$ & Urea. & $\begin{array}{l}\text { (a) Benzoyl-c hlorid. } \\
\text { (b) Sodium hydrate. }\end{array}$ & Benzoyl-urea. & $\begin{array}{l}\text { To concent, sol. of sub- } \\
\text { stance add } a \text { and ex- } \\
\text { cess of } b \text {. }\end{array}$ & \\
\hline Uffelmann's test. & $\begin{array}{l}\text { Free hydrochloric } \\
\text { acid in gastric } \\
\text { juice. }\end{array}$ & $\begin{array}{l}\text { Extract of bilberries } \\
\text { in amylic alcohol. }\end{array}$ & $\begin{array}{l}\text { Color changes } \\
\text { from grayish- } \\
\text { blue to rose-tint. }\end{array}$ & $\begin{array}{l}\text { Dip filter-paper, satur- } \\
\text { ated with R. and } \\
\text { dried, into gastric } \\
\text { juice. }\end{array}$ & \\
\hline Uffelmann's test. & $\begin{array}{l}\text { Hydrochloric and } \\
\text { lactic acids in } \\
\text { gastric juice. }\end{array}$ & $\begin{array}{l}\text { Sol. ferric chlorid } 3 \\
\text { drops, concent. sol. } \\
\text { carbol. acid } 3 \text { drops, } \\
\text { water } 20 \text { c.c. }\end{array}$ & $\begin{array}{l}\text { Sol. of hydrochlor- } \\
\text { ic acid decolor- } \\
\text { izes or produces } \\
\text { steel-gray color: } \\
\text { la ct ic-acid sol. } \\
\text { a yellow color. }\end{array}$ & Add liquid to $\mathrm{R}$. & $\begin{array}{l}0.05 \text { per cent. lactic } \\
\text { acid. R. must } \\
\text { be fresh. }\end{array}$ \\
\hline Uffelmann's test. & Nitric acid. & $\begin{array}{l}\text { (a) Diphenylamin. (b) } \\
\text { Sulphuric acid. }\end{array}$ & Blue color. & $\begin{array}{l}\text { To } a \text { add I.5 c.c. } b, \\
\text { stir; then add } 3 \text { or } 4 \\
\text { drops of the liquid. }\end{array}$ & \\
\hline Ultzmann's test. & $\begin{array}{l}\text { Bile-pigments in } \\
\text { urine. }\end{array}$ & $\begin{array}{l}\text { (a) Sol. potass. hy- } \\
\text { drate (I to } 3) \text {. (b) } \\
\text { Hydrochloric acid. }\end{array}$ & $\begin{array}{l}\text { Emerald-green } \\
\text { color. }\end{array}$ & $\begin{array}{l}\text { To ro c.c. urine add } 3 \\
\text { or } 4 \text { c.c. } a \text {, and then } \\
\text { excess of } b \text {. }\end{array}$ & \\
\hline Urate-test. & Urates in urine. & & $\begin{array}{l}\text { Are dissolved on } \\
\text { heating. }\end{array}$ & & \\
\hline Urea-test. & Urea. & See Nitric-acid test. & & & \\
\hline Urobilin-test. & Urobilin in urine. & $\begin{array}{l}\text { (a) Ammonia. }(b) \text { Io } \\
\text { per cent. sol. zinc } \\
\text { chlorid. }\end{array}$ & $\begin{array}{l}\text { Filtrate green by } \\
\text { reflected, rose- } \\
\text { red by trans- } \\
\text { mitted light. }\end{array}$ & $\begin{array}{l}\text { Alkalinize urine with } \\
a \text {, add 8-Io drops } b \text {; } \\
\text { filter rapidly. }\end{array}$ & \\
\hline Valser's test. & Alkaloids. & $\begin{array}{l}\text { Mercuric io did and } \\
\text { potassium iodid. }\end{array}$ & Precipitate. & & \\
\hline Van Deen's test. & Blood in urine, etc. & $\begin{array}{l}\text { (a) Tr.guaiaci. }(b) \\
\text { Ozonized (old) tur- } \\
\text { pentine (French } \\
\text { best). }\end{array}$ & Biue color. & $\begin{array}{l}\text { To urine add } 2 \text { c.c. } a \\
\text { and } 2 \text { c.c. } b \text {; shake. }\end{array}$ & $\begin{array}{l}\text { Delicate; other } \\
\text { substances re - } \\
\text { spond : pus, } \\
\text { urine containing } \\
\text { potass. iodid, and } \\
\text { saliva. }\end{array}$ \\
\hline $\begin{array}{l}\text { Van der Velden's } \\
\text { test. }\end{array}$ & $\begin{array}{l}\text { Free hydrochloric } \\
\text { acid in gastric } \\
\text { juice. }\end{array}$ & See Maly's test. & & $\cdot$ & \\
\hline $\begin{array}{l}\text { V a u ghan and } \\
\text { Novy's test. }\end{array}$ & Tyrotoxicon. & $\begin{array}{l}\text { (a) Sulphuric acid. (b) } \\
\text { Carbolic acid. }\end{array}$ & $\begin{array}{l}\text { Yellow to orange- } \\
\text { red color. }\end{array}$ & $\begin{array}{l}\text { Place on porcelain sur- } \\
\text { face } 2 \text { or } 3 \text { drops each } \\
\text { of } a \text { and } b ; \text { add a } \\
\text { few drops of aqueous } \\
\text { sol, of ethereal res- } \\
\text { idue of substance. }\end{array}$ & $\begin{array}{l}\text { Is only to be re- } \\
\text { garded as a pre- } \\
\text { liminary test; the } \\
\text { physiologic test } \\
\text { should always be } \\
\text { made. }\end{array}$ \\
\hline Vidan's test. & Sugar. & $\begin{array}{l}\text { Equal volume sesame- } \\
\text { oil and hydrochloric } \\
\text { acid. }\end{array}$ & Pink color. & $\begin{array}{l}\text { Heat R. to boiling; add } \\
\text { liquid. }\end{array}$ & \\
\hline Violette's test. & Glucose. & Similar to Fehling's & test. & & \\
\hline Vitali's test. & Alkaloids. & $\begin{array}{l}\text { (a) Fuming nitric acid. } \\
(b) \text { Alcoholic sol. po- } \\
\text { tass. hydrate. }\end{array}$ & Color-reactions. & $\begin{array}{l}\text { Evaporate to dryness } \\
\text { with } a \text {; add I drop } b \text {. }\end{array}$ & \\
\hline Vitali's test. & Alkaloids. & \begin{tabular}{|} 
(a) Sulphuric acid. $(b)$ \\
Potass. chlorate. $(c)$ \\
An alkaline sulphid.
\end{tabular} & $\begin{array}{l}\text { Color-reactions in } \\
\text { presence of } c \text {. }\end{array}$ & & \\
\hline Vitali's test. & Atropin. & $\begin{array}{l}\text { (a) Fuming nitric acid. } \\
\text { (b) Alcoholic sol. po- } \\
\text { tass. hydrate. }\end{array}$ & $\begin{array}{l}\text { Violet color, turn- } \\
\text { ing red. }\end{array}$ & $\begin{array}{l}\text { Evaporate with } a \\
\text { when cold add I drop } \\
b \text {. }\end{array}$ & $\begin{array}{l}\text { Delicacy } 0.00000 r \\
\text { gram. }\end{array}$ \\
\hline Vitali's test. & $\begin{array}{l}\text { Biliary coloring- } \\
\text { matter. }\end{array}$ & $\begin{array}{l}\text { (a) Sol. quinin bisul- } \\
\text { phate. }(b) \text { Ammonia. } \\
\text { (c) Sulphuric acid. } \\
\text { (d) Sugar. (e) Alco- } \\
\text { hol. }\end{array}$ & Violet color. & $\begin{array}{l}\text { Add } a \text {, neutralize with } \\
b, \text { add } c \text {, crystal of } \\
d, \text { and } e \text {. }\end{array}$ & \\
\hline
\end{tabular}


TABLE OF TESTS.-Continued.

\begin{tabular}{|c|c|c|c|c|c|}
\hline NAME. & USE. & REAGENTS. & REACTION. & APPLICATION. & REMARKS. \\
\hline Vitali's test. & Chloroform. & $\begin{array}{l}\text { (a) Hydrogen sulphid. } \\
\text { (b) Piece copper wire. }\end{array}$ & Intense-hlue color. & $\begin{array}{l}\text { Pass current of } a \\
\text { through liquid, then } \\
\text { through glass tube; } \\
\text { ignite; hold } b \text { in } \\
\text { flame. }\end{array}$ & \\
\hline Vitali's test. & Chloroform. & $\begin{array}{l}\text { (a) Hydrogen sulphid. } \\
\text { (b) Solution potass. } \\
\text { hydrate and thymol. }\end{array}$ & Red color. & $\begin{array}{l}\text { Pass current of } a \\
\text { through liquid, then } \\
\text { into } b \text {. }\end{array}$ & \\
\hline Vitali's test. & Fusel-oil. & Sulphuric acid. & $\begin{array}{l}\text { Red, ch a nging } \\
\text { finally to green. }\end{array}$ & $\begin{array}{l}\text { Pour liquid on top of } \\
\text { R.; stir gently. }\end{array}$ & \\
\hline Vitali's test. & Morphin. & $\begin{array}{l}\text { (a) Sulphuric acid. }(b) \\
\text { Sol. sodium sulphid. }\end{array}$ & $\begin{array}{l}\text { Flesh color, violet, } \\
\text { dark-green. }\end{array}$ & $\begin{array}{l}\text { Dissolve in } a \text {; add } 2 \\
\text { drops } b \text {; heat cau- } \\
\text { tiously. }\end{array}$ & \\
\hline Vitali's test. & Thymol. & $\begin{array}{l}\text { Mixture of chloroform } \\
\text { and sol. potassium } \\
\text { hydrate. }\end{array}$ & Red color. & $\begin{array}{l}\text { Distil off, passing va- } \\
\text { por into } R \text {. }\end{array}$ & \\
\hline Vogel's test. & Carbon disulphid. & $\begin{array}{l}\text { (a) Alcohol. sol. potass. } \\
\text { hydr a te. (b) Sol. } \\
\text { copper sulphate. }\end{array}$ & $\begin{array}{l}\text { Lemon-yellow pre- } \\
\text { cipitate. }\end{array}$ & Add $a$, then $\bar{b}$. & \\
\hline Vogel's test. & Ferric salts. & Sol. salicylic acid. & Violet color. & Add R. & \\
\hline Vogel's test. & Glucose. & Litmus-solution. & Decolorization. & $\begin{array}{l}\text { Boil with a few drops } \\
\text { of } \mathrm{R} \text {. }\end{array}$ & \\
\hline Vogel's test. & $\begin{array}{l}\text { Nitric acid in pot- } \\
\text { able water. }\end{array}$ & $\begin{array}{l}\text { (a) Gold-leaf. (b) } \mathrm{Hy}- \\
\text { drochloric acid. }(c) \\
\text { Stannous chlorid. }\end{array}$ & $\begin{array}{l}\text { Red d is } \mathrm{h} \text { - violet } \\
\text { color. }\end{array}$ & $\begin{array}{l}\text { To I5 c.c. water add a } \\
\text { little } a \text { and } b \text {; boil; } \\
\text { filter; add } c \text {. }\end{array}$ & \\
\hline Vogel's test. & Quinin. & $\begin{array}{l}\text { (a) Chlorin-water. }(b) \\
\text { Powdered potass. } \\
\text { ferrocyanid. }\end{array}$ & $\begin{array}{l}\text { Pink to deep-red } \\
\text { color. }\end{array}$ & Mix with $a$, and add $b$. & \\
\hline Vogel's test. & $\begin{array}{l}\text { Free sulphuric } \\
\text { acid in vinegar. }\end{array}$ & Potassium chlorate. & $\begin{array}{l}\text { Evolution of chlor- } \\
\text { in. }\end{array}$ & Add R. & \\
\hline Vogel's test. & Tannin. & $\begin{array}{l}\text { (a) Chlorin-water. (b) } \\
\text { Ammonia. }\end{array}$ & Blood-red color. & Add $a$ and $b$. & \\
\hline Vohl's test. & Sulphur. & $\begin{array}{l}\text { Mix water i with gly- } \\
\text { cerin } 2 \text {; s a r a te } \\
\text { with slaked lime } \\
\text { and fresh lead hy- } \\
\text { drate; decant. }\end{array}$ & Black color. & $\begin{array}{l}\text { Heat R. with the sub- } \\
\text { stance. }\end{array}$ & \\
\hline Vortmann's test. & Hydrocyanic acid. & $\begin{array}{l}\text { (a) Sol. potass. nitrite. } \\
\text { (b) Sol. ferric chlorid. } \\
\text { (c) Dil. su l p h u i ic } \\
\text { acid. (d) Ammonia. } \\
\text { (e) Ammon. sulphid. }\end{array}$ & $\begin{array}{l}\text { Bluish-green to } \\
\text { violet-red color. }\end{array}$ & $\begin{array}{l}\text { Add a few drops } a \\
2 \sim 4 \text { drops } b ; c \text { until } \\
\text { color light-yellow; } \\
\text { heat to boiling: al- } \\
\text { low to cool a add } d ; \\
\text { filter; to filtrate add } \\
e \text {. }\end{array}$ & \\
\hline De Vrij's test. & Alkaloids. & $\begin{array}{l}\text { Phosphomolybdic } \\
\text { acid. }\end{array}$ & Precipitates. & & \\
\hline Vulpius' test. & Sulphonal. & Potass. cyanid. & $\begin{array}{l}\text { Repulsive odor of } \\
\text { mercaptan. }\end{array}$ & $\begin{array}{l}\text { Heat substance with } \\
\text { R. }\end{array}$ & \\
\hline Wagner's test. & Eosin. & Collodium. & $\begin{array}{l}\text { Color discharged } \\
\text { by } R \text {. }\end{array}$ & & \\
\hline Warren's test. & Glucose. & Similar to Trommer's & test, $q . v$ & & \\
\hline Wartha's test. & Anthrachinon. & $\begin{array}{l}\text { (a) Sol. potass, hy- } \\
\text { drate. }(b) \text { Alcohol. }\end{array}$ & $\begin{array}{l}\text { Green to bluish- } \\
\text { purple color. }\end{array}$ & Heat with $a$ and $b$. & \\
\hline Waier-test. & Water. & See Nigrosin-test. & & & \\
\hline Watson's test. & Gallic acid. & $\begin{array}{l}\text { (a) A mmonia. } \\
\text { Hydrochloric acid. }\end{array}$ & Red color. & $\begin{array}{l}\text { Dissolve in water; add } \\
a \text { and } b .\end{array}$ & \\
\hline Watson's test. & Pyrogallic acid. & Ammonia. & $\begin{array}{l}\text { Lemon-yellow } \\
\text { color. }\end{array}$ & $\begin{array}{l}\text { Dissolve in water; add } \\
\mathrm{R} \text {. }\end{array}$ & \\
\hline Watson's test. & Tamnin. & $\begin{array}{l}\text { (a) Ammonia. (b) } \\
\text { Nitric acid. }\end{array}$ & Purple color. & $\begin{array}{l}\text { Dissolve in water; add } \\
a \text { and } b \text {. }\end{array}$ & \\
\hline Weber's test. & Indican in urine. & $\begin{array}{l}\text { (a) Hydrochloric acid. } \\
\text { (b) Ether. }\end{array}$ & $\begin{array}{l}\text { Blue foam; red } \\
\text { color of the } \\
\text { ether. }\end{array}$ & $\begin{array}{l}\text { Heat } 30 \text { c.c. of urine to } \\
\text { boiling with } 30 \mathrm{c.c} \text {. } \\
a \text {; let cool; shake } \\
\text { with } b \text {. }\end{array}$ & . \\
\hline
\end{tabular}


TABLE OF TESTS.-Continued.

\begin{tabular}{|c|c|c|c|c|c|}
\hline NAME. & USE. & REAGENTS. & REACTION. & APPLICATION. & REMARKS. \\
\hline Weidel's test. & Xanthin. & $\begin{array}{l}\text { (a) Freshly prepared } \\
\text { chlorin-water, }(b) \\
\text { Nitric acid. (c) Am- } \\
\text { monia-vapor. }\end{array}$ & $\begin{array}{l}\text { Pink or purplish- } \\
\text { red color. }\end{array}$ & $\begin{array}{l}\text { Warm substance with } \\
a \text { and trace } b \text { as long } \\
\text { as gas is evolved } \\
\text { then evaporate to } \\
\text { dryness and bring } \\
\text { in contact with } c \text {. }\end{array}$ & \\
\hline Weidel's test. & Xanthin bodies. & $\begin{array}{l}\text { (a) Chlorin-water. }(b) \\
\text { Ammonia. (c) Potass. } \\
\text { or sodium hydrate. }\end{array}$ & $\begin{array}{l}\text { Dark-pink or } \\
\text { purple; violet } \\
\text { on final addition } \\
\text { of } c \text {. }\end{array}$ & $\begin{array}{l}\text { Dissolve in the warm } \\
\text { in } a \text {; evaporate on } \\
\text { water-bath; treat } \\
\text { under bell-jar with } b .\end{array}$ & $\begin{array}{l}\text { Reaction obtained } \\
\text { with xanthin, } \\
\text { heteroxanthin, } \\
\text { paraxanthin, and } \\
\text { carnin. }\end{array}$ \\
\hline Wellcome's test. & Morphin. & Chlorinated lime. & Red color. & Add $\mathbf{R}$. & \\
\hline Weltzien's test. & Hydrogen dioxir. & $\begin{array}{l}\text { Mixture of sol. of fer- } \\
\text { ric chlorid and po- } \\
\text { tass. ferricyanid. }\end{array}$ & Blue color. & Add R. & \\
\hline Wenzell's test. & Strychuin. & $\begin{array}{l}\text { Sol. potass. perman- } \\
\text { ganate } \mathrm{I} \text { in sulphuric } \\
\text { acid } 2000 \text {. }\end{array}$ & Color-reaction. - & & Delicacy I : 900,000. \\
\hline Weppen's test. & Morphin. & $\begin{array}{l}\text { (a) Sugar. (b) Sul- } \\
\text { phuric acid. }(c) \\
\text { Bromin. }\end{array}$ & Red color. & Add $a, b, c$. & \\
\hline Weppen's test. & Veratrin. & $\begin{array}{l}\text { (a) Sugar. (b) Sul- } \\
\text { phuric acid. }\end{array}$ & $\begin{array}{l}\text { Light-y ellow to } \\
\text { dark-green and } \\
\text { dark-blue color. }\end{array}$ & Add $a$ and $b$. & \\
\hline Werber's test. & Nitroglycerin. & $\begin{array}{l}\text { (a) Ether or chloroform. } \\
\text { (b) Anilin. (c) Sul- } \\
\text { phuric acid. }\end{array}$ & $\begin{array}{l}\text { Purple to da r k- } \\
\text { green color. }\end{array}$ & $\begin{array}{l}\text { Extract with } a \text {, add } \\
\text { two drops } b \text {, evapo- } \\
\text { rate; add } c \text {. }\end{array}$ & \\
\hline Weyl's test. & Kreatinin. & $\begin{array}{l}\text { (a) Dil. sol. sodium } \\
\text { nit roprussid. (b) } \\
\text { Dil. sodium hydrate. } \\
\text { (c) Acetic acid. }\end{array}$ & $\begin{array}{l}\text { Transient } r u b y- \\
\text { red color; if } c \text { is } \\
\text { added greenish, } \\
\text { then blue color. }\end{array}$ & $\begin{array}{l}\text { Add a few drops } a \\
\text { then drop by drop } b \\
\text {-gives ruby-red } \\
\text { color. Add } c \text { and } \\
\text { warm. }\end{array}$ & $\begin{array}{l}\text { Very delicate; } .0257 \\
\text { per cen t. pure, } \\
.066 \text { in urine. }\end{array}$ \\
\hline Weyl's test A. & $\begin{array}{l}\text { Nitric acid in } \\
\text { urine. }\end{array}$ & $\begin{array}{c}\text { (a) Hydrochloric or } \\
\text { sulphuric acid. }(b) \\
\text { Potass. hydrate. }(c) \\
\text { Meta-phenyldiamin. }\end{array}$ & Yellow color. & $\begin{array}{r}\text { Distil } 200 \text { c.c. urine } \\
\text { with } \frac{1}{6-t} \text { vol. } a \text {, re- } \\
\text { ceiving distillate in } \\
b \text {; add } c \text { to distillate. }\end{array}$ & \\
\hline Weyl's test B. & $\begin{array}{l}\text { Nitric acid in } \\
\text { urine. }\end{array}$ & $\begin{array}{l}\text { (a) Hydrochloric or } \\
\text { sulphuric acid. }(b) \\
\text { Potass, hydrate. }(c) \\
\text { Aq. sol. pyrogallic } \\
\text { acid with a little sul- } \\
\text { phuric acid. }\end{array}$ & $\begin{array}{l}\text { Yellowish-b rown } \\
\text { color. }\end{array}$ & See $W e y l$ 's test $A$. & \\
\hline Weyl's test C. & $\begin{array}{l}\text { Nitric acid in } \\
\text { urine. }\end{array}$ & $\begin{array}{l}\text { Hydrochloric or } \\
\text { sulphuric acid. (b) } \\
\text { Potass, hydrate. (c) } \\
\text { Sol. sulphanilic acid. } \\
\text { (d) Naphthylamin } \\
\text { hydrochlorate. }\end{array}$ & Red color. & $\begin{array}{l}\text { Distil as in W ey l's } \\
\text { test } A \text {; treat distill- } \\
\text { ate with dilute sul- } \\
\text { phuric acid; add at } \\
\text { once } c \text {; in } 8 \text {-ro min- } \\
\text { utes } d \text {. }\end{array}$ & \\
\hline Wiesner's test. & Cellulose. & $\begin{array}{l}\text { (a) } 1 / 2 \text { per cent. sol. } \\
\text { phloroglucin. }(b) \\
\text { Hydrochloric acid. }\end{array}$ & Red or violet color. & Moisten with $a$; add $b$. & \\
\hline Winckler's test. & Alkaloids. & $\begin{array}{l}\text { Sol. mercuric chlorid } \\
\text { in excess of potass. } \\
\text { iodid. }\end{array}$ & White precipitate. & Add $\mathbf{R}$. & \\
\hline Winckler's test. & Iodin. & $\begin{array}{l}\text { (a) Sodium nitrite. } \\
\text { (b) Starch-paste. }\end{array}$ & Blue color. & Mix with $a$ and $b$. & \\
\hline Winckler's test. & Water in alcohol. & Cobalt chlorid. & $\begin{array}{l}\text { Blue color turns } \\
\text { red. }\end{array}$ & Add $\mathbf{R}$. & \\
\hline Wittstein's test. & $\begin{array}{l}\text { Foreign starch in } \\
\text { chocolate. }\end{array}$ & Iodin. & Blue color. & $\begin{array}{l}\text { Boil; filter; test filtrate } \\
\text { with R. Na tura } 1 \\
\text { starch does not pass } \\
\text { through filter. }\end{array}$ & \\
\hline Witz's test. & $\begin{array}{l}\text { Hydrochloric acid } \\
\text { in gastric juice. }\end{array}$ & $\begin{array}{l}\text { Aqueous sol. methyl- } \\
\text { violet, strength } 0.025 \\
\text { per cent. }\end{array}$ & $\begin{array}{l}\text { Violet colorchang- } \\
\text { ed to blue } \\
\text { hydrochloric } \\
\text { acid in strong } \\
\text { sol. gives green- } \\
\text { ish tint. }\end{array}$ & Add liquid to $R$. & $\begin{array}{l}\text { Lactic acid in } \\
\text { strong sol. gives } \\
\text { similar but less } \\
\text { distinct reaction. }\end{array}$ \\
\hline
\end{tabular}


TABLE OF TESTS.-Continued.

\begin{tabular}{|c|c|c|c|c|c|}
\hline NAME. & USE. & REAGENTS. & REACTION. & APPLICATION. & REMARKS. \\
\hline Witz's test. & $\begin{array}{l}\text { Mineral acids in } \\
\text { vinegar. }\end{array}$ & Methyl-violet. & $\begin{array}{l}\text { Violet color turned } \\
\text { blue or green. }\end{array}$ & $\begin{array}{l}\text { Add } 2 \text { drops } R \text {, to } 25 \\
\text { c.c. vinegar. }\end{array}$ & Delicacy I : 10,000 \\
\hline Woehler's test. & Phosphorus. & & $\begin{array}{l}\text { Green color of } \\
\text { flame. }\end{array}$ & $\begin{array}{l}\text { Place liquid in Marsh's } \\
\text { apparatus, ignite the } \\
\text { hydrogen phosphid, } \\
\text { and let flame strike } \\
\text { against a porcelain } \\
\text { plate. }\end{array}$ & \\
\hline Woodbury's test. & Alcohol in urine. & $\begin{array}{l}\text { (a) Sulphuric acid. } \\
\text { (b) Potass. bichrom- } \\
\text { ate. }\end{array}$ & Green color. & $\begin{array}{l}\text { To r gm. } a \text { add } 2 \text { gm. } \\
\text { urine; drop in crys- } \\
\text { tal of } b \text {; mix. }\end{array}$ & $\begin{array}{l}\text { Delicacy } 2 \text { to } 3 \text { in } \\
1000 .\end{array}$ \\
\hline $\begin{array}{l}\text { Worm-M üller's } \\
\text { test. }\end{array}$ & Glucose in urine. & $\begin{array}{l}\text { (a) } 2.5 \text { per cent. sol. } \\
\text { copper sulphate. }(b) \\
\text { Sodic potassium tar- } \\
\text { trate Io, } 4 \text { per cent. } \\
\text { sol. sodium hydrate } \\
\text { I0o. }\end{array}$ & $\begin{array}{l}\text { Yellowish-red or } \\
\text { red precipitate. }\end{array}$ & $\begin{array}{l}\text { Boil in one test-tube } 5 \\
c . c \text {. urine, in another } \\
1-3 \text { c.c. } a \text { and } 2.5 \text { c.c. } \\
b \text {; discontinue boil- } \\
\text { ing of both at same } \\
\text { moment; wait } 20-25 \\
\text { sec, then mix. }\end{array}$ & \\
\hline Wormley's test. & Alkaloids. & $\begin{array}{l}\text { Alcohol. sol. picric } \\
\text { acid. }\end{array}$ & $\begin{array}{r}\text { Yellow, amorphous } \\
\text { or crystalline ppt. }\end{array}$ & & \\
\hline Wormley's test. & Alkaloids. & $\begin{array}{l}\text { Sol. iodin I, potass. } \\
\text { iodid 2, water } 60 .\end{array}$ & $\begin{array}{l}\text { Colored precipi- } \\
\text { tate. }\end{array}$ & & \\
\hline Wormley's test. & $\begin{array}{l}\text { Free } s u 1 p \text { huric } \\
\text { acid. }\end{array}$ & Veratrin. & Crimson color. & $\begin{array}{l}\text { Add } R \text {., and evaporate } \\
\text { to dryness on water- } \\
\text { bath. }\end{array}$ & \\
\hline Wurster's test. & Tyrosin (pure). & Chinon. & $\begin{array}{l}\text { Ruby-red color, } \\
\text { changing to } \\
\text { brown after } 24 \\
\text { hours. } \\
\end{array}$ & $\begin{array}{l}\text { Dissolve crystals in } \\
\text { boiling water and } \\
\text { add a little R. }\end{array}$ & \\
\hline Xanthoproteic test. & Proteids. & $\begin{array}{l}\text { (a) Strong nitric acid. } \\
\text { (b) An alk aline } \\
\text { hydrate. }\end{array}$ & $\begin{array}{l}\text { Yellow color with } \\
a, \text { turning to } \\
\text { deep-orange } \\
\text { with } b \text {. }\end{array}$ & $\begin{array}{l}\text { Heat substance with } \\
a ; \text { add } b \text {. }\end{array}$ & \\
\hline Xylidin-test. & Carbohydrates. & See Schiff's test. & & & \\
\hline Young's test. & Gallic acid. & Sol. potass. cyanid. & $\begin{array}{l}\text { Red color which } \\
\text { soon disappears; } \\
\text { on shaking reap- } \\
\text { pears. } \\
\end{array}$ & Add R. & \\
\hline Yvon's test. & $\begin{array}{l}\text { Acetanilid (anti- } \\
\text { febrin) in urine. }\end{array}$ & $\begin{array}{l}\text { Chloroform. }(b) \\
\text { Mercurous nitrate. }\end{array}$ & Green color. & $\begin{array}{l}\text { Extract urine with } a \\
\text { heat residue of ex- } \\
\text { tract with } b \text {. }\end{array}$ & \\
\hline Yvon's test. & Alkaloids. & $\begin{array}{l}\text { Bismuth subnitrate } 3 \\
\text { gm., water } 40 \text { gm., } \\
\text { boil; add pot as s. } \\
\text { iodid I4 gm., hydro- } \\
\text { chloric acid } 40 \text { drops. }\end{array}$ & Red color. & Add R. & \\
\hline Yvon's test. & $\begin{array}{l}\text { Purity of chloro- } \\
\text { form. }\end{array}$ & $\begin{array}{l}\text { Sol. potass. perman- } \\
\text { ganate I, potass. hy- } \\
\text { drate ro, water } 250 . \\
\end{array}$ & $\begin{array}{l}\text { Green color indi. } \\
\text { cates impurity. }\end{array}$ & Add $\mathrm{R}$. & \\
\hline Zeise's test. & Carbon disulphid. & See Vogel's test. & & & \\
\hline Zeisel's test. & Colchicin. & $\begin{array}{l}\text { (a) Hydrochloric acid. } \\
\text { (b) Ferric chlorid. } \\
\text { (c) Chloroform. }\end{array}$ & $\begin{array}{l}\text { Boiled with } b, \\
\text { green color; } c \\
\text { extract, brown- } \\
\text { ish, granite-red, } \\
\text { or dark. }\end{array}$ & $\begin{array}{l}\text { Boil sol. in } a \text { with } b \text {; } \\
\text { agitate with } c \text {. }\end{array}$ & \\
\hline Zeller's test. & Melanin in urine. & Bromin-water. & $\begin{array}{l}\text { Yellow ppt, gradu- } \\
\text { ally blackening. }\end{array}$ & Add R. & \\
\hline Zouchlos' test A. & Albumin in urine, & $\begin{array}{l}\text { Acetic acid I, mercuric } \\
\text { chlorid, I per cent. } \\
\text { sol., } 6 .\end{array}$ & Precipitate. & Add R. & 0.0r4 per cent. \\
\hline Zouchlos' test B. & Albumin in urine. & $\begin{array}{l}\text { Potass. sulphocyanid, } \\
\text { ro per cent. sol., roo, } \\
\text { acetic acid } 20 .\end{array}$ & Precipitate. & Add $\mathrm{R}$. & $\begin{array}{l}\text { Delicacy } 0.007 \% . \\
\text { Precipitates also } \\
\text { propeptone. }\end{array}$ \\
\hline Zouchlos' test C. & Albumin in urine. & $\begin{array}{c}\text { Potass, sulphocyanid, } \\
\text { succinic acid equal } \\
\text { parts, in solid form. }\end{array}$ & Precipitate. & Add $\mathbf{R}$. & $\begin{array}{l}\text { Not as delicate as } \\
\text { Zouchlos' test B. }\end{array}$ \\
\hline
\end{tabular}


Testis (tes'-tis) [L.]. I. See Testes. 2. Any organ fancied to have the shape of a testicle. T., Caput, the epididymis. T. cerebri, testis of the brain, the postgeminum; either of the posterior pair of the corpora quadrigemina.

Testitis (tes-ti'-tis). See Orchitis.

Testudo (tes-tu'to [L., a tortoise-shell]. A figure-of eight bandage about an articulation, the turns crossing on the flexor surface and the spirals overlapping, so as to cover the extensor surface of the joint.

Testule $\left(\right.$ test' $\left.^{\prime}-\bar{u} l\right)$ [testa, a shell]. In biology, the frustule, or silicious skeleton, of a diatom.

Tetanic (tet-an'-ik) [ [x́tavos, tetanus]. Pertaining to tetanus.

Tetaniform (tet'-an-if-orm) [тétavos, tetanus; forma, form]. Resembling tetanus.

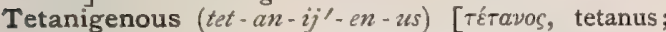

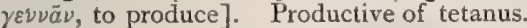

Tetanilla (tet-an-il'-ah) [ TÉTavos, tetanus]. A form of tetanic spasm affecting the fingers and toes. It is observed mainly among children, and is a concomitant of rachitis.

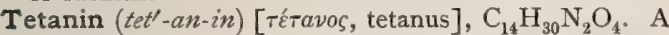
toxin present in the blood in tetanus; a ptomain obtained by cultivating tetanus-microbes in beef-broth. It has been obtained from the amputated arm of a tetanus-patient by Brieger, who thus demonstrated the presence of tetanin in tetanus-patients during life, Nevertheless, it has not been found in the brain and nerve-tissue of persons dead from tetanus. The base produces the characteristic symptoms of tetanus, though probably not all, as three other toxins, including spasmotoxin, occur with tetanin in cultures of the tetanus-microbe. See Ptomains, Table of.

Tetanium (tet-an'-e-um). Synonym of Strychnin.

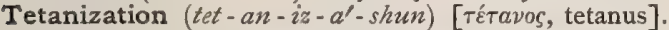
The production of tetanus, or of tetanic spasms. The induction of a protracted contraction in a nerve by an electric current.

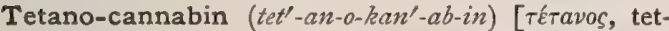
anus; cannabis]. A basic substance found in some samples of cannabis, or hemp. Its action on the system resembles that of strychnin. Unof.

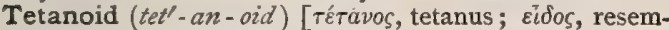
blance]. Resembling tetanus.

Tetanomotor (tet-an-o-mo'-tor) [TÉTavos, tetanus; motor, a mover]. An instrument (usually a rapidly vibrating hammer) for stimulating a nerve mechanically.

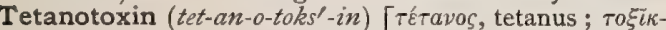
ov, poison], $\mathrm{C}_{5} \mathrm{H}_{11} \mathrm{~N}$. A poisonous ptomain obtained by Brieger as one of the products of the culture of the tetanus-microbe. It is tetanizing in its action, producing first tremor, then paralysis and violent convulsions. See Ptomains, Table of.

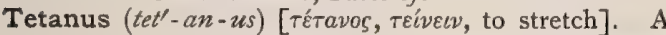
spasmodic and continuous contraction of muscles, causing rigidity of the parts to which they are attached. See Trismus, Opisthotonos, Emprosthotonos, Pleurosthotonos. Brieger has isolated four toxie ptomain-substances from cultivations of so-called tetanus-bacilli : Tetanin, which produced symptoms of tetanus (in mice); Tetatoxin, which caused tremor, paralysis, and convulsions; Muriate of Toxin, which produced tetanus and salivation; Spasmotoxin, which prostrated quickly, with clonic and tonic spasms. T., Acoustic. See Acoustic. T., Cephalic, T., Cerebral, T., Hydrophobic, T., Kopf-, a special form of tetanus that has sometimes been observed to follow injuries of the head, especially those in the neighborhood of the eyebrow. Trismus and facial paralysis occur upon the side of the injury. There is dysphagia, and death frequently results. T. dolorificus. Synonym of
Cramp. T., Extensor, a form of tetanus in which the extensors act more powerfully than the flexors. T., Hydrophobic. See $T$., Cerebral. T., Imitative, hysteria which simulates tetanus. $T$. infantum. See $T$. neonatomem. T., Localized, tetanic spasm of a part. T., Post-operative, that following operation. Chrostek's Sign, a diagnostic and pathognomonic sign of post-operative tetany. A slight tap upon the side of the face, over the point where the facial nerve emerges from the parotid, suffices to call forth a sudden spasm of that side of the face. T., Ritter's, the series of contractions, or apparent tetanus, observed on the opening or interrupting of an electric current which has been passing through the nerve for some time. Opening tetanus. T., Toxic, tetanus produced by an overdose of nux vomica or its alkaloids. T., Traumatic, tetanus following an injury

Tetany (tet'-an-e) [те́тã of the extremities occurring chiefly in rickety infants and lasting a variable time. The fingers, hands, and wrists are the portions mainly affected. It occasionally occurs in nursing women also. See Tetanilla. $\mathbf{T}$. Epidemic, $T$., Rheumatic; a form occurring over large portions of Europe, especially in the winter season. It is acute, lasting only two or three weeks, and rarely proving fatal. T., Gutturo-, a stammering due to tetanoid spasm of the laryngeal muscles. T., Rheumatic. See 1., Epidemic.

Tetartophya, Tetartophyia (tet-ar-toff'-e-ah, tet-ar-

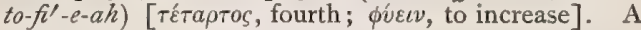
quartan remittent malarial fever.

Tetatoxin (tet-at-oks'-in). See Tetanus.

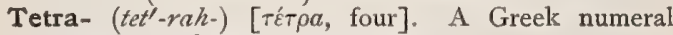
used as a prefix and denoting four.

Tetrabasic (tet'-rab-a $\left.a^{\prime}-z i k\right)$ [ $\tau \dot{\varepsilon} \tau \rho a$, four; $\beta a ́ \sigma \iota c$, base]. Having a basicity of four; having four atoms of replaceable hydrogen.

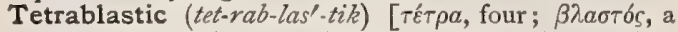
germ]. In biology, applied to an embryo having four germ-layers, i. e., an ectoderm, entoderm, somatopleure, and a splanchnopleure.

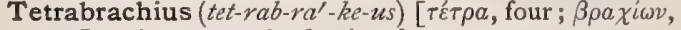
arm]. A monstrosity having four arms.

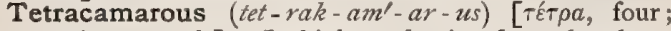
$\kappa \alpha \mu a ́ \rho a$, a vault]. In biology, having four chambers, as a fruit of four carpels.

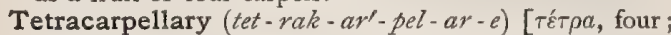
$\kappa a \rho \pi b \varsigma$, fruit]. In biology, having four carpels.

Tetracheirus $\left(t e t-r a k-i^{\prime}-r u s\right)$ [ $\tau \dot{t} \tau \rho a$, four ; $\chi \varepsilon \varepsilon \rho$, hand]. A monster with four hands.

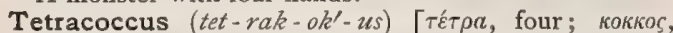
berry]. I. A micrococcus occurring in clusters and forming groups of four. 2. In biology, a fruit of four carpels.

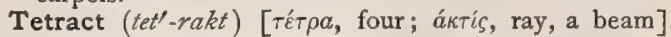
In biology, having four rays.

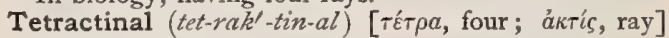
Having four rays.

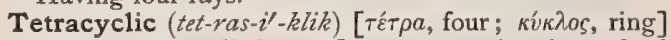
In biology, applied to a flower possessing four whorls of floral organs.

Tetrad (tet'-rad) [ $\tau \dot{\tau} \tau \rho a$, four]. An element having an atomicity of four.

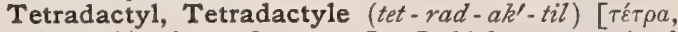

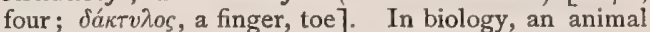
having four digits on each limb.

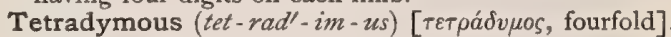
In biology, in sets of four each.

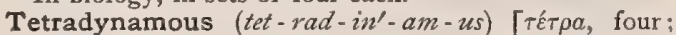

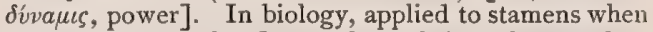
there are six in the flower, four of them longer than the other two. 
Tetra-ethyl-ammonium (tet-rah-eth-il-am-o'-ne-um). A proposed solvent for uric acid and urea. It is best used in a 10 per cent. solution, the dose being $\mathbf{I} 0$ to 20 minims. It is obtained by decomposing its iodid by moist $\mathrm{AgNO}_{3}$ or its sulphate by baryta. It occurs in deliquescent, hair-like needles, as bitter as quinin. It is strongly alkaline and caustic.

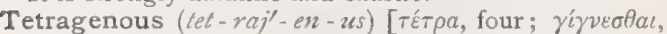
to be born]. In biology, applied to bacteria and other organisms which produce square groups of four as the result of fission.

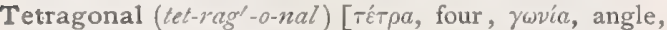
corner]. Four-angled.

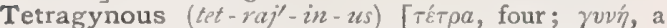
female]. Having a gynecium of four carpels.

Tetrahydrobetanaphthylamin (tet-rah-hi-dro-be-tan aff-thil'-am-in). See Hydronaphthylamin.

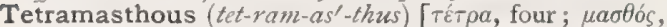
breast]. Having four breasts.

Tetramastigate (tet-ram- $\left.a s^{\prime}-t i g-\bar{a} t\right)$ [ $\tau \dot{\tau} \tau \rho \alpha$, four; $\mu a ́ \sigma \tau \iota \xi$, a whip]. In biology, applied to microorganisms having four flagella.

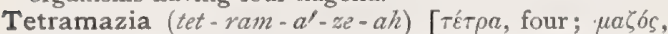
breast]. The presence, normal or abnormal, of four teats or mammary glands.

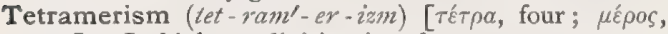
part]. In biology, division into four parts

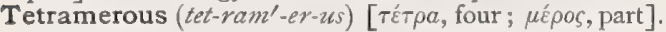
In biology, having the parts or organs arranged in fours or multiples of four.

Tetramethylalloxantin (tet-ram-eth-il-al-oks-an'-tin). See Acid, Analic.

Tetramethylenediamin (tet-ram-eth'-il-ên-di'-an-in), $\mathrm{C}_{4} \mathrm{H}_{8}\left(\mathrm{NH}_{2}\right)_{2}$. A substance identical with putrescin, which has been isolated from decaying animal matter. It is a liquid with a peculiar odor. It fumes in the air and boils at from $156^{\circ}$ to $160^{\circ} \mathrm{C}$. On cooling, it solidifies to a crystalline mass.

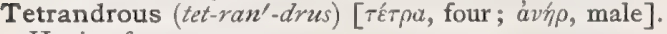
Having four stamens.

Tetranerythrin (tet-ran-er'-ith-rin) [ $\tau \dot{\varepsilon} \tau \rho \alpha$, four ; $\varepsilon \rho v \theta-$ oos, red]. See Tetronerythrin.

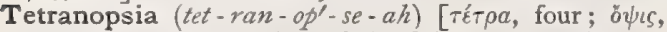
vision]. A contraction of the field of vision limited to one quadrant.

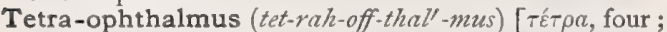
$\dot{\partial} \phi \theta a \lambda \mu o \varsigma$, eye]. A form of monster having four eyes.

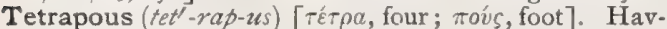
ing four feet.

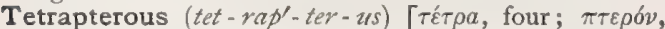
wing]. In biology, having four wings; said of a fruit or stem.

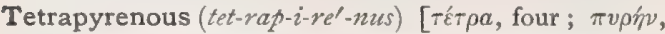
the stone of a fruit]. In biology, characterized by four stones, or pyrenes.

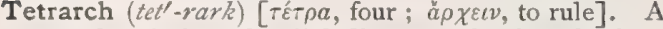
term descriptive of radial fibro-vascular bundles having four rays.

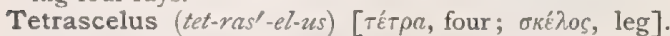
A monster with four legs.

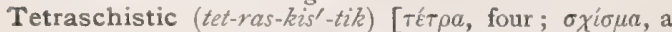
cleft, division]. In biology, dividing into four similar parts.

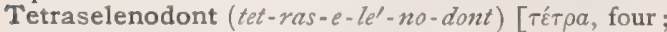

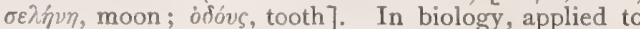
an animal with molar teeth exhibiting four crescentic ridges.

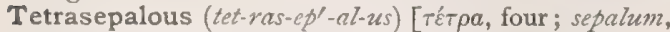
sepal]. In biology, having four sepals.

Tetraspermous (tet-ras-per'-mus) [ $\tau \dot{\varepsilon} \tau \rho a$, four; $\sigma \pi \hat{\varepsilon} \rho \mu a$, seed]. In biology, having four seeds.

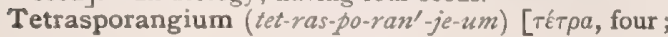

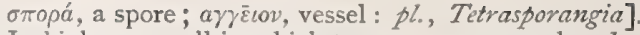
In biology, a cell in which tetraspores are produced.

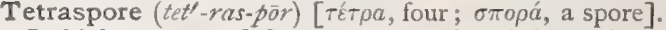
In biology, one of four spores produced in a single mother-cell or sporangium, as in the Red Marine Alga (Floridea).

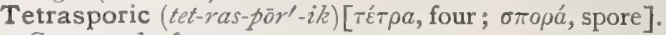
Composed of tetraspores.

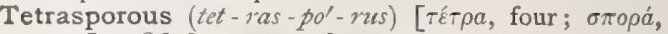
spore]. Of the nature of tetraspores.

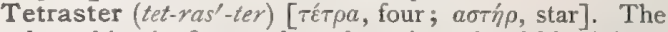
karyokinetic figure when there is a fourfold division of the nucleus and four centers of radiation.

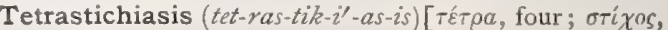
row]. Anomalous arrangement of the eyelashes in four rows.

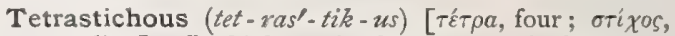
row, line]. In biology, in four perpendicular rows. Applied to phyllotaxy.

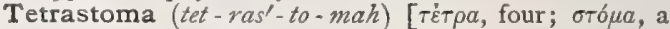
mouth]. A genus of entozoa. See $T$. renalis, under Parasites (Animal), Table of

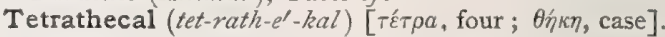
In biology, applied to a four-chambered ovary.

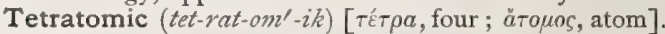
Containing four atoms; having four atoms of replaceable hydrogen.

Tetravalent (tet-rav'-al-ent). Synonym of Quadrivalent.

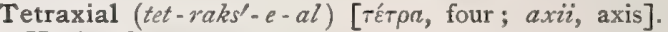
Having four axes.

Tetrazone (tet'-raz-ōn) [tater, foul; $\ddot{\zeta} \eta \eta$, smell], $\left(\mathrm{C}_{2} \mathrm{H}_{5}\right)_{2} \mathrm{~N} . \mathrm{N}: \mathrm{N} . \mathrm{N}\left(\mathrm{C}_{2} \mathrm{H}_{5}\right)_{2}$, A basic liquid of alliaceous odor.

Tetrol (tet'-rol). See Furan.

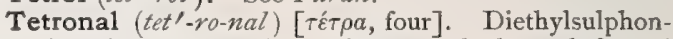
diethylmethane. A disulphone of the ethyl and methyl groups, harmless in ordinary doses, and having marked hypnotic properties. Dose gr. $\mathrm{x}-\mathrm{xx}$, as with sulphonal. Unof.

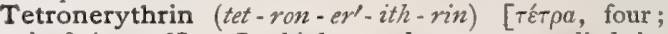
$\varepsilon \rho v \theta \rho \delta s$, red]. In biology, the name applied by Merejkowsky to a group of lipochrome pigments found in animals, and formerly supposed to have a respiratory function. See Pigments, Conspectus of.

Tetrophthalmus (tet-roff-thal'-mus). See Diprosopus.

Tetrose (tet'-röz). See Erythrose.

Tetrotus (tet-ro'-tus). See Diprosopus.

Tetter (tet'-er) [ME., teter, tetter]. A common name for various skin-eruptions, particularly herpes and eczema. See Herpes. T., Brawny, seborrhcea capitis. T., Dry, dry or squamous eczema. T., Humid. See Eczema. T., Milky. See Crusta lactea. T., Moist. See Eczema. T., Running, includes various forms of eczema. T., Scaly, psoriasis and squamous eczema.

Tety $\left(\right.$ tet $\left.^{\prime}-\ell\right)$ [Madagascar]. A skin-disease peculiar to Madagascar, and characterized by a pustular or squamous eruption in the neighborhood of the mouth and nostrils.

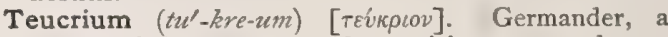
genus of the Ajugea. T. maritimum, cat-thyme, has errhine and antispasmodic properties, and was formerly used in coughs and nervous affections. $T$. scordium, water-germander, or garlic-germander, formerly used as a tonic, diaphoretic and anthelmintic.

Texan Fever. See Texas Fever.

Texas Fever. A specific fever communicated by apparently healthy cattle living within a certain permanently infected area in the Southern United States to cattle north of this area, when the former are taken north 
during the warm season of the year. The period of incubation varies from ten to fifty days or more. There is high fever, hemoglobinuria, and occasionally jaundice. The infected cattle frequently die within a week. See Bacillus of Southern Cattle-plague, under Bacteria, Synonymatic Table of. T. Mange. Same as Army Itch.

Textural (teks'-tu-ral) [textura, texture]. Pertaining to any tissue.

Texture (teks'-tur) [textura; textere, to weave]. In physiology, any organized substance or tissue of which the body is composed. Also, and more correctly, the arrangement of the elementary parts of tissue.

Thalamencephal (thal-am-en'-sef-al). See Thalcmencephalon.

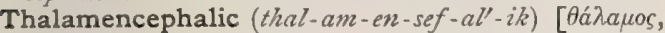
chamber; $\kappa \varepsilon \phi a \lambda \eta$, head]. Pertaining to the thalamencephalon.

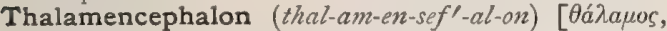
thalamus; $\varepsilon v \kappa \varepsilon \phi a \lambda o v$, the brain]. In embryology, the posterior portion of the anterior brain-vesicle; in anatomy, that part of the brain that is derived from this portion of the anterior vesicle; the diencephalon or interbrain.

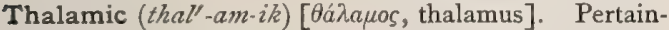
ing to a thalamus.

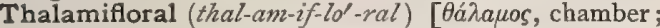
flos, flower]. In biology, having the petals and stamens arising immediately from the thalamus.

Thalamiflorous (thal-am-if-lo'-rus). Same as Thalamiforal.

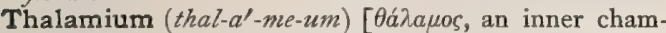
ber, a bedroom: pl., Thalamia]. In biology, applied to various fruit-bearing organs in cryptogams.

Thalamocele, Thalamocelia (thal-am-o-sêl, thal-am-

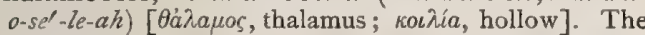
third ventricle, so called, as the cavity of the diacele or thalamencephalon.

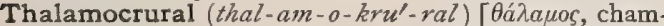
ber; crus, leg]. Pertaining to the thalamus and the crus cerebri.

Thalamophorous (thal-am-off'-or-us). See Polythalamic.

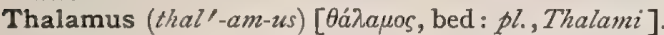
Thalamus opticus. Either one (right or left) of two masses at the base of the brain, the origin, in part, of the optic nerves; they are the developed sides of the third ventricle. In biology, the receptacle, or torus. T. corporum cavernosorum. See Crus penis. T. regalis. See Pericardium.

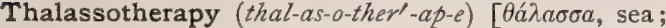

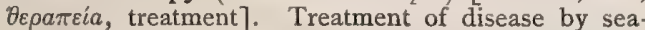
voyages, sea-bathing, etc.

Thallic (thal'-ik) [ $\theta a \lambda \lambda \sigma^{\prime}$, a green shoot]. Pertaining to the metal, thallium.

Thallin (thal'-in) [ $\theta a \lambda \lambda \sigma$ s, a green shoot], $\mathrm{C}_{10} \mathrm{H}_{13} \mathrm{ON}$. A synthetic chemic product and a derivative of coaltar. It is a powerful antipyretic, but its effects are not so lasting as those of antipyrin. It is likely to produce collapse. Dose gr. iv. Unof.

Thallina (thal-i'-nah) [ $\theta a \lambda \lambda o ́ s$, a green shoot: gen., Thallina]. The pharmaceutic name of thallin.

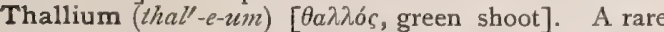
metallic element, having some features in common with lead, discovered by Crookes, in England, and one year later by Lamy, in France. Symbol Tl ; at. wt., 204.2. Glass containing it is singularly brilliant and refractive. Its salts are active poisons. See Elements, Table of.

Thallome $($ thal'-om) [ $\theta a \lambda \lambda \sigma s$, a young shoot]. A thallus.

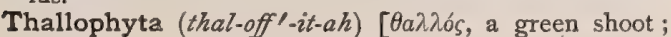

фvтóv, a plant]. Plural of Thallophytum. A comprehensive term for the lower cryptogams, in which there is no well-defined differentiation of root, stem, or leaf.

Thallophyte (thal'-o-fit) $[\theta a \lambda \lambda o ́ s$, a green shoot ; $\phi v \tau \delta v$, a plant]. One of the lower cryptogams.

Thallus (thal'-us) [ $\theta a \lambda \lambda \sigma^{\prime}$, a young shoot]. In biology, applied to a plant-body in which there is no differentiation into root, stem, and leaves.

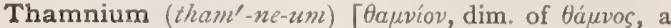
bush]. In biology, a bushy thallus.

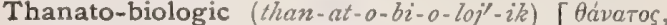
death ; $\beta$ เos, life]. Pertaining to life and death

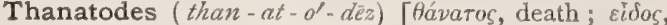
like]. Mortal. Lethal.

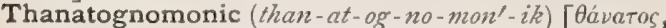
death; $\gamma \nu \omega \mu \omega v$, sign ]. Indicative of death.

Thanatoid (than'-at-oid) [Aávaros, death ; eidos, resemblance]. Resembling or having the appearance of death.

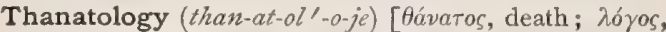
science]. The sum of scientific knowledge regarding death.

Thanatomania (than-at-o-ma'-ne-ah) [Advaros, death

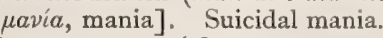

Thanatometer (than - at-om'-et-er) [Aávaros, death ; $\mu \varepsilon ́ \tau \rho o \nu$, measure]. A thermometer introduced into the stomach or rectum to determine if the depression of temperature is so great as to be a sign of death.

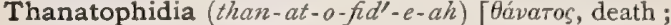
$\ddot{\phi} \phi \iota$, a serpent]. Those serpents whose bite produces toxic symptoms or death.

Thanatophobia (than-at-o-fo'-be-ah) [távaros, death; $\phi b \beta o \varsigma$, dread]. A morbid fear of death.

Thanatosis (than-at-o'-sis). See Mortification.

Thane's Method. A method of finding the fissure of Rolando. The upper end of the fissure is half an inch behind the mid-point of a line drawn from the glabella to the inion. Its lower end is close to the posterior limb, and about an inch behind the bifurcation of the fissure of Sylvius. The bifurcation of the latter corresponds to a point one-and-a-quarter inches behind and one-quarter inch above the level of the external angular process of the frontal bone.

Thapsia (thap'-se-ah) [ $\theta a \psi i a]$. A genus of old-world umbelliferous plants. Thapsia resin (resina thapsia) is the product of $T$. garganica, $T$. silphium, and $T$. villose. The resin is strongly counter-irritant. The root of $T$. garganica is used by the natives of $\mathrm{N}$. Africa as a counter-irritant. Internally a tonic. Dose of the fld ext. $m x-x x x$. Unof. The root of $T$. villosa (deadly carrot) is purgative. Unof.

Tharandt Normal Culture-solution. A solution employed at the Foret Academie Experiment Station of Tharandt, Saxony, for the study of the life-history of plants by "water-culture." The formula given by Knop is: Calcic nitrate 4 parts by weight, potassic nitrate I part by weight, magnesic sulphate (crystallized) I part by weight, potassic phosphate I part by weight. These salts are to be thoroughly mixed and the mixture used in the proportion of $\mathbf{I}: 2000$, I : I000, I : 500 parts of water. To the solutions when ready for use a drop or two of a solution of some iron-salt, or a decigram of ferric phosphate, must be added.

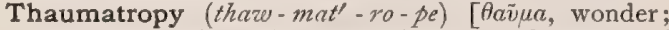
$\tau \rho \circ \pi \dot{n}$, change]. The extraordinary transformation of one organ or part into another.

Thea $\left(t h \ell^{\prime}-a h\right)$. A former genus of plants now included as a section under Camellia. See Tea. T. nigra, black tea, is less pungent and less fragrant than green tea and is made from leaves that have undergone fermentation and are then slowly dried. T. viridis, green tea, 
is prepared from leaves that have been dried quickly, having undergone no fermentation. The poorer grades are frequently colored with gypsum, Prussian blue, etc.

Thebain (the'-ba-in) [ $\theta \tilde{\eta} \beta a$, Thebes], $\mathrm{C}_{19} \mathrm{H}_{21} \mathrm{NO}_{3}$ Called also paramorphin - a poisonous alkaloid found in opium, consisting of silvery plates, melting at $193^{\circ}$ C., with an acrid taste and analogous to strychnin in its physiologic effects. It is a powerful tetanizer, ex alting the activity of the cerebro-spinal centers. Unof.

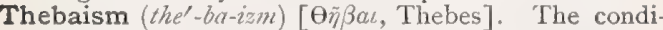
tion induced by thebain or paramorphin.

Thebesius, Foramina of. See Foramina, Table of.

Thebolactic Acid (theb-o-lak'-tik). See Acid.

Theca (the'-kah) [Hijkn, a case, box: pl., Thece]. In biology, a case, sac, capsule, or sheath, as a sporangium or anther-cell. T. cerebri, the cranium. T cordis, the pericardium. T. vertebralis, the investing membranes of the vertebral cord, with tubular processes to each of the spinal nerves.

Thecal (the'-kal) [ $\theta \dot{\eta} \kappa \eta$, a case]. Pertaining to the theca. T. Abscess, tenosynovitis, paronychia, or whitlow.

Thecaphore (the'-kaf-or) [ $\theta \dot{\eta} k \eta$, case ; фópos, bear]. See Gynophore.

Thecasporal (the-kas-po'-ral) [ $\theta \dot{n} \kappa \eta$, case; $\sigma \pi o \rho a ́$, spore]. Thecasporous.

Thecaspore (the'-kas-pōr) [ $\theta \dot{\eta} \kappa \eta$, case; $\sigma \pi o \rho a ́$, spore]. In biology, a spore formed in the interior of a saclike cell; the theca or ascus; an ascospore.

Thecasporous (the-kas-po'-rus) [ $\theta \dot{\eta} \kappa \eta$, case ; $\sigma \pi о \rho a ́$, spore]. Having thecaspores.

Thecate $\left(t h e^{\prime}-k \bar{a} t\right)[\theta \dot{\eta} \kappa \eta$, a case $]$. In biology, sheathed; held within a theca, or furnished with a theca.

Theciferous (the-sif'-er-us) [ $\theta \dot{\eta} \kappa \eta$, case ; ferre, to bear]. Bearing thecæ.

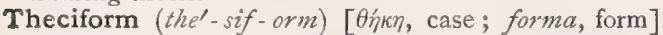
Resembling a theca.

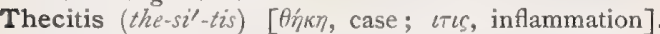
Inflammation of tendons and their sheaths, or of any fibrous sheath.

Thecodont (the'-ko-dont) [ $\theta \dot{\eta} k \eta$, case; odovs, tooth]. Having the teeth covered or sheathed in alveoli.

Thecostegnosis (the-ko-steg - no'-sis) [ $\theta \eta \sigma^{\prime}$, sheath ; $\sigma \tau \varepsilon \gamma \nu \sigma \varepsilon \varepsilon v$, to contract]. The shrinking or contraction of the sheath of a tendon.

Theden's Bandage. See Bandage.

Theic $\left(\right.$ the $\left.e^{\prime}-i k\right)$ [thea, tea]. A tea-drunkard; an immoderate user of tea.

Thein $($ the'-in). See Tea.

Theism (the'-izm) [thea, tea]. The morbid condition due to the excessive use of tea. It is characterized by headache, palpitation of the heart, tremor, insomnia, cachexia, etc

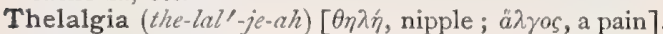
Pain in the nipples.

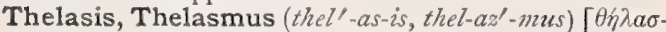
$\mu$ s, a sucking]. The act of sucking.

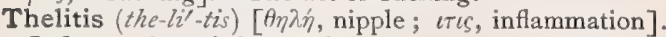
Inflammation of the nipple.

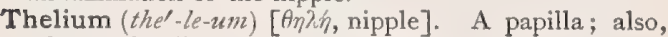
a layer of cells.

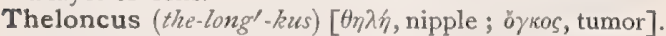
Tumor of the nipple.

Thelothism (the'-lo-thizm) $[\theta \eta \lambda \dot{n}$, nipple; $\dot{\omega} \theta \varepsilon \varepsilon \iota \nu$, to push]. Projection of the nipple, caused by contraction of the transverse muscular fibers.

Thelyblast (thel' $-i b$-last) $[\theta \bar{\eta} \lambda v s$, female; $\beta \lambda \alpha \sigma \tau o s$, germ]. In biology, the female element of the bisexual nucleus (or genoblast) of a cell; a mother-cell. Cf. Arsenoblast.

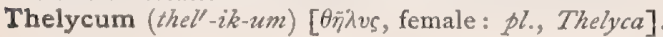

In biology, a structure on the ventral surface of the perion of certain crustaceans; peculiar to the females. Thelygonia (thel-ig-o'-ne-ah). See Nymplomania.

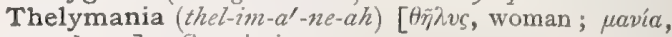
madness]. Satyriasis.

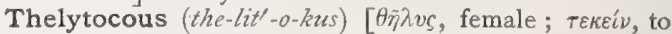
bear]. In biology, producing females only.

Thelytoky (the-lit'-o-ke) [ $\theta \bar{\eta} \lambda v \varsigma$, female; $\tau \varepsilon \kappa \varepsilon i \nu$, to bear, produce]. In biology, caused and conditioned by an over-supply of females.

Thenad (the'-nad) [ $\theta \dot{\varepsilon} v \alpha \rho$, palm]. Toward the thenal side or aspect.

Thenal (the'-nal) [ $\theta \dot{\varepsilon} v \alpha \rho$, the palm]. Pertaining to the palm or the sole; also, toward the palm.

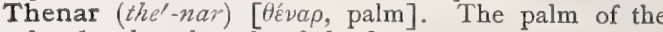
hand; also, the sole of the foot.

Thenard's Blue. Same as Cobalt Blue.

Thenen (the'-nen) [Áva $\rho$, palm]. Belonging to the thenar aspect in itself.

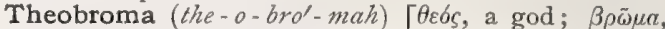
food]. A genus of sterculiaceous plants of tropical America, T. cacao is the cacao-plant, or chocolatetree. See Chocolate, Cacao. T., Ceratum, "red lip-salve," cacao-butter, white wax, āā 35 ; oil of almond 30 ; oil of rose, to flavor, and carmin to color, āa q. s. T., Oleum, butter of cacao. The fixed oil of the seed of the chocolate-tree, $T$. cacao. It consists mainly of stearin with a little olein, and is demulcent, not becoming rancid. It is used in making suppositories.

Theobromin, Theobromina (the-o-bro'-min, the-o-bro$\left.m i^{\prime}-n a h\right)$ [Acós, a god; $\beta \rho \tilde{\omega} \mu a$, food: gen., Theobromince $], \mathrm{C}_{7} \mathrm{H}_{8} \mathrm{~N}_{4} \mathrm{O}_{2}$. A feeble alkaloid obtained from Cacao-butter. It is a white, crystalline powder, with a bitter taste, but no odor. It is insoluble in water, alcohol, ether, chloroform, etc., when cold. It is said to have about the same effect upon the system as caffein and thein.

Theolin (the'-o-lin). Same as Heptane.

Theomania (the-o-ma'-ne-ah) [Acós, a god; $\mu a v i a$, madness]. Religious mania; insanity in which the patient believes himself to be a divine being.

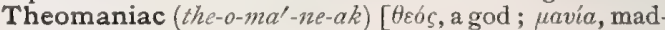
ness]. One who is affected with theomania.

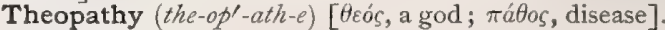
Cure by prayer.

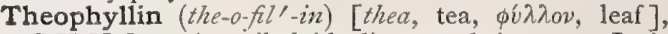
$\mathrm{C}_{7} \mathrm{H}_{8} \mathrm{~N}_{4} \mathrm{O}_{2}$. An alkaloid discovered in tea. It is isomeric with the base obtained from cacao (theobromin) and with paraxanthin, but differs from them in its reactions

Theoretic, Theoretical (the-o-ret'-ik, the-o-ret'-ik-al)

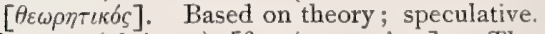

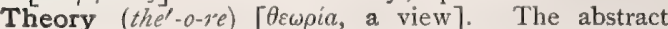
principles of a science. Also, a reasonable supposition or assumption, generally one that is better developed and more probable than a mere hypothesis. T., Cohnheim's (of Inflammation). See $T$., Samuel's. T., Darwin's. See Darvinism, NeoDarvinism, Evolution. 'T., Fluss' (of Infammation). See T., Landerer's. T., Hammarsten's ; that the coagulation of the blood is due to the decomposition of a substance called fibrinogen, which is dissolved in the blood-plasma. This decomposition is brought about by the agency of the fibrin-ferment, which is the product of the disintegration of the colorless corpuscles. The most important product of this action is the comparatively insoluble material called fibrin. $\mathbf{T}$., Lamarckian; the doctrines based upon the teachings of the French naturalist, J. B. P. A. de Monet de Lamarck (1744-1829), who attempted to explain the progressive evolution of nature by virtue of an inherent 
tendency to development and the efforts excited by change of conditions. T., Landerer's (of Inflammation); that the tension of the tissues (Gervebspannung) during inflammation is much lower than under normal conditions. The capillaries surrounded by these inflamed tissues are unable to withstand the pressure of the blood and, therefore, dilate. The immediate effect of this dilatation is an acceleration of the movement of the blood, which rushes in to fill the widened capillaries. But after a certain lapse of time, as the surrounding tissues lose their elasticity more and more, the blood-stream slows, thus producing the condition of the circulation typical of inflammation. (Metschnikoff.) T., Metschnikoff's Biologic or Comparative (of Inflammation); "inflammation generally must be regarded as a phagocytic reaction on the part of the organism against irritants. This reaction is carried out by the mobile phagocytes, sometimes alone, sometimes with the aid of the vascular phagocytes or of the nervous system. The essential phenomena of inflammation represent an actual struggle between the phagocytes and the irritant agent." T., Paralytic (of Inflammation); the doctrine that regards hyperemia as the most essential act in inflammation, and caused by paralysis of the vasomotor nerves. T. of Peptogeny and Peptogenous Substances of Schiff and Corvisart; this theory adduces the noteworthy peculiarity whereby the secretory tissues of the stomach yield gastric juice only when in contact with certain alimentary substances, because these substances furnish an indispensable element in the production of pepsin. T., Podwyssozki's (of Inflammation); "inflammation is a local reaction, often beneficial, of the living tissues against the irritant substance. This reaction is chiefly produced by a phagocytic activity of the mesodermic cells. This reaction, however, may precipitate not only changes in the vascular system, but also the chemic action of the blood-plasma and tissue-fluids in liquefying and dissolving the irritant agent." $\mathrm{T}$. of Preformation. See Preformation and Incasement. T., Recapitulation; according to which each animal in its own development repeats the history of its ancestry, "climbs up its own genealogical tree." This theory was first clearly enunciated by Fritz Müller, and has since been elaborated by many, notably by Balfour and Ernst Hæckel. 'T., Rokitansky's (of Infammation); the theory that inflammation is an abnormal process of nutrition in which, as a result of stasis, exudation takes place. The stasis is the most important factor. Its cause is to be found in the commingling and adhesion of the red cells, the condensation of the plasma by transudation of serum, and the accumulation of white cells. The exudation is explained, aside from molecular attraction, by the continued pressure under which the plasma in the area of stasis exists. T., Roser's (of Inflammation); according to this theory inflammation is a true disease, due to infection by microbes, the reparatory phenomena constituting its cure. T., Sachs' (of Infammation) ; is that a single process represents a salutary reaction against some injurious influence; that regeneration, cicatrization, and the primary processes of inflammation, such as emigration and the alteration in the vessel-walls, are reparatory acts serving to counteract the damage brought about by the irritant, $i . e_{\text {. }}$, true inflammation never occurs except where there has been a primary lesion of the tissues. This theory has been accepted and developed by Buchner and Neumann. T., Samuel's (of Inflammation); according to this theory the main factor in all inflammatory states consists in a lesion of the vessels, which are attacked by the irritating cause. The inflamed vessels, being more perme- able, allow the fluid and corpuscular elements of the blood to flow through them in a purely passive manner. These exuded products collect in a situation where they meet with least resistance and there produce the inflammatory tumor. T., Schimper's (of the Arrangement of Leaves) ; according to which all relations of position are referred to a single principle. "This principle lies in the idea that growth in a stem has an upward direction in a spiral line, and that the formation of leaves is a local exaggeration of this spiral growth." (Sachs.) T., Schwann's (of Inflammation). Same as Rokitansky's Theory, q.v. T. of Schwendener. See Schwendenerism. 'T., Spasmodic (of Inflammation); the doctrine that hyperemia is the most essential phenomenon in inflammation, and holds it to be caused by a spasmodic contraction of the affected arteries, accompanied by an afflux of blood to the neighboring part. T., Stricker's (of Inflammation); the theory that the tissue-cells, under the influence of the inflammatory irritant, return to their former undifferentiated embryonic condition, and then rapidly proliferate, forming similar cells. T., Virchow's Nutritional (of Parenchymatous Infammation); according to Virchow, hyperemia is but a subordinate process and entirely secondary to an increased nutritive and reproductive activity of the cells at the seat of inflammation, which gives rise to the formation of a large quantity of exudation-cells at the expense of the cells of the damaged tissue.

Therapeia (ther-ap-i'-ah). See Therapeutics.

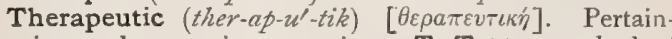
ing to therapeutics; curative. T. Test, a method of diagnosis by administering certain remedies which are known to influence a given disease, e. g., quinin in malaria, potassic iodid and mercury in syphilis.

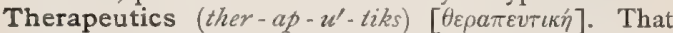
branch of medical science which considers the application of remedies as a means of cure. T., Mediate, medicating a child through its mother's milk. T., Suggestive, hypnotic suggestion in the treatment of disease.

Therapeutist (ther-ap-u'-tist) [ $\theta \varepsilon \rho a \pi \varepsilon i a$, therapy]. One skilled in therapeutics.

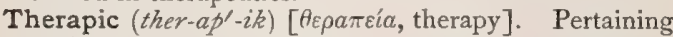
to therapy; therapeutic.

Therapol (ther'-ap-ol) [ $\theta \varepsilon p a \pi \varepsilon i ́ a$, cure; oleum, oil]. A vegetable oil containing ozone. It has been used in diphtheria.

Therapy, Therapeia (ther'-ap-e, ther-ap-i'-ah) [ $[\varepsilon \varepsilon \rho a-$ $\pi \varepsilon i a$, therapy]. Therapeutics-now used chiefly as a suffix, e. g., serotherapy, aërotherapeutics.

Therg's Fistula. See Fistula.

Theriac (the'-re-ak). See Theriaca.

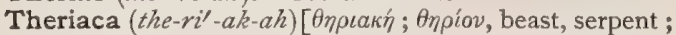
it was at first the name of a medicine used for snakebite]. Treacle; molasses. The non-crystallizing residue of the juice of the cane, left after the process of evaporation. It consists of cane-sugar-solution, caramel, and various impurities. It was formerly used in pharmacy and also as the name of an antidote to the bites of venomous snakes or insects. $T$. andromachi, Venice treacle, a compound (no longer official) of some seventy or more drugs mixed with honey, and given as an antidote in cases of snakebite.

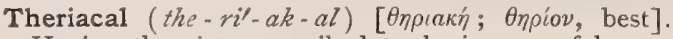
Having the virtues ascribed to theriaca; useful as an antidote for venomous bites.

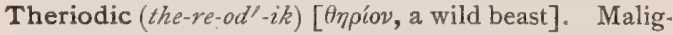
nant.

Therioma (the-re-o'-mah) [ $[\theta \eta \rho \iota \delta \varepsilon \nu$, to make or be wild: pl., Theriomata]. A rare name for a malig. nant ulcer; a tumor. 
Theriotomy (the-re-ot'-o-me) [tnpiov, beast; rouń, a cut]. Zoötomy; the anatomy or dissection of animals.

Therm [ $\theta \dot{\varepsilon} \rho \mu \eta$, heat]. The amount of heat required to raise the temperature of one gram of water from $\mathrm{O}^{\circ} \mathrm{C}$. to $\mathrm{I}^{\circ} \mathrm{C}$. It is equal to $\mathbf{I 0 0 0}$ calories. See Unit.

Thermæ (thur'-nue) [ $\theta \varepsilon \dot{\rho} \mu \eta$, heat]. Hot baths; hot springs.

Thermæsthesia (thur-mes-the'-ze-ah). See Thermesthesia.

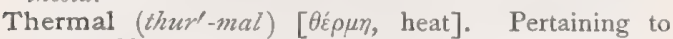
heat. T. Ataxia. See Ataxia. T. Springs, warm, or hot springs.

Thermality (thur-mal'-it-e) [Á́s $\rho \eta$, heat]. Exaggerated generation of heat, symptomatic of infection.

Thermanesthesia (thur-man-es-the'ze-ah). See Thermo-anesthesia.

Thermantidote $\left(t h u r-m a n^{\prime}-t i d-o ̈ t\right)[\theta \dot{\varepsilon} \rho \mu \eta$, heat; antidote]. An apparatus for cooling the air, much used in some hot regions, as India.

Thermasma (thur-maz'-mah) $[\theta \varepsilon \rho \mu a \sigma \mu a]$. A warm fomentation.

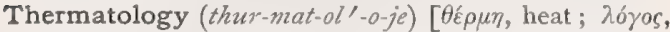
science]. The scientific use or understanding of the waters of thermal springs in the cure of disease.

Thermesthesia (thur - mes - the' $z \ell-a h$ ) [ $\theta \varepsilon \rho u \eta$, heat ; ai $\sigma \theta \eta \sigma \varsigma$, sensation]. The sensation of heat or of the temperature of bodies.

'Thermesthesiometer (thur-mes-the-ze-om'-et-er) [ $\theta \dot{\varepsilon} \rho \mu \eta$,

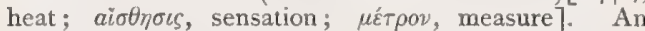
instrument for measuring the sensibility to heat of different regions of the skin.

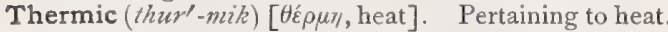
T. Fever, sunstroke; heat-fever.

Thermifugin (thur-mif'-u-jin) [ $\theta \dot{\varepsilon} \rho \mu \eta$, heat; fugare, to expel], $\mathrm{C}_{9} \mathrm{H}_{8}\left(\mathrm{CH}_{3}\right) \mathrm{NCOONa}$. Sodium carbamate, recommended as an antipyretic. Unof.

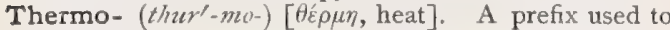
denote connection with or relation to heat or temperature.

Thermo-anesthesia (thur-mo-an-es-the'-ze-ah) [ $\theta^{\prime} \dot{\rho} \rho \eta \eta$ heat; anesthesia]. Loss of the perception of thermal impressions.

Thermo-cautery (thur-mo-kaw'-ter-e). See Cautery.

Thermo-chemic (thur-mo-kem'-ik) [ $\theta \varepsilon \rho \mu \eta$, heat; $\chi \varepsilon \mu \varepsilon \iota$, chemistry]. Pertaining to thermo-chemistry.

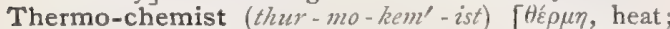
$\chi \varepsilon \mu \varepsilon \iota a$, chemistry]. One versed in thermo-chemistry.

Thermo-chemistry (thur-mo-kem'-is-tre) [ $\theta \varepsilon \rho \mu \eta$, heat ; $\chi \varepsilon \mu \varepsilon i a$, chemistry]. That branch of chemic science embracing the mutual relations of heat and chemic changes.

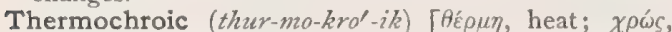
surface]. Pertaining to a quality of certain substances that transmit some thermal radiations, but absorb or change others.

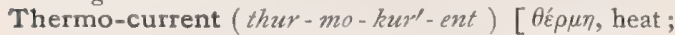
currere, to run]. An electric current produced by heat.

Thermo-diffusion (thur-mo-dif-u'-zhun) [ $\theta \dot{\varepsilon} \rho \mu \eta$, heat ; diffusion]. Diffusion of a gas by inequalities in temperature.

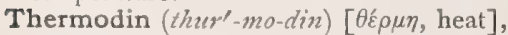

$$
\mathrm{C}_{6} \mathrm{H}_{4} / \text { N.CO.C. } \mathrm{CH}_{3} \cdot \mathrm{COO} . \mathrm{C}_{2} \mathrm{H}_{5} .
$$

Acetyl-ethoxyphenylurethan; acetyl-ethoxyphenylcarbamate ethyl ester. A hydrocarbon that crystallizes in white needles, which are odorless and almost tasteless, melt at $86^{\circ}-88^{\circ} \mathrm{C}$, and are slightly soluble in water. The drug is antipyretic. The dose is from 7.5 to Io grains. Unof.
Thermo-electricity (thur-mo-e-lek-tris'-it-e) [ Aćp $\mu \eta$, heat; $\ddot{\eta} \lambda \varepsilon \kappa \tau \rho \circ \nu$, amber]. Electricity generated by heat.

Thermo-excitory (thur-mo-ek-si'-to-re) [ $\theta \varepsilon \dot{\varepsilon} \rho \eta$, heat; excitor, excitor]. Having the function of exciting the production of heat (opposed to thermo-inlibitory).

Thermogenesis (thur - mo-jen'-es - is) [ $\theta \varepsilon \dot{\rho} \mu \eta$, heat ;

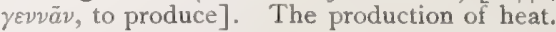

Thermogenetic (thur-mo-jen-et'-ik). Same as Thermogenic

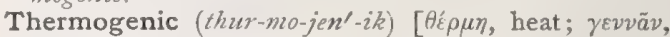
to produce]. Pertaining to thermogenesis; producing heat.

Thermogenous (thur-moj'-en-us) [ $\theta \dot{\varepsilon} \rho \mu \eta$, heat; $\gamma^{\prime} \varepsilon \eta$, producing]. Producing heat.

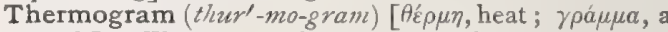
mark]. The record of a thermograph.

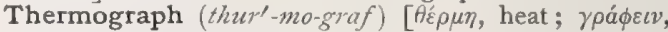
to write]. Any automatic device for registering variations of temperature.

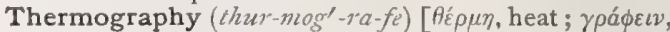
to write]. Writing by means of heat. The use of the thermograph.

Thermohemia (thur-mo-hem'-e-ah). See Insolation.

Thermo-inhibitory (thur-mo-in-hib'-it-o-re) [ $\theta \dot{\varepsilon} p \mu \eta$, heat; inhibitory]. Having the function of inhibiting or controlling the production of heat; as thermoinhibitory nerves or centers.

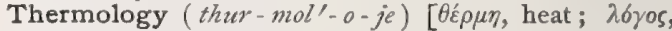
science]. A treatise on heat.

Thermolysis (thur-mol'-is-is) [ $\theta \dot{\varepsilon} \rho \mu \eta$, heat; $\lambda \hat{v} \sigma \iota s$, a loosening]. The dissipation of heat. This is mainly accomplished by means of the skin and lungs. It is regulated by nervous influence.

Thermolytic (thur-mo-lit'-ik) [ $[\dot{\varepsilon} \rho \mu \eta$, heat; $\lambda v \sigma \iota$, a loosening]. 1. Pertaining to or promoting thermolysis. 2. An agent that promotes the discharge of heat from the body.

Thermomagnetism (thur - mo - mag'-net - izm) [ $\theta \varepsilon \dot{\rho} \rho \eta$,

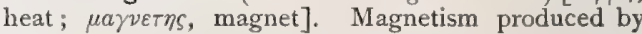
heat.

Thermometer (thur-mom'-et-er) [ $\theta \dot{\varepsilon} \rho \mu \eta$, heat ; $\mu \varepsilon ́ \tau \rho o \nu$, measure]. An instrument for measuring the intensity of heat, consisting of a reservoir of mercury (or alcohol) expanding into a vacuous capillary tube, the intensity being measured by the length of the column of mercury. $\mathbf{T}$, Centigrade, one in which the freezing-point is at $0^{\circ}$ and the boiling-point at $100^{\circ}$. T., Clinical, a thin-bulbed, self-registering thermometer for ascertaining the bodily temperature. T., Fahrenheit, one in which the interval between freezing and boiling is divided into 180 equal parts, each called a degree, the zero-point being 32 degrees or divisions below the freezing of water. T., Reaumur, one in which the freezing-point is $0^{\circ}$, and the boiling-point $80^{\circ}$. To convert the registration of one thermometer into that of another the following formulæ are useful :-

$$
\begin{aligned}
& \text { Let } F=\text { No. of degrees Fahrenheit. } \\
& \text { " } C=\text { " } R=\text { " } \\
& \text { Then to convert } \\
& \begin{array}{c|c}
\text { Fahr. into Cent. } & \text { Fahr. into Reaum. } \\
\frac{5\left(F-3^{2}\right)}{9}=C . & \frac{4(F-32)}{9}=R .
\end{array} \\
& \text { Cent. into Fahr. } \\
& \frac{9 C}{5}+32=F . \quad \frac{9 R}{4}+32=F \text {. }
\end{aligned}
$$

T., Surface, a thermometer for registering the surface temperature of any portion of the body. See next page for Table of Comparison of Thermometers. 
COMPARISON OF THERMOMETERS.

\begin{tabular}{|c|c|c|c|c|c|c|c|c|}
\hline$\underset{\Sigma}{\dot{\alpha}}$ & $\underset{v}{\mathbf{y}}$ & 选 & $\frac{a}{4}$ & 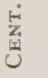 & $\frac{5}{2}$ & $\frac{a}{x}$ & $\underset{z}{3}$ & $\underset{\Sigma}{2}$ \\
\hline 212 & 100 & 80 & 122 & 50 & 40 & 32 & 0 & 0 \\
\hline 210 & 98.9 & $79 . \mathrm{I}$ & 120 & 48.9 & 39.1 & 30 & -I.I & -0.9 \\
\hline 208 & 97.8 & 78.2 & 118 & 47.8 & 38.2 & 28 & -2.2 & $-1 . \overline{8}$ \\
\hline 206 & 96.7 & 77.3 & 116 & 46.7 & $37 \cdot 3$ & 26 & -3.3 & -2.7 \\
\hline 204 & 95.6 & 76.4 & 114 & 45.6 & 36.4 & 24 & -4.4 & -3.6 \\
\hline 202 & 94.4 & 75.6 & 112 & 44.4 & 35.6 & 22 & -5.6 & $-4 \cdot 4$ \\
\hline 200 & 93.3 & 74.7 & IIO & $43 \cdot 3$ & 34.7 & 20 & -6.7 & -5.3 \\
\hline 198 & 92.2 & 73.8 & 108 & 42.2 & 33.8 & 18 & -7.8 & -6.2 \\
\hline 196 & $91 . I$ & 72.9 & 106 & $41 . I$ & 32.9 & 16 & -8.9 & $-7 \cdot I$ \\
\hline 194 & 90 & 72 & 104 & 40 & 32 & 14 & -10 & -8 \\
\hline 192 & 88.9 & 7 L.I & 102 & 38.9 & 31.1 & 12 & -II.I & -8.9 \\
\hline Igo & 87.8 & 70.2 & 100 & 37.8 & 30.2 & Io & -12.2 & -9.8 \\
\hline I88 & 86.7 & 69.3 & 98 & 36.7 & 29.3 & 8 & -13.3 & -10.7 \\
\hline 186 & 85.6 & 68.4 & 96 & 35.6 & 28.4 & 6 & -14.4 & -11.6 \\
\hline 184 & 84.4 & 67.6 & 94 & 34.4 & 27.6 & 4 & -15.6 & -12.4 \\
\hline 182 & 83.3 & 66.7 & 92 & 33.3 & 26.7 & 2 & -16.7 & -13.3 \\
\hline 180 & 82.2 & 65.8 & 90 & 32.2 & 25.8 & 0 & -17.8 & -14.2 \\
\hline 178 & 8I. I & 64.9 & 88 & 3I.I & 24.9 & -2 & -18.9 & $-15 . I$ \\
\hline I76 & 80 & 64 & 86 & 30 & 24 & -4 & -20 & -16 \\
\hline 174 & 78.9 & 63.1 & 84 & 28.9 & 23.1 & -6 & $-2 I . I$ & -16.9 \\
\hline 172 & 77.8 & 62.2 & 82 & 27.8 & 22.2 & -8 & -22.2 & -17.8 \\
\hline I7o & 76.7 & $6 \mathrm{r} .3$ & 80 & 26.7 & 21.3 & -IO & -23.3 & -18.7 \\
\hline 168 & 75.6 & 60.4 & 78 & 25.6 & 20.4 & -12 & -24.4 & -19.6 \\
\hline I66 & 74.4 & 59.6 & 76 & 24.4 & I9.6 & -14 & -25.6 & -20.4 \\
\hline$I 64$ & 73.3 & 58.7 & 74 & 23.3 & 18.7 & -16 & -26.7 & $-2 I \cdot 3$ \\
\hline 162 & 72.2 & $5 \% .8$ & 72 & 22.2 & 17.8 & -18 & -27.8 & -22.2 \\
\hline 160 & 71.1 & 56.9 & 70 & $2 I . I$ & 16.9 & -20 & -28.9 & $-23 . I$ \\
\hline $15^{8}$ & 70 & 56 & 68 & 20 & 15 & -22 & -30 & -24 \\
\hline I 56 & 68.9 & 55.1 & 66 & 18.9 & I5.I & -24 & $-3 \mathrm{I} .1$ & -24.9 \\
\hline 154 & 67.8 & 54.2 & 64 & 17.8 & 14.2 & -26 & -32.2 & -25.8 \\
\hline$I_{5} 2$ & 66.7 & 53.3 & 62 & 16.7 & 13.3 & -28 & -33.3 & -26.7 \\
\hline I 50 & 65.6 & 52.4 & 60 & 15.6 & I 2.4 & -30 & -34.4 & -27.6 \\
\hline 148 & 64.4 & 51.6 & $5^{8}$ & 14.4 & 11.6 & -32 & -35.6 & -28.4 \\
\hline 146 & 63.3 & 50.7 & 56 & 13.3 & 10.7 & -34 & -36.7 & -29.3 \\
\hline 144 & 62.2 & 49.8 & 54 & 12.2 & 9.8 & -36 & -37.8 & -30.2 \\
\hline 142 & 6r.I & 48.9 & $5^{2}$ & II.I & 8.9 & -38 & -38.9 & -31.1 \\
\hline 140 & 60 & $4^{8}$ & 50 & 10 & 8 & -40 & -40 & -32 \\
\hline 138 & 58.9 & 47.1 & $4^{8}$ & 8.9 & 7.1 & -42 & $-4 I . I$ & -32.9 \\
\hline I 36 & 57.8 & 46.2 & 46 & 7.8 & 6.2 & -44 & -42.2 & -33.8 \\
\hline 134 & 56.7 & 45.3 & 44 & 6.7 & $5 \cdot 3$ & -46 & $-43 \cdot 3$ & -34.7 \\
\hline 132 & 55.6 & 44.4 & $4^{2}$ & 5.6 & 4.4 & -48 & -44.4 & -35.6 \\
\hline I30 & 54.4 & 43.6 & 40 & 4.4 & 3.6 & -50 & -45.6 & -36.4 \\
\hline 128 & 53.3 & 42.7 & $3^{8}$ & 3.3 & 2.7 & -52 & -46.7 & $-37 \cdot 3$ \\
\hline 126 & .52 .2 & 41.8 & 36 & 2.2 & 1.8 & -54 & -47.8 & -38.2 \\
\hline 124 & $51 . \mathrm{I}$ & 40.9 & 34 & I.I & 0.9 & -56 & -48.9 & $-39 \cdot \mathrm{I}$ \\
\hline
\end{tabular}

Thermometric (thur-mo-mel'-rik) [ $\theta \varepsilon \rho \mu \eta$, heat ; $\mu$ '́ $\rho \circ \nu$, measure]. Pertaining to the thermometer or to thermometry.

Thermometry (thur-mom'-et-re) $[\theta \dot{\varepsilon} \rho \mu \eta$, heat; $\mu \dot{\varepsilon} \tau \rho o \nu$, measure]. The scientific use of the thermometer, and the facts and theories relating thereto.

Thermonanesthesia (thur-mo-nan-es-the'-ze-ah). See Thermo-anesthesia.

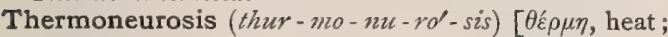
vยच̃ $\rho \circ$, nerve]. Pyrexia of vasomotor origin.

Thermopalpation (thur-mo-pal-pa'-shun) [ $\theta \varepsilon \rho \mu \eta$, heat ; palpare, to palpate]. Palpation of the surface of the body with a view to the determination of variations of temperature, and the diagnosis of local or visceral inflammations.

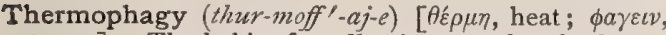
to eat]. The habit of swallowing very hot food.

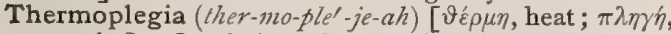
a stroke]. Insolation; heat-stroke.

Thermopolypnea (thur-mo-pol-ipp-ne'-ah) [ $\theta \varepsilon ́ \rho \mu \eta$, heat ; $\pi o \lambda u ́ s$, many; $\pi \nu \varepsilon i \nu$, to breathe]. Rapid respiration due to high temperature.

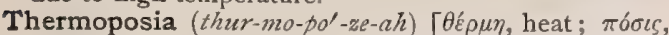
a drinking]. The practice of swallowing excessively hot drinks.

Thermo-regulator (thur-mo-reg'-ti-la-tor). See Thermostat.

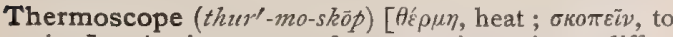
view]. An instrument for measuring minute differences of temperature without registering the degree or amount of heat.

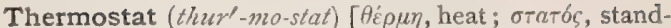
ing]. Any automatic device for regulating and maintaining a constant temperature.

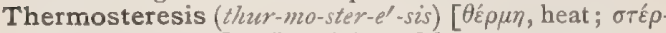

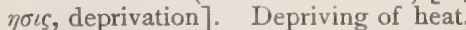

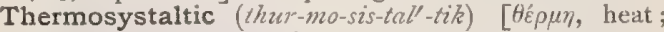
$\sigma v \sigma \tau^{\prime} \lambda \lambda \varepsilon \iota \nu$, to contract]. Muscular contraction due to heat.

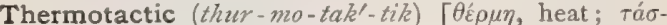
$\sigma \varepsilon \iota \nu$, to regulate]. Regulating the heat of the body; as a thermotactic center.

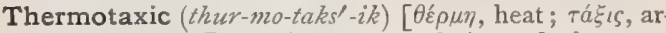
rangement]. Pertaining to regulation of the temperature of the body; thermotactic.

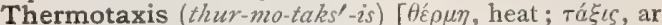
rangement]. The regulation and correlation of heatproduction and heat-dissipation.

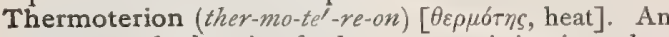
apparatus for keeping food warm, consisting in a glass case surrounded by a hot water chamber and an airspace to prevent the radiation of heat.

Thermotherapy (thur - mo-ther' - ap-e) [ $\theta \varepsilon \dot{\varepsilon} \rho \eta$, heat ; $\theta \varepsilon \rho a \pi \varepsilon i \alpha$, cure]. The treatment of disease by heat.

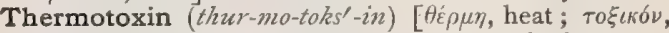
poison]. A poison produced by heat in the body.

Thermotropism (thur-mot'-ro-pizm) [ $\theta \dot{\varepsilon} \rho \mu \eta$, heat ;

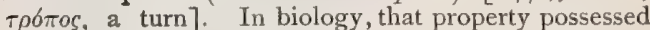
by some organs of bending toward or away from a source of heat.

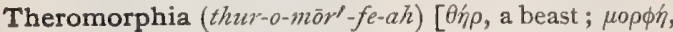
form]. A monstrosity resembling a lower animal.

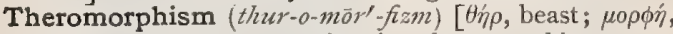
form]. Apparent reversion, in a human subject, to an animal form of lower type.

Thesis (the'-sis) [ $\theta \dot{\varepsilon} \sigma \iota s$, a proposition]. A dissertation. Usually, the essay presented by an undergraduate at the time of his candidature for a degree.

Thesocyte (thes'-o-sit $)[\theta \varepsilon s$, from $\tau i \theta \eta \mu \iota$, to lay up; кvтós, cell]. One of certain reserve cells found in several sponges.

Thetismus (the-tiz'-mus). Synonym of Lisping.

Thevetia (the-ve'-she-ah) [after André Thevet, a French monk and traveler]. A genus of tropical apocynaceous shrubs and trees. $T$. iccotit and $T$. neriifolia, of tropical America, and Asia, are poisonous, febrifugal, and emeto-cathartic. Unof.

Thevetin (thev'-et-in) [after André Thevet, a French monk and traveler]. A poisonous glucosid from certain species of Thevetia.

Thiazole $\left(t h i^{\prime}-a z-\bar{o} l\right), \mathrm{C}_{3} \mathrm{H}_{3} \mathrm{NS}$. A substance produced by exchanging hydrogen for the amido-group in amidothiazole. It is a colorless liquid, boiling at $I I 7^{\circ}$ C.; it closely resembles pyridin.

Thick Wind. A colloquial term for impeded respiration in the horse, somewhat louder and less free than normal breathing

Thiersch's Method of Skin-grafting. The part to be grafted is made aseptic and then washed with a saltsolution $(6: 1000)$. The granulations are removed with a sharp curet; the bleeding surface is covered with protective and compressed, to check all bleeding. From a portion of the arm or leg, free from fat and previously sterilized, broad strips of the upper layers of the skin are removed by a to-and-fro movement of a razor continually flooded with salt-solution. These grafts are then placed upon the prepared surface, covering it completely. Lattice-work protective strips are applied, then a compress moist with salt-solution, the whole being covered with protective and dry cotton and bandaged. An antiseptic dressing should be placed upon the surface from which the grafts were removed. 
Thigh (thi) [ME, thigh, thigh]. The femur. The part of the lower limb extending from the pelvis to the knee. T.bone, the femur or os femoris. T.-joint, the hipjoint; the articulation between the innominate bone and the femur.

'Thilanin (thil'-anin), a sulphuretted lanolin designed to replace ichthyol and thiol in the treatment of itching skin-diseases

Thillaye's Bandage. See Bandage.

Thimblewe ed $($ thim' $-b l$-wèd). The herb Rubeck. ia lanciniata; diuretic and tonic. It has balsamic properties. Dose of the fld. ext $m \times x-3 j$. Unof.

Thin [MiE., thinne, thin ]. Slender; meager; lean; spare

Thio- (thit - o- ) [HEiov, sulphur]. A prefix denoting the presence of sulphur, or a sulphur radicle.

Thio-acetals (thi$o$-as'-et-alz). See Mercapials.

Thio-acid (thi'-o$\left.a s^{\prime}-i d\right)$. One of the acids derived from others by the substitution of sulphur for oxygen, generally but not always in the hydroxyl group. They are liquids of disagreeable odor, less soluble in water and possessing a lower boiling - temperature than the corresponding oxygen acids.

Thio-a l c o hols (thi-o-al'-ko-hols) See Mercaptans.

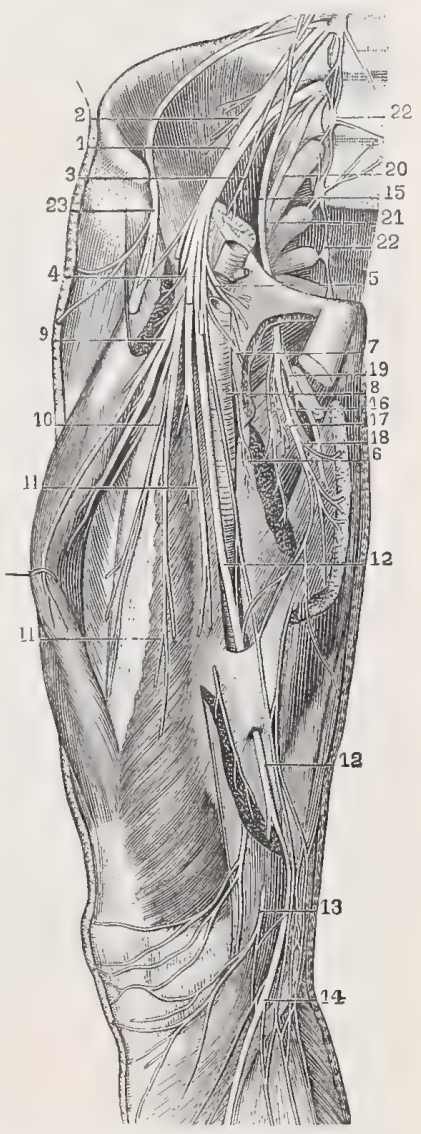

MUSCULAR NERVES OF THE ANTEROINTERNAL ASPECT OF THE THYGH.

. Anterior crural nerve. 2. Branches to iliacus muscle. 3. Branch to inner part of psoas. 4. Large cutaneous branch 5, 6 . Muscular filaments of small musculo-cutaneous branch. Cutaneous branches. 8. Deep, or anastomotic filament of internal cutaneous branch. 9. Branches to rectus femoris. Io: Branches to vastus externus. II, II. Branches to vastus internus, I2, I2. Internal saphenous nerve. I3. Its patellar branch. nerve, I3. Its patellar branch. I4. Vertical, or tibial branch. 15. Obtu-
rator nerve. I6. Branch to adductor rator nerve. I6. Branch to adductor
longus. 17. Branch to adductor brevis. I8. Branch to gracilis. I0. Branch to adductor magnus, 20. Lumbo-sacral trunk. mas this trunk and the first sacral nerve 22,22 . Lumbar and sacral portions of sympathetic. 23. External inguinocutaneous branch.

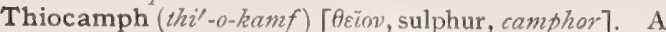
fluid disinfectant, used for fumigation. It is formed by the action of sulphurous acid on camphor and is used in the strength of one ounce to a pint or quart. Unof.

Thio-ethers (thi'-o-e'-therz). See Alkyl-sulphids.

Thiol (thi'-ol) [Aciov, sulphur]. German Ichthyol; prepared from gas-oil by heating with sulphur. It occurs in two forms, the dry and the liquid. It has been used largely in gynecic practice. Dose of $d r y$ thiol, gr. ij-x. Unof.

Thionin (thi' o-nin). Same as Lauth's Violet.

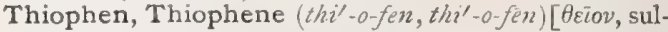
phur ], $\mathrm{C}_{4} \mathrm{H}_{4} \mathrm{~S}$." A hydrocarbon of the aromatic series ; a colorless, limpid oil, of faint odor, and miscible with water in all proportions The sodium salt, $\mathrm{C}_{4} \mathrm{H}_{3} \mathrm{CNaS}_{3}$, is a white powder, precipitated in the form of scales; it contains 33 per cent. of sulphur and has a disagreeable odor. It is used in a 5-Io per cent. ointment in prurigo. The biniodid, $\mathrm{C}_{4} \mathrm{H}_{2} \mathrm{I}_{2} \mathrm{~S}$, has been used as a substitute for iodoform. It crystallizes in beautiful plates, insoluble in water, but very soluble in ether, alcohol, and chloroform. Its odor is characteristic, but not disagreeable. It is a vigorous disinfectant and deodorant, superior to iodoform. Unof. T., diiodid, has been recommended as an antiseptic.

Thiophen Iodid (thi-a-fen-i'-o-did). Iodothiophen, a halogen compound of thiophen, a substance obtained from benzene. The experiments of Spiegler have shown it to be an antiseptic possessing varying degrees of power in retarding the development of bacteria in culture-media. It is preferable to iodoform in having a faint, agreeable, aromatic odor.

Thiophenol (thi-o-fen'-ol) [ $\theta \varepsilon i o v$, sulphur; phenyl], $\mathrm{C}_{6} \mathrm{H}_{5} . \mathrm{SH}$. Phenylmercaptan; obtained by the action of phosphorus pentasulphid on phenol. It is a mobile, ill-smelling liquid, boiling at $168^{\circ} \mathrm{C}$.; its specific gravity at $14^{\circ} \mathrm{C}$. is 1.078 ; it dissolves readily in alcohol and ether.

Thiophtene (thi-of'-tèn) [ $\theta \varepsilon \bar{\imath} o v$, sulphur], $\mathrm{C}_{6} \mathrm{H}_{4} \mathrm{~S}_{2}$. A substance produced when citric acid is heated with phosphorus pentasulphid. It is an oil, boiling at $225^{\circ} \mathrm{C}$.

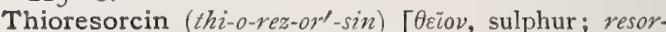
cin], $\mathrm{C}_{6} \mathrm{H}_{4}\left(\mathrm{SH}_{2}\right)_{2}$. Bisulphydrate of phenyl. It possesses the therapeutic properties of iodoform, and is harmless and odorless. It is used either as a powder or as an ointment, $3 \mathrm{ss}-\mathrm{j}$ in $3 \mathrm{v}$ of lard. Unof.

Thiosinamin (thi-o-sin'-am-in) [ $\theta \varepsilon i o v$, sulphur; sinapis, mustard], $\mathrm{C}_{4} \mathrm{H}_{8} \mathrm{~N}_{2} \mathrm{~S}$. A body prepared from allyl, mustard-oil, alcohol, or ammonia. It is useful in cutaneous affections, lupus, glandular enlargements, night-sweats. It is used by hypodermatic injection in doses of from 3 to 30 minims of a 15 per cent. alcoholic solution. Unof.

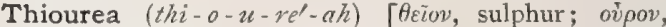
urine $], \mathrm{CS}\left(\mathrm{NH}_{2}\right)_{2}$. Sulphocarbanid; a substance obtained from urea. It crystallizes in fine, silky needles or in thick, rhombic prisms, which dissolve easily in water and in alcohol, but with difficulty in ether. They possess a bitter taste and have a neutral reaction. They melt at $169^{\circ} \mathrm{C}$. and decompose at higher temperatures.

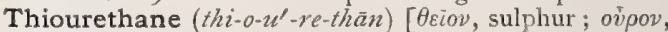
urine]. Any one of the crystalline esters of sulphocarbamic acid.

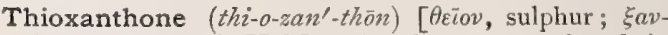
Hos, yellow], $\mathrm{C}_{13} \mathrm{H}_{8} \mathrm{SO}$. A substance produced in the condensation of diphenyl-sulphido-carboxylic acid effected by $\mathrm{H}_{2} \mathrm{SO}_{4}$. It consists of yellow needles that become colorless upon distillation; it melts at $207^{\circ} \mathrm{C}$, and boils at $372^{\circ} \mathrm{C}$.

Third (thurd) [ME., thirde, third]. Next after the second. T. Eye. See Pineal Eye. T. Intention. See Healing. T. Tonsil. See Luschka's Tonsils. T. Ventricle. See Ventricle.

Thirst (thurst) [ME., thurst]. The state manifested by a desire for drink. It is marked by dryness of the mouth and fauces, together with constriction of the pharynx and esophagus. See Dipsosis and Polydipsia. T-cure, See Schroth's Cure.

Thistle, Barnaby's. See Centaurea. 
Thiuret (thi'-u-ret) [ $\theta \varepsilon i o v$, sulphur $], \mathrm{C}_{8} \mathrm{H}_{7} \mathrm{~N}_{3} \mathrm{~S}_{2}$, An antiseptic which readily yields its sulphur in a nascent condition. On this property depends its antiseptic action. It is a crystalline powder, practically insoluble in water, and is best used in combination as the borate, or perhaps best as the parasulphophenate.

Thlipsencephalon (thlip-sen-sef'-al-on). See Thlip. sencephalus.

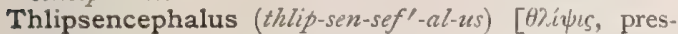

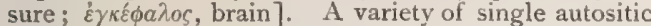
monsters of the species pseudencephalus, in which there is extensive exposure of the base of the skull from non-development of the occipital bone and even of the upper vertebræ.

Thlipsis (thlip'-sis) [ $\theta \lambda i \psi u s$, pressure]. Compression, especially of blood-vessels.

Thoka-Losi (tho-kah-lo'-se). An Australian and Fijian form of mutilation, consisting in the incision of the urethra at the membranous portion. The object is supposed to be a superstitious method of treating rheumatism and sundry fevers. Another similar method of mutilation for supposed similar reasons is called Targangalengale, incision of the urethra from the meatus to the frenum. Similar mutilations are practised by some of the Arabs and by certain African tribes.

Thomas's Decalcifying Solution. See under Stains, Table of. T.'s Operation. See Cesarean Operation.

Thompson's Line. See Lines, Table of. T.'s Sounds. Graduated metal bougies, employed to dilate urethral strictures in the male.

Thomsen's Disease. Myotonia congenita; a disease commonly congenital and occurring in families, and characterized by tonic spasm or rigidity of the muscles, coming on when they are first put in action after a period of rest. As the muscles are used the stiffness gradually wears off. The disease usually appears first in childhood at about the age of eight or nine years. The etiology is obscure; the duration indefinite. No treatment is of any avail. The Myotonic Reaction is characterized as follows: The contraction of the muscles upon mechanical stimulation of the motor nerves is normal. Mechanical stimulation of the muscles easily induces contraction lasting from five to thirty seconds. The galvanic current applied to the muscle shows that opening contractions are very difficult to obtain, that the closing contractions are of very long duration, and that upon stabile application well-formed, wave-like contractions may be seen to pass from the kathode to the anode. The reflexes are normal. See Diseases, Table of.

Thomsonianism (tom-so'-ne-an-izm) [after Dr. Samuel Thomson]. A form of empiric medicine introduced by one Samuel Thomson (1769-1843) of Massachusetts. Sweating, lobelia, and capsicum were the principle curative agents relied upon in this school.

Thoöid $\left(t h o^{\prime}-o i d\right)[\theta \omega s$, a beast of prey of the wolf kind; हiঠos, form]. In biology, lupine, resembling or related to a wolf.

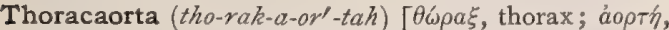
aorta ]. The thoracic aorta.

Thoracentesis (tho-ras-en-te'sis) [ $\theta \omega \rho a \xi$, chest; $\kappa \varepsilon v v \tau$ $\eta \sigma \iota$, a piercing]. The piexcing of the thorax for the removal of any abnormal collection of matter.

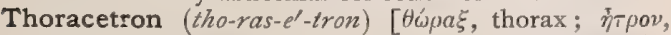
the abdomen: pl., Thoracetra ]. In biology, the second division of the body of the king-crab ( Limulus). Cf. Cephaletron, Pleon.

Thoracic $\left(t^{\prime} \circ-\right.$ ras $\left.^{\prime}-i k\right)$ [ $\theta \omega \omega a \xi$, thorax]. Pertaining to the chest or thorax, and also to certain of its organs. T. Aorta. See Arteries, Table of. T. Choke, in the horse, the lodgment of a foreign body in the thoracic portion of the esophagus. T. Duct. See Duct. T. Index. See Index. T. Nerve. See Nerves, Table of.

Thoracico-abdominal (tho-ras'-ik-o-ab-dom'-i-nal)

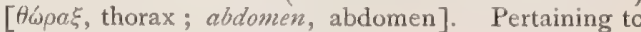
the thorax and the abdomen.

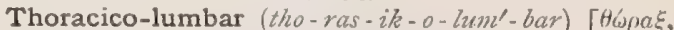
thorax; humbus, the loin]. Pertaining to the thoracic and lumbar regions.

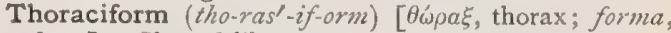
form]. Shaped like a thorax, as the mesonotum.

Thoracispinal (tho-ras - is - $p i^{\prime}-n a l$ ) [ $\theta \dot{\omega} \rho a \xi$, thorax; spina, spine]. Relating to the thoracic portion of the spinal column.

Thoracocentesis $($ tho-rak-o-sen-te'-sis). See Thoracentesis.

Thoracocyllosis (tho-rak-o-sil-o'-sis) [ $\theta \omega \rho n \xi$, thorax; кi $\lambda \lambda \omega \sigma \iota s$, curvation]. Deformity of the thorax.

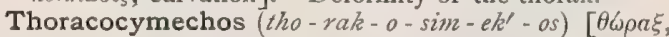
thorax; $\kappa \dot{v} \mu a$, a wave; $\eta^{\gamma} \chi 0 \varsigma$, a sound]. A splashing sound heard in the chest on succussion.

Thoracodidymus (tho-rak-o-did'-im-us) [ $\theta \omega \rho a \xi$, chest; didvuos, double]. A double monster joined by the thoraces.

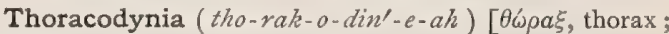
ofvvin, pain]. Pain in the chest.

Thoracometer (tho-rak-om'-et-er) [ $\theta \dot{\omega} \rho a \xi$, thorax ;

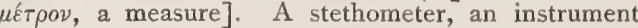
for measuring the movements of the walls of the chest.

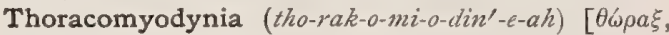
thorax; $\mu v s$, muscle; $6 \delta v v \eta$, pain $]$. Pain in the muscles of the chest.

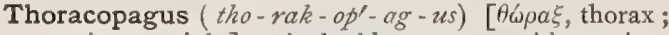
$\pi m \gamma \nu$ viva, to join]. A double monster with portions of the thorax or abdomen coalescent. T tribrachius, with two of the upper limbs coalescent. T. tripus, with two of the lower limbs coalescent. Prosopothoracopagus, with the heads, breasts, and bellies coalesced; it is also called Cephalo-thoracopagus, or Syncephalus.

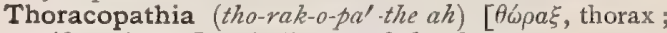
$\pi a$ tos, disease]. A disease of the thorax.

Thoracoplasty (tho-rak'-o-plas - te) $[\theta \omega \rho \alpha \xi$, thorax; $\pi \lambda a ́ \sigma \sigma \varepsilon \iota \nu$, to form]. Plastic operation upon the thorax.

Thoracopneumoplasty (tho-rak - o- nu' - mo - plas - te)

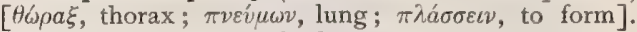
Plastic operation upon the lung and chest.

Thoracoscopy (tho-rak-os'-ko-pe) [ $\theta \dot{\omega} \rho a \xi$, thorax; $\sigma \kappa о \pi \varepsilon i v$, to examine]. Examination of the chest for diagnostic purposes, especially by the stethoscope.

Thoracostenosis (tho-rak-o-sten-o'-sis) $[\theta \omega \rho a \xi$, thorax; stenosis]. Contraction or coarctation of the chest.

Thoracotheca (tho-rak-o-the'-kah) [ $\theta \omega \rho a \xi$, the thorax; $\theta \eta \kappa \eta$, a case: $p l$. . Thoracothece]. In biology, that portion of the pupa-case which covers the thoracic region of the pupa.

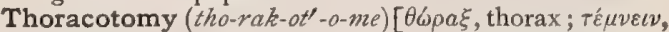
to cut]. Incision of the thorax. The same as Thoracentesis.

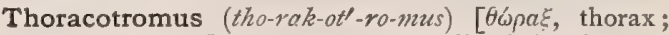
$\tau \rho b \mu \mathrm{s}$, tremor]. Tremor, or thrill, of the chest, or chest-wall.

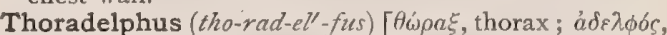
brother]. A monocephalic dual monstrosity with the bodies united above the umbilicus, and with four lower and two upper extremities.

Thorax (tho'-raks) [Abpak]. The chest, or the conic framework of bones and soft tissues, is bounded by the diaphragm below, the ribs and sternum in front, the ribs and corresponding portion of the vertebral column 
behind and above by the structures in the lower part of the neck; it contains the heart inclosed in the pericardium and the lungs invested by the pleura, etc. $T$., Regions of. See Regions.

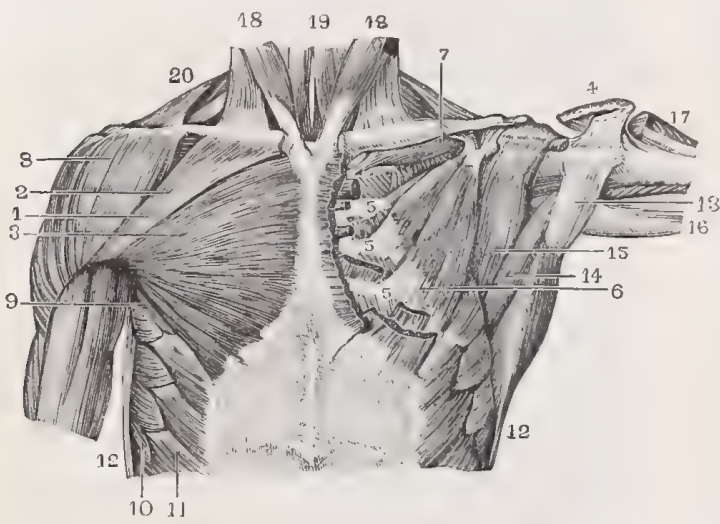

Muscles of Ventral Aspect of Thorax.

I. Pectoralis major. 2. Its clavicular portion. 3. Its sternocostal portion. 4. Its humeral attachment, divided and displaced upward. 5, 5, 5. Its fasciculi of attachment to ribs. 6 . Pectoralis minor. Subclavius. 8. Deltoid. Inferior border of pectoralis minor. 10. Digitations of serratus border of pectoralis minor. 10. Digitations of serratus
magnus. 11. Corresponding digitations of the external oblique. 12, 12. Ventral border of latissimus dorsi. 13. Its tendon of attachment to humerus. 14. Teres major. 15. Subscapularis. 16. Long head of triceps. 17. Lower portion of deltoid. 18. Sterno-mastoid. 19. Lower portion of sterno-hyoid. 20. Trapezius.

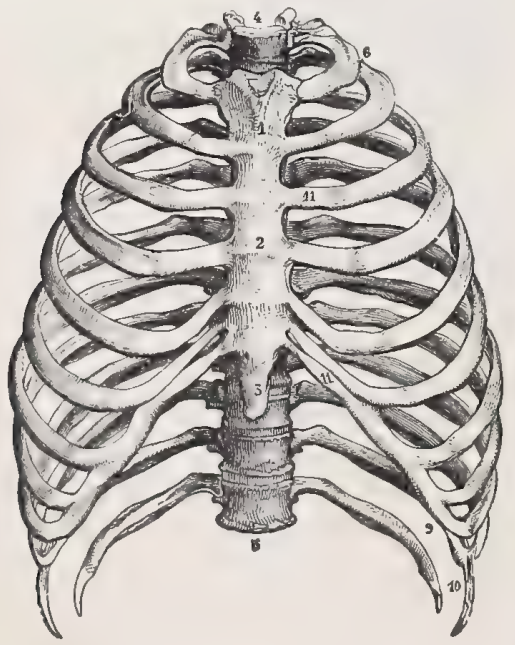

THORAX, ANTERIOR VIEW.

1. Manubrium sterni, 2. Gladiolus, 3. Ensiform cartilage of xiphoid appendix. 4. Circumference of apex of thorax. 5. Circumference of base. 6. Ist rib. 7. 2d rib. 8, 8. 3d, 4 th 5th, 6 th and 7 th ribs. 9. 8 th, 9 th and ioth ribs. 10. IIth and 12th ribs. II, I1. Costal cartilages.

Thorium $\left(t h o^{\prime}-r e-u m\right)$ [Icel., Thōr $r$ ]. A rare metal discovered by Berzelius in $\mathbf{I} 828$; symbol $\mathrm{Th}$, at. wt. 231.9. It is chemically related to tin. Its medicinal qualities are unknown. See Elements, Table of.

Thorn [ME, thorn, thorn]. A sharp excrescence on a plant. T-apple. See Datura and Stramonium. T.-apple Crystals. See Hedgehog Crystals. T.headed Worms. See Acanthocephala. See under Parasites (Animal), Table of.
Thorncliffe Disinfectant. See Tzal.

Thornwaldt's Bursitis, or Disease. Thornwaldtitis. A form of naso-laryngeal stenosis associated with the abnormal formation of a cyst-like cavity in the midst of the pharyngeal gland, containing pus or mucopus. See Diseases, Table of.

Thorough (thwr'-o) [ME., thorou, through ]. Through, complete. T.-joint. Same as Arthro dia or Diarthrosis. T.-pin, a swelling in the hollow of the hock of the horse, on both inner and outer aspects, caused by distention of the synovial sheath of the flexor perforans pedis tendon. T.-wort. See Eupatorium.

Thorter-ill (thor'-ter-il). Same as Louping-ill, $q . v$. Thought-transference See Telepathy.

Thread (thred) [ME., threed, thread]. The spun and twisted fibers of cotton, linen, or silk. The last, uncolored, is preferable for sutures. Ts., Mycelial, the hyphæ of the mycelium. Ts., Nuclear, chromatin fibrils of the cell-nucleus. T.-worm, applied loosely to any nematode worm, also specifically to Oxyuris vermicularis. See under Parasites (Animal), Table of

Thready (thred'-e) [ME., threed, thread]. Like a thread. See Pulse.

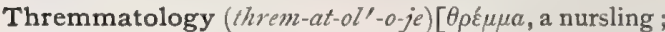
$\lambda 6 \gamma o s$, science $]$. In biology, experimental or artificial evolution.

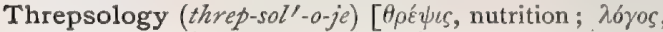
treatise]. The sum of knowledge regarding the nature and processes of nutrition. The science of trophic phenomena and conditions.

Threshold (thresh'-old) [ME., threshold, threshold]. The limit of perceptibility of a stimulus. See Schwelle, also Fechner's Law.

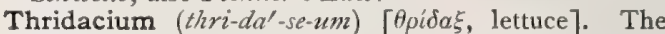
expressed and inspissated juice of the lettuce; a variety of lactucarium.

Thrift [ME., thrift, thrift]. A plumbagineous plant, Armeria vulgaris, native of both continents. The flowers are diuretic. 'Unof.

Thrill (thril) [ME., thrillen, to thrill]. Fremitus. A sort of quiver or shiver of the arteries or other organs in certain cases of cardiac disease, aneurysm, or other arterial disease. Varieties are purring thrill, q. $v$., and hydatid thrill, obtained over a hydatid cyst.

Throat (lhröt) [ME., throte, throat]. A term for the fauces, pharynx, larynx, etc. ; the ventral part of the neck; jugulum. In biology, the opening or gorge of a monopetalous corolla, where the border and the tube join, and a little below. See Faux. T.-cough, a cough due to irritation of the pharynx apart from diseases of the respiratory tract, as from an elongated uvula. T.-mirror. See Laryngeal Mirror. T.wort, the genera Trachelium and Liatris; also species of Campanula, the Digitalis purpurea and Scrophularia nodosa.

Throaty $\left(\right.$ thro $\left.t^{\prime}-e\right)$ [ME., throte, throat]. Having a peculiar guttural sound, as a throaty voice.

Throb (throb) [ME, throbben, to throb]. A pulsation or beat.

Throbbing (throb'-ing) [ME, throbben, to throb]. A rhythmic beating, as in an inflamed part. T. Aorta, a characteristic symptom of hysteria and neurasthenia; it is an epigastric pulsation, often very forcible and suggesting abdominal aneurysm.

Thrombin (throm'-bin) [Hpo $\mu \beta \cap \varsigma$, thrombus]. Fibrinferment.

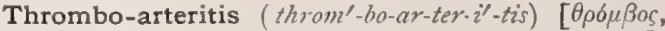

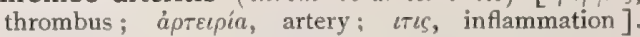
Acute arteritis with thrombosis. Either process may be primary. 


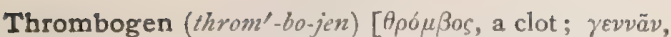
to produce]. In biology, producing or giving rise to clots.

Thrombogenic (throm-bo-jen'-ik) $[\theta \rho \delta \mu \beta o s$, thrombus ;

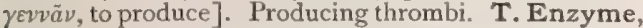
an unorganized ferment having power to form a curd, clot, or coagulum by enzymosis or hydrolysis ; e. $g$. rennet (Armstrong).

Thromboid (throm'-boid) $[\theta \rho \sigma u \beta 0 \varsigma$, thrombus; Eidos, like]. Resembling or having the nature of a thrombus.

Thrombolymphangitis (throm-bo-lim-fan-ji'-tis) [ $\theta p o ́ \mu-$ Bos, thrombus; lympha, lymph; $\iota \tau \iota$, inflammation] Lymphangitis, with thrombosis.

Thrombophlebitis (throm-bo-fle-bi'-tis) [Aoó $u$ Bos, thrombus; $\phi \lambda \dot{\varepsilon} \psi$, vein; $\iota T i \zeta$, inflammation]. Phlebitis with thrombosis.

Thrombosis (throm-bo'-sis) [ $\theta \rho 6 \mu \beta o s$, thrombus $]$. The formation of a thrombus. T., Cardiac, thrombosis of the heart. T., Marantic. See Marantic. T., Puerperal Venous, puerperal thrombosis of the uterine veins.

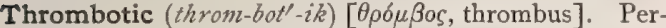
taining to or of the nature of thrombosis

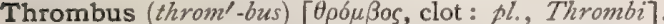
A clot of blood formed within the heart or blood-vessels, due usually to some impediment to the circulation or to alteration of the blood or vessel-walls. See Embolus. T., Ante-mortem, the white thrombi in the heart and large vessels formed before death. $T$., Ball, a small or large, rounded, ante-mortem clot found in the heart, especially in the auricles. $T$., Currant-jelly, a soft, reddish, post-mortem clot. T., Lateral, a clot attached to the vessel-wall, and not obstructing the lumen completely. T., Obstructing, one completely obstructing the lumen of the vessel. T., Progressive, one that grows into the lumen of the vessel. T., Stratified, one in which there are successive layers of fibrinous deposit and of varying color. T., White. See T., Ante-mortem.

Throttle (throt'-l) [ME., throtel, throat; throtten, to choke]. I. The throat. 2. To choke; to suffocate.

Through Illumination. See Voltolini's Method.

Thrush [ME., thrushe, thrush]. I. Mycotic stomatitis, a form characterized by the presence of diffuse, white patches. It occurs especially in weakly children, but may affect adults depressed by some form of wasting disease. It is also called Parasitic Stomatitis and Aphtha, but the latter is more frequently reserved for a vesicular form of stomatitis. The cause is not definitely known; according to some it is the oidium or saccharomyces albicans. 2. A diseased condition of the frog of the horse's foot, with a foul-smelling discharge.

Thrust-culture (thrust kul'-tür). A culture of bacteria in a solid culture-medium, inoculated by thrusting the infected oese into the sterilized gelatin; a Stab-culture or Stick-culture.

Thuja (thu'-jah) [0vía: gen., Thuja]. I. A genus of coniferous trees, the arbor vitæ. 2. The pharmacopeial name for $T$. occidentalis, a tree of $\mathrm{N}$. America, Arbor vitce. The leaves and twigs are diuretic, sudorific, and stimulant. T., Oleum, a volatile oil of camphoraceous odor, composed of thujol and terpene. Dose $\mathrm{mj}_{\mathrm{j}} \mathrm{v}$.

Thujol (thu-jol) $\mathrm{C}_{10} \mathrm{H}_{16} \mathrm{O}$. An oily liquid, the chief constituent of Thuja occidentalis. It increases the blood-pressure and has antipyretic qualities.

Thumb (thum) [ME., thoumbe, thumb]. The first finger or toe ; pollex or hallux. It differs from the other digits in having but two phalanges and in that its metacarpal bone is separately movable. T.-method of Palpation. See Palpation, Glenard's Method of.

T.-pad, a pad-like formation over the inner metacarpal bone of some batrachians.

Thumb (thum) [corruption of thrum]. Palpitation of the heart in the horse.

Thumps [origin obscure]. An affection in the horse identical with hiccough in man, due to spasmodic action of the diaphragm.

Thunbergia (thun-ber'-je-ah) [after K. P. Thunberg, I743-1828, a Swedish botanist]. Thunbergia fragrans, a native plant of East India, is cultivated in the West Indies and used as an aromatic tonic.

Thunder-struck Disease. Synonym of Apoplexy.

Thus [L., thus, tues: gen., Thuris or Turis]. I. True frankincense, or olibanum. 2. Turpentine of pine trees.

Thymacetin (thi-mas'-e-tin) [Aviov, thyme; acetum, vinegar], $\mathrm{C}_{6} \mathrm{H}_{2} \mathrm{CH}_{3} \mathrm{C}_{3} \mathrm{H}_{2}<\mathrm{OC}_{2} \mathrm{H}$

ive of thymol introduced as an a gr. iij-xv. Unof.

Thymasthma (thi-maz'-mah). See Thymic Asthmu. Thyme (tim) [ $\theta \dot{v} \mu o v$, thyme]. Thymus, a genus of plants. T., Oil of. A stimulant and antiseptic oil containing thymol, chiefly used topically in veterinary practice.

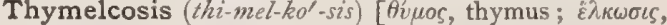
ulceration]. Ulceration of the thymus gland.

Thymene (thi'-mèn) [Aíuos, thyme]. An eleopten existing in oil of thyme, along with thymol, $q . v$.

Thymic (thi'-mik) [O'veos, thymus]. Pertaining to the thymus gland. Also, pertaining to thyme. $T$. Asthma, Laryngismus stridulus, popularly known as "crowing breath," "holding the breath." It consists in a temporary suspension or difficulty of respiration from laryngeal spasm. It has been attributed to enlargement of the thymus, and also to reflex spasm; the latter is now the accepted view.

Thymitis (thi-mi'-tis) [A'ves, thymus; iTis, inflammation]. Inflammation of the thymus gland, a rare condition.

Thymol (thi'-mol) [ tíuns, thyme; oleum, oil], $\mathrm{C}_{10} \mathrm{H}_{13}$ HO. A stearoptene, with active antiseptic and anesthetic properties. It exists in oil of thyme and othe? vegetable oils. It occurs in large, colorless plates, melting at $44^{\circ} \mathrm{C}$. and boiling at $230^{\circ} \mathrm{C}$. It has a thyme-like odor and is slightly soluble in water, but readily soluble in alcohol. It forms thymates with metallic bases. It is used chiefly as an antiseptic, and is as efficient as and more agreeable than carbolic acid. Dose gr. ss-ij. T.-gauze, contains I per cent. of thymol. T.-inhalation, thymol gr. $\mathrm{xx}$, alcohol $z$ iij, magnesium carbonate gr. $x$, water ad $\zeta$ iij; add a teaspoonful to a pint of water. T.-solution, for spraying, I : 1000 T., Ung., contains gr. $v$ to $\bar{\zeta}$ j. Volkmann's Thymol-solution, thymol 1 , alcohol 20 , glycerin 20; dissolve and add to water Iooo. It is used as a spray and antiseptic lotion; it does not produce eczema, as carbolic lotions do.

Thymopathia (thi-mo- $p a^{\prime}-$ the -

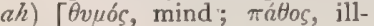
ness]. Mental disorder.

Thymus (thi'-mus) [A'ves, thymus: gen., Thymi ]. I. The $T$. Gland, a body of glandular appearance situated in the anterior superior mediastinum. In fetal life it is doubtless func-

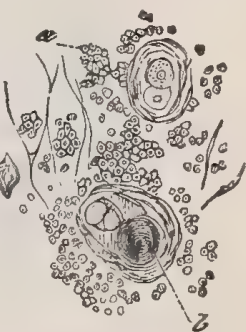

ELEMENTS OF THE THYMUS GLAND.

Leukocytes. b. Concentric corpuscles. $\times 300$. (From Stirling.) tional, and it is probably a true lymph-gland. After the second year of life it undergoes fatty metamorpho. 
sis and atrophy and in the adult is completely vestigial. See Sweetbread. 2. An old term for condyloma. A genus of labiate plants; thyme. T. vulgaris affords the official Thymi Oleum. Thymi Oleum, the volatile oil of garden thyme; it is important as a source of thymol. It has the general properties of the terpenes and mints; it is often $d$ sold as Oil of Marjoram, which it resembles.

Thyro-. See Thyreo-, the more correct form.

Thyreo- (thi'-re-o-) [0vpeór, a shield, and a. Cortex. b. Medulla c. Bloodhence, from simi- vessels. $d$. Septum of co larity of shape and

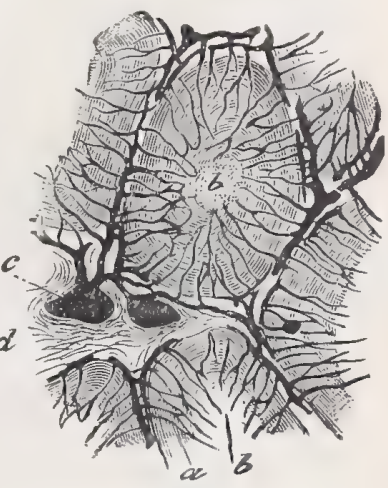

NJECTED LOBULES OF THYMUS OF

function, the thyreoid gland or cartilage]. A prefix signifying relationship to the thyreoid gland. T.arytenoid, pertaining conjointly to the thyreoid and arytenoid cartilages. Also applied to a muscle. T.epiglottideus. See Mruscles, Table of. T.hyyoid, pertaining conjointly to the thyreoid cartilage and the hyoid bone. Also, the name of a muscle.

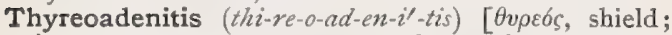
$\dot{a} \eta \eta \dot{v}$, gland; $\iota \tau \iota s$, inflammation]. Inflammation of the thyreoid gland.

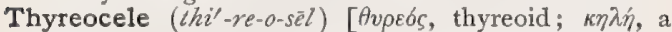
tumor]. A tumor affecting the thyreoid gland. Goiter

Thyreo-cricotomy (thi-re-o-kri-kot'-o-me) [ $\theta v \rho \varepsilon b s$, thyreoid; cricotomy]. Tracheotomy performed through the crico-thyreoid membrane alone.

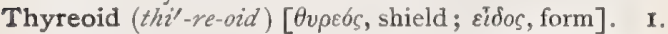
Shield-shaped. 2. Pertaining to the thyreoid gland. 3. The lobes called "kernels" or "glands" in myxe-

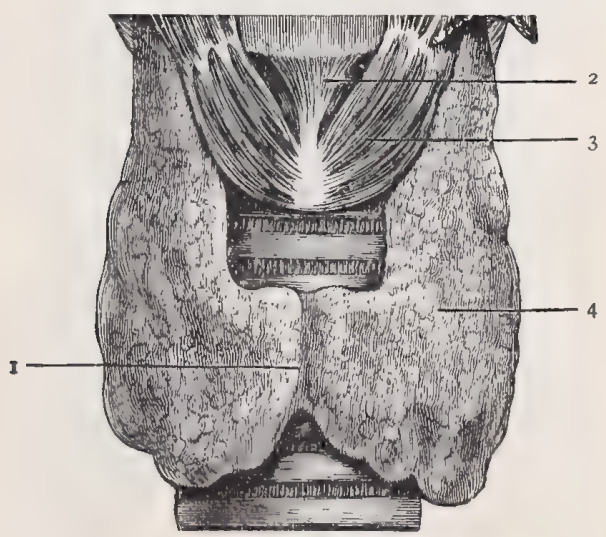

VIEW OF THYREOID BODY.

1. Thyreoid isthmus. 2. Median portion of crico-thyreoid membrane. 3. Crico-thyreoid muscle. 4. Lateral lobe of thyreoid body.

dema. T. Axis. See Arteries, Table of. T. Body. See $T$. Gland. T. Cartilage, the largest of the laryngeal cartilages, united at an angle in front called the pommm adami. T.-extract, a glycerin extract of the sheep's thyreoid gland, used in the treatment of myxedema, cretinism, psoriasis, and other diseases. It may be given dry, in powder, or in liquid form, in quantities corresponding to an eighth or a quarter of an entire thyreoid from the sheep, every day or on alternate days. See Organotherapy. T. Foramen. See Foramen, Oburator. T. Gland, a ductless, glandlike body of unknown function, on the anterior aspect of the upper part of the trachea, consisting of two lateral lobes, one upon either side, connected centrally by an isthmus. See Cachexin and Myxedima. T.therapy, the treatment of disease by the administration of thyreoid-extract. See Organolierapy.

Thyreoidectomy (thi-re-oi-dek'-to-me) [ $\theta$ vpeos, shield; Eкто $\mu$, excision]. Excision of the thyreoid gland.

Thyreoidin (thi-re-oi'-din) [Avpeós, shield; Eidos, like]. The extract of thyreoid gland. See Organotherapy.

Thyreoiditis (thi-re-oi-di' $\left.i^{\prime}-t i s\right)$ [ $\theta v \rho \varepsilon o ́ s$, shield; $\iota \tau \iota s$, inflammation]. Inflammation of the thyreoid gland.

Thyreoidotomy (thi-re-oi-dot'-o-me) [0rpeós, shield ; $\tau o \mu$, incision]. Incision of the thyreoid gland.

Thyreoitis (thi-re-o-i'-tis) [ $\theta v \rho \varepsilon o ́ s$, shield; iTis, inflam. mation]. Inflammation of the thyreoid gland.

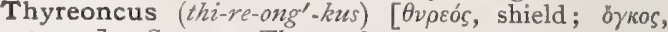
tumor]. Same as Thyreocele.

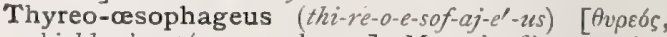

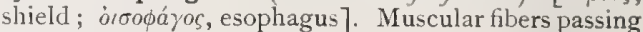
between the esophagus and the thyreoid cartilage.

Thyreopalatine (thi-re-opal'-at-in) [0vpeos, thyreoid; palatine]. Pertaining to the thyreoid gland and the palate. T. Muscle, the palato-pharnygeus. See Muscles, Table of.

Thyreophraxia (thi-re-ofraks'-e-ah). Synonym of Goiter.

Thyreophyma (thi-re-o-f'-

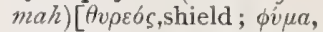
a tumor]. Enlargement of the thyreoid gland.

Thyreoprotein (thi-re-opro'-te-in] [ $\theta v p \varepsilon \sigma s$, shield; $\pi \rho \tilde{\omega} T о \varsigma$, first]. An albumin isolated by Bubnoff from the thyreoid gland.

Thyreotomy (thi-re-ot'-ome). See Thyreoidotomy.

Thyroid (thi'-roid). See Thyreoid, the preferable form.

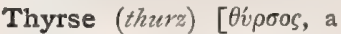
stalk, stem]. In biology, a compact panicle like that of the grape, lilac, or horse-chestnut.

'Thyrsiform (thur'-sif-orm) [Óóoos, a stalk; forma, form]. Having the form of a thyrse.

Thyrsoid (thur'-soid)

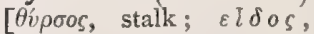
form]. Having the form of a thyrse.

Tibia $\left(t i b^{\prime}-e-a h\right)[L$., shin; also, flute or pipe]. The larger of the two bones of the leg, commonly called the shin-bone, articulating with the femur, fibula, and astragalus.

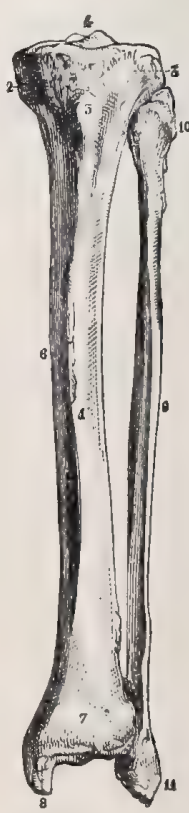

Tibia AND FibUla, ANTERIOR ViEW.

Shaft of tibia. 2. Internal tuberosity. 3. External tuberosity. 4. Spine. 5. Tubercle. 6. Crest. 7. Inferior extremity. 8. Internal maileolus. 9. Shaft of fibula. Io. Superior extremity, II. Inferior extremity and external malleolus. 
Tibiad $\left(t i b^{\prime}-\ell-a d^{\prime}\right)$ [tibia, tibia]. Toward the tibial aspect.

Tibial (tib'-e-al) [tibialis, tibiale; tibia, tibia]. Pertaining or belonging to the tibia. T. Artery. See Arteries, Table of. T. Muscle. See Muscles, Table of. T. Nerve. See Nerves, Table of.

Tibiale $\left(t i b-e-a^{\prime}-l e\right)$ [tibia, tibia]. One of the bones of the tarses.

Tibien $\left(t i b^{\prime}-e-e n\right)$ [tibia, tibia]. Belonging to the tibia in itself.

Tibio-calcanean (tib-e-o-kal-ka-ne'-an) [tibia, tibia ; calcaneum, the heel-bone]. Pertaining to the tibia and the calcaneus.

Tibio-femoral (tib-e-o-fem'-o-ral) [tibia, tibia; femur, femur]. Pertaining to the tibia and the femur. $T$. Amputation, removal of the leg at the knee-joint.

Tibio-fibular (tib-e-o-fibl-u-lar) [tibia, tibia; fibula, fibula]. Pertaining to the tibia and the fibula.

Tibio-peroneal (tib-e-o-per-o-ne'-al). Same as Tibio. fibular.

Tibio-tarsal (tib-e-o-tar'-sal) [tibia, tibia; tapбós, tarsus]. Pertaining to both the tibia and the tarsus. $T$. Amputation, removal of the foot at the ankle-joint.

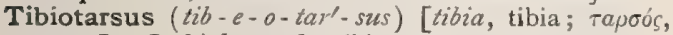
tarsus]. In biology, the tibia.

Tic (tik) [Fr., a twitching, a vicious habit]. A twitching, especially of the facial muscles. $T$. douloureux [Fr., "painful twitch"]. Neuralgia of one or more branches of the fifth nerve. The term has been applied to painless, spasmodic twitchings or distortions of muscles supplied by the seventh nerve. These affections have been called antalgia dolorosa, dolor crucians faciei, neuralgia faciei, prosopalgia trismus dolorificus, and trismus maxillaris. T. non-douloureux (of Trousseau). Synonym of Myoclonus. T. rotatoire, or T. giratoire, spasmodic torticollis, spinal accessory spasm; a spasm of certain muscles by which the head and neck are forcibly rotated to one side or from one side to the other.

Tick (tik) [ME., tike, tick]. A name applied indiscriminately to several species of acarids; also, to various parasitic insects of low type, some of which occasionally attach themselves to man. See Parasites (Animal), Table of. T., Lone-star. See Argas americanus in Parasites (Animal), Table of.

Tickle $\left(t^{\prime} k^{\prime}-l\right)$ [ME, tiklen, to touch lightly]. To cause a spasmodic muscular contraction, with a sense of peculiar distress, by a slight irritation of peripheral nerve-fibers of the skin. See Titillatio.

Ticklishness (tik'-lish-nes) [ME., tiklen, to touch lightly]. Proneness to muscular contraction, with a sense of peculiar distress, due to slight irritation of the skin ; its exercise may or may not be accompanied by involuntary laughter.

Ticorea $\left(t i-k o^{\prime}-r e-a h\right)$ [from the native Guiana name]. A genus of rutaceous S. American plants. The bark of T. febrifuga is prized in fevers; other species also are medicinal. Unof.

Ticuna Poison (ti-ku'-nah) [S. Amer.]. A powerfully convulsant arrow-poison of S. American origin and of unknown derivation. It probably contains picrotoxin.

Tidal Air $\left(t i^{\prime}-d a l \bar{a} r\right)$. See Air.

Tide ( $t \bar{i} d)$ [ME., tide, tide]. A definite period of time. T., Acid, a transient condition of increased acidity of the urine, sometimes seen after fasting. T., Alkaline, the transient condition of alkalinity of the urine, occurring during digestion, when by reason of the determination of acid to the stomach there is a diminution of the acid salts secreted by the kidney.

Tidy's Method. A method of estimating the quantity of organic matter present in water. It is done by means of the following solutions: 1 . Dilute $\mathrm{H}_{2} \mathrm{SO}_{4}$ (I part of pure $\mathrm{H}_{2} \mathrm{SO}_{4}$ with 3 parts of distilled water). 2. Solution of potassium permanganate, 0.286 gram per liter, ro c.c. $=.714$ milligram of available oxygen. 3. Solution of potassium iodid, free from iodate, 1 part in Io of water. 4. Sodium thiosulphate (hyposulphite), 0.77 gram in $I$ liter of distilled water. 5. Starchsolution carefully prepared, about $11 / 3$ gram in $100 \mathrm{c} . \mathrm{c}$. of water.

Tigella (ti-jel'-ah) [L.]. Same as Tigelle.

Tigellate (tij'-el-ât) [tigella, a stalk]. In biology, having or bearing a tigelle.

Tigelle $\left(t i-j e l^{\prime}\right)$ [tigella, a tigella]. In biology, the radicle or caulicle.

Tigellus $(t i-j e l '-u s)$. Same as Tigelle.

Tiglium (tig'-le-um). See Croton. Tiglii, Oleum. Croton-oil. The fixed oil of the seed of Croton tiglium, native to India. Externally it is a powerful irritant, producing pustular eruptions. It is useful as a counter-irritant in various chronic inflammatory conditions, e.g., ovaritis, bronchitis, rheumatism, glandular swellings, etc. Internally, it is a drastic, hydragogue cathartic; its use is indicated when prompt evacuation of the bowels is required. Dose $\eta^{1} / 3-i j$. Linimentum crotonis (B.P.), a counterirritant for sprains and in muscular rheumatism.

Til (til) [Hind.]. The plant Sesamum, q. v., and its seed.

Tilia $\left(t i l^{\prime}-\ell-a h\right)[\mathrm{L}$.$] . A genus of exogenous trees-$ linn, linden, or basswood. $T$. americana, a $\mathrm{N}$. American species ; a mucilage from its inner bark is said to be a good application for burns. T. europœea affords flowers used in dyspepsia and hysteria. Unof.

Tillandsia (til-and'-se-ah) [after Tillands, a Swedish botanist]. A genus of bromeliaceous plants, of some 220 species, mostly epiphytic. T. usneoides, growing in the Southern United States and Central America, called Spanish moss, is astringent, and is used as a cure for piles. Unof.

Tilletia (til-e'-she-ah) [L.]. A genus of ustilagineous fungi. See Smut.

Tilmus (til'-mus) [ $\tau \iota \lambda \mu o ́ s$, a pulling]. Carphologia, or floccitation; the picking of the bedclothes by a delirious patient.

Timbre $\left(\operatorname{tam}^{\prime}-\right.$ ber $)$ [Fr.; Ger, Klang]. The peculiar quality of a tone, other than pitch and intensity, that makes it distinctive. It depends upon the overtones of the vibrating body.

Time $(t \bar{i} m)$ [ME., time, time]. The duration of an event or phenomenon. T., Inertia, in the stimula. tion of a muscle or sense-organ, the latent time required to overcome the inertia of the muscle or organ after the reception of the stimulus through the nerve. T., Reaction, that required for the conduction of a sensory impulse to the center, combined with that of the duration of the perception, of the direction of attention (apperception), of the voluntary impulse, and of the return of a motor impulse to the muscles, with their consequent activity. The reaction-time varies according to the part and sense, etc., stimulated. Dolley and Cattell found, by experiments upon themselves, that the sensory reactions of electric stimuli were the shortest when the stimulus was applied to the upper arm and the movement made with the hand. They were about $\frac{1}{7}$ or $\frac{1}{9}$ second. See, also, Dilemma. T., Recogition, the time required for the recognition of the kind of stimulus after its application. T.-sense, the perception of the lapse of time.

Tin $(\operatorname{tin})$ [ME., $\operatorname{tin}, \operatorname{tin}]$. Stannum. Sn $=\mathbf{I I} 8$; quantivalence II, IV. A silvery-white metallic element 
known from the remotest antiquity, harder than lead and very malleable. When exposed to the air it becomes superficially oxidized. Tin is a constituent of a number of alloys: bronze, bell-metal, pewter, solder, gun-metal, britannia, speculum-metal, etc. See Elements, Table of. T.-amalgam, tin 3 parts and mercury I part. It is used for filling teeth and as a vermifuge. T.-block, a thin plate of iron coated with tin. T. Chlorid, stannous chlorid, a disinfectant. T.-foil, tin in thin sheets, or layers; used in pharmacy, chiefly as a material for wrapping various drugs. T., Powdered, Pulvis Stanni; formerly used as an anthelmintic. All unof.

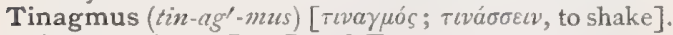
A concussion. See Rectal Tenesmus.

Tinca $\left(\operatorname{tin}^{\prime}-k a h\right)[\mathrm{L}$.$] . A tench; a small fish$

Tincæ, Os. The tench's mouth; an old name for the os uteri.

Tincal (ting'-kal) [Malay, tingkal]. An oriental name for crude borax.

Tinction (ting $k^{\prime}-s / 2 u n$ ) [tingere, to dye]. A staining material. A tint. The process of staining.

Tinctorial (tingk-to'-pe-al) [tingere, p.p., tinctus, to dye]. Pertaining to staining or dyeing.

Tincturation (tingk-tu-ra'shun) [tinctura, tincture]. The preparation of a tincture; the treatment of a substance in such a way as to make a tincture from it.

Tincture, Tinctura $\left(t i n g k^{\prime}-t \bar{u} r\right.$, tingk-tu'-rah) [L.: gen., Tincture; tingere, to tinge]. A tincture. In pharmacy, an alcoholic solution of the medicinal principles of a drug, and, excepting the tincture of iodin, of non-volatile bases. The strength of tinctures varies from $\frac{4}{10}$ per cent. to 65 per cent. of the active principles of the drug. There are 72 official tincture, besides $3 \mathrm{I}$ in the National Formulary. T. amara. See Bitter Tincture. T., Ammoniated, a solution of a medicinal substance in spirit of ammonia. $T$. antacrida. See Guaiac-mixture, Fenner's. T. capsici et myrrhæ. (N. F.) Same as Hot Drops. T., Ethereal, the solution of a drug in ethereal spirit. T., Huxham's. See $T$. cinchone composita. T., Warburg's. See Warburg's Tincture.

\section{Tinder, German. See Amadon.}

Tinea $\left(\operatorname{tin}^{\prime}-e-a h\right)$ [tinea, a moth-worm]. A generic term applied to a class of skin-diseases caused by the presence of filamentous fungi. T. amiantacea. Synonym of Sehorrhea. T. asbestina. Synonym of Seborrhea. T. axillaris, ringworm of the axilla. T. barbæ. Same as $T$. sycosis. T. ciliorum. Same as Eczema tarsi. T. circinata, $T$. corporis; Herpes circinatus; ringworm of parts devoid of hair. It is of frequent occurrence in children with ringworm of the scalp, but is seen especially in adults. The patches are most commonly situated on the neck, face, and hands, but may occur anywhere. They are at first sharply defined, circular, slightly raised, pinkish, and covered with fine gray scales. They form rings and gyrate patches. Itching is seldom marked. $\mathbf{T}$. corporis. See $T$. circinata. T. cruris, a variety of ringworm occurring upon the inner surface of the thighs, and accompanied by a considerable degree of inflammation. T. decalvans. See Alopecia arente. T. favosa. See Favus. T. imbricata, Tokelau Ringworm; Boneditch Island Rinuworm; Le Pita: Gune; Cascadöe; Herpes desquamans; a tropical, vegetableparasitic, contagious disease, characterized by the formation of patches of concentric, scaly rings. It attacks any part of the body except the head. The scales vary in size up to half an inch square and are free at their edges, which are slightly curled, or in old cases large, thick, and horny. Intense itching is the only other symptom. 'T. kerion, a suppurative form of
$T$. tonsurans. T. lupinosa. Synonym of Favus. T. nodosa, Paxton's Disease; a nodose condition of the hair of the moustache, accompanied by thickening, roughness, and some fragility. T. sycosis, MentaGra parasitica; Sycosis parasitica ; Barbers' Itch; ring. worm of the beard; a common affection the result of the irritating effect of tricophyton upon the follicles of the hairy portions of the face. It consists of circular, scaly, itchy patches or rings in the beard, very rarely on the upper lip, extending at the periphery and coalescing to form gyrate areas. If allowed to go on a pustular folliculitis is produced. T. tarsi. See Eczema palpebrarum. T. tondens. Synonym of T. tonsurans. T. tonsurans, Herpes tonsurans; ringworm of the scalp, a common and troublesome disease among children. It appears as single or multiple, circular or oval, irregularly distributed, reddish or grayish, scurfy spots on the scalp, attended with slight itching. A slight vesication may be present at the spreading edge. The hairs over the spots are scanty, lusterless, stumpy, swollen at the root, with fringed or twisted ends, and are often pigmented. Gradually these patches coalesce to form irregular patches over the scalp. In some cases smooth, bald, shining white patches are produced (bald ringzorm). The affection is a chronic one. T. trichophytina, Ringworm; a contagious disease of the skin due to the presence of a vegetable parasite. T. vera. Synonym of Favus. T. versicolor, Pityriasis versicolor; a common disease of the skin due to the presence of a vegetable parasite (microsporon furfur). It is characterized by the existence of fawn-colored or brown, slightly scaly patches, usually confined to the trunk. It is essentially a disease of middle life (between fifteen and fortyfive years), runs a chronic course, and produces slight or no subjective symptoms. The favorite seats of the disease are the front of the chest, the abdomen, and the interscapular region. The lesions consist, at first, of small, circular, discrete spots, which soon coalesce to cover extensive, irregular areas, or even the whole trunk. These patches are sharply defined, and their surface is finely scaly. They may become inflamed.

Tingible (tinj'-ib-l) [tingere, to tinge]. That which may be tinged; stainable.

Tingle (ting' $\left.{ }^{\prime}-g l\right)$ [ME., tinglen, to tingle]. A pricking or stinging sensation; the feeling of a slight, sharp, and sudden thrill, as of pain.

Tingling (ting'-gling). See Pins and Needles.

Tinker's Weed. See Triosteum.

Tinkling (ting $k^{\prime}$-ling) [ME., tinklen, to tinkle]. A sharp sound, like that caused by striking one piece of metal lightly by another. T., Metallic, an auscultatory chinking sound, heard mainly in pneumothorax.

Tinnitus (tin-i'-tus or $t i^{\prime}$-it-us) [tinnire, to tinkle]. Any subjective tinkling or ringing sound. T. aurium, the subjective ringing, roaring, or hissing sound heard in the ears in various affections of the tympanum and internal ear, and also after the administration of certain drugs in large doses, notably quinin. $\mathbf{T}$., Telephone, a professional neurosis or abnormal nervous condition of the auditory apparatus, believed to be caused by the continual use of the telephone.

Tip [ME, tip, tip]. The point or summit of anything. T.-foot, talipes equinus; a variety of club-foot.

Tire (tir) [ME., tiren, to tire]. A sense of weariness and exhaustion; fag.

Tire-balle $(t \bar{e} r-b a l)$ [Fr. ]. An instrument for extracting bullets from a part.

Tire-fond $(\operatorname{te} r-f o n z(g))[\mathrm{Fr}$.$] . An instrument for pene-$ trating a cavity or tissue, transfixing and withdrawing foreign bodies, and usually made in the form of a gimlet. 
Tisane $\left(i e-5 a h n^{\prime}\right)$ [see Prisun]. Any decoction or beverage having slight curative or restorative qualities.

Tissue (tish'-u) [ME., tissue, tissue]. Any web-like structure. Applied generally to the organic elements of a part or organ. "In the widest sense of the term, every aggregate of cells which obeys a common law of growth (usually, however, not uniform in its action) may be termed a tissue." "The term tissue may be applied par excellence to aggregations of similar cells, which, without any well-defined external form, consist, in whatever direction the section be made, of numbers of cells." T., Adenoid, or Lymphoid, a modified form of retiform connective tissue in which the reticular meshes contain lymphoid cells, which closely resemble pale blood-corpuscles or lymph-corpuscles, but have a larger nucleus and less protoplasm. This tissue composes the greater part of the lymphatic glands, and is found in the spleen, the tonsils, and the alimentary mucosa. T., Adipose, fatty tissue ; it consists of numerous nucleated vesicles of an average diameter of $\frac{1}{500}$ of an inch, which are composed of oily matter inclosed in a delicate, structureless membrane, and are lodged in the meshes of the areolar tissue, which, with the blood-vessels, serve to bind the vesicles or fat-cells into round or irregular masses visible to the naked eye. Adipose tissue is copiously supplied with blood-vessels and lymphatics, but no nerves have been seen to terminate therein. This tissue is distributed very generally throughout the body where areolar tissue is found, but is absent from the subcutaneous tissue of the eyelids, the penis and scrotum, the nymphre, and the cavity of the cranium. T., Animal, a general name for any of the textures which form the elementary structures of the body, and of which there are four classes: Epithelial tissues, Connective tissues, Muscular tissues, and Nervous tissues. T., Areolar, a form of fibrous connective tissue which consists of delicate, soft, elastic threads or fibers interlacing in every direction, and quite colorless, like spun glass. These are intermixed with fine, transparent films, leaving interstices or areolæ between them. It is one of the most generally distributed of the tissues, and is continuous throughout the body. T., Basement, the tissue of the basementmembrane. T., Cancellous, the spongy tissue of hones. T., Cartilaginous. See Cartilage. T., Cellular, texture composed of rounded (or dodecahedral) cells. T., Conducting, in biology, the inner tissue of the stigma and style of a pistil. T., Connective, a general term for all those tissues of the body that support and connect the tissues of the frame. They are divided into three groups: fibrous connective tissue, cartilage, and bone. The fibrous connective tissue is soft, while cartilage and bone are hard and dense. All are derived from the mesoderm. $\mathbf{T}$., Corneous, tissue found in the nails, hair, epidermis, etc. T., Dental. See Dentine. T., Embryonal Connective. See T., Mucoid. T., Endothelial, the endothelia of the body. T., Epithelial, the epithelia of the body. See Epithelium. T., Erectile, tissue of a spongy nature, which is expanded when turgid with blood or other fluid. T., Fibro-cellular, tissue in the form of long fibers. T., Fibrous Connective, there are three varieties: white fibrous, yellow elastic, and areolar, the variety depending upon the character of the fibers. The fibers are imbedded in a matrix or a soft, homogeneous material that contains mucin. The matrix is clouded by acetic acid, and when treated with nitrate of silver and exposed to the light takes a brownish stain. T., Gelatinous, a variety of connective tissue, very abundant in Medusce and Ctenophora. It is secreted by the epithe96 lium, and contains many migrated cells. T., Germinal, the tissue that gives rise to the ova and the spermatozoids. T., Granulation. See Granulation Tissue. T., Inflammatory, tissue formed during inflammation. T., Interstitial Connective. See $T$., Areolar. T., Mucoid, Mucous, or Gelatinous, connective tissue such as is present in the umbilical cord of the fetus. T., Muscular. See Muscle. T., Nervous. See Nerve. T., Osseous. See Bone. T., Osteogenic. See Bone. T., Parenchymal, the areolar tissues that accompany vessels and nerves into the interior of organs and glands, giving them protection. $T$., Pitted. See Bothrenchyma; Taphrenchyma. T., Simple, that having but one or two structural elements, e.g. blood, lymph, epithelium, connective tissue of cartilage and bone, and nervous and muscular tissues. T., Tubular, or Vascular, tissue in the form of long, cylindric tubes. T., Vegetable, a term used to distinguish the web-like substance which composes vege table structure. T., White Fibrous, a form of fibrous, connective tissue which is made up of fine, inelastic, transparent, homogeneous filaments, about $5 \frac{1}{5000}$ to $\frac{1}{25000}$ of an inch in thickness. These are usually united in bundles and lamina by the matrix and appear as white threads or films. White, fibrous tissue forms the greater part of ligaments, tendons, fascia or sheaths of muscles, periosteum, etc. T., Woody, tissue composing the woody fibers of plants. T., Yellow Elastic, tissue of a yellowish color and possessing great elasticity, predominating in the ligamentum subflava, vocal bands, the inner coats of the blood-vessels, and the longitudinal coats of the trachea and bronchi. Viewed with the microscope, it is seen to consist of straight, well-defined, homogeneous, highly-refracting, elastic fibers, and, especially at the broken ends, having a decided tendency to curl up.

Tit [ME., tit, tit]. The nipple. See Teat.

Titanium (tit-a -ne-um) [T $\iota \tau^{\prime} \alpha$, Titan]. A metal having a certain relationship to iron, chromium, and tin. It is extremely infusible and will scratch glass. Symbol $\mathrm{Ti}$, at. wt. 48. I. Its medicinal properties are not well understood. See Elenents, Table of.

Titillation (lit-il-a'-shun) [titillatio; titillare, to tickle]. The act of tickling; a momentary or transient excitation.

Titration (tit-ra'-shun) [Fr., titre, standard of fineness]. Volumetric analysis by the aid of standard solutions.

Titubating (tit'-u-ba-ting) [titubare, to stagger]. A term applied to the gently swaying ataxia of cerebellar disease and posterior spinal sclerosis.

Titubation (tit-u-ba'-shun) [titubatio; tibubare, to stag ger]. 1. The staggering gait and incoördination of motion accompanying certain diseases of the spine and cerebellum; also, the staggering gait of the drunkard. 2. Restlessness, or inquietude. 3. In biology, Dujardin's name for pedesis, more commonly known as Brownian motion, or molecular motion.

Tizwin (tiz'-win) [Am. Ind.]. An intoxicating drink made by the Apaches and other Indians from some species of yucca.

Tlalsahuate (tlal-sa-hwa'-te) [Mex. Ind.]. See Tetranychus tlalsahuate, Lemaire, under Parasites (Animal), Table of.

Toad $(t \bar{o} r l)$ [ME., tode, toad]. A tailless, terrestrial batrachian or amphibian. T.-flax. See Antirrhinum linaria and Linaria.

To-and-fro Sound. See Auscultntory Sounds.

Toast (tōst) [ME., tosten, to toast]. Bread browned by the fire. T.-water, water in which toasted bread has been steeped; it is used as a beverage by invalids.

Tobacco $\left(t o-b a k^{\prime}-0\right)$ [Sp., tabaco, tobacco]. See Taba. 
cum. T.-bag Suture. See Stolt's Operation in Table of Operations. T.-dyspepsia. See Dyspepsia. $\mathrm{T}$.-habit, a term employed to designate the custom of using tobacco in any form; it is also used to indicate overindulgence in tobacco. T.-heart, functional heart-disorder due to the misuse or excessive use of tobacco. T.-poisoning. See Nicotinism. T.-pouch Operation. Same as Stollz's Operation.

Tobin's Tubes. A method of ventilation of rooms by the introduction of air through tubes placed in the walls. See Ventilation.

Tobold's Apparatus. An illuminating apparatus with a movable reflector for use with the laryngoscope.

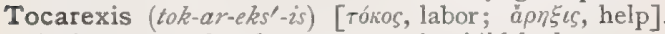
Assistance rendered to a woman in child-bed.

Tocodynamometer (tok-o-di-nam-om'-et-er) [ тóкos,

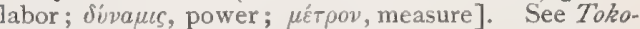
dynamometer.

Tocograph (tok'-o-graf). See Tokcgraph.

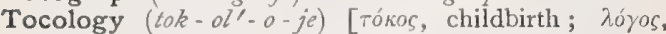
science]. The science of obstetrics.

Tocometer (tok-om'-et-er). See Tocodynamometer.

Toddalia $\left(t o d-a^{\prime}-l e-a h\right)$ [Malabar]. A genus of rutaceous plants. T. aculeata, of S. Asia, is a useful aromatic stimulant and tonic. Unof.

Toddy $\left(t o d^{\prime \prime}-e\right)$ [Hind., tadi, a palm tree]. The fermented juice of the cocoa-nut palm, obtained by incision of the palm, and collected in pots hung to the tree under the cuts. It is then fermented and distilled. See Punch.

Toe (to) [ME., to, toe]. A finger or digit of the foot. T.-drop, inability to lift the toes, or the anterior part of the foot, due to a local paralysis, usually from peripheral neuritis. T., Great, the innermost and largest of the toes. Ts., Numbering of. See Fingers and Toes, Numbering of. T.-reflex. See Reflexes, Table of.

Toilet (toi'-let) [OF, toilette, a cloth]. In surgery, the cleansing, washing, and dressing that follows an operation, especially of the abdominal cavity.

Tokelau ( $\left(0^{\prime}-k e l-o\right)$ [native name]. A cutaneous disease peculiar to Oceanica, the Fiji Islands, and the Society Islands. It is due to a parasitic fungus, and is characterized by scaliness of the skin, to which the early navigators, Dampier, Dentracastaux, Marsden, Cook, Wielhies, etc., refer in speaking of "des hommes poissons." T. Ringworm. See Tinea imbricata.

Tokodynamometer (tok-o-di-nam-om'-et-er) [ тóкos, birth; dynamometer]. An instrument for measuring the force of the expulsive efforts in childbirth.

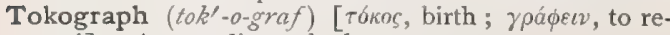
cord]. A recording tokodynamometer.

Tokology (tok-ol'-o-je). See Tocology.

Tolane $\left(t^{\prime}\right.$-lann $), \mathrm{C}_{14} \mathrm{H}_{10^{\circ}}$ A substance produced from boiling stilbene bromid with alcoholic potash. It is easily soluble in alcohol and ether, and consists of large crystals, melting at $60^{\circ} \mathrm{C}$.

Tolerance (tol'-er-ans) [tolerantia; tolerare, to bear]. The capacity of a patient to withstand certain drugs or certain doses of drugs without injurious consequences, particularly when acquired by a continued use of the drug.

Tolerant (tol'-er-ant) [tolerare, to bear]. Withstanding the action of a medicine without injury

Tolu $\left(t o-l u^{\prime}\right)$. See Balsam.

Toluene $\left(t o l^{\prime}-\imath t-\hat{e} n\right)[$ Tolu $], \mathrm{C}_{7} \mathrm{H}_{8}$. Methyl-benzene. See Balsam of Tolutan. A hydrocarbon obtained from coal-tar and also produced in the dry distillation of tolu-balsam and many resins. It is very similar to benzene, is fluid at ordinary temperatures, boils at $110.3^{\circ} \mathrm{C}$, and has a specific gravity at $0^{\circ}$ of 0.882 . It is employed in the production of nitrotoluene, toluidin, benzylchlorid, benzalchlorid, and benzaldehyd.

Toluidin $\left(\right.$ tol- $\left.u^{\prime}-i d-i n\right)[$ Tolu $], \mathrm{C}_{7} \mathrm{H}_{7}, \mathrm{NH}_{2}$. A methylated homologue of anilin, prepared by heating dimethylanilin to $300^{\circ} \mathrm{C}$

Toluol $\left(t o l^{\prime}-u-o l\right)$. Same as Toluene.

Tolutan (tol'-u-tan). See Balsam.

Toluylene $\left(t o l-u^{\prime}-i t-\bar{e} n\right)$. See Stilbene. T.-blue. See Pigments, Conspectus of. T--red, $\mathrm{C}_{15} \mathrm{H}_{16} \mathrm{~N}_{4}$, Dimethyl diamidotoluphenazin; a substance that crystallizes in orange-red needles. It is applied in dyeing under the name Neutral Red. See Pigments, Conspectus of.

Tolysal (tol'-is-al), $\mathrm{C}_{12} \mathrm{H}_{14} \mathrm{~N}_{2} \mathrm{O} . \mathrm{C}_{7} \mathrm{H}_{6} \mathrm{O}_{3}$. Tolydi methylpyrazolon salicylate; it occurs in colorless crystals that melt between $\operatorname{IO}^{\circ}$ and $\mathrm{IO}^{\circ} \mathrm{C}$. It is scarcely soluble in water, but readily soluble in alcohol.

Tomato $\left(t o-m a^{\prime}-t o\right.$, or to-mah'-to) [Sp.,tomale]. The ripe fruit of the common tomato, Lycopersicum esculentum. It is claimed to be useful in canker of the mouth, nurse's sore-mouth, etc. Dose of the fluid extract 3 ss $-\mathrm{j}$. Unof.

'Tomentose, Tomentous $\left(t o-m e n^{\prime}-t \bar{z} z\right.$, to $\left.-m e n^{\prime}-t u s\right)$ [tomentum, a stuffing of wool, hair, feathers]. In biology, applied to surfaces that are covered with matted hairs.

Tomentum (to-men'-tum) [L.]. A lock of wool. A flocculent pubescence; specifically applied to the ental surface of the pia; the tomentum cerebri. T. cerebri, the numerous small blood-vessels of the pia penetrating the cortex of the brain. When detached they have a fanciful resemblance to a lock of wool.

Tomes, Fibers of. See Fibers of Tomes.

Tomium (to'-me-um) [Touos, cutting, sharp: pl., Tomia ]. In biology, the edge of a bird's beak.

Tommasoli, Bacillus of. See Bacteria, Symonymatic Table of.

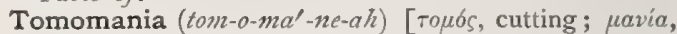
madness]. An excessive desire or habit on the part of a surgeon to use the knife to perform unnecessary operations.

Tone $(t \bar{n} n)[\tau \delta$ vos, from $\tau \varepsilon \dot{v} v \varepsilon / v$, to stretch]. I. A distinct sound. 2. The normal activity, strength, and excitability of the various organs and functions as observed in a state of health.

Tonga (tong'-gah) [native name]. A drug obtained in the Fiji Islands, consisting of a mixture of barks, roots, and leaves of Raphidophora vitiensis and Premna taitensis. It is of reputed service in neuralgia. Dose of the proprietary fld. ext. $m \times x x-z j$. Unof.

Tongue (tung) [ME., tonge, tongue]. The muscular organ in the cavity, and attached to the floor, of the mouth. It is very movable and can be protruded from the mouth. It aids in mastication, in sucking, and in articulation, and contains, in its mucous membrane, the peripheral organs of taste. T., Adherent, one which is abnormally attached to the floor of the mouth by folds of mucosa. T., Base of, that portion of the dorsum of the tongue which lies between the circumvallate papillæ and the frenum. T., Bifid, a tongue the anterior portion of which is cleft in the median line. T., Black, a condition in which the dorsal surface of the tongue is covered with a black coating. Various causes have been assigned for this condition. Ciaglinski and Hewelke found a fungus allied to the Mucor rhizopodipinus. Mason inclines to the view that it is not parasitic, but is a benign neoplastic condition. T.-bone. See Hyoid. 'T., Cleft. Synonym of $T$., Bifid. T., Coated, a tongue covered with a coating which is usually white, but often yellowish and dirty. It seems to be related to gastro- 
intestinal disorders. The coating consists of desquamated epithelium, fungi, bacteria, and debris of these. T.-compressor, a clamp for holding down the tongue during dental operations. T.-depressor, a spatula

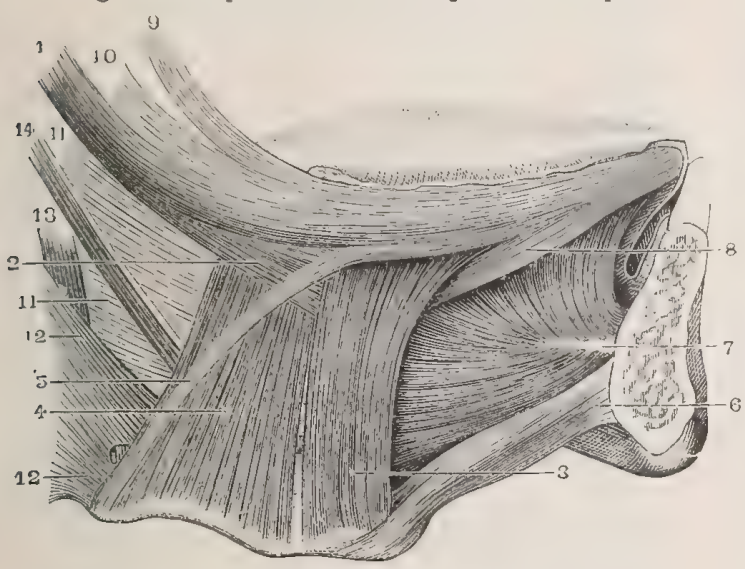

Muscles of TONGUe, Superficial Layer.

x. Stylo-glossus. 2. Inferior fibers of stylo-glossus. 3. Anterior fibers of hyo-glossus or basio-glossus. 4. Posterior fibers. 5. Accessory fibers. 6. Genio-hyoid. 7. Genioglossus, 8. Inferior lingual. Palato-glossus. Io. Upper glossus. 8 . Anferior pharynx). I1, I1. Inferior portion. 12, 12. Middle constric pharynx). I1, II. Inferior portion. 12, 12. Middle constric-
tor of pharynx. I3. Stylo-pharyngeus. I4. Stylo-hyoid ligator of pharynx. I3. Stylo-pha
ment and stylo-hyoid muscle.

for pushing down the tongue during the examination, or in the surgery, of the mouth and throat. T., Dotted. See T., Stippled. T., Dry, one the surface of which is dry. The condition is seen in the low fevers. $\mathbf{T}$. Earthy, a tongue upon which dry, rough layers of calcareous matter are deposited. T., Fern-leaf Pattern, a name given by Hutchinson to a tongue presenting a wellmarked central furrow (midrib) with lateral branches. The condition is due to hypertrophy of the papillæ. T., Filmy, one with whitish symmetrical patches on both sides of the tongue, but usually larger on one side than on the other. These are slightly firmer than the surrounding tissue, and consist of rounded, filiform papillæ, which are glued together by a filmy, white material. ' $T$., Furred, a coated tongue of which the papillæ are prominent, giving the mucous membrane the appearance of a whitish fur. T., Geographic, one with localized thickening of the epithelium of the lingual mucous membrane. This is seen in leukoplakia and gives to the surface of the tongue the appearance of a geographic chart. T. Hairy, one with a hyperplasia of its papillæ, giving rise to hair-like projections from their tips. See also $T$., Black. T.holder. See T-depressor. T., Parrot, a shriveled, dry tongue that cannot be protruded; it is seen especially in typhus fever. T., Plastered, a tongue covered by an abundant, thick coat. T., Post-tip of, that portion of the dorsum of the tongue which extends from the tip for about an inch, and is usually dis tinguished by a median, linear depression when the tongue is at rest. T., Pre-base of, that region of the dorsum of the tongue which lies in advance of the base and is included between the circumvallate papillae and the end of the linear groove of the post-tip. It is often furnished in the center with an oval clump of coarse papillæ. T., Shaggy, a furred tongue of which the papillæ are much elongated. T., Split, Synonym of T., Bifid. T., Stippled, one the papillæ of which are distinct and separate and covered by a whitish patch of epithelium. T., Strawberry, a hyperemic tongue of which the fungiform papillæ are very prominent; it is seen especially in scarlet fever. T.swallowing, a condition in which there is an abnormal mobility of the tongue, so that it will slip or fall backward, giving rise to the danger of suffocation. T.-tie, a congenital shortening of the frenum of the tongue, interfering with its mobility; ankyloglossia. T.-tied, affected with tongue-tie. T., Tip of, the hem which unites the two borders. It extends from the anterior end of the tongue only a short distance backward. T., Triangle, the triangular or wedge-shaped red arch at the tip of the otherwise coated tongue in typhoid fever. T., Wooden, one the seat of actinomycosis. Tonguelet (tung'-let). Same as Pentastoma.

Tonic $\left(\right.$ ton $\left.^{\prime}-i k\right)$ [Tovlkós; $\tau$ towos, tone]. I. Invigorating, or strengthening the economy ; bracing, or strengthening. 2. Characterized by continuous tension; not clonic. 3. A medicine or agent which promotes nutrition and gives tone to the system. T. Spasm, the continued, rigid contraction of a muscle or muscles. T. Treatment: I. Treatment of diseases by tonics, as, e.g., of rheumatism, by iron and remedies of the group of tonics. 2. The continuous treatment of syphilis by the use of the protoiodid of mercury for two or three years. The dose is $1 / 6$ grain after each meal, gradually increased until there are positive evidences of intestinal irritation, when the dose is cut down to the initial one, and that maintained for a time.

Tonicity $\left(t o n-i s^{\prime}-i t-e\right)[\tau 6 v o s$, tone $]$. The condition of tissues or organs in regard to tone or tension.

Tonka, or Tonka Bean (tong'-kah) [tonca, the name of the bean in Guiana]. The fragrant seed of Dip. teryx odorata, a tree of $\mathrm{S}$. America; it abounds in coumarin.

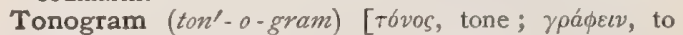
write]. A record made by a tonograph.

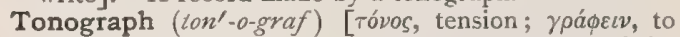
write]. A machine for recording the tension of the arterial blood-current.

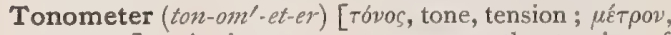
measure]. An instrument to measure the tension of the eyeball.

Tonomittor (ton-o-mit'-or) [T6́os, tone; mittere, to send]. An instrument to improve the hearing.

Tonopsychagogia (ton-o-si-kag-o'-je-ah) [Tóvos, vigor;

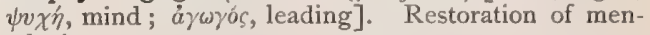
tal vigor.

Tonsil (ton'-sit) [tonsilla, tonsil]. A small, almondshaped body, situated one on each side of the fauces, between the antexior and posterior pillars of the soft palate. It is a compound lymphatic gland, consisting of an aggregation of from ten to eighteen lymph-follicles. It is covered by epithelium, which also dips into the depressions or crypts. T. of Cerebellum. See Tonsilla and Amygdala. T., Faucial. See Tonsil. T.-guillotine. See Guillotine. T., Lingual, an 
accumulation of lymphadenoid tissue at the base of the tongue. T., Luschka's. See Luschka. T., Palatine. See Fonsil. T., Pharyngeal, a mass of lymphadenoid tissue in the pharynx, between the Eustachian tubes: Luschka's tonsil, q.

Tonsilla $\left(\right.$ ton $\left.-s i l^{\prime}-a / 2\right)$ [L.]. One of the five lobes of the hemisphere of the cerebellum, situated on the mesal side of the hemisphere, by the vallicula. Called also Aneygialic. T. tubulis gerlachii. Synonym of Tonsil, Pharyngeal.

Tonsillar, Tonsillary (ton'sil-ar, ton'-sit-a-re) [tonsilla, tonsil]. Pertaining to a tonsil. T. Artery. See Arteries, Table of.

Tonsillitic (ton-sil-it'-ik) [consilla, tonsil ; $t$ Tes, inflammation]. Pertaining to or affected with tonsillitis.

Tonsillitis (ton-sil-i'-tis) [tonsilla, tonsil; tTlC, inflammation]. Inflammation of the tonsils, T., Follicular, inflammation of the tonsils, with special involve ment of the follicles. T., Herpetic, a form of inflammation of the mucosa of the palate, tonsils, uvula, and pharynx, characterized by an eruption of herpetic vessels, which soon rupture, leaving little, circular ulcers that coalesce and become covered with a fibrinous exudation. The disease has an acute onset, a continuous fever, and a critical decline ; its course is not unlike that of pneumonia. It affects especially those subject to herpes elsewhere, and tends to recur. T., Lacunar. Same as T., Follicular. T., Mycotic, that form due to fungous parasites. T., Pustular, one characterized by the formation of pustules, as in smallpox. T., Suppurative. Synonym of Quinsy.

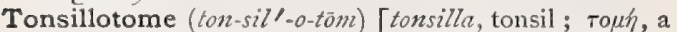
cutting]. An instrument for abscission of the tonsils.

Tonsillotomy (ton-sil-ot'-o-me) [tonsilla, tonsil ; тoprí, a cutting]. Ablation of the tonsils.

Tonsure $\left(\right.$ ton $\left.^{\prime}-s \bar{u} r\right)$ [tondere, to clip]. The shaving or removal of the hair from any part.

Tonus $\left(t o^{\prime}-n u s\right)[\tau 6 v o s$, tone $]$. The quality of tension or tonicity of an organ or part.

Toohutia $\left(t o o^{\prime}-h u-s h e-a h\right)$. Synonym of Dengue.

Toot-poison (toot'-poi-zn). See Coriaria.

Tooth (tooth) [ME, toth, tooth]. See Teeth. T.ache, any pain in or about the teeth. See Odontalgia. T.-ache Tree. See Prickly $A s / 2$ and Xanthoxylum fraxineum. T.-cough, reflex cough due to dental irritation. T.-paste, See Dentifrice. T.-plugger, a dental instrument for filling teeth. T.-pulp. See Pulp. T.-rash, a skin-eruption sometimes occurring during dentition; strophulus. T.-sac, in the fetus the connective tisste surrounding the germ of a tooth.

Toothed (tootht) [ME., toth, tooth]. Provided with teeth or indentations; dentate.

Topalgia (top-al'-je-ah) [тóros, place; a $\lambda$ yos, pain]. Pain in a circumscribed area not referable to the distribution of any nerve.

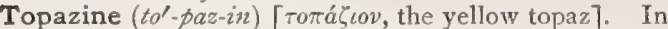
biology, resembling yellow topaz in color and luster, as the ocelli and eyes of certain insects.

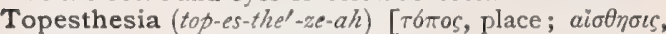
sense]. Local sensibility to touch.

Toph (tof). See Tophus.

Tophaceous $\left(\right.$ tof- $\left.a^{\prime}-s h u s\right)[\tau \delta \phi o s$, stone $]$. Of the nature of tophus; sandy, or gritty.

Tophi $\left(t^{\prime}-f\right)$. Plural of Tophus.

Tophus $\left(t o^{\prime}-f u s\right)$ [ $\tau \delta \phi o s$, stone $]$. I. The hard, stonelike deposit occurring in gout, especially about the knuckles and the cartilages of the ear. It consists of sodium urate. 2. Concretion in the kidneys. 3. The tartar of the teeth.

Tophyperidrosis $(t o f-i$-per-id-ro'-sis) [tótos, place ; $i \pi \varepsilon \rho$, in excess; is $\rho \omega s$, sweat]. Local sweating in excess.

Topic $\left(t o p^{\prime}-i k\right)$. Synonym of Topicum.

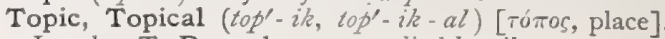
Local. T. Remedy, one applied locally.

Topicum (lop'-ik-um) [тótos, place: pl., Topica]. Any remedy for local and external application.

Topinard, Angle of. See Angle. T.'s Profile Line. See Lines, Table of

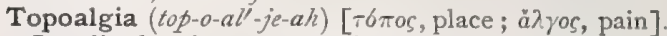
Localized pain, common in neurasthenia, often appearing suddenly after strong emotional disturbance, recurring with paroxysmal intensity, not in the distribution of a particular nerve and without appreciable central or local lesion.

Topographic (top-o-graf'-ik) [Tómus, place; yoádetv, to write]. Pertaining to the relief-features of a locality. T. Anatomy, the study of the comparative locality of the various organs and parts of the body as determined by external landmarks.

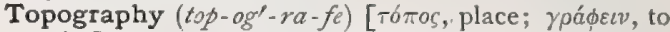
write]. A description of an area with reference to its relief-features. In anatomy, applied to a study of the regions of the body, or of the brain ; regional or topographic anatomy. See Localization and Center.

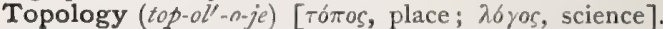
I. Topographic anatomy. 2. The relation of the presenting part of the fetus to the pelvic canal.

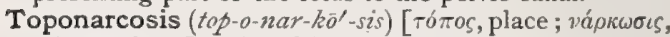
a benumbing]. Local insensibility, or anesthesia.

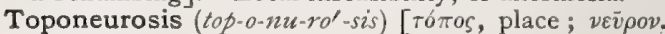
nerve]. A local neurosis.

Toponomy (top-on'-o-me). See Toponymy.

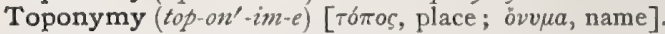
Topical terminology; the system of anatomic terms that indicate the direction and position of parts. It is either intrinsic, having reference only to the organism; or extrinsic, based upon the relation of the organism toward the earth's surface.

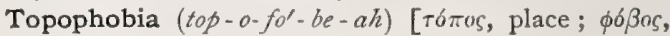
fear]. Morbid dread of places.

Topothermesthesiometer (top-o-therm-es-the-ze-onn'-eter) $[\tau \delta \pi o \varsigma$, place; $\theta \varepsilon \dot{\varepsilon} \mu \eta$, heat; ai $\sigma \theta \eta \sigma \iota$, sensation; $\mu \varepsilon \tau \rho o \nu$, measure]. An instrument for estimating local sensitiveness to impressions of heat.

Torcular or Torcular Herophili (tor'-ku-larher-off' $i-l i$ ) [the wine-press of Herophilus]. The expanded extremity of the superior longitudinal sinus, placed in a depression on the ental surface of the occipital bone. It receives the blood from the occipital sinus, and from it the lateral sinus of the side to which it is deflected is derived.

Tori $\left(t o^{\prime}-r i\right)$. Genitive and plural of Torus.

Toric $\left(t 0^{\prime}-y_{i k}\right)$ [torus]. Having the properties of a torus. T. Lens, See Torus.

Tormentilla (tor-men-til'-ah) [L.]. The root of Potentilla tormentilla, a mild tonic and astringent. Dose of fld. ext. $m x-x l$. Unof.

Tormentum (tor-men'-tum) [L., a "rack"]. An old name for various obstructive disorders of the intestine. $\mathrm{T}$. intestinorum. Synonym of Dysentery.

Tormina (tor'-min-ah) [pl. of tormen, a racking pain]. Griping pains in the bowels. T. alvi, colic. $\mathrm{T}$. celsi, dysentery. $\mathrm{T}$. intestinorum. Synonym of Dysentery. T., Post-partum, the after-pains of parturition.

Torminal, Torminous (tor'-min-al, tor'-nin-us). Affected with tormina.

Tormodont (tor'-mo-dont) [róphos, a hole or socket; ódoís, tooth]. In biology, having teeth set in sockets.

Tornaria (tor-na'-re-ah) [tornus, a lathe]. In biology, the name applied to the peculiar larva of the acorp- 
worm (Balanoglossus), which in many ways resembles a young Bipinnaria.

Tornwaldt's Disease. See Thornwaldt's Disease.

Torose $\left(t o^{\prime}-r \bar{z} z\right)$ [torus, a bulging, protuberance]. In biology, cylindric, with constrictions and enlargements at intervals.

Torpedinous (tor-ped'-in-us) [torpere, to be numb] Benumbing, like a torpedo.

Torpedo $($ tor-pe'-do) [L., torpedo, torpedinis, a cramp fish; torpere, to be numb]. Numbness; stupor: narcosis. [Rare.]

Torpent (tor'-pent) [torpere, to be numb]. I. Incapable of the active performance of a function. 2. A medicine or agent that reduces or subdues any irritative action.

Torpid (tor'-pid $)$ [torpere, to be numb]. Affected with torpor.

Torpidity (tor-pid'-it-e). Synonym of Torpor.

Torpor (tor'-por) [L., numbness]. A condition of sluggishness, abnormal inactivity, numbness, or deficient sensation. T. retinæ, dulled perceptive power of the retina.

Torporific (tor-por-if'-ik) [torpor, numbness; facere, to make]. Causing, or producing, torpor

Torquate (tor'-kwät) [torques, a neck-chain]. In biology, ringed about the neck.

Torques (tor'-kweéz) [torques, a neck-chain]. In biology, a collar-like marking of the skin, hair or feathers of the neck.

Torrefaction (tor-e-fak'-shun). Synonym of Torreffication.

Torrefication (tor-e- $f k-a^{\prime}-$ shun) [torrefacere, to dry by heat]. Roasting; drying by means of high artificial heat.

Torrefied Bread. Ordinary bread toasted in thin slices until it is almost blackened.

Torrid (tor'-id) [torrere, to parch]. Hot; burning. $\mathrm{T}$. Zone, the climatic zone lying between the isotherms of $70^{\circ} \mathrm{F}$., north and south.

Torsion (tor'-shun) [torquere, to twist]. A twisting; also, the rotation of the eye about the visual axis. T. of an Artery, twisting of the free end of an artery to check hemorrhage. T. of Teeth, the forcible turning of teeth in their cavities for the purpose of correcting irregularity in position. $T$. of the Umbilical Cord, the spontaneous twisting of the umbilical cord. From eight to ten twists are normal; great torsion usually occurs after the death of the fetus.

Torsoclusion (tor-sok-lu'-zhun) [torquere, to twist; cludere, to close]. A form of acupressure in which the point of the pin is pushed through a portion of tissue parallel with the course of the vessel to be secured, then carried over its anterior surface, and at the same time swept round until brought to a right angle with the artery, when the point is thrust into the soft parts beyond.

Torticollar (tor-tik-ol'-ar) [tortus, twisted; collum, neck]. Affected with wry-neck, or torticollis.

Torticollis (tor-tik-ol'-is) [tortus, twisted; collum, neck]. A congenital or acquired contraction of one or more of the cervical muscles, usually of one side, resulting in an abnormal position of the head-wryneck, T., Intermittent. See $T$., Spasmodic. T. Spasmodic, spasmodic contraction of the sternocleido-mastoid muscle of one side, causing a drawing of the head toward the opposite side.

Tortulous (tor'-tu-lus) [torta, a twist]. In biology, twisted, or like a string of beads, moniliform.

Tortuose (tor'-tu-ozz) [torluosus winding]. In biology, bent and twisted, as some stems.

Tortuosity (tor-tu-os'-it-e) [tortus, twisted]. A twisted or devious course, as of a blood-vessel.
Tortuous $($ tor'-tu-us) [tortus, twisted]. Twisted, sinuous.

Torula (tor'-u-lah) [torus, a swelling, protuberance: $p l .$, Torula $]$. In biology, a genus of budding fungi (Blastomycetes). See Saccharomyces cerevisia, under Bacteria, Synonymatic Table of: also, Yeast.

Toruliform (tor'-u-lif-orm) [torula, torula; forma, form]. Resembling an organism of the genus Torula.

Toruloid (tor'-u-loid). Synonym of Tomliform.

Torulose (tor'-u-lōz) [torula, a little swelling, knob]. In biology, knobbed.

Torulous (lor'-u-lus). Same as Torulose.

Torulus (tor'-u-lus) [torus, a swelling, protuberance : pl., Toruli]. In biology, a knob-like articulation for receiving a spine, antenna or other appendage.

Torus $\left(\right.$ tor $\left.^{\prime}-u s\right)$ [L.: gen. and pl., Tori]. I. A surface having a regular curvature, with two principal meridians of dissimilar curvature at right angles to each other. 2. An elevation or prominence, as of the belly of a muscle. Torus, used without qualifying adjective, sometimes designates the tuber cinereum of the brain. $T$. frontalis, a protuberance in the region of the frontal sinuses, at the root of the nose, in the median line and on the external surface of the skull. T. palatinus, a protuberance on the surface of the hard palate, marking the point of junction of the intermaxillary and palato-maxillary sutures.

Totem (to'-tem) [Algonkin, otem, with a prefixed poss. pron. nt' otem, my family token]. The word generally given by travelers and interpreters to the family crests of the Red Indians (Lang).

Totemism $\left(t^{\prime}-t e m-i z m\right)$ [Algonkin, otem $]$. The derivation of the family name and crest or badge from some natural object, plant or animal. ithe names totem and to temis $m$ have been in use at least since I792, among writers on the North Americ an tribes: Prof. Max Muiller says the word should be, not totem, but ote or otem. Long, an interpreter among Indians, introduced the word totemism in I792." (And. Lang.)

Touch (tuch) [Fr., toucher]. I. The tactile sense; the act of judging by the tactile sense ; palpation. 2. In obstetrics, digital examination of the female genital organs and adjacent parts through the vagina. T., Abdominal, application of the hands to the abdomen for the diagnosis of intra-abdominal conditions. T., After, the sensation which persists for a short time after contact

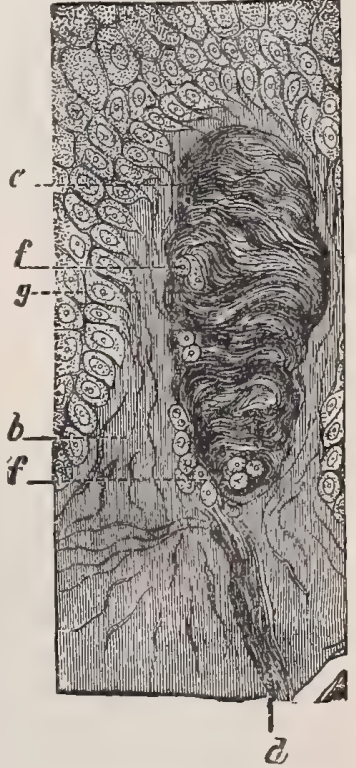

Vertical Section of the SkIN, PALM OF HAND.

b. Papilla of cutis. $d$. Nerve-fiber of touch-corpuscle. $e, f$. Nervefiber in touch-corpuscle. $g$. Cells of Malpighian layer. (From Stir. ling.) with an object has ceased. T.-corpuscle, a touchbody; a tactile corpuscle. See under Tactile. T.. 
Double, combined vaginal and abdominal or vaginal and rectal palpation. T.-me-not. See Noli me tangere and Impatiens. T., R e c t al, examination $\mathrm{made}$ by the finger in the rectum. T., Royal, the laying on of the hands by a king, formerly believed to be effic acious in scrofula or kings' evil. T., Vaginal. See Touch (ad def.). T., Vesical, examination through the bladder, the urethra having been dilated to admit the finger. The latter can only be done in the female. T.-wood. See Amadou.

Touching (tuch'-ing) [Fr., toucher, to touch ]. I. The application of the hand or fingers. Touching

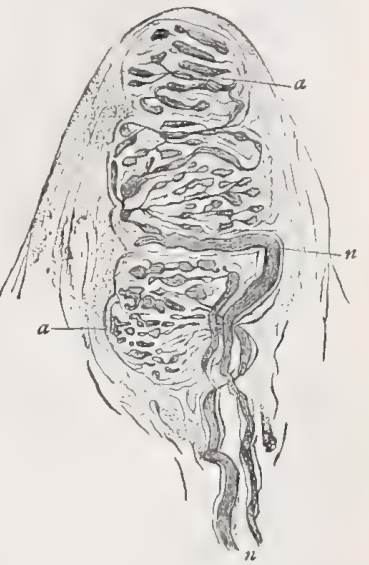

WAGNER'S TOUCH-CORPUSCLE, SKIN OF HAND.

$n$. Nerve. $a, a$. Terminations of $\boldsymbol{n}$. (From Stirling.) was formerly practised by the kings of England for the cure of scrofula, hence called Kings' Evil. 2. See Adenochirapsology.

Tour de Maitre (toor-de-māts) [Fr., "the master's turn" "]. A maneuver in passing the catheter in a fat person. The surgeon stands on the right side of the patient and introduces the catheter, with its convexity upward, the shaft lying obliquely across the left thigh of the patient, and as the point enters the bulb, the handle is swept around toward the abdomen, when the beak enters the membranous urethra and is carried into the bladder by depressing the shaft between the patient's thighs. The sound may be introduced into the uterus in an analogous manner, entering the instrument with the convexity upward, and then sweeping the shaft around.

Tourette's (Gilles de (a) $\mathrm{D}$ is ease. Motor incoördin ation with echola li a and coprolalia; a convulsive form of tic.

Tourniquet (toor'- niket) $[\mathrm{Fr}$., tourner, to turn]. An instrument for control. ling the circulation by means of compression. It usually con-

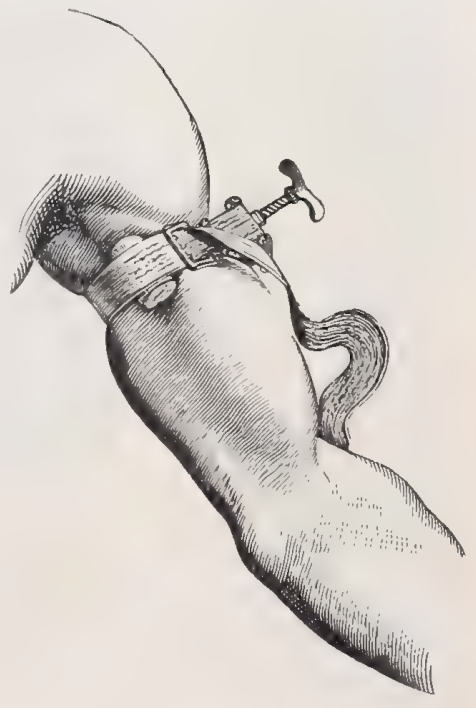

Petit's Tourniquet. sists of two metallic plates united by a thumb-screw and a strap provided with a pad. The strap is fastened about the part, the pad being placed over the artery to be occluded. The screw is placed diametrically opposite the pad, and the strap is tightened by separating the metallic plates of the screw. T., Dupuytren's, one for compressing the abdominal aorta, consisting of a semicircle of metal with a pad at one extremity. $\mathbf{T}$. Esmarch's, consists of a stout, elastic rubber hand applied above the proximal turn of an elastic bandage passing around the part to be rendered exsanguine. T., Field, one consisting of a strap and buckle with a pad to pass over the artery. T., Horse-shoe, one shaped like a horse-shoe, to compress (by a screw) only two points, and thus permit venous return. T., Lip, one consisting of a U-shaped piece of steel, the arms being provided with plates which are approximated by a central screw. T., Provisional, one applied loosely, so that it may be tightened at once upon the recurrence of hemorrhage. T., Signorini's. See 7:, Horse-shoe. T., Skey's, also a modification of the horse-shoe or Signorini's. T., Spanish Windlass, a knotted bandage or handkerchief twisted by a stick and used as a tourniquet. T., Torcular, same as $T$., Spanish Windlass.

Tous-les-mois (too-la-mwah) [F., "every month" ]. A variety of arrow-root starch prepared from Canna edulis; canna-starch.

Toussaint's Theory. A theory as to the cause of immunity conferred by inoculation. After one attack of a disease (e. $g$., anthrax) the lymphatic glands undergo a hardening of their surrounding envelop, thus rendering them impervious to the after-entrance of infectious agents by this, the usual, portal.

Tow (to) [ME., tow, tow]. The refuse of flax or hemp; coarse flax; it has a limited use in surgery.

Towel-gourd. See Luffa.

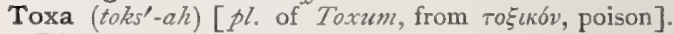
Diseases due to poisons.

Toxæmia (toks-e'-me-ah). See Toxemia.

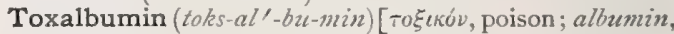
white of egg]. A proteid substance resembling a ferment rather than a poison. Any one of the poisonous albuminoids which are produced or separated from the albumin of the tissues by the agency of bacteria, and entering the circulation, constitute the cause of the general symptoms of infectious diseases. Toxalbumins have been obtained from cultures of a number of bacteriaamong others from those of diphtheria, typhoid fever, cholera, tetanus, glanders, tuberculosis, anthrax, and pneumonia ; likewise, also, from cultures of the staphylococcus pyogenes aureus, the swine-plague bacillus; from those of certain germs found by Booker in the stools of the summer diarrhea of infants, and from those of two toxicogenic germs isolated by Vaughan from drinking-water. It is possible that poisonous albuminous substances are also produced by animal parasitic organisms. Thus Viron has isolated a toxic proteid from the fluid of hydatid cysts.

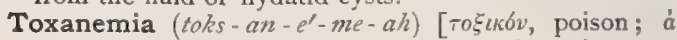
priv. ; aipa, blood]. Anemia produced by poisons.

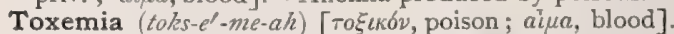
A condition of the blood in which it contains poisonous products, either those produced by the body-cells and not properly eliminated, or those due to the growth of microörganisms.

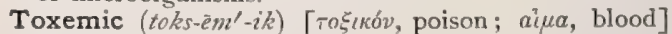
Pertaining to, affected with, or of the nature of toxemia.

Toxic $\left(t^{\prime} k^{\prime}-i k\right)$ [ or associated with, poisoning.

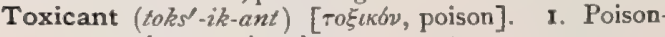
ous or toxic. 2. A poisonous agent. 
Toxication (toks-ik-a'shun). Synonym of Poisoning Toxicemia (toks-is-e'-me-ah). Synonym of Toxemia.

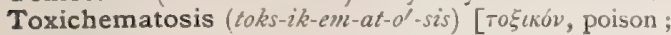
aira, blood]. Blood-poisoning.

Toxichemia (toks-ik-e'-me-ah). Synonym of Toxemia.

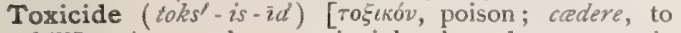
kill]. A remedy or principle that destroys toxic agents.

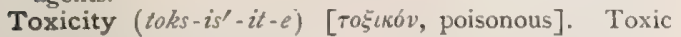
quality; poisonousness.

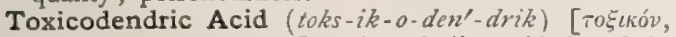
poison; $\delta \varepsilon ́ v \delta \rho o v$, tree]. A volatile acid found in Rhus toxicodendron, and considered its active principle. Locally applied, it acts as a vesicant.

Toxicodendron (toks-ik-o-den'-dron). See Rhus.

Toxicoderma (toks-ik-o-der'-mah) [ $[\tau o \xi \iota k \delta$, poison; $\delta \varepsilon \dot{\rho} \mu \alpha$, skin]. Disease of the skin due to poisonous substances.

Toxicodermatitis (toks-ik-o-der-mat-i'tis). See Toxicoderma.

Toxicodermitis (toks-ik-o-der-mi'-tis). See Toxicoderma.

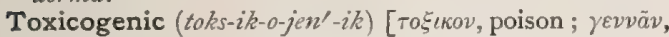
to produce]. Giving rise to poisons; producing a toxic substance, as a toxicogenic microörganism.

Toxicohemia (toks-ik-o-hemi-e-ah). See Toxemia.

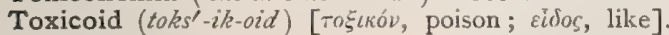
Resembling a poison.

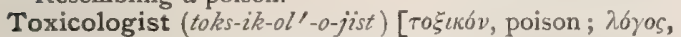
science]. One versed in toxicology.

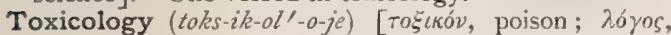
science]. The science of the nature and effects of poisons, their detection, and the treatment of poisoning.

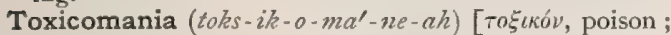
pavia, madness]. Morbid desire to take some poison.

Toxicosis (toks-ik-o'-sis) [ $\tau_{0} \xi \kappa b v$, poison]. A toxic or poisoned state; the state of disease induced by a poisonous principle. Von Jaksch classifies toxicoses as follows: T., Auto-, one with clinical symptoms that are caused by the formation of toxic basic products from morbid matter, such as pathologic fluids lodged in certain parts of the system. T., Exogenic, one with clinical symptoms induced by the action of toxic bases taken into the system with the food, such as the poison of sausages and cheese. T., Noso-, one with clinical symptoms referable to the presence of basic products which are formed in the system (blood, etc.) in disease and eliminated with the urine. T., Retention, one with clinical symptoms depending upon the retention of the physiologic bases (e.g. uremia).

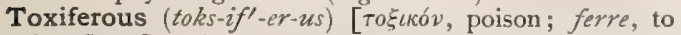
bear]. Carrying or conveying poison.

Toxihemia (toks-e-hem'-e-ah). Synonym of Toxemia.

Toxin, Toxine $\left(t o k s^{\prime}-i n\right)$ [ $\tau 0 \xi \iota \kappa b v$, poison]. In biology, any diffusible alkaloidal substance analogous to the vegetable alkaloids. Cf. Antitoxin.

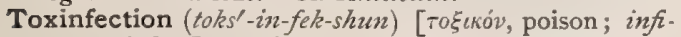
cere, to infect]. Infection by means of a toxin.

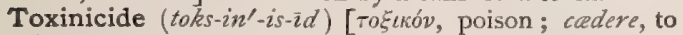
kill]. Any substance that destroys a toxin.

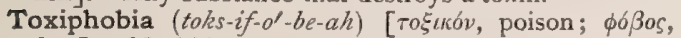
fear]. Morbid dread of being poisoned.

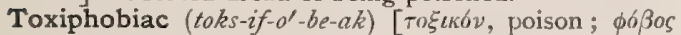
fear]. A person affected with toxiphobia.

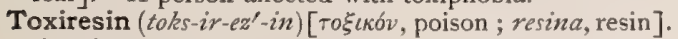
A poisonous decomposition-product of digitalis, resulting when the latter is treated with dilute acids or heated to $240^{\circ} \mathrm{C}$. It has the characters of a resin.

Toxophylaxin $\left(\right.$ to $\left.x-0-f i-i a k s^{\prime}-i n\right)[\tau o \xi \iota \kappa o ́ v$, poison ; $\phi \hat{\jmath} \lambda \alpha \xi$, a guardian, protector]. In biology, "a defensive pro- teid produced in the body of an animal which has an acquired immunity for a given infectious disease, and which has the power of destroying the toxic products of the pathogenic bacteria to which the disease is due.' (Sternberg.) Cf. Toxosozin. See Phylaxin.

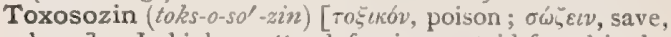
keep]. In biology, "a defensive proteid found in the body of a normal animal, which has the power of de stroying the toxic products of bacterial growth." (Sternberg.) See under Phylaxin. Cf. Toxophylaxin.

Toynbee's Experiment. The rarefaction of the air of the middle-ear by swallowing, with coincident closure of the mouth and nares. T.'s Law. See Lazo.

Trabal (tra'-bal) [trabs, beam]. Pertaining to the trabs; callosal.

Trabecula (tra-bek'-u-lah) [Lat, a small beam: $p l$., Trabecula]. Any fibrous process, layer, or cord which goes to make up a framework in an organ or viscus; any medullary or commissural band of cerebral nerve-fibers. Also, the fleshy part of the cardiac columnæ carner.

Trabecular (tra-bek'-u-lar) [trabecula, little beam]. Of the nature of a trabecula. T. Duct, a duct whose cavity or lumen is crossed by ligneous threads or bands.

Trabecularism (tra-bek'-u-lar-izm) [trabecula, little beam ]. Arrangement like the beams of a framed building; support by a trabecular structure.

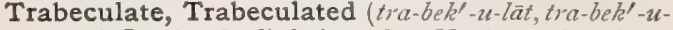
la-ted) [trabecula, little beam]. Having trabeculæ.

Trabs (trabz) [L., " a beam "']. The callosum or corpus callosum; called also Trabs cerebri.

Trace $(\operatorname{tr} \bar{a} s)$ [ME., tracen, to trace]. I. A track or mark. 2. A bareliy recognizable quantity, as a trace of albumin. T., Primitive. See Primitive Traci.

Tracer $\left(t r a^{\prime}-s e r\right)$ [ME., tracen, to follow]. An instrument used in dissection for isolating nerves and vessels by tearing the connective tissue.

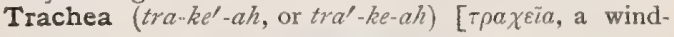

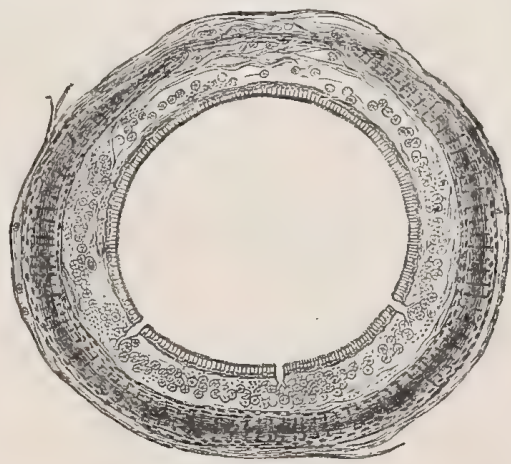

TRANSVERSE Section OF TRACHEA OF KitTEN. X 15 . (From Stirling.)

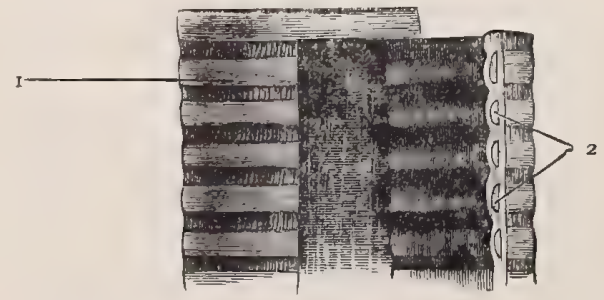

THE Trachea.

I. Trachea. 2. Section through cartilages.

pipe]. The windpipe. A cartilaginous and mem' 
branous cylindric tube extending from the lower part of the larynx to its division into the two bronchi. It is about four and a half inches in length. In biology : (a) One of the branched respiratory tubes of an arthropod; these tracheal tubes first appear in Myriapoda, (b) a plant, vessel, or duct formed by the confluence of serially arranged cells. T., Book-leaf, a respiratory organ found in the Arachnoidea, and consisting of a sac filled with air, into which there project from the anterior wall numerous leaves arranged like those of a book.

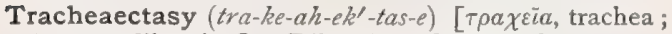

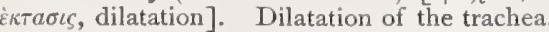

Tracheal $\left(t r a^{\prime}-k e-a l\right)[\tau \rho a \chi \varepsilon \bar{u} \alpha$, trachea]. Pertaining to the trachea or windpipe. T. Catarrh. See Traiheitis. T. Tugging, the feeling of a downward tugving movement of the larynx when the thyroid cartilage is pushed upward from without, sometimes observed in aneurysm of the aortic arch.

Trachealgia (tra-ke-al'-je-ah) [ $\tau \rho \alpha \chi \varepsilon \bar{\imath} a$, trachea; ànyos, pain ]. 1. Pain in the trachea. 2. Croup.

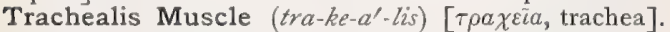
The intrinsic muscle of the windpipe; it is represented in man by a set of circular or transverse fibers.

Tracheary $\left(t r a^{\prime}-k e-a-r e\right)$ [ $\tau \rho \alpha \chi \varepsilon \bar{c} \alpha$, trachea]. Pertaining to the trachea. T. Tissue, in biology, a term which includes both tracheids and tracheæ, or ducts.

Tracheid (tra-ke'-id) [trachea, the windpipe]. In biology, an elongated tubular plant-cell. Applied mainly to one having bordered pits.

Tracheitis (tra-ke-i'-tis). See Trachitis.

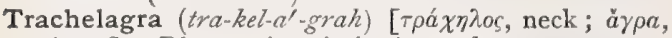
seizure]. Rheumatic pain in the neck.

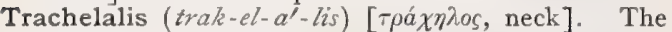
trachelomastoid muscle.

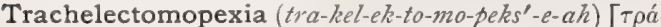

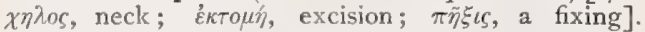
Partial excision with fixation of the neck of the uterus.

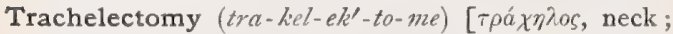
Eктoun, excision]. Excision of the uterine cervix.

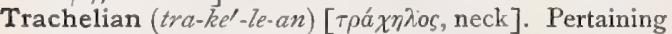
to the neck, particularly its dorsal part.

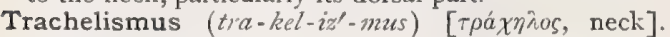
Spasmodic contraction of the muscles of the neck.

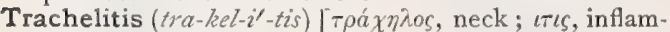
mation]. Inflammation of the neck of the uterus.

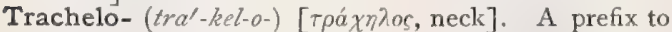
denote connection with or relation to the neck. T.mastoid, pertaining conjointly to the neck and the mastoid process. See Muscles, Table of.

Trachelocele (tra'-kel-o-sel). Same as Tracheocele.

Trachelocyllosis ( $\left.t r a-k e l-o-s i l-l o^{\prime}-s i s\right)$. Synonym of Torticollis.

Trachelocyrtosis (tra-kel-o-sir-to'-sis). Synonym of Trachelokyphosis.

Trachelocystitis (tra-kel-o-sis-ti'-tis) [ $\tau \rho a ́ x \eta \lambda o s$, neck;

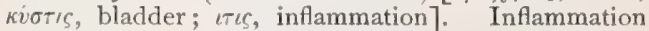
of the neck of the bladder.

Trachelo-diaphragmatic (tra-kel-o-di-af-rag-mat'-ik)

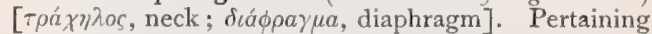
to the neck and the diaphragm.

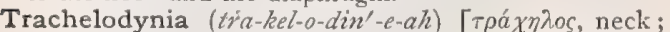
ofón, pain]. Pain in the neck.

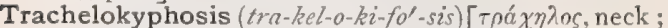

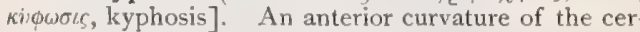
vical portion of the spinal column.

Trachelomyitis (tra-kel-o-mi-i'-tis) [ [ $\rho a ́ \chi \eta \lambda o s, ~ n e c k$; $\mu \bar{v} \varsigma$, muscle; $t \tau \iota \zeta$, inflammation]. Inflammation of the muscles of the neck.

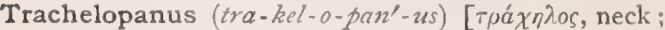
panus, swelling]. Tumefaction of the cervical lymphatic glands.

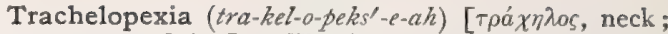
$\pi \bar{\eta} \xi \iota s$, a fixing]. Fixation of the neck of the uterus.

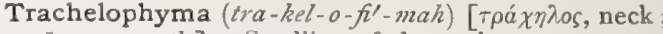
$\phi \bar{v} \mu a$, growth]. Swelling of the neck.

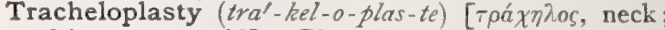
$\pi \lambda \dot{a} \sigma \sigma \varepsilon \iota \nu$, to mold]. Plastic surgery of the neck of the uterus.

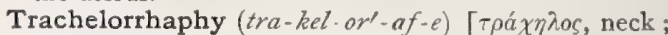
$\dot{\rho} \alpha \dot{\phi} \eta$, suture]. Suture of the edges of a laceration of the cervix.

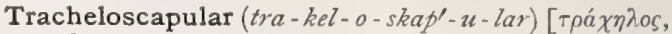
neck; scapula, scapula]. Common to the neck and the scapular region.

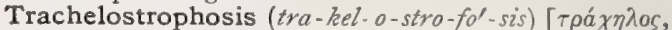

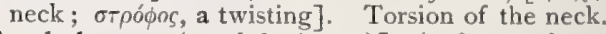

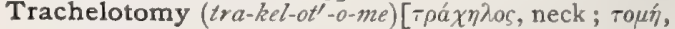
a cutting]. I. Incision into the cervix uteri. 2. Decapitation.

Trachenchyma (tra-keng'-kim-ah). Same as Tracheary Tissue.

Tracheo- $\left(t r \alpha^{\prime}-k e-o\right)$ [ $\tau \rho a \chi \varepsilon i \bar{a}$, trachea]. A prefix to denote connection with or relation to the trachea or wind pipe.

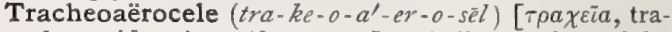
chea; $a \dot{n} \rho$, air; $\kappa \dot{n} \lambda \eta$, tumor]. A diverticulum of the trachea.

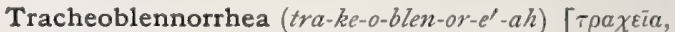
trachea; $\beta \lambda$ évva, mucus; $\rho \circ i ́ \alpha$, a flow]. A profuse discharge of mucus from the trachea.

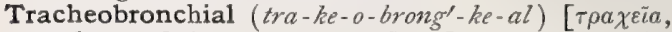

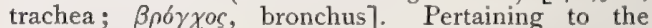
trachea and a bronchus, or the bronchi.

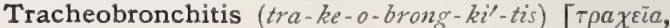

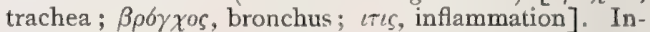
flammation of the trachea and bronchi.

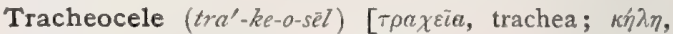
tumor]. I. Hernia of the lining membrane of the trachea. 2. Goiter.

Tracheocynanche (tra-ke-o-sin-ang'-ke). Synonym of Tracheitis.

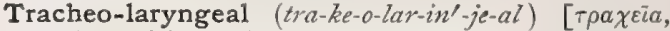
trachea; $\lambda a ́ \rho v \gamma^{\prime} \xi$, larynx]. Pertaining to the trachea and the larynx.

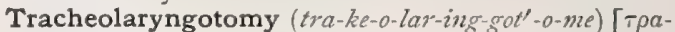
$\chi \varepsilon \bar{i} a$, trachea ; $\lambda \dot{a} \rho v \gamma \xi$, larynx; $\tau o \mu \eta \dot{n}$, a cutting]. Incision into the larynx and trachea ; combined tracheotomy and laryngotomy.

Tracheo-cesophageus $\left(t r a^{\prime}-k e-o-e-s o f-a j^{\prime}-e-u s\right)[\tau \rho a-$

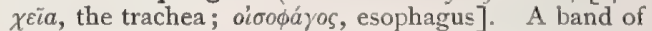
muscular tissue sometimes uniting the esophagus and the trachea.

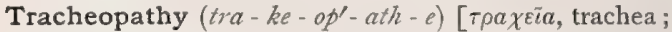
$\pi a ́$ Aos, disease]. Any disease of the trachea.

Tracheo-pharyngeus $\left(t r a^{\prime}-k e-o-f a r-i n^{\prime}-j e-u s\right)[\tau \rho a \chi \varepsilon i a$, the trachea; $\phi a ́ \rho v \gamma \xi$, the pharynx]. An anomalous band sometimes uniting the inferior pharyngeal constrictor and the trachea.

Tracheophony (tra-ke-off'-o-ne) [ $\tau \rho a \chi \varepsilon i a$, trachea ; $\phi \omega v \eta$, voice]. The sound heard over the trachea on auscultation.

Tracheophyma (tra-ke-o-fi'-mah). Synonym of Goiter.

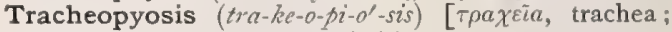
$\pi$ íov, pus]. Purulent tracheitis.

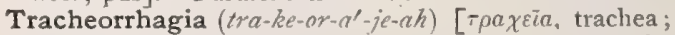
onvvivas, to burst forth]. Hemorrhage from the trachea.

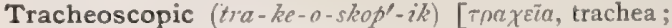

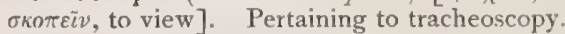

Tracheoscopist (tra-ke-os'-ko-pist) [ т бколеiv, to view]. One versed in tracheoscopy.

Tracheoscopy $\left(t r a-k e-o s^{\prime}-k o-p e\right) \quad[\tau p a \chi \varepsilon i a$, trachea 
$\sigma \kappa \cap \pi \varepsilon \bar{\nu}$, to inspect]. Inspection of the interior of the trachea, by means of a laryngoscopic mirror and reflected light.

Tracheostenosis (tra-ke-o-ste-no'-sis) [ $\tau \rho a \chi \varepsilon i a$, trachea :

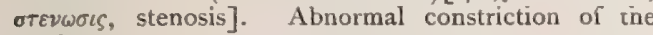
trachea.

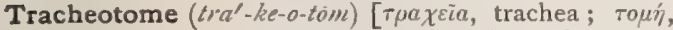
a cutting]. A cutting instrument used in tracheotomy.

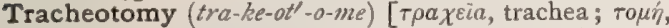
a cutting]. Surgical incision of the trachea. T., Inferior, one performed below the isthmus of the thyroid gland. T., Plunge-. See Plunge-tracheotomy. T., Superior, one performed above the isthmus of the thyroid gland. T.-tube, a tube to be worn in the opening made in tracheotomy, and through which breathing is carried on.

Trachitis $\left(t r a-k i^{\prime}-t i s\right)$ [ $T \rho a \chi \varepsilon \bar{\varepsilon} a$, trachea ; $\iota \tau \iota \zeta$, inflammation]. Inflammation of the trachea; it may be acute or chronic. It is marked by tenderness along the course of the trachea and pain on swallowing.

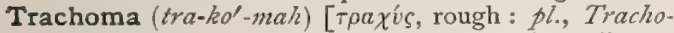
mata]. Granular conjunctivitis, a contagious disease of the eyelids that may in severe cases extend to the globe of the eye. It is at first characterized by sagolike elevations of the palpebral conjunctiva, and later by fibrous and cicatricial tissue that by friction produces pannus. The disease is due to a specific diplococcus. $\mathbf{T}$. arlti, the granular form. $\quad T$ : , Brawny, a late stage of mixed trachoma in which the surface of the conjunctiva is rather smooth, although lymphoid infiltration persists. T.-coccus. See Bacteria, Synonymatic Table of. T. diffusum, a high degree of mixed trachoma in which large growths cover the tarsal conjunctiva. T., Follicular, T., Mixed, the usual form of trachoma. See $T$. arlti. $T$.-gland. See Gland. T.verum. See T. arlti. Horny Epithelium, or Summer Granulations, a form of tracho-

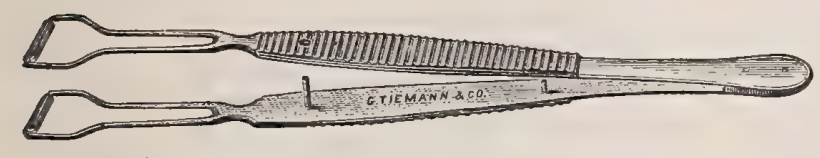

KNAPP'S IMPROVED ROLLER TRACHOMA-FORCEPS,

matous conjunctivitis similar in appearance to follicular trachoma, but differing from it in the fact that the granules or excrescences are horny or teat-like elevations. The name Hypertrophic Trachomatous Conjunctivitis has been proposed for it. Knapp's Roller-forceps Method (of treating trachona), the expression of the gelatinous matter in follicular trachoma by a roller-forceps.

'Trachycarpous (trak-ik-ar'-pus) [ [ $\rho a \chi v ́ s$, rough ; $\kappa a \rho \pi b$ s, fruit]. In biology, having the fruit roughened.

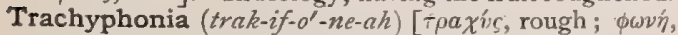
voice]. Roughness, or hoarseness, of voice.

Trachysma (trak-iz'-mah). Synonym of Trachoma.

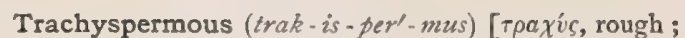
$\sigma \pi \varepsilon \rho \mu a$, seed]. In biology, having the seed roughened.

Tract (trakt) [tractus]. I. An extended area, usually much longer than it is broad. 2. Any one of the columns of white matter of the spinal cord. See Column. 3. A track or course. T., Alimentary, a musculomembranous canal, about 30 feet in length, extending from the mouth to the anus. Digestion is its chief function, and in this it is aided by certain accessory organs. T., Anterior Cerebro-pontile, a tract of fibers of the crus cerebri extending from the anterior portion of the frontal lobe to the pons. $T$., Anterior Pyramidal. See T., Pyramidal. T., Antero-lateral Ascending. Synonym of $T$., Gozers'. T., Bechterew's. See T., Tegmental. T., Bulbar, any of the tracts of fibers found in the bulb or oblongata. T., Central Medullary, the gray matter of the spinal cord immediately about the central canal. T., Cerebellar. See T., Direct Cerebellar. T., Cerebro-pontile, a tract of fibers passing from the cerebrum through the internal capsule and crus to the pons. 'T., Commissural, the cerebellar peduncle (Owen). T., Crossed Thalamo-tegmental, a tract of fibers passing through the tegmentum and connecting the thalamus with the spinal cord (Spitzka). T., Digestive. See T., Alimentary. T., Direct Cerebellar, an ascending tract of fibers placed at the periphery of the posterior portion of the lateral column of the cord. It passes upward through the lateral tract of the oblongata, the restiform body, and the inferior cerebellar peduncle to the vermiform process of the cerebellum and to the cerebellar lobes. T., Fillet, a tract of fibers passing from the fillet along the upper and outer side of the red nucleus through the internal capsule to the parietal lobe. T., First Projection, the corona radiata (Meynert). T. of Flechsig. See T., Principal. T., Frontal Pontile. Synonym of T., Cerebro-pontile. T., Fronto-cerebellar, the tract of fibers connecting the frontal lobe of the brain with the cerebellum. T., Funicular. See Funiculus gracilis. T., Genito-urinary, the genitourinary organs in continuity. 'T., Goll's, See Column, Goll's. T., Gowers', a tract of fibers from the posterior roots which run cephalad in the lateral column. One portion of the fibers disappears in the cervical part of the spinal cord, the other terminates in the medulla. $\mathrm{T}$., Habenular, a tract of fibers passing from the habenula to the mesal side of the red nucleus at the base of the brain. T., Intellectual. Synonym of $T$. Fronto-cerebellar. T., Intermediary Lateral, $T$., Intermedio-lateral, a tract of nerve-fibers in the lateral column of the spinal cord, placed midway between the anterior and posterior gray horns. T., Internidal, the fibers extending from the nuclei of origin of the third, fourth, and six th cranial nerves. $T$., Intestinal, the large and small intes tine, T., Lateral. See Column, Lateral. T., Lemniscus, a tract of fibers beginning in the upper region of the pons, below the formatio reticularis, and separating into three bundles, the superior, median, and inferior lemnisci. 'T., Lissauer's, a small tract of fibers in the spinal cord at the junction of the posterior horn and the lateral column. The fibers are derived from the posterior roots, and after a short upward course enter the posterior horn. T., Motor, the path for motor impulses from the brain to a muscle, consisting of a central and a peripheral portion. The former extends from the cerebral cortex to the gray matter in the anterior horns of the spinal cord; the latter includes the motor cells 
in the cord, the fibers passing to the anterior root, the anterior root and the nerve-trunk to the muscle. T., Myelo-cerebellar. See T., Direct Cerebellar. T., Olfactory, the narrow portion of the olfactory lobe of the brain. T., Ophthalmic, T., Optic, this arises by two arms or brachia, one from the stratum opticum of the quadrigeminal bodies, the other from the optic thalamus. From the junction of the two arms it winds obliquely across the under surface of the crus cerebi, to which it is attached by its anterior margin, then passes forward, being connected with the tuber cinereum and the lamina cinerea. Finally, it unites with the tract of the opposite side to form the chiasm. $T$., Peduncular, any tract of fibers in the crus cerebri. T., Posterior Cortical, a tract of fibers passing from the cortex of the occipital and temporal lobes to the nerve-cells in the pons. T., Postpyramidal, the dorsal pyramid of the cord. T., Prepyramidal, the ventral pyramid of the cord. T., Principal, that portion of the ventral column of the cord not belonging to the direct pyramidal tract. $T$., Pyramidal, the continuation in the spinal cord of the ventral pyramids of the oblongata. At the decussation of the pyramids about three-quarters of the fibers usually cross to the opposite side. These pass down the cord in the lateral column and constitute the lateral (or crossed) pyramidal tract. Those that do not decussate pass down in the inner part of the ventral column at the side of the ventral median fissure and constitute the ventral (or direct) pyramidal tract. T., Radicular, the portion of the spinal cord dorsad of the principal tract. T., Respiratory, the respiratory organs in continuity. T., Restiform, the restiform bodies. T., Semilunar, a semilunar band of fibers in the outer portion of the cerebellar hemisphere. T., Sensory, any tract of fibers conducting sensation to the brain. T., Speech, a group of fibers passing from the cortex of the sub-frontal gyrus of the left side, usually to the nuclei of origin in the oblongata of the nerves connected with the apparatus of speech. T., Spiral, the spiral impression in the large fossa of the cribriform plate. It is pierced by foramina for transmiting filaments of the auditory nerve. $\mathbf{T}$., Tegmental, a tract of fibers in the tegmentum, probably connecting the olivary body with the mid-brain. T., Teretial. Synonym of Fasciculus teres. T., Tertiary Projection, the peripheral nerves originating from the nuclei surrounding the aqueduct, and from the cells in the gray matter of the spinal cord. T., Urogenital. Synonym of 7:, Genito-urinary. T., Uveal. Synonym of Uvea. T., Voluntary Motor, that portion of the motor tract extending from the cortex of the brain to the ventral horns of the cord.

Tractellum (trak-tel's $-\imath m)$ [dim. of tractus, a tract: $p l$., Tractella ]. In biology, that flagellum of an infusorian which precedes in locomotion.

Traction (trak'-shun) [trahere, to draw]. The act of drawing or pulling. T.-aneurysm, an aneurysm most commonly seen in children, and if seen in adults to be referred to childhood, due to traction on the aorta by an incompletely atrophied ductus Botalli. $T$., Axis, traction in the axis or direction of a channel, as of the pelvis, through which a body is to be drawn. T., Axis Forceps, an obstetric forceps for performing axis-traction in the delivery of the fetus. T.-diverticulum, a circumscribed sacculation of the esophagus from the traction of circum-esophageal adhesions. T., Elastic, traction by an elastic force.

Tractor (trak'-tor) [trahere, to draw]. I. An instrument for making traction. 2. See Perkinism.

Tractoration (trak-tor- $a^{\prime}$-shun) [trahere, to draw]. Treatment by metallic tractors; Perkinism.
Tractus (trak'-tus). See Tract.

Tragacanth (trag'-a-kanth). See Tragacantha.

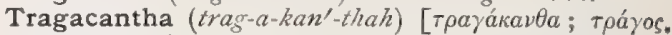

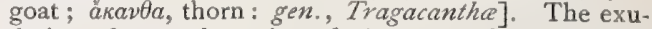
dation of several species of Astragalus found in Asia Minor. A natural mixture of gum arabic and bas. sorin. A demulcent employed mainly as a vehicle for resins and insoluble powders. T., Glycerinum (B.P.), tragacanth, glycerin, and distilled water; a translucent jelly. T., Mucilago, tragacanth 6, glycerin I8, water to 100 parts. Dose $3 \mathrm{j}$, ad libitum. T., Pulv., Comp. (B.P.), tragacanth, gum acacia, starch, and refined sugar. Dose gr. $x x-3 \mathrm{j}$.

Tragacanthin (trag-a-kan'-thin). See Bassorin.

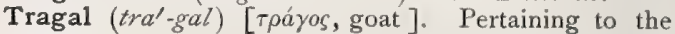
tragus.

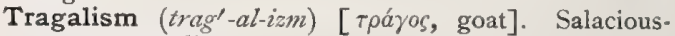
ness; sensuality.

Traganthin (trag-an'-thin). See Bassorin

Tragicus (traj-ik'-us). See Muscles, Table of.

Tragophonia (trag-off-o'-ne-ah), Synonym of Egophony.

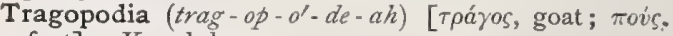
foot]. Knock-knee.

Tragus $\left(t r \alpha^{\prime}\right.$-gus) [toáyos, goat]. The small prominence of cartilage projecting over the meatus of the external ear.

Trailing Arbutus (tra'-lino $\left.a r^{\prime}-b u-t u s\right)$. Ground Laurel, May Flower. The leaves of Epigea repens. Diuretic and astringent. It has been used to allay irritability of the urinary organs. Dose of fld. ext. $3 \mathrm{ss}-\mathrm{j}$. Unof.

Train (trän) [ME.,trainen, to draw]. A following; that which is drawn after. T.-murmur. See Fisher's Murmur in Signs and Symptoms, Table of. T-oil. See Whale-oil.

Training (trān'-ing) [ME., trainen, to draw]. Systematic exercise for physical development or for some special attainment. T.-school, an institution where persons are instructed in nursing. The majority of the large hospitals have established such institutions.

Trait (trât) [Fr., trait, a line]. Any natural characteristic or feature that is peculiar to an individual.

Tramosericeous (tram-o-ser-ish'-us) [trama, weft; sericeus, silken]. In biology, having a satin-like luster.

Trampling (tram'-pling) [ME., trampelen, to trample]. The killing and bruising of animals in conveyance by rail or sea by being thrown down and trampled upon by the feet of their companions.

Trance (trans) [transitus, a passing or passage]. I. A form of catalepsy, characterized by a prolonged condition of abnormal sleep, in which the vital functions are reduced to a very low minimum, and from which the patients ordinarily cannot be aroused. The breathing is almost imperceptible, and sensation is abolished. The onset and awakening are both very sudden. 2 . The state of syncope much protracted. T.-doctor, a mesmerist. T., Hysteric, the trance-like condition sometimes met with in hysteria.

Trans- [trans, across]. A Latin preposition used as a prefix to denote across.

Transcendental (tran-sen-den'-tal) [trans, across; scandere, to climb]. Beyond the bounds of experience. T. Anatomy, philosophic anatomy.

Transductor (trans-duk'-tor). Synonym of Transversus pedis.

Transect (tran-sekt') [trans, across; secare, to cut]. To make a transection.

Transection (tran-sek'-shun) [trans, across; secare, to cut]. Any section made across the long axis of a part, or of the whole body, in the latter case dividing it into 
cephalic and caudal regions. See Position and Direction, Table of Intriwsic Terms.

Transfer (trans'-fer). See Phenomena of Transfer.

Transference (trans-fer'-ens) [trans, across; ferre, to bear]. Supposed transmission of thought from one individual to another through the agency of a hypothetic psychic force; mind-reading, or thoughtreading; hypnotic suggestion. $T$. of Sensibility. See Sensitivization.

Transfix (trans-fiks') [trans, across; figere, to fix]. To pierce.

Transfixion (trans-fik'-shun) [trans, across; figere, to fix ]. In amputation, the passage of the knife directly through the soft parts, cutting being done from within outward.

Transforation (trans - fo-ra'-shun) [trans, across; forare, to pierce]. Applied especially to perforation of the fetal skull. Synonym of Perforation.

Transformation (trans-for-ma'-shun) [trans, across; formare, to form]. A change of form or constitution ; degeneration. In biology, the series of changes or metamorphoses undergone by certain animals during the early stages of their individual life-history. Cf. Pleomorphism.

Transformism (trans-for'-mizm) [trans, over; formare, form, shape]. In biology, the doctrine of descent with modification; the transmutation of species.

Transfrontal (trans-fron'-tal) [trans, across; frons, forehead]. Crossing the frontal lobe of the brain.

Transfusion (trans-fu'-zhun) [trans, across; fundere, to pour]. The transfer of liquid from one vessel to another; applied especially to the introduction into a vessel of the body of blood from another body. T., Arterial, the transfusion of blood into an artery. T., Auto-, the driving of the blood from the periphery to the center-the heart and the brain-in order to maintain the circulation, as in bandaging of the limbs in post-partum hemorrhage. T., Direct, or Immediate, the transfusion of blood from one person to another without exposure to the air. T., Indirect or Mediate, the introduction of blood that has first been drawn into a vessel. T., Nervous. See Organotherapy. T., Peritoneal, transfusion into the peritoneal cavity. T., Reciprocal, the exchange of equal volumes of blood between a patient suffering from a febrile disease and one who is convalescent from that disease, the blood of the latter being supposed to contain an antitoxin. $\mathbf{T}$., Venous, transfusion into a vein.

Transiliac (trans-il'-e-ak) [trans, across; ilium, ilium]. Passing across from one ilium to the other, as the transiliac diameter or axis.

Transilient (trans-il'-e-ent) [trans, over; salire, to leap]. Extending across. T. Fiber, a nerve-fiber passing from one convolution of the brain to another not immediately adjacent.

Transillumination (trans-il-lu-min- $\Omega^{\prime}-$ shun) [trans, through ; illuminare, to illuminate]. The throwing of an intense light through the substance of a hollow organ as a means of diagnosis.

Transinsular (trans-in'-su-lar) [trans, across ; insula, island]. Traversing the insula of the brain, as $e . g .$, a fissure.

Transischiac (trans-is'-ke-ak) [trans, across; ischium]. Extending transversely from one ischium to the other. T.-convolutions, connecting gyri or isthmuses.

Transition (trans-ish'-un) [transive, to go over]. Change; passage from one state to another. T.resistance, the resistance introduced into an electric current by the accumulation of decomposition-products upon the electrodes.

Transitory (trans'-it-or-e) [transire, to go over].
Temporary ; not permanent; as transitory mania, or frenzy.

Translocate (trans-lo'-kât). Same as Dislocate.

Translucent (trans-lu'-sent) [trans, across; lucere, to shine]. Permitting a partial transmission of light: semitransparent.

Translucid (trans-lu'-sid'). Synonym of Translucent,

Translumination (trans-lu-min-a'-shun). Synonym of Transillumination.

Transmigration (trans-mi-grn'-shun) [trans, across; migrare, to wander]. The passage of cells or particles through a membranous septum, as, e.g., the colorless corpuscles of the blood in inflammation, or the passage of cells across a space. T., External, the passage of an ovum from one ovary to the opposite oviduct without traversing the uterus, that is, by way of the peritoneal cavity. T., Internal, the passage of the ovum through its proper oviduct into the uterus and across to the oviduct of the opposite side.

Transmissibility (trans-mis-ib-il'-it-e) [trans, across; mittere, to send]. The capability of being transmitted or communicated from one person to another.

Transmission (trans-mish'-un) [trans, across; mittere, to send]. I. The communication or transfer of anything, especially disease, from one person or place to another. 2. See Heredity. T., Duplex, the property of nerves of transmitting impulses in two directions.

Transmutation (trans-mu-ta'-shun) [transmutare, to change]. The process of changing; the conversion of one substance or one form into another substance or form,

Transocular (trans-ok'-u-lar) [trans, across; oculus, eye]. Extending across the eye.

Transpalatine (trans-pal'-at-in) [trans, across ; palatine $]$. I. Transverse, as a palatine bone, which extends on either side from the median line. 2. A bone of certain sauropsidan vertebrates.

Transpalmar (trans-pal'-mar') [trans, across; palma, palm]. Situated across the palm.

Transpalmaris (trans-pal-ma'-ris) [trans, across; palma, palm]. The palmaris brevis muscle. See Muscles, Table of.

Transparent (trans-pa'-rent) [trans, across; parere, to appear]. Having the property of permitting the passage of light-rays without material obstruction, so that objects beyond the transparent body can be seen. T. Finger. See Finger.

Transperinæus (trans-per - in - $\left.e^{\prime}-u s\right)$ [trans, across; perincum, perineum]. The transversus perinæi muscle.

Transpinalis (tran-spi-na'-lis) [trans, across; spinalis, spinal]. Any intertransverse muscle of the spinal tract.

Transpiration (tran-spi-ra'-shun) [trans, across ; spirare, to breathe]. I. The act of passing fluid, vapor, or gas through a membrane, especially through the skin; perspiration. 2. The material passed off. 3. In biology, the evaporation of water or other vaporizable matter from the plant, T., Pulmonary, the exhalation of watery vapor from the lungs.

Transplantar (trans-plan'-tar) [trans, across; planta, sole]. Lying across the sole.

Transplantation (trans-plan-ta'-shun) [trans, across; plantare, to plant]. The operation of grafting. See Graft. T. of Cornea. See Keratoplasty.

Transpleural (trans-plu'-ral) [trans, across; $\pi \lambda \varepsilon v \rho a ́$, side]. Crossing the pleural sac.

Transposition (trans-po-zish'-un) [trans, across ; ponere, to place]. An interchange of position, as of the viscera; also termed Situs inversus.

Transprocess (trans-pros'-es) [trans, across; processus, process]. A transverse process. 
Transsubstantiation (trans-sub-stan - she- $a^{\prime}-\operatorname{shun}$ ) [trans, through; substantia, substance]. The replacement of one tissue by another.

Transtemporal (trans-tem'-po-ral) [trans, across; tempus, temple]. Crossing the temporal lobe. (Wilder.)

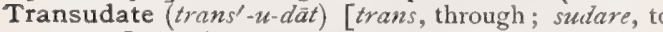
perspire]. A liquid or other substance the result of transudation.

Transudation (trans-u-da'-shun) [trans, through; sudare, to perspire]. I. The passing of any fluid through a membrane or tissue, especially the blood-serum through the vessel-walls. 2. Transudate.

Transudatory (trans- $\left.u^{\prime}-d a-t o-r e\right)$ [trans, through; sudare, to perspire]. Passing by or pertaining to transudation.

'Transversal (trans-ver'-sal) [trans, across; vertere, to turn]. Transverse; running across.

Transversalis (trans-ver-sa'-lis) [trans, across; vertere, to turn]. See Muscles, Table of. T. Fascia, the fascia on the inner surface of the transversalis muscle, between the latter and the peritoneum.

Transverse (trans-vers') [trans, across; vertere, to turn ]. Cross-wise ; at right angles to the longitudinal axis of the body. T. Presentation, a presentation of the fetus at right angles to the longitudinal axis of the uterus.

Transversus (trans-ver'-sus). See Muscles, Table of.

Trap (trap) [ME, trappe, trap]. A device intended to prevent the escape of foul vapors from sewers and waste-pipes into a house. It generally consists of one or more S-shaped pipes, filled with water; some are provided also with valves. T.-door Flap, a semicircular or horseshoe flap made in trephining the skull.

Trapezate (trap'-ez-ät). Same as Trapeziform.

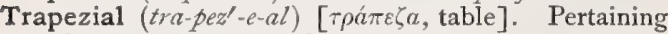
to the trapezium, or to the trapezius.

Trapeziform (tra-pez'-if-orm) [ $\tau \rho a ́ \pi \varepsilon \zeta \alpha$, table ; forma, form]. Having the shape of a trapezium.

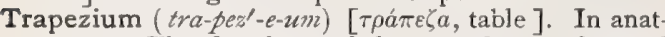
omy: I. The first bone of the second row of carpal bones. 2. A tract of the brain consisting of a trans. verse fiber-mass situated in the ventral part of the oblongata nearly coinciding with the level of entry of the cephalic acoustic root. Cephalad it extends into the lateral part of the lemniscus. It is probably a part of the centripetal auditory tract. Exposed in most animals, it is in man covered by the caudal extension of the pons.

Trapezius (tra-pez'-e-us). See Muscles, Table of.

Trapezoid (trap'-ez-oid) [ $\tau \rho a ́ \pi \varepsilon \zeta \alpha$, a table; $\varepsilon i \delta o s, ~ l i k e]$ One of the bones of the wrist. See Bone. T Ligament. See Ligaments, Table of.

Trapp's Formula or Coëfficient. A figure employed in the estimation of the quantity of solid matters in a sample of urine. In Trapp's formula the figure is 2, while in Heser's Coefficient it is 2.33 . The approximation to the quantity of solid matters present may be obtained by multiplying the last two figures of the specific gravity by 2 in Trapp's formula, or 2.33 in Hreser's formula,

Traube's Plugs. The same as Dittrich's Plugs. T.'s Semilunar Space, a space on the left side of the chest where there normally is found a vesiculo-tympanitic sound, due to air in the stomach. T.-Hering's Curves, pulse-curves showing that the varying activity of the vasomotor center suffices to produce undulations in the blood-pressure tracing.

Trauber-Rosenstein Theory, A theory of the cause of puerperal eclampsia. It is claimed that the convulsions are due to an anemia brought about by an edema of the brain, the result of some poison circulating in the blood.
Traulism, or Traulismus (traw'-lizm, traw-liz'-mus)

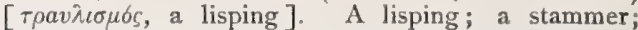
drawling, or imperfect utterance.

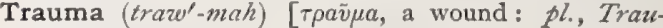
mata]. A wound.

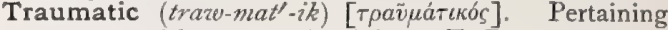
to or caused by a wound or injury. T. Degeneration, the degeneration of the ends of nerves at the point of section, extending to the nearest node of Ranvier, after which fatty degeneration begins. T. Fever, fever following within from eight to thirty-six hours of an operation or injury. It is due to absorption of poisonous material from the seat of injury. T. Hysteria. See Fright-neuroses. T. Infective Diseases, a class of diseases characterized by definite symptoms following wounds or abrasions. Koch has demonstrated that each of these diseases is caused by a distinct microbe that is capable of reproducing the disease if inoculated into other animals. T. Suggestion. See Auto-suggestion.

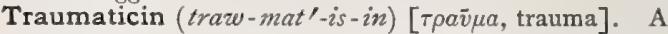
Io per cent. solution of gutta percha in chloroform, used locally in superficial wounds and skin-affections; chrysophanic acid is sometimes added, or other appropriate medicament. Unof.

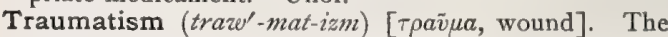
condition of one suffering from injury. The systemic condition following trauma. $T$. of Motion, injury re. sulting to a diseased joint from improper fixation.

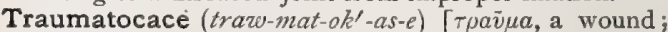
какós, bad]. Synonym of Hospital Gangrene.

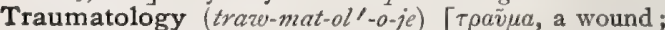

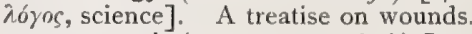

Traumatonesis (traze-mat-o-ne'-sis) [ трaṽua, a wound; $v \bar{\gamma} \sigma \iota s$, a suture]. Suture of a wound.

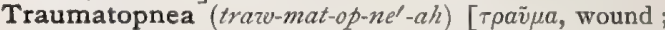
$\pi \nu 0 \eta$, breath]. The passage of air through a wound in the chest-wall during the respiratory movements.

Traumatopyra (traw-mat-o-pi'-rah) [тpaṽ $\mu a$, wound; $\pi \tilde{\nu} \rho$, fever]. Synonym of Traumatic Fever.

Traumatosepsis (traw-mat-o-sep'-sis) [ roaṽua, a wound; $\sigma \bar{\eta} \psi \iota s$, putrefaction]. Synonym of Hospital Gangrene.

Traumatosis (traze-mat-o'-sis) [ $o^{\prime} \rho a \tilde{v} \mu \alpha$, a wound] Traumatism.

Traumatyphus (traze-mat-i'-fus) [ $\tau \rho a \tilde{v} \mu a$, a wound ;

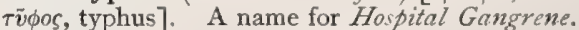

Travail (trav'-āl). Labor in childbed.

Tray $(\operatorname{tr} a)$ [ME., treye, tray]. A flat, shallow vessel of glass, hard rubber, or metal, for holding instruments during a surgical operation.

Treacle $\left(\right.$ tre' $\left.^{-k l}\right)$. See Theriaca and Molasses.

Tread (tred). See Cicatricula.

Treadlers' Cramp. See Cramp.

Treat (trêt) [ME, treten, to treat]. To manage disease by the application of remedies.

Treatment (trêt'-ment) [tracture, to treat]. The means employed in effecting the cure of disease; therapeutic management or methods. T., Method of, a manner or way of managing a certain pathologic condition. Some of the various methods of treatment are appended: T., Apostoli's, the treatment of diseases of the uterus by electricity; the positive pole being inserted in the uterus itself and the negative pole applied externally. Arnott's Method, the use of ice and salt to produce local anesthesia. Bain's Method, a method of artificial respiration; the operator, at the head of the subject, places the fingers of each hand in the axillæ in their front aspect, with the thumbs on the clavicles, and pulls the shoulders horizontally toward him with a certain degree of force. T., Balfour's, the method of treating aneurysm by 
means of iodid of potassium. It lowers the bloodtension of the artery, and also brings about a thickening and contraction of the aneurysmal sac. T., Banting, a treatment of obesity; the withdrawal of carbohydrates from the food and the use of a diet of nitrogenous food. Barnes's Method: I. For placenta prævia: (a) puncture the membranes; (b) apply a firm binder over the uterus; (c) tampon the cervix and vagina; $(d)$ detach the placenta from its lower polar zone; $(e)$ dilate the cervix ; $(f)$ deliver at once; $(r)$ introduce the hand and remove the placenta. 2. Reduction of uterine inversion by first incising the cervix on each side, so as to divide the circular fibers. Barrier's Method of treating uterine inversion. The uterus is grasped in the whole hand, and, using the sacrum as a point of resistance, the cervix is forced up against it, at the same time depressing the fundus with the thumb. Baudelocque's Method of converting a face-presentation into a vertex-presentation. The hand is passed into the vagina and the thumb placed in the mouth or on the chin of the child, while the fingers are passed up over the occipital protuberance. Pressure is then made by the thumb in succession upon the chin, the fossæ caninæe, and the brow, the fingers at the same time making traction upon the occiput. The head is thus flexed. Baunscheidt's Method, acupuncture by means of numerous needles fixed in a framework, and which are forcibly projected by releasing a spring. Bergeon's Method; the treatment of pulmonary tuberculosis by rectal injections of hydrogen sulphid gas mixed with carbon dioxid. T., Bettman's. See Subvolution. T., Bier's, of strumous joints; it consists in causing congestion of the part by bandaging and elevating the unaffected extremities. Bigelow's Method; extension of the thigh in luxations of the hip, with the limb at a right angle with the body. Bird's Method of treating bed-sores consists in the application of a constant mild galvanic current. Bouchard's Diet for dilatation of the stomach. Twelve ounces only of fluid at breakfast and dinner, and this must be non-fermenting; red wines are prohibited, but mineral (table) waters, water containing one-third of beer, or a quarter pint of white wine, or a dessertspoonful of brandy, may be taken. No drink is to be taken between meals. Bouchard's Method of treating typhoid fever. The patient is bathed eight times each day, the bath in which he is placed being three degrees lower than the rectal temperature. The water is then gradually cooled down to $86^{\circ} \mathrm{F}$. Every third day the patient receives half an ounce of sulphate of magnesium. During the first four days of treatment seven grains of calomel are given daily in divided doses. During the period of intestinal disorder a dram of naphthol and half a dram of salicylate of bismuth are given in divided doses, and every morning and evening the bowels are washed out with warm water containing naphthol. Quinin is administered as required. The diet consists of broths, gruels, and lemonade. Opiates are given to allay delirium. T., Bouchardat's, of diabetes consists in a dietary which allows meat and fresh vegetables, but prohibits milk, sugar, and all substances rich in carbohydrates. T., Boynton's, the application of adhesive straps to ulcers of the leg. T., Braithwaite's, for carcinoma of the uterus, consists in the continual application of chlorid of zinc to the affected part. Brand Method of treating fever consists in immersion in a bath at the temperature of $68^{\circ} \mathrm{F}$., every 3 hours, when the bodily temperature reaches $102^{\circ} \mathrm{F}$. Friction of the surface is essential; cold should be applied to the head; stimulants may be administered after the bath, and the patient is put back to bed and dried between sheets. The duration of the bath is from 5 to 15 minutes. Brandt's Method of treating diseased Fallopian tubes. It consists in attempting to empty the dis. tended tube into the uterus by massage, rolling it gently between the fingers of both hands. Brémond's Method of treating syphilis. The patient is placed in a box with his head out, and a spray of numerous jets of steam containing particles of corrosive sublimate or potassium iodid is directed upon the body. Bronson's Method of preventive treatment of syphilis. This has been worked out on a purely theoretic basis. Bronson believes that rapid disappearance of the initial lesion may be caused, together with the probable abortion or prevention of the secondary stage, by hypodermatic injections of mercurial solutions around and under the nodule on the penis and into the substance of the inguinal lymphatic glands. T., Brown-Séquard, the use of injections of testicular extract. See Organotherapy. Bryant's Method for treating fracture of the femur in children. It consists in vertical extension of the legs. Both limbs are flexed at a right angle with the trunk, and attached to a bar above the bed. Buck's Method of treating fractures by continuous extension by means of a weight and pulley. T., Bülau's, for empyema consists in the aspiration of the pleural cavity by means of a siphon. Byrd's Method. See Artificial Respiration. Byrne's Method; reduction of uterine inversion by applying pressure by means of a cup having a false bottom, which advances, while counter-pressure is made above by means of a bell-shaped cup, having a conical plug, which serves to dilate the inverted cervix. Cameron's Method, a method of treating foreign bodies in the alimentary canal. See Cure, Potate. T., Cantani's, of cholera: $(a)$ The repeated introduction high up into the bowel, at a temperature of from 100. $4^{\circ}$ to $104^{\circ} \mathrm{F}$., of from 3 to 4 pints of water or infusion of chamomile containing from 75 grs. to $5 \mathrm{drs}$. of tannic acid and from 30-50 drops of tincture of opium, at times with from an ounce to an ounce and a half of gum arabic (enteroclysis); (b) the introduction into the subcutaneous connective tissue of 2 pints of sterilized water, at a temperature of from Ioo. $4^{\circ}$ to IO4 $4^{\circ} \mathrm{F}$, containing in solution a dram of sodium chlorid and 45 grs. of sodium carbonate (hypodermatoclysis, subcutaneous infusion). Carr's Method of treating placenta previa. It consists in detaching and removing the placenta, and then removing the child as rapidly as possible. Cohen's Method of treating placenta prævia. It consists in detaching the smaller flap of the placenta which passes over the os internum to the side opposite from the main body, thus converting a central into a lateral implantation. Cohen's Method of inducing premature labor. It consists in passing an elastic catheter between the membranes and the uterine wall, and slowly injecting 7 or 8 ounces of warm water, so as to partially separate the membranes. Cooper's Method of extension in luxation of the thigh. The patient is in the recumbent position. Extension is made by means of a band passed around the thigh above the knee, and a counter-extending band is passed between the thighs close to the dislocated member, and fixed in a line with the body. Copeman's Method of treating pernicious vomiting of pregnancy. It consists in dilating the cervical canal with the forefinger or with special instruments devised for the purpose. The results are said to be good. Corbin (Dr. Job Corbin), of Brooklyn (New York), Method of treating diphtheria. It consists in the sublimation of calomel and compelling the patient covered by a temporary tent made of sheets, blankets, or 
other available articles, to inhale the air impregnated with the sublimed material. Corning's Method of inducing local anesthesia. The production of local anesthesia by multiple cutaneous puncture and the introduction of cocain by the aid of a galvanic battery. Courty's Method of treating uterine inversion. Reduction is accomplished in the usual manner by effecting counter-pressure by two fingers passed into the rectum and hooked over the mass. Crédé's Method of removing an adherent placenta. It consists in manual expression. Crédés Prophylaxis of Ophthalmia neonatorum; immediately after birth the eyes of the child are cleansed with clean water and cloth or cotton, and one drop of a 2 per cent. sol. of silver nitrate dropped into each eye. Dancel's Method of treat ing obesity. It was to prescribe as dry a diet as possible. The food taken should contain very little water, and very little drink should. be taken at any time. Soups and fluid foods were forbidden. Not more than from six to twelve ounces of fluid were allowed at each meal. Abstinence from fatty and farinaceous foods was enforced, frequent purges were enjoined, and much exercise on foot. Daremberg's Method of feeding consists in the employment of peptonized enemata. Davy's Method of controlling hemorrhage in hipjoint amputation; by means of a lever introduced into the rectum. Débove's Method; the method of overalimentation or forced feeding in the treatment of tuberculosis. The stomach is first washed out with cold water, and then, through the stomach-tube, a mixture is introduced containing a liter of milk, an egg, and 100 grams of very finely powdered meat. This is given three times a day. Denneth's System of reducing obesity. It has for its aim the exclusion as far as possible of alimentary hydrocarbons, while permitting a certain proportion of fat. It closely resembles Ebstein's method. Detmold's Method; the arrest of hemorrhage by the withdrawal of a considerable amount of blood from the circulation by means of ligatures placed around one or more limbs, just tightly enough to arrest the venous return without obstructing the arterial flow. Deventer's Method of Extraction after Version; the after-coming head and the extended arms are extracted together by simple traction on the feet and shoulders. When the shoulders appear at the vulva, the head is swung sharply backward, one hand grasps the feet, the other the shoulders, and both hands make traction simultaneously and directly toward the floor. Dew's Method. See $A r$ tificial h'espiration. Diday's Method; the expectant plan of treatment of syphilis. Dublin Method; treatment of aneurysm by compression of the diseased vessel on the cardiac side of the tumor. 'T., Durande's, for biliary lithiasis : ether 3 parts, oil of turpentine 2 parts; of this 20-30 drops are given three times daily. Duverger's Method, or Suture, for wounds of the intestines. The trachea of a calf is inserted into the intestine and the wound closed over it with interrupted sutures. T., Ebstein's, for obesity ; a modification of the Banting method, but with the inclusion of fatty substances. Emmet's Method of treating uterine inversion; the body of the womb is grasped in the hand firmly and the fingers immediately expanded so as to put the tissues around the cervix on the stretch, while the hand above aids in dilating the cervical ring. If only partial reduction can be secured, the lips of the os are stitched together over the fundus. Fenwick's Method of treating pyrexia consists in passing a constant current of cool air over the patient. This is accomplished by placing ice or ice-water near, but not in contact with, the patient. See Ice-cradle. Fergusson's Method of treating aneurysm; the tumor is manipulated so as to detach a fragment of fibrin or old clot, which will plug the efferent artery. T., Filleaw's; the method of treating pulmonary tuberculosis by subcutaneous injections of carbolic acid. Finsen's Method; a method of treating smallpox, by confining the patients in a room from which the ultra-violet rays of light are shut out by red window-panes or by covering the windows with red curtains. Fleury's Method of treating aneurysm; compression by flexion of the limb. Forest's Method. See Artificial Respiration. Fournier's Method; the interrupted treatment of syphilis. It consists in administering mercury for a period of two months, then stopping for a certain time, at least a month, during which the patient becomes unaccustomed to the remedy. This is followed by a course of treatment for six weeks or two months, and then a respite for three months, and so on. Gerst's Method of massage of the neck; the patient faces the masseur with the head thrown back, so as to expose the neck. The operator places his hands at the lobes of the ears and performs a stroking downward to the shoulder, the patient breathing freely and easily. 'T., Goats' Blood; a method of treating pulmonary tuberculosis by the free administration of goats' blood. Gould's Method of Treating Monocular Amblyopia; by perfect correction of the ametropia and muscular imbalance, and monocular exercise of the amblyopic eye, the other being covered by a blinder. G.'s Method of Treating Exophoria; innervational gymnastics with prisms, bases toward the temples, of a higher degree than the patient can at first overcome at 20 feet, coupled with fusion-exercises, the object being gradually carried from the near-point to the distant point. G.'s Method of Treating Functional Lacrymal Stenosis; submergence of the puncta with an antiseptic and astringent solution and synchronous massage of the sac. Gram's Method. See Actinomycosis. T., "Grape-cure," for cardiac hypertrophy consists in the daily consumption of large quantities of grapes. Guérin's Method of dressing an amputation; the encasing of the stump after amputation in a dense mass of cotton as a permanent dressing. T., Guthrie's, for hospital gangrene; the local use of the mineral acids. Hall's Method. See Artificial Respiration. Hay's (Matthew) Method of treating hydrothorax; by means of a concentrated solution of Epsom salt, together with dry diet. Hegar-Kohrn Method of preventing ophthalmia neonatorum; as soon as the head is born the closed eyelids are carefully dried with two or three pledgets of antiseptic absorbent cotton moistened with Van Swieten's solution (corrosive sublimate I part, alcohol 100 parts, water 900 parts). As soon as the child is born the eyelids and all the surrounding tissues are cleansed with the same solution until an absolutely aseptic surface is obtained. Hicks' Method; a method of performing bimanual version; especially adapted to the treatment of placenta prævia. Hilton's Method of treating deep abscesses consists in a simple incision through the skin with a scalpel, and the separation of the deep parts by means of a blunt instrument, as, $e . g$., the blades of a dressing forceps. Hœffinger's Method for massage of the neck; the patient sits with the head erect. The operator stands behind and places his hands beneath the patient's ears, and strokes downward toward the shoulder, the hand covering the principal part of the trapezius muscle. Honing's Method of expression of retained fragments after abortion; one finger is placed in the vaginal vault while the fingers of the other hand grasp the uterus through the abdominal wall and gradually squeeze out 
the contents of that organ. Hoffmann's Method; a method of treating chronic inflammation of the tonsils. It consists in breaking down the tonsils by means of a blunt hook introduced into the crypts. Howard's Method. See Artificial Respiration. Huchard's Diet for dilatation of the stomach; the strict limitation of liquids, a glass and a half only at each meal; all food-substances and fruits contain. ing much water are to be rejected, and only very thick soups permitted; roast meat, eggs, and the drier kinds of vegetables are allowed. T., Hutchinson's, in hip-disease; the weight of the limb is utilized as the extending force, a patten being worn on the sound foot. T., Hutchinson's, of lupus erythematosus; it consists in rubbing the part with lint dipped in benzoline every night, and then applying a weak (4 grains to the ounce) yellow oxid of mercury ointment. T., Indian, of goiter, consists in the inunction of an ointment of biniodid of mercury. This is to be followed by exposure of the goiter to the direct rays of the sun until the smarting becomes unbearable. T., Jürgenssen's, of pneumonia, consists in the exhibition of large doses of quinin. Kibbie's Method of reducing temperature; the pouring of tepid water $\left(95^{\circ}\right.$ to $\left.80^{\circ}\right)$ over the patient's body, covered from the axillæ to the thighs with a wet sheet, and laid upon a cot, through the open canvas of which the water passes, and is caught on a rubber cloth beneath the cot and conveyed into a bucket at the foot of the bed. Kisch's Method of reducing obesity. It is based upon the administration of a large quantity of albuminous food. Free and abundant use of water is permitted. T., Koch's, of tuberculosis; the subcutaneous injection of tuberculin. T., Krause's, for tuberculous laryngitis consists in the local application of concentrated solutions of lactic acid. T., Krull's, of cholangitis; from one to four pints of water at a temperature of $59^{\circ} \mathrm{F}$. are slowly injected into the rectum once daily. The fluid must be retained as long as possible. On successive days the temperature of the water is gradually raised until it reaches $72^{\circ} \mathrm{F}$. Laborde's Method; the treatment of asphyxiated patients by rhythmic tractions of the tongue. Lannellongue's Method of treating tuberculosis consists in the deep injection of dilute solutions of chlorid of zinc into or about the tuberculous deposits. T., Le Peines. Same as Goats' Blood Treatment. Lewsaschew's Method of treating pleuritic effusion consists in replacing a small portion of the fluid to be withdrawn by an equal amount of a sterilized salt-solution. A continuance of this ultimately leaves only pure salt-solution in the cavity. T., Liebreich's, for tuberculosis, consists in the hypodermatic injection of a solution of from $\frac{1}{6} \frac{1}{48}$ to $\frac{1}{3} \frac{1}{2}$ of a grain of cantharidate of potassium. MacEwen's Method of treating aneurysm consists in inducing consolidation of the sac by irritating its inner surfaces with a pin-point. MacEwen's Method of controlling the circulation in the lower extremities consists in manual compression of the abdominal aorta. $T$. Martineau's, for diabetes. It consists in drinking daily about a liter of carbonic-acid water. It is especially valuable in those cases having a close or remote connection with gout. Mason's Method; the method of keeping the fragments in proper position in fracture of the nasal bones by the insertion of needles, which are allowed to remain in situ for about a week. Mauriceau's Method, Veit-Sinellie Method, a method of delivering the after-coming head. Proceed in the same manner as in the Wiegand Method until the disengaged hand is to be used. The middle finger of this hand, pronated, is passed along the back of the neck until it finds the occiput, when pressure is employed to further flex the head. The index and ring fingers are now flexed over the clavicles, and traction is made in the axis of the parturient canal (downward and outward), the trunk is carried toward the mother's abdomen, and at the same time the fingers in the mouth and on the occiput are securing complete flexion of the head. Michel's Method, the after-treatment of cataract-operations in a light room, and with light dressings to the eyes. T., Weir Mitchell's, of neurasthenia. This consists in rest in bed, isolation, fattening or plenteous nourishment, and the use of massage and electricity. See Rest-cure. T., Mitchell's (S. Weir), of obesity. He advocates rest, milk-diet, and massage. The milk is skimmed, and is given alone, with the usual precautions. All other foods and fluids are forbidden. When it is found what quantity of milk will sustain the weight, the amount is diminished by degrees until the patient is losing a half pound of weight each day, or less or more, as seems to be well borne. This is combined with rest and massage. Moore's Method, a method of dressing in Colles' fracture by a small roller and a strip of adhesive plaster. Moore's Method of treating aneurysm. The introduction of foreign bodies, such as metallic wire, watch-spring, horse-hair, catgut, silken or sea-tangle threads into the aneurysmal sac. Morgan's Method of treating dislocation of the hip. A foot is placed between the thighs and against the perineum to effect counterextension; extension and rotation are made by assistants, by means of a band attached above the knee; the limb being adducted, the foot becomes a fulcrum and presses the bone off from the pelvis. Morton's Method of treating spina bifida. It consists in injecting into the sac a dram of a preparation of $I 0$ grains of iodin and 30 of iodid of potassium in an ounce of glycerin. About a dram of the fluid of the sac is first withdrawn, so that the tension of the sac may not be increased by the injection. T., Murray's, of aneurysm. Favoring the rapid formation of a red clot in the aneurysmal sac by firmly applying an Esmarch bandage below the sac, carrying it lightly over the sac, and then making four turns above. Nélaton's Method, suspending the patient by the legs to counteract the hypothetic cerebral anemia of too profound anesthesia. Nélaton's Method of treating dislocation of the jaw ; the operator stands in front of the patient, grasps the back of the head on each side with the outstretched fingers, and presses with the thumbs on the coronoid processes to bring the condyles in place. T., Newman's, of laryngeal strictures; by tupelo dilators after tracheotomy, with, finally, introduction of an artificial larynx. Nœggerath's Method, reduction of uterine inversion by commencing the operation by indenting the fundus at one or the other cornu. Noyes' Method of crushing trachoma-granulations; the lids are everted and the two ends of the tarsus are grasped by special forceps and opposing traction made. The granulations are thus squeezed and stripped out. O'Dwyer's Method; intubation for obstructions of the larynx. Oertel's Method ; the treatment of the circulatory disturbances of heart-disease, obesity, emphysema, etc., by mechanical means. The objects aimed at are: (I) diminution in the quantity of fatty tissue depositedachieved by regulation of diet, etc.; (2) a reduction in the quantity of fluids in the body-accomplished by diminished ingestion of fluids of all kinds; (3) strengthening of the heart-muscle and promotion of the development of compensatory hypertrophy-attained by methodic mountain-climbing and other systematic 
exercise; (4) stimulation of the circulation by massage, passive movements, and sanitary gymnastics. Pacini's Method. See Arlificial Respiration. Parsons' Method, treatment of carcinoma of the cervix uteri by the use of the interrupted galvanic current. $T$., Pavy's, for diabetes consists in a dietary the main points of which are avoidance of sugar, starches, milk, all kinds of pastry and puddings, and-fruits, both fresh and preserved. 'T., Payne's, of Lupus erythematosus; it consists in the topical application daily of salicylic acid $1 / 2$ dram, and collodion I ounce. T., Pirogoff's Camphor, a method of treating erysipelas; the patient takes every hour or two hours 3 grains of powdered camphor, and drinks large quantities of hot tea, to promote perspiration. T., Preumatic, of asthma, consists in the inhalation of compressed air. Politzer's Method, a method of inflating the middle ear for middle-ear disease. The exit-tube of a rubber bulb is introduced into one naris, while the other is occluded, and the patient swallows a little water held in the mouth as the bulb is compressed. T., Prochownik's, of asphyxia neonatorum. The child is held inverted by the feet, and compression of the chest is practised. Reid's Method: I. The reducing of dislocations of the hip by manipulation. 2. The use of the Esmarch bandage and tube in the treatment of aneurysm. Richet's Method of treating tuberculosis consists in the hypodermatic injection of the serum of dogs' blood. Ricord's Method of treating syphilis; a course of mercury for six months, followed by a three months' course of iodid of potassium. 'T., Roberts', for diabetes, consists in avoidance of all saccharine or farinaceous foods, the livers of all animals or shell-fish, all sweet fruits, and sweet wines. T., Roussel's, of tuberculosis; by hypodermatic medication only, with the desire to save the stomach for food-purposes. Various substances dissolved in sterilized olive-oil are injected, as follows: eucalyptol, 25 in 100 ; turpentine, 15 in 100; metallic jodin 2 to 5 , eucalyptol 5 to $\mathrm{xo}$, oil IO0; iodoform 2, eucalyptol 5, oil 100; camphor Io, eucalyptol IO, oil IOO; paraldehyd 5 to Io, oil IOO; crystallized carbolic acid 5 to 20 , eucalyptol IO, oil roo. The dose is always 15 minims. T., Salis bury, for obesity, consists in a diet of beefsteak and hot water. Satterthwaite's Method. See Artificial Respiration. Sayre's Method for treating lateral currature of the spine; suspension of the patient for the purpose of extension during the application of a plaster-of-Paris jacket. Scarenzio's Method of treating syphilis; by subcutaneous injections of calomel suspended in glycerin and mucilage of acacia. The amount injected varies from $3 / 4$ to 2 grains once or twice a week, suspended in Io or 12 drops of the vehicle used. The site of the injection may be the sides of the chest, the belly, or the depression in the buttocks, an inch behind the posterior border of the great trochanter. Abscesses may develop at the point of injection. Schatz's Method of converting a face-presentation into a vertex-presentation. It is done by external manipulation only. His manuever consists in restoring the normal attitude of the body by flexing the trunk, and leaving the head to spontaneously resume its proper position as it sinks into the pelvis. It is performed by seizing the shoulder and chest with the hand through the abdominal walls; then lifting the chest upward and pressing it backward, at the same time steadying or raising the breech with the other hand applied near the fundus, so as to make the long axis of the child conform to that of the uterus, and, finally, pressing the breech directly downward. As the child is raised, the occiput is allowed to descend, and then, as the body is bent forward, head-flexion is produced by the resistance of the lateral walls of the pelvis. This maneuver is only applicable before the rupture of the membranes. Schede's Method, a method of obtaining healing in cases of operations upon bones and other structures which leave cavities that cannot be obliterated. It aims at union under a moist blood-clot. Ordinary chemic antiseptics are used; wads of sublimate-cotton wrapped in mull and kept in sublimate-solution are used in place of sponges. During the operation the wound is washed out with sublimate-solution every five minutes. All bleeding vessels are tied, the wound, thoroughly irrigated, first with 5 per cent. carbolic solution, then with the bichlorid of mercury lotion, closed by relaxation sutures of silk or silver and a continuous. catgut suture, and dressed with protective or guttapercha tissue, Io per cent. iodoform-gauze wrung out in 5 per cent. carbolic lotion, and a moss pillow. T., Schott's, of heart-disease; saline or carbonated baths at from 86 to $92^{\circ} \mathrm{F}$. for 5 to 7 weeks; systematic exercise-flexion, extension, and rotation-resisted by another person. Schrœder's Method. See Artificial Respiration. Schroth's Method of treating obesity consists in the exclusion, as far as possible, of water or fluid in any form. Schultz's Method. See Artificial Respiration. 'T., Schuster's, of syphilis; it consists in inunction of the skin with a mercurial soap. A good lather is made with water, and this is allowed to dry on the skin, upon which it leaves a thin film of mercury. If applied too freely it may cause dermatitis. Schwalbe's Method of treating reducible herniæ; injection of alcohol with a Pravaz syringe. Schweninger Cure for obesity; the same as Oertel's method $(q . v$.$) , with the sole modification$ of the forbidding of any fluid at meals. T., Sée's (Germain), of obesity; he advises a régime of albuminoids and fats, together with a great quantity of drink, especially of warm, aromatic fluids. Hot tea is the beverage he especially favors. Alcoholic drinks are strictly interdicted. T., Seegen's, for diabetes, consists in the avoidance of farinaceous food of all kinds, sweet fruits, sugar, and all sweet wines. and syrups. He allows shell-fish and berries. ' $T$., Seibert's, for diphtheria: the application of pulverized sodium chlorid to the membrane twice daily until it becomes, as it were, "corned." T., Seiler's, a method of treating pulmonary tuberculosis by inhalation of the fumes of hydrofluoric acid. T., Shurly-Gibbes', of tuberculosis. Hypodermatic injection of solutions in glycerin of either iodin or gold and sodium chlorid, or both in alternation, in conjunction with chlorininhalations. The commencing dose of the iodinsolution should be about $\frac{1}{12}$ of a grain, gradually increased to $1 / 2$ or I grain; that of the gold salt $\frac{1}{30}$ of a grain gradually increased to $\frac{1}{5}$ or $\frac{1}{3}$ of a grain. Simpson's Method of treating placenta pravia; complete separation of the placenta. Small's Method of extension of the thigh; it consists in the application of a wicker-work sheath like the "Indian finger," from which the extension is made. Smith's (Tyler) Method of treating uterine inversion; by distending the vagina with an inflated rubber bag, after having applied massage to the uterus for Io days. "String" Method; the method of dilating a strictured canal by passing a strand of braided silk through and drawing it back and forth. Abbe operated by this means in a case of stricture of the esophagus, by performing esophagotomy and gastrotomy and passing the thread through the stricture by means of a thin bougie. Sylvester's Method. See Artificial Respiration. Thin's Method of treating bromidrosis. It consists in shaking finely powdered boric acid into the socks and stockings, chang- 
ing the latter once a day, T., Thomas's Damming, of fractures with delayed union. The circulation was obstructed by compression above the fracture and congestion maintained for a few minutes. ThureBrandt's Method. Same as Brandt's Method. T., Towers-Smith, for obesity, is essentially the same as the Salisbury treatment. Tranjen's Method of treating tuberculosis consists first in injection into the gluteal muscles, every eight days, of a solution of hydrargyrum thymolo-aceticum. Secondly, the exhibition, by the mouth, of a solution of potassium iodid. Trendelenburg's Method, the method of operating by placing the patient in the Trendelenburg position to favor sagging upward of the intestines. Tuffnell's Method, the method of treatment of aortic aneurysm by means of a restricted diet, so that the solids taken during the day will amount to but ten ounces, and the liquids to eight. These are divided as follows: Break fast-bread and butter, 2 ounces; cocoa or milk, 2 ounces. Dinner-boiled or broiled meat, 3 ounces potatoes or bread, 3 ounces; light claret, 4 ounces. Sup per-bread and butter, 2 ounces; milk or tea, 2 ounces. The presence of aortic regurgitation is a distinct contra indication to this method. T., Unna's, of acne consists in the application of an ointment containing resorcin, corrosive sublimate, and zinc oxid. T., Valentine's, of uterine inversion. The uterus is seized with the fingers and thumb of one hand, and counter-pressure is made in the hypogastrium with the other. Valsalva's Method of treating aortic aneurysm: it consisted in starving the patient, in the belief that by such a process the blood became more coagulable. T., Van Buren's, of prolapse of the rectum. The patient under ether, the smallest tip of the Paquelin cautery, heated only to a dull-red, is drawn over the length of the prolapsed tumor with just sufficient force to go through the mucous membrane. Five or six linear eschars should be made, very lightly at the upper portion, more heavily below. The tumor should then be replaced and the sphincter burned at two points on opposite sides with the same iron; these cuts should be made into the substance of the muscle, so that the resulting contraction will lessen the size of the anus. Veit-Smellie Method. See Mauriceàu's Method. T., Vogel's, for obesity is a slight modification of the Banting method. Vulliet's Method of controlling severe hemorrhage after abortion. It consists in packing the whole uterine cavity with small balls of iodoformized cotton, tamponing the vagina as usual. Weber's Method for the arrest of hemorrhage; by turning the vessel inside out by means of the arterio-verter. See Arterio-version. T., Welander's, for abortion of buboes; the injection of mercuric benzoate into the affected glands. If fluctuation is present, a minute puncture is made to evacuate the pus, the cavity is washed with corrosive sublimate $\mathbf{I}: \mathbf{I 0 0 0}$ and closed. "Whey-cure" treatment of cardiac hypertrophy consists in the daily administration of large quantities of whey. Wiegand's Method of delivery of the after-coming head. Introduce the first three fingers of the supinated hand into the vagina (using that hand the palm of which corresponds to the abdomen of the child), at the same time resting the abdomen of the child upon the forearm with a leg hanging on either side. Insert the index finger in the child's mouth, and exert sufficient traction on the lower jaw to induce and maintain flexion of the head. The disengaged hand now locates the head through the abdominal wall above the pubes, and pressure is made in the axis of the parturient canal, the child's body being elevated toward the mother's abdomen. Wing's Method of treating uterine inversion; it is done by means of a wooden instrument, shaped something like an old-fash- ioned, wooden stethoscope, but with a very shallow depression for the fundus, to prevent the edges from cutting the tissues. Continuous pressure is obtained by means of two pieces of elastic tubing, passed between the thighs and fastened to the stem of the instrument, which projects beyond the vulva; the ends of the tubing are fastened to a waistband. Witzel's Method of removing an acute pneumothorax resulting from penetrating wounds of the thorax. It aims at the conversion of the pneumothorax into an artificial hydrothorax, the latter being finally emptied by aspiration. A solution of boric acid at blood-temperature is used for this purpose. Yeo's Method of treating obesity consists in a dietary which limits the amount of farinaceous food, prohibits sugar, limits the amount of food taken with the meals, but encourages the drinking of large amounts of hot or warm, aromatic beverages between meals. Ziemssen's Method of treating anemia; by subcutaneous injections of defibrinated human blood under strict antiseptic precautions. The injections vary in amount from 1.6 to 3.3 ounces at a sitting.

Trechoma (tre-kol-mah). Synonym of Trachoma.

Tree (tre) [ME., tree, tree]. A perennial plant with a single, self-supporting, woody trunk, reaching usually the height of 25 or 30 feet. T--cotton. See Mocmain. T. of Heaven. See Ailanthus, 'T., Vascular, the arbor-like appearance of the bloodvessels when removed from the body.

Trehala (Ire-hah'-lah) [Turkish]. Turkish manna; a variety of manna derived from the cocoons of Larimus maculatus, an insect that feeds upon an Asiatic thistle, Echinops persica.

Trehalase (tre'-hal-äs) [trehala]. A soluble ferment first found by Bourquelot in Aspergillus niger. Its function is to convert trehalose into glucose.

Trehalose (tre-hal'-öz) [trehala]. A complex carbohydrate or crystallizable sugar derived from ergot, and also from trehala. See Mycose, and Carbohydrates, Table of.

Trélat's Method. See Anesthetic.

Trema (tre'-mah) $[\tau \rho \tilde{\eta} \mu a$, a hole $]$. I. A synonym of Foramen. 2. A genus of the Ulmacea. T. orientalis, Indian nettle-tree. The bark, leaves, and root are used as a remedy for epilepsy.

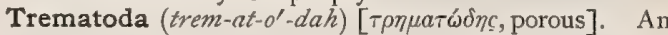
order of entozoa, including worms parasitic in the liver and intestinal tract; fluke-worms.

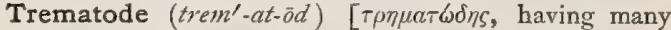
holes]. In biology, a member of the class Trematoda, parasitic, unsegmented platodes, without a covering of cilia, mostly with a forked intestine, mouth and pharynx at the anterior end of the body. See Distoma and Fasciola, under Parasites (Animal), Table of.

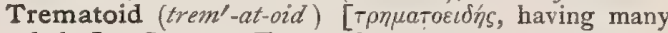
holes]. Same as Trematode.

Tremble $\left(\right.$ trem $\left.^{\prime}-b l\right)$ [ME., tremblen, to tremble ; $\mathbf{L}$. tremere, to tremble]. To be affected with slight, quick, and continued vibratory movements ; to quiver.

Trembles (trem'-blz) [tremere, to tremble]. Synonym of Milk-sickness. Also used as a synonym of Paralysis agitans.

Trembling (trem'-bling) [tremere, so tremble]. A tremor; quivering; affected with involuntary muscular agitation. T. Chair, a chair used in the treatment of paralysis agitans for giving vibratory motion to the body of the patient seated in it. T. Palsy. Synonym of Paralysis agitans.

Tremellose (trem'-el-ōz) [tremere, to tremble]. In biology, jelly-like.

Tremens (tre'-menz). See Delirium

Trementina (tra-men-te'-nah) [Sp.]. The resin of Espelitia grandiflora, used medicinally. T. Común, 
[Mex. Ph.], a thick, granular turpentine used as a balsamic stimulant.

Tremogram (trem'-o-gram) [tremare, to tremble; $\gamma \rho a ́ \mu \mu \alpha$, a writing]. The tracing of tremor made by means of the tremograph.

Tremograph (trem'-o-graph) [tremare, to tremble;

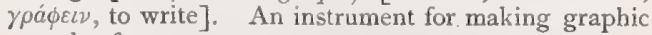
records of tremor.

Tremor (trem'-or) [tremere, to shake]. An involuntary trembling or agitation of the body, or some part of it. T., Arsenical, a tremor the result of arsenical intoxica tion. T. capitis, tremor affecting the muscles of the neck and head. T. coactus. Synonym of T., Forced. T., Continuous, a form of tremor which resembles that of paralysis agitans; it is, however, likely to be remittent, and may be diminished or arrested by voluntary effort. T., Convulsive. See Paramyoclonus. . T., Epileptoid, intermittent clonus with tremor. T., Fibrillary, tremor caused by consecutive contractions of separate muscle-fibrillæ. T., Forced, the convulsive movements persisting during repose after voluntary motion, due to an intermittent and rhythmic irritation of the nervous centers. T., Hysteric, the tremor observed in bysteria, and due to the uncertainty of nervous impulse. T., Intention, one appearing on voluntary movement. T., Intermittent, the tremor commonly observed in hemiplegics on any attempt at voluntary motion. T., Mercurial, a peculiar form of tremor observed among smelters and others exposed to the fumes of mercury. It is sudden or gradual in onset, and is usually unaccompanied by salivation. The arms are first involved, and then the entire muscular system. If allowed to go on, paralysis, mania, and idiocy may result. T., Muscular, slight, oscillating, rhythmic muscular contractions. T., Purring. Synonym of Purring Thrill. T. saturninus, the tremor of leadpoisoning. T. tendinum. Synonym of Subsultus tendinum. T., Vibratile. Synonym of Fremitus. T., Volitional, a trembling of the entire body during voluntary effort, as observed in multiple sclerosis. See $T$., Intentional.

Tremorless (trem'-or-less) [tremere, to tremble]. Free from tremor.

Tremulation (trem-u-la'-shun) [tremulare, to tremble]. A tremulous condition.

Tremulous (trem'-u-lus) [tremere, to shake]. Trembling. T. Iris. See Iris.

Trendelenburg Posture. See Postures, Table of.

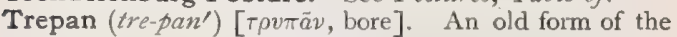
word trephine. See Trephine.

Trepanatio (trep-an-a'she-o) [L.]. See Trephining. $\mathbf{T}$. corneæ, an operation for conical cornea, by means of the conical trephine. $\Lambda$ small circular piece is removed from the center of the cornea. The membrane of Descemet only is penetrated. A hernia at once forms, which is daily punctured until the cicatricial process is complete.

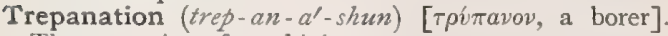
The operation of trephining.

Trepang (tre-pang') [Malay, tripang]. The sea-slug, or bichodomar, Holothuria edulis;" a worm-like seaanimal highly prized in China as an ingredient of soups; regarded as analeptic. Unof.

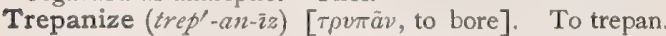

Trepanning (tre-pan'-ing $)$ [ $\tau \rho v \pi a \tilde{\nu} t$, to bore]. Boring; using the trephine. T.-elevator, a lever used to raise the piece of bone detached by the trepan.

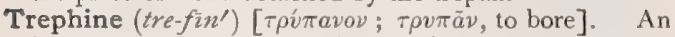
instrument for excising a circular piece of bone, usually from the skull. T., Brace, a trephine with an ordinary carpenters' hrace. T., Conical, a trephine with a truncated cone-shaped crown and provided with oblique ridges on its outer surface to stop its progress as soon as the bone is penetrated. T., Corneal, a small cutling trephine used to remove a circular section from the summit of a conical cornea. It is manipulated with the thumb and finger. T. of Galt, a form of conical trephine. T., Nasal, an instrument made of a steel shaft ending in a small, fenestrated tube, having a knife or saw edge. T., Tympanic, an instrument made of a small steel shaft ending in a small, polished tube, $2 \mathrm{~mm}$. in diameter, with a cutting edge.

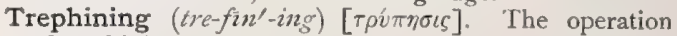
of trephining.

Trepidant Chair. See Trembling Chair.

Trepidatio (trep-id-a'-she-o) [trepidare, to be agitated]. The state of agitation. T. cordis, palpitation of the heart.

Trepidation (trep-id-a'-shun) [trepidare, to tremble]. A rhythmic movement of the foot in certain forms of paraplegia and in epilepsy.

Treppe (trep'-eh) [Ger.]. See Summation.

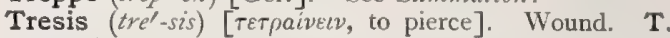
causis. See Burn. T. punctura, a puncture. T. vulnus, a wound.

Tri- [ $\tau \rho \varepsilon \tilde{c} s$, or tres, three]. A numeral used as a prefix to denote three, or triple.

Triacetamid (tri-as-et'-an-id) [tres, three; acetamid], $\left(\mathrm{C}_{2} \mathrm{H}_{3} \mathrm{O}\right)_{3} \mathrm{~N}$. A chemic substance obtained by treating acetonitril with acetic anhydrid.

Triacetin (tri-as'-et-in) [tres, three; acetzm, vinegar], $\mathrm{C}_{3} \mathrm{H}_{5}\left(\mathrm{C}_{2} \mathrm{H}_{3} \mathrm{O}_{2}\right)_{3^{\circ}}$. An oily liquid found in cod-liver oil, in some of the fats, in the oil of Euonymus europeceus and in a mixture of glycerin and glacial acetic acid.

Triacetonamin (tri-as-et-ön'-am-in) [tres, three; acetone; amin], $\mathrm{C}_{9} \mathrm{H}_{17} \mathrm{NO}$. A substance produced by the action of ammonia on acetone. It crystallizes in anhydrous crystals that melt at $39.6^{\circ} \mathrm{C}$.

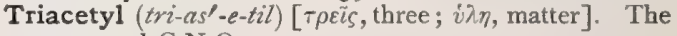
compound $\mathrm{C}_{2} \mathrm{~N}_{3} \mathrm{O}$.

Triacetylene ( $\left.t r i-a s-e t^{\prime}-i l-\bar{e} n\right)$. Synonym of Benzene.

Triacid (tri-as'-id) [tres, three; acidum, acid]. An acid containing three atoms replaceable by $\mathrm{H}$.

Triad (tri'-ad) [tres, three]. See Quantivalence. $T$. of Hutchinson, the combination (notched teeth, interstitial keratitis and otitis) found in subjects of hereditary syphilis.

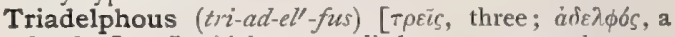
brother]. In biology, applied to stamens that are united by their filaments into three sets.

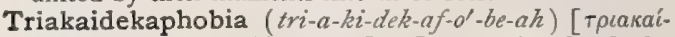
$\delta \varepsilon \kappa a$, thirteen; $\left.\phi \hat{\beta} \beta{ }_{0}, \mathrm{fear}\right]$. Insane dread of the number thirleen.

Trial $\left(\right.$ tri $\left.^{\prime}-a l\right)$ [Fr., trier, to try]. The act of trying or testing. T.-case, a box of lenses for testing and estimating the refraction of the eye, containing biconvex, biconcave, cylindric, prismatic, and other lenses. T.frame, a spectacle-frame into which the trial-lenses may be slipped. T.-glasses or T.-lenses, a graduated set of concave, convex, cylindric, and prismatic lenses used in testing vision. See Spectacle-lenses. T.-jar, a jar in which mixed liquids are allowed to stand in order that they may separate by gravity.

Trialate (tri-a'-lāt) [tres, three; alatus, winged]. In biology, having three wings.

Trialkylic (tri-al-kil'-ik) [tres, three; alkali]. Containing three molecules of an alkyl.

Triallylamin (tri-al-il'-am-in). A chemic compound, $\left(\mathrm{C}_{3} \mathrm{H}_{5}\right)_{3} \mathrm{~N}$.

Triallylin (tri-al'-il-in) [tres, three; allyl], $\mathrm{C}_{12} \mathrm{H}_{20} \mathrm{O}_{3}$. An oxid of allyl and glyceryl.

Triamin (tri-am'-in). See Amin.

Triammonic (tri-am-mon'-ik) [tres, three; antmonia]. Containing three molecules of ammonium. 
Triamylamin (tri-am-il' -am-in) [tres, three; amyl, amin], $\mathrm{N}\left(\mathrm{C}_{5} \mathrm{H}_{11}\right)_{3}$. Tertiary amin of amyl.

Triamylin (tri-am'-il-in) [tres, three; amyl], $\mathrm{C}_{3} \mathrm{H}$ $\left(\mathrm{C}_{5} \mathrm{H}_{11}\right)_{3} \mathrm{O}_{3}$. A compound produced by heating amylalcohol and acrolein with acetic acid.

Triamylphosphin (tri-aml-il-fos'-fin). A compound with the formula $\left(\mathrm{C}_{5} \mathrm{H}_{11}\right)_{3} \mathrm{P}$.

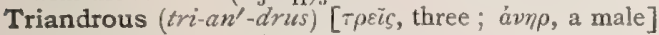
In biology, having three stamens.

Triangle (tri'-ang-gl) [tres, three; angulus, angle]. A space bounded by three lines or sides and with three corners or angles. T. of Assegat, a triangle formed by lines uniting the projection of the nasion on the alveolo-condylar plane and the alveolar and nasal points and one uniting the two latter. T. of Bryant. See $T$., Ilio-femoral. T., Carotid, Inferior " Triangle of necessity "), located in the neck ; it is bounded ventrad by the median line of the neck, dorsad by the ventral margin of the sterno-mastoid, and cephalad by the ventral belly of the omo-hyoid. Its floor is formed by the longus colli below and the scalenus anticus above. The common carotid artery, internal jugular vein, vagus nerve, superficialis colli nerve, a branch of the communicans noni, the inferior thyreoid artery, the recurrent laryngeal nerve, the sympathetic nerve, the trachea, thyreoid gland, and larynx are the important structures within it. T., Carotid, Superior " Triangle of election "), located in the neck; it is bounded dorsad by the sterno-mastoid, ventrad by the ventral belly of the omo-hyoid, and cephalad by the dorsal belly of the digastric. Its floor is formed by the thyreo-hyoid, hyo-glossus, and inferior and middle constrictors of the pharynx. The important structures contained within it are the common carotid artery and its bifurcation into the external and internal carotids, the superior thyreoid artery, the lingual artery, the facial artery, the occipital and ascending laryngeal arteries, the internal jugular vein and the veins corresponding to the arteries mentioned, the descendens noni, hypoglossal, pneumogastric, sympathetic, spinal accessory, superior laryngeal, and external laryngeal nerves. T., Cephalic, a triangle on the antero-posterior plane of the skull bounded by lines joining the occiput with the forehead and with the chin and a line joining the latter two. T., Digastric. See T., Submaxillary. T. of Elbow, a triangle lying in front of the elbow with the base directed upward toward the humerus, bounded externally by the supinator longus and internally by the pronator radii teres. Its floor is formed by the brachialis anticus and supinator brevis. Its contents are the brachial artery and veins, the radial and ulnar arteries, the median and musculo-spiral nerves, and the tendon of the biceps. T. of Election. See T., Carotid, Superior. T., Facial, a triangle formed by lines uniting the basion with the alveolar and nasal points and a line joining the latter two. T., Frontal, a triangle bounded by the maximum frontal diameter and lines joining its extremities and the glabella. T. of Hesselbach, a triangle at the lower part of the abdomen bounded laterad by the deep epigastric artery, caudad by Poupart's ligament, and mesad by the margin of the rectus muscle. It is of importance in direct inguinal hernia. T., Ilio-femoral, a triangle located at the hip. Its hypothenuse is formed by Nélaton's line, a second side by the continuation outward of a line drawn through the two superior iliac spines, and the third by a line drawn at right angles to this from the summit of the greater trochanter. It contains the external abdominal ring. $\mathbf{T}$., Inferior Occipital, a triangle having the bimastoid diameter for its base and the inion for its apex. T., Infra-clavicular, a triangle situated below the clavicle; it is bounded above by the clavicle, below and to the inner side by the upper border of the great pectoral muscle, and to the outer side by the anterior border of the deltoid. It contains the axillary artery. T., Inguinal. Same as $T$., Scarpa's, q. v. T. of Lesser, a triangle located in the neck. Its boundaries are as follows: at its upper border the hypoglossal nerve; the two sides are formed by the ventral and dorsal bellies of the digastric muscle. It is covered by the skin, superficial and deep fasciæ, and apex of the submaxillary gland. The floor is formed by the hyo-glossus muscle. It contains the ranine vein and hypoglossal nerve. $T$. Lumbo-costo-abdominal, a triangle which is bounded anteriorly by the external oblique, superiorly by the lower border of the serratus posticus inferior and the point of the I 2 th rib, posteriorly by the outer edge of the erector spinæ and inferiorly by the internal oblique. T., Mandibulo-condylar, a triangle having its apex at the symphysion and its base between the two condyles. T. Mandibulo-coronal, a triangle having its apex at the symphysion and its base between the two corona. $\mathrm{T}$., Mandibulo-gonial, a triangle having its apex at the symphysion and its base between the two gonia. $T$., Mento-condylar, a triangle formed by lines joining the mental point to the condyles of the inferior maxilla and these with each other. T., Mento-condylial, the triangle of $\mathrm{A}$. von Török having its base between the condyles of the inferior maxilla and its apex at the gnathion. T., Mento-coronal, a triangle formed by lines joining the mental point with each extremity of a line joining the two corona. T., Mento-gonial, a triangle of A. von Török having the bigoniac diameter as its base and the gnathion as its apex. T., Mentomastoid, a triangle of $\mathrm{A}$. von Török with the bi-mastoid diameter as a base and the gnathion as an apex. T., Mylo-hyoid, the three-cornered space bounded by the mylo-hyoid and the two bellies of the digastric. T. of Necessity. Same as T., Carotid, Inferior. T. of the Neck, Anterior, a triangle bounded ventrad by a line extending from the chin to the sternum, dorsad by the ventral margin of the sterno-mastoid, and the base is formed by the lower border of the body of the inferior maxilla and a continuation of this line to the mastoid process of the temporal bone. It is covered by the integument, the superficial and deep fasciæ, and the platysma myoides. It is subdivided into three smaller triangles by the digastric muscle above and the ventral belly of the omo-hyoid below. These are named from below upward the inferior carotid, the superior carotid, and the submaxillary.q. $v$. T. of the Neck, Posterior, a triangle bounded ventrad by the sterno-mastoid muscle, dorsad by the ventral margin of the trapezius; the base is formed by the upper border of the clavicle. The apex corresponds to the occiput. It is divided by the dorsal belly of the omo-hyoid muscle into two triangles, the occipital or upper, and the subclavion or lower, $q$. $v$. T., Occipital, a triangle with the following boundaries: ventrad, the sterno-mastoid muscle; dorsad, the trapezius, and caudad, the omo-hyoid muscle. Its floor is made up of the splenius, the levator anguli scapulæ, and the middle and posterior scaleni. Its important contents are the spinal accessory nerve, the ascending and descending branches of the cervical plexus, and the transversalis colli artery and vein. T., Omoclavicular. Same as T., Subclavian, q. v. T., Omohyoid. Same as T., Superior Carotid. T., Omotracheal. See T., Carotid Inferior. T., Palatal, a triangle of A. von Török having the width of the palate as its base and the alveolar point as its apex. $T$. of Petit, an abdominal triangle bounded below by the crest of the ilium and laterally by the external oblique and latissimus dorsi. It is covered by the skin and fascia and its floor is formed by the internal oblique. T., Pubo- 
urethral, a triangle situated in the perineum. Its boundaries are externally the ischio-cavernosus muscle, internally the bulbo-cavernosus muscle, and posteriorly the transversus perinai. T. of Scarpa, a triangle located in the proximal third of the thigh. The bounda ries are externally the sartorius muscle, internally the adductor longus muscle, and above Poupart's ligament. It is covered by skin and the superficial and deep fasciae. Its floor is formed by the iliacus, psoas, pectineus, adductor longus, and part of the adductor brevis. Its important contents are the femoral artery and vein, the anterior crural nerve, and the crural branch of the genito-crural nerve. Ts., Simon's, the groin, the internal face of the thighs, and the hypogastric region form the femoral triangle of Simon; the surface of the axilla, the pectoral region, and the inner aspect of the arm, the brachial triangle of Simon. These regions are often the seat of variolous rashes, or roseole variolose, which appear on the second and third days of the invasion-stage of smallpox. T., Subclavian, a triangle of the neck bounded cephalad by the dorsal belly of the omo-hyoid muscle, caudad by the upper border of the clavicle. Its base, directed ventrad, is formed by the sterno-mastoid muscle. Its floor is made up of the first rib, with the first digitation of the serratus magnus. It contains the subclavian artery and occasionally the vein, the brachial plexus of nerves, the supra-scapular vessels, the transversalis colli artery and vein, and the external jugular vein. T., Submaxillary, a triangle of the neck formed cephalad by the lower border of the body of the inferior maxilla and a continuation of this line to the mastoid process of the temporal bone, caudad by the dorsal belly of the digastric and the stylo-hyoid muscle, and ventrad by the middle line of the neck. Its floor is made up of the ventral belly of the digastric, the mylohyoid and hyo-glossus muscles. It contains the submaxillary gland, the facial artery and vein, the submental artery, the mylo-hyoid artery and nerve, and the stylo-maxillary ligament, behind which is the external carotid artery. T., Suboccipital, a triangle in the dorsal part of the neck. It is formed by the rectus capitis posticus major, and superior and inferior oblique muscles. It is covered by the complexus muscle, and contains the vertebral artery. T., Superior (of the neck). Same as T., Carotiit, Superior. T., Surgical, a triangular space containing important vessels and nerves which may require to be operated upon. ' $T$., Upper Cervical. See $T$., Carotid, Superior. T., Vesical, a triangle at the base of the bladder-the trigonum of the urinary bladder. The apex is at the beginning of the urethra, and the other two angles at the orifices of the ureters.

Triangular (tri-ang'-gu-lar) [triangulus, three-cornered]. Pertaining to figures with three sides, and applied to a number of such-shaped organs or parts of the body.

Triangulare (tri-ang-gu-la'-re) [triangularis, threecornered]. A peculiar bone of the tarsus of some animals.

Triangularis (tri-ang-gu-la'-ris). See Muscles, Table of.

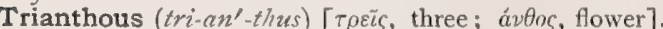
In biology, three-flowered.

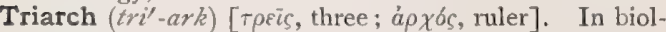
ogy, a term descriptive of radial fibro-vascular bundles having three rays.

Triarsenate $\left(t r i-a r^{\prime}-\operatorname{sen}-\bar{a} t\right)$. See Arsenate.

Triatomic (tri-at-om'-ik) [tres, three; atomus, an atom]. In chemistry, consisting of three atoms; applied to the molecules of elements when the atoms are of the same kind. Also, the same as trivalent. Also, having three hydroxyl groups by which other atoms or radicles may be attached without altering the structure of the rest of the molecule.

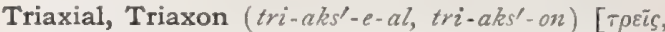
three; $\dot{a} \xi \omega v$, axis]. Having three axes, as some sponge-spicules.

Tribadism $\left(t r i^{\prime}-b a d^{\prime}-i z m\right)$ [ $\tau \rho i \beta \varepsilon \omega$, to rub]. Unnatural sexual relations between women.

Tribaritic (tri-bar-it'-ik) [tres, three; barium]. Possessing three atoms of barium.

Tribas $\left(t^{\prime} b^{\prime}-a s\right)[\tau \rho i \beta \varepsilon \imath \nu$, to rub]. One who practises tribadism.

Tribasic (tri-ba'-sik) [tres, three; basis, a base]. In chemistry, an acid having three hydrogen atoms replaceable by basic atoms

Tribracteate (tri-brak'-te-ät) [tres, three; bractea, a thin plate]. In biology, having three bracts.

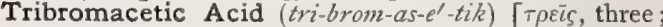
$\beta \rho \tilde{\omega} \mu o s$, stench; acetum, vinegar $], \mathrm{C}_{2} \mathrm{Br}_{3} \mathrm{HO}_{2}$. A monobasic acid derived from acetic acid and occurring in transparent, prismatic crystals.

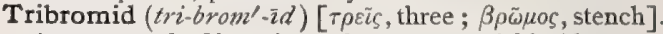
A compound of bromin analogous to a trichlorid.

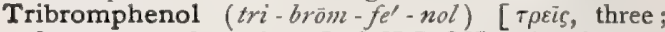
$\beta \rho \bar{\omega} \mu$ s, stench ; phenol ], $\mathrm{C}_{6} \mathrm{H}_{2} \mathrm{BrOH}$. A substance prepared by the reaction of carbolic acid with bromin. It is antiseptic, especially for the intestinal tract. Dose gr. j-iv. Unof. T.-bismuth, a remedy recommended as a specific against Asiatic cholera. It is a yellow, neutral, insoluble powder, destitute of odor and taste and scarcely poisonous. It contains 49.5 per cent. of bismuth oxid and 50 per cent. of tribromphenol. The dose is gr. vijss (gram $1 / 2$ ). Unof.

Tribulus (trib'-u-lus) [ $\tau \rho i \beta o \lambda o s$, a caltrop]. A genus of polypetalous plants, several varieties of which are used medicinally in European countries and in Africa.

Tributum (trib-u'-tum) [tribuere, to render]. A tribute. T. lunare. Synonym of Menstruation.

Tributyrin (tri-bu'-tir-in) [tres, three; butyrum, butter $], \mathrm{C}_{3} \mathrm{H}_{5}\left(\mathrm{O} . \mathrm{C}_{4} \mathrm{H}_{7} \mathrm{O}\right)_{3}$. A compound found in butter. It is liquid, and has a sharp, bitter taste.

Tricaprin (tri-kap'-rin) [tres, three; caper, a goat], $\mathrm{C}_{3} \mathrm{H}_{5}\left(\mathrm{O} \cdot \mathrm{C}_{10} \mathrm{H}_{19} \mathrm{O}\right)_{3}$. A substance found in butter and milk.

Tricaproin (tri-kap'-ro-in) [tres, three; caper, a goat], $\mathrm{C}_{3} \mathrm{H}_{5}\left(\mathrm{O} \cdot \mathrm{C}_{6} \mathrm{H}_{11} \mathrm{O}\right)_{3}$. A substance found in milk and butter.

Tricaprylin (tri-kap'-ril-in) [tres, three; caper, a goat], $\mathrm{C}_{3} \mathrm{H}_{5}\left(\mathrm{O} \cdot \mathrm{C}_{8} \mathrm{H}_{15} \mathrm{O}\right)_{3}$. A substance found in milk and butter.

Tricapsular (tri-kap'-su-lar) [tres, three; capsula, capsule ]. In biology, having three capsules.

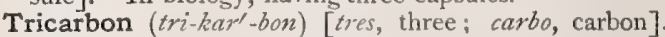
A radicle containing three atoms of carbon.

Tricarpellary (tri-kar'-pel-a-re) [tres, three; carpellus, carpel]. In liology, having three carpels.

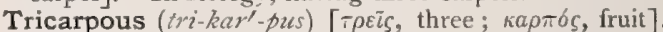
In biology, bearing three fruits or three carpels.

Tricaudalis ( $\left.t r i-k a w-d a^{\prime}-l i s\right)$ [tres, three; cauda, a tail]. The retrahens aurem muscle. So called because it is composed of three slips.

Tricellular (tri-sel'-u-lar) [tres, three; cellula, a cell]. Having three cells.

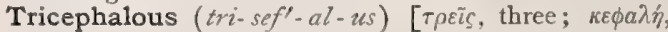
head ]. Having three hearls.

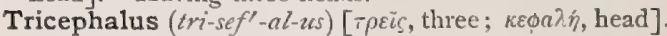
A form of triple monstrosity in which there is the development of three heads on one body.

Triceps (tri'-seps) [tres, three; caput, head]. Applied to certain muscles that have three roots at origin. See Muscles, Table of.

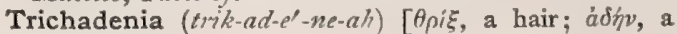
gland]. A genus of the Bixinea. T. zeylanica, 
a tree of Ceylon. An oil is made from the seeds and is used as an application in certain skin-diseases. Unof.

Trichamomillol (tri-kam-o-mil' -ol) [tres, three; chamomile], $\mathrm{C}_{30} \mathrm{H}_{48} \mathrm{O}_{3}$. A deep-blue, viscid substance obtained from the oil of chamomile, ethereal oil of wormwood, and oil of galbanum.

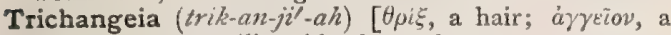
vessel]. The capillary blood-vessels.

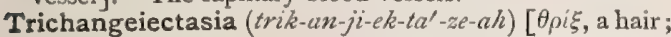

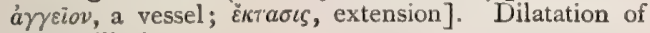
the capillaries.

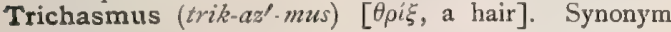
of Hypertrichosis.

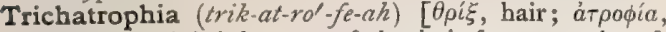
atrophy]. A brittle state of the hair from atrophy of the hair-bulbs.

Trichauxis (trik-awek'-is). See Hirsuties.

Trichia (trik'-e-ah) [ $\theta \rho i \xi$, a hair]. Synonym of Entropion.

Trichiasis (trik-i'-as-is) [ $\theta \rho i \xi$, a hair]. I. Abnormal direction or position of the eyelashes, so that they produce irritation by friction upon the globe. See, also, Distichiasis. 2. A disease of the kidneys or bladder in which filamentous substances resembling hairs are passed in the urine. 3. A swelling of the breasts of puerperal women, the milk being excreted with difficulty.

Trichidium (tri-kid"-e-um) [ $\theta \rho i \xi$, hair : pl., Trichidia]. In biology, a delicate, hair-like structure supporting the spores of certain fungi.

Trichilia (tri-kil'-e-ah) [ $\rho^{\prime} i \chi \varepsilon \iota \lambda o s$, three-lipped]: A genus of polypetalous plants occurring in tropical Africa and America. The bark and fruits of certain varieties have been used medicinally.

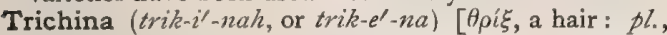
Trichina]. A genus of nematode worms. See Parasites (Animal), Table of.

Trichiniasis (trik-in-i'-as-is) [ $\theta \rho i \xi$, a hair]. The same as Trichinosis.

Trichiniferous (trik-in-if'-er-us) [ $\theta \rho i \xi$, hair; ferre, to bear]. Containing trichinæ.

Trichinization (trik-in-iz-a'-shun) [ $\theta \rho i \xi$, hair]. Infestation with trichinæ.

Trichinophobist (trik-in-o-fo'-bist) [ $\theta \rho i \xi$, hair ; $\phi \circ \beta \varepsilon i \nu$, to fear]. One who has a morbid fear of trichiniasis.

Trichinosis (trik-in-o'-sis) [ $\theta \rho i \xi$, hair ; vooús, disease]. A disease produced by the ingestion of meat, pork, or sausage, containing the Trichina spiralis. The parasites lie coiled up in capsules between the muscular

A

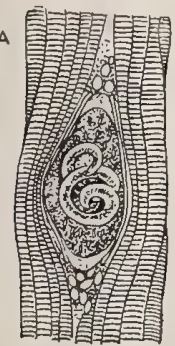

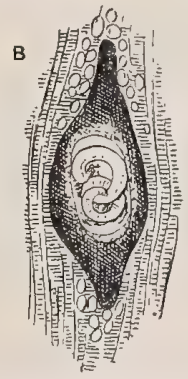

TRICHINA SPIRALIS, Owen: (A) encapsulated with connective-tissue covering (in situ); (B) calcified. (After Leuckart.)

fibers of the meat. After their entrance into the human body their presence gives rise to nausea, vertigo, fever, diarrhea, prostration, stiffness and painful swelling of the muscles, edema of the face, and in some cases perspiration, insomnia, delirium, and death from exhaustion or some complication, as pneumonia.

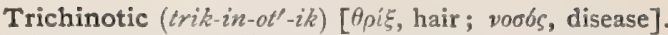
Pertaining to or affected with trichinosis.

Trichinous (trik'-in-us) [ $\theta \rho i \xi$, hair]. Infested with or containing trichinæ.

Trichismus (trik-iz'-mus) [ $\theta \rho i \xi$, a hair]. In surgery, a scarcely perceptible fracture; also, a capillary fissure or crack.

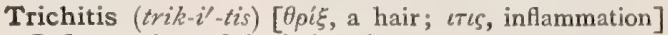
Inflammation of the hair-bulbs.

Trichloracetic Acid (tri-klo-ras-e $-t i k)$. See Acid, Trichloracetic

Trichlorphenol (tri-klor-fel-nol) $[\tau \rho \varepsilon i s$, three; $\chi \lambda \omega \rho \delta ́ s$, green; phenol]. A derivative of carbolic acid, used as a disinfectant, and said to be twenty-five times stronger than carbolic acid. A 2 per cent. solution has been used in purulent ophthalmia.

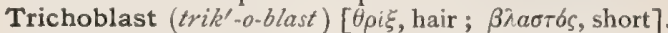
In biology, an internal hair, like those which project into the intercellular spaces of the stems of some waterlilies. Also, a name proposed by Sachs for such idioblasts as are especially distinguished by size and branching.

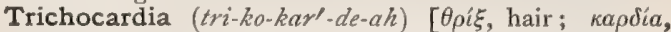
heart]. A peculiar condition of the inflamed pericardium roughened by pseudo-membranous elevations.

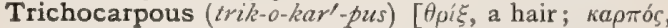
fruit]. In biology, having the fruit covered with hairs

Trichocephaliasis (trik - 0 - sef-al-i'-as - is) $[\theta \rho i \xi$, hair; $\kappa \varepsilon \phi a \lambda \dot{n}$, head]. The diseased condition produced by the presence of a parasite of the genus Trichocephalus.

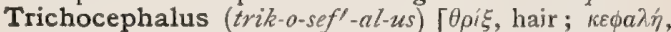
head]. A worm popularly known as threadworm, parasitic in the intestinal tract. See Parasites (Animal), Table of.

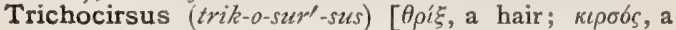
varix ]. A term applied to abnormal capillary dilatation.

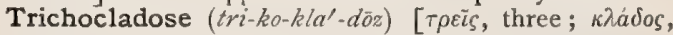
branch]. In biology, trifid or trichotomous.

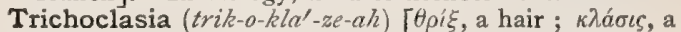
fracture]. Synonym of Trichorrhexis nodosa.

Trichocryptosis (trik-o-krip-to'-sis) [ $\theta \rho^{\prime} \xi$, hair; $\kappa \rho v \pi$ tós, hidden]. Any disease of the hair-follicles.

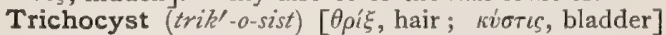
In biology, a small vesicle containing a thread, which can be shot out rapidly, like the nematocyst of a coelenterate, and found in the ectoplasm of the Infusoria and in some of the Flagellata.

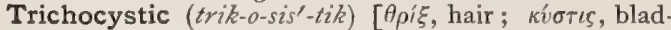
der]. Pertaining to or of the nature of a hair-cell or trichocyst.

Trichodangeia (trik-od-an'-je-ah) [ $\tau \rho \iota \chi \dot{\omega} \delta \eta s$, hair-like ; áryeiov, vessel; pl. of Trichodangeium]. A term synonymous with capillaries.

Trichodangeitis (trik-od-an-je-i'-tis) $[\tau \rho \iota \chi \omega \delta \eta s$, hair like ; á $\gamma \gamma \varepsilon \dot{\varepsilon} i o v$, vessel ; $\iota \tau \iota$, inflammation]. Capillary inflammation.

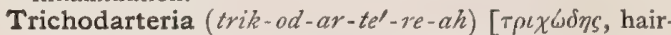
like; ápтnír, an artery]. An arteriole.

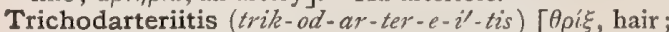
á $\rho \tau \eta \rho i a$, artery; $\iota \tau \iota \varsigma$, inflammation]. Inflammation of the arterioles.

Trichodo-phlebitis (trik-od-o-fleb-i'-tis) $[\tau \rho t \chi \omega \delta \delta \eta s$, hair-like; $\phi \lambda \hat{\psi} \psi$, a vein; $\iota \tau \iota s$, inflammation]. Inflam mation of the venules.

Trichogen (trik'-o-jen) [Api A substance that stimulates the growth of the hair.

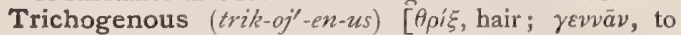
produce]. Encouraging the growth of hair.

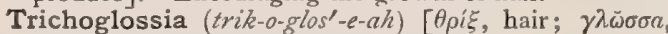
tongue]. The appearance of hair-like villi on the tongue. The filaments are formed by the thickening of the sheaths of the papillæ. 


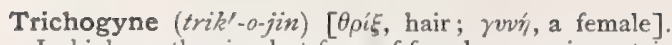
In biology, the simplest form of female organ in certain Alga (Porphyracea and Nemalica) before fertilization. It consists of a single cell with a lateral hair-like prolongation.

Trichogynic (trik-o-jin'-ik) [ $\theta \rho i \xi$, hair; yv'n, a female]. Pertaining to a trichogyne.

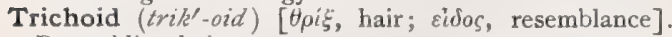
Resembling hair.

Tricholeukosis (trik-o-lu-ko'-sis) [ $\theta \rho i \xi$, a hair; $\lambda \varepsilon u ́ k \omega \sigma \iota s$, whiteness]. Synonym of Canities.

Tricholithus (trik-ol'-ith-us) [ $\theta \rho i \xi$, a bair; $\lambda i \theta 0 s$, a stone]. A hairy concretion.

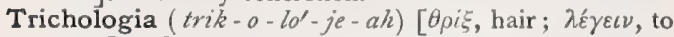
collect]. Carphologia; floccillation.

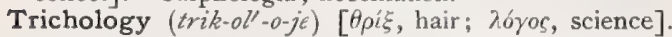
The sum of what is known regarding the hair, its nature and diseases.

Trichoma (trik-o'-mah) [ $\rho^{\prime}(\chi \omega \mu a$, a growth of hair]. 1. In biology, a general term for a plant-hair or hair-like structure; specifically applied to the string of cells or pseudocysts contained in the filament of algæ of the sub-class Nostochinea. 2. See Trichomatosis.

Trichomaphyte (trik-o'-maf-it) [ $\tau \rho i \chi \omega \mu a$, a growth of hair; $\phi v \tau \delta v$, a plant]. A cryptogamic growth which was formerly thought to be the cause of trichomatosis.

Trichomatose $\left(t r i k-o^{\prime}-m a t-\bar{o} z\right)[\tau \rho \iota \chi o \tilde{v} v$, to cover with hair]. Matted together, as hair.

Trichomatosis (trik-o-mat-o'-sis) [ $\theta \rho i \xi$, hair]. An affection of the hair characterized by a matted condition and coherence, due to fungoid growths; plica polonica.

Trichome (tri'-kōm). [ $\theta \rho i_{\xi}$, hair]. See Trichoma.

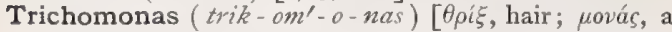
monad]. A genus of infusorians. See Parasites (Animal), Table of.

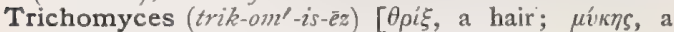
mushroom]. Synonym of Trichophyton.

Trichomycosis (trik-o-mi-ko'-sis) [ $\theta \rho i \xi$, hair; $\mu i \kappa \eta \zeta$, a mushroom]. Any disease of the hair produced by a vegetable parasite. T. barbæ. Synonym of Sycosis parasitaria. T. capillitii. Synonym of $T$. circinata. $T$. circinata, ringworm of the scalp, produced by the Trichophyton tonsurans. 'T. favosa. See Favus. T. nodosa, a peculiar condition, generally nodose in character, affecting the hairs of the axilla and scrotum, and due to the growth and encapsulation in the cortical layers of the shaft of a small rod-shaped bacterium. T. pustulosa, a pustular, parasitic disease affecting hairy regions.

Trichonosis, Trichonosos (trik-on'-o-sis, trik-on'-osos) $\left[\theta_{\rho} i \xi\right.$, hair; v6бos, disease $]$. Any disease of the hair. T. cana. See Canities. T. discolor. See Canities. T. furfuracea. Synonym of Tinea tonsurans, T. versicolor. See Ringed Hair.

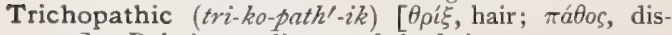
ease]. Relating to disease of the hair.

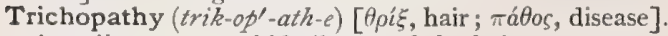
Any disease or morbid ailment of the hair.

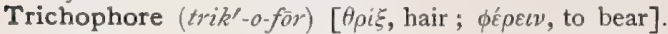
In biology: $(a)$ the cell or cells immediately supporting a trichogyne; $(b)$ a process of the integument inclosing the base of the bundle of setæ in certain annelids (Polychata).

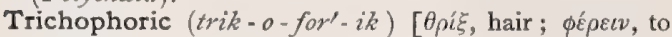
bear]. Pertaining to the trichophore.

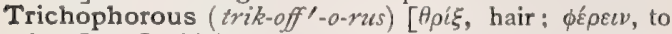
bear]. In biology, bearing hairs or hair-like structures.

Trichophytinous (trik-off-it-i'-nus) [ $\phi \rho^{\prime} \xi$, hair; $\phi v \tau b v$, a plant]. Pertaining to the presence of Trichophyton tonsurans.

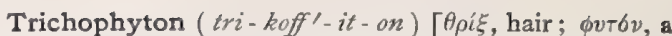
plant]. A genus of fungoid, vegetable organisms parasitic upon or affecting the hair. $T$. tonsurans is the cause of tinea tonsurans, or ringworm.

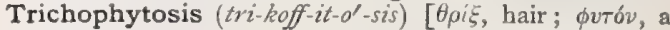
plant]. A contagious disease of the skin and hair, occurring most often in children, due to the invasion of the epidermis by the trichophyton-fungus, and characterized by the formation of circular or annular, scaly patches and partial loss of hair. See Tinea. T. barbæ. Synonym of Sycosis parasitaria. T. capitis, trichophytosis of the scalp. T. corporis. Synonym of Dermatomycosis maculo-vesiculosa. T. cruris. Synonym of Marginal Eczenn.

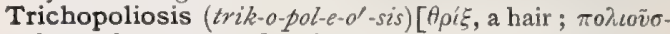
$\theta a \iota$, to become gray]. Synonym of Canities.

Trichoptilosis (trik-op-til-o'-sis). Synonym of Trichorrhexis nodosa.

Trichoptylose (trik-op'-til-oz). Synonym of Trichorrhexis nodosa.

Trichorrhea (trik-or-e'-ah) [ $\theta \rho i \xi$, hair; poía, a flow]. Rapid loss of the hair.

Trichorrhexis (trik-o-reks'-is) [ $\theta \rho i \xi$, hair; $\dot{\rho} \bar{\eta} \xi \iota s$, a breaking]. Brittleness of the hair. T. nodosa, an atrophic condition of the hair affecting more often the male beard, wherein several irregular thickenings resembling nodes can be recognized on each shaft, the hairs often breaking with a "green-stick fracture" immediately through the node.

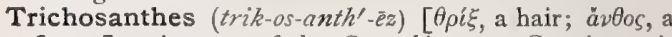
flower]. A genus of the Cucurbitacece. Certain varieties, chiefly East Indian, are used medicinally.

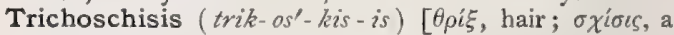
splitting]. The splitting of the hair.

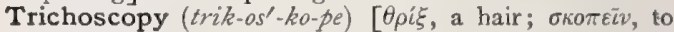
examine]. The examination of the hair.

Trichosis (trik-o'-sis) [ $\theta \rho i \xi$, hair; vóoos, disease $]$. Any morbid affection of the hair. T. athrix. Synonym of Alopecia. T. decolor, morbid discoloration of the hair. T. deformis, a morbid change in the quality of the hair. T. distrix. Synonym of Trichoptilosis. T. hirsuties. Same as Hirsuties. T. plica. See Plica polonica and Trichomatosis. T. poliosis. See Canities. T. sensitiva, a sensitive state of the scalp; any manipulation causing pain. T. setosa, a disease in which the hair grows thick, rigid, and bristly.

Trichosporangium (trik-o-spo-ran'-je-um) [ $\theta \rho i \xi$, hair ;

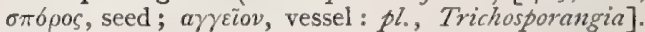
In biology, a sporangium having the function of a hair.

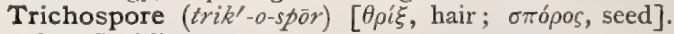
See Conidium.

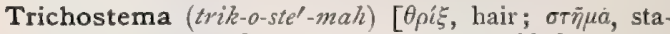
men]. A genus of gamopetalous plants. T. lanatum, black sage. It is used as a hair-tonic and to make the hair dark.

Trichostereticus (trik-o-ster-et'-ik-us) [ $\theta p i \xi$, a hair;

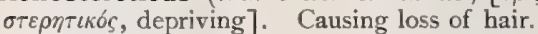

Trichosyphilis (trik-o-sif'-il-is) [ $\theta \rho i \xi$, hair; syphilis, syphilis]. Any syphilitic disease, or affection of the hair.

Trichosyphilosis (trik-o-sif-il-o'sis). Synonym of Trichosyphilis.

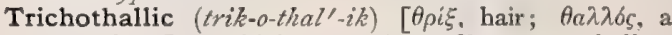
green shoot]. In biology, having a filamentous thallus.

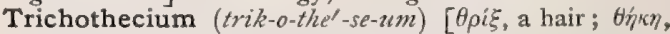
a chest]. A vegetable parasite of the hair. T. roseum, A fungous growth found in the ear.

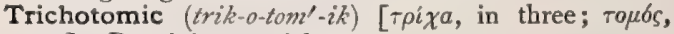
cut]. Pertaining to trichotomy.

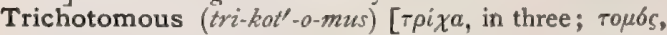
cut]. In biology, three-forked.

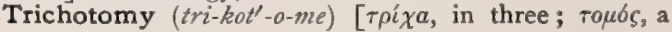
cut]. Division into three parts. 


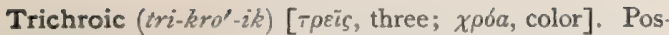
sessing the property of trichroism.

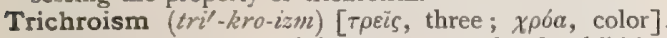
The property possessed by some crystals of exhibiting different colors in three different directions when viewed by transmitted light.

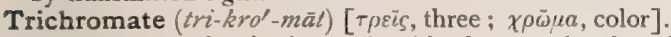
A compound of a basic oxid with three molecules of chromium trioxid.

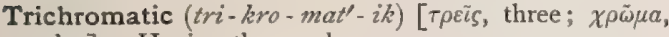
color]. Having three colors.

'Trichromic (tri-kro'-mik) [ $\tau \rho \varepsilon i s$, three; $\chi \rho \tilde{\omega} \mu \alpha$, color]. Trichromatic.

Tricipital (tri-sip'-it-al) [triceps, three-headed]. Threeheaded. Having three origins.

Triclinate (trik'-lin-ät). Same as Triclinic.

Triclinic (tri-klin'-ik) [ $\tau \rho \varepsilon \bar{c} \varsigma$ three; $\kappa \lambda i \nu \varepsilon \omega \nu$, to incline]. Pertaining to the inclination of three intersecting axes with one another.

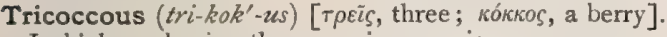
In biology, having three cocci, or mericarps.

Tricocephalus (trik-o-sef'-al-us) [ $\theta \rho \dot{\prime} \xi$, hair; $\kappa \varepsilon \phi a \lambda \eta \dot{~}$ head]. See Trichocephalus, and Parasites (Animal), Table of.

Tricodein (tri-kol-de-in) [tres, three; codein]. A compound formed by the action of sulphuric acid on codein. Given to animals in full doses it causes vomiting, ptyalism, and catharsis.

Tricolor (tri'-kul-or) [L.]. Three-colored.

Tricornate $\left(\right.$ tri-korn' $\left.^{\prime}-\bar{t}\right)$ [tres, three; cornu, horn]. Three-horned, or having three horn-like appendages.

Tricorni, Bacillus of. See Bacteria, Synonymatic Table of.

Tricornigerous (tri-kor-nij'-er-us). Same as Tricornute.

Tricornis (tri-kor'-nis) [tres, three; cornu, horn]. Having three processes or prominences. A descriptive name applied to the lateral ventricles of the brain.

Tricornute (tri-kor'-nüt) [tres, three; cornutus, horned]. In biology, having three horn-like appendages.

Tricostate (tri-kos'-tât) [tres, three; costalus, ribbed]. In biology, having three ribs, or costæ.

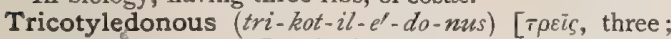

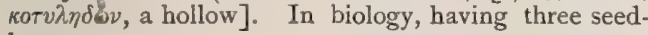
leaves.

Tricrotic (tri-krot'-ik) [трikpotos, with three strokes]. Having three waves, as a tricrotic pulse; exhibiting tricrotism.

Tricrotism (tri'-kro-tizm) [то'кротоs, having three strokes]. The presence of three elevations on the down-stroke of a pulse-tracing; the quality of being tricrotic.

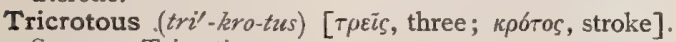
Same as Tricrotic.

Tricrural (tri-kru'-ral) [tres, three; crus, leg]. In biology, having three branches from a common center.

Tricuspid (tri-kus'-pid) [tres, three; cuspis, point]. Having three cusps or leaflets. See Valve. T. Incompetence. See Endocarditis. T. Stenosis. See Endocarditis. T. Valve. See Valve.

Tricuspidal (tri-kus'-pid-al). Same as Tricuspid.

Tricuspidate (tri-kus'-pid-ât) [tres, three; cuspis, a point]. In biology, tipped with three cusps, or small, hard teeth.

Tricyanic Acid (tri-si-an'-ik). See Acid.

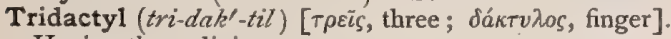
Having three digits.

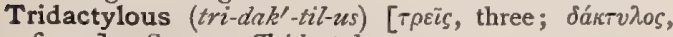
finger]. Same as Tridactyl.

Tridentate (tri-den'-tät) [tres, three; dens, tooth]. In biology, three-toothed.

Trideroatlodymus (tri-der-o-at-lod'-im-us) [tres, three; deroatlodymus]. A rare variety of triple monster, pre senting features of the derodidymus and of the atlodymus.

Tridigitate (tri-dij'-it-ät) [tres, three; digitus, finger]. Having three fingers or digitations.

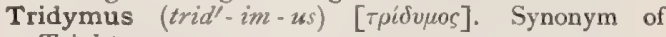
Triplet.

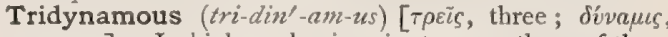
power]. In biology, having six stamens, three of them longer than the others.

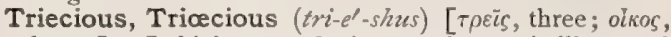
house]. In biology, producing staminate, pistillate, and perfect flowers respectively on different plants.

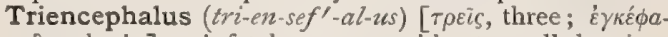
hos, brain]. A fetal monster without smell, hearing, or sight.

Triethylamin (tri-eth-il'-am-in) [tres, three; ethyl, amin]. A ptomain obtained from haddock left to putrefy in an open vessel for five days in summer. As a free base, it has an oily character and an ammoniacal odor. It is but slightly soluble in water; boils at $89^{\circ}$ $89.5^{\circ} \mathrm{C}$; and is but slightly toxic. See Ptomains, Table of.

Trifacial (tri-fa'-shal). See Trigeminus.

Trifarious (tri-fa'-re-us) [trifarius, of three sorts, threefold]. In biology, arranged in three rows or series.

Trifasciated (tri-fash'-e-a-ted) [tres, three; fascia, band]. In biology, three-banded.

Trifid $\left(t i^{\prime}-f d\right)$ [tres, three; findere, to cleave]. Threecleft.

Triflagellate (tri-flaj'-el-ät) [tres, three; fugellum, a whip]. Having three flagella; trimastigate.

Trifloral, Triflorous $\left(t r i-f o^{\prime}-r a l\right.$, tri $\left.-f o^{\prime}-r u s\right)$ [tres, three; flos, a flower]. In biology, three-flowered.

Trifluorid (tri-flu'-or-id) [tres, three; fuorin]. A fluorin compound analogous to a trichlorid.

Trifoliate (tri-fo'-le-ät) [tres, three; folium, a leaf ]. In biology, three-leaved.

Trifolium (tri- $\left.f o^{\prime}-l e-u m\right)$ [tres, three; folium, leaf ]. A genus of leguminous herbs; the clover. T. pratense (common red clover) is vaunted in the treatment of whooping-cough, syphilis, and carcinoma. Unof. $T$. Compound, a syrup containing in each fluid-ounce the active principles of red clover gr. 32 , stillingia, burdock, poke, berberis, aquefolium, and cascara amarga āā gr. 16, prickly-ash bark 4, potassium iodid gr. 8 . It is recommended in syphilis. Dose $3 \mathrm{j}$-ij. Unof.

Trifoveolate (tri-fo'-ve-o-latt) [tres, three; foveola, a little pit]. Having three foveæ.

Trifurcate (tri-fur-kät) [tres, three; furca, fork]. Three-forked.

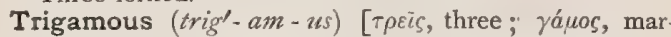
riage]. In biology, having staminate, pistillate, and perfect flowers in the same head.

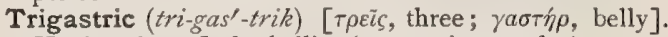
Having three fleshy bellies (as certain muscles).

Trigeminal $\left(t r i-j e m^{\prime}-i n-a l\right)$ [tres, three; geminus, twin-born]. Triple; pertaining to the trigeminus. $T$. Cough. See Cough.

Trigeminous (tri-jem'-in-us) [tres, three ; gemini, double]. I. Born three at a time. 2. Same as Trigeminal.

Trigeminus (tri-jem'-in-us) [tres, three; gemini, double]. The descriptive name of the fifth pair of nerves, which divide each into three branches.

Trigger (trig'-er) [Ger, Drücker, a trigger]. A device by means of which a catch or spring is released. $T$--area, a sensitive region of the body, irritation of which may give rise to certain peculiar phenomena, either physiologic or pathologic, in some part of the body. T.-finger, a condition in which flexion or ex- 
tension of a finger is at first obstructed, but finally accomplished with a jerk or sweep. T.-material, an apheter; any theoretic catastatic substance whose sudden breaking up communicates an explosive decomposition to the protoplasm directly concerned in any function. The trigger-material itself must be acted upon by another trigger-material; and thus every nerve-impulse and every functional act must be accompanied by the destruction of a fuse-like train of protoplasm. See Apheter.

Triglans (tri'-glanz) [tres, three; glans, acorn, nut]. In biology, having three nuts within an involucre.

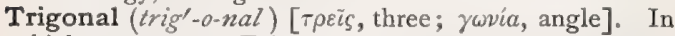
biology, same as Trigonous.

Trigone $\left(\right.$ tri' $\left.^{\prime}-g o ̄ n\right)$. Synonym of Trigonum. T., Olfactory. Synonym of Caruncula mammillaris. $\mathbf{T}$. of Bladder. See Trigonum vesice.

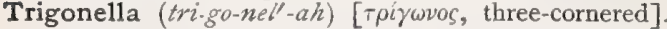
A genus of Leguminose. T. elatior, a variety, the seeds of which bave been used in affections of the bladder and in poultices. T. fœenum græcum, a variety used in plasters and salves and in veterinary medicine, $T$. monspeliaca, a variety a decoction of the seeds of which is used by the Italians in various forms of diarrhea.

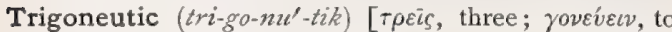
beget]. In biology, producing three sets of offspring in a season.

Trigonocephalic (trig-o-no-sef-al'-ik) $[\tau \rho i \gamma \omega v o s$, threecornered; $\kappa \varepsilon \phi a \lambda \eta$, head]. Pertaining to trigonocephaly.

Trigonocephalus (trig-o-no-sef'-al-us) [ $\tau \rho i \gamma \omega v o s$, three-

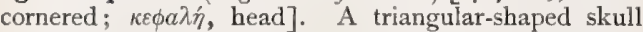
with the small end anterior, due to a premature union of the coronal suture.

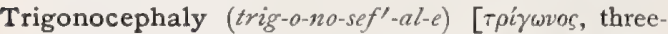
cornered; $\kappa \varepsilon \phi a \lambda \dot{\eta}$, head]. A deformity of the skull produced by a premature union of the medio-frontal or metopic suture. See Trigonocephahus.

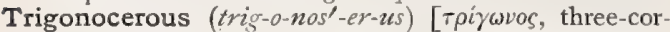
nered; ке́ $\rho \varsigma$, horn]. In biology, having three-edged horns.

Trigonous (trig'-o-nus) [ $\tau \rho \dot{\prime} \gamma \omega \nu o s$, three-cornered]. In biology, three-angled.

Trigonum (tri-go'-num) [ $\tau \rho i \gamma \omega v o s$, three-cornered]. A triangle; also the interpeduncular space. T.acustici, a three-cornered space on the dorsal surface of the medulla. T. cerebrale. Synonym of Fornix cerebri. $\mathbf{T}$. cervicale, the base of the dorsal gray cornu of the spinal cord. T. clavipectorale, a triangle of the chest. Its boundaries are the clavicle, the pectoralis minor muscle, and the thorax. T. colli medianum, relating to the space occupied by the two anterior triangles of the neck. $T$. coraco-acromiale, a triangular space whose boundaries are the coracoid process, the apex of the acromion, and the concave border of the clavicle. T. dorsale the space between the anterior pair of the corpora quadrigemina. $T$. fluctuans, the posterior cerebral commissure. $\mathbf{T}$. habenulæ, the triangular space behind the upper surface of the optic thalamus, in front of the lamina quadrigemina, and between the sulcus habenulae and the sulcus subpinealis. T. hypoglossi, a triangular space on the dorsal surface of the oblongata. Its boundaries are, above, the striæ medullares acusticæ, internally, the posterior longitudinal fissure, and, externally, the ala cinerea. T. inferius commissuræ posterioris, the lower triangular half of the posterior commissure of the brain. T. pensile, the posterior cerebral commissure. T. vagi, a small, triangular space on the medulla oblongata, marking the origin of the vagus nerve, $T$. ventriculi lateralis, a triangular projection located between the entrances to the posterior and descending horns of the lateral ventricle. T.vesicx, the triangular surface of the bladder immediately behind the urethral orifice.

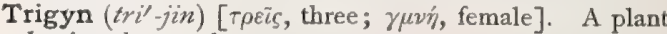
having three styles.

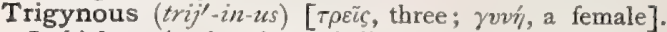
In biology, having three pistils.

Trihaloid (tri-hal'-oid) [tres, three; haloia]. A compound of a radicle with three atoms of hydrogen.

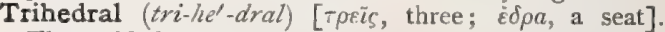
Three-sided.

Trihilate (tri-hi'-lät) [tres, three; hilum, a hilum]. Having three hila or scars, as a seed.

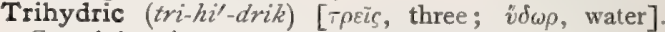
Containing three atoms of hydrogen in the molecule.

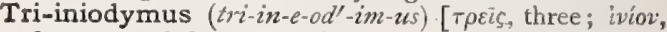
the nape of the neck; $\delta i \delta v \mu o s$, double]. A monster having three heads united posteriorly and attached to a single body.

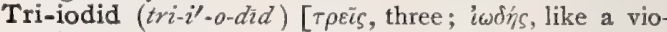
let]. A compound of iodin analogous to a trichlorid.

Trijugate, Trijugous (tri-ju'-gāt, tri-ju'-sus) [tres, three; jugum, a yoke]. In biology, having three pairs of leaflets.

Trilabe $\left(t r i^{\prime}-l \bar{a} b\right)[\tau \rho \varepsilon \tilde{c}$, , three; $\lambda \alpha \mu \beta a$ ive $\nu$, to grasp]. An instrument with three prongs, for withdrawing small calculi through the urethral passage

Trilabiate $\left(t r^{\prime}-l a^{\prime}-b e-\bar{a} t\right)$ [tres, three; labium, lip]. Three-lipped.

Trilaminar (tri-lam'-in-ar) [tres, three; lamina, plate]. In biology, three-layered.

Trilineate (tri-lin'-e-ät) [tres, three; linea, line]. In biology, marked with three longitudinal lines.

Trilisa (tril'-is-ah) [L.]. A genus of composite eupatoriaceous plants. T. odoratissima. See Deer's Tongue.

Trilliin (tril'-e-in) [tres, three]. A precipitate from a tincture of the root of Trillium pendulum, styptic, tonic, expectorant, antiseptic, and emmenagogue. Dose, 2 to 4 grains. Unof. See Beth-root.

Trilobate $\left(t r i-l o^{\prime}-b \bar{a} t\right.$, or tri'-lo-bāt $)$ [tres, three; lobatus, lobed]. In biology, three-lobed.

Trilobed $\left(t r i^{\prime}-l o b d\right)$. Same as Tritobate.

Trilocular (tri-lok'-u-lar) [tres, three; loculus, cell]. In biology, having three chambers.

Triloculate (tri-lok'-u-lāt) [tres, three; loculus, a cell]. In biology, same as Trilocular.

Trimacular, Trimaculated (tri-mak'-u-lar, tri-mak' . $u$-la-ted) [tres, three; macula, spot]. In biology, marked with three spots.

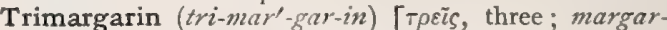
in ]. A mixture of tripalmitin and tristearin.

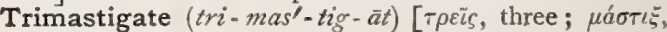
whip, scourge]. In biology, having three flagella; triflagellate.

Trimembral (tri-mem'-bral) [tres, three; membrum, member]. Having three members.

Trimercuric (tri-mer-ku'-rik) [tres, three; mercury]. Containing three atoms of bivalent mercury.

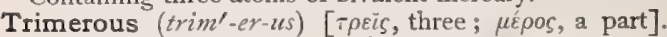
In biology, having three parts or segments; in three's.

Trimesic Acid (tri-mes'-ik). See Acid.

Trimester (tri-mes'-ter) [trimestris, of three months]. A stage or period of three months.

Trimestral, Trimestrial (tri-mes'-tral, tri-mes'-tre-al) [trimestris, of three months]. Pertaining to a trimester.

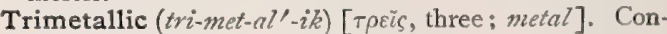
taining three atoms of a metal in each molecule.

Trimethyl $\left(\right.$ rri $^{-}-$meth' $\left.^{\prime}-i l\right)[$ tres, three; methyl]. The chemic group $\left(\mathrm{CH}_{3}\right)_{3}$.

Trimethylamin (tri-meth-i $\left.\bar{l}^{\prime}-a m-i n\right)$ [tres, three; 
methyl; amin ]. Secalin, $\left(\mathrm{CH}_{3}\right)_{3} \mathrm{~N}$. A thin, colorless, alkaline liquid obtained from herring-brine, formerly prepared by the action of caustic alkali on ergot, hence its name, secalin. Used in acute rheumatism internally, or as a liniment $\mathbf{I}$ to 3 of glycerin. The hydrochlorate is a soluble, crystalline salt. Dose of trimethylamin $m^{v}-3 \mathrm{j}$; of the hydrochlorate gr. ij-iij. Unof.

Trimethylene (tri-meth'-il-ên) [tres, three; methylene], $\mathrm{C}_{3} \mathrm{H}_{6}$. A substance obtained by heating trimethylene bromid with metallic sodium. It is a gas. T.-diamin, a ptomain obtained, with other toxic bases, from cultures of the comma-bacillus on beef-broth. It causes violent convulsions and muscle-tremor. See Ptomains, Table of.

Trimethylic (tri-meth-il'-ik) [tres, three; methyl]. Containing three molecules of methyl.

Trimorphic (tri-mor'-fik). Same as Trimorphous.

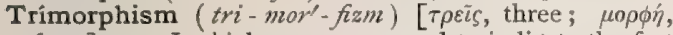
form]. I. In biology, a term used to indicate the fact that hermaphrodite flowers of three different kinds, short-styled, mid-styled, and long-styled, are produced on the same species of plant. 2. Existing under three distinct forms, as certain insects.

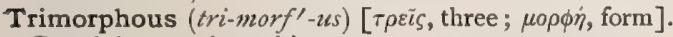
Pertaining to trimorphism.

Trimyarian $\left(t r i-m i-a^{\prime}-r e-a n\right)[\tau \rho \varepsilon i c$, three; $\mu \nu \bar{s}$, a muscle]. In biology, applied to such bivalve molluscan shells as present three muscular impressions.

Trumyristin (tri-mir-is'-tin) [tres, three; myristin]. $\mathrm{C}_{3} \mathrm{H}_{5}\left(\mathrm{C}_{14} \mathrm{H}_{27} \mathrm{O}_{2}\right)_{3}$. A crystalline substance obtained from butter.

Trinervate (tri-nur'-vatt) [tres, three; nervus, nerve]. In biology, thiee-nerved, or having three slender ribs.

Trinerved (tri'-nurvd). Same as Trinervate.

Trinitrate $\left(t^{\prime} i-n i^{\prime}-t r a \bar{t}\right)$ [tres, three; nitrate]. A nitrate containing three nitric-acid radicles. T. of Glyceryl. See Nitroglycerin.

Trinitrin (tri-ni'-trin). See Nitroglycerin.

Trinoctial (tri-nok'-shal) [tres, three; nox, night]. Comprising three nights.

Trinodal (tri-no'-dal) [tres, three; nodus, knot]. In biology, having three nodes or joints.

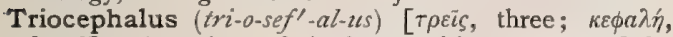
head]. A variety of single autositic monsters of the species otocephalus, in which there is an entire absence of the ocular, nasal, and buccal apparatus. The head is merely a small, spheroidal mass, covered uniformly with skin.

Triœecious (tri-el-shus). See Triecious.

Triolein (tri-o'-le-in) [tres, three; oleum, oil], $\mathrm{C}_{3} \mathrm{H}_{5}$ $\left(\mathrm{O} . \mathrm{C}_{18} \mathrm{H}_{33} \mathrm{O}\right)_{3}$. A glycerol ester containing three oleicacid radicles. It is a clear, colorless, oily liquid, and is the chief constituent of all fatty acids. See Olein.

Trional (tri'-o-nal) [ $\tau \rho \varepsilon i s$, three $], \mathrm{C}_{2} \mathrm{H}_{5} \mathrm{CH}_{3}-\mathrm{C}-\left(\mathrm{SO}_{2}\right.$ $\left.\mathrm{C}_{22} \mathrm{H}_{5}\right)_{2}$, Diethylsulphonemethylmethane. A disulphone belonging to the ethyl and methyl groups; in ordinary doses it is harmless and possesses marked hypnotic properties. It is a powder consisting of shining tablets with a melting-point of $76^{\circ} \mathrm{C}$, and which dissolve in 320 parts of water at ordinary temperature, readily in alcohol and ether, and have a distinctly bitter taste. It is administered in a finely powdered state, dissolved in liberal quantities of soup, warm water, milk, or tea, or it may be administered by the rectum in the form of a watery solution. Dose gr. Ix daily. Unof.

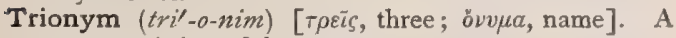
name consisting of three terms.

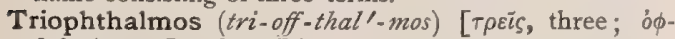
$\theta a \lambda \mu \delta$, eye]. See Diprosopus.

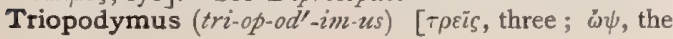

face; $\delta i \delta v \mu o s$, double] and but a single head.

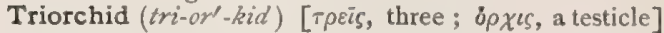
Having three testicles.

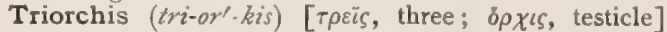
An individual that has three testicles.

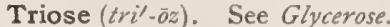

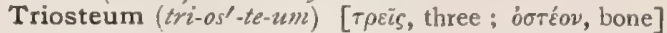
A genus of caprifoliaceous plants of Asia and America. T. perfoliatum (tinkers' weed) and T. angustifolium, of the U. S., are purgative and emetic. Unof.

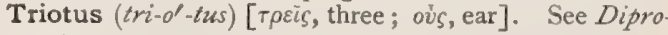
sopus.

Triovulate (tri-ov'-u-lāt) [tres, three; ovulum, an ovule]. Having three ovules.

Trioxid (tri-oks'-id) [ $\tau \rho \varepsilon i \bar{s}$, three; oxid]. An oxygen compound analogous to a trichlorid.

Tripaleolate (tri-pal-le-o-lät) [tres, three; paleola, a little straw]. In biology, provided with three paleæ, as the flower of a bamboo.

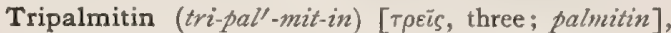
$\mathrm{C}_{3} \mathrm{H}_{5}\left(\mathrm{O} . \mathrm{C}_{16} \mathrm{H}_{31} \mathrm{O}\right)_{3}$. One of the solid fats of the body. Tripapillated (tri-pap'-il-a-ted) [tres, three; papilla, a nipple]. Having three papillæ.

Tripartite (trip'-ar-tit, or tri-par'-tit) [tres, three; partiri, to part, divide]. In biology, three-parted.

Tripe de Roche (trêp-de-rösh') [Fr.]. See Gyrophora.

Tripennate (tri-pen'-ät). Same as Tripinnate.

Tripes $\left(\operatorname{tri}^{\prime}-p \bar{e} z\right)[\mathrm{L}$.$] . I. Three-footed. 2. A monster$ having three feet.

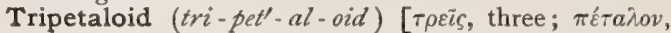
leaf ]. In biology, appearing as if furnished with three petals.

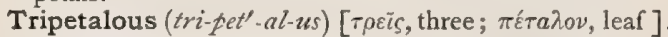
In biology, three-petaled.

Tripharmacum (lri-far'-mak-um) [ $\tau \rho \dot{\imath} i s$, three; фá $\rho-$

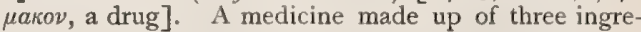
dients.

Triphenyl (tri-fen'-il) [tres, three; phenyl]. The chemic group $\left(\mathrm{C}_{6} \mathrm{H}_{5}\right)_{3^{*}}$ T.-amin, $\left(\mathrm{C}_{6} \mathrm{H}_{5}\right)_{3} \mathrm{~N}$, a substance obtained on heating dipotassium anilin or sodium diphenylamin with brombenzene. It crystallizes from ether in large plates, melts at $127^{\circ} \mathrm{C}$, and distils without decomposition. T.-dihydro-glyoxalin. See Amarin. T. - methane, $\mathrm{C}_{19} \mathrm{H}_{16}$, a product of the reaction between benzol chlorid and mercury diphenyl. It dissolves with difficulty in cold alcohol and glacial acetic acid, easily in ether, benzene, and hot alcohol, crystallizing from the latter in thin, shining leaflets, melting at $93^{\circ} \mathrm{C}$. T.-rosanilin. See Rosanilin-blue.

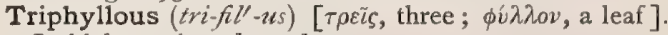
In biology, three-leaved.

Tripier's Amputation. In surgery, horizontal section through the os calcis, leaving the upper part of this bone, together with the astragalus. See Operations, Table of.

Tripinnate (tri-pin'-īt) [tres, three; pinnatus, winged] In biology, three times pinnately compounded.

Tripinnatifid (tri-pin-at'-if-id) [tres, three; pinnatus winged; findere, to cleave]. Pinnatifid with the seg ments twice divided in a pinnatifid manner.

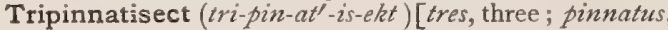
winged; sectus, cut]. Parted to the base in a tripinnate manner.

Triple $\left(t r i p^{\prime}-l\right)[\tau \rho \iota \pi \lambda \sigma o s$, triple $]$. Consisting of three. T. Phosphate, ammonio-magnesic phosphate, a precipitate thrown down from urine when ammonia is set free by the decomposition of urea.

Triplet (trip'-let) [tres, three; plica, a fold]. A series of three. In the plural, three offspring at one birth. In optics, a system consisting of three lenses. T., Achromatic. See Microscope. T. Monster, a monster having its parts tripled. 
Triplex (trip'-lex) [L.]. Threefold. T. Pills, the Pilute triplices, N. F. ; so called from containing three principal ingredients.

Triplicostate (trip-lik-os'-tät) [triplus, threefold; costa, rib]. In biology, triplinerved.

Triplinerved (trip'-lin-ervd) [triplus, threefold; nervus, nerve]. In biology, denoting a leaf in which two prominent nerves emerge from the middle nerve a little above its base.

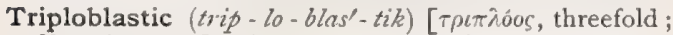
$\beta \lambda a \sigma \tau o ́ s$, germ]. Possessing three blastodermic membranes, consisting of epiblast, mesoblast, and hypoblast. Most animals are triploblastic.

Triplokoria (trip-lo-ko'-re-ah) [ $[\rho \iota \pi \lambda$ óos, threefold; $\kappa \delta \rho \eta$, pupil]. An iris having three pupils.

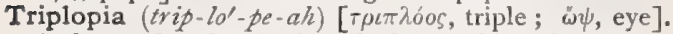
A form of polyopia, in which an object is seen as three.

Triplopy (trip'-lo-pe). Same as Triplopia

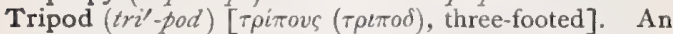
object having three legs or supports. T. Magnifier. See Microscope. T., Vital, the brain, heart, and lungs, viewed as the triple support of life.

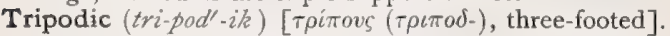
In biology, three-footed. T. Walk, the term applied by Dixon to the locomotion of certain insects, earwigs, water-scorpions, aphides, and some beetles. The front and hind legs of one side are found to be moved almost simultaneously with the middle leg of the other.

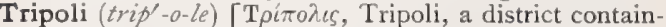
ing three cities]. A kind of rotten-stone used in polishing; also, a silicious diatomaceous earth, likewise used in polishing. T. Senna. See Senna.

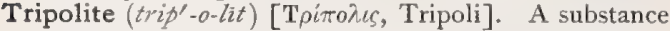
composed of lime, silicon, and oxid of iron, sometimes used in dressings and bandages instead of plaster-of-Paris.

Tripper-fäden. "Gonorrheal threads." A whitish filamentous discharge occurring in the urine in chronic urethritis. It consists of mucus and pus and contains gonococci. T.-kokken, gonococci.

Triprosopus (trip-ros'-o-pus) [ $\tau \rho \varepsilon i s$, three; $\pi \rho \circ \sigma o \pi \sigma v$, face]. A form of fetal monstrosity in which there is a fusion of three faces in one.

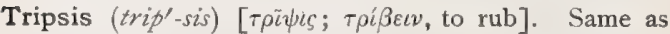
Trituration.

Tripterous (trip̧-ter-us) [ Having three wings or alæ.

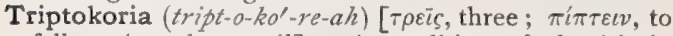
fall; $\kappa \delta \rho \eta$, the pupil]. A condition of the iris in which there are three distinct pupils.

Tripudiatio- (tri-pu-de-a'-she-o) [tripudiare, to dance] Synonym of Chorea. T. spartica. Synonym of Chorea, Epidemic.

Tripupillate (tri-pu'-pil-ät) [tres, three; pupilla, pupil]. In biology, having three central spots or pupils close together.

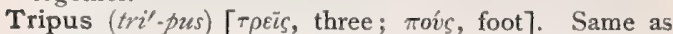
Tripod. T. cœliacus, the three branches of the celiac artery.

Triquetral (tri-kzvet'-ral) [triquetrus, triangular]. Same as Triquetrous.

Triquetrous (tri-kwet'-rus) [triquetrus, three-cornered]. In biology, three-angled or triangular-prismatic. Applied to certain stems and leaves.

Triquetrum (tri-kwet'-rum) [triquetrus, three-cornered: pl., Triquetra]. Any Wormian bone; also, the cuneiform bone of the carpus. See Bones, Table of.

Triquinate (tri-kwin'-ät) [tres, three; quini, five each]. In biology, divided into three parts or lobes and then into five.

Triradial, Triradiate (tri-ra'-de-al, tri-ra'-de-äl)$[$ tres, three; radiatus, rayed]. Radiating in three directions; trifurcate.

Trisalt (tri'-sawlt) [tres, three; ME., salt, salt]. A salt containing three atoms of base to one of acid.

Trisection (tri-sek'-shun) [tres, three; secare, to cut] Division into three parts.

Trisepalous (tri-sep'-al-us) [tres, three; sepalum, sepal]. Denoting calyxes which have three sepals.

Triseptate (tri-seṕ-tât) [tres, three; septum, a septum]. Having three septa.

Triserial, Triseriate (tri-se'-re-al, tri-se'-re-ät) [tres, three; series, series]. Disposed in three horizontal rows, one above the other.

Trisetose (tri-se'-tozz) [tres, three; seta, a bristle]. Having three bristles.

Trisetum (tri-se'-tum) [tres, three; seta, bristle]. A genus of plants belonging to the order Graminacece. They are closely related to Avena. T. flavescens, a grass having yellow flowers, found in North America, Europe, and Asia.

Trisinuate (tri-sin'-u-ät) [tres, three; sinus, a fold]. Having three sinuses.

Trismoid (triz'-moid) [ of trismus neonatorum thought to be due to pressure on the occipital bone during labor.

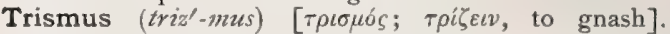
Spasm of the muscles of mastication, the condition commonly called lockjaw, a tetanic condition of the muscles of mastication. T. capistratus, a condition in which the jaws cannot be separated because of adhesions between the cheeks and the gums, following ulceration of the parts. T. catarrhalis maxillaris, neuralgia of the jaw. T. of Cerebral Origin, persistent spasm of the muscles of the lower jaw, due to cerebral disease. $T$. cynicus, risus sardonicus. T. dolorificus, tic douloureux. T. maxillaris. See $T$. catarrhalis maxillaris. T. nascentium. See Tetanus neonatorum. $T$. neonatorum, a form of tetanus only met with in infants, almost invariably occurring in the first five days of life. It is a very fatal disease, and the more so the earlier it appears. It is marked by frequent convulsions occurring in paroxysms, with rigidity of the muscles and an involvement of the muscles of the mouth and throat, causing inability to swallow. It is possibly due to some form of infection at birth. $T$. sardonicus. See T.cynicus. T., Traumatic, trismus following a weund or injury. T. uteri, trismus occurring during and as a result of the puerperium.

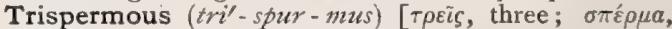
seed ]. In biology, three-seeded.

Trisplanchnia (tri-splang $\left.\bar{k}^{\prime}-n e-n h\right)$. Synonym of Asiatic Cholera.

Trisplanchnic (tri-splangk'-nik) [ $\tau \rho \varepsilon i \varsigma_{\text {s, }}$ three; $\sigma \pi \lambda a ́ \gamma \chi-$ vov, viscus]. The descriptive name of the sympathetic nerve, from the fact that it is connected with the viscera of the three largest cavities of the body.

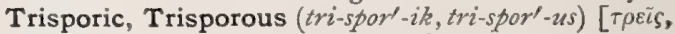
three; $\sigma \pi \circ \rho a$, spore]. Having three spores.

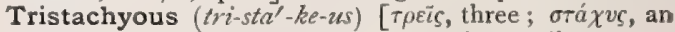
ear of corn]. In biology, bearing three spikes.

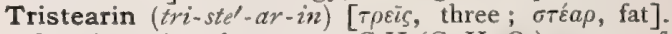
Stearin ; tritenyl stearate, $\mathrm{C}_{3} \mathrm{H}_{5}\left(\mathrm{C}_{18} \mathrm{H}_{35} \mathrm{O}_{2}\right)_{3}$; one of the solid fats of the body.

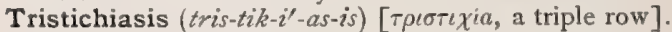
A form of congenital distichiasis in which there are three rows of cilia.

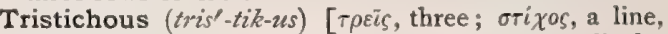
row]. In biology, arranged in three perpendicular rows. Applied to phyllotaxy.

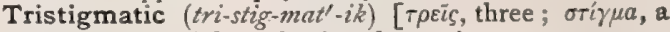
mark]. In biology, having three stigmata.

Tristigmatose (tri-stig'-mat-oz). Same as Tristigmatic. 
Tristimania (tris-tim-a'-ne-ah) [tristis, sad; $\mu a v i a$, mania]. Melancholia.

Tristis (tris'-tis) [L.]. Sad; gloomy; having a dull color.

Tristitia (tris-lish'-e-ah) [L., "sadness'"]. Melan. cholia.

Trisubstituted (tri-sub'-stit-u-ted) [tres, three; substituere, to substitute]. In chemistry, having three elements substituted by equivalent elements.

Tri-sulcate (tri-sul'-kāt) [tres, three; sulca, a furrow] In biology, three-grooved.

Trisulfuretum $\left(t r i-s u l-f u-r e^{\prime}-t u m\right)$. See Trisulphuretum.

Trisulphid (tri-sul'-fid) [tres, three; sulphur]. compound of sulphur analogous to a trichlorid.

Trisulphuretum (tri-sul-fu-re'-tum) [tres, three; sulphur, sulphur]. A trisulphid.

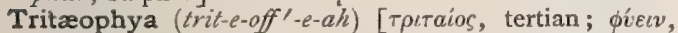
to augment]. A tertian fever. $T$. americana, the pernicious malarial fever to which immigrants to Spanish America are subject.

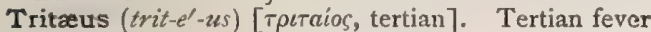

Tritellurid (tri-tel'-u-rid) [tres, three; tellurium]. A compound of tellurium analogous to a trichlorid.

Tri-ternate (tri-tur'-nät) [tres, three; ternatus, arranged in threes?. Applied to a leaf that is thrice compounded on the ternate plan.

Triticeo-glossus (trit-is'-e-o-glos'-us) [triticum, wheatlike; $\gamma \lambda \tilde{\omega} \sigma \sigma a$, tongue]. An anomalous muscle having its origin from the arytenoid cartilage and its insertion in the side of the tongue.

Triticeous (trit-ish'-us) [triticum, wheat]. Having the appearance of a grain of wheat; pertaining to wheat. T. Nodule (corpus triticeum, "wheat-like body"), one of the small cartilaginous nodules of the larynx.

Triticeum (trit-is'-e-um) [triticum, wheat]. The triticeous nodule.

Triticin (trit'-is-in) [triticum, wheat], $\mathrm{C}_{12} \mathrm{H}_{22} \mathrm{O}_{11}$. A gum-like substance found in Triticum repens.

Triticum (trit'-ik-um $)$ [L.: gen., Tritici]. I. Wheat; a genus of graminaceous plants which produce the various kinds of wheat. 2. The rhizome of $T$. repens deprived of its rootlets. T. acutum, a species growing in Europe. T. caninum, dog's-tooth grass. It is thought to possess the same properties as $T$. repens. Dogs eat the blades to induce emesis. T. durum, hard-grained wheat, the seeds of which are richer in nitrogen than the soft wheats; it is cultivated in Southern Europe. T. monococcum, single-grained wheat it grows wild in Greece and Mesopotamia, and is an inferior species in cultivation. T. repens, couch- grass ; it grows in Europe, Northern Asia, North and South America. The rhizome is smooth, straw-colored, and has a sweetish taste. It contains malates, sugar, triticin, and a nitrogenous principle, and is emollient, diuretic, and antiphlogistic. It is best administered in a decoction made from 2 to 4 ounces of the plant in 2 pints of water, and reduced one-half by boiling. $T$. sativum, common wheat. The ground and sifted seeds constitute flour, official in the pharmacopeia as farina tritici. $T$. spelta, spelt-wheat, indigenous in the Persian mountains, and cuitivated in Europe. It yields flour of fine quality. T. vulgare. See $T$. sativum. Tritici, Amylum, wheat-starch. T., Extractum, Fluidum, a preparation made by exhausting $T$. repens with boiling water, and then adding a certain quantity of alcohol. Dose $f \mathbf{z}$. T., Carina, wheat-flour. T., Farina, Tosta, baked sour. T., Saccharum, a sugar obtained from the extract of $T$.repens, which dissolves readily in alcohol.
Triticumina Food (trit-ik-u'-min-ah) [triticum, wheat]. A malt food prepared in England by malting wheat so as to cause it to contain about twice as much soluble carbohydrates as ordinary wheaten flour.

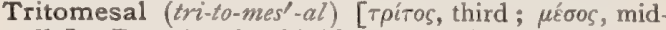
dle]. Denoting the third longitudinal series of cells in the wing of hymenopters.

Tritopin (trit-to-pin), $\mathrm{C}_{42} \mathrm{H}_{54} \mathrm{~N}_{2} \mathrm{O}_{7 "}$ An alkaloid obtained from opium.

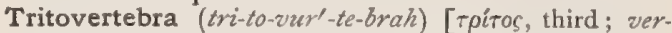
tebra, vertebra]. Carus's term for a limb-bone, or the bony framework of the limbs considered as vertebral elements developed in special relation with the muscular system.

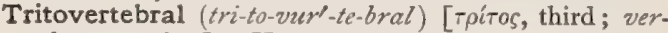
tebra, vertebra]. Having the character of a tritovertebra.

Tritovum (tri-to'- r'um) [трiтos, third; orum, egg]. The third stage of an ovum.

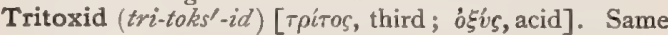
as Trioxid.

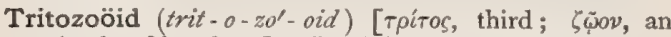
animal; eidos, form ]. In biology, a zoöid of the third generation; the immediate offspring of a deuterozoöid.

Tritubercular (tri-tu-bur'-ku-lar) [tres, three; tuberculum, tubercle]. Having three tubercles or cusps; tricuspid.

Trituberculate (tri-tu-bur'-ku-lāt). Same as Tritubercular.

Trituberculism (tri-tu-bur'-ku-lizm) [tres, three; tuberculum, a tubercle]. A peculiarity of molar teeth, indicating the possession of three cusps.

Triturate (trit'-u-rāt) [triturare, to rub together]. As a verb, to reduce to fine powder. As a noun, a finely divided powder. T., Tablet, a small disc of some soluble material, usually sugar of milk, charged with a certain dose of a medicinal substance. See Tablet.

Trituration (trit-u-ra'-shun) [trituratio; tritus, a rubbing]. The process of reducing a solid substance to a powdered state by grinding or rubbing. In pharmacy, a class of powders having sugar of milk as their diluent in the proportion of ten parts of the substance to 90 of the sugar. Trituration of elaterin is official.

Tritus (tri'-tus) [L.]. See Trituration

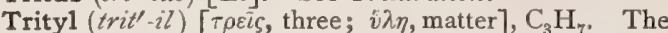
third of the methyl series of hydrocarbon radicles. T.-alcohol, $\mathrm{C}_{3} \mathrm{H}_{7} \mathrm{HO}$, propyl-alcohol.

Tritylene (trit'-il-èn). Same as Propylene.

Triungulin (tri-ung'-gu-lin) [tres, three; ungula, a hoof, claw ]. In biology, the first larval stage of certain beetles ( $M$ eloidce).

Trivalence (tri'-va-lens, or triv'-al-ens) [tres, three; valere, to be worth]. The quality of being trivalent.

Trivalent (triv'-al-ent) [tres, three; valere, to be worth]. In chemistry, equivalent in combining or displacing power to three monad atoms.

Trivalerin (tri-val'-er-in) [tres, three; valere, to be worth], $\mathrm{C}_{3} \mathrm{H}_{5}\left(\mathrm{C}_{5} \mathrm{H}_{9} \mathrm{O}_{2}\right)_{3}$. A substance which exists in the oil of marine animals, like the seal.

Trivalve (tri'-valv) [tres, three; valva, door]. In biology, applied to a structure having three valves, as a shell.

Trivalvular (tri-val'-vu-lar) [tres, three; valvula, a small valve]. Having three valves.

Trivertebral (tri-vur'-te-bral) [tres, three; vertebra, vertebra]. Composed of three vertebræ.

Trivia (triv'-e-ah) [trivius, of three roads]. The point of intersection of the three semicircular canals of the cochlea.

Trivial (triv'-e-al) [trivialis, common]. Denoting the popular name of a plant or animal; the specific name. 
Trivium (triv'-e-um) [tres, three; via, way : pl., Trivia]. In biology, the three anterior ambulacra of an echinoderm.

Trixis (triks'-is) [L.]. A Mexican plant allied to rhubarb. The root is used as a laxative.

Trocar (tro'-kar) [Fr., trois-quarts, from its triangular point]. An instrument used in paracentesis, or tapping a cavity, as in hydrocele. It consists of a perforator and a metallic tube. T., Lancet, a trocar having a lancet-shaped perforator. T., Piloting, Durham's trocar, used for introducing the articulated tracheotomy-tube. T., Rectal, a curved trocar used in tapping the bladder through the rectum.

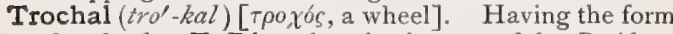
of a wheel. T. Disc, the wheel-organ of the Rotifera, the ciliated and usually retractile apparatus which projects at the anterior end of the body of the wheel-animalcule.

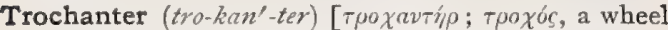
or pulley]. The process on the upper extremity of the femur. The major and minor processes at the extremity of the femur which receive the extensor and flexor muscles of the thigh are respectively called the greater and the lesser trochanter. T. tertius, an anomalous process at the upper portion of the popliteal space of the femur.

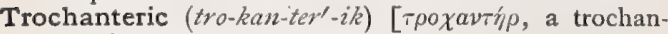
ter]. Pertaining to a trochanter.

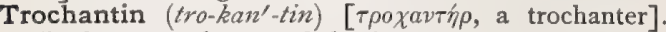
The lesser trochanter of the femur.

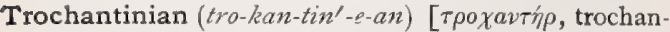
ter]. Pertaining to the trochantin.

Trochate $\left(t r o^{\prime}-k \bar{a} t\right)[\tau \rho o \chi o ́ s$, a wheel]. I. Same as Trochal. 2. Trochiferous.

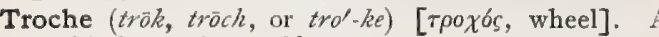
trochischus. A round lozenge.

Trochia $\left(t r o^{\prime}-k e-a h\right)$ [ $\tau \rho \circ \chi o_{\varsigma}$, a wheel]. A term formerly applied to the orbit.

Trochiferous (tro-kif'-er-us) [ $\tau \rho \circ \chi$ ós, wheel ; ferre, to bear]. In biology, provided with a trochal organ.

Trochiform (tro'-kif-orm) [Tpoxos, wheel; forma, form ]. In biology, having the form of a top-shell.

Trochilia (tro-kil'-e-ah). See Trochlea.

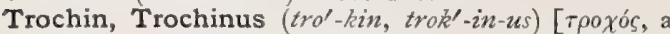
wheel]. The lesser tuberosity of the head of the humerus.

Trochinian (tro-kin'-e-an) [ $\tau \mu o \chi o ́ s$, wheel]. Pertaining to the trochin.

Trochiscus (tro-kis'-kus) [трохiokos, a little wheel : pl., Trochisci]. A troche, pastil, tablet, or lozenge. In pharmacy, a small, flattened cake prepared from a mass of sugar and mucilage as an excipient, with a prescribed medicinal substance. There are 15 official trochisci.

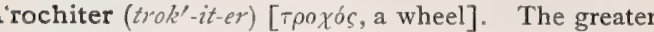
tuberosity of the proximal end of the humerus.

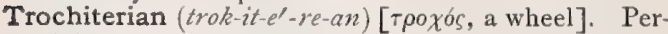
taining to the trochiter.

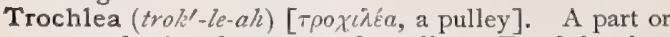
process having the nature of a pulley. T. of the Astragalus, the surface of the astragalus articulating with the tibia. T. of the Femur, the intercondyloid fossa of the femur. T. of the Humerus, an articulation at the extremity of the humerus, over which a band of cartilage passes. T. labyrinthi. See Cochlea. $\mathbf{T}$. of the Obliquus oculi superior, $\mathbf{T}$. of the Orbit, the ligamentous ring or pulley, attached to the upper margin of the orbit, which transmits the tendon of the superior oblique muscle of the eye.

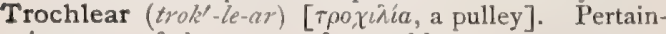
ing to or of the nature of a trochlea.

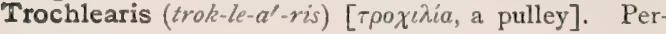

taining to the trochlea. Also, applied to the superior oblique muscle of the eye.

Trochleary $($ trok'-le-a-re). Same as Trochlear.

Trochleate $\left(t_{r o} k^{\prime}-l e-\bar{a} t\right)$. Same as Trochlear.

Trochocephalus (trok-o-sef'-al-us) [ $\tau \rho \circ \chi \sigma o s$, wheel; $\kappa \varepsilon \phi a \lambda$, head]. A rounded appearance of the head, due to partial synostosis of the frontal and parietal bones.

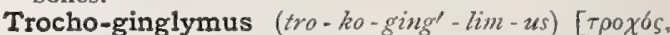
wheel; $\gamma^{\prime} \gamma \gamma \lambda v \mu o s$, ginglymus]. A combination of a hinge-joint and a pivot-joint, as in the humero-radial articulation.

Trochoid (tro'koid) [ $\tau \rho \circ \chi o ́ s$, wheel]. Serving as a pulley or pivot; involving a pivotal action.

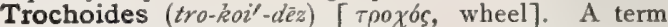
given to pivot-joints or pulley-joints, such as the atlanto-axial.

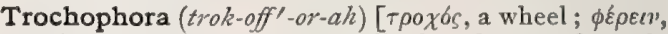
to bear]. In biology, a peculiar larval stage of certain Vermes, having a characteristic preoral ciliated ring.

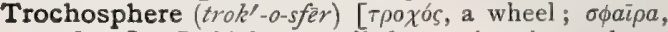
a sphere]. In biology, applied to various invertebrate larvæ bearing a circlet of cilia.

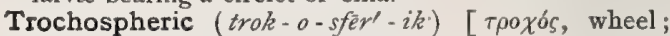

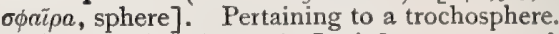

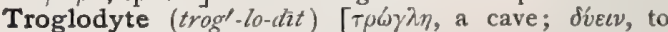
enter]. Inhabiting caverns.

Troisier's Ganglion. A large lymphatic gland sometimes found above the clavicle in cases of retrosternal tumor.

Trolard's Vein. The large anastomotic vein between the superior longitudinal and lateral sinuses. See Vein.

Tröltsch (von), Corpuscles of. See Corpuscle.

Troma (tro'-mah). Same as Trauma.

Trommer's 'Test. A test for the presence of grapesugar, or glucose. The liquid to be tested is filtered, and to the filtrate a solution of ammonio-cupric tartrate is added. If glucose be present, the copper is precipitated in the form of a bright, orange-red, basic cuprous oxid. Boiling facilitates the precipitation, which is sometimes stubborn. See Tests, Table of.

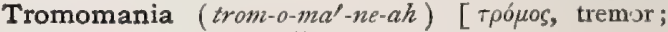
ucvía, madness]. Delirium tremens.

Tropacocain (tro-pak-o'-ka-in) [atropin; cocain]. A powerful anesthetic and mydriatic, derived "from a small-leaved coca of Java." It has the general qualities of cocain, but appears to be more active.

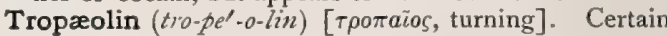
azo-dyes, so named because their colors resemble those of the flower of Tropaolum majus. See Orange Colors in Pigments, Conspectus of.

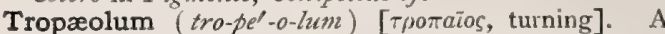
genus of the Pelargoniece including the larkspur, garden nasturtium. T. majus, Indian cress; a Peruvian species. The buds and fruit are used as a condiment. It is said to be stomachic, diuretic, and laxative. T. minus $\mathrm{L}_{0}$, dwarf nasturtium. It is a native of Peru, and has the same properties as $T$. majus.

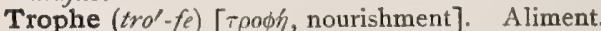

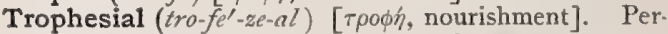
taining to or of the nature of a trophesy.

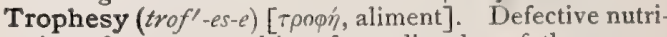
tion of a part resulting from disorder of the nerve: regulating nutrition; trophoneurosis.

Trophi (tro'-fe) [ $\tau \rho \circ \phi o ́ s$, a feeder]. In biology, a collective term for those mouth-parts of an invertebrate employed in feeding.

Trophic (trö $\left.f^{\prime}-i k\right)$ [ $\tau \rho \circ \phi \dot{\eta}$, nourishment]. Dertaining to the functions concerned in nutrition, digestion, and assimilation. T. Centers, centers regulating the nutrition of nerves, or through them, of organs. 
Trophis $\left(t r o^{\prime}-f i s\right)$ [ $\tau p \delta \phi \iota s$, well-fed]. The ramoon-tree. $\mathbf{T}$. americana, a shrub of the West Indies, used as an alterative and mild astringent. $T$. aspera, papertree of Siam and India. The berries possess astringent and antiseptic properties, and the juice of the leaves and young shoots is used in the treatment of ulcers and cutaneous eruptions. Unof.

Trophoblast (trof'-o-blast) [ $\tau \rho o \phi \eta ́$, nourishment; $\beta \lambda a \sigma-$ Tós, a germ]. In biology, the outer epiblastic layer of the extra-embryonic somatopleure.

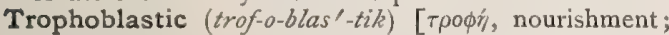
$\beta \lambda a \sigma \tau \delta \varsigma$, germ]. Pertaining to a trophoblast.

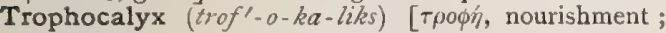

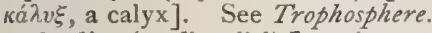

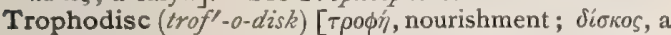
disc]. See Trophosphere.

Tropholecithal (trof-o-les'-ith-al) [ $\tau \rho \circ \phi \dot{y}$, nourishment ; $\lambda \varepsilon \kappa \iota t o \varsigma$, the yolk of an egg]. Pertaining to a tropholecithus.

Tropholecithus (trof-o-les'-ith-us) [ $\tau \rho \circ \phi \dot{n}$, nourishment ; $\lambda \varepsilon \kappa_{i} \theta 0 \varsigma$, the yolk of an egg]. In biology, the foodyolk of a meroblastic egg. Cf. Morpholecithus.

Trophology (trof-ol'-o-je) [ science]. The science which treats of or relates to nutrition.

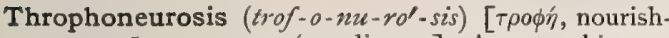

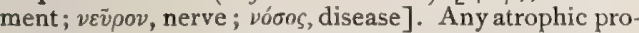
cess due to injury or perverted action of the nerves or nerve-centers. T., Disseminated. Synonym of Scleroderma. T., Facial, progressive facial atrophy; facial hemiatrophy. T., Musuclar, trophic changes in the muscles in connection with disease of the nervous system. T. of Romberg, unilateral atrophy of the face; hemiatrophy.

Trophoneurotic (trof-o-nu-rot'-ik) [ $\tau \rho o \phi n$, nourish-

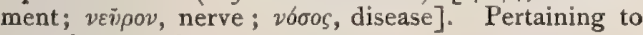
a trophoneurosis.

Trophonosus (trof-on'-o-sus). See Trophopathy.

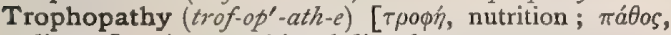
disease]. Any nutritional disorder.

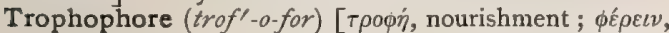
to bear]. In biology, one of the ameboid cells of sponges, giving rise to gemmules.

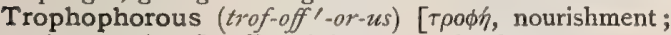
$\phi \varepsilon \varepsilon \rho \varepsilon \iota v$, to bear]. Pertaining to trophophores.

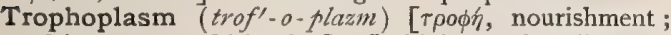
$\pi \lambda \alpha \dot{\sigma \sigma \varepsilon \varepsilon} \nu$, to mold in clay]. In biology, Nægeli's term for the vital substance of the cell, the formative plasm, or morphoplasm, in contrast to the idioplasm.

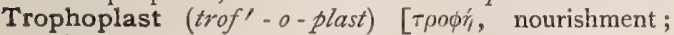
$\pi \lambda \dot{a} \sigma \sigma \varepsilon \imath \nu$, to mold or form in clay]. In biology, a plastid; a mass of formative plasm.

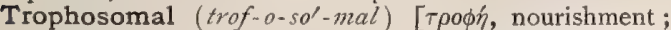
$\sigma \bar{\omega} \mu \alpha$, body]. Nutritive. Pertaining to a trophosome.

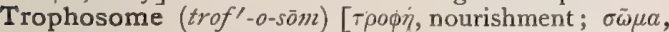
body]. In biology, the mass of nutritive zoöids of a hydrozoan. Cf, Gonosome.

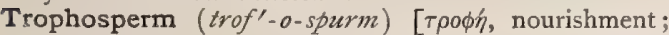
$\sigma \pi \varepsilon \rho^{\prime} \Omega$, seed]. The portion of an ovary that bears the ovules.

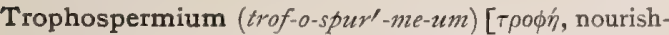
ment; $\sigma \pi \dot{\varepsilon} \rho \mu a$ seed]. In biology, the placenta.

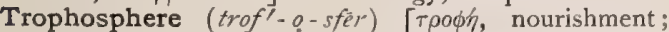
бpaipa, a sphere]. In biology, the tissue between the decidual stroma and the blastocyst in Erinaceus. See Trophodise, Trophocalyx, Trophoblast, Trophospongia.

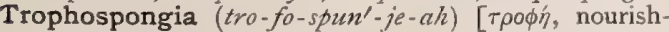
ment; $\sigma \pi 0 \gamma \gamma t a ́$, a sponge]. In biology, the outer or maternal layer of the trophoblast, trophodisc, or tro. phocalyx.

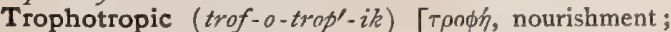
$\tau \rho \varepsilon ́ \pi \varepsilon \iota \nu$, to turn ]. In biology, exhibiting trophotropism.
Trophotropism (trof-o-tro'-pizm) [ $\tau \rho \circ \phi \dot{\eta}$, nourishment ; $\tau \rho \varepsilon ́ \pi \varepsilon \iota v$, to turn]. In biology, the term applied by Stahl (I884) to the attraction (positive trophotropism) and repulsion (negative trophotropism) exhibited by certain organic cells to various nutritive solutions. A phenomenon now included under Chemotaxis, $q . v$. Trophozoöid (trof-o-zol-oid) [ [ $\rho \circ \phi \dot{n}$, nourishment; $\zeta \bar{\omega} O \nu$, an animal ; عiঠos, form ]. In biology, nutritive zoöid.

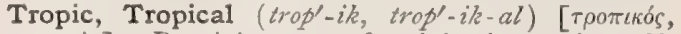
tropic]. Pertaining to or found in the tropics. $T$. Acid. See Acid. T. Big Leg. See Elephantiasis arabum. T. Boil. See Boil, Aleppo. T. Chlorosis. See Ankylostomiasis and Dochmiasis. T. Fruit Laxative. See Senna. T. Measles, a name suggested by Cautlie for a disease that was prevalent among the foreign residents of Hong Kong, during September and October, in 1888. Mild cases were regarded as "German measles," severe cases as a form of dengue. He defines it as follows: "Rubeola tropica is a specific eruptive fever, the primary, rosered rash appearing on the face and neck on the second day of the illness; the second rash, miliary and papular, on the body, face, and occasionally on the limbs on the fourth day. The third rash, of small, coalescent wheals, appears on the arms and legs, or legs only, on the sixth day, when the fever subsides. The severe form attacks adults chiefly. It is epidemic, contagious, but seldom associated with catarrh or desquamation, and characterized by the intensity of the pain in the back, head, and orbit on the third and fourth days of the illness." The duration of the disease was much shorter than that of dengue, the termination was invariably favorable, and the complications and sequelæ of measles were not observed in any case.

Tropidin $\left(\right.$ trop $\left.^{\prime}-i d-i n\right)$ [atropin $], \mathrm{C}_{8} \mathrm{H}_{13} \mathrm{~N}$. A substance resulting from the decomposition of atropin in the presence of hydrochloric and glacial acetic acids ; it is an oily fluid having an odor resembling that of coniin.

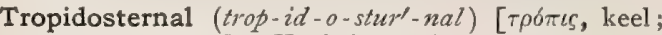

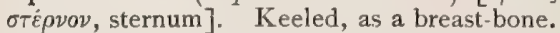

Tropin (tro'-pin) [atropin], $\mathrm{C}_{8} \mathrm{H}_{15} \mathrm{NO}$. A substance obtained by the decomposition of the alkaloid atropin; it crystallizes from ether in plates, melts at $63^{\circ} \mathrm{C}$, and boils at $229^{\circ} \mathrm{C}$.

Tropis (tro'-pis) [ $[\tau b \pi \iota s$, keel]. In biology, the keel or backward curve of a cymba, as in sponge-spicules.

Tropsin $\left(\right.$ trop $\left.^{\prime}-\sin \right)$. Same as Tropacocain.

Trousseau's Phenomenon or Sign. A diagnostic sign of post-operative tetany. The spasm of an extremity which may be produced by compression of its principal blood-supply or nerve-supply for a brief period of time, from a few seconds to a few minutes. The spasm will continue as long as the pressure is maintained. T.'s Spots, Taches cérébrales; red spots which may appear on the skin after it has been mechanically irritated; they were thought by Trousseau to be diagnostic of meningitis.

Trouts $\left(t u^{\prime}-u t z\right)$ [Irish]. A form of chloasma occurring among the Irish peasantry in places where they have turf-fires.

Trouser-leg Culture. A bacterial growth, as that of Vibrio proteus, in which the liquified area of the nutritive gelatin corresponds to the form of an empty stocking-leg. (Schenk.)

True (tru) [ME., true, true]. The opposite of false. Applied to organs functionally active or perfect. $\mathbf{T}$. Corpus luteum, the corpus luteum of pregnancy. T. Pelvis, that part of the pelvic cavity situated below the brim or ilio-pectineal line. T. Resins. See 
Resins. T. Ribs. See Ribs. T. Skin, the corium. T. Vocal Bands, the inferior bands, or those concerned in the production of voice.

Trumpet (trum'-pet) [ME, trumpet, trumpet]. A musical wind-instrument; any instrument or apparatus shaped like a trumpet. 'T., Ear, an instrument having a flaring mouth-piece or a parabolic cup, from the focal point of which the sound-waves are collected by another receiver projecting into the cup and connected with the ear-piece. T.-plant, Venus flycatcher; huntsman's cup, the rhizome of Sarracenia flava, common in Southern U. S. Of high repute in the cure of diarhea. Dose of fld. ext. $m v-x v$. Unof: See also Sarracenia and Tecoma. T.-weed. See Eupatorium purpureum.

Truncal (trung-kal) [truncus, a trunk]. Pertaining to the trunk, or to a trunk.

Truncate (trung'-kāt) [truncare, to cut off]. In biology, ending abruptly, as if cut off.

Truncated (trung'-ka-ted) [tmucus, trunk]. Deprived of limbs or accessory parts.

Truncus (trung'-kus) [truncare, lop, maim: pl., Trunci ]. In biology, the trunk or main body, as of a tree, an animal, a nerve. See Trunk.

Trunk [ME., trunke, trunk; truncus, a trunk]. All of the body except the head and limbs. Also, the main stem or body of a nerve or vessel.

Trunkal (trung'-kal). See Truncal.

Truss (trus) [Fr., trousse]. An instrument for maintaining a part in proper position in hernia and other malpositions of organs. T., Carotid, a truss for compressing the carotid artery. T., French, a truss for inguinal hernia, in which pressure is exerted by an elastic, steel spring that supports the pad. T., Hainsby's, a truss for approximating the edges of a wound; it is used in the operation for harelip. T., Suspensory, a suspensory bandage.

Truxillic Acid (truks-il'-ik) [from Truxillo, the commercial source of coca], $\mathrm{C}_{9} \mathrm{H}_{8} \mathrm{O}_{2}$. An acid obtained from cocain, and known in three isomeric forms, $a$-truxillic, $\beta$-truxillic, and $\gamma$-truxillic acid.

Truxillin (truks-il'-in). Synonym of Cocamin.

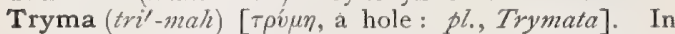
biology, a drupe-like fruit, which is commonly twocelled and has a bony nucleus and a thickish but fibrous epicarp. Example: a hickory-nut.

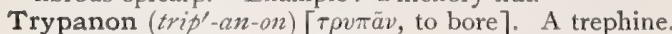

Trypesis (trip-e'-sis) [ $\tau \rho v \pi \tilde{a} v$, to bore $]$. The operation of trephining.

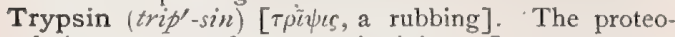
lytic enzyme of pancreatic juice. Its powers are manifested in an alkaline medium, converting proteids into peptones. Traces of trypsin have been stated to be found in urine, but this is doubtful. It is recommended for spraying the throat in membranous or diphtheric croup. Thirty grains are dissolved in one ounce of water and Io grains of sodium bicarbonate added, and the mixture applied by means of a brush or as a spray. Unof.

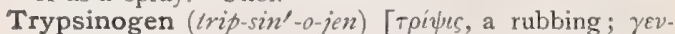
$\nu \tilde{a} \nu$, to produce]. A catastatic granular substance found in pancreatic cells; by a slight chemic change it becomes trypsin, and is cast out of the cell ; the zymogen from which trypsin is formed

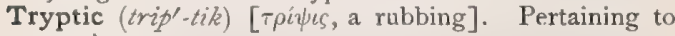
trypsin.

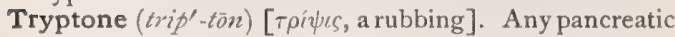
peptone.

Tryptonemia (trip-to-ne'-me-ah). See Piptonemia.

Tryptophan (trip'-to-fan). See Proteinchromogen.

Tsetse (tset'-se) [S. African]. Glossina morsitans; a dipterous insect of South Africa, whose bite is highly dangerous to horses and cattle, though not to man See Parasites (Animal), Table of.

Tsin (tzin). Synonym of Arrack.

Tuba $\left(t u^{\prime}-b a h\right)$ [L., a tube]. A Eustachian or Fallopian tube.

Tubage $\left(t u^{\prime}-b \bar{a} j\right)$ [tuba, a tube]. The introduction of a tube or catheter. T. of the Glottis. See Intubation. Tubal $\left(t u^{\prime}-b a l\right)$ [tubus, a pipe]. Pertaining to an oviduct. T. Abortion, of Bland-Sutton, internal rupture of the ovum in extra-uterine gestation, with a pouring out of blood through the fimbriated extremity of the tube into the abdominal cavity. T. Mole, a tubal ovum that has been destroyed by hemorrhage. It is at first spheric, but after attaining the dimensions of a walnut becomes ovoid. In the majority of cases the amniotic cavity occupies an excentric position, hence rupture easily occurs, and the embryo is lost. $T$. Pregnancy, pregnancy in one or the other Fallopian tube.

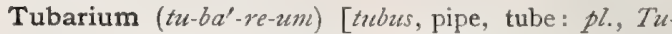
baria]. The tube formed and inhabited by a polyite.

Tubate $\left(t u^{\prime}-b a \bar{t}\right)$ [tuba, tube]. Tubiform; provided with a tube.

Tube $(t \bar{u} b)$ [tubus, or tuba, a tube]. Any pipe-like structure in the body, especially the oviduct or Fallopian tube. Also, a hollow, cylindric, surgical appliance, made variously of rubber. glass, bone, silver, etc. T., Absorption, a glass tube used in Bunsen's method of volumetric analysis of gases; it is graduated and closed at one extremity, and collects gas and conducts it to the eudiometer. T., Air, a bronchial tube; e.g., the larynx, trachea, bronchi, and bronchial tubes. T., Aus cultation, a tube for testing the acuteness of hearing. It has three branches, two of which are placed in the patient's ears, the third in the ear of the auscultator; the sound of a vibrating tuning-fork placed in contact with the top of the patient's head will then be transmitted to the observer from the patient's ears. $T$. of Bellini, the large excretory ducts of the uriniferotis tubules formed by the frequent union of canals of smaller size. T., Bellocq's, an instrument used for plugging the posterior nares in nasal hemorrhage. T., Binocular, the tube of a binocular microscope. T. breather, an animal breathing through tubes. T., Bronchial. See Bronchia. T., Calcigerous. See Dental Canals. T.-casts, urinary casts; casts of the renal tubules, and indicative of kidney-disease. They vary in size, shape, and appearance. Their length ranges up to $200 \mu$ or more ; their diameter from $4 \mu$ to $40 \mu$. They are usually straight, but may be curved, twisted, convoluted, or branched. T. $-c_{\text {. }}$, Blood, those composed of coagulated blood with corpuscles embedded. They show that the hematuria originates in the secreting structure of the kidney. T.-c., Epithelial, those composed of plastic matter with cells embedded, and denoting desquamative inflammation. $Z_{0}: c_{1}$, Fatty, those containing free fatglobules in the coagulated matter, indicating fatty degeneration in a chronic nephritis. T.-c., Granular, those containing finely divided, granular débris, either in scattered masses or completely filling the casts. They are usually found in cases of contracted kidney. T.-c., Hyaline, transparent, soft, delicate casts, also called Mucous Casts. T.-c., Mucous, See T.-c., Hyaline. T. C., $_{\text {. }}$ Pus, those that contain degenerated leukocytes; indicative of involvement of the interstitial kidney-substance. T.-c., Seninal, molds of the seminal tubules found in the urine, and recognized by the presence of spermatozoids. T.-c., Waxy, those that give the amyloid reaction; they are large and yellowish in appearance, and are indicative of serious nephritis. T.,Chaussier's (for insuffation), 
a metallic tube trumpet-shaped at one extremity and curved at the other to faciliate its introduction into the larynx, and provided with a perforated collar to which suitable material is attached for the purpose of closing the aperture of the larynx. T., Collecting. See Tubule. T., Communicating. See Tubulus, Communicating. T.-culture. See Culture. T., Dentinal. See Canal, Dentinal. T., Depaul's (for insuffation), an instrument similar to Chaussier's. 'T., Drainage, a hollow tube of glass, rubber, or other material to be inserted into a wound or cavity to allow of the escape of fluids. T., Draw, the tube which slides within the tube of a microscope. Ts., Egg. See Ts., Ovarian. T., Emmett's Fistula, a trumpetshaped tube for draining a fistula. T., Enterotomy, an instrument used in establishing an artificial anus, to prevent protrusion of the gut. 'T., Esbach's, Esbach's albumimeter; a graduated glass cylinder for estimating the percentage of albumin in urine. 'T., Esmarch's Elastic, an elastic tube furnished with a hook and chain, and used to render a limb bloodless. T., Esophageal, a soft, flexible tube used for lavage and gavage. T., Eustachian, the canal extending obliquely from behind the soft palate to the tympanum. It is partly osseous and partly cartilaginous, lined by mucosa, about $36 \mathrm{~mm}$. long and $2 \mathrm{~mm}$. wide. T., Fallopian. See Oviduct. Ts. of Ferrein, a prolongation of the strix of the Malpighian pyramids into the cortex of the kidney. They are also known as Medullary rays. T., Geissler's, an instrument for showing the strix which are produced by an electric discharge in a highly rarefied medium. T., Germ, a tube formed in the germination of a spore by distention of the endospore. T., Hearing, a tube consisting of a spiral wire encased in leather and covered with closetextured silk or woollen tissue, with an oval ear-piece and a cup-shaped mouth-piece. It is for the use of persons whose hearing is impaired. T., Henle's Looped. See Tubulus. T., Intestinal, the intestinal canal. T., Kobelt's, in the paroöphoron, the remains of tubules in the Wolffian bodies. Ts., Leiter's. See Leiter's Tubes. T.-length, the length of the tube of the microscope at which corrections must be made for the formation of the image at a definite distance. This distance is set arbitrarily by most makers, hence the lack of uniformity. Ts., Lieberkuihn's. See Crypt. T., Lithotomy, an instrument used in operations for calculi. Ts., Lobular Bronchial, the bronchioles. T., Loop. See Tubulzes. T., Medullary, the neural canal in the embryo. T., Microscopic, the metallic cylinder that contains the draw-tube of a microscope. Ts., Miescher's. See Sarcocystis miescheri under Parasites (Animal), Table of. T., Milk, one of the lactiferous ducts. T., Muscle. See Muscle-fiber. T., Nerve, a primitive nerve-fibril. T., Neural. See T., Medullary. T., O'Beirne's, a tube of rubber for irrigating the colon. T., Otopharyngeal. See T., Eustachian. Ts., Ovarian, ova-chains ; germinal epithelium in a developing ovary. Ts., Peptic, the gastric glands. Ts., Perforating, uncalcified perforating tubules, or Sharpey's fibers in bone. T., Perineal. See T., Lithotomy. Ts., Pflüger's. See T., Ovarian. Ts., Pflüger's Salivary, ducts of the acini of salivary glands. T., Pituitary. See Hypophysis cerebri. Ts., Pulp, tubular masses of the tissue proper of an organ, as of the spleen. T., Receiving (of the kidney). See Tubulus, Straight Collecting. T., Rectal, a flexible, rubber tube for introduction into the rectum. Ts., Respiratory Bronchial. See Bronchioles, T. Ribemont's Laryngeal, a tube used for insufflation in asphyxia neonatorum. T., Safety, a small extent of the ectal portion of the Eustachian tube which is slightly open and permits equalization of pressure in the tympanum from the pharynx, and also allows a recoil of air from the tympanum when the tympanic membrane is suddenly driven in, as in explosions. Ts., Seminal, the tubes constituting the lobules of the testis. See Cells, Seminal. T., Speaking. See $T$., Hearing. T., Spray, an apparatus consisting of two tubes so adjusted that a current of air or steam through one will cause' a spray to issue from the other. $T$., Stomach. See T., Esophageal. T., Straight. Set Tubules, Straight Collecting. T., Toynbee's Conic Metal, a tube used for washing out the mastoid cells and the tympanum. T., Tracheal, a tracheal cannula. Ts., Uriniferous, Ts., Uriniparous. See Tubulus. $T$., Uterine, a tube used for injecting the uterus. T., Voltolini's, a small tube used to keep open an incision in the tympanic membrane.

Tuber (tu'-ber) [tuber, a bump, swelling: pl., Tubera] In biology, a thickened portion of an underground stem. T. anatomica, a protuberance, tumor, or swelling. $\mathbf{T}$. annulare. See Pons varolii. $\mathbf{T}$. anterius. See $T$. cinereum. $T$. brumale. See $T$. cibarium. T. calcanei, the tuberosity of the calcaneum. Tubera candicantia. See Corpora mammitlaria. T. cinereum, a tract of gray matter extending from the optic chiasma to the corpora mammillaria, and forming part of the floor of the third ventricle. $T$. corporis callosi, the splenium. $T$. eustachii, a slight protuberance below the fenestra ovalis on the inner wall of the tympanic cavity. $T$. frontale, the frontal eminence. Tubera geniculata, the internal and external geniculate bodies. T. gutturosum. See Goiter. T. ischii, the tuberosity of the ischium. T. maxille, the tuberosity of the superior maxilla. T. omentale hepatis, a prominence on the left lobe of the liver, corresponding to the lesser curvature of the stomach. T. omentale pancreatis, a prominence of the middle part of the pancreas, corresponding to the lesser omentum. $\mathrm{T}$. parietale, the parietal eminence. $T$. supracondyloideum, an eminence opposite the distal end of the internal border of the linea aspera of the fibula. $T$. supraorbitale, the superciliary ridge. T. syphiliticum. See Syphiloma. T. tympani. See $T$. eustachii. T. valvulæ (cerebelli), a small prominence of the cerebellum on its inferior vermiform process at its anterior extremity in front of the uvula. T. verrucosum, a callosity often found on the great toe at the metatarso-phalangeal joint. T. zygomaticum, a prominence of the zygoma on its lower border near the union of the superior maxilla and the zygomatic process.

Tubercle $\left(t u^{\prime}-b u r-k l\right)$ [tuberculum, a tubercle]. I. In anatomy, a rounded prominence on a bone or other part; also, the rounded end of a bone. '2. In dermatology, a small protuberance in the corium or subcutaneous tissue, produced by a morbid deposit. 3. In pathology, a small, hard, granular body, $\frac{1}{10} \mathrm{~mm}$. to 2 $\mathrm{mm}$, in diameter, yellowish at the center and bounded by a reddish, vascular zone. 4 . In biology, applied specifically to the enlargements found on the roots of leguminous plants; first described by Dalechamps in Ornithopodium tuberosum (1587) and since by Woronin, Beyerinck, Prazmowski, Frank, Schlösing Jr., Laurent, Sachmann, Körnicke, etc. T., Adductor (of the femur), a slight protuberance at the lower end of the internal supracondylar line of the femur, giving attachment to the tendon of the adductor magnus. T., Amygdaloid, a prominence on the roof of the descending cornu of the lateral ventricle. T., Anatomic, a wart-like tuberculous growth sometimes appearing 
on the hands of dissectors. It is also called necrooenic verruca. Ts., Anterior Pair of, the anterior pair of the corpora quadrigemina. T., Anterior (of a vertebra), a tubercle at the anterior part of the extremity of the transverse process of certain vertebre. $T$., Anterior (of the atlas), a protuberance upon the ventral arch of the atlas at the meson. T., Anterior (of the calcaneum), a prominence on the anterior inferior surface of the os calcis. T., Anterior (of the optic thalamus), a rounded prominence of the thalamus at its anterior extremity. T., Anterior (of the vagina), a rough eminence at the upper part of the vaginal orifice, behind the meatus urinarius. T., Black, a synonym of Melanosis. T. of the Calcaneum, a tubercle on the external surface of the os calcis. T., Carotid, a prominence of the sixth cervical vertebra on the anterior part of its transverse process. T., Conoid, a broad projection of the clavicle on its posterior border at the union of its middle and outer thirds, to which is attached the conoid ligament. $T$. of the Cuboid, a tubercle on the plantar surface of the cuboid bone, also called the tuberosity

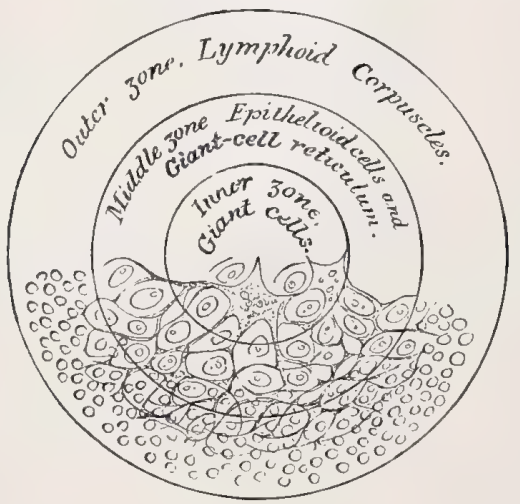

Diagram of the Minute Structure of Tubercle.

of the cuboid. T., Cuneate, of Schwalbe, a prominence on the cuneate fasciculus. T., Cuneiform. See T., Painful. T., Deltoid, a projection on the anterior border of the clavicle, giving origin to a part of the deltoideus. T., External, the outermost of the three tubercles on the transverse process of some of the dorsal vertebræ. T., External Supracondyloid, the projection at the lower end of the femur on the outer portion of its posterior surface, giving rise to the plantaris muscle. T. of the Femur, a tubercle on the neck of the femur, on the anterior surface near its junction with the trochanter major. T., Fibrous, a tubercle which has been modified by the formation of connective tissue within its structure. Ts., Genial, double pairs of tubercles on each side of the middle line on the inner surface of the lower maxilla. $T$., Genital, the rudimentary penis or clitoris in the uro-genital region of the embryo in front of the cloaca. 'T., Gray. See T., Miliary. T., Gray, of Rolando, a prominence between the prolongation of Burdach's column and the postero-lateral groove. T., Greater (of the humerus), the greater tuberosity. T., Hyaline, a miliary tubercle the reticulum of which has undergone hyaline degeneration. T., Inferior, the lowest of the three tubercles at the extremity of some of the dorsal vertebræ. T., Inferior Obturator, a projection on the pubic margin of the obturator foramen. T., Infraglenoid, a prominence from which arises the long head of the triceps, below the glenoid cavity of the scapula. T., Internal, the innermost of the three tubercles at the extremity of some of the dorsal vertebre. T., Internal Supracondyloid, a prominence from which arises the internal head of the gastrocnemius, on the posterior and inner surface of the lower end of the femur. T., Intravascular, a prominence on the intima of a blood-vessel. T., Jugular, a ridge near the outer wall of the anterior condyloid foramen on the inner surface of the occipital bone. T., Lacrymal, the small papillary prominence at the margin of the eyelid, and in the center of which is the punctum lacrymalia. Ts., Leprous, the tubercles found in tubercular leprosy. T., Lesser (of the humerus), the lesser tuberosity. T. of Lower, a small eminence on the wall of the right auricle, between the orifices of the pre-cava and inferior post-cava. T., Lymphoid. See under Tuberculosis. T., Mammillary. See Corpora manmillaria. T., Miliary, a small, globular tubercle in the stroma of an organ, showing microscopically giant-cells in the center, next smaller cells, and round cells like leukocytes at the periphery. Ts. of Montgomery, the prominences on the surface of the areola of the nipple; they are formed by the sebaceous glands. T., Mucous. See Mucous Patch. T., Nuchal, the spinous process of the seventh cervical vertebra. T., Olfactory. See Bulb, Olfactory. T., Painful, a painful tubercle in the subcutaneous tissue in the region of the joints; the nature of the affection is uncertain. T., Papillary (of the liver), a projection of the lobulus spigelii into the transverse fissure. $T$ s. Pearly, milium; small, whitish, non-inflammatory elevations situated in the upper part of the corium. T., Pharyngeal, the pharyngeal spine. Ts., Pisiform, the corpora mammillaria. T., Plantar, a tubercle on the first metatarsal bone ; it gives attachment to the tendon of the peroneus longus. Ts., Posterior Pair of, the posterior tubercles of the corpora quadrigemina. T., Posterior (of a vertebra). a tubercle at the posterior end of the lumbar and several of the thoracic vertebræ. T., Posterior (of the atlas), a tubercle on the dorsal arch of the atlas; it is situated in the median line on the external surface. Sometimes it is replaced by a depression with an elevated rim. T., Posterior (of the optic thalamus), a tubercle on the ventricular surface of the thalamus, toward the posterior end. T., Pterygoid, a tubercle on the inner surface of the inferior maxilla; it gives attachment to the internal pterygoid muscle. T., Quadrigeminal. See T., Posterior Pair of. 'T. of the Radius, the bicipital tuberosity of the radius. 'T., Retrograde, a tubercle that has undergone calcification. T. of a Rib, a tubercle on a rib, articulating with the transverse process of a vertebra. Ts, of Rolando, rounded masses close under the surface of the lateral columns of the oblongata, formed by the enlarged dorsal horns of the gray matter. T. of Santorini, a small eminence on the mucous surface of the larynx, due to the cartilage of Santorini. T., Scalene, a tubercle on the first rib ; it gives attachment to the anterior scalene muscle. $\mathbf{T}$. of the Scaphoid Bone, a projection on the outer surface of the bone which gives attachment to the annular ligament. T., Secondary, a tubercle that sometimes follows the breaking down of a caseous mass, as in catarrhal pneumonia. T., Superior Obturator, a tubercle on the margin of the obturator foramen. T., Supraglenoid, a tubercle above the glenoid fossa of the scapula; it gives attachment to the long head of the biceps. T. of the Thyroid Cartilage, a tubercle on the outer surface of the ala of the thyroid cartilage, at the posterior end of the upper margin. $T$. of the Tibia, the tuberosity on the anterior surface of 
the tibia. T. of the Ulna, a prominence at the base of the coronoid process which gives attachment to the brachialis anticus. T. of the Zygoma, a tubercle at the junction of the anterior root with the zygoma ; it gives attachment to the external lateral ligament of the lower jaw.

Tubercular (tu-bur'-ku-lar) [mberculum, a tubercle]. Presenting the physical appearance of a tubercle.

Tuberculate, Tubercled ( $\left.u-b u r-k u-l a \bar{t}, t u^{\prime}-b u r-k l d\right)$ [tuberculum, a tubercle]. Warty; bearing tubercles.

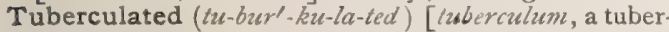
cle]. Furnished with tubercles; tuberculous.

Tuberculation ( $\left.t u-b u r-k u-l a^{\prime}-\operatorname{shun}\right)$ [tuberculum, a tubercle]. The formation, development, or arrangement of tubercles; the process of affecting a part with tubercles.

Tubercule ( $\left.t \bar{u}^{\prime}-b u r-k u \bar{l}\right)$ [tuberculum, a tubercle]. tubercle.

Tuberculiform (tu-bur'-ku-lif-orm) [tuberculum, tubercle; forma, form $]$. Shaped like a tubercle.

Tuberculin (tu-bur'-ku-lin) [tuberculum, a tubercle]. Koch's Lymph: Paratoloid; a glycerin-extract of cultures of the bacillus of tuberculosis. It is a brownish, neutral, albuminoid liquid, soluble in water, and consists probably of ptomains of the tubercle-bacilli. Dose hypodermatically $m \mathrm{II}^{\mathrm{I}} / 2$ of a $\mathrm{I}$ per cent. solution. It is to be used therapeutically only with great care. It is extremely valuable in the diagnosis of tuberculosis in cattle. Unof. Klebs and Hunter have endeavored to eliminate from tuberculin its dangerous elements. Hunter has prepared certain modifications of which he has named the two principal, respectively $\mathbf{B}$, and $\mathbf{C B}$. Trudeau has concluded that Modification CB contains much less of the remedial element than tuberculin, and is quite as dangerous, while Modification $\mathbf{B}$ is as efficacious as tuberculin, and free from some of its dangers. See also Tuberculocidin.

Tuberculinized (tu-bur'-ku-lin-izd) [tuberculum, tuber cle]. Submitted to the action of tuberculin.

Tuberculinose (tu-bur-ku-lin-ōz) [tuberculum, tubercle]. A term applied to some of the modifications of tuberculin. See also Tuberculin.

Tuberculitis (tu-bur-ku-li'-tis) [tuberculum, tubercle; erıs, inflammation]. The inflammation in the tissues surrounding a tuberculous node.

Tuberculization (tu-bur-ku-liz-a'-shun) [tuberculum, tubercle]. I. The formation of tubercles, or the condition of being charged with tubercles. 2. Treatment with tuberculin.

Tuberculocidin ( $\left.t u-b u r-k u-l o^{\prime} \cdot s i d-i n\right)$ [tuberculum, tubercle; cadere, to kill ]. Alexin; a precipitate obtained by Klebs from Koch's tuberculin by precipitating the noxious substances with platinum chlorid, the albumoses remaining in solution. See also Tuberculin.

Tuberculoid (tu-bur'-ku-loid) [tuberculum, tubercle; cidos, like]. Resembling tubercle.

Tuberculose (tu-bur'-ku-lōz). See Tuberculate.

Tuberculosis $\left(t u-b u r-k u-l o^{\prime}-s i s\right)$ [tuberculum, a tubercle]. An infectious disease due to the introduction into the system of the bacillus tuberculosis, discovered by Koch in I 882 . It has a very wide-spread, almost a universal, distribution, and it is estimated that fully one-seventh of all mankind die of it. The bacillus, the essential etiologic factor, gains entrance into the body with the inspired air, with the food, and by direct inoculation. The commonest mode of introduction is by inhalation; in consequence, the respiratory tract is the most frequent seat of tuberculosis. The bacilli become disseminated in the air chiefly through the agency of the sputum of persons afflicted with pulmonary tuberculosis. The sputum of such individuals contains countless bacilli, which are held in it as long as it is moist, but are scattered through the air when the sputum becomes dry and pulverulent. When tuberculosis is acquired through the food, an occurrence not rare in childhood, it localizes itself primarily in the intestinal tract. The food which most often conveys the disease is milk from tuberculous animals, more rarely tuberculous meat. Direct inoculation does not play an important rôle in the causation of the disease. The status of heredity as a factor in the propagation of tuberculosis is not yet fully settled. Isolated instances of apparently hereditary transmission, both in man and in animals, are recorded, and demonstrate that the disease may be inherited; but in the majority of cases the acquisition of tuberculosis is post-natal. There is, however, a manifest tendency of the disease to attack the offspring of tuberculous parents, which, as it is not the result of hereditary transmission, must indicate the existence of a predisposition or susceptibility which is transmitted from parent to child. The lesion produced by the growth of the bacillus of tuberculosis is known as the tubercle (miliary or gray tubercle or nodule). This is a small, grayish, translucent nodule, from $\frac{1}{10}$ to $2 \mathrm{~mm}$. in diameter, firmly imbedded in the surrounding tissues. By the coalescence of neighboring tubercles larger masses, the so-called tuberculous infiltrations, are produced. Histologically a typical tubercle consists of three groups of cells, the epithelioid, the giant-cells, and the round or lymphoid cells. The first are oval in shape, have a vesicular nucleus, and are the result of the proliferation of the fixed connective tissue and endothelial cells; perhaps, also, of epithelial cells. The formation of the oval cells is the first effect produced by the tubercle-bacillus. The giant-cell is a large multinuclear mass, usually situated in the center of the tubercle. It may be the product of repeated nuclear multiplication in a single cell, without division of the cell-protoplasm, or the result of the coalescence of several adjacent cells. The round cells are leukocytes that have emigrated from the blood-vessels, and they may be so numerous as to conceal the other cells (lymphoid tubercle). The bacilli are found in the giant-cells, between and in the epithelioid cells, and, in later stages, in the round cells. New blood-vessels are not formed in the tubercle. The tendency of the tuberculous formation is to undergo a peculiar form of coagulation, known as cheesy necrosis. This gives rise to a structureless, yellowishwhite mass, which microscopically shows an almost total absence of nuclei in the central area, while at the periphery nuclei, both normal and in various stages of degeneration, are found. The necrotic tissue does not as a rule take any stain. For this degeneration two factors are responsible: the absence of blood-vessels and the action of peculiar poisons elaborated by the bacillus. The breaking down of tuberculous areas in the interior of organs gives rise to cavities, which may be seen in muscles, bones, brain, lymphatic glands, and elsewhere, but are most pronounced in the lungs, where they may attain a very large size. On surfacesskin and mucous membranes-tuberculosis often leads to the formation of ulcers, which are characterized by an irregular, eroded appearance and by the presence of tubercles. Tuberculous areas occasionally become secondarily infected with pyogenic or saprophytic organisms. The tubercle-bacillus itself is capable of producing pus, but the majority of the so-called tuberculous cold abscesses are merely collections of fatty and disintegrated cells and tissue-detritus. Tuberculosis is primarily a local disease-extension takes place by continuity and contiguity, along the lymph-channels, along the respiratory and intestinal 
tracts, and through the blood. It is usually possible in secondary tuberculosis to demonstrate the original focus, but in the case of tuberculous lymphatic glands the source of infection is not always discoverable. This has been explained by assuming that infection may take place in utero and the bacilli lie dormant in the lymphatic glands for varying periods after birth (latent tuberculosis). The possibility has also been suggested that the bacilli may penetrate a mucous membrane, be carried to the nearest lymphatic gland, and unfold their activity there. In the human subject tuberculosis appears under various forms, presenting clinical differences, but identical from the pathologic standpoint. Since the discovery of the tuberclebacillus such diseases as scrofula, lupus vulgaris, Pott's disease, many forms of chronic joint-disease, and the anatomic tubercle have been proved to be tuberculous in nature. The most frequent seats of tuberculosis are the lung, the intestinal tract, the lymphatic glands, the serous membranes, the bones, the skin, the testicle, the epididymis, the brain, the Fallopian tubes, the uterus, the spleen. Tuberculosis is very frequent in the lower animals, attacking especially the domestic herbivora and fowls and wild animals kept in captivity. In cattle the lesions take the form of nodes and conglomerates, which, on serous membranes, may be pedunculated (pearldisease). Histologically there is in bovine tuberculosis a greater tendency to the formation of fibrous tissue than in the human form. The symptoms of tuberculosis vary with the localization of the disease. A few general phenomena are common to nearly all forms, viz, : emaciation, loss of strength, anemia, fever, and sweats. Amyloid degeneration may occur in various organs in cases of the disease associated with prolonged suppuration. In the diagnosis of tuberculosis the demonstration of the presence of the bacillus is of the highest importance. T., Acute Miliary, an acute, febrile disease, characterized by the formation of minute tubercles in great numbers in various parts of the body. It is due to the discharge into the circulatory stream of the constituent elements of some tuberculous focus, scattering the bacilli throughout the system. Three forms are usually described: I. A general or typhoid form. 2. One with marked pulmonary symptoms. 3. One in which cerebral symptoms predominate. T., Anatomic. See Tubercle, Anatomic. T., Avian, tuberculosis affecting birds. T., Bovine, tuberculosis as it occurs in catlle ; pearldisease. See Tuberculosis. T., Cerebral: I. Tuberculous meningitis. 2. Tuberculosis of the brain itself. T. cutis, tuberculosis of the skin; lupus vulgaris is the most common form. T., General Miliary. See T., Acute Miliary. T., Hematogenous (of the lung), this may be a miliary tuberculosis, affecting both lungs or a greater portion of one only, or it may be a localized tuberculosis, characterized by the appearance of tubercles in a limited area of the lung. T., Inoculated, tuberculosis caused by direct inoculation of tuberculous material. T., Intestinal, tuberculosis affecting the intestinal tract. T., Laryngeal, tuberculosis of the larynx, It is usually secondary to tuberculosis of the lungs, but in rare cases appears to be primary. T., Latent. See under Tuberculosis. T., Meningeal, tuberculosis of the cerebral or spinal meninges. The tubercles are scattered along the course of the bloodvessels. T., Miliary, tuberculosis characterized by the deposit of miliary tubercles in the viscera. T., Parasitic, tubercular growths produced by parasitic nematodes. T., Pseudo, a disease producing lesions similar to those of tuberculosis, but due to a pleomorphic organism, the Cladothrix asteroides (Eppinger). T.,
Pulmonary, tuberculosis of the lungs. T., Renal, tuberculosis of the kidney. T., Surgical, tuberculosis of parts amenable to surgical treatment. T., Urogenital, tuberculosis, apparently primary, of the genitourinary tract. T. verrucosa cutis. See Verruca necrogenica. T. zoöglceica, also known as pseudo-tuberculosis. A disease of guinea-pigs, rabbits, lambs, and horses, which is characterized by cheesy nodules. The cause is a pleomorphic bacillus forming zoöglea masses.

Tuberculous (tu-bur-ku-lus) [tuberculum, tubercle]. Affected with, or pertaining to, a tubercle. Caused by the bacillus tuberculosis. T. Disease of the Foot. See Foot, Fungus.

Tuberculum (tu-bur'-ku-lum) [L.]. See Tubercle, T. sebaceum. See Milium.

Tuberculus (tu-bur'-ku-lus) [tuberculum, tubercle]. In entomology, a supplementary eye.

Tuberiferous (tu-ber-if'-er-us) [tuber, a tuber; ferre, to bear]. Producing tubers.

Tuberiform (tu'-ber-if - orm) [tuber, tuber; forma, form ]. Tuber-shaped.

Tuberoid (tu'-ber-oid) [tuber, a swelling; cidos, like]. Resembling a tuber.

Tuberose $\left(t u^{\prime}-b e r-\bar{o} z\right)$. See Tuberous.

Tuberosity $\left(t u-b e r-o s^{\prime}-i t-e\right)$ [tuber, a swelling]. In anatomy, any protuberance of a bone or process. T., Greater (of the humerus), a rough projection on the outer side of the head of the humerus. T. of the Ischium, a thick, downward projection of the ischium, on which the body rests when in a sitting posture. $\mathbf{T}$., Lesser (of the humerus), a small tuberosity in front of the head and on the inner side of the bicipital groove of the humerus. T., Maxillary, a rounded eminence at the lower part of the zygomatic surface of the superior maxillary bone, especially prominent after the growth of the wisdom-teeth. Ts. of the Os calcis, two prominences, an external and an internal, on the posterior inferior aspect of the os calcis. $T$. of the Palate Bone, a pyramidal process at the lower part of the posterior border of the external surface of the palate bone. $\mathbf{T}$. of the Radius, a rough eminence at the inner and anterior aspect of the bone just beneath the neck.

Tuberous (tu'-ber-us) [tuberosus, like a tuber]. Characterized by the presence of tuberosities, as e.g., a tuberous angioma.

Tubicolous (tu-bik'-o-lus) [tuba, tube; colere, to inhabit]. In biology, inhabiting a tube.

Tubifacient (tu-be-fa/shent) [tuba, a tube; facere, to make]. In biology, tube-forming, as certain polyps and worms.

Tubiferous (tu-bif'-er-us) [tuba, a tube; ferre, to bear]. Bearing or having tubes.

Tubiflorous (tu-be-flo'-rus) [tuba, tube; flos, flower]. In biology, having tubular flowers.

Tubiform ( $t u^{\prime}-b e$-form $)$ [tuba, a tube; forma, form]. Trumpet-shaped; also, tubaform.

Tubilingual (tu-be-ling'-gwal) [tuba, tube; lingua, tongue]. In biology, having a tubular tongue.

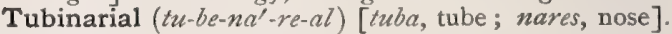
Having tubular nares.

Tubiparous (tu-bip'-ar-us) [tuba, tube; parere, to produce]. Producing tubes or tubules.

Tubo-abdominal (tu-bo-ab-dom'-in-al) [tuba, a tube; abdomen, abdomen ]. Pertaining to an oviduct and to the abdomen. T. Pregnancy, one that begins in the tube, but that finally becomes abdominal.

Tubo-ovarian $\left(t u-b o-0-v a^{\prime}-r e-a n\right)$ [tuba, a tube; ovarius, an ovary]. Pertaining conjointly to the Fallopian tubes and the ovaries. T. Pregnancy, an extrauterine pregnancy in which the ovum develops between the fimbrix of the oviduct and the ovary. 
Tubo-uterine [ $t u b a$, tube; uterus, uterus]. Pertaining to the oviduct and the uterus. T. Pregnancy, a form of tubal pregnancy in which the ovule develops in the uterine wall, a portion of the sac often projecting into the uterus, and having on the outer side the round ligament and the greater portion of the tube. Also known as interstitial pregnancy.

Tubular $\left(t u^{\prime}-b u\right.$-lar) [tubulus, a small tube]. I. Pertaining to or having the form of a tubulus. 2. Applied to a sound heard on auscultating the chest, and resembling a current of air passing through a tube. 3 . Nearly cylindric and hollow, like a tube, as a tubular corolla or calyx. T. Adenoma, an adenoma after the type of tubular glands. T. Breathing. Synonym of Breathing, Bronchial. T. Epithelioma, a carcinoma found in the salivary glands composed of irregular cells, the cell-masses extending in tubes or cylindric plugs in various directions. Pearly bodies are also present. T. Gland, a secreting gland tubelike or cylindric in shape. There are three varieties -the simple, the compound, and the modified or coiled tubular gland. In a special sense the term tubular glands is used to designate the enteric glands or follicles of Lieberkühn. T. Looseness. Synonym of Memöranous Enteritis. T. Membrane. See Neurilemma. T. Pneumonia. Synonym of Pneumonia, Lobular. T. Râle, one produced in a bronchial tube.

Tubulate $\left(t u^{\prime}-b u-l \bar{a} t\right)$ [tubulus, a small tube]. Formed like a tube.

Tubule $\left(t u^{\prime}-b \vec{u} l\right)$ [tubulus, dim. of tubus, a tube]. A small tube. In anatomy, any minute, tube-shaped structure. See also Tubulus. T., Communicating, or Junctional, that part of a uriniferous tubule between the distal convoluted, and the straight collecting tubule. T., Dentinal, the tubular structure of the teeth. $\mathbf{T}$. of Ferrein. See Tube of Ferrein.

Tubulicolous $\left(t u-b u\right.$-li $\left.k^{\prime}-o-l u s\right)$ [tubuhus, tubule ; colere, to inhabit]. Inhabiting a tubule.

Tubuliferous (tu-bu-lifi-er-us) [tubulus, tubule; ferre, to bear]. Having tubules, or tube-like ovipositors.

Tubuliflorus (tu-bu-lif'-lo-rus) [tubulus, a little tube ; flos, flower]. In biology, having the heads composed of tubular flowers.

Tubuliform (tu'-bu-lif-orm) [tubulus, tubule; forma, form]. Shaped like a tubule.

Tubulose $\left(t u^{\prime}-b u-l \bar{o} z\right)$. Same as Tubular.

Tubulus (tu'-bu-lus) [tubulus,a small tube: $p l ., T u$ buli]. In biology: $(a)$ a small, tube-like organ; a tubule; $(b)$ the ovipositor of certain insects; (c) see Cormu, Neck. T. lactiferi, the excretory ducts of the mammæ, $15^{-20}$ in number. $T$. seminiferi, the tubular threads, arranged in fasciculi, which compose the substance of the testicle. They are lined with epithelium from which the spermatozoids develop and are about $\frac{1}{20}$ inch in diameter. $T$. uriniferi, the urinary tubes of the kidneys. Beginning at the Malpighian capsules, each forms-Ist, a constricted neck; 2 d, a wide canal, called the proximal, or first convoluted tubule; $3 \mathrm{~d}$, a spiral tube, called the spiral tubule of Schachowa; 4th, the narrow, straight tube, called the descending limb of Henle's loop; 5th, the ascending limb of Henle's loop; 6th, the irregular tubule; 7 th, the distal or second convoluted tubule; 8th, the curved tubule; 9th, the straight collecting tubule opening at the apex of a pyramid.

Tubus $\left(t u^{\prime}-b u s\right)$ [L.: $\left.p l ., T u b i\right]$. A tube. In biology, the basal portion of the labium of the bee. T. proximus convolutus. See under Tubulus.

Tufnell's Bandage. An immovable bandage stiffened with a paste of white of egg and flour. It is also called egg-and-flour bandage. T.'s Diet or Treatment. See Diet.
Tuft [ME., tuft, a tuft]. I. A rete; a glomerulus. 2. A fascicle of flowers or leaves. T., Malpighian. See Malpighian Bodies.

Tulbaghia (tul-bag'-e-ah) [L.]. A genus of liliaceous plants, with the smell of garlic. The thick, fibrous roots of $T$. alliacea and $T$. cepacea are used in $\mathrm{S}$. Africa in pulmonary tuberculosis and as a cure for worms. Unof.

Tulip $\left(t u^{\prime}-l i p\right)$ [tulipa, tulip]. A common European flowering-plant, Tulipa gesneriana L. It is a sialagogue and cardiac poison. See Tulipin. Unof. T.tree. See Liviodendron.

Tulipin $\left(t u^{\prime}-l i p-i n\right)$ [tulipa, tulip]. An alkaloida] principle from the common tulip. It is strongly sialogogue, acts on the heart like veratrin, and on the spinal cord like scillitin or colchicin. Dose $\frac{1}{64}-\frac{1}{20}$ of a grain, in granules, or pills. Unof.

Tuliy's Powder. See Morphina.

Tulpius, Valve of. The ileo-cecal valve.

Tumefacient (tu-me-fa'-shent) [tumefacere, to swell]. Swelling; swollen.

Tumefaction (tu-me-fak'-shun) [tumere, to swell; facere, to make]. A swelling or enlargement of a part arising from any cause.

Tumenol (tu'-men-ol) [bitumen; oleum, oil]. A sulphonated preparation of certain hydrocarbons. It may be used in three forms: I. Tumenol itself, a dark-brown or brownish-black liquid; 2. Tumenol sulphone, an aromatic, syrupy liquid; 3. Tumenol sulphonic acid, a black powder, soluble in water. A Io per cent. tincture is used in the itching dermatoses. Unof.

Tumescence (tu-mes'-ens) [tumescere, to swell]. The state of growing tumid; a swelling.

Tumescent (tu-mes'-ent) [tumescere, to become swollen]. Swelling or enlargement due to absorption of moisture.

Tumid ( $t u^{\prime}-$ mid) [tumere, to swell]. Swollen.

Tumidity (tu-mid'-it-e) [tumidus, swollen]. The state of being swollen.

Tumor $\left(t u^{\prime}-m o r\right)$ [tumere, to swell]. I. Any enlarge ment or swelling of a part. 2. A new growth not the result of inflammation or hyperplasia. (See Tumors, Table of, p. 1558, etc.) A tumor is an atypical growth when it differs from the tissue in which it develops. True tumors are variously classified. The following classification is based, at least as regards classes A and $\mathrm{B}$, on the blastodermic origin of the dominant tissue of the tumor. Many combinations occur-these are not given in the table, but will be found under their proper headings elsewhere.

$\begin{array}{ll}\text { I. Sarcoma. } & \left\{\begin{array}{l}\text { Melanotic. } \\ \text { Alveolar. } \\ \text { Endothelioma. } \\ \text { Angio-sarcoma. } \\ \text { Cylindroma. } \\ \text { Chloroma. } \\ \text { Psammoma. }\end{array}\right. \\ \text { 2. Fibroma. } & \text { Hard. }\end{array}$

A. Mesodermic Tumors.

$\left\{\begin{array}{l}\text { Round-cell. } \\ \text { Spindle-cell. } \\ \text { Giant-cell. } \\ \text { Melanotic. } \\ \text { Alveolar. } \\ \text { Endothelioma. } \\ \text { Angio-sarcoma. } \\ \text { Cylindroma. } \\ \text { Chloroma. } \\ \text { Psammoma. } \\ \text { Hard. } \\ \text { Soft. }\end{array}\right.$

Myxoma

5. Chondroma. $\left\{\begin{array}{l}\text { Hyaline. } \\ \text { Fibrous. }\end{array}\right.$

6. Osteoma. $\quad$ O. durum or O. eburneum.

O. spongiosum or O. medullare.

7. Hemangioma. $\left\{\begin{array}{l}\text { Telangiectatic. } \\ \text { Cavernous. }\end{array}\right.$

8. Lymphangioma, Simple.

9. Myoma. $\left\{\begin{array}{l}\text { Cystic. } \\ \text { Leiomyoma }\end{array}\right.$

Rhabdomyoma. 
B. ECTODERMIC AND ENTODERMIC TUMORS.

I. Glioma.

ฉ. Neuroma.

3. Epithelioma. $\begin{cases}\text { Adenoma. } & \left\{\begin{array}{l}\text { Tubular. } \\ \text { Racemose. } \\ \text { Carcinoma. }\end{array}\right. \\ \text { Equamous. } \\ \text { Cyithelial cystoma. } \\ \text { Glandular. }\end{cases}$

C. TERATOID TUMORS OR TERATOMATA.

I. Dermoid cysts.

2. Cholesteatuma.

T. albus, white swelling; tuberculous arthritis. T., Adenoid. Synonym of Adenoma. T., Adipose. Synonym of Lipoma. T., Aneurysmal. Synonym of Aneurysm. T., Anthracoid. Synonym of T., Melanotic. T., Benign, one which does not give a metastasis or recur after removal. T., Blood. Synonym of Hematoma. T., Connective-tissue, any tumor made up of connective tissue. The tumors of the connective-tissue class are sometimes termed Parablastomata. T., Cystic, a tumor containing cysts or cavities filled with fluid. Also a cyst forming a tumor. T., Dermoid, a dermoid cyst. T., Desmoid, a hard fibroma. T., Erectile, a tumor composed of blood-vessels, the filling of which causes the tumor to become swollen. T., Fatty, lipoma. T., Fibro-calcareous, a fibroma, the seat of calcareous infiltration. T., Fibro-cellular. Synonym of Fibroma, Soft. T., Fibro-cystic, a fibrous tumor containing cysts. T., Fibro-fatty, a fibro-lipoma. T., Fibro-muscular, a fibro-myoma. T., Fibronucleated. Synonym of Sarcoma, Spindle-cell. T., Fibro-plastic. Synonym of Sarcoma, Spindle-cell. T., Fibrous, a fibroma. T., Fibro-vascular, a telangiectatic fibroma. T., Floating, a tumor that changes its place in a cavity of the body, as the abdomen. T., Fol licular, an atheroma. T., Fungating, a tumor proliferating actively on its surface ; usually applied to cysts, the lining wall of which is proliferating. T. gallicus. Synonym of Bubo. T., Gaseous, a tumor containing gas. T., Glandular, an adenoma. T., Gubler's, a prominence on the back of the wrist occasionally seen in lead-palsy. T., Gummatous, T., Gummous, T., Gummy, a syphilitic gumma. T., Hair, T., Hairy, a dermoid cyst containing hair. T., Heteradenic, a hyaline cylindroma. T., Heterochronic, a tumor made up of tissue which is not normally found in the individual at the period of life at which the tumor occurs. T., Heteroplastic, a tumor differing from the tissue in which it grows. T., Heterotopic, a tumor growing in tissue differing from that of which it is composed. T., Homeomorphous. Synonym of $T$. Homeoplastic. T., Homeoplastic, a tumor resembling the tissue from which it grows. T., Homologous. Synonym of T., Homeoplastic. T., Horny, cornu cutaneum. T., Infectious Granulation-, a nodule or node, due to infection with a specific microörganism. T., Infiltrating, a tumor growing into the surrounding tissues. T., Innocent. Synonym of $T$., Benign. T., Irritable (of the breast), this may be a painful adenoma or a painful subcutaneous tubercle. T., Lacteal, a galactocele. T., Lymph, a lymphangioma. T., Lymphadenoid, a lymphadenoma. T., Malignant, one which gives metastasis or recurs, or does both, and eventually destroys life. T., Melanic, T., Melanotic, a tumor the seat of pigmentation by melanin. $\mathbf{T}$. Mesoblastic, T. Mesodermic, a tumor developed from mesodermic tissue. T., Molluscous. Synonym of Molluscum contagiosum. T., Movable, a tumor which can be moved about. T., Mucoid, T., Mucous-tissue, T., Mucous. Synonym of Myxoma.
T., Muscular. Synonym of Myoma. T., Myelogenic. Synonym of Sarcoma, Giant-cell. T., Myeloid, one containing giant-cells. T., Myoid. Synonym of Leiomyoma. T., Nerve. Synonym of Neuroma. T., Osseous. Synonym of Osteoma. T., Osteoid, one in which bony tissue is developing. T., Papillary. Synonym of Papilloma. T., Pearl, 'T., Pearly. Synonym of Cholesteatoma. T., Pearly (of the iris), a small cystic tumor of the iris, containing a whitish, tallowy material. T., Perineal, the bulging of the perineum produced by the fetal head in childbirth. T., Phantom, an apparent abdominal tumor, due to flatus or contraction of a section of an abdominal muscle; seen in hysterical persons. T., Pilocystic, a dermoid cyst containing hair. T., Recurrent, one which returns after removal. T., Recurrent Fibroid, a spindle-cell sarcoma. 'T., Scalp. Synonym of Caput succedaneum. T. of the Scalp, Cock's Peculiar, a fungating growth of the sebaceous glands of the scalp. T., Sebaceous, a tumor of a sebaceous gland; an atheroma. T., Serocystic, a proliferation-cyst. T., Splenic, a term sometimes applied to an enlarged spleen. T., Stercoral, a tumor formed by impacted feces. T., Teratoid. Synonym of Teratoma. T., Vascular. Synonym of Angioma. T., Villous. Synonym of Papilloma. See Tumors, Table of, beginning on page 1558 .

Tumultus (tu-mul'-tus) [L.]. Tumult. T. sermonis. See Aphasia.

Tungsten (tungl-sten) [Swed., "heavy stone"']. A metal, symbol W, at. wt. I83.5, having properties like those of uranium and molybdenum. Some of its compounds have been employed in medicine. They are now chiefly used as reagents. See Elements, Table of.

Tunica (tu'-nik-ah) [L., a cloak: pl., Tunica]. An enveloping or covering membrane. T. adventitia. See Artery. T. albuginea oculi, a tendinous mem brane of the sclerotic coat. $\mathbf{T}$. albuginea ovi, tho thin, compact, distinctly marked zone of connective tissue immediately under the epithelium of the cortex of the ovary. T. albuginea testis, the fibrous covering of the testis. T. cellulosa. See $T$. submucosa. $T$. fibrosa, the external layer of the connective-tissue envelop of the Graafian follicle. T. fibrosa intestinalis. See T. submucosa. T. granulosa, the layer of epithelial cells lining the follicle of the Graafian vesicle. $\mathbf{T}$. intima. See Artery. T. media. See Artery, also $T$. uvea. T. mucosa, the mucous membrane of a part. T. muscularis, the muscular coat surrounding certain organs, as the intestine, the uterus, etc. T. nervosa. See T. sub-mucosa. T. propria, one of the layers of the Graafian follicle. T. reflexa, the parietal portion of the tunica vaginalis. $T$. ruyschiana, a name given to the internal layer of the choroid coat of the eye, consisting of a plexus of capillary vessels. T. serosa, the serous coat of the small intestines. $T$. submucosa, the submucous areolar tissue of the small intestines and some other organs. T. uvea, the uveal tract of the eye, composed of the iris, ciliary body, and choroid. $T$. vaginalis, a name given to the serous covering of the testis, and also to the membranous sac (capsule of Tenon) enveloping the eye. T. vasculosa, the vascular layer of the testis, called also the pia mater of the testis. See $T$. uvea.

Tunicate $\left(t u^{\prime}-n i k-\bar{a} t\right)$ [tunica, tunic]. In biology: I. Having coverings or coats. A bulb like that of the onion is tunicated. 2. An Ascidian.

Tunicin (tu'-nis-in) [tunica, a coat]. Animal cellulose; a carbohydrate constituting the chief part of the mantle of Tunicata (Ascidians). It is soluble in 
Schweitzer's reagent, and is colored blue by the addition of iodin after preliminary treatment with sulphuric acid.

Tunicle $\left(\hbar u^{\prime}-n i k-l\right)$ [tunicula, a tunicle]. A little tunic.

Tuning-fork ( $t u^{\prime}$-ning-fork). A pronged, metallic instrument capable of vibrating so as to form a certain definite note

Tunnel ( $\left.u n^{\prime} \cdot e l\right)$ [ME., tonnell, tunnel]. A long pipelike passage. T-anemia. See Ankylostomiasis. T. of Corti. See Canal. T.-disease, See Caissondisease.

Tupelo $\left(t u^{\prime}-p e-70\right)$. See Nyssa and Tent.

Turacin (tu'-ras-in) [African, turakoo]. A crimson coloring-matter obtained from the feathers of the turakoo. It is slowly soluble in water, but easily soluble in alkaline fluids, and contains about 6 per cent. of copper. See Pigments, Conspectus of.

Turacoverdin (tu-rak-o-ver'-din) [African, turakoo; viridis, green]. A green coloring-matter obtained from the feathers of certain birds.

Turbid Pneumonia (tur'-bid nu-mo'-ne-ah). A term applied to the indistinct pneumonic symptoms following injections of tuberculin; it is also called Injectionpneumonia.

Turbinal $\left(t u r^{\prime}-b i n-a l\right)$ [turbo, top]. A turbinated bone.

Turbinate, Turbinated (tur'-bin-ät, tur'-bin-a-ted) [turbo, a top]. Top-shaped. Scroll-like. T. Bones, the common name given to the three, sometimes four, bony projections upon the outer wall of each nasal fossa. The lowest of these, alone, is a separate bone.

Türck, Column of. See Column. T., Fasciculus of. See Fasciculus.

Turf. See Coal.

Turgescence (tur-jes'-ens) [turgescere, to become swelled]. The swelling or enlargement of an organ or part, from any cause whatsoever.

Turgid (tur'-jid) [turgidus, swollen]. Swollen, congested.

Turgidity, Turgidness (tur-jid'-it-e, tur'-jid-nes). See Turgescenie.

Turicatas (tur-ik'-a-tas) [Mex.]. The popular Mexican name for the parasitic mite, Argas turicata, Dugess. See under Parasites (Animal), Table of.

Turio (tu'-re-o) [turio, a shoot: pl., Turiones]. A strong, young shoot, or sucker, springing out of the ground.

Turkey $($ tur $-k e)$ [F., Turquie, Turkey, because it was thought to have originally come from Turkey]. An American gallinaceous bird of the genus Meleagris. T. Corn. See Carydatis. T.-red. Same as Madder. T.-red Oil, two entirely distinct oils are known under this name. One is simply an inferior grade of olive-oil, known as “ Gallipoli oil," prepared from somewhat unripe olives, and containing a large proportion of extractive matters, hence easily becoming rancid. It is used in the old process of Turkey-red dyeing, under the name huile tournante. The other, used for producing alizarin-reds by the quick process, is the ammonium salt of sulpho-ricinoleic acid $\left(\mathrm{C}_{18} \mathrm{H}_{33}\right.$ $\left.\left(\mathrm{HSO}_{3}\right) \mathrm{O}_{3}\right)$

Turkish (tur'-kish). Pertaining to Turkey or the Turks. T. Bath. See Bath. T. Saddle. See Sella turcica.

Turmeric (tur'-mer-ik) [turmerica, turmeric]. The rhizome of Curcuma longa, an aromatic and stimulant. The coloring-matter is used as a test for soluble salts of boron. Dose of fld. ext. $m x v-z j$. T.-paper, unsized white paper steeped in tincture of turmeric and dried by exposure to the air. A test for alkaline solutions, which give a reddish-brown coloration. See
Curcuma and Cucurmin. T., Tinct. (B.P.), used to make turmeric paper.

Turn [ME., turnen, to turn]. To cause to revolve about an axis. T. of Life. See Menopause.

Turnbull's Blue. Same as Berlin Blue.

Turner's Cerate. The ceratum calaminæ or ointment of calamin (20 per cent.). T.'s Yellow. Same as Cassel Yellow.

Turnera (tur'-ner-ah). See Damiana.

Turnesol Rag. Same as Bezette.

Turning (turn'-ing) [ME., turnen, to turn]. I. See Version.

Turnip $\left(u r^{\prime}-n i p\right)$ [ME., turn, something round; nepe, a turnip]. The thick, fleshy root of the plant Brassica rapa (Linnaus). T. Braxy. See Braxy. T., Indian. See Dragon-root.

Turpentine (tur'-pen-tin). See Terebinthina. T.tree. See Terebinth.

Turpeth (tur'-peth) [ME., turbyte, a purgative root]. The root of Ipomaa turpethum, a purgative plant, much resembling jalap, found in Asia and Australia. Unof. T. Mineral. See Hydrargyrum.

Turps [ME, turbentyne, turpentine]. The trade-name for oil of turpentine.

Turtle $($ tur'-ll) [a corruption of tortoise]. A tortoise; a member of the Testudinata. T.-back Nail. See Nail. T.-lung. See Bronchiectasis.

Turunda, Turundula (tu-run'-dah, tu-run'-du-lah) [L. : pl., Turunde, Turundula]. A surgical tent.

Tussal (tus'-al) [tussis, cough]. Pertaining to or of the nature of a cough.

Tussilago (tus - il - $\left.a^{\prime}-g o\right)$ [gen., Tussilaginis]. See Coltsfoot.

Tussis $\left(t u s^{\prime}-i s\right)$ [L.]. A cough. T. convulsiva, $T$. ferina, $T$. quinta, $T$. stomachalis, $T$. strangulans. Synonyms of Whooping-cough.

Tussive $\left(t^{\prime} s^{\prime}-i v\right)$ [tussis, cough]. Pertaining to or caused by cough. T. Fremitus. See Fremitus.

Tutamen $\left(t u-t a^{\prime}-m e n\right)$ [L., defense: pl.,Tutamina]. A defense or protection. Tutamina cerebri, the skull and meninges of the brain. $T$. oculi, the appendages of the eyes-the lids, brows, lashes, etc.

Tutsan (tut'-san) [totus, all; sanus, well]. See St. John's Wort.

Twang [ME., twangue]. A personal quality of the voice, usually nasal.

Tweenbrain $($ twẽn' $-b r \bar{a} n)$. See Diencephalon, and Interbrain.

Tweezers (twe'-zers). See Volsella.

Twin (twin) [ME, twin, twins]. One of two persons born at the same birth. T. Leaf, the rhizome and rootlets of Jeffersonia diphylla. It is diuretic, alterative, and antispasmodic, and in large doses emetic. Dose of the fld. ext. $m x x-3 j$. Unof. See, also, Jeffersonia diphylla.

Twist, Aberdeen. A variety of acupressure in which the pin is given a half or a quarter rotation before fixing it in the tissues on the side of the artery opposite to the point of insertion of the pin.

Twitch(trich) [ME., twicchen, to twitch]. To give a short, sudden pull or jerk. See, also, Uvular Twitch. T.-grass, Triticum repens. See Triticum.

'Twitches (trich'-es). See Palmus.

Twitching (twich'-ing) [ME., twicchen, to twitch] An irregular spasm of a minor extent.

Twixt-Brain (twikst'-brān). See Interbrain.

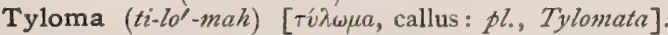
See Callositas.

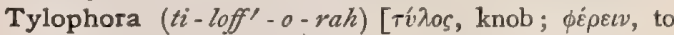
bear]. A genus of asclepiadaceous old-world plants. T. asthmatica is used as a substitute for ipecac. Unof. 


\section{TABLE OF TUMORS.}

\begin{tabular}{c|c|} 
Name. & Histologic Constituents. \\
\hline $\begin{array}{c}\text { Adenoma. } \\
\text { I. Acinous. }\end{array}$ & $\begin{array}{c}\text { Acini lined with spheroidal epithelium, } \\
\text { with varying amount of connective } \\
\text { tissue, as in a normal gland. }\end{array}$ \\
2. Tubular. & $\begin{array}{c}\text { Tubules lined with cylindrical epithe- } \\
\text { lium. }\end{array}$
\end{tabular}

Angioma.
2. Cavernous. tatic.

\section{Encephaloid} (soft, spheroidalcelled).
3. Colloid (probably a degeneration of one of the preceding varieties).
1. Telangiectatic.

Dilated blood-vessels.

2. Cavernous

Spaces lined with endothelial cells and filled with blood, like corpora cavernosa of penis.

\section{Scirrhous \\ (hard, sphe- \\ roid al}

Large epithelial cells containing one or more nuclei, without visible intercellular matrix, grouped into acini (cancer-nests). Vessels have walls of normal thickness and constitution, and ramify in the stroma, and not among the cells themselves.

Three varieties are described histologically: (a) squamous, made up of squamious or flat epithelium; (b) cylindrical, containing columnar cells: (c) glandular, composed largely of polyhedral cells, like those of secreting glands.
Physical Manifestations.

1. Acinous.

Firm, rather hard consistence inelastic; lobulated; light-gray or slightly yellow color; mov able; encapsulated; generally single; rounded; when on lar.

2. Tubular.

Soft ; frequently pedunculated; grayish-white or reddish color: translucent.

\section{r. Telangiectatic,}

Surface often covered with small, granular elevations, resembling a strawberry; often well circumscribed.

2. Cavernous.

oft, doughy; non-pulsating; leaden or blue color.

\section{Scirrhous.}

Hard, irregular, tuberous ; adherent to surrounding tissues ulcerated. Non-encapsulated. Ulcer.-Irregular in outline and depth; margins hard, nodular, everted.

\section{Encephaloid.}

Soft, globular, or bossellated : elastic, compressible : fluctuating; non-encapsulated.

3. Colloid (usually mucoid).

oft ; jelly-like ; contains mucoid material ; semitratıslucent; glistening ; at places diffluent mucous surfaces, flat and irregu-

APPEARANCE OF SECTION.

SIZE.

Gray or yellowishwhite: of variable density often intermingled with cysts.

1. Acinous. Cherry or walnut; in $\mathrm{th}$ e breast: large.

2. Tubular. Small.

Red color; affecting in part the corium; in part the subcutaneous adipose tissue. the skin the size of a millet-seed to several inches in extent.

2. Cavernous.

Us u a $11 \mathrm{y}$ smalt.

\section{Scirrhous.}

I. Scir-

Firm; white; often rhous.

traversed by fibrous Moderate. septa : creaking under the knife cupped. Scraping exposes a milky fluid, the so-called "cancer-juice."

\section{Encephaloid.}

2. Encepha-

Resembles brain-tissue.

Considerable.

3. Colloid.
Amorphous; jelly-like. Lolloid.
La rge or

3. Colloid.
Amorphous; jelly-like. Colloid. small.

\section{Small nodules.}

Cholesteatoma. (which see)

of round-celled sarcoma Concentric layers formed of flat cells of an epithelial character, arranged in whorls enclosing cholesterin plates. Belongs probably to the Teratomata from the occurrence in it of sebaceous glands, hair-follicles, etc.

\begin{tabular}{ll|l}
\hline $\begin{array}{c}\text { Solitary or multiple nodules or } \\
\text { nodes. }\end{array}$ & Shining, glistening. \\
\end{tabular}


TABLE OF TUMORS.

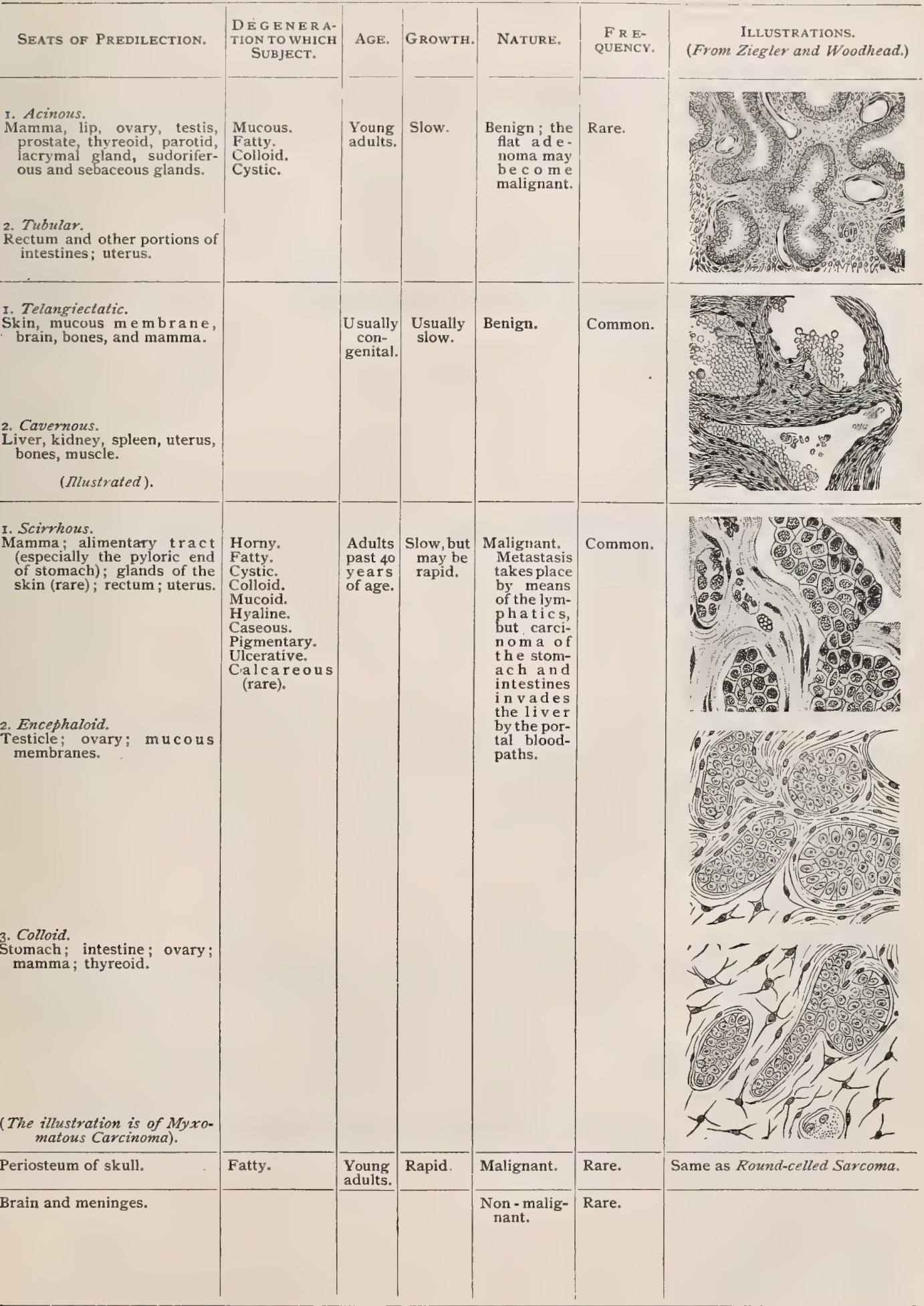


TABLE OF TUMORS-Continued.

\begin{tabular}{|c|c|c|c|c|}
\hline NAME. & Histologic Constituents. & Physical Manifestations. & $\begin{array}{l}\text { APPEARANCE OF SEC. } \\
\text { TION. }\end{array}$ & SIZE. \\
\hline $\begin{array}{l}\text { Chondroma. } \\
\text { (Enchond- } \\
\text { roma.) }\end{array}$ & $\begin{array}{l}\text { Hyaline or fibro-cartilage, with few } \\
\text { blood-vessels. The cells are ar- } \\
\text { ranged irregularly and have irregu- } \\
\text { lar shapes, many being stellate or } \\
\text { spindle-shaped. }\end{array}$ & $\begin{array}{l}\text { Hard; elastic; nodular or lobu- } \\
\text { lated,sometimes smooth; round; } \\
\text { encapsulated; usually single, } \\
\text { but may be multiple and sym- } \\
\text { metric. }\end{array}$ & $\begin{array}{l}\text { Homogen eous or } \\
\text { coarsely granular; } \\
\text { translucent; bluish- } \\
\text { gray or pinkish- } \\
\text { white; often marked } \\
\text { by connective-tissue } \\
\text { septa. }\end{array}$ & $\begin{array}{l}\mathrm{Sma} 11 \text { if } \\
\text { multiple; } \\
\text { large if } \\
\text { single. }\end{array}$ \\
\hline Dermoid Cyst. & See page 1564 & & & \\
\hline Endothelioma & $\begin{array}{l}\text { Multiplication of endothelial cells } \\
\text { lining lymph-passages. A variety } \\
\text { of sarcoma. Large, round cells con- } \\
\text { taining one or two nuclei. Resem- } \\
\text { bles epithelial new-grawths. }\end{array}$ & $\begin{array}{l}\text { Circumscribed or extensive flat } \\
\text { growths, spreading over the ser- } \\
\text { ous membranes; white in color. }\end{array}$ & & $\begin{array}{l}\text { Small nod- } \\
\text { ules or } \\
\text { exten- } \\
\text { sive infil- } \\
\text { tration. }\end{array}$ \\
\hline $\begin{array}{l}\text { Epithelioma. } \\
\text { I. Squamous. }\end{array}$ & $\begin{array}{l}\text { Composed of pegs or columns of } \\
\text { cuboidal epithelial cells which first } \\
\text { infiltrate the subjacent connective } \\
\text { tissue, then every underlying struc- } \\
\text { ture, including bone, in their track. } \\
\text { These ingrowths contain the cell- } \\
\text { nests, epidermal pearls, or pearly } \\
\text { bodies. }\end{array}$ & $\begin{array}{l}\text { Dense; inelastic; non-encapsu- } \\
\text { lated; ulcerated; edges of ulcer } \\
\text { indurated. }\end{array}$ & $\begin{array}{l}\text { I. Squamous. } \\
\text { White; dense; homo- } \\
\text { geneous; poor in } \\
\text { juice; when scraped } \\
\text { a gruel-like material } \\
\text { is obtained, which } \\
\text { consists of plugs of } \\
\text { cells and individual } \\
\text { cells. }\end{array}$ & \\
\hline $\begin{array}{l}\text { 2. Cylindric- } \\
\text { celled or } \\
\text { columnar- } \\
\text { celled. }\end{array}$ & $\begin{array}{l}\text { Originates either from the cylindric } \\
\text { surface-epithelium of a mucous } \\
\text { membrane, or from that of glands } \\
\text { lined by columnar epithelium. Con- } \\
\text { tains no "cell-nests." Consists of al- } \\
\text { veoli containing cylindric cells at the } \\
\text { periphery, and irregular cells in the } \\
\text { center. Presents the character of } \\
\text { adeno-carcinoma. }\end{array}$ & $\begin{array}{l}\text { Soft, infiltrating masses or nodes, } \\
\text { or papillomatous growths. }\end{array}$ & $\begin{array}{l}\text { 2. Cylindrical. } \\
\text { Soft, juicy, gelatinous } \\
\text { if mucoid or colloid. }\end{array}$ & \\
\hline Fibroma. & $\begin{array}{l}\text { 1. Hard. } \\
\text { White, fibrous tissue, consisting of } \\
\text { fibers and few connective-tissue cor- } \\
\text { puscles; blood-vessels few. }\end{array}$ & $\begin{array}{l}\text { I. Hard. } \\
\text { Ovoidal or spherical ; lobulated; } \\
\text { nodular or bossellated; pedun- } \\
\text { culated or sessile; firm, elastic : } \\
\text { encapsulated; glistening white, } \\
\text { yellowish, or slightly red color; } \\
\text { unattached to overlying tissues; } \\
\text { single or multiple. } \\
\text { 2. Soft. } \\
\text { Soft, compressible ; sessile or pen- } \\
\text { dulous ; single or multiple; en- } \\
\text { capsulated. }\end{array}$ & $\begin{array}{l}\text { I. Hard. } \\
\text { Simo th, glistening. } \\
\text { firm; grayish-white } \\
\text { color. } \\
\text { Moft. } \\
\text { ing; mot so glisten- }\end{array}$ & $\begin{array}{l}\text { From a } \\
\text { grain of } \\
\text { shot to } \\
\text { fetal } \\
\text { head or } \\
\text { much } \\
\text { larger. }\end{array}$ \\
\hline Glioma. & $\begin{array}{l}\text { Round cells, with large nuclei, em- } \\
\text { bedded in a scanty, granular, inter- } \\
\text { cellular substance. After the type } \\
\text { of the neuroglia of the brain. }\end{array}$ & $\begin{array}{l}\text { Soft, gelatinous, glue-like tumor; } \\
\text { not distinctly outlined; some- } \\
\text { what translucent. Us u ally } \\
\text { single. }\end{array}$ & $\begin{array}{l}\text { Like brain-tissue, but } \\
\text { usually a little harder } \\
\text { and more reddish in } \\
\text { color. }\end{array}$ & 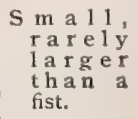 \\
\hline
\end{tabular}


TARLE OF TUMORS-Continued.

The bones, especially on or in the phalanges; scapula, ili- Mucoid. um, upper jaw ; subcutane- Calcareous. ous tissue; salivary Cystic. glands (parotid); testicle: bronchial cartilages.
Seats of Predilection.

DEGENERA-
TIONTOWHICH
SUBJECT.
Fatty.
Mucoid.
Calcareous.
Cystic.

Pleura and peritoneum ; mem branes of brain

\section{Squamous.}

Nose, lower lip, penis, scro- Horny.

gums, palate, tonsils, larynx.

pharynx, esophagus, blad-

der, os uteri, hands and feet (rare). tum, vulva, anus, tongue, Ulceration.
2. Cylindrical.

Stomach; intestinal tract; Mucoid. uterus ; gall-bladder, biliary Colloid. passages; respiratory tract.
AgE. Growth. Nature.

Usually Slow or

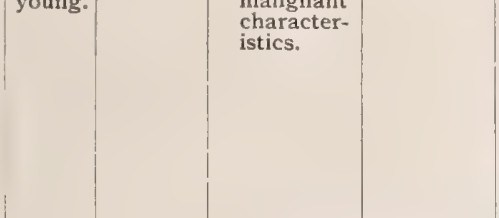

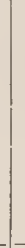

fore 40 .

,

Uterus ; periosteum ; ovary ; Ulceration. labium majus; mamma; Calcification. testicle; tendons; aponeuro- Myxomatous. sis; neurilemma of nerves: Fatty. around articulations; subcutaneous tissue; rectum. tatic.

Brain : retina; spinal cord ; op-
tic and auditory nerves; su-
prarenal capsules.

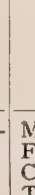

FREILLUSTRATIONS.

QUENCY. (From Ziegler and Woodhead.)
U sually Slow or

inay Common

young.

Young Rapid.

adults.

40.

Inuter- Varies
us be- in its

us be- in its
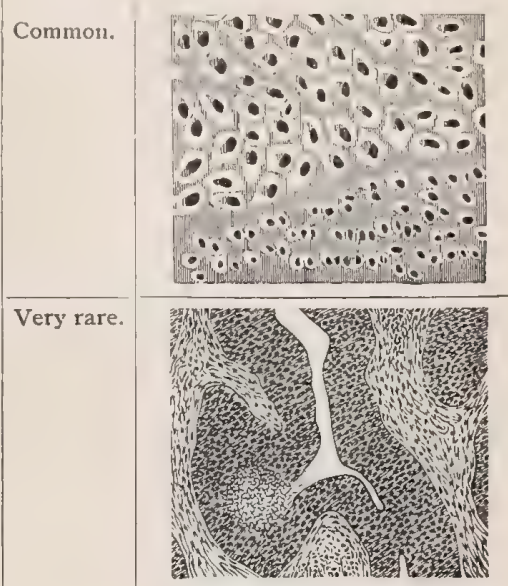

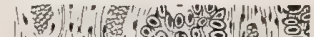

Common.

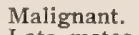
rapid,

Malignant. tasis.

to situa-

Malignant.

Quite compecially in digestive tract.
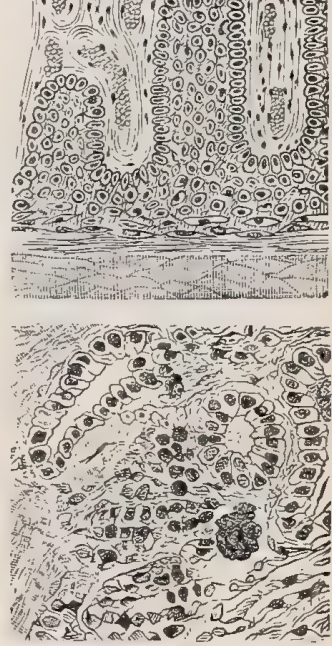

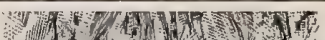

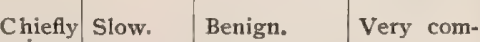
mon.

\section{in}

from

35 to 55

years

of age.

mon.

Rare.

cept in the

eye, where

it is usual-

$1 \mathrm{y} \mathrm{com}$ -

bined with

sarcoma.

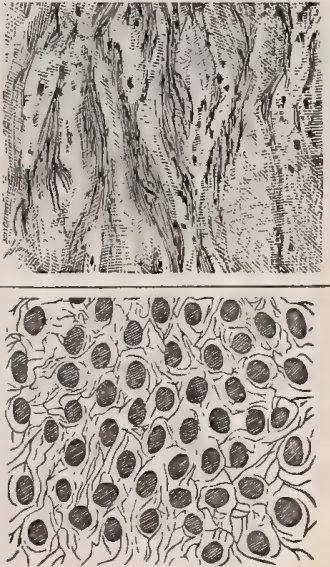


TABLE OF TUMORS-Continued.

\begin{tabular}{|c|c|c|c|c|}
\hline NAME. & Histologic Constituents. & Physical Manifestations. & $\begin{array}{c}\text { APPEARANCE OF SEC- } \\
\text { TION. }\end{array}$ & Size. \\
\hline Lipoma. & $\begin{array}{l}\text { Adipose tissue (fat-vesicles larger than } \\
\text { normal) bound together by delicate } \\
\text { connective tissue. }\end{array}$ & $\begin{array}{l}\text { Circumscribed ; lobulated, soft, } \\
\text { doughy, pseudo-fluctuating, in- } \\
\text { elastic; attached to the skin- } \\
\text { hence dimpled; ovoidal, spheri- } \\
\text { cal, or flattened; occasionally } \\
\text { pedunculated; us ually sur- } \\
\text { rounded by a thin capsule; usu- } \\
\text { ally single; when multiple, usu- } \\
\text { ally hereditary. }\end{array}$ & Like adipose tissue. & $\begin{array}{l}\text { From size } \\
\text { of hick- } \\
\text { ory-nut } \\
\text { to very } \\
\text { l a r g e } \\
\text { size. }\end{array}$ \\
\hline $\begin{array}{l}\text { Lymphangi- } \\
\text { oma. }\end{array}$ & $\begin{array}{l}\text { Aggregation of dilated lymphatic ves- } \\
\text { sels and lymph-spaces supported by } \\
\text { connective tissue. }\end{array}$ & $\begin{array}{l}\text { Soft, doughy, transparent sacs or } \\
\text { vesicles, filled with lymph; often } \\
\text { feels like a series of tangled } \\
\text { cords. }\end{array}$ & . & $\begin{array}{l}\text { From a } \\
\text { cherry } \\
\text { to fetal } \\
\text { head. }\end{array}$ \\
\hline $\begin{array}{l}\text { Ly y pho-sar- } \\
\text { coma. }\end{array}$ & $\begin{array}{l}\text { Hyperplasia of the lymphoid cells of } \\
\text { the lymphatic glands. }\end{array}$ & $\begin{array}{l}\text { Glands for a time preserve their } \\
\text { shape, but soon extends to } \\
\text { neighboring tissues. }\end{array}$ & & Large. \\
\hline $\begin{array}{l}\text { Myoma. } \\
\text { I. Leiomyoma. }\end{array}$ & $\begin{array}{l}\text { Smooth, non-striated, muscular fibers, } \\
\text { such as occur in the uterus, with } \\
\text { varying quantities of fibrous tissue; } \\
\text { few blood-vessels. The fibers are } \\
\text { composed of spindle-shaped cells } \\
\text { containing large, rod-shaped nuclei. }\end{array}$ & $\begin{array}{l}\text { Rounded or pyriform, well-circum- } \\
\text { scribed; hard; firm; sinooth or } \\
\text { nodular; white or flesh-colored ; } \\
\text { encapsulated or non-encapsu- } \\
\text { lated; often multiple. }\end{array}$ & $\begin{array}{l}\text { A striated appearance } \\
\text { as in the fibroma. }\end{array}$ & $\begin{array}{l}\text { Often quite } \\
\text { large. }\end{array}$ \\
\hline $\begin{array}{l}\text { 2. Rhabdomy- } \\
\text { oma. }\end{array}$ & $\begin{array}{l}\text { Striated muscular fibers, often unde- } \\
\text { veloped, being spindle-shaped, and } \\
\text { associated with sarcomatous tissue. }\end{array}$ & $\begin{array}{l}\text { Large roundish masses or small } \\
\text { nodules. }\end{array}$ & & $\begin{array}{l}\text { Very large } \\
\text { if in kid- } \\
\text { ney; small } \\
\text { in heart. }\end{array}$ \\
\hline Myxoma. & $\begin{array}{l}\text { Delicate network of stellate cells en- } \\
\text { closing a mucoid intercellular sub- } \\
\text { stance. Type-Wharton's jelly ; } \\
\text { vitreous humor. }\end{array}$ & $\begin{array}{l}\text { Round or lobular; soft, gelatinous; } \\
\text { semi-translucent; encapsulated; } \\
\text { elastic ; may be fluctuating. }\end{array}$ & $\begin{array}{l}\text { Pinkish or yellowish- } \\
\text { gray, exuding a } \\
\text { glairy fluid, or a } \\
\text { trembling, gelatinous } \\
\text { mass. }\end{array}$ & $\begin{array}{l}\text { Usua } 11 \mathrm{y} \\
\text { small. }\end{array}$ \\
\hline Neuroma. & $\begin{array}{l}\text { Medullated or non-medullated nerve- } \\
\text { fibers. Very rarely may contain } \\
\text { ganglionic cells; usually combined } \\
\text { with fibrous tissues. }\end{array}$ & $\begin{array}{l}\text { Spheric, ovoid, oblong, or bul- } \\
\text { bous; sometimes plexiform; } \\
\text { firm ; painful on pressure; few } \\
\text { or many (even hundreds). }\end{array}$ & $\begin{array}{l}\text { Often resembles fibro- } \\
\text { ma. }\end{array}$ & Small. \\
\hline Osteoma. & $\begin{array}{l}\text { Osseous tissue (cancellous or compact } \\
\text { bone). }\end{array}$ & $\begin{array}{l}\text { Hard; often lobulated; sometimes } \\
\text { spheric; may be spinous or } \\
\text { spiculated : pedunculated or } \\
\text { sessile; usually single; may be } \\
\text { multiple and symmetric. }\end{array}$ & Like bone-tissue. & $\begin{array}{l}\text { Variable: } \\
\text { grain of } \\
\text { coffee to } \\
\text { cocoanut. }\end{array}$ \\
\hline Papilloma. & $\begin{array}{l}\text { Hypertrophied papillæe of the skin ; } \\
\text { varying amount of connective tissue } \\
\text { surrounding two or more central } \\
\text { blood-vessels, and covered by seve- } \\
\text { ral layers of epithelial cells. }\end{array}$ & $\begin{array}{l}\text { Circumscribed; hard (on the } \\
\text { skin); soft (on mucous mem- } \\
\text { brane); surface smooth, brush- } \\
\text { like, or caulifiower-like; single } \\
\text { or multiple. }\end{array}$ & & $\begin{array}{l}\text { Us u a } 11 \mathrm{y} \\
\text { s ma } 11 \\
\text { may be } \\
\text { large. }\end{array}$ \\
\hline
\end{tabular}


TABLE OF TUMORS-Continued.

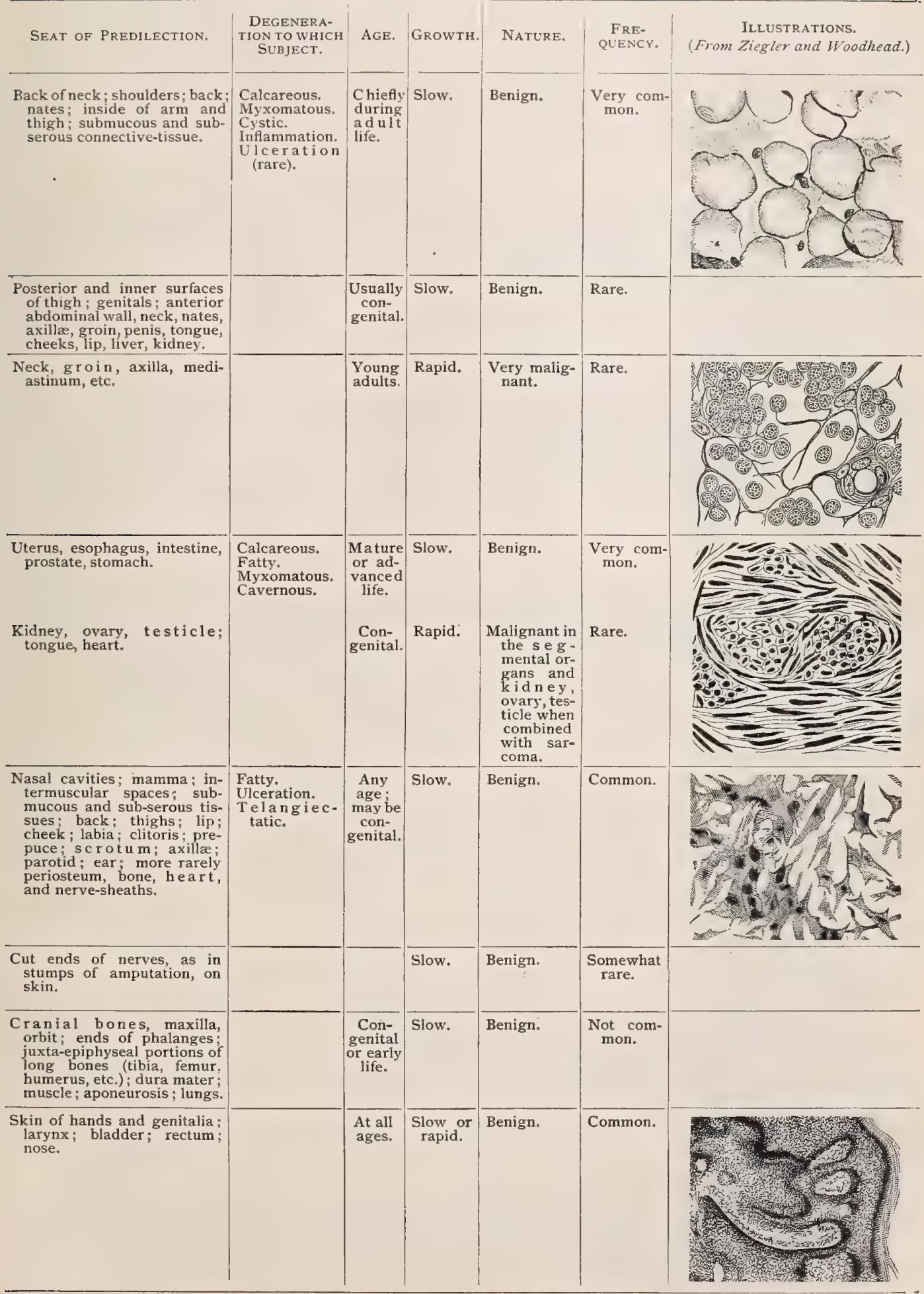


TABLE OF TUMORS-Continued.

\begin{tabular}{|c|c|c|c|c|}
\hline NAME. & Histologic Constituents. & Physical Manifestations. & $\begin{array}{l}\text { APPEARANCE OF SEc- } \\
\text { TION. }\end{array}$ & SizE. \\
\hline Psammoma. & $\begin{array}{l}\text { A form of sarcoma (nest-celled). Con- } \\
\text { nective tissue composed of flat, } \\
\text { elongated cells of great size and in } \\
\text { which are embedded gritty con- } \\
\text { cretions that are composed of cal- } \\
\text { cium carbonate. }\end{array}$ & Hard, circumscribed; light color. & $\begin{array}{l}\text { White; gritty on sec- } \\
\text { tion. }\end{array}$ & Small. \\
\hline $\begin{array}{l}\text { Sarcoma } \\
\text { I. Round- } \\
\text { celled. }\end{array}$ & $\begin{array}{l}\text { Embryonic or immature connective } \\
\text { tissue. Blood-vessels without walls, } \\
\text { or thin walled, ramifying among } \\
\text { the cells. Small or large round cells, } \\
\text { embedded in a small amount of } \\
\text { granular or homogeneous intercel- } \\
\text { lular substance. }\end{array}$ & $\begin{array}{l}\text { Soft; vascular; whitish; some- } \\
\text { what translucent; on pressure } \\
\text { after some hours exudes a milky } \\
\text { fluid ; round or ovoid, or oblong. }\end{array}$ & $\begin{array}{l}\text { Resembles brain-mat- } \\
\text { ter: of a yellow, gray, } \\
\text { or brick-dust hue. }\end{array}$ & $\begin{array}{l}\text { Often very } \\
\text { large. }\end{array}$ \\
\hline $\begin{array}{l}\text { 2. Spindle- } \\
\text { celled. }\end{array}$ & $\begin{array}{l}\text { Cells varying much in size, spindle- } \\
\text { shaped, with long, fine, tapering } \\
\text { extremities, separated by very little } \\
\text { intercellular substance. Often have } \\
\text { afbrous appearance (Recurrent } \\
\text { Fibroid). }\end{array}$ & $\begin{array}{l}\text { Firm; reddish; does not exude } \\
\text { milky fluid. Shape as foregoing. }\end{array}$ & $\begin{array}{l}\text { Fibrous or flesh-like } \\
\text { aspect; pinkish color. }\end{array}$ & $\underset{\text { large. }}{\text { Ma y e }}$ \\
\hline 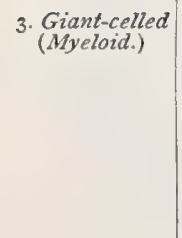 & $\begin{array}{l}\text { Masses of protoplasm containing two } \\
\text { or more nuclei-up to } 20 \text { or } 50-\text { with } \\
\text { a varying amount of round and } \\
\text { spindle cells. }\end{array}$ & $\begin{array}{l}\text { Jelly-like consistence or firm, like } \\
\text { muscle. Shape as foregoing. }\end{array}$ & $\begin{array}{l}\text { Smooth, shining, suc- } \\
\text { culent; no appear- } \\
\text { ance of fibrillation, } \\
\text { greenish or livid red } \\
\text { or maroon color, } \\
\text { varied by pink or } \\
\text { darker red spots, due } \\
\text { to extravasation of } \\
\text { blood. }\end{array}$ & Large. \\
\hline 4. Alveolar. & $\begin{array}{l}\text { Alveolar space filled with sarcoma } \\
\text { cells the trabeculæ composed of } \\
\text { spindle-cells. }\end{array}$ & Very vascular; soft. & & $\begin{array}{c}\text { Small or } \\
\text { large. }\end{array}$ \\
\hline 5. Melanotic. & $\begin{array}{l}\text { Sarcomata of various kinds in which } \\
\text { brownish or black pigment becomes } \\
\text { deposited as amorphous granules } \\
\text { in the cells as well as the connective } \\
\text { tissue and blood-vessel walls of the } \\
\text { tumor. }\end{array}$ & $\begin{array}{l}\text { Rounded, nodular, dark-colored } \\
\text { tumors of varying size and con- } \\
\text { sistency, usually hard. }\end{array}$ & Brownish or black. & $\underset{\text { large. }}{M a y} b$ \\
\hline Dermoid Cyst. & $\begin{array}{l}\text { Cyst wall contains hair-follicles and } \\
\text { sebaceous glands. Contents. -Dis- } \\
\text { intregating epithelial cells, hair, } \\
\text { sebaceous matter, teeth, etc. }\end{array}$ & $\begin{array}{l}\text { Globular; tense; smooth; freely } \\
\text { movable. }\end{array}$ & & $\overline{\text { May be }}$ \\
\hline
\end{tabular}


TABLE OF TUMORS-Continued.

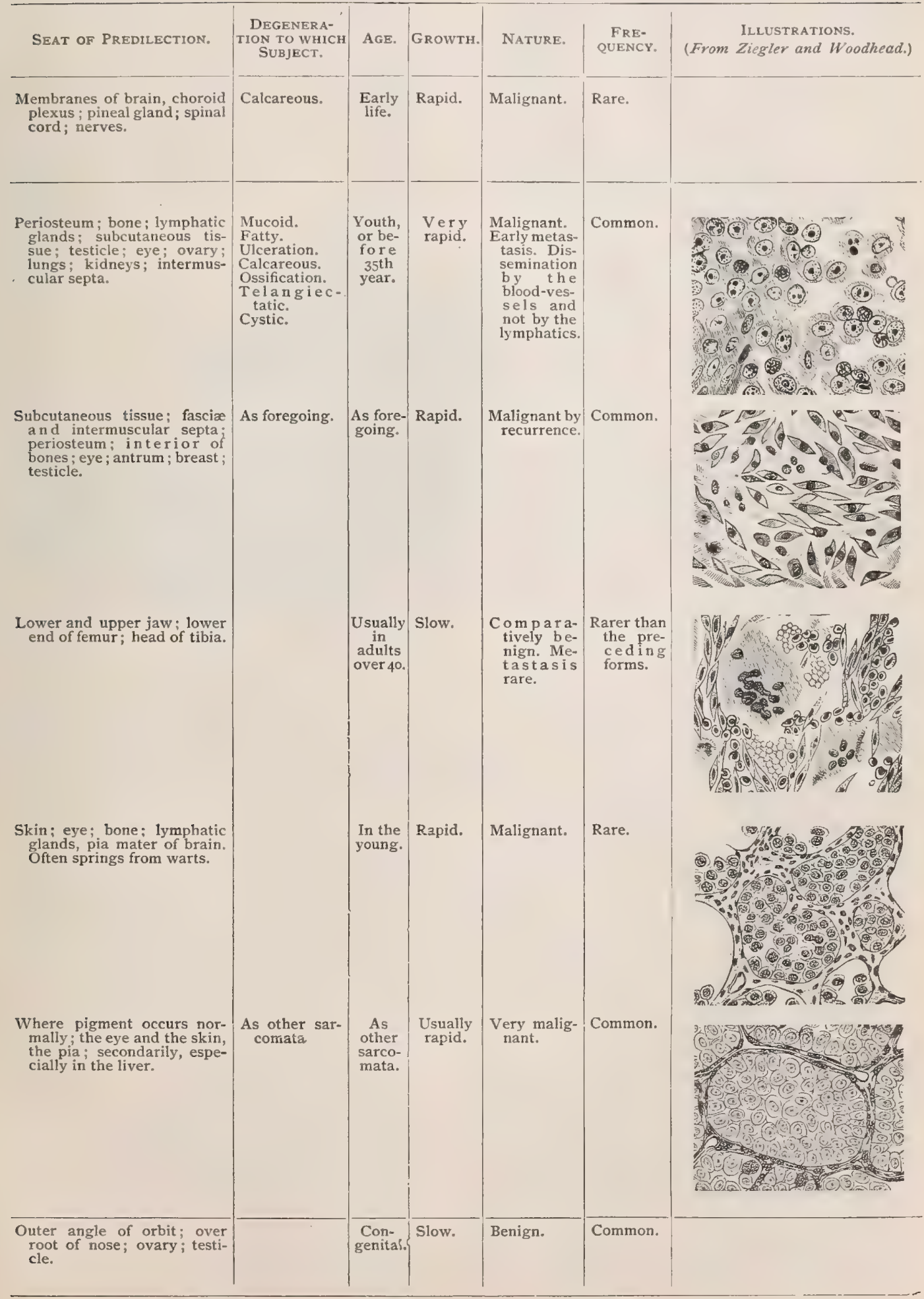




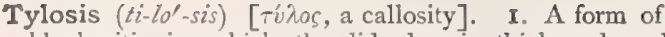
blepharitis in which the lid-edge is thickened and hardened. See, also, Callositas. 2. In biology, a protuberance of the wall of a plant-cell through the pit in the wall of an adjacent duct. T. palmæ vel palmaris, a synonym of callosity of the palm. T. plantæ vel plantaris, a callosity occurring on the foot.

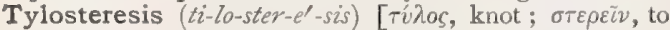
deprive]. Extirpation or removal of a callosity.

Tylotic $\left(t i-l o t^{\prime}-i k\right)$ [ $\tau \dot{i} \lambda o \varsigma$, a knot]. Pertaining to, affected with, or of the nature of tylosis.

Tylus ( $t i^{\prime}$-lus) [ $\tau \dot{v} \lambda o s$, a knob: pl., Tyli]. In biology, a median projection of the upper surface of the head of certain insects.

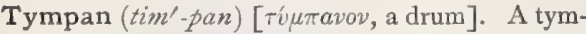
panum.

Tympanal (tim'-pan-al). See Ring, Tympanic. $T$. Organs, peculiar sense-organs found in certain insects (Saltatoria). They have long been universally regarded as auditory organs, although the animals continue to hear after their removal. See Chordotonal.

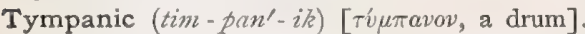
Pertaining to the tympanum. $T$. Bone, the thin roof or plate of bone separating the tympanic and cranial cavities. T. Membrane. See Membrane. T. Orifice. See Orifice. T. Plate. See Plate. T. Resonance, tympanitic resonance. T. Ring. See Ring. T. Tegmen, the bony plate forming the roof of the tympanum:

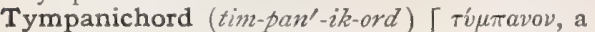
drum; кор $\delta$, a string]. The chorda tympani, a branch of the facial nerve.

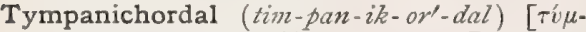

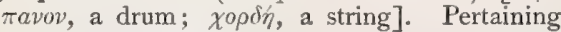
to the tympanichord.

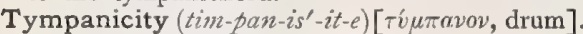
The quality of being tympanic

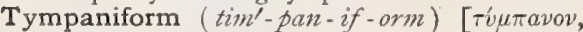
drum; forma, form]. Shaped like a tympanum.

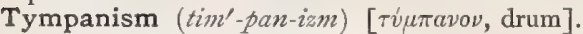
Distention with gas; tympanites.

Tympanites (tim-pan-i'-têz) [ The symptom popularly known as "drumbelly," a distention of the abdominal walls caused by paralysis of the muscular coat of the intestines and their inflation with gas. T., Acute, that due to intestinal irritation. $\mathbf{T}$. hysterica, enormous distention of the abdomen in hysteria. T. universalis, general emphysema.

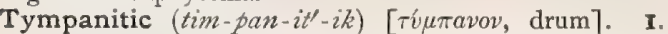
Caused by, associated with, or exhibiting tympanites. 2. Applied to a percussion-note like that produced by percussing a tympanitic abdomen.

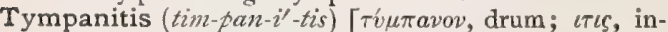
flammation]. Inflammation of the tympanum, or middle ear. See Otitis media.

Tympanodisc. The membrana tympani.

Tympano-Eustachian (tim-pan-o-u sta'-ke-an) [tó $\mu \pi$. avov, drum; Eustachius, an anatomist]. Pertaining to the tympanum and the Eustachian tube.

Tympano-hyal (tim-pan-o-hi'-al) [Tiutavov, drum; ioeidn's, hyoid]. A small cartilage of the human fetus subsequently fusing with its surroundings.

Tympano-malleal (tim-pan-o-mal'-e-al) [tí $\mu \pi a v o v$, drum; malleus, hammer]. Pertaining to the tympanic bone and the malleus.

Tympano-mandibular (tim-pan-o-man - dib'-u-lar) [Tí $\mu \pi a v o v$, drum; mandible]. Pertaining to the tympanum and the mandible.

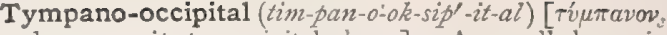
drum; occiput, occipital bone]. A small bone in relation with the exoccipital bone and the outer ear of a bird.

Tympano-periotic (tim-pan-o-per-e-ot'-ik) [ [úfuavov. drum; $\pi \varepsilon \rho i$, around; oús, ear]. Consisting of a tympanic bone united with the periotic bone proper.

Tympano-squamosal ( $i m-p a n-0$-skwa-mo'-zal),

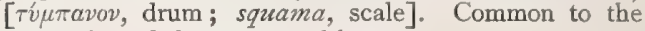
tympanic and the squamosal bone.

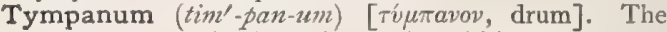
middle ear. The irregular cavity within the petrous

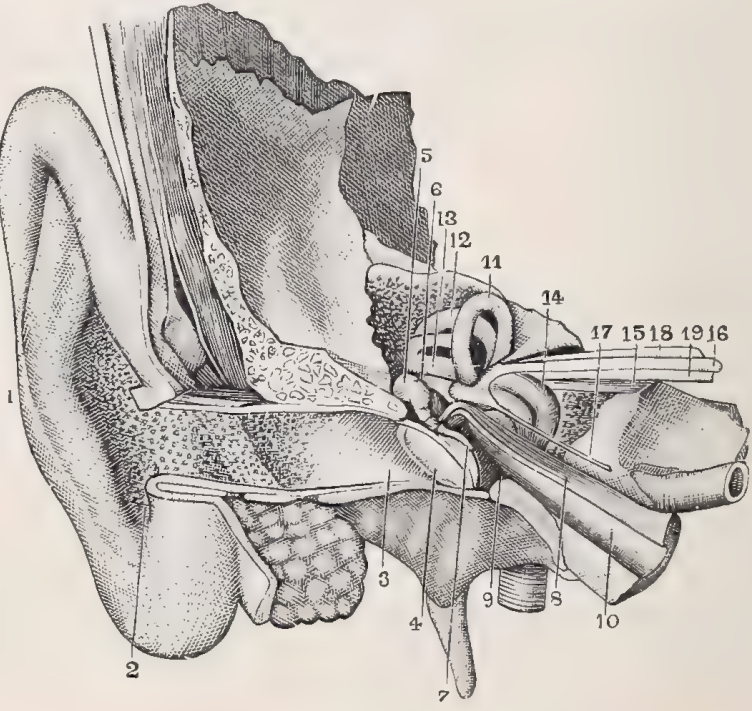

EAR AND TYMPANUM.

Pinna, or auricle. 2. Concha. 3. External auditory canal, 4. Membrana tympani. 5. Incus. 6. Malleus. 7. Manubrium mallei. 8. Tensor tympani. 9. Tympanic cavity. Io. Eustachian tube. II. Superior semicircular canal, I2, Posterior semicircular canal. ${ }_{3}$. External semicircular canal. I4. Cochlea. 15. Internal auditory canal. I6. Facial nerve. I7. Large petrosal nerve, I8. Vestibular branch of auditory nerve. 19. Cochlear branch.

portion of the temporal bone communicating with the pharynx through the Eustachian tube.

Tympany (tim'-pan-e). See Tympanites.

Type $(t i \bar{p})$ [ $\tau \hat{\text { T }}$ os, a stamp]. Imprint; emblem; symbol; character. A normal average example. In pathology, the distinguishing features of a fever, disease, etc., whereby it is referred to its proper class.

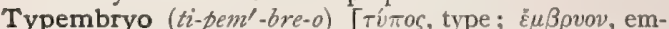
bryo]. That stage or period in the development of an embryo when the characteristics of the main type to which it belongs are first discoverable.

Typewriters' Backache. An occupation-neurosis; is is said to be best guarded against by the use of a high seat and a footstool.

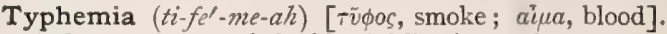
A depraved state of the blood following typhus.

Typhia $\left(t i^{\prime}-f e-a h\right)$. See Fever, Typhoid.

Typhinia $\left(t i-f n^{\prime}-e-a h\right)$. Synonym of Relapsing Fever.

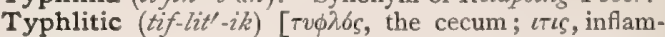
mation ]. Pertaining to, affected with, or of the nature of typhlitis.

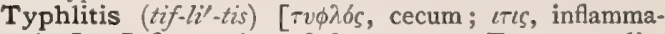
tion]. Inflammation of the cecum. T. stercoralis, typhlitis due to constipation.

Typhlo-enteritis (tif-lo-en-ter-i'tis). See Typhlitis. 


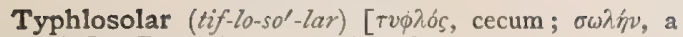
tube]. Pertaining to a typhlosole,

Typhlosole (tif'-lo-sōl) [ $\tau v \phi \lambda o ́ s$, cecum; $\sigma \omega \lambda \eta \dot{v}$, tube, pipe]. In biology, a tube lying in the dorsal middle line of the intestine of certain worms (Lumbricida). It is open longitudinally toward the body-cavity, and is formed to increase the absorbing surface of the stomachintestine by a longitudinal fold of its dorsal wall into the lumen of the gut.

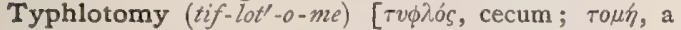
cutting]. Division or section of the cecum.

Typhogenic $\left(t i-f o-j e n^{\prime}-i k\right)[\tau \tilde{v} \phi o s$, stupor; $\gamma \varepsilon v \nu a ̈ v$, to produce]. Producing typhus.

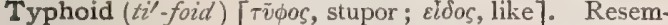
bling typhus. T. Fever. See Fever. T. Spine, Gibney's term for a neurosis sometimes following typhoid fever, characterized by the production of acute pains in the vertebral column on the slightest movement, whether lateral or forward, and the absence of any marked febrile disturbance or neuralgia. Gibney regarded the condition as a perispondylitis. T. State, the condition of stupor and hebetude, with dry, brown tongue, sordes on the teeth, rapid, feeble pulse, incontinence of feces and urine, and rapid wasting, seen in fully developed typhoid fever and other adynamic diseases.

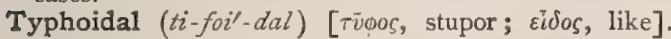
Resembling typhoid.

Typhoidet, Typhoidette (ti-foi-det') [Fr.]. A mild or benign type of typhoid fever.

Typho-malarial $\left(t i^{\prime}-f_{0}-m a l-a^{\prime}-r e-a l\right)$ [ $\tau \bar{v} \phi o s$, stupor; malaria]. Applied to fevers exhibiting symptoms of both typhoid and malarial disorders.

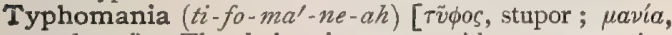
madness]. The lethargic state, with accompanying delirium, sometimes observed in typhus. See, also, Periencephalitis.

Typhonia (ti-fol-ne-ah). Same as Typhomania.

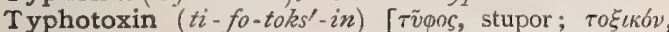
poison]. A ptomain discovered by Brieger, and believed to be the special product of the Koch-Eberth typhoid-hacillus. It is isomeric with the base $\mathrm{C}_{7} \mathrm{H}_{17}$ $\mathrm{NO}_{2}$, obtained from putrefying horseflesh, but is very different in its properties, being strongly alkaline, while the latter base possesses a slightly acid reaction, and the physiologic effects of each are also different. Typhotoxin induces lethargy, paralysis, and death without convulsions, while the unnamed base produces strongly marked convulsive symptoms. After death from typhotoxin the heart is found to be contracted in systole. See Ptomains, Table of.

Typhous $\left(t i^{\prime}-f u s\right)$ [ $\tau \tilde{v} \phi o s$, stupor $]$. Pertaining to or having the nature of typhus.

Typhus ( $t i^{\prime}$-fus) [Tĩ $\phi o s$, stupor]. Jail-fever; shipfever. See Fever. T. anthracicus, T. bubonicus,
T. gravissimus, $\mathbf{T}$. pestilentialis. Synonyms of the Plague, q. v. T. petechialis. Synonym of Fever, Cerebro-spinal. T. siderans, a malignant form of typhus fever, ending fatally in two or three days. T. syncopalis. Synonym of Fever, Cerebro-spinal.

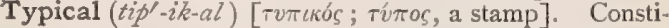
tuting a type or form for comparison; illustrative; complete.

Typus $\left(t i^{\prime}-p u s\right)$. See Type.

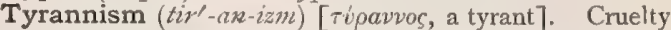
of morbid inception, of which sadism is an erotic variety.

Tyremesis (ti-rem'-es-is) [ iting]. The vomiting of caseous matter; an ailment common among mursing infants.

Tyrian Purple. See Pigments, Conspectus of.

Tyrol White. Same as Hamburo White.

Tyroline (tir'-o-lin). Anilin Violet; a violet dye.

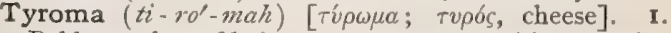
Baldness; loss of hair. 2. A tumor caused by caseation of lymphatic glands.

Tyrosin (ti'-ro-zin $)$ [ $\tau$ voós, cheese $], \mathrm{C}_{9} \mathrm{H}_{11} \mathrm{NO}_{3}$. An amido-acid occurring in pancreatic digestion; a decomposition-product of proteids, etc. It is found in the urine in acute yellow atrophy of the liver and in phos. phorus-poisoning, and occurs in the liver, spleen, pancreas, in stale cheese, and is formed on boiling animal substances (albumin, horn, hair) with $\mathrm{HCl}$ or $\mathrm{H}_{2} \mathrm{SO}_{4}$. Tyrosin crystallizes in exceedingly fine needles, usually collected into colorless, feathery masses; snow-white in color, tasteless and odorless, sparingly soluble in cold water but much more so in boiling water; it dissolves with difficulty in alcohol, and is insoluble in ether. See Hoffmann's Test and Piria's Test.

Tyrosis ( $i$-ro'-sis) [ $\tau v \rho b s$, cheese]. Curdling. See Caseation.

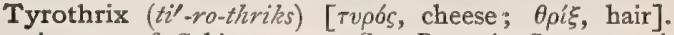
A genus of Schizomycetes. See Bacteria, Synonymatic Table of.

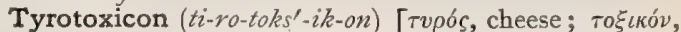
poison]. A ptomain obtained by Vaughan from poisonous cheese, poisonous milk, poisonous ice-cream, etc. Chemically it is very unstable; it may disappear altogether in twenty-four hours from milk rich with the poison. It induces vertigo, nausea, vomiting, chills, rigors, severe pains in the epigastric region, dilatation of the pupils, griping and purging, a sensation of numbness, or "pins and needles," especially in the limbs, and marked prostration, or death. The symptoms may vary somewhat in different individuals. The poison is thought to be the cause of the summer diarrhea of infants. See Ptomains, Table of.

Tyrrell's Hook. A hook used in certain operations upon the eye, as in iridectomy.

Tyson, Glands of. The sebaceous glands secreting the smegma of the prepuce and of the labia pudendi. 
U., the symbol of Uranium.

Uaterium (u-at-e'-re-um) [ovs, ear]. A medicament used in the treatment of diseases of the ear.

Uber $\left(\boldsymbol{u}^{\prime}\right.$-ber) [L., udder; $p l$., Ubera]. The mamma; also the nipple.

Uberous $\left(u^{\prime}-b e r-u s\right)$ [uber, fruitful]. Fruitful, prolific.

Udder $\left(u d^{\prime \prime}-e r\right)$ [ME, udder, udder]. The mammary apparatus, especially of the cow.

Uffelmann's Gelatin. See Stains, Table of. U's. Solution, to distinguish hydrochloric from lactic acid in suspected gastric contents: Add a few drops of neutral ferric-chlorid solution to a 4 per cent. solution of carbolic acid. This is turned yellow by lactic acid, but is not affected by hydrochloric acid when diluted to the strength of gastric juice, 0.2 per cent. See Tests, Table of.

Ukambin (u-kam'-bin) [African]. An African arrowpoison, presumably a combination of juices from various plants. Its physiologic effects are the same as those of strophanthin, but in a considerably augmented degree. Unof.

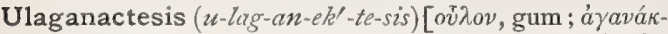
$\tau \eta \sigma \iota$, irritation]. Irritation or uneasy sensations in the gums.

Ulatrophia, Ulatrophy $\left(u-l a t-r o^{\prime}-f e-a h, u\right.$-lat'-ro-fe) [ov $\lambda o v$, gum; $\alpha \tau \rho \circ \phi i a$, atrophy]. Atrophy of the gums. Ulcer $\left(u l^{\prime}-s e r\right)$ [ulcus, a sore]. A destructive loss of cutaneous substance, extending into the corium. The size is quite indefinite; the shape is variable, usually round, but may be reniform, irregular, or serpiginous. It may be deep or hollow, with steep or sloping sides, and a smooth or irregular base. Its edges may be sharp or rounded, everted or undermined; the surface bleeds readily, and is clean or sloughy, and covered with pus or serum. It always leaves a scar. U., Aden. See Phagedena tropica. U., Adherent, an ulcer of the skin, the base of which becomes adherent to the underlying fascia. U., Amputating; an ulcerating process which encircles a member, destroying the tissues to the bone. U., Anamite, a phagedenic sore of hot countries; it is very unyielding to treatment. U., Arterial, a superficial ulcer due to arterial disease. U., Atheromatous. See Endarteritis, Chronic. U., Atonic, an ulcer having unhealthy granulations, with little or no tendency to cicatrization. U., Autochthonous. Synonym of Chancre. U., Cancroid. See U., Rodent. U., Carcinomatous, an ulcerating carcinoma. U., Carious, an ulcer producing gangrene. U., Chancroidal. Synonym of Chancre. U., Cochin-China, a chronic phagedenic ulcer affecting foreigners in Cochin-China, U., Cock's-comb, an ulcer having rough, irregular outgrowths. U., Cold, a small, inflammatory ulcer occurring spontaneously upon the ends of the fingers or toes. U., Constitutional. See Syphilis. U., Contagious. Synonym of Chancre. U., Corrosive. An old synonym of Stomatitis gangranosa. U., Crateriform, a variety of malignant, epithelial ulcer, which affects the same regions on the upper part of the face as does ordinary rodent ulcer. It occurs in the same class of people, but runs a much more rapid course. Ulceration occurs at the conical summit, and assumes a crater-like form. There is no tendency to fungate or become warty. U., Creeping (of the comea), a serpiginous corneal ulcer. U., Curling's, an ulceration of the duodenum observed after severe burns of the body and limbs. U., Diphtheric, the ulcer occurring in diphtheria; it is covered with false membrane. U., Dys- peptic. See Herpes facialis. U., Endemic, an ulcer more or less local as regards the countries in which it is found, as Aleppo boil, Penjdeh sore, etc. U., Erethistic, a name given to an extremely sensitive ulcer. These ulcers occur in regions that are liberally supplied with sensitive nerve-fibers, as about the anus or the matrix of the nail. U., Fissurated, laceration of the cervix uteri. U., Fistulous, an ulceration communicating with a fistula. U., Follicular, ulceration of a mucous membrane, having its origin in the lymphfollicles. U., Fungiform. A synonym of Epitheliona. U., Gastric, perforating ulcer of the lining membrane of the stomach. U., Gummatous, an ulcer due to the breaking down of a gumma. U., Gwalior, an endemic ulcer observed at Gwalior. U., Hemorrhagic, a bleeding ulcer. U., Indolent, one with an indurated, elevated edge, and a non-granulating floor, usually occurring on the leg. U., Inflamed, an ulcer surrounded by marked inflammation. U., Initial (of syphilis). Synonym of Chancre. U., Intractable. Synonym of $U$., Indolent. U., Inveterate. Synonym of $U$., Indolent. U., Jacob's, a rodent ulcer of the eyelid. U., Lupoid, an ulceration resembling lupus. U., Lupous. Synonym of Lupus. U., Lymphatic, an ulcer having an exudate which resembles lymph. U., Malabar. See Phagedana tropica. U., Malignant. Synonym of Carcinoma. U., Marjolin's, an ulcer having for its seat an old cicatrix. U., Menstrual, an ulcer from which vicarious menstruation takes place. U., Mercurial, an ulcer due to chronic mercurial poisoning. U., Mozambique, a single, highly contagious ulceration, prevalent in Mozambique and in Reunion Island. U., Perforating, an ulcer that perforates the surrounding tissues. U., Persian, an ulcer prevalent in Persia. U., Phagedenic, a form of ulceration in which the process extends insidiously but obstinately. U., Phlegmonous. Synonym of U., Inflamed. U., Putrid. See Gangrene, Hospital. U., Rodent, a form of ulceration, probably epitheliomatous, which involves all tissues, bones and soft tissues alike. U., Round, (of the stomach). Perforating ulcer of the stomach. U., Round (of the uterus), a rapid ulceration of the uterus, probably epitheliomatous. U., Sæmisch's, an infectious ulcer of the cornea. U., Scorbutic, an indolent ulcer found in scurvy. U., Serpiginous, an irregularly burrowing ulceration. U., Simple, a mild form of ulceration, not due to a poison or to systemic disease. U., Stercoral, a small ulcer of the bowel, produced in cases of long-standing constipation, with fecal impaction, from the irritation of the hard masses of feces. Usually no symptoms are produced. U., Sublingual, an ulcer upon the frenum of the tongue, due, probably, to irritation by the lower incisor teeth. U., Symptomatic, an ulcer indicative of general disease. U., Syphilitic, ulceration due to syphilis. U., Syriac, malignant angina. U., Toe-nail, ulceration caused by an ingrowing toenail. U., Tuberculous, ulceration due to tuberculosis. U., Turkestan, a form of ulcetation noticed among the Russian soldiers in Turkestan. It was attended with profuse suppuration and adenitis. $U$., Varicose, an ulcer due to varicose veins. U., Venereal. Synonym of Chancre or Chancroid. U., Weak, one with exuberant and flabby granulations. U., Yemen. Synonym of $U$., Cochin-China.

Ulcerate $\left(u l^{\prime}-s c r-\bar{a} t\right)$ [ulcus, ulcer]. To become ulcerated.

Ulcerated $\left(u l^{\prime}\right.$-ser-a-ted $)$ [ulcus, ulcer]. Affected with ulceration. 
Ulceration (ul-ser-a'-shun) [ulcus, a sore]. The process of the formation of an ulcer. $U$. of the Cervix. See Erosion. U., Fissured. See Ulcer, Fissurated. U., Heryng's Pharyngeal, a rather diffuse ulcer of the bard palate and fauces. U., Malignant, ulceration caused by carcinoma or sarcoma. U., Puerperal, ulceration of the genitals due to injury during labor. U., Tuberculous (of the larynx), an ulcer usually found on the dorsal wall of the larynx, and caused by tuberculosis.

Ulcerative (ul'-ser-a-tiv) [ulcus, ulcer]. Pertaining or belonging to ulceration. U. Scrofuloderma. See Mycosis.

Ulcerous (ul'-ser-us) [ulcerosus]. Exhibiting ulceration; having the character of an ulcer.

Ulcus $\left(u l^{\prime}\right.$-kus $)$ [L.]. See Ulcer. U. excedens. See Rodent Ulcer. U., Grave. See Fungus Foot. U. rodens, Mooren's term for a form of creeping ulcer which begins at the upper edge of the cornea as a superficial lesion, separated from the healthy portion by a gray, opaque rim which is undermined. The whole cornea is liable to be traversed and the sight destroyed.

Ulcuscle, Ulcuscule, Ulcusculum (ul-kws'-kl, ulkus'-kül, ul-kus'-ku-lum) [ulcusculum: pl., l'lcusculc]. A small ulcer.

Ulemorrhagia (u-lem-or-a'-je-ah) [oinov, the gum; ripa, blood; jpyvüval, to burst forth]. Hemorrhage or bleeding at the gums.

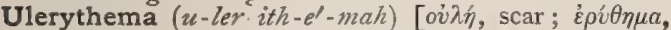
erythema]. An erythematous disease marked by the formation of cicatrices. U. sycosiforme. See Sycosis, Lupoid.

Uletic $\left(u-\left\lfloor e t^{\prime}-i k\right)[o \bar{v} \lambda o v\right.$, gum]. Pertaining to the gums.

Ulex $\left(u^{\prime}-l e k s\right)$ [L.]. A genus of leguminous shrubs of Europe and Africa. U. europæus is the common gorse, whin, or furze.

Ulexin (u-leks'-in) [ulex, a shrub], $\mathrm{C}_{11} \mathrm{H}_{14} \mathrm{~N}_{2} \mathrm{O}$. An alkaloid found in the seed of Ulex europaus. It is a powerful diuretic, and causes local anesthesia. Dose gr. $\frac{1}{10}$ in pill ; to be used with caution. Unof.

Uliginose, Uliginous ( $u$-lij'-in-oz, $u$-lij'-in-us) [uligo, moisture]. Pertaining to or growing in a marshy soil.

Ulitis $\left(u-l i^{\prime}-t i s\right)$ [ov $\lambda o v$, gum; $\iota \tau \iota \zeta$, inflammation]. Inflammation of the gums.

Ullem $\left(u l^{\prime}-\mathrm{em}\right)$. A form of indigestion met with in Lapland, and probably due to the use of smoked meat.

Ulmic $\left(u l^{\prime}-m i k\right)$ [ulmus, elm]. Denoting an acid found in earth-mold, a product of the decay of vegetable matter.

Ulmin $\left(u l^{\prime}-\min \right)$ [ulmus, elm]. A brown substance produced by the action of strong acids or alkalies on various organic bodies, especially by heating treacle or alcohol with strong sulphuric acid.

Ulmous ( $u l^{\prime \prime}$-mus) [ulmus, elm]. In chemistry, denoting a group of brown or black substances containing ulmin or ulmic acid.

Ulmus (ul'-mus) [L.: gen., Ulmi]. Elm, slippery elm. The inner bark of $U$. fulva. It contains a large percentage of mucilage, and is demulcent and slightly astringent. It is valuable in diarrhea, and as an emollient in acute inflammations. U., Mucilago, elm 6 , boiling water 100 , macerated for two hours and strained. Dose ad lib. Cf. Fremontia.

Ulna $\left(u l^{\prime}-n a h\right)$ [L., a cubit]. The large bone of the forearm, articulating with the humerus and the head of the radius above and with the radius below. See p. 229 .

Ulnad (ul'nad) [ulna, ulna]. Toward the ulnar aspect.

Ulnar (ul'-nar) [ulnaris, ulnar]. Pertaining to the ulna. U. Nerve, a nerve both of motion and sensa- tion springing from the brachial plexus and supplying the ulnar region of the arm.

Ulnare, or Os ulnare $\left(u l-n a^{\prime}-r e\right)[u l n a, u l n a]$. The cuneiform bone of the carpus. See Bones, Table of.
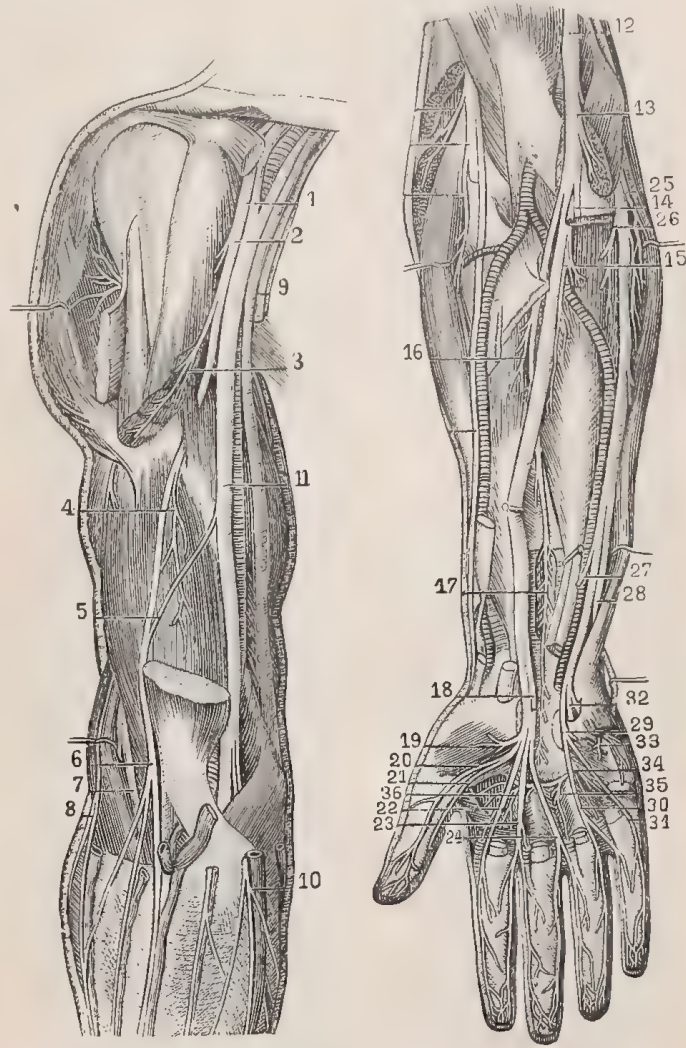

Brachial Portion of Muscu- Terminal Portion of MeLO-CUTANEOUS, MEDIAN AND DIAN NERVE AND OF ULNAR ULNAR NERVES. NERVE.

I. Musculo-cutaneous nerve. 2. Branch to coraco-brachialis. 3. Branch to biceps. 4. Branch to brachialis anticus. 5 . Anastomotic branch from median. 6. Division of musculocutaneous. 7. Radial nerve. 8. Its external cutaneous branch. 9. Internal cutaneous. Io. Its anterior, or ulnar branch. II. Upper portion of median and ulnar nerves. 12. Their middle portion. I3. Branch to pronator radii teres. I4. Trunk giving rise to anterior muscular branches. 15. Branches to flexor profundus digitorum. I6. Branch to flexor longus proprius pollicis. 17. Interosseous branches. I8. Palmar cutaneous branch. 19. Branch for muscles of thenar eminence. 20. External collateral branch to thumb. 2I. Internal collateral branch. 22. External collateral branch to index finger. 23. Common trunk of internal collateral to index finger. 23. Common trunk of internal collateral dle finger. 24. Trunk of internal collateral branch to middle finger and external collateral branch to ring finger. 25. Branch of ulnar nerve to flexor carpi ulnaris. 26. Branches to two inner fasciculi of flexor profundus digitorum. 27. Cutaneous and anastomotic filament. 28. Dorsal branch. 29. Superficial palmar branch. 30. Common trunk of internal collateral branch to ring finger and external collateral branch to little finger. 3I. Internal collateral branch to little finger. 32. Deep palmar branch. 33. Branch of the latter to hypothenar muscles. 34. Branches to muscles of fourth interosseous and to fourth lumbricalis. 35 . Branches to interis of third interosseous space and to third lumbricalis. muscles of third interosseous space and the adductor of the thumb and to the muscles of the first two interosseous spaces.

Ulnaris $\left(u l-n \alpha^{\prime}\right.$-ris) [L.]. See Muscles, Table of.

Ulnen $\left(u l^{\prime}\right.$-nen $)$ [ulna, ulna]. Belonging to the ulna in itself. 


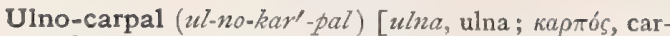
pus]. Pertaining to the una and the carpus.

Uino-metacarpalis (ul-no-met-ak-ar-pal-lis) [ulna,

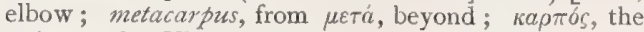
wrist: pl., Ulnometacarpales]. One of the wing. muscles of a bird; it arises from the ulna and is inserted into a metacarpal bone.

Ulno-radial (ul-no-ra'-de-al) [ulna, ulna; radius, radius]. Pertaining to the ulna and the radius.

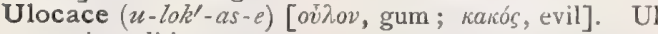
cerative ulitis.

Ulocarcinoma (u-lo-kar-sin-of-mah) [ov̀ov, gum; carcinoma]. Carcinoma of the gums.

Ulon $\left(u^{\prime}\right.$-lon $)$ [où $\alpha v$, gum]. The gums.

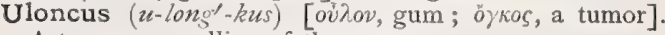
A tumor or swelling of the gums.

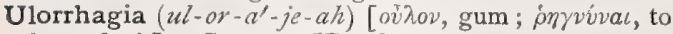
burst forth]. Same as Ulorrhea.

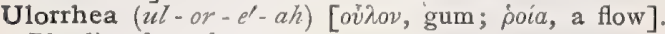
Bleeding from the gums.

Ulosis $\left(u-l o^{\prime}-s i s\right)$. Synonym of Cicatrization.

Ulotic $\left(u-l o t^{\prime}-i k\right)\left[o v^{\prime} \hat{\eta}\right.$, scar $]$. Pertaining to or tending toward cicatrization.

Ulotrichous $\left(u-l o t^{\prime}-v_{i k}-u s\right)$ [ovios, woolly; $\theta \rho i \xi$, hair]. Having woolly hair.

Ulterior (ul-te'-re-or) [L.]. Toward the periphery; applied to lesions of the spinal cord.

Ultimate $\left(u l^{\prime}\right.$-tim-at $)$ [ultimus, super. of ultra, beyond]. Farthest, or most remote. U. Analysis. See Analysis. U. Principle. See Principle.

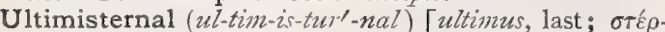
vov, sternum]. Pertaining to the last or lowest segment of the sternum.

Ultimum $\left(u l^{\prime}-t i m-u m\right)$ [L.]. Last. U. moriens ("last dying"). The right auricle; so called from the belief that it is the last part of the heart to cease its contractions. U., Stadium. See Stadium.

Ultra-brachycephaly (ul'-tra-brak-is-ef'-al-e) [ultra, beyond; brachycephaly]. Brachycephaly in which the cephalic index exceeds $90^{\circ}$

Ultracentenarian (ul-trah-sen-ten-a'-re-an) [ultra, beyond; centenarius, pertaining to a hundred]. A person who has lived more than roo years.

Uitradolichocephaly (ul-trah-do-tik-a-sef'-al-e) [ultra, beyond; dolichocephaly]. Dolichocephaly in which the cephalic index is less than $64^{\circ}$.

Ultramarine (ul'-tram-ar-ēn). See Pigments, Conspectus of. U. Green, U. Yellow. See Pigments, Conspectus of.

Ultramicroscopic (ul-trah-mi-kro-skop'-ik) [ultra, beyond; microscopic]. Too small to be seen by the aid of the microscope.

Ultromotivity (ul-tro-mo-tiv'-it-e) [ultro, spontaneously; motivity]. Power or capability of moving spontaneously.

Ultzmann's Test. See Tests, Table of

Ululation $\left(u l-u-l a^{\prime}-s h u n\right)$ [ululare, to howl]. hysteric howling.

-ulus $\left(u^{\prime}-l u s\right)$. A Latin suffix denoting the diminutive degree.

Umbel (um'-bel) [umbra, shade]. In biology, that form of indeterminate inflorescence in which the axis is very short and the pedicels radiate from it like the rays of an umbella.

Umbellal (um'-bel-al) [umbella, an umbel]. Pertaining to an umbel.

Umbellar (um'-bel-ar). Same as Umbellate.

Umbellaria (un-bel-la'-re-ah). See California Laurel.

Umbellate $\left(u m^{\prime}-b e l-a \bar{t}\right)$ [umbella, an umbel, dim. of umbra, shade]. In biology, bearing umbels.

Umbellet (um'-bel-et) [umbella, umbel]. In biology, a little umbel.
Umbellic Acid (um-bel'-ik). See Acid.

Umbelliferon (um - bel - if'-er - on) [umbella, umbel ; ferre, to bear $], \mathrm{C}_{9} \mathrm{H}_{6} \mathrm{O}_{3}$. Oxycoumarin, found in the bark of Daphne mezereum; it is obtained by distilling different resins, such as galbanum and asafetida. It consists of fine needles, sparingly soluble in hot water and ether; it melts at $224^{\circ} \mathrm{C}$

Umbelliferous (um-bel-if'-er-us) [umbella, umbel ; ferre, to bear]. Bearing umbels.

Umbelliform (um-bel'-if-orm) [umbella, umbel; forma, form $]$. Having the form of an umbel.

Umbellulate (um-bel'-u-lāt) [umbelluld, an umbellule]. Provided with umbellules.

Umbellule (um'-bel-ül) [umbellula, a little umbel]. A partial umbel; an umbellet.

Umber (um'-ber) [umbra, shade]. A dark-brown pigment somewhat resembling ocher. See Pigments, Conspectus of.

Umbilical (um-bil'-ik-al) [umbilicus, the navel]. Pertaining to the umbilicus. U. Cord. See Cord. U. Fistula, a fistulous opening communicating with the umbilicus. U. Hernia. See Hernia. U. Region, the central of the regions into which the abdomen is conveniently divided. U. Ring, the aperture, closed in the adult, through which the umbilical vessels pass in fetal life. U. Souffle, the peculiar sound heard occasionally over the umbilical cord of the fetus. U. Vesicle, in embryology, a spheroid sac appearing early in the ovum and disappearing about the seventh week after fecundation. The navel-sac. In lower animals it is called the vitelline sac or yolk-sac.

Umbilicate, Umbilicated (um-bil'-ik-ät, um-bil'-ik-ated) [umbiticus, navel]. Having a depression like that of the navel.

Umbilication (um-bil-ik-a'shun) [umbilicus, navel]. A navel-like depression; the quality of being umbilicated.

Umbilicular (um-bil-ik'-u-lar) [umbilicaris, pertaining to the navel]. Pertaining to the navel.

Umbilicus (um-bil-i'-kus) [L.]. The navel. The round, depressed cicatrix in the median line of the abdomen, marking the site of the aperture which, in fetal life, gave passage to the umbilical vessels. U., Posterior, a depression in the spinal region due to imperfect closure of the vertebral groove.

Umbiliferous (um-bil-if'-er-us) [umbilicus, navel ; ferre, to bear]. Having an umbilicus.

Umbiliform (um-bill-if-orm) [umbilicus, navel; forma, form]. Having the form of an umbilicus.

Umbo $\left(u n^{\prime}-60\right)$ [L. : pl., Umbones]. I. A boss, or bosselation; any central convex eminence; less correctly, a central concave depression. 2. Specifically, the depressed spot in the center of the membrana tympani. In biology, the apex of the valve of a bivalve shell.

Umbonal (um'-bo-nal) [umbo, a boss]. Protuberant, like a knob.

Umbonate $\left(u m^{\prime}-b_{0}-n \bar{a} t\right)$ [umbo, the boss of a shield]. Bossed ; furnished with a low, rounded projection, like a boss (umbo).

Umbonic $\left(u m-b o n^{\prime}-i k\right)[u m b o$, boss $]$. Pertaining to an umbo.

Umbonulate $\left(u m-b o n^{\prime}-u\right.$-lāt $)$ [umbo, boss]. Pertaining to an umbo.

Umbraculate (um-brak'-u-tāt ) [umbraculum, umbrella]. In biology, applied to the heads of certain insects when furnished with an awning-like frontal process.

Umbraculiferous (um-brak-u-lif'-er-us) [umbraculum, umbrella; ferre, to bear]. In biology, bearing ar organ resembling an umbrella.

Umbraculiform (um-brak'-u-lif-orm) [umbraculum, 
umbrella; forma, form]. Having the form of an umbrella.

Umbraculum (um-brak'-u-lum) [umbraculum, shade, shady place, umbrella: pl., Umbracula]. In biology, an umbrella-shaped appendage.

Umbrascopy (um-bras'-ko-pe). Synonym of Retinoscopy.

Umbrel (um'-brel). Same as Umbrella.

Umbrella (um-brel'-ah) [umbra, shade]. In biology, the swimming-bell of a jelly-fish, or Medusa. U. Clasp. See Peronium.

Umbrose (um'-bröz) [umbra, shade]. Shady.

Unarmed Tape-worm. See Tania saginata under Parasites (Animal), Table of.

Uncaria (ung-ka'-re-ah). See Gambir.

Uncate (ung -kât) [uncus, a hook]. In biology, bent into the form of a hook.

Uncia $\left(u n^{\prime}-s e-a h\right)$ [L.]. An ounce. See Weights and Measures.

Uncial (un'-se-al) [uncia, inch]. An inch in length.

Unciform Bone (un'sif-orm) [os unciforme; uncus, a hook; forma, form ]. The hook-shaped bone in the lower row of the bones of the carpus. See Bones, Table of. U. Eminence, the hippocampus minor, or calcar. U. Process. See Process.

Uncinal $\left(u n^{\prime}-\sin -a l\right)$. Same as Uncinate.

Uncinate $\left(u n^{\prime}-\sin -\bar{a} t\right)$ [uncus, hook]. Hooked. U. Convolution, or Gyrus, the continuation of the hippocampal convolution or gyrus fornicatus, ending in a hook-like process near the end of the temporal lobe.

Uncinatum (un-sin- $a^{\prime}$-tum) [uncinatus, hooked]. In anatomy, the unciform bone of the carpus.

Uncinus (un-si'-nus) [uncinus, a hook, barb: pl., Uncini]. In biology, a hook, or hook-like structure or appendage.

Uncipression, Uncipressure (un-sip-resh'-un, un'-sippresh-ür) [uncus, hook]. A method of arresting hemorrhage by the use of two hooks dug into the sides of the wound so as to compress the vessel.

Uncirostrate (un-se-ros'-trât) [uncus, hook; rostratus, beaked]. In biology, having a hooked beak.

Unconscious (un-kon'-shus) [un, not ; consciens, knowing]. Not conscious. U. Cerebration. See Cerebration.

Unconsciousness (un - kon'-shus - nes) [un, not; consciens, knowing]. The state of being without sensibility and having abolished reflexes: a symptom of apoplexy, insolation, asphyxia, etc.

Unction (unk'-shun) [unctio, an anointing]. The act of anointing. Also, an ointment.

Unctuous (unk'-tu-us) [unctus, a smearing]. Greasy, oily.

Uncus $\left(u n g^{\prime}-k u s\right)$ [L.]. I. The hook-like anterior extremity of the uncinate gyrus of the brain. 2. A hook.

Undate $\left(u n^{\prime}-d \bar{a} t\right)$. See Undulate.

Undecolic Acid (un-dek-ol'-ik). See Acid.

Under (un'-der) [ME., under, under]. Below; beneath. U.-shrub, partially shrubby, or a very low shrub. U.-toe, a variety of Hallux varus in which the great toe underlies its neighbors.

Undulate, Undate $\left(u n^{\prime}-d u-l \vec{a} t, u n^{\prime}-d \vec{a} t\right)[u n d a$, a wave]. In biology, wavy; having a margin that flows gently in and out. Applied to leaves and other flattened organs.

Undulated ( $u n^{\prime}-d u$-la-ted) [dim. of $u n d a$, a wave]. Marked by or propagated in waves; wave-like.

Undulation (un-du-la'-shun) [undulatus, waved]. Fluctuation, as of pus, or any liquid effusion; also, the subjective sensation as of a wave-like motion about the heart. U., Jugular, the venous pulse. U., Respiratory, the variations in the blood-pressure due to respiration.
Undulatory $\left(u n^{\prime}-d u\right.$-lat-or-e) [undulare, to undulate]. Vibratory. Moving like waves. In physics, the undulatory theory of light presupposes the existence of an imponderable, tenuous medium called the ether, the undulations of which give rise to the phenomena of light, heat, and electricity. See Wave-length.

Unequal (un-e'-kwal) [un, not; equus, equal]. Having different proportions, dimensions, or qualities.

Unfruitfulness (un-früt'-ful-nes) [un, not; fructus, fruit]. Barrenness. Sterility.

Ungual (ung-gwal) [unguis, a claw]. Pertaining to a nail of the hand or foot. Applied to nail-like structures, as the U. Bones. See Lacrymal Bones.

Ungueal (ung'-grve-al). Same as Ungual.

Unguen (ung'-gwen). Synonym of Unguentum.

Unguent (un'-gwent) [unguentum, ointment]. See Unguentum.

Unguentary (ung'-gzen-ta-re) [unguentarius]. Pertaining to an unguent, or ointment.

Unguentine (ung-gzen'-tin) [unguentum, an ointment]. A popular local application for use in cutaneous diseases and as a dressing for burns and scalds.

Unguentous (ing-green'-tus) [unguentum, ointment]. Resembling an unguent.

Unguentum (ung-green'-tum) [L.: gen., Unguenti: pl., Unguenta]. An ointment. In pharmacy, a soft, fatty mixture, usually of lard or of vaselin as an excipient, with a prescribed medical substance, intended for application, by inunction, to the skin. The melting-temperature of the ointment should be below that of the body. Unguentum simplex consists of lard 80 and wax 20 parts. There are 23 unguenta described in the U. S. P., besides as many more in the B. P., and 5 others in the N. F.

Unguicorn (ung'-gwik-orn) [unguis, nail, claw ; cornu, horn]. In biology, the horny integument of the tip of the upper mandible of certain birds-ducks, geese, petrels, albatross, etc. Cf. Dertrotheca, Myxotheca.

Unguicular (ung-gwik'-u-lar) [unguis, nail]. Having or pertaining to a claw or nail. Having a length of half an inch.

Unguiculate (ung-greit $k^{\prime}-u$-lāt) [unguis, nail]. Clawed. Applied to petals that have stalks or claws.

Unguiferous (ung-gwif'-er-us) [unguis, nail ; ferre, to bear]. Provided with an unguis.

Unguiform (ung'-grif-orm) [unguis, nail ; forma, form]. Shaped like a claw.

Unguinal (ung'-gzin-al) [unguis, nail]. Pertaining to a nail, or to the nails.

Unguirostral (ung-gwe-ros'-tral) [unguis, nail ; rostrum, beak]. In biology, having a nail at the end of the bill, as a duck.

Unguis (ung'-gris) [L. : pl., Ungues]. A claw; the nail of the finger or toe. Also, the lacrymal bone, which is shaped like a finger-nail; also the calcar or hippocampus minor. Ungues adunci. See Ony. chogryposis.

Ungula (ung'-gu-lah) [L.]. I. A hoof; a claw. 2. In surgery, an instrument for extracting a dead fetus from the womb. 3. In botany, same as Unguis.

Ungular (ung'-gu-lar) [ungula, a claw]. Of the character of an ungula.

Ungulate $\left(u n g^{\prime}-g u\right.$-lāt) [ungula, a hoof]. Having hoofs; applied to certain orders of mammalia.

Unguligrade (ung'-gu-lic-rād) [ungula, hoof; gradi, to walk]. Walking upon hoofs.

Ungulous (ung'-gu-lus) [ungula, hoof]. Pertaining to a hoof.

Uni- ( $\left.u^{\prime}-n e-\right)$ [unus, one]. A Latin prefix denoting one.

Uniarticulate $\left(u-n e-a r-t i k^{\prime}-u\right.$-lāt $)$ [unus, one ; articulus, joint]. Having but one joint. 
Uniauriculate (u-ne-azv-rik'-u-lāt) [unus, one ; auric$u l a$, ear]. Having one ear-like process.

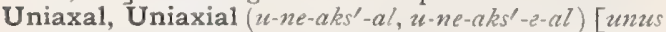
one; axis, axis]. Having but one axis. Synonym of Monaxial.

Unibasal (u-nib-a'-zal) [unus, one; basis, base] Having but one base.

Unibranchiate (u-nib-rang-ke-ät) [unus, one; branchie, gills]. Having but one gill.

Unicapsular (u-nik-ap'-su-lar) [unus, one; capsula, capsule]. Composed of a single capsule.

Unicella (u-nzis-el'-ah) [unus, one; cella, cell]. Having one cell. U. of Nägeli, in biology, the particles theoretically supposed to compose the plastidule, or gemmule, q.v.

Unicellate (u-nis-el'-ät) [unus, one; cella, cell]. Onepronged.

Unicelled $\left(u^{\prime}\right.$-nis-eld $)$. Same as Unicellular.

Unicellular (u-nis-el'-u-lar) [unus, one ; cellula, dim. of cella, a cell]. Composed of or having but one cell.

Unicentral (u-nis-en'-tral) [umus, one ; centrum, center]. Having a single center of growth.

Uniciliate $\left(u-n i s-i l^{\prime}-\ell-\vec{a} t\right)$ [unus, one; cillum, cilium]. Having one cilium; uniflagellate.

Unicism ( $u^{\prime}$-nis-izm) [unicus, single]. The belief or opinion that there is but a single venereal virus.

Unicist (u'-nis-ist) [unicus, single]. A believer in unicism.

Unicorn $\left(u^{\prime}-n i k-o r n\right)$ [unus, one; cornu, horn]. Having a single horn. U. Root. See Aletris. U. Uterus, a uterus with but a single cornu.

Unicostate $\left(u-n i \bar{k}-o^{\prime \prime}-t a \bar{t}\right)$ [unus, one; costa, rib]. Having a single rib.

Unicotyledonous (u-nik-ot-it-e'-do-nus) [unus, one; cotyledonous]. In biology, having one cotyledon.

Unicuspid (u-nik-us'-pid) [unus, one ; cuspis, point]. I. Having but a single cusp (as a tooth). 2. A tooth with but a single cusp or point.

Unicuspidate $\left(u-n i k-u s^{\prime}-p i d-\bar{a} t\right)$ [unus, one; cuspis, point]. Having but a single point, or cusp; unicuspid.

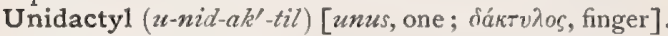
Having a single digit.

Unifacial (u-nif-a'-shal) [unus, one; facies, a face]. Having only one face.

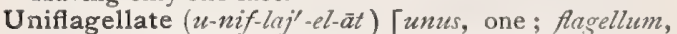
a tail]. In biology, having a single flagellum. See Monoflagellate.

Uniflorous (u-nif-lo'-rus) [unus, one; flos, flower]. Producing a single flower.

Unifoliate (u-nif-óle-ät) [unus, one; folium, leaf]. Bearing a single leaf.

Unifoliolate (u-nif-o'-le-o-lāt) [unus, one; folizm, a leaf ]. In biology, applied to a compound leaf that has but one leaflet, as the leaves of the orange and lemon.

Unijugate $(u$-ne-ju'-gät) [unus, one; jugum, yoke]. In biology, consisting of one pair.

Unijugous (u-ne-ju'-gus). Same as Unijugate.

Unilabiate $\left(u-n i l^{\prime}-a-b \vec{b}-\bar{a} t\right)$ [unus, one; labium, lip]. Having a single lip.

Unilateral (ut-nil-at'-er-al) [unus, one; latus, a side]. Pertaining to or affecting but one side. U. Chorea. See Hemichorea.

Unilocular (u-nil-ok'-u-lar) [unus, one; loculus, dim. of locus, a place]. Having but one cell or cavity.

Uninervate $\left(u-n i n-u \psi^{\prime}-v \bar{a} t\right)$ [umus, one; nervus, nerve]. Having a single rib or midrib.

Uninterrupted (un-in-ter-up'-ted) [un, not; interrupted ]. Continuous; not broken.

Uninuclear (u-nin-u'-kle-ar) [unus, one; mucleus, nucleus]. Having a single nucleus.
Uniocular (u-ne-okl-u-lar) [unus, one; oculus, eye]. With but a single or cyclopean 'eye.

Union (un'-yun) [unio, oneness]. The process of joining or uniting two or more parts or things, and the state of being united. See Healing. U., Dissolved, the condition, in a fracture, in which the callous is finally dissolved and absorbed. U. by Granulation, healing by third intention. U., Primary, healing by first intention. U., Secondary, healing by second intention. U., Vicious, union with deformity.

Unioval (u-ne-o'-val) [unus, one; ovum, egg]. Having but one egg.

Uniovular (u-ne-ov'-u-lar) [unus, one; ovulum, ovule]. Having a single ovule.

Unipara (u-nip'-ar-ah) [znus, one; parere, to bear]. A woman who has borne but one child.

Uniparous $(u$-nip'-ar-us) [unzes, one ; parere, to produce]. Having borne but one child.

Unipetalous $\left(u-n i p-e t^{\prime}-a l-u s\right)[u n u s$, one; $\pi \dot{\tau} \tau a \lambda o v$, leaf ]. Possessing a single petal.

Unipolar (u-nip-o'-lar) [unus, one; polus, a pole]. Applied to nerve-cells each having but one process.

Uniramose, Uniramous ( $\left.u-n e-r a^{\prime}-m \bar{o} z, u-n e-r a^{\prime}-m u s\right)$ [umzs, one; ramus, branch]. Having but one ramus.

Unisexual (u-nis-eks'-u-al) [unus, one; sexus, sex]. Provided with the sexual organs of but one sex.

Unit $\left(u^{\prime}-n i t\right)$ [unus, one]. A single thing or value. The lowest integral value. Ampère. See Ampère. Calory: the quantity of heat necessary to raise the temperature of $\mathbf{I}$ kilogram of water $\mathbf{I}^{\circ} \mathrm{C}$. is sometimes called the Great Calory (when used alone, calory is the same as the great calory), while that required to raise the temperature of $\mathbf{1}$ gram $\mathbf{I}^{\circ} \mathrm{C}$. is called the Little Calory'. Coulomb. See Coulonzh. U. of Current, a conductor I cm. long which, if bent into an arc of $\mathbf{I}$ $\mathrm{cm}$. radius, will act with a force of I degree on a unit magnet pole at the center. Erg. See Unit of Work. Ergten, I0,000,000,000 ergs. Farad. See Farad. Foot-pound, the work expended in raising 1 pound I foot, $=\mathbf{I 3}, 562,69 \mathrm{I}$ ergs. Horse-power, I,980,0 foot-pounds per hour, or 550 foot-pounds per second. Joule, I0,000,000 ergs. U. Magnet Pole, a magnet having a strength of pole sufficient to repel a similar pole at a distance with a force of I degree. Megalerg, I, 000,000 ergs. Ohm. See Ohm. U., Photometric, the light emitted by I sq. cm. of melted platinum at its solidification-temperature. U. Quantity of Light, the quantity of light that falls on a surface of I square foot placed at a distance of I foot from a standard candle, and so that a normal drawn to the surface at any point passes through the source of light. This unit quantity of light is termed a candle-foot. Us., Herbert Spencer's Physiologic. See under Physiologic. U. of Time, I second. Watt, Io megalergs per second. U. of Work, the Erg, or the work done in raising $\mathbf{I . 9 8} \mathbf{I}$ gram, = I Dyne, to the height of I centimeter. Volt. See Voll. See, also, Metric System, and Weights and Measures.

Unitary $\left(u^{\prime}-n i t-a-r e\right)$ [unus, one]. Pertaining to or having the qualities of a unit. Also, pertaining to monsters having the organs of a single individual.

Univalence (u-niv'-al-ens) [unus, one; valere, to be worth]. The state of being univalent.

Univalent (u-niv'-al-ent) [unus, one; valere, to be worth]. In chemistry, having a valence of one; capable of replacing a single hydrogen atom in combination.

Univalve $\left(u^{\prime}-n i v-a l v\right)$ [ums, one; valva, valve]. Provided with a single valve.

Universal (u-niv-ur'-sal) [universalis]. General. U. Joint, a ball-and-socket joint, movable in any direction. 
University (u-niv-un'-sit-e) [universitas, the whole]. A collection of colleges, each having a special curric ulum of studies, under one academic government.

Unna's Paste. A paste for extensive eczematous patches. It consists of oxid of zinc, $x$ ounce ; mucil age of acacia and glycerin, each 2 ounces. It is ap plied with a brush several times a day. Unna, Seborrhea of. See Seborrhea.

Unnatural (un-nat'-u-ral) [un, not; natura, nature]. Not according to nature. U. Offences, the gratifying of the sexual appetite by methods other than the usual. See Sodomy, Bestiality, Tribadism, Sexual Perversion, Homosexuality, Necrophilism, Masochism, Sadism.

Unoculus (u-nok'-u-lus). Synonym of Uniocular.

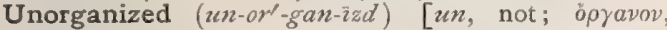
organ]. Without organs, but not necessarily life less.

Unsaturated (un-sat'-u-rn-ted) [un, not; saturare, to saturate]. A qualification applied to carbon compounds that are capable of saturating two valence units.

Unsound (un-sozend') [ME., unsozend, unsound]. Not healthy; diseased.

Unsoundness (un-sorend'-nes) [ME., unsozend, unsound]. The state of being unsound. U. of Mind, incapacity to govern one's affairs.

Unstratified (un-strat'-if-i d) [un, not; stratum, stratum]. Not arranged in strata or layers.

Unsymmetric (un-sim-et'-rik) [un, not; symmetric]. Lacking in symmetry; having unequal arrangement. U. Kidney. See Kidney.

Unwell (un-zvel') [un, not; well]. I. III ; sick. 2. Menstruating.

Unwhole (un-höl') [ME., unhol, not whole]. Not sound; infirm.

Unwholesome (un-hōl'sum) [ME., unholsum, un wholesome]. Insalubrious; unhealthful.

Upas ( $u^{\prime}$-pas) [Malay, upas, poison]. A name applied to several trees found in the East Indies and containing a poisonous principle probably identical with strychnin. It is used as an arrow-poison. U. antiar, Javanese arrow-poison; it acts directly on the vasomotor centers.

Urachal $\left(u^{\prime}-r a-k a l\right)$ [ouja $\chi \dot{b} s$, urachus]. Pertaining to the urachus.

Urachus ( $u^{\prime}$-ra-kus) [ov $\rho \alpha \chi b s$, the urinary canal of a fetus: pl., Urachi]. The prolongation of the fusiform vesicle formed by the dilatation of the embryonic portion of the allantois: the allantoic stalk.

Uracratia (u-ra-kra'-she-ah). See Enuresis.

Uracyl $\left(u^{\prime}-r \alpha-s i l\right)$ [ovoov, urine], $\mathrm{C}_{4} \mathrm{H}_{4} \mathrm{~N}_{2} \mathrm{O}_{2}$. The ureid of $\beta$-oxyacrylic acid; only known in the form of its derivatives.

Uræmatin $(u$-rem'-at-in). See Urohematin.

Uræmia $\left(u-r e^{\prime}-m e-a h\right)$. See Uremia.

Uræmic $\left(u-r e^{\prime}-m i k\right)$. See Uremic.

Ural $\left(u^{\prime}-r a l\right)$. I. See Uralium. 2. See Caudal.

Urali $\left(u-r a^{\prime}-l e\right)$. Synonym of Curare.

Uralium $\left(u-r a^{\prime}-l e-u m\right)$ [ovjoov, urine: gen., Uratii] Ural. Chloral-urethane, $\mathrm{CCl}_{3} \mathrm{CH}: \mathrm{OH}$. $\mathrm{NHCO} \mathrm{C}_{2} \mathrm{H}_{5}$. A combination of chloral hydrate and urethane, discovered in 1889. An excellent hypnotic, but very bitter. Dose gr. $\mathrm{x}-\mathrm{xx}$. Unof.

Uramil ( $u^{\prime}$-ram-il), $\mathrm{C}_{4} \mathrm{H}_{5} \mathrm{~N}_{3} \mathrm{O}_{3}$. Amido-barbituric acid, obtained by boiling alloxanthin with an ammoniumchlorid solution. It occurs in colorless, shining needles, which redden on exposure, and are but slightly soluble in water.

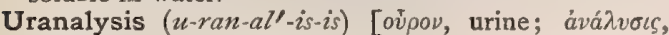
analysis]. Urine-analysis.

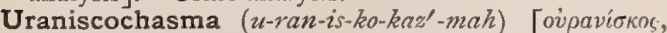
the roof of the mouth; $\lambda \alpha \sigma \mu \alpha$, chasm]. Cleft palate.
Uranisconitis (u-ran-is-ko-ni'-tis) [oupavíros, the roof of the mouth; $\iota \tau \iota s$, inflammation]. Inflammation of the uraniscus, or palate.

Uraniscoplasty (u-ran-is'-ko-plas-te) [ovjoaviokos, palate; $\pi \lambda a ́ \sigma \sigma \varepsilon \iota v$, to form]. Plastic operation for the repair of cleft palate.

Uraniscorrhaphy $\left(u-r a n-i s-k o r^{\prime}-a f-e\right)$ [ovoavíokos, palate; $\rho a \phi n ́, ~ s u t u r e]$. Suture of a palatal cleft.

Uraniscus $(u$-ran-is'-kus) [ovpaviokos]. The roof of the mouth.

Uranium $\left(u-r a^{\prime}-n e-u m\right)$ [Uranze, Uranus]. $\mathrm{U}=\mathrm{I} 20$; quantivalence II. A metal occurring in pitchblende and other minerals. The nitrate, a freely soluble, astringent salt, and an irritant poison, is used in diabetes and as a throat-spray. Dose gr. ss-v. Unof. The oxid is employed to give a fluorescent yellow to glass.

Uranocoloboma (u-ran-o-kol-o-bo'-mah) [ovpavos, the roof of the mouth; coloboma $]$. Cleft palate.

Uranomania (u-ran-o-ma'-ne-ah) [ovpavos, heaven; uavio, madness]. Religious mania with exaltation.

Uranoplastic (u-ran-o-plas'-tik) [ov́pavós, palate; $\pi \lambda \tilde{\alpha} \sigma \sigma \varepsilon v$, to form]. Belonging or pertaining to uranoplasty.

Uranoplasty $\left(u^{\prime}\right.$-ran-o-plas -te). Same as Uraniscoplasty. See Avery's, Beaufils', Blasius', DaviesColley's, Krimer's, Langenbeck's, Rotter's, Smith's, Thiersch's, and Warren's Operations, in Operations, Table of.

Uranorrhaphy (u-ran-or'-af-e). See Uraniscorrhaphy.

Uranoschisis (u-ran-os'-kis-is) [oủpavós, vault; $\sigma \chi i \sigma \iota s$, a cleft]. Cleft palate.

Urano-staphylorrhaphy $\left(u^{\prime}\right.$-ran-o-staf-il-or'-af-e) [oúavós, vault; staphylorrhaphy]. Same as Uraniscorrhaphy.

Uranostomatoscopy (u-ran-o-sto-mat-os'-ko-pe) [ov-

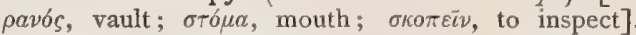
Diagnostic, or professional, inspection of the roof of the mouth.

Urao $\left(u-r a^{\prime}-o\right)$. See Trona.

Urapostema (u-rap-os'-tem-ah) [ovjoov, urine; aposte$m a]$. An abscess containing urine.

Urare, Urari $\left(u-r a h^{\prime}-r e\right)$. See Curare.

Urarin (u-rah'-rin). Same as Curarine.

Urarthritis (u-rar-thri'-tis). See Arthritis uritica.

Urate $\left(u^{\prime}-r \bar{a} t\right)$ [ov $\rho o v$, urine]. Combination of uric or lithic acid with a base. It is present in normal urine. U.-cells. In biology, the cells containing doubly refractive granules and uric acid; they are found in the photogenic plate of Lampyris. (Schulze.) U.-test, heat the upper part of a column of turbid urine; if the turbidity be due to urates it will clear up; or, add potassium hydrate, and the sediment of urates will dissolve.

Uratic $\left(u-r a t^{\prime}-i k\right)$ [ovjov, urine]. Pertaining to or characterized by urates. U. Diathesis, a condition in which there is a tendency to the deposition of urates in the joints and elsewhere; a tendency to gout.

Uratoma $\left(u-r a t-o^{\prime}-m a h\right)$ [ov $\rho o \nu$, urine; óua, tumor : $p l$, Uratomata]. A tophus, or uratic calculus, formed in any tissue.

Uratosis (u-rat-o'-sis) [ovpov, urine]. A diseased condition, characterized by the deposition of urates.

Uraturia (u-rat-u'-re-ah) [ovpov, urine]. A condition in which there is an increase of urates in the urine.

Urbanization (ur-ban-iz-a'-shun) [urbs, a city]. A term devised to express the tendency of modern society to develop into cities at the expense of the country population, with a consequent influence upon disease, the death-rate, etc.

Urbantschitsch's Method. A method for the introduction of the Eustachian catheter. 
Urceolate $\left(u r^{\prime}\right.$-se-o-lāt) [urceolus, a little pitcher or urn]. In biology, pitcher-shaped, urn-shaped.

Urceolus (ur-se'-o-lus) [urceolus, a little pitcher: $p l$., Urceoli]. In biology, an urn-shaped structure, as the zoöthecium of a rotifer.

Urea $\left(u-r e^{\prime}-a h\right)[o v j o v$, urine $], \mathrm{CO}\left(\mathrm{NH}_{2}\right)_{2}$. The chief solid constituent of urine, and principal nitrogenous end-product of tissue-metamorphosis; a carbamid, derived mainly from the decomposition of uric acid. It was first obtained artificially in 1832 by Wöhler. U.-ferment, an enzyme existing in mucous urine passed in inflammatory conditions of the bladder. U., Test for, concentrate urine to syrupy consistence by evaporation, and add nitric acid. The nitrate of urea will form a crystalline precipitate of rhombic plates. The quantity may be accurately estimated by Fowler's method, by that of Russell and West, by Liebig's volumetric method, or by Lyon's apparatus. See Hypobromite Method.

Ureal ( $\left.\mathfrak{u}^{\prime}-r e-a l\right)$ [ovpov, urine]. Pertaining to or containing urea.

Urechites suberecta $\left(u-r e k-i^{\prime}-t e ̄ z s u b-\ell-r e k^{\prime}-t a h\right)$. See Savanna Flower.

Urechitin $\left(u\right.$-rek'-it-in), $\mathrm{C}_{28} \mathrm{H}_{42} \mathrm{O}_{8}$. A poisonous glucosid from Urechites suberecta. Unof.

Urechitoxin ( $u$-rek-it-oks'-in) [urechites; $\tau \delta \xi$ เkov, poison], $\mathrm{C}_{13} \mathrm{H}_{20} \mathrm{O}_{5}$. A highly poisonous principle from the leaves of Urechites suberecta. Unof.

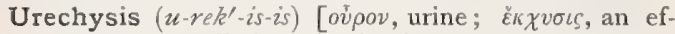
fusion]. An effusion of urine into areolar tissue.

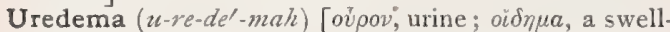
ing]. A tumefaction arising from the distention of a tissue or cavity by the escape of urine.

Uredinous $\left(u-r e d^{\prime \prime}-i n-u s\right)$ [L., a blight]. Affected with uredo.

Uredo $\left(u-r e^{\prime}-d o\right)$ [uredo, a blight]. I. A form, genus, or stage in the life-cycle of certain fungi (Uredinea). 2. See Urticaria. U.-gonidium. Same as Uredospore.

Uredoform ( $u$-re'-do-form) [uredo, blight; forma, form]. The form assumed by a fungus of the class Uredinee at the stage in which uredospores are produced.

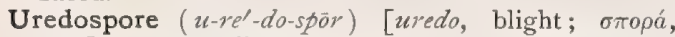
seed]. A peculiar spore, borne on erect basids, springing from cushion-like masses of mycelial hyphæ situated beneath the epiderm of the hostplant by parasitic uredinous fungi.

Uredosporic (u-re-do-spōor -ik) [uredo, blight; $\sigma \pi o \rho a ́$, spore]. Pertaining to a uredospore.

Ureid $\left(u^{\prime}-r e-i d\right)$ [ovpov, urine]. A compound of urea and an acid radicle.

Urelcosis $\left(u-r e l-k o^{\prime}-s i s\right)$ [oṽoov, urine; $\dot{\varepsilon} \lambda \omega \omega \sigma \iota s$, ulceration]. Ulceration of the urethra or urinary organs.

Uremia (u-re'-me-ah) [ovpov, urine; aiua, blood]. The combination of symptoms due to the retention in the blood of excrementitious substances normally excreted by the kidneys.

Uremic $\left(u-r e m t^{\prime}-i k\right)$ [ovpov, urine; aipa, blood]. Due to or characterized by uremia.

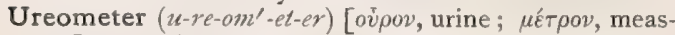
ure]. An instrument for measuring the quantity of urea in urine.

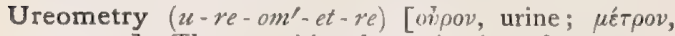
measure]. The quantitive determination of urea.

Ureorrhea (u-re-or-e'-ah) [ovpov, urine; poí, a flow]. Polyuria; an increased flow of urine.

Uresiesthesis (u-res-e-es'-the-sis) [ovpnols, urination; aiofinoıs, sensation]. Constant desire to urinate.

Uresis $\left(u-r e^{\prime}-\right.$ sis $)$ [oup

-uret $\left(-u^{\prime}\right.$-ret $)$. In chemistry, a suffix formerly used to denote a binary compound of carbon, sulphur, etc., with another element. In modern chemistry the suffix $i d$ is used.

Uretal (u-re'-tal). Same as Ureteric.

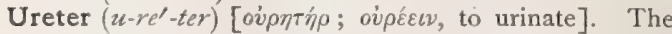
canal or tube conveying the urine from the pelvis of the kidney to the bladder.

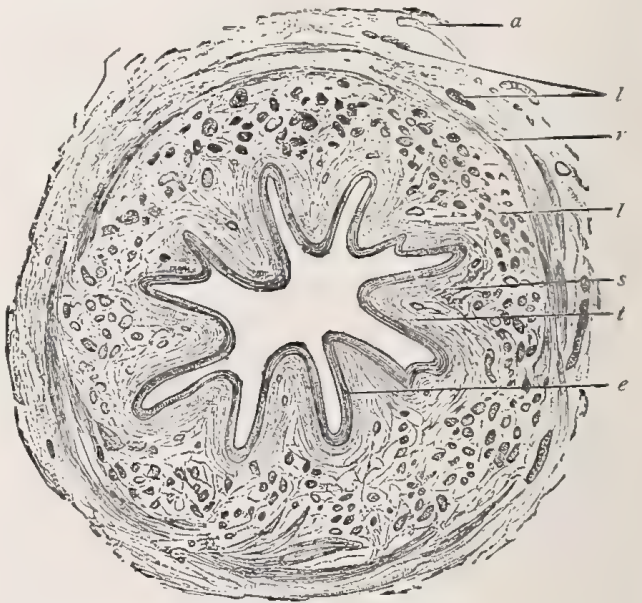

TRANSVERSE SEction OF LOWER PART OF HuMaN URETER.

e. Transitional epithelium. s. Submucosa. $l$ and $r$. Longitudinal and circular smooth muscular fibers. $t$. Tunica propria. a. Adventitia. X 15 . (From Stirling.)

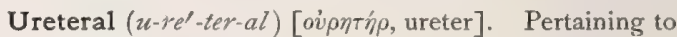
the ureter.

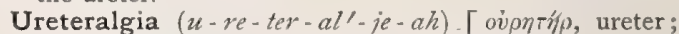
à $\lambda$ yos, pain $]$. Any pain in the ureters.

Ureterectomy $\left(u-r e-t e r-e k^{\prime}-\right.$ to - me) [ovj $\eta \tau^{\prime} \rho$, ureter;

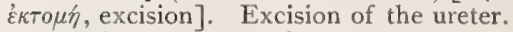

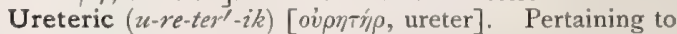
the ureters or to a ureter.

Ureteritis $\left(u-r e-t e r-i^{\prime}-t i s\right)$ [ov $\rho \eta \tau^{\prime} \rho$, ureter; $\iota \tau \iota \zeta$, inflammation]. Inflammation of a ureter.

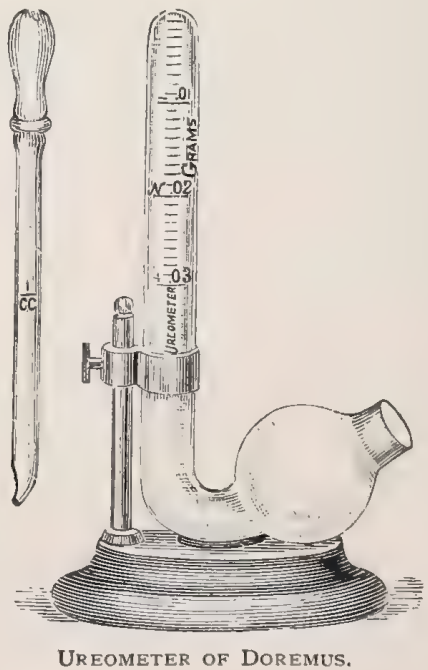

Uretero-cystostomy, Uretero-cystoneostomy (u-re' ter-o-sis-tos'-to-me, $\left.u-r e^{\prime}-t e r-o-s i s-t o-n e-o s^{\prime}-t o-m e\right)$ [ovjo- 


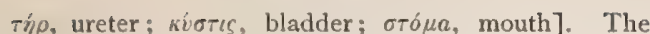
establishment of an artificial communication between a ureter and the bladder.

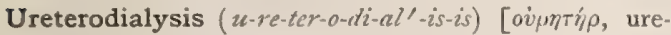
ter; $\delta \iota \dot{\lambda} \lambda v \sigma \iota s$, dialysis]. Rupture of the ureter.

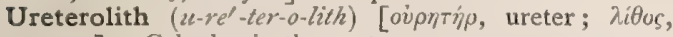
stone]. Calculus in the ureter.

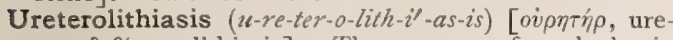
ter; $\lambda$ Afiaoı, lithiasis ]. The presence of a calculus in the ureter.

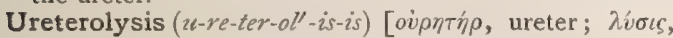
a loosening]. Same as Utero-dialysis.

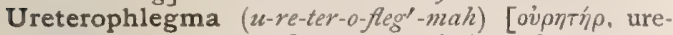
ter; $\phi \lambda \varepsilon ́ \gamma \mu a$, phlegm]. Accumulation of mucus in the ureter.

Ureterophlegmasia (u-re-ter-o-flg-ma'-ze-ah). Synonym of Ureteritis.

Ureteropyosis ( $u$-re-ter-o-pi-ó-sis) [oi $\rho \eta \eta \hat{\eta} \rho$, ureter ; $\pi$ íov, pus]. Purulent inflammation of the ureter.

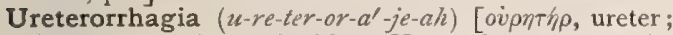
pryvoviva, to burst forth]. Hemorrhage from the ureter.

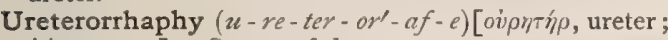
páp $\eta$, seam]. Suture of the ureter.

Ureterostegnosis $\left(u-r e-t e r-o-s t e g n o^{\prime}\right.$-sis) [ov $p \eta \tau \dot{\eta} \rho$, ure-

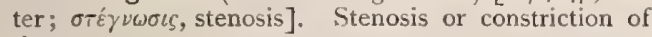
the ureter.

Ureterostenoma (u-re-ter-o-ste-no'-mah) [ov่ $\eta \tau \eta \dot{p} \rho$, ure-

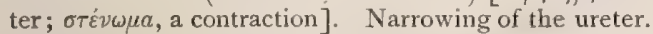

Ureterostoma ( $u$-re-ter-os'-to- $m u h)[o v \rho \eta t h \rho$, ureter; $\sigma \tau \delta \mu a$, mouth]. The renal or the cystic opening or mouth of the ureter.

Ureterostomy $\left(u-r e-t e r-o s^{\prime}-t o-m e\right)[o \dot{\nu} \rho \eta \dot{\eta} \rho$, ureter; oтó $\mu \Omega$, mouth]. The formation of a ureteral fistula.

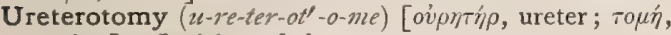
cutting]. Incision of the ureter.

Uretero-ureterostomy $\left(u-r e^{\prime}-t e r-o-u-r e-t e r-o s^{\prime}-t o-m e\right)$

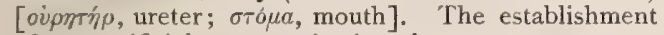
of an artificial communication between one ureter and another, or between different parts of the same ureter.

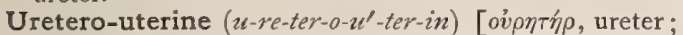
uterus, uterus]. Belonging to both ureter and uterus.

Uretero-vaginal (u-re-ter-o-vaj'-in-al) [ov $\rho \eta \hat{\eta} \rho$, ureter; vagina, vagina]. Belonging to both ureter and vagina.

Urethane ( $u^{\prime}$-re-than) [ovjoov, urine ; ether $], \mathrm{NH}_{2} \mathrm{CO}_{2}$ $\mathrm{C}_{2} \mathrm{H}_{5}$. Ethyl Carbamate. A hypnotic and antipyretic. A decided antagonist to strychnin and other tetanizers. It has yielded excellent results in convulsions and in tetanus. In very large doses it is toxic. Dose gr. $\mathrm{xx}-1 \mathrm{x}$. Unof. In a wider sense, any ester of carbamic acid may be called a urethane. Urethanes are crystalline, volatile bodies, soluble in alcohol, in ether, and in water.

Urethra (u-re'-thrah) [ovprip $\rho$, urethra]. The excretory canal of the bladder, extending from the neck of the bladder to the meatus urinarius. It is divided in the male into a prostatic portion, a membranous portion, and a spongy portion, and is from 8 to 9 inches long. In the female it is about $x \frac{1}{2}$ inches in length.

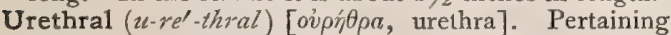
to the urethra. U. Crest. See Verumontanum. U. Fever. A series of febrile reactions that may follow the introduction of a catheter or bougie into the bladder. When not due to actual traumatism, it is a neurotic condition apparently produced by a kind of shock following an unwonted local stimulus.

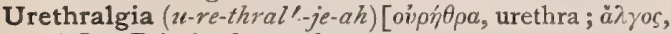
pain]. Pain in the urethra.

Urethratresia (u-re-thrat-re'-ze-ah) [ov $\rho \dot{y} \theta \rho a$, urethra ; atresia]. Imperforate urethra.
Urethremorrhagia (u-re-threm-or- $\left.\alpha^{\prime}-j e-a h\right)$ [ov $\rho \hat{i} \theta \rho \alpha$,

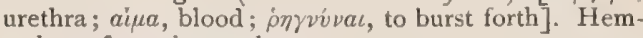
orrhage from the urethra.

Urethrism, Urethrismus ( $u^{\prime}-r e$-thrizm, $u$-re-thriz' mus) [ov $\rho$ h $(\theta \rho a$, urethra]. Urethral irritability.

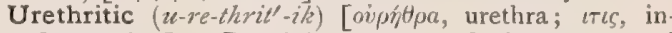
flammation]. Pertaining to or of the nature of urethritis.

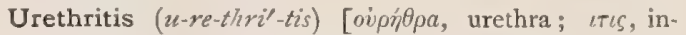
flammation]. Inflammation of the urethra. U., Anterior, that affecting the penile portion of the urethra, U. catarrhalis, simple non-specific urethritis. U. granulosa, chronic urethritis with urethral granulations. U. membranacea, chronic urethritis with the formation of membranes in the urethra. U., Posterior, inflammation of the prostatic and membranous portions of the urethra. U., Specific. See Gonorrhea. U. venerea. See Gonorrhea.

Urethrito-syphilis (u-re-thri-to-sif'-il-is) [ov $\rho \dot{n} \theta \rho \alpha$, urethra; tтes, inflammation; syphilis, syphilis]. Gonorrhea accompanied by syphilis.

Urethrocele $\left(u-r e^{\prime}-t h r o-s e ́ l\right)$ [oivpí $\theta \rho a$, urethra; $\kappa \dot{\eta} \lambda \eta$, a tumor]. A pouch-like thickening of the wall of the urethra in females.

Urethrocystitis ( $u$-re'-thro-sis-ti'-tis) [ov $\rho \dot{\theta} \theta \rho a$, urethra ;

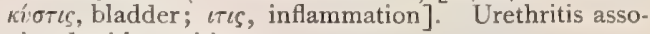
ciated with cystitis.

Urethrograph (u-re'-thro-graf) [ovpin $\theta \rho a$, urethra ; $\gamma \rho a ́ \phi \varepsilon(\nu$, to record]. A recording urethrometer.

Urethrometer $\left(u-r e-t h r o m^{\prime}-e t-e r\right)$ [ov $\rho \eta^{\prime} \theta \rho \alpha$, urethra;

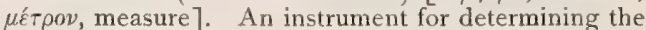
caliber of the urethra or for measuring the lumen of a stricture.

Urethrophraxis (u-re-thro-fraks'-is) [ov $\rho$ hH $\rho a$, urethra; $\phi \rho a ́ \xi \iota \varsigma$, a blocking]. Urethral obstruction.

Urethroplastic (u-re-thro-plas'-tik) [ov́pít $\rho a$, urethra ;

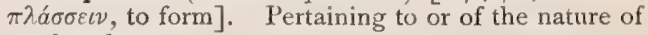
urethroplasty.

Urethroplasty $\left(u-r e^{\prime}-t h r o-p l a s-t e\right)$ [ov $\rho \hat{n} \theta \rho a$, urethra; $\pi \lambda a ́ \sigma \sigma \varepsilon \iota v$, to form]. Plastic operation upon the urethra.

Urethrorrhagia (u-re-thror-a'-je-ah) [ovppit $\rho \rho a$, urethra ; onyvival, to burst forth]. I. Hemorrhage from the urethra. 2. A gonorrheal or gleety discharge from the urethra.

Urethrorrhaphy (u-re-thror'-af-e) [oúpin $\rho \rho \alpha$, urethra ; pá $\emptyset$, seam]. The closure with sutures of an abnormal opening into the urethra.

Urethrorrhea (u-re-thror-e'-ah) [ov́pht $\theta \rho a$, urethra; poía, a flow]. Any morbid discharge from the urethra.

Urethroscope $\left(u-r e^{\prime}-t h r o-s k o ̄ p\right)$ [ov $\rho \hat{\eta} \theta \rho \alpha$, urethra;

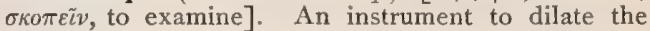
urethra and to allow inspection of its lining membrane.

Urethroscopy (u-re-thros'-ko-pe) [ov́phipa, urethra ; $\sigma \kappa о \pi \varepsilon \tilde{\nu}$, to view]. Inspection of the mucous membrane of the urethra.

Urethrospasm $(u$-re'-thro-spazm) [ovंṕ, $\theta \rho a$, urethra ; $\sigma \pi \kappa \sigma \mu \delta_{s}$, spasm]. A spasmodic stricture of the urethra.

Urethrostenosis ( $u$-re'-thro-ste-no'-sis) [oijpít $\rho a$, urethra; $\sigma \tau^{\prime} \nu \omega \sigma \iota s$, a constriction]. Stricture of the urethra.

Urethrostomy (u-re-thros' - to - me) [oípí $\theta \rho a$, urethra ; $\sigma \tau b \mu \alpha$, mouth]. Perineal section with permanent fixation of the membranous urethra in the perineum.

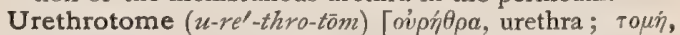
a cutting]. A cutting instrument used in urethrotomy. U., Dilating, a combined urethrotome and dilator.

Urethrotomic $(u$-re-thro-tom'-ik) [ovph́t $\rho a$, urethra; roun, a cutting]. Pertaining to urethrotomy. 
Urethrotomy $\left(u-r e-t_{\text {hrot' }}-\sigma-m e\right)$ [ovoń $\theta \rho \alpha$, urethra ;

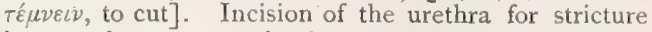
by a urethrotome or other instrument. U., Cock's External, laying open the perineum without a guide, for an impervious stricture of the urethra. U., External, incision of the urethra through its external wall. U., Internal, incision of urethral stricture by a blade introduced into its lumen. U., Syme's External, an operation in which an incision is made through the perineum upon a grooved director passed through the stricture. U., Wheelhouse's External, an operation in which an opening is made into the urethra anterior to the stricture and a grooved director is passed through it into the bladder and the stricture divided. See, also, Operations, Table of.

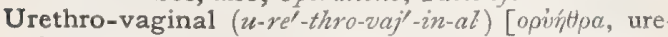
thra; vagina, vagina]. Pertaining to the urethra and the vagina.

Urethro-vesical (u-re-thro-ves'-ik-al) [oijpí $\theta \rho a$, urethra ; vesica, bladder]. Pertaining to the urethra and the bladder.

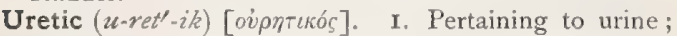
stimulating the flow of urine. 2. An agent or medicine that stimulates the flow of urine.

Urginea (ur-jin'-e-ah) [urgere, to press]. A genus of liliaceous plants. U. scilla, the plant that produces the official squill. See Scilla.

Uric $\left(u^{\prime}-r^{\prime} k\right)$ [urina, urine]. Derived from or belonging to the urine. U. Acid, one of a series of three substances $\left(\mathrm{C}_{5} \mathrm{H}_{4} \mathrm{~N}_{4} \mathrm{O}=\right.$ hypoxanthin; $\mathrm{C}_{5} \mathrm{H}_{4} \mathrm{~N}_{4} \mathrm{O}_{2}=$ xanthin; $\mathrm{C}_{5} \mathrm{H}_{4} \mathrm{~N}_{4} \mathrm{O}_{3}=$ uric acid), each differing from the preceding by an atom of oxygen. Horbaczewski has indicated the possibility of the formation of uric acid from the nuclein of cells.

Uricacidemia $\left(u-r i k-a s-i d-e^{\prime}-m e-a h\right)$ [ urina, urine; acidus, acid; aiua, blood]. The presence of a demonstrable amount of uric acid in the blood. It is said to produce various nervous symptoms, such as headache; according to Haig, it is reponsible for many and varied phenomena.

Uricedin (u-re-se'-din) [urina, urine]. A new proprietary remedy suggested for the treatment of gout. It is said to dissolve uric acid. It is a white, granular substance, readily soluble in water. After its administration the urine is capable of dissolving, in vitro or on a uric-acid filter, large quantities of uric acid.

Uricemia, Uricæmia (u-ris-e'-me-ah) [urina, urine ; aifu, blood]. The presence of uric acid in the blood on account of the failure of the red blood-corpuscles to oxidize the acid; lithemia. See Uricacidemia.

Uridrosis (u-rid-ro'-sis) [urina, urine; idpws, sweat]. Sudor urinosus, a pathologic condition characterized by the presence of urea in the sweat. It is noticeable in cholera, uremia, atrophy of the kidneys, and in some cases of artificially induced diaphoresis. U. crystallina, a condition in which the salines of the sweat, together with elements of the urine, crystallize upon the skin in reddish-white granules.

Urinaccelerator (u-rin-ak-sel'-er-a-tor) [urina, urine; accelerare, to accelerate]. The accelerator urinæ. See Muscles, Table of.

Urinal $\left(u^{\prime}\right.$-rin-al) [urina, urine]. A vessel for receiving urine.

Urinalysis (u-rin-al'-is-is) [urina, urine; $\lambda \iota \sigma \iota$, loosing]. The analysis of the urine.

Urinary $\left(u^{\prime}-r i n-a-r e\right)$ [urina, urine]. Pertaining to the urine. U. Bladder. See Bladder. U. Calculus, a stony concretion found in the urinary passages. A table of the different varieties of urinary calculi is appended:-

\section{ANALYSIS OF URINARY CALCULI.}

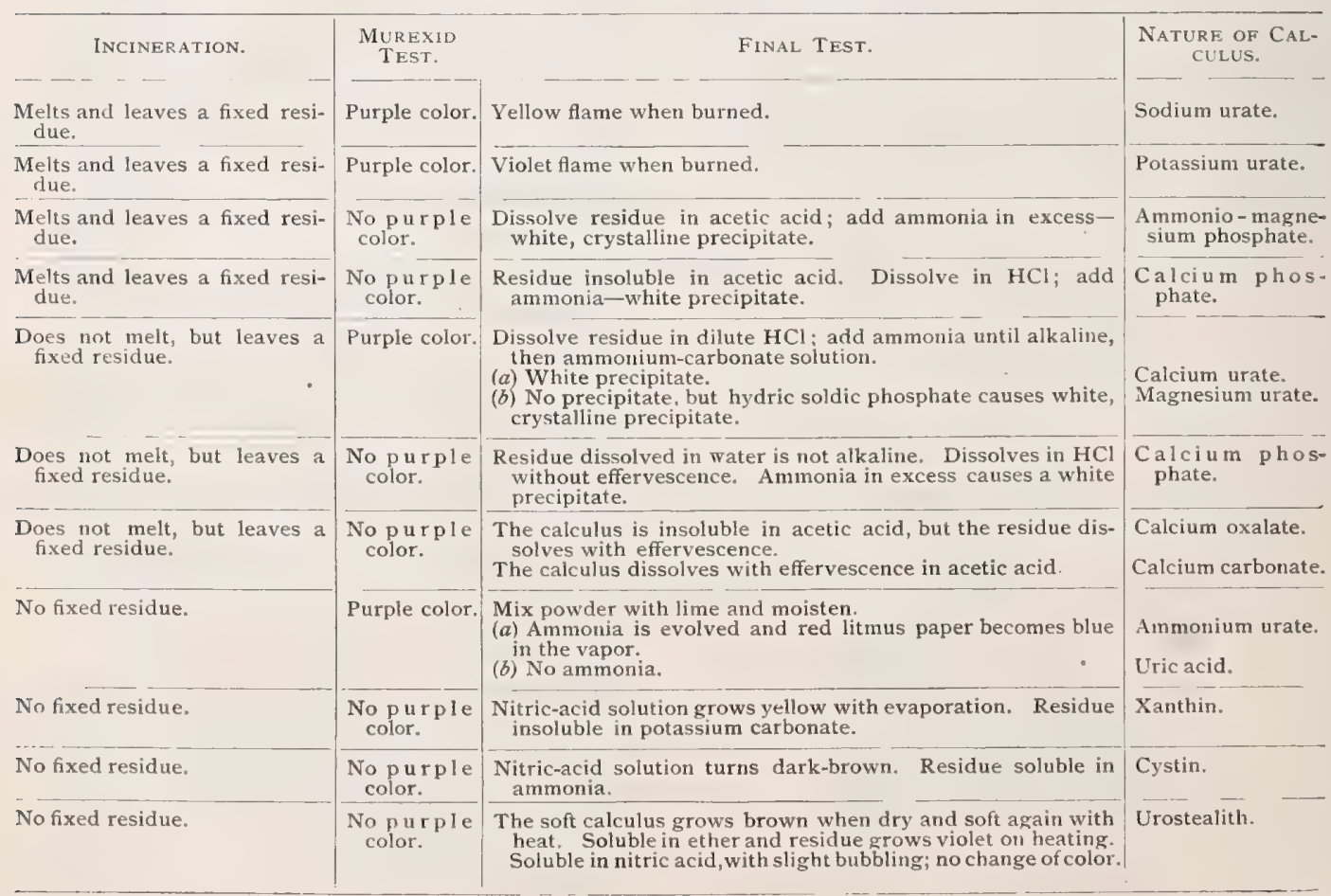


U. Canal, a primitive urinary passage. U. Cast, a tube-cast. U. Organs, the organs concerned in the secretion and excretion of the urine. They include the kidneys, bladder, ureters, and urethra. $U$.
Sediment, the deposit of sabulous and other material left after urine has been allowed to stand for some hours in a vessel. A table of the principal materials that may be found in urinary sediment is appended :-

\section{TABLE OF URINARY SEDIMENTS.}

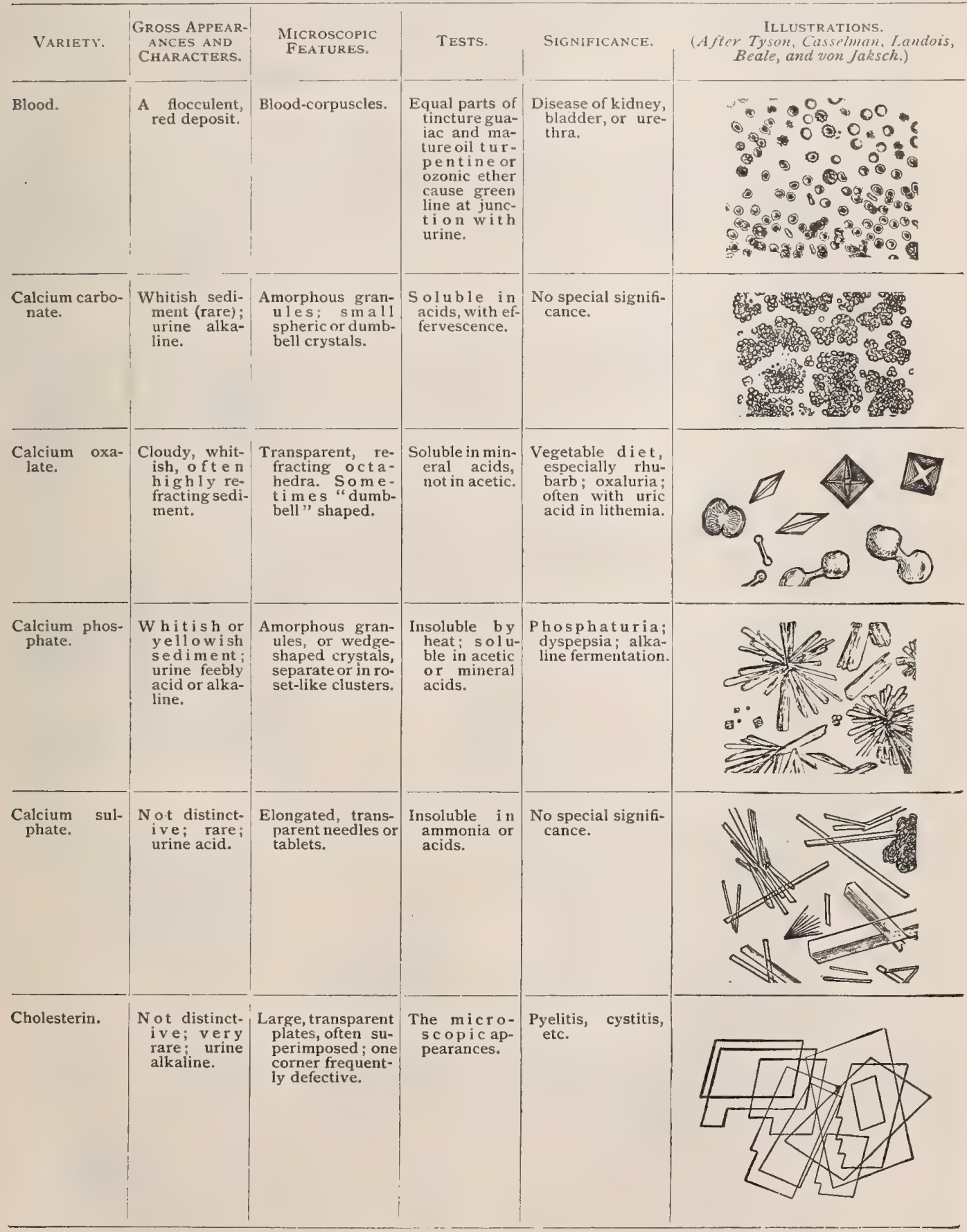


TABLE OF URINARY SEDIMENTS.-Continued.

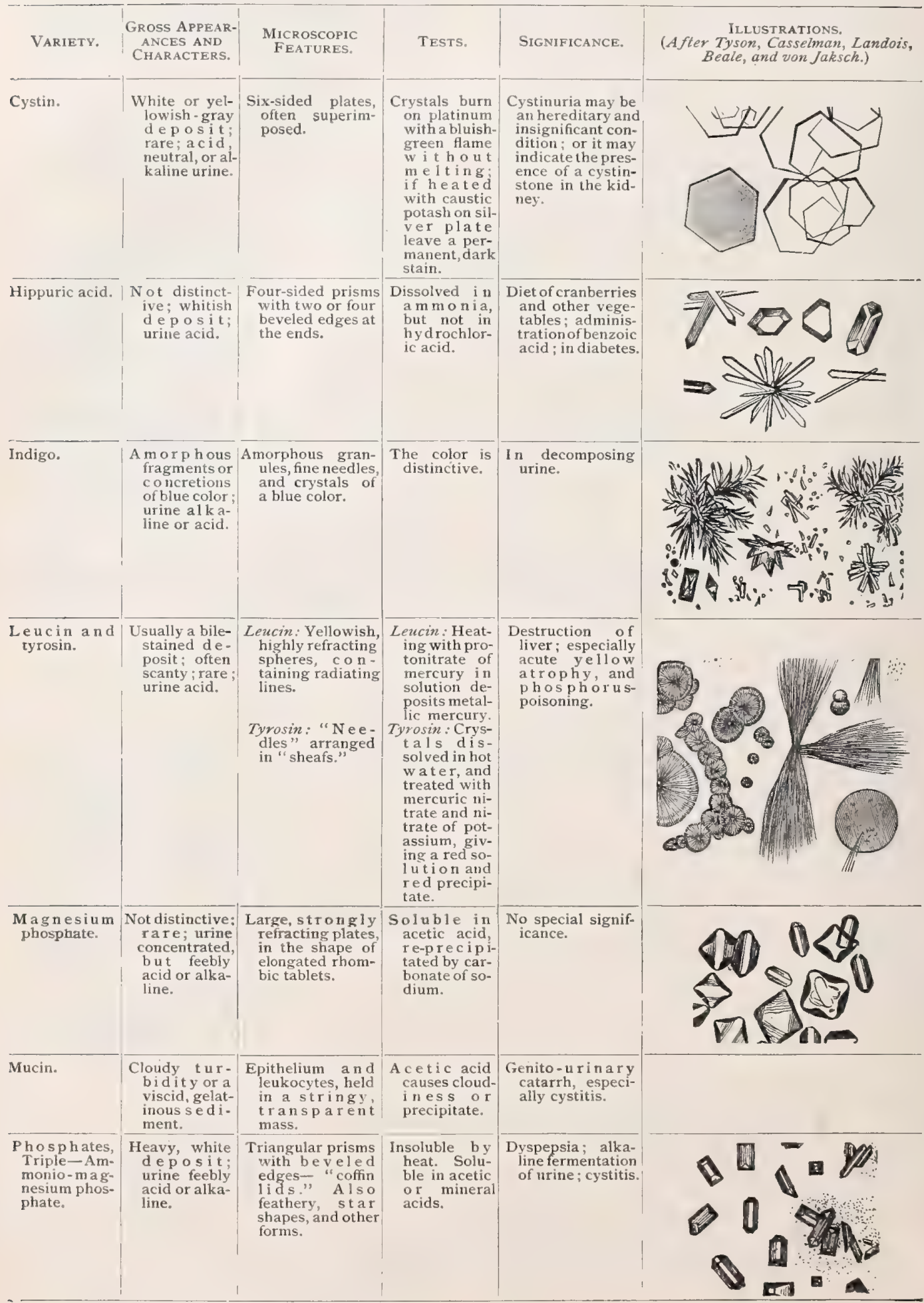


TABLE OF URINARY SEDIMENTS.-Continued.

VARIETY

Pus.

Tyrosin.

Urates of sodium, ammonium, and potassium.

(The illustration is of am. monizum ur. ate.)

(a)

See Leucin.

Brick-dust" deposit, the color due to the color of the urine. Dissolved and cleared by heating Urine acid: somet imes alkaline.

Uric acid.

Small grains, rese mbling red pepper urine acid.

anthin.
Amorphous grannium urate appears as spheric crystals s u r rounded by spicules-"he dge hog crystals."
TESTS.

SigNIFICANCE.

The dark-red In acid urine, with color of pusc orp uscles o $n$ adding iodo - potassiculodid sicriodid uric acid and no mucus : pyelitis : or alkaline urine with triple phos phates: cystitis.$$
\text { phates: cystitis. }
$$

Dissolved by
heat or on
adding acids.

Crystals of vari- The crystals o us shapes dissolve in colored brownish-red by the urinary pigments. The com monest form resembles caustic pot-
ash. Ih he murexid-test produces purple color. whetstone.

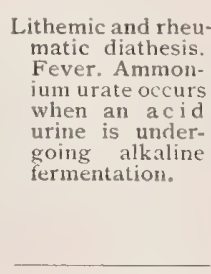

Lithemic or rheumatic diathesis.

\section{ILLUSTRATIONS. \\ (After Tyson, Casselman, Landois, Beale, ant von Jaksch.)}

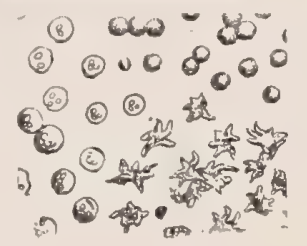

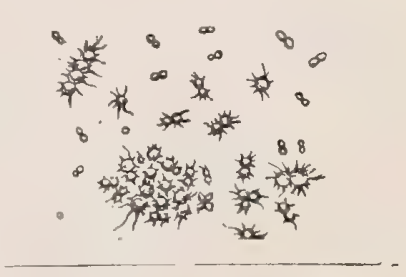

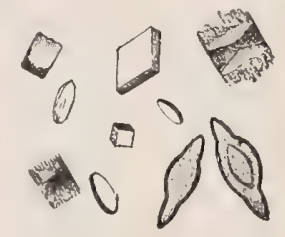

Xanthin-stone in Insoluble in acetic acid; ammonia.

the kidney. stance in the urine of a lad who had three years previously exhibited the symptoms of renal colic. It was seen in the sedinent in the form of autet in the sedinent in the form of whet stone crystals, which were insoluble in acetic acid and soluble in anmonia (thus distinguished from uric acid).-Von Jaksch.

Urinate $\left(u^{\prime}-\operatorname{rin}-\bar{a} t\right)$ [urin $\alpha$, urine]. To evacuate urine from the bladder.

Urination (u-rin-a'-shun) [urina, urine; uninare, to urinate]. The act of voiding urine.

Urine $\left(u^{\prime}-r i n\right)$ [urina, urine]. The excretion of the kidneys. The urine in health has an amber color, a slightly acid reaction, a faint odor, a saline taste, and a specific gravity of about IOI8. The average quantity excreted in 24 hours, in health, is about three pints. The constitution and the amount of the urine are modified considerably by the food and drink taken, also by drugs, temperature, occupation, etc. U., Anemic, the urine in anemia. U., Black, urine containing melanin. U., Chylous, a milky urine due to the presence of fat or chyle. U., Diabetic, urine passed in diabetes, containing glucose. U., Dyspeptic, the urine of a dyspeptic patient. It often contains crystals of calcium oxalate. U., Gouty, urine scanty in amount, highly colored, and containing an excess of uric acid. U., Incontinence of, inability to retain the urine. See Enuresis. U., Mucilaginous, urine containing a large amount of mucus. U., Nebulous, urine cloudy from earthy phosphates. U., Residual, urine that remains in the bladder after urination in prostatic hypertrophy and in cystic disease. U., Re- tention of. Inability to pass the urine. See Ischuria. U., Suppression of. See Ischuria. U., Tests for Serum-albumin in. From a series of experiments with mucoid nucleo-albumin (so-called mucin), Dr. D. D. Stewart concludes that the old-fashioned heat-test is the only reliable one for the recognition of serum-albumin in the urine, but that no dependence can be placed on a reaction occurring while the urine is cooling if an acid has been added to assist in the precipitation of serum-albumin or to maintain phosphates in solution. This author also asserts that metaphosphoric acid is untrustworthy as a serumalbumin test, on account of reacting to traces of socalled mucin in a manner indistinguishable from the serum-albumin reaction. Trichloracetic acid is also so delicate a reagent for the detection of albumin, that, by it, a normal, constant trace of albumin is proved. With careful technique, an albumin-reaction occurs with all cold urines, either instantly or within a few moments after contact, and this reaction may be made to appear almost instantly in any normal, unfil. tered, clear urine, if the test-tube is placed for a short time in water at the boiling point. So extraordinarily sensitive is this reagent that it gives an albumin-ring with distilled water which has been passed through 
filtering paper of the finest grades, including the best Swedish paper, which is supposed to contain the least amount of vegetable albumin. See Tests, Table of. A table of the ciolors of the Urine is appended.

COLORS "OF THE URINE.

\begin{tabular}{|c|c|c|}
\hline COLOR. & $\begin{array}{l}\text { CAUSE OF THE } \\
\text { COLOR. }\end{array}$ & $\begin{array}{l}\text { PATHOLOGIC CONDI- } \\
\text { TION OR CAUSE. }\end{array}$ \\
\hline Nearly colorless. & $\begin{array}{l}\text { Dilution or dimin- } \\
\text { ished pigments. }\end{array}$ & $\begin{array}{l}\text { Various nervous } \\
\text { conditions, hy- } \\
\text { druria, diabetes } \\
\text { mellitus, diabetes } \\
\text { insipidus, con- } \\
\text { tracted kidney. }\end{array}$ \\
\hline $\begin{array}{l}\text { Normal color, be- } \\
\text { coming black on } \\
\text { standing. }\end{array}$ & $\begin{array}{l}\text { Unknown; glyco- } \\
\text { suric acid. }\end{array}$ & $\begin{array}{l}\text { Sometimes in pul- } \\
\text { monary tuberculo- } \\
\text { sis. Pathology } \\
\text { unknown. }\end{array}$ \\
\hline Milky. & $\begin{array}{l}\text { Fat-globules; pus- } \\
\text { corpuscles. }\end{array}$ & $\begin{array}{l}\text { Chyluria; fatty kid- } \\
\text { ney: purulent } \\
\text { disease in the } \\
\text { urinary tract. }\end{array}$ \\
\hline $\begin{array}{l}\text { Dark-amber to red- } \\
\text { dish-brown. }\end{array}$ & \begin{tabular}{|} 
Increase of nor- \\
mal or occur- \\
rence of patho- \\
logic pigments \\
concentration of \\
the urine.
\end{tabular} & $\begin{array}{l}\text { Fever; pernicious } \\
\text { anemia; excessive } \\
\text { sweating. }\end{array}$ \\
\hline Yellow. & Excreted drugs, & e.g., picric acid. \\
\hline Orange. & Excreted drugs, & $\begin{array}{l}\text { e. } g \text {, santonin, chry- } \\
\text { sophanic acid. }\end{array}$ \\
\hline Brown to black. & $\begin{array}{l}\text { Hematin, methem- } \\
\text { oglobin mela- } \\
\text { nin, hydrochinon, } \\
\text { and catechol. }\end{array}$ & $\begin{array}{l}\text { Small hemorrhages; } \\
\text { methemoglobin- } \\
\text { uria antipyrin; } \\
\text { chlorate of potash; } \\
\text { melanotic sarcoma; } \\
\text { carbolic acid; } \\
\text { creasote. }\end{array}$ \\
\hline $\begin{array}{r}\text { Brownish-yellow to } \\
\text { red, becoming } \\
\text { blood }-\mathrm{red} \text { on } \\
\text { adding alkalies. } \\
\end{array}$ & $\begin{array}{l}\text { Substances intro- } \\
\text { duced with } \\
\text { senna, rhubarb, } \\
\text { and chelidonium. }\end{array}$ & \\
\hline Red or reddish. & $\begin{array}{l}\text { Hemoglobin or free } \\
\text { blood. } \\
\text { Pigments in food, }\end{array}$ & $\begin{array}{l}\text { Hemoglobinuria or } \\
\text { hematuria. } \\
\text { e.g., logwood mad- } \\
\text { der, bilberries, } \\
\text { fuchsin. }\end{array}$ \\
\hline $\begin{array}{l}\text { Greenish to brown } \\
\text { or black. }\end{array}$ & Bile-pigments. & Jaundice. \\
\hline Dirty- & $\begin{array}{c}\text { D a rk serum on } \\
\text { surface, and blue } \\
\text { deposit d u e to } \\
\text { indigo-forming } \\
\text { substances. }\end{array}$ & $\begin{array}{l}\text { Cholera, typhus, } \\
\text { hepatic, and intes- } \\
\text { tinal a ffections, } \\
\text { Especially marked } \\
\text { in stale urine. }\end{array}$ \\
\hline
\end{tabular}

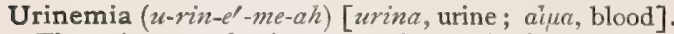
The existence of urinary constituents in the blood.

Uriniferous (u-rin-ift-er-us) [urina, urine; ferre, to bear]. Carrying or conveying urine. U. Tubules. See under Tubulus.

Urinific $(u$-rin-if'-ik) [urina, urine ; facere, to make]. Excreting or producing urine.

Uriniparous (u-rin-ip'-ar-us) [urina, urine; parere, to produce]. Preparing or excreting urine.

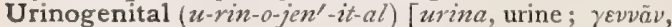
to produce]. Pertaining to urination and the genital function; urogenital.

Urinogenitary $\left(u-r i n-o-j e n^{\prime}-i t-a-r e\right)$. Same as Urinogenital.

Urinology (u-vin-ol'-o-je) [urina, urine; $\lambda 6 \gamma_{0}$, science]. The science of the analysis and diagnostic significance of urine.

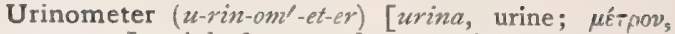
measure]. A hydrometer for ascertaining the specific gravity of urine.
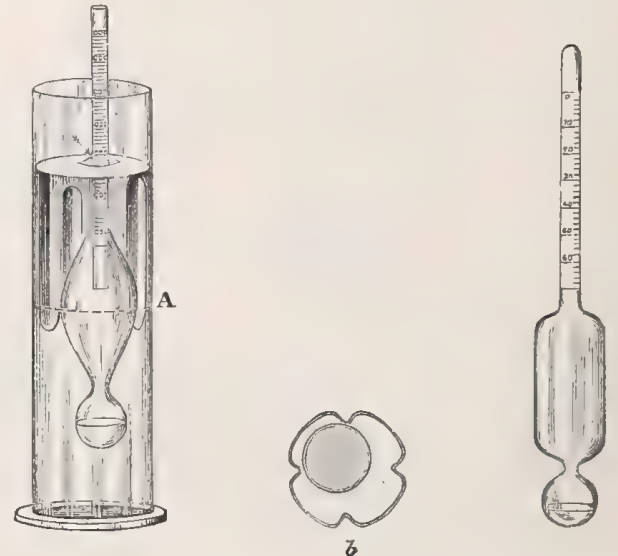

A. SQuibi's Urinometer and Jar. b. Section of Same.

Urinometric (u-rin-o-met'-rik) [urina, urine; $\mu \varepsilon ́ \tau \rho o v$, measure]. Pertaining to urinometry.

Urinometry (u-rin-on'-et-re) [urina, urine; $\mu \dot{\tau}$ - $\rho o v$, measure]. The determination of the specific gravity of the urine by the urinometer

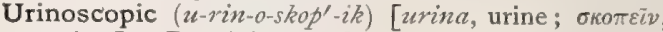
to view]. Pertaining to the inspection of the urine.

Urinoscopy (u-rin-os'-ko-pe). See Uroscopy.

Urinose $\left(u^{\prime}-r i n-\bar{o} z\right)$. Same as Urinous.

Urinous $\left(u^{\prime}\right.$-rin-us) [urina, urine]. Having the nature of urine.

Urite $\left(u^{\prime}-r \bar{t} t\right)$ [ovjó, tail]. In biology, the ventral sec. tion of an arthropodan uromere.

Uritis ( $u$-ri'tis) [ureve, to burn; $\iota \tau \iota s$, inflammation] Inflammation following a burn.

Urning (umn'-ing) [ 0 vopavós, the Greek personification of heaven ]. A homo-sexual individual; a pervert in whom the desire is only for individuals of the same sex.

Uro- (u'-ro-) [ovoov, urine]. As a prefix, denotes connection with or relation to the urine, uric acid, or a urate.

Uro-acidimeter $\left(u-r o-a s-i d-i m^{\prime}-e t-e r\right)$ [ovipov, urine; acidum, acid; $\mu \varepsilon ́ \tau \rho o v$, measure]. An instrument for measuring the acidity of urine.

Urobacillus (u-ro-bas-il'-us) [ovpov, urine; bacillum, a rod]. A bacillus derived from decomposed urine. There are several varieties. See Bacteria, Table of.

Urobenzoic Acid ( $\left.u-r o-b e n-z o^{\prime}-i k\right)$. Synonymous with Hippuric Acid, q. v.

Urobilin $(u-r o-b i l l-i n)$ [ov́pov, urine; bilis, bile], $\mathrm{C}_{32} \mathrm{H}_{40} \mathrm{~N}_{4} \mathrm{O}_{7}$. A derivative of bilirubin. It is a yellowish-brown, amorphous pigment, almost insoluble in water. It is the principal pigment of the urine, and is increased in the deeply colored urine of febrile and other conditions. U., Pathologic, the excessive coloring-matter of certain dark urines occurring in various diseases, as pernicious anemia, febrile diseases, etc. See Urine, Colors of.

Urobilinoidin (u-ro-bil-in-oidl'-in) [oṽ $\rho o v$, urine; bile]. A form of urinary pigment derived from hematin and resembling urobilin, though not identical with it. It occurs in certain pathologic conditions.

Urobilinuria (u-ro-bil-in-u'-re-ah) [ovtpov, urine; bilis, bile; ovpov, urine]. The presence of an abnormally large proportion of urobilin in the urine. 
Urobutylchloralic Acid (u-ro-bu-til-klo-ral'-ik) [ov̉pov, urine, butyl; $\chi \lambda \omega \rho o s$, green]. A body obtained from the urine after the ingestion of butyl-chloral.

Urocanic Acid (u-ro-kan'-ik) [oupon, urine; canis, dog], $\mathrm{C}_{6} \mathrm{H}_{6} \mathrm{~N}_{2} \mathrm{O}_{2}+2 \mathrm{H}_{2} \mathrm{O}$. An acid found in the urine of dogs when there is a diminution in the amount of urea. By heating to $212^{\circ} \mathrm{C}$. it is decomposed into carbonic acid, water, and a base, Urocanin, $\mathrm{C}_{11} \mathrm{H}_{10}$ $\mathrm{N}_{4} \mathrm{O}$.

Urocanin (u-ro-kan'-iu). See Urocanic Acid.

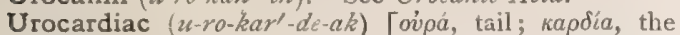
heart]. Of or pertaining to the caudal part of the cardiac division of the stomach of certain crustaceans.

Urocele $\left(u^{\prime}-r o-s \bar{e} l\right)$ [ovjoov, urine; $\kappa \dot{\eta} \lambda \eta$, a tumor]. A tumefaction of the scrotum, arising from an effusion of urine into its cavity or into the areolar tissue.

Urocelia, Urocœlia $\left(u-r o-s e^{\prime}-l e-a h\right)$ [ vं $\rho o v$, urine; кoinia, belly]. Swelling of the abdomen from infiltra tion of urine.

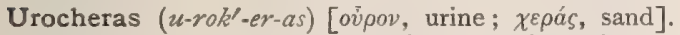
The sabulous matter deposited from standing urine.

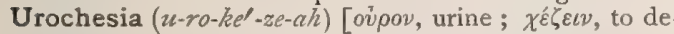
fecate]. The discharge of urine per anum.

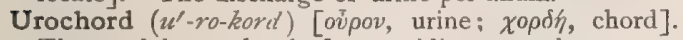
The caudal notochord of an ascidian or tunicate.

Urochrome $\left(u^{\prime}-r o-k r o ̄ m\right)$ [ỡ $\rho \circ$, urine ; $\chi \rho \tilde{\omega} \mu a$, color]. One of the coloring-matters of the urine. Exposed to the air, the watery solution oxidizes, forming Uroerythin.

Uroclepsia $\left(u-r o-k l e p^{\prime}-s e-a h\right)$ [ovpov, urine; $\kappa \lambda \varepsilon \psi i a$, theft]. Micturition of which one is unconscious.

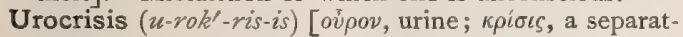
ing]. A crisis of disease attended with excessive urination. Also, diagnosis by examination of the urine.

Urocyanosis (u-ro-si-an-o'-sis) [ovjpov, urine; kv́avos, blue]. Blue discoloration of the urine, due to the presence of indican.

Urocyst, Urocystis $\left(u^{\prime}-r o-s i s t, u-r o-s i s t^{\prime}-i s\right)$ [ov pov,

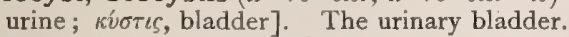

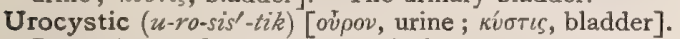
Pertaining to the urocyst; vesical.

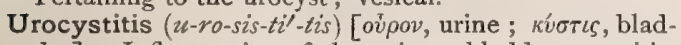
der]. Inflammation of the urinary bladder; cystitis.

Urodela $\left(u-r^{\prime \prime} d^{\prime}-e l-a h\right)$. A term applied to the tailed amphibia, salamanders, etc.

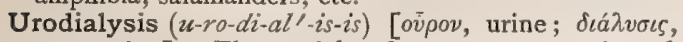
a cessation]. The partial and temporary cessation of the secretion of urine by the kidneys concomitant with many acute diseases. U. neonatorum, retarded secretion of urine in the newborn.

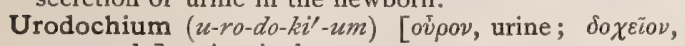
receptacle]. A urinal.

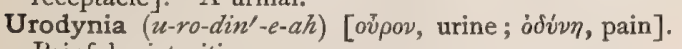
Painful micturition.

Urœdema (u-re-de'-mah). See Uredema.

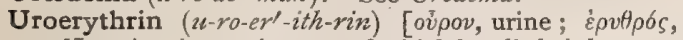
red]. A urinary pigment of which but little is known. It is the coloring-matter of certain pink urinary deposits, and is probably present in highly colored urine of rheumatic diseases. It is an amorphous, reddish substance, with an acid reaction, slowly soluble in water, alcohol, and ether. See Purpurin.

Urofuscohematin $\left(u-r o-f u s-k o-h e m^{\prime}-a t-i n\right)$ [oupov, urine; fuscus, dark; aipa, blood]. A red pigment of the urine, derived from hematin.

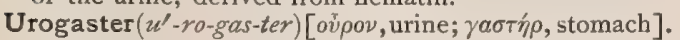
The urinary intestine, or urinary passages collectively, which are developed from the original cavity of the allantois in connection with the primitive intestinal tract.

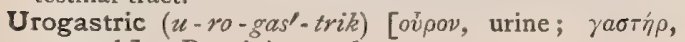
stomach]. Pertaining to the urogaster.
Urogenital (u-ro-jen'-it-al) [ov́pov, urine; yevväv, to produce]. Pertaining conjointly to the urinary and genital organs. U. Sinus, the anterior part of the cloaca, into which the Müllerian ducts open.

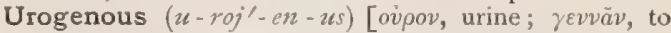
produce]. Producing urine.

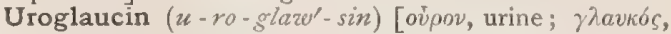
green]. A decomposition-product of indican; it is called also cyanurin, urocyanin, and indigotin.

Urogravimeter $\left(u-r o-g r a v-i m t^{\prime}-e t-e r\right)$. See Urinometer.

Urohematin $\left(u-r o-h e m^{\prime}-a t-i n\right)$. Altered hematin in the urine.

Urohematoporphyrin (u-ro-hem-at-o-por'-fir-in) [ov pov, urine; aipa, blood; $\pi \dot{\rho} \rho \phi v p o s$, purple]. Same as Urohematin. It is a urinary pigment occasionally occurring in certain pathologic urines, as of acute rheuma tism, Addison's disease, etc. It is soluble in alcohol, ether, and chloroform.

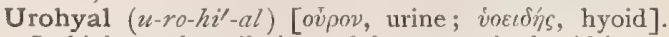
In biology, the tail-piece of the composite hyoid bone.

Uroleucic Acid (u-ro-hu'-sik). See Acid.

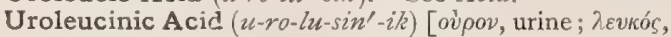
white]. A substance found by Kirk in a specimen of urine. It is trioxyphenylpropionic acid.

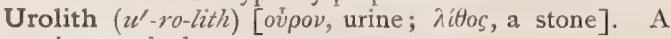
urinary calculus.

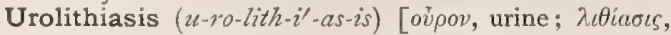
lithiasis]. That condition of the body which favors, or is characterized by, the formation of urinary calculi.

Urolithic (u-ro-lith'-ik) [ovpov, urine; $\lambda i \theta o s$, stone]. Pertaining to or having the nature of urinary calculus.

Urolithotomy (u-ro-lith-ot'-o-me). See Lithotomy.

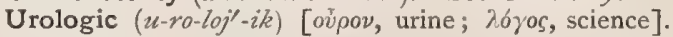
Pertaining to urology.

Urologist $\left(u-r o l^{\prime}-o-j i s t\right)$ [ovpov, urine; $\lambda 6 \gamma o \varsigma$, science]. One versed in urology.

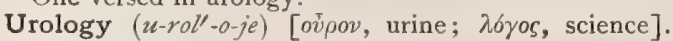
The scientific study of the urine.

Uromancy ( $\left.u^{\prime}-r o-m a n-s e\right)$ [ovpov, urine ; $\mu a v \tau \varepsilon i \alpha$, divination]. Diagnosis or prognosis by observation of the urine.

Uromelanin (u-ro-mel'-an-in) [ovoov, urine; melanin]. A black pigment found in the urine. It is probably derived from the decomposition of urochrome.

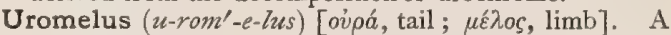
single autositic monster of the species symelus, in which there is more or less complete fusion of the limbs, with but a single foot.

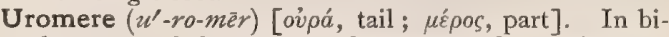
ology, one of the abdominal segments of an arthropod.

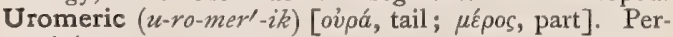
taining to a uromere.

Urometer (u-rom'-et-er). See Urinometer.

Uroncus (u-rong'-kus) [ov́pov, urine; b̆кos, tumor]. A tumor containing urine.

Uronephrosis (u-ro-nef-ro'-sis). See Hydronephrosis.

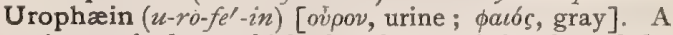
pigment-body to which the characteristic odor of the urine has been ascribed.

Urophthisis (u-roff'-this-is) [ovpov, urine; $\phi \theta i \sigma \iota s$, washing]. Synonym of Diabetes mellitus.

Uropittin (u-ro-pit'-in) [ovpov, urine], $\mathrm{C}_{9} \mathrm{H}_{10} \mathrm{~N}_{2} \mathrm{O}_{3}$. A derivative of urochrome.

Uroplania (u-ro-pla'-ne-ah) [ovpov, urine ; $\pi \lambda a ́ v \eta$, wandering]. The abnormal appearance of urine in other than the urinary organs.

Uropod ( $u^{\prime}$-ro-pod) [ov́á, tail ; $\pi$ ov́s, foot]. In biology, one of the abdominal limbs of an arthropod.

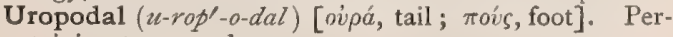
taining to uropods. 


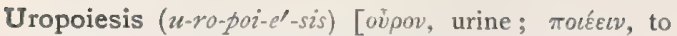
make]. The secretion of the urine by the kidneys.

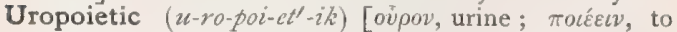
make]. Concerned in uropoiesis; uriniparous.

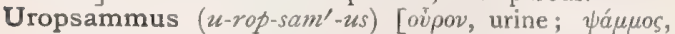
sand]. Urinary sand, or gravel.

Uropygial $\left(u-r o-p i j^{\prime}-e-a l\right)$ [ớpotívıov, rump]. Pertaining to the Uropygium.

Uropygii, Glandula. The uropygial gland of a bird. See Gland.

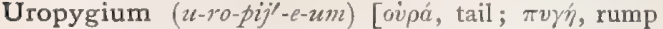
pl., Uropygia]. In biology, the rump.

Uropyloric $\left(u-r o-p i-l o \gamma^{\prime}-i k\right)[o v \rho a$, tail ; $\pi v \lambda \omega \rho o ́ s$, a gatekeeper]. In biology, of or pertaining to the posterior portion of the pyloric division of the stomach of certain Crustaceans.

Urorhodin (u-ro-ro'-din) [ơpov, urine; pódov, rose]. A red pigmentary deposit found in urine and derived by alteration from uroxanthin.

Urorosein (u-ro-ro'-ze-in) [ov́pov, urine; rosein]. A rose-colored pigment found in the urine in various diseases.

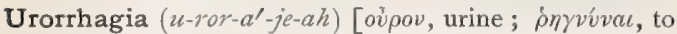
burst forth]. Excessive secretion and discharge of urine.

Urorrhea $\left(u-r o r^{\prime}-e^{\prime}-a h\right)$ [ov $\rho o v$, urine; joia, a flow]. I. The ordinary, normal flow of the urine. 2. The involuntary passage of urine.

Urorubin $\left(u-r o-r u^{\prime}-b i n\right)$ [ov $\rho o v$, urine; rubus, red]. A red urinary pigment.

Urorubrohematin $\left(u-r o-r u-b r o-h e m^{\prime}-a t-i n\right)$ [ov pov, urine; rubrum, red; ai $\mu a$, blood]. A urinary pigment obtained from the urine of leprous patients.

Urosacral ( $\left.u-r o-s a^{\prime}-k r a l\right)$ [ov $\alpha a$, the tail; sacrum, sacrum]. Pertaining to the tail and the sacrum.

Uroscheocele $\left(u-r^{\prime}-s^{\prime}-k e-o-s e \bar{l}\right)$. See Urocele.

Uroschesis (u-ros'-kes-is) [ovpov, urine ; $\sigma \chi^{\prime} \sigma \iota s$, retention]. Suppression of urine.

Uroscopic $(u$-ro-skop'-ik). Same as Urinoscopic.

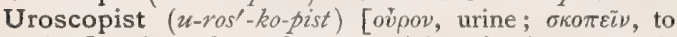
view]. One who makes a specialty of urinary examinations.

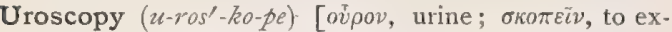
amine]. Examination and analysis of the urine.

Urosepsis (u-ro-sep'-sis) [ôjpov, urine; $\sigma \tilde{\eta} \psi \iota s$, sepsis]. The condition of intoxication due to the extravasation of urine.

Uroseptic (u-ro-seṕ-tik) [ovंpov, urine; $\sigma \tilde{\eta} \psi u s$, sepsis]. Relating to or characterized by urosepsis.

Urosis $\left(u-r 0^{\prime}-s i s\right)$ [ovoov, urine; vóros, disease : $p l$, Uroses]. In pathology, any disease of the urinary organs.

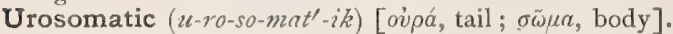
Pertaining to the urosome.

Urosome $\left(u^{\prime}-r o-s o m\right)$ [ớpá, tail; $\sigma \tilde{\omega} \mu n$, body]. In biology: $(a)$ The last segment of the tail of a vertebrate ; (b) the abdomen or post-abdomen of an arthropod.

Urosomite $\left(u-r o-s o^{\prime}-m i t\right)$. Same as Uromere.

Urosomitic (u-ro-so-mit'-ik) [ovpá, tail ; $\sigma \tilde{\omega} \mu \alpha$, body]. Pertaining to a urosomite.

Urospasm $\left(u^{\prime}-r o-s p a z m\right)$ [óvoov, urine ; $\sigma \pi a \sigma \mu o ́ s$, spasm]. Spasm of some part of the urinary tract.

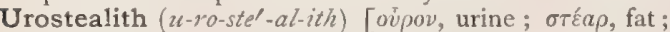
$\lambda i t o s$, stone]. A fatty or saponaceous matter occurring in some urinary calculi.

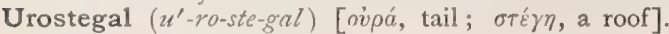
Pertaining to the urosteges.

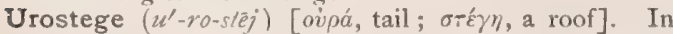
biology, one of the large scales on the ventral side of the tail of a snake. Cf. Gastrostege.

Urostegite ( $u^{\prime}-r(-s t e-j i t)$ [oúpí, tail ; $\sigma \tau \dot{t} \gamma \eta$, roof ]. One of the urosteges, or urostegal scales.
Urosteon (u-ros'-te-on) [óvpá, tail ; óøréov, bone]. In biology, the caudal portion of the sternum of certain birds, having a separate center of ossification.

Urosternite (u-ro-ster'-nūt) [oúpá, tail ; oréphov, sternum ]. The sternite, or ventral median sclerite, of any somite of the urosome of an arthropod.

Urosthene ( $u^{\prime}$-ros-thēn) [ovpá, tail ; oftévos, strength] In biology, an animal possessing an unusual development of the tail.

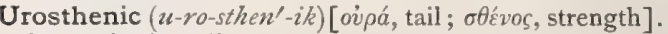
Strong in the tail.

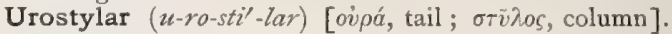
Pertaining to a urostyle.

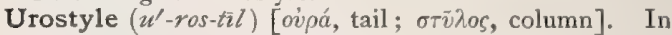
biology, the elongated terminal vertebra of the spinal column of certain animals, as the os coccygis of the frog.

Urotheobromin (u-ro-the-o-bro'-min). See Paraxanthin

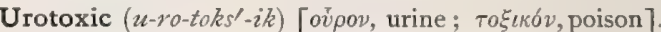
Pertaining to poisonous substances eliminated in the urine.

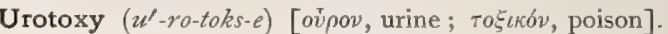
A term invented by Bouchard to denote the standard of toxicity of urine necessary to kill a kilogram of living substance.

Urous ( $\left.u^{\prime}-r u s\right)$ [ovjpov, urine]. Having the nature of urine.

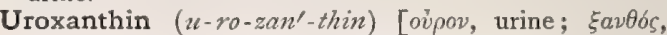
yellow]. Indigogen. A pigmentary substance occurring normally in human urine. Its secretion is enormously increased in the first stage of cholera and in certain affections of the liver and of the myelon.

Uroxin $(u$-roks'-in) [ovpov, urine; óv $v s$, sharp]. Same as Alloxantin.

Urrhodin (ur-rod"-in) [ovpov, urine; $\dot{\rho} 6 \delta$ cvos, rosy]. A red, purple, or violet urinary pigment, derived from uroxanthin.

Urrhosacin (ur-o'-sas-in). See Urrhodin.

Ursone $\left(u r^{\prime}-s o ̄ n\right)$. See Ericolin.

Urtica $\left(u r^{\prime}-t i k-a h\right)$ [L.: gen., Urtica]. A genus of apetalous plants including the nettles. See Nettle and Pomphus.

Urtical $\left(u r^{\prime}-t i k-a l\right)$ [urtica, nettle]. Belonging to the nettles.

Urticaria (ur-tik-a'-re-ah) [urtica, a nettle]. Nettlerash; Cnidosis; Hives; an inflammatory disorder of the skin characterized by the development of wheals, which give rise to subjective sensations of burning and itching. These appear suddenly in large or small numbers, remain for from a few minutes to several hours, and disappear as suddenly as they came, leaving no trace behind. The disease may be acute or chronic, and due to various agencies acting upon the vaso-motor system, such as gastro-intestinal disorders, intestinal worms, the ingestion of shell-fish, etc. U. acuta, an acute form often associated with fever of IOI-2 $\mathrm{F}$. ( $U$. febrilis). The pulse is quick, and there are marked signs of gastric irritation, with headache and prostration. The eruption may not appear for a day or two, and then comes out copiously all over. It disappears rapidly after removal of the cause of gastric irritation. U. bullosa, an exaggerated form of U. vesicans. U. chronica, a term referring to the duration of the disease as a whole, and not to that of the successive crops of wheals individually. The disease may last for an indefinite period. U. conferta, a form in which the lesions occur in groups. U. endemica, an irritative cutaneous eruption occurring in some districts, notably the Kahlberger Schweiz, and caused by the procession caterpillars, particularly the species Cnethocampa. The eruption is papular and wheal-like in 
character, and is accompanied by intolerable itching. It is usually seen on the flexor surfaces of the extremities, but may appear on any part of the body, also on the mucous membranes. Domestic animals are also subject to the affection. The poisonous agent secreted by these insects is formic acid. Their influence is said to be either mechanical or chemical, and it is even said that contact is not necessary to its production. U. evanida, a variety in which there is a rapid disappearance of the symptoms. $U$. factitia, Dermographia, Aulographism, Dermographism, the form produced in individuals with an irritable skin by any slight external irritation. U. febrilis. See $U$. acuta. U. gigans. See $U$. tuberosa. U. hæmorrhagica, Purpura urticans; hemorrhage into the urticarial wheals from rupture of the extremely congested capillaries. U. medicamentosa, that variety resulting from the use of certain drugs. U., Nervous. Synonym of $U$. factitia. U. œdematosa, Giant Urticaria, a variety characterized by the sudden appearance of large, soft, edematous swellings of the skin and subcutaneous tissue, which may measure several inches in diameter. These are especially prone to develop about the eyelids, but may also attack the trunk and limbs in the neighborhood of the joints. A sense of tension is all that is complained of. If the mucous membrane of the throat and larynx is involved the symptoms are alarming but not dangerous. A variety of this is the so-called Quincke's Disease, or acute circumscribed edema, in which the orbital tissue or the tissue of other parts of the face may swell up into a large tumor, or there may be a large, ill-defined swelling of a considerable portion of the limb or other part of the body from subcutaneous edema ( $U$. subcutanea). It is generally limited to the loins and thighs. U. papulosa, Lichen urticatus, a form occurring in children, in which, as a result of the inflammatory effusion, a small, solid papule runains after the subsidence of the wheal. It is most abundant about the loins and buttocks, but may appear on any other part of the body. It is often associated with irregular, flat, scabbed pustular lesions. U. pigmentosa, xanthelasmoidea, a rare type of urticaria, which begins within the first few months of life. It consists of large, reddish, wheal-like tubercles that eventually change to a brownish-red or yellowish color. Itching may or may not be present. The disease runs a protracted course, but tends to spontaneous recovery at puberty. It is most abundant on the neck and trunk, next upon the limbs, face, and head, and is only occasionally present on the palms and soles. Boys are commonly affected. U., Provoked. Synonym of $U$. factitia. U. subcutanea. See $U$. cedematosa, $\mathbf{U}$. toxica, that due to certain articles of food. U. tuberosa, $U$. gigans, a form in which the wheals assume a tuberous form and become very large, as big as a walnut, hen's egg, or even larger. The lesions are few in number, and the disease occurs mainly in persons with broken-down constitutions, beyond middle age. See Angio-neurotic edema. U. vesicans, excessive serous effusion into the center of the wheals, producing vesicles. U. vesiculosa. Same as $U$. papulose.

Urticarial, Urticarious ( $u r-t i k-a^{\prime}-r e-a l, u r-t i k-a^{\prime}-r e-u s$ ) [urticaria, nettle-rash]. Pertaining to urticaria.

Urticate $\left(u r^{\prime}-t i k-\bar{a} t\right)$ [urticare, to sting]. To sting like a nettle.

Urtication (ur-tik-a'-shun) [urticatio; urtica, nettle]. Flagellation with nettles, a method of treatment formerly employed in paralysis, and also to produce irritation; also, a sensation as if one has been stung with nettles.
Usage $\left(u^{\prime}-s \vec{a} j\right)$ [usus, use]. Any common habit, custom, or manner.

Uschinsky's Solutions. Non-albuminous culturemedia for the cultivation of pathogenic bacteria, especially. Uschinsky suggests the following two mixtures: $(a)$ Water 1000 , glycerin $40-50$, sodium chlorid 5-7, calcium chlorid 0.1 , magnesium sulphate 0.2 , dipotassic phosphate I.O, ammonium lactate 10.0. (b) Water 1000, glycerin 30-40, calcium chlorid 0.1 , sodium chlorid $5-7$, magnesium sulphate $0.2-0.4$, dipotassic phosphate 2-2.5, ammonium lactate 6-7, sodium asparaginate 3.4 .

Usquebaugh (us'-kwe-baw) [Irish]. A strong cordial made in Ireland. It furnishes the name from which the word whiskey is derived.

Ustilaginous (us-til-aj'-in-us) [ustilago, ustilago]. Affected with ustilago; smutty.

Ustilago (us-til-a'-go) [L.: gen., Ustilaginis]. A genus of parasitic fungi; the smuts. U. maydis, Cornsmut, a fungus parasitic upon maize or Indian corn, Zea Mays. In medicinal properties, it resembles nux vomica and ergot of rye combined, but it is rarely employed. U., Ext., Fld., unof. Dose $m \mathrm{xv}-3 \mathrm{j}$.

Ustion (us'-chun) [ustio; urere, to burn]. A burning. In chemistry, incineration. In surgery, cauterization.

Ustulation (us-tu-la'-shun) [ustulatio]. The roasting, drying, or parching of a drug as a step in preparing it for use.

Ustus (us'-tus) [urere, to burn]. Calcined. Dehy. drated by intense heat.

Uterectomy. Same as Hysterectomy.

Uteri, Adscensus ( $u^{\prime}$-ter-i-ad-sen'-sus). Synonym for: Hysteria.

Uterine $\left(u^{\prime}-t e r-i n\right)$ [uterinus]. Pertaining to the uterus. U. Anteflexion, and Anteversion. See Uterus. U. Appendages, the ovaries and oviducts. U. Gestation, the period of time between conception. and delivery ; the development of the product of conception within the cavity of the uterus. U. Inertia. See Uterus, U. Inversion. See Uterus, U. Involution. See Uterus. U. Milk : I. A fluid between the villi of the placenta in the cow. 2. The small quantity of albuminous fluid contained in the small spaces between the epithelial covering of the villi of the chorion and the crypts or depressions in the decidua. U. Pregnancy, normal pregnancy. $U$. Segments. See Contraction-ring. U. Souffle, a vascular sound heard on auscultation through the abdominal wall between the fifth and sixth months of pregnancy. See Placental Murmur.

Uteritis (u-ter-i\%-tis) [uterus, uterus; $\iota \tau \iota s$, inflammation]. Inflammation of the womb. See Metritis.

Utero- $\left(u^{\prime}\right.$-ter-o-) [uterus, uterus]. A prefix to denote connection with or relation to the womb.

Utero-abdominal ( $u$-ter-o-ab-dom'-in-al). Pertaining conjointly to the uterus.and the abdomen.

U terocopulatory $(u$-ter-o-kop'-u-la-tor-e) [uterus, uterus; copulate]. Vaginal or copulatory, as certain sexual passages of hermaphrodite gasteropods.

Uterodeferent (u-ter-o-def'-er-ent) [uterus, uterus; deferent]. Oviducal or deferent, as certain sexual passages of hermaphrodite gasteropods.

Utero-fixation (u-ter-o-fiks- $\left.a^{\prime}-\operatorname{sh} u n\right)$. Hysteropexia, or abdominal fixation of the uterus by surgical operation.

Utero-gestation (u-ter-o-jes-ta'-shun) [uterus, uterus; gestatio, gestation]. The uterine period of gestation; pregnancy; gestation within the cavity of the uterus.

Uteromania (u-ter-a-ma'-ne-ah). See Nymphomania. 


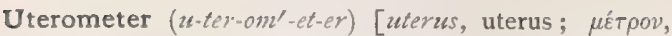
measure]. An instrument used to accurately determine the depth and position of the uterus and to locate and estimate the dimensions of structures therein contained.

Utero-ovarian $\left(u-t e r-o-0-v a^{\prime}-r e-a n\right)$ [uterus, uterus; ovarium, ovary]. Pertaining conjointly to the uterus and the ovaries.

Uteropexia, Uteropexy $(u-t e r-o-$ peks'-e-ah, $\left.u^{\prime}-t e r-o-p e k s-e\right)$. See Hysteropitict.

Uteroscope $\left(u^{\prime}\right.$-ter-o-skōp) [uterus, uterus; $\sigma \kappa a \pi \varepsilon i \nu$, to inspect ]. A uterine speculum.

Uterotome $\left(u^{\prime}-\right.$ ter-o-tōm $)$ [uterus, uterus; rop'́, a cutting]. A cutting instrument used in uterotomy. See Hysterotome.

Uterotomy (u-ter-ot'-o-mue) [uterus,

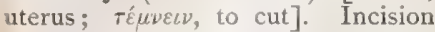
into the uterus. See Hysterotomy.

Uterus $\left(u^{\prime}-\right.$ ter-us $)$ [L. : gen., Uieri]. The womb; the organ of gestation; it receives the fecundated ovum in its cavity, retaining and supporting it during the development of the fetus, and becoming the principal agent in its expulsion during parturition. The uterus in the non-gravid state in the human subject is a hollow, pear-shaped, muscular organ, three inches long, two inches wide, and one inch thick, and is divided into three portions, the fundus, the body, and the cervix. The fundus is the upper and broad portion; the body gradually narrows to the neck, which is the contracted portion. The mesal orifice, os uteri, communicates with the vagina. The ental surface is covered with mucosa continuous with that of the vagina. The ectal surface of the fundus and body is covered with peritoneum. The whole organ is suspended in the pelvis by means of the broad ligament. Its cavity measures two and a half inches in length. The Fallopian tubes enter one on either side of the fundus at the cornua of the organ. U., Anteflexion of. See Anteflexion. U., Anteversion of. See Anteversion. U., Arbor vitæ of, branch-like elevation of the mucous membrane of the cervix. U. bicornis, when, from arrested development, the uterus is divided into two horns or compartments. U., Body of, that part above the isthmus. U., Cervix of, that part below the isthmus. U., Columns of, the ridges or elevations of the mucous membrane of the cervix from which extend the branches that with three columnar central axes are called the arbor vitæ. U., Contraction of, the intermittent contractile action of the uterus whereby the fetus is expelled. U.cordiformis, an arrest of development, as a result of which the uterus is heart-shaped, or with a depression in the fundus. U., Corpus of. See $U$. Body of. U. duplex, a double uterus from an arrest of development. U., Fundus of, the portion above a line drawn from one oviduct to the other. U., Gravid, a uterus containing a fecundated ovum. U., Hour-glass Contraction of, the formation of two distinct cavities of the body and neck, the narrowed internal os marking the boundary between them. U. Impregnated. See $U .$, Gravid. U., Incarceration of, strangulation by pressure or constriction. U., Inertia of, deficiency of uterine contractions in labor. U., Infantile, a uterus normally formed, but arrested in development. U., Inversion of, the organ is " upside-down, and wrong-side out." U ., Involution of, the process whereby the uterus is reduced to its normal size and weight after labor. U., Isthmus of, a slight depression or constriction upon the ectal surface of the uterus separating the body from the cervix. U. masculinus, the little passage formed by the sinus pocularis in the substance of the prostate. It is so called from its resemblance in structure to the female uterus. See Prostatic Vesicle. U., Neck of, same as $U .$, Cervix of. U., One-horned, an arrest of devel-

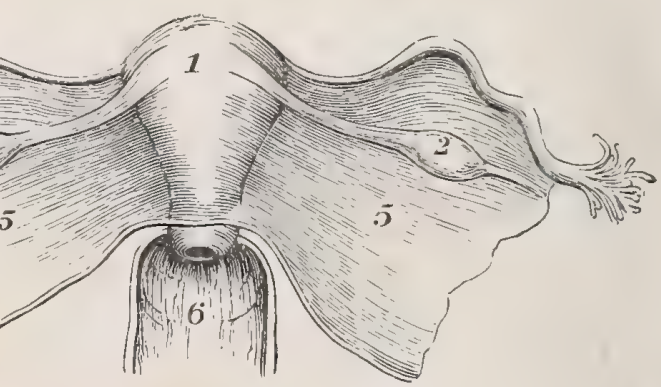

Dorsal Aspect of Female Internal Genitalia.

erus. 2, 2. Ovaries. 3. Left oviduct. 4. Fimbriated extremity of Broad ligaments. 6. Ventral vaginal cul-de-sac.

opment resulting in a uterus composed of a single lateral half, usually with but one oviduct. Uteri, Os Externum, the external mouth or opening of the uterus into the vagina. U., Os Internum, the internal anatomic limit between the body and the cervix of the uterus. Plicæ palmatæ, the radiate branchings of the arbor vitæ from the central axis. U., Procidentia of, protrusion of the uterus from the vulvar orifice.

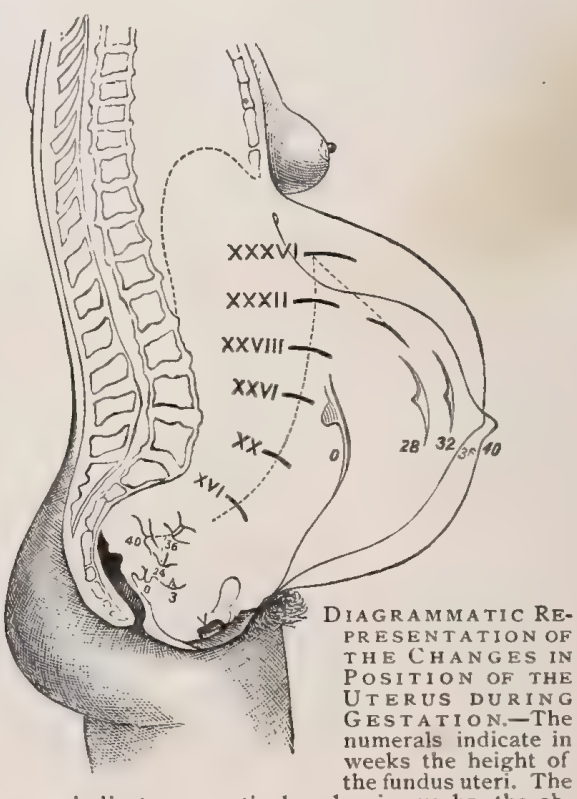

italic figures indicate respectively, also in weeks, the abdominal enlargement and position of cervix uteri. (After Schultze.)

U., Prolapse of, falling of the uterus, but without protruding from the vulvar orifice. U., Puerperal Atrophy of, the rare condition of super-involution of the uterus produced when puerperal involution goes further than to restore the uterus to the size that it had before delivery. The organ may become infantile in 
size. U., Retraction of, the constant property of the uterus that tends to keep the uterine walls in apposition. U., Retroflexion of, a bending of the posterior uterine surface upon itself. U., Retroversion of, when the fundus is so posteriorly displaced that the axis of the body forms an obtuse angle with the axis of the pelvic inlet. U., Souffle of. See Uterine. U. unicornis. See $U$., One-horned.

Utpadel, Bacillus of. See Bacteria, Synonymatic Table of.

Utricle $\left(u^{\prime}\right.$-trik-l) [utriculus, dim. of uter, a small bag]. Any minute cell or vesicle; a membranous sac. Also, a depression, the sinus pocularis, between the ejaculatory ducts. Also, a cavity communicating with the semicircular canals of the ear. See Prostatic Vesicle.

Utricular (u-trik'-u-lar) [utricularis]. Relating to the utricle. Resembling a small bag or bottle.

Utricularia (u-trik-u-la'-re-ah) [utriculus, a bag]. A genus of aquatic plants of some 160 species, of wide distribution; the bladderworts. They are classed as insectivorous plants ; their bladder-like leaves imprison insects, crustaceans, and worms. The fresh plants are said to make a good application for burns and wounds. Some species have diuretic properties. Unof.

Utriculate (u-trik'-u-lāt) [utriculus, a little bag]. Having a utricle.

Utricule $\left(u^{\prime}-t_{i k}-\vec{u} l\right)$ [utriculus: pl., Utricules]. A utricle.

Utricules of Miescher. See Sarcocystis miescheri, Lankester, under Parasites (Animal), Table of.

Utriculiferous (u-trik-u-lif'-er-us) [utriculus, a utricle ; ferre, to bear]. In biology, bearing or producing utricles or bladders.

Utriculiform (u-trik'-u-lif-orm) [utriculus, a little bag ; forma, form]. Like a utricle; utricular.

Utriculoid (u-trik'-u-loid) [utriculus, a little bag; eidos, like]. Same as Utriculiform.

Utriculose (u-trik'-u-lōz) [utriculus, a utricle]. Same as Utricular.

Utriculus (u-trik'-u-lus) [L.]. I. A utricle, q. $v, 2$. Same as Vesicula prostatica. U. hominis, U. masculinus, U. prostaticus, U. urethræ. Same as Sinus pocularis.

Uva $\left(u^{\prime}-v a h\right)$ [uva, a grape, a cluster of grapes]. In biology, a succulent indehiscent fruit having a central placenta. U. ursi, bearberry. The leaves of Arc. tostaphylos uva ursi. It contains gallic and tannic acids, arbutin (resolvable into hydroquinone) and other extractives; it is astringent, tonic, and diuretic. It was formerly much employed in calculous disorders of the bladder. Dose gr. x-zj. U., Ext., Fld. Dose $m x-3 j$. U., Infusio $(B, P),. \zeta j-O j$. Dose $\bar{j}$ ij. Arbutin, the glucosid. Unof. Dose gr, iij-v.

Uvæ $\left(u^{\prime}-v e\right)$ [uva, a grape]. Raisins. The ripe fruit of Vitis vinifera, imported from Spain; official ir the B. P. They are contained in Tinctura cardamomi composita and Tinctura senna. U. passæe majores, ordinary raisins. U. passæ minores, Corinth raisins, or true currants.

Uvea $\left(u^{\prime}-v e-a h\right)$ [L., a grape, from the resemblance to its color]. Also called the Urealtract. The choroid membrane or vascular tunic as a whole, especially the iris and ciliary body. See Entiri

Uveal $\left(u^{\prime}-v e-a l\right)$ [uvea, a grape]. Pertaining to the uvea.

Uveitis $\left(u-v e-i^{\prime}-t i s\right)$. See Iritis.

Uveous (u'-ve-us). Same as Uveal.

Uvitic Acid $(u$-vit'-ik), See Acid.

Uvula $\left(u^{\prime}-v u\right.$-lah) [L.]. The conic membranous appendix hanging from the free edge of the palate. U. cerebelli, a small lobule of the postvermis of the cerebellum. U. of Lieutaud. See Lieutaud. U.twitch, an expedient for keeping the uvula forward in posterior rhinoscopy. U., Vesical, a prominence at the internal or external orifice of the urethra.

Uvulaptosis (u-vu-lap-to'-sis) [uvula, uvula ; $\pi \tau \omega \tilde{\sigma} \sigma \varsigma_{\text {, }}$ falling]. A relaxed and pendulous condition of the uvula.

Uvular $\left(u^{\prime}-v u\right.$-lar) [uvularis]. Pertaining to the uvula. Uvularia (u-vu-la'-re-ah) [uvula, the soft palate]. A genus of liliaceous plants. U. perfoliata, of N. America, is demulcent, tonic, and nervine; useful in the treatment of sore mouth. U. latifolia and $U$. flava have similar uses. Unof.

Uvularis (u-vu-la'-ris) [uvula, uvula]. The azygos uvulæ muscle. See Muscles, Table of.

Uvulatome (u'-vu-lat-ōm) [uvula, uvula ; тo $\mu \eta^{\prime}$, cutting]. A cutting instrument used in performing uvulatomy.

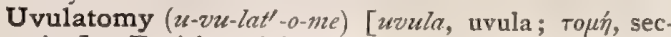
tion]. Excision of the uvula. See Staphylotory.

Uvulitis ( $u$-vu-li'-tis) [uvula, uvula; $\iota \tau \iota s$, inflammation]. Inflammation of the uvula.

Uvuloptosis $6 u$-vul-lo-to'-sis). Same as Uvulaptosis.

Uvulotomy (u-vu-lot'-o-me). See Uvulatomy. 
V. Abbreviation of Vision, or Acuity of Vision. Also, the symbol of Vanadium.

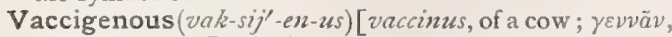
to produce]. Producing or cultivating vaccine-virus.

Vaccin $\left(v a k^{\prime}-\sin \right)$ [vacca, a cow]. See Vaccine.

Vaccina $\left(v a k-s i^{\prime}-n a h\right)$. Same as Vaccinia.

Vaccinable (vak'-sin-a-bl) [vaccinus, of a cow]. Susceptible of successful vaccination.

Vaccinal (vak'-sin-al) [vacca, a cow]. Pertaining to vaccination or to vaccine.

Vaccinate (vak'-sin-ät) [vaccinare, to vaccinate]. To inoculate with vaccine-virus in such a way as to produce cowpox.

Vaccination (vak-sin- $\left.a^{\prime}-\operatorname{shun}\right)$ [vacca, a cow]. Inoculation of the body with the virus of a pustular disease of bovidx, called cowpox, in order to protect from or modify the virulence of smallpox. V., Ani-

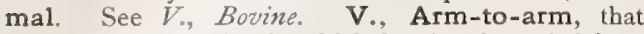
method of vaccination in which the virus is carried from the arm of one patient to that of another. V., Bovine, that practised by the aid of vaccine-lymph cultivated in bovine animals. V., Compulsory, the law compelling the vaccination of infants within a certain period after birth. V.-rash, a rash sometimes following vaccination; it is usually transitory but sometimes assumes an eczematous or erythematous form. It may also be syphilitic. V.-syphilis. See Vaccino-syphilis.

Vaccinationist $\left(v a k-\sin -a^{\prime}-\operatorname{shun}-i s t\right)$ [vaccinare, to vaccinate]. One who depends upon or believes in the efficacy of vaccination as a preventive of smallpox.

Vaccinator $\left(v a k^{\prime}-\sin -a-t o r^{\circ}\right)$ [vaccinare, to vaccinate]. One who vaccinates; an instrument used in vaccinating.

Vaccine $\left(v a k^{\prime}-s e \tilde{n}\right)$ [vacca, cow]. The lymph occurring within the eruptive vesicle of cowpox. V., Bovine, that derived from the vesicles of heifers. V.farm, a farm upon which vaccine-virus is systematically produced and collected. V., Humanized, that from vaccinal vesicles of man. V., Lichen, the most common eruption consequent upon vaccination. It may be either papular, papulo-vesicular, or pustular, and very rarely bullous. It appears between the fourth and the eighteenth day, most frequently on the eighth; begins on the arms usually, though it may commence on the face, neck, or trunk, and appears in successive crops covering the greater portion of the body. The papules are acuminate, pin's-point sized, and bright-red; usually discrete, but they may coalesce into patches. The rash lasts from a few days to a week or two. V.lymph. See Vaccine. V.-point, a slip of quill or bone coated at one end with vaccine-lymph. V.-virus, the same prepared for use in vaccination.

Vaccinella $\left(v a k-\sin -e l^{\prime}-a h\right)[v a c c a$, cow $]$. The secondary eruption sometimes following cowpox; spurious vaccinia; a sore that sometimes follows vaccination, but is not genuine cowpox

Vaccinia (vak-sin'-e-ah) [vacca, cow]. Cowpox. If the human subject be inoculated with cowpox, a small papule appears at the site of inoculation in from one to three days, which becomes a vesicle about the fifth day, and at the end of the first week is pustular, umbilicated, and surrounded by a red areola. Desiccation begins in the second week and a scab forms, which soon falls off, leaving a pitted cicatrix.

Vaccinic (vak-sin'-ik) [vacca, cow]. Pertaining to vaccine, or to vaccinia.

Vaccinifer (vak-sin'-if-er) [vaccinus, of a cow; ferre, to bear]. A person or animal from whom vaccinevirus is taken; a vaccine-point.
Vacciniform (vak-sin'-if-orm) [vaccinus, of a cow ; forma, form]. Resembling vaccinia.

Vacciniola (vak-sin-i'-o-lah) [dim. of vaccinia]. A secondary eruption, resembling, and sometimes following, vaccinia. It may closely resemble the eruption of smallpox.

Vaccinist (vak'-sin-ist) [vaccinus, of a cow]. A practiser, or defender, of vaccination; one who believes in the efficacy of vaccination.

Vaccinium (vak-sin'-e-um) [vaccinus, of a cow]. A genus of ericaceous plants to which belong the cranberry, blueberry, bilberry, etc., of many species. See Cranberry and Brousnika. V. crassifolium, a plant having therapeutic properties resembling those of uva ursi. It is useful in catarrhal inflammations of the urinary tract. Dose of the fld. ext. $m \times x \times x-3 j$. Unof.

Vaccinization (vak-sin-iz-a'shun) [vaccinare, to vaccinate]. Thorough vaccination by inoculations, repeated frequently, with the view of establishing complete immunity to smallpox.

Vaccinogen (vak-sin'-o-jen) [vaccinus, of a cow; yevväv, to produce]. The person or animal from which, or from whom, vaccine-virus is taken.

Vaccinogenous (vak-sin-oj'-en-us). See Vaccigenous.

Vaccinoid (vak'-sin-oid) [vaccinus, of a cow; eisós, like]. Resembling vaccinia.

Vaccinophobia $\left(v a k-\sin -o-f o^{\prime}-b e-a h\right)$ [vaccinus, of a

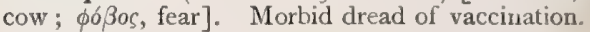

Vaccino-syphilis (vak-sin-o-sif'-il-is) [vaccinus, of a cow; syphilis, syphilis]. Syphilis conveyed by vaccination.

Vacuolar (vak'-u-o-lar) [vacuolum, vacuum, vacuum]. Pertaining to or of the nature of a vacuole.

Vacuolation (vak-ut-o-la'-shun) [vacuolum, a vacuole]. The first stage in the process of vascularization of a clot, in which cracks and fissures appear in it. According to W. Hunter, vacuolation appears in small clots as early as the tenth day.

Vacuole (vak'-u-öl) [vacuum, an empty space]. In biology : $(a)$ a vesicle in the protoplasm of a protozoön, either permanent or contractile (pulsatins). It is sometimes spoken of as gastric, from having in some way a direct connection with the function of digestion; $(b)$ the cavity in a plant-cell containing cell-sap.

Vacuolization (vak-u-o-liz-a'-shun) [vacuolum, vacuole]. The formation of vacuoles, such as sometimes takes place in diseased tissues.

Vacuum $\left(v a k^{\prime}-u t u m\right)$ [L.]. A space from which the air has been exhausted. V.-plate, in dentistry, a term applied to a plate on which artificial teeth are mounted, having an air-chamber to assist in its retention in the mouth.

Vadum $\left(v a^{\prime}-d u m\right)$ [L., a shallow]. A shallow in the depths of any fissure of the brain, commonly in the central nearer the dorsal end. It represents a possible isthmus or complete interruption.

Vagabonds' Disease, or Discoloration. Parasitic Melanoderma; a pathologic condition of the skin in which it takes on a deep-brown tint, resembling that of Addison's disease. It results from chronic irritation from pediculi.

Vagal (va'-gal) [vagare, to wander]. Pertaining to the vagus nerve.

Vagina $\left(v a-j i^{\prime}-n a h\right)[\mathrm{L}$. , a sheath $]$. The musculomembranous canal extending from the vulval opening to the cervix uteri, the organ of copulation in the female, the excretory canal for uterine secretions, and a part of the birth-canal. In biology, the term is ap- 
plied to various sheath-like structures, as the basal portion of certain leaves, or a portion of the mouthapparatus of sucking insects, etc: V., Bulbs of, two erectile organs upon the lateral and anterior parts of the vagina. V., Columns of, two longitudinal elevations of the mucous membrane, on the ventral and dorsal wall. V. cordis, See Pericardium. V., Cul-de-sacs of, four arches (anterior, posterior, right and left lateral) made Dy the junction of the vaginal walls with the uterus. V., Double, an anomaly of development consisting in a duplication of the vaginal canal. V. femoris. See Fascia lala. V., Fornix of, the combined cul-de-sacs of the vagina. V., Rugae of, transverse elevations of the mucous membrane branching from the columns.

Vaginal (vaj" - in - al) [vaginalis]. Pertaining to the vagina, V. Process. See Process. V. Pulse. See Pulse. V. Respiration, the breathing of a child while its head is still in the vagina, a rare event. V. Tunic. See Tinica. V. Vault, the roof of the vagina surrounding the cervix uteri. It is divided into an anterior and a posterior portion.

Vaginalitis (vaj-in-al-i, $\left.i^{\prime}-t i s\right)$ [vaginalis, of a sheath; iTıs, inflammation]. Inflammation of the tunica vaginalis of the testicle; hydrocele.

Vaginant (vaj'-in-ant) [vaginare, to sheathe]. Sheathing; vaginal.

Vaginate (vaj'-in-ät) [vagina, sheath]. Sheathed.

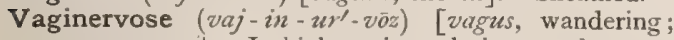
nervus, nerve]. In biology, irregularly nerved.

Vaginicoline (vaj-in-ik'-o-lin) [vagina, vagina; colere, to inhabit]. Living in a vagina, as an animalcule.

Vaginiferous (vaj-in-if'-er-us) [vagina, vagina; ferre, to bear]. Producing or bearing a vagina.

Vaginigluteal (vaj-in-e-glu'-te-al) [vagina, vagina ; gluteus]. Pertaining to the vaginigluteus.

Vaginigluteus, Vaginiglutæus $\left(v a j-i n-e-g l u-t e^{\prime}-\imath t s\right)$ [vagina, sheath; glutous]. The tensor vaginæe femoris. See Muscles, Table of.

Vaginipennate (vaj-in-ip-en'-at) [vagina, a sheath; pennatus, winged]. In biology, having wing-covers or elytra, $e_{.} \xi_{0}$, beetles.

Vaginismus (vaj-in-iz'-mus) [vagina, sheath]. Pain, spasm, and hyperesthesia of the vagina and surrounding parts. V., Perineal, that due to spasm of the perineal muscles. V., Posterior, that due to spasm of the levator ani muscle. V., Vulvar, that due to spasm of the constrictor cunni.

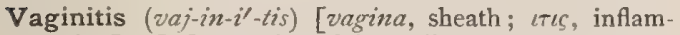
mation]. Inflammation of the walls of the vagina. $\mathrm{V}$. adhæsiva, vaginitis with partial or complete atresia of the vagina. V., Diphtheric, diphtheria of the vagina. V., Granular, a granular inflammation of the vagina.

Vagino- (vaj'-in-o-) [vagina, vagina]. A prefix to de note relation to the vagina.

Vaginodynia (z'aj-in-o-din'-e-ah) [z'agina, vagina ; odivi, pain]. Pain in the vagina. In vaginodynia there is muscular contraction along the whole vaginal canal, whereas in vaginismus the contraction is merely at the introitus.

Vaginofixation (vaj-in-o-fiks-a'-shun) [vagina, sheath; fixation]. An operation whereby the vagina is rendered immovable.

Vaginopennous $\left(v a j-i n-o-p e n^{\prime}-u s\right)$ [vagina, vagina; penna, feather]. Same as Vaginipennate.

Vaginotomy (vaj-in-ot'-o-me) [vagine, vagina; Touí, section]. Incision of the vagina.

Vaginovesical (vaj-in-o-ves'-ik-al). See Vesicovaginal.

Vaginula (vaj-in'-u-lah) [L., dim. of vagina, sheath]. In biology, a diminutive sheath.

Vaginulate (vaj-in'-u-lät) [vaginula, a small sheath]. Having a vaginula.
Vaginule $(v a j$-in- $\bar{u} l)$ [vaginula, vaginule]. Same as Vaginula.

Vagitus (va-jitus) [vagire, to cry]. The cry of an infant. V. uterinus, the cry of a child in utero. V. vaginalis. See Vaginal Respiration.

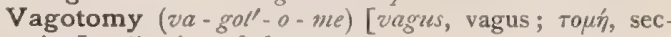
tion]. Section of the vagus.

Vagous (va'-gus) [vagure, to wander]. Wandering, as the vagus nerve.

Vagrant (va'-grant) [vagare, to wander]. Wandering, as a vagrant cell. V.s' Disease, a discoloration of the skin occurring especially in elderly persons, who are of uncleanly habits and infested with vermin. This discoloration is often deepest on the chest, abdomen, and back, is superficial in nature, and the dark cuticle is harsh and raised, not soft and smooth. The condition may be mistaken for Addison's disease.

Vagus (vut'-gus) [vagare, to wander]. See Nerves, Table of.

Valdivin (val'-div-in). An emetic principle derived from the fruit of Simaba valdivia. (See Simaba.) Unof.

Valence (va'-lens) [valere, to be worth]. In chemistry, the relative saturating or combining capacity of an atom compared with the standard hydrogen atom; the quality or force which determines the number of atoms with which any single atom will chemically unite. See Quantivalence. In biology, taxonomic or morphologic value.

Valency (va'-len-se) [valere, to be worth]. Same as Valence, q. $\%$. Also, a single unit of combining capacity. Thus, carbon has four valencies.

Valentin's Corpuscles. See Corpuscle. V.'s Ganglion. See Ganglia, Table of. V.'s Pseudo-ganglion. See Pseudo-ganglion.

Valerate (val'-er-ät) [valere, to be strong]. Any salt of valeric acid. V. of Cerium, a sait useful in the vomiting of pregnancy. Dose gr. jss. V. of Zinc. See Zinc

Valerene (z'al'-er-èn). See Anylene.

Valerian $\left(v a-l \ell^{\prime}-r e-a n\right)$ [vaiere, to be strong]. A plant of the genus Valeriana. V., American. See Cypripedium.

Valeriana (va-le-re-an'-ah) [valere, to be worth: gen., Valeviance]. A genus of gamopetalous plants; valerian. The rhizome and rootlets of $V$. officinalis. Its properties are due to a volatile oil, which yields several derivatives. It is antispasmodic and gently stimulant to the nervous system and organs of circulation. In full doses it increases heart-action, producing exhilaration ; in toxic doses, diarrhea, vomiting, reduced sensibility, and mental disturbance. It is excellent in hysteria, convulsions due to worms, the coma of typhus fever, and in whooping-cough. V., Abstr. Dose gr. $v-x x$. Unof. V., Ext., Fld. Dose $\eta x-x \times x$. V., Infus. (B.P.) Dose $ろ$ j-ij. V., Tinct., 20 per cent. Dose $3 \mathrm{ss}-\mathrm{ij}$. V., Tinct., Ammoniat., valerian 20, arom. spt. ammonia to IOO parts. Dose $3 \mathrm{ss}-\mathrm{ij}$. V., O1., the volatile oil. Dose $m i j-v$. To the sanie genus belong some 150 species, many of which have properties somewhat similar to those of the official plant. See, also, Ammonizm, Zinc, Iron, and Quinin.

Valerianate (vo-le'-re-an-āt) [valere, to be strong]. Same as Valerate. V. of Amyl. See Apple-oil.

Valerianic Acid (vo-le-re-an'-ik). See Acid, Valeric.

Valeric Acid $\left(v a-l e^{\prime}-r i k\right)$. See Acid.

Valerin (val'-er-in) [valere, to be strong]. A terpene obtained from Valerian. See Amvlene.

Valerolactone (va-ler-o-lak'-tonn) [valere, to be strong: lac, milk], $\mathrm{C}_{5} \mathrm{H}_{8} \mathrm{O}_{3}$. A substance prepared by heating bromvaleric acid with water above $100^{\circ} \mathrm{C}$. It is a colorless liquid that does not solidify at $18^{\circ} \mathrm{C}$., and that boils at $206^{\circ}$ or $207^{\circ} \mathrm{C}$. ; it is miscible with water. 
Valetudinarian (val-et-u-din-a'-re-an) [valetudinarius, valetudo, health]. An invalid.

Valetudinarium $\left(v a l-e t-u-d i n-a^{\prime}-r e-u m\right)$ [ L. ]. An infirmary or hospital. [Old.]

Valeur globulaire, of Lepine. The proportion of hemoglobin to the number of red corpuscles, expressed in terms of the amount of hemoglobin in an individual corpuscle.

Valgus (val'-gus) [L.] I. A bow-legged man. 2. See Talipes. V., Nervous, valgus of neurotic origin. V., Paralytic, valgus caused by paralysis of the tibialis anticus. V., Spurious. Same as Splay-foot.

Validirostral (val-id-ir-os'-tral) [validus, strong; rostrum, beak]. In biology, furnished with a stout beak.

Vallate $\left(v a l^{\prime}-\bar{a} t\right)$ [vallum, rampart]. In. anatomy, surrounded with a walled depression; cupped.

Vallecula (val-ek'-u-lah) [valles, vale: pl., Vallecula]. In biology, a groove, depression, or furrow. A name applied to several slight furrows or pits of the body. Specifically, a deep mesal crevice of the cerebellum. V. cerebelli. See Valley of the Cerebellum.

Vallecular (val-ek'-u-lar) [vallecula, a little furrow]. Pertaining to or resembling a vallecula. V. Canal, an intercellular canal in the stem of certain Equisetacece, opposite a groove on the surface.

Valleculate $\left(v a l-e k^{\prime} \cdot u\right.$-lät $)$ [vallecula, a little furrow]. Marked with valleculæ.

Valleix, Tender Points of. Certain painful points observed in intercostal neuralgia: (I) at the exit of the nerve from the spinal canal; (2) in the axillary region; (3) close to the sternum or in the epigastrium. See Points douloureux.

Vallet's Mass. See Ferrum.

Valley of the Cerebellum. The depression dividing the lateral hemispheres of the cerebellum.

Valli-Ritter's Law. See Law.

Vallicula (val-ik'-u-lah). See Vallecula.

Vallum (val'-um) [L.]. In anatomy, the supercilium or eyebrow.

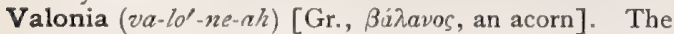
commercial name for the acorn-cups of several species of oak (Quercus agilops and $Q$. macrolepis) coming from Asia Minor, Roumelia, and Greece. They are of a bright-drab color and contain 25 to 35 per cent. of a tannin somewhat resembling that of oak-bark, but giving a browner color and a heavier bloom. They are generally used in admixture with oak-bark, myrobalans, or mimosa bark, because of themselves, they produce too brittle a leather.

Valsalva's Experiment, V.'s Method. In the normal subject if the patient be directed to hold the nose tightly, shut his mouth, and forcibly expire, the air passes up the Eustachian tubes and distends the cavity of the tympanum. V., Sinus of. See Sinus.

Valva (val'-vah) [valva, the leaf of a door: $p l$, Valva]. In biology, a valve. The maxilla of a bee.

Valval (val'-val) [valva, valve]. Pertaining to a valve.

Valvar (val'-var) [valva, valve]. Pertaining to or of the nature of a valve.

Valvate $\left(v a l^{\prime}-v a \bar{t}\right)$ [valua, the leaf of a door]. In biology, resembling or functioning as a valve. Applied in botany to a form of dehiscence of some anthers and to a form of estivation in which the pieces of the whorl touch each other by their edges, but do not overlap.

Valve (valv) [valva, folding doors]. A membrane or lid so affixed to a tube or canal that it opens to permit free passage one way, but closes to intercept passage in the opposite direction. V., Aortic, the semilunar valve of three segments situated at the junction of the aorta with the heart. V. of Bauhin, the ileo-cecal valve. See Ileo-cecal valve. V., Bicuspid. Same as $V$., Mitral. V., Connivent. See Duodenum. V., Coronary, the valve that protects the orifice of the coronary sinus and prevents regurgitation of blood during the contraction of the auricle. V., Eustachian, that between the post-cava and the right auricle. $\mathrm{V}$. of Hasner, an imperfect valve at the inferior meatus of the nose. V., Heister's, folds of mucous membrane of the neck of the gall-bladder. V., Houston's, three oblique folds in the mucous membrane of the rectum at about the level of the prostate. V., Ileocolic, the valve that guards the communication of the ileum with the colon. V. of Kerkring. See Duodenum. Vs. of the Lymphatics, semilunar folds of the inner coat opposite each other. V., Mitral, the valve that controls the opening from the left auricle to the left ventricle; it is constituted of two leaflets. V., Pulmonary, the three semilunar leaflets at the junction of the pulmonary artery and the right ventricle. V., Pyloric, a thick fold of mucosa covering the pyloric sphincter. Vs., Semilunar, the three-valves guarding the orifice of the pulmonary artery; also the three valves at the orifice of the aorta. $V_{0}$-test (Azoulay's), auscultation of the heart while the patient is lying with the arms raised perpendicularly and the legs lifted obliquely. V. of Thebesius, the coronary valve or fold of the endocardium of the right auricle which protects the coronary sinus. V., Tricuspid, that which controls the opening from the right auricle to the right ventricle; it is constituted of three segments. V. of Tulpius, the ileo-cecal valve. V. of Varolius, the ileo-cecal valve. Vs. of a Vein, semilunar folds of the ental coat of veins. $\mathbf{V}$. of Vieussens, a thin leaf of medullary substance between the prepeduncles of the cerebellum; the valvula.

Valviferous (val-vif'-er-us) [valva, valve; ferre, to bear]. Bearing a valve.

Valviform (val'-vif-orm) [valva, valve; forma, form]. Valvular.

Valvula (val'-vu-lah) [dim. of valva, a valve]. A small valve; a valvule. Specifically, a transparent lamina between the gemina and the lingula, constituting the caudal portion of the mesocelian roof. Valvula conniventes (or valves of Kerkring). See Duodenum.

Valvular (val'-v'u-lar) [valvula, a small valve]. Pertaining to a valvula or to a valve.

Valvule (val'-vül) [valva, the leaf of a door]. In biology, a little valve.

Valvulitis (val-vu-li'-tis) [valvula, a small valve; $\iota \tau \iota s$, inflammation]. Inflammation of a valve, especially of a cardiac valve.

Valylene (val'-il-ên), $\mathrm{C}_{5} \mathrm{H}_{6 .}$ A hydrocarbon with an alliaceous odor; it boils at $50^{\circ} \mathrm{C}$. and is a homologue of vinyl acetylene.

Vampirism (vam'-pirr-izm) [Russ., vampirü, a vampire]. The (imaginary) practice of sucking the blood of living persons; the insane belief that some person sucks one's blood by night. This belief is endemic in some countries, and is not uncommon among lunatics.

Vanadium $\left(v a n-a^{\prime}\right.$-de-um) [Vrnadis, a goddess of the Scandinavian mythology]. A metal of the antimony group; symbol V; at. wt. 5i.2. Its oxids are the vanadic and vanadous acids. See Elements, Table of. V. Bronze. See Pioments, Conspectus of.

Van Bemmelen, Papilliform Bodies of. See Meralesthete.

Van Deen's Test. See Tests, Table of.

Vandellia (van-del'-e-ah) [after Vandelli, an Italian botanist]. A genus of scrophulariaceous plants. V. 
diffusa, of S. America, is emetic and purgative, and said to be useful in hepatic and intestinal diseases. Dose of ext. gr. xv-xxiv. Unof.

Van der Kolk's Law. See Lazu.

Vandyke Brown. See Pigments, Conspectus of.

Van Gehuchten's Fixing Solution. See under Stains, Tiable of.

Van Harlingen's Formula. A formula for the treat. ment of acne rosacea. It consists of I dram of precipitated sulphur, with five grains of powdered camphor, Io of powclered gum tragacanth, and one ounce each of rose-water and lime-water.

Vanilla $\left(v a n-i l^{\prime}-a / 2\right)[\mathrm{L}$.$] . The fruit of V$.planifolia, an orchid found in tropical America, and of other species of the genus. Its odor is due to a methyl-ether, zanillin, $\mathrm{C}_{8} \mathrm{H}_{8} \mathrm{O}_{3}$. It is an aromatic stimulant, sometimes em. ployed in hysteria and low fevers, but it is used chiefly as a flavor. V., Tinct., Io per cent. Dose as desired.

Vanillin (van-ill-in) [vanilla, vanilla], $\mathrm{C}_{8} \mathrm{H}_{8} \mathrm{O}_{3}$. The active and odorous constituent of the vanilla-bean pods. It crystallizes in stellate groups of colorless needles, is soluble in hot water, alcohol and ether, and melts at $80-81^{\circ} \mathrm{C}$. It has a warm, aromatic taste. Commercial vanillin is in part prepared from the inner bark of white pine and from eugenol. Dose gr. 1/2. See Vanilla.

Vanillism (van-il'-izm) [vanilla, vanilla]. The symptoms among the workmen in vanilla-factories, due to the action of the volatile principles of vanilla.

Van Swieten's Liquid, or Solution. A solution of use as a local application to the secondary and tertiary lesions of syphilis about the head, face, and neck, and may also be taken internally. It is composed of the following: Corrosive chlorid of mercury 2 grains, alcohol 3 drams, distilled water sufficient to make 4 ounces. Of this one teaspoonful contains $\frac{1}{16}$ of a grain of corrosive sublimate. It has been used by d'Arsonval in preparing glands (thyreoid, etc.) for administration in organotherapy.

Vao $\left(v a h^{\prime}-0\right)$ [S. Am.]. A South American arrowpoison.

Vapo-cresolin (va-po-kres'-o-lin) [vapor, vapor ; cresolin]. A popular remedy in the treatment of laryngeal diphtheria.

Vapor (va'-por) [L.: gen., Vaporis; pl., Vapores]. The gaseous form of a substance which at ordinary temperatures is a liquid. In the B. P., certain vapores, or medicinal vapurs, to be exhibited by inhalation, are officially recognized. V.-bath, the application for therapeutic purposes of steam (medicated or otherwise), or of some other vapor, to the surface of the body, in a suitable apartment or apparatus. V.douche, a jet of vapor impinging upon the surface of the body or some part thereof; used therapeutically.

Vapores uterini. Synonym of Hysteria.

Vaporarium (va-por-a'-re-zum) [L.]. A Russian bath, or a vapor-bath; or an establishment or apparatus for such baths.

Vaporizable $\left(v a-p o r-i^{\prime}-z a-b l\right)$ [vapor, vapor]. Capable of being vaporized.

Vaporization (va-por-iz-a'shun) [vapor,vapor]. The process by which volatile matters are separated from rixed substances by means of heat. The conversion of a solid or liquid into a vapor.

Vaporize $\left(v \alpha^{\prime}\right.$-por-iz) [vapor, vapor]. To reduce to vapor.

Vaporizer (va'-por-i-zer) [vapor, vapor]. An atomizer, a nebulizer.

Vaporole $\left(v a^{\prime}-p o r^{-}-\ddot{l}\right)$ [vapor, vapor]. A friable, glass capsule containing a drug for inhalation.
Vaporous (va'-por-u) [vapor, vapor]. x. Pertaining to or consisting of vapor. 2. Arterial.

Vapors $\left(v a^{\prime}\right.$-porz) [unpor, vapor]. Hypochondriasis ; lowness of spirits; hysteria.

Variability (va-re-a-bil'-it-e) [variare, to change]. In biology, morphologic and physiologic plasticity, or the ability of the organism or race to adapt itself to its environment.

Variation $\left(v a-r e-a^{\prime}-\operatorname{shun}\right)$ [variare, to change]. In biology, morphologic or physiologic deviation from a given type as the result of environment, natural selection, or cultivation and domestication. Cornevin establishes the following list of the modes of variation among animals :-

I. Morphologic VARtations.

Variations through disap $\{$ Absence of horns, ears, pearance. $\quad \begin{aligned} & \text { Absence of horns, ear } \\ & \text { hair, pigment, etc }\end{aligned}$

Total: Dwarfing, dis
coloration. Partial coloration. Partial:
Niatism, partial discoloration, reduction in the $n u m b e r$ of limbs, etc.

ariations through arrested

Variations through juxtaposition.

$n$ in some hybrids when the characters of both progenitors co-exist side by side.

Variations through fusion. Diminished number of vertebra, etc.

Variations through transformation.

Wool replaced by bair, scales replaced by feathers, etc.

Total: Giants, melanism, extreme hairiness. Partial : Drooping ears, very long horns, hairs or feathhors, hairs or feath-

Variations tbrough hypertrophy.

Variations through division or repetition.

II. Physiologic Variations.

Variations through diminished activity.

Variations through earlier activity.

Variations through exagger ated activity.

Variations through stronger activity.

Supplementary vertebra, ribs, teeth, horns digits, etc.

To this list De Varigny adds Chemic VARIATION.

V., Double, the double current produced in a muscle by the passage of a single induction-shock. V., Negative (of a muscle-current), the diminution of the muscle-current caused by stimulation of the motor nerve.

Varicated (varl-ik-a-ted) [varix, varix]. Having varices.

Varication (var-ik-a'shun) [varix, varix]. The formation of a varix; a system of varices.

Varicella (var-is-ell-ah) [dim; of variola, smallpox]. An acute, specific, infectious disease of children, popularly known as chicken-pox. It has an incubation-period of from eight to fourteen days, and is rarely preceded by a premonitory stage of slight fever and roseolous rash. This latter appears first on the back or chest, as scattered, slightly elevated, round, rose-colored spots; these are quickly followed by an eruption of glabrous, transparent vesicles, which appear in successive crops on different parts of the bodythere may be four or five of these crops-bursting the third to the fifth day from their appearance, finally leaving small, punctured scabs. There are generally but slight febrile symptoms. V. coniformis, swinepox; varicella in which the vesicles are conic. V., Conoidal. Same as $V$. coniformis. V. gangrænosa. 
See Dermatitis gangranosa infontum. V. globata, swine-pox; hives; varicella in which the vesicles are hemispheric. V. Prurigo, Hutchinson's term for the occurrence in the mildest cases of varicelli of fresh crops of papules and pustules, the process lasting for weeks, and being accompanied by a good deal of itching, but by very little if any ulceration. V., Pustular. Same as Varioloid. V. syphilitica, a syphiloderm having the form of a varicellar eruption.

Varicellar (var-is-el'-ar) [varicella, dim. of variola, smallpox]. Pertaining to varicella.

Varicellate (var-is-el'-ât) [varicella, varicella]. Having small varices.

Varicelloid (var-is-el'-oid) [varicella, varicella ; eidos, like]. Resembling varicella.

Varices $\left(v_{a}^{\prime}-i s-\bar{e} s\right)$ [L.]. Plural of Varix, q.v. V. gelatinosæ. Gelatinous accumulations in the umbilical cord.

Variciform (var-is-if-orm) [varix, a swollen vein; forma, a form]. Having the form of a varix or swelled vein.

Varicoblepharon (var-ik-o-blef'-ar-on) [varix, varix ; $\beta \lambda \varepsilon$ $\phi a \rho o \nu$, eyelid]. A varicosity of the eyelid.

Varicocele (var'-ik-o-sél) [varix, varix; $\kappa \eta \dot{\lambda} \eta$, a tumor]. Dilatation of the veins of the scrotum or of the spermatic cord. V., Ovarian, varicosity of the veins of the broad ligament. V., Utero-ovarian, varicocele in the female.

Varicocelectomy (var-ik-o-se-lek'-to-me) [varix, varix ; $\kappa \dot{\eta} \lambda \eta$, tumor; $\varepsilon \kappa \tau o \mu \dot{\eta}$, excision]. Excision of a varicocele.

Varicoid (var'-ik-oid) [varix, varix : $\varepsilon i \delta o s, l i k e] . ~ R e-$ sembling a varix.

Varicomphalus (var-ik-om'-fal-us) [varix, varix ; ó $\phi a \lambda o ́ s$, navel]. A varicosity at the navel.

Varicose $\left(v a \gamma^{\prime}-i k-\bar{o} z\right)$ [varix, varix]. Swollen, knotted, and tortuous. V. Aneurysm. See Aneu. rysm. V. Fibers, medullated axis-cylinders provided with Ranvier's nodes and with incisures; they are destitute of neurilemma, and show, after death, swellings due to the accumulation of fiuid between the myelin and the axis-cylinder; they form the white matter of the spinal cord and brain.

Varicosis (var-ik- $o^{\prime}-$ sis) [varix, varix ]. An abnormal dilatation of the veins.

Varicosity (var-ik-os'-it-e) [varix, varix]. The condition of being varicose; a varicose portion of a vein.

Varicotomy (var-ik-ot'-o-me). Same as Cirsotony.

Varicula (var-ik'-u-lah) [dim. of varix, varix]. A varix of the conjunctiva. Same as Cirsophthrimia.

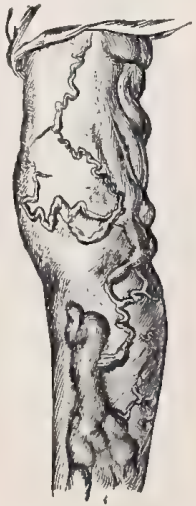

Variety $\left(v a-r i^{\prime}-\ell t-\ell\right)$ [varieta, difference : pl., Varieties]. In biologic taxonomy, a subdivision of a species; a stock, strain, breed.

Variola $\left(v a-r^{\prime}-o-l a h\right)$ [varius, variegated, spotted]. Smallpox. A specific infectious disease ushered in with severe febrile symptoms, which, in the course of two or three days, are followed by a papular eruption spreading over all parts of the body. During the succeeding two weeks the eruption passes through periods of vesiculation, pustulation, and incrustation. The falling off of the crusts leaves the well-known pockmarks or pitted appearance on the skin. The period of incubation is about thirteen days. A secondary fever usually sets in during the pustular stage. V. confluens. Same as $V$., Confluent. V., Confluent, a severe form, in which the pustules spread and run together. V., Congenital, variola of the newborn, due to intra-uterine infection. V. cornea, hornpox; a variety of variola in which papular growths take the place of pustules. V., Discrete, a form in which the pustules preserve their distinct individuality. V. dysenterica, smallpox complicated with a form of persistent diarrhea. V., Emphysematous, a form of variola in which the pustules contain gas. V. equina, horse-pox, V., Hemorrhagic, variola in which hemorrhages into the vesicles occur, which gives them a blackish appearance. V. maligna, black smallpox; a severe and very fatal form of variola, of the hemorrhagic type. V., Malignant, often called black smallpox and hemorrhagic smallpox. Its distinguishing feature is hemorrhage into the skin. It is invariably fatal. V., Mitigated, or Modified. See Varioloid. V. notha. Synonym of Varicella. Variolæ ovinæ. Same as Sheep-pox. V. spuria. Synonym of Varicella. V., Tubercular, variola in which the pustules assume a tubercular form. V. vaccina atrophica, stonepox; an abortive form of variola in which the vesicle dries before reaching the pustular stage. V. vaccina bullosa, a form of vaccinia in which large single bullæ take the place of the ordinary vesicles. V. vaccina erysipelatosa, the association of vaccinia and erysipelas at the point of inoculation. V. vaccina ulcerosa, vaccinia attended with ulceration at the point of inoculation. V. vera, true smallpox, as distinguished from varioloid. V. verrucosa, wartpox; a mild, abortive form of variola.

Variolad (va-ri'-o-lad) [variola, variola]. An infectious germ of the smallpox virus.

Variolar (va-ri'-o-lar) [variola, smallpox]. Pertaining to smallpox.

Variolate $\left(v a r^{\prime}-e-o-l a \bar{t}\right)$ [variola, variola]. I. Having small pustules like those of variola. 2. To inoculate with smallpox.

Variolated (var'-e-o-la-ted) [variola, smallpox]. Having or having had variola.

Variolation, Variolization (var-e-o-la'-shun, va-re-oliz'-a-shun) [variola, yariola]. The inoculation of smallpox.

Variolator (var'-e-o-la-tor) [variola, variola]. One who inoculates with smallpox.

Variolic (var-e-ol'-ik) [variola, variola]. Pocky, variolous.

Varioliform (var-i'-o-lif-orm) [v'ariola, variola ; forma, form]. Resembling variola.

Variolin (var-i'-o-lin) [variola, variola]. The specific virus of smallpox.

Varioloid (var'-e-o-loid) [variola, variola; sidos, re semblance]. The slight form of the disease variola or smallpox as modified by vaccination or inoculation. It is chiefly important from the possibility that the patient may become a source of infection to others.

Variolous (var-i'-o-lus) [variola, variola]. Pertaining to or having the nature of variola.

Variolo-vaccine $\left(v a r-i^{\prime}-0-10-v a k^{\prime}-\sin \right)$ [variola, variola; vacca, cow]. A vaccine-lymph or crust obtained from a heifer which has been inoculated with smallpox virus.

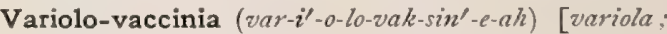
vacca, cow]. A form of vaccinia or cowpox induced in the heifer by inoculating her with smallpox virus.

Varix (var'-iks) [varus, crooked: pl., Vavices]. 'A'venous dilatation. V., Aneurysmal. See Aneurysm. V. lymphaticus. See Lymph-scrotum.

Varnish (var'-nish) [ME., vernysh, varnish]. A quickly-drying solution of some resin. Varnishes are 
popularly used to exclude the air from wounds, and in suitable cases they often act happily.

Varoli's Bridge. See Pons varolii.

Varolii, Pons. See Pons.

Varolius, Bridge of. See Bridge.

Varrentrapp and Will, Method of. A method for the determination of nitrogen in organic compounds. The substance to be analyzed is reduced to the finest powder, dried, and weighed; then mixed with soda-lime It is then placed in a combustion-tube, loosely plugged with asbestos, and heated. The nitrogen is converted into ammonia, which is absorbed by hydrochloric acid contained in a bulb connected with the tube. This is then treated with platinic chlorid, which precipitates ammonium-platinum chlorid, and the nitrogen is estimated.

Varus $\left(v a^{\prime}-r u s\right)$ [L., bent]. See Acne and Talipes. V., Arterial, a cirsoid aneurysm. V. comedo. Same as Acne punclala. V., Equino-. See Talipes. V. gutta rosea. Same as Rosacea. V. punctatus. Same as Acne punctata. V. sebaceus. Same as Seborrhea.

Vas (vas) [L., a vessel: pl., Vasa]. A vessel. A generic term for the tubules or canal-like structures for the conduction of liquids, secretions, etc., through the body or from one organ to another; used particu larly to designate vessels carrying blood. V. aberrans. See Vasculum aberrans. V. deferens, the excretory duct of the testis, the continuation of the epididymis.

Vasa $\left(v a^{\prime}-z a h\right)[\mathrm{L}$.$] . Plural of V'as, q . v$. V. aberrantia: I. Vessels that sometimes connect the brachial or axillary artery with one of the arteries of the forearm. 2. Isolated bile-ducts on the surface of the liver which have no relation to any system of hepatic lobules, as if the lobules to which they originally be longed had atrophied and disappeared. V.afferentia, the branches of a lymphatic or lacteal vessel previous to entering a gland. $\boldsymbol{V}$. brevia, gastric branches of the splenic artery. V. efferentia, the terminal ducts of the rete testis; applied also to the efferent vessels of lymphatic glands. V. intestini tenuis, small vessels arising from the superior mesenteric artery and distributed to the jejunum and ileum. See Intestinal Artery in Arteries, Table of. V. recta, the tubules of the rete testis. V. vasorum, the vessels supplying the arteries and veins with blood,-i.e., the vessels supplying the vessels themselves. V. vorticosa. See Vena

Vasal $\left(v a^{\prime}-z a l\right)$ [vas, a vessel]. Pertaining to a vessel or to vessels. Vascular.

Vasalium (vaz-a -le-um) [vas, a vessel: pi., Vasalia]. In biology, tissues peculiar to vascular or closed cavities; Endothelium, Colarium.

Vascoa (vas-ko'-ah) [L.]. A genus of leguminous plants. The roots of the S. African V. amplexicaulis are used as a substitute for liquorice. V. perfoliata, an African plant, is a strong diuretic. Unof.

Vascula (vas'-ku lah) [L.]. Plural of Vasculum, q. v. Vascular (vas'-ku-lar) [vasculum, a small vessel]. Consisting of, pertaining to, or provided with ves sels. V. Fibers, centrifugal nerve-filers exciting contraction of blood-vessels. Vasomotor fibers. V. Lamellæ. See Plate, Cathammal. V. System, the venous and arterial system.

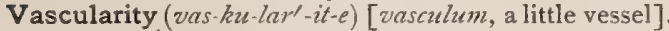
The quality of being vascular.

Vascularization (vas-ku-lar-iz-(a'-shun) [vasculum, a little vessel']. The formation and extension of vascular capillaries. The process of becoming vascular.

Vasculiform (vas'-ku-lif-orm) [vasculum, a small vessel; forma, form]. In biology, having the form of a vessel; like a flower-pot.
Vasculin (vas'-ku-lin) [vasculum, a little vessel]. tract of vascular tissue.

Vasculomotor (vas-ku-lo-mo'-tor) [vasculum, a little vessel; motor, a mover]. Acting as a vasomotor upon the capillaries.

Vasculose (vas'-ku-lō $)$ [vasculum, a vessel]. I. Same as Vascular. 2. The substance forming the vascular tissue of plants.

Vasculum (vas'-ku-lum) [L. : pl., Vascula]. A small vessel. In biology, a botanist's collecting-case. V. aberrans, a tube extending from the lower part of the epididymis into the cord.

Vaselin (vaz'-el-in) [irregular; Ger., wasser, water; Ė^aıov, oil]. Same as Petrolatum. The vaselins are paraffins that liquefy readily and fuse between $30^{\circ}$ and $40^{\circ} \mathrm{C}$. ; they are employed as bases for ointments. V., Liquid, a liquid paraffin used as a vehicle for active medicines.

Vasifactive (vaz-if-ak'-tiv) [vas, vessel; facere, make]. Giving rise to new blood-vessels. See Angioplastic.

Vasiform (vas'-if-orm) [vas, vessel ; forma, form]. In biology, resembling a vessel or duct.

Vaso- $\left(v a^{\prime}-z o^{-}\right)$[vas, a vessel]. A prefix employed to denote connection with the vessels.

Vaso-constrictive (val-zo-kon-strik'-tiv) [vas, vessel; constringere, to constrict]. Promoting or stimulating the constriction of blood-vessels.

Vaso-constrictor $\left(v a^{\prime}-z o-k o n\right.$-strik'-tor) [ $z^{\prime} a s$, vessel ; constrictor, constrictor]. I. Causing a constriction of the blood-vessels. 2. A nerve or a drug that causes constriction of blood-vessels.

Vaso-corona (va'-zo-ka-ro'-nah) [vas, vessel; corona, crown]. The system of arterioles that supply the periphery of the spinal cord.

Vaso-dentinal ( $v a^{\prime}-z o-d e n^{\prime}$-tin-al) [z'as, vessel; dens, a tooth ]. Pertaining to or of the nature of vaso-dentine.

Vaso-dentine $\left(v a^{\prime}-z o-d e n^{\prime}-t i n\right)$ [vas, vessel ; dens, tooth]. Dentine having capillaries large enough for the passage of red blood-corpuscles.

Vaso-dilator (va'-zo-di-la'-tor) [vas, vessel; dilator, a dilator]. I. Pertaining to the positive dilating motility of the non-striped muscles of the vascular system. A nervous mechanism, with a center and efferent nerves, probably exists. 2. A nerve-element or a drug that causes dilatation of blood-vessels.

Vaso-formative (va'-zo-for'-mat-iv) [vas, vessel; formare, to form]. Forming or producing vessels. See Vasofactive. V. Cells, those engaged in the production of vascular tissue.

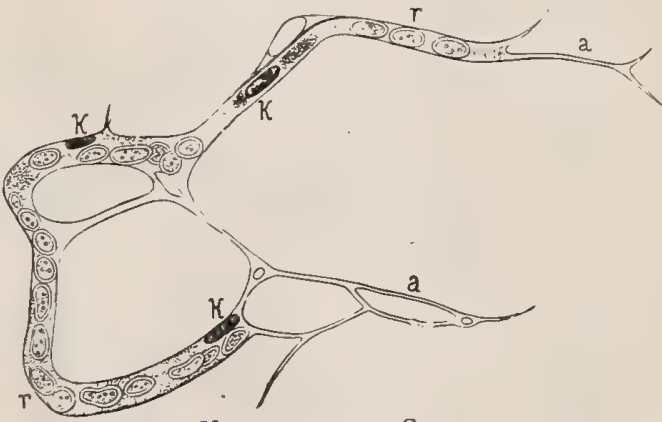

VASO-FORMATIVE CElls.

$r, r$. Red blood-corpuscles. $k, k$ Nuclei of vaso-formative cells. $a, a$. Processes that ultimately unite to form capillaries.

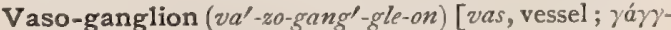
$\lambda \iota \%$, ganglion]. A knot, or rete, of blood-vessels.

Vasogen $\left(\tau^{\prime} a^{\prime}-z o-j e n\right)$ [vaselin; yevvã $v$, to produce]. Oxygenated vaselin. 
Vaso-hypertonic $\left(v a^{\prime}-z o-h i-p e r^{\prime}-t^{\prime} n^{\prime}-i k\right)$. See Vaso

Vaso-inhibitory $\left(v a t^{\prime}-z o-i n-h i b^{\prime}-i t-o r-e\right)$ [vas, vessel ; inlibere, to inhibit]. Pertaining to the function of inhibition of vasomotor action or of vascular con traction.

Vasomotion (va'-zo-mo'-shun) [vus, vessel; motio, motion]. Increase or decrease of the caliber of a blood-vessel.

Vasomotor (va'-zo-mo'-tor) [vas, vessel; motor, motor]. Pertaining to the motility of the non-striped muscles of the arterial system; regulating the tension of a blood-vessel; vaso-constrictor. V. Ataxia, a condition of instability of the circulatory mechanism, described by S. Solis-Cohen and characterized by abnormal readiness of disturbance of the equilibrium of the cardio-vascular apparatus, with tardiness of restoration. In some cases the phenomena are of paretic, in others of spasmodic character. Usually the two kinds of phenomena are displayed in varying degree in the same patient. Dermographism is an essential feature and in most cases factitious urticaria can be induced; mottlings of the skin, peculiar markings of the nails, telangiectases and stigmata are common. There is usually a hemorrhagic tendency. In some cases the thyreoid gland has been altered. The action of the heart is usually rapid, irregular, and easily disturbed; palpitation is common, and intermittent tachycardia has been noticed; hemic and functional murmurs are not uncommon. V. Bronchitis. See Asthma. V. Center. See Center. Subordinate centers are distributed throughout the spinal axis. V. Nerves, the nerves passing to the blood-vessels; stimulation causing contraction, narrowing of the lumen, and consequent increase of blood-pressure. Paralysis of the center produces the opposite effects. V. Rhinitis. See Hay-fever.

Vasomotorial, Vasomotory $\left(v a^{\prime}-z 0-m o-t o^{\prime}-r e-a l, v a^{\prime}\right.$. zo-mo'-tor-e) [vas, vessel; motor, motor]. Relating to the vasomotor function.

Vasomotricity $\left(v a^{\prime}-z o-11 o_{0}-t^{\prime} i^{\prime}-i t-e\right)$ [vas, vessel ; motor, motor]. The quality of having a vasomotor action.

Vaso-peritoneal $\left(v \alpha^{\prime}-z o-p e r-i t-o n^{\prime}-e^{\prime}-a l\right)$ [vas, vessel; peritoneal]. In biology, pertaining to the closed sac which results from the cutting off from the archenteron of a cecal diverticulum to which the anterior part of that cavity gives rise.

Vaso-sensory (va'-zo-sen'-so-re) [vas, vessel ; sensory]. Serving as a sensory apparatus for the vessels.

Vastus (vas'-tus). See Muscles, Trable of.

Vat-blue $\left(v a t^{\prime}-b l u\right)$. Same as Indigo-blue.

Vater's Ampulla. See Ampulla. V.'s Corpuscles. See Pacinian Bodies or Corpuscles. V.'s Diverticulum. Same as $V$.'s Ampulla. V.'s Fold. See Fold. Vatrax (va'-traks) [L.]. See Vatricose.

Vatricose (vat'-rik-öz) [vatricosus]. Club-footed.

Vault (vawit) [ME, varute, vault]. The dome or arch of the skull; the hollow of the roof of the mouth. V. of Cranium. See Calvaria.

Vecordia (ve-kor'-de-ah) [vecors, destitute of reason]. Insanity ; especially dementia or idiocy.

Vectis (vek'tis) [vehere, to carry]. An instrument similar to the single blade of a forceps, used in expediting the delivery of the head in labor.

Vegetable (vej'-et-a-bl) [F., végétable, vegetable]. (a) A plant, especially a kitchen herb. (b) See Vegetal. V. Athiops, a kind of charcoal produced by the incineration of Fucus vesiculosus in closed vessels. It has been employed in glandular and scrofulous affections, and contains a small quantity of iodin. V. Albumin. See Phytalbumose. V. Bezoar. See Calapitte. V. Coloring-matters. See Conspectus of
Pigments, under Pigment. V. Economy, the systematic arrangement of the parts and organs of plants V. Gum. See Bassorin. V. Mercury. See Manaca and Anchieta salutaris. V. Proteids. See Proteid. V. Sponge. See Luffa. V. Sulphur. See Lycopodium.

Vegetal (vej'-e-tal) [vegetus, lively; vegere, to move, quicken]. In biology, of or pertaining to plants, characteristic of plants, plant-like in habit. V. Functions, the vital phenomena common to plants and animals, viz., irritability, digestion, assimilation, growth, secretion, excretion, circulation, respiration, generation.

Vegetality $(v e j-c$-tal'-it-e) [vegere, to move, excite, quicken]. In biology, the possession of Vegetal Functions, $q . v$. ; the opposite of animality.

Vegetarian (vej-e-ta'-re-an) [vegetare, to quicken]. One who lives on vegetable food alone.

Vegetarianism (vejee-ta'-re-an-izm) [vegetare, to quicken]. The doctrine that vegetable fond is the only kind proper for man, and the practice of this doctrine.

Vegetatio (vej-e-ta'-she-o). Same as Vegetation.

Vegetation (vej-e-ta'-shun) [vegetatio; vegere, to grow]. Morbid or fungous growth, such as abnormal granulations, excresences, warts, etc. V., Adenoid, morbid growths in the naso-pharyngeal cavity. Vs., Digital, prominent, villous vegetations. Vs., Fibrinous, small, wart-like bodies growing on a serous surface. Vs., Urethral, papillomata of the urethra.

Vegetative (vej"-e-tr-tiv) [vegere, to grow]. Having the power of growth, like a vegetable; applied to certain tumors.

Vegeto- (vej'-et-o) [vegere, to grow]. A prefix employed to denote connection with or relation to the vegetable kingdom.

Vehicle (ve'-hik-l) [vehiculum; vehere, to carry]. Anything which carries or conveys. In pharmacy, any excipient or substance serving as a medium of administration.

Veiel's Paste. A paste used in the treatment of furuncles. It consists of equal parts of oxid of zinc and vaselin, with 4 per cent. of boric acid. It is to be well rubbed into the skin around the boil three times a day.

Veil (väl) [velum, veil]. See Velum, Velamen and Calyptra. V., Acquired, an obscuration or imperfection of voice from exposure to cold, catarrhal conditions, or overuse, or from bad training. V., Uterine, a cap fitted over the cervix uteri, to prevent the entrance of the semen.

Vein $(v \vec{a} n)$ [ven $\pi$, vein]. The veins are tube-like vessels that receive the blood from the lungs and peripheral organs of the body and convey it to the auricles of the heart. They are divided into three systems or groups: the Pulmonary, Systemic, and Portal, the latter being an appendage of the systemic, its capillaries ramifying in the liver. In biology, one of the fibro-vascular bundles of a leaf. V., Acromial Thoracic, a small vein accompanying the artery of the same name. V., Angular, a continuation of the frontal vein downward to become the facial at the lower margin of the orbit. V., Auricular (anterior and posterior). I. The vein of the ear. 2. A vein from the cardiac auricles. V., Axillary, a large vein formed by the junction of the inner brachial venæe. It lies to the inner side of the axillary artery and becomes the subclavian at the border of the first rib. Vs., Azygos (three in number), situated ventrad of the bodies of the thoracic vertebræ; they are a means of communication between the superior and inferior venæ cavæ. V., Basilar, a large vein passing back over the crus cerebri to unite with the veins of Galen. V., Basilic, a vein on the inner 
side of the arm. It unites with the inner brachial to form the axillary. Vs., Brachial, the veins accompanying the brachial artery. V., Brachio-cephalic. See $V$., Innominute. Vs. of Breschet, the veins of the diploē. Vs., Bronchial, veins that correspond to the bronchial arteries. V.-brooch, an instrument for compressing varicose veins. V., Buccal, a vein coming from the buccinator muscle; it empties into the pterygoid plexus. V., Capsular, the suprarenal vein. Vs., Cardiac, the veins from the heart. V., Cephalic, a large vein of the arm, formed by the union of the median cephalic and superficial radial. It opens into the axillary. Vs.,

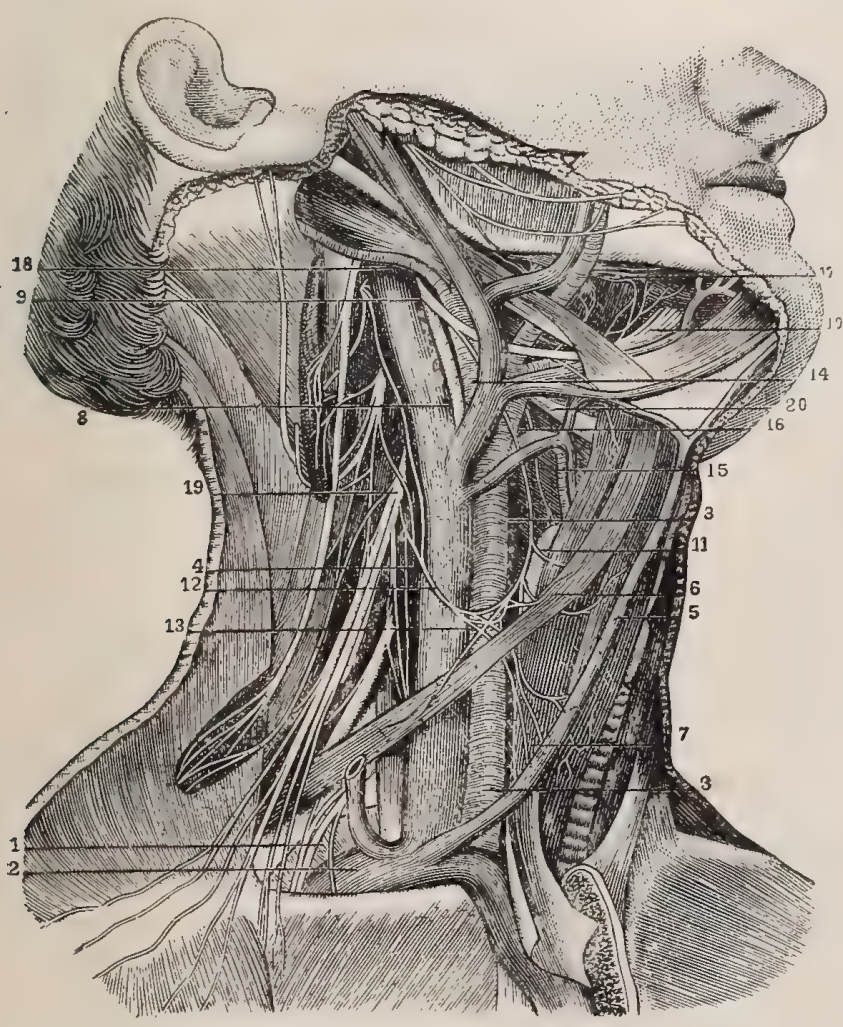

VESSEls AND NeRVES OF THE NECK.

I. Subclavian artery. 2. Subclavian vein. 3,3. Common carotid artery. 4 Internal jugular vein. 5. Anterior jugular vein. 6. Omo-hyoid muscle. 7. Sterno-hyoid muscle. 8. Trunk of pneumogastric nerve. 9. Hypoglossal nerve. 10. Its terminal portion. II. Its descending branch. 12. Internal descending branch of cervical plexus. 13. Plexus formed by last two branches. 14. External carotid artery. 15. Superior thyreoid artery and vein. 16. Lingual and facial arteries. 17. Facial artery and vein. 18. Occipital artery. 19. Anterior branches of the first four cervical nerves. 20. Superior laryngeal nerve.

Cerebellar, veins coming from the cerebellum; they empty into the various sinuses. Vs., Cerebral, veins coming from the cerebrum. They are cortical and central ; the former are from 8 to $\mathbf{I} 2$ in number on each side and empty into the superior longitudinal sinus. The central veins unite to form the venæ Galeni. V., Cervical, Deep, the second or deeper division of the posterior portion of the vein of the scalp. V., Cervical, Transverse, a vein accompanying the artery of the same name. V., Choroid, a vein of the choroid plexus. It unites with the vein of the corpus striatum to form the veins of Galen. Vs., Ciliary, small veins from the eyeball. Vs., Circumflex Iliac (deep and superficial), veins accompanying the arteries of the same name. V., Conarial, a vein originating in the fine venous plexus over the conarium. It is one of the prebasal veins that unite to form the subcerebral. Vs., Coronary: 1. Same as $V$., Cardiac. 2. Veins surrounding the margins of the lips. 3. See $V$, Gastric. V., Cystic, a vein returning the blood from the gallbladder; it empties into the portal vein. Vs., Dental, veins conveying the blood from the alveoli of the jaws. V., Diaphragmatic. See $V$., Phrenic. Vs., Emissary, small veins passing through the cranial foramina and connecting the cerebral sinuses with external veins. Vs., Emulgent, a synonym of the renal veins. V., Epigastric, Deep, a vein emptying into the external iliac above Poupart's ligament. Vs., Ethmoid, veins corresponding to the arteries of the same name. Vs., Extraspinal, veins ramifying over the external surfaces of the vertebræ. V., Facial, a continuation of the angular vein; it joins the internal jugular at the level of the hyoid bone. V., Femoral, Common, a short, thick trunk corresponding to the femoral artery; it becomes the external iliac at Poupart's ligament. V., Femoral, Deep, a vein accompanying the femoral artery; it empties into the superficial femoral. V., Femoral, Superficial, a name given to the femoral vein before it is joined by the deep femoral vein to form the common femoral vein. V., Frontal, a name given to the anterior vein of the scalp as it crosses the frontal bone. V. of Galen, a synonym for the anterior cardiac vein. Vs. of Galen, two large veins of the brain, continuations of the internal cerebral veins; they open into the straight sinus. Sometimes there is but a single vein of Galen instead of two. V., Gastric, a vein accompanying the artery of the same name. V., Gluteal, a vein passing through the great sacro-sciatic foramen with the gluteal artery. Vs., Hemiazygos, small, acces sory veins of the azygos veins. Vs., Hemorrhoidal, a plexus of veins surrounding the rectum. Vs., Hepatic, the largest tributaries to the inferior vena cava; they return the blood from the liver. Vs., Iliac, Common, two veins formed opposite the sacro-iliac synchondrosis by the confluence of the external and internal iliac veins. They unite opposite the fifth lumbar vertebra to form the inferior vena cava. V., Iliac, External, a continuation upward of the common femoral; it extends from the lower border of Poupart's ligament to the lower border of the sacro. iliac synchondrosis. V., Iliac, Internal, a short trunk extending from the great sacrosciatic foramen to the sacro-iliac synchondrosis. Vs., Innominate, two large valveless veins returning the blood from the head, neck, and upper extremity. They are formed by the union of the internal jugular and subclavian veins, and unite to form the superior vena cava. Vs., Intra-spinal, the veins within the spinal column. V., Jugular, Anterior, a vein beginning at the level of the chin and ending at the clavicle in the external jugular vein. V., Jugular, External, a vein formed at the angle of the lower jaw by the union of the posterior auricular and temporo-maxillary veins; it empties into the subclavian. V., Jugular, Internal, a continuation of the lateral 
sinus, beginning at the jugular fossa ; it accompanies the internal and common carotid arteries, and joins the subclavian vein to form the innominate. V., Jugular, Posterior, External, a small vein in the dorsal portion of the neck. V. of Labbé. See $V$., Posterior Anastomosing. V., Lingual, the vein returning the blood from the tongue. It empties into the internal jugular. Vs., Lumbar (four on either side), veins corresponding to the lumbar arteries. Vs., Mammary, Internal, veins formed by the union of the venæ comites of the superior epigastric and internal mammary arteries; they empty into the innominate vein. V. of Marshall. See $V$, Oblique. V., Maxillary, Anterior, a small vein of the anterior portion of the face. V., Maxillary, Internal, a vein accompanying the first part of the internal maxillary artery. V., Median Basilic, the largest of the two divisions of the median; it unites with the superficial ulnar to form the basilic. It is chosen for venesection. V., Median Cephalic, the smaller branch of the median; it unites with the superficial radial to form the cephalic. V., Median, Deep, a vein formed by the union of the outer vena comes of the ulnar artery and the muscular and radial recurrent veins. V., Median, Superficial, a vein that starts at the anterior plexus of the wrist and unites with the deep median to form the median. V., Mesenteric, Inferior, one formed by the superior and middle hemorrhoidal veins at the rectum; it accompanies the inferior mesenteric artery, and joins the splenic vein behind the pancreas. V., Mesenteric, Superior, one that accompanies the superior mesenteric artery, and joins the splenic vein to form the portal. V., Oblique (of Marshall), a vein crossing the dorsal portion of the left auricle of the heart. It is the remnant of the left duct of Cuvier. V., Obturator, a vein accompanying the artery of the same name. V., Ophthalmic, a short trunk carrying the blood from the eye; it empties into the cavernous sinus. Vs., Ovarian, two veins beginning as the pampiniform plexus in the broad ligament; the right one empties into the inferior vena cava, the left one into the left renal. V., Pancreatic, a vein returning the blood from the pancreas. V., Peroneal, a vein accompanying the peroneal artery. Vs., Phrenic, veins accompanying the phrenic arteries. V., Popliteal, one formed by the union of the venæ comites of the anterior and posterior tibial arteries; it accompanies the popliteal artery, and becomes the femoral at the junction of the lower with the middle third of the thigh. V., Portal, a short trunk formed by the junction of the superior mesenteric and splenic veins; it enters the liver. V., Posterior Anastomosing (of Labbé), one of the cortical cerebral veins. V., Pudic, a vein accompanying the pudic artery; it empties into the internal iliac. Vs., Pulmonary, two veins on each side returning the aërated blood from the lungs to the heart. V., Radial, Superficial, a vein accompanying the musculo-cutaneous nerve up the radial side of the forearm. V., Renal, a vein returning the blood from the kidneys. V., Salvatella, a vein of the little finger, situated in the fourth metacarpal space and entering into the formation of the posterior ulnar vein. V., Saphenous, Long or Internal, a long vein running up the inner aspect of the leg, terminating in the femoral vein below Poupart's ligament. V., Saphenous, Short or External, a vein running up the outer aspect of the foot, leg, and back of the calf; it empties into the popliteal vein. Vs., Sciatic, veins accompanying the sciatic artery. V., Spermatic, a vein returning the blood from the testicle; on the right side it terminates in the inferior vena cava and on the left in the left renal vein. V., Splenic, a vein returning the blood from the spleen; it forms the vena porta by uniting with the superior mesenteric vein. V.-stone. See Phlebolith. V., Subcerebral, a large vein at the base of the brain. V., Subclavian, a continuation of the axillary; it unites with the internal jugular vein to form the innominate vein at the sterno-clavicular articulation. Vs., Submaxillary, veins returning the blood from the submaxillary gland. Vs., Temporal, veins returning the blood from the temporo-maxillary region of the head; they join the internal maxillary vein to form the temporo-maxillary vein. V., Temporo-maxillary, one formed by the union of the temporal and internal maxillary veins in the parotid gland; it terminates in the external jugular. Vs., Thyreoid, veins returning the blood from the thyreoid gland. V. of Trolard, a vein of the cerebrum passing along the posterior branch of the fissure of Sylvius and emptying into the superior petrosal sinus. V., Tympanic, a vein accompanying the tympanic artery. V., Ulnar, Superficial, a vein running from the wrist up the anterior and inner surface of the forearm. V., Umbilical, in the fetus, a vein extending from the navel along the falciform ligament to the liver. Vs., Uterine, a plexus of veins returning the blood from the uterus. V., von Burow's. See Burow's Teins. V. of Vesalius, a vein forming the channel of communication between the pterygoid plexus of veins and the cavernous sinus. V., Vidian, one of the branches of the pharyngeal vein.

Veinage $\left(v a^{\prime}-n \bar{a} j\right)$ [z'ena, vein]. Veining.

Veined (väd) [vena, vein]. Provided with veins.

Veining $\left(v \bar{a} n^{\prime}-i n g\right)$. Same as Venation.

Veinless (vān'-les) [vena, vein]. Without veins.

Veinlet (vān'let). See Venule.

Veinous (va'-nus) [vena, vein]. Same as Venous.

Veinule $\left(v \bar{a} n^{\prime}-u l\right)$. See Venule.

Veinulet $\left(v \bar{a} n^{\prime}-u\right.$-let $)$ [vena, vein]. A branch of a veinlet.

Veiny $\left(v a^{\prime}-n e\right)$. Same as Venose.

Velamen (ve-la'-men) [L.: pl., Velamina]. A veil, or envelop. V. nativum, the skin. V. vulvæ. See Apron.

Velamentous (vel-am-en'-tus) [velanen, a veil]. Vei!like.

Velamentum (vel-am-en'-tum) [L. : pl., Velamenta]. A veil, or covering membrane. Velamenta cerebri, meninges. V. infantis, the fetal membranes.

Velar (ve'-lar) [velum, veil]. Pertaining to a velum, especially to the velum palati.

Velarium (ve-la'-re-um) [velum, veil: pl., Velaria]. In biology, the peculiar velum of the Cubomeduse and Rhizostoma, differing from the true velum of the Craspedota by its supply of gastro-canals.

Velate $\left(v e^{\prime}\right.$-lät) [velare, cover, veil]. Furnished with a veil.

Velation (ve-la'-shun) [velare, to veil]. The formation of a velum.

Veliferous (ve-lif'-er-us) [velifer, sail-bearing]. Having a velum; velamentous.

Veliform (vel'-if-orm) [velum, veil; forma, form]. Forming a velum.

Veliger (vell-ij-er) [velum, a veil; gerere, to bear]. In biology, a larval stage of development in Mollusca, characterized by the presence of a velum, or ciliated swimming-membrane.

Veligerous (ve-lij'-er-us) [velum, a sail, veil ; gerere, to bear]. In biology, bearing a veil, or velum.

Vella's Fistula. See Fistula.

Vellarin (vel'-ar-in). The active principle of Hydrocotyle asiatica; alterative, astringent, tonic. Unof.

Velleity $\left(v e l-e^{\prime}-i t-e\right)$ [velleitas; velle, to wish]. A weak form of volition; feeble desire or inclination. 
Vellicate (vell ik-äl) [vellicare, to pluck]. To twitch ; to move spasmodically.

Vellication (vel-ik-a'-shun) [vellicatio; vellicare, to twitch]. The spasmodic twitching of muscular fibers as observed in tic.

Velpeau's Apparatus. An immovable dressing for fractures, consisting of a compress and card-board splints, hardened by a solution of dextrin. V.'s Bandage. See Bandage. V.'s Hernia, femoral hernia in front of the vessels. See Hernia, and Diseases, Tuble of.

Velum $\left(v e^{\prime}\right.$-lum) [velum, veil, sail : pl., Vela]. In biology, a veil or veil-like structure, variously applied to membranous growths in both plants and animals, as the swimming-membrane of molluscan larvæ; the turned-in margin of the umbrella of certain medusa, or the envelop covering the sphorophore of a hymenomycetous fungus. $\mathrm{V}$. interpositum, the membranous roof of the third ventricle. V. palati. Same as $V$. pendulum palati. V. partiale, a membrane or veil which in some of the Hymenomycetes stretches from the margin of the pileus to the stipe. V. pendulum palati, the soft palate, and especially the uvula. V., Posterior Medullary, the commissure of the flocculus of the cerebellum. V. tarini. Same as $V$., Posterior Medullary. V. universale, a membrane which in some of the Hymenomycetes covers the entire sporocarp.

Velumen (ve-lu'-men). [velumen, a fleece]. In biology, the velvety integument of certain parts of plants or animals.

Velutinous (ve-lu'-tin-us) [velutem, velvet]. Velvety to the touch.

Vena $\left(v e^{\prime}-n a h\right)$ [L.]. A vein. See Vein. V. cava. See Cava. Vena cava inferior, is formed by the junction of the two common iliac veins and empties into the right auricle of the heart. It receives lumbar, right spermatic, renal, suprarenal, phrenic, and hepatic branches. Vena cava superior, formed by the union of the innominate veins, conveys the blood from the upper half of the body to the right auricle.

Venæ $\left(v e^{\prime}-n e\right)$. Plural of Vena. Veins. See Vein. Venæ comites, veins that accompany arteries in their course. V. Galeni, the two trunks formed by the union of the vein of the corpus striatum and that of the choroid plexis; they empty into the straight sinus. V. thebesii, the small veins by which blood passes from the walls of the heart to the right auricle. Venæ vorticosæe, the venous network and trunks of the choroid coat of the eye.

Venal (ve'-nal). Same as Venous.

Venalization (ven-al-iz-a'-shun) [vena, vein]. The acquirement of venous qualities by the blood.

Venatio (ven- $a^{\prime}-$ she-o) [venari, to hunt]. I. Same as Venation. 2. A hunting.

Venation (ven-a'-shun) [vena, a vein]. In biology, the distribution of veins in a leaf, or in the wing of an insect. See Nervation. V., Forked, venation in which the veins branch in repeated equal divisions. V., Reticulate, venation in which the veins have the form of a network. V., Unbranched, venation in which the veins run parallel and unconnected from the base to the tip of a leaf.

Venenate $\left(v e n^{\prime}-e n-\bar{a} t\right)$ [venenum, poison]. Poisonous.

Venenation (ven-en-a'-shun) [venenum, a poison]. The condition of one affected by the venom of a poisonous insect or reptile.

Venenatus (ven-en-a'-tus) [venenum, a poison]. Poisonous.

Venenific (ven-en-if'-ik) [venenum, poison]. Poisonforming.
Venenifluous (ven-en-if'-lu-us) [venenum, poison, fuere, to flow]. In biology, exuding a poisonous fluid or juice.

Venenose, Venenous (uen'-en-ōz, ven'-en-us) [venenosus]. Toxic ; poisonous; acting by a toxic property.

Venenum (ven'-en-um). Same as Poison.

Venereal (ven-e'-re-al) [Venus, the goddess of love]. Pertaining to the sexual passion. V. Bubo, a swelling of the glands of the groin secondary to some venereal disease. V. Diseases, gonorrhea, syphilis, and chancroid. V. Sore. See Chancre. V. Wart. See Verruca acuminata.

Venereology (ven-e-re-ol'-o-je) [Venus, the goddess of love; $\lambda$ бos, science]. The science of venereal disease.

Venery $\left(v e n^{\prime}-e r^{-}-e\right)$ [Venus, the goddess of love]. Sexual intercourse.

Venesection (ven-e-sek'-shun). See Blood-letting.

Venesuture (ven-e-su'-tūr) [vena, vein; sutura, suture]. The suturing of a vein.

Venetian Red. See Pigments, Conspectus of.

Venice $\left(v e n^{\prime}-i s\right)$ [Ital.]. A city of Italy. V. Treacle, V. Turpentine. See Theriaca, Turpentine, V. White. Same as Hamburg White.

Veniplex (ven'-ip-leks) [vena, vein; plexus, plexus]. A venous plexus; a plexus of veins.

Venom (ven'-om) [venenum, poison]. The poison secreted by certain reptiles and insects, as the rattlesnake, the scorpion, etc. V.-albumin, the albumin of the venom of a snake. V.-globulin, a globulin found in snake-poisons; there are various kinds described. V.-peptone, a peptone found in the venom of certain serpents. V., Quickening, V., Vital, semen.

Venomous $\left(v e n^{\prime}\right.$-om-us) [venenum, a poison]. Poisonous; belonging or pertaining to venom; secreting venom.

Venosal (ven-o'-zal) [vena, vein]. Venous.

Venose $\left(v^{\prime} n^{\prime}-\bar{o} z\right)$ [ven $a$, vein]. In biology, veiny; furnished with conspicuous veins. V.-costate, in biology, between ribbed and veined.

Venosity (ven-os'-it-e) [vena, vein]. Venous quality ; a condition in which the arterial blood shows venous qualities; general congestion of the veins.

Venous (ve'-nus) [venoszs]. Pertaining to a vein. V. Hum, the murmur or rushing sound observed in auscultation of a vein. V. Nevus. See Novus vascularis.

Vent (vent) [ME., z'ente, vent]. An outlet, especially the anal opening.

Venter (ven'-ter) [venter, belly]. The belly or abdomen. Applied to structures having a concave or a bellylike appearance. V. of Ilium, the iliac fossa. V. of Kidney, the pelvis of the kidney. V. of Scapula, the anterior surface of the scapula.

Ventilation. The dilution and removal of all impurities that collect in the air of inhabited rooms, the most common of which is $\mathrm{CO}_{2}$, which may be tested by Lanye's Method, q. $v$. In hospitals the fundamental principle of ventilation observed is that each adult person confined in a space of 1000 cubic feet requires 3000 cubic feet of fresh air per hour in order to prevent the proportion of carbon dioxid in the room from rising above 0.06 per cent. This estimate is based on the fact that each adult expires, on the average, 0.6 of a cubic foot of carbon dioxid per hour. Ventilation may be natural, due to the forces constantly acting in nature, or artificial, the result of measures introduced by man. The former is brought about by the agency of the wind and by diffusion, or the power which gases of different densities possess of mixing with each other. Artificial ventilation is brought 
about either by extracting the foul air from the room, or by forcing pure air into the room, and is effected by means of fans, heat, gas, or steam. Natural ventilation is aided by means of tubes or shafts employed as inlets and outlets. The outlets are guarded by Cowls, which prevent the entrance of rain, increase the extracting effect of the wind, and check the tendency to down-draught. A most valuable agent in this ventilation is the chimney. Windowsalso may be utilized for the same purpose. The estimation of $\mathrm{CO}_{2}$ in the air may be made by the following methods: I. Minimetric Method, when the proportion of $\mathrm{CO}_{2}$ is not less than one part per 10oo. The analysis is made by the use of a solution of sodium carbonate with phenolphthalein as an indicator. 2. Pettenkofer's Method has for its basis the fact that if air containing $\mathrm{CO}_{2}$ is brought into contact with barium hydroxid in solution a combination takes place between the barium and $\mathrm{CO}$, immediately, and insoluble barium carbonate is precipitated. 5. Szydlozeski's Method consists in comparing a given volume of the air to be tested with a sample of air from which $\mathrm{CO}_{2}$ has been removed, and the difference of pressure recorded by means of a mercurial column. 4. Reiset's Method, calculates the amount of $\mathrm{CO}_{2}$ in the air from the difference found between the titration of a given volume of barium-water before and after the passage of the air through it. V., Methods of; there are various methods of securing ventilation, some of which are as follows: Auburn or Pentonville System of ventilating prisons. The cells are arranged in blocks of several tiers in height, and each block is surrounded by an outer building, between the walls of which and the doors of the tiers of cells on each side is an open corridor, not divided by floors corresponding to the floors of the several tiers. The air is drawn from this corridor into the cells. Boyle's Ventilator, an arrangement of mica valves allowing air to pass out, but allowing no backdraught. Cooper's Ventilator, a series of apertures in the glass of a window-pane arranged in a circle so as to be more or less completely closed by a circular disc having corresponding apertures and moving upon a central pivot. Ellison's Ventilating Bricks, are bricks perforated with conical holes, and fixed in the walls, with the apices of the cone on the outside. They are not likely to produce a draught. Hinckes-Bird's Method consists in placing a movable block of wood under the entire length of the lower window-sash. Louvred Panes, a form of window-ventilation by which an upward direction is imparted to the incoming air. These panes take the place of one or more of the squares of glass, and may be either opened or closed. MCKinnell s Ventilator, a combined outlet and inlet ventilator, which is applicable in the case of upper rooms or rooms in singlestory houses. It consists of two tubes, the one encircling the other, the inner acting as the outlet, and being fitted with a cowl. Sheringham Valve, a common form of inlet in windows or walls for the purposes of ventilation. The entrance to the opening in the wall is guarded by a strainer to keep out dust, while on the inside is a valved iron plate with closed sides and hinged at the bottom. This opening is usually placed near the ceiling. Smpad-Dozod System of Ventilation, an artificial system of ventilation in which the outlets are at the bottom of the sheeting along the floor-line and open into spaces beneath the floor. These spaces are connected with flues down which the air is drawn by the powerful action of the furnace-chimney. Tobin's Tube, a means of ventilation, the air from without entering through a hole in the wall and being conducted by an upright tube into the upper portion of the room. V., Pulmonary, the supply of pure air to the lungs and the removal of the vitiated air. V., Respiratory, the supply of a fluid containing oxygen to a respiratory membrane and its removal after the oxygen has been given up.

Ventilator (ven'-til-a-tor) [ventilare, to fan]. An apparatus for effecting ventilation.

Ventrad (ven'-trad) [venter, stomach; $a d$, toward]. Toward the ventral aspect or surface; not dorsad nor neurad, and not laterad.

Ventral (ven'-tral) [ventralis; venter, belly, or abdominal cavity]. Pertaining to the belly. At or in the direction of the venter or belly-side of the body or the ventral aspect of an organ. Hemal is sometimes used instead of ventral. See the opposite, Dorsal; also, Position and Direction, Table of Intrinsic Terms.

Ventrally (ven'-tral-e). Synonym of Ventrad.

Ventricle (ven'-trik-l) [ventriculus : dim. of venter, a belly]. Applied to certain structures or parts having a bellied appearance. V., Aortic, the left ventricle of the heart. V. of Arantius, a cul de-sac 'in the oblongata. Vs. of Brain, the third, fourth, fifth, and two lateral. $\quad V$., Third, between the optic thalami and extending to the base of the brain; $V$. Fourth, the space between the oblongata and pons in front, and the cerebellum behind; $V$., Fifth, the cavity between the lamine of the septum lucidum; $V$, Lateral, the considerable cavity of either half of the cerebrum, communicating with the third through the foramen of Monro. Each ventricle consists of a triangular central cavity or body, and three smaller cavities, called cornua. The corpus callosum forms the roof of the body, the septum lucidum the mesal boundary, and the floor is formed by the corpus striatum, tænia semicircularis, optic thalamus, choroid plexus, corpus fimbriatum, and fornix. The anterior cornu curves forward and outward into the anterior lobe of the brain, the middle cornu descends into the middle lobe, and the posterior cornu or digital cavity curves backward into the occipital lobe. V. of Cerebellum, the extension of the fourth ventricle into the substance of the cerebellum. V. of Cord. See Canal, Central. V. of Corpus callosum, the space between the labium cerebri and the callosum; the callosal fissure. V. of Larynx, a depression between the true and false vocal bands. V., Left, of Heart, that upon the dorsal and left side of the heart, and which, through the aorta, forces the blood over the general system. V. of Morgagni. a small cavity hounding each vocal band externally. V., Optic, the cavity of either optic or geminal lobe. V., Right, of Heart, that forcing the blood through the pulmonary artery toward the lungs. V., Sixth. See Verga's V., and Canal, Central. V., Sylvian. Same as $\dot{V}$., Fifth. V., Verga's, a space occasionally found between the callosum and the fornix.

Ventricornu (ven-trik-or'-nu) [venter, venter; cornu, cornu]. The ventral extension, or anterior horn, of the gray matter of the myelon.

Ventricornual (ven - trik-or'-nu-al) [venter, venter; cornu, cornu]. Pertaining to the ventricornu.

Ventricose (ven'-trik-öz) [venter, abdomen]. Inflated or swelled out on one side, resembling an abdomen.

Ventricous (ven'trik-zes) [venter, belly]. In biology, distended, resembling an abdomen.

Ventricular (ven-trik'-u-lar) [ventriculus, a ventricle]. Belonging or pertaining to a ventricle. V. Aqueduct. See Aqueductus Svlvii. V. Bands, the longitudinal folds of mucous membrane above and parallel to the vocal bands. The false vocal hands.

Ventriculose (ven-trik'-u-lōz) [ventriculus, belly]. Minutely ventricose.

Ventriculous (ven-trik'-ut-lus). Same as Ventricular. Ventriculus (ven-trik'-u-lus), See Ventricle. 
Ventricumbent (ven-trik- $u m \iota^{\prime}$-bent) [venter, belly; cubere, to lie]. Prone; lying with the ventral surface down.

Ventriduct (ven'-irid-ukt) [venter, belly; ducere, to lead]. To carry toward the belly.

Ventriloquism (ven-tril'-o-kwizm) [venter, belly; loqui, to speak]. Peculiar vocal utterance without the usual modifications of the resonance-organs, so that the voice seems to come from a closed space or from a distance.

Ventrimesal (ven - trim - $\left.e^{\prime}-z a l\right)$ [venter, belly ; $\mu$ ćoov, middle]. Pertaining to or situated on the ventrimeson. At or toward the ventral edge of the meson, or ventral mesal or median line. See the oppositeDorsimesal; also, Position and Direction, Table of Intrinsic Terms.

Ventrimeson (ven-trim-e'-zon) [venter, belly; $\mu$ ḱov, middle]. The mesial line on the ventral aspect of the body. The ventral edge of the meson or median plane of the body. The ventral median or mesal line. Cf. Dorsimeson; also, Position and Direction, Table of Intrinsic Terms.

Ventripyramid (ven - trip - in' $a m$ - id) [venter, belly ; pyramis, pyramid]. An anterior pyramid of the ob. longata.

Ventrocystorrhaphy (ven-tro-sis-tor'-a-fe) [venter,

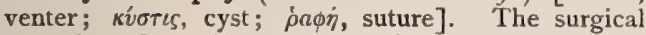
operation of attaching to the wall of the abdomen the opened cyst-wall, so as to provide a free discharge of its contents.

Ventrodorsally (ven-tro-dor'-sal-e) [venter, belly ; dorsum, back]. In a direction between the dorsal and ventral aspects.

Ventrofixation (ven-tro-fiks-a'-shun) [ventrofixatio]. The fixation of a displaced viscus to the abdominal wall.

Ventroinguinal (ven-tro-in'-gwin-al) [venter, belly; inguinal ]. Pertaining to the abdomen and the groin.

Ventro-laterad (ven-tro-lat'-er-ad) [venter, belly; latus, side]. Toward the ventral and lateral aspects.

Ventromesal (ven-tro-me'-zal). Same as Ventrimesal.

Ventrose (ven'-trōs) [ventrosus]. Having a belly, or a swelling like a belly.

Ventrosity (ven-tros'-it-e) [ventrositas]. Corpulence; pendulousness of the abdomen.

Ventrotomy (ven-trot'-o-me) [venter, belly; rou'́, a cut]. The operation of surgical incision of the abdominal cavity.

Venula (ven'-u-lah) [venula, dim, of vena, a vein: pl., Venula $]$. In biology, a small vein or veinlet.

Venule $\left(v e n^{\prime}-\bar{u} l\right)$. See Venula.

Venulose (ven'-u-lōs) [venula, dim. of vena, a vein]. In biology, furnished with veinlets.

Venulous (ven'-u-lus) [venula, a small vein]. Full of veinlets.

Venus Flycatcher, or Flytrap. See Dionca.

Veratralbin (ver-at-ral'-bin) [veratrum, veratrum; albus, white]. An alkaloid obtained from White Hellebore.

Veratria (ver-a'-tre-ah). See Verairina.

Veratric Acid (ver-a'trik). See Acid.

Veratrin (ver-a -trin) [veratrum, veratrum], $\mathrm{C}_{32} \mathrm{H}_{49}$. $\mathrm{NO}_{9^{-}}$1. See Veratrina. 2. Cevadin. This occurs, together with veratric acid and other alkaloids, in white hellebore and in Sabadilla seeds. It crystallizes from alcohol in prisms and melts at $205^{\circ} \mathrm{C}$. 3. A precipitate from a tincture of the root of Veratrum viride; it is cathartic, nervine, arterial sedative, resolvent, anodyne, etc. Dose $1 / 8$ to $1 / 2$ grain. Unof. V., Oleat., veratrin 2, oleic acid 98 parts. V., Ung., veratrin 4 , alcohol 6 , benzoinated lard 90 parts.
Veratrina, Veratrine (ver-at-ri'-nah, ver at'-rin) [L.] A mixture of alkaloids obtained from the seeds of Asagrac officinalis. It is an exceedingly poisonous local irritant, and is used mainly as an external application for neuralgia, gout, and rheumatism. Dose gr. $\frac{1}{50}-\frac{1}{10}$

Veratrization (ver-at - riz- $a^{\prime}-\operatorname{shun}$ ) [veratrum, vera trum]. Subjection to the influence of veratrin; veratrin. poisoning.

Veratrum (ver-a'-trum) [L, hellebore]. A genus of liliaceous plants. V. album, white hellebore, a European plant closely related to $V$. viride. It is a violent emetic and cathartic, and is actively poisonous; it is now little used, except as an insect-powder. For this use it is highly valued, as it destroys many insects which the ordinary buhach does not affect. Unof. V. sabadilla. Cevadilla, cebadilla, a bulbous plant of the order Melanthacec; it contains a number of alkaloids, and is the source of Veratrina. The seeds are official in the B. P. under the name Sabadilla. V. viride [gen., Veratriviridis], American hellebore; the rhizome and rootlets of the plant contain jervin, veratrin, and other alkaloids. It is a powerful depressant of the heart and a paralyzant of the spinal cord. Its action is similar to that of aconite, but is regarded as inferior. It is highly esteemed in puerperal fevers, pneumonia, and aneurysm. V., Ext., Fld. Dose mi-iv. V., Tinct., 5o per cent. Dose $m$ ij- $x$.

Verbascum (ver-bas'-kum) [L., mullein]. A genus of scrophulariaceous plants, including mullein, the leaves of $\mathbf{V}$. thapsus L., or common mullein. The latter is emollient, demulcent, and slightly anodyne, and is a popular domestic remedy in pulmonary tuberculosis and other pulmonary affections, being palliative to the cough. It is useful in diarrhea and in inflammations of the urinary tract. Dose of fluid extract gtt. $\mathrm{x}-\mathrm{xx}$,

Verbena (ver-be'-nah) [L.]. A genus of flowering plants of some 80 species, once highly esteemed in medicine, but now little used. V. hastata, blue vervain, is expectorant and emetic; V. officinalis and V. triphylla, antispasmodic; V. urticifolia, diuretic. Unof.

Verbigerate (ver-bij'-er-ât) [verbigere, to talk]. To make use of verbigeration.

Verbigeration (ver-bij-er-a'-shun) [verbigere, to talk]. The frequent and uncontrollable repetition of one and the same word, sentence, or sound, without reference to its meaning; abnormal repetition of words.

Verdet $\left(v \bar{a} r-d a^{\prime}\right)$ [Fr.]. A fungous disease of maize due to the presence of parasites - Ustilago segetum, Uredo carbo, or Sporisorium maidis-on the grains. It was erroneously believed to cause pellagra.

Verdigris (ver'-dig-ris) [ME., verdegrese, verdigris]. A deposit upon copper vessels from the formation of cupric salts. See Copper, and Pigments, Conspectus of. V., Blue, a deposit consisting in the main of bibasic acetate of copper. V., Common, basic cupric acetate. V., Green, a bright, very bluish-green verdigris composed of a mixture of several acetates, but mainly of sesquibasic cupric acetate.

Verditer (ver'-dit-er) [Fr., verde de terve, earth green]. A name applied to two pigments. V., Blue, is either a carbonate of copper or a mixture of copper oxid with hydrated lime. V., Green, is an impure carbonate of copper with chalk. Both are used as pigments.

Verdure (ver'-dīr) [viridis, green]. Green vegetation.

Verdurous $\left(v e^{\prime}-d i \mu^{\prime}-u s\right)$ [viridis, green]. Covered with verdure; verdant.

Veretrum (ver-et'-rum). Synonym of Penis.

Verga's Ventricle. A cleft-like space occasionally found between the fornix and the callosum. 
Verge (vurj) [virga, a rod]. In biology, the male organ of crabs, arising from the sternum or from the coxal joint of the posterior feet.

Vergens (vur'-jenz) [L.]. Inclining. V. deorsum, tending or inclining downward, as of the axis of vision of one eye in strabismus. V. sursum, upward inclination or tending.

Verheyen, Stars of. Venous plexuses of stellate form situated on the surface of the kidney, berreath its capsule. They unite to form the interlobular veins.

Verin (ver-in) [veratrum, hellebore], $\mathrm{C}_{28} \mathrm{H}_{45} \mathrm{NO}_{8}$. An amorphous alkaloid obtained from veratrin.

Verjuice (ver'-jüs) [Fr., verjus]. The expressed juice of unripe fruits.

Vermian (ver'-me-an) [vermis, a worm]. In biology, of or pertaining to worms; worm-like.

Vermicelli (ver-mis-ell-e) [It., little worms]. An Italian paste consisting mainly of flour, cheese, and egg, rolled into small, worm-like cylinders. It is a favorite ingredient of soups.

Vermicidal (ver-mis-i'-dal) [vermis, worm; cadere, to kill]. Destroying worms.

Vermicide (ver'-mis-z $d^{\prime}$ ) [vermis, a worm; cadere, to kill]. A medicine or agent that kills intestinal worms.

Vermicular (ver-mik'-u-lar) [vermicularis; vermis, worm]. Worm-shaped or with worm-like motion.

Vermiculate (ver-mik'-u-lät) [vermiculatus]. Resembling or shaped like a worm. In biology, (a) marked with tortuous, wavy lines or depressions; (b) infested with worms.

Vermiculation (ver - mik-u-la'-shun) [vermiculatio]. The peculiar motion of certain tubular organs, such as the esophagus and the intestines, consisting in the progressive contraction of successive parts of the tube.

Vermicule (ver'-mik-iul) [vermiculus, a small worm]. A little worm or grub.

Vermiculose (ver-mik'-u-loz) [vermiculus, a little worm]. Full of worms; worm-like.

Vermiculus (ver-mik'-u-lus) [L.]. A little worm or grub.

Vermiform (ver'-mif-orm) [vermiformis; vermis, worm; forma, a form]. Having a shape like a worm. V. Appendage, or Appendix, a worm-shaped tube at the lower and back part of the cecum. V. Process, Inferior and Superior, the vermis of the cerebellum.

Vermifugal (ver-mif'-u-gal) [vermis, worm; fugare, to flee]. Having the qualities of a vermifuge; expelling worms.

Vermifuge (ver'-nif-uij) [vermis, worm; fugare, to expel]. A medicine or agent that expels intestinal worms.

Vermigrade (ver'-mig-rād) [vermis, worm; gradi, to walk $]$. Moving like a worm.

Vermilion (ver-mil'-yun). See Pigments, Conspectus of.

Vermin (ver-min) [vermis, worm]. A general (and mainly collective) name for parasitic animals and for semi-parasites, such as fleas and bed-bugs.

Vermination (ver-min-a'shun) [vernis, worm]. Infestation with worms; the condition of one affected with worms.

Verminous (ver'-min-us) [vermis, worm]. Affected with or having the characters of worms.

Vermiparous (ver-mip'-ar-tes) [vermis, worm; parere, to bear]. Producing or breeding worms.

Vermis (ver'-mis) [L.: pl., Vermes]. I. A worm. See Worm. 2. The mesal lobe of the cerebellum.

Vermivorous (ver-miv'-or-us) [vermis, worm; vorare, to devour]. Worm-eating.

Vermix (ver'-miks). A contraction, used by Minot and some German writers, of the term Vermiform Appendix.
Vermouth (ver'-muth) [Ger., wermuth, wormwood]. A cordial prepared from white wine and flavored with wormwood; esteemed as an appetizer.

Vernacular (ver-nak'-u-lar) [vernaculus, nalive]. The language or dialect of one's own country.

Vernal (ver'-nal) [vernalis, of the spring]. Pertaining to the spring. V. Conjunctivitis, a conjunctival inflammation or congestion, occurring chiefly in the young, recurring each spring or summer, and disappearing with frost.

Vernation (ver-na'-shun) [vernare, to flourish, bloom]. In biology, the arrangement of leaves within the bud; prefoliation.

Verneuil's Neuroma. A plexiform neuroma or neuroma cirsoideum.

Vernicose (ver'-nik-öz) [vernix, varnish]. Glistening, having a varnished appearance.

Vernier (ver'-ne-a) [after Paul Vernier, the inventor]. In physics, a contrivance attached to various instruments of precision for the estimation of minute fractions of any unit of distance.

Vernin (ver'nin). A leukomain base found in young vetch, clover, ergot, etc. ; it yields guanin on heating with hydrochloric acid. See Leukomains, Table of.

Vernix (ver'-niks) [L.]. Same as Varnish. V. caseosa, "Cheesy Varnish." A sebaceous deposit covering the surface of the fetus.

Verona Brown. See Pigments, Conspectus of.

Veronese Green. See Pigmenis, Conspectus of.

Vernonia (ver-no'-ne-ah) [after William Vernon, an English botanist]. A genus of composite-flowered plants of some 500 recognized species. V.cinerea is esteemed in India as a febrifuge; V. anthelmintica affords a kind of wormseed; V. nigritiana, of Africa, is febrifugal and acts on the heart. Unof.

Vernonin (ver-no'-nin) [after William Vernon, an English botanist]. A glucosid, the active principle of the root of Vernonia nigritiana, an African plant. Its properties are similar to those of digitalis, though its poisonous properties are much less.

Veronica (ve-ron'-ik-a/h) [vern, true; zikisv, image]. A genus of scrophulariaceous herbs and shrubs of some 200 species. V. beccabunga, antiscorbutic. Unof. V. officinalis is diuretic and diaphoretic. V. virginica. See Culver's Physic.

Verriculate (ver-ik'-u-lāt) [verriculum, a drag-net]. Covered with verricules.

Verricule (ver'-ik-ül) [verriculum, a drag-net]. In biology, a thick-set tuft of upright parallel hairs.

Verruca (ver $\left.-r \mathcal{U}^{\prime}-k a h\right)$ [L.: pl., Verruce]. Wart; single or multiple, hard or soft, rounded, flattened, or acuminate, circumscribed, papillary excrescences on the skin, variable in color and smooth at the summit, or studded with moniliform elevations or with clusters of minute, pointed, horny filaments. V.acuminata, Condyloma ; moist wart; fig veurt; cauliftozerer excrescence; venereal wart; a warty growth occuring in parts especially subjected to maceration with sweat, venereal secretions, and mucous discharges, such as the genital and anal regions of both sexes. They are flat, acuminate, whitish, reddish, pinkish, or flesh-tinted, sessile or pedanculated masses of vegetations, com. monly smeared with a thin, excessively offensive secretion. They may be single and small, or as large as the fist; often they are very numerous. They are highly vascular. V. ani, condylomata about the anus. V. congenita, a wart appearing at or shortly after birth. V. digitata, flat warts characterized by digitations springing from the center or border. V. febrilis. Same as Variola verrucosa. V. filiformis, a thread-like wart, single or multiple, congenital ov acquired, seen often on the face, neck, eyelids, and ears, 
as well as the trunk. V. follicularis, wart-like accumulations around the mouths of the sebaceous follicles. They are composed of dried epithelium and sebaceous matter. V. glabra, a smooth wart. V. necrogenica, Anatomic tubercle; post-mortem wart: warty tubercle; tuberculosis verrucosa cutis; a warty excresence found usually on the fingers of those who frequently handle the tissues of tuberculous subjects. It begins as a vesicular or pustular lesion rising from an engorged base, and may be a purely local disorder, or give rise to general infection. V. perstans, a wart that does not tend to spontaneously disappear. V. plana, a flattish wart with a slight elevation and broad and relatively smooth surface; seen in older patients. V. sebacea, the type met with in persons of seborrheic tendency and uncleanly habits. V. senilis, Keralosis pigmentosa; a flattened and markedly pigmented wart of old people. It occurs on the face, trunk, hands, and genital regions usually. It often undergoes an epitheliomatous metamorphosis. V. sessilis. Same as $V$. plana. V. subunguinalis, a soft wart growing under the nails. V. syphilitica, syphilitic condylomata. Verrucæ venereæ, tubercular syphiloderm arranged in clusters. V. vulgaris, the single or multiple horny warts, in size from a pinhead to a pea, seen often on the hands of young persons of both sexes.

Verruciform (ver-u'-sif-orm) [verruca, wart; forma, form]. Wart-like.

Verrucose, Verrucous (ver'-u-kôz, ver'-u-kus) [verrucosus]. Warty; covered with or having warts.

Verrucula (ver-u'-ku-lah) [L.: pl., Verrucula]. little wart; a minute, wart-like eminence.

Verruculose (ver-u'-ku-loz) [verrucula, a little wart]. Marked by small, warty growths.

Yerrugas (ver-u'-gahs) [Sp.]. See Verruca. V. peruana, Carrion's Disease (after Daniel A. Carrion, a Peruvian medical student). Peruvian Wart; a narrowly endemic, specific disease of the skin occurring in the Western Andes, in Peru. It consists in the development of raised spots, in size from a lentil to a pea, which become cylindric, conic, or hemispheric tumors, in size from a raspberry to an orange. Severe febrile symptoms precede the eruption of the lesions. The consistence is soft or elastic ; the epidermis thins over the tumor; cracks and bleeding, often copious, follow. There may be hundreds of the tumors, which ulcerate and fungate. Death usually results from profound anemia. The disease is believed to be due to a special bacillus known as Yzquierdo's bacillus, having been first described by Professor Yzquierdo of Santiago de Chile.

Versatile (ver'-sat-il) [versare, to turn]. In biology, swinging or moving freely; reversible.

Versicolor (ver-sik-ul'-or) [versare, to change ; color, color]. Of variegated or changing color.

Versio (ver'-zhe-o). Same as Version.

Version (ver'-zhun) [versio; vertere, to turn]. Turning : an obstetric operation whereby one end of the fetal ovoid is made to replace the other. V., Abdominal. Same as $V$., External. V., Ano-pelvic, a variety of pelvic version, the child being seized by the pubic arch through the mother's pelvis. V., Bipolar, version by acting upon both poles of the fetus. V., Cephalic, turning the fetus so as to bring the head to present. V., Combined, bipolar version, consisting of a combination of external and internal version. V., External, version effected by external manipulation. V., French Method of, podalic version, in which the hand is first directed to the breech and then follows down the thighs to the feet. V., German Method of, podalic version, in which the hand is carried directly over the abdominal aspect of the fetus to the feet. V., Internal, by entering the hand within the uterus. V., Mixed. Same as $V$., Combined. V., Pelvic, turning the fetus so as to bring about a breechpresentation. V., Podalic, bringing down one or both feet. V., Spontaneous, the process whereby a transverse position is, without external influence, changed into a longitudinal one. V., Two-finger, version by the introduction of two fingers into the uterus.

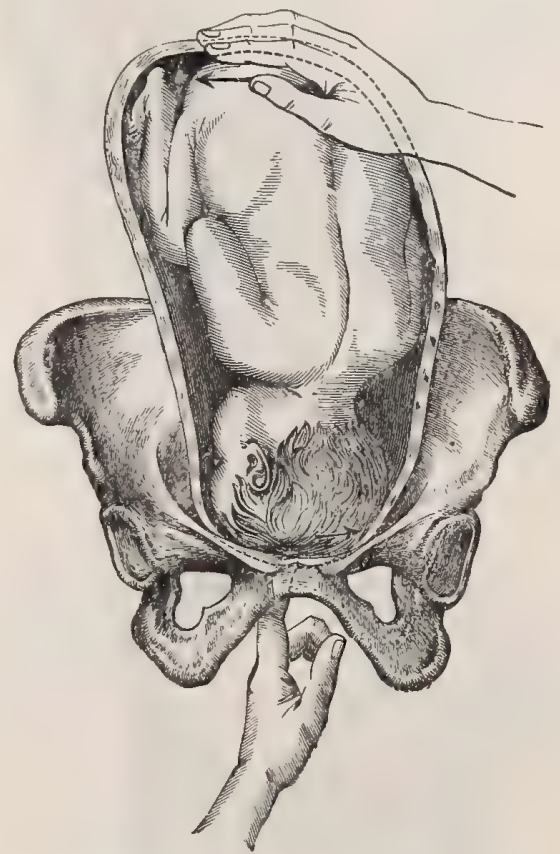

First Stage of Bipolar Version. (After $R$. Batnes.)

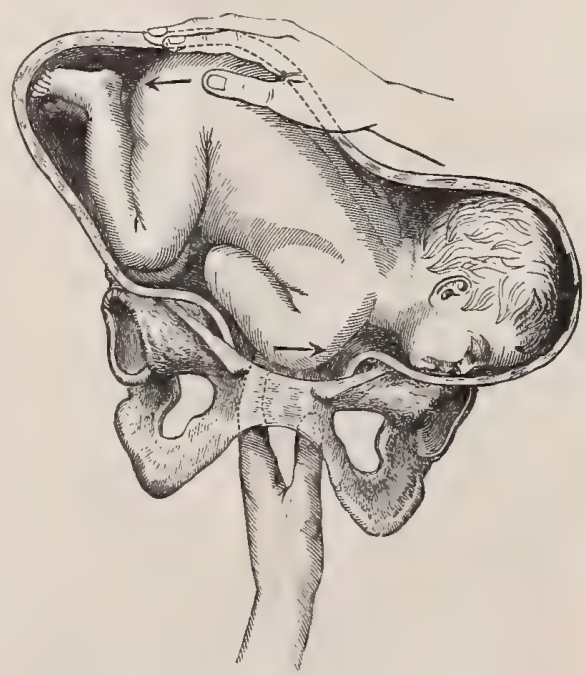

Second Part of the First Stage of Bipclar Version. WHEN HEAD BECOMFS EXTFNDED, (After R. Barnes.) 


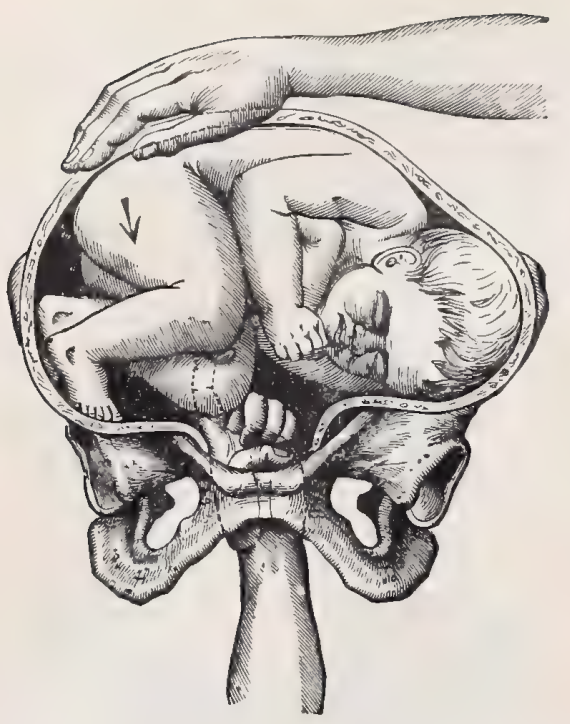

Second Stage of Bipolar Version. (Afler R. Bames.)

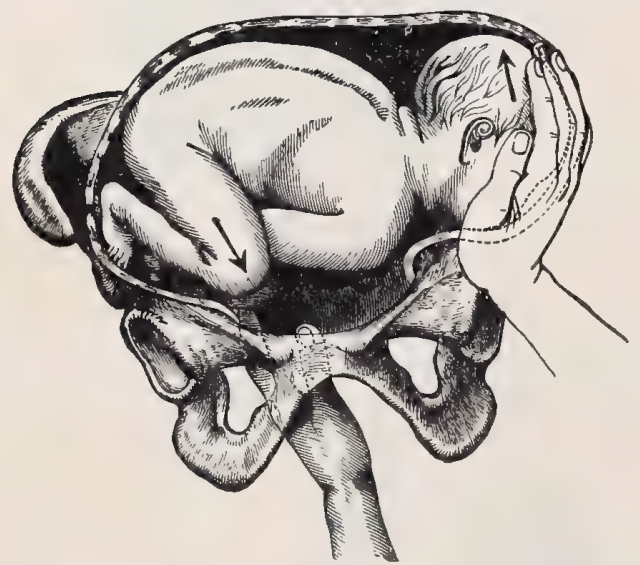

Commencement of Third Stage of Bipolar Version. (After R. Barnes.)

Vertebra (ver'-te-brah) [vertere, to turn: pl., Vertebra]. The vertebre in man are the 33 bones forming the spine or vertebral column, divided into 7 cervical, 12 thoracic or dorsal, 5 lumbar, 5 sacral, 4 coccygeal. In a wider sense any axial metamere of the skull or of the neuroskeleton is called a vertebra. V., Basilar, the last lumbar vertebra. Væ., Caudal, the vertebræ of the tail. Væ., Cephalic, the bones of the skull considered as vertebral in type. Væ., Cranial, vertebræ formed of the cranial bones and the osseous and cartilaginous appendages of the skull. V. dentata, the axis, or second cervical. Væ., Dorsal, same as $V \mathfrak{a}$., Thoracic. Væ., False, or Fixed, the united portions of the coccyx and the sacrum. Væ., Pelvic. Same as Va., Sacral. V. prominens, the seventh cervical. Væ., Sacral, the five bones entering into the formation of the sacrum. Væ., Thoracic, the costiferous vertebræ, numbering twelve in man. V.,

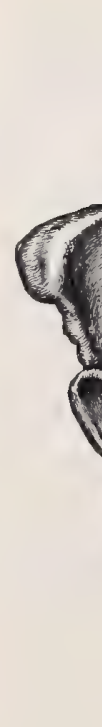

SECOND PART OF THIRD STAGE OF BIPOLAR VERSIoN. (After R. Barnes.)

Tricuspid, in lower animals the sixth cervical vertebra. Væ., True, the cervical, thoracic, and $1 \mathrm{umbar}$ vertebræ. Those which are not fused in adult life. Væ., United. Same as Va., False.

Vertebral (ver'-te-bral) [vertebralis]. Pertaining to or characteristic of a vertebra; made up of or possessing vertebræ. V. Canal. See Canal. V. Column, the spine, or back-bone, composed of the vertebræ.

Vertebrarterial (ver-tebrar-te'-re-al) [vertebra, vertebra; ả $\rho \tau \varepsilon \varepsilon \varepsilon i a$, artery]. Belonging or pertaining to the vertebral arteries or veins.

Vertebrata (ver-te-bra'tah) [vertebra, a vertebra]. In biology, a great division of the animal kingdom, including all animals having a spinal column, or its equivalent body axis.

Vertebrate (ver'-te-bra $\bar{a} t)$ [vertebra, vertebra]. Having or pertaining to vertebræ.

Vertebration (ver-te-bra'-shun) [vertebra, vertebra]. 
Separation into vertebre, or into metameres resembling the vertebre.

Vertebro-basilar (ver-te-bro-bnz'-il-ar) [vertebra, verte-

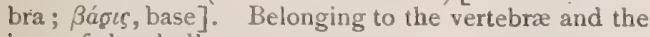
base of the skull.

Vertebro-chondral (ver-te-bro-kon'-dral) [vertebra

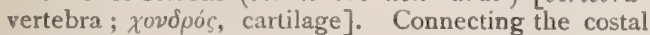
cartilages with the vertebræ.

Vertebro-costal (ver-te-bro-kos'-tal) [vertebra, vertebra; costa, rib]. Pertaining to the vertebræ and the ribs.

Vertebrodidymia (ver-te-bro-did-im'-e-ah) [vertebra,

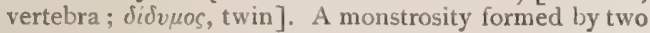
individuals united by the vertebre.

Vertebro-femoral (ver-te-bro-fent'-or-al) [vertebra, vertebra; femur, femur]. Pertaining to the vertebral column and the femur.

Vertebro-iliac (ver-te-bro-ill-e-ak) [vertebra, vertebra; ilium, ilium]. Pertaining to the vertebræ and the ilium.

Vertebrosacral (ver-te-bro-sa'-kral) [vertebra, vertebra; sacmu, sacrum]. Pertaining to the sacral and antecedent vertebræ.

Vertebrosternal (ver-te-bro-stur'-nal) [vertebra, vertebra; ớ́pvov, sternum]. Extending, as a rib, from the spinal column to the sternum. V. Ribs, the true ribs.

Vertebrum (ver'te-brum) [L.]. The head of the femur.

Vertex (ver'-teks) [L.]. The crown or top of the head. The apex of an organ. See Craniometric Points.

Vertical (ver'-tik-al) [vertex, a polar axis]. Pertaining to the vertex. In a direction at an angle of $90^{\circ}$ with the horizontal. V. Diameter of Cranium, an imaginary line from the basion to the bregma.

Verticil (ver'-tis-il) [verticillus, the whirl of a spindle]. In biology, a whorl; a circle of leaves, tentacles, hairs, organs, or processes radiating from an axis on the same horizontal plane.

Verticillaster (ver-tis-il-as'-ter) [verticillus, the whirl of a spindle]. In biology, a term applied to the pairs of opposite cymes that occur in the axils of the leaves of mints, and at first sight resemble whorls.

Verticillastrate (ver-tis-il-as'-trât) [verticillus, the whirl of a spindle]. Arranged in verticillasters.

Verticillate (ver-tis-il'-at) [verticillus, a whirl]. Whorled. V.-pilose, pilose or hairy in whorls.

Verticillation ( $\left.\tau^{\prime} e r^{\prime}-t i s-i l-a^{\prime}-s h u n\right)$ [verticillus, a whirl]. The formation of a verticil.

Verticillus (ver-tis-il'-us) [L.]. A verticil.

Vertico-mental (ver-tik-o-men'-tal) [vertex, vertex; mentum, chin]. Pertaining to the vertex and the chin. V. Triangle. See Triangle.

Vertiginous (ver-tij'-in-us) [vertere, to turn]. Resembling or affected with vertigo. V. Status, a term applied to the condition in which paroxysms of vertigo occur in rapid succession.

Vertigo (ver'-tig-o) [L., vertere, to turn]. Giddiness, dizziness. The sensation of a lack of equilibrium. This condition may be due to pathologic conditions of the ears (Auditory $V$.), the eyes (Ocular $V$.), the brain (Cerebral $V_{\text {.) }}$, the stomach (Gastric $V$.), the blood, etc. It may be subjective or objective. V., Auditory. See Menière's Disease. V., Aural, labyrinthine vertigo, or Ménière's Disease. V., Bilious, vertigo due to derangement of hepatic function. V., Cerebral, vertigo caused by cerebral disorder. V., Epileptic, vertigo due to or associated with epilepsy. V., Essential, when no abnormalism of the body can be found to account for it. V., Gastric. Same as $V$., Stomachal. V., Horizontal, vertigo which appears IOI when the patient assumes a horizontal position. V., Intestinal, vertigo caused by intestinal disorder. V., Labyrinthine. See Ménière's Disease. V., Laryngeal, a name applied to a group of symptoms of rare occurrence that may appear in connection with recognized nervous diseases, as posterior spinal sclerosis or epilepsy, or without obvious explanation. It is acconpanied by pain or spasm of the larynx, and perhaps syncope. V., Lateral, vertigo which is due to the rapid passing of similar objects, as fence-palings. V., Mechanical, vertigo caused by mechanical movements. V., Ménière's. See Ménière's Disease. V., Neurasthenic, subjective vertigo found in neurasthenia. V., Objective, when objects seem to the patient to move. V., Paralyzing. See Gerlier's Disease. V., Riders', dizziness occurring in some persons from riding in the cars. V., Rotatory, vertigo produced by rotation of the body, or by seeing rotating objects. V., Smokers', a form of vertigo occurring chiefly in men past fifty years of age, especially those accustomed to smoke before meals. It may be arterio-sclerotic in character. V. Stomachal, vertigo arising from dys pepsia. V., Subjective, when the patient himself seems to move. V., Vertical, vertigo caused by looking downward from or upward to a height.

Verugas (ver-u'-gas). Same as Verrugas.

Verumontanum (ver-u-mon'-ta-num) [veru, a spit ; mons, a mountain ]. The caput gallinaginis, a longitudinal ridge on the floor of the canal of the male urethra.

Vesalius, Foramen of. See Foramina, Table of. V., Glands of. See Gland. V., Ligament of, Poupart's ligament: V., Vein of. See Vein.

Vesania (ves-a'-ne-ah) [L.]. Unsoundness of mind.

Vesica $\left(v e s^{\prime}-i k-a h\right)$ [L.: gen, and pl., Vesica]. The bladder.

Vesical (ves'-ik-al) [vesicalis; vesica, a bladder]. Pertaining to or having the nature of a bladder. $\mathbf{V}$. Triangle. See Triangles, Table of.

Vesicant (ves'-ik-ant) [vesicare, to blister]. I. Blistering. 2. A blistering agent or application.

Vesication (ves-ik-n'-shun) [vesicatio; vesicare, to blister]. The formation of a blister; a blister.

Vesicatory (ves'-ik-at-or-e) [vesicatorium]. A medicine or agent that, applied to the skin, produces a blister.

Vesicle $\left(\right.$ ves $\left.^{\prime}-i k-l\right)$ [vesica, bladder, blister]. In biology, a small, membranous, bladder-like formation. See also Prpule. V., Allantoic, the internal portion of the allantois. V., Auditory, the sac in the fetus from which the internal ear is formed. V. of Baer, the ovum of the Graafian vesicle. V. of Balbiani. Same as Yolk-nucleus. V., Blastodermic. See Blastoderm. V., Blood. A Blood-corpuscle. Vs., Cerebral. Same as $V_{s}$., Encephalic. Vs., Encephalic, the divisions of the cephalic extremity of the primitive neural tube; they are formed early in fetal life and constitute the protons of the segments of the brain. V., Germinal. See Macula and Zona pellucida. V., Gland. Same as Acinus. Vs., Graafian, the ovisacs of the ovary containing the ova. V., Kupffer's. See Kupffer. V., Malignant. Synonym of Contarious Anthrax. Vs. of Naboth. Same as Ovule of Naboth, q. v. V., Ocular, a protrusion in the fetus that is the first indication of the eye. V., Olfactory, the primitive vesicle which develops into the olfactory lobe. V., Otic, a pear-shaped, closed sac of the embryonic inner ear formed by the fusion of the lips of the auditory pit, and giving rise by a diverticulum to the recessus vestibuli. See $V$., Auditory. V., Pituitary, the primitive vesicle which develops into the hypophysis. V. of Purkinje. See 
Macula. V., Seminal, the lobulated pouches of a membrane between the base of the bladder and the rectum that serve as reservoirs for the semen. V., Umbilical. See Yolk-sac.

Vesico-(ves'-ik-o-) [vesica, bladder]. A prefix to denote relation to or connection with the bladder.

Vesico-abdominal (ves'-ik-o-ab-dom'-in-al) [vesica, bladder; abdomen, abdomen]. Belonging to the abdomen and the urinary bladder.

Vesicocele (ves'-ik-o-sèl) [vesica, bladder; $\kappa \eta n \lambda \eta$, hernia]. Hernia of the bladder.

Vesico-cervical (ves'-ik-o-ser'-vik-al) [vesica, bladder; cervix, cervix]. Belonging to the cervix uteri and the urinary bladder.

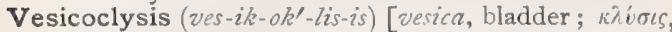
a drenching]. The injection of fluid into the bladder.

Vesico-prostatic (ves'-ik-o-pros-tat'-ik) [vesica, bladder; $\pi \rho \circ \sigma \tau a ́ \tau \eta s$, prostate]. Belonging to the prostate gland and the urinary bladder.

Vesico-pubic (ves'-ik-o-pu'-bik) [vesica, bladder; pubis, pubis]. Pertaining to the urinary bladder and to the pubes.

Vesico-rectal (ves'-ik-o-rek'-tal) [vesica, bladder; rectum, rectum]. Pertaining conjointly to the bladder and the rectum.

Vesico-spinal (ves'-ik-o-spi'-nal) [vesica, bladder; spina, spine]. Belonging to the urinary bladder and the spinal cord.

Vesicotomy (ves-ik-ot'-o-me) [vesica, bladder; $\tau \hat{\varepsilon} \mu \nu \varepsilon \iota \nu$, to cut]. Incision of the bladder, usually of the urinary bladder.

Vesico-umbilical (ves-ik-o-um-bil'-ik-al) [vesica, bladder; umbilicus, umbilicus]. Belonging to the umbilicus and the urinary bladder.

Vesico-uterine (ves-ik-o-u'-ter-in) [vesica, bladder; uterus, uterus]. Belonging to the uterus and the urinary bladder. V.-u. folds, two semilunar folds which pass between the neck of the uterus and the posterior surface of the bladder.

Vesico-vaginal (ves'-ik-o-vaj'-in-al) [vesica, bladder; vagina, vagina]. Pertaining conjointly to the bladder and the vagina.

Vesicula (ves-ik'-u-lah) [dim. of vesica, a bladder : $p l$., Vesicula]. A vesicle or papule containing lymph. Applied, also, to a number of pouches or bladder-like bodies. V. cordylares, cordylar auditory vesicles of the Marmonemide and Geryonide among Medusce. V. graafianz, the vesicles in the outer layer and stroma of the ovary, each of which contains an ovum. V. nabothi, the small glandular bodies within the mouth of the uterus. V. prostatica, the depression or cul-de-sac, called, also, the sinus pocularis, which traverses the prostate gland beneath its middle lobe. It is the male homologue of the uterus, developed from the Müllerian ducts. V. seminales, the two lobulated, membranous pouches between the base of the bladder and the rectum. They constitute reservoirs for the semen. V. serosa, the false amnion. See Amnion.

Vesicular (ves-ik'-u-lar) [vesicula, a little bladder]. Pertaining to or having vesicles. V. Breathing or Murmur, the fine, normal, inspiratory, auscultatory sound heard over the chest. V. Column, the ganglionic column of the spinal cord. V. Column, Posterior. See Clarke's Column. V. Cylinder, Clarke's column. V. Eczema, eczema attended with the formation of vesicles. V. Emphysema. See Emphysema. V. Erysipelas, erysipelas attended with the formation of vesicles. V. Fever. Synonym of Pemphigus. V. Germ. See Blastosphere. V. Glands, in biology, glands containing a volatile oil placed just beneath the epidermis of a leaf or of the bark. V. Quality, the quality of sound characterizing the vesicular respiratory murmur. V. Râle. See Râle. V. Resonance. See Resonance. V. Stomatitis. Same as Stomatitis, Aphthous.

Vesiculate (ves-ik'-u-lāt) [vesicula, a little bladder]. I. Having a vesicle. 2. To become vesicular.

Vesiculated (ves-ik'-u-la-ted) [vesicula, a little bladder]. Hydatidiform; appearing like a bunch of grapes.

Vesiculation (ves-ik-u-la'-shun) [vesicula, a little bladder]. The formation of vesicles; the condition of having vesicles.

Vesicule (ves'-ik-iul). Same as Vesicle.

Vesiculiferous (ves-ik-u-lif'-er-us) [vesicula, bladder; ferre, to bear]. Bearing or having vesicles.

Vesiculiform (ves-ik'-u-lif-orm) [vesicula, a little bladder; forma, form]. Having the form of a vesicle.

Vesiculitis (ves-ik-u-li'-tis) [vesicula, vesicle; $\iota T \iota s$, inflammation]. Inflammation of the seminal vesicles.

Vesiculo-bronchial (ves-ik'-u-lo-brong'-ke-al) [vesic$u l a$, vesicle; $\beta \rho b \gamma$ xos, bronchus]. Both vesicular and bronchial, as a vesiculo-bronchial respiratory murmur.

Vesiculo-cavernous (ves-ik'-u-lo-kav'-er-nus) [vesicula, vesicle; cavernous]. Partaking of both vesicular and cavernous qualities.

Vesiculose (ves-i $\left.k^{\prime}-u-l \bar{o} z\right)$ [vesicula, a vesicle]. Vesiculiform.

Vesiculo-tubular (ves-ik'-u-lo-tu'-bu-lar) [vesicula, vesicle; tubulus, a tubule]. Both vesicular and tubular (a qualification for certain respiratory sounds).

Vesiculo-tympanitic (ves-ik'-u-lo-tim-pan-it'-ik) [ves-

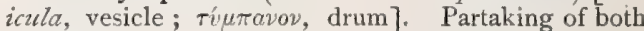
vesicular and tympanitic qualities.

Vesiculous (ves-ik'-u-lus). Same as Vesicular.

Vesiculus (ves-ik'-u-lus) [L.]. Same as Vesicle.

Vespajus (ves-pa'-jus) [vespa, a wasp]. A follicular and suppurative inflammation of the hairy part of the scalp.

Vespertine (ves'-per-tin) [vesper, evening]. In biology, of or pertaining to the evening ; crepuscular, as many beetles, moths, bats, and birds, which are active at twilight.

Vespiary (ves'-pe-a-re) [vespa, a wasp]. In biology, a wasp's nest. Cf. Apiary.

Vespiform (ves'-pif-orm) [vespa, wasp; forma, form] Wasp-like.

Vesque's Method. A method of producing crystals, resembling in most respects those which are found in plant-cells. Three test-tubes are placed side by side; in the first is a moderately strong solution of calcic chlorid, in the middle one a 5 per cent. solution of sugar, and in the third a solution of potassic oxalate, From the liquid in the first a short strip of filtering paper runs to that in the second, and a similar strip passes from the second to the third test-tube ; and thus the liquids in the three tubes are brought into direct contact. Crystals will be formed in the middle tube, their character depending upon the nature of the liquid there. In a solution of sugar, raphides are produced; in pure water, prisms of small size, but with sharply defined faces and angles. (Goodale.)

Vessel (ves'-el) [ME., vessel, vessel]. Any tube or canal through which the fluids, especially the blood, of the body circulate. See Vas, Artery, Vein, Capillary, Lymphatic. Vs., Absorbent, the lymphatics and lacteals. V., Chyliferous, absorbent vessels extending from the intestinal walls to the thoracic duct. Vs., Hemorrhoidal, varicose veins of the rectum. Vs., Lacteal. Same as $V_{s}$, Chyliferous. Vs., Umbilical, the umbilical arteries and veins.

Vestibular (ves-tib'-u-lar) [vestibulum, porch]. Pertaining to any vestibulum or vestibule. 
Vestibulate (ves-tib'-u-lāt) [vestibulum, vestibule] Having a vestibule; vestibular.

Vestibule (ves'-tib-ül) [vestibulum, a porch]. A porch or threshold. V., Aortic, the space formed by the left ventricle adjoining the root of the aorta. $\mathbf{V}$. of the Ear, the oval cavity of the internal ear, which forms the entrance to the cochlea. V. of the Mouth, that portion of the mouth outside of the teeth. V. of the Nose, the external nostrils. V. of the Ventricles, the entrance to the ventricles of the brain. V. of the Vulva. See Bulbi vestibuli.

Vestibulum (ves-tib'-u-lum) [L. : gen., Vestibuli; pl., Vestibula]. See Vestibule. Especially applied to the vestibule or cavity of the internal ear. It is situated behind the cochlea and in front of the semicircular canals.

Vestige (ves'-tij) [vestigium, foot-print]. In biology, a trace, sign, or remnant of something formerly present or more fully developed. See Rudiment, Vestigial.

Vestigia (ves-tij'-e-ah) [L, plural of Vestigizm ]. Parts of the body that may have no evident use in man, and yet may subserve important functions in lower animals, $e . g$., the muscles of the external ear. V. rerum [L., "foot-prints of things"], the hypothetic changes which sensations impress upon the brain-substance, and which serve as a physical basis for memory.

Vestigial (ves-tij'-e-al) [vestigium, a vestige]. Of the nature of the vestigia. Existing only as a trace or vestige of what formerly existed; rudimentary. V. Reflex. See Reflex.

Vestigiary (ves-tij'-e-a-re) [vestigizm, foot-print]. Vestigial.

Vestigium (ves-tij'-e-um) [L., a foot-print: $p l$., Vestigia]. An anatomic relic of fetal or embryonic life. Thus, the thymus gland becomes in adults a vestigium.

Vestiture (ves'-tit-vir $)$ [vestire, to dress, clothe]. In biology, the epidermal investment, as hair, feathers, scales.

Vesuvin (ve-su'-vin) [Vesuvius, a volcano near Naples]. Bismarck brown; triamidobenzol; phenylene-brown; used as a histologic stain. See Pigments, Conspectus of.

Veta $\left(v e^{\prime}-t a h\right)$. See Mareo.

Veterinarian (vet-er-in-a'-re-an) [veterinarius, of or belonging to beasts of burden]. One who practises veterinary medicine.

Veterinary (vet'-er-in-a-re) [veterinarius]. Pertaining to animals. V. Medicine, the art and science of medicine as applied to the domestic animals.

Veternomania (vet-er-no-ma'-ne-ah) [veternus, lethargic ; $\mu a v i \alpha$, mania]. Typhomania.

Veternositas (vet-er-nos'-it-as) [veternus, old, lethargic]. Same as Coma-vigil.

Vetiveria (vet-iv-e'-re-ah) [E. Ind, vettivayr]. A grass, Andropogon muricatus, of S. Asia. It affords a highly fragrant, volatile oil, and its infusion is refrigerant. Unof.

Vexillar (veks'-il-ar) [vexillum, standard]. Same as Vexillary.

Vexillary (veks'-il-a-re) [vexillarius, a standard-bearer]. In biology, applied to that form of imbricate estivation observed in the corolla of the pea, in which the other petals are enwrapped by the vexillum.

Vexillate (veks'-it-ât) [vexillum, a standard]. In biology, having vexilla or pogonia.

Vexillum (veks-il'-um) [vehere, to carry: pl., Vexilla]. In biology, the upper and largest of the five petals of a papilionaceous flower.

Via $\left(v i^{\prime}-a h\right)[$ L. : pl., Via]. A way. Vice naturales, the natural passages. See also Prima via.
Viability (vi-ab-il/-it-e) [viabilis, viable]. Ability to live; applied to the condition of a child at the time of birth.

Viable $\left(v i^{\prime}-a b-l\right)$ [viabilis, viable]. Capable of living, or likely to live; applied to a child born in a condition of development which will permit of its living.

Vial $\left(\nu i^{\prime}-a l\right)[\phi i a ́ \lambda \eta]$. A small, glass bottle.

Viand (vi'-and) [Fr., viande]. Food; sustenance.

Vibex (vi'-beks) [L.: pl. Vibices]. Any ecchymosis occurring in lines of varying width, from about an eighth of an inch to one inch. See Purpura.

Vibracularium (vi-brak-ul-la'-re-um). Same as Vibraculum.

Vibraculum (vi-brak'-u-lum) [vibrare, to shake: pl., Vibracula]. In biology, one of the peculiar appendages found on the stocks of many chilostome Bryozoa. They consist of prominences on the wall of the ordinary individuals (zöecia) each of which carries a long seta, by the free movement of which the water surrounding the colony is kept in motion and particles of food brought within reach. Cf. Avicularia and Flabellarium.

Vibratile (vi'-bra-til) [vibrare, to shake]. Capable of vibrating.

Vibrating (vi'-bra-ting) [vibrare, to shake]. Shaking; oscillation. V.Arm-chair. See Shaking-cure.

Vibration (vi-bra'-shun) [vibratio; vibrare, to shake]. A swinging, oscillation, or thrill, like that of the string of a musical instrument; fremitus. In massage, a modification of the kneading-movement. It consists in making the alternate successive pressures and relaxations with very great rapidity. This may be done by the hand, but is better performed by means of some form of machine.

Vibrative (vi'-bra-tiv). See Consonants.

Vibrio (vib'-re-o) [vibrare, to vibrate]. A genus of Schizomycetes. See Bacteria, Synonymatic Table of.

Vibrion (vib'-re-on) [vibrare, to vibrate: $p l$, Vibriones]. A member of the genus Vibrio.

Vibrissa (vi-bris'-ah) [vibrissa, the hairs in the nostrils : pl., Vibrissa]. In biology, one of the tactile bristles growing about the mouths of various animals, as cats, the whippoorwill, and other birds, insects, etc.

Vibrophone (vi'-bro-fon) [vibrare, to vibrate; ' $\phi \omega v \eta \dot{n}$, sound]. An instrument for conveying vocal vibrations to the ear.

Viburnin (vi-bur'-nin) [viburnum, the wayfaring tree]. A precipitate from a tincture of Viburnum opulus; anti-spasmodic, anti-periodic, expectorant, tonic. Dose I to 3 grains. Unof.

Viburnum (vi-bur'-num) [L.;gen., Viburni]. I. A genus of caprifoliaceous trees and shrubs, of some 80 species. V. dentatum, is diuretic. V. lantana is vesicant. V. obovatum has antiperiodic properties. V. opulus, "Cranberry tree," "Cranebark," is an efficient remedy in uterine and abdominal pains. V. prunifolium, black have; the bark is used. It contains a resin, viburnic acid, identical with valerianic acid and other extractives. It is astringent and antispasmodic, with decided nervine properties. It is useful in the nervous diseases of pregnancy. Dose

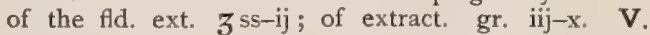
tinus is purgative. Liquor sedans, a utero-ovarian sedative and anodyne. Each fluid-ounce contains of black haw and golden seal each gr. Ix, Jamaica dogwood gr. xxx, aromatics q.s. Dose $3 \mathrm{j}-\mathrm{ij}$. The socalled Hayden's Viburnum Compound is said to be composed of the active principles of $V$. opulus, Dioscorea villosa, Scutellaria lateriflora, and aromatics. See, also, Dockmackamus.

Vicarious (vi-kn'-re-us) [vicarius; vice, in the place of ]. Substitutive; taking the place of another; 
applied to the assumption of the functions of one organ by another. V. Menstruation. See Menstru ation.

Vice (viss) [ME., vice, vice]. Defect, fault, or deformity. V. of Conformation, defect of structure, organs or parts being either absent or imperfect. See Malformation.

\section{Vichy Salt}

-she) [Fr.]. A compound salt (sal vichyanum) supposed to represent the saline constituents of the Grande Grille spring at Vichy, in France. The N.F. has a formula for its preparation. It is recommended as diuretic, alterative, and antiarthritic Unof. V. Water, a well-known, mildly laxative and antacid mineral water. Its main constituent is sodium bicarbonate.

Vicq d'Azyr, Bundle of. See Bundle. V., Foramen of. See Foramina, Table of. V., Operation of, rapid tracheotomy. Incision of the crico-thyreoid membrane. V.'s White Line, a thin stratum of white matter between the strata of the cinerea in the occipital region of the brain. See Lines, Table of.

Victoria (vik-to'-re-ah) [L., victory]. A genus of water-lilies. V. Blue. Same as Night Blue. V. Green. Same as Chrome Green and Malachite Green. V. Orange, Same as $V$. Yellow. V. Yellow. See Pigments, Conspectus of.

\section{Vicuna (vi-ku'-nah). See Alpaca}

Vidard (ve-dahr') [Fr.]. The French term for a horse affected with chronic intestinal catarrh due to the presence of Ascaris megalocephala.

Vidian (vid'-e-an) [after Guido Guidi, Latinized Vidius, an Italian anatomist]. Relating to Vidius the anatomist. V. Artery. See Arteries, Table of. V. Canal. See Canal. V.Foramen. See Foramina, Table of. V. Nerve, the union of the great petrosal and carotid nerves entering Meckel's ganglion. See Nerves, Table of.

Vienna (ve-en'-ah): The capital of Austria. V. Caustic. Same as $V$. Paste. V. Draught, compound infusion of senna. V. Green. Same as Schweinfurth Green. V. Lime. Same as V. White. V.Method, a method of examining the spinal cord from the front in performing an autopsy. The thoracic and abdominal viscera having been removed, the body of the fifth lumbar vertebra is cut away, and then the pedicles of the vertebræ are successively divided from below upward. The bodies being lifted off, the spinal canal is exposed. V. Mixture. See Anesthetic. V. Paste. See Potassium. V. Powder. See Powder. V. System. See Merz System. V. White. See Pigments, Conspectus of.

Vieussens, Annulus of. See Ammulus. V., Valve of. See Valve.

Vigilantia (vij-il-an'-she-ah) [L.]. Wakefulness; insomnia.

Vignal, Bacillus of. See Bacteria, Synonymatic Table. Vigo's Powder. See Powder

Villatte's Liquor. A preparation used for injecting into carious bones. It consists of sulphate of zinc and sulphate of copper, each fifteen grains, solution of the subacetate of lead, half a dram, and dilute acetic acid, three and a half drams.

Villi (vil'-i). Plural of Villus, a tuft. Tufts of hair, or hair-like processes or projections of a mucous membrane giving it a velvety. appearance. V. of the Chorion, fringes growing from the external surface of the vitelline membrane, finally covering the entire chorion. V., Intestinal, minute, highly vascular tonguelike processes projecting from the free surface of the mucous membrane of the small intestine throughout its whole extent. They are larger and more numerous in the duodenum and jejunum and are fewer and smaller in the ileum. They constitute the chief organs of absorption of fatty emulsions. V. pericardiaci, villi upon the ental surface of the pericardium. V. peritoneales, villi upon the free surface of the peritoneum. V.plurales, villi on the parietal pleura. V. Synovial, small, tongue-like processes projecting from the fringes of synovial membranes.

Villiform (vil'-if-orm) [villus, villus; forma, form]. Villose in form

Villiplacental (vil-ip-las-en'-tal) [villus, villus; placenta]. Having a tufted or villous placenta.

Villitis (vil-i'-tis) [villus, villus; $\iota T \iota S$, inflammation]. Inflammation of the cusbion or soft part of the wall of a horse's hoof. See Coronitis.

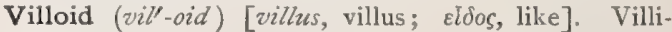
form.

Villose, Villous (vill'-ōz, vill'-us) [zillus, hair]. Pertaining to or having the nature of villi. Having a pile like that of velvet. See Villi. Covered with long, soft, shaggy hairs.

Villosity (vil-os'-it-e). [villous, shaggy]. The state of being villous.

Villus (vil'-us) [L., a shaggy hair: pl., Villi, q.v.]. In anatomy: $\mathbf{I}$. One of numerous minute vascular projections from the $\mathrm{mu}$ cous membrane of the intestine, of a conic, cylindric, clubbed, or filiform shape. It consists essentially of a lacteal vessel as a central axis, with an arteriole and a veinlet enclosed in a layer of epithelium. 2. One of the vascular tufts of the chorion. In biology, one of the long, straight, and soft hairs occasionally covering the fruit, flowers, and other parts of plants.

Vimen $\left(v i^{\prime}-\right.$ men $)$ [L.]. A long and flexible shoot of a plant.

Vimenal (vim'-en-al) [vimen, a twig]. Pertaining to twigs or shoots.

Vimeneous (vi-men'-e-us) [vimen, a pliant twig]. In biology, producing slender twigs, such as those used for wicker-work

Vina (vi'-nah) [L., Plural of Vinum, wine]. Wines. V. medicata, medicated wines.

Vinaceous $\left(v i-n a^{\prime}-s h u s\right)$ [vinaceus, pertaining to wine].

Vinasse (ve-nas') [Fr.]. Potash obtained from the marc or residue of the wine-press. Also, the residuum in a still after distillation.

Vinca (ving'-kah) [L., periwinkle]. A genus of apocynaceous plants, the periwinkles. V. major and $\mathrm{V}$. minor are astringent, vulnerary, and antigalactic. Unof.

Vincula (vin'-ku-lah) [L.]. Plural of Vinculum. V. accessoria tendinum. The slender, tendinous filaments which connect the phalanges with their tendons.

Vine ( $\tilde{i}_{n} n$ ) [vinea, a vine]. A climbing plant with a woody stem. V.-disease, a disease of the grapevine due to the phylloxera.

Vinegar (vin'-e-gar) [vin, wine; aigre, sour]. Dilute and impure acetic acid, obtained by acetous fermen. 
tation. See Acelum, and Acill, Acetic. Wine-vinegar varies in color from light-yellowish to red, according as it has been derived from white or red wines, that from the former being the most highly esteemed. The vinegar from red wines, however, can be decolorized by filtration through purified bone-black. Winevinegar has a specific gravity of $\mathbf{1 . 0 1 4}$ to $\mathbf{I . 0 2 2}$, and contains from six to nine per cent. (rarely 12) of absolute acetic acid. Malt-vinegar and Beer-vinegar have a specific gravity of from I.O2I to I.O25, and contain dissolved dextrin, maltose, soluble albuminoids, and similar constituents of the malt-extract. It contains only from three to six per cent. of acetic acid. Spirit-vinegar is colorless as produced, but is frequently colored with caramel to imitate the appearance of wine or cider vinegar. It contains from three to eight per cent. of acetic acid, although the so-called "vinegar essence" (double vinegar) may contain as much as I4 per cent. Cider-vinegar is yellowish-brown, has an odor of apples, a density of from I.OI3 to I.OI5, and contains from three and a half to six per cent. of acetic acid. It is distinguished from the other varieties by yielding on evaporation a mucilaginous extract smelling and tasting like baked apples and containing malic acid, which replaces the tartaric acid of the winevinegar. Glucose-vinegar, or Sugar-vinegar, prepared from different saccharine and amylaceous materials by conversion with dilute acid, followed by fermentation and acetification, contains dextrose, dextrin, and often calcium sulphate. It is said to be employed in France and England for adulterating wine-vinegar, or malt-vinegar. Factitions vinegars are often made from pyroligneous acid flavored with acetic ether and colored with caramel. Such a product differs from malt-vinegar in containing no phosphates, and from wine-vinegar or cider-vinegar in the absence of tartaric and malic acids respectively. V. Essence. See Vinegar.

Viniferous (vi-nif'-er-us) [vimum, wine; ferre, to bear]. Wine-bearing.

Vinometer $\left(v i^{\prime}-n o m-e t-e r\right)$ [vimum, wine; $\mu \varepsilon ́ t \rho o \nu$, measure]. An instrument for measuring the percentage of alcohol in a liquor.

Vinose $\left(v i^{\prime}-n z \bar{o} z\right)$. Same as Vinous.

Vinous (vi'-nus) [vinosus; vinum, wine]. Having the nature or flavor of wine, alcoholic

Vinum $\left(v i^{\prime}-n u m\right)$ [L.: gen., Vini; pl., Vina]. Wine. The fermented juice of fruits, especially that of grapes. White wines are made from the pulp; red wines from the pulp and skins, the latter yielding the coloring-matter. Each should contain 10-12 per cent. of alcohol. There are nine official vina. V.absinthiatum, wormwood-wine; made by macerating Artemisia absinthium in white wine. V. album, white wine, an alcoholic liquid made by fermenting the juice of the fresh grape; it contains from to to 14 per cent. by weight of absolute alcohol. V. album fortius is made from $V$. album by fortifying the latter until it contains 20-25 per cent. of alcohol. Sureet zuines, such as Burgundy, Tokay, Muscatel, Angelica, etc., seldom exceed 6-7 per cent. of alcohol unless fortitied. Light red wines, such as claret, contain normally about 5 per cent. Sparkling wines, such as champagne, derive their quality from the presence of carbon dioxid, being bottled before fermentation. They contain 1O-I2 per cent. of alcohol. V. antimonii, wine of antimony. Dose $m_{x-x x x} \quad V$. aromaticum consists of strong white wine 94 per cent., with one per cent. each of lavender, origanum, peppermint, rosemary, sage, and worm wood. $\mathrm{V}$. colchici radicis, wine of colchicum-root. Dose $\eta_{v-x x} V$. colchici seminis, wine of colchicum-seed. Dose $m_{\mathrm{x}-\mathrm{xxx}}$. V. ergotæ, wine of ergot. Dose $\mathrm{f} \mathbf{z}-$ iij. V. ferri amarum, bitter wine of iron. Dose

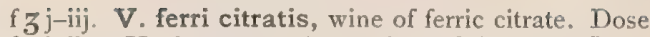

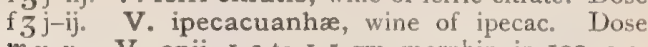
m v-x. V. opii, I. 3 to $1.5 \mathrm{gm}$. morphin in roo c.c. Dose $m^{\nabla-x v}$. V. portense, Port wine, is fortified with 25-30 per cent., and V. xericum, Sherry wine, until it contains about 25 per cent. of alcohol. There are I4 official vini, of which II are medicated. V. rubrum, red wine. An alcoholic liquid made by fermenting the juice of the fresh, colored grapes, the fruit of Vitis vinifera, in the presence of their skins. It contains from IO-I 4 per cent. by weight of absolute alcohol. Vini, Spiritus, Gallici, brandy.

Vinyl (vin'-il), $\mathrm{C}_{2} \mathrm{H}_{3}$, a hypothetical trivalent radicle existing in acetic aldehyde.

Viola $\left(v i^{\prime}-0-l a / l\right)$ [L., violet]. A genus ${ }^{\circ}$ of plants, including the true violets and pansies. $\mathrm{V}$. canina has an emetic and cathartic root. V. odorata has fragrant flowers, which are made into a lenitive syrup. V. pedata of the U.S. is demulcent and expectorant. V. tricolor, pansy; a wild flower sometimes known as heart's-ease pansy. It contains an alkaloid, violin, with emeto-cathartic properties. It is mucilaginous and expectorant. Dose gr. $x-z \mathrm{j}$.

Violanilin (vi-o-Lan'-il-in). See Pigments, Conspectus of.

Violation (vi-o-la'-shun) [violatio; violare, to ravish]. Rape. Sometimes used to express the fact of coitus without force, but by deception, with the weakminded, etc.

Violet (vi'-o-let) [viola, violet]. I. A popular name for viola. 2. One of the colors of the rainbow which very closely resembles the purple of violets. 3. A dye-stuff. V.-blindness, retinal insensibility to violet tints. V., Gentian, a violet anilin dye used for staining in histologic and bacteriologic work. V., Methyl, an anilin dye used in the same way as $V$., Gentian.

Violette's Solution. See Sugror.

Violin (vi'-o-lin) [viola, violet]. An emetic principle found in Viola odorata, V. tricolor, and other violets; said to be probably identical with emetin. Unof.

Violinists' Cramp. See Cramp.

Viraginity (vir-aj-in'-it-e) [virago, a woman]. A form of sexual perversion in which the male individual is essentially effeminate in his feelings and tastes.

Viragint (vir'-aj-int) [virgo, a virgin]. A male given to viraginity.

Virchow's Method (of opening the heart). The heart is opened in situ. The first incision is made in the right ventricle (many open the right auricle first) along the ventricular ridge, from near the auriculo-ventricular groove to near the apex. The second incision opens the right auricle midway between the entrances of the venæ cavæ. In the left auricle the incision is carried from the left superior pulmonary vein to near the auriculo-ventricular ring. The incision through the left ventricle begins just behind the base and ends just short of the apex. It must be carried deeply through the wall of the heart. The heart is now removed. To do this the organ is grasped with the index finger of the left hand in the left ventricle and the thumb in the right; the heart is then raised by the apex and the venæ cavæ, the pulmonary veins, and the pulmonary artery, and the aorta divided, taking care that the incisions are not too close to the heart. The next step is to open the ventricles. For this purpose the heart is placed exactly in the position it occupied in the body. One blade of the scissors is then introduced near the lower end of the incision in the right ventricle and carried outward in the direction of the pulmonary artery. The incision for the left ventricle commences at the apex of the heart and divides the anterior wall of the ventricle close to the septum, and is continued out through 
the aorta. These are the principal incisions; it is cus tomary, however, to make at least two others, viz., one connecting the incision in the right auricle with that in the right ventricle, and one connecting that in the left auricle with the incision in the left ventricle. V.'s Theory of Cellular Physiology; this is sum. marized in the formula, omnis cellula e cellula, $i, e$. every cell is derived from a cell. It is the theory of the hereditary succession of the cells and tissues. V.'s Theory of Inflammation. See Theory.

\section{Virchow and Holder, Angle of. See Angle}

Virchow-Robin Lymph-spaces. The spaces between the ental coats of the cerebral blood-vessels and the adventitia.

Virescence (vir-es'-ens) [virescere, to grow green]. In biology, greenness, especially a green petal or leaf, normally some other color

Virescent (vir-es'-ent) [virere, to be green]. Becoming green.

Virgate $\left(v i r^{\prime}-g \vec{a} t\right)$ [virga, a rod, twig]. Straight and slender, like a wand.

Virgin (vir'-jin) [virgo; virginis, a virgin]. A woman who has never had sexual connection with a man. V.-tooth, the milk-tooth of a horse not worn by use.

Virginal (vir'-jin-al) [virgo, a virgin]. Pertaining to virginity.

Virginale Claustrum (vir-jin-a $a^{\prime}-l e k l a w^{\prime}$-strum) [L.]. The hymen.

Virginia (vir-jin'-e-ah) [Virginia, a female name]. A State of the United States. V. Creeper. See Ampelopsis. V. Snake-root. See Serpentaria.

Virginity (vir-jin'-it-e) [virgo, a virgin]. The condition of being a virgin.

Viridescence (vir-id-es'-ens) [viridis, green]. The state of being greenish.

Viridescent (vir-id-es'-ent) [viridis, green]. Slightly green.

Viridian (vir-id'-e-an). Same as Veronese Green.

Viridigenous (vir-id-ij'-en-us) [viridis, green; genus, producing]. In biology, producing greenness, as the diatoms eaten by certain molluscs. Cf. Marennin.

Viridin (vir'-id-in) [viridis, green]. An alkaloid obtained from Veratrum viride, and supposed to be identical with jervin.

Viridity $\left(v i r-i d^{\prime}-i t-e\right)$ [viridis, green]. In biology, greenness.

Virile (vir'-il) [virilis; vir, a man]. Pertaining to mature manhood. V. Member, the penis.

Virilescence (vir-il-es'-ens) [virilis, virile]. The assumption of male characters by an aged woman; the growth of a beard, the development of a manly voice on the part of a woman after the menopause.

Virilia (vir-il'-e-ah). Plural of Viritis, manly. The male generative organs.

Virility (vir-il'-it-e) [virititas]. The condition of mature manhood; procreative power.

Virose $\left(v i^{\prime \prime}-r \bar{o} z\right)$ [virosus, poisonous]. Poisonous; having a poisonous taste or smell.

Virous (vi'-rus) [virosus, poisonous]. Possessing poisonous properties.

Virulence (vir'-u-lens) [virulentia; virus, a poison]. Malignity, noxiousness, infectiousness.

Virulent (vir'-u-lent) [virulentus]. Having the nature of a poison. See Virus.

Viruliferous (vir-u-lif'-er-us) [virus, virus; ferre, to carry]. Containing or conveying a virus.

Virus $\left(v i^{\prime}-r u s\right)[\mathrm{L}$.$] . A poison that causes a morbid$ process or disease; any pathogenic microbe. The word was formerly applied to the specific contagium of an infectious disease, especially to that of cowpox. V., Attenuated, virus deprived of some of its patho- genic quality by culture and modification by animal inoculation-experiments, so that inoculated in another person or animal it preserves the same against attack or the usual violence of the disease. V., Humanized, vaccine-lymph that is not taken directly from the cow or calf, but from the vaccine-pustule of a human being, usually a child, who may have been inoculated with matter obtained from another child or from the cow. V., Specific, the characteristic poison of a disease.

Vis [L.]. Force or energy. V. conservatrix, the healing power of nature. V. formativa, the energy of nature as manifest in the formation of new tissue to replace that which has been destroyed. V.a fronte, energy exerted in front; resistance. V. inertix, that force by virtue of which a body at rest remains at rest; or, if in motion, continues in motion. V. medicatrix. Same as $V$. conservatrix. V. plastrix, in biology, growth-force. See Bathmism, Physiobathmism, Statobathmism. V. a tergo, force applied from behind. V. vitæ, vital force.

Visage $\left(v i z^{\prime}-i j\right)$ [visus, a look]. The face.

Viscera (vis'-er-ah). See Viscus.

Viscerad (vis'-er-ad) [viscus, a viscus]. Toward the visceral cavity.

Visceral (vis'-er-al) [viscera]. Pertaining to the viscera. V.Arches and Clefts, four slit-like depressions with intermediate thickenings of the lateral wall of the cervical region of the embryo. They are persistent slits in fishes.

Visceralgia (vis - er-all-je-ah) [viscus, viscus; ànjos, pain]. Pain or neuralgia in a viscus.

Viscerate $\left(v i s^{\prime}-e r-\bar{a} t\right)$ [viscera]. To eviscerate or disembowel.

Viscericardiac (vis-er-ik-ar'-de-ak) [viscera; кapdia, heart]. Pertaining to the viscericardium.

Viscericardium (vis-er-ik-ar'-de-um) [viscera, viscera ; кapdía, heart]. The visceripericardial sac.

Viscerimotor (vis-er-im-o'-tor) [viscus, viscus; motor, motor]. Conveying motor impulses to a viscus.

Visceripericardial (vis-er-ip-er-ik-ar'-de-al) [viscera, $\pi \varepsilon \rho i$, around; kapdia, heart]. Common to the pericardium and the viscera.

Visceropleural (vis-er-o-plu'-ral) [viscera; $\pi \lambda \varepsilon v p a ́$, side]. Same as Pleurovisceral.

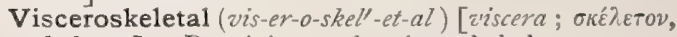
skeleton]. Pertaining to the visceral skeleton.

Viscid (vis'-id) [viscidus]. Clammy; slimy; adhesive; glutinous. See Viscous.

Viscidity (vis-id'-it-e). Same as Viscosity.

Viscin (vis'-in) [viscum, bird-lime]. Bird-lime. A mucilaginous extraction of the mistletoe, Viscum flavescens, Gentiana lutea, and other plants.

Viscose $\left(v i s^{\prime}-k \bar{o} z\right)$ [viscum, bird-lime]. A gummy secretion or product of the Micrococcus viscosus.

Viscosity (vis-kos'-it-e) [viscositas]. The property of glutinousness, ropiness, or tenacity.

Viscous (vis'-kus) [viscoszus]. Glutinous, ropy, sticky. Also, pertaining to a viscus or internal organ.

Viscum (vis'-kum) [L.: gen., Visci]. Mislletoe. The leaves and stems of $V$. album, the European, and $V$. favescens, the American, species. It contains a mucilage, viscin, bird-lime, and various other extractives. In large doses it induces vomiting and purging. The American plant has alleged properties similar to those of digitalis. Dose gr. $x-3 j$, in decoction; of

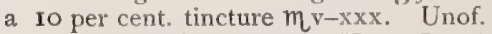

Viscus (vis'-kus) [L.: pl, Viscera]. Any organ enclosed within either of the four great cavities, the cranium, thorax, abdominal cavity, or pelvis; as the brain, intestine, spleen, bladder, uterus, lungs, liver, etc. 
Vishucki (vis-huk'-e) [Ind.]. Synonym of Asiatic Cholera among Hindoo physicians.

Visibility $\left(v i z-i b-i l^{\prime}-i t-e\right)$ [visibilitas; videre, to see] Capability of being seen.

Vision (vizh'-un) [visio; videre, to see]. I. Sight; acuity of visual power. See also, Acuteness. 2. A visual hallucination, or illusion. V., Binocular. See Binocular. V., Central, direct vision, or vision when the image falls on the fovea centralis. V. for Color, pertains to the chromatic sense. V., Direct, that when the image is formed at the macula. V., Double. See Diplopic. V., Field of. See Field. V. for Form, the acuteness of vision with white light. V., Indirect, that when the image is formed upon the peripheral portions of the retina. V., Peripheral, that when the image is not formed at the macula. V., Qualitative, vision in which there is ability to distinguish objects. V., Quantitative, mere perception of light. V., Solid, or V., Stereoscopic, the visual perception of the third dimension of space, or the perception of relief or depth of objects obtained by binocular vision. See Hering's Experiment. V., Triple. See Triplopia.

Visit (viz'-it) [videre, to see]. A call upon a patient.

Visual (vizh'-u-al) [visualis; visus, sight]. Pertaining to vision. V. Acuteness, or Acuity. See Acuteness. V. Amnesia. See Mind-blindness. V. Angle. See Angle. V. Axis. See Axis. V. Field. See Field. V. Logagnosia. Synonym of Wordblindness. V. Purple, a substance in the retina reacting to light in a peculiar manner, and thought to be intimately connected with vision. See Rhodopsin.

Visus $\left(v i^{\prime}-z u s\right)$ [videre, to see]. Vision. V. dimidiatus. Synonym of Hemiopia. V. diurnus. Synonym of Henteralopia. V. senilis. Synonym of Presbyopia.

Vita $\left(v i^{\prime}-t a h\right)$ [L.]. Life.

Vital (vi'-tal) [vitalis; vita, life]. Pertaining to life. V. Capacity, the volume of air that can be expelled after a full inspiration. V. Knot, a term applied by Flourens to the respiratory center in the oblongata. V. Principle, the energizing principle on which individual life depends. V. Statistics, the statis tics of vital facts, the science of numbers as applied to the life-history of communities and nations.

Vitalism (vi'-tal-izm) [vita, life]. In biology, the doctrine that ascribes the phenomena exhibited by living organisms to the action of a supersensuous vital force.

Vitalist $\left(v i^{\prime}\right.$-tal-ist) [vita, life]. A believer in the existence of vital force.

Vitality (vi-tal'-it-e) [vitalitas, vitality]. The vital force or principle of life; also, the condition of having life; vigor; activity.

Vitalize $\left(v i^{\prime}-t a l-i z\right)$ [vitc, life]. To endow with life.

Vitals (vi'-talz) [vita, life ]. A vulgar term for the intestines and the organs essential to life.

Vitellarium (vit-el-a $a^{\prime}-r e-u m$ ) [vitellus, yolk: $p l$, Vitellaria]. In biology, one form of the female germglands in platode worms, in which the work of supplying the egg-germs with nutritive yolk is carried on. "Comparative research has shown that the vitellaria are not newly formed accessory glands of the female sexual apparatus, but that they are metamorphosed ovaries or portions of ovaries adapted to a special function." (Lang.) Cf Germarium.

Vitellary (vit'-el-a-re) [vitellus, yolk]. Pertaining to the vitellus.

Vitellicle (vit-el'-ik-l) [vitellus, yolk]. The yolk-sac; umbilical vesicle.

Vitelligenous (vit-el-ij'-en-us) [vitellus, yolk; genus, producing]. In biology, producing yolk. Cf. Vitellarium and Vitellogene.
Vitellin (vit-el'-in) [vitellus, yolk]. In biology, the chief proteid of egg-yolk. According to Weyl, it also occurs in chyle and the amniotic fluid.

Vitelline (vit-ell-in) [vitellus, yolk]. Pertaining to the vitellus, the yolk of an egg. V. Circulation, the circulation through the yolk. V. Membrane. See Zona pellucida. V. Spheres. See Sphere.

Vitello-ducts (vit'-el-o-dukls) [vitellus, yolk; d'uctus, a duct]. The yolk-ducts; applied to the ducts of the vitellaria of platode worms.

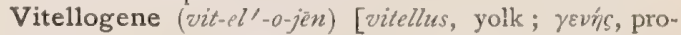
ducing]. In biology, yolk-producing. Cf. Vitellarium and Vitelligenous.

Vitellogenous (vit-el-oj'-en-us). Same as Vitelligenous.

Vitellolutein (vit-el-o-lu'-te-in) [vitellus, yolk; luteus, golden-yellow]. The yellow pigment obtained from the eggs of the spider-crab (Maia squinado).

Vitellorubin (vit-el-o-ru'-bin) [vitellus, yolk; ruber, red]. The reddish-brown pigment obtained from the eggs of the spider-crab (Muia squinado).

Vitellus (vit-el"-us) [vilellus, a yolk]. In biology, the yolk of an egg, including both the formative and the nutritive yolk. Specifically the yolk of the egg of the common barnyard fowl (Gallus donesticus). A viscid, orange-colored liquid containing oil, cholesterin, vitellin, and albumin. It is bland and nutritive. It is used mainly to emulsionize oils and camphors. In pharmacy, the yolk of egg, ovi vitellus.

Vitex (vi'-teks) [L.]. See Agnus castus.

Vitiation (vish-e-a'-shun) [vitiatio; vitiare, to corrupt]. The contamination of any substance, especially of the air.

Viticolous (vit-ik'-o lus) [vitis, the vine ; colere, to inhabit]. Inhabiting or produced upon the vine.

Viticula (vit-ik'-u-lah) [dim. of vitis, vine: pl., Viticule]. In biology, a small, trailing vine, like that of a melon or cucumber.

Viticulose (vit-ik'-u-lâa) [vitis, vine]. In biology, producing long, trailing, vine-like twigs or stems.

Viticulture (vit'-ik-ul-tūr) [vitis, vine; cultura, culture]. The culture of the vine.

Vitiligo (vit-il-i'-go) [L., tetter]. Piebald skin; white leprosy; an acquired disease of the skin characterized by the appearance of one or many well-defined, circular, oval, irregularly-shaped, or reticulated patches, having a milky-white color, without other manifest change in the integument; the hairs growing upon these patches are usually destitute of color. At the periphery of the patches there is usually a hyperpigmented border, varying in color from a light-fawn to a deep-chocolate. The disease is most common in warm weather. See Leukoderma. V. capitis. Synonym of Alopecia arenta.

Vitiligoidea (vit-il-ig-oi'-de-ah) [vitiligo, tetter; $\varepsilon^{\top} i \delta o s$, likeness]. Xanthoma of the eyelids.

Vitrella (vit-rel'-ah) [vitreus, glassy: pl., Vitrella]. In biology, same as Retinophora.

Vitreodentinal (vit-re-o-den'-tin-al) [vitreus, of glass; dens, tooth]. Pertaining to vitreodentine.

Vitreodentine (vit-re-o-den'-tin) [vitreus, of glass; dens, a tooth]. A variety of dentine of particularly hard texture.

Vitreous (vit'-re-us) [vitreus; vitrum, glass]. Glasslike, hyaline. V., Artificial. See Evisceration. V. Chamber, the portion of the globe of the eye posterici to the crystalline lens. V. Degeneration, disease of the intima of arteries. V. Humor, or Body, the transparent, jelly-like substance filling the vitreous chamber of the eye. V. Tables, the dense, osseous laminx on the inner and outer surfaces of the cranial bones.

Vitreum (vit'-re-um). Same as Vitreous Hunor. 
Vitriol (vit'-re-ol) [vitriohum; vitrum, glass]. In chemistry, a term formerly used to designate any substance having a glassy fracture or appearance. V. Blue, copper sulphate, or "blue stone," $\mathrm{CuSO}_{4}$. V. Green, ferrous sulphate, or "copperas," $\mathrm{FeSO}_{4}$. V., Oil of, sulphuric acid, $\mathrm{H}_{2} \mathrm{SO}_{4}$. V., White, zinc sulphate, $\mathrm{ZnSO}_{4}$.

Vitta (vit'-ah) [vitta, a band, a fillet: pl., Vitta]. In biology, $(a)$ a band, or stripe, either of color or tissue; (b) one of the longitudinal, tubular oil-receptacles in the fruits of the Umbelliferce. An oil-tube.

Vittate $\left(v i t^{\prime}-\bar{a} t\right)$ [vitta, a band, a fillet]. Possessing vittx.

Vitular (vit'-u-lar') [vitulus, calf]. Relating to a calf or to calving. V. Apoplexy, apoplexy of cows occurring at parturition. V. Fever, vitular apoplexy, or, more correctly, a fever following parturition in the cow. See Collapse, Parturient.

Vitus' Dance, St. See Chorea.

Viviparous (viv-iph-ar-zs) [vivus, alive; parere, bring forth, produce]. In biology, applied to such animals as bring forth the young at an advanced stage of development, as distinguished from oviparous and ovoviviparous.

Vivipation (viv-ip- $a^{\prime}-$ shun) [vivus, alive; parere, to bring forth]. In embryology, that form of generation in which the ovum, expelled from the ovary, clings to the maternal organ and derives its nourishment directly from the mother until birth.

Viviperception (viv-ip-er-sep'-shun) [vivus, alive; percipere, to perceive]. The study or observation of physiologic processes without dissection or vivisection. Vivisection (viv-is-ek'-shun) [vizus, alive; sectio, cutting]. The dissection of an animal, or experimentation upon it, while still alive, for scientific purposes. See Callisection, and Sentisection.

Vivisectionist (viv-is-ek'-shun-ist) [vivus, alive ; sectio, a cutting]. A practiser or defender of vivisection.

Vivisector (viv-is-ek'-tor) [virus, alive; sector, a cutter]. One who practises vivisection.

Vivisectorium (viv-is-ek-to'-re-zm) [L.]. A place or laboratory where vivisection is performed.

Vleminckx's Solution. An application used in Austria and Germany for treating acne. It consists of lime I part, sulphur 2 parts, and water 20 parts. Slake the lime, add the sulphur, and boil to 12 parts.

Vocal $\left(v \bar{o}^{\prime}-k a l\right)$ [vox, the voice]. Pertaining to the voice or its organs. V. Bands, a name given to certain membranes of the larynx by which the sounds of the voice are produced. They consist of superior, ventricular or false bands, and inferior or true bands. The latter are covered by the mucous membrane of the larynx and are thin bands of elastic tissue, reaching from the wings of the thyreoid to the arytenoid cartilages. V. Fremitus, the thrill conveyed to the hand when applied to the chest during phonation. It is increased in consolidation of the lungs, and decreased or absent when there is a pleural effusion. $\mathrm{V}$. Resonance, the resonance produced by the voice as heard on auscultating the lung. This is increased with slight degrees of consolidation of the lung and decreased with extreme consolidation and with large pleural effusions.

Vogt, Angle of, See Angle.

Vohsen's Method. A method of illuminating the frontal sinus. It is done by placing the source of illumination over the orbital surface of the sinus.

Voice (vois) [ME., voice, voice]. The sound produced by the vibration of the vocal bands and moditied by the resonance-organs. The utterance of articular sounds. V., Change of. In the transition-period of youth the voice loses its treble quality and (sometimes irregularly) assumes the qualities of the adult voice. This is called the change of voice.

Void [ME., voiden, to void]. To evacuate, e.g., from the intestine or bladder.

Voisin's Method. See Hypnotism.

Vola $\left(v o^{\prime}-L h\right)$ [L.: gen, and $p l$. , Vola $]$. The palm, or rather the hollow of the hand; the hollow of the foot.

Volar (vol-lar) [volaris; vola, palm]. Pertaining to the palm of the hand. See Palmar.

Volatic $\left(v o-l a t^{\prime}-i k\right)$ [volaticus; volare, to fly]. Flying: momentary

Volatile (vol'-at-il) [volatilis]. Capable of assuming, or prone to assume a state of vapor; evaporating. V. Oils. See Essential Oils

Volatility (vol-at-il'-it-e) [volatilitas]. The quality of being volatile.

Volatilization (vol-at-il-iz-a'-shun) [volatilizatio]. The change of a solid or liquid to a gas or vapor by heat.

Volhard, Volumetric Method of. A method for estimating halogens by means of ammonium sulphocyanid.

Volition (vo-lish'-un) [volitio, will]. The will or determination to act.

Volitional (vo-lish'-un-al) [volitio, will]. Pertaining to volition. V. Insanity, insanity characterized by perversions of the will, or by abulia or hyperbulia.

Volitive (vol'-it-iv) [volitio, will]. Pertaining to the will; volitional.

Volkmann's Deformity. Congenital tibio-tarsal luxation. See Diseases, Table of. V.'s Solution. See Thymol.

Volsella (vol-sel'-ah) [vellere, to pluck]. A forceps having one or more hooks at the end of each blade. Also called Vulsella

Volt (volt) [volvere, to turn around]. The unit of electro-motive force, or the force sufficient to cause a current of one ampere to flow against a resistance of one ohm. The following is the voltage of several popular cells: Smee 0.65, Bunsen 1.90, Daniell I.05, Callaud 0.60 , Leclanche I.50. V.-ampère, the amount of pressure developed by a current of one ampère having an electro-motive force of one volt. Its mechanic equivalent is about 44.2 foot-pounds per minute. It is sometimes called a Watt. See Electric Units. V.-coulomb. See Electric Units.

Volta's Law. A law for the differences of electric potential produced by the contact of dissimilar metals or other substances. See Lazu.

Voltaic (vol-ta'-ik) [Volta, an Italian scientist]. Pertaining to the constant electric current or to galvanic electricity. V. Alternatives, a term used in medical electricity to indicate sudden reversals in the polarity of the electrodes of a voltaic battery.

Voltaism (vol'ta-izm). See Galvanism.

Voltameter (vol-tam'-et-er) [volt, a unit of electro-mo-

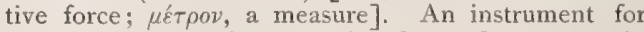
ascertaining the electro-motive force of a current in volts.

Voltmeter (volt'-ne-ter) [volt, a unit of electric force;

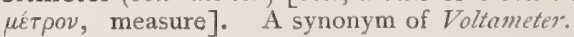

Voltolini's Disease. A purulent, labyrinthine otitis accompanied with violent pains in the ear, complete unconsciousness, high fever, and delirium. See Diseases, Table of. V.'s Method, the examination of the anterior nasal region by means of transmitted light. This method is also called examination by "through illumination," and transillumination, q. $v$.

Voluble $\left(v o l^{\prime}-u-b l\right)$ [volubilis, whirling]. See Trvining.

Volume (vol'-um) [volumen]. In physics, the space which a substance fills. Cubic dimension. V. Specific, the molecular weight divided by the specific gravity; referred to hydrogen as a unit. 
Volumetric (vol-u-met'-rik) [volumen, a roll; $\mu$ ítpov, measure]. Pertaining to measurement by volume. V. Analysis. See Analysis.

Voluntary (vol"-un-ta-re) [voluntarius]. Pertaining to or under the control of the will. V. Muscle, striped muscle.

Voluntas (vol-un'-tas) [L.]. Desire or will.

Voluntomotory (vol-un-to-mo'-tor-e) [voluntus, will ; motor, motor]. Pertaining to voluntary motion.

Voluptuary (vo-lup tu-a-re) $_{\text {[voluptuarius, pertaining }}$ to pleasure]. I. Promoting sensual indulgence; voluptuous, 2. A sensualist.

Voluptuous (vo-lupp'-tu-us) [voluptuosus, full of gratification]. Contributing to sensual pleasure.

Voluptuousness (vo-lup'-tu-zls-nes) [voluphosus, full of gratification]. The state of being voluptuous.

Volupty (vo-lup'-te) [voluptas]. Voluptuousness; orgasm.

Volute (vo-lüt') [voluta, a spiral scroll]. In biology, rolled up like a scroll.

Volva (vol'-vah) [volva, a wrapper, covering: $p l$, Volva]. In biology, a covering possessed by the fruiting organs of some fungi. The same as Velum universale.

Volvulus (vol'-vu-lus) [volvere, to roll]. An old name was Ileac Passion. A twisting of the bowel upon itself or upon its mesenteric axis, so as to occlude the lumen, It occurs most frequently in the sigmoid flexure.

Vomer $\left(v o^{\prime}-m e r\right)$ [L., a plowshare]. The thin plate of bone situated vertically between the nasal fossæ, and forming the posterior portion of the septum of the nose. V., Cartilaginous, a cartilaginous plate that forms the anterior portion of the septum of the nose.

Vomerine $\left(v o^{\prime}-m e r-i n\right)$ [vomer, vomer]. Pertaining to the vomer.

Vomic (vom'-ik) [vomicus]. Ulcerous; purulent.

Vomica (vom'-ik-ah) [vomere, to vomit: pl., Vomica]. A pulmonary cavity; a collection of pus in the lungs or adjacent organs that may discharge through the bronchi and mouth. V. laryngis. A synonym for Perichondritis of the Larynx.

Vomit $($ vom' $-i t)$ [vomere, to vomit]. I. To expel from the stomach by vomiting. 2. Vomited matter; an emetic. V., Bilious, vomit stained with bile. V., Black, the characteristic vomit of yellow fever. The dark fluid ejected is a mixture of decomposed blood and the contents of the stomach. V., Bloody. See Hematemesis. V., Coffee-ground, vomit composed of broken-down blood-clots and tissue, together with the contents of the stomach. It is seen frequently in carcinoma of the stomach. V.-nut. See $N u x$ vomica.

Vomiting (vom'-it-ing) [vomere, to vomit]. The forcible, convulsive ejection of the contents of the stomach, duodenum, or intestines through the mouth. V. of Blood. See Hematemesis. V., Dry, persistent nausea with attempts at vomiting, but with the ejection of nothing but gas. V., Pernicious, the variety of vomiting occasionally seen in pregnancy that becomes so excessive as to threaten the patient's life. V., Stercoraceous, the ejection of fecal matter in emesis, usually due to intestinal obstruction.

Vomitive $\left(v o m^{\prime}-i t-i v\right)$ [vomere, to vomit]. Emetic.

Vomito $\left(v o m^{\prime}-i t-o\right)$ [Sp.]. Vomit.

Vomitonigro. Black vomit. A name for yellow fever. V., Priests'. A name for Vellowe Fever, q. v.

Vomitory $\left(\right.$ vom $\left.^{\prime}-i t-o r-e\right)$ [vomitorius]. I. Emetic, or vomitive. 2. Any agent or substance that induces emesis. Also, a vessel to receive the ejecta.

Vomiturition (vom-it-u-rish'-un) [vomituritio]. Ineffectual attempt at vomiting, with a strong feeling of desire to vomit. 2. Vomiting with but slight effort.
Vomitus (vom'-it-sts) [vomsre, to vomit]. Vomited matters; the act of vomiting. V. cruentus, bloody vomit.

Von Baer's Law. The law that the embryos of higher animals pass through a succession of metamorphoses resembling the adult forms of lower types of animals. See Law.

Von Gieth's Oil-jacket. A dressing especially of value in the pleurisy of infants or young children. Pure olive oil is poured in sufficient quantity into a previously warmed bowl, and a strip of old, soft, cottoncloth, large enough to encircle the chest, is placed in the bowl and completely saturated with the oil. This is then applied to the patient's chest, and outside of it a second strip of dry cloth is placed, and, if necessary, a third, which completes the dressing.

Von Mering's Mixture. See Anesthetic

Von Troeltsch, Corpuscles of. Peculiar, spindleshaped corpuscles; the connective-tissue corpuscles of Virchow.

Voodoo $\left(v u^{\prime}-d u\right)$ [Creole Fr., vaudoux, a negro sorcerer]. A system of charms and enchantments of African origin, practised in part as a healing art in the U. S. and W. Indies.

Voracious (vor-a'-shus) [vorax; vorare, to devour]. Having an insatiable appetite or desire for food. See, also, Bulimia.

Voracity (vor-as'-it-e) [voracitas, voracity]. Greediness or rapaciousness for food.

Voronej, Elixir of. A famous mixture used in Russia. It occurs in a stronger and a weaker form, as follows : I: The stronger: sal. ammon. $3 \mathrm{x}$, ol. naphthæ $3 \mathrm{vj}$, ol. caryophyl. $3 \mathrm{x}$, acid. nitric. $3 \mathrm{vj}$, potas. nitrat. and Turkey pepper each $\bar{\xi}$ jss, menth. virid $\bar{z}$ viij, acetum Oj, spts. vin. gall. Oiv, 2. The reeaker: camphor, ol. naphthæ, ess. terebinth., acid, nitric., each 3 ij, Turkey pepper 2 pods, acetum 3 vjss, spts. vin. gall. $\exists$ iv.

Vortex (vor'-teks) [L., a whirl]. A structure having the appearance of being produced by a rotary motion about an axis. V. of the Heart, a name applied to the spiral arrangement of the muscular fibers of the walls of the heart.

Vorticose (vor'-tik-äz) [voriex, vortex]. Whirling. In anatomy, specifying the veins of the external layer of the choroid coat of the eyeball, the vence sorticose. V. Veins. See Vence vorticosa.

Vowel $($ vow'-el) [Fr., voyelle, vowel]. Any one of the chief sounds of the voice, formed by the vibrations of the vocal organs unmodified by the resonance-organs.

Vox (voks). Voice.

Voyeur $\left(v i^{i}-y r^{\prime}\right)$ [Fr.]. A sexual pervert who indulges in witnessing coitus.

Vries, Plasmolytic Method of. A method of determining osmotic pressure by the use of living plant-cells.

Vulcanite (vul'-kan-itt) [Vulcan, the god of fire]. Ebonite, or hard, vulcanized caoutchouc (india-rubber). V. Base, in dentistry, a vulcanized, India-rubber plate adapted to such portion of the alveolar arch as is deprived of natural teeth and is to be supplied with an artificial substitute. V., Dental, India-rubber combined with sulphur or sulphur compounds, and colored with vermilion. A combination of rubber 48 parts, sulphur 24 parts, and vermilion 36 parts. Compare Rubber.

Vulcanizer (vul'-kan-i-zer) [Vulcan, the god of fire]. In dentistry the apparatus in which the prepared rubber is hardened by the action of steam. It consists of a copper boiler, with a screw-top, having connected with it a thermometer for regulating the steam necessary to harden the rubber, and a safety-valve to prevent explosion. 
Vulcanol (vul'-kan-ol) [Vulcan, the god of fire]. A thick, lubricating oil formed in great quantities in petroleum-refineries and in paraffin and solar-oil works.

Vulgar (vul'-gar) [vulgaris, common]. Common. Coarse. Unrefined. Popular.

Vulnera (vul'-ner-ah) [L.]. Plural of Vulnus. A wound.

Vulnerary (vul'-ner-a-re) [vulnus, a wound]. In therapeutics, any remedy or agent useful in healing wounds.

Vulnus (vul'-nus) [L.: gen., Vulneris; pl., Vulnera] A wound. V. sclopetarium, a gun-shot wound. V. simplex, an incised wound.

Vulpian's Law. See Laze.

Vulpic Acid (vul'-pik). See Acid

Vulsella (vul-sel'-ah). See Vulsellum.

Vulsellum (vul-sel'-um) [L.: pl., Vulsella]. A kind of forceps; volsella. See Volsella.

Vultus (vul'-tus) [L.]. The face, countenance, or looks.

Vulva (vul'-vah) [volvere, to roll up]. The female pudendum, though not, strictly speaking, including the mons veneris. V. connivens, a form of vulva in which the labiı majora are in close apposition. V., Garrulity of, vaginal tlatus. V. hians, the form of vulva in which the labia majora are gaping.

Vulval, Vulvar (vul'-val, vul'-var) [vulva, vulva]. Pertaining to the vulva.

Vulvate, Vulviform (vul'-vät, vul'-vi-form) [vulz'a, vulva; forma, form]. Shaped like or resembling the vulva.

Vulvismus (vul-viz'-mus). See Vaginismus.

Vulvitis (vul-vi'-tis) [vulva, vulva; $\iota \tau \iota s$, inflammation]. Inflammation of the vulva. V., Diphtheric, vul vitis with diphtheric deposit. V., Follicular, inflammation of the mucous follicles of the vulva.

Vulvo-(vul'-vo-) [vulva, vulva]. A prefix denoting relation to the vulva

Vulvo-vaginal (vul-vo-vaj'-in-al) [vulva, vulva; vagina, vagina]. Pertaining conjointly to the vulva and the vagina. V. Glands, the small glands situated one on each side of the vulva near the vagina. See Glands.

Vulvo-vaginitis (vul-vo-vaj-in-i'-tis) [vulva, vulva; vagina, vagina; $\iota \tau \iota$, inflammation ]. Inflammation of the vulva and the vagina.
W. The symbol of Tungsten (Wolfram).

W. L. or $\lambda$. Wave-length.

Wachendorf's Membrane. The fetal membrane of the pupil of the eye. It atrophies about the seventh month. See Membrane, Pupillary.

Wachsmuth's Mixture. See Anesthetic.

Waddle (wod-l') [dim of wade]. To sway or rock from side to side in walking.

Wade's Balsam. Friars' Balsam; Jesuits' Drops; a favorite vulnerary, essentially the same as the compound tincture of benzoin.

Wafer (wa'-fer) [ME., wafre, wafer]. A pharmaceutic preparation made by pouring a thick, smooth mixture of flour and water between greased, hot, polished plates or cylinders, so adjusted that a thin sheet or wafer is produced. When dry this is hard and brittle, but when moistened it becomes soft, tough, and slippery, and is well adapted for taking medicines in the form of powder. W.-ash. See Ptelea trifoliata.

Wagner's Spot. The germinal spot or nucleolus of the ovum.

Wagner, Tactile Corpuscles of. Oval-shaped bodies at the termination of nerve-fibers, regarded by Wagner as directly concerned in the sense of touch. W. and Meissner's Corpuscles, tactile end-organs lying in the papillæ of the skin.

Wagnerian Corpuscles (wag-ner'-e-an). See Tactile Corpuscle.

Wahoo (wah-hoo'). See Euonymus.

Waist (wâst) [ME., wast, waist]. The narrowest portion of the trunk above the hips.

Waistcoat, Straight (wāst'-kōt, strāt). See Jacket.

Walcher's Posture. The woman in the dorsal position, the hips at the edge of the table, the lower extremities hanging.

Walcheren Fever (wall-cher-en) [from Walcheren, Netherland]. A severe type of malarial fever.

Waldenburg's Apparatus. An apparatus constructed on the principle of a gasometer, and used for compress- ing or rarefying air, which is inhaled, or into which the patient exhales.

Waldeyer's Glands. Acino-tubular glands at the attached border of the tarsus. W.'s Plasma-cells. See Plasma. W., Sulcus of, a spiral sulcus of the limbus of the ear.

Wale $(w \bar{a} l)$. See Wheal.

Walk (wawk) [ME., walken, to walk.] I. Manner of walking. See Gait. 2. In Swedish physical training certain forms of progression are specified as walks. See Stretch-zolk, Yard-walk.

Wallerian Degeneration. Degeneration of nerves after separation from their trophic centers. W. Law. See Law.

Wall-eye (wawl'-i). A vulgarism used to express the appearance of leukoma of the cornea, or of eyes with a light-colored iris; also, a divergent strabismus. W.pepper. See Sedum acne.

Walnut (wol'-nut). See Juglans.

Walter's Ganglion. See Ganglia, Table of.

Walther's Angle. See Angle. W.'s Ducts, ducts in the sublingual gland. W., Oblique Ligament of, a band of capsular ligament of the ankle-joint, extending from the external malleolus to the eminence on the astragalus for the flexor longus pollicis.

Wamble (wom $\left.{ }^{\prime}-b l\right)$ [ME., wamlen, mawkish]. A feeling of nausea; a heaving of the stomach. [Vulgar.] W.-cropped. Nauseated; sick at the stomach. [Vulgar.]

Wan (won) [ME., zoan, wan]. Pale; pallid; of sickly hue or exptession.

Wandered $($ won'-derd $)$ [ME., wanderen, to wander]. Out of the usual or normal place; out of the proper habitat; as a wandered scolex.

Wandering (won'-der-ing) [ME., wanderen, to wander]. x. Delirium; incoherence of speech or thought. 2. Having no fixed place. W. Abscess, one that points at a considerable distance from its real seat. W. Cell, an ameboid connective-tissue cell; a leukocyte, so 
called from its power of leaving the blood-current and entering the tissues. See Leukocyte. W. Erysipelas, Erysipelas migrans, erysipelas with frequent change of localization. W. Kidney. See Floating Kidney. W. Liver. See Liver. W. Pneumonia, a migrant, or locally progressive pneumonia; one that changes its seat. See Pneumonia. W. Rash, Geographic Tongue, Lichenoid, Circinate Eruption, a peculiar and rare disease of the tongue occurring, as a rule, in children under two years of age. It consists in the appearance on the dorsum of the tongue of round, raised, whitish patches surrounded by a raised ring of epithelial tissue yellowish in color. These rings may intersect and cover the tongue with sinuous lines. It is a chronic disease of a harmless nature, very resistant to treatment. See Geographic Tongue. W. Spleen, a rare condition in which the attachments of the spleen become relaxed to such a degree that it descends by the force of gravity into the left iliac fossa, or may be found upon the opposite side of the body when the patient lies upon the right side. W. Tumor, usually a displaced or floating viscus.

Wane $(w a \bar{n})$ [ME., waney, to wane]. To decrease; to decline; to fade.

Wang [ME., wange, cheek]. I. The jaw, jaw-bone, or cheek-bone. 2. A cheek-tooth or grinder. W.-tooth. A cheek-tooth; a grinder or molar.

Wanklyn's Ammonia Process. A process for the estimation of nitrogenous organic matter in water. This process operates on the water itself, and not on the residue obtained on evaporation, and it gives as characteristic data the "free ammonia" and " albuminoid ammonia" yielded by waters. The principle of the method is the measurement of the nitrogenous organic matter in waters by the quantity of ammonia yielded by the destruction of the organic matter. For the measurement of the quantities of ammonia, the very delicate test of Nessler is utilized.

War Fever. Synonym of Typhus Fever.

Warble (war'-bl) [also zuormil, wornul, zuarnle, wornit, wornal. Origin obscure, perhaps connected with ME., zuar, pus, humor, or with worm]. (a) A small, boillike tumor on the back of horses, cattle, deer, etc., produced by the galling of a saddle or by the presence of the larva of the warble-fly. The inflammation produces a condition of the surface of the carcass beneath the warble known as "licked beef," or "butchers" jelly." W.-fly: See Hypoderma bovis, under Parasites (Animal), Table of.

Warburg's Tincture, Tinctura pyrexialis. It consists of aloes soc. $1 \mathrm{to}$ j, rad. rhei, sem. angelica, confec. Damocratis āà $\bar{\zeta}$ iv; rad. helenii, croci sativi, sem. foniculi, cretæ præp. āà $\bar{\jmath}$ ij; rad. gentianæ, rad. zeodariæ, pip. cubebæ, myrrh. elect., camphoræ, holet. laricis, $\bar{a} \bar{a} \bar{\jmath}$ j. Digest with proof spt. $\xi_{3} 500$, and add quinin disulph. $\zeta \mathrm{x}$. Filter. Dose $\xi \mathrm{j}$ in two doses three hours apart.

Ward [ME., zuard, ward]. A division or room of a hospital. W.-carriage, an apparatus for hospital service mounted upon wheels, and containing a reservoir of water, and other materials, instruments, etc., used in surgical operations and dressings.

Ward's Paste, confection of black pepper. See Paste.

Wardrop's Disease. Malignant onychitis. See Diseases, Table of. W.'s Operation, ligature of the artery beyond an aneurysm.

Warega-fly (war-a'-gah-fi $)$ [S. A. Ind., warega, fly]. See Musca sp. (?) under Parasites (Animal), Table of.

Warehousemen's Itch. See Grocers' Itch.

Waring's System. A system of sewage-disposal by means of sub-surface irrigation. It should be called "Moule's System" because invented by the late Rev. Henry Moule, Vicar of Fordington.
Warm [ME., warm, warm]. Having a moderate degree of heat. W. Bath. See Bath. W.-blooded, a term applied to animals that maintain a uniform temperature, whatever the changes of temperature in the surrounding medium.

Warming [ME., warmen, to warm]. Making warm. W. Plaster. See Cantharis.

Warner's Laudanum. See Laudamm.

Warras (zvar'-as) [Ind.]. A variety of kamala, said to be obtained from Flemingia grahamiana, a leguminous tree of India; it is a teniafuge and useful in skin-diseases. Dose of powder $\bar{z}$ iss-v; of tincture $\mathrm{f} z \mathrm{j}$. Unof.

Warren's Styptic. See Lotio adstringens

Wart [ME., wert, wart]. See Verruca and Condyloma. A small, circumscribed elevation on the skin, with an uneven papillary surface and a broad base. In farriery, a spongy excrescence in the pastern of the horse. In biology, a small glandular or gland-like excrescence on the surface of a plant. W., Peruvian. See Virruca peruana.

Warty [ME., wert, wart]. Resembling a wart; covered with warts. W. Smallpox, Hornpox, a name given to those cases of smallpox in which the eruption does not develop beyond the papular stage. W. Tubercle. See Verruca necrogenica. W. Ulcer. See Marjolin's Ulcer.

Wash [ME., washen, to wash]. To cleanse with a liquid. See Lotion. W., Black. See Lotio hydrargyrinigra. W.-leather Skin, that condition of the skin in which certain metals, especially silver, mark it with a black line. It occurs, as a rule, in patients suffering from diseases which directly or indirectly affect either the trophic or the sensory nerves. It sometimes precedes the occurrence of bed-sores. W.-rag. See Luffa. W., Yellow. See Lotio hydrargyri fava.

Washerwoman's Hand. See Cholera-hand. W.'s Itch or Scall, psoriasis of the hand, occurring in washerwomen.

Washing (wash'-ing) [ME., washen, to wash]. Ablution. The mechanical operation of separating soluble from insoluble matter.

Waste (wāst) [ME., wast, waste]. Any ultimate product of katabolism; loss by reason of disease, inanition, or over-use. W. and Garbage. See Servage. W. Silk, that which proceeds from perforated and double cocoons, and such as are soiled in steaming or in any other way. This waste silk is washed, boiled with soap, and dried. When carded and spun like cotton it yields the so-called furt-silk.

Wasting (wäst'-ing) [ME., wasten, to waste]. Destroying; running; laying waste. See Atrophy. W. Disease, a popular term for Pulmonary Tuberculosis and for tuberculous disease of cattle. W. Palsy. See Atrophy, Progressive Muscular.

Watchmakers' Cramp. See Cramp.

Water (waw'-ter) [ME., water, water], $\mathrm{H}_{2} \mathrm{O}$. A transparent, inodorous, tasteless fluid, boiling at $2 \mathrm{I} 2^{\circ} \mathrm{F}$. $\left(100^{\circ}\right.$ C. $)$, and freezing at $32^{\circ} \mathrm{F} .\left(0^{\circ} \mathrm{C}\right.$. $)$. The specific gravity of water at $39.2^{\circ} \mathrm{F} .\left(4^{\circ} \mathrm{C}\right.$ ) is $\mathbf{1}$. See Aqua. W.-analysis, the analysis of water. W.bag, the reticulum of the stomach of the camel and other Camelide. A rubber bag in which water of varying degrees of temperature can be introduced for topical application. W.-bed. See Bed. W.-blue. See Pigments, Conspectus of. W.-brain, gid or staggers of sheep, caused by the brain-worm. W. Brainfever. See Meningitis, Tuberculous. W. on Brain. See Hydrocephalus. W.-brash. See Pyrosis. W.braxy, a disease of sheep in which there is hemorrhage into the peritoneal cavity. W.-breather, any branchiate which breathes water by means of gills. W.-cancer. Synonym of Cancrum oris. W.- 
canker. Synonym of Cancrum oris. W.-cell, one of several diverticula of the paunch of the camel, serv ing to store up water. W.-closet, an apparatus for the reception of excrement, which is connected with a sewer by a pipe, and in which water must be used to carry away the excrement deposited in it. W.-closets, Varieties of: I. Those in which there is no movable apparatus for retaining water in the basin-the hopper and wash-out closets. 2. Those in which there is a movable apparatus-the pan, valve, and plug closets. W.-colors. See Pigments, Colors, and Dyestuffs. W. of Crystallization, the water employed in giving molecular structure to the crystals of chemic salts, to which their physical qualities are due. W.-cure. See Hydropathy and Hydrotheripeztics. W., Distilled. See Aqua. W.-dressing, the treatment of ulcers and wounds by the application of water. W.farcy, lymphangitis of the leg of a horse. W. Florida, a perfume consisting of oleum bergamii $亏$ iv, comp. tinct. benzoini $\zeta^{\mathrm{ij}}$, alcohol Oj. W.-gas, a gas, non-luminous in its pure form, derived in part from the decomposition of steam passed over ignited coals. It is used as an illuminating gas when enriched by the addition of a bydrocarbon, as petroleum or naphtha. It is also used in metallurgic operations, in chemic works, and in the laboratory. W.-gurgle Test, a gurgling sound heard when water is swallowed on auscultation over the seat of narrowing in cases of organic stricture of the esophagus. W.-hammer Pulse. See Corrigan's Pulse. W., Hard, natural waters containing soluble calcium salts, distinguished by their curdling action on soap. W.-hemlock. See Cozubane. W., Ice, water obtained by the melting of ice. W.-immersion. See Objective. W., Javelle, a solution of potassium hypochlorite, $\mathrm{KClO}$. W.jugs. Synonym of Varicella. W.-melon, the fruit of Cucumis citrullus. Its sweet and watery fruit, and especially the seeds, are diuretic. Unof. W., Mineral. See Mineral Water. W.-pang, pyrosis, W.-passage, the urethra. W.-pepper. See Polygonum hydropiperoides. W.-plantain. See Alisma. W.-pock. Synonym of Varicella. W.-pore, in biology, an aperture in the epidermis of the leaves of certain plants (..$g$., Caladium esculentum) directly over the extremity of a vein. It is a modified stroma and serves to facilitate the transpiration of water. W.pox, chicken-pox. W.-proof Drawing-ink, powdered, bleached shellac 4 parts, borax I part, water 24 parts; dissolve by the aid of heat. To this solution the coloring-principle, as India ink, lampblack, different tints and shades of anilin colors, is added, after being dissolved in or triturated with a small quantity of water. W.-qualm, pyrosis. W., Rice. See Oryza. W., Soda. See Soda-water. W., Softening of, the process of removing from water certain mineral constituents that render it "hard" or unsuited for technical or domestic purposes. This may be accomplished either by heat or the use of chemicals. The Clarke Process of softening consists in bringing steam directly into contact with the water. W.-vascular, in biology, applied to the system of circulation of water through the tissues of many invertebrates; a respiratory process. W. - wheel Sound. See Bruit de Moulin and Hydropneumopericardium.

Watered-silk Reflex. See Reflex.

Waters (waw'terz) [ME., water, water]. Plural of Water, q. v. W., Bag of. The amnion. See Ammii, Liquor. W., False, a discharge of fluid before labor, due to a catarrhal endometritis.

Watt (wot) [after James Watt, the Scottish engineer]. In electro-mechanics, one voltampère. See Volt and Electric Units.
Wattle (wot'-l) [ME., watel, a hurdle]. I. See Mimosa-bark. 2. In biology, a lobe or flap of the skin, usually paired and pendent, on the head and near the mouth of certain birds, fishes, and mammals. A dew-lap, a barbel.

Wave (wäu) [ME., zuave, wave]. A cycle of rhythmic alternating movements. W.-lengths and Frequencies of Light, the ethereal wave-lengths, together with their frequencies, of the visible portion of the spectrum are given in the appended table. The average vibrational frequency of white light has been estimated at 554 millions of millions per second. W. Pulse. See Pulse.

TABLE OF THE WAVE-LENGTHS ANI) FREQUENCIES OF LIGHT.

(From Daniell.)

\begin{tabular}{|c|c|c|}
\hline & $\begin{array}{c}\text { FREQUencies- } \\
\text { PER SEC }\end{array}$ & $\begin{array}{l}\text { LENGTHS } \\
\text { IN CM. }\end{array}$ \\
\hline 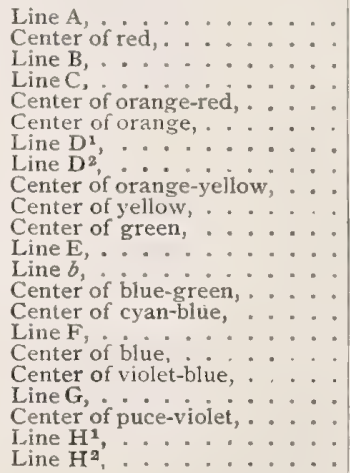 & $\begin{array}{c}395,000,000,000,000 \\
437,300,000,000,000 \\
457,700,000,000,000 \\
\cdots \\
508,905,810,000,000 \\
510,604,000,000,000 \\
\vdots \vdots \\
\vdots\end{array}$ & $\begin{array}{l}.00007604 \\
.00007000 \\
.00006867 \\
.00006562 \\
.00006208 \\
.00005972 \\
.00005895 \\
.00005889 \\
.00005879 \\
.00005) 08 \\
.00005271 \\
.00005269 \\
.0005183 \\
.00005082 \\
.00004960 \\
.00004861 \\
.00004732 \\
.00004383 \\
.00004307 \\
.00004059 \\
.00003968 \\
.00003933\end{array}$ \\
\hline
\end{tabular}

Wavy $\left(w a^{\prime}-v e\right)$ [ME., wave, wave]. Of the nature of a wave. W. Breathing. See Breath-sounds.

Wax (waks) [ME., wax , wax]. I. To grow; to increase in size. 2. See Cera and Cerumen. W., Bees', a wax deposited by the honey-bee in the honeycomb. W., Carnauba, obtained from the leaves of the carnauba tree; it melts at $83^{\circ} \mathrm{C}$; contains free ceryl-alcohol and various acid esters. W., Chinese, ceryl cerotic ester. W., Mineral. See Ozocerite. W.-myrtle. See Myrica. W.-work. See Celastrus.

Waxing (rvaks'-ing) [ME, waxen, to increase]. Growing; increasing in size. W.-kernels, enlarged inguinal and submaxillary lymph-glands in children; popularly associated with the growth of the child. W.pains. See Growing Pains. W. and Waning Pulse. See Pulsus inciduus.

Waxy (waks'-e) [ME., wax, wax]. Of the nature of or like wax. W. Degeneration. See Degeneration. W. Kidney. See Bright's Discase.

Weak (wekk) [ME., weik, weak]. Not strong. W. Ankle, a condition in which there is an abnormal relaxation of the ligaments of the ankle-joint, with such weakness of the leg-muscles as may allow the foot to bend involuntarily, either inward or outward, in the act of standing or walking. It is common in feeble children. W.-minded, having a feeble intellect.

Weaken $\left(w e^{\prime}-k e n\right)$ [ME, weik, weak]. To reduce the strength.

Weakness (reèk'-nes) [ME., weik, weak]. See Asthenia. W., Inward, a popular term for leukorrhea.

Weal (wèl). 1. Well-being. 2. See Wheal. 
Wean (ween) [ME, wenen, to wean]. To cease to give suck to offspring at a period when the latter is capable of taking substantial food from external sources.

Weaning $\left(\right.$ weèn $\left.^{\prime}-i n g\right)$. See Ablactation.

Weasel-faced (we'-sl-fäst) [ME., wesel, weasel; face]. Having a thin, sharp face.

Weather-plant (zeth'-er plant). Jequirity,aq.v.

Web [ME., zeb, web]. A woven fabric; a membranelike structure. The thin, soft tissue between any two adjacent fingers or toes, lying distad of the knuckles. W. of the Brain, the bindweb, or neuroglia. W. Choroid, the velum interpositum. W.-eye. See Pterygium. W.-eyed, affected with pterygium. W.-fingered, having the fingers united by web-like tissue. W.-foot, a foot whose toes are webbed. W.footed, having web-feet. W.-footedness, webfoot. W.-toed, web-footed.

Webbed (zebd) [MF., web, web]. Having, or of the nature of a web. W. Fingers (or Toes), union of two adjacent digits by a thin band of connecting tissue.

Weber $\left(w e b^{\prime}-e r\right)$. I. Same as Coulomb. 2. Same as Ampere. See Electric Units.

Weber's Chronometer. A kind of metronome consisting of a weight and a graduated and adjustable cord. W.'s Corpuscle. See Corpuscle. W.'s Experiment, for testing hearing. A vibrating tuningfork set on the median line of the skull will be heard best by the ear the external meatus of which is occluded by the finger. In unilateral ear-disease the tuning-fork is best heard by the ear in which pathologic changes have occurred in the external meatus or the middle ear. W.'s Glands. See Gland. W.'s Law, a law of sense-perceptions. When the excitation is increased in geometric proportion, the sensation is increased in arithmetic proportion, or, in other words, the reaction varies as the logarithm of the excitation. See Law. W.'s Paradox, the fact that a muscle, when so stretched that it cannot contract, may elongate. W.'s Symptom, paralysis of the oculo-motor of one side and hemiplegia of the opposite side. W.'s

Test. See $W$.'s Experiment.

Weber and Hasner, Theory of. See Aspiration-theory.

Webster's Condenser. In microscopy, an apparatus consisting of two lenses, used for intensifying the light thrown on the object. W.'s (Lady) Pill, a pill of aloes and kina.

Wedge (wej) [ME., wegge, wedge]. A prismoidal mass used by dentists to separate the teeth. W.-bone, an ossicle sometimes found at a vertebral joint.

Wedl's Solution. A solution of a coloring-matter obtained from the lichen Roccella tinctoria. The free ammonia is driven off by gentle heat from the French extract of orseillin, and this powder is added to the following mixture until a deep-red fluid is obtained: absolute alcohol 20 c.c., hydric acetate 5 c.c., distilled water $40 \mathrm{c.c}$.

Weed (wēe $\left.d^{\prime}\right)$ [origin obscure]. 1. Milk-fever. See Garget and Ephemera. 2. Lymphangitis in the legs of a horse.

Weep (wepp) [ME., wepen, to weep]. To shed tears.

Weeping (wêt $\left.p^{\prime}-i n \sigma\right)$ [ME., wepen, to weep]. I. Lacrymation. 2. Exudation, or leakage of a fluid. Exuding; applied to raw or excoriated surfaces bathed with a moist discharge.
W. Leg. See Leg. W. Sinews, a colloquial term applied to torn or broken tendons, because of the appearance of the structures after certain injuries.

Weibel, Spirilli of. See Bacteria, Synonymatic Table of. Weid (wed). Same as Weed.

Weight (wät) [ME., weight, weight]. The measure of the force of gravitation. A table or system for the measurement of weight. W., Atomic. See Atomic Weight. W., Molecular. See Molecular Weight. Ws. and Measures: The U. S. Standard Unit of Weight is the Troy Pound; it was copied in 1827 from the imperial troy pound of England, for the use of the U.S. Mint, and there deposited. It is standard in air, at $62^{\circ} \mathrm{Fah}$, the barometer at 30 inches.

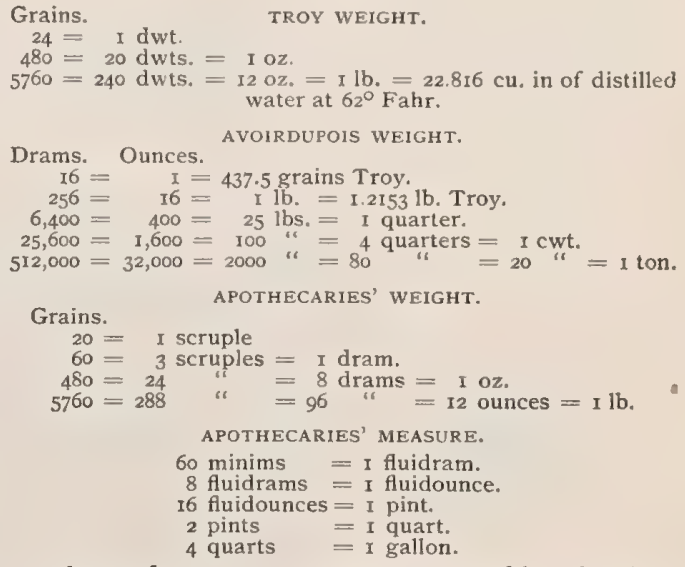
45 drops of water, or a common teaspoonful, make about I fluidram; 2 tablespoonfuls about I fluidounce; a wineglassful is about $I \frac{1}{2}$ fluidounces; and a teacupful about 4 fluidounces.

LIQUID, OR WINE MEASURE.

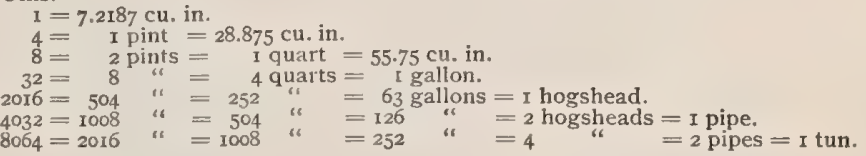

The Standard Unit of Liquid Measure adopted by the U. S. Government is the Winchester Wine Gallon, which contains $23 \mathrm{I}$ cubic inches, and holds $8.339 \mathrm{tbs}$ avoir. of distilled water, at its maximum density, weighed in air, the barometer being at 30 inches. The Imperial Gallon adopted by Great Britain contains 277,274 cubic inches, and equals I. 20032 U. S. gallons. The Standard Unit of the U. S. and British Linear Measure is the yard. It was intended to be exactly the same for both countries, but in reality the U. S. yard exceeds the British standard by .00087 inch. The actual standard of lenoth of the U. S. is a brass scale 82 inches long prepared for the Coast Survey and deposited in the Office of Weights and Measures at the U. S. Treasury Dept., Washington. The yard is between the 27 th and the $63 \mathrm{~d}$ inch of this scale. The temperature at which this scale is designed to be standard, and at which it is used in the U. S. Coast Survey, is $62^{\circ}$ Fahrenheit.

$$
\begin{aligned}
& \text { Inches. LONG MEASURE. }
\end{aligned}
$$

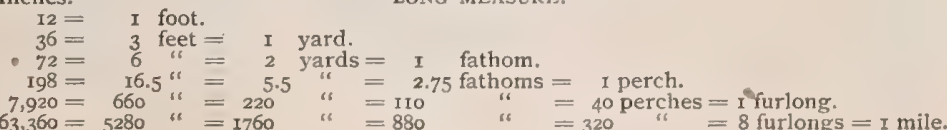


SQUARE MEASURE,

Sq. Inches, Sq. Feet.

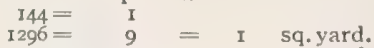

$1290=$
$39,204=$
272.25

$1,568,160=10,890=1210$ " " $=40$ perches $=1 \mathrm{rood}$

$6,272,640=43,560=4840 \quad$ " $\quad=160$ " $=40$ " $=4$ roods $=1$ acre An acre is 69.5701 square yards; or, 208.710321 square feet.

$$
\begin{aligned}
& \begin{array}{l}
\text { A township is } 6 \text { miles square }=36 \text { sections. } \\
\text { A section "I mile " }=640 \text { acres. }
\end{array} \\
& \text { A section " " } 1 / \text { mile " " }=640 \text { acres. }
\end{aligned}
$$

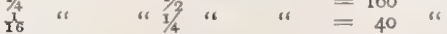

The Standard U. S. Bushel is the Winchester Bushel, which is, in the cylinder form, $181 / 2$ in. in diameter and 8 in. deep, and contains $2150.42 \mathrm{cub}$. inches.

$\begin{aligned} & \text { The English Imperial bushel }=\left\{\begin{array}{r}22 \text { I } 8.192 \text { cubic inches. } \\ 1.03152 \text { U. S. bushel. }\end{array}\right. \\ & \text { The English quarter }=\left\{\begin{aligned} 8 \text { Imperial bushels. } \\ 81 / 4 \text { (nearly) U. S. bushels. } \\ \text { I0.2694 cubic feet. }\end{aligned}\right.\end{aligned}$
Cu. in.
$\begin{aligned} & 1,728= \\ & 46,656\end{aligned}=27$ cubic foot.

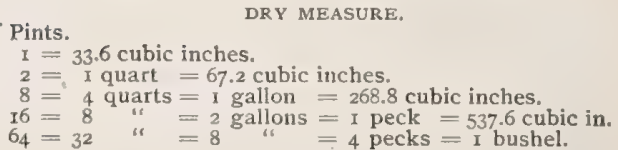

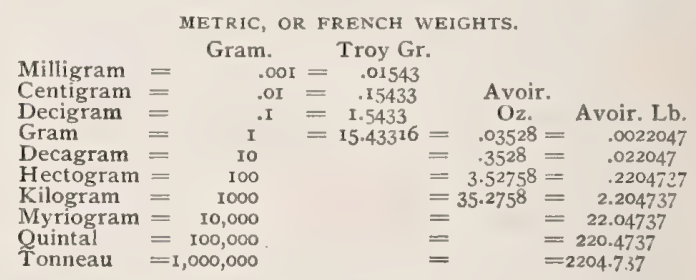

METRIC, OR FRENCH DRY AND LIQUID MEASURE.

\begin{tabular}{|c|c|c|c|c|c|c|c|c|c|}
\hline & & MET & IC, OR FR & $\mathrm{ICH}$ & H LINEAL M & EAS & URE. & & \\
\hline & & Meter. & U. S. In. & & $\mathrm{Ft}$. & & & & \\
\hline Millimeter* & $=$ & $.00 \mathrm{I}$ & $=.03937$ & $=$ & .00328 & & & & \\
\hline Centimetert & $=$ & $.0 I$ & .3937 & $=$ & .03280 & & Yd. & & \\
\hline Decimeter & $=$ &.$I$ & $=3.937$ & $=$ & .32807 & $=$ & .10936 & & \\
\hline Meter & $=$ & I & $=39.3685$ & $=$ & 3.2807 & $=$ & I. 0936 & & \\
\hline Decameter & $=$ & ro & $=$ & $=$ & 32.807 & $=$ & 10.936 & & Mile. \\
\hline Hectometer & $=$ & 100 & $=$ & $=$ & 328.07 & $=$ & 109.36 & $=$ & .0621 \\
\hline Kilometer & $=$ & 1000 & $=$ & $=$ & 3.280 .7 & $=$ & 1093.6 & $=$ & .6213466 \\
\hline Myriameter & $=$ & $\begin{array}{l}10,000 \\
\text { Jearly th }\end{array}$ & $\overline{\bar{x}}$ & $=$ & $3^{2,807}+\mathrm{F}$ & & 10,936 & $=$ & 6.213466 \\
\hline
\end{tabular}

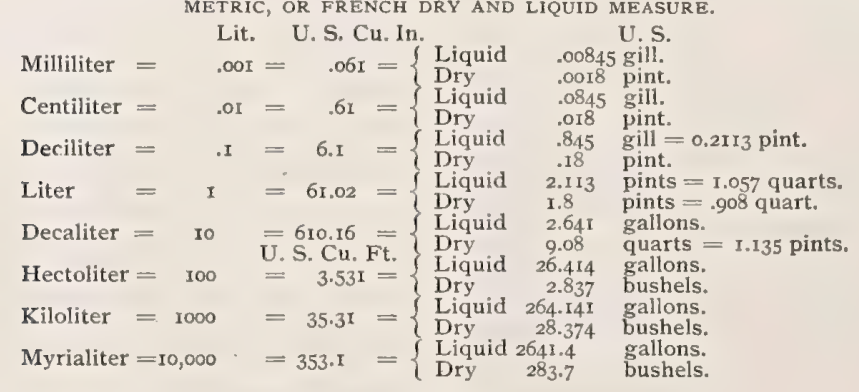

METRIC, OR FRENCH SQUARE MEASURE.

Sq. Meter. U. S. Sq. In,

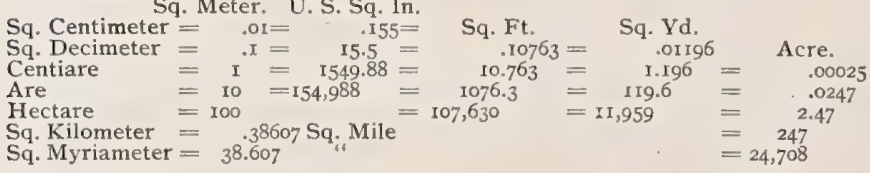

COMPARISON OF U. S. FOREIGN WEIGHTS AND MEASURES.

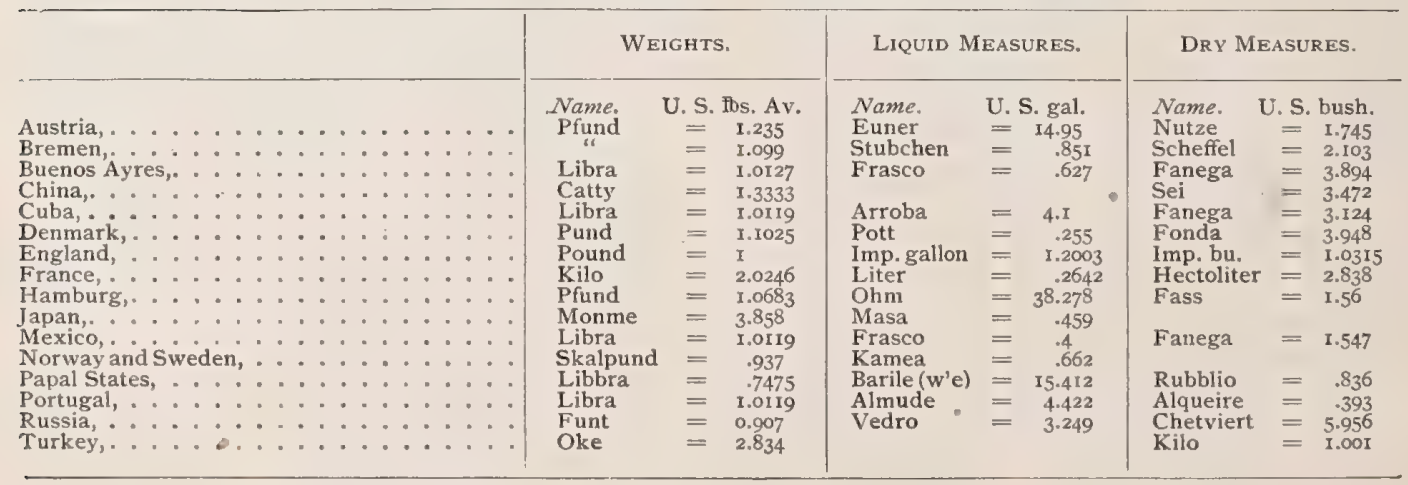




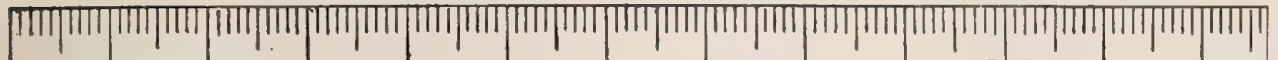
$\begin{array}{llllllllllllll}1 & 2 & 3 & 4 & 5 & 6 & 7 & 8 & 9 & 10 & 1 & 1 & 1 & 2\end{array}$

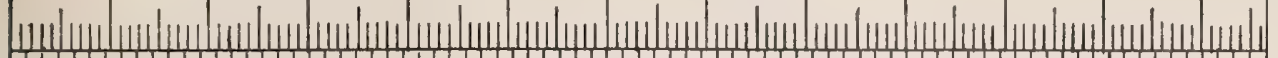

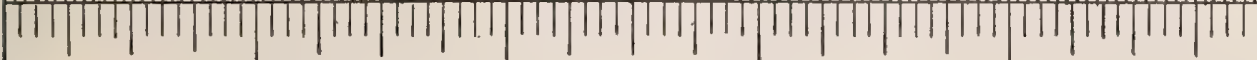
$\frac{\text { ONE BEER QUART }}{140.9 \mathrm{~mm} \text { in height. }}$
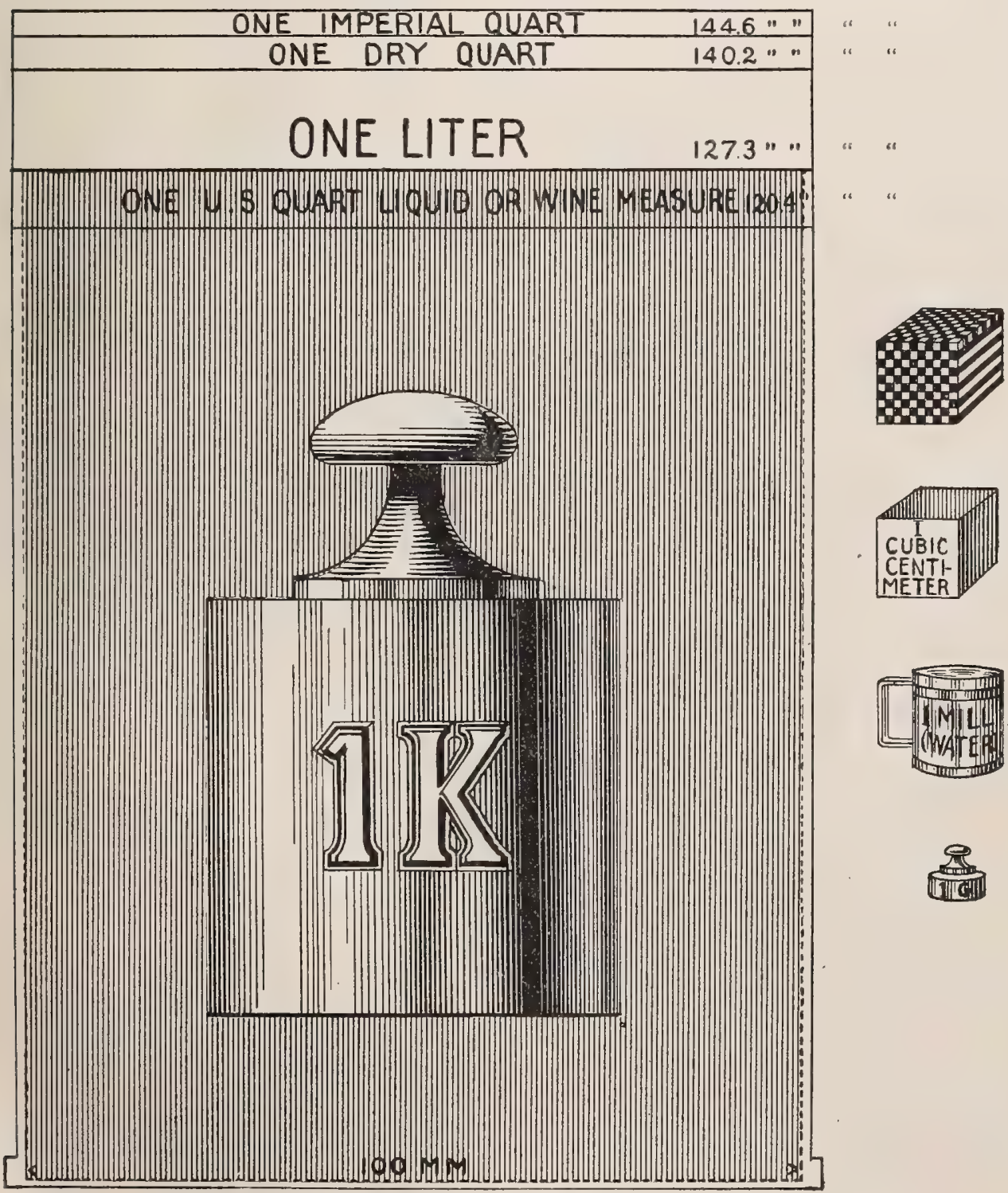

Circular base roo millimeters in diameter.

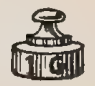


TABLE FOR CONVERTING METRIC WEIGHTS INTO TROY WEIGHTS.

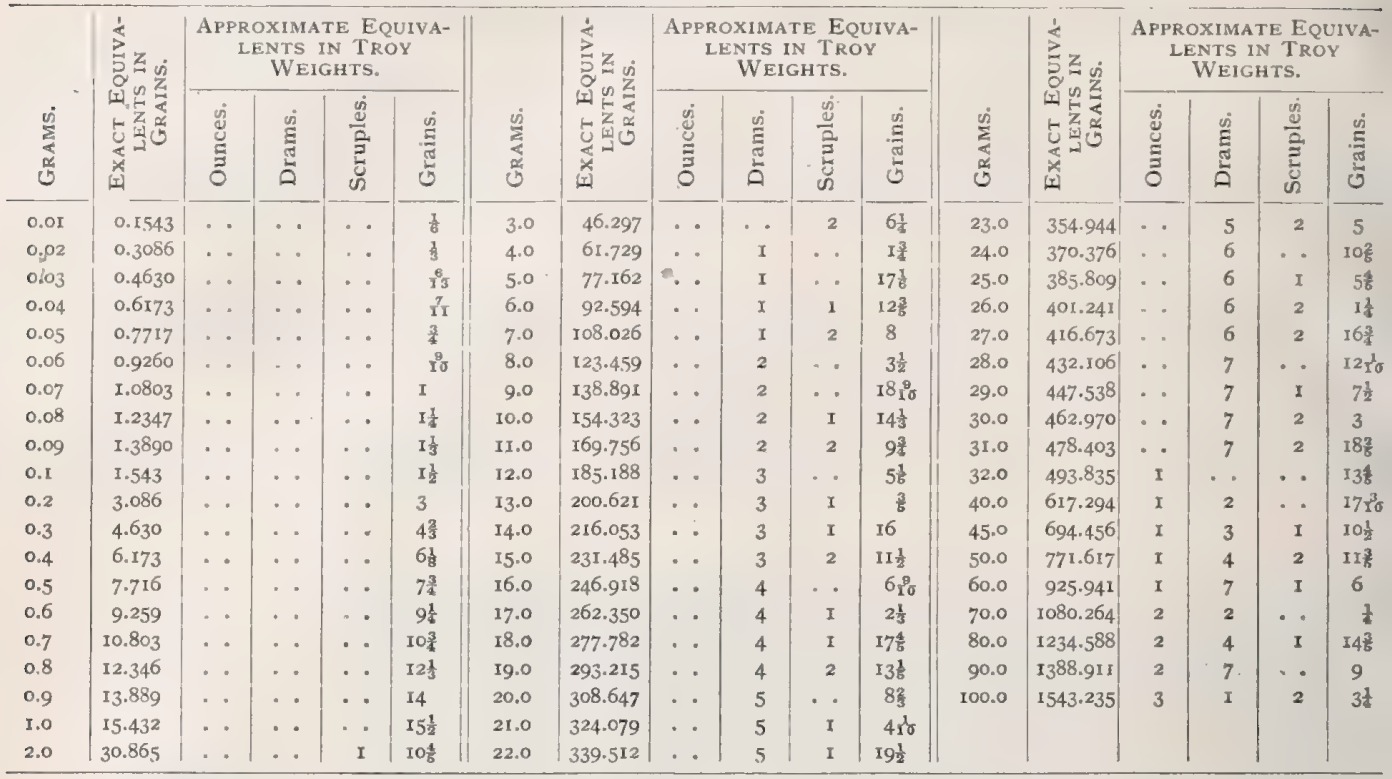

TABLE FOR CONVERTING TROY WEIGHTS INTO METRIC WEIGHTS.

\begin{tabular}{|c|c|c|c|c|c|c|c|c|c|c|c|c|c|c|c|}
\hline 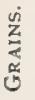 & $\sum_{0}^{\frac{1}{2}}$ & 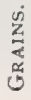 & 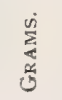 & $\frac{n}{z}$ & $\sum_{0}^{\infty}$ & $\frac{\dot{n}}{Z}$ & 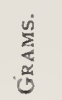 & $\begin{array}{l}\stackrel{y}{ } \\
Z \\
Z \\
\stackrel{\alpha}{u}\end{array}$ & 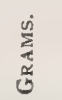 & 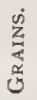 & 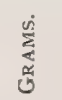 & $\frac{n}{Z}$ & $\sum_{\frac{0}{2}}^{\frac{\dot{n}}{5}}$ & $\begin{array}{l}\dot{n} \\
Z \\
z \\
0 \\
0 \\
0\end{array}$ & $\underset{\substack{n \\
\vdots}}{\frac{\dot{n}}{b}}$ \\
\hline I & 0.0648 & I6 & I.037 & $3 I$ & 2.009 & 46 & 2.980 & $6 I$ & 3.952 & 76 & 4.924 & $9 \mathrm{r}$ & 5.896 & 300 & I9.440 \\
\hline 2 & 0.1296 & I7 & 1.102 & 32 & 2.073 & 47 & 3.045 & 62 & 4.017 & 77 & 4.989 & 92 & 5.961 & 360 & 23.328 \\
\hline 3 & 0.1944 & I8 & 1.166 & 33 & 2.138 & 48 & 3.110 & 63 & 4.082 & 78 & 5.054 & 93 & 6.026 & 400 & 25.920 \\
\hline 4 & 0.2592 & 19 & I. 231 & 34 & 2.203 & 49 & 3.175 & 64 & 4.147 & 79 & 5.118 & 94 & 6.090 & 480 & 31.103 \\
\hline 5 & 0.3240 & 20 & I. 296 & 35 & 2.268 & 50 & 3.234 & 65 & 4.211 & 80 & 5.183 & 95 & 6.155 & 500 & 32.396 \\
\hline 6 & 0.3888 & 2 I & $1.36 \mathrm{I}$ & 36 & 2.332 & $5 I$ & 3.304 & 66 & 4.276 & $8 I$ & 5.248 & 96 & 6.220 & 600 & 38.875 \\
\hline 7 & 0.4536 & 22 & I. 426 & 37 & 2.397 & 52 & 3.369 & 67 & $4.34 I$ & 82 & $5.3 I_{3}$ & 97 & 6.285 & 700 & 45.354 \\
\hline 8 & 0.5184 & 23 & I. 490 & 38 & 2.462 & 53 & 3.434 & 68 & 4.406 & 83 & $5.37^{8}$ & 98 & $6.35^{\circ}$ & 800 & 51.833 \\
\hline 9 & 0.5832 & 24 & I. 555 & 39 & 2.527 & 54 & 3.499 & 69 & 4.471 & 84 & 5.442 & 99 & 6.414 & 900 & 58.313 \\
\hline 10 & 0.6480 & 25 & 1.620 & 40 & 2.592 & 55 & 3.564 & 70 & 4.535 & 85 & 5.507 & 100 & 6.479 & 960 & 62.207 \\
\hline II & 0.7130 & 26 & I. 685 & $4 I$ & 2.656 & 56 & 3.628 & $7 x$ & 4.600 & 86 & 5.572 & 120 & 7.776 & 1000 & 64.792 \\
\hline 12 & 0.7776 & 27 & I. 749 & 42 & 2.721 & 57 & 3.693 & 72 & 4.665 & 87 & 5.637 & I5O & 9.719 & & \\
\hline 13 & 0.8424 & 28 & 1.814 & 43 & 2.786 & $5^{8}$ & 3.758 & 73. & 4.730 & 88 & 5.702 & 180 & Ix. 664 & & \\
\hline 14 & 0.9072 & 29 & I. 869 & 44 & 2.851 & 59 & 3.823 & 74 & 4.795 & 89 & 5.766 & 200 & $12.95^{8}$ & & \\
\hline I5 & $0.97^{2}$ & 30 & I. 944 & 45 & 2.916 & 60 & 3.888 & 75 & 4.859 & 90 & 5.831 & 240 & I $5.55^{2}$ & & \\
\hline
\end{tabular}

Weil's Disease. An infectious febrile disease, somewhat resembling typhoid fever, accompanied by muscular pain and grave disturbance of the digestive organs. See Diseases, Table of.

Weisner's Tests. Tests for lignin. The specimen is first acted on by hydrochloric acid, and then moistened with a solution of phloroglucin in water and alcohol. If the cell-walls are lignified, they will at once assume a red color. Höhnel suggests the employment of a strong decoction of cherry-wood instead of phloroglucin. Used in the same way, it imparts a violet color to lignified cells (Goodale).

Weiss' Reflex. A peculiar curved reflex seen with the ophthalmoscope parallel with and to the nasal side of the papilla or disc of the fundus of the eye. It is thought to be a sign of myopia.

Weissmann's Ahnenplasma. See Heredity, Weissmann's Theory of. W.'s Theory. See Blastogenesis, Germ-plasm, and Heredity.

Weissmannism. See Heredity, Weissmann's Theory of.

Weitbrecht, Cartilage of. See Cartilage. W., Cord of. See Cord. W.'s Ligament. See Ligament. W., Retinacula of. See Retinacula.
Welcker's Angles. See Angle.

Welk. See Whelk.

Well [ME, wel, well]. In good health, not diseased. An artificially made spring of water. A cavity or pit.

Wells' Facies. The facies of ovarian disease.

Welt. See Wheal.

Wen. See Sebaceous Cyst.

Wenz's Method. A method of removing all the proteids from a liquid. Saturate the solutions with ammonium sulphate, and all the proteids but peptones will be precipitated, and may be filtered off.

Werlhoff's Disease. Purpura hæmorrhagica. See Diseases, Table of.

Wernekinck, Commissure of. The decussation of the prepeduncles of the cerebellum.

Wernicke's Fissure. See Fissure. W.'s Sign, Hemiopic pupillary inaction. If a bright light is thrown into the eye and the pupil reacts, the integrity of the reflex arc is demonstrated. It is possible in cases of lateral hemianopsia to throw the light into the eye so that it falls upon the blind half of the retina. If when this is done the pupil contracts, the indica- 
tion is that the reflex arc referred to is perfect, by which is meant that the optic nerve-fibers from the retinal expansion to the center, the center itself, and the third nerve are uninvolved. In such a case the conclusion would be justified that the cause of the hemianopsia was central; that is, situated behind the geniculate bodies, either in the tibers of the optic radiation or in the visual cortical centers. If, on the other hand, when the light is carefully thrown on the hemiopic half of the retina, the pupil remains inactive, the conclusion is justifiable that there is interruption in the path between the retina and the geniculate bodies, and that the hemianopsia is not central, but dependent upon a lesion situated in the tract.

Wertheim's Ointment. An ointment used in treating chloasmata. It consists of the ammoniated chlorid of mercury and bismuth, each two drams, and glycerin ointment one ounce. This is to be smeared over the blotches.

Werwolf, Werewolf (we'r'-wulf) [ME., werwolf]. A lycanthrope. See Lycanthropy and Zoänthropy.

West Indian Colic. See Colic.

Westphal's Nucleus. See Nucleus. W., Paradoxic Contraction of, this consists in the contraction of a muscle, caused by the passive approximation of its extremities. It is best known in the tibialis anticus, in which it can be produced in proper cases by rapid dorsal flexion of the foot ; the foot remains firmly fixed in this position for some time. It has been observed in cases of combined sclerosis of the posterior and lat eral columns and in paralysis agitans (Westphal). It is found only in disease. W.'s Phenomenon, or Symptom, loss of the knee-jerk, as in tabes dorsalis. See Signs and Symptoms, Table of. W.-Erb's Symptom. Same as Westphal's Phenomenon.

Wet [ME., wet, wet]. Moist; not dry. W. Brain, an excessively serous condition of the brain, seen postmortem in cases of alcoholism, etc. W.-cupping, cupping combined with scarification, whereby some blood is drawn. W.-nurse. See Nurse. W. Pack, wrapping a patient with a wet sheet covered with dry blankets. W.-scald, eczema in sheep, occurring in wet and cold weather. W. Tetter. See Ecsema.

Weyl's Test (for kreatinin). See Tests, Table of.

Whale-oil [AS., hwal, whale]. Train-oit. An oil extracted from the blubber of the common or Greenland whale. It is yellowish or brownish in color and of disagreeable odor. Its specific gravity is .920 to .93I. It is used for illumination and for soap-making.

Wharl (hvoarl) [a variety of whirl]. The uvular or rattling utterance of the $R$ sound.

Wharton's Canal. See Duct. W., Duct of. See Duct. W.'s Jelly, the gelatin-like connective tissue of the umbilical cord.

Wheal (hweel) [ME., wheel, a pimple]. A raised stripe or ridge on the skin, usually of short duration and accompanied with violent itching. It may be produced by a stroke or from the bite or sting of an insect, or it occurs as a symptom in urticaria. See Pomphus. W.worm, the Acarus scabiei, or itch-insect.

Wheat (hwèt). See Triticum.

Wheatena (hrwet-e'-nah) [ME., whete, wheat]. An artificial food said to contain all the elements of the wheatberry except the husk. The starch-granules have already been ruptured by heat, and only a few moments cooking is necessary.

Wheel (hwēl) [ME., wheel, wheel]. A circular frame or solid disc turning on an axis. In biology, the trocheal disc of Rotifera. W.-crutch, a contrivance used in orthopedic surgery whereby children unable to walk from hip-disease, paralysis, etc., may move themselves from place to place. W., Knight's, a small wheel 102 rotating in the horizontal plane, with a number of seeds attached to its circumference, devised by Andrew Knight to ascertain the effect of geotropism. W. of Life. See Zoetrope.

Wheelhouse's Operation. Incision into the urethra through the perineum for the treatment of stricture. See under Urethrotomy.

Wheeze (hrwēz) [ME., hrvezen, to wheeze]. To breathe hard; to puff and blow; to breathe with difficulty and audibly.

Wheezing (hwëz-ing) [ME., hruesen, to wheeze]. The half-stertorous, sibilant sound occasionally observed in the breathing of persons affected with croup, asthma, or coryza.

Whelk (hroelk) [ME., welk]. A protuberance upon the face, due to alcoholism; acne rosacea; a pimple.

Whetstone Crystals (hret'-stōn). Peculiar crystals of xanthin found in urine.

Whey (hwa) [ME., whey, whey]. The liquid part of milk separating from the curd in coagulation. W., Alum, whey separated by stirring milk with a lump of alum; a popular remedy for sore eyes. W.-cure, a cure for chronic catarrh of the respiratory organs. This consists in drinking warm whey, either alone or mixed with.a mineral water, in definite quantities at set times. About 20 ounces are taken daily. This is regarded by many as in all respects similar to the use of skimmed milk. Sometimes the method is combined with baths of whey. See Serotherapy and Aponipsis. W., Wine, a whey prepared by adding Rhine wine, I part, to hot milk, 4 parts, and straining. Whiff (hrwif) [origin obscure]. A puff of air. W., Oral, a peculiar sound heard during expiration from the open mouth, principally in cases of thoracic aneurysm.

Whipping (hwip'-ing). See Flagellation and Perrussion.

Whip-worm (hwip'-7eurm). See Thread-worm.

Whirl (hreurl) [ME., whirlen, to whirl]. To revolve rapidly. W.-bone: $\mathbf{I}$. The head of the femur. 2. The patella.

Whirling (hreurl'-ing) [ME., whirlen, to whirl]. Revolving rapidly. W.-chair. See Chair.

Whiskers (hwis'-kerz) [origin obscure]. I. The beard, especially that of the cheeks. 2. The vibrissæ of the cat.

Whiskey, Whisky (hwis'-ke) [Sc., whuskey]. See Spiritus frumenti. W.-nose. See Acne rosacex.

Whisper (hwis'-per) [ME, whisperen, to whisper]. An utterance of words by the breath, without vocalization; in auscultation, the sound of a whispering voice, as a cavernous whisper.

Whispered (hwir's-perd) [ME., whisperen, to whisper]. Uttered beneath the breath. W. Bronchophony. See Bronchophony.

Whispering Pectoriloquy. See Pectoriloquy.

Whistle (hwis'-l) [ME., whistle, a whistle]. A sound produced by forcing the breath through the contracted lips. W., Galton's. See Galton's Whistle.

Whistling (hwis'-ling) [ME., whistle, whistle]. Broken wind in the horse.

White (hwint) [ME., whit, white]. The opposite of black. In chromatics, the color-effect produced by a mixture of the primary colors. W. Blisters, a gangrenous eruption, following varicella and other pustular eruptions in children; varicella gangræenosus, rupia escharotica, pemphigus gangræenosus, dermatitis gangrænosa infantum. W.-browed, having a white superciliary streak. W.-celled Blood. Synonym of Leukemia. W. Clay. See Krolin. W. Clot, a clot occurring in the heart or vessels, devoid of red coloring-matter. It is usually formed before death. W. Cohosh. 
See Actea. W. Commissure, the ventral commissure of the spinal cord. W.-crowned, having the crown or top of the head white. W. Diarrhea, diarrhea in which there is a large amount of thin mucus in the stools. W., Dutch, a mixture of white lead and barium sulphate, I: 3 . W. Dysentery, dysentery without admixture of blood in the stools. W. Flake, lead subcarbonate. W. Flux (of India), "Hill diarrhea;" tropical diarrhea associated with the presence of the ankylostoma. See Diarrhea. W. Galls, the nutgalls procured after the escape of the insect; they are inferior to the blue or black galls. W. Gangrene. See Gangrene. W. Gum, Milia strophulus albidus of Willan. W., Hamburg, a mixture of white lead and barium sulphate, I: 2 . W. Infarct. See Infarct. W. Lead, lead car. bonate. See Pigments, Conspectus of. W. Lead Substitute. See Pigments, Conspectus of. W. Leg. See Phlegmasia alba dolens and Leg. W. Leprosy. See Vitiligo. W. Lettuce. See Nabalus. W. Line (of the pelvic fascia), a thickened, whitish band in the pelvic fascia, extending from the lower part of the symphysis pubis to the spine of the ischium. This line marks the point of division of the fascia into two layers, the obturator and the recto-yesical. W.lipped, having white lips. W. Matter. See Brain. W. Mole. See Mole. W. Mustard, sinapis alba. W. Nail, a condition of the nail in which spots and bands of white are seen on its surface. Occasionally the whole nail may be white. The mechanical cause is the presence of air between the affected lamellæ, but the origin is unknown. The condition is sometimes associated with gout, syphilis, or leprosy, or is a part of trophic changes. The white spots commonly seen on the nails of young persons are due to trauma. W. Oak Bark. See Quercus alba. W., Paris, whiting. W., Pearl, bismuth subnitrate. W., Permanent, pulverized barium sulphate mixed with white lead. W. Pneumonia. See Pneumonia. W. Precipitate. See Precipitate and Hydrargyrum. W. Rosin, ordinary rosin which has been melted and mixed with water. W. Sage. See Erotia lanata. W. Sandalwood. See Santalum. W. Softening, a form of cerebral softening in which the affected area presents a dirty-white color, due to embolism of one of the larger arteries or to gradual narrowing of the arteries by chronic endarteritis. W. Substance of Schwann. See Schwann. W. Swelling. See Hydrarthrosis. W. Tâche, a form of tâche observed in typhoid fever, in which the vessels of the area irritated by the nail undergo contraction and remain empty. W. Tanned Leather. See Leather. W., Venetian, a mixture of equal parts of white lead and barium sulphate. W. Vervain, the root of $V e r$ bena urticifolia; of reputed value in malarial fevers. W. Vitriol, zinc sulphate. See Pigments, Conspectus of. W. Wax, yellow wax bleached by exposure to air, light, and moisture. W. Wine. See Wine. W.winged, having white wings.

White's Disease. Same as Darier's Disease.

Whites (hwitz). See Leukorrhea.

Whiting (hrent'-ing) [ME., whit, white]. Purified calcium carbonate.

Whitleather (hwit'-leth-er) [ME., whittlether]. The ligamentum nuchæ, or packwax, of the ox.

Whitlow (hreit'-lo). See Panaris. W., Painless. See Morvan's Disease.

Whole (höl) [ME., hol, whole]. Hale; healthy; sound.

Whoop (hoop) [ME., houpen, to whoop]. The inspiratory crow which precedes or occurs during a paroxysm in whooping-cough.
Whooping Cough (hoo'-ping-kawf). See Pertussis and Bacillus tussis convulsive, Afanassiew, under Bacteria, Synonymatic Table of.

Whorl (hworl) [ME., whorle, whorl]. See Vortex. In biology, organs disposed in a circle about a cen tral axis are said to be arranged in a whorl. W. of Heart. See Vortex of Heart.

Whytt's Disease. Acute hydrocephalus. W.'s Tincture, a preparation consisting of cinchona 6 , orangepeel 2, gentian 2, cinnamon I, dilute alcohol 50 .

Wickersheimer's Fluid. A fluid employed chiefly for the preservation of museum specimens. There are two formula, the first for injecting, and the second for immersing. They are as follows:-

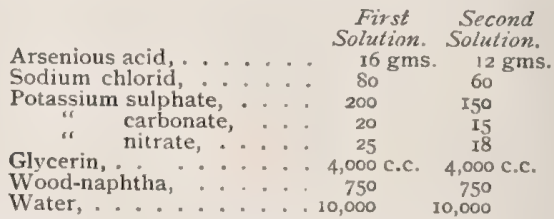

Widal Reaction (Gruber-Widal Reaction, Agglutination-test). The clumping and sedimentation, with loss of mobility, of certain bacteria on addition of blood-serum from persons who have passed or are passing through the disease to which the respective bacterium gives rise.

Wig [abbr. of periwig]. A covering of false hair for the head.

Wigger's Ergotin. An alcoholic extract prepared from ergot deprived of fixed oil by means of ether. W.'s Method, a Method of Generating Chlorin. Mix I8 parts of finely ground common salt with 15 parts of finely pulverized good manganese dioxid. Put the mixture in a flask and pour a completely cooled mixture of 45 parts of concentrated sulphuric acid and $2 \mathrm{I}$ parts of water upon it, and shake.

Wild (willd) [ME., reilde, wild]. Not domesticated. W. Bean. See Apios. W. Bergamot, the herb Monarda fistulosa, in large doses a powerful diaphoretic. A reputed antiperiodic. Dose of the fld. ext. $m \times x-3 j$. W. Cherry. See Prunus virginiana. W.-fire. Synonym of Erysipelas. W. Ginger. See Asarum. W. Indigo. See Baptisia. W. Liquorice. See Abrus. W.-mare, the night-mare. W. Marjoram. See Orighnum. W. Potato. See Convolvulus panduratus. W. Sage. See Serra salvia. W. Silk. See Silk. W. Sunflower. See Grindelia. W. Yam. See Dioscorea.

Wilde, Cords of. Transverse striæ of the corpus callosum. W.'s Incision, in operations in the mastoid region, the incision of the soft parts. See Operations, Table of.

Wilder's Fissures. See Fissure. W., Foramen of. See Foramina, Table of.

Wildermuth's Ear. See Ear, Deformities, and Diseases, Table of.

Wilkinson's Formula. An animal parasiticide used in dermatology. It consists of sulphur, tar, and lard, of each two ounces, precipitated chalk one ounce, ammonium sulphid one-half dram. It is used for tinea tonsurans and scabies. W.'s Ointment, or Salve, for psoriasis; it consists of sublimed sulphur and oil of cade, of each four drams, green soap and lard each one ounce, prepared chalk two and onehalf drams.

Wilks's Kidney. The large white kidney of chronic parenchymatous nephritis. See Diseases, Table of.

Will (wil) [ME, willen, to will]. Volition; desire, with more or less engagement of the motor centers and of the muscular system. 
Will and Varrentrap's Method. See Ailrogen.

Williamson's Diabetic Blood Test. Place in a test tube of small caliber $40 \mathrm{c} . \mathrm{mm}$. of water and 20 c. mm. of blood taken from the finger-tip or lobule of the ear; add to this $\mathbf{I}$ c.c. of methyl blue solution (I : 6000 ) and $40 \mathrm{c} . \mathrm{mm}$. of liquid potassæ. Place the test-tube in boiling water for three or four minutes without shaking. If the blood is that of a diabetic patient, the blue color will disappear and the fluid will become yellow. In nondiabetic blood the blue color will remain.

Williams' Tracheal Tone. The peculiar resonance, sometimes found in the second intercostal space in cases of very large pleural effusions. It is a dull tympanitic resonance, becoming higher on opening the mouth, and arises from the vibrations of air in a large bronchus surrounded by compressed lung.

Willis, Chords of. Fibrous bands, which extend transversely across the inferior angle of the superior longitudinal sinus. W., Circle of. See Circle W.'s Disease, diabetes. See Diseases, Table of. W., Nerve of. See Nerves, Table of.

Willow (wil'-o) [ME, wilowe, willow]. See Salix. W.-bark, the bark of several species of willow, notably Salix arenaria and S. capraa, used in Russia and Denmark for the tanning of lighter skins, for the manufacture of glove-leather and the so-called Russia leather. The percentage of tannin it contains is usually given as from three to five per cent., although Eitner found over 12 per cent. in several species W.-herb. See Epilobium and Lythrum.

Wilson's Disease. General exfoliative dermatitis. See Diseases, Table of. W.'s Formula, an animal parasiticide used in dermatology. It contains sulphur I ounce, potassium carbonate 2 drams, benzoated lard 5 ounces, oil of chamomile $1 / 2$ dram. W.'s Muscle. See Muscles, Table of.

Winch (winch) [ME., winche, the crank of a wheel]. 'The handle for turning a wheel or other revolving apparatus; the apparatus thus revolved. W., Verona, an apparatus having a cog-wheel and used for tightening a ligature around a hemorrhoid.

Wind [ME., wind, wind]. 1. A current of air. 2 Flatus. W. of a Ball, the compression of air said to be produced by the passage of a ball close to the body, and to give rise to an injury called a "windcontusion." W., Broken. See Hear'es. W.-colic. See Bloat. W.-contusion. See $W$. of a Ball. W.-dropsy, a synonym for flatulence. W., Electric, that form of electric current which, coming in contact with the person, gives the sensation of a gentle blowing upon the parts. W.-fertilized, anemophilous. W.-flower, anemone. W.-galls, in farriery, dilated bursæ found at the posterior part of the fetlock joint, and due to a dropsical condition of the bursæ and tendon. W.-getting, in the process of training, a gradual increase in the capability of the heart, especially of the right chambers. W.-pipe. See Trachea. W.-pox, chicken-pox, or varicella. W.puff, the collection of air or gas beneath the skin of a fowl following the operation of caponizing. Simple puncture affords relief. W.-stroke, acute spinal paralysis in the horse. W.-sucking: $\mathbf{I}$. The habit of a horse that carries his nose in the air. 2. More correctly, the habit of a horse, called crib-biting.

Windlass (wind'-las) [ME.]. An apparatus for winding a cord on an axle, the cord being tightened by means of a weight. W., Spanish. See Tourniquet and Garrot.

Window (win'-do) [ME., windoneve, window]. An aperture in a wall for the admission of light and air. W. Oval. See Fenestra ovalis. W., Round. See Fienestra rotunda.
Wine (win) [ME., win, wine]. The fermented juice of various species of litis. A srevet wine is one in which a notable portion of the original grape-sugar of the must has escaped fermentation, or to which an ad dition of sugar has been made subsequent to the main fermentation. A dry wine is one in which the sugar, whether originally present or subsequently added, has almost all undergone change in the processes of fermentation. A sparkling wine is one in which a supplemen tary fermentation is purposely developed subsequent to the bottling, whereby quantities of carbon dioxid are developed and held dissolved under pressure. See Vinum. W., Barley, beer. W.-blue, the color ing-matter of red wines, a blue substance similar to litmus, possessing the property of turning red in the presence of acids. W., Burgundy, a heavy red or white wine from Burgundy, France. W., Champagne. See Chompagne. W.-glassful, two fluidounces. Ws., Heavy, wines containing more than 12 per cent. by weight of alcohol. W. High, commercial ethyl-alcohol. Ws., Light, wines containing less than 12 per cent. by weight of alcohol, as claret, Sauterne, or Moselle. W., Low, the products of the first distillation. W., Madeira, a heavy wine from the island of Madeira, having a nutty flavor. W.-madness, a form of insanity associated with and caused by alcoholism. See Oinomania. W., Malaga, a sweet wine from Malaga in Spain; it contäns between $I_{3}$ and I4 per cent. of alcohol. W., Milk, fermented milk. See Kefyr. W., Moselle, a light wine from the valley of the Moselle in Germany. W., Mulled, a preparation made by adding eggs and spices to wine and then heating it. W.nose, a popular term for acne rosacea. W. Oil of. See $W$., Oil of, Heavy. W., Oil of, Concrete. See Etherin. W., Oil of, Heavy, ethereal oil. W., Oil of, Light, etherol, a yellowish liquid of a peculiar odor obtained from ethereal oil. W., Port, a heavy wine from Oporto, Portugal. W., Raisin, wine consisting mainly of a fermented infusion of raisins; it contains also the fermented juice of fresh grapes, sugar, and tartaric acid. W., Red. See Vinum rubrum. W., Sherry, a heavy wine from the region of Xeres, in Spain ; it is white or brown in color. The sherry wine often obtained seldom contains any wine at all, but consists of alcohol, water, and flavoring ingredients. W., Spirit of, ethyl-alcohol. W.-vinegar. See Vinegar. W.-whey, a nutritious and slightly stimulating preparation used in adynamic states. It is made of white wine and milk, from two to eight ounces of the former being added to a pint of the latter at the boiling temperature; the whey is then strained off and sweetened. W., White. See Vinum album.

Wing [ME., winge, wing]. In biology, an organ adapted for flight. See Ala. W. of Ingrassias, the alæ of the sphenoid. W.-seed. See Ptelea trifoliata.

Winged (wingd) [ME., winge, wing]. Possessing alæ, or wings. W. Scapulæ, the peculiar deflection of the scapulæ in tuberculous patients, or in those so inclined. See Angel-wing.

Wink (wingk) [ME., winken, to wink]. To close and open the eyelids quickly.

Winker (wing'-ker) [ME., winken, to wink]. An eyelash. See Haw

Winking (wing'-king). See Nititation.

Winogradsky, Nitrifying Bacillus of. See Bacteria, Synonymatic Table of.

Winslow, Foramen of. See Forrmina, Table of W., Ligament of. See Liganent.

Winter (win'-ter) [ME., winter, winter]. The cold season of the year. W.-berry, black alder; fever- 
bush. W. Clover, partridgeberry ; checkerberry. W. Cough. See Coush and Bronchitis. W. Egg, in biology, a reproductive body in an encysted or resting condition, and capable of retaining its vitality through out the winter season. Cf. Statoblast, Spherula. W. Epidemic. Synonym of Cerebro-spinal Meningitis. W.-fat. See Erotia lanata. W.-green. See Gaultheria. W. Itch. Same as Army Itch.

Wintera, Winter's Bark (win'-ter-ah) [L.]. The aromatic and tonic bark of Drimys veinteri. See Drimys. Unof.

Wintrich's Sign. The change in the pitch of the per cussion-note over a cavity in the lungs when the mouth is open or closed. See Signs and Symptoms, Table of.

Wire $(w \bar{r} r)$ [ME., wir, a wire]. A filament of metal, as steel, iron, silver, or the like. Wire is used in surgical operations for suturing, etc. Woven-wire splints are also employed. Wire is an essential part of the electric circuit

Wiring (wir-ing) [ME, wir, wire]. Securing or staying by means of wire. W. Pin, a method of fix ing the fragments of a broken bone by means of pins, as in fracture of the olecranon or patella.

Wirsung, Canal of. See Canal. W., Duct of. See Duct.

Wiry $\left(w i^{\prime}-r e\right)$ [ME, wir, wire]. Resembling wire; tough and flexible. W. Pulse. See Pulse.

Wisdom-teeth. See I'eth.

Wish-bone (wish'-bän). See Furcula.

Wisp [ME., wisp, a little sheaf or bundle]. An inflammation of the interdigital substance of the hind foot of the ox or cow.

Wistar's Lozenges. See Lozenge. W.'s Pyramids. The cornua of the sphenoid

Wistaria (wis-ta'-re-ah) [after Caspar Wistar, an American anatomist]. A genus of shrubs belonging to the Leouminose, indigenous to Japan, China, and the United States. The flowers of the Chinese species are said to be distilled for their perfume.

Wistarin (wis'-tar-in) [after Caspar Wistar, an American anatomist]. A poisonous glucosid extracted from the bark of Wistaria chinensis.

Witch (wich) [ME, witche, a witch]. A person (of either sex) given to necromancy; a sorcerer. W.grass. Triticum repens. See Triticum, W.-hazel. See Hamanelis. W.-meal. See Lycopodium. W.'s Milk, the popular name for the small quantity of milk secreted for a few days after birth by the mammary glands of new-born animals of both sexes. W.-wood. Mountain ash.

Withania (with-a'-ne-ah) [L.]. A genus of solanaceous plants. W. coagulans curdles milk, is alterative, diuretic, and emetic. W. somnifera is emetic and hypnotic. See Somniferin. Unof.

Wither (zvith'-er) [ME., vidder, to wither]. To become sapless and shrunken; to become dry and wrinkled; to decay generally.

Withering (with'-er-ing) [ME., widder, to wither] The shriveling or atrophy of an organ. W. Carcinoma, carcinoma showing a tendency to atrophy and shrinkage.

Withers (with'-erz) [origin obscure]. The ridge above the shoulders of the horse, formed by the spinous processes of the first eight or ten thoracic vertebræ.

Wither-wrung (with'-er-rung). Hurt or galled in the withers.

Withy $($ with' $-\ell) \cdot[\mathrm{ME}$, withy, a willow $]$. The name of several species of Salix.

Witt's Theory of Colors. See Pigments.

Wittich and Kistiakowsky's Method. A method of extracting soluble animal ferments. This consists in hardening the organ in alcohol for three days and then cutting it up into very small pieces, extracting with glycerol, and filtering. On the addition of alcuhol to the filtrate the ferment is precipitated.

Wladimiroff's Operation. See Operations, Table of.

Woad (wöd) [ME., wod, woad]. The Isatis tinctoria. See Pigments, Conspectus of. W., Waxen, the Genista tinctoria. W., Wild, the Reseda luteola.

Woillez' Disease. A name given to active congestion of the lungs, on the supposition that it is an in dependent primary affection. See Diseases, Table of.

Wolf [ME., wolf, wolf]. A digitigrade carnivorous canine quadruped, Canis lupus. W.'s-bane. See Aconite. W.'s Bast, Daphne mezereum. W.'s Claw, W.'s Foot. See Lycopodium. W.-madness. See Lycanthropy. W.-teeth (of the horse), premolars of a peculiar shape, not occurring in every animal, and resembling the incisive teeth of the carnivora.

Wolff, Canal of. See Canal.

Wolffian (wool'-fe-an) [after K. F. Wolff, a German anatomist]. Pertaining to the anatomist Wolff. W. Body, "The chief occupant of the embryonic Wolffian ridge; in anamnia it is the chief renal organ throughout life; in amniota it disappears during embryonic life, being replaced by the true kidney, except that a small part of the cephalic end is retained and enters into special relations with the sexual organs. In its primitive form the Wolffian body appears to have consisted of a series of transverse tubules (Wolffian or segmental tubules) emptying into the Wolffian or pronephric duct. The Wolffian bodies were discovered by Casper Fr. Wolff, 'Theoria generat. ' in $\mathbf{I 7 5 9}$ They received their present name from $H$. Rathke in I 820 , but Rathke termed the same organs in mam mals Oken'sche Körper. In I824 Jacobson introduced the name Primordial Niere, and discovered that in birds the bodies secreted uric acid. The bodies were recognized in man by J. Fr. Meckel and Johannes Müller. The older writers held them to be either the beginnings of the kidneys, or spermaducts, or horns of the uterus, etc. Rathke, by discovering the origin of the true kidney, led the way to true conceptions." (Minot.) Also, called Corps de Wolff. Urniere, Mesonephros, Primitive Kidney, q. v. W. Cysts. See Cyst. W. Duct. See Duct. W. Ridge, "The protuberance produced by the increase in size and number of the Wolffian tubules, and its inclusion of the genital ridge is a secondary result of its enlargement in the higher vertebrata. Out of the Wolffian ridge there arise three primary organs, the pronephros (head kidney), the Wolffian body (anamniate or primitive kidney, and the true kidney of the amniota (metanephros)." (Minot.) Also, called Nephridial ridge, q. v.

Wollaston's Camera Lucida. See Camera. W.'s Method, a method for the determination of the refractive indices of liquids, based on the total refraction caused by a layer of liquids.

Woman [AS., wifman, a wife man]. The adult female of the human species.

Womb (woom) ' [ME., wombe, womb]. See Uterus. W.-grain. See Ergot. W.-passage. See Vagina, W.-stone. See Husterolith and Calculus.

Wonder (wun'-der) [ME, render, wonder]. Astonishment and admiration. W.-apple. See Balsantapple. W.-net. See Rete mirabile.

Wongshy (wong-she). See Pigments, Conspectus of.

Wooba $\left(w 0 o^{\prime}-b a h\right)$ [E. Ind.]. A form of diarrhea.

Wood [ME., wode, wood]. The main part of a tree. The part within the bark. W.-alcohol. See Pyroxylic Spirit. W.-alcohol, W.-naphtha. 
See Methyl-alcolool. W.-Cells, libriform cells and other elongated, taper-pointed cells, not distinctly marked with pits, spiral or annular markings, found in the wood of plants. W.-fiber. See Cellulose. W.flour, finely powdered wood, which, variously medicated, serves as a dressing for surgeons' use. W. Heart, the older, harder, usually darker, central part of an endogenous stem. W.-oil. See Gurjun Batsam. W.-parenchyma, elongated parenchyma-cells associated with wood-cells. W.-spirit. See Alcohol, Wethyl, and Pyroxylic Spirit. W.-tar Creasote. See Creasole. W.-vinegar. See Pyroligneous Acid, and Acid, Acetic, Dilute. W.-wool, prepared fiber of wood used mainly as a surgical dressing.

Wood's Therapeutic Test. In all cases of doubtful diagnosis of cerebral syphilis, iodid of potassium in daily doses of 60 grains should be given, and if this fails to produce iodism, for all practical purposes the person may be considered to be a syphilitic. This is now considered a fallacy, as personal idiosyncrasy to the iodids is perhaps as great in non-syphilitics as in syphilitics.

Wooden Tongue (wood'-entung). See Actinomycosis.

Wool [ME., woll, wool]. A variety of hair, found in greater or less quantity on almost all mammals, on a few of which, as the domestic sheep, it forms the principal covering of the body. The woolen fiber is finely crimped or curled, so that it becomes longer when drawn out, and shortens again when the strain is removed. This spring gives woolen fabrics notable elasticity. Wool is very hygroscopic. The best variety is colorless, but inferior grades are often yellowish, and sometimes even brown or black in color. True wool-fiber, when cleansed of impurities, has approximately the following composition: Carbon, 49.25 per cent.; hydrogen, 7.57 per cent. ; oxygen, 23.66 per cent.; nitrogen, I5.86 per cent.; sulphur, 3.66 per cent. The presence of sulphur is very distinctive of wool, and serves to distinguish it from silk, the other nitrogenous fiber. Wool is decomposed by heat; at $130^{\circ} \mathrm{C}$. ammoniacal vapors are given off, and at $140^{\circ}$ to $150^{\circ} \mathrm{C}$. sulphur compounds are also present in the vapors. When incinerated it emits the odor of burnt feathers. W., Antiseptic, wool that has been sterilized and subjected to the action of some antiseptic. W.-fat, esypus; an impurity of wool, consisting of a mixture of cholesterin, together with isocholesterin and the compounds of these bodies with several of the fatty acids. See Suint, Agnin, Lanolin. Ws., Holmgren's, a collection of colored wools used in the detection and estimation of subnormal color-perception. W.perspiration, an impurity of wool consisting essentially of the potassium salts of oleic and stearic acids, possibly other fixed fatty acids, also potassium salts of volatile acids, like acetic and valerianic acids, and small quantities of chlorids, phosphates, and sulphates. W.sorters' Disease, anthrax ; wool-sorters are liable to blood-poisoning from various causes, especially to the disease anthrax.

Woolen Black. See Pigments, Conspectus of.

Woolf, System of. A system of purifying water by the admixture of electrolyzed sea-water.

Woorara (woo-rar'-ah). See Curare.

Word (wurd) [ME., word, word]. A term; a sound used in any language as the sign of a conception. W.-blindness, visual logagnosia. See Aphasia. W.-deafness, auditory logagnosia. See Aphasia. W.-mania, a symptom of mental disease consisting in a repeated pronunciation of certain words (Wortbesessenheit of the Germans). See Verbigeration. W.-photism. See Phonism and Photism.
Work (wurk) [ME., worken, to work]. I. To labor ; to put forth effort. 2. Effort; labor. W., Internal, the force exerted in respiration, circulation, and other organic function. It is estimated as being daily equal to 260 foot-tons.

Working (wurk'-ing) [ME., zuorken, to work]. Active ; busy; operation. W. Distance. See Distance. W. Ocular. See Ocular.

Worm (wurm) [ME., worm, worm]. (a) Any member of the third and fourth races or phyla of the animal kingdom, i.e., the Platodes and the Vermes. (b) The lytta or glossohyal cartilage or fibrous tissue of the tongue of a carnivora, sometimes mistaken by dog. fanciers for a parasitic worm and extracted. ( $c$ ) The vermis or mesal lobe of the cerebellum. W. Bladder, the Tenia echinococcus. W.-seed, American. See Chenopodium. W.-seed, Levant. See Santonica. W.-sickness, a serious affection of sheep in Holland caused by the fly Lucilia sericata. See Parasites (Animal), Table of. W.-tea. See Spigelia. W.-wood. See Absinthum.

Wormian (zur'-me-an) [after Olaus Worm, a Danish physician, 1588-1654]. Pertaining to the physician, Olaus Worm. W. Bones, a name given to the supernumerary bones of the skul], which are frequently formed owing to the absorption or imperfect ossification of the tabular bones.

Worremberg's Apparatus. An apparatus for polariza tion by reflection.

Worry $($ zeur'-e) [ME., worryen, to worry]. Harass ment; perplexity due to annoying cares and troubles; a frequent factor in nervous and cerebral troubles.

Worsted Test. See Holmoren's Test.

Wort (zourt) [ME., wort, wort]. An infusion of malt it is antiscorbutic, and is used sometimes in the dress. ing of ulcers. Unof.

Woulfe's Apparatus, W.'s Bottles. An apparatus consisting of a series of three-necked bottles connected by suitable tubes, and used for washing gases or saturating liquids therewith.

Wound (zvoond, or worend) [ME., zound, wound]. A break or division of continuity of the soft parts caused by mechanical violence; trauma. W., Complicated, a wound in which a foreign body is present, or in which there is great hemorrhage or pain. W., Contused, one produced by a blunt body. W.-fever. See Traumatic Fever. W., Flesh, a wound involving only skin and muscular tissue. W., Gunshot, one caused by a projectile. W., Incised, one caused by a cutting instrument. W., Lacerated, one in which the tissues are torn. W., Open, a wound having a free external opening. W., Poisoned, one in which toxic materials are introduced, as in a dissection-wound, etc. W., Punctured, one made by a pointed instrument. W., Simple, one attended with a simple division of the soft parts without complication. W., Subcutaneous, a wound with a very small external opening in the skin. W., Uterine, the portion of the uterus from which the placenta has been removed.

Wourali (woo'-ra-le). See Curare.

Wreath (rêth) [AS., wreth, a twisted band]. In biology, applied to a stage in karyokinesis, as the mother-wreath, daughter-7ereath. See Aster.

Wredin's Test. A test of live-birth. It consists in the absence of gelatinous matter from the middle ear; this is regarded as a proof that the fetus was born alive and has breathed.

Wrightia (ri'-te-ah) [after William Wright, a physician and botanist in Jamaica]. A genus of apocynaceous shrubs and trees. The bark of $W$. antidysenterica (or Holarrhena antidysenterica) of India is highly valued as a remedy for dysentery. Unof. 
Wrinkle (ring'-kl). See Ruga.

Wrisberg, Abdominal Brain of. The solar plexus. W., Ansa of. See Ansa. W., Cartilages of. See Carlitage. W., Ganglion of. See Ganglia, Table of. W., Lingula of. See Lingula. W., Nerves of: I. The nerves supplying the skin of the arm. 2. Portio inter duram et mollem; portio intermedia. A small nerve-fasciculus arising from the oblongata and coursing between the facial and auditory nerves. See Nerves, Table of.

Wrist (rist) [ME., zurist, wrist]. That part of the fore-limb or fore-arm which joins the fore-arm and the hand. See Carpus. W.-clonus. See Reflexes, Table of. W.-drop, a paralysis of the extensor muscles of the hand accompanying lead-poisoning See Dropped Wrist. W.-ganglion, a hernial pouch of a tendon-sheath upon the back of the wrist. W.joint, the carpus, the articulations between the forearm and the hand.

Writers' Cramp, W.s' Palsy. See Cramp, Occupation-neuroses, Paralysis.

Writing Hand ( $r i^{\prime}$-ting-hand). A peculiar position assumed by the hand in paralysis agitans. See Paralysis ayitans.

Wry-neck (ri'-nek). See Torticollis. W., Rotatory, a variety of spasmodic rotatory movements of the head.

Wurali (wu-ra'-le). Same as Curare.

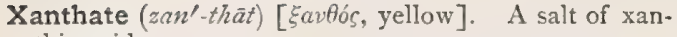
thic acid.

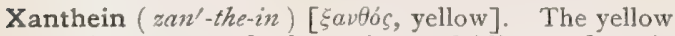
coloring-matter of plants (e.g., dahlia, sunflower), soluble in water, but not in alcohol, in which respect it differs from xanthin.

Xanthelasma (zan-thel-az'-mah) [ Eavtós, yellow ; $\varepsilon \grave{\lambda} \alpha \sigma \mu a$, a lamina]. Spots of yellowish discoloration of the skin of the face, especially about the eyes. X. multiplex. Same as Xanihoma multiplex. $\mathbf{X}$. palpebrarum, xanthelasma of the skin of the eyelids. $\mathrm{X}$. vitiligoides. Same as Xanthoma vitiligoides.

Xanthelasmoidea (zan-thel-az-moi-d $\left.c^{\prime}-a h\right)$. Synonym of Urticaria pigmentosa.

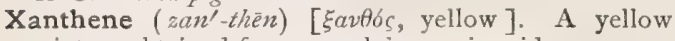
mixture obtained from persulphocyanic acid.

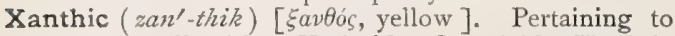
xanthin; yellowish. X. Acid. See Acid. X. Calculus, urinary calculus composed mainly of xanthin.

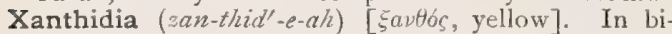
ology, small bodies found in the flints of the chalkbeds of England and held by Carter to be the petrified orbicular statoblasts of the Polvzor.

Xanthin $\left(z a n^{\prime}\right.$-thin $)$ [ Eavtiós, yellow $], \mathrm{C}_{5} \mathrm{H}_{4} \mathrm{~N}_{4} \mathrm{O}_{2}$. I. A leukomain found in nearly all the tissues and liquids of the animal economy, and also in many plants; also in minute quantities as a normal constituent of urine. It is formed at the same time with adenin, guanin, and hypoxanthin in the decomposition of nuclein by dilute acids. Guanin is convertible into xanthin, which is thought to be one step lower as an intermediate product of nuclein-decomposition, and nearer the uricacid limit of oxidation. It probably is oxidized in the body as fast as it is formed. It is a colorless powder, almost insoluble in cold water, but readily soluble in dilute acids and alkalies. It is non-poisonous and a muscle-stimulant, especially of the heart. See Leukomains, Table of. 2. The name given by Fremy and Cloez to the yellow coloring-matter of plants, which is insoluble in water, but soluble in alcohol, in which respect it is distinguished from Xanthein. See Pigments, Conspectus of.

Xanthinuria (zan-thin- $\left.u^{\prime}-r^{*}-a h\right)$ [ $\xi a v \theta b c$, yellow; ov $\rho \circ v$, urine]. The presence of xanthin in excess in the urine.

Xanthium (zan'-the-um). See Clotbur.
Xanthiuria (zan-the- $\left.\boldsymbol{u}^{\prime}-r e-a h\right)$. See Xanthinuria.

Xantho- (zan'-tho-) [ $\xi a v \theta 6 s$, yellow]. A prefix to denote yellow or yellowness.

Xanthocarpous (zan - tho-kar'-pus) [ $\xi a v \theta 0$ s, yellow ; $\kappa a \rho \pi \delta ́ s$, fruit]. In biology, characterized by yellow fruit.

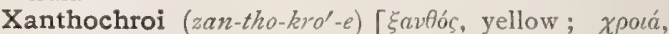
the complexion]. In biology, Huxley's term for the yellow-haired, pale-complexioned people spread over Asia, forming as it were, an ocean in which the Calmuck and Tartar tribes from Mongolian islands were engulfed. They form the prevalent races of northern Europe, the fair whites, and are largely represented in northern Africa (Berbers). Cf, Leukon, Melanochroi.

Xanthochroia (zan-tho-kro'-e-ah) [ [avfóc, yellow; xpotá, skin]. Yellow discoloration of the skin.

Xanthochromia (zan-lho-kro'-me-ah) [ $\xi a v \theta o s$, yellow ; $\chi \rho \tilde{\omega} \mu a$, a color]. A persistent condition of yellow skin, resembling but not identical with jaundice.

Xanthochroöus (zan-tho-kro'-us) [ [ $a v \theta b s$, yellow ; $\chi \rho o ́ \alpha$, skin]. Yellow-skinned.

Xanthocyanopia, Xanthocyanopsia (zan-tho-si-an-o'-

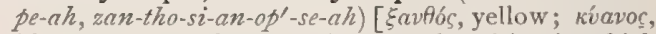
blue; ǒ $\psi \iota$, sight]. A defect of color-vision in which yellows and blues are perceived, while reds are imperceptible.

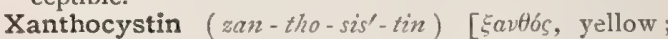
kírtı, bladder]. A nitrogenous substance found in the whitish tubercles in the mucosæ and organs of a corpse.

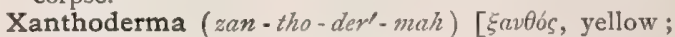
$\delta \varepsilon \rho \mu a$, skin]. Yellowness of the skin.

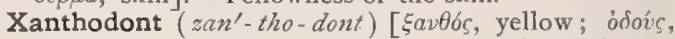
tooth]. In biology, having yellow teeth, as the incisors of rodents.

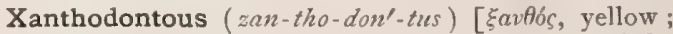
ofois, tooth]. Having a yellow discoloration of the teeth.

Xanthogen (zan'-tho-jen). Same as Xanthein.

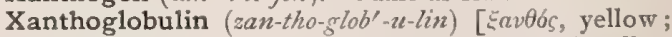
globulus, a ball]. Same as Hypoxanthin. A yellow substance found in the liver and the pancreas.

Xantho-kreatinin (zan-tho-kre-at'-in-in) [ $\xi a v \theta$ ós, yellow; крвas, flesh]. The most abundant of muscleleukomains, named from the sulphur-yellow color of its crystals and its resemblance to kreatinin. It appears 
in the physiologically active muscle at the same time with kreatinin, constituting sometimes one-tenth of the kreatinin present. It has been found by Monari in aqueous extracts of the muscles of a tired dog, and in the urine of soldiers fatigued by marching. In large doses it is decidedly poisonous, producing depression, somnolence, extreme fatigue, frequent defecation, and vomiting. See Leukomains, Table of.

Xanthokyanopy (zan-tho-ki-an'-o-pe) [ [ $a v \theta o ́ s$, yellow ; кvávos, blue; $\omega \psi$, eye]. Red-green blindness; with undiminished spectrum. See Xanthocyanopsia.

Xantholin (zan'-tho-lin). Same as Santonica.

Xanthoma (zan-tho' mah) [ $\xi a \nu \theta o ́ s$, yellow ; ŏ $\mu a$, tumor]. Xanthelasma; a form of new-growth of the skin, occurring as plaques imbedded in the skin, or as nodules from a pin's head to a bean in size, rarely larger. The color is yellow, usually the tint of chamois-leather. The plaques are slightly raised above the surface, but are scarcely perceptible to the touch when pinched. They are frequently seen in the form of plates imbedded in the eyelids, especially in people past middle age who have been subject to migraine. $\mathbf{X}$. diabeticorum, Lichen diabeticorum: a rare disease of the skin always associated with diabetes mellitus. It develops rapidly and sometimes intermittently; the lesions are denser and firmer than those of true xanthoma, and are dull-red, discrete, and solid, though at the apex they present a yellowish point, like pus. They are abundant on the scalp and face, but never exist on the eyelids, nor are they ever associated with jaundice. Itching and tingling are always present. $X$. lineare vel striatum, a form of $X$. planum in which the lesions occur in lines or striæ. X. maculatum et papulatum, a form of $X$. planam in which the lesions occur in papules and macules as well as in plaques. $\mathrm{X}$. multiplex, a form occurring usually in women about middle life. It is frequently hereditary and is usually associated with jaundice, which. as a rule, precedes it by a year or more. The lesions are generally distributed. X. palpebrarum. See X. planum. X. planum, X. palpebranum; the commoner form of Xanthoma, usually situated on the eyelids. $\mathbf{X}$. tuberculatum, $\mathbf{X}$. tuberosum, a rarer form of Xanthoma characterized by tubercular lesions upon the extensor surfaces of the extremities, and on parts exposed to pressure, as the elbows and knees, shoulders, buttocks, backs of fingers and toes, palms and soles. The lesions vary in size from a hemp-seed to a pea, are hard to the touch, deeply set in the skin, and project prominently from it. They may coalesce to form veritable tumors. The disease is a chronic one.

Xanthomatosis (zan - tho-mat-o'-sis) [ $\xi a v \theta o s$, yellow ; or $\mu \alpha$, tumor]. Xanthoma of so marked a type as to indicate a special diathesis.

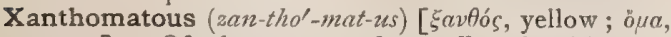
tumor]. Of the nature of or affected with xanthoma.

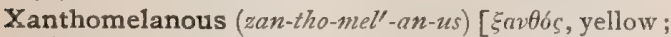
$\mu \varepsilon \dot{\lambda} \lambda \varsigma$, black]. The lighter of the Melanochroi, or races with black hair and yellow or olive skin, as distinguished from the Melanous, those with black hair and black skin.

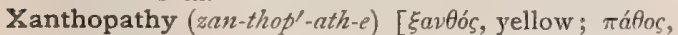
a suffering]. Yellowness of the skin from morbid conditions.

Xanthophane (zan'-tho-fän). See Chromophane.

Xanthophyl, Xanthophyll (zan'-tho-fil) [ $\xi a v \theta o ́ s$, yellow; $\phi v i \lambda \lambda o v$, leaf]. In biology, leaf-yellow, a special pigment isolated by Berzelius from autumn leaves. See Pigments, Conspectus of.

Xanthophyllin (zan-tho-fil'-in). Same as Xanthophyl.
Xanthopicrin (zan-tho-pik'-rin) [ savtlós, vellow; $\pi \iota k-$ pós, bitter]. A yeliow coloring-matter derived from the bark of Xanthoxylum caribcum. Same as Berberin.

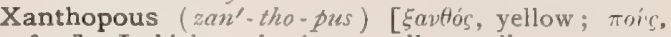
foot]. In biology, having a yellow stalk or support. Xanthoproteic $(z a n-t h o-p r o$-te-ik) [ $\xi a v \theta o s$, yellow; protein]. Derived from or related to xanthoprotein. $\mathrm{X}$. Reaction, the deep-orange color obtained by the addition of ammonia to the yellow reaction of proteids heated with strong nitric acid.

Xanthoprotein (zan-tho-pro'-te-in) [ $\xi a v \theta o s$, yellow; protein]. A yellow substance formed from proteids by the action of nitric acid.

Xanthopsia (zan-thop'-se-ah) [ [̧avfós, yellow ; ò $\psi$ es, vision]. The yellow vision sometimes accompanying jaundice.

Xanthopsin (zan-thop'-sin). Same as Xanthophane.

Xanthopsy (zan'-lhop-se). See Xanthopsia.

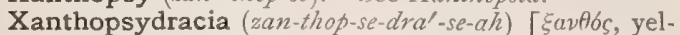
low; $\psi v \delta \rho a \xi$, pustule]. The presence on the skin of small, yellow pustules.

Xanthopuccin (zan-tho-puk'-sin) [ $\xi a v \theta 0$ s, yellow; puccoon]. An alkaloid found in Hydrastis.

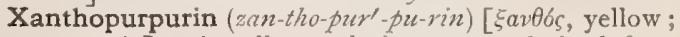
purpurin]. A yellow coloring-matter derived from the Rubia tinctorum.

Xanthorhamnin (zan-tho-ram'-nin) [Eavtós, yellow ; óavos, buckthorn]. A yellow coloring-matter contained in the ripe Persian or Turkish berries and in Avignon grains. See Pigments, Conspectus of.

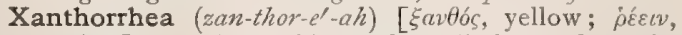
to flow]. I. An acrid, purulent discharge from the vagina. 2. A genus of tree-like liliaceous Australian plants, called black-boy and grass-tree. They afford an abundant resin. See Acaroid.

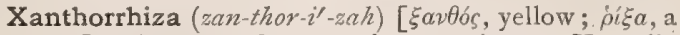
root]. A genus of ranunculaceous plants. X. apiifolia, of the United States (yellow-root), is a good, bitter tonic. Unof.

Xanthosis (zan-tho'-sis) [ gavfors, yellow]. The yellow pigmentation sometimes observed in carcinorna. $\mathbf{X}$. of the Nasal Septum, a dirty-yellow appearance in the nasal mucous membrane due to hemorrhage and the subsequent disintegration of the blood.

Xanthospermous (zan-tho-sper'-muts) [ $[\xi \alpha \nu 0 s$, yellow ;

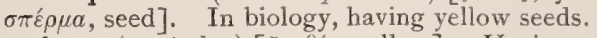

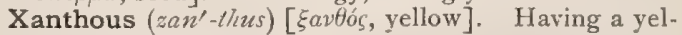
low skin, or complexion.

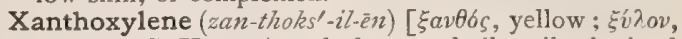
wood $], \mathrm{C}_{10} \mathrm{H}_{16^{\circ}}$ A colorless, volatile oil obtained from the fruit of Xanthoxylum alatum.

Xanthoxylin (zan-thoks'-il-in) [ [ $a v \theta 0$ s, yellow; $\xi v \lambda o v$, wood]. I. A precipitate from a tincture of Xanthoxjlum fraxineum; stimulant, styptic, tonic, sialagogue. Dose I-2 grains. Unof. 2. A stearopten from the volatile oil of Xanthoxylum piperitum.

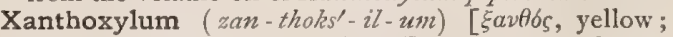
छviov, wood: gen., Xanthoxyli]. A genus of rutaceous trees and shrubs of many species, including the prickly ash ( $X$. fraxineum). In many, if not all the species, the root-bark is stimulant and tonic. $\mathrm{X}$. alatum, of India, is anthelmintic and sudorific. $\mathrm{X}$. cribrosum, of the U. S. and W. Indies, is strongly diuretic and stimulant. Its bark is locally used in a wide range of diseases. Dose of $\mathrm{fl}$. ext., gtt. $\mathrm{x}-\mathrm{xx}$. Unof. X., Decoctum, unof., $\xi_{j}$-Oij. Dose 3 j-ij. X., Ext., Fld. Dose $\mathbf{3}_{\mathrm{ss}-\mathrm{j} .} \quad \mathbf{X}$. fraxineum, prickly ash, tooth-ache tree, angelica tree-a North American species of the Xanthoxylacee which belong to the Rutacece. The bark, the Xanthoxylum of the U. S. $\mathrm{Ph}$., is chewed in odontalgia. It is a stimulant, aromatic, bitter, sialagogue and emmenagogue, and is 
of repute in chronic rheumatism and "biliousness." Dose gr. $x-x x x$. X. naranjillo, of the Argentine Republic, is recommended as a substitute for jaborandi. $X$. nitidum, of China, is febrifugal. $X$. senegalense, of Africa, has similar properties, but appears to be poisonous.

Xanthuria (zan-thu'-re-ah). See Xanthinuria

Xarheb (zar'-heb). See Paraschistes.

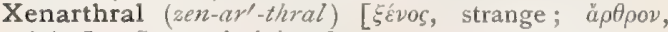
joint]. Strangely jointed.

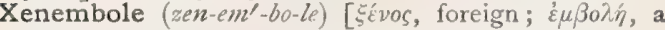
hurling]. Same as Xenenthesis.

Xenenthesis (zen-en'-the-sis) [ $\xi \dot{\varepsilon} \nu o s$, strange; $\dot{\varepsilon} \nu$, in; $\theta \dot{\varepsilon} \sigma \iota \varsigma$, a placing]. The introduction of a foreign body into the economy.

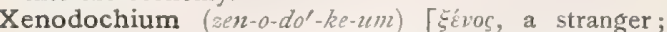
$\delta \delta^{\prime} \chi \varepsilon \sigma \theta a \iota$, to receive]. A hospital; a public house.

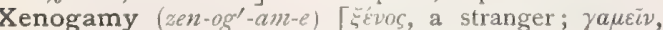
to marry]. A form of cross-fertilization in which fertilization is effected by pollen from another plant of the same species.

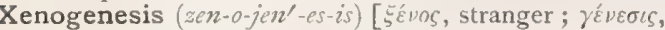
birth]. In biology, Mr. Milne Edwards' term for the generation of something foreign, $i . e$., of offspring varying in their characters and life-cycle from the parents. Cf. Heterogenesis.

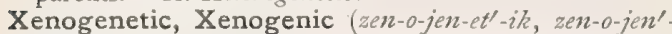

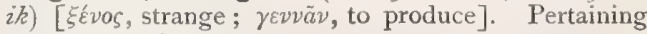
to xenogenesis.

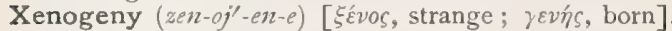
Same as Xenovenesis.

Xenomenia (zen-0-me'-ne-ah). See Menstruation, Vicarious.

Xenonomia (zen-o-no'-me-ah). Same as Heteronomy. Xenophthalmia (zen-off-thal'-me-ah) [ '́vos, foreign; $\dot{\phi} \phi \theta a \lambda \mu \delta \varsigma$, eye]. Conjunctivitis due to injury.

Xenopneumonypostasis (zen-op-nu-1non-ip-os'-tas-is)

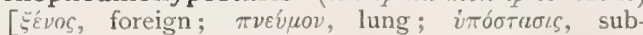
sidence]. The settling of foreign bodies into the lower portions of the lungs.

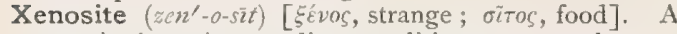
parasite in an intermediate condition, organ, or host.

Xeransis (zer-an'-sis) [ ¿łnpavols]. The drying up or desiccation of a part or of a drug

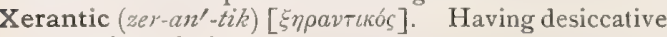
properties; drying

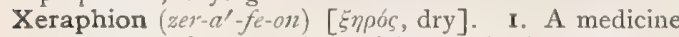
to be taken dry. 2. A medicine to check discharges.

Xerasia $\left(z e r-a^{\prime}-z e-a / h\right)$ [รnpós, dry]. A disease of the hair marked by cessation of growth and excessive dryness.

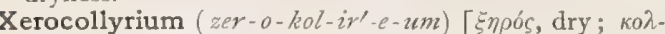
hoúp oov, collyrium]. Any dry collyrium; an eyesalve.

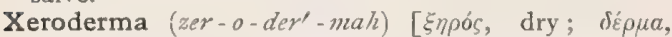
skin]. Xerosis; a congenital dryness, harshness, and roughness of the skin, commonly appearing within the first two years of life, unaccompanied by subjective sensations, and exhibiting to the eye a fine, scaly desquamation and a characteristic, dull, grayish, yellowish, dirt-colored discoloration, chiefly involving the temples and the extremities. See Ichthyosis. X.ichthyiodes. See Ichthyosis. X. of Kaposi, a diffuse atrophy of the skin, idiopathic in origin. X. pigmentosum, Atrophoderma pismentosum; Angioma pismentosum atrophicum; Melanosis lenticularis progressiva; Kaposi's Disease; a very rare skin-disease, beginning generally in summer and occurring during the second or third year of life. It is characterized by minute, measly, erythematous blotches upon parts exposed to the sun, which soon disappear, leaving pigment-spots like ordinary freckles, which persist even during winter: A spontaneous atrophy of the skin then occurs, resulting in the formation of non-pigmented, glistening scar-tissue, and finally in this tissue malignant, epitheliomatous growths form. Death generally results about puberty.

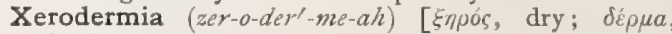
skin]. A dryness of the skin. See, also, Xeroderma and Tchthvosis.

Xerodes $\left(z e r-o^{\prime}-d \bar{e} z\right)$ [ $\xi \varepsilon \rho \omega \delta \eta \eta$, dryish]. A tumor that is dry and hard.

Xeroma (zer-o'-mah). See Xerophthalmia.

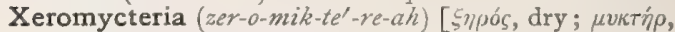
the nose]. Lack of moisture in the nasal passages.

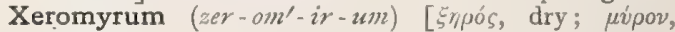
ointment: gen, Xeromyri]. A hard, stiff ointment.

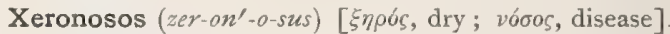
A condition of dryness of the skin.

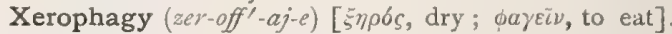
The use of dry or desiccated aliment.

Xerophilous (zer-off'-il-us) [ $\xi \eta \rho \sigma \varsigma$, dry ; $\phi \iota \lambda \varepsilon i \nu$, to love]. In biology, a term applied to plants which, like the cactuses, are adapted to dry regions.

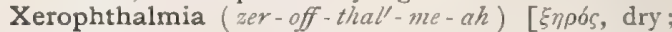
$b \phi \theta a \lambda \mu \delta s$, eye]. A dry and thickened condition of the conjunctiva, sometimes following chronic conjunctivitis or disease of the lacrymal apparatus.

Xerophthalmos (zer-off-thal'-mos). See Xerophthalmia.

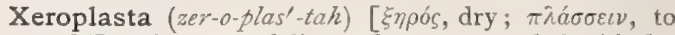
mold]. A group of diseased states, attended with defective secretion; it includes sterility, anuria, atrophy, marasmus, etc.

Xerosis (zer-o'-sis) [ $\xi \eta j \omega \sigma \iota s$, a dry state]. A dry condition. See Xeroderma. X. of the Conjunctiva. See Xerophthalmia. See Bacillus of Xerosis epithelialis conjunctiva, in Bacteria, Synonymatic Table of.

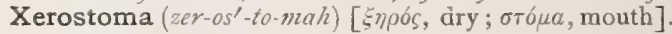
Aptyalism, or dry mouth.

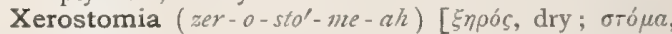
mouth]. Dry Mouth. A rare condition of the mouth, in which the tongue is red, cracked, and dry; the buccal surfaces of the cheeks and the hard and the soft palate are also dry, and the mucous membrane becomes pale, smooth, and glistening. Speech is difficult, as is also swallowing. There appears to be no pathologic condition of the salivary glands. The disease occurs in women only, and usually after middle life.

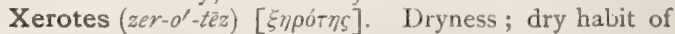
body.

Xerotic $\left(z e r^{2}-o t^{\prime}-i k\right)$ [ร̌npós, dry]. Characterized by xerosis; dry.

Xerotribia, Xerotripsis (zer-o-trib'-e-ah, zer-o-trip'-sis)

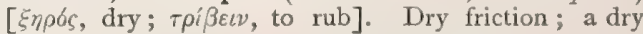
rubbing.

Xiphicostal (zif-ik-os'-tal) [ $\xi i \phi o s$, sword; costa, rib]. Pertaining to the xiphoid cartilage and to the ribs. $X$. Ligament, a ligament extending from the xiphoid cartilage to the cartilage of the eighth rib.

Xiphihumeralis (zif-e-hu-mer-a'-lis) [ $\xi i \phi o s$, sword; humerus, humerus]. A muscle which in some animals passes from the xiphoid cartilage to the proximal end of the humerus.

Xiphiplastral (zif-ip-las'-tral) [รiфos, sword; plastron]. Pertaining to the xiphiplastron.

Xiphiplastron (zif-ip-las'-tron) [ Eipos, a sword; plastron, a breast-plate: pl., Xiphiplastra]. One of the paired posterior bony scutes of the plastron or breastplate of a tortoise or turtle. Also called Xiphister. mum.

Xiphisternal (zif-is-tur'-nal) [ breast-bone]. Pertaining to the xiphisternum. 


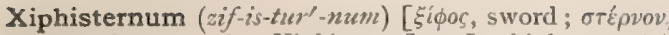
breast-bone: pl., Xiphistema]. In biology: $(a)$ the most posterior of the sternal elements; the meta. sternum or ensiform cartilage. See Xiphoid and Ensisternum. (b) See Xiphiplustron.

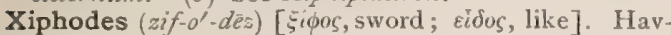
ing the shape of a sword.

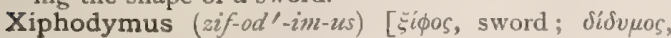
double]. A sysomic monstrosity with united pelvic and thoracic cavities, two legs, and with an occasional rudimentary third leg.

Xiphoid (zif'-oid) [รiøos, sword; eidos, like]. Ensiform; sword-shaped. X. Appendix, or Process, the third piece, or ensiform process, of the sternum ; xiphisternum. It is cartilaginous in youth and osseous in mature age.

Xiphoidian (zif-oid'-e-an) [ Belonging or pertaining to the ensiform cartilage.

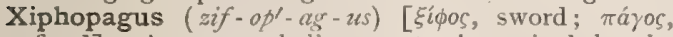
fixed]. A monomphalic monstrosity united by the xiphoid cartilages or the epigastrium. The Siamese twins furnished an example.

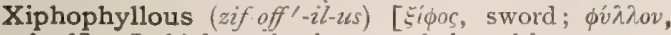
leaf ]. In biology, having sword-shaped leaves.

X-Rays, or Röntgen Rays (rent'-jen). The peculiar rays or ether-waves discovered by Professor Röntgen, of Würzburg. A vacuum-tube (called a Geissler, Hittorf, or Crooke tube) is used with two wires sealed through the glass, these being connected with the two poles of a battery. The rays from the cathode have a penetrating power through matter opaque to other ether-rays, and by their use photographs (skiagraphs, shadowgrams, etc.) may be taken of bones, metallic substances, etc., situated in the tissues, thus proving of great service in the diagnosis of fractures of bones, the location of foreign bodies, etc.

Xylem $\left(z i^{\prime \prime}-l e m\right)$ [ $\xi i \lambda o v$, wood]. In biology, that portion of the fibro-vascular bundle which contains ducts or tracheids.

Xylic $\left(z i^{\prime}-l i k\right)[\xi i \lambda . v$, wood]. Pertaining to or derived from wood. X. Acid. See Acid.

Xylidic Acid $\left(z i-l i d^{\prime}-i k\right)$. See Acid.

Xylidin $\left(z i l^{\prime}-i d-i n\right)$ [ $\xi i n o v$, wood], $\mathrm{C}_{8} \mathrm{H}_{9} . \mathrm{NH}_{2}$. A methylated homologue of anilin, obtained from dimethylanilin. It serves for the preparation of red azodyestuffs. See Pigments, Conspectus of.

Xylo- $\left(z i^{\prime}-l a-\right)[\zeta v i \lambda o v$, wood]. A prefix to denote connection with or relation to wood.

Xylobalsamum $\left(z i-l o-b a l^{\prime}-s a m-u m\right)$ [ $\xi u \lambda o v$, wood;

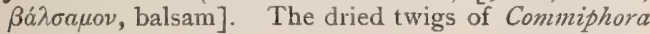

opobalsamum, the balm of Gilead of Asia; also, a balsam extracted from the same. Unof.

Xylocarp $\left(z i^{\prime}-l o-k a r p\right)$ [ $\xi i \lambda n w$, wood; $\kappa a \rho \pi \delta \zeta$, fruit]. In biology, a hard, woody fruit.

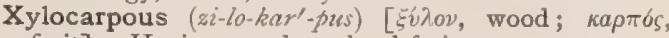
fruit]. Having woody or hard fruit.

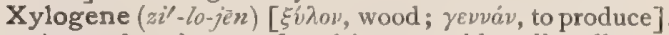
A woody substance found in vegetable cell-walls.

Xyloid $\left(z i^{\prime}-l o i d\right)$ [ $\xi i \lambda o v$, wood; Eirfos, resemblance]. Resembling or having the nature of wood; ligneous.

Xyloidin $\left(z i-l o i^{\prime}-d i n\right)$ [ $\mathrm{H}_{9} \mathrm{NO}_{7^{\circ}}$ A white, inflammable, pulverulent substance described by Braconnet (1833) and obtained by the action of concentrated nitric acid upon starch or various forms of woody fiber. Also called Xylidin.

Xylol $\left(z i^{\prime}-l o l\right)$ [ $\xi u \lambda o v$, wood; oleum, oil], $\mathrm{C}_{8} \mathrm{H}_{10^{\circ}}$. Dimethyl benzene. A volatile hydrocarbon somewhat resembling benzol. It has proved serviceable in smallpox. Dose $\eta_{\text {iij-x. X. }}$-balsam, Canada balsam dissolved in xylol. For its uses in microscopy, see Mounting-media.

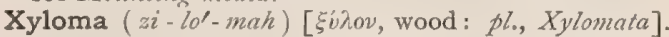
In biology, a sclerotoid, spore-producing body of certain fungi (Polystigma and Ascomycetes).

Xylon (zi'-lon) [ $\xi i \lambda o v$, wood]. I. Wood. 2. The cotton plant. 3. A substance identical with woodcellulose.

Xylonite $\left(z i^{\prime}-\right.$ lon-ît $)$. Same as Zylonite. See Celluloid.

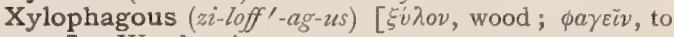
eat]. Wood-eating.

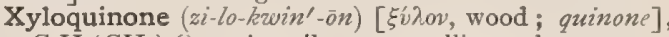
$\mathrm{C}_{6} \mathrm{H}_{2}\left(\mathrm{CH}_{3}\right)_{2} \mathrm{O}_{2}$. A yellow, crystalline substance occurring in three isomeric forms.

Xylose $\left(z i^{\prime}-10 z\right)$ [ $\xi \dot{v} \lambda$ ov, wood], $\mathrm{C}_{5} \mathrm{H}_{10} \mathrm{O}_{5}$. One of the glucoses, alloisomeric with arabinose. It is obtained by boiling wood-gum (beechwood, jute, etc.) with dilute acids. See Carbohydrates, Table of.

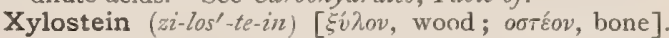
An indifferent, bitter substance obtained from the berries of Lonicera xylosteum by Hübschmann.

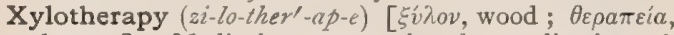
therapy]. Medical treatment by the application of certain woods.

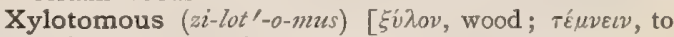
cut]. Wood-cutting, as an insect.

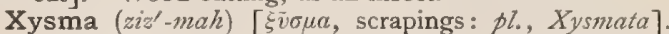
The fragmentary and flocculent pseudomembrane seen in the stools in some cases of diarrhea.

Xyster (zis'-ter) [ $\xi v \sigma \tau \eta ́ p$, a rasp]. A surgeon's rasp, or scraping instrument.
$\mathbf{Y}$, the chemic symbol of Ytrium. $\mathbf{X}$-Ligament, the ilio-femoral ligament. See Ligament.

Yabin $\left(y a b^{\prime}-i n\right)$. An amorphous, bitter alkaloid obtained from the bark of Andira excelsa.

Yam. The esculent root of several species of Dioscorea; also, incorrectly, a coarse variety of the sweet potato. Wild Yam. See Dioscorea.

Yang-tasi (yang-ta'-se) [Chinese]. A gelatinous substance employed in China and Japan in cookery. It is obtained Som the alga Laurencia papillosa (Tanshwai).

Yaourt (yowrt) [Turk.]. An oriental, fermented drink prepared from milk. See Koumiss, Kephyr, Leban, Matzoon, Galactozyme.

Yapon (yaw'-pon). See Yaupon.

Yard [ME, yerd, yard]. Membrum virile; penis. Y.-sitting, in massage, sitting with the arms stretched out laterally and horizontally. Y.-walk, in physical culture, a mode of progression with the arms extended laterally.

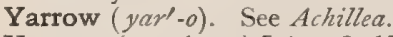

Yaupon (yaw'-pon) [Am. Ind.]. The Ilex vomitoria, a shrub or tree of the Southern U. S. Its leaves are purgative and emetic; called also cassena. Unof. Y.tree. See Cassena.

Yava-skin (yav'-ah-skin). Same as Elephantiasis.

Yaw. [African, yaw, a raspberry.] A frambesia sore. Y.-weed. A West Indian shrub, Morinda royoc; used as a remedy for yaws.

Yawey $($ yaw $-e)$ [African, yaw, a raspberry]. Pertaining to or affected with yaws.

Yawn [ME., zanon, to yawn]. To gape, to open the mouth wide.

Yawning (yaw'-ning). See Oscitation, Pandiculation. 
Yaws (yawz). See Frambesia. Y., Ringworm, a variety of yaws in which the nodules form rings around the eyes, nose, mouth, or anus.

Yeast (yêst) [ME., zeest, yeast]. The name applied to any of the various species of fungi of the genus Saccharomyces. It is best known as a ferment thriving in saccharine solutions, breaking up the sugar molecule into carbon dioxid and alcohol. In domestic economy, it is used in leavening bread, the porosity of the latter being due to the escaping carbon dioxid. It is also the essential principle in alcoholic fermentation. In medicine, it has proved of value as an application to foul ulcers and as an internal remedy in putrid fevers. "Of great theoretical interest are some recent researches of Hensen's which open out great possibilities in the future. In these investigations he has found that it is possible to produce artificial varieties of yeast, the acquired properties being transmitted from one generation to another, apparently indefinitely; it is obvious that we have here the beginning, on a microscopic scale, of practices which have long been carried out on the higher plants in floriculture." (Frankland.) Y., Beer, the ferment used in brewing beer. It is a more or less pure culture of the saccharomyces cerevisivæ. Y., Bottom, yeast found at the bottom of a chilled fermentation. Y.-cakes, cakes made of yeast which has been washed, dried, and pressed. $\mathbf{Y}$., German, a mixture of beer-yeast and dry starch, used for baking purposes. Y.-plant, the saccharomyces. Y.-poultice, a fermenting poultice containing yeast. Y., Top, the yeast found on the surface of fermenting liquids.

Yelk (yelk) [a variety of yolk]. See Yolk.

Yellow $\left(y e l^{\prime \prime}-0\right)$ [ME., yelow, yellow]. A compound color of the spectrum. Y. Atrophy of the Liver, malignant jaundice; acute yellow atrophy of the liver. See under Icterus. Y. Body, the Corpus luteum, $q . v$. Y. Carmin. See Pigments, Conspectus of.

- Y. Cartilage. See Cartilage, Reticular. Y. Cells, peculiar cells in the Actinea, which give the spectrum of Chlorofucin. Cf. Chlorophore, Chloroplast. Y.crowned, having the top of the head yellow. Y. Disease, hemorrhagic malarial fever. Y. Dock. See Rumex. Y. Fever. See Fever. Y. Jack, a popular name for Yellow Fever, q. v. Y. Jasmine. See Gelsenium. Y.-root. See Xanthorrhiza. Y.-shafted, having the shafts of certain feathers yellow. Y.. shouldered, having the bend of the wing yellow. Y. Spot. See Macula lutea. Y. Spot of Sommering. See Semmering. Y.-vented, having the ventfeathers yellow: Y. Wash, a lotion consisting of hydrarg. oxychlorid gr. ij, liquor calcis $\mathrm{z}^{\mathrm{j}}$.

Yellows $\left(y e l^{\prime}-\bar{a} z\right)$. See Jaundice.

Yerba $\left(y e r^{\prime}-b a h\right)$ [Sp.]. An herb. Y. buena. See Micromeria. Y. mansa, the root of Amenopsis californica, stimulant, astringent, and tonic. It is employed in California and Arizona for malarial disorders. Dose of the fld. ext. $m x v-3 j$. Unof. Y. reuma, the herb, Frankenia grandifolia, common in California. It is astringent and is recommended in catarrhal affections of the urinary tract. Dose of the fld, ext. $m_{\mathrm{x}-\mathrm{xx}}$. Unof. See Frankenia. Y. sagrada. See Lantana brasiliensis. Y. santa. See Eriodictyon.
Yerbin (yer'-bin) [Sp., yerba, herb]. Caffein obtained from llex paraguaiensis.

Yew $(u)$. See Taxus.

Ylang-Ylang $\left(e^{\prime}-\operatorname{lan} g-e^{\prime}-\operatorname{lan} g\right)$ [E. Ind.]. A tree of the E. Indian islands, Canangi odorata. Its flowers afford a fragrant oil.

Yok [Eng. colloq.]. The grease obtained from wool.

Yoke-bone. The malar bone.

Yolk [also yelk; AS., geolca, yolk, the yellow part]. Popularly applied to the yellow portion of the hen's egg as distinguished from the white. In biology, the term yolk has no exact meaning, being sometimes used to designate the Deutoplasm, q.v., alone, while at other times the entire ovum proper is indicated. See under Ovum. See also Yelk and Vitellum. Y., Accessory, Food, Nutritive, Subordinate, or Supplemental. See Nutritive Vitellus. Y.-cleavage, segmentation of the vitellus. Y.-duct, the vitelline duct. See under Duct. Y.-food. See Deutoplasm. Cf. Ovum. Y., Formative, the active, living portion of the protoplasm of an ovum, with the nucleus it encloses; a whitish disc situated at the animal pole of an ovum, and which undergoes segmentation and enters directly into the formation of the embryo. Cf. Germinal Disc, Cicatricula, Discus proligerus. Also called the Tread, Narbe, Hahnentritt. Y.-grains, granules of nutritive substance (deutoplism) directly produced by the egg-cell itself. Y.-sac, the larger of the two globes formed by the blastodermic membrane in the early development of the embryo. Y.-segmentation. Same as $Y$-cleavage. Y.-skin, the vitelline membrane. $\mathbf{Y}$., Xellow, the yellow mass centrally located. Y., White, the albuminous white of the egg. Y. of Wool. See Suint.

Young (yung) [ME, yong, young]. Being in the first or early stage of life. Not long born.

Young's Rule. A rule of dosage. Add 12 to the age and divide the result by the age, to get the denominator of the fraction, the numerator of which is $\mathbf{I}$.

Young-Helmholtz Theory. See Color-sensation.

Youngling (yung-ling) [ME, yongling]. A young person.

Youpon (yu'-pon). See Yaupon.

Youth (uth) [ME., youthe, youth]. The period between childhood and manhood.

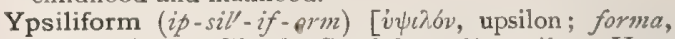
form ]. Shaped like the Greek letter $\Upsilon$, upsilon. Hypsiliform. Y. Figure, a peculiar figure seen in the development of certain eggs, as that of Ascaris megalo. cephala.

Ytterbium (it-tur'-be-um) [Y'terby, in Sweden]. A metal, not yet isolated, having the symbol $\mathrm{Yb}$ and an atomic weight of 173.01. See Elements, Table of.

Yttrium (it'-re-um) [Ytterby, in Sweden]. Symbol Y, at. wt. 89. A rare metallic element of the cerium group. See Elements, Table of.

Yucca $\left(y u k^{\prime}-a h\right)$ [A. Ind.]. A genus of liliaceous plants, Y. filamentosa, Adam's needle, of the Southern U. S., is diuretic. Its tincture is employed in urethritis. Unof.

Yupon $\left(y u^{\prime}-p o n\right)$. See Yaupon.

Yzquierdo's Bacillus. See Vorruga peruana. 
Zalambdodont $\left(a a-\ln m^{\prime}-d o-d o n t\right) \quad[\zeta \alpha$, intensive ; $\lambda a ́ \mu-$ $\beta \delta a$, the letter $\lambda$; odoús, tooth]. In biology, having short molar teeth with one $\mathrm{V}$-shaped ridge.

Zalefski's Method. For ascertaining the presence of iron compounds in the liver or other tissues. The tissues are treated in bulk instead of in separate sections. The methods are as follows: $(a)$ dmmoniumsulplid Method. (I) The pieces of tissue are left in 65 per cent. alcohol for twenty-four hours. (2) They are then hardened for twenty-four hours in 96 per cent. alcohol, to which a few drops of strong, yellow ammonium sulphid have been added. They must be shaken up from time to time. (3) They are next hardened in absolute alcohol, to which several drops of ammonium sulphid are added. (4) They may then be cut. The alcohol should completely fill the bottle; corks must not be used, because they give an iron reaction with ammonium sulphid. (b) Potassium-ferrocyanid Method. (I) The pieces are left in 65 per cent. alcohol for twenty-four hours. (2) They are then placed for two or three days in a I per cent. solution of potassium ferrocyanid in 96 per cent. alcohol. (3) They are then kept in a I per cent. solution of potassium ferrocyanid in 65 per cent. alcohol. (4) They are now placed in I or 2 per cent. acid alcohol (alcohol, 96 per cent.) for two or three days. (5) The sections may then be cut and may afterward be stained in carmin. Treatment with 65 per cent. alcohol (as in 3) is employed to aid the penetration of the acid used subsequently. For ferrous compounds potassium ferrocyanid may be similarly used.

Zamia ( $\left.z \iota^{\prime}-m e-a h\right)$ [L.]. A genus of cycadaceous plants. $Z$. integrifolia, of Florida, and some West Indian species, afford a kind of sago, known incorrectly as arrowroot.

Zanaloin (sa-nal'-o-in) [Zanzibar; $\dot{a} \lambda$ on, aloes]. The aloin derived from Zanzibar aloes.

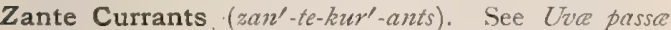
minores.

Zaraath $\left(z a^{\prime}-r a-a t h\right)$ [Heb.]. The Hebrew term for Leprosy.

Zarathan $\left(z a r-a t h^{\prime}-a n\right)$. Scirrhous hardening of the breast.

Zea $\left(z e^{\prime}-a h\right)$ [ $\xi^{\prime} \alpha$, a sort of grain]. A genus of grasses. Z. mays, Maize, Indian Corn. The stigmata of maize or "corn silk" (Stigmata maydis) have an active principle thought to be an organic (maizenic) acid. It is a mild diuretic, used with success in incontinence of urine and rheumatism. Dose of the fld. ext. $3 \mathrm{j}-$ ij. All unof.

Zedoary (zed'-o-a-re). An East Indian drug or spice, the rhizome of Curcuma zedoaria and C. aromatica. It resembles ginger, but is less agreeable, and is not much used in medicine. Unof.

Zein $\left(z e^{\prime}-i n\right)$ [ל̌́a, maize]. A yellowish, soft, insipid proteid obtained from maize.

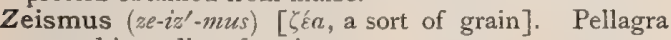
caused by a diet of maize

Zeiss's Glands. See Gland.

Zeissian Sty. See Horderium

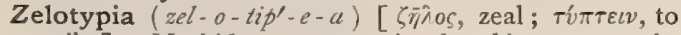
strike]. Morbid or monomaniacal zeal in any pursuit.

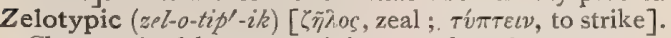
Characterized by or pertaining to zelotypia.

Zenker's Degeneration. A peculiar form of degeneration of the muscular fibers of the body, by which they are rendered extremely brittle, so that they readily give way if the muscle be forcibly contracted. This degeneration is liable to occur in cases of continued or high fever, and is not uncommon in typhoid fever. See Degeneration, and Signs and Symptoms, Table of.

Zenkerism (zen'-ker-izm) [after Zenker, an anatomist]. The condition of Zenker's degeneration.

Zeorine (ze'-o-rin) [zeora, a genus of lichens]. In biology, denoting, in lichens, an apothecium in which a proper exciple is inclosed in the thalline exciple.

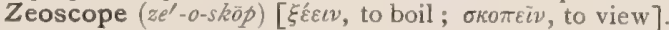
An apparatus for determining the alcoholic strength of a liquid by means of its boiling-point.

Zero $\left(z e^{\prime}-r o\right)$ [origin obscure]. Any character denoting absence of quantity. In physics, the point from which thermometers are graduated. Z., Natural, the temperature to which the earth would fall were the heat of the sun withdrawn entirely.

Zerumbet $\left(z e-r u m t^{\prime}-b e t\right)$ [E. Ind.]. An E. Indian drug or spice, by some asserted to be the same as cassimuniar; probably the rhizome of Zinuiber zerumbet. It resembles ginger; little used. Unof.

Zest [OF., zeste, one of the partitions which divide the kernel of a walnut]. The expressed oil of the peel of the orange or lemon.

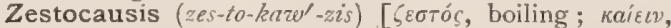
to burn]. Cauterization with instruments heated by steam.

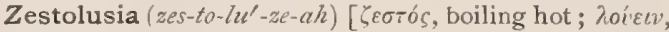
to wash ]. Washing with boiling or nearly boiling water.

Zeugite $\left(z u^{\prime}-g i t\right)$. See Zygite.

Zibet $\left(z i b^{\prime}-e l\right)$ [zibethum, "ren., Zibethi]. A variety of civet produced by Vivierra zibetha, an animal of S. E. Asia. It was formerly used as a substitute for musk.

Zimb (zim) [Ar., zimb, a fly]. See Glossina morsitans and Panronia, under Parasites (Animal), Table of.

Zimmermann, Elementary Particles, or Corpuscles of. Minute, colorless, highly refractive particles encountered floating in the liquor sanguinis; bloodplates. Cf. Granules of Max Siluultze.

Zimocca Sponge $\left(z i-m o k^{\prime}-a h\right)$. A sponge of fine grade, Euspongia zimocca.

Zinalin $\left(z_{i n}^{\prime}-a l-i n\right), \mathrm{C}_{20} \mathrm{H}_{19} \mathrm{~N}_{2} \mathrm{O}_{6}$. A yellow coloringmatter obtained from anilin by the action of nitrous acid.

Zinc, Zincum (zin $k^{2}$, zing $\left.k^{\prime}-u m \iota\right)$ [L.: gen., Zinci]. $\mathrm{Z}_{\mathrm{n}}=64.9$; quantivalence II. A metallic element with a lead-like luster. It is represented in medicine by several of its salts, all of which are more or less poisonous. In small doses it is tonic and astringent; in larger quantities, a strong emetic. It is used mainly in the form of lotions in conjunctivitis, in various catarrhs, and certain skin-diseases. See Elements, Table of. $\boldsymbol{Z}$., acetas, Zn $\left(\mathrm{C}_{2} \mathrm{H}_{3} \mathrm{O}_{2}\right)_{2} \cdot 3 \mathrm{H}_{2} \mathrm{O}$. Dose, internally, gr. $1 / 2-\mathrm{ij}$; as lotion, gr. ij to 3 j of water. Z., Aërated. See Zinc Carbonate. $\mathrm{Z}$. bromidum, $\mathrm{ZnBr}_{2}$, zinc bromid. Dose gr. $\mathrm{x} / 2$ to ij. Z., Butter of. See Z. Chlorid. Z . carbonas præcipitat., $\left(\mathrm{ZnCO}_{3}\right)_{2} \cdot 3 \mathrm{Zn}(\mathrm{HO})_{2}$, dusted over wounds as a protection. Z. Carbonate. See Pigments, Conspectus of. $Z$. chloridum, $\mathrm{ZnCl}_{2}$, tonic and escharotic. Dose, internally, gtt. iv-viij of a $\bar{s}$ ss to ziij solution in spt. ætheris; as a collyrium, gr. $\mathrm{j}-\mathrm{ij}$ to $Z_{j}$ of water $Z$. Chloridum, Liq., $1 / 2$ to $I$ per cent. in strength. Z.-colic. See Colic. Z., Flowers of. See Z. Oxid. Z-green. See Pigments, Conspectus of. $Z$. iodidum, $\mathrm{ZnI}_{2}$. Dose gr. ss-ij. Z Z. lactas, $\mathrm{Zn}_{2} \mathrm{C}_{3} \mathrm{H}_{4} \mathrm{O}_{3}$. Used in epilepsy. Dose gr. ij-x. $\boldsymbol{Z}$. oleat., Ung. (B.P.), oleate of zinc and soft paraffin. $\boldsymbol{Z}$. oxidum, $\mathrm{ZnO}$. Dose gr. j-x. Z. oxidum, Ung., 20 per cent. in benzoinated lard. $Z$. oxychloridum, a dental filling- 
material composed of powdered oxid of zinc, and fluid chlorid of zinc. Z. Oxyphosphate, a dental filling-material which is a basic compound of zinc with phosphoric acid, and is made by adding a syrupy solution of glacial phosphoric acid to calcined oxid of zinc. $\boldsymbol{Z}$. Phosphate, this dental fillingmaterial consists of a powder-the calcined and pulverized oxid of zinc, and a fluid or crystals-glacial phosphoric acid. Z. Phosphid, $\mathrm{Zn}_{3} \mathrm{Ph}_{2}$. A nervestimulant in spinal irritation. Dose gr. $\frac{1}{16}-\frac{1}{4}$. Z., Sea-salt of. See Z. Chlorid. Z.-spar. See Calamin. Z. Sulphas, $\mathrm{ZnSO}_{4} \cdot 7 \mathrm{H}_{2} \mathrm{O}$. Dose, as tonic and astringent, gr. $\frac{1}{10}-\mathrm{ij}$; as emetic, gr. $\mathrm{x}-\mathrm{xxx}$. Z. Sulphid, Hydrated, a white preparation of zinc useful in chronic eczema, psoriasis, and other diseases when the skin needs stimulation. It is used externally in ointments; internally, in pills, each containing six grains of the sulphid. Z sulphocarbolas, $\mathrm{Zn}\left(\mathrm{C}_{6} \mathrm{H}_{5} \mathrm{SO}_{4}\right)_{2} \mathrm{H}_{2} \mathrm{O}_{2}$, an intestinal antiseptic. Dose gr. $x-x v$. $Z$. valerianas, $\mathrm{Zn}\left(\mathrm{C}_{5} \mathrm{H}_{9} \mathrm{O}_{2}\right)_{2} \cdot 2 \mathrm{H}_{2} \mathrm{O}$, useful in neurasthenic conditions. Dose, gr. $\frac{1}{10}-\mathrm{ij}$. See, also, Allen's Test. Z.-white, commercial oxid of zinc. Z.-yellow, basic zinc chromate. See Pigments, Conspectus of.

Zinciber $\left(z^{\prime} n^{\prime}-s i b-e r\right)$. Same as Zingiber.

Zincic $\left(\right.$ zing $\left.g^{\prime}-i k\right)$ [zincum, zinc]. Containing or pertaining to zinc

Zincolith (zing $\left.k^{\prime}-o-l i t h\right)$. See Pigments, Conspectus of.

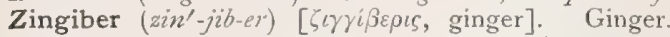
The rhizome of $Z$. officinale. Its properties are due to an oleo-resin. It is a stimulant and carminative, and is excellent to relieve flatulence; to correct the griping of purgatives, and as a flavoring adjuvant. Z., Fld. Ext. Dose $m_{\mathrm{x}}-z^{\mathrm{ss}}$. $\boldsymbol{Z}$., Oleoresina, extracted by ether. Dose $m_{1} 1 / 2-i j$. $Z$., Syr., 2 per cent. of the fld. ext. in syrup. Dose

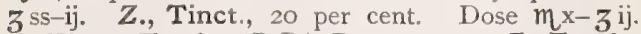
Z., Tinct., Fortior (B.P.) Dose $m_{\mathrm{v}-\mathrm{xx}}$ Z., Troch., each contains gr. ij of the tinct., with tragacanth, sugar, etc.

Zinn, Ligament of. See Ligament. Z.'s Corona, an arterial plexus about the optic nerve, in the sclerotic. Z.'s Membrane. See Zonule of Zinn. $Z$., Zone or Zonule of. See Zonule.

Zirconium ( zir-ko'-ne-um ) [Pers., zargün, goldcolored]. A chemic element (symbol $\mathrm{Zr}$.; at. wt., 89.6), resembling titanium and silicon, and soluble in aqua regia and in hydrofluoric acid. It is obtained from a mineral called zircon. See Elements, Table of.

Zittman's Decoction. A drink for old, obstinate cases of syphilis. It is constituted as follows: $\mathbb{R}$. Sarsapar illa, cut, $121 / 2$ ounces; water 325 Troy ounces. Digest for 24 hours, and add alum and sugar each 6 drams, enclosed in a linen rag. Heat in a steam bath in a covered vessel for 3 hours, adding, toward the close, anise and fennel each 4 drams, senna 3 ounces, liquorice-root $\mathrm{I}^{1 / 2}$ ounces. Express, strain, and after several hours decant. It should weigh $3 \mathbf{I} 2$ Troy ounces. Put aside as a strong decoction. A weaker decoction is made from the dregs.

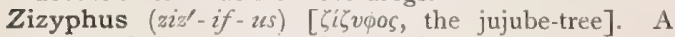
genus of rhamnaceous plants. See Jujube.

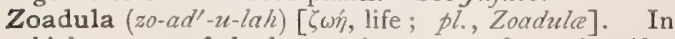
biology, one of the locomotive spores of certain Alge (Confervce). See Zoöspore.

Zoamylin $\left(z 0-a n^{\prime}-i t-i n\right)$. See Glycogen.

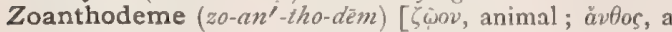
flower; $\delta \varepsilon ́ \mu a$, a bundle ]. In biology, the compound organism produced by the budding of an actinozoan polyp.

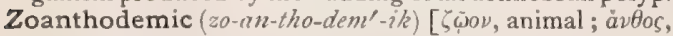
a flower; $\delta \dot{\varepsilon} \mu a$, a bundle]. Pertaining to a zoanthodeme.

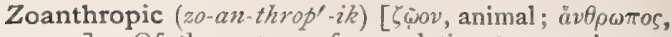
man]. Of the nature of, or relating to zoanthropy.

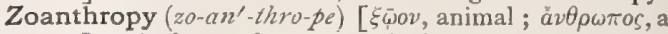
man]. A form of monomania in which the person affected imagines himself transformed into an animal, or inhabited by, or subject to the obsession of some animal.

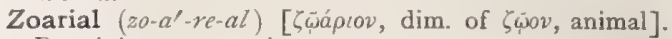
Pertaining to a zoarium.

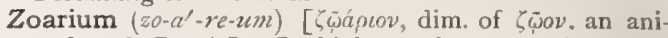
mal: pl. Zoaria]. In biology, the composite structure formed by repeated gemmation in the Polyzoa.

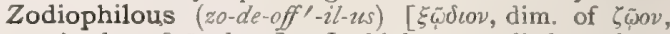
animal; $\phi i n \varepsilon i v$, love ]. In biology, applied to plants which are frequented by animals and pollinated by their agency. Cf. Anemofluilous, Hydrophilous, Anthophilous.

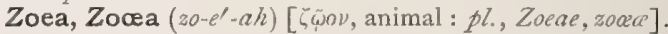
In biology, the developmental stage in which the larvæ of most of the Decapoda leave the egg. It is characterized by the presence of a large cephalothoracic shield, caudal segments well developed but with out appendages, tail forked, six posterior thoracic segments rudimentary or non-existent, and seven anterior pairs of appendages. Cf. Nauplius, Megalops.

Zoeal $\left(z o-e^{\prime}-a l\right)$ [

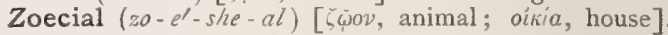
Pertaining to a zoecium.

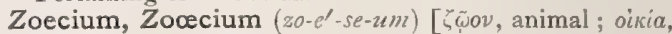
house: pl., Zoecio]. In biology, the chamber in which the polyp is lodged in Polyzoa: the Cystid of Nitsche and the Brutkapsel of Reichert.

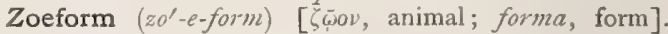
Having the form of a zoea.

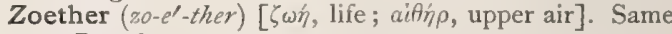
as Protyl.

Zoetic $\left(z 0-e t^{\prime}-i k\right)[\zeta \omega \dot{\eta}$, life]. Vital.

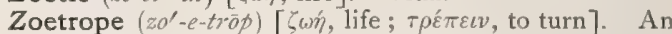
instrument that by the revolution of a series of pictures before the eye gives the appearance of a person or animal in motion, the pictures successively representing single phases of a compound act. Called, also, a phanakistoscope.

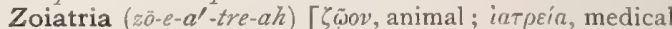
treatment]. The art and science of veterinary surgery.

Zoiatrics (zo-i-at'-riks). See Zoiatria.

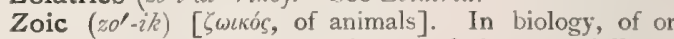
pertaining to living organisms; relating especially to animal life.

Zoidin $\left(z 0^{\prime}-i d-i n\right)$. See Glairin.

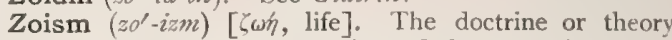
that life is the manifestation of the operations of a peculiar vital principle; the doctrine of vital force.

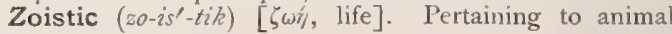
life ; vitalistic.

Zöllner's Lines. A device to illustrate false estimates of direction or paral. lelism by intersecting lines crossing parallel lines at a certain angle. Zona $\left(z o^{\prime}-n a h\right)$ [gen. and pl., Zone]. I. A zone; a belt or girdle. A name given to certain spaces traversing the cortical envelop of the kidney, as $Z$. glomerosa, $Z$. fasciculata, Z. reticularis, etc. 2 Herpes zoster. $Z$. alba, the white zone of

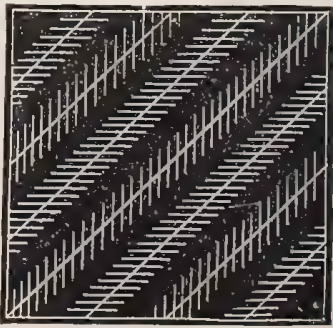

ZÖLLNER'S LINES. the eyeball. $\boldsymbol{Z}$. arcuata, the inner zone of the basilar 
membrane extending from the lower edge of the spiral groove of the cochlea to the external edge of the base of the outer rods of Corti. $\boldsymbol{Z}$. cartilaginea, the limbus of the spiral lamina. $Z$. choriacea. Same as $Z$. cartilagi$n e a . Z$. ciliaris, the ciliary zone, or ciliary processes collectively; the zone of Zinn, or the suspensory ligament of the crystalline lens; a radially plicated modified anterior continuation of the hyaloid membrane of the vitreous body (Piersol). $\boldsymbol{Z}$. denticulata, the inner zone of the basilar membrane, together with the limbus of the spiral lamina. $\boldsymbol{Z}$. fasciculata, the central portion of the cortex of the suprarenal capsule, composed of tube-like transverse bands. Z ganglionaris, a collection of gray matter on the filaments of the cochlear branch of the auditory nerve. Z $\mathbf{Z}$. glomerulosa, a zone of the cortical portion of the suprarenal capsule, which has a net-like appearance on section, situated near the surface of the organ. $\mathbf{Z}$. ignea. Synonym of Herpes zoster. Z . incerta. See Regio subthalanica. Z. lævis. Same as $Z$. arcuata. $Z$. mediana. Same as $Z$. cartilaginea. $Z$. nervea. Same as $Z$. arcuata. $Z$. orbicularis, a thickening of the capsular ligament around the acetabulum. $\mathbf{Z}$. pectinata, the outer zone of the basilar membrane, extending from the rods of Corti to the spiral ligament. $\boldsymbol{Z}$. pellucida, the thick, solid, elastic envelop of the ovum, corresponding to the cell-wall of a cell. It is also called the vitelline membrane. It contains the vitellus or yolk, corresponding to the cell-contents of the cell; the Germinal Vesicle (corresponding to the nucleus of the cell), which last contains the Germinal Spot, corresponding to the cell-nucleolus. $Z$. perforata, the lower edge of the spiral groove of the cochlea. $Z$. perforata of the Cochlea, the inner and perforated division of the lamina spiralis membranacea. $Z$. radiata, the zona pellucida when the radiating pore-canals are very distinct. $\boldsymbol{Z}$. repens. Same as Herpes zoster. Z, reticularis: I. The portion of the cortex of the suprarenal capsule next to the medullary portion. Here the spaces formed by the transverse bands are of small extent. 2. The inner layer of the cortical portion of the suprarenal body. $\boldsymbol{Z}$. serpiginosa. Synonym of Herpes zoster. $\mathbf{Z}$. spongiosa, the extreme dorsal tip of the posterior horn of the gray matter of the spinal cord. $\boldsymbol{Z}$. tecta, the inner part of the lamina spiralis membranacea covered by the organ of Corti. $\boldsymbol{Z}$. tendinosa, a fibrous ring situated at each auriculo-ventricular opening in the heart. $\boldsymbol{Z}$. valsalvæ, the membranous spiral lamina of the cochlea. $\boldsymbol{Z}$. vasculosa, the medullary substance of the Graafian vesicles. $\boldsymbol{Z}$. volatica. Same as Herpes zoster.

Zonzsthesia (zonn-es-the'-ze-ah). See Zonesthesic.

Zonal (zo'-nal) [zona, zone]. Pertaining to a zone, or to the disease called zona. In biology, of or pertaining to the subdivisions of an articulate or annulose animal.

Zonary $\left(z o^{\prime}-n a r^{-}-e\right)$ [zona, zone]. Characterized by or pertaining to a zone. Z F . Fauna, Hæckel's name for the intermediate pelagic fauna discovered by Murray to inhabit the zones of different depths of the ocean between the surface and the deep-sea bottom. Z Z. Placenta. See Placenia.

Zonate $\left(z \bar{o}^{\prime}-n \bar{a} t\right)$ [zona, a zone]. In biology, girdled or ringed; marked with concentric bands.

Zone (zōn) [zona, a band]. See Zona. Z., Anelectrotonic. See Z., Polar. Z., Cervical, the lowest fourth of the internal surface of the uterus. $Z$. Ciliary. See Zonula ciliaris. Z., Epileptic, a tract of the integument irritation of which may give rise to an epileptic attack, $\boldsymbol{Z}$. of Haller. Same as Z. of Zinn. Z., Hepatic. See Hepatic. Z., Hyperesthetic, a zone of the integument characterized by exalted sensibility. Z., Hysteroepileptogenous, Z, Hysterogenic, hyperesthetic areas in hysteric persons, where pressure on the one hand calls forth well-marked phenomena of hysteria, such as convulsions, or catalepsy, or on the other hand checks an attack that is in progress. The ovarian region and areas near the mamma are hysterogenic zones. $\boldsymbol{Z}$., Internal, of the Lenticular Nucleus, a zone connected by transverse white fibers with the internal capsule. $\boldsymbol{Z}$., Katelectrotonic. See Z., Peripolar. Z., Lissauer's. Same as Lissauer's Tract. Z., Ophthalmic. See Herpes. Z., Peripolar, a term proposed for the zone or region surrounding the polar zone on the body of a patient undergoing electrotherapeutic treatment. $\quad \boldsymbol{Z}$., Placental, that portion of the uterus to which the placenta is attached. Z., Polar, a term proposed for the zone or region surrounding the therapeutic electrode applied to the human body for electric treatment.

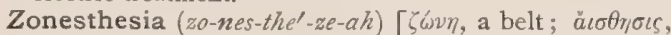
sensation]. Perverted feeling in which there is a sense as of a cincture, or halter, or constriction about a part; also called Strangalesthesia and girdle-sensation.

Zonociliate (zo-no-sil'-e-āt) [zona, zone; cilium, eyelid]. In biology, characterized by a circlet or zone of cilia.

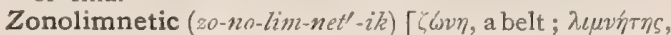
living in marshes]. In biology, applied to such freshwater or limnetic organisms as are limited to certain depths, as distinguished from autolimnetic (living only at the surface), and bathylimnetic (dwellers in deep waters).

Zonoplacental (zo-no-plas-en'-tal) [ $\zeta \omega \omega \eta$, girdle; placenta]. Having a zonary deciduate placenta.

Zonula $\left(z o^{\prime}-n u-l a h\right)$ [zomula, dim. of zona, zone]. A little zone or belt. Z $\mathbf{Z}$. ciliaris. See Zona ciliaris.

Zonular (zo'-nu-lar) [zonula, a little zone]. Pertaining to or of the character of a zonula, or a zone. $Z$. Cataract. See Cataract.

Zonule $\left(z \bar{o} n^{\prime}-u l\right)$ [zonula, a little zone]. A small zone. $\boldsymbol{Z}$. of Zinn, the suspensory ligament of the crystalline lens of the eye. See Ligament.

Zonulet $\left(z o^{\prime}-n u\right.$-let $)[z o n u l a$, zonule $]$. A little zone.

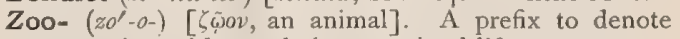
connection with or relation to animal life.

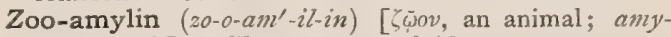
lum, starch]. Glycogen; amyloid.

Zoo-amylum (zo-o-an'-il-um). See Paranylum.

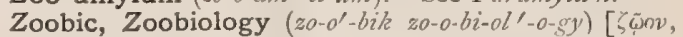

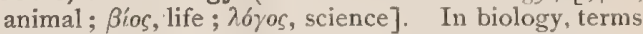
employed indifferently by Ducrotay de Blainville to express the internal phenomena of the organism in their relation to external conditions.

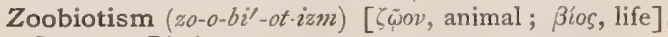
Same as Biotics.

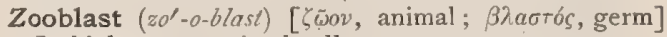
In biology, an animal cell.

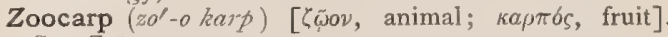
See Zoöspore.

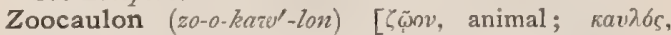
stem, stalk]. In biology, the branching stalk of certain colonial infusorians.

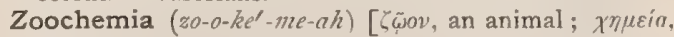
chemistry]. The chemistry of animal life and tissies. Biochemistry.

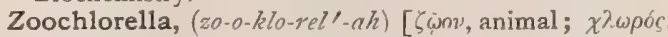
pale-green: pl., Zoochlorelle]. In biology, one of the green granules found in certain invertebrates, e.g., Hydra viridis, Euglena, Stentor. Cf. Zooxanthella.

Zoo-currents, or Zoorema (zo-o-kur'-ents, zo-o-r"e'-

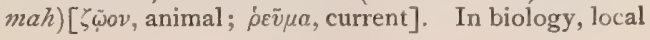


planktonic streams or very crowded animal roads in the sea. They occur in the open ocean, as well as on the coast, and are especially pronounced at Messina and at Lanzarote.

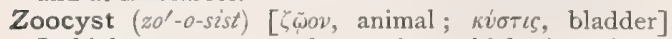
In biology, an encysted organism which gives rise to zoospores

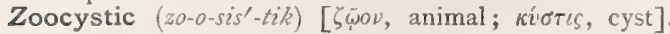
Pertaining to a zoocyst.

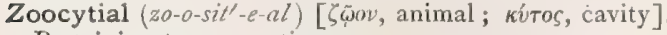
Pertaining to a zoocytium.

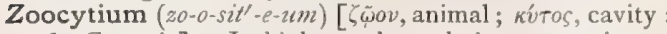
pl., Zoocytia $]$. In biology, the gelatinous matrix secreted by certain colonial infusorians.

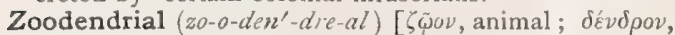
tree]. Pertaining to a zoodendrium.

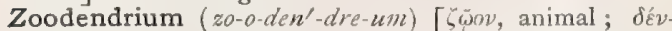
$\delta \rho \circ v$, tree]. In biology, a branched zoocytium.

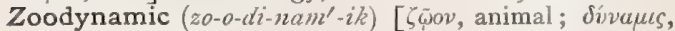
power]. Pertaining to zoodynamics.

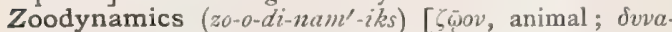
$\mu$ нкós, dynamic]. In biology, animal physiology.

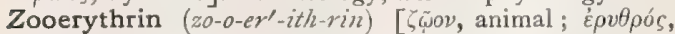
red]. In biology, a red lipochrome-pigment abundant in sponges; also spelled zoonerythrin. Cf. Turacin.

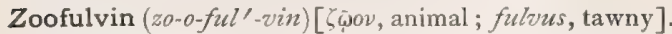
A yellow coloring-matter obtained from certain birds, the turakoos.

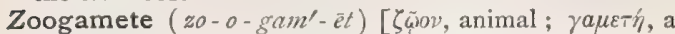
wife]. In biology, a gamete or sexual spore endowed with the power of locomotion.

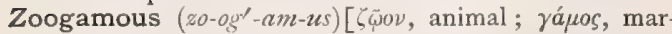
riage]. Pertaining to zoogamy.

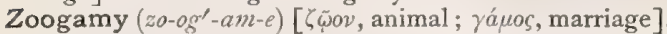
In biology, the sexual generation of animals; copulation, conjugation, mating.

Zoogene $\left(z 0^{\prime}-0-j e j n\right)$. See Glairin.

Zoogenesis (zo-o-jen'-es-is) [G Gov, animal; yevvav, to beget]. The generation of animal forms. Animalbreeding.

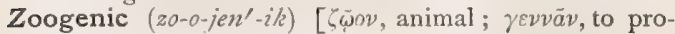
duce]. Pertaining to zoogeny.

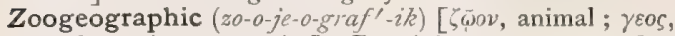
earth; $\gamma \rho a ́ \phi \varepsilon \iota \nu$, to write]. Pertaining to zoogeography.

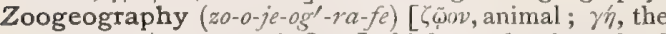
earth; $\gamma \rho a$ á $\varepsilon v v$, to write]. In biology, that branch of zoology which treats of the geographic distribution of animals. Cf. Phytogreography.

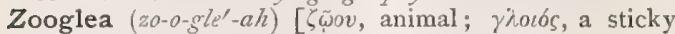
substance]. In biology, a stage in the life-history of certain Schizonycetes, or bacteria, in which they lie embedded in a gelatinous matrix secreted by the microbes themselves.

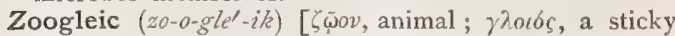
substance]. In biology, pertaining to a zooglea.

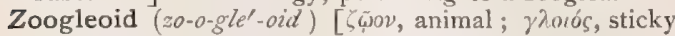
substance]. In biology, zooglea-like.

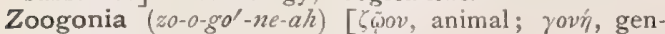
eration $]$. Viviparous generation.

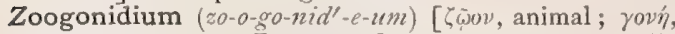
generation: pl., Zoogonidia]. In biology, a motile gonidium; one furnished with cilia.

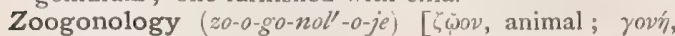
generation; $\lambda o ́$ yos, a treatise]. A scientific view of the origin and development of animal life.

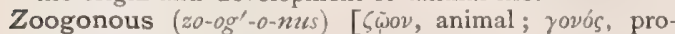
ducing]. Same as Viviparous.

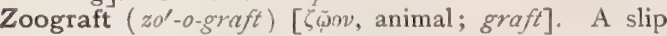
or graft of tissue derived from any one of the lower animals, and surgically implanted upon the human body.

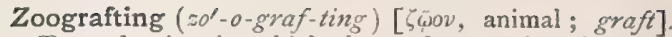
Transplanting in which the grafts are taken from the skin of the lower animals.

Zoographer (zo-og'-ra-fer). See Zoographist

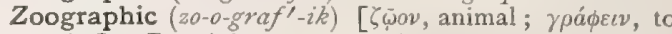
write]. Pertaining to zoography.

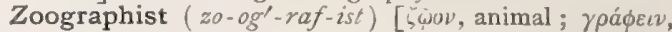
to write]. One who describes animals.

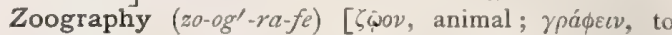
write]. A descriptive treatise on the distribution of animals.

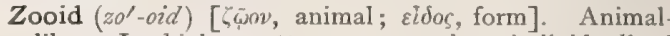
like. In biology, " a more or less individualized animal organism, which may or may not be capable of independent existence, and which constitutes one of a series whose members are related to each other by some form of non-sexual reproduction and morphologically repeat one another, either actually or homologically." (Allman.) "The introduction of the term zooid into the language of zoology is of very re cent date. This term is intended to indicate each of the distinct organisms which, with various degrees of independence, express, when taken together, the total result of the development of a single ovum. It is a valuable addition to our terminology, enabling us to avoid the ambiguous sense which attaches itself to the word individual when this word is used in its biological signification as the logical element of a species." (Huxley.)

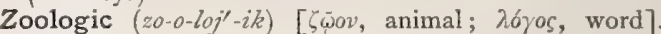
Relating to zoology.

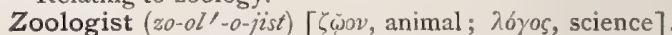
One who is versed in zoology.

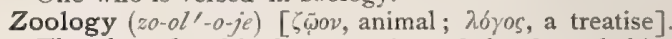
That branch of biology treating of the form, habits, structure, development, and classification of animals. Z., Medical, the study of drugs of animal origin.

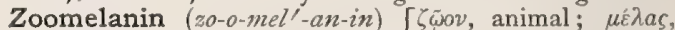
black]. In biology, the black pigment of the feathers of certain birds.

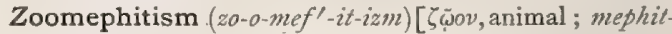
ism $]$. Mephitic exhalations of animal origin.

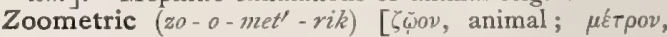
measure]. Pertaining to zoometry.

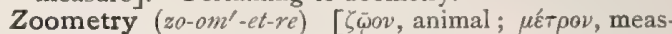
ure]. The measurement of the proportionate lengths or sizes of the parts of animals.

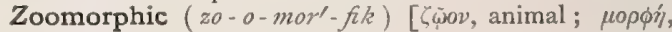
form]. Pertaining to zoomorphism.

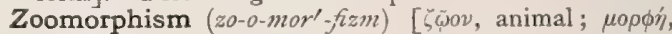
form]. Representation of animal forms as distinguished from the human form.

Zoomorphy (zol-o-mor-fe). Same as Zoomorphism.

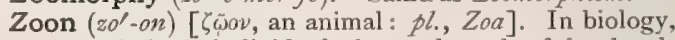
a morphologic individual, the total result of the deve? opment of a single ovum. Cf. Zooid.

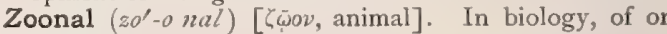
pertaining to a zoon.

Zoonerythrin (zo-on-er'-ith-rin). The red coloringmatter extracted by chloroform from the red excrescence over the eyes of certain birds, from the feathers of Calurus auriceps, and from other sources. It is soluble in ether, chloroform, and alcohol. It is bleached by light. See Zooerythrin, and Pigments, Conspectus of.

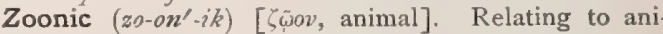
mals.

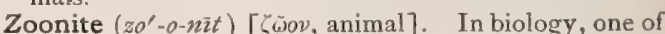
the segments or somites, metameres, or arthromeres of which an articulate animal is composed.

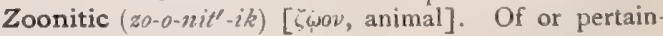
ing to a zoonite. 


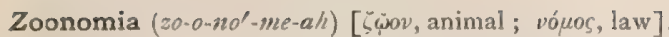
The principles or laws of animal hife.

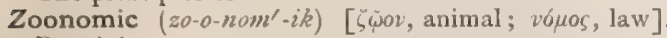
Pertaining to zoonomy.

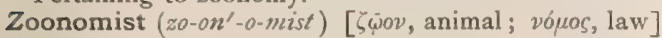
One versed in zoonomy.

Zoonomy (zo-on'-o-me). Same as Zconomia.

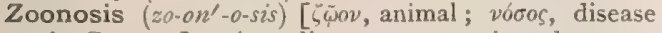
pl., Zoonoses]. Any disease communicated or communicable from one of the lower animals to man.

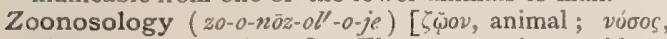
disease; loyos, science]. The systematic considera tion of the diseases of lower animals; zoopathology zoopathy.

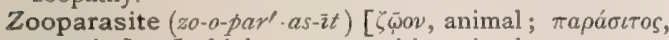
parasite]. In biology, a parasitic animal.

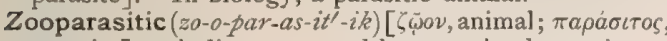
- parasite]. A disease caused by an animal parasite.

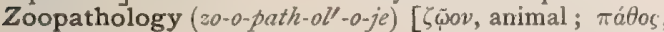
suffering; $\lambda$ óyos, science]. The science of the dis eases of animals.

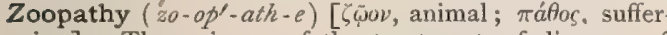
ing]. The science of the treatment of diseases of animals.

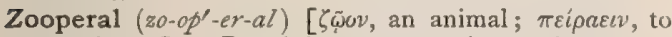
experiment]. Pertaining to experimentation upon animals.

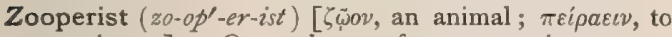
experiment]. One who performs experiments on animals.

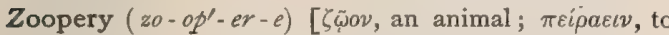
experiment]. A term proposed by Wilder to express experimentation upon animals. Cf. Callisection and Sentisection.

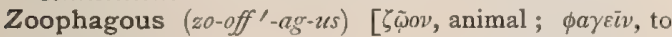
eat]. Subsisting on animal food.

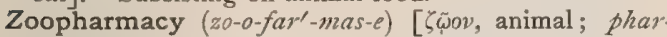
macy $]$. The science or art of veterinary pharmacy.

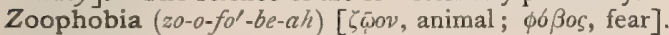
Morbid dread of certain animals.

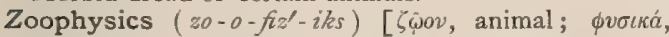
physics]. In biology, comparative anatomy.

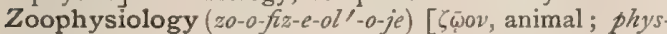
iology]. Animal physiology.

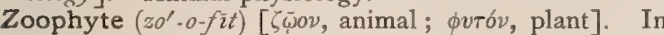
biology, a member of the lower invertebrata, the whole animal structure, whether a single animal (zooid), or consisting of a large number of animals, as in most corals, sea anemones, acalephs, and sponges. "The word has been applied to the lower animals by most writers in natural history since Pliny. It was first used by Sextus Empiricus and no doubt suggested by a passage of Aristotle in which the gradation from the higher animals to the plants is alluded to. But far from constituting a progress in science, that designation introduced only confusion, or at least served to propagate a false impression that there were living beings truly partaking at the same time of the nature of animals and plants. Nothing can be farther from the truth than to ascribe such a view to Aristotle, as his commentators, Goza and Budæus, have done; for, though Aristotle alludes to a gradation among animals and to a sort of transition from them to plants, he nowhere regards those animals as ambiguous in their character, but every where speaks of them as living animals and alludes to the sponges as plants. These erroneous notions had been entertained for nearly two thousand years until Peysonnel demonstrated the animal nature of the expanded in dividuals of the so-called zoophytes, in which some of his predecessors had fancied they saw real flowers." (L. Agassiz.)

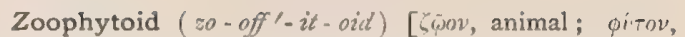
plant]. Resembling a zoophyte.

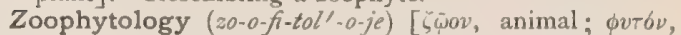
plant; $\lambda 6 \gamma 05$, a treatise]. The study of zoophytes.

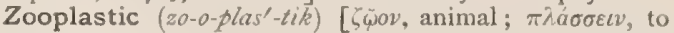
form ]. Pertaining to or of the nature of zooplasty.

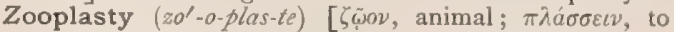
form]. The surgical transfer of zoografts; the trans. plantation of tissue from any of the lower animals to man.

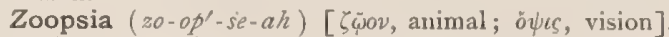
The seeing of animals, as an illusion or as an halluci nation or in dream.

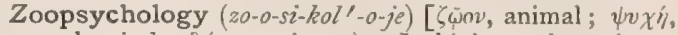
soul, mind; $\lambda 6$ yos, science). In biology, the science of the mental activities of lower animals.

Zoorema. See Zoo-currents.

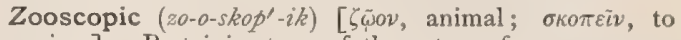
view]. Pertaining to or of the nature of zooscopy.

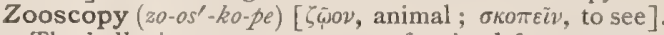
The hallucinatory appearance of animal forms.

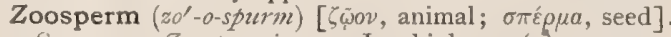
Same as Zoospermium. In biology, (a) same as Zoospore; (b) a spermatozoid, a Zoospermium.

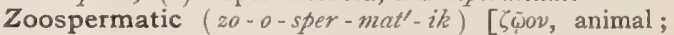
$\sigma \pi \varepsilon p \mu a$, seed]. Pertaining to a zoosperm.

Zoospermium (zo-o-spur $\left.{ }^{\prime}-m e-u m\right)$. See Zoosperm.

Zoosporange (zo'-o-spör-anj). Same as Zoosporangium.

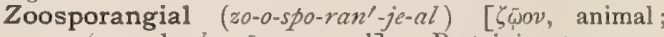

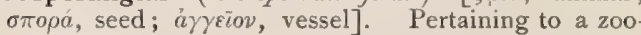
sporangium.

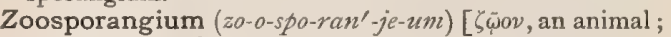

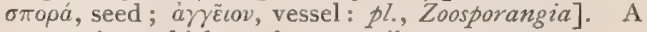
sporangium which produces motile spores.

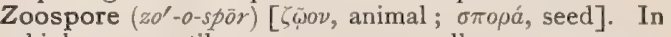
biology, a motile spore, a swarm-cell or swarm-spore.

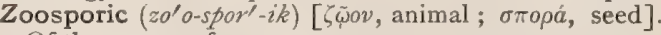
Of the nature of a zoospore.

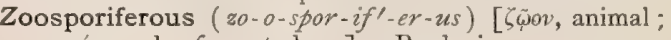

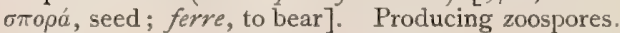

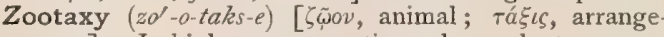
ment]. In biology, systematic zoology; the taxonomy of animals.

Zootechnics, or Zootechny (zo-o-tek'-niks, zo'-o-lek-ne)

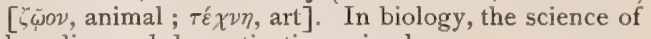
breeding and domesticating animals.

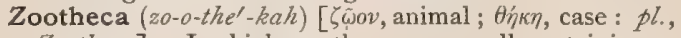
Zoothece]. In biology, the case or cell containing a zoospore or a spermatozoid.

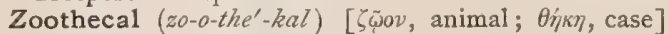
Pertaining to a zootheca.

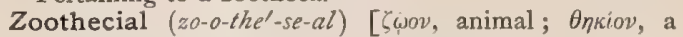
casket]. Pertaining to a zoothecium.

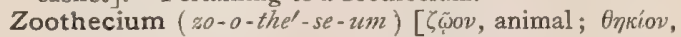
dim. of $\theta \dot{\eta} \kappa \eta$, case : pl., Zoothecia]. In biology, an aggregation of simple loricæ incasing certain colonial infusorians.

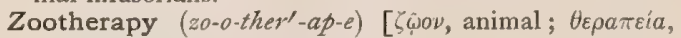
therapy]. Veterinary therapeutics.

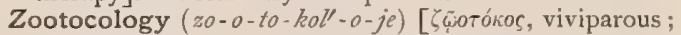
$\lambda 6$ yos, science]. A term proposed by Dr. Field, of Norwich, England, to supplant the word biology.

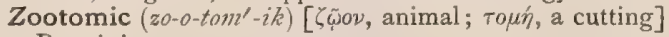
Pertaining to zootomy.

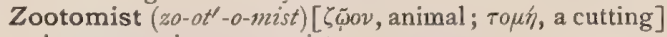
A comparative anatomist.

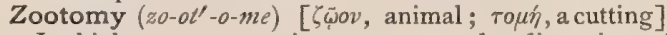
In biology, comparative anatomy; the dissection of animals.

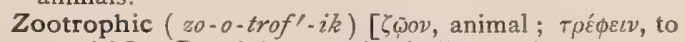
nourish]. Pertaining to animal alimentation. 


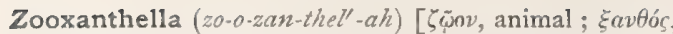
yellow: pl., Zooxanthellee]. In biology, one of the yellow pigment-granules forming the phæodium of certain radiolarians.

Zopissa $\left(z 0-p i s^{\prime}-a h\right)[\zeta \omega \pi \iota \sigma \sigma a]$. In the older phar racy, the pitch and tar scraped from a ship's sides. It was regarded as a strong xerantic and discutient remedy

Zoster $\left(z \circ s^{\prime}\right.$-ter $)$ [ $\zeta \omega \sigma i \eta \rho$, a girdle]. See Herpes zoster. $Z$. atypicus gangrænosus et hystericus. Kaposi's term for a vesicular affection characterized by an eruption of vesicles and papules, chiefly in groups, followed by central scabbing, and which was often surrounded by a corona of pus or minute pustules. In some parts, from coalescence, large areas of gangrene are produced, followed by sloughing, and keloid development in the scar. The eruption is symmetric, shows a marked tendency to recur, and occurs in hysteric individuals. $Z$. auricularis, a form of zoster affecting the ear. $Z$. brachialis, zoster affecting the arm or forearm. $Z$. capillitii et frontalis, zoster of the forehead and scalp over the distribution of the first branch of the fifth nerve. $\boldsymbol{Z}$. cerebralis, zoster which sometimes affects the whole of one side of the body and is of cerebral origin. $\boldsymbol{Z}$. cervico-subclavicularis, zoster affecting the neck and anterior portion of the chest. $\boldsymbol{Z}$. facialis, zoster in the distribution of the trigeminus nerve. $Z$., Herpes, shingles. An acute berpetic vesicular eruption in the distribution of a cutaneous nerve, often an intercostal nerve. $\boldsymbol{Z}$. hystericus, zoster due to hysteria. Z. lumbo-femoralis, zoster appearing on the nates, thigh, and calf of the leg. Z. lumbo-inguinalis, zoster of the back and groin. $Z$. ophthalmicus, an eruption in the course of the ophthalmic division of the fifth nerve. It is confined to the orbital region, the side of the nose, the forehead, and the anterior part of the scalp. $\boldsymbol{Z}$. pectoralis, zoster affecting the pectoral region. $Z$. perinæalis, zoster affecting the vulva, or the penis and scrotum, and the perineum.

Zuckerkandl's Convolution. See Convolutions, Table of.

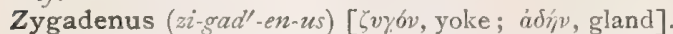
A genus of liliaceous plants, mostly N. American, the zygadenes. $Z$. venenosus, of the Pacific States (death camass, or hogs' potato), is a violent poison, narcotic, convulsant, and acrid stimulant. Unof,

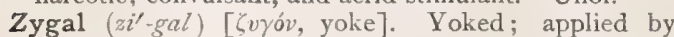
Wilder to cerebral fissures which, like the paroccipital, consist of two pair of branches connected by a stem or zygon.

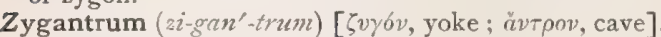
In biology, a depression on the posterior face of the neural arch of each vertebra of certain reptiles, receiv. ing the zygosphene of the succeeding vertebra and thus interlocking the vertebra.

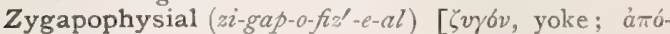
$\phi v \sigma \iota s$, apophysis]. Pertaining to a zygapophysis.

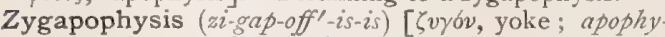
sis]. Any articular or (so-called) oblique process of a vertebra.

Zygobranchiate $\left(z i-g o-b r a n g^{\prime}-k e-\bar{a} t\right)$ [ $\zeta v \gamma b v$, yoke ; $\beta \rho a ́ \gamma \chi \imath a$, gills ]. In biology, having paired and, as it were, yoked gills or ctenidia.

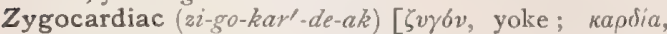
heart]. In biology, denoting a certain hard protuberance of the stomach of a crustacean, formed by a thickening of the chitinous lining of the cardiac division.

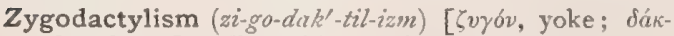
Tvגos, finger]. The yoking of the toes of a bird's foot in anterior and posterior pairs.

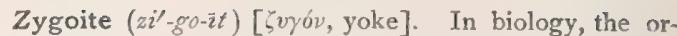
ganism resulting from the process of zygosis, or conjugation of two gametes.

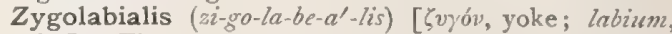
lip]. The zygomaticus minor muscle. See Muscles, Table of.

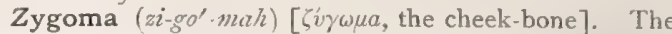
arch in the bones of the face formed by the interarticulation of the temporal with the malar bone.

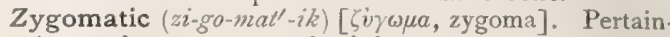
ing to the zygoma, or cheek-bone.

Zygomatico-auricular (zi-go-mat'-ik-onaze-rik'-u-lar)

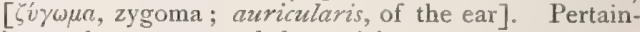
ing to the zygoma and the auricle.

Zygomatico-auricularis (zi-go-mat'-ik-o-aw-rik-u-la'.

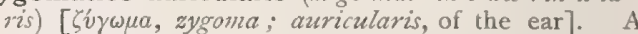
muscle of the external ear; the attrahens aurem. See Muscles, Table of.

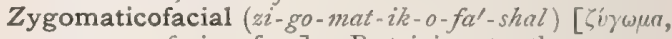
zygoma; facies, face]. Pertaining to the zygoma and the face.

Zygomaticotemporal (zi-go-mat-ik-o-tem'-po-ral) [کi $\gamma \omega \mu a$, zygoma; temporal]. Pertaining to the zygo$\mathrm{ma}$ and the temporal bone or fossa.

Zygomaticus $\left(z i-g o-m a t^{\prime}-i k-u s\right)$ [ $\zeta v \omega \omega \alpha$, zygoma]. One of several small subcutaneous muscles arising from or in relation with the zygoma. See Muscles, Table of.

Zygomorphic (zi-go-mor'-fik). Same as Zygomorphous.

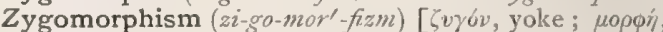
form]. The character of being zygomorphous.

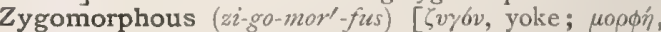
form]. In biology, applied to such flowers as may be divided into similar halves in one plane, or into similar halves in two planes at right angles to one another, but in which the halves produced by the two bisections are of different shapes.

Zygomorphy (zi'-go'mor-fe). Same as Zygomorphisnn.

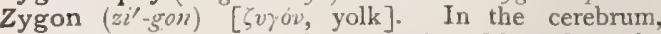
the bar that connects the two pairs of branches of a zygal fissure

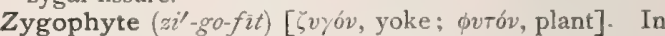
biology, a zygospore-producing plant.

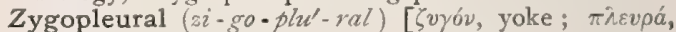
side]. In biology, bilaterally symmetric. Cf. $D i$ pleural and Tetrapleural.

Zygose $\left(z i^{\prime}-g \bar{o} z\right)$ [ $\zeta v \gamma o ́ v$, yoke]. In biology, pertaining to or characteristic of zygosis.

$Z$ ygosis $\left(z i-g o^{\prime}-s i s\right)[\zeta v \gamma o \bar{v} v$, to join, yoke]. In biology, the process of asexual reproduction by conjugation or fusion of two protoplasmic bodies or gametes.

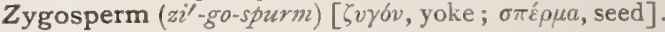
Same as Zygospore.

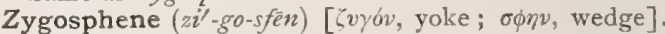
In biology, a process on the anterior face of the neural arch of each vertebra of certain reptiles, interlocking the vertebra by fitting into a fossa (the zygantrum) on the posterior face of the preceding vertebra.

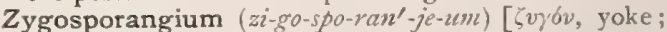

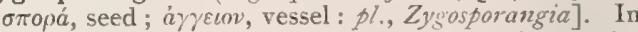
biology, a sporangium resulting from zygosis and giving rise to zygospores.

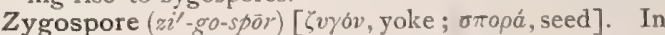
biology, the spore resulting from the zygosis or conjugation of two protoplasmic bodies or gametes.

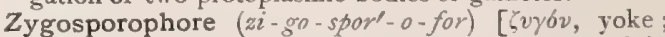

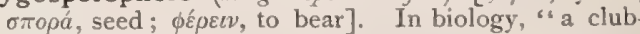
shaped or conic section of a hypha adjoining a gamete-cell after its delimitation.'

Zygote $\left(z i^{\prime}-g o t\right)$ [ ['vyouvv, to yoke]. Same as Zygospore.

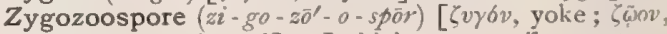
animal; $\sigma \pi \circ \rho a ́$, seed]. In biology, a motile zygote or zygospore. 


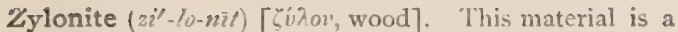
modified form of celluloid, and, like the latter, is composed is pyroxylin and camphor, though in different proportions. It is claimed that zylonite is a chemic combination, while celluloid is a mechanical mixture. Zylonite has uses in dentistry and surgery. See Celluloid.

Zymase $\left(z i^{\prime}-m a \bar{z}\right)$. See Microzymc.

Zyme (sim) [ $\zeta i \mu \eta$, leaven]. In biology, an organized ferment. Cf. Ensl'me.

Zymic $\left(z i m^{i}-i k\right)$ [ $i m, m$, leaven]. Of or pertaining to organized ferments.

Zymin $\left(z i^{\prime}-m i n\right)$ [ל่um, a ferment]. A product prepared from the pancreas for the treatment of diabetes mellitus. See Zyme.

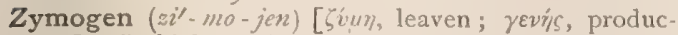
ing]. In biology, the condition of an unorganized chemic ferment as it exists in the resting seed; during the process of germination it gives rise to an enzyme, diastase, etc.

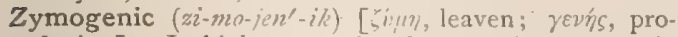
ducing]. In biology, causing fermentation, as certain anaërobic microorganisms

Zymogenous (zi-moi'-en-us). Same as Zymogenic.

Zymogic $\left(z i-n n j^{\prime}-i k\right)$. Same as Zymogenic

Zymoid (zi'-moid) [siun, leaven; cidos, form]. In biology, resembling an organized ferment.

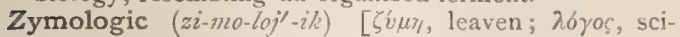
ence]. Pertaining to zymology.

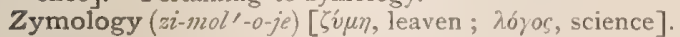
That department of science which deals with fermentation.

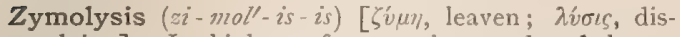
solving]. In biology, fermentation produced by an organized ferment. Sheridan Lea and others have incorrectly employed this term to designate unorganized fermentation, implying a vital origin of the agent. Same as Zymosis, which is preferable. Cf. Enzyme and Enzymosis.

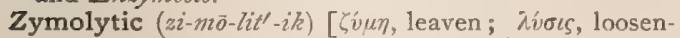
ing]. Due to, attended with, or relating to zymolysis; zymotic.

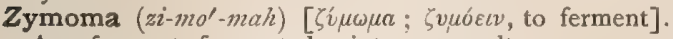
Any ferment, fermented mixture, or culture.
Zymome $\left(z i^{\prime}-m \ddot{m} n\right)$ [ $\zeta \dot{\nu} \mu \omega \mu a$, a fermented mixture]. An old name for the gluten of wheat that is insoluble in alcohol.

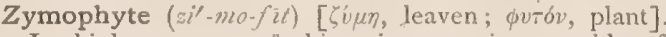
In biology, an anaërobic microorganism capable of producing fermentation: a zyme.

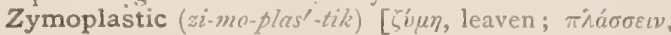
to form ]. Applied to certain substances of the bloodplasma derived from cells.

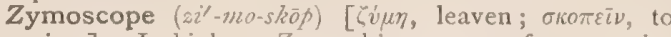
view ]. In biology, Zenneck's apparatus for ascertaining the zymotic power of yeast by gauging the amount of carbonic anhydrid given off.

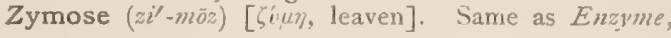
$q . v$.

Zymosimeter (zi-mo-sin'

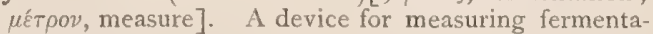
tive processes.

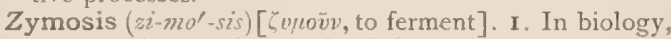
fermentation as the result of the vital activity of certain microorganisms, organized ferments, or zymes. It is a synonym of fermentation, but is preferable to symolysis, as the effect is not one of simplification. 2. The condition of one affected with a zymotic disease.

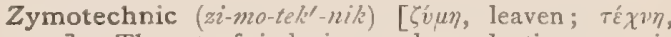
art]. The art of inducing and conducting zymotic processes in connection with vinification, acetification, etc.

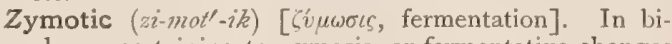
ology, pertaining to zymosis, or fermentative changes produced by an organized ferment, or zyme. Z. Diseases, those generally classed as epidemic, endemic, infectious, or contagious, now believed to be due to specific viruses, as small-pox, measles, scarlet-fever, diphtheria, whooping-cough, and "fever" (typhus, simple continued, enteric, and others).

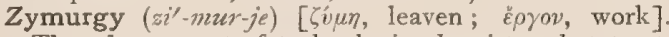
That department of technologic chemistry that treats of the scientific principles of wine-making, brewing, and distilling, and the preparation of yeast and vinegar, in which processes fermentation plays the principal part. 



. 






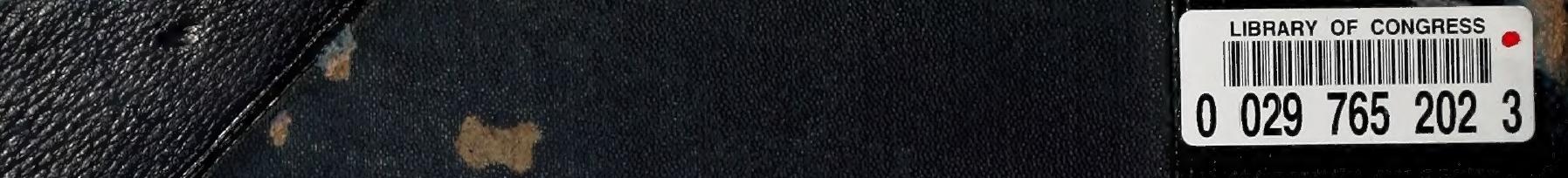

